THE ENVIRONMENTAL PROTECTION DEPARTMENT ENVIRONMENTAL MONITORING SECTION

\title{
THE SAVANNAH RIVER SITE'S GROUNDWATER MONITOR!NG PROGRAM
}

\section{THIRD QUARTER 1992 (U)}

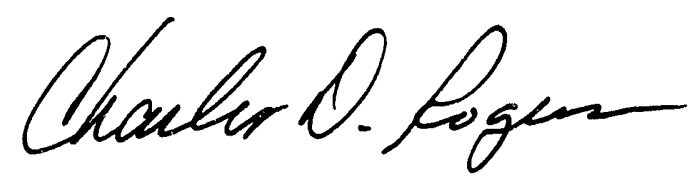

Environmental Protection Department

Westinghouse Savannah River Company

Aiken, SC

and

Exploration Resources, Inc.

Athens, GA

Publication Date: February 4, 1993

Westinghouse Savannah River Company

Savannah River Site

Aiken, SC 29808

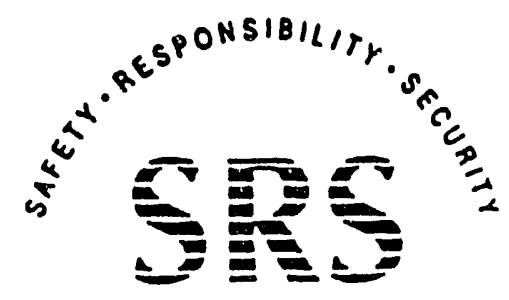

SAVANNAH RIVER SITE

Prepared for the U.S. Department of Energy under Contract No. AA46317P

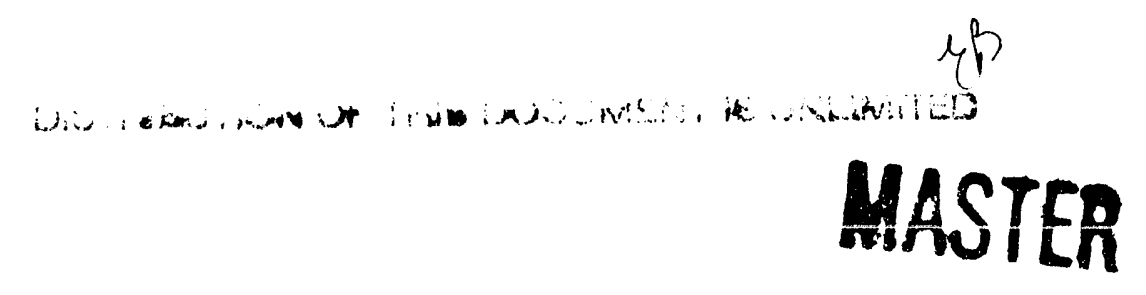


This page was left blank intentionally. 


\section{CONTENTS}

1. EXECUTIVE SUMMARY $\ldots \ldots \ldots \ldots \ldots \ldots \ldots \ldots \ldots \ldots \ldots \ldots \ldots \ldots \ldots$

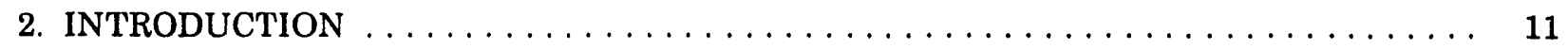

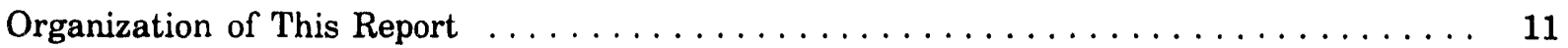

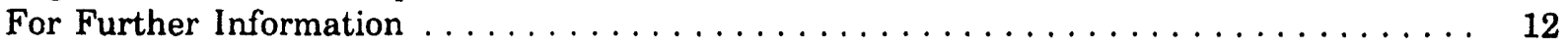

3. FLAGGING CRITERIA $\ldots \ldots \ldots \ldots \ldots \ldots \ldots \ldots \ldots \ldots \ldots \ldots \ldots \ldots$

4. SAMPLE SCHEDULING $\ldots \ldots \ldots \ldots \ldots \ldots \ldots \ldots \ldots \ldots \ldots \ldots \ldots \ldots \ldots \ldots$

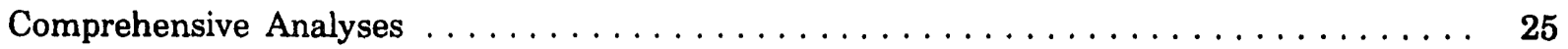

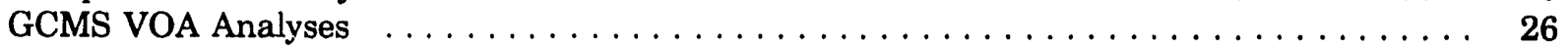

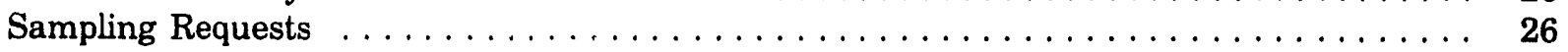

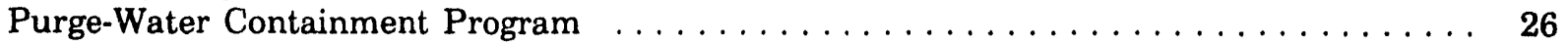

5. FIELD NOTES $\ldots \ldots \ldots \ldots \ldots \ldots \ldots \ldots \ldots \ldots \ldots \ldots \ldots \ldots \ldots \ldots \ldots$

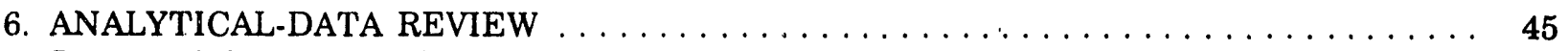

Review of the Analytical Data for Errors $\ldots \ldots \ldots \ldots \ldots \ldots \ldots \ldots \ldots \ldots \ldots \ldots \ldots \ldots$

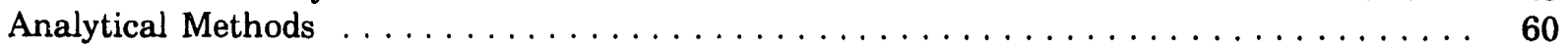

7. QUALITY CONTROL SAMPLES $\ldots \ldots \ldots \ldots \ldots \ldots \ldots \ldots \ldots \ldots \ldots \ldots \ldots \ldots \ldots$

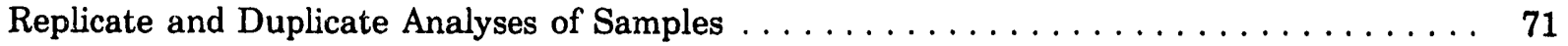

Comments on the Replicate and Duplicate Analyses . . . . . . . . . . . . . . . 81

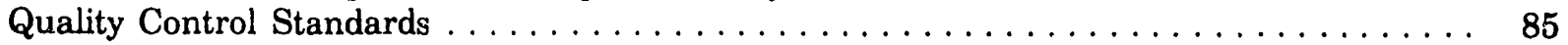

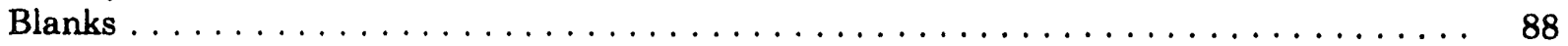

8. WATER LEVEL DATA $\ldots \ldots \ldots \ldots \ldots \ldots \ldots \ldots \ldots \ldots \ldots \ldots \ldots \ldots \ldots$

9. SITE INDEX BY WELL SERIES $\ldots \ldots \ldots \ldots \ldots \ldots \ldots \ldots \ldots \ldots \ldots \ldots$

10. GLOSSARY $\ldots \ldots \ldots \ldots \ldots \ldots \ldots \ldots \ldots \ldots \ldots \ldots \ldots \ldots \ldots \ldots \ldots$

11. REFERENCES $\ldots \ldots \ldots \ldots \ldots \ldots \ldots \ldots \ldots \ldots \ldots \ldots \ldots \ldots \ldots \ldots \ldots$

Appendix A. ANALYTICAL RESULTS $\ldots \ldots \ldots \ldots \ldots \ldots \ldots \ldots \ldots \ldots \ldots \ldots \ldots \ldots$

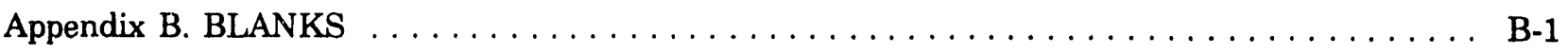




\section{LIST OF FIGURES}

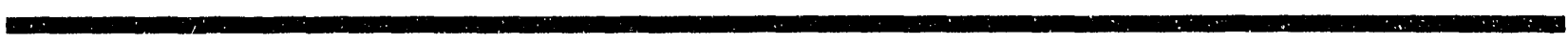

Figure 1. Areas and Locations Monitored for Groundwater Quality at the

Savannah River Site .............................. 14

Figure 2. Separations and Waste Management Areas Monitored for

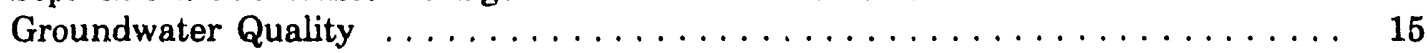

Figure 3. Two Types of Groundwater Monitoring Wellheads $\ldots \ldots \ldots \ldots \ldots \ldots \ldots \ldots$ 


\section{LIST OF TABLES}

Table 1. Analytes Above Flag 2 Criteria $\ldots \ldots \ldots \ldots \ldots \ldots \ldots \ldots \ldots \ldots \ldots \ldots \ldots$

Table 2. Flagging Criteria $\ldots \ldots \ldots \ldots \ldots \ldots \ldots \ldots \ldots \ldots \ldots \ldots \ldots \ldots$

Table 3. Number of Analyses Performed During Third Quarter $1992 \ldots \ldots \ldots \ldots \ldots$

Table 4. Comprehensive-Analyses Constituents $\ldots \ldots \ldots \ldots \ldots \ldots \ldots \ldots \ldots \ldots \ldots \ldots$

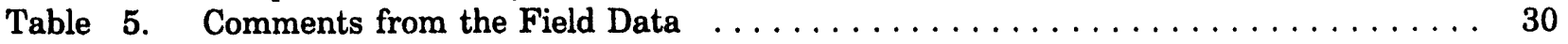

Table 6. GE Laboratory Blanks with Elevated Results $\ldots \ldots \ldots \ldots \ldots \ldots \ldots \ldots \ldots \ldots$

Table 7. EPD/EMS Blind Blanks with Elevated Results from GE $\ldots \ldots \ldots \ldots \ldots \ldots \ldots \ldots$

Table 8. GE Samples with High Analytical Results as Compared

to Historical Data . . . . . . . . . . . . . . . . . . . . . . 49

Table 9. GE Samples with Low Analytical Results as Compared

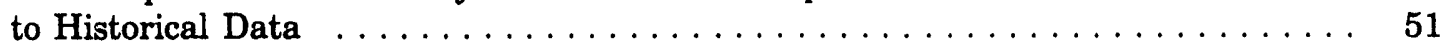

Table 10. Analyses Not Performed by GE $\ldots \ldots \ldots \ldots \ldots \ldots \ldots \ldots \ldots \ldots$

Table 11. Environmental Physics Samples with High Analytical Results as Compared

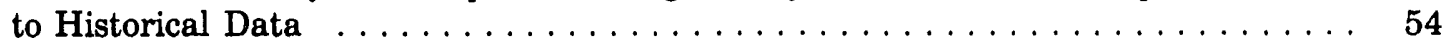

Table 12. Analyses Not Performed by Environmental Physics $\ldots \ldots \ldots \ldots \ldots \ldots \ldots \ldots$

Table 13. Weston Laboratory Blanks with Elevated Results $\ldots \ldots \ldots \ldots \ldots \ldots \ldots \ldots \ldots$

Table 14. EPD/EMS Blind Blanks with Elevated Results from Weston . . . . . . . . . . . 55

Table 15. Weston Samples with High Analytical Results as Compared

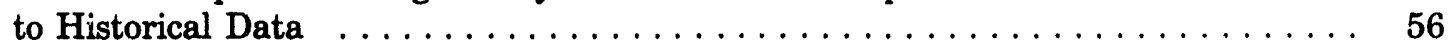

Table 16. Weston Samples with Low Analytical Results as Compared

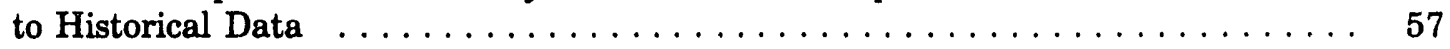

Table 17. Analyses Not Performed by Weston $\ldots \ldots \ldots \ldots \ldots \ldots \ldots \ldots \ldots \ldots$

Table 18. Clemson TC Samples with High Analytical Results as Compared

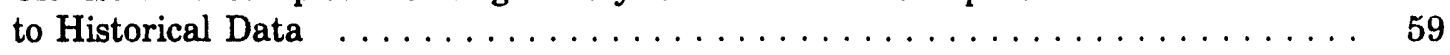

Table 19. Clemson TC Samples with Low Analytical Results as Compared to Historical Data . . . . . . . . . . . . . . . . . . . . . . . . . $\quad 59$

Table 20. EPD/EMS Laboratory Samples with High Analytical Results as Compared

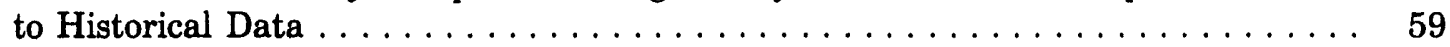

Table 21. Methods and Detection Limits Used by the Primary Laboratories . . . . . . . 60

Table 22. Methods and Detection Limits Used by the Radionuclide Laboratories . . . . . . 67

Table 23. Wells Providing Blind Replicate Samples $\ldots \ldots \ldots \ldots \ldots \ldots \ldots \ldots \ldots \ldots \ldots$

Table 24. Analytes Not Showing Measurable Concentrations Above Detection Limits in Any Replicated or Duplicated Samples $\ldots \ldots \ldots \ldots \ldots \ldots \ldots \ldots \ldots \ldots$

Table 25. Intralaboratory MRD Index for GE $\ldots \ldots \ldots \ldots \ldots \ldots \ldots \ldots \ldots \ldots \ldots \ldots$

Table 26. Intralaboratory MRD Index for Weston $\ldots \ldots \ldots \ldots \ldots \ldots \ldots \ldots \ldots \ldots$

Table 27. Interlaboratory MRD and $t$-Test Results for Analytes with at Least One Pair

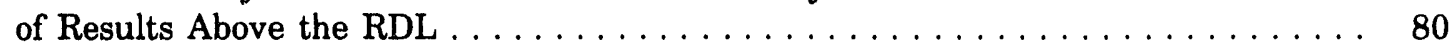


Table 28. GE Samples and Laboratory Duplicates Yielding Results Where One Is More than Twice Another . . . . . . . . . . . . . . . . 81

Table 29. GE Samples and Blind Replicates Yielding Results Where One Is More than Twice Another $\ldots \ldots \ldots \ldots \ldots \ldots \ldots \ldots \ldots 2$

Table 30. Weston Samples and Laboratory Duplicates Yielding

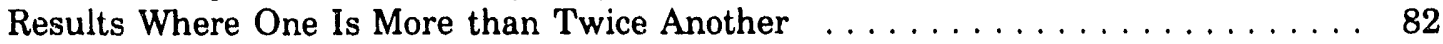

Table 31. Weston Samples and Blind Replicates Yie!ding Results Where One Is More than Twice Another . . . . . . . . . . . . . . . 83

Table 32. Analytes with One Laboratory's Resuit Greater than Twice the Result from the Other Laboratory . . . . . . . . . . . . . . . . . . . . 84

Table 33. Quality Control Standards for Selected Analyses $\ldots \ldots \ldots \ldots \ldots \ldots \ldots \ldots$

Table 34. GE Laboratory Blanks Having Elevated Results and Accompanying

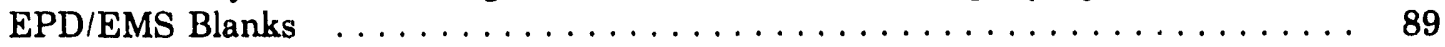

Table 35. Weston Laboratory Blanks Having Elevated Results and Accompanying Equipment Blanks . . . . . . . . . . . . . . . . . . . . 89

Table 36. EPD/EMS Blind Blanks Having Elevated Results from GE and Accompanying

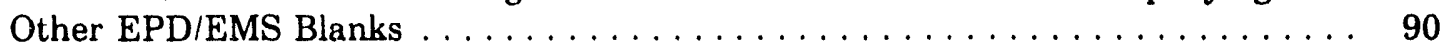




\section{EXECUTIVE SUMMARY}

The Environmental Protection Department/ Environmental Monitoring Section (EPD/EMS) administers the Savannah River Site's (SRS) Groundwater Monitoring Program. During third quarter 1992, EPD/EMS conducted extensive sampling of monitoring wells.

EPD/EMS has established two sets of flagging criteria to assist in managing sample results. The flagging criteria do not define contamination levels; instead, they aid personnel in sample scheduling, interpretation of data, and trend identification. Since 1991, the flagging criteria have been based on the federal Environmental Protection Agency (EPA) drinking water standards and on method detection limits. A detailed explanation of the flagging criteria is presented in the Flagging Criteria section of this document. Analytical results from third quarter 1992 are included in this report, which is distributed to all site

\section{Table 1. Analytes Above Flag 2 Criteria}

$\underline{\text { Site }}$

Well

$\underline{\text { Series }}$

100 ARFAS

\section{Area}

C-Area Burning/Rubble Pit

CRP

C-Area Disassembly Basin

CDB

C-Area Reactor Seepage Basins

CSB

$\boldsymbol{K}$ Area

K-Area Acid/Caustic Basin

KAC

K-Area Ash Basin

$\mathrm{KAB}$

K-Area Burning/Rubble Pit

KRP custodians. Thirteen wells scheduled for analyses during third quarter 1992 were not sampled pending full establishment of a purgewater containment program. For more information, see the Sample Scheduling section.

One or more analytes exceeded Flag 2 during third quarter 1992 in 103 monitoring well series. Analytes exceeded the current Flag 2 criteria for the first time since 1984 in 21 of the 103 monitoring well series, two of which (FSL and HSL) were first sampled this quarter.

Table 1 lists those well series with constituents in the groundwater above Flag 2 during third quarter 1992, organized by location. Results from all laboratory analyses are used to generate this table. Specific conductance and $\mathrm{pH}$ data from the field also are included in this table.

Analytes Above Flag 2 Criteria Third Quarter 1992 
Table 1. Analytes Above Flag 2 Criteria (cont.)

$\underline{\text { Site }}$

Well Analytes Above Flag 2 Criteria

Series Third Quarter 1992

100 AREAS (cont.)

K Area (cont.)

K-Area Coal Pile Runoff Containment Basin

$\mathrm{KCB}$

Manganese, specific conductance, sulfate, total alpha-emitting radium

K-Area Diesel Tank

KDT

Manganese, tritium

K-Area Disassembly Basin

$\mathrm{KDB}$ Lead, manganese, total organic halogens, total alpha-emitting radium, tritium

K-Area Reactor Seepage Basin

KSB Tritium

K-Area Retention Basin

KRB Iron, lead, tritium

K-Area Tritium Monitoring Well

KSM

Iron, manganese, tritium

K-Area Wind Tower Piezometers at B Road

K

Tritium

\section{Area}

L-Area Burning/Rubble Pit

LRP Lead

L-Area Disassembly Basin

LDB Lead, total organic halogens

L-Area Oil and Chemical Basin

LCO Specific conductance, tetrachloroethylene, technetium-99, tritium

L-Area Reactor Seepage Basin

LSB Tritium

L-Area Research Wells

LAW Iron, lead, $\mathrm{pH}$

\section{P Area}

P-Area Acid/Caustic Basin

PAC Iron, manganese

P-Area Burning/Rubble Pit

PRP Lead, manganese, total organic halogens

P-Area Coal Pile Runoff Containment Basin

PCB

Iron, lead, manganese

P-Area Disassembly Basin

PDB

Tritium

P.Area Reactor Seepage Basins

PSB

Lead, tritium

\section{R Area}

R-Area Acid/Caustic Basin

RAC Gross aipha

R-Area Burning/Rubble Pits

RRP Iron

Note: Analytes in bold were detected at levels above the current Flag 2 criteria for the first time since 1984. 
Table 1. Analytes Above Flag 2 Criteria (cont.)

Site

Well Analytes Above Flag 2 Criteria

Series Third Quarter 1992

100 AREAS (cont.)

$\boldsymbol{R}$ Area (cont.)

R-Area Coal Pile Study

RCP Manganese

R-Area Disassembly Basin

RDB Iron, manganese

Series A, R-Area Reactor Seepage Basins

RSA Cadmium, iron, total organic carbon, potassium-40, total alpha-emitting radium

Series B, R-Area Reactor Seepage Basins

RSB

Cadmium

Series C, R-Area Reactor Seepage Basins

RSC

Specific conductance

Series D, between R-Area Reactor Seepage

RSD

Basins and R-Area Disassembly Basin

Series E, R-Area Reactor Seepage Basins

RSE

Series F, R-Area Reactor Seepage Basins

Cadmium, iron, gross alpha, nonvolatile beta, strontium-90

Cadmium, iron, manganese, total organic halogens, gross alpha, nonvolatile beta, strontium-90, tritium

Total organic carbon, tritium

\section{AREAS}

\section{Burial Grounds (E Area)}

Burial Grounds

BG

Burial Grounds Perimeter Wells

BGO

Cadmium, iron, lead, manganese, mercury, gross alpha, total alpha-emitting radium, tritium

Aluminum, antimony, chloroethene (vinyl chloride), dichlorodifluoromethane, 1,1dichloroethane, 1,1-dichloroethylens, iron, lead, manganese, $\mathrm{pH}$, specific conductance, tetrachloroethylene, thallium, total organic halogens, trichloroethylene, vinyl acetate, gross alpha, total alpha-emitting radium, tritium

E-Area Vaults near the Burial Grounds

BGX

Cadmium, iron, manganese, $\mathrm{pH}$, specific conductance, trichloroethylene, nonvolatile beta, tritium

Series C, Monitoring Grid Wells for Burial Grounds

MGC Tritium

Series G, Monitoring Grid Wells for Burial MGG Gross alpha, tritium

Note: Analytes in bold were detected at levels above the current Flag 2 criteria for the first time since 1984. 
Table 1. Analytes Above Flag 2 Criteria (cont.)

Site

Well Analytes Above Flag 2 Criteria

Series Third Quarter 1992

200 AREAS (cont.)

F Area

Burma Road Rubble Pit

F-Area A Line

F Area and H Area

F-Area Acid/Caustic Basin

F-Area Burning/Rubble Pits

F-Area Canyon Building

F-Area Coal Pile Runoff Containment Basin

F-Area Inactive Process Sewer Lines

F-Area Microbiology Wells for Bedrock Exploration (P 28 Cluster)

F-Area Seepage Basins

F

F-Area Seepage Basins

F-Area Sludge Land Application Site

F-Area Tank Farm

Old F-Area Seepage Basin

$\mathbf{P}$
BRR Manganese, total alpha-emitting radium, tritium

FAL 1,2-Dichloroethane, lead, manganese, trichloroethylene, trichlorofluoromethane

ZW Tritium

FAC Manganese, nitrate as nitrogen, total organic halogens

FBP

Total organic halogens

FCA Lead, manganese, nitrate-ritrite as nitrogen, total organic halogens, trichloroethylene, trichlorofluoromethane, gross alpha, nonvolatile beta, total alpha-emitting radium, strontium $89 / 90$, strontium-90, tritium

FCB Iron, total alpha-emitting radium

FSI Lead, manganese, nitrate-nitrite as nitrogen, trichloroethylene, trichlorofluoromethane, tritium

Iron

Gross alpha, nonvolatile beta, tritium

FSS

FTF

FNB
Aluminum, antimony, arsenic, cadmium, cobalt, iron, lead, manganese, mercury, nickel, nitrate-nitrite as nitrogen, $\mathrm{pH}$, specific conductance, tirallium, total silica, trichloroethylene, trichlorofluoromethane, uranium, cesium-137, gross alpha, nonvolatile beta, total alpha-emitting radium, tritium

Iron, lead, manganese, mercury, tritium

Nitrate-nitrite as nitrogen, $\mathrm{pH}$, specific conductance, gross alpha, nonvolatile beta, total alpha-emitting radium, tritium

Manganese, nitrate-nitrite as nitrogen, trichloroethylene, gross alpha, nonvolatile beta, total alpha-emitting radium, tritium, uranium-234, uranium-238

Note: Analytes in bold were detected at levels above the current Flag 2 criteria for the first time since 1984. 
Table 1. Analytes Above Flag 2 Criteria (cont.)

$\underline{\text { Site }}$

Well Analytes Above Flag 2 Criteria

$\underline{\text { Series }}$

Third Quarter 1992

200 AREAS (cont.)

F Area (cont.)

Wells between the F-Area Canyon Building

NBG

Iron, lead, nitrate-nitrite as nitrogen, specifir: and the Naval Fuel Material Facility conductance, trichloroethylene, total organic halogens, tritium

\section{H Area}

H-Area Acid/Caustic Basin

HAC Iron, radium-228, tritium

H-Area Canyon Building

HCA Carbon tetrachloride, lead, manganese, tetrachloroethylene, trichloroethylene, tritium

H-Area Coal Pile Runoff Containment Basin

HCB

H-Area Effluent Treatment Cooling Water Basin

HET

Iron, lead, manganese, specific conductance, sulfate, tritium

H-Area Inactive Process Sewer Lines

HSL

H-Area Retention Basin

HR8

H-Area Seepage Basins

$\mathrm{H}$

Tritium

H-Area Seepage Basins

HSB

H-Area Sludge Land Application Site

HSS

\section{Manganese, nitrate-nitrite as nitrogen,} nonvolatile beta, tritium

Lead, trichloroethylene, tritium

H-Area Tank Farm

HTF

Gross alpha, tritium

Aluminum, antimony, arsenic, cadmium, cobalt, iron, lead, manganese, mercury, nitratenitrite as nitrogen, $\mathrm{pH}$, specific conductance, tetrachloroethylene, total organic halogens, total silica, vanadium, cobalt-60, gross alpha, nonvolatile beta, total alpha-emitting radium, tritium

HT

Lead

Old H-Area Retention Basin

HR3

Cadmium, lead, mercury, specific conductance, gross alpha, strontium-90, total alphaemitting radium, tritium

\section{S Area}

S-Area Defense Waste Processing Facility Background Wells

Tritium

S-Area Vitrification Building

SCA

Note: Analytes in bold were detected at levels above the current Flag 2 criteria for the first time since 1984. 
Table 1. Analytes Above Flag 2 Criteria (cont.)

$\underline{\text { Site }}$

Well Analytes Above Flag 2 Criteria

Series Third Quarter 1992

200 AREAS (cont.)

Y Area

Y-Area Waste Solidification and Disposal Facility

YSC $\quad \mathrm{pH}$, specific conductance

\section{Z Area}

Z-Area Low Point Drain Tank

ZDT

Tritium

Z-Area Saltstone Facility Background Wells

ZBG

Antimony

300/700 AREAS

A-Area Burning/Rubble Pits

ARP

A-Area Coal Pile Runoff Containment Basin

ACB

A-Area Metals Burning Pit

$\mathrm{ABP}$

M-Area Hazardous Waste Management Facility MSB (HWMF) and Plume Definition Wells

M-Area Recovery Wells

RWM

Metallurgical Laboratory Seepage Basin

AMB

Miscellaneous Chemical Basin

MCB

Motor Shop Oil Basin

AOB

Tetrachloroethylene, total organic halogens, trichloroethylene

Manganese, tetrachloroethylene, trichloroethylene, gross alpha, total alpha-emitting radium

Aluminum, lithium, manganese, $\mathrm{pH}$, specific conductance, tetrachloroethylene, trichloroethylene

Aluminum, antimony, cadmium, carbon tetrachloride, chloroethane, 1,1-dichloroethylene, iron, lead, manganese, mercury, nitrate as nitrogen, nitrate-nitrite as nitrogen, $\mathrm{pH}$, specific conductance, tetrachloroethylene, thallium, trichloroethylene, trichlorofluoromethane, total organic halogens, uranium, gross alpha, nonvolatile beta, total alphaemitting radium

Chloroform, tetrachloroethylene, trichloroethylene

Iron, manganese, $\mathrm{pH}$, specific conductance, tetrachloroethylene, total organic halogens, trichloroethylene, total alpha-emitting radium

Aluminum, carbon tetrachloride, lithium, pH, specific conductance, tetrachloroethylene, total organic halogens, trichloroethylene

Oil \& grease, tetrachloroethylene, total organic halogens, trichloroethylene

Note: Analytes in bold were detected at levels above the current Flag 2 criteria for the first time since 1984. 
Table 1. Analytes Above Flag 2 Criteria (cont.)

Site

Well Analytes Above Flag 2 Criteria

300/700 AREAS (cont.)

Savannah River Technology Center (SRTC)

ASB $\mathrm{pH}$, tetrachloroethylene, total organic halogens, trichloroethylene, tritium

Silverton Road Waste Site

SRW

Carbon tetrachloride, lead, trichloroethylene

400 AREA

D Area

D-Area Burning/Rubble Pits

DBP Manganese

D-Area Coal Pile Runoff Containment Basin and Ash Basins

DCB Chromium, fluoride, iron, manganese, $\mathrm{pH}$, sulfate, trichloroethylene, specific conductance, gross alpha, nonvolatile beta, total alpha. emitting radium, tritium

D-Area Oil Disposal Basin

DOB Iron, tetrachloroethylene, tin, total organic halogens, trichloroethylene

\section{AREAS}

\section{Central Shops}

Central Shops Diesel Spill Characterization and Remediation Wells

CSD Benzene, $\mathrm{pH}$, trichloroethylene

Ford Building Seepage Basin

HXB

Tritium

Potential New Production Reactor Site

NPM

Cadmium, lead, pH, specific conductance

Characterization Wells near Central Shops

\section{General Areas}

Adjacent tr SRS Ruad E-2 near the Proposed Sanitary Landfill Site (P 14 Cluster)

B-Area Microbiology Wells (P 29 Cluster)

Chemicals, Metals, and Pesticides Pits

$\mathrm{P}$

Aluminum, iron

$\mathbf{P}$

Benzene, iron

CMP Lead, manganese, $\mathrm{pH}$, tetrachl:: oethylene, trichloroethylene, nonvolatile beta, radium. 228

Hazardous Waste/Mixed Waste Disposal
Facility

HMD

Antimony, manganese, thallium

Interim Waste Technology Site B:

IDB

Iron, lead, $\mathrm{pH}$, specific conductance

Note: Analytes in bold were detected at levels above the current Flag 2 criteria for the first time since 1984. 
Table 1. Analytes Above Flag 2 Criteria (cont.)

Site

Well Analytes Above Flag 2 Criteria

Series Third Quarter 1992

600 AREAS (cont.)

\section{General Areas (cont.)}

Interim Waste Technology Site P: Characterization Wells

IDP

Iron, $\mathrm{pH}$

Interim Waste Technology Site $Q$ :

IDQ Iron, lead, manganese, pH, specific Characterization Wells conductance

Kato Road Sewage Sludge Application Site (SSS 19-21)

Total organic halogens

Orangeburg Sewage Sludge Application Site (SSS 7-9)

Total organic halogens

Par Pond Sludge Land Application Site

PSS

Lead

Road A Chemical Basin (Baxley Road)

BRD

Manganese, total organic halogens

Road F Sewage Sludge Application Site (SSS 22-24)

Sandy (Lucy; Sewage Sludge Application Site (SSS 10-12)

Sanitary Landfill

Second Par Pond Borrow Pit Sewage Sludge

Total organic carbon, total organic halogens

Application Site (SSS 25-27)

40-Acre Hardwood Sewage Sludge

Manganese, total organic carbon, total organic halogens

Application Site (SSS 1-3)

\section{TNX Area}

New TNX Seepage Basin

YSB

Total inorganic carbon

Old TNX Seepage Basin

XSB Carbon tetrachloride, iron, manganese, nitrate-nitrite as nitrogen, total inorganic carbon, total organic halogens, trichloroethylene, gross alpha, nonvolatila beta, radium228

Note: Analytes in bold were detected at levels above the current Flag 2 criteria for the first time since 1984. 
Table 1. Analytes Above Flag 2 Criteria (cont.)

Site

Well

$\underline{\text { Series }}$

600 AREAS (cont.)

TNX Area (cont.)

TNX-Area Assessment Wells

TNX Burying Ground
Analytes Above Flag 2 Criteria Third Quarter 1992
TNX

Carbon tetrachloride, iron, manganese, nitratenitrite as nitrogen, tetrachloroethylene, total inorganic carbon, total organic halogens, trichloroethylene, gross alpha, radium-228, total alpha-emitting radium

TBG Carbon tetrachloride, iron, lead, manganese, nitrate-nitrite as nitrogen, total inorganic carbon, total organic halogens, trichloroethylene, gross alpha, total alpha-emitting radium

Note: Analytes in bold were detected at levels above the current Flag 2 criteria for the first time since 1984. 
NOTES 


\section{INTRODUCTION}

This report summarizes the Savannah River Site (SRS) groundwater monitoring program conducted by the Environmental Protection Department's Environmental Monitoring Section (EPD/EMS) during the third quarter of 1992. It includes the analytical data, field data, data review, quality control, and other documentation for this program; provides a record of the program's activities; and serves as an official document of the analytical results.

EPD/EMS is responsible for monitoring for constituents in the groundwater at approximately 135 waste sites in 16 areas at SRS (see Figures 1 and 2, pp. 14-15). The majority of this monitoring is required by U.S. Department of Energy (DOE) orders and by federal and state regulations administered by the U.S. Environmental Protection Agency (EPA) and the South Carolina Department of Health and Environmental Control (SCDHEC). The groundwater monitoring program includes the following activities:

- installation, maintenance, and abandonment of monitoring wells

- environmental soil borings

- development of sampling and analytical schedules

- collection and analyses of groundwater samples

- review of analytical and other data

- maintenance of the databases containing groundwater monitoring data

- quality assurance (QA) evaluations of laboratory performance
- reports of results to waste-site facility custodians and the Environmental Protection Section (EPS) of EPD

EPD/EMS is responsible for monitoring wells but not for the facilities that are monitored. It is the responsibility of the custodian of each waste site to ensure that EPD/EMS is informed of sampling requirements and special requests for the sampling schedule, to assist in reviewing the data, and to make any decisions regarding groundwater monitoring at the waste site.

Each custodian receives a copy of this report; also, each custodian receives site-specific data upon request, including the following:

- a computer printout of the analytical data for the current quarter and for the previous seven quarters, designed to assist in identifying trends

- a computer printout of analytical values at or above Flag 1 and Flag 2 criteria for the quarter, designed to assist in identifying elevated analytical values

\section{ORGANIZATION OF THIS REPORT}

This report is divided into sections that focus on specific aspects of the SRS groundwater monitoring program. The Executive Summary section presents a tabular listing by waste site and well series of all analytes detected at or above Flag 2 criteria during the quarter. Analytes detected at or above Flag 2 criteria for the first time since 1984 are indicated in bold type.

The following five sections address sampling and assessment of groundwater quality at SRS. 
The Flagging Criteria section lists flagging criteria for analytes and provides a short description of how the criteria were derived. The Sample Scheduling section discusses the preparation of the sampling schedule and the criteria for analyte selection.

During sample collection, samplers often write comments in the field logbooks that may be pertinent to the analysis of the sample. Many of the comments concern wells that went dry during sampling or the appearance of water that is colored, turbid, or aerated. These comments are given in the Field Notes section.

Samples are analyzed by the EPD/EMS and M-Area laboratories at SRS and by one or more off-site laboratories. During the third quarter, General Engineering Laboratories and Roy F. Weston, Inc., were the primary off-site laboratories; radionuclide analyses were conducted by Environmental Physics (a division of General Engineering Laboratories), Teledyne Isotopes, Clemson Technical Center, Inc., and TMA/Eberline; asbestos analyses were conducted by Spencer Laboratories. The Analytical Data Review section contains two subsections. The Review of the Analytical Data for Errors subsection is a discussion of discrepancies in each laboratory's analytical data, including results that are considerably higher or lower than previous results, analyses that were omitted, and laboratory blanks that showed elevated results. The Analytical Methods subsection lists the methods the laboratories used for measuring concentrations of each analyte.

A number of replicate samples are analyzed by the primary off-site laboratories as part of the EPD/EMS quality control program. The Quality Control Samples section contains four subsections. The Replicate and Duplicate Analyses of Samples subsection explains the replicate analysis program, gives the statistical methods used for comparison, and lists the results of the comparisons. The Comments on the Replicate and Duplicate Analyses subsection discusses the replicate and duplicate analyses comparison results and their meanings. The laboratory's performance is tested using solutions with known analyte concentrations; the results and percentage of analyses within limits are found in the Quality Control Standards subsection.
The Blanks subsection discusses various types of sampling blanks and lists anomalous results obtained from analysis of samples of deionized water to aid in determining if detected constituents were in rinsewater, in sample containers, or introduced during analysis.

The Water Level Data section includes concurrent water elevations obtained in the $\mathrm{A} / \mathrm{M}$ and other areas; these data are used by SRS personnel in hydrogeologic studies.

The Site Index by Well Series assists the reader in identifying the site associated with each well series. A list of terms, abbreviations, and acronyms used in this report can be found in the Glossary section. References cited are listed in the References section.

The Analytical Results section (íppendix A) includes tables listing the analytical results from all the laboratories and field data for all wells sampled during the quarter. The tables appear in alphabetical order by well name. Appendix B contains tables listing the analytical results of laboratory tests on sampling blanks.

\section{FOR FURTHER INFORMATION}

The following is a brief description of documents pertaining to the groundwater monitoring program.

\section{Quarterly Reports}

EPD/EMS has published a description of its groundwater monitoring program for each quarter since the beginning of 1986. A list of these quarterly reports follows.

Report

Document Number

Second Quarter 1992

First Quarter 1992

Fourth Quarter 1991

Third Quarter 1991

Second Quarter 1991

First Quarter 1991

Fourth Quarter 1990

Third Quarter 1990

Second Quarter 1990

First Quarter 1990
ESH-EMS-920036

ESH-EMS-920035

ESH-EMS-910090

ESH-EMS-910089

ESH-EMS-910088

ESH-EMS-910087

ESH-EMS-900134

ESH-EMS-900133

ESH-EMS-900132

ESH-EMS-90-0131 
Report

Fourth Quarter 1989

Third Quarter 1989

Second Quarter 1989

First Quarter 1989

Fourth Quarter 1988

Third Quarter 1988

Second Quarter 1988

First Quarter 1988

Fourth Quarter 1987

Third Quarter 1987

Second Quarter 1987

First Quarter 1987

Fourth Quarter 1986

Third Quarter 1986

Second Quarter 1986

First Quarter 1986 (revised)

\section{Annual Reports}

DOE's Savannah River Site Environmental Report, which includes groundwater data for the year, site descriptions, and site maps, is a public document issued annually. A list of recent reports follows.

$\begin{array}{ll}\text { Report } & \text { Document Number } \\ 1991 & \text { WSRC-TR-92-186 } \\ 1990 & \text { WSRC-IM-91-28 (Vols. I and II) } \\ 1989 & \text { WSRC-IM-90-60 (Vols. I and II) } \\ 1988 & \text { WSRC-RP-89-59-1 (Vols. I and II) } \\ 1987 & \text { DPSPU-88-30-1 (Vols. I and II) } \\ 1986 & \text { DPSPU-87-30-1 (Vols. I and II) } \\ 1985 & \text { DPSPU-86-30-1 (Vols. I and II) }\end{array}$

\section{Inventory and Maps of Wells}

The Environmental Protection Department's Well Inventory provides a historical record of wells monitored by EPD/EMS, contains a list of wells currently in the EPD/EMS Groundwater
Monitoring Program, and provides pertinent information about all wells listed in EPD/EMS documents. The latest version is ESH-EMS920039, which includes site maps for active and abandoned wells.

Prior to 1991, information on well abandonment, maintenance, construction and stabilization, environmental soil borings, and surveying was included in the quarterly report. All of that information now is published separately in The Savanraah River Site's Groundwater Monitoring Program annual Well Installation Report. The current version is ESH-EMS-910093.

\section{Other Data Reports}

DOE's Geoscience Implementation Plan and Geohydrology Program Report describe SRS geohydrology program projects and their current status and administration.

Christensen and Gordon's Technical Summary of Groundwater Quality Protection Program at Savannah River Plant, Volume I-Site Geohydrology, and Solid and Hazardous Wastes, (DPST-83-829, December 1983) describes SRS waste disposal sites and analytical monitoring data.

Stone and Christensen's Technical Summary of Groundwater Quality Protection Program at Savannah River Plant, Volume II-Radioactive Waste (DPST-83-829, December 1983) presents representative monitoring data for radioactivity in groundwater at SRS.

Full bibliographical listings of these and other documents cited can be found in the References section of this report. 


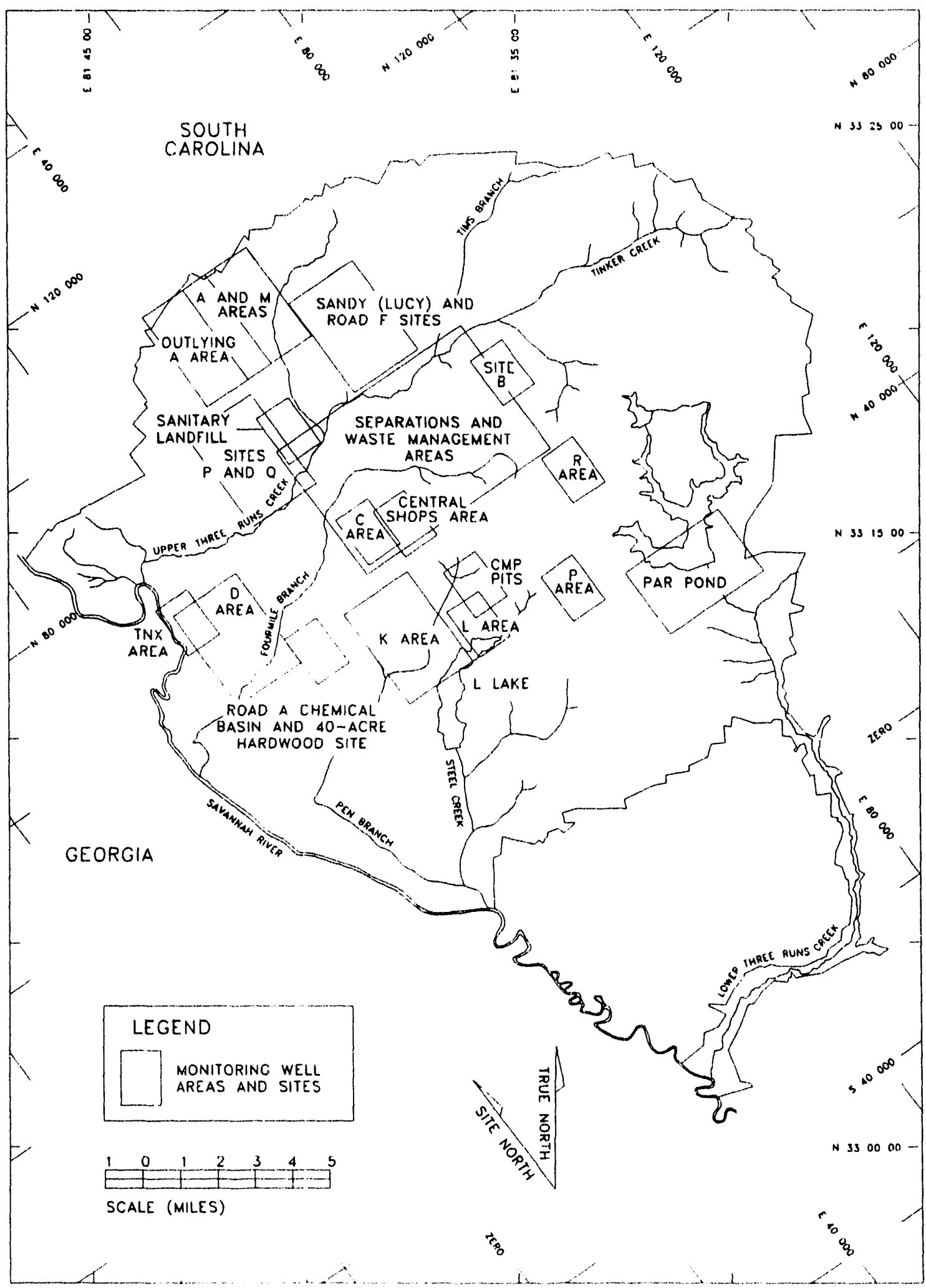

Figure 1. Areas and Locations Monitored for Groundwater Quality at the Savannah River Site 


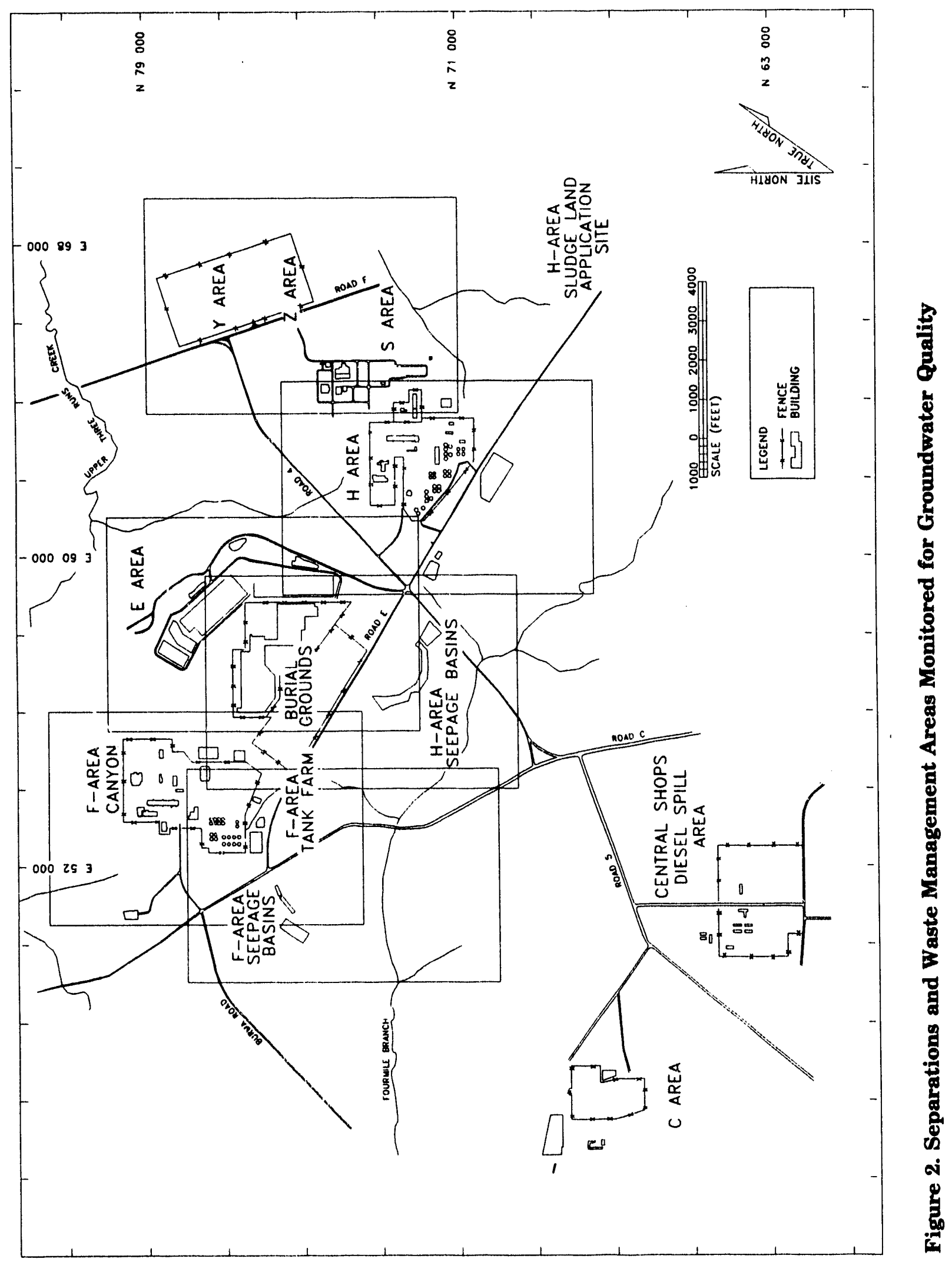


NOTES 


\section{FLAGGING CRITERIA}

Analyses in the data tables are assigned a flagging level $(0,1$, or 2$)$ depending on their concentration in a groundwater sample. Beginning in 1991, EPD/EMS modified its guidelines for setting flagging levels for the Groundwater Monitoring Program. The flagging criteria in Table 2 were determined as follows.

Flag 0: Analytical results below Flag 1 or for a constituent having no flagging criteria are classified as Flag 0 .

Flag 1: The Flag 1 criterion for a constituent was set as one-half of the Environmental Protection Agency (EPA) final primary drinking water standard, the EPA proposed primary drinking water standard, or the EPA secondary drinking water standard for that constituent. If a constituent did not have an EPA drinking water standard, the Flag 1 criterion was set as five times a recently published 90 th percentile detection limit obtained by one of the primary laboratories.

Flag 2: The Flag 2 criterion for a constituent was set as the EPA final primary drinking water standard, the EPA proposed primary drinking water standard, or the EPA secondary drinking water standard for that constituent. If a constituent does not have a drinking water standard, the Flag 2 criterion was set as 10 times a recently published 90 th percentile detection limit obtained by one of the primary laboratories.

The following major cations, aesthetic analyses, and indicator parameters are not assigned flagging criteria: alkalinity, calcium, color, corrosivity, magnesium, odor, potassium, silica, sodium, total dissolved solids, total phosphorus, total phosphates (as P), and turbidity.

Common laboratory contaminants and cleaners, including ketones, dichloromethane (methylene chloride), and phthalates, are not assigned flagging criteria.

The following acronyms are used as abbreviated sources in the flagging criteria table. Complete information concerning documents cited can be found in the References section of this document.

APHA Method-A specific analytical method for testing constituent levels in a sample as established by the American Public Health Association, American Water Works Association, and Water Pollution Control Federation. See American Public Health Association et al. in References.

DWS-Drinking Water Standards.

EPA-Environmental Protection Agency.

EPA Method-A specific analytical method for testing constituent levels. Descriptions of these methods may be found in the EPA publications Methods for Chemical Analysis of Water and Wastes and Test Methods for Evaluating Solid Waste, and in the Code of Federal Regulations, Title 40, Part 136. See Environmental Protection Agency in References.

EPD/EMS-The Environmental Protection Department, Environmental Monitoring Section, at the Savannah River Site. 
Table 2. Flagging Criteria

\begin{tabular}{|c|c|c|c|c|}
\hline Analyte & Unit & Flag 1 & Flag 2 & Source \\
\hline Acenaphthes:e & $\mu g / L$ & 50 & 100 & EPA Method 8270 \\
\hline Acenaphthylene & $\mu g / L$ & 50 & 100 & EPA Method 8270 \\
\hline Acetone & $\mu g / L$ & 50 & 100 & $*$ \\
\hline Acetonitrile (Methyl cyanide) & $\mu \mathrm{g} / \mathrm{L}$ & 500 & 1,000 & EPA Method 8240 \\
\hline Acetophenone & $\mu \mathrm{g} / \mathrm{L}$ & 50 & 100 & EPA Method 8270 \\
\hline 2-Acetylaminofluorene & $\mu g / L$ & 50 & 100 & EPA Method 8270 \\
\hline Acrolein & $\mu g / L$ & 100 & 200 & EPA Method 8240 \\
\hline Acrylonitrile & $\mu g / L$ & 100 & 200 & EPA Method 8240 \\
\hline Aldrin & $\mu \mathrm{g} / \mathrm{L}$ & 2.5 & 5 & EPA Method 8080 \\
\hline Allyl chloride & $\mu g / L$ & 250 & 500 & EPA Method 8240 \\
\hline Aluminum & $\mu g / L$ & 25 & 50 & Secondary DWS (CFR, 1991c) \\
\hline 4-Aminobiphenyl & $\mu g / L$ & 50 & 100 & EPA Method 8270 \\
\hline Ammonia & $\mu \mathrm{g} / \mathrm{L}$ & 500 & 1,000 & APHA Method 417B \\
\hline Ammonia nitrogen & $\mu g / L$ & 50 & 100 & EPA Method 350.1 \\
\hline Aniline & $\mu g / L$ & 50 & 100 & EPA Method 8270 \\
\hline Anthracene & $\mu \mathrm{g} / \mathrm{L}$ & 50 & 100 & EPA Method 8270 \\
\hline Antimony & $\mu \mathrm{g} / \mathrm{L}$ & 2.5 & 5 & Proposed DWS (EPA, 1990) \\
\hline Aramite & $\mu \mathrm{g} / \mathrm{L}$ & 50 & 100 & EPA Method 8270 \\
\hline Arsenic & $\mu \mathrm{g} / \mathrm{L}$ & 25 & 50 & Final DWS (EPA, 1991b) \\
\hline Barium & $\mu \mathrm{g} / \mathrm{L}$ & 1,000 & 2,000 & Final DWS (EPA, 1991b) \\
\hline Benzene & $\mu \mathrm{g} / \mathrm{L}$ & 2.5 & 5 & Final DWS (EPA, 1991b) \\
\hline alpha-Benzene hexachloride & $\mu \mathrm{g} / \mathrm{L}$ & 2.5 & 5 & EPA Method 8080 \\
\hline beta-Benzene hexachloride & $\mu \mathrm{g} / \mathrm{L}$ & 2.5 & 5 & EPA Method 8080 \\
\hline delta-Benzene hexachloride & $\mu \mathrm{g} / \mathrm{L}$ & 2.5 & 5 & EPA Method 8080 \\
\hline Benzidine & $\mu \mathrm{g} / \mathrm{L}$ & 250 & 500 & EPA Method 8270 \\
\hline Benzo[a]anthracene & $\mu \mathrm{g} / \mathrm{L}$ & 0.05 & 0.1 & Proposed DWS (EPA, 1990) \\
\hline Benzo[b]fluoranthene & $\mu \mathrm{g} / \mathrm{L}$ & 0.1 & 0.2 & Proposed DWS (EPA, 1990) \\
\hline Benzo[k]fluoranthene & $\mu g / L$ & 0.1 & 0.2 & Proposed DWS (EPA, 1990) \\
\hline Benzoic acid & $\mu g / L$ & 250 & 500 & EPA Method 8270 \\
\hline Benzo[g,h,i]perylene & $\mu \mathrm{g} / \mathrm{L}$ & 50 & 100 & EPA Method 8270 \\
\hline Benzo[a]pyrene & $\mu \mathrm{g} / \mathrm{L}$ & 0.1 & 0.2 & Proposed DWS (EPA, 1990) \\
\hline 1,4-Benzoquinone & $\mu \mathrm{g} / \mathrm{L}$ & 50 & 100 & EPA Method 8270 \\
\hline Benzyl alcohol & $\mu \mathrm{g} / \mathrm{L}$ & 100 & 200 & EPA Method 8270 \\
\hline Beryllium & $\mu \mathrm{g} / \mathrm{L}$ & 0.5 & 1 & Proposed DWS (EPA, 1990) \\
\hline Bis(2-chloroethoxy) methane & $\mu \mathrm{g} / \mathrm{L}$ & 50 & 100 & EPA Method 8270 \\
\hline Bis(2-chloroethyl) ether & $\mu \mathrm{g} / \mathrm{L}$ & 50 & 100 & EPA Method 8270 \\
\hline Bis(2-chloroisopropyl) ether & $\mu \mathrm{g} / \mathrm{L}$ & 50 & 100 & EPA Method 8270 \\
\hline Bis(chloromethyl) ether & $\mu \mathrm{g} / \mathrm{L}$ & 50 & 100 & EPA Method 8270 \\
\hline Bromide & $\mu \mathrm{g} / \mathrm{L}$ & 5,000 & 10,000 & EPA Method 300.0 \\
\hline Bromodichloromethane & $\mu \mathrm{g} / \mathrm{L}$ & 50 & 100 & Final DWS† (EPA, 1991b) \\
\hline Bromoform & $\mu \mathrm{g} / \mathrm{L}$ & 50 & 100 & Final DWS† (EPA, 1991b) \\
\hline Bromomethane (Methyl bromide) & $\mu \mathrm{g} / \mathrm{L}$ & 5 & 10 & EPA Method 8240 \\
\hline 4-Bromophenyl phenyl ether & $\mu \mathrm{g} / \mathrm{L}$ & 50 & 100 & EPA Method 8270 \\
\hline 2-sec-Butyl-4,6-dinitrophenol & $\mu \mathrm{g} / \mathrm{L}$ & 3.5 & 7 & Proposed DWS (EPA, 1990) \\
\hline Cadmium & $\mu \mathrm{g} / \mathrm{L}$ & 2.5 & 5 & Final DWS (EPA, 1991b) \\
\hline Carbonate & $\mu \mathrm{g} / \mathrm{L}$ & 500 & 1,000 & EPA Method 310.1 \\
\hline Carbon disulfide & $\mu \mathrm{g} / \mathrm{L}$ & 5 & 10 & EPA Method 8240 \\
\hline Carbon tetrachloride & $\mu \mathrm{g} / \mathrm{L}$ & 2.5 & 5 & Final DWS (EPA, 1991b) \\
\hline Chlordane & $\mu \mathrm{g} / \mathrm{L}$ & 1 & 2 & Final DWS (EPA, 1991b) \\
\hline
\end{tabular}

\footnotetext{
* General Engineering's detection limit and the Flag 2 criterion for acetone, a common laboratory contaminant, are set at $100 \mu \mathrm{g} / \mathrm{L}$.

$\dagger$ Based on the drinking water standard for total trihalomethanes.
} 
Table 2. Flagging Criteria (cont)

\begin{tabular}{|c|c|c|c|c|}
\hline Analyte & Unit & Flag 1 & Flag 2 & Source \\
\hline Chloride & $\mu \mathrm{g} / \mathrm{L}$ & 125,000 & 250,000 & Secondary DWS (EPA, 1991c) \\
\hline 4-Chloroaniline & $\mu \mathrm{g} / \mathrm{L}$ & 50 & 100 & EPA Method 8270 \\
\hline Chlorobenzene & $\mu \mathrm{g} / \mathrm{L}$ & 5 & 10 & EPA Method 8240 \\
\hline Chlorobenzilate & $\mu \mathrm{g} / \mathrm{L}$ & 50 & 100 & EPA Method 8270 \\
\hline para-Chloro-meta-cresol & $\mu \mathrm{g} / \mathrm{L}$ & 50 & 100 & EPA Method 8270 \\
\hline Chloroethane & $\mu \mathrm{g} / \mathrm{L}$ & 5 & 10 & EPA Method 8240 \\
\hline Chloroethene (Vinyl chloride) & $\mu \mathrm{g} / \mathrm{L}$ & 1 & 2 & Final DWS (EPA, 1991b) \\
\hline Chloroethyl vinyl ether & $\mu \mathrm{g} / \mathrm{L}$ & 5 & 10 & EPA Method 8240 \\
\hline 2-Chloroethyl vinyl ether & $\mu \mathrm{g} / \mathrm{L}$ & 5 & 10 & EPA Method 8240 \\
\hline Chloroform & $\mu \mathrm{g} / \mathrm{L}$ & 50 & 100 & Final DWS† (EPA, 1991b) \\
\hline Chloromethane (Methyl chloride) & $\mu g / L$ & 5 & 10 & EPA Method 8240 \\
\hline 2-Chloronaphthalene & $\mu \mathrm{g} / \mathrm{L}$ & 50 & 100 & EPA Method 8240 \\
\hline 2-Chlorophenol & $\mu g / L$ & 50 & 100 & EPA Method 8270 \\
\hline 4-Chlorophenyl phenyl ether & $\mu \mathrm{g} / \mathrm{L}$ & 50 & 100 & EPA Method 8270 \\
\hline Chloroprene & $\mu \mathrm{g} / \mathrm{L}$ & 1,000 & 2,000 & EPA Method 8240 \\
\hline Chromium & $\mu \mathrm{g} / \mathrm{L}$ & 50 & 100 & Final DWS (EPA, 1991b) \\
\hline Chrysene & $\mu g / L$ & 0.1 & 0.2 & Proposed DWS (EPA, 1990) \\
\hline Cobalt & $\mu \mathrm{g} / \mathrm{L}$ & 20 & 40 & EPA Method 6010 \\
\hline Copper & $\mu \mathrm{g} / \mathrm{L}$ & 650 & 1,300 & Final DWS (EPA, 1991b) \\
\hline m-Cresol (3-Methylphenol) & $\mu \mathrm{g} / \mathrm{L}$ & 50 & 100 & EPA Method 8270 \\
\hline o-Cresol (2-Methylphenol) & $\mu \mathrm{g} / \mathrm{L}$ & 50 & 100 & EPA Method 8270 \\
\hline p-Cresol (4-Methylphenol) & $\mu \mathrm{g} / \mathrm{L}$ & 50 & 100 & EPA Method 8270 \\
\hline Cyanide & $\mu \mathrm{g} / \mathrm{L}$ & 100 & 200 & Proposed DWS (EPA, 1990) \\
\hline$p, p^{\prime}-D D D$ & $\mu \mathrm{g} / \mathrm{L}$ & 2.5 & 5 & EPA Method 8080 \\
\hline$p, p^{\prime}-D D E$ & $\mu \mathrm{g} / \mathrm{L}$ & 2.5 & 5 & EPA Method 8080 \\
\hline$p, p^{\prime}-D D T$ & $\mu \mathrm{g} / \mathrm{L}$ & 2.5 & 5 & EPA Method 8080 \\
\hline Diallate & $\mu \mathrm{g} / \mathrm{L}$ & 50 & 100 & EPA Method 8270 \\
\hline Dibenz $[a, h]$ anthracene & $\mu \mathrm{g} / \mathrm{L}$ & 0.15 & 0.3 & Proposed DWS (EPA, 1990) \\
\hline Dibenzofuran & $\mu \mathrm{g} / \mathrm{L}$ & 50 & 100 & EPA Method 8270 \\
\hline Dibromochloromethane & $\mu \mathrm{g} / \mathrm{L}$ & 50 & 100 & Final DWS† (EPA, 1991b) \\
\hline Dibromochloropropane & $\mu g / L$ & 0.1 & 0.2 & Final DWS (EPA, 1991b) \\
\hline 1,2-Dibromo-3-chloropropane & $\mu \mathrm{g} / \mathrm{L}$ & 0.1 & 0.2 & Final DWS (EPA, 1991b) \\
\hline 1,2-Dibromoethane & $\mu \mathrm{g} / \mathrm{L}$ & 100 & 200 & EPA Method 8240 \\
\hline Dibromomethane (Methylene & & & & \\
\hline bromide) & $\mu \mathrm{g} / \mathrm{L}$ & 5 & 10 & EPA Method 8240 \\
\hline 1,2-Dichlorobenzene & $\mu \mathrm{g} / \mathrm{L}$ & 300 & 600 & Final DWS (EPA, 1991b) \\
\hline 1,3-Dichlorobenzene & $\mu \mathrm{g} / \mathrm{L}$ & 50 & 100 & EPA Method 8270 \\
\hline 1,4-Dichlorobenzene & $\mu \mathrm{g} / \mathrm{L}$ & 37.5 & 75 & Final DWS (EPA, 1991b) \\
\hline 3,3'-Dichlorobenzidine & $\mu \mathrm{g} / \mathrm{L}$ & 50 & 100 & EPA Method 8270 \\
\hline trans-1,4-Dichloro-2-butene & $\mu \mathrm{g} / \mathrm{L}$ & 150 & 300 & EPA Method 8240 \\
\hline Dichlorodifluoromethane & $\mu \mathbf{g} / \mathrm{L}$ & 5 & 10 & EPA Method 8240 \\
\hline 1,1-Dichloroethane & $\mu \mathrm{g} / \mathrm{L}$ & 5 & 10 & EPA Method 8240 \\
\hline 1,2-Dichloroethane & $\mu \mathrm{g} / \mathrm{L}$ & 2.5 & 5 & Final DWS (EPA, 1991b) \\
\hline cis-1,2-Dichloroethene & $\mu \mathrm{g} / \mathrm{L}$ & 35 & 70 & Final DWS (EPA, 1991b) \\
\hline 1,1-Dichloroethylene & $\mu \mathrm{g} / \mathrm{L}$ & 3.5 & 7 & Final DWS (EPA, 1991b) \\
\hline 1,2-Dichloroethylene & $\mu \mathrm{g} / \mathrm{L}$ & 25 & 50 & EPA Method 8240 \\
\hline trans-1,2-Dichloroethylene & $\mu \mathrm{g} / \mathrm{L}$ & 50 & 100 & Final DWS (EPA, 1991b) \\
\hline 2,4-Dichlorophenol & $\mu \mathrm{g} / \mathrm{L}$ & 50 & 100 & EPA Method 8270 \\
\hline 2,6-Dichlorophenol & $\mu \mathrm{g} / \mathrm{L}$ & 50 & 100 & EPA Method 8270 \\
\hline 2,4-Dichlorophenoxyacetic acid & $\mu \mathrm{g} / \mathrm{L}$ & 35 & 70 & Final DWS (EPA, 1991b) \\
\hline 1,2-Dichloropropane & $\mu \mathrm{g} / \mathrm{L}$ & 2.5 & 5 & Final DWS (EPA, 1991b) \\
\hline
\end{tabular}

† Based on the drinking water standard for total trihalomethanes. 
Table 2. Flagging Criteria (cont.)

\begin{tabular}{|c|c|c|c|c|}
\hline Analyte & Unit & Flag 1 & Flag 2 & Source \\
\hline cis-1,3-Dichloropropene & $\mu \mathrm{g} / \mathrm{L}$ & 5 & 10 & EPA Method 8240 \\
\hline trans-1,3-Dichloropropene & $\mu \mathrm{g} / \mathrm{L}$ & 5 & 10 & EPA Method 8240 \\
\hline Dieldrin & $\mu \mathrm{g} / \mathrm{L}$ & 2.5 & 5 & EPA Method 8080 \\
\hline Dimethoate & $\mu \mathrm{g} / \mathrm{L}$ & 50 & 100 & EPA Method 8270 \\
\hline p-Dimethylaminoazobenzene & $\mu \mathrm{g} / \mathrm{L}$ & 50 & 100 & EPA Method 8270 \\
\hline p-(Dimethylamino)ethylbenzene & $\mu \mathrm{g} / \mathrm{L}$ & 50 & 100 & EPA Method 8270 \\
\hline 7,12-Dimethylbenz [a]anthracune & $\mu \mathrm{g} / \mathrm{L}$ & 50 & 100 & EPA Method 8270 \\
\hline 3,3'-Dimethylbenzidine & $\mu \mathrm{g} / \mathrm{L}$ & 50 & 100 & EPA Method 8270 \\
\hline a,a-Dimethylphenethylamine & $\mu \mathrm{g} / \mathrm{L}$ & 50 & 100 & EPA Method 8270 \\
\hline 2,4-Dimethyl phenol & $\mu \mathrm{g} / \mathrm{L}$ & 50 & 100 & EPA Method 8270 \\
\hline 1,3-Dinitrobenzene & $\mu \mathrm{g} / \mathrm{L}$ & 50 & 100 & EPA Method 8270 \\
\hline 4,6-Dinitro-ortho-cresol & $\mu \mathrm{g} / \mathrm{L}$ & 250 & 500 & EPA Method 8270 \\
\hline 2,4-Dinitrophenol & $\mu \mathrm{g} / \mathrm{L}$ & 250 & 500 & EPA Method 8270 \\
\hline 2,4-Dinitrotoluene & $\mu \mathrm{g} / \mathrm{L}$ & 50 & 100 & EPA Method 8270 \\
\hline 2,6-Dinitrotoluene & $\mu \mathrm{g} / \mathrm{l}$ & 50 & 100 & EPA Method 8270 \\
\hline 1,4-Dioxane & $\mu \mathrm{g} / \mathrm{L}$ & 50 & 100 & EPA Method 8270 \\
\hline Diphenylamine & $\mu \mathrm{g} / \mathrm{L}$ & 50 & 100 & EPA Method 8270 \\
\hline 1,2-Diphenylhydrazine & $\mu \mathrm{g} / \mathrm{L}$ & 50 & 100 & EPA Method 8270 \\
\hline Dissolved organic carbon & $\mu \mathrm{g} / \mathrm{L}$ & 5,000 & 10,000 & EPA Method 9060 \\
\hline Disulfoton & $\mu \mathrm{g} / \mathrm{L}$ & 50 & 100 & EPA Method 8270 \\
\hline alpha-Endosulfan & $\mu \mathrm{g} / \mathrm{L}$ & 50 & 100 & EPA Method 8270 \\
\hline beta-Endosulfan & $\mu \mathrm{g} / \mathrm{L}$ & 50 & 100 & EPA Method 8270 \\
\hline Endosulfan I & $\mu \mathrm{g} / \mathrm{L}$ & 2.5 & 5 & EPA Method 8080 \\
\hline Endosuifan II & $\mu \mathrm{g} / \mathrm{L}$ & 2.5 & 5 & EPA Method 8080 \\
\hline Endosulfan sulfate & $\mu \mathrm{g} / \mathrm{L}$ & 2.5 & 5 & EPA Method 8080 \\
\hline Endrin & $\mu \mathrm{g} / \mathrm{L}$ & 0.1 & 0.2 & Final DWS (EPA, 1991b) \\
\hline Endrin aldehyde & $\mu \mathrm{g} / \mathrm{L}$ & 2.5 & 5 & EPA Method 8080 \\
\hline Ethylbenzene & $\mu \mathrm{g} / \mathrm{L}$ & 350 & 700 & Final DWS (EPA, 1991b) \\
\hline Ethyl methacrylate & $\mu \mathrm{g} / \mathrm{L}$ & 50 & 100 & EPA Method 8270 \\
\hline Ethyl methanesulfonate & $\mu \mathrm{g} / \mathrm{L}$ & 50 & 100 & EPA Method 8270 \\
\hline Famphur & $\mu \mathrm{g} / \mathrm{L}$ & 50 & 100 & EPA Method 8270 \\
\hline Fluoranthene & $\mu \mathrm{g} / \mathrm{L}$ & 50 & 100 & EPA Method 8270 \\
\hline Fluorene & $\mu \mathrm{g} / \mathrm{L}$ & 50 & 100 & EPA Method 8270 \\
\hline Fluoride & $\mu \mathrm{g} / \mathrm{L}$ & 2,000 & 4,000 & Final DWS (EPA, 1991b) \\
\hline Heptachlor & $\mu \mathrm{g} / \mathrm{L}$ & 0.2 & 0.4 & Final DWS (EPA, 1991b) \\
\hline Heptachlor epoxide & $\mu \mathrm{g} / \mathrm{L}$ & 0.1 & 0.2 & Final DWS (EPA, 1991b) \\
\hline $1,2,3,4,6,7,8-\mathrm{HPCDD}$ & $\mu \mathrm{g} / \mathrm{L}$ & .00325 & .00650 & EPA Method 8280 \\
\hline Heptachlorodibenzo-p-dioxin isomers & $\mu \mathrm{g} / \mathrm{L}$ & .00325 & .00650 & EPA Method $\mathbf{8 2 8 0}$ \\
\hline $1,2,3,4,6,7,8 \cdot \mathrm{HPCDF}$ & $\mu \mathrm{g} / \mathrm{L}$ & .00225 & .00450 & EPA Method 8280 \\
\hline Heptachlorodibenzo-p-furan isomers & $\mu \mathrm{g} / \mathrm{L}$ & .00225 & .00450 & EPA Method 8280 \\
\hline Hexachlorobenzene & $\mu \mathrm{g} / \mathrm{L}$ & 0.5 & 1 & Proposed DWS (EPA, 1990) \\
\hline Hexachlorobutadiene & $\mu \mathrm{g} / \mathrm{L}$ & 50 & 100 & EPA Method 8270 \\
\hline Hexachlorocyclopentadiene & $\mu \mathrm{g} / \mathrm{L}$ & 25 & 50 & Proposed DWS (EPA, 1990) \\
\hline $1,2,3,4,7,8-\mathrm{HXCDD}$ & $\mu \mathrm{g} / \mathrm{L}$ & .00225 & .00450 & EPA Method 8280 \\
\hline Hexachlorodibenzo-p-dioxin isomers & $\mu \mathrm{g} / \mathrm{L}$ & .00225 & .00450 & EPA Method 8280 \\
\hline $1,2,3,4,7,8-\mathrm{HXCDF}$ & $\mu \mathrm{g} / \mathrm{L}$ & .00200 & .00400 & EPA Method 8280 \\
\hline Hexachlorodibenzo-p-furan isomers & $\mu \mathrm{g} / \mathrm{L}$ & .00200 & .00400 & EPA Method 8280 \\
\hline Hexachloroethane & $\mu \mathrm{g} / \mathrm{L}$ & 50 & 100 & EPA Method 8270 \\
\hline Hexachlorophene & $\mu \mathrm{g} / \mathrm{L}$ & 250 & 500 & EPA Method 8270 \\
\hline Hexachloropropene & $\mu \mathrm{g} / \mathrm{L}$ & 50 & 100 & EPA Method 8270 \\
\hline 2-Hexanone & $\mu \mathrm{g} / \mathrm{L}$ & 100 & 200 & EPA Method 8240 \\
\hline Indeno $[1,2,3-c, d]$ pyrene & $\mu \mathrm{g} / \mathrm{L}$ & 50 & 100 & EPA Method 8270 \\
\hline Iodine & $\mu \mathrm{g} / \mathrm{L}$ & 500 & 1,000 & APHA Method 415 \\
\hline Iodomethane (Methyl iodide) & $\mu \mathrm{g} / \mathrm{L}$ & 75 & 150 & EPA Method 8240 \\
\hline
\end{tabular}


FLAGGING CRITERIA

Table 2. Flagging Criteria (cont.)

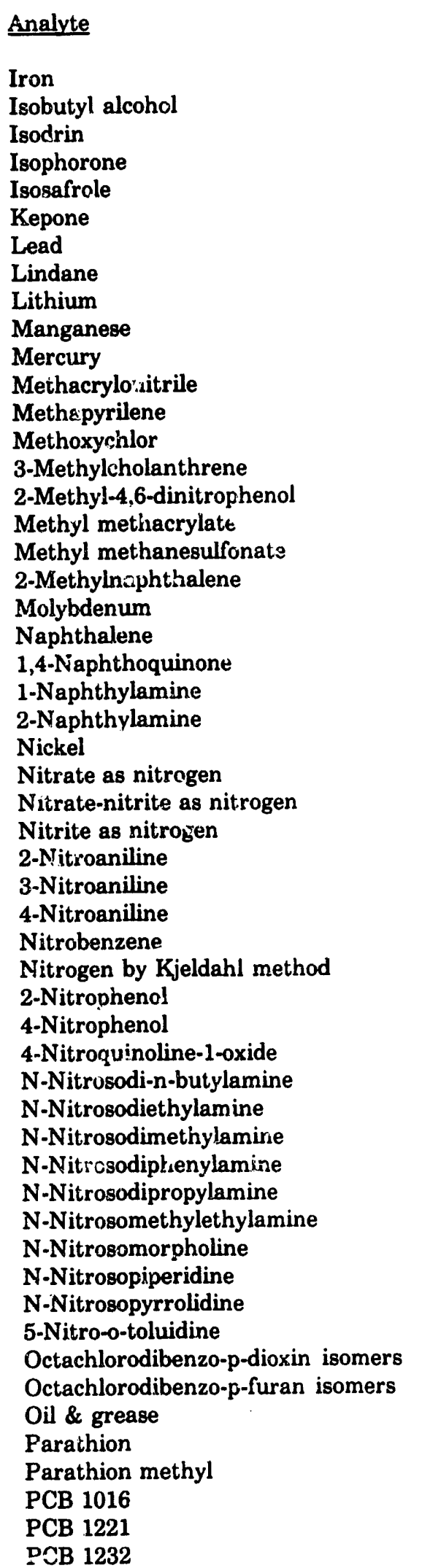

\begin{tabular}{|c|c|c|c|}
\hline Unit & Flag 1 & Flag 2 & Source \\
\hline$\mu \mathrm{g} / \mathrm{L}$ & 150 & 300 & Secondary DWS (EPA, 1991c) \\
\hline$\mu \mathrm{g} / \mathrm{L}$ & 500 & 1,000 & EPA Method 8240 \\
\hline$\mu \mathrm{g} / \mathrm{L}$ & 50 & 100 & EPA Method 8270 \\
\hline$\mu \mathrm{g} / \mathrm{L}$ & 50 & 100 & EPA Method 8270 \\
\hline$\mu \mathrm{g} / \mathrm{L}$ & 50 & 100 & EPA Method 8270 \\
\hline$\mu \mathrm{g} / \mathrm{L}$ & 50 & 100 & EPA Method 8270 \\
\hline$\mu \mathrm{g} / \mathrm{L}$ & 7.5 & 15 & Final DWS (EPA, 1991b) \\
\hline$\mu \mathrm{g} / \mathrm{L}$ & 0.1600 & 9.2000 & Final DWS (EPA, 1991b) \\
\hline$\mu \mathrm{g} / \mathrm{L}$ & 25 & 50 & EPA Method 6010 \\
\hline$\mu \mathrm{g} / \mathrm{L}$ & 25 & 50 & Secondary DWS (EPA, 1991b) \\
\hline$\mu \mathrm{g} / \mathrm{L}$ & 1 & 2 & Final DWS (EPA, 1991b) \\
\hline$\mu \mathrm{g} / \mathrm{L}$ & 250 & 500 & EPA Method 8240 \\
\hline$\mu \mathrm{g} / \mathrm{L}$ & 50 & 100 & EPA Method 8270 \\
\hline$\mu \mathrm{g} / \mathrm{L}$ & 20 & 40 & Final DWS (EPA, 1991b) \\
\hline$\mu \mathrm{g} / \mathrm{L}$ & 50 & 100 & EPA Method 8270 \\
\hline$\mu, \mathrm{g} / \mathrm{L}$ & 250 & 500 & EPA Method 8270 \\
\hline$\mu \mathrm{g} / \mathrm{L}$ & 50 & 100 & EPA Method 8270 \\
\hline$\mu \mathrm{g} / \mathrm{L}$ & 50 & 100 & EPA Method 8270 \\
\hline$\mu \mathrm{g} / \mathrm{L}$ & 50 & 100 & EPA Method 8270 \\
\hline$\mu \mathrm{g} / \mathrm{L}$ & 250 & 500 & EPA Method 6010 \\
\hline$\mu \mathrm{g} / \mathrm{L}$ & 50 & 100 & EPA Method 8270 \\
\hline$\mu g / L$ & 50 & 100 & EPA Method 8270 \\
\hline$\mu \mathrm{g} / \mathrm{L}$ & 50 & 100 & EPA Method 8270 \\
\hline$\mu \mathrm{g} / \mathrm{L}$ & 50 & 100 & EPA Method 8270 \\
\hline$\mu \mathrm{g} / \mathrm{L}$ & 50 & 100 & Proposed DWS (EPA, 1890) \\
\hline$\mu \mathrm{g} / \mathrm{L}$ & 5,000 & 10,000 & Final DWS (EPA, 1991b) \\
\hline$\mu \mathrm{g} / \mathrm{L}$ & 5,000 & 10000 & Final DWS (EPA, 1991b) \\
\hline$\mu \mathrm{g} / \mathrm{L}$ & 500 & 1,000 & Final DWS (EPA, 1991b) \\
\hline$\mu \mathrm{g} / \mathrm{L}$ & 50 & 100 & EPA Method 8270 \\
\hline$\mu \mathrm{g} / \mathrm{L}$ & 50 & 100 & EPA Method 8270 \\
\hline$\mu \mathrm{g} / \mathrm{L}$ & 50 & 100 & EPA Method 8270 \\
\hline$\mu \mathrm{g} / \mathrm{L}$ & 50 & 100 & EPA Method 8270 \\
\hline$\mu \mathrm{g} / \mathrm{L}$ & 500 & 1,000 & EPA Method 351.2 \\
\hline$\mu \mathrm{g} / \mathrm{I}$ & 50 & 100 & EPA Method 8270 \\
\hline$\mu \mathrm{g} / \mathrm{L}$ & 50 & 100 & EPA Method 8270 \\
\hline$\mu \mathrm{g} / \mathrm{L}$ & 50 & 100 & EPA Method 8270 \\
\hline$\mu \mathrm{g} / \mathrm{L}$ & 50 & 100 & EPA Method 8270 \\
\hline$\mu \mathrm{g} / \mathrm{L}$ & 50 & 100 & EPA Method 827? \\
\hline$\mu \mathrm{g} / \mathrm{L}$ & 50 & 100 & EPA Method 8270 \\
\hline$\mu \mathrm{g} / \mathrm{L}$ & 50 & 100 & EPA Method 8270 \\
\hline$\mu \mathrm{g} / \mathrm{L}$ & 50 & 100 & EPA Method 8270 \\
\hline$\mu \mathrm{g} / \mathrm{L}$ & 50 & 100 & EPA Method 8270 \\
\hline$\mu \mathrm{g} / \mathrm{L}$ & 50 & 100 & EPA Mathod 8270 \\
\hline$\mu \mathrm{g} / \mathrm{L}$ & 50 & 100 & EPA Method 8270 \\
\hline$\mu \mathrm{g} / \mathrm{L}$ & 50 & 100 & EPA Method 8270 \\
\hline$\mu \mathrm{g} / \mathrm{L}$ & 50 & 100 & EPA Method 8270 \\
\hline$\mu \mathrm{g} / \mathrm{L}$ & 0.00500 & 0.01000 & EPA Method 8280 \\
\hline$\mu \mathrm{g} / \mathrm{L}$ & 0.00500 & 0.01000 & EPA Method 8280 \\
\hline$\mu \mathrm{g} / \mathrm{L}$ & 5,000 & 10,000 & EPA Method 413.1 \\
\hline$\mu \mathrm{g} / \mathrm{L}$ & 2.500 & 5.000 & EPA Method 8080 \\
\hline$\mu \mathrm{g} / \mathrm{L}$ & 2.500 & 5.000 & EPA Method 8080 \\
\hline$\mu \mathrm{g} / \mathrm{L}$ & 0.25 & 0.50 & Final DWS (EPA, 1991b) \\
\hline$\mu \mathrm{g} / \mathrm{L}$ & 0.25 & 0.50 & Final DWS (EPA, 1991b) \\
\hline$\mu \mathrm{g} / \mathrm{L}$ & 0.25 & 0.50 & Final DWS (EPA, 1991b) \\
\hline
\end{tabular}


Table 2. Flagging Criteria (cont.)

\begin{tabular}{|c|c|c|c|c|}
\hline Analyte & Unit & Flag 1 & Flag 2 & Source \\
\hline PCB 1242 & $\mu \mathrm{g} / \mathrm{L}$ & 0.25 & 0.50 & Final DWS (EPA, 1991b) \\
\hline PCB 1248 & $\mu \mathrm{g} / \mathrm{L}$ & 0.25 & 0.50 & Final DWS (EPA, 1991b) \\
\hline PCB 1254 & $\mu \mathrm{g} / \mathrm{L}$ & 0.25 & 0.50 & Final DWS (EPA, 1991b) \\
\hline PCB 1260 & $\mu \mathrm{g} / \mathrm{L}$ & 0.25 & 0.50 & Final DWS (EPA, 1991b) \\
\hline PCB 1262 & $\mu \mathrm{g} / \mathrm{L}$ & 0.25 & 0.50 & Final DWS (EPA, 1991b) \\
\hline Pentachlorobenzene & $\mu \mathrm{g} / \mathrm{L}$ & 50 & 100 & EPA Method 8270 \\
\hline $1,2,3,7,8-P C D D$ & $\mu \mathrm{g} / \mathrm{L}$ & 0.00275 & 0.00550 & EPA Method 8280 \\
\hline Pentachlorodibenzo-p-dioxin isomers & $\mu \mathrm{g} / \mathrm{L}$ & 0.00275 & 0.00550 & EPA Method 8280 \\
\hline 1,2,3,7,8-PCDF & $\mu \mathrm{g} / \mathrm{L}$ & 0.00275 & 0.00550 & EPA Method 8280 \\
\hline Pentachlorodibenzo-p-furan isomers & $\mu \mathrm{g} / \mathrm{L}$ & 0.00275 & 0.00550 & EPA Method 8280 \\
\hline Pentachloroethane & $\mu g / L$ & 50 & 100 & EPA Method 8270 \\
\hline Pentachloronitrobenzene & $\mu \mathrm{g} / \mathrm{L}$ & 50 & 100 & EPA Method 8270 \\
\hline Pentachlorophenol & $\mu \mathrm{g} / \mathrm{L}$ & 0.5 & 1 & Final DWS (EPA, 1991b) \\
\hline $\mathrm{pH}$ & $\mathrm{pH}$ & 8 & 10 & Set by EPD/EMS* \\
\hline $\mathrm{pH}$ & $\mathrm{pH}$ & 4 & 3 & Set by EPD/EMS* \\
\hline Phenacetin & $\mu g / L$ & 50 & 100 & EPA Method 8270 \\
\hline Phenanthrene & $\mu \mathrm{g} / \mathrm{L}$ & 50 & 100 & EPA Method 8270 \\
\hline Phenol & $\mu \mathrm{g} / \mathrm{L}$ & 50 & 100 & EPA Method 8270 \\
\hline Phenols & $\mu \mathrm{g} / \mathrm{L}$ & 25 & 50 & EPA Method 420.1 \\
\hline p-Phenylenediamine & $\mu \mathrm{g} / \mathrm{L}$ & 50 & 100 & EPA Method 8270 \\
\hline Phorate & $\mu \mathrm{g} / \mathrm{L}$ & 2.5 & 5 & EPA Method 8080 \\
\hline 2-Picoline & $\mu \mathrm{g} / \mathrm{L}$ & 50 & 100 & EPA Method 8270 \\
\hline Pronamid & $\mu \mathrm{g} / \mathrm{L}$ & 50 & 100 & EPA Method 8270 \\
\hline Propionitrile & $\mu \mathrm{g} / \mathrm{L}$ & 1,000 & 2,000 & EPA Method 8240 \\
\hline Pyrene & $\mu \mathrm{g} / \mathrm{L}$ & 50 & 100 & EPA Method 8270 \\
\hline Pyridine & $\mu \mathrm{g} / \mathrm{L}$ & 50 & 100. & EPA Method 8270 \\
\hline Safrole & $\mu \mathrm{g} / \mathrm{L}$ & 50 & 100 & EPA Method 8270 \\
\hline Selenium & $\mu \mathrm{g} / \mathrm{L}$ & 25 & 50 & Final DWS (EPA, 1991b) \\
\hline Silver & $\mu \mathrm{g} / \mathrm{L}$ & 25 & 50 & Final DWS (EPA, 1991b) \\
\hline Specific condi tance & $\mu \mathrm{S} / \mathrm{cm}$ & 250 & 500 & Set by EPD/EMS* \\
\hline Styrene & $\mu \mathrm{g} / \mathrm{L}$ & 50 & 100 & Final DWS (EPA, 1991b) \\
\hline Sulfate & $\mu \mathrm{g} / \mathrm{L}$ & 200,000 & 400,000 & Proposed DWS (EPA, 1990) \\
\hline Sulfide & $\mu \mathrm{g} / \mathrm{L}$ & 5,000 & 10,000 & EPA Method 9030 \\
\hline Sulfotepp & $\mu \mathrm{g} / \mathrm{L}$ & 50 & 100 & EPA Method 8270 \\
\hline 1,2,4,5-Tetrachlorobenzene & $\mu g / L$ & 50 & 100 & EPA Method 8270 \\
\hline $2,3,7,8-\mathrm{TCDD}$ & $\mu g / L$ & 0.00225 & 0.00450 & EPA Method 8280 \\
\hline $2,3,7,8-\mathrm{TCDF}$ & $\mu \mathrm{g} / \mathrm{L}$ & 0.00200 & 0.00400 & EPA Method 828C \\
\hline Tetrachlorodibenzo-p-dioxin isomers & $\mu \mathrm{g} / \mathrm{L}$ & 0.00225 & 0.00450 & EPA Method 8280 \\
\hline Tetrachlorodibenzo-p-furan isomers & $\mu \mathrm{g} / \mathrm{L}$ & 0.00200 & 0.00400 & EPA Method 8280 \\
\hline 1,1,1,2-Tetrachloroethane & $\mu \mathrm{g} / \mathrm{L}$ & 5 & 10 & EPA Method 8240 \\
\hline i,1,2,2-Tetrachloroethane & $\mu \mathrm{g} / \mathrm{L}$ & 5 & 10 & EPA Method 8240 \\
\hline Tetrachloroethylene & $\mu \mathrm{g} / \mathrm{L}$ & 2.5 & 5 & Final DWS (EPA, 1991b) \\
\hline 2,3,4,6-Tetrachlorophenoi & $\mu \mathrm{g} / \mathrm{L}$ & 50 & 100 & EPA Method 8270 \\
\hline Tetraethyl dithiopyrophosphate & $\mu \mathrm{g} / \mathrm{L}$ & 50 & 100 & EPA Method 8270 \\
\hline Thallium & $\mu \mathrm{g} / \mathrm{L}$ & 0.5 & 1 & Proposed DWS (EPA, 1990) \\
\hline Thionazin & $\mu \mathrm{g} / \mathrm{L}$ & 50 & 100 & EPA Method 8270 \\
\hline Tin & $\mu \mathrm{g} / \mathrm{L}$ & 10 & 20 & EPA Method 282.2 \\
\hline Toluene & $\mu \mathrm{g} / \mathrm{L}$ & 500 & 1,000 & Final DWS (EPA, 1991b) \\
\hline o-Toluidine & $\mu \mathrm{g} / \mathrm{L}$ & 50 & 100 & EPA Method 8270 \\
\hline Total carbon & $\mu \mathrm{g} / \mathrm{L}$ & 5,000 & $1 \mathrm{C}, 000$ & EPA Method 9060 \\
\hline Total hydrocarbons & $\mu \mathrm{g} / \mathrm{L}$ & 5,000 & 10,000 & EPA Method 418.1 \\
\hline
\end{tabular}

* Will no. trigger scheduling of samples. 
Table 2. Flagging Criteria (cont.)

Analyte

Total inorganic carbon

Total organic carbon

Total organic halogens

Total organic nitrogen

Total petroleum hydrocarbons

Total silica

Toxaphene

2,4,5-T

2,4,5-TP (Silvex)

Tributyl phosphate

1,2,4-Trichlorobenzene

1,1,1-Trichloroethane

1,1,2-Trichloroethane

Trichloroethylene

Trichlorofluoromethane

2,4,5-Trichlorophenol

2,4,6-Trichlorophenol

1,2,3-Trichloropropane

0,0,0-Triethyl phosphorothioate

1,3,5-Trinitrobenzene

Uranium

Vanadium

Vinyl acetate

Xylenes

Zinc

Americium-241

Americium-243

Antimony-125

Barium-140

Beryllium-7

Carbon-14

Cerium-141

Cerium-144

Cesium-134

Cesium-137

Chromium-51

Cobalt-57

Cobalt-58

Cobalt-60

Curium-242

Curium-243

Curium-244

Curium-246

Europium-154

Europium-155

Gross alpha

Iodine-129

Iodine-131

Iron-55

Iron-59

\begin{tabular}{|c|c|c|}
\hline Unit & Flag 1 & Flag 2 \\
\hline$\mu \mathrm{g} / \mathrm{L}$ & 5,000 & 10,000 \\
\hline$\mu \mathrm{g} / \mathrm{L}$ & 5,000 & 10,000 \\
\hline$\mu \mathrm{g} / \mathrm{L}$ & 25 & 50 \\
\hline$\mu \mathrm{g} / \mathrm{L}$ & 500 & 1,000 \\
\hline$\mu \mathrm{g} / \mathrm{L}$ & 5,000 & 10,000 \\
\hline$\mu \mathrm{g} / \mathrm{L}$ & 500 & 1,000 \\
\hline$\mu \mathrm{g} / \mathrm{L}$ & 1.5 & 3 \\
\hline$\mu \mathrm{g} / \mathrm{L}$ & 2.5 & 5 \\
\hline$\mu \mathrm{g} / \mathrm{L}$ & 25 & 50 \\
\hline$\mu \mathrm{g} / \mathrm{L}$ & 50 & 100 \\
\hline$\mu \mathrm{g} / \mathrm{L}$ & 4.5 & 9 \\
\hline$\mu \mathrm{g} / \mathrm{L}$ & 100 & 200 \\
\hline$\mu \mathrm{g} / \mathrm{L}$ & 2.5 & 5 \\
\hline$\mu \mathrm{g} / \mathrm{L}$ & 2.5 & 5 \\
\hline$\mu \mathrm{g} / \mathrm{L}$ & 5 & 10 \\
\hline$\mu \mathrm{g} / \mathrm{L}$ & 50 & 100 \\
\hline$\mu \mathrm{g} / \mathrm{L}$ & 50 & 100 \\
\hline$\mu \mathrm{g} / \mathrm{L}$ & 5 & 10 \\
\hline$\mu \mathrm{g} / \mathrm{L}$ & 50 & 100 \\
\hline$\mu \mathrm{g} / \mathrm{L}$ & 50 & 100 \\
\hline$\mu \mathrm{g} / \mathrm{L}$ & 10 & 20 \\
\hline$\mu \mathrm{g} / \mathrm{L}$ & 50 & 100 \\
\hline$\mu \mathrm{g} / \mathrm{L}$ & 5 & 10 \\
\hline$\mu \mathrm{g} / \mathrm{L}$ & 5,000 & 10,000 \\
\hline$\mu \mathrm{g} / \mathrm{L}$ & 2,500 & 5,000 \\
\hline$\mu \mathrm{Ci} / \mathrm{mL}$ & $3.17 \mathrm{E}-09$ & $6.34 E-09$ \\
\hline$\mu \mathrm{Ci} / \mathrm{mL}$ & $3.19 E-09$ & $6.37 \mathrm{E}-09$ \\
\hline$\mu \mathrm{Ci} / \mathrm{mL}$ & $1.5 E-07$ & $3 E-07$ \\
\hline$\mu \mathrm{Ci} / \mathrm{mL}$ & $4.5 E-08$ & $9 E-08$ \\
\hline$\mu \mathrm{Ci} / \mathrm{mL}$ & $3 E-06$ & $6 E-06$ \\
\hline$\mu \mathrm{Ci} / \mathrm{mL}$ & $1 E-06$ & $2 E-06$ \\
\hline$\mu \mathrm{Ci} / \mathrm{m} \mathrm{L}$ & $1.5 E-07$ & $3 E-07$ \\
\hline$\mu \mathrm{Ci} / \mathrm{mL}$ & $1.31 \mathrm{E}-07$ & $2.61 \mathrm{E}-07$ \\
\hline$\mu \mathrm{Ci} / \mathrm{mL}$ & $4.07 E-08$ & $8.13 E-08$ \\
\hline$\mu \mathrm{Ci} / \mathrm{mL}$ & $1 E-07$ & $2 E-07$ \\
\hline$\mu \mathrm{Ci} / \mathrm{mL}$ & $3 E-06$ & $6 \mathrm{E}-06$ \\
\hline$\mu \mathrm{Ci} / \mathrm{mL}$ & $5 E-07$ & $1 E-06$ \\
\hline$\mu \mathrm{Ci} / \mathrm{mL}$ & $4.5 E-06$ & $9 E-06$ \\
\hline$\mu \mathrm{Ci} / \mathrm{mL}$ & $5 E-08$ & $1 \mathrm{E}-07$ \\
\hline$\mu \mathrm{Ci} / \mathrm{mL}$ & $6.65 E-08$ & $1.33 E-07$ \\
\hline$\mu \mathrm{Ci} / \mathrm{mL}$ & $4.15 \mathrm{E}-09$ & $8.3 E-09$ \\
\hline$\mu \mathrm{Ci} / \mathrm{mL}$ & $4.92 \mathrm{E}-09$ & $9.84 \mathrm{E}-09$ \\
\hline$\mu \mathrm{Ci} / \mathrm{mL}$ & $3.14 \mathrm{E}-09$ & $6.27 \mathrm{E}-0.9$ \\
\hline$\mu \mathrm{Ci} / \mathrm{mL}$ & $1 E-07$ & $2 \mathrm{E}-07$ \\
\hline$\mu \mathrm{Ci} / \mathrm{mL}$ & $3 E-07$ & $6 \mathrm{E}-07$ \\
\hline$\mu \mathrm{Ci} / \mathrm{mL}$ & $7.5 E-09$ & $1.5 \mathrm{E}-08$ \\
\hline$\mu \mathrm{Ci} / \mathrm{mL}$ & $5 E-10$ & $1 E-09$ \\
\hline$\mu \mathrm{Ci} / \mathrm{mL}$ & $1.5 \mathrm{E}-09$ & $3 E-09$ \\
\hline$\mu \mathrm{Ci} / \mathrm{mL}$ & $1 E-06$ & $2 E-06$ \\
\hline$\mu \mathrm{Ci} / \mathrm{mL}$ & $1 E-07$ & $2 E-07$ \\
\hline
\end{tabular}

Source

EPA Method 9060

EPA Method 9060

EPA Method 9020

APHA Method 420

EPA Method 418.1

EPA Method 6010

Final DWS (EPA, 1991b)

EPA Method 8150

Final DWS (EPA, 1991b)

EPA Method 8270

Proposed DWS (EPA, 1990)

Final DWS (EPA, 1991b)

Proposed DWS (EPA, 1990)

Final DWS (EPA, 1991b)

EPA Method 8240

EPA Method 8270

EPA Methol 8270

EPA Method 8240

EPA Method 8270

EPA Method 8270

Proposed DWS (EPA, 1991d)

EPA Method 6010

EPA Method 8240

Final DWS (EPA, 1991b)

Secondary DWS (EPA, 1991b)

Proposed DWS (EPA, 1991d)

Proposed DWS (EPA, 1991d)

Final DWS (EPA, 1977)

Final DWS (EPA, 1977)

Final DWS (EPA, 1977)

Final DWS (EPA, 1977)

Final DWS (EPA, 1977)

Proposed DWS (EPA, 1991d)

Proposed DWS (EPA, 1991d)*

Final DWS (EPA, 1977)

Final DWS (EPA, 1977)

Final DWS (EPA, 1977)

Final DWS (EPA, 1977)

Final DWS (EPA, 1977)

Proposed DWS (EPA, 1991d)

Proposed DWS (EPA, 1991d)

Proposed DWS (EPA, 1991d)

Proposed DWS (EPA, 1991d)

Final DWS (EPA, 1977)

Final DWS (EPA, 1977)

Final DWS (EPA, 1991b)

Final DWS (EPA, 1977)

Final DWS (EPA, 1977)

Final DWS (EPA, 1977)

Final DWS (EPA, 1977) * EPD/EMS set these flagging criteria using the 1991 proposed DWS because the final DWS in 1977 may have been
in error. 
Table 2. Flagging Criteria (cont.)

\begin{tabular}{|c|c|c|c|c|}
\hline Analyte & Unit & Flag 1 & Flag 2 & Source \\
\hline Lanthanum-140 & $\mu \mathrm{Ci} / \mathrm{mL}$ & $3 E-08$ & $6 \mathrm{E}-08$ & Final DWS (EPA, 1977) \\
\hline Manganese-54 & $\mu \mathrm{Ci} / \mathrm{mL}$ & $1.5 E-07$ & $3 E-07$ & Final DWS (EPA, 1977) \\
\hline Neptunium-237 & $\mu \mathrm{Ci} / \mathrm{mL}$ & $3.53 \mathrm{E}-09$ & $7.06 \mathrm{E}-09$ & Proposed DWS (EPA, 1991d) \\
\hline Nickel-59 & $\mu \mathrm{Ci} / \mathrm{mL}$ & $1.5 \mathrm{E}-07$ & $3 E-07$ & Final DWS (EPA, 1977) \\
\hline Nickel 63 & $\mu \mathrm{Ci} / \mathrm{mL}$ & $2.5 E-08$ & $5 E-08$ & Final DWS (EPA, 1977) \\
\hline Niobiu:n-95 & $\mu \mathrm{Ci} / \mathrm{mL}$ & $1.5 \mathrm{E}-07$ & $3 E-07$ & Final DWS (EPA, 1977) \\
\hline Nonvolatile beta & $\mu \mathrm{Ci} / \mathrm{mL}$ & $2.5 E-08$ & $5 E-08$ & Proposed DWS (EPA, 1986a) \\
\hline Plutonium-238 & $\mu \mathrm{Ci} / \mathrm{mL}$ & $3.51 \mathrm{E}-09$ & $7.02 E-09$ & Proposed DWS (EPA, 1991d) \\
\hline Plutonium-239 & $\mu \mathrm{Ci} / \mathrm{mL}$ & $3.11 \mathrm{E}-08$ & $6.21 \mathrm{E}-08$ & Proposed DWS (EPA, 1991d) \\
\hline Plutonium-239/240 & $\mu \mathrm{Ci} / \mathrm{mL}$ & $3.11 \mathrm{E}-08$ & $6.21 \mathrm{E}-08$ & Proposed DWS (EPA, 1991d)* \\
\hline Plutonium-240 & $\mu \mathrm{Ci} / \mathrm{mL}$ & $3.11 \mathrm{E}-08$ & $6.22 \mathrm{E}-08$ & Proposed DWS (EPA, 1991d) \\
\hline Plutonium-241 & $\mu \mathrm{Ci} / \mathrm{mL}$ & $3.13 E-08$ & $6.26 \mathrm{E}-08$ & Proposed DWS (EPA, 1991d) \\
\hline Plutonium-242 & $\mu \mathrm{Ci} / \mathrm{mL}$ & $3.27 \mathrm{E}-08$ & $6.54 \mathrm{E}-08$ & Proposed DWS (EPA, 1991d) \\
\hline Potassium-40 & $\mu \mathrm{Ci} / \mathrm{mL}$ & $1.5 \mathrm{E}-07$ & $3 E-07$ & Proposed DWS (EPA, 1986a) \\
\hline Radium-226 & $\mu \mathrm{Ci} / \mathrm{mL}$ & $7.85 \mathrm{E}-09$ & $1.57 \mathrm{E}-08$ & Proposed DWS (EPA, 1991d) \\
\hline Radium-228 & $\mu \mathrm{Ci} / \mathrm{mL}$ & $3.93 \mathrm{E}-09$ & $7.85 \mathrm{E}-09$ & Proposed DWS (EPA, 1991d) \\
\hline Radon-222 & $\mu \mathrm{Ci} / \mathrm{mL}$ & $1.5 \mathrm{E}-07$ & $3 \mathrm{E}-07$ & Proposed DWS (EPA, 1991d) \\
\hline Ruthenium-103 & $\mu \mathrm{Ci} / \mathrm{mL}$ & $1 E-07$ & $2 E-07$ & Final DWS (EPA, 1977) \\
\hline Ruthenium-106 & $\mu \mathrm{Ci} / \mathrm{mL}$ & $1.5 E-08$ & $3 E-08$ & Final DWS (EPA, 1977) \\
\hline Sodium-22 & $\mu \mathrm{Ci} / \mathrm{mL}$ & $2.33 \mathrm{E}-07$ & $4.66 \mathrm{E}-07$ & Proposed DWS (EPA, 1991d) \\
\hline Strontium-89 & $\mu \mathrm{Ci} / \mathrm{mL}$ & $1 E-08$ & $2 E-08$ & Final DWS (EPA, 1977) \\
\hline Strontium-89/90 & $\mu \mathrm{Ci} / \mathrm{mL}$ & $4 E-09$ & $8 E-09$ & Final DWS (EPA, 1991b)* \\
\hline Strontium-90 & $\mu \mathrm{Ci} / \mathrm{mL}$ & $4 E-09$ & $8 \mathrm{E}-09$ & Final DWS (EPA, 1991b) \\
\hline Technetium-99 & $\mu \mathrm{Ci} / \mathrm{mL}$ & $4.5 \mathrm{E}-07$ & $9 E-07$ & Final DWS (EPA, 1977) \\
\hline Thorium-228 & $\mu \mathrm{Ci} / \mathrm{mL}$ & $6.25 \mathrm{E}-08$ & $1.25 \mathrm{E}-07$ & Proposed DWS (EPA, 1991d) \\
\hline Thorium-230 & $\mu \mathrm{Ci} / \mathrm{mL}$ & $3.96 \mathrm{E}-08$ & $7.92 \mathrm{E}-08$ & Proposed DWS (EPA, 1991d) \\
\hline Thorium-232 & $\mu \mathrm{Ci} / \mathrm{mL}$ & $4.4 \mathrm{E}-08$ & $8.8 E-08$ & Proposed DWS (EPA, 1991d) \\
\hline Thorium-234 & $\mu \mathrm{Ci} / \mathrm{mL}$ & $2 E-07$ & $4.01 E-07$ & Proposed DWS (EPA, 1991d) \\
\hline $\operatorname{Tin}-113$ & $\mu \mathrm{Ci} / \mathrm{mL}$ & $1.5 \mathrm{E}-07$ & $3 \mathrm{E}-07$ & Final DWS (EPA, 1977) \\
\hline $\begin{array}{l}\text { Total alpha-emitting radium } \\
\text { (radium-223, }-224 \text {, and }-226 \text { ) }\end{array}$ & $\mu \mathrm{Ci} / \mathrm{mL}$ & $2.5 \mathrm{E}-09$ & $5 E-09$ & $\begin{array}{l}\text { Final DWS for radium-226 plus } \\
-228 \text { (EPA, 1991b) }\end{array}$ \\
\hline Tritium & $\mu \mathrm{Ci} / \mathrm{mL}$ & $1 E-05$ & $2 E-05$ & Final DWS (EPA, 1991b) \\
\hline Uranium alpha activity & $\mu \mathrm{Ci} / \mathrm{mL}$ & $1.5 \mathrm{E}-08$ & $3 E-08$ & Proposed DWS (EPA, 1991d) \\
\hline Uranium-233/234 & $\mu \mathrm{Ci} / \mathrm{mL}$ & $6.9 E-09$ & $1.38 \mathrm{E}-08$ & Proposed DWS (EPA, 1991d)* \\
\hline Uranium-234 & $\mu \mathrm{Ci} / \mathrm{mL}$ & $6.95 \mathrm{E}-09$ & $1.39 E-08$ & Proposed DWS (EPA, 1991d) \\
\hline Uranium-235 & $\mu \mathrm{Ci} / \mathrm{mL}$ & $7.25 \mathrm{E}-09$ & $1.45 \mathrm{E}-08$ & Proposed DWS (EPA, 1991d) \\
\hline Uranium-238 & $\mu \mathrm{Ci} / \mathrm{mL}$ & $7.3 E-09$ & $1.46 \mathrm{E}-08$ & Proposed DWS (EPA, 1991d) \\
\hline Zinc-65 & $\mu \mathrm{Ci} / \mathrm{mL}$ & $1.5 \mathrm{E}-07$ & $3 E-07$ & Final DWS (EPA, 1977) \\
\hline Zirconium-95 & $\mu \mathrm{Ci} / \mathrm{mL}$ & $1 E-07$ & $2 E-07$ & Final DWS (EPA, 1977) \\
\hline Zirconium/Niobium-95 & $\mu \mathrm{Ci} / \mathrm{mL}$ & $1 E-07$ & $2 E-07$ & Final DWS (EPA, 1977)* \\
\hline
\end{tabular}

* When radionuclide analyses are combined, the lower DWS of the two isotopes is used for flagging. 


\section{SAMPLE SCHEDULING}

Scheduling of sampling and analyses for the SRS Groundwater Monitoring Program conducted by EPD/EMS is determined by several factors. Comprehensive analyses (see Table 4) are scheduled on a regular basis. Additional scheduling is based on previous flagging levels, regulatory requirements, and special requests that fall within the scope of the Groundwater Monitoring Program. All this information was used to generate The Savannah River Site's Groundwater Monitoring Program 1992 Sampling Schedule.

A breakdown by laboratory of the total number of analyses performed for third quarter 1992 is shown in Table 3.

Table 3. Number of Analyses Performed During Third Quarter 1992

\section{Laboratory}

Clemson Technical Center, Inc.

Environmental Physics, Inc.

EPD/EMS Laboratory

General Engineering Laboratories

Spencer Testing Services, Inc.

Teledyne Isotopes

TMA/Eberline

Roy F. Weston, Inc.

\section{COMPREHENSIVE ANALYSES}

New wells are scheduled initially for four quarters of comprehensive analyses, except that the herbicide/pesticide suite is scheduled only during the first of the four quarters. Comprehensive analyses include indicator parameters, groundwater quality characteristics, and some drinking water characteristics. After the initial four quarters of analyses for new wells, comprehensive analyses including herbicides/pesticides are scheduled once every two years. Wells sampled exclusively for radionuclide analyses are not included in these biennial comprehensive analyses.

\section{Table 4. Comprehensive-Analyses Constituents}

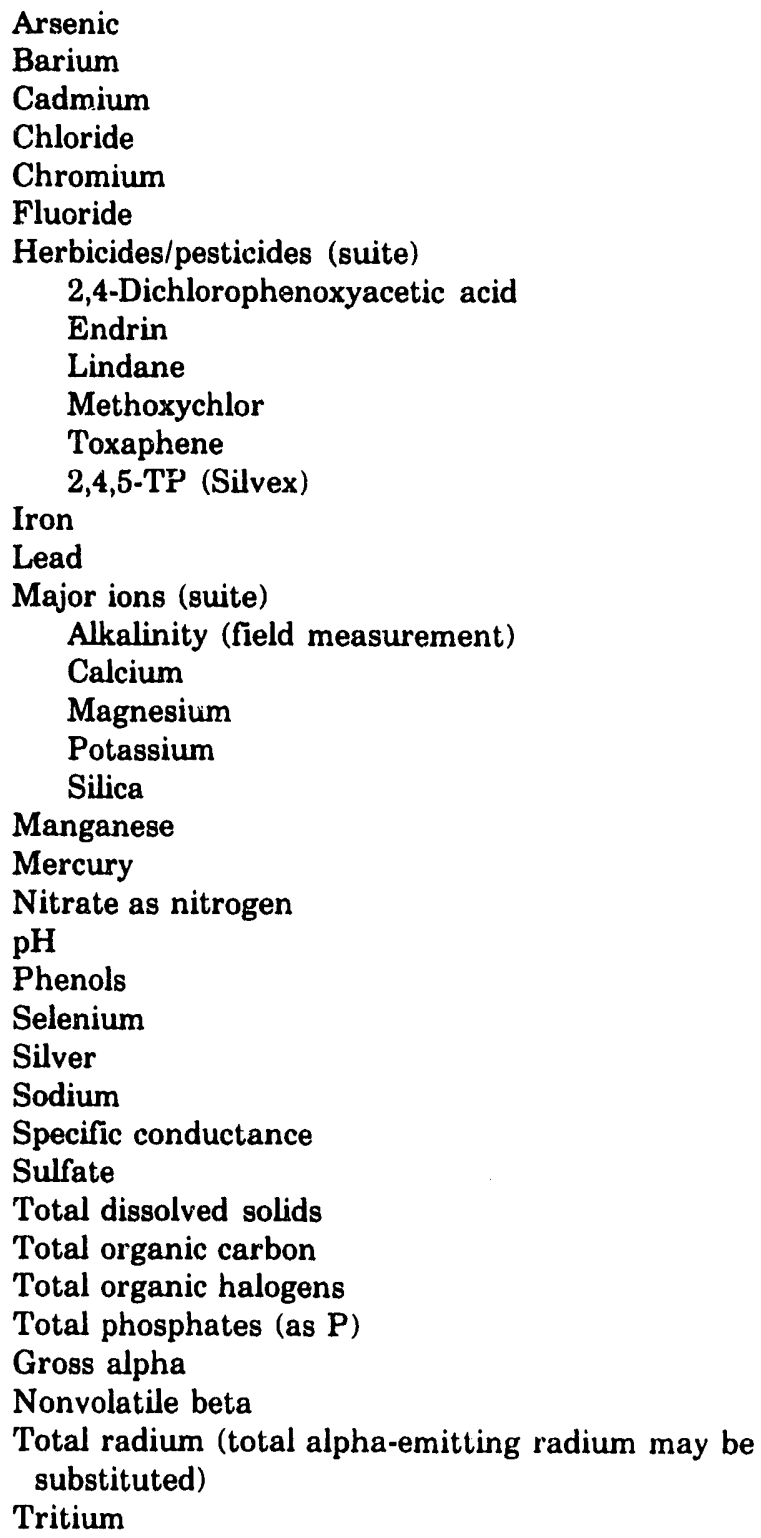




\section{Scheduling Based on Flagging Levels}

Beginning first quarter 1992, only the flagging criteria for comprehensive and herbicide/pesticide analyses are used to trigger scheduling. Wells are grouped for scheduling by the monitoring site or by the investigation for which they are sampled. Specific criteria for Flag 1 and Flag 2 designations are found in the Flagging Criteria section of this report.

Constituents classified as Flag 0 in each well series are scheduled for analyses only by custodian request or as part of the biennial comprehensive analysis program. If an analytical result for a constituent of comprehensive analyses in any well exceeds Flag 1, all wells in the same scheduling series are sampled and analyzed for that constituent once a year. If a constituent falls below Flag 1 for three consecutive sampling episodes, the individual well's lag is reduced from Flag 1 status to Flag 0 status and the flagging-based sampling ceases.

If an analytical result for a comprehensiveanalyses constituent exceeds Flag 2, all wells in the same scheduling series are sampled and analyzed for that constituent twice a year. If a constituent falls below Flag 2 for three consecutive sampling episodes, the individual well's flag is reduced from Flag 2 status to Flag 1 or Flag 0 status, depending on the results, and the well is scheduled according to the lower flag.

If a comprehensive-analyses constituent has ever been flagged in a well series, it is automatically flagged for all new wells of that series. For removal from a new well, a constituent's flag must follow the rules referred to earlier.

The following constituents, although included in comprehensive analyses, do not receive flaggingbased scheduling:

- Two indicator constituents, specific conductance and $\mathrm{pH}$, have flagging criteria but do not trigger the scheduling mechanism.

- No flags are set for the following indicator parameters and major cations: sodium, total dissolved solids, potassium, calcium, magnesium, silica, total phosphates (as P), and alkalinity (a field measurement).

When one of the six constituents of the herbicide/pesticide suite of comprehensives is flagged, the entire suite is flagged for analyses.

\section{GCMS VOA ANALYSES}

Twice a year all total organic halogens (TOH) are reviewed. GCMS VOA analysis is scheduled once for individual wells that have had two results for TOH greater than $10 \mu \mathrm{g} / \mathrm{L}$ (excluding the first $\mathrm{TOH}$ analysis) and have never received GCMS VOA analysis.

\section{SAMPLING REQUESTS}

Many analyses are scheduled at the request of various SRS groups. The person or group requesting the analyses must submit a formal sampling request form to EPD/EMS. If the request is within the scope of the groundwater monitoring program, and if provision for the analyses has been made in the current laboratory contract, the analyses are added to the sampling schedule. Likewise, if a sampling request needs to be deleted, the originator of the request must submit a deletion form.

\section{Regulatory Requirements}

All regulatory sampling requirements, such as those for the Resource Conservation and Recovery Act (RCRA), are scheduled by request.

\section{PURGE-WATER CONTAINMENT PROGRAM}

Beginning in 1991, a purge-water containment program was partially implemented to containerize and properly dispose of the water purged from certain wells before sampling. However, pending full implementation of this program, the following wells that had been scheduled for analyses as part of the groundwater monitoring program during third quarter were not sampled: 


$\begin{array}{ll}\text { BGO 26A } & \text { LFW } 7 \\ \text { BGO 37C } & \text { P 28TC } \\ \text { CRP 1 } & \text { TBG } 3 \\ \text { CRP 3 } & \text { TBG } 4 \\ \text { CSB 2A } & \text { TBG 5 } \\ \text { CSB 6A } & \text { TBG } 6\end{array}$

Only water level measurements were taken from the above wells. 


\section{NOTES}




\section{FIELD NOTES}

Sample collection and field data measurements were performed by EPD/EMS personnel and Ge-Hy Environmental Sampling of New Ellenton, SC.

Each sampler maintained a field notebook. These notebooks are located in the third quarter 1992 section of the EPD/EMS Groundwater Monitoring Library. Field measurements may include alkalinity, $\mathrm{pH}$, temperature, specific conductance, air temperature, depth to the water prior to pumping, and volume of water purged prior to sampling.

All well visitations were routine during third quarter 1992 except as indicated in Table 5. The samplers' observations about water samples, well conditions, and any special collection methods are noted in the table. All wells were pumped except for those from the following series, which were bailed: the F series; the FAC series except FAC 4; the FCA series except FCA 19D; the H series; the SSS series except SSS 20. The following individual wells also were bailed, although the other wells in the series were pumped: BG 121; CSD 1D; IDP 3D and 4; IDQ 1; K 301P; MSB 15C, 16C, 17C, $44 \mathrm{C}$, and $46 \mathrm{C}$; SCA $3 \mathrm{~A}$ and $4 \mathrm{~A}$; TBG $5 \mathrm{D}$; and ZBG 1A.

Among $\mathrm{Z}$ series wells, only wells $\mathrm{Z} 3$ and $\mathrm{Z} 9$ have casings large enough to allow sampling. Well $\mathrm{Z} 3$ has a bailer stuck in it. All other Z wells have very narrow casings ( $3 / 4$ in.), making bailing impractical. Even if any $\mathrm{Z}$ wells other than $\mathrm{Z} 9$ are scheduled, they are not sampled and water elevation measurements are not taken.

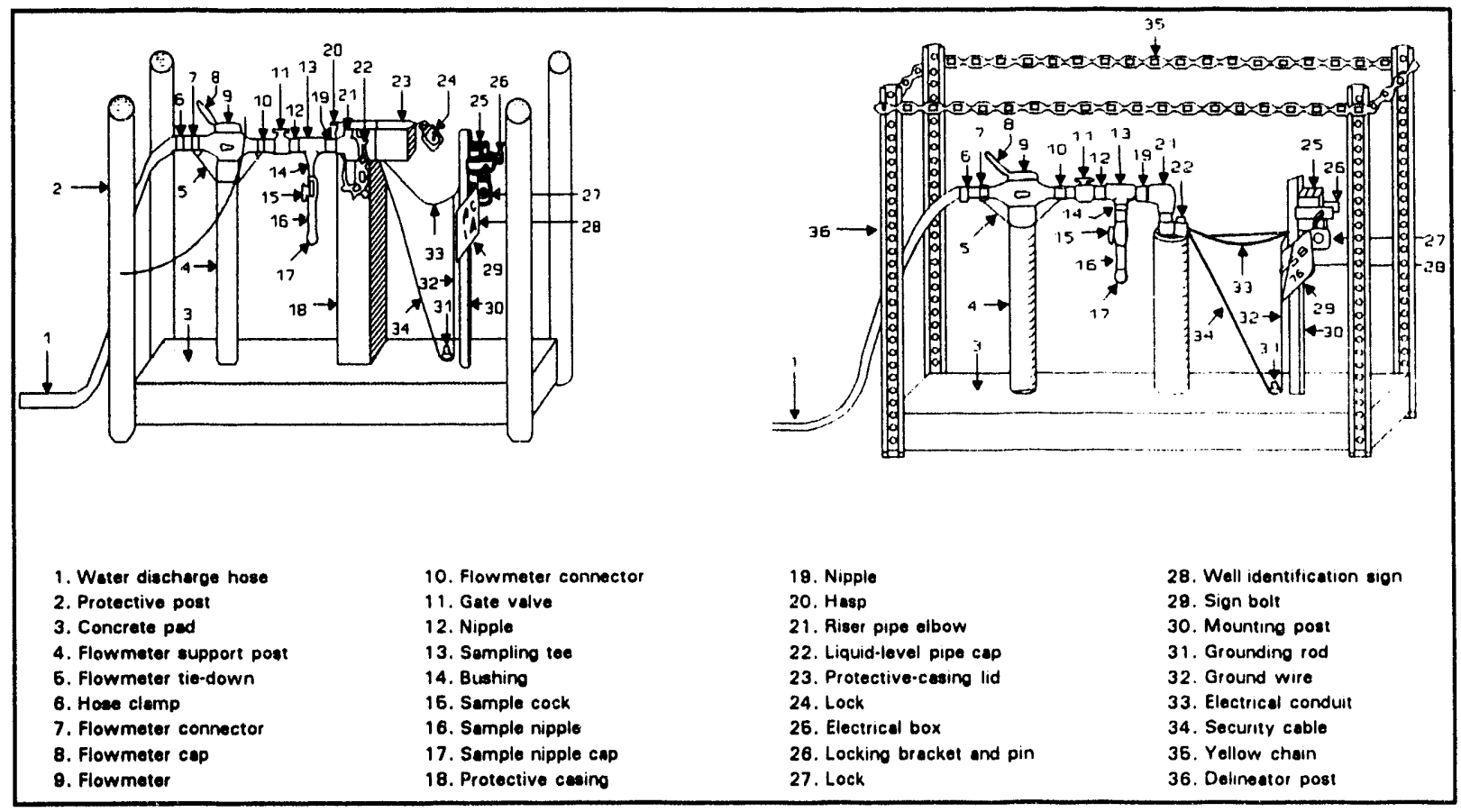

Figure 3. Two Types of Groundwater Monitoring Wellheads 
If a well runs dry during purging before a sample is collected and the well is revisited and sampled within 24 hours, this is considered one sampling event, yielding a single set of field and analytical data. For such wells, the volume purged before the well went dry during the first visitation is given in this section. The total

\section{Table 5. Comments from the Field Data}

\begin{tabular}{|c|c|c|c|}
\hline Well & & Date & Comments \\
\hline BP & Ser & & \\
\hline ABP & $2 A$ & $07 / 14 / 92$ & $\begin{array}{l}\text { Very weakly turbid; brown } \\
\text { small amount of fine sand }\end{array}$ \\
\hline $\mathrm{AB}$ & $3 \mathrm{C}$ & $07 / 14 / 92$ & $\begin{array}{l}\text { Weakly turbid; brown; } \\
\text { small amount of fine sand }\end{array}$ \\
\hline $\mathrm{ABP}$ & $8 \mathrm{C}$ & $\begin{array}{l}07 / 14 / 92 \\
07 / 15 / 92\end{array}$ & $\begin{array}{l}\text { Dry after } 4 \mathrm{gal} \\
\text { Aerated }\end{array}$ \\
\hline ABP & $8 \mathrm{D}$ & $07 / 14 / 92$ & $\begin{array}{l}\text { The well went dry before } \\
\text { sampling began; depth to } \\
\text { water was unavailable or } \\
\text { not reported }\end{array}$ \\
\hline
\end{tabular}

$\begin{array}{llll}\text { ACB } & 2 A & 07 / 03 / 92 & \begin{array}{l}\text { Discharge hose sprays; } \\ \text { aerated }\end{array} \\ \text { ACB } & 3 A & 07 / 03 / 92 & \begin{array}{l}\text { Discharge hose leaks } \\ \text { DA }\end{array}\end{array}$

AMB Series

\begin{tabular}{|c|c|c|}
\hline AMB 4D & $07 / 24 / 92$ & $\begin{array}{l}\text { Well identification sign } \\
\text { reads "AMB 4DR" } \\
\text { Well identification sign } \\
\text { reads "AMB 4DR" }\end{array}$ \\
\hline AMB & $07 / 23 / 92$ & Dry after $7 \mathrm{gal}$ \\
\hline DI & 07/23/92 & $\begin{array}{l}\text { Sample valve doesn't work; } \\
\text { discharge hose sprays }\end{array}$ \\
\hline & $07 / 2$ & Dry after $70 \mathrm{gal}$ \\
\hline & $07 / 23 / 92$ & Sprays from gate valve \\
\hline AR & $07 / 25 / 92$ & Dry after $60 \mathrm{gal}$ \\
\hline
\end{tabular}

AOB Series

AOB $3 \quad 07 / 13 / 92$ Dry after 8 gal

07/14/92 Discharge hose sprays

ARP Series

$\begin{array}{llll}\text { ARP } & \text { 1A } & 07 / 03 / 92 & \text { Aerated } \\ \text { ARP } & 3 & 08 / 13 / 92 & \text { Weakly turbid; light brown } \\ \text { ARP } & \text { 4A } & 07 / 03 / 92 & \text { Elbow cracked; aerated }\end{array}$ amount of water purged from each well in one sampling event is given in the Analytical Results section.

Comments about dry wells, continuously pumping wells, and malfunctioning wells can be found in the Analytical Results section.

\begin{tabular}{|c|c|c|c|}
\hline ASB & $3 \mathbf{A}$ & $07 / 16 / 92$ & $\begin{array}{l}\text { Discharge-side flowmeter } \\
\text { connector leaks }\end{array}$ \\
\hline ASB & $6 A$ & $08 / 06 / 92$ & Aerated \\
\hline ASB & $6 \mathrm{C}$ & $08 / 06 / 92$ & $\begin{array}{l}\text { Flowmeter not working, } \\
\text { estimated volume purged }\end{array}$ \\
\hline ASB & $\mathrm{TA}$ & $08 / 11 / 92$ & Dry after 52 gal \\
\hline
\end{tabular}

BG Series

BG $91 \quad 07 / 02 / 92$ Turbidity varied; light

BG $92 \quad 07 / 01 / 92 \quad \begin{aligned} & \text { brown } \\ & \text { Dry after } \sim 11.8 \mathrm{gal}\end{aligned}$

07/02/92 Very weakly turbid; very light brown

BG $93 \quad 07 / 01 / 92$ Flowmeter did not work properly, estimated volume purged

BG $96 \quad 07 / 02 / 92$ Very weakly turbid; very light brown

BG $101 \quad 07 / 06 / 92$ Very weakly turbid; very light brown

BG $104 \quad 07 / 01 / 92$ Dry after $\sim 2$ gal

BG 110

Dry after $-33.4 \mathrm{gal}$

BG $121 \quad 07 / 01 / 92$ Dry after $\sim 5.3 \mathrm{gal}$

07/02/92 Weakly turbid; light brown

BGO Series

\begin{tabular}{|c|c|c|c|}
\hline BGO & 1D & $\begin{array}{l}07 / 27 / 92 \\
07 / 28 / 92\end{array}$ & $\begin{array}{l}\text { Dry after }-7.9 \text { gal } \\
\text { Turbidity varied; light } \\
\text { brown; aerated }\end{array}$ \\
\hline BGO & $3 D$ & $\begin{array}{l}07 / 27 / 92 \\
07 / 28 / 92\end{array}$ & $\begin{array}{l}\text { Dry after }-3.6 \text { gal } \\
\text { Turbidity varied; light } \\
\text { brown; aerated }\end{array}$ \\
\hline BGO & 4D & $08 / 03 / 92$ & Unable to sample, no access \\
\hline BGO & $5 \mathrm{C}$ & $\begin{array}{l}07 / 27 / 92 \\
07 / 28 / 92\end{array}$ & $\begin{array}{l}\text { Dry after } \sim 15.4 \text { gal } \\
\text { Turbidity varied; light } \\
\text { brown }\end{array}$ \\
\hline BGO & $5 \mathrm{D}$ & $\begin{array}{l}07 / 27 / 92 \\
07 / 28 / 92\end{array}$ & $\begin{array}{l}\text { Dry after }-4.3 \text { gal } \\
\text { Turbidity varied; very light } \\
\text { brown }\end{array}$ \\
\hline BGO & $6 \mathrm{D}$ & $08 / 03 / 92$ & Dry after $\sim 5.9 \mathrm{gal}$ \\
\hline
\end{tabular}


Table 5. Comments from the Field Data (cont.)

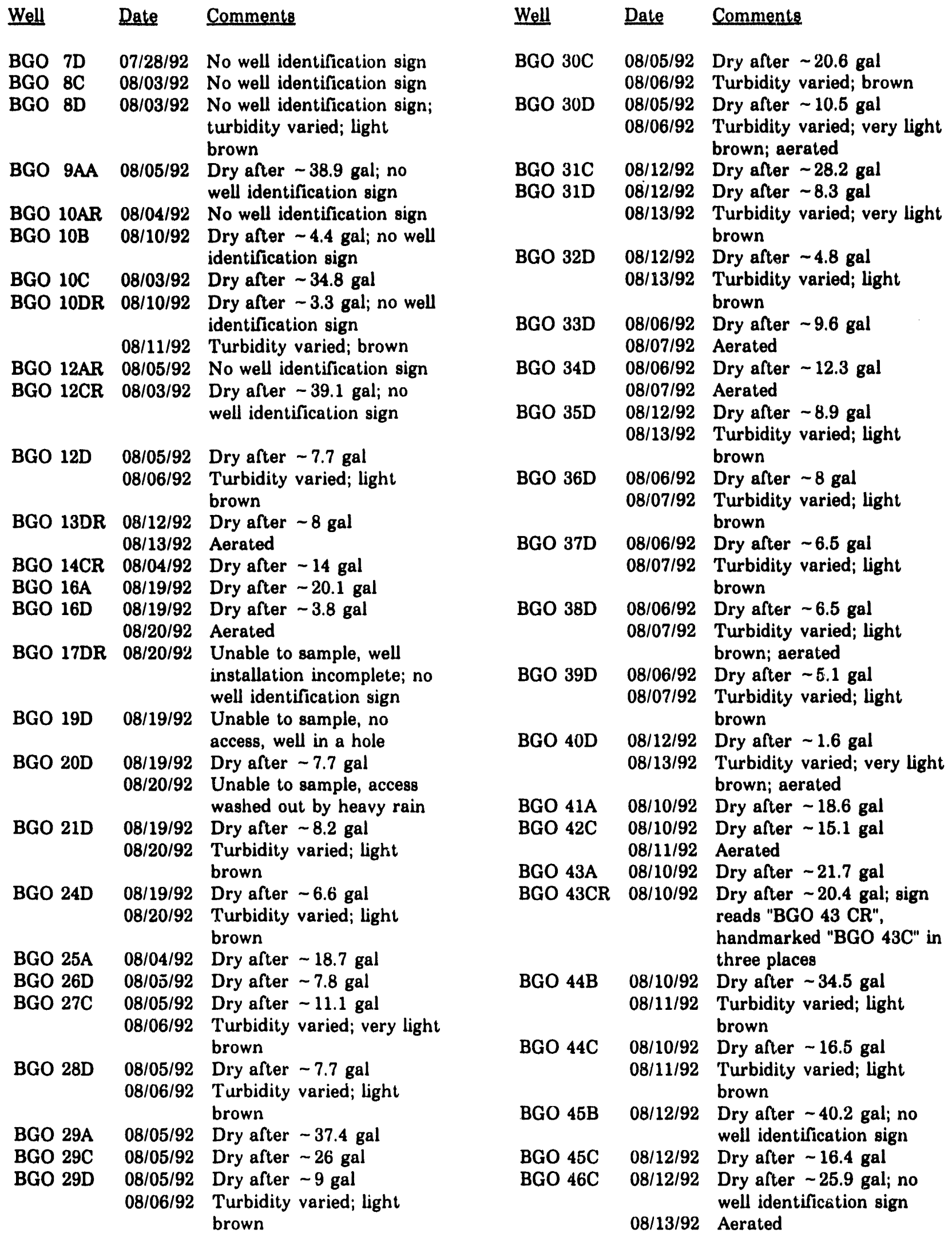


Table 6. Comments from the Field Data (cont.)

\begin{tabular}{|c|c|c|}
\hline Well & Date & Comments \\
\hline BGO 49D & $\begin{array}{l}08 / 12 / 92 \\
08 / 13 / 92\end{array}$ & $\begin{array}{l}\text { Dry after }-8.2 \mathrm{gal} \\
\text { Aerated }\end{array}$ \\
\hline BGO 50A & $08 / 12 / 92$ & $\begin{array}{l}\text { Dry after }-34.4 \mathrm{gal} \text {; no } \\
\text { well identification sign }\end{array}$ \\
\hline BGO 50C & 08/13/92 & $\begin{array}{l}\text { Dry after }-33.9 \text { gal; no } \\
\text { well identification sign }\end{array}$ \\
\hline BGO 50D & $08 / 14 / 92$ & No well identification sign \\
\hline \multicolumn{3}{|l|}{ BGX Series } \\
\hline BGX IA & $07 / 29 / 92$ & $\begin{array}{l}\text { Dry after } 10 \text { gal; no well } \\
\text { identification sign } \\
\text { Aerated }\end{array}$ \\
\hline BGX 1C & $07 / 29 / 92$ & $\begin{array}{l}\text { Dry after } 13 \mathrm{gal} \text {; no well } \\
\text { identification sign }\end{array}$ \\
\hline & $07 / 30 / 92$ & $\begin{array}{l}\text { Weakly turbid; brown; } \\
\text { aerated }\end{array}$ \\
\hline BGX ID & $07 / 29 / 92$ & $\begin{array}{l}\text { Dry after } 6 \text { gal; no well } \\
\text { identification sign }\end{array}$ \\
\hline & 07/30/92 & $\begin{array}{l}\text { Weakly lurbid; brown; } \\
\text { aerated }\end{array}$ \\
\hline BGX 2B & $\begin{array}{l}07 / 29 / 92 \\
07 / 30 / 92\end{array}$ & $\begin{array}{l}\text { Dry after } 45 \mathrm{gal} \\
\text { Aerated }\end{array}$ \\
\hline BGX 2D & $\begin{array}{l}07 / 29 / 92 \\
07 / 30 / 92\end{array}$ & $\begin{array}{l}\text { Dry after } 18.5 \mathrm{gal} \\
\text { Aerated }\end{array}$ \\
\hline BGX 7D & 07/29/92 & Unable to sample, no access \\
\hline BGX 8DR & 07/31/92 & $\begin{array}{l}\text { Well identification sign } \\
\text { reads "BGX } 8 \mathrm{D} \text { " }\end{array}$ \\
\hline BGX 10D & $\begin{array}{l}07 / 29 / 92 \\
07 / 30 / 92\end{array}$ & $\begin{array}{l}\text { Dry after } 2.5 \text { gal } \\
\text { Turbidity varied; brown; } \\
\text { aerated }\end{array}$ \\
\hline BGX 11D & $\begin{array}{l}07 / 30 / 92 \\
07 / 31 / 92\end{array}$ & $\begin{array}{l}\text { Dry after } 6 \mathrm{gal} \\
\text { Moderately turbid; orange- } \\
\text { brown }\end{array}$ \\
\hline BGX 12D & $\begin{array}{l}07 / 29 / 92 \\
07 / 30 / 92\end{array}$ & $\begin{array}{l}\text { Dry after } 4.5 \text { gal } \\
\text { Weakly turbid; brown; } \\
\text { aerated }\end{array}$ \\
\hline
\end{tabular}

\begin{tabular}{|c|c|c|}
\hline Well & Date & Comments \\
\hline BRR 4D & $\begin{array}{l}08 / 22 / 92 \\
08 / 23 / 92\end{array}$ & $\begin{array}{l}\text { Dry after } 9 \text { gal } \\
\text { Turbidity varied; brown }\end{array}$ \\
\hline RR $5 \mathrm{D}$ & $08 / 22 / 92$ & Dry after $6 \mathrm{gal}$ \\
\hline
\end{tabular}

\section{CBR Serie日}

CBR 3D 07/29/92 Discharge hose sprays

\section{CCB Series}

CCB 2 07/17/92 Mederately turbid; red

\section{BRD Series}
BRD $2 \quad 08 / 03 / 92$ Discharge hose sprays; sample nipple snapped at $\mathrm{T}$. joint
BRD $3 \quad 08 / 03 / 92$ Dry after 6.5 gal; discharge hose sprays; weakly turbid; brown

CDB Series

$\begin{array}{lll}\text { CDB } 1 & 08 / 18 / 92 & \begin{array}{l}\text { Dry after } 13 \text { gal; gate valve } \\ \text { leaks when throttled }\end{array} \\ \text { CDB } 2 & 08 / 18 / 92 & \text { Dry after } 10 \text { gal }\end{array}$

\section{CMP Series}

\begin{tabular}{|c|c|c|}
\hline CMP 11 & $09 / 09 / 92$ & Dry after $-18 \mathrm{gal}$ \\
\hline CMP 11B & $09 / 10 / 92$ & $\begin{array}{l}\text { Discharge hose leaks, } \\
\text { sprays }\end{array}$ \\
\hline CMP 12A & 09/09/92 & $\begin{array}{l}\text { Discharge hose leaks, } \\
\text { sprays }\end{array}$ \\
\hline CMP 12B & $09 / 09 / 92$ & $\begin{array}{l}\text { Discharge hose leaks, } \\
\text { sprays }\end{array}$ \\
\hline CMP 13 & $\begin{array}{l}09 / 09 / 92 \\
09 / 10 / 92\end{array}$ & $\begin{array}{l}\text { Dry after } \sim 7.6 \mathrm{gal} \\
\text { Very weakly turbid; very } \\
\text { light brown }\end{array}$ \\
\hline CMP 13B & $09 / 10 / 92$ & $\begin{array}{l}\text { Discharge hose leaks, } \\
\text { sprays }\end{array}$ \\
\hline CMP 14B & $09 / 11 / 92$ & Sample cock broken \\
\hline CMP 15A & 09/09/92 & $\begin{array}{l}\text { Discharge hose leaks, } \\
\text { sprays }\end{array}$ \\
\hline CMP 15B & $09 / 09 / 92$ & Dry after -20.5 gal \\
\hline CMP 15C & $\begin{array}{l}09 / 09 / 92 \\
09 / 10 / 92\end{array}$ & $\begin{array}{l}\text { Dry after } \sim 10 \text { gal } \\
\text { Aerated }\end{array}$ \\
\hline CMP 16B & $09 / 09 / 92$ & $\begin{array}{l}\text { Discharge hose leaks, } \\
\text { sprays }\end{array}$ \\
\hline & $09 / 09 / 92$ & $\begin{array}{l}\text { Unable to sample, pump } \\
\text { has been removed }\end{array}$ \\
\hline
\end{tabular}

\section{CSA Series}

CSA $207 / 27 / 92$ Weakly turbid; brown

\section{CSB Series}

\section{BRR Series}

$\begin{array}{llll}\text { BRR 1D } & 08 / 22 / 92 & \text { Dry after } 8 \text { gal } \\ & 08 / 23 / 92 & \text { Turbidity varied; brown } \\ \text { BRR 2D } & 08 / 22 / 92 & \text { Dry after 11 gal } \\ \text { BRR 3D } & 08 / 22 / 92 & \text { Dry after } 8 \text { gal } \\ & & 08 / 23 / 92 & \text { Discharge hose leaks }\end{array}$
CSB 1A
$08 / 01 / 92$
Dry after 9 gal 08/02/92 Discharge hose sprays
CSB 3A
08/01/92
Dry after $15 \mathrm{gal}$
08/02/92 Very weakly turbid; pink
CSB 4A 
Table 5. Comments from the Field Data (cont.)

\begin{tabular}{|c|c|c|}
\hline Well & Date & Comments \\
\hline CSB 5A & $\begin{array}{l}08 / 01 / 92 \\
08 / 02 / 92\end{array}$ & $\begin{array}{l}\text { Dry after } 8 \mathrm{gal} \\
\text { Discharge hose sprays; } \\
\text { weakly turbid; pink }\end{array}$ \\
\hline \multicolumn{3}{|c|}{ CSD Series } \\
\hline CSD 1D & 07/29/92 & $\begin{array}{l}\text { Dry after } 15 \mathrm{gal} ; \\
\text { moderately turbid; tan }\end{array}$ \\
\hline CSI & $07 / 27 / 92$ & $\begin{array}{l}\text { Dry after } 2 \text { gal; no well } \\
\text { identification sign }\end{array}$ \\
\hline 4D & 07/27/92 & $\begin{array}{l}\text { Dry after } 16 \mathrm{gal} \text {; no well } \\
\text { identification sign }\end{array}$ \\
\hline & $\begin{array}{l}07 / 28 / 92 \\
07 / 27 / 92 \\
07 / 28 / 92\end{array}$ & $\begin{array}{l}\text { Aerated } \\
\text { Dry after } 11 \mathrm{gal} \\
\text { Aerated }\end{array}$ \\
\hline
\end{tabular}

CSR Seriee
CSR $207 / 29 / 92$ Dry after 17 gal; weakly
CSR $3 \quad 07 / 29 / 92$ turbid; brown

DCB Series

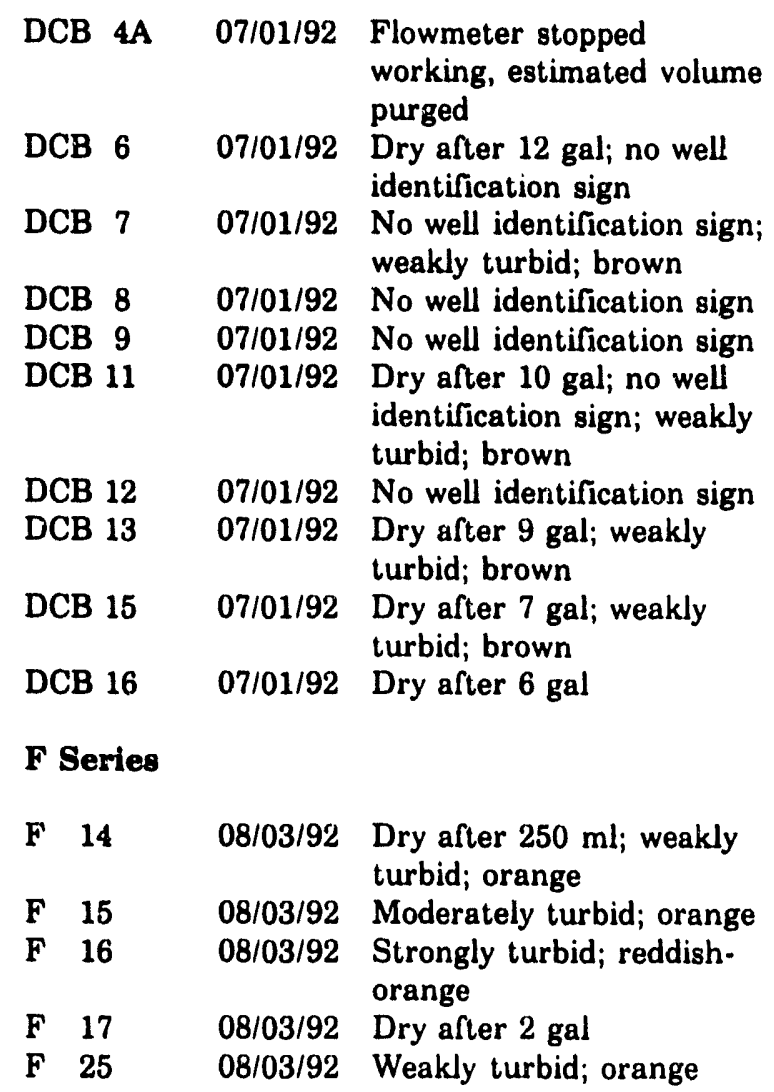

Well Date Comments

FAC Series

FAC $3 \quad 08 / 29 / 92$ Dry after 9 gal 08/30/92 Moderately turbid; yellowbrown; sand

FAC $4 \quad 08 / 29 / 92$ Sample valve leaks

FAC $5 \quad$ 09/02/92 Turbidity varied; light brown

FAC $6 \quad 08 / 29 / 92$ Dry after $10 \mathrm{gal}$

08/30/92 Weakly turbid; light brown

FAC $7 \quad 09 / 02 / 92$ Turbidity varied; light brown

FAC $8 \quad 09 / 02 / 92$ Turbidity varied; light brown

FAL Series

FAL 1

$09 / 21 / 92$

FAL 2

$09 / 21 / 92$

$09 / 22 / 92$

Dry after $\sim 9 \mathrm{gal}$

Dry after $-5.1 \mathrm{gal}$

Moderately turbid; brown

FCA Series

FCA $1 N$

09/22/92 Dry after 1/2 gal

09/23/92 Turbidity varied; light brown

FCA 2C 09/21/92 Dry after $-1.1 \mathrm{gal}$ 09/22/92 Turbidity varied; brown

FCA 2D 09/21/92 Dry after $\sim 4$ gal

09/22/92 Turbidity varied; brown

FCA 9C 09/21/92 Unable to sample, trash in well prevented access

FCA 9D 09/21/92 Dry after $-11.3 \mathrm{gal}$ 09/22/92 Turbidity varied; brown

FCA 9DR 09/22/92 Unable to sample, bailer would not go beyond $-10 \mathrm{ft}$

FCA 10A 09/22/92 Dry after $\sim 10$ gal; no well identification sign

09/23/92 Turbidity varied; brown

FCA 10B 09/22/92 No well identification sign

FCA 10D 09/21/92 Dry after $\sim 1.1 \mathrm{gal}$

09/22/92 Turbidity varied; brown; strong odor of freshly painted surface from nearby

FCA 16A 09/22/92 Dry after $\sim 9$ gal

09/23/92 Turbidity varied; brown

FCA 16B 09/22/92 Dry after $\sim 1.3$ gal; no well identification sign

09/23/92 Turbidity varied; brown

FCA 16D 09/22/92 Dry after - $2.2 \mathrm{gal}$

09/23/92 Turbidity varied; brown; strong odor of painting in process nearby

FCA 16T 09/22/92 No well identification sign 
Table 5. Comments from the Field Data (cont.)

$\begin{array}{lll}\text { Well } & \text { Date } & \text { Comments } \\ \text { FCA 19D } & 09 / 21 / 92 & \text { Dry after } \sim 5 \text { gal } \\ & 09 / 22 / 92 & \text { No discharge hose }\end{array}$

\section{FCB Series}

$\begin{array}{llll}\text { FCB } & 4 & 09 / 21 / 92 & \text { Dry after } \sim 14 \text { gal } \\ & & 09 / 22 / 92 & \text { Weakly turbid; light brown } \\ \text { FCB } & 5 & 08 / 27 / 92 & \text { Dry after }-3.5 \mathrm{gal} \\ \text { FCB } & 6 & 08 / 27 / 92 & \text { Dry after }-1.1 \mathrm{gal}\end{array}$

\section{FET Serie日}

FET 1D 07/09/92 Dry after $-7.8 \mathrm{gal}$

FIW Series

\begin{tabular}{|c|c|c|c|}
\hline FIW & IID & $08 / 18 / 92$ & $\begin{array}{l}\text { No well identification sign; } \\
\text { weakly turbid; light brown; } \\
\text { onion-like odor }\end{array}$ \\
\hline FIW & 1MC & 08/18/92 & No well identification sign \\
\hline w & IMD & 08/18/92 & No well identification sign \\
\hline & $2 \mathrm{C}$ & $08 / 17 / 92$ & No well identification sig? \\
\hline FI & 2IC & $08 / 17 / 92$ & No well identification sign \\
\hline & 2MA & 08/19/92 & $\begin{array}{l}\text { No well identification sign; } \\
\text { sulfur odor }\end{array}$ \\
\hline F & M & $08 /$ & No well identification si \\
\hline & 2MD & $08 / 17 / 92$ & $\begin{array}{l}\text { No well identification sign; } \\
\text { onion-like odor }\end{array}$ \\
\hline
\end{tabular}

\section{FNB Series}

FNB $2 \quad 08 / 24 / 92$ Weakly turbid; light brown

\section{FSB Serie日}

$\begin{array}{lll}\text { FSB 1TA } & 07 / 08 / 92 & \begin{array}{l}\text { Unable to sample, pump } \\ \text { not working }\end{array} \\ & 07 / 19 / 92 & \begin{array}{l}\text { No standpipe; no flowmeter } \\ \text { FSB 77 }\end{array} \\ & 07 / 05 / 92 & \begin{array}{l}\text { Sample nipple broken off at } \\ \text { T-joint }\end{array} \\ \text { FSB 78 } & 07 / 05 / 92 & \text { Surges; aerated } \\ \text { FSB 78C } & 07 / 04 / 92 & \text { Dry after 23 gal } \\ & 07 / 05 / 92 & \text { Aerated } \\ \text { FSB 88D } & 07 / 03 / 92 & \text { Dry after 7.2 gal } \\ \text { FSB 89D } & 07 / 07 / 92 & \text { Dry after 5 gal } \\ \text { FSB 90D } & 07 / 04 / 92 & \text { Dry after 6 gal } \\ & 07 / 05 / 92 & \text { Aerated } \\ \text { FSB 91C } & 07 / 04 / 92 & \text { Dry after 20 gal } \\ \text { FSB 92D } & 07 / 08 / 92 & \text { Weakly turbid; yellow } \\ \text { FSB 93D } & 07 / 08 / 92 & \text { Dry after 7 gal } \\ \text { FSB 94C } & 07 / 08 / 92 & \text { Dry after 33 gal } \\ \text { FSB 97A } & 07 / 09 / 92 & \text { Unable to sample, pump } \\ & & \text { not working }\end{array}$

\begin{tabular}{|c|c|c|}
\hline Vell & Date & Comments \\
\hline FSB 97D & $07 / 16 / 92$ & $\begin{array}{l}\text { Well went dry during } \\
\text { purging; date, time, and } \\
\text { volume of initial sampling } \\
\text { attempt were not reported }\end{array}$ \\
\hline SB 98D & $07 / 10 / 92$ & $\begin{array}{l}\text { Well vent dry during } \\
\text { purging; date, time, and } \\
\text { volume of initial sampling } \\
\text { attempt were not reported }\end{array}$ \\
\hline SB 99D & $07 / 14 / 92$ & Dry after $6 \mathrm{gal}$ \\
\hline SB1 & $07 / 13 / 92$ & Dry after $8 \mathrm{gal}$ \\
\hline SB1 & $07 / 14 / 92$ & $\begin{array}{l}\text { The well went dry during } \\
\text { purging; date, time, and } \\
\text { volume of the initial } \\
\text { sampling attempt were not } \\
\text { reported }\end{array}$ \\
\hline FSB113C & $\begin{array}{l}07 / 03 / 92 \\
07 / 04 / 92\end{array}$ & $\begin{array}{l}\text { Dry after } 25 \mathrm{gal} \\
\text { Ant body parts }\end{array}$ \\
\hline FSB114A & 07/04/92 & Surges \\
\hline FSB114C & 07/04/92 & Surges \\
\hline FSB115C & $07 / 04 / 92$ & Dry after 11 gal; aerated \\
\hline FSB115D & $07 / 04 / 92$ & Weakly turbid; light brown \\
\hline FSB116D & 07/04/92 & $\begin{array}{l}\text { Dry after } 2 \text { gal; weakly } \\
\text { turbid; brown; aerated }\end{array}$ \\
\hline FSB & $07 / 16$ & Dry after $3 \mathrm{gal}$ \\
\hline FSB12 & $07 / 19 / 92$ & $\begin{array}{l}\text { Dry after } 7 \text { gal; no well } \\
\text { identification sign; turbidity } \\
\text { varied; brown }\end{array}$ \\
\hline
\end{tabular}

FSL Series

FSL 6D

$08 / 30 / 92$

Very weakly turbid; light brown

FSL 8D

08/30/92

Unable to sample, well installation incomplete

\section{FSS Serie日}

\begin{tabular}{|c|c|c|}
\hline FSS 1D & $\begin{array}{l}07 / 09 / 92 \\
07 / 10 / 92\end{array}$ & $\begin{array}{l}\text { Dry after } \sim 6 \text { gal } \\
\text { Turbidity varied; light } \\
\text { brown }\end{array}$ \\
\hline FSS 2D & $\begin{array}{l}07 / 09 / 92 \\
07 / 10 / 92\end{array}$ & $\begin{array}{l}\text { Dry after } \sim 9.9 \mathrm{gal} \\
\text { Turbidity varied; light } \\
\text { brown }\end{array}$ \\
\hline & $07 / 09 / 92$ & Dry after $-5.2 \mathrm{gal}$ \\
\hline & $\begin{array}{l}07 / 09 / 92 \\
07 / 10 / 92\end{array}$ & $\begin{array}{l}\text { Dry after } \sim 10.5 \text { gal } \\
\text { Turbidity varied; light } \\
\text { brown; aerated }\end{array}$ \\
\hline
\end{tabular}

GBW Series

GBW $1 \quad 07 / 25 / 92$ Dry after 13 gal; very weakly turbid 
Table 5. Comments from the Field Data (cont.)

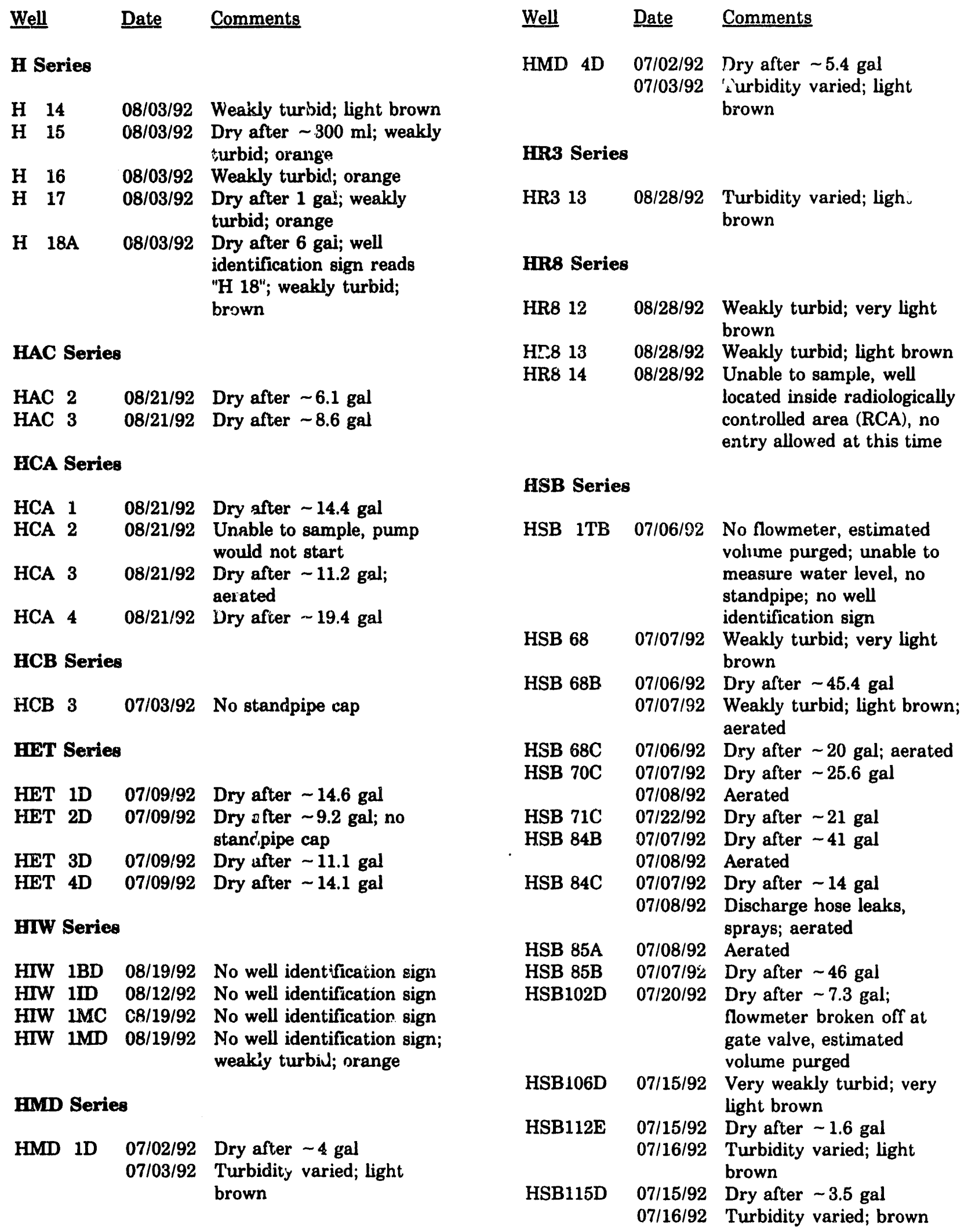


Table 5. Comments from the Field Data (cont.)

\begin{tabular}{|c|c|c|}
\hline Well & Date & Comments \\
\hline 16D & 07/16/92 & $\begin{array}{l}\text { Riser pipe elbow and } \\
\text { bushing leak spray }\end{array}$ \\
\hline BB117A & $07 / 22 / 92$ & Well pad covered with dirt \\
\hline SB117C & $07 / 22 / 92$ & Well pad covered with dirt \\
\hline ISB117D & $07 / 22 / 92$ & Well pad covered with dirt \\
\hline ISB119A & 07/21/92 & Dry after $\sim 34.5 \mathrm{gal}$ \\
\hline HSB124AR & 07/17/92 & No well identification sign \\
\hline HSB126D & $07 / 21 / 92$ & Dry after $\sim 7.3 \mathrm{gal}$ \\
\hline HSB129C & $07 / 21 / 92$ & Dry after $\sim 29 \mathrm{gal}$ \\
\hline HSE & $\begin{array}{l}07 / 23 / 92 \\
07 / 24 / 92\end{array}$ & $\begin{array}{l}\text { Dry after } \sim 29 \mathrm{gal} \\
\text { Aerated }\end{array}$ \\
\hline 2D & 07/23/92 & Dry after $\sim 6.2 \mathrm{gal}$ \\
\hline LBB136C & 07/21/92 & Dry after $\sim 25 \mathrm{gal}$ \\
\hline HSB137C & $07 / 21 / 92$ & Dry after $\sim 24 \mathrm{gal}$ \\
\hline HSB & 07/21/92 & $\begin{array}{l}\text { Discharge hose leaks, } \\
\text { sprays }\end{array}$ \\
\hline HSB139C & $07 / 22 / 92$ & Dry after $\sim 27 \mathrm{gal}$ \\
\hline HSB & $07 / 22 / 92$ & Discharge hose leaks \\
\hline HSB14 iC & 07/23/92 & Dry after $-40.2 \mathrm{gal}$ \\
\hline HSB & $\begin{array}{l}07 / 23 / 92 \\
07 / 24 / 92\end{array}$ & $\begin{array}{l}\text { Dry after } \sim 13.9 \mathrm{gal} \\
\text { Turbidity varied; very light } \\
\text { brown; aerated }\end{array}$ \\
\hline HSB & $07 / 23 / 92$ & Dry after $-3.6 \mathrm{gal}$ \\
\hline & $07 / 27$ & Dry after $\sim 9.8 \mathrm{ga}$ \\
\hline HSB & $07 / 23 / 92$ & Dry after $\sim 21 \mathrm{gal}$ \\
\hline SB. & 07/23/92 & Dry after $\sim 4.7 \mathrm{gal}$ \\
\hline & $7 / 27 / 92$ & $\begin{array}{l}\text { No water in standpipe; } \\
\text { turbidity varied; light } \\
\text { brown; aerated }\end{array}$ \\
\hline
\end{tabular}

HSL Series

HSL ID 08/30/92 No well identification sign HSL 2D 09/01/92 No well identification sign HSL 3D 09/01/92 No well identification sign; very weakly turbid; light brown

HSI 6D 09/07/92 Flowmeter leaks at bottom; weakly turbid; light tan

HSL 7D 09/07/92 Weakly to moderately turbid; orange-brown

HSL 8D 09/07/92 Flowmeter leaks at bottom; no well identification sign

\section{HSS Serie日}

HSS 1D 07/09/92 Dry after $\sim 19.1$ gal

HSS 3D 07/09/92 Dry after $\sim 15.1$ gal

07/10/92 Weakly turbid; very light brown

\begin{abstract}
Well Date
HTF Series

HTF $2 \quad 08 / 24 / 92$ Unable to sample, highly contaminated area

HTF $3 \quad 08 / 24 / 92$ Unable to sample, highly contaminated area

HTF 4 08/24/92 Unable to sample, highly contaminated area

HTF $5 \quad 08 / 24 / 92$ Unable to sample, pump not working

HTF 6 08/24/92 Unable to sample, pump not working

HTF $8 \quad 08 / 24 / 92$ Unable to sample, pump not working

HTF $34 \quad 08 / 20 / 92$ Unable to sample, pump not working
\end{abstract}

HXB Series

HXB $2 \quad 07 / 29 / 92$ Gate valve leaks

HXB 4D 07/27/92 Dry after 10 gal; no well identification sign

07/28/92 Weakly turbid; brown

HXB 5D 07/27/92 Dry after 10 gal; no well identification sign

07/28/92 Weakly turbid; light brown

\section{IDB Series}

IDB IA

07/18/92 Dry after $24 \mathrm{gal}$

IDB 1B

$07 / 18 / 92$

Dry after 12 gal; weakly turbid; brown

IDB 2B 07/18/92 Dry after $45 \mathrm{gal}$

IDB $3 \quad 07 / 18 / 92$ Dry after $E$, gal

IDB $407 / 18 / 92$ Dry after 7.5 gal; no water in standpipe; aerated

IDB $5 \quad 07 / 18 / 92$ Dry after $7.5 \mathrm{gal}$

IDB $8 \quad 07 / 18 / 92$ Dry after $9 \mathrm{gal}$

IDB $9 \quad 07 / 18 / 92$ Dry after $29 \mathrm{gal}$

IDB $10 \quad 07 / 18 / 92$ No well identification sign

\section{IDP Series}

IDP 1

07/04/92 Flowmeter connector leaks

IDP $3 \mathrm{C}$ $07 / 04 / 92$

Dry after $15 \mathrm{gal}$

IDP 4 $07 / 05 / 92$

IDP 8

$07 / 04 / 92$

Dry after $\sim 4$ gal

IDP 9

$07 / 04 / 92$

Dry after 10.5 gal

IDQ Series

IDQ 2

07/10/92 Dry after $27.5 \mathrm{gal}$

07/11/92 Weakly turbid; brown; fine sand 
Table 5. Comments from the Field Data (cont.)

\begin{tabular}{|c|c|c|}
\hline Well & Date & Comments \\
\hline IDQ 3 & $07 / 10 / 92$ & Dry after $11 \mathrm{gal}$ \\
\hline IDQ 3 & $07 / 10 / 92$ & Dry after $10 \mathrm{gal}$ \\
\hline IDQ 4 & $07 / 10 / 92$ & Dry after $11.5 \mathrm{gal}$ \\
\hline IDQ 5 & $07 / 10 / 92$ & Dry after $3 \mathrm{gal}$ \\
\hline IDQ 6 & $07 / 10 / 92$ & Dry after $6.5 \mathrm{gal}$ \\
\hline IDQ 7 & $07 / 10 / 92$ & Dry after $6 \mathrm{gal}$ \\
\hline & $07 / 11 / 92$ & $\begin{array}{l}\text { Gate valve sprays when } \\
\text { throttled }\end{array}$ \\
\hline IDQ 9 & $07 / 10 / 92$ & Dry after $1.6 \mathrm{gal}$ \\
\hline IDQ 10 & $07 / 10 / 92$ & Dry after $3.8 \mathrm{gal}$ \\
\hline IDQ 11 & $07 / 10 / 92$ & $\begin{array}{l}\text { Unable to sample, pump } \\
\text { has been removed; well } \\
\text { struck by lightning }\end{array}$ \\
\hline
\end{tabular}

K Series

K $301 P \quad 07 / 19 / 92$ Weakly turbid; light brown

KAB Series

KAB $107 / 18 / 92$ Dry after $11 \mathrm{gal}$

07/19/92 Discharge hose and valve spray; weakly turbid; dark brown

KAB $207 / 18 / 92$ Dry after 2 gal

07/19/92 Weakly turbid; brown

\section{KAC Series}

KAC $2 \quad 08 / 01 / 92$ Weakly turbid; light brown

KAC $6 \quad 08 / 01 / 92$ Dry after $7 \mathrm{gal}$

KAC $7 \quad 08 / 01 / 92$ Dry after 6 gal

KAC $8 \quad 08 / 02 / 92$ No well identification sign

KAC $908 / 02 / 92$ No well identification sign

\section{KCB Series}

\begin{tabular}{|c|c|c|c|}
\hline KCB & 1 & $07 / 16 / 92$ & $\begin{array}{l}\text { Discharge hose sprays; } \\
\text { weakly turbid; brown }\end{array}$ \\
\hline $\mathrm{KC}$ & 2 & $07 / 16 / 92$ & $\begin{array}{l}\text { Brown; small amount of } \\
\text { sand }\end{array}$ \\
\hline $\mathrm{C}$ & & $07 / 16 / 92$ & Well has been abandoned \\
\hline
\end{tabular}

\section{KDB Series}

$\begin{array}{lll}\text { KDB } 1 & 08 / 27 / 92 & \begin{array}{l}\text { Dry after 16 gal; no } \\ \text { discharge hose }\end{array} \\ \text { KDB 2 } & 08 / 27 / 92 & \begin{array}{l}\text { No discharge hose; leaks at } \\ \text { T-joint; aerated }\end{array} \\ \text { KDB 3 } & 08 / 27 / 92 & \begin{array}{l}\text { Dry after 17 gal } \\ \hline\end{array}\end{array}$

Well Date

KDT Series

KDT 1D 08/27/92 Dry after 10.5 gal; no discharge hose; no well identification sign; weakly turbid; tan; aerated

KRB Series

KRB 18D 09/20/92 Dry after $12 \mathrm{gal}$

KRB 19D 09/20/92 Dry after $10 \mathrm{gal}$

KRP Series

KRP $2 \quad 07 / 17 / 92$ Discharge hose sprays

KSB Series

KSB $1 \quad 07 / 19 / 92$ Weakly turbid; brown

KSB 4A 07/19/92 Pump has been removed, unable to sample

08/31/92 Moderately turbid; brown

KSM Series

KSM ID 07/31/92 Dry after 8 gal; no well identification sign; moderately turbid; brown

08/27/92 Dry after 9 gal; no well identification sign; aerated

09/28/92 Dry after 9 gal; no well identification sign; moderately turbid; brown

\section{KSS Series}

KSS 1D 08/01/92 Dry after 13 gal; aerated KSS 2D 08/01/92 Weakly turbid; tan

LAC Series

LAC 2 08/01/92 Very weakly turbid; beige LAC 3 08/01/92 Weakly turbid; brown

\section{LAW Series}

$\begin{array}{ccl}\text { LAW 1D } & 08 / 01 / 92 & \begin{array}{l}\text { No discharge hose; no } \\ \text { standpipe cap; no well } \\ \text { identification sign } \\ \text { No discharge hose; T. } \\ \text { coupling leaks } \\ \text { No sample nipple; T- } \\ \text { coupling leaks }\end{array} \\ \text { LAW 3C } & 08 / 01 / 92\end{array}$


Table 5. Comments from the Field Data (cont.)

Well Date Comments Well Date

LCO Series

\begin{tabular}{|c|c|c|}
\hline LCO 1 & $08 / 27 / 92$ & Discharge hose leaks \\
\hline LCO 2 & $08 / 27 / 92$ & $\begin{array}{l}\text { Discharge hose leaks, } \\
\text { sprays }\end{array}$ \\
\hline LCO & $08 / 27 / 92$ & $\begin{array}{l}\text { Discharge hose leaks, } \\
\text { sprays; very weakly turbid; } \\
\text { very light brown }\end{array}$ \\
\hline
\end{tabular}

LDB Series

LDB $108 / 26 / 92$ Dry after $19 \mathrm{gal}$; unable to measure depth to water due to well encased in insulation; plumbing leaks

LDB 2 08/26/92 Dry after 20 gal; unable to measure depth to water due to well encased in insulation; plumbing leaks

LFW Series

\begin{tabular}{|c|c|c|}
\hline LFW 8 & $08 / 25 / 92$ & Weak odor \\
\hline LFW 10A & $08 / 24 / 92$ & Weak odor \\
\hline LFW 17 & $08 / 25 / 92$ & Weak odor \\
\hline LFW 18 & $08 / 25 / 92$ & Weak odor \\
\hline LFW 20 & $08 / 24 / 92$ & $\begin{array}{l}\text { Unable to sample, above- } \\
\text { ground plumbing broken }\end{array}$ \\
\hline LFW 21 & 08/24/92 & $\begin{array}{l}\text { Discharge hose leaks, } \\
\text { sprays; strong odor }\end{array}$ \\
\hline LFW 22 & 08/24/92 & Strong odor \\
\hline LFW 28 & $08 / 31 / 92$ & Dry after $\sim 14 \mathrm{gal}$ \\
\hline LFW 30 & $08 / 31 / 92$ & T-joint leaks, sprays \\
\hline LFW 36 & $09 / 01 / 92$ & Very weak odor \\
\hline LFW 37 & $09 / 0.1 / 92$ & Very weak odor \\
\hline LFW 40 & $09 / 01 / 92$ & $\begin{array}{l}\text { Weakly turbid; clear to light } \\
\text { brown; very weak odor }\end{array}$ \\
\hline LFW 48D & 09/03/92 & Weak odor \\
\hline LFW 60D & $\begin{array}{l}09 / 03 / 92 \\
09 / 04 / 92\end{array}$ & $\begin{array}{l}\text { Dry after } \sim 10 \mathrm{gal} \\
\text { Aerated }\end{array}$ \\
\hline $62 \mathrm{~B}$ & 09/08/92 & $\begin{array}{l}\text { Moderately turbid; very } \\
\text { light brown }\end{array}$ \\
\hline LFW 62D & $\begin{array}{l}09 / 03 / 92 \\
09 / 04 / 92\end{array}$ & $\begin{array}{l}\text { Dry after } \sim 9 \mathrm{gal} \\
\text { Turbidity varied; light } \\
\text { brown to clear; aerated }\end{array}$ \\
\hline
\end{tabular}

\section{LRP Series}

LRP 2 07/03/92 Sample valve does not close; discharge hose sprays; aerated

\section{LSB Series}

\section{LSB $1 \quad 08 / 22 / 92$ Discharge hose sprays}

\section{MCB Series}

$\begin{array}{llll}\text { MCB } & 2 & 07 / 26 / 92 & \text { Dry after 14 gal } \\ \text { MCB } & 4 & 07 / 26 / 92 & \text { Dry after 11 gal } \\ \text { MCB } & 5 C & 08 / 13 / 92 & \text { Dry after 11.5 gal } \\ & & 08 / 14 / 92 & \text { Weakly turbid; light brown } \\ \text { MCB } & 6 & 07 / 26 / 92 & \text { Dry after 4.5 gal } \\ \text { MCB } & 7 C & 08 / 13 / 92 & \text { Dry after 12 gal }\end{array}$

MSB Series

\begin{tabular}{|c|c|c|c|}
\hline ASB & C & $07 / 13 / 92$ & ter $25 \mathrm{gal}$ \\
\hline & $1 \mathrm{CC}$ & 07/13/92 & Dry after $11 \mathrm{gal}$ \\
\hline [S] & 1D & 07/13/92 & $\begin{array}{l}\text { Flowmeter stopped, } \\
\text { estimated volume purged }\end{array}$ \\
\hline MSB & $2 B$ & $\begin{array}{l}08 / 11 / 92 \\
08 / 12 / 92\end{array}$ & $\begin{array}{l}\text { Dry after } 34 \mathrm{gal} \\
\text { Weakly turbid; brown }\end{array}$ \\
\hline MSB & $2 \mathrm{C}$ & $08 / 11 / 92$ & Dry after $9 \mathrm{gal}$ \\
\hline SB & 2D & $07 / 09 / 92$ & No well identification sign \\
\hline MSB & $3 \mathrm{C}$ & $\begin{array}{l}08 / 11 / 92 \\
08 / 12 / 92\end{array}$ & $\begin{array}{l}\text { Dry after } 14 \mathrm{gal} \\
\text { Turbidity varied; brown }\end{array}$ \\
\hline SB & D & $08 / 11 / 92$ & $\begin{array}{l}\text { Pump has been removed, } \\
\text { unable to sample }\end{array}$ \\
\hline ISB & IC & $08 / 11 / 92$ & Dry after $27 \mathrm{gal}$ \\
\hline SB & $5 \mathrm{C}$ & 07/09/92 & $15 \mathrm{gal}$ \\
\hline SB & $6 \mathrm{C}$ & 07/09/92 & ter $16 \mathrm{gal}$ \\
\hline SB & $7 \mathrm{~B}$ & 07/14/92 & Dry after $37 \mathrm{gal}$ \\
\hline [SB & $7 \mathrm{C}$ & $07 / 14 / 92$ & Dry after $12 \mathrm{gal}$ \\
\hline ISB & $9 \mathrm{~B}$ & $\begin{array}{l}08 / 17 / 92 \\
08 / 18 / 92\end{array}$ & $\begin{array}{l}\text { Dry after } \sim 7 \text { gal } \\
\text { Flowmeter not working, } \\
\text { estimated volume purged }\end{array}$ \\
\hline MSB & $9 \mathrm{C}$ & $08 / 18 / 92$ & $\begin{array}{l}\text { Flowmeter connector leaks; } \\
\text { no water in standpipe }\end{array}$ \\
\hline & & $07 / 09 / 92$ & No discharge hose \\
\hline & & 07/09/92 & $\begin{array}{l}\text { No discharge hose; no } \\
\text { flowmeter connector }\end{array}$ \\
\hline & & 08/11/92 & Gate valve leaks \\
\hline & & 07/09/92 & $\begin{array}{l}\text { Metal box } \sim 1 \mathrm{ft} \text { above well } \\
\text { with line down well; no well } \\
\text { identification sign, unable } \\
\text { to sample }\end{array}$ \\
\hline & & 08 & No water in standpipe \\
\hline & & 07/09/92 & Dry \\
\hline & $\mathrm{D}$ & $07 / 09 / 92$ & Dry after $10 \mathrm{gal}$ \\
\hline & & 07/08/92 & $\begin{array}{l}\text { Dry after } 1 \text { gal; no water in } \\
\text { standpipe; weakly turbid; } \\
\text { brown; aerated }\end{array}$ \\
\hline & & $\begin{array}{l}08 / 20 \\
08 / 21\end{array}$ & $\begin{array}{l}\text { Dry after }-.7 \mathrm{gal} \\
\text { Turbidity varied; brown }\end{array}$ \\
\hline
\end{tabular}


Table 5. Comments from the Field Data (cont.)

\begin{tabular}{|c|c|c|c|c|c|}
\hline Well & Date & Comments & Well & Date & Comments \\
\hline MSB 15D & $08 / 20 / 92$ & Dry \&fter $2 \mathrm{gal}$ & MSB 51D & $07 / 25 / 92$ & Dry after $7 \mathrm{gal}$ \\
\hline & 08/21/92 & Aerated & & & Weakly turbid; brown; \\
\hline MSB 16C & $\begin{array}{l}08 / 20 / 92 \\
08 / 21 / 92\end{array}$ & $\begin{array}{l}\text { Dry after }-3 \text { gal } \\
\text { Turbidity varied; brown }\end{array}$ & & & $\begin{array}{l}\text { aerated } \\
\text { Dry after } 5 \mathrm{gal}\end{array}$ \\
\hline MSB 18B & 07/08/92 & Very weakly turbid; brown & MSB 53B & 08/08/92 & Discharge hose connection \\
\hline MSB 18C & 07/08/92 & Dry after $7 \mathrm{gal}$ & & & to flowmeter leaks \\
\hline MSB 20C & 07/21/92 & Dry after $9.4 \mathrm{gal}$ & MSB 53D & $08 / 08 / 92$ & Aerated \\
\hline MSB 24 & 08/13/92 & Dry after $7 \mathrm{gal}$ & MSB 54TA & $07 / 25 / 92$ & Discharge hose sprays \\
\hline MSB 24A & 08/13/92 & $\begin{array}{l}\text { Pump has been removed, } \\
\text { unable to sample }\end{array}$ & $\begin{array}{l}\text { MSB 55B } \\
\text { MSB 55HC }\end{array}$ & $\begin{array}{l}07 / 25 / 92 \\
08 / 20 / 92\end{array}$ & $\begin{array}{l}\text { No standpipe cap } \\
\text { Dry after } 9 \text { gal; weakly }\end{array}$ \\
\hline MSB 26 & $08 / 14 / 92$ & No water in standpipe & & & turbid; light brown \\
\hline MSB 27A & $08 / 11 / 92$ & $\begin{array}{l}\text { Pump has been removed, } \\
\text { unable to sample }\end{array}$ & MSB 56D & 08/07/92 & $\begin{array}{l}\text { Discharge hose sprays; } \\
\text { aerated }\end{array}$ \\
\hline MSB 29A & 07/26/92 & Elbow leaks & MSB 57D & 07/25/92 & Dry after $13 \mathrm{gal}$ \\
\hline MSB 30AA & $08 / 04 / 92$ & Dry after $72 \mathrm{gal}$ & MSB 58D & $08 / 17 / 92$ & Dry after $\sim 9.3 \mathrm{gal}$ \\
\hline MSB 33A & $07 / 07 / 92$ & Discharge hose split, sprays & & $08 / 18 / 92$ & Turbidity varied; clear to \\
\hline MSB 33TA & $07 / 07 / 92$ & Discharge hose split, sprays & & & light brown \\
\hline MSB 35TA & 08/04/92 & Discharge hose sprays & MSB 60D & $07 / 25 / 92$ & Dry after $13 \mathrm{gal}$ \\
\hline MSB 36A & $07 / 24 / 92$ & Dry after $82 \mathrm{gal}$ & MSB 61D & $08 / 08 / 92$ & Dry after 8 gal; weakly \\
\hline MSB 36D & 07/24/92 & $\begin{array}{l}\text { Dry after } 4 \text { gal; turbid; } \\
\text { brown }\end{array}$ & MSB 62D & $07 / 21 / 92$ & $\begin{array}{l}\text { turbid; brown; aerated } \\
\text { Dry after } 6.5 \text { gal }\end{array}$ \\
\hline MSB 37A & 08/08/92 & Dry after $68 \mathrm{gal}$ & MSB 63D & $07 / 22 / 92$ & Dry after $8 \mathrm{gal}$ \\
\hline & 08/09/92 & $\begin{array}{l}\text { Leaks around howmeter } \\
\text { glass }\end{array}$ & MSB 66D & $08 / 09 / 92$ & $\begin{array}{l}\text { Pump not working; } \\
\text { discharge hose not }\end{array}$ \\
\hline MSB 37D & $08 / 08 / 92$ & $\begin{array}{l}\text { Pump has been removed, } \\
\text { unable to sample }\end{array}$ & & & $\begin{array}{l}\text { connected to flowmeter, } \\
\text { unable to sample }\end{array}$ \\
\hline MSB 38C & 08/17/92 & $\begin{array}{l}\text { Riser pipe elbow, 'T-joint, } \\
\text { and gate valve leak, spray }\end{array}$ & $\begin{array}{l}\text { MSB 68B } \\
\text { MSB 68D }\end{array}$ & $\begin{array}{l}08 / 07 / 92 \\
08 / 13 / 92\end{array}$ & $\begin{array}{l}\text { No well identification sign } \\
\text { No well identification sign }\end{array}$ \\
\hline MSB 38D & 08/08/92 & $\begin{array}{l}\text { Water level tape was on } \\
\text { botlom of standpipe }\end{array}$ & $\begin{array}{l}\text { MSB 69C } \\
\text { MSB 70D }\end{array}$ & $\begin{array}{l}08 / 07 / 92 \\
08 / 08 / 92\end{array}$ & $\begin{array}{l}\text { Dry after } 29 \mathrm{gal} \\
\text { Dry after } 3 \mathrm{gal} \text {; no well }\end{array}$ \\
\hline MSB 39A & 07/07/92 & Dry after $61.5 \mathrm{gal}$ & & & identification sign \\
\hline MSB 40C & 07/24/92 & Dry after $8 \mathbf{~ g a l}$ & MSB 71B & 08/08/92 & Dry after $43 \mathrm{gal}$ \\
\hline MSE & $07 / 24 / 92$ & $\begin{array}{l}\text { Pump has been removed, } \\
\text { unable to sample }\end{array}$ & $\begin{array}{l}\text { MSB 74B } \\
\text { MSB 74C }\end{array}$ & $\begin{array}{l}08 / 21 / 92 \\
08 / 08 / 92\end{array}$ & $\begin{array}{l}\text { Weakly turbid; light brown } \\
\text { Dry after } 17 \text { gal }\end{array}$ \\
\hline MSB 41D & 08/08/92 & Dry after $0.5 \mathrm{gal}$ & MSB 74D & 08/08/92 & Dry after $7 \mathrm{gal}$ \\
\hline & $08 / 09 / 92$ & $\begin{array}{l}\text { No water in standpipe; } \\
\text { weakly turbid; brown }\end{array}$ & MSB 75B & $\begin{array}{l}08 / 09 / 92 \\
08 / 21 / 92\end{array}$ & $\begin{array}{l}\text { Very weakly turbid; brown } \\
\text { No well identification sign }\end{array}$ \\
\hline MSB 42D & $08 / 07 / 92$ & $\begin{array}{l}\text { Pump has been removed, } \\
\text { unable to sample }\end{array}$ & $\begin{array}{l}\text { MSB 75C } \\
\text { MSB 76C }\end{array}$ & $\begin{array}{l}08 / 08 / 92 \\
08 / 21 / 92\end{array}$ & $\begin{array}{l}\text { Dry after } 4 \text { gal } \\
\text { No well identification sign }\end{array}$ \\
\hline MSB 42C & 08/07/92 & Discharge hose sprays & MSB 77C & $07 / 26 / 92$ & Weakly turbid; tan \\
\hline MSB 43B & $07 / 20 / 92$ & Discharge hose leaks & MSB 77D & $07 / 25 / 92$ & Dry after $9 \mathrm{gal}$ \\
\hline MSB 43TA & 07/20/92 & Discharge hose sprays & & $07 / 26 / 92$ & Very weakly turbid; tan \\
\hline A & 08/09/92 & Discharge hose sprays & MSB 77TA & 07/25/92 & Dry after $54.5 \mathrm{gal}$ \\
\hline MSB & 08/09/92 & Discharge hose sprays & MSB 78D & $08 / 08 / 92$ & Pump has been removed, \\
\hline MS & 08/09/92 & $\begin{array}{l}\text { Strongly turbid; brown; } \\
\text { sand }\end{array}$ & MSB 79B & 08/08/92 & $\begin{array}{l}\text { unable to sample } \\
\text { Dry after } 36 \mathrm{gal}\end{array}$ \\
\hline MSB & 08/08/92 & $\begin{array}{l}\text { Dry after } 46 \text { gal; leaks at } \\
\text { elbow and T-joint }\end{array}$ & $\begin{array}{l}\text { MSB 79C } \\
\text { MSB 82A }\end{array}$ & $\begin{array}{l}08 / 08 / 92 \\
08 / 09 / 92\end{array}$ & $\begin{array}{l}\text { Dry after } 6 \mathrm{gal} \\
\text { Dry after } 30 \mathrm{gal}\end{array}$ \\
\hline MSB 46B & 08/09/92 & No water in standpipe & MSB 83D & 08/09/92 & Dry after $10 \mathrm{gal}$ \\
\hline MSB & 08/09/92 & y lurbid; brown & MSB 85C & $08 / 10 / 92$ & Dry after 44 gal \\
\hline MSB & $07 / 25 / 92$ & Dry after $3 \mathrm{gal}$ & MSB 85TA & 08/09/92 & Dry after $34 \mathrm{gal}$ \\
\hline MS & $\begin{array}{l}07 / 26 / 92 \\
08 / 06 / 92\end{array}$ & $\begin{array}{l}\text { Weakly turbid; brown } \\
\text { Dry after } 13 \mathrm{gal}\end{array}$ & & $08 / 10 / 92$ & $\begin{array}{l}\text { Weakly turbid; olive-green; } \\
\text { diesel-like odor }\end{array}$ \\
\hline
\end{tabular}


Table 5. Comments from the Field Data (cont.)

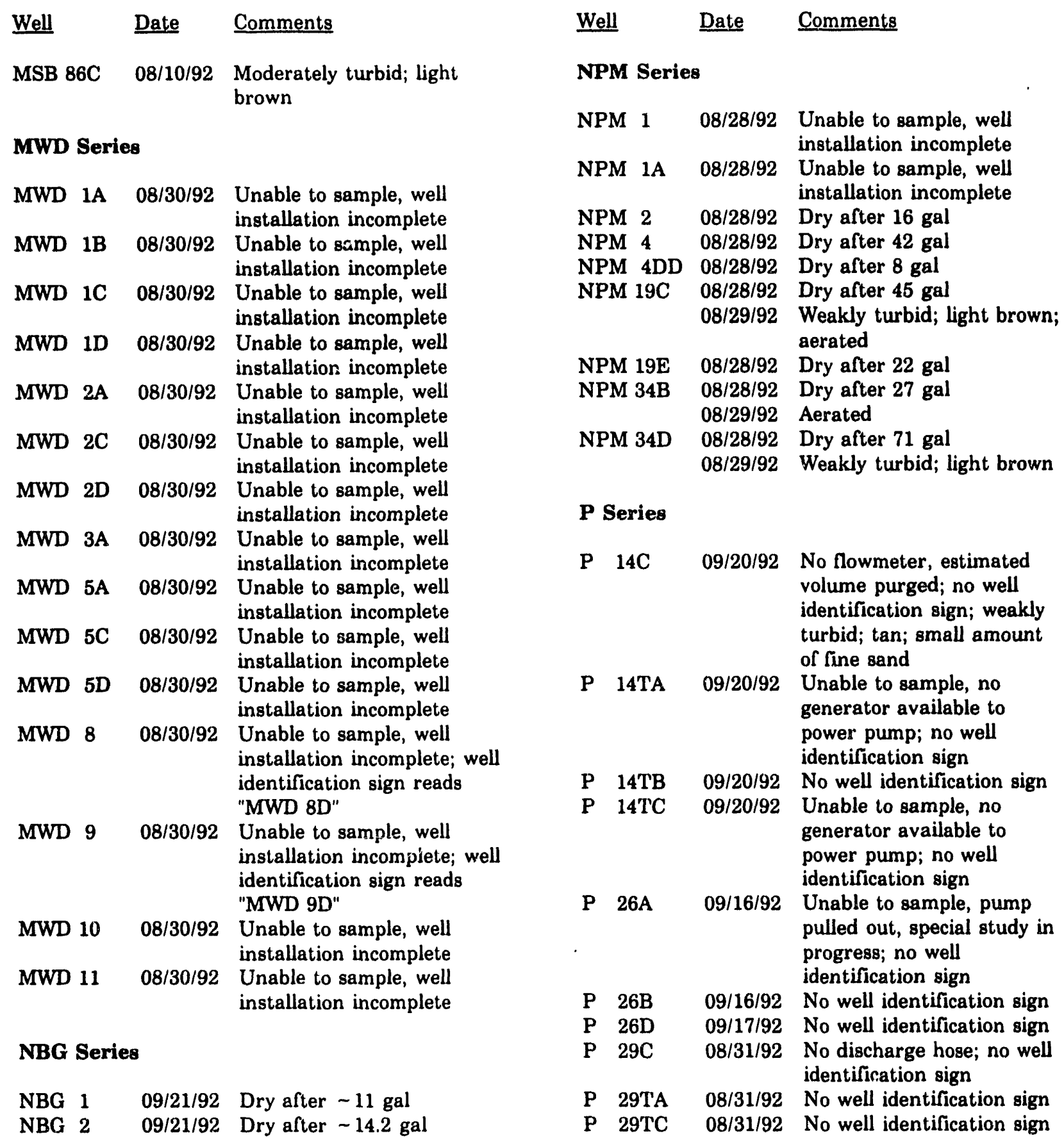

PAC Series

$\begin{array}{lll}\text { PAC } 5 & 08 / 15 / 92 & \text { Dry after } 10 \text { gal } \\ \text { PAC } 6 & 08 / 15 / 92 & \text { Dry after } 10 \text { gal }\end{array}$

PCB Series

PCB 1A 08/23/92 Discharge hose sprays PCB 2A 08/23/92 Discharge hose sprays 
Table 5. Comments from the Field Data (cont.)

$\begin{array}{lll}\text { Well } & \text { Date } & \text { Comments } \\ \text { PCB 4A } & 08 / 23 / 92 & \begin{array}{l}\text { Discharge hose sprays; } \\ \text { sample valve leaks }\end{array} \\ \text { PDB Series } & & \\ \text { PDB 2 } & 08 / 26 / 92 & \begin{array}{l}\text { Leaks at T-joint; aerated } \\ \text { Well located inside barri- } \\ \text { PDB 3 }\end{array} \\ & 08 / 26 / 92 & \begin{array}{l}\text { caded area next to open } \\ \text { hole }\end{array}\end{array}$

\section{PRP Series}

PRP 3 08/23/92 Flowmeter not working, estimated volume purged

\section{PSB Serie日}

$\begin{array}{lll}\text { PSB 5A } & 08 / 26 / 92 & \begin{array}{l}\text { Discharge hose leaks, } \\ \text { sprays }\end{array} \\ \text { PSB 6A } & 08 / 26 / 92 & \begin{array}{l}\text { Flowmeter not working, } \\ \text { estimated volume purged }\end{array}\end{array}$

\section{PSS Series}

PSS 3D 08/23/92 Dry after 5 gal; no water in standpipe; weakly turbid; light brown

\section{RAC Series}

RAC $108 / 22 / 92$ Moderately turbid; white

\section{RCP Series}

$\begin{array}{lll}\text { RCP 1A } & 09 / 18 / 92 & \begin{array}{l}\text { No discharge hose; sign } \\ \text { reads "RCP 1D" }\end{array} \\ \text { RCP 1D } & 09 / 18 / 92 & \begin{array}{l}\text { No discharge hose; sign } \\ \text { reads "RCP 1A" }\end{array}\end{array}$

\section{RDB Series}

RDB 1D 09/18/92 Dry after -16.2 gal; very weakly turbid, very light brown

RDB 3D 09/18/92 Weakly turbid; light brown

\section{RRP Series}

RRP $2 \quad 08 / 22 / 92$ Discharge hose sprays

\section{RSE Series}

RSE 12 09/16/92 Unable to sample, puller

RSE $24 \quad 09 / 18 / 92$ Dry after -37.5 gal $\begin{array}{lll}\text { Well } & \text { Date } & \text { Comments } \\ \text { RSE 25 } & 09 / 18 / 92 & \text { Dry after } \sim 25.4 \mathrm{gal}\end{array}$

RSF Series

RSF $109 / 15 / 92$ No well identification sign

RSF $209 / 15 / 92$ Discharge hose leaks, sprays; no well identification sign

RSF $3 \quad 09 / 15 / 92$ No well identification sign

\section{RWM Series}

RWM $107 / 13 / 92$ No water in standpipe; aerated

$08 / 11 / 92$ No water in standpipe; aerated

$09 / 12 / 92$ No water in standpipe; aerated

RWM $207 / 13 / 92$ No water in standpipe; aerated

08/11/92 No water in standpipe; aerated

09/12/92 No water in standpipe; aerated

RWM $16 \quad 08 / 21 / 92$ No well identification sign

SBG Series

SBG $3 \quad 08 / 14 / 92$ No discharge hose

SCA Series

SCA $3 \quad 09 / 28 / 92$ Dry after $\sim 14$ gal; no discharge hose; weakly turbid; light brown

SCA 3A 09/28/92 Dry after $\sim 2.9$ gal; turbidity varied; light brown

SCA $4 \quad 09 / 28 / 92$ Dry after -10 gal; turbidity varied; light brown

SCA 4A 09/28/92 Dry after -1.5 gal; turbidity varied; brown

SCA $5 \quad 09 / 28 / 92$ Dry after -8 gal; no discharge hose; weakly turbid; light brown

SCA $6 \quad 09 / 28 / 92$ Dry after $\sim 11.5$ gal; weakly turbid; light brown

\section{SLP Series}

$\begin{array}{lll}\text { SLP } 1 & 08 / 14 / 92 & \begin{array}{l}\text { No discharge hose; weakly } \\ \text { turbid; light brown }\end{array} \\ \text { SLP } 2 & 08 / 14 / 92 & \text { No discharge hose }\end{array}$


Table 5. Comments from the Field Data (cont.)

\begin{tabular}{|c|c|c|}
\hline Well & Date & Comments \\
\hline \multicolumn{3}{|c|}{ SRW Series } \\
\hline SRW 1 & $07 / 11 / 92$ & $\begin{array}{l}\text { Pump has been removed, } \\
\text { unable to sample }\end{array}$ \\
\hline SRW 2 & $07 / 11 / 92$ & Very weakly turbid; tan \\
\hline SRW 9 & $07 / 12 / 92$ & Discharge hose sprays \\
\hline SRW 9A & $07 / 12 / 92$ & Discharge hose sprays \\
\hline SRW 9B & 07/12/92 & Discharge hose sprays \\
\hline SRW 10 & $07 / 13 / 92$ & $\begin{array}{l}\text { No water in standpipe; } \\
\text { sample T split and sprays; } \\
\text { discharge hose sprays; } \\
\text { surges }\end{array}$ \\
\hline & 07/13/92 & Discharge hose split \\
\hline & $07 / 12 / 92$ & $\begin{array}{l}\text { No water in standpipe; } \\
\text { discharge hose sprays }\end{array}$ \\
\hline SRW 15A & 07/11/92 & Discharge hose sprays \\
\hline SRW 16B & 07/11/92 & Discharge hose sprays \\
\hline SRW 15C & 07/11/92 & Discharge hose sprays \\
\hline \multirow[t]{2}{*}{ SRW 16A } & $07 / 11 / 92$ & Dry after $23 \mathrm{gal}$ \\
\hline & $07 / 12 / 92$ & Moderately turbid; brown \\
\hline & $07 / 11 / 92$ & Discharge hose sprays \\
\hline
\end{tabular}

Well Date Comments

SSS $23 \quad 08 / 25 / 92 \quad$ Moderately turbid; orangebrown

SSS $24 \quad 08 / 16 / 92$ Dry after $-550 \mathrm{ml}$; strongly turbid; brown; sand

08/25/92 Dry after $-4.6 \mathrm{~L}$

$08 / 26 / 92$ Strongly turbid; brown; sand

SSS $25 \quad 08 / 16 / 92$ Moderately turbid; light brown

SSS $26 \quad 08 / 15 / 92$ Strongly turbid; pink; sand

SSS $27 \quad 08 / 16 / 92$ Moderately turbid; brown

TBG Series

TBG $1 \quad 09 / 21 / 92 \quad$ T-joint leaks

TNX Series

TNX 3D 09/16/92 Dry after $\sim 7.6 \mathrm{gal}$

SSS Series

09/17/92 Turbidity varied; light brown

TNX 4D 09/16/92 Dry after $-9.1 \mathrm{gal}$

SSS $1 \quad 08 / 25 / 92$ Strongly turbid; brown; sand

SSS $208 / 25 / 92$ Moderately turbid; tan

SSS $3 \quad 08 / 25 / 92$ Dry after 5 gal

08/25/92 Moderately turbid; brown

SSS 4 08/16/92 Strongly turbid; orange; sand

SSS $5 \quad 08 / 16 / 92$ Moderately turbid; orangebrown, sand

SSS $6 \quad 08 / 16 / 92$ Strongly turbid; orange; sand

SSS $7 \quad 08 / 16 / 92$ Moderately turbid; orangebrown

SSS $8 \quad 08 / 16 / 92$ Strongly turbid; orange; sand

SSS 10 08/25/92 Moderately turbid; yellowbrown

SSS $11 \quad 08 / 25 / 92$ Dry after $1.5 \mathrm{~L}$

08/26/92 Strongly turbid; brown; sand

SSS $12 \quad 08 / 25 / 92$ Dry after $1.2 \mathrm{~L}$

08/26/92 Strongly turbid; brown

SSS $17 \quad 08 / 16 / 92$ Strongly turbid; red; sand

SSS $19 \quad 08 / 16 / 92$ Dry after - 2 gal; weakly turbid; light brown

SSS $21 \quad 08 / 16 / 92$ Dry after -3 L; moderately turbid; yellow-brown

SSS $22 \quad$ 08/25/92 Moderately turbid; light brown

09/17/92 Turbidity varied; light brown

TNX 5D 09/16/92 Dry after $\sim 3.9 \mathrm{gal}$

TNX 6D 09/16/92 Dry after $-7.3 \mathrm{gal}$

TNX 11D 09/17/92 Turbidity varied; brown

XSB Series

XSB 1A 09/11/92 Gate valve and discharge

XSB 2D

hose leak

09/16/92 Dry after $\sim 8 \mathrm{gal}$

09/17/92 Aerated

YSB Serie8

YSB 1A $\quad 09 / 16 / 92 \quad$ Very weakly turbid; very light brown

YSB 2A 09/16/92 Discharge hose leaks, sprays

YSB 4A 09/16/92 Very weakly turbid; very light brown

YSC Series

YSC 1A 08/25/92 Unable to sample, well hit by lightning; no well identificstion sign

YSC 1C 08/25/92 No well identification sign

YSC 2A 08/25/92 No well identification sign

YSC 2D 08/25/92 Dry after $\sim 12.6$ gal; no well identification sign 
Table 5. Comments from the Field Data (cont.)

Well Date Comments

YSC 2D 08/26/92 Moderately turbid; light

brown

YSC 4C 08/26/92 No well identification sign

ZBG Series

ZBG 1A 08/25/92 Dry after $6 \mathrm{gal}$

ZW Series

ZW $1 A$ UA Unable to sample, gate to well locked

ZW $7 \quad 07 / 15 / 92$ Unable to sample, sampler could not get to well safely 
NOTES 
Sample analyses performed for EPD/EMS during third quarter 1992 were conducted by EPA methods, except as noted in Tables 21 and 22 on pages $60-69$.

General Engineering Laboratories (GE) of Churleston, SC, and Roy F. Weston, Inc. (Weston or WA), of Lionville, PA, the primary contracting laboratories for sample analysis, performed all analyses, with the following exceptions:

- The EPD/EMS Laboratory (EM Lab or EM) at SRS conducted total-activity analyses of samples for shipping clearance. The EM Lab also conducted gross alpha, nonvolatile beta, tritium, and selected radionuclide analyses of samples from specified well series.

- Environmental Physics (GP) and Clemson Technical Center, Inc. (Clemson TC or CN) had radionuclide contracts; Teledyne Isotopes (Teledyne or TE) subcontracted radionuclide analyses for Environmental Physics; and TMA/Eberline (TM) subcontracted radionuclide analyses for Weston.

\section{REVIEW OF THE ANALYTICAL DATA FOR ERRORS}

Exceeded holding time is indicated by a notation of $Q$ in the analytical-results tables. See page A-2 for further information.

EPD/EMS reviews analytical data from the laboratories for errors and unusual results before entering this information into the database. All suspect data are brought to the attention of the laboratories for review, corrections, and comments.
Typical errors corrected for entry into the database include incorrect sample dates, run dates, and sample identifications; incorrectly entered analytical units, methods, and corresponding detection limits; incorrect dilution factor calculations; and analytical-data entry errors.

Analytical results that appear different from historical data collected since 1988 are brought to the attention of the appropriate laboratory. Thus, the laboratory is able to identify problems with some of these analyses, including incorrect dilution factor calculations and data entry errors. EPD/EMS corrects data files after receiving written notification from the laboratory.

Specific details concerning the corrections are entered in the EMS Groundwater Monitoring Program Changes to the Database Logbook, where the corrections are recorded.

\section{Review of GE's Analytical Data}

Some of GE's results for laboratory blanks are qualified with $J 1$ because of problems associated with the blank itself or with the batch that the blank is in. For example, acids and base/ neutrals may have a $J 1$ modifier if any surrogates failed. For metals analyses exhibiting surrogate failure, GE flagged $J 1$ those samples with results above detection limit and $J 2$ those samples with results below detection limit instead of using the numeric qualifier to indicate the direction of bias; see page A-2. Surrogate failure is not accounted for individually in letters accompanying data from GE.

In the past, GE has omitted $V$ qualifiers from certain GCMS volatiles results because of insufficient space in the data record for all applicable qualifiers. In the future, $V$ qualifiers will be applied with priority over numerical qualifiers. 
The tetrachloroethylene and trichlororethylene results from well BRR $1 D$ are suspect because of the possibility of carryover from the previous sample; the sample was not reanalyzed because holding time had expired.

$\begin{array}{lll}\text { AMB 4A } & \text { FSB 90C } & \text { HSB 66 } \\ \text { AMB 10D } & \text { FSB 91C } & \text { HSB 68A } \\ \text { BGO 8C } & \text { FSB 96AR } & \text { HSB 68B } \\ \text { BGO 10AR } & \text { FSB 99A } & \text { HSB 69A } \\ \text { BGO 27C } & \text { FSB100A } & \text { HSB 70 } \\ \text { FSB 76A } & \text { FSB101A } & \text { HSB 76B } \\ \text { FSB 76B } & \text { FSB123C } & \text { HSB 83A } \\ \text { FSB 76C } & \text { FSB123D } & \text { HSB 83B } \\ \text { FSB 78B } & \text { HSB 1TB } & \text { HSB 83C } \\ \text { FSB 87A } & \text { HSB 65 } & \text { HSB 84A } \\ \text { FSB 87B } & \text { HSB 65A } & \text { HSB 84B } \\ \text { FSB 87C } & \text { HSB 65B } & \text { HSB 85A } \\ \text { FSB 89C } & \text { HSB 65C } & \text { HSB 85B }\end{array}$

Some, but not all, of the results are flagged with $\mathrm{J} 1$ in Appendix A.

Matrix interferences also caused unusually low spike recoveries for the following analyses: antimony for FSB113A and HSB 86B; lead for BG 67 and DCB 11; sulfate for FSB 97D; and thallium for FSB 91D. The spike recovery for
Matrix interferences appear to be responsible for low selenium-spike recoveries for the following wells:
MSB 14C
MSB 17A
MSB 18A
MSB 19A
MSB 19B
MSB 19C
MSB 39A
MSB 39B
MSB 39C
MSB 39D
MSB 39TA
MSB 40TA

Table 6. GE Laboratory Blanks with Elevated Results

$\begin{array}{lll}\text { Analyte } & \text { Run Date } & \text { Result } \\ \text { Methyl ethyl ketone } & 7 / 02 / 92 & 6.0 \mu \mathrm{g} / \mathrm{L} \\ \text { Methyl ethyl ketone } & 7 / 28 / 92 & 8.8 \mu \mathrm{g} / \mathrm{L} \\ \text { Phenols } & 7 / 30 / 92 & 6.8 \mu \mathrm{g} / \mathrm{L}\end{array}$

Tin $8 / 13 / 92 \quad 3.43 \mu g / L$

Nonvolatile beta $\quad \begin{gathered}8 / 13 / 92 \\ \mu \mathrm{E}-09 \\ \mu \mathrm{Ci} / \mathrm{mL}\end{gathered}$

GE found no errors upon reviewing the records of the EPD/EMS blind blanks having elevated results. All five of the trip blanks for total inorganic carbon showed elevated results (above $5,000 \mu \mathrm{g} / \mathrm{L}$ ). This parameter is calculated as the difference between analytical results for total

\section{Well Samples Accompanying Blanks}

HMD 2D, HMD 3D

AMB 7A, AMB 10A, AMB 11B, MSB 62B, MSB 63C, MSB 63D

ABP 8C, FSB121DR, FSB122D, HSB140A, HSB140C, HSB140D, HSB141D, HSB142C, HSB142D, HSB143C, HSB143D, MSB 20C, MSB 21A, MSB 23B, MSB 21C, MSB 29B, MSB 36C, MSB 36TA, MSB 40A, MSB 62B, MSB 62C, MSB 62D, MSB 63B, MSB 63C, MSB 63D, MSB 77D

BGO 6A, BGO 6C, BGO 8C, BGO 8D, BGO 9D, BGO 11D, BGX 1A, BGX 1C, BGX 1D, BGX 3D, BGX 8DR, BGX 11D

FSB121DR, FSB122D, HSB143C, MSB 62B, MSB 62C, MSB 62D

carbon and total organic carbon. The blanks for those analyses were not elevated. Table 7 lists the groundwater samples from the same analytical batches as the elevated blanks for other analyses. 
Table 7. EPD/EMS Blind Blanks with Elevated Results from GE

Analyte

as nitrogen

Nitrate-nitrite as nitrogen

Nitrate-nitrite as nitrogen

Nitrate-nitrite as nitrogen

Nitrate-nitrite as nitrogen

Nitrate-nitrite as nitrogen

Nitrate-nitrite as nitrogen

Nitrate-nitrite as nitrogen
Blank $\quad$ Regult

QA $22 \mathrm{C} \quad 350 \mu \mathrm{g} / \mathrm{L}$

QA $42 \mathrm{C} \quad 600 \mu \mathrm{g} / \mathrm{L}$

QA $32 C \quad 160 \mu \mathrm{g} / \mathrm{L}$

QA $36 C \quad 1,510 \mu \mathrm{g} / \mathrm{L}$

QA $52 \mathrm{C} \quad 150 \mu \mathrm{g} / \mathrm{L}$

QA $60 \mathrm{C} \quad 640 \mu \mathrm{g} / \mathrm{L}$

QA $100 \mathrm{C} \quad 890 \mu \mathrm{g} / \mathrm{L}$

QA 116C $792 \mu \mathrm{g} / \mathrm{L}$
Well Samples Accompanying Blanks

ASB 1A, ASB 2A, ASB 2C, ASB 3A, ASB 9, ASB 9B, ASB 9C, DOB 1, DOB 2, DOB 3, DOB 4, FSB 92D, FSB 93D, FSB 94C, FSB 94DR, FSB 95CR, FSB 97C, FSB 98C, FSB 98D, FSB 99A, FSB 99C, FSB104D, FSB107D, FSB109D, FSB110C, FSB110D, FSB112A, HSB 70C, HSB 86C, HSB 86D, HSB101D, HSB103D, HSB109C, HSB110C, HSB110D

FSB 76A, FSB 76B, FSB 76C, FSB 78B, FSB 87C, FSB 88C, FSB 88D, FSB 90C, FSB 91C, FSB 96AR, FSB101A, HSB 64A, HSB 65, HSB 70, HSB 84A, HSB 84B, HSB 85A, HSB 85B, HSB 85C, HSB 86A, HSB 86B, HSB100C, MSB 4B, MSB 4D, MSB 10A, MSB 10B, MSB 11A, MSB 11B, MSB 14B, MSB 14C, MSB 15AA, MSB 17A, MSB 17D, MSB 18A, MSB 18B, MSB 18C, MSB 19A, MSB 19B, MSB 19C, MSB 32, MSB 33, MSB 33A, MSB 33B, MSB 33C, MSB 33TA, MSB 39A AOB 1, AOB 2, AOB 3, FSB 89C, FSB 98AR, FSB 99D, FSB100A, FSB102C, FSB103C, FSB104C, FSB106C, FSB106D, FSB107C, FSB108D, FSB111C, FSB111D, FSB118D, HSB 68A, HSB 68B, HSB 69A, HSB 70, HSB 83A, HSB 83B, HSB 83C, HSB102C, HSB103C, HSB104C, HSB104D, HSB105C, MSB 1B, MSB 1C, MSB 1CC, MSB 1D, MSB 7A, MSB 7B, MSB 7C, MSB 8A, MSB 8B, MSB 8C FSB 78A, FSB 79A, FSB 79B, FSB 87A, FSB 87B, FSB 88C, FSB113A, FSB113C, FSB113D, FSB114A, FSB114C, FS114D, FSB115C, FSB115D, FSB116C, FSB116D, FSB123C, FSB123D, HMD 1D, HMD 4D, HSB 1TB, HSB 65B, HSB 65C, HSB 66, MSB 39B, MSB 39C, MSB 39D, MSB 39TA

BGO 1D, BGO 2D, BGO 3D, BGO 5C, BGO 5D, BGO 8AR, BGX 2B, BGX 2D, BGX 10D, BGX 12C, BGX 12D, CBR 3D, CSA 1, CSA 2, CSA 3, CSA 4, HSB147D, HSB149D, MSB 57D, MSB 60D, MSB 64C, MSB 64D

FSB 76, FSB 87D, FSB 89D, FSB 93C, HSB 69, HSB 83D, HSB 84C, HSB 84D, HSB100D, HSB101C, MSB 2D, MSB 5A, MSB 5B, MSB 5C, MSB 6A, MSB 6C, MSB 13A, MSB 13CC, MSB 13D

BGO 21D, BGO 23D, FCB 2, FCB 3, FTF 2, FTF 9, FTF 10, FTF 11, FTF 27, HTF 14, HTF 17, HTF 20, HTF 21, HTF 29, HTF 31, HTF 32, LCO 2, LCO 3, LCO 4, MSB 6B, MSB 9C, MSB 12A, MSB 12B, MSB 12C, MSB 13B, MSB 40B, MSB 47B, MSB 47C, MSB 58D, PSB 4A, PSB 5A, ZBG 1, ZBG 2 BGO 16A, BGO 16D, BGO 18A, BGO 18D, BGO 22D, BGO 24D, HAC 4, HCA 4, HTF 18, HTF 19, HTF 22, HTF 23, HTF 24, HTF 25, HTF 26, HTF 27, HTF 28, MSB 15C, MSB 15D, MSB 16C, MSB 42A, MSB 45A, MSB 47TA, MSB 48B, MSB 55HC, MSB 74B, MSB 76C, PSS 2D 
Table 7. EPD/EMS Blind Blanks with Elevated Results from GE (cont.)

\begin{tabular}{|c|c|c|c|}
\hline Analyte & Blank & Result & Well Samples Accompanying Blanks \\
\hline $\begin{array}{l}\text { Nitrate-nitrite } \\
\text { as nitrogen }\end{array}$ & QA $112 C$ & $624 \mu \mathrm{g} / \mathrm{L}$ & $\begin{array}{l}\text { FSL 6D, FTF 1, FTF 12, FTF 13, FTF 18, FTF 19, } \\
\text { FTF 24A, FTF 25A, FTF 26, HCA 3, HSL 1D, KSM 1D, } \\
\text { LCO } 1 \text {, LFW 6, NPM 4, NPM 19B }\end{array}$ \\
\hline Silica & QA $12 \mathrm{C}$ & $19,400 \mu \mathrm{g} / \mathrm{L}$ & BGO 49C, BGO 49D, BGO 50A, BGO 50C \\
\hline Silica & $\begin{array}{l}\text { QA } 76 C \text {; } \\
\text { QA } 78 C\end{array}$ & $\begin{array}{l}16,300 \mu \mathrm{g} / \mathrm{L} \\
19,000 \mu \mathrm{g} / \mathrm{L}\end{array}$ & $\begin{array}{l}\text { FSL 6D, HSL 1D, NPM 4, NPM 19B, P 29C, P 29TA } \\
\text { P 29TC }\end{array}$ \\
\hline Silica & QA $90 \mathrm{C}$ & $12,300 \mu \mathrm{g} / \mathrm{L}$ & $\begin{array}{l}\text { FAL 1, FAL 2, KRB 18D, P 14C, P 14TB, RCP 1D, } \\
\text { TBG } 1\end{array}$ \\
\hline Silica & $\begin{array}{l}\text { QA } 80 C ; \\
\text { QA } 92 C\end{array}$ & $\begin{array}{l}12,400 \mu \mathrm{g} / \mathrm{L} \\
12,500 \mu \mathrm{g} / \mathrm{L}\end{array}$ & P 26D, TNX 4D, TNX 5D, TNX 6D, TNX 10D \\
\hline Silica & QA $94 C$ & $14,600 \mu \mathrm{g} / \mathrm{L}$ & $\begin{array}{l}\text { TNX 3D, TNX 8D, TNX 9D, TNX 11D, TNX 12D, } \\
\text { XSB 2D }\end{array}$ \\
\hline Silica & QA $96 C$ & $19,100 \mu \mathrm{g} / \mathrm{L}$ & TBG 5A, TBG 5B, YSB $1 \mathrm{~A}$, YSB $2 \mathrm{~A}$, YSB $3 \mathrm{~A}$, YSB $4 \mathrm{~A}$ \\
\hline Silica & QA $108 \mathrm{C}$ & $29,600 \mu \mathrm{g} / \mathrm{L}$ & HAC 4 \\
\hline Silica & QA $112 C$ & $25,400 \mu \mathrm{g} / \mathrm{L}$ & FCB 2, FCB 3, LFW 6 \\
\hline Silica & QA 82C & $16,200 \mu \mathrm{g} / \mathrm{L}$ & $\mathrm{P} \quad 28 \mathrm{~A}$ \\
\hline Silica & QA 114C & $16,300 \mu \mathrm{g} / \mathrm{L}$ & HSL 6D, HSL 7D, HSL 8D, LFW 59D \\
\hline $\begin{array}{l}\text { Total dissolved } \\
\text { solids }\end{array}$ & QA $76 C$ & $\begin{array}{l}31,000 \mu \mathrm{g} / \mathrm{L} \\
25,000 \mu \mathrm{g} / \mathrm{L}\end{array}$ & $\begin{array}{l}\text { FCB 5, FCB 6, KSM 1D, NPM 2, NPM 3, NPM 4, } \\
\text { NPM 4DD, NPM 19A, NPM 19B, NPM 19C, NPM 19D, } \\
\text { NPM 34C, NPM 34E }\end{array}$ \\
\hline $\begin{array}{l}\text { Total dissolved } \\
\text { solids }\end{array}$ & QA $78 \mathrm{C}$ & $27,000 \mu \mathrm{g} / \mathrm{L}$ & $\begin{array}{l}\text { FSL 6D, HSL 1D, NPM 4, NPM 19B, NPM 19E, } \\
\text { NPM 34A, NPM 34B, NPM 34D }\end{array}$ \\
\hline $\begin{array}{l}\text { Total dissolved } \\
\text { solids }\end{array}$ & QA $96 \mathrm{C}$ & $23,000 \mu \mathrm{g} / \mathrm{L}$ & $\begin{array}{l}\text { 26B, RSF 1, RSF 2, RSF 3, TBG 5B, TBG } 7 \text {, } \\
\text { TNX 2D, YSB 1A, YSB 2A, YSB } 3 A \text {, YSB } 4 A\end{array}$ \\
\hline $\begin{array}{l}\text { Total dissolved } \\
\text { solids }\end{array}$ & QA $94 \mathrm{C}$ & $71,000 \mu \mathrm{g} / \mathrm{L}$ & TNX 1D, TNX 7D, XSB 3A, XSB 4D, XSB 5A \\
\hline $\begin{array}{l}\text { Total dissolved } \\
\text { solids }\end{array}$ & QA $108 C$ & $37,000 \mu \mathrm{g} / \mathrm{L}$ & HAC 4, MSB 74B, MSB 75B, MSB 76C, PSS 2D \\
\hline $\begin{array}{l}\text { Total dissolved } \\
\text { solids }\end{array}$ & QA 114C & $26,000 \mu \mathrm{g} / \mathrm{L}$ & HSL 6D, LFW 59D \\
\hline $\begin{array}{l}\text { Total petroleum } \\
\text { hydrocarbons }\end{array}$ & QA $106 C$ & $1,800 \mu \mathrm{g} / \mathrm{L}$ & CMP 11B, CMP 14C \\
\hline $\begin{array}{l}\text { Total phosphates } \\
\text { (as P) }\end{array}$ & QA $20 \mathrm{C}$ & $240 \mu \mathrm{g} / \mathrm{L}$ & $\begin{array}{l}\text { ASB 4, ASB 5A, ASB 6A, ASB 6C, ASB 7, BGO 6A, } \\
\text { BGO 6C, BGO 6D, BGO 8C, BGO 8D, BGO 9D, } \\
\text { BGO 10AA, BGO 10AR, BGO 10C, BGO 11D, BGO 12CR, } \\
\text { BGO 12D, BGO 25A, BGO 26D, BGO 27D, BGO 29A, } \\
\text { BGO 29C, BGO 29D, BGO 33D, BGO 34D, BGO 35C, } \\
\text { BGO 36D, BGO 37D, BGO 38D, BGO 39D, BGO 43AA, } \\
\text { BGX 1A, BGX 1C, BGX 1D, BGX 3D, BGX 8DR, } \\
\text { BGX 11D, CBR 2D, KAC 8, LAW 1D, LAW 2B, } \\
\text { LAW 3B, LAW 3C, MSB 31A, MSB 31B, MSB 47BB }\end{array}$ \\
\hline $\begin{array}{l}\text { Total phosphates } \\
\text { (as P) }\end{array}$ & QA $26 \mathrm{C}$ & $62 \mu \mathrm{g} / \mathrm{L}$ & $\begin{array}{l}\text { FSB 78A, FSB 79A, FSB 79B, FSB 88C, FSB 88D, } \\
\text { FSB113A, FSB113C, FSB113D, FSB114A, FSB114C, } \\
\text { FSB114D, FSB115C, FSB116C, FSB116D, HMD 1D, } \\
\text { HMD 4D }\end{array}$ \\
\hline $\begin{array}{l}\text { Total phosphates } \\
\text { (as P) }\end{array}$ & QA $46 \mathrm{C}$ & $165 \mu \mathrm{g} / \mathrm{L}$ & $\begin{array}{l}\text { ASB 1A, ASB 3A, FSB 99A, FSB 99C, FSB 99D, } \\
\text { FSB100A, FSB102C, FSB103C, FSB104C, FSB106C, } \\
\text { FSB106D, FSB107C, FSB107D, FSB108D, FSB109D, } \\
\text { FSB110C, FSB111D, HSB102C, HSB103C, HSB104C, } \\
\text { HSB104D, HSB109C, HSB110C, HSB110D, MSB 1B, } \\
\text { MSB 1C, MSB 1CC, MSB 1D, MSB 7A, MSB 7B, } \\
\text { MSB 7C, MSB 8A, MSB 8B, MSB 8C }\end{array}$ \\
\hline Zinc & QA $16 \mathrm{C}$ & $24.8 \mu \mathrm{g} / \mathrm{L}$ & 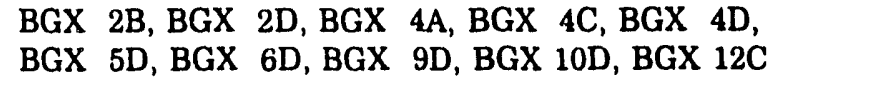 \\
\hline
\end{tabular}


Table 7. EPD/EMS Blind Blanks with Exevated Results from GE (cont.)

\begin{tabular}{|c|c|c|c|}
\hline Analyte & Blank & $\underline{\text { Result }}$ & Well Samples Accompanying Blanks \\
\hline Gross alpha & QA 60C & $\begin{array}{r}7.7 \mathrm{E}-08 \\
\mu \mathrm{Ci} / \mathrm{mL}\end{array}$ & $\begin{array}{l}\text { FET 2D, FET 3D, FET 4D, FSB } 76 \text {, FSB 89D, FSB 93C } \\
\text { HSB } 69 \text {, HSB 83D }\end{array}$ \\
\hline Nonvolatile beta & QA 60C & $\begin{array}{r}7.3 \mathrm{E}-08 \\
\mu \mathrm{Ci} / \mathrm{mL}\end{array}$ & FSB 76, FSB 89D, FSB 93C, HSB 69, HSB 83D, MSB 13D \\
\hline $\begin{array}{l}\text { Total alpha-emitting } \\
\text { radium }\end{array}$ & QA 72C & $\begin{array}{r}1.2 \mathrm{E}-08 \\
\mu \mathrm{Ci} / \mathrm{mL}\end{array}$ & $\begin{array}{l}\text { FSB121DR, FSB122D, HSB126C, HSB127C, HSB143C, } \\
\text { HSB143D, MSB 20C, MSB 62B }\end{array}$ \\
\hline
\end{tabular}

A technical review of the quarter's analytical data identified at least one reported result for the analyses in Table 8 as high in comparison to historical data. A review of the laboratory records did not reveal any problems with the anaiyses, except as noted previously.

\section{Tablo 8. GE Samples with High Analytical Results as Compared to Historical Data}

Analyte

Aluminum
Arsenic
Barium
Benzene
Bis(2-ethylhexyl) phthalate
Carimium
Calcium
Carbon tetrachloride
Chloride
Chloroethane
Chloroform
Chromium
Copper
1,1-Dichloroethylene
Dichloromethane (Methylene
chioride)

Fluoride

Iron

Lead

Magnesium

Wells

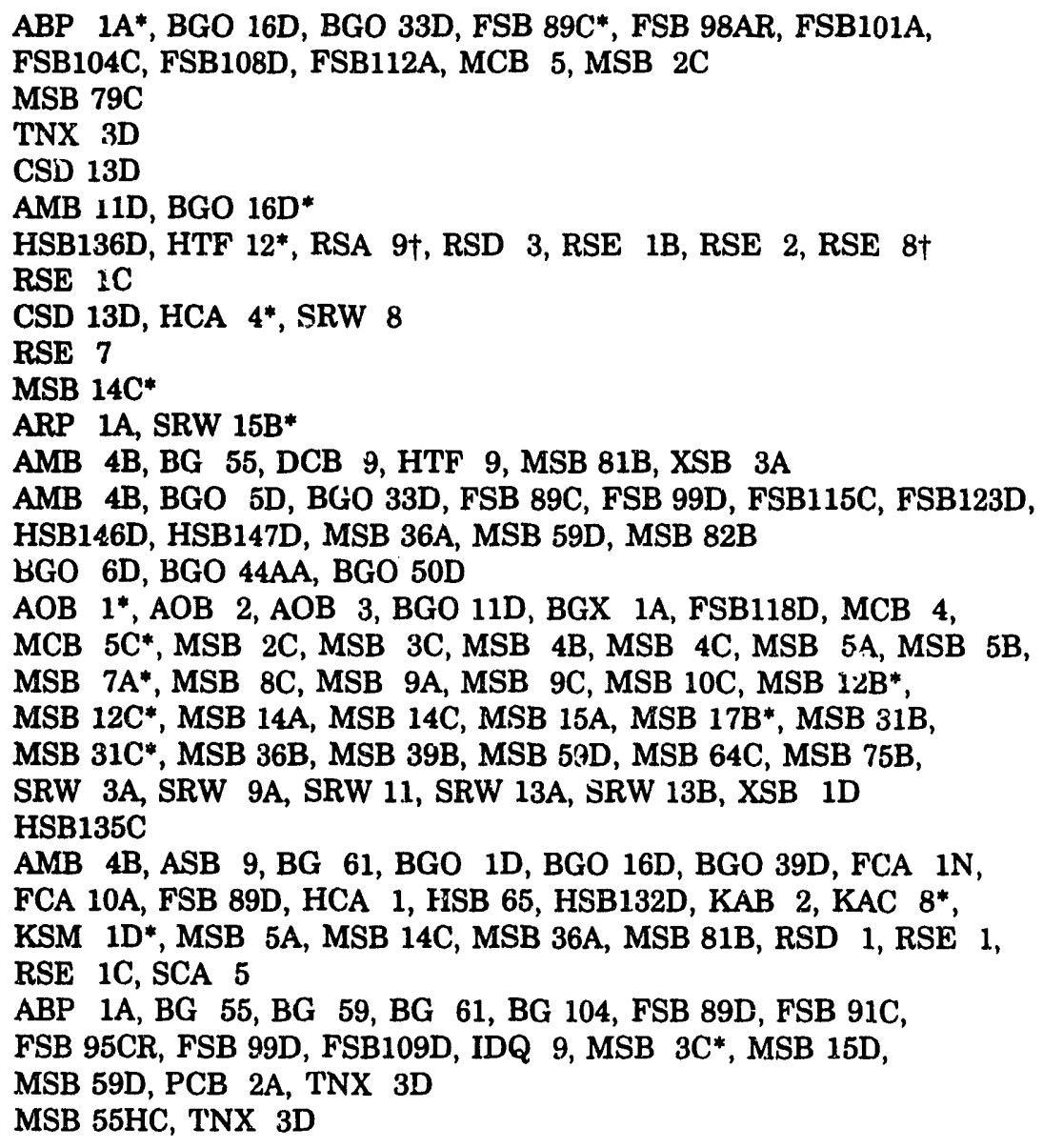

\footnotetext{
* The questioned result was at least 10 times higher than historical data. Because holding time had not been exceeded, the laboratory was asked to reanalyze the sample.

$\dagger$ This result was more than 10 times higher than historical results, but all third-quarter samples had been discarded before reanalysis was requested.
} 
Table 8. GE Samples with High Analytical Results as Compared to Historical Data (cont.)

Analyte

Manganese

Mercury

Nickel

Nitrate-nitrite as nitrogen

Potassium

Silica

Silver

Sodium

Specific conductance

Sulfate

Tetrachloroethylene

Thallium

Tin

Toluene

Total dissolved solids

Total inorganic carbon

Total organic carbon

Total organic halogens

Total petroleum hydrocarbons

Total phosphates (as P)

Tributyl phosphate

1,1,1-Trichloroethane

Trichloroethylene

Trichlorofluoromethane

Turbidity

Uranium

Vanadium
Wells

ABP 2A, ACB 4A, BG 55, BG 59, BG 61, BGO 24D, BRD 3, FSB 78A, FSB 89C, KAB 2*, MSB 36A, PCB 2A*

BG 55, BG 59, BG 61, BGO 46D, BGO 48D*, DOB 2, FCB 6 , FSB117D, FSB123C, HSB111C, HSB113D, HSB114D*, HSB115D*, HSB116C*, HTF 17, HTF 22, HTF 23, HTF 25, LFW 59D, MSB 64C, TNX 3D

AMB 4B, MSE 6B, MSB 12TB, MSB 36A, RSA 8, RSA 9, RSE 1A, RSE 1B十, RSE 2, RSE 8†, RSE 9, RSE 10

FAL 1, FSB 79A, FSB 97D, FSB122D, HR3 13, HSB 1TB, HSB 68A, HSB 83A, HSB 83B*, HSB108C, HTF 10, LFW 6, MSB 31C*,

MSB 39D*, MSB 39TA*, NPM 34E, RDB 3D, RSE 3A, YSB 2A

BGX 2B, HSB136C, MSB 83B, NPM 4

BGO $3 D^{*}$

MSB 43D

BGX 2B, FSB 94DR, FSB 97D, FTF 6, TNX 35

NPM 34D

PCB 2A*, RCP 1D, RSE 1A, RSE 1C, YSB 2A

ABP 1A, BGO 23D, BGO 35C, BGO 44AA, BGO 44D, BRR 1D,

MSB 1C, MSB 12A*, MSB 12C*, MSB 18C, MSB 23B, MSB 32,

MSB 47D, MSB 74C, MSB 75C, RWM 4

MSB $1 \mathrm{C}$

BGO 8C, BGO 13DR, BGO 25A, BGO 36D, BGO 45C, MSB 2C,

MSB 4C, MSB 62C

MCB 5C*, MSB 9A, MSB 11D, SRW 10

BGO 44D, RSB 7

TNX 1D, XSB 3A, XSB 4D

FSB 79, HSB136C, HSB137C, MSB 29A, MSB 46C, RSA 9*, RSE 1C,

RSF $1^{*}$, TNX 11D, YSB 2A

ABP 8C, ASB 8A, BGO 18A, BGO 34D, BGO 50D, FSB106D,

HSB112E, KAC 8, MSB 1C, MSB 2B, MSB 9C, MSB 12C, MSB 15AA, MSB 23B, MSB 27B, MSB 33, MSB 33TA*, MSB 36A*, MSB 82A,

MSB 85D, SRW 10

DOB 3

ASB 10C, BGX 1A, BGX 1C, BGX 2B, CBR 2D, FAL 2, FSB 76, FSB 99D, FSB103C, FSB108D, FSB116C, HSB141D, HSB142D,

KRB 17D, MSB 15C*, RSF 3, YSB 2A

FSB 79C, FSB110D

BGO 44AA, MSB ICC

ABP 1A*, ACB 2A, ARP 4, BGO 23D, BGO 35C, BRR 1D, MSB 11B,

MSB 12C*, MSB 18C*, MSB 26, MSB 32*, MSB 36A*, MSB 47D*,

MSB 70D*, MSB 75C, MSB 82A, RWM 8, TNX 3D

BGO 6D, BGO 7D, BGO 14AR, BGO 39D, FSB115C*, HSB 85A,

MSB 7B, MSB 31B*, SRW 4

BGO $5 \mathrm{C}$

MSB 3C

MSB 3C, MSB 62D

* The questioned result was at least 10 times higher than historical data. Because holding time had not been exceeded, the laboratory was asked to reanalyze the sample.

† This result was more than 10 times higher than historical results, but all third-quarter samples had been discarded before reanalysis was requested. 
Table 8. GE Samples with High Analytical Results as Compared to Historical Data (cont.)

Analyte

Zinc

Gross alpha

Nonvolatile beta

Total alpha-emitting radium

Tritium
Wells

BGO 1D, FSB 87D, FSB114A, FSB115C, HSB 68B, HSB129C, MSB 6C, MSB 70D, MSB 75C, RSA 8, RSA 9, RSE 1A, RSE 1B, RSE 7, RSE 8†, RSE 9

BG 59, BG 91, FCA 10A, FTF $6 *$, FTF 7 , FTF 13, FTF 19, H 17*, HSB 71C, HSB143D, KDB 1, MGG 28, MSB 14C, MSB 31B, MSB 31C, MSB 34C, MSB 49D, MSB 54D, MSB 55D, MSB 57D, MSB 65D, MSB 69D, RSA 7, RSC 10, RSD 1, RSE 1B, RSE 11, TNX 3D, XSB 1Dt, XSB 3A, YSC 1C

ASB 3C, BGX 2D, CBR 1D, CBR 3D, DCB 7, FSB122D, FTF 2, FTF 6*, FTF 9, FTF 13, HSB 84C, HSB118A, HSB134C, HSB139A*, HTF 11, HTF 15, MGG 28, MSB 14C, MSB 31B, MSB 36D, MSB 37A, MSB 49D, MSB 55D, MSB 57D, MSB 69D, MSB 82B, RSC 10, RSD 2B, RSE 11, XSB 1D†

AMB 10B, BRR 2D, DCB 9, FCA 10A, FSB122D, FTF 6, FTF 7, FTF 13, HSB126C, HSB127C*, HSB143C, HSB143D*, HTF 15, MSB 20C*, MSB 29A*, MSB 69D, RSA 7, RSA 10, RSE 3A, SCA 4, TNX 3D

BGO 48D, BGO 50D, BGX 1C, F 16, FSB 79A, KSB $3^{*}$, MSB 20C

† The questioned result is at least 10 times higher than historical data, but all third-quarter samples had been discarded before reanalysis was requested.

* The questioned result is at least 10 times higher than historical data. Because holding time had not been exceeded, the laboratory was asked to reanalyze the sample. Both the original and reanalysis results appear in the results table.

A technical review of the quarter's data identified at least one result of the analyses in Table 9 as low in comparison to historical data. A review of the laboratory records did not reveal any problems with the analyses except that $\mathrm{GE}$, appears to have had a problem in the analysis of gross alpha and nonvolatile beta for a period of time; the reanalysis results are much higher.

\section{Table 9. GE Samples with Low Analytical Results as Compared to Historical Data}

Analyte

Aluminum

Arsenic

Cadmium

Chloroform

Cobalt

1,2-Dichloroethane

1,1-Dichloroethylene

Fluoride

Iron
Wells

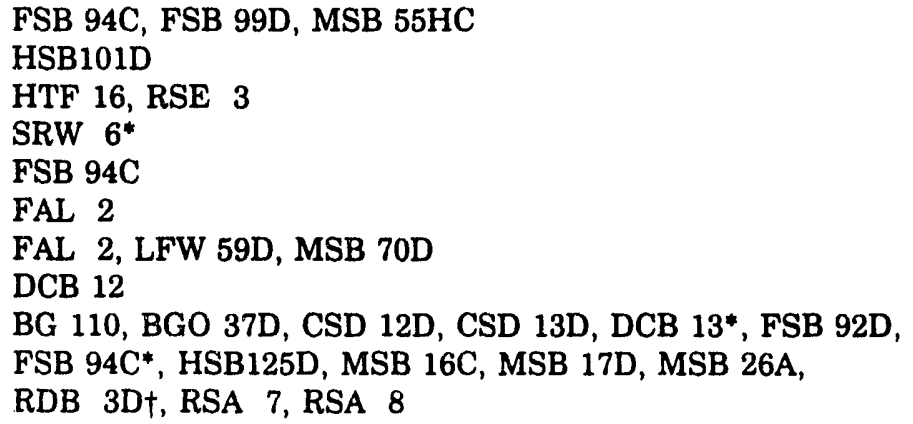

\footnotetext{
* The questioned value is at least 10 times lower than historical data. The laboratory was asked to reanalyze the sample. Both the original and reanalysis results appear in the results tables.

† This result is more than 10 times lower than historical results, but all third-quarter samples had been discarded before reanalysis was requested.
} 


\section{ANALYTICAL-DATA REVIEW}

Table 9. GE Samples with Low Analytical Results as Compared to Historical Data (cont.)

Analyte
Lead
Magnesium
Manganese
Nitrate-nitrite as nitroge

Potassium
Silica
Sodium
Specific conductance
Sulfate
Tetrachloroethylene
Trichloroethylene
Total dissolved solids
Total organic carbon
Total organic halogens

Total phosphates (as·P)
1,1,1-Trichloroethane
Trichloroethylene
Turbidity
Uranium
Gross alpha

Nonvolatile beta

Total alpha-emitting radium

Tritium
Wells

BG 52, MCB 5C

FCA 19D, FSB 94C

FSB 94C, HSB136C, MSB 62B*, RDB 3D, RSB 7

FCA $16 A^{*}$, FCB 2, FSB 89C*, FSB 89D*, FSB 93C, FSB120D, FTF 7, HSB 70, HSB 71, HSB 83D, HSB117C, HSB149D*, MSB 8A, MSB 18A, MSB 21TA*, MSB 39B*, MSB 62B, RSE 1A MSB 55HC

NPM 4

MSB 5A

FSB 92D, FSB 95DR*, MSB 55HC

BGO 12CR, DCB 8, DCB 12*, FSB 78, RSD 1

MSB 11D, MSB 11F, MSB 18A, MSB 19C*, MSB 70D*

MSB 1CC, MSB 79B, XSB 5A

RSF $3^{*}$

FCA 16A, FSB 98AR, RSE 2, RSE $8^{*}$

AMB $4 A^{*}$, AMB 7B, BGO 49C, BGO 50A, FCA 16B, IDB 1A, IDB 1C, MSB 2C, MSB 9A, MSB 11F, MSB 12TA*, MSB 14C, MSB 16C, MSB 18B, MSB 28A, MSB 32, MSB 42C, MSB 52B, MSB 79B*, NPM 19C, PDB 2, RRP 1 BGO 36D, FCA 2D, FCA 9D, FCA 16A, HSB144A, RSA 7, RSA 8, RSA 10, RSE 10*

LFW 59D

LFW 59D, MSB 1CC*, MSB 18A*, MSB 19C*, MSB 42B, MSB 50B*, XSB 5A

BGO 14DR, HAC 4

MSB 55B*

BGO 16D, FSB 94C*, HSB136C, RSE 25

FSB 76, FSB 87D*, FSB 89D*, FSB 91C*, FSB 94C, FSB106C*, FSB112D, HCB 2, HSB 68*, HSB 69*, HSB 86C, HSB 86D, HSB102D*, HSB103D*, HSB104D*, HSB105D*, HSB107D*, HSB108D*, HSB112E*, HSB113D*, HSB114D*, HSB115D*, HSB116D*, HSB136D*, KRB 18D, MSB 44C*, MSB 46C*

FCA 2D, FSB 76, FSB 87D*, FSB 89D*, FSB 93C*, HSB 69*, HSB 83D, HSB100D*, HSB110D, MSB 44C*, MSB 46C*, NBG 2†, RSD $1 \dagger$

BGX 1A*, FSB 95CR*, HSB102D*, HSB111E*, HSB113D*, HSB114C*, HSB114D*, HSB115D*, HSB116D*, MSB 16C, MSB 44C

BGO 46B*, BGX 1A, FTF 7, LCO 3, LCO 4, MCB 5C, MSB 16C, RDB 3D, XSB 3A

\footnotetext{
* The questioned value is at least 10 times lower than historical data. The laboratory was asked to reanalyze the sample. Both the original and reanalysis results appear in the results tables.

† The questioned value is at least 10 times lower than historical data, but all third-quarter samples had been discarded before reanalysis was requested.

Table 10 lists the reasons GE did not perform certain analyses on samples from wells that could be sampled. See the Sample Schedul-

ing, Field Notes, and Analytical Results sections of this report for more information on wells scheduled but not sampled this quarter.
} 
Table 10. Analyses Not Performed by GE

\begin{tabular}{|c|c|}
\hline Wells & Analytes \\
\hline $\begin{array}{l}\text { BGO 9AA, HTF } 20 \\
\text { CSD 2D }\end{array}$ & $\begin{array}{l}\text { Sulfide } \\
\text { Herbicides }\end{array}$ \\
\hline F $\quad 14, \mathrm{H} \quad 15$ & Gross alpha, nonvolatile beta \\
\hline FCA $1 N$ & $\begin{array}{l}\text { Chloride, fluoride, nitrate-nitrite (as } \\
\text { nitrogen), pH, specific conductance, } \\
\text { sulfate, total phosphates (as } \mathrm{P} \text { ), gross } \\
\text { alpha, nonvolatile beta, total alpha- } \\
\text { emitting radium, tritium }\end{array}$ \\
\hline FCA $2 C$ & $\begin{array}{l}\text { All scheduled analyses other than GCMS } \\
\text { VOA and total organic carbon }\end{array}$ \\
\hline FCA 10D & $\begin{array}{l}\text { Gross alpha, nonvolatile beta, total alpha- } \\
\text { emitting radium }\end{array}$ \\
\hline FCA 16B & $\begin{array}{l}\text { Gross alpha, nonvolatile beta, total alpha- } \\
\text { emitting radium, tritium }\end{array}$ \\
\hline $\begin{array}{l}\text { FSB 79C, FSB 91D, } \\
\text { FSB110D, HSB102D, } \\
\text { HSB107D, HSB112D, } \\
\text { HSB116C, HSB119A }\end{array}$ & Colloidal silica, dissolved silica \\
\hline FSB106D & $\begin{array}{l}\text { Chloride, fluoride, herbicides/pesticides, } \\
\text { pH, specific conductance, sulfate, total } \\
\text { dissolved solids, gross alpha, nonvolatile } \\
\text { beta, total alpha-emitting radium, tritium }\end{array}$ \\
\hline MSB 13B & $\begin{array}{l}\text { Appendix IX base-neutral/acids, Appendix } \\
\text { IX dioxins/furans, Appendix IX herbicides/ } \\
\text { pesticides, Appendix IX PCBs, herbicides/ } \\
\text { pesticides }\end{array}$ \\
\hline MSB 15C & $\begin{array}{l}\text { Chloride, cyanide, } \mathrm{pH} \text {, specific } \\
\text { conductance, sulfate, gross alpha, } \\
\text { nonvolatile beta, total alpha-emitting } \\
\text { radium }\end{array}$ \\
\hline MSB 81B & GCMS VOA \\
\hline $\mathrm{RCP} \quad 1 \mathrm{~A}$ & All scheduled analyses \\
\hline
\end{tabular}

RWM 1, RWM 12 All scheduled analyses except GC VOA

\author{
Reason \\ Insufficient sample aliquot \\ Insufficient water for complete \\ sample collection \\ Insufficient water for complete \\ sample collection \\ Insufficient water for complete \\ sample collection
}

Insufficient water for complete sample collection

Insufficient water for complete sample collection

Insufficient water for complete sample collection

Not in contract (with filtered samples, however, analysis for silica measures dissolved silica)

Insufficient water for complete sample collection

Insufficient water for complete sample collection

Insufficient water for complete sample collection

Laboratory error ( 3 of 4 vials were broken; the fourth didn't yield any results) Chain of custody says "unable to sample due to slow (beginning) pump rate"

Samplers did not receive chains of custody

\section{Review of the Environmental Physics Data}

A technical review of the quarter's analytical data identified at least one result of the Environmental Physics analyses in Table 11 as high in comparison with historical data. A review of the laboratory records did not reveal any problems with the analyses. Analyses subcontracted to Teledyne also are included in this section. 
Table 11. Environmental Physics Samples with High Analytical Results as Compared to Historical Data

Analyte

Cesium-137

Radium-226

Radium-228

Strontium-90

Thorium-230

Uranium-234

Uranium-238
Wells

FSB 92D

ASB 10C, KAC 8, SRW 16B

HAC 4, KAC 8, TBG 5A, TNX 4D, TNX 7D, XSB 1B, XSB 1D

HTF 18, HTF 23, RDB 2D, RSD 1, RSE 3A

TNX 2D

FNB 2

FNB 2
Table 12 lists the reasons Environmental Fhysics did not perform certain analyses on samples from wells that could be sampled. See the Sample Scheduling, Field Notes, and
Analytical Results sections of this report for more information on wells scheduled but not sampled this quarter.

Table 12. Analyses Not Performed by Environmental Physics

$\begin{array}{ll}\text { Wells } & \text { Analytes } \\ \text { FCA 1N, FCA 2C, FCA 10D, } & \begin{array}{l}\text { Gamma PHA, strontium-89, } \\ \text { strontium-90 } \\ \text { FCA 16B }\end{array} \text { Uranium isotopes by alpha } \\ \text { MSB 15C } & \begin{array}{l}\text { spectroscopy } \\ \text { All scheduled analyses }\end{array} \\ \text { RCP 1A } & \text { Uranium isotopes by alpha } \\ \text { RWM 1 } & \text { spectroscopy }\end{array}$

Reason

Insufficient water for complete sample collection

Insufficient water for complete sample collection

There is insufficient information in field $\log$ to determine reason Samplers did not receive chains of custody

\section{Review of the Weston Analytical Data}

Weston subcontracted radionuclide analyses to TMA/Eberline. The results from these analyses are discussed in this section.

In narratives accompanying data, Weston provided detailed information on quality control analyses that were outside of guidance or control limits. These included a number of matrix spike recoveries for metals and blank spike recoveries for semivolatiles; nitrate calibration verification checks; and surrogate recoveries for semivolatiles and GCMS volatiles. Weston also specified a number of samples for which the relative percent difference between duplicate results for various metals is greater than $20 \%$. These results are not consistently qualified in the analytical-results tables.

The presence of lindane in samples LFW 10A and LFW 21A was not positively confirmed on a second chromatographic column because of an interference; its presence, though reported, is questionable.

Because of elevated levels of total dissolved solids, the replicate from well ZDT 2 has a very high percent error for tritium. Samples from well BGO 50D analyzed for gross alpha, nonvolatile beta, total radium, and tritium also contained high levels of total dissolved solids, as did samples from well RAC 1 for gross alpha.

The analytical modifier $V$ was to be used, beginning fourth quarter 1991, to flag sample results associated with internal laboratory blanks having elevated results. (See p. A-2.) This modifier has been used inconsistently.

During third quarter, Weston qualified a few instances of laboratory blanks containing levels of silica, nitrate, and total organic halogens above the contract-specified detection limit. In 
most of these, the sample result was many times greater than the blank result. However, positive metals analyses associated with elevated blanks sometimes were flagged with $J 3$ if the concentration in the sample was above detection limit but less than five times the concentration found in the blank. Table 13 associates well samples with specific blanks having elevated results, without regard to the modifiers used in Appendix A.

Table 13. Weston Laboratory Blanks with Elevated Results

$\begin{array}{llll}\text { Analyte } & \text { Run Date } & \text { Result } & \text { Well Samples Accompanying Blanks } \\ \text { Aluminum } & 8 / 03 / 92 & 64.1 \mu \mathrm{g} / \mathrm{L} & \text { FSB120A } \\ \text { Antimony } & 7 / 30 / 92 & 5.9 \mu \mathrm{g} / \mathrm{L} & \text { FSB123D } \\ \text { Antimony } & 7 / 30 / 92 & 12.2 \mu \mathrm{g} / \mathrm{L} & \text { HSB 65, HSB 70 } \\ \text { Antimony } & 7 / 31 / 92 & 6.5 \mu \mathrm{g} / \mathrm{L} & \text { HSB105C } \\ \text { Antimony } & 7 / 31 / 92 & 4.8 \mu \mathrm{g} / \mathrm{L} & \text { MSB 1B } \\ \text { Antimony } & 8 / 03 / 92 & 57.9 \mu \mathrm{g} / \mathrm{L} & \text { FSB120A } \\ \text { Antimony } & 8 / 05 / 92 & 8.6 \mu \mathrm{L} / \mathrm{L} & \text { MSB 62B } \\ \text { Antimony } & 8 / 05 / 92 & 4.9 \mu \mathrm{g} / \mathrm{L} & \text { HSB140C } \\ \text { Antimony } & 9 / 11 / 92 & 8.6 \mu \mathrm{g} / \mathrm{L} & \text { LFW 25, LFW 26, LFW 27, LFW 29, LFW 30, } \\ & & \text { LFW 31, LFW 32, LFW 33, LFW 34 } \\ \text { Bis(2-ethylhexyl) } & 8 / 03 / 92 & 46.6 \mu \mathrm{g} / \mathrm{L} ; & \text { DOB 2 } \\ \text { phthalate } & & 41.0 \mu \mathrm{g} / \mathrm{L} & \\ \text { Magnesium } & 7 / 31 / 92 & 42.0 \mu \mathrm{g} / \mathrm{L} & \text { HSB105C } \\ \text { Magnesium } & 8 / 25 / 9 ? & 25.9 \mu \mathrm{g} / \mathrm{L} & \text { PAC 1, PAC 2, PAC 3, PAC 4, PAC 5, } \\ & & \text { PAC 6, SSS 4, SSS 5, SSS 6, SSS 7, SSS 8, } \\ \text { Magnesium } & & \text { SSS 17, SSS 19, SSS 21, SSS 25, SSS 26, SSS 27 } \\ \text { Magnesium } & 9 / 11 / 92 & 32.1 \mu \mathrm{g} / \mathrm{L} & \text { LFW 25, LFW 26, LFW 27, LFW 29, LFW 30, } \\ \text { Silica } & 9 / 20 / 92 & \text { LFW 31, LFW 32, LFW 33, LFW 34 } \\ \text { Tin } & 9 / 20 / 92 & 22.8 \mu \mathrm{g} / \mathrm{L} & \text { P 28A }\end{array}$

Weston found no errors upon reviewing the records of the EPD/EMS blind blanks having

elevated results. The blanks are listed in Table 14 , along with their associated samples.

Table 14. EPD/EMS Blind Blanks with Elevated Results from Weston

\begin{tabular}{|c|c|c|c|}
\hline Analyte & $\underline{\text { Blank }}$ & $\underline{\text { Result }}$ & Associated Samples \\
\hline Cadmium & QA $110 \mathrm{C}$ & $7.6 \mu \mathrm{g} / \mathrm{L}$ & $\begin{array}{llll}\mathrm{KAC} & 1, \mathrm{KAC} & 2, \mathrm{KAC} & 3, \mathrm{KAC} \\
\mathrm{KAC} & 6, \mathrm{KAC} & 7\end{array}$ \\
\hline Silica & QA $108 \mathrm{C}$ & $27,100 \mu \mathrm{g} / \mathrm{L}$ & HAC 1, HAC 2, HAC 3, HAC 4 \\
\hline Silica & QA $112 C$ & $19,000 \mu \mathrm{g} / \mathrm{L}$ & $\begin{array}{l}\text { LFW 6, LFW 8, LFW 10A, LFW 16, LFW 17, } \\
\text { LFW 18, LFW 19, LFW 21, LFW 22, LFW 23, } \\
\text { LFW 24 }\end{array}$ \\
\hline Silica & QA 114C & $13,200 \mu \mathrm{g} / \mathrm{L}$ & $\begin{array}{l}\text { FAC 5, FAC 7, FAC 8, LFW 47C, LFW 47D, } \\
\text { LFW 48C, LFW 48D, LFW 55C, LFW 55D, } \\
\text { LFW 56D, LFW 57B, LFW 57C, LFW 57D, } \\
\text { LFW 58D, LFW 59D, LFW 60D, LFW 62D }\end{array}$ \\
\hline Total dissolved solids & QA $110 \mathrm{C}$ & $88,000 \mu \mathrm{g} / \mathrm{L}$ & 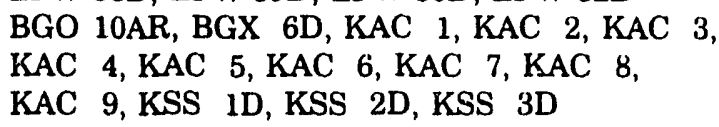 \\
\hline Total phosphates & QA 108C & $244 \mu \mathrm{g} / \mathrm{L}$ & $\begin{array}{l}\text { FAC 3, FAC 4, FAC } 6 \text {, NPM 4, NPM 19B, } \\
\text { NPM 34C, SSS 1, SSS 2, SSS 3, SSS 10, } \\
\text { SSS 11, SSS 22, SSS 23, SSS } 24\end{array}$ \\
\hline
\end{tabular}


Weston reported no problems, other than those discussed on pages 54 and 55 , when asked to review its records of the analyses listed in Table
15 , in which at least one analytical result was high as compared to historical data.

Table 15. Weston Samples with High Analytical Results as Compared to Historical Data

Analyte
Antimony
Arsenic
Barium
Bis(2-ethylhexyl) phthalate
Cadmium
Calcium
Chloride
Chromium
Di-n-butyl phthalate
1,1-Dichloroethane
Dichloromethane (Methylene
chloride)

Ethylbenzene

Iron

Lead

Magnesium

Manganese

Mercury

Nickel

Nitrate as nitrogen

Phenols

Potassium

Selenium

Silver

Sodium

Specific conductance

Tetrachloroethylene

Thallium

Tin

Toluene

Total dissolved solids
Wells

BGO 10AR, FSB120A*, HSB 70, HSB140C, LFW 26, LFW 28, LFW 30, LFW 32, LFW 33, LFW 34, LFW 38, MSB 1B, ZBG 1 FSB120A*, HSB122A, KAC 9, LFW 21

ASB 3A, LCO 3, LFW 6, SSS 1

DOB 2*

BGX 12C*, CMP 12A, HAC 4, LFW 43B, LFW 43D, NPM 4, P 26D, SSS 27

KAC 3, LFW 19, LFW 21, LFW 22, LFW 41, NPM 4, SSS 26

FAC 4, HSB 85C*, LFW 8, LFW 17, LFW 18, LFW 21, LFW 22, LFW 37, LFW 58D, MSB 11B, MSB 62B*, SSS 22, YSB 2A

FSS 4D, HSB105C, LFW 16, NPM 34C

KSS 2D, KSS 3D, PSS 1D

LFW 21, LFW 40, LFW 58D

ABP 4, CMP 9B, CMP 12A, CMP 12B, CMP 14C, CMP 15B, CMP 15C, CMP 16B, DOB 2, FAC 3, FAC 4*, FAC 5, FAC 6, FAC $8^{*}$, FSB123D*, FSS 1D, FSS 4D, LCO 3, LFW 33, LFW 40, LFW 47C*, LFW 48C, LFW 48D, LFW 55C, LFW 59B, MSB 1B, MSB 11B, MSB 12TB, MSB 19B, MSB 39C, MSB 62B,* $P$ 26D, P 28A*, SRW 4, SRW 13A, XSB 3A

LFW 40

FSB120A, FSS 3D*, HSB 65, KAC 8*, LFW 19, LFW 21*, LFW 22, LFW 38, LFW 40*, LFW 45D, LFW 55C, LFW 55D, LFW 56D, LFW 58D, LFW 59D, LFW 61C*, LFW 62C, MSB 43D, MSB 70C, NPM 19B, PAC 2, PSS 2D, SSS 21

ABP 4, KAC 8, KSS 3D, LFW 43B, LFW 47C, LFW 47D, LFW 48C, LFW 59D, NPM 19B, NPM 34C*, P 26D, SSS 21, $\mathrm{XSB} 3 \mathrm{~A}$

KAC 3, LFW 21, LFW 40, LFW 61C

KAC 9, LFW 40, PAC 5, SSS 8

ASB 3A, FSS 2D*, LFW 48C, LFW 59D, MSB 19B

FSB120A

FAC 4, FAC 5*, FAC 7*, FAC 8, HMD 2D, HSB122A, HSB140C, KAC 8, LFW 6, LFW 36, LFW 40, MSB 11B, MSB 12TB, NPM 19B, NPM 34C, SSS 21

LFW 21, SSS 2, SSS 7, SSS 8, SSS 17, SSS 26, SSS 27

KAC 8, LFW 24, NPM 4, SSS 19

FSB120A

FSS 1D, LFW 47C, LFW 47D, SSS 4, SSS 21

FAC 4, FAC 8, LFW 21, LFW 22, LFW 58D

KAC 9, LFW 21

LFW 10A, LFW 16, LFW 22, LFW 40, MSB 11B, MSB 62B

FSB120A

DOB $2^{*}$

LFW 21*, LFW 22, LFW 40

BGX 12C, HSB140C

\footnotetext{
* The questioned value is at least 10 times higher than historical data. Because holding time had not been exceeded, the laboratory was asked to reanalyze the sample.
} 
Table 15. Weston Samples with High Analytical Results as Compared to Historical Data (cont.)

Analyte

Total organic carbon

Total organic halogens

Total phosphates

1,1,1-Trichloroethane

Trichloroethylene

Trichlorofluoromethane

Turbidity

Zinc

Nonvolatile beta

Radium-226

Tritium
Wells

CMP 14B, LFW 21, LFW 35, LFW 37, LFW 43B, LFW 43D, SSS 19 , SSS 24, SSS 26

BRD $1^{*}$, FSB100A, FSB123D, HMD 2D, HSB 65, HSB 70*, HSB146C, LFW 38, LFW 42, LFW 58D, LFW 62C, MSB 11B, MSB 19B, MSB 62B, SSS 1 , SSS $8^{*}$, SSS $10^{*}$, SSS 19 , SSS 23*, SSS 24, SSS 26, SSS 27

FAC 4, FAC 6, HAC 1, HAC 2, HAC 3, HAC 4*, KAC 2, MSB 62B, NPM 4, NPM 19B, NPM 34C, PAC 2, PAC 3, PAC 5, PAC 6, SSS 7, SSS 8, SSS 17, SSS 26

LFW 37, LFW 42

LFW 40, MSB 11B

LFW 42

$\mathrm{KAC} 2$

FSB 99A, HSB 65, HSB146C, MSB 39C, SRW 4, SRW 13A* MSB 39C, RAC 1

BGO $10 \mathrm{AR}^{*}$

BGO 50D

* The questioned value is at least 10 times higher than historical data. Because holding time had not been exceeded, the laboratory was asked to reanalyze the sample.

A technical review of the quarter's analytical data identified at least one result of the analyses in Table 16 as low in comparison to histor- ical data. When asked to review the laboratory records, Weston did not report any problems with the analyses.

Table 16. Weston Samples with Low Analytical Results as Compared to Historical Data

Analyte

Chromium

Iron

Lead

Magnesium

Manganese

Nickel

Silica

Sulfate

Total dissolved solids

Total organic carbon

Total organic halogens

Total phosphates

Turbidity
Wells

SSS 17

CMP 15C, HSB146C, KAC 7, LCO 3, LFW 35, LFW 42, PSS 3D, SSS 10, SSS 17 , SSS 26

MSB 12TB

KAC 7

CMP 14C*, KAC 7, LFW 41, MSB 62B

MSB 62B*

NPM 4

PAC 3, PAC 4, PAC 5, PAC 6, SSS 17, SSS 27

BGO 8D, FAC 8, FSB 99A*, FSS 3D, LFW 48C, LFW 59D*, LFW 60D*, LFW 62D, NPM 4, PSS 1D, PSS 2D*

FAC 6, FAC 8

CMP 13, HAC 1, KAC 9, LFW 43B*, LFW 46D*, LFW 48C, LFW 60D SSS 11 , SSS 21

BGO 8D, FAC 5, FAC 7, FAC 8 
Table 16. Weston Samples with Low Analytical Results as Compared to Historical Data (cont.)

Analyte

Radium-226

Radium.228

Tritium
Wells

FSB123D

ZBG 1*

FSB100A

* The questioned value is at least 10 times lower than historical data. Because holding time had not been exceeded, the laboratory was asked to reanalyze the sample.

Table 17 lists scheduled analyses that were not performed by Weston or its subcontractor, along with the reasons. The two primary laboratories (GE and Weston) differ in their analytical suite assignments for certain constituents. When samples are sent to Weston only as splits or blind replicates, no adjustments are made for these differences in suites. Thus, some analytes may not be analyzed by both laboratories. These analytes are not presented in Table 17. See the Sample Scheduling, Field Notes, and Analytical Results sections of this report for more information on wells scheduled but not sampled this quarter.

\section{Table 17. Analyses Not Performed by Weston}

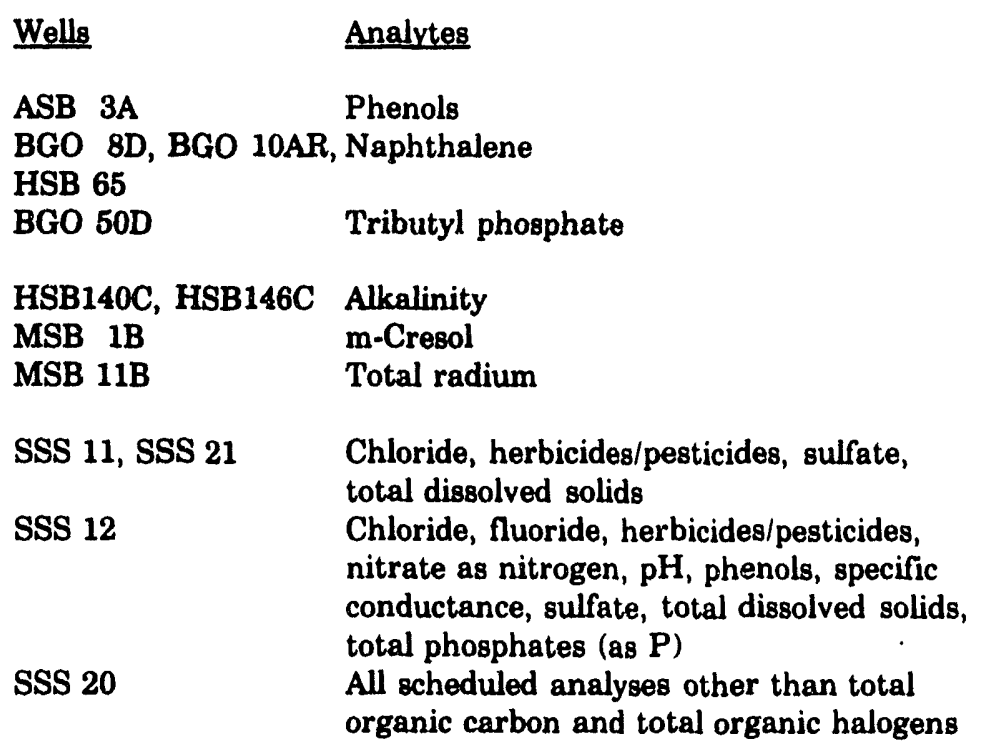

\author{
Reason \\ Broken sample container \\ Not requested by EPD/EMS because nol \\ in contract \\ Not requested by EPD/EMS because not \\ in contract \\ Not in contract \\ Laboratory error \\ Insufficient water for complete sample \\ collection \\ Insufficient water for complete sample \\ collection \\ Insufficient water for complete sample \\ collection \\ Insufficient water for complete sample \\ collection
}

\section{Review of the Clemson TC Analytical Data}

Clemson TC performed some of the radionuclide analyses during third quarter. The laboratory noted that samples from wells LFW 21 and LFW 22 contained high levels of dissolved solids that interfered with the gross alpha and nonvolatile beta analyses, causing elevated detec- tion limits. The laboratory reported no problems when asked to review its records of the analyses listed in Tables 18 and 19, in which the analytical results were high or low, respectively, as compared to historical data. 
Table 18. Clemson TC Samples with High Analytical Results as Compared to Historical Data

\author{
Analyte \\ Gross alpha \\ FAC 5, LFW 26, LFW 30, LFW 32, LFW 37, PAC 3, PAC 6 \\ Nonvolatile beta \\ Radium-226 \\ Radium-228 \\ CMP 9B, CMP 10, FAC 5, FSS 3D†, LFW 26, LFW 30, LFW 47C, LFW 48C \\ LFW 41, PAC 6 \\ Tritium \\ FAC 4, LFW 10A, LFW 17, LFW 21, LFW 25, LFW 62B \\ FAC 4, LFW 61D*
}

† The questioned value is at least 10 times higher than historical data. Because holding time had not been exceeded, the laboratory was asked to reanalyze the sample. However, insufficient sample remained to perform the reanalysis.

* The questioned values are at least 10 times higher or lower than historical data. Because holding time had not been exceeded, the laboratory was asked to reanalyze the sample. Both the original and reanalysis results appear in the results tables.

\title{
Table 19. Clemson TC Samples with Low Analytical Results as Compared to Historical Data
}

Analyte

Wells

Radium-226

ASB 3A, FAC 3, FAC 4, FAC 5, FAC 7, SSS 17, SSS 27

Radium-228

LFW 33, LFW 43B*, SSS 1 , SSS $17^{*}$, SSS $27^{*}$

\begin{abstract}
- The questioned values are at least 10 times higher or lower than historical data. Because holding time had not been exceeded, the laboratory was asked to reanalyze the sample. Both the original and reanalysis results appear in the results tables.
\end{abstract}

Clemson TC did not perform the scheduled analyses (gross alpha, nonvolatile beta, radium-

wells SSS 11, SSS 12, SSS 20 , and SSS 21 226 , radium-228, and tritium) on samples from

because the wells produced insufficient water.

\section{Review of the EM Lab Radioactive Analytical Data}

A technical review of the quarter's analytical data from the EM Lab identified the total activity result for BG 55 as low in comparison with historical data and the results for analyses in Table 20 as high in comparison with historical data.

Table 20. EM Lab Samples with High Analytical Results as Compared to Historical Data

\section{Analyte}

Tritium

Total activity

\section{Wells}

$\mathrm{KSB} 3$

BGO 48C, BGO 48D, BGO 50D, BGX 1C, F 14, HSB111E 


\section{ANALYTICAL METHODS}

GE and Weston performed most of the analyses conducted during third quarter, using the methods listed in Table 21.

Spencer Testing Services, Inc. (SP), conducted analyses for asbestos by electron microscopy, with a detection limit of 0.15 million structures per liter (MSL).

The EM Lab at SRS conducted selected radionuclide analyses of samples required by the groundwater monitoring program. The gross alpha and nonvolatile beta analytical methods used by the EM Lab are in-house and based on applicable EPA methods. Methods used by EPD/EMS for testing other radioisotopes also are in-house analytical methods. The EM Lab radioactivity determinations are reported as the absolute concentrations calculated from the analytical tests.

Environmental Physics, Teledyne, TMA/Eberline, and Clemson TC performed the radionuclide analyses. Their methods and detection limits, including in-house methods based on applicable EPA and DOE procedures, are listed in Table 22.

If the laboratories used more than one analyti. cal method for an analyte, the methods are listed in the tables in descending order according to frequency of use. Generally, the method listed first was used for at least half of the analyses.

Table 21. Methods and Detection Limits Used by the Primary Laboratories

Analyte
Acenaphthene
Acensphthylene
Acetone
Acetonitrile (Methyl cyanide)
Acetophenone
2-Acetylaminofluorene
Acrolein
Acrylonitrile
Aldrin
Alkalinity
Allyl chloride
Aluminum
4-Aminobiphenyl
Ammonia nitrogen
Aniline
Anthracene
Antimony
Aramite
Arsenic
Barium
Benzene

\begin{tabular}{ll} 
GE & \\
Method & Detection \\
& Limit \\
\hline & \\
EPA8270 & $10 \mu \mathrm{g} / \mathrm{L}$ \\
EPA8270 & $10 \mu \mathrm{g} / \mathrm{L}$ \\
EPA8240 & $100 \mu \mathrm{g} / \mathrm{L}$ \\
EPA8240 & $1 \mu \mathrm{g} / \mathrm{L}$ \\
EPA8270 & $10 \mu \mathrm{g} / \mathrm{L}$ \\
EPA8270 & $10 \mu \mathrm{g} / \mathrm{L}$ \\
EPA8240 & $20 \mu \mathrm{g} / \mathrm{L}$ \\
EPA8240 & $20 \mu \mathrm{g} / \mathrm{L}$ \\
EPA8080 & $0.05 \mu \mathrm{g} / \mathrm{L}$ \\
EPA8270 & $10 \mu \mathrm{g} / \mathrm{L}$ \\
EPA310.1 & $1,000 \mu \mathrm{g} / \mathrm{L}$ \\
EPA8240 & $50 \mu \mathrm{g} / \mathrm{L}$ \\
EPA6010* & $20 \mu \mathrm{g} / \mathrm{L}$ \\
EPA8270 & $10 \mu \mathrm{g} / \mathrm{L}$ \\
EPA 350.1 & $100 \mu \mathrm{g} / \mathrm{L}$ \\
EPA8270 & $10 \mu \mathrm{g} / \mathrm{L}$ \\
EPA8270 & $10 \mu \mathrm{g} / \mathrm{L}$ \\
EPA7041 & $2 \mu \mathrm{g} / \mathrm{L}$ \\
EPA8270 & $10 \mu \mathrm{g} / \mathrm{L}$ \\
EPA7060 & $2 \mu \mathrm{g} / \mathrm{L}$ \\
EPA6010 & $3 \mu \mathrm{g} / \mathrm{L}$ \\
EPA8240 & $1 \mu$ \\
EPAg/L &
\end{tabular}

\begin{tabular}{|c|c|}
\hline Method & $\begin{array}{l}\text { Detection } \\
\text { Limit } \\
\end{array}$ \\
\hline EPA8270 & $10 \mu \mathrm{g} / \mathrm{L}$ \\
\hline EPA8270 & $10 \mu \mathrm{g} / \mathrm{L}$ \\
\hline EPA8240 & $10 \mu g / L$ \\
\hline EPA8240 & $20 \mu \mathrm{g} / \mathrm{L}$ \\
\hline EPA8270 & $10 \mu \mathrm{g} / \mathrm{L}$ \\
\hline EPA8270 & $10 \mu \mathrm{g} / \mathrm{L}$ \\
\hline EPA8240 & $10 \mu \mathrm{g} / \mathrm{L}$ \\
\hline EPA8240 & $10 \mu g / L$ \\
\hline EPA8080 & $0.05 \mu \mathrm{g} / \mathrm{L}$ \\
\hline- & - \\
\hline - & -- \\
\hline EPA8240 & $20 \mu \mathrm{g} / \mathrm{L}$ \\
\hline EPA200.7* & $14.6 \mu \mathrm{g} / \mathrm{L}$ \\
\hline EPA8270 & $10 \mu \mathrm{g} / \mathrm{L}$ \\
\hline- & - \\
\hline EPA8270 & $10 \mu \mathrm{g} / \mathrm{L}$ \\
\hline EPA8270 & $10 \mu \mathrm{g} / \mathrm{L}$ \\
\hline EPA200.7 & $2.6 \mu \mathrm{g} / \mathrm{L}$ \\
\hline EPA8270 & $20 \mu \mathrm{g} / \mathrm{L}$ \\
\hline EPA206.2 & $2 \mu \mathrm{g} / \mathrm{L}$ \\
\hline EPA208.2 & $4 \mu \mathrm{g} / \mathrm{L}$ \\
\hline EPA200.7 & $6.6 \mu \mathrm{g} / \mathrm{L}$ \\
\hline EPA8240 & $5 \mu \mathrm{g} / \mathrm{L}$ \\
\hline
\end{tabular}

- No detection limit or not analyzed.

* Methods 200.7 and 6010 are both inductively coupled plasma atomic emission spectroscopy methods for metals determination. Method 200.7 is published for Safe Drinking Water Act investigations; method 6010 is published for RCRA determinations. 
Table 21. Methods and Detection Limits Used by the Primary Laboratories (cont.)

\begin{tabular}{|c|c|c|}
\hline Analyte & Method & $\begin{array}{l}\text { Detection } \\
\text { Limit }\end{array}$ \\
\hline \multirow[t]{2}{*}{ alpha-Benzene hexachloride } & EPA8080 & $0.05 \mu \mathrm{g} / \mathrm{L}$ \\
\hline & EPA8270 & $10 \mu \mathrm{g} / \mathrm{L}$ \\
\hline \multirow[t]{2}{*}{ beta-Benzene hexachloride } & EPA8080 & $0.05 \mu \mathrm{g} / \mathrm{L}$ \\
\hline & EPA8270 & $10 \mu \mathrm{g} / \mathrm{L}$ \\
\hline \multirow[t]{2}{*}{ delta-Benzene hexachloride } & EPA8270 & $10 \mu \mathrm{g} / \mathrm{L}$ \\
\hline & EPA8080 & $0.05 \mu \mathrm{g} / \mathrm{L}$ \\
\hline Benzidine & EPA8270 & $10 \mu \mathrm{g} / \mathrm{L}$ \\
\hline Benzo[a]anthracene & EPA8270 & $10 \mu \mathrm{g} / \mathrm{L}$ \\
\hline Benzo[b]fluoranthene & EPA8270 & $10 \mu \mathrm{g} / \mathrm{L}$ \\
\hline Benzo[k]fluoranthene & EPA8270 & $10 \mu \mathrm{g} / \mathrm{L}$ \\
\hline Benzoic acid & - & - \\
\hline Benzolg, $h, i]$ perylene & EPA8270 & $10 \mu \mathrm{g} / \mathrm{L}$ \\
\hline Benzo[a]pyrene & EPA8270 & $10 \mu \mathrm{g} / \mathrm{L}$ \\
\hline Benzyl alcohol & EPA8270 & $10 \mu \mathrm{g} / \mathrm{L}$ \\
\hline Beryllium & EPA6010 & $3 \mu \mathrm{g} / \mathrm{L}$ \\
\hline Bis(2-chloroethoxy) methane & EPA8270 & $10 \mu \mathrm{g} / \mathrm{L}$ \\
\hline Bis(2-chloroethyl) ether & EPA8270 & $10 \mu \mathrm{g} / \mathrm{L}$ \\
\hline \multirow[t]{2}{*}{ Bis(2-chloroisopropyl) ether } & EPA8240 & $10 \mu \mathrm{g} / \mathrm{L}$ \\
\hline & EPA8270 & $10 \mu \mathrm{g} / \mathrm{L}$ \\
\hline Bis(2-ethylhexyl) phthalate & EPA8270 & $10 \mu \mathrm{g} / \mathrm{L}$ \\
\hline Bromodichloromethane & EPA8240 & $1 \mu \mathrm{g} / \mathrm{L}$ \\
\hline Bromoform & EPA8240 & $1 \mu g / L$ \\
\hline $\begin{array}{l}\text { Bromomethane (Methyl } \\
\text { bromide) }\end{array}$ & EPA8240 & $1 \mu \mathrm{g} / \mathrm{L}$ \\
\hline 4-Bromophenyl phenyl ether & EPA8270 & $10 \mu \mathrm{g} / \mathrm{L}$ \\
\hline Butylbenzyl phthalate & EPA8270 & $10 \mu \mathrm{g} / \mathrm{L}$ \\
\hline 2-sec-Butyl-4,6-dinitrophenol & EPA8270 & $10 \mu \mathrm{g} / \mathrm{L}$ \\
\hline Cadmium & EPAŌ010 & $2 \mu \mathrm{g} / \mathrm{L}$ \\
\hline Calcium & EPA6010 & $10 \mu \mathrm{g} / \mathrm{L}$ \\
\hline Carbon disulfide & EPA8240 & $1 \mu \mathrm{g} / \mathrm{L}$ \\
\hline \multirow[t]{2}{*}{ Carbon tetrachloride } & EPA8240 & $1 \mu \mathrm{g} / \mathrm{L}$ \\
\hline & EPA8010 & $1 \mu \mathrm{g} / \mathrm{L}$ \\
\hline \multirow[t]{2}{*}{ Chlordane } & EPA8080 & $0.5 \mu \mathrm{g} / \mathrm{L}$ \\
\hline & EPA8270 & $10 \mu \mathrm{g} / \mathrm{L}$ \\
\hline Chloride & EPA300.0 & $250 \mu \mathrm{g} / \mathrm{L}$ \\
\hline 4-Chloroaniline & EPA8270 & $10 \mu \mathrm{g} / \mathrm{L}$ \\
\hline Chlorobenzene & EPA8240 & $1 \mu \mathrm{g} / \mathrm{L}$ \\
\hline Chlorobenzilate & EPA8270 & $10 \mu \mathrm{g} / \mathrm{L}$ \\
\hline para-Chloro-meta-cresol & EPA8270 & $10 \mu \mathrm{g} / \mathrm{L}$ \\
\hline Chloroethane & EPA8240 & $1 \mu \mathrm{g} / \mathrm{L}$ \\
\hline Chloroethene (Vinyl chloride) & EPA8240 & $1 \mu \mathrm{g} / \mathrm{L}$ \\
\hline \multirow[t]{2}{*}{ 2-Choroethyl vinyl ether } & EPA8240 & $1 \mu \mathrm{g} / \mathrm{L}$ \\
\hline & EPA8270 & $10 \mu \mathrm{g} / \mathrm{L}$ \\
\hline \multirow[t]{2}{*}{ Chloroform } & EPA8240 & $1 \mu \mathrm{g} / \mathrm{L}$ \\
\hline & EPA8010 & $1 \mu \mathrm{g} / \mathrm{L}$ \\
\hline Chloromethane (Methyl chloride) & EPA8240 & $1 \mu \mathrm{g} / \mathrm{L}$ \\
\hline 2-Chloronaphthalene & EPA8270 & $10 \mu \mathrm{g} / \mathrm{L}$ \\
\hline 2-Chlorophenol & EPA8270 & $10 \mu \mathrm{g} / \mathrm{L}$ \\
\hline 4.Chlorophenyl phenyl ether & EPA8270 & $10 \mu \mathrm{g} / \mathrm{L}$ \\
\hline
\end{tabular}

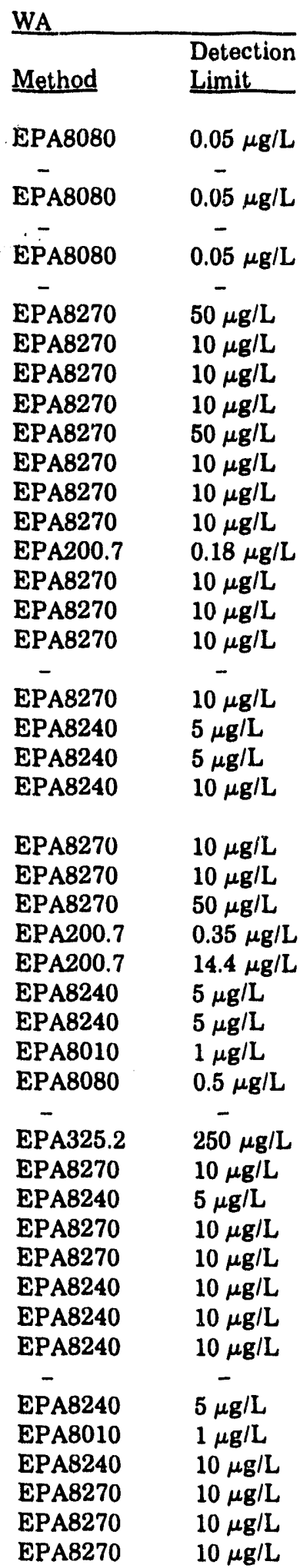

- No detection limit or not analyzed. 
Table 21. Methods and Detection Limits Used by the Primary Laboratories (cont.)

Analyte

Chloroprene

Chromium

Chrysene

Cobalt

Copper

m-Cresol (3-Methylphenol)

o-Cresol (2-Methylphenol)

p-Cresol (4-Methylphenol)

Cyanide

p,p'-DDD

p,p'-DDE

p,p'-DDT

Diallate

Dibenz $[a, h]$ anthracene

Dibenzofuran

Dibromochloromethane

1,2-Dibromo-3-chloropropane

Dibromomethane (Methylene bromide)

1,2-Dibromoethane

Di-n-butyl phthalate

1,2-Dichlorobenzene

1,3-Dichlorobenzene

1,4-Dichlornbenzene

3,3' 'Dichlorobenzidine

trans-1,4-Dichloro-2-butene

Dichlorodifluoromethane

1,1-Dichloroethane

1,2-Dichloroethane

cis-1,2-Dichloroethene

1,1-Dichloroethylene

trans-1,2-Dichloroethylene

Dichloromethane (Methylene

chloride)

2,4-Dichlorophenol

2,6-Dichlorophenol

2,4-Dichlorophenoxyacetic acid

1,2-Dichloropropane

cis-1,3-Dichloropropene

trans-1,3-Dichloropropene

Dieldrin

Diethyl phthalate
GE

\begin{tabular}{ll} 
Method & $\begin{array}{l}\text { Detection } \\
\text { Limit }\end{array}$ \\
\cline { 2 - 3 } EPA8240 & $200 \mu \mathrm{g} / \mathrm{L}$ \\
EPA6010 & $4 \mu \mathrm{g} / \mathrm{L}$ \\
EPA8270 & $10 \mu \mathrm{g} / \mathrm{L}$ \\
EPA6010 & $4 \mu \mathrm{g} / \mathrm{L}$ \\
EPA6010 & $4 \mu \mathrm{g} / \mathrm{L}$ \\
EPA8270 & $10 \mu \mathrm{g} / \mathrm{L}$ \\
EPA8270 & $10 \mu \mathrm{g} / \mathrm{L}$ \\
EPA8270 & $10 \mu \mathrm{g} / \mathrm{L}$ \\
EPA9012 & $5 \mu \mathrm{g} / \mathrm{L}$ \\
EPA8080 & $0.1 \mu \mathrm{g} / \mathrm{L}$ \\
EPA8270 & $10 \mu \mathrm{g} / \mathrm{L}$ \\
EPA8080 & $0.1 \mu \mathrm{g} / \mathrm{L}$ \\
EPA8270 & $10 \mu \mathrm{g} / \mathrm{L}$ \\
EPA8080 & $0.1 \mu \mathrm{g} / \mathrm{L}$ \\
EPA8270 & $10 \mu \mathrm{g} / \mathrm{L}$ \\
EPA8270 & $10 \mu \mathrm{g} / \mathrm{L}$ \\
EPA8270 & $10 \mu \mathrm{g} / \mathrm{L}$ \\
EPA8270 & $10 \mu \mathrm{g} / \mathrm{L}$ \\
EPA8240 & $1 \mu \mathrm{g} / \mathrm{L}$ \\
EPA8240 & $1 \mu \mathrm{g} / \mathrm{L}$ \\
EPA8240 & $1 \mu \mathrm{g} / \mathrm{L}$
\end{tabular}

EPA8240

$20 \mu \mathrm{g} / \mathrm{L}$

EPA8270 $10 \mu \mathrm{g} / \mathrm{L}$

EPA8270 $\quad 10 \mu \mathrm{g} / \mathrm{L}$

EPA8240 $1 \mu \mathrm{g} / \mathrm{L}$

EPA8270 $\quad 10 \mu \mathrm{g} / \mathrm{L}$

EPA8240 $1 \mu \mathrm{g} / \mathrm{L}$

EPA8270 $10 \mu \mathrm{g} / \mathrm{L}$

EPA8240 $1 \mu \mathrm{g} / \mathrm{L}$

EPA8270 $\quad 10 \mu \mathrm{g} / \mathrm{L}$

EPA8240 $30 \mu \mathrm{g} / \mathrm{L}$

EPA8240 $1 \mu \mathrm{g} / \mathrm{L}$

EPA8240 $1 \mu \mathrm{g} / \mathrm{L}$

EPA8240 $1 \mu \mathrm{g} / \mathrm{L}$

EPA8240 $1 \overline{\mu g / L}$

EPA8240 $1 \mu \mathrm{g} / \mathrm{L}$

EPA8240 $1 \mu \mathrm{g} / \mathrm{L}$

EPA8270 $10 \mu \mathrm{g} / \mathrm{L}$

EPA8270 $10 \mu \mathrm{g} / \mathrm{L}$

EPA8150 $0.3 \mu \mathrm{g} / \mathrm{L}$

EPA8240 $1 \mu \mathrm{g} / \mathrm{L}$

EPA8240 $1 \mu \mathrm{g} / \mathrm{L}$

EPA8240 $1 \mu \mathrm{g} / \mathrm{L}$

EPA8080 $0.5 \mu \mathrm{g} / \mathrm{L}$

EPA8270 $\quad 10 \mu \mathrm{g} / \mathrm{L}$

EPA8270 $10 \mu \mathrm{g} / \mathrm{L}$
WA

$\begin{array}{ll}\text { Method } & \begin{array}{l}\text { Detection } \\ \text { Limit }\end{array} \\ \text { EPA8240 } & 20 \mu \mathrm{g} / \mathrm{L} \\ \text { EPA200.7 } & 1.1 \mu \mathrm{g} / \mathrm{L} \\ \text { EPA8270 } & 10 \mu \mathrm{g} / \mathrm{L} \\ \text { EPA200.7 } & 0.88 \mu \mathrm{g} / \mathrm{L} \\ \text { EPA200.7 } & 1.1 \mu \mathrm{g} / \mathrm{L} \\ \text { EPA8270 } & 10 \mu \mathrm{g} / \mathrm{L} \\ \text { EPA8270 } & 10 \mu \mathrm{g} / \mathrm{L} \\ \text { EPA8270 } & 10 \mu \mathrm{g} / \mathrm{L} \\ \text { EPA335.3 } & 5 \mu \mathrm{g} / \mathrm{L} \\ \text { EPA8080 } & 0.1 \mu \mathrm{g} / \mathrm{L} \\ - & - \\ \text { EPA8080 } & 0.1 \mu \mathrm{g} / \mathrm{L} \\ - & - \\ \text { EPA8080 } & 0.1 \mu \mathrm{g} / \mathrm{L} \\ - & - \\ \text { EPA8270 } & 10 \mu \mathrm{g} / \mathrm{L} \\ \text { EPA8270 } & 10 \mu \mathrm{g} / \mathrm{L} \\ \text { EPA8270 } & 10 \mu \mathrm{g} / \mathrm{L} \\ \text { EPA8240 } & 5 \mu \mathrm{g} / \mathrm{L} \\ \text { EPA8240 } & 20 \mu \mathrm{g} / \mathrm{L} \\ \text { EPA8240 } & 10 \mu \mathrm{g} / \mathrm{L}\end{array}$

EPA8240

EPA8270

EPA8270

-

EPA8270

-

EPA8270

-

EPA8270

EPA8240

EPA8240

EPA8240

EPA8240

EPA8240

EPA8240

EPA8240

EPA8240

$20 \mu \mathrm{g} / \mathrm{L}$

$10 \mu \mathrm{g} / \mathrm{L}$

$10 \mu \mathrm{g} / \mathrm{L}$

$10 \mu \mathrm{g} / \mathrm{L}$

$-$

$10 \mu \mathrm{g} / \mathrm{L}$

$20 \mu \mathrm{g} / \mathrm{L}$

$100 \mu \mathrm{g} / \mathrm{L}$

$10 \mu \mathrm{g} / \mathrm{L}$

$5 \mu \mathrm{g} / \mathrm{L}$

$5 \mu \mathrm{g} / \mathrm{L}$

$5 \mu \mathrm{g} / \mathrm{L}$

$5 \mu \mathrm{g} / \mathrm{L}$

$5 \mu \mathrm{g} / \mathrm{L}$

$5 \mu \mathrm{g} / \mathrm{L}$

EPA8270 $\quad 10 \mu \mathrm{g} / \mathrm{L}$

EPA8270 $10 \mu \mathrm{g} / \mathrm{L}$

EPA8150 $1 \mu \mathrm{g} / \mathrm{L}$

EPA8240 $5 \mu \mathrm{g} / \mathrm{L}$

EPA8240 $5 \mu \mathrm{g} / \mathrm{L}$

EPA8240 $5 \mu \mathrm{g} / \mathrm{L}$

EPA8080 $0.1 \mu \mathrm{g} / \mathrm{L}$

-

EPA8270 $10 \mu \mathrm{g} / \mathrm{L}$

- No detection limit or not analyzed. 
Table 21. Methods and Detection Limits Used by the Primary Laboratories (cont.)

\begin{tabular}{|c|c|c|c|c|}
\hline & $\underline{\mathbf{G E}}$ & & WA & \\
\hline Analyte & Method & $\begin{array}{l}\text { Detection } \\
\text { Limit } \\
\end{array}$ & Method & $\begin{array}{l}\text { Detaction } \\
\underline{\text { Limit }} \\
\end{array}$ \\
\hline Dimethoate & EPA8270 & $10 \mu \mathrm{g} / \mathrm{L}$ & - & - \\
\hline p-Dimethylaminoazobenzene & EPA8270 & $10 \mu \mathrm{g} / \mathrm{L}$ & EPA8270 & $10 \mu \mathrm{g} / \mathrm{L}$ \\
\hline 7,12-Dimethylbenz $[a]$-anthracene & EPA8270 & $10 \mu \mathrm{g} / \mathrm{L}$ & EPA8270 & $10 \mu \mathrm{g} / \mathrm{L}$ \\
\hline 3,3'-Dimethylbenzidine & EPA8270 & $10 \mu \mathrm{g} / \mathrm{L}$ & EPA8270 & $10 \mu \mathrm{g} / \mathrm{L}$ \\
\hline a,a-Dimethylphenethylamine & EPA8270 & $10 \mu \mathrm{g} / \mathrm{L}$ & EYA8270 & $10 \mu \mathrm{g} / \mathrm{L}$ \\
\hline 2,4-Dimethyl phenol & EPA8270 & $10 \mu \mathrm{g} / \mathrm{L}$ & EPA8270 & $10 \mu \mathrm{g} / \mathrm{L}$ \\
\hline Dimethyl phthalate & EPA8270 & $10 \mu \mathrm{g} / \mathrm{L}$ & EPA8270 & $10 \mu \mathrm{g} / \mathrm{L}$ \\
\hline 1,3-Dinitrobenzene & EPA8270 & $10 \mu \mathrm{g} / \mathrm{L}$ & EPA8270 & $10 \mu g / L$ \\
\hline 4,6-Dinitro-ortho-cresol & - & - & EPA8270 & $50 \mu \mathrm{g} / \mathrm{L}$ \\
\hline 2,4-Dinitrophenol & EPA8270 & $45 \mu \mathrm{g} / \mathrm{L}$ & EPA8270 & $50 \mu \mathrm{g} / \mathrm{L}$ \\
\hline 2,4-Dinitrotoluene & EPA8270 & $10 \mu \mathrm{g} / \mathrm{L}$ & EPA8270 & $10 \mu \mathrm{g} / \mathrm{L}$ \\
\hline 2,6-Dinitrotoluene & EPA8270 & $10 \mu \mathrm{g} / \mathrm{L}$ & EPA8270 & $10 \mu \mathrm{g} / \mathrm{L}$ \\
\hline Di-n-octyl phthalate & EPA8270 & $10 \mu \mathrm{g} / \mathrm{L}$ & EPA8270 & $10 \mu \mathrm{g} / \mathrm{L}$ \\
\hline 1,4-Dioxane & EPA8270 & $10 \mu \mathrm{g} / \mathrm{L}$ & EPA8270 & $10 \mu \mathrm{g} / \mathrm{L}$ \\
\hline Diphenylamine & EPA8270 & $10 \mu \mathrm{g} / \mathrm{L}$ & EPA8270 & $10 \mu \mathrm{g} / \mathrm{L}$ \\
\hline 1,2-Diphenylhydrazine & EPA8270 & $10 \mu \mathrm{g} / \mathrm{L}$ & - & - \\
\hline Dissolved organic carbon & EPA9060 & $1,000 \mu \mathrm{g} / \mathrm{L}$ & EPA415.1 & $500 \mu \mathrm{g} / \mathrm{L}$ \\
\hline Disulfoton & EPA8270 & $10 \mu \mathrm{g} / \mathrm{L}$ & - & - \\
\hline Endosulfan I & EPA8080 & $0.1 \mu \mathrm{g} / \mathrm{L}$ & EPA8080 & $0.05 \mu \mathrm{g} / \mathrm{L}$ \\
\hline Endosulfan II & $\begin{array}{l}\text { EPA8270 } \\
\text { EPA8080 }\end{array}$ & $\begin{array}{l}10 \mu \mathrm{g} / \mathrm{L} \\
0.1 \mu \mathrm{g} / \mathrm{L}\end{array}$ & EPA8080 & $0 . \overline{1} \mu \mathrm{g} / \mathrm{L}$ \\
\hline & EPA8270 & $10 \mu \mathrm{g} / \mathrm{L}$ & - & - \\
\hline Endosulfan sulfate & EPA8080 & $0.1 \mu \mathrm{g} / \mathrm{L}$ & EPA8080 & $0.1 \mu \mathrm{g} / \mathrm{L}$ \\
\hline & EPA8270 & $10 \mu \mathrm{g} / \mathrm{L}$ & - & - \\
\hline Endrin & EPA8080 & $0.006 \mu \mathrm{g} / \mathrm{L}$ & EPA8080 & $0.1 \mu \mathrm{g} / \mathrm{L}$ \\
\hline & EPA8270 & $10 \mu \mathrm{g} / \mathrm{L}$ & - & - \\
\hline Endrin aldehyde & EPA8080 & $0.1 \mu \mathrm{g} / \mathrm{L}$ & EPA8080 & $0.1 \mu \mathrm{g} / \mathrm{L}$ \\
\hline & EPA8270 & $10 \mu \mathrm{g} / \mathrm{L}$ & - & - \\
\hline Ethylbenzene & EPA8240 & $1 \mu \mathrm{g} / \mathrm{L}$ & EPA8240 & $5 \mu \mathrm{g} / \mathrm{L}$ \\
\hline Ethyl methacrylate & EPA8270 & $10 \mu \mathrm{g} / \mathrm{L}$ & EPA8270 & $10 \mu \mathrm{g} / \mathrm{L}$ \\
\hline Ethyl methanesulfonate & EPA8270 & $10 \mu \mathrm{g} / \mathrm{L}$ & EPA8270 & $10 \mu \mathrm{g} / \mathrm{L}$ \\
\hline Famphur & EPA8270 & $10 \mu \mathrm{g} / \mathrm{L}$ & - & - \\
\hline Fluoranthene & EPA8270 & $10 \mu \mathrm{g} / \mathrm{L}$ & EPA8270 & $10 \mu \mathrm{g} / \mathrm{L}$ \\
\hline Fluorene & EPA8270 & $10 \mu \mathrm{g} / \mathrm{L}$ & EPA8270 & $10 \mu \mathrm{g} / \mathrm{L}$ \\
\hline Fluoride & EPA340.2 & $100 \mu \mathrm{g} / \mathrm{L}$ & EPA340.2 & $100 \mu \mathrm{g} / \mathrm{L}$ \\
\hline Heptachlor & EPA8080 & $0.05 \mu \mathrm{g} / \mathrm{L}$ & EPA8080 & $0.05 \mu \mathrm{g} / \mathrm{L}$ \\
\hline & EPA8270 & $10 \mu \mathrm{g} / \mathrm{L}$ & - & - \\
\hline Heptachlor epoxide & EPA8080 & $0.05 \mu \mathrm{g} / \mathrm{L}$ & EPA8080 & $0.05 \mu \mathrm{g} / \mathrm{L}$ \\
\hline & EPA8270 & $10 \mu \mathrm{g} / \mathrm{L}$ & - & - \\
\hline $\begin{array}{l}\text { Heptachlorodibenzo-p-dioxin } \\
\text { isomers }\end{array}$ & EPA8280 & $0.00065 \mu \mathrm{g} / \mathrm{L}$ & - & - \\
\hline 1,2,3,4,6,7,8-HPCDD & EPA8280 & $0.00065 \mu \mathrm{g} / \mathrm{L}$ & - & - \\
\hline $\begin{array}{l}\text { Heptachlorodibenzo-p-furan } \\
\text { isomers }\end{array}$ & EPA8280 & $0.00045 \mu \mathrm{g} / \mathrm{L}$ & - & - \\
\hline 1,2,3,4,6,7 8-HPCDF & EPA8280 & $0.00045 \mu \mathrm{g} / \mathrm{L}$ & - & - \\
\hline Hexachlorobenzene & EPA8270 & $10 \mu \mathrm{g} / \mathrm{L}$ & EPA8270 & $10 \mu g / L$ \\
\hline Hexachlorobutadiene & EPA8270 & $10 \mu \mathrm{g} / \mathrm{L}$ & EPA8270 & $10 \mu \mathrm{g} / \mathrm{L}$ \\
\hline Hexachlorocyclopentadiene & EPA8270 & $10 \mu \mathrm{g} / \mathrm{L}$ & EPA8270 & $10 \mu \mathrm{g} / \mathrm{L}$ \\
\hline Hexachlorodibenzo-p-dioxin isomers & EPA8280 & $0.00045 \mu \mathrm{g} / \mathrm{L}$ & EPA8280 & $0.0017 \mu \mathrm{g} / \mathrm{I}$ \\
\hline
\end{tabular}

- No detection limit on not analyzed. 
Table 21. Methods and Detection Limits Used by the Primary Laboratories (cont.)

\begin{tabular}{|c|c|c|c|c|}
\hline & $\underline{G E}$ & & $\underline{\text { WA }}$ & \\
\hline Analyte & Method & $\begin{array}{l}\text { Detection } \\
\text { Limit } \\
\end{array}$ & Method & $\begin{array}{l}\text { Detection } \\
\text { Limit }\end{array}$ \\
\hline 1,2,3,4,7,8-HXCDD & EPA8280 & $0.00045 \mu \mathrm{g} / \mathrm{L}$ & - & - \\
\hline Hexachlorodibenzo-p-furan isomers & EPA8280 & $0.0004 \mu \mathrm{g} / \mathrm{L}$ & EPA8280 & $0.0011 \mu \mathrm{g} / \mathrm{I}$ \\
\hline $1,2,3,4,7,8 \cdot \mathrm{HXCDF}$ & EPA8280 & $0.0004 \mu \mathrm{g} / \mathrm{L}$ & - & - \\
\hline Hexachloroethane & EPA8270 & $10 \mu \mathrm{g} / \mathrm{L}$ & EPA8270 & $10 \mu \mathrm{g} / \mathrm{L}$ \\
\hline Hexachlorophene & EPA8270 & $10 \mu \mathrm{g} / \mathrm{L}$ & EPA8270 & $90 \mu \mathrm{g} / \mathrm{L}$ \\
\hline Hexachloropropene & EPA8270 & $10 \mu \mathrm{g} / \mathrm{L}$ & EPA8270 & $10 \mu \mathrm{g} / \mathrm{L}$ \\
\hline 2-Hexanone & EPA8240 & $1 \mu \mathrm{g} / \mathrm{L}$ & EPA8240 & $10 \mu \mathrm{g} / \mathrm{L}$ \\
\hline Indeno $[1,2,3-c, d]$ pyrene & EPA8270 & $10 \mu \mathrm{g} / \mathrm{L}$ & EPA8270 & $10 \mu \mathrm{g} / \mathrm{L}$ \\
\hline Iodine & APHA415A & $50 \mu \mathrm{g} / \mathrm{L}$ & - & - \\
\hline Iodomethane (Methyl iodide) & EPA8240 & $15 \mu \mathrm{g} / \mathrm{L}$ & EPA8240 & $10 \mu \mathrm{g} / \mathrm{L}$ \\
\hline Iron & EPA6010 & $4 \mu \mathrm{g} / \mathrm{L}$ & EPA200.7 & $1.9 \mu \mathrm{g} / \mathrm{L}$ \\
\hline Isobutyl alcohol & EPA8240 & $100 \mu \mathrm{g} / \mathrm{L}$ & EPA8240 & $20 \mu \mathrm{g} / \mathrm{L}$ \\
\hline Isodrir. & EPA8270 & $10 \mu \mathrm{g} / \mathrm{L}$ & EPA8080 & $0.1 \mu \mathrm{g} / \mathrm{L}$ \\
\hline Isophorone & EPA8270 & $10 \mu \mathrm{g} / \mathrm{L}$ & EPA8270 & $10 \mu \mathrm{g} / \mathrm{L}$ \\
\hline Isosafrole & EPA8270 & $10 \mu \mathrm{g} / \mathrm{L}$ & EPA8270 & $10 \mu \mathrm{g} / \mathrm{L}$ \\
\hline Kepone & EPA8270 & $10 \mu \mathrm{g} / \mathrm{L}$ & EPA8080 & $0.1 \mu \mathrm{g} / \mathrm{L}$ \\
\hline Lead & EPA7421 & $3 \mu \mathrm{g} / \mathrm{L}$ & EPA239.2 & $2 \mu \mathrm{g} / \mathrm{L}$ \\
\hline Lindane (gamma-Benzene & EPA8080 & $0.005 \mu \mathrm{g} / \mathrm{L}$ & EPA8080 & $0.05 \mu \mathrm{g} / \mathrm{L}$ \\
\hline hexachloride) & EPA8270 & $10 \mu \mathrm{g} / \mathrm{L}$ & - & - \\
\hline Lithium & EPA6010 & $5 \mu \mathrm{g} / \mathrm{L}$ & EPA200.7 & $2.8 \mu \mathrm{g} / \mathrm{L}$ \\
\hline Magnesium & EPA6010 & $2 \mu \mathrm{g} / \mathrm{L}$ & EPA200.7 & $8.9 \mu \mathrm{g} / \mathrm{L}$ \\
\hline Manganese & EPA6010 & $2 \mu \mathrm{g} / \mathrm{L}$ & EPA200.7 & $0.35 \mu \mathrm{g} / \mathrm{L}$ \\
\hline Mercury & EPA7470 & $0.2 \mu \mathrm{g} / \mathrm{L}$ & EPA245.1 & $0.2 \mu \mathrm{g} / \mathrm{L}$ \\
\hline Methacrylonitrile & EPA8240 & $50 \mu \mathrm{g} / \mathrm{L}$ & EPA8240 & $20 \mu \mathrm{g} / \mathrm{L}$ \\
\hline Methapyrilene & EPA8270 & $10 \mu \mathrm{g} / \mathrm{L}$ & EPA8270 & $30 \mu \mathrm{g} / \mathrm{L}$ \\
\hline Methoxychlor & EPA8080 & $0.5 \mu \mathrm{g} / \mathrm{L}$ & EPA8080 & $0.5 \mu \mathrm{g} / \mathrm{L}$ \\
\hline 3-Methylcholanthrene & EPA8270 & $10 \mu \mathrm{g} / \mathrm{L}$ & EPA8270 & $10 \mu \mathrm{g} / \mathrm{L}$ \\
\hline 2-Methyl-4,6-dinitrophenol & EPA8270 & $10 \mu \mathrm{g} / \mathrm{L}$ & - & - \\
\hline Methyl ethyl ketone & EPA8240 & $1 \mu \mathrm{g} / \mathrm{L}$ & EPA8240 & $10 \mu \mathrm{g} / \mathrm{L}$ \\
\hline Methyl isobutyl ketone & EPA8240 & $1 \mu \mathrm{g} / \mathrm{L}$ & - & - \\
\hline Methyl methacrylate & EPA8270 & $10 \mu \mathrm{g} / \mathrm{L}$ & EPA8270 & $10 \mu \mathrm{g} / \mathrm{L}$ \\
\hline Methyl methanesulfonate & EPA8270 & $10 \mu \mathrm{g} / \mathrm{L}$ & EPA8270 & $10 \mu \mathrm{g} / \mathrm{L}$ \\
\hline 2-Methylnaphthalene & EPA8270 & $10 \mu \mathrm{g} / \mathrm{L}$ & EPA8270 & $10 \mu \mathrm{g} / \mathrm{L}$ \\
\hline 4-Methyl-2-pentanone & - & - & EPA8240 & $10 \mu \mathrm{g} / \mathrm{L}$ \\
\hline Naphthalene & EPA8270 & $10 \mu \mathrm{g} / \mathrm{L}$ & EPA8270 & $10 \mu \mathrm{g} / \mathrm{L}$ \\
\hline 1,4-Naphthoquinone & EPA8270 & $10 \mu \mathrm{g} / \mathrm{L}$ & EPA8270 & $10 \mu \mathrm{g} / \mathrm{L}$ \\
\hline 1-Naphthylamine & EPA8270 & $10 \mu \mathrm{g} / \mathrm{L}$ & EPA8270 & $10 \mu \mathrm{g} / \mathrm{L}$ \\
\hline 2-Naphthylamine & EPA8270 & $10 \mu \mathrm{g} / \mathrm{L}$ & EPA8270 & $10 \mu \mathrm{g} / \mathrm{L}$ \\
\hline Nickel & EPA6010 & $4 \mu \mathrm{g} / \mathrm{L}$ & EPA200.7 & $3.1 \mu \mathrm{g} / \mathrm{L}$ \\
\hline Nitrate as nitrogen & - & - & EPA353.2 & $20 \mu \mathrm{g} / \mathrm{L}$ \\
\hline Nitrate-nitrite as nitrogen & EPA353.3 & $50 \mu \mathrm{g} / \mathrm{L}$ & - & - \\
\hline Nitrite as nitrogen & EPA300.0 & $10 \mu \mathrm{g} / \mathrm{L}$ & EPA353.2 & $10 \mu \mathrm{g} / \mathrm{L}$ \\
\hline 2-Nitroaniline & EPA8270 & $10 \mu \mathrm{g} / \mathrm{L}$ & EPA8270 & $50 \mu \mathrm{g} / \mathrm{L}$ \\
\hline 3-Nitroaniline & EPA8270 & $10 \mu \mathrm{g} / \mathrm{L}$ & EPA8270 & $50 \mu \mathrm{g} / \mathrm{L}$ \\
\hline 4-Nitroaniline & EPA8乏70 & $10 \mu \mathrm{g} / \mathrm{L}$ & EPA8270 & $50 \mu \mathrm{g} / \mathrm{L}$ \\
\hline Nitrobenzene & EPA8270 & $10 \mu \mathrm{g} / \mathrm{L}$ & EPA8270 & $10 \mu \mathrm{g} / \mathrm{L}$ \\
\hline 2-Nitrophenol & EPA8270 & $10 \mu \mathrm{g} / \mathrm{L}$ & EPA8270 & $10 \mu \mathrm{g} / \mathrm{L}$ \\
\hline 4-Nitrophenol & EPA8270 & $10 \mu \mathrm{g} / \mathrm{L}$ & EPA8270 & $50 \mu \mathrm{g} / \mathrm{L}$ \\
\hline 4-Nitroquinoline-1-oxide & EPA8270 & $10 \mu \mathrm{g} / \mathrm{L}$ & EPA8270 & $20 \mu \mathrm{g} / \mathrm{L}$ \\
\hline
\end{tabular}

- No detection limit or not analyzed. 
Table 21. Methods and Detection Limits Used by the Primary Laboratories (cont.)

\author{
Analyte \\ N-Nitrosodi-n-butylamine \\ N-Nitrosodiethylamine \\ N-Nitrosodimethylamine \\ N-Nitrosodiphenylamine \\ N-Nitrosodi-propylamine \\ N-Nitrosomethylethylamine \\ N-Nitrosomorpholine \\ N-Nitrosopiperidine \\ N-Nitrosopyrrolidine \\ 5-Nitro-o-toluidine \\ Octachlorodibenzo-p-dioxin \\ isomers \\ Octachlorodibenzo-p-furan \\ isomers \\ Oil \& grease \\ Parathion \\ Parathion methyl \\ PCB 1016
}

PCB 1221

PCB 1232

PCB 1242

PCB 1248

PCB 1254

PCB 1260

Pentachlorobenzene

Pentachlorodibenzo-p-dioxin isomers

1,2,3,7,8-PCDD

Pentachlorodibenzo-p-furan isomers

1,2,3,7,8-PCDF

Pentachloroethane

Pentachloronitrobenzene

Pentashlorophenol

Phenacetin

Phenanthrene

Phenol

Phenols

p-Phenylenediamine

Phorate

2-Picoline
GE

Method
EPA8270
EPA8270
EPA8270
EPA8270
EPA8270
EPA8270
EPA8270
EPA8270
EPA8270
EPA8270
EPA8280

Detection

$\underline{\text { Limit }}$

$10 \mu \mathrm{g} / \mathrm{L}$

$10 \mu \mathrm{g} / \mathrm{L}$

$10 \mu \mathrm{g} / \mathrm{L}$

$10 \mu \mathrm{g} / \mathrm{L}$

$10 \mu \mathrm{g} / \mathrm{L}$

$10 \mu \mathrm{g} / \mathrm{L}$

$10 \mu \mathrm{g} / \mathrm{L}$

$10 \mu \mathrm{g} / \mathrm{L}$

$10 \mu \mathrm{g} / \mathrm{L}$

$10 \mu \mathrm{g} / \mathrm{L}$

$0.001 \mu \mathrm{g} / \mathrm{L}$

EPA8280 $\quad 0.001 \mu \mathrm{g} / \mathrm{L}$

EPA413.1

EPA8080

EPA8080

EPA8080

EPA8270

EPA8080

EPA8270

EPA8080

EPA8270

EPA8080

EPA8270

EPA8080

EPA8270

EPA8080

EPA8270

EPA8080

EPA8270

EPA8270

EPA8280

EPA8280

EPA8280

EPA8280

EPA8270

EPA8270

EPA8270

EPA8270

EPA8270

EPA8270

EPA420.2

-

EPA8270

EPA8080

EPA8270
$1,000 \mu \mathrm{g} / \mathrm{L}$

$0.05 \mu \mathrm{g} / \mathrm{L}$

$0.05 \mu \mathrm{g} / \mathrm{L}$

$0.5 \mu \mathrm{g} / \mathrm{L}$

$150 \mu \mathrm{g} / \mathrm{L}$

$0.5 \mu \mathrm{g} / \mathrm{L}$

$150 \mu \mathrm{g} / \mathrm{L}$

$0.5 \mu \mathrm{g} / \mathrm{L}$

$150 \mu \mathrm{g} / \mathrm{L}$

$0.5 \mu \mathrm{g} / \mathrm{L}$

$150 \mu \mathrm{g} / \mathrm{L}$

$0.5 \mu \mathrm{g} / \mathrm{L}$

$150 \mu \mathrm{g} / \mathrm{L}$

$0.5 \mu \mathrm{g} / \mathrm{L}$

$150 \mu \mathrm{g} / \mathrm{L}$

$0.5 \mu \mathrm{g} / \mathrm{L}$

$150 \mu \mathrm{g} / \mathrm{L}$

$10 \mu \mathrm{g} / \mathrm{L}$

$0.00055 \mu \mathrm{g} / \mathrm{L}$

$0.00055 \mu \mathrm{g} / \mathrm{L}$

$0.00055 \mu \mathrm{g} / \mathrm{L}$

$0.00055 \mu \mathrm{g} / \mathrm{L}$

$10 \mu \mathrm{g} / \mathrm{L}$

$10 \mu \mathrm{g} / \mathrm{L}$

$10 \mu \mathrm{g} / \mathrm{L}$

$10 \mu \mathrm{g} / \mathrm{L}$

$10 \mu \mathrm{g} / \mathrm{L}$

$10 \mu \mathrm{g} / \mathrm{L}$

$5 \mu \mathrm{g} / \mathrm{L}$

-

$10 \mu \mathrm{g} / \mathrm{L}$

$0.1 \mu \mathrm{g} / \mathrm{L}$

$10 \mu \mathrm{g} / \mathrm{L}$
WA

Method $\quad$ Detection

EPA8270 $\quad 10 \mu \mathrm{g} / \mathrm{L}$

EPA8270 $10 \mu \mathrm{g} / \mathrm{L}$

EPA8270 $\quad 10 \mu \mathrm{g} / \mathrm{L}$

EPA8270 $10 \mu \mathrm{g} / \mathrm{L}$

EPA8270 $10 \mu \mathrm{g} / \mathrm{L}$

EPA8270 $10 \mu \mathrm{g} / \mathrm{L}$

EPA8270 $10 \mu \mathrm{g} / \mathrm{L}$

EPA8270 $50 \mu \mathrm{g} / \mathrm{L}$

EPA8270 $10 \mu \mathrm{g} / \mathrm{L}$

EPA8270 $10 \mu \mathrm{g} / \mathrm{L}$

-

EPA413.1 $\quad 1,000 \mu \mathrm{g} / \mathrm{L}$

- $\quad-$

-

EPA8080 $\quad 0.5 \mu \mathrm{g} / \mathrm{L}$

- -

EPA8080 $\quad 0.5 \mu \mathrm{g} / \mathrm{L}$

EPA8080 $0 . \overline{5} \mu \mathrm{g} / \mathrm{L}$

- 0.5

EPA8080 $\quad 0.5 \mu \mathrm{g} / \mathrm{L}$

- $\quad-$

EPA8080 $0.5 \mu \mathrm{g} / \mathrm{L}$

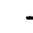

EPA8080

-

EPA8080

-

EPA8270

EPA8280

EPA8280

EPA8270

EPA8270

EPA8270

EPA8270

EPA8270

EPA8270

EPA420.2

EPA420.1

EPA8270

$-$

EPA8270
$0.0025 \mu \mathrm{g} / \mathrm{L}$

-

$1 \mu \mathrm{g} / \mathrm{L}$

$1 \mu \mathrm{g} / \mathrm{L}$

$-$

$10 \mu \mathrm{g} / \mathrm{L}$

$0.0033 \mu \mathrm{g} / \mathrm{L}$

$10 \mu \mathrm{g} / \mathrm{L}$

$50 \mu \mathrm{g} / \mathrm{L}$

$50 \mu \mathrm{g} / \mathrm{L}$

$10 \mu \mathrm{g} / \mathrm{L}$

$10 \mu \mathrm{g} / \mathrm{L}$

$10 \mu \mathrm{g} / \mathrm{L}$

$5 \mu \mathrm{g} / \mathrm{L}$

$5 \mu \mathrm{g} / \mathrm{L}$

$10 \mu \mathrm{g} / \mathrm{L}$

$10 \mu \mathrm{g} / \mathrm{L}$

- No detection limit or not analyzed. 
Table 21. Methods and Detection Limits Used by the Primary Laboratories (cont.)

Analyte

Potassium

Pronamid

Propionitrile

Pyrene

Pyridine

Safrole

Selenium

Silica

Silica, total

Silver

Sodium

Specific conductance

Styrene

Sulfate

Sulfide

Sulfotepp

1,2,4,5-Tetrachlorobenzene

Tetrachlorodibenzo-p-dioxin isomers

2,3,7,8-TCDD

Tetrachlorodibenzo-p-furan

isomers

2,3,7,8-TCDF

1,1,1,2-Tetrachloroethane

1,1,2,2-Tetrachloroethane

Tetrachloroethylene

2,3,4,6-Tetrachlorophenol

Thallium

Thionazin

Tin

Toluene

o-Toluidine

Total dissolved solids

Total organic carbon

Total organic halogens

Total petroleum hydrocarbons

Total phosphates (as P)

Total suspended solids

Toxaphene

2,4,5-TP (Silvex)

Tributyl phosphate

1,2,4-Trichlorobenzene

1,1,1-Trichloroethane

1,1,2-Trichloroethane
GE

\begin{tabular}{ll} 
Method & $\begin{array}{l}\text { Detection } \\
\text { Limit }\end{array}$ \\
\hline
\end{tabular}

EPA6010 $500 \mu \mathrm{g} / \mathrm{L}$

EPA8270 $10 \mu \mathrm{g} / \mathrm{L}$

EPA8240 $200 \mu \mathrm{g} / \mathrm{L}$

EPA8270 $10 \mu \mathrm{g} / \mathrm{L}$

EPA8270 $10 \mu \mathrm{g} / \mathrm{L}$

EPA8270 $10 \mu \mathrm{g} / \mathrm{L}$

EPA7740 $2 \mu \mathrm{g} / \mathrm{L}$

EPA6010 $\quad 100 \mu \mathrm{g} / \mathrm{L}$

EPA6010 $\quad 100 \mu \mathrm{g} / \mathrm{L}$

EPA6010 $2 \mu \mathrm{g} / \mathrm{L}$

EPA6010 $\quad 10 \mu \mathrm{g} / \mathrm{L}$

EPA120.1 $1 \mu \mathrm{S} / \mathrm{cm}$

EPA8240 $1 \mu \mathrm{g} / \mathrm{L}$

EPA300.0 $1,000 \mu \mathrm{g} / \mathrm{L}$

-

EPA9030 $1,000 \mu \mathrm{g} / \mathrm{L}$

EPA8270

EPA8270

EPA8280

EPA8280

EPA8280

EPA8280

EPA8240

EPA8240

EPA8240

EPA8010

EPA8270

EPA7841

EPA8270

EPA6010

EPA8240

EPA8270

EPA160.1

EPA9060

EPA9020

EPA418.1

EPA365.1

EPA8080

EPA8270

EPA8150

EPA8270

EPA8270

EPA8240

EPA8010

EPA8240
EPA160.2
$10 \mu \mathrm{g} / \mathrm{L}$

$10 \mu \mathrm{g} / \mathrm{L}$

$0.00045 \mu \mathrm{g} / \mathrm{L}$

$0.00045 \mu \mathrm{g} / \mathrm{L}$

$0.0004 \mu \mathrm{g} / \mathrm{L}$

$0.0004 \mu \mathrm{g} / \mathrm{L}$

$1 \mu \mathrm{g} / \mathrm{L}$

$1 \mu \mathrm{g} / \mathrm{L}$

$1 \mu \mathrm{g} / \mathrm{L}$

$1 \mu \mathrm{g} / \mathrm{L}$

$10 \mu \mathrm{g} / \mathrm{L}$

$2 \mu \mathrm{g} / \mathrm{L}$

$10 \mu \mathrm{g} / \mathrm{L}$

$2 \mu \mathrm{g} / \mathrm{L}$

$1 \mu \mathrm{g} / \mathrm{L}$

$10 \mu \mathrm{g} / \mathrm{L}$

$1,000 \mu \mathrm{g} / \mathrm{L}$

$1,000 \mu \mathrm{g} / \mathrm{L}$

$5 \mu \mathrm{g} / \mathrm{L}$

$1,000 \mu \mathrm{g} / \mathrm{L}$

$50 \mu \mathrm{g} / \mathrm{L}$

$1,000 \mu \mathrm{g} / \mathrm{L}$

$0.24 \mu \mathrm{g} / \mathrm{L}$

$10 \mu \mathrm{g} / \mathrm{L}$

$0.09 \mu \mathrm{g} / \mathrm{L}$

$10 \mu \mathrm{g} / \mathrm{L}$

$10 \mu \mathrm{g} / \mathrm{L}$

$1 \mu \mathrm{g} / \mathrm{L}$

$1 \mu \mathrm{g} / \mathrm{L}$

$1 \mu \mathrm{g} / \mathrm{L}$

\begin{tabular}{ll} 
WA & \\
\hline Method & Detection \\
\hline & Limit \\
EPA200.7 & $83.5 \mu \mathrm{g} / \mathrm{L}$ \\
EPA8270 & $10 \mu \mathrm{g} / \mathrm{L}$ \\
EPA8240 & $50 \mu \mathrm{g} / \mathrm{L}$ \\
EPA8270 & $10 \mu \mathrm{g} / \mathrm{L}$ \\
EPA8270 & $10 \mu \mathrm{g} / \mathrm{L}$ \\
EPA8270 & $10 \mu \mathrm{g} / \mathrm{L}$ \\
EPA270.2 & $2 \mu \mathrm{g} / \mathrm{L}$ \\
EPA200.7 & $25.5 \mu \mathrm{g} / \mathrm{L}$ \\
- & - \\
EPA200.7 & $0.7 \mu \mathrm{g} / \mathrm{L}$ \\
EPA200.7 & $111 \mu \mathrm{g} / \mathrm{L}$ \\
EPA120.1 & $1 \mu \mathrm{S} / \mathrm{cm}$ \\
EPA8240 & $5 \mu \mathrm{g} / \mathrm{L}$ \\
EPA300.0 & $250 \mu \mathrm{g} / \mathrm{L}$ \\
EPA375.4 & $2,500 \mu \mathrm{g} / \mathrm{L}$ \\
EPA376.2 & $100 \mu \mathrm{g} / \mathrm{L}$ \\
- & - \\
EPA8270 & $10 \mu \mathrm{g} / \mathrm{L}$ \\
EPA8280 & $0.0033 \mu \mathrm{g} / \mathrm{L}$ \\
& \\
EPA8280 & $0.0023 \mu \mathrm{g} / \mathrm{L}$ \\
EPA8280 & $0.0023 \mu \mathrm{g} / \mathrm{L}$ \\
& - \\
EPA8240 & $10 \mu \mathrm{g} / \mathrm{L}$ \\
EPA8240 & $5 \mu \mathrm{g} / \mathrm{L}$ \\
EPA8240 & $5 \mu \mathrm{g} / \mathrm{L}$ \\
EPA8010 & $1 \mu \mathrm{g} / \mathrm{L}$ \\
EPA8270 & $10 \mu \mathrm{g} / \mathrm{L}$ \\
EPA279.2 & $2 \mu \mathrm{g} / \mathrm{L}$ \\
- & - \\
EPA200.7 & $1.9 \mu \mathrm{g} / \mathrm{L}$ \\
EPA8240 & $5 \mu \mathrm{g} / \mathrm{L}$ \\
EPA8270 & $10 \mu \mathrm{g} / \mathrm{L}$ \\
EPA160.2 & $1,000 \mu \mathrm{g} / \mathrm{L}$ \\
EPA415.1 & $500 \mu \mathrm{g} / \mathrm{L}$ \\
EPA9020A & $5 \mu \mathrm{g} / \mathrm{L}$ \\
EPA418.1 & $1,020 \mu \mathrm{g} / \mathrm{L}$ \\
EPA365.2 & $20 \mu \mathrm{g} / \mathrm{L}$ \\
- & - \\
EPA8080 & $1 \mu \mathrm{g} / \mathrm{L}$ \\
- & - \\
EPA8150 & $0.5 \mu \mathrm{g} / \mathrm{L}$ \\
- & - \\
EPA8270 & $10 \mu \mathrm{g} / \mathrm{L}$ \\
EPA8240 & $5 \mu \mathrm{g} / \mathrm{L}$ \\
EPA8010 & $1 \mu \mathrm{g} / \mathrm{L}$ \\
EPA8240 & $5 \mu \mathrm{g} / \mathrm{L}$ \\
&
\end{tabular}

- No detection limit or not analyzed. 
Table 21. Methods and Detection Limits Used by the Primary Laboratories (cont.)

\begin{tabular}{|c|c|c|c|c|}
\hline \multirow[b]{2}{*}{ Analyte } & \multicolumn{2}{|l|}{ GE } & \multicolumn{2}{|l|}{ WA } \\
\hline & Method & $\begin{array}{l}\text { Detection } \\
\text { Limit }\end{array}$ & Method & $\begin{array}{l}\text { Detection } \\
\text { Limit }\end{array}$ \\
\hline Trichloroethylene & EPA8240 & $1 \mu \mathrm{g} / \mathrm{L}$ & EPA8240 & $5 \mu \mathrm{g} / \mathrm{L}$ \\
\hline & EPA8010 & $1 \mu \mathrm{g} / \mathrm{L}$ & EPA8010 & $1 \mu \mathrm{g} / \mathrm{L}$ \\
\hline Trichlorofluoromethane & EPA8240 & $1 \mu \mathrm{g} / \mathrm{L}$ & EPA8240 & $5 \mu \mathrm{g} / \mathrm{L}$ \\
\hline 2,4,5-Trichlorophenol & EPA8270 & $10 \mu \mathrm{g} / \mathrm{L}$ & EPA8270 & $50 \mu \mathrm{g} / \mathrm{L}$ \\
\hline 2,4,6-Trichlorophenol & EPA8270 & $10 \mu \mathrm{g} / \mathrm{L}$ & EPA8270 & $10 \mu \mathrm{g} / \mathrm{L}$ \\
\hline 2,4,5-Trichlorophenoxyacetic acid & EPA8150 & $0.09 \mu \mathrm{g} / \mathrm{L}$ & EPA8150 & $0.5 \mu \mathrm{g} / \mathrm{L}$ \\
\hline 1,2,3-Trichloropropane & EPA8240 & $1 \mu \mathrm{g} / \mathrm{L}$ & EPA8240 & $10 \mu \mathrm{g} / \mathrm{L}$ \\
\hline 0,0,0-Triethyl phosphorothioate & EPA8270 & $10 \mu \mathrm{g} / \mathrm{L}$ & - & - \\
\hline 1,3,5-Trinitrobenzene & EPA8270 & $10 \mu \mathrm{g} / \mathrm{L}$ & EPA8270 & $10 \mu \mathrm{g} / \mathrm{L}$ \\
\hline Turbidity & EPA180.1 & $0.1 \mathrm{NTU}$ & EPA180.1 & $0.2 \mathrm{NTU}$ \\
\hline Uranium & EPA6010 & $20 \mu \mathrm{g} / \mathrm{L}$ & - & - \\
\hline Vanadium & EPA6010 & $8 \mu \mathrm{g} / \mathrm{L}$ & EPA200.7 & $0.88 \mu \mathrm{g} / \mathrm{L}$ \\
\hline Vinyl acetate & EPA8240 & $1 \mu \mathrm{g} / \mathrm{L}$ & EPA8240 & $10 \mu \mathrm{g} / \mathrm{L}$ \\
\hline Xylenes & EPA8240 & $2 \mu \mathrm{g} / \mathrm{L}$ & EPA8240 & $5 \mu \mathrm{g} / \mathrm{L}$ \\
\hline Zinc & EPA6010 & $2 \mu \mathrm{g} / \mathrm{L}$ & EPA200.7 & $0.35 \mu \mathrm{g} / \mathrm{L}$ \\
\hline Gross alpha & EPA900.0 & $2 \mathrm{E}-09 \mu \mathrm{Ci} / \mathrm{mL}$ & - & - \\
\hline Nonvolatile beta & EPA900.0 & $2 \mathrm{E}-09 \mu \mathrm{Ci} / \mathrm{mL}$ & - & - \\
\hline Total alpha-emitting radium & EPA900.1 & $1 \mathrm{E}-09 \mu \mathrm{Ci} / \mathrm{mL}$ & - & - \\
\hline Tritium & EPA906.0 & $7 \mathrm{E}-07 \mu \mathrm{Ci} / \mathrm{mL}$ & - & - \\
\hline
\end{tabular}

Table 22. Methods and Detection Limits Used by the Radionuclide Laboratories

Environmental Physics (GP) and Teledyne Isotopes (TE)

\begin{tabular}{|c|c|c|c|c|}
\hline \multirow[b]{2}{*}{ Analyte } & \multicolumn{2}{|l|}{ GP } & \multicolumn{2}{|l|}{$\mathrm{TE}$} \\
\hline & Method & $\begin{array}{l}\text { Detection } \\
\text { Limit }\end{array}$ & Method & $\begin{array}{l}\text { Detection } \\
\text { Limit }\end{array}$ \\
\hline Americium-241 & HASL300 & $1 \mathrm{E}-09 \mu \mathrm{Ci} / \mathrm{mL}$ & - & - \\
\hline Antimony-125 & HASL300 & $2 \mathrm{E}-08 \mu \mathrm{Ci} / \mathrm{mL}$ & - & - \\
\hline Cerium-144 & HASL300 & $6 \mathrm{E}-08 \mu \mathrm{Ci} / \mathrm{mL}$ & - & - \\
\hline Cesium-134 & HASL300 & $1 \mathrm{E}-08 \mu \mathrm{Ci} / \mathrm{mL}$ & - & - \\
\hline Cesium-137 & HASL300 & $1 \mathrm{E}-08 \mu \mathrm{Ci} / \mathrm{mL}$ & - & - \\
\hline Cobalt-57 & HASL300 & $1 \mathrm{E}-08 \mu \mathrm{Ci} / \mathrm{mL}$ & - & - \\
\hline Cobalt-60 & HASL300 & $1 \mathrm{E}-08 \mu \mathrm{Ci} / \mathrm{mL}$ & - & - \\
\hline Curium-242 & HASL300 & $1 \mathrm{E}-09 \mu \mathrm{Ci} / \mathrm{mL}$ & - & - \\
\hline Curium 243/244 & HASL300 & $1 \mathrm{E}-09 \mu \mathrm{Ci} / \mathrm{mL}$ & - & - \\
\hline Europium-152 & HASL300 & $4 \mathrm{E}-08 \mu \mathrm{Ci} / \mathrm{mL}$ & - & - \\
\hline Europium-154 & HASL300 & $2 \mathrm{E}-08 \mu \mathrm{Ci} / \mathrm{mL}$ & - & - \\
\hline Europium-155 & HASL300 & $3 \mathrm{E}-08 \mu \mathrm{Ci} / \mathrm{mL}$ & - & - \\
\hline Gross alpha & EPA900.0 & $2 \mathrm{E}-09 \mu \mathrm{Ci} / \mathrm{mL}$ & - & - \\
\hline Iodine-129 & HASL300 & $2 \mathrm{E}-09 \mu \mathrm{Ci} / \mathrm{mL}$ & HASL300 & $2 \mathrm{E}-09 \mu \mathrm{Ci} / \mathrm{mL}$ \\
\hline Manganese-54 & HASL300 & $1 \mathrm{E}-08 \mu \mathrm{Ci} / \mathrm{mL}$ & - & - \\
\hline Neptunium-237 & - & - & HASL300 & $1 \mathrm{E}-08 \mu \mathrm{Ci} / \mathrm{mL}$ \\
\hline Nonvolatile beta & EPA900.0 & $2 \mathrm{E}-09 \mu \mathrm{Ci} / \mathrm{mL}$ & - & - \\
\hline Plutonium-238 & HASL300 & $1 \mathrm{E}-09 \mu \mathrm{Ci} / \mathrm{mL}$ & - & - \\
\hline Plutonium-239/240 & HASL300 & $1 \mathrm{E}-09 \mu \mathrm{Ci} / \mathrm{mL}$ & - & - \\
\hline Potassium-40 & HASL300 & $1.1 \mathrm{E}-07 \mu \mathrm{Ci} / \mathrm{mL}$ & - & - \\
\hline Promethium-144 & HASL300 & $1 \mathrm{E}-08 \mu \mathrm{Ci} / \mathrm{mL}$ & - & - \\
\hline
\end{tabular}

- No detection limit or not analyzed. 
Table 22. Methods and Detection Limits Used by the Radionuclide Laboratories (cont.)

Analyte
Promethium-146
Radium-226
Radium-228
Ruthenium-106
Sodium-22
Strontium-89
Strontium-90
Technetium-99
Thorium-228
Thorium-230
Thorium-232
Tritium
Uranium-234
Uranium-235
Uranium-238
Yttrium-88
Zinc-65

TMA/Eberline (TM)

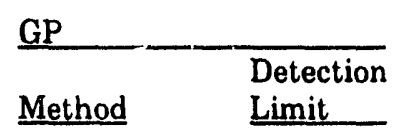

HASL300

HASL300

HASL300

HASL300

HASL 300

HASL 300

HASL300

HASL300

HASL300

HASL300

HASL300

EPA906.0

HASL 300

HASL300

HASL300

HASL300

HASL300
TE

Method $\quad \begin{aligned} & \text { Detection } \\ & \text { Limit }\end{aligned}$

$1 \mathrm{E}-08 \mu \mathrm{Ci} / \mathrm{mL}$

$1 \mathrm{E}-09 \mu \mathrm{Ci} / \mathrm{mL}$

$1 \mathrm{E}-09 \mu \mathrm{Ci} / \mathrm{mL}$

$9 \mathrm{E}-08 \mu \mathrm{Ci} / \mathrm{mL}$

$1 \mathrm{E}-08 \mu \mathrm{Ci} / \mathrm{mL}$

$2 \mathrm{E}-09 \mu \mathrm{Ci} / \mathrm{mL}$

$2 \mathrm{E}-09 \mu \mathrm{Ci} / \mathrm{mL}$

$3 \mathrm{E}-07 \mu \mathrm{Ci} / \mathrm{mL}$

$1 \mathrm{E}-09 \mu \mathrm{Ci} / \mathrm{mL}$

$1 \mathrm{E}-09 \mu \mathrm{Ci} / \mathrm{mL}$

$1 \mathrm{E}-09 \mu \mathrm{Ci} / \mathrm{mL}$

$7 \mathrm{E}-07 \mu \mathrm{Ci} / \mathrm{mL}$

$1 \mathrm{E}-09 \mu \mathrm{Ci} / \mathrm{mL}$

$1 \mathrm{E}-09 \mu \mathrm{Ci} / \mathrm{mL}$

$1 \mathrm{E}-09 \mu \mathrm{Ci} / \mathrm{mL}$

$6 \mathrm{E}-08 \mu \mathrm{Ci} / \mathrm{mL}$

$2 \mathrm{E}-08 \mu \mathrm{Ci} / \mathrm{mL}$
TM

\section{Analyte}

Gross alpha

Nonvolatile beta

Radium-226

Radium-228

Tritium

Uranium

$\begin{array}{ll}\text { Method } & \text { Detection } \\ \text { Limit }\end{array}$

$\begin{array}{ll}\text { EPA900.0 } & 1 \mathrm{E}-09 \mu \mathrm{Ci} / \mathrm{mL} \\ \text { EPA900.0 } & 1.4 \mathrm{E}-09 \mu \mathrm{Ci} / \mathrm{mL} \\ \text { EMLRA-05 } & 5.5 \mathrm{E}-10 \mu \mathrm{Ci} / \mathrm{mL} \\ \text { EPA904.0 } & 3 \mathrm{E}-10 \mu \mathrm{Ci} / \mathrm{mL} \\ \text { EPA906.0 } & 5.5 \mathrm{E}-07 \mu \mathrm{Ci} / \mathrm{mL} \\ \text { ASTMD5174 } & 0.03 \mu \mathrm{g} / \mathrm{L}\end{array}$

Clemson Technical Center, Inc. (CN)

\author{
Analyte \\ Americium-241 \\ Antimony-125 \\ Cerium-144 \\ Cesium-134 \\ Cesium-137 \\ Cobalt-57 \\ Cobalt-60 \\ Curium-242 \\ Curium-243/244 \\ Europium-152 \\ Europium-154 \\ Europium-155
}

$\begin{array}{ll}\text { CN } & \\ \text { Method } & \begin{array}{l}\text { Detection } \\ \text { Limit }\end{array} \\ \text { CTC0009 } & 1 \mathrm{E}-9 \mu \mathrm{Ci} / \mathrm{mL} \\ \text { EPA901.1 } & 2.5 \mathrm{E}-08 \mu \mathrm{Ci} / \mathrm{mL} \\ \text { EPA901.1 } & 5 \mathrm{E}-08 \mu \mathrm{Ci} / \mathrm{mL} \\ \text { EPA901.1 } & 1 \mathrm{E}-08 \mu \mathrm{Ci} / \mathrm{mL} \\ \text { EPA901.1 } & 1 \mathrm{E}-08 \mu \mathrm{Ci} / \mathrm{mL} \\ \text { EPA901.1 } & 1 \mathrm{E}-08 \mu \mathrm{Ci} / \mathrm{mL} \\ \text { EPA901.1 } & 1.2 \mathrm{E}-08 \mu \mathrm{Ci} / \mathrm{mL} \\ \text { CTC0009 } & 1 \mathrm{E}-09 \mu \mathrm{Ci} / \mathrm{mL} \\ \text { CTC0009 } & 1 \mathrm{E}-09 \mu \mathrm{Ci} / \mathrm{mL} \\ \text { EPA901.1 } & 5 \mathrm{E}-08 \mu \mathrm{Ci} / \mathrm{mL} \\ \text { EPA901.1 } & 2.5 \mathrm{E}-08 \mu \mathrm{Ci} / \mathrm{mL} \\ \text { EPA901.1 } & 2.5 \mathrm{E}-08 \mu \mathrm{Ci} / \mathrm{mL}\end{array}$

- No detection limit or not analyzed. 
Table 22. Methods and Detection Limits Used by the Radionuclide Laboratories (cont.)

\author{
Analyte \\ Gross alpha \\ Iodine-129 \\ Manganese-54 \\ Neptunium-237 \\ Nonvolatile beta \\ Plutonium-238 \\ Plutonium-239/240 \\ Potassium-40 \\ Promethium-144 \\ Promethium-146 \\ Radium-226
}

Radium-228

Ruthenium-103

Ruthenium-106

Sodium-22

Strontium -89

Strontium-90

Technetium-99

Thorium-228

Thorium-230

Thorium-232

Tritium

Uranium-234

Uranium-235

Uranium-238

Yttrium-88

Zinc-65
CN

$\begin{array}{ll}\text { Method } & \text { Detection } \\ \text { CTC0002 } & \text { Limit } \\ \text { EPA901.1 } & 2 \mathrm{E}-09 \mu \mathrm{Ci} / \mathrm{mL} \\ \text { EPA901.1 } & 1 \mathrm{E}-08 \mu \mathrm{Ci} / \mathrm{mL} \\ \text { EPA901.1 } & 4.5 \mathrm{E}-08 \mu \mathrm{Ci} / \mathrm{mL} \\ \text { CTC0002 } & 2 \mathrm{E}-09 \mu \mathrm{Ci} / \mathrm{mL} \\ \text { CTC0009 } & 1 \mathrm{E}-09 \mu \mathrm{Ci} / \mathrm{mL} \\ \text { CTC0009 } & 1 \mathrm{E}-09 \mu \mathrm{Ci} / \mathrm{mL} \\ \text { EPA901.1 } & 2.5 \mathrm{E}-07 \mu \mathrm{Ci} / \mathrm{mL} \\ \text { EPA901.1 } & 1 \mathrm{E}-08 \mu \mathrm{Ci} / \mathrm{mL} \\ \text { EPA901.1 } & 2.3 \mathrm{E}-08 \mu \mathrm{Ci} / \mathrm{mL} \\ \text { EPA903.1 } & 1 \mathrm{E}-09 \mu \mathrm{Ci} / \mathrm{mL} \\ \text { EPA901.1 } & 2.2 \mathrm{E}-07 \mu \mathrm{Ci} / \mathrm{mL} \\ \text { EPA903.0 } & 1 \mathrm{E}-09 \mu \mathrm{Ci} / \mathrm{mL} \\ \text { EPA904.0 } & 1 \mathrm{E}-09 \mu \mathrm{Ci} / \mathrm{mL} \\ \text { EPA904.0 } & 1 \mathrm{E}-09 \mu \mathrm{Ci} / \mathrm{mL} \\ \text { EPA901.1 } & 1 \mathrm{E}-08 \mu \mathrm{Ci} / \mathrm{mL} \\ \text { EPA901.1 } & 8 \mathrm{E}-08 \mu \mathrm{Ci} / \mathrm{mL} \\ \text { EPA901.1 } & 1 \mathrm{E}-08 \mu \mathrm{Ci} / \mathrm{mL} \\ \text { EPA905.0 } & 2 \mathrm{E}-09 \mu \mathrm{Ci} / \mathrm{mL} \\ \text { EPA905.0 } & 2 \mathrm{E}-09 \mu \mathrm{Ci} / \mathrm{mL} \\ \text { MMEC038 } & 3 \mathrm{E}-07 \mu \mathrm{Ci} / \mathrm{mL} \\ \text { EPA901.1 } & 4 \mathrm{E}-07 \mu \mathrm{Ci} / \mathrm{mL} \\ \text { CTC0009 } & 1 \mathrm{E}-09 \mu \mathrm{Ci} / \mathrm{mL} \\ \text { CTC0009 } & 1 \mathrm{E}-09 \mu \mathrm{Ci} / \mathrm{mL} \\ \text { CTC0009 } & 1 \mathrm{E}-09 \mu \mathrm{Ci} / \mathrm{mL} \\ \text { EPA906.0 } & 7 \mathrm{E}-07 \mu \mathrm{Ci} / \mathrm{mL} \\ \text { CTC0009 } & 1 \mathrm{E}-09 \mu \mathrm{Ci} / \mathrm{mL} \\ \text { CTC0002 } & 1 \mathrm{E}-09 \mu \mathrm{Ci} / \mathrm{mL} \\ \text { EPA901.1 } & 1.5 \mathrm{E}-08 \mu \mathrm{Ci} / \mathrm{mL} \\ \text { CTC0009 } & 1 \mathrm{E}-09 \mu \mathrm{Ci} / \mathrm{mL} \\ \text { CTC0002 } & 1 \mathrm{E}-09 \mu \mathrm{Ci} / \mathrm{mL} \\ \text { CTC0009 } & 1 \mathrm{E}-09 \mu \mathrm{Ci} / \mathrm{mL} \\ \text { CTC0002 } & 1 \mathrm{E}-09 \mu \mathrm{Ci} / \mathrm{mL} \\ \text { EPA901.1 } & 1 \mathrm{E}-08 \mu \mathrm{Ci} / \mathrm{mL} \\ \text { EPA901.1 } & 2.3 \mathrm{E}-08 \mu \mathrm{Ci} / \mathrm{mL} \\ & \end{array}$


NOTES 


\section{QUALITY CONTROL SAMPLES}

\section{REPLICATE AND DUPLICATE ANALYSES OF SAMPLES}

Blind replicate and duplicate samples are analyzed by the primary laboratories, General Engineering (GE) and Roy F. Weston, Inc. (Weston or WA), in order to satisfy quality assurance standards. The replicate and duplicate analytical results are used to generate Mean Relative Difference (MRD) indexes, which are used to evaluate a laboratory's performance.

For intralaboratory comparisons, $10 \%$ of the samples generally are analyzed in duplicate. In addition, EPD/EMS sends blind replicates of approximately $5 \%$ of the total samples to the laboratories for analysis. The results of the blind replicate analyses are used for both intralaboratory and interlaboratory comparisons.

All of these results are included in the Analytical Results section of this report. Results from duplicate samples are included in the main table for a given well and sample date. Results from analyses of replicate samples and from any duplicate analyses made on the replicates are repurted in a second table for the same well and sample date.

Table 23 lists the names and sample dates of wells used as blind replicates for GE and Weston.

Table 23. Wells Providing Blind Replicate Samples

To GE

Well

ABP 4

ASB 3A

ASB 5A

BGO 8D

BGO 10AR

BGO 50D

BGX 6D

BGX $12 \mathrm{C}$

BRD 1

CBR 2D

DOB 2

FNB 4

FSB 78A

FSB 88C

FSB 99A

FSB100A

FSB120A

FSB123D

HIMD 2D

HSB 65

Sample Date
$07 / 14 / 92$
$07 / 16 / 92$
$08 / 06 / 92$
$08 / 03 / 92$
$08 / 04 / 92$
$08 / 14 / 92$
$07 / 31 / 92$
$07 / 30 / 92$
$08 / 03 / 92$
$08 / 01 / 92$
$07 / 15 / 92$
$08 / 24 / 92$
$07 / 05 / 92$
$07 / 04 / 92$
$07 / 15 / 92$
$07 / 10 / 92$
$07 / 19 / 92$
$07 / 06 / 92$
$07 / 01 / 92$
$07 / 06 / 92$

To GE (cont.)

$\begin{array}{ll}\text { Well } & \text { Sample Date } \\ \text { HSB 70 } & 07 / 07 / 92 \\ \text { HSB 85C } & 07 / 08 / 92 \\ \text { HSB105C } & 07 / 10 / 92 \\ \text { HSB122A } & 07 / 17 / 92 \\ \text { HSB140C } & 07 / 22 / 92 \\ \text { HSB146C } & 07 / 24 / 92 \\ \text { LAC 4 } & 08 / 01 / 92 \\ \text { LCO 3 } & 08 / 27 / 92 \\ \text { MSB 1B } & 07 / 13 / 92 \\ \text { MSB 11B } & 07 / 09 / 92 \\ \text { MSB 12TB } & 07 / 17 / 92 \\ \text { MSB 19B } & 07 / 08 / 92 \\ \text { MSB 39C } & 07 / 07 / 92 \\ \text { MSB 43D } & 07 / 20 / 92 \\ \text { MSB 48A } & 07 / 25 / 92 \\ \text { MSB 62B } & 07 / 21 / 92 \\ \text { MSB 70C } & 08 / 08 / 92 \\ \text { NPM 19B } & 08 / 29 / 92 \\ \text { NPM 34C } & 08 / 28 / 92 \\ \text { P 26D } & 09 / 17 / 92\end{array}$


Table 23. Wells Providing Blind Replicate Samples (cont.)

To GE (cont.)

\begin{tabular}{|c|c|}
\hline Well & Sample Dat \\
\hline $28 \mathrm{~A}$ & $09 / 02 / 92$ \\
\hline RAC 1 & $08 / 22 / 92$ \\
\hline SRW 4 & $07 / 11 / 92$ \\
\hline SRW 13A & $07 / 12 / 92$ \\
\hline TBG 1 & $09 / 21 / 92$ \\
\hline TNX 9D & $09 / 17 / 92$ \\
\hline XSB 3A & $09 / 14 / 92$ \\
\hline YSB 2A & 09/16/92 \\
\hline YSC $4 \mathrm{C}$ & $08 / 26 / 92$ \\
\hline ZBG 1 & $08 / 26 / 92$ \\
\hline & 07/27/92 \\
\hline
\end{tabular}

Certain analytes were not present in concentrations above detection limits in any well samples having replicates or duplicates. These analytes are not considered in further evaluation of rep-
To Weston

$\begin{array}{ll}\text { Well } & \text { Sample Date } \\ \text { CMP 11B } & 09 / 10 / 92 \\ \text { CMP 14C } & 09 / 11 / 92 \\ \text { HAC } 4 & 08 / 21 / 92 \\ \text { KAC } 8 & 08 / 02 / 92 \\ \text { LFW 6 } & 08 / 25 / 92 \\ \text { LFW 59D } & 09 / 04 / 92 \\ \text { PSS 2D } & 08 / 23 / 92\end{array}$

licate and duplicate analyses. They are listed in Table 24. See Tables 21 and 22 on pages 60-69 for the detection limits that are effective this quarter.

Table 24. Analytes Not Showing Measurable Concentrations Above Detection Limits in Any Replicated or Duplicated Samples

\begin{tabular}{lrr} 
Analyte & Number of Analyses \\
\cline { 2 - 3 } & GE & WA \\
Acenaphthene & 66 & 29 \\
Acenaphthylene & 66 & 37 \\
Acetonitrile (Methyl cyanide) & 29 & 14 \\
Acetophenone & 50 & 28 \\
2-Acetylaminofluorene & 36 & 17 \\
Acrolein & 48 & 14 \\
Acrylonitrile & 48 & 14 \\
Aldrin & 80 & 15 \\
Allyl chloride & 29 & 4 \\
4-Aminobiphenyl & 36 & 17 \\
Ammonia nitrogen & 2 & - \\
Aniline & 36 & 17 \\
Anthracene & 66 & 37 \\
Aramite & 36 & 17 \\
alpha-Benzene hexachloride & 80 & 19 \\
beta-Benzene hexachloride & 80 & 19 \\
delta-Benzene hexachloride & 80 & 19 \\
Benzidine & 12 & 20 \\
Benzoic acid & - & 4 \\
Benzo[a]anthracene & 66 & 37 \\
Benzo[b]nuoranthene & 66 & 37 \\
Benzo[k]fluoranthene & 66 & 37 \\
Benzo[g,h,i]perylene & 66 & 37 \\
Benzo[a]pyrene & 66 & 37 \\
Benzyl alcohol & 36 & 17 \\
Bis(2-chloroethoxy) methane & 66 & 37 \\
& &
\end{tabular}

Analyte

Bis(2-chloroethyl) ether

Bis(2-chloroisopropyl) ether

Bromodichloromethane

Bromoform

Bromomethane (Methyl bromide)

4-Bromophenyl phenyl ether

2-sec-Butyl-4,6-dinitrophenol

Chlordane

4-Chloroaniline

Chlorobenzene

Chlorobenzilate

Chloroethene (Vinyl chloride)

Chloromethane (Methyl chloride)

para-Chloro-meta-cresol

2-Chloroethyl vinyl ether

2-Chloronaphthalene

2-Chlorophenol

4-Chlorophenyl phenyl ether

Chloroprene

Chrysene

m-Cresol (3-Methylphenol)

o-Cresol (2-Methylphenol)

p-Cresol (4-Methylphenol)

Diallate

$p, p^{\prime}-D D D$

$p, p^{\prime}-D D E$
Number of Analyges

GE WA

$\begin{array}{rr}66 & 37 \\ 12 & 24 \\ 201 & 110 \\ 201 & 110 \\ 201 & 110 \\ 66 & 37 \\ 34 & 17 \\ 80 & 19 \\ 36 & 17 \\ 201 & 98 \\ 36 & 17 \\ 201 & 110 \\ 201 & 110 \\ 64 & 29 \\ 209 & 96 \\ 66 & 37 \\ 64 & 29 \\ 66 & 37 \\ 29 & 24 \\ 66 & 37 \\ 34 & 13 \\ 34 & 17 \\ 34 & 17 \\ 36 & 17 \\ 80 & 19 \\ 80 & 19\end{array}$

- No replicate or duplicate analyses performed. 
Table 24. Analytes Not Showing Measurable Concentrations Above Detection Limits in Any Replicated or Duplicated Samples (cont.)

\begin{tabular}{|c|c|c|}
\hline \multirow{2}{*}{ Analyte } & \multicolumn{2}{|c|}{ Number of Analyses } \\
\hline & $\underline{G E}$ & $\underline{\text { WA }}$ \\
\hline p,p'-DDT & 80 & 15 \\
\hline Dibenz $[a, h]$ anthracene & 66 & 37 \\
\hline Dibenzofuran & 36 & 36 \\
\hline Dibromochloromethane & 201 & 110 \\
\hline 1,2-Dibromo-3-chloropropane & 29 & 14 \\
\hline 1,2-Dibromoethane & 29 & 14 \\
\hline Dibromomethane & & \\
\hline (Methylene bromide) & 29 & 14 \\
\hline 1,2-Dichlorobenzene & 56 & 36 \\
\hline 1,3-Dichlorobenzene & 56 & 36 \\
\hline 1,4-Dichlorobenzene & 56 & 28 \\
\hline 3,3'-Dichlorobenzidine & 66 & 37 \\
\hline trans-1,4-Dichloro-2-butene & 29 & 14 \\
\hline Dichlorodifluoromethane & 48 & 14 \\
\hline cis-1,2-Dichloroethene & - & 2 \\
\hline trans-1,2-Dichloroethylene & 201 & 108 \\
\hline 2,4-Dichlorophenol & 64 & 37 \\
\hline 2,6-Dichlorophenol & 34 & 17 \\
\hline 1,2-Dichloropropane & 201 & 110 \\
\hline cis-1,3-Dichloropropene & 201 & 110 \\
\hline tran8-1,3-Dichloropropene & 196 & 106 \\
\hline Dieldrin & 80 & 15 \\
\hline Dimethoate & 36 & - \\
\hline p-Dimethylaminoazobenzene & 36 & 17 \\
\hline 3,3'-Dimethylbenzidine & 36 & 17 \\
\hline 7,12-Dimethylbenz[a]anthracene & 36 & 17 \\
\hline a,a-Dimethylphenethylamine & 36 & 17 \\
\hline 2,4-Dimethyl phenol & 64 & 37 \\
\hline Dimethyl phthalate & 66 & 37 \\
\hline Di-n-octyl-phthalate & 66 & 37 \\
\hline 1,3-Dinitrobenzene & 36 & 17 \\
\hline 4,6-Dinitro-ortho-cresol & - & 36 \\
\hline 2,4-Dinitrophenol & 64 & 37 \\
\hline 2,4-Dinitrotoluene & 66 & 29 \\
\hline 2,6-Dinitrotoluene & 66 & 37 \\
\hline 1,4-Dioxane & 36 & 17 \\
\hline Diphenylamine & 36 & 17 \\
\hline 1,2-Diphenylhydrazine & 12 & - \\
\hline Disulfoton & 36 & - \\
\hline Endosulfan I & 80 & 19 \\
\hline Endosulfan II & 80 & 19 \\
\hline Endosulfan sulfate & 80 & 19 \\
\hline Endrin & 173 & 98 \\
\hline Endrin aldehyde & 80 & 19 \\
\hline Ethyl methacrylate & 36 & 17 \\
\hline Ethyl methanesulfonate & 36 & 17 \\
\hline Famphur & 36 & - \\
\hline Fluoranthene & 66 & 37 \\
\hline Fluorene & 66 & 37 \\
\hline 1,2,3,4,6,7,8-HPCDD & 42 & - \\
\hline
\end{tabular}

Analyte

Number of Analyses

A

Anglyte

GE WA

Heptachlor $80 \quad 15$

Heptachlor epoxide $\quad 80 \quad 19$

Heptachlorodibenzo-p-dioxin isomers 42

$1,2,3,4,6,7,8 \cdot \mathrm{HPCDF}$

Heptachlorodibenzo-p-furan isomers 42

Hexachlorobenzene $\quad 66 \quad 37$

Hexachlorobutadiene $\quad 66 \quad 37$

Hexachlorocyclopentadiene $\quad 66 \quad 37$

1,2,3,4,7,8-HXCDD 42

$1,2,3,4,7,8-\mathrm{HXCDF}$

Hexachlorodibenzo-p-furan isomers $42 \quad 10$

Hexachloroethane $\quad 66 \quad 37$

Hexachlorophene $\quad 34 \quad 17$

Hexachloropropene $\quad 36 \quad 17$

Indeno $[1,2,3-c, d]$ pyrene $\quad 66 \quad 37$

Iodomethane (Methyl iodide) $\quad 29 \quad 14$

Isobutyl alcohol $\quad 29 \quad 14$

Isodrin $\quad 36 \quad 19$

Isophorone $\quad 66 \quad 37$

$\begin{array}{lll}\text { Isosafrole } & 36 & 17\end{array}$

Lindane (gamma-Benzene

hexachloride)

Methacrylonitrile

$173 \quad 98$

$\begin{array}{lll}\text { Methapyrilene } & 36 & 17\end{array}$

$\begin{array}{lrr}\text { Methoxychlor } & 141 & 122\end{array}$

3-Methylcholanthrene $\quad 36 \quad 17$

2-Methyl-4,6-dinitrophenol 64 -

Methyl isobutyl ketone 29

$\begin{array}{lll}\text { Methyl methacrylate } & 36 & 17\end{array}$

Methyl methanesulfonate $\quad 36 \quad 17$

2-Methylnaphthalene $\quad 36 \quad 17$

4-Methyl-2-pentanone $\quad-\quad 14$

$\begin{array}{lll}\text { Naphthalene } & 80 & 37\end{array}$

1-Naphthylamine $\quad 36 \quad 17$

2-Naphthylamine $\quad 36 \quad 17$

1,4-Naphthoquinone $\quad 36 \quad 17$

Nitrate as nitrogen $\quad 24 \quad 11$

2-Nitroaniline $\quad 36 \quad 17$

3-Nitroaniline $\quad 36 \quad 17$

4-Nitroaniline $\quad 36 \quad 17$

$\begin{array}{lll}\text { Nitrobenzene } & 66 & 37\end{array}$

5-Nitro-0-toluidine $\quad 36 \quad 17$

2-Nitrophenol $\quad 64 \quad 37$

4-Nitrophenol $\quad 64 \quad 29$

4-Nitroquinoline-1-oxide $\quad 36 \quad 17$

N-Nitrosodi-n-butylamine $\quad 36 \quad 17$

$\begin{array}{lll}\text { N-Nitrosodiethylamine } & 36 & 17\end{array}$

N-Nitrosodimethylamine $\quad 66 \quad 37$

N-Nitrosodiphenylamine $\quad 66 \quad 37$

N-Nitrosomethylethylamine $\quad 36 \quad 17$

- No replicate or duplicate analyses performed. 
Table 24. Analytes Not Showing Measurable Concentrations Above Detection Limits in Any Replicated or Duplicated Samples (cont.)

\begin{tabular}{|c|c|c|c|c|c|}
\hline \multirow[t]{2}{*}{ Analyte } & \multicolumn{2}{|c|}{ Number of Analyses } & \multirow[t]{2}{*}{ Analyte } & \multicolumn{2}{|c|}{ Number of Analyses } \\
\hline & GE & $\underline{\text { WA }}$ & & GE & WA \\
\hline N.Nitrosomorpholine & 36 & 17 & 1,2,4-Trichlorobenzene & 66 & 29 \\
\hline N-Nitrosopiperidine & 36 & 17 & 2,4,5-Trichlorophenol & 34 & 17 \\
\hline N-Nitrosodipropylamine & 66 & 29 & 2,4,6-Trichlorophenol & 64 & 37 \\
\hline N-Nitrosopyrrolidine & 36 & 17 & 1,2,3-Trichloropropane & 29 & 14 \\
\hline Octachlorodibenzo-p-dioxin isomers & 42 & - & 0,0,0-Triethyl phosphorothioate & 36 & - \\
\hline Octachlorodibenzo-p-furan isomers & 42 & - & 1,3,5-Trinitrobenzene & 36 & 17 \\
\hline Oil \& Grease & 2 & 2 & Vinyl acetate & 29 & 14 \\
\hline Parathion & 48 & - & Xylenes & 49 & 26 \\
\hline Parathion methyl & 48 & - & Americium-241 & 45 & - \\
\hline PCB 1016 & 80 & 31 & Antimony-125 & 102 & - \\
\hline PCB 1221 & 80 & 31 & Cerium-144 & 102 & - \\
\hline PCB 1232 & 80 & 31 & Cesium-134 & 102 & - \\
\hline PCB 1242 & 80 & 31 & Cesium-137 & 102 & - \\
\hline PCB 1248 & 80 & 31 & Curium-242 & 28 & - \\
\hline PCB 1254 & 80 & 31 & Curium-243/244 & 28 & - \\
\hline PCB 1260 & 80 & 31 & Cobalt-57 & 102 & - \\
\hline 1,2,3,7,8-PCDD & 42 & - & Europium-152 & 102 & - \\
\hline Pentachlorobenzene & 36 & 17 & Europium-154 & 102 & - \\
\hline Pentachlorodibenzo-p-dioxin isomers & 42 & 10 & Europium-155 & 102 & - \\
\hline $1,2,3,7,8-P C D F$ & 42 & - & Iodine-129 & 6 & - \\
\hline Pentachloroethane & 36 & 17 & Manganese-54 & 102 & - \\
\hline Pentachloronitrobenzene & 36 & 17 & Plutonium-238 & 41 & - \\
\hline Pentachlorophenol & 64 & 29 & Plutonium-239/240 & 41 & - \\
\hline Phenacetin & 36 & 17 & Promethium-144 & 102 & - \\
\hline Phenanthrene & 66 & 37 & Promethium-146 & 102 & - \\
\hline p-Phenylenediamine & 36 & 17 & Ruthenium-106 & 102 & - \\
\hline Phorate & 48 & - & Sodium-22 & 102 & - \\
\hline 2-Picoline & 36 & 17 & Thorium-228 & 37 & - \\
\hline Pronamid & 36 & 17 & Thorium-232 & 37 & - \\
\hline Propionitrile & 29 & 14 & Uranium-235 & 79 & - \\
\hline Pyrene & 66 & 29 & Yttrium-88 & 102 & - \\
\hline Pyridine & 36 & 17 & Zinc-65 & 102 & - \\
\hline Safrole & 36 & 17 & & & \\
\hline Styrene & 29 & 14 & & & \\
\hline Sulfide & 62 & 16 & Intralaboratory Compariso & & \\
\hline Sulfotepp & 36 & - & & & \\
\hline 1,2,4,5-Tetrachlorobenzene & 36 & 17 & There are two iypes of intralab & tory c & ari- \\
\hline $2,3,7,8-\mathrm{TCDD}$ & 42 & 10 & sons: in-house duplicates and & ad re & tes. \\
\hline $2,3,7,8-$ TCDF & 42 & - & The mean relative difference & RD) & de- \\
\hline Tetrachlorodibenzo-p-dioxin isomers & 42 & 10 & veloped by EPD/EMS person & to as & \\
\hline 1,1,1,2-Tetrachloroethane & 29 & 14 & 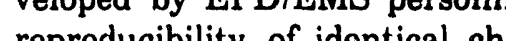 & d & \\
\hline 2,3,4,6-Tetrachlorophenol & 34 & 17 & reproducibility of identical ch & cal a & ses. \\
\hline Thionazin & 36 & - & For both intralaboratory compe & ons, $t$ & IRD \\
\hline o-Toluidine & 36 & 17 & is defined as the average abs & te di & nce \\
\hline Toxaphene & 173 & 122 & between an original sample an & dup & e or \\
\hline Tributyl phosphate & 13 & - & blind replicate, expressed as a & entag & the \\
\hline $2,4,5-T$ & 37 & 3 & mean of those two values. It & calcu & d as \\
\hline
\end{tabular}

- No replicate or duplicate analyses performed. 


$$
M R D=\left\{\frac{\sum_{i=1}^{n}\left(\left|x_{i}-y_{i}\right| /\left[\left(x_{i}+y_{i}\right) / 2\right]\right)}{n}\right\} \times 100,
$$

where

$$
\begin{aligned}
& x_{i}= \text { an analyte's meais concentration in } \\
& \text { a water sample for the } i^{\text {th }} \text { well, } \\
& y_{i}= \text { the analyte's mean concentration in } \\
& \text { the replicate or duplicate, and } \\
& n=\text { the number of pairs of observations. }
\end{aligned}
$$

For the in-house duplicate comparisons, the quantities $x_{i}$ and $y_{i}$ represent the results for the original sample and the in-house duplicate, respectively. For the blind replicate comparisons, $x_{i}$ and $y_{i}$ represent the results for the known sample and the EPD blind replicate, respectively. Generally, the closer the original results and their replicate or duplicate results are to each other, the lower the MRD.

\section{Normalizing Data to the Reference Detection Limit}

Because some detection limits may be anomalously high (due to dilution or other effects, for example), it is necessary to use a reference detection limit (RDL) in the MRD calculations. This is set as the 90th percentile value. All the results less than the RDL are adjusted up to that value. Results that are detection limit values above the RDL are eliminated from the MRD index calculations. By definition, fewer than $10 \%$ of the detection limit values are above

\begin{tabular}{|c|c|c|c|c|c|}
\hline \multirow[b]{2}{*}{ Analvte } & \multirow[b]{2}{*}{$\underline{\mathrm{RDL}}$} & \multicolumn{2}{|c|}{ In-house Duplicates } & \multicolumn{2}{|c|}{ Blind Replicates } \\
\hline & & $\begin{array}{l}\text { Number of } \\
\text { Analyses }\end{array}$ & $\underline{\text { MRD }}$ & $\begin{array}{l}\text { Number of } \\
\text { Analyses }\end{array}$ & $\underline{\text { MRD }}$ \\
\hline Acetone & $100 \mu \mathrm{g} / \mathrm{L}$ & 10 & - & 4 & - \\
\hline Alkalinity (as $\mathrm{CaCO}_{3}$ ) & $*$ & 3 & 1.29 & 2 & 6.23 \\
\hline Aluminum & $20 \mu \mathrm{g} / \mathrm{L}$ & 82 & 0.49 & 25 & 2.2 \\
\hline Antimony & $2.0 \mu \mathrm{g} / \mathrm{L}$ & 59 & 2.00 & 25 & - \\
\hline Arsenic & $2.0 \mu g / L$ & 93 & 0.35 & 50 & 0.29 \\
\hline Barium & $3.0 \mu \mathrm{g} / \mathrm{L}$ & 102 & 0.44 & 50 & 3.87 \\
\hline Benzene & $1.0 \mu \mathrm{g} / \mathrm{L}$ & 50 & - & 37 & 0.49 \\
\hline Beryllium & $3.0 \mu \mathrm{g} / \mathrm{L}$ & 52 & - & 8 & - \\
\hline Bis(2-ethylhexyl) phthalate & $10 \mu \mathrm{g} / \mathrm{L}$ & 17 & - & 8 & - \\
\hline Butylbenzyl phthalate & $10 \mu \mathrm{g} / \mathrm{L}$ & 17 & _- & 8 & - \\
\hline Cadmium & $2.0 \mu \mathrm{g} / \mathrm{L}$ & 122 & 0.12 & 52 & - \\
\hline Calcium & $10 \mu \mathrm{g} / \mathrm{L}$ & 86 & 2.31 & 35 & 8.18 \\
\hline Carbon disulfide & $1.0 \mu \mathrm{g} / \mathrm{L}$ & 10 & 6.36 & 4 & - \\
\hline Carbon tetrachloride & $1.0 \mu \mathrm{g} / \mathrm{L}$ & 74 & 0.17 & 39 & 2.10 \\
\hline Chloride & $250 \mu \mathrm{g} / \mathrm{L}$ & 102 & 1.64 & 44 & 4.91 \\
\hline Chloroethane & $1.0 \mu \mathrm{g} / \mathrm{L}$ & 50 & - & 37 & 4.40 \\
\hline Chloroform & $1.0 \mu \mathrm{g} / \mathrm{L}$ & 73 & 1.18 & 39 & 1.06 \\
\hline Chromium & $4.0 \mu \mathrm{g} / \mathrm{L}$ & 106 & 0.03 & 51 & 1.90 \\
\hline Cobalt & $4.0 \mu \mathrm{g} / \mathrm{L}$ & 77 & 0.19 & 20 & - \\
\hline Copper & $4.0 \mu \mathrm{g} / \mathrm{L}$ & 97 & 0.26 & 33 & 2.84 \\
\hline Cyanide & $5.0 \mu \mathrm{g} / \mathrm{L}$ & 55 & - & 25 & - \\
\hline Di-n-butyl phthalate & $10 \mu \mathrm{g} / \mathrm{L}$ & 17 & - & 8 & - \\
\hline
\end{tabular}
the RDL.

The intralaboratory MRD indexes for GE and Weston are listed in Tables 25 and 26, respectively.

Table 25. Intralaboratory MRD Index for GE

- No results above RDL among those analyses included in calculating the MRD.

* No detection limit, or no duplicate or replicate results below detection limit. 
Table 25. Intralaboratory MRD Index for GE (cont.)

\begin{tabular}{|c|c|c|c|c|c|}
\hline \multirow[b]{2}{*}{ Analyte } & \multirow[b]{2}{*}{$\underline{\mathrm{RDL}}$} & \multicolumn{2}{|c|}{ In-house Duplicates } & \multicolumn{2}{|c|}{ Blind Replicates } \\
\hline & & $\begin{array}{l}\text { Number of } \\
\text { Analyses }\end{array}$ & $\underline{\text { MRD }}$ & $\begin{array}{l}\text { Number of } \\
\text { Analyses }\end{array}$ & MRD \\
\hline 1,1-Dichloroethane & $1.0 \mu \mathrm{g} / \mathrm{L}$ & 50 & - & 37 & 6.06 \\
\hline 1,2-Dichloroethane & $1.0 \mu \mathrm{g} / \mathrm{L}$ & 50 & - & 37 & 0.49 \\
\hline 1,1-Dichloroethylene & $1.0 \mu \mathrm{g} / \mathrm{L}$ & 50 & - & 37 & 2.63 \\
\hline Dichloromethane & & & & & \\
\hline (Methylene chloride) & $1.0 \mu \mathrm{g} / \mathrm{L}$ & 53 & 15.46 & 39 & 35.92 \\
\hline 2,4-Dichlorophenoxyacetic acid & $0.3 \mu \mathrm{g} / \mathrm{L}$ & 46 & - & 28 & - \\
\hline Diethyl phthalate & $10 \mu \mathrm{g} / \mathrm{L}$ & 17 & - & 8 & - \\
\hline Dissolved organic carbon & $1,000 \mu \mathrm{g} / \mathrm{L}$ & 6 & 0.95 & 2 & - \\
\hline Ethylbenzene & $1.0 \mu \mathrm{g} / \mathrm{L}$ & 60 & 0.33 & 37 & - \\
\hline Fluoride & $100 \mu \mathrm{g} / \mathrm{L}$ & 64 & 0.82 & 35 & 1.18 \\
\hline $\begin{array}{l}\text { Hexachlorodibenzo-p-dioxin } \\
\text { isomers }\end{array}$ & $0.45 \mu \mathrm{g} / \mathrm{L}$ & 17 & - & 5 & - \\
\hline 2-Hexanone & $1.0 \mu \mathrm{g} / \mathrm{L}$ & 10 & 3.19 & 4 & 7.98 \\
\hline Iodine & - & 1 & 6.67 & $\mathbf{0}$ & - \\
\hline Iron & $4.0 \mu \mathrm{g} / \mathrm{L}$ & 124 & 2.73 & 50 & 13.36 \\
\hline Kepone & $10 \mu \mathrm{g} / \mathrm{L}$ & 14 & - & 5 & - \\
\hline Lead & $3.0 \mu \mathrm{g} / \mathrm{L}$ & 124 & 0.85 & 55 & 3.67 \\
\hline Lithium & $5.0 \mu \mathrm{g} / \mathrm{L}$ & 35 & - & 2 & - \\
\hline Magnesium & $2.0 \mu \mathrm{g} / \mathrm{L}$ & 86 & 11.01 & 36 & 7.27 \\
\hline Manganese & $2.0 \mu \mathrm{g} / \mathrm{L}$ & 129 & 0.62 & 52 & 6.58 \\
\hline Mercury & $0.2 \mu \mathrm{g} / \mathrm{L}$ & 123 & 0.68 & 52 & 2.70 \\
\hline Methyl ethyl ketone & $1.0 \mu \mathrm{g} / \mathrm{L}$ & 10 & 10.08 & 4 & 19.88 \\
\hline Nickel & $4.0 \mu \mathrm{g} / \mathrm{L}$ & 98 & 2.55 & 36 & 6.59 \\
\hline Nitrate-nitrite as nitrogen & $50 \mu \mathrm{g} / \mathrm{L}$ & 90 & 2.29 & 47 & 23.79 \\
\hline $\begin{array}{l}\text { Pentachlorodibenzo-p-furan } \\
\text { isomers }\end{array}$ & $0.55 \mu \mathrm{g} / \mathrm{L}$ & 17 & - & 5 & - \\
\hline $\mathrm{pH}$ & - & 100 & 0.77 & 47 & 1.18 \\
\hline Phenol & $10 \mu \mathrm{g} / \mathrm{L}$ & 16 & - & 8 & - \\
\hline Phenols & $5.0 \mu \mathrm{g} / \mathrm{L}$ & 59 & 0.03 & 37 & - \\
\hline Potassium & $500 \mu \mathrm{g} / \mathrm{L}$ & 86 & 0.99 & 34 & 1.84 \\
\hline Selenium & $2.0 \mu \mathrm{g} / \mathrm{L}$ & 90 & - & 49 & 0.64 \\
\hline Silica & $100 \mu \mathrm{g} / \mathrm{L}$ & 85 & 0.85 & 35 & 7.20 \\
\hline Silver & $2.0 \mu \mathrm{g} / \mathrm{L}$ & 103 & - & 50 & 0.57 \\
\hline Sodium & $10 \mu \mathrm{g} / \mathrm{L}$ & 100 & 2.38 & 43 & 6.05 \\
\hline Specific conductance & $1.0 \mu \mathrm{S} / \mathrm{cm}$ & 96 & 0.89 & 45 & 4.53 \\
\hline Sulfate & $1,000 \mu \mathrm{g} / \mathrm{L}$ & 98 & 1.39 & 43 & 5.42 \\
\hline Tetrachlorodibenzo-p-furan & & & & & \\
\hline isomers & $0.40 \mu \mathrm{g} / \mathrm{L}$ & 17 & - & 5 & - \\
\hline 1,1,2,2-Tetrachloroethane & $1.0 \mu \mathrm{g} / \mathrm{L}$ & 50 & 0.07 & 37 & - \\
\hline Tetrachloroethylene & $1.0 \mu \mathrm{g} / \mathrm{L}$ & 75 & 1.71 & 40 & 5.39 \\
\hline Thallium & $2.0 \mu \mathrm{g} / \mathrm{L}$ & 41 & 0.07 & 14 & - \\
\hline Tin & $2.0 \mu \mathrm{g} / \mathrm{L}$ & 55 & 10.72 & 12 & 14.22 \\
\hline Toluene & $1.0 \mu \mathrm{g} / \mathrm{L}$ & 50 & 1.07 & 37 & - \\
\hline Total dissolved solids & $1,000 \mu \mathrm{g} / \mathrm{L}$ & 73 & 7.06 & 32 & 10.40 \\
\hline Total inorganic carbon & * & 0 & - & 5 & 28.02 \\
\hline Total organic carbon & $1,000 \mu \mathrm{g} / \mathrm{L}$ & 96 & 2.41 & 44 & 5.63 \\
\hline Total organic halogens & $5.0 \mu \mathrm{g} / \mathrm{L}$ & 118 & 2.67 & 52 & 9.38 \\
\hline
\end{tabular}

- No results above RDL among those analyses included in calculating the MRD.

- No detection limit, or no duplicate or replicate results below detection limit. 
Table 25. Intralaboratory MRD Index for GE (cont.)

\begin{tabular}{|c|c|c|c|c|c|}
\hline \multirow[b]{2}{*}{ Analyte } & \multirow[b]{2}{*}{$\underline{\mathrm{RDL}}$} & \multicolumn{2}{|c|}{ In-house Duplicates } & \multicolumn{2}{|c|}{ Blind Replicates } \\
\hline & & $\begin{array}{l}\text { Number of } \\
\text { Analyses }\end{array}$ & $\underline{\text { MRD }}$ & $\begin{array}{l}\text { Number of } \\
\text { Analyses }\end{array}$ & $\underline{\text { MRD }}$ \\
\hline Total petroleum & & & & & \\
\hline Total phosphates (as P) & $50 \mu \mathrm{g} / \mathrm{L}$ & 77 & $\overline{3.35}$ & 40 & $\begin{array}{l}13.08 \\
17.34\end{array}$ \\
\hline 2,4,5-TP (Silvex) & $0.09 \mu \mathrm{g} / \mathrm{L}$ & 46 & - & 29 & - \\
\hline 1,1,1-Trichloroethane & $1.0 \mu \mathrm{g} / \mathrm{L}$ & 73 & 0.58 & 40 & 4.87 \\
\hline 1,1,2-Trichloroethane & $1.0 \mu \mathrm{g} / \mathrm{L}$ & 50 & - & 37 & - \\
\hline Trichioroethylene & $1.0 \mu \mathrm{g} / \mathrm{L}$ & 76 & 3.13 & 42 & 8.61 \\
\hline Trichlorofluoromethane & $1.0 \mu \mathrm{g} / \mathrm{L}$ & 50 & 5.39 & 37 & 13.32 \\
\hline Turbidity & $0.10 \mathrm{NTU}$ & 15 & 2.69 & 6 & 18.44 \\
\hline Uranium & $20 \mu \mathrm{g} / \mathrm{L}$ & 62 & 0.69 & 12 & - \\
\hline Vanadium & $8.0 \mu \mathrm{g} / \mathrm{L}$ & 81 & 0.07 & 24 & - \\
\hline Zinc & $2.0 \mu \mathrm{g} / \mathrm{L}$ & 93 & 0.82 & 30 & 9.78 \\
\hline Cobalt-60 & $1.0 \mathrm{E}-08 \mu \mathrm{Ci} / \mathrm{mL}$ & 38 & 0.76 & 15 & - \\
\hline Gross alpha & $2.0 \mathrm{E}-09 \mu \mathrm{Ci} / \mathrm{mL}$ & 103 & 4.41 & 52 & 7.76 \\
\hline Nonvolatile beta & $2.0 \mathrm{E}-09 \mu \mathrm{Ci} / \mathrm{mL}$ & 103 & 6.03 & 52 & 10.28 \\
\hline Potassium-40 & $1.1 \mathrm{E}-07 \mu \mathrm{Ci} / \mathrm{mL}$ & 38 & 4.24 & 15 & - \\
\hline Radium-226 & $1.0 \mathrm{E}-09 \mu \mathrm{Ci} / \mathrm{mL}$ & 11 & 7.66 & 15 & 34.55 \\
\hline Radium-228 & $1.0 \mathrm{E}-09 \mu \mathrm{Ci} / \mathrm{mL}$ & 5 & 11.88 & 13 & 55.37 \\
\hline Strontium-89 & $2.0 \mathrm{E}-09 \mu \mathrm{Ci} / \mathrm{mL}$ & 9 & 1.93 & 6 & - \\
\hline Strontium-90 & $2.0 \mathrm{E}-09 \mu \mathrm{Ci} / \mathrm{mL}$ & 13 & 0.34 & 6 & - \\
\hline Technetium-99 & $3.0 \mathrm{E}-07 \mu \mathrm{Ci} / \mathrm{mL}$ & 7 & 0.26 & 5 & - \\
\hline Thorium-230 & $1.0 \mathrm{E}-09 \mu \mathrm{Ci} / \mathrm{mL}$ & 13 & 7.73 & 6 & 5.44 \\
\hline Total alphamitting radium & $1.0 \mathrm{E}-09 \mu \mathrm{Ci} / \mathrm{mL}$ & 102 & 3.88 & 50 & 10.16 \\
\hline Tritium & $7.0 \mathrm{E}-07 \mu \mathrm{Ci} / \mathrm{mL}$ & 101 & 3.58 & 47 & 8.97 \\
\hline Uranium-234 & $1.0 \mathrm{E}-09 \mu \mathrm{Ci} / \mathrm{mL}$ & 27 & 0.10 & 14 & - \\
\hline Uranium-238 & $1.0 \mathrm{E}-09 \mu \mathrm{Ci} / \mathrm{mL}$ & 27 & 0.30 & 14 & - \\
\hline
\end{tabular}

- No results above RDL among those analyses included in calculating the MRD.

Table 26. Intralaboratory MRD Index for Weston

\begin{tabular}{|c|c|c|c|c|c|}
\hline \multirow[b]{2}{*}{ Analyte } & \multirow[b]{2}{*}{$\underline{\mathrm{RDL}}$} & \multicolumn{2}{|c|}{ In-house Duplicates } & \multicolumn{2}{|c|}{ Blind Replicates } \\
\hline & & $\begin{array}{l}\text { Number of } \\
\text { Analyses }\end{array}$ & $\underline{\text { MRD }}$ & $\begin{array}{l}\text { Number of } \\
\text { Analyses }\end{array}$ & MRD \\
\hline Acetone & $50 \mu \mathrm{g} / \mathrm{L}$ & 2 & - & 5 & - \\
\hline Aluminum & $14.6 \mu \mathrm{g} / \mathrm{L}$ & 13 & 14.95 & 25 & 18.58 \\
\hline Antimony & $2.6 \mu \mathrm{g} / \mathrm{L}$ & 14 & 19.04 & 25 & 24.67 \\
\hline Arsenic & $2.0 \mu \mathrm{g} / \mathrm{L}$ & 18 & - & 50 & 7.16 \\
\hline Barium & $4.0 \mu \mathrm{g} / \mathrm{L}$ & 18 & 6.26 & 50 & 12.53 \\
\hline Benzene & $5.0 \mu \mathrm{g} / \mathrm{L}$ & 5 & - & 38 & - \\
\hline Beryllium & $0.18 \mu \mathrm{g} / \mathrm{L}$ & 9 & 3.39 & 8 & 16.36 \\
\hline Bis(2-ethylhexyl) phthalate & $11 \mu \mathrm{g} / \mathrm{L}$ & 13 & 22.64 & 8 & 25.77 \\
\hline Butylbenzyl phthalate & $11 \mu \mathrm{g} / \mathrm{L}$ & 12 & - & 7 & - \\
\hline Cadmium & $0.35 \mu \mathrm{g} / \mathrm{L}$ & 18 & 34.44 & 52 & 23.48 \\
\hline Calcium & $14.4 \mu \mathrm{g} / \mathrm{L}$ & 17 & 9.75 & 35 & 5.06 \\
\hline
\end{tabular}

- No results above RDL among those analyses included in calculating the MRD. 
Table 26. Intralaboratory MRD Index for Weston (cont.)

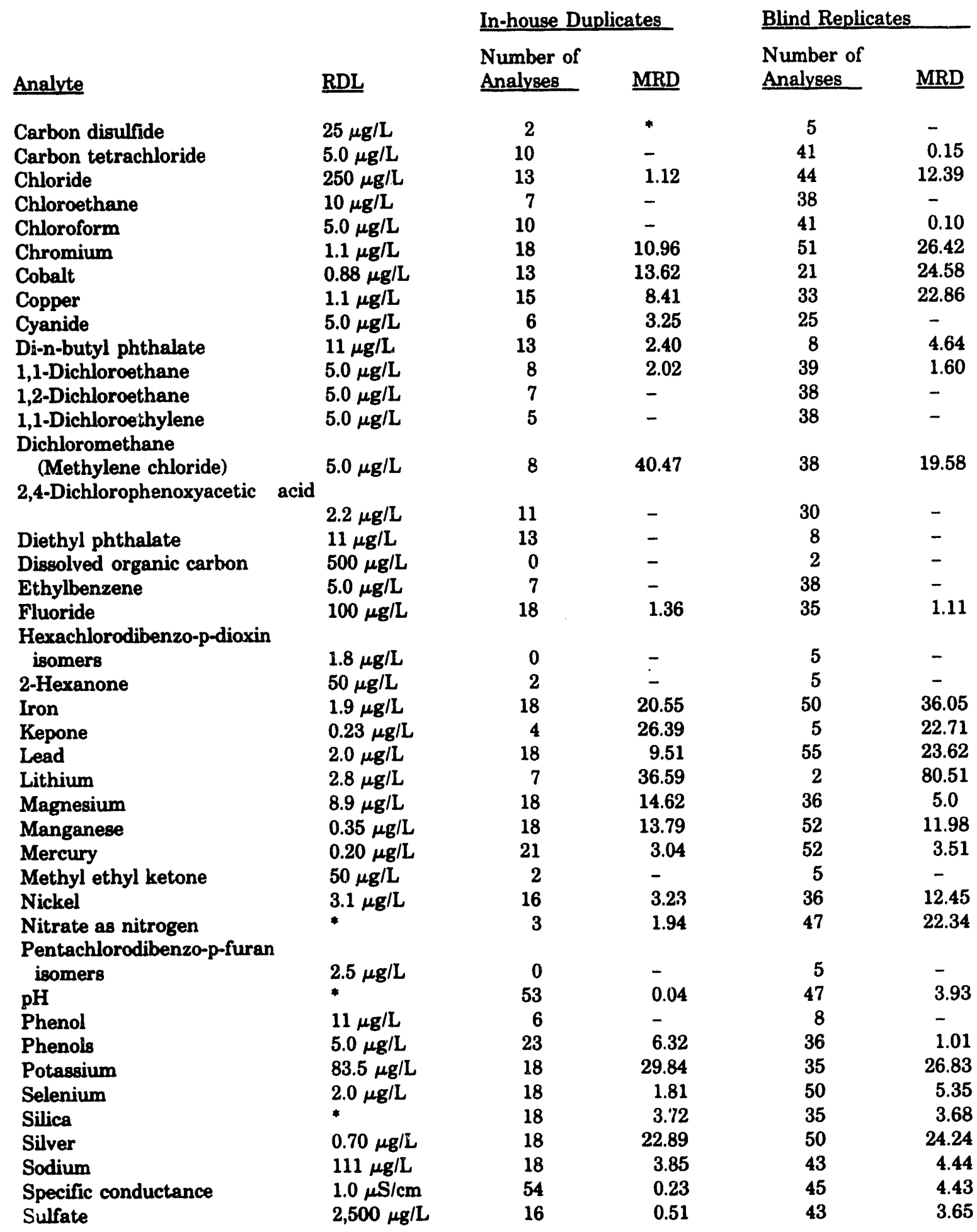

- No results above RDL among those analyses included in calculating the MRD.

- No detection limit, or no duplicate or replicate results below detection limit. 
Table 26. Intralaboratory MRD Index for Weston (cont.)

\begin{tabular}{|c|c|c|c|c|c|}
\hline \multirow[b]{2}{*}{ Analyte } & \multirow[b]{2}{*}{$\underline{\mathrm{RDL}}$} & \multicolumn{2}{|c|}{ In-house Duplicates } & \multicolumn{2}{|c|}{ Blind Replicates } \\
\hline & & $\begin{array}{l}\text { Number of } \\
\text { Analyses }\end{array}$ & $\underline{\text { MRD }}$ & $\begin{array}{l}\text { Number of } \\
\text { Analyses }\end{array}$ & $\underline{\text { MRD }}$ \\
\hline $\begin{array}{l}\text { Tetrachlorodibenzo-p-furan } \\
\text { isomers }\end{array}$ & $2.3 \mu \mathrm{g} / \mathrm{L}$ & 0 & - & 5 & . \\
\hline 1,1,2,2-Tetrachloroethane & $5.0 \mu \mathrm{g} / \mathrm{L}$ & 7 & - & 38 & - \\
\hline Totrachloroethylene & $5.0 \mu \mathrm{g} / \mathrm{L}$ & 9 & 1.44 & 41 & 0.60 \\
\hline Thallium & $2.0 \mu \mathrm{g} / \mathrm{L}$ & 11 & - & 14 & 9.09 \\
\hline $\operatorname{Tin}$ & $1.9 \mu \mathrm{g} / \mathrm{L}$ & 11 & 47.77 & 12 & 22.94 \\
\hline Toluene & $5.0 \mu \mathrm{g} / \mathrm{L}$ & 5 & - & 38 & - \\
\hline Total dissolved solids & $1,000 \mu \mathrm{g} / \mathrm{L}$ & 24 & 4.57 & 32 & 34.27 \\
\hline Total inorganic carbon & * & 0 & - & 5 & 3.53 \\
\hline Total organic carbon & $500 \mu \mathrm{g} / \mathrm{L}$ & 3 & 5.77 & 45 & 16.64 \\
\hline Total organic halogens & $10 \mu \mathrm{g} / \mathrm{L}$ & 13 & 8.86 & 53 & 22.96 \\
\hline Total petroleum & & & & & \\
\hline hydrocarbons & $1,020 \mu \mathrm{g} / \mathrm{L}$ & 2 & - & 3 & - \\
\hline Total phosphates (as P) & $20 \mu \mathrm{g} / \mathrm{L}$ & 8 & 7.72 & 40 & 28.33 \\
\hline 2,4,5-TP (Silvex) & $1.1 \mu \mathrm{g} / \mathrm{L}$ & 11 & - & 30 & - \\
\hline 1,1,1-Trichloroethane & $5.0 \mu \mathrm{g} / \mathrm{L}$ & 7 & - & 41 & 0.77 \\
\hline 1,1,2-Trichloroethane & $5.0 \mu \mathrm{g} / \mathrm{L}$ & 7 & - & 38 & - \\
\hline Trichloroethylene & $5.0 \mu \mathrm{g} / \mathrm{L}$ & 10 & 8.98 & 42 & 1.80 \\
\hline Trichlorofluoromethane & $5.0 \mu \mathrm{g} / \mathrm{L}$ & 7 & - & 38 & 0.37 \\
\hline Turbidity & $0.20 \mathrm{NTU}$ & 11 & 0.04 & 6 & 33.08 \\
\hline Uranium & $0.03 \mu \mathrm{g} / \mathrm{L}$ & 24 & 0.72 & 16 & 44.69 \\
\hline Vanadium & $0.88 \mu \mathrm{g} / \mathrm{L}$ & 15 & 16.79 & 24 & 32.60 \\
\hline Zinc & * & 13 & 30.87 & 30 & 36.34 \\
\hline Gross alpha & $1.2 \mathrm{E}-09 \mu \mathrm{Ci} / \mathrm{mL}$ & 33 & 20.71 & 43 & 18.25 \\
\hline Nonvolatile beta & $2.2 \mathrm{E}-09 \mu \mathrm{Ci} / \mathrm{mL}$ & 33 & 22.35 & 46 & 21.36 \\
\hline Radium-226 & $6.4 \mathrm{E}-10 \mu \mathrm{Ci} / \mathrm{mL}$ & 33 & 25.93 & 46 & 20.32 \\
\hline Radium-228 & $9.0 \mathrm{E}-10 \mu \mathrm{Ci} / \mathrm{mL}$ & 34 & 29.56 & 45 & 24.39 \\
\hline Tritium & $5.5 \mathrm{E}-07 \mu \mathrm{Ci} / \mathrm{mL}$ & 26 & 4.76 & 35 & 7.74 \\
\hline
\end{tabular}

- No results above RDL among those analyses included in calculating the MRD.

* No detection limit, or no duplicate or replicate results below detection limit.

\section{Calculations for Interlaboratory Comparisons}

For interlaboratory comparisons, the MRD is calculated as the average absolute difference between the laboratories for the $i^{\text {th }}$ well expressed as a percentage of the mean of both laboratories. For these comparisons, $x_{i}$ and $y_{i}$ represent the mean analyte concentrations for the $i^{\text {th }}$ well; $x_{i}$ represents the mean from one laboratory and $y_{i}$ represents the mean from the other. The means are calculated from the known sample results and the EPD blind replicate results.

\section{Choosing an RDL}

For interlaboratory comparisons, a new RDL must be established for calculation of the MRD. The interlaboratory RDL is chosen as the 90th percentile value from the array of detection limits from both laboratories; i.e., that detection limit value at or below which are $90 \%$ of the detection limit values from both laboratories.

\section{Normalizing Data to the RDL}

All the results less than the RDL are adjusted to the new RDL value. Results that are de- 
tection limit values above the RDL are eliminated from the MRD index comparison and from the $t$-tests. By definition, fewer than $10 \%$ of the detection limit values are above the RDL.

In addition to the interlaboratory MRD calculations, paired $t$-tests are performed to see if the difference between the mean concentrations of an analyte from the same well reported by each laboratory is significant. The $t$-test tests the null hypothesis that there is no significant difference in the concentrations reported by the two laboratories. The MRD and the $t$-test results for analytes with at least one pair of results above the interlaboratory RDL are listed in Table 27.

Table 27. Interlaboratory MRD and $t$-Test Results for Analytes with at Least One Pair of Results Above the RDL

\begin{tabular}{|c|c|c|c|}
\hline Analyte & $\underline{\mathrm{RDL}}$ & MRD & t-Test Proba \\
\hline Aluminum & $20 \mu \mathrm{g} / \mathrm{L}$ & 11.53 & .251 \\
\hline Antimony & $2.6 \mu \mathrm{g} / \mathrm{L}$ & 25.86 & .008 \\
\hline Arsenic & $2.0 \mu \mathrm{g} / \mathrm{L}$ & 5.41 & .260 \\
\hline Barium & $4.0 \mu \mathrm{g} / \mathrm{L}$ & 8.85 & .758 \\
\hline Bis(2-ethylhexyl) phthalate & $10 \mu \mathrm{g} / \mathrm{L}$ & 23.24 & .243 \\
\hline Cadmium & $2.0 \mu \mathrm{g} / \mathrm{L}$ & 5.59 & .082 \\
\hline Calcium & $14.4 \mu \mathrm{g} / \mathrm{L}$ & 11.09 & .701 \\
\hline Carbon tetrachloride & $5.0 \mu \mathrm{g} / \mathrm{L}$ & 0.13 & .323 \\
\hline Chloride & $250 \mu \mathrm{g} / \mathrm{L}$ & 18.00 & .153 \\
\hline Chloroform & $5.0 \mu \mathrm{g} / \mathrm{L}$ & 0.61 & .323 \\
\hline Chromium & $4.0 \mu \mathrm{g} / \mathrm{L}$ & 4.60 & .357 \\
\hline Copper & $4.0 \mu \mathrm{g} / \mathrm{L}$ & 6.05 & .365 \\
\hline Cyanide & $5.0 \mu \mathrm{g} / \mathrm{L}$ & 0.28 & .327 \\
\hline Di-n-butyl phthalate & $10 \mu \mathrm{g} / \mathrm{L}$ & 2.35 & .210 \\
\hline 1,1-Dichloroethane & $5.0 \mu \mathrm{g} / \mathrm{L}$ & 2.71 & .416 \\
\hline \multicolumn{4}{|l|}{ Dichloromethane } \\
\hline (Methylene chloride) & $5.0 \mu \mathrm{g} / \mathrm{L}$ & 27.26 & .0003 \\
\hline Fluoride & $100 \mu \mathrm{g} / \mathrm{L}$ & 1.31 & .741 \\
\hline Hexachlorodibenzo-p-dioxin isomers & $0.45 \mu \mathrm{g} / \mathrm{L}$ & 13.27 & .391 \\
\hline Iron & $4.0 \mu \mathrm{g} / \mathrm{L}$ & $\mathbf{4 7 . 4 7}$ & .281 \\
\hline Lead & $3.0 \mu \mathrm{g} / \mathrm{L}$ & 16.88 & .204 \\
\hline Lithium & $5.0 \mu \mathrm{g} / \mathrm{L}$ & 14.96 & .303 \\
\hline Magnesium & $2.0 \mu \mathrm{g} / \mathrm{L}$ & 13.20 & .520 \\
\hline Manganese & $2.0 \mu \mathrm{g} / \mathrm{L}$ & 9.80 & .474 \\
\hline Mercury & $0.20 \mu \mathrm{g} / \mathrm{L}$ & 4.62 & .960 \\
\hline Nickel & $4.0 \mu \mathrm{g} / \mathrm{L}$ & 9.75 & .409 \\
\hline $\mathrm{pH}$ & $\dagger$ & 6.81 & .750 \\
\hline Phenols & $5.0 \mu \mathrm{g} / \mathrm{L}$ & 0.73 & .161 \\
\hline Potassium & $500 \mu \mathrm{g} / \mathrm{L}$ & 8.44 & .493 \\
\hline Selenium & $2.0 \mu \mathrm{g} / \mathrm{L}$ & 4.39 & .275 \\
\hline Silica & $100 \mu \mathrm{g} / \mathrm{L}$ & 11.79 & .0004 \\
\hline Silver & $2.0 \mu \mathrm{g} / \mathrm{L}$ & 4.12 & .016 \\
\hline Sedium & $111 \mu \mathrm{g} / \mathrm{L}$ & 7.09 & .102 \\
\hline Specific conductance & 1.0 & 11.09 & .447 \\
\hline Sulfate & $2,500 \mu \mathrm{g} / \mathrm{L}$ & 6.02 & .594 \\
\hline Tetrachloroethylene & $5.0 \mu \mathrm{g} / \mathrm{L}$ & 2.42 & .357 \\
\hline Thallium & $2.0 \mu \mathrm{g} / \mathrm{L}$ & 6.67 & .336 \\
\hline Tin & $2.0 \mu \mathrm{g} / \mathrm{L}$ & 27.89 & .208 \\
\hline Total dissolved solids & $1,000 \mu \mathrm{g} / \mathrm{L}$ & 59.87 & .964 \\
\hline
\end{tabular}

* Values less than .050 indicate a probability of less than 1 in 20 that the results for that analyte are the same from both laboratories.

$\dagger$ No detection limit, or no replicate or duplicate results below detection limit. 
Table 27. Interlaboratory MRD and $t$-Test Results for Analytes With at Least One Pair of Results Above the RDL (cont.)

Analyte
Total inorganic carbon
Total organic carbon
Total organic halogens
Total petroleum
hydrocarbons
Total phosphates (as P)
2,4,5-TP (Silvex)
1,1,1-Trichloroethane
Trichloroethylene
Trichlorofluoromethane
Turbidity
Zinc
Gross alpha
Nonvolatile beta
Radium-226
Radium-228
Tritium

$\underline{\mathrm{RDL}}$
+
$1,000 \mu \mathrm{g} / \mathrm{L}$
$5.0 \mu \mathrm{g} / \mathrm{L}$
$1,020 \mu \mathrm{g} / \mathrm{L}$
$50 \mu \mathrm{g} / \mathrm{L}$
$0.58 \mu \mathrm{g} / \mathrm{L}$
$5.0 \mu \mathrm{g} / \mathrm{L}$
$5.0 \mu \mathrm{g} / \mathrm{L}$
$5.0 \mu \mathrm{g} / \mathrm{L}$
$0.20 \mathrm{NTU}$
$2.0 \mu \mathrm{g} / \mathrm{L}$
$2.0 \mathrm{E}-09 \mu \mathrm{Ci} / \mathrm{mL}$
$2.0 \mathrm{E}-09 \mu \mathrm{Ci} / \mathrm{mL}$
$1.0 \mathrm{E}-09 \mu \mathrm{Ci} / \mathrm{mL}$
$1.0 \mathrm{E}-09 \mu \mathrm{Ci} / \mathrm{mL}$
$7.0 \mathrm{E}-07 \mu \mathrm{Ci} / \mathrm{mL}$

MRD

50.41

7.32

40.29

14.99

34.43

0.03

1.19

4.30

3.37

65.24

57.67

11.94

30.18

31.10

44.96

17.77

\author{
t-Test Probability*
}

.765

.240

.015

.252

.648

.324

.500

.741

.323

.709

.007

.095

.00004

.542

.227

.306

* Values less than .050 indicate a probability of less than 1 in 20 that the results for that analyte are the same from both laboratories.

† No detection limit, or no replicate or duplicate results below detection limit.

\section{COMMENTS ON THE REPLICATE AND DUPLICATE ANALYSES}

There were no high MRDs (greater than 20) for GE laboratory duplicate analyses (see Table 25). Table 28 lists the analytes and wells for which a sample result was greater than twice or less than one-half the result for its duplicate.

Table 28. GE Samples and Laboratory Duplicates Yielding Results Where One Is More than Twice Another

Analyte

Antimony

Iron

Magnesium

Tin

Total organic carbon

Trichloroethylene

Trichlorofluoromethane

Zinc

Gross alpha

Nonvolatile beta

Potassium-40

Radium-226

Thorium-230
Wells

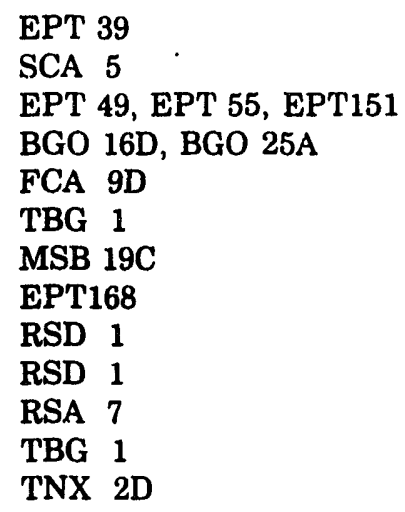

High MRDs (greater than 20) for blind replicates from GE (see Table 25) were calculated for dichloromethane (methylene chloride), nitrate-nitrite as nitrogen, total inorganic carbon, radium-226, and radium-228. Table 29 lists the analytes and wells from which one result for a sample or its blind replicate was more than twice the other. 
Table 29. GE Samples and Blind Replicates Yielding Results Where One Is More than Twice Another

\author{
Analyte \\ Barium \\ Calcium \\ Carbon tetrachloride \\ Chloride \\ Chromium \\ Chloroethane \\ 1,1-Dichloroethane \\ 1,1-Dichloroethylene \\ Dichloromethane \\ (Methylene chloride) \\ Iron \\ Magnesium \\ Manganese \\ Mercury \\ Methyl ethyl ketone \\ Nickel \\ Nitrate-nitrite as nitrogen \\ Silica \\ Sodium \\ Sulfate \\ Tetrachloroethylene \\ Total inorganic carbon \\ Total organic carbon \\ Total organic halogens \\ Total phosphates (as P) \\ 1,1,1-Trichloroethane \\ Trichloroethylene \\ Trichlorofluoromethane \\ Zinc \\ Radium-226 \\ Radium-228 \\ Tritium
}

\author{
Wells \\ LFW 59D \\ LFW 59D \\ LWF 59D \\ CBR 2D \\ XSB 3A \\ LFW 6, LFW 59D \\ LFW 59D \\ LFW 59D
}

BGO 10AR, CMP 11B, LFW 59D, MSB 1B, SRW 13A, XSB 3A LFW 59D, XSB 3A

LFW 59D

LFW 59D

DOB 2

HMD 2D

MSB 12TB

HSB 70, MSB 39C, MSB 62B, NPM 34C, TBG 1

LFW 59D

LFW 59D

YSB 2A

BGO 50D, LFW 59D

YSB 2A

MSB 62B, YSB 2A

HSB 70

CBR 2D, HSB146C, KAC 8, YSB 2A

LFW 59D

LFW 59D

LFW 6, LFW 59D, SRW 4

MSB 48A

CMP 14C, TBG 1

CMP 14C, HAC 4, KAC 8, LFW 59D, TBG 1, XSB 3A

LCO 3
High MRDs (greater than 20) were calculated for the Weston laboratory duplicate analyses of bis (2-ethylhexyl) phthalate, cadmium, dichloromethane (methylene chloride), iron, kepone, lithium, potassium, silver, tin, zinc, gross alpha, nonvolatile beta, radium-226, and radium-228 (see Table 26). Table 30 lists analytes and wells from which samples and laboratory duplicates yielded results where one result was more than twice the other. The high MRD for iron is caused by differences in duplicate samples in wells BGO 50D, BGX 12C, EPT101, EPT103, EPT116, EPT121, EPT124, FAC 5, FSB 78A, FSB100A, HMD 2D, HSB140C, LFW 28, and LFW 43B. The high MRD for zinc is caused by differences in duplicate samples in wells BGX 12C, EPT101, EPT103, EPT106, EPT111, EPT116, EPT121, EPT124, FSB 78A, FSB100A, HMD 2D, HSB 85C, and HSB140C.

Table 30. Weston Samples and Laboratory Duplicates Yielding Results Where One Is More than Twice Another

Analyte

Aluminum

Antimony

Bis(2-ethylhexyl) phthalate
Wells

BGO 8D

EPT111, HMD 2D

DOB 2 
Table 30. Weston Samples and Laboratory Duplicates Yielding Results Where One Is More than Twice Another (cont.)

Analyte

Cadmium

Cobalt

Dichloromethane

(Methylene chloride)

Kepone

Lead

Lithium

Manganese

Phenols

Potassium

Silver

Tin

Vanadium

Gross alpha

Nonvolatile beta

Radium-226

Radium-228
Wells

BGO 50D, BGX 12C, EPT116, EPT124, LFW 43B

EPT106

LFW 47D, MSB 1B, MSB 39C

BGX 12C

EPT111

EPT101, EPT111

EPT101

SSS 7

BGO 8D, EPT103, EPT124

BGO 8D, FSB 78A, EPT116, LFW 28

BGX 12C, HMD 2D

EPT101

FNB 4, P 27TC

FSB 78A

RAC 1

ABP 4, FSB 88C, FSB100A, P 28A, TBG 1
High MRDs (greater than 20) from Weston for blind replicates (see Table 26) were calculated for antimony, bis(2-ethylhexyl phthalate), cadmium, chromium, cobalt, copper, iron, kepone, lead, lithium, nitrate as nitrogen, potassium, silver, tin, total dissolved solids, total organic halogens, total phosphate (as P), turbidity, uranium, vanadium, zinc, nonvolatile beta, radium-226, and radium-228. Table 31 lists the analytes and wells from which samples and blind replicates yielded results where one result was more than twice the other.

Table 31. Weston Samples and Blind Replicates Yielding Results Where One Is More than Twice Another

Analyte

Antimony

Arsenic

Barium

Beryllium

Bis(2-ethylhexyl) phthalate

Cadmium

Chloride

Chromium

Cobalt

Copper

Dichloromethane

(Methylene chloride)

Iron

Kepone

Lead

Lithium

Manganese

Mercury
Wells

BGO 10AR, FSB 78A, FSB120A, MSB 1B, ZBG 1

FSB120A, HSB122A

ASB 3A

SRW 13A

DOB 2, MSB 1B

BGX 6D, HMD 2D, HSB 65, MSB 1B, NPM 19B, NPM 34C,

TNX 9D, ZBG 1

HSB 85C, MSB 62B

BGX 6D, CBF 2D, FSB120A, HSB105C, NPM 19B, NPM 34C, SRW 13A

FSB123D, SRW 13A

FSB120A, HMD 2D, HSB105C, MSB 62B

CMP 14C, LCO 3, MSB 39C, MSB 62B

CMP 11B, FSB 78A, FSB 88C, FSB100A, FSB120A, HSB146C, LFW 59D, NPM 34C, SRW 4, TBG 1

BGX 12C

HSB 70, KAC 8, LFW 59D, NPM 19B, NPM 34C, P 26D, TBG 1

ABP 4, BRD 1

FSB100A

ASB 3A, MSB 19B 
Table 31. Weston Samples and Blind Replicates Yielding Results Where One Is More than Twice Another (cont.)

Analyte

Nickel

Nitrate as nitrogen

Potassium

Selenium

Silver

Sulfate

Tin

Thallium

Total dissolved solids

Total organic carbon

Total organic halogens

Total phosphates (as P)

Turbidity

Uranium

Vanadium

Zinc

Gross alpha

Nonvolatile beta

Radium-226

Radium-228

Tritium

Wells

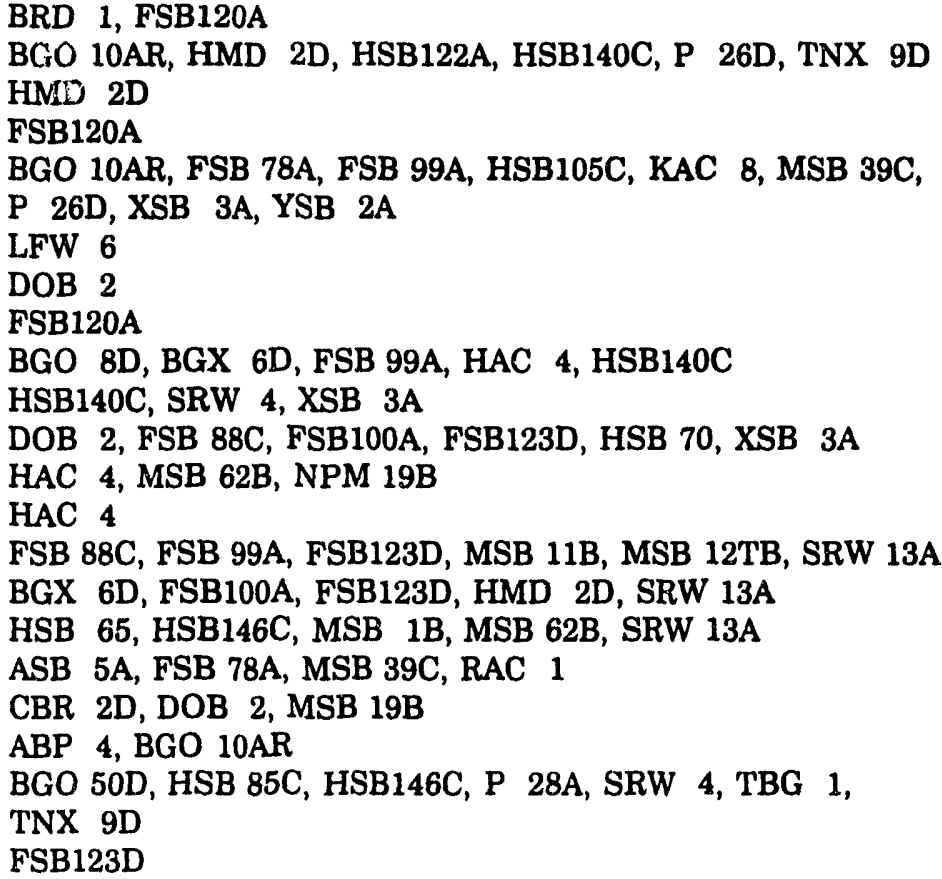

BRD 1, FSB120A

BGO 10AR, HMD 2D, HSB122A, HSB140C, P 26D, TNX 9D

HMD 2D

FSB120A

BGO 10AR, FSB 78A, FSB 99A, HSB105C, KAC 8, MSB 39C, P 26D, XSB 3A, YSB 2A

LFW 6

DOB 2

FSB120A

BGO 8D, BGX 6D, FSB 99A, HAC 4, HSB140C

HSB140C, SRW 4, XSB 3A

DOB 2, FSB 88C, FSB100A, FSB123D, HSB 70, XSB 3A

HAC 4, MSB 62B, NPM 19B

HAC 4

FSB 88C, FSB 99A, FSB123D, MSB 11B, MSB 12TB, SRW 13A

BGX 6D, FSB100A, FSB123D, HMD 2D, SRW 13A

HSB 65, HSB146C, MSB 1B, MSB 62B, SRW 13A

ASB 5A, FSB 78A, MSB 39C, RAC 1

CBR 2D, DOB 2, MSB 19B

ABP 4, BGO 10AR

BGO 50D, HSB 85C, HSB146C, P 28A, SRW 4, TBG 1 ,

TNX 9D

FSB123D

Interlaboratory comparison results (see Table 27) yielded MRDs greater than 20 for several analytes: antimony, bis(2-ethylhexyl) phthalate, dichloromethane (methylene chloride), iron, tin, total dissolved solids, total inorganic carbon, total organic halogens, total phosphates (as P), turbidity, zinc, nonvolatile beta, radium-226, and radium-228. Table 32 lists analytes and wells where a result from one laboratory was more than twice the corresponding result from the other laboratory. The high MRDs for antimony, dichloromethane (methylene chloride), total organic halogens, zinc, and nonvolatile beta correspond with low $t$-test probabilities. High MRD values indicate imprecise data. Low probability values indicate a significant, consistent bias between the laboratories, with one laboratory reporting results as consistently higher or lower than another.

Table 32. Analytes with One Laboratory's Result Greater than Twice the Result from the Other Laboratory

Analyte

Antimony

Arsenic

Barium

Bis(2-ethylhexyl) phthalate

Cadium

Calcium

Chloride

Chromium
Wells

BGO 10AR, FSB 78A, FSB 88C, HSB 70, MSB 1B, ZBG 1

FSB120A, HSB122A

ASB 3A

DOB 2

BGX 12C, NPM 34C, QA 110C*

LFW 59D, QA 110C, QA 112C*

HSB 85C, MSB 11B, MSB 62B

HSB105C

* Results for blind blanks are given in Apperidix B. 
Table 32. Analytes with One Laboratory's Result Greater than Twice the Result from the Other Laboratory (cont.)

Analyte

1,1-Dichloroethane

Dichloromethane

(Methylene chloride)

Iron

Lead

Magnesium

Manganese

Mercury

Nickel

Selenium

Silica

Specific conductance

Sulfate

Thallium

Tin

Total dissolved solids

Total inorganic carbon

Total organic carbon

Total organic halogens

Total phosphates (as P)

Trichlorofluoromethane

Turbidity

Zinc

Gross alpha

Nonvolatile beta

Radium-226

Radium-228

Tritium
Wells

LFW 59D

FSB123D, LCO 3, LFW 59D, MSB 1B, MSB 11B, P 28A, QA 104C*, QA 106C*, QA $114 C^{*}$

ASB 5A, BGO 8D, BGO 10AR, BGO 50D, FSB 88C, FSB120A, LAC 4, LCO 3, LFW 59D, MSB 70C, NPM 19B, NPM 34C, SRW 4, SRW 13A, XSB 3A

ABP 4, NPM 19B, NPM 34C, P 26D, TBG 1, XSB 3A

QA $110 C^{*}$, QA $112 C^{*}$

FSB 78A

ASB 3A, DOB 2

MSB 12TB

FSB120A

QA $110 C^{*}$

QA $110 C^{*}$

YSB 2A

FSB120A

DOB 2

BGO 8D, BGO 50D, BGX 6D, BGX 12C, HMD 2D, HSB 65, HSB 70, LFW 59D, PSS 2D, QA 110C*, QA 114C*, QA 116C*

XSB 3A, YSB 2A

YSB 2A

ABP 4, BRD 1, DOB 2, FSB 78A, FSB 88C, FSB100A, FSB123D, HMD 2D, HSB 65, HSB 70, HSB146C, MSB 19B, MSB 48A, QA 106C*, QA 108C*, QA 110C*

BGO 50D, HAC 4, HSB 70, KAC 8, NPM 19B, NPM 34C, QA $108 C^{*}$

LFW 59D

HSB 65, KAC 8, QA $108 C^{*}$

ASB 5A, FSB120A, HSB 65, HSB 85C, HSB122A, HSB146C, MSB 19B, MSB 39C, MSB 62B, SRW 13A, YSB 2A

BGO 50D, RAC 1

DOB 2, FSB100A, HSB105C, MSB 11B, MSB 39C, RAC 1

ASB 3A

TNX 9D

P 26D, TNX 9D

* Results for blind blanks are given in Appendix B.

Analytes with significance-of-probability values of less than .050 (see Table 27) have a 95\% chance that one laboratory's results are significantly higher than those from the other laboratory. Among the seven analytes with values less than .050 , only silica had significantly higher values for GE. Results for antimony, dichloromethane (methylene chloride), silver, total organic halogens, zinc, and nonvolatile beta are significantly higher for analyses from Weston. The laboratories use different methods for analyzing antimony and nonvolatile beta. See the Methods subsection of the Analytical Data Review section of this report for more information.

\section{QUALITY CONTROL STANDARDS}

During third quarter 1992, EPD/EMS conducted a quality assessment of GE. The laboratory was sent a set of certified environmental quality control standards purchased 
from Environmental Resource Associates (ERA) of Arvada, CO (Batch Numbers 414, 540, 544, 2536, 2539, 8906, 9941, and 9944). The results are listed in Table 33.

GE's results were compared with the ERAcertified values and advisory ranges. GE did not analyze for 1,2-dichlorobenzene, 1,3dichlorobenzene, and 1,4-dichlorobenzene as volatiles because of a discrepancy in analytical suites on the chain-of-custody form; there was insufficient sample volume to run both suites.

The nutrients vial was not analyzed for ammonia as $\mathrm{N}$ because the vial was broken in the lab. The organics (herbicides/pesticides) and toxaphene vials were accidentally thrown away before the analyses were performed. Of 81 analyses reported by GE, 78 , or $96.3 \%$, fell within the advisory range.

Table 33. Quality Control Standards for Selectèd Analyses

Anglyte

Cyanide ( $\mu \mathrm{g} / \mathrm{L})$

Phenol ( $\mu \mathrm{g} / \mathrm{L})$

Turbidity (NTU)

\section{Inorganice}

Alkalinity $(\mu \mathrm{g} / \mathrm{L})$

Chloride $(\mu \mathrm{g} / \mathrm{L})$

Fluoride $(\mu \mathrm{g} / \mathrm{L})$

Nitrate plus nitrite as nitrogen ( $\mu / \mathrm{L} / \mathrm{L}$ )

$\mathrm{pH}$

Total phosphates (as P) $(\mu \mathrm{g} / \mathrm{L})$

Potassium ( $\mu \mathrm{g} / \mathrm{L})$

Specific conductance $(\mu \mathrm{S} / \mathrm{cm})$

Sodium $(\mu \mathrm{g} / \mathrm{L})$

Sulfate $(\mu \mathrm{g} / \mathrm{L})$

Total dissolved solids ( $\mu \mathrm{g} / \mathrm{L})$

Metals

Aluminum $(\mu \mathrm{g} / \mathrm{L})$

Antimony $(\mu \mathrm{g} / \mathrm{L})$

Arsenic $(\mu \mathrm{g} / \mathrm{L})$

Barium ( $\mu \mathrm{g} / \mathrm{L})$

Beryllium $(\mu \mathrm{g} / \mathrm{L})$

Boron $(\mu \mathrm{g} / \mathrm{L})$

Cadmium ( $\mu \mathrm{g} / \mathrm{L})$

Chromium ( $\mu \mathrm{g} / \mathrm{L})$

Cobalt $(\mu \mathrm{g} / \mathrm{L})$

Copper (ug/L)

Iron $(\mu \mathrm{g} / \mathrm{L})$

Lead ( $\mu \mathrm{g} / \mathrm{L})$

Manganese ( $\mu \mathrm{g} / \mathrm{L})$

Mercury ( $\mu \mathrm{g} / \mathrm{L})$

Molybdenum $(\mu \mathrm{g} / \mathrm{L})$

Nickel $(\mu \mathrm{g} / \mathrm{L})$

Selenium $(\mu \mathrm{g} / \mathrm{L})$

$\begin{array}{lll}\begin{array}{l}\text { Certified } \\ \text { Value }\end{array} & \begin{array}{l}\text { Advisory } \\ \text { Range }\end{array} & \text { GE } \\ & & \text { Result } \\ 315 & 180-400 & 318 \\ 92 & 61-140 & 85.8 \\ 3.2 & 2.8-3.6 & 2.72^{*}\end{array}$

155,000

159,000

7,820

6,470

9.1

8,010

169,000

1,260

175,000

188,000

996,000

$\begin{array}{ll}138,000-172,000 & 157,000 \\ 147,000-172,000 & 189,000^{*} \\ 6,600-9,000 & 8,140 \\ 5,800-7,200 & 6,130 \\ 8.9-9.3 & 9.12 \\ 6,800-9,200 & 7,900 \\ 144,000-195,000 & 167,000 \\ 1,080-1,460 & 1,120 \\ 148,000-201,000 & 181,000 \\ 162,000-215,000 & 200,000 \\ 867,000-1,130,000 & 938,000\end{array}$

559

94.8

93

119

129

139

129

139

172

154

155

138

175

3.26

119

117

108

$\begin{array}{ll}458-660 & 571 \\ 71-112 & 104 \\ 69-110 & 90 \\ .97-140 & 126 \\ 105-152 & 119 \\ 114-164 & 135 \\ 105-152 & 132 \\ 114-164 & 144 \\ 141-203 & 173 \\ 126-182 & 165 \\ 127-183 & 158 \\ 113-163 & 140 \\ 143-206 & 177 \\ 2.4-4.1 & 2.79 \\ 97-140 & 123 \\ 96-138 & 119 \\ 81-127 & 119\end{array}$

* Results out of range. 
Table 33. Quality Control Standards for Selected Analyses (cont.)

Analyte

Silver $(\mu \mathrm{g} / \mathrm{L})$

Strontium ( $\mu \mathrm{g} / \mathrm{L})$

Thallium ( $\mathrm{gg} / \mathrm{L})$

Vanadium $(\mu \mathrm{g} / \mathrm{L})$

Zinc (ug/L)

\section{Cations}

Calcium ( $\mu \mathrm{g} / \mathrm{L}$ )

Magnesium ( $\mu \mathrm{g} / \mathrm{L})$

Potassium ( $\mu \mathrm{g} / \mathrm{L})$

Sodium $(\mu \mathrm{g} / \mathrm{L})$

\section{Grease and Oil}

Grease and oil

\section{Herbicides/Pesticides}

2,4-D ( $\mu \mathrm{g} / \mathrm{L})$

Endrin ( $\mu \mathrm{g} / \mathrm{L})$

Lindare (gamma-Benzene hexachloride) $(\mu \mathrm{g} / \mathrm{L})$

Methoxychlor $(\mu \mathrm{g} / \mathrm{L})$

Toxaphene $(\mu \mathrm{g} / \mathrm{L})$

2,4,5-TP (Silvex) ( $\mu \mathrm{g} / \mathrm{L}$ )

\section{Halomethanes}

Bromodichloromethane $(\mu \mathrm{g} / \mathrm{L})$

Bromoform $(\mu \mathrm{g} / \mathrm{L})$

Chloroform ( $\mu \mathrm{g} / \mathrm{L})$

Dibromochloromethane ( $\mu \mathrm{g} / \mathrm{L})$

\section{Volatiles}

Benzene ( $\mu g / L)$

Carbon tetrachloride $(\mu \mathrm{g} / \mathrm{L})$

Chlorobenzene $(\mu \mathrm{g} / \mathrm{L})$

1,2-Dichlorobenzene ( $\mu \mathrm{g} / \mathrm{L})$

1,3-Dichlorobenzene ( $\mu \mathrm{g} / \mathrm{L})$

1,4-Dichlorobenzene $(\mu \mathrm{g} / \mathrm{L})$

1,2-Dichloroethane $(\mu \mathrm{g} / \mathrm{L})$

Dichloromethane

(Methylene chloride) ( $\mu \mathrm{g} / \mathrm{L})$

Ethyl benzene ( $\mu \mathrm{g} / \mathrm{L})$

2-Hexanone $(\mu \mathrm{g} / \mathrm{L})$

1,1,2,2-Tetrachloroethane ( $\mu \mathrm{g} / \mathrm{L})$

Tetrachloroethylene $(\mu \mathrm{g} / \mathrm{L})$
Certified

Value

105

84.2

89.2

93.4

117

60,500

180,000

76,400

54,500

$60.1 \mathrm{mg} /$ bottle

5.10

0.71

.813

1.02

4.80

2.54

26.1

108

10.0

9.40

34.4

32.8

10.1

24.7

16.9

47.5

32.0

14.3

7.30

44.8

107

28.6
Advisory

Range

86-124

69-99

66-105

76-110

96-138

$51,000-70,000$

$153,000-207,000$

$64,000-88,000$

$46,000-63,000$

45-75 mg/bottle

1.5-6.6

$0.21-1.0$

$0.26-1.0$

$0.39-1.6$

2.0-6.0

0.76-3.3
GE

$\underline{\text { Result }}$

106

84

103

94.4

120

59,600

189,000

82,400

57,700

$42.7 \mathrm{mg} /$ bottle $^{*}$

$-$

$-$

$-$

22

99.7

7.76

7.6

* Results out of range.

- Results not received.

$\begin{array}{ll}13-52 & 27.3 \\ 23-46 & 26.4 \\ 3.7-16 & 7.88 \\ 14-39 & - \\ 10-26 & - \\ 28-74 & - \\ 16-50 & 27.9 \\ & \\ 5.0-29 & 12.2 \\ 2.7-12 & 5.8 \\ 6.7-81 & 41.2 \\ 49-170 & 86.4 \\ 18-42 & 21.8\end{array}$


Table 33. Quality Control Standards for Selected Analyses (cont.)

\begin{tabular}{|c|c|c|c|}
\hline Analyte & $\begin{array}{l}\text { Certified } \\
\text { Value } \\
\end{array}$ & $\begin{array}{l}\text { Advisory } \\
\text { Range } \\
\end{array}$ & $\begin{array}{l}\text { GE } \\
\text { Resu }\end{array}$ \\
\hline Toluene $(\mu \mathrm{g} / \mathrm{L})$ & 30.2 & $14-45$ & 22 \\
\hline 1,1,1-Trichloroethane $(\mu \mathrm{g} / \mathrm{L})$ & 42.9 & 22-69 & 35.4 \\
\hline Trichloroethylene $(\mu \mathrm{g} / \mathrm{L})$ & 14.1 & $10-22$ & 11 \\
\hline \multicolumn{4}{|l|}{ Base/Neutrals } \\
\hline Acenaphthene $(\mu \mathrm{g} / \mathrm{L})$ & 17.8 & $8.4-26$ & 19.9 \\
\hline Acenaphthylene $(\mu \mathrm{g} / \mathrm{L})$ & 87.7 & $29-130$ & 70.7 \\
\hline Anthracene $(\mu g / L)$ & 20.2 & $5.5-27$ & 18.9 \\
\hline Benro(b)fuoranthene $(\mu \mathrm{g} / \mathrm{L})$ & 36.1 & $8.7-57$ & 31.1 \\
\hline Bis(2-chloroethyl) ether $(\mu \mathrm{g} / \mathrm{L})$ & 59.3 & 14-94 & 35.9 \\
\hline Bis(2-ethylhexyl) phthalate $(\mu g / L)$ & 85.1 & $14-130$ & 85.8 \\
\hline Chrysene $(\mu \mathrm{g} / \mathrm{L})$ & 35.1 & $6.0-59$ & 37.9 \\
\hline Dibenzofuran $(\mu \mathrm{g} / \mathrm{L})$ & 112 & $63-130$ & 79.4 \\
\hline 1,2-Dichlorobenzene & 280 & $90-360$ & 173 \\
\hline 2,4-Dinitrotoluene $(\mu \mathrm{g} / \mathrm{L})$ & 176 & $68-240$ & 89.4 \\
\hline Hexachloroethane $(\mu \mathrm{g} / \mathrm{L})$ & 26.9 & $11-30$ & 17 \\
\hline Naphthalene ( $\mu \mathrm{g} / \mathrm{L})$ & 85.7 & $33-110$ & 63.8 \\
\hline Nitrobenzene $(\mu \mathrm{g} / \mathrm{L})$ & 152 & $53-270$ & 108 \\
\hline N-Nitrosodi-n-propylamine $(\mu \mathrm{g} / \mathrm{L})$ & 43.0 & $16-69$ & 39.5 \\
\hline Phenanthrene $(\mu \mathrm{g} / \mathrm{L})$ & 23.0 & $12-28$ & 20.8 \\
\hline 1,2,4-Trichlorobenzene $(\mu \mathrm{g} / \mathrm{L})$ & 30.8 & $14-44$ & 22.8 \\
\hline
\end{tabular}

Acids

2,4-Dimethyl phenol ( $\mu \mathrm{g} / \mathrm{L})$

59.2

$19-70$

46.9

para-Chloro-meta-cresol ( $\mu \mathrm{g} / \mathrm{L})$

36.4

Pentachlorophenol (ug/L)

102

Phenol ( $\mu \mathrm{g} / \mathrm{L})$

86.5

$16-54$

24.6

$15-180 \quad 88.8$

2,4,6-Trichlorophenol (ug/L)

42.3

13-97

39.8

16-61

29

PCBs

PCB $1248(\mu \mathrm{g} / \mathrm{L})$

3.77

$1.4-6.0$

2.96

Total Petroleum Hydrocarbons

Sample 1, no fatty acids

Sample 2, containing fatty acids

$63.2 \mathrm{mg} / \mathrm{bottle}$ $130 \mathrm{mg} / \mathrm{bottle}$
38-79

$78-160$
$52.3 \mathrm{mg} /$ bottle $121.9 \mathrm{mg} /$ bottle

\section{BLANKS}

Blanks are among the quality control measures discussed in the RCRA Ground-water Monitoring Technical Enforcement Guidance Document (EPA, 1986d). There are two general categories of blanks: sampling blanks, which test the integrity of field sample collection methods and equipment, and laboratory quality control blanks, which test for contamination or other

false positives when samples are analyzed in the laboratory.

\section{Sampling Blanks}

Two types of sampling blanks were sent to the laboratories during third quarter. Trip blanks (denoted as QA samples throughout this report) 
are sample containers of deionized water that are transported to the well sample location, left unopened, and sent to the laboratory for analysis. They can be used to check for contamination resulting from transport, shipping, and site conditions. They also are used as blind blanks to test the laboratory's reliability.

Equipment blanks (EPT) are samples of deionized water that are opened at the sampling location and poured or pumped through the sampling device or metals filter to test for equipment contamination. Results from these blanks are used to identify possible contaminants in the sampling equipment.

\section{Laboratory Quality Control Blanks}

Laboratory blanks, also called internal blanks, are generated internally by a laboratory to test the integrity of its procedures and equipment.

\section{Analytical Results and Review}

During third quarter, four trip blanks were each reported with one constituent (cadmium, total inorganic carbon, radium-228, or total alpha-emitting radium) at Flag 2 levels; another was reported with gross alpha and nonvolatile beta above Flag 2 criteria. Antimony was detected abovo the Flag 2 criterion in eight equipment blanks, aluminum in three equipment blanks, cadmium in one equipment blank, and uranium in one equipment blank.

The Analytical Data Review section lists third-quarter laboratory blanks and EPD/EMS blind blanks (trip blanks) with elevated results, along with the groundwater samples that accompanied them in their respective analytical batches.

GE found that matrix interferences appear to be responsible for low spike recoveries for antimony for EPT 6, mercury for EPT 22, and selenium for EPT 2, EPT 20, EPT 21, EPT 22, EPT 23, EPT 24, EPT 25, EPT 26, EPT 27, EPT 80, QA 36C, QA 40C, QA 42C, QA 44C, and QA 66C. Also, because of matrix interferences, GE's spike recoveries for arsenic for EPT 13 and EPT 80 were unusually high.

A number of blanks were associated with laboratory and EPD/EMS blind blanks yielding elevated results for various constituents. The following tables list the blanks having elevated results with other laboratory and EPD/EMS blind blanks analyzed in the same batches.

Table 34. GE Laboratory Blanks Having Elevated Results and Accompanying EPD/EMS Blanks

\begin{tabular}{|c|c|c|c|}
\hline Analyte & Run Date & Blank Results & EPD/EMS Blanks Accompanying Laboratory Blanks \\
\hline $\begin{array}{l}\text { Phenols } \\
\text { Tin }\end{array}$ & $\begin{array}{l}7 / 30 / 92 \\
8 / 13 / 92\end{array}$ & $\begin{array}{l}6.8 \mu \mathrm{g} / \mathrm{L} \\
3.43 \mu \mathrm{g} / \mathrm{L}\end{array}$ & $\begin{array}{l}\text { QA 50C, QA 70C, QA 72C } \\
\text { EPT } 67, \text { EPT } 68, \text { QA } 8 \mathrm{C}\end{array}$ \\
\hline
\end{tabular}

Table 35. Weston Laboratory Blanks Having Elevated Results and Accompanying Equipment Blanks

\begin{tabular}{|c|c|c|c|}
\hline Analyte & Run Date & Blank Results & Equipment Blanks Accompanying Laboratory Blanks \\
\hline Aluminum & $8 / 25 / 92$ & $61.2 \mu \mathrm{g} / \mathrm{L}$ & EPT101, EPT102 \\
\hline Antimony & $9 / 09 / 92$ & $8.9 \mu \mathrm{g} / \mathrm{L}$ & EPT111, EPT112, EPT113, EPT115 \\
\hline Antimony & 9/29/92 & $4.4 \mu \mathrm{g} / \mathrm{L}$ & EPT121, EPT122 \\
\hline Lithium & 9/20/92 & $8.4 \mu \mathrm{g} / \mathrm{L}$ & EPT116 \\
\hline Magnesium & $9 / 04 / 92$ & $41.1 \mu \mathrm{g} / \mathrm{L}$ & EPT106, EPT107, EPT108, EPT109, EPT110 \\
\hline Magnesium & $9 / 20 / 92$ & $30.5 \mu \mathrm{g} / \mathrm{L}$ & EPT118, EPT119 \\
\hline Thallium & 9/15/92 & $2.5 \mu \mathrm{g} / \mathrm{L}$ & EPT114, EPT116, EPT117, EPT118, EPT119 \\
\hline Tin & $9 / 04 / 02$ & $3.8 \mu \mathrm{g} / \mathrm{L}$ & EPT106, EPT107, EPT108, EPT109, EPT110 \\
\hline
\end{tabular}


Table 36. EPD/EMS Blind Blanks Having Elevated Results from GE and Accompanying Other EPD/EMS Blanks

\begin{tabular}{|c|c|c|c|}
\hline Analyte & Blank & Blank Results. & Qther Blanks Accompanying Blind Blanks \\
\hline $\begin{array}{l}\text { Nitrate-nitrite } \\
\text { as nitrogen }\end{array}$ & $\begin{array}{lr}\text { QA } & 4 C_{i} \\
\text { QA } & 22 C\end{array}$ & $\begin{array}{l}140 \mu \mathrm{g} / \mathrm{L} \\
350 \mu \mathrm{g} / \mathrm{L}\end{array}$ & QA $30 \mathrm{C}$ \\
\hline $\begin{array}{l}\text { Nitrate-nitrite } \\
\text { as nitrogen }\end{array}$ & $\begin{array}{ll}\text { QA } & 28 C \\
\text { QA } & 42 C\end{array}$ & $\begin{array}{l}100 \mu \mathrm{g} / \mathrm{L} \\
600 \mu \mathrm{g} / \mathrm{L}\end{array}$ & QA 40C, QA 44C, QA 64C, QA 66C \\
\hline $\begin{array}{l}\text { Nitrate-nitrite } \\
\text { as nitrogen }\end{array}$ & QA $32 \mathrm{C}$ & $160 \mu \mathrm{g} / \mathrm{L}$ & QA 46C, QA 58C \\
\hline $\begin{array}{l}\text { Nitrate-nitrite } \\
\text { as nitrogen }\end{array}$ & QA $36 \mathrm{C}$ & $1,510 \mu \mathrm{g} / \mathrm{L}$ & QA 26C \\
\hline $\begin{array}{l}\text { Nitrate-nitrite } \\
\text { as nitrogen }\end{array}$ & QA $52 \mathrm{C}$ & $150 \mu \mathrm{g} / \mathrm{L}$ & QA $16 \mathrm{C}$ \\
\hline $\begin{array}{l}\text { Nitrate-nitrite } \\
\text { as nitrogen }\end{array}$ & QA $100 \mathrm{C}$ & $890 \mu \mathrm{g} / \mathrm{L}$ & QA $56 C$ \\
\hline $\begin{array}{l}\text { Nitrate-nitrite } \\
\text { as nitrogen }\end{array}$ & QA $112 C$ & $624 \mu \mathrm{g} / \mathrm{L}$ & QA $76 \mathrm{C}, \mathrm{QA} \quad 78 \mathrm{C}$ \\
\hline Silica & QA $\quad 12 C$ & $19,400 \mu \mathrm{g} / \mathrm{L}$ & EPT 79, EPT 80 \\
\hline Silica & $\begin{array}{ll}\text { QA } & 76 C ; \\
\text { QA } & 78 C\end{array}$ & $\begin{array}{l}16,300 \mu \mathrm{g} / \mathrm{L} \\
19,000 \mu \mathrm{g} / \mathrm{L}\end{array}$ & EPT 95 \\
\hline Silica & QA 90C & $12,300 \mu \mathrm{g} / \mathrm{L}$ & EPT157, EPT158 \\
\hline Silica & $\begin{array}{ll}\text { QA } & 80 C \text {; } \\
\text { QA } & 92 C\end{array}$ & $\begin{array}{l}12,400 \mu \mathrm{g} / \mathrm{L} \\
12,500 \mu \mathrm{g} / \mathrm{L}\end{array}$ & EPT154 \\
\hline Silica & QA $94 \mathrm{C}$ & $14,600 \mu \mathrm{g} / \mathrm{L}$ & EPT155, EPT156 \\
\hline Silica & QA $112 C$ & $25,400 \mu \mathrm{g} / \mathrm{L}$ & EPT 94 \\
\hline Silica & QA $114 C$ & $16,300 \mu \mathrm{g} / \mathrm{L}$ & EPT150 \\
\hline $\begin{array}{l}\text { Total dissolved } \\
\text { solids }\end{array}$ & QA $108 \mathrm{C}$ & $37,000 \mu \mathrm{g} / \mathrm{L}$ & QA $116 C$ \\
\hline $\begin{array}{l}\text { Total petroleum } \\
\text { hydrocarbons }\end{array}$ & QA $106 \mathrm{C}$ & $1,800 \mu \mathrm{g} / \mathrm{L}$ & QA $104 C$ \\
\hline $\begin{array}{l}\text { Total phosphates } \\
\text { (as P) }\end{array}$ & QA $20 \mathrm{C}$ & $240 \mu \mathrm{g} / \mathrm{L}$ & QA 6C, QA 8C, QA 10C \\
\hline $\begin{array}{l}\text { Total phosphates } \\
\text { (as P) }\end{array}$ & QA $26 \mathrm{C}$ & $62 \mu \mathrm{g} / \mathrm{L}$ & QA $28 \mathrm{C}$ \\
\hline $\begin{array}{l}\text { Total phosphates } \\
\text { (as P) }\end{array}$ & QA $46 C$ & $165 \mu \mathrm{g} / \mathrm{L}$ & QA 30C, QA 32C, QA 58C \\
\hline \multicolumn{3}{|c|}{$\begin{array}{l}\text { Radium-228 was detected in two trip blanks } \\
\text { (QA } 112 \text { C and QA 108C) from Environmental } \\
\text { Physics; this finding was not confirmed in split } \\
\text { samples sent to Clemson TC. }\end{array}$} & $\begin{array}{l}\text { The blanks tables in Appendix B list the dates, } \\
\text { field measurements, and analytical results for } \\
\text { all three types of sampling blanks. See Appen- } \\
\text { dix A for a key to abbreviations used in the } \\
\text { tables. }\end{array}$ \\
\hline
\end{tabular}




\section{WATER LEVEL DATA}

During third quarter 1992, water level measurements were obtained for hydrogeologic projects. Most of the data presented here were obtained as concurrent data for hydrogeologic interpretation in the $A / M$ areas. Some wells not routinely monitored for the EPD/EMS ground-

WELL ABP $1 A$

MEASUREMENTS CONDUCTED IN THE FIELD

Sample date: 09/23/82 $141.54 \mathrm{~m}$ ) below TOC Time: $14: 05$ Water elevation: $223.61 \mathrm{ft}(68.16 \mathrm{~m}) \mathrm{ms}$

WELL ABP 1DD

MEASUREMENTS CONDUCTED IN THE FIELD

Semple date: 08/23/92 $140.12 \mathrm{~m} /$ below TOC Time: 14:07 Weter elevation: $228.46 \mathrm{ft}(68.64 \mathrm{~m}) \mathrm{ms}$

WELL ABP $2 A$

MEASUREMENTS CONOUCTED IN THE FIELD

Semple date: 09/23/82 $145.74 \mathrm{~m} /$ below TOC Time: $13: 13$ Depth to water: $160.08 \mathrm{ft}(46.74 \mathrm{~m})$ below TOC
Weter elevation: $221.82 \mathrm{ft}(67.61 \mathrm{~m} / \mathrm{msl}$

WELL ABP 2DD

MEASUREMENTS CONDUCTED IN THE FIELD

Somple dore: $08 / 23 / 92$ Time: $13: 15$ Depth to water: $148.77 \mathrm{ft}(46.36 \mathrm{~m} /$ below
Weter elevotion: $221.83 \mathrm{ft}(67.61 \mathrm{~m}) \mathrm{ms} \mid$

\section{WELL ABP 3}

MEASUREMENTS CONOUCTED IN THE FIELO

Semple date: $08 / 23 / 82$

Time: $13: 23$

No water in standpipe.

Time: $13: 23$

WELL ABP $3 C$

MEASUREMENTS CONOUCTED IN THE FIELD

Sample date: 08/23/92

(4) $(46.61 \mathrm{~m})$ below TOC

Water elevation: $204.85 \mathrm{ht}(82.44 \mathrm{~m}) \mathrm{ms}$

Time: 13:26

WELL ABP 4

MEASUREMENTS CONDUCTED IN THE FIELD

Semple date: 09/24/82

Depth to water: $142.87 \mathrm{ft}(43.58 \mathrm{~m})$ below TOC Time: $9: 48$

Water elevation: $221.33 \mathrm{ft}(67.46 \mathrm{~m}) \mathrm{msl}$

WELL ABP 4DD

MEASUREMENTS CONOUCTED IN THE FIELD

Sample date: 08/23/82

Depth to water: $142.44 \mathrm{ft}(43.42 \mathrm{~m})$ below TOC

Weter elevation: $222.66 \mathrm{it}(67.84 \mathrm{~m} / \mathrm{ms}$ water monitoring program, as well as some wells outside the $A / M$ areas, are included in these data. Only water levels were measured for this project; no field tests of water characteristics were conducted. Ge-Hy Environmental Sampling of New Ellenton, SC, collected the data.

WELL ABP 6D

MEASUREMENTS CONDUCTED IN THE FIELO

Sample dace: $08 / 23 / 92 \mathrm{fl}(43.74 \mathrm{~m})$ below TOC Time: $13: 18$ Water elevation: $221.80 \mathrm{f}(67.61 \mathrm{~m}) \mathrm{ms}$

WELL ABP 7D

MEASUREMENTS CONDUCTED IN THE FIELD

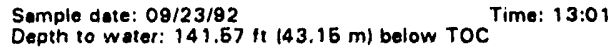
Water elevation: $222.63 \mathrm{ft}(67.86 \mathrm{~m}) \mathrm{ms}$

WELL ABP 8C

MEASUREMENTS CONDUCTED IN THE FIELD

Sample dete: $09 / 23 / 92$ ft $(63.34 \mathrm{~m})$ below roc Time: $13: 10$ Woter elevation: $197.11 \mathrm{ft}(60.08 \mathrm{~m}) \mathrm{ms}$

WELL ABP 8D

MEASUREMENTS CONDUCTED IN THE FIELD

Sample date: $08 / 23 / 82$ ft $(46.61 \mathrm{~m})$ below TOC Time: $13: 06$ Weter elevetion: $221.26 \mathrm{ft}(67.44 \mathrm{~m}) \mathrm{msi}$

WELL ABW 1

MEASUREMENTS CONDUCTED IN THE FIELD

Semple date: $09 / 26 / 92 \mathrm{~h}(30.28 \mathrm{~m})$ below TOC Time: 10:68 Water elovation: $225.45 \mathrm{ft}(68.72 \mathrm{~m}) \mathrm{msl}$

WELL AC $1 \mathrm{~A}$

MEASUREMENTS CONDUCTED IN THE FIELL

Sample date: $09 / 23 / 92$ Time: $16: 18$ Depth to water: $48.71 \mathrm{ft}(14.85 \mathrm{~m})$ below TOC
Woter elevation: $213.39 \mathrm{ft}(66.04 \mathrm{~m} / \mathrm{mgl}$

WELL AC 1B

MEASUREMENTS CONDUCTED IN THE FIELL

Semple date: $08 / 23 / 92 \quad 14.83 \mathrm{~m} /$ below TOC Time: $16: 20$ Weter elevation: $213.36 \mathrm{ti}(66.03 \mathrm{~m}) \mathrm{ms}$

WELL AC 2A

MEASUREMENTS CONDUCTED IN THE FIELD

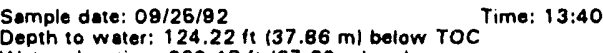
Water elevation: $220.48 \mathrm{ft}(67.20 \mathrm{~m}) \mathrm{msl}$ 
WELL AC 2B

MEASUREMENTS CONDUCTED IN THE FiELD

Somple date: 09/25/82 Timo: 13:37

Depth to water: $117.66 \mathrm{ft} 136.86 \mathrm{mi}$ below TOC

WELL AC $3 A$

MEASUREMENTS CONDUCTED IN THE FIELO

Somple dote: 09/23/92 Time: 15:04

Depth to water: $82.05 \mathrm{ft}(28.06 \mathrm{~m})$ below TOC

WELL AC 3B

MEASUREMENTS CONDUCTED IN THE FIELO

Sample date: 09/23/92 Time: 16:06

Depth to water: $80.33 \mathrm{ft} 127.63 \mathrm{~m} /$ below TOC

WELL ACB 1 A

MEASUREMENTS CONDUCTED IN THE FIELD

Sample date: 09/26/82 Time: 8:43

Depth 10 water: $123.17 \mathrm{ft}(37.64 \mathrm{~m})$ below TOC

WELL ACB $2 A$

MEASUREMENTS CONDUCTED IN THE FIELD

Sample date: 08/26/82 2 Time: 8:48

Depth to water: $111.58 \mathrm{Ht}(34.01 \mathrm{~m})$ below TOC

WELL ACB $3 A$

MEASUREMENTS CONDUCTED IN THE FIELO

Sample date: 09/26/92 TIme: $8: 34$ Depth to water: $110.60 \mathrm{ft}(33.68 \mathrm{~m} /$ below
Woter olevetion: $237.80 \mathrm{ft} 172.48 \mathrm{~m}) \mathrm{ms} /$

WELL ACB 4A

MEASUREMENTS CONOUCTED IN THE FIELD

Semple date: 09/26/82 Time: 8:28 Depth to water: $121.29 \mathrm{ft}(36.97 \mathrm{~m} /$ below

WELL AMB 4A

MEASUREMENTS CONDUCTED IN THE FIELD

Somple date: 09/26/92 Time: 10:38 Depth to weter: $161.83 \mathrm{ft} 149.33 \mathrm{ml}$ below

WELL AMB 4B

MEASUREMENTS CONDUCTED IN THE FIELL

Sample date: 09/26/92 Tune: 10:43 Depth to water: $166.65 \mathrm{H} 147.72 \mathrm{ml}$ below

WELL AMB 4D

MEASUREMENTS CONDUCTED IN THE FIELD

Semple dete: 09/26/92 10960 Depth to weter: $147.89 / \mathrm{t} / 46.08 \mathrm{~m} /$ below

\section{WELL AMB 5}

MEASUREMENTS CONDUCTED IN THE FIELD

Sample date: 08/26/92 Time: 10:46 Depth to water: $146.82 \mathrm{ft}(44.76 \mathrm{~m})$ below
Water elevation: $232.78 \mathrm{ft}(70.96 \mathrm{mi}$ ms
WELL AMB 6

MEASUREMENTS CONDUCTED IN THE FIELD

Sample date: 09/26/92 $43.99 \mathrm{~m})$ below TOC Time: 10:61

Water elevation: $232.89 \mathrm{ft}(70.89 \mathrm{~m}) \mathrm{msl}$

WELL AMB 7

MEASUREMENTS CONOUCTED IN THE FIELD

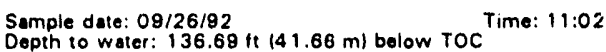
Wepth to water: $136.68 \mathrm{ft}(41.66 \mathrm{~m})$ bolow

WELL AMB 7A

MEASUREMENTS CONDUCTED IN THE FIELD Sample date: $08 / 26 / 82$ Time: $10: 68$

Water elevation: $218.69 \mathrm{ft}(66.66 \mathrm{~m}) \mathrm{msl}$

WELL AMB 7B

MEASUREMENTS CONDUCTED IN THE FIELD

Somple date: 09/26/92 $145.39 \mathrm{ml}$ tolow TOC Time: 11:00 Depth to water: $148.90 \mathrm{ft}(46.39 \mathrm{~m} /$ below
Water olevation: $224.10 \mathrm{ft}(68.31 \mathrm{~m}) \mathrm{ms}$ )

WELL AMB 8D

MEASUREMENTS CONDUCTED IN THE FIELD

Somple date: 09/26/92 $141.68 \mathrm{~m} /$ below TOC Time: 10:33 Depth 10 woter: $136.75 \mathrm{ft}(41.68 \mathrm{~m})$ below
Woter elevotion: $232.85 \mathrm{ft}(70.97 \mathrm{~m}) \mathrm{mgl}$

WELL AMB 9D

MEASUREMENTS CONDUCTED IN THE FIELD

Sample date: 09/26/82 $4(4)$ Time: 10:28 Depth to water: $134.79 \mathrm{ft}(4) .08 \mathrm{~m})$ bolow
Water elevation: $233.11 \mathrm{ft}(71.06 \mathrm{~m}) \mathrm{ms}$ )

WELL AMB 10A

MEASUREMENTS CONDUCTED IN THE FIELD

Sample dare: 09/26/92 $145.35 \mathrm{~m} /$ Telow Time: 10:21 Depth to water: $148.78 \mathrm{ft}(46.36 \mathrm{~m} /$ below

WELL AMB 10B

MEASUREMENTS CONDUCTED IN THE FIELD

Somple date: 09/26/92 $1033.90 \mathrm{ml}$ Time: 10:23 Depth to water: $144.03 \mathrm{ft}(43.80 \mathrm{~m})$ below
Weter elevetion: $222.37 \mathrm{ft}(67.78 \mathrm{~m}) \mathrm{msl}$

WELL AMB 100

MEASUREMENTS CONDUCTED IN THE FIELD

Sample date: 09/26/92 $139 / 94 \mathrm{~m} /$ below Time: 10:18 Depth to water: $131.06 \mathrm{ft}(38.94 \mathrm{~m})$ below
Water elevation: $234.45 \mathrm{ft}(71.46 \mathrm{~m}) \mathrm{mal}$

\section{WELL AMB 10DD}

MEASUREMENTS CONDUCTED IN THE FIELO

Sample date: 09126192

Depth to weter: $6.83 \mathrm{tt}(2.08 \mathrm{~m} /$ below TOC

Time: 10:18

Water elovation:

\section{WELL AMB 11B}

MEASUREMENTS CONOUCTED IN THE FIELO

Sample date: 09/26/82 Time: 11:13 Wepth to water: $142.16 \mathrm{ft}(43.33 \mathrm{~m})$ belo 


\section{WFLL. AMB 11D}

MEASUREMENTS CONDUCTED IN THE FIELD

Sample date: 09/26/92 Time: 11:15 Woter olevation: $236.46 \mathrm{ft}(71.77 \mathrm{~m}) \mathrm{msl}$

\section{WELL AMB 12D}

MEASUREMENTS CONDUCTED IN THE FIELD

Sample date: 08/26/92 $141,40 \mathrm{~m} /$ below TOC Time: $11: 08$ Depth to water: $136.81 \mathrm{ft}(41.40 \mathrm{~m})$ below

\section{WELL AMB 13AR}

MEASUREMENTS CONDUCTED IN THE FIELD Sample date: 08/26/82 Time: 10:13 Depth to water: $147.04 \mathrm{ft}(44.82 \mathrm{~m})$ below TOC Water alevetion: $218.06 \mathrm{ft} 168.47 \mathrm{ml} \mathrm{msl}$

\section{WELL AOB 1}

MEASUREMENTS CONDUCTEO IN THE FIELO

Somple dete: 08/25/92 Time: 15:37

Depth to water: $105.36 \mathrm{ft}(32.11 \mathrm{~m} /$ below TOC

\section{WELL AOB 2}

MEASUREMENTS CONDUCTED IN THE FIELD

Somple date: 09/26/92 $13323 \mathrm{~m} /$ telow TOC $16: 46$ Depth to water: $109.01 \mathrm{ft} 133.23 \mathrm{~m} /$ below TOC

Water olevetion: $236.39 \mathrm{ft} 172.05 \mathrm{ml}$

\section{WELL AOB 3}

MEASUREMENTS CONDUCTED IN THE FIELD

Somple date: 08/25/92 TIme: 15:53 Depth to water: $116.19 \mathrm{ft}(35.11 \mathrm{~m})$ below $T O C$

Weter elovation: $237.41 \mathrm{ft} 172.36 \mathrm{ml} \mathrm{ms}$

WELL ARP $1 \mathrm{~A}$

MEASUREMENTS CONDUCTED IN THE FIELD

Sample date: 09/24/92 $\quad$ Time: 10:01 Depth to water: $139.86 \mathrm{ft}(42.63 \mathrm{~m})$ below TOC Water elevetion: $216.26 \mathrm{ft}(66.61 \mathrm{~m}) \mathrm{ms}$

WELL ARP 2

MEASUREMENTS CONDUCTED IN THE FIELD

Somple date: $09 / 24 / 92 \mathrm{fo}(36.20 \mathrm{~m} /$ below TOC Time: $10: 07$ Woter elevation: $218.64 \mathrm{ft}(66.61 \mathrm{~m}) \mathrm{ms}$

\section{WELL ARP 3}

MEASUREMENTS CONDUCTED IN THE FIELO

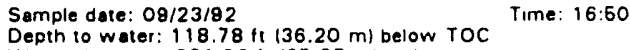
Water elevation: $221.02 / 167.37 \mathrm{~m} / \mathrm{ms}$

\section{WELL ARP 4}

MEASUREMENTS CONDUCTED IN THE FIELD

Sample date: 08/24/82 $139.78 \mathrm{~m} /$ below TOC Time: $8: 67$ Woter elevation: $217.88 \mathrm{ft}(66.41 \mathrm{~m} / \mathrm{ms}$

\section{WELL ASB 1 A}

MEASUREMENTS CONDUCTED IN THE FIELD

Sample date: $08 / 26 / 92$ Time: $12: 16$ Water elevation: $236.24 \mathrm{tt} 172.01 \mathrm{ml} \mathrm{msl}$
WELL ASB 2A

MEASUREMENTS CONDUCTED IN THE FIELD Sample date: $09 / 25 / 92$
Depth io water: $111.46 \mathrm{ft}(33.97 \mathrm{~m} /$ below TOC Tıme: $12: 20$
Water elevation: $237.65 \mathrm{ft}(72.41 \mathrm{~m}) \mathrm{ms} \mid$

WELL ASB 2C

MEASUREMENTS CONDUCTED IN THE FIELD

Sample date: $09 / 26 / 92 \mathrm{ft}(38.60 \mathrm{~m})$ below TOC Time: $12: 21$ Water elevation: $223.08 \mathrm{ft}(68.00 \mathrm{nt}) \mathrm{mal}$

WELL ASB 3A

MEASUREMENTS CONDUCTED IN THE FIELD

Semple date: 09/26/92 $32.60 \mathrm{~m})$ below TOC Time: 12:66 Water elevation: $238.36 \mathrm{ft}(72.66 \mathrm{~m}) \mathrm{msl}$

WELL ASB 3C

MEASUREMENTS CONDUCTED IN THE FIELD

Sample date: $09 / 25 / 92$ Time: $12: 67$ Depth to water: $123.28 \mathrm{ft}(37.68 \mathrm{~m} /$ below

W'ELL ASB 4

MEASUREMENTS CONDUCTED IN THE FIELD

Sample date: 09/26/92 250 Depth to water: $98.27 \mathrm{ft}(29.95 \mathrm{~m})$ below

WELL ASB 5A

MEASUREMENTS CONDUCTED IN THE FIELD

Sample date: $09 / 25 / 92$ it $133.07 \mathrm{~m} /$ below TOC Time: 13:30

Water elevstion: $236.49 \mathrm{ft} 172.08 \mathrm{ml} \mathrm{msl}$

\section{WELL ASB 6A}

MEASUREMENTS CONDUCTED IN THE FIELD

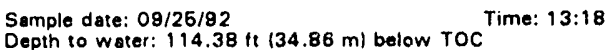

Water elevation: 235.82 th $171.88 \mathrm{~m} / \mathrm{mal}$

\section{WELL ASB 6AA}

MEASUREMENTS CONDUCTED IN THE FIELD

Sample date: $09 / 26 / 92 \mathrm{f}(41.43 \mathrm{~m})$ below TOC Time: $13: 16$

Depth to water: $136.93 \mathrm{ft}(41.43 \mathrm{~m})$ below
Water elevation: $218.27 \mathrm{ft}(66.63 \mathrm{~m}) \mathrm{ms}$ )

WELL ASB 6C

MEASUREMENTS CONDUCTED IN THE FIELD

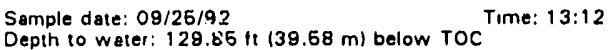
Water elevation: $223.76 \mathrm{ft}(68.20 \mathrm{~m}) \mathrm{ms}$

\section{WELL ASB 6TA}

MEASUREMENTS CONDUCTED IN THE FIELD

Sample date: $09 / 26 / 92 \mathrm{f}(42.26 \mathrm{~m})$ below TOC Time: $13: 16$ Water elevation: $214.24 \mathrm{ft}(65.30 \mathrm{~m}) \mathrm{ms}$

WELL ASB 7

MEASUREMENTS CONDUCTED IN THE FIELD

Sample date: 09/25/92 $(36.20 \mathrm{~m})$ below TOC Time: 13:08 Water elevation: $234.63 \mathrm{ft}(71.52 \mathrm{~m}) \mathrm{ms}$ 


\section{WELL ASB 8}

MEASUREMENTS CONOUCTED IN THE FIELD

Sample date: 09/25/82 $135.13 \mathrm{~m})$ betow TOC Time: $12: 01$ Weter elevation: $233.76 \mathrm{tt} 171.26 \mathrm{ml} \mathrm{mal}$

WELL ASB 8A

MEASUREMENTS CONOUCTED IN THE FIELD

Somple dato: 09/26/92 $139.06 \mathrm{~m} /$ below TOC Time: 12:06 Depth to woter: $130.12 \mathrm{H}(38.06 \mathrm{~m})$ below
Wotor olevation: $219.18 \mathrm{ft}(68.81 \mathrm{~m}) \mathrm{ms}$

WELL ASB 8B

MEASUREMENTS CONDUCTED IN THE FIELD

Sample date: 00/26/82

Depth to water: $129.47 \mathrm{ft}(39.46 \mathrm{~m} /$ below TOC

Woter olevation: $220.33 \mathrm{fl}(67,16 \mathrm{~m}) \mathrm{mal}$

WELL ASB $8 \mathrm{C}$

MEASUREMENTS CONDUCTED IN THE FIELD

Semple deta: 09/26/82 $138.69 \mathrm{~m})$ below TOC Time: 12:08 Weter elevation: $223.08 \mathrm{f}(68.00 \mathrm{~m} / \mathrm{msl}$

WELL ASB 8TA

MEASUREMENTS CONOUCTED IN THE FIELD

Sample date: $08 / 26 / 92$

Depth to water: $133.814(40.79 \mathrm{~m})$ below TOC Tima: 12:03

Weter olevato? (33.8) $(40.78$ m) bolow TOC

WELL ASB 9

MEASUREMENTS CONDUCTED IN THE FIELD

Sample date: $09 / 26 / 92$

Depth to water: 87.89 it $120.69 \mathrm{~m} /$ below TOC

Woter elevation: $241.11 \mathrm{ft}(73.48 \mathrm{~m}) \mathrm{ms}$

Tirne: $11: 48$

WELL ASB 9B

MEASUREMENTS CONOUCTED IN TKE FIELO

Sample date: $08 / 26 / 82$

Depth 10 water: $88.74 \mathrm{ft}(27.05 \mathrm{~m} /$ below TOC

Woter elevation: $220.26 \mathrm{ft}(87.14 \mathrm{~m}) \mathrm{msl}$

Tıme: 11:46

WELL ASB 9C,

MEASUREMENTS CONOUCTED IN THE FIELD

Sample dato: 09/26/92.

Time: $11: 43$

Weter olovetion: $220.6411167 .22 \mathrm{ml}$ mal

\section{WELL ASB 10C}

MEASUREMENTS CONDUCTED IN THE FIELD

Sample date: $09 / 26 / 92$ Time: $12: 40$

Depth to water: $126.94 \mathrm{Ht} 138.38 \mathrm{~m} /$ below $T O C$

WELL MCB 2

MEASUREMENTS CONDUCTED IN THE FIEL.O

Somple date: 08/23/92 Time: $12: 28$

Depth 10 water: $102.88 \mathrm{Ht}(31.36 \mathrm{~m})$ below TOC

WELL MCB 4

MEASUREMENTS CONDUCTED IN THE FIELO

Somple dete: $08 / 23 / 82$ Trine: 12:44

Depth to water: $126.83 \mathrm{ft} 138.36 \mathrm{~m} /$ below TOC

Weter slovation: $224.67 \mathrm{Ht} 168.46 \mathrm{ml} \mathrm{msl}$
WELL MCB 5

MEASUREMENTS CONDUCTED IN THE FIELD

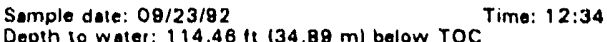

Weter elovation: $226.14 \mathrm{ft} 168.82 \mathrm{~m} / \mathrm{msl}$

WELL MCB 5C

MEASUREMENTS CONDUCTED IN THE FIELD

Somple dote: $09 / 23 / 92$ ' $143.84 \mathrm{~m} /$ bolow TOC Time: $12: 36$ Water elevation: $196.28 \mathrm{it}(58.62 \mathrm{~m}) \mathrm{ms}$

WELL MCB 6

MEASUREMENTS CONDUCTED IN THE FIELD

Samplo dato: 08/23/92 $134 \mathrm{~m} /$ below TOC Timo: 12:23 Depth to water: $112.03 \mathrm{ft}(34.16 \mathrm{~m})$ below TOC Water elevation: $220.07 \mathrm{ft} 107.08 \mathrm{~m} / \mathrm{msl}$

WELL MCB 6C

MEASUREMENTS CONDUCTED IN THE FIELD

Semple date: $08 / 23 / 82 \mathrm{it}(41.54 \mathrm{~m} /$ below TOC Time: $12: 21$

Watar alevalton: $186.81 \mathrm{ft} 158.68 \mathrm{~m} / \mathrm{mel}$

WELL MCB $7 \mathrm{C}$

MEASUREMENTS CONDUCTED IN THE FIELD

Semple dele: 09/23/92 $143.72 \mathrm{~m} /$ below TOC Time: $12: 38$

Water alevelion: $184.26 \mathrm{it} 168.21 \mathrm{~m} / \mathrm{ms}$

WELL MCB 8D

MEASUREMENTS CONDUCTED IN THE FIELD

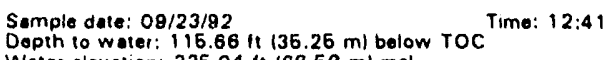

Woter elevetion: $226.04 \mathrm{it} 168.69 \mathrm{~m} / \mathrm{mal}$

WELL MCB 9D

MEASUREMENTS CONDUCTED IN THE FIELLD

Somple dace: $08 / 23 / 92$ Tima: 12:30

Depth to water: $119.82 \mathrm{Ht}(36.65 \mathrm{~m})$ below

Weter alevation: $222.98 \mathrm{ft} 167.97 \mathrm{mi} \mathrm{mal}$

WELL MSB 1B

MEASUREMENTS CONDUCTED IN THE FIELD

Somple dute: 08/26/92 $144.82 \mathrm{~m})$ below TOC Time: 10:44 Depth to woter: $147.05 \mathrm{ft}(44.82 \mathrm{~m})$ below

WELL MSB 1C

MEASUREMENTS CONDUCTED IN THE FIELO Sample date: 09/26/82 $4(42.67 \mathrm{~m} /$ bolow TOC Time: 10:48

WELL. MSB $1 \mathrm{CC}$

MEASUREMENTS CONDUCTED IN THE FIELD

Semple date: 08/26/82 $141.94 \mathrm{ml}$ below Time: 10:46 Depth io walar: $137.60 \mathrm{ft}(41.94 \mathrm{~m})$ below

WELL MSB 1D

MEASUREMENTS CONDUCTED IN THE FIELD

Sample date: 09/26/92 Time: 10:4 Depth to water: 124.87 it $(38.06 \mathrm{~m})$ below 


\section{WATER LEVEL DATA}

WELL MSB 2B

MEASUREMENTS CONDUCTED IN THE FIELD

Sample dats: 09/25/92 Time: 9:66

Weter elevation: $209.76 \mathrm{ft}(83.83 \mathrm{~m}) \mathrm{msl}$

WELL MSB 2C

MEASUREMENTS CONOUCTED IN THE FIELD

Semple date: 09/25/92 $142.00 \mathrm{~m} /$ below TOC Time: $8: 64$ Water elevation: $216.89 \mathrm{ft} 166.11 \mathrm{ml} \mathrm{ms}$

WELL MSB 2D

MEASUREMENTS CONDUCTED IN THE FIELD

Semple date: 09/26/82

Depth to wster: $123.27 \mathrm{ft}(37.67 \mathrm{~m} /$ below TOC

Woter olevetion: $230.63 \mathrm{ft}(70.27 \mathrm{~m}) \mathrm{ms}$

\section{WELL MSB 3B}

MEASUREMENTS CONDUCTED IN THE FIELD

Somple dace: $09 / 25 / 9$

Time: 10:04

WELL MSB 3C

MEASUREMENTS CONDUCTED IN THE FIELD

Sample date: $08 / 26 / 92$ it $(43.43 \mathrm{~m} /$ below TOC Time: $10: 06$ Water elevation: $218.33 \mathrm{ft}(66.55 \mathrm{~m} / \mathrm{ms}$

WELL MSB 3D

MEASUREMENTS CONDUCTED IN THE FIELD

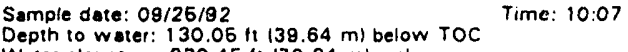

Water elevation: $230.45 \mathrm{ht}(70.24 \mathrm{~m} / \mathrm{ms}$

\section{WELL MSB 4B}

MEASUREMENTS CONDUCTED IN THE FIELD

Sample date: $09 / 25 / 92 \mathrm{ft}(46.64 \mathrm{~m} /$ below TOC Time: $10: 28$ Water elevation: $205.68 \mathrm{ft} 162.66 \mathrm{~m}) \mathrm{ms}$ |

WELL MSB 4C

MEASUREMENTS CONDUCTEO IN THE FIELO

Sample date: 09/25/92 $(43.14 \mathrm{~m})$ below TOC Time: 10:30 Water elevation: $213.65 \mathrm{ft}(66.12 \mathrm{~m}) \mathrm{ms}$

WELL MSB 4D

MEASUREMENTS CONDUCTED IN THE FIELD

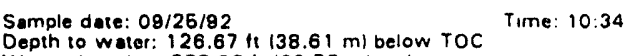
Weter elevation: $228.93 \mathrm{ft}(69.78 \mathrm{~m}) \mathrm{msl}$

WELL MSB 5A

MEASUREMENTS CONDUCTED IN THE FIELD

Sample date: $09 / 26 / 92 \quad$ Time: $12: 04$ Depth to water: $117.22 \mathrm{ft} 136.73 \mathrm{~m} /$ below TOC Water elevation: $227.38 \mathrm{ft}(69.31 \mathrm{~m}) \mathrm{ms}$

\section{WELL MSB 5B}

MEASUREMENTS CONDUCTED IN THE FIELD

Sample date: 09/25/92 $4(41.88 \mathrm{~m})$ below TOC Time: 12:01 Depth to water: $137.73 \mathrm{ft}(41.88 \mathrm{~m})$ below TOC
WELL MSB 5C

MEASUREMENTS CONOUCTED IN THE FIELD

Sarnple date: 09/25/92 Time: 11:69 Water elevation: $223.18 \mathrm{ft} 168.03 \mathrm{~m} / \mathrm{mgl}$

WELL MSB 6A

MEASUREMENTS CONDUCTED IN THE FIELD

Sample date: $09 / 24 / 92$ f $(35.84 \mathrm{~m})$ below TOC Time: $12: 23$ Water elevation: $226.32 \mathrm{ft}(68.98 \mathrm{~m}) \mathrm{ms} \mid$

WELL MSB 6B

MEASUREMENTS CONDUCTEO IN THE FIELD

Somple date: 09/24/82 $141.80 \mathrm{~m} /$ below TOC Time: 12:20

Depth to water: $137.46 \mathrm{ft}(41.80 \mathrm{~m})$ below TOC
Water olevetion: $207.85 \mathrm{ft}(63.36 \mathrm{~m}) \mathrm{msl}$

WELL MSB 6C

MEASUREMENTS CONDUCTED IN THE FIELO

Sample date: $09 / 24 / 92$ (10 $136.63 \mathrm{~m} /$ below TOC Time: $12: 18$ Water elevation: $224.01 \mathrm{ht} 168.28 \mathrm{~m} / \mathrm{msl}$

WELL MSB 7A

MEASUREMENTS CONDUCTED IN THE FIELD

Sample date: 09/24/92 $135.73 \mathrm{ml}$ below TOC Time: 12:07 Depth to water: $117.21 \mathrm{ft}(36.73 \mathrm{~m} /$ below
Woter elevation: $227.29 \mathrm{ft}(69.28 \mathrm{~m}) \mathrm{ms})$

\section{WELL MSB 7B}

MEASUREMENTS CONDUCTED IN THE FIELD

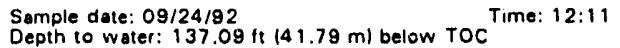
Wepth to water: $137.09 \mathrm{ft}(41.79 \mathrm{~m})$ below

WELL MSB 7C

MEASUREMENTS CONDUCTED IN THE FIELD

Somple date: 09/24/92 12012 Depth to water: $122.08 \mathrm{ft}(37.21 \mathrm{~m})$ below TOC

Watet elevation: $222.62 \mathrm{ft} 167.82 \mathrm{ml} \mathrm{ms}$

WELL MSB 8A

MEASUREMENTS CONDUCTED IN THE FIELD

Sample date: $09 / 26 / 82$
Depth to water: $116.03 \mathrm{ft}(36.06 \mathrm{~m} /$ below roc Time: $8: 30$ Depth to water: $115.03 \mathrm{ft}(36.06 \mathrm{~m})$ below

\section{WELL MSB 8B}

MEASUREMENTS CONDUCTED IN THE FIELD

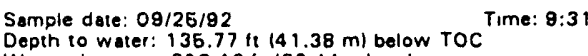

Woter elevation: $208.13 \mathrm{ft} 163.44 \mathrm{ml}$ mst

\section{WELL MSB $8 C$}

MEASUREMENTS CONDUCTEO IN THE FIELD

Semple date: 09/25/92 $34.84 \mathrm{~m} /$ below TOC Time: 8:34 Depth to woter: $124.16 \mathrm{ft}(37.84 \mathrm{~m})$ below
Water elevation: $219.86 \mathrm{ft}(67.01 \mathrm{~m}) \mathrm{ms} /$

\section{WELL MSB 9A}

MEASUREMENTS CONDUCTED IN THE FIELO Sample date: $09 / 25 / 82 \mathrm{ft}(46.88 \mathrm{~m})$ below TOC Time: 10:22 Water elevation: $208.87 \mathrm{tt} 163.66 \mathrm{~m} / \mathrm{ms}$ 


\section{WELL MSB 9B}

MEASUREMENTS CONDUCTED IN THE FIELD

Somple date: 09/26/92 Time: 10:23

Depth to weter: $130.16 \mathrm{ft}(39.67 \mathrm{~m})$ below TOC

\section{WELL MSB 9C}

MEASUREMENTS CONDUCTED IN THE. FIELD

Somple date: $09 / 26 / 92$

Time: 10:20

No water in etendpipe.

WELL MSB $10 A$

MEASUREMENTS CONDUCTED IN THE FIELD

Somple dete: 09/25/92 $145.00 \mathrm{~m})$ below TOC Time: 11:27

Water elovation: $207.36 \mathrm{ft}(63.20 \mathrm{mi}$ msi

\section{WELL MSB 10B}

MEASUREMENTS CONDUCTED IN THE FIELD

Somple date: 09/26/92 3431 Time: $11: 22$

Depth to water: $146.38 \mathrm{ft}(44.31 \mathrm{~m})$ below TOC

Water elevetion: $209.32 \mathrm{ft}(63.80 \mathrm{~m}) \mathrm{ms} \mid$

\section{WELL MSB 10C}

MEASUREMENTS CONDUCTED IN THE FIELO

Semple date: 09/26/92

Depth to wis: Time: 11:26

Water elevetion: $227.57 \mathrm{ft}(69.36 \mathrm{~m}) \mathrm{mst}$

\section{WELL MSB 11A}

MEASUREMENTS CONDUCTED IN THE FIELD

Sample date: 09/26/82

Depth to Time: 11:16

Weter elevation: $210.71 \mathrm{ft}(64.23 \mathrm{~m}) \mathrm{mst}$

\section{WELL MSB 11B}

MEASUREMENTS CONDUCTEO IN THE FIELD

Semple dete: $08 / 26 / 92$

Semple date: $08 / 26 / 92$
Depth to water: $149.42 \mathrm{ft}(45.54 \mathrm{~m} /$ below TOC TIme: $11: 13$
Water

\section{WELL MSB 11C}

MEASUREMENTS CONDUCTED IN THE FIELD

Semple dete: 0 125/82

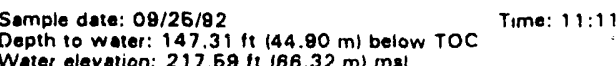

\section{WELL MSB 11D}

MEASUREMENTS CONDUCTED IN THE FIELD

Somple dete: $09 / 25 / 82$

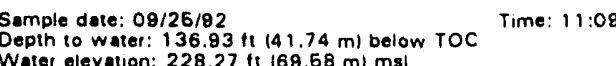

\section{WELL MSB $11 E$}

MEASUREMENTS CONDUCTED IN THE FIELD

Sample date: $09 / 26 / 92$

Time: $11: 07$

The well wes dry.

\section{WELL MSB $11 \mathrm{~F}$}

MEASUREMENTS CONDUCTED IN THE FIELD

Somple date: $08 / 25 / 92$

Time: $11: 17$
WELL MSB 12A

MEASUREMENTS CONDUCTED IN THE FIELD

Somplo dole: 09/25/92

Somple date: 09/26/92
Depth to water: $141.07 \mathrm{ft}(43.00 \mathrm{~m} /$ below TOC Time: $11: 32$
Water elevation: $206.73 \mathrm{ft}(63.01 \mathrm{~m} / \mathrm{msl}$

WELL MSB 12B

MEASUREMENTS CONDUCTED IN THE FIELD

Semple date: $09 / 26 / 92$ (t) $140.20 \mathrm{~m} /$ below TOC Time: $11: 41$

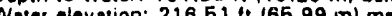

WELL MSB $12 \mathrm{C}$

MEASUREMENTS CONDUCTED IN THE FIELO

Sample date: $09 / 26 / 92 \mathrm{fl}(38.61 \mathrm{~m})$ below TOC Time: $11: 34$

Weter evation: $221.5711167 .54 \mathrm{ml}$ mat

WELL MSB 12D

MEASUREMENTS CONDUCTED IN THE FIELD

Sample date: $08 / 26 / 92$

Time: $11: 42$

No water in stendpipe.

WELL MSB 12TA

MEASUREMENTS CONDUCTED IN THE FIELL

Sample date: 09/26/82 $(47.69 \mathrm{~m})$ below TOC Time: $11: 37$

Wator elevation: $182.36 \mathrm{ft}(58.63 \mathrm{~m}) \mathrm{ms}$

WELL MSB 12 TB

MEASUREMENTS CONDUCTED IN THE FIELD

Sample date: $09 / 25 / 92$ is $(47.66 \mathrm{~m})$ below TOC Time: $11: 39$ Woter elevation: $182.65 \mathrm{ft}(68.68 \mathrm{mi} \mathrm{ms}$

WELL MSB 13A

MEASUREMENTS CONDUCTED IN THE FIELD

Semple date: 09/25/92 $32.63 \mathrm{~m} /$ below TOC Time: $11: 61$ Depth to water: 138.87 f $(42.63 \mathrm{~m})$ below TOC

Water elevation: $205.3311(62.58 \mathrm{~m} / \mathrm{mal}$

WELL MSB 13B

MEASUREMENTS CONDUCTED IN THE FIELD

Somple date: 09/26/92 $148.46 \mathrm{~m} /$ below TOC Time: $11: 48$ Depth to water: $168.00 \mathrm{ft}(48.46 \mathrm{~m})$ below
Water alevation: $186.60 \mathrm{ft}(66.88 \mathrm{~m}) \mathrm{msi}$

\section{WELL MSB 13CC}

MEASUREMENTS CONDUCTED IN THE FIELD

Semple dote: 09/25/92 3 Depth to weter: $122.77 \mathrm{ft}(37.42 \mathrm{~m} /$ below TOC Time: $11: 63$ Depth io water: $122.77 \mathrm{ft}(37.42 \mathrm{~m})$ below

WELL MSB 13D

MEASUREMENTS CONDUCTED IN THE FIELD

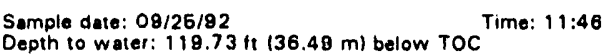
Depth to water: $119.73 \mathrm{ft}(36.49 \mathrm{~m})$ below
Weter elevation: $227.97 \mathrm{ft}(69.49 \mathrm{~m}) \mathrm{msl}$

WELL MSB 14A

MEASUREMENTS CONDUCTED IN THE FIELO

Somple date: 08/25/92 $140.82 \mathrm{ml}$ below TOC Time: $8: 48$ Depth to woter: $133.92 \mathrm{ft}(40.82 \mathrm{~m} /$ below
Woter elevetion: $214.38 \mathrm{ft} 165.34 \mathrm{~m}) \mathrm{met}$ 
WELL MSB 14B

MEASUREMENTS CONDUCTED IN THE FIELD

Sample date: 09/25/82 $40.27 \mathrm{~m} /$ below TOC Time: $9: 46$

Weter elevetion: $216.58 \mathrm{ft}(66.02 \mathrm{~m}) \mathrm{ms}$

WELL MSB 14C

MEASUREMENTS CONOUCTED IN THE FIELD

Somple date: 08/25/92
No woter in stendpipe. Time: $9: 46$

WELL MSB 15A

MEASLIREMENTS CONDUCTED IN THE FIELO

Semple date: $09 / 25 / 92 \mathrm{ft}(46.28 \mathrm{~m})$ below TOC Time: 16:00

Depth to water: $148.66 \mathrm{ft}(46.28 \mathrm{~m})$ below
Weter elevation: $218.66 \mathrm{ft}(66.66 \mathrm{~m}) \mathrm{ms}$

\section{WELL MSB 15AA}

MEASUREMENTS CONDUCTED IN THE FIELD

Sample date: 08/26/92

Depth 10 water: $156.37 \mathrm{ft}(47.66 \mathrm{~m})$ below TOC Time: 16:04

Water elevation: $213.13 \mathrm{ft}(64.86 \mathrm{~m}) \mathrm{ms}$ !

WELL MSB 15C

MEASUREMENTS CONDUCTED IN THE FIELD

Somple date: $09 / 26 / 92 \mathrm{H}(37.76 \mathrm{~m})$ below TOC Time: 14:67

Water elevation: $242.73 \mathrm{ft}(73.98 \mathrm{~m}) \mathrm{rns}$ !

WELL MSB 15D

MEASUREMENTS CONDUCTED IN THE FIELD

Sample date: 09/26/92 $34.04 \mathrm{ml}$ below TOC Time: 16:02 Water elevation: $230.88 \mathrm{ft}(70.37 \mathrm{~m} / \mathrm{msl}$

\section{WELL MSB 16A}

MEASUREMENTS CONDUCTED IN THE FIELD

Sample date: 09/25/92
Depth to water: $148.87 \mathrm{ft}(46.38 \mathrm{~m})$ below TOC TIme: $14: 52$ Weter elevation: $217.83 \mathrm{ft}(66.40 \mathrm{~m} / \mathrm{ms}$

\section{WELL MSB 16C}

MEASUREMENTS CONDUCTED IN THE FIELD

Sample date: 09/26/82 4 Time: 14:63 Woter olevetion: $228.98 \mathrm{tt}(68.79 \mathrm{~m}) \mathrm{msl}$

\section{WELL MSB 17A}

MEASUREMENTS CONDUCTED IN THE FIELD

Sample date: $09 / 26 / 92$ Time: $12: 61$ Water elevation: $216.03 \mathrm{ft}(65.64 \mathrm{~m} / \mathrm{ms})$

WELL MSB $17 B$

MEASUREMENTS CONOUCTED IN THE FIELD

Somple dete: 08/25/92 $140.72 \mathrm{ml}$ below ToC $12: 49$ Depth to water: $133.68 \mathrm{ft}(40.72 \mathrm{~m})$ below

\section{WELL MSB 17BB}

MEASUREMENTS CONDUCTED IN THE FIELD

Sample dote: 09/25/82 $144 / 79 \mathrm{ml}$ telow TOMe: $12: 48$ Depth to water: $146.94 \mathrm{ft}(44.79 \mathrm{~m})$ below
WELL MSB 17D

MEASUREMENTS CONDUCTED IN THE FIELD

Sample date: $09 / 26 / 92$ Tima: $12: 63$

Water elevation: $227.13 \mathrm{ft}(69.23 \mathrm{~m}) \mathrm{ms}$

\section{WELL MSB 18A}

MEASUREMENTS CONDUCTED IN THE FIELD

Sample date: 09/23/92 $13992 \mathrm{~m} /$ below TOC Time: 14:67

Water elevation: $210.63 \mathrm{ft}(64.17 \mathrm{~m}) \mathrm{ms}$ )

\section{WELL MSB 18B}

MEASUREMENTS CONDUCTED IN THE FIELD

Sample date: $09 / 23 / 92$ (t $136.68 \mathrm{~m})$ below TOC Time: $14: 64$

Water elevation: $220.02 \mathrm{ft}(67.06 \mathrm{~m}) \mathrm{mst}$

\section{WELL MSB 18C}

MEASUREMENTS CONDUCTED IN THE FIELD

Sample date: 09/23/92 $134.83 \mathrm{~m} /$ below TOC Time: 14:63

Water

\section{WELL MSB 19A}

MEASUREMENTS CONDUCTED IN THE FIELD

Sample date: 09/26/92 $126.30 \mathrm{~m})$ below TOC Tima: $9: 66$

Woter elevation: $213.22 \mathrm{ft}(64.98 \mathrm{~m}) \mathrm{msl}$

\section{WELL MSB 19B}

MEASUREMENTS CONDUCTED IN THE FIELD

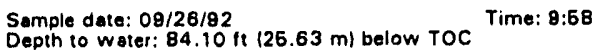

Depth to woter: $84.10 \mathrm{ft}(26.63 \mathrm{~m})$ below
Weter elevation: $216.80 \mathrm{ft}(66.78 \mathrm{~m}) \mathrm{ms}$

\section{WELL MSB 19C}

MEASUREMENTS CONDUCTED IN THE FIELD

Somple date: 08/26/92 Time: 8:67 Depth to weter: $62.77 \mathrm{ft}(19.13 \mathrm{~m})$ below TOC

Water elevation: $237.43 \mathrm{ft}(72.37 \mathrm{~m}) \mathrm{ms}$

WELL MSB 20A

MEASUREMENTS CONDUCTED IN THE FIELD

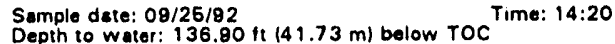
Woter elevation: $217.10 \mathrm{ft}(66.17 \mathrm{~m}) \mathrm{msl}$

WELL MSB 20C

MEASUREMENTS CONDUCTED IN THE FIELD

Sample date: $09 / 26 / 92$ ft $138.96 \mathrm{~m} /$ below TOC Time: 14:21 Water elevation: $226.48 \mathrm{ft}(68.73 \mathrm{~m} / \mathrm{msl}$

\section{WELL MSB $21 \mathrm{~A}$}

MEASUREMENTS CONDUCTED IN THE FIELD

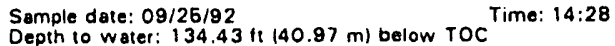
Water elevation: $218.97 \mathrm{ft}(66.74 \mathrm{~m}) \mathrm{mgl}$

\section{WELL MSB 218}

MEASUREMENTS CONDUCTED IN THE FIELD

Sample date: $09 / 25 / 92 \mathrm{f}(41.24 \mathrm{~m})$ below TOC Time: $14: 38$ Water elevation: $219.99 \mathrm{ft}(67.06 \mathrm{~m}) \mathrm{ms}$ ! 
WELL MSB $21 \mathrm{C}$

MEASUREMENTS CONOUCTED IN THE FIELD

Sample date: $08 / 26 / 92 \quad(38.34 \mathrm{~m})$ below TOC Time: $14: 27$

Depth to water: $126.78 \mathrm{ft}(38.34 \mathrm{~m})$ below
Wetef elevetion: $227.82 \mathrm{ft}(69.38 \mathrm{~m}) \mathrm{ms}$ )

WELL MSB 21TA

MEASUREMENTS CONDUCTED IN THE FIELD

Semple dete: $08 / 26 / 92$
Depth to water: $180.10 \mathrm{ft}(48.80 \mathrm{~m} /$ bolow TOC Time: $14: 30$ Depth to water: $180.10 \mathrm{ft}(48.80 \mathrm{~m} /$ bolo
Weter elovation: $184.60 \mathrm{ft}(69.31 \mathrm{~m} / \mathrm{msl}$

\section{WELL MSB 22}

MEASUREMENTS CONDUCTED IN THE FIELD

Sample date: $09 / 26 / 92$

No water in atondpipe.

Time: 10:08

WELL MSB 23

MEASUAEMENTS CONDUCTED IN THE FIELD

Somple date: 09/23/92

Time: 12:31

WELL MSB 23B

MEASUAEMENTS CONDUCTED IN THE FIELD

Somple date: $08 / 23 / 92$ TIme: $12: 29$

Depth to water: $147.67 \mathrm{tt}(44.98 \mathrm{~m})$ below TOC
Watet elevetion: $224.03 \mathrm{tt}(68.29 \mathrm{~m}) \mathrm{msl}$

WELL MSB 23TA

MEASUREMENTS CONDUCTED IN THE FIELD

Somple date: $08 / 23 / 82$ Time: 12:27 Weter elevetion: $201.42 \mathrm{fi}(61.38 \mathrm{~m}) \mathrm{ms}$

\section{WELL MSB 24}

MEASUREMENTS CONDUCTED IN THE FIELD

Semple date: 09/23/82
Depth to water: $144.81 \mathrm{ft}(44.17 \mathrm{~m} /$ below TOC TIme: 12:16 Water elevation: $236.29 \mathrm{ft}(71.72 \mathrm{~m}) \mathrm{ms}$

\section{WELL MSB 24A}

MEASUREMENTS CONDUCTED IN THE FIELD

Semple date: 09/23/92 140 Time: $12: 18$ Woter sievation: $226.88+168.16 \mathrm{~m} / \mathrm{msl}$

\section{WELL MSB 25}

MEASUREMENTS CONDUCTED IN THE FIELD Somple date: 09/23/82
No water in stondpipe.

\section{WELL MSB 25A}

MEASUREMENTS CONDUCTED IN THE FIELD

Sample dote: 09/23/82 $(45.17 \mathrm{~m})$ below TOC TIme: 13:01 Depth to water: $148.20 \mathrm{ft}(46.17 \mathrm{~m})$ below
Water elevation: $218.20 \mathrm{ft}(66.61 \mathrm{~m} / \mathrm{msl}$

\section{WELL MSB 26}

MEASUREMENTS CONDUCTED IN THE FIELD

Somple date: $09 / 26 / 82 \quad$ Time: 1446

\section{WELL MSB 26A}

MEASUREMENTS CONDUCTED IN THE FIELD

Somple dete: 09/25/92 $\quad$ Time: 14:43 Depth to water: $138,62 \mathrm{ft}(42.25 \mathrm{~m} /$ below
Whet elevation: $222.28 \mathrm{ft}(67.76 \mathrm{~m} / \mathrm{msl}$
WELL MSB 26B

MEASUREMENTS CONDUCTED IN THE FIELD

Sample date: $09 / 25 / 92$
Depth to water: 146.11 it $(44.23 \mathrm{~m})$ below TOC Time: $14: 46$

Depth to water: $146.11 \mathrm{ft}(44.23 \mathrm{~m})$ below
Water elevation: $218.08 \mathrm{ft}(66.47 \mathrm{~m}) \mathrm{ms}$

WELL MSB 27

MEASUREMENTS CONDUCTED IN THE FIELD

Semple date: $09 / 23 / 92$
Depth to water: $139.33 \mathrm{ft}(42.47 \mathrm{~m})$ below TOC Time: $12: 46$

Depth to water: $139.33 \mathrm{ft}(42.47 \mathrm{~m})$ bolow
Water aievation: $236.17 \mathrm{H}(71.89 \mathrm{~m}) \mathrm{msl}$

WELL MSB 27A

MEASUREMENTS CUNDUCTED IN THE FIELD

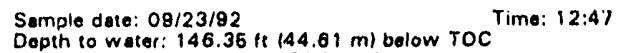

Dopth to weter: $146.36 \mathrm{ft}(44.61 \mathrm{~m})$ below

WELL MSB 27B

MEASUREMENTS CONOUCTED IN THE FIELD

Sarnple date: $09 / 23 / 92$
Depth io water: $160.16 \mathrm{ft}(46.77 \mathrm{~m})$ below TOC Time: $12: 6$ )

Depth to water: $160.16 \mathrm{ft}(46.77 \mathrm{~m})$ belo
Water elevation: $226.64 \mathrm{ft}(88.08 \mathrm{~m}) \mathrm{mal}$

WELL MSB 27TA

MEASUREMENTS CONDUCTED IN THE FIELD

Somple deie: $08 / 23 / 92$
Depth to water: $176.62 \mathrm{ft}(63.60 \mathrm{~m} /$ below TOC Time: $12: 49$ Depth to water: $176.62 \mathrm{ft}(63.60 \mathrm{~m} / \mathrm{bel}$
Woter olevetion: $201.08 \mathrm{ft}(61.28 \mathrm{~m}) \mathrm{mal}$

\section{WELL MSB 28}

MEASUREMENTS CONDUCTED IN THE FIELD

Semple date: $09 / 25 / 92$
Depth 10 water: $124.87 \mathrm{Ht}(38.06 \mathrm{~m})$ below roc Time: $14: 12$ Depth 10 water: $124.87 \mathrm{ft}(38.06 \mathrm{~m})$ below
Weter elevation: $228.63 \mathrm{ft}(68.96 \mathrm{~m}) \mathrm{mal}$

\section{WELL MSB 28A}

MEASUREMENTS CONOUCTED IN THE FIELD

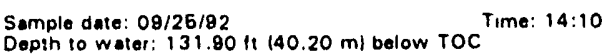
Depih to water: $131.80 \mathrm{ft}(40.20 \mathrm{~m} /$ below
Wetel oleveltion: $222.30 \mathrm{ft} 167.76 \mathrm{~m} / \mathrm{mal}$

\section{WELL MSB 29A}

MEASUREMENTS CONDUCTED IN THE FIELD

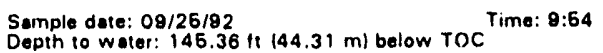
Depth to whter: $146.36 \mathrm{ft}(44.31 \mathrm{~m})$ below
Wotel olevetion: $220.04 \mathrm{ft}(67.07 \mathrm{~m}) \mathrm{ms}$

WELL MSB 29B

MEASUREMENTS CONDUCTED IN THE FIELD

Sumple date: 09/26/92 4 Time: 8:60 Depth to water: $141.02 \mathrm{ft}(42.88 \mathrm{~m})$ below
Water elevetion: $224.18 \mathrm{ft}(68.33 \mathrm{~m}) \mathrm{mst}$

WELL MSB 29C

MEASUREMENTS CONDUCTED IN THE FIELD

Semple date: $09 / 26 / 92$
Depth to water: $134.84 \mathrm{fl}(41.10 \mathrm{~m})$ below TOC Time: $8: 48$ Depth to water: $134.84 \mathrm{H}(41.10 \mathrm{~m})$ bolow
Whter elevation: $230.36 \mathrm{t}(70.21 \mathrm{~m}) \mathrm{msl}$

WELL MSB 29D

MEASUREMENTS CONDUCTED IN THE FIELD

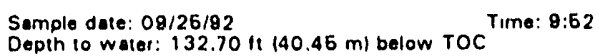
Depth to water: $132.70 \mathrm{ft}(40.46 \mathrm{~m})$ below
Water elovation: $232.40 \mathrm{ft}(70.84 \mathrm{~m} / \mathrm{ms}$ ) 
WELLL MSB 29DD

MEASUREMENTS CONDUCTED IN THE FIELD

Sample date: $09 / 26 / 82$
Depth to water: $131.99 \mathrm{ft}(40.23 \mathrm{~m})$ below TOC Time: $8: 46$

Ner evetion: $232.81 \mathrm{tt} 170.90 \mathrm{ml}$ mst

WELL MSB 29TA

MEASUREMENTS CONDUCTED IN THE FIELO

Sample date: 09/25/92 Time: $9: 66$

Dopth to water: 152.70 it 148

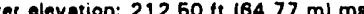

\section{WELL MSB 30A}

MEASUREMENTS CONDUCTED IN THE FIELD

Sample date: 09/26/92 $147.58 \mathrm{ml}$ time: 13:66

Depth to water: $156.09 \mathrm{ft}(47.68 \mathrm{~m} /$ below TOC

Water elevotion: $198.51 \mathrm{ft}(60.61 \mathrm{~m}) \mathrm{ms}$

\section{WELL MSB 30AA}

MEASUREMENTS CONDUCTED IN THE FIELD

Sample date: $09 / 25 / 92 \mathrm{ft}(39.43 \mathrm{~m})$ below TOC Time: $13: 46$

Water alevation: $223.23 \mathrm{ft}(68.04 \mathrm{~m}) \mathrm{ms}$ !

WELL MSB 30B

MEASUREMENTS CONDUCTED IN THE FIELO

Sample date: $08 / 26 / 92 \mathrm{H}(39.19 \mathrm{~m})$ below TOC Time: $13: 48$

Water olevation: $224.61 \mathrm{ft}(68.43 \mathrm{~m}) \mathrm{msl}$

WELL MSB 30C

MEASUREMENTS CONDUCTED IN THE FIELD

Sample date: 09/26/92 3 Time: $13: 62$ Water elevetion: $230.72 \mathrm{ft}(70.32 \mathrm{~m}) \mathrm{msl}$

WELL MSB 30CC

MEASUREMENTS CONDUCTED IN THE FIELD

Sample date: $09 / 26 / 92 \mathrm{ft}(39.41 \mathrm{~m})$ below TOC Time: $13: 49$ Weter elevation: $224.40 \mathrm{ft}(68.40 \mathrm{~m}) \mathrm{ms}$ !

\section{WELL MSB $31 \mathrm{~A}$}

MEASUREMENTS CONDUCTED IN THE FIELD

Semple date: 09/26/92 a $145.67 \mathrm{~m} /$ below TOC Time: $15: 25$ Woter elevation: $187.36 \mathrm{tt}(60.16 \mathrm{~m}) \mathrm{ms}$ !

\section{WELL MSB 31B}

MEASUREMENTS CONDUCTED IN THE FIELD

Semple date: $09 / 26 / 92$ i $(41.36 \mathrm{~m})$ below TOC Time: $16: 29$ Weter elevation: $211.78 \mathrm{ft}(64.66 \mathrm{~m}) \mathrm{ms}$

WELL MSB 31C

MEASUREMENTS CONDUCTED IN THE FIELD

Somple date: $09 / 25 / 92$ (t) $(34.79 \mathrm{~m})$ below TOC Time: $15: 27$ Watet elevation: $233.16 \mathrm{ft}(71.07 \mathrm{~m} / \mathrm{msl}$

\section{WELL MSB 31CC}

MEASUREMENTS CONDUCTED IN THE FIELD

Semple date: 09/26/92

Time: 16:30 Water elevation: $212.78 \mathrm{ft}(64.86 \mathrm{~m}) \mathrm{msl}$
WELL MSB 32

MEASUREMENTS CONDUCTED IN THE FIELD

Sample date: 09/26/92 Time: 10:06 Depth to water: $30.40 \mathrm{ft}(9.27 \mathrm{~m})$ below TOC

Water elevation: $224.90 \mathrm{ft}(68.65 \mathrm{~m}) \mathrm{ms}$

WELL MSB 33

MEASUREMENTS CONDUCTED IN THE FIELD

Sample date: 09/26/92 Time: 11:60 Woth tevation: $218.61 \mathrm{tt}(66.60 \mathrm{~m}) \mathrm{ms}$

WELL MSB 33A

MEASUREMENTS CONDUCTED IN THE FIELD

Sample date: 09/26/92 $115.44 \mathrm{~m})$ below TOC Time: $11: 64$

Water elevation: $204.76 \mathrm{ft}(62.41 \mathrm{~m}) \mathrm{msl}$

WELL MSB 33B

MEASUREMENTS CONDUCTED IN THE FIELD Semple date: 09/26/92 $(14.40 \mathrm{~m})$ below TOC Time: $11: 66$

Depth to water: $47.26 \mathrm{fi}(14.40 \mathrm{~m}) \mathrm{bel}$.

WELL MSB 33C

MEASUREMENTS CONDUCTED IN THE FIELD

Semple date: 09/26/92 Time: 11:67 Depth to water: $44.42 \mathrm{ft}(13.64 \mathrm{~m})$ below TOC Water elevation: $210.88 \mathrm{ft}(64.28 \mathrm{~m} / \mathrm{ms}$

WELL MSB 33TA

MEASUREMENTS CONDUCTED IN THE FIELD

Sample date: 09/26/92 $(18.40 \mathrm{~m})$ below Toc Time: $11: 62$ Water elevation: $195.12 \mathrm{ft}(68.47 \mathrm{~m}) \mathrm{ms}$

\section{WELL MSB 34A}

MEASUREMENTS CONDUCTED IN THE FIELD

Semple date: 09/25/92 $160.63 \mathrm{~m} /$ below TOC Time: 16:16 Depth to water: $166.77 \mathrm{t}(60.63 \mathrm{~m})$ below
Water elevation: $217.43 \mathrm{tt}(66.27 \mathrm{~m}) \mathrm{msl}$

\section{WELL MSB 34B}

MEASUREMENTS CONDUCTED IN THE FIELD

Sample date: $09 / 25 / 92$ (t $148.16 \mathrm{~m} /$ below TOC Time: $16: 13$ Water eievation: $226.10 \mathrm{ft}(88.61 \mathrm{~m}) \mathrm{ms}$

\section{WELL MSB 34C}

MEASUREMENTS CONDUCTED IN THE FIELD

Sumple date: 09/26/92 $(47.22 \mathrm{~m})$ below TOC Time: 16:10 Woter elevation: $228.27 \mathrm{ft}(68.68 \mathrm{~m}) \mathrm{ms}$

\section{WELL MSB 34TA}

MEASUREMENTS CONDUCTED IN THE FIELD

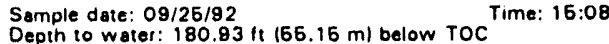
Water elevation: $201.67 \mathrm{ft}(61.44 \mathrm{~m}) \mathrm{ms}$

\section{WELL MSB 34TB}

MEASUREMENTS CONDUCTED IN THE FIELD

Semple date: 09/25/92 $155.01 \mathrm{~m})$ below TOC Time: 16:06 Water elevation: $202.33 \mathrm{ft}(61.67 \mathrm{~m}) \mathrm{ms}$ 
WELL MSB 35A

MEASUREMENTS CONDUCTED IN THE FJELD

Somple date: 09/25/92

Time: 16:66

Watel dovation: 218.3811 .05 .06 mibelow TOC

WELL MSB 35B

MEASUREMENTS CONDUCTED IN THE FIELD

Somple dote: 09/25/92
Depth to water: $132.62 \mathrm{ft}(40.42 \mathrm{~m})$ below TOC Time: $16: 58$

Oepth to water: $132.82 \mathrm{ft}(40.42 \mathrm{~m})$ below
Whter olevation: $218.18 \mathrm{ft}(86.81 \mathrm{~m}) \mathrm{ms}$

WELL MSB 35D

MEASUREMENTS CONDUCTED IN THE FIELD

Somple dace: 09/25/92

Time: 16:02

WELL MSB 35TA

MEASUREMENTS CONDUCTED IN THE FIELD

Semple dare: 08/25/92 $36.73 \mathrm{~m})$ beiow TOC Time: $16: 00$ Water elevation: $200.36 \mathrm{ft}(61.07 \mathrm{~m} / \mathrm{mal}$

\section{WELL MSB 36A}

MEASUREMENTS CONDUCTED IN THE FIELD

Somple dete: 09/26/92 $139.95 \mathrm{~m})$ below TOC Time: $11: 23$ Weter elevation: $209.63 \mathrm{ft}(63.87 \mathrm{~m}) \mathrm{msl}$

WELL MSB 36B

MEASUREMENTS CONDUCTED IN THE FIELD

Sumple date: $09 / 26 / 82 \mathrm{~h}$ TIme: $11: 26$ Weter elevetion: $213.80 \mathrm{tt}(66.17 \mathrm{~m} / \mathrm{msl}$

WELL MSB 36C

MEASUREMENTS CONDUCTED IN THE FIELD

Somple date: $08 / 28 / 92$
Depth to woter: $126.96 \mathrm{ft}(38.69 \mathrm{~m})$ below TOC TIme: $11: 29$ Water elevation: $213.86 \mathrm{ft}(66.18 \mathrm{~m} / \mathrm{msi}$

WELL MSB 36D

MEASUREMENTS CONDUCTED IN THE FIELL Somple date: $09 / 26 / 92$
Depth 10 water: $103.66 \mathrm{ft}(31.69 \mathrm{~m})$ below TOC Time: $11: 32$
Weter elevetion: $237.85 \mathrm{ft}(72.60 \mathrm{~m} / \mathrm{msl}$

Weter elevation: $237.86 \mathrm{ft} 172.60 \mathrm{~m} / \mathrm{msl}$

WELL MSB 36TA

MEASUREMENTS CONDUCTED IN THE FIELL

Semple dete: $09 / 26 / 92$ it $(44.31 \mathrm{~m})$ below TOC TIme: $11: 21$ Water slevation: $195.24 \mathrm{ft}(59.51 \mathrm{~m}) \mathrm{ms} /$

WELL MSB 37A

MEASUREMENTS CONDUCTED IN THE FIELD

Sample date: $08 / 26 / 82$
Depth to water: $176.46 \mathrm{fl} 163.48 \mathrm{~m} /$ below TOC Time: $14: 02$ Depth to water: $175.46 \mathrm{ft} 163.48 \mathrm{~m} /$ below TOC

WELL MSB 37B

MEASUREMENTS CONOUCTED IN THE FIELO

Semple date: $09 / 25 / 92 \mathrm{ft} 149.90 \mathrm{~m} /$ below TOC Time: $14: 04$ Water elovetion: $219.10 \mathrm{ft}(66.78 \mathrm{~m} / \mathrm{ms}$ )
WELL MSB 37C

MEASUREMENTS CONDUCTED IN THE FIELD

Sample date: $09 / 26 / 92 \mathrm{ft}(47.37 \mathrm{~m})$ below TOC Time: $14: 06$

Depth to water: $165.42 \mathrm{ft}(47.37 \mathrm{~m})$ bolow TOC
Water elevation: $227.68 \mathrm{ft}(68.40 \mathrm{~m}) \mathrm{mal}$

WELL MSB 37D

MEASUREMENTS CONDUCTED IN THE FIELO

Somple date: $09 / 25 / 82 \mathrm{ft}(46.19 \mathrm{~m})$ below TOC Time: $14: 08$ Depth to water: $161.65 \mathrm{ft}(46.19 \mathrm{~m})$ below
Water elevation: $231.26 \mathrm{ft}(70.49 \mathrm{~m}) \mathrm{mal}$

WELL MSB 37TA

MEASUREMENTS CONDUCTEO IN THE FIELD

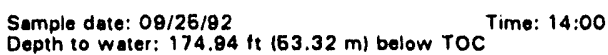

Depth to water: $174.94 \mathrm{ft}(53.32 \mathrm{~m})$ below
Water elevation: $207.46 \mathrm{ft}(63.23 \mathrm{~m} / \mathrm{ms})$

WELL MSB 38B

MEASUREMENTS CONDUCTED IN THE FIELO

Semple date: $09 / 26 / 92$
Depth to water: $144.69 \mathrm{ft}(44.10 \mathrm{~m})$ below TOC Time: $8: 20$ Depth to water: $144.69 \mathrm{ft}(44.10 \mathrm{~m})$ below
Water elevation: $211.81 \mathrm{ft}(64.58 \mathrm{~m}) \mathrm{ms}$

WELL MSB 38C

MEASUREMENTS CONDUCTED IN THE FIELD

Sample date: 09/26/82 $14.11 \mathrm{~m})$ below TOC Time: $9: 18$ Depth to water: $141.43 \mathrm{ft}(43.11 \mathrm{~m})$ below
Weter elevation: $214.87 \mathrm{ft}(66.49 \mathrm{~m}) \mathrm{ms})$

WELL MSB 38D

MEASUREMENTS CONDUCTED IN THE FIELD

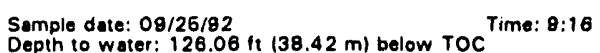
Depth to water: $126.06 \mathrm{ft}(38.42 \mathrm{~m} /$ below
Water elevation: $228.94 \mathrm{ft} 170.09 \mathrm{~m}) \mathrm{msl}$

WELL MSB 38TA

MEASUREMENTS CONDUCTED IN THE FIELD

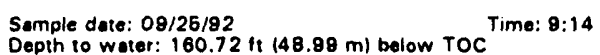
Depth to woter: $160.72 \mathrm{ft}(48.98 \mathrm{~m})$ below
Water elevetion: $185.88 \mathrm{ft}(68.74 \mathrm{~m}) \mathrm{mal}$

WELL MSB 39A

MEASUREMENTS CONDUCTED IN THE FIELD

Sample dote: 09/25/92
Depth to water: $133.02 \mathrm{ft}(40.64 \mathrm{~m})$ below TOC Time: $16: 46$ Depth to water: $133.02 \mathrm{ft}(40.64 \mathrm{~m})$ below
Weter elevetion: $208.68 \mathrm{ft}(63.68 \mathrm{~m}) \mathrm{mal}$

\section{WELL MSB 39B}

MEASUREMENTS CONDUCTED IN THE FIELD

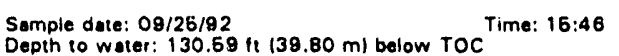
Depth to water: $130.59 \mathrm{ft}(39.80 \mathrm{~m})$ below
Watet elevation: $211.21 \mathrm{ft}(64.38 \mathrm{~m}) \mathrm{msl}$

WELL MSB 39C

MEASUREMENTS CONDUCTED IN THE FIELD

Semple date: $09 / 25 / 92$
Depth to water: $126.67 \mathrm{fl}(38.68 \mathrm{~m} /$ below roc Depth to water: $126.67 \mathrm{H}(38.68 \mathrm{~m} /$ below
Water elevation: $214.93 \mathrm{th}(65.61 \mathrm{~m} / \mathrm{msl}$

\section{WELL MSB 39D}

MEASUREMENTS CONDUCTED IN THE FIELD

Semple date: 09/26/92 109.48 m) below TOC Time: 16:60 Depth to water: $109.85 \mathrm{ft}(33.48 \mathrm{~m})$ below
Woter olevation: $231.86 \mathrm{ft}(70.67 \mathrm{~m} / \mathrm{msl}$ 
WELL MSB 39TA

MEASUREMENTS CONDUCTED IN THE FIELD

Semple date: $08 / 26 / 82$

Time: 16:43

WELL MSB 40A

MEASUREMENTS CONDUCTED IN THE FIELD

Sample date: $09 / 25 / 82$
Depth to water: $118.35 \mathrm{Ht}(36.07 \mathrm{~m} /$ below TOC Time: 16:02

Water elevetion: $202.86 \mathrm{ft}(61.83 \mathrm{~m} / \mathrm{ms}$

\section{WELL MSB 40B}

MEASUREMENTS CONDUCTED IN THE FIELD

Semple dete: $08 / 25 / 92 \mathrm{ft}(35.71 \mathrm{~m})$ below TOC Time: $16: 03$

Water elevation: $204.66 \mathrm{tt}(62.35 \mathrm{~m}) \mathrm{mal}$

\section{WELL MSB 40C}

MEASUREMENTS CONDUCTED IN THE FIELD Semple date: $09 / 26 / 92$
Depth to woter: $119.47 \mathrm{ft}(36.81 \mathrm{~m} /$ below TOC TIme: $16: 06$

Water elevation: $204.63 \mathrm{ft}(82.37 \mathrm{~m}) \mathrm{msl}$

\section{WELL MSB 40D}

MEASUREMENTS CONDUCTED IN THE FIELD

Semple date: $09 / 26 / 92$ (2) $(28.64 \mathrm{~m})$ below TOC

Depth to water: $93.85 \mathrm{ft}(28.64 \mathrm{~m})$ below

\section{WELL MSB 40TA}

MEASUREMENTS CONDUCTED IN THE FIELD

Sample date: $09 / 25 / 92$
Depth to water: $131.14 \mathrm{ft}(39.97 \mathrm{~m} /$ below TOC Time: 16:00 Wotet elevetion: $189.66 \mathrm{ft} 157.8 \mathrm{im} / \mathrm{msl}$

\section{WELL MSB $41 \mathrm{~A}$}

MEASUREMENTS CONDUCTED IN THE FIELD

Sample date: 09/26/82 $10.67 \mathrm{~m} /$ below TOC Time: $11: 31$ Woter elevation: $216.86+166.13 \mathrm{~m}) \mathrm{msl}$

\section{WELL MSB 41B}

MEASUREMENTS CONDUCTED IN THE FIELD

Somple date: 09/28/92 $132.69 \mathrm{~m} /$ below TOC Time: $11: 32$ Weter elevation: $217.08 \mathrm{ft}(66.17 \mathrm{~m} / \mathrm{msl}$

\section{WELL MSB 41C}

MEASUREMENTS CONDUCTED IN THE FIELD

Sample date: $09 / 26 / 82 \mathrm{ft}(32.62 \mathrm{~m})$ below TOC Time: $11: 34$ Water elevation: $217.58 \mathrm{ft}(66.32 \mathrm{~m}) \mathrm{ms}$.

\section{WELL MSB 41D}

MEASUREMENTS CONDUCTED IN THE FIELD

Sample date: 09/26/92 Time: $11: 36$ No wotet in stendpipe.

\section{WELL MSB 41 TA}

MEASUREMENTS CO'JDUCTED IN THE FIELD

Somple date: 08/26/82 $135,72 \mathrm{ml}$ telow TOMe: 11:29 Depth to water: $117.19 \mathrm{ft}(36.72 \mathrm{~m})$ below
Woter elevation: $206.61 \mathrm{ft}(62.86 \mathrm{~m}) \mathrm{ms} 1$
WELL MSB 42A

MEASUREMENTS CONDUCTED IN THE FIELD

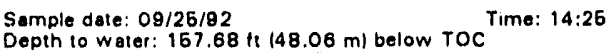

Depth to water: $167.68 \mathrm{H} 148.06 \mathrm{ml}$ below
Watel elevation: $218.92 \mathrm{ft} 166.73 \mathrm{ml} \mathrm{msl}$

WELL MSB 42B

MEASUREMENTS CONOUCTED IN THE FIELD

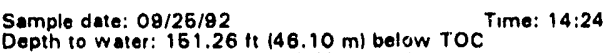

Depth to water: $161.26 \mathrm{ft}(46.10 \mathrm{~m})$ below

WELL MSB 42C

MEASUREMENTS CONOUCTED IN THE FIELD

Semple date: $08 / 25 / 92$ ft $(44.44 \mathrm{~m})$ below TOC Time: $14: 20$

Depth to water: $146.80 \mathrm{ft}(44.44 \mathrm{~m})$ below

WELL MSB 420

MEASUREMENTS CONDUCTED IN THE FIELD

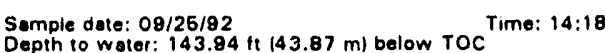
Depth to woter: $143.84 \mathrm{ft}(43.87 \mathrm{~m})$ below
Water elevation: $232.56 \mathrm{ft}(70.89 \mathrm{~m}) \mathrm{mel}$

WELL MSB 42TA

MEASUREMENTS CONDUCTED IN THE FIELD

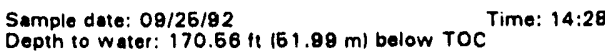
Water elevation: $206.14 \mathrm{ft}(62.83 \mathrm{~m} / \mathrm{msl}$

WELL MSB 43A

MEASUREMENTS CONDUCTED IN THE FIELD

Samplè date: 09/25/92 $139 \mathrm{~m}$ below TOC Tima: 8:34 Water elevation: $228.12 \mathrm{ft}(89.84 \mathrm{~m}) \mathrm{msl}$

\section{WELL MSB 43B}

MEASUREMENTS CONDUCTED IN THE FIELD Somple date: 09/25/82
Depth to water: $128.76 \mathrm{ft}(39.24 \mathrm{~m} /$ below TOC Time: $8: 36$
Water elevetion: $229.26 \mathrm{ft}(89.88 \mathrm{~m}) \mathrm{mal}$

WELL MSB 43D

MEASUREMENTS CONDUCTED IN THE FIELD

Sample dete: 09/26/92 ${ }_{\text {Depth lo water: } 126.74 \mathrm{ft}(38.63 \mathrm{~m}) \text { below TOC }}^{\text {Time: 8:37 }}$ Water elevation: $230.76 \mathrm{ft}(70.34 \mathrm{~m}) \mathrm{ms}$

WELL MSB 43DD

MEASUAEMENTS CONDUCTED IN THE FIELD

Semple date: $09 / 25 / 92 \mathrm{fo}(38.63 \mathrm{~m})$ below TOC Time: $9: 38$ Water elevation: $231.69 \mathrm{ft}(70.62 \mathrm{~m}) \mathrm{ms}$

WELL MSB 43TA

MEASUREMENTS CONOUCTEO IN THE FIELO

Sample date: $09 / 25 / 92$ i $147.02 \mathrm{~m} /$ below TOC Time: $8: 32$ Water elevation: $203.33 \mathrm{ft} 161.98 \mathrm{ml} \mathrm{mgl}$

WELL MSB 44A

MEASUREMENTS CONDUCTED IN THE FIELD

Sample date: $09 / 26 / 92$ is $(48.60 \mathrm{~m})$ below TOC Time: $14: 39$ Watet elevation: $217.46 \mathrm{ft}(66.28 \mathrm{~m}) \mathrm{ms}$ 


\section{WELL MSB 44B}

MEASUREMENTS CONDUCTED IN THE FIELD

Sample date: 08/25/92

TIme: 14:43

Weter elovation: 223.191148 .68 mi below TOC

WELL MSB 44C

MEASUREMENTS CONDUCTED IN THE FIELD

Somple dete: $09 / 25 / 82 \mathrm{ft}(43.62 \mathrm{~m})$ below TOC Time: $14: 41$

Water elevation: $236.11 \mathrm{ft}(71.66 \mathrm{~m}) \mathrm{me}$

WELL MSB 45A

MEASUREMENTS CONDUCTED IN THE FIELD

Eample date: $09 / 26 / 92 \mathrm{ft}(60.38 \mathrm{~m} /$ below TOC Time: $14: 66$

Water elevation: $215.82 \mathrm{ft} 166.78 \mathrm{~m} / \mathrm{msl}$

WELL MSB 45B

MEASUREMENTS CONDUCTED IN THE FIELO

Sample date: $09 / 26 / 92$ (t $(47.60 \mathrm{~m})$ below TOC Time: $14: 69$

Depth to water: $166.15 \mathrm{ft}(47.60 \mathrm{~m})$ below TOC
Woter elevation: $224.26 \mathrm{ft}(68.67 \mathrm{~m}) \mathrm{mal}$

WELL MSB 45C

MEASUREMENTS CONDUCTED IN THE FIELD

Semple date: $08 / 26 / 92$

Time: 14:67

The well was dry.

WELL MSB 46A

MEASUREMENTS CONDUCTED IN THE FIELD

Sample date: $09 / 25 / 82$ Hepth to water: $167.62 \mathrm{H}(48.04 \mathrm{~m})$ below TOC Time: $14: 48$ Depth to water: $167.62 \mathrm{ft}(48.04 \mathrm{~m})$ below
Weter elevation: $216.08 \mathrm{ft}(65.66 \mathrm{~m}) \mathrm{msl}$

WELL MSB 46B

MEASUREMENTS CONDUCTED IN THE FIELO

Somple date: $09 / 26 / 82$

Tıme: 14:62

No water in stendpipe.

WELL MSB 46C

MEASUREMENTS CONDUCTED IN THE FIELD

Sample date: $08 / 26 / 92$ fi $140.34 \mathrm{~m} /$ below TOC Time: $14: 60$ Water olevation: $240.46 \mathrm{ft}(73.29 \mathrm{~m}) \mathrm{msl}$

WELL MSB 47B

MEASUREMENTS CONDUCTED IN THE FIELO

Sample date: 09/23/92 $143.81 \mathrm{~m})$ below TOC Time: $11: 62$ Weter olevation: $225.27 \mathrm{tt}(68.66 \mathrm{~m}) \mathrm{msl}$

\section{WELL MSB 47BB}

MEASUREMENTS CONDUCTED IN THE FIELD

Sample date: $08 / 23 / 92$ (t $(45.45 \mathrm{~m})$ below TOC TIme: $11: 47$ Weter elevestion: $220.00 \mathrm{ft} 167.06 \mathrm{ml} \mathrm{msl}$

\section{WELL MSB 47C}

MEASUREMENTS CONDUCTED IN THE FIELD

Semple date: 09/23/92 $141.62 \mathrm{~m} /$ below TOC Time: $11: 66$

Depth to water: $136.64 \mathrm{Ht}(41.62 \mathrm{~m})$ below TOC
Water elevation: 232.76 (t $(70.86 \mathrm{~m}) \mathrm{msl}$
WELL MSB 47D

MEASUREMENTS CONDUCTED IN THE FIELD

Sample date: 09/23/92 $141.26 \mathrm{~m} /$ below TOC Time: $11: 66$

Depth to water: $136.36 \mathrm{H}(41.26 \mathrm{~m})$ bolow

WELL MSB 47TA

MEASUREMENTS CONDUCTED IN THE FIELD

Sample dete: $09 / 23 / 92$ f $(46.33 \mathrm{~m})$ below TOC ${ }^{\text {Time: } 11: 60}$

WELL MSB 48A

MEASUREMENTS CONDUCTED IN THE FIELD

Semple date: 08/25/92 3 (4)

Depth to weter: $139.20 \mathrm{ht}(42.43 \mathrm{~m})$ below
Weter olevation: $223.00 \mathrm{ft}(67.97 \mathrm{~m}) \mathrm{mal}$

WELL MSB 48B

MEASUREMENTS CONDUCTED IN THE FIELD

Sample date: 09/26/92 $141.97 \mathrm{~m})$ below TOC Time: $11: 47$

Depth to water: $137.71 \mathrm{ft}(41.97 \mathrm{~m})$ below

WELL MSB 48C

MEASUREMENTS CONDUCTED IN THE FIELD

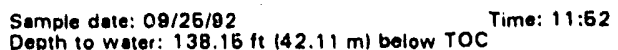

Depth to woter: $138.16 \mathrm{ft}(42.11 \mathrm{~m})$ below

WELL MSB 48D

MEASUREMENTS CONDUCTED IN THE FIELD

Sample date: 09/25/92 $139.62 \mathrm{~m})$ belol " TOC Time: $11: 64$

\section{WELL MSB 48TA}

MEASUREMENTS CONDUCTED IN THE FIELD

Semple date: 08/25/82 Time: 11:61

Depth to water: $139.74 \mathrm{ft}(42.69 \mathrm{~m})$ balow

Water alevation: $222.66 \mathrm{ft}(67.87 \mathrm{~m}) \mathrm{mal}$

WELL MSB 49A

MEASUREMENTS CONOUCTED IN THE FIELD

Sample date: 09/23/82 Time: 14:45

Depth to water: $137.23 \mathrm{ft}(41.83 \mathrm{~m})$ bolow

Water elevation: $198.17 \mathrm{ht}(60.40 \mathrm{~m}) \mathrm{ms}$

WELL MSB 49B

MEASUREMENTS CONDUCTED IN THE FIELD

Sample date: $09 / 23 / 92 \mathrm{ft}(39.88 \mathrm{~m})$ below TOC Time: $14: 42$

Weter olevation: $203.64 \mathrm{ft}(62.07 \mathrm{~m}) \mathrm{mal}$

WELL MSB 49D

MEASUREMENTS CONOUCTED IN THE FIELD

Somple date: 09/23/92 ${ }_{\text {Depth to water: } 104.75 \mathrm{ft}(31.83 \mathrm{~m}) \text { velow TOC Time: } 14: 47}$

Water elevation: $228.46 \mathrm{lt}(69.84 \mathrm{~m} / \mathrm{ms}$

WELL MSB 50B

MEASUREMENTS CONDUCTED IN THE FIELD

Sample date: 09/20/92

Depth to water: $21.24 \mathrm{ft}(6.47 \mathrm{~m})$ below rOC

Water olevation: $202.76 \mathrm{ft}(61.80 \mathrm{~m}) \mathrm{msl}$ 


\section{WELL MSB 50D}

MEASUREMENTS CONDUCTED IN THE FIELD

Semple date: 09/26/82

Depth to water: $20.52 \mathrm{ft}(6.25 \mathrm{~m})$ below TOC

Dopth to water: $20.62 \mathrm{ft}(6.25 \mathrm{~m})$ below TOC

Time: $8: 34$

WELL MSB 'S1B

MEASUREMENTS CONDUCTED IN THE FIELD

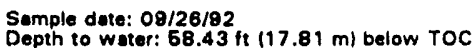
Time: 8:63

Water elevation: $205.07 \mathrm{ft}(62.61 \mathrm{~m}) \mathrm{ms}$

WELL MSB 51D

MEASUREMENTS CONDUCTED IN THE FIELD

Semple dete: 08/26/92

Depth to water: $61.76 \mathrm{ft}(16.78 \mathrm{~m})$ below TOC

Time: $8: 61$

Water elevation: $210.74 \mathrm{ft} 164.23 \mathrm{ml} \mathrm{mal}$

\section{WELL MSB 52B}

MEASUREMENTS CONDUCTED IN THE FIELD

Sample date: $09 / 26 / 92$
Depth to water: $102.69 \mathrm{ft}(31.27 \mathrm{~m} /$ below TOC TIme: $11: 21$

Water elovar: $21.691 \mathrm{~h}(31.27 \mathrm{~m} /$ below TOC

WELL MSB 52D

MEASUREMENTS CONDUCTED IN THE FIELD

Sample date: 09/26/82

Depth to water: $83.46 \mathrm{ft}(25.44 \mathrm{~m} /$ below TOC

Water elevation: $238.34 \mathrm{ft}(72.65 \mathrm{~m}) \mathrm{mst}$

Time: $11: 22$

WELL MSB 53B

MEASUREMENTS CONDUCTED IN THE FIELD

Sample date: 09/26/82

Depth to water: 122.24 it $(37.26 \mathrm{~m})$ below TOC Time: 10:26 Water elevetion: $222.36 \mathrm{ft}(67.78 \mathrm{~m}) \mathrm{msl}$

WELL MSB 53C

MEASUREMENTS CONDUCTED IN THE FIELD Sample date: $09 / 28 / 92 \mathrm{fl} 137.27 \mathrm{~m} /$ below TOC Time: $10: 31$ Weter elevation: $223.22 \mathrm{ft}(68.04 \mathrm{~m}) \mathrm{ms}$

WELL MSB 53D

MEASUREMENTS CONDUCTED IN THE FIELD

Semple date: 09/26/92 $133.97 \mathrm{ml}$ below TOC Time: 10:27 Water elevation: $233.64 \mathrm{ft}(71.21 \mathrm{~m}) \mathrm{msi}$

\section{WELL MSB 54B}

MEASUREMENTS CONDUCTED IN THE FIELD

Somple date: 08/25/82 $(46.13 \mathrm{~m})$ below TOC Time: 10:67 Water elevetion: $222.36 \mathrm{ft}(67.77 \mathrm{~m}) \mathrm{ms}$

\section{WELL MSB 54C}

MEASUREMENTS CONDUCTED IN THE FIELD

Sample date: 08/26/92 $144.81 \mathrm{~m} /$ below TOC Time: 10:66 Woter elevation: $226.70 \mathrm{ft} 169.10 \mathrm{ml} \mathrm{msl}$

\section{WELL MSB 54D}

MEASUREMENTS CONDUCTED IN THE FIELD

Sample tote: 09/26/82 4142 mi below TOC 11:02 Woter elevetion: $233.67 \mathrm{ft}(71.22 \mathrm{~m} / \mathrm{ms})$
WELL MSB 54TA

MEASUREMENTS CONDUCTED IN THE FIELD

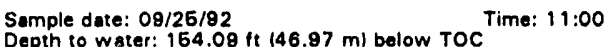
Woter olevation: $218.71 \mathrm{f}(66.87 \mathrm{~m}) \mathrm{msl}$

\section{WELL MSB 55B}

MEASUREMENTS CONDUCTED IN THE FIELD

Somple date: 09/25/92 $40.80 \mathrm{~m}$ below TOC Time: $11: 13$ Noter olevation: $221.81 \mathrm{ft}(67.64 \mathrm{~m}) \mathrm{msl}$

WELL MSB 55C

MEASUREMENTS CONDUCTED IN THE FIELD

Sample date: 08/25/82 Time: 11:18 Depth to water: $140.29 \mathrm{ft}(42.76 \mathrm{~m})$ below TOC

Weter elevetion: $228.21 \mathrm{ft}(69.86 \mathrm{~m}) \mathrm{msl}$

WELL MSB 55D

MEASUREMENTS CONDUCTED IN THE FIELD

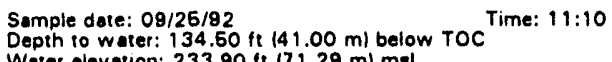

WELL MSB 55HC

MEASUREMENTS CONDUCTED IN THE FIELD

Somple date: 08/25/92 10 water: 136.92 \&t $(41.43 \mathrm{~m}$ ) below TOC Time: $11: 14$ Depth to water: $136.92 \mathrm{ft}(41.43 \mathrm{~m})$ below
Weter elevetion: $232.88 \mathrm{ft}(70.88 \mathrm{~m}) \mathrm{msl}$

WELL MSB 55TA

MEASUREMENTS CONDUCTED IN THE FIELD

Semple date 09/25/82 $14.13 \mathrm{~m})$ below TOC Time: $11: 16$ Water elevation: $2.14 .16 \mathrm{ft}(66.28 \mathrm{~m}) \mathrm{msl}$

WELL MSB 56D

MEASUREMENTS CONDUCTED IN THE FIELD

Sample date: $09 / 25 / 92 \mathrm{ft}(17.98 \mathrm{~m})$ below TOC Time: $9: 23$ Woter elevation: $220.81 \mathrm{ft}(67.30 \mathrm{~m}) \mathrm{msl}$

\section{WELL MSB 57D}

MEASUREMENTS CONOUCTED IN THE FIELD

Sample dote: $09 / 26 / 92 \mathrm{ft} 138.24 \mathrm{~m})$ below TOC Time: $0: 61$ Water elevation: $230.73 \mathrm{ft}(70.33 \mathrm{~m} / \mathrm{ms}$

\section{WELL MSB 58D}

MEASUREMENTS CONDUCTED IN THE FIELD

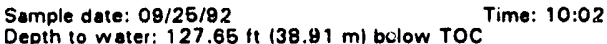
Water elevation: $230.26 \mathrm{ft}(70.18 \mathrm{~m}) \mathrm{ms}$

WELL MSB 59D

MEASUREMENTS CONDUCTED IN THE FIELD

Sample date: 09/25/92 $(39.61 \mathrm{~m})$ below TOC ${ }^{\text {Time: } 10: 25}$ Water elevation: $229.34 \mathrm{ft}(69.90 \mathrm{~m}) \mathrm{ms}$

WELL MSB 60D

MEASUREMENTS CONDUCTED IN THE FIELD

Sample date: $09 / 26 / 92 \mathrm{ft}(38.05 \mathrm{~m})$ below TOC Time: 10:36 Water elevation: $228.68 \mathrm{ft}(70.01 \mathrm{~m}) \mathrm{mst}$ 


\section{WATER LEVEL DATA}

\section{WELL MSB 61C}

MEASUREMENTS CONDUCTED IN THE FIELD

Semple date: 08/26/82 $28.62 \mathrm{~m}$ below roC Water devation: $223.70 \mathrm{it}(68.18 \mathrm{~m}) \mathrm{me}$

\section{WELL MSB 61D}

MEASUPEMENTS CONDUCTED IN THE FIELD

Semple date: 08/28/92 $128.17 \mathrm{ml}$ below TOC Depth 10 woter: $92.42 \mathrm{ft}(28.17 \mathrm{~m} /$ below

\section{WELL MSB 62B}

\section{MEASUREMENTS CONDUCTED IN THE FIELD}

Sample date: $00 / 26 / 92$. $143.10 \mathrm{~m} /$ below TOC

Time: 10:56

Water elevetion: $207.71 \mathrm{ft}(63.31 \mathrm{~m}) \mathrm{ma}$

\section{WELL MSB 62C}

MEASUREMENTS CONDUCTED IN THE FIELD

Sumple date: 09/26/92 $138.67 \mathrm{~m})$ below TOC Weter olevation: $222.56 \mathrm{H}(67.83 \mathrm{~m}) \mathrm{mel}$

WELL MSB 62D

MEASUREMENTS CONOUCTEO IN THE FIELD

Sample date: 08/25/82

Time: 10:58

(20.84 f $(36.83 \mathrm{~m})$ below TOC

WELL MSB 63B

MEASUREMENTS CONDUCTED IN THE FIELD

Sample date: 08/26/82

Wepth to water: 138.66 h $\{42.26 \mathrm{~m} /$ below TOC

water slevation: $208.34 \mathrm{ir} 163.50 \mathrm{ml} \mathrm{msl}$

Time: $8: 43$

WELL MSB 63C

MEASUREMENTS CONOUCTED IN THE FIELD

Sumple date: 08/26/82

Depth to water: $127.02 \geqslant(38.72 \mathrm{~m})$ below TOC

Weter elovation: 220.02 "t $138.72 \mathrm{~m})$ bolow

Tıne: $8: 41$

WELL MSB 63D

MEASUREMENTS CONOUCTED IN THE FIELD

Sample dete: 08/25/82 Time: 8:38

Depth to water: 117.61 1t $135.82 \mathrm{~m} /$ below TOC

\section{WELL MSB 64B}

MEASUREMENTS CONOUCTED IN THE FIELD

Sample date: 09/24/92 Time: 13:26 Depth to water: $140.64 \mathrm{ft}(42.84 \mathrm{~m})$ below TOC

\section{WELL MSB 64C}

MEASUREMENTS CONDUCTED IN THE FIELL

Sample date: 09/26/92 Time: 12:38 Depth to water: $126.86 \mathrm{H}(38.39 \mathrm{~m})$ below $T O C$

\section{WELL MSB 64D}

MEASUREMENTS CONDUCTED IN THE FIELO

Semple date: 09/25/82 Time: 12:40 Depth to water: $121.68 \mathrm{ft}(37.06 \mathrm{~m})$ below $Y O C$ Weter elevetion: $227.4211 .68 .32 \mathrm{ml} \mathrm{msl}$

\section{WELL MSB 65D}

MEASUREMENTS CONDUCTED IN THE FIELD

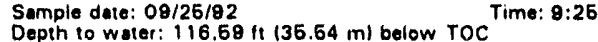

Weter elevetion: $232.91 \mathrm{~h}(70.89 \mathrm{~m}) \mathrm{me}$

\section{WELL MSB 668}

MEASUREMENTS CONDUCTED IN THE FIELD

Sample date: $09 / 26 / 22$ it $(60.11 \mathrm{~m} /$ below TOC Time: $13: 62$ Weter olevation: $219.09 \mathrm{ft}(68.78 \mathrm{~m}) \mathrm{ms}$

\section{WELL MSB 66C}

MEASUREMENTS CONDUCTED IN THE FIELD Semple dete: 09/25/92
Oepth to water: 156.36 it $(47.36 \mathrm{~m})$ below TOC Time: 13:60 Weter alevation: $228.14 \mathrm{~h}(68.54 \mathrm{~m}) \mathrm{ms}$

\section{WELL MSB 66D}

MEASUREMENTS CONDUCTED IN THE FIELD

Semple dale: 09/25/92 $146.54 \mathrm{~m} /$ below TOC Time: 13:48 Wetet alevation: $230.61 \mathrm{ft} 170.28 \mathrm{ml}$ mal

\section{WELL MSB 66TA}

MEASUREMENTS CONDUCTED IN THE FIELD

Semple dete: $09 / 26 / 92$ it 163.88 mi below TOC Time: $13: 63$ Depth to woter: $176.14 \mathrm{ft} 163.88 \mathrm{~m} /$ below TOC Water alevation: $206.88 \mathrm{ft}(62.88 \mathrm{~m}) \mathrm{mal}$

WELL MSB 67B

MEASUREMENTS CONDUCTED IN THE FIELD

Semple dele: 08/23/92 $14.5 \mathrm{~m}$ below TOC Time: 11:00 Woter elevation: $218.94 \mathrm{ft}(66.73 \mathrm{mi} \mathrm{ma}$

WELL MSB 67C

MEASUREMENTS CONDUCTED IN THE FIELD

Semple dere: 09/23/82 $142,28 \mathrm{~m}$ Time: $11: 02$ Depth to water: $138.64 \mathrm{Ht}(42.26 \mathrm{~m})$ below

WELL MSB 67D

MEASUREMENTS CONDUCTED IN THE FIELD

Semple date: $09 / 23 / 92$ Time: $11: 04$ Depth to water: $132.25 \mathrm{ft}(40.31 \mathrm{~m})$ below

WELL MSB 68B

MEASUREMENTS CONDUCTED IN THE FIELD Somple date: $08 / 23 / 92$
Depth to water: $137.48 \mathrm{ft}(41.90 \mathrm{~m})$ below TOC Time: $11: 23$
Weter

\section{WELL MSB 68C}

MEASUREMENTS CONDUCTED IN THE FIELD Semple dete: $08 / 23 / 82$
Depth 10 woter: $132.32 \mathrm{ft}(40.33 \mathrm{~m})$ below TOC Time: $11: 20$
Water olevation: $224.38 \mathrm{ft}(68.38 \mathrm{~m} / \mathrm{mal}$

\section{WELL MSB 68D}

MEASUREMENTS CONDUCTED IN THE FIELD

Semple date: $08 / 23 / 82$ Time: $11: 18$ Wepth to wator: $123.41 \mathrm{ft}(37.62 \mathrm{~m})$ below 
WELL MSB 69B

MEASUREMENTS CONDUCTED IN THE FIELO

Sample date: 08/25/82 Time: 10:23

Depth 10 water: $160.69 \mathrm{ft}(48.96 \mathrm{~m})$ below TOC

Weter olevation: 221.11 th $167.40 \mathrm{ml} \mathrm{mst}$

\section{WELL MSB 69C}

MEASUREMENTS CONDUCTED IN THE FIELD

Sample date: $09 / 25 / 92 \mathrm{H}(47.06 \mathrm{~m})$ below TOC Time: 10:24

WELL MSB 69D

MEASUREMENTS CONDUCTED iN THE FIELD

Sample date: 09/26/92 4 Time: 10:26 Depth to water: $148.72 \mathrm{ft}(45.33 \mathrm{~m})$ below TOC

Werer elevation: $233.48 \mathrm{ft} 171.17 \mathrm{~m} / \mathrm{msl}$

\section{WELL MSB 69TA}

MEASUREMENTS CONDUCTED IN THE FIELD

Somple dote: $08 / 26 / 92$
Depth to woter: $166.12 \mathrm{ft}(60.63 \mathrm{~m} /$ below TOC Time: $10: 21$

Water elevation: $216.38 \mathrm{H}(66.66 \mathrm{~m} / \mathrm{ms}$ !

WELL MSB 70C

MEASUREMENTS CONDUCTED IN THE FIELD

Somple date: $09 / 25 / 92 \mathrm{ft}(43.97 \mathrm{~m} /$ below TOC Time: $12: 58$ Water elevation: $217.83 \mathrm{ft}(66.43 \mathrm{~m}) \mathrm{ms}$

WELL MSB 70D

MEASUREMENTS CONDUCTED IN THE FIELD

Sample date: $08 / 26 / 92 \mathrm{H}(42.93 \mathrm{~m})$ below TOC Time: $12: 68$ Water olevation: $221.64 \mathrm{ft}(67.66 \mathrm{~m}) \mathrm{ms} /$

WELL MSB 71B

MEASUREMENTS CONDUCTED IN THE FIELD

Semple date: $09 / 26 / 92$ Time: $13: 20$ Water elevation: $217.68 \mathrm{ft}(66.32 \mathrm{~m}) \mathrm{ms}$

WELL MSB 72B

MEASUREMENTS CONDUCTED IN THE FIELD

Sample date: 09/26/92 $139.06 \mathrm{~m} /$ below TOC Time: 15:66 Weter elevation: $200.09 \mathrm{ft}(60.99 \mathrm{~m}) \mathrm{ms}$

WELL MSB 73B

MEASUREMENTS CONDUCTED IN THE FIELD

Somple date: 09/23/92 $142.05 \mathrm{~m} /$ below TOC Time: 14:37 Water elevation: $202.43 \mathrm{ft} 161.70 \mathrm{ml} \mathrm{ms}$

WELL MSB 74B

MEASUREMENTS CONOUCTED IN THE FIELD

Sample date: $09 / 26 / 92 \mathrm{ft}(31.63 \mathrm{~m})$ below TOC Time: $11: 40$ Water elevation: $210.73 \mathrm{ft}(64.23 \mathrm{~m}) \mathrm{ms}$ )

\section{WELL MSB 74C}

MEASUREMENTS CONDUCTED IN THE FIELD

Sample date: 08/26/92 Time: 11:43 Depth to water: $104.28 \mathrm{ft}(3) .78 \mathrm{~m})$ below
WELL MSB 74D

MEASUREMENTS CONDUCTED IN THE FIELD

Sample date: 09/26/92 $125.04 \mathrm{~m} /$ below TOC Time: $11: 44$ Depth to water: $82.15 \mathrm{ft}(26.04 \mathrm{~m})$ below
Water elevation: $232.85 \mathrm{ft}(71.00 \mathrm{~m}) \mathrm{ms}$

\section{WELL MSB 75B}

MEASUREMENTS CONDUCTED IN THE FIELD

Sarnple date: $08 / 26 / 92$ ( $(35.70 \mathrm{~m})$ below TOMa: $12: 08$ Depth to water: $117.12 \mathrm{ft} 135.70 \mathrm{~m}$

Water elovation: $209.68 \mathrm{ft}(63.88 \mathrm{~m}) \mathrm{msi}$

\section{WELL MSB 75C}

MEASUREMENTS CONDUCTED IN THE FIELD

Sample date: 09/26/82 $136.02 \mathrm{~m} /$ below TOC Time: 12:06

Water elevetion: $208.31 \mathrm{ft}(63.80 \mathrm{~m}) \mathrm{mel}$

\section{WELL MSB 76C}

MEASUREMENTS CONDUCTED IN THE FIELD Sample date: $09 / 25 / 92 \mathrm{fl}(40.12 \mathrm{~m})$ below TOC Time: $13: 10$

Water elevation: 221.16 ft $167.41 \mathrm{~m}) \mathrm{ms}$

\section{WELL MSB 77B}

MEASUREMENTS CONDUCTED IN THE FIELD Sample dete: 09/26/92 $141.30 \mathrm{~m} /$ below TOC Time: 10:12

Water elevation: $222.20 \mathrm{ft}(67.73 \mathrm{~m}) \mathrm{ms}$

WELL MSB 77C

MEASUREMENTS CONDUCTED IN THE FIELD

Semple date: $09 / 26 / 92$
Depth to water: $133.45 \mathrm{ft}(40.68 \mathrm{~m})$ below TOC Time: $10: 16$ Depth to water: $133.45 \mathrm{ft}(40.68 \mathrm{~m})$ below
Water elevation: $224.26 \mathrm{ft}(68.36 \mathrm{~m}) \mathrm{ms}$

WELL MSB 77D

MEASUREMENTS CONDUCTED IN THE FIELD

Sample date: $09 / 26 / 92 \mathrm{ft}(37.69 \mathrm{~m})$ below TOC Time: $10: 17$ Water elevation: $234.47 \mathrm{ft}(71.47 \mathrm{~m} / \mathrm{ms}$

WELL MSB 77TA

MEASUREMENTS CONDUCTED IN THE FIELD

Sample date: $09 / 26 / 92 \mathrm{ft}(41.29 \mathrm{~m})$ below TOC Time: 10:09 Water elevation: $221.84 \mathrm{ft}(67.66 \mathrm{~m}) \mathrm{mal}$

WELL MSB 78D

MEASUREMENTS CONDUCTED IN THE FIELD

Somple dete: $09 / 26 / 92 \mathrm{ft}(42.66 \mathrm{~m})$ below TOC Time: $13: 28$ Woter elevation: $223.98 \mathrm{ft}(68.27 \mathrm{~m}) \mathrm{ms}$

\section{WELL MSB 79B}

MEASUREMENTS CONOUCTED IN THE FIELD

Somple dute: $09 / 25 / 92$ f $\left(42.88 \mathrm{~m} /\right.$ below TOC ${ }^{\text {Time: } 16: 32}$ Water elevation: $207.31 \mathrm{ft}(63.19 \mathrm{~m}) \mathrm{ms} \mid$

\section{WELL MSB 79C}

MEASUREMENTS CONDUCTED IN THE FIELD

Sample date: $08 / 25 / 92$ f $(42.15 \mathrm{~m})$ below TOC Time: $15: 36$ Water elevation: $209.61 \mathrm{tt} 163.86 \mathrm{ml} \mathrm{ms}$ ! 


\section{WELLL MSB 81B}

MEASUREMENTS CONDUCTED IN THE FIELD

Sample date: $08 / 28 / 92$
Dopth to water: $47.21 \mathrm{ft}(14.39 \mathrm{~m})$ below TOC Time: $11: 06$
Woter elevetion: $219.98 \mathrm{ft}(67.05 \mathrm{~m}) \mathrm{mg}$ )

WELL MSB 82A

MEASUREMENTS CONDUCTED IN THE FIELD

Sample date: $09 / 25 / 92$ it $144.93 \mathrm{ml}$ below TOC Time: $10: 12$

Woter elevetion: $227.11 \mathrm{ft}(68.22 \mathrm{ml} \mathrm{ms}$

WELL MSB 82B

MEASUREMENTS CONDUCTED IN THE FIELD

Somple date: 09/26/92 $\quad$ Time: 10:14 Depth 10 water: $154.06 \mathrm{ft}(46.86 \mathrm{~m})$ below TOC Woter elevelion: $220.3411187 .18 \mathrm{ml}$ m

WELL MSB 82C

MEASUREMENTS CONDUCTED IN THE FIELD Sample date: $09 / 25 / 92$
Depth to water: $146.04 \mathrm{Ht}(44.51 \mathrm{~m})$ below TOC Time: 10. vo
Wuter

WELL MSB 82D

MEASUREMENTS CONDUCTED IN THE FIELD

Somple date: 08/26/92 Time: 10:07 Depth to water: $140.66 \mathrm{ft} 142.87 \mathrm{~m}$ ) below

WELL MSB 82TA

MEASUREMENTS CONDUCTED IN THE FIELD

Somple duse: 08/25/82 Time: 10:10 Water elevation: $214.60 \mathrm{ft}(65.41 \mathrm{~m}) \mathrm{msl}$

WELL MSB 83B

MEASUREMENTS CONDUCTEO IN THE FIELO

Sarnple date: $09 / 26 / 92$ Time: $10: 44$ Water elevation: $221.93 \mathrm{ft} 167.65 \mathrm{ml} \mathrm{msl}$

WELL MSB 83C

MEASUREMENTS CONDUCTED IN THE FIELO

Somple date: 08/25/92 3 Time: 10:47 Weter to wation: $228.20 \mathrm{ft}(89.66 \mathrm{~m}) \mathrm{ms}$ )

WELL MSB 83D

MEASUREMENTS CONDUCTED IN THE FIELD

Sample dote: $08 / 26 / 82$ Tine: $10: 46$ Water elevation: 233.46 \& $171.16 \mathrm{~m} / \mathrm{mal}$

WELL MSB 83TA

MEASUREMENTS CONDUCTED IN THE FIELD

Sample date: $08 / 25 / 82$ Tepth to water: $168.16 \| 147.60 \mathrm{~m} /$ below TOC Time: $10: 42$ Weter elovation: $216.65 \mathrm{t} 166.73 \mathrm{ml} \mathrm{ms}$ !

WELL MSB 84C

MEASUREMENTS CONDUCTED IN THE FIELD

Sample date: 08/25/82

Depth

Weter elevation: $228.64 \mathrm{it}(70.00 \mathrm{~m}) \mathrm{ms}$ l

\section{WELL MSB 85B}

MEASUREMENTS CONDUCTED IN THE FIELD

Sample dete: $09 / 26 / 92$
Depth to water: 168.85 it $(48.42 \mathrm{~m})$ below TOC Time: $11: 30$ Water elevation: $221.95 \mathrm{ft} 187.65 \mathrm{~m} / \mathrm{msl}$

WELL MSB 85C

MEASUREMENTS CONOUCTEO IN THE FIELD

Sample date: $09 / 26 / 92 \mathrm{ft}(47.69 \mathrm{~m})$ below TOC Time: $11: 34$ Water elevation: $224.86 \mathrm{ft}(88.67 \mathrm{~m}) \mathrm{msl}$

WELL MSB 85D

MEASUREMENTS CONDUCTED IN THE FIELD

Semplo date: $08 / 26 / 82$
Depth 10 water: $147.83 /(46.06 \mathrm{~m} /$ balow TOC

WELL MSB 85TA

MEASUREMENTS CONOUCTEO IN THE FIELO

Sample date: $09 / 26 / 82$
Depth 10 water: $159.64 \mathrm{Ht} 148.63 \mathrm{ml}$ below TOC Time: $11: 32$

WELL MSB 86C

MEASUREMENTS CONDUCTED IN THE FIELD

Somple dase: 09/25/92 $140.34 \mathrm{~m} /$ betow TOC Time: $11: 41$ Depth to water: $132.36 \mathrm{ft}(40.34 \mathrm{~m})$ betow TOC

\section{WELL SLW 1}

MEASUREMENTS CONDUCTED IN THE FIELO

Semple date: 09/20/92 3 Time: 15:34 Depth to water: $129.36 \mathrm{f}(39.43 \mathrm{~m})$ below
Woter elevetion: $174.74 \mathrm{ft}(53.26 \mathrm{~m}) \mathrm{msl}$

\section{WELL SLW 2}

MEASUREMENTS CONDUCTED IN THE FIELD Sample date: $09 / 20 / 92$
Depth to water: $113.36 \mathrm{ft}(34.65 \mathrm{~m})$ below roc Time: $16: 14$
Woter elevation: $191.24 \mathrm{ft}(58.29 \mathrm{~m}) \mathrm{ms}$

\section{WELL SLW 3}

MEASUAEMENTS CONDUCTED IN THE FIELD

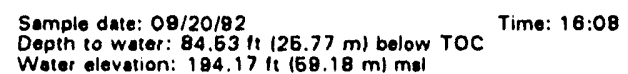

\section{WELL SLW 4}

MEASUREMENTS CONDUCTED IN THE FIELD Sample date: $09 / 20 / 92$
Depth to water: 100.80 it $130.72 \mathrm{~m} /$ below TOC Time: $16: 38$
Weter elevation: $198.80 \mathrm{ft}(60.83 \mathrm{~m} / \mathrm{mal}$

WELL SLW 5

MEASUREMENTS CONDUCTED IN THE FIELD

Semple date: $09 / 20 / 92$ (1) $13.99 \mathrm{~m} /$ below TOC Time: 16:47 Water elevation: $196.08 \mathrm{ft} 158.77 \mathrm{~m} / \mathrm{mal}$

WELL SLW 6

MEASUREMENTS CONDUCTED IN THE FIELD

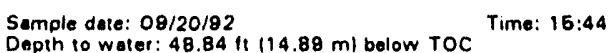
Depth to water: $48.84 \mathrm{ft} 114.89 \mathrm{~m} /$ below
Wotet elevation: $202.66 \mathrm{ft} 181.77 \mathrm{mi} \mathrm{mst}$ 
WELL SLW 7

MEASUREMENTS CONOUCTED IN THE FIELD

Sample date: 08/20/92

Depth to water: $65.63 \mathrm{ft}(16.96 \mathrm{~m})$ below TOC

Time: 15:66

Weter elevetion: $175.47 \mathrm{ft} 153.48 \mathrm{ml} \mathrm{ms}$

\section{WELL SLW 8}

MEASUREMENTS CONDUCTED IN THE FIELD

Sample date: 09/20/82

Depth 10 weter: $62.04 \mathrm{ft}(18.91 \mathrm{~m})$ below TOC

Time: 16:00

Water alevetion: 195.46 it $159.68 \mathrm{ml}$ met

\section{WELL SRW 1}

MEASUREMENTS CONDUCTED IN THE FIELD

Sample dote: 08/24/82

Depth to water: $102.44 \mathrm{ft}(31.22 \mathrm{~m} /$ below TOC

Time: 10:38

Woter elevetion: $212.76 \mathrm{ft} 164.85 \mathrm{ml}$ mel

\section{WELL. SRW 2}

MEASUREMENTS CONDUCTED IN THE FIELD

Sample date: 09/24/92

Time: 10:31

water elevetic

WELL SRW 2A

MEASUREMENTS CONDUCTED IN THE FIELD

Sample dete: 09/24/92

Time: 10:35

Weter elevelion: 20.846 it 134.73 mi below

\section{WELL SRW 2B}

MEASUREMENTS CONDUCTED IN THE FIELD

Semple dete: 09124192

Semple dete: $09 / 24 / 92 \mathrm{fop}(134.38 \mathrm{~m} /$ below TOC

Time: 10:33

WELL SRW 3A

MEASUREMENTS CONDUCTED IN THE FIELD

Sample date: $08 / 24 / 92$
Depth to woter: $118.73 \mathrm{ht}(36.19 \mathrm{~m})$ below TOC

Depth to woter: $118.73 \mathrm{ft}(36.19 \mathrm{~m})$ below
Woter elevation: $213.37 \mathrm{ft}(66.04 \mathrm{~m}) \mathrm{msl}$

\section{WELL SRW 4}

MEASUREMENTS CONDUCTED IN THE FIELD

Depth to water: $107.16 \mathrm{ft}(32.66 \mathrm{~m})$ below TOC Time: 10:56

Depth to water: $107.16 \mathrm{ft}(32.86 \mathrm{~m})$ below

\section{WELL SRW 5}

MEASUREMENTS CONDUCTED IN THE FIELD

Semple date: 00124182

Depth to water: $98.22 \mathrm{ft}(29.84 \mathrm{~m})$ below TOC
Water elevation: $211.18 \mathrm{ft}(64.37 \mathrm{~m}) \mathrm{ms}$ !

Time: 10:63

\section{WELL SRW 6}

MEASUREMENTS CONDUCTED IN THE FIELD

Sample dete: $09 / 24 / 82$

Depth to water: 95.73 th $(29.18 \mathrm{~m})$ below TOC

Depth to water: $96.73 \mathrm{Ht}(29.18 \mathrm{~m})$ below

Tine: $10: 40$

\section{VVELL SRW 7}

ME.ASUREMENTS CONDUCTED IN THE FIELD

Sample date: 09/24/82 Time: 10:47

Deptlo to water: $88.32 \mathrm{ft}(26.92 \mathrm{~m})$ below TOC Water alevation: $210.78 \mathrm{ft}(64.25 \mathrm{~m}) \mathrm{ms}$
WELL SRW 8

MEASUREMENTS CONDUCTED IN THE FIELD

Sample date: 09/24/92 $124.23 \mathrm{~m} /$ below TOC Time: $11: 26$ Depth to water: $79.48 \mathrm{ft}(24.23 \mathrm{~m})$ below
Water elevation: $208.62 \mathrm{ft}(63.69 \mathrm{~m}) \mathrm{mgl}$

\section{WELL SRW 9}

MEASUREMENTS CONDUCTED IN THE FIELO

Sample date: 09/24/82 $121,16 \mathrm{~m} /$ below TOC Time: $11: 46$ Depth to water: $69.43 \mathrm{ft}(21.16 \mathrm{~m} /$ below
Water elevation: $183.97 \mathrm{ft}(66.07 \mathrm{~m}) \mathrm{mal}$

\section{WELL SRW 9A}

MEASUREMENTSS CONDUCTED IN THE FIELD

Sample date: 09/24/92 $116.63 \mathrm{~m})$ below TOC Time: $11: 43$ Depth to water: $64.67 \mathrm{~h}(16.63 \mathrm{~m})$ below

\section{WELL SRW 9B}

MEASUREMENTS CONDUCTED IN THE FIELD

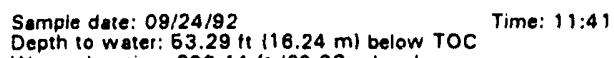

Water elevation: 200.11 t $160.99 \mathrm{mlmal}$

\section{WELL SRW 10}

MEASUREMENTS CONDUCTED IN THE FIELD

Sample date: 09/24/92 Time: 10:48 No water in standpipe.

WELL SRW 11

MEASUREMENTS CONDUCTED IN THE FIELD

Sample date: 08/24/92 $126 / 01 \mathrm{ml}$ Time: 10:43 Depth to water: $86.321 t(26.01 \mathrm{~m})$ below TOC

\section{WELL SRW 12A}

MEASUREMENTS CONDUCTED IN THE FIELD

Sample date: $08 / 24 / 92$ Time: $11: 33$

Depth to water: $42.10 \mathrm{ft}(12.83 \mathrm{~m})$ below TOC

\section{WELL SRW 12B}

MEASUREMENTS CONDUCTED IN THE FIELD

Somple date: 08/24/92 Time: 11:30

Depth to weter: $47.64 \mathrm{ft}(14.49 \mathrm{~m} /$ below TOC

\section{WELL SRW 12C}

MEASUREMENTS CONDUCTED IN THE FIELD

Sample date: $09 / 24 / 82$ Time: 11:28 Depth to watel: $40.14 \mathrm{ft} 112.23 \mathrm{~m}^{\prime}$ below

\section{WELL SRW 13A}

MEASUREMENTS CONDUCTED IN THE FIELD

Somple dete: $09 / 24 / 92$ Time: $11: 16$ Depth to water: $96.16 \mathrm{ft}(29.31 \mathrm{~m})$ below TOC

\section{WELLL SRW 13B}

MEASUREM SNTS CONDUCTED IN THE FIELD Somple date: 08/24/92 Time: 11:17 Depth to noter: $94.23 \mathrm{ft}(28.72 \mathrm{~m})$ below 
WELL SRW 13C

MEASUREMENTS CONDUCTED IN THE FIELD

Somple date: 08/24/82 Time: 11:20 .

WELL SRW 14A

MEASUREMENTS CONDUCTED IN THE FIELD

Semple date: 09/24/92 Tirne: $11: 08$ Water elevation: $203.60 \mathrm{ft}(62.03 \mathrm{~m} / \mathrm{ms}$ )

WELL SRW 14B

MEASUREMENTS CONDUCTED IN THE FIELD

Sumple date: 09/24/82 TIme: 11:11 Depih to weter: $121.47 \mathrm{ft}(37.02 \mathrm{~m})$ below TOC

Water elevation: $205.43 \mathrm{ft}(62.62 \mathrm{~m}) \mathrm{ms}$

WELL SRW 14C

MEASUREMENTS CONDUCTED IN THE FIELD

Somple dete: 09/24/92

Time: 11:08

WELL SRW 15A

MEASUREMENTS CONOUCTED IN THE FIELD

Somple date: 00/24/92 $133.44 \mathrm{~m}$ below TOC Tinne: 10.21 Depth to water: 109.71 (1 $(33.44 \mathrm{~m})$ below TOC Weter olevetion: $209.39 \mathrm{ft} 163.82 \mathrm{~m} / \mathrm{mg}$

WELL SRW 15B

MEASUREMENTS CONDUCTED IN THE FIELD

Somple dete: 08/24/82

Depth to water: 109.66 \&s $(33.38 \mathrm{~m})$ below TOC Time: 10:17 Water elevetion: $209.64 \mathrm{fi}(63.87 \mathrm{~m} / \mathrm{msi}$
WELL SRW 15C

MEASUREMENTS CONDUCTED IN THE FIELD

Semple date: $09 / 24 / 92$ Time: 10:18 Depth to water: 108.63 "t $(32.47 \mathrm{~m})$ below

Weter elevation: $212.57 \mathrm{ft} 184.79 \mathrm{mt} \mathrm{msl}$

\section{WELL SRW 16A}

MEASUREMENTS CONDUCTED IN THE FIELD

Sample date: $08 / 23 / 92$ Time: 16:28 Water elevation: $214.03 \mathrm{fl}(66.24 \mathrm{~m}) \mathrm{mal}$

WELL SRW 16B

MEASUREMENTS CONDUCTED IN THE FIELD

Somple dete: 09/23/92 $140.21 \mathrm{~m} /$ below TOC Tirie: $17: 17$ Water elevation: $214.87 \mathrm{ft}(66.49 \mathrm{~m}) \mathrm{mal}$

WELLL SRW 16C

MEASUREMENTS CONOUCTED IN THE FIELD

Sample date: 09/23/92 $140.04 \mathrm{~m}$ ) below TOC Time: 17:08 Water alevation: $216.24(t(66.61 \mathrm{~m}) \mathrm{mal}$

WELL YSC 1D

MEASUREMENTS CONDUCTED IN THE FIELD

Sumple dete: $08 / 26 / 92$ Time: 16:13 Depth to water: $63.32 \mathrm{ft}(16.26 \mathrm{~m})$ below
Weter elevation: $221.08 \mathrm{H(}(67.39 \mathrm{~m}) \mathrm{ms}$

\section{WELL YSC 4A}

MEASUREMENTS CONDUCTED IN THE FIELD

Sempie dete: 08/26/92 $37.49 \mathrm{~m} /$ below TOC Time: 16:38 Depth to water: $122.98 \mathrm{ft}(37.48 \mathrm{~m})$ below
Weter alevation: $167.21 \mathrm{ft}(50.87 \mathrm{~m} / \mathrm{mal}$ 


\section{SITE INDEX BY WELL SERIES}

Well Series

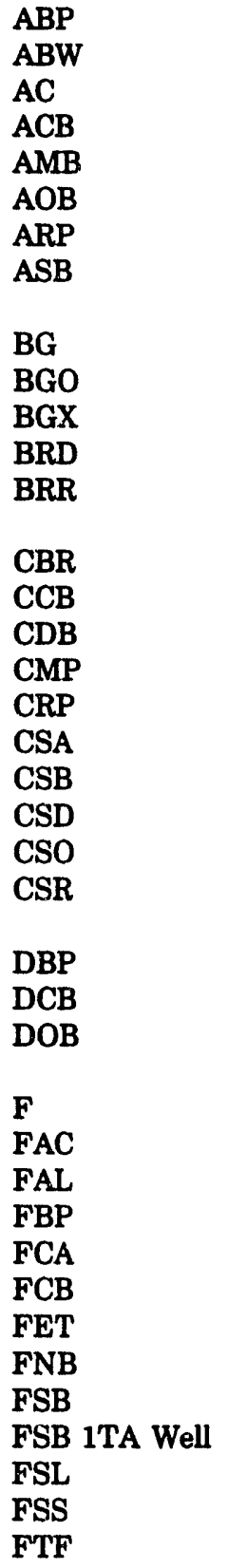

GBW
Site Description

A-Area Metals Burning Pit

A Area near Firing Range: Background Well

A/M Area: Cluster Perimeter Wells and Plume Definition Wells

A-Area Coal Pile Runoff Containment Basin

Metallurgical Laboratory Seepage Basin

Motor Shop Oil Basin

A-Area Burning/Rubble Pits

Savannah River Technology Center (SRTC) Seepage Basins

Burial Grounds

Burial Grounds Perimeter

E-Area Vaults near the Burial Grounds

Road A Chemical Basin (Baxley Road)

Burma Road Rubble Pit

Central Shops Burning/Rubble Pit South of the Ford Building Seepage Basin C-Area Coal Pile Runoff Containinent Basin

C-Area Disassembly Basin

Chemicals, Metals, and Pesticides (CMP) Pits

C-Area Burning/Rubble Pit

Hydrofluoric Acid Spill Area

C-Area Reactor Seepage Basins

Central Shops Diesel Spill Site: Characterization and Remediation Wells

Fire Department Training Facility

Central Shops Burning/Rubble Pits

D-Area Burning/Rubble Pits

D-Area Coal Pile Runoff Containment Basin and Ash Basins

D-Area Oil Disposal Basin

F-Area Seepage Basins

F-Area Acid/Caustic Basin

F-Area A Line

F-Area Burning/Rubble Pits

F-Area Canyon Building

F-Area Coal Pile Runoff Containment Basin

F-Area Effluent Treatment Cooling Water Basin

Old F-Area Seepage Basin

F-Area Sefpage Basins

F-Area Seepage Basins: Production Well

F-Area Inactive Process Sewer Lines

F-Area Sludge Land Application Site

F-Area Tank Farm

Near Hawthorne Fire Tower: Background Well 
Well Series

H

HAC

HAP

HCA

HCB

HET

HMD

HR3

HR8

HSB

HSB 1TB Well

HSL

HSS

HTF

HWS

HXB

IDB

IDP

IDQ

K

$\mathrm{KAB}$

$\mathrm{KAC}$

KCB

$\mathrm{KDB}$

$\mathrm{KDT}$

KRB

KRP

KSB

KSM

KSS

LAC

LAW

LCO

LDB

LFW

LRP

LSB

MCB

MGA

MGC

MGE

MGG

MSB

MWD

NBG

NPM
Site Description

H-Area Seepage Basins

H-Area Acid/Caustic Basin

H-Area Auxiliary Pump Pil

H-Area Canyon Building

H-Area Coal Pile Runoff Containment Basin

H-Area Emuent Treatment Cooling Water Basin

Hazardous Waste/Mixed Waste Disposal Facility

Old H-Area Retention Basin

H.Area Retention Basin

H.Area Seepage Basins

H.Area Seepage Basins: Production Well

H-Area Inactive Process Sewer Lines

H-Area Sludge Land Application Site

H-Are: Tank Farm

Hazardous Waste Storage Facility

Ford Building Seepage Basin

Interim Waste Technology Site B: Characterization Wells Interim Waste 'Technology Site P: Characterization Wells Interim Waste Technology Site Q: Characterization Wells

K-Area Wind Tower at B Road: Piezometers

K-Area Ash Basin

K-Area Acid/Caustic Basin

K-Area Coal Pile Runofr Containment Basin

K-Area Disassembly Basin

K-Area Diesel Tank

K-Area Retention Basin

K-Area Burning/Rubble Pit

K-Area Reactor Seepage Basin

106-K Sump Monitor

K-Area Sludge Land Application Site

L-Area Acid/Caustic Basin

L-Area: Research Wells

L-Area Oil and Chemical Basin

L-Area Disassembly Basin

Sanitary Landfill

L-Area Burning/Rubble Pit

L-Area Reaclor Seepage Basin

Miscellaneous Chemical Basin

Series A, Burial Grounds Grid

Series C, Burial Grounds Grid

Series E, Burial Grounds Grid

Series G, Burial Grounds Grid

M-Area Hazardous Waste Management Facility (HWMF)

Potential Hazardous Waste/Mixed Waste Disposal Facility

Between the F.Area Canyon Building and the Naval Fuel Material Facility

Potential New Production Reactor Site (near Central Shops): Characterization Wells 
Well Series

P

PAC

PCB

PDB

PRP

PSB

PSS

RAC

RCP

RDB

RRP

RSA

RSB

RSC

RSD

RSE

RSF

RWM

SBG

SCA

SLP

SLW

SRW

SSS

TBG

TNX

XSB

YSB

YSC

2

ZBG

ZD'T

ZW
Site Description

SRS Baseline Hydrogeologic Investigation: Observation Wells

B Area: Microbiology Wells [P 29 cluster]

East of $\mathrm{H}$ Area $\mathrm{P}$ r rimeter Fence [P 27 cluster]

East of P Area, outside the P-Area Perimeter Fence [P 24 cluster]

F Area: Microbiology Wells [P 28 cluster]

L Area: Near and to the East of 186-L [P 15 cluster]

North of H Area [P 14 cluster]

TNX Area: Background Wells [P 26 cluster]

P-Area Acid/Caustic Basin

P-Area Coal Pile Runoff Containment Basin

P-Area Disassembly Basin

P-Area Burning/Rubble Pit

P.Area Reactor Seepage Basins

Par Pond Sludge Land Application Site

R-Area Acid/Caustic Basin

R-Area Coal Pile Study

R-Area Disassembly Basin

R-Area Burning/Rubble Pits

Series A, R-Area Reactor Seepage Basins

Series B, R-Area Reactor Seepage Basins

Series C, R.Area Reactor Seepage Basins

Series D, Between R-Area Reactor Seepage Basins and R-Area Disassembly Basin

Series E, R-Area Reactor Seepage Basins

Series F, R-Area Reactor Seepage Basins

M Area: Recovery Wells (also used for plume definition)

S-Area Defense Waste Processing Facility (DWPF): Background Wells

S-Area Vitrification Building

S-Area Low-Point Pump Pit

New Sanilary Landfill: Piezometers

Silverton Road Waste Site

Sewage Sludge Application Sites

40-Acre Hardwood Site

Kato Road Site

Lower Kato Road Site

Orangeburg Site

Par Pond Borrow Pil

Road F Site

Sandy (Lucy) Sile

Second Par Pond Borrow Pit

'T'NX Burying Ground

TNX Area: Assessment Wells

Old TNX Seepage Basin

New TNX Seepage Basin

Y-Area Waste Solidification and Disposal Facility

F Area

H Area

Z-Area Saltstone Facility: Background Wells

Z-Area Low-Point Drain Tank

F Area

H Area 


\section{SITE INDEX}

Well Series

241-H

$905103 \mathrm{~F}$
Site Description

H-Area Tank Farm Well, between Tanks 9 and 11

F-Area Production Well 


\section{GLOSSARY}

See also pp. A-1 and A-2 for keys to abbreviations used in the results tables in Appendix A.

2,4-D. 2,4-Dichlorophenoxyacetic acid.

absolute difference. The unsigned result of the subtraction of any two numbers.

advisory range. A range of acceptable analytical results established by the provider of known samples.

aerated sample. Groundwater sample supplied or charged with air. Aeration can occur naturally or during well pumping.

aliquot. A portion of a sample being used for analysis.

analyte. Analyzed constituent.

analytical detection limit. The lowest reasonably accurate concentration of an analyte that can be detected; this value varies depending on the method, instrument, and dilution used.

analytical modifier. See result qualifier.

APHA. American Public Health Association.

Appendix IX. List of constituents specified by Appendix IX in the Code of Federal Regulations, Title 40, Part 264. Analyses for Appendix IX constituents are required by the Resource Conservation and Recovery Act (RCRA) under specified conditions.

associated samples. Samples analyzed by a laboratory in the same batch with blind blanks or laboratory blanks.

ASTM. American Society for Testing and Materials. bail. To remove water from a well by lowering a container into the water, allowing it to fill with water, and removing it from the well.

blank. Aliquot of deionized water generated by laboratory or sampling personnel and analyzed like a groundwater sample. See blind blank, internal blank, laboratory blank, and trip blank. See also the Blanks subsection of the Quality Control Samples section of this report.

blind blank. A sample container of deionized water sent to a laboratory under an alias as a quality control check.

blind replicate. A second sample taken from a well at the same time as the primary sample and sent to the laboratory for analysis as an unknown.

BNA. Base/neutral and acid extractables; groups of organic compounds analyzed as part of the Appendix IX and Priority Pollutants suites; also, a group of compounds that can be analyzed by EPA Method 625 .

cation. Positively charged ion.

CERCLA. Comprehensive Environmental Response, Compensation, and Liability Act.

certified value. The known concentration of an analyte in a referenced sample.

CFR. Code of Federal Regulations; sections of this annual document contain EPA standards and regulations for environmental monitoring.

chain-of-custody record. A form that documents the collection, transport, analysis, and disposal of well samples. 
Clemson Technical Center, Inc. Clemson Technical Center, Inc., of Anderson, SC.

common analyses. Common parameters

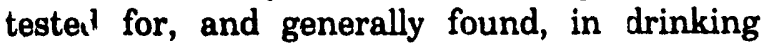
water.

comprehensive analyses. A group of analyses that forms the core of the EPD/EMS Groundwater Monitoring Program each quarter. See the Sample Scheduling section of this report for a complete list of constituents.

CN. See Clemson Technical Center, Inc.

deionized water. Water from which all charged species or ionizable organic and inorganic salts have been removed.

detection limit. See analytical detection limit.

dilution factor. The mathematical factor by which a sample is diluted in order to bring the concentration of an analyte in the sample within the analytical range of an instrument (e.g., $1 \mathrm{~mL}$ sample $+9 \mathrm{~mL}$ solvent $=1: 10$ dilution, or a dilution factor of 10 ).

\section{See analytical detection limit.}

DOE. United States Department of Energy.

drinking water standards. Federal primary and secondary drinking water standards, as set forth by EPA.

duplicate. Duplicate sample; an aliquot of a primary sample.

duplicate result. A result obtained from identical analyses performed on more than one aliquot of a primary sample.

DWS. Drinking water standards (federal primary and secondary drinking water standards, as set forth by EPA).

E. A code letter used in the analytical data tables signifying an exponential (e.g., $3.4 \mathrm{E}+3=$ $3.4 \times 10^{3}=3,400$ ).

EM. EPD/EMS Laboratory at SRS.
EMS. The Environmental Monitoring Section of the Environmental Protection Department at SRS.

EPA. United States Environmental Protection Agency.

EPD. Environmental Protection Department at SRS.

EPD/EMS. Environmental Protection Department's Environmental Monitoring Section.

flagging criteria. Criteria established to help determine the relative concentration and testing frequency for analytes. See the Flagging Criteria section of this report for further information.

gamma PHA. A group of analyses performed to determine activities of $g$ amma-emitting radio. nuclides.

GC VOA. Gas Chromatographic Volatile Organics Analyses. Also used to refer to a group of volatile organic compounds that can be analyzed by gas chromatography.

GCMS VOA. Gas Chromatograph/Mass Spectrometer Volatile Organics Analyses. Also used to refer to a group of volatile organic compounds analyzed by gas chromatography and mass spectrometry methods.

GE. General Engineering Laboratories of Charleston, SC.

Ge-Hy. Ge-Hy Environmental Sampling of New Ellenton, SC.

\section{General Engineering. See GE.}

GP. Environmental Physics of Charleston, SC (subcontractor for General Engineering).

halogen. Any of the elements of the halogen family, consisting of fluorine, chlorine, bromine, iodine, and astatine.

herbicides/pesticides. A suite of analyses. See the Sample Scheduling section of this report for further information. 
holding time. The length of time during which an analysis of a sample can be reliably performed; holding times vary depending on which constituents are being analyzed.

interlaboratory comparisons. Comparisons conducted between two or more laboratories.

iL.cernal blank. Deionized water or solvent sample generated by the laboratory; one is analyzed with each batch of samples as an inhouse check of analytical procedures and equipment (same as a laboratory blank).

intralaboratory comparisons. Comparisons conducted within a single laboratory.

ion. An isolated electron or positron or an atom or molecule that, by loss or gain of one or more electrons, has acquired a net electric charge.

laboratory blank. See internal blank.

major ions. A group of analyses performed in the EPD/EMS Groundwater Monitoring Program to determine the concentrations of calcium, magnesium, potassium, and silica ions and the alkalinity of the sample.

mean. The arithmetic mean; a single number that typifies a set of numbers.

method detection limit. A reproducible analyte- and method-specific detection limit.

$\boldsymbol{\mu} \mathbf{C i}$. Microcurie; unit of radiation equivalent to 37,000 disintegrations per second.

$\boldsymbol{\mu g} / \mathbf{L}$. Micrograms per liter.

$\boldsymbol{\mu} \mathbf{S} / \mathbf{c m}$. Microsiemens per centimeter, equivalent to micromhos per centimeter; the unit of conductance across two points, used as the measure of specific conductance in analytical data tables.

$\mathbf{m g} / \mathbf{L}$. Milligrams per liter.

MRD. Mean relative difference. For further information, see the Quality Control Samples section of this report.

msl. Mean sea level.
NTU. Nephelometric turbidity units; the standard unit of turbidity measurement.

null hypothesis. The assumption that there is no validity to the claim that two treatments of the same thing can be distinguished by a specific procedure.

organic. A chemical compound based on carbon chains or rings and containing hydrogen with or without oxygen, nitrogen, or other elements.

PCB. Polychlorinated biphenyl.

pCi. Picocurie; a unit of radiation equivalent to $3.7 \times 10^{-2}$ disintegrations per second.

piezometer. An instrument used to measure the potentiometric surface of groundwater. Also, a well designed for this purpose.

plume. A volume of contaminated air or water originating at a point-source emission (e.g., a smokestack) or a waste source (e.g., a hazardous-waste disposal site).

potentiometric surface. The surface to which water in an aquifer would rise by hydrostatic pressure if unconfined.

primary laboratory. A laboratory having a contract with EPD/EMS to perform a specific set of analyses; a primary laboratory may subcontract this work to other laboratories.

purge. To remove water from a well prior to sampling, generally by pumping or bailing. Under the EPD/EMS Groundwater Monitoring Program, four well volumes generally are purged before sampling.

QA. Quality assurance.

QC. Quality control.

R. Following a well name, denotes a blind replicate.

radioisotopes. Radioactive isotopes.

radionuclide. A nuclide at an unstable, highenergy level that seeks a more stable, lowerenergy level by emitting particles of energy. 


\section{GLOSSARY}

Through these emissions, the nuclear configuration decays to simpler nuclides.

RCRA. Resource Conservation and Recovery Act.

RCRA site. Solid-waste management unit under RCRA regulation.

RDL. See reference detection limit.

reference detection limit. The detection limit chosen to allow comparison of several analyses with different detection limits. For the purposes of this report, the individual detection limits of at least $90 \%$ of the analyses are less than the reference detection limit. See the Quality Control Samples section of this report for further information.

replicate. Replicate sample; used in this report to mean only those duplicate samples sent to the laboratory as unknowns. See blind replicate.

Resource Conservation and Recovery Act (RCRA). Federal legislation that regulates the transport, treatment, and disposal of solid and hazardous wastes.

result qualifier. A code used to convey additional information about an analytical result. Also called an analytical modifier. See p. A-2 for additional information.

RFI Program. RCRA Facility Investigation Program; EPA-regulated investigation of a solid-waste management unit with regard to its potential impact on the environment.

RFI/RI Program. RCRA Facility Investigation/Remedial Investigation Program; at SRS, an expansion of the RFI Program to include CERCLA and hazardous-substance regulations.

run date. The date on which an analysis is performed.

sampling device. Anything used in sampling, especially portable (nondedicated) pumps and bailers. Possible source of sample contamination if not cleaned thoroughly between uses.
SCDHEC. South Carolina Department of Health and Environmental Control.

seepage basin. An excavation that receives wastewater. Designed to prevent overflow or surface runoff.

settling basin. A temporary holding basin (excavation) that receives wastewater.

significance of probability. The probability of observing a statistical value as significant as, or even more significant than, the value actually observed.

site custodian. WSRC employee responsible for a site being monitored.

SP. Spencer Testing Services, Inc., of Spencer, WV (subcontractor for General Engineering).

SRL. Savannah River Laboratory at SRS; now Savannah River Technology Center (SRTC).

SRP. Savannah River Plant; now Savannah River Site (SRS).

SRS. Savannah River Site.

SRTC. Savannah River Technology Center.

STORET. EPA national database for storage and retrieval of water quality information and monitoring data; some of the result qualifiers listed in the Analytical Results section of this report are based on STORET codes.

surrogate. An organic compound similar in composition and test performance to one of the analytes of interest; known quantities are used in an analysis as a quality assurance measure.

tank farm. An installation of interconnected underground tanks used for storage of highlevel radioactive liquid wastes.

TE. Teledyne Isotopes of Northbrook, IL (subcontractor for General Engineering).

TM. TMA/Eberline of Oak Ridge, TN (subcontractor for Weston). 
trip blank. A sample container oî deionized water that is transported to the well sample location, treated as a well sample, and sent to the laboratory for analysis; trip blanks are used to check for coniamination resulting from trans. port, shipping, and site conditions.

t-test. Statistical method ased to determine if the means of groups of observations are equal.

turbidity. A measure of the concentration of sediment or suspended particles in solution.

(U). Uncilassified.

USDWS. United States Publir Health Service drinking water siandard.

volatile organic compounds. A broad range of organic compounds, commonly halogenated, that vaporize at embient, or relatively low, temperatures (e.g., acetone, ienzene, chloroform, and methyl alcohol).

WA. Roy F. Weston, Inc., Lionvilie Laboratory, Lionvilie, PA.

Weston. See WA.

wellhead. The top of a well.

well volume. The volume of water between the well water surface and the bottom of the screen; the volume of water standing inside the well casing.

WSRC. Westinghouse Savannah River Company. 


\section{NOTES}




\section{REFERENCES}

American Public Health Association, American Water Works Association, and Water Pollution Control Federation. 1985. Standard Methods for the Examination of Water and Wastewater, 16th edition. Washington, DC.

American Society for Testing and Materials. 1992. Annual Book of ASTM Standards, Volume 11.02. Philadelphia, PA.

Christensen, E.J., and D.E. Gordon, eds. 1983. Technical Summary of Groundwater Quality Protection Program at Savannah River Plant, Volume I-Site Geohydrology and Solid and Hazardous Wastes, DPST-83-829. Aiken, SC: E.I. du Pont de Nemours \& Company, Savannah River Laboratory.

Environmental Monitoring (Environmental and Health Protection Department) and Exploration Resources. 1989a. The Savannah River Site's Groundwater Monitoring Program Conducted by the Environmental anc Health Protection Department for the First uarter 1989, ESHEMS-890043. Aiken, SC: Westinghouse Savannah River Company, Savannah River Site.

Environmental Monitoring (Environmental and Health Protection Department) and Exploration Resources. 1989b. The Savannah River Site's Groundwater Monitoring Program Conducted by the Environmental and Health Protection Department for the Second Quarter 1989, ESHEMS-890044. Aiken, SC: Westinghouse Savannah River Company, Savannah River Site.

Environmental Monitoring (Environmental and Health Protection Department) and Exploration Resources. 1989c. The Savannah River Site's Groundwater Monitoring Program Conducted by the Environmental and Health Protection De- partment for the Third Quarter 1989, ESHEMS-890045. Aiken, SC: Westinghouse Savannah River Company, Savannah River Site.

Environmental Monitoring (Environmental and Health Protection Department) and Exploration Resources. 1989d. The Savannah River Site's Groundwater Monitoring Program Conducted by the Environmental and Health Protection Department for the Fourth Quarter 1989, ESHEMS-890046. Aiken, SC: Westinghouse Savannah River Company, Savannah River Site.

Environmental Monitoring (Environmental Pro. tection Department) and Exploration Resources. 1990. The Savannah River Site's Groundwater Monitoring Program, First Quarter 1990, ESHEMS-90-0131. Aiken, SC: Westinghouse Savannah River Company, Savannah River Site.

Environmental Monitoring (Environmental Protection Department) and Exploration Resources. 1991a. The Savannah River Site's Groundwater Monitoring Program, Second Quarter 1990, ESH-EMS-900132. Aiken, SC: Westinghouse Savannah River Company, Savannah River Site.

Environmental Monitoring (Environmental Protection Department) and Exploration Resources. 1991b. The Savannah River Site's Groundwater Monitoring Program, Third Quarter 1990, ESH-EMS-900133. Aiken, SC: Westinghouse Savannah River Company, Savannah River Site.

Environmental Monitoring (Environmental Protection Department) and Exploration Resources. 1991c. The Savannah River Site's Groundwater Monitoring Program, Fourth Quarter 1990, ESH-EMS-900134. Aiken, SC: Westinghouse Savannah River Company, Savannah River Site. 
Environmental Monitoring (Environmental Protection Department) and Exploration Resources. 1991d. The Savannah River Site's Groundwater Monitoring Program, First Quarter 1991, ESH-EMS-910087. Aiken, SC: Westinghouse Savannah River Company, Savannah River Site.

Environmental Monitoring (Environmental Protection Department) and Exploration Resources. 1992a. The Savannah River Site's Groundwater Monitoring Program, Second Quarter 1991, ESH-EMS-910088. Aiken, SC: Westinghouse Savannah River Company, Savannah River Site.

Environmental Monitoring (Environmental Protection Department) and Exploration Resources. 1992b. The Savannah River Site's Groundwater Monitoring Program, Third Quarter 1991, ESH-EMS-910089. Aiken, SC: Westinghouse Savannah River Company, Savannah River Site.

Environmental Monitoring (Environmental Protection Department) and Exploration Resources. 1992c. The Savannah River Site's Groundwater Monitoring Program, Fourth Quarter 1991, ESH-EMS-910090. Aiken, SC: Westinghouse Savannah River Company, Savannah River Site.

Environmental Monitoring (Environmental Protection Department) and Exploration Resources. 1992d. The Savannah River Site's Groundwater Monitoring Program, First Quarter 1992, ESH-EMS-920035. Aiken, SC: Westinghouse Savannah River Company, Savannah River Site.

Environmental Monitoring (Environmental Protection Department) and Exploration Resources. 1992e. The Savannah River Site's Groundwater Monitoring Program, Second Quarter 1992, ESH-EMS-920036. Aiken, SC: Westinghouse Savannah River Company, Savannah River Site.

Environmental Monitoring (Health Protection Department) and Exploration Software. 1987a. The Savannah River Plant's Groundwater Monitoring Program Conducted by the Health Protection Department for the Second Quarter 1987, HPR-87-286. Aiken, SC: E.I. du Pont de Nemours \& Company, Savannah River Plant.

Environmental Monitoring (Health Protection Department) and Exploration Software. 1987b. The Savannah River Plant's Groundwater Monitoring Program Conducted by the Health
Protection Department for the Third Quarter 1987, HPR-87-339. Aiken, SC: E.I. du Pont de Nemours \& Company, Savannah River Plant.

Environmental Monitoring (Health Protection Department) and Exploration Software. 1988a. The Savannah River Plant's Groundwater Monitoring Program Conducted by the Health Protection Department for the Fourth Quarter 1987, HPR-88-098. Aiken, SC: E.I. du Pont de Nemours \& Company, Savannah River Plant.

Environmental Monitoring (Health Protection Department) and Exploration Software. 1988b. The Savannah River Plant's Groundwater Monitoring Program Conducted by the Health Protection Department for the First Quarter 1988, HPR-88-238. Aiken, SC: E.I. du Pont de Nemours \& Company, Savannah River Plant.

Environmental Monitoring (Health Protection Department) and Exploration Software. 1988c. The Savannah River Plant's Groundwater Monitoring Program Conducted by the Health Protection Department for the Second Quarter 1988, HPR-88-300. Aiken, SC: E.I. du Pont de Nemours \& Company, Savannah River Plant.

Environmental Monitoring (Health Protection Department) and Exploration Software. 1988d. The Savannah River Plant's Groundwater Monitoring Program Conducted by the Health Protection Department for the Third Quarter 1988, HPR-88-489. Aiken, SC: E.I. du Pont de Nemours \& Company, Savannah River Plant.

Environmental Monitoring (Health Protection Department) and Exploration Software. 1989. The Savannah River Site's Groundwater Mon. itoring Program Conducted by the Health Protection Department for the Fourth Quarter 1988, HPR-89-193. Aiken, SC: Westinghouse Savannah River Company, Savannah River Site.

Environmental Protection Agency. 1977. National Interim Primary Drinking Water Regulations, EPA-570/9-76-003. Washington, DC.

Environmental Protection Agency. 1980. Prescribed Procedures for Measurement of Radioactivity in Drinking Water. EPA-600/4-80-032. Cincinnati, $\mathrm{OH}$. 
Environmental Protection Agency. 1983. Methods for Chemical Analysis of Water and Wastes. PB84-128677 (methods 282.2, 310.1, 350.1, 351.2, 413.1, 418.1, and 420.1). Cincinnati, $\mathrm{OH}$.

Environmental Protection Agency. 1986a. Water Pollution Control; National Primary Drinking Water Regulations; Radionuclides; Advance Notice of Proposed Rulemaking. Federal Register, September 30, 1986, pp. 34835-34862. Washington, DC.

Environmental Protection Agency. 1986b. RCRA Ground-Water Monitoring Technical Enforcement Guidance Document, OSWER-9950.1. Washington, DC: Office of Waste Programs Enforcement.

Environmental Protection Agency. 1986c. Test Methods for Evaluating Solid Waste, Volumes 1A, $1 B$, and 1C, Third edition. SW-846 (methods 6010 , $8080,8150,8240,8270,8280,9020,9030$, and 9060). Washington, DC.

Environmental Protection Agency. 1990. National Primary and Secondary Drinking Water Regulations; Synthetic Organic Chemicals and Inorganic Chemicals; Proposed Rule. Federal Register, July 25, 1990, pp. 30369-30448. Washington, DC.

Environmental Protection Agency. 1991a. Guidelines Establishing Test Procedures for the Analysis of Pollutants. Code of Federal Regulations, Title 40, Part 136, pp. 293-575. Washington, DC.

Environmental Protection Agency. 1991b. National Primary Drinking Water Regulations. Code of Federal Regulations, Title 40, Part 141, pp. 578-715. Washington, DC.

Environmental Protection Agency. 1991c. National Secondary Drinking Water Regulations. Code of Federal Regulations, Title 40, Part 143, pp. 758762. Washington, DC.

Environmental Protection Agency. 1991d. National Primary Drinking Water Regulations; Radionuclides; Proposed Rule. Federal Register, July 18, 1991, pp. 33052-33127. Washington, DC.

Environmental Protection Agency. Revised August 1991. Test Method: The Determination of Inorganic Anions in Water by Ion Chromatography-Method 300.0. Cincinnati, OH.
Environmental Protection Department and Exploration Resources. 1991. The Savannah River Site's Groundwater Monitoring Program 1991 Well Installation Report, ESH-EMS910093. Aiken, SC: Westinghouse Savannah River Company, Savannah River Site.

Environmental Protection Department and Exploration Resources. 1992a. Environmental Protection Department's Well Inventory (Includes Current and Past Monitoring [through the second quarter of 1992]), ESH-EMS-920039. Aiken, SC: Westinghouse Savannah River Company, Savannah River Site.

Environmentai Protection Department and Exploration Resources. 1992b. The Savannah River Site's Groundwater Monitoring Program 1992 Sampling Schedule, ESH-EMS-910175. Aiken, SC: Westinghouse Savannah River Company, Savannah River Site.

Heath, E.M., L.B. Taus, C.M. Olson, and Exploration Software. 1986. The Savannah River Plant's Waste-Site Groundwater Monitoring Program Conducted by the Health Protection Department for the Third Quarter 1986, HPR-87-002. Aiken, SC: E.I. du Pont de Nemours \& Company, Savannah River Plant.

Heath, E.M., L.B. Taus, C.M. Olson, and Exploration Software. 1987a. The Savannah River Plant's Groundwater Monitoring Program Conducted by the Health Protection Department for the Fourth Quarter 1986, HPR-87-072. Aiken, SC: E.I. du Pont de Nemours \& Company, Savannah River Plant.

Heath, E.M., L.B. Taus, C.M. Olson, and Exploration Software. 1987b. The Savannah River Plant's Groundwater Monitoring Program Conducted by the Health Protection Department for the First Quarter 1987, HPR-87-158. Aiken, SC: E.I. du Pont de Nemours \& Company, Savannah River Plant.

Olson, C.M., and Exploration Software. 1986a. The Savannah River Plant's Waste-Site Groundwater Monitoring Program Conducted by the Health Protection Department for the First Quarter 1986, HPR-86-158 (Revised). Aiken, SC: E.I. du Pont de Nemours \& Company, Savannah River Plant. 
Olson, C.M., and Exploration Software. 1986b. The Savannah River Plant's Waste-Site Groundwater Monitoring Program Conducted by the Health Protection Department for the Second Quarter 1986, HPR-86-226. Aiken, SC: E.I. du Pont de Nemours \& Company, Savannah River Plant.

Stone, J.A., and E.J. Christensen, eds. 1983. Technical Summary of Groundwater Quality Protection Program at Savannah River Plant, Volume II-Radioactive Waste, DPST-83-829. Aiken, SC: E.I. du Pont de Nemours \& Company, Savannah River Laboratory.

U.S. Department of Energy. 1988. Geohydrology Program Report. Aiken, SC: Environmental Division, U.S. Department of Energy, Savannah River Operations Office.

U.S. Denartment of Energy. 1989. Geoscience Implementation Plan. Aiken, SC: Environmental Division, U.S. Department of Energy, Savannah River Operations Office.

U.S. Department of Energy. 1986. Savannah River Plant Environmental Report for 1985, Volumes I and II, DPSPU-86-30-1. Aiken, SC.

U.S. Department of Energy. 1987. Savannah River Plant Environmental Report for 1986, Volumes I and II, DPSPU-87-30-1. Aiken, SC.

U.S. Department of Energy. 1988. Savannah River Plant Environmental Report for 1987, Volumes I and II, DPSPU-88-30-1. Aiken, SC.

U.S. Department of Energy. 1989. Savannah River Site Environmental Report for 1988, Volumes I and II, WSRC-RP-89-59-1. Aiken, SC.

U.S. Department of Energy. 1990. Savannah River Site Environmental Report for 1989, Volumes I and II, WSRC-IM-90-60. Aiken, SC.

U.S. Department of Energy. 1991. Savanr.ah River Site Environmental Report for 1990, Volumes I and II, WSRC-IM-91-28. Aiken, SC.

U.S. Department of Energy. 1992. Savannah River Site Environmental Report for 1991, WSRC-TR-92-186. Aiken, SC. 


\section{Appendix A. ANALYTICAL RESULTS}

This section presents the field and analytical results for samples collected during third quarter 1992. The tables are presented in alphabetical order by well series and in numerical order within each series. The Site Index by Well Series section of this report contains the area name(s) for each series.

The tabular data cortain all field and analytical results for well samples collected during this quarter. Results of laboratory analyses on blanks are in Appendix B of this report.

Further information on inability to sample or unusual conditions of sample collection, as well as samplers' observations on the samples, may be found in the Field Notes section of this report.

Key to the tables:

$\mathrm{CN}=$ Clemson Technical Center, Inc.

$\mathrm{E}=$ exponential notation (e.g., $1.1 \mathrm{E}-09=1.1 \times 10^{\cdot 9}=0.0000000011$ )

$\mathrm{EM}=\mathrm{EPD} / \mathrm{EMS}$ Laboratory

$\mathrm{F}=$ Flag

GE = General Engineering Laboratories

$\mathrm{GP}=$ Environmental Physics

1,2,3,4,6,7,8-HPCDD $=1,2,3,4,6,7,8$-Heptachlorodibenzo-p-dioxin

$1,2,3,4,6,7,8$-HPCDF $=1,2,3,4,6,7,8$-Heptachlorodibenzo-p-furan

$1,2,3,4,7,8$-HXCDD $=1,2,3,4,7,8$-Hexachlorodibenzo-p-dioxin

1,2,3,4,7,8-HXCDF = 1,2,3,4,7,8-Hexachlorodibenzo-p-furan

Lindane = gamma-Benzene hexachloride

$\mu \mathrm{Ci} / \mathrm{mL}=$ microcuries per milliliter

$\mu \mathrm{g} / \mathrm{L}=$ micrograms per liter

$\mu \mathrm{S} / \mathrm{cm}=$ microsiemens per centimeter

$\mathrm{mg} / \mathrm{L}=$ milligrams per liter

Mod = analytical modifier; see p. A-2 for explanation

$\mathrm{msl}=$ mean sea level

MSL = million structures per liter (for asbestos)

NTU $=$ nephelometric turbidity units

1,2,3,7,8-PCDD $=1,2,3,7,8$-Pentachlorodibenzo-p-dioxin

$1,2,3,7,8-\mathrm{PCDF}=1,2,3,7,8$-Pentachlorodibenzo-p-furan

SP $=$ Spencer Testing Services, Inc.

2,4,5-T $=2,4,5$-Trichlorophenoxyacetic acid

2,3,7,8-TCDD $=2,3,7,8$-Tetrachlorodibenzo-p-dioxin

2,3,7,8-TCDF $=2,3,7,8$-Tetrachlorodibenzo-p-furan

$\mathrm{TE}=$ Teledyne Isotopes

$\mathrm{TM}=\mathrm{TMA} /$ Eberline

TOC $=$ top of casing

$\mathrm{WA}=$ Roy $\mathrm{F}$. Weston, Inc. 


\section{ANALYTICAL RESULTS}

Interpreting data with analytical modifiers (result qualifiers):
Analytical modifier
Definition

(Blank)

$\mathrm{A}^{*}$

$J^{* *}$

$\mathrm{L}^{*}$

$\mathrm{M}^{*}$

$Q^{* *}$

$\mathrm{R}^{* *}$

$\mathrm{T}^{*}$

$\mathrm{V}^{* *}$

$\mathrm{Y}^{* *}$

1

2

3

4

5

6
Data not qualified. Result should be interpreted exactly as reported.

Value reported is the mean of two or more determinations.

Estimated because quantitation in the sample or in associated quality control samples did not meet specifications.

Off-scale high. The actual value is not known but is known to be greater than the value shown.

Presence of the analyte is verified but not quantified.

Sample held beyond normal holding time. If the holding time is exceeded by less than 30 days, the sample is coded JQ; if the holding time is exceeded by 30 days or more, the sample is coded QR.

Rejected because performance requirements in the sample analysis or associated quality control analyses were not met.

Undetected; if present, below the criteria of detection.

Indicates the analyte was detected in the associated method blank.

The sample was unpreserved or improperly preserved when received by the laboratory.

The associated result may be an underestimation of the true value due to analytical bias.

The associated result may be an overestimation of the true value due to analytical bias.

The associated result may be of poor precision (high variability) due to analytical bias. For Weston analyses, replicate results were outside the $20 \%$ relative percent difference (RPD) guidance limit, or, for metals, the result is between the instrument detection limit and the contract-required detection limit.

Matrix interference.

The sample result is four or more times greater than the standard concentration.

Reanalyzed out of holding time because of problems with the original analysis.

- This code is based on the CLP Laboratory Data Qualifiers from the U.S. Environmental Protection Agency.

** This code is based on the STORET codes from the U.S. Environmental Protection Agency. 
ANALYTICAL RESULTS

WELL ABP $1 A$

MEASUREMENTS CONDUCTED IN THE FIELD

Sample date: 07/14/92 $\mathrm{A}(11.76 \mathrm{~m})$ below TOC Depth to water: $138.99 \mathrm{ft}(41.76 \mathrm{~m})$ below
Water olovation: $222.91 \mathrm{ft}(87.84 \mathrm{~m}) \mathrm{msl}$

Water evacuated bolore sampling: $131 \mathrm{gal}$

LABORATOAY ANALYSES

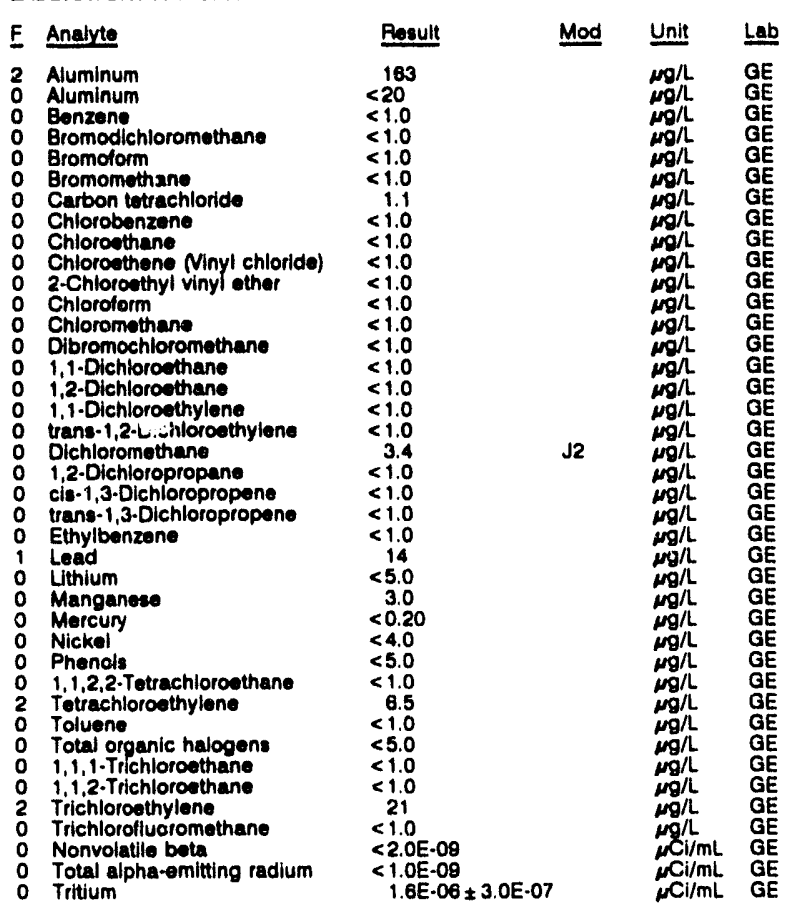

\section{WELL ABP 2A}

MEASUREMENTS CONDUCTED IN THE FIELD

Sample date: $07 / 14 / 92 \mathrm{ft}(45.85 \mathrm{~m})$ below TOC Water olevation: $221.48 \mathrm{n}$ (日).5

Sp. conductance: $34 \mu \mathrm{s} / \mathrm{cm}$
Water evacuated bolore sampling: $106 \mathrm{gal}$

LABORATOAY ANALYSES

\begin{tabular}{|c|c|c|c|c|}
\hline $\mathbf{E}$ & Analyze & Result & Mod & Unit \\
\hline $\begin{array}{l}0 \\
0 \\
0 \\
0 \\
0 \\
0 \\
0 \\
0 \\
0 \\
0 \\
0 \\
0 \\
0 \\
0 \\
0\end{array}$ & $\begin{array}{l}\text { Aluminum } \\
\text { Aluminum } \\
\text { Benzene } \\
\text { Benzene } \\
\text { Bromodichloromethane } \\
\text { Bromodichloromethane } \\
\text { Bromolorm } \\
\text { Bromoform } \\
\text { Bromomethane } \\
\text { Bromomethane } \\
\text { Carbon tetrachloride } \\
\text { Carbon tetrachloride } \\
\text { Chlorobenzene } \\
\text { Chiorobenzene } \\
\text { Chloroethane } \\
\text { Chloroethane } \\
\text { Chloroethene Ninyl chloride) } \\
\text { Chloroethene Ninyl chloride) } \\
\text { 2-Chloroethyl vinyl ether } \\
\text { 2-Chloroethyl vinyl ether } \\
\text { Chloroform } \\
\text { Chloroform } \\
\text { Chloromethane } \\
\text { Chloromethane } \\
\text { Dibromochloromethane } \\
\text { Dibromochloromethane } \\
\text { 1,1-Dichloroethane } \\
\text { 1,1-Dichloroethane } \\
\text { 1,2-Dichloroethane } \\
\text { 1,2-Dichloroethane } \\
\text { 1,1-Dichloroethylene }\end{array}$ & $\begin{array}{l}<20 \\
<20 \\
<1.0 \\
<1.0 \\
<1.0 \\
<1.0 \\
<1.0 \\
<1.0 \\
<1.0 \\
<1.0 \\
<1.0 \\
<1.0 \\
<1.0 \\
<1.0 \\
<1.0 \\
<1.0 \\
<1.0 \\
<1.0 \\
<1.0 \\
<1.0 \\
1.0 \\
<1.0 \\
<1.0 \\
<1.0 \\
<1.0 \\
<1.0 \\
<1.0 \\
<1.0 \\
<1.0 \\
<1.0 \\
<1.0\end{array}$ & & $\begin{array}{l}\mu g / L \\
\mu g / L \\
\mu g / L \\
\mu g / L \\
\mu g / L \\
\mu g / L \\
\mu g / L \\
\mu g / L \\
\mu g / L \\
\mu g / L \\
\mu g / L \\
\mu g / L \\
\mu g / L \\
\mu g / L \\
\mu g / L \\
\mu g / L \\
\mu g / L \\
\mu g / L \\
\mu g / L \\
\mu g / L \\
\mu g / L \\
\mu g / L \\
\mu g / L \\
\mu g / L \\
\mu g / L \\
\mu g / L \\
\mu g / L \\
\mu g / L \\
\mu g / L \\
\mu g / L \\
\mu g / L\end{array}$ \\
\hline
\end{tabular}

WELL ABP 2A collected on 07/14/92, laboratory analyses (cont.)

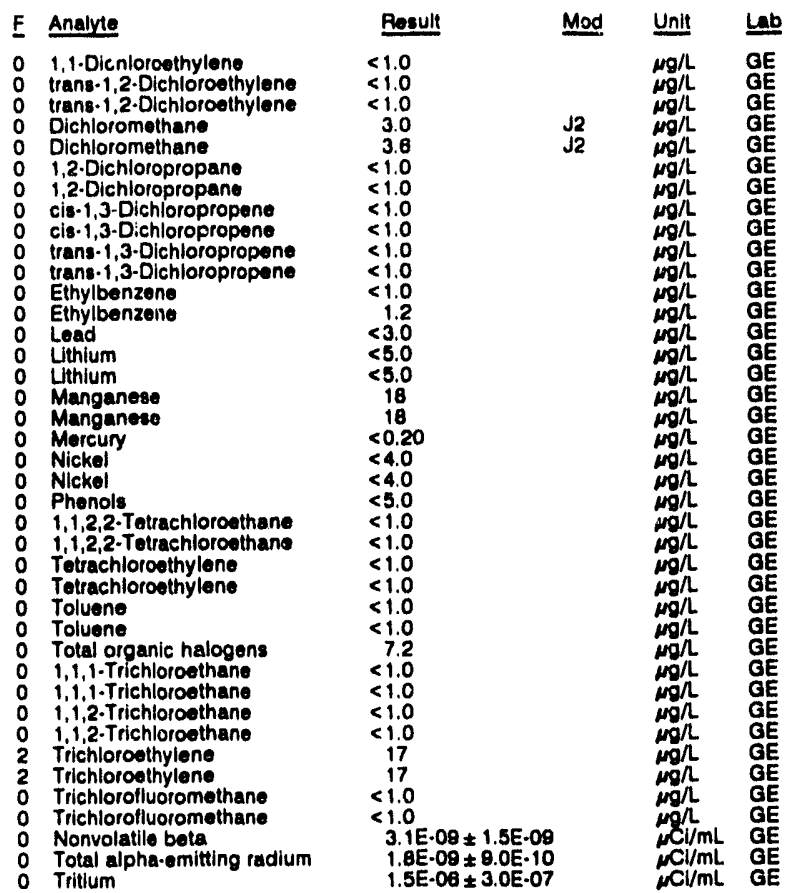

\section{WELL ABP 3}

MEASUREMENTS CONDUCTED IN THE FIELD

Sample date: 07/14/92 Depth to water: $130.01 \mathrm{ft}(39.63 \mathrm{~m})$ below TOC Water olevation: $223.69 \mathrm{H}(68.18 \mathrm{~m}) \mathrm{ms}$ ! Water ovacuated before sampling: $44 \mathrm{gal}$

PH: 4.9

Water temperature: $21.6^{\circ} \mathrm{C}$

LABORATOFY ANALYSES

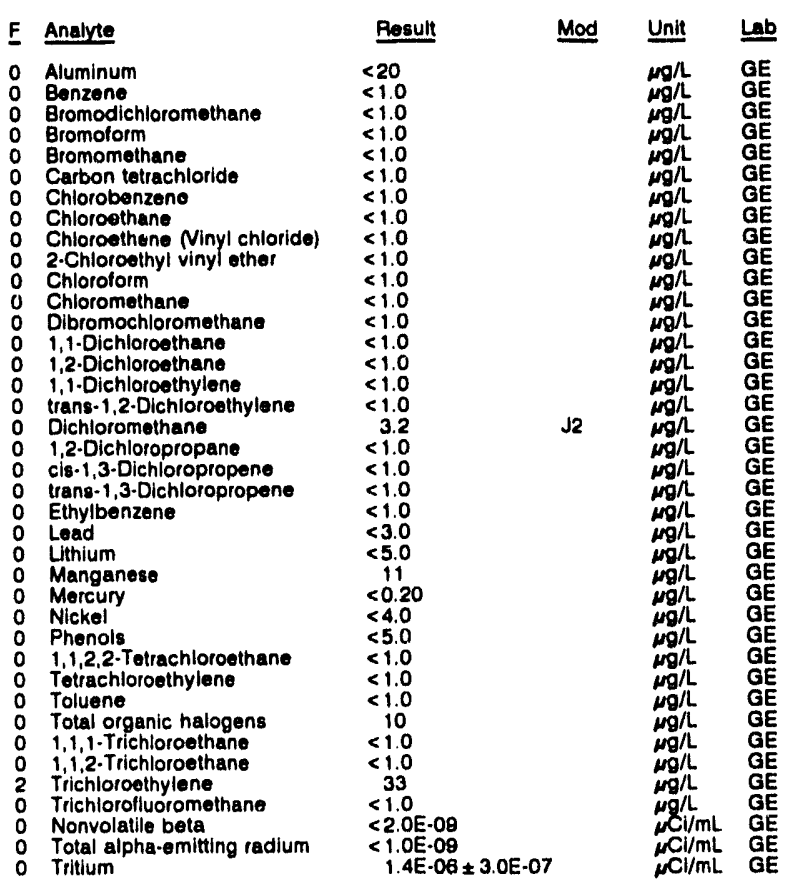


WELL ABP 3C

MEASUREMENTS CONOUCTED IN THE FIELD

Bample data: 07/14pe

Depth to water: 187.60 n $(48.06 \mathrm{~m})$ bolow TOC

Water dovation: $100.64 \mathrm{~h} / 00.00$

Wp. conductance: $01 \mathrm{H} / \mathrm{cm}$.

LABOPATOFY ANALYSES

\begin{tabular}{|c|c|c|c|}
\hline 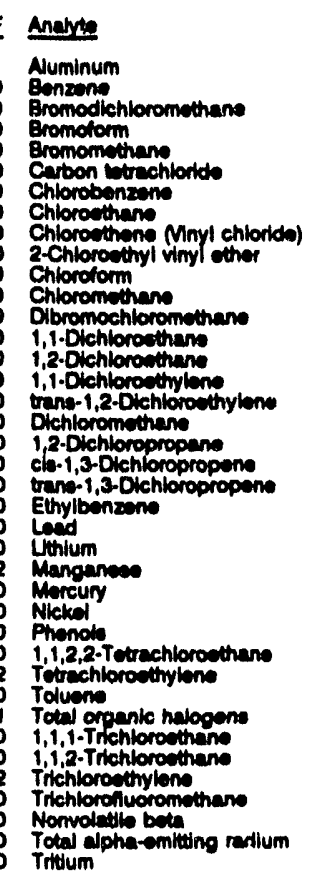 & 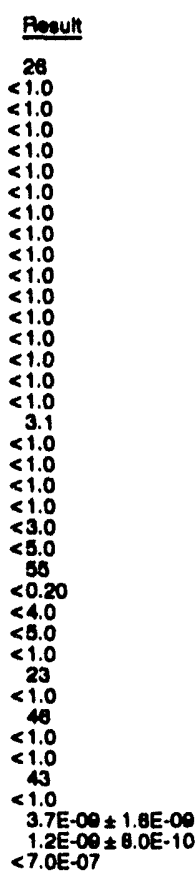 & Mod & 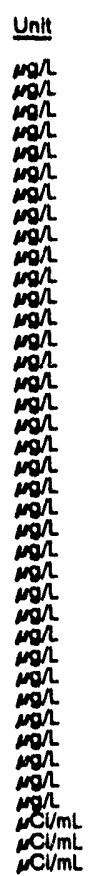 \\
\hline
\end{tabular}

WELL ABP 4

MEABUREMENTS CONDUCTED IN THE FIELD

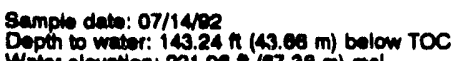
Wepth to water: $143.24 n(43.69 \mathrm{~m})$ below

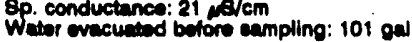

LABORATOFY ANALYES

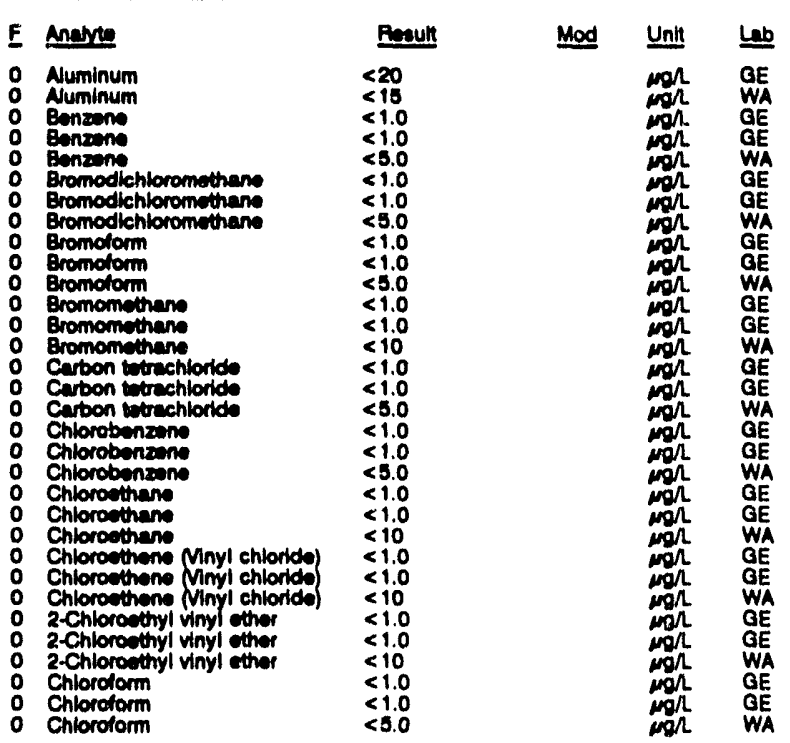

WELL ABP 4 collected on 07/1482, laboratory analyese (cont.)

\begin{tabular}{|c|c|c|c|c|c|}
\hline 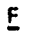 & Anabrte & Roeuli & Mod & Unth & Lab \\
\hline $\begin{array}{l}0 \\
0 \\
0\end{array}$ & 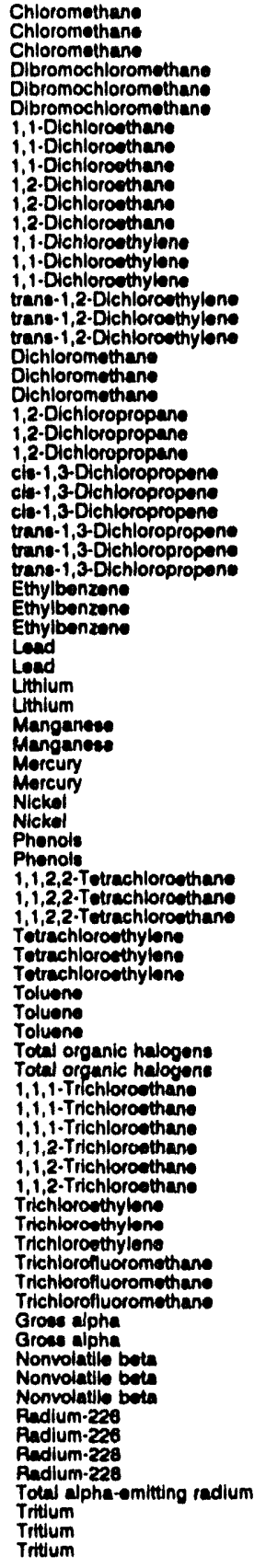 & 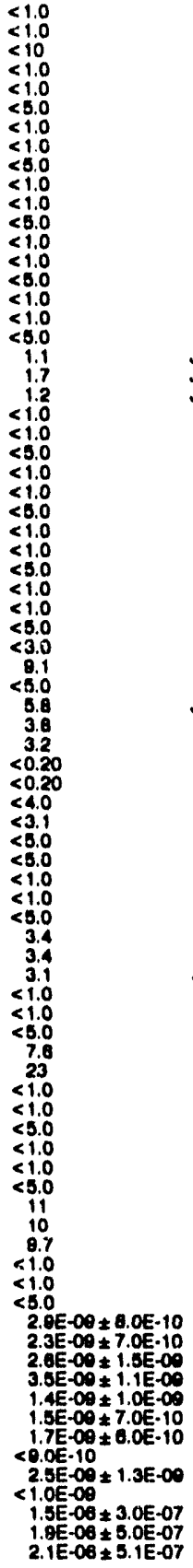 & $\begin{array}{l}\sqrt{2} \\
\mathbf{J} 2 \\
\mathbb{N}\end{array}$ & 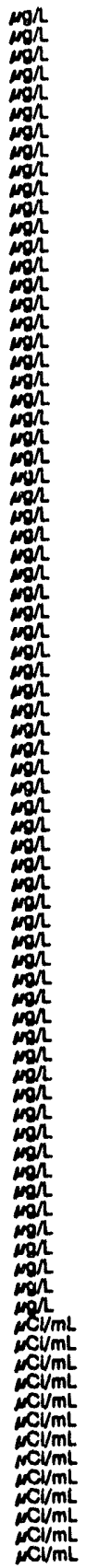 & 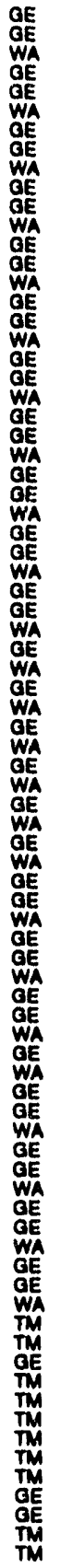 \\
\hline
\end{tabular}


ANALYTICAL RESULTS

WELL ABP 4 Replicate

MEASUREMENTS CONDUCTED IN THE FIELD

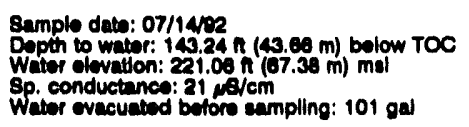

Time: 11:55

Alkalinity: $1 \mathrm{mgh}$

Water tomporalure: $21.4{ }^{\circ} \mathrm{C}$

LABOPATORY ANALYSES

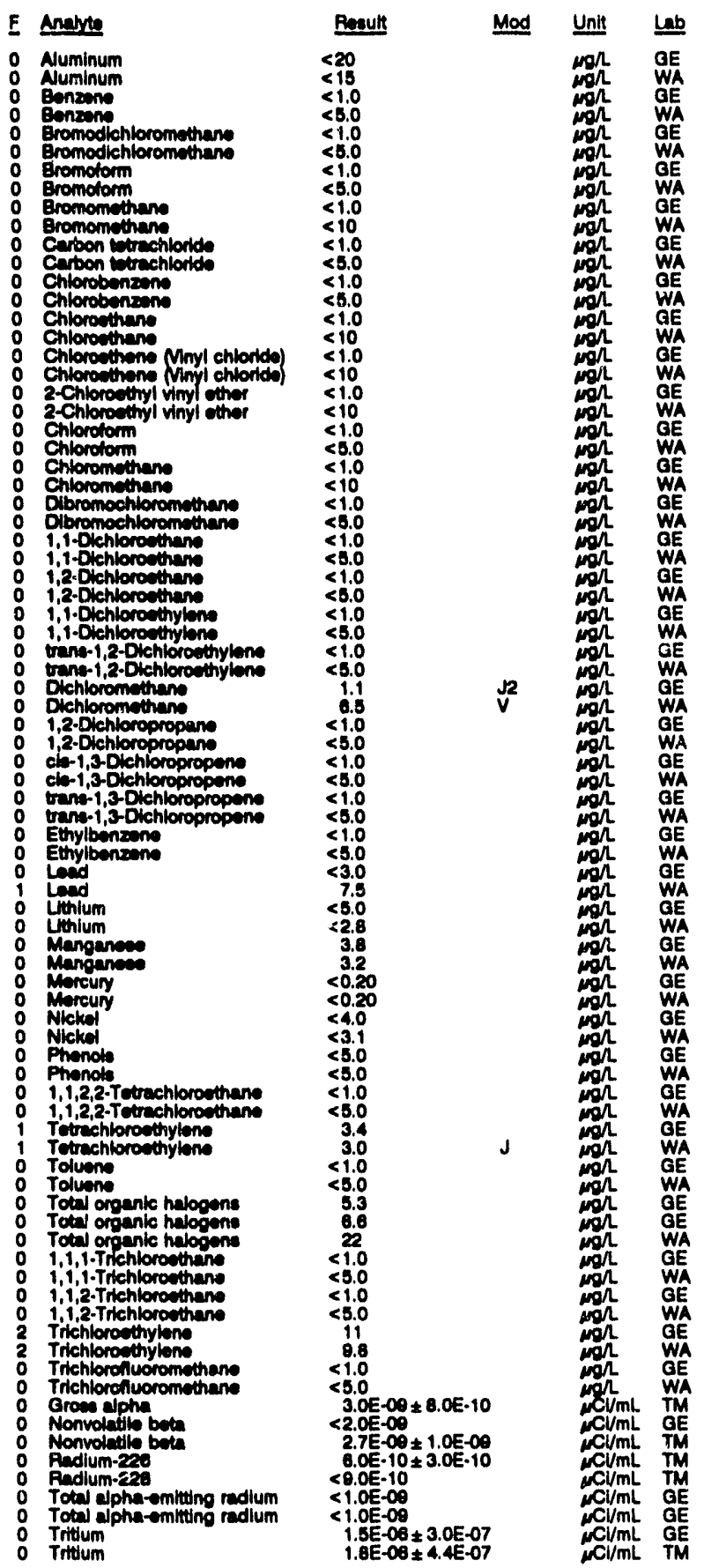

WELL ABP 8C

MEASLAREMENTS CONDUCTED IN THE FIELD

Sample date: 07/15/92

Depth to water: $175.19 \mathrm{ft}(53.40 \mathrm{~m})$ bolow TOC

Wator elevation: $188.91 \mathrm{t}(60.02 \mathrm{~m}) \mathrm{mal}$

The wall went dry during purging: 5 gal

LABORATOAY ANALYSES

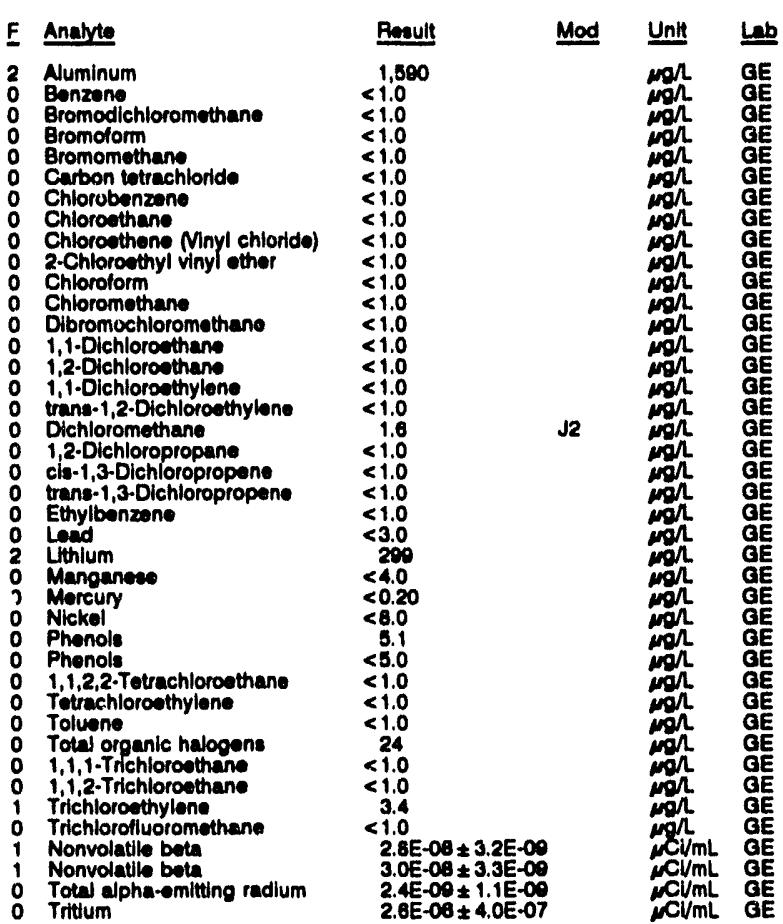

WELL ABP 8D

MEASUREMENTS CONDUCTED IN THE FIELD

Sample dato: 07/14/92

The well went dry before sampling began.

Time: 7:00

Alkalinity: $774 \mathrm{mgh}$

Water tomperature: $19.6 \cdot \mathrm{C}$

WELL ABW 1

MEASUREMENTS CONDUCTED IN THE FIELD

Samplo dato: 08/08/92

Depth to water: $89.80 \mathrm{fh}(30.12 \mathrm{~m})$ bolow TOC

Wator olevation: $225.00 \mathrm{~h}(38.58 \mathrm{~m}) \mathrm{mal}$

Wator evacuated before sampling: $105 \mathrm{gal}$

Time: 12:15

WELL AC IA

MEASUREMENTS CONDUCTED IN THE FIELD

Sample date: 07/02/92

Depth to wator: $48.55 \mathrm{n}(14.80 \mathrm{~m})$ below TOC

Water elevation: $213.65 \mathrm{~h}(85.00 \mathrm{~m}) \mathrm{mal}$

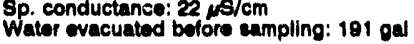

LABORATORY ANALYSES

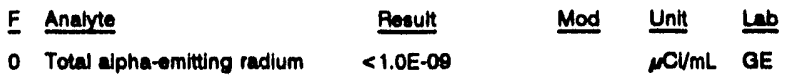

Time: 7:40

PH: 4.9 Water tomperature: $18.8^{\circ} \mathrm{C}$

Alkalinity: $0 \mathrm{~mol}$

Water temperature: $18.2{ }^{\circ} \mathrm{C}$

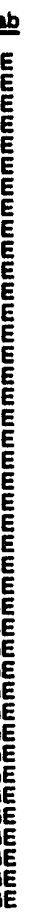


WELL AC 1B

MEASUAEMENTS CONOUCTED IN THE FIELD

Sample date: $07102 / 92$

Oopth to water: $46.45 \mathrm{f}(14.77 \mathrm{~m})$ bolow TOC

Walor covation: $213.55 \mathrm{~h}(05.00 \mathrm{~m}) \mathrm{mal}$

Sp. conductanco: $32 \mathrm{\mu} / \mathrm{cm}$

Wator evecuatod betoro sempling: $43 \mathrm{gal}$

LABORATORY ANALYSES

\begin{tabular}{|c|c|c|c|}
\hline Analste & Besult & Mod & \\
\hline 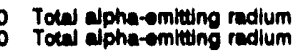 & $\begin{array}{l}1.1 E-09 \pm 1.0 E-09 \\
1.2 E-00 \pm 1.0 E-09\end{array}$ & & 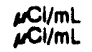 \\
\hline
\end{tabular}

WELL AC 2A

MEASUREMENTS CONOUCTED IN THE FIELD

8amplo dalu: $07 / 02 / 02$ (37.01 m) bolow TOC Dopth to wadr: $124.05 \mathrm{n}(37.81 \mathrm{~m})$ bolow TOC 8p. conductanco: $34 \mathrm{~s} / \mathrm{cm}$

Wator evecuatiod betore eampling: $208 \mathrm{gal}$

LABOPUTORY ANLLYSES

E Anderte

Time: 6:50

Akalinity: $8 \mathrm{mgh}$

Wator tomporature: $19.0^{\circ} \mathrm{C}$

Time: 7:30

Nkedinity: 2 moll

Water tomperalure: $18.6^{\circ} \mathrm{C}$

WELL AC $2 B$

MEASUREMENTS CONDUCTED IN THE FIELD

8ample dato: 07/00pe

Dopth to mot $117.30 \mathrm{n}(35.75 \mathrm{~m})$ bolow TOC

Weter elevetion: 227.00 n $(00.34 \mathrm{~m}) \mathrm{mal}$

Sp. conductance: $20 \mathrm{r} / \mathrm{cm}$

Watar evecuated befors eampling: $29 \mathrm{gal}$

LABOPATOPY ANAL YBES

E Anelve Benult

0 Total alpha-mining redium <1.0E--00

WELL AC 3A

MEASUPEMENTS CONOUCTED IN THE FIELD

Dample data: $07 / 02922$ (20.15 m) bolow TOC

Wotor elvation: $200.04 \mathrm{~h}(183.00 \mathrm{~m}) \mathrm{mal}$

Whiter evecueted betore eampling: $161 \mathrm{gal}$

LABOPUTOAY ANAL YSES

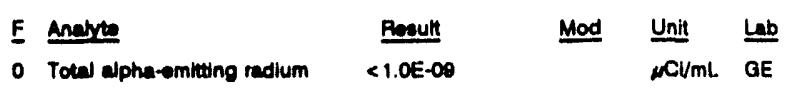

WELL AC 3B

MEASUAEMENTS CONOUCTED IN THE FIELO

Sample dete 07 reare

Depth to water: 0.062 ( 27.63 m) below TOC Wopth to water: $00.65 \mathrm{~h}(27.63 \mathrm{~m})$ bolow $70 \mathrm{C}$

Sp conductance 72 is/cm

Sp. conductunce: 72 $18 / \mathrm{cm}$.

LABOPATOAY ANUL YBES

E Anevte

o Total alphe-omitting nodium <1.0E-00
Time: 7:00

pH: 4.9

Alkalinity: $1 \mathrm{mg} / \mathrm{L}$

Water tomperaturo: $19.1^{\circ} \mathrm{C}$

Mod Unit Lab

NUML GE

Time: $8: 30$

$\mathrm{pH}: 5.6$

Alkalinity: $14 \mathrm{moh}$

Water tempernture: $18.8^{\circ} \mathrm{C}$

Mod $\frac{\text { Unit }}{\text { MCV/mL. }} \frac{\text { Lab }}{G E}$

Time: : $: 40$

Phalinity: $31 \mathrm{mon}$

Water tomperature: $18.1 \cdot \mathrm{C}$

Mod Unit Lab
$\mathrm{NCl} / \mathrm{mL}$ GE
WELL ACB $1 A$

MEASUREMENTS CONDUCTED IN THE FIELD

Sample date: 07/03/92

Depth to water: $122.81 \mathrm{n}(37.40 \mathrm{~m})$ below TOC

Water elevation: $236.69 \mathrm{st}(72.14 \mathrm{~m})$ bolow

Sp. conductance: $75 \mathrm{\mu} 9 / \mathrm{cm}$

Time: $8: 15$

oH: 5.5

Alkalinity: $17 \mathrm{mo}$ Water temperature: $18.0^{\circ} \mathrm{C}$

Water evacuated before sampl.,.1g: 50 gal

LABORATORY ANALYSES

\begin{tabular}{|c|c|c|c|c|c|}
\hline$F$ & Analyte & Result & Mod & Unif & \\
\hline o & 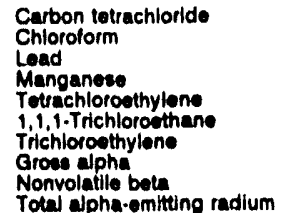 & $\begin{aligned}<1.0 \\
<1.0 \\
<3.0 \\
2.3 \\
7.7 \\
<1.0 \\
8.0 \\
<2.0 \mathrm{E}-00 \\
<2.0 \mathrm{E}-09 \\
1.1 \mathrm{E}-09 \pm 1.1 \mathrm{E}-09\end{aligned}$ & & 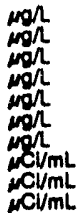 & $\begin{array}{l}\mathrm{GE} \\
\mathrm{GE} \\
\mathrm{GE} \\
\mathrm{GE} \\
\mathrm{GE} \\
\mathrm{GE} \\
\mathrm{GE} \\
\mathrm{GE}\end{array}$ \\
\hline
\end{tabular}

\section{WELL ACB 2A}

MEASUREMENTS CONDUCTED IN THE FIELD

Sample date: 07/03/92

Whth to water: $111.80 \mathrm{Ht}(34.08 \mathrm{~m})$ bolow TOC

Water elevation: $238.00 \mathrm{Ht}(72.54 \mathrm{~m}) \mathrm{msl}$

Watof evacuated bofore sampling: $79 \mathrm{gal}$

LABOPATOAY ANALYSES

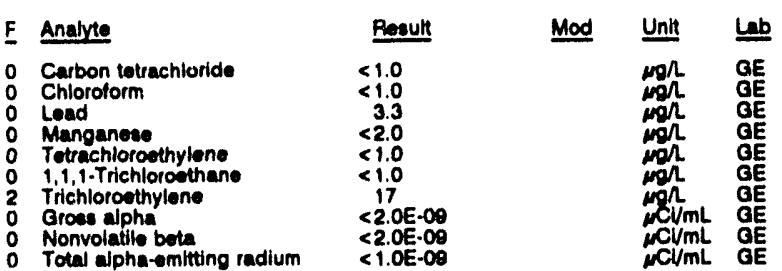

WELL ACB 3A

MEASUREMENTS CONDUCTED IN THE FIELD

Sample date: 07/03/92

Depth to water: $110.42 \mathrm{Ht}(33.68 \mathrm{~m})$ bolow TOC

Water olovation: $237.68 \mathrm{At}(72.51 \mathrm{~m}) \mathrm{msl}$

Sp. conductance: $124 \mu \mathrm{s} / \mathrm{cm}$
Water evacuated bofore eampling: 83 gal

LABORATORY ANALYSES

Timo: 9:25

PH: 5.0

Wkalinity: $1 \mathrm{mgh}$

Water temperature: $20.3^{\circ} \mathrm{C}$

- Carbon totrachiorido

- Chloroform

0 Lead

2 Manganese

1,1,1.Trichlorothen

o Trichloroethylene

1 Gross alphs

o Nonvolatil bata

Total alpha-emitting radium

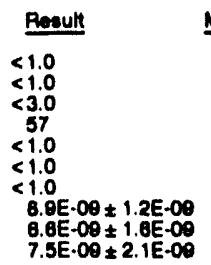

Mod Unit Ub

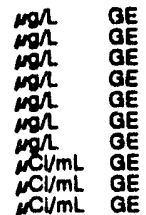

WELL ACB 4A

MEASUREMENTS CONDUCTED IN THE FIELD

Sample date: 07/03/92

Time: $8: 40$

Alkalinity: $7 \mathrm{malh}$

Water temperalure: $18.8 \bullet \mathrm{C}$

LABOPATORY ANALYSES

E Analyte

- Carbon totrachloride

1 Lead

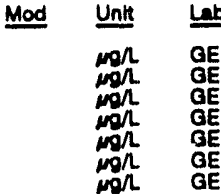

Depth to water: $120.89 \mathrm{ht}(36.88 \mathrm{~m})$ below TOC

Wator olovation: $236.11 \mathrm{t}(72.56 \mathrm{~m}) \mathrm{mal}$

Sp. conductance: $325 \mu \mathrm{s} / \mathrm{cm}$

Water ovacuated bofore eampling: 68 gal

o Chloroform

2 Manganese

O Tetrachlorosthylene

$1,1,1-$ Trichloroethane
o Trichloroethylene

\begin{tabular}{c} 
Roouth \\
\hline$<1.0$ \\
$<1.0$ \\
6.1 \\
468 \\
$<1.0$ \\
$<1.0$ \\
$<1.0$
\end{tabular}

Time: $0: 00$

Alkallinity: $2 \mathrm{mon}$

Water tomperature: $20.4 \cdot \mathrm{C}$ 
ANALYTICAL RESULTS

WELL ACB 4A collected on 07/03/92, laboratory analyses (cont)

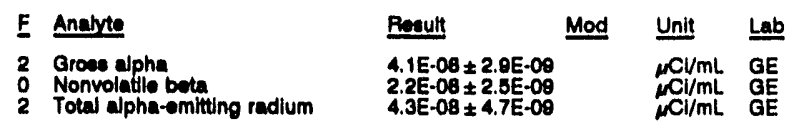

WELL AMB 4A

MEASUREMENTS CONOUCTED IN THE FIELD

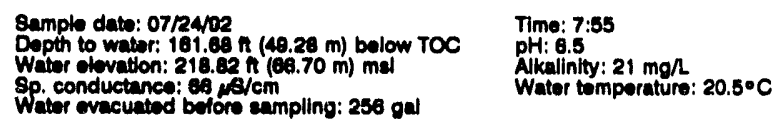

LABOFATORY ANALYEES

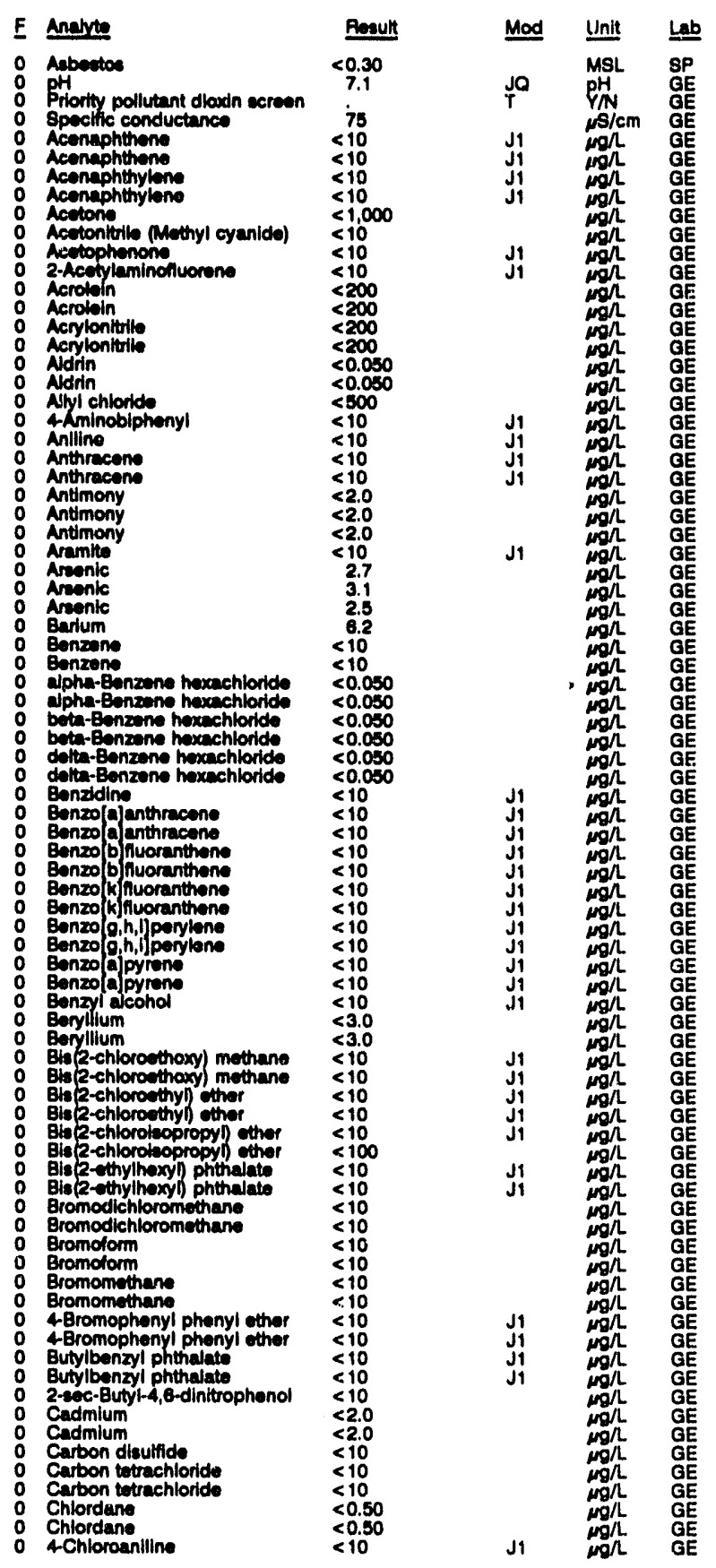

WELL AMB 4A collected on 07/24/92, laboratory analyses (cont.)

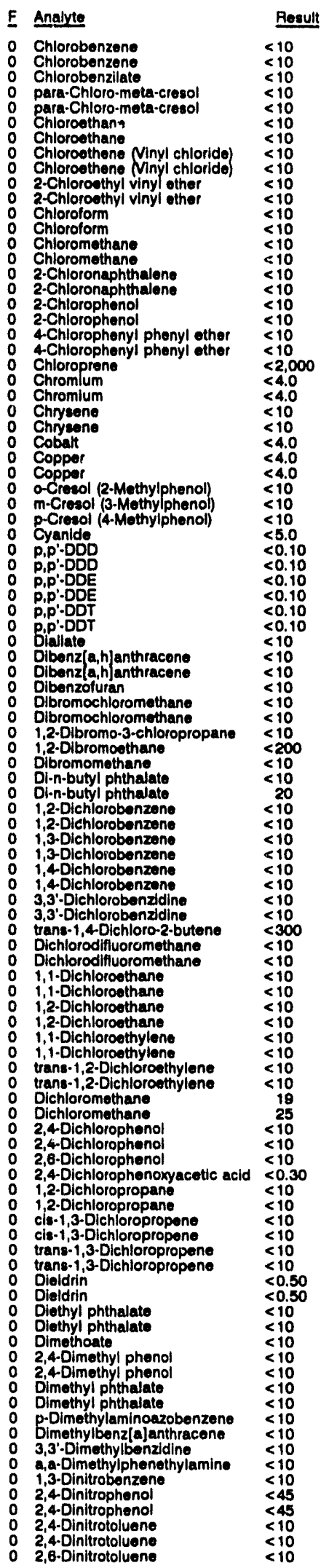

Lab

GE

GE

GE 
WELL AMB A collected on 07/24/02, laboratory analyees (cont.)

E Anavite

- 2,0-Dintrotoluene

: Di-n-octyl phthalate

0 1,4Dioxane

o

Diculitoton

- Endosultan I

Endoultan II

O Endosullan sulfato

0 Endin

: Endrin

Endrin aldohydo

: Ethyl mothacrylotionato

OEthylbonzane

Ethylbonzeno

F Fluorantinen

o Fluorente

- Fluorene

O Hoptechlor

o Hoptechlilor opoxide

O Heptachior opoxtio

- Hop,echiorodilbenzo-p-dioxine

$1,2,3,4,0,7,8-H P C D F$
Hoptechiorodibenzo-p-furans

Heptachiorodibonzon-p-p

Hexuchiorobonzeno

o Hoxachlorobutadione

Hexachlorobutadions

Hexachlorocyclopentadien

Hoxachlorodibenzo-p-dloxins

Hoxachiorodibenzo-p-furan

Hoxechloromenten

Hexachlorophen

Hoxachlorophono

2.Hexanone

indeno: $1,2,3-c, d]$ pyrene

lodomol 1,2,3-c,djpyrenc

iron

liobutyl alcohol

bodrin

leophorone

teoeafrole

Kapone

Lead

Lead

Undane

Manganese

Morcury

Mercury

Methapyrilene

Methoxychlor

2-Mnethyl-4,8-dinitroph

Methyl raobutyl ketone

Methyl methacrylate

3-Methylchoianthreno

2.Methylnephthalene

Naphthalene

1. N Naphthoquinone

1.Naphthylamine

2-Narhthylamin

Nicke!

2-Nitroaniline

3-Nitroaniline

4Nitroaniline

Nitrobonasen

Nhrobonzone

2. Ntropheno

4 Nitrophend

4 Nitropheno

4-Nitroguinoline-1-oxide

N.Nitrosodl-n-butylamin

N-Nitrosodlethylamine

N.Nitroeodimathylamine

N-Nitrocodimothylamine
N-Nitrosodiphenylamine
$<10$

$<10$

$<10$

$<10$

$<0.10$

$<0.10$

$<0.10$

$<0.10$

$<0.0060$

$<0.10$

$<10$
$<10$

$<10$

$<10$

$<10$
$<10$

$<10$
$<10$

$<10$

$<0.060$

$<.050$
$<0.050$

$<0.00068$

$<0.00045$

$<10$

$<10$
$<10$

$<10$

$<10$

$<10$
$<0.0004$

$<0.00045$

$<0.00040$

$<10$

$<10$

$<10$

$<10$
$<10$

$<10$
$<150$

$<150$
$<1,000$

$<10$

$<10$
$<10$
$<10$
$<10$

$<10$

$<10$

$<3.0$

$<0.0050$

7.8

$<0.20$

$<500$

$<10$

$<10$

$<10$

$<10$

$<10$

$<10$

$<10$

$<10$

$<<10$

$<10$

$<<$

$<4.0$

$<10$

$<10$

$<10$

$\leq 10$

$\leq 10$

$<10$

$<10$
$<10$
$<10$

$<10$
$<10$
$<10$

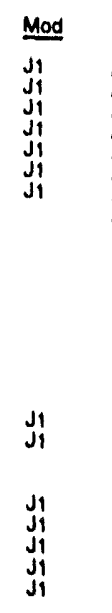

Unit Lab

$\begin{array}{ll}m g / & G E \\ \mu g / L & G E\end{array}$

$G E$

GE

GE

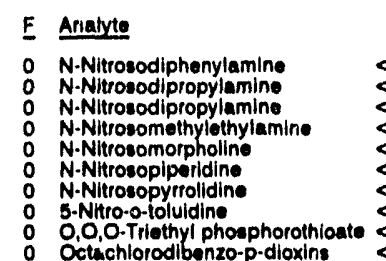

\begin{tabular}{ll}
\multicolumn{1}{c}{ Result } & Mod \\
\cline { 2 - 2 }$<10$ & $J 1$ \\
$<10$ & $J 1$ \\
$<10$ & $J 1$ \\
$<10$ & $J 1$ \\
$<10$ & $J 1$ \\
$<10$ & $J 1$ \\
$<10$ & $J 1$ \\
$<10$ & $J 1$
\end{tabular}

Unit Lي

Octuchlorodibenzo-p-furans $<0.0010$

: Perathion methyl

PC8 1018

PCG 1221

PCB 1221

- PCB 1232

O PCB 1242

0 PCB 1248

o PCB 1248

O PCE 1254

O
0

PCE 1260

- Pentachlorobenzene

Pentuchlorodlbenzo-p.dloxins

Pentachlorodibenzo-p.turans

1,2,3,7,8-PCDF

- Pontachloroothane

Pentachloronitrobenzene

Pentachlorophonol

o Phenacetin

o Phenanthrene

Phenol

Phenol

o p-Phonylenediamine

Phorate

o 2-Picoline

O Propionitirl

0 Pyrene

o Pyridine

Salrole

o solenium

o Selanium

o Sitver

o Styrene

0 Sulfide

Sulictepp

2,3,8-TCDD

: 2,3,7,8-TCDD

o Tetrachlorodibenzo-p-dioxine

o Totrachlorodibenzo-p-furans

o 1,1,1,2. Totrachloroothane

o 1,1,2,2-Totrachloroothane

- 1,1,2,2-Tetrachloroethan

2 Tetrachlorosthylone

2 Tetrachloroethylene

Thallium

Thallium

o Thlonazin

0 Tin

Toluene

0 o.Toluldine

Total diseolved solids

Total organlc carbon

o Toxaphono

- roxaphene

1,2,4-Trichlorobenzene

1,2,4-Trichlorobenzene

1,1,1-Trichlorosthane

i,

i, T.2.Thloroethane

Trichlorothylen

Trichlorogthytene

Trichlorofluoromethane

Triehlorofluoromothane

2,4,5-Trichlorophenol

2,4,6. Trichlorophenol

2,4,5.T

1,2,3-Ttichloropropane

o 1,3,E-Triniltrobenzene

o Vanadium

$$
\text { (n) }
$$


ANALYTICAL RESULTS

WELL AMB 4 A collectad on 07/24/92, laboratory analyses (cont)

\begin{tabular}{|c|c|c|c|}
\hline I Anajyta & Result & Mod & Unit \\
\hline $\begin{array}{ll}0 & \text { Vinyl acetate } \\
0 & \text { Xylones } \\
0 & \text { Zinc } \\
0 & \text { Znc } \\
0 & \text { Growe alpha } \\
0 & \text { Total alphn-omilting radium } \\
0 & \text { Tritium }\end{array}$ & $\begin{array}{l}<10 \\
<20 \\
? 5 \\
2.3 \\
<2.0 E-09 \\
<1.0 E-09 \\
<7.0 E-07\end{array}$ & & 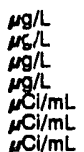 \\
\hline
\end{tabular}

\section{WELL AMB 4B}

MEASUREMENTS CONDUCTED IN THE FIELD

Sample date: $07 / 24 / 92$
Depth to water: $156.54 \mathrm{ft}(47.71 \mathrm{~m})$ bolow TOC
Water stevation: $223.08 \mathrm{Ht}(68.23 \mathrm{~m}) \mathrm{msl}$
Sp. conductarice: $33 . \mathrm{s} / \mathrm{cm}$

Tims: $7: 1$

alinity: $0 \mathrm{mg} /$ Water evacuated bofore sampling: $188 \mathrm{gal}$

\section{LABOPATOFY ANALYSES}

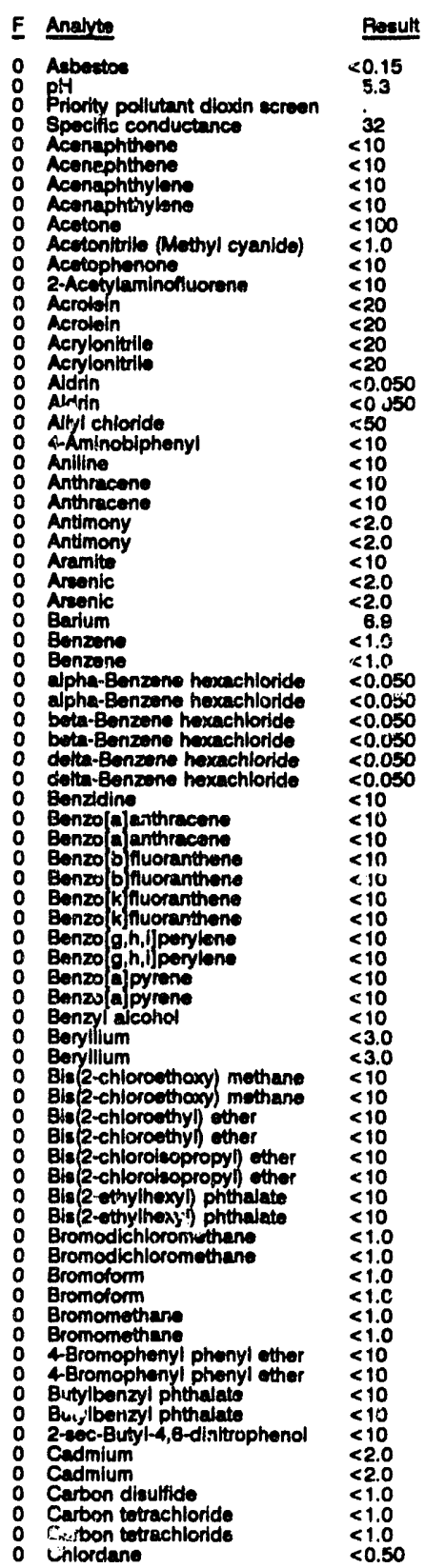

WELL AMB $4 B$ collected on 07/24/82, laboratory analyses (cont.)

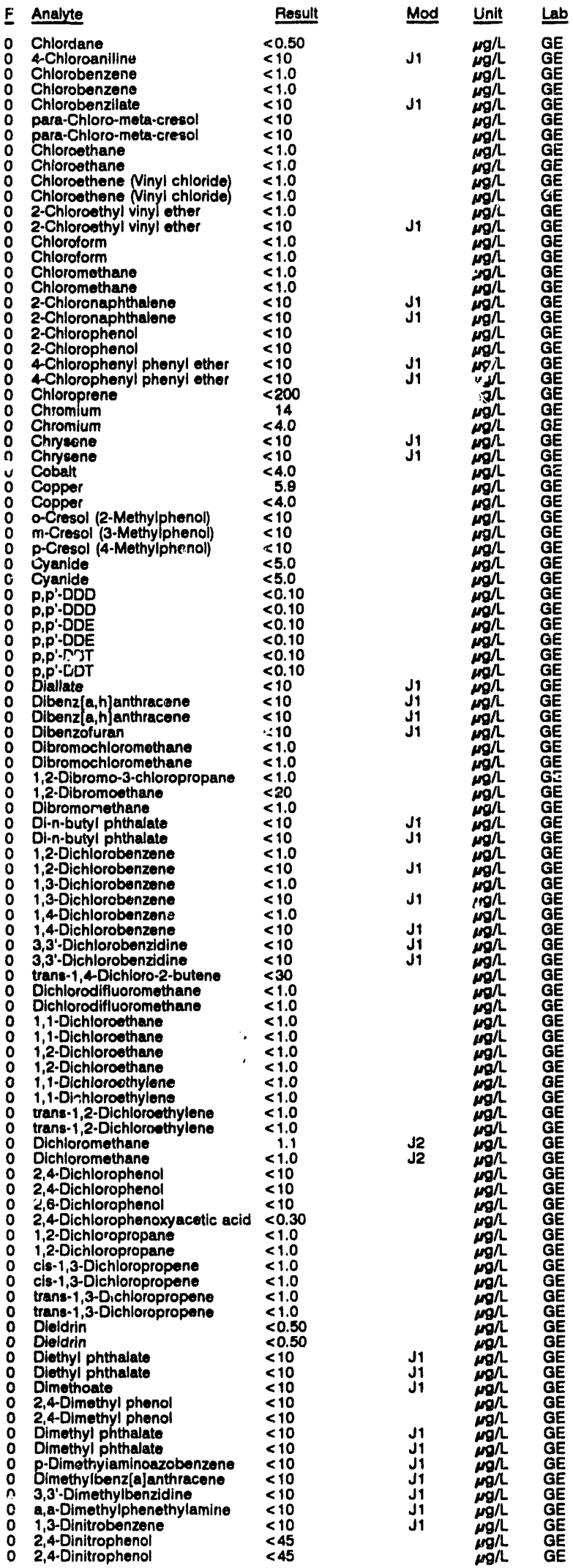




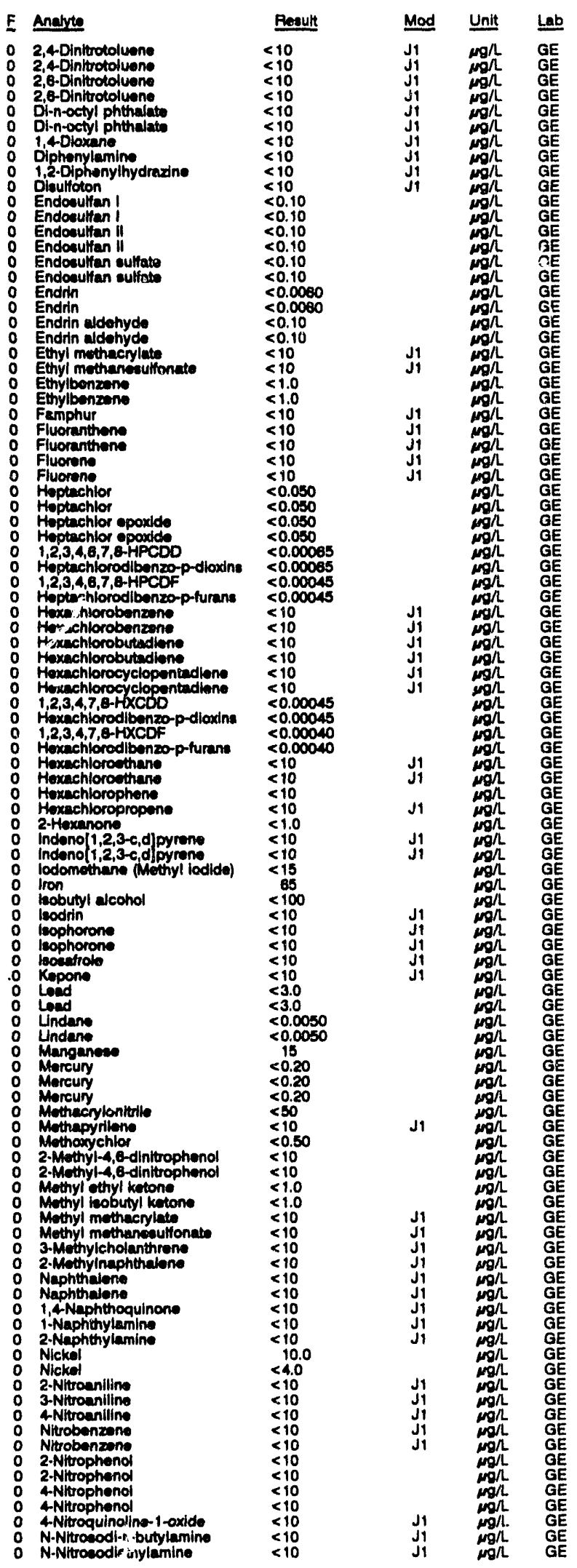

WEL AMB 4 B collected on 07/24/92, laboralory analyses (cont.)

WELL AMB 48 collected on 07/24/92, laboratory analyeses (cont.)

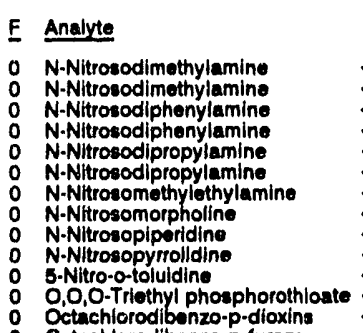

$\begin{array}{r}\text { Result } \\ <10\end{array}$
$<10$
$<10$
$<10$

Mod Unit Lab $\therefore$ Parathion

Parathion mothyl

PCB 1016
PCC 1016
0

PCB 122

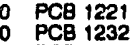

PCO 1232

: PCB 1242

0 PCB 1246

: PCB 1228

O PCB 1254

0 PCE 280

Pentachlorobonzeno

$1,2,3,7,8, P C D D$
0

Pentachlorodibenzo-p-dioxins

Pentachlorodlberizo-p-furans

0 1,2,3,7,8-PCDF

P Pentachloronitrobenzene

Pontachlorophenol

Pentachlorophen

Phenaceln

Phonanthrene

Phenol

p.Phenylenediamine

o Phorate

o 2-Picoline

O Propionitrile

o Pyrene

0 Pyrene

o Safrola

o Selenium

Silver

o Silver

o Styrene

O Sulfide

0 Sutiotop

0 1,2,4,5-Tetrach

2,3,7,8-TCOD

- Totrachlorodibenzo-p-dloxins

o Tetrachlorodibenzo-p-furans

o 1,1,1,2-Totrachlorosthane

o 1,1,2,2-Tetrachloroethane

O 1,1,2,2. Tetrachloroethan

Totrachlorosthyion

o 2,3,4,6-Tetrachlorophenol

o Thallium

Thallium

Thionazin

Tin

o Toluene

o o-Toluidine

o Total dissolved solide

Total organic carbon

Total organic halogens

Toxaphene

Toxaphene

1,2,4-Trichlorobenzene

1,2,4-Trichlorobenzene

$1,2,4$ Trichlorobonzeno

i, Trichloroethene

i.i. Trichloroethane

1,1,2-Trichloroethane

Trichloroethylene

Trichloroethylene

Irichlorofluoromethane

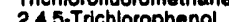

2,4, Trehlophen

2,4,6-Trichlorophenol

2,4,5-T

1,2,3-Trichloropropane

$<10$

10

$<10$
$<10$

$<10$

$<10$
$<10$

$<10$ 
ANALYTICAL RESULTS

WELL AMB 48 collectod on 07/24/82, laboratory analyeses (cont.)

\begin{tabular}{|c|c|c|c|c|}
\hline Analyte & Rosult & Mod & Unit & Lab \\
\hline $\begin{array}{l}\text { Vanadium } \\
\text { Vinyl acetate } \\
\text { Xylenes } \\
\text { Zine } \\
\text { Zne } \\
\text { Groes ajpha } \\
\text { Total alpha-emitting radium } \\
\text { Trtium }\end{array}$ & $\begin{aligned}<8.0 \\
<1.0 \\
<2.0 \\
6.5 \\
4.5 \\
<2.0 \mathrm{E}-09 \\
<1.0 \mathrm{E}-09 \\
<7.0 \mathrm{E}-07\end{aligned}$ & & 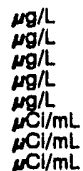 & $\begin{array}{l}\mathrm{GE} \\
\mathrm{GE} \\
\mathrm{GE} \\
\mathrm{GE} \\
\mathrm{GE} \\
\mathrm{GE} \\
\mathrm{GE} \\
\mathrm{GE}\end{array}$ \\
\hline
\end{tabular}

WELL AMB 4D

MEASUREMENTS CONDUCTED IN THE FIELD

Sample date: 07/24/92

Water olevation: $232.93 \mathrm{n}$ '

Sp. conductance: $42 \mu \mathrm{s} / \mathrm{cm}$.

LABORATOFY ANALYSES

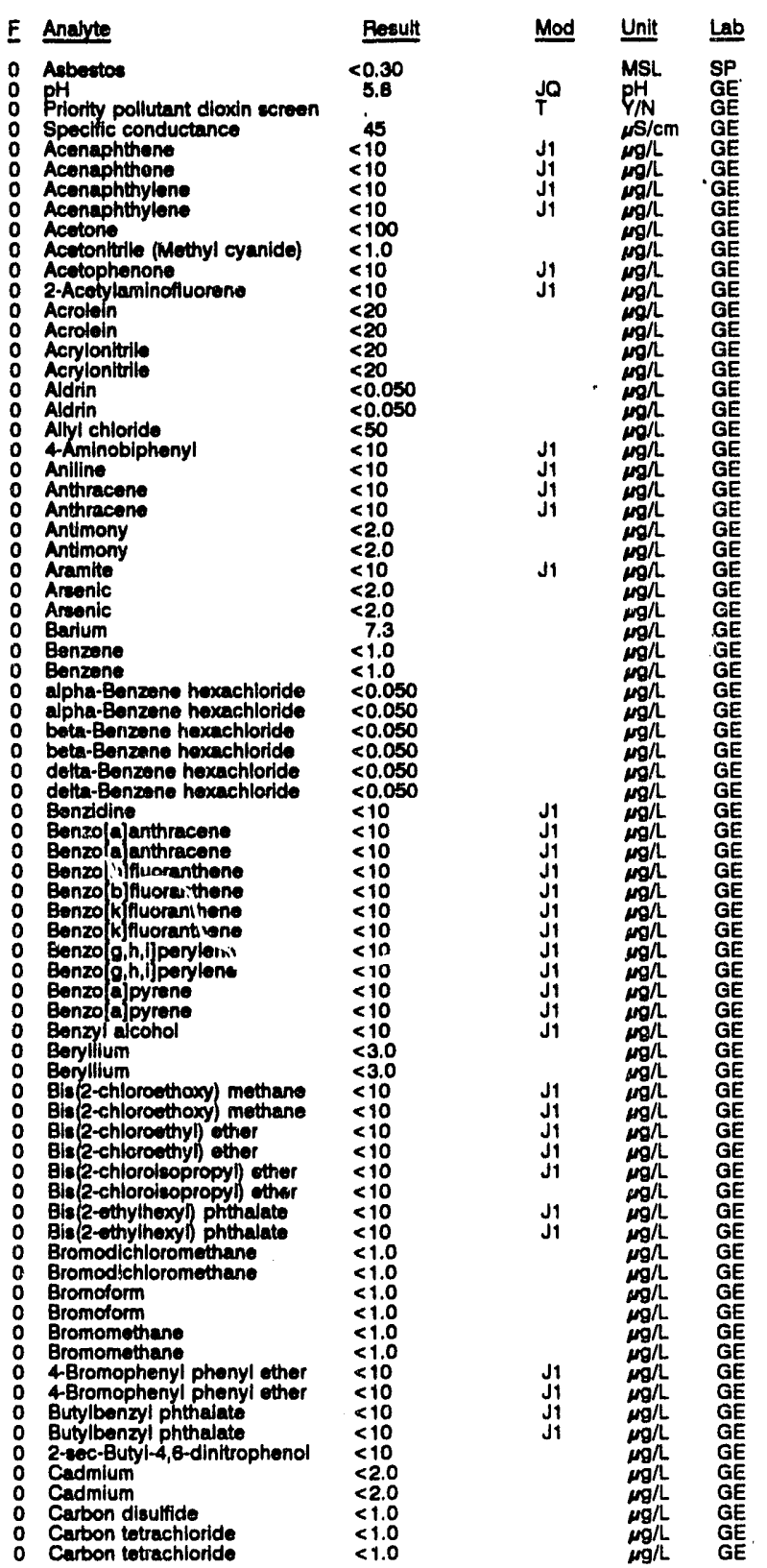

WELL AMB $4 D$ collected on 07/24/92, laboratory analyses (cont.)

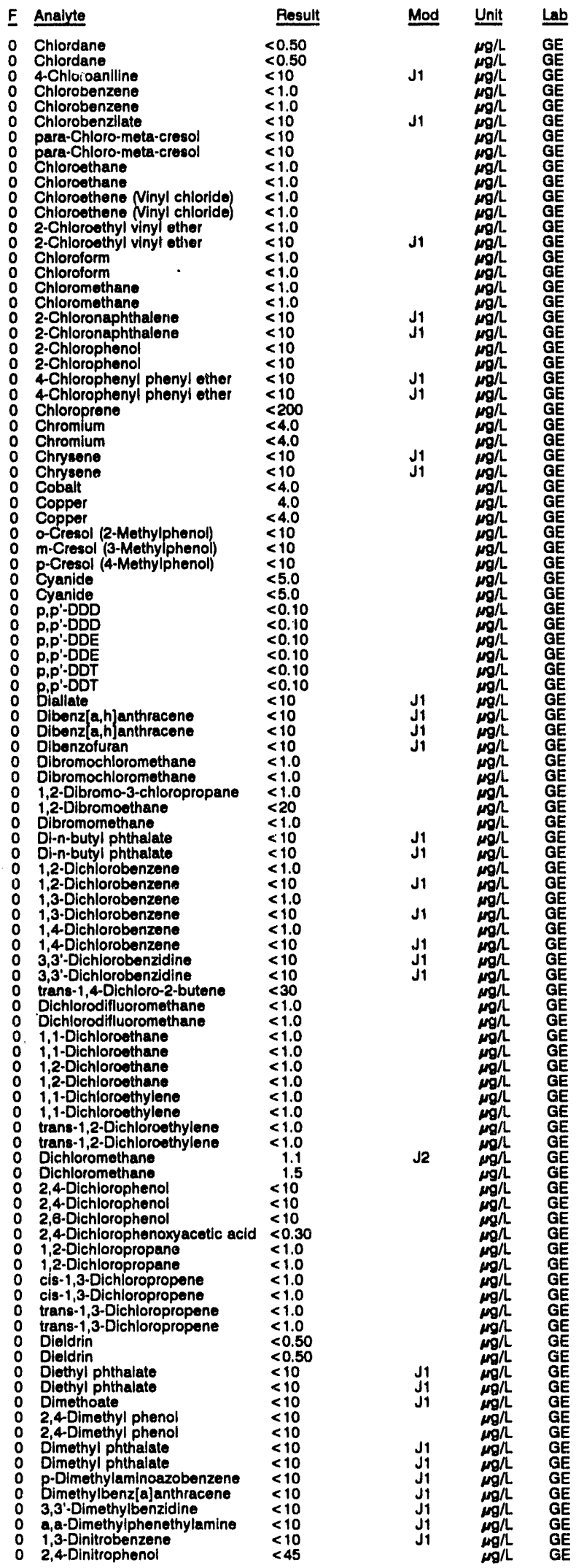


WELL AMB 40 collocted on 07/24/82, laboratory analyses (cont.)

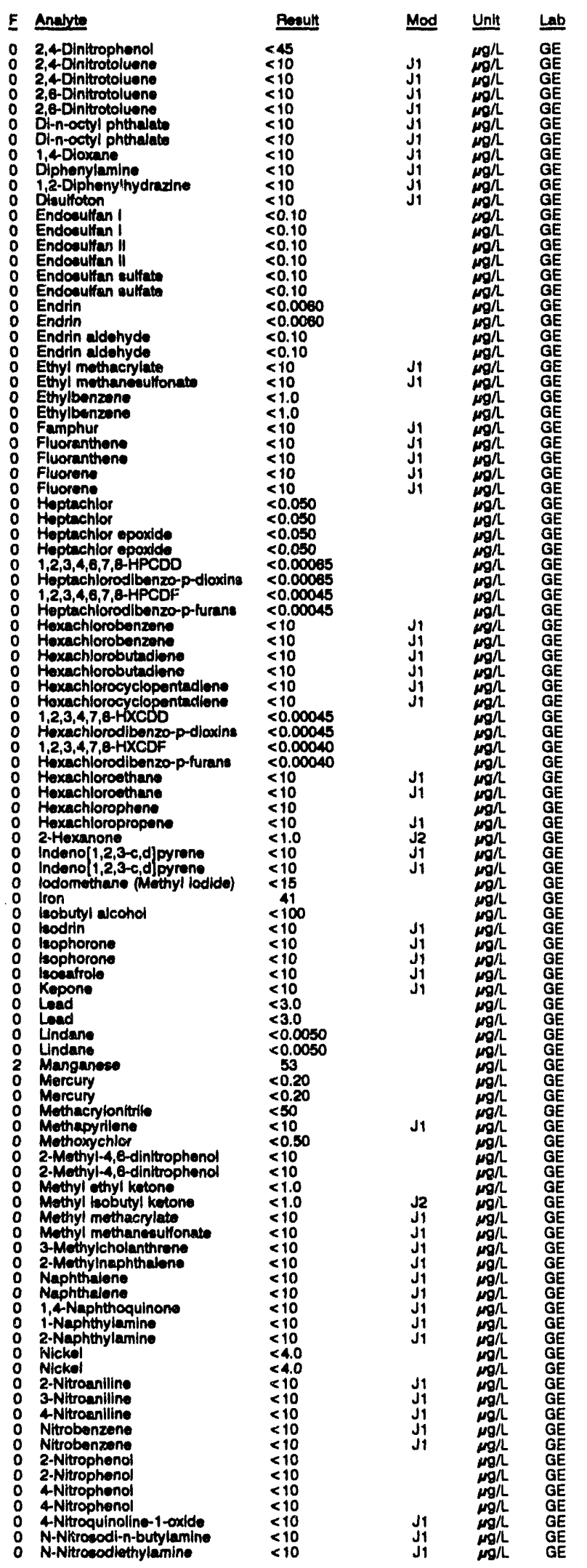

WELL AMB 4D collocted on 07/24/92, laboratory analyses (cont.)

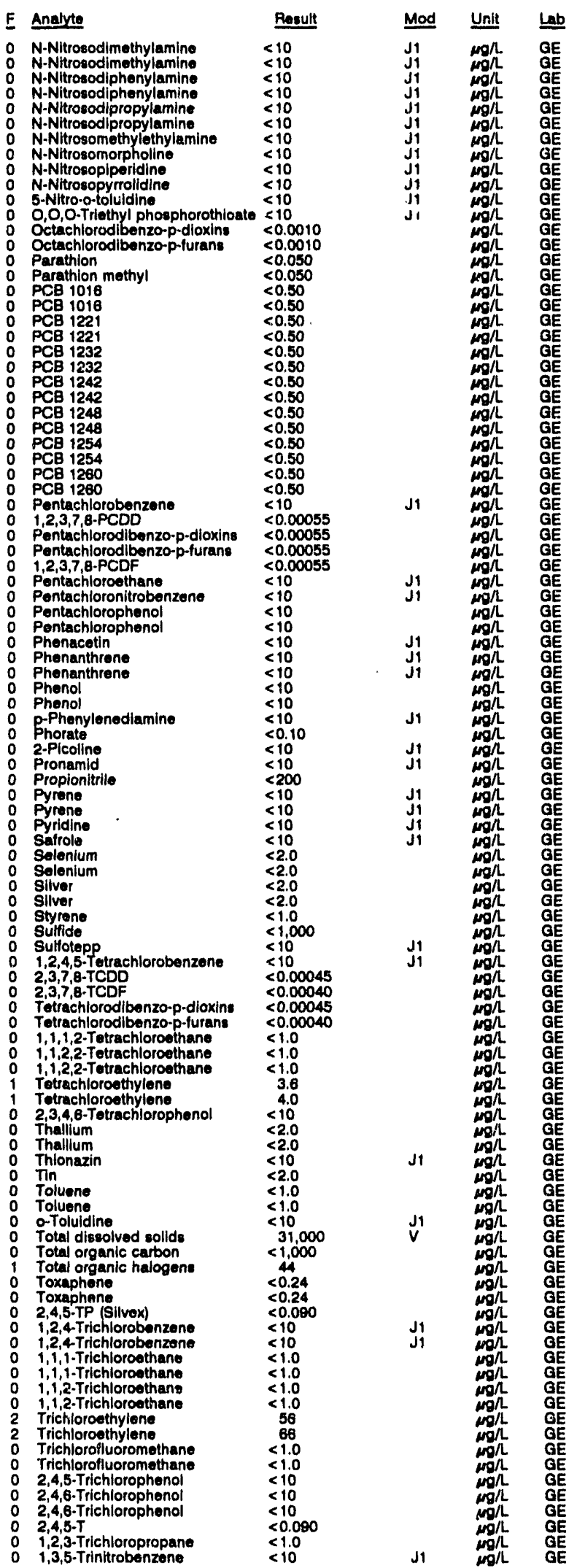


ANALYTICAL RESULTS

WELL AMB 40 collected on 07/24/92, laboratory analyses (cont.)

\begin{tabular}{|c|c|c|c|}
\hline & Analyto & Result & Unit \\
\hline & $\begin{array}{l}\text { Vanadium } \\
\text { Vinyl acetate } \\
\text { Xylenes } \\
\text { Zinc } \\
\text { Zinc } \\
\text { Gross alpha } \\
\text { Nonvolatile beta } \\
\text { Total alpha-mitting radium } \\
\text { Tritium }\end{array}$ & $\begin{array}{l}<8.0 \\
<1.0 \\
<2.0 \\
12 \\
9.7 \\
7.5 E-09 \pm 2.4 E-09 \\
4.8 E-09 \pm 1.7 E-09 \\
2.4 E-09 \pm 8.0 \mathrm{E}-10 \\
7.3 \mathrm{E}-07 \pm 3.0 \mathrm{E}-07\end{array}$ & 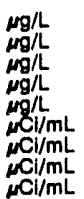 \\
\hline
\end{tabular}

WELL AMB 5

MEASUREMENTS CONDUCTED IN THE FIELD

Sample date: 07/24/92 3 ( $14.33 \mathrm{~m})$ below TOC Water olevation: $234.15 \mathrm{f}(71.37 \mathrm{~m}) \mathrm{msl}$

Sp. conductance: $47 \mathrm{NS} / \mathrm{cm}$.

Time: 8:15

Water temperature: $21.1^{\circ} \mathrm{C}$ LABORATORY ANALYSES

E Analyte

- Acenaphthene

Acenaphthylene

Acotonitrile (Methyl cyanide)

2-Acotylaminofluorene

Acrolein

Acryion

Alyl chloride

4Aminobiphonyl

Anlline

Antimony

Aramite

Barium

Benzone

alpha-Benzene hexachloride

beta-Benzene hexachloride

Benzolajanthracene

Benzo b] fluoranthen

Benzo $k$ fluoranthene

Benzo $\left.g_{,}, 1,1\right)$ perylene

Benzola alpyrene

Beryllium

Bis(2-chloroethoxy) methane

Bis (2-chloroethyl) ether

Bis (2-chloroisopropyl) ether

Bis(2-athylhexyl) phthalaco

Bromoform

4-Bromophenyl phenyl ether

Butylbenzyl phthalate

2-rec-Buty

Carbon disulfide

Carbon tetrachloride

Chlordane

Chlorobanzene

Chlorobenzilate

para-Chloro-meta-creas

Chloroethene (Ninyl chloride)

2-Chloroethyl vinyl ether

Chloroform

Chloromethane

2-Chloronaphth

4-Chlorophenyl phenyl ether

O Chloroprene

o Chrysense

Cobar

O-Cresol (2-Methylphenol)

o m-Cresol (3-Methylphenol)

o-Cresol (3-Methylphenol)

Cyanido

P., $-\mathrm{DDD}$

P.P.DOE

0 biallat

$<0.10$

年 $<10$

$<10$

$\begin{array}{lll}0 & \text { Dibromochloromethane } & <2.0 \\ 0 & 1,2 \text {-Dibromo-3-chloropropane } & <2.0\end{array}$

1,2.Dibromo-3-chloropl

Dibromomethane

Di-n-butyl phthalate

\section{Result Mod Unit}

$<10$
$<10$

$<200$
$<2.0$

$<10$

$<10$
$<40$
$<40$

$<0.050$

$<100$

$<10$

$<2.0$

$<2.0$

$<2.050$

$<0.050$

$<10$

$<10$

$<10$

$<10$

$<3.0$

$<10$

$<10$

$<2.0$

$<2.0$

$<10$
$<10$

$<10$

$<2.0$
$<2.0$
2.7

$<0.50$

$<10$

$<10$

$<2.0$

$<2.0$

$<10$
$<2.0$
$<2.0$

$<10$

$<10$
$<10$

$<400$

$<10$
$<4.0$

4.8

$<10$

410

$<5.0$

0.10

10

$<40$

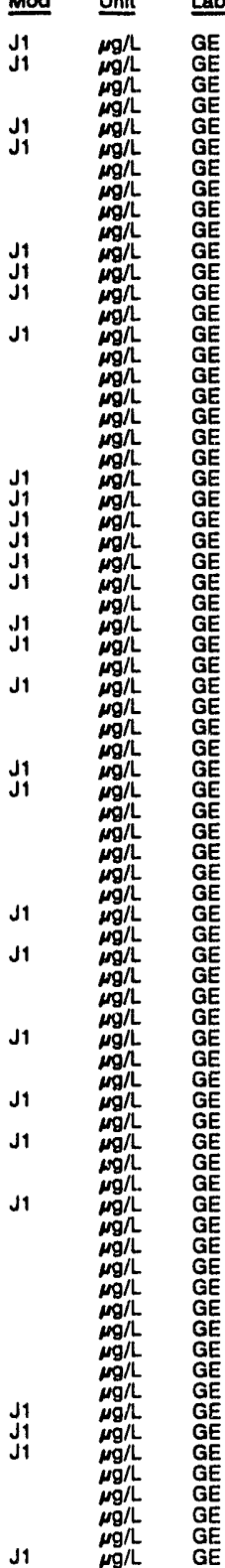

WELL AMB 5 collected on 07/24/92, laboratory analyses (cont.)

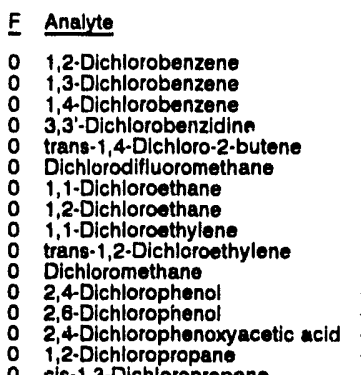

Result

Mod Unit Lab

$<10$

$<10$

$<60$

$<.0$
2.3

$<2.0$

$<.0$
4.3

$<10$

2,4-Dichlorophenoxyac

cis-1,3-Dichloropropene

Dieldrin

Diethyl phthalate

2,4-Dimethyl phenol

Dimethyl phthalate

p-Dimethylaminoazobenzene

3,3'-Dimethytbenzidine

a,a-Dimethylphenethylamine

1,3-Dinitrobenzene

2,4-Dinitrophenol

2,4-Dinitrotoluene

$2,6-D i n i t r o t o l u e n e$
0

1,4-Dioxane

D Diphenylamine

Disulíoton

Endosulfan I

Endosulfan II

Endrin

Endrin aldehyde

Ethyl methacrylate

Ethyl methanes

Ethylbenzento

Fluoranthen

Fluorene

O Heptachior epoxide

1,2,3,4,6,7,8-HPCDD

Heptachlorodibenzo-p-dioxins

Heptachlorodibenzo-p-dioxins

$1,2,3,4,6,7,8-\mathrm{HPCDF}$

1,2,3,4,6,7,8-HPCDF

Heptachlorodibenzo-p-furans

o Hexachlorobenzene

Hexachlorobutadiene

$1,2,3,4,7,8$-HXCDD

$1,2,3,4,7,8-H X C D D$
0 Hexachlorodibenzo-p-dioxins

Hexachlorodibenzo-p-dioxin

$1,2,3,4,7,8-H X C D F$

$1,2,3,4,7,8-H X C D F$
Hexachiorodibenzo-p-furans

Hexachlorodibenzo-p-furans
Hexachlorodibenzo-p-furans

Hexachloranzo-p

Hexachlorosthan

Hexachloropropene

2-Hexanone

Indeno[1,2,3-c,d]pyrene

lodomethane (Methyl lodide)

Isobutyl alcohol

Isodrin

o isophorone

Isosafrole

Kepone
Lead

Lindane

Magnesium

Manganese

Methacrylonitrile

Methapyrilene

Methapyrilene
Methoxychlor

2.Methyl-4,6-dinitrophenol

Methyl ethyl kotone

Mothyl isobutyl keton

Methyl methanesulfonate

3-Methylcholanthrene

2-Methylnaphthalene

Naphthaiene
1,4-Naphthoquinone

1-Naphthylamine

2-Naphthylamine

2-Nitroaniline

3-Nitroaniline
$<10$
$<0.30$
$<2.0$

$<2.0$
$<2.0$
$<2.0$
$<0.50$

$<10$
$<10$

$<10$

$<10$

$<10$
$<10$

$<10$

$<10$
$<10$

$<45$

$<10$

$<10$

$<10$
$<10$

$<0.10$

$<0.10$

$<0.0080$

$<0.10$

$<10$

$<2.0$

$<10$
$<10$

$<10$

$<0.050$

$<0.00065$

$<0.00065$

$<0.00065$

$<0.00045$

$<0.00045$

$<0.00045$

$<10$

$<10$

$<0.00045$

$<0.00045$

$<0.00045$

$<0.00045$

$<0.00040$

$<0.00040$

$<10$
$<10$

$<10$
$<10$
$<2.0$

$<2.0$

$<10$

7.6
$<200$

$<200$
$<10$
$<10$

$<10$
$<10$
$<3.0$

$<3.0$
$<0.0050$

623

$<0.20$

$<100$

$<0.50$

$<10$

$<2.0$

$<10$

$<10$

$<10$
$<10$

$<10$
$<10$

$<10$

$<10$

$<4.0$

$<10$
$<10$

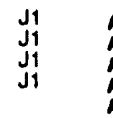

$j 1$
J1
$j 1$
$j 1$
J1
J1
J1
J1
J1
J1
J1
J1
J1

J1
J1

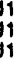

J1

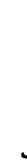

J1

J1

J1

J1
j1
J1

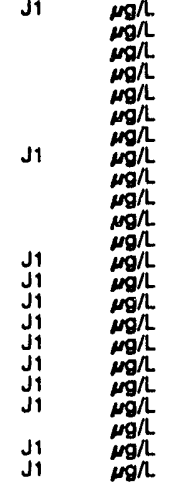

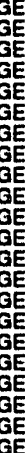


WELL AMB 5 collocted on 07/24/92, laboratory enalyses (cont.)

E Analyte

- A-Nitroaniline

2-Ntrophenol

4Nitropheno

A-Nitrogulnolina-y-oxide

N-Nitrosodiethyiamino

N-Nitrowodimethylemin

N-Nitrosodiphonylamin

N-Nitrosomothylethylamine

N-Nitrosomorpholino

N-Nltrosopyrrolidine

5.Nitro-o-rolulalin

oate $<10$

Octuchlorodibenzo-p-dloxins $<0.0010$

Octachlorodibenzo-p-dloxins

Octachlarodibanzo-p purans

Parathion

- Parathion mathyl

P PCB 1018

0 PCB 1232

PCB 1242

PCE 1248

0 PCB 1260

- Pentachlorobenzene

$1,2,3,7,8-P C D D$

Pentichlorodibonzo-p-dioxins

Pentachlorodibenzo-p-dioxime

Pentachlorodibonzo-p-furano

o $1,2,3,7,6$-PCDF

$1,2,3,7,8-P C D F$

Pentachloroethane

Pentachlosopheno

Phonacetin

Phonol

o P-Phenylenediamine

2.Picolin

Pronamid

Propionitrilo

Pyrene

Pyndine

Safrole

Selenium

Styrene

8uliotepp

$2,2,4,8-T C D D$
$2,3,7,8-T C D D$

2,3,7,8-TCDF

2,3,7,8-TCDF

Tetrachlorodibenzo-p-dioxins

Telrachlorodibenzo-p-furans

Tetrachlorodibenzo-p-furans

1 1,1,2-Tetrachloroothan

0
2 Tetrachloroethylone

o 2,3,4,6-Tatra

Thionuzin

Tin

Toluene
0 o-Toluldine

0 O-Toluldina
0
2 Total organic carbon
2 Total organic halogens

o Taxaphone

$1,2,4$-Trichlorobenzene

o $1,1,1$-Trichloroethane

1,1,2-Trichloroethan

2 Trichioroethylene

2,4,5-Trichlorophenol

0 2,4,6-Trich

1,2,3-Trichioropropane

o 1,3,5-Trinitrobe

Vinyl acotate

O Xylenes

o Znc

2 Total alpha-emitting radium

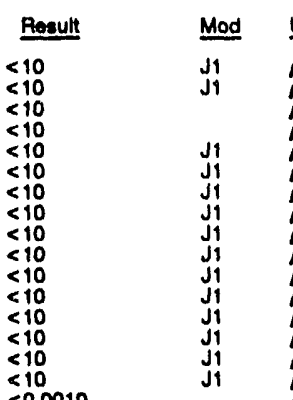

$<0.0010$

$<0.050$

$<0.50$

$<0.50$

$<0.50$

$<0.80$

$<0.50$

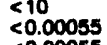

$<0.00055$

$<0.00055$

$<000055$

$<0.00055$

$<0.0005$
$<10$

$<10$

$<10$

$<10$
$<10$

$<10$

$<10$

$<10$
$<400$

10

$<10$
$<10$

$<10$
$<2.0$

$<2.0$

$<1,000$

$<10$

$<0.00045$

$<0.00045$

$<0.00040$

$<0.00045$

$<0.00045$

$<0.00040$

$<2.0$

$<2.0$

$<10$

$<2.0$

$<10$
$<2.0$
$<2.0$

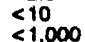

85
$<0.24$

$<0.24$

$<10$

$<2.0$
$<2.0$

$<2.0$
167
$<2.0$
$<10$

$<2.0$
$<10$
$<10$

$<0.000$

$<2.0$

$<8.0$
$<2.0$
$<4.0$

3.7

3. $2 E-09 \pm 1.0 E-00$

$4.4 E-09+8.6 E-09$
$5 . \theta E-09 \pm 1.4 E-0 \theta$

WELL AMB 6

MEASUREMENTS CONDUCTED IN THE FIELD

Sample date: 07/24/92

Depth to water: 144.65 ft $(44.09 \mathrm{~m})$ below TOC

Water elevation: $232.55 \mathrm{ft}$

Sp. conductance: $36 \mu \mathrm{s} / \mathrm{cm}$.

Water evacuated bofore sampling: $28 \mathrm{gal}$

LABORATORY ANALYSES

F Anatyte Reault

- Acenaphthene

$<10$
$<10$

Acenaphthylene

Acetonitrile (Methyl cyanida)

Acetophenone

Acrolein

Acrylonitrile

Aldrin

Allyl chloride

4 Áminoblphenyl

Anthracene

Antimony

Aramite

Arsenic

Barium

alpha-Benzene hoxachloride

delta-Benzene hexachlorido

Bonzo[a]anthracene

Bonzo b) fuoranthene

Benzo / $k$ ffivoranthene

Benzo g, $h, 1]$ perylone

Benzyl alcohol

Bervilium

Bis 2.chloroethoxy) methane

gis 2.chlorill ather

Bis(2-ethylhexyl) phthalate

Bromodichloromethane

Bromoform

4-Bromophenyl phenyl ether

Butylbenzyl phthalate

2-soc-Butyl-4,6-dinitsophenol

Cadmium disulfido

Carbon tetrachloride

Chlordane

4-Chloroanline

Chlorobenzene

para-Chioro-meta-cresol

Chioroethane

Chloroethene Ninyl chloride)

2-Chloroethyl vinyl other

Chloroform

2.Chloronaphthalen

4hlophonol

Chloropren

Chrusene

Cobalt

o o-Cresol (2-Methylphenol)

m-Cresol (3-Methylpheno)

p-Cresol (4-Methylphenol)

Cyanido

0 p, $p^{\prime}-D D D$

0

p,p'-DD

Dibenz\{a,h]anthracene

D Denzla,h]anth

o Dibromochloromethane

1,2-Dibromo-3-chloropropane

- 1,2.Dibromoothane

0 Di-n-butyl phthalate

1,2-Dichlorobenzene

- 1,3-Dichlorobenzene

1,4-Dichlorobenzene

trans-1,4-Dichloro-2-butene

Dichlorodifluoromethane

1,1-Dichloroethane

1,2-Dichloroethane

1,1-Dichloroethylene

Dichloromethane

2,4-Dichloropheno

$\begin{array}{ll}2,6 \cdot \text { Dichlorophenol } & <10 \\ \text { 2,4-Dichlorophenoxyacetic acid } & <0.30\end{array}$

Timo: 8:45

Alkalinity: $6 \mathrm{mgn}$

Water tomperature: $21.7^{\circ} \mathrm{C}$

$<100$
$<1.0$
$<10$

$<10$

$<<20$

$<50$

$<10$

$<2.0$

$<10$

$<3.0$

$<<0.050$

$<0.050$

$<10$

$<10$
$<10$

$<10$
$<10$

$<10$

$<10$

$<10$

$<1.0$

$<1.0$

$<10$
$<10$

$<10$

$<2.0$

$<1.0$

$<10$

$<10$

$<10$

$<1.0$

$<1.0$

$<10$

$<10$
$<10$
$<200$

$<200$

$<10$

$<4.0$

$<10$

$<10$

$<0.10$

$<0.10$

$<10$

$<10$

$\leq 1.0$

$<20$

$<10$
$<10$

$<10$

$<10$
$<10$

$<30$

$<1.0$

$<1.0$

$<1.0$

1.0
$<10$
$<10$

mgh GE

$\mathrm{mgh}$ aE

. 
ANALYTICAL RESULTS

WELL AMB 6 collected on 07/24/92, laboratory analyses (cont.)

\section{E Analyte}

1,2-Dichloropropane

trane-1,3-Dichloropropene

Dieldrin

Dlethyl phthalate

2,4Dimethyl phenol

Dimethyl phthalate

Gimethylbenz(a)anthracene

3,3'-Dimethylbenzidine

a, Dimethylphenethylamine

1,3-Dinitrobenzene

2,4-Dinitrophenol

2,6-Dinitrotolueno

1,4-Dioxane

Diphenytamin

Diaulfoton

Endosulfan I

Endosulfan sulfato

Endrín

Endrin aldetryde

Ethyl methacrylate

Ethylbenzene

Famphur

Fluorent

Hoptachior

Heptachlor epoxide

Hoptachlorodibenzo-p-dioxins

Heptachlorodibenzo-p-turane

Hexachlorobenzene

Hexachlorobutadiene

$1,2,3,4,7,6-H \times C D D$

Hexachlorodlbenzo-p-dloxins

1,2,3,4,7,8-HXCDF

Hexachloroethane

Hexachiorophene

2-Hexanone

Indeno $[1,2,3-c, d]$ pyrene

lodom

leobutyl alcohol

leodrin

leophorone

0 Kepon

Lead

Magnesium

Manganes

Methacrylonitrile

Mothapyrilen

2-Methyl-4,6-dinitrophenol

Methyl ethyl ketono

Mothyl methacryinte

Methyl methanesulfonato

3-Methylcholanthrene

2-Methylnaphth

1,4Naphthoquinone

1-Naphthylamino

2.Naph

2-Nitroaniline

3-Nitroanilline

4-Nitroanillne

2-Nitropheno

2-Nitrophonol

4-Nitroquinoline-1-oxide

N-Nitrosodi-n-butylamine

N-Nitrocodiethyly mine

N-Nitrosodimethylamine

N-Nitrosodiphenylamina

N-Nitrosodipropylamine

N-Nitrosomothylothylan

N-Nitrosomorpholine

N-Nitrosopiperidine

5-Nitro-o-toluidine

$0,0,0$-Triethyl phosphorothio

Oetachlorodibenzo-p-dioxins

Octachlorodit

Parathion methyl

PCB 1016

Regult

$<1.0$

$<1.0$

$<0.50$

$<10$
$<10$

$<10$

$<10$

$<10$

$<10$

$<10$

$<10$

$<10$

$<10$

$<10$
$<10$

$<10$

$<0.10$

$<0.10$

$<0.10$

0.10

$<10$
$<10$

$<1.0$

$<10$

$<10$
$<10$

$<0.050$
$<0.050$

$<0.00065$

$<0.00085$

$<0.00045$

$<10$
$<10$

$<0.00045$

$<0.00045$

$<0.00040$

$<10$
$<10$

$<10$

1.0

$<10$

$<15$

31
$<100$

$<10$

$<10$
$<10$

$<10$
$<10$

$<3.0$
$<0.0050$

$<0.0050$

4.5
$<0.20$

$<50$

505

$<0.50$

$<1.0$

$<1.0$

$<10$

$<10$

$<10$
$<10$

$<10$

$<i 0$

$<10$

$<10$

$<4.0$

$<10$

$<10$
$<10$

$<10$
$<10$

$<10$
$<10$

$<10$

$<10$

$<10$

$<10$

$<10$

$<10$

10

$<10$

$<10$

$<0.0010$
$<0.0010$

$<0.050$

$<0.050$

$<0.50$
Mod

Unit La

$\mu g / L \quad G E$

$\mu g / L \quad G E$

$\mu g / L \quad G E$

$\mu g / L$ GE

g/L GE

$\begin{array}{ll}G / L & G E \\ G / L & G E\end{array}$

g/L GE

g/L GE

$g / \mathrm{GE}$

g/L GE

g/L GE

$\begin{array}{ll}g / L & G E \\ g / L & G E\end{array}$

gE

g/L $\quad$ GE

GE

$g / L \quad G E$

$g / L \quad G E$

WELL AMB 6 collected on 07/24/82, laboratory analyses (cont.)

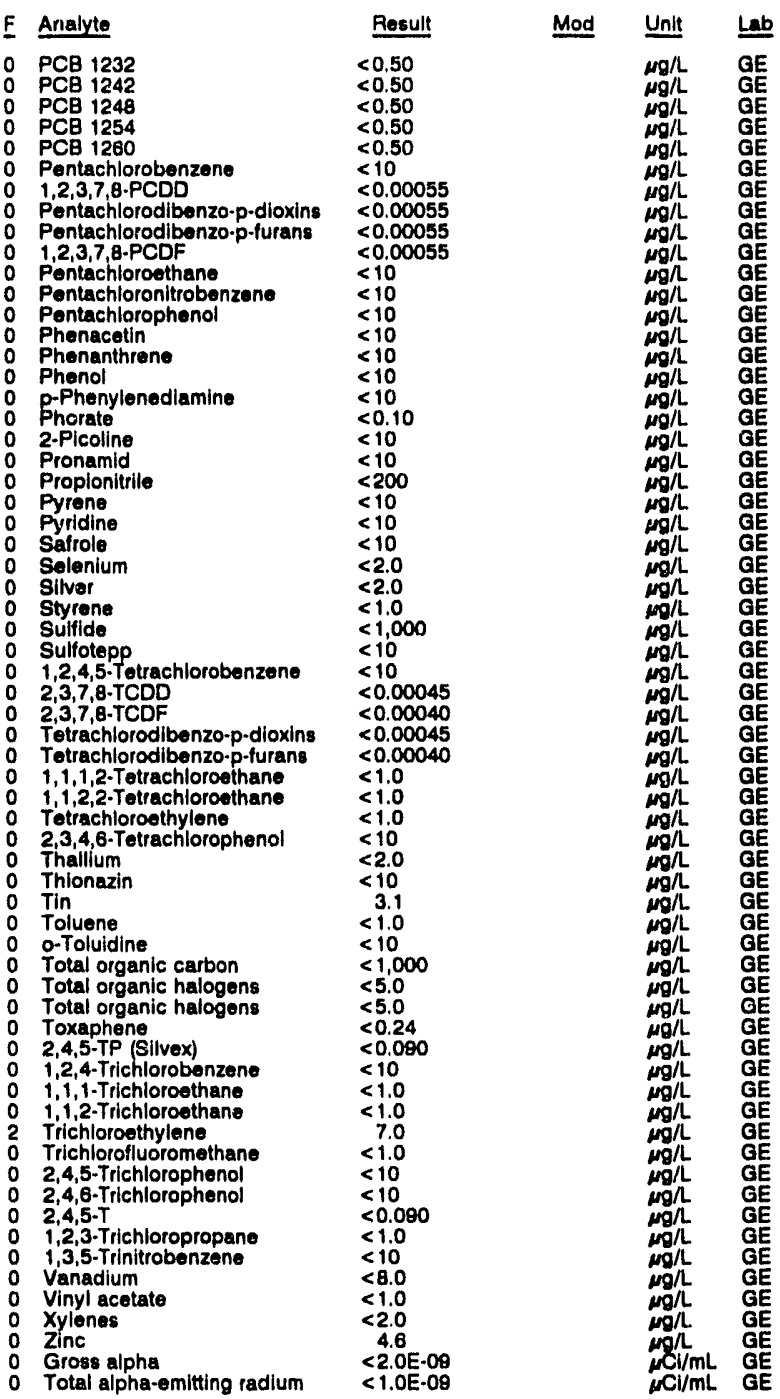

WELL AMB 7

MEASUREMENTS CONDUCTED IN THE FIELD

Sample date: 07/24/02

Depth to water: $136.54 \mathrm{ft}(41.62 \mathrm{~m})$ below TOC

Water elevation: $233.38 \mathrm{ft}(71.13 \mathrm{~m}) \mathrm{msl}$

Sp. conductance: $83 \mu \mathrm{S} / \mathrm{cm}$

The evacuated before sampling: 8 gal

LABORATOAY ANALYSES

\begin{tabular}{|c|c|c|c|}
\hline F Analyte & Peosult & Mod & Unit \\
\hline 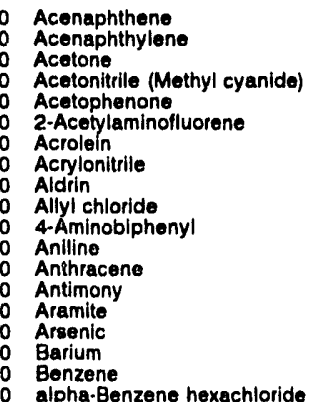 & $\begin{array}{l}<10 \\
<10 \\
<100 \\
<1.0 \\
<10 \\
<10 \\
<20 \\
<20 \\
<0.050 \\
<50 \\
<10 \\
<10 \\
<10 \\
2.1 \\
<10 \\
<2.0 \\
8.1 \\
<1.0 \\
<0.050\end{array}$ & & 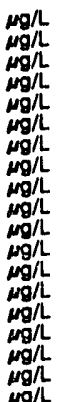 \\
\hline
\end{tabular}


ANALYTICAL RESULTS

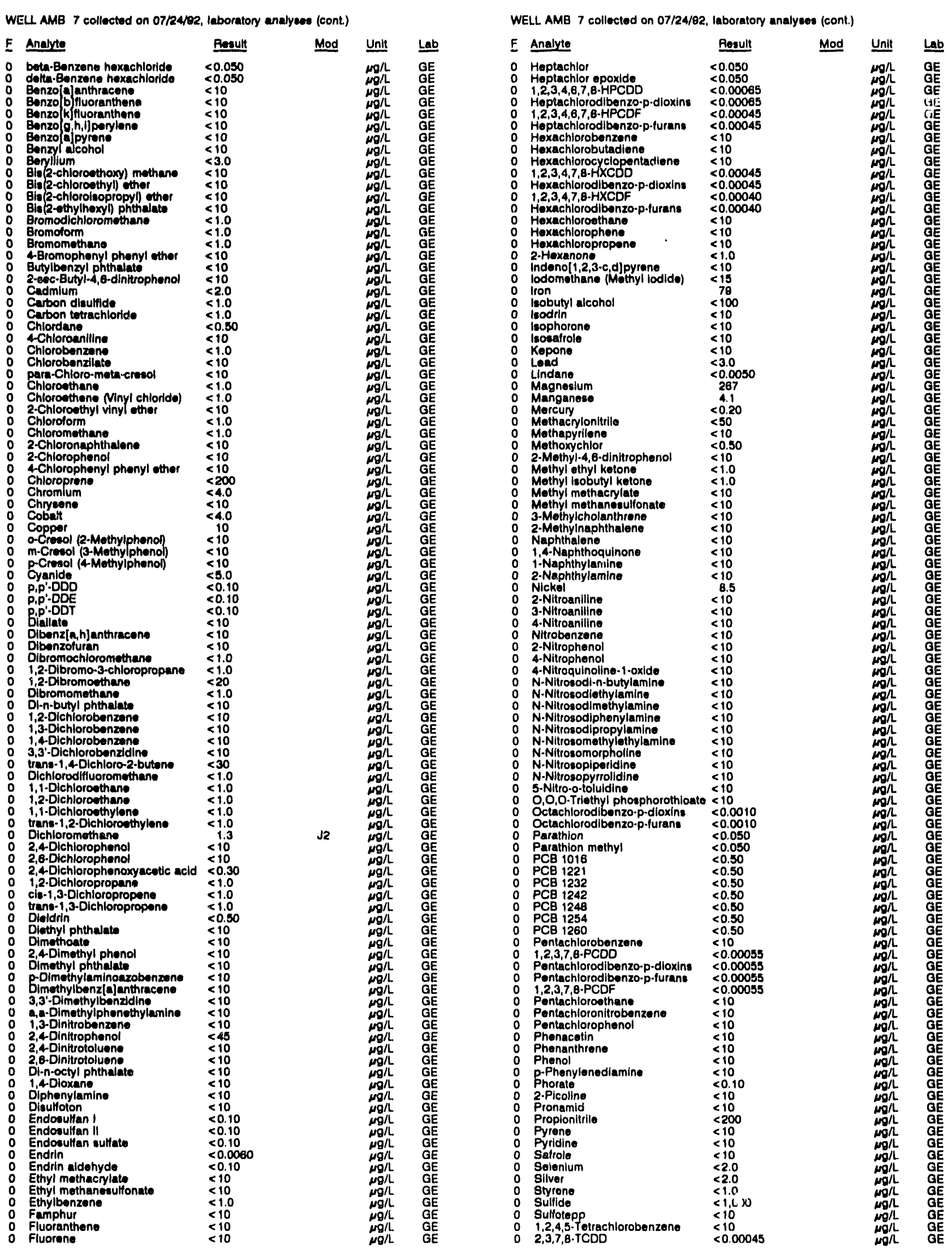


ANALYTICAL RESULTS

WELL AMB 7 collocted on 07/24/92, laboratory analyses (cont.)

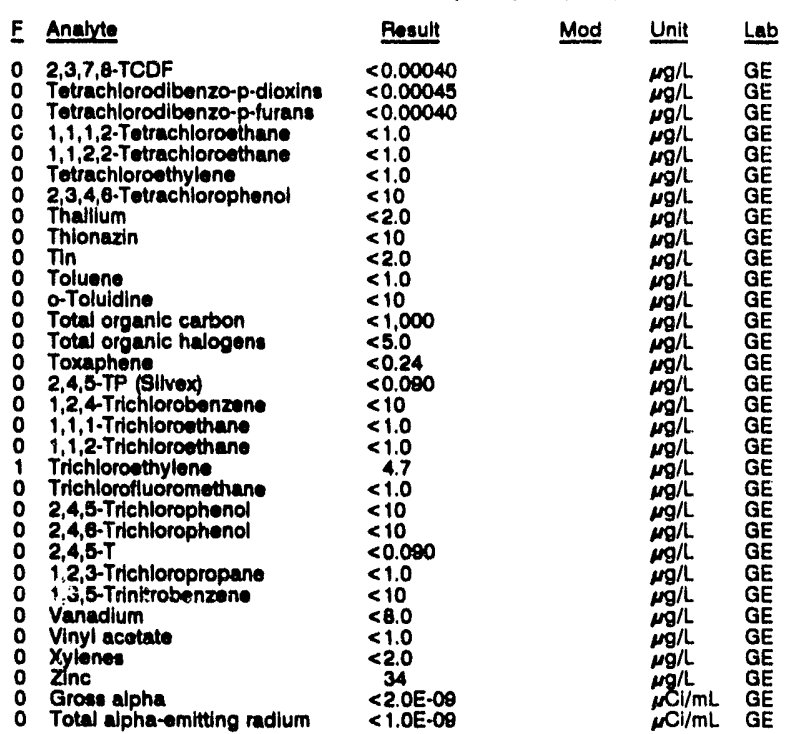

WELL AMB 7A

MEASUPEMENTS CONDUCTED IN THE FIELD

Sample dato: 07/23/92

Depth to water: $154.78 \mathrm{n}(47.18 \mathrm{~m})$ below TOC

Water elovation: $216.82 \mathrm{H} /(86.7$

Sp. conductance: $43 \mu \mathrm{s} / \mathrm{cm}$.

LABORATORY ANALYSES

\begin{tabular}{|c|c|}
\hline to & $\operatorname{los} 4$ \\
\hline 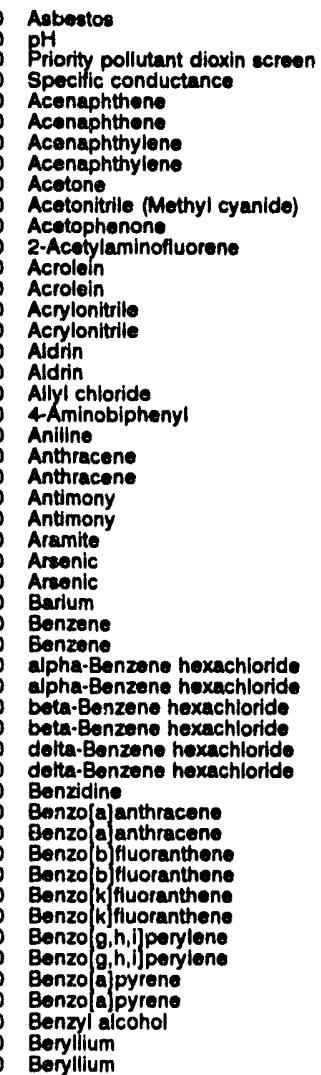 & $\begin{array}{l}\quad 10 \\
<10 \\
<10 \\
<10 \\
<10 \\
<100 \\
<100 \\
<1.0 \\
<10 \\
<10 \\
<20 \\
<200 \\
<200 \\
<20 \\
<200 \\
<0.050 \\
<0.050 \\
<50 \\
<10 \\
<10 \\
<10 \\
<10 \\
<10 \\
<2.0 \\
<2.0 \\
<10 \\
<2.0 \\
<2.0 \\
<1.0 \\
<1.0 \\
<10 \\
<0.050 \\
<0.0 \\
<0.050 \\
<0.050 \\
<0.050 \\
<0.050 \\
<0.050 \\
<10 \\
<10 \\
<10 \\
<10 \\
<10 \\
<10 \\
<10 \\
<10 \\
<10 \\
<10 \\
<10 \\
<10 \\
<10 \\
<3.0 \\
<3.0\end{array}$ \\
\hline
\end{tabular}

Time: 15:00

Alkalinity: $15 \mathrm{mg} / \mathrm{L}$

Water temperature: $21.3^{\circ} \mathrm{C}$

Rosult

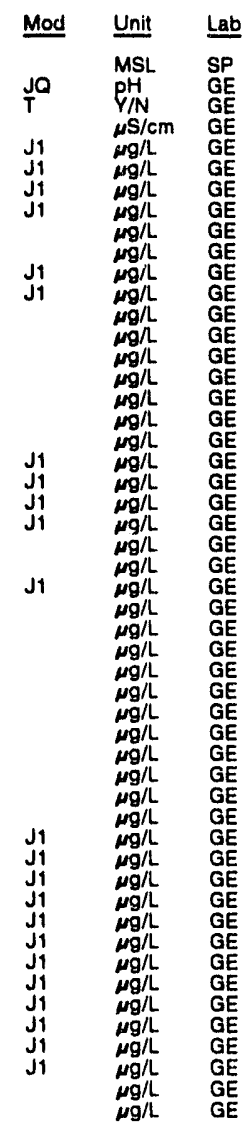

WELL AME 7A collected on 07/23/82, laboratory analyses (cont.)

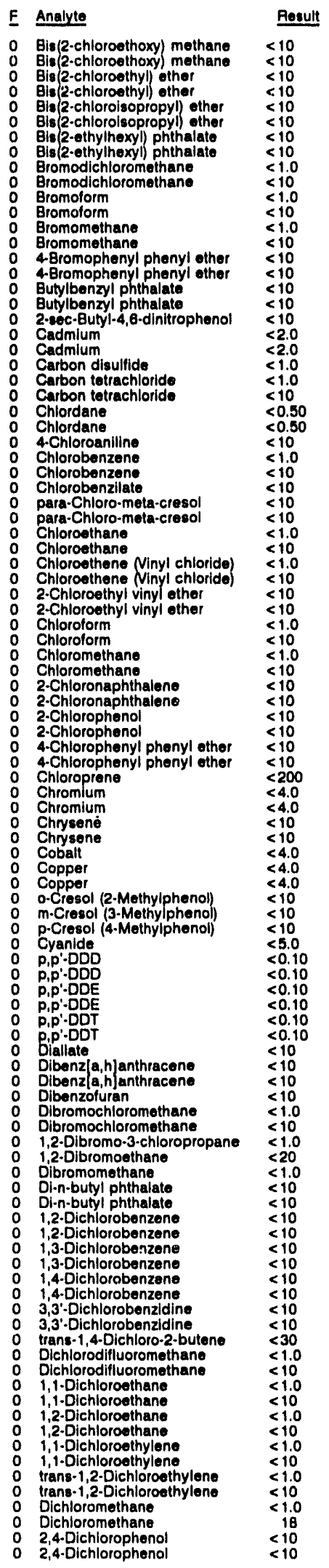


WELL AMB 7A collected on 07/23/92, laboratory unalyses (cont.)

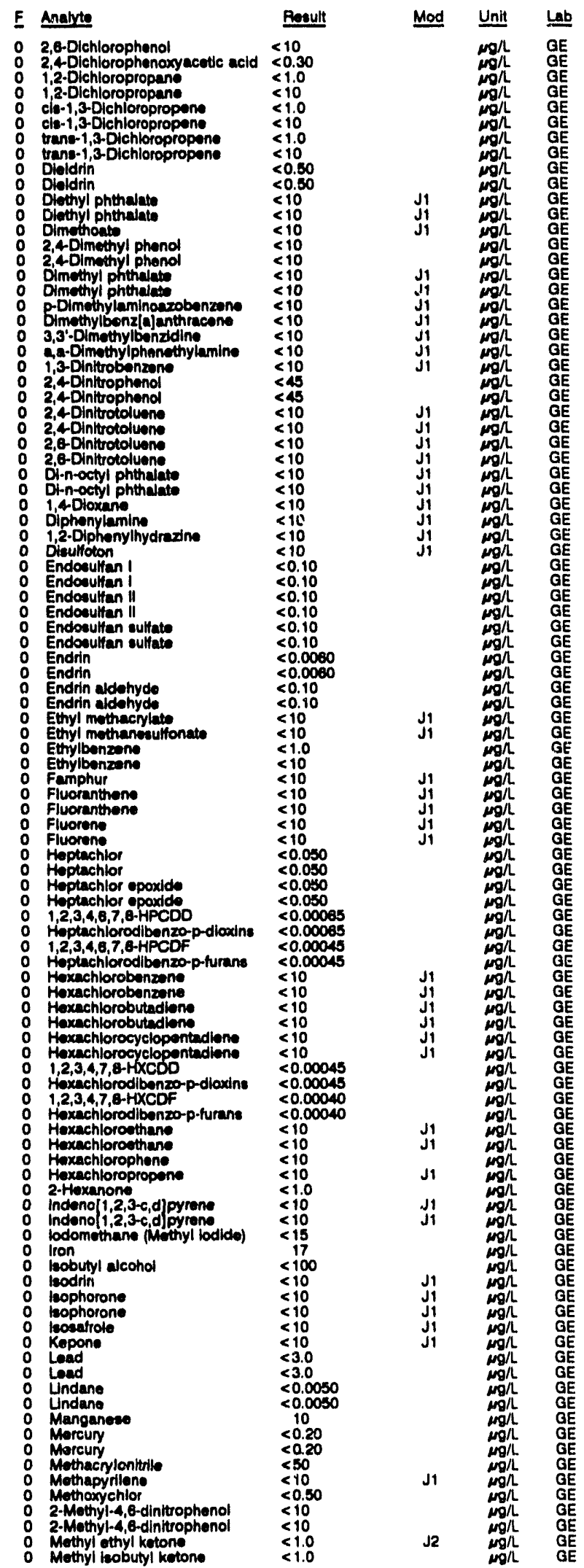

WELL AMB 7A collected on 07/23/82, laboratory analyees (cont)

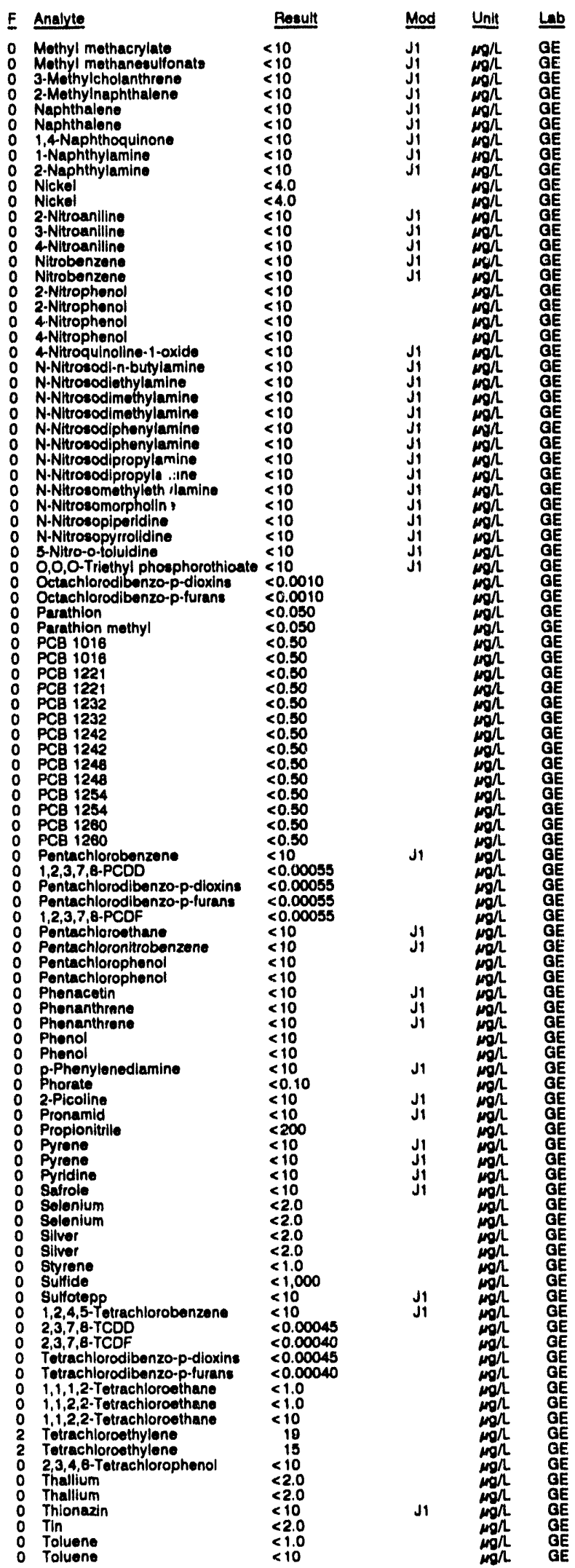


ANALYTICAL RESULTS

WELL AMB 7A collected on 07/23/82, laboratory analyees (cont.)

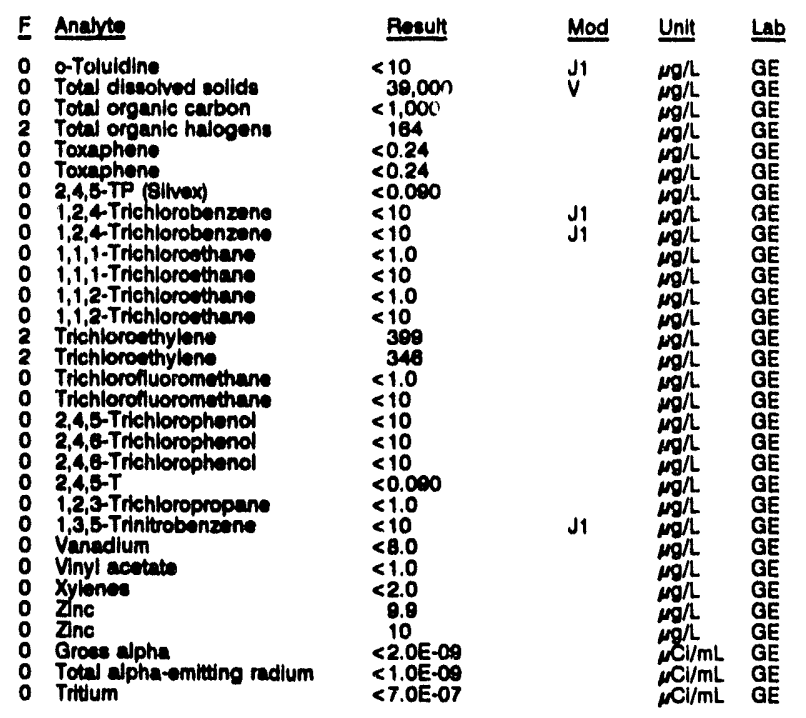

WELL AMB 7B

MEASUREMENTS CONDUCTED IN THE FIELD

Sample date: 07/23/82

Depth to water: 148.58 ( $145.20 \mathrm{~m}$ ) bolow TOC

Water elovation: $224.42 \mathrm{H}$ ( 89.44
Bp. conductance: $53 \mu \mathrm{cm}$

Witor evecuated before eampling: $188 \mathrm{gal}$

LABORATOAY ANALYSES

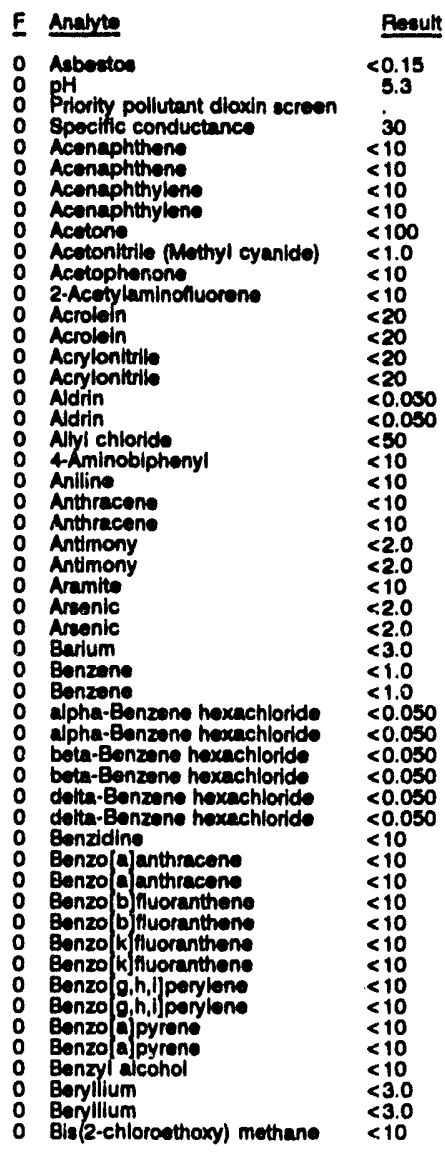

Time: 14:50

pH: 4.9

Water temperature: $20.1^{\circ} \mathrm{C}$
Lab
WELL AMB 78 collected on 07/23/82, laboratory analyses (cont.)

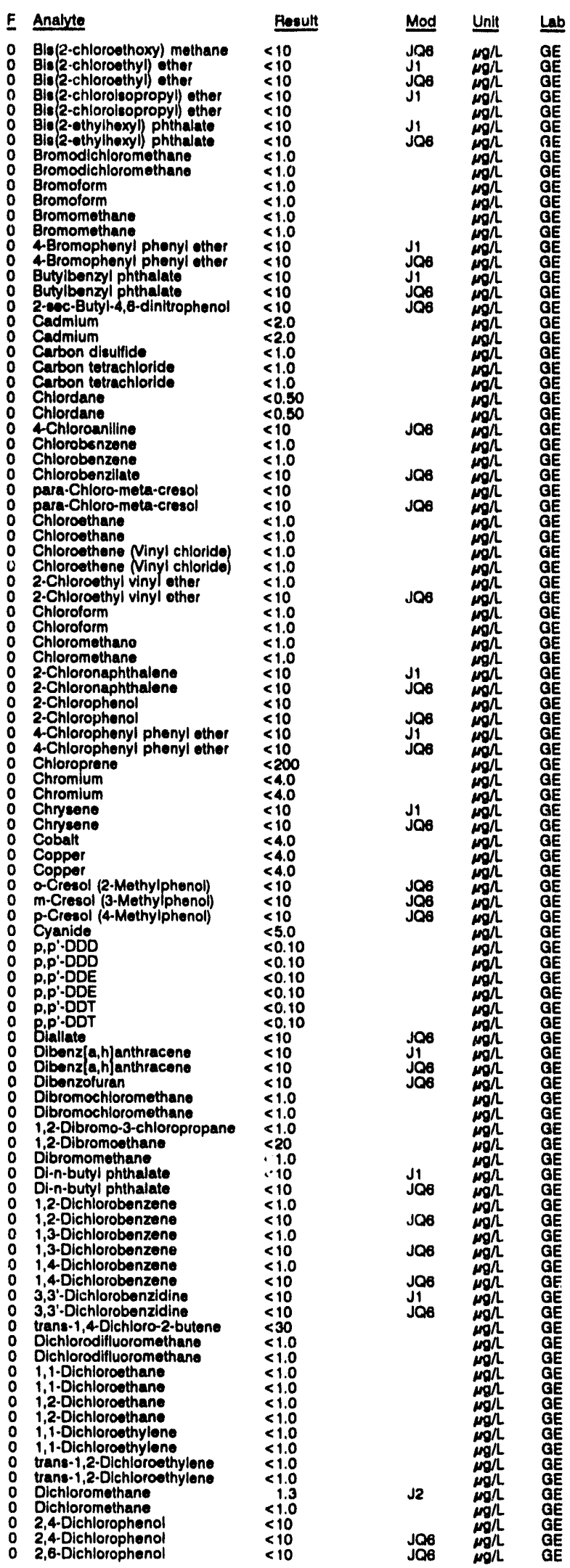


WELL AMB 78 collectod on 07/23/02, Laboratory analyeen (cont.)

\section{E Anearte}

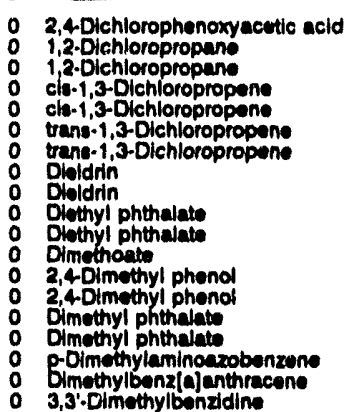

3,3'-Dimethylbenzidine

a a. Dimethylphonethylamine

o 24 -

0 2,4 Dintrophend

o 2,4Dinitrotoluen.

2.0.Dintrotoluene

Di-n-octyl phthalate

Di-n-octyl phthalato

0 1,40loxane

o Diphenylamine

Dibulfoton

Endocultan 1

Endoculfan I

Endoculfan II

Endocultan cullato

Endrin

Endrin aldohydo

Endrin wdohyde

Ethy! methacrylate

Ethylbenzens

O Ethylbenzan

F Fivoranthene

Fluoranthen

Fluorem

O Heptachlor

Heptachlor upoxido

Heptachlor epoxide

Heptachlorodlbenzo-p-dioxins

o
O Hipptachlorodibenzo-p-turane

Hoxachlorobonzens

H Hexachlorobutadiene

Hoxachlorobutadione

o Hexachorocyciopentadion

1,2,3,4,7,0-HecDo

Hoxachiorodibenzo-p-dloxins

o Hexachiorodibenzo-p-hurans

Hoxachloroethan

Hoxachloroethan

H Hexachlorophene

2-Haxanone

indono $[1,2,3-c, d]$ pyrene

Indenol $1,2,3-c$, djpyrene

: lion

l leobutyl alcohol

o leodrin

o teophorone

o koeafrole

o Kepone

0 Loed

o L Lindane

O Munganese

o Morcury

o Morcuny

o Mercury

Mothacrionitrile

Methapyrilene

Mothoxychio

2-Methyl-4,0-dinittrophenol

2-Methyl-4,8-dinitrophenol

Methyl ethyl ketone

Mothyl isobutyl ketone
$<0.30$

$<1.0$

$<1.0$

$<1.0$

$<1.0$
$<0.50$
$<0.50$

$\leq \leq 10$

$\leqslant 10$

$<10$

$<10$

$<10$

$<10$

$<10$

$<45$

$<10$

$<10$
$<10$
$<10$

$<10$

$<10$

$<10$
$<10$

$<0.10$
$<0.10$

$<0.10$

$<0.10$

$<0.0080$

$<0.10$

$<0.10$

$<10$

$<1.0$

$<1.0$

510
$\leq 10$
$<10$
$<10$

210
510
510
$<10$

$<0.050$

$<.050$
$<0.050$
$<0.000$

$<0.050$

$<0.00065$

$<0.00045$

$<0.00046$

$<10$
$<10$
$<10$
$<10$

$<10$
$<10$

$<10$
$<10$

$<0.00045$

\begin{tabular}{l}
0.00045 \\
\hline 0.00040
\end{tabular}

$<0.00040$

$<10$
$<10$

$<10$
$<10$
$<1.0$
$<10$

$<1.0$
$<10$

$<10$
$<15$

$<15$
5.1
$<100$

$<10$
$<10$

$<10$
$<10$
$<10$

$<10$
$<3.0$

$<3.0$
$<0.0050$

$<0.0050$
$<0.0050$

3.2

$<0.20$
$<0.20$
$<0.20$
$<50$

$<50$
$<10$

$<0.60$

$<10$

$<1.0$
$<1.0$

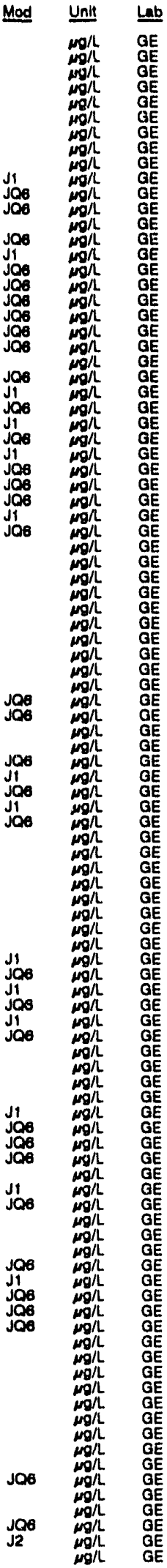

WELL AMB 78 collected on 07/23/82, laboratory analyees (cont.)

E Analyte

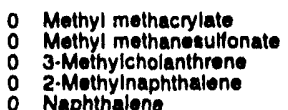

Naphthalene

1,4-Naphthoquinone

2-Naphthylamine

Nickol

2.Nitroaniline

3. Nitroaniline

4.Nitroaniline

Nitrobenzane

2-Nitrophenol

2-Nitrophenol

4-Nitrophenol

4.Nitroquinoline-1.oxlde

N-Nitrosodi-n-butylamine

N-Nitrosodimothylamine

N-Nitrosodimathylamine

N.Nitrosodiphenyiamine

N-Nitrosodiphenylamine

N-Nitrosodipropylamino

N.Nitrosomethylethylamine

N-Nitrosomorpholine

N-Nitrosoplperidine

N-Nitrosopyrrolidino

5-Nitro-0-10luidine

Oreso

Octachlorodibenzo-p.dioxin

Parathion

Parathion mothyl

\begin{tabular}{l} 
PCG 1016 \\
0.10 \\
\hline
\end{tabular}

- PCE 1221

PCB 1232

PCB 1232

PCB 1242

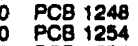

PCB 1254

PCB 1260

Pentachlorobonzono

Pentichlofodibenzo-p-dloxins

Pentachlorodibenzo-p-furams

$1,2,3,7,8 \cdot P C O F$

Pentachloronitrobonzene

Pentachlorophenol

Pentachloropheno

Phonanthrone

O Phonanthrone

o Phonol

p-Phonylenediamine

0 Phorate

2-Picoline

0 Proplonitrile

0 Pyrene

0 Pyrene

Salrolo

o Solenium

Silver

Silver

S Styrene

0 Sulfotepp

o 1,2,4,5-Potrachlorobenzene

$2,3,7,6 \cdot T C D D$

2,3,7,8-TCDF

Totrachlorodibenzo-p-dioxine

i, 1,2 Trachlocothane

1,

Totrachloroethylene

23,46.Totrachlorophenol

o Thallium

Thallium

Tin

Tolvene

Toluene
$<10$
$<10$

$<10$

$<10$

$<10$

$<10$
$<10$

$<10$
$<4.0$

$<4.0$
$<10$
$<10$
$<10$

$<10$
$<10$

$<10$

$<10$
$<10$

$<10$
$<10$

$<10$

$<10$

$<10$

$<10$

$<10$

$<10$

$<10$

$<10$

$<0.0010$

$<0.0010$
$<0.050$

$<0.050$

$<0.30$

$<0.50$

$<0.50$

$<0.50$

$<0.50$

$<0.50$

$<0.50$
$<0.50$

$<0.50$

$<0.50$

$<0.50$

$<0.0005$

$<0.00055$

$<0.00055$

$<10$

$<10$

$<10$
$<10$

$<10$

$<10$

$<10$
$<10$
$<10$
$<10$

$<10.10$

$<10$
$<10$

$<200$

$<10$

$<10$
$<10$

$<10$

$<2.0$

$<2.0$

$\leq 1.0$

$<1,000$

$<10$

$<0.00045$

$<0.00040$

$<0.00040$

$<1.0$

$<1.0$

$<1.0$

$<1.0$

$<10$

$<2.0$
$<10$

$<2.0$
$<2.0$

$<2.0$
$<1.0$
$<1.0$

Mod Unit Let

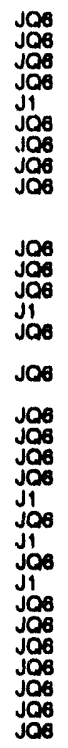

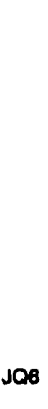

Jo9

$J 08$
$J 06$

Jas
Ja6

JOO

$J^{200}$

$\mathrm{J} 06$
$\mathrm{JCO}$

$J 1$
$j \propto 6$
$j \propto 6$
$j 08$ 
ANALYTICAL RESULTS

WELL. AMB 78 colloctad on 07/23/82, laboratory analyees (cont.)

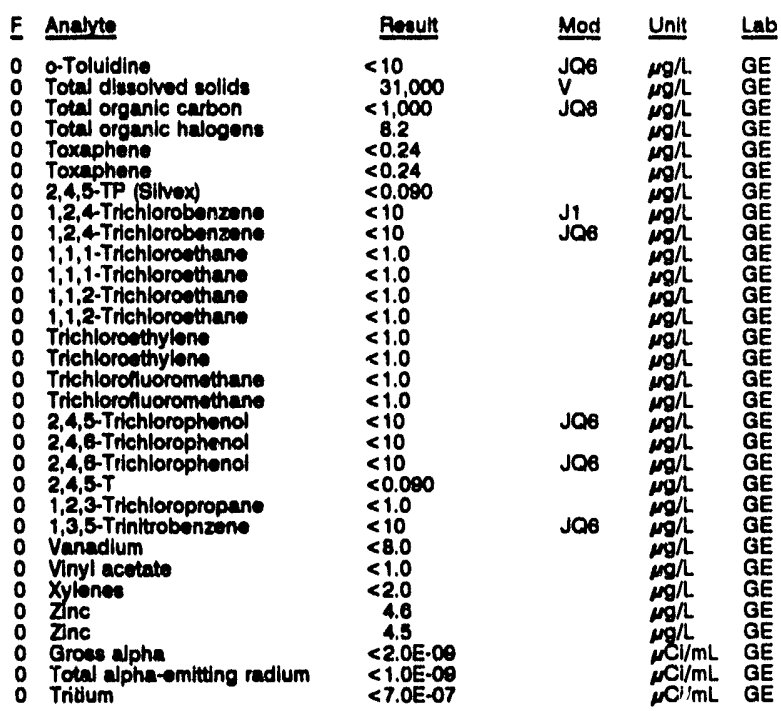

WELL AMB 8D

MEASUREMENTS CONDUCTED IN THE FIELD

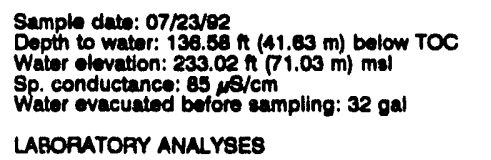

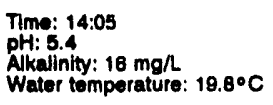

F Analyte

o Acenaphthene

0 Acetone

Acetone

Acetophenone

Acrolein

o Acrylon

Aldin

4-Aminobiphenyl

o Aniline

Anthracene

Aramite

Arsenic

Doha-Benzene hoxachloride

beta-Benzene hoxachloride

beta-Benzene hoxachlorids

Benzo(a)enthracene

Benzo b fluoranthen

Benzo g, h,ilperylene

Benzold pyrone

Benzyl alcohol

Beryllium

Bis (2-chloroethyl) ether

Bis (2-chlorolsopropyl) ether

Bis(2-ethylhexy) phthalate

Bromodich

Bromomethane

4-Bromophenyl phonyl cthor

2-eoc-Buty

Carbon disulfide

Carbon tistrachloride

Chlordane

4-Chloroaniline

Chlorobenzene

para-Chioro-meta-cresol

Chloroethane

o Chloroethene (Ninyl chloride)

2-Chloroothyl vinyl ether

Chlorotorm

2-Chloronaphthalene
2-
WELL AMB BD collected on 07/23/92, laboratory analyses (cont.)

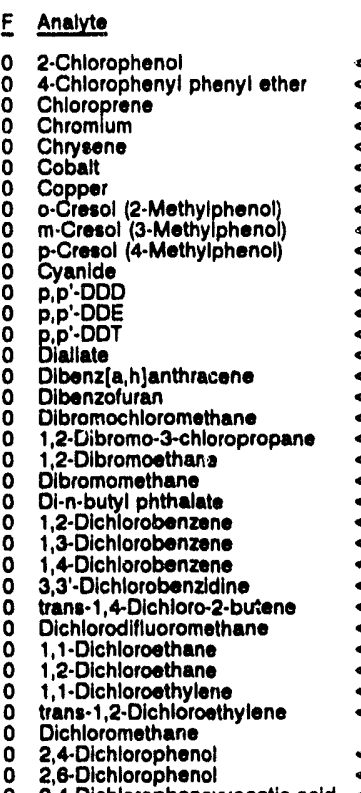

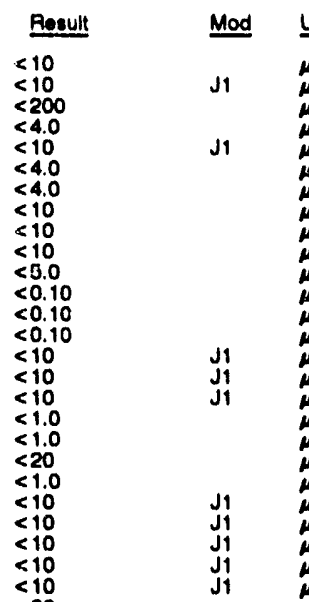

$<30$

$<1.0$

$<1.0$

$<1.0$

1.2
$<10$
$<10$

2,4-Dichlorophenoxyacetic acid $<0.30$

2,4-Dichlorophenoxyacetic acld $<0.30$

1,2-Dichloropropane

trans-1,3-Dichloropropene

Dieldrin

Diethyl phthalate

2,4-Dimethyl phenol

Dimethyl phthalate

Dimethylbenz [a]anthracene

0 3,3'-Dimethylbenzidine

a,a-Dimethylphenethylamine

2,3-Dinitrobenzone

2,4-Dinitrotoluene

o 2,6-Dinitrotoluene

$\begin{array}{ll}0 & \text { Di-n-octyl phthalate } \\ 0 & 1,4-\text { Dloxane }\end{array}$

Diphenylamin

D Disulfoton

o Endosulfan I

O Endosulfan sulfate

0 Endrin aldehydo

O Ethyl methacrylate

0 Ethyl methanesul

0 Ethylbenzene
0 Famphur

o Fluoranthene

0 Fluorene

Heptachlor epoxide

0 1,2,3,4,6,7,8-HPCDD

o Heptachlorodibenzo-p-dioxins

$1,2,3,4,6,7,8 \cdot H P C D F$
0 Hoptachlorodibenzo-p-furans

Hexachlorobenzene

O Hoxachlorobutadiene

o Hoxachlorocyclopentad

o Hexachlorodibenzo-p-dioxins

$1,2,3,4,7,8 \cdot \mathrm{HXCDF}$

Hexachlorodibenzo-p-turans

o Hexachloroethane

Hexachlorophene

Hexachloroprope

$\begin{array}{ll}0 & 2 \cdot H e x a n o n e \\ 0 & \text { Indenol1,2,3-c, d]pyrene }\end{array}$

o lodomethane (Methyl lodide)

0 lion

o lsobutyl alcohol

o Isodrin

o leophorone

o lsosafrole

0 Kepone

0 Lead

- Magnesium

o Manganese

o Mercury

o Methapyrilene

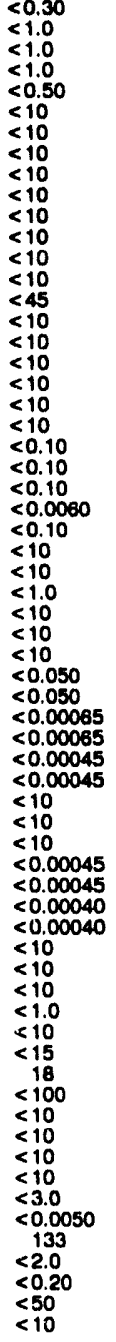

$<10$
$<10$

$<10$
$<0.00045$

$<0.00045$

$<0.0004$

$<10$

$<10$
$<1.0$

10

18

$\leq 10$

10

0.0050

0.20

$<10$

Unit Lab

$\mu g / L \quad G E$

ag

GE

E

GE

GE

GE

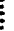

E

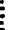

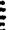

跣 
WELL AMB 80 collocted on 07/23/92, laboratory analyses (cont.)

E Anave

Methoxychior 2. Methyl-4,6-dintrophenol

Mothyl bobutyl keton

Methyl methanepultonate

2-Methylcholanthrene

Naphthalene

i.Nephthylamino

2-Naphthyiamine

2-Nitroaniline

3-Nitroaniline

ANitrownillime

2.Nitrophenol

4Nitrophenol

4-Ntroquinoline-1-oxdde

N-Nitrocodj-n-butylamino

N-Nitrocodiethylamino
N-Nitroeodimethylamino
N-Nitrocodiphenylamine

N-Nitrosodiphenylamine $<$

N-Nitrosomethylethyliumine

N-Nitrosomorpholins

N-Nitrocopliperidin

O N-Nitrosopycrolidine

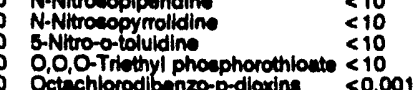

o Octachlorodibenzo-p-furane $\quad<0.0010$

- Parathion

Parathion methyl $<0.050$

$\begin{array}{ll}0 \mathrm{PCB} 1221 & <0.50 \\ 0 & <0.50\end{array}$

PCB $1242<<0$

0 PCB $1246 \quad<0.50$

$\begin{array}{lll}0 & \text { PCE } 1234 & <0.50 \\ 0 & \text { PCE } 1200 & <0.50\end{array}$

o Pentachlorobenzano

o 1,2,3,7,8-PCOD

o Pentachlorodlbenzo-p-furans

o 1,2,3,7, \&-PCOF

o Pentachloroethane

o Pentachlorophenol

Phenacetin

0 Phenanthrer

P.Phenylenediamine

o Phorato

o 2-Picoline

o Proplonituilo

Pyrene

o Pyridin

o Eelenium

o Sitver

o Surinde

O Sulfotep

1,2,4,5-Tetrachlorobenzene

2,3,7,8-TCDD

0 Tetruchlorodibenzo-p-dioxins $<0.0004$

o Tetrachlorodibenzo-p-furans

1,1,2 Tetrechloroethans

1,1,2,2-Tetrachloroethan

2,3,4,6-Tetrachlorophenol

Thallum

O Thion

O Toluene

o Total organic carton

- Total oroanic halogens

- Toxaphono

0 2,4,5-TP Bitwax

o 1,2,4-Trichlorobonzane

o $1,1,1$-Trichloroethane

1,1,2-Trichloroethan

Trichloroethylone

o 2,4,5-Trichlorophenol

2,4,5-Thiorophenol

O 2,4,3-T

0 1,2,3-Trichloropropane

o 1,3,5-Trinterobenzent

- Vanedium

0 Vinyl acot

O Xylenea

Pesuit

1.0

$<10$

$<10$
$<10$

10

4.0

10

$<10$

(10

(1)

$<10$

$<10$
$<10$

$<10$
$<0.00055$

$<0.00055$

$<0.000$

$<10$
$<10$
$<10$

$<10$

$<10$
$<10$

$<10$

$<10$
$<10$

$<200$

$<10$
$<10$

$<2.0$

(1)

$<1,000$

$<0.00004$

$<1.0$
$<1.0$
$<1.0$
$<10$

$<10$

$<2.0$
$<10$
$<20$

$<2.0$

$<10$

$<1,000$

$<0.24$

$<0.000$

$<10$

$<1.0$

$<1.0$
$<1.0$

$<1.0$

$<10$

$<0.090$

$<1.0$

$<10$

$<8.0$

$<1.0$
$<2.0$
2.3

Mod Unit

Lab

$\mu / L$ GE

GE

E

WELL AMB $8 D$ collected on 07/23/02, laboratory analysese (cont.)

\begin{tabular}{|c|c|c|c|c|}
\hline$F$ & Analyte & Result & Mod & Unit \\
\hline 0 & $\begin{array}{l}\text { Grose alpha } \\
\text { Total alpha-emitting radium }\end{array}$ & $\begin{array}{r}2.0 \mathrm{EE} \cdot 0 \\
<1.0 \mathrm{E} \cdot 0\end{array}$ & & $\stackrel{\mu \mathrm{Cl} / \mathrm{mL}}{\mathrm{NCl} / \mathrm{mL}}$ \\
\hline
\end{tabular}

WELL AMB 9D

MEASUREMENTS CONDUCTED IN THE FIELD

\begin{tabular}{|c|c|}
\hline 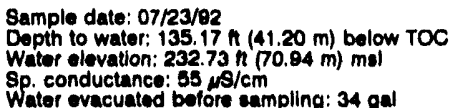 & $\begin{array}{l}\text { Time: } 13: 45 \\
\text { pH: } 5.3 \\
\text { Alkalinity: } 9 \mathrm{mg} / \\
\text { Water tomperature: } 21.5^{\circ} \mathrm{C}\end{array}$ \\
\hline BOPATORY ANALYSES & \\
\hline
\end{tabular}

F Anabyte Rowult Mod Unit Lab

0 Aconaphthene

Acenaphthylene

$<10$

o Acetonitrile (Methyl cyanide)

Acetophenone

Acrolein

A Acrylonitril

Alyl chloride

4Aminobliphenyl

Anllino

Antimony

Aramite

Arrenic

0 Barium

alpha-Benzene hoxachloride

o beta-benzene hoxachioride

delta-Benzene hexachloride

Benzolalanthracene

Benzo b) Huoranthene

Benzo gh,ilperylene

Benzola pyrene

Banzyl alco

Bia(2-chloroethoxy) mothane

Bis (2-chloroethyl) ather

Bis(2-ethylhoxyl) phithalate

Bromodichioromothane

Bromolorm

Aromomethane

Butylbenzyl phthalate

2-ese-Buty-4

O Cadmium

Carbon disulfide

Carbon totrachloride

Chlordane

4-Chloroanilline

Chlorobenzene

para-Chloro-meta-cresol

Chloroothene Minyl chloride)

Chlorosthene Minyl chloride

Chlorolorm

Chloromethane

2-Chloronaphthalen

2.Chlorophenol
4-Chlorophenyl phenyl ether

O Chloroprene

o Chromium

o Chryean

o Cobalt

o o-Cresol (2-Methylphenol)

o m-Cresol (3-Methylpheno)

m-Cresol (3-Mothy phono)

o p-Cresol

0 P,P'DDD

0 P.P'-DDE

0 Biallato

o Dibenz[a,h]anthracene

D Dibenzofuran

o Dibromochloromothane

1,2.Dibromo-3-chloroprop

o 1,2-Dibromoethane

D Dibromomethane

o Di-n-butyl phthalate

o 1,2-Dichlorobenzene

1,4-Dichlorobenzente

o 3,3 -Dichlorobenzidine

trans-1,4-Dichloro-2-buten

o 1,1-Dichloroethane

$<10$

$<1.0$

$<10$

$<10$

$<0.050$

$<50$

$<10$

$<10$
$<10$
$<2.0$

$<2.0$
3.4
$<1.0$

$<0.050$

$<0.050$
$<0.050$

$<10$
$<10$

$<10$
$<10$

$<10$

$<10$

$<3.0$
$<10$
$<10$
$<10$

$<10$
$<10$

$<1.0$

$<1.0$

$<10$

$<10$
$<10$
$<10$

$<2.0$

$<1.00$

$<0,50$
$<10$

$<1.0$

$<10$
$<10$

$<1.0$
$<1.0$

$<1.0$
$<10$

$<1.0$

$<1.0$
$<10$

$<10$
$<10$

$<200$
$<4.0$

$<10$
$<4.0$
$<.7$
$<10$

$<10$
$<10$

$<10$

$<5.0$

$<0.10$
$<0.10$
$<0.10$

$<10$
$<10$

$<10$
$<10$

$<1.0$

$<20$
$<1.0$
$<10$
$<10$

$<10$
$<10$

$<10$
$<10$

$<30$
$<10$

$<1.0$
$<1.0$

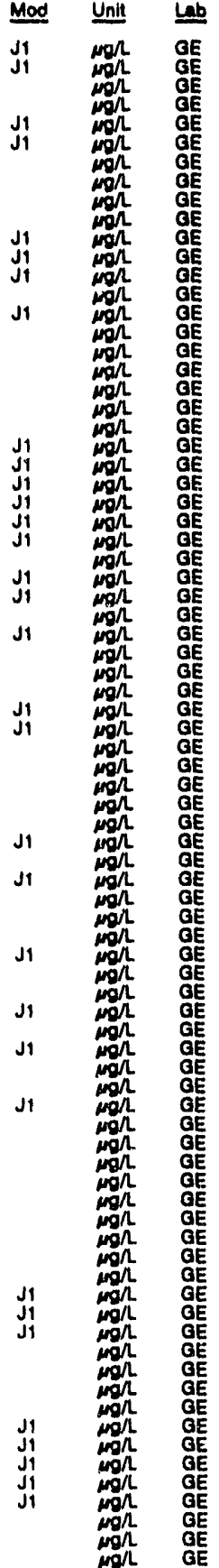


ANALYTICAL RESULTS

WELL AM8 00 collected on 07/23/92, laboratory analysos (cont.)

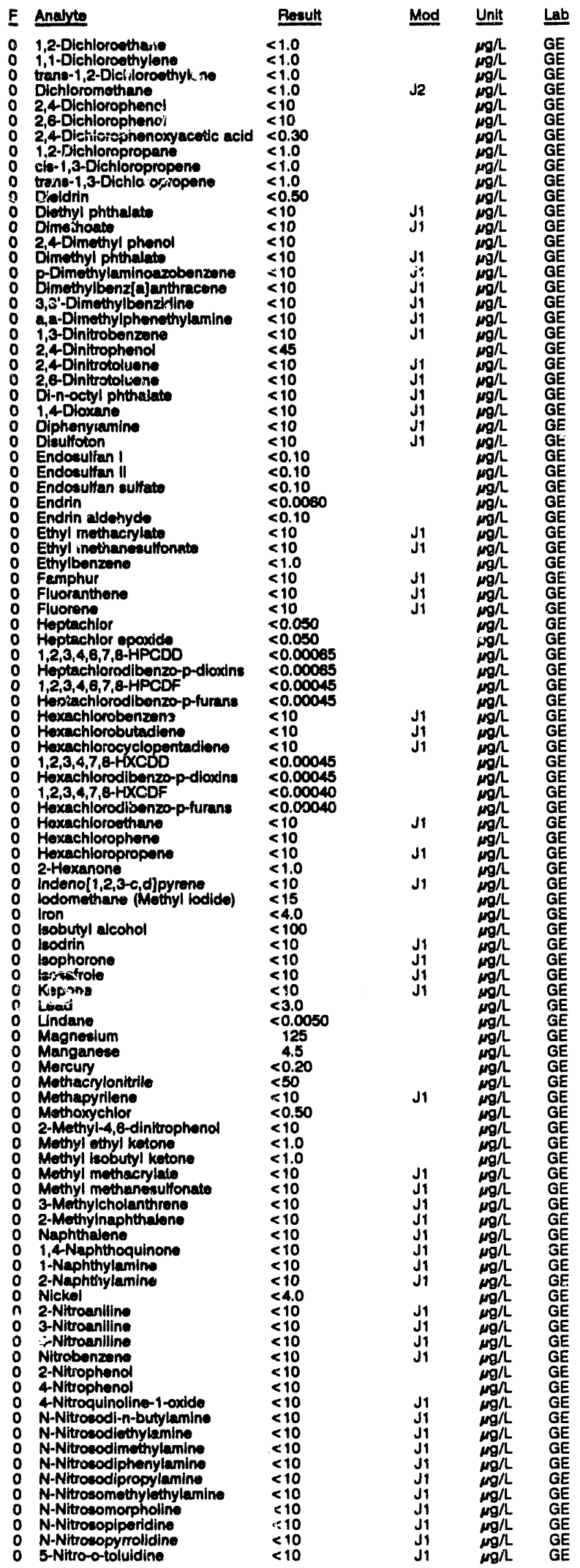

WELL AMB 9D collected on 07/23/82, laboratory analyses (cont.)

\begin{tabular}{|c|c|c|c|c|c|}
\hline & Analyte & Rosult & Mod & Unit & Lab \\
\hline $\begin{array}{l}0 \\
0 \\
0 \\
0 \\
0 \\
0 \\
0 \\
0 \\
0\end{array}$ & 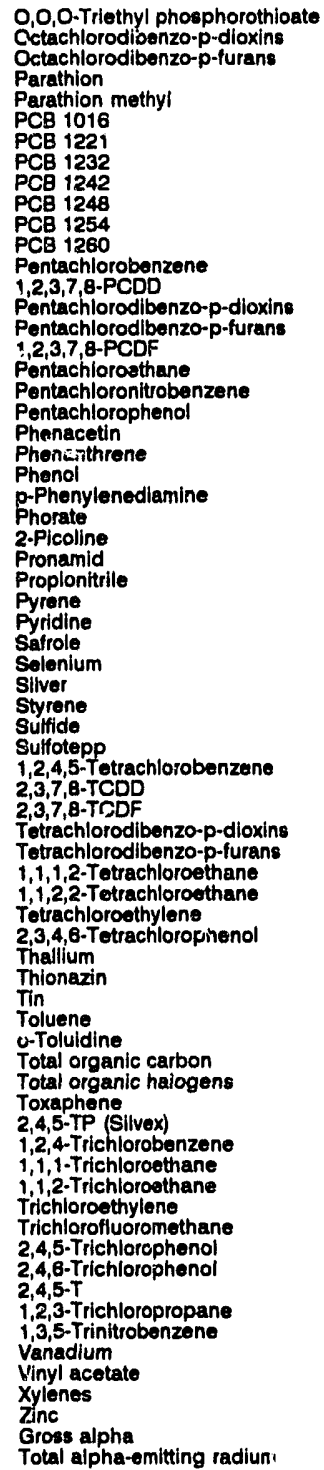 & $\begin{array}{l}<10 \\
<0.0010 \\
<0.0010 \\
<0.050 \\
<0.050 \\
<0.50 \\
<0.50 \\
<0.50 \\
<0.50 \\
<0.50 \\
<0.50 \\
<0.50 \\
<10 \\
<0.00055 \\
<0.00055 \\
<0.0055 \\
<0.00055 \\
<10 \\
<10 \\
<10 \\
<10 \\
<10 \\
<10 \\
<10 \\
<0.10 \\
<10 \\
<10 \\
<200 \\
<10 \\
<10 \\
<10 \\
<2.0 \\
<2.0 \\
<1.0 \\
<1,000 \\
<10 \\
<10 \\
<0.00045 \\
<0.00040 \\
<0.00045 \\
<0.00040 \\
<1.0 \\
<1.0 \\
<1.0 \\
<10 \\
<2.0 \\
<10 \\
<2.0 \\
<1.0 \\
<10 \\
<1,000 \\
<5.0 \\
<0.24 \\
<0.090 \\
<10 \\
<1.0 \\
<1.0 \\
<1.0 \\
<1.0 \\
<10 \\
<10 \\
<0.090 \\
<1.0 \\
<10 \\
<8.0 \\
<1.0 \\
<2.0 \\
23 \\
<2.0 E-09 \\
1.7 E .09 \pm 8.0 E-1 C\end{array}$ & $\begin{array}{l}\text { J1 } \\
\text { J1 } \\
\text { J1 } \\
\text { J1 } \\
\text { J1 } \\
\text { J1 } \\
\text { J1 } \\
\text { J1 }\end{array}$ & 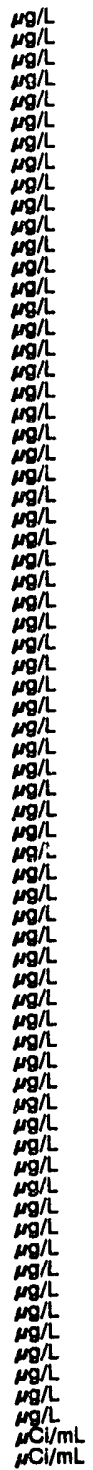 & $\begin{array}{l}\mathrm{GE} \\
\mathrm{GE} \\
\mathrm{GE} \\
\mathrm{GE} \\
\mathrm{GE} \\
\mathrm{GE} \\
\mathrm{GE} \\
\mathrm{GE} \\
\mathrm{GE} \\
\mathrm{GE} \\
\mathrm{GE} \\
\mathrm{GE} \\
\mathrm{GE} \\
\mathrm{GE} \\
\mathrm{GE} \\
\mathrm{GE} \\
\mathrm{GE} \\
\mathrm{GE} \\
\mathrm{GE} \\
\mathrm{GE} \\
\mathrm{GE} \\
\mathrm{GE} \\
\mathrm{GE} \\
\mathrm{GE} \\
\mathrm{GE} \\
\mathrm{GE} \\
\mathrm{GE} \\
\mathrm{GE} \\
\mathrm{GE} \\
\mathrm{GE} \\
\mathrm{GE} \\
\mathrm{GE} \\
\mathrm{GE} \\
\mathrm{GE} \\
\mathrm{GE} \\
\mathrm{GE} \\
\mathrm{GE} \\
\mathrm{GE} \\
\mathrm{GE} \\
\mathrm{GE} \\
\mathrm{GE} \\
\mathrm{GE} \\
\mathrm{GE} \\
\mathrm{GE}\end{array}$ \\
\hline
\end{tabular}

WELL AMB 10A

MEASUREMENTS CONDUCTED IN THE FIELD

Sample date: 07/23/92

Depth to water: $148.18 \mathrm{ft}(45.47 \mathrm{~m})$ below TOC

Water elevation: $217.32 \mathrm{ft}(68.24 \mathrm{~m}) \mathrm{msl}$

Water evacuated before sampling: 75 gal

Alkalinity: $221 \mathrm{mg} / \mathrm{h}$

The well went dry during purging.

LARORATORY ANALYSES

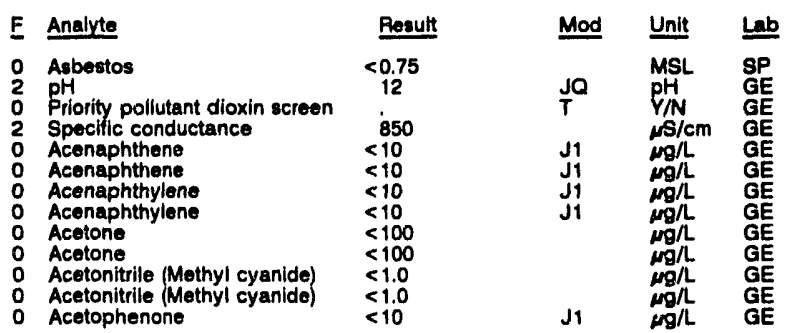


ANALYTICAL RESULTS

WEL AMB 10A collected on 07/23/92, laboratory analyses (cont.)

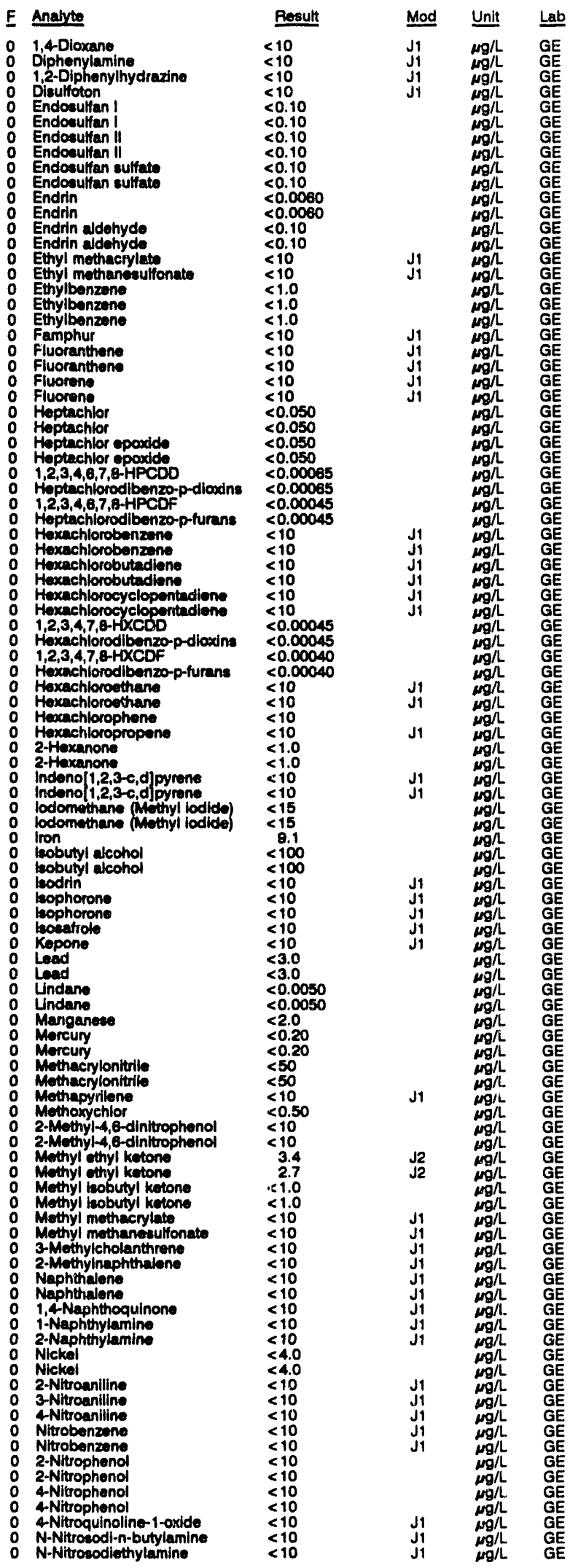

WELL. AMB 10A collected on 07/23/82, laboratory analyses (cont.)

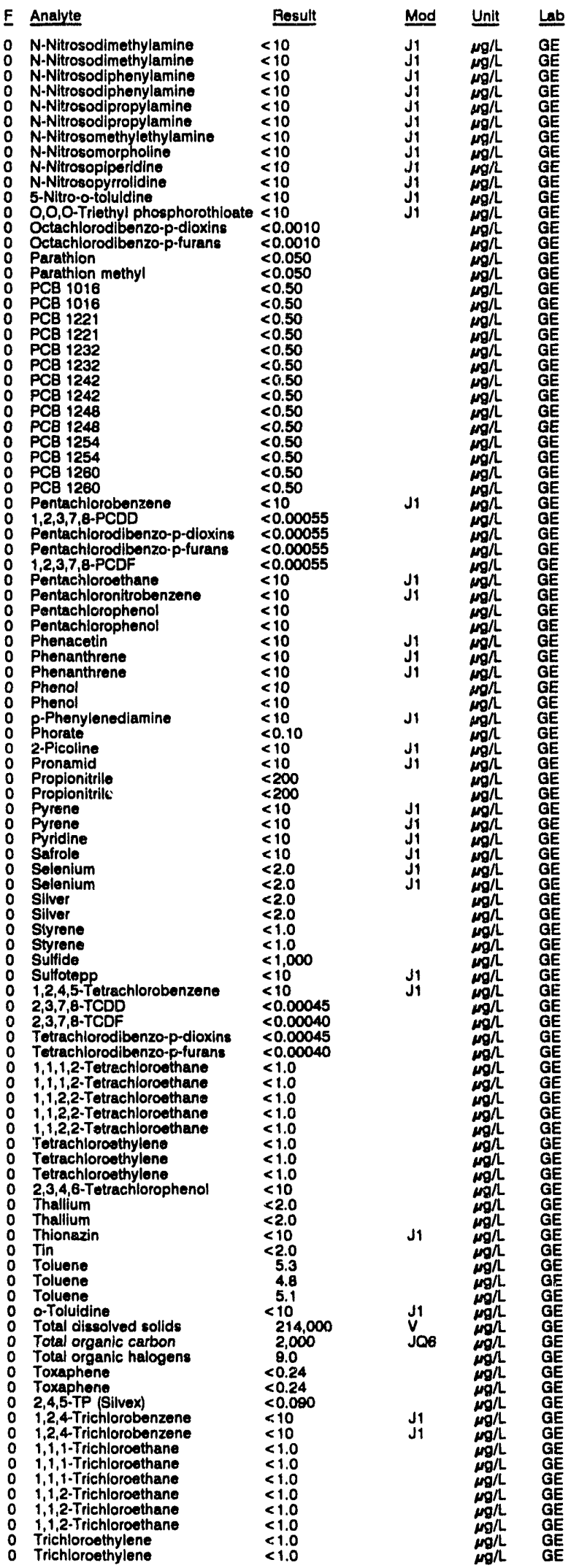


WELL AMB 104 collectod on 07/23/82, laboratory analyees (cont.)

\begin{tabular}{|c|c|c|c|c|c|}
\hline & Analyte & Result & Mod & Untt & Lab \\
\hline $\begin{array}{l}0 \\
0 \\
0 \\
0 \\
0 \\
0\end{array}$ & 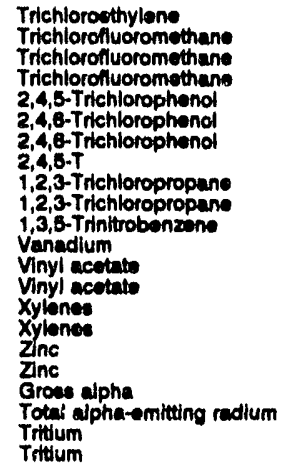 & $\begin{array}{l}<1.0 \\
<1.0 \\
<1.0 \\
<1.0 \\
<10 \\
<10 \\
<10 \\
<0.000 \\
<1.0 \\
<1.0 \\
<10 \\
10 \\
<1.0 \\
<1.0 \\
<2.0 \\
<2.0 \\
<2.0 \\
<2.0 \\
<2.0 E-09 \\
2.0 E-09 \pm 1.1 E-09 \\
<7.0 E-07 \\
<7.0 E-07\end{array}$ & J1 & 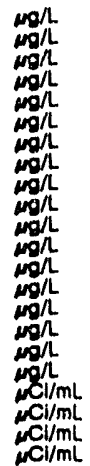 & $\begin{array}{l}G E \\
G E \\
G E \\
G E \\
G E \\
G E \\
G E \\
G E \\
G E \\
G E \\
G E \\
G E \\
G E \\
G E \\
G E \\
G E \\
G E \\
G E \\
G E \\
G E \\
G E \\
G E\end{array}$ \\
\hline
\end{tabular}

\section{WELL AMB 10B}

MEASUREMENTS CONDUCTED IN THE FIELD

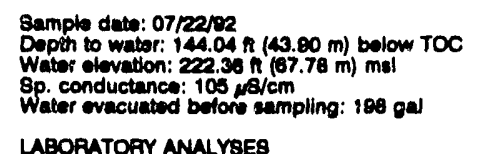

Time: $14: 20$

Alkalinity: $40 \mathrm{mon}$

Wator tempernture: $22.00 \mathrm{C}$

\section{LABORATOFY ANALYSES}

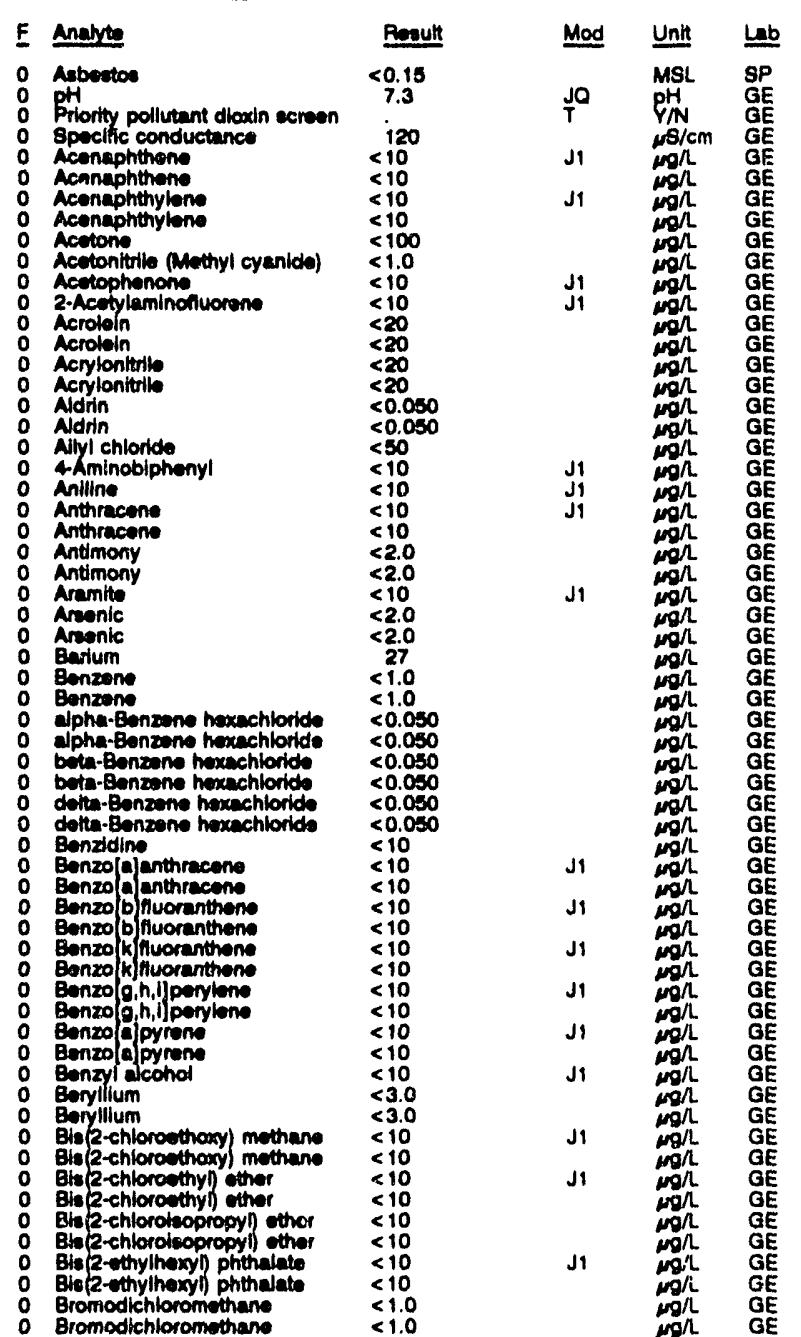

WELL AMB 10B collected on 07/22/82, laboratory analyees (cont.)

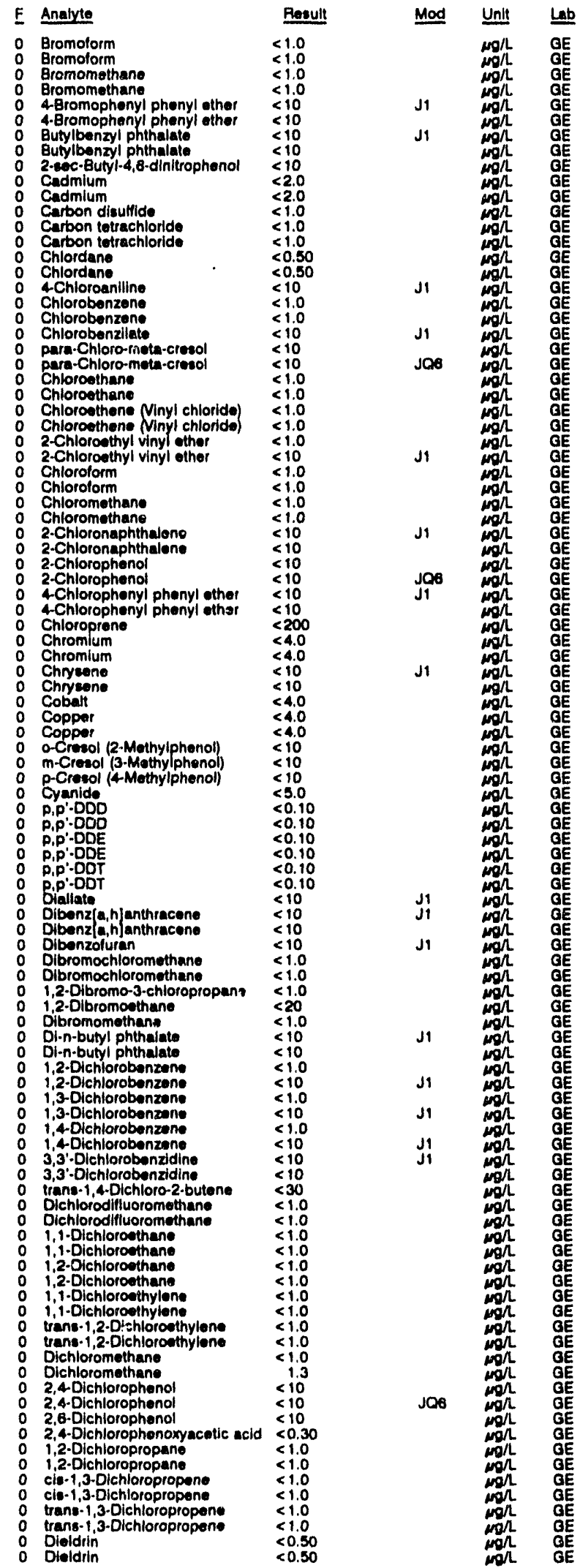


ANALYTICAL RESULTS

WELL AMB $10 B$ collected on 07/22/92, laboratory analyses (cont.)

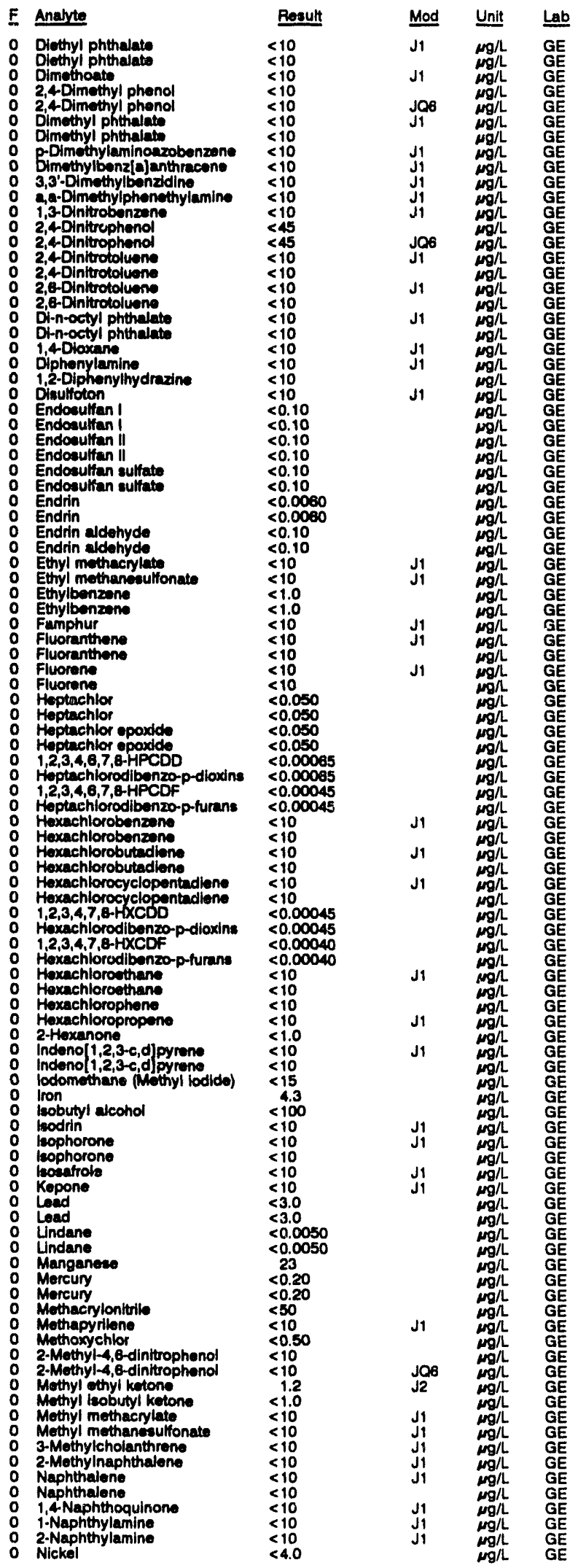

WELL AMB $10 B$ collected on 07/22/82, laboratory analyes (cont)

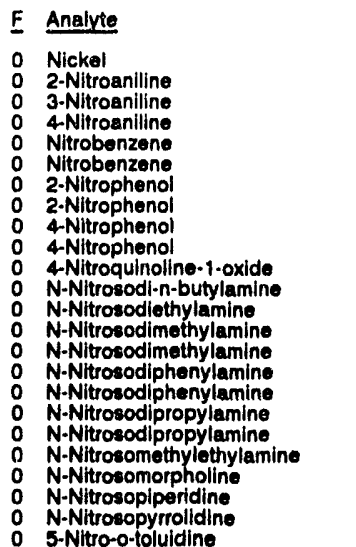

$0,0,0$-Triethyl phosphorothicate $<10$

$0,0,0-T r i e t h y l$ phosphorothicate $<10$
0 Octachlorodibenzo-p-dioxins $<0.0010$

o Octachlorodibenzo-p-furans $<0.0010$

0 Parathion methyl $\quad<0.050$

O PCB 1016

0
0 PCE 1221

o PCB 1221

O $\mathrm{PCB} 1232$

0 PCB 1242

- PCB 1242

0 PCB 1248

0 PCB 1254

O PCB 1254

- PCB 1280

- Pentachlorobenzen

0 1,2,3,7,8-PCDD

Pentachlorodibenzo-p-furans

o $1,2,3,7,8 \cdot$ PCDF

o Pentachloroethane

- Pentachloronitrobenzen

Pentachlorophenol

o Pentachlorophenol

0 Phenacetin

o Phenanthrene

0 Phenol

0 Phenol

0 p-Phenylenediamine

Phorate

o 2-Picoline

o Propionitrile

0 Pyrene

0 Pyrene

0 Safrole

O Selenium

o Silver

o Silver

0 Styrone

0 Sulfide

O Sulfotepp

o $2,3,7,8$-TCDD

2,3,7,8-TCDF

0 Tetrachlorodibenzo-p-dioxin

Totrachlorodibenzo-p-furan

1,1,1,2-Tetrachloroethane

$1,1,2,2$ - Tetrachloroothane

1,1,2,2-Tetrachioroethan

T Tetrachloroethylone

o 2,3,4,6-Tetrachlorophenol

0 Thallium

o Thallium

o Thionazin

0 Tin

- Toluene

Tolvene

${ }_{0}$ Total dissolved solids

al organic carba

- Total organic carbon

- Total organic halogens

- Toxaphene

Toxaphene

2,4,5.TP (Silvex)

0
0
$1,2,4-T r i c h l o r o b e n z e n e$
Result Mod Uni

$<4.0$

$<10$

$<100$

$<10$

$<\leq 10$

$<10$

$<10$

$<10$

$<10$

$<10$

10

$<0.50^{2}$

$<0.50$

$<0.50$

$<0.50$

$<0.50$

$<0.50$

$<0.50$

$<0.50$

$<0.50$

$<0.50$

$<0.00055$

$<0.00055$

$<0.00055$

$\leq 10$

$<10$

$<10$

$<10$
$<10$
$<10$

$<10$

$\leq 10$

$<10$

510

$<200$

$<10$

$<10$

$<10$

$<2.0$

$<2.0$

$<2.0$

$<1,000$

$<10$

$<0.00045$

$\div 0.00040$

$<0.00045$

$<1.0$

$<1.0$

$<1.0$

$<1.0$

$<10$

$<2.0$

$<10$

$<2.0$

$\leq 1.0$

$<10$

$<1,000$
$<1,000$

7.2

$<.24$
$<0.24$

$<0.24$
$<0.090$

$<0.090$
$<10$

$<10$
$<10$

Lab

GE

gE

GE 
WEU AMB 108 colloctod on 07/22/92, laboratory analyses (cont.)

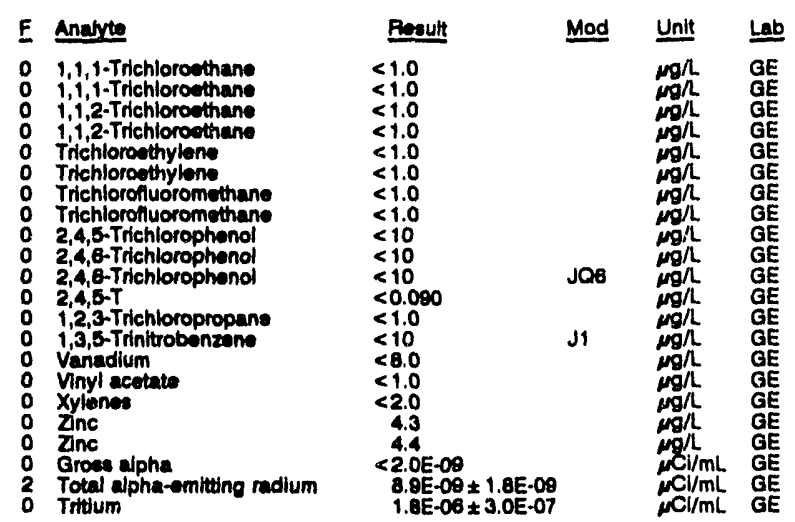

WELL AMB 10D

MEASUREMENTS CONDUCTED IN THE FIELD

Sample date: 07 rea/92

Depth to water: 131.24 it $(40.00 \mathrm{~m})$ below TOC Water olevation: $234.26 \pi$ i 7

Sp. conductence: $32 \mu \mathrm{s} / \mathrm{cm}$.

LABORATORY ANALYSES

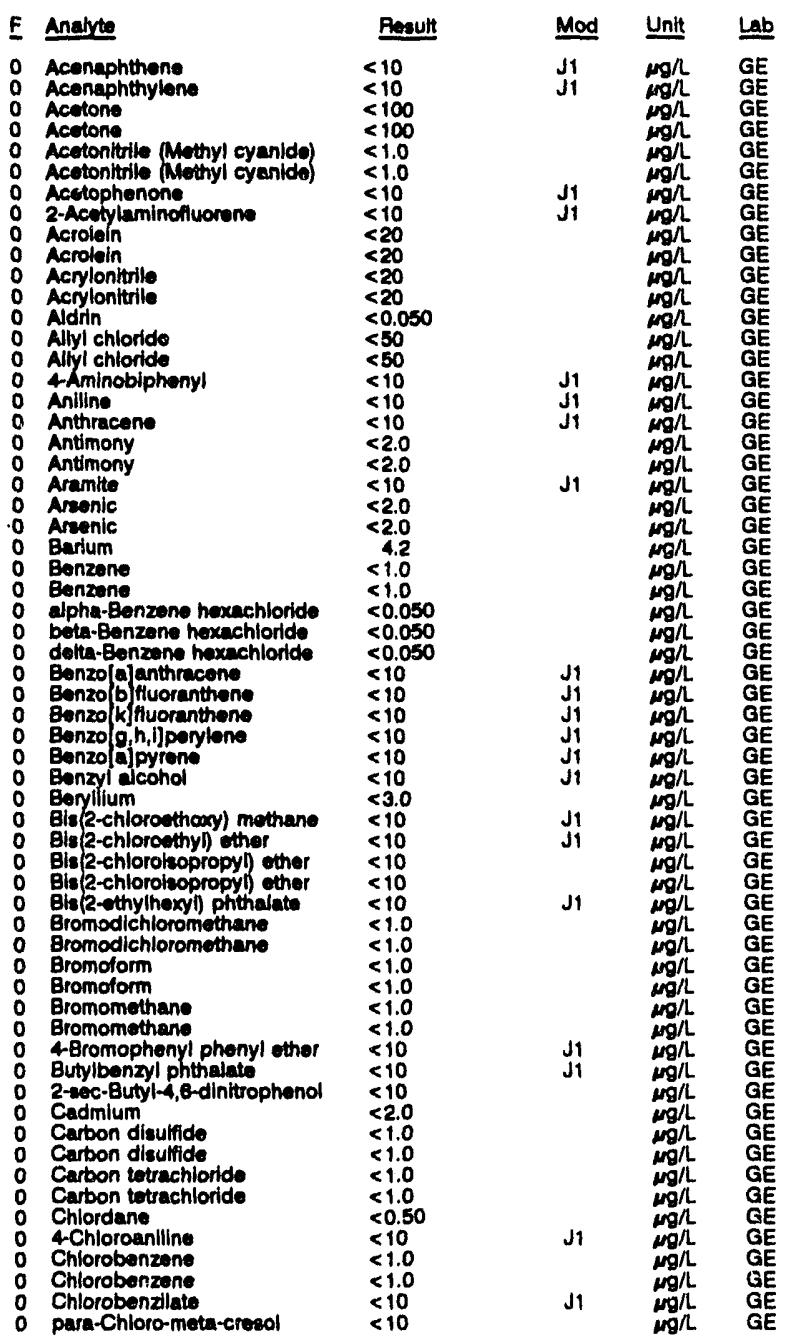

WELL AMB 100 collected on 07/22/82, laboratory analyeses (cont.)

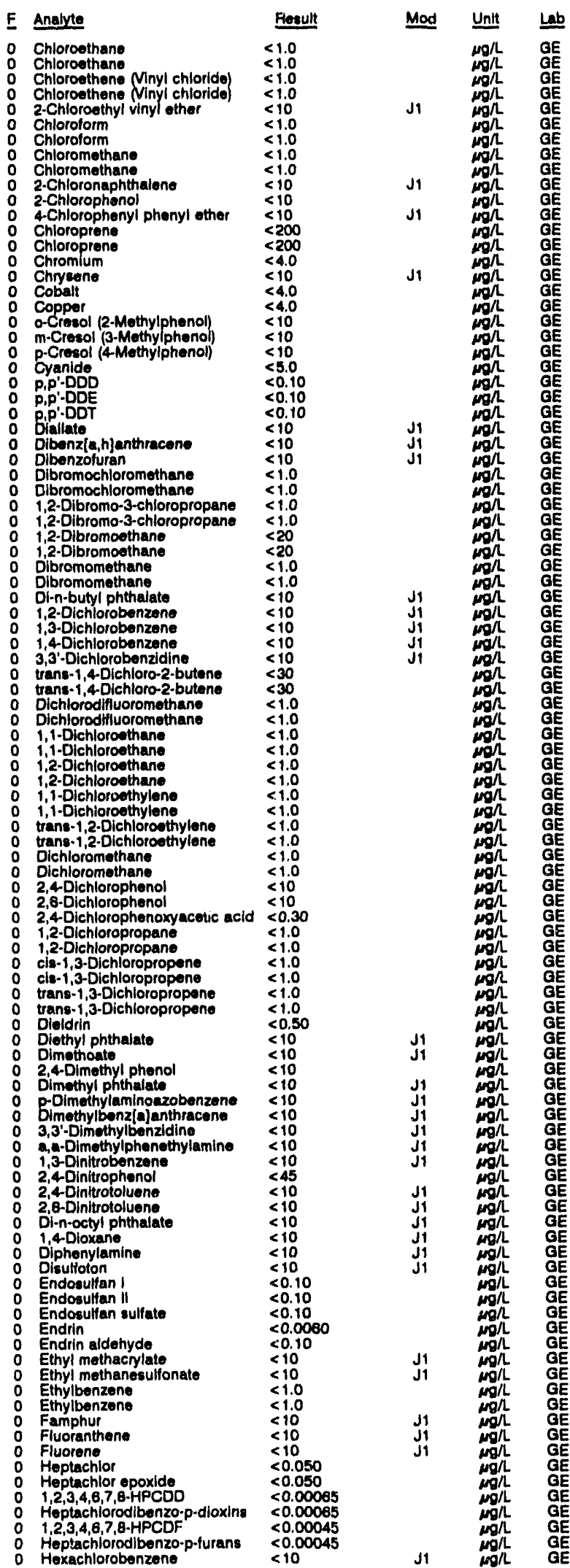


ANALYTICAL RESULTS

WELL AMB 10D collected on 07/22/82, laboratory analyses (cont)

F Aralyte

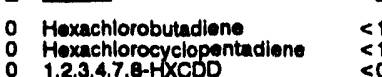

Hoxachlorocyciopontadione
0 Hi,3,4,7,8-HXCDD
0 Hexachlorodlbenzo-p-dioxins

o Hexachlorodibenzo-p-furans $<0.00040$

o Hexachloroethane

Hexachloropropene

2.Hoxanone

Indeno[1,2,3-c,d]pyrene

lodomethane Methyl lodida

tron

leobutyl alcohol

leobutyl sleohol

bodrin

leophorone

Kepone

Load

Lindane

Magnesilum

Manganear

Methacrylonitrile

Methacrylonitril

Methapyriene

2-Methyl-4,6-dinitropheno

Methyl ethyl ketone

Mathyl leobutyl ketion

Methyl bobutyl ketone

Mothyl methecrylate

Mathyl methaneaulfonat

2-Methylcholanthrene

Naphthalene

i Naphuthoquinone

2-Naphthylamine

2-Nitroanilline

4-Nitroaniline

Nitrobenzene

2-Nitropheno

4 -Nitrophend

4-Nitroquinoline-1-axdde

N-Nitrocodil-n-butylamine

N-Nitrosodinthylamine

N-Nitrosod mothylamine

N-Nitrosodipropylamine

N-Nitrosomethylethylamine

N-Nitrosomorpholine

N-Nitrosopymolidine

5-Nitro-o-toludine

o O,0,0-Triethyl phosphorothioate

Octuchlorodibenzo-p-dioxins

Octachlorodibenzo-p-furans

Parathion

Parathion mothyl

PCB 1010

O PCB 1221

0 PCB 1242

o PCB 1248

P PCB 1254

PCB 1280

1,2,3,7,8-PCDD

Pentachiorodibenzo-p-dioxin

Pentachlorodlbonzo-p-furans

$1,2,3,7,8-P C D F$

Pentachlorowhane

Pentachlorophenol

Phenacetin

Phenanthre

P-Phenylenediamine

Phorats

2.Plcoline

Propionitrile

Propionitrit

O Pyrene

Pyridine

Solonium

Solenium
Silver

Styrene

Styrene
Sulfide

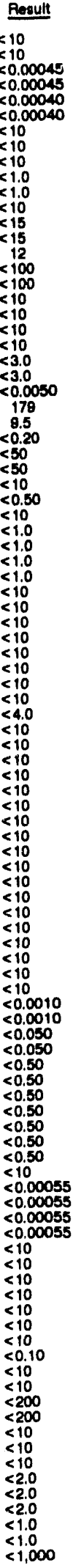

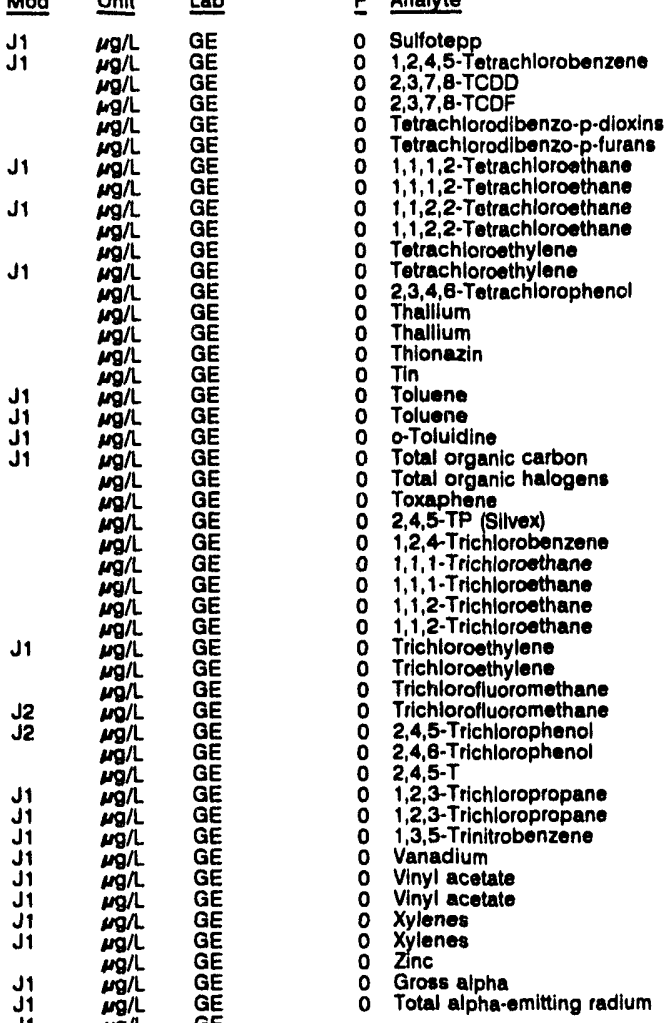

WELL AMB 10D collected on 07/22/92, laboratory analyses (cont.)

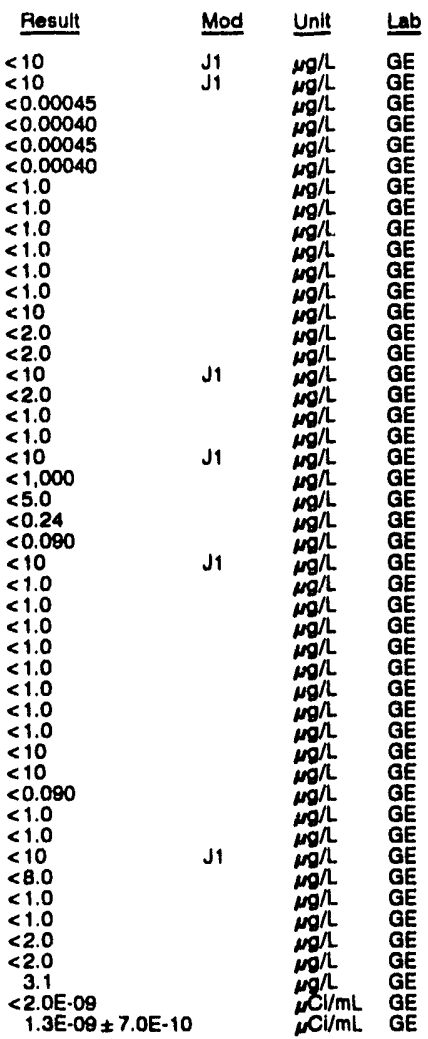

WELL AMB 10DD

MEASUREMENTS CONDUCTED IN THE FIELD

Sample date: $07 / 22 / 92$
Depth to water: $6.79 \mathrm{ft}(2.07 \mathrm{~m})$ below TOC
Water elevation: $358.61 \mathrm{th}(109.31 \mathrm{~m}) \mathrm{msl}$
Sp. conductance: $149 \mu \mathrm{cm} / \mathrm{cm}$
Water evacuated before sampling: $53 \mathrm{gal}$
LABORATORY ANALYSES

Time: $14: 40$
pH: 6.3
Alkalinity: $68 \mathrm{mg} \Omega$
Water temperature: $21.9^{\circ} \mathrm{C}$

LABORATORY ANALYSES

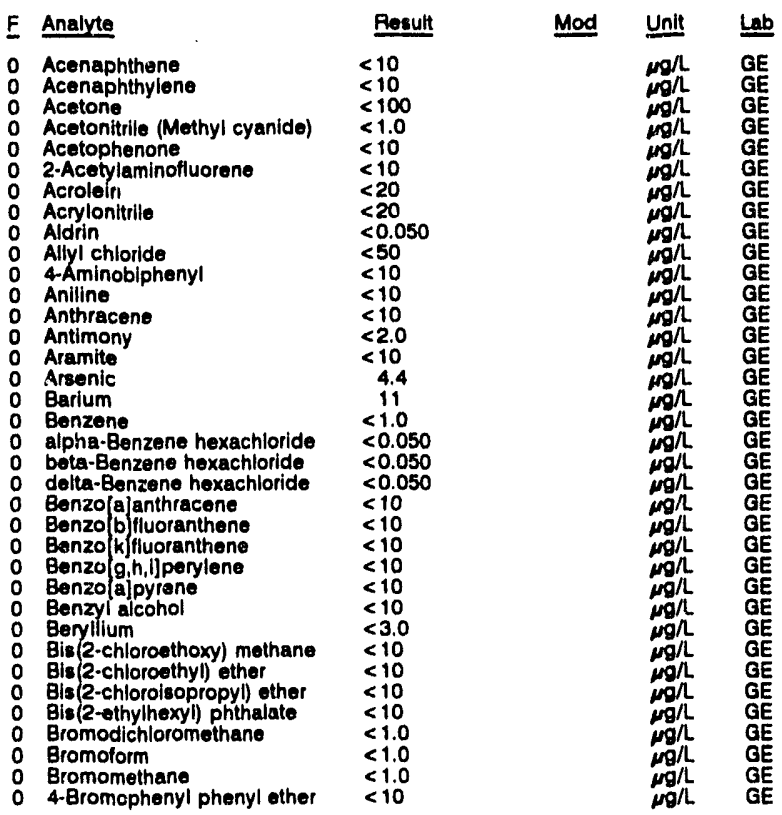


WELL AMB 100D collected on 07/22/92, laboratory analyses (cont.)

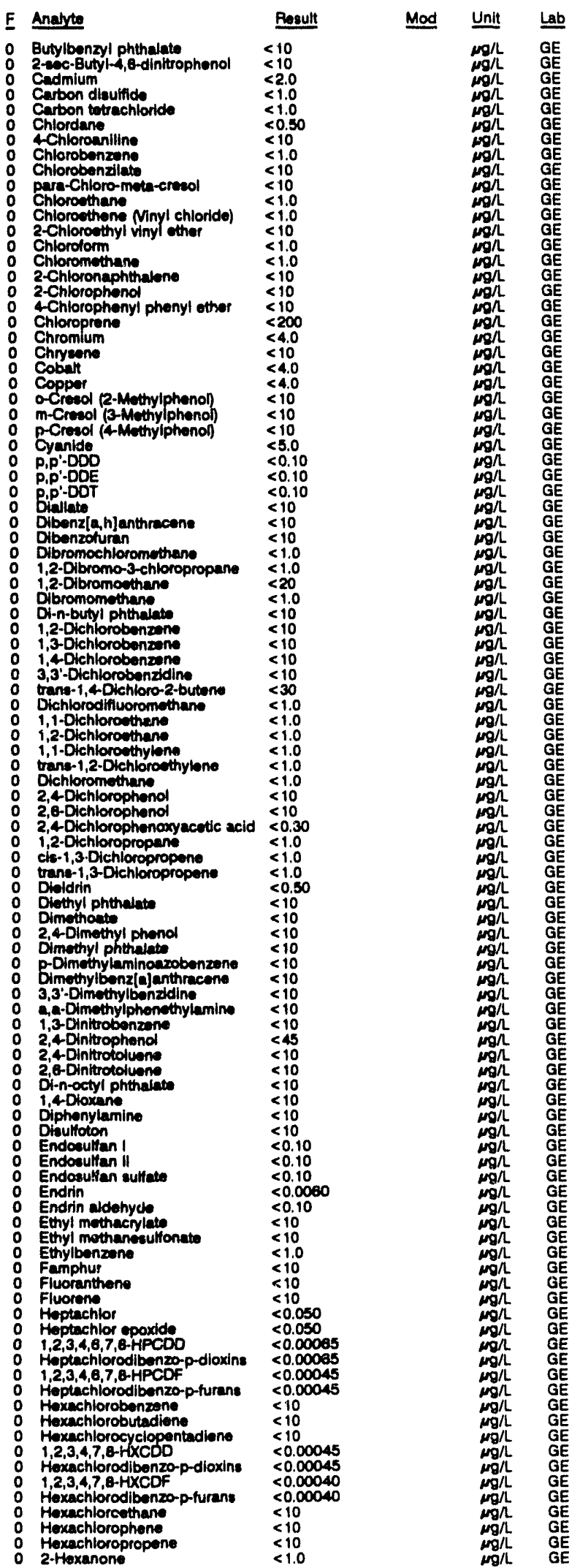

WELL AMB 10DD collected on 07/22/92, laboratory analyses (cont.)

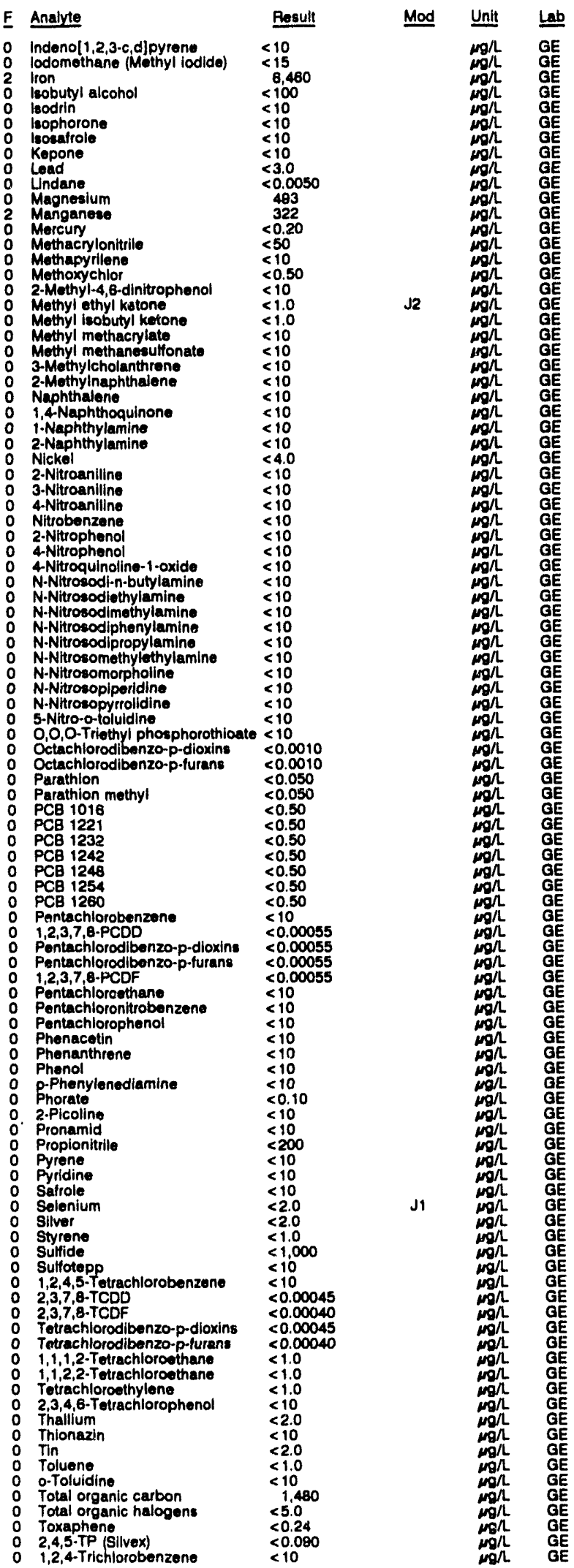


ANALYTICAL RESULTS

WELL AMB 10DD collected on 07/22/02, laboratory analyees (cont.)

\begin{tabular}{|c|c|c|c|}
\hline Analyte & Result & Mod & Unit \\
\hline 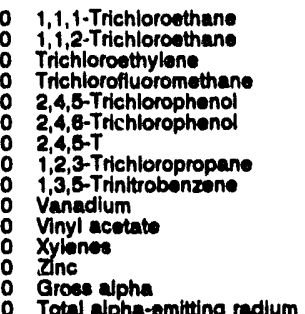 & $\begin{array}{l}<1.0 \\
<1.0 \\
<1.0 \\
<1.0 \\
<10 \\
<10 \\
<0.090 \\
<1.0 \\
<10 \\
<8.0 \\
<1.0 \\
<2.0 \\
<2.0 \\
<2.0 \mathrm{E}-09\end{array}$ & & 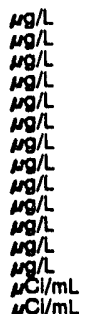 \\
\hline
\end{tabular}

\section{WELL AMB 11B}

MEASUREMENTS CONDUCTED IN THE FIELD

\section{Sample date: 07/23/02}

Depth to water: $142.83 \mathrm{ft}(43.54 \mathrm{~m})$ bolow TOC

Wator olevation: $221.77 \mathrm{n}(87.80 \mathrm{~m}) \mathrm{msl}$

Water evecuated betore sampling: $124 \mathrm{gal}$

LABORATORY ANALYSES

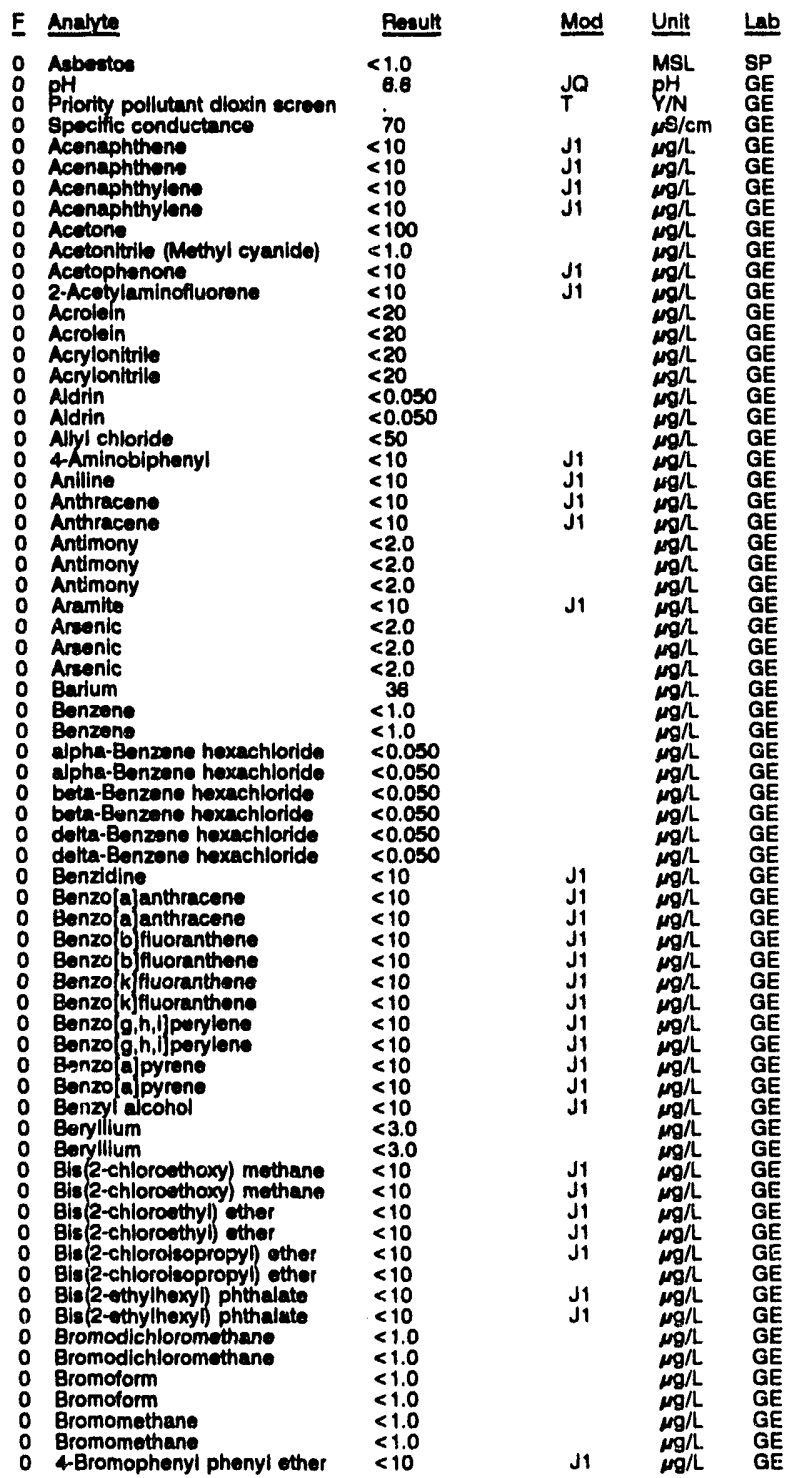

WELL AMB 11 B collected on 07/23/92, laboratory analyses (cont.)

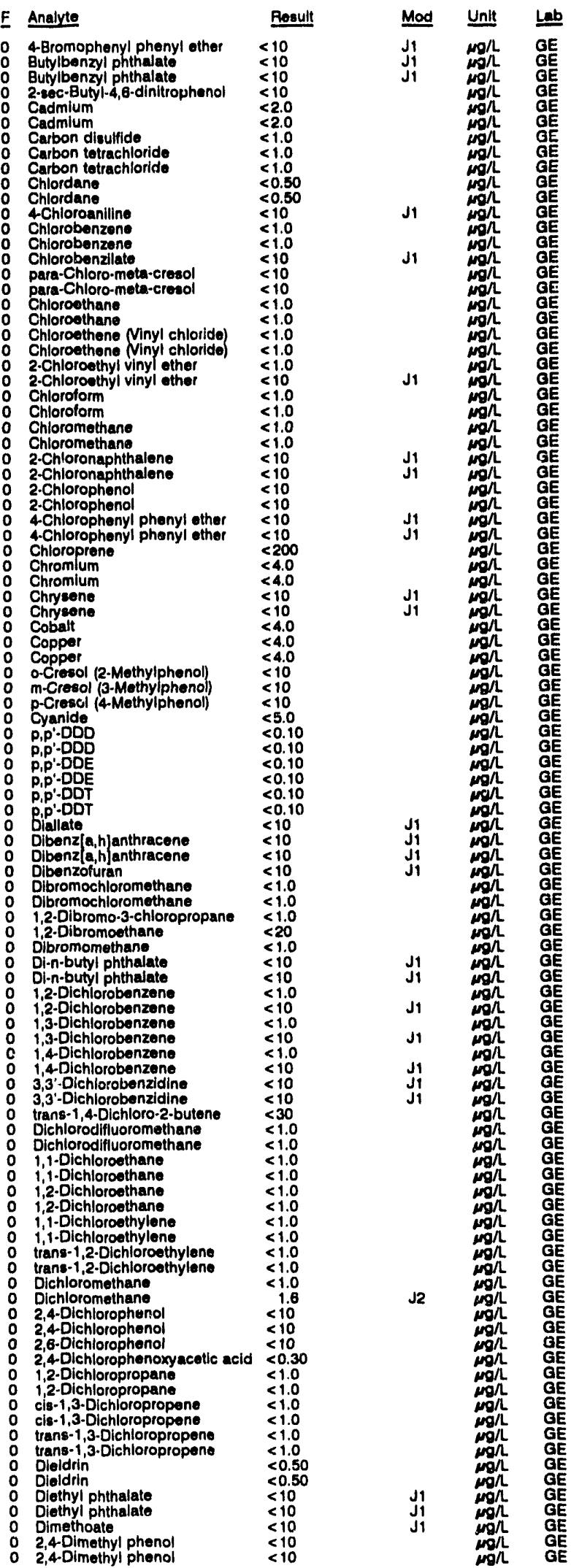


WELL AMB 118 collectad on 07/23/02, laboratory analyees (cont.)

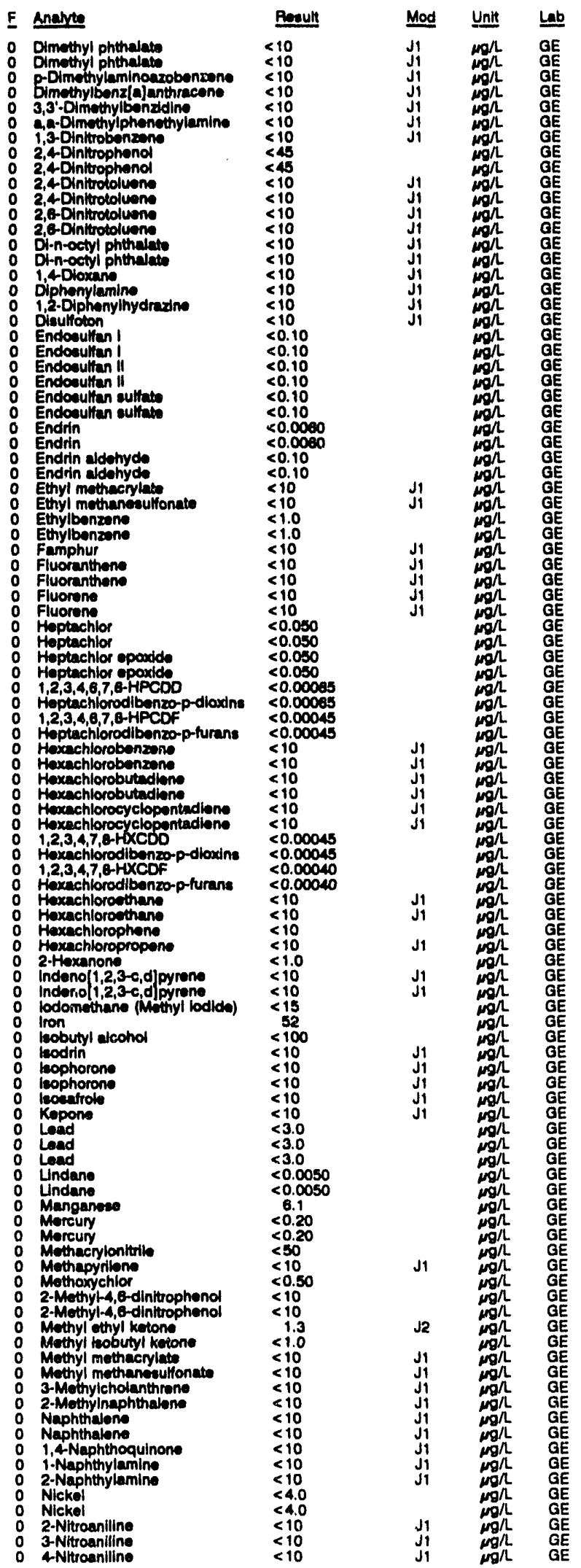

WELL AME 11B collectod on 07/23/82, laboratory analysese (cont)

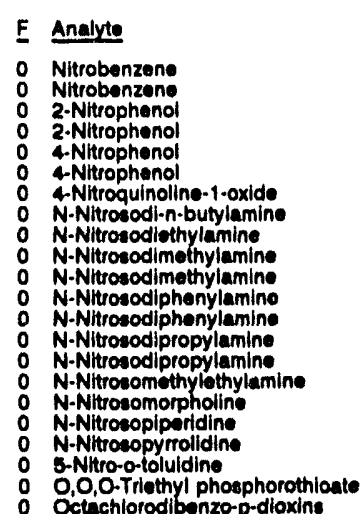

Reault Mod Unit Lab

$<10$

$<10$

$<10$
$<10$

$<10$

$<10$

$\leq 10$

$<10$

$<10$

$<10$

$\leq 10$

$<10$

$<10$

10

$<10$

O.0.0.Triethyl phosphorothiloalo s Octachlorodibenzo-p-dioxins

Octachlorodibe

Parathion mothyl

PCB 1016

PCE 1221

PCB 1221

PCB 1232

P PB 1232

PCB 1242

PCB 1242

PCB 1248

PCB 1254

PCB 1254

PCB 1260

Pentachlorobenzene

$1,2,3,7,6 \cdot P C D D$

Pentachlorodibenzo-p-dioxins

Pentachlonodiben

Pentichor

Pentachloronitrobenzene

Pentachlorophenol

Pentachlorophenol

Phonanthron

Phenanthrene

Phenol

o Phenol

Phorato

2.Picoline

Proplonitrile

Pyrene

0 Pyrene

Safrolo

o $\begin{aligned} & \text { Solenium } \\ & \text { Solenlum }\end{aligned}$

Solenium

Silver

o Silver

o Styrena

: Sulfide

1,2,4,5-Tetrachlorobenzene

$2,3,7,8-T C D D$

o 2,3,7,8-TCDF

Tetrachlorodibenzo-p-furans

o 1,1,1,2-Tetrachloroethane

o 1,1,2,2-Tetrachloroethane

o Tetrachloroethylene

o Tetrachloroethylene

2,3,4,6-Tetrachlorophenol

0 Thallium

Thallum

Thallium

o Thionazin

o Tin

o Toluene

$\begin{array}{ll}0 & \text { Toluene } \\ 0 & \text { o-Toluidine }\end{array}$

Total dissolved solide

- Total organic carbon

O Total organic

o $2,4,5$ TP (Silvex)

0 2,4,5-TP (Silvex)

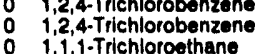

$\begin{array}{ll}0 & 1,1,1-\text { Trichloroethane } \\ 0 & 1,1,1-\text { Trichloroethane } \\ 0 & 1,1,2-\text { Trichloroethane }\end{array}$

$<0.0010$

Mod Unit Lab

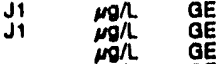

$<10$

$\leqslant 10$

$<10$

$<.10$
$<10$
$<10$

$<10$
$<200$
$<10$

$<200$
$<10$
$<10$

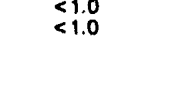


ANALYTICAL RESULTS

WELL AMB 118 collectod on 07/23/02, laboratory analyses (cont.)

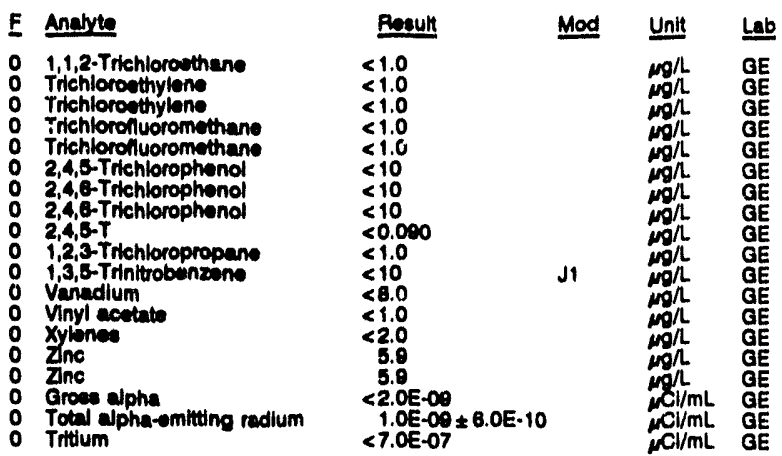

WELL AMB 11D

MEABUREMENTS CONDUCTED IN THE FIELD

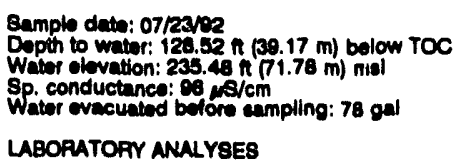

Time: 15:35

PH: 6.2 Alkalinity: $21 \mathrm{~mol}$.

Water temperature: $21.6^{\circ} \mathrm{C}$

LABORATORY ANALYSES

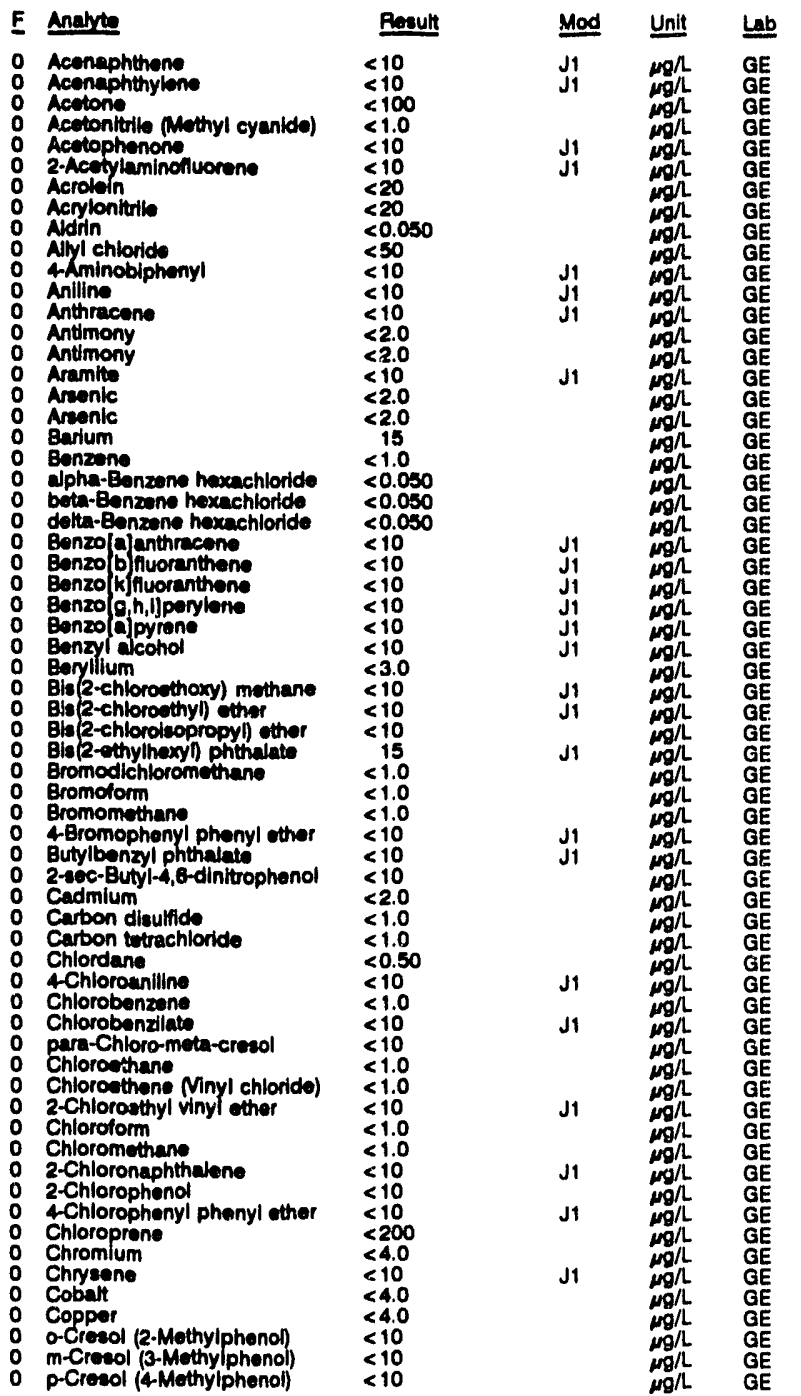

WELL AMB 11D collected on 07/23/82, laboratory analyees (cont.)

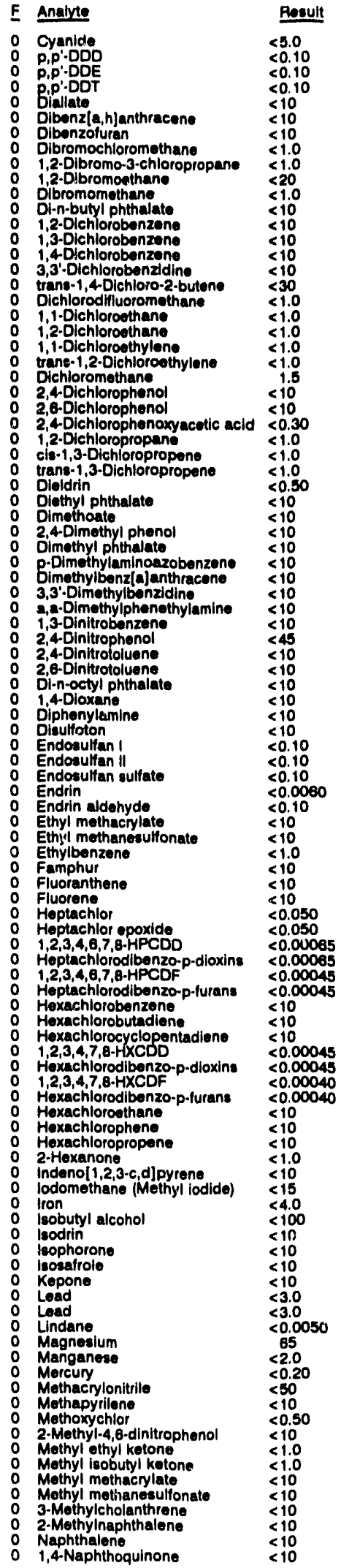

Mod Unli Let

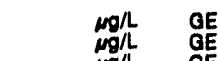

$J 1 \quad \log _{\mathrm{g} \Omega} \mathrm{aE}$

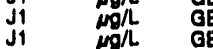

的

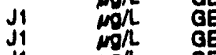

Ji

mog a

J2 
WELL AMB 11D collected on 07/23/92, laboratory analyees (cont.)

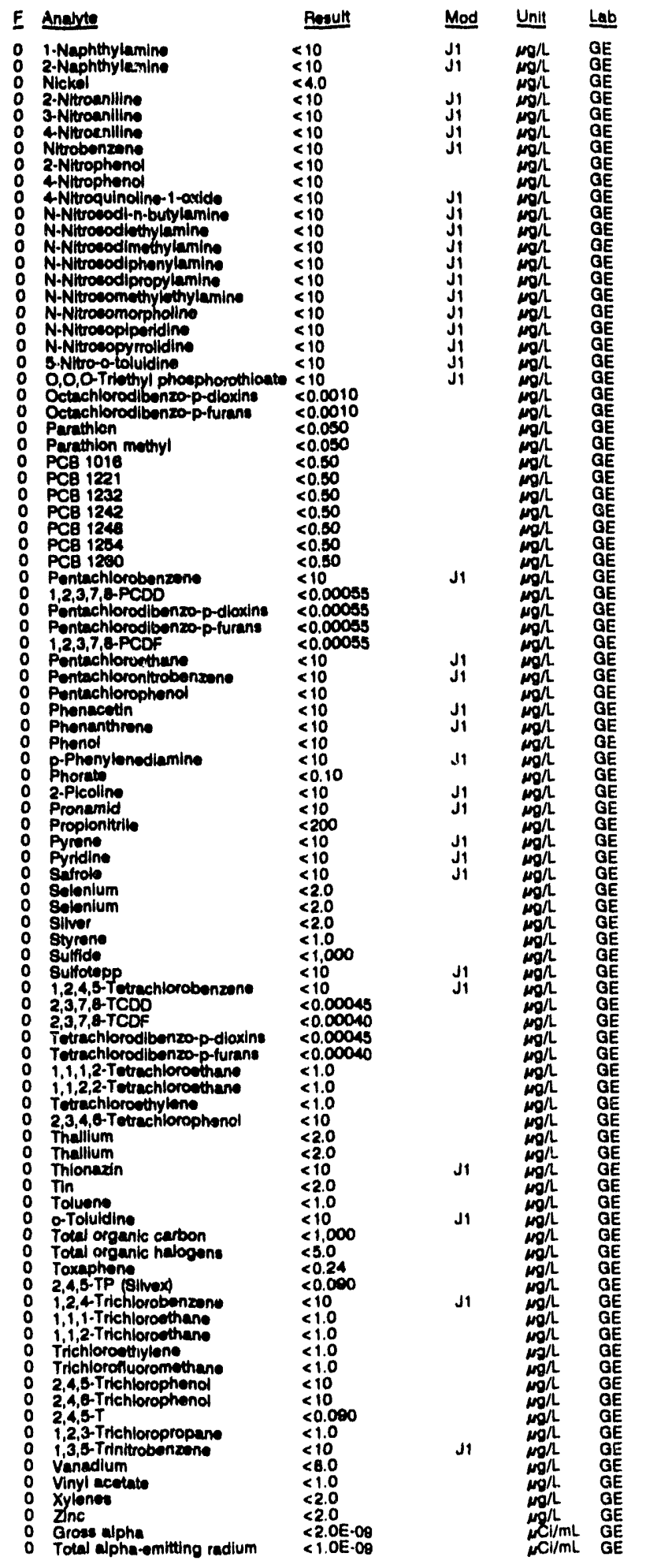

WELL AMB 12D

MEASUREMENTS CONDUCTED IN THE FIELD

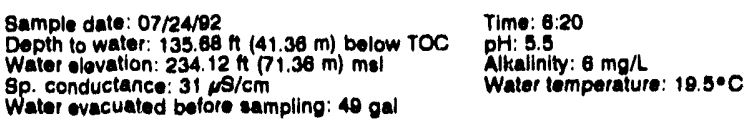
LABORATORY ANALYSES

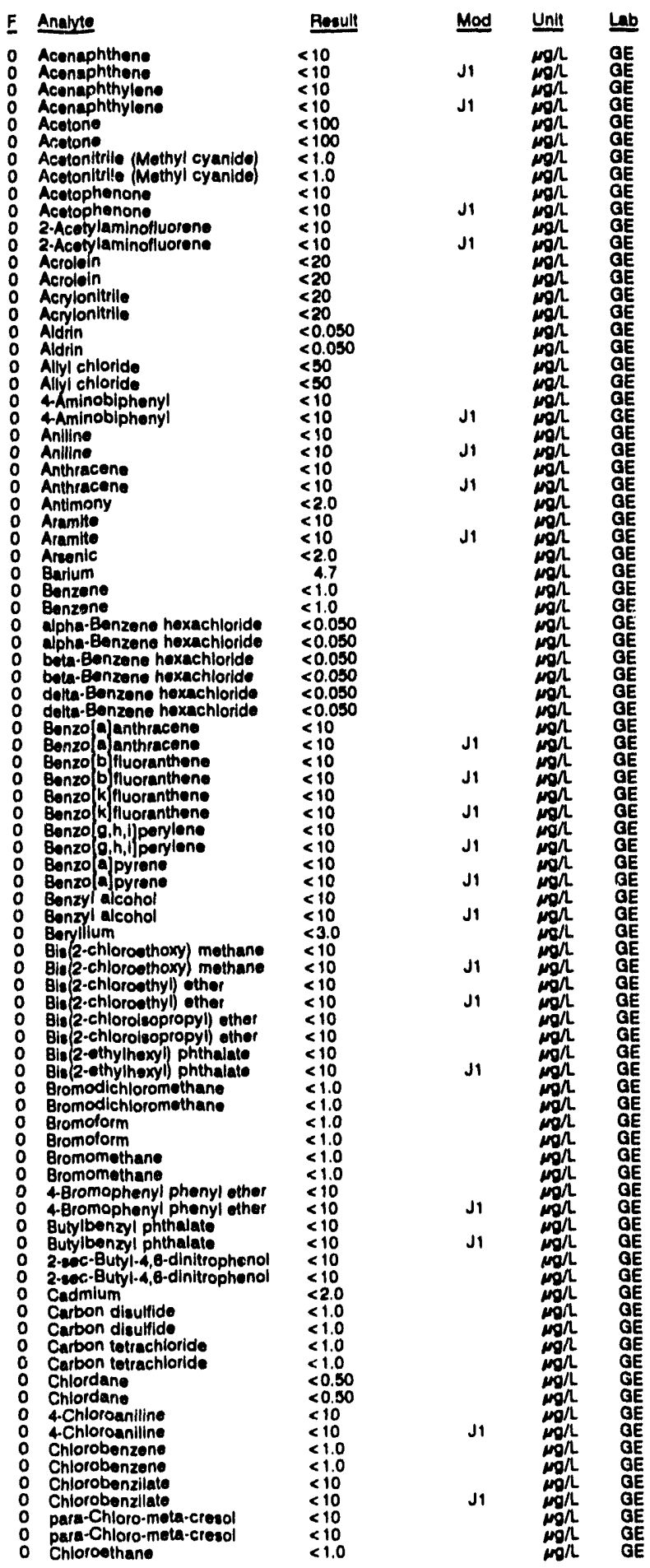


ANALYTICAL RESULTS

WELL AMB 120 collected on 07/24/92, laboratory analyees (cont.)

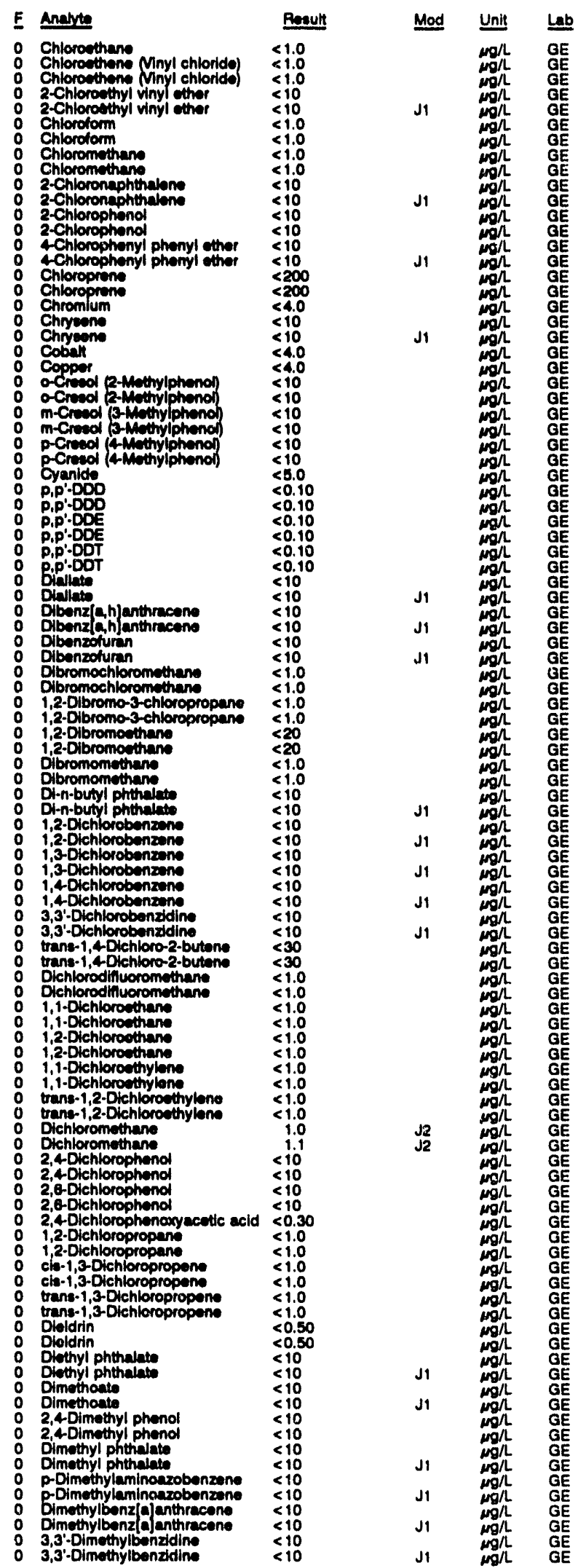

WELL AMB 120 collected on 07/24/92, laboratory analyese (cont.)

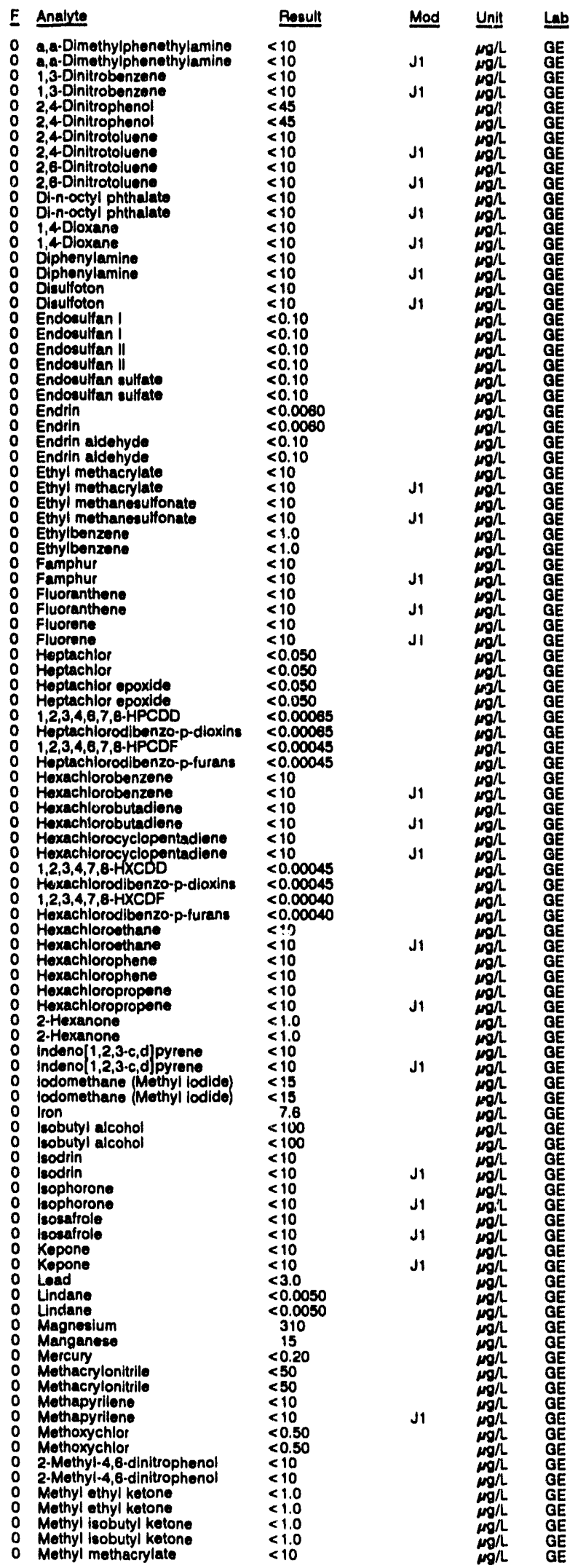


WELL AMB 120 collected on 07/24/92, laboratory analyees (cont)

E Anarte

o Mothyl methecrylate

Methyl methanecullonato

3-Methyleholanthrene

3-Methylcholanthrens

2. Mothy inaphthabene

Nephthalone

1,4Naphthoquinone

1.4Nephthoquinone

i- Naphthylamine

2-Naphthylanin

2-Nitroanlilin

3-Nitroaniling

3-Nitroaniline

4Nitroanilin

Nitrobenzene

Nitrobenzen

2.Nitropheno

2-Nhroptisno

4-Nitrophenol

4Nfroquinoline-1-axide

4Nitroquinolino-1-odide

N-Nituosodt-n-butylamine

NNftrosodicthylemin

N-Nitrocodimethyinin

N-Nitrocodimethylamine

N.Nitrocodiphenylamine

N-Nitrosodiphenylamin

N-Nitrocodipropylamins

N-Nitrosomethylathylamine

N-Nitrocomothylethylaming

N-Nitrosomorpholine

N-Nroeplperidino

N-Nhosoplpordina

N-Nutropprraldine

S-Nitro-o-boluldin

S-Nitro-o-toluidino

0,0,0-Triethyl phoephorothiante

0,0,0-Triathyl phoephorothioest

Octuchlorodibonzo-p-dioxin.

Parachlor

Parathion

Parathion mothyl

PCB 1016

PCB 1221

PCA 1221

PCE 1232

- PCE 1242

PCg 1242

PCB 1248

PCB 1234

PCB 1254

PCE 1260

Pentachlorobenzon

Pentachiorobon

Pentechlorodibenzo-p-dioxins

Pentachiorodibenzo-p-furane

1,2,3,7,6-PCDF

Pentachloroethan

Pentachloronltrobenzen

Pentuchloronltrobenzen

Pentuchlorophenol

Pontuchlorophong

Phenacetin

Phonacetin

Phonanthrene

Phonol

p-Phenylenedlamine

p-Phenylonedlamine

Phorate

Phorato

2.Plcoline

2-Plcoline

Pronamid

Propioniturite

Propionitrile
$<10$

$<10$
$<10$

$<0.0010$

$<0.050$

$<0.050$

$<0.050$
$<0.050$

$<0.50$

$<-0.50$

$<0.50$

$<0.50$

$<0.50$

$<0.50$

$<0.50$

$<0.50$

$<0.50$

$<0.50$

$<0.50$

$<10$

$<0.00055$

$<0.00055$

$<0.00055$

$<10$

$<10$
$<10$

$<10$

$<10$
$<10$

$<10$

$<10$

$<10$

$\leq 10$

$<10$
$<10$

$<10$
$<0.10$
$<0.10$
$<10$

$<10$

$<10$
$<10$
$<10$

$<200$
$<200$

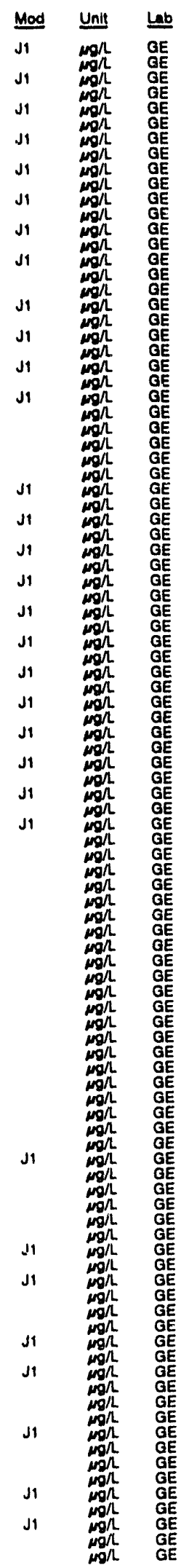

WELL AMB 120 collected on 07/24/92, laboratory analyees (cont.)

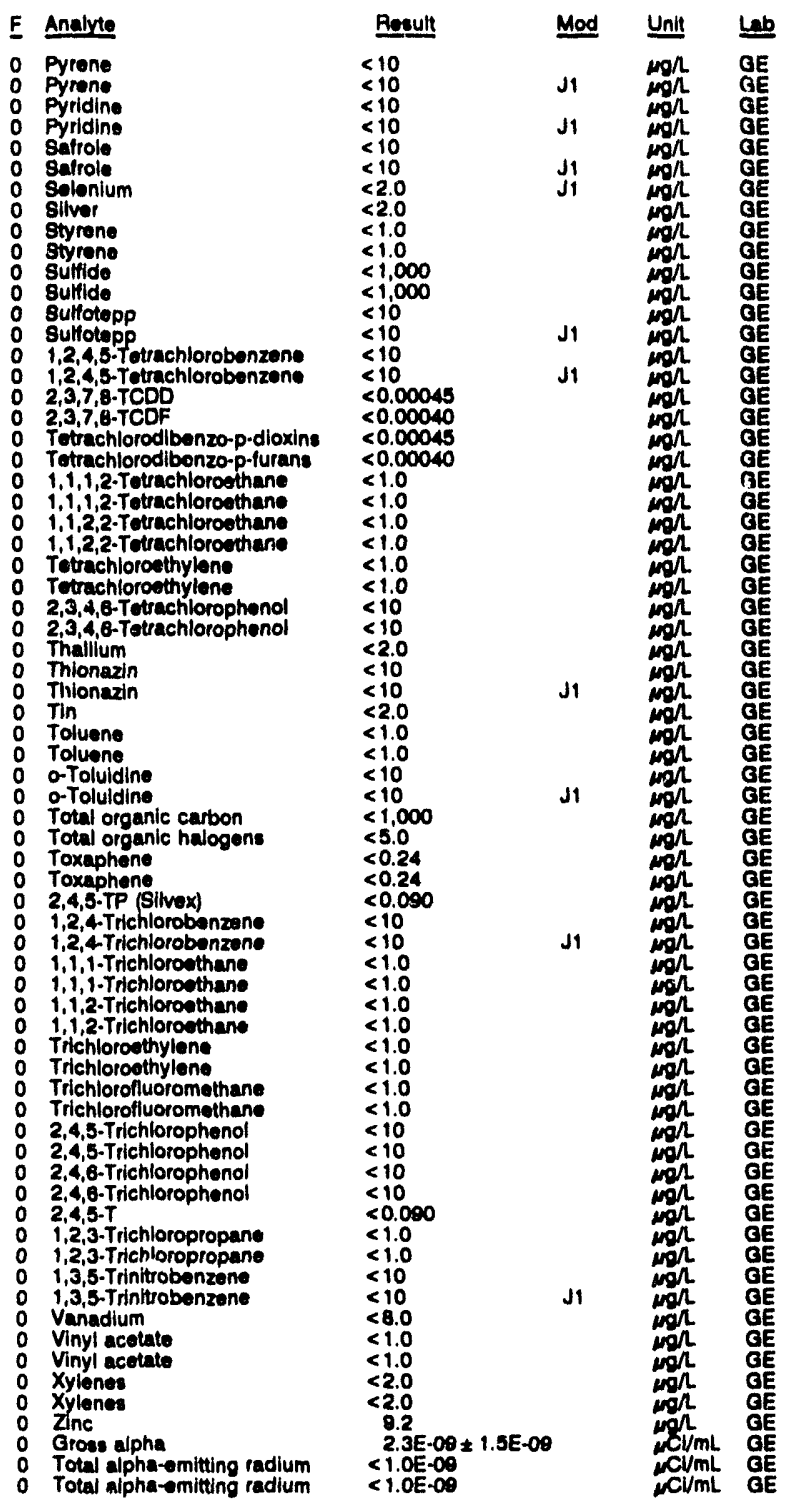

\section{WELL AMB 13AR}

MEASUREMENTS CONDUCTED IN THE FIELD

Sample date: 07/28/92 3 (4)

Sp. conductance 213 $5 / \mathrm{cm}$

Water evacuated before sampling: $67 \mathrm{gal}$

The well went dry during purging.

LABORATOPY ANALYSES

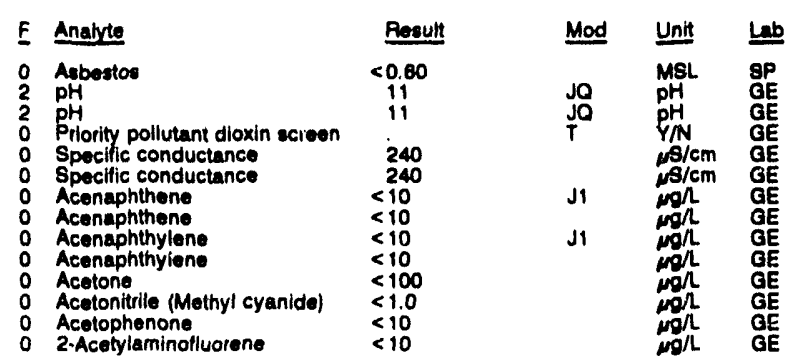


ANALYTICAL RESULTS

WEL AMB 13AP collocted on 07/28/92, laboratory analyses (cont.)

F Analyte

o Acrolein

Acrolein

O Acrylonitivite

0 Ndirisi

o Alyl chloride

4.Aminobiphenyl

Antinine

- Anthracene

o Antimony

- Antimony

0 Arrmita

Areonic

Beilum

Berizene

alpha-Benzene haxachloride

betd-Benzene hoxechioride

beta-Benzene hoxuchloride

delta-Eon

delta-Benzens hexechlorido

Benzidine

Benzus ajanthruceno

Benz? a anthraceno

Benzo b fluorenthen

Benzo ik fluoranthene

Benzo k fluoranthen

Benzo [o,h,l) perylons

Benzo fápyrene

Eenzola pyrane

Beryllium

Boryllium

Bis 2-chloroethoxy) methan

Es (2-chloroethoxy) methan

Bistions

Bis (2-chlorolsopropyl) ether

Bis (2-chlorolsopropyl) ether

Bis (2-thylhexyl) phthalate

Bromodichloromethane

Bromodichloromethane

Bromotorm

Bromotorm

Bromomethane

-Bromophenyl phenyl ther

4-Bromophenyl phenyl the

Butylbonzyl phthalate

2-ecc-Butyl-4,6-dinitrophenol

Cadmium

Carbon disulfide

Carbon tetrachloride

Carbon tetrachlorido

Chlordane

Chiordano

Chlorobenzene

Chlopobenzene

Chlorobenzilate

para-Chloro-meta-cresol

para-Chioro-mota-cresel

Chloroethane

Chloroethane

Chiorosthene Ninyl chloride)

2-Chloroethyl vinyl other

Chloroform

Chioromethane

Chloromethane

2.Chloronaphthajene

2-Chloronaphthalene

2-Chlorophenol

4-Chlon sphanyl phenyl cther

4-Chlorophenyl phenyl ether

Chloroprene

Chromium

Chromium

Chrysene

Cobalt

Copper

o-Cresol (2-Methylphenol

m-Cresol (3-Methylphonol)

m-Cresol (2-Mothylphonol)

O Cyanide

Cyanide

\section{Result}

$<20$
$<20$
$<20$
$<20$
$<0.050$
$<0.050$
$<50$
$<10$
$<10$
$<10$
$<10$
$<2.0$
$<2.0$
$<10$
$<2.0$
$<2.0$
81
$<1.0$
$<1.0$
$<0.050$

$<0.050$

$<0.050$

$<0.050$

$<0.050$

$<10$

$<10$

$<10$

$<<10$

$\leq<10$

$<10$

$<<10$

$<10$

$<3.0$

$<10$

$<10$

$<10$

$<10$

$<10$

$<1.0$

$<1.0$

$<1.0$

$<10$

$<<10$

$<10$

$<10$

$<2.0$

$<1.0$

$<1.0$

$<0.50$

$<10$

$<1.0$

$<10$

$<10$

$<1.0$

$<1.0$

$<1.0$

$\leq 10$

$<1.0$

$<1.0$

$<1.0$

$<10$

$<10$

$<10$
$<10$

$<200$
$<4.0$

$<4.0$

$<10$
$<10$

$<4.0$

$<4.0$

$<10$
$<10$

$<10$
$<5.4$

\section{Mod Unit}

$\mu g / L \quad$ GE

GE

GE

GE

GE

E

E

E

EE

EE

EE

GE

GE

E

E

E

EE

GE

تז:

GE

E

EE

GE

GE

GE

GE

EE

GE

GE

GE

GE

GE

GE

GE

GE

GE

GE

GE

GE

GE

GE

GE

GE

WELL AMB 13AP collected on 07/28/92, laboratory analyses (cont.)

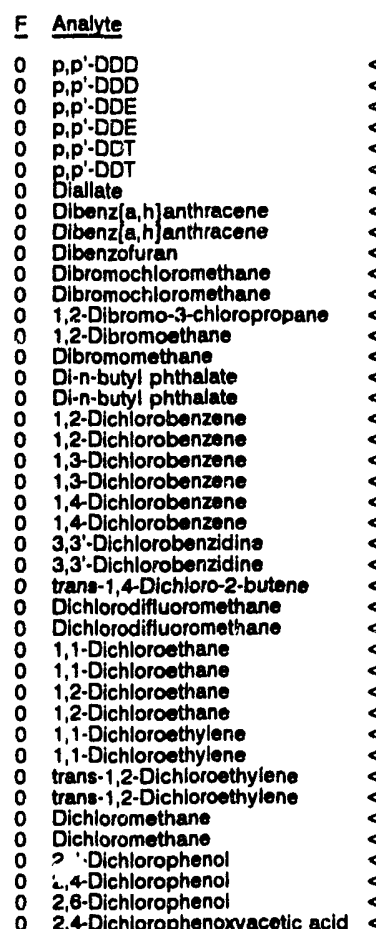

Result Mod Unit

$<0.10$

0.10

$<0.10$

$<0.10$
$<10$

$<10$

$\leq 10$

$<1.0$
$<1.0$
$<1.0$

$<1.0$

$<1.0$

$<10$

$<1.0$
$<10$
$<10$

$<1.0$

$<10$
$<10$

$<10$

$<10$

$<30$

$\leq 1.0$

$<1.0$

$<1.0$

$\leq 1.0$

$<1.0$
$<1.0$
$<1.0$

$\leq 1.0$

$<1.0$

$<10$

2,4-Dichlorophenoxyacotic acid $<0.30$

1,2-Dichloropropano

o cis-1,3-Dichloropropene

cis-1,3-Dichloropropene

trans-1,3-Dichloropropene

Dieldrin

Dieldrin

Diethyl phthalate

Dimethoate

0 2,4-Dimothyl phenol

2,4-Dimethyl pheno

Dimethyl phthalate

Dimethyl phthalate

p-Dimelhylaminoazobenzene

3,3'-Oimethylbenzidine

o a.Dimethylphenethylamine

1,3-Dinitrobenzene

2,4-Dinitrophenol

2,4-Dinitrophenol

2,4-Dinitrotoluene

2,6-Dinitrotoluene

2,6-Dinitrotoluene

Di-n-octyl phthalate

1,4-Dioxane

0 Diphenylamine

Disulfoton

Endosulfan

indosultan

endosulfan I

Endosultan II

Endosulfan sulfato

0 Endrin

O Endrin aldehyde

0 Endrin aldehyde

0 Ethyl mathacrylate

o Ethyl mothanesulfonate

o Ethylbenzene

o Famphur

O) Fluoranthene

Fluoranthene

Fluorerie

Heptachlor

Heptachlor epoxide

Heptachlor epoxide

Heptachlorodibenzo-p-dioxins

$<1.0$
$<1.0$

$<1.0$

$<1.0$

$<0.50$

$<10$
$<10$
$=10$

$<10$

$<10$

$<10$

$<10$

$<10$
$<10$

$<10$

$<45$

$<45$

$<10$

$<10$

$<10$
$<10$

$<10$

$<10$
$<10$

$<10$

$<0.10$

$<0.10$

$<0.10$

$<0.0060$

$<0.10$

$<0.10$

$<10$
$<10$ 
WELL AMB 13AR collected on 07/26/82, laboratory analyees (cont.)

\section{F Anable}

O Heptachlorodibanzo-p-turans Hoxachiorobenzene

Haxechlorobena

Hexachiorobutadiene Hexachlorocyclopentadione

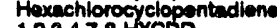

$1,2,3,4,7,8-H \times C D D$
Hexachlorodtbenzo-p-dloxins

$1,2,3,4,7,8-10 \times C D F$
Hexachlorodibenzo-p-furans

Hexachlorodibenzo-

Hoxachlorowthan

Hexachloroprepene

indeno $[1,2,3-c, d$ pyrene

indenoli,2,3-c, d pyrene

lodom

Iron

leobutyl alcohol

bophorone

teophorone

boadrois

Lead

Lindan

Manganea

Mercury

Mothacryionitrile

Methapyrilene

2-Methyl-6,8-dinitropheno

2-Mothyl-4,6-dinitrophen

Methy chyl ketrone

Methyl moutyl kolono

Methy methaneaulitonato

3-Methylcholanthren

2-Methyinaphthaiene

Naphthalene

1,4-Naphthoquinone

1 1-Naphthylemine

O 2-Neph

Nickol

2-Nitroaniline

3-Nhroanline

Nitroanilin

Nitrobenzene

2-Nitropheno

2-Nitropheno

4-Nitropheno

4 Nitroquinoline-1-oxide

$N$-Nitrosodi-n-butylamine

N-Nitrocodiathylamins

N-Nitrosodimethylamin

N-Nitrosodimethylamino

N-Nitroeodiphenylamine

N-Nitroeodipropylamino

N-Nitrocodipropylamine

N-Nitrosomethylethylemine

N-Nitrosomorpholine

N-Nitroeopiperfdine

N-Nitrosopyrrolidin

$\begin{array}{llll}<0.00045 & & \mathrm{mg} / \mathrm{L} & \mathrm{GE} \\ <10 & \mathrm{J1} & \mathrm{mgh} & \mathrm{GE} \\ <10 & & \mathrm{mg} / \mathrm{GE} & \mathrm{GE}\end{array}$

$<10$

$<10$

$<10$

$<0.00045$

$<0.00045$

$<0.00040$

$<10$

$<i 0$

$<10$

$<10$

$<10$

$<15$

$<4.00$

$\leq 10$

$<10$

$<10$

$<10$

$<3.0$

$<0.0050$

$<2.0$

$<0.20$

$<50$

$<10$
$<0.50$

$<10$

$<10$

$<1.8$

$<<10$

$<10$

$\leq 10$
$\leq 10$
$<10$

$<10$

$<10$

$<<10$

$<4.0$

$<4.0$

$<10$

$<10$

$\leq 10$

$<10$

$<10$

$<10$

$<10$

$<10$

$<10$

$<10$

$<10$

$<10$

$<10$

$<10$

o,o,-Triethyl phomphorothionte $<10$

Octachlorodibonzo-p-dioxins $<0.0010$

Oetachlorodibenzo-p-turans $<0.001$

Parathion

PC 1018

- PCE 1221

O PCB 1221

PCB 1232

PCB 1242

PCB 1242

PCB 1246

PCB 1248

PCB 1254

PCB 1280

PCB 1260

Pontachlorobon

Pentachlorodibenzo-p-dioxins

Pentachlorodibenzo-p-furans

$1,2,3,7,8-P C D F$

Puntachioroethane

Pentachloronitrobenzeno

J1 11

J1

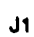

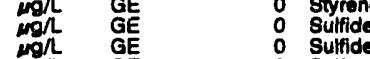

Sulfide

1,2,4,5-Tetrachlorobenzene

2,3,7,8-TCDD

Totrachlorodibenzo-p-dioxins

Tetrachiorodibenzo-p-furans

1,1,1,2-Tetrachloroothane

1,1,2,2-Tetrachloroethane

T Tetrachloroethylene

2,3,4,6-Tetrachlorophenol

Thallium

Thallum

o Tin

o Toluene

O Tolvene

Total dissolved solid

Total organic carbon

Total organic carbon

Total organic halogens

- Toxaphene

2,4,5-TP (Silvex)

1,2,4-Trichlorobenzene

1,2,4-Trichlorobenzene

i, i, Theroshane

,i, Irichlorosthan

1,1,2-Trichloroethane

Trichloroethylon

Trichlorofluoromethan

Trichlorofluoromethane

2,4,5-Trichlorophenol

2,4,6-Trichloropheno

2,4,6-7ric

1,2,3-Trichloropropane

Vinyl acetato

0 Xylenes

Zinc

Gross alpha

Total alpha-emitting radium

Tritium
Result Mod Unit Lيo

$<10$

$<10$

$<10$

$<10$
$<10$

$<10$

$<10$

$<10$

$<10$

$<10$

$<2.0$

$<2.0$

$<1.0$

$<1,000$

$<10$

$<0.00045$

$<0.00040$

$<0.000$

$<1.0$

$<1.0$
$<1.0$
$<1.0$

$<1.0$

$<10$

$<2.0$

$<10$
$<2.0$

1.6
$<1.0$

$<10$
151,000

151,000

1,000

1,000
$<5.0$
$<0.24$

$<0.24$

$<0.080$
$<10$

$<10$

$<1.0$

$<1.0$

$<10$

$<1.0$

$<1.0$

$<10$

$<10$

$<0.090$

$<1.0$

$<8.0$

$<1.0$

$<2.0$

$2.8 E-09 \pm 2.1 E-00$

$2.0 E-09 \pm 2.1 E-09$
$2.4 E-09 \pm 8.0 E-10$

$\mu g / L$ GE

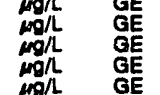

$\operatorname{mgn}_{\mu \mathrm{g} / \mathrm{K}} \mathrm{GE}$

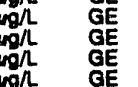

WELL AOB 1

MEASUREMENTS CONDUCTED IN THE FIELD

Sample date: 07/14/92

Dopth to water: $106.04 \mathrm{At}(32.32 \mathrm{~m})$ below TOC

Waler elevation. $235.08 \mathrm{H}(71.85 \mathrm{~m}) \mathrm{ms}$

W. conductance: 41

$3 \mathrm{gal}$

Time: : 8:20

PH: 5.1 . $0 \mathrm{mg}$

Water tomperature: $20.6 \circ \mathrm{C}$

LABORATORY ANALYSES

\begin{tabular}{|c|c|c|c|c|}
\hline$F$ & Analyte & Posult & Mod & Unit \\
\hline $\begin{array}{l}0 \\
0 \\
0 \\
0 \\
0 \\
0\end{array}$ & $\begin{array}{l}\text { Acenaphthene } \\
\text { Acenaphthylene } \\
\text { Aldrin } \\
\text { Anthracene } \\
\text { Antimony } \\
\text { Arsenic } \\
\text { Barium } \\
\text { Benzene } \\
\text { alpha-Benzene hexachloride } \\
\text { beta-Benzene hexachloride }\end{array}$ & $\begin{array}{l}<10 \\
<10 \\
<10 \\
<10 \\
<2.0 \\
<2.0 \\
14 \\
<5.0 \\
<10 \\
<10\end{array}$ & $\begin{array}{l}J 1 \\
J 1 \\
J 1 \\
J 1\end{array}$ & 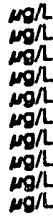 \\
\hline
\end{tabular}


ANALYTICAL RESULTS

WELL AOB 1 collected on 07/14/92, laboratory analyees (cont.)

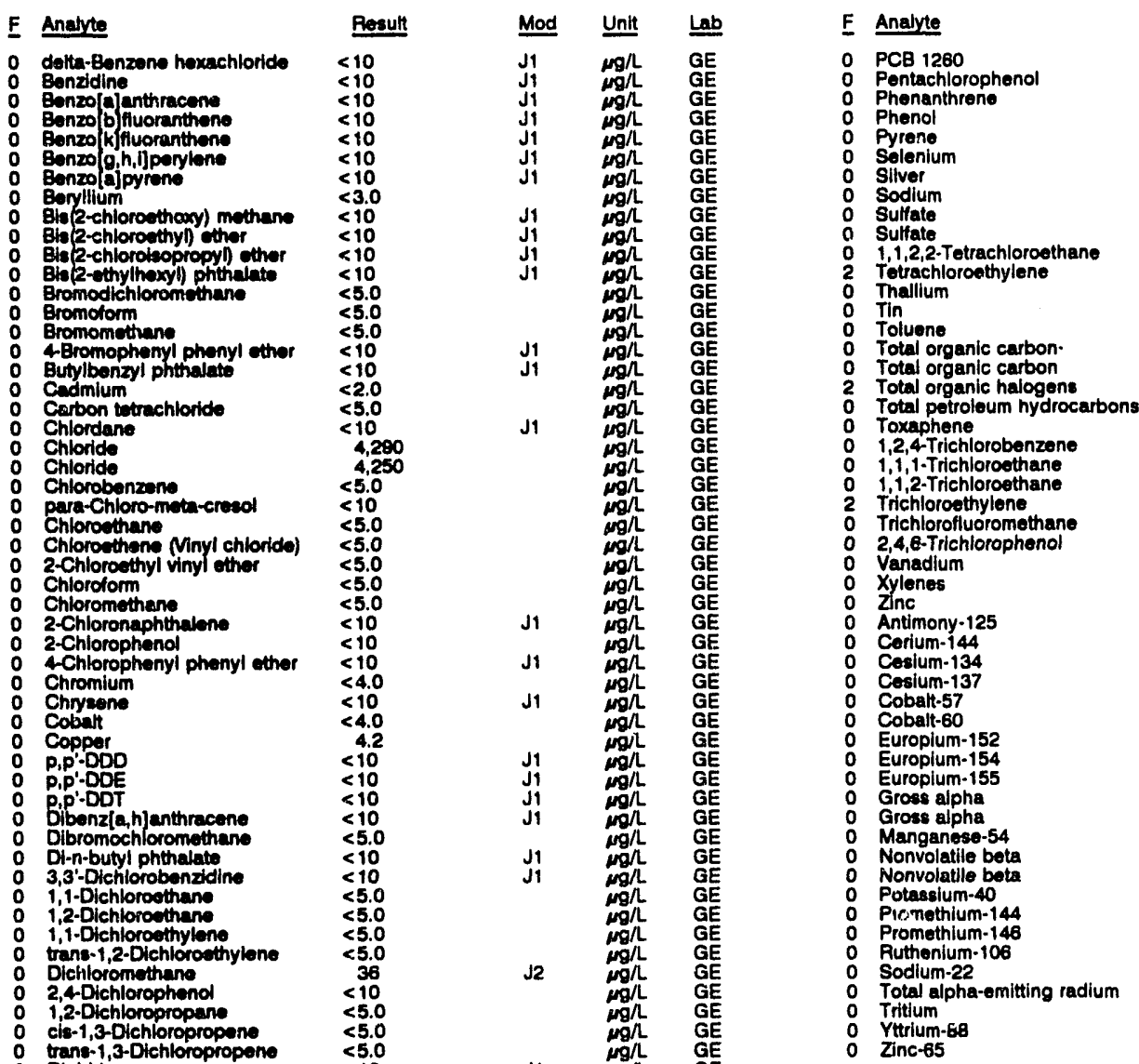

WELL AOB 1 collected on 07/14/82, laboratory analyses (cont.)

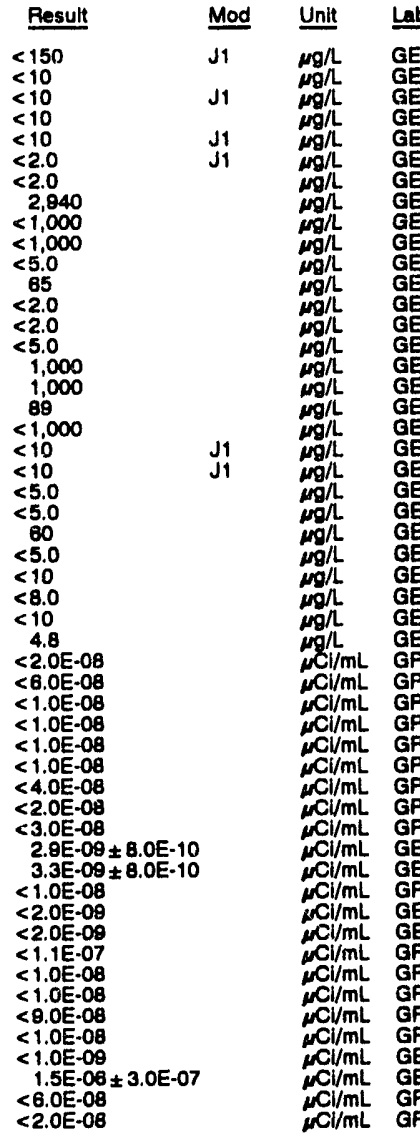

WELL AOB 2

MEASUREMENTS CONDUCTED IN THE FIELD

Sample date: 07/14/82

Depth to water: $108.87 \mathrm{At}(33.18 \mathrm{~m})$ below TOC Water elevation: $238.53 \mathrm{ft} / 7$.

(2)

LABORATORY ANALYSES

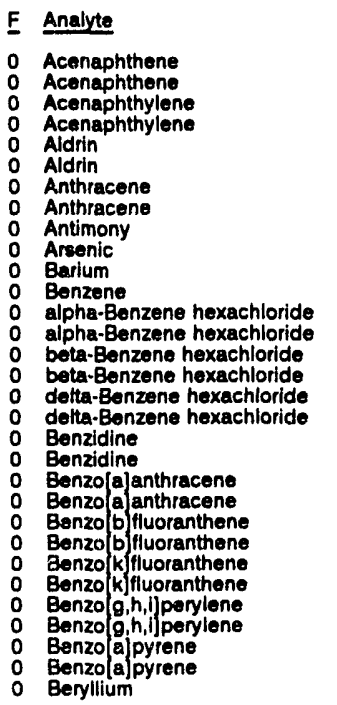

0 Beryllium

$\begin{aligned} & \text { Result } \\ &<10 \\ &<10 \\ &<10 \\ &<10 \\ &<10 \\ &<10 \\ &<10 \\ &<10 \\ &<2.0 \\ &<2.0 \\ &<3.0 \\ &<1.0 \\ &<10 \\ &<10 \\ &<10 \\ &<10 \\ &<10 \\ &<10 \\ &<10 \\ &<10 \\ &<10 \\ &<10 \\ &<10 \\ &<10 \\ &<10 \\ &<10 \\ &<10 \\ &<10 \\ &<10 \\ &<10 \\ &<3.0 \\ &<10\end{aligned}$

Time: : 8:00

pH: 5.3 . 200 Water temperature: $20.9^{\circ} \mathrm{C}$

Endosultan sultate

Endrin

Endrin aldehyde

Fluoranthene

Fluorene

Heptachlor

Heptachlor epoxido

Hoxachlorobenzene

Hexachlorocyclopentadiene

Hexachioroethane

indeno $[1,2,3-c, d]$ pyrene

leophorone

Lindane

Manganese

2-Methyl-4,6-dinitiophenol

Naphthalene

Nitrate-nitrite as nitrogen

Nitrobenzene

2-Nitrophend

N-Nitrosodimethylamine

N-Nitrosodiphenylamine

O Oll \& grease

PCB 1016

P PCB 1232

PCB 1242

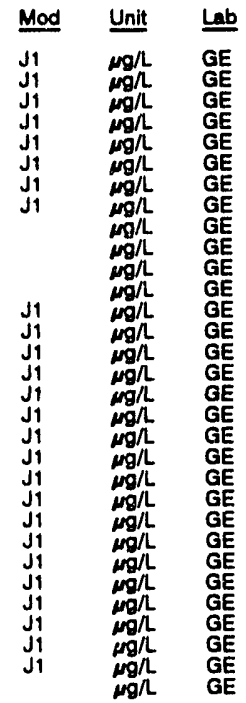


WELL AOB 2 collected on 07/14/92, laboratory analysee (cont)

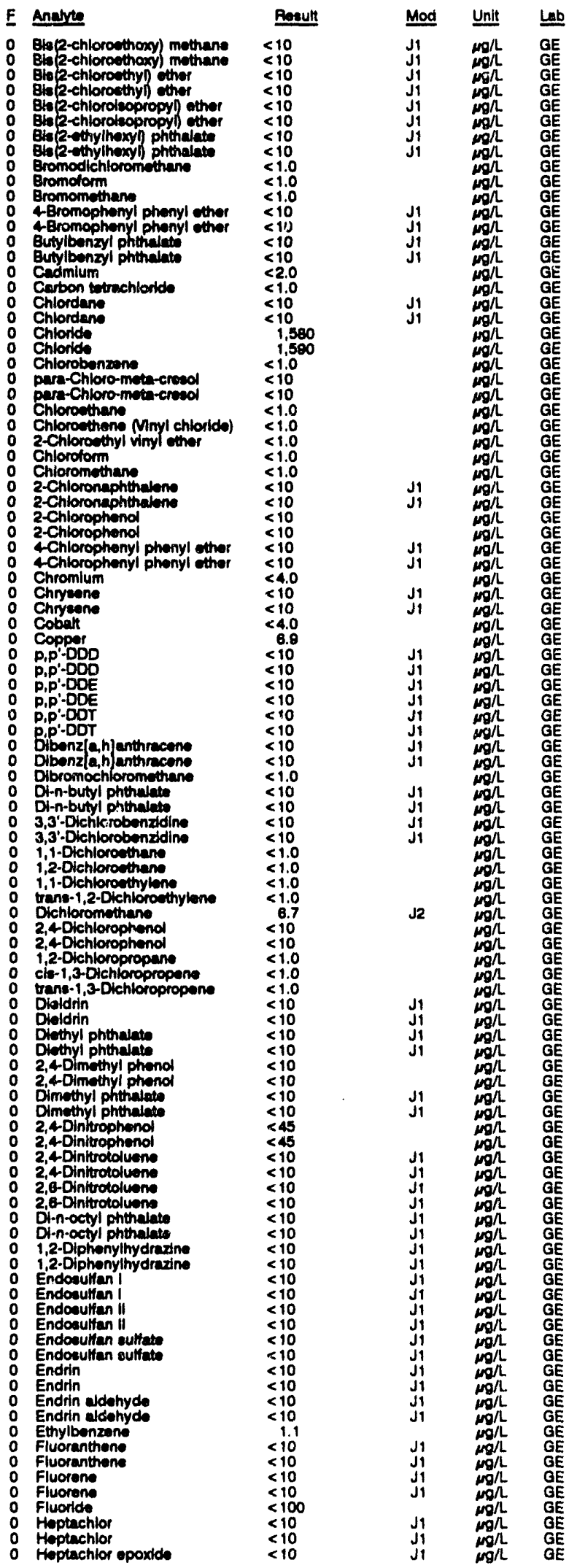

WELL AOB 2 collected on 07/14/92, laboratory analyese (cont)

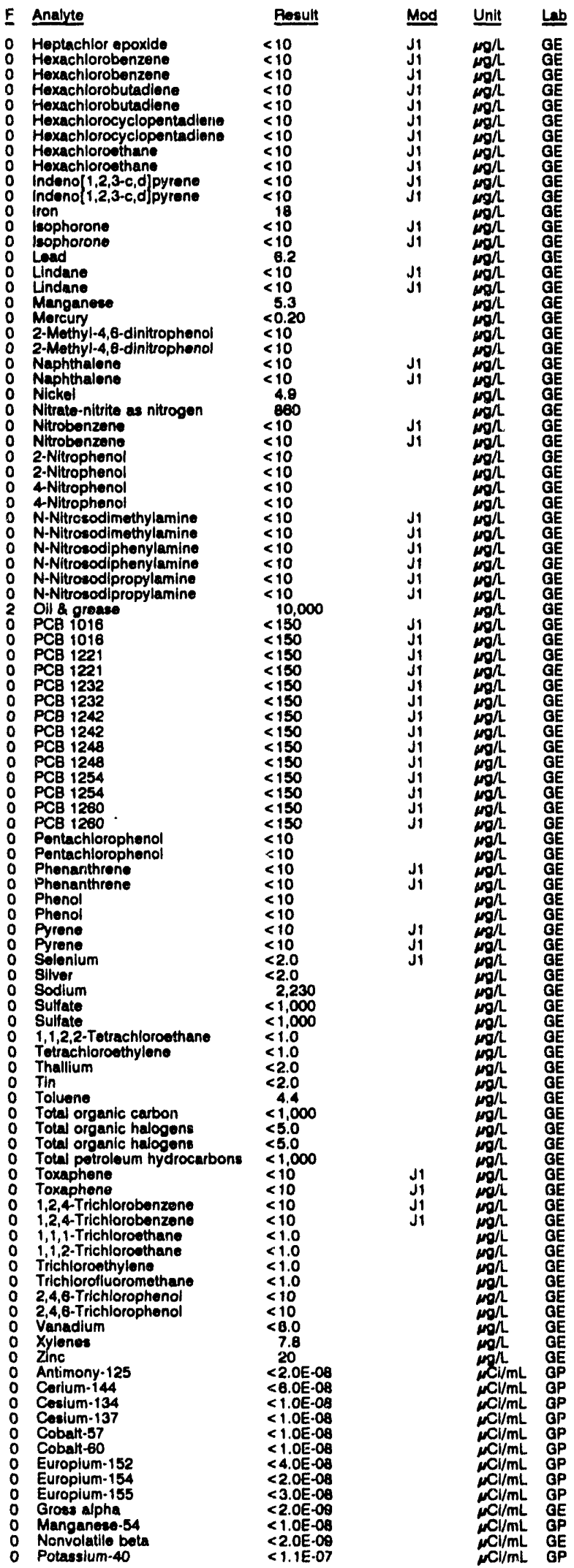


ANALYTICAL RESULTS

WELL AOB 2 collected on 07/14/82, laboratory analyses (cont.)

\begin{tabular}{|c|c|c|c|c|c|}
\hline E & Analyte & Result & Mod & $\underline{\text { Unit }}$ & Lab \\
\hline & $\begin{array}{l}\text { Promethlum-144 } \\
\text { Promethlum-146 } \\
\text { Ruthenium-108 } \\
\text { Sodium-22 } \\
\text { Total alphe-emitting radium } \\
\text { Tritium } \\
\text { Yttrium-88 } \\
\text { Zinc-65 }\end{array}$ & $\begin{array}{l}<1.0 E-08 \\
<1.0 \mathrm{E}-08 \\
<0.0 \mathrm{E}-08 \\
<1.0 \mathrm{E}-08 \\
<1.0 \mathrm{E}-09 \\
1.2 \mathrm{E} \cdot 08 \pm 3.0 \mathrm{E} \cdot 07 \\
<6.0 \mathrm{E} \cdot 08 \\
<2.0 \mathrm{E}-08\end{array}$ & & 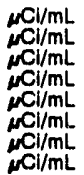 & $\begin{array}{l}\text { GP } \\
G P \\
G P\end{array}$ \\
\hline
\end{tabular}

WELL AOB 3

MEASUREMENTS CONDUCTED IN THE FIELD

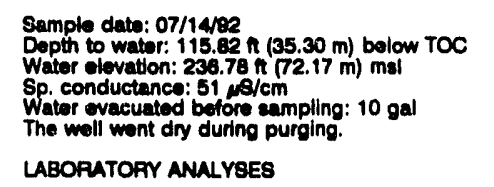

Time: $7: 30$
$\mathrm{pH}: 5.3$

Water temperature: $20.4^{\circ} \mathrm{C}$

LABOFATORY ANALYSES

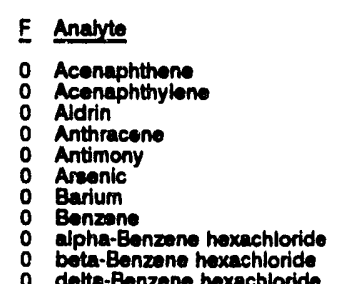

detta-Benzene hoxachloride

Denzidine

O Benzo(a)anthracene

Benzo k fluorantinen.

Benzolg, h,llperylene

Boryllum

Bis (2-chloroethaxy) methane

Bis (2-chloroethyi) ether

Bis(2-chloroleopropyl) ether

Bisomodichloromethane

Bromoform

4Bromophenyl phenyl other

Butylbenzyl phthalate

Carbon tetrachioride

Chlordane

Chloride

Chlorobenzene

para-Chloro-mota-cresol

Chloroethene Minyl chloride)
2-Chloroethyl vinyl ether

Chloroform

2-Chloronaphthalene

2-Chlorophenol
4-Chlorophenyl phenyl ether

Cnromium

O Cobalt

Coppor

P,P-DDD

P,P-DDT

D Dibromziachlanthracene

0 Di-n-butyl phthalate

3,3'-Dichlorobenzidino

i, -Dichlorothane

1,2-Dichloroethane

trans-1,2-Dichloroethylene

Dichloromethane

2,4-Dichlorophenoi

1,2-Dichloropropane

trans-1,3-Dichloropropene

Dieldrin

o Diethyl phthalate

2,4-Dimethyl phenol

0 Dimethyl phthalate

2,4-Dinltrophenol

2,4-Dinitrotoluene

2,6-Dinitrotoluene

1,2-Diphenylhydrezine

0 Endosultan I

Endosulfan II

Endosultar

0 Endrin

\begin{tabular}{|c|c|c|}
\hline Result & Mod & Unit \\
\hline $\begin{array}{l}<10 \\
<10 \\
<10 \\
<10 \\
<2.0 \\
<2.0 \\
4.7 \\
<1.0 \\
<10 \\
<10 \\
<10 \\
<10 \\
<10 \\
<10 \\
<10 \\
<10 \\
<10 \\
<3.0 \\
<10 \\
<10 \\
<10 \\
<10 \\
<1.0 \\
<1.0 \\
<1.0 \\
<10 \\
<10 \\
<2.0 \\
<1.0 \\
<10 \\
1.680 \\
<1.0 \\
<10 \\
<1.0 \\
<1.0 \\
<1.0 \\
<1.0 \\
<1.0 \\
<10 \\
<10 \\
<10 \\
<4.0 \\
<10 \\
<4.0 \\
<4.0 \\
<10 \\
<10 \\
<10 \\
<10 \\
<1.0 \\
<10 \\
<10 \\
<1.0 \\
<1.0 \\
<1.0 \\
<1.0 \\
6.2 \\
<10 \\
<1.0 \\
<1.0 \\
<1.0 \\
<10 \\
<10 \\
<10 \\
<10 \\
<45 \\
<10 \\
<10 \\
<10 \\
<10 \\
<10 \\
<10 \\
<10 \\
<10 \\
<10 \\
<10 \\
\end{array}$ & 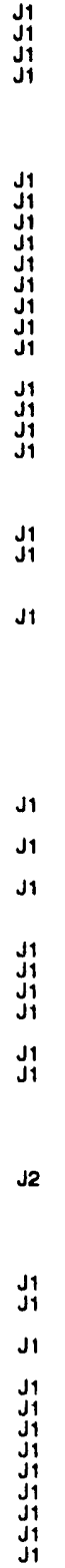 & $\begin{array}{l}\mu g / \\
\mu g / L \\
\mu g / L \\
\mu g / L \\
\mu g / L \\
\mu g / L \\
\mu g / L \\
\mu g / \\
\mu g / L \\
\mu g / L \\
\mu g / L \\
\mu g / L \\
\mu g / \\
\mu g / \\
\mu g / L \\
\mu g / L \\
\mu g / L \\
\mu g / L \\
\mu g / L \\
\mu g / L \\
\mu g / L \\
\mu g / L \\
\mu g / L \\
\mu g / L \\
\mu g / L \\
\mu g / L \\
\mu g / L \\
\mu g / L \\
\mu g / L \\
\mu g / L \\
\mu g / L \\
\mu g / L \\
\mu g / L\end{array}$ \\
\hline
\end{tabular}

WELL. AOB 3 collected on 07/14/82, laboratory analyses (cont.)

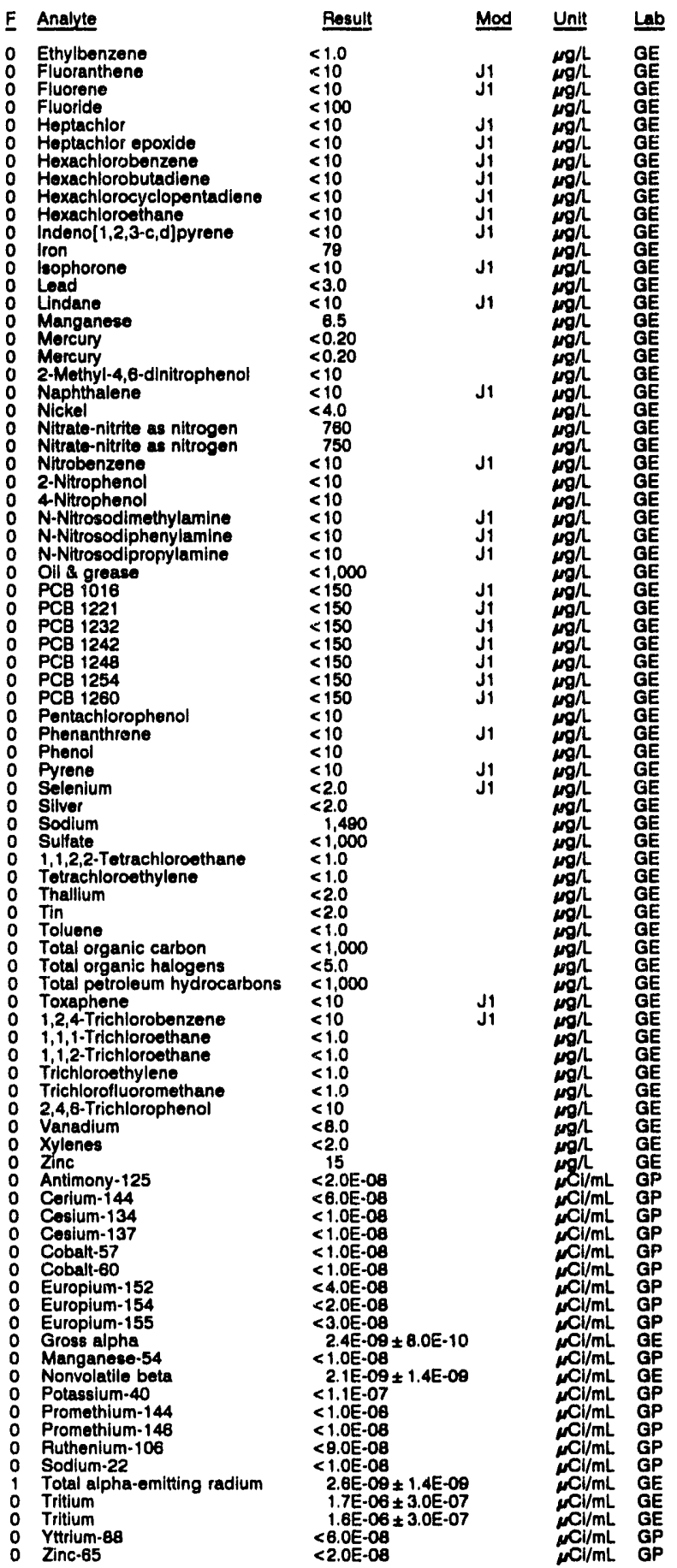


WELL ARP 1A

MEASUREMENTS CONDUCTED IN THE FIELD

Sample data: 07/03/92

Depth to water: 130.06 in $(42.08 \mathrm{~m})$ bolow TOC Wator olovation: $215.14 \mathrm{~h}(65.58 \mathrm{~m}) \mathrm{ms}$ Water wacuated before sampling: 58 gal LABOFUTOAY ANMLYSES

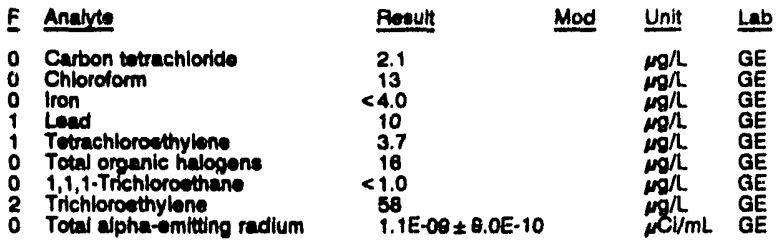

\section{WELL ARP 2}

MEASUREMENTS CONDUCTED IN THE FIELD

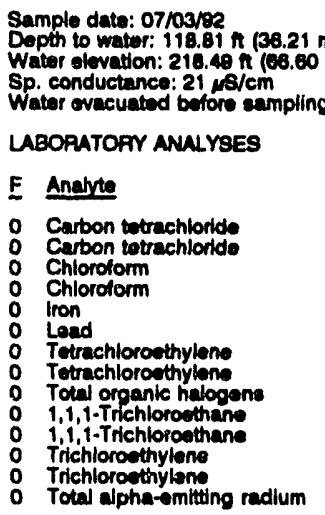

Time: 7:50

Alkalinity: $1 \mathrm{mg} / \mathrm{h}$

Water temperature: $19.2{ }^{\circ} \mathrm{C}$

$\lim _{0,7}: 7.25$

Akalinity: $0 \mathrm{mg} / \mathrm{h}$

Whater temperature: $19.6 \circ \mathrm{C}$

LABOPATOFY ANULYSES

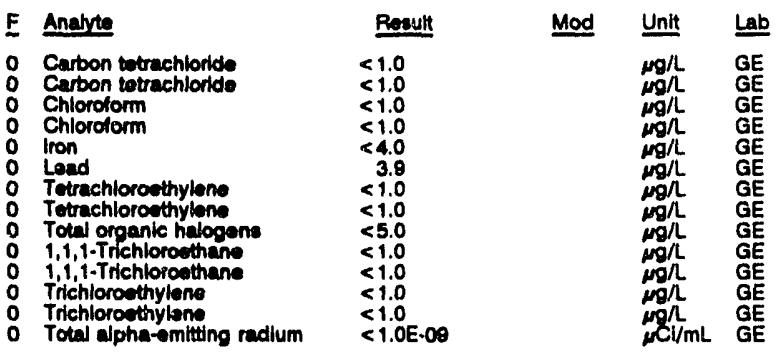

\section{WELL ARP 3}

MEASUREMENTS CONDUCTED IN THE FIELD

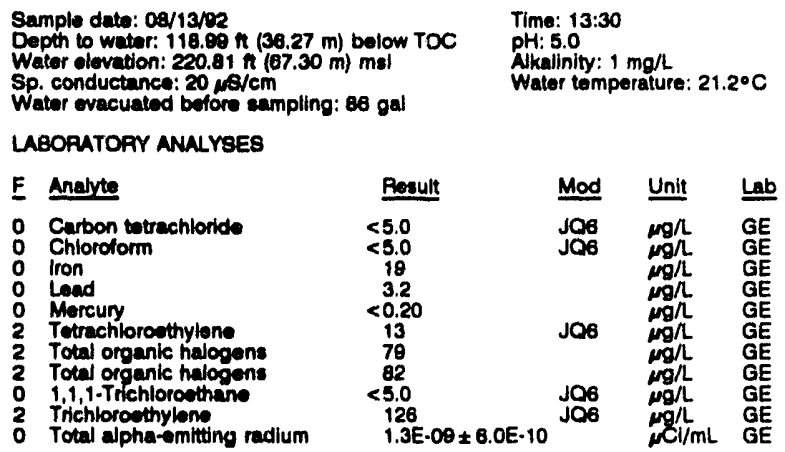

\section{WELL ARP 4}

MEASUREMENTS CONDUCTED IN THE FIELD

Sample dato: 07/03/102

Depth to water: $130.70 \mathrm{tt}$ (39.64 m) below rOC

Watef alevation: $217.70 \mathrm{n}(68.38 \mathrm{~m}) \mathrm{msl}$

Sp. conductance: 23 foistm
Water evecuated bolore sampling: 52 gal

LABORATORY ANALYSES

$\begin{array}{llccc}\text { E Anajyte } & \text { Result } & \text { Mod } & \text { Unit } & \text { Lab } \\ 0 \text { Carbon tetrachloride } & <1.0 & & \mathrm{mg} / \mathrm{L} & \mathrm{GE} \\ 0 & \text { Chloroform } & & \mathrm{mg} / \mathrm{L} & \mathrm{GE} \\ 0 & \text { Iron } & 5.0 & \mathrm{mg} / \mathrm{L} & \mathrm{GE}\end{array}$

WELL ARP 4 collected on 07/03/92, laboratory analyses (cont.)

\begin{tabular}{|c|c|c|c|}
\hline Analyte & Result & Mad & Unit \\
\hline $\begin{array}{l}\text { Lead } \\
\text { Totrachloroethylene } \\
\text { Total organic halogens } \\
1,1,1 \text {-Trichloroethane } \\
\text { Trichloroethylene } \\
\text { Total alpha-omitting radium } \\
\text { Total alpha-emitting radium }\end{array}$ & $\begin{aligned} 6.6 \\
4.1 \\
<5.0 \\
<1.0 \\
8.9 \\
1.3 \mathrm{E}-00 \pm 1.1 \mathrm{E}-09 \\
1.5 \mathrm{E}-09 \pm 1.1 \mathrm{E}-00\end{aligned}$ & & 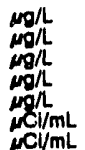 \\
\hline
\end{tabular}

WELL ASB $1 A$

MEASUAEMENTS CONDUCTED IN THE FIELD

Sample date: 07/16/82

Wepth to water: $112.67 \mathrm{~h}(34.34 \mathrm{~m})$ below TOC

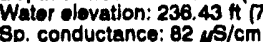

$06 \mathrm{~m}) \mathrm{mal}$ A Alkalinity: $4 \mathrm{mg} / \mathrm{L}$

Water temperature: $20.7{ }^{\circ} \mathrm{C}$

LABOAATOAY ANALYSES

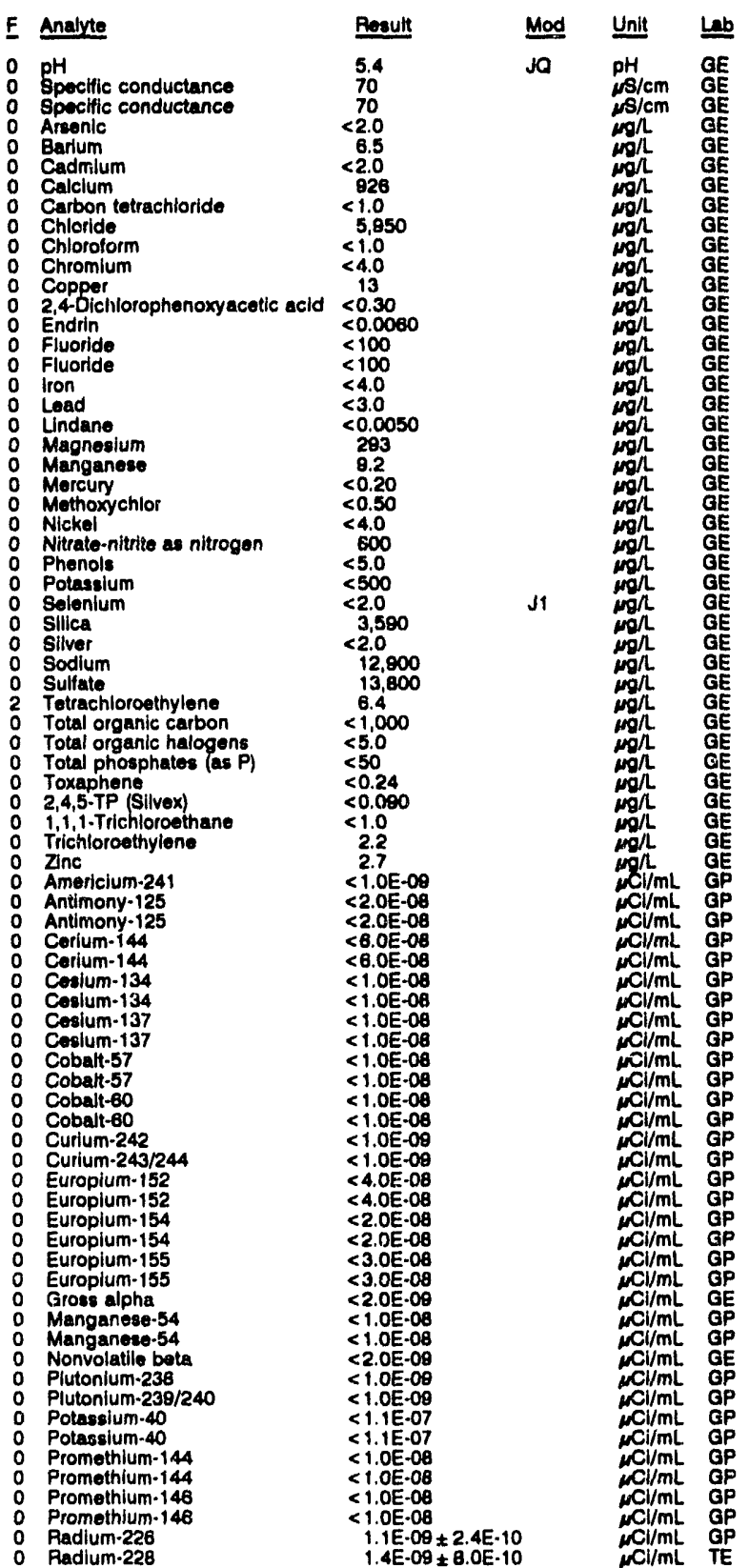


ANALYTICAL RESULTS

WELL ASB 1 A collected on 07/18/92, laboratory analyses (cont.)

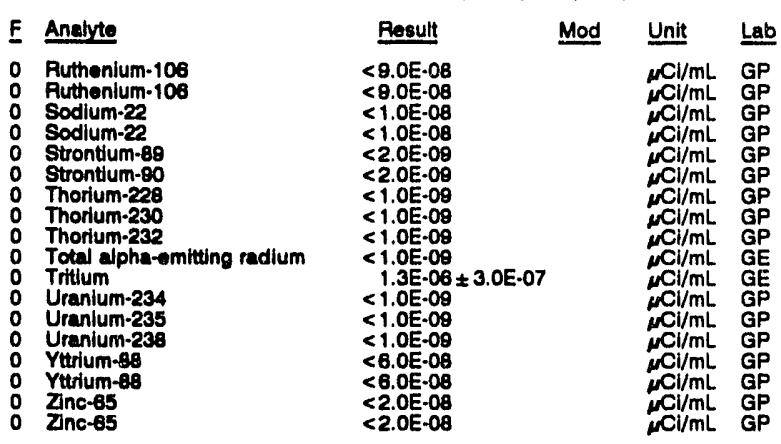

\section{WELL ASB 2A}

MEASUREMENTS CONDUCTED IN THE FIELD

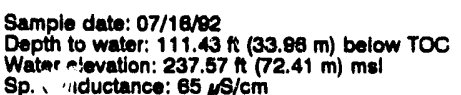

Time: 10:30

Alkalinity: $14 \mathrm{mg} / \mathrm{L}$

Alkalinity: $14 \mathrm{mg} / \mathrm{L}$ : $20.8 \circ \mathrm{C}$

Water "lvactance: bofore sampling: $54 \mathrm{gat}$

LABORATORY ANALYSES

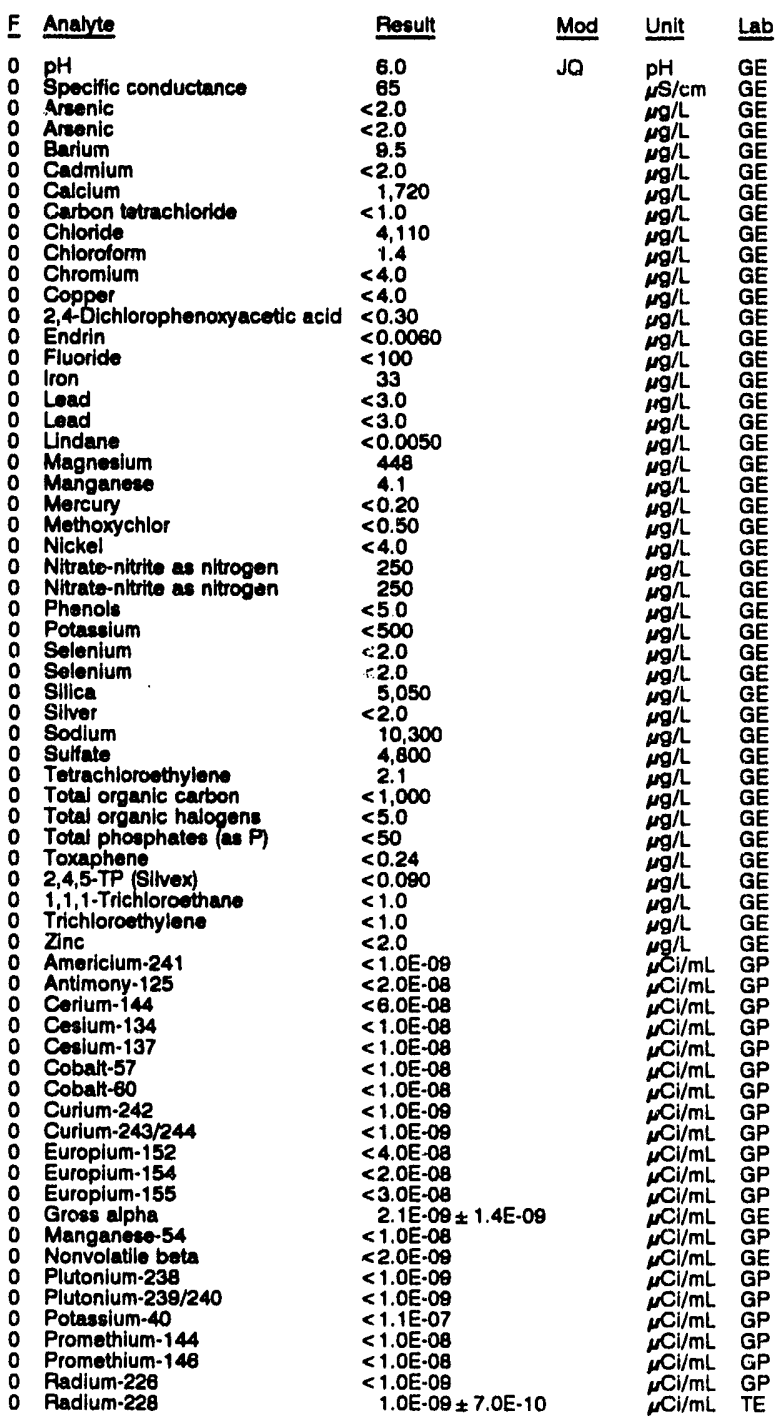

WELL ASB 2A collected on 07/18/82, laboratory analyses (cont.)

$\begin{array}{ll}\text { F } & \text { Analyte } \\ 0 & \text { Ruthenium-106 } \\ 0 & \text { Sodium-22 } \\ 0 & \text { Strontium-89 } \\ 0 & \text { Strontium-90 } \\ 0 & \text { Thorium-228 } \\ 0 & \text { Thorlum-230 } \\ 0 & \text { Thorlum-232 } \\ 1 & \text { Total alpha-emitting radium } \\ 0 & \text { Tritium } \\ 0 & \text { Tritlum } \\ 0 & \text { Uranium-234 } \\ 0 & \text { Uranium-235 } \\ 0 & \text { Uranium-238 } \\ 0 & \text { Yttrium-88 } \\ 0 & \text { Zinc-65 }\end{array}$

WELL ASB 2C

MEASUREMENTS CONDUCTED IN THE FIELD

Sample cate: 07/16/82

Depth to water: $128.27 \mathrm{ft}(38.48 \mathrm{~m})$ below TOC Water elevation: $223.13 \mathrm{Ht}(68.01$

Sp. conductance: $63 \mu \mathrm{S} / \mathrm{cm}$
Water evacuated before sampling: $145 \mathrm{gal}$

LABORATORY ANALYSES

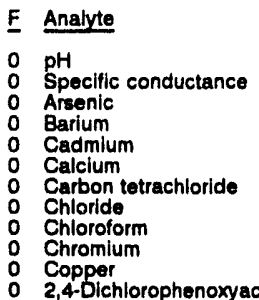

0 Endrin

$\begin{array}{ll}0 & \text { Fluoride } \\ 0 & \text { Iron } \\ & \text { Lead }\end{array}$

0 Lead

0 Lindane

Magnesium

Mercury

Methoxychlor

Nicke

Nitrate-nitrite as nitrogen

Phenols

Potassium

Selenium

Sillica

S Silver

Sodium

2 Sulfate

Total dissolved solids

Total organic carbon

Total phosphates (as P)

Toxaphene

1,1.1-Trichloroethane

Trichioroethylene

o Zinc

Americium-241

Antimony-125

Cerium-144

Cesium-134

Cesium-137

Cobalt-57

Curium-242

Curium-243/244

Europium-152

Europium-154

Europium-15

Gross alpha

Nonvolatile beta

Plutonium-238

Potonium-238

Promethium-144

Promethium-146

Radium-226

Radium-228

Ruthenium-108

Sodium-22

Strontium-88

Strontium-90

Thorium-228

Result
$<0.0 \mathrm{E}-08$
$<1.0 \mathrm{E} \cdot 08$
$<2.0 \mathrm{E}-09$
$<2.0 \mathrm{E}-09$
$<1.0 \mathrm{E}-09$
$<1.0 \mathrm{E}-09$
$<1.0 \mathrm{E}-09$
$2.6 \mathrm{E}-09 \pm 1.0 \mathrm{E} \cdot 09$
$<7.0 \mathrm{E}-07$
$<7.0 \mathrm{E}-07$
$<1.0 \mathrm{E}-09$
$<1.0 \mathrm{E} \cdot 09$
$<1.0 \mathrm{E}-09$
$<8.0 \mathrm{E} \cdot 08$
$<2.0 \mathrm{E}-08$

Mod Unit Lab

$\begin{array}{cc}\mu \mathrm{Cl} / \mathrm{mL} & \mathrm{GP} \\ \mu \mathrm{Cl} / \mathrm{mL} & \mathrm{GP} \\ \mu \mathrm{Cl} / \mathrm{mL} & \mathrm{GP} \\ \mu \mathrm{Cl} / \mathrm{mL} & \mathrm{GP} \\ \mu \mathrm{Cl} / \mathrm{mL} & \mathrm{GP} \\ \mu \mathrm{Cl} / \mathrm{mL} & \mathrm{GP} \\ \mu \mathrm{Cl} / \mathrm{mL} & \mathrm{GP} \\ \mu \mathrm{Cl} / \mathrm{mL} & \mathrm{GE} \\ \mu \mathrm{Cl} / \mathrm{mL} & \mathrm{GE} \\ \mu \mathrm{Cl} / / \mathrm{mL} & \mathrm{GE} \\ \mu \mathrm{Cl} / \mathrm{mL} & \mathrm{GP} \\ \mu \mathrm{Cl} / \mathrm{mL} & \mathrm{GP} \\ \mu \mathrm{Cl} / \mathrm{mL} & \mathrm{GP} \\ \mu \mathrm{Cl} / \mathrm{mL} & \mathrm{GP} \\ \mu \mathrm{Cl} / \mathrm{mL} & \mathrm{GP}\end{array}$
Time: $10: 45$

PH: 5.3

Water tomperature: $20.6^{\circ} \mathrm{C}$

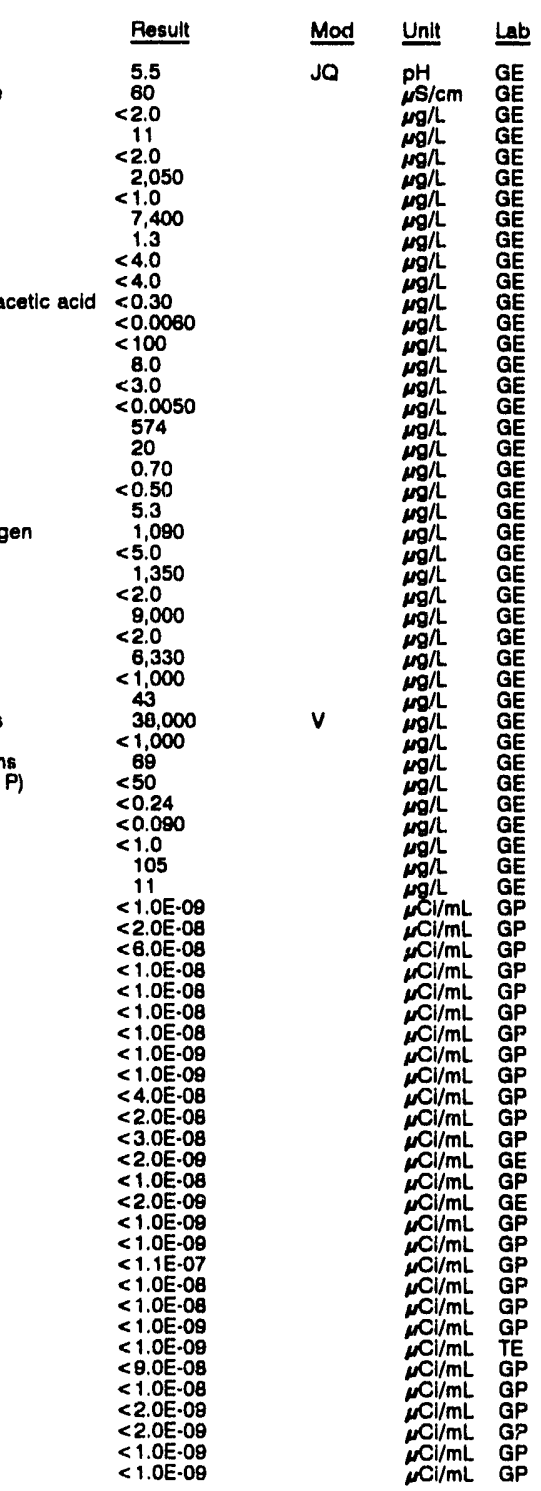


ANALYTICAL RESULTS

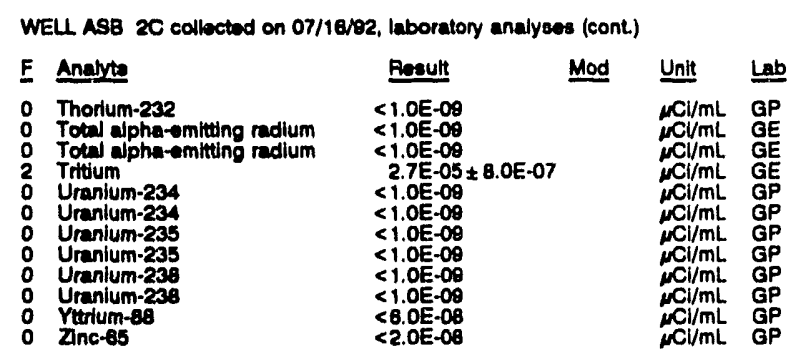

WELL ASB 3A

MEASUREMENTS CONDUCTED IN THE FIELD
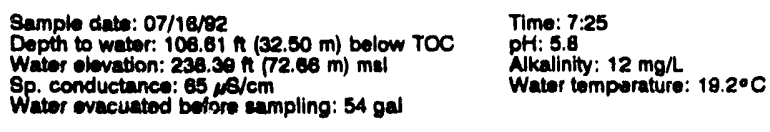

LABOPATOPY ANALYSES
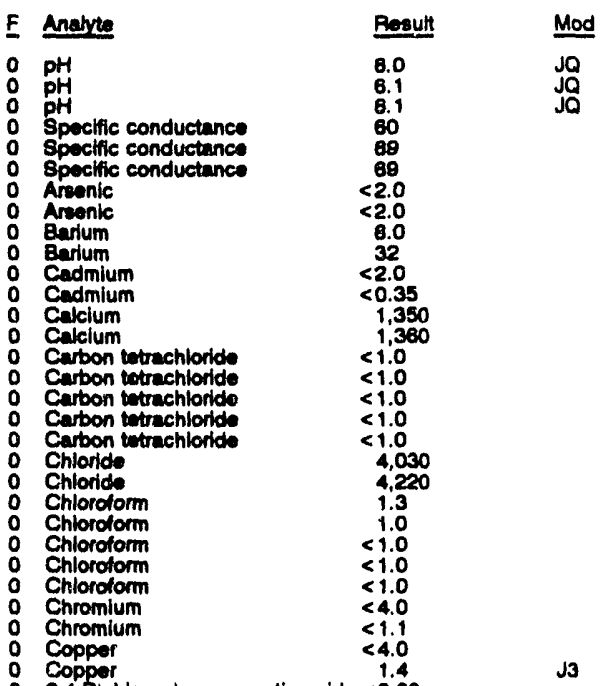

2,4Dchlorophenoxyecetic ecid

o 2,4-Dichlorophenoxyacetic acid

O E Endric

: Endrin

o Fluoride

0 Iron

0 Iron

o Load

O Undane

o Magnealum

- Magneslum

o Manganese

O Mercury

Methoxychlor

Methoxychior

Nickel

Nitrate ae nitrogen

N Nitrato-nituite es nitrogen

o Phenols

Phenols

Potansium

o Potasalum

o Selenium

o Silica

o Silver

0 Silver

o Sodium

o Sulfato

O Sulfato

o Tetrachloroethylene
$<0.30$

Water tomporature: $18.2^{\circ} \mathrm{C}$

Mod Unit Lab

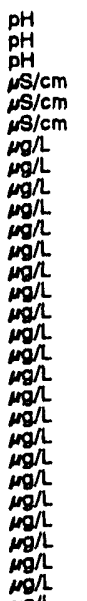

$<2.2$

$<0.11$

$<100$

36

$<2.0$

$<0.0050$

0.05

439
230

2.0
$<0.20$
0.70

$<0.20$
0.76
$<0.50$

$<0.50$
$<0.56$

4.2
$<3.1$

596

480
$<5.0$
$<5.0$
$<500$
351

351
$<2.0$
$<2.0$

$<2.0$
5,280

5,040

$<0.70$

11,000
11,000

5,750

8,000
$<1.0$

WELL ASB 3A collected on 07/16/82, laboratory analyees (cont.)

$E$ Analyte

O Tetrachloroethylene

Totrachloroethylene

o Total organic carbon

o Total organic carbon

Total organic halogens

- Total organic halogens

Total phosphates (as P)

o Toxaphene

Toxaphone

2,45.TP (Silvox)

2,4,5.TP Silvox

1,1,1.Trichloronthane

1,i, -Trichloroethan

O Trichlorosthylene

- Trichloroethylene

I Trichloroethylene

: Titchlorosthylone

: Znche

Zinc

Amoricium-24

- Antimony-125

Corium-144

Corium-144

Cosium.134

Cosium-134

Cosium.137

Cosium-137

Cobalt-57

Cobalt-60

Cobalt-60

C Curlum-242

Curlum-243/244

Curium-243/244

Europium-152

Europium 152

Europlum.154

Europium-154

Europlum-155

Europlum-155

Grose alpha

Groses alpha

Gross alphs

Manganeso-54

Nonvolatilie bota

Nonvolatilio beta

Plutonium-238

Plutonium-238

Plutonium-239/240

Plutonium-239/240

Potassium-40

Promethium-1

Promethium-144

Promethium.146

Radium-228

Radium-226

Radlum-226

Radium-228

Radium-226

Radium-226

Radium-228

Radium-228

Radium-228

Ruthenium-103

Ruthenium-106
Ruthenium.106

Sodium-22

Sodium-22

Strontium-88

Strontum-80

Strontium-80

Thorium-228

Thorium-228

Thorium-228

Thorium-230

Thorium-230

0 Thorium-232

0 Thorium-232

Total alpha-emitting radium

Tritlum

Tritlum

Tritium

Uranium-234

0 Uranium-234

Uranium-235
Pesuit

$<1.0$

$<1.0$

$<1,000$

526
$<50$

$<5.0$

450

$<0.24$

$<0.090$

$<1.1$

$\leq 1.0$

$<1.0$

$<1.0$

$<1.0$

$<1.0$

7.0
$<1.0 E-09$
$<1.0 E-00$

$<2.0 \mathrm{E} \cdot 08$

$<2.0 E-08$

$<5.0 E-08$

$<1.0 E-06$

$<1.0 E-00$

$<1.0 E-06$

$<$ <.

$<1.0 E-06$

$<1.0 E-06$

$<1.0 E-06$

$<1.0 \mathrm{E}-09$

$<1.0 E-09$

$<1.0 E-09$

$<4.0 \mathrm{E}-00$

$<2.0 E-06$

$<2.5 E-09$

$<2.5 E .00$

$2.7 E-09 \pm 1.5 E-C 0$

$3.3 E-09 \pm 8.0 E-10$
$3.9 E-00 \pm 8.0 E-10$

3.9E-00

$<1.0 E-08$
$<1.0 E-00$

$<4.0 E-08$

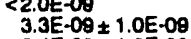

$3.3 E-09 \pm 1.0 E-09$
$2.4 E-09 \pm 1.0 E-00$

$<1.0 E-09$

$<1.0 \mathrm{E}-09$

$<1.0 E .09$

$<1.1 E-07$

$<1.0 E-08$

$<1.0 E .06$

$<1.0 E-08$

$<2.0 E-08.2 .6 E-10$

$1.0 E-\infty \theta$

$<1.8 \mathrm{E}-07$

$1.1 E-09+2.6 E-10$

$5.5 E-09+1.1 E-00$

$<1.0 E-09$

$1.0 E-09 \pm 8.0 E-10$

$<9.0 E-10$

$<1.0 E .0$

$<8.0 E-00$

$<7.0 E-08$

$<1.0 E-09$

$<1.0 E-08$

$<2.0 E-09$

$<2.0 E-09$

$<2.0 E-09$

$<1.0 E-097$

$<1.0 E .09$

$<1.0 E-09$

$<1.0 \mathrm{E}-00$

$<1.0 E-09$

$<1.0 E-09$

$<7.0 E-07$

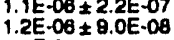

$<1.0 E-09$

$<1.0 \mathrm{E}-0.09$

$<1.0 E-09$

Mod Unt Lab

$m, \quad W h$ WA

$\mu g \Omega$
$G E$
$G E$
$\mu g h$

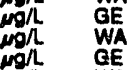

mog $G E$

wog WA

$\operatorname{mon}_{\mathrm{GE}} \mathrm{GE}$

Mg G GE

wa

$\operatorname{mon}_{W A}$

$\mathrm{NCl/mL}$ CN

CI/mL GP

CCI/mL GP

$\mu \mathrm{CVMm}$ GP

$\mu \mathrm{C} / \mathrm{mL}$ CN

$\mu \mathrm{Cl} / \mathrm{mL} \mathrm{CN}$

$\mu \mathrm{Cl} / \mathrm{mL}$ GP

$\stackrel{M C V / m L}{G P}$

$\mu \mathrm{Cl} / \mathrm{ml}$. GP

$\mu \mathrm{CV} / \mathrm{mL}$ GP

$\mu \mathrm{Cl} / \mathrm{mL}$ CN

NCl/mL CN

$\mu \mathrm{C} / \mathrm{mL} \quad \mathrm{CN}$

NC/mL GP

NCI//mL GN

$\mathrm{NCl/mL}$ TM

$\mu \mathrm{Cl} / \mathrm{mL}$ GP

$\mu \mathrm{Cl} / \mathrm{mL} \mathrm{CN}$

$N$ CI/mL TE

Cl/mL TM

NCLI/mL GP

$\mathrm{MClmL} G$

$\mathrm{N} / \mathrm{mL}$ GP

$\mathrm{NCl/mL} \quad \mathrm{CN}$

NCi/mL CN

$\mu \mathrm{Cl} / \mathrm{mL}$

$\mu \mathrm{Cl} / \mathrm{mL}$ GP

$M \mathrm{C} / \mathrm{mL} \mathrm{G}$

$\mu \mathrm{Cl} / \mathrm{mL}$ CN

$\mu \mathrm{Cl} / \mathrm{mL} \mathrm{CN}$

$\mu \mathrm{Cl/mL}$ CN

$\mathrm{NCI/mL}$ TE

$\mu \mathrm{Cl} / \mathrm{mL}$ TM

MCl/mL GP

$\omega \mathrm{Cl} / \mathrm{mL} \quad \mathrm{CN}$

$\mathrm{wCl/mL} \mathrm{CN}$

Cl/mL GP

$\mathrm{wCl/mL}$ GN

climL $\mathrm{CN}$

CClmL $\mathrm{GP}$

NCI/mL CN

climL GP

$\mathrm{NCl/mL} G P$

$\mathrm{MCl/mL} C N$

$\mu \mathrm{Cl} / \mathrm{mL}$ GE

Cl/mL TM

CI/mL TM

$\mathrm{MCl/mL}$ CN 
WELL ASB 3C

MEASUREMENTS CONDUCTED IN THE FIELD

8amplo data: 08/11/32
Dapth to water: $123.58 \mathrm{n}(37.87 \mathrm{~m})$ bolow TOC
Water olovation: $222.42 \mathrm{n}(87.79 \mathrm{~m}) \mathrm{mal}$ Op. conductance: $82, \mathrm{~N} / \mathrm{cm}$

Wetor ovecuated betore exmpling: $141 \mathrm{gal}$

LABOPATORY ANALYSEES

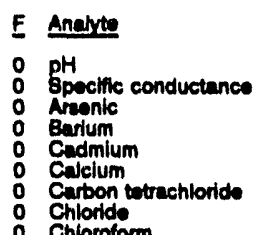

Chiloride

Chioroform

Copper

2,4Dichlorophenoxyacetic ecld

0 Fluorida

O Iron

Undano

Magnealum

Manganese

Methoxychior

Nickol

Nitrato-nitertte as nitrogen

Phonols

Solonium

sillen

Siver

Sodium

Totrechloroethylone

Toral diasolvod solide

Totid organic carbon

Total organic halogens

2,4,5-TP Bilvex

1,1-Trichloroe thun

Trichioroethylone

anc

Americlum-241

Antimony-125

Ceclum-134

Cealum-137

Cobalt.57

Curlum-248

Curlum-243/244

Europium-152

Europlum-154

Europlum-155

Manganew-54

Nonvolatile bete

Putonlum-235.

Potheslum-40

Promothlum-144

Promethlum-148

Radium-220

Ruthenlum.106

Sodium-22

Strontlum-48

Strontum-e0

Thorium-228

Thorlum-232

Totel alpha-emitting radium

Total alpha-omitting radium

Tritium

Uranium-234

Uranlum-23:

Yturlum-80

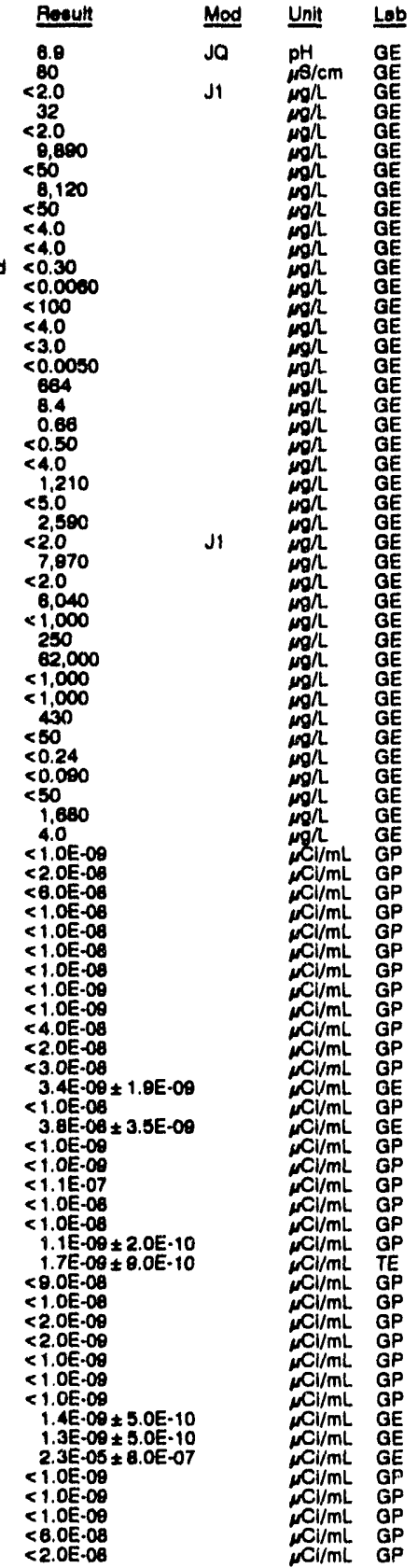

WELL ASB 4

MEASUREMENTS CONDUCTED IN THE FIELD

Sample date: 08/06/62

Wepth to water: $88.22 \mathrm{n}(28.84 \mathrm{~m})$ bolow TOC

Water olovation: $237.38 \mathrm{Ht}$

8p. conductance: $46 \mathrm{Ms} / \mathrm{cm}$.

Alinalinity: $9 \mathrm{mgll}$

Water temperature: $22.0^{\circ} \mathrm{C}$

LABORATORY ANALYSES

F Analyte Pesull

o $\mathrm{pH}$

0 Araonic

Barium

O Cadmium

o Carbon totrachloride

O Chlorido

Chloroform

Coporm

o 2,4bichlorophenoxyucetic acid $<4.0$

o Fluoride

O Iron

0 Undane

- Magnesium

o Manganese

Mothoxychior

0 Nickor

Nitrate-nitrite as nitrogen

0 Phenols

O Potasslum

o silica

o Silvor

Sodium

- Tetrachioroethylene

Total oranic carbon

Total phosphates (as PI

o Toxaphene

0 2,4,5-TP (Silvex)

o $1,1,1$-Trichioroethane

1 Trichloroethylene

Zinc

Americium-24

- Antimony-125

Cosium-134

Ceslum-137

Cobalt-57

0 Cobalt-60

Curium-242

Curlum-243/24

- Europlum-152

0 Europlum-164

- Europium-155

Grose alpha

Gross alpha

Nonvolatile bote

Nonvolatile bete

Plutonium-239/240

Potassium-40

Promethium-144

Promethium-146

Radium-228

Radium-228

Ruthenlum

Sodlum-22

Strontlum-89

Strontum-80

Thorlum-230

Thorium-232

o Total alpha-ornitting radium

Tiltium

Uranium-234

Uranium-235

Yinc-85

Zinc-85

\begin{tabular}{l} 
Resul \\
\hline 8.0 \\
42. \\
$<2.0$ \\
8.6 \\
$<2.0$ \\
867 \\
$<1.0$ \\
2.840 \\
$<1.0$ \\
$<4.0$ \\
54.0 \\
$<0.30$ \\
$<0.000$
\end{tabular}

$<0.00$
$<100$
19

$<<3.0$

643

$<2.0$

$<0.20$

$<4.0$

480
$<5.0$

$<5.0$
$<500$
$<2.0$
5,180

$<2.00$

$<\begin{array}{r}4,270 \\ <1.0\end{array}$

$<1,000$

$<50$

$<0.24$

$<1.0$

8.2
$<1.0 \mathrm{E}-00$

$<2.0 E-08$

$<1.0 \mathrm{0} .00$

$<1.0 \mathrm{E} \cdot 00$

$<1.0 E \cdot 00$

$<1.0 E .08$

$<1.0 \mathrm{E}-00$

$<4.0 E-00$

$<2.0 \mathrm{C}-0$

$<3.0 E-09$

$2.8 \mathrm{E} \cdot 09 \pm 7.0 \mathrm{E}-10$

$2.6 E-09 \pm 7.0 E-10$

$<1.0 E-009$

$<2.0 E .09$
$<2.0 E .009$

$<<1.0 E .009$

$<1.0 E-098$

$<<1.1 E-07$

$<1.0 E-06$

$1.5 E-00 \pm 2.6 E-10$

$<1.0 E-09$

$<9.0 E-08$

$<1.0 E-06$

$<2.0 E-09$

$<1.0 E .09$

$<1.0 \mathrm{cos}$

$<1.0 E-09$

$<1.0 E-08$

$<7.0 E-00$

$<1.0 E .09$

$<1.0 \mathrm{E}-08$

$\leq 6.0 E-06$

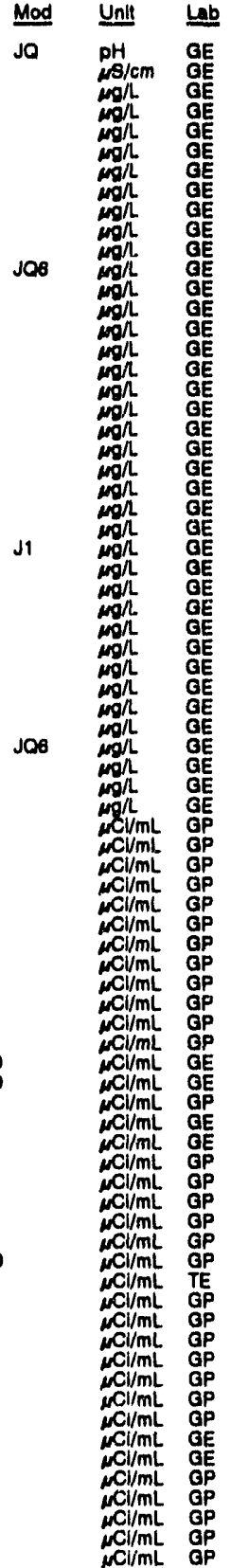


ANALYTICAL RESULTS

WELL ASB 5A

MEASUREMENTS CONDUCTED IN THE FIELD

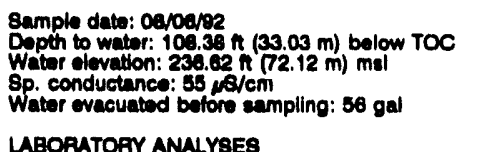

Time: 11:35

pH: 5.6

Alkalinity: $6 \mathrm{mg} / \mathrm{L}$

Water temperature: $22.00 \mathrm{C}$

\section{LABORATOPY ANMLYSES}
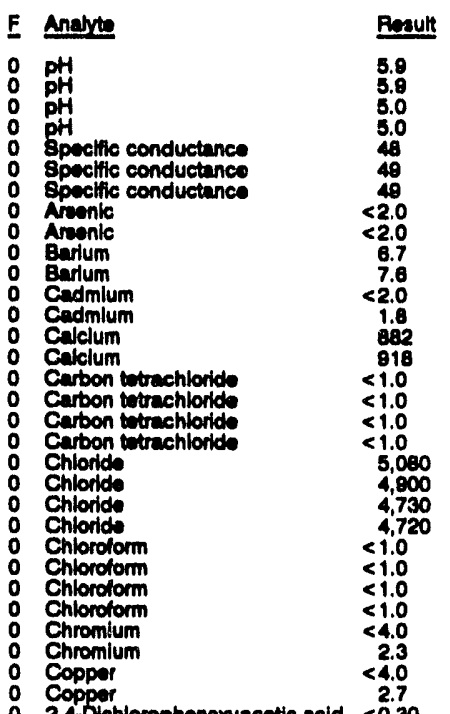

2 2,4bichlorophenoxyacetic acid

2,4-Dichlorophenowyacetic acid $<$

0 Endrin

O Endrin

o Endrin

0 Fluoride

iron

0 Iron

0 Load

0 Undane

o Magneelum

o Magnesium

Manganese

Mareury

Mercury

Marcury

Methoxychlor

o Nickel

o Nitrate as nitrogen

P Phonola

Phenols

Potaselum

o Potassium

- Solenium

o Silica

0 Silver

0 Silver

: Sodium

0 Sulfato

0 Sulfate

O Sulfate

o Tetrachloroethylene

Tetrachloroethylone

Totrachloroethylane

Total organic carbon

- Total organic carbon

o Total organic halogens

- Total organic halogene

o Total phoophates as P

o Total phosphat

o Toxaphene

$\begin{array}{ll}0 & \text { Toxaphene } \\ 0 & 2,4,5-T P \\ 0 & 2,4,5-T P \\ \text { Silvox }\end{array}$

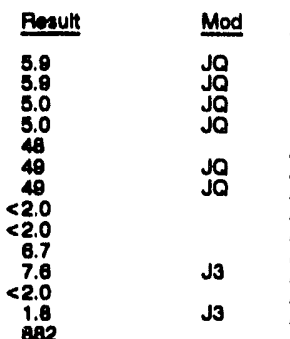

Unit

$<1.0$

$<1.0$

5,080

4,730
4,720

$<1.0$

$<1.0$

2.3
$<4.0$
2.7

2.7
$<0.30$
$<0.30$

$<1.1$
$<0.0060$

$<0.0080$

$<0.11$

$<100$

23
$<3.0$
$<3.0$

$<2.0000$

$<0.053$

477

3.2

3.9
$<0.20$

$<0.20$

$<0.50$
$<0.53$

$<3.1$

629

580

$<5.0$
$<5.0$

$<500$

523
$<2.0$
$<2.0$

4,880

5,050
$<2.0$

$<0.70$

8,240
8,050
4,570

4,690
5,440

$<1.0$

$<1.0$

$<1,000$

$<500$
12
13

13
9.7
$<50$
37

$<50$

$<0.24$

$<1.090$
$<0.55$

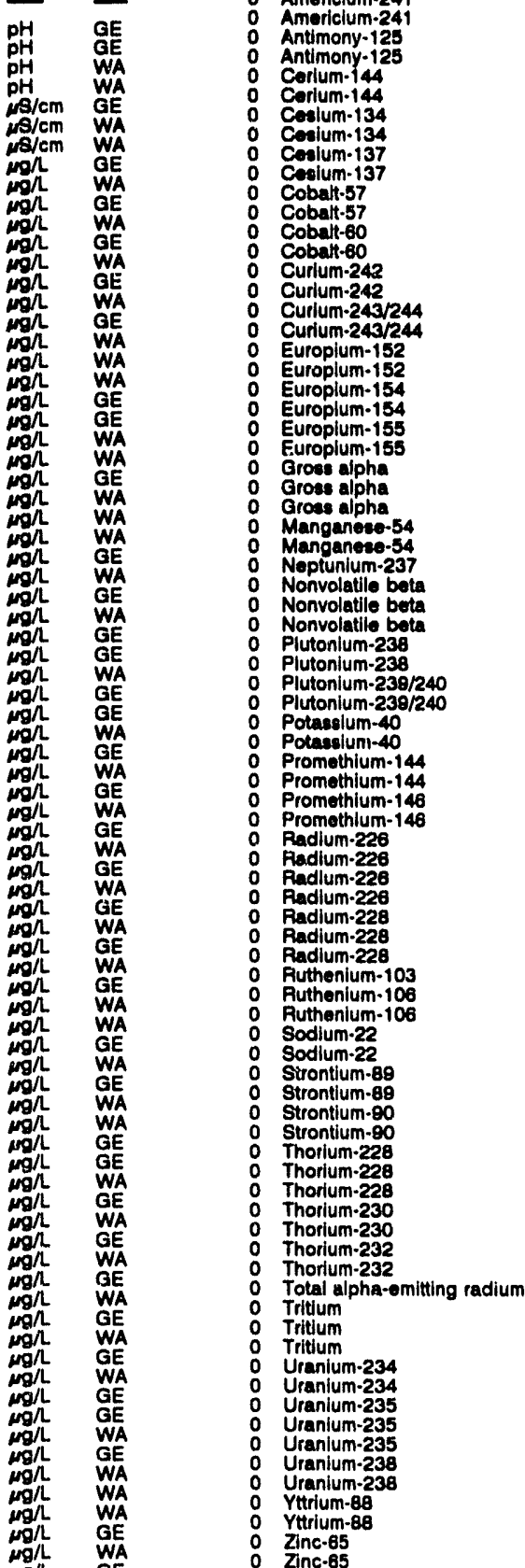

\section{$E$ Analyte}

o 1,1,1-Trichioroothane

2 Trichloroethylene

2 Trichloroethylone

2 Trichloroethylene

o Zine

Une

Americlum-24

Amoriclum.24

WELL. ASB 5A collectod on 08/06/82, laboratory analyses (cont.)

Result

$<1.0$

29
30

15
15
$<2.0$

$<7.0 \mathrm{E} .09$

$<1.0 E-09$

$<2.0 E \cdot 00$

$<2.0 E .06$

$<5.0 \mathrm{C} .06$

$<1.0 \mathrm{E} \cdot 00$

$<1.0 E-06$

$<1.0 E-00$

$<1.0 E-06$

$<1.0 E-08$
$<1.0 E .06$

$<1.0 E .06$

$<1.0 E .08$

$<1.0 E-09$

$<1.0 E-09$

$<4.0 E-06$

$<4.0 E-08$

$<2.0 E-08$

$<3.0 E-08$

2. $0 E-09 \pm 4.9 E-10$

2.7E-09 $\pm 1.5 \mathrm{E}-00$

$<1.0 E-09$

$<1.0 E-08$

2.1E-09 $0.1 E-10$

3.5E-09 $51.5 \mathrm{EE}-09$

$1.5 \mathrm{E}-09$
$<1.0 \mathrm{E}-09$

$<1.0 E-09$

$<1.0 E-09$

$<1.1 E-07$

$<1.8 E-07$

$<1.0 \mathrm{E}-08$

$<1.0 \mathrm{E}-08$

$2.1 \mathrm{E}-09 \pm 3.0 \mathrm{E} \cdot 10$

$<1.6 E-07$

$2.2 E-09 \pm 5.8 E-10$

$<1.0 \mathrm{E}-00$

1.2E- $09 \pm 6.0 E-10$

$<4.0 E-10$

$<1.0 \mathrm{E}-08$
$<8.0 \mathrm{E} .08$

$<><.0 E .09$

$<1.0 E .09$

$<1.0 E-08$

$<2.0 \mathrm{E}-09$

$<2.0 E-09$

$<2.0 E \cdot 08$

$<1.0 E-09$

$<1.0 \mathrm{E}-00$

$<1.0 \mathrm{E}-09$

$<1.0 E-09$

$<1,0 E .00$

$<1.0 E-00$

$1.3 \mathrm{E}-06 \pm 5.0 \mathrm{E}-07$

$.5 \mathrm{E} .06 \pm 1.6 \mathrm{E}-07$

$<1.0 E-09$

$<1.0 \mathrm{0}-09$

$<1.0 E-09$

$<1.0 E-09$

$<1.0 \mathrm{0}-0$

$<8.0 E-00$

$<1.0 E-08$

$<2.0 E-08$
Unit Lab

$M g / L$
$M g / L$
$W G /$
$G E$

wa WA

W

CVImL $\mathrm{aP}$

$\mathrm{NCl/mL}$ CN

Cl/mL $\mathrm{GN}$

NCVmL $Q P$

CCl/mL $G P$

$\mathrm{MCl} / \mathrm{mL}$ CN

$\mathrm{N} / \mathrm{mL} \mathrm{CN}$

$\mathrm{MCl} / \mathrm{mL}$ QP

cymL GP

Cl/mL $\mathrm{CN}$

climL CN

Cl/mL CN

Cl/mL GP

C $/ / m L$ GP

$\mathrm{Cl} / \mathrm{mL}$ CN

Cl/mL $G$

NCV/mL GE

CI/mL TM

$\mathrm{Cl} / \mathrm{mL}$ GP

$\mathrm{Cl} / \mathrm{mL}$ CN

$\mathrm{Cl} / \mathrm{mL}$ GE

$\mathrm{NCl/mL}$ TM

MCI/mL GP

CCUmL CN

$\mu \mathrm{Cl} / \mathrm{mL} \mathrm{CN}$

$\mathrm{N} / \mathrm{mL}$ GP

Cl/mL GP

Cl/mL CN

$\mu \mathrm{Cl} / \mathrm{mL} \mathrm{CN}$

$\mathrm{C} / \mathrm{mL}$ CN

CEl/mL CN

$\mathrm{NCl} / \mathrm{mL}$ CN

$\mu \mathrm{Cl} / \mathrm{mL}$ TE

$\mathrm{NCl/mL}$ CN

Cl/mL GP

CCI/mL CN

$\omega \mathrm{Cl} / \mathrm{mL} \mathrm{CN}$

$\mu C I / m L$ GP

CI/mL CN

CI/mL CN

$\mathrm{cl} / \mathrm{mL}$ CN

$\mu C / m L ~ C N$

$\mu \mathrm{Cl} / \mathrm{mL}$ CN

$\mathrm{Cl} / \mathrm{mL}$ GP

$\mu \mathrm{C} / \mathrm{mL}$ CN

$\mathrm{NCl} / \mathrm{mL}$ GE

$\mathrm{CC} / \mathrm{mL}$ TM

$\mathrm{cl} / \mathrm{mL} \quad \mathrm{GP}$

CII/mL GP

$\mu \mathrm{Cl} / \mathrm{mL}$ CN

CCI/mL GP

Cl/mL CN

$\mathrm{Cl} / \mathrm{mL} \mathrm{CN}$

$\mu \mathrm{MCl} / \mathrm{mL}$ GP 


\section{WELL ASB 5A Replicate}

MEASUAEMENTS CONOUCTED IN THE FIELL

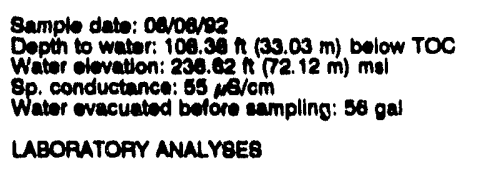

\section{Esortory}

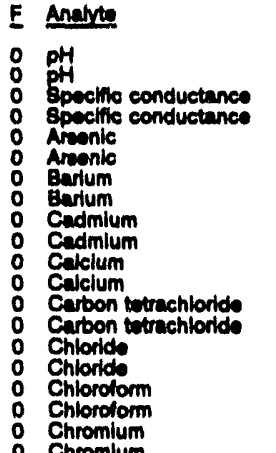

Chromium

Coppor

Coppor
0 Coppor
0 2, fbichlorophenaxyacetic acid
0 Endrin

0 Fluoride

Iron

0 L Loen

0 Lindan

Lindane

Magnealum

Manganee.

Moreury

Mereury

Methonychior

Nickel

Nitrate as nitrogen

Nitrationilutite nitrogen

Phenols

Potuselum

Potasilum

Selonium

Billea

silver

Silver

Sodlum

Sulfata

Tetrachloroethyleme

Trtrachtordithylon.

Total organic carbon

Total organic halogene

Total organic halogene

o Total phosphates (as P)

T Toxaphen

2,4,5.TP (Sitrox

2,4,5-TP silvex

1,1,1-Trichlorosthane

2 Trichlorosthylene

2 Trich

Americium-241

Americium-241

Antimony-125

Antmony-125

Corlum-144

Cosium-134

Cealum-134

Cealum-137

Cobalt-57

$<1.0$

$<1,000$

$<500$

11
$<50$
48

$<0.24$

$<0.000$

$<0.56$

$<1.0$

$<2.0$

$<1.0 \mathrm{E}-09$

$<1.0 \mathrm{E}-09$

$<2.0 E .00$

$<6.0 \mathrm{E} .08$

$<5.0 E .08$

$<1.05 .08$

$<1.0 \mathrm{E}-00$

$<1.0 E .00$

$<1.08 .08$

\begin{tabular}{|c|c|c|c|c|}
\hline 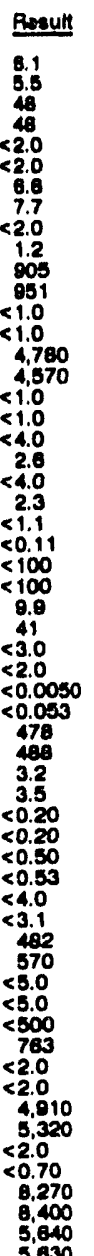 & $\begin{array}{l}\text { Mod } \\
\text { Jo } \\
\text { Ja }\end{array}$ & 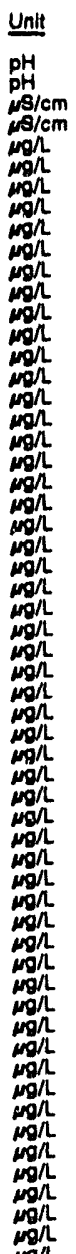 & $\begin{array}{l}\text { LAb } \\
\text { GE } \\
W A \\
G E \\
W A \\
G E \\
W A \\
G E \\
W A \\
G E \\
W A \\
W E \\
G E \\
W A \\
G E \\
W A \\
G E \\
W A \\
G E \\
W A \\
G E \\
W A \\
G E \\
W A \\
W A \\
W A \\
G E \\
W A \\
G E \\
W A \\
G E \\
W A \\
G E \\
W A \\
G E \\
W A \\
G E \\
W A \\
G E \\
W A \\
G E \\
W A \\
G E \\
W A \\
W A \\
G E \\
G E \\
W A \\
G E \\
W A \\
G E \\
W A \\
G E \\
W A \\
G E \\
W A \\
G E \\
W A \\
G E \\
W A \\
W A \\
W E \\
W E\end{array}$ & 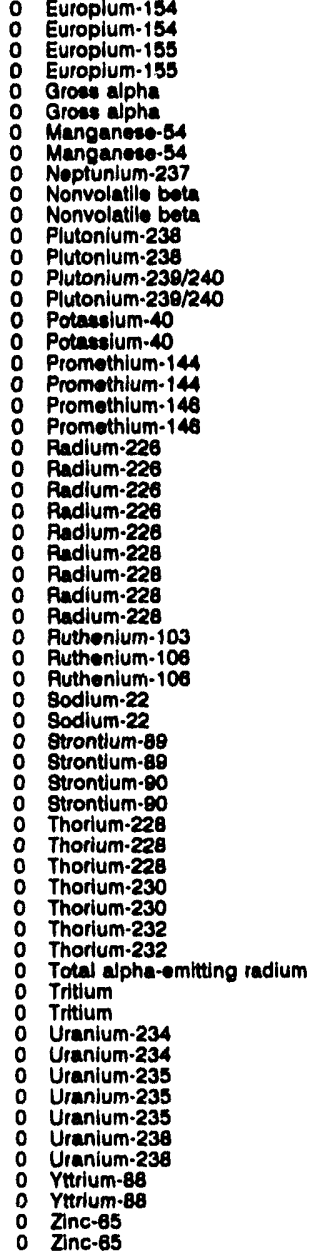 \\
\hline
\end{tabular}

Time: 11:35

PH: 5.8

Alkalinity: $8 \mathrm{mgh}$

Wator temperature: $22.0^{\circ} \mathrm{C}$

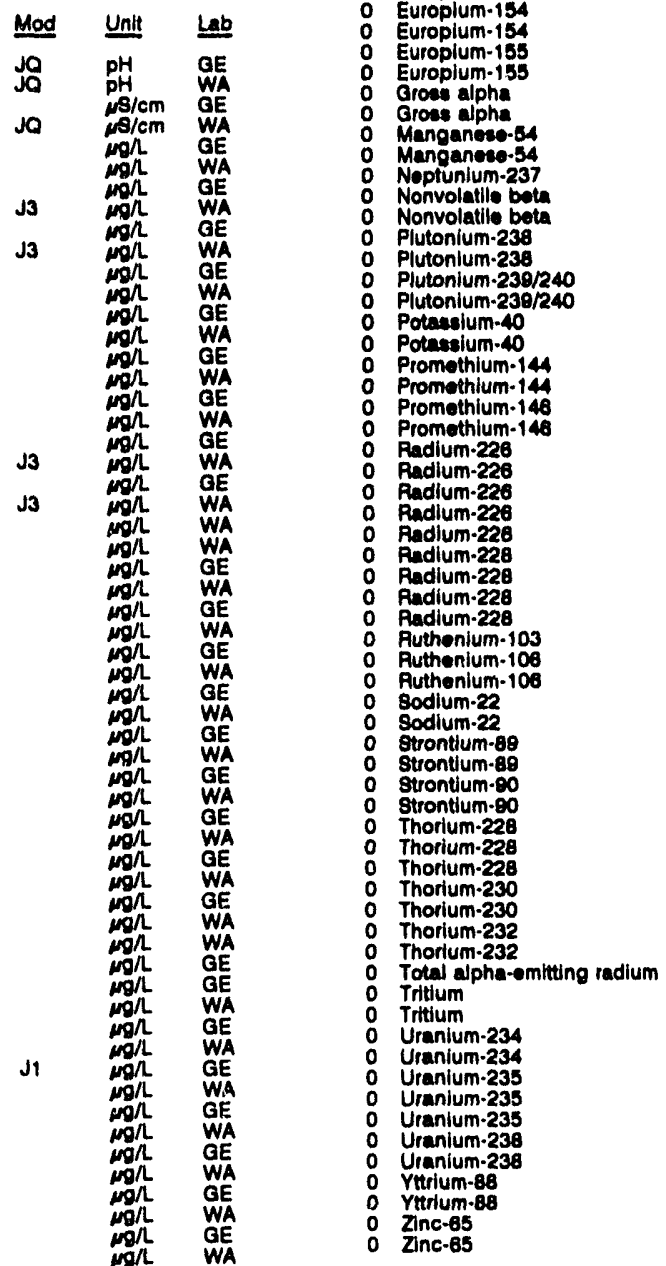

WELL ASB SA collected on 06/06/02, laboratory analyeen (cont.)

\begin{tabular}{|c|c|c|}
\hline Analyte & Result & Unit \\
\hline 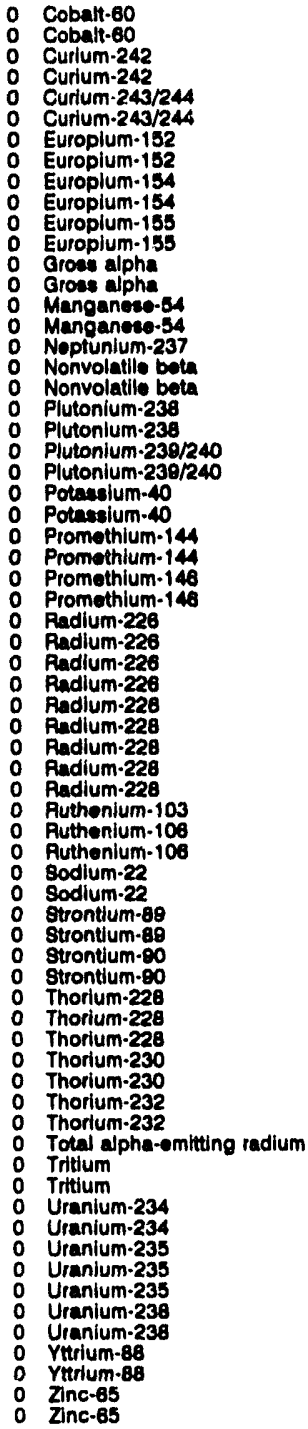 & 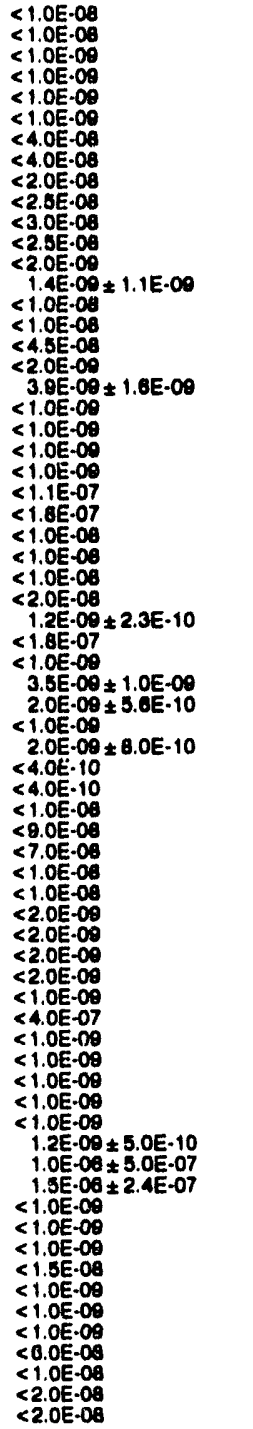 & 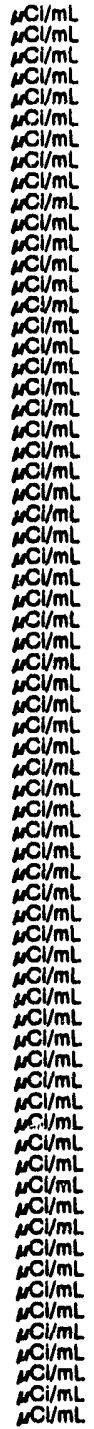 \\
\hline
\end{tabular}

WELL ASB 6A

MEASUREMENTS CONDUCTED IN THE FIELD

Sample date: 08/08/92 3 (34.84 m) bolow TOC

Depth to waler: $114.30 \mathrm{ht}(34.84 \mathrm{~m})$ bolow TOC $\mathrm{pH:5}$.

Water elovation: $235.80 \mathrm{~h}(71.90 \mathrm{~m}) \mathrm{ms}$ Alkalinity: $2 \mathrm{mg} / \mathrm{l}$

Water ovacuated before sampling: $\mathbf{4 6} \mathrm{gal}$

LABORATOAY ANALYYSES

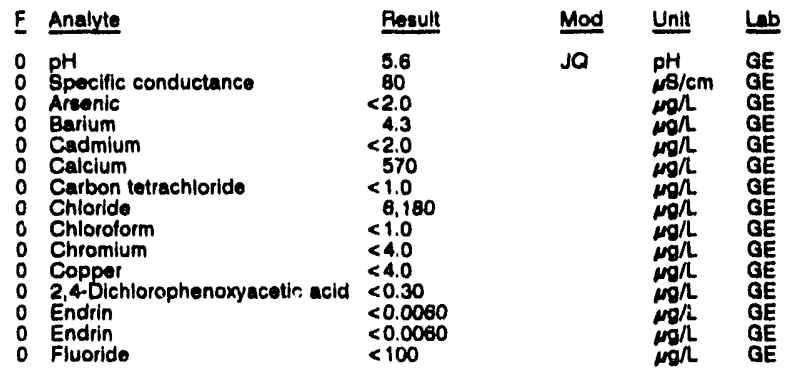


ANALYTICAL RESULTS

WEL ASB aA colloctod on 08/08/82, laboratory analyees (cont.)

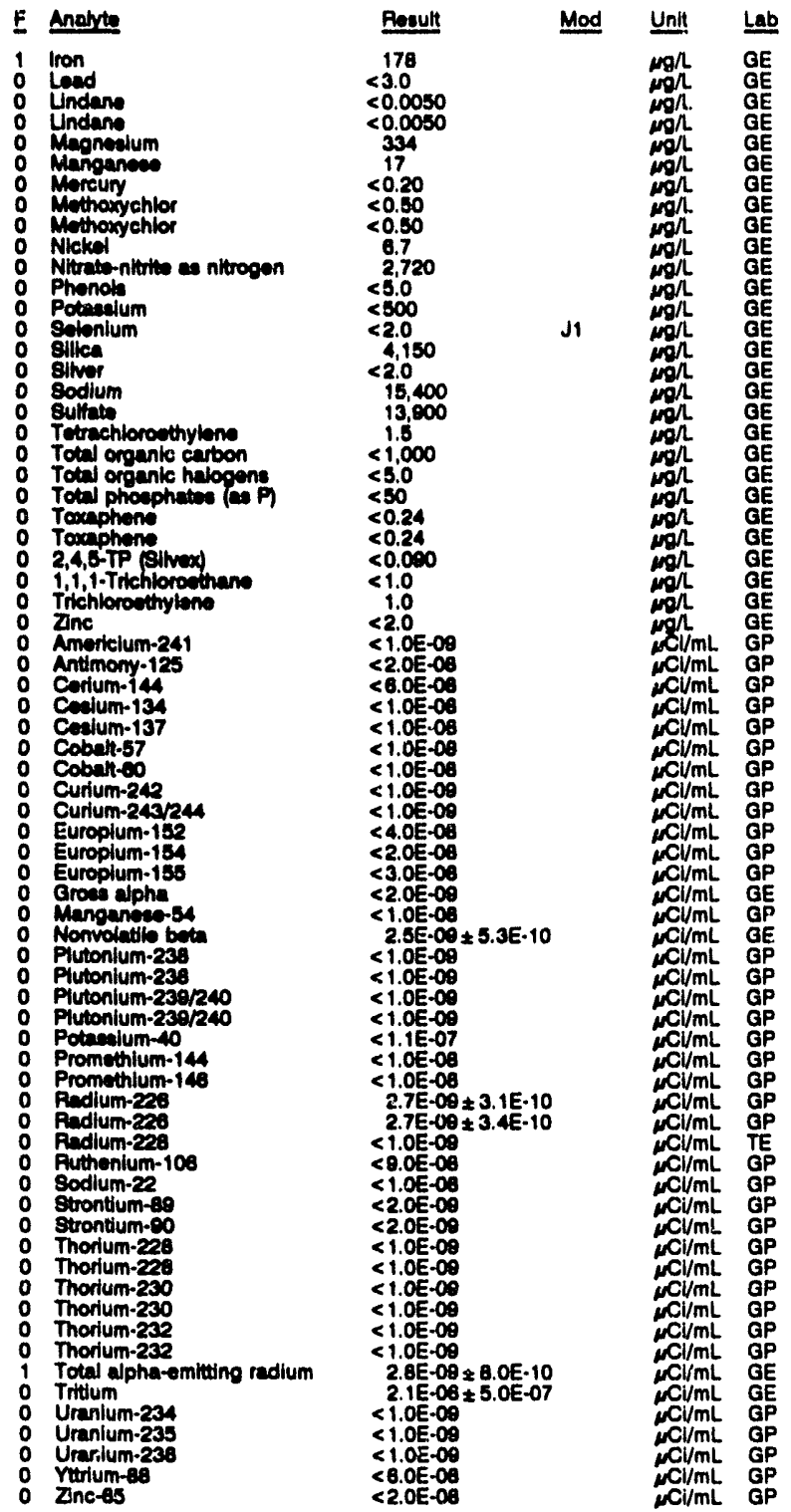

WELL ASB 6AA

MEASUREMENTS CONDUCTED IN THE FIELD

Sample data: 08/11/92

Depth to water: $135.17 \mathrm{n}(41.20 \mathrm{~m})$ bolow TOC

Water elovation: 218.03 it (68.78

Sp. conductance. 180 $\mu_{3} \mathrm{~cm}$.

LABORATORY ANALYSES

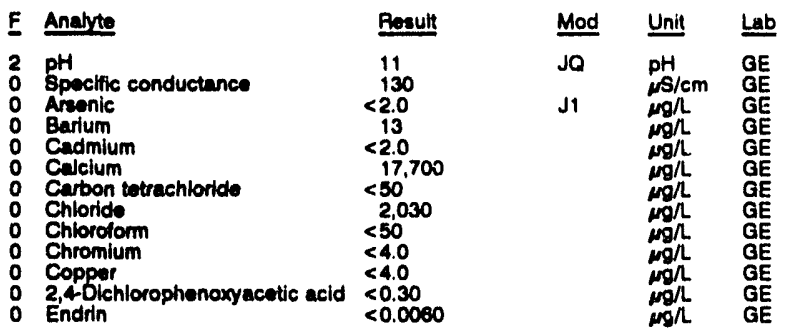

pH: $10.5 .50 \mathrm{man}$

Nalinity: $60 \mathrm{mgh}$ : $22.6 \circ \mathrm{C}$

Lab

FP

GP

WELL ASB 6AA collected on 08/11/82, laboratory analyees (cont.)

\begin{tabular}{|c|c|c|c|c|}
\hline Analyte & Result & Mod & Unit & Lئ \\
\hline 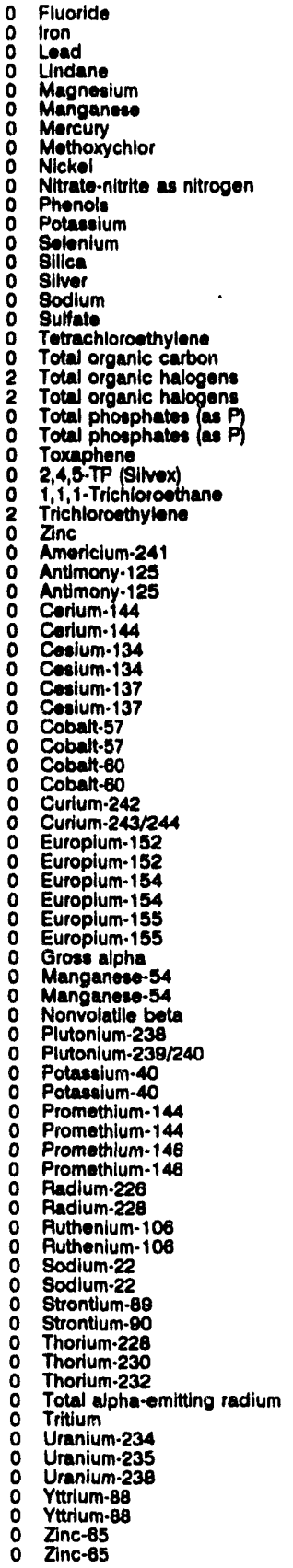 & 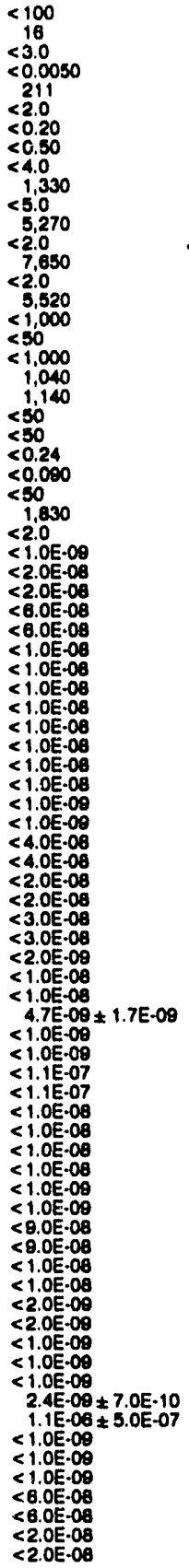 & J1 & 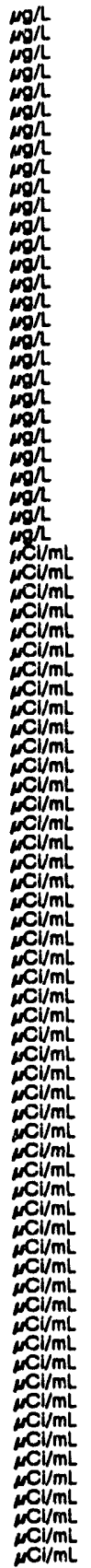 & 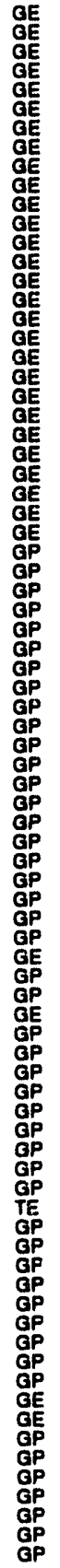 \\
\hline
\end{tabular}


WELL ASB 6C

MEASUREMENTS CONDUCTED IN THE FIELD

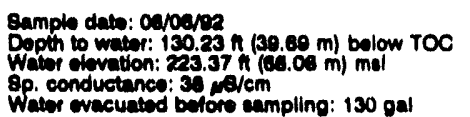

Time: 14:35

phi: 8.3

Water wacuated before campling: 130 ga

LABORATORY ANALY YES

\begin{tabular}{|c|c|c|c|c|}
\hline Analyte & Result & Mod & Unit & $a b$ \\
\hline 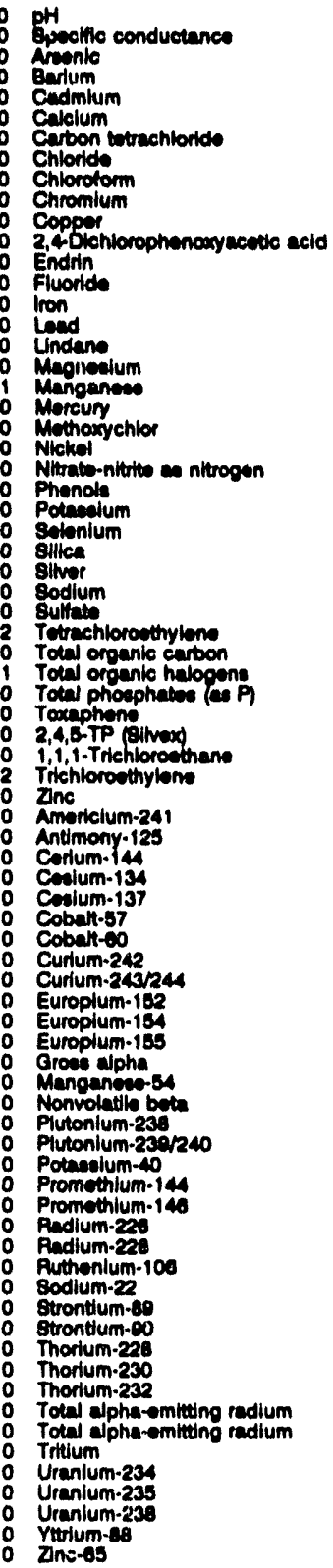 & 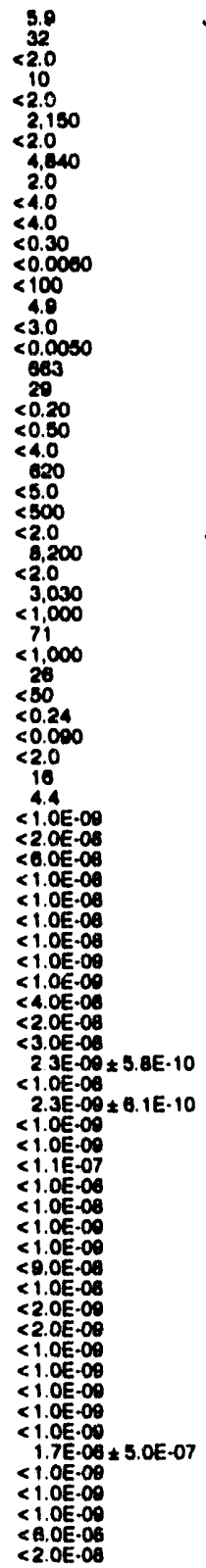 & J & 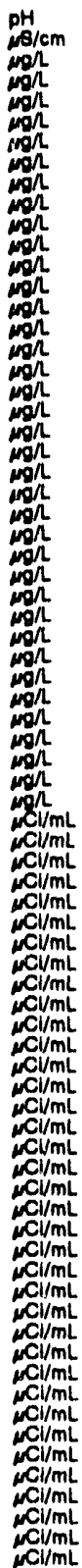 & 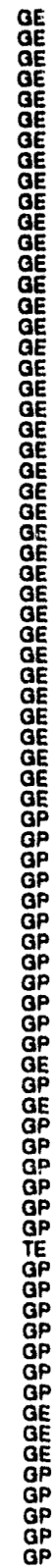 \\
\hline
\end{tabular}

WELLL ASB 6TA

MEASUREMENTS CONDUCTED IN THE FIELD

Dopth to water: $138.60 \mathrm{n}(42.25 \mathrm{~m})$ bolow TOC

Water olevalion: $214.30 \mathrm{H}(05.32 \mathrm{~m}) \mathrm{mal}$

Wator ovacuated botore sampling: $60 \mathrm{gal}$

The wall went dry during purging.

LABOPATORY ANALYEES

\begin{tabular}{|c|c|c|c|}
\hline Analyte & Reoult & Mod & Unit \\
\hline 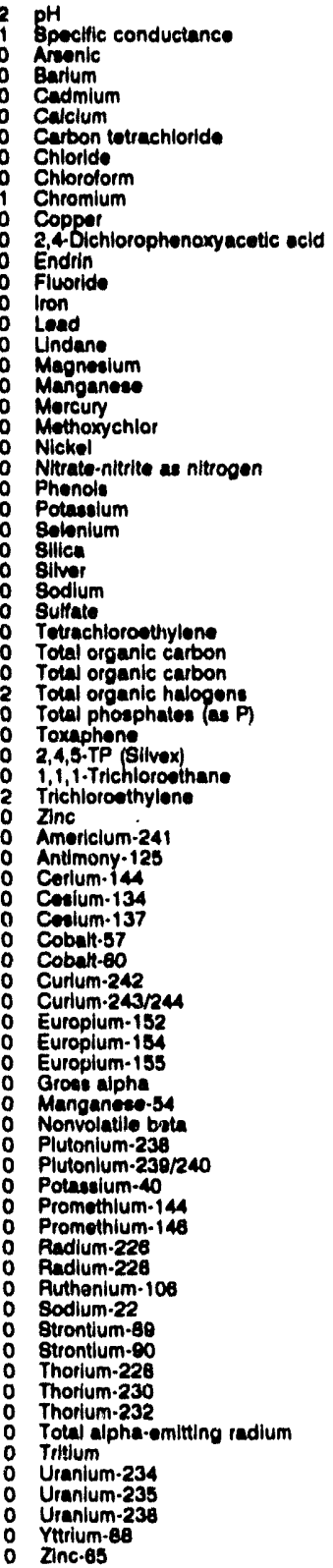 & 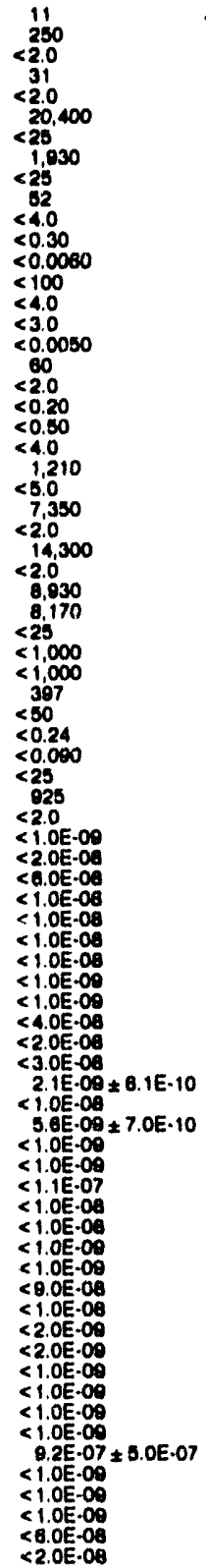 & Jo & 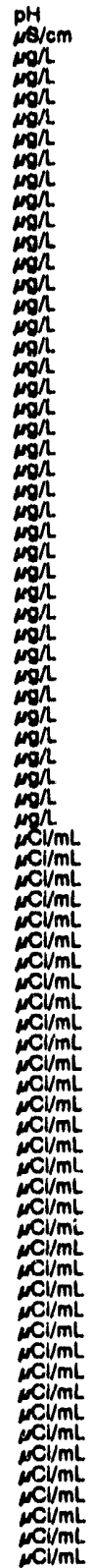 \\
\hline
\end{tabular}


ANALYTICAL RESULTS

WELL ASB 7

MEASUREMENTS CONDUCTED IN THE FIELD

Sample dato: 09/06re2

Depth to water: $118.74 \mathrm{n}(38.19 \mathrm{~m})$ below TOC

Water elevation: 234.66 in (7)

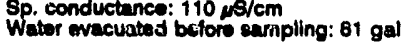

LABORATOAY ANALYSES

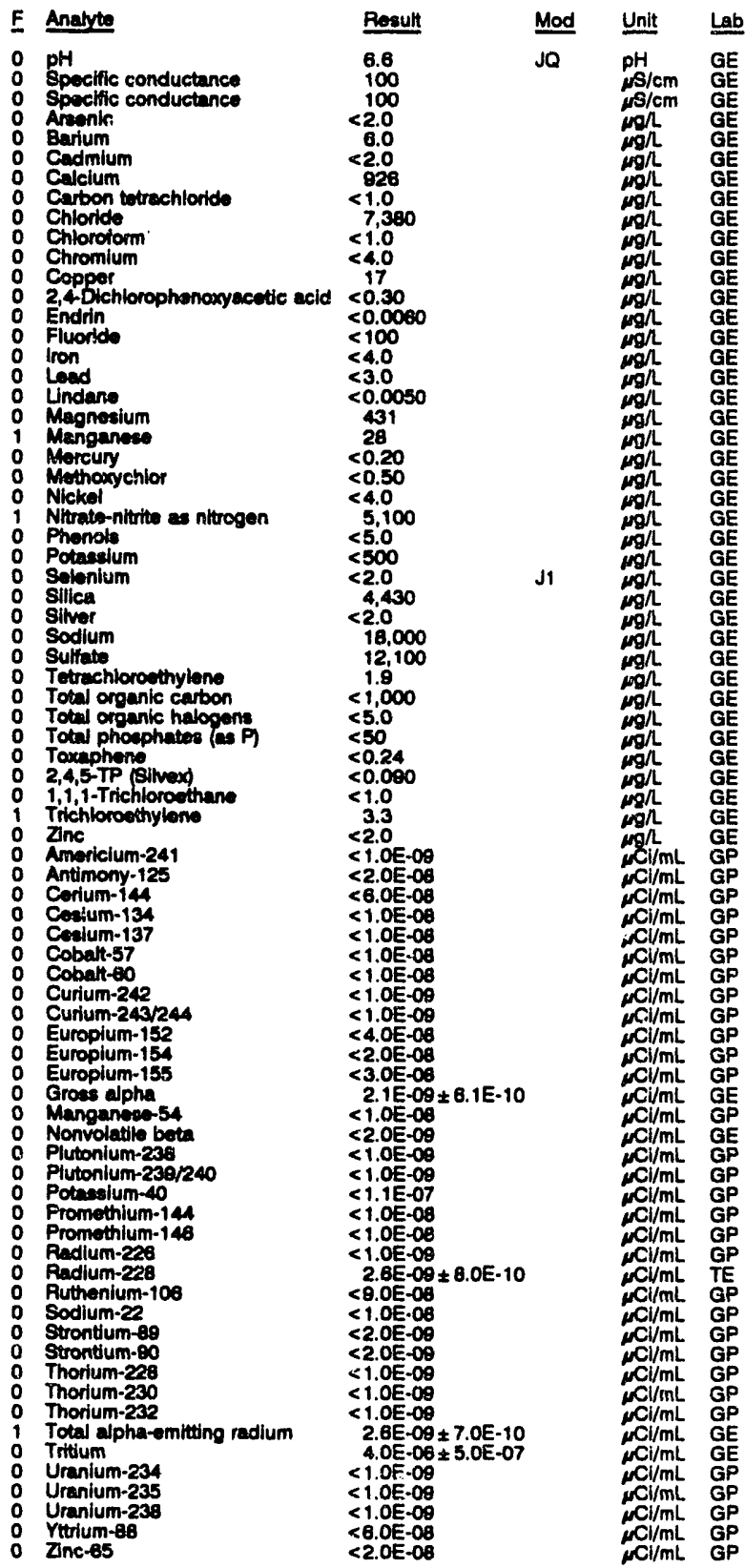

WELL ASB 8

MEASUREMENTS CONDUCTED IN THE FIELD

Sample date: 08/05/92

Depth to water: 115.82 ft $(35.30 \mathrm{~m})$ below TOC

Water olovation: $233.18 \mathrm{ft}$ (

Sp. conductance: $30 \mathrm{HS} / \mathrm{cm}$.

sampling: 85 gal

LABORATORY ANALYSES

O $\mathrm{pH}$ Specilic conductance

o Arsenic

- Cadmium

Calclum

Chloride

Chlorolorm

Chromium

Copper

Eluoride

0 Iron

o Load

Lindane

Manganes

Mercury

Methoxychior

Nicker

Nitrato-nitrite as nitrogen

Phenols

Potassium

Selenium

Silica

Sodium

Sodium

Tetrachloroethylene

Total organic carbon

Total organic halogene

Total phosphates (as P)

Toxaphene

2,4,5-TP (Silvex)

1,1,1-Trichloroethane

Zinc

o Americium-241

Antimony-125

Cerium-144

Cesium-134

Cobalt.57

Cobalt-60

Curium-242/244

Europium-152

Europlum-154

Europium-155

Gross alpha

Nonvolatile beta

Plutonium-238

Plutonium-239/240

Potansium-40

Promethium-144

Radium-226

Ruthenium-106

Sodium-22

Strontium-88

Strontium-80

Thorium-228

Thorium-230

Thorium-232

Total alpha-emitting rarism

Total alpha

O Uritium

Uranium-235

Uranium-238

Zinc-65
Time: $9: 05$

PH: 4.5 . $0 \mathrm{mg}$

Water temperature: $20.5^{\circ} \mathrm{C}$

Result

Mad Unit Lab

5.6

$\begin{aligned} & 5.8 \\ & 30<0 \\ &<2.0 \\ & 4.2 \\ &<2.0 \\ & 353 \\ &<1.0 \\ & 3.500 \\ &<1.0 \\ &<4.0 \\ & 46 \\ &<0.30 \\ &<0.0060\end{aligned}$

$<0.0060$

8.1
5.9

292

292
$<2.0$
$<0.20$

$<0.50$

$<4.0$
1,000
$<5.0$

$<500$

$<2.0$

$<2.0$

3,250
1,030

$<1.0$

$<1,000$

6.3
$<50$

$<0.24$

$<0.080$

$<1.0$

18

8.6
$<1.0 \mathrm{E}-09$

$<2.0 \mathrm{E}-08$

$<6.0 \mathrm{E}-08$

$<1.0 E-08$

$<1.0 E-08$

$<1.0 E-00$

$<1.0 \mathrm{E}-09$

$<1.0 E .09$

$<4.0 \mathrm{E}-08$

$<2.0 E-08$

$<3.0 E-06$

$<1.0 E-08$

$3.1 \mathrm{E}-00 \neq 2.8 \mathrm{E}-10$

$<1.0$ E-09

$<1.0 E-00$

$<1.1 E-07$

$<1.0 E-09$

$<1.0$ E-08

$<1.0 E-09$

$1.1 E-09$
$<8.0 E-08$

$<0.0 E-08$
$<1.0 E-08$

$<2.0 E-09$

$<2.0 E-09$

$<1.0 E-09$

$<1.0 \mathrm{E}-09$

$<1.0 \mathrm{C}-09$

$1.1 \mathrm{E} .09 \pm 4.0 \mathrm{E}-10$

$<7.0$ E-07

$<1.0 E-09$

$<1.0 E-09$

$<6.0 \mathrm{E}-08$
$<2.0 \mathrm{E}-08$
PH GE

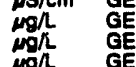

$\operatorname{mon}_{\mathrm{m} h} \mathrm{GE}$

$\operatorname{mgh}_{\mathrm{m} / \mathrm{G}} \mathrm{GE}$

moh GE

$\operatorname{mon}_{\mathrm{g}} \mathrm{GE}$

mgh GE

$m g$ GE

$\mathrm{mg}$ GE



gn GE

$\underset{\substack{m g / \\ m g h}}{\operatorname{mon}}$

$\mathrm{mg}$ GE

$\mu g /$ GE

woh GE

ugh GE

Mg GE

$\mu \mathrm{CL} / \mathrm{GE}$

$\mu \mathrm{C} / \mathrm{mL}$

$\mu \mathrm{cl} / \mathrm{mL}$

$\mu \mathrm{Cl} / \mathrm{mL}$

$\mu \mathrm{C} / \mathrm{mL}$

$\omega \mathrm{Cl} / \mathrm{mL} \quad \mathrm{GP}$

ClimL GP

C

$\omega \mathrm{Cl/mL}$ GP

MCVIML GE

$\mathrm{Cl} / \mathrm{mL}$ GP

$\mathrm{Cl} / \mathrm{mL}$ GP

Cl/mL GP

c C $/ / \mathrm{mL}$ GP

$\mathrm{Cl} / \mathrm{mL}$ GP

$\mathrm{CCl} / \mathrm{mL}$ IE

$\mathrm{Cl/mL} G P$

$\mathrm{cl} / \mathrm{mL}$ GP

Cl/mL op

Cl/mL GP

$\mathrm{Cl} / \mathrm{mL}$ GP

$\mathrm{C} / / \mathrm{mL}$ GE

Ci/mL GE

$\mathrm{CCl} / \mathrm{mL}$

$\mathrm{C} / \mathrm{mL} \mathrm{mL}$

$\mathrm{ci/mL}$ GP 
WELL ASB 8A

MEASUAREMENTS CONDUCTED IN THE FIELD

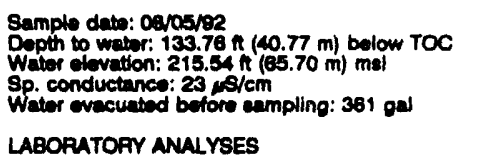

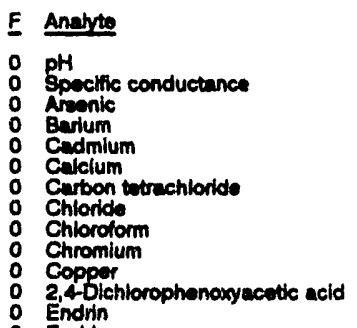

Posult

6.1
20
$<2.0$
5.8
52.0
1,000
$<1.0$
1,970
$<1.0$
$<4.0$
$<40$

$<4.0$

Endrin

P Fluoride

Iron

O Lindane

L Lindane

o Magnedium

Mercury

Mercury

Methoxychlor

Nitrato-nitrito as nitrogen

Phenots

Potasalum

Silica

Siver

Sodium

Tetrachioroethyione

Total organic carton

Total organic halogons

Toxaphene

$<0.24$

$<0.090$

Trichloroenthylene $<1.0$

Anc

- Americium-241

Antimony-125

Conum-144

Cowium-137

Cobalt-o

Curium-242

Curium-2432424

Curium-243/24

Europium-152

Europium-154

Groes aipha

Manganeace-54

Plutonium-238

Potonium-230/2

Promethium-144

Promethium-14

Radium-220

Puthenium-100

Sodium-22

Strontium-es

Thorlum-228

Thorium-230

Total afpha-emituing radium

Tritium

Uranium-234

Uranium-234

Uranium-235

Uranium-233

Uranium-23:

Znc-65
Time: 8:35

pH: 5.0

Akalinity: $1 \mathrm{mgh}$

Water tomperature: $20.2^{\circ} \mathrm{C}$

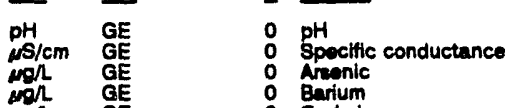

Cadmium

Carbon tetrachtoride

Chloride

Chloroform

Copper

2,4Dichlorophenoxyacetic ecid

0 Endrin

Iron

o Lead

- Magnesium

o Manganese

Methoxychlor

Nickel

Nitrate-nitrite as nitrogen

Phenola

Potassium

Selenium

Silver

Sodium

o Sultate

Total organic carbon

Total organic hajogens

- Toxaphene

$2,4,5$-TP (Sitvex)
1,1, Trichioroethane

Trichloroethylene

Americium-241

Antimony 125

Cerium-144

Cesium-134

Cobalt-57

Cobalt-80

Curium-242

Europlum-132

Europium-154

Grops dpha

Groes alpha

Nonganeso-54

Nonvolatil bet

Plutonium-238

Plutonium-239/240

Potassium-40

Promethium-144

Promethium-146

Radium-228

Puthenium-100

Sodium-22

Strontium-e0

Thorlum-22e

Thoriun-230

Thorium-232

Total ulpha-omiting radium

Tritium

Uranium-234

Uranium-235

0
Time: 10:55

pH: 4.8

Alkalinity: $1 \mathrm{mg} / \mathrm{L}$ Water temperature: $20.8^{\circ} \mathrm{C}$ $(67.17 \mathrm{~m}) \mathrm{ms}$ ) ampling: $256 \mathrm{gal}$

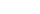

5.7
28
$<2.0$
8.9
$<2.0$
1.470
$<50$
1.890
$<50$
$<4.0$
$<4.0$
$<0.30$
$<0.0060$
$<100$

$<3.0$
$<0.0050$

$<0.005$

4.9
$<0.20$

$<0.20$

$<4.0$

2,030
$<5.0$

$<500$
$<2.0$

$<2.0$

$<2.0$
2,590

2,590
$<1,000$

$<1,000$

$<1,000$

$<50$

$<0.24$
$<0.090$

$<50$
1,810

9.1
$<1.0 E-09$

$<1.0 E-09$
$<2.0 E-08$

$<6.0 E-08$

$<1.0 E-06$

$<1.0 E-00$

$<1.0 E-00$

$<1.0 E-09$

$<4.0 E-08$

$<2.0 E-06$

$<2.0 E-00$

$<2.0 E-\infty$

$<1.0 E-06$

$<2.06-00$

$<1.06-09$

$<1.0 E-09$

$<1.1 E-07$

$<1.0 \mathrm{E}-08$

$<1.0=-00$

$<1.0 E-09$

$<8.0 E-06$

$<1.0 E-06$

$<2.0 E-00$

$<1.0 E-09$

$<1.0 E-09$

$<1.0 E-\infty$

$1.5 E-00 \pm 6.0 E-10$

$\begin{array}{r}2.6 E-08 \\ <1.0 E-08 \\ \hline\end{array}$

$<1.0 E-08$

$<1.0 E-09$

$<6.0 E-08$
$<2.0 E-00$ 
ANALYTICAL RESULTS

WELL ASB 8C

MEASUREMENTS CONDUCTED IN THE FIELD

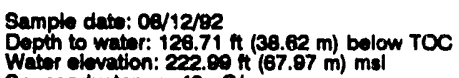
Woter colovation: $222.09 \mathrm{ft}(67.87 \mathrm{~m}) \mathrm{msl}$ Wator evacuatod boforo rampling: $106 \mathrm{gal}$

LABOPATOFY ANALYSES

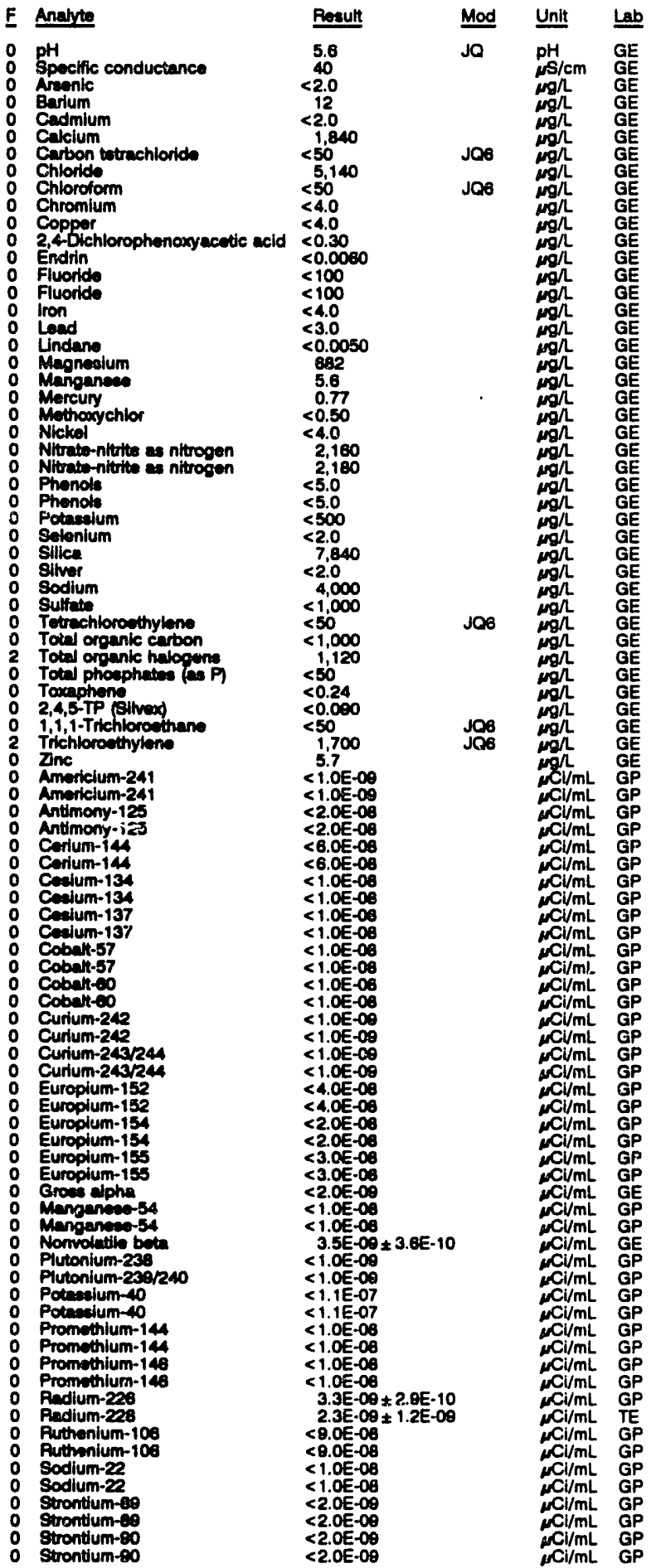

WELL ASB 8C collected on 08/12/92, laboratory analyees (cont)

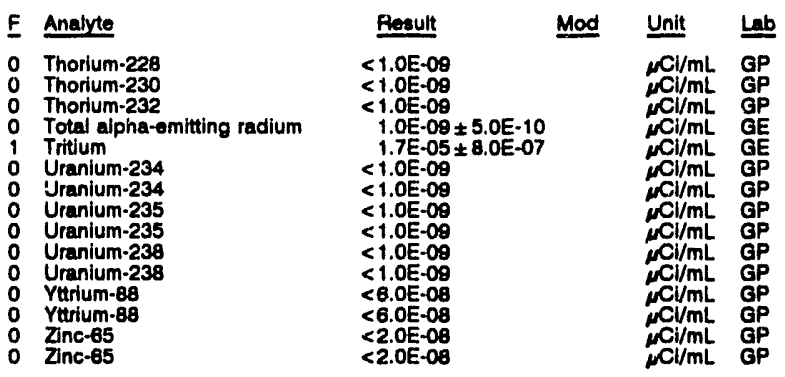

WELL ASB 8TA

MEASUREMENTS CONDUCTED IN THE FIELD

\begin{tabular}{|c|c|}
\hline $\begin{array}{l}\text { Sample date: } 08 / 05 / 92 \\
\text { Depth to water: } 130.03 \mathrm{H}(39.63 \mathrm{~m}) \text { below TOC } \\
\text { Water elevation: } 218.57 \mathrm{ft}(66.83 \mathrm{~m}) \mathrm{msi} \\
\text { Sp. conductance: } 21 \mu \mathrm{s} / \mathrm{cm}\end{array}$ & $\begin{array}{l}\text { Time: } 8: 45 \\
\text { pH: } 4.9 \\
\text { Alkalinity: } 1 \mathrm{mg} / \mathrm{L} \\
\text { Water temperature: } 20.0^{\circ} \mathrm{C}\end{array}$ \\
\hline
\end{tabular}

LABORATORY ANALYSES

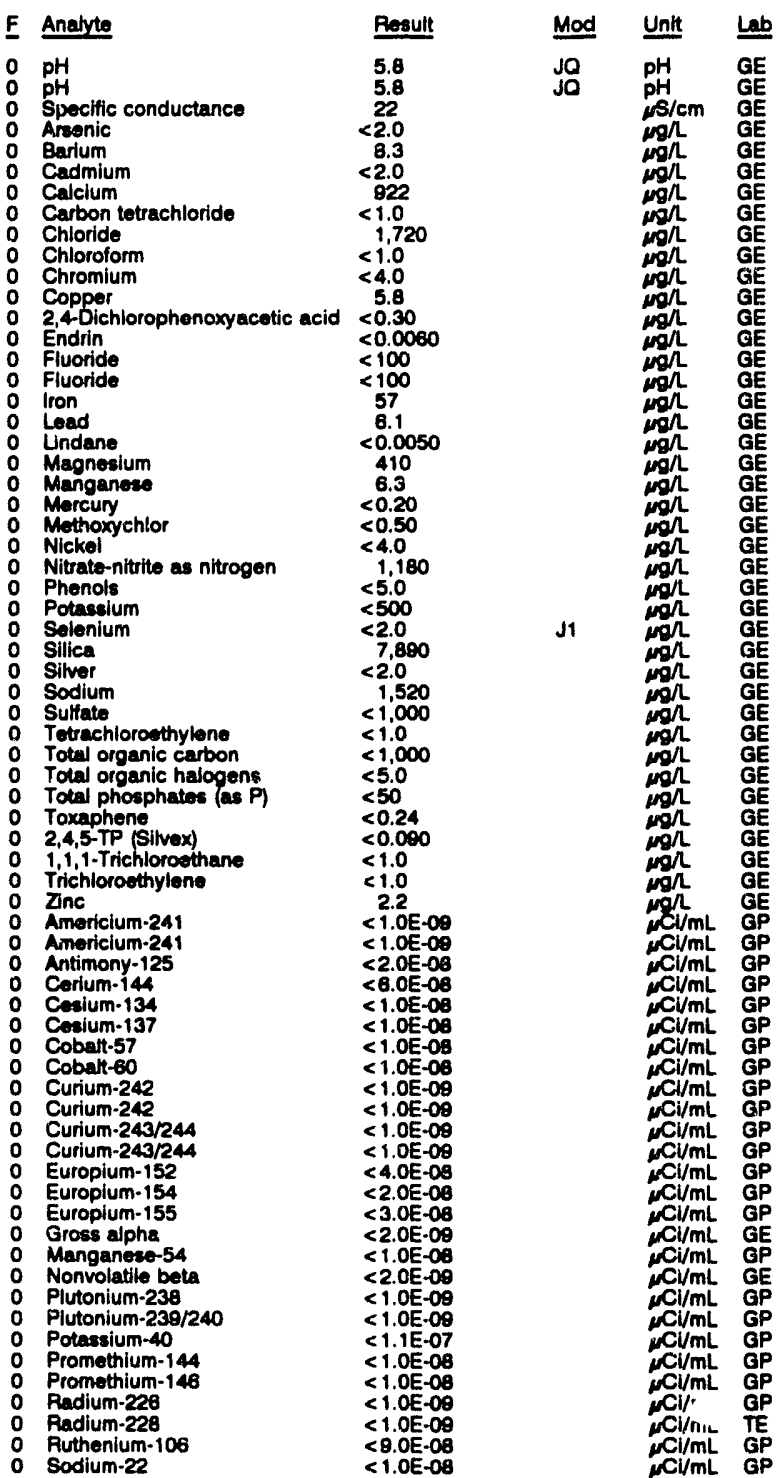


ANALYTICAL RESULTS

WELL ASB OTA colloctod on 08/05/92, laboratory analyses (cont.)

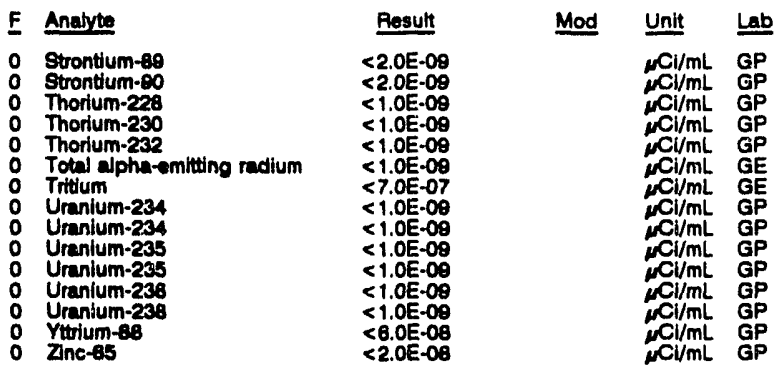

WELL ASB 9

MEABUREMENTS CONDUCTED IN THE FIELD
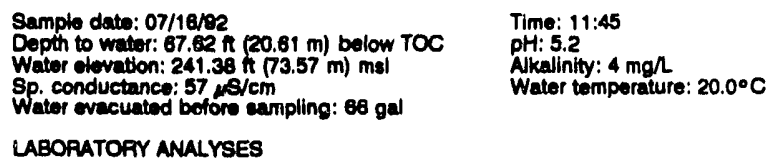

LABORATORY ANALYSES

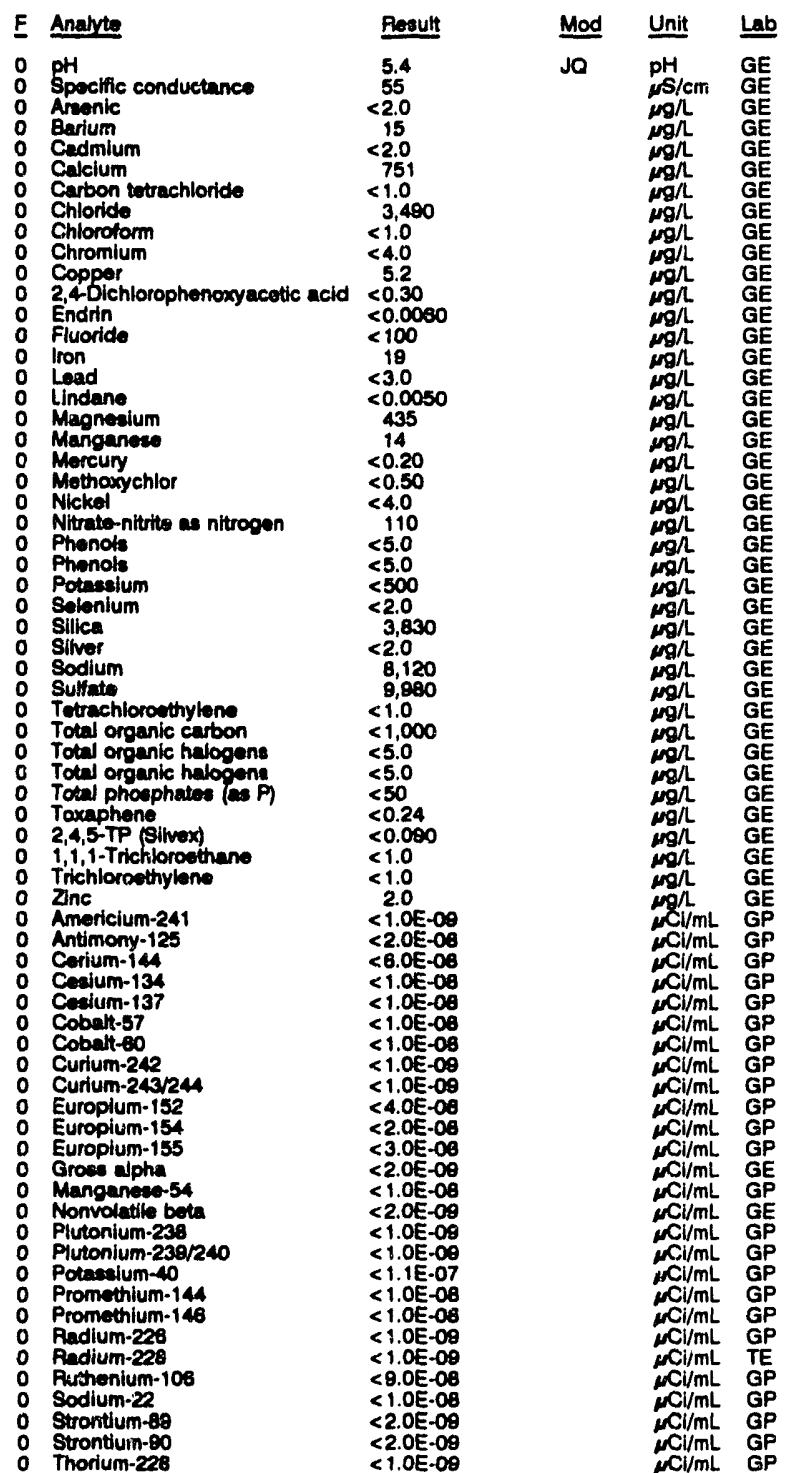

WELL ASB 8 collected on 07/18/92, taboratory analyses (cont.)

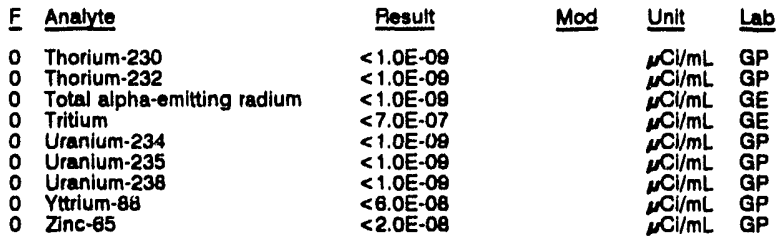

\section{WELL ASB 9B}

MEASUREMENTS CONOUGTED IN THE FIELD

Sample dato: 07/1810

Depth to water: $89.01 \mathrm{in}(27.13 \mathrm{~m})$ below TOC

Water olevation: $219.99 \mathrm{it}(87.05 \mathrm{~m}) \mathrm{msl}$

Water ovacuatod bofore sampling: 237 gal

Time: 12:10

Alkalinity: $31 \mathrm{mg} /$ Water temperature: $20.2^{\circ} \mathrm{C}$

LABORATORY ANALYSES

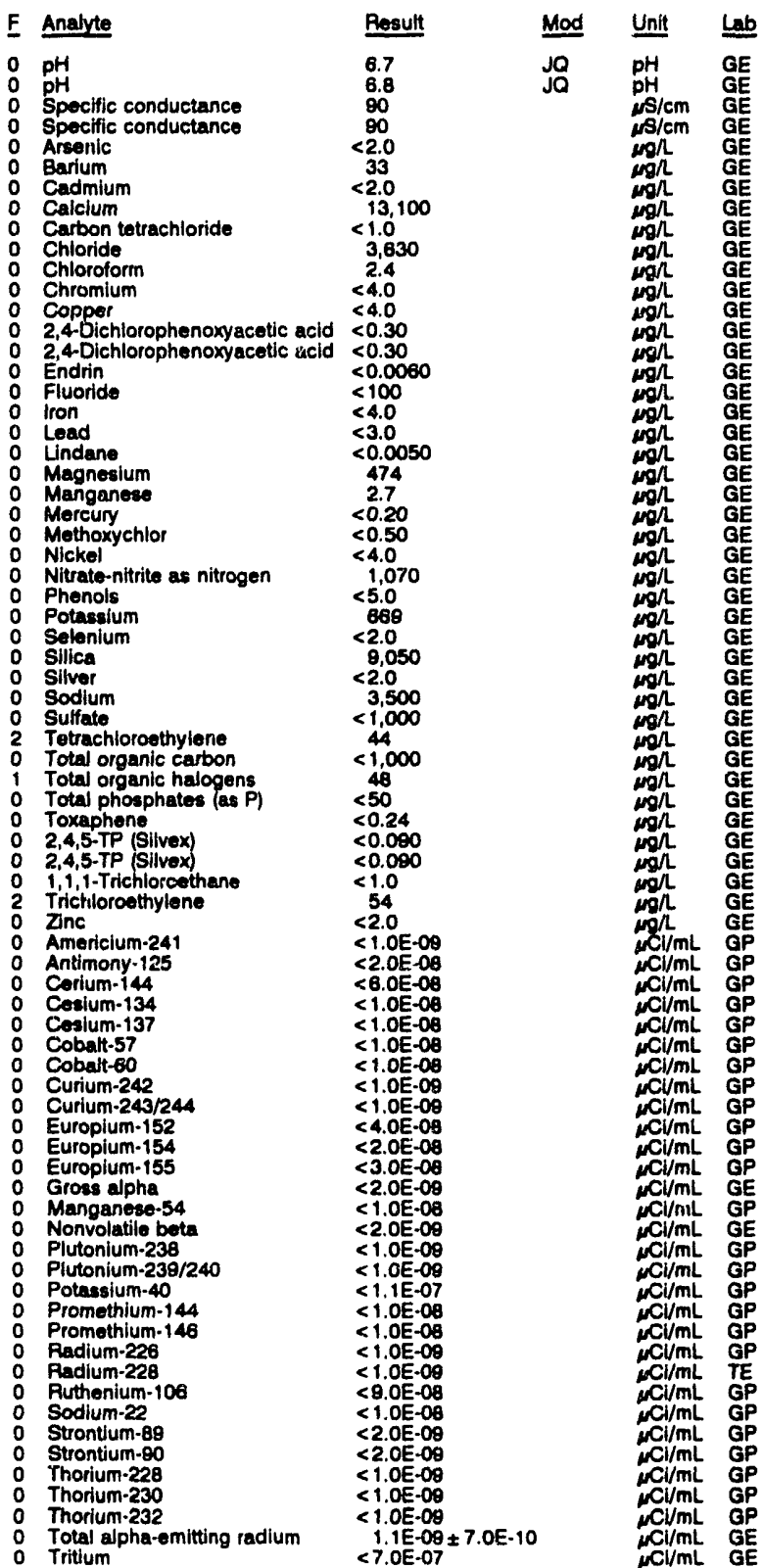


ANALYTICAL RESULTS

WELL ASB 98 collected on 07/18/92, laboratory analyses (cont.)

\begin{tabular}{|c|c|c|c|}
\hline F Analyte & Result & Mod & Unit \\
\hline $\begin{array}{ll}0 & \text { Uranium-234 } \\
0 & \text { Uranlum-235 } \\
0 & \text { Uranlum-238 } \\
0 & \text { Yutrium-68 } \\
0 & \text { Znc-65 }\end{array}$ & $\begin{array}{l}<1.0 E-09 \\
<1.0 E-09 \\
<1.0 E-09 \\
<6.0 E-08 \\
<2.0 E-08\end{array}$ & & 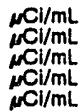 \\
\hline
\end{tabular}

WELL ASB 9C

MEASUREMENTS CONDUCTED IN THE FIELD

\begin{tabular}{|c|c|}
\hline 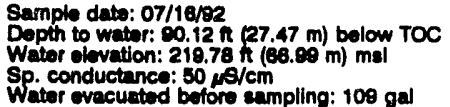 & $\begin{array}{l}\text { Time: } 11: 30 \\
\text { pH: } 5.7 \\
\text { Alkalinity: } 11 \mathrm{mg} / \mathrm{h} \\
\text { Water temperature: } 20.2^{\circ} \mathrm{C}\end{array}$ \\
\hline
\end{tabular}

LABOAATOAY ANALYBES

\begin{tabular}{|c|c|c|c|c|c|}
\hline & Analyte & Result & Mod & Unit & Lab \\
\hline $\begin{array}{l}0 \\
0 \\
0 \\
0 \\
0 \\
0 \\
0 \\
0 \\
0 \\
0 \\
0 \\
0 \\
0 \\
0 \\
0 \\
0\end{array}$ & 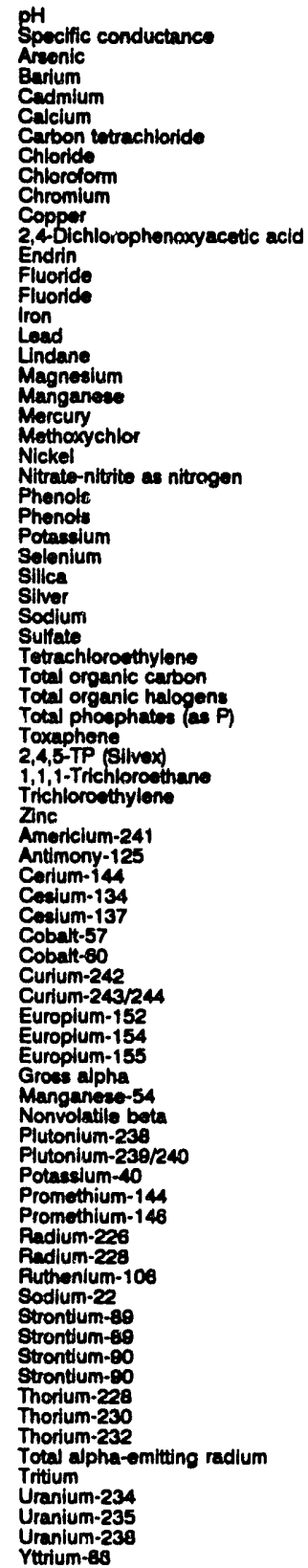 & 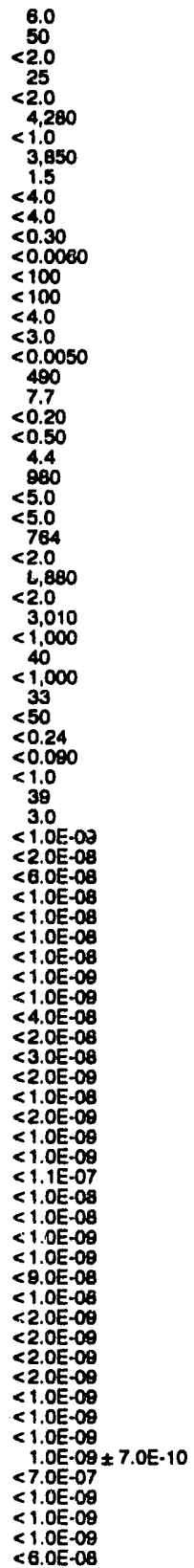 & JO & 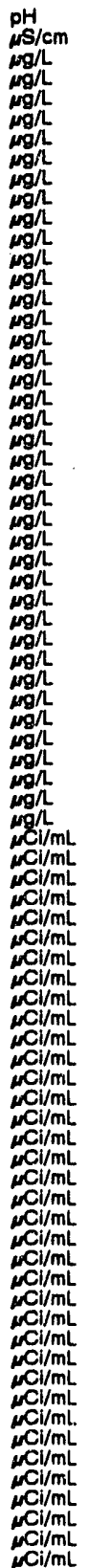 & $\begin{array}{l}\mathrm{GE} \\
\mathrm{GE} \\
\mathrm{GE} \\
\mathrm{GE} \\
\mathrm{GE} \\
\mathrm{GE} \\
\mathrm{GE} \\
\mathrm{GE} \\
\mathrm{GE} \\
\mathrm{GE} \\
\mathrm{GE} \\
\mathrm{GE} \\
\mathrm{GE} \\
\mathrm{GE} \\
\mathrm{GE} \\
\mathrm{GE} \\
\mathrm{GE} \\
\mathrm{GE} \\
\mathrm{GE} \\
\mathrm{GE} \\
\mathrm{GE} \\
\mathrm{GE} \\
\mathrm{GE} \\
\mathrm{GE} \\
\mathrm{GE} \\
\mathrm{GE} \\
\mathrm{GE} \\
\mathrm{GE} \\
\mathrm{GE} \\
\mathrm{GE} \\
\mathrm{GE} \\
\mathrm{GE} \\
\mathrm{GE} \\
\mathrm{GE} \\
\mathrm{GE} \\
\mathrm{GE} \\
\mathrm{GE} \\
\mathrm{GE} \\
\mathrm{GE} \\
\mathrm{GE} \\
\mathrm{GE} \\
\mathrm{GP} \\
\mathrm{GP} \\
\mathrm{GP} \\
\mathrm{GP} \\
\mathrm{GP} \\
\mathrm{GP} \\
\mathrm{GP} \\
\mathrm{GP} \\
\mathrm{GP} \\
\mathrm{GP} \\
\mathrm{GP} \\
\mathrm{GP} \\
\mathrm{GE} \\
\mathrm{GP} \\
\mathrm{GE} \\
\mathrm{GP} \\
\mathrm{GP} \\
\mathrm{GP} \\
\mathrm{GP} \\
\mathrm{GP} \\
\mathrm{GP} \\
\mathrm{GP} \\
\mathrm{GP} \\
\mathrm{GE} \\
\mathrm{GE} \\
\mathrm{GP} \\
\mathrm{GP} \\
\mathrm{GP} \\
\mathrm{GP} \\
\mathrm{GP} \\
\end{array}$ \\
\hline
\end{tabular}

WELL ASB 9 C collected on 07/16/92, laboratory analyses (cont.)

E Analyte $\frac{\text { Result }}{<2.0 \mathrm{E}-08} \quad$ Mod $\frac{\text { Unit }}{\mathrm{NCi} / \mathrm{mL}} \frac{\text { Lab }}{\mathrm{GP}}$

WELL ASB $10 C$

MEASUREMENTS CONDUCTED IN THE FIELD

Depth to water: $126.00 \mathrm{ft}(38.41 \mathrm{~m})$ below TOC

Water elevation: $222.00 \mathrm{ft}(67.84 \mathrm{~m}) \mathrm{msl}$

Time: $8: 35$

Alkalinity: $8 \mathrm{~mol}$

Water tomperature: $21.0^{\circ} \mathrm{C}$

LABORATORY ANALYSES

$0 \mathrm{pH}$

Specific conductance

0 Arsenic

Cadmium

Calcium

0 Chloride

O Chloride

O Chloroform

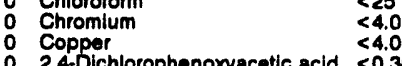

2,4-Dichlorophenoxyacetic acid <0.30

E Endrin

0 Iron

0 Lindane

O Magnesium

o Manganeso

Mercury

Mercury

Nickel

Nitrate-nitrite as nitrogen

Phenols

Potassium
Solenium

Silica

o Silver

Sulfate

2 Totrachloroethylene

Total dissolved solids

Total dissolved solids

Total organic carbon

Total organic halogens

Toxaphene

2,4,5-TP (Silvex)

1,1,1-Trichloroethan

Zinc

Americium-241

Americium-241

Antimony-125

Cerlum-144

Cesium-137

Cobalt-57

Cobalt-60

Curium-242

Curlum-242

Curium-243/244

Europium-152

Europium-154

Europium-155

Gross alpha.

Nonvolatile bete

Plutonium-238

Plutonium-239

Promethium-144

Promethium-146

Radium-228

Radium-228

Ruthenium-106

Sodium-22

Strontium-68

Strontium-90

Thorium-228

Thorium-232

To:al alpha-emitting radium

Tritium

Uranium-234

Uranium-234

Uranium-235

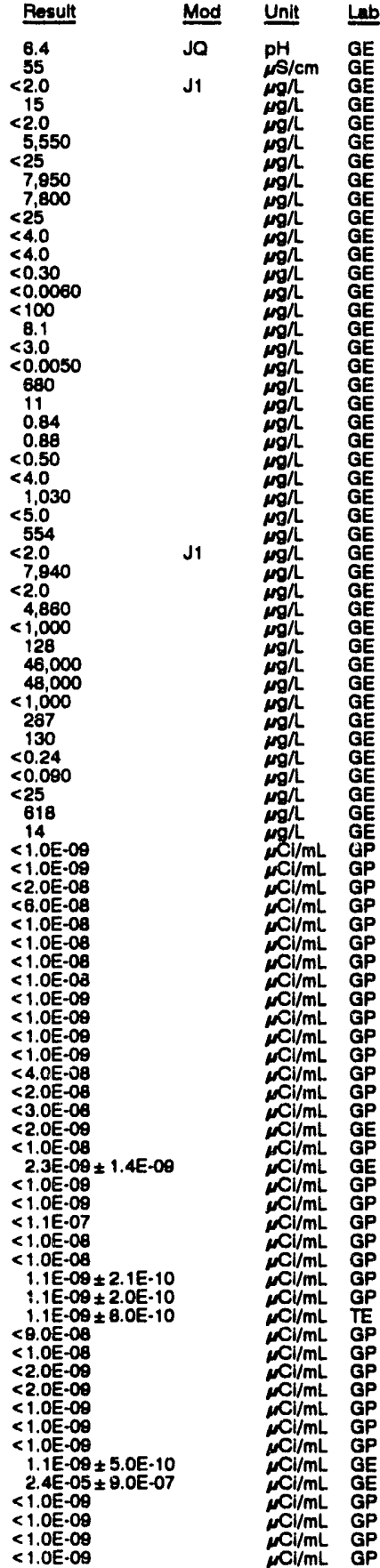




\begin{tabular}{|c|c|c|c|c|}
\hline $\boldsymbol{E}$ & Anabyte & Reeult & Mod & Unit \\
\hline $\begin{array}{l}0 \\
0 \\
0 \\
0\end{array}$ & $\begin{array}{l}\text { Uranium-238 } \\
\text { Uranium-236 } \\
\text { Ytrium-68 } \\
\text { Znc-65 }\end{array}$ & $\begin{array}{l}<1.0 \mathrm{E}-09 \\
<1.0 \mathrm{E}-09 \\
<6.0 \mathrm{E}-08 \\
<2.0 \mathrm{E}-08\end{array}$ & & 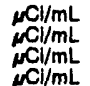 \\
\hline
\end{tabular}

WELL BG 52

\begin{tabular}{|c|c|c|c|c|c|}
\hline \multicolumn{6}{|c|}{ MEASUREMENTS CONDUCTED IN THE FIELD } \\
\hline \multicolumn{3}{|c|}{ 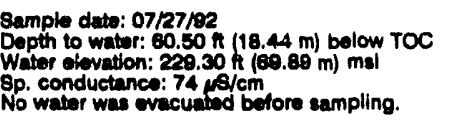 } & \multicolumn{3}{|c|}{$\begin{array}{l}\text { Time: } 10: 00 \\
\mathrm{pH}: 5.7 \\
\text { Water temperature: } 23.1^{\circ} \mathrm{C}\end{array}$} \\
\hline \multicolumn{6}{|c|}{ LABOPATOFY ANALYSES } \\
\hline $\mathbf{E}$ & Analyte & Reeult & Mod & Unit & Lab \\
\hline $\begin{array}{l}0 \\
2 \\
2 \\
2 \\
1 \\
1\end{array}$ & $\begin{array}{l}\text { Cadmium } \\
\text { Chromium } \\
\text { Iron } \\
\text { Lead } \\
\text { Manganese } \\
\text { Mercury } \\
\text { Groes alpha } \\
\text { Total alpha-emitting radium } \\
\text { Total alphe-emiting radium } \\
\text { Tritum }\end{array}$ & $\begin{array}{l}<2.0 \\
<4.0 \\
1,210 \\
26 \\
441 \\
2.0 \\
3.0 \mathrm{E}-08 . \\
7.0 \mathrm{E}-09 \pm \\
7.2 \mathrm{E}-09 \pm \\
4.6 \mathrm{E}-05\end{array}$ & $\begin{array}{l}E-09 \\
E-09 \\
E-09 \\
E-06\end{array}$ & 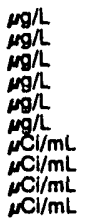 & $\begin{array}{l}\mathrm{GE} \\
\mathrm{GE} \\
\mathrm{GE} \\
\mathrm{GE} \\
\mathrm{GE} \\
\mathrm{GE} \\
\mathrm{GE} \\
\mathrm{GE} \\
\mathrm{GE} \\
\mathrm{GE}\end{array}$ \\
\hline
\end{tabular}

\section{WELL BG 54}

MEASUREMENTS CONDUCTED IN THE FIELD

$\begin{array}{ll}\text { Sample date: } 07 / 15 / 92 & \text { Time: } 10: 00 \\ \text { Depth to water: } 48.50 \mathrm{n}(14.17 \mathrm{~m}) \text { below TOC } & \text { pH: } 6.2 \\ \text { Water elevation: } 230.70 \mathrm{~h}(70.32 \mathrm{~m}) \mathrm{msl} & \text { Water temperature: } 22.0 \circ \mathrm{C} \\ \text { Sp. conductanco: } 51, \mu \mathrm{s} / \mathrm{cm} & \\ \text { No water was evacuated before sampling. } & \end{array}$
LABORATORY ANALYSES

\begin{tabular}{|c|c|c|c|c|}
\hline Analyte & Rosult & Mod & Unit & Lab \\
\hline $\begin{array}{ll}1 & \text { Cadmium } \\
0 & \text { Chromium } \\
2 & \text { Iron } \\
2 & \text { Lead } \\
2 & \text { Manganose } \\
0 & \text { Morcury } \\
0 & \text { Groes alpha } \\
1 & \text { Total alphe-emitting radium } \\
1 & \text { Tittium }\end{array}$ & $\begin{array}{l}3.9 \\
<4.0 \\
702 \\
32 \\
302 \\
0.31 \\
7.1 E-09 \pm 2.5 E-09 \\
3.6 E-09 \pm 1.4 E-09 \\
1.4 E-05 \pm 6.0 E-07\end{array}$ & & $\begin{array}{l}m g / L \\
\mu g / L \\
\mu g / L \\
\mu g / L \\
\mu g / L \\
m g / L \\
\mu C i / m L \\
\mu C i / m L \\
\mu C i / m L\end{array}$ & $\begin{array}{l}\mathrm{GE} \\
\mathrm{GE} \\
\mathrm{GE} \\
\mathrm{GE} \\
\mathrm{GE} \\
\mathrm{GE} \\
\mathrm{GE} \\
\mathrm{GE} \\
\mathrm{GE}\end{array}$ \\
\hline
\end{tabular}

\section{WELL BG 55}

MEASUREMENTS CONDUCTED IN THE FIELD

\begin{tabular}{|c|c|c|c|c|c|}
\hline \multicolumn{3}{|c|}{ 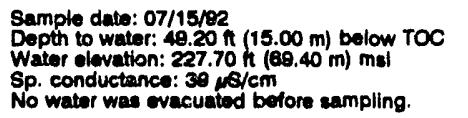 } & \multicolumn{3}{|l|}{$\begin{array}{l}\text { Time: } 9: 50 \\
\text { pH: } 6.6\end{array}$} \\
\hline \multicolumn{6}{|c|}{ LABORATORY ANALYSES } \\
\hline- & Analyte & Result & Mod & Unit & Lab \\
\hline $\begin{array}{l}2 \\
2 \\
0 \\
0 \\
2 \\
2 \\
2 \\
2 \\
2 \\
1 \\
2 \\
0\end{array}$ & $\begin{array}{l}\text { Cadmium } \\
\text { Cadmium } \\
\text { Chromium } \\
\text { Chromlum } \\
\text { Iron } \\
\text { lron } \\
\text { Lead } \\
\text { Manganese } \\
\text { Manganese } \\
\text { Mercury } \\
\text { Groes alpha } \\
\text { Total activity } \\
\text { rotal alpha-omitting radium } \\
\text { Tritum }\end{array}$ & $\begin{array}{l}11 \\
11 \\
9.2 \\
9.2 \\
10,800 \\
10,800 \\
161 \\
212 \\
211 \\
1.5 \\
3.0 \mathrm{E}-00 \\
1.5 \mathrm{E}-04 \\
9.1 \mathrm{E}-00 \\
5.1 \mathrm{E}-04\end{array}$ & $\begin{array}{l}5 E-09 \\
E-06 \\
7 E-09 \\
4 E-08\end{array}$ & 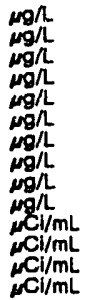 & $\begin{array}{l}\mathrm{GE} \\
\mathrm{GE} \\
\mathrm{GE} \\
\mathrm{GE} \\
\mathrm{GE} \\
\mathrm{GE} \\
\mathrm{GE} \\
\mathrm{GE} \\
\mathrm{GE} \\
\mathrm{GE} \\
\mathrm{GE} \\
\mathrm{EM} \\
\mathrm{GE} \\
\mathrm{GE}\end{array}$ \\
\hline
\end{tabular}

WELL BG 59

\begin{tabular}{|c|c|c|c|c|c|}
\hline \multicolumn{6}{|c|}{ MEASUREMENTS CONDUCTED IN THE FIELD } \\
\hline \multirow{2}{*}{\multicolumn{3}{|c|}{ 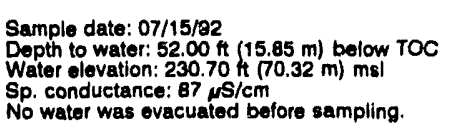 }} & \multicolumn{3}{|l|}{$\begin{array}{l}\text { Time: } 9: 20 \\
\text { pH: } 6.3\end{array}$} \\
\hline & & & \multicolumn{3}{|c|}{ Water temperature: $24.0^{\circ} \mathrm{C}$} \\
\hline \multicolumn{6}{|c|}{ LABORATOAY ANALYSES } \\
\hline $\mathbf{E}$ & Analyte & Pessult & Mod & $\underline{\text { Unit }}$ & La \\
\hline $\begin{array}{l}0 \\
2 \\
2 \\
2 \\
2 \\
2 \\
2 \\
2 \\
1\end{array}$ & $\begin{array}{l}\text { Cadmium } \\
\text { Chromium } \\
\text { lron } \\
\text { Load } \\
\text { Manganose } \\
\text { Moreuny } \\
\text { Groes alpha } \\
\text { Totala alpha-emitting radium } \\
\text { Trtium }\end{array}$ & $\begin{array}{c}28 \\
<4.0 \\
1,800 \\
155 \\
1,120 \\
2.8 \\
3.6 E-08 \\
1.2 E-08 \\
1.1 E-05\end{array}$ & $\begin{array}{l}5.3 E-09 \\
2.5 E-09 \\
6.0 E-07\end{array}$ & 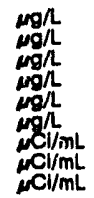 & $\begin{array}{l}G E \\
G E \\
G E \\
G E \\
G E \\
G E \\
G E \\
G E \\
G E \\
G E\end{array}$ \\
\hline
\end{tabular}

WELL BG 60

MEASUREMENTS CONDUCTED IN THE FIELD

$\begin{array}{ll}\text { Sample date: } 07 / 15 / 82 & \text { Time: } 9: 30 \\ \text { Depth to water: } 43.00 \mathrm{H}(13.11 \mathrm{~m}) \text { below TOC } & \text { pH: } 7.2 \\ \text { Water elevation: } 232.50 \mathrm{H}(70.87 \mathrm{~m}) \mathrm{ms} & \text { Water tomperature: } 22.0^{\circ} \mathrm{C} \\ \text { Sp. conductance: } 37, \mu \mathrm{S} / \mathrm{cm} & \end{array}$

Sp. conductance: $37 \mu \mathrm{\mu} / \mathrm{cm}$
No water was evacuated before sampling.

LABORATORY ANALYSES

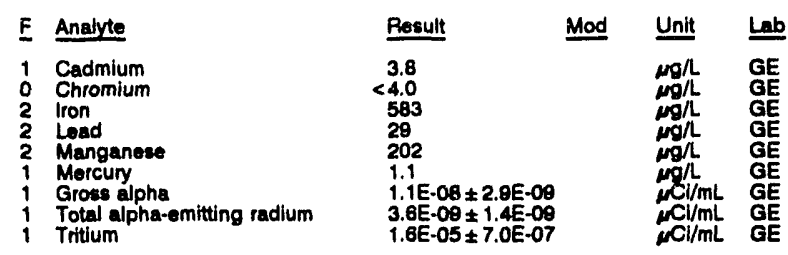

\section{WELL BG 61}

MEASUREMENTS CONOUCTED IN THE FIELD

Sample deve:07/15/82

Depth to water: $40.50 \mathrm{ft}(12.34 \mathrm{~m})$ below TOC

Water olevation: $234.50 \mathrm{H}(71.48 \mathrm{~m}) \mathrm{ms}$

No water was ovacuated before sampling.

$\mathrm{pH}: 6.5$

Water temperature: $23.0^{\circ} \mathrm{C}$

LABORATORY ANALYSES

\begin{tabular}{|c|c|c|c|c|}
\hline Analyte & Rosult & Mod & Unit & Lab \\
\hline $\begin{array}{l}\text { Cadmium } \\
\text { Cadmium } \\
\text { Chromium } \\
\text { Chromium } \\
\text { ron } \\
\text { lron } \\
\text { Lead } \\
\text { Manganese } \\
\text { Manganese } \\
\text { Mercury } \\
\text { Gross alpha } \\
\text { Total alpha-emilting radium } \\
\text { Tritium }\end{array}$ & $\begin{array}{r}4.9 \\
5.0 \\
<4.0 \\
<4.0 \\
421 \\
433 \\
47 \\
287 \\
291 \\
2.9 \\
7.9 \mathrm{E}-09 \pm 2.6 \mathrm{E}-09 \\
4.8 \mathrm{E}-09 \pm 1.6 \mathrm{E}-09 \\
9.1 \mathrm{E}-06 \pm 5.0 \mathrm{E}-07\end{array}$ & & 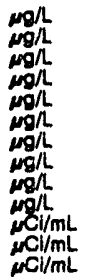 & $\begin{array}{l}\mathrm{GE} \\
\mathrm{GE} \\
\mathrm{GE} \\
\mathrm{GE} \\
\mathrm{GE} \\
\mathrm{GE}\end{array}$ \\
\hline
\end{tabular}

WELL BG 67

MEASUREMENTS CONDUCTED IN THE FIELD

Sample date: $07 / 27 / 92$
Depth to water: $59.00 \mathrm{ft}(17.98 \mathrm{~m})$ below TOC

Water elevation: $235.70 \mathrm{~h}(71.84 \mathrm{~m}) \mathrm{msl}$

Sp. conductance: $38 \mu \mathrm{s} / \mathrm{cm}$
No water was evacuated before sampling.

Time: 11:00
pH: 5.8

Water temperature: $22.7^{\circ} \mathrm{C}$

LABORATORY ANALYSES

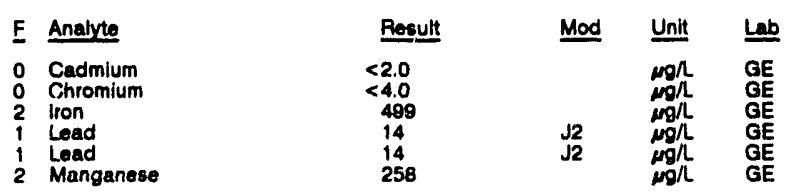


ANALYTICAL RESULTS

WELL 8687 collocted on 07/27/92, laboratory analyees (cont.)

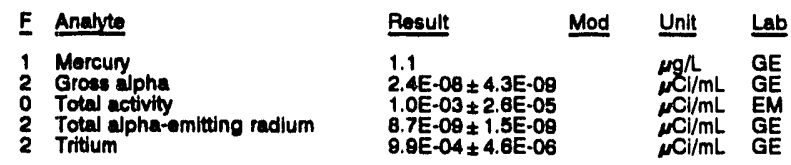

\section{WELL BG 91}

MEASUREMENTS CONDUCTED IN THE FIELD
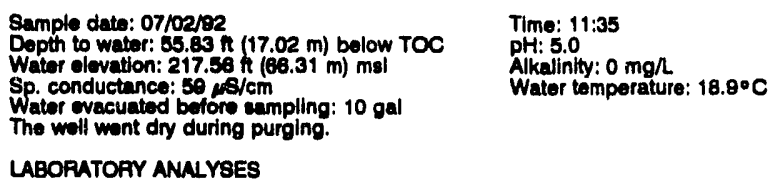

LABOPATORY ANALYSES

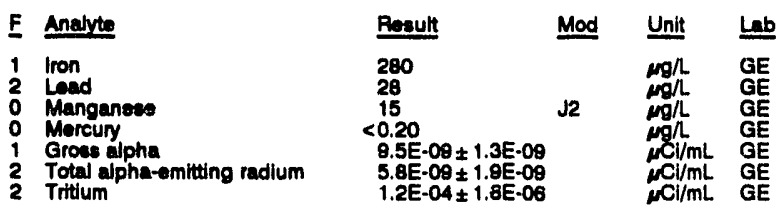

WELL BG 92

MEASUREMENTS CONDUCTED IN THE FIELD
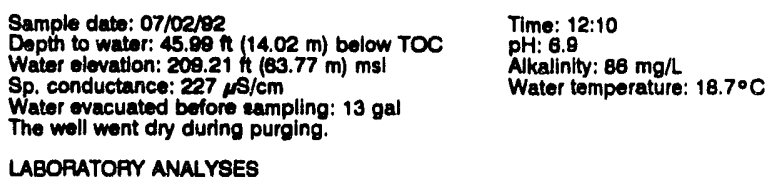

Water temperature: $18.7^{\circ} \mathrm{C}$

LABOFATORY ANALYSES

\begin{tabular}{|c|c|c|c|c|}
\hline Analyte & Result & Mod & Unit & Lab \\
\hline $\begin{array}{l}\text { Iron } \\
\text { Lead } \\
\text { Manganese } \\
\text { Mercury } \\
\text { Groes alpha } \\
\text { Total alpha-emitting radium } \\
\text { Trttium }\end{array}$ & $\begin{array}{l}30 \\
6.0 \\
27 \\
<0.20 \\
4.3 E-09 \pm 2.1 E-09 \\
1.8 E-09 \pm 1.2 E-09 \\
7.3 E-06 \pm 5.0 E-07\end{array}$ & $\sqrt{2}$ & $\begin{array}{l}\mathrm{mg} / \mathrm{L} \\
\mathrm{\mu g} / \mathrm{L} \\
\mathrm{\mu g} / \mathrm{L} \\
\mu g / L \\
\mu \mathrm{L} / \mathrm{mL} \\
\mu \mathrm{Cl} / \mathrm{mL} \\
\mu \mathrm{Cl} / \mathrm{mL}\end{array}$ & $\begin{array}{l}\mathrm{GE} \\
\mathrm{GE} \\
\mathrm{GE} \\
\mathrm{GE} \\
\mathrm{GE} \\
\mathrm{GE}\end{array}$ \\
\hline
\end{tabular}

WELL BG 93

MEASUREMENTS CONDUCTED IN THE FIELD

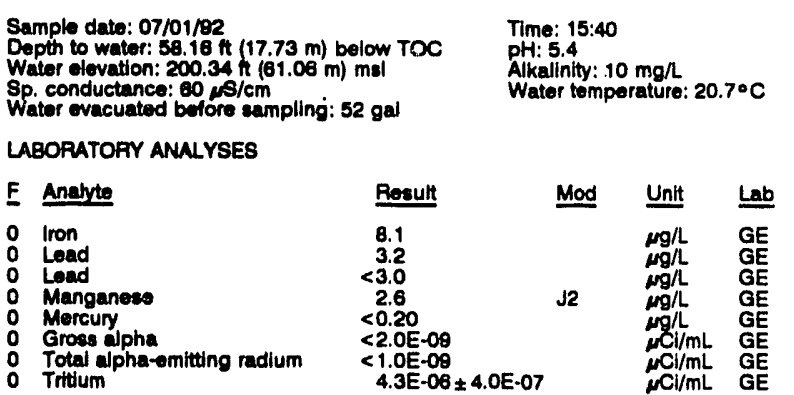

\section{WELL BG 94}

MEASUREMENTS CONDUCTED IN THE FIELD

Sample date: $07 / 02 / 02$

Dopth to water: $80.23 \mathrm{ft}(18.36 \mathrm{~m})$ below TOC

Water olevation: $180.57 \mathrm{~h}(58.09 \mathrm{~m}) \mathrm{msl}$

Sater evacuated bofore eampling: $89 \mathrm{gal}$

LABOAATOFY ANALYSES

\begin{tabular}{|c|c|c|c|}
\hline E Analyte & Rosult & Mod & Unit \\
\hline $\begin{array}{ll}0 & \text { Iron } \\
0 & \text { Iron } \\
0 & \text { Lead } \\
1 & \text { Mangancese } \\
1 & \text { Manganese }\end{array}$ & $\begin{array}{r}30 \\
30 \\
<3.0 \\
50 \\
50\end{array}$ & & 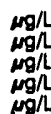 \\
\hline
\end{tabular}

WELL BG 94 collected on 07/02/92, laboratory analyees (cont.)

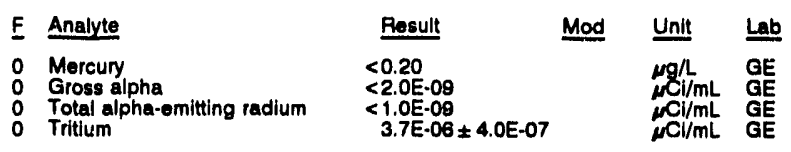

\section{WELL BG 95}

MEASUREMENTS CONDUCTED IN THE FIELD

Sample date: 07/02/92

Time: 8:40

Water elevation: $192.15 \mathrm{ft}(58.57 \mathrm{~m}) \mathrm{msl} \quad$ Alkallity: $1 \mathrm{mg}$

Sp. conductance: $47 \mathrm{\mu s} / \mathrm{cm}$ Water tomperature: $18.6^{\circ} \mathrm{C}$

LABORATORY ANALYSES

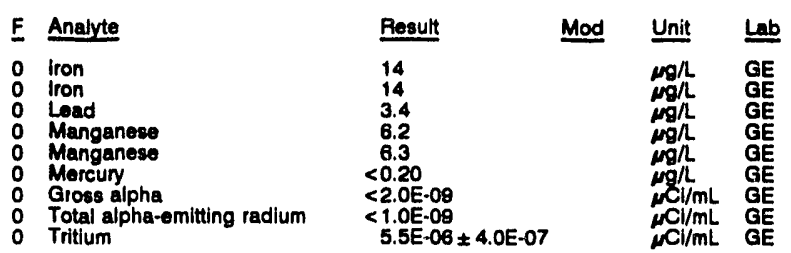

\section{WELL BG 96}

MEASUREMENTS CONDUCTED IN THE FIELD

$\begin{array}{ll}\text { Sample date: } 07 / 02 / 92 & \text { Time: } \theta: 10 \\ \text { Depth to water: } 47.36 \mathrm{ft}(14.44 \mathrm{~m}) \text { below TOC } & \text { pH: } 5.5 \\ \text { Water olevation: } 197.84 \mathrm{ft}(60.30 \mathrm{~m}) \mathrm{mst} & \text { Alkalinity: } 2 \mathrm{mg} / \mathrm{h} \\ \text { Sp. conductance: } 31 \mu \mathrm{s} / \mathrm{cm} & \text { Water temperature: } 19.4^{\circ} \mathrm{C} \\ \text { Water evacuated before sampling: } 54 \mathrm{gal} & \end{array}$

sampling: 54 ga

LABORATORY ANALYSES

\begin{tabular}{|c|c|c|c|c|c|}
\hline $\mathbf{E}$ & Analyte & Result & Mod & Unit & Lab \\
\hline & $\begin{array}{l}\text { Iron } \\
\text { Lead } \\
\text { Manganese } \\
\text { Mercury } \\
\text { Gross alpha } \\
\text { Total alpha-emitting radium } \\
\text { Tritium } \\
\text { Tritlum }\end{array}$ & $\begin{array}{l}61 \\
6.6 \\
5.3 \\
<0.20 \\
<2.0 \mathrm{E} \cdot 00 \\
<1.0 \mathrm{E}-09 \\
8.5 \mathrm{E}-06 \pm 5.0 \mathrm{E}-07 \\
8.8 \mathrm{E}-06 \pm 5.0 \mathrm{E}-07\end{array}$ & & 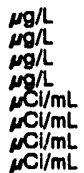 & $\begin{array}{l}\mathrm{GE} \\
\mathrm{GE} \\
\mathrm{GE} \\
\mathrm{GE} \\
\mathrm{GE} \\
\mathrm{GE} \\
\mathrm{GE} \\
\mathrm{GE}\end{array}$ \\
\hline
\end{tabular}

WELL BG 101

MEASUREMENTS CONOUCTED IN THE FIELD

$\begin{array}{ll}\text { Sample date: } 07 / 08 / 92 & \text { Time: } 8: 10 \\ \text { Depth to watter: } 36.38 \mathrm{H}(11.09 \mathrm{~m}) \text { below TOC } & \text { pH: } 5.1 \\ \text { Water elevation: } 185.02 \mathrm{ft}(59.44 \mathrm{~m}) \mathrm{msl} & \text { Alkalinity: } 0 \mathrm{mg} / \mathrm{L} \\ \text { Sp. conductance: } 22, \mu \mathrm{S} / \mathrm{cm} & \text { Water temperature: } 18.0 \circ \mathrm{C} \\ \text { Water evacuated before sampling: } 88 \mathrm{gal} & \end{array}$

Water evacuated bofore sampling: $88 \mathrm{gal}$

LABORATORY ANALYSES

\begin{tabular}{|c|c|c|c|c|}
\hline F & Analyte & Result & Mod & Unit \\
\hline 0 & $\begin{array}{l}\text { Iron } \\
\text { Lead } \\
\text { Manganese } \\
\text { Mercury } \\
\text { Mercury } \\
\text { Gross alpha } \\
\text { Total actlvity } \\
\text { Total alpha-emitting radium } \\
\text { Tritium }\end{array}$ & $\begin{array}{l}13 \\
<3.0 \\
9.9 \\
<0.20 \\
<0.20 \\
2.0 \mathrm{E}-09 \pm 8.0 \mathrm{E}-10 \\
2.2 \mathrm{x}-04 \pm 3.7 \mathrm{E}-06 \\
1.1 \mathrm{E}-09 \pm 8.0 \mathrm{E}-10 \\
2.1 \mathrm{E}-04 \pm 2.2 \mathrm{E}-06\end{array}$ & & 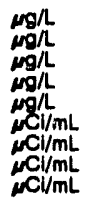 \\
\hline
\end{tabular}

Time: 10:20

PH: 5.6

Water temperature: $19.1^{\circ} \mathrm{C}$

2 Tritium 


\section{ANALYTICAL RESULTS}

WELL BG 103

MEASUREMENTS CONDUCTED IN THE FIELD

\begin{tabular}{|c|c|c|c|c|c|}
\hline \multicolumn{3}{|c|}{ 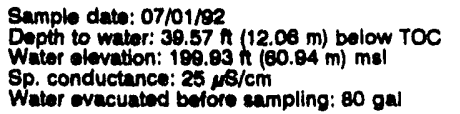 } & \multicolumn{3}{|c|}{$\begin{array}{l}\text { Time: } 14: 00 \\
\text { pH: } 4.8: 00: 1 \mathrm{mg} / \mathrm{h} \\
\text { Alkalinhy: } 1 \text { mgle: } 20.2^{\circ} \mathrm{C} \\
\text { Water tomperature }\end{array}$} \\
\hline \multicolumn{6}{|c|}{ LABORATORY ANALYSES } \\
\hline- & Anabyte & Resutt & Mod & Unit & 뇨뇨 \\
\hline & $\begin{array}{l}\text { Iron } \\
\text { Load } \\
\text { Manganeses } \\
\text { Morcuny } \\
\text { Growe alpha } \\
\text { Nonvolutlo bett } \\
\text { Total alpha-emitting radium } \\
\text { Thttum }\end{array}$ & $\begin{aligned} 10 \\
<3.0 \\
5.0 \\
<0.20 \\
<2.0 E-00 \\
<2.0 E-00 \\
<1.0 E-00 \\
8.7 E-05:\end{aligned}$ & $4 E-00$ & 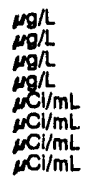 & $\begin{array}{l}\mathrm{GE} \\
\mathrm{GE} \\
\mathrm{GE} \\
\mathrm{GE} \\
\mathrm{GE} \\
\mathrm{GE} \\
\mathrm{GE} \\
\mathrm{GE}\end{array}$ \\
\hline
\end{tabular}

\section{WELL BG 104}

MEASUREMENTS CONDUCTED IN THE FIELD

\begin{tabular}{|c|c|c|c|c|c|}
\hline \multicolumn{3}{|c|}{$\begin{array}{l}\text { Sample dute: 07/02/92 } \\
\text { Depth to water: Nol avaliable } \\
\text { Water olevation: Not avallable } \\
\text { Sp. conductance: } 78 \text { ps/cm } \\
\text { Water evacuated before sampling: } 2 \text { gal } \\
\text { The woll went dry during purging. }\end{array}$} & \multicolumn{3}{|c|}{$\begin{array}{l}\text { Time: } 8: 35 \\
\text { pH: } 6.5 \\
\text { Alkalinity: } 16 \mathrm{mg} / \mathrm{L} \\
\text { Water temperature: } 18.4^{\circ} \mathrm{C}\end{array}$} \\
\hline \multicolumn{6}{|c|}{ LABORATOFY ANALYSES } \\
\hline $\boldsymbol{E}$ & Analyte & Result & Mod & Unit & \\
\hline $\begin{array}{l}0 \\
2 \\
0 \\
0 \\
0 \\
0\end{array}$ & $\begin{array}{l}\text { Iron } \\
\text { Lead } \\
\text { Manganese } \\
\text { Mercury } \\
\text { Groes alpha } \\
\text { Total alpha-emitting radium } \\
\text { Trttum }\end{array}$ & $\begin{array}{l}6.6 \\
23 \\
6.8 \\
<0.20 \\
<2.0 E-09 \\
<1.0 E-09 \\
1.2 E-05 \pm\end{array}$ & $E \cdot 07$ & $\begin{array}{l}\mu g / L \\
\mu g h \\
\mu g / L \\
\mu g / L \\
\mu C i / m L \\
\mu C l / m L \\
\mu C l / m L\end{array}$ & $\begin{array}{l}\text { GE } \\
\text { GE } \\
\text { GE } \\
\text { GE } \\
\text { GE } \\
\text { GE } \\
\text { GE }\end{array}$ \\
\hline
\end{tabular}

\section{WELL BG 107}

MEASUAEMENTS CONDUCTED IN THE FIELD

\begin{tabular}{|c|c|c|c|c|c|}
\hline \multicolumn{3}{|c|}{ 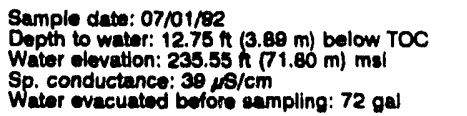 } & \multicolumn{3}{|c|}{$\begin{array}{l}\text { Time: } 13: 00 \\
\text { pH: } 5.2 .2 \\
\text { Alkalinity: } 7 \mathrm{mg} / \mathrm{h} \\
\text { Water temperature: } 18.6^{\circ} \mathrm{C}\end{array}$} \\
\hline \multicolumn{6}{|c|}{ LABORATORY ANALYSES } \\
\hline & Analyte & Result & Mod & Unit & \\
\hline & $\begin{array}{l}\text { Iron } \\
\text { Load } \\
\text { Manganeas } \\
\text { Mercury } \\
\text { Grose alpha } \\
\text { Total alpha-emiting redium } \\
\text { Tritum }\end{array}$ & $\begin{array}{l}1,230 \\
34 \\
67 \\
<0.20 \\
<2.0 \mathrm{E}-09 \\
1.0 \mathrm{E}-09 \pm \\
1.7 \mathrm{E}-05 \pm\end{array}$ & 19 & 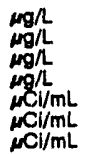 & : \\
\hline
\end{tabular}

\section{WELL BG 108}

MEASUREMENTS CONDUCTED IN THE FIELD

\begin{tabular}{|c|c|c|c|c|c|}
\hline \multicolumn{3}{|c|}{$\begin{array}{l}\text { Sample date: } 07 / 01 / 92 \\
\text { Dopth to water: } 28.20 \mathrm{n}(8.60 \mathrm{~m}) \text { below TOC } \\
\text { Water elevation: } 239.10 \mathrm{H}(72.86 \mathrm{~m}) \mathrm{mal} \\
\text { Sp. conductunce: } 43,88 / \mathrm{cm} \\
\text { Water evacuated belore sumpling: } 57 \mathrm{gal}\end{array}$} & \multicolumn{3}{|c|}{$\begin{array}{l}\text { Time: } 12: 15 \\
\text { pH: } 5.0 \\
\text { Alkalinity: } 4 \mathrm{mg} / \mathrm{h} \\
\text { Water temperature: } 20.2^{\circ} \mathrm{C}\end{array}$} \\
\hline \multicolumn{6}{|c|}{ LABORATOFY ANALYSES } \\
\hline $\mathbf{E}$ & Analyte & Peosult & Mod & Unit & $\underline{\text { Lab }}$ \\
\hline $\begin{array}{l}0 \\
0 \\
0 \\
0 \\
0 \\
0 \\
0 \\
0 \\
2\end{array}$ & $\begin{array}{l}\text { Iron } \\
\text { Load } \\
\text { Manganese } \\
\text { Mercury } \\
\text { Groes alpha } \\
\text { Nonvolatile beta } \\
\text { Total alpha-emitting radium } \\
\text { Total alpha-emitting radium } \\
\text { Tritium }\end{array}$ & $\begin{array}{l}60 \\
3.6 \\
7.3 \\
<0.20 \\
<2.0 E-09 \\
<2.0 E-09 \\
<1.0 E-09 \\
<1.0 E-09 \\
2.7 E-05=\end{array}$ & $E-07$ & 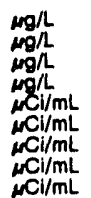 & $\begin{array}{l}\mathrm{GE} \\
\mathrm{GE} \\
\mathrm{GE} \\
\mathrm{GE} \\
\mathrm{GE} \\
\mathrm{GE} \\
\mathrm{GE} \\
\mathrm{GE} \\
\mathrm{GE}\end{array}$ \\
\hline
\end{tabular}

WELL BG 109

MEASUREMENTS CONDUCTED IN THE FIELO

\begin{tabular}{|c|c|c|c|c|}
\hline $\begin{array}{l}\text { Sample date: } 07 / 01 / 82 \\
\text { Depth to water: } 46.14 \mathrm{Ht} / 14.06 \\
\text { Wator olovation: } 240.28 \mathrm{~h} / 73.2 \\
\text { Sp. conductance: } 43 \mathrm{\mu S} / \mathrm{cm} \\
\text { Wator ovacuated before sampl }\end{array}$ & $\begin{array}{l}\text { mal } \\
31 \mathrm{gal}\end{array}$ & $\begin{array}{l}\text { Time: } 11: 45 \\
\text { pHe: } 4.8 \\
\text { Alkalinity: } 1 n \\
\text { Wator tompe }\end{array}$ & (8): $18.5^{\circ}$ & \\
\hline LABORATORY ANALYSES & & & & \\
\hline Analyte & Result & Mod & Unit & \\
\hline $\begin{array}{ll}0 & \text { Iron } \\
2 & \text { Load } \\
0 & \text { Manganese } \\
0 & \text { Morcuny } \\
0 & \text { Gross alpha } \\
0 & \text { Nonvolatili beta } \\
0 & \text { Total alpha-emitting radium } \\
2 & \text { Tritium }\end{array}$ & $\begin{array}{l}32 \\
55 \\
11 \\
<0.20 \\
<2.0 \mathrm{E}-09 \\
<2.0 \mathrm{E} \cdot 09 \\
1.9 \mathrm{E} \cdot 09 \pm \\
2.8 \mathrm{E}-05 \pm\end{array}$ & $\begin{array}{l}E-09 \\
E-07\end{array}$ & 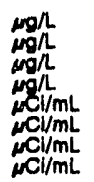 & $\begin{array}{l}G E \\
G E \\
G E \\
G E \\
G E \\
G E \\
G E \\
G E \\
G E\end{array}$ \\
\hline
\end{tabular}

\section{WELL BG 110}

MEASUREMENTS CONDUCTED IN THE FIELD

Sample date: $07 / 02 / 82$

Depth to water: $52.84 \mathrm{Ht}(16.11 \mathrm{~m})$ below TOC

Water elevation: $241.46 \mathrm{~h}(73.80 \mathrm{~m}) \mathrm{msl}$

Water evacuated bofore sampling: $36 \mathrm{ga}$

Akalinity: $0 \mathrm{moll}$

Water tomperature: $18.8 \circ \mathrm{C}$

The woll went dry during purging.

LABORATORY ANALYSES

\begin{tabular}{|c|c|c|c|c|}
\hline & Analyte & Pessult & Mod & Unit \\
\hline & $\begin{array}{l}\text { Iron } \\
\text { Lead } \\
\text { Manganose } \\
\text { Mercury } \\
\text { Gross alpha } \\
\text { Total alpha-emitting radlum } \\
\text { Tritium }\end{array}$ & $\begin{array}{l}44 \\
31 \\
53 \\
50.20 \\
3.0 E-09 \pm 8.0 E-10 \\
1.5 E .09 \pm 1.2 E-09 \\
2.7 E-05 \pm 8.0 E-07\end{array}$ & & 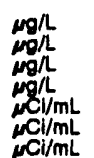 \\
\hline
\end{tabular}

WELL BG 121

MEASUREMENTS CONDUCTED IN THE FIELD

Sample dalo: 0710202

Sample dale: 07/02/92

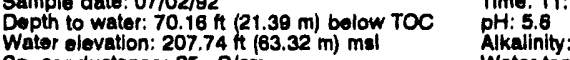

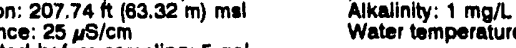
The woll went dry during purging.

LABORATOAY ANALYSES

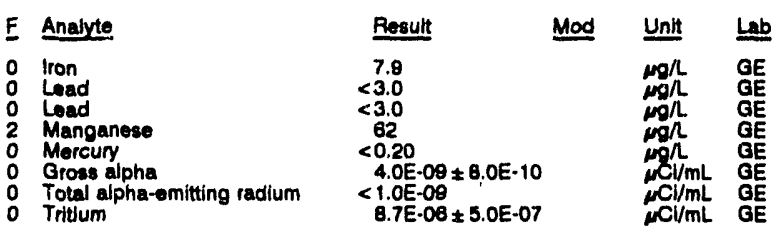

WELL BG 122

MEASUREMENTS CONDUCTED IN THE FIELD

Sample date: 07/01/82 Depth to water: $38.73 \mathrm{Ht}(11.20 \mathrm{~m})$ below TOC Time: 15:05 Water elevation: $211.17 \mathrm{ft}(64.37 \mathrm{~m}) \mathrm{msl}$ PA: 5.0 : $1 \mathrm{mal}$

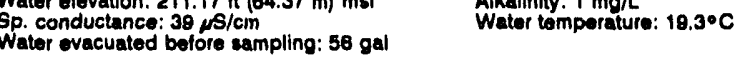
LABORATORY ANALYSES

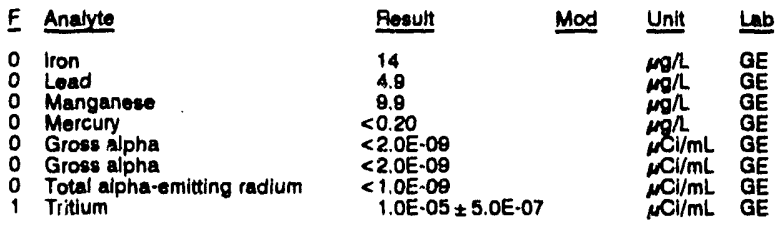


WELL BG 125

MEASUREMENTS CONDUCTED IN THE FIELD

Sample date: 08/07/02
The wall was dry.

Time: 13:50

\section{WELL BGO 1D}

MEASUREMENTS CONDUCTED IN THE FIELD

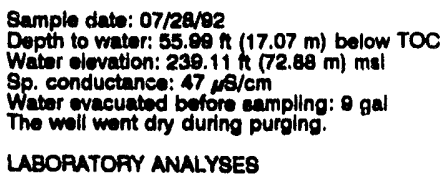

Time: $8: 30$

PHikalinity: $0 \mathrm{mg} / \mathrm{L}$

Water tomporature: $21.5^{\circ} \mathrm{C}$

\section{LABOPATOFY ANALYSES}

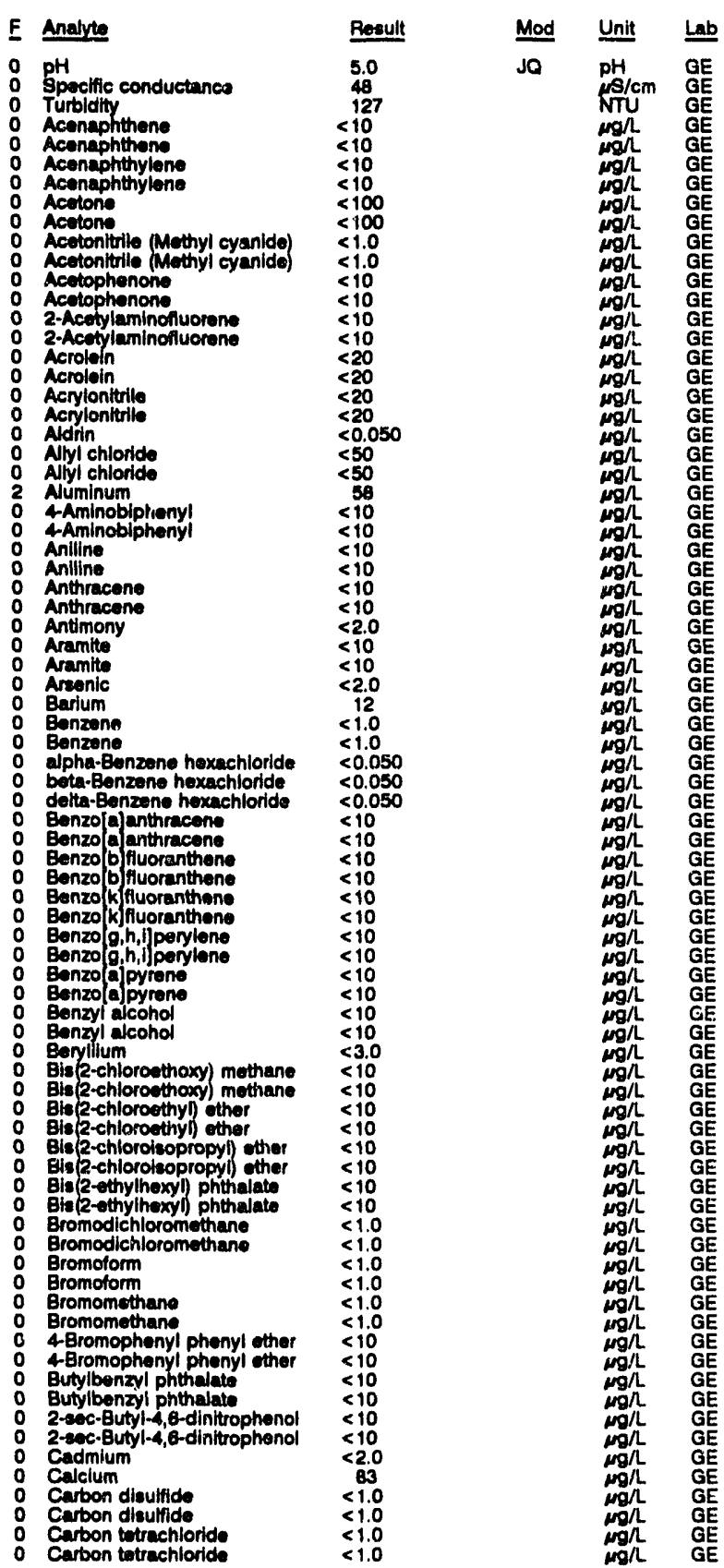

WELL BGO 1D collected on 07/28/82, laboratory analyses (cont.)

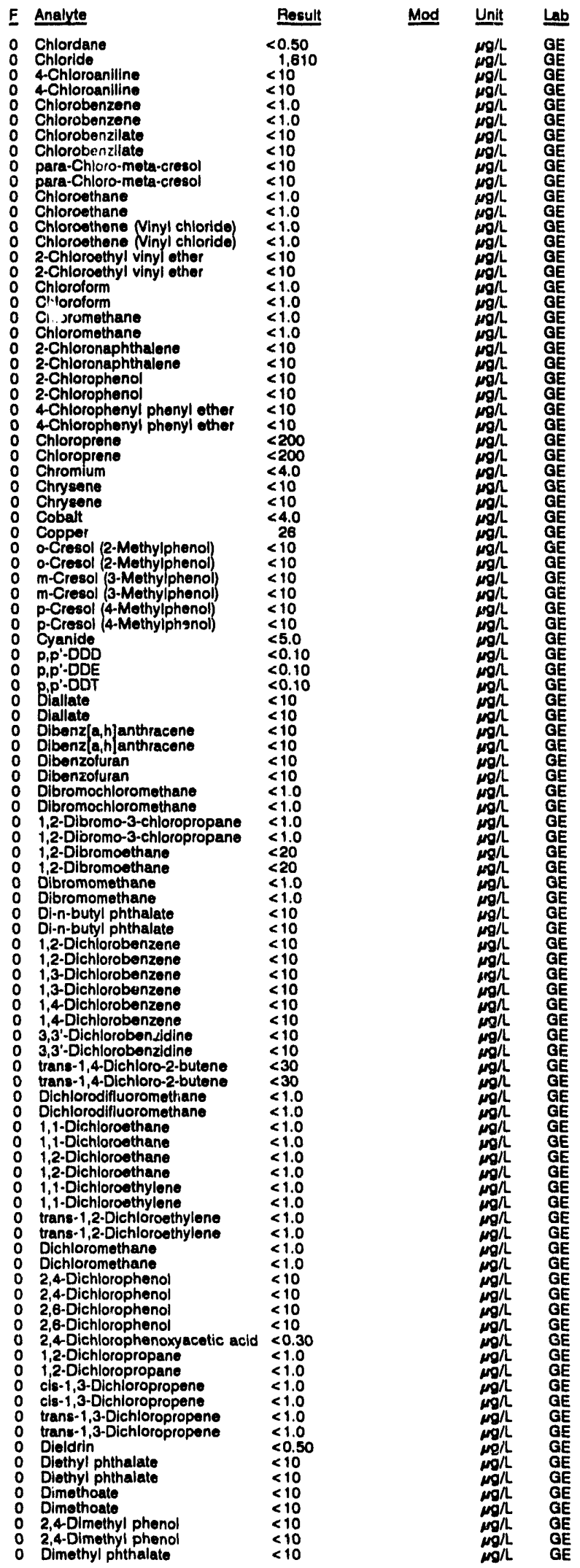


ANALYTICAL RESULTS

WELL BGO 10 collected on 07/28/92, laboratory analyses (cont.)

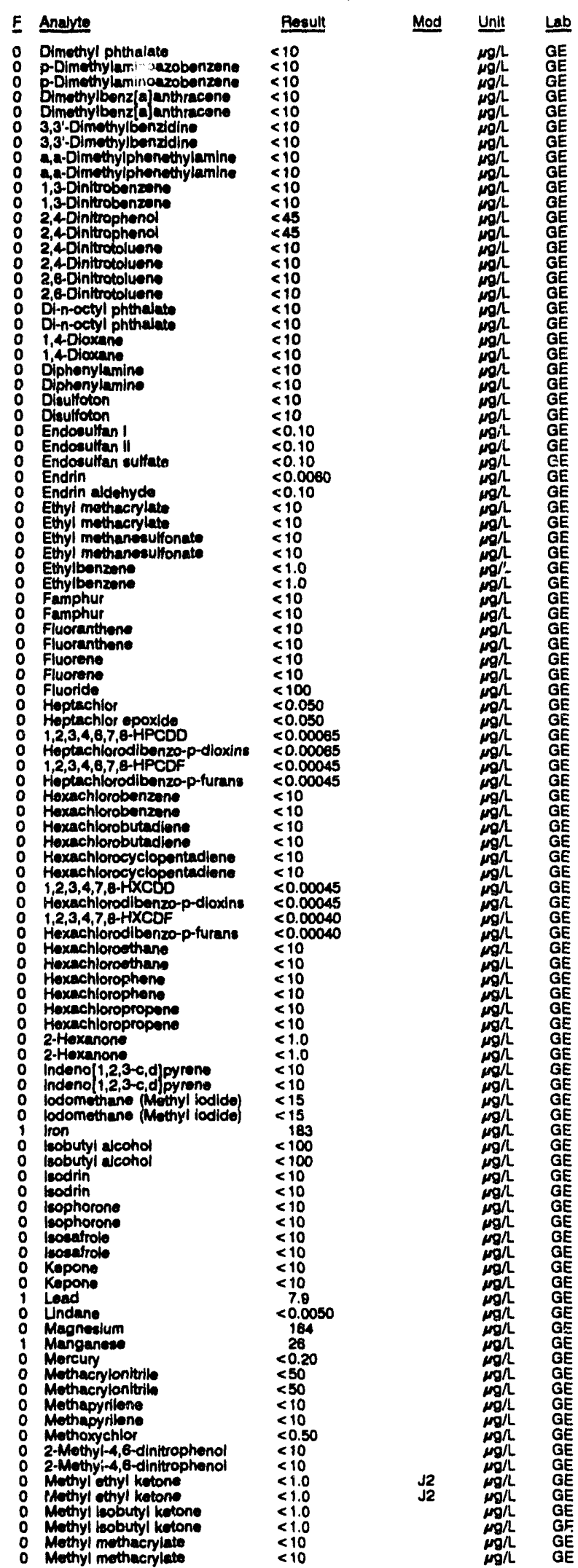

WELL BGO 10 collected on 07/28/92, laboratory analyees (cont.)

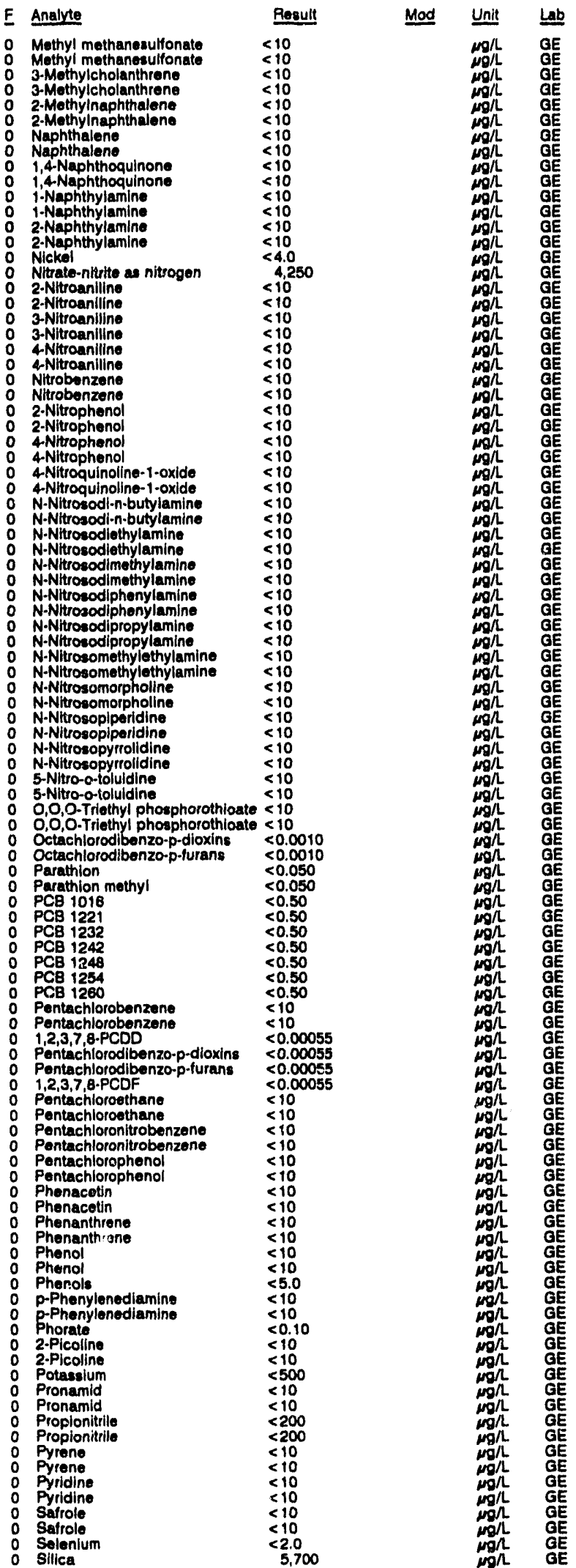


ANALYTICAL RESULTS

WELL BCO TO collected on 07/28/82, laboratory analyees (cont.)

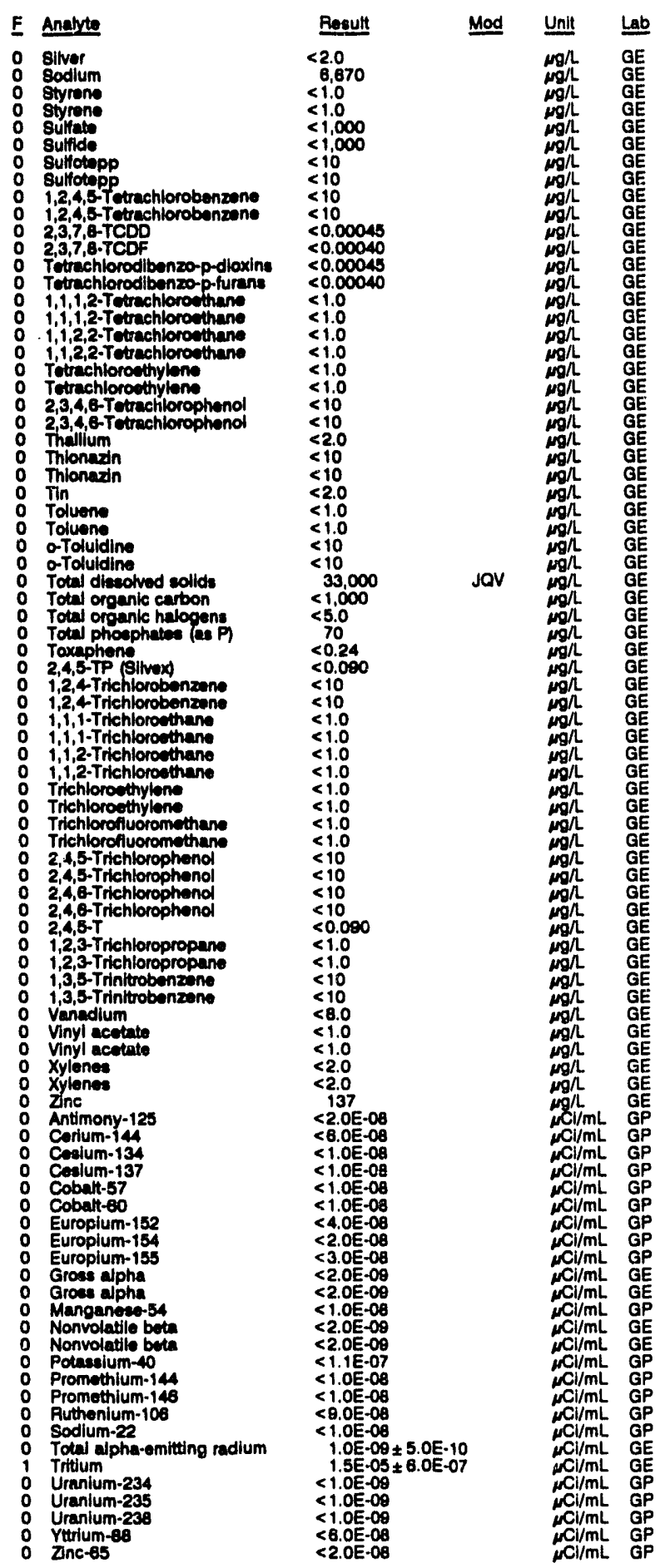

WELL BGO 2D

MEASUREMENTS CONDUCTED IN THE FIELD $\begin{array}{ll}\text { Sample date: } 07 / 27 / 92 & \text { Time: } 13: 40 \\ \text { Depth to water: } 58.60 \mathrm{th}(17.86 \mathrm{~m}) \text { below TOC } & \text { pH: } 4.3 \\ \text { Water elevation: } 238.30 \mathrm{H}(72.63 \mathrm{~m}) \mathrm{mal} & \text { Alkalinity: } 0 \mathrm{mg} / \mathrm{h} \\ \text { Sp. conductance: } 45 \mu \mathrm{cs} / \mathrm{cm} & \text { Water temperature. } 21.7 \cdot \mathrm{C} \\ \text { Water evacuated bolore sampling: } 51 \mathrm{gal} & \end{array}$

LABORATORY ANALYSES

Analyte Rosult

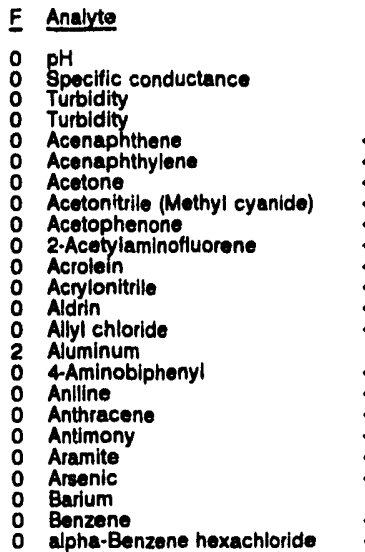

o alpha-Benzene hoxachloride

$\begin{array}{lll}0 & \text { beta-Benzene hexachloride } \quad<0.050 \\ 0 & \text { delta-Benzene hexachloride } & <0.050\end{array}$

O Benzolalanthracene

O Bonzo b) fluoranthene

0 Benzolg, h,ijperylene

0 Benzolajpyrene

0
0
0 Benzyl alcohol

Bis(2-chloroethoxy) methane

Bia 2-chioroethyl) other

Bis 2-chlorolsopropyl) ether

Bis(2-othythexyl) phthalat

Bromodichloromethane

Bromoform

Bromomethane

4.Bromophenyl phenyl ether

2-soc-Butyl-4,6-dinitrophenol

Cadmium

Calcium

Carbon tetrachloride

Chiordane

Chloride

Chlorobenzene

Chlorobenzilate

para-Chloro-meta-cresol

Chloroothane

Chloroethene (Ninyl chloride)

2-Chlorosthyl vinyl ether

Chloroform

Chloromethane
2.Chloronaphthalene

2-Chlopophenol

4-Chlorophenyl phenyl other

Chromium

O Chrysene

Cobalt

o-Cresol (2-Methylphenol)

m-Cresol (3-Methylphenol)

p-Cresol (4-Methylphenol)

Cyanide

0
0

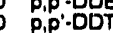

0 Biallaic

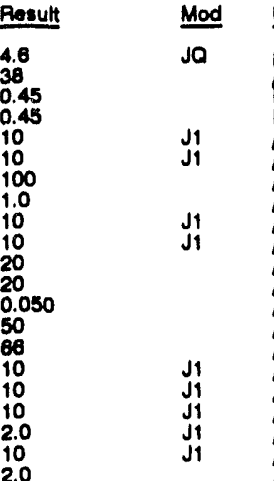

Unit Lab

Dlbenz[a,h]anthracene

Dibenzofuran

1,2-Dibromo-3-chloropropane 1,2.Dibromoethane

Dibromomethane

1,2-Dichlorobenzone

1,3-Dichlorobenzene

1,4-Dichlorobenzene

trans-1,4-Dichloro-2-butene

Dichlorodifluoromethane

1,1-Dichloroethane

$<10$
$<10$

$<10$
$<50$

$<0.10$

$<0.10$

$<10$
$<10$

$<10$

$<1.0$

$<1.0$

$<20$
$<1.0$

$<10$

$<10$
$<10$

$<10$
$<10$

$<10$
$<10$

$<10$
$<30$

$<30$
$<1.0$ 
WELL BGO $2 D$ colloctod on 07/27/82, laboratory analyser (cont)

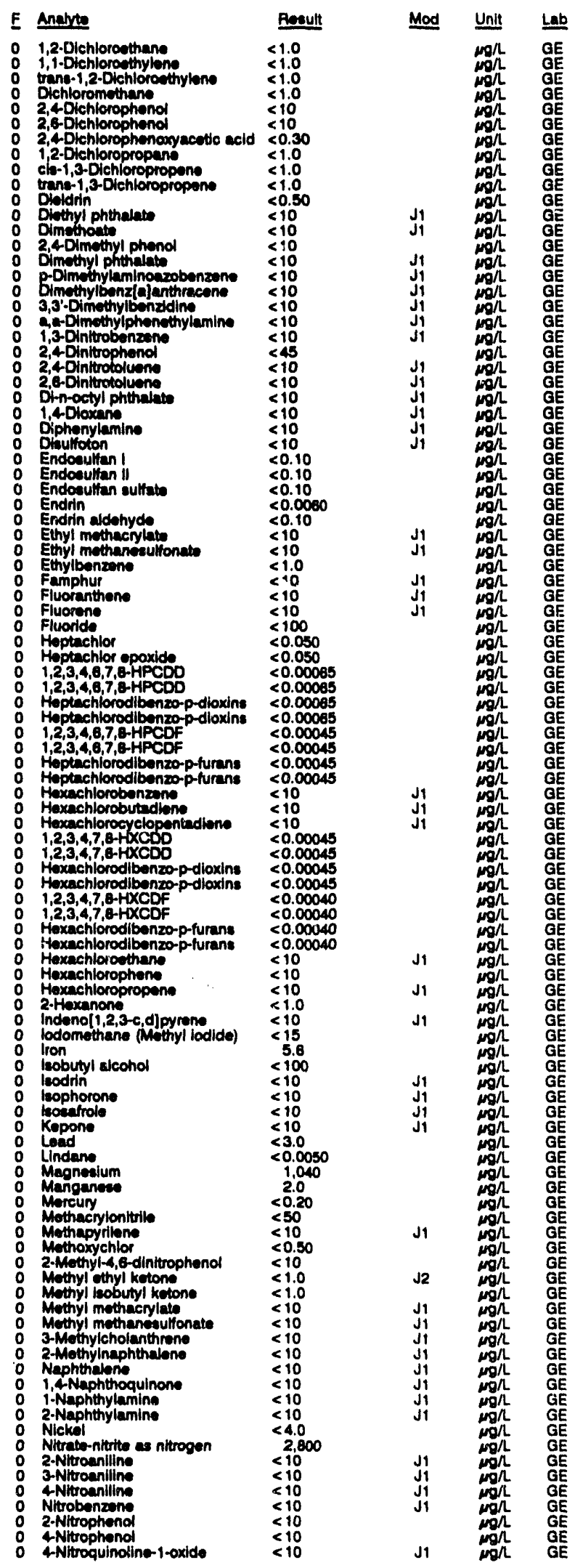

WELL BGO 20 collected on 07/27/82, laboratory analyese (cont.)

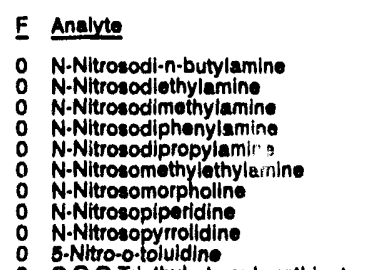

\begin{tabular}{|c|c|}
\hline Reenult & Mod \\
\hline $\begin{array}{r}<10 \\
<10 \\
<10 \\
<10 \\
<10 \\
<10 \\
<10 \\
<10 \\
<10 \\
<10 \\
<10\end{array}$ & 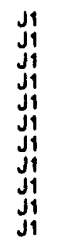 \\
\hline
\end{tabular}

Unit Let

O,O,O-Triethyl shosphorothioato

Oethehlorodibenzo-p.diloxins $<0.0010$

Octachlodions $<0.0010$

Oetachlorodibonzo-p-turans

Parathion

Parathion mothyl

PCA 1018

PCE 1232

PCB 1242

PCE 1248

PCB 1250

Pentachlorobenzent

Pentachlorodibenzo-p-dioxins

Pentachlorodibenzo-p-dioxing

Pentachlorodibenzo-p-oflurans

- Pentachlorodlibenzo-p-turans

$1,2,3,7,8$.PCDF

Pentachloroethan

Pontachloronitrober

- Pontuchiorophanol

Phenanthron

Phenol

Phenols

Phenols
p-Phenylenediamine

Phorate

2-Picoline

Pronamida

Propionitrilo

Pyrene

o Safrolio

S Solonium

: sllica

sodium

S Styrene

Sulfide

S Sulfide

1,2,4,5-Tetrachlorobenzene

2,3,7,8-TCDD

$2,3,7,8-\mathrm{TCO}$

$2,3,7,-T C D F$

Tetrachlorodibenzo-p-dioxins

Tetrachlorodibenzo-p-dioxins

Totrachlorodibonzo-p-furane

Tetrachlorodibenzo-p-furan

1,1,2,2-Tetrachloroethan

2,3,4,6-Tetrachlorophenol

0 Thallium

0 Thion

O Toluene

o-Toluidine

Total dissolved solids

O Total organic halogons

0 Toxaphene

1,2,4-Trichlorobenzene

o $1,1,1$-rrichloroethane

1,1,2-Trichloroethan

o Trichloroethylene

2,4,5-Trichlorophenol

$2,4,6 \cdot$ Trichlorophenol
$2,4,5-T$

1,2,3-Trichloropropan

1,3,5.Trinitrobenzene

Vanadlum

0 Xylenes

o Znc

A Antimony-125

0 Antimony-125

$<0.0010$

$<0.050$

$<0.50$

$<0.50$
$<0.50$

$<0.50$

$<0.50$
$<0.50$
$<0.50$

$<0.50$

$<<10.00055$

$<0.00055$

年

$<0.00055$

$<0.00055$

$<0.00055$

$<10$
$<10$
$<10$

$<10$
$<10$

$<10$

$<10$

$<5.0$

$<5.0$

$<10$
$<0.10$

$<10$

$<10$

$<200$

$<10$

$<10$
$<10$

$<2.0$

$<2.0$

2,420
$<1.0$

$<1,000$

$<1,000$

$<10$

$<0.00045$

$<0.00045$

$<0.00040$

$<0.00045$

$<<0.00045$

$<0.00040$

$<0.00040$
$<1.0$
$<1.0$

$<1.0$
$<10$

$<2.0$

$<10$
$<2.0$

$<1.0$

34,000
$<1,000$

$<5$

$<50$

$<<<0.24$

$<10$

$<1.0$

$<1.0$

$<1.0$
$<10$
$<10$
$<0.090$

$<0.090$

$<1.0$
$<10$

$<8.0$

$<2.0$

2.1

$<2.0 E .08$

$<2.0 E-008$

mol $\mathrm{OE}$

E 
ANALYTICAL RESULTS

WELL BCO 2D collectod on 07/27/82, laboratory analyees (cont)

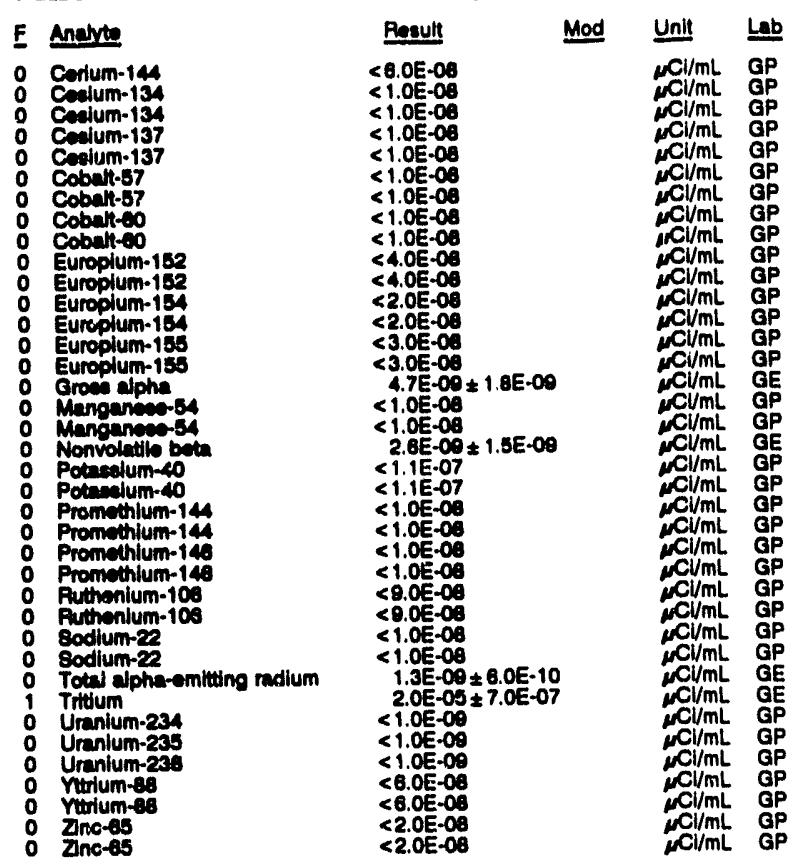

WELL BGO 3D

MEASUREMENTS CONDUCTED IN THE FIELD

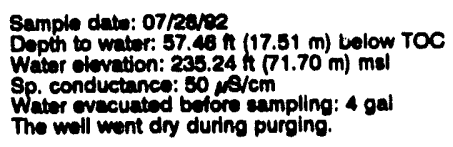

LABOFATOAY ANUL YSES

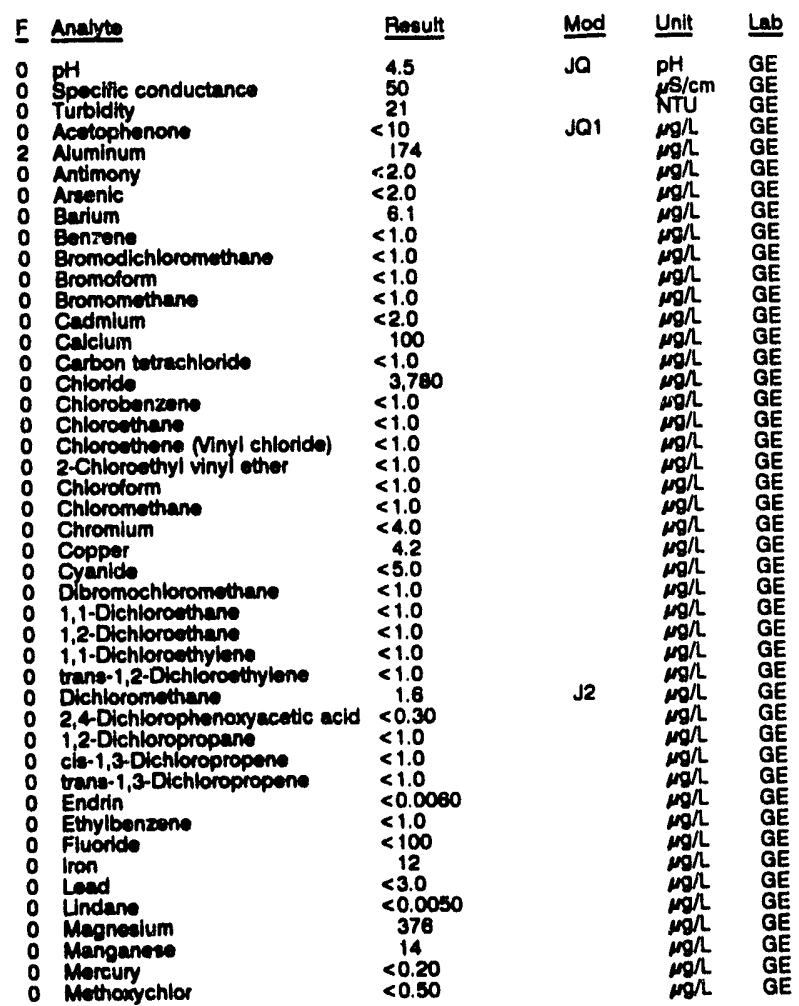

WELL BGO 3D collected on 07/28/82, laboratory analyese (cont.)

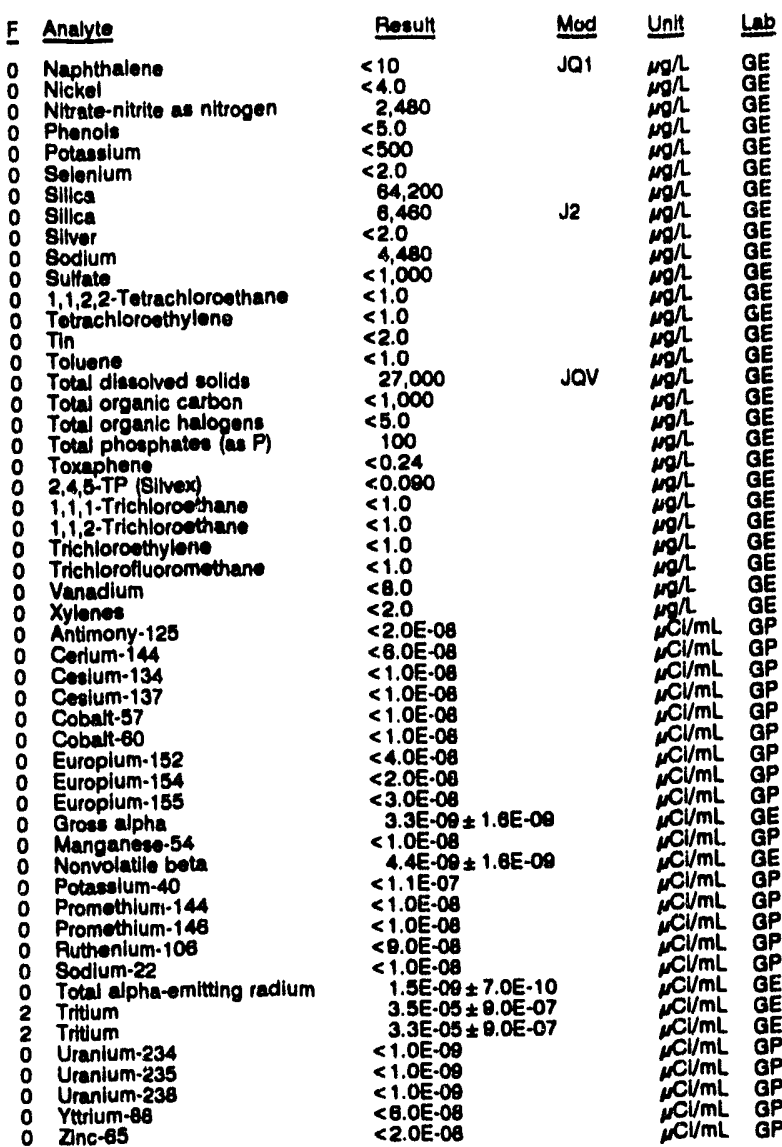

WELL BGO 4D

MEASUREMENTS CONDUCTED IN THE FIELD

Sample date: 08/03/82

Time: ::05

The woll was dry.

WELL BGO 5C

MEASUREMENTS CONDUCTED IN THE FIELD

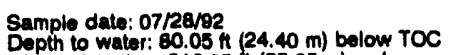

Depth to wator: $80.05 \mathrm{~h}(24.40 \mathrm{~m})$ bolow 100

Sp. conductance: $32 \mu \mathrm{s} / \mathrm{cm}$

Water ovacuated befors campling: $17 \mathrm{gal}$

The well went dry during purging.

LABORATORY ANALYSES

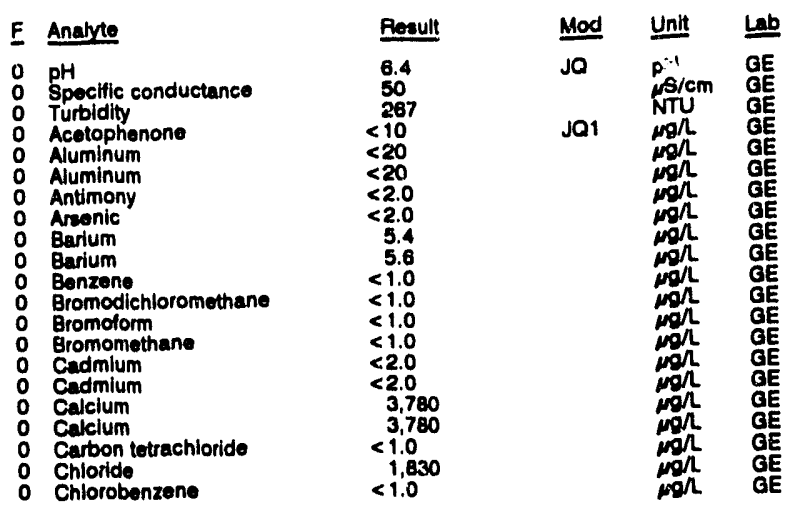


WEL BCO SC collected on 07/28/92, laboratory analyees (cont.)

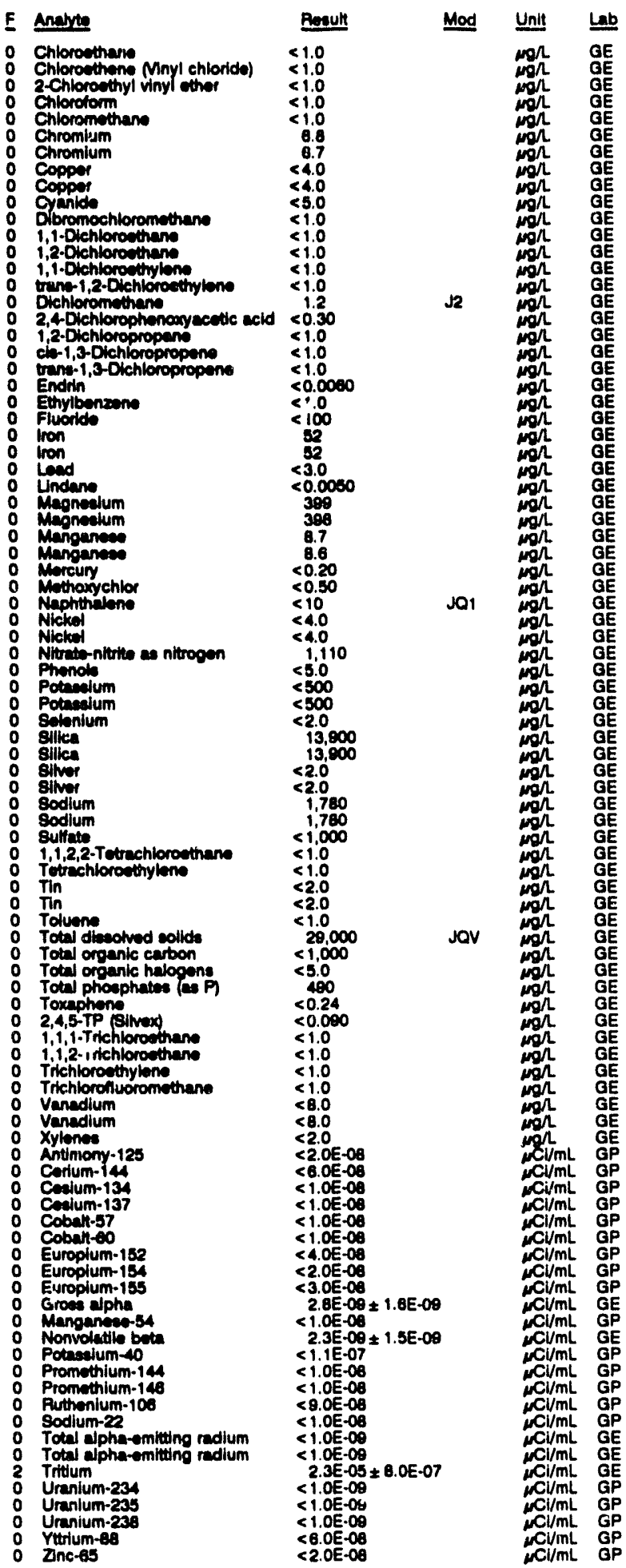

WELL BGO 5D

MEASUAEMENTS CONDUCTED IN THE FIELD

Samplo date: 07/28/92

Depth to water: $65.63 \mathrm{ft}(20.00 \mathrm{~m})$ below TOC

Sp. conductance $230.67 \mathrm{ht}$

Water evecuated bo tore

The woll wont dy during purging:

LABORATORY ANALYSES

$\therefore \mathrm{pH}$

Specific conductance

T Turbldity

Acotophionone

2 Aluminum

Antimony

O Barium

Bromodichloromothane

- Bromoform

- Bromomethane

- Cadmilim

Carbon totrachloride

C Chloride

Chlorobenzene

Chlorosthane

Chloroethene Ninyl chloride)

2.Chloroethyl vinyl athar

o Chloromethane

o Chromium

- Copper

O Coppar

o Dibromochloromethane

1,1-Dichlorosthano

o 1,2-Dichloroethane

o trans-1,2-Dichloroethylone

- Dichloromethane

o 2,4-Dichlorophenoxyncetic acid

- 1,2-Dichloropropane

o cis-1,3-Dichloroprypene
0 trans-1,3-Dichloropropene

Endrin

Ethylbenzene

Iron

Lead

Magnesium

1 Manganese

Mercury

Mothoxychlor

Naphthalene

Nitrato-nitrite as nitrogen

Phenols.

Potassluin

0 Selenium

o Sillica

o Siver

Sulfato

1,1,2,2-Tetrachioroethane

Tetrachloroethylene

Tin

Total dissulved solids

O Total organic carbon

- Total organic halogone

T Total organic halogens

Total phosphates (as P)

Toxaphene

1,1,1-Trichloroethane

1,1,2-Trichloroethane

Trichioroethylene

T Trichloroflueror

Vanadium

Antimony-125

Corium-144

Cosium-134

Cobatt-57

Cobatt-57

Europium-152

Europlum-154

Grose alphe

Manganess-54

Nonvolatile bela

Potassium-40

Promethium-144
Promethium-148

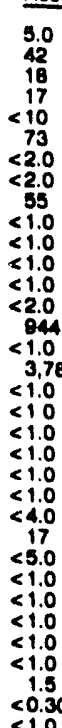

$<1.0$

$<1.0$

$<0.0000$
$<1.0$

$<1.0$
$<100$

$<100$
30

$<0.0050$

$<0.0050$

$\begin{aligned} & 37 \\ &<0.20 \\ &<0.50\end{aligned}$

$<10$

2.320
$<5.0$
$<500$

$<2.0$

$<.020$
$<2.0$

3,330
$<1,000$

$<1.0$

$<1.0$

$<7,000$
$<1,000$

55.0

$<.0$
70

$<0.24$

$<1.0$

$<1.0$

$<1.0$

$<2.0$

$<2.0 E-08$
$<8.0 E-08$

$<1.0 E .08$

$<1.0 E-00$

$<1.0 \mathrm{E} .08$

$<2.0 \mathrm{E}-08$

$<1.0 \mathrm{E}-00$

$<1.1$ E.07

$<1.0 E-08$
$<1.0 \mathrm{E}-08$
Time: 10:05

PH: 4.6 . $0 \mathrm{~mol}$

Water tomperature: $21.8^{\circ} \mathrm{C}$

$1.2 E-08 \pm 2.8 E-00$

6.0E-08 $\pm 1.8 E-00$ 
ANALYTICAL RESULTS

WELL BGO SD collected on 07/28/82, laboratory analyses (cont)

\begin{tabular}{|c|c|c|c|c|}
\hline$E$ & Analyte & Result & Mod & Unit \\
\hline $\begin{array}{l}0 \\
0 \\
0\end{array}$ & $\begin{array}{l}\text { Ruthenium-108 } \\
\text { Sodium-22 } \\
\text { Total alph-omitting radiurn } \\
\text { Trittum } \\
\text { Uranium-234 } \\
\text { Uranium-235 } \\
\text { Uranlum-238 } \\
\text { Yrium-68 } \\
\text { Znce-65 }\end{array}$ & $\begin{aligned} &< 9.0 \mathrm{EE}-08 \\
&<1.0 \mathrm{E}-08 \\
& 3.4 \mathrm{E}-09 \pm 8.0 \mathrm{E}-10 \\
& 2.5 \mathrm{E}-05 \pm 8.0 \mathrm{E}-07 \\
&<1.0 \mathrm{E}-09 \\
&<1.0 \mathrm{E}-09 \\
&<1.0 \mathrm{E}-09 \\
&<6.0 \mathrm{E}-08 \\
&<2.0 \mathrm{E}-08\end{aligned}$ & & $\begin{array}{c}\mu \mathrm{Ci} / \mathrm{mL} \\
\mu \mathrm{Ci} / \mathrm{mL} \\
\mu \mathrm{Ci} / \mathrm{mL} \\
\mu \mathrm{Cl} / \mathrm{mL} \\
\mu \mathrm{Cl} / \mathrm{mL} \\
\mu \mathrm{Cl} / \mathrm{mL} \\
\mu \mathrm{Ci} / \mathrm{mL} \\
\mu \mathrm{Ci} / \mathrm{mL} \\
\mu \mathrm{Cl} / \mathrm{mL}\end{array}$ \\
\hline
\end{tabular}

\section{WELL BGO 6A}

MEASUREMENTS CONDUCTED IN THE FIELD

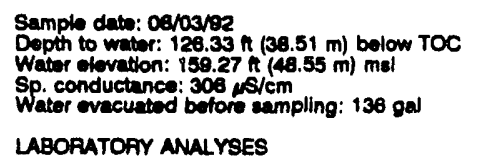

Time: $8: 50$

Alkalinity: $126 \mathrm{mgl}$

Water temperature: $18.9^{\circ} \mathrm{C}$

\section{LABOAATOAY ANALYSES}

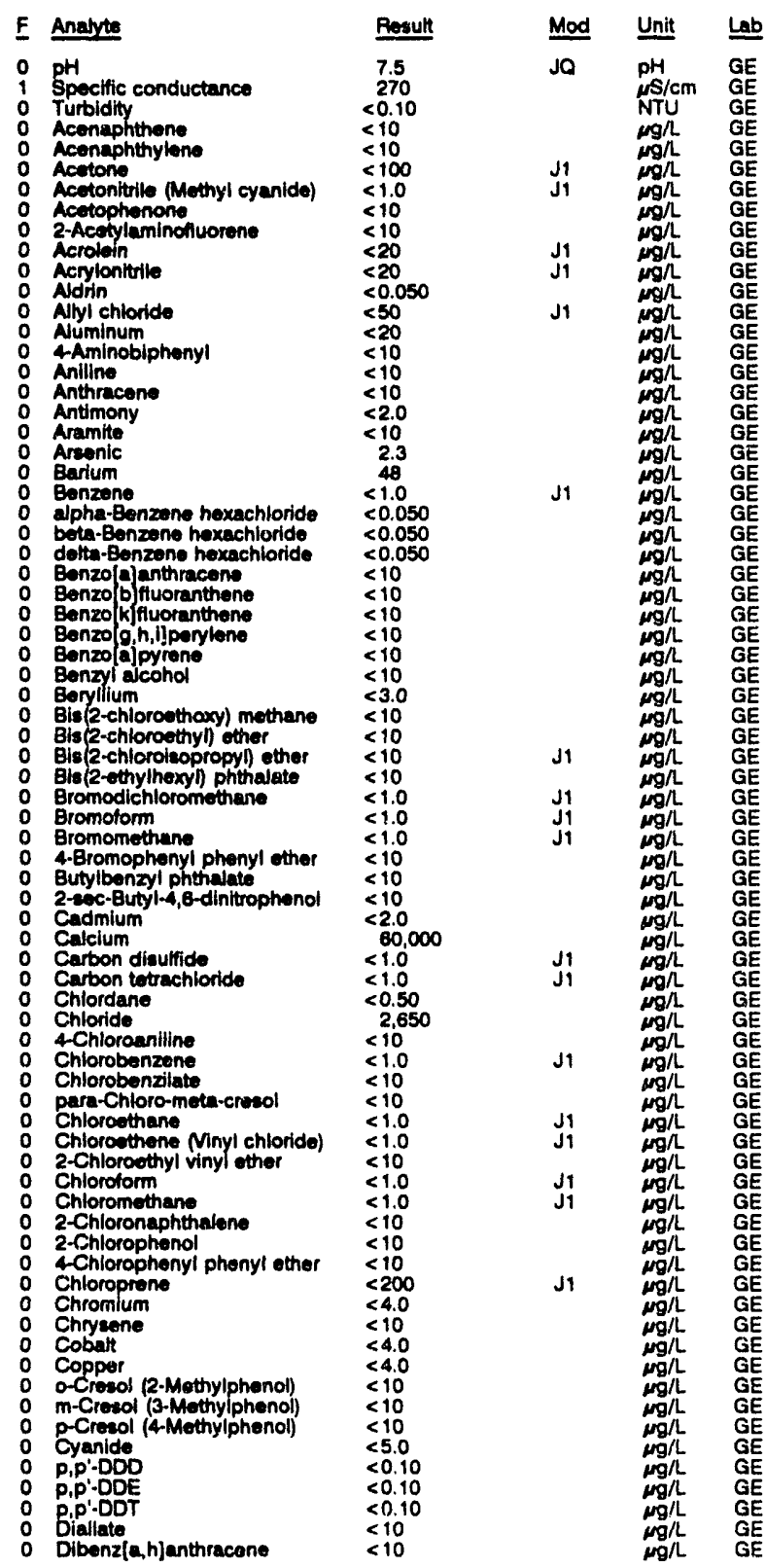

WELL BGO GA collected on 08/03/92, laboratory analyses (cont.)

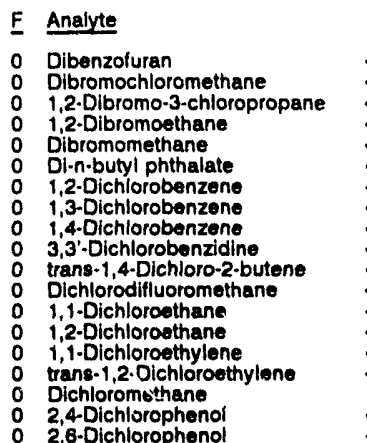

2,4-Dichlorophenoxyacetic acid $<0.30$

1,2-Dichloropropane $<1.0$

cis-1,3-Dichloropropene

trans-1,3-Dichloropropene

0 Diethyl phthalate

2,4-Dimethyl phenol

D Dimethyl phthalate

p-Dimethylaminuazobenzene

Dimethylbenziajanthracene

3,3-Dimethylbenzidine

1,3-Dinitrobenzene

o 2,4-Dinitrophenol

2,4-Dinitrotoluene

Di-n-octyl phehalate

1,4-Dioxane

o Diphenyla

Endosulfan I

o Endosultan II

O Endosulfan sulfate

Endrin aldohyde

0 Ethyl methanesulfonate

o Ethyibenzene

o Famphur

0 Fluoranthene

Fluorene

Fluoride

- Heptachlor epoxide

Heptachlorodibenzo-p-dioxins

Heptachlorodibenzo-p-dioxins

Hexachlorobenzene-p.furans

Hexachlorobutadiene

: Hexachlorocyclopen

Hexachiorodibenzo-p-dioxins

$1,2,3,4,7,8-H \times C D$

Hexuchlorodibenzo-p-furans

Hexachloroethane

Hexachloropher:

Hexachlorop

2-Hexanone

Indeno[1,2,3-c, d)pyrene

Isobutyl alcohol

Iscodrin

0 isophorone

Isosafrole

0 Kepone

0 Lead

L Lindane

Manganes

Methacryionitrile

Methapyrilene

Methoxychlor

2-Methyl-4,6-dinitrophenol

Methyl ethyl ketone

Methyl isobutyl ketone

Methyl methacrylate

Methyl methanesulfonate

3.Mothylcholanthrene

2-Methylnaphthalene

Naphthalene

1,4-Naphthoquino

1-Naphthylamine
2-Naphthylamine

2-Naph

Nitrate-nitrite as nitrogen

2-Nitroaniline $\begin{aligned} & r \text { Res } \\ &<10 \\ &<1.0 \\ &<1.0 \\ &<1.0 \\ &<20 \\ &<1.0 \\ &<10 \\ &<10 \\ &<10 \\ &<10 \\ &<10 \\ &<30 \\ &<1.0 \\ &<1.0 \\ &<1.0 \\ &<1.0 \\ &<1.0 \\ & 5.0 \\ &<10 \\ &<10\end{aligned}$

Result Mod

$<1.0$
$<1.0$
$<20$

$<1.0$

$<1.0$

1.0

$<0.30$
$<1.0$
$<1.0$

$<1.00$

$<10$

$<10$

$<10$

$<10$

$<10$

$<10$

$<45$

$<10$

$<10$

$<10$

$<10$
$<0.10$

$<0.10$

$<0.0080$

$<0.10$

$<10$

$<1.0$

$<10$
$<10$

$<10$

$<0.050$

$<0.00065$

$<0.00065$

$<0.00045$

$<10$

$<10$

$<0.00045$

$<0.00040$

$<0.00040$

$<10$

$<10$

$<1.0$
$<10$

$<15$
60

$<100$

$<10$

$<10$
$<10$
$<10$

$<10$

$<0.0050$

1.590
4.7

$<0.20$

$<50$
$<10$

$<0.50$

$<10$

$<1.0$

$<10$

$<10$
$<10$

$<10$

$<10$

$<10$

$<10$
$<10$

$<4.0$

$<50$
$<10$
Mod Unit Lat

$\begin{array}{lll}J 1 & \mu g / L & G E \\ j 1 & \mathrm{Ng} / \mathrm{LE}\end{array}$

GE

E 
ANALYTICAL RESULTS

WELL BGO 6A collectad on 08/03/92, laboratory analyeos (cont)

E Analyte

O Anitroaniline

Nitrobenzene

2-Nitrophenol

4Nitroquinoline-1-oxide

N-Nitroeodi-n-butylamine

N.Nitrocodiethylamine

N-Nitrosodimethylamine

N-Nitrocodipropylamine

N-Nitrocomethylethy

N-Nitrosopiperidine

N-Nitrocopyrrolldine

$0,0,0$-Triethyl phosphorothioate $<10$

Octachlorodibenzo-p-dloxins $\quad<0.0010$
Octachlorodibenzo-p-furans

Parattion mothyl
PCB 1018
PCB 1221

PCB 1221

PCB 1242

PCE 1240

PCE 1280

Pontachiorobenzene

Pentachlorodibonzo-p-dioxins

Pentachlorodibonzo-p-furans

Pentachloronitrobenzene

Pentachlorophenol

Phenanthron

Phend

Phenols

Phorate

2-Picoline

Pronamid

Propionterito

Pyrene

0 Salrole

Solenium

Silver

Sodlum

Styreno

Sulfate

Sulfotepp

1,2,4,8-Tetrech

Totrachlorodibenzo-p-dioxins

- Totrachlorodibenzo-p-furane

o 1,1,1,2-Tetrachloroethane

T Ti,2,2-Totrachloroethan

2,3,4,6-Tetrachlorophenol

Thionezin

Tin

Tolvene

- Total diseolved solids

- Total organic carbon

Total organic halogens

0 Toxaphene

1,2,4-Trichlorobenzene

1,1,1-Trichloroethane

1,1,2-Trichloroeth

Trichlorofluoromethane

2,4,5-Trichlorophenol

$2,4,6$

o $1,2,3$-Trichloropropane

o Vanadium

O Vinyl acetato

Xylenes

o Antimony-125

Corium-144

Cesium-134

Cobatt-57

Europlum-15

Europlum-155

$<10$

$<10$

$<10$

$<10$

$<10$

$<10$

$<0.050$

$<0.50$

$<0.50$

$<0.50$

$<0.50$

$<10$

$<0.00055$

$<0.00055$

$<0.00055$

$<10$

$<10$

$<10$

$<10$
$<10$

$<5.0$
$<10$

$<10$
$<10$

$<10$
830

$<10$

$<10$

$<10$
$<10$
$<20$

$<2.0$

$<2.0$
2,350

$<\begin{array}{r}2,350 \\ 8.570\end{array}$

$<\begin{array}{r}8,570 \\ <1,000\end{array}$

$<10$

$<0.00045$

$<0.00045$

$<0.00040$

$<1.0$
$<1.0$

$<1.0$
$<10$

$<10$
$<2.0$

$<10$

4.8
$<1.0$

203,000

1,000
$<50$

$<5.0$
$<50$

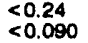

$<10$

$<1.0$

$<1.0$

$<1.0$

$<1.0$
$<10$

$<0.090$

$<1.0$

$<8.0$

$<1.0$

$<2.00 .08$

$<2.0 E-08$
$<6.0 E-08$

$<1.0 E-08$

$<1.0 E-08$

$<1.0 E-08$

$<2.0 \mathrm{E}-08$

$<3.0 E .08$
Mod Unit

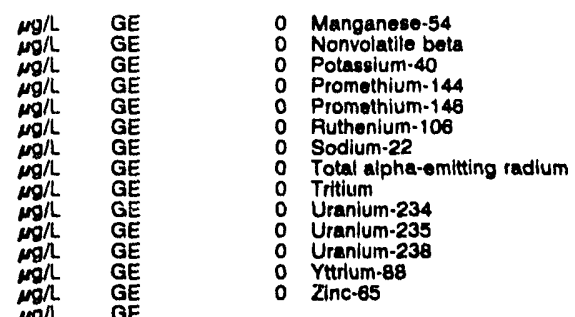

Besult

$<1.0 \mathrm{E} \cdot 08$

$<1.1 \mathrm{E} .07$

$<1.0 E \cdot 08$

$<1.0 \mathrm{E}-08$

$<1.0 \mathrm{E}-08$

$<1.0 \mathrm{E} .08$

$<7.0 \mathrm{E}-07$
$<1.0 \mathrm{E}-09$

$<1.0 \mathrm{E}-09$

$<6.0 \mathrm{E} \cdot 08$

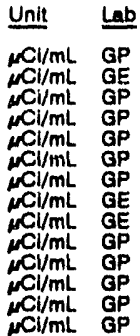

WELL BGO 6C

MEASUREMENTS CONDUCTED IN THE FIELO

Sample date: 08/03/92

Depth to water: $65.48 \mathrm{ft}(18.89 \mathrm{~m})$ bolow TOC

Water elevation: $220.12 \mathrm{ft}(67.09 \mathrm{~m}) \mathrm{msl}$

Water ovacuated belore eampling: $163 \mathrm{gal}$

pH: 6.7

Plkalinity: $82 \mathrm{mg}$

Akalinity: $62 \mathrm{mg} / \mathrm{h}, 20.5 \circ \mathrm{C}$

LABOAATORY ANALYSES

F Analyto. Resull Mod

O $\mathrm{pH}$ Specific conductance

0 Turbidity

Acenaphthene

Acenaphthylene

Acetonltrile (Methyl cyanide)

Acetophenone

2.Acetylam

Acrylonitrile

Aldin

Allyl chloride
Aluminum

4Aminobiphenyl

Anilline

O Anthracen

0 Aramite

0 Arsenic

Benzene

alpha-Benzene hexachloride

beta-Benzeno hexachlorid

delta-Benzeno hexachloride

Benzo[a]anthracene

Benzo b) fluoranthene

Benzo $g, h, i j$ perylene

- Benzo g, h, Iporylong

Benzylalcohol

o Beryllium

Bis(2-chloroothoxy) mothane

Bis 2-chloroethyll) ether

Bis(2-chloroisopropyl) ether

Bromodichloromethane

Bromoform

Bromomethane
4-Bromophenyl phenyl other

Butylbenzol phthalate

2-sec-Butyl-4,6-dinitrophenol

Cadmium

Calcium

Carbon disulfide

0 Chlorido

4-Chloroaniline

Chlorobenzene

para-Chloro-mota-cresol

para-Chloro-mota-cresol
Chlorosthane

Chloroethene (Ninyl chloride)

2.Chioroethyl vinyl ether
Chloroform

Chloromethan

2-Chloronaphthalon

4-Chlorophenyl phenyl ether

Chloroprene

Chromlum

Cobalt

Copper

m-Cresol (3-Methylphenol

Cyanide

\begin{tabular}{|c|c|c|}
\hline Result & Mod & Unit \\
\hline $\begin{array}{r}7.3 \\
125 \\
<0.10\end{array}$ & JO & $\begin{array}{l}\mathrm{pH} \\
\text { NTS } \\
\text { NTU }\end{array}$ \\
\hline$<10$ & J1 & $\mathrm{\mu g} / \mathrm{L}$ \\
\hline $\begin{array}{l}<10 \\
<100\end{array}$ & $\begin{array}{l}J 1 \\
\text { J1 }\end{array}$ & $\mu g / L$ \\
\hline$<1.0$ & & $\mu g / L$ \\
\hline $\begin{array}{l}<10 \\
<10\end{array}$ & Ji & $m g h$ \\
\hline $\begin{array}{r}100 \\
<20\end{array}$ & Ji & $\operatorname{mog} \Omega$ \\
\hline $\begin{array}{l}<20 \\
<0.050\end{array}$ & J1 & ign \\
\hline $\begin{array}{l}<50 \\
<20\end{array}$ & JI & $m$ \\
\hline$<10$ & JI & $m g / L$ \\
\hline $\begin{array}{l}<10 \\
<10\end{array}$ & Ji & mon \\
\hline $\begin{array}{l}<10 \\
<2.0\end{array}$ & J1 & $\operatorname{mg} h$ \\
\hline $\begin{array}{l}<10 \\
<2.0\end{array}$ & J1 & $\operatorname{mg} h$ \\
\hline $\begin{array}{r}12 \\
<1.0\end{array}$ & & mg/L \\
\hline $\begin{array}{l}<1.0 \\
<0.050\end{array}$ & J1 & $\mu g / L$ \\
\hline $\begin{array}{l}<0.050 \\
<0.050\end{array}$ & & $m$ \\
\hline $\begin{array}{l}<10 \\
<10\end{array}$ & J1 & mon \\
\hline $\begin{array}{r}<10 \\
<10\end{array}$ & $\begin{array}{l}\text { J1 } \\
\text { J1 }\end{array}$ & $\operatorname{mon}$ \\
\hline $\begin{array}{l}<10 \\
<10\end{array}$ & J1 & $m$ \\
\hline $\begin{array}{r}<10 \\
<10\end{array}$ & $\begin{array}{l}J 1 \\
\text { J1 }\end{array}$ & $\operatorname{mogh}$ \\
\hline $\begin{array}{l}<3.0 \\
<10\end{array}$ & & $\mathrm{No/L}$ \\
\hline $\begin{array}{r}<10 \\
<10\end{array}$ & 11 & $\operatorname{mog} /$ \\
\hline $\begin{array}{r}<10 \\
<10\end{array}$ & $\mathbf{J 1}$ & $\mathrm{mgh}$ \\
\hline $\begin{array}{l}<10 \\
<1.0\end{array}$ & J1 & $\mathrm{mg} / \mathrm{L}$ \\
\hline $\begin{array}{l}<1.0 \\
<1.0\end{array}$ & $J$ & $m g / L$ \\
\hline $\begin{array}{l}<1.0 \\
<10^{\circ}\end{array}$ & jt & $m$ \\
\hline $\begin{array}{l}<10 \\
<10\end{array}$ & JI & $\operatorname{mg} h$ \\
\hline $\begin{array}{r}<10 \\
<10\end{array}$ & & $\mu \mathrm{m} / \mathrm{L}$ \\
\hline $\begin{array}{l}<2.0 \\
24,400\end{array}$ & & $\mu / L$ \\
\hline $\begin{array}{l}<1.0 \\
<1.0\end{array}$ & $d 1$ & $\operatorname{mg}$ \\
\hline $\begin{array}{l}<1.0 \\
<0.50\end{array}$ & J1 & $\mathrm{mg} / \mathrm{h}$ \\
\hline $\begin{aligned} & 2,140 \\
&<10\end{aligned}$ & & $\stackrel{\mu g / L}{M g / L}$ \\
\hline $\begin{array}{l}<10 \\
<1.0\end{array}$ & $J 1$ & $\mathrm{mg} / \mathrm{h}$ \\
\hline$<10$ & $\begin{array}{l}J 1 \\
\mathrm{~J} 1\end{array}$ & No/ \\
\hline $\begin{array}{l}<10 \\
<1.0\end{array}$ & & \\
\hline $\begin{array}{l}<1.0 \\
<1.0\end{array}$ & J1 & $\mathrm{mg} / \mathrm{L}$ \\
\hline $\begin{array}{l}<1.0 \\
<10\end{array}$ & $\begin{array}{l}J 1 \\
\text { J1 }\end{array}$ & 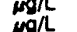 \\
\hline$<1.0$ & J1 & $\mu g / h$ \\
\hline $\begin{array}{l}<1.0 \\
<10\end{array}$ & $J 1$ & $\mu g / L$ \\
\hline$<10$ & & $\operatorname{mg} n$ \\
\hline$<10$ & J1 & $\mathrm{mg} / \mathrm{L}$ \\
\hline $\begin{array}{r}<200 \\
<4.0\end{array}$ & J1 & $\mu g h /$ \\
\hline $\begin{array}{l}<10 \\
<4.0\end{array}$ & J1 & $\mu g / L$ \\
\hline$<4.0$ & & $\operatorname{mgh}$ \\
\hline$<1$ & & $g / L$ \\
\hline $\begin{array}{l}<10 \\
<10\end{array}$ & & \\
\hline$<5.0$ & & \\
\hline
\end{tabular}


ANALYTICAL RESULTS

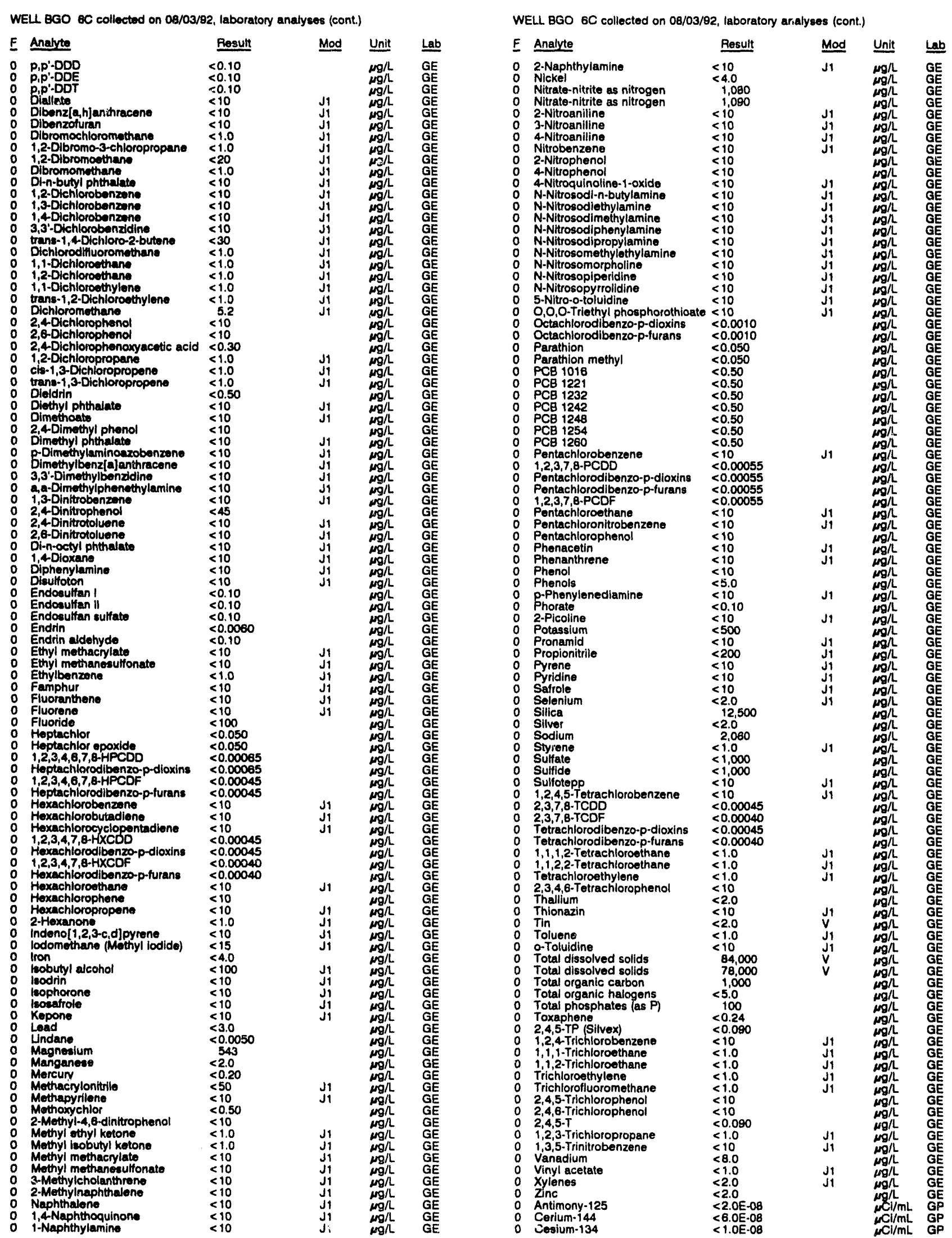


WELL BGO BC collectod on 08/03/92, laboratory analyses (cont.)

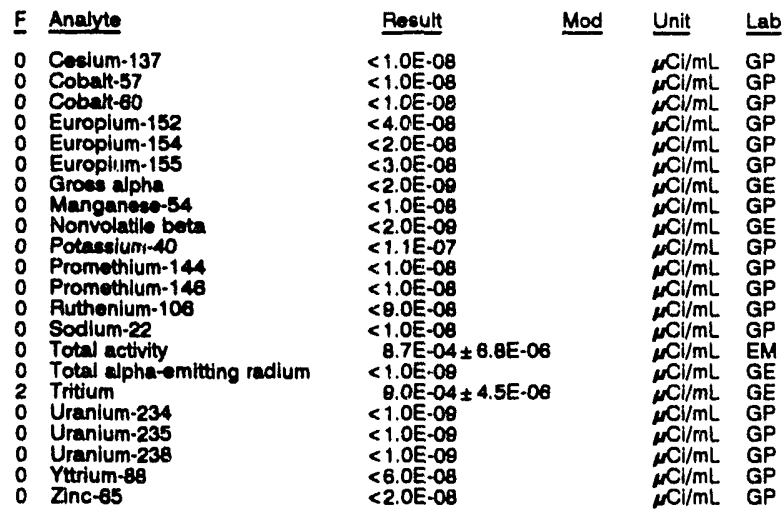

WELL BGO 6D

MEASUREMENTS CONDUCTED IN THE FIELD

Sample date: 08/04/92

Depth to water: $54.58 \mathrm{n}(16.63 \mathrm{~m})$ below TOC

Water olovation: 230.84 ft $(70.30$

Sp. conductance: $118 \mu \mathrm{s} / \mathrm{cm}$

The

LABOFATORY ANALYSES

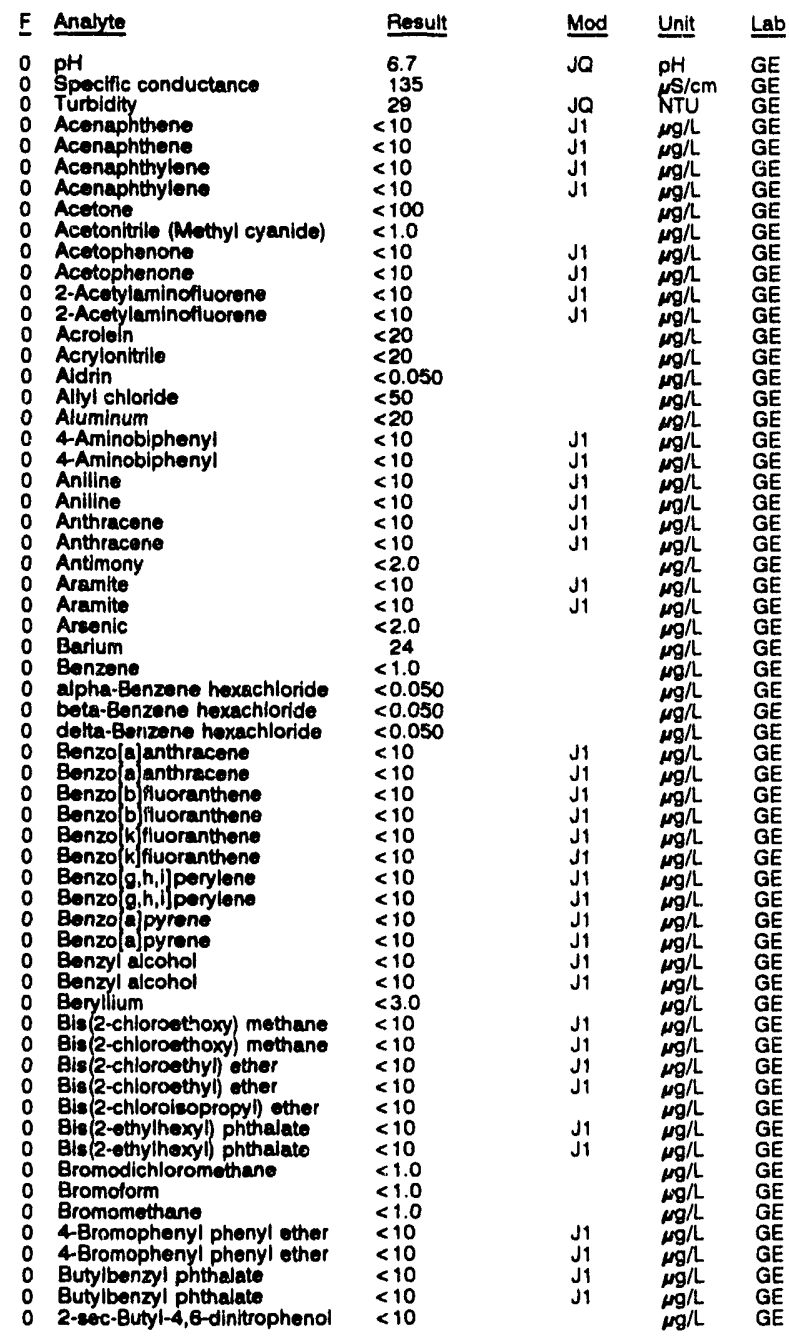

Time: 8:35

Alkalinity: $40 \mathrm{mgl}$

Water temperature: $20.1{ }^{\circ} \mathrm{C}$
WELL BGO 6D collected on 08/04/92, laboratory analyses (cont.)

$\begin{array}{ll}\text { E } & \text { Analyte } \\ 0 & \text { 2-sec-Butyl-4,6-dinitrophenol } \\ 0 & \text { Cadmium } \\ 0 & \text { Calcium } \\ 0 & \text { Carbon disulfide } \\ 0 & \text { Carbon tetrachloride } \\ 0 & \text { Chlordane } \\ 0 & \text { Chloride } \\ 0 & 4 \text {-Chloroaniline } \\ 0 & \text { 4-Chloroanilline } \\ 0 & \text { Chlorobenzene } \\ 0 & \text { Chlorobenzilate } \\ 0 & \text { Chlorobenzilate } \\ 0 & \text { para-Chloro-meta-cresol } \\ 0 & \text { para-Chioro-meta-cresol } \\ 0 & \text { Chloroethane } \\ 0 & \text { Chloroethene Ninyl chloride) } \\ 0 & 2 \text {-Chloroethyl vinyl other } \\ 0 & 2 \text {-Chloroethyl vinyl ether } \\ 0 & \text { Chloroform } \\ 0 & \text { Chloromethane } \\ 0 & 2 \text {-Chloronaphthalene } \\ 0 & 2 \text {-Chloronaphthalene } \\ 0 & 2 \text {-Chlorophenol } \\ 0 & 2 \text {-Chlorophenol }\end{array}$

Mod Unit Le

$<10$

$<2.0$

$<1.0$

1,860

$<10$

1.0

$<1.0$
$<10$
$<10$

$<10$

$<1.0$

$<10$

$<1.0$

$<10$

$<10$
$<10$
$<10$

2-Chloropheno 4-Chlorophenyl phenyl other

Chloroprene

Chromium

Chrysen

Cobalt

o-Cresol (2-Methylphenol)

o-Cresol (2-Methylphenol)
m-Cresol (3-Methylphenol

m-Cresol (3-Methyphenol)

p-Cresol (4-Methylphenol)

p-Cresol (4-Methylphenol)

Cyanide

Cyanide

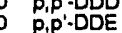

P.P'-DDT

Diallate

Dibenz $[a, h] a n t h r a c e n e$

Dibenzla, $h]$ anthracene

Dibenzofuran

Dibromochloromethane

1,2-Dibromo-3-chloropropane

1,2-Dibromoethane

Dibromomethane

Di-n-butyl phthalate

Oi-n-butyl phthalate

1,2-Dichlorobsenzene

1,2-Dichlorobenzene

o 1,3-Dichlorobenzene

1,3-Dichlorobenzene

1,4-Dichlorobenzene

3,4'-Dichlorobenzidine

3,3'-Dichlorobenzidine

trans-1,4-Dichloro-2-buten

1,1-Dichloroethet

0 1,1-Dichloroethane

1,1-Dichloroethylene

trans-1,2-Dichloroethylene

Dichloromethane

2,4-Dichlorophenol

2,4-Dichlorophenol

2,6-Dichlorophenol

2,4-Dichlorophenoxyacetic acid $<0.30$

o 1,2-Dichioropropane

cis-1,3-Dichloropropene

trans-1,3-Dichloropropene

Dieldrín

Diethyl phthalate

o Diethyl phthalat

D Dimethoate

0 2,4-Dimethyl phenol

0 2,4-Dimethyl pheno

O Dimethyl phthalate

o p-Dimethylaminoazobenzene

- p.Dimethylaminoazobenzene

Dimethylbenz [a]anthracene

Dimethylbenz (a) anthracen

0 $3,3^{\prime}$-Dimethylbenzidine

3,3'-Dimethylbenzidine

o a,a-Dimothylphenethylamine

1,3-Dinitrobenzene

1,3-Dinitrobenzene

2,4-Dinitrophenol

2,4-Dinitrotoluene 
ANALYTICAL RESULTS

WELL BGO 6D collocted on 08/04/82, laboratory analyees (cont.)

$E$ Anayste

- 2,4-Dintrotoluene

$\begin{array}{ll}0 & 2,6-\text { Dinitrotoluene } \\ 0 & 2,6-\text { Dinitrotoluene }\end{array}$

Di-n-octyl phthalate

1,4-Dloxane

0 Diphenylamine

Diphenylamine

Diaulfoton

Endosulfan I

Endosulfan II sulfate

Endrin

Endrin aldehydo

Ethyl mothacrylate

Ethyl methanosulfonate

Ethylbenzene

Famphur

Fluoranthene

Fluoranthone

Fluorene

o Fluorene

0 Fluoride

Heptachlor opoxide

$1,2,3,4,6,7,8-H P C D D$
0 Heptachlorodibenzo-p-dloxins

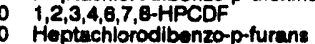

o Heptuchlorodibenzo-

Hexachlorobenzento

o Hexachlorobenzento

Hexachlorobutadien

o Hexachlorocyclopentadiene

Hexachlorocyclopen

Hoxachlorodibenzo-p-dioxins

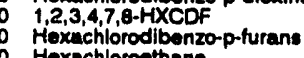

Hexachloroothane

Hoxachloroethane

Hexachlorophene

Hexachloropropene

2-Hexanone

Indeno $\{1,2,3-c, d\}$ pyrene

Indeno $1,2,3-c, d$ pyrone
0 lodomethane (Mithyl lodide)

Iron

leodrin

o leodrin

leophorone

lsosafrole

Isonatrol

Kepone

Kepon

Lindane

Magneslum

Mangan

Methacrylonituile

Mothapyrilene

Methapyrilene

2-Methyl-4,6-dinitropheno

2-Methyl-4,6-dinitrophenol

Methyl ethyl ketone

Methyl methacrylate

Methyl methacrylate

Mothyl mothanesulfonate

3-Methylcholanthrene

3-Methyicholanthrene

-Methylnaphthalene

Naphthalene

1,4-Naphthoquinone

1,4-Naphthoquinone

1. Naphthylamine

1-Naphthylamine

2-Naphthylamine
2-Naphthylamine

2-Naphthy

Nitrate-niturte as nitrogen

2-Nitroanilin

2-Ntroaniling

3.Nitroaniline

\section{Besult}

$<10$

$<10$

$<10$

$<10$

$<10$

$<10$

$<10$

$<10$

$<0.10$

$<0.10$

$<<<.10$

$<0.10$

$<10$

$<10$

$<10$

$<10$

$<10$

$<10$

$<10$

$<10$

$<0.050$

$<0.00065$

$<0.00065$

$<0.00045$

$<10$
$<10$
$<10$

$<10$
$<10$
$<10$

$<10$
$<10$

$<10$

$<0.00045$

$<0.00040$

$<0.00040$

$<10$
$<10$

$<10$
$<10$

$<10$
$<10$

$<1.0$
$<10$
$<10$

$<10$
$<10$
$<15$

$<4.0$

$<10$

$<10$
$<10$

$<10$

$<10$

$<10$

$<10$

$<0.0050$

979

$\begin{aligned} & 6.8 \\ < & 0.20 \\ < & 50\end{aligned}$

$<50$
$<10$
$<10$

$<0.50$
$<10$

$<10$
$<10$

$<10$
$<1.0$
$<1.0$
$<10$

$<10$

$<10$
$<10$

$<10$

$<10$

$<10$

$<10$
$<10$

$<10$

$<10$

$<10$

$<10$

$<10$

$<10$
$<10$

$<10$

$<<10$
Mod Unit

J1 $\mathrm{mg} / \mathrm{L}$ GE

$\mathrm{GE}$

$G E$
WELL BGO 60 collected on 08/04/82, laboratory analyses (cont.)

\begin{tabular}{|c|c|c|}
\hline Analyte & Result & Mod \\
\hline 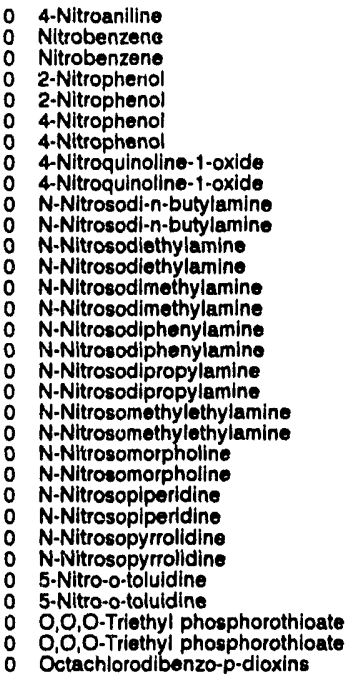 & $\begin{array}{l}<10 \\
<10 \\
<10 \\
<10 \\
<10 \\
<10 \\
<10 \\
<10 \\
<10 \\
<10 \\
<10 \\
<10 \\
<10 \\
<10 \\
<10 \\
<10 \\
<10 \\
<10 \\
<10 \\
<10 \\
<10 \\
<10 \\
<10 \\
<10 \\
<10 \\
<10 \\
<10 \\
<10 \\
<10 \\
<10 \\
<10 \\
<0.0010\end{array}$ & 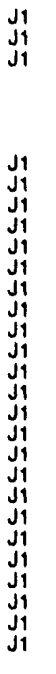 \\
\hline
\end{tabular}

o Octachlorodibenzo-p-dioxins

0 Octachlorodibenzo-p.furans $<0.0010$

Parathion methyl $<0.050$

0 PCB $1018 \quad<0.50$

- PCB 1221

0 PCB 1242

PCB 125

$\begin{array}{ll}0 & \text { PCB } 1260 \\ 0 & \text { Pontachlorobenzene }\end{array}$

O Pentachlorobenzene

0 1,2,3,7,8.PCDD

0 Pentachlorodibenzo-p-dioxins

o Pentachlorodibenzo-p-furans

$1,2,3,7,8-P C D F$

Pentachloroethane

o Pentachloronitrobenzene

o Puntachloronitrobenzene

o Pentachlorophenol

o Pentachlorophenol

o Phenacetin

o Phenanthrene

0 Phenanthren

$\begin{array}{ll}0 & \text { Phenol } \\ 0 & \text { Phenol }\end{array}$

0 Phenols

O p-Phenylenediamine

0 p-Phenylenediamine

0 2-Picoline

o 2.Picoline

0 Potassium

o Pronamid

o Propionitrile

o Pyrene

0 Pyridine

0 Pyridine

0 Safrole

o Solenium

o sllica

o Silver

o Styrene

o Sulfate

0 Sulfide

0 Sulfotepp

o 1,2,4,5-Tetrachlorobenzene

o 1,2,5-Tetrachlorobenzene

0 2,3,7,8-TCDD

0 Tetrachlorodibenzo-p-dioxins

o Tetrachlorodibenzo-p-furans

o $1,1,1,2-$ Tetrachloroethane

0 1,1,2,2-Totrachloroethan

1 Totrachloroethyleno

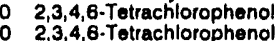

0 2,3,4,6-Tolra

0 Thallium

o Thlonazin

$<0.50$

$<0.50$

$<0.50$

$<0.50$

$<10$
$<10$

$<0.00055$

$<0.00055$

$<0.00055$

$<10$

$\leq 10$

$<10$
$<10$
$<10$
$<10$

$<10$

$<10$

210
$<10$
$<10$

$<10$
$<10$
$<10$
$<10$

$<10$

$<5.0$
$<10$
$<10$

$<10$
$<10$

$<10$

$<10$
$<10$
$>100$

700
$<10$
$<10$

$<<00$

$\leq 10$

$<10$
$<10$

$<10$
$<\leq 10$
$<10$

$<10$
$<10$
$<2.0$

$<2.0$

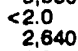

2,640
$<1,0$
2,070

2,070
$<1.000$
$<$

$<<10$

$<<10$

$<0.00045$

$<0.00040$

$<0.00045$

$<1.0$
$<1.0$

4.2
$<10$
$<10$

$<10$

$<10$
$<2.0$
$<10$

$<10$
$<10$
$<2.0$
Unit Lab

$\mu g / L$ GE

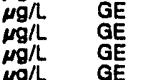

$\mu g / L$
$\mu g / h$
$\mu g / h$
$G E$

$\begin{array}{ll}\mu g / L & G E \\ \mu g / h & G E \\ g, h & G E\end{array}$

gh GE

$\mu \mathrm{g} / \mathrm{L}$ GE

$\mu g /$
$\mu g h$

ge

$\mu g$ aE



gE

$\mu g$ GE

$\mu g h$ GE

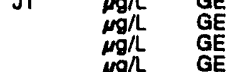

(n) 
WELL BGO 80 collected on 08/04/82, laboratory analyees (cont.)

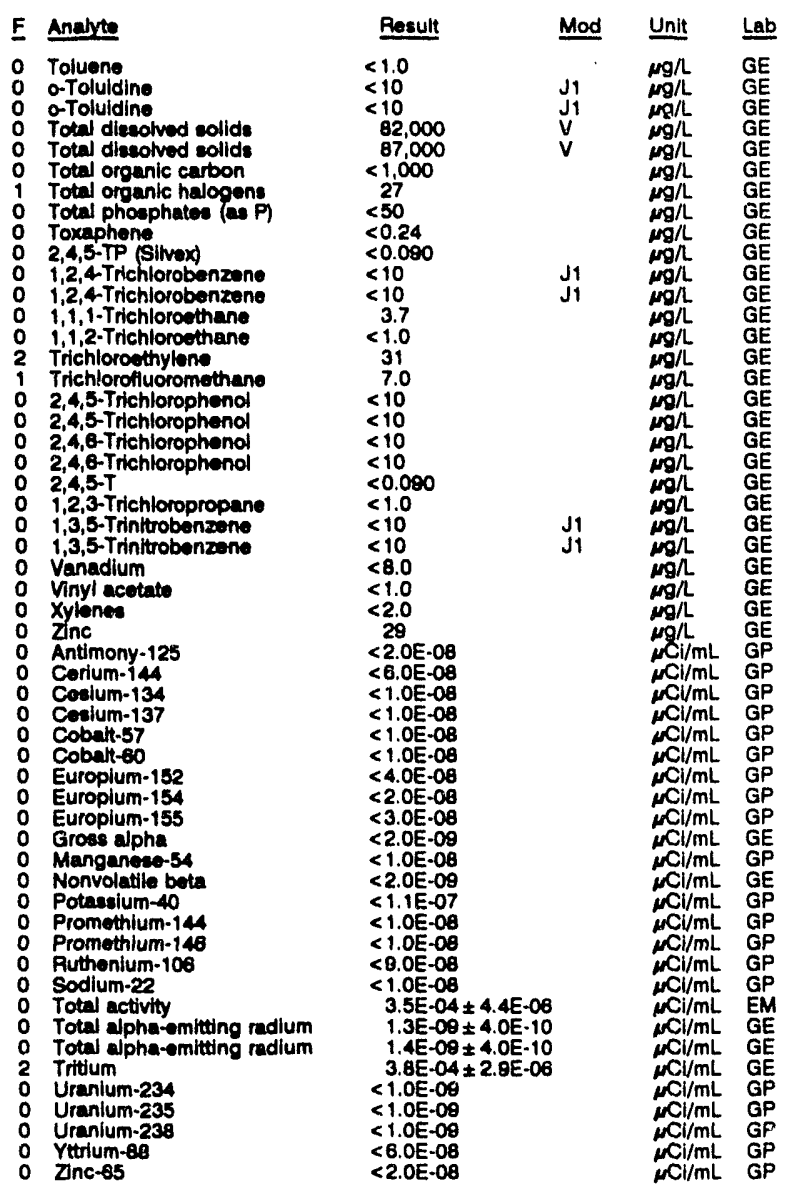

\section{WELL BGO 7D}

MEASUREMENTS CONDUCTEO IN THE FIELD

Sample dato: OTr2aroz

Depth to water: $55.54 \mathrm{ft}(16.93 \mathrm{~m})$ below TOC

Water elevation: $231.46 \mathrm{~h}(70.55 \mathrm{~m}) \mathrm{mal}$

Sp. conductance: $33, \mathrm{SS} / \mathrm{cm}$
Water ovacuated before 2 ampling: $30 \mathrm{gal}$

LABORATOFY ANALYSES

\begin{tabular}{|c|c|c|c|c|}
\hline E Analyte & Result & Mod & Unit & Lab \\
\hline $\begin{array}{ll}0 & \text { pH } \\
0 & \text { Spectific conductance } \\
0 & \text { Turbidity } \\
0 & \text { Turbidity } \\
0 & \text { Acetophenone } \\
1 & \text { Aluminum } \\
0 & \text { Antimony } \\
0 & \text { Arsenic } \\
0 & \text { Barium } \\
0 & \text { Eenzenen } \\
0 & \text { Bromodichloromethane } \\
0 & \text { Bromotorm } \\
0 & \text { Bromomethane } \\
0 & \text { Cadmium } \\
0 & \text { Calclum } \\
0 & \text { Carbon tetrachloride } \\
0 & \text { Chloride } \\
0 & \text { Chlorobenzene } \\
0 & \text { Chioroethane } \\
0 & \text { Chloroethene Ninyl chloride) } \\
0 & 2 \text {-Chlorothyl vinylether } \\
0 & \text { Chloroform } \\
0 & \text { Chloromethane } \\
0 & \text { Chromium } \\
0 & \text { Copper } \\
0 & \text { Cyanlde } \\
0 & \text { Dlbromochloromethane } \\
0 & 1,1 \text {-Dichloroethane } \\
0 & \text { i,2-Dichloroethane }\end{array}$ & $\begin{array}{l}5.6 \\
60 \\
0.84 \\
0.80 \\
<10 \\
35 \\
<2.0 \\
<2.0 \\
6.7 \\
<2.0 \\
<2.0 \\
<2.0 \\
<2.0 \\
<2.0 \\
710 \\
<2.0 \\
2.430 \\
<2.0 \\
<2.0 \\
<2.0 \\
<2.0 \\
2.9 \\
<2.0 \\
<4.0 \\
<4.0 \\
<5.0 \\
<2.0 \\
<2.0 \\
<2.0\end{array}$ & $\begin{array}{l}\mathrm{JQ} \\
\mathrm{JQ} \\
\mathrm{JQ}\end{array}$ & 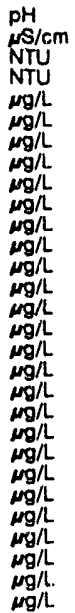 & $\begin{array}{l}\mathrm{GE} \\
\mathrm{GE} \\
\mathrm{GE} \\
\mathrm{GE} \\
\mathrm{GE} \\
\mathrm{GE} \\
\mathrm{GE} \\
\mathrm{GE} \\
\mathrm{GE} \\
\mathrm{GE} \\
\mathrm{GE} \\
\mathrm{GE} \\
\mathrm{GE} \\
\mathrm{GE} \\
\mathrm{GE} \\
\mathrm{GE} \\
\mathrm{GE} \\
\mathrm{GE} \\
\mathrm{GE} \\
\mathrm{GE} \\
\mathrm{GE} \\
\mathrm{GE} \\
\mathrm{GE} \\
\mathrm{GE} \\
\mathrm{GE} \\
\mathrm{GE} \\
\mathrm{GE} \\
\mathrm{GE} \\
\mathrm{GE}\end{array}$ \\
\hline
\end{tabular}

WELL BGO 7D collected on 07/28/82, laboratory analyses (cont.)

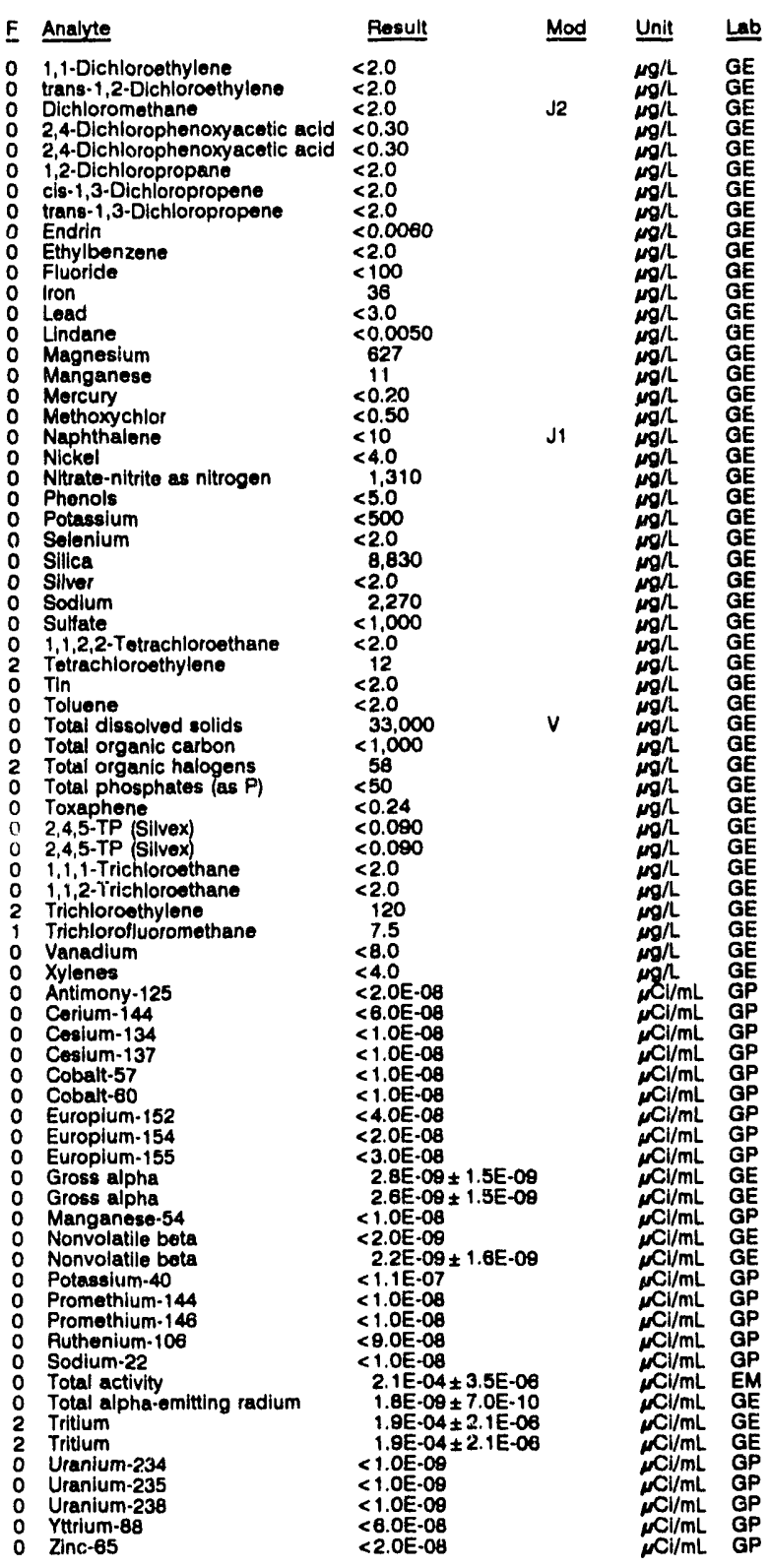

WELL BGO 8AR

MEASUREMENTS CONDUCTED IN THE FIELL

Sample date: 07/28/92

Water elevation: $100.27 \mathrm{~h}(48.85 \mathrm{~m}) \mathrm{mgl}$ Alkalinity: $100 \mathrm{mg}$

Sp. conductance: $247 \mu \mathrm{\mu sm}$. $172 \mathrm{gal}$

LABORATORY ANALYSES

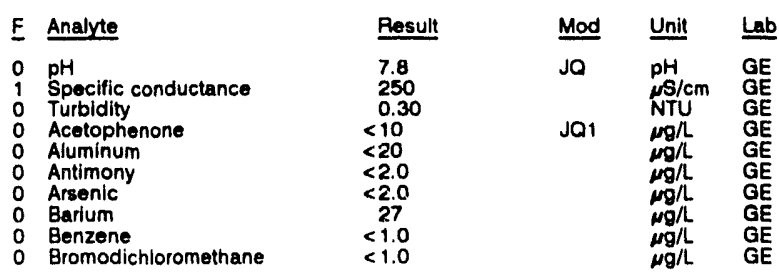


ANALYTICAL RESULTS

WELL BGO AAR collectod on 07/28/92, laboratory analyses (cont.)

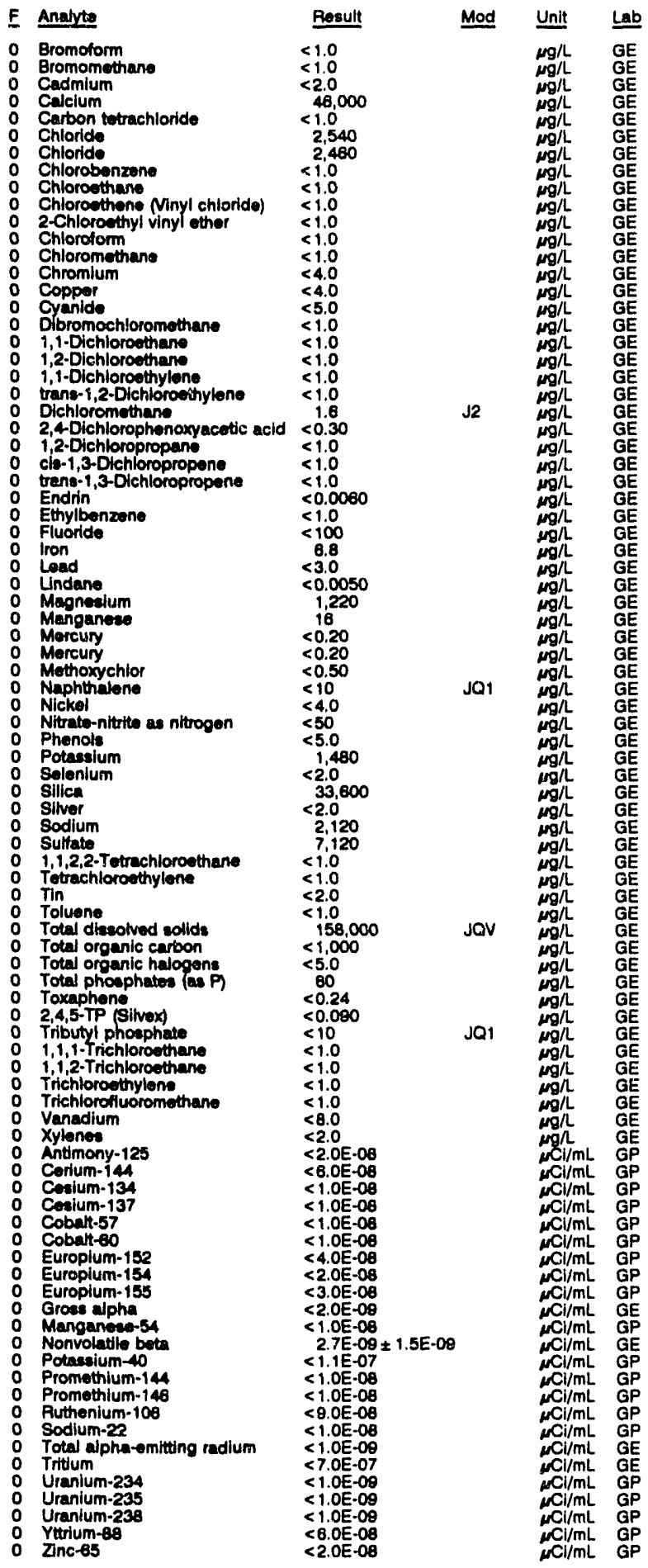

WELL BGO $8 \mathrm{C}$

MEASIJREMENTS CONDUCTED IN THE FIELD

Sample date: 08/03/92

Depth to water: $64.58 \mathrm{ft}(19.68 \mathrm{~m})$ bolow TOC

Water elevation: $223.32 \mathrm{ft}(68.0$

Sp. conductance: $124 \mu \mathrm{s} / \mathrm{cm}$

Water evacuated bofore sampling: $128 \mathrm{gal}$

LABORATORY ANALYSES

F Analyte

Specific conductance

0 Turbidity

Acetophenone

A Aluminum

Antimony

Arsenic

0 Arsenic

O Barium

Bromodichloromethane

o Bromoform

o Bromomethane

Cadmium

Carbon totrachloride

o Chloride

o Chlorobenzene

0 Chloroethane

Chloroethene Ninyl chloride)

2-Chloroethyl vinyl ether

- Chloroform

Chloromethane

0 Chromium

O Copper

Dybromochloromethane

1,1-Dichloroethane

o 1,2-Dichloroethane

1,1-Dichloroethyon

0 trans-1,2-Dichioroethylene

o Dichloromethane

o 2,4-Dichlorophenoxyacetic acid

o 1,2-D!chloropropane

o cis-1,3-Dichloropropene

0 trans-1,3-Dichioropropene

0 Endrin

o Ethylbenzeno

o Fluorido

0 Lead

0 Lead

- Lindane

o Manganese

0 Mercury

O Methoxychlor

Naphthalene

Nickel

Nitrate-nitrite as nitrogen

Phenols

0 Potassium

Selenium

Silica

Silver

Sodium

1,1,2,2-Tetrachloroethane

Totrachloroethylene

Tin

o Total dissolved solids

Total organic carbon

Total organic halogens

- Total phosphates (as

2,4,5-TP (Silvex)

1,1,1-Trichloroothane

1,1,2-Trichloroethan

Trichloroethylens

Trichlorofluy

Vanadium

Antimony-125

Cerium-144

Cosium-137

Cobalt -57

Cobalt-60

Europium-152

Europlum-154

Europlum-155

Gross alpha

Nonvolatile beta
Result Mod Unit$$
7.2
$$

100
3.3
3.3
$<10$

3.3
$<10$
24

$<2.0$

$<2.0$

$<2.0$

$<14$

$<1.0$
$<1.0$

$<1.0$

22,000

$<1.0$

2,440
$<1.0$

$<1.0$

$<1.0$

$<1.0$
$<1.0$

$<4.0$

$<4.0$
$<5.0$

$<5.0$
$<1.0$

$<1.0$
$<1.0$

$<1.0$

$<.0$
4.5
$<0.30$

$<0.30$
$<1.0$

$<1.0$
$<1.0$

$<0.0060$

$<1.0$
$<100$

$<100$
$<4.0$

$<4.0$

$<0.0050$

571
$<2.0$

$<2.0$
$<0.20$

$<0.20$
$<0.50$

$<10$

$<4.0$

860
$<5.0$

1.640
$<2.0$

$<2.0$
$<2.0$

14,500
$<2.0$

3,610
$<1,000$

$<1,000$

$<1.0$
$<1.0$

$<1.0$
4.4
$<1.0$

$<6,000$

66,000
1,000

90
90

$<0.24$

$<0.090$

$<1.0$

$<1.0$

$<1.0$

$<8.0$

$<2.0 \mathrm{E}-08$

$<6.0$ E-08

$<1.0 \mathrm{E} \cdot 08$
$<1.0 \mathrm{E}-08$

$<1.0 E-08$

$<1.0 E \cdot 08$

$<4.0 E-08$

$<2.0 E .08$

$<3.0 E \cdot 08$

$<2.0 E-09$
$<1.0 E-08$

$<2.0 \mathrm{E} .09$
Time: 12:15

Alkalinity: $30 \mathrm{mg} / \mathrm{L}$

Water temperature: $20.4^{\circ} \mathrm{C}$

JO $\begin{array}{ll}\text { PH } \\ \text { NS/cm } \\ \text { NTUU }\end{array}$


ANALYTICAL RESULTS

WELL BGO $8 C$ collected on 08/03/82, laboratory analyser (cont.)

\begin{tabular}{|c|c|c|c|c|c|}
\hline F & Analyte & Result & Mod & Unit & Lab \\
\hline $\begin{array}{l}0 \\
0 \\
0 \\
0 \\
0 \\
0 \\
0 \\
0 \\
0 \\
0\end{array}$ & $\begin{array}{l}\text { Potacsium-40 } \\
\text { Promethium-144 } \\
\text { Promethium-148 } \\
\text { Ruthenium-108 } \\
\text { Sodium-22 } \\
\text { Total alpha-emitting radium } \\
\text { Titdum } \\
\text { Uranium-234 } \\
\text { Uranium-235 } \\
\text { Uranlum-238 } \\
\text { Ytrium-68 } \\
\text { Znc-65 }\end{array}$ & $\begin{array}{l}<1.1 \mathrm{E}-07 \\
<1.0 \mathrm{E}-08 \\
<1.0 \mathrm{E}-08 \\
<8.0 \mathrm{E}-08 \\
<1.0 \mathrm{E}-08 \\
<1.0 \mathrm{E}-09 \\
<7.0 \mathrm{E}-07 \\
<1.0 \mathrm{E}-09 \\
<1.0 \mathrm{E}-09 \\
<1.0 \mathrm{E}-09 \\
<6.0 \mathrm{E}-08 \\
<2.0 \mathrm{E}-08\end{array}$ & & 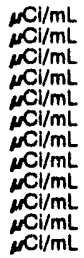 & $\begin{array}{l}\text { GP } \\
\text { GP } \\
\text { GP } \\
\text { GP } \\
\text { GP } \\
\text { GE } \\
\text { GE } \\
\text { GP } \\
\text { GP } \\
\text { GP } \\
\text { GP } \\
G P\end{array}$ \\
\hline
\end{tabular}

WELL BGO 8D

MEASUREMENTS CONOUCTED IN THE FIELD

Sample dato: 08/03/92

Dopth to water: $51.13 \mathrm{n}(15.56 \mathrm{~m})$ bolow TOC

Water elovation: $236.67 \mathrm{~h}$ (72.14

Sp. conductance: $27 \mathrm{\mu S} / \mathrm{cm}$.

LABORATORY ANALYSES

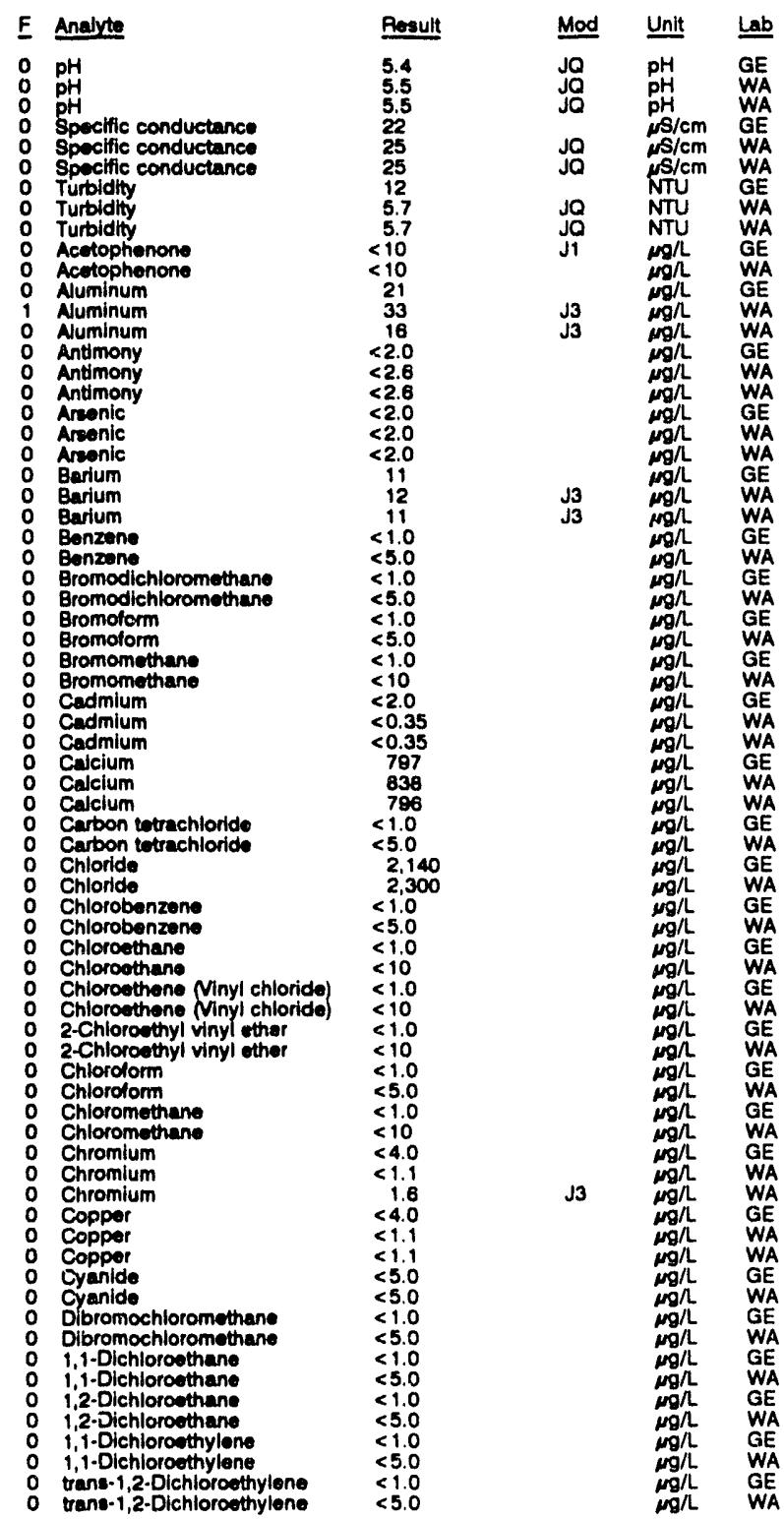

Time: $11: 20$

Alkalinity: $0 \mathrm{mon}$

Waler tomperature: $20.7^{\circ} \mathrm{C}$
WELL BGO $8 D$ collected on 08/03/82, laboratory analyees (cont.)

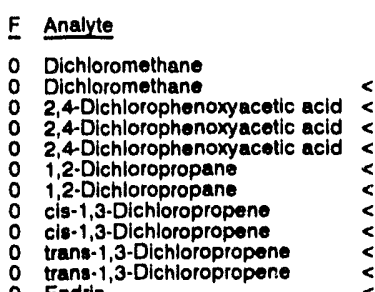

Result

Mod Un

$<5.0$

$<1.0$

$<1.0$

$<1.0$

$<5.0$

$<1.0$

0 Endrin

$<0.0060$

Endribenzene $\quad<0.11$

Ethylbenzene $\quad<5.0$

Fluoride

Iron

Iron
0
Iron

0 Load

0 Lead

o Uindane

L Lindane

Thane

Magnesium

Magnesium

Manganece

Manganese

Mercury

Mothoxychlor

Methoxychlor

Methoxychlor
Naphthalene

Naphthalon
Nickel

Nickel

Nickel

Nitrate as nitrogen

Nitrate-nitrite as nitrogen

Phenols

Potassium

Potassium

Potassium

Solenium

Solenium

Silica

Silica

Silvor

0 Silver

Sodium

Sodium

Sulfate

Sulfato

$1,1,2,2$-Tetrachloroethane

1,1,2,2-Tetrachloroethane

Tetrachloroothylone

0 Tin

0 Tin

Tin

Toluene

Total dissolved solld

Total dissolved solids

Total organic carbon

Total organic carbon

o Total organic halogens

Total organic halogens

o Total phosphates (as P)

Total phosphates (as P)

o Toxaphene

O Toxaphene

T Toxaphene

0 2,4,5-TP (Silvex)

0 2,4,5-TP Silvex

0 2,4,5-TP (Silvex)

0 1,1. Trichloroothane

o 1,i,2-Trichloroethane

o 1,1,2-Trichloroethan

Trichloroethylene

Trichloroethylene

Trichlorofluoromethane

Vanadium

Vanadlum

Xylenes

Xylenes
Xylenes

$<5.0$
$<100$

$<100$
$<4.0$

16

$<3.0$

$<0.0050$

$<0.0050$

$<0.054$

501

478

12
11
10

$<0.20$

$<0.20$

$<0.50$

$<0.54$

$<10$

$<4.0$

$<3.1$

1,020

$<5.0$

$<5.0$

116
256

$<2.0$
$<2.0$

$<2.0$

8,300
7,550

7,450

$<.0$
2.4

2.4
1.2

1.2
2,190
2,110

2,110
2,150

$<1,000$

<i,

$<1.0$
$<5.0$

$<1.0$

$<5.0$

3.7
$<1.8$
$<1.9$

$<1.0$
$<1.0$
$<5.0$

$<5.0$
20,000

1,000
$<1,000$ 
ANALYTICAL RESULTS

WELL BGO $8 D$ collocted on 08/03/92, laboratory analyses (cont.)

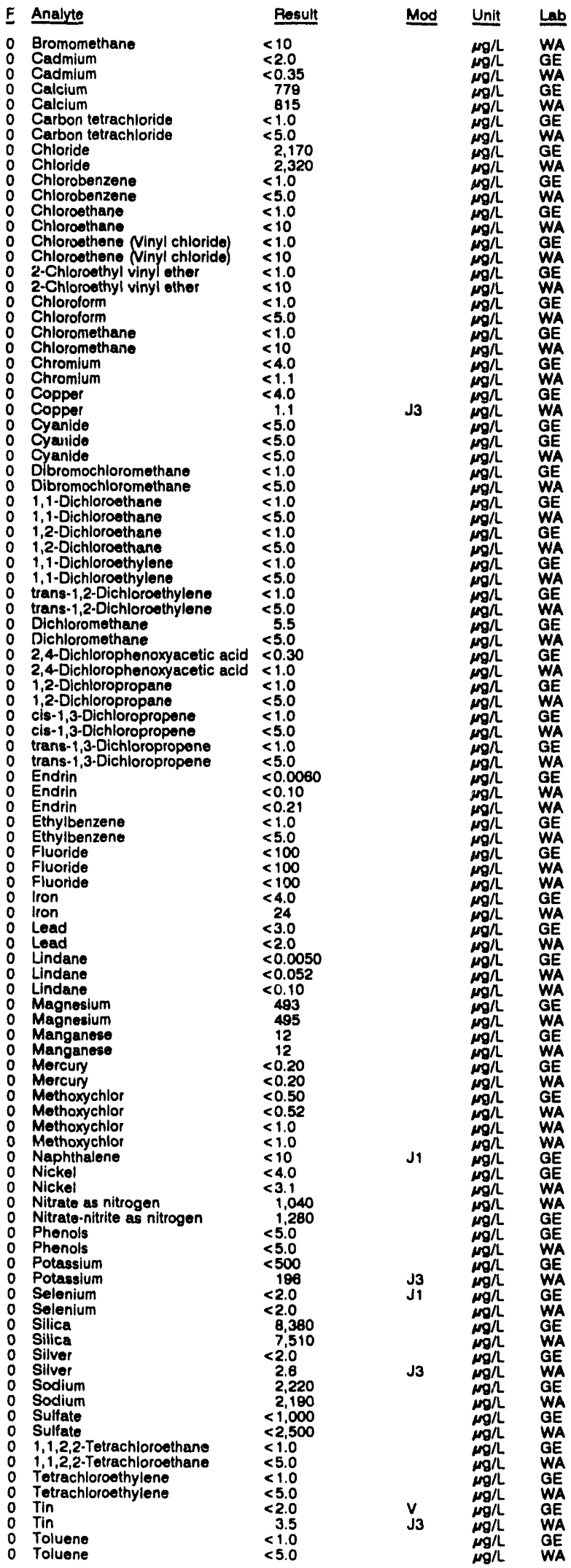

WELL BGO $8 D$ colloctod on 08/03/92, laboratory analyses (cont)

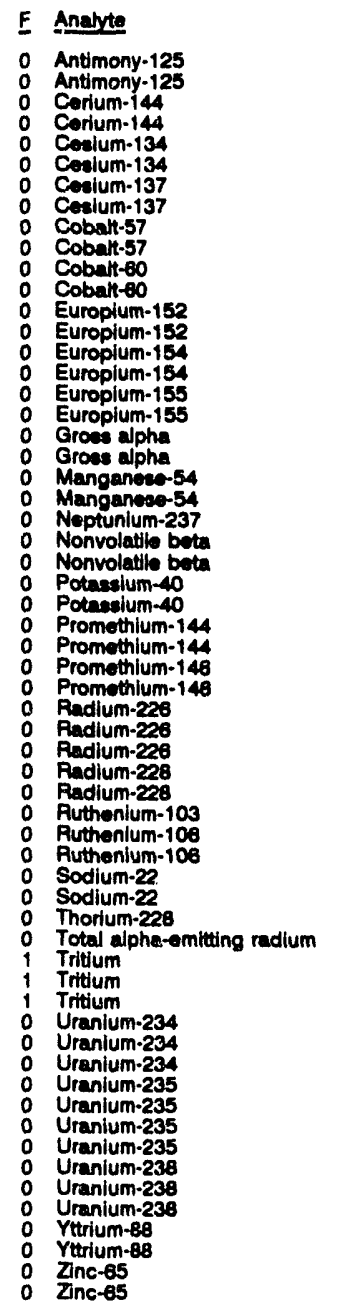

\section{WELL BGO 8D Replicate}

MEASUREMENTS CONDUCTED IN THE FIELD

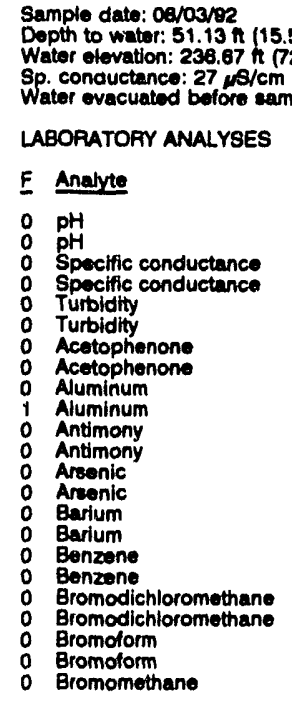

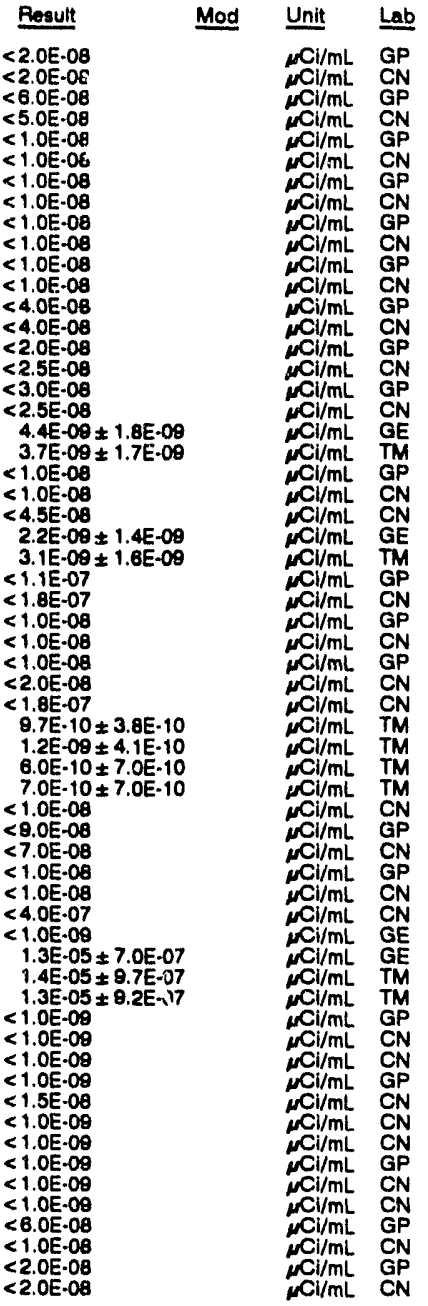

Time: 11:20

PH: 4.6 Alkalinity: $0 \mathrm{mgh}$ Water temperature: $20.7^{\circ} \mathrm{C}$ (72.14 m) msi

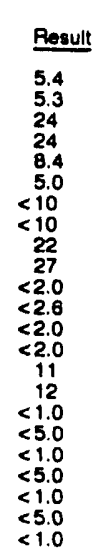

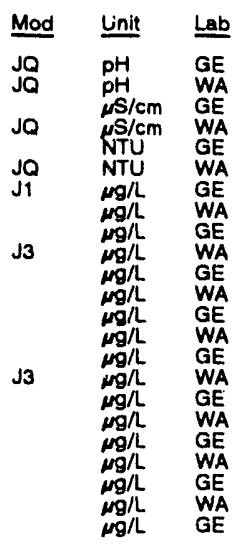

$\stackrel{a b}{C N}$

Water ovacuated bolore sampling: 42 gal

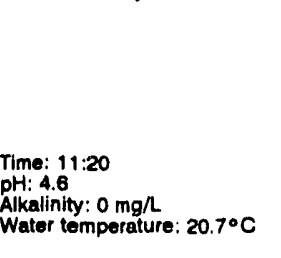


WELL BGO $8 D$ collected on 08/03/92, laboratory analyses (cont.)

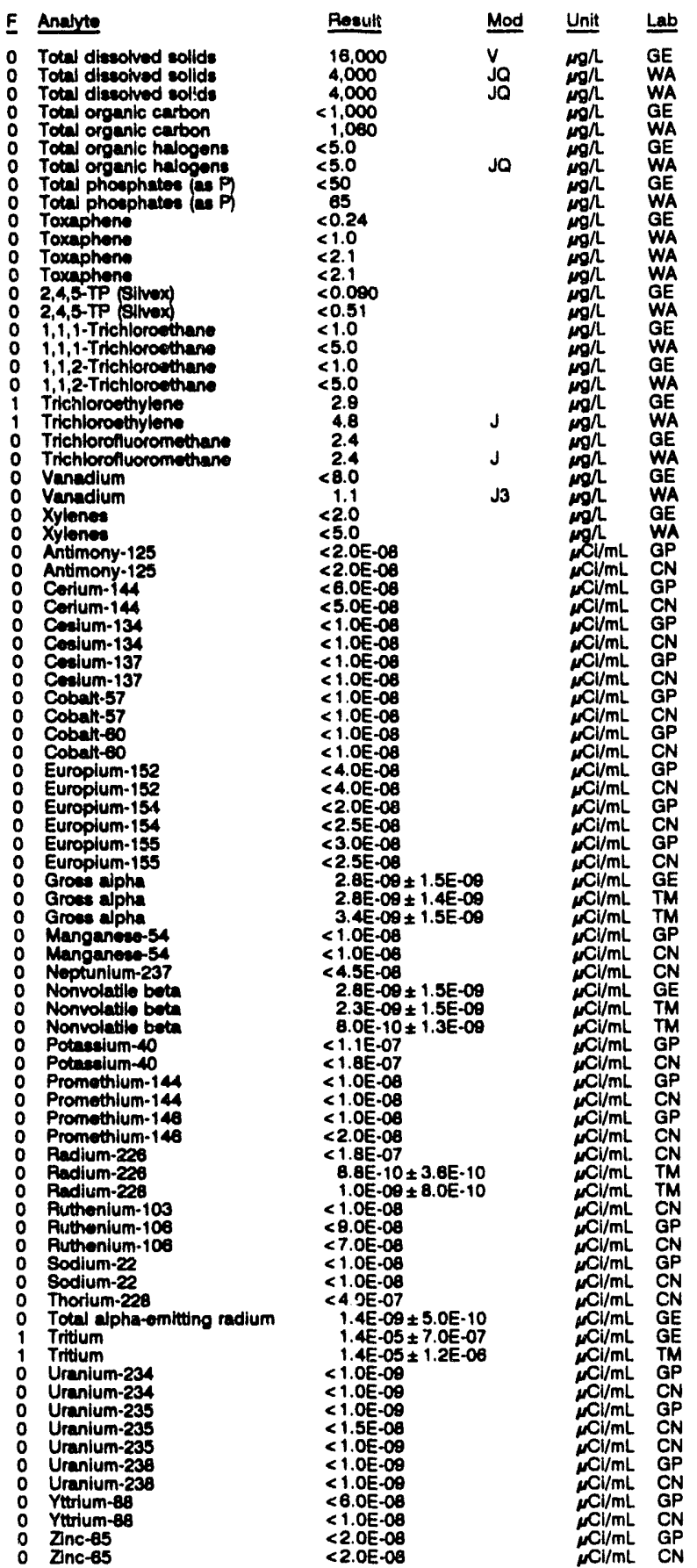

\section{WELL BGO 9AA}

MEASUREMENTS CONDUCTED IN THE FIELD

Sample date: 08/08/92

Dopth to water: $127.40 \mathrm{H}(38.83 \mathrm{~m})$ below TOC

Water olevation: $157.40 \mathrm{tt}(47.88 \mathrm{~m}) \mathrm{ms}$.

Sp. conductance: $4880 \mathrm{\mu s} / \mathrm{cm}$

Wator evacuated boforo sampling: $\mathbf{4 3}$ gal

The well went dry during purging.

pH: 12.4

Alkalinity: $1363 \mathrm{mg} / \mathrm{L}$ Walor temperature: $18.0^{\circ} \mathrm{C}$

LABORATORY ANALYSES

E Analyte Rosult Mod

\begin{tabular}{|c|}
\hline $\begin{array}{l}\text { PH } \\
\text { Specilic conductance } \\
\text { Turbidity } \\
\text { Acenaphthene } \\
\text { Acenaphthylene } \\
\text { Acetone } \\
\text { Acotonitrile (Methyl cyanide) } \\
\text { Acetophenone } \\
\text { 2-Acetylaminofluorene } \\
\text { Acrolein } \\
\text { Acrlonitrile } \\
\text { Alditi }\end{array}$ \\
\hline
\end{tabular}
13
5.000
8.8
$<10$
$<10$
$<100$
$<1.0$
$<10$
$<10$
$<20$
$<20$
$<0.0$

Aldrin

O Aldrin

2 Aluminum

Aniline

Anthracene

Aramite

Arzonic

Barium

Benzone

alpha-bonzono ho

beta-enzene hexachloride $<0.050$

beta.Benzene hexachloride $<0.050$

delta-Benzene hexachloride

delta-Benzene hexachloride

Benzola anthracene

Benzo b fluoranthene

Benzo kffluoranthene

Benzo (n) pyrene

Benzyl alcohol

Bis (2-chloroethoxy) methane

Bis (2-chlorothyl) ether

Bis (2-chlorolsopropy) ether

Biserethylhoxyl) phthala

Bromoform

Bromomothane

48romophenyl phenyl ether

2-ece-Butyl-4,6-dinitrophenol

0 Cadmium

o Calcium

206,000

Carbon tetrachloride $\quad<1.0$

Chlordane

Chlordane $<0.50$

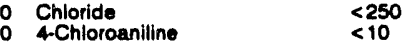

$\begin{array}{lll}0 & \text { Chlorobenzene } & <1.0 \\ 0 & \text { Chlorobenzilate } & <10\end{array}$

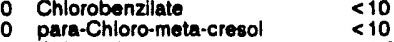

O Chloroethane $\quad<1.0$

$\begin{array}{lll} & \text { Chloroothene Ninyl chloride) } & <1.0 \\ 0 & 2 \text { Chloroethyl vinyl other } & <10 \\ 0 & & <1.0\end{array}$

Chloroform

2-Chloronaphthalene

2-Chlorophenol

$\begin{array}{ll}2 & 2 \text { Chlorophenol } \\ 0 & 4 \text { Chlorophenyl phenyl ether }<10\end{array}$

o Chromium $\quad<200$

o Chrysene

o Cobalt

O Copper

m-Cresol (3-Methylpheno)

p-Cresol (4-Methylphenol)

Cyanide

P.,P.DD

每

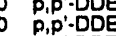

P,p'-DDE
P,DDT

p,p'-DD

Dibenz $[a, h]$ anthracene

Dibenzofuran

$\begin{array}{ll}\text { Dibenzofuran } & <10 \\ \text { Dibromochloromethane } & <1.0 \\ 1,2 \cdot \text { Dibromo-3-chloropropane } & <1.0\end{array}$

1,2-Dibromoothan

Di-n-butyl phthaiate
8
80
00
0
0
0
0
.050
.050
0
.070
0
0
.0
0
.0
05
.0
.050
.050
.050
.050
.050

$<10$
$<10$

$<10$

$<10$

$<10$
$<10$
$<10$

$<10$

1.0

10

,

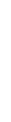

$<10$

$<8.0$

$<8.0$

$<10$

$<10$

$<10$

$<0.10$

$<0.10$

$<0.10$

$<0.10$

$\leq 10$

$<1.0$
$<1.0$

$<20$
$<1.0$
$<10$

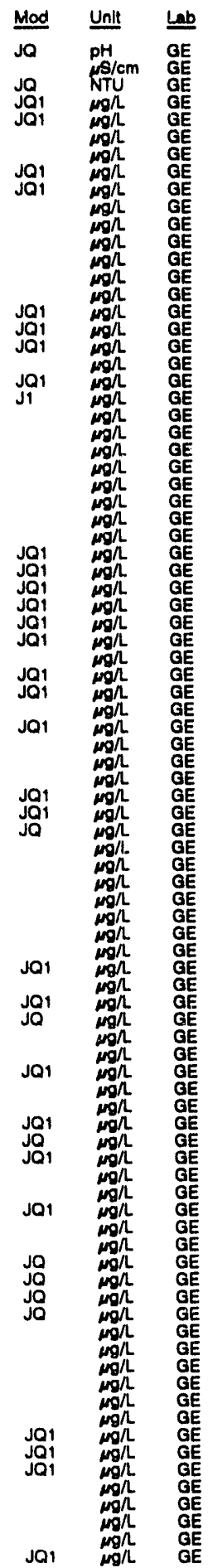


ANALYTICAL RESULTS

WELL BGO SAA collactod on 08/08/92, laboratory analyses (cont.)

E Analyte

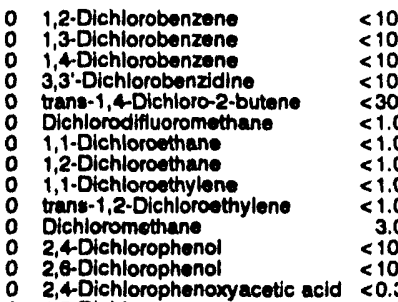

1,2-Dichloropropane $<1.0$

trans-1,3-Dichloropropene

Dloldrin

Diethyl phthalate

2,4-Dimethyl phenol

Dimethyl phthalate

p-Dimethylaminoazobonzene

o 3,3'-Dimethylbenzidine

a a-Dimethylphonethylamine

1,3-Dinitrobenzene

2,4-Dinltrophenol

2,8-Dinitrotoluene

1,4-Dioxano

Oiphenylam

Endosulfan

Endosulfan

Endosulfan II

Endosulfan II

Endosulfan sulfato

Endrin

Endrin aldehydo

Endrin aldehyde

Ethyl methanesulfonate

Ethylbenzene

.0 Famphur

Fluoranthen

Fluoride

Heptachlor

Heptachlor spoxida

Heptachlor epoxide

Heptachloradibenzo-p-dioxins

$1,2,3,4,6,7,8-H P C D F$
Heptachiorodibenzo-p-furans

Hoxachlorobutadlene

Hexachlorocyclopentadiene

Hexachlorodibenzo-p-dioxins

$1,2,3,4,7,8-H X C D F$
Hexachlorodibenzo-p-furans

Hexachloroethane

Hexachlorophene

2.Hexanone

indeno[1,2,3-c,d]pyrene

lodomethane (Methyl iodide)

lron

leophorons

leophorone

O Kepone

L Lead

L Lindane

Magneaium

Manganees

o Mercury

Methapyrilene

0 Methoxychlor

- Methoxychlor

Mothyl ethyl hatone

Methyl teobutyl ketone

Methyl methicrylate

o Methyl methaneryulfonate

3.Methylcholanthrene

Naphthaleno

1, Naphthoquinon

1-Naphthylamine
Result Mod Unit

$<10$

$<30$

$<1.0$

1.0

$<1.0$

3.0

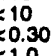

$<1.0$
$<1.0$

$<1.0$
$<0.50$
$<0.50$

10

$<10$

$<10$

$<10$

$<10$

$<10$

$<45$

$<10$

$<10$

$<10$
$<10$

$<10$
$<0.10$
$<0.10$
$<0.10$

$<0.10$

$<0.10$

$<0.10$

$<0.006$

$<0.10$

$<10$

$<10$

$<1.0$
$<10$

$<10$
$<10$
$<10$

$<100$

$<0.050$

$<0.050$

0.050

$<0.00065$

$<0.000045$

0.0004

$<10$

$<<0.00045$

$<0.00045$

$<0.000040$

$<0.00040$
$<10$
$<10$
$<10$

$<10$

$<1.0$

$<10$
$<15$

$<15$
$<15$
$<100$

$<10$

$<10$
$<10$
$<10$

$<10$
$<10$
$<3.0$

$<0.0050$
$<0.0050$

16
$<4.0$

$<0.20$

$<50$
$<10$

$<0.50$
$<0.50$
$<10$

$<10$
$<1.0$
$<1.0$

$<1.0$
$<10$

$<10$
$<10$

$<10$

$<10$

$<10$
$<10$
$<10$

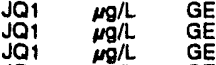

Ja1 $\mu g /$ GE

$\begin{array}{ll}\mu g \Omega & G \Omega \\ \mu g & G E \\ \mu g & G E \\ \omega g & G E\end{array}$

$\begin{array}{lll}j 2 & \mu_{\mu g} h . & G E \\ j O & G E \\ \mu g h & G E\end{array}$

Jo

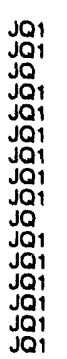

Ja1
Ja1
JQ1

jo1
jo1
ja1

Jo1
JQ1
Ja1

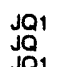

jol

Ja1

JO1
JQ1
JQ1
JQ1

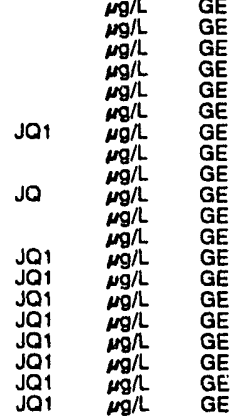

WELL BGO SAA collected on 08/08/82, laborstory analyses (cont.

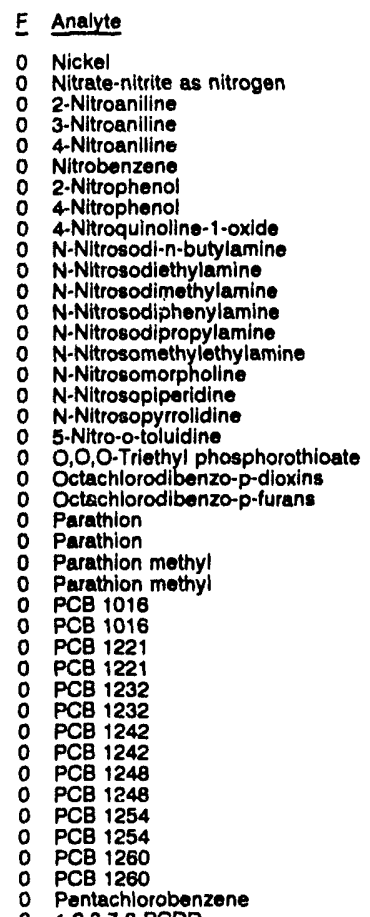

Result

Mod Unit Lab

$<8.0$

$<10$

$<10$

$<10$

$<10$
$<10$

$<10$

10

$<10$

$<10$

$<10$

$<10$

$<10$

$<0.0010$

0.050

$<0.050$

$<0.050$

$<0.50$

$<0.50$

$<0.50$

$<0.50$

$<0.50$

$<.50$

$<0.50$
$<0.50$
$<0.50$
$<0.50$

$<0.50$
$<0.50$
$<0.50$

Pentachlorobenzen

Pentachlorodibenzo-p-dioxins

Pentachlorodibenzo-p-furans

1,2,3,7,8-PCDF

Pentachloronitrobenzene

Phenacetin

Phenanth

0 Phenols

p-Phenylenediamine

Phorate

2-Picoline

Pronamid

Propionitril

Pyridine

0 Safrole

Selenium

Sillica

Sodium

0 Styrene

Sulfotepp

$1,2,4,5$-Tetrach
0

Tetrachlorodibenzo-p-dioxins

Tetrachlorodibenzo-p-furan

1,1,2,2-Tetrachioroethane

o Tetrachloroethylene

0 2,3,4,6-Tetrachlorophenol

o Thallium

Tin

o Toluene

o.Toluidine

Total dissolved solids

Total organic carbon

Total organic halogens
Total phosphates (as P)

o Toxaphene

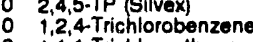

o $1,1,1$. Trichloroethane

o 1,1,2-Trichloroethan

o Trichloroothylone

Trichlorofluoromethan

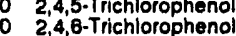

$\begin{array}{ll}0 & 2,4,5-Y \\ 0 & 1,2,3-\text { Trichloropropane }\end{array}$

1,3,5-Trinitrobenzene

$<0.50$
$<10$

$<0.00055$

$<0.00055$

$<0.00055$

$<10$

$<10$

$<10$
$<10$

$<10$
$<10$

$<10$
20
$<10$
$<0.10$
$<0.10$

$<0.10$

$<10$
61,100

$<10$

$<200$

$<10$
$<10$
$<10$
$<2.0$

$<2.0$

4.0
33,600

$<1.0$

4,750
$<10$

$<10$

$<0.00045$

$<0.00045$

(1)

$<1.0$

$<1.0$

$<1.0$

$<10$
$<2.0$

$<10$
$<4.0$

$<4.0$
3.6
$<10$

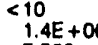

7.520
$<50$

$<50$

$<0.24$

$<0.000$

$<10$
$<1.0$

$<1.0$

$<1.0$

$<10$
$<10$
$<10$

$<0.080$

$<1.000$
$<10$

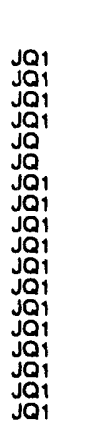

$\mu g / 2$ GE

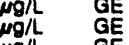

$\mathrm{GE}$
$\mathrm{g} / \mathrm{GE}$

$\begin{array}{ll}g / L & G E \\ g / h & G E\end{array}$

GE

茨

g GE

g/L GE

GE

GE

E


WELL BGO oM collected on 08/08/02, laboratory analyese (cont.)

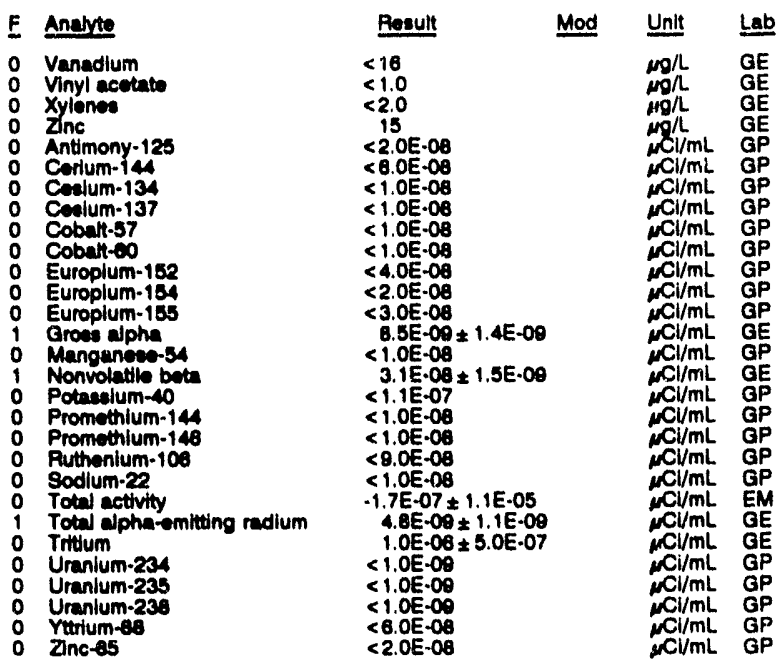

\section{WELL BGO 9D}

\section{MEASUREMENTS CONDUCTED IN THE FIELD}

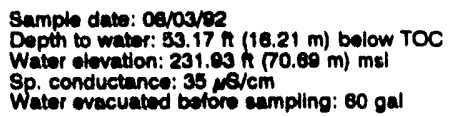

Timo: $15: 10$

PH: 4.7

Water temperature: $21.0^{\circ} \mathrm{C}$

LABORATOFY ANALYYES

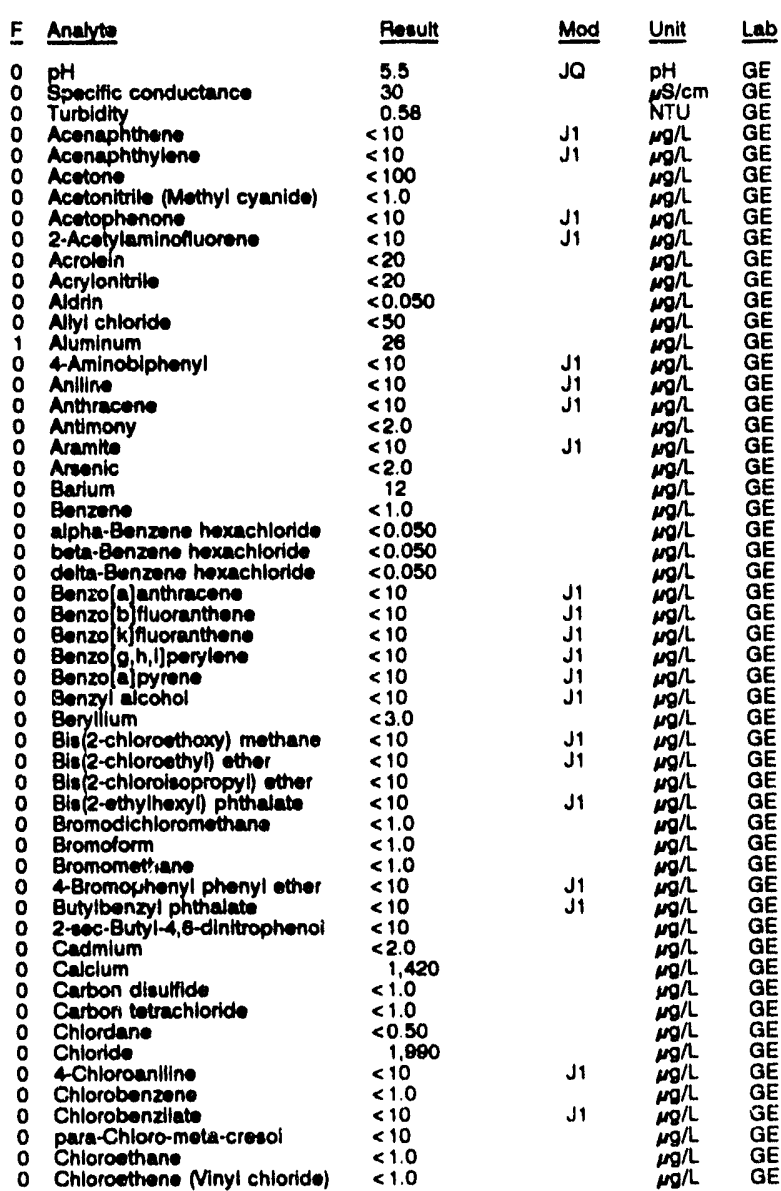

WELL BGO OD collected on 08/03/82, laboratory analyeen (cont.)

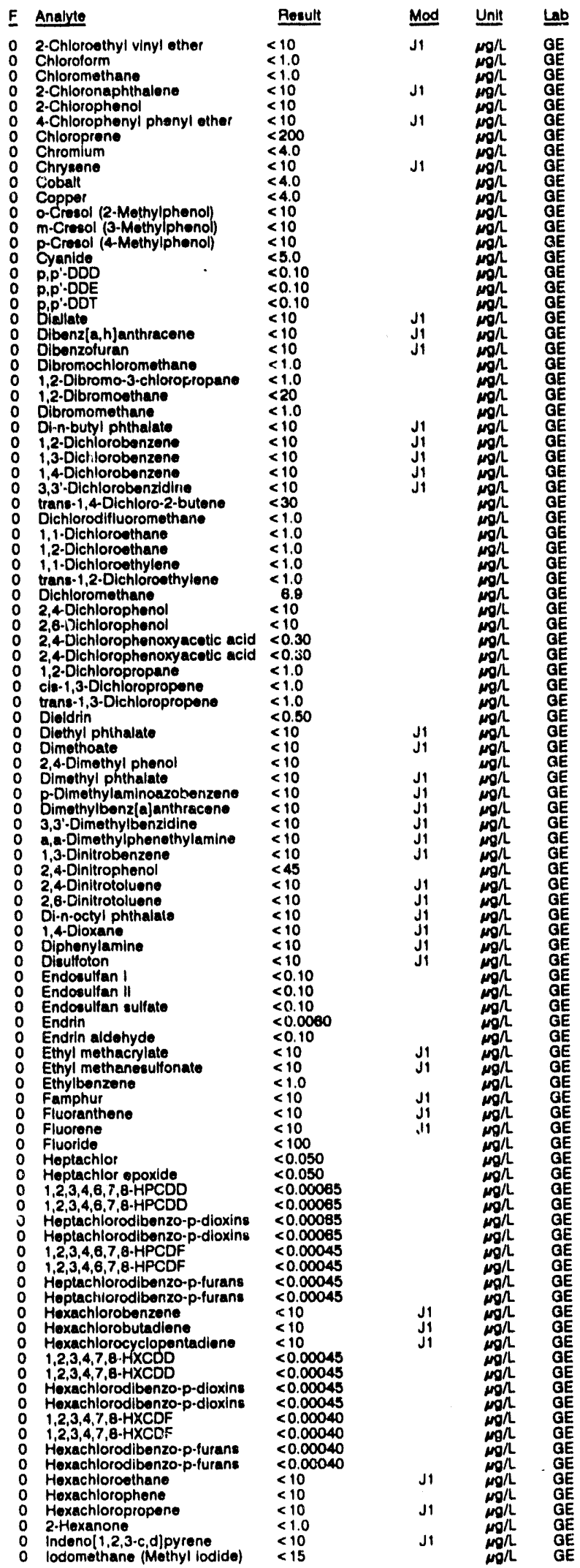


ANALYTICAL RESULTS

WEL BGO 80 collectind on 08/03/92, laboratory analyes (cont)

E Analyte

O ron

trobutyl alcohol

: bodin

o. comatrote

O Kepone

- Undane

Magnealum

Morcury

Morcury

Mechacrylonltrin

Mropylomo

2-Methyta, e-dinttroptionol Methyl ethyl ketone

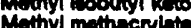

Methyl methaneaultionet

3-Acthylcholenthren

2-Methyinaphthalone

1.4Naphthoquinone

1-Naphthylamin

2-Naphthyl

Nitraternitrite es nitungess

2-Nitroaniline

3-Nitroar lin

4Nitroanilin

2-Nitropheno

\& Nitiophenol

noline-1-oudde

N-Nitrocodi-n-butylamin

N-Nircocodint

N-Nitrosodimethylamine

N-Nitrocodiphenylamine

N-Nurosodipropylamino

N-Ntroeomerpholing

N-Nitrocopiperidine

N-Nitrocoportidin

N-Nitrocopyrrolidine
S-Nitro-o-toluteline
$0,0,0$-Triathyl phosphorothloate

Otachlorodibenzo-p-djoxins

Octachlorodibenzo-p-dioxins

Octachlorodibenzo-p-furans

Parathion

Parathion methy!

PCB 1018

PCB 1221

PCB 1232

PCB 1248

PCB 1234

Pentachlorobenzene

1,2,3,7,8-PCDD

Pentachlorodibenzo-p-dloxins

Pentachlorodibenzo-p-dioxin

Pentachlorodibenzo-p-furans

Pentachlorodlibena

$1,2,3,7,8-P C D F$

Pentachloroethane

Pentechlorophond

Phenacetin

Phenol

Phenols

Phenols

P-Phenylon

2.Picoling

Potaselum

Pronamid

Proplon

Pyrene

Sarrole

Solen

Silica

Sodium

Styrene

Sulfete

Sulfide

Sulfotepp

1,2,4,5-Tetrachlorobenzene

2,3,7,8-TCDD

$2,3,7,8-T C O$

2,3,7,8-TCD

$2,3,7,0-1 \mathrm{COF}$

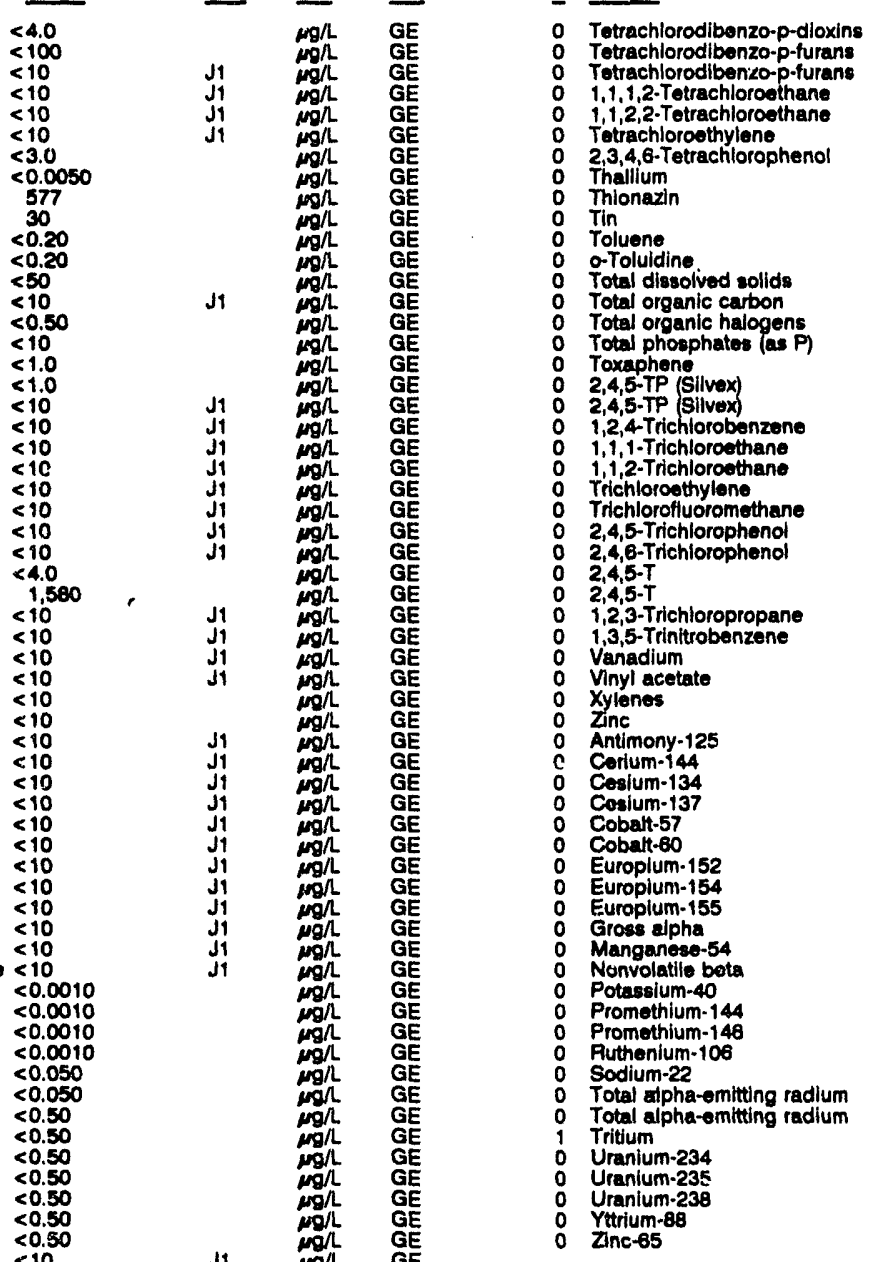

10

$<0.00055$

$<0.00055$

$<0.00055$

$<0.00055$

$<0.00055$

$<0.0005$

$<10$

$<10$

$<10$
$<10$

$<10$

$<10$
$<5.0$
$<5.0$

$<10$

$<10$
$<0.10$
$<10$
$<500$

$<10$

$<200$

$<10$

$<10$

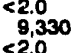

$<2.0$

$<1.0$

$<1,000$

$<1,000$

$<10$
$<10$

$<0.00045$

$<0.00040$

$<0.00040$
WELL BGO 10AA

MEASUAEMENTS CONDUCTED IN THE FIELD

Sample date: 08/04/82 Depth to water: $143.00 \mathrm{ft}(43.59 \mathrm{~m})$ below TOC Water elevation: $157.70 \mathrm{ft}(46.07 \mathrm{~m}) \mathrm{ms}$

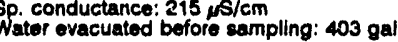
LABORATORY ANALYSES

E Analyte

$\mathrm{pH}$

Specific

Acetophenon

1 Aluminum

0 Antimony

0 Arsenic

Bonzen

Bromodichloromethan

B Bromoform

Bromoform

Bromomethane

Cadmium

O Carbon tetrachloride

Chloride

Chiorobenzens

Chlorobenzene
Result

$<0.00045$

$<0.00040$

$<1.0$

$<1.0$

$<10$

$<10$
2.7
$<1.0$

$<10$

1,000
$<5.0$

$<50$

$<0.080$

$<0.090$

$<1.0$

$<1.0$

$<10$
$<10$

$<0.090$

$<1.0$
$<10$

$<8.0$

$<1.0$
$<2.0$

$<2.0 E-08$

$<8.0 E-08$

$<1.0 E .00$

$<1.0 E-06$

$>4.0 E-08$

C...

$4.2 E-09 \pm 1.8 E-08$

2. $3 E-09 \pm 1,4 E-00$

$<1.1 E-07$

$<1.0 E-08$

$<8.0 E .08$

$<1.0 \mathrm{E}-08$

$<1.0 E-09$

1.5E-05 \pm 7.0E-07

$<1.0 E-09$

$<1.0 E-09$

$<1.0 E-09$
$<6.0 E-08$

$<2.0 E-08$
Mod Unit

$\begin{array}{ll}\mu g / L & G E \\ \mu g h & G E \\ M g h & G E\end{array}$

$\mathrm{GE}$
$\mathrm{GE}$
$\mathrm{GE}$
$\mathrm{GE}$
$\mathrm{GE}$
$\mathrm{GE}$
$\mathrm{GE}$

GE

政

E

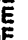

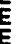

E

E

E

EE 
ANALYTICAL RESULTS

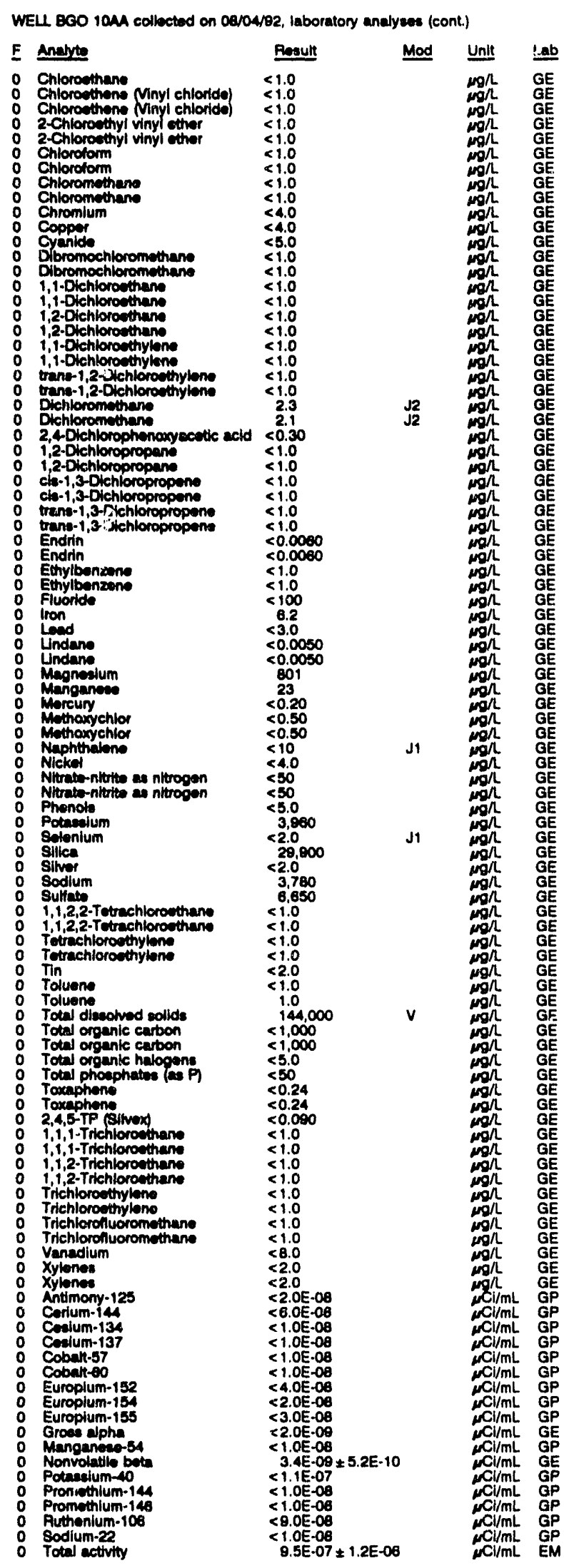

WELL BGO 10AA collocted on 08/04/82, laboratory analyees (cont.)

\begin{tabular}{|c|c|c|c|c|c|}
\hline F & Analute & Result & Mod & Unlt & $\underline{\underline{L}}$ \\
\hline $\begin{array}{l}0 \\
0 \\
0 \\
0\end{array}$ & $\begin{array}{l}\text { Total alpha-emitting radium } \\
\text { Tritum } \\
\text { Tritum } \\
\text { Uranium-234 } \\
\text { Uranium-235 } \\
\text { Uranium-238 } \\
\text { Ytrium-88 } \\
\text { Zinc-65 }\end{array}$ & $\begin{array}{l}<1.0 E \cdot 09 \\
<7.0 \mathrm{E}-07 \\
<7.0 \mathrm{E}-07 \\
<1.0 \mathrm{E}-09 \\
<1.0 \mathrm{E}-09 \\
<1.0 \mathrm{E}-09 \\
<6.0 \mathrm{E} \cdot 08 \\
<2.0 \mathrm{E}-00\end{array}$ & & 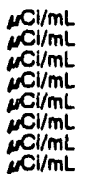 & $\begin{array}{l}G E \\
G E \\
G E \\
G P \\
G P \\
G P \\
G P \\
G P\end{array}$ \\
\hline
\end{tabular}

\section{WELL BGO 10AR}

MEASUREMENTS CONDUCTED IN THE FIELD

Sample date: 08/04/92

Depth to water: 142.26 H $(43.38 \mathrm{~m})$ bolow TOC Water elevation: $158.24 \mathrm{H}(48.23 \mathrm{~m}) \mathrm{mal}$ Witer evacuated betore sampling: $164 \mathrm{gal}$

Alkalinity: $104 \mathrm{mo} / \mathrm{h}$ Water temperature: $20.5^{\circ} \mathrm{C}$

\section{LABOAATOAY ANALYSES}

\begin{tabular}{|c|c|c|c|}
\hline E Analute & Result & Mont & Un! \\
\hline 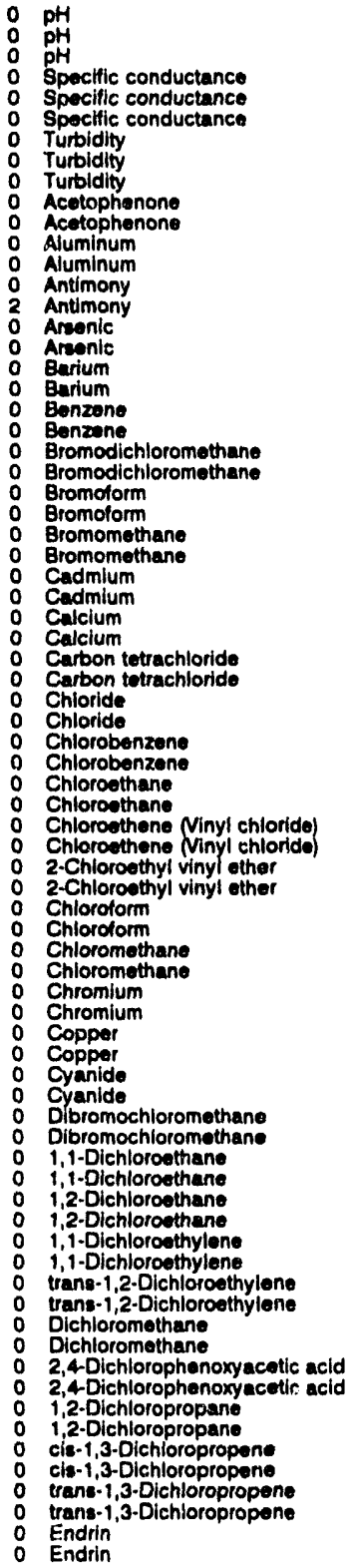 & 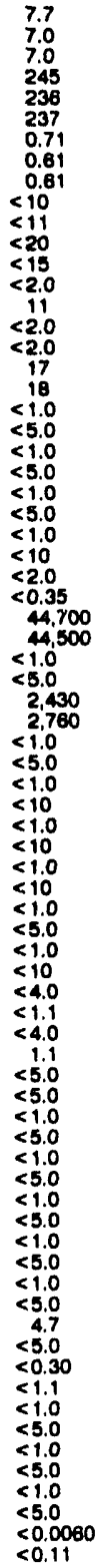 & $\begin{array}{l}\text { JO } \\
\text { JO } \\
\text { JO } \\
\text { Jo } \\
\text { Ja } \\
\text { Jo } \\
\text { Ja } \\
\text { Ji }\end{array}$ & 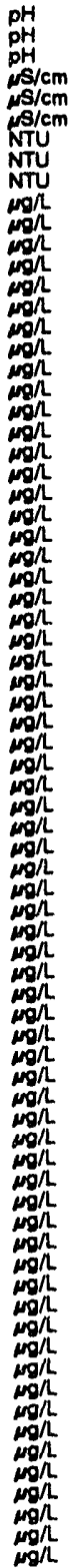 \\
\hline
\end{tabular}


ANALYTICAL RESULTS

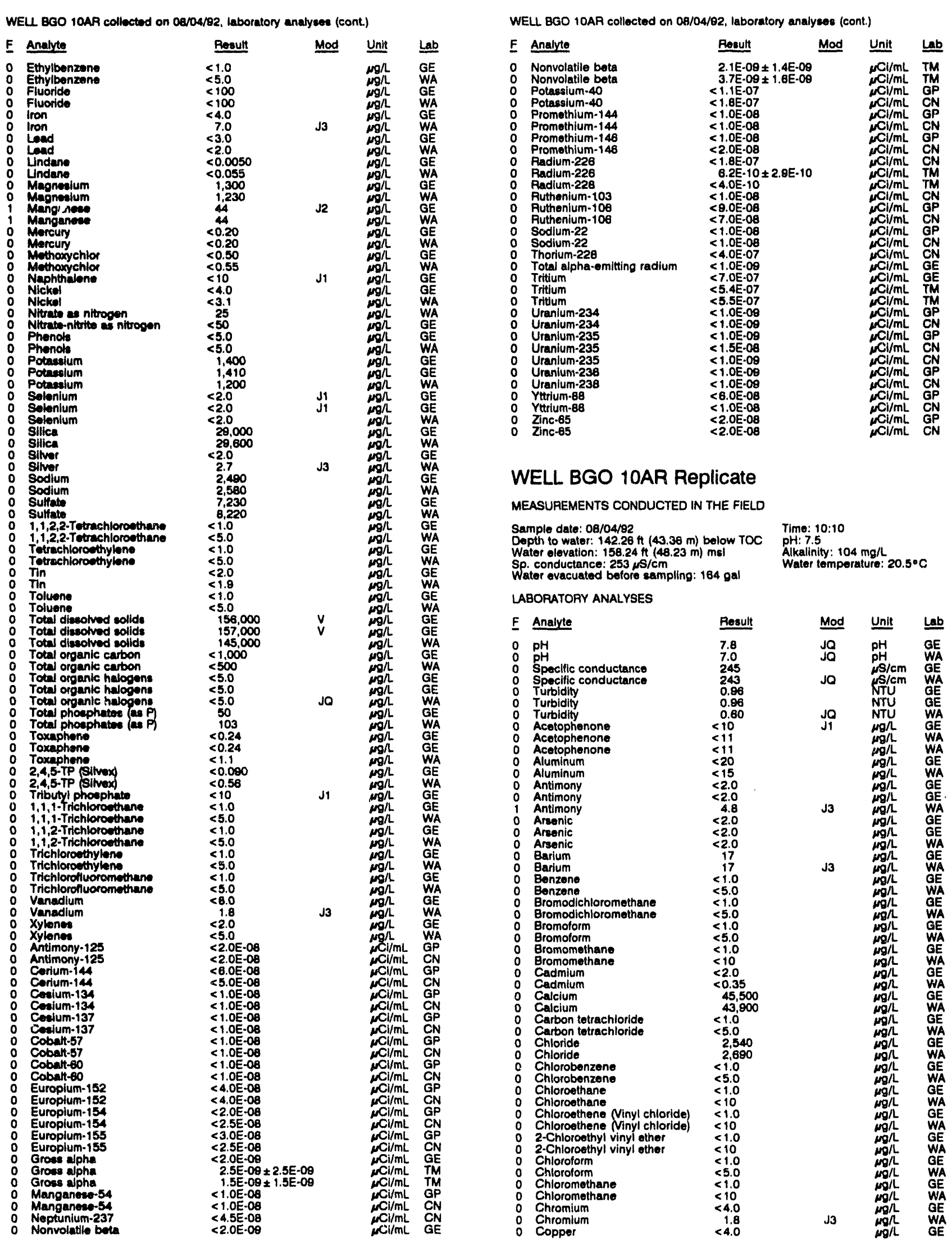


ANALYTICAL RESULTS

WELL BCO 1OAR collocted on 08/04/82, laboratony analyses (cont.)

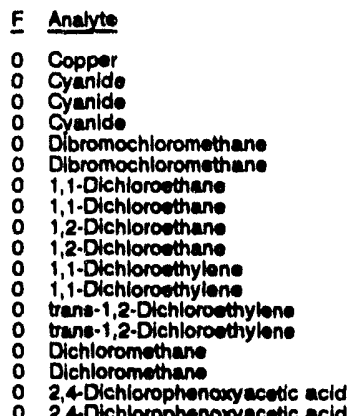

2,4-Dichlorophenoxy acetic acid

- 1,2-Dlchloropropana

clo-1,3-Dichloropropen

cite-1,3-Dichloropropen

trane-1,3-Dlchloropropen

Endrin

E Endrin

Ethylbenzene

Fluoride

O Iron

$\begin{array}{ll}0 \\ 0 & \text { Iron } \\ 0 & \end{array}$

0 Lead

0 Load

0 Lindane

Undano

Magnedum

Manganeese

Mercury

Morcury

Methoxychlor

Methoxychlor

Nickel

Nitrate un nitrogen

Nitrate-niturits a nitrogen

Phonols

Phonols

Potaeslum

Solenium

Sillea

silica

Silvor

Sodium

Sultate

1,1,2,2-Tetrachloromthane

1,1,2,2.Tetrachloroethan

Tetrachloroathylone

Tin

o Tin

o Tolvene

Total dienotved collide

Tot diesolved collide

Total organic carton

Total organic carton

Total organic halogen

Total phosphates (as P)

Toxaphen

2,4,5-TP Sitwex

Tirbutyl phosphate

1,1,1-Inchloroethan

1, 1, 2-Trichloroothene

i, 2-Trichloroethan

- Trichlorothylene

Trichlorothylone

Trichlorofluoromethane

Vanadium

Vanadium

Xylences

Antimony-125

Antimony-125
Resuli

$<1.1$
$<5.0$
$<5.0$
$<5.0$
$<1.0$
$<5.0$
$<1.0$
$<5.0$
$<1.0$
$<5.0$
$<1.0$
$<5.0$
$<1.0$
$<5.0$
1.6
1.4
$<0.30$
$<1.1$
$<1.0$
$<5.0$
$<1.0$
$<5.0$
$<1.0$
$<5.0$
$<0.006$

$<5.0060$

$<0.11$

51.0
550

$\leq 100$

$<4.0$

231.0

$<2$

$<0.0050$

1,300
1,240

44

$<0.20$

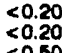

20.50

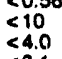

$<3.1$.

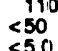

550
55.0
550

55.0
1,900
$<20$

1.200
$<2.0$
$<2.0$

29,400
29,600

29,600
$<2.0$

2,470

7,000

7,840

51.0

51.0

$<2.0$

si:

$<1.0$
$<157,000$
157,000

157,000
147,000

$<1,000$

$<5.0$

$<5$

80
$<1.1$

$<0.090$

$<0.58$

$<110$

$<1.0$
$<50$

$<1.0$

$<5.0$

$<1.0$

$<1.0$

$<8.0$

2.8
$<2.0$
$<5.0$

$<5.0$

$<2.0 E .08$
$<2.0 \mathrm{E} .08$
Mod Unit Lab

作

JV

g/L WA

WE

WE

WA

WA

WA

WA

WA

WA

GE

GE

WA

WA

WA

WA

WE

GE

WE

WE

GE

WA

E

WA

WA

WA

WA

GE

E

E

WE

E

GE

GE

WA

WA

GE

WA

WA
WELL BGO 10AR collected on 08/04/82, laboratory analyses (cont.)

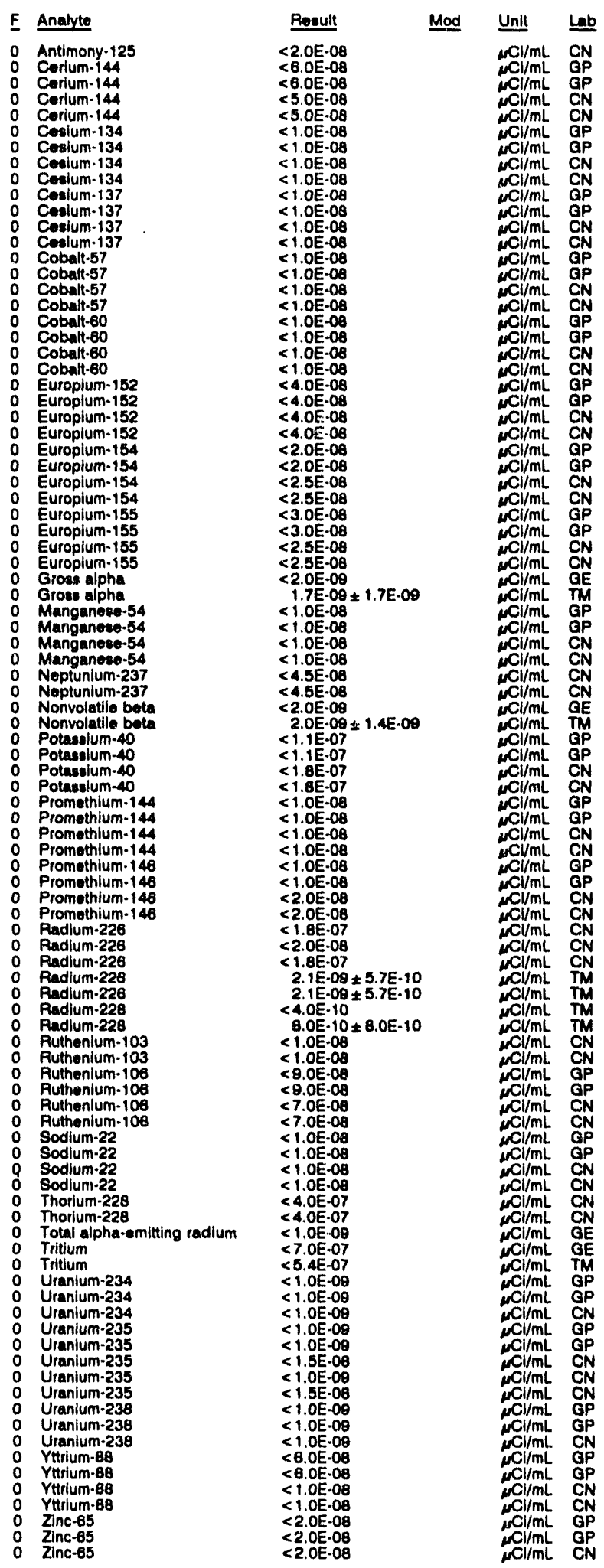


WELL BGO 10B

MEASUREMENTS CONDUCTED IN THE FIELD

Sample date: $08 / 11 / 02$

Depth to water: $80.86 \mathrm{ft}(24.68 \mathrm{~m})$ bolow TOC

Water elevation: $220.04 \mathrm{~h}$ (67.07

Water evacuated bofore eampling: $48 \mathrm{gal}$

LABORATORY ANALYSES

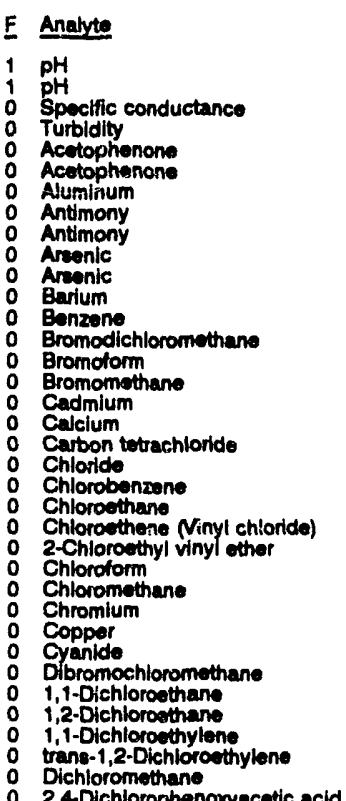

\begin{tabular}{|c|c|c|c|c|c|}
\hline Result & Mod & Unit & Lab & 0 & Total alpha-emitting radium \\
\hline $\begin{array}{l}8.8 \\
10.0\end{array}$ & $\begin{array}{l}\mathrm{J} Q \\
\mathrm{JQ}\end{array}$ & $\mathrm{pH}$ & GE & $\begin{array}{l}0 \\
0 \\
0\end{array}$ & $\begin{array}{l}\text { Uranium-234 } \\
\text { Uranium-235 } \\
\text { Uranium-238 }\end{array}$ \\
\hline $\begin{array}{r}4.1 \\
<10\end{array}$ & $\begin{array}{l}\mathrm{JQ} \\
\mathrm{J1}\end{array}$ & NTU & GE & $\begin{array}{l}0 \\
0\end{array}$ & $\begin{array}{l}\text { Yttrium-88 } \\
\text { Zinc- } 65\end{array}$ \\
\hline
\end{tabular}

Time: 7:05

PH: 10.3

Alkalinity: $44 \mathrm{mg} / \mathrm{L}$

$<10$

$<20$

$<2.0$

$<2.0$

38

$<1.0$

$<1.0$

$<1.0$
$<2.0$
37.500

$<1.0$

$<1.0$

$<1.0$

$<1.0$
$<1.0$
$<1.0$
$<1.0$

$<1.0$

$<4.0$

$<5.0$

$<1.0$

$<1.0$

$<1.0$

$<1.0$

2,4-Dichlorophenoxyacetic acid $<0,30$

1,2-Dichloropropane

cla-1,3-Dichloropropene
trans-1,3-Dichloropropene

Ethylbenzene

Fluoride

Iron

Lead

Undane

Manganes.

Morcury

Methaxychlor

Naphthaione

Nickel

Nitrate-nituite as nitrogen

Phenols

Potaselum

Setenium

silica

Silica

Sodium

1,1,2 -Tetrachloroethane

Tetrachloroethylene

Tin

Total dissolved solids

Total organic carbon

Total organic halogons

Total phosph

2,4,5-TP (Sitvex)

1,1,1-Trichloroethane

1,1,2-Trichloroethen

Trichloroethylene

Vanadium

Xylenes

Corium-144

Cosium-134

Ceslum-137

Cobatt-57

Cobalt-60

Europium-152

Europium-154
Europium-155
WELL BGO 108 collected on 08/11/82, laboratory analyses (cont)

E Analyte

- Gross alpha

Manganese-54

Ponvolatile beta

Promethlum-144

Promethium-146

Ruthenium-106

Sodium-22

Total alpha-emitting radium

Uranium-234

O Uranlum-23

Zinc-65

\begin{tabular}{|c|c|c|}
\hline Result & Mod & Unit \\
\hline $\begin{aligned}<2.0 \mathrm{E}-09 \\
<1.0 \mathrm{E}-08 \\
4.5 \mathrm{E}-09 \pm 2.0 \mathrm{E} \cdot 10 \\
<1.1 \mathrm{E}-07 \\
<1.0 \mathrm{E}-08 \\
<1.0 \mathrm{E}-08 \\
<8.0 \mathrm{E}-08 \\
<1.0 \mathrm{E}-08 \\
3.0 \mathrm{E}-05 \pm 1.7 \mathrm{E}-08 \\
1.4 \mathrm{E}-09 \pm 7.0 \mathrm{E}-10 \\
2.5 \mathrm{E}-05 \pm 8.0 \mathrm{E}-07 \\
<1.0 \mathrm{E}-09 \\
<1.0 \mathrm{E}-09 \\
<1.0 \mathrm{E}-09 \\
<6.0 \mathrm{E}-08 \\
<2.0 \mathrm{E}-08\end{aligned}$ & & $\begin{array}{c}\mu \mathrm{Cl} / \mathrm{mL} \\
\mu \mathrm{Cl} / \mathrm{mL} \\
\mu \mathrm{Cl} / \mathrm{mL} \\
\mu \mathrm{Cl} / \mathrm{mL} \\
\mu \mathrm{Cl} / \mathrm{mL} \\
\mu \mathrm{Cl} / \mathrm{mL} \\
\mu \mathrm{Cl} / \mathrm{mL} \\
\mu \mathrm{Cl} / \mathrm{mL} \\
\mu \mathrm{Cl} / \mathrm{mL} \\
\mu \mathrm{Cl} / \mathrm{mL} \\
\mu \mathrm{Cl} / \mathrm{mL} \\
\mu \mathrm{Cl} / \mathrm{mL} \\
\mu \mathrm{Cl} / \mathrm{mL} \\
\mu \mathrm{Ci} / \mathrm{mL} \\
\mu \mathrm{Cl} / \mathrm{mL} \\
\mu \mathrm{Cl} / \mathrm{mL}\end{array}$ \\
\hline
\end{tabular}

WELL BGO 10C

MEASUREMENTS CONDUCTED IN THE FIELL

Sample date: 08/04/92

Depth to water: $80.56 \mathrm{ft}(24.55 \mathrm{~m})$ below TOC

Water elevation: $220.74 \mathrm{ft}(67.28 \mathrm{~m}) \mathrm{msl}$

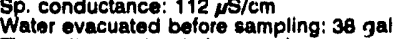

The well went dry during purging.

LABORATORY ANALYSES

E Analyte

PH

0 Turbidity

Acetophenone

Aluminum

Antimony

Arsenic

Barium

Barium

Benzene

Bromodichloromethane

Bromoform

Cadmium

Cadmium

Calcium

Calcium

Carbon tetrachloride

Chloride

Chlorobenzeno

Chloroethene Ninyl chloride)

-Chloroothyl vinyl other

Chloroform

Chloromethane

Chromium

Chromium

Copper

Copper

Dibromochloromethane

1,1-Dichloroethane

1,2-Dichloroethane

1,1-Dichloroethylene

trans-1,2-Dichloroethylene

2.8

2,4-Dichlorophenoxyacetic acid $<0.30$

1,2-Dichloropropane

cis-1,3-Dichloropropene

trans-

Ethylbenzene

Fluoride

Fluorido

iron

Iron

Uindane

Magnesium

Magnosium

Manganise

Mercury

Methoxychlor

Naphthalene

Nickel

Nitrate-nitrite as nitrogen

Phenols

Potassium

Potassium

Silica
Sllica
Time: $9: 20$

Alkalinity: $30 \mathrm{mg} / \mathrm{L}$

Water temperature: $20.1^{\circ} \mathrm{C}$

Rosult

Mod
Ja
$J 1$
J2
$\sqrt{2}$

Unit Lab

510

55
510
$<20$

$<20$

$<2.0$

28

$<1.0$

$<1.0$

$<1.0$

45, 100

$<1.0$

$<1.0$

$<1.0$

$<1.0$

$<4.0$

$<4.0$
$<4.0$

$<4.0$

$<5.0$

1.0

$<1.0$

2.8
$<0.30$
$<0.30$

$<1.0$
$<1.0$

$<1.0$

$<0.0060$

$<1.0$

$<100$

$<100$
23
23

$<3.0$

$<0.0050$

1,050

3.2
3.3

3.3
$<0.20$
$<0.20$

$<0.20$
$<0.50$

$<10$

4.0
$<4.0$

550
45.0

$<5.0$

676

$<2.0$
25,800
25,500 $\begin{array}{ll}\text { PH } & \text { GE } \\ \text { NSTU } & \text { GEm } \\ \text { GE } & \text { Gem }\end{array}$ 
WELL BGO $10 \mathrm{C}$ collected on 09/04/92, laboratory analyees (cont)

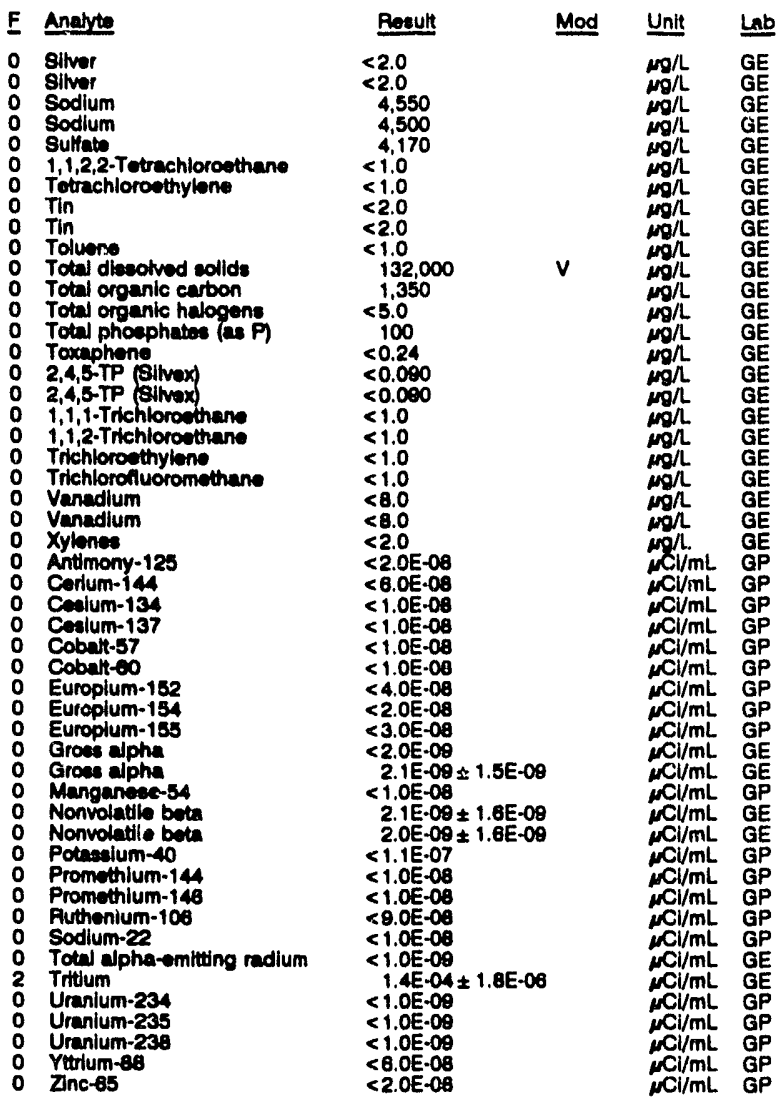

WELL BGO 10D

MEASUREMENTS CONDUCTED IN THE FIELD

Sample date: $08 / 03 / 92$
Depth to water: $69.89 \mathrm{ft}(21.30 \mathrm{~m})$ below TOC

Time: 15:30

Water wevation: $231.82 \mathrm{~h}(70.00 \mathrm{~m}) \mathrm{msl}$

WELL BGO 10DR

MEASUREMENTS CONDUCTED IN THE FIELD

Sample date: 08/11/02

Depth to water: 68.81 in $(20.97 \mathrm{~m})$ bolow TOC

Water elevation: 231.59 h $(70.69 \mathrm{~m}) \mathrm{mal}$

Sp. conductance: $71 \mathrm{\mu s} / \mathrm{cm}$

pling: 3 gal

LABORATOFY ANALYSES

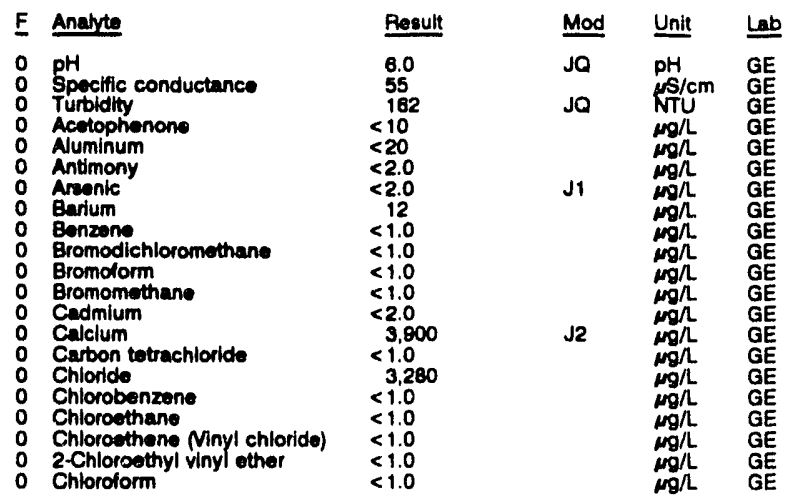

WELL BGO 10DR collected on 08/11/92, laboratory analyeos (cont)

\begin{tabular}{|c|c|c|c|c|}
\hline Analyte & Result & Mod & Unit & Lab \\
\hline 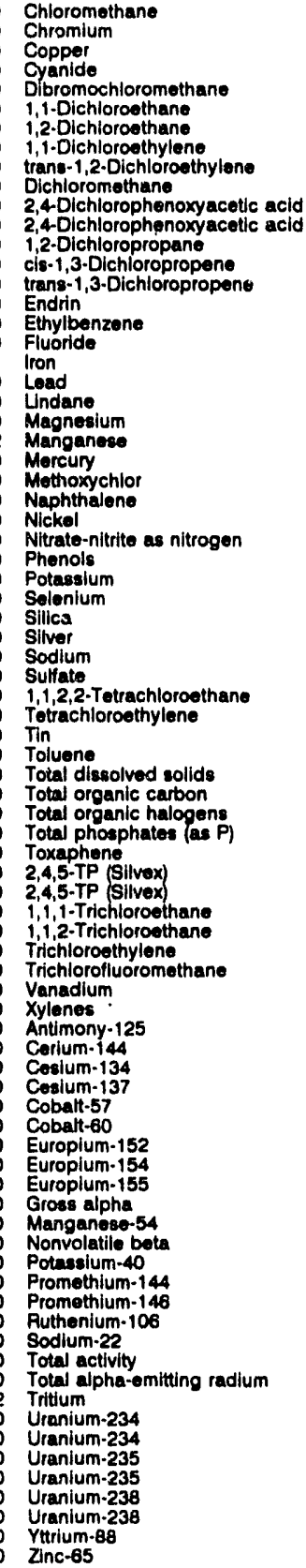 & 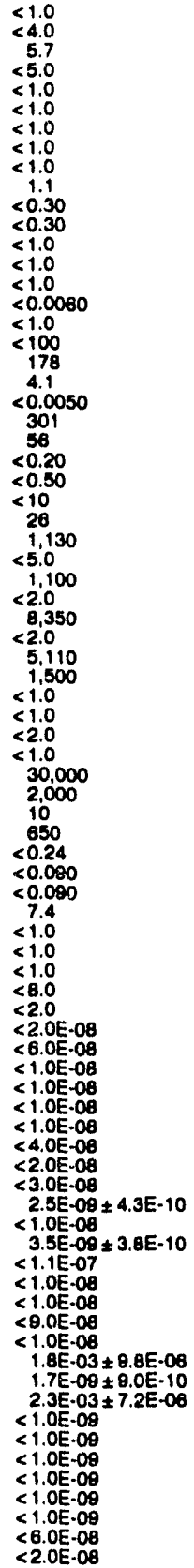 & 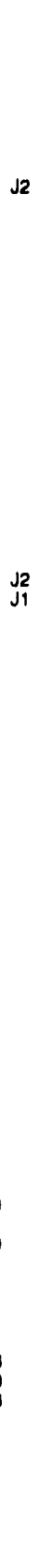 & 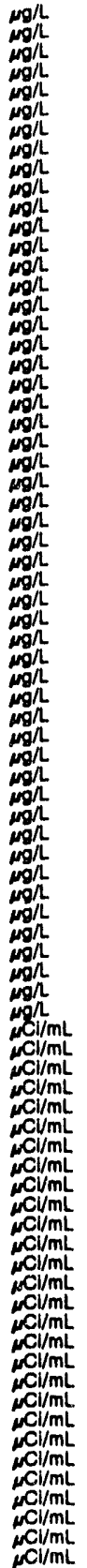 & 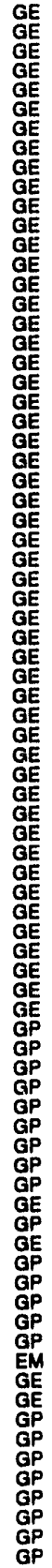 \\
\hline
\end{tabular}

\section{WELL BGO 11D}

MEASUREMENTS CONDUCTED IN THE FIELD

Sample date: 08/03/82

Time: 16:00

Depth to water: $73.54 \mathrm{ht}(22.42 \mathrm{~m})$ bolow TOC PH: 4.5
Water elevation: $231.76 \mathrm{~h}(70.64 \mathrm{~m}) \mathrm{msl}$
Aikalinity: $0 \mathrm{mg}$

Sp. conductance: $36 \mathrm{~s} / \mathrm{cm}$. Whalinity: $0 \mathrm{mg} / \mathrm{h}) \mathrm{ms} \quad 21.5 \circ \mathrm{C}$

Water ovacuated bofore sampling: $41 \mathrm{gol}$

LABORATORY ANALYSES

\begin{tabular}{|c|c|c|c|}
\hline F Analyte & Result & Mod & Unit \\
\hline $\begin{array}{ll}0 & \mathrm{pH} \\
0 & \text { Specific conductance } \\
0 & \text { Turbidity }\end{array}$ & $\begin{array}{l}5.2 \\
30 \\
0.18\end{array}$ & JO & $\begin{array}{l}\mathrm{pH} \\
\text { NTIS } \\
\text { NTI }\end{array}$ \\
\hline
\end{tabular}


ANALYTICAL RESULTS

WELL BGO 11D collected on 08/03/92, laboratory analyses (cont.)

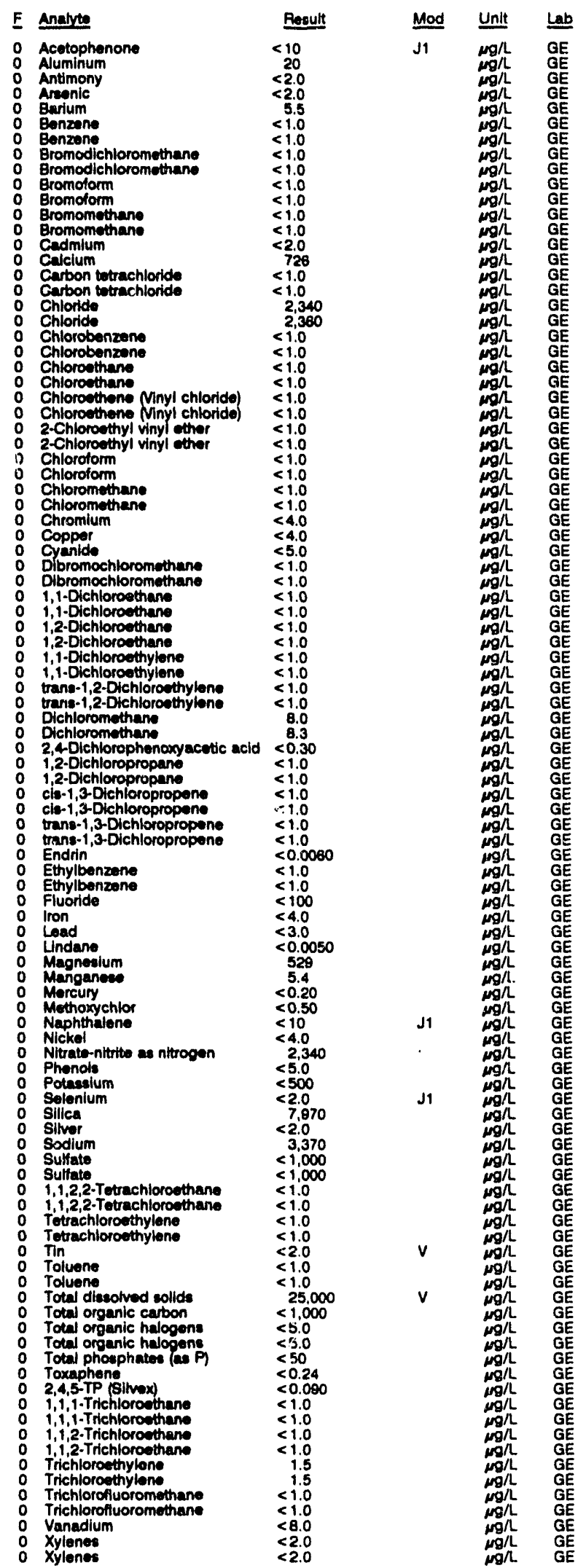

WELL BGO 110 collected on 08/03/82, laboratory analyees (cont.)

\begin{tabular}{|c|c|c|}
\hline Analyte & Result & Unit \\
\hline $\begin{array}{l}\text { Antimony-125 } \\
\text { Corium-144 } \\
\text { Ceslum-134 } \\
\text { Cosium-137 } \\
\text { Cobalt-57 } \\
\text { Cobatt-60 } \\
\text { Europium-152 } \\
\text { Europium-154 } \\
\text { Europlum-155 } \\
\text { Gross alpha } \\
\text { Manganese-54 } \\
\text { Nonvolatile bola } \\
\text { Potassium-40 } \\
\text { Promothium-144 } \\
\text { Promothium-148 } \\
\text { Ruthonium-106 } \\
\text { Sodium-22 } \\
\text { Total activity } \\
\text { Total alpha-emitting radium } \\
\text { Tritlum } \\
\text { Uranium-234 } \\
\text { Uranlum-235 } \\
\text { Uranium-238 } \\
\text { Yttrium-88 } \\
\text { Zinc-65 }\end{array}$ & 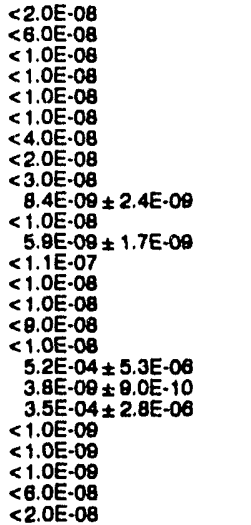 & 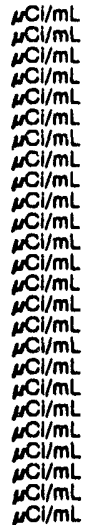 \\
\hline
\end{tabular}

\section{WELL BGO 12AR}

MEASUREMENTS CONDUCTED IN THE FIELD

Sample date: 08/05/92

Depth to water: $155.88 \mathrm{ft}(47.51 \mathrm{~m})$ below TOC Water olevation: $157.54 \mathrm{ft}(48.02 \mathrm{~m}) \mathrm{ms}$ Water ovacuated before sampling: $154 \mathrm{gal}$

PH: 10.7 . $121 \mathrm{mgl}$

Alkalinity: $121 \mathrm{mg} / \mathrm{L}$.

LABORATOAY ANALYSES

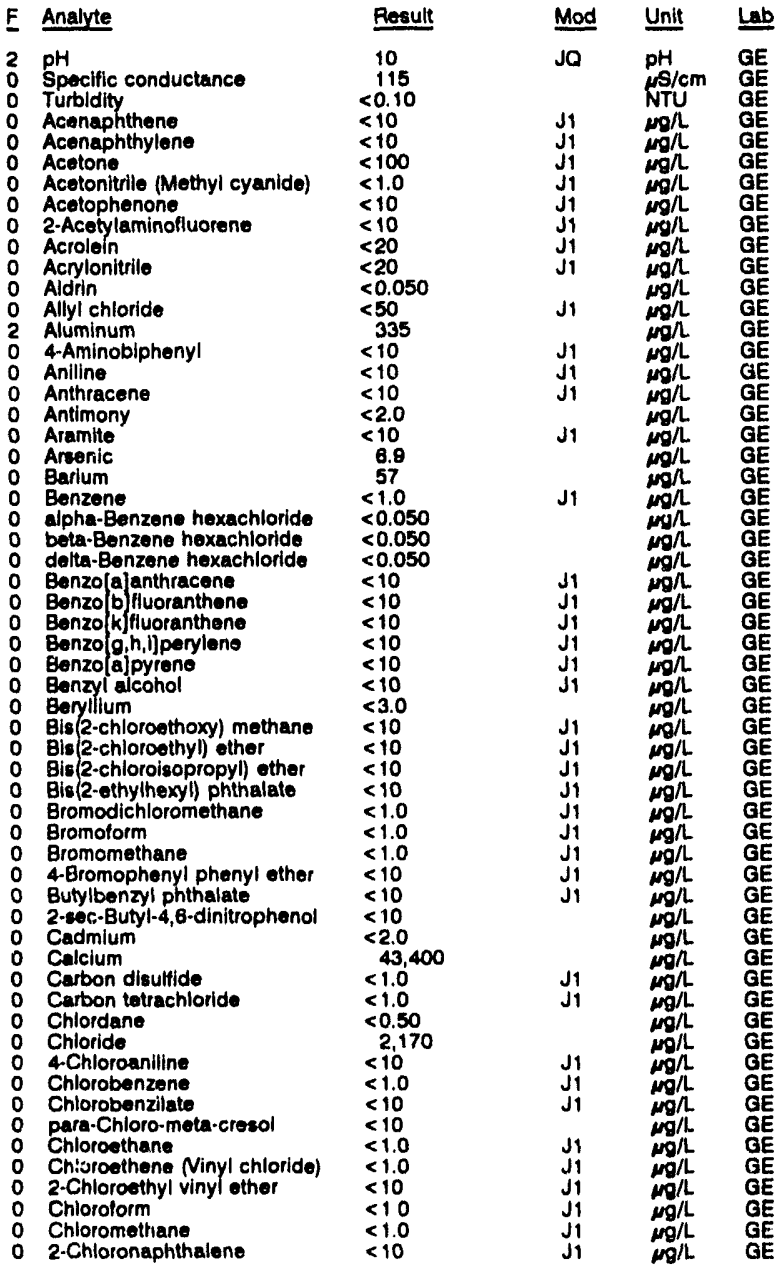


WELL BGO 12AR collected on 06/05/92, laboratory analyses (cont.)

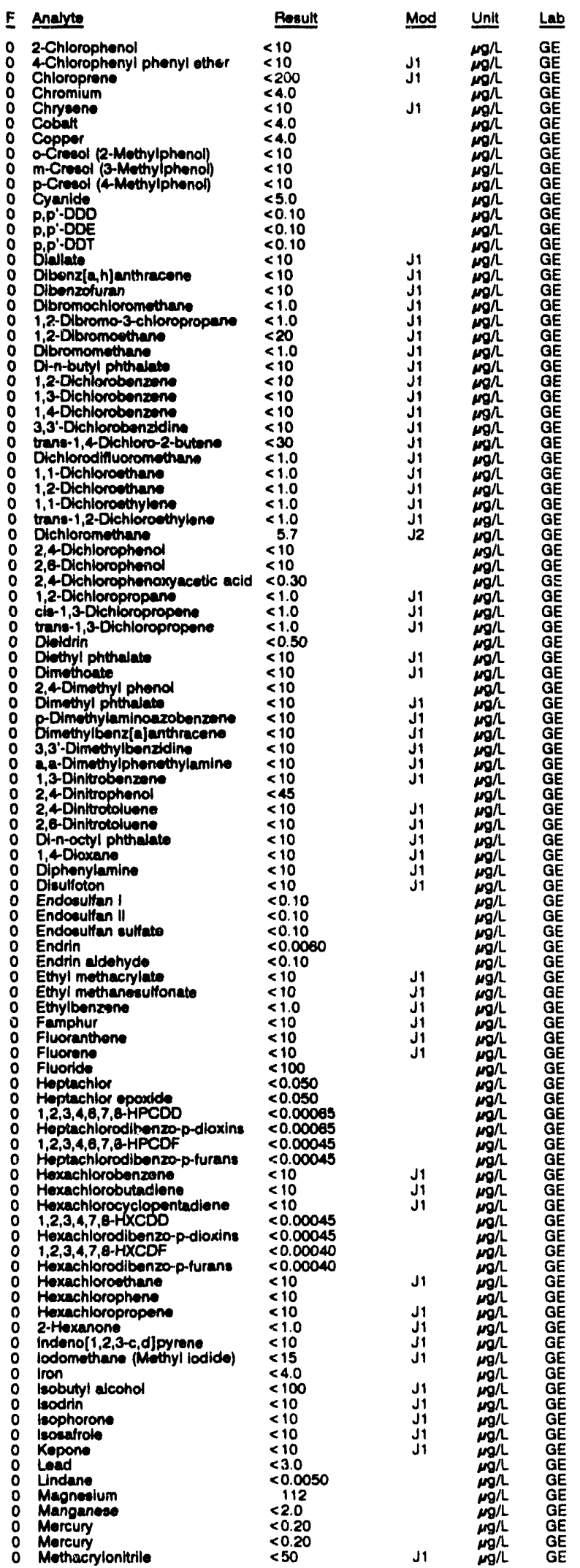

WELI. BGO 12AR collocted on ' 8 /05/82, laboratory analyses (cont.)

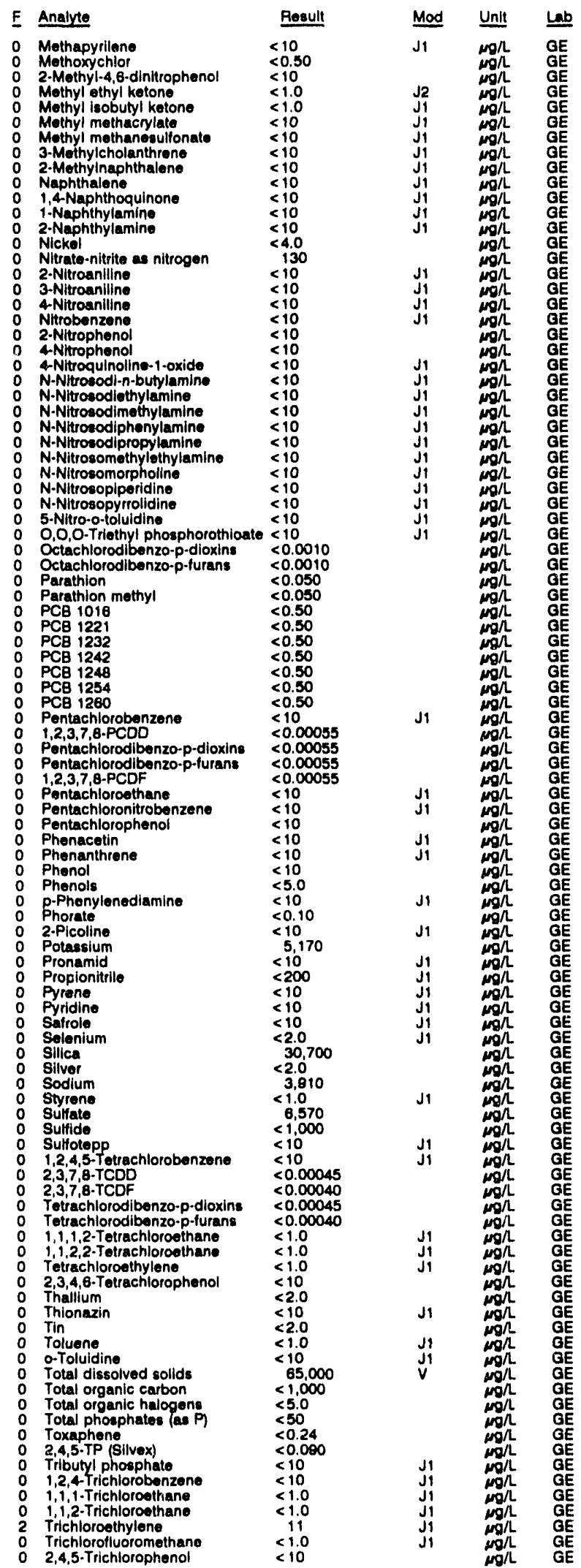


ANALYTICAL RESULTS

WELL BGO 12AR colloctod on 08/05/92, laboratory analyses (cont.)

\begin{tabular}{|c|c|c|c|c|c|}
\hline E & Analyte & Rosult & Mod & Unit & Lab \\
\hline $\begin{array}{l}0 \\
0 \\
0 \\
0 \\
2 \\
0 \\
0 \\
0 \\
0 \\
0 \\
0 \\
0 \\
0 \\
0 \\
0 \\
0\end{array}$ & 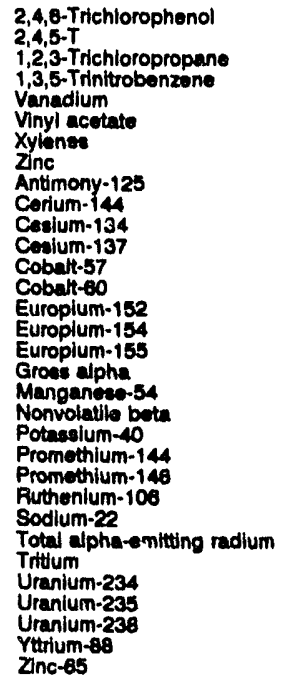 & 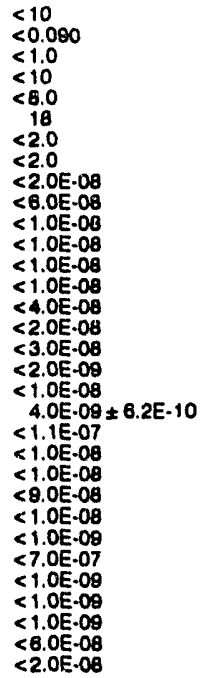 & $\begin{array}{l}\mathrm{J}_{1} \\
\mathrm{~J}_{1} \\
\mathrm{~J}_{1} \\
\mathrm{~J}_{1}\end{array}$ & 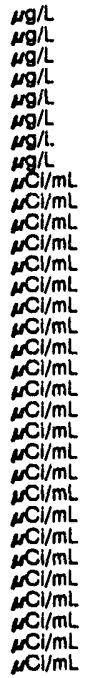 & $\begin{array}{l}G E \\
G E \\
G E \\
G E \\
G E \\
G E \\
G E \\
G E \\
G P \\
G P \\
G P \\
G P \\
G P \\
G P \\
G P \\
G P \\
G P \\
G E \\
G P \\
G E \\
G P \\
G P \\
G P \\
G P \\
G P \\
G E \\
G E \\
G P \\
G P \\
G P \\
G P \\
G P\end{array}$ \\
\hline
\end{tabular}

WELI. BGO 12CR

MEASUREMENTS CONDUCTED IN THE FIELO

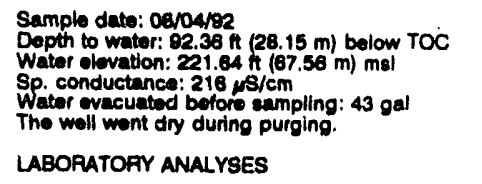

Time: 11:20

pH: 10.5

Waler temperature: $22.5^{\circ} \mathrm{C}$

LABORATORY ANALYSES

F Anabyte

2 pH

o Acensph

o Acenaphthene

Acenaphthylone

Acotoniturio (Methyl cyanide) Acetophenonv

2-Acetyonon

2-Acetylaminofiuorene

- Acrololn

o Acrylonitril

Aldrin
2 Alyl chloride
2 Numinum

4Aminobiphenyl

Aniline

Anthracene

- Anthracene

Antimony

O Aramito

Arronic

Barium

Benzeno

bota-Banzene troxachloride

delta-Benzene hexachiorlde

Benzo[ajanthracone

Benzo a anthracen

B Eenzo bluoranthene

- Benzo kffluoranthene

o Benzo $k$ fficuoranthene

o Benzolg.h.lyperylene

Benzo g, $h, 1$ perylone

Bonzo ajpyrene

Benzyl alcoho

Bonzyl alcohol

Beryllium

Bis(2-chloroethoxy) methene

Bia(2-chloroethoxy) methan

Bis (2-chloroothyl) ther

Bis (2-chloroethyl) ether
Bis (2-chioroisopropyl) ether

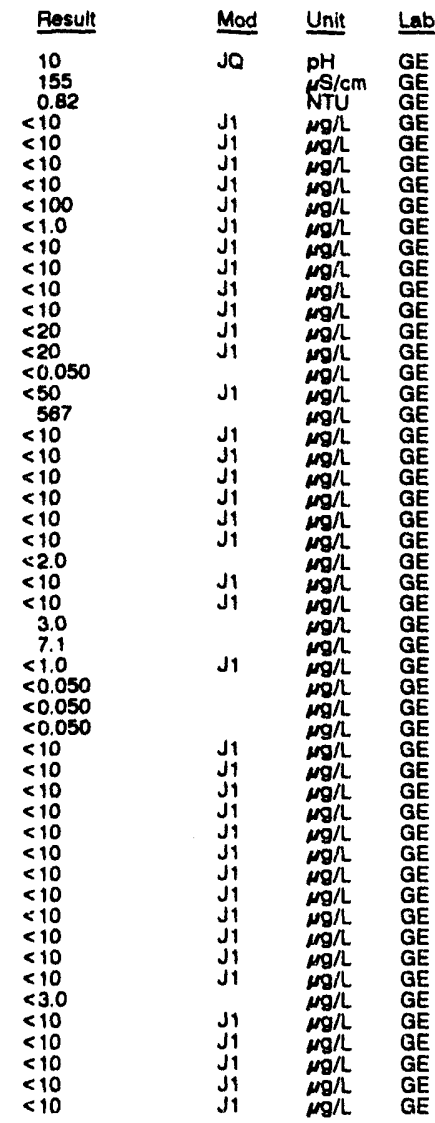

WELL BGO 12CA collected on 08/04/92, laboratory analyses (cont.)

\begin{tabular}{|c|}
\hline Analyte \\
\hline 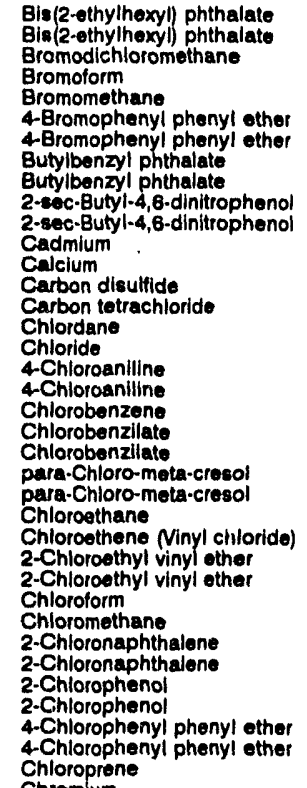 \\
\hline
\end{tabular}

Result Mod

$<10$

$<10$

$<1.0$

$<1.0$

$<10$

$<10$

$<10$

$<10$
$<2.0$

15,300

$<1.0$
$<1.0$

$<0.50$

$<10$
$<10$

$<1.0$

$<10$

$<10$

$<1.0$

$<10$

$<1.0$

$<1.0$

10

$<10$

$<10$

Chromium

0 Chrysene

Chryeene

0 Cobalt

o-Cresol (2-Mothylphonol)

o-Cresol (2-Methylphenol)

m-Cresol (3-Methylphenol)

p-Cresol (4-Methylphenol)

Cyanide

0 P,P'-DOD

P,P'-DDE

biallate

0 Diallate

Dibenz[a,h]anthracene

Dibenz $[a, h]$ anthracene

Dibenzofuran

Dibromochloromethane

1,2-Dibromo-3-chloropropane

1,2-Dibromoethane

Dibromomethanane

Di-n-butyl phthalate

0 Di-n-butyl phthalate

1,2-Dichlorobenzeno

o 1,3-Dichlorobenzene

1,3-Dichlorobenzen

1,4-Dichlorobenzen

1,4-Dichlorobenzeno

0 3,3. Oichlorobenzidine

trans-1,4-Dichloro-2-butene

Dichlorodifluoromethane

1,1-Dichloroethane

1,2-Dichloroethane

0 1,1-Dichloroothylene

o trang-1,2.Dichloroethylene

0 Dichloromethane

2,4-Dichlorophenol

2,6-Dichlorophenol

2,4-Dichlorophenoxyacetic acid

1,2-Dichloropropane

cis-1,3-Dichloropropene

trans-1,3-Dichloropropene

Dieldrin

Diethyl phthalate

Dimethoate

Dimothoate

2,4-Dimethyl phenol

Dimethyl phthalate

Dimethyl phthalate

p.Dimeinylaminoazobenzene

p-Dimethylaminoazobenzeno

Dimethylbenz(a)anthracene
$<200$
5.8

$<10^{\circ}$
$<10$

$<4.0$

$<4.0$

$<10$

$<10$
$<10$

$<10$

$<5.0$

$<0.10$

$<0.10$

$<10$

$<10$

$<10$

$<10$

$<1.0$

$<1.0$

$<10$

$<10$

$<10$

$<10$

$<10$
$<10$

$<10$

$<10$

$<1.0$

$<1.0$

$<1.0$

$<1.0$

$<10$

$<10$
$<10$

$<10$

$<0.30$

$<1.0$
$<1.0$

$<0.50$

$<10$

$<10$

$<10$
$<10$

$<10$

$<10$

$<10$

$<10$
$<10$

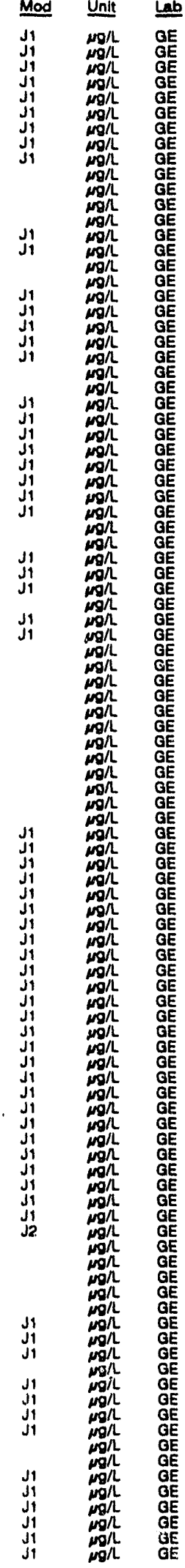


WELL BGO 12CA collected on 08/04/92, laboratory analyses (cont.)

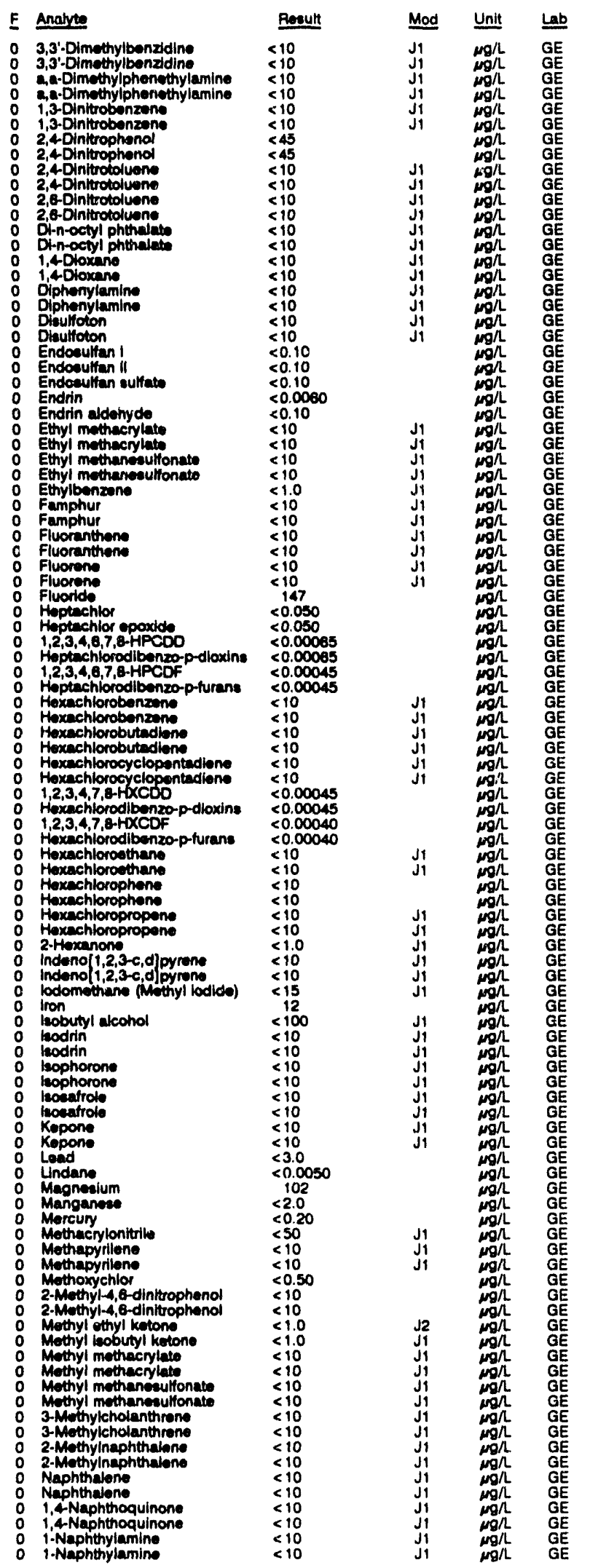

WELL BGO 12CR collocted on 08/04/92, laboratory analyses (cont.)

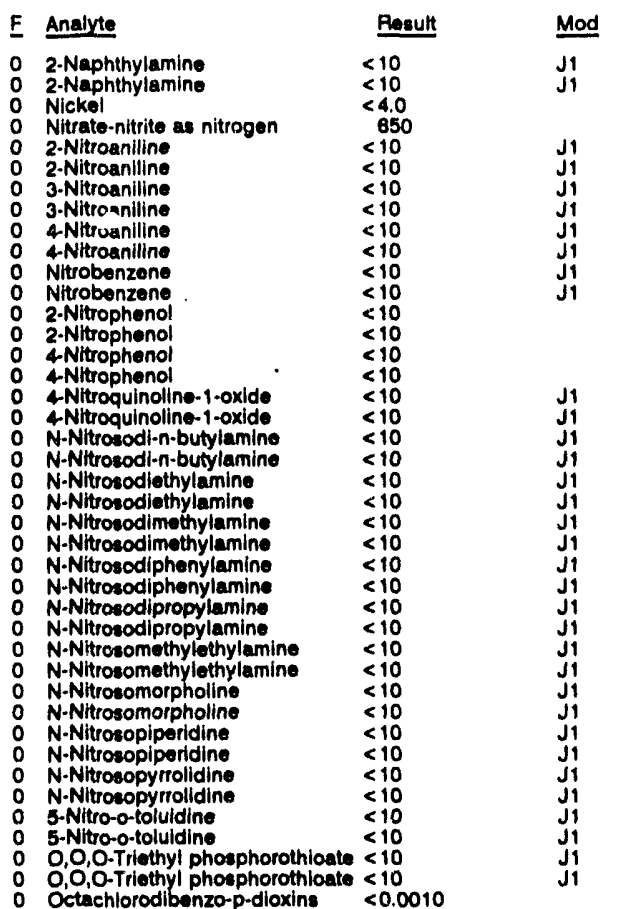

Unit Lيb

$\mathrm{mol} / \mathrm{GE}$

$\begin{array}{ll}\operatorname{mon}_{\ln } & \mathrm{GE} \\ \mathrm{GE} & \mathrm{GE} \\ \mathrm{GE} & \mathrm{GE}\end{array}$

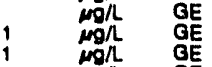

g

G

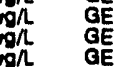

ân

mon GE

$\operatorname{mog}_{\text {ge }}$ ge

$\operatorname{mon}_{\operatorname{mon}} \mathrm{GE}$

of

a

aE

$\operatorname{mogh}_{\cos } \mathrm{GE}$

$\operatorname{mogh}_{\text {gE }}$

at

woh GE

Octachlorodibenzo-p-dioxins $<0.0010$

o Parathion methyl $<0.050$

0 PCB $1016 \quad<0.50$

PCB $1221<0.50$

PCE $1232<0.50$

0 PCB $1248 \quad<0.50$

$\begin{array}{lll}0 & \text { PCB } 1254 & <0.50 \\ 0 & \text { PCB } 1260 & <0.50\end{array}$

0 Pentachlorobenzene $<10$

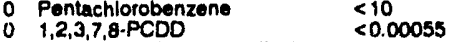

<0.00055

0 Pentachlorodibenzo-p-furans $<0.00055$

0 1,2,3,0 0

o Pentachlorouthane

Pentachloronltronenzene $<10$

Pentachloronitsobenzene $<10$

$<10$

Pentachlorophenol

Phenacetin

Phenacetin

Phenanthrene

Phenol

Phenol

p-Phenylenediamine

p.Phenylenediamine

2-Picoline

2-Picoline
2-Picollne

2-Picollne

Pronamid

Pronamionitrile

Pyrene

: Pyrone

Pyrdine

Safrole

Selenium

Sillica

Sodium

Styrene

Styrene
Sulfate

Sulfide

Sulfide

Sulfotopp

1,2,4,5-Tetrachlorobenzene

1,2,4,5.Tetrachlorobenzene

o 2,3,7,8-TCDD

2,3,7,8-TCDF
Tetrachiorodibenzo-p-dioxins

10
10
10
10
10
$<10$

$<10$
$<10$
$<10$

$<10$
$<10$
$<10$
$<10$

$\leq<10$

$<10$
$<5.0$
$<10$
$<10$

$\leq 10$

$<0.10$

$<10$

$<10$

$<10$

$<10$

$<10$

$\leq 10$

$<10$

$<2.0$

$<2.0$

$<1.0$

$<1,000$

$<1,000$

$<10$
$<10$

$<10$

$<10$

$<0.00045$

$<0.00040$
$<0.00045$ 
ANALYTICAL RESULTS

WELL BGO 12CR collected on 08/04/82, laboratory analyeses (cont)

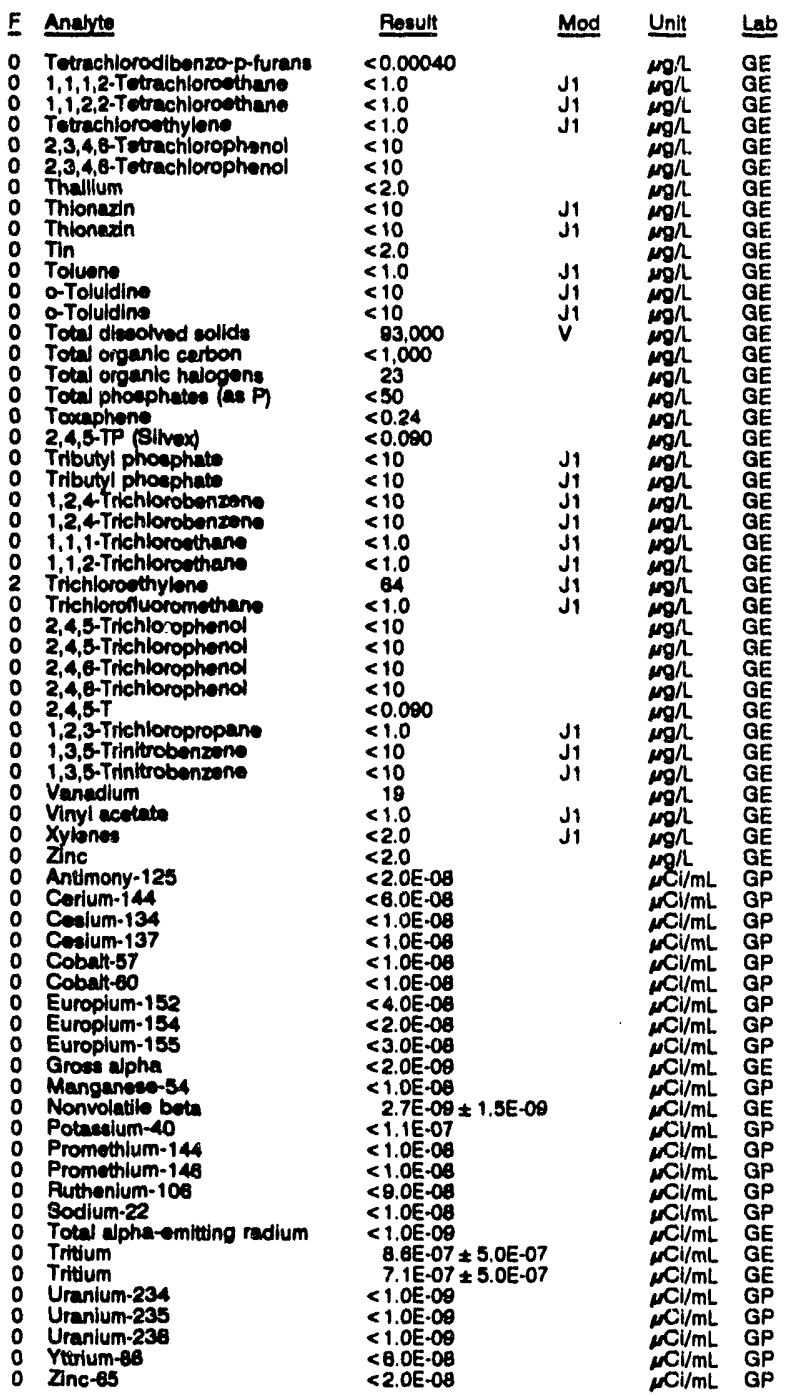

\section{WELL BGO 12D}

MEASUREMENTS CONDUCTED IN THE FIELD

Sample dala: 0avoserer

Water alevation: 23157 h $(70.58 \mathrm{~m}) \mathrm{mal}$

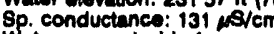

$$
\begin{array}{ll}
03 \mathrm{~m} / \text { below TOC } & \text { pH: } 8.4 \\
0.58 \mathrm{~m}) \mathrm{mal} & \text { Alkalinity: } 25 \mathrm{mg} / \mathrm{L} \\
\text { Water temperature: } 20.5^{\circ} \mathrm{C}
\end{array}
$$

Time: $8: 10$

The well wont dry during purging.

\section{LABORATORY ANALYSES}

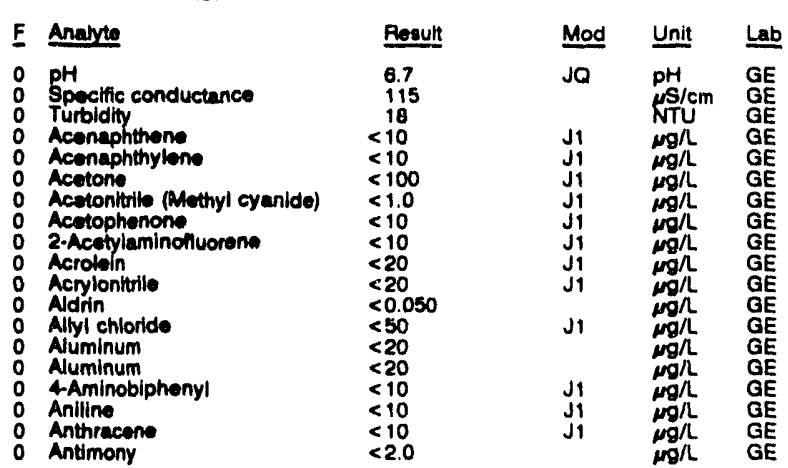

WELL BGO 120 collected on 08/08/82, laboratory analyees (cont.)

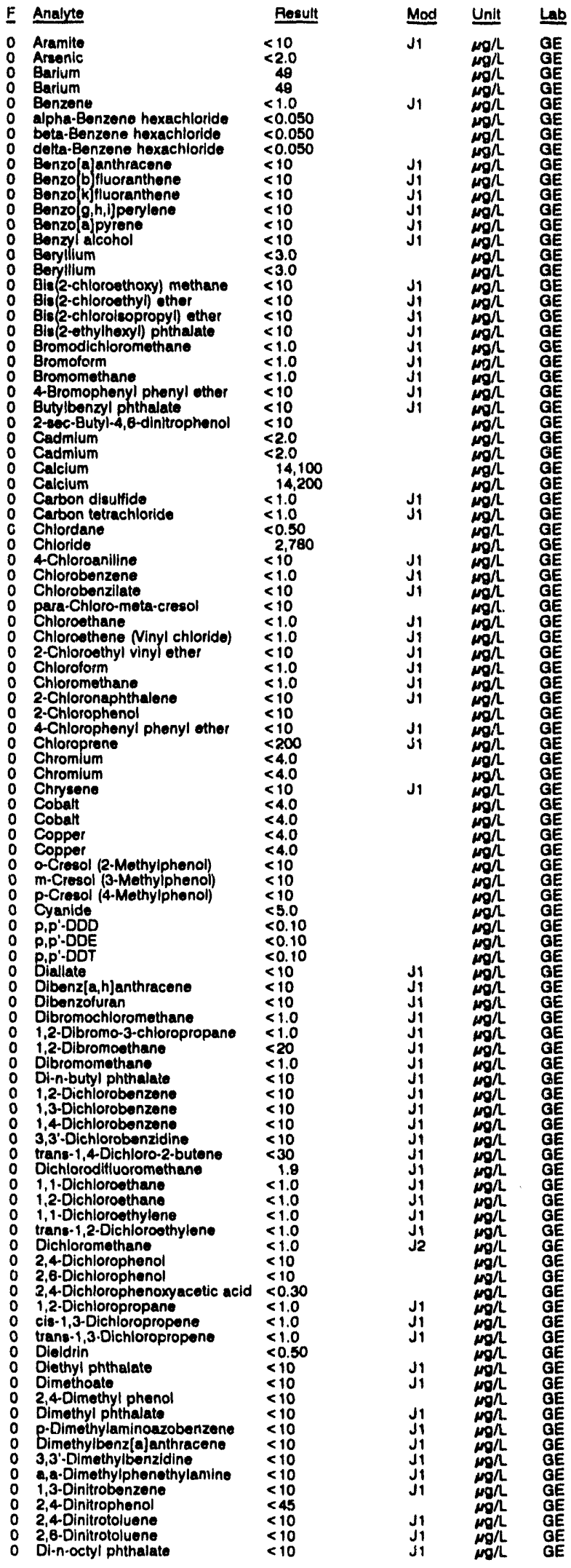


WELL 800120 collected on 08/08/92, laboratory analyees (cont.)

Oiphenyla

0 Endowultan

Endrin aldohyde

Ethyl methecrylate

Ethylbenzeno

Fluoranthene

Fluoren

Fiuorlde

Heptimchlor epoxide.

$1,2,3,4,6,7,8-H P C D O$
$1,2,3,4,6,7,6-H P C D D$

Heptechlorodibenzo-p-dioxins

1,2,3,4,6,7,8-HPCDF

o 1,2,3,4,6,7,6-HPCDF

o Heptechlorodibenzo-p-furans

o Hexechlorobenzane

o Hexechlorocyclopentiadien

$1,2,3,4,7,8+4 \times C D O$

Hexchlorodibenzo-p-dlaxins

o Hexechlorodibenzo-p-dioxin

o $1,2,3,4,7,8-4 \times C D F$

o Hoxichiorodibenzo-p-turans

o Hoxachlorodibenzo-p-furane

H Hoxachlorowthan

o Hexechloropropent

2-Hoxanom

indeno[1,2,3-c,d]pyrene

lodomothane (Mhthyl lodide) Iron

bobutyl alcohol

0 leodin

o leophorone

Kepone

o Lead

O Undane

o Magneclum

Manganees

Mangan

Methacryionturle

Methapyriton

a)-Methyl-4, e-dinitrophene

Aethyl ethyl ketone

Mothyl mothecrylate

Mothyl mothaneaulionato

2. Mutyulcholnthrono

Naphthatene

1.4Nephthoquinon

2-Nephtriylamino

Nickel

Nitrieto-nituite a nitrogen

2-Nitroanlline

4 Nltroanilline

Nitrobenzane

2-Nitrophenol

Nitropuinoline-1-axide

N-Nitroedi-n-butylamine

N-Nitrosodiethylamine

N-Nitrosodimethylamine

N-Nitrosodiphonylamine

N-Nitrocodipropylamine

N-Nitrosomorpholine

N-Nitrosopiperidine

N-Nitrocopyrrolldin

O,0,0-Triethyl phomphorothicate < < 10,0010

ctachlorodibonzo-p-dioxins

Octechlorodibenzo-p-doxine

Octachorodibanzo-p-furans

Perntion

Parathion methyl

PCB 1016
PCB 1221

PCB 1221
PCB 1232
$<10$
$<10$
$<10$

$<0.10$

$<0.10$

$<0.0060$

$<10$

10

$<10$
$<10$

$<10$

$<0.050$

$<00005$

$<0.00065$

$<0.00065$

(

$<0.0004$

$<0.00045$

$<10$
$<10$

$<10.00045$

$<0.00045$

$<0.0004$

$<0.0004$

(0.00040

$<0.00040$

$<10$

$<10$

$<10$
$<1.0$

$<10$

$<15$

43

$<100$

$<10$

$<10$
$<10$

$<0.0050$

1,500

14

$<0.20$

$<10$

$<0.50$

$<1.0$

$<1.0$

$<10$

$<10$
$<10$
$<10$

$<10$

$<10$

$<10$
$<4.0$

4.4
1.680

$<10$

$<10$
$<10$

$<10$

$<10$

$<10$

$<10$

$<10$

$<10$

$<0.0010$

$<<0.0010$

$<0.050$

$<0.50$

$<0.50$
J1 No/L GE

GE

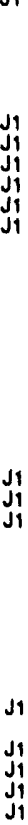

J1
J1

J1

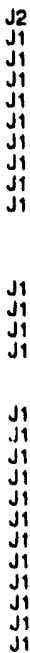

WELL BGO 120 collectod on 08/06/82, laboratory analysese (cont.)

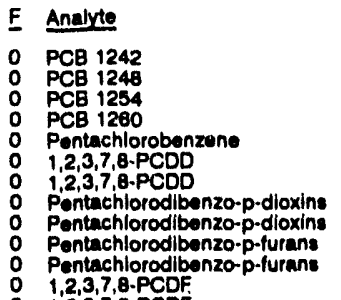

Preaul

$<0.50$

$<0.50$

$<100.0005$

$<0.00055$

$<0.0005$

$<0.00055$

$<0.00055$

$<0.00055$

$1,2,3,7,0$-PCDF

- Pentuchloronitrobenzene

o Pontachlorophenol

Phonacotin

Phonanthrene

Phenol

O Phenols

p-Phenylenediamine

Phorato

2.Plcolline

$\therefore$ Potacklum

Pronamid

Propion

Pyridino

o safrote

o Solenium

o silica

o Silver

Sodium

Sodium

Styrene

Sulfide

Sulfolepp

1,2, $4,5 \cdot$ Tetrach
$2,3,7,8$, TCDO

$2,3,7,6-T C D O$
$2,37,6 . T C D F$

2,3,7,8-TCDF

Totrachlorodibonzo-p-dioxins

Tetrachlorodibenzo-p-furans

Tetrachlorodibenzo-p-furan

1,1,2,2-Tetrachloroethen

2,3,46-Tetrachloropheno

o Thallium

Tin

Toluene

Total dissolved solids

Total organic carbon

2 Total organic halogens

Total phosphates (as P)

Toxaphene

1,2,4-Trichlorobenzene

- 1,1,1-Trichlorcethane

1,1,2-Trichloroethan

2 Trichloroethylone

Trichlorofluoromethane

2,4,5-Trichlorophenol

2,4,6-Trichloropheno

1,2,3-Trichloropropane

1,3,5-Trinitrobs

o Vinyl acetate

0 Xylenes

Zine

Antimony. 12

Cerium-144

Cosium-134

Cesium-137

Cobalt-57

Cobalt-60

Europlum-152

Europium-155

Groses alpha

Nonvolatile beta

Potassium.40

Promethium-146

Ruthenlum-106

Sodium-22
$<<10$

$<10$
$<10$

$<10$
$<10$

$<10$

$<5.0$

$<10$

$<10$

2,010

2,010
$<10$
$<200$

$<10$

$<<10$

$<2.0$

8.4
-2.0

$<2.0$

4,680
4,850
$<+, 0$

$<\begin{array}{r}<.0 \\ 8,540\end{array}$

$<1,000$

$<10$

$<0.00045$

$<0.00040$

$<0.00040$

$<0.00045$

$<0.00040$

$<0.00040$

$<1.0$
$<1.0$

$<1.0$

$<10$

$<2.0$

2.1
$<2.0$

$<1.0$

$<10$

$<1,000$

$\begin{array}{r}54 \\ <50 \\ \hline\end{array}$

$<0.24$
$<0.000$

$<0.080$

$<1.0$

160

1.7
$<10$

$<100$

$<0.090$

$<1.0$
$<10$

$<8.0$

$<8.0$

$<2.0$

4.9

$<2.20-00$

$<$ <..0E-08

$<1.0 E-00$

$<1.0 E-00$

$<1.0 \mathrm{0} .06$

$<2.0 \mathrm{E} .00$

$<3.06 .08$

$<2.0 E-09$

$<2.0 E-09$

$<1.0 E-00$

$<10 \mathrm{0} 00$

$<8.0 E-08$

$<8.0 E-08$

Mod Unit Le

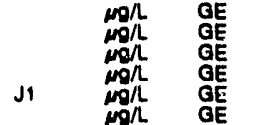

J1 
ANALYTICAL RESULTS

WELL 890120 collected on 08/08/92, laboratory analyeses (cont.)

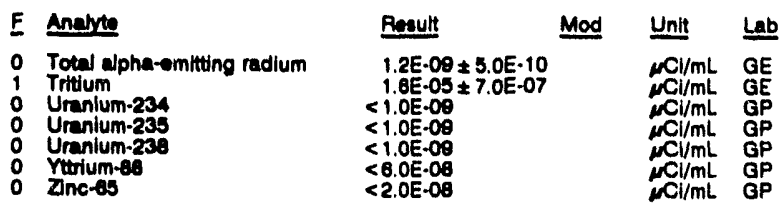

WELL BGO 13DR

MEASUAEMENTS CONDUCTED IN THE FIELD

Sample date; cev13ver

Depth to water: $87.62 \mathrm{f}(28.77 \mathrm{~m})$ bolow TOC

Water elevation: $231,48 \mathrm{~h} 77$

Witor evecuated bofore eampling: $9 \mathrm{gal}$

The woll went dry during purging.

LABORATORY ANALYEES

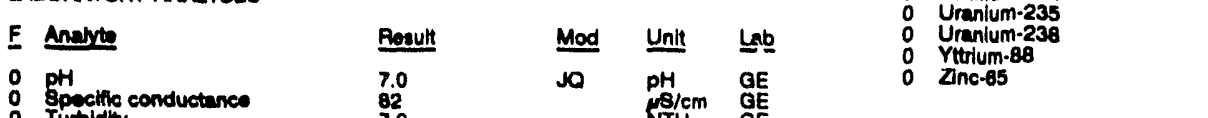

Time: $8: 10$

Alkelinity: $21 \mathrm{mgl}$

Water temperature: $20.2 \circ 0$

Turbidity

Acetophenon

Antimony

Amonic

Earium

Bromodichloromethane

Bromotorm

Bromomethane

Cadmium

Cerbon vetrechloride

Chiorldo.

Chlorobenzene

Chloroethane

C-Chloroethyl Minyl chloride

Chloromethan

Chromium

Copper

Dibromochloromethane

1,1-Dichloroethane

1,2-Dichioroathane

1,1-Dichloroethylene

Dichloromethane

2,4-Dichiorophenanyacetic acid

1,2-Dichloropropane

tran'-1,3-Dichloropropone

Endrin

Ethylbenzene

Fluoride

Iron

Unden

Magnealum

Mangane.

Moreury

Mothoxychlor

Naphthalene

Nitrata-nitutite as nitrogen

Phenols

Potackium

setanium

silica

siturer

Sodium

1,1,2,2-Tetrachloroethane

Tetrechloroethylone

O Tin

Toluene

Totwl diseotwed solide

-

Totw phosphetios (es P

Toxaphene

2,4,5-TP (Bivex)

Tributyl phosphate

1,1,1. Tnchloroethane

Trichloroethylene

Trichlorofluoromothane

Venadium

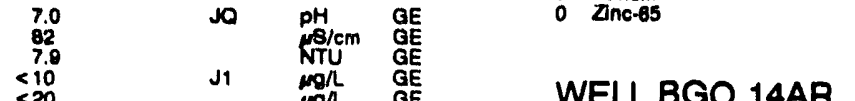

MEASUAEMENTS CONDUCTED IN THE FIELD

Sample date: 08/05/82

Depth to water: $141.39 \mathrm{n}(43.10 \mathrm{~m})$ bolow TOC

Water elevation: $159.31 \mathrm{n}(48.58 \mathrm{~m}) \mathrm{msl}$

Water evacuated bofore sampling: $165 \mathrm{gal}$

Time: 8:20

PH: 11.1

Water tomperature: $20.4^{\circ} \mathrm{C}$

LABORATORY ANALYYSES

\begin{tabular}{|c|c|c|c|}
\hline Anaivite & Prosult & Mod & Unit \\
\hline 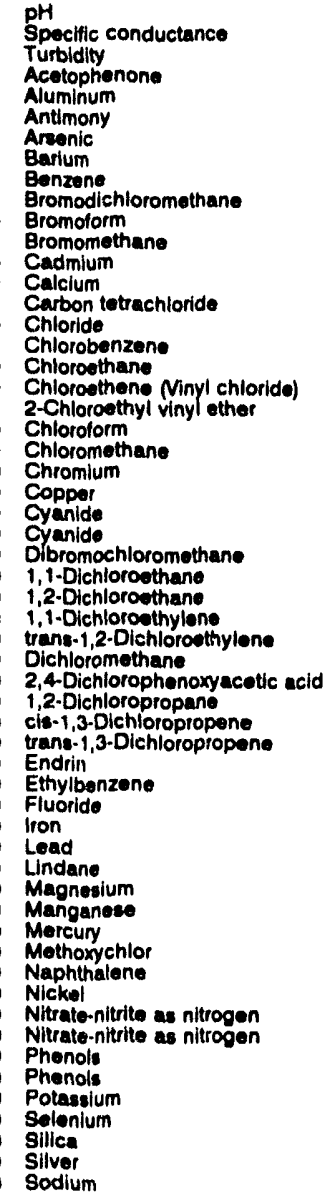 & $\begin{array}{l}11 \\
430 \\
0.11 \\
<10 \\
814 \\
<2.0 \\
5.9 \\
100 \\
<1.0 \\
<1.0 \\
<1.0 \\
<1.0 \\
<2.0 \\
45,300 \\
<1.0 \\
2.140 \\
<1.0 \\
<1.0 \\
<1.0 \\
<1.0 \\
<1.0 \\
<1.0 \\
<4.0 \\
<4.0 \\
<5.0 \\
<5.0 \\
<1.0 \\
<1.0 \\
<1.0 \\
<1.0 \\
<1.0 \\
11.1 \\
<0.30 \\
<1.0 \\
<1.0 \\
<1.0 \\
<0.0060 \\
<1.0 \\
100 \\
41.1 \\
<3.0 \\
<0.0050 \\
458 \\
6.9 \\
<0.20 \\
<0.50 \\
<10 \\
<4.0 \\
240 \\
240 \\
<5.0 \\
<5.0 \\
13,200 \\
<2.0 \\
21,600 \\
<2.0 \\
10.800\end{array}$ & $\begin{array}{l}\text { Jo } \\
\text { J1 }\end{array}$ & 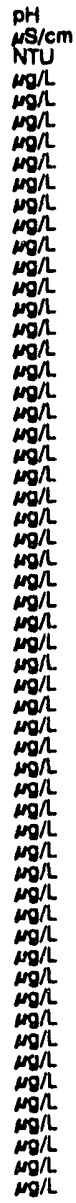 \\
\hline
\end{tabular}


ANALYTICAL RESULTS

WELL $8 G 0$ 14AF collected on 06/05/92, laboratory analyees (cont.)

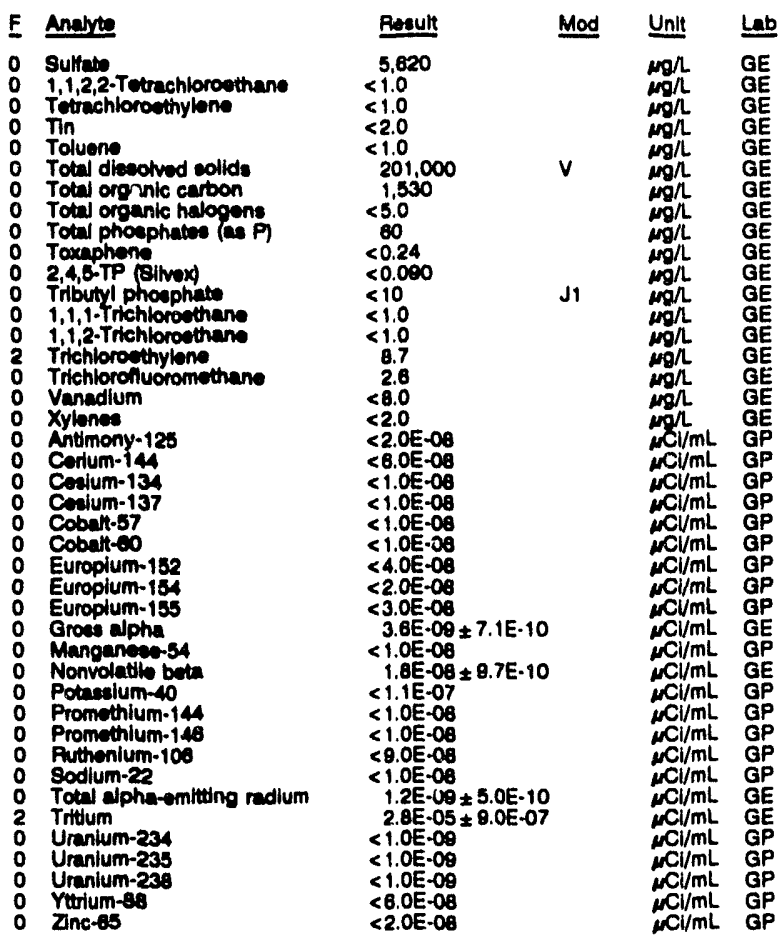

\section{WELL BGO 14CR}

MEASUREMENTS CONDUCTED IN THE FIELO

Sample dete: 0apospon

Depth to wator: 76.46 in $(23.31 \mathrm{~m})$ below TOC Wator olevation: $224.04 \mathrm{~h}(68.29 \mathrm{~m}) \mathrm{mol}$

Sp. conductence: $123, \mathrm{~s} / \mathrm{cm}$

Pkalinity: $24 \mathrm{mgh}$

Whater temperature: $20.80 \mathrm{C}$

The well went dy during purging.

LABORATORY ANALYSES

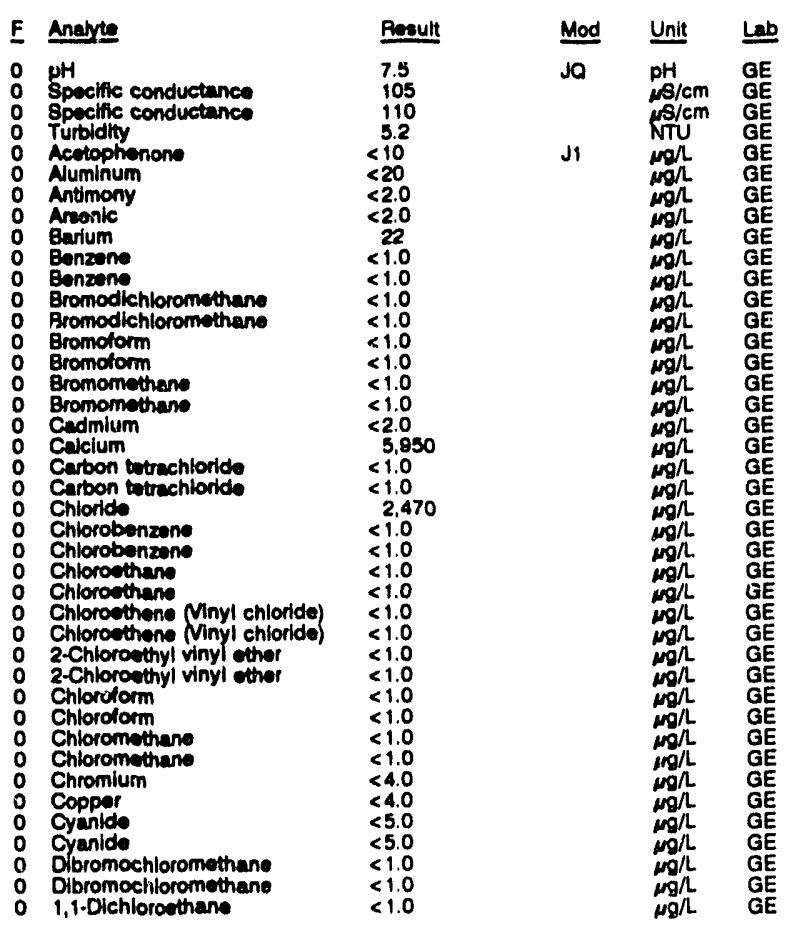

WELL BGO 14CR collected on 08/05/92, laboratory analyees (cont.)

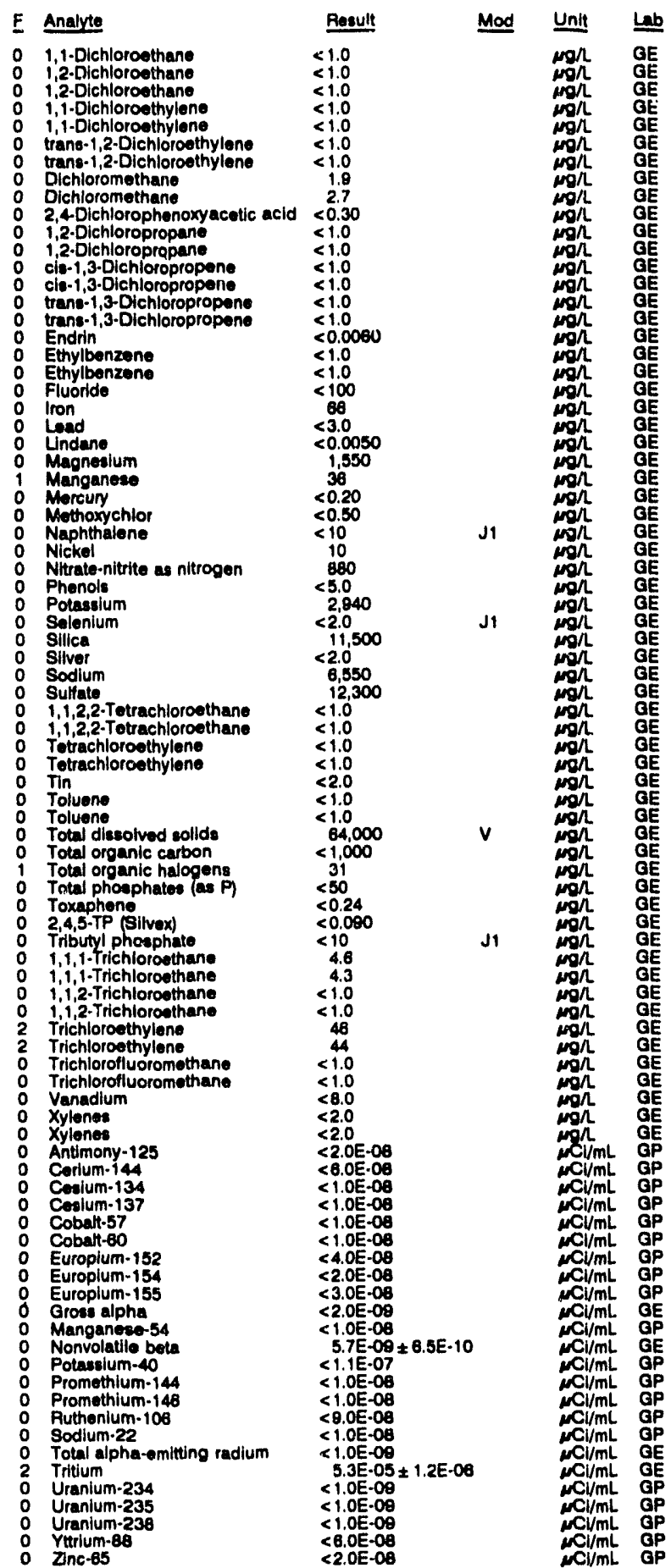


ANALYTICAL RESULTS

WELL BGO 14DR

MEASUREMENTS CONDUCTED IN THE FIELD

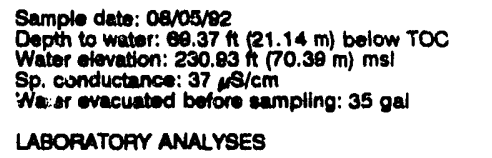

E Anajyte

0 pH

Speific conductance

- Acetophenono

: Alteminum

- Aveonic

o Barlum

Bromodichloromethane

Bromotorm

: Bromomethine

- Calcium

Carbon tetrachlorido

Chiorobenzene

Chorosthene Minyl chloride)

2-Chloroethyl vinyl wher

Chlorotom

Chirromethan

Chromium

Ocopots

Dibromoctionomethane

o 1,1 -itchloroethans

1,2-Dichloroctinane

o trans-1,2-Dichloroethylene

O Dichlorsmethane 2,4 Dichlorophenoxyecetic acid $<1$.

1,2-Dichloropropane

to-1,3-1,3-0htoroprojene

Envrin

Ethylbonzons

of Fluorid

0 Iron

o Undane

1 Magnealum

Mencury

Nethoxychlor

Nieitel

Nitrito-niturise niviogen

Phenols

Potionium

silica

siluear

Sodium

Sulfato-Tutrachlorouthan

Tetrachloroethylom

Tin

Toluene

Totwal diasolved sollids

Total organic carton

- Total phoesphates (as P)

Toxaphon

2,4,5-TP Blivexd

1,1,1-Trichiorowthan

1, , 2-Trichlorosthen

Trichlonsethylone

Trichlorofluor

- Varadium

Antimony-125

Corium-144

Cosium-134

Coblum-137

Cobalt 60

Europium-159

Europlum-15a

Groplumiso

Groso aphe

Nonvolntile bat

Potassium- 40

Promethlum-14

Promethium-146

Ruthenium-106

0.58

$<\rightarrow 0$

$<2.0$

8.7
$<1.0$

$<1.0$

$<1.0$

$<2,680$

$<1.0$

$<1.0$

$<1.0$

$<1.0$

$<1.0$

$<4.0$
6.1

$<5.0$

$\leq 1.0$

<1.0

$<1.0$

$<1.0$

0.30

$<1.0$

$<1.0080$

$<0.00$
$<1.0$
$<100$

8.4
3.1
$<0.0050$

$<0.0050$

620
30

$<0.20$

$<<0$

4.3
1,150

$<5.0$

$<2.0$

8,350

$<2.0$

1.470

$<1.0$

$<2.0$

20,000

$<1,000$

10
$<50$

$<0.24$

$<0.090$

$<10$

$<1.0$

$<1.0$

$<8.0$

$<2.0 E-00$

$<1.0 E-08$

$<1.0 E-08$

$<1 . G E-00$

$<1.6 E-08$

<

政

. 0 E-09

$<1.0 \mathrm{0}-08$

$<1.1 \mathrm{E}-07$

$<1.0 \mathrm{E}-00$

$<8.0 \mathrm{E} .08$

\section{Result Mod Unit Lab \\ 8.3
40

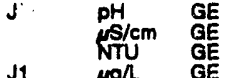 \\ WELL BGO 15D}

$2.6 E-09 \pm 4.0 E-10$

J1

$\operatorname{mogh}_{\cos h}$

gin $G E$

$G E$
$G E$
$G E$
$G E$
$G E$
$G E$
$G E$
$G E$
$G E$
$G E$
$G E$
$G E$
$G E$
$G E$
$G E$
$G E$
$G E$
$G E$
$G E$
$G E$

LABOPATORY ANALYSES
Time: 8:45

Alkalinity: $1 \mathrm{mon}$

Water temperature: $20.6^{\circ} \mathrm{C}$

MEASUREMENTS CONDUCTED IN THE FIELD

Sample date: $08 / 08 / 92$
Depth to water: $68.16 \mathrm{ft}(20.78 \mathrm{~m})$ below TOC
Water elevation: $230.54 \mathrm{ft}(70.27 \mathrm{~m}) \mathrm{msl}$
Sp. conductance: 37 . $5 / \mathrm{cm}$
Water evacuated betore sampilng: $31 \mathrm{gal}$

Time: 13:50

Alkalinity: $2 \mathrm{mg} / \mathrm{l}$

Water tomperature: $20.0^{\circ} \mathrm{C}$

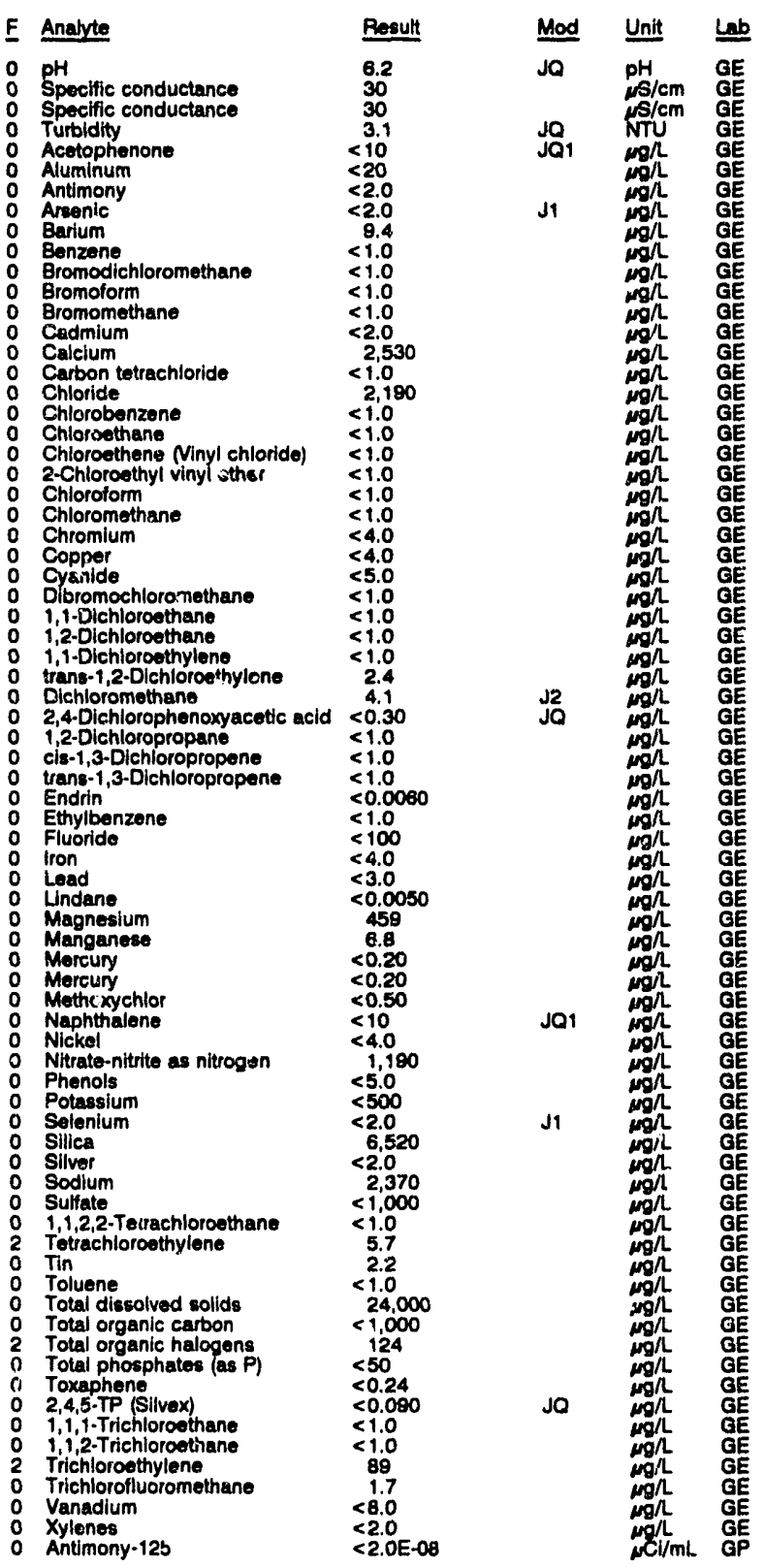


WELL BGO 180 collected on 08/06/82, taboratory analyees (cont.)

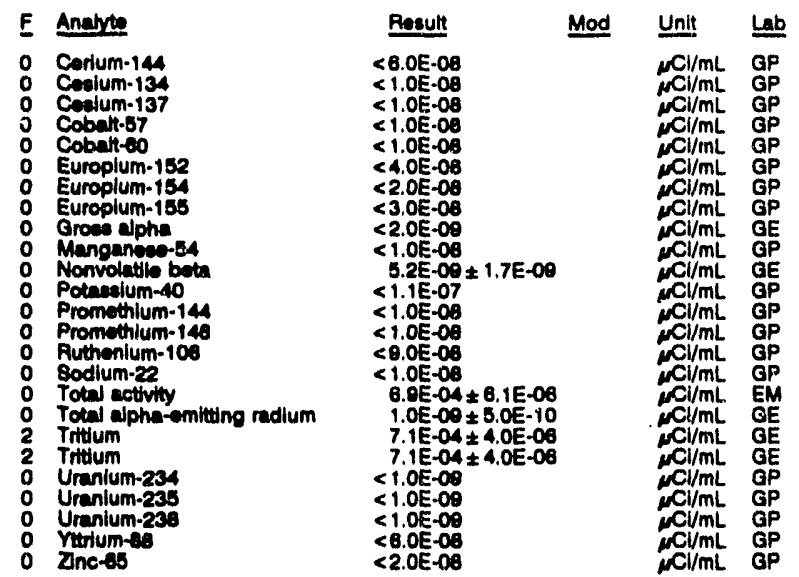

WELL BGO 16A

MEASUREMENTS CONDUCTED IN THE FIELD

\begin{tabular}{|c|c|}
\hline 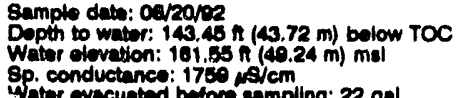 & $\begin{array}{l}\text { Time: } 8: 10 \\
\text { pH: } 11.7 \\
\text { Nkallinity: } 401 \mathrm{mg} / \\
\text { Water tomperature: } 20.3^{\circ} \mathrm{C}\end{array}$ \\
\hline
\end{tabular}

Witer evecuated before sampling: 22 gal

The woll went dry during purging

LABORATOFY ANALYEES

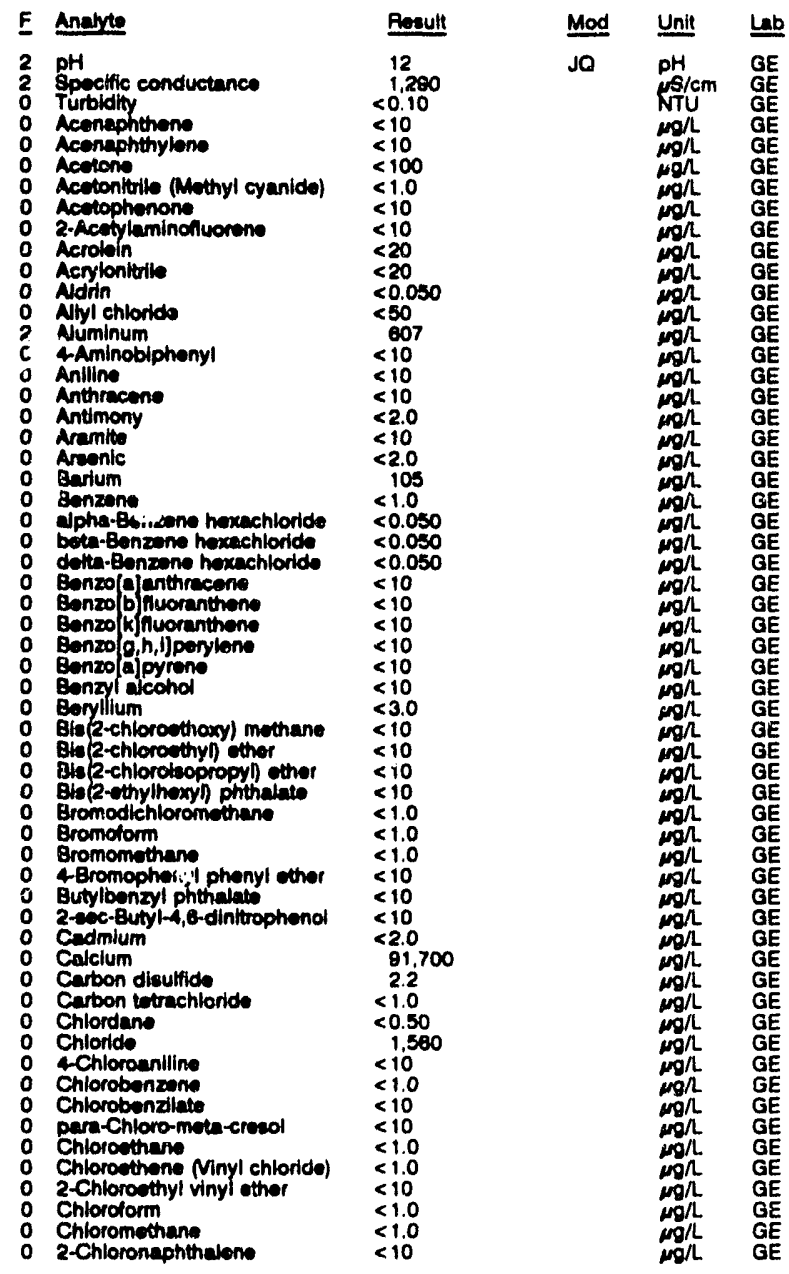

WELL BGO $16 \mathrm{~A}$ collected on 08/20/82, laboratory analyees (cont.)

\begin{tabular}{|c|c|c|c|}
\hline Analyte & Rasult & Mod & Unit \\
\hline 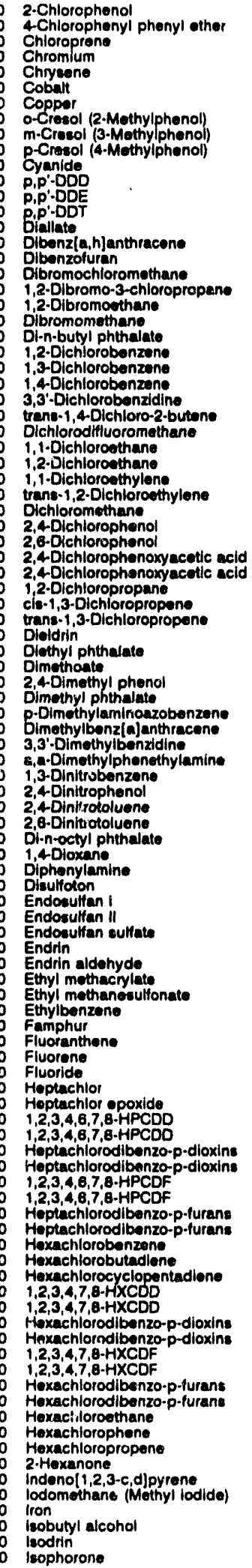 & 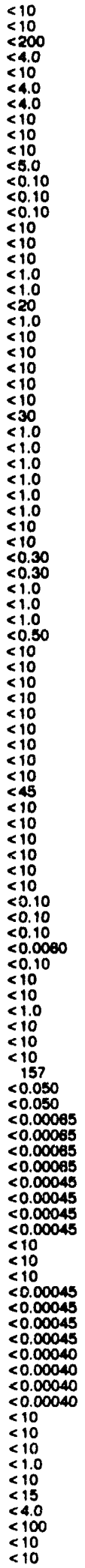 & J2 & 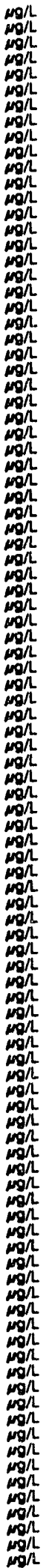 \\
\hline
\end{tabular}


WELL BGO 184 colloctod on 08/20/82, laboratory analyses (cont)

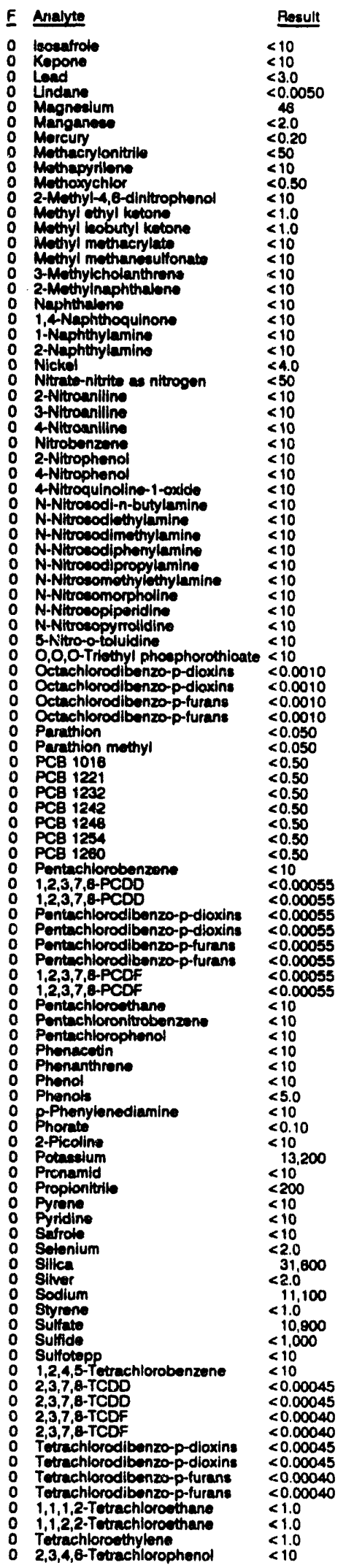

WELL BGO 16A collected on 08/20/92, laboratory analyees (cont.)

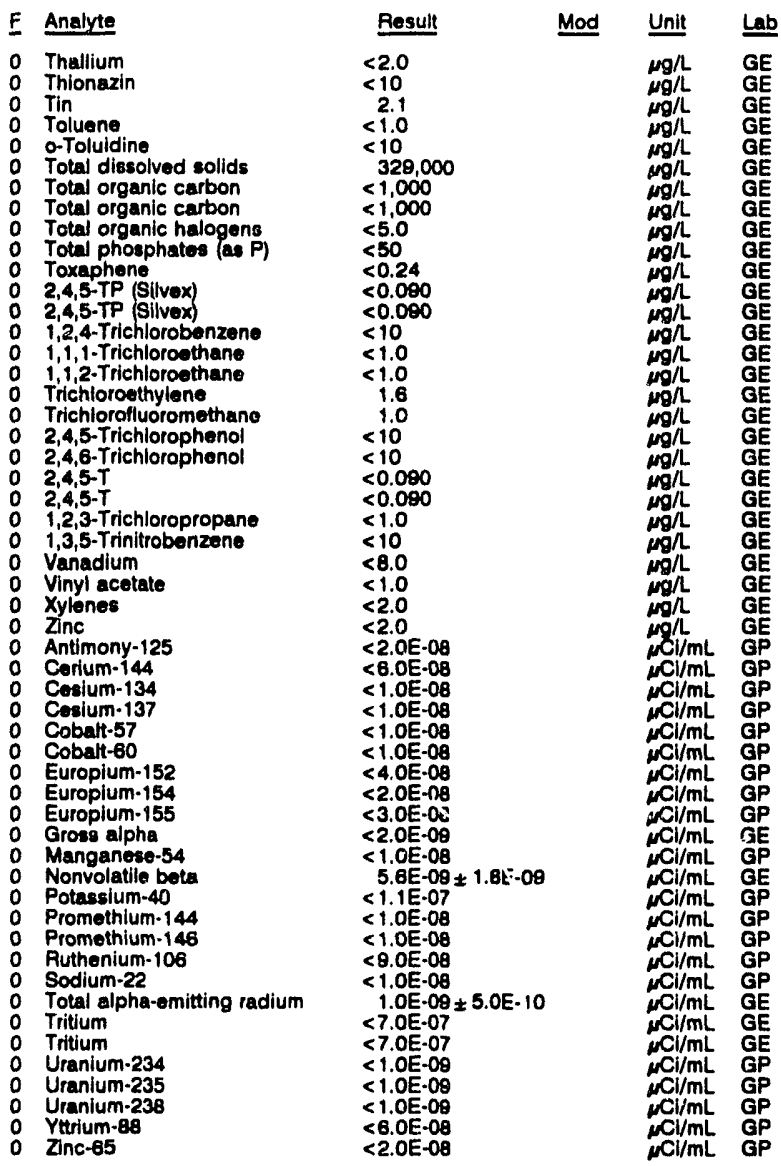

WELL BGO 16D

MEASUREMENTS CONDUCTED IN THE FIELD

$\begin{array}{ll}\text { Sample date: } 08 / 20 / 92 & \text { Time: } 9: 35 \\ \text { Depth to water: } 73.15 \mathrm{nt}(22.30 \mathrm{~m}) \text { bolow TOC } & \text { pH: } 10.7 \\ \text { Water elevation: } 231.45 \mathrm{~h}(70.55 \mathrm{~m}) \mathrm{msl} & \text { Alkalinity: } 132 \mathrm{mg} / \mathrm{h} \\ \text { Sp. conductance: } 385 \mu \text { S } \mathrm{cm} & \text { Water temperature: } 20.5 \circ \mathrm{C} \\ \text { Water ovacuated bofore sampling: } 4 \mathrm{gal} & \\ \text { The well went dry during purging. } & \end{array}$

The well went dry during purging.

LABORATORY ANALYSES

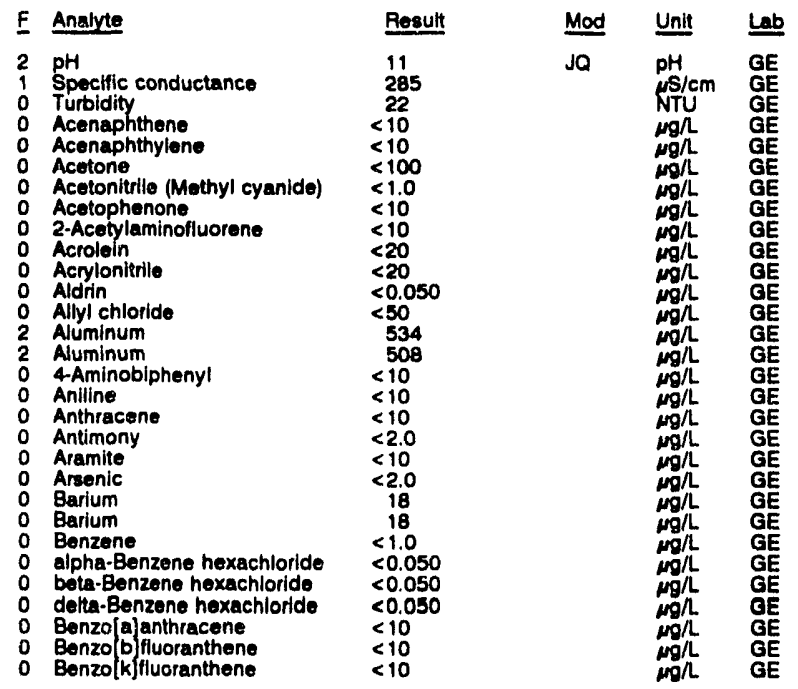


ANALYTICAL RESULTS

WELL BGO 18D collocted on 06/20/92, laboratory analyses (cont.)

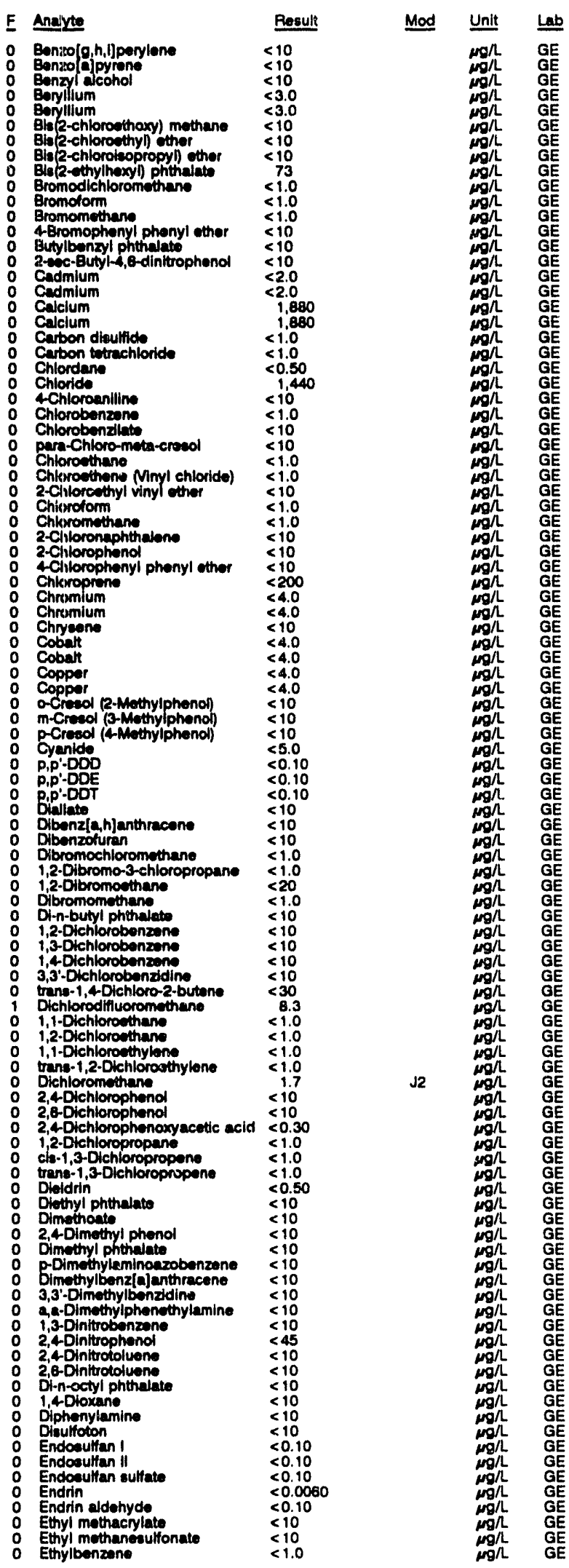

WELL BGO 160 collocted on 08/20/92, laboratory analyees (cont.)

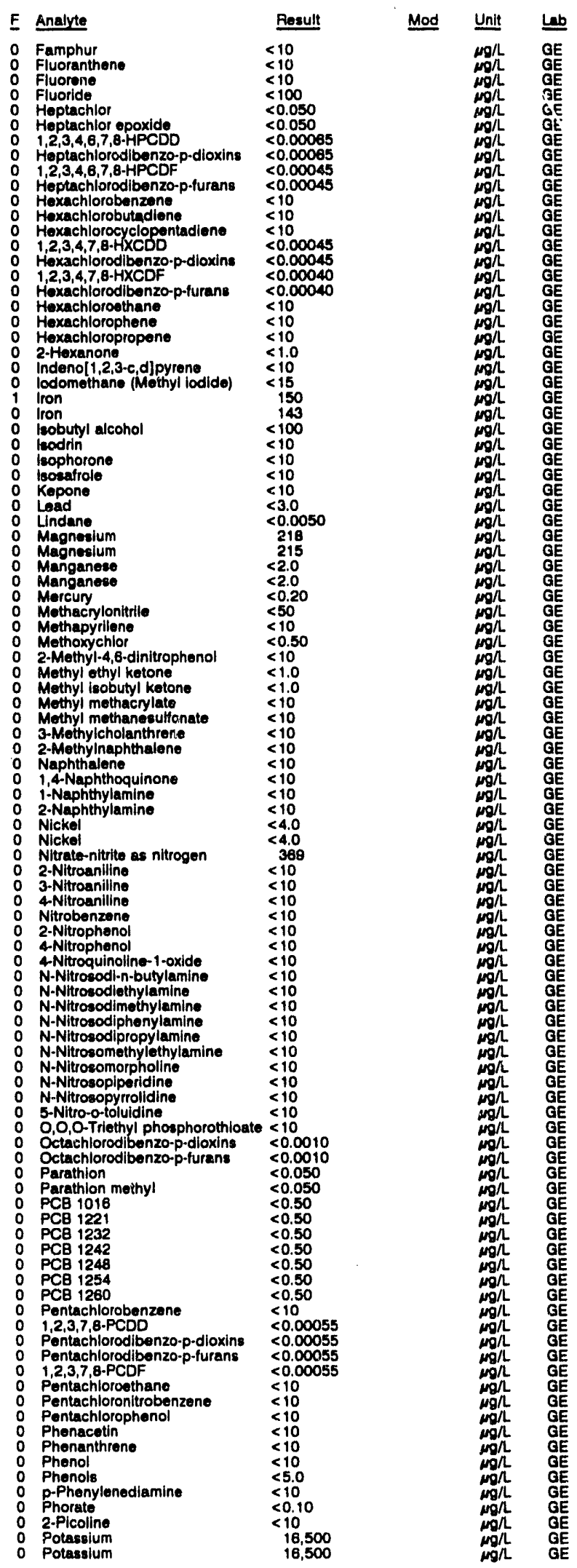


ANALYTICAL RESULTS

WELL BGO 180 collected on 08/20/82, laborktiry anaiyses (cont.)

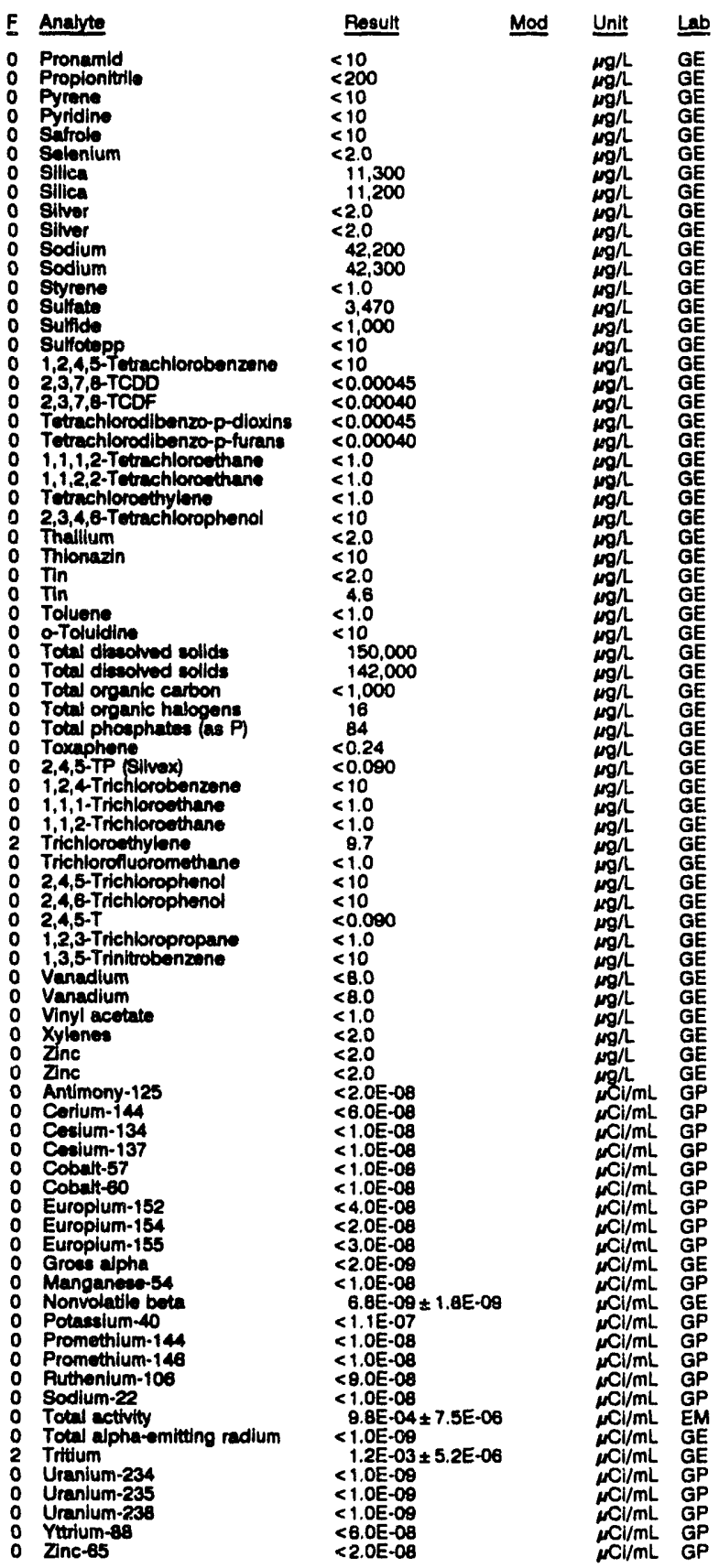

WELL BGO 17DR

MEASUREMENTS CONDUCTED IN THE FIELD

Sample date: 08/20/92 Time: 10:25

WELL BGO 18A

MEASUREMENTS CONDUCTED IN THE FIELD

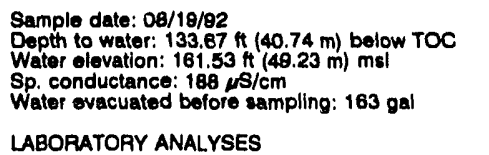

Time: $8: 20$

AH: 8.8 : $69 \mathrm{mg} / \mathrm{h}$

Water temperature: $20.2^{\circ} \mathrm{C}$

LABORATORY ANALYSES

\section{$E$ Analyte}

$0 \mathrm{pH}$

Specific

Acetophenone

Aluminum

Arsenle

Barium

Bromodichloromethane

Eromoform

Bromomethan

Calclum

Carbon tetrachloride

Chloride

Chlorobenzene

Chlorosthene Ninyl chloride)

2.Chlopoethyl vinyl ether

Chioroform

Chioromethan

Chromium

Copper

Dibromochloromethane

1,1-Dichloroethane

1,1-Dichloroothyiene

trans-1,2-Dichloroethylene

bicholno

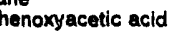

1,2-Dichloropropano

trans-1,3-Dichloroprene

Endrin

Ethylbenzene

o rioon

0 Load

Lindane

Manganese

Mercuny

Methoxychlor

O Nickel

Nitrate-nitrite as nitrogen

Phonols

o Solenium

Silica

Silver

Sodium

1,1,2,2-Tetrachloroethane

- Tetrachloroethylene

0 Tin

Toluene

Total dissolved sollds

Total organic carbon

2 Total organic halogens

Toxaphene

1.1,1-Trichloroethane

- $1,1,2$-Trichloroethane

- Trichloroethylene

Trichlorofluoromethane

Vanadium

Xylenes

Antimony-125

Corrium-144

Cosium-134

Cesium-134

Cosium-137

Cosbalt-57 73

Cobalt-57

Cobalt-60

Cobalt-60

Europlum-152

Europium-154

Europlum-154

- Europium-155

Result

7.5
1.8
$<0.10$
$<10$

$<10$
$<20$

$<2.0$

36
$<1.0$

$<1.0$

$<1.0$
$<1.0$

$<2.0$

$<1.0$

$<1.0$

$<1.0$

$<1.0$

$<1.0$

$<4.0$

$<4.0$

$<5.0$

$<1.0$

$<1.0$

$<1.0$
$<1.0$

$<0.30$

$<1.0$
$<1.0$

$<1.0$
$<1.0$

$<0.008$

$<1.0$

$<32$

$<0.0050$

52,180

$<0.20$

$<0.50$

$<4.0$
$<50$

$<5.0$

1.190
$<2.0$

$<35,300$

$\begin{array}{r}2,420 \\ \hline\end{array}$

8,080
$<1.0$

$<1.0$

$<2.0$

129,000

$<1,000$

80
116

$<0.24$

$<1.0$

$<1.0$

1.2
$<1.0$

$<8.0$

$<2.0$

$<2.0 \mathrm{E}-08$

$<6.0 \mathrm{E} .08$

$<6.0 E-08$

$<1.0 \mathrm{E}-0 \mathrm{\theta}$

$<1.0 E-08$

$<1.0 E-08$

$<1.0 E-08$

$<1.0 E-08$

$<1.0 E-08$

$<1,0 E-09$

$<4.0 \mathrm{C} .08$

$<2.0 \mathrm{E} .08$

$<2.0 \mathrm{OE} .08$

$<3.0 E-08$

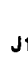

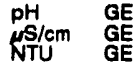

$\begin{array}{lll}j 1 & \mu g h & G E \\ \mu g / L & G E\end{array}$

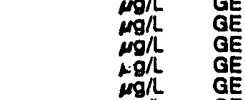

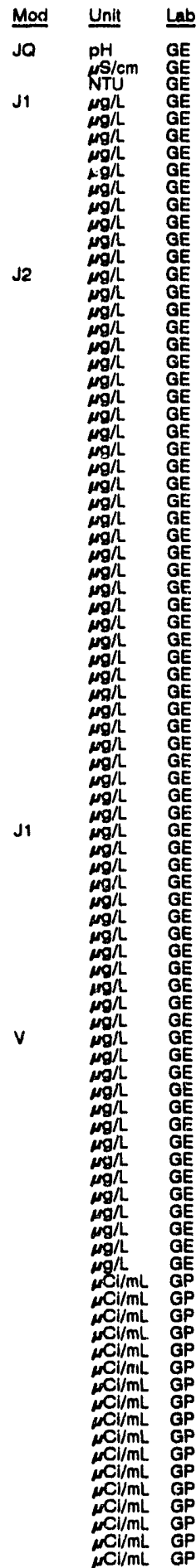


WELL BCO 18A collected on 08/19/92, laboratory snalyses (cont.)

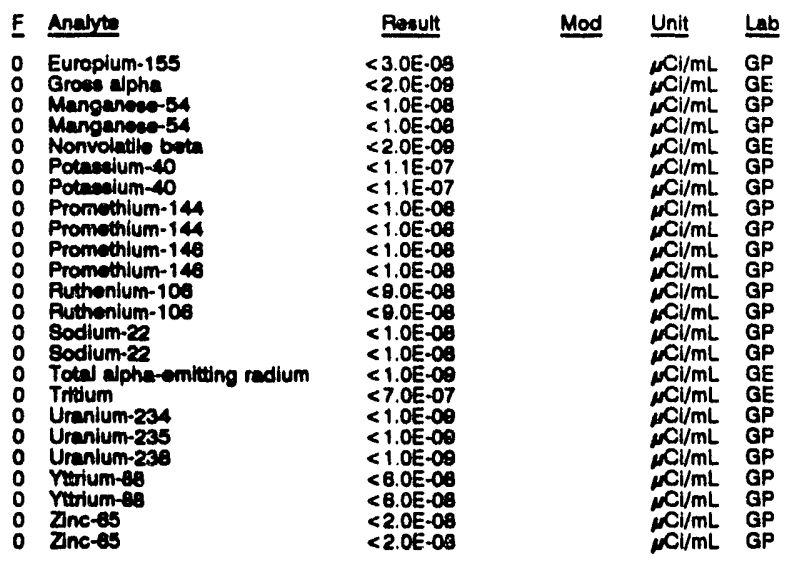

\section{WELL BGO 18D}

MEASUREMENTS CONDUCTED IN THE FIELD

Semple deto corrope

Dopth to weter: $02.45 \mathrm{n}(18.03 \mathrm{~m})$ below TOC

Watior olovation: 232.45 h $(70.85 \mathrm{~m}) \mathrm{ms}$ )

Wator ovecuatod before emplingling: $34 \mathrm{gal}$

LABOPATOFY ANALYSES

\begin{tabular}{|c|c|c|c|c|c|}
\hline$\underline{\mathbf{F}}$ & Analyte & Result & Mod & Unit & Lab \\
\hline & 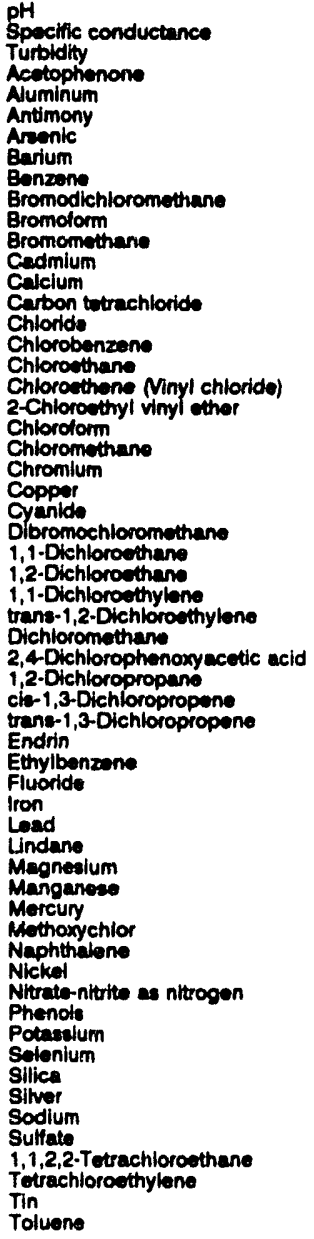 & 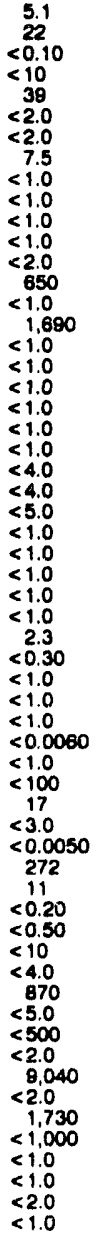 & $\begin{array}{l}\text { JO } \\
\text { J1 }\end{array}$ & 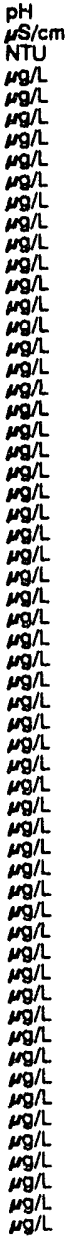 & $\begin{array}{l}\mathrm{GE} \\
\mathrm{GE} \\
\mathrm{GE} \\
\mathrm{GE} \\
\mathrm{GE} \\
\mathrm{GE} \\
\mathrm{GE} \\
\mathrm{GE} \\
\mathrm{GE} \\
\mathrm{GE} \\
\mathrm{GE} \\
\mathrm{GE} \\
\mathrm{GE} \\
\mathrm{GE} \\
\mathrm{GE} \\
\mathrm{GE} \\
\mathrm{GE} \\
\mathrm{GE} \\
\mathrm{GE} \\
\mathrm{GE} \\
\mathrm{GE} \\
\mathrm{GE} \\
\mathrm{GE} \\
\mathrm{GE} \\
\mathrm{GE} \\
\mathrm{GE} \\
\mathrm{GE} \\
\mathrm{GE} \\
\mathrm{GE} \\
\mathrm{GE} \\
\mathrm{GE} \\
\mathrm{GE} \\
\mathrm{GE} \\
\mathrm{GE} \\
\mathrm{GE} \\
\mathrm{GE} \\
\mathrm{GE} \\
\mathrm{GE} \\
\mathrm{GE} \\
\mathrm{GE} \\
\mathrm{GE} \\
\mathrm{GE} \\
\mathrm{GE} \\
\mathrm{GE} \\
\mathrm{GE}\end{array}$ \\
\hline
\end{tabular}

WELL BGO $18 D$ collocted on 08/19/82, laboratory analyeos (cont).)

\begin{tabular}{|c|c|c|c|}
\hline Analyte & Pesult & Mod & Unit \\
\hline 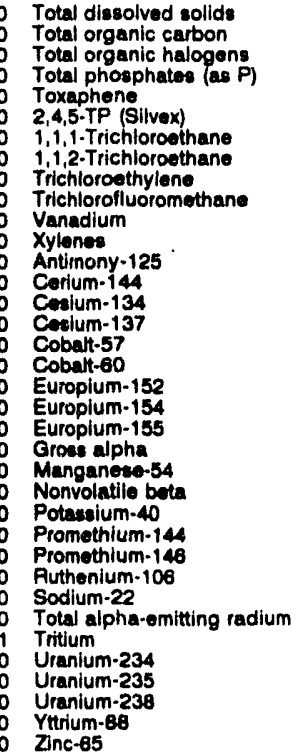 & 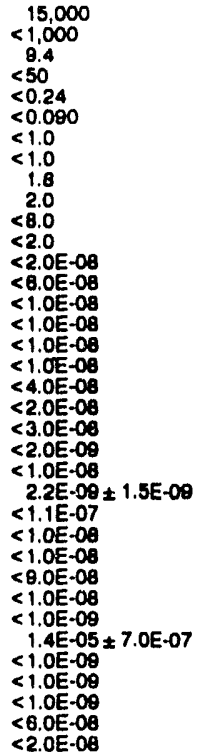 & & 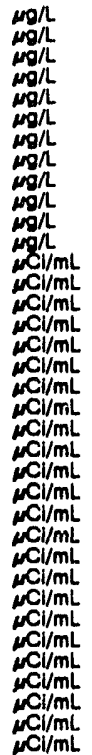 \\
\hline
\end{tabular}

WELL BGO 19D

MEASUREMENTS CONDUCTED IN THE FIELD

Sample date: 0e/18/02 Time: 10:30

inaccessibility or mochanical problem preventod eample collection.

\section{WELL BGO 20D}

MEASUREMENTS CONDUCTED IN THE FIELD

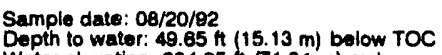

Depth to water: $49.65 \mathrm{Ht}(15.13 \mathrm{~m})$ bolow

The well went dry betore sampling began.

Tirne: 10:30

WELL BGO 21D

MEASUREMENTS CONOUCTED IN THE FIELD

Sample date: 08/20/92

Woter elevation: $235.24 \mathrm{ht}(71.70 \mathrm{~m}) \mathrm{msl}$

Sp. conductance: $81 \mu \mathrm{s} / \mathrm{cm}$

mpling: $\theta$ gal

The well went dry during purging.

LABOFATORY ANALYSES

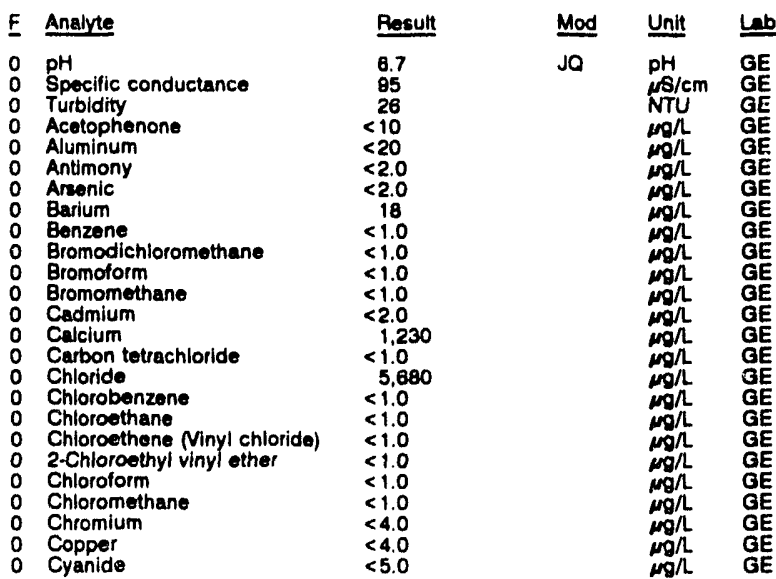


ANALYTICAL RESULTS

WELL BGO 21D collected on 08/20/82, laboratory analyses (cont.)

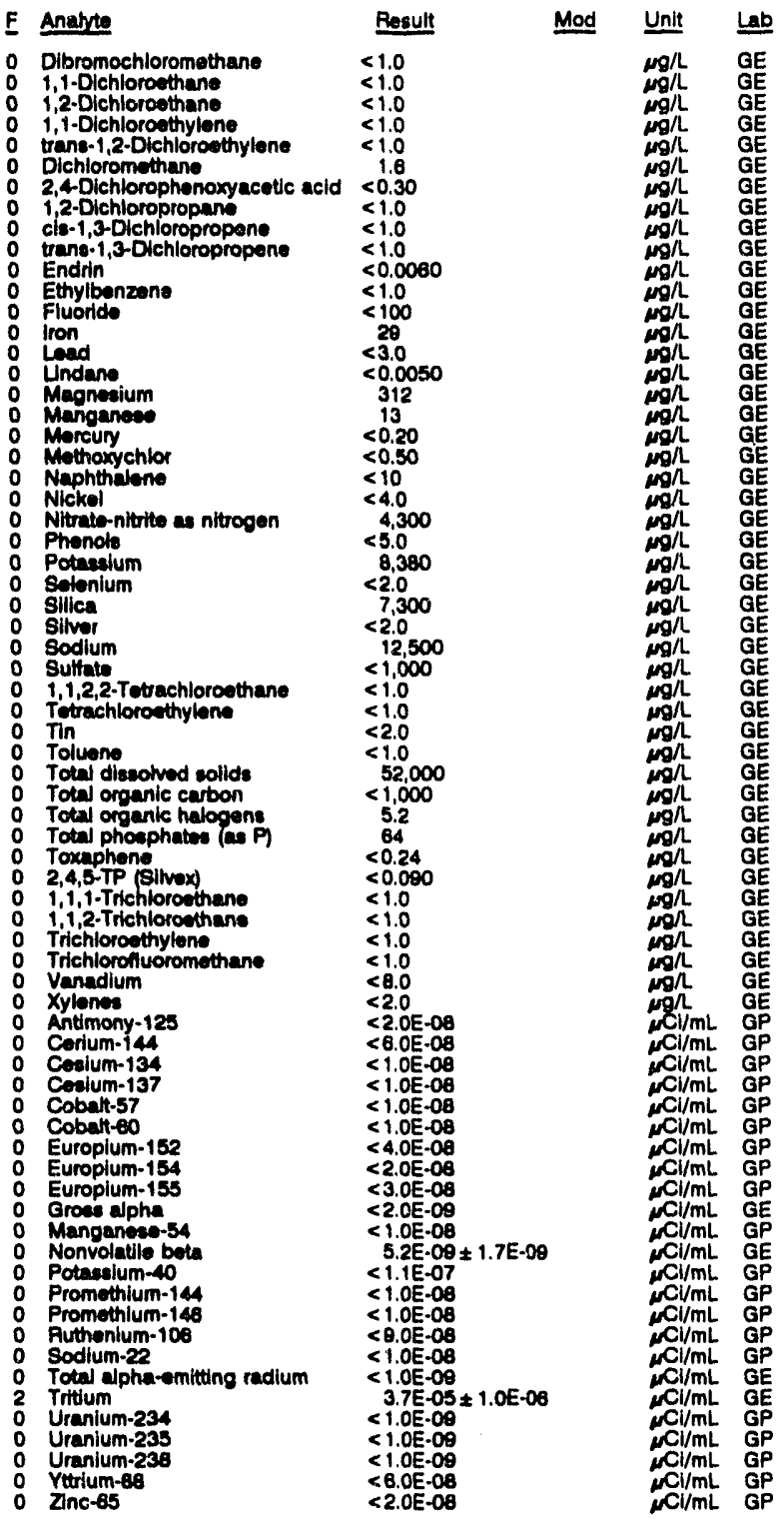

WELL BGO 22D

MEASUREMENTS CONDUCTED IN THE FIELD

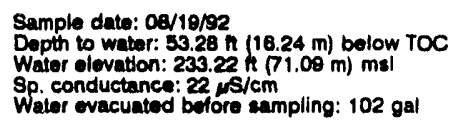

Time: 11:05

$\mathrm{pH}: 4.6$

Alkalinity: $1 \mathrm{mg} /$
Water temperature: $21.60^{\circ} \mathrm{C}$

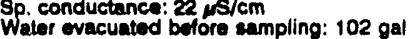

LABORATORY ANALYSES

\begin{tabular}{|c|c|c|c|}
\hline Analyte & Resunt & Mod & Unit \\
\hline $\begin{array}{ll}0 & \text { pH } \\
0 & \text { Speclific conductance } \\
0 & \text { Specific conductance } \\
0 & \text { Turbldity } \\
0 & \text { Acenaphthene } \\
0 & \text { Acenaphthylene } \\
0 & \text { Acetone } \\
0 & \text { Acetonitrile (Mothyl cyanide) } \\
0 & \text { Acelophenone } \\
0 & 2 \text {-Acetylaminofluorene } \\
0 & \text { Acrolein } \\
0 & \text { Acrylonitrile } \\
0 & \text { Aldrin }\end{array}$ & $\begin{array}{l}5.6 \\
28 \\
30 \\
0.48 \\
<10 \\
<10 \\
<100 \\
<1.0 \\
<10 \\
<10 \\
<20 \\
<20 \\
<0.050\end{array}$ & $\begin{array}{l}\text { J1 } \\
\text { J1 } \\
\text { J1 }\end{array}$ & $\begin{array}{l}\mathrm{pH} \\
\mu \mathrm{H} / \mathrm{cm} \\
\mu \mathrm{s} / \mathrm{cm} \\
\mathrm{NTU} \\
\mu g / \mathrm{h} \\
\mu g / \mathrm{h} \\
\mu g / \mathrm{L} \\
\mu g / \mathrm{h} \\
\mu g / \mathrm{L} \\
\mu g / \mathrm{L} \\
\mu g / \mathrm{L} \\
\mu g / \mathrm{L} \\
\mu g / \mathrm{L}\end{array}$ \\
\hline
\end{tabular}

WELL BGO 220 collected on 08/19/82, laboratory analyses (cont.)

$\begin{array}{ll}\text { F } & \text { Analyte } \\ 0 & \text { Allyl chloride } \\ 0 & \text { Aluminum } \\ 0 & 4 \text {-Aminobiphenyl } \\ 0 & \text { Anilline } \\ 0 & \text { Anthracene } \\ 0 & \text { Antimony } \\ 0 & \text { Aramite } \\ 0 & \text { Arsenic } \\ 0 & \text { Barlum } \\ 0 & \text { Benzene } \\ 0 & \text { alpha-Benzene hexachloride }\end{array}$

$<$

Result

Mod Unit Lo

$<20$
$<10$

$<10$

$<2.0$

$<2.0$
8.0
$<1.0$

beta-Benzene hexachloride

delta-Benzene hoxachloride

Benzo (a) anthracene

Benzo b fluoranthene

Benzo

Benzo ajpyrene

Benzylalcohol

Big (2.chloroethoxy) methane

Bis (2-chloroothyl) other

Bis 2-chloroisopropyl) other

Bis (2-ethylhexyl) phthalat

Bromodichloromethane

Bromoform

4-Bromophenyl phenyl ether

4-Bromophenyl phonyl ol

2-sec-Butyl-4,6-dinitrophenol 2-soc-Butyl-4

Calcium

Carbon disulfido

Carbon totrachloride

Chlordane

4-Chloroaniline

Chlorobenzene

Chlorobenzilate

para-Chloro-meta-cresol

Chloroethene (Ninyl chloride)

2-Chloroethyl vinyl other

Chlorororm

2-Chloronaphthalene

2-Chlorophenol

4-Chlorophenyl phenyl ether Chloroprene

Chromlum

Chryeene

Cobatt

Copper

m-Cresol (3-Methylpheno)

p-Cresol (4-Methyiphenol)

Cyanide

P,P'-DDD

P.P'-DDE

P,P'DDT

Dibenz $[a, h]$ anthracene

1,2.

propane

1,2. Dibromosthane

Di-n-butyl phthalate

1,2-Dichlorobenzene

1,3-Dichlorobenzene

3,3'-Dichlorobenzidine

trans-1,4-Dichloro-2-butene

Dichlorodifluoromethan

1,j-Oichloroethane

1,1-Dichloroethylone

trans-1,2-Dlehlorethylene

2,4-Dichlorophene

2,6-Dichlorophenol

2. $<10$

1,2 -Dichloropropane

o cis-1,3-Dichloropropene

trans-1,3-Dichloropropene

D Dleldrin

$<10$

2,4-Dimethyl phenol

Dimethyl phthalate $<10$

p-Dimethylaminoazobenzene

a

a,a.Dimethylphenethylamine

a,a-Dimethylphenethy

o 2,4-Dinitrophenol

2,4-Dinitrotoluene

Di-n-octyl phthalate

o 1,4-Dioxane 
WELL BGO 22D collected on 08/19/82, laboratory analyses (cont.)

F Anabte

- Diphenylamine

Endosuttan

Endosulfan II

Endoauta

Endrin aldehyde

Ethyl methacrylate

Ethylbenzene

Famphup

Fluorantione

Fluoride

Heptachior epoxide

$1,2,3,4,0,7,0$-HPCDD

Heptachlorodibenzo-p-dioxins

1,2,3,4,6,7,8-HPCDF

1,2,3,4,6,7,8-HPCDF

Heptachlorodibonzo-p-furans

Hoxachlorobenzene

Hoxachlorobutadient

$1,2,3,4,7,8-H \times C D O$

Hexachlorodlbenzo-p-dioxins

Hexachiorodibanzo-p-dioxine

$1,2,3,4,7,8-4 \times C O F$

Hexachlorodibenzo-p-furans

Hoxachlorodibenzo-p-furans

Hoxachtoromthan

Hexachioropropene

2-Hexanone

Indeno $[1,2,3-c, d] p y r e n e$
lodomothine (M.thyl lodide)

bobutyl alcohol

boonin

lisoestrole

Kepon

Lead

Magnetum

Morcury

Mothacrytonitrive

Methapyrilene

Methoxychlor

2-Methyt-4,6-dinitrophenol

Mothyl ethyl ketone

Methyl leobutyl ketone

Methyl methaneaulfonate

3-Mothylcholanthrene

2.Mechylinaphthalon

Haphthoguin

1, -Naphthoquinon

2-Naphthymin

Nickol

Nitrate-nituite a nitrogen

2-Nltroaniline

4-Nitroanilitim

Nitrobenzene

2-Nitropheno

4-Nitrophenol

N-Nitrosodi-n-butylamine

$N$-Nitrosodiethylamine

N-Nitrosodimethylamine

N-Nitroeodipropylamine

N-Nitroeomethylethyle

N N-Nitrosopiperidine

N-Nitrocopynolidine

5-Nitro-atoluldine

Nitro-o-toluidine

Octachlorodibenzo-p-dioxins

octechlorodibenzo-p-dioxins

Octachlorodibenzo-p-furans

Pctachlorod

o Parathion methyl

o PCB 1016

o PCB 1221

O PCB 1232

P
0

PCB 1254

Pentachlorobenzene

$<10$

$<0.10$

$<0.10$

$<0.0060$

$<10$

$<1.0$

$<10$

$<100$

$<0.050$

$<0.09065$

$<0.00085$

$<0.00065$

$<0.00045$

$<0.00045$

$<C .00045$

$<10$
$<10$

$<0.00045$

$<0.00045$

0.00045

$<0.00040$

$<0.00040$

$<0.00040$

$<10$
$<10$

$<10$

1.0

(1)

$<15$
$<4.0$
$<100$

$<10$

$<10$
$<10$
$<10$

$<10$
$<3.0$
$<0.0050$

588
8.7

$<0.20$

$<50$
$<10$

$<0.50$

$<10$
$<1.0$
$<1.0$

$<10$

$<10$

$<10$
$<10$

$<10$
$<10$

$<10$
$<10$

$<10$
$<4.0$

4.0
2.080

2,060

$<10$
$<10$

$<10$
$<10$
$<10$

$<10$
$<10$

$<10$

$<10$
$<10$

$<10$

$<10$

$<10$

$<10$
$<10$

$<10$

$<10$

$<10$
$<10$

$<10$

$<0.0010$
$<0.0010$

$<0.0010$

$<0.0010$

$<0.050$

$<0.50$

$<0.50$

$<0.50$

$<0.50$

$<0.50$

$<0.50$

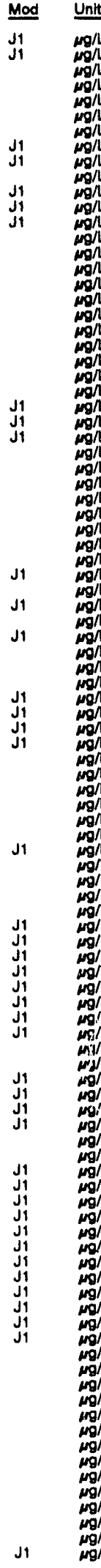

WELL BGO 220 collected on 08/19/82, laboratory analyees (cont.)

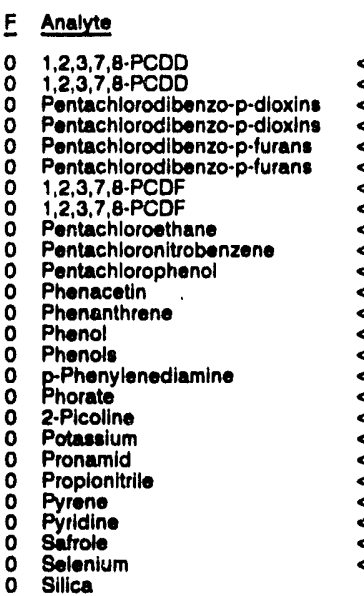

Mod Unit Lab

$<0.00055$

$<0.00055$

$<0.0005$

$<0.0005$

$<0.00055$

$<0.00055$
$<10$

$<10$
$<10$
$<10$

$<10$

$<10$
$<10$

$<5.0$

$<10$

$<10$

$<10$

$<10$

$<10$

$<2.0$

Silica

Silver

o Styrene

0 Sulfide

0 Suffotepp

1,2,4,5-Tetrachiorobenzene

o 2,3,7,6-TCDD

2,3,7,8-TCDD

2,3,7,8-TCD

Tetrachlorodibenzo-p-dioxins

Tetrachlorodibenzo-p-dioxins

Totrachlorodibenzo-p-furans

Tetrachlorodibenzo-p-furans

o 1,1,1,2-Totrachloroethane

- Totrachloroethylene

2,3,4,6-Tetrachlorophenol

o Thionazin

Tin

O Toluene

O-Tolvidine

- Total organic carbon

- Total organic cartion

- Total organic halogens

0 2,4,5-TP (Silvex)

1,2,4-Trichlorobenzene

o $1,1,1-$ Trichloroethane

1,1,2-Trichloroethan

o Trichlorofluoromethane

2,4,5.Trichlorophenol

0 2,4,6-T T

o 1,2,3-Trichloropropane

0 1,3,5-Trinitrobenzene

0 Vanadium

O Vinyl acetate

O Zyinc

o Antimony-125

o Corium- 144

o Cosium-134

O Cosium-137

0 Cobalt-60

0 Europlum-152

Europium-154

0
0 Grops alpha

Manganese-54

Nonvolatile beta

O Potasslum.40

P Promothium-144

Promethium-14

O Rodium.22

o Total alpha-emitting radium

1 Tritium

o Uranlum-234

0 Uranlum-238

O Zinc-65

$<2.00$

$<1.0$

$<1,000$

$<1,000$
$<10$
$<10$

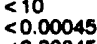

$<0.00045$

$<0.00040$

$<0.00045$

$<0.00045$

$<0.00040$

$<1.0$

$<1.0$

$<1.0$

$<2.0$

$<10$
2.2
$<1.0$

$<1.0$

$<10$
19,000

$<1,000$
$<1,000$

6.3
$<50$

$<0.24$

$<0.080$

$<1.0$

$<1.0$

$<1.0$

$<10$

$<0.000$

$<1.0$

$<10$

$<8.0$
$<1.0$
$<2.0$

$<2.0$

$<2.0 E \cdot 08$

$<6.0 \mathrm{0} .09$

$<1.0 E-09$

$<1.0 E-08$

$<1.0 E-08$

$<4.0 E .08$

$<2.0 \mathrm{E} .08$

$<3.0 E-08$

$<2.0 \mathrm{E}-09$

$<.0 \mathrm{0}$

$<1.007$

$<1.08$

$<1.0 E .08$

$<1.0 \mathrm{E} .08$

$1.2 \mathrm{E}-09 \pm 5.0 \mathrm{E}-10$

$<1.0 E-09$
$<1.0 E-09$

$<1.0 \mathrm{E}-0$

$<6.0$ E-C

$<2.0 E \cdot 0.7$

(cont)

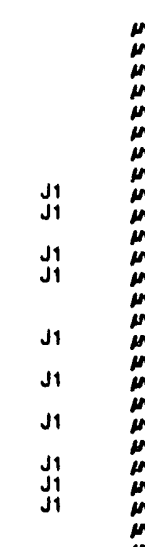

$\mathrm{mol}$ GE

$\mathrm{de}$
$\mathrm{gol}$

aE
aE

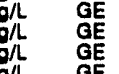


WELL BGO 23D

MEASUREMENTS CONDUCTED IN THE FIELD

Samplo dato: 08/19/92

Wopth to wator: $53.01 \mathrm{n}(16.16 \mathrm{~m})$ below TOC Water olovation: $238.19 \mathrm{~h}$ (7)

Wator evecunted botore campling: $37 \mathrm{gal}$

LABOPATOFY ANALYYES

$E$ Analyte

$\therefore$ pH

Spocific conductanco

- Acotophenone

Aluminum

Antic

0 Barium

Benzono

Bromodichloromethane

o Bromomothane

Codmium

- Carbon tetrachionide

- Chloride

Chlorbenzeno

Chloroethene Minyt chloride)

2-Chloroesthyl vinyl ether

- Chloroform

O Chloromethen

- Chromium

Coppar

D

1,1-Dichloroethane

1,2.Dichloroethane

trans $-1,2-$ Dichlorosthylene

2,4-Dichlorophenoryacetic acid

2 2,4-Dichlorophonoxyacetic acid

o 1,2-Dichloropropanyacotic acid < <1.

o cis-1,3-Dichloropropene $\quad<1.0$

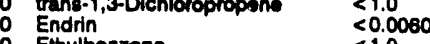

- Ethylbenzone

o fluorite

Load

Mandane

Manganose

Mercury

Naphthalene

Nikkol

Nitrato-niturte as nitrogen

Phonols

Potaasium

Silica

Silver

- Sodium

1,1,2,2-Tetrachloroethane

Totrachloroethylone

Tin

Toluene

Total dissolved solide

- Total organic carbon

Total phosphatios (as P)

T Toxphone

2,4,5-TP (Silvox)

1,1,1-Trichloroethene

1,1,2-Trichloroethane

1 Trichloroethyione

Trichlorofluoromethane

V Vanadium

Xylenes
Antimony-125

Corium-144

Cesium-134

Cosium-137

Cobalt-60

Europlum-152

Europlum-154

Europium-15:

Gross alpha

Manganeso-54

Nonvolatile boto

Potassium 40

Promethium-144

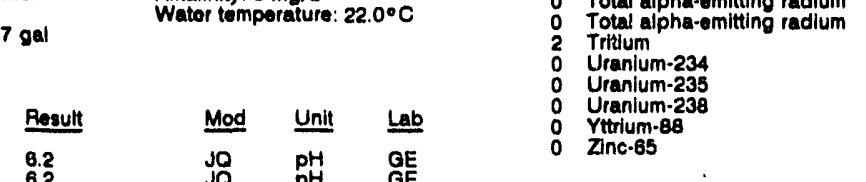

Time: $10: 10$

pH: 5.7 : $5 \mathrm{mgl}$

Whalnty: $5 \mathrm{mg} / \mathrm{L}$

\section{WELL BGO 24D}

MEASUREMENTS CONDUCTED IN THE FIELD

Sample date: 08/20/92

(17.03 m) below TOC

Water elevation: $237.32 \mathrm{~h}(72.34 \mathrm{~m}) \mathrm{ms}$

Sp. conductance: 68 $18 / \mathrm{cm}$

Water evacuated bofore sampling: 8 gal

LABORATOAY ANALYSES

$\begin{array}{ll}1 & \text { pH } \\ 1 & \text { pH } \\ 0 & \text { Specific conductance } \\ 0 & \text { Turbidity } \\ 0 & \text { Turbidity } \\ 0 & \text { Acetophenone } \\ 2 & \text { Aluminum } \\ 0 & \text { Antimony } \\ 0 & \text { Arenic } \\ 0 & \text { Barlum } \\ 0 & \text { Benzene } \\ 0 & \text { Bromodichloromethane } \\ 0 & \text { Bromoform } \\ 0 & \text { Bromomethane } \\ 0 & \text { Cadmium } \\ 0 & \text { Calcium } \\ 0 & \text { Carbon tetrachloride } \\ 0 & \text { Chloride } \\ 0 & \text { Chlorobenzene } \\ 0 & \text { Chloothane }\end{array}$

Chlorothane

2-Chloroothyl vinyl ether

2-Chloroothy

Chloromethane

Chromium

Copper

Cyanide

Dibromochloromethane

1,1-Dichloroethane

1,2-Dichloroethane

1,1-Dichloroethylene

O trans-1,2-Dichloroe

2,4-Dichlorophenoxyacetic acid

1,2-Dichloropropane

cis-1,3-Dichloropropene

trans-1,3-Dichloropropen

Ethylbenzene

Fluoride

0 Fluoride

0 Iron

0 Lindane

- Magnesium

o Manganes

O Mercury

Naphthalene

Nickol

Nitrate-nitrite as nitrogen

Nitrate-nitrite as nitrogen

Phenols

Potassium

0 Selenium

${ }_{0}$ Silver

0 Sodium

Sulfate -Tetrachloroethane

Totrachloroethylene

0 Tin

O Tin

0 Total dissolved solids

- Total organic carbon

Total phosphates (as P)

o Toxaphene

0 2,4,5-TP (Silvex)

o 1,1,1-Trichloroothane

1,1,2-Trichloroethane
Trichloroethylene

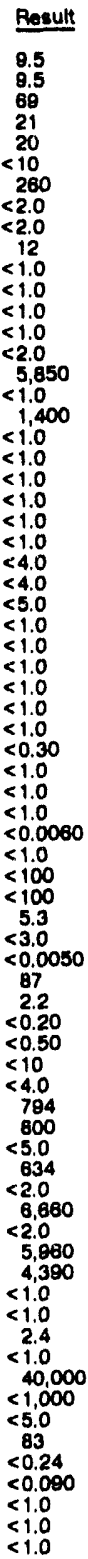

Time: 8:05

Alkallinity: $23 \mathrm{mg} /$

Water temperature: $21.0 \circ \mathrm{C}$

2.4E. 00

$<1.0 \mathrm{E} \cdot 09$

6.0E-08

\begin{tabular}{|c|c|}
\hline Mod & Unit \\
\hline & 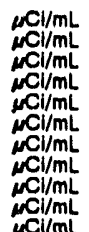 \\
\hline
\end{tabular}

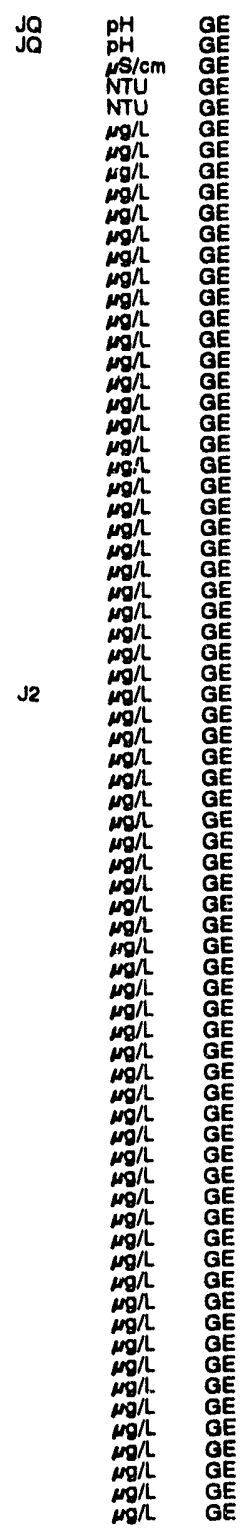


WEL BGO 240 collected on OarzO/O2, laboratory analyeer (cont.)

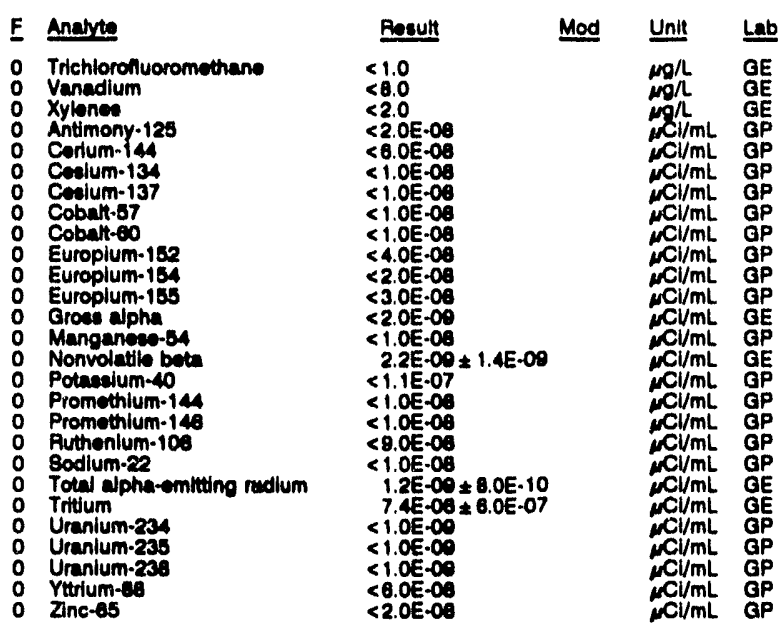

WELL BGO 25A

MEASUAEMENTS CONDUCTED IN THE FIELD
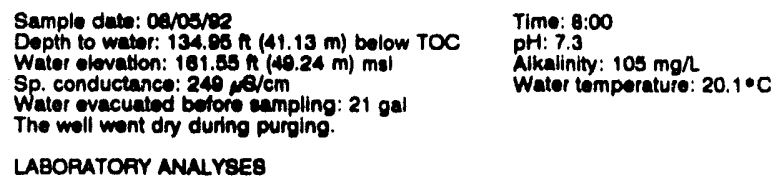

Water tomperature: $20.1 \cdot \mathrm{C}$

LABORATORY ANALYSES

\begin{tabular}{|c|c|c|c|c|c|}
\hline & Analute & Result & Mod & Unit & Lab \\
\hline $\begin{array}{l}0 \\
0 \\
0 \\
0 \\
0 \\
0 \\
0 \\
0 \\
0 \\
0 \\
0 \\
0 \\
0 \\
0 \\
0 \\
0 \\
0 \\
0 \\
0 \\
0 \\
0 \\
0 \\
0 \\
0 \\
0 \\
0 \\
0 \\
0 \\
0 \\
0 \\
0 \\
0 \\
0 \\
0 \\
0\end{array}$ & 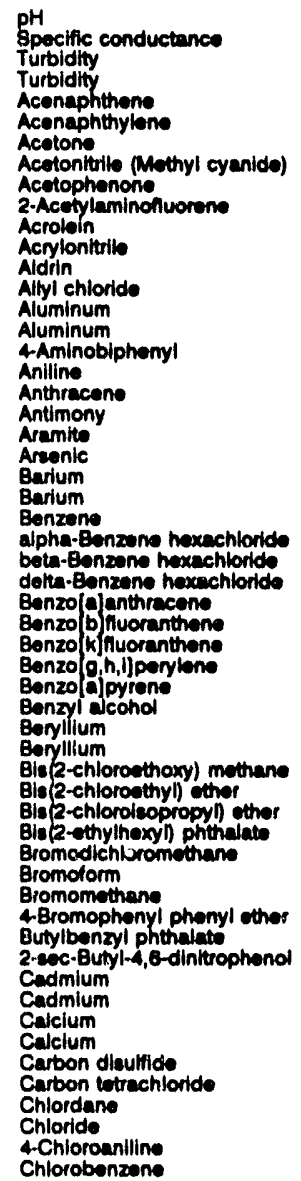 & 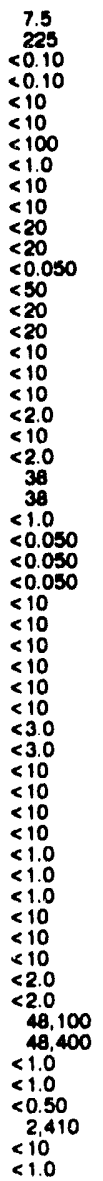 & $\begin{array}{l}\mathrm{J1} \\
\mathbf{J 1} \\
\mathrm{J1} \\
\mathrm{J1} \\
\mathrm{J1} \\
\mathrm{J1} \\
\\
\mathrm{J1} \\
\mathrm{J1} \\
\mathrm{J1}\end{array}$ & 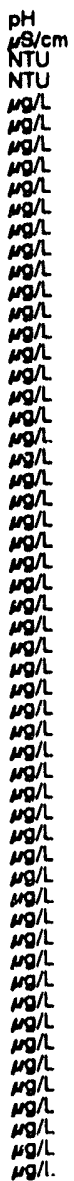 & $\begin{array}{l}G E \\
G E \\
G E \\
G E \\
G E \\
G E \\
G E \\
G E \\
G E \\
G E \\
G E \\
G E \\
G E \\
G E \\
G E \\
G E \\
G E \\
G E \\
G E \\
G E \\
G E \\
G E \\
G E \\
G E \\
G E \\
G E \\
G E \\
G E \\
G E \\
G E \\
G E \\
G E \\
G E \\
G E \\
G E \\
G E \\
G E \\
G E \\
G E \\
G E \\
G E \\
G E \\
G E \\
G E \\
G E \\
G E \\
G E \\
G E \\
G E \\
G E \\
G E \\
G E \\
G E \\
G E \\
G E \\
G E\end{array}$ \\
\hline
\end{tabular}

WELL BGO 25A collected on 08/05/82, laboratory analyees (cont.)

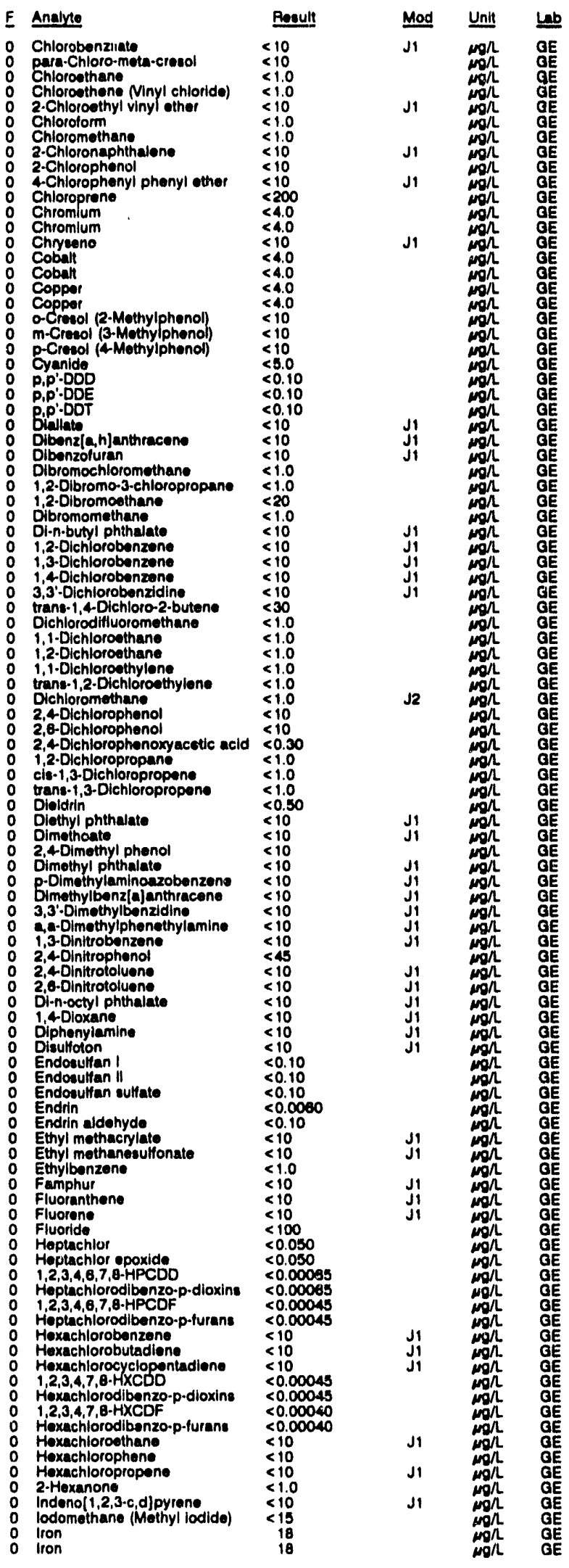


ANALYTICAL RESULTS

WELL BCO 23A collected on 0eros/92, laboralory andyese (cont.)

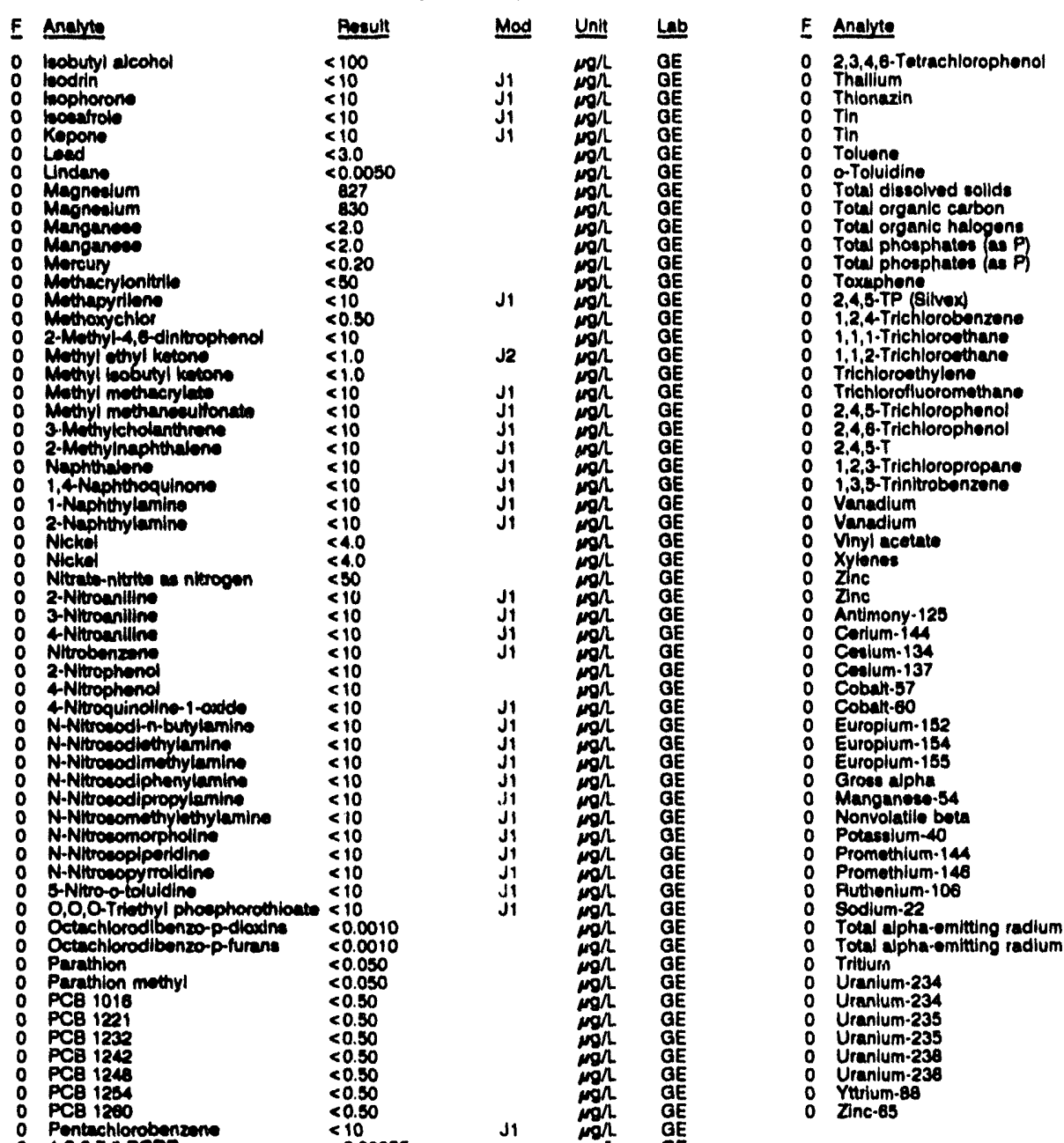

WELL BGO 25A collocted on 08/05/82, laboratory analyees (cont.)

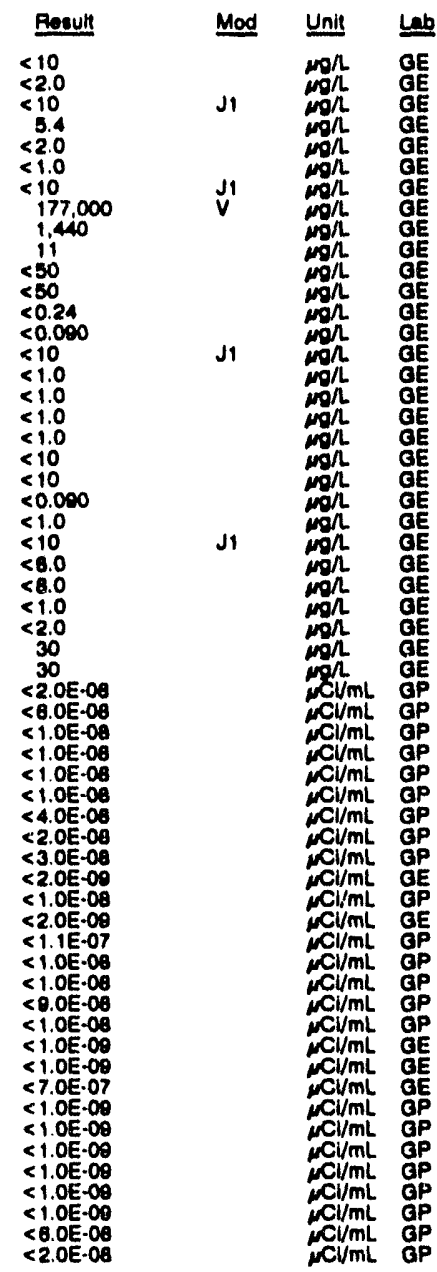

WELL BGO 26A

MEASUREMENTS CONDUCTED IN THE FIELO

Sample dato: 08/05/9?

Depth to water: $128.48 \mathrm{H}(38.16 \mathrm{~m})$ below TOC

Water elevation: $158.72 \mathrm{At}(48.38 \mathrm{~m}) \mathrm{ms}$

Inaccessibility or mechanical problem prevented sample collection.

\section{WELL BGO 26D}

MEASUREMENTS CONOUCTED IN THE FIELD

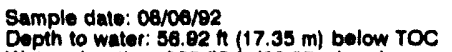

Depth to water: $56.02 \mathrm{~h}(17.35 \mathrm{~m})$ bolow TOC
Water elovation: $228.58 \mathrm{~h}(89.67 \mathrm{~m}) \mathrm{ms}$

Sp. conductance: $28 \mu \mathrm{s} / \mathrm{cm}$

The woll went dry during puping: $9 \mathrm{gal}$

Alkalinity: $1 \mathrm{mg}$

Water tomporature: $18.8 \circ \mathrm{C}$

LABORATORY ANALYSES

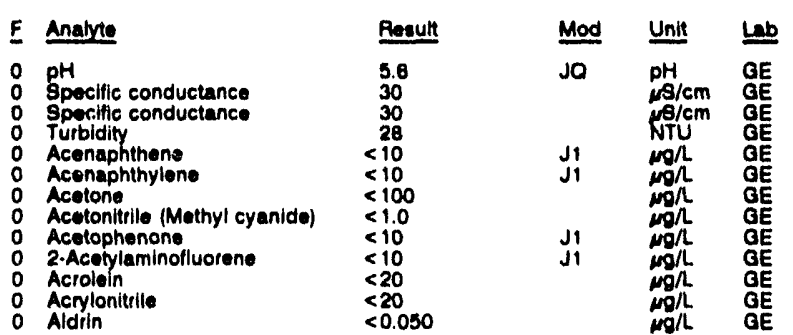




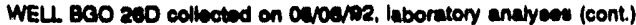

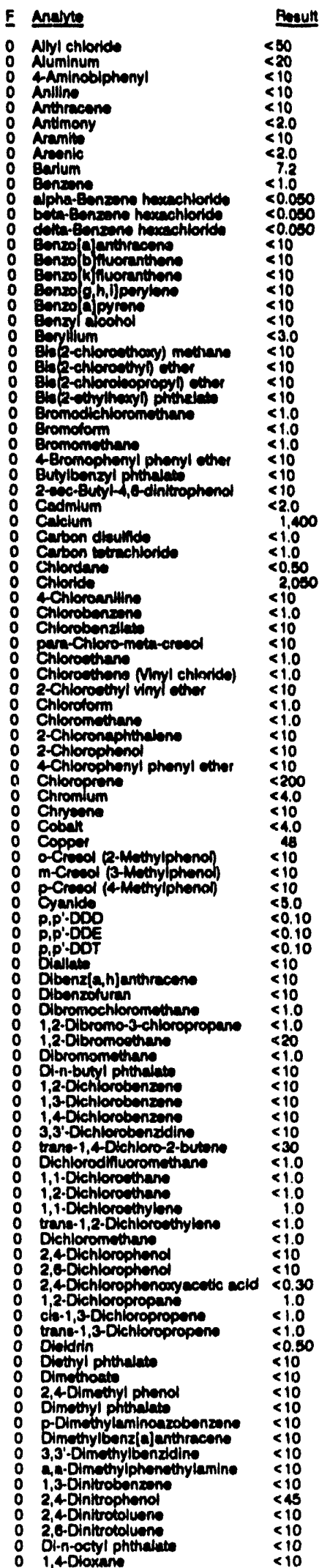

Mod Unit Ler

mogh OE

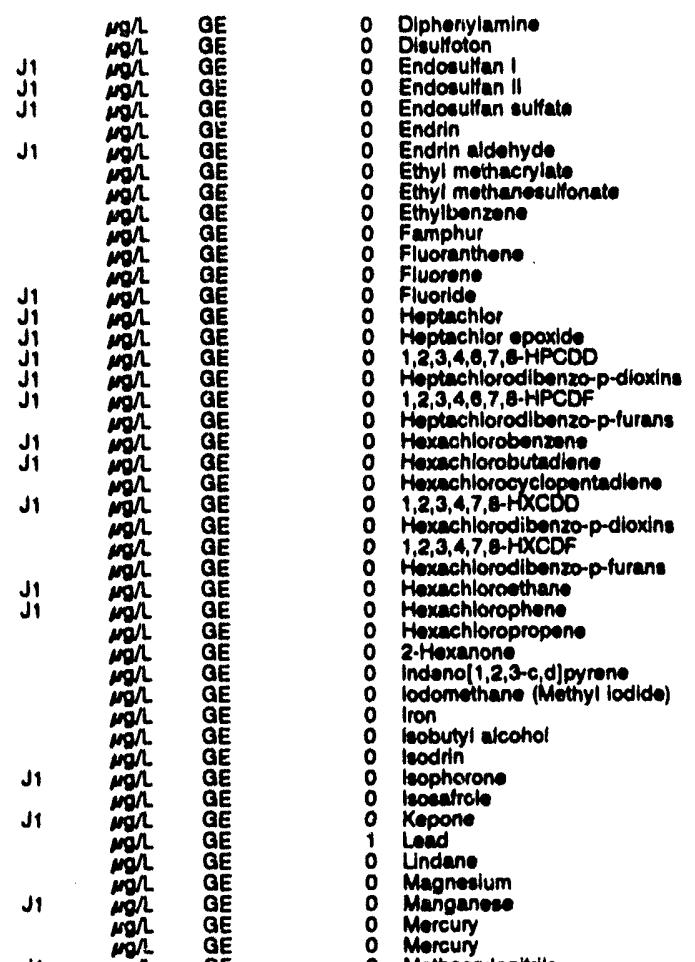

Mothacylonitrile

Mothapyrilione

2-Mbthyl-4,6-dinitropheno

Methyl ethyl ketone

Mothyl isobutyl keton

Mothyl mothacrylate

Methyl methansilionato

2-Muthylnaphthalene

Naphthalene

2.Naphthylamino

Nitrato-nitutte as nitrogon

2.Nitroaniline

3-Nitroanilline

Nitrobanzene

2-Nitrophanol

4Nitrophonol 1-oxide

N-Nitrosodj-n.butylamine

N.Nitrosodiethylamine

N-Nitrosodimethylamin

N-Nitrosodiphenyiamine

N-Nitrosomethylathylamine

N.Nitrosomorpholine

N-Nitrosopipenidine

N.Nitrosopyrrollidine

5-Nitro-o-toluidine

0,0 . Triethyl phoshorothionto Octuchlorodibenzo-p-dioxina Octachlorodibenzo-pefurans

Parathion

- Purathion methyl

- PCB 1018

- PCB 1221

PCB 1232

PCB 1242

PCB 1254

o Pentachlorobenzene

O Pontachlorobonzon

Pentechlorodibenzo-p dioxins

Pontachlordibenzo-p.dioxins

Pentachlorodibenz

Pentachloroothane

Pentachloronitrobenzene

Pentachloropheno

Phenanthren

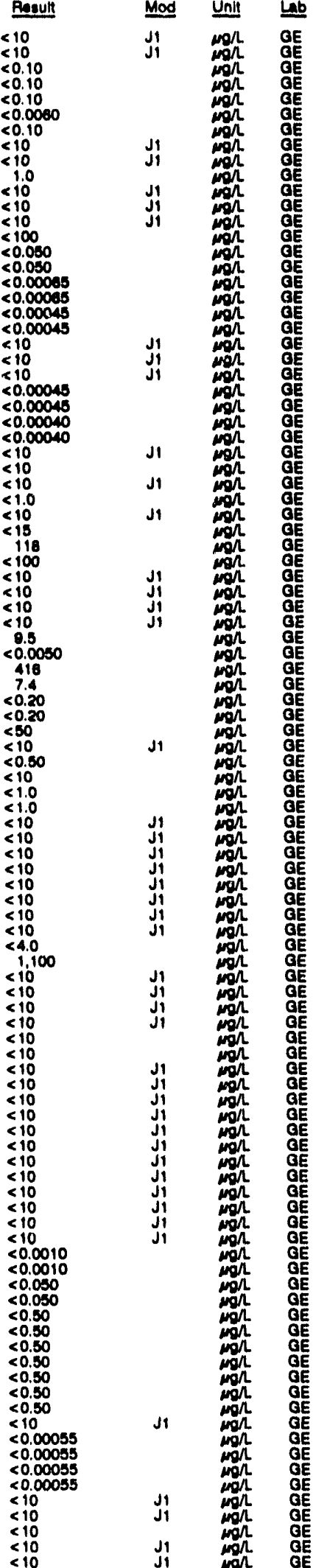


ANALYTICAL RESULTS

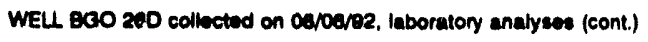

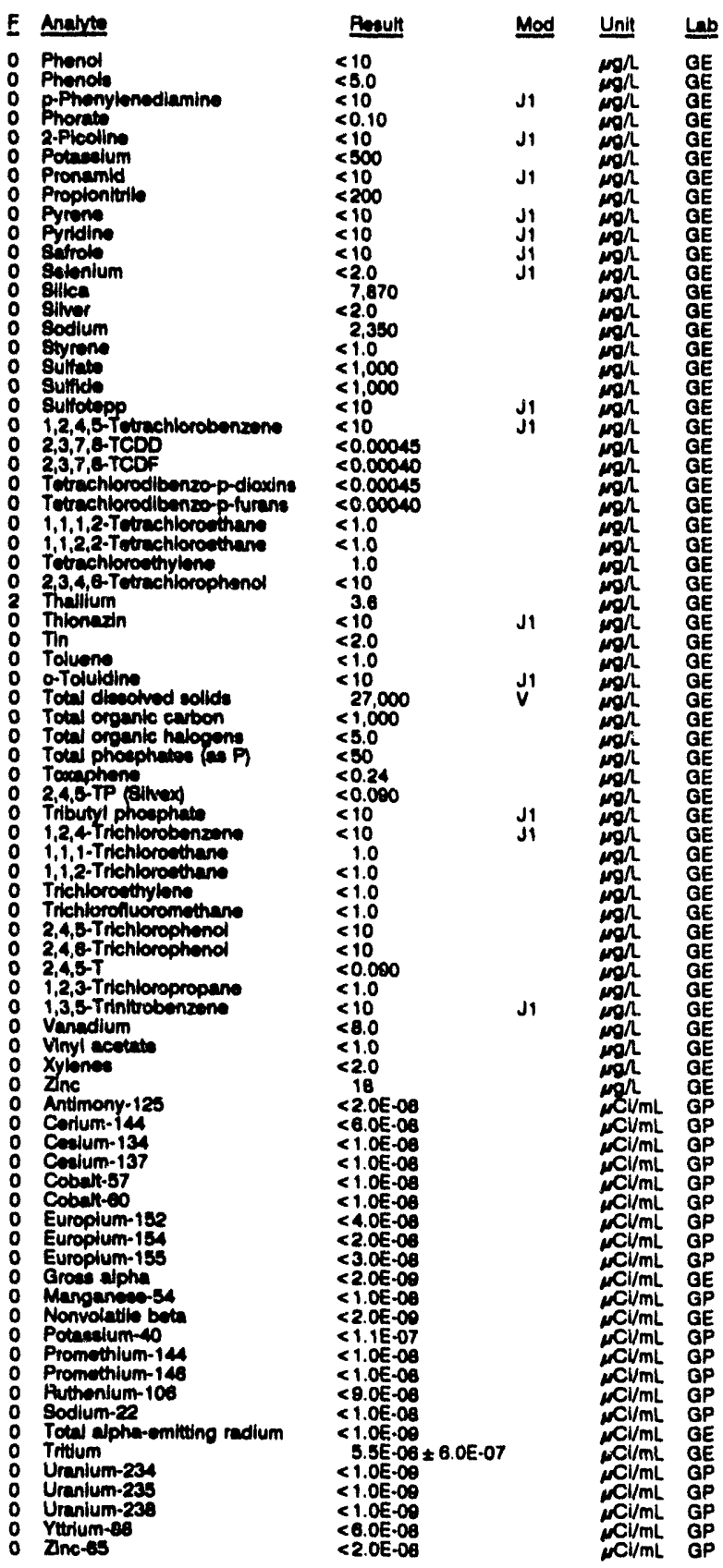

\section{WELL BGO 27C}

MEABUREMENTS CONDUCTED IN THE FIELD

\begin{tabular}{|c|c|c|c|c|c|}
\hline \multicolumn{3}{|c|}{ 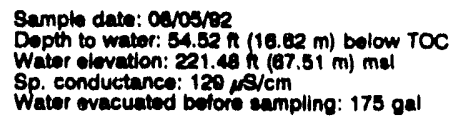 } & \multicolumn{3}{|c|}{$\begin{array}{l}\text { Time: } 12: 30 \\
\text { pH: } 6.9 \\
\text { Alkalinity: } 35 \mathrm{mg} / \mathrm{L} \\
\text { Water temperature: } 20.2^{\circ} \mathrm{C}\end{array}$} \\
\hline \multicolumn{6}{|c|}{ LABOPUTOFY ANALYSES } \\
\hline & Anabote & Recult & Mod & Unit & Lab \\
\hline $\begin{array}{l}0 \\
0 \\
0 \\
0 \\
0\end{array}$ & $\begin{array}{l}\text { pH } \\
\text { Speclific conductance } \\
\text { Turbidtity } \\
\text { Acenaphthene } \\
\text { Acenaphthylone }\end{array}$ & $\begin{array}{l}7.6 \\
112 \\
0.75 \\
<10 \\
<10\end{array}$ & $\begin{array}{l}\text { J1 } \\
\text { J1 }\end{array}$ & $\begin{array}{l}\text { pH } \\
\operatorname{sicm} \\
\operatorname{Nigh} \\
\operatorname{mgh}\end{array}$ & $\begin{array}{l}\mathrm{GE} \\
\mathrm{GE} \\
\mathrm{GE} \\
\mathrm{GE} \\
\mathrm{GE}\end{array}$ \\
\hline
\end{tabular}

WELL BOO 27 C collected on 08/05/82, laboratory analyses (cont.)

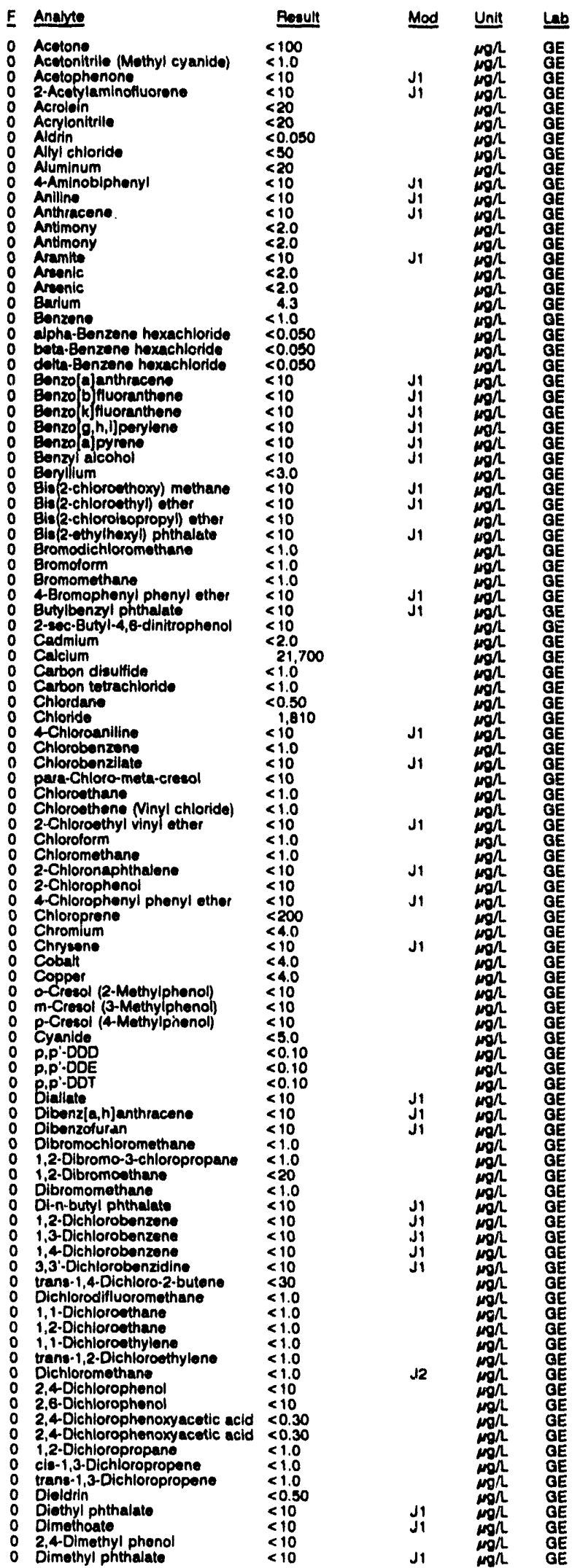


WELL BCO $27 \mathrm{C}$ collected on Oavese2, laboratory analyees (cont)

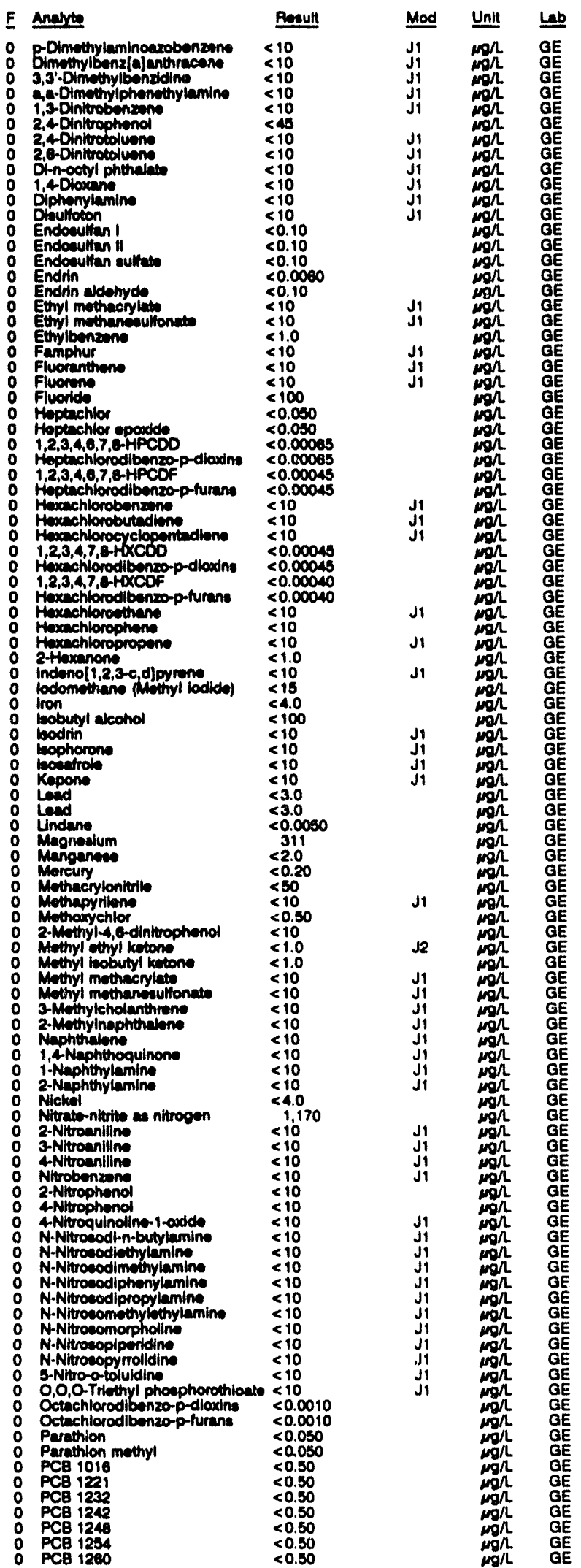

WELL BGO $27 \mathrm{C}$ collected on 09/05/92, laboratory analyees (cont.)

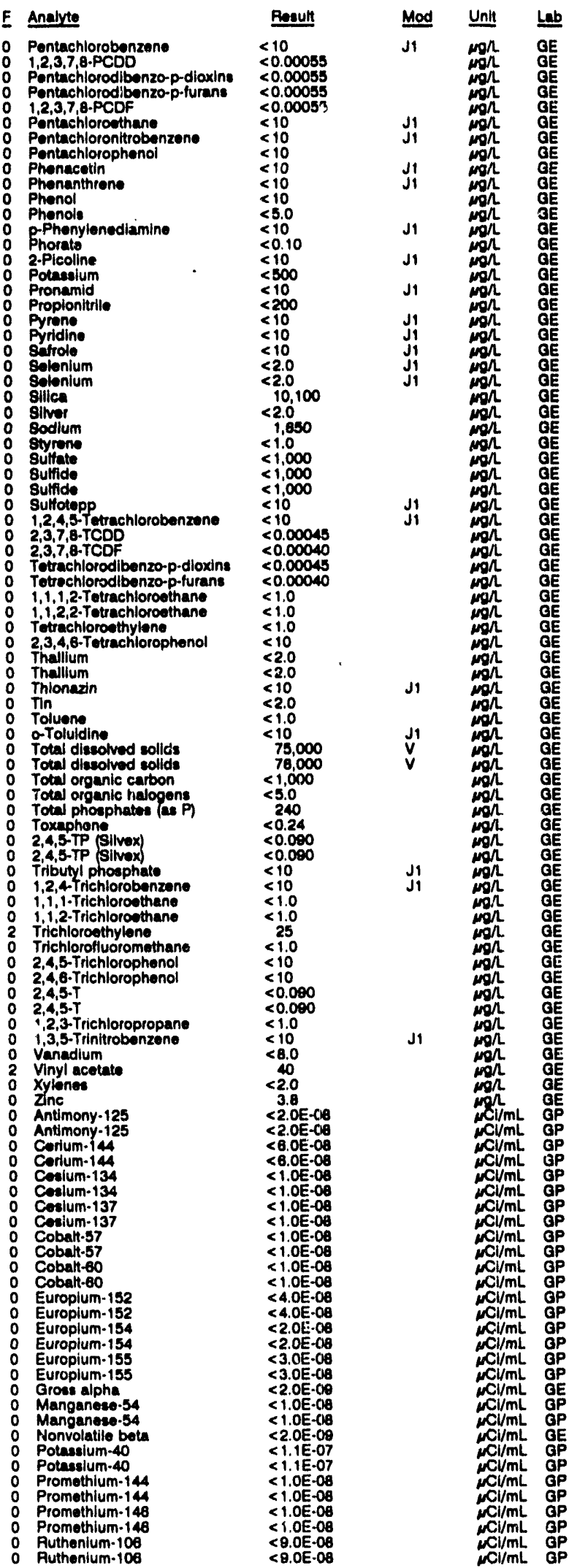


ANALYTICAL RESULTS

WEL BGO $27 C$ collectod on 08/05/82, laboratory analyses (cont.)

\begin{tabular}{|c|c|c|}
\hline Analyte & Result & Unit \\
\hline $\begin{array}{l}\text { Sodium-22 } \\
\text { Sodium-22 } \\
\text { Total dipha-emitting radium } \\
\text { Trittum } \\
\text { Uranium-234 } \\
\text { Uranium-235 } \\
\text { Uranlum-238 } \\
\text { Vutrium-68 } \\
\text { Ytrium-68 } \\
\text { Znc-65 } \\
\text { Znc-65 }\end{array}$ & $\begin{aligned}<1.0 E-08 \\
<1.0 E-08 \\
<1.0 E-09 \\
4.6 E-05 \\
<1.0 E-09 \\
<1.0 E-08 \\
<1.0 E-09 \\
<6.0 E-08 \\
<6.0 E-08 \\
<2.0 E-06 \\
<2.0 E-08\end{aligned}$ & 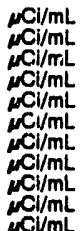 \\
\hline
\end{tabular}

\section{WELL BGC 27D}

MEASUREMENTS CONDUCTED INI THE FIELD

\begin{tabular}{|c|c|}
\hline $\begin{array}{l}\text { Sample date: 08/08/92 } \\
\text { Depth to water: } 48.16 \mathrm{th}(14.68 \mathrm{~m}) \text { below TOC } \\
\text { Water olevation: } 228.14 \mathrm{~h}(69.54 \mathrm{~m}) \mathrm{msl} \\
\text { Sp. conductance: } 34 / \mathrm{s} / \mathrm{cm} \\
\text { Water eveculted before eampling: } 12 \mathrm{gal}\end{array}$ & $\begin{array}{l}\text { Time: } 8: 15 \\
\text { pH: } 4.8 \\
\text { Alkalinity: } 0 \mathrm{mg} / \mathrm{L} \\
\text { Water temperature: } 20.0^{\circ} \mathrm{C}\end{array}$ \\
\hline
\end{tabular}

LABORATOFY ANALYSES

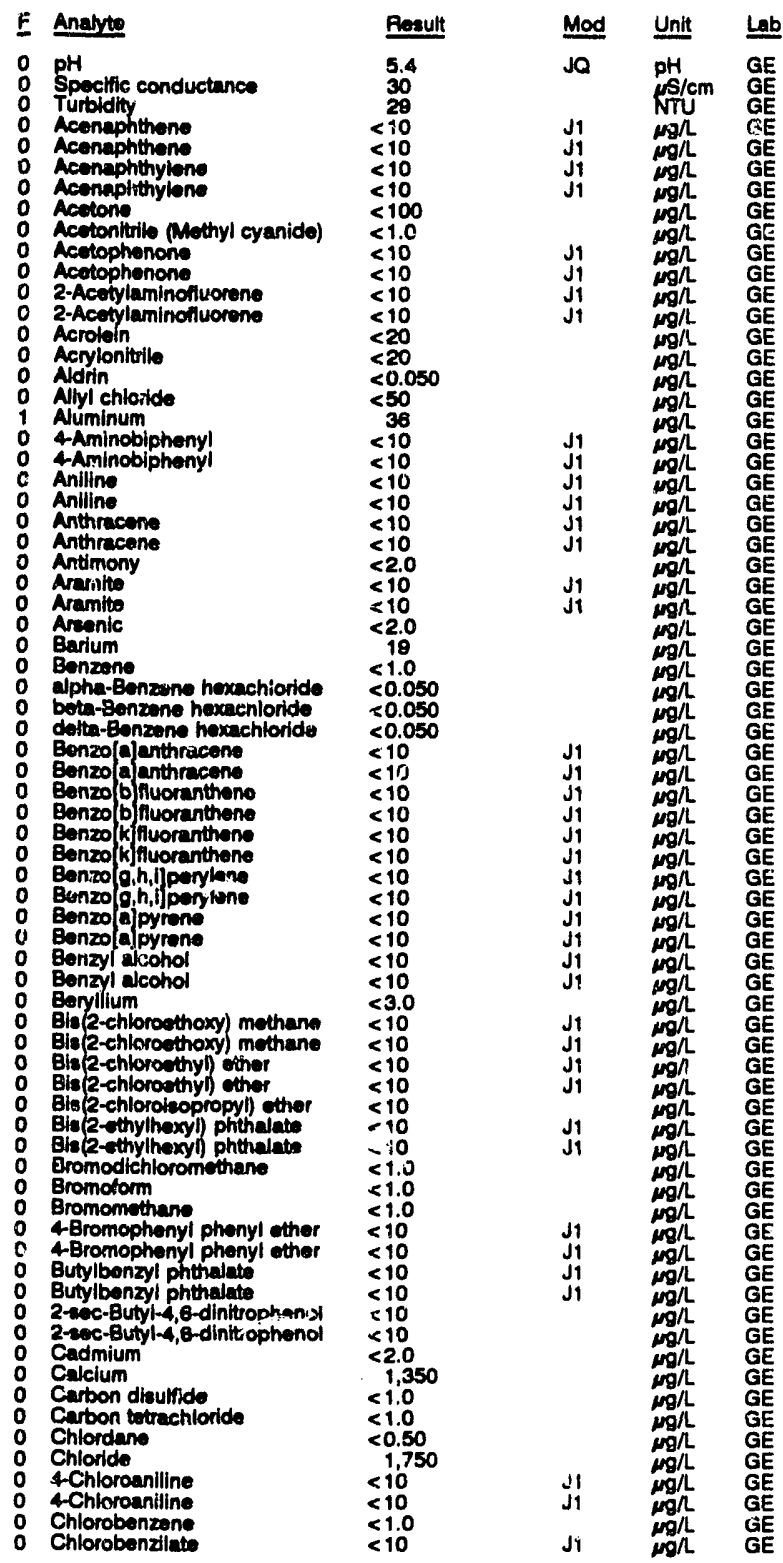

WELL BGO 27D collected on 08/06/82, laboratory analyees (cont.)

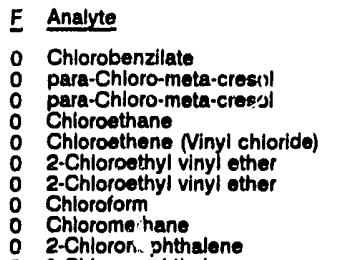
Result

$<10$

$<10$

$<1.0$

$<10$

$<1.0$

2.Chloronaphthalene

2-Chlorophenol

2.Chlorophenol

4Chlorophenyl phenyl other

Chloroprenenyl phenyl ether

Chloroprent

0 Chrysune

O Chryati

Copper

o o-Cresol (2-Methylphenol

0 o-Cresol (2-Mothylphonol

m-Cresol (3-Methylpheno)

m-Cresol (3-Methylphenol

0 p-Creeol (4-Methylphor.ol)

0 p-Cresol (4-Mothylphenol) $<10$

0 p,p.ode

0 p.p.DD

0 Diallate

o Dibenzla,hlanthracerie

O Dlbenzla, hanjanthracene

D Dibenzofuran

Dibromochloromethane

1,2.Dibromn-3-chloropropene

1,2-Dibromoethane

Olbromomethane

o Oi-n-butyl phthalate

1,2-Dichlorobenzene

1,2-Dichlorobenzene

$0 \quad 1,3 \cdot$ Dichlorobenzene

1.3-jichlorobenzene

1,4-Dichlorobenzene

3,3'-Oichlorobenzidine

trans-1,4-Dichloro-2-butene

(trans-1,4-Dichloro-2-buten

1,1-Dichloroethane

1,2-Dichloroethane

o 1,1 -Dichloroethylene

0 trans-1,2-Dichloroeth

2,4-Dichlorophenol

2,4-0ichlorophenol

2,8-Dichlorophenol

2,6-Dichlorophenol

2, 2 , Dichlorophenoxyacetic acid $<0.30$

2,4-Dichlorophenoxyacutic acid $<0.30$

1,2-Dichloropropane

cis-1,3-Dichloropropene

Drans-1,

Diethyl phthalate

D Dirnothostha

Dimethoate

2,40imethyl phenol

2,4-Dimethyl pheno

0 Dimethy! phthalate

D Dimethyl phthalate

p-DImethylaminoazobenzeno

p-Dimethylaminoazobenzen

Dimethylbenz(a) anthracene

3,3'-Dimethylbenzidine

3,3'-Dimethylbenzidino

a,a-Dimethylphenethylamine

1,3-Dinitrobenzene

1,3-Dinitrobenzene

2,4-Dinitrophenol

2,4-Oinitrophenol

2,4-Dinitrotoluene

2,4-Dinitrotoluene

2,6-Dinitrotoluene

2,6-Dinitrotoluene

D Di-n-octyl phthalate

1,4Dloxane

1,4Dloxane

Diphenylamine

Diphanylamin
0 Disulfoton
0

: Disulfoton

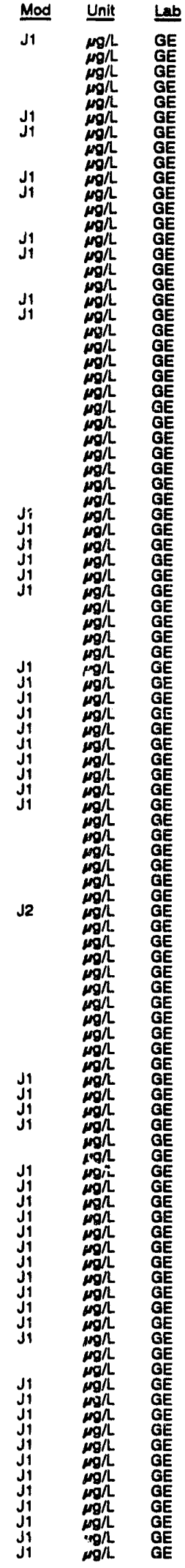


WEL BGO 270 collected on 06/08/92, laboratory analyses (cont.)

E Aneyle

o Endowultan I

O Endooulfan II

O Endsin

O Endrin aldohyds

o Ethyl mothecrylate

O Ethyl is thaneaulfonats

Ethylbenzone

F Famphur

Fluoranthene

Fluorene

Fluorene

Fluoride

Fluoride.

Heptinchlor epoudde

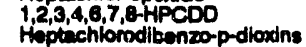

1,2,3,4,6,7,8-HPCDF-

Heptachlorodilbenzo-

Hoxachlorobenzens

Hexachlorobutadions

Hercehlorocyelopentindiene

Hexnchlorocyclopentadions

$1,2,4,7,0$ Helopen

Hoxachlorodibenzo-p-dloxins

Hiexchechlorodibenzo-p-furnns

Hexachloroethan

Haxachloroethane

Hoxachlorophens

Hoxachiorophens

Hexachioropropene

2-Hoxanone

indeno $1,2,3-c, d$ pyrens

Indeno(1,2,3-c,d]pyrene

lodom

Iroobutyl alcohol

rodn

loophorone

leophorone

licenafrole

Kespone

Kepono

Load

Undane

Magnealum

Manganece

Methacrylonitirile

Methapyrilone

Methapylon

2-Mothyla, 6-dinitrophenol

2-Methyt-4, b-dinitrophonol

Methyl ethyl ketono

Methyl metheconten

Methyl methacryinte

Methyl methaneaultonate

Methyl methaneaulionato

3-Mothylcholanthrene

3-Methylcholanthreno

2-Mothyinaph thaien

Naphthalene

1,4Naphthoquinon

1, ANephthoquinon

i-Naphtoviamin

2-Nephthylamine

2.Naphthylamine

Nitrato-niturite as nitrogen

2. Nitrannlitine

3-Nitroanilino

3-Nitroaniline

4-Nitroanilin

4-Nitroennilim

Nijobenzan

Nitrobonzent

2-Nitropheno

4 Nitropheno

4Nturopheno

4Nitroquinollna-1-oxid

N-Nitroquinoline-1-oxide
Pesuin

$<0.10$

$<0.10$

$<0.0080$

$<10$

$<10$

$<10$

$<1.0$

$<10$

$<10$

$<10$

$<10$

$<100$

$<0.050$

$<0.00065$

$<0.00065$

$<0.0004$

$<10$

$<10$

$<10$

$<10$

$<0.00045$

$<0.00045$

$<0.00040$

$<10$

$<<10$

$<10$

$<10$

$<10$
$<1.0$

$<10$
$<10$

$<15$

241
$<100$

$<10$

$<10$

$<10$

$<10$

$<10$
$<10$

8.6

1,250

$<0.20$

$<50$

$<10$

$<10$

$<1.0$

$<1.0$

$<10$
$<10$

$<10$

$<10$

$<10$

$<10$

$<10$

$<10$

$<10$

$<10$

$<10$

$<10$

$<10$
$<10$

2,320

$<10$

$<10$
$<10$

$<10$

$<10$

$<10$

$<10$

$<10$

$<10$

$<10$

$<10$
$<10$
$<10$

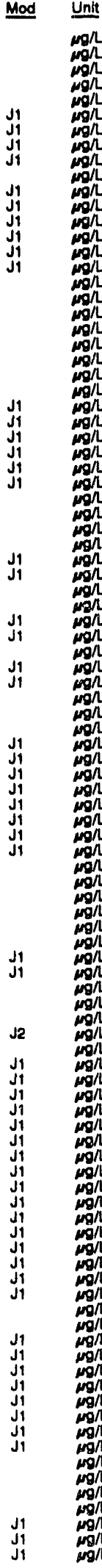

WELL BGO 27 D collected on 08/08/92, laboratory analyzes (cont)

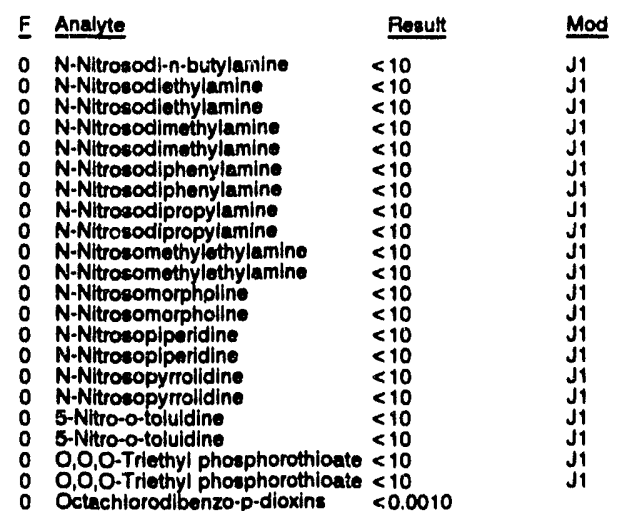

O,O,O-Triethyl phosphorothicate $<10$

o Octachlorodilbenzo-p-piurans $\quad<0.0010$

$<0.050$

PCB $<0.050$

PCA $1221<0.50$

OCB 1242

PCB 1248

PCB 1250

Pontachiorobenzene

Pentachlorobenzent

Pentachlorodlbenzo-p-dioxins

Pentachlorodiben

$1,2,3,7,8 \cdot P C D F$

Pentachloroethane

Pentachloronitrobenzene

Pentachloronitrobenzene

Pentachlorophenol

Phenachophen

Phonacotin

Phenanthren

Phonanthrene

Phenol

Phenol

Phenols

p-Phonylenediamine

p-Phenylenediamin

Phorato

2-Picoline

2.Picoline

Pronamid

Pronamid

Propionit
Pyrene

Pyrene

0 Pyridine

Pyrdin

Sarrole

Solenium

Silica

Silver

Sodium

Styrene

Sulfide

Sulfotepp

1,2,4,5-Tetrachlorobenzene

1,2,4,5-Tetrachlorobenzeno

2,3,7,6-TCDD

T,

Tochos

Truchloribenzo-p-furan

-

T T,2,2 Tetrachloroethan

2,3,4,6-Totrachlorophenol

2 3,4,6-Totrachlorophenol

0 Thellium

Thlonazin

Thionazin

0 Toluen

o-Toluidine

o-Toluidine

Total dissolved solide

Total organic carbon

Total organic halogens

Total phosphat

2,4,5-TP (Silvex)
$<0.50$

$<0.50$
$<0.50$
$<0.50$

$<0.50$

$<10$

$<10$

$<0.0005$

$<0.00055$

$<0.0005$

$<10$

$<10$

$<10$

$<10$

$<10$

$<10$
$<10$
$<10$
$<10$

$<10$

$<10$
$<5.0$

$<10$

$<10$

$<0.10$
$<10$
$<10$

837

$<10$
$<10$

$<200$

$<10$

$<10$

$<10$
$<10$

$<2.0$

$\begin{array}{r}6,300 \\ <2.0 \\ \hline\end{array}$

1,260

$<1,000$

$<1,000$

$<10$

$<10$

$<0.00045$

$<0.00045$

$<1.0$

$<1.0$

$<1.0$

$<10$

$<10$
$<10$
$<2.0$

$<2.0$

$<10$
$<10$

27,000

$<1,000$

$<50$

$<0.24$
Jit

J1
J1
J1

$J 1$
$J 1$
$J 1$
$J 1$

Mod Unit Lab

$\mu /$ GE

$m$, GE

g G

w

ol $G E$

gI GE

mon GE

GE



ugh GE

Non GE

mat

ga 
ANALYTICAL RESULTS

WELL BGO 27D colluctod on 08/06/82, laboratory analyeos (cont)

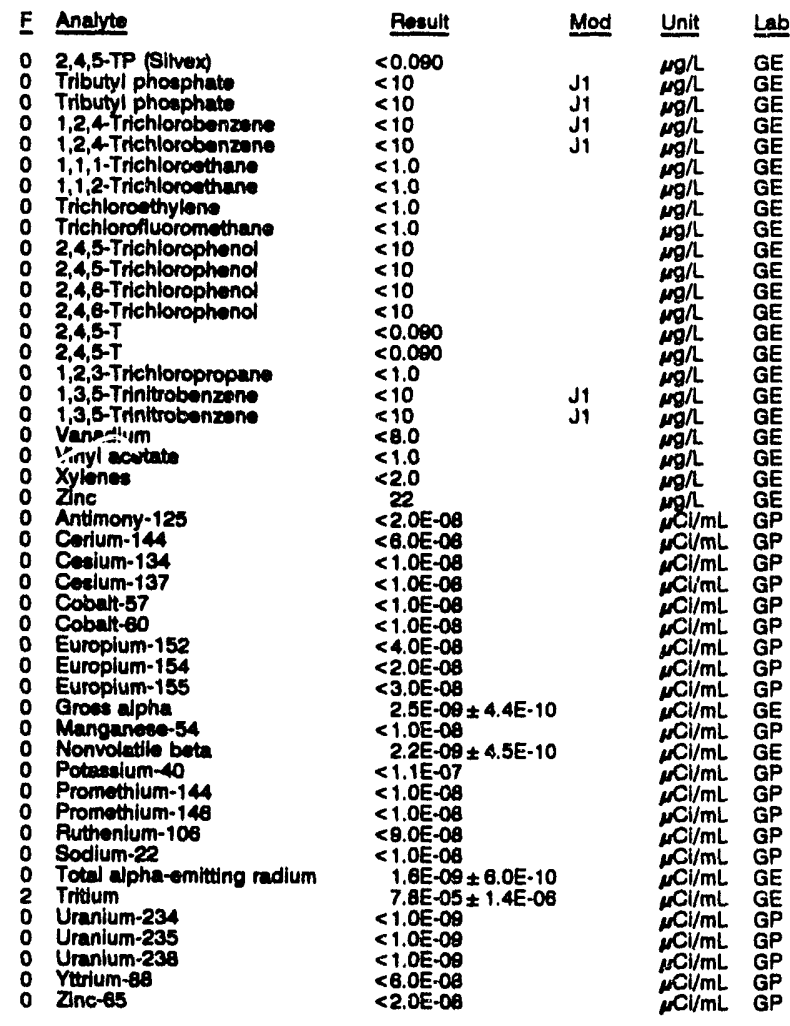

\section{WELL BGO 28D}

MEASUREMENTS CONDUCTED IN THE FIELD

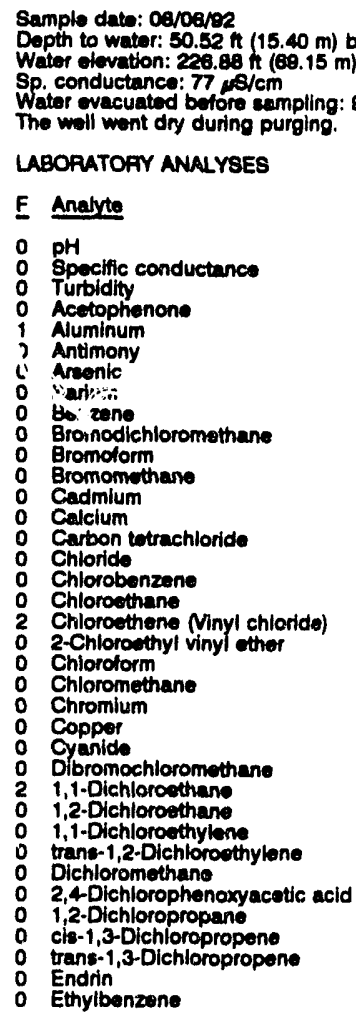

LABOAATOFY ANALYSES

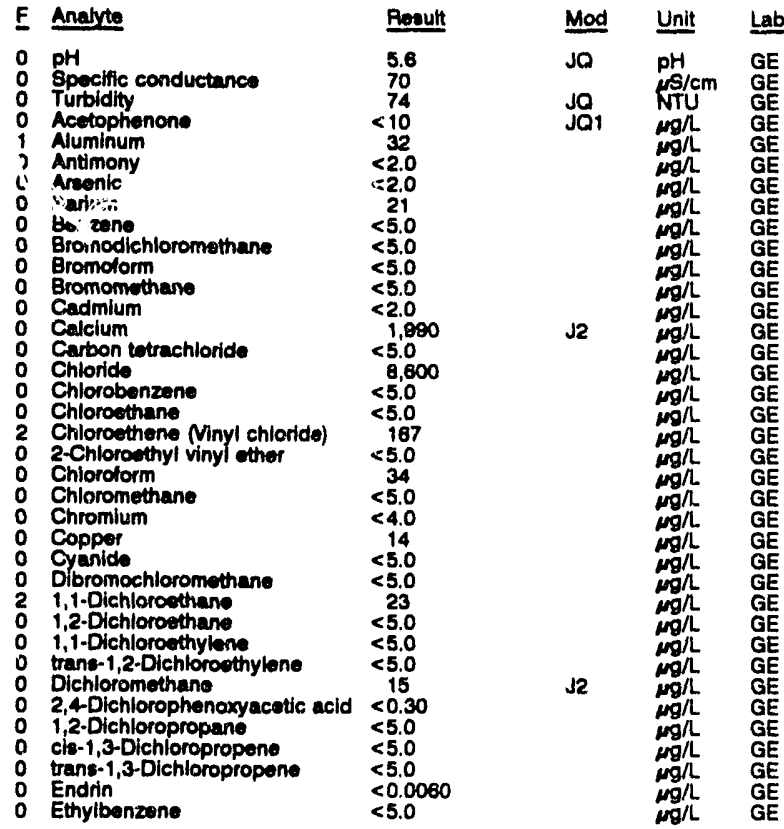

WELL BGO 28D collected on 08/08/82, laboratory analyses (cont.)

\begin{tabular}{|c|c|c|c|}
\hline Analyte & Result & Mod & Unit \\
\hline 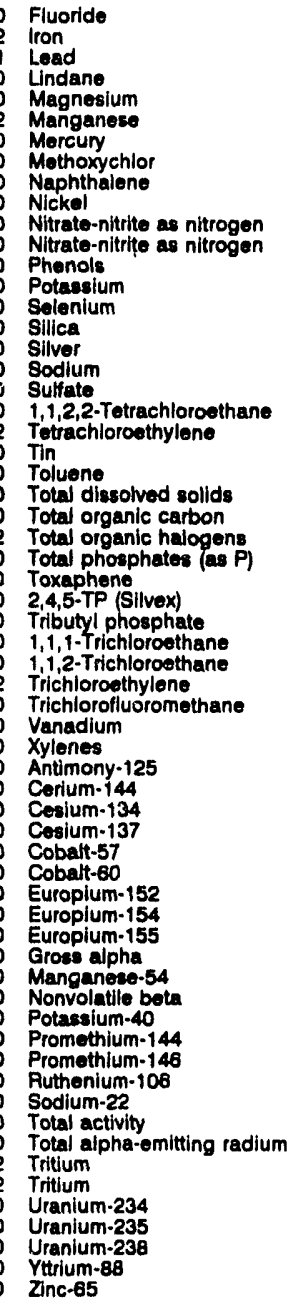 & 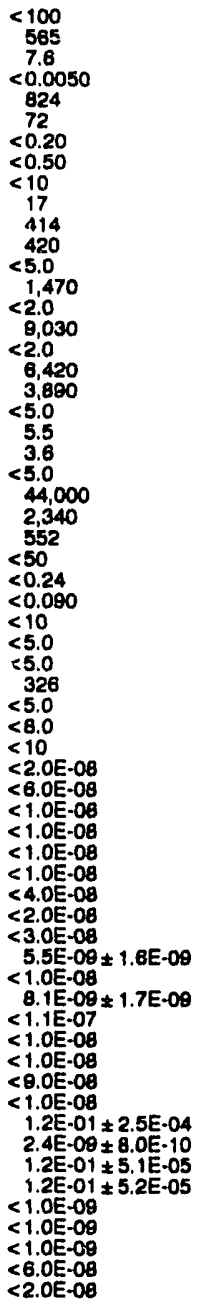 & $\begin{array}{l}\text { JO } \\
\text { jOS }\end{array}$ & 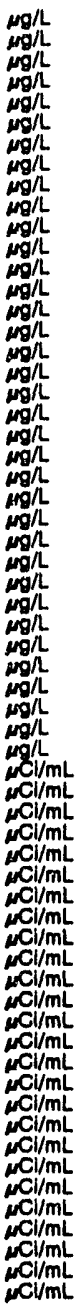 \\
\hline
\end{tabular}

\section{WELL BGO 29A}

MEASUAEMENTS CONDUCTED IN THE FIELO

Depth to water: $102.84 \mathrm{~h}(31.35 \mathrm{~m})$ below TOC

Water elovation: $161.38 \mathrm{ft}(49.18 \mathrm{~m}) \mathrm{ms}$

Sp. conductance: $108 \mathrm{~s} / \mathrm{cm}$

Water evacuated before sampling: $\mathbf{4 0} \mathrm{gal}$

The well went dry during purging.

LABORATORY ANALYSES

\begin{tabular}{|c|c|c|c|}
\hline Analyte & Result & Mod & Unit \\
\hline $\begin{array}{l}\text { pH } \\
\text { Specific conductance } \\
\text { Turbidity } \\
\text { Turbidity } \\
\text { Acelophenone } \\
\text { Aluminum } \\
\text { Antimony } \\
\text { Antimony } \\
\text { Arsenic } \\
\text { Areenic } \\
\text { Barium } \\
\text { Benzene } \\
\text { Bromodichloromethane } \\
\text { Bromoform } \\
\text { Bromomethane } \\
\text { Cadmlum } \\
\text { Calclum } \\
\text { Carbon tetrachloride } \\
\text { Chloride } \\
\text { Chlorobenzene } \\
\text { Chloroethane }\end{array}$ & $\begin{array}{l}6.1 \\
95 \\
9.4 \\
8.8 \\
<10 \\
<20 \\
<2.0 \\
<2.0 \\
<2.0 \\
<2.0 \\
22 \\
<1.0 \\
<1.0 \\
<1.0 \\
<1.0 \\
<2.0 \\
23,000 \\
<1.0 \\
<1.630 \\
<1.0 \\
<1.0\end{array}$ & Jo & 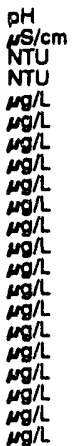 \\
\hline
\end{tabular}




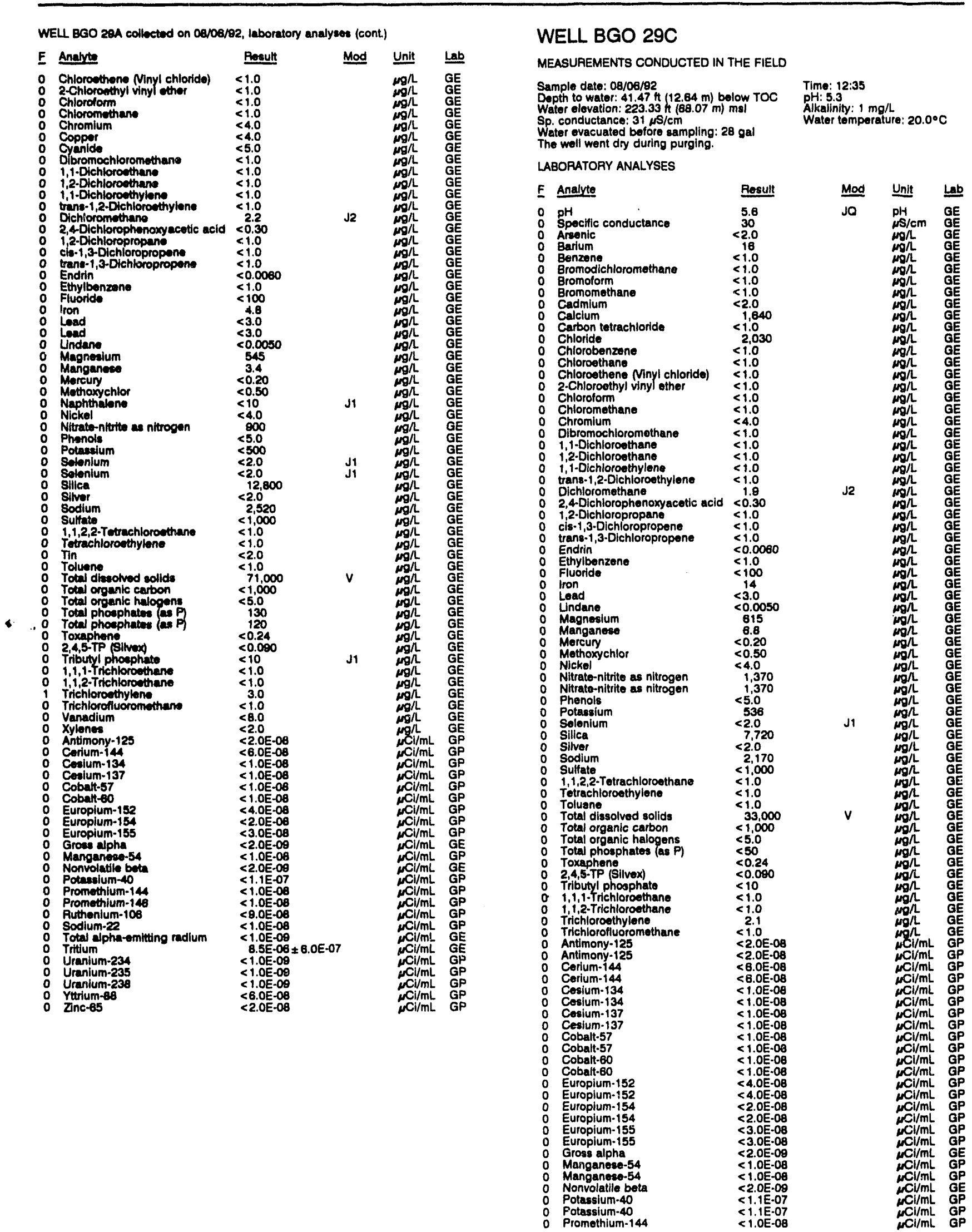


ANALYTICAL RESULTS

WELL BGO $28 C$ collocted on 08/08/82, laboratory analyses (cont.)

\begin{tabular}{|c|c|c|}
\hline Anoiyte & Resulit & Unit \\
\hline 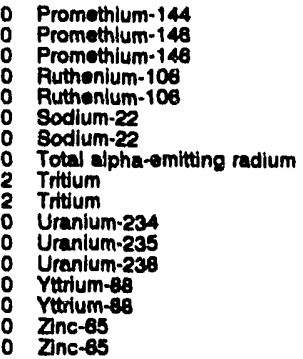 & $\begin{array}{r}<1.0 \mathrm{E}-08 \\
<1.0 \mathrm{E}-08 \\
<1.0 \mathrm{E}-08 \\
<8.0 \mathrm{E}-08 \\
<9.0 \mathrm{E}-08 \\
<1.0 \mathrm{E}-08 \\
<1.0 \mathrm{E}-08 \\
<1.0 \mathrm{E}-09 \\
8.4 \mathrm{E}-05 \pm 1.0 \mathrm{E}-06 \\
8.7 \mathrm{E}-05 \pm 1.5 \mathrm{E}-06 \\
<1.0 \mathrm{E}-09 \\
<1.0 \mathrm{E}-09 \\
<1.0 \mathrm{E}-09 \\
<6.0 \mathrm{E}-08 \\
<8.0 \mathrm{E}-08 \\
<2.0 \mathrm{E}-08 \\
<2.0 \mathrm{E}-08\end{array}$ & 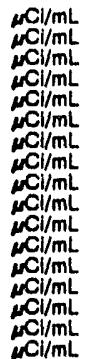 \\
\hline
\end{tabular}

WELL BGO 29D

MEASUAEMENTS CONDUCTED IN THE FIELD

Sample date: 08/08/82

Dopth to water: $38.58 \mathrm{n}(11.76 \mathrm{~m})$ bolow TOC

Sp. conductance: $73 \mathrm{\mu s} / \mathrm{cm}$

Waier evacuated before sampling: $11 \mathrm{gal}$

LABORATORY ANALYSES

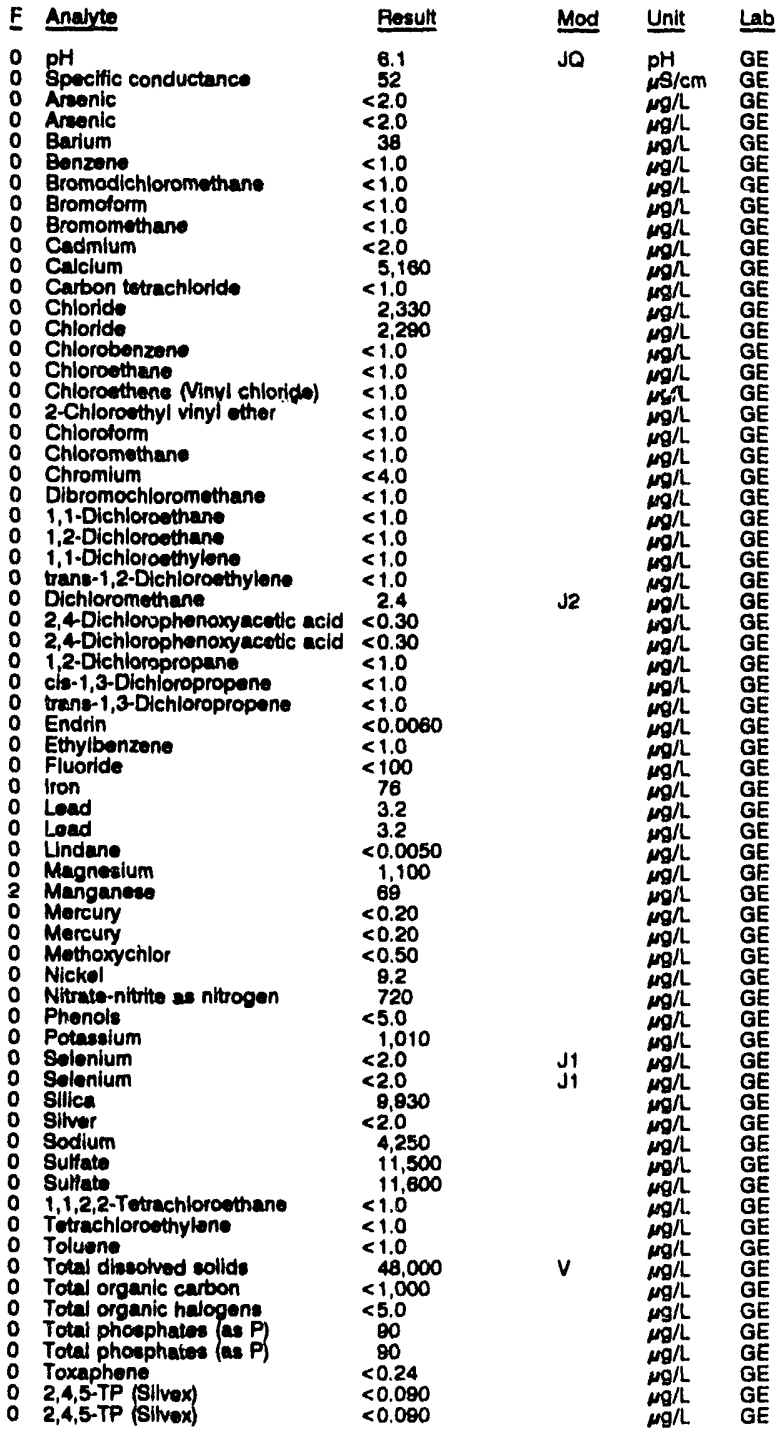

WELL BGO 29D collected on 08/08/92, laboratory analyses (cont)

\begin{tabular}{|c|c|c|c|c|}
\hline Analyte & Result & Mod & Unit & $a b$ \\
\hline 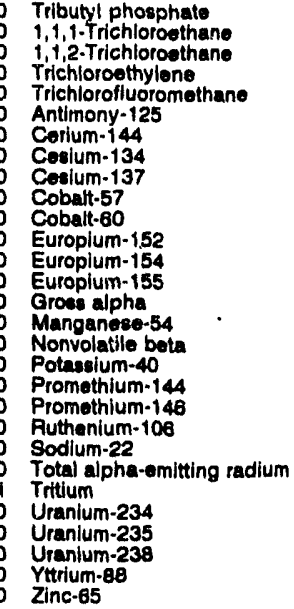 & 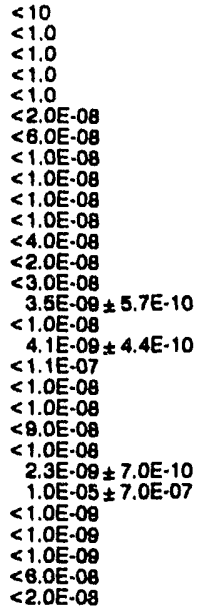 & $J_{1}$ & 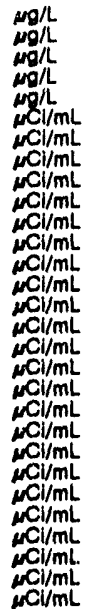 & $\begin{array}{l}\mathrm{GE} \\
\mathrm{GE} \\
\mathrm{GE} \\
\mathrm{GE} \\
\mathrm{GE} \\
\mathrm{GP} \\
\mathrm{GP} \\
\mathrm{GP} \\
\mathrm{GP} \\
\mathrm{GP} \\
\mathrm{GP} \\
\mathrm{GP} \\
\mathrm{GP} \\
\mathrm{GP} \\
\mathrm{GE} \\
\mathrm{GP} \\
\mathrm{GE} \\
\mathrm{GP} \\
\mathrm{GP} \\
\mathrm{GP} \\
\mathrm{GP} \\
\mathrm{GP} \\
\mathrm{GE} \\
\mathrm{GE} \\
\mathrm{GP} \\
\mathrm{GP} \\
\mathrm{GP} \\
\mathrm{GP} \\
\mathrm{GP}\end{array}$ \\
\hline
\end{tabular}

\section{WELL BGO $30 \mathrm{C}$}

MEASUI IEMENTS CONDUCTED IN THE FIELD

\begin{tabular}{|c|c|}
\hline $\begin{array}{l}\text { Sample date: } 08 / 06 / 92 \\
\text { Depth to water: } 54.59 \mathrm{nt}(18.64 \mathrm{~m}) \text { below TOC } \\
\text { Water olovation: } 219.91 \mathrm{t}(67.03 \mathrm{~m}) \mathrm{msl} \\
\text { Sp. conductance: } 64 \text { ss/cm } \\
\text { Water ovacuated before eampling: } 23 \mathrm{gal}\end{array}$ & $\begin{array}{l}\text { Time: } 10: 25 \\
\text { pH: } 8.3 \\
\text { Alkalinity: } 15 \mathrm{mg} / \\
\text { Water temperature: } 20.7^{\circ} \mathrm{C}\end{array}$ \\
\hline
\end{tabular}

LABOPATORY ANALYSES

\begin{tabular}{|c|c|c|c|}
\hline Analyte & Result & Mod & Unit \\
\hline 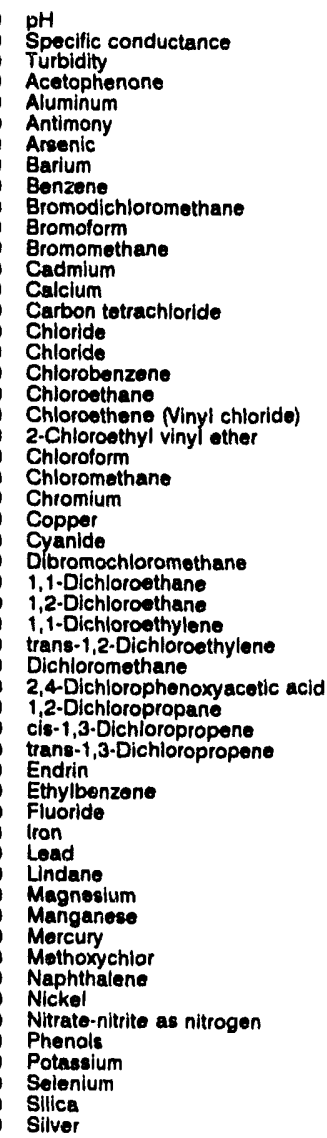 & $\begin{array}{l}7.1 \\
50 \\
526 \\
<10 \\
<20 \\
<2.0 \\
<2.0 \\
13 \\
<1.0 \\
<1.0 \\
<1.0 \\
<1.0 \\
<2.0 \\
3,460 \\
<1.0 \\
2,280 \\
2,240 \\
<1.0 \\
<1.0 \\
<1.0 \\
<1.0 \\
<1.0 \\
<1.0 \\
<4.0 \\
<4.0 \\
<5.0 \\
<1.0 \\
2.5 \\
<1.0 \\
<1.0 \\
<1.0 \\
3.6 \\
<0.30 \\
<1.0 \\
<1.0 \\
<1.0 \\
<0.0060 \\
<1.0 \\
<100 \\
16 \\
<3.0 \\
<0.0050 \\
238 \\
12 \\
<0.20 \\
<0.50 \\
<10 \\
<4.0 \\
600 \\
<5.0 \\
1.450 \\
<2.0 \\
8.570 \\
<2.0 \\
<\end{array}$ & $\begin{array}{l}\text { JQ } \\
\text { JQ } \\
\text { JQ1 } \\
\text { J1 }\end{array}$ & 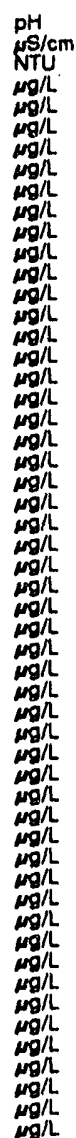 \\
\hline
\end{tabular}


ANALYTICAL RESULTS

WELL EGO 31C collected on 08/13/92, laboratory analyees (cont.)

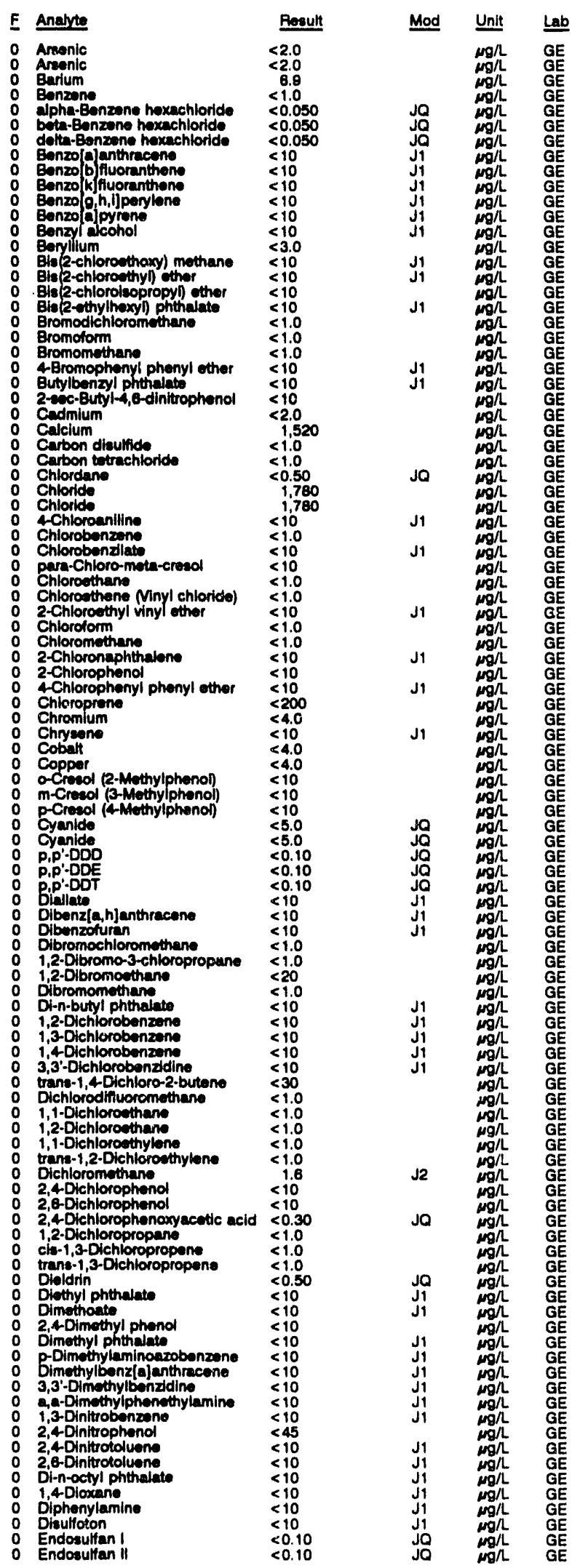

WELL BGO 31C collected on 08/13/92, laboratory analyses (cont)

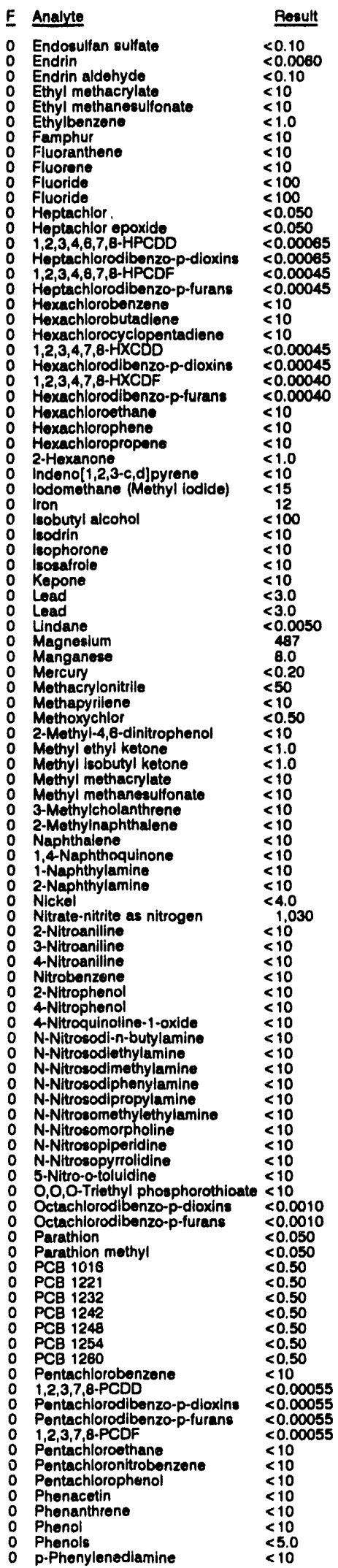


WELL BGO 31C collected on 08/13/82, laboratory analyese (cont.)

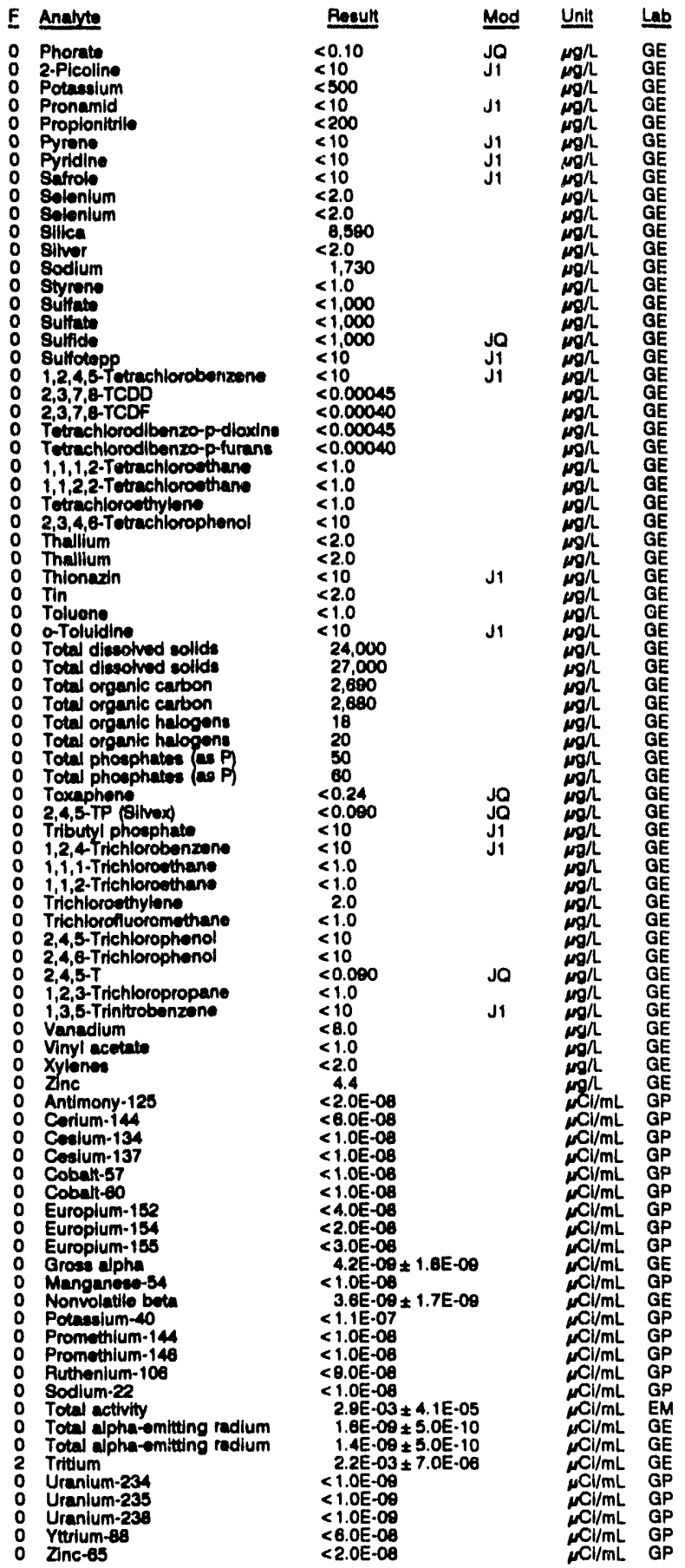

WELL BGO 31D

MEASUREMENTS CONDUCTED IN THE FIELE,

$\begin{array}{ll}\text { Sample date: } 08 / 13 / 92 & \text { Time: } 8: 45 \\ \text { Depth to water: } 46.28 \mathrm{Ht}(14.11 \mathrm{~m}) \text { below TOC } & \text { PH: } 4.6 \\ \text { Water olovation: } 227.42 \mathrm{~h}(89.32 \mathrm{~m}) \mathrm{msl} & \text { Alkalinity: } 0 \mathrm{mg} / \mathrm{h} \\ \text { Sp. conductance: } 34 \mu \mathrm{s} / \mathrm{cm} & \text { Water temperature: } 21.10 \mathrm{C} \\ \text { Water evacuated belore sampling: } 8 \mathrm{gal} & \end{array}$

Sp. Conductance: $34 \mu \mathrm{s} / \mathrm{cm}$
Water evacuated belore sampling: $8 \mathrm{gat}$

The well went dry during purging.

LABORATORY ANALYSES

F Analyte

O $\mathrm{gH}$

Turbidity

o Aconaphthene

O Aconaph hy

Acetone

Acetonitrile (Mothyl cyanide)

Acetophenons

2-Acotylam

o Acrylonitril

o Addrin

Altyl chloride

Aluminum

4Aminobipl

Anthracenne

Antimony

Aramite

Areenic

Barium

Benzene

alpha-Eenzene hexachloride

beta-Banzene hoxachloride

delta.Benzene hexachlorld

Eenzolajanthracene

Benzo bluoranthen

Benzolg, $h, i j$ perylene

Benzolajpyrene

Benzyl alcohol

Bis (2-chloroethoxy) methan

Bis 2-chloroethyl) other

Bis 2-chlorolsopropyl) other

Gis(2-othylhexyl) phthalate

Bromodichloromethane

Bromoform

4-8romophenyl phenyl ether

4-Bromophenyl phenyl ther

2-sec-Butyl-4,6-dinitrophenol Cadmium

Calcium

Carbon diaulfide

Carbon tetrachloride

Chlordane

4-Chloroanilin

Chlorobenzene

Chlorobenzllate

para-Chloro-meta-cresol

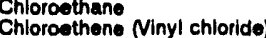

Chloroethene Ninyl chloride
2-Chloroethyl vinyl ether

Chloroform

2-Chloronaphthalene

2-Chloronaphthal

4.Chlorophenyl phenyl ether

$<10$

Chloroprene

Chryeane

Cobalt

O-Cresol (2-Methylphenol)

m-Cresol (3-Methylphenol)

p-Cresol (4-Mothyiphenol)

Cyanide

$p, p^{\prime} \cdot$ DOD
$p, p^{\prime} \cdot D D E$

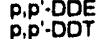

p.p.DDT

Dibenz[a,h]anthracene

Dibenzofuran

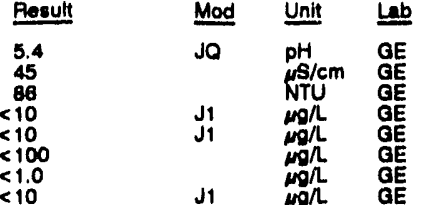

$<10$

Ji $\mathrm{mol}$ GE

0.050

$<50$

$<10$
$<10$

$<10$
$<10$

$<2.0$

$<.0$
7.2

$<1.0$

$<0.050$
$<0.050$

$<10$
$<10$

$<10$
$<10$

$<10$
$<10$

$<10$

$<3.0$

$<10$

$<10$
$<10$

51.0
$<1.0$

$<1.0$

$<10$
$<10$
$<10$
$<20$

563
$<1.0$
$<1.0$

$<1.0$

3,490

$<10$

$<10$
$<10$

$<1.0$

$<1.0$
$<10$

1.0

10

$x: 10$

$<200$

$<4.0$
$<10$

$<.0$
8.0

8.0
$<10$

$<10$

$<5.0$
$<0.10$

$<0.10$

$<0.10$

$<10$

1, Dromochloromethane 1,2-Dibromoethane

D.2-Dlbromoothano

Di-n.butyl phthalate

1,2-Dichlorobenzene

1,3-Dichlorobenzene

1,4-Dichlorobenzene

3,3-Olchlorobenzidine

trans-1,4-Dichloro-2-bute

1,1.Dichloroethane

1,2-Dichloroethane 
ANALYTICAL RESULTS

WELL BGO 31D collected on 08/13/92, laboratory analyees (cont.)

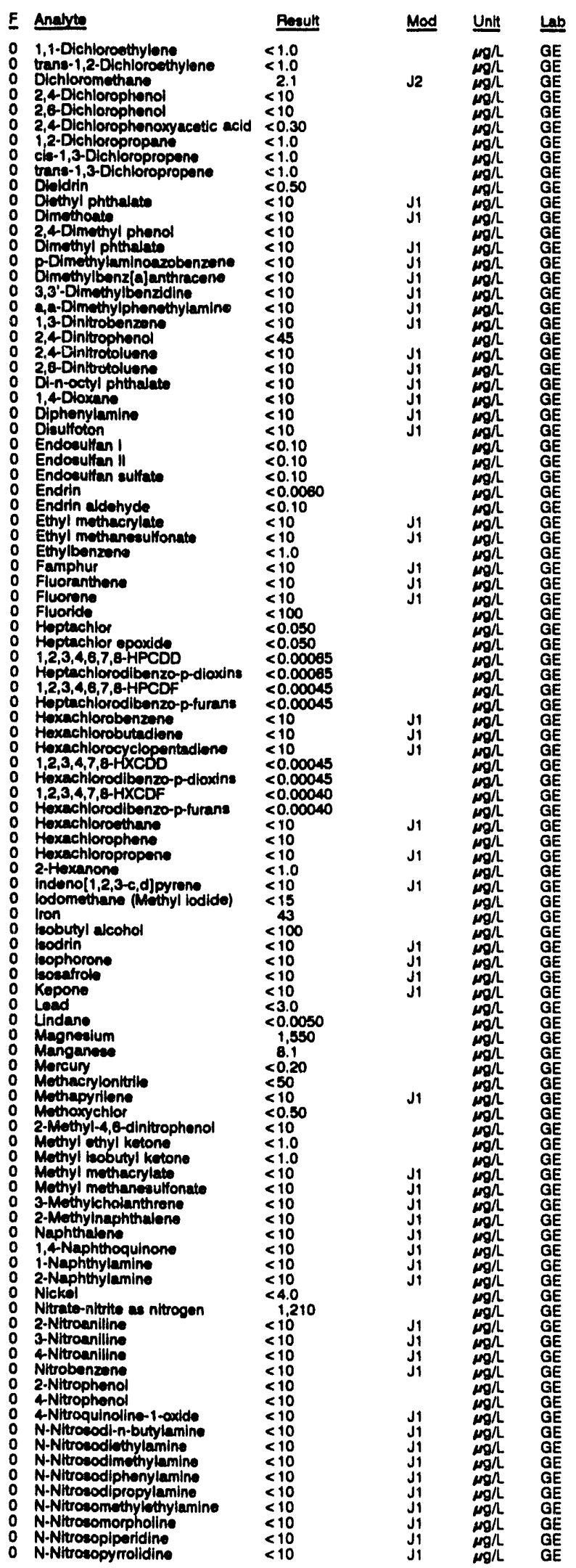

WELL BGO 310 collected on 08/13/82, laboratory analyees (cont.)

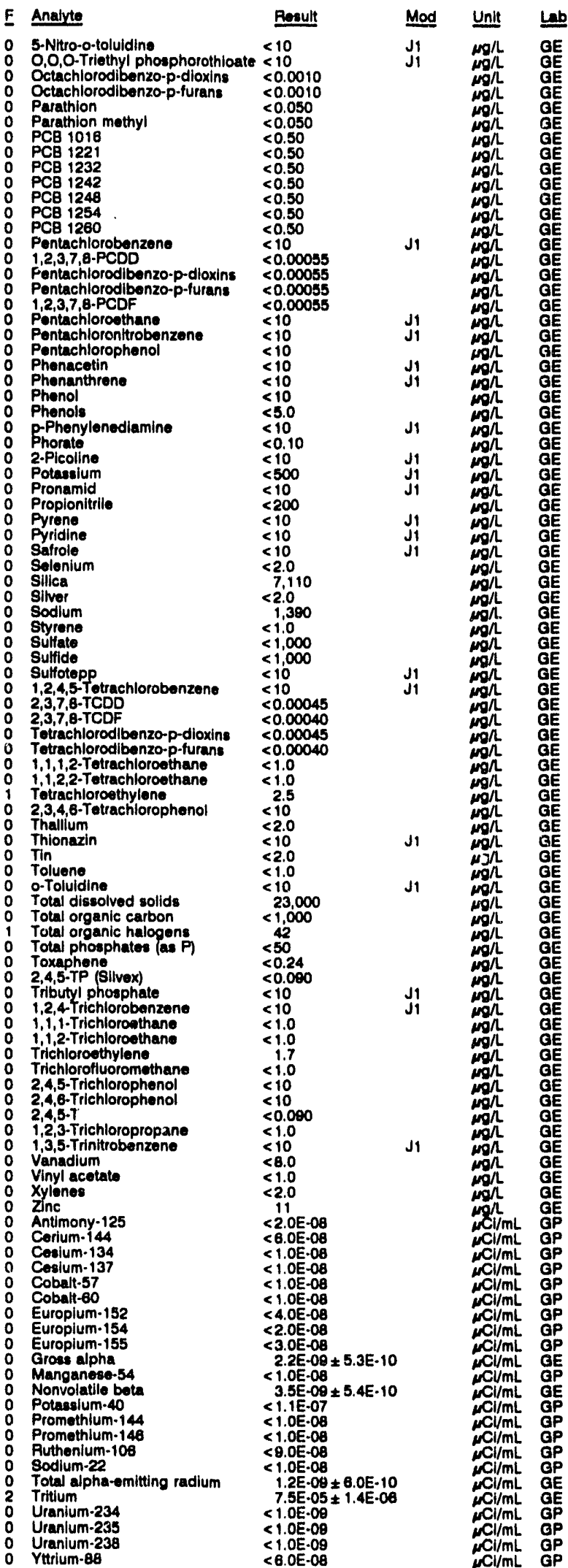


WELL BCO 310 collectad on 06/13/92, laboratory analyees (cont.)

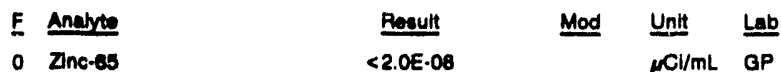

WELL BGO 32D

MEASUREMENTS CONDUCTED IN THE FIELD

Sample date: oa/13ver

Depth to water: $83.51 \mathrm{~h}(16.31 \mathrm{~m})$ below ToC Wate colvation: $228.19 \mathrm{~h} / \mathrm{log}$

water avacuatiod belore sampling: $6 \mathrm{gal}$

The well womt dry during purging.

LAOPATOFY ANALYSES

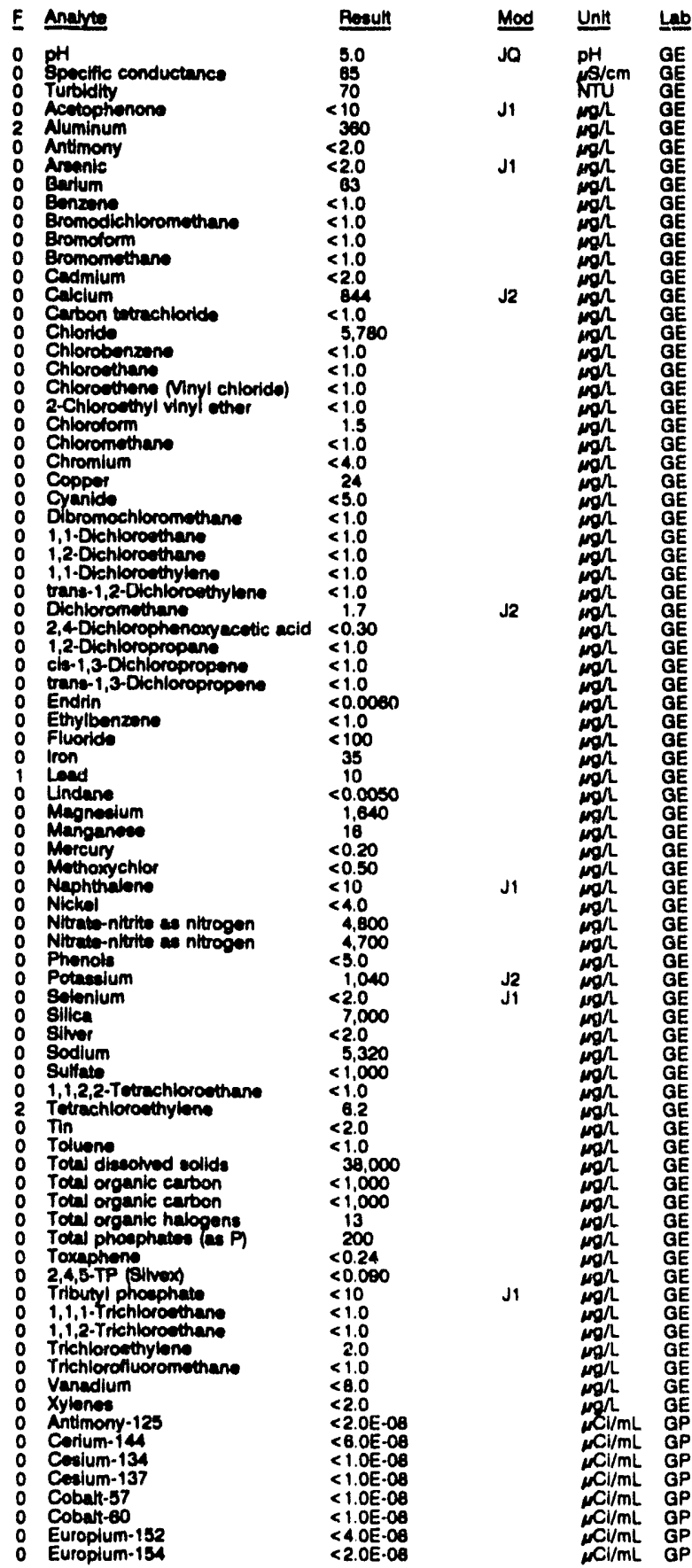

WELL BGO 32D collocted on 08/13/92, laboratory analyees (cont.)

\begin{tabular}{|c|c|c|c|c|}
\hline F & Analyte & Result & Unit & 느 \\
\hline $\begin{array}{l}0 \\
0\end{array}$ & 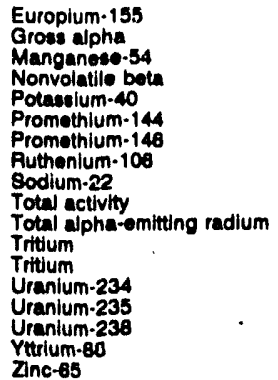 & 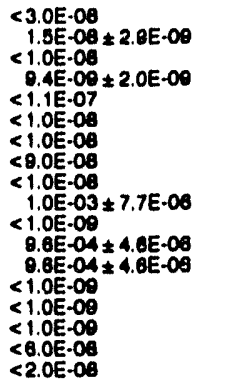 & 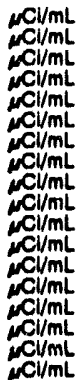 & 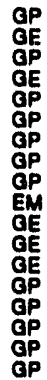 \\
\hline
\end{tabular}

V':LLL BGO $33 \mathrm{C}$

ME ISUREMENTS CONDUCTED IN THE FIELD

8am,ile date: 08/08/92

Depth to water: 53.89 h $(16.38 \mathrm{~m})$ below TOC

Wator elevation: $225.71 \mathrm{ft}$ (es.

Water wacuatod before sampling: $126 \mathrm{gal}$

LABORATORY ANALYSES

E Analyte

$0 \mathrm{pH}$

Spectific conductance

Turbidtty

O Acenaphthene

Acetone

- Acetonitrile (Mothyl cyanide)

Acetophenone

2-Acetyla

- Acrylonitrile

Aldrin

Allyl chlorido

4-Aminoblphenyl

o Anilino

o Anthracene

Antimony

0 Arramite

Barium

Sonzene

lpha-Bonzene hexachloride

beta-Benzene hoxachloride

delta-Benzene hexachloride

Benzo/a) anthracene

Benzo b fluoranthene

Benzo kf huoranthene

Bonzo g,h,ilporylono

Benzolajpyren

Benzyl alcohr

Bis(2-chloroethoxy) mothane

Bis (2-chloroethyl) ether

Bis (2-chloroisopropyl) ether

Bis(2-ethylhexyl) phthalato

Bremolorm

Bromomethane

4-Bromophenyl phenyl ther

Butylbenzyl phthalato

2-ecc-Buty

Cadmium

Calcium

Cerbon tetrachloride

Chlordane

o 4-Chloroaniline

Chlorobenzene

Chlorobenzene

para-Chloro-meta-cresol

Chloroethane

Chloroethene Ninyl chloride)

2.Chloroethy

o Chlorolorm

o Chloromethane

2-Chloronaphthaien

4-Chlorophenyl phenyl ether

o Chloroprene

O Chromium

o Chrysene

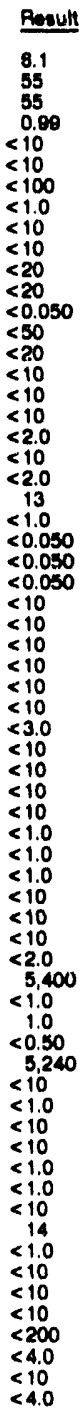

Time: 14:35

pH: 5.6 Alkalinity: $10 \mathrm{mg} \Omega$, $20.6^{\circ} \mathrm{C}$ Water tomperature: $20^{\circ} \mathrm{C}$

Mod Unit Lab

Jo

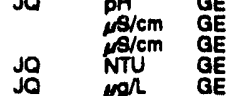

JO J M/ GE

Jo
Jo
jo

$\begin{array}{lll}\text { Jo } & \omega 9 & G E \\ \text { Jo } & \text { Ge } \\ \text { Jo } & \text { GE } \\ \text { Jo } & \text { GE }\end{array}$

Jo

Ja

Jo

Ja

Jo

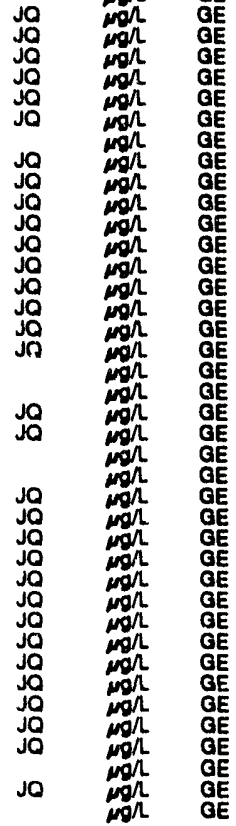


ANALYTICAL RESULTS

WELL BCO $33 C$ collected on 0avav2, laboratory analyees (cont)

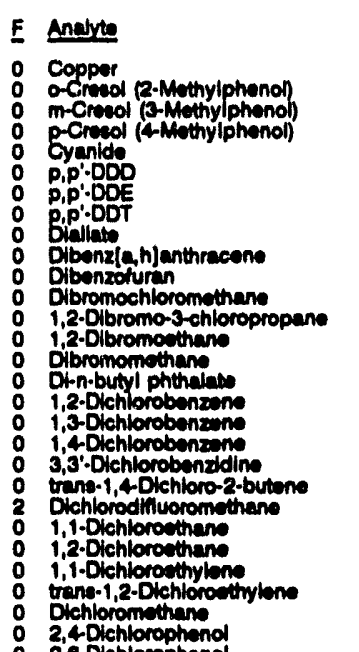

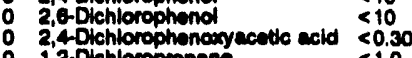

1,2-Dlchloropropan

thin-1,3-Dichioropropen

Dleldrin'

Oiethyl phthelate

2,4Dimethyl phenol

Dimethyl phthalate

p-Dimethylaminoazobonzone

3imethylbenziajenthracen

a. Dimethylphenethylamine

, Dintrophen ot

2,4-Dinitrotoluene

2,6-Dinftrotoluene

1,4-Dloxans

Diphenylamine

Disulfoton

Endosulten !

Endosulfan sulfate

Endrin

Endrin aldehydo

Ethyl methacrytate

Ethyl methanesul

Famphur

Fluoranthene

Fluorens
Fluoride

Heptachior

Heptachlor epoxide

$1,2,3,4,6,7,8-H P C D P$

Heptuchlorodibenxo-p-dioxine Heptachlorodibenzo-p-dioxine $1,2,3,4,6,7,8-H P C D F$

$1,2,3,4,6,7,2$ HPCDF Hoptachlorodlibenzo-p-furans

Hoxachlorobonzens

Hexachlorobutadiene

$1,2,3,4,7,8-1 \times C D D$

$1,2,3,4,7,8-H \times C D D$

Hoxachlorodlbenzo-p-dioxins

Hoxachlorodibenzo-

$1,2,3,4,7,8-H \times C D$

Hoxuchlorodibenzo-p-hurans

Hoxachorodbenzo-p-turans

Hexachlorophene

Hexachloropropene

2.Hoxenon

indeno[1, 2,3-c,d]pyrene

lodomethane (Methyl lodide)

leobutyl alcohol

bodrin aco

reoufrote

Kepon

Lead

Undane

Manganew

Mercury

$<4.0$
$<10$
$<10$
$<10$
$<5.0$
$<0.10$
$<0.10$
$<0.10$
$<10$
$<10$
$<10$
$<1.0$
$<1.0$
$<20$
$<1.0$
$<10$
$<10$
$<10$
$<10$
$<10$
$<30$
$<15$
$<1.0$
$<1.0$
$<1.0$
$<1.0$
$<1.7$
$<10$
$<10$
$<0.30$
$<1.0$
$<11.0$
$<1.0$
$<0.50$

1.0

$<.30$
$<1.0$
$<1.0$

$<1.0$

$<0.50$
$<10$
$<10$

$<10$

$<10$
$<10$

$\leq 10$

$<10$

$<10$

$<45$

$<10$

$<10$

$<10$

$<0.10$

$<0.10$

$<0.0080$

$<0.10$

$<10$
$<10$

$<1.0$

$<10$
$<10$

$<10$
$<10$

$<100$

$<0.050$
$<0.050$

0.00065

$<0.00065$

$<0.00085$

$<0.00045$

$<0.00045$

$<0.00048$
$<10$
$<10$

$<10$

$<0.00045$

0.00045

$<0.00045$

$<0.00040$

$<0.00040$

(20040

$<10$
$<10$
$<10$

$<1.0$

$<10$
$<15$

$<4.0$

$<4.00$

$<<10$

$<10$
$<10$

$<3.0$

728
30
Mod Unt

Lab

JO
JO
JOB

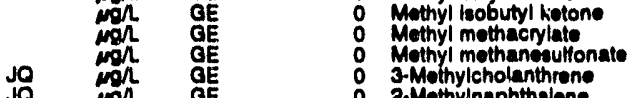

2.Methylnaph

1.4Naphthequinone

2.Naphthylamine

Nlokel

Nitrate-nitrite as nitrogen

2-Nitroaniline

4-Nitroaniline

Nitrobenzene

2.Nittrophenol

4-Nitrophenol

ENitroquinolin-1.oxide

Nintrosodintbutylamino

N.Nitrosodisthylamino

N-Nitrosodiphenylamine

N.Nitroeodipropylamine

N-Nitroeomethylothylamine

N-Nitrosomorpholine

N-Nitrosopipentidino

N-Nitresopyrrolldine

N-Nhro-o-toluidine

Octachlorodtbenzo-p.dloxine

Octachlorod benzo-p-dlorins

Octachlorodibenzo-p.furans

Octachlorodibenzo-p-furan

Parathion

PCB 1016

PCB 1221

PCE 1242

PCB 1248

PCB 1234

Pentachlorobenzene

1,2,3,7,8-PCDD

Pentachlorodibenzo-p-dloxin:

Pentachlorodibonzo-p-dloxins

Pentachlorodibenzo-p-furans

Pentachlorodib

1,2,3,7,8-PCDF

Pentachloroethane

Pentachloronitrobenzene

Pentachlorophenol

Phenacetin
Phenanthiene

Phenol

p Phenylenediamine

Phorato.

Potassium

P Pronamid

Proplonitril

O Pyrene

0 Safrole

Solonium

Silver

O Sodium

o Styrene

0 Sulfido

1,2,4,5-Totrachlorobenzene

2,3,7,8-TCDD

2,3,7,8-TCDO

2,3,7,8-TCDF

o Tetrachlorodibenzo-p-dioxins

- Totrachlorodibenzo-p-furans

- Totrachlorodibenzo-p-furans

o 1,1,1,2-Tetrachloroethane

o 1,1,2,2-Tetrachloroothan

2 Tetrachloroethylone

0 2,3,4,6-Totract

o Thallium

Thlonazin

o Toluene

o-Toluldine

Total dissolved solid

Total organic carbon

\section{Pesult}

$<50$
$<10$

$<0.80$

$<10$

$\leq 1.0$

$<10$
$<10$
$\leq 10$

$<10$

510

$<10$
$<10$
$<4$

510
510
$<40$

$<4.0$

$<10$

$<10$

$\leq 10$

$\leq 10$

$<10$
$<10$
5

$<10$

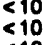

$<<10$

$<10$
$<10$
$<10$

$<10$

$<10$

$<<10$

$<0.0010$

$<0.0010$
$<0.0010$

$<0.050$

$<0.050$

$<0.50$

0.50

$<0.50$

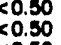

$<0.50$

$<0.00055$

$<0.0005$

$<0.00055$

$<0.00055$

$<0.00055$

$<0.000$

$<10$
$<10$

$<10$

$<10$

$<10$
$<5.0$
$<10$
$<0.10$

$<0.10$

$<10$

$<10$

$<200$

$<10$
$<10$

$<2.0$

10,800

3,220

$<1.000$

$<1,000$

$<10$

$<10$
$<0.00045$

$<0.0004$

$<0.00040$

$<0.00045$

$<0.00045$

$<0.00040$

$<1.0$

$<1.0$

5.5
$<10$
$<2.0$

$<2.0$

$<2.0$

$<10$

45,000
$<1,000$
Mod Unit 늠

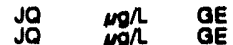

jo

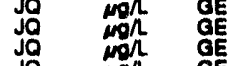

Jo

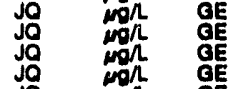

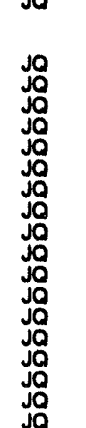

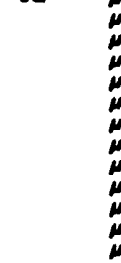

Jo

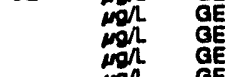

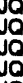

Jo

Jo

Jo
JO
JO
JO

促

sa

Ja

jo

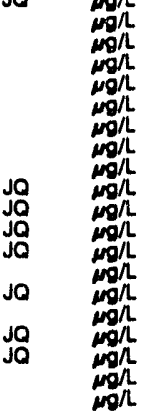

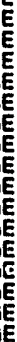


WEUL BOO 33C collected on oaroap2, laboratory enayses (cont.)

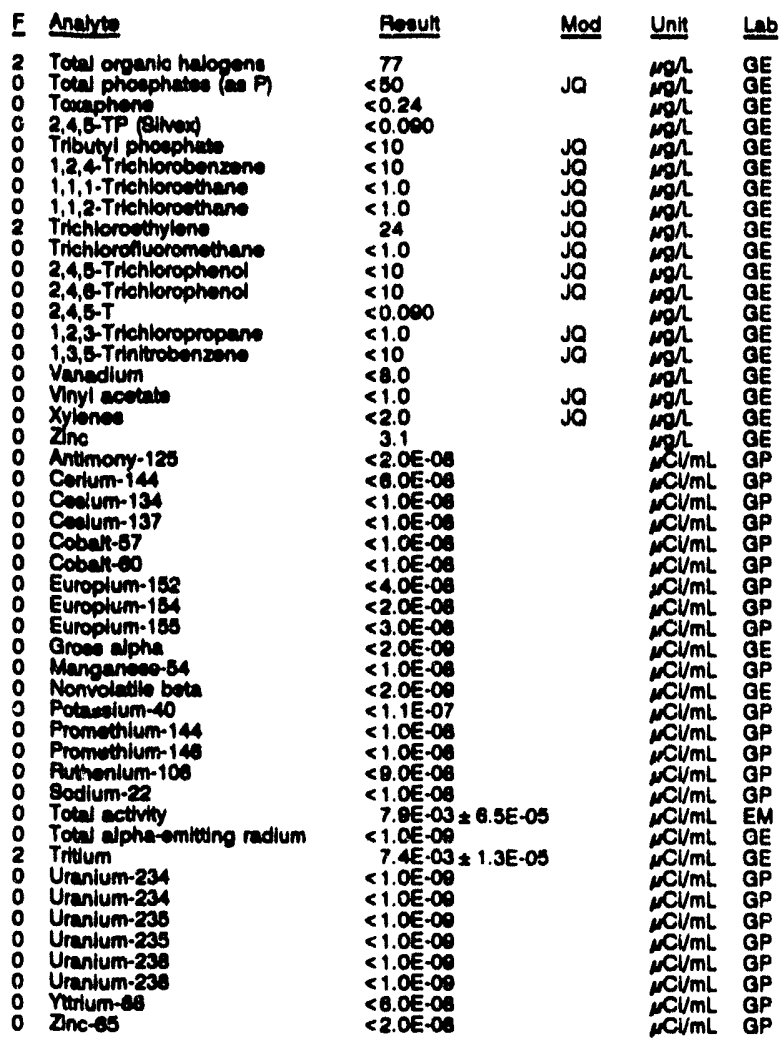

WELL BGO 33D

MEASUAEMENTS CONDUCTED IN THE FIELD

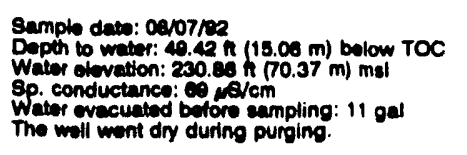

Time: $7: 10$
pH: 4.6
Nhalinity: $0 \mathrm{mgh}$
Water tomperature: $21.2{ }^{\circ} \mathrm{C}$ The well went dry during punging.

LABORATOFY ANALYES

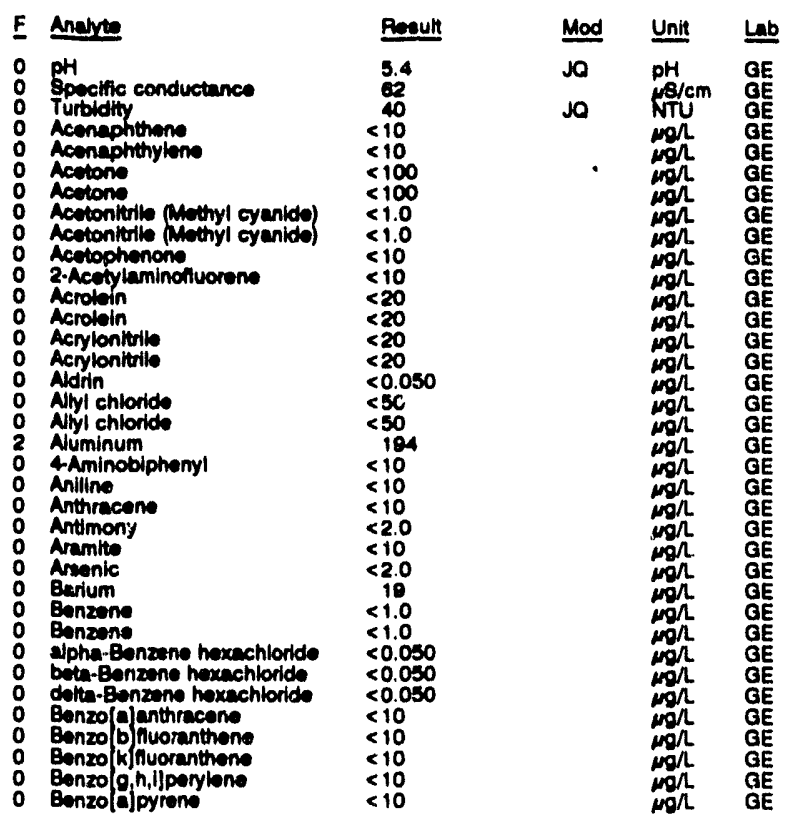

WELL BOO 330 collected on 0Q/OT/O2, laboratory analyeere (cont.)

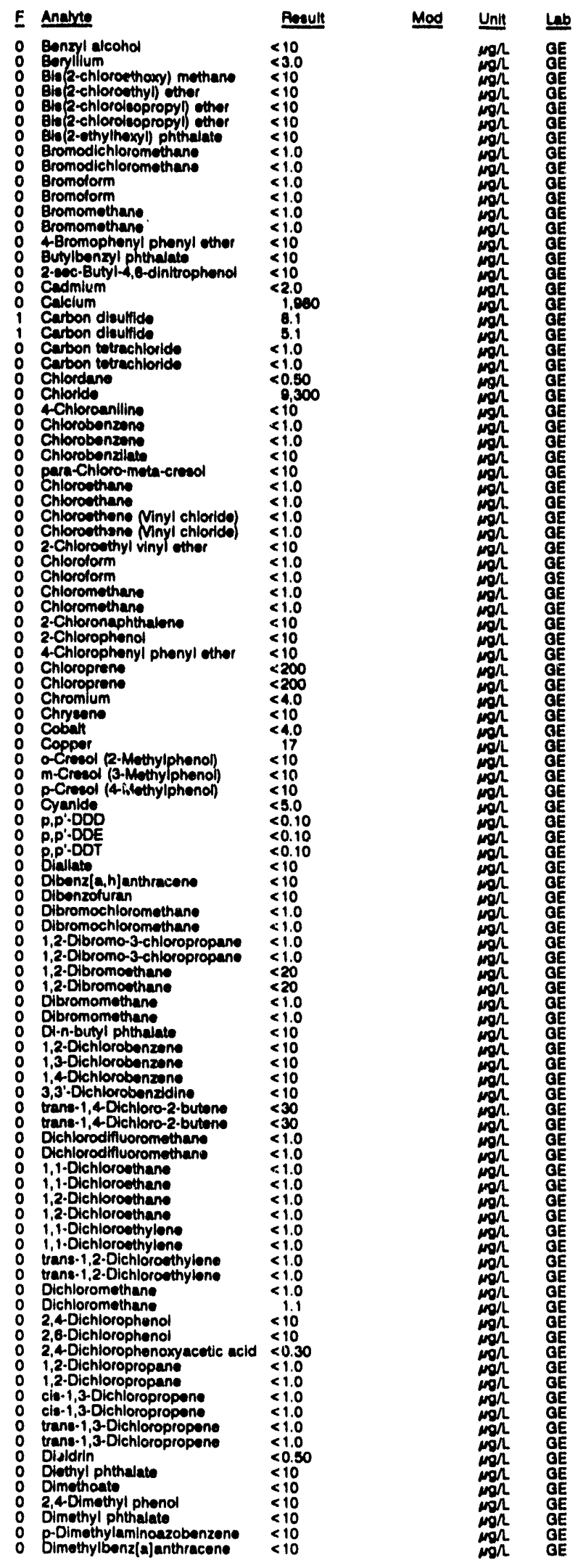


ANALYTICAL RESULTS

WELL ECO 330 collectad on 0av7/02, taboratory analyeas (cont)

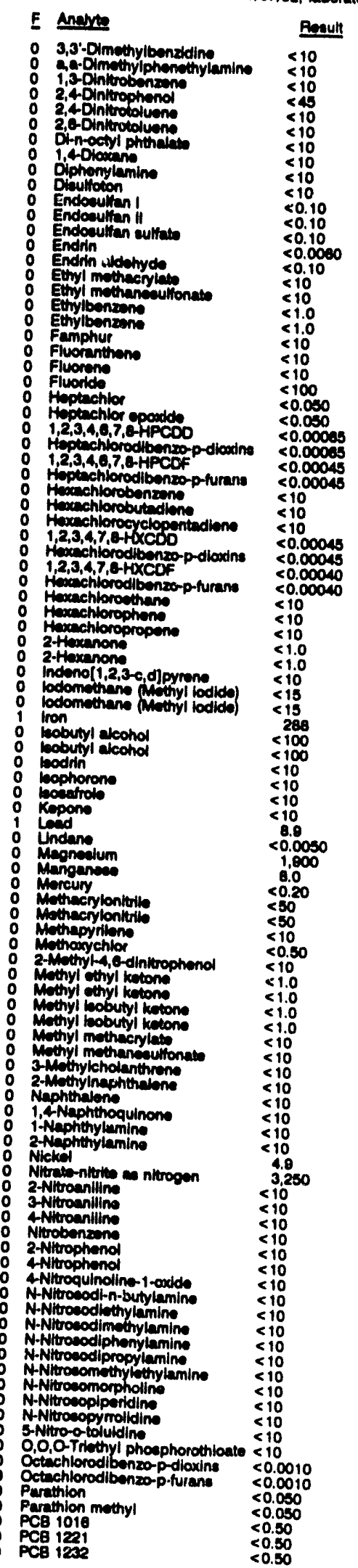

Mod

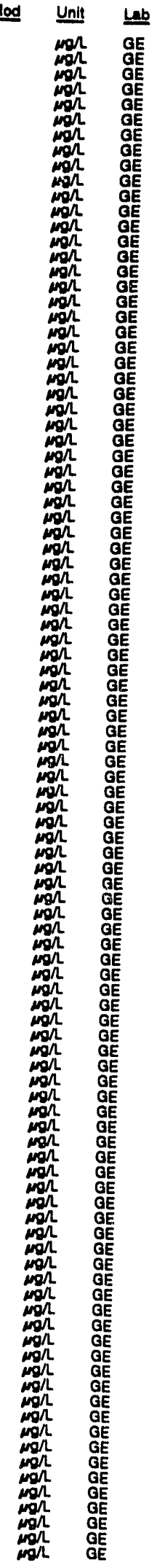

WELL BOO 330 collected on 08/07/82, laboratory analyees (cont)

\section{E Arabyte}

PCB 1242

0 PCB 1254

- Pentachlorobonzone

0 1,2,3,7, A-PCDO

- Pontachlorodibonzo-p-cloxina

o Pentachlorodibenzo-p-i Jruna

$1,2,3,7,8 \cdot P C D F$

- Pontichloroothanc.

o Pontachloronitroba nzeno

Pontachloroption

Phenanthrono

$\therefore$ Phenol

p-Phonylenediamine

2.Pleolino

0 Potasesium

o Pronamida

Propionitrile

0 Pyrente

0 safrotio

0 Solenium

: Sillicar

: Silvor

o styren

o styrene

o Sulfate

0 Sulfotepp

1,2,4,0-Tetrachlorobenzene 2,3,7, , TCDD

o Totriechlorodibenzo-p-dioxin

- Totrachlorodibenzo-p-turane

o $1,1,1,2$ - Totrachloroethane

i,i,2-Totrachloroethane

i, 2,2-Totrachloroethane

o Totrachloroethylene

2,3,4,6-Totrachloroptionol

: Thallium

Tin

Tolvene

o-Toluidino

Total diseolved sollds

- low organle carbon

o Toter organlc halogons

2,4,5-TP Silvox

intivex)

1,2,4-Trichlorobenzene

1,1,1-Irichloroethane

1,1,1-Trichloroothane

i, i, 2. Trichlorosthane

Trichlorouthylene

Irichloroethylono

Inchlorofluoromethane

Trichlorofluoromothane

2,4,5-Trichlorophnonol

2,4,6-Trichlorophenol

1,2,3-Trichloropropane

1,3,5-Trichloropropane

Vanadium

Vinyl acotato

xylenes

0 Xylonos

O Znc

- Antimony-125

Cosium-134

Conium-137

Cobatt-57

Europlum-152

Europium-154

Europium-15s

Mangarpeova 54

Norivolatilie beta

Potangium 40

Promathium-14a

Promethium-146

Ruthonium.140

Total alpha-emitting radium
Beaun

$<0.50$

$<0.50$

$<0.60$

$<0.00055$

$<0.0005$

$<0.0005$

$<10$
$<10$

$<10$

$<10$

$<10$
$<10$
$<8.0$

$<10$

$<0.10$

$<10$

$<10$

$<200$

$<200$

$<10$

$<10$
$<2.0$

$<2.00$

$<2.610$

$<1.0$

$<1.0$

$<1,000$

$<1,000$
$<10$
$<10$

$<0.00046$

$<0.00040$

$<0.00045$

$<1.0$

$<1.0$

$<1.0$

$<1.0$

$<10$

$<2.0$

$<10$

$<2.0$

$<1.0$

<1,000

$<1,000$

$<5.0$

$<0.24$

$<0.090$

$<10$
$<10$

$<1.0$

$<1.0$

$<1.0$

1.2
$<1.0$

$<1.0$
$<1.0$

$<10$

$<10$

$<0.000$

$<1.0$

$<10$

$<8.0$

$<1.0$

$<2.0$

$<21.0 E-00$

$<\forall .0 E-0$

$<1.0 E-06$

$<1.0 E-00$

$<1.0 E-08$

$<1.0 E-00$

$<2.0 E-08$

$4.0 E-00 \pm 1.8 E-00$

$<1.0 \mathrm{E}-06$

$6.0 E-09 \pm 1.8 E-09$

<1. TE-07

$<1.0 \mathrm{E} .00$

$<\theta .0 E-0 \theta$

$<1.0 E-00$

2.6E.00 $\pm 5.0 E \cdot 10$
Mod Untt Leb

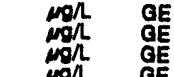

的

憉 de

mon de 
ANALYTICAL RESULTS

WELL BOO 330 collectiod on 08/07/92, laboratory analyese (cont)

\begin{tabular}{|c|c|c|c|}
\hline F Analyte & Result & Mod & Unit \\
\hline 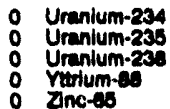 & $\begin{array}{l}<1.0 E-00 \\
<1.0 E-00 \\
<1.0 E-09 \\
<6.0 E-08 \\
<2.0 E-08\end{array}$ & & 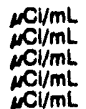 \\
\hline
\end{tabular}

WELL BGO 34D

MEASUREMENTS CONDUCTED IN THE FIELO

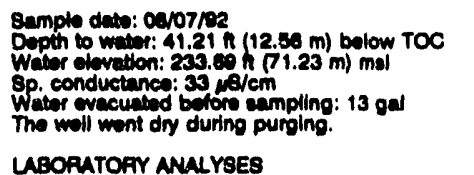

Time: 7:46

Akalinity: $2 \mathrm{~mol}$

Wator tomperature: $20.4 \cdot \mathrm{C}$

LABORATOFY ANALYSES

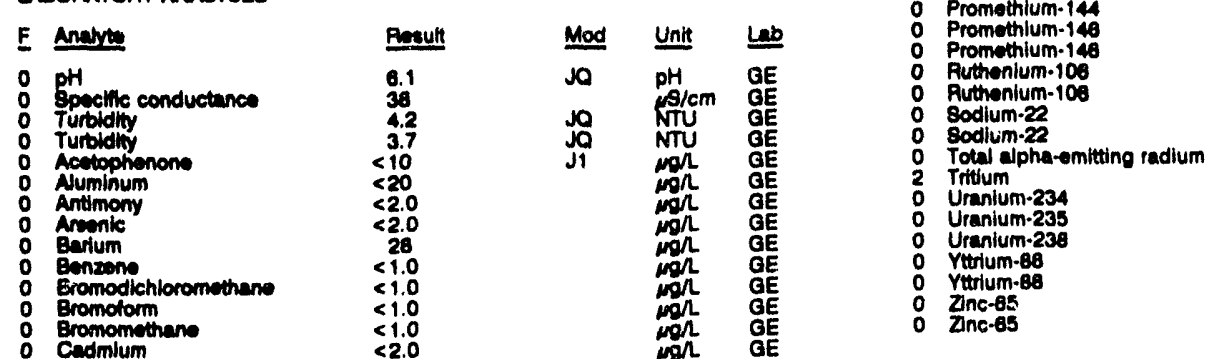

WELL BOO 34D collected on 06/07/92, laboratory analyeme (cont.)

\begin{tabular}{|c|c|c|}
\hline Analyte & Renult & Unit \\
\hline 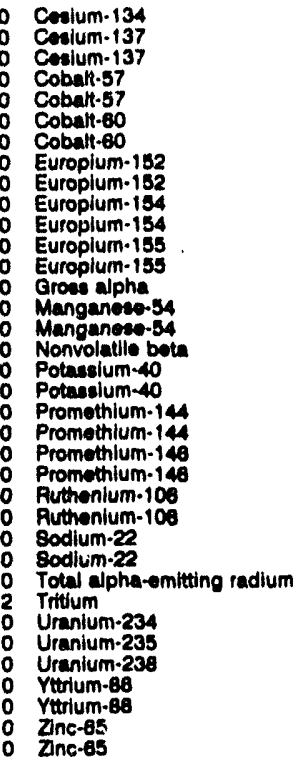 & 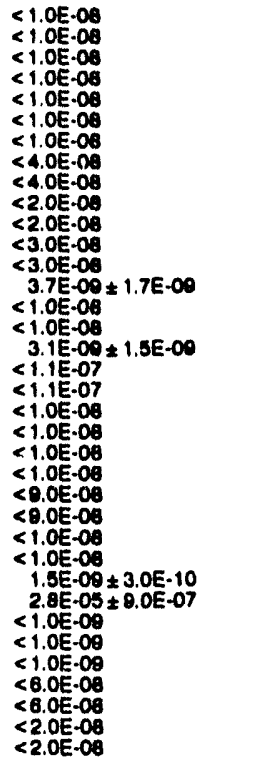 & 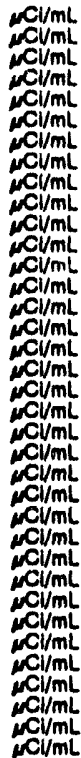 \\
\hline
\end{tabular}

\section{WELL BGO 35C}

MEASUREMENTS CONDUCTED IN THE FIELD

Depth to water: $44.62 \mathrm{n}(13.60 \mathrm{~m})$ below TOC Wator olovation: $228.77 \mathrm{~h}(00.73 \mathrm{~m}) \mathrm{msi}$

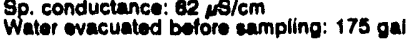

Alkalinity: $18 \mathrm{mgh}$

Water temperature: $20.0 \circ \mathrm{C}$ LABORATOAY ANALYSES

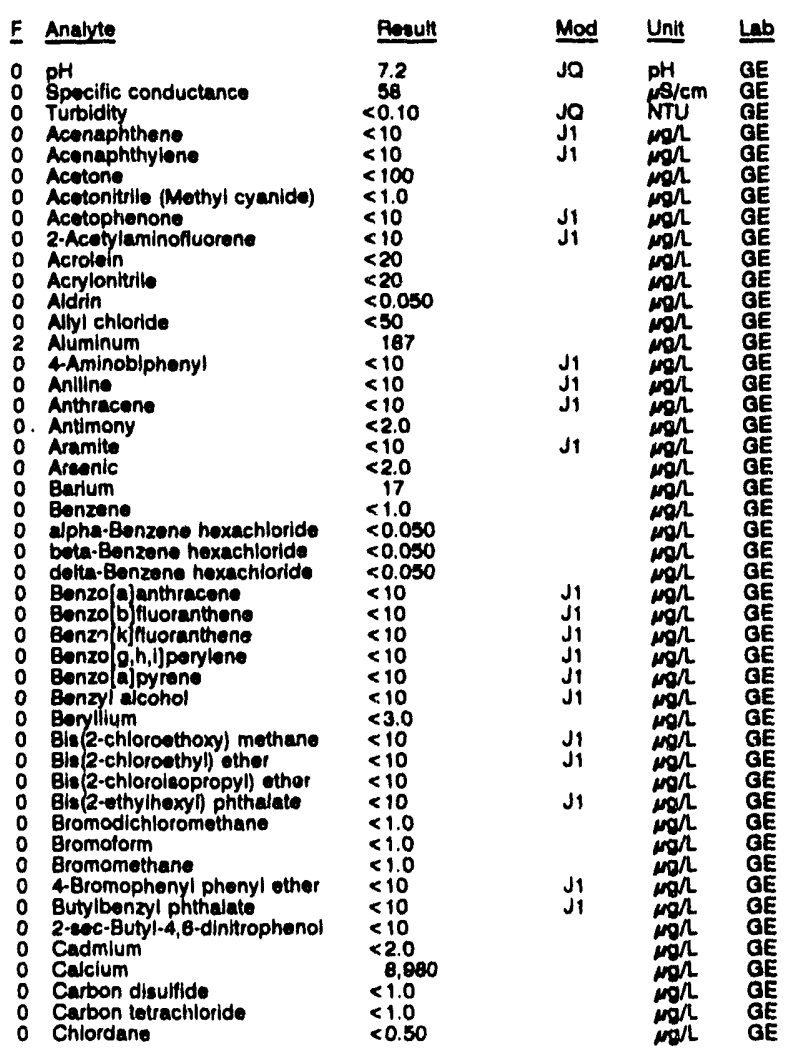


ANALYTICAL RESULTS

WELL BGO 35C collectod on 08/07/82, laboratory ana'ywas (cont.)

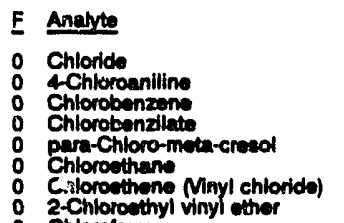

2-Chloroethyl Mnyl chloridel

Chloroform

2-Chloronaphthalen

4-Chiorophenyl phenyl ether

Chloroprens

O Chromlum

o Cobalt

o Copper (2.Methylphonol

o m-Cread (3-ilethylphonol)

0 Cyanide

0 p,p'-DDo

0 p.p'-Dot

Diallata

Dibenz[a,h]anthracens

o Dibonzoturas

0 1,2-Dibromo-3-chloropropan

o 1,2-Dibromoethen

Dibromomethene

Di-n-butyl phthalete

1,2-Dichlorobenzense

o 1,3-Dichlorobenzene

o 3,3'-Dicitlorobenzidine

trane-1,4-Oichloro-2-butione

o 1,1-Dichloroethane

1,2-Dichloroethan

1,1-Oichlorocthylene

Dich 1,2-Dichloro

2,4-Dictiorsphend

2,4-Dchlorophond

1,2-Dtchloropropane

o cis-1,3-Dlehloropropene

0 trana-1,3-Dichloropropente

Dieldrín

Diethyl plithalat

2,4-Dimethyl phenol

p-Dimothylaminoarobenzen

Dimethylbenzi (a) anthracen

a,a-Dimethyiphenethylamine

1,3-Dintrobiphens

2,4-Dinitrotoluen

Di-n-octyl phthalate

1,4-Dioxan

Diaultoton

Endosulfan I

Endosulfan

Endowín

Endrin aldehyde

Etron motnacryiato

Ethylbenzone

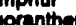

Fluranthen

Fluoride

Heptachlor

1,2,3,4,6,7,8-HPCDD

O Hoptachlorodlbenzo-p-dioxins

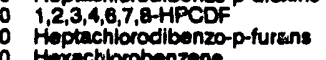

Hexachlorobutedione

Hexachlorocyclopent

Hexechlorodibenzo-p-dioxins

$1,2,3,4,7,0-t x c 0$ r

Hexechloroethane

Hoxuchlorophone

Hexachloroprop

Indexino $[1,2,3-c, d] p y r e n e$

lodomethane (Methyl iodide)

bobutyl alcohol
Pesult

1,790

$<1.0$

$<10$

$<1.0$

$<1.0$

$<1.0$

$<10$

$<200$

$<4.0$

$<10$
$<4.0$
$<4.0$

$<10$

$<10$

$<5.0$

$<0.10$

$<10$
$<10$

$<10$
$<1.0$

$<1.0$

$<1.0$

$<10$
$<10$

$<10$

$<30$

$<30$

$<1.0$

$<1.0$

$<1.0$

1.9
$<10$

$<10$

$<1.0$

Mod Unit Lab

J1 $\mu g /$ GE

J

J1

J4

J1

J1

J1
J1

$<1.0$

$<10$

$<100$

$<10$

$<10$

$<10$

$<<10$

$<45$
$<10$
$<10$

$\leq 10$

$\leq 10$

$<10$

$<0.10$

$<0.10$

$<0.0080$

$<10$

$<10$

$<1.0$

$<10$

$<10$
$<10$
$<100$

$<0.050$

$<0.00005$

$<0.00065$

$<0.000045$

$<10$

$<10$

$<00045$

$<0.00045$

$<0.00040$

$<10$

$<10$

$<10$

$<10$

$<15$

$<4.0$
$<100$

WELL BGO 35C collocted on 08/07/82, laboratory analyeee (cont.)

E Analyte

O lsodrin

o lecsafrole

K Kepone

o Undane

o Manganese

o Morcury

o Methacrylonitrile

o 2-Methyl-4,6-dinitrophenol

2-Methyl-4,6-dinitrophe

Methyl isobutyl ketone

Mothyl methacrylate

Methyl methanesulfonate

3-Methyicholanthrene

D Naphthalene

o 1,4-Naphthoquinone

$\begin{array}{ll}0 & 1 \text {-Naphthylamine } \\ 0 & \text { 2-Naphthylamine }\end{array}$

o Nickel

o Nitrato-nitrite as nitrogen

2-Nitroanilline

4-Nitroaniline

S Nitroanlins

2-Nitrophenol

0 4-Nitrophenol

4-Nitroquinoline-1-oxide

o N-Nitrosodinn-butylamine

N-Nitrosodiethylamine

N-Nitrosodimethylamine

O N-Nitrosodiphenylamine

N-Nitrosomothylethylamine

N-Nitrosomorpholine

N-Nitrosopiperidine

N-Nitrosopyrrolidin

0,0,0-Triethyl phosphorothioate

Octachlorodibenzo-p-dioxins

Octachlorodibenzo-p-dioxins

Parathion

- Parathion methyl

PCB 1016

PCB 1221

PCB 1240

PCB 1248

PCB 1254

Pentachlorobenzen

1,2,3,7,8-PCDD

Pentachorodibenzo-p-dioxins

$1,2,3,7,8-P C D F$

Pentachloronitrobenzene

Pentachlorophenol

Phenacetin

Phenanth

Phenols

p.Phenylenediamine

Phorate

2-Picoline

Pronamid

Propionitrile

Pyrene

Pyridine

o Selenium

O Sillica

S Sodium

Styrene

Sulfate

Sulfide

Sulfotepp

2,3,7,8-TCDD

$2,3,7,8-1 C D F$

Thachorodibenzo-p-dioxins

1,1,1,2-Tetrachloroethane

$1,1,2,2$-Tetrachloroethane

Totrachloroethylene

2,3,4,6-Totrachlorophenol

Thallium

0 Tin

Toluene

Total dissolved solids

Total organic carbon

- Total organic carbon

Result

$<10$

$<10$
$<10$
$<10$

$<0.000$

268
5.5

$<0.20$
$<50$

$<10$
$<0.50$

$<10$

$<1.0$

$<10$
$<10$

$<10$
$<10$
$<10$

$<10$
$<10$

$<10$

$<10$
$<4.0$

1,150

$<10$
$<10$

$<10$
$<10$
$<10$

$<10$

$<10$
$<10$
$<10$

$<<10$

$<10$
$<10$
$<10$

$<10$

$<10$

$<10$

$<10$

$<0.0010$

$<0.0010$

$<0.050$

$<0.50$

$<0.50$

$<0.50$

$<0.50$

$<0.50$

$<0.00055$

$<0.00055$

$<0.00055$

$<10$

$<10$
$<10$

$<10$

$<10$
$<10$

$<5.0$

$<10$.

$<0.1$.

$<500$

$<10$

$<10$

$<10$

$<10$

8,710

2,020

$<1,000$

$<1,000$

$<10$
$<10$

$<0.00045$

$<0.0004$

$<0.00040$

$<1.0$

$<1.0$

$<10$

$<2.0$

$<2.0$

$<10$ 
WELL BCO 350 collected on 09/07/82, laboratory analyees (cont.)

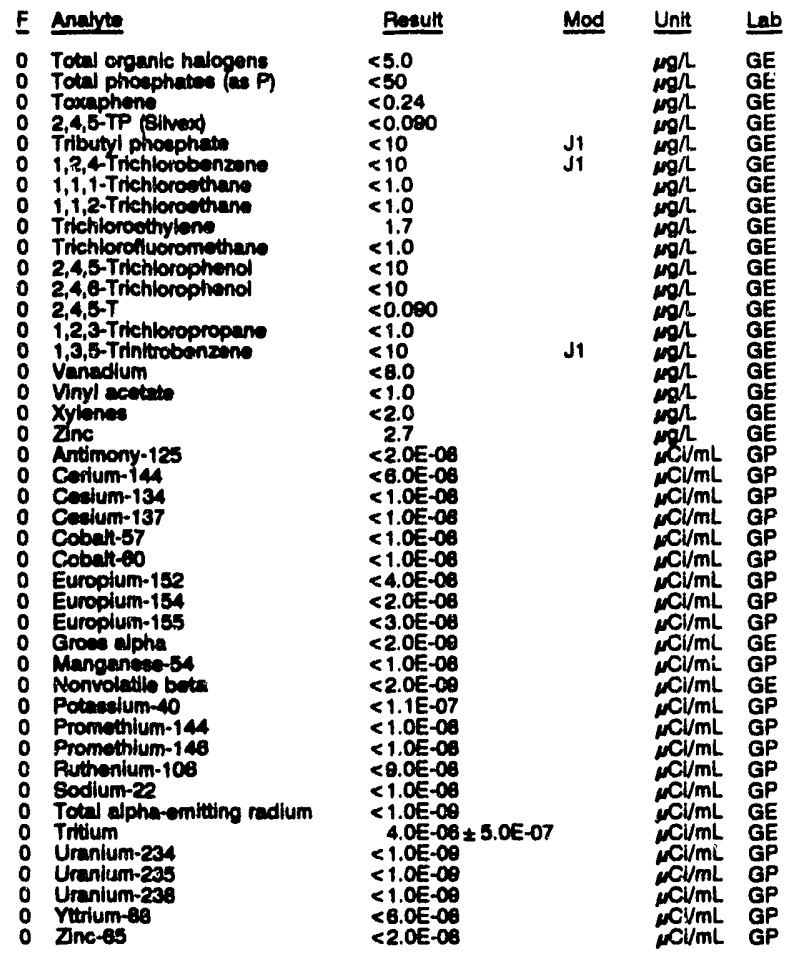

\section{WELL BGO 35D}

MEASUFEEMENTS CONDUCTED IN THE FIELD

Sample dates: 08/13/92

Depth to water: $36.41 \mathrm{~A}(11.71 \mathrm{~m})$ kelow TOC

Water elevation: 235.00 \& $(71.08 \mathrm{~m}) \mathrm{ms}$

Sp. conductance: $37 \mathrm{\mu s} / \mathrm{cm}$

The cull went diy during purging: $10 \mathrm{gal}$

LABOPATOPY AMALYESS

\begin{tabular}{|c|c|c|c|}
\hline Anclyte & Result & lood & Unit \\
\hline 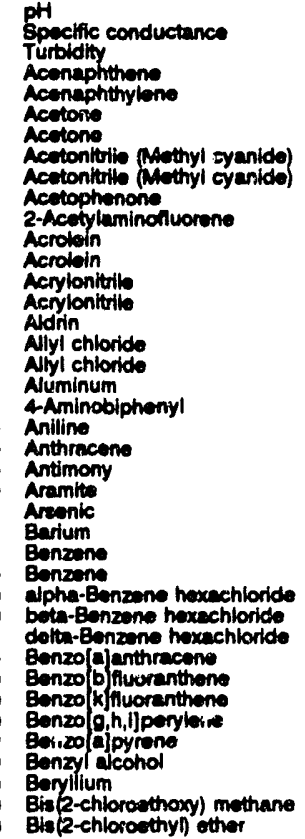 & $\begin{array}{l}5.1 \\
40 \\
180 \\
<10 \\
<10 \\
<100 \\
<100 \\
<1.0 \\
<1.0 \\
<10 \\
<10 \\
<20 \\
<20 \\
<20 \\
<20 \\
<0.050 \\
<50 \\
<50 \\
86 \\
<10 \\
<10 \\
<10 \\
<2.0 \\
<10 \\
<2.0 \\
13 \\
<1.0 \\
<1.0 \\
<0.050 \\
<0.050 \\
<0.050 \\
<10 \\
<10 \\
<10 \\
<10 \\
<10 \\
<10 \\
<3.0 \\
<10 \\
<10 \\
<10\end{array}$ & $\begin{array}{l}\mathrm{J} 1 \\
\mathrm{~J} 1 \\
\mathrm{~J} 1 \\
\mathrm{~J} 1 \\
\mathrm{~J} 1 \\
\mathrm{~J} 1\end{array}$ & 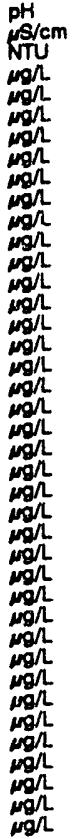 \\
\hline
\end{tabular}

WEL BGO 35D collected on 08/13/92, laboratory analyees (cont)

F Analyte
o Bis(2-chloroisopropyl) other
0 Bis(2-chlorolsopropyl) other
0 Bis (2-ethylhexyl) phthalate
0 Bromodichloromethane
0 Bromodichloromethane
0 Bromoform
0 Bromolorm
0 Bromomethane

Roent

$<10$

$<10$

$<1.0$

$<1.0$

Bromomethane

4-Bromophenyl phenyl ether

Butylbenzy! phthalate
2-ecc-Butyl-4,6-dinitrophenol

Cadmium

Cadcium

- Carbon disulfide

o Curbon disulfide

o Carbon tetrachloride

Chlordane

4-Chloroaniline

Chlorobenzene

o Chlorobenzene

para-Chloro-meta-cresol

Para-Chloro-m

Chloroethane

Chiorothene Ninyl chloride

Chioroethene Ninyl chioride

2-Chloroethyl vinyl ether

Chloroform

Chloroform

o Chloromethane

2-Chioronaphthalene

2-Chlorophenol

o 4 -Chlorophenyl phenyl ether

Chloroorene

Chloroprene

C Chryeene

O Cobalt

o Copper

o m-Cresol (3-Methylpheno)

p p-Cresol (4-Methylphenon)

Cyanide

0 P.,

P p,p'-DDT

O Diallate

o Dibenzofuran

o Dibromochloromethane

O Dibromochloromethane

1,2-Dibromo-3-chloropropane

1,2-Dibromo-3-chloropropane

1,2-Dibromoethane

- 1,2-Dibromoethane

o Dibromomethane

O Dibromomethane

Di-n-butyl phthalate

o 1,2-Dichlorobenzene

o 1,4-Dichlorobenzene

O 3,3'-Dichlorobenzidine

trans-1,4-Dichloro-2-butone

Dichliadifluoromethune

Dichlorodifluoromethen

1,1-Dichloroethene

1,i-Dichloromthane

1,2-Dichiorcethane

1,2-Dichloroethane

1,1-Dichloroethylene

trans-1,2-Dichloroethylene

trans-1,2.Dichloroethylene

Dichloromethane

2,4-Dichlorophenol $<10$

2,4-Dichlorophenoxyacetic acid <0.30

1,2-Dichlor propany

1,2-Dichlore propane

cis-1,3-Dichloropropene

cis-1,3-Dichloropropene

trans-1,3-Dichloropropone

trans-1,3-1

Dieldrin

Diethyl phthalate

2,4-Dimethyl phenol

Dimethyl phithalate

p-Dimethylaminoazobenzene

Bimethylbenzina anthracen

a, a-Dimethylphenethylamine

1,3-Dinitrobenzen

$<1.0$

$<10$
$<10$

$<1.0$

$<1.0$

$<1.0$

$<1.0$

$<1.0$

$<10$

$<10$
$<200$
520

$<4.0$

$<.0$
25

$<10$

510

$<0.10$

$<0.10$

$\leq 10$

$<10$

$\leq 1.0$

$<1.0$

$<20$

$<>1.0$

$<10$

$<10$

$<10$

$<30$

$<1.0$

$<1.0$

$<1.0$

$<1.0$

$<1.0$

$<1.0$

1.8
$<10$
$<10$

$<0.30$

$<1.0$

$<1.0$

$<1.0$

$<1.00$

$<0.50$
$<10$
$<10$

$<10$

$<10$
$<10$

$<10$

$<10$
$<10$

$<10$
$<45$

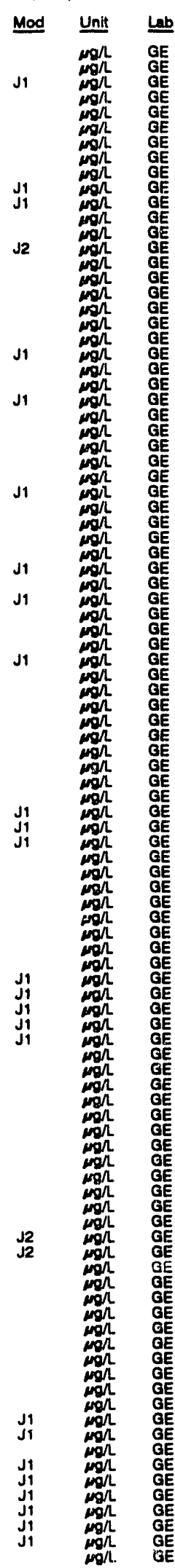


ANALYTICAL RESULTS

WELL BGO 35D collected on 08/13/92, laboratory analyses (cont)

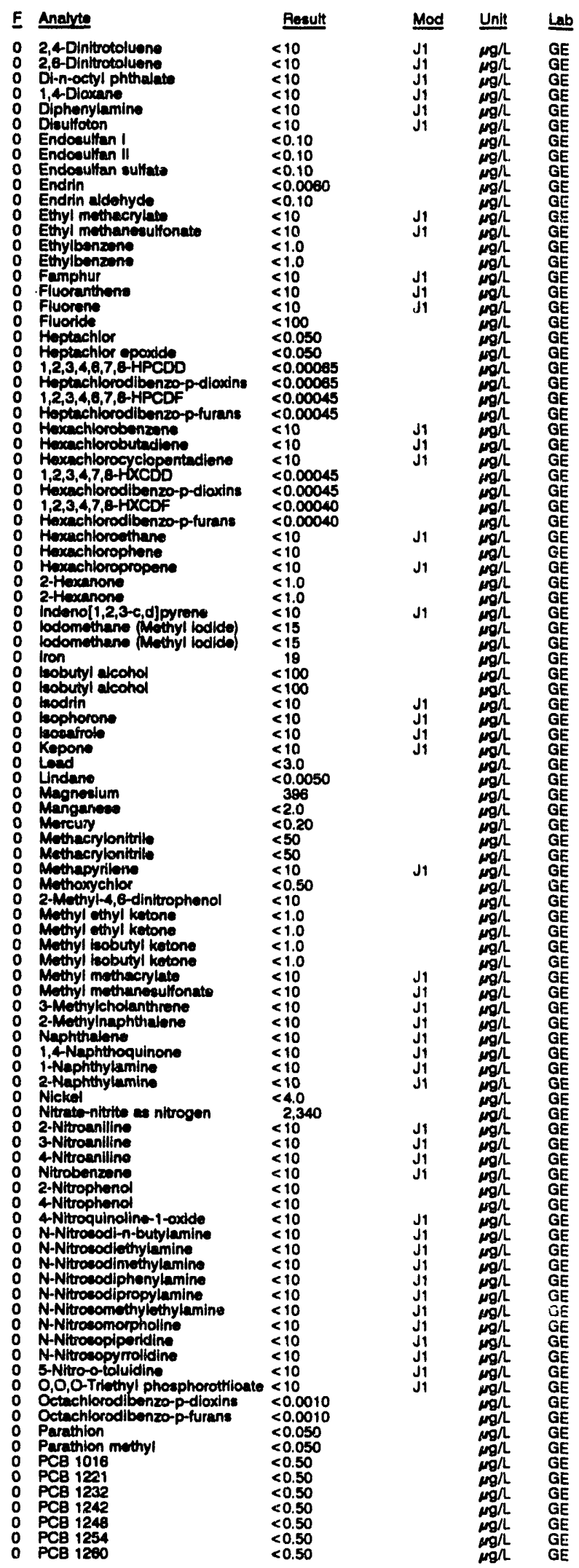

WELL BGO 35D collected on 08/13/82, taboratory analyese (cont)

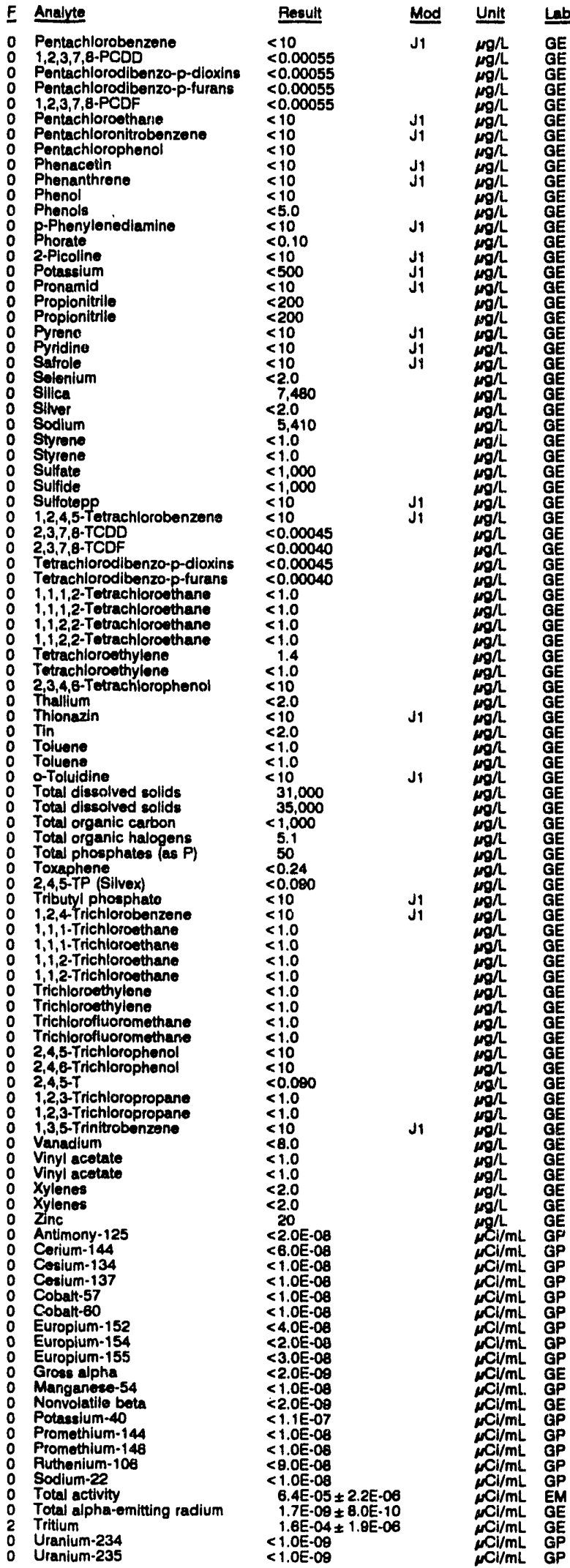


WELL BGO 350 collected on 08/13/82, laboratory analyses (cont.)

\begin{tabular}{|c|c|c|c|}
\hline F Anate & Result & Mod & Unit \\
\hline $\begin{array}{l}0 \text { Uranium-238 } \\
0 \text { Vutum-68 } \\
0 \text { Znc-6s }\end{array}$ & $\begin{array}{l}<1.0 \mathrm{E}-09 \\
<6.0 \mathrm{E}-08 \\
<2.0 \mathrm{E}-00\end{array}$ & & 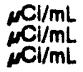 \\
\hline
\end{tabular}

\section{WELL BGO 36D}

MEASUREMENTS CONDUCTED IN THE FIELD

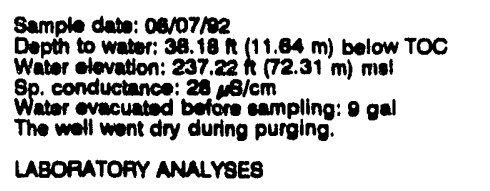

Time: $9: 00$

PH: 4.8 : 0 ilkalinity: $0 \mathrm{~mol}$

Water tomperature: $20.8 \cdot \mathrm{C}$

\section{LABOPUTOFY ANALYSES}

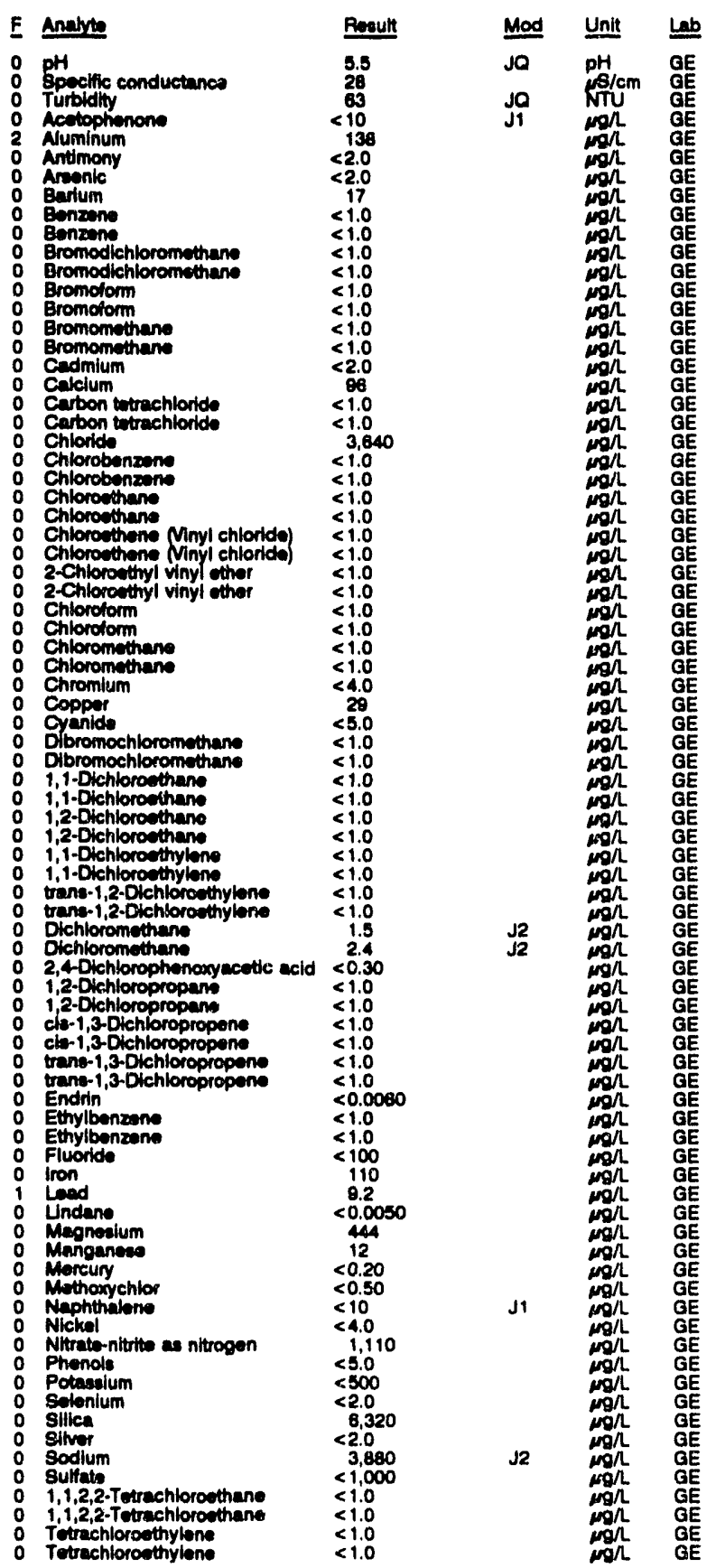

WELL BGO 36D collected on 08/07/82, laboratory analyses (cont.)

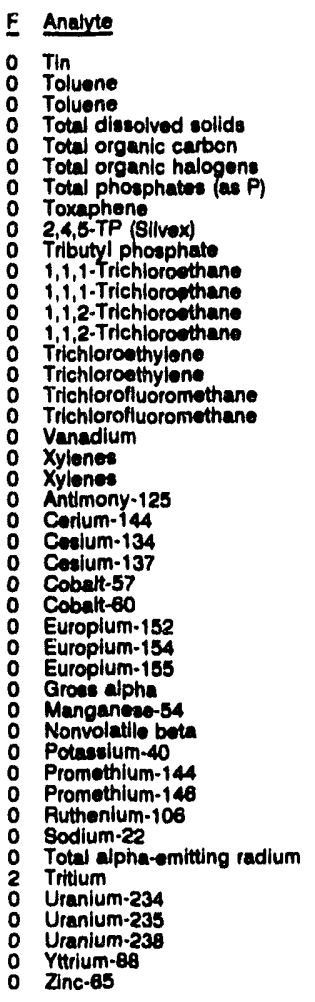

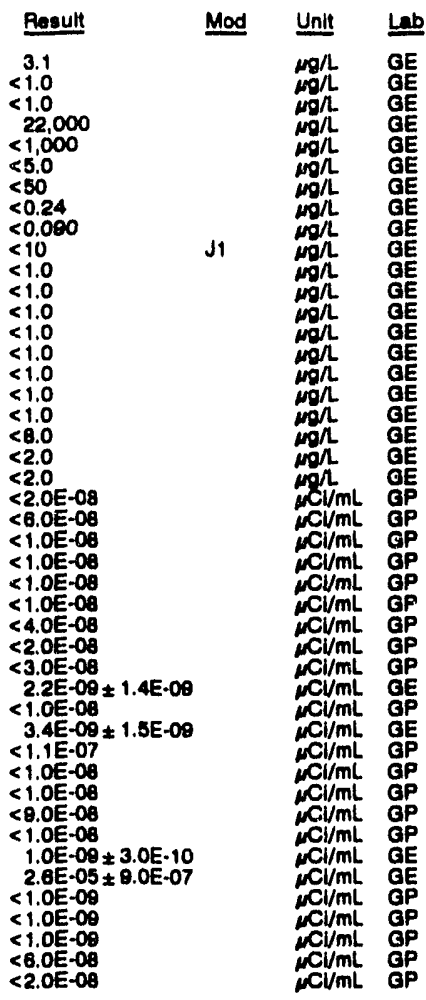

\section{WELL BGO 37C}

MEASUREMENTS CONDUCTED IN THE FIELD

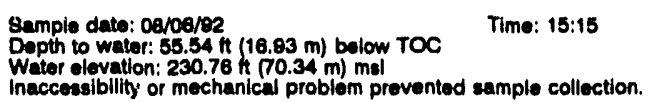

WELL BGO 37D

MEASUREMENTS CONDUCTED IN THE FIELO

Sample date: 08/07/82

Dupth to water: $49.14 \mathrm{~h}(14.88 \mathrm{~m})$ below rOC

Wator elovation: 238.16 h $(72.59 \mathrm{~m}) \mathrm{mal}$

Sp. conductance: $33 \mu \mathrm{s} / \mathrm{cm}$

Water wacuated before sampling: 8 gal

The well went dry during purging.

LABOPATOPY ANALYSES

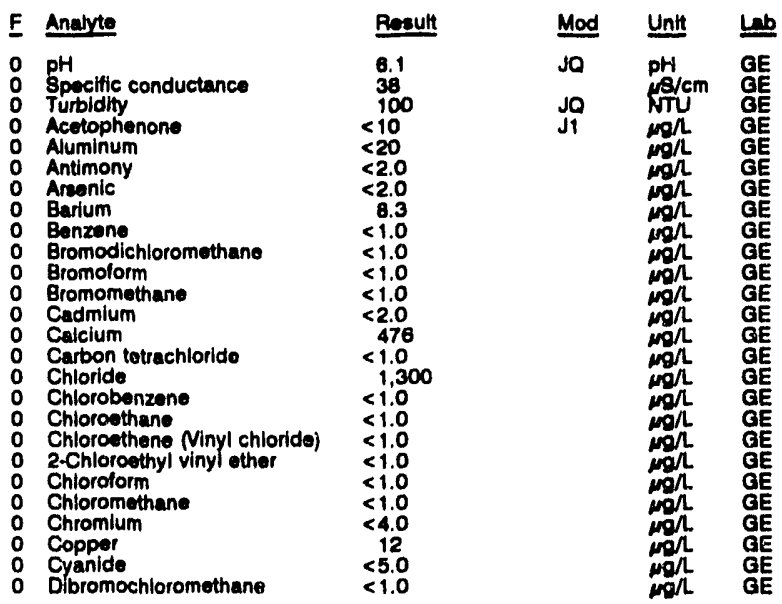

Time: $8: 35$

PH: 5.1 .

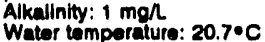


ANALYTICAL RESULTS

WELL BGO 37D collected on 08/07/92, laboratory enalyees (cont.)

\begin{tabular}{|c|c|c|c|c|}
\hline F Anabte & Result & Mod & Unit & Lيb \\
\hline 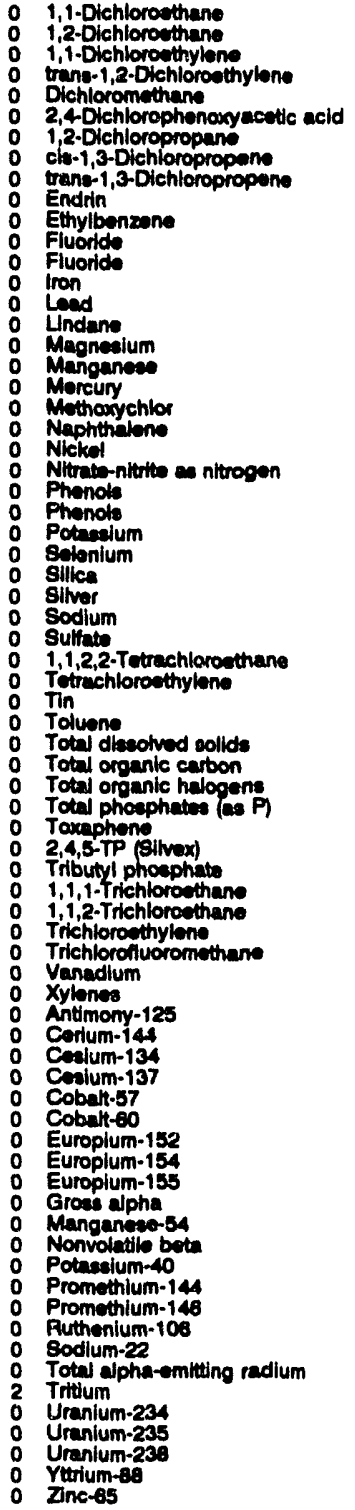 & 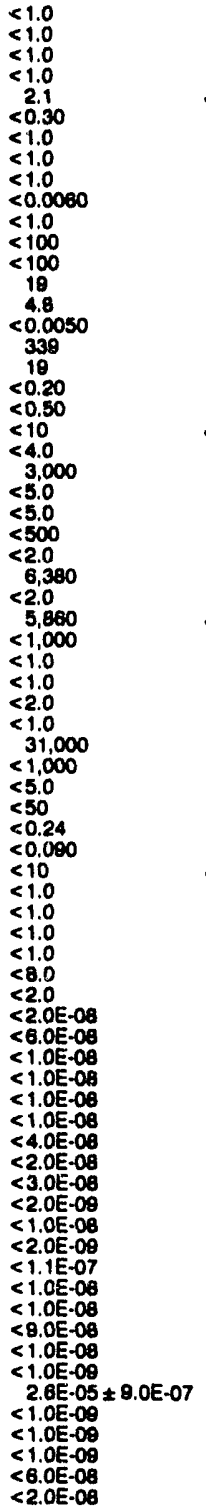 & J1 & 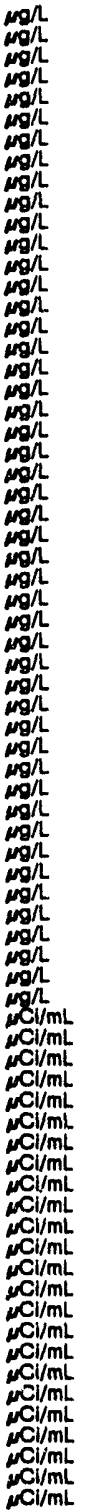 & $\begin{array}{l}\mathrm{GE} \\
\mathrm{GE} \\
\mathrm{GE} \\
\mathrm{GE} \\
\mathrm{GE} \\
\mathrm{GE} \\
\mathrm{GE} \\
\mathrm{GE} \\
\mathrm{GE} \\
\mathrm{GE} \\
\mathrm{GE} \\
\mathrm{GE} \\
\mathrm{GE} \\
\mathrm{GE} \\
\mathrm{GE} \\
\mathrm{GE} \\
\mathrm{GE} \\
\mathrm{GE} \\
\mathrm{GE} \\
\mathrm{GE} \\
\mathrm{GE} \\
\mathrm{GE} \\
\mathrm{GE} \\
\mathrm{GE} \\
\mathrm{GE} \\
\mathrm{GE} \\
\mathrm{GE} \\
\mathrm{GE} \\
\mathrm{GE} \\
\mathrm{GE} \\
\mathrm{GE} \\
\mathrm{GE} \\
\mathrm{GE} \\
\mathrm{GE} \\
\mathrm{GE} \\
\mathrm{GE} \\
\mathrm{GE} \\
\mathrm{GE} \\
\mathrm{GE} \\
\mathrm{GE} \\
\mathrm{GE} \\
\mathrm{GE} \\
\mathrm{GE} \\
\mathrm{GE} \\
\mathrm{GE} \\
\mathrm{GE} \\
\mathrm{GE} \\
\mathrm{GE} \\
\mathrm{GP} \\
\mathrm{GP} \\
\mathrm{GP} \\
\mathrm{GP} \\
\mathrm{GP} \\
\mathrm{GP} \\
\mathrm{GP} \\
\mathrm{GP} \\
\mathrm{GP} \\
\mathrm{GE} \\
\mathrm{GP} \\
\mathrm{GE} \\
\mathrm{GP} \\
\mathrm{GP} \\
\mathrm{GP} \\
\mathrm{GP} \\
\mathrm{GP} \\
\mathrm{GE} \\
\mathrm{GE} \\
\mathrm{GP} \\
\mathrm{GP} \\
\mathrm{GP} \\
\mathrm{GP} \\
\mathrm{GP}\end{array}$ \\
\hline
\end{tabular}

WELL BGO 38D

MEASUAEMENTS CONDUCTED IN THE FIELD

Sample data: 0aprpe

Depth to waler: $36.11 \mathrm{~h}(17.10 \mathrm{~m})$ below TOC

Water elevation: $235.40 \mathrm{~h}(71.78 \mathrm{~m}) \mathrm{ms}$

Water ovacuated before sampling: 8 gol

The wall went dry during purging.

LABORATOFY ANALYBES

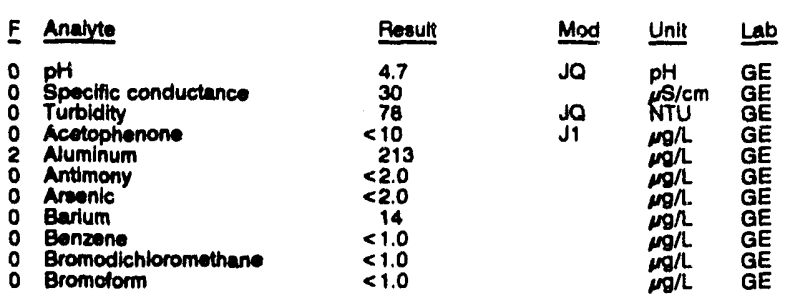

WELL BGO $38 \mathrm{D}$ collocted on 08/07/82, laboratory analyses (cont.)

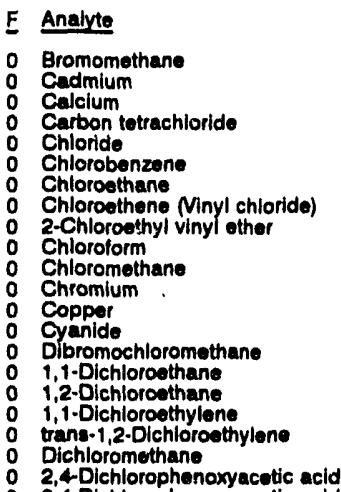$$
\text { Rasult }
$$$$
\begin{gathered}
<1.0 \\
<2.0 \\
85
\end{gathered}
$$$$
<1.0
$$$$
1,290
$$$$
<1.0
$$$$
\begin{array}{r}
<1.0 \\
<1.0 \\
<1.0 \\
<1.0
\end{array}
$$$$
\begin{array}{r}
<.0 \\
6.0
\end{array}
$$$$
\begin{aligned}
& <5.0 \\
& <1.0 \\
& <1.0
\end{aligned}
$$$$
<1.0
$$$$
<1.0
$$$$
<1.0
$$

2,4 Dichlorophenoxyacotic acid $<0.30$
$0 \quad 2,4-$ Dichlorophonoxyacotic acld $<0.30$

1,2-Dichloropropane

o cla-1,3-Dichioropropene

Endrin

0 Ethylbenzene

0 Iron

0 Lead

o Magnesium

- Manganese

Methoxychlor

o Naphthalene

0 Nickel

Nitrate-nitrite as nitrogen

Phenols

o Potassium

O Solenlum

o Sillica

0 Sitver

0 Sulfate

1,1,2,2-Tetrachlorooth

O Tetrach

O Tolvene

o Total diseolved solids

Total diweolved solids

Total organic halogens
o Total phosphates (as P)

o Toxaphene

0 2,4,5-TP (Silvex)

0 2,4,5-TP (Silvex)

o Tributyl phosphate

0 1,1,1-Trichloroethane

o 1,1,2-Trichloroethan

o Trichloroethylene

o Trichloroflus

0 Xylenes

0 Antimony-125

Corium-144

O Cesium-134

0 Cobatt-57

0 Cobalt-60

o Europium-152

Europlum-154

Europium-155

Mangantese-54

Nonvolatilo beta

Potasslum-40

Prometnium-144

Promethium-146

Pluthenlum-10

Total alpha-emitting radium

Total alphs-emitting radium

2 Tritium

- Uranium-234

- Uranium-235

U Uranium-235

Uranlum-238

- Uranium-238

0 Zinc-85

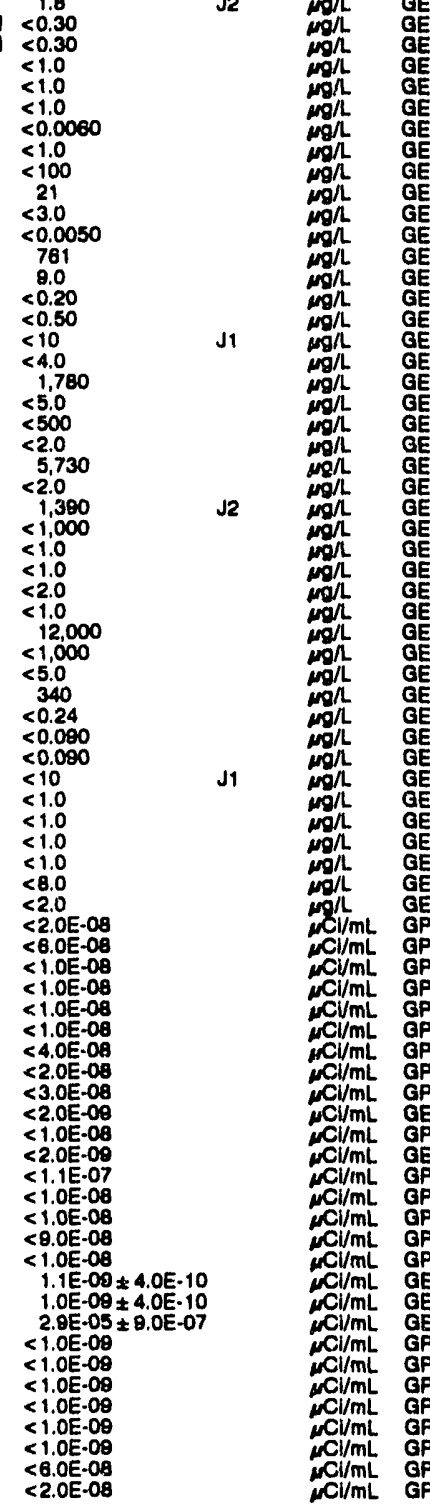


WELL BGO 39D

MEASUREMENTS CONDUCTED IN THE FIELD

Semple delas: 00107/82

Depth to water: $60.13 \mathrm{~h}(18.33 \mathrm{~m})$ below TOC

Water elovation: 235.57 h

Sp. conductanca: $31 / \mathrm{s} / \mathrm{cm}$.

Wempling: 6 an

LABORATOFI ANALYSES

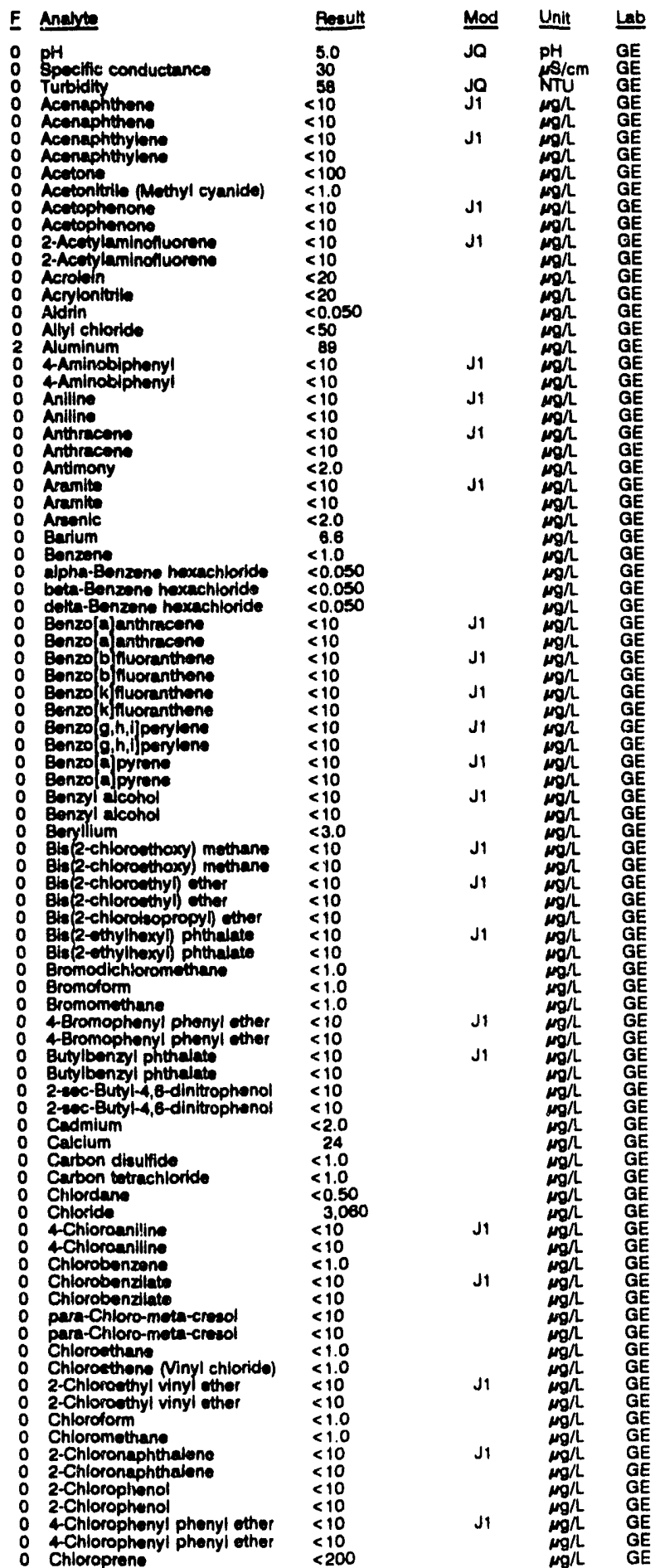

WELL. BGO 39D collected on 08/07/82, laboratory analyses (cont.)

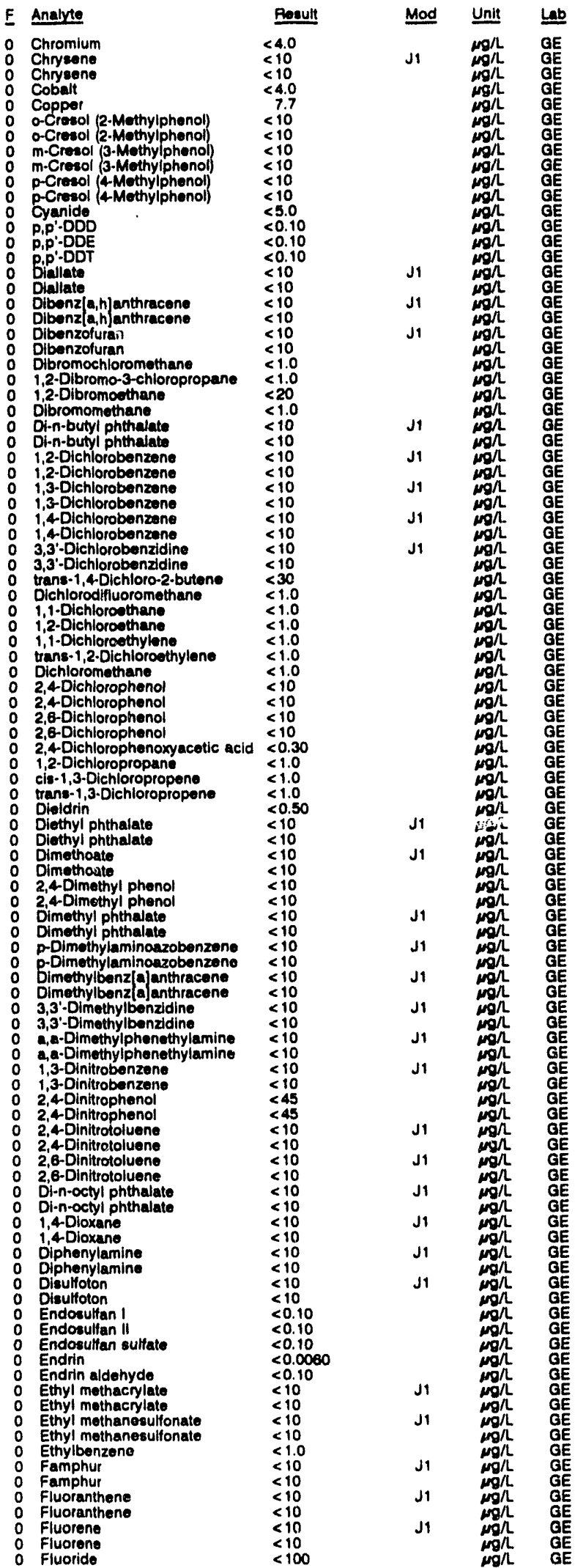


ANALYTICAL RESULTS

WELL BGO 39D collectod on 08/07/92, laboratory analyses (cont.)

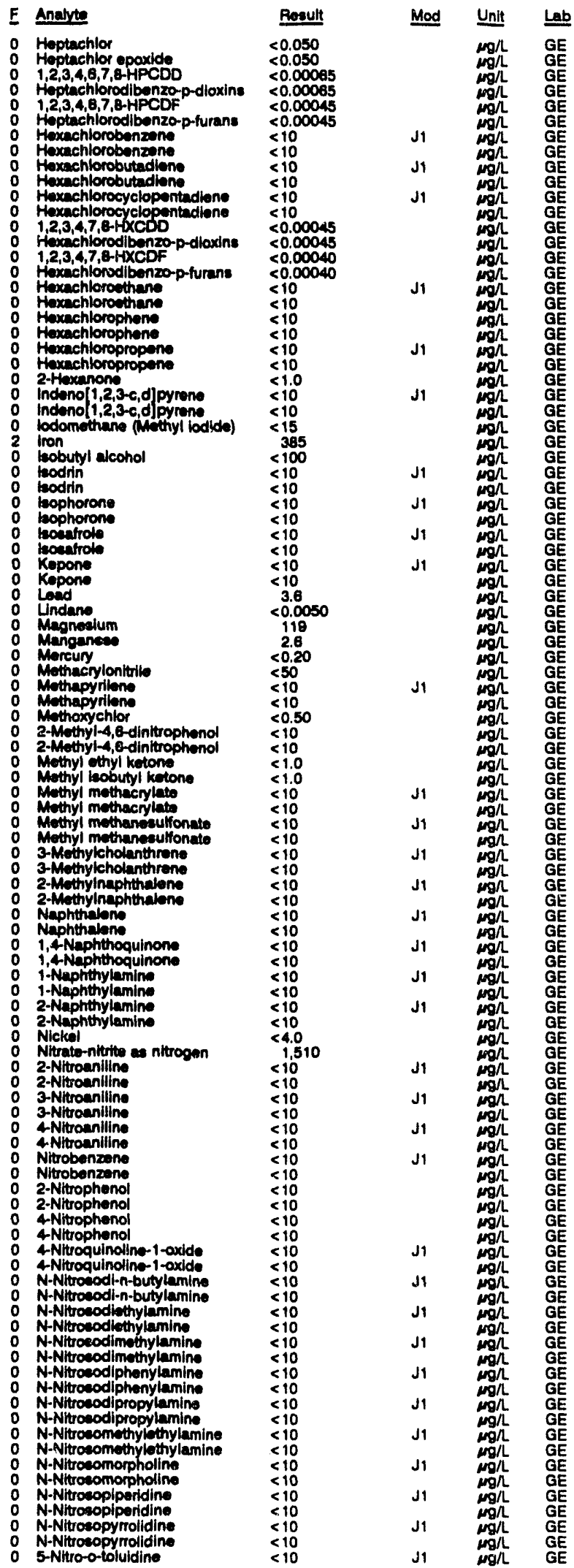

WELL BGO 39D collected on 08/07/92, taboratory analyses (cont.)

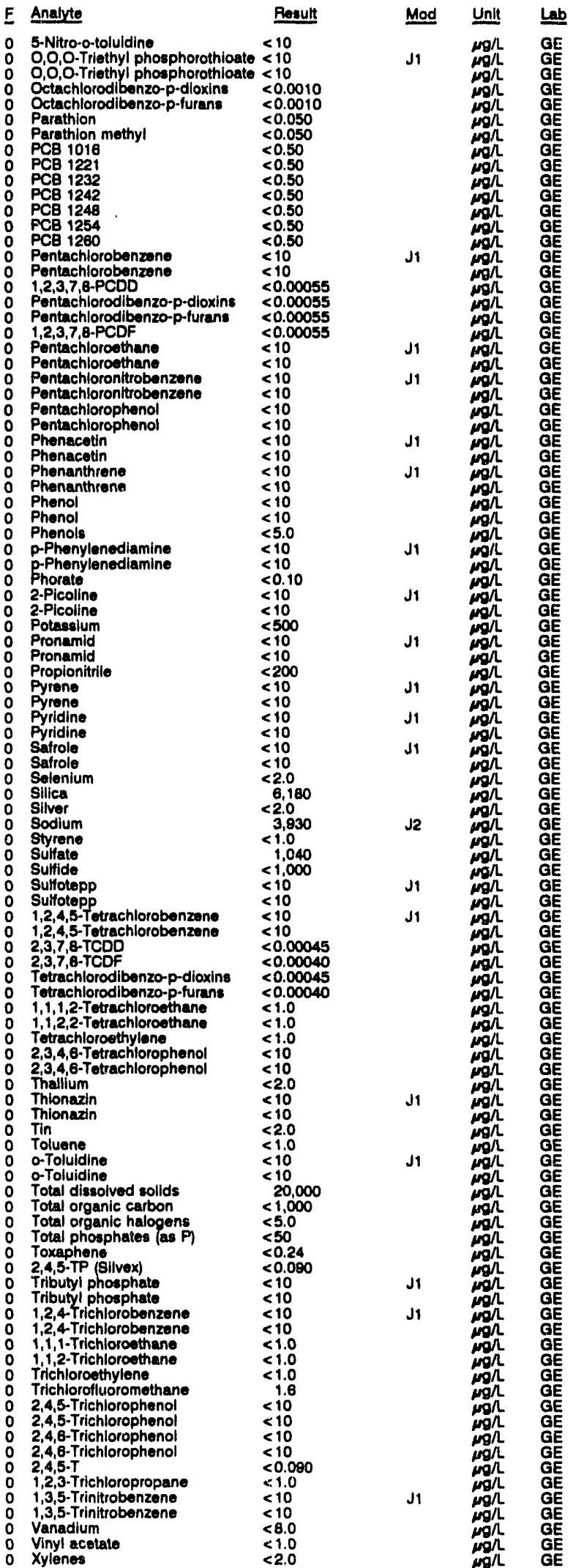


WELL BGO 300 collected on 08/07/92, laboratory analyses (cont.)

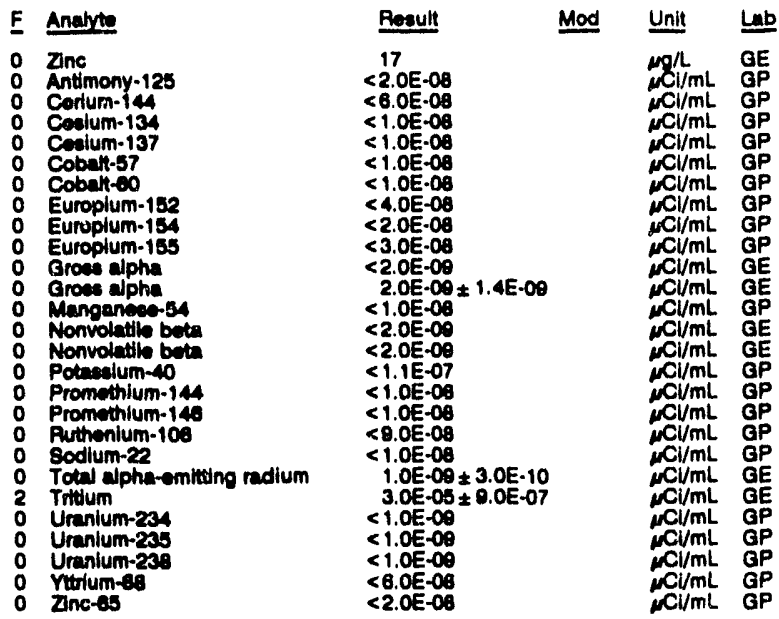

\section{WELL BGO 40D}

MEASUREMENTS CONDUCTED IN THE FIELD

Samplo date: Cer/3rog

Depth to water: 05 Se. $19.80 \mathrm{~m})$ below TOC

Watior otovation: $222.80 \mathrm{~h}(67.03 \mathrm{~m}) \mathrm{ms}$

P. conductance: $401 \mathrm{H} / \mathrm{cm}$

Wator weculated botore eampling: 2 ga

LABOPATOAY ANALYSES

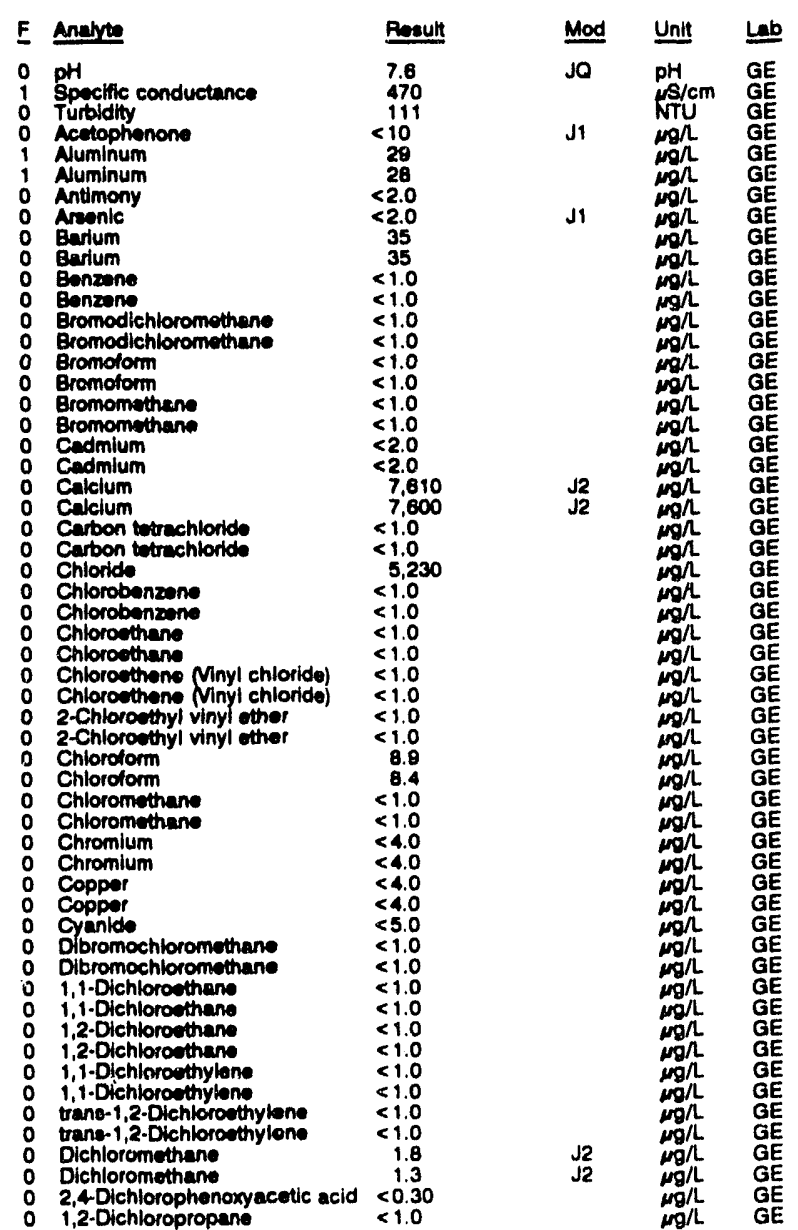

WELL BGO 40D collected on 08/13/92, laboratory analyses (cont.)

\begin{tabular}{|c|c|c|c|}
\hline Analyte & Resull & Mod & Unit \\
\hline 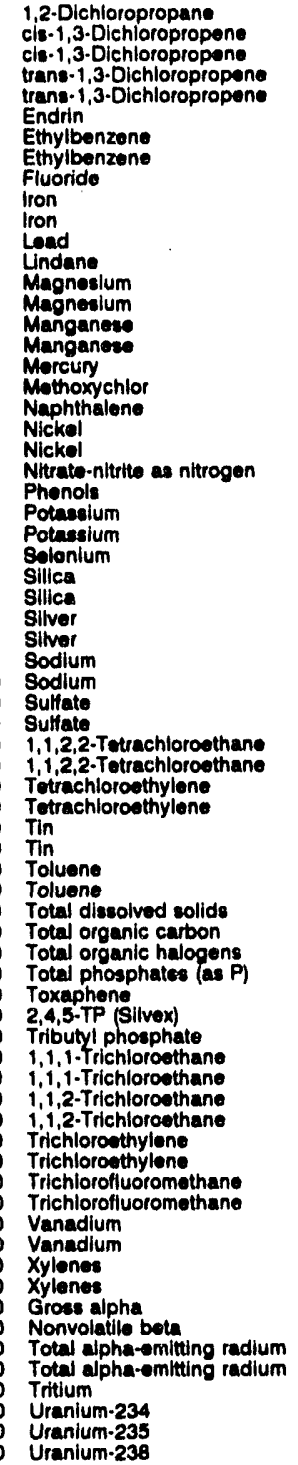 & 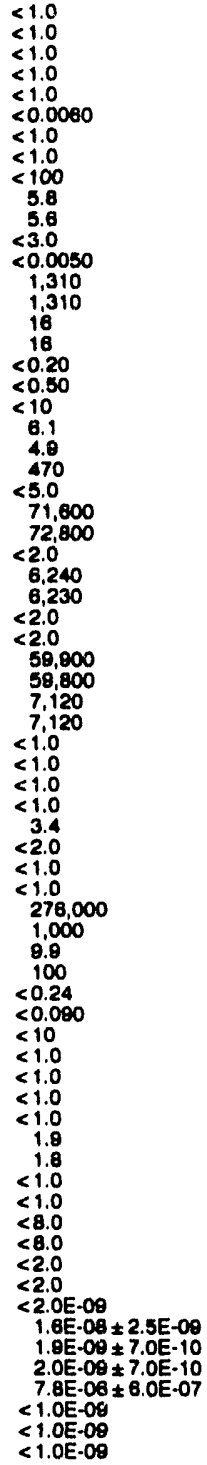 & $\begin{array}{l}\sqrt{2} \\
\sqrt{2} \\
J_{1}\end{array}$ & 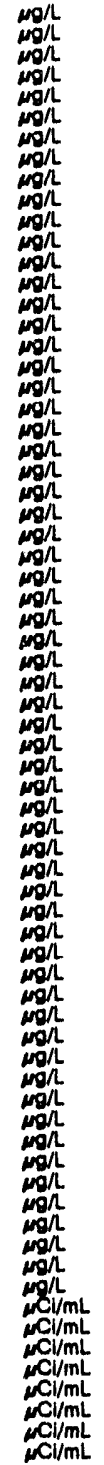 \\
\hline
\end{tabular}

WELL BGO 41A

MEASUREMENTS CONDUCTED IN THE FIELD

Sample date: 08/11/82

Dopth to water: $142.06 \mathrm{H}(43.30 \mathrm{~m})$ bolow TOC

Weter olevalor: $142.004(43.30 \mathrm{~m})$ bolow

Sp. conductance: $1736 \mu \mathrm{s} / \mathrm{cm}$

Water evacuated before sampling: $21 \mathrm{ga}$

PH: $11.7 .975 \mathrm{mg} / \mathrm{h}$

Water tomperature: $20.2^{\circ} \mathrm{C}$

LABORATORY ANALYSES

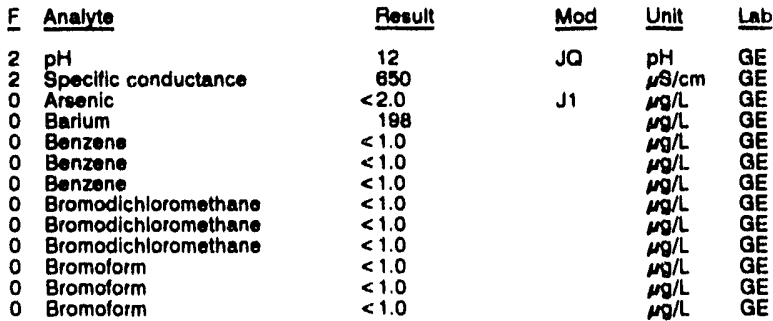


ANALYTICAL RESULTS

WELL BGO 41A collected on 08/11/92, laboratory analyces (cont.)

E Analyte

- gromomothane

Bromomethans

O Cedmium

Carbon trachlorida

O Carbon trachlorlde

- Chlorido

Chlorobonzone

Chlorobenzene

Chlorobenzene

Chlorouthane

Chlorodtene Minyl chloride

Chlorsetheno Minyl chloride

Chloroetione (Minyl chlorida)

2-Chlorouthyl viny? ether

2.Chloroethyl winyl ther:

Chiortorm

Chlorotom

Chlorolorm

Chloromethane

Chloromethane

Dbromochloromethane

D Dibromochloromernethene

1,1-Dichloromthene

i,i.Dichlorouthane

1,i-Dichlorouthane

1,2-Dichoromenthen

1,2.Dichloromethene

1,i-Dehlorosthylono

1,i.plehlorouthylone

trana-1,2-Dichlorodthylene

trana-1,2-Oichlorosthylons

Dichloromethane

Dichloromethan

2,4-Dichlorophenosyacetic acid

1,2-Dichloropropana

1,2-Dlchloropropano

1,2-Dichloropropane

ch-1,3-Dichioropropono

cia-1,3-Dichloropropane

trane-1,3-Dichloropropene

trans-1,3-Dichloropropene

Ethylbenzene

Ethylbenzone

Ethylbenzene

Fluoride

Iron

Leand

Lindane

Magnedum

Morcury

Methorychlor

Nickol

Phenote

Phenote

Potasalum

Selonium

Billan

Siver

Sodium

Sullato

1,1,2,2-Tetrachiorowthan

i, $1,2,2$. Tetrechlorothan

Tetrachloroethylone

Tetrachloroethylone

Toluents

Toluene

Tolvene

Total diseolved sollds

Total organic carbon

Total organic halogens

Toxaphene

2,4,5-TP (Bilvex)

Trbutyl phosphate

1,1,i-Trichloroethane

1,1,1-Trichlorosthane

1,1,2-Trichloroethane
Result Mod

$<1.0$

$<1.0$

<2.0 200

$<1.0$

$<1.0$

2,230

$<1.0$

$<1.0$

$<1.0$

$\leq 1.0$

$<1.0$

$<1.0$

$<1.0$

$<1.0$

$<1.0$

$<1.0$

$<1.0$

$<1.0$

$<4.0$

$<1.0$

$<1.0$

$<1.0$

$<1.0$

$<1.0$

$<1.0$

$<1.0$

$<1.0$

$<1.0$

$<1.0$

1.3
1.2
$<1.0$
$<0.30$

$<1.0$

$<1.0$

$<1.0$

$<1.0$

$<1.0$

$<0.0060$

$<1.0$

$<1.0$

$<1.0$

$<100$
7.5
3.0

$<0.0050$

$\begin{array}{r}71 \\ <2.0 \\ \hline\end{array}$

$<0.20$
$<0.50$

$<4.0$

50
$<5.0$
$<5.0$

$<5.040$

26,400
$<2.0$

24,100

28,100
10,700

1.1
1.0

1.0
$<1.0$

$<1.0$

1.0

1.4
1.4
1.5

227,000

2.130
$<5.0$

$<50$

$<0.24$

$<10$

1.8
1.6
1.7
1.0

$<1.0$
$<1.0$

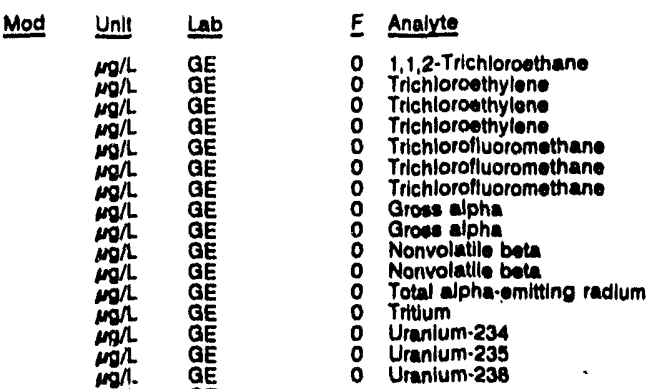

E Analyte

o 1,1,2-Trichloroethane

Trichlorosthylone

- Trichlorolluoromethane

Trichlorofluoromethane

Gross alpha

Nonvolatile bon

Total alpha-emitting radium

Uranium-23

Uranium-236

WELL BGO 42C

MEASUREMENTS CONDUCTED IN THE FIELD

Sample date: 08/11/92

Depth to water: $74.14 \pi f(22.60 \mathrm{~m})$ below TOC

Water elevation: $223.78 \mathrm{~h}$

Water evacuated bofore eampling: $17 \mathrm{gal}$
The well went dry during purging.

LABORATORY ANALYSES

o $\mathrm{pH}$

Specific conductance

Areanic

Earlum

Bromodichloromethane

Bromolorm

Bromomethan

Cadmium

Carbon tetrachloride

Carbon

Chlorobenzene

Chloroethane

Chloroethene Ninyl chloride

2-Choroethyl vinyl cher

Chlorolorm

Chloromethane

Chromium

Dibromochloromethane

1.1.Dichloroothan

1,2-Dichlorosthane

trane-1,2-Olchloroothylene

Otchloromothane

2,4-Dichlorophenoxyacetic aclo

1,2-Dichloropropane

tran-1,3-Dichloropene

Endrin

Ethylbonzene

Iron

Lead

Magnesium

Manganeaso

Methoxychlor

Nickel

Nitrato-nitrite as nitrogen

Phonole

Potasslum

silica

Sllver

Sodium

Sultate

1,1,2,2-Tetrachloroethan

Totrachioro

Total diseolved solids

Total organic carbon

Total organic halogens

Total phosphates (is P

o Toxaphene

2,4,5-TP (Sllvox)

Tributyl phosphate

1,1,1-Trichloroethane

2 Trichloroothylono

Trichlorofluoromethane

Noss alpha

Total alpha-emitting radium

Tritlum
$20 \mathrm{~m}) \mathrm{mal}$

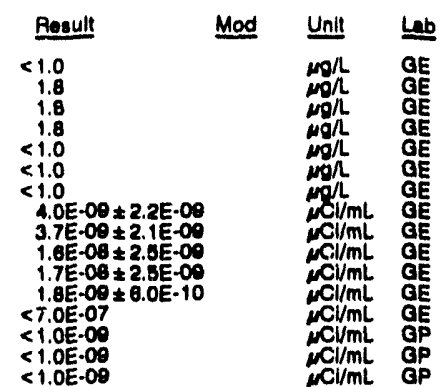

pH: 0.1

Nkalinity: $22 \mathrm{mg} / \mathrm{h}$

Water temporature: $10.8^{\circ} \mathrm{C}$

\section{Preuth}

Reeult Mod Unit Lab

6.6
6.4

35
$<2.0$

$<1.0$

$<1.0$

$<1.0$
$<1.0$

$<1.0$
$<2.0$

1.610
$<1.0$

$<.0$
2,730

$<1.0$

$<1.0$

$<1.0$

$<1.0$

$<1.0$

$<1.0$

$<1.0$

$<1.0$
2.8
$<0.30$

$<1.0$
$<1.0$

$<1.0$

$<1.0$

$<100$

$<3.0$

$<0.0050$
462

482

16
$<0.20$

$<0.50$

$<4.0$

$\begin{aligned} & 1,090 \\ < & \$ .0 \\ & 1.110\end{aligned}$

1,110
$<2.0$

8.590
$<2.0$

4,820
1,270

$<><1.0$

$<1.0$

34,000

56

30
$<0.24$
$<.24$

$<0.24$

$<10$
$<1.0$

$<1.0$

$<1.0$

$<2.0 E .09$

$3.6 \mathrm{E}-09 \pm 1.6 \mathrm{E}-00$

$<1.0 E .09+1.00 .00$

JO

J

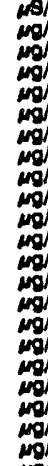

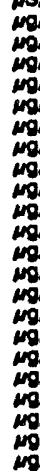

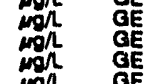


ANALYTICAL RESULTS

WELL BGO 420 collectad on 06/11/82, laboratory analyees (cont)

\begin{tabular}{|c|c|c|c|}
\hline E Anchts & Reault & Mod & Unt: \\
\hline $\begin{array}{l}\text { - Uranium-234 } \\
0 \text { Uranium } \\
0\end{array}$ & $\begin{array}{l}<1.0 E-00 \\
<1.0 E-00 \\
<1.0 E-00\end{array}$ & & 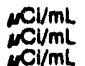 \\
\hline
\end{tabular}

WELL BGO 43A

MEABUREMENTS CONDUCTEO IN THE FIELD

Sample dab: 0a/1 $1 / 02$

Dopth to water: $180.07 \mathrm{n}(48.18 \mathrm{~m})$ bolow TOC

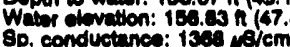

Wator evacuetid beforo eampling: $24 \mathrm{gal}$

The weil twont dry durting purging.

LABORATORY ANATYEES

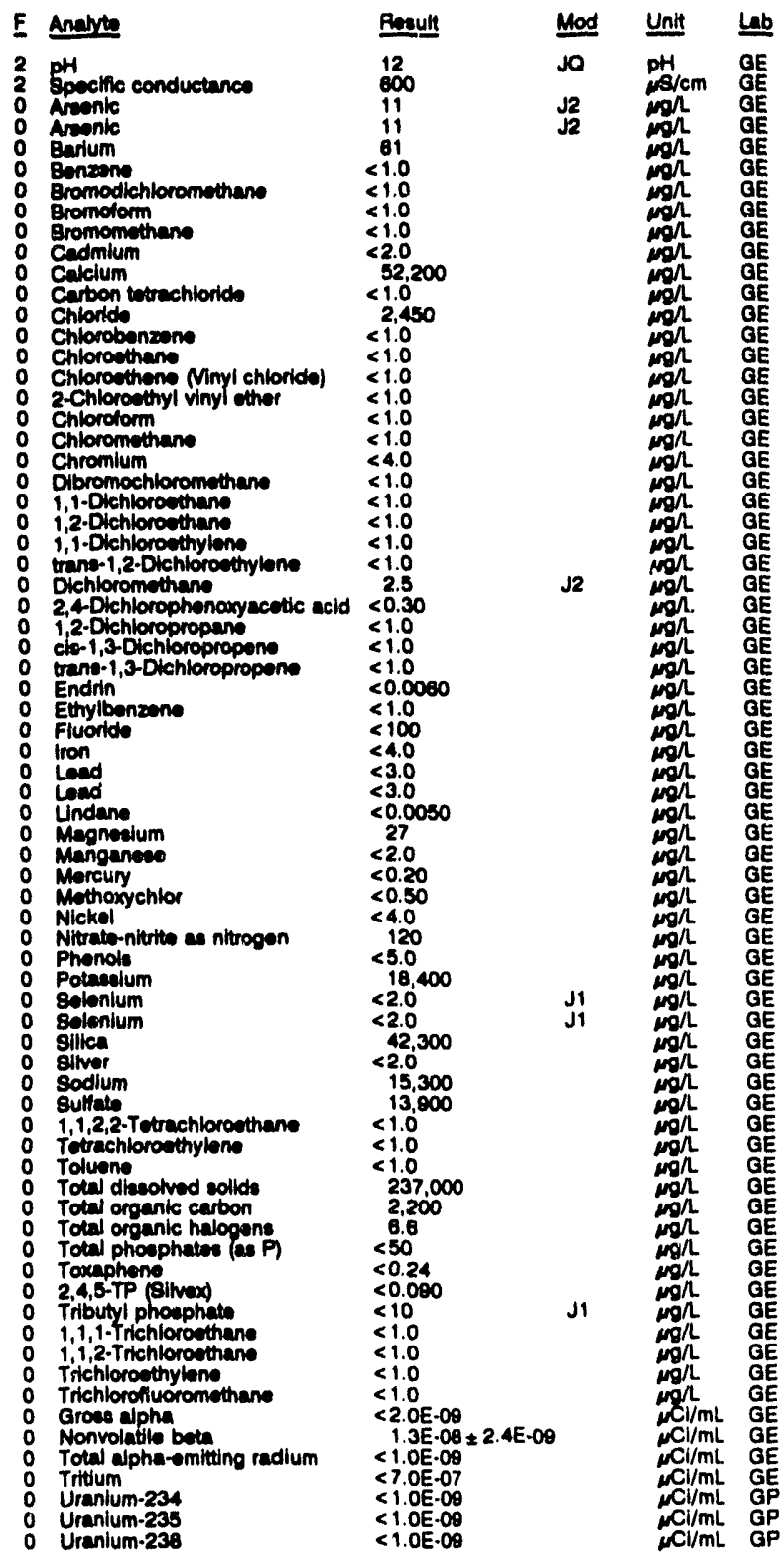

WELL BGO 43AA

MEASUAEMENTS CONDUCTED IN THE FIELD

Gample date: 08/07/02

Dopth to water: $157.02 \mathrm{n}(48.13 \mathrm{~m})$ below TOC

Water olovation: $158.38 \mathrm{~h}$ (A7.

Bp. conduclance: 180 rascm

Time: 13:36

PH: 10.1 : $71 \mathrm{mal}$

Nadinity: $71 \mathrm{mg} / \mathrm{h}$

LABORATORY ANALYBES

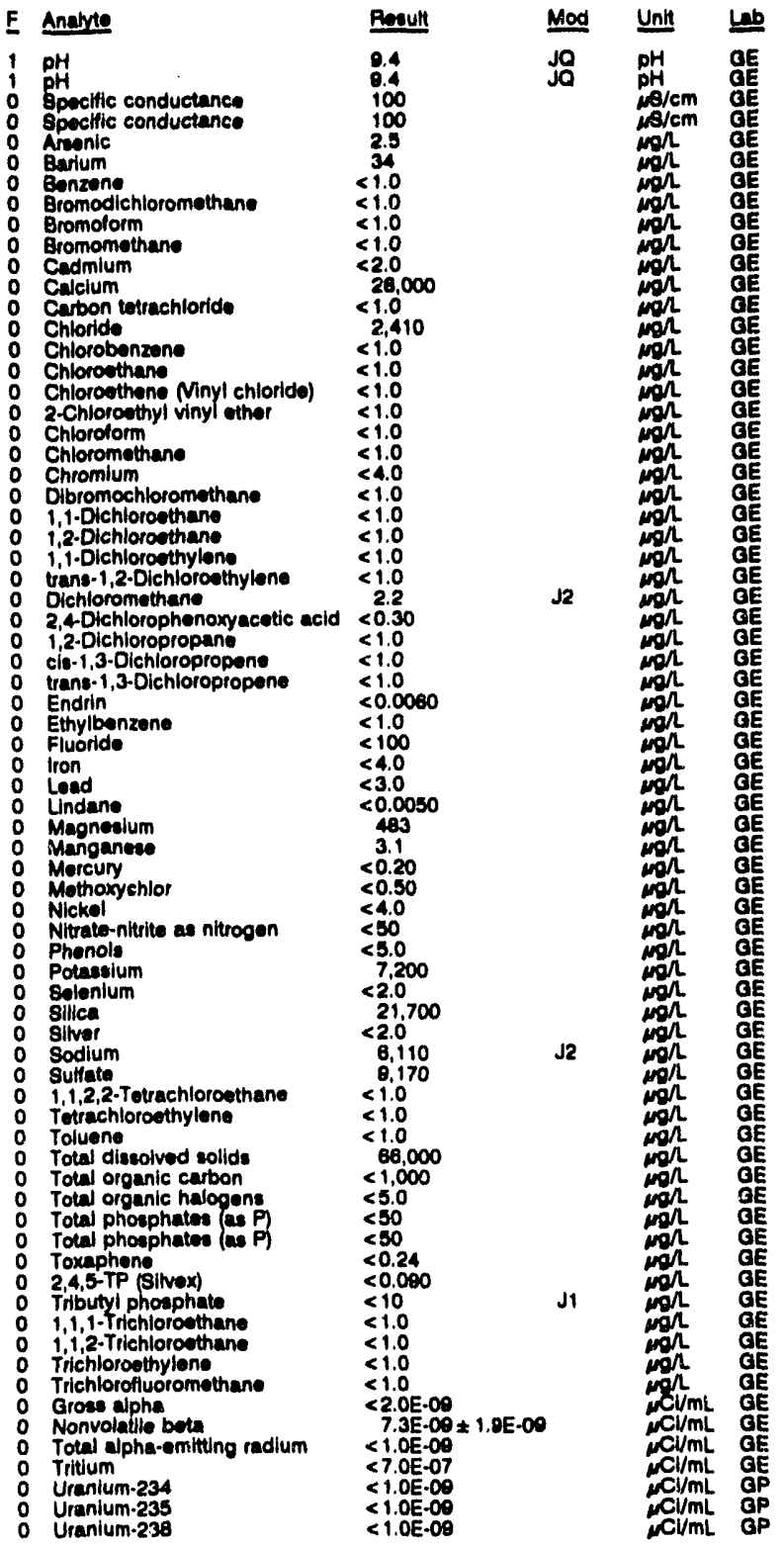


ANALYTICAL RESULTS

WELL BGO 43CR

MEASUAEMENTB CONDUCTED IN THE FIELD

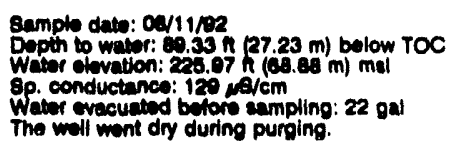

LABOFATOFY ANUL YBES

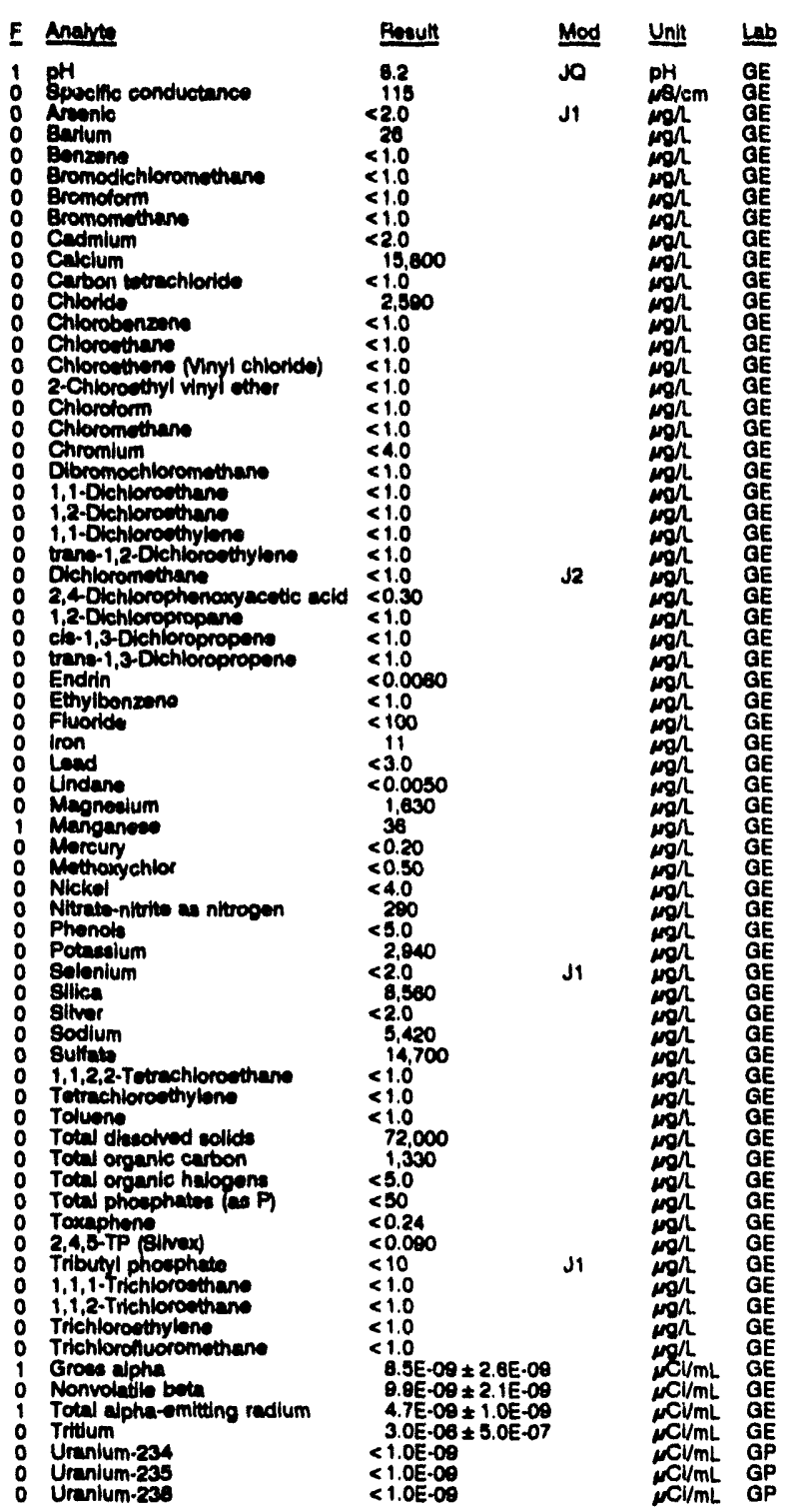

\section{WELL BGO 43D}

MEASUREMENTS CONOUCTED IN THE FIELD

Sample date: 08/07/02

Wopth to water: $33.82 h(25.55 \mathrm{~m})$ bolow TOC

W. conductunce $231,49 \mathrm{At}$.

Water evacuated bolore sempling: $87 \mathrm{gal}$

LABOFUTOAY ANALYSES

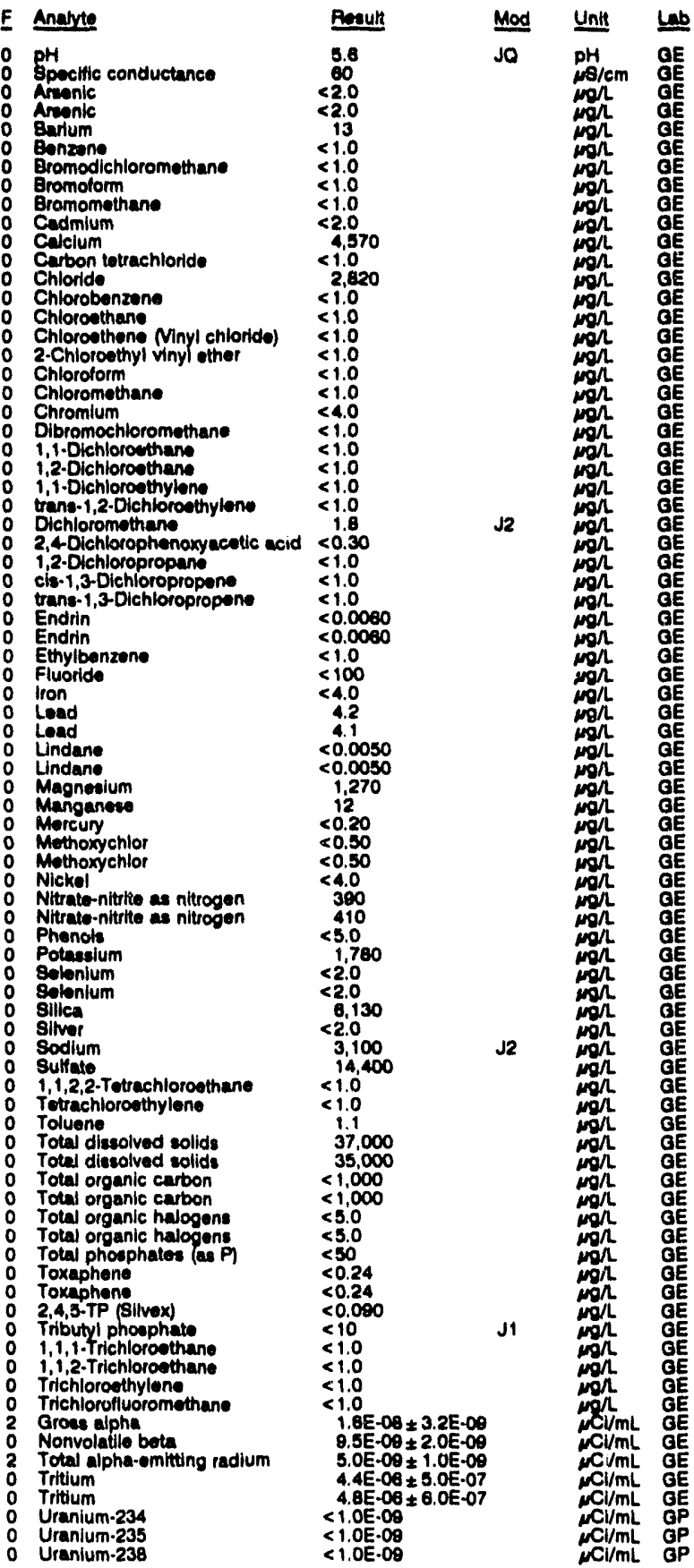


WELL BGO 44A

MEASUREMENTS CONOUCTED IN THE FIELD

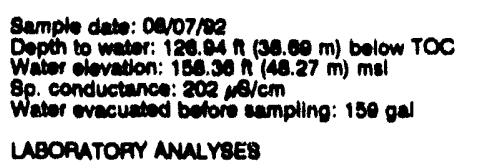

Time: 19:23

PH: 7.3 .

Wator tomporature: $20.2 \cdot \mathrm{C}$

LABOPATOFY ANALYEES

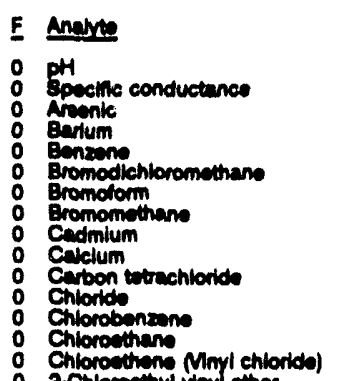

2-Chloroethyl vinyl thior

Chlorotom

Chromium

Dibromoehionomethane

1,i.Dichlorosthan

1,1-Dichlorosthylens

tren-1,2-Dichloreethyions

2,4-Olohiorophenoxyacetic acid

1,2-Dichloropropans

ch-1,3-Dichioropropons

Endin 1 .

Ethylbenzene

iron

Lind

Meonealum

Manganes

Mercuny

Mithoxychlor

Nielice

Nitrato-nititio wa nitroven

Phench

Potenolum

Solonium

gillea

Sodjum

1, 1,2,2-Tetrechloroethane

Totrachlorom

Total diseotved eollas

Total organic carbon

Total organic halogems

Toxaphine

2,4,5-TP Bimax

Tributyl phoephato

1,1.1-Inchloroethane

1,1,2-Trichloroethen

Trichlorofluoromethene

Groes elpha

Totw ulpha-emituing radium

Uranlum-234

Uranium-238

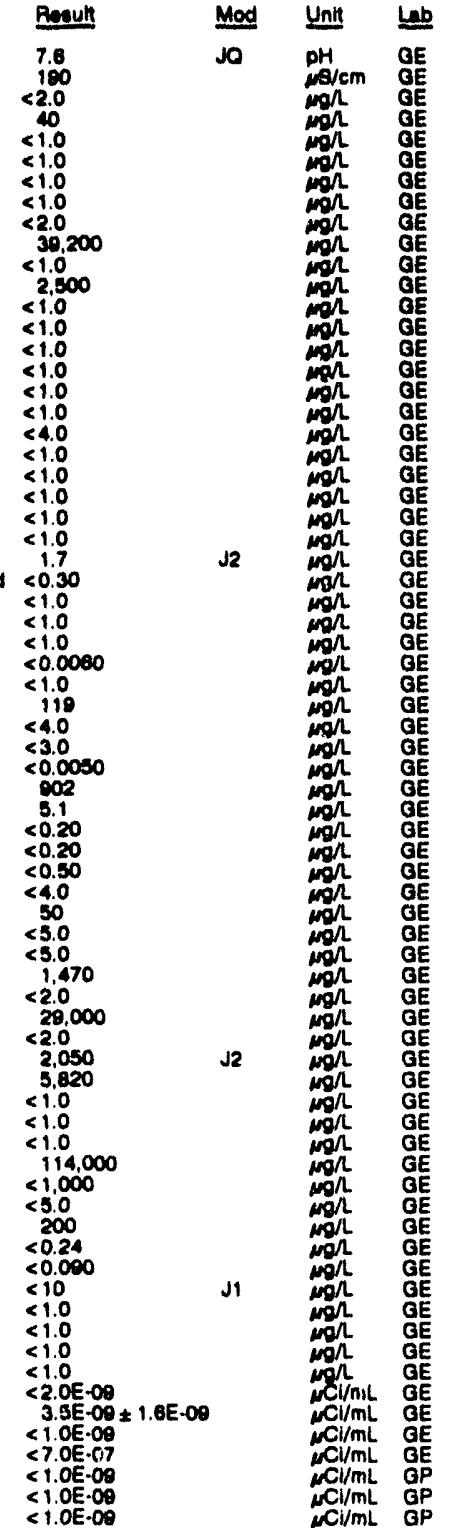

WELL BGO 44AA

MEASUREMENTS CONDUCTED IN THE FIELD

Sample dala: 08/07/02

Qppth to wator: 128.83 h $(33.68$ m) bulow TOC

Whater olovation: $138.47 \mathrm{~h} / 46 \mathrm{cos}$

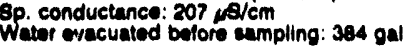

Time: $15: 00$

LABORATORY ANALYSES

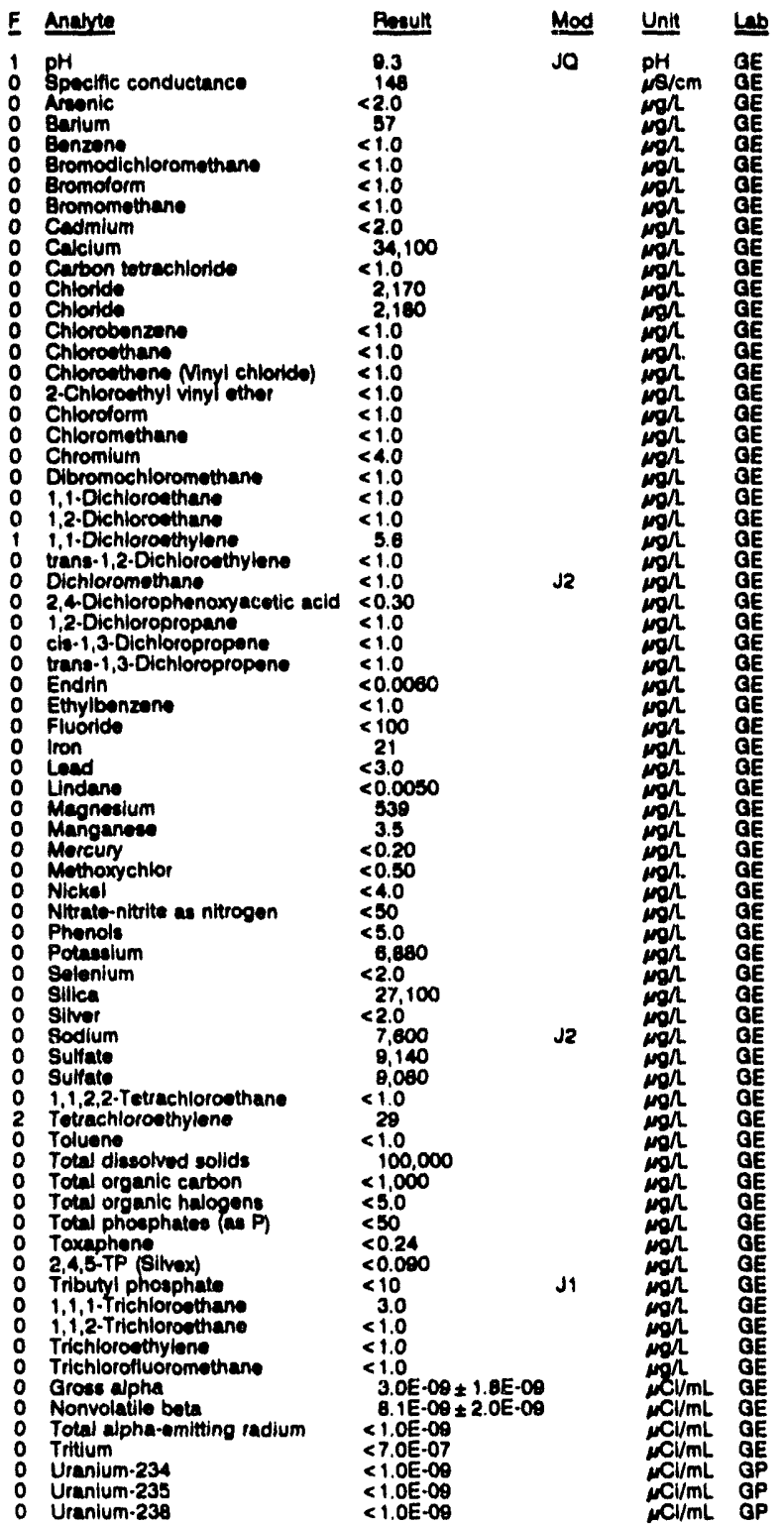


ANALYTICAL RESULTS

WELL BGO 44B

MEASUAEMENTS CONOUCTED IN THE FIELO

8umple deta: Ca/11/02

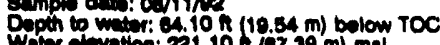

Waler enveviton: 221.10 h (o7,39

The r.tl want belore eampling: $30 \mathrm{gal}$

LABOAATOFY ANALVES

E Answa

2 pH

0 Arente

Butum

o Eromodichloromethan

Bromotorm

Bromomethan

Cadimium

Carbon intrachioride

Chioride

Chlorids

Chlorobonamo

Chloroethare Minul chlorido)

2-Chlorouthyl vimyl ether

Chloreform

Chloromethene

Dibromochloromethan

1,1-Oichloroethan

1,2-Dehloroethan

tene-1,2-Dichloroethyleme

2,4-Dichlorophemonyecetic ecid

1,2-Dlehlorppropans

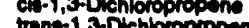

o Endirn

o Ethylbenaene

Fluorde

Leed

Undane

Mndane

Manganear

Merouny

Mrinowychlor

Nickel

Nitretio-nititive as nitrooen

Phonots

Potassium

Eelonium

gillea

Sodium

1,1,2,2-Tetrechloroethan

Tetrechloroethylione

Toluene

Totel diesolved sollds

Total oromic halogen

Total phosphetes (e)

Trociphene

Touphone

Tributyl phosphate

1,1, Irichlorocthan

1,1,2-Trichloroethen

Trichlorethyoromethane

Trichionolluoram

Nonvoladilo bet

Total elpha-amiting radium

Tritum

Uranium-23

Uranlum-230
Time: 7:30

PH: 11.8 $177 \mathrm{mgl}$

Water temporature: $20.0 \circ \mathrm{C}$

\section{Renult}

12
1.150
4.2
8.6
51.0
$<1.0$
$<1.0$
$<1.0$

$<2.0$ 10,700

$<1.0$

1,040

$<1.0$

$<1.0$

$<1.0$

$<1.0$

$<4.0$

$<1.0$

$<1.0$

$<1.0$

$<1.0$

$<0.30$

$<1.0$

$<0.0000$

$<0.0060$

$<31$
231

11
$<3.0$

$<<0.0050$

$<0.00$

$<<.0$

$<0.20$
$<0.50$
$<0.50$

$<0.30$

$<4.0$
100
$<5.0$

$<11,000$

$<2.0$
48.700

$<2.0$

13,000
10.300

$<1.0$
$<1.0$

2.4 3000

2,000

$<5.0$

$<0.24$

$<0.24$

$<0.000$

$<10$

$<1.0$

1.9

$<1.0$

$8.3 E-00 \div 1.8 E-09$

. $8 E-04 \pm 2.4 E-05$

$2.3 E-00 \pm 1.1 E-09$

$<1.0 E-09$

$<1.0 E-00$

$<1.0 E-000$
WELL BGO 44C

MEASUREMENTS CONOUCTED IN THE FIELD

Sample date: 08/11/92

Sample date: $08 / 11 / 92$
Depth to water: $64.68 \mathrm{~h}(19.71 \mathrm{~m})$ below TOC
Water olovation: $220.04 \mathrm{~h}(87.34 \mathrm{~m}) \mathrm{ms}$

Water olovation: $220.04 \mathrm{~h}(87.34 \mathrm{~m}) \mathrm{msl}$
Sp. conductance: $147 \mathrm{\mu} / \mathrm{cm}$

Wator ovacustod botors sampling: $20 \mathrm{gal}$

The woll went dry during purging.

LABORATORY ANALYSES

E Ancute

1 Splific conductance

Arente

Barium

Benzene

Bromodichloromethane

Bromotorm

Bromomothan

Cadmium

Carbon totrachicide

Chlorobenzane

Chlorothane

2.Chloresthyl vinyl chrord

Chloretorm

Chloromethane

Dibromochloromethan

1,1.Dichioroethen

1,2-Dichloroethane

1,1-Dichloroethylene
tring 1,2 -Dichloroethylene

trang-1,2-Dichioroethy

Dichloromothane

1,2-Otchloropropene

cia-1,3-Dichloropropene

trane-1, 2-Dichloropropen

Endrin

Ethylbenzene

Iron

Lead

Lindane

Magnesium

Marcuny

Methoxychlor

Nickol

Nitrato-nitute as nitrogen

Potasalum

Sotasilum

Sllica

silver

Sodium

0 Sulfate

1,1,2,2-Tetrachloroethane

Tetrachloroethylone

Toluene

Total diseolved solids

Total organic cartoon

Total phosphates (as P)

Toxaphene

2,4,5-TP (Bilvox)

$1,1,1$. Trichloroethan

i, , 2-Trichloroethan

Trichloroethylene

Trichlorofluoromethane

Grose alpha

- Nonvolatile bot

Total activity

Total alpha-omitting radium

Tritum

Uranium-234

Uranium-235

Aleoult

9.9
180
$<2.0$

Mod Unit Leb

JO $\mathrm{PH}$ OE

35

$<1.0$

$<1.0$

$<1.0$

$<2.0,600$

$<1.000$

$<1.0$

$<1.0$

$<1.0$

$<1.0$

$<4.0$

$<1.0$

$<1.0$

$<1.0$

$<1.0$

$<0.30$

$<1.0$

$<1.0$

$<<1.0$

$<0.0080$

580

4.1
$<0.20$

$<0.50$

$<4.0$

$<5.0$

5,810
$<2.0$
7,370

7,370
$<2.0$

18,300
4,600

4.600
$<1.0$
$<1.0$
$<1.0$

$<1.0$

1,000

7.0

$<0.24$

$<0.080$

$<10$
$<1.0$
$<1.0$

$<1.0$

2.3E-09 $01.6 E-0 \theta$

$8.2 E-09 \pm 2.0 E-09$

$3.3 E-04 \pm 4.4 E-06$

$3.3 E-09$
$3.0 E-04 \pm 2.7 E-06$

$<1.0 E-09$

$<1.0 E-09$
$<1.0 E-00$

Nemperature: $18.5^{\circ} \mathrm{C}$

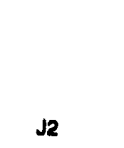



GE


WELL BGO 44D

MEASUAREMENTS CONDUCTED IN THE FIELD

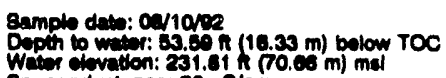

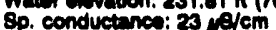

Wetor cuecuetod botore sempling: 23 gal

LABORATORY ANULYRES

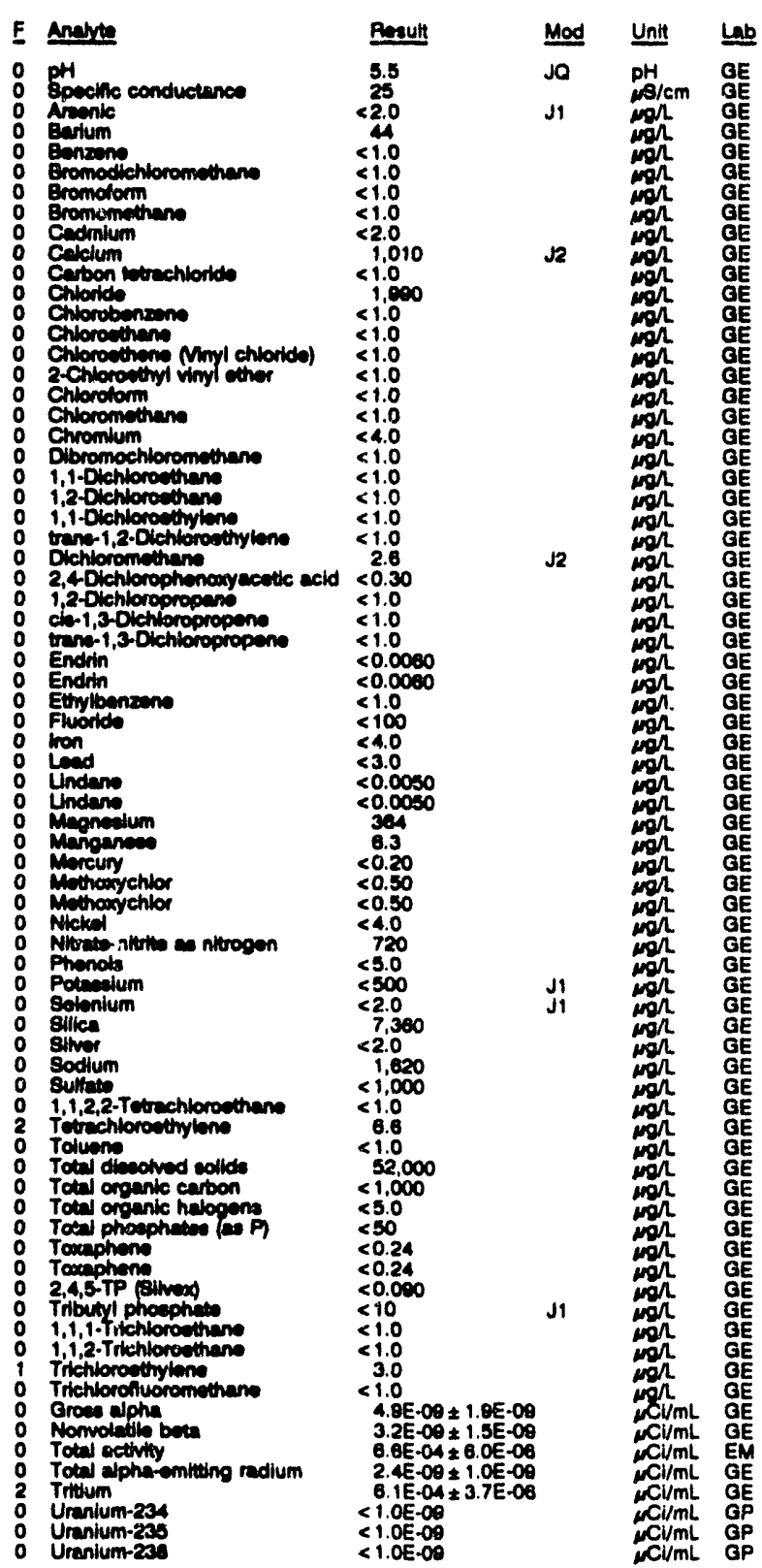

PH: 4.8 . 0

Watar tomperature: $20.00^{\circ} \mathrm{C}$
WELL BGO 45A

MEASUREMENTS CONDUCTED IN THE FIELD

Qamplo data: $08 / 11 / 22$ n $(30.04 \mathrm{~m})$ below TOC Whoth to wator: $116.25 \mathrm{~h}(39.04 \mathrm{~m})$ bolow Sp. conductunce: 185 ps/cm

Time: 12:15

Hi: 7.4. $73 \mathrm{mon}$

LABOPATORY ANALYSES

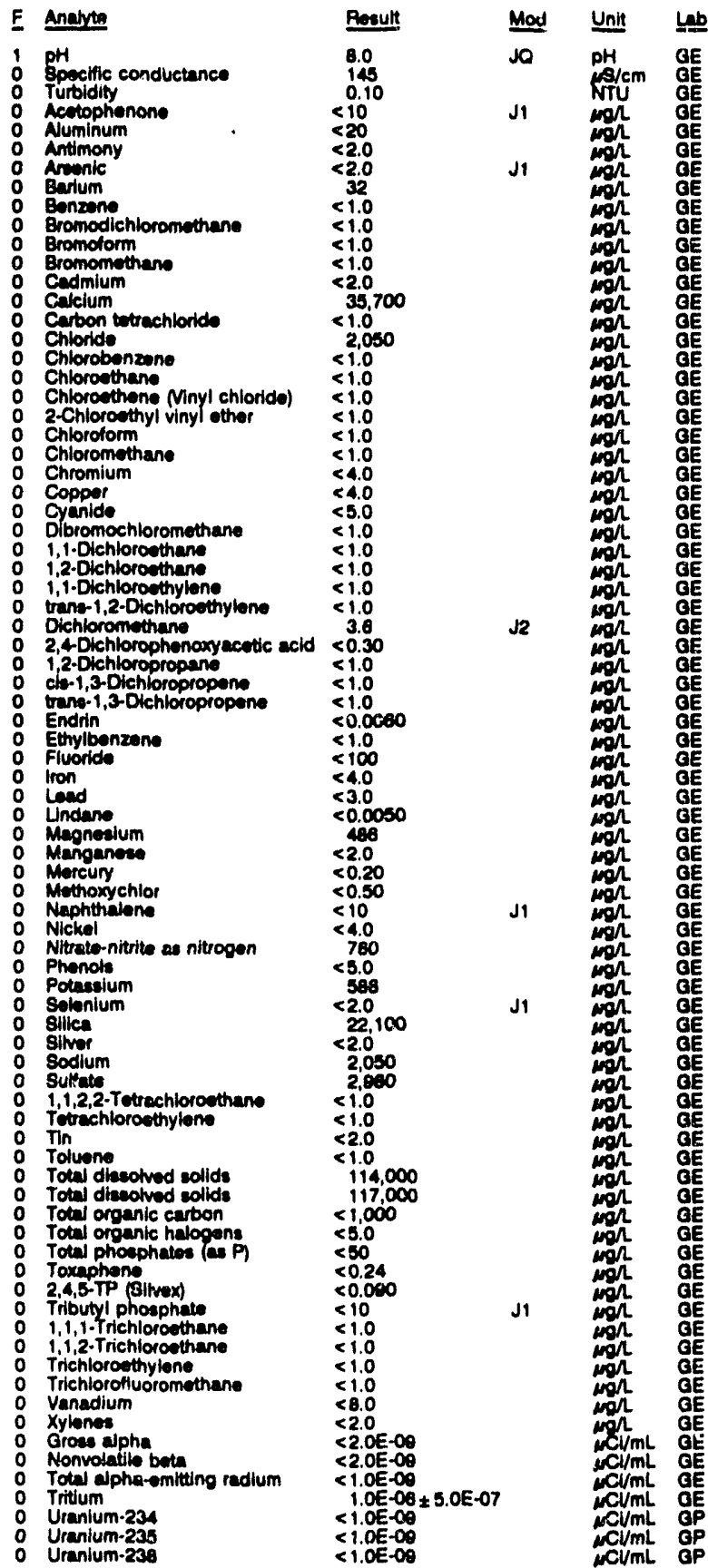


WELL BGO 45B

MEASUAEMENTS CONDUCTED IN THE FIELD

Sample dato: 08/13/92

Dopth to wat: $58.45 \mathrm{n}(17.82 \mathrm{~m})$ bolow TOC

Sp. conductance: 20.15 .

Whater wrecuettod betore sempling: $4 \mathrm{gal}$

The woll went dry during purging.

LABOPATORY ANALYSES

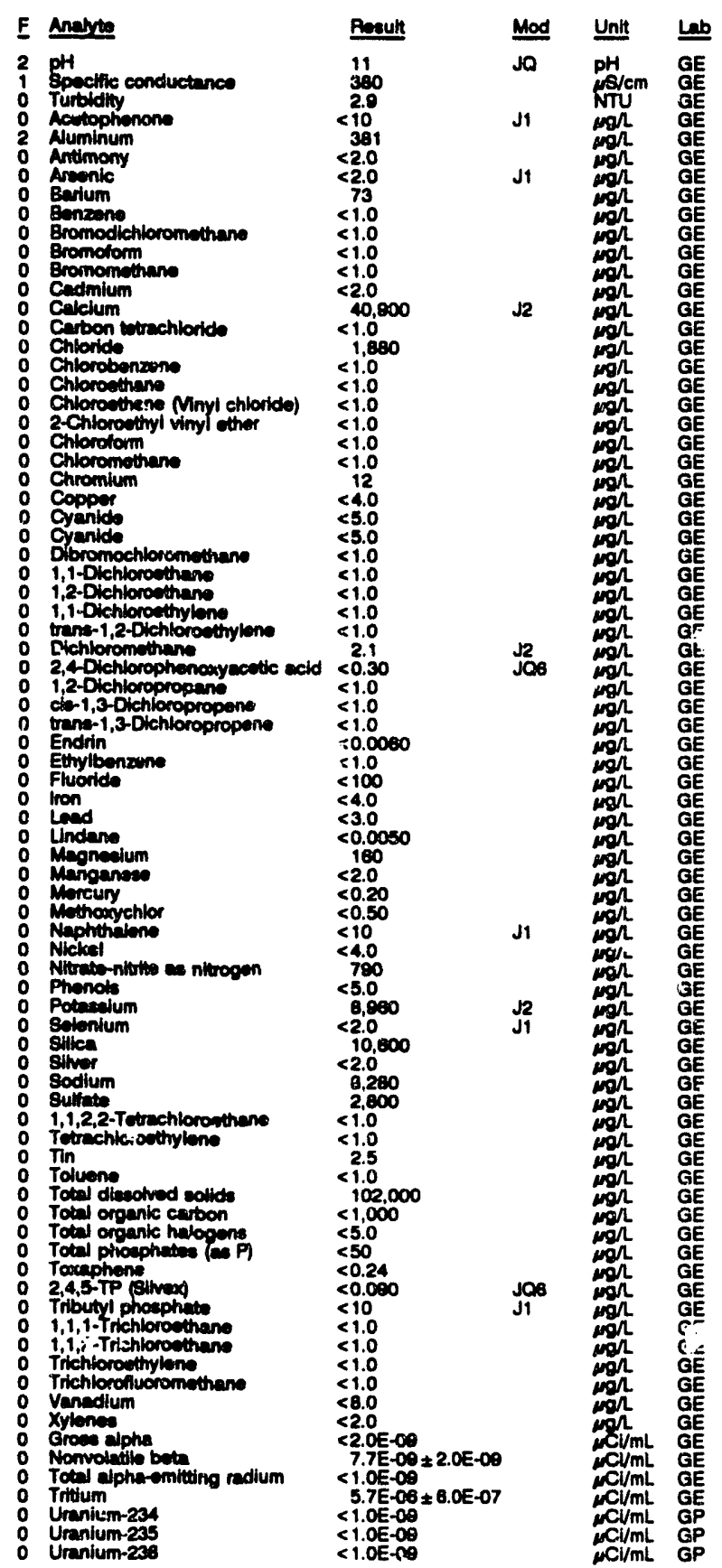

Time: 10:10
pH: 10.8
Akalinity: $45 \mathrm{mg} / \mathrm{h}$

Waler tomporature: $19.6^{\circ} \mathrm{C}$
WELL. BGO 45C

MEASUREMENTS CONDUCTED IN THE FIELD

Sample date: 08/13/92

Depth to water: $55.08 \mathrm{~h}(16.78 \mathrm{~m})$ bolow TOC

Sp. conductance: $80 \mathrm{\mu S} / \mathrm{cm}$

Weter evacuated bofore sempling: 19 a

PH: 8.2

The well went dry during purging.

LABOFUTORY ANALYSES

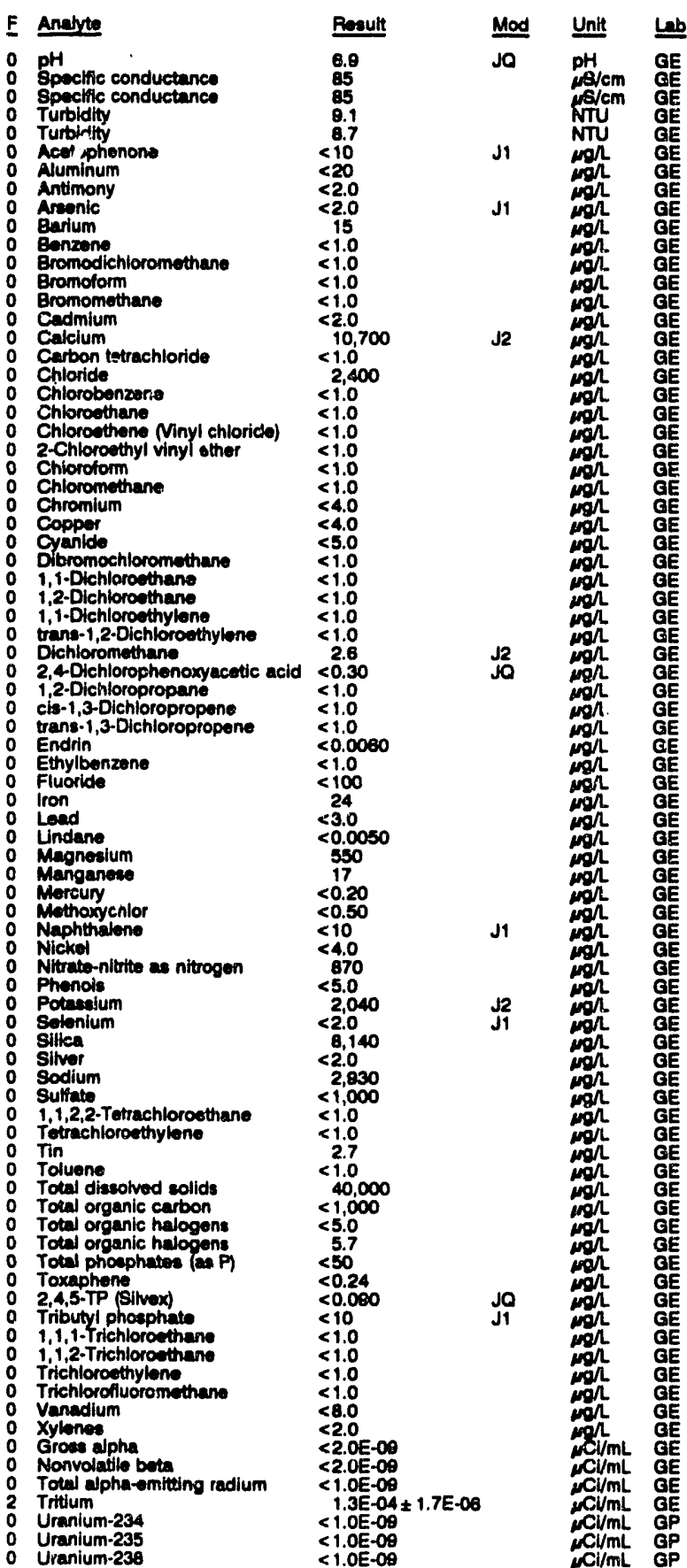




\section{WELL BGO 45D}

MEASUPEMENTS CONDUCTED IN THE FIELD

Sample data: 00/11/02

Wpth to wher: $50.35 n(15.35 \mathrm{~m})$ below TOC

Sp. conductonce: 28 is/cm

Wator evecuabed betoro eampling: $40 \mathrm{gal}$

LABOPATOFY ANALY YES

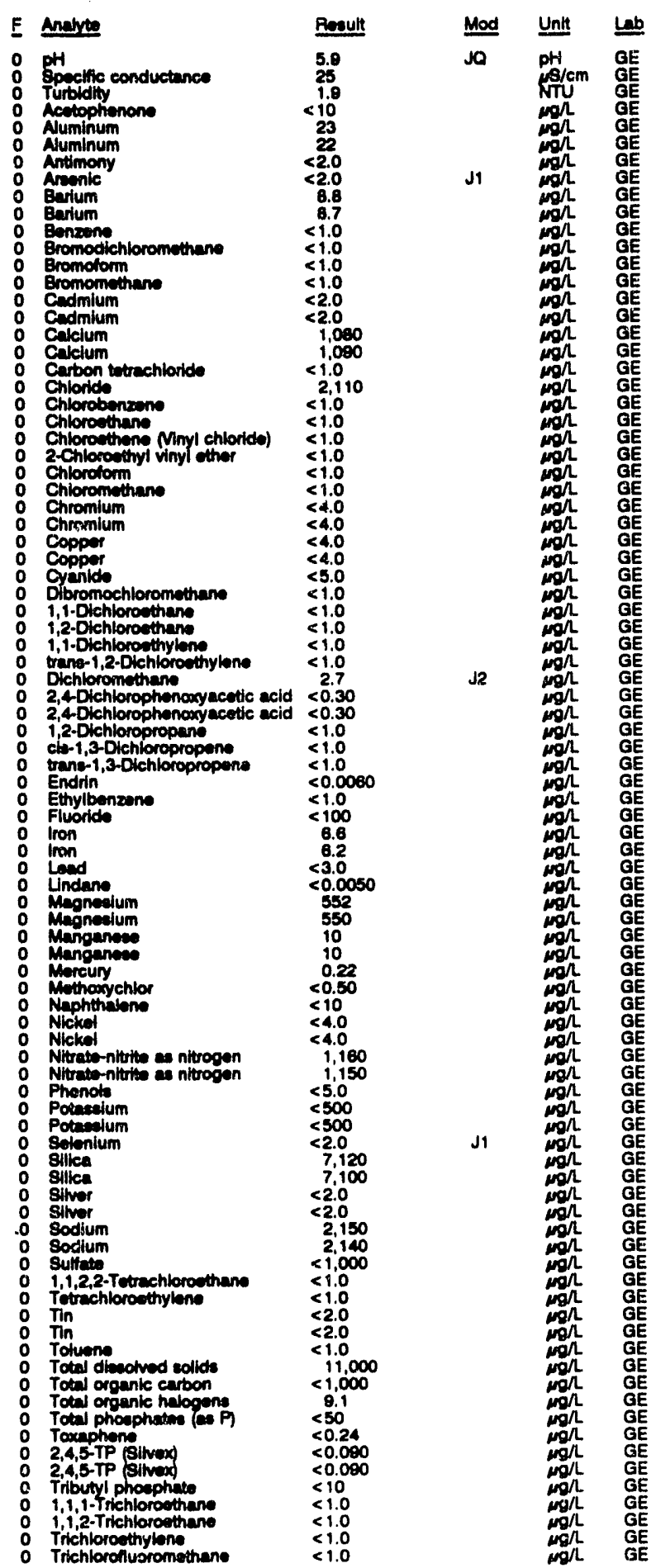

WELL BGO 450 collectod on 08/11/82, laboratory analyses (cont.)

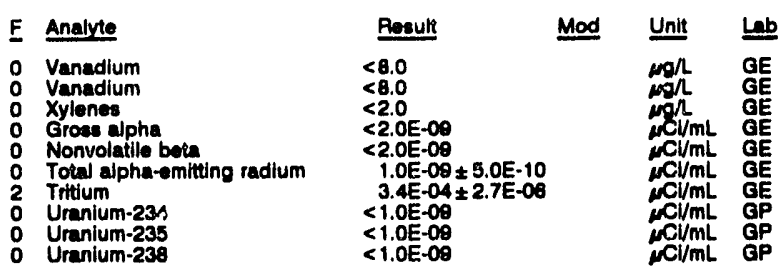

WELL BGO 46B

MEASUREMENTS CONDUCTED IN THE FIELD

Sample dato: 08/11/92 Dopth to water: $47.14 \mathrm{~h}(14.37 \mathrm{~m})$ bolow TOC Wator elovation: $218.25 \mathrm{~h}(86.52 \mathrm{~m}) \mathrm{mal}$ Sp. conductance: $62 \mu \mathrm{s} / \mathrm{cm}$
Wator evacuatod before sampling: $208 \mathrm{gal}$ LABOPATOAY ANALYSES

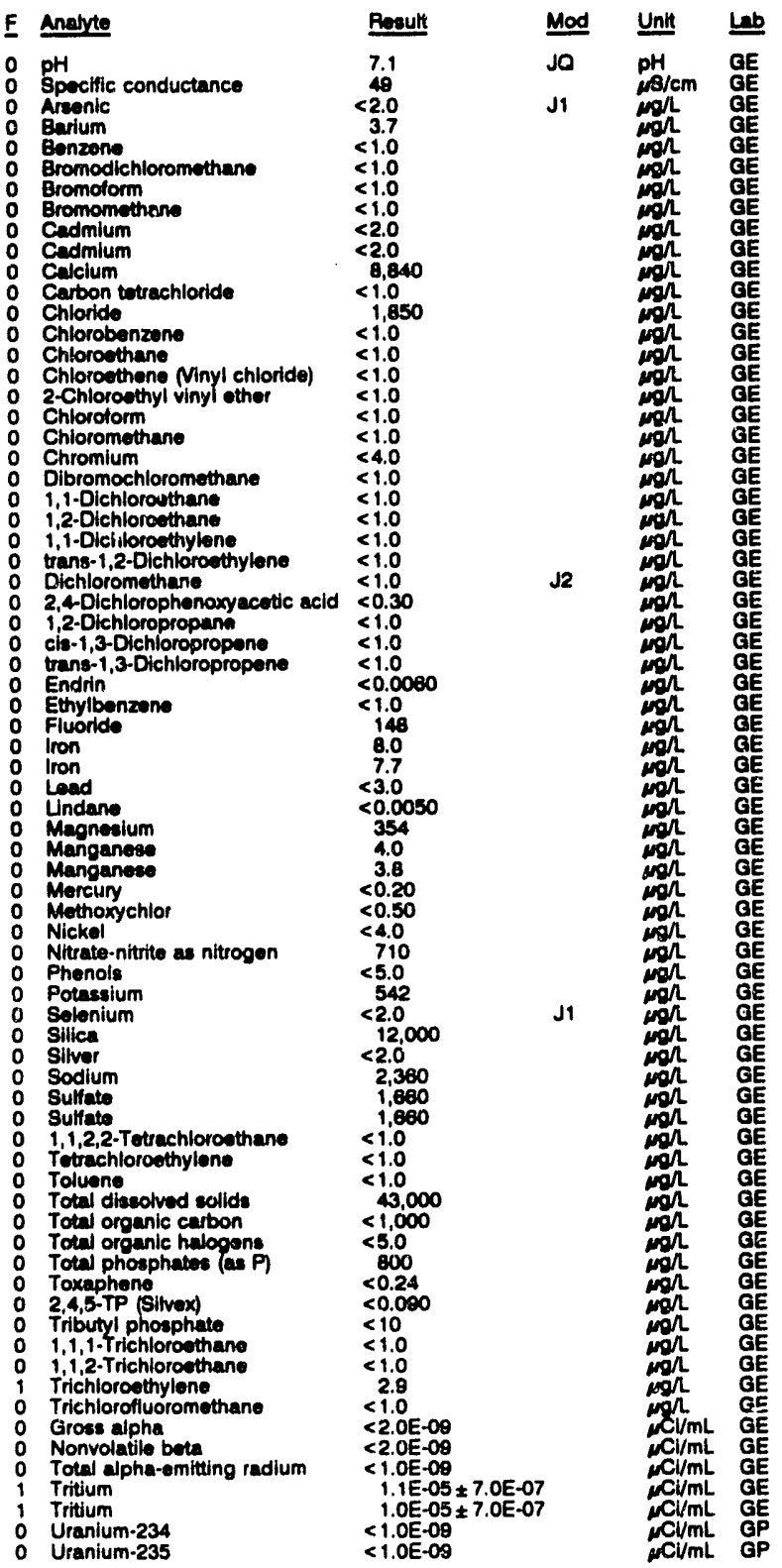


WELL BGO 488 collected on 08/11/82, labofutory analyees (cont)

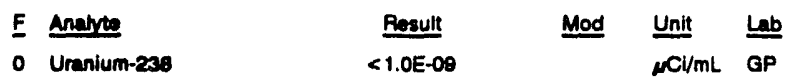

WELL BGO 46C

MEASUPEMENTS CONOUCTED IN THE FIELD

Semple dete: 0o/13/0e

Depth to watar: $45.31 \mathrm{fl}(13.81 \mathrm{~m})$ bolow TOC

Sp. conductance: $70 \mathrm{H} / \mathrm{cm}$

$.09 \mathrm{~m}) \mathrm{mel}$

Witor ovecuatiod betors eampling: $30 \mathrm{gal}$

The well went dy during purging.

LABOAATOAY ANALYESS

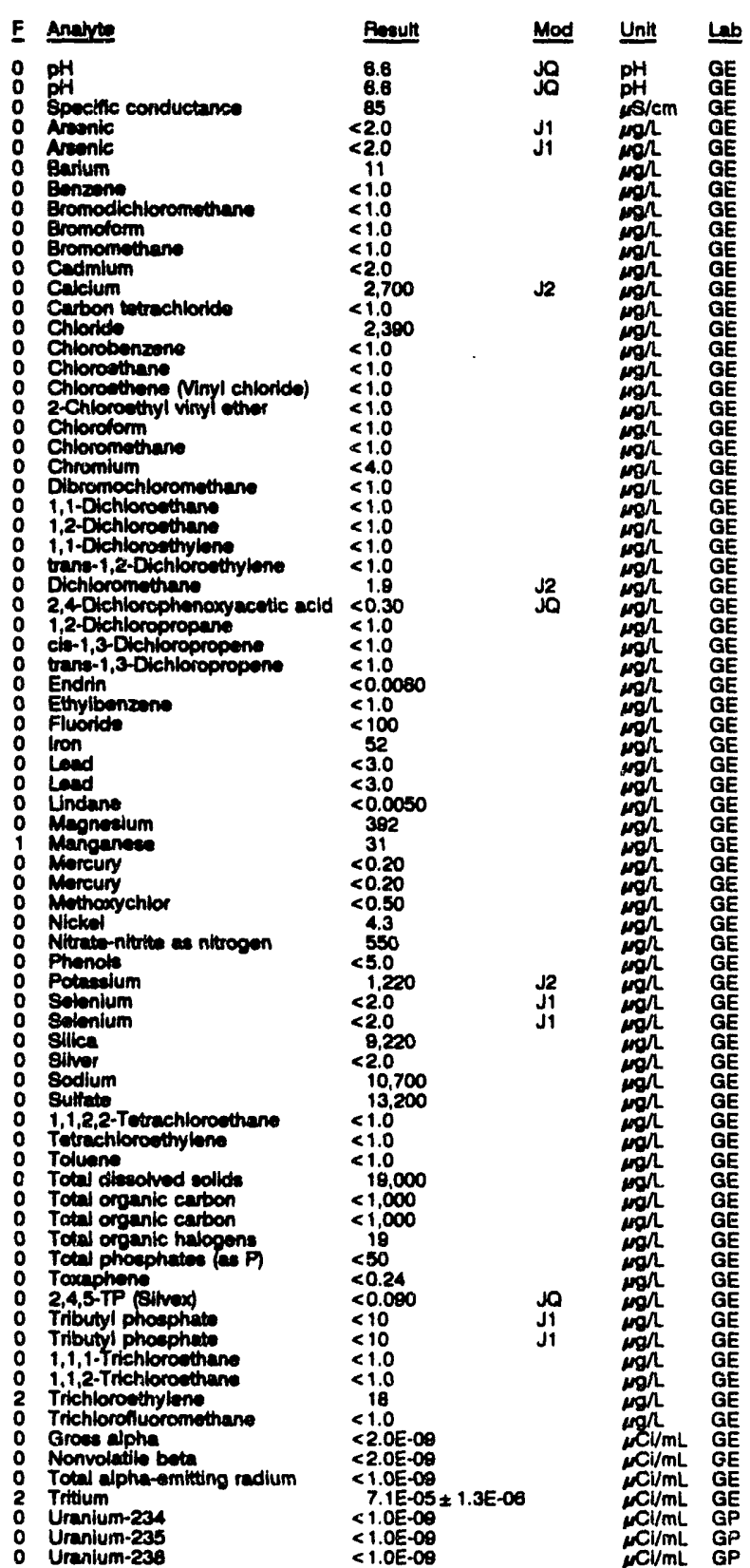

Time: $12: 10$

Nkalinity: $11 \mathrm{mar}$

Whalinity: $11 \mathrm{mgh}$. $20.8^{\circ} \mathrm{C}$

WELL BGO 46D

MEASUREMENTS CONDUCTED IN THE FIELD Sumple date: $08 / 11 / 92$
Depth to water: 38.38 . $(12.00 \mathrm{~m})$ bolow TOC
Water olevation: $225.74 \mathrm{~K}(68.81 \mathrm{~m})$ mil Wetor ovacuated before sampling: $63 \mathrm{gal}$

Time: 14:05

Alkalinity: $0 \mathrm{mgl}$ Water tomperature: $21.6 \circ 0$ LABORATORY ANALYSES

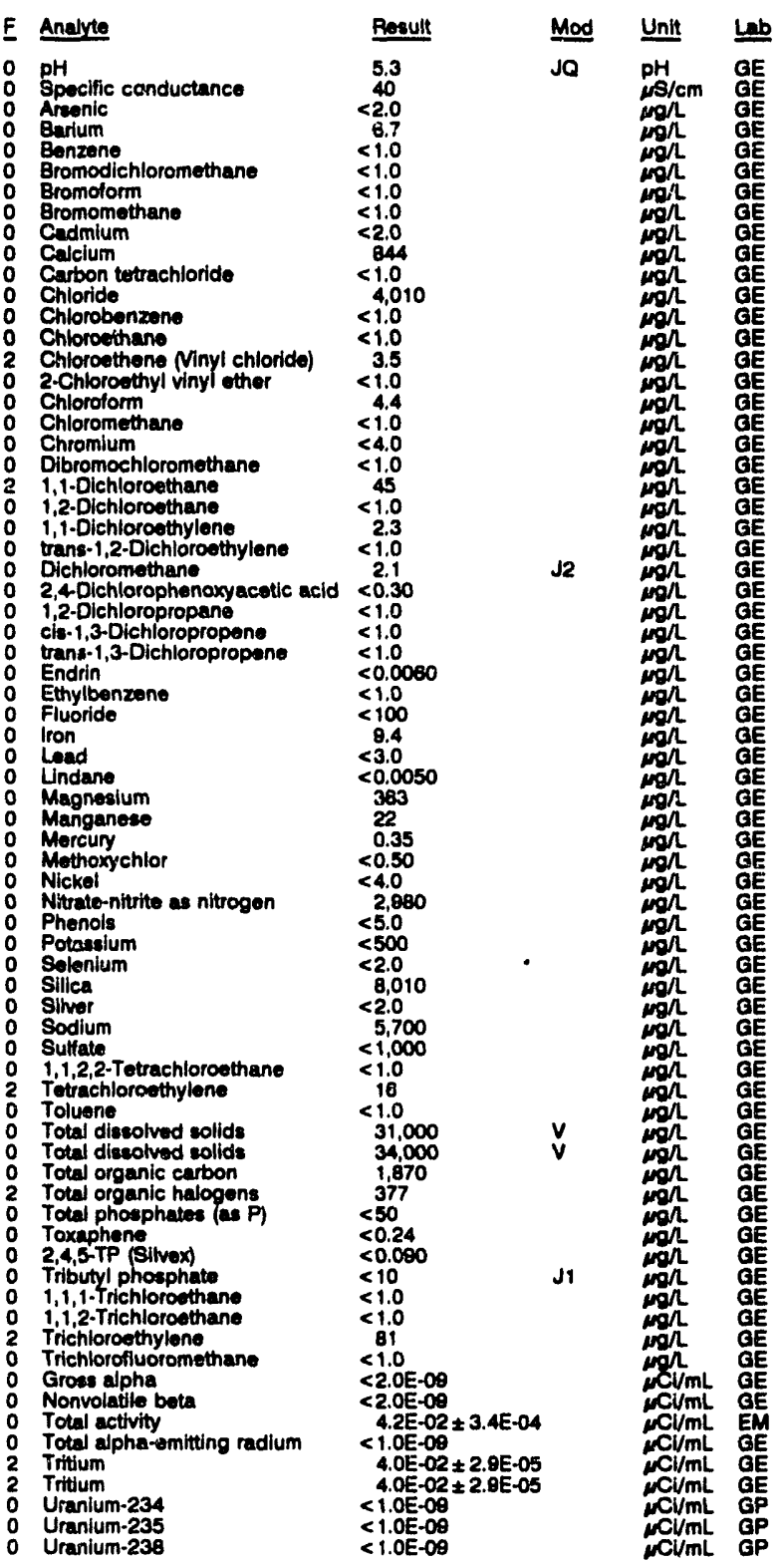


WELL BGO 47A

MEASUREMENTS CONDUCTED IN THE FIELD

Sample dato: 08/12/02 $\mathrm{n}(31.00 \mathrm{~m})$ below TOC Depth to water: $104.08 \mathrm{~h}(31.00 \mathrm{~m})$ below
Weter cevetion: $162.23 \mathrm{ft}(49.45 \mathrm{~m}) \mathrm{mal}$ Sp. conductance: $152 \mathrm{\mu s} / \mathrm{cm}$
Wator evecuated betors eampling: $180 \mathrm{gal}$

LABOAATOAY ANALY YES

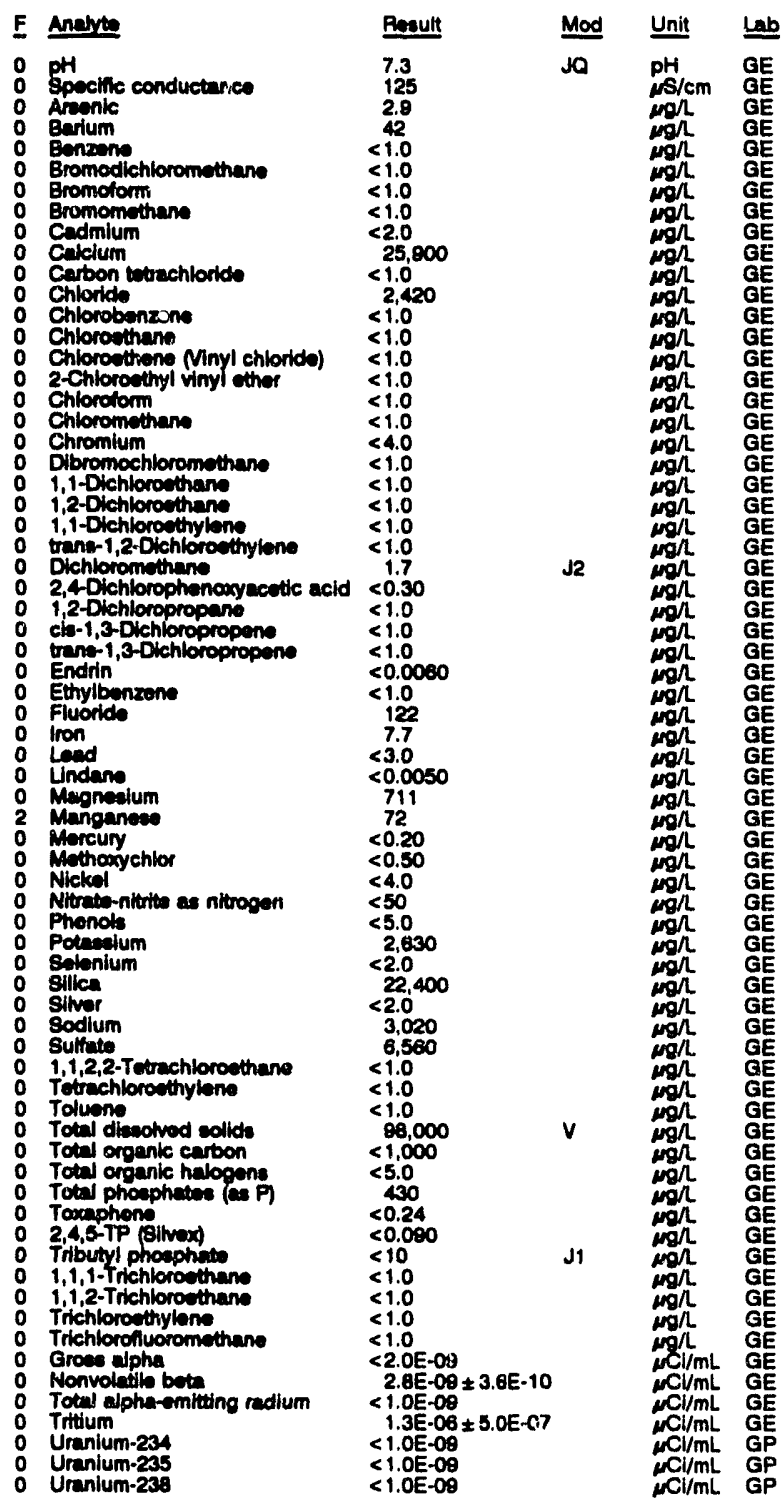

PH: 8.7 .5

Water tomporature: $20.8^{\circ} \mathrm{C}$
WELL BGO 47C

MEASUREMENTS CONDUCTED IN THE FIELD

Sample date: 08/12/92

Depth to water: $44.72 \mathrm{ft}(13.63 \mathrm{~m})$ below TOC

Wator alovation. $222.88 \mathrm{k}(67.83 \mathrm{~m}) \mathrm{mal}$

Water evacuated bofore sampling: $118 \mathrm{gal}$

pH: 5.4. 2 man

LABORATORY ANALYSES

o $\mathrm{Speclific}_{0}^{\mathrm{H}}$ conductance

o Areonic

0 Benzene

Bromodichloromethane

Bromolorm

Bromomothan

Cedmlum

o Carbon tetrachloride

o Chioride

o Chtorobenzene

Chloroethene Minyl chloride)

2-Chloroethyl vinyl ether

o Chloroform

o Chioromothane

o Chromlum

0 1,1-Dichloroethane

o 1,2 -Dichloroethane

0
0
trane-1,2-Dichloroethylene

2,4Dichlorophenoxyacetic acid

2,4 Dichlorophonoxyacotic acid $<0$

o cto-1,3-Dichloropropen

cis-1,3-Dichloropropeno

0 trans: 0 Endrin

0 Endrin

0 Ethylbenzerse

o Fluoride

o lion

0 Lead

o Lindane

o Magnesium

Manganeso

Mercuny

Methoxychlor

Mickol

Nitrato-nitrite as nitrogen

Phenols

Potassium

Solentum

O Sillca

o Silver

Sodium

Sulfate

Tetrachloroethylene

Toluene

Total dissolved solide

Total organic carbon

Total phosphntes (as P)

Toxaphone

Toxaphone

2,4,5-TP (Silvex)

1,1,1-frichloroethen

o 1,1,2-Trichloroethan

Trichloroethylene

- Gross alpha

Nonvolatile bota
Total activity

Total alpha-omitting radium

Tritium

Uranium-234

Uranium-235

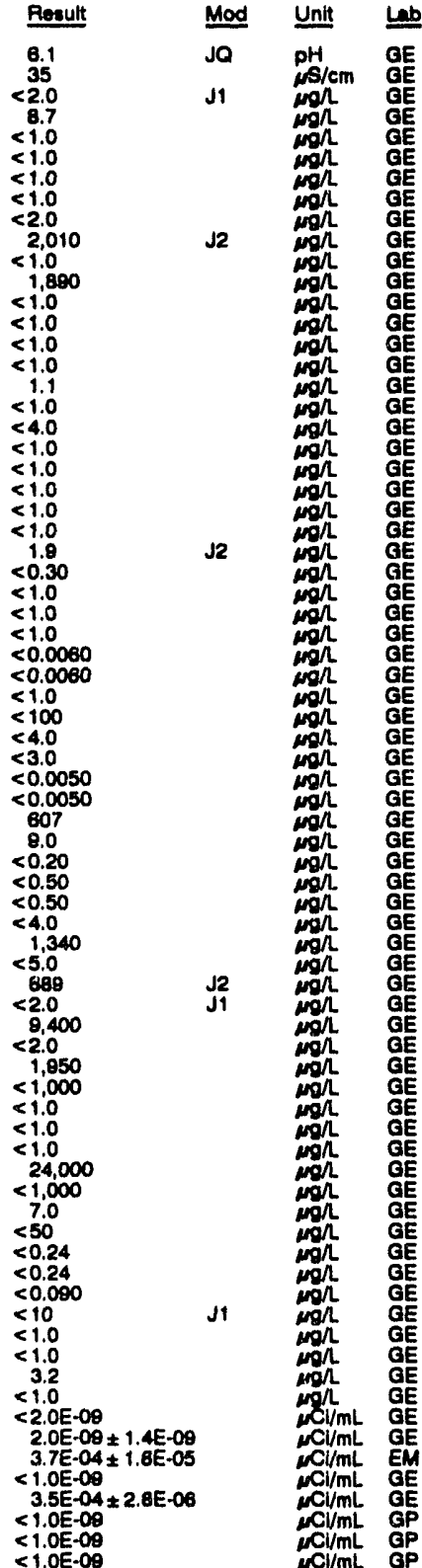


ANALYTICAL RESULTS

WELL BGO 47D

MEASUREMENTS CONDUCTED IN THE FIELD

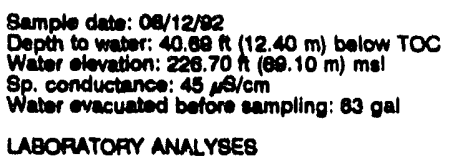

Time: 14:10

Alkalinity: $2 \mathrm{mon}$

Water tomperature: $21.3^{\circ} \mathrm{C}$

LABOPATOFY ANALYSES

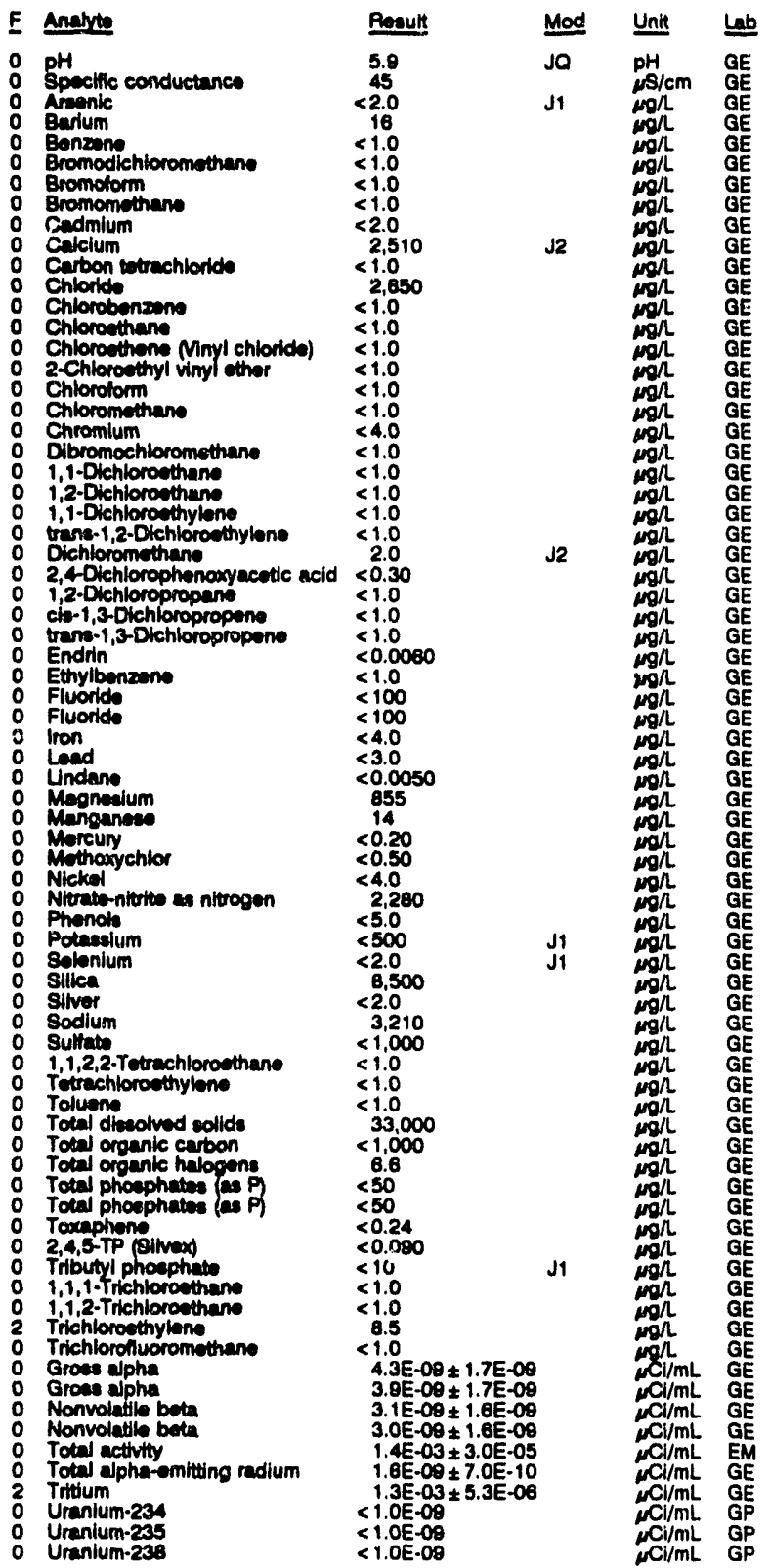

WELL BGO 48C

MEASUAEMENTS CONDUCTED IN THE FIELD

Sample date: 08/12/82

Dopth to water: $52.88 \mathrm{nt}(16.12 \mathrm{~m})$ bolow TOC

Water alovation: $223.72 \mathrm{k} / 68$

Sp. conductanco. $34 \mu \mathrm{s} / \mathrm{cm}$.

Water evacuated botore sampling: $125 \mathrm{gal}$

LABORATORY ANALYSES

$F$ Analyte

O $\mathrm{pH}$ Specific conductance

Areenic

Barlum

Bromodichloromethine

Bromolorm

Bromomethane

Cadmium

Carbon tetrachloride

Chlorobenzene

Chloroethere (Mnyl chloride)

2-Chloroethyl vinyl ether

Chloroformi

Chloromethane

Chromium

Dibromochloromethane

1,1-Dichloroethane

1,2-Dichloroethane

$1,1-$ Dichloroethylene
trans-1,2-Dichiorosthyiene

o Dichloromethane

1,2-Dichloropropane

o cis-1,3-Dichloropropene

trans-1,

E Ethylbenzene

0 Fivoride

Iron

0 Lindane

O Magnesium

0 Mangarea

Methoxychlor

Nickel

Nitrato-nitrite as nitrogen

Phonols

Solasium

0 Silica

O Silver

o Sodium

1,1,2,-Tetrachloroethane

o Totrachlorosthylene

Toluene

Toluene

- Total organic carbon

1 Total organic halogens

Toxaphene

2,4,5-TP (Silvex)

Tilbutyl phosphato

1,1,1-Irichloromthane

Ti,

Trichlorofluoromethane

Gross alphe

o Nonvolatile beta

o Total activity

Trttium

- Uranium-234

0 Uranlum-235

\begin{tabular}{|c|c|c|}
\hline Result & Mod & Unit \\
\hline 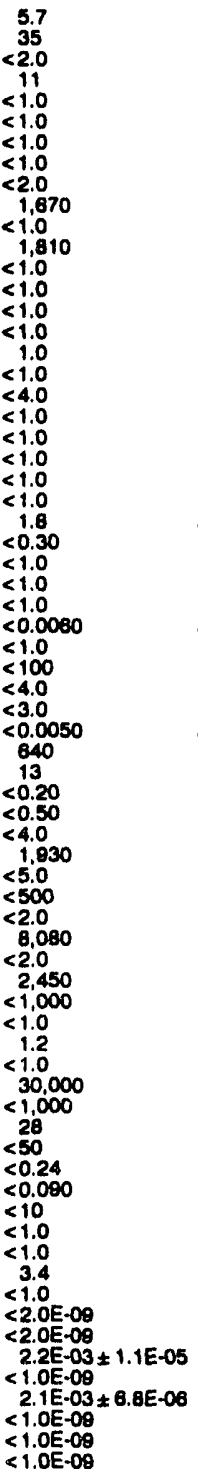 & $\begin{array}{l}\text { Ja } \\
\text { Ja } \\
\text { Ja1 }\end{array}$ & 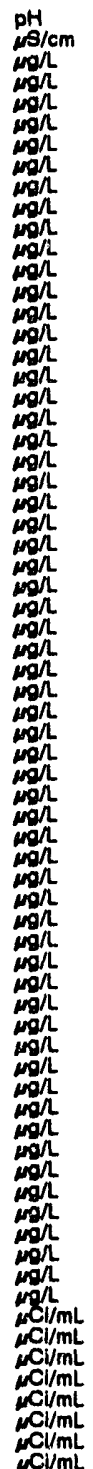 \\
\hline
\end{tabular}

Time: 12:55

Alkalinity: $1 \mathrm{~mol}$

Water tomperature: $20.0 \circ \mathrm{C}$ 
WELL BGO 48D

MEASUAEMENTS CONDUCTED IN THE FIELD

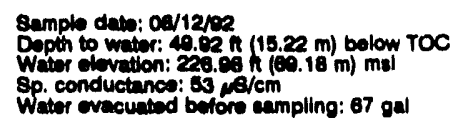

LABORATOFY ANLLYSES

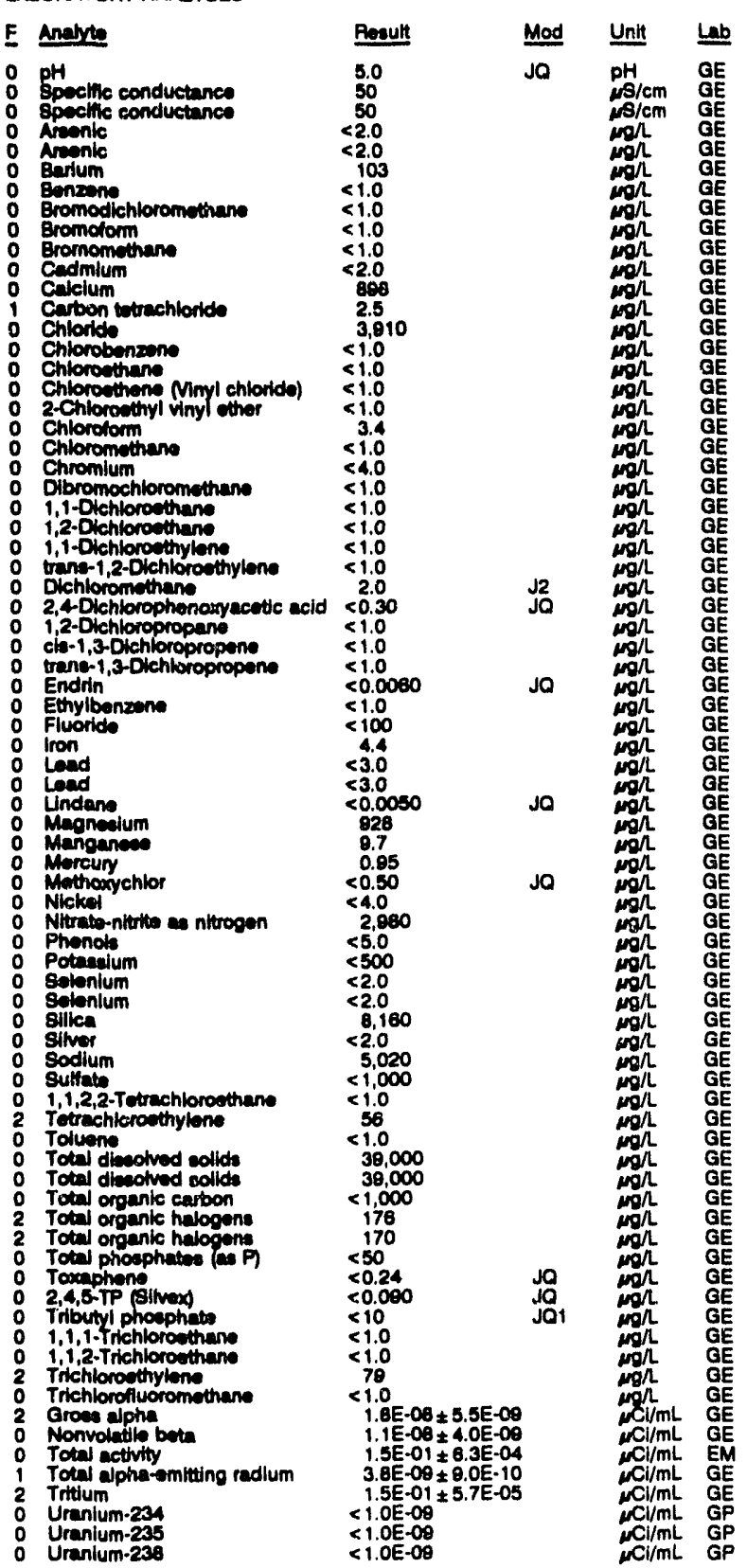

WELL BGO 49A

MEASUREMENTS CONDUCTED IN THE FIELD

Sample dato: 08/13/02

Wopth to wator: $105.89 \mathrm{ft}(32.28 \mathrm{~m})$ bolow TOC

So. conductance: $188 \mu 8 / \mathrm{cm}$

Water evacuated betore sampling. 238 on

Time: 14:40

Alkulinity: $82 \mathrm{mg} \Omega$

Water tomperature: $20.2{ }^{\circ} \mathrm{C}$

LABOPATORY ANALYSES

\begin{tabular}{|c|}
\hline 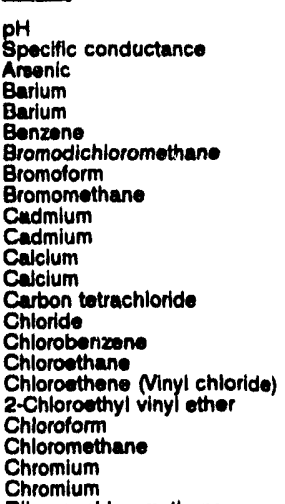 \\
\hline
\end{tabular}

- Chloroform

Chromium

o Dibromochloromethane

1.1-Oichloroethane

$\begin{array}{ll}0 & 1,2-\text { Dichloroethane } \\ 0 & 1,1-D i c h l o r o s t h y l e n e\end{array}$

$1,1-D i c h l$ - Dothylene
0
trans-1,2-Dichloreethylene

: trang-1,2-Dichloreethy

2,4-Dichlorophenoxyacetic acid $<.0$

o 1,2-Dichloropropane

0
0
0
trana-1, 1,3 -Dichloropropene
0

: Endrin

O Ethylbenzone

$\therefore$ Fluorida

Iron

: lron

o Undane.

: Lindane

: Magnesium

Manganeac

Manganeso

Morcury

Methoxychlor

Methoxychlor

Nickel

Nickel

Nitrato-nitrite as nitrogen

Nitrate-nitrite as nitrogen

Phenols

Potanalum

Solonium

Sillica

Silica

Silver

Sodium

Sodium

sulfat

1,1,2,2-Tetrachloroethane

Tetrachloroothylene

Toluene

Total diseolved solids

Total organic carbon

Total organic halogens

Total phosphates (as P)

Toxaphene

2,4,5.TP (SHuex)

Tributyl phosphate

1,1,1-Trichloroethane

1,1,2-Trichloroethan

Trichloroethylene

Trichloroftuorom

Groes alpha

Total alpha-emitting radium

Trittum

Tritium

Uranlum-234

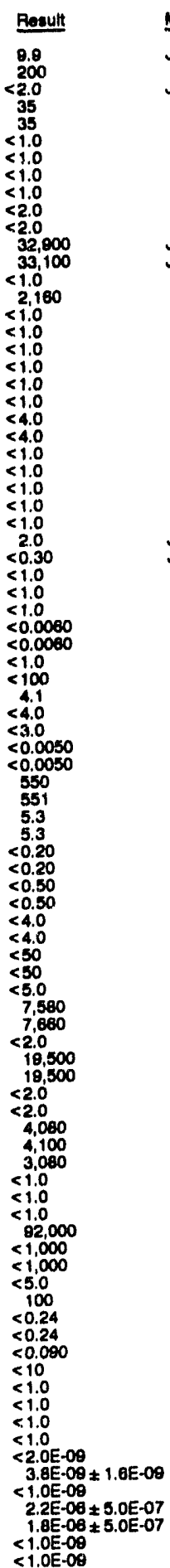

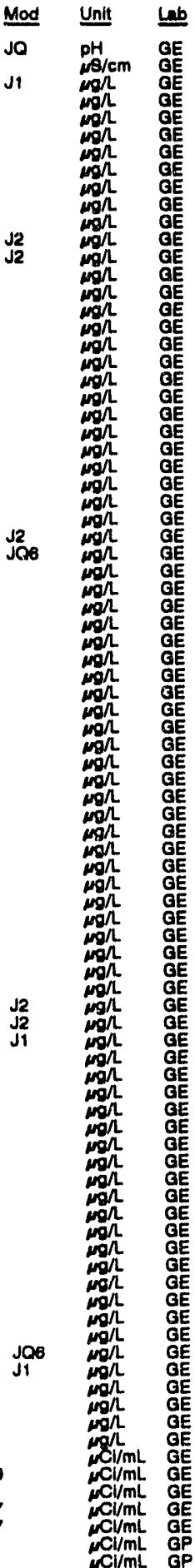


ANALYTICAL RESULTS

WELL BGO $49 A$ collectod on 08/13/92, laboratory analyees (cont.)

\begin{tabular}{|c|c|c|c|}
\hline F Analyte & Presult & Mod & Unit \\
\hline 0 Uranium-238 & $<1.0 E-00$ & & $\mu \mathrm{Cl} / \mathrm{mL}$ \\
\hline
\end{tabular}

WELL BGO $49 C$

MEASUAEMENTS CONDUCTED IN THE FIELD

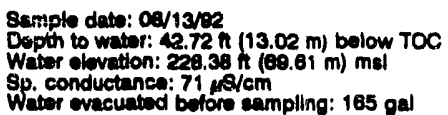

Time: 14:05

PH: 7.5 Alkalinity: $20 \mathrm{mg} /$.

Wator temperature: $18.0^{\circ} \mathrm{C}$ LABORATOFY ANALYSES

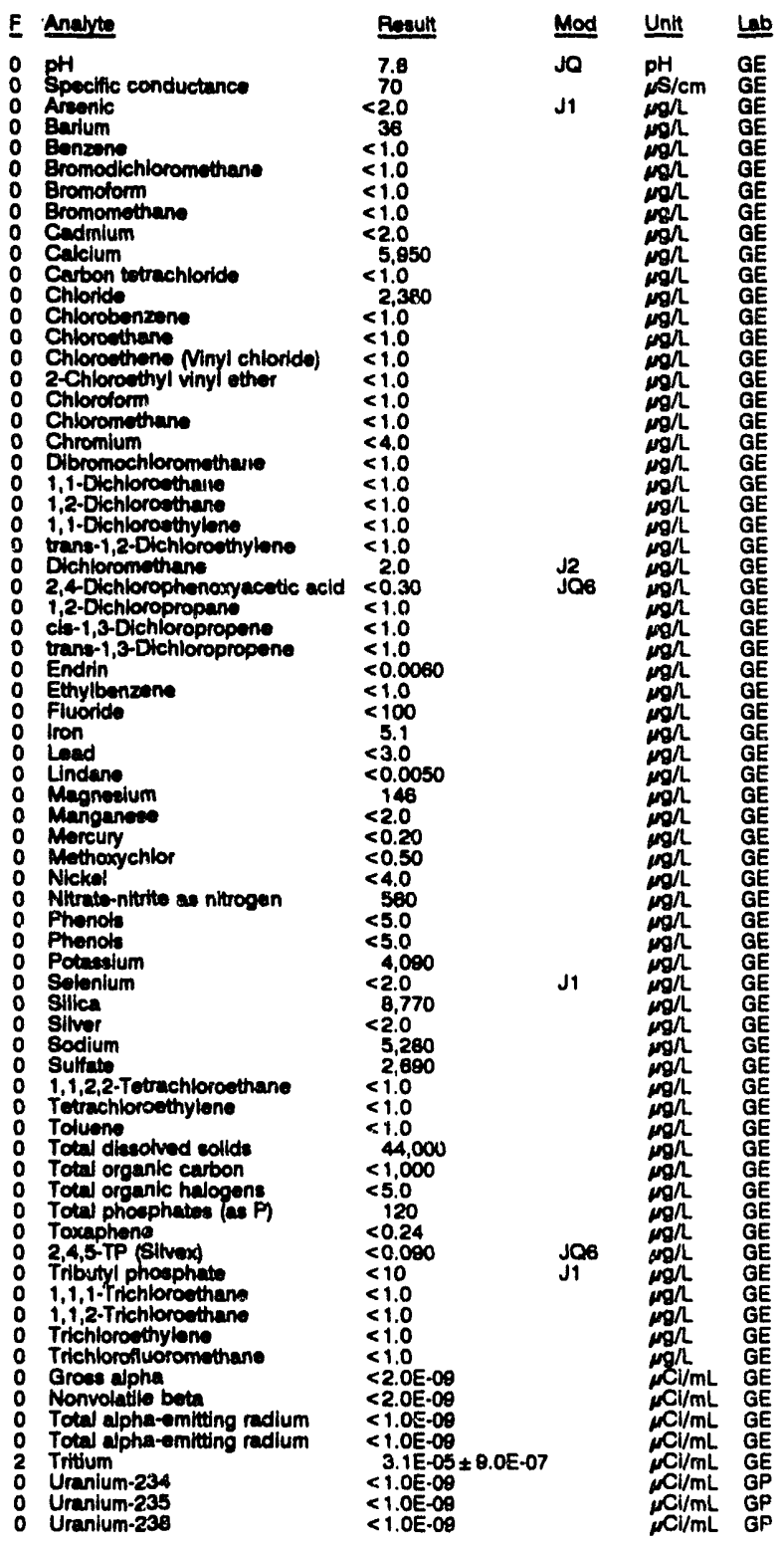

WELL BGO 49D

MEASUREMENTS CONDUCTED IN THE FIELD

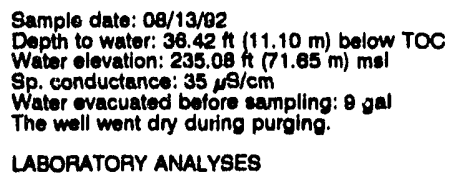

Time: 13:25

PH: 5.1 . 1 mo/h

Water tomporature: $20.00 \mathrm{C}$

LABORATORY ANALYSES

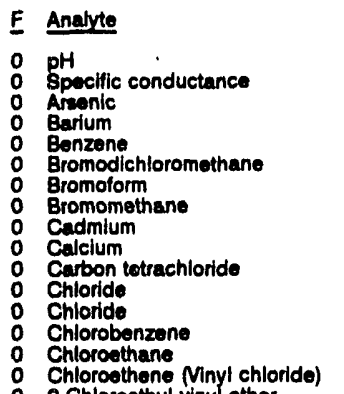

Chloroethene Ninyl chloride)

Chlorolorm

Chioromethane

Chromium

Dibromochloromethane

1,1-Dichloroethane

1,2-Dichloroothane

trans-1,2-Dichloroethylene

Dichloromethane

24-Dichorophenoxyacete actd

1,2-Dichloropropane

cis-1,3-Dichloropropene

trans-1,3-

Ethylbenzene

Fluoride

Iron

Lindane

Magnesium

Manganeso

Mercury

Nittrate-nitrite as nitrogen

Phenols

Phenols

Solenium

Silica

Sodium

Sodlum

Sulfate

$1,1,2,2$-Tetrachioroethane

Tetrachloroethylene

Tolueno

Total dissolved sollds

Total organic carbon

Total phosphates (as PI

Toxaphene

2,4,5-TP (Sitvox)

1,1,1-Trichloroethane

1,1,2-Trichloroethane

Trichloroethylene

Trichlorofluoromethane

Grose alpha

Nonvolatilo beta

Total alp

Uranium-234

Uranium-238

Result

Mod Unit Lab

5.8

$<2.0$

12
$<1.0$
$<1.0$

$<1.0$

$<1.0$

550
$<1.0$

1.460
1,440
$<1.0$

$<1.0$

$<1.0$

$<1.0$

$<1.0$

$<1.0$

$<1.0$

$<1.0$

$<1.0$

$<1.0$

$<0.30$

$<1.0$
$<1.0$

$<1.0$

$<0.00$

$<1.0$
$<100$

$<3.0$

$<0.0050$

35.4
3.4

3.4
$<0.20$

$<0.50$

$<4.0$

$<5.0$
$<5.0$

503
503

$<2.0$

5.780
$<2.0$
3.050

3.950
$<1,000$

$<1,000$

$<1.000$
$<1.0$
$<1.0$
$<1.0$

$<1.0$

2,000

2,000
$<5.0$
$<50$

$<0.24$

$<0.080$

$<1.0$

$<1.0$

$<1.0$

$<2.0 E-09$

$<2.0 E-09$

<. $2.0 E-09$ - $05 \pm 8.0 E-07$

$<1.0 E-09$

$<1.0 \mathrm{E}-09$

Jo PH GE

गI

(



$\operatorname{gog}_{n} \operatorname{gon}_{n}$

GE 
WELL BGO 50A

MEASUREMENTS CONDUCTED IN THE FIELD

Sample delas: 00/13/02

Depth to water: $05.54 \mathrm{ft}(20.12 \mathrm{~m})$ bolow TOC

Water elevation: $159.68 \mathrm{ht}(49.73$

We. conductance. S100 1 s/cm

The well went dry during purging: $36 \mathrm{gal}$

LABOFATOFY ANAL.YBES

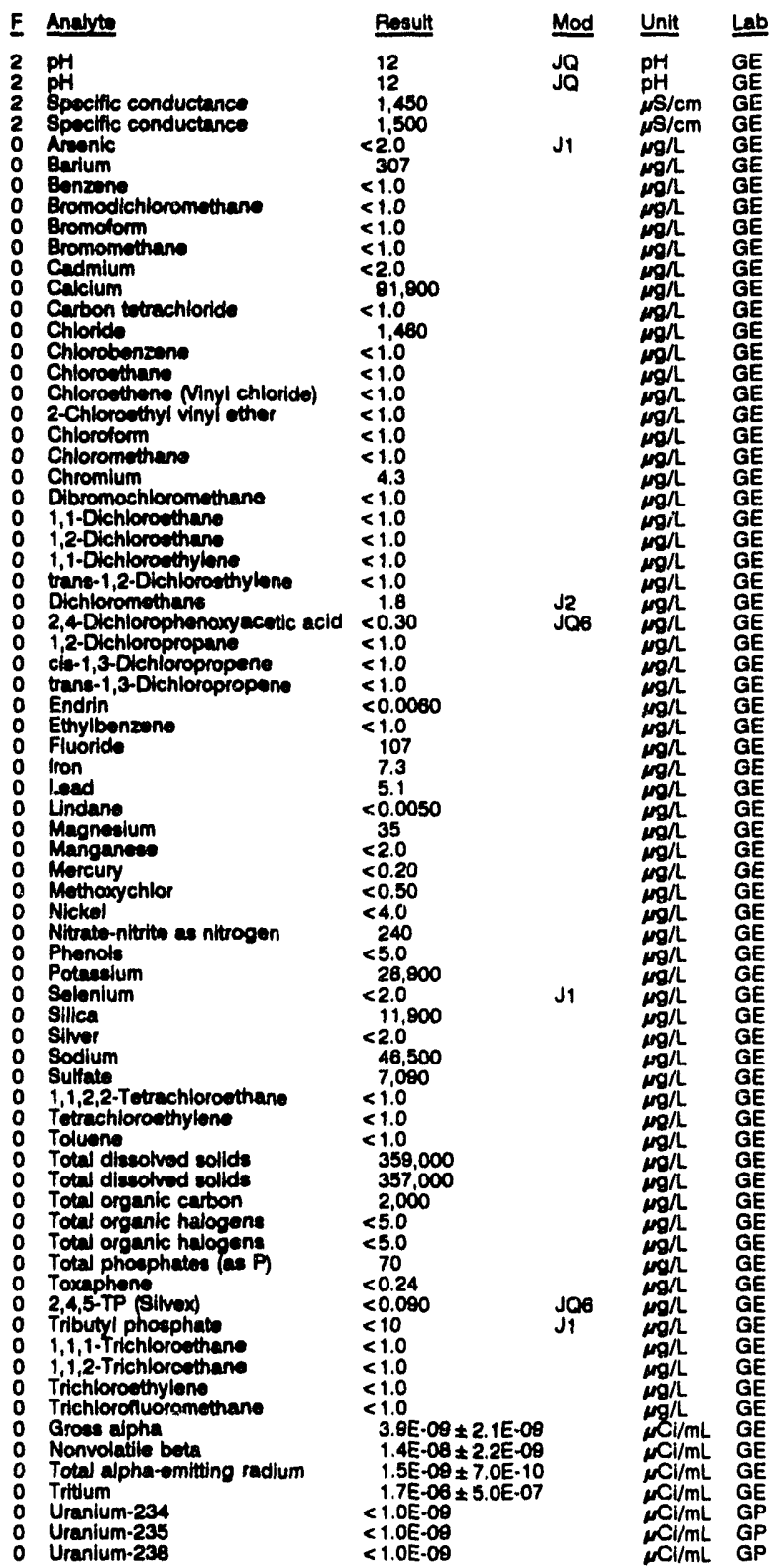

WELL BGO 50C

MEASUREMENTS CONDUCTED IN THE FIELD

Sample date: 08/14/92

Depth to water: $36.53 \mathrm{~h}(11.13 \mathrm{~m})$ bolow TOC

Wator elovalion: $218.97 \mathrm{~h}(86.74 \mathrm{~m}) \mathrm{mal}$

Sp. conductance: $22 \mu \mathrm{s} / \mathrm{cm}$.

The well went dry during purging.

LABORATORY ANALYSES

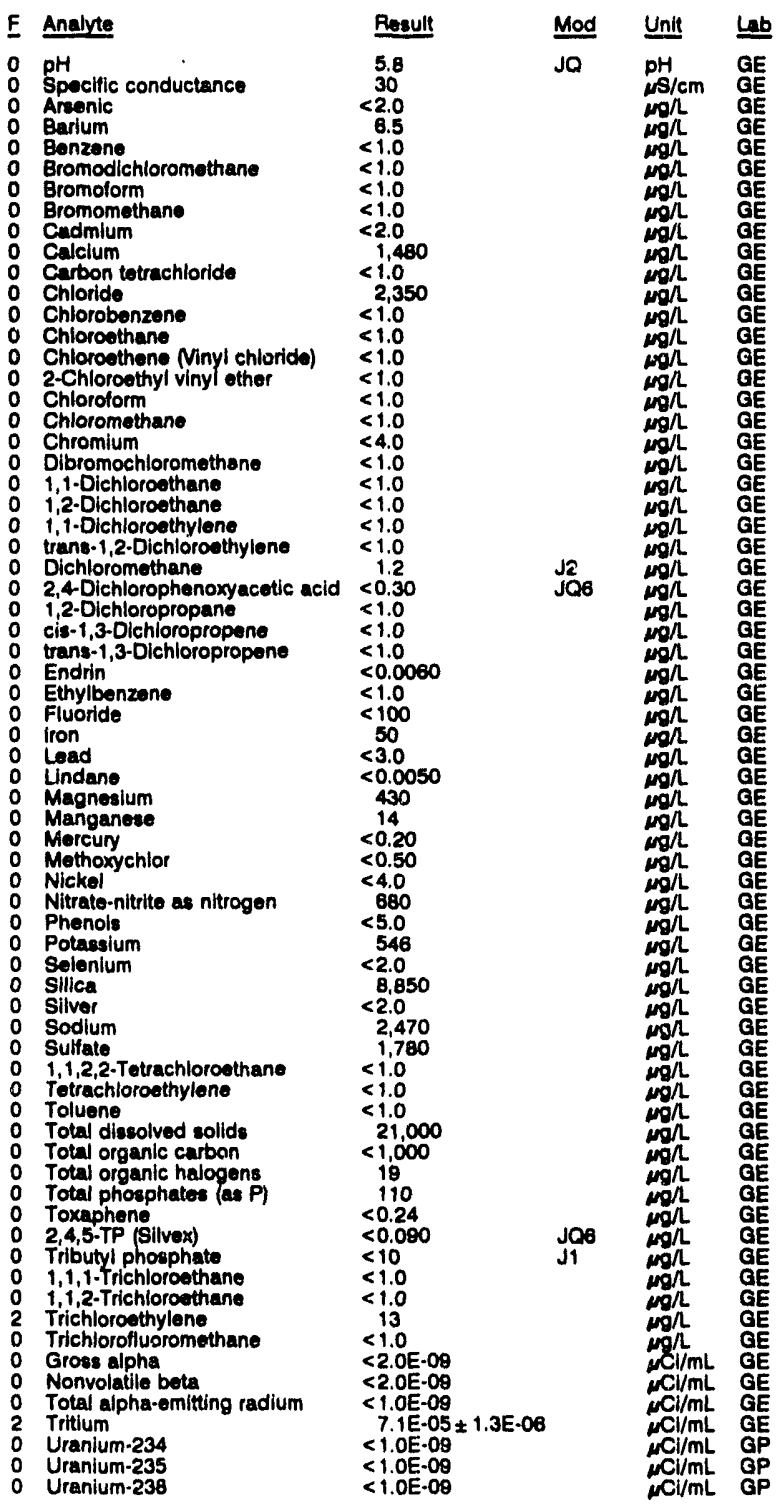


WELL BGO 50D

MEASUREMENTS CONDUCTED IN THE FIELD

Sample data: 08/1402

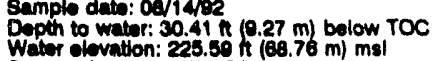

Bp. conductanco: $70 \mu \mathrm{s} / \mathrm{cm}$

Wator ovecuntad betoro eampling: 47 gal

LABOFATOFY ANULYSES

E Anayte

:

0 Spocine conductance

spectic conductence

A Arenic

Arsonic

Barium

: Earrum

Bonzente

o Bromodichloromethane

o Bromodichloromethane

Bromotorm

Bromomethene

Cadmium

Cadmium

Cadmium

Cavelum

Calclum

Carton wrachloride

carbon tutrachiorido

Chlonde

Chiorobenzene

Chlorobenzane

Chlorouthane

Chlorosthene Minyl chlorlde)

Chlorostheno Ninyi chloride

2-Chloroethyl vinyl ther

Chloroform

Chloroform

Chloromethane

Chromium

Chromlum

Dibromochioromethane

Dibromochloromethene

1 1,1-Dichlorosthane

1,1-Dichlorothan

1,2-Dichlorothan

o 1,1-Dichoroetthylone

o trane-1,2-Dichloroethyiene

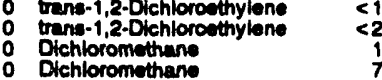

o Dehloromethane

2,4-Dichlorophenoxyacotic acid

2,4-Dichlorophonoxyacentic acid $<1.1$

1,2-Diehloropropane

0 cia 1 -

cie-1,3-Dichloropropene

trans-1,3-Dichloropropene

trane-1,3-Dichloropropone

Endrin

E Endrin

0 Ethylbenzen

0 Ethylbenzone

O Fluoride

Fluoride

ofron

Iron

Liond

Lond

Load

Lindane

Lindane

Magnealum

Magnealum

Magnealum

Manganese

Manganese

\section{Rosult}

$<1.0$
$<50$
$<2.0$

0.82
$<0.35$

8,220
0,220

8,140
$<1.0$

$<1.0$
$<25$

3,310
3,270

$<1.0$

$<250$

$<10$

$<50$
$<50$
$<50$
1.4

$<25$

$<50$
$<4.0$

$<1.1$

$<1.1$
$<1.0$

8.

5.7
$<1.0$
$<25$

$<1.0$

$<25$

$<5$
1.8

7.3
$<0.30$

$<1.0$
$<25$

$<1.0$

$<25$

$<25$

$<0.0060$

$<0.11$

$<1.0$

$<25$

$<100$
$<100$
$<100$

$<4.0$

13
16
$<3.0$

$<3.0$

$<0.0050$

$<0.055$

$<0.11$

518

509
493
6.0
6.2
6.8
6.3
6.1
6.1
80
62
62
$<2.0$
$<2.0$
$<2.0$
$<1.0$
112
$<1.0$
$<2.0$
$<1.0$
$<25$
$<1.0$
$<25$
$<1.0$
$<50$

Time: 8:35

Alkalinity: $23 \mathrm{mg} / \mathrm{L}$

Water temperature: $20.0 \circ \mathrm{C}$

Mod Unit L

Jo PH GE

JO $\mathrm{PH} / \mathrm{cm}$

Jo

$\sqrt{33}$

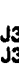

$\mathrm{S} / \mathrm{cm}$
$\mathrm{NS} / \mathrm{cm}$
$\mathrm{Nol}$

Nol WE



Nog

WA

WELL $8 G O 500$ colloctod on 08/14/82, laboratory analyses (cont.)

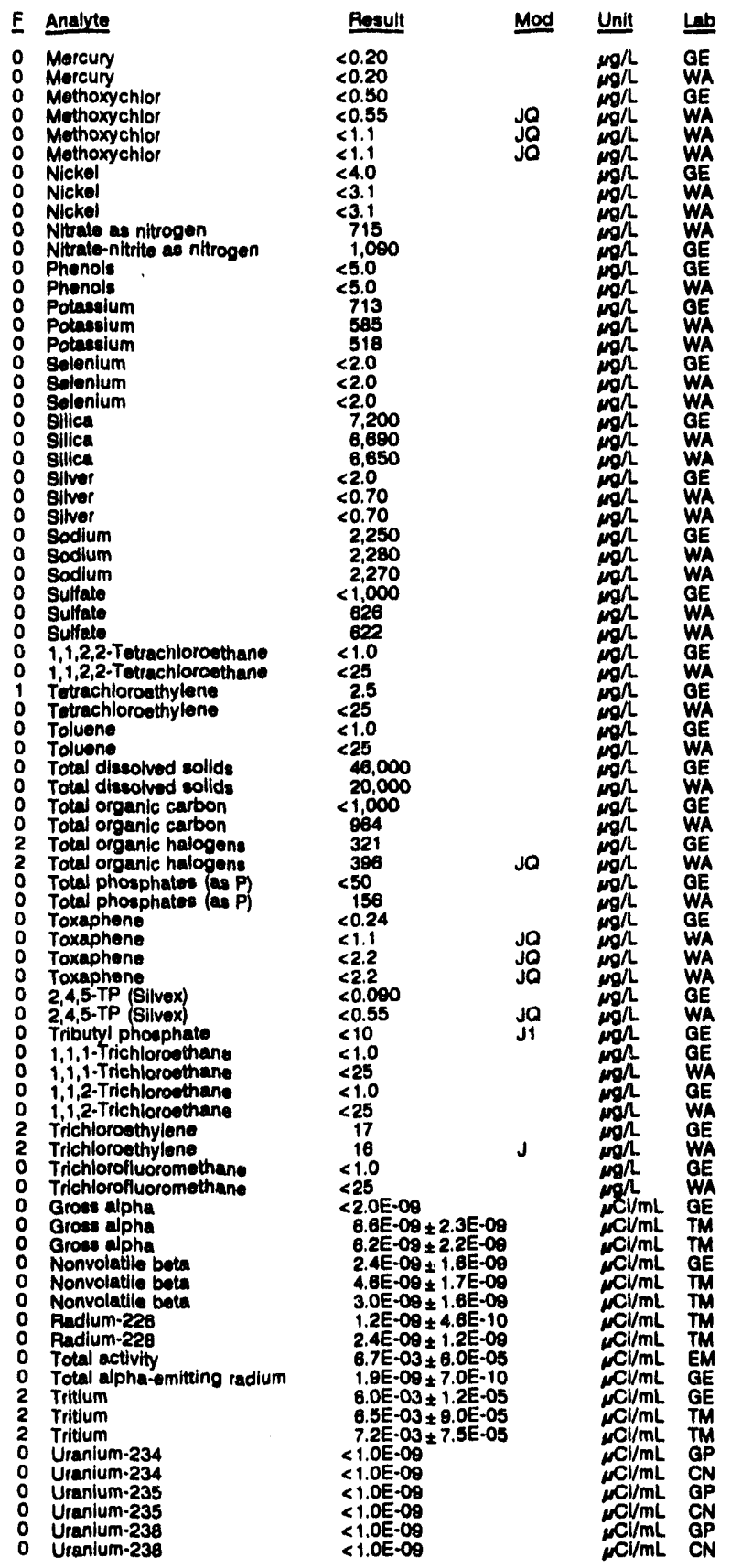

\section{WELL BGO 50D Replicate}

MEASUREMENTS CONOUCTED IN THE FIELD

\begin{tabular}{|c|c|c|c|c|c|}
\hline \multicolumn{3}{|c|}{$\begin{array}{l}\text { Sample date: } 08 / 14 / 92 \\
\text { Depth to water: } 30.41 \mathrm{ht}(9.27 \mathrm{~m}) \text { below TOC } \\
\text { Water elevation: } 225.59 \mathrm{~h}(68.76 \mathrm{~m}) \mathrm{msl} \\
\text { Sp. conductance: } 70 \mu \mathrm{s} / \mathrm{cm} \\
\text { Water ovacuatod bofore sampling: } 47 \mathrm{gal}\end{array}$} & \multicolumn{3}{|c|}{$\begin{array}{l}\text { Time: } 8: 35 \\
\text { pH: } 6.2 \\
\text { Alkalinity: } 23 \mathrm{mg} / \mathrm{h} \\
\text { Water temperature: } 20.0^{\circ} \mathrm{C}\end{array}$} \\
\hline \multicolumn{6}{|c|}{ LABORATORY ANALYSES } \\
\hline F & Analyte & Result & Mod & Unit & Lob \\
\hline & $\begin{array}{l}\mathrm{pH} \\
\text { pH } \\
\text { Specific conductance }\end{array}$ & $\begin{array}{l}6.3 \\
6.2 \\
60\end{array}$ & JO & $\begin{array}{l}\mathrm{pH} \\
\mathrm{pH} \\
\mu \mathrm{S} / \mathrm{cin}\end{array}$ & $\begin{array}{l}\text { GE } \\
\text { WA } \\
\text { GE }\end{array}$ \\
\hline & Specific conductance & 62 & Jo & $\mathrm{s} / \mathrm{cm}$ & $\overline{\text { wa }}$ \\
\hline
\end{tabular}


ANALYTICAL RESULTS

WEUL BCO SOD collected on 02/14/A2, laboratory analyees (cont.)

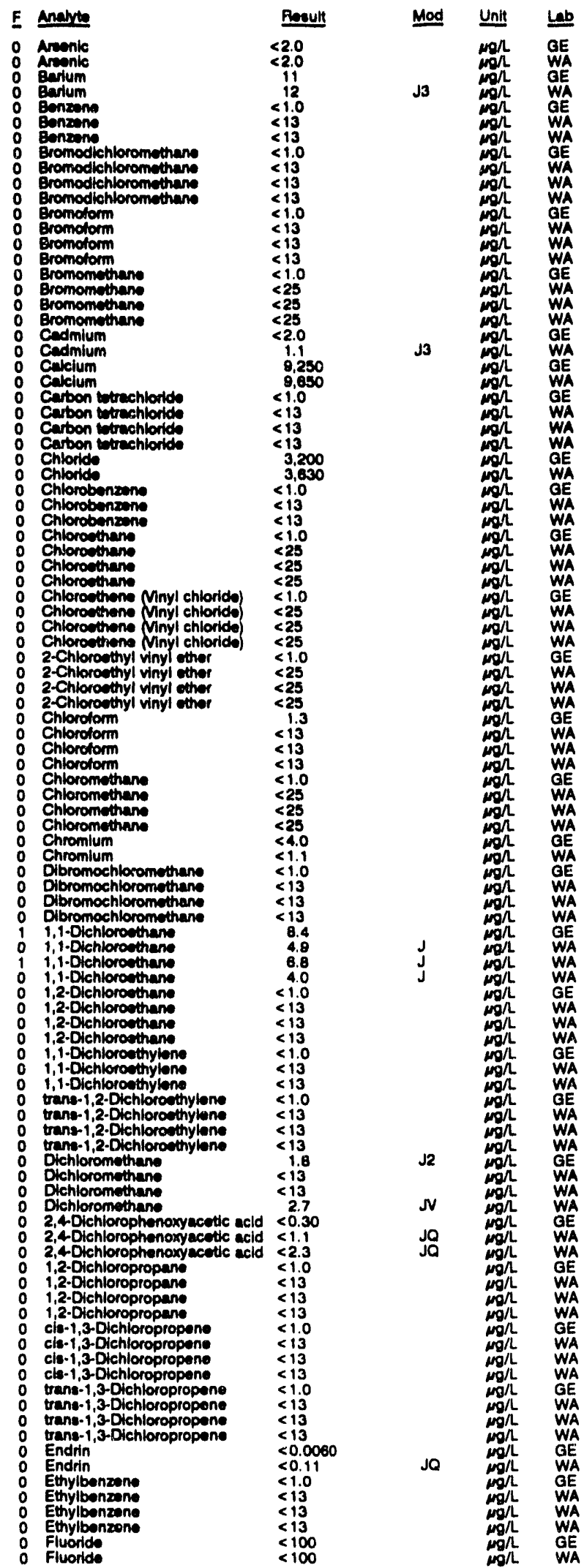

WELL BOO 50D collocted on 08/14/92, laboratory enalyees (cont.)

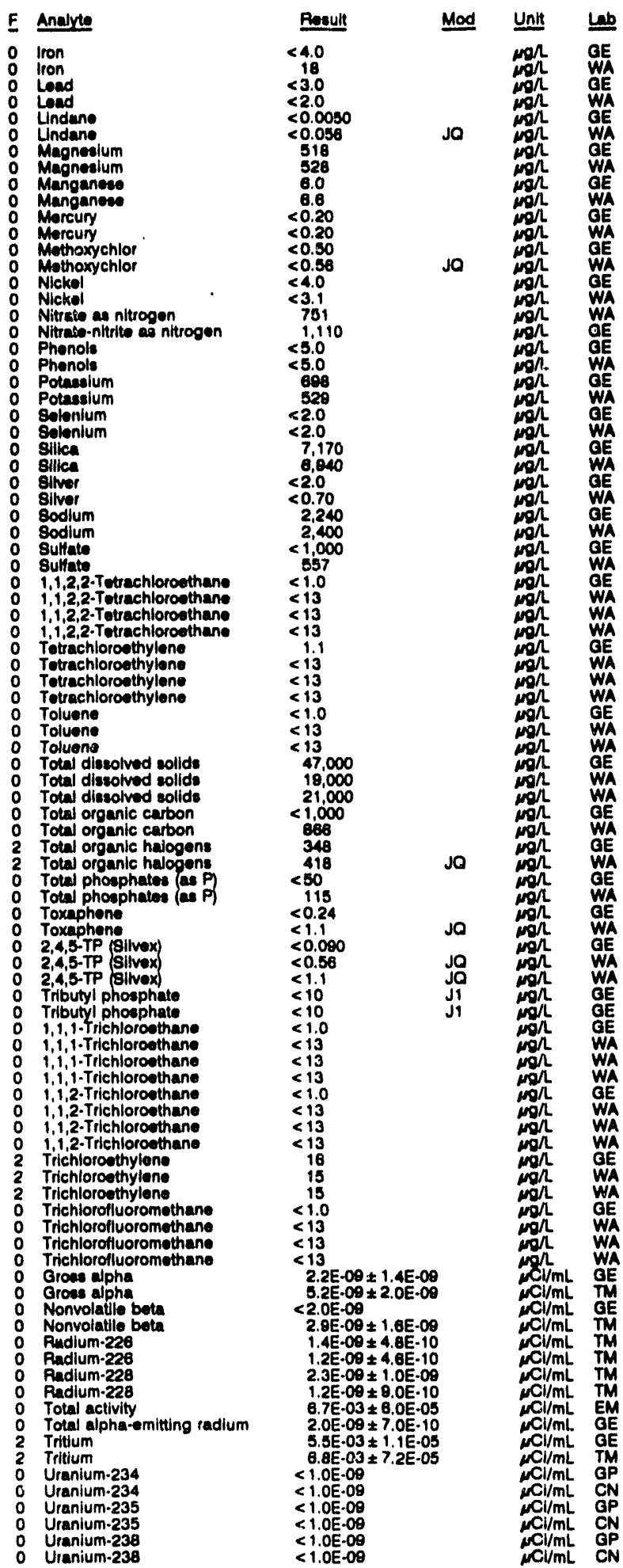


WELL BGX IA

MEASUREMENTS CONDUCTED IN THE FIELD

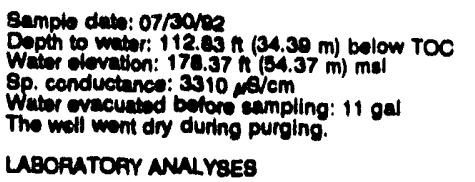

LABORATOAY ANALEES

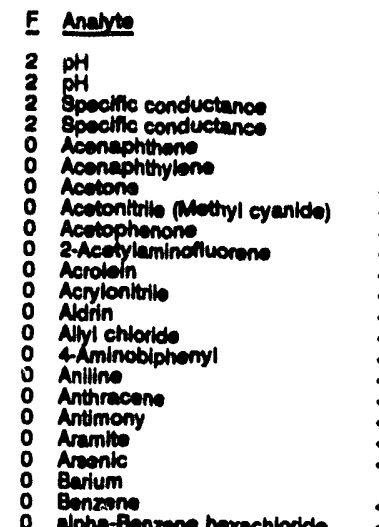

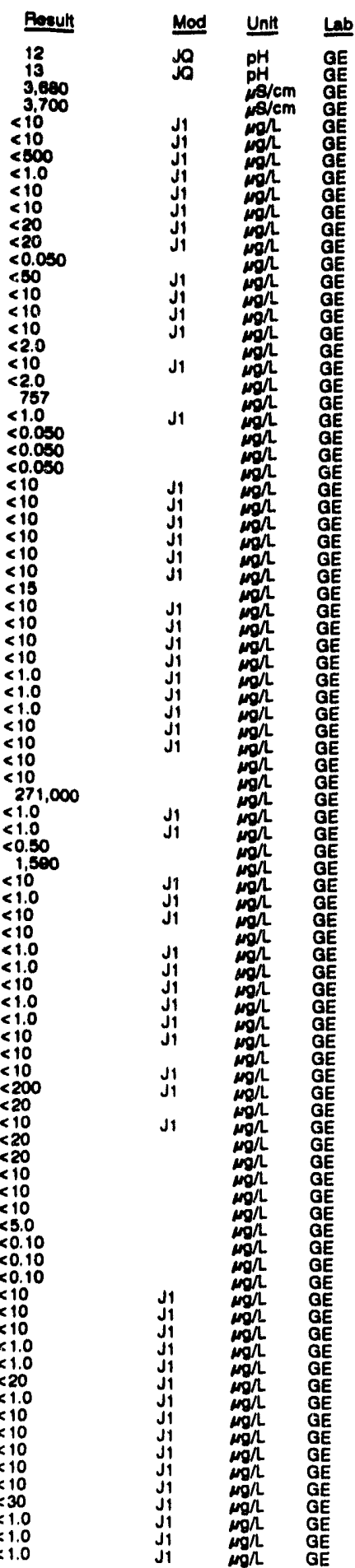

WELL BGX 1A colloctod on 07/30/82, laboratory analyeos (cont)

\section{E Analyte}

Time: $13: 10$

Althelinity: $878 \mathrm{mgh}$

Wator tomporature: $22.4^{\circ} \mathrm{C}$

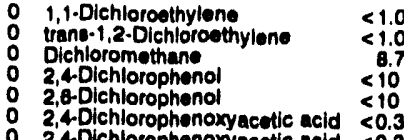

2,4Dichlorophonoxy acetic acid $<0.30$

o cie-1,3-Dichlopopropono <1.0

0 tans-1,3-Dichloropropene $<1.0$

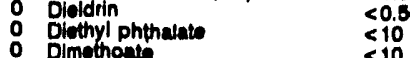

2,4-Dimethyl phonol

D.Dimothylaminacazobenzone

- Bimethylibenziajanthrecone

3,3'-Dimothylbonzidine

a a. Dimethylphenethylamine

$1,3-$ Onitrobonzone

2,40initrophenol

2.8-Dinitrotoluenono

Di-n-octyl phthwlats

1,40ioxane

- Diphonylam

Disulfoton

: Endosuttan 1

o Endosulfan sutfate

: Endout

: Endrin aldehydo

: Endrin aldehyde

E Ethyl mothanesulfonate

Ethylbonzone

0 Fluoranthene

0 Fluorente

Hoptechior

O Heptachlor epoxide

$1,2,3,4,6,7,8, H P C D D$

O Heptachlorodibonzo-p-dioxins

1 1,2,3,4,6,7,0-HPCOF

O Heptachlorodibenzo-p-fut

- Hexachlorobutedione

o Hexachlorocyclopentadiene

$1,2,3,4,7,8-\mathrm{H} \times \mathrm{CDD}$

$1,2,3,4,7,8-H X C D F$
0
0

Hexachlorodibanzo-pr

- Hoxachlorosthane

o Hoxachioropropene

2.Hoxanone

- indeno(1,2,3-c,d)pyrene

- lodomethano (Mothyl lodido)

Iron

boodin'

0 keophoron

troadrole

Kopon

Lindune

Magnealum

Mangan

Methecrylonitrile

Mothapyrilene

2-Muthyl-4,8-dinitrophenol

Mothyl ethyl ketone

Mothyl isobutyl ketone

Methyl methacrylate

Methyl methanesulfonate

3-Methylcholanthrene

2.Methyinaphthalene

Naphthalene

1.4 Naphthoquinone

1.Naphthylamine

2-Naphthylamino

Nltrato-nitrtito as nitrogon

2.Nitroanilin

4Ntuanilino

Nitrobenzeno

2.Nitropheno

4-Nitrophono

4Nitroquinolino-1-oxide

N-Nitrosodi-n-butylamin

$\mathrm{N}$-Nitrosodiethylamine

N-Nitrosodimethylaming

N-Nitrosodiphenylamine

N-Nitrosomethylothylamine

N-Nitrosomorphollne
N-Nitrosopiperidine
$<1.0$

8.7
10
10
.30
.30
10
1.0
1.0
0.80
10
10

$<10$
$<10$

$<10$

$<10$

$<10$

$<10$

$<10$

$<10$

$<10$

$<10$

$<0.10$

$<0.10$

$<0.0060$

$<0.10$

$<10$

$<1.0$

$<10$

$<10$

$<0.050$

$<0.050$

$<0.00095$

$<0.00045$

$<10$

$<10$

$<0.00045$

$<0.00045$

$<0.00040$

$<10$

$<10$

$<10$
$<1.0$
$<10$

$<10$
$<15$

$<15$

$<100$

$<10$

$<10$
$<10$

$<3.0$

$<0.0050$

16
$<10$

$<0.20$

$<50$

$<0.50$

$<10$
$<1.0$
$<1.0$

$<10$

$<10$
$<10$
$<10$

$<10$
$<10$

$<10$

$<20$
$<20$

160

$<160$
$<10$
$<10$

$<10$

$\leq 10$

$<10$
$<10$

$<10$
$<10$

$<10$

$<10$
$<10$

$<10$
$<10$

$<10$
$<10$
$<10$
Mod Unit Le

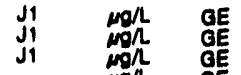

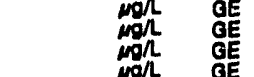

Ji

J1 $\operatorname{mon}_{\operatorname{mon}}^{\mathrm{ag}}$

Ji

J

J

J1

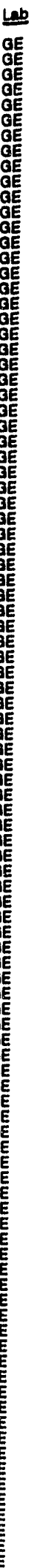


WEL $80 \times$ 1A collocted on 07/30/2, laboretory analyeee (cont.)

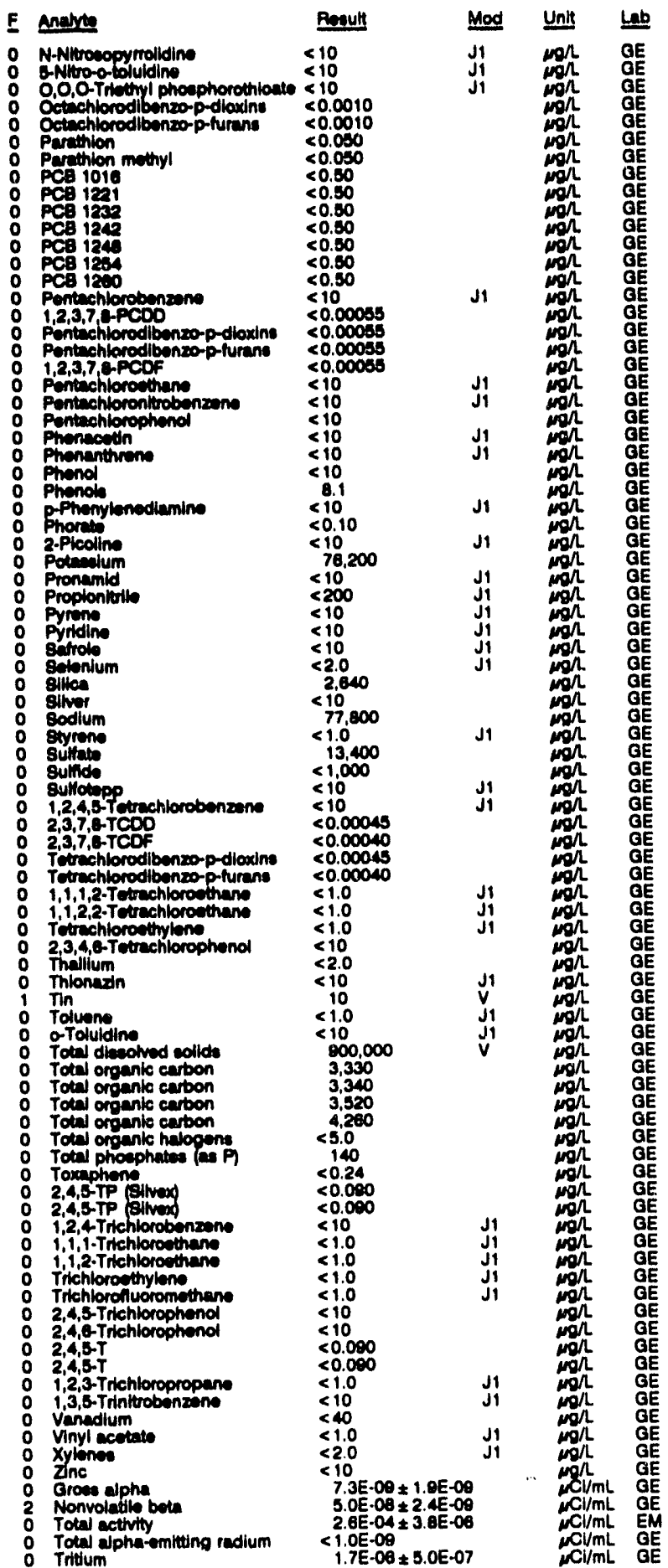

WELL BGX 1C

MEASUREMENTS CONDUCTED IN THE FIELD

\begin{tabular}{|c|c|}
\hline 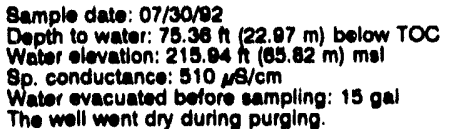 & $\begin{array}{l}\text { Tima: } 12: 45 \\
\text { pH: } 11.4 \\
\text { Alkalinity: } 171 \mathrm{mg} / \\
\text { Water tomperature: } 22.1^{\circ} \mathrm{C}\end{array}$ \\
\hline
\end{tabular}

The well went dry during purging.

LABOPUTOAY ANALYSES

\begin{tabular}{|c|}
\hline 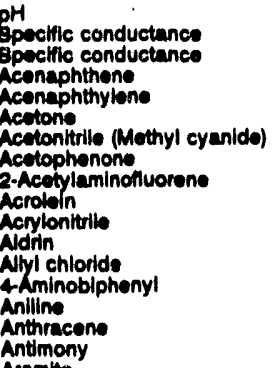 \\
\hline
\end{tabular}

A Antimony

o Arsonic

Barlum

Benzene

alpha-Bonzene hoxachlorido

beta-Bonzeno hexachloride

dolta-Benzene hoxzchlor

Eonzola anthracene.

Bonzo G fluoranthone

Benzo g, h,ljperyione

Bonzo dijpyrene

Bonzo a pyron

Bonzyl alcoh

Bily(2-chlorowthoxy) mothane

Bise-chlorothyn ethet

Bis (2-chloroleopropyl) ether

Bis (2-athylhexyl) phithalato

Bromodichloromethane

Bromotorm

Bromomethane

\&Bromophenyl phanyl ether

Butylbanzzyl phthalato
2-eec-Butyl-4,6-dinitrophenol

Cadmium

Carton disutido

Carbon tetrachloride

Chlordane

Chloride

LChlorouniline

Chlorobenzene

Chlorobanilite

para-Chloro-meta-creanl

Chloroethane

Chlorostheno Minyl chloride)

2-Chloroethyl vinyl ether

Chiorolorm

2-Chloronaphthalene

2-Chlorophenol

4-Chlorophenyl phenyl ather

Chropion

Chromium

Cobut

$\begin{array}{ll} & \text { Copper } \\ 0 & \text { o-Cresol (2-Mothylphenol) } \\ \text { m-Cresol (3-Mothy phenol) }\end{array}$

p-Cresol (4-Methylphonol)

Cyanida

P,P':DOD

Dibenz $\{a, h]$ anthracene

Dibenzofuran

Dibromochloromethane

1,2-Dibromo-3-chloropropane

1,2-Dibromosthane

Dibromomethane

1,2-Diehlorobenzene

1,3-Dichlorolienzene

1,4-Dichlorobenzene

tians-1,4-Dichloro-2-butene

trans-1,4-Dichloro-2.bute
Dichlorodifluoromethane

1,1-Dichloroethane

1,2-Dichlorosthane

\begin{tabular}{|c|c|}
\hline Ponult & Mod \\
\hline 120 & JO \\
\hline $\begin{array}{r}800 \\
<10 \\
<10\end{array}$ & J1 \\
\hline $\begin{array}{l}<10 \\
<100\end{array}$ & J1 \\
\hline & $\mathbf{J 1}_{1}$ \\
\hline $\begin{array}{l}<20 \\
<0.050 \\
<50\end{array}$ & \\
\hline $\begin{array}{l}10 \\
<10 \\
<10 \\
<10\end{array}$ & $\begin{array}{l}\text { J1 } \\
\text { J1 } \\
\text { J1 }\end{array}$ \\
\hline $\begin{array}{l}10 \\
10 \\
20\end{array}$ & $\mathbf{J 1}$ \\
\hline
\end{tabular}

Unit Leb

14

$<1.0$

$<0.050$

$<10$

$<10$

$<10$

$<10$

$<3.0$

$<10$

$<10$

$<1.0$

$<1.0$

$<10$
$<10$

$<10$

69,600

$<1.0$

$<0.50$

1,300
1.280

1,280
$<10$
$<1.0$

$<1.0$

$<10$

$<1.0$

$<1.0$

$<1.0$
$<10$

$<10$

$<10$
$<200$
$<4.0$

$<4.0$
$<10$

$<4.0$

$<10$

$<10$

$<10$

$<0.10$

$<0.10$

$<10$
$<10$

$<10$
$<1.0$
$<1.0$

$<20$

$<1.0$
$<10$
$<10$

$<10$

$<10$

$<10$

$<30$

$<1.0$
$<1.0$

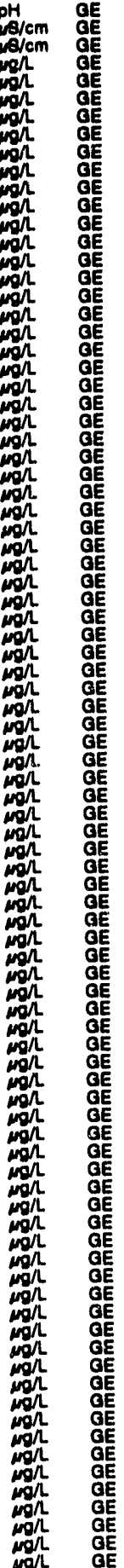


ANALYTICAL RESULTS

WELL BaX tC collected on 07/30/e2, laboratory analyees (cont)

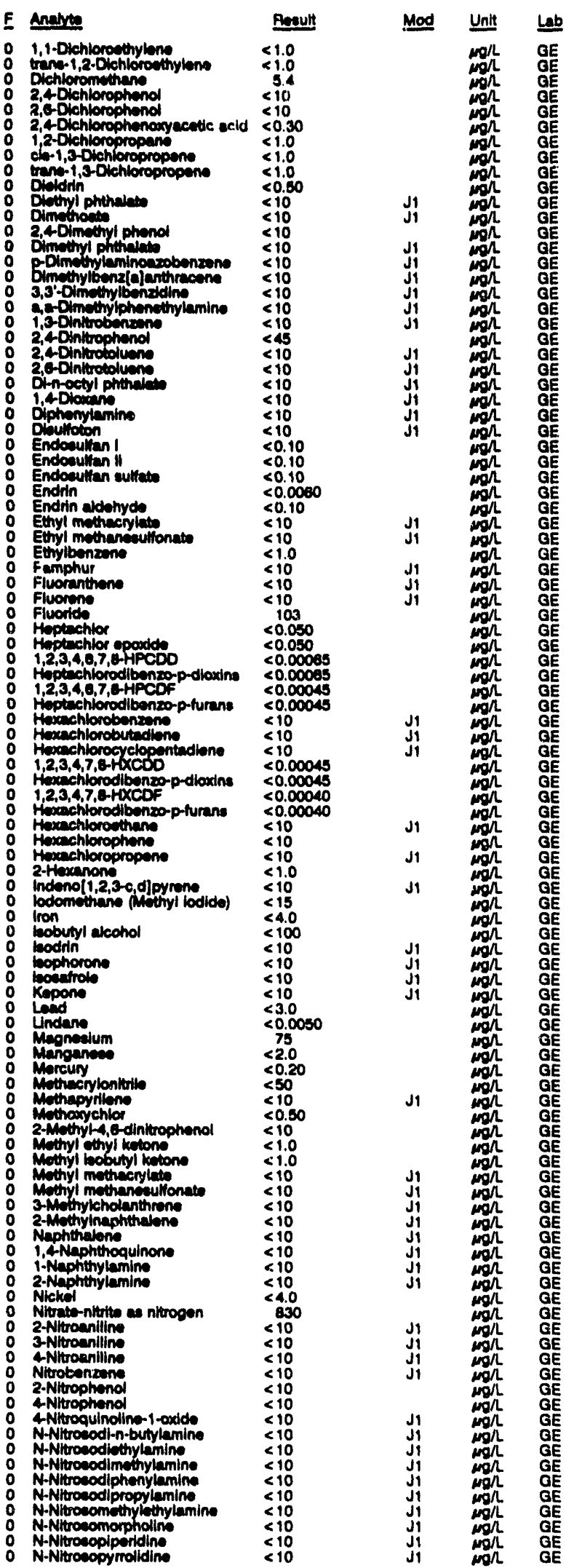

WELL BQX $1 \mathrm{C}$ collected on 07/30/92, laboratory analysese (cont.)

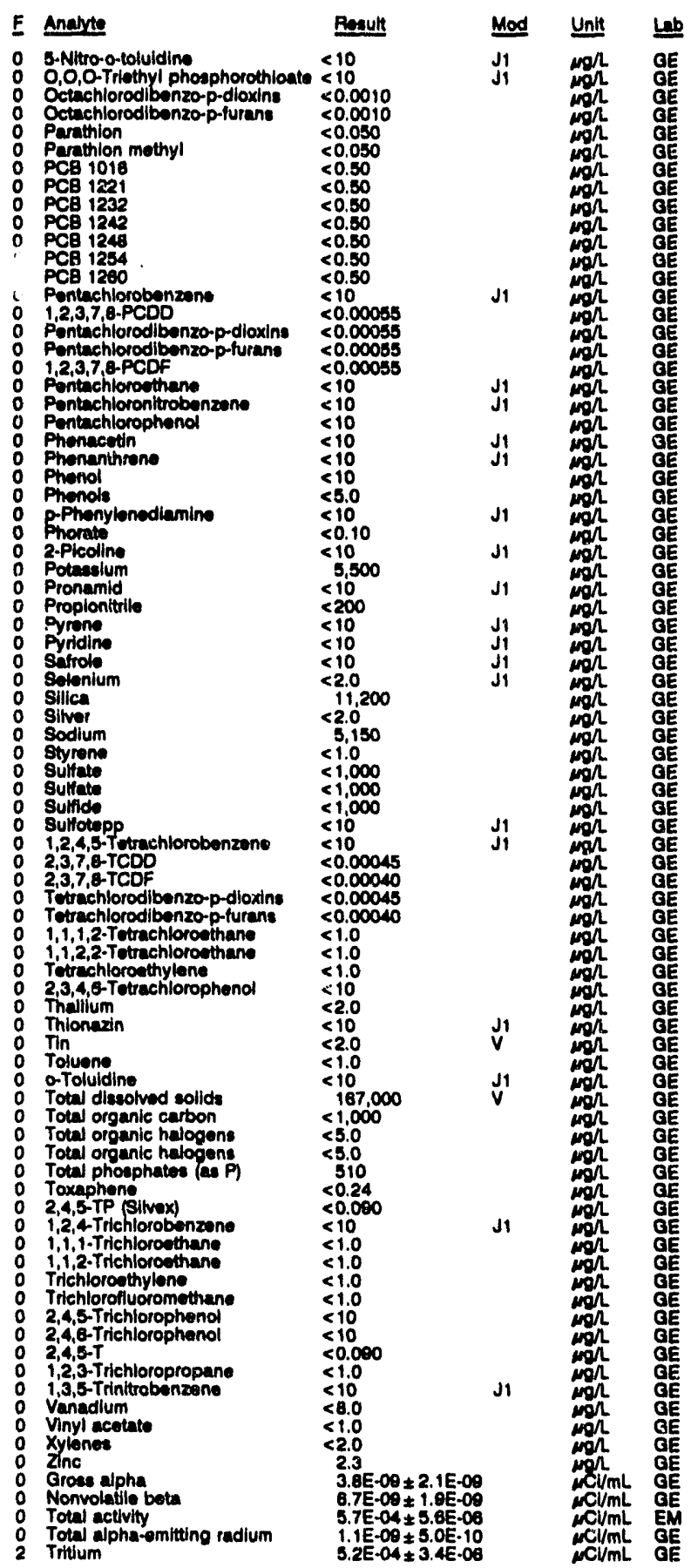




\section{WELL BQX 1D}

MEASUREMENTB CONOUCTED IN TME FIELD

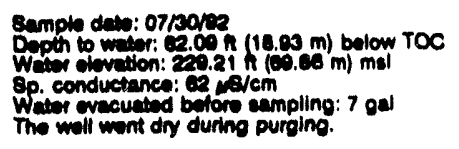

LABOPATOAY ANUL YBEES

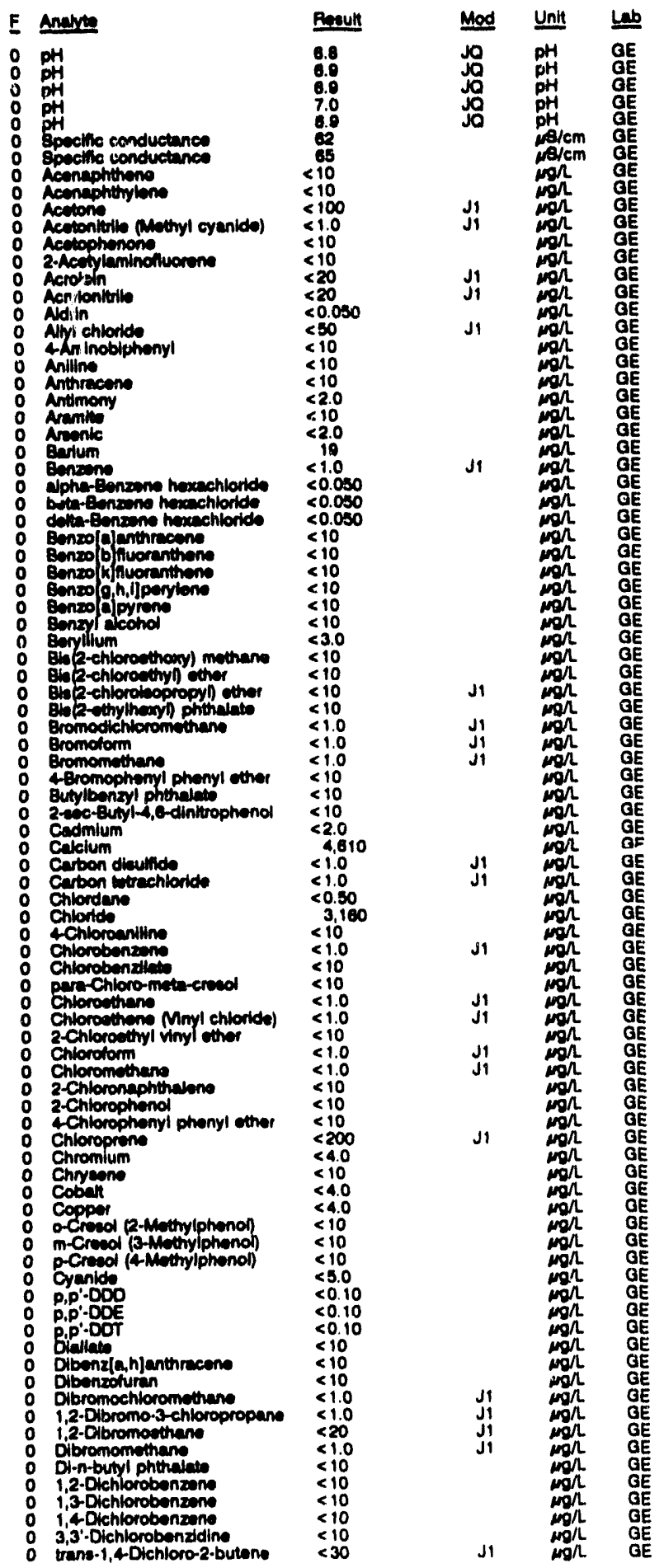

Time: $12: 15$
pH: 8.5
Alkalinity: 14 mgn
Water tomporature: $22.0^{\circ} \mathrm{C}$

WELL BOX 1D collected on 07/30/92, laboratory analyees (cont.)

E Anabce

Dichlorodifluoromothane

Amant

Mod
$J 1$
$J 1$
$J 1$
$J 1$
$J 1$
$J 1$

o 1,1-Dichloroethylone

o Dichloromethene

2,4-Oichlorophonol

2,6-Dichlorophenol $\quad<10$

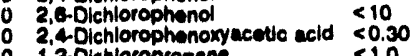

o 1,2-Dichloropropano

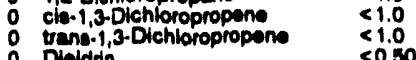

0 Dimethonto $>10$

2,401methyl phanol $<10$

p-Dimelhylaminoszobonzone

Bimethylbenz(a)anthracens

3,3'. Dimethylbanzidine

a a-Oimethylphonethy

1,3-Dinitrobenzane

2,4-Oinltuotoluna

2,e-Dintrotoluen

Di-n-octyl phthalate

Diphenylamin

Disulfoton

Endosulfan I

Endosulfan sulfate

Endrin

Endin slahydo

Ethyl mothanesulfonate

E Ethylbonzane

Fluoranthone

F Fluorene

Fluoride

Heptachior

1,2,3,4,6,7,8-HPCDD

1,2,3,4,6,7,6-HPCDF-doxin

Heptachlorodibanzo-

Hoxachlorobanzono

Hexechlorocyclopentedione

$1,2,3,4,7,6-H \times C D D$

Hoxnchiorodibenzo-p-dioxins

$1,2,3,4,7,8-H \times C D$

Hoxactilorodibonzo-p-furans

Hoxachloroethano

Hexachlorophente

Hexachloroprop

incieno(1,2,3-c.d) pyrene

lodomothane (Mothyl lodlde)

lion

leobutyl alcohol

bodin

cophorone

Kepone

0 Lad

Undane

Magnesium

Manganes

Methacrylonitrilo

Mothapystiene

2-Methyl-4,6-dinitrophenol

2.Mothyl-4, $0-d$

Mothyl ethyl ketone

Mothyl izobutyl keton

Mothyl mothaneaultonate

3-Methylcholanthrene

2.Mothylnaphthalene

Nephthalens

1,4.Naphthoquinone

1.Naphthylamine

2-Naphthylamine

0 Nickol

0 Nitrate-nitrite as nitrogen

o 2-Nitroanilline

3-Nitroanilline

ANitroaniline

N Nitrobenzene

2-Nitrophono

4Nitrophenol

-Nitroquinoline-1-oxide

N.Nitroesodi-n.bulylam

N.Nitrosodimethylamin

N-Nhtrosediphenylamine

O N.Nitrosodipropylamine
$<1.0$

$<1.0$

.

$<10$
$<10$

$<10$
$<10$
$<10$

$\leq \leq 10$

$<45$

$\leq 10$

$<10$

$\leq 10$

$<10$

$<0.10$

$<0.10$

$<0.10$

$\leq \leq 10$

$<1.0$

$<10$

$<10$

$<100$

$<0.050$

$<0.00065$

$<0.00046$

$<0.00040$

$<10$

$<0.00045$

$<0.00045$

$<0.00040$

$<10$
$<10$

$<10$

$<1.0$

$<10$
$<15$
$<40$

$<4.0$

$<100$

$<10$

$<10$
$<3.0$

$<3.0000$

851

$<0.20$

$<50$
$<10$

$<0.50$

$<10$

$<1.0$

$<10$

$<10$

$<10$

$<10$
$<10$

$<10$
$<10$

$\$ .8$
1,340

$<10$
$<10$

$<10$
$<10$
$<10$

$<10$

<10

$<10$

$<10$
$<10$

$<10$
$<10$

$<10$
$<10$

Unit

$\operatorname{mon}_{\operatorname{con}} \mathrm{GE}$

GE

oE

$\begin{array}{lll}\text { J1 } & \text { mon } \\ \text { J1 } & \text { GE } \\ \text { di } & \text { Ge }\end{array}$


ANALYTICAL RESULTS

WEUL BCX 10 colbetid on 07/30/82, laboratory analyees (cont)

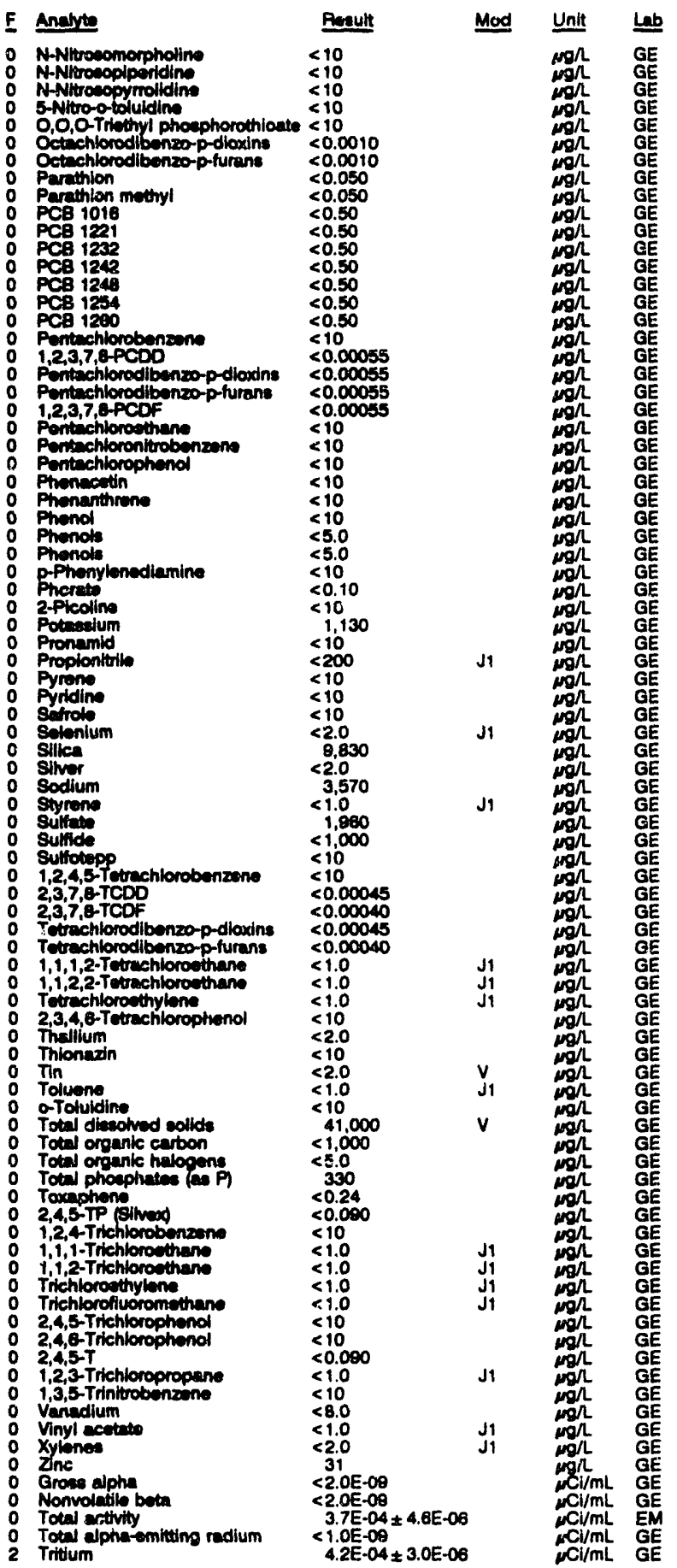

WELL BGX 2B

MEASUREMENTS CONDUCTED IN THE FIELO

Sample date: 07/30/82

Dopth to wator: $78.57 \mathrm{ht}(24.25 \mathrm{~m})$ below TOC Time: 13:35

Water slovation: $211.73 \mathrm{~h}(84.54 \mathrm{~m}) \mathrm{msl}$ Alkalinity: $77 \mathrm{mg} / \mathrm{h}$

Sp. conductance: $212 \mu \mathrm{S} / \mathrm{cm}$ Water tomperature: $22.10^{\circ} \mathrm{C}$

The worl wacuatod bolore eampling: 48 gal

LABORATOAY ANALYSES

$E$ Anatyte

$\therefore$ pH

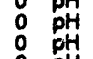

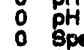

Specitic conductance

o Aconaphthenten

- Aconaph

Acetone

Acetophenone

2-Acetylaminofluorene

Acrotein

Acrylonitrile

Adrin

Allyin chlorid

A-Aminobipheny!

Aniline

Anthracene

: Antimony

- Arsenic

Aarium

(a)

alpha-Benzone hexachloride

apha-Benzento hoxachloride

beta-Bonzene hoxachloride

beta-Bonzente hoxachloride

dolta-Benzene hexachloride

Eonzo alanthracene

Eenzo b nuorantrenese

Bonzo ks Huoranthene

Eonzo g, h, lperyla

Benzil adicohol

Boryllium

Bhe (2-chloroethoxy) methane

Bie (2-ehloroethyl) ether

Bisz2-chlorolsopropyl) ether

Bise-chloryespropylt other

Bromodichloromethane

Bromolorm

Bromomethane

4-Bromophenyl phenyl ethor

2-ecc-Butyi-4, B-dinitrophenol

2-coc-Buty

cadmium

Carbon disulfido

Carbon tetrachloride

Chiordane

Chlordane

Chloride

Chlorobenzilate

para-Chloro-meta-cresel

Chloroethene Minyl chloride)

2-Chloroethyl vinyl ether

Chloroform

Chlormane $<1.0$

2-Chlorophenol

a-Chlorophenyl phenyl ether

Chloroprene

Chroritum

Chry resis

Cotar:

Coppar (2-Methylphenol)

m-Cresol (3-Methylphenol)

Cyanido

P,p'-DDD

P,P.DDE

P,P'-DDE

P.P.DDT

p.p'-DDT

Diallate $<10$

Dibenzofuran $\quad<10$

Dibromocinloromethane $<1.0$

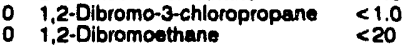

Mod
$j 0$
$j Q$
$j 0$
$j O$
$j O$

Unit Lab

$\begin{array}{ll}\mathrm{pH} & \mathrm{GE} \\ \mathrm{cH} & \mathrm{GE} \\ \mathrm{pH} & \mathrm{GE} \\ \mathrm{pH} & \mathrm{GE} \\ \mathrm{GH} & \mathrm{GE}\end{array}$ s/cm com $\operatorname{mogh}$ GE

10

$<2.0$

$<2.0$

$<0.050$

0.050

$<0.050$

$<10$

$<10$

$<10$

$<3.0$

$<10$

$<10$
$<1.0$
$<1.0$

$<1.0$

$<10$

$<10$
$<2.0$
16,000

$<1.0$

$<0.50$

2,080

$<1.0$

$<10$

1.0

1.0

1.0

$<10$

4.3
$<10$
$<4.0$

$<4.0$

$<10$

$<10$

$<10$
$<5.0$
$<0.10$

$<.10$

0.10

10
10

政

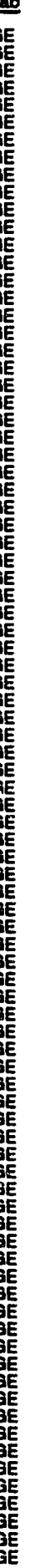


WELL BCX 28 collected on 07/30/92, laboratory analyees (cont)

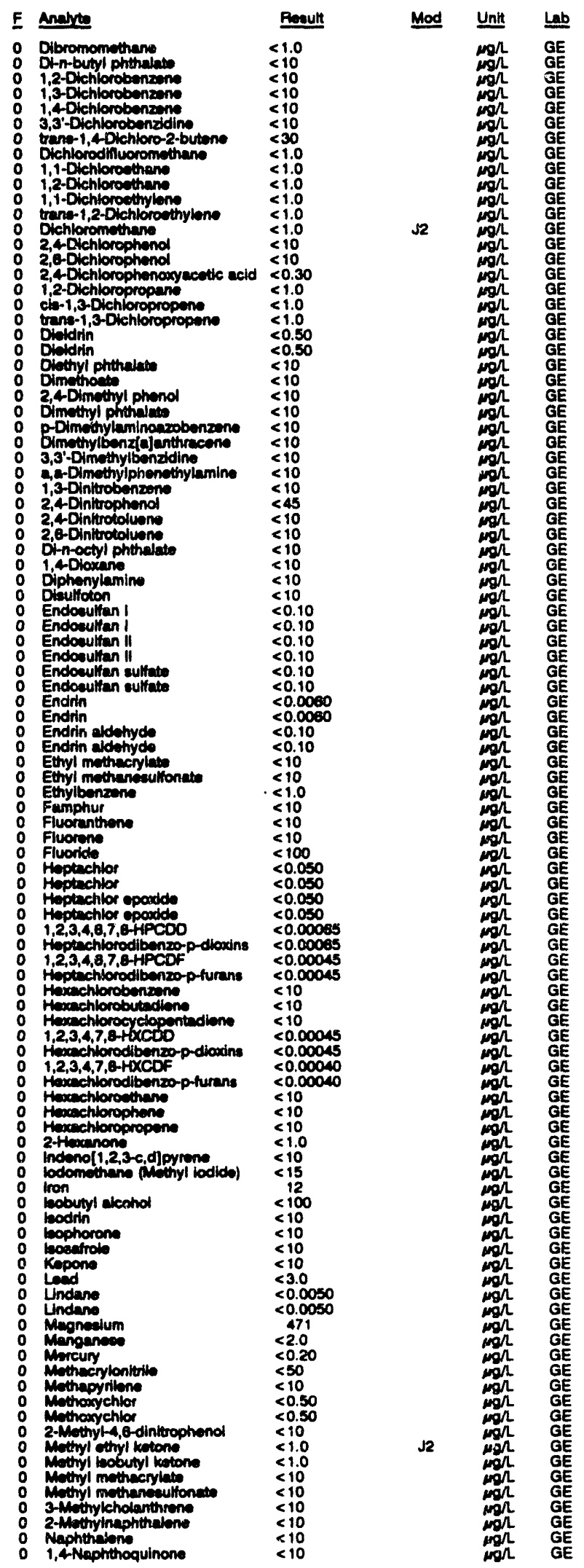

WELL BGX 28 collected on 07/30/92, laboratory analyses (cont.)

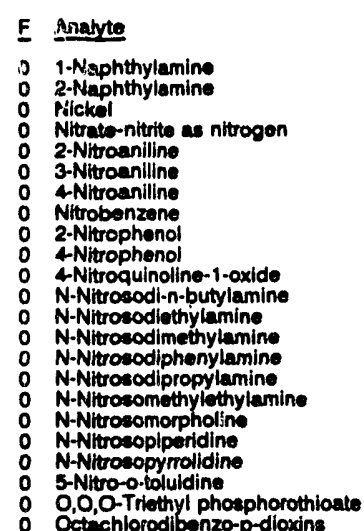

Result Mod Unit Lab

$<$

$<10$
$<10$
$<10$

$<4.0$

$<10$

$<10$

$<10$

$<10$

$<10$

$<10$

$<10$

$<10$

$<10$

$<10$

Octachlorodibenzo-p-diauns

Octechlorodibenzo-p-

Parathion

Parathion methyl

Parathion meth

PCE 1018

P PCB 1221

PCB 1221

PCB 1232

PCB 1242

PCB 1242

PCB 1248

PCB 1248

PCB 1254

PCB 1280

Pentechlorobenzane

1,2,3,7, \&-PCDD
Pentachlorodibenzo-p-dioxins

Pentach orodibonzo-p-dioxdn

$\uparrow, 2,3,7,8$-PCDF

Pentichioroethane
Pentachloronltrobenzens
Pentachlorophenol

Phenacetin

Phenant

Phinots

P-Phenylenediemine

Phornte

2-Picoline

P Potasivium

Propionititive

o Pyrene.

o Pyridine

Solonium

Sillien

o Sitver

0 Siyrene

Sulfate

0 Sulfide

Sulfobpp

2,3,7,8-TCDO

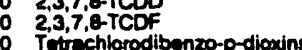

- Tetrachlorodibenzo-p-dioxins

o Tetrechlorodibenzo-p-tura

o 1, 1,2,2-Tetrachloroethan

o Tetrinchloroethylene

2,3,4,6-Tetrachlorophenor

o Thallium

0 Thion

T Tolvene

o-Toluidine

Total discolved solids

o Total organic carbon

Total organic carbon

o Total organic halogens

- Total phosph

- Toxaphen

o Toraphene

o 1,2,4-Trichlorobenzent

o 1,1,1-Trichioroethane

o 1,1,2-Trichloroethan

$<0.0010$
$<0.0010$

$<0.050$

$<0.050$

$<0.050$
$<0.050$

$<0.50$

$<0.50$

$<0.50$
$<0.50$
$<0.50$

$<0.50$

$<0.50$
$<0.50$

$<0.50$

$<0.50$
$<0.50$
$<0.50$
$<0.50$

$<0.50$

$\leq 0.50$

$<0.00055$

30.00053
50.0055
$<0.00055$

$<10$
$<10$

$<10$
$<10$

$<10$

$<10$

$<10$
$<5.0$
$<5.0$

$<5.0$

$<0.10$

$<10$
12,300

$<12,300$
$<200$

$<10$

$<10$
$<10$
$<2.0$
$<20.500$

$<.0$
20,500

$<2.0$

$<\begin{aligned} & 3.0 \\ & 3,340\end{aligned}$

$<1,000$

$<10$

$<0.00045$

$<0.00040$

$<0.00045$

$<1.0$

$<1.0$

$<1.0$
$<10$

$<2.0$

$<10$
$<2.0$

$<1.0$

146,000

1,060

1,230
$<1,000$
$<5.0$
290

200
$<0.24$

$<0.24$

$<0.000$

$<10$

$<1.0$

Mod Unit Le 
ANALYTICAL RESULTS

\begin{tabular}{|c|c|c|c|}
\hline Anayte & Besult & Mod & Unit \\
\hline 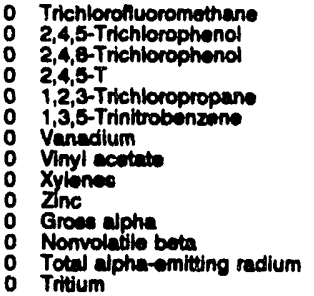 & $\begin{array}{l}<1.0 \\
<10 \\
<10 \\
<0.090 \\
<1.0 \\
<10 \\
<8.0 \\
<1.0 \\
<2.0 \\
<2.0 \\
<2.0 E-09 \\
<2.0 E-09 \\
<1.0 E-09 \\
3.5 E-00 \pm 4.0 E-07\end{array}$ & & 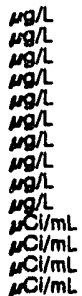 \\
\hline
\end{tabular}

WELL BGX 2D

MEASUREMENTS CONDUCTED IN THE FIELD

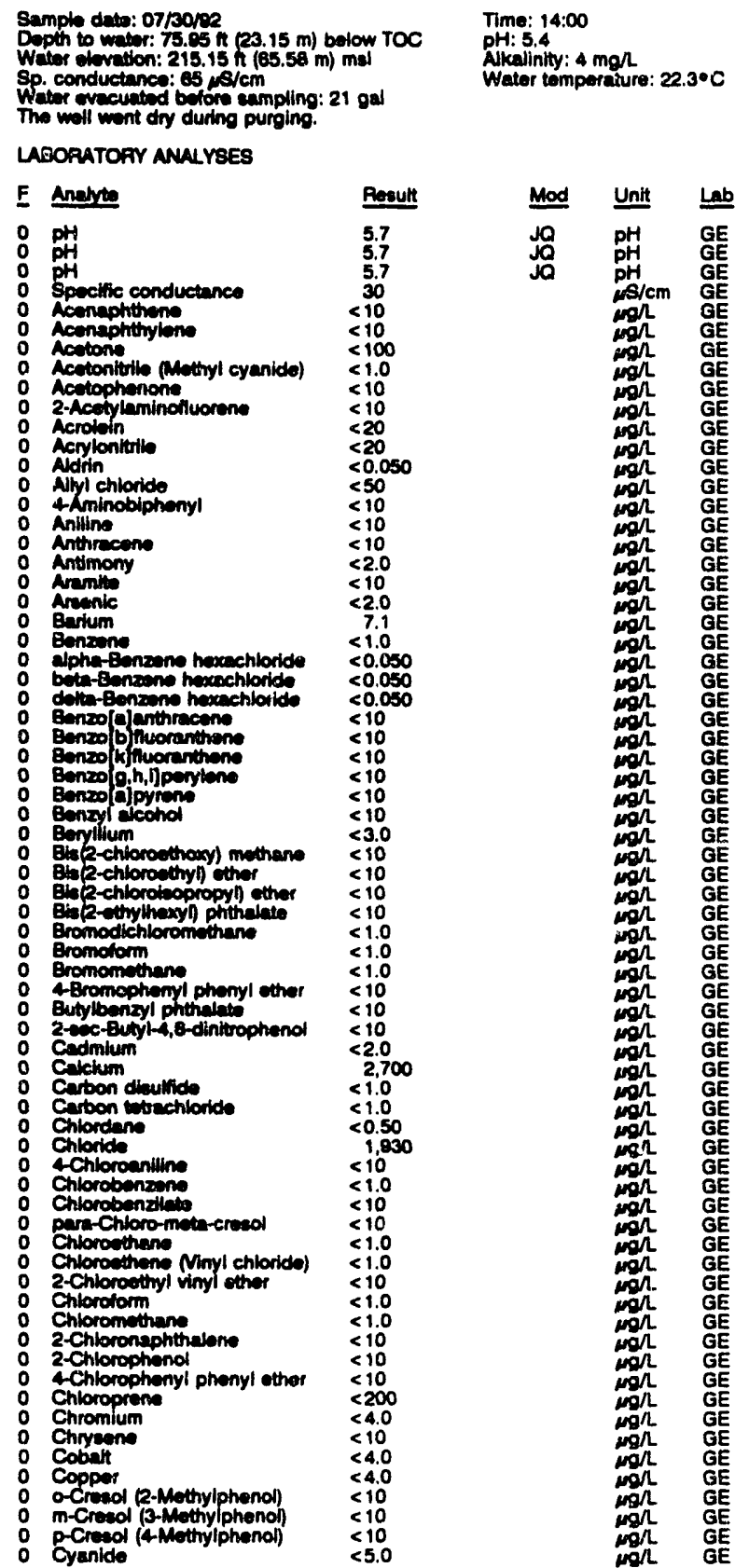

WELL BGX 2D collected on 07/30/92, laboratory analyeese (cont.)

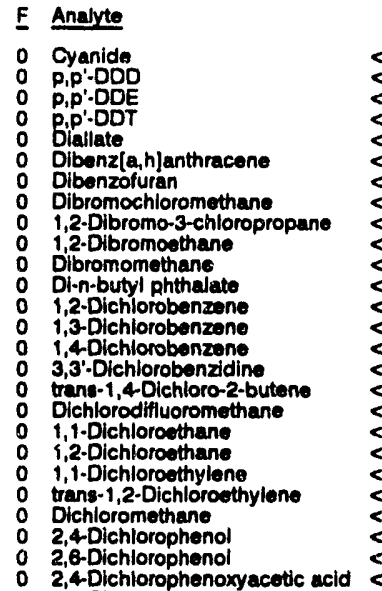

Result Mod

$<5.0$

$<0.10$

$<0.10$

$<10$

$<1.0$

$<1.0$

$<1.0$

$<10$

(1)

$<10$

$<1.0$

1.0

1.0

2,4-Dichlorophenoxyacetic acid

1,2-Dienloropropano

<is $<1.0$

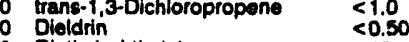

o Diethyl phthelate

o Dimethoate

2,4-Dimethyl phenol

0 Dimothyl phthalate

- p-Dimethylaminoezzobenzeno

3,3'-Dimethyllbenzidine

a. - Dimethylphenothylamine

1,3-Dinitrobenzono

2,4Dinitrophenol

$2,4-1 i n t r o t o l u e n e$
0

: 2, b-Dinitrotoluene

o 1,4-Dioxane

O Diphenylamine

O Disulfoton

- Endosultan II

- Endosulfan sulfate

0 Endrin

Endrin aldohydo

: Exthyl mothacrylate

O Emylbenzene

: Famphur

: Fluoranthen

F Fluorene

$\begin{array}{lll}0 & <100 \\ 0 & \text { Fluoflde } & <0.050 \\ 0 & \text { Heptachlor } & <0.050\end{array}$

- 1,2,3,4,6,7,8-1PCCDD$<<0.00005$

0 Hoptachlorodibenzo-p-dioxins $<0.00065$

Hoptachiojodibenzo-p-turans $<0.00045$

: Hexachlorobenzenene

- Hexachlorocyclopentadiene

$1,2,3,4,7,8-H \times C D D$

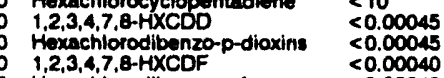

Hexactionedibenzo-p-turans $\quad<0.000040$

0 Hexachioroethengo-

- Hexachlorophene

Hexachloropene

2-Hexanone

Indeno[1,2,3-c,d]pyrene

lodom

Iron

teodin

bophorone

O Kopone

L Kepone

0 Lead

O Magnesium

Manganese

0 Mercury

Methacrylonitrile

Methapyrilene

Methoxychlor
0 2-Methyl-4,6-dinitrophenol

Methyl ethyl ketone

o Methyl isobutyl ketone

- Methyl methacrylate

o Methyl methanesulfonate

3-Mothylcholanthrene

2-Methyinaphthal

1,4-Naphthoquinone

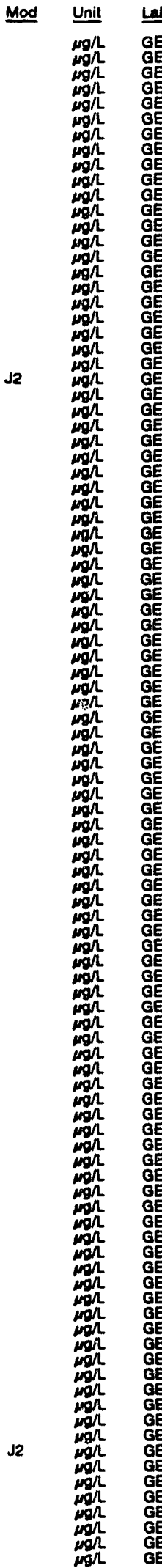


WELL BGX 20 collected on 07/30/82, laborusory analyses (cont)

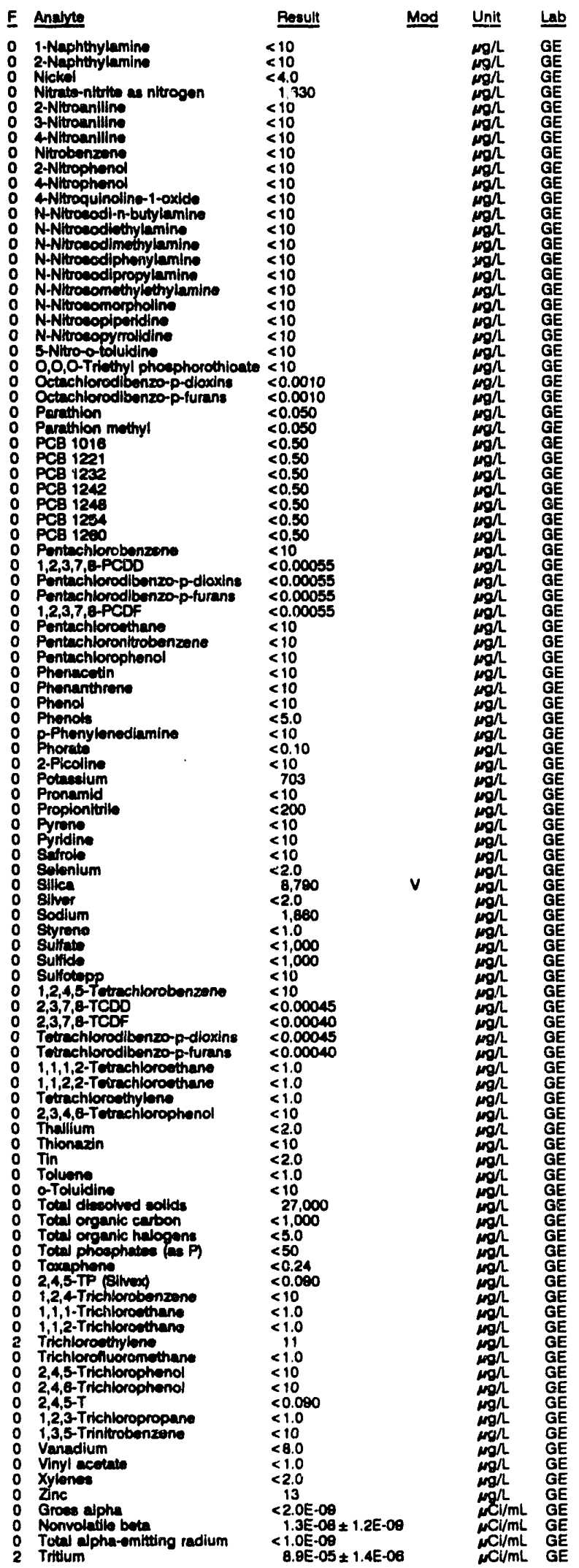

WELL BGX 3D

MEASUREMENTS CONDUCTED IN THE FIELD

Sample date: 07/31/92

Depth to water: $76.28 \mathrm{Ht}(23.25 \mathrm{~m})$ bolow TOC Water olevation: $214.92 \mathrm{H}(85.51 \mathrm{~m}) \mathrm{ms}$ Water evacuatod before eampling: $35 \mathrm{gal}$

LABORATORY ANALYSES

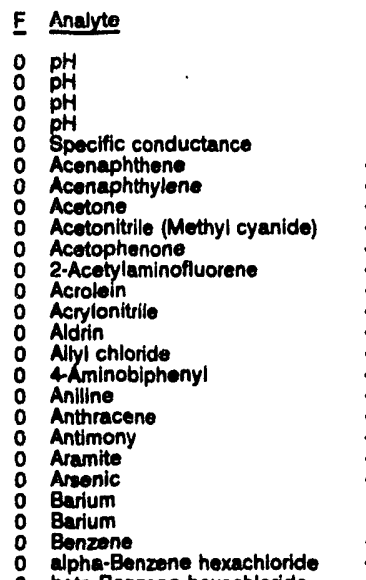

\begin{tabular}{l} 
Reoult \\
\hline 6.4 \\
8.5 \\
6.5 \\
6.6 \\
30
\end{tabular}

Time: 7:10

Alkalinity: $2 \mathrm{moll}$

Wikalinity: $2 \mathrm{mghl}$ : $20.3^{\circ} \mathrm{C}$ Whater tomporatu $20.3^{\circ} \mathrm{C}$

beta-Benzene hexachloride
dolte-Benzene hexachloride

Benzojajanthracene

Benzo k f fluoranthene

Benzo k fuorantiene

Benzolajpyrene

Benzyl alcohol

Boryllium

Bis (2-chloroethoxy) methane

Bis 2-chloropthyl) other

Bis (2-chloroisopropyl) ether

Bis (2-ethylhexyl) phthaiat

Bromotorm

4-Bromophenyl phenyl ether

4Eromophonyl phonyl ether

2-eoc-Butyl-4,6-dinitropheno

cadmium

Cadmiun

Calcium

Calcium

Carbon tetrachloride

Chlordane

Chioride

Chlorobenzene

Chlorobenzilate

para-Chloro-meta-cresol

Chlorosthane

Chloroethene Ninyl chloride)

2-Chloroethyil vinyl ether

Chloroform

Chloromethane

2-Chloronaphtha

2.Chlorophenol

Chloroprene

Chromlum

Chromium

Cobalt

Cobalt

Copper

a-Cresol (2-Methyiphenol)

m-Cresol (3-Methylphenol

p-Cresol (4-Methyiphenol)

Cyanide

P.p.ODE

Dip'-DDT

Dibenz[a, h]anthracene

Dibenzofuran

1,2-Dibromo-3-chloropropane

1,2-Dibromo-3-chloropropane $<1$

Dibromomethane

Di-n-butyl phthalate 
ANALYTICAL RESULTS

WELL 83X 30 collectod on 07/31/82, laboratory analyses (cont)

E Anabte

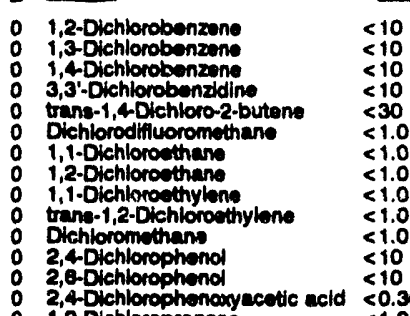

1,2-Dichloropropans

tran-1,3-Dichloropropene

Dinderín

Diethyl phthalete

2,4-Dimethyl phenol

D-Dimethylaminoazobenzene

3imethylbenzin]anthracane

a.Dimethyiphenethylamine

1,3 - Dinlthylphone

0 2,4-Dintrophenol

2,4-Dinitrotoluene

Dith-octyl phthelato

1,4-Oloxarne

Diphenylan

Endoution

Endoaultan II

Endosulfan sulfato

Endrin

Endrin aldehydo

Ethyl methanesulate

Ethylbenzene

Famphur

Fluoranthene

Fluorente

Heptachior

Heptachlor epoxide

Heptachlorodlbenzo-p--10xins

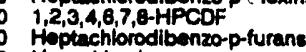

Hexachlorobenzens

Hexachlorocyclopentudiene

Hexachlorocyclopen

H Hoxachlorodilbenzo-p-dioxins

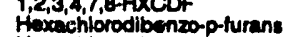

Hexachlorodibenze

Hexachlorophene

Hexachloroprope

indeno[1,2,3-c,d]pyrene

lodomethane (Muthyl iodide)

iron

bobutyl skcohol

leodrin

kophorone

Kepone

Lead

Undane.

Magnealim

Manganea

Mangani:

Mothecryloniturite

Methapyrilen

2-Methyl-4,6-dinitrophenol

Methyl ethyl ketone

Mothyl bobutyl keton

Methyl methangesulitonat

3-Methyicholanthrene

2-Methyinaphthelene

1,4-Naphthoquinone

1-Naphthylamine

Nicket

Nitrate-nitotite as nitrogen

2-Nitroseniline

4-Nitroenilin

Nitrobaninen
Besult

$<10$

$<10$
$<10$
$<10$

$<30$

$<1.0$

$<1.0$

$<1.0$

10

$<0.30$

$<1.0$

$<1.00$

$<0.50$
$<10$
$<10$
$<10$

$<<10$

$<10$

$<10$

$<10$

$<45$

$<10$

$<10$

$<10$
$<10$
$<10$

$<0.10$

$<0.10$

$<0.0060$

$<10$

$<1.0$

$<10$

$\leq 10$

$<0.050$

0.00065

$<0.00065$

$<0.00045$

$<10$

$<10$
$<10$

$<0.00045$

$<0.00045$

$<0.00040$

$<10$

$<10$
$<10$

$<1.0$

$<15$

4.3
$<4.0$
$<100$

$<100$

$<10$
$<10$
$<10$

$<10$
$<10$
4.1

4.1
$<0.0050$

744
747

35

$<0.20$

$<50$
$<10$
$<10$

$<0.50$

$<10$
$<1.0$

$<1.0$

510
$\leq 10$
$\leq 10$

$<10$
$<10$
$<10$

$<10$
$<10$
$<10$

$<10$
$<10$

4.8

1.120

$<10$

$<10$
$<10$
$<10$
Mod Un

JO6 $\mathrm{NOL}$ GE

$\mathrm{JOS}$
$\mathrm{JOS}$

$\mathrm{J}$
$\mathrm{j}$

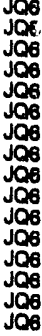

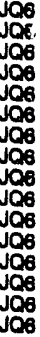

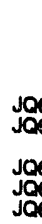

200

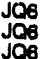

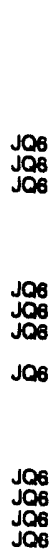

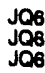

G

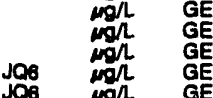

Jas

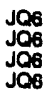

$\mathrm{J} Q 6$
$\mathrm{~J} 66$

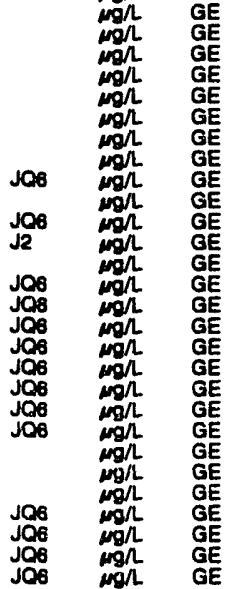

WELL BGX 3D collected on 07/31/82, laboratory analyees (cont.)

\begin{tabular}{|c|c|c|c|}
\hline$F$ & Analyte & Rosult & Mod \\
\hline $\begin{array}{l}0 \\
0 \\
0 \\
0 \\
0 \\
0 \\
0 \\
0 \\
0\end{array}$ & $\begin{array}{l}\text { 2-Nitrophenol } \\
\text { 4-Nitrophenol } \\
\text { 4-Nitroquinoline-1-oxide } \\
\text { N-Nitrosodi-n-butylamine } \\
\text { N-Nitrosodiethylamine } \\
\text { N-Nitrosodimethylamine } \\
\text { N-Nitrosodiphenylamine } \\
\text { N-Nitrosodipropylamine } \\
\text { N-Nitrosomethylethylamine } \\
\text { N-Nitrosomorpholine } \\
\text { N-Nitrosopiperidine } \\
\text { N-Nitrosopyrnolldine } \\
5 \text {-Nitro-o-toluldine } \\
\text { O,O,O-Triethyl phosphorothioate }\end{array}$ & $\begin{array}{l}<10 \\
<10 \\
<10 \\
<10 \\
<10 \\
<10 \\
<10 \\
<10 \\
<10 \\
<10 \\
<10 \\
<10 \\
<10 \\
<10\end{array}$ & 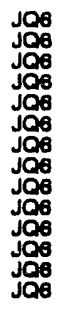 \\
\hline
\end{tabular}

O Octachlorodibenzo-p-dioxins

Octachlorodibenzo-p-furans $\quad<0.0010$

0 Parathion methyl $\quad<0.050$

O PCg 1016 <16 $<0.50$

O PCB 1242

O PCG 1248

P PCB 1254

o Pentachiorobenzene

Pentachlorodibenzo-p-dloxins

Pentachlorodibenzo-p-furans

1,2,3,7,6-PCDF

o Pentachloroethane

o Pentachlorophenol

Phenacetin

o Phenol

o Phenois

0 p-Phenylonediamin

o Phorate

Potasstum

o Pronamid

o Propionitrile

o Pyrene

0 Safrole

o Solenium

o Silica

o Sitica

o $\begin{array}{ll}0 & \text { Silver. } \\ 0 & \text { Sitver. }\end{array}$

Sodium

o Sodium

o Sulfate

0 Sulfide

o $1,2,4,5$-Tetrachiorobenzene

1,2,4,5-Tetrach

o $2,3,7,8$-TCDF

- Tetrachlorodibenzo-p-dioxins

- Tetrachlorodibenzo-p.furans

- 1,1,1,2-Tetrachloroethane

1,1,2,2-Tetrachloroeth

o 2,3,4,6-Totrachloropheno

Thailium

Tin

o Tin

Tolvene

O O-Toluidine

Total organic carbon

Total organic halogens

Total phosphates (as P)

Toxaphone

2,4,5-TP (Silvex)

1,2,4-Trichlorobenzene

1,1,1-Trichloroethane

1 Trichloroethylene

thane

2,4,5-Trichlorophen

$2,4,6-$

1,2,3-Trichloropropane

1,3,3-Trichloropropan

- Vanadium

0 Vinyl acetuto

Xylenes

Z Znc

O Zinc

Gross alpha

Nonvolabile beta

$<0.50$

$<0.50$

$<0.50$

$<0.50$

$<0.00055$

$<0.00055$

$<0.00055$

$<10$

$<10$

$<10$

$<10$

$<5.0$

$<10$

$<10$
812

586

$<<200$

$<<10$

$<10$
$<2.0$

8.570
8.580

$<2.0$

2.110
2,110

$<1.0$

$<1,000$

$<10$

$<0.00045$

$<0.00040$

$<0.00040$

$<1.0$

$<1.0$

$<10$

$<2.0$

$<10$

4.0
$<1.0$

$<5,000$
25,000

$<1,000$

$<50$

$<50$

$<0.24$

$<10$

$<1.0$

4.9

$<1.0$
$<10$

$<10$

$<1.0$

$<10$

$<8.0$

$<8.0$

$<2.0$

66

$<2.0 E-09$

$<2.0 E-09$
$<2.0 E-09$
$<2.0 E-09$

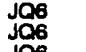

$\mathrm{J} 06$
$\mathrm{~J} 06$
$\mathrm{~J} 06$

J06
J06
J06
J1

J1

jog

Unit Lab

$\mu \mathrm{g} / \mathrm{L}$ GE

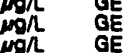

mon $\mathrm{GE}$

on GE

of

E

E 
WELL BGX 30 collected on 07/31/92, laboratory analyees (cont)

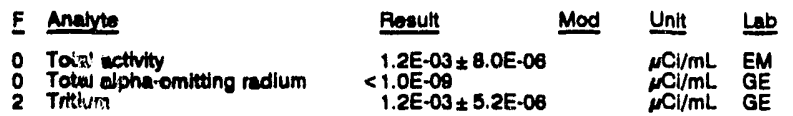

WELL BGX 4A

MEASUREMENTS CONDUCTEO IN THE FIELD

Sample date: 07/31/2e
Dopth to wation: $138.15 \mathrm{~h}(41.50 \mathrm{~m})$ bolow TOC
Water elevetion: $154.75 \mathrm{ft}(47.17 \mathrm{~m}) \mathrm{mal}$ Wetier elvevation: $154.75 \mathrm{ft}(47.17 \mathrm{~m}) \mathrm{msl}$ Water ovecuatiod bofore rampling: $126 \mathrm{gal}$ LABORATORY ANALYSES

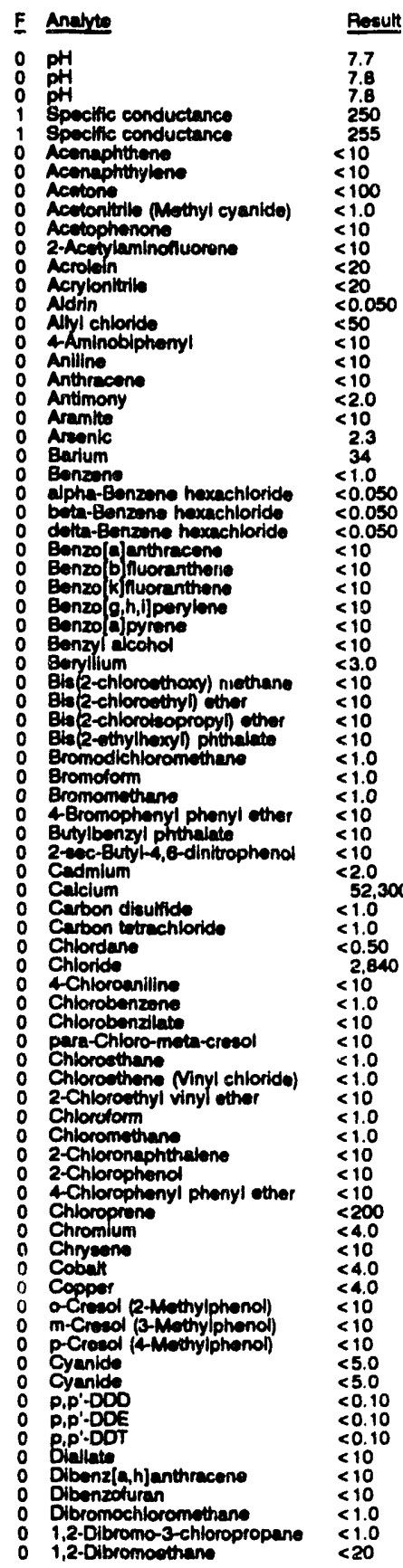

Time: 15:50

PH: 7.3 . $150 \mathrm{mgh}$ Whalinity: $150 \mathrm{mghl}$. $220^{\circ} \mathrm{C}$

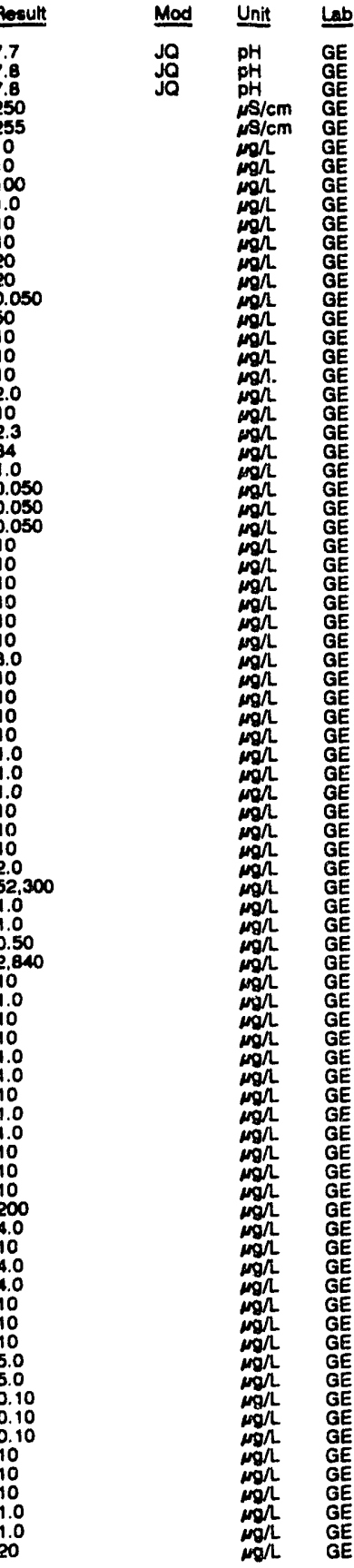

WELL BGX 4A collected on 07/31/92, laboratory analyses (cont)

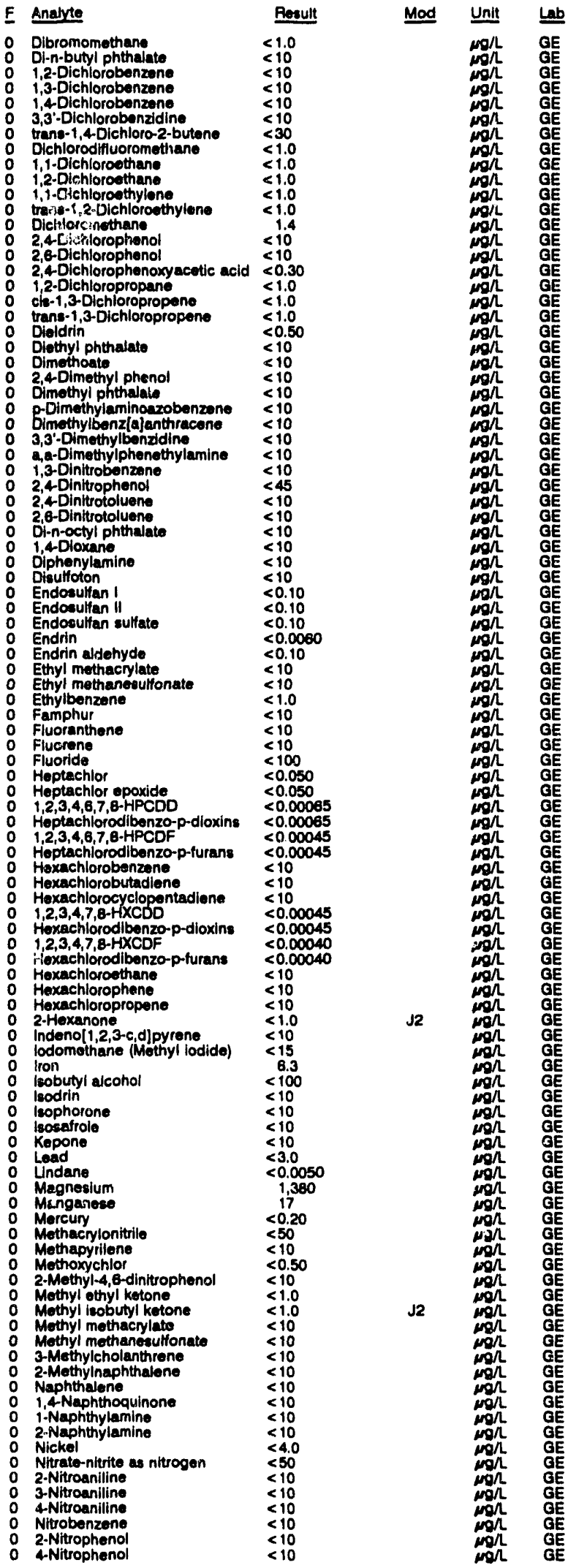


ANALYTICAL RESULTS

WELL BCX 4 collected on 07/31/02, laboratory analyses (cont)

E Anatyte

o Anitroquinoline-1-oxide

N-Nitrocodil-n-butylamine

N-Nitroeodiethylamine

: N-Nitrocodimediphylamine

N N-Nitrocodiphropylaminine

N-Nitrosomethyllothy lamine

- N-Nitrocoopipophidine

O N-Nitroeopy rollidine

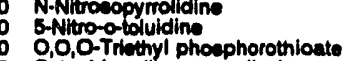

octechlorodibonzo-p-dioxins

$\begin{array}{lll} & \\ 0 & \text { Oetachlorodibonzo-p-turans } & <0.0010 \\ & <0.050 \\ 0 & <0.050\end{array}$

$\begin{array}{ll}0 & <0.050 \\ 0 & <0.050\end{array}$

- PCA 1018

: $P C B 1221$

: PCE 124

PCB 1234

- PCB 1200

- Pentechiorodibenzo-p-dioxins

- Pontechlorodlbonzo-p-turans

1,2,3,7,8-PCDF

o Pentachioroofthano

: Pontachlorontitrobenzing

o Phenacetin

o Phonol

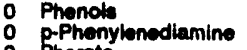

2.Picollina

Potanalum

o Proploniturive

o Pyrence

: syndiolo

o Solentum

S Silica

sodium

: Styrem

: Sulfatio

Sulfotepp

: 1,2,4,5-Tetrach

: $2,3,7$, , TCDD

o Totrachlorodibenzo-p-dloxins

- Tetrachlorodibonzo-p-furans

o 1,1,1,2-Tetrachlorosthane

1,1,2,2-Tetrachloroeth

o 2,3,4,6-Tetrechloropheno

: Thallium

in

o o-Toluidine

Total discoived colide

: Total orgenic carbon

- Total organic hajogens

- Total phosphates fae P P

: Total phouph

: Toxaphong

- 1,2,4 Trichlorobenzene

o 1,1,1-Tichloroethane

o $1,1,2-T$-Tichlorom the

o Trichloroethylene

Thentoronuoromothen

2,4,5-Trichlorophenol

\begin{tabular}{ll}
0 & $2,4,6-T$ \\
0 & $2,4,5-T$ \\
\hline
\end{tabular}

o 1,2,3-Trichloropropune

- 1,3,5-Trinitrobenzene

o Vanadium

O Vinyl acolate

o Xylonces

o Groes alphe

o Groes alpha

- Nonvolatile beta

- Total alphe-miting redium

O Tritium

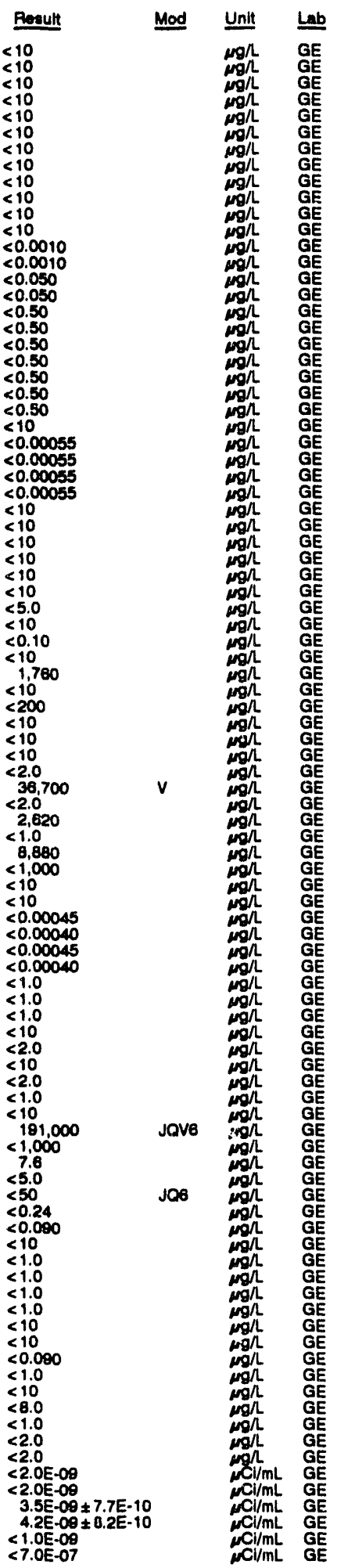

\section{WELL BGX 4C}

MEASUREMENTS CONDUCTED IN THE FIELD

Sample date: 07/31/82

Depth to water: 78.12 ft $(23.20 \mathrm{~m})$ bolow TOC

Water elevation: $214.68 \mathrm{ft}(\mathrm{Es} .4$

Sp. conductance: $95 \mu \mathrm{s} / \mathrm{cm}$

Water evacuated before sampling: $115 \mathrm{gal}$

Time: 16:15

pH: 8.4

$35 \mathrm{mg} / \mathrm{L}$

LABORATOAY ANALYSES

$E$ Anabte

$0 \mathrm{pH}$

$0 \mathrm{pH}$

Specific conductance

- Acenaphthone

O Acenaph hith

Acetonitrile (Methyl cyanide)

Acotophenone
2-Acotylaminofluorene

Acrolén

Acylonitrilo

Aldrin chlorido

4 Aminobipheny

Aniline

Anthracone

Aramite

Aranine

Arsenic

Benzone

alpha-Benzene hexachloride

beta-Benzene hexachloride

delta-Benzene hexachlorido

Benzola anthracesono

Benzo

Bonzo k) fuoranthene

Bonzog,

Benzyl aicohol

Beryllum

Bis 2-2hloroothy) athor

Bis (2- hylhoxyl) ght

Bromodichloromethane

Bromoform

4.Bromophenyl phenyl ethor

Butylbonzyl phthalate

2-soc-Buty

Calcium

Carbon disulfide

Carbon tetrachloride

Chlordane

4Chloroantino

Chlorobenzene

para-Chloro-mota-cresol

Chloroethene Minyl chloride) 2.Chloroethyl vinyl ether

Chloroform

Chioromethan

2-Chloronaphth

2-Chlorophenol
AChlorophenyl phenyl ether

Chloropreno

Chromium

Chrysent

Copper

o-Cresol (2-Methylphonol)

m-Cresol (3-Methylphenol)

Cyanide

0 P.P.ODD

P,P-DDE

P,P.DDT

a.h]anthracene

Dibenzofuran

Dibromochloromethane

1,2-Dibromo-3-chloropropane

1,2-Dibromoethan

Oibromomothane

Di-n-butyl phthalate

1,3-Dichlorobenzene

1,4-Oichlorobenzene

trans-1,4-Dichloro-2-buten

Dichlorodifluoromethene

1,1 .
37

7.1
7.1
7.1
90
$<10$
$<10$
$<100$
$<1.0$
$<10$
$<10$
$<20$
$<20$
$<2050$
$<10$

$<0.050$

$<10$

$<10$

$<2.0$

$<2.0$

$<0.050$

$<0.050$

$<10$

$<10$

$<10$
$<10$

$<10$

$<3.0$
$<10$

$<10$

$<10$

$<1.0$

$<1.0$

$<10$

$<2.0$

$<1.0$

$<1.0$

$<.50$
2,380

$<10$

$<1.0$
$<10$
$<10$

$<10$

$<1.0$

$<10$

$<1.0$

$<10$

$<10$

$<200$

$<10$

$<4.0$

$<10$
$<10$

$<10$

$<0.10$

$<0.10$

$<10$

$<10$

$<1.0$

$<20$

$<1.0$

$<10$

$<10$

$\leq 10$

$<10$
$<30$

$<1.0$ 
WELL BOX 4 collected on 07/31/82, laboratory analyese (cont)

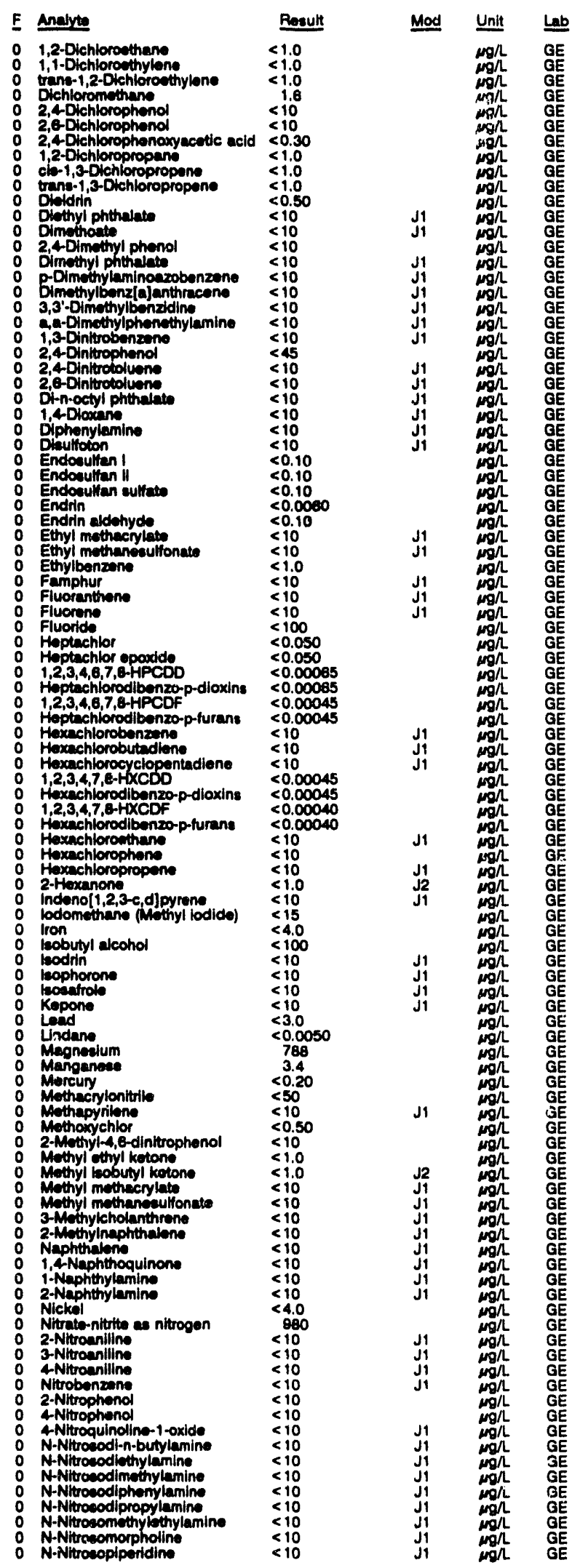

WELL BGX $4 \mathrm{C}$ collected on 07/31/92, laboratory analyees (cont.)

E Analyte Reault Mod Unit Lab

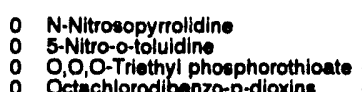

Octachlorodibenzo-p-dioxins $\quad<0.0010$
0 Octachlorodibenzo-p-fureng

$\begin{array}{ll}\text { O Octachlorodibenzo-p-furans } & <0.0010 \\ \text { P Parathion } & <0.050\end{array}$

0 Parathion mothyl $<0.050$

O PCB 1018

O PCB 1221

O PCB 1242

O PCB 1248

P PB 1260 < $<0.50$

o $1,2,3,7,8 \cdot P C D D$

- Pentachlorodibenzo-p-dioxins $\quad<0.00055$

o Pentachlorodibenzo-p-furans $<0.00055$

$01,2,3,7,8 \cdot P C D F \quad<0.0005$

0 Pentachloroethane $<10$

o Pentachloronitrobenzene

o Pentachlorophenol

Phenacetin

o Phonanthror

Phenol

$\begin{array}{ll}0 & \text { Phenols } \\ 0 & \text { P-Phenylenediamine } \\ 0 & \text { Phorate }\end{array}$

2.Picoline

0 Potasilum

Pronamid

o Proplonitrilo

0 Pyrene

O Safrole

O Solenium

0 Silica

O Silver

Styrene

Sulfate

o $\begin{array}{ll}\text { Sulfide } \\ \text { Sulfotepp }\end{array}$

1,2,4,5-Tetrachlorobenzene

$\begin{array}{lll}0 & 2,3,7,8-T C D D & <0.00045 \\ 0 & 2,3,7,8-T C D F & <0.00040\end{array}$

Totrachlorodibenzo-p-dioxins $<0.00045$

1,1, Totrachloro-p-furans

1,1,2-Totrachloroethane

Tetrachloroethylene

o 2,3,4,6-Tetrachlorophenol

0 Thallium

o Thionarin

o Toluene

o o-Toluidine

Total dissolved solids

Total organic carbon

- Total orgenlc halogens

Toxaphene

o 1,2,4-Trichlorobenzene

1,1,1-Trichloroethane

1,1,2-Trichloroethane

Trichloroethylene

Trichlorofluoromethane

2,4,5-Trichlorophenol

2,4,6-T

1,2,3-Trichloropropane

1,3,5-Trinitrobenzene

Vanadium

Vinyl acot

Xylones

Gross alpha

Nonvolatil bata

Total alpha-enilting radium

$<0.00040$

$<1.0$

$<1.0$

$<10$

$<2.0$

$<10$

$<1.0$

$<10$
62,000

$<1,000$

$<5.0$

$<50$

$<0.24$

$<0.090$
$<1.0$

$<1.0$

2.2
$<1.0$

$<1.0$
$<10$

$<10$

$<0.090$
$<1.0$

$<10$

$<8.0$

$<2.0$

$<2.06 .09$

$<2.0 \mathrm{E}-09$

$<\begin{aligned} & <.0 E-09 \\ & 3.5 E-06\end{aligned}$ × 4.0E-07 
ANALYTICAL RESULTS

WELL BGX 4D

MEASUREMENTS CONDUCTED IN THE FIELD

Sample date: 07/31/02

Depth to weter: $75.01 \mathrm{tt}(22.88 \mathrm{~m})$ bolow TOC

Sp. conductance: $37 \mathrm{~s} / \mathrm{cm}$

Water evecunted before sampling: $32 \mathrm{gal}$

LABOFATOFY ANALYSES

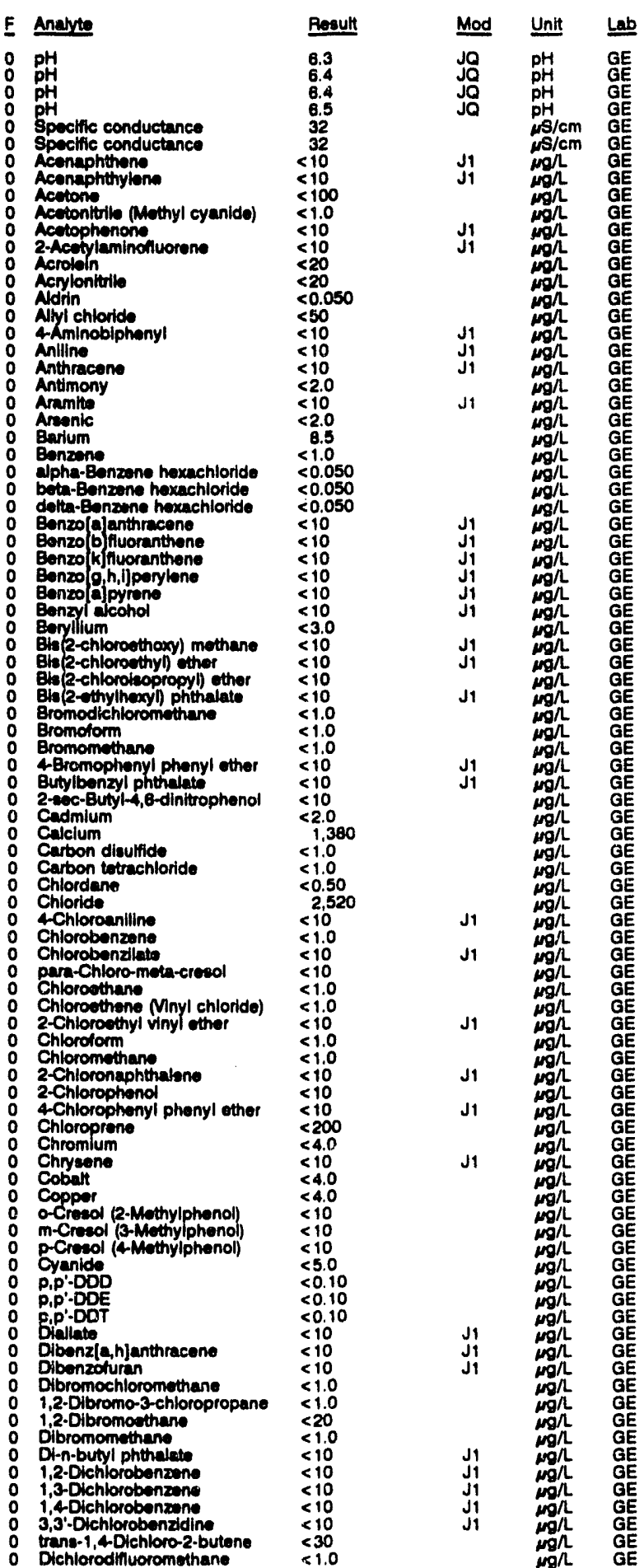

WELL BGX 40 collected on 07/31/82, laboratory analyses (cont.)

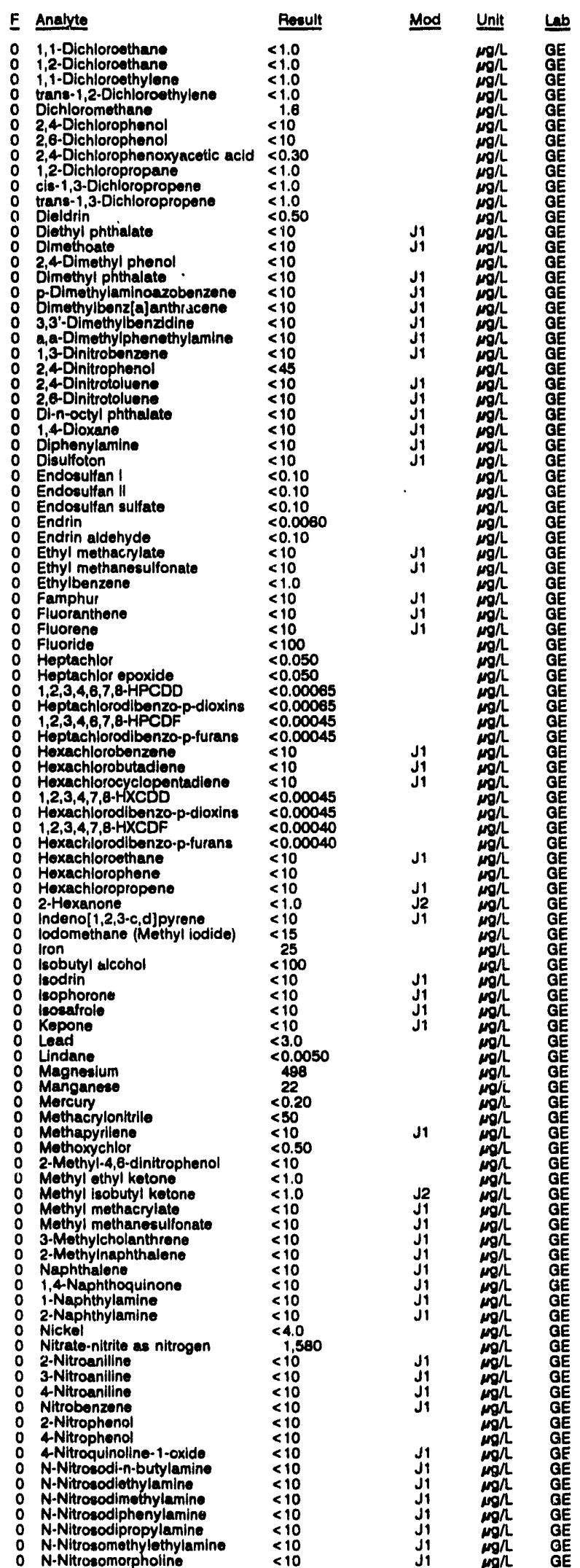


WEL SGX 40 collectad on 07/31/02, laboratory analywes (cont)

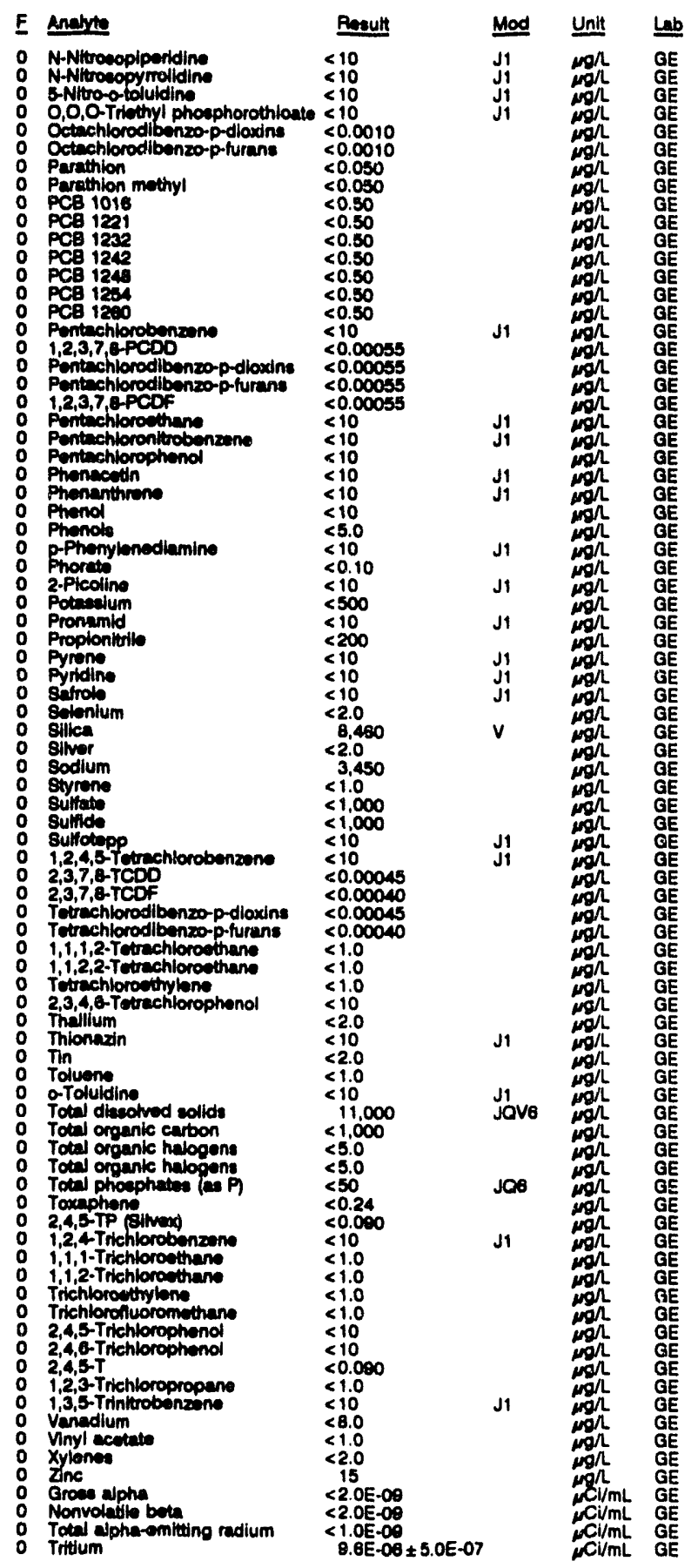

WELL BGX 5D

MEASUREMENTS CONDUCTEO IN THE FIELD Sample date: $07 / 31 / 92$
Depth to water: $75.55 \mathrm{n}(23.03 \mathrm{~m})$ bolow TOC
Water olevation: $209.45 \mathrm{~h}(83.84 \mathrm{~m}) \mathrm{mal}$ Water evacuated bofore sampling: $38 \mathrm{gal}$

Time: $16: 45$

Alkalinity: $3 \mathrm{mon}$

Water temporature: $22.5^{\circ} \mathrm{C}$

\section{LABORATORY ANALYSES}

F Analyie

$0 \mathrm{pH}$

$0 \begin{array}{cc}0 \\ 0 & \mathrm{pH} \\ 0 & \mathrm{pH}\end{array}$

0 pH

- Specific conductance

o Acenaphtheno

Acenaphthylene

Acetonitrile (Methyl cyanide)

- Acetophenone.

o 2-Acetylaminofluorene

Acroloin

${ }_{0}$ Acrylon

o Alyl chloride

o Aminobiphenyl

o Anlline

o Anthracen

o Aismito

o Areonic

0 Barium

Benzeno

alpha-Benzene hexachlorido

o deth-Benzene hexachloride

delta-Benzene hexac

o Eenzo/ajanthracene

Benzo b] fluoranthene

o Benzolg, h,l]perylone

Benzolajpyren

o Benyllium

0 Bis(2-chloroethoxy) methane

Bial2-chlorosthyln other

Bis (2-chloroleopropyl) ether

Bis (2-ethylhexyl) phithalate

Bromodichloromethane

Bromoform

Bromomethane
\&Bromophenyl phenyl ether

Butylbenzyl phthalate

o 2-ecc-Buty|-4,8-dinitrophenol

Cadmium

- Culcium

- Carbon disulfide

Carbon tetrachloride

Chlordane

4-Chloroaniline

Chlorobenzene

Chlorobenzlate

para-Chloro-meta-cresol

Chloroethane

O Chloroethene (Minyl chloride)

O Chlorotorm

O Chloromethane

o 2-Chloronaphthal

2-Chlorophenol

4Chlorophenyl phenyl ether

Chloropren

o Chromium

O Chryeano

Cobalt

O O-Ciesol (2-Methylphenol)

m-Cresol (3-Methylpheno

0 Cyanide

${ }_{0}$ p.p.DDD

0 P.P.DDE

o pip'-DD

0 Dibenz $(a, h) a n t h r a c e n e$

O Dibonzofuran

Dibromochloromethane

1,2-Dloromo-3-chloropropane

1,2-Dibromothan

Dibromomethane

Dirn-butyl phthalate

1,2-Dichlorobenzene

1,3-Dichlorobenzene

3,4-Dichlorobenzene

trans-1,4-Dichloro-2-buten

Dichlorodifluoromothane

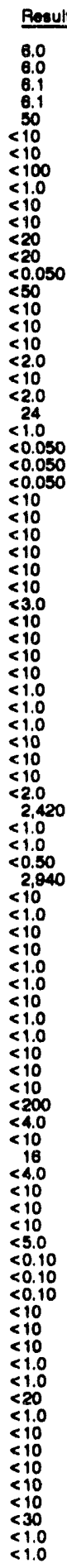

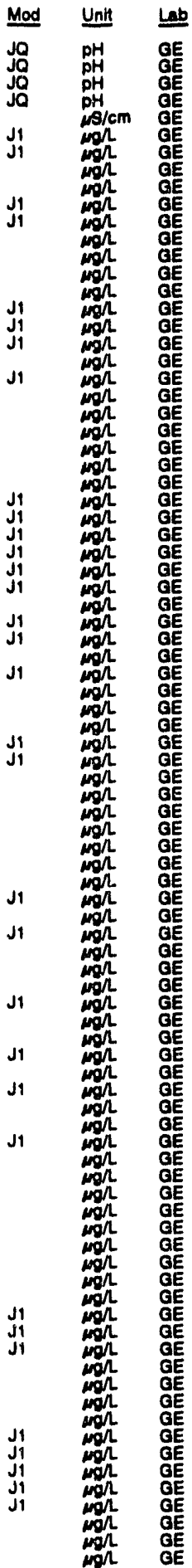


ANALYTICAL RESULTS

WEL BOX 50 colloctad on 07/31/92, laboratory analyese (cont)

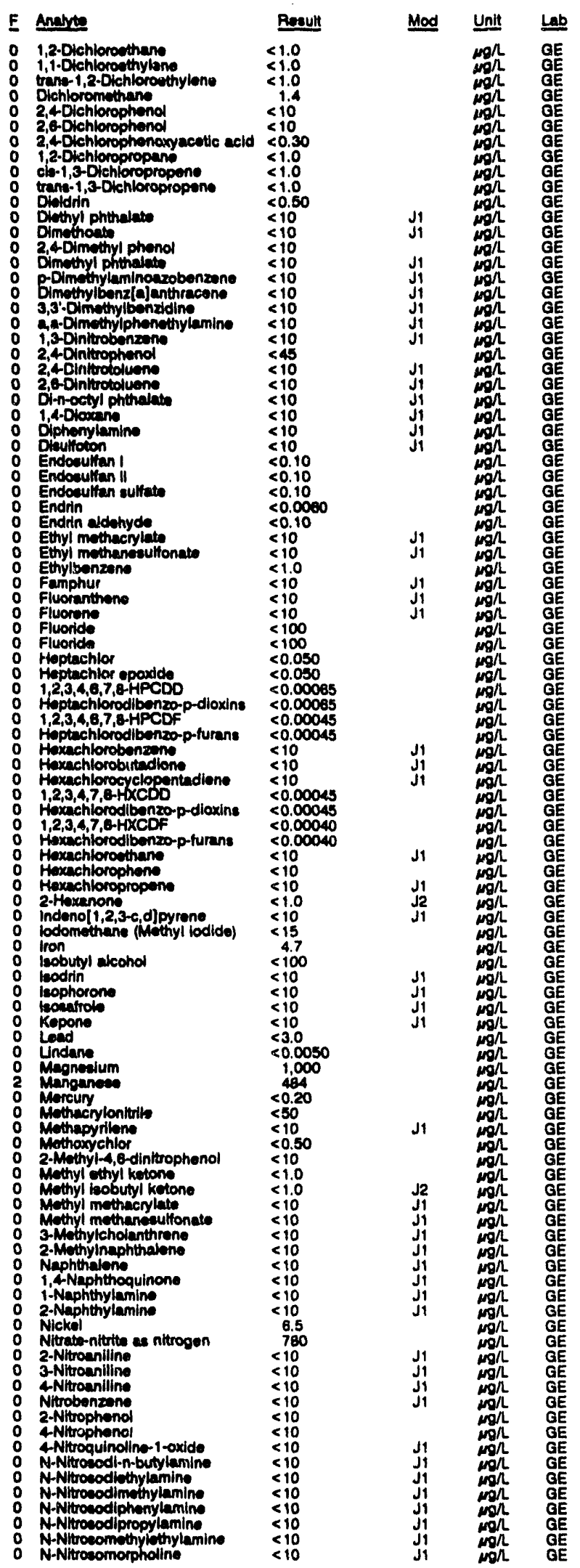

WELL BGX 5D collected on 07/31/92, laboratory analyees (cont)

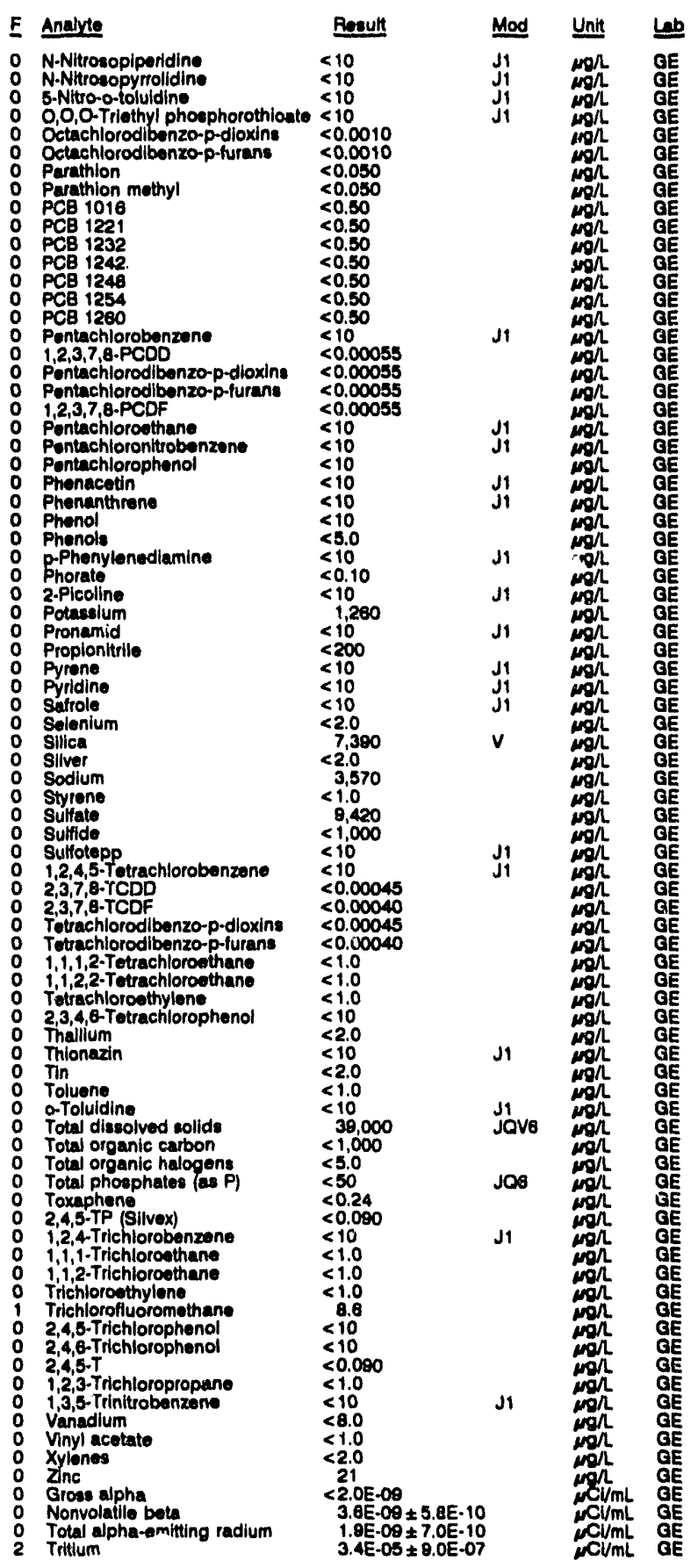


WELL BGX 6D

MEASUREMENTS CONOUCTED IN TME FIELD

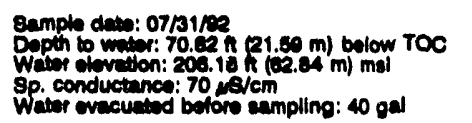

Sp. conductunce: 70 ef/cm

\section{UBOALTOAY ANALYSES}

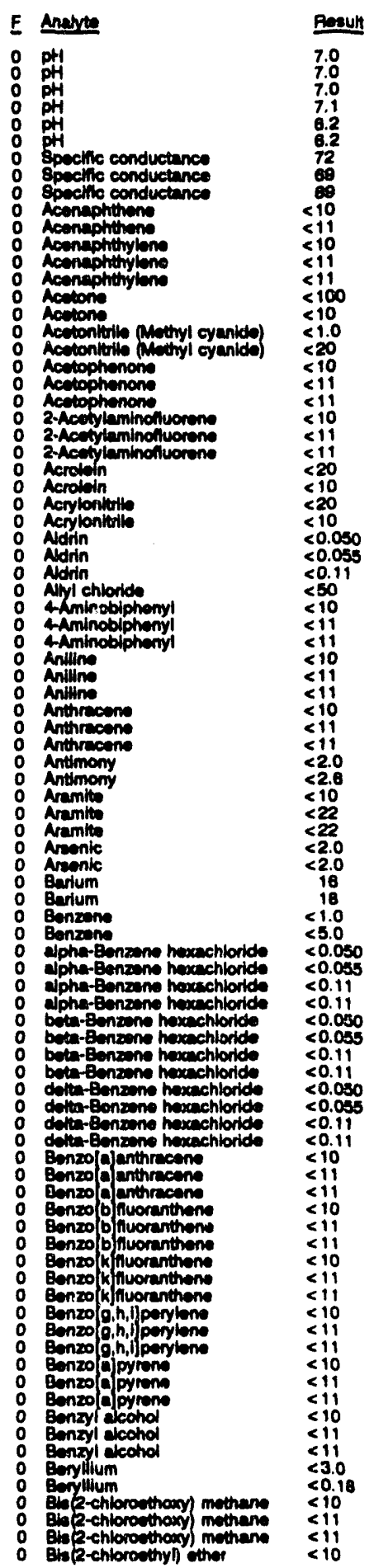

WELL BCX 80 collectod on 07/31/92, laboratory analyees (cont)

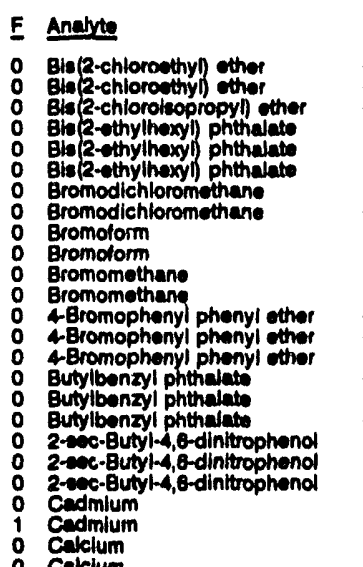
Tima: 7:40 PH: 6.0 $10 \mathrm{mal}$

Water tomporature: $20.7 \circ \mathrm{C}$

Carbon disulfide

Carbon titrechioride

Carbon tutrachioride

Chlordane

Chlordane

Chlordane

Chloride:

4-Chioroaniling

4-Chloroaniline

Chioroanlline

Chlorobenzenene

Chlorobenzilate

Chlorobonzilate

para-Chioro-mota-creseol

para-chloro-mota-cresol

Chlorouthane

Chloroethane

Chloroethene Minyl chloride)

Chlorodthens Ninyl chloride

2-Chloroethyl vinyl ther

Chloroform

Chloromothane

2-Chloronaphithalone

2.Chloronaphthalene

2-Chioronaphthalene

2.Chlorophonol

-Chlorophenyl phenyl other

4-Chlorophenyl phenyl ther

4Chlorophenyl phenyl other

Chloroprene

Chloropren

Chromium

Chrysone

Chyoen

Cobati

Cobart

Copper

- Crosel (2-Methyiphenal

- Crosol 2-Methylphenol

a-Crosol (2-Methylphenol

m-Cresol (3-Methy pheno

m-Cresol (3-Methylptono

m-Cresol

p-Cresol 4 -Methylphenol

p-Crecol (a-Methylpheno)

Cyanide

P,P.

$p, p^{\prime} \cdot 0 D 0$

P,P'Dog

P,P.DDE

P.P.DOE

- P,p'-OOE

p,p.Dol

pipiod

Diallato

Dibenz[a, h]anthracone
Besult Mod Unit Lab

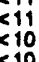<smiles></smiles>
$\begin{array}{ll}8.6 & \text { J } \\ 5.3 & \text { JV }\end{array}$

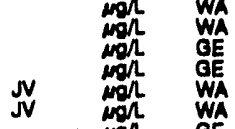

wa

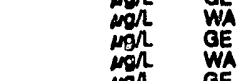

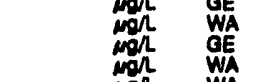

0,150

$<1.0$

$\leq 1.0$

$<0.50$

$<1.1$

2,750
2,240
5

2,890
$<11$
$<11$
$<11$

$<1.0$

$<5.0$

$\leq 11$

$\leq 11$

$<11$

$<1.0$

$<10$

$<1.0$

$<1.0$

$<10$

$<11$

$<10$

$<11$

$<20$

$<4.0$

$<10$

$<11$

$<4.0$

$<4.0$

$<10$

$\leq 11$

$<11$

$<1$

$<1$

$<11$.

$<5.0$

$<0.11$

$<0.22$

$<0.10$

$<0.11$

$<0.22$

$<0.10$

$<0.11$

$<+0$

<11
J3

J3

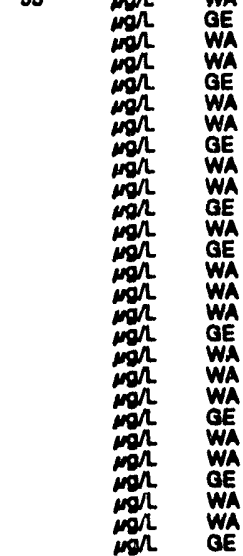


ANALYTICAL RESULTS

WELL BOX 6D collected on 07/31/02, laboratory analyees (cont) .

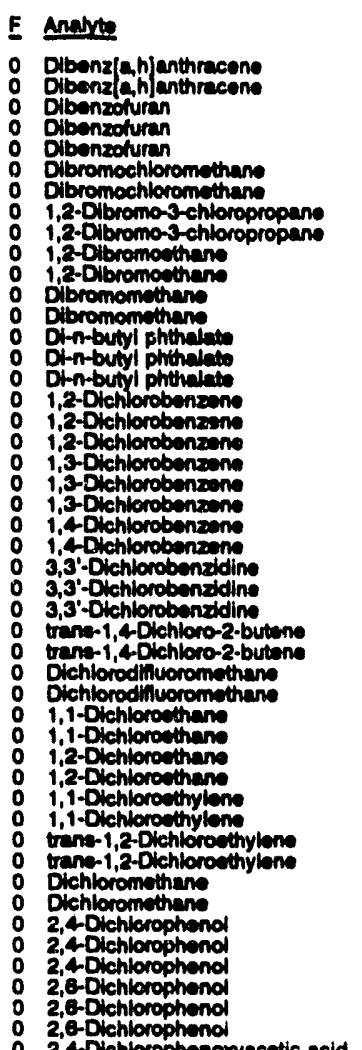

$<11$

2,4-Dichlorophenoxy ucetic acid

2,4-Dichlorophenomyecetic acld

1,2-Dichloropropane

o di-1,3-Dichlorepropen

cli-1,3-Dichioropropen

o tran-1,3-Dichloropropene

0 Dieldrin

0 Dialdin

0 Divinyi phthalete

o Diethyl phthedate

Dimethont

o 2,4-Dimethyl phenol

2.4-Dimethyl phenol

2,4-Dimethyl phend

Dimetry phithate

Dimethyl phthalete

p-Dimethylaminoszobenzene

4Dimethylamino mobonnesen

4-Dimetry inminosabonzano

Dimethylbenzfalenthrucene

Dimethylbenz a anthrecene

Dimethylbenz a anthracon

3,3'-Dimethylbenzdin

3,3 Oimmylbenzadin

o a-Dimethylphenethylamine

- a, Dimethyphenethylamin

a a-Dimatrylphencthylamin

1,3-Dintrobenamano

1,3-Dinftrobenzane

4,0-Dinlito-ortho-eresel

4,0-Ointro-ertho-eneed

2,40initrophene

2,4-Dinitrophone

2,4Dinitrotoluan

2,4-Dinitrotoluen

2,e-Dintrotion

2,6-Dinitrotoluen

Dt-n-oetyl phthalat:

Di-n-oetyl phthalate

1,40loxane

1, Hovane

Diphenylamine
Aenult

$<10$

$<11$

$<5.0$

$<1.0$

$<20$

$<20$

$<1.0$
$<10$
$<10$
7.7

7.7
10.0
$<10$

$<11$

$<10$

$\leq 11$

$<11$

$<30$

$\leq 100$

$<1.0$

$<10$

$<5.0$

$<1.0$

$<1.0$

1.3
5.0

$<10$

$\leq 11$

$\leq 11$

Mod Unit Lub

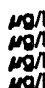

WA

WA

WA

WA

WA

WA

GE

WA

WA

GE

WA

WA

GE

mgo

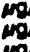

mol GE

on

wa

mor WA

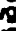

WELL BGX $6 D$ collected on 07/31/92, laboratory analyees (cont.)

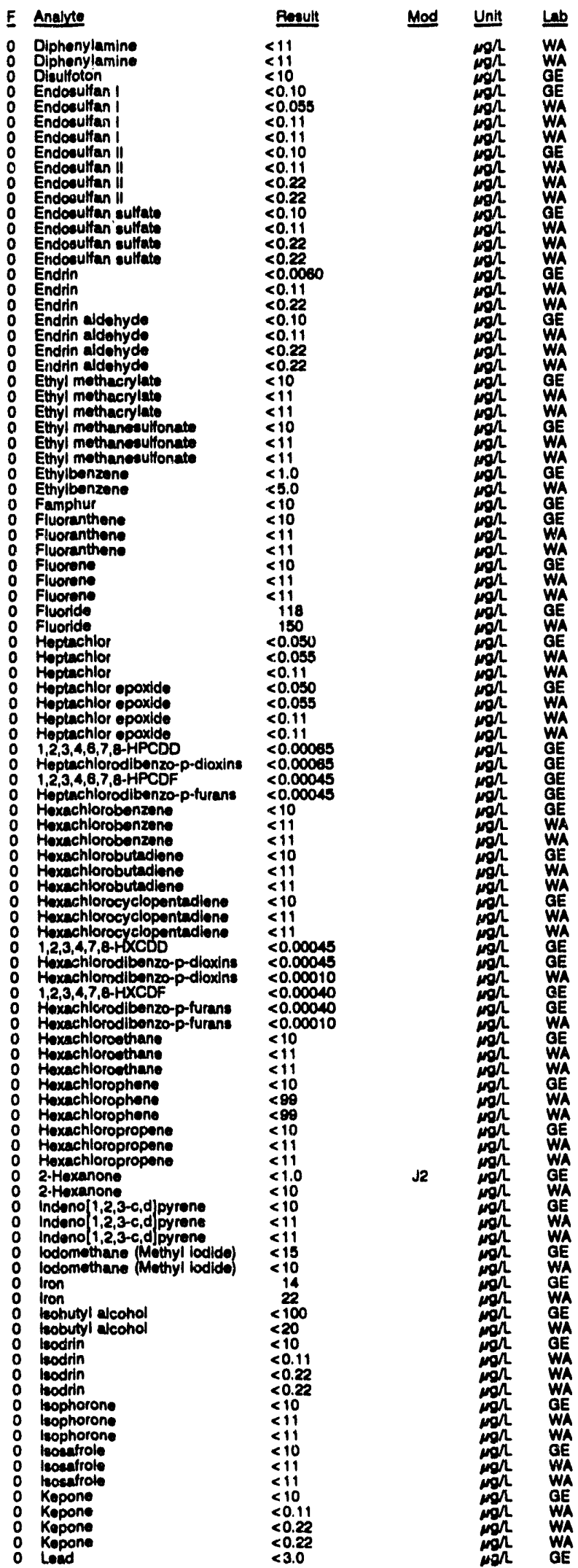


ANALYTICAL RESULTS

WELL BaX 00 collectad on 07/31/92, laboratory andyeen (cont)

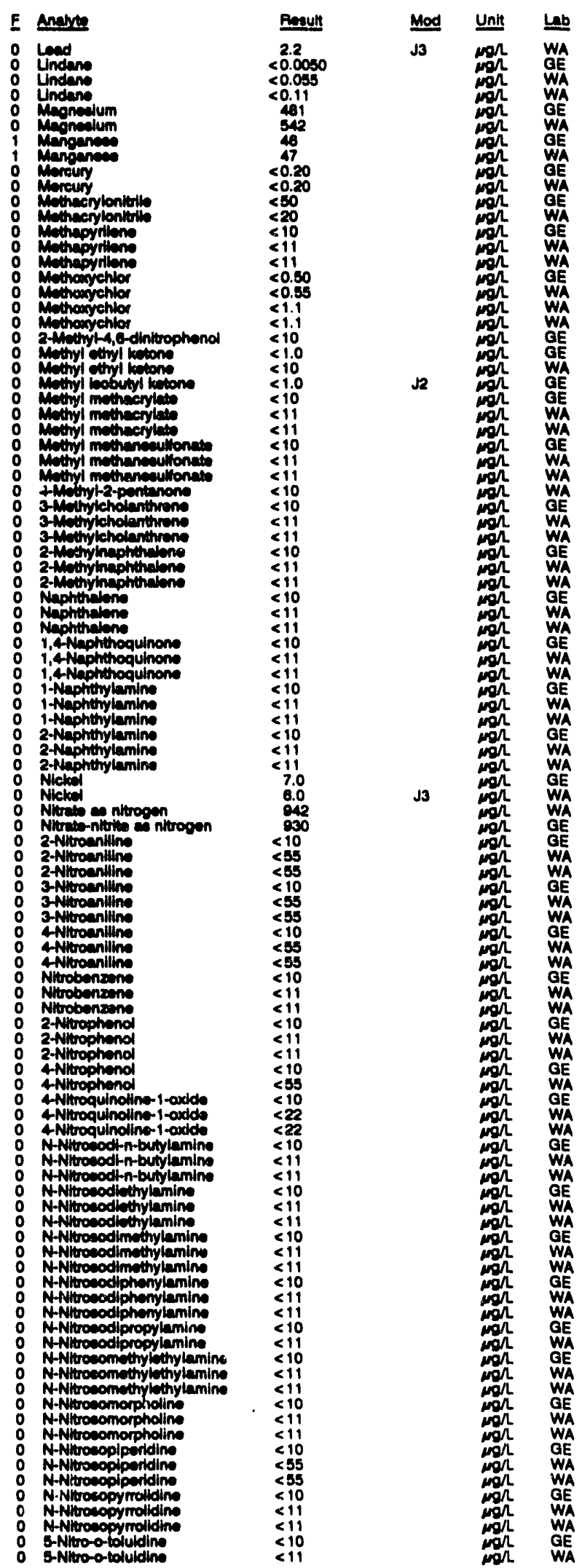

WELL BQX 6D collected on 07/31/92, laboratory analyees (cont.)

\begin{tabular}{|c|c|c|c|c|c|}
\hline E & Analyte & Romult & Mod & Unalt & Lab \\
\hline $\begin{array}{l}0 \\
0 \\
0 \\
0 \\
0 \\
0 \\
0 \\
0 \\
0 \\
0 \\
0 \\
0 \\
0 \\
0 \\
0 \\
0 \\
0 \\
0 \\
0 \\
0 \\
0 \\
0 \\
0 \\
0 \\
0 \\
0 \\
0 \\
0 \\
0 \\
0 \\
0 \\
0 \\
0 \\
0 \\
0 \\
0 \\
0 \\
0 \\
0 \\
0 \\
0 \\
0 \\
0 \\
0 \\
0 \\
0 \\
0 \\
0 \\
0 \\
0 \\
0 \\
0 \\
0 \\
0 \\
0 \\
0 \\
0 \\
0 \\
0 \\
0 \\
0 \\
0 \\
0 \\
0 \\
0 \\
0 \\
0 \\
0 \\
0 \\
0 \\
0\end{array}$ & 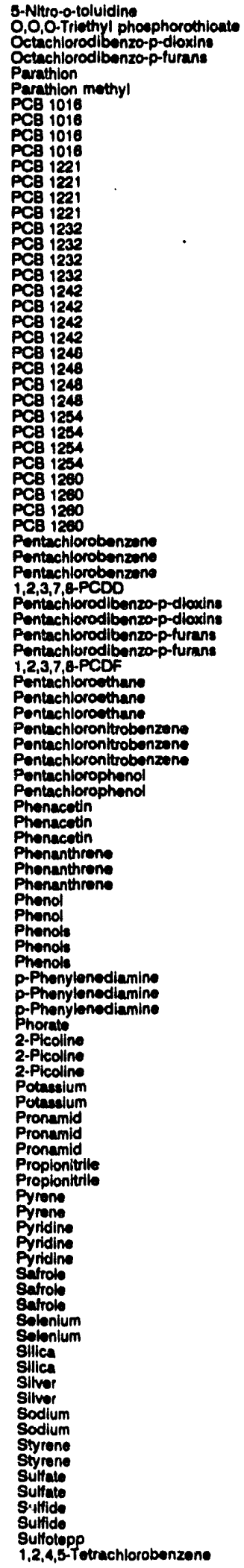 & 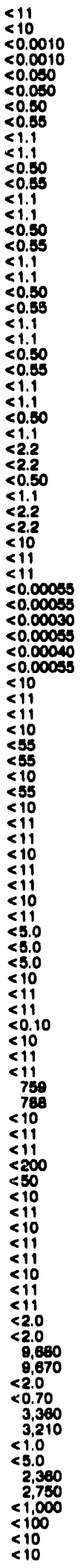 & $v$ & 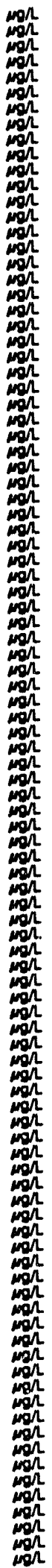 & 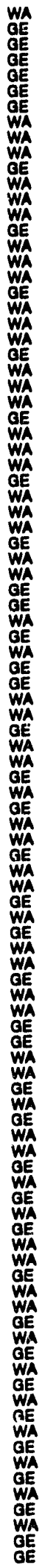 \\
\hline
\end{tabular}


ANALYTICAL RESULTS

WELL BGX 6D collected on 07/31/92, laboratory analyces (cont)

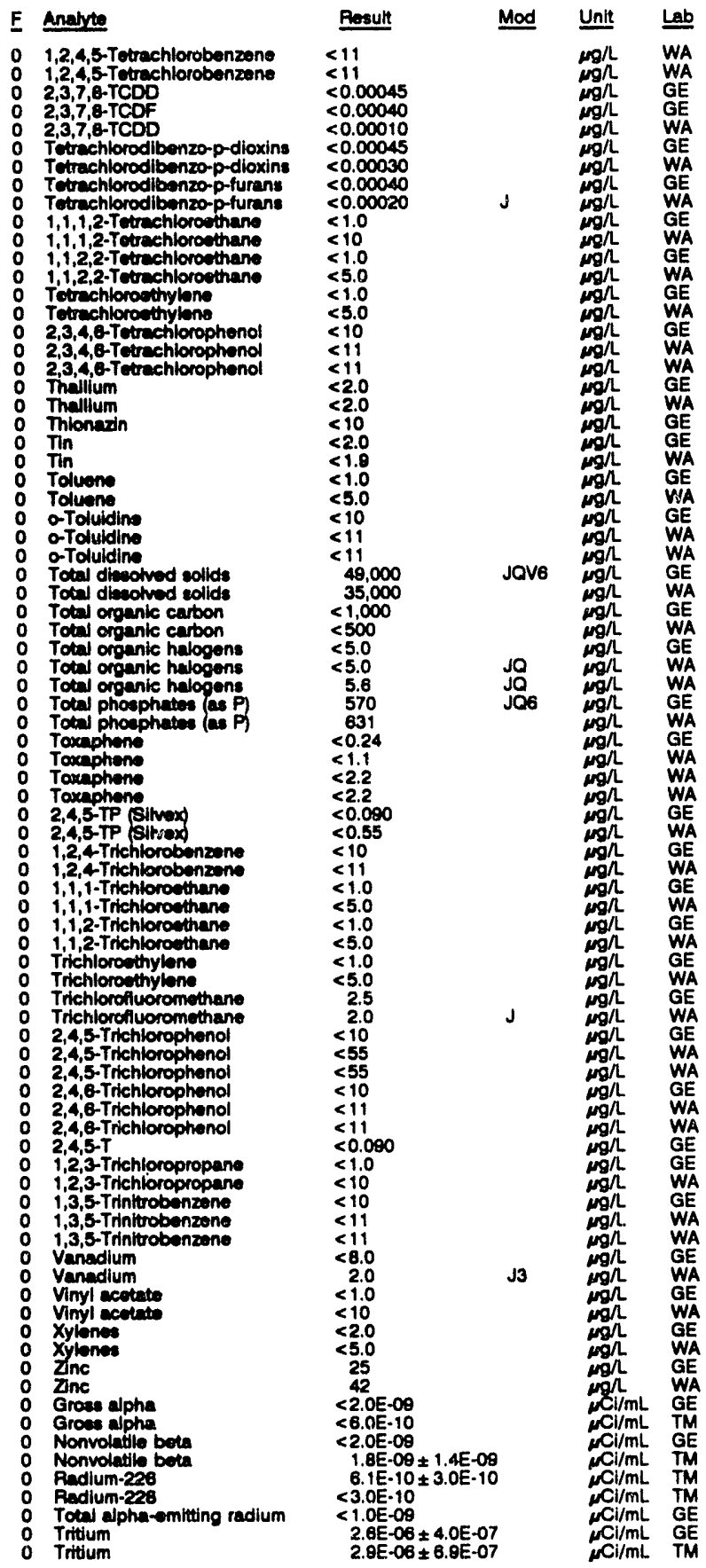

WELL BGX 6D Replicate

MEASUREMENTS CONDUCTED IN THE FIELD

Sample date: $07 / 31 / 92$

Depth water: $70.82 \mathrm{At}(21.59 \mathrm{~m})$ below TOC Water olevation: $208.18 \mathrm{Ht}(62.84 \mathrm{~m}) \mathrm{mst}$ Water ovacuated belore sampling: $40 \mathrm{gal}$

LABORATORY ANALYSES

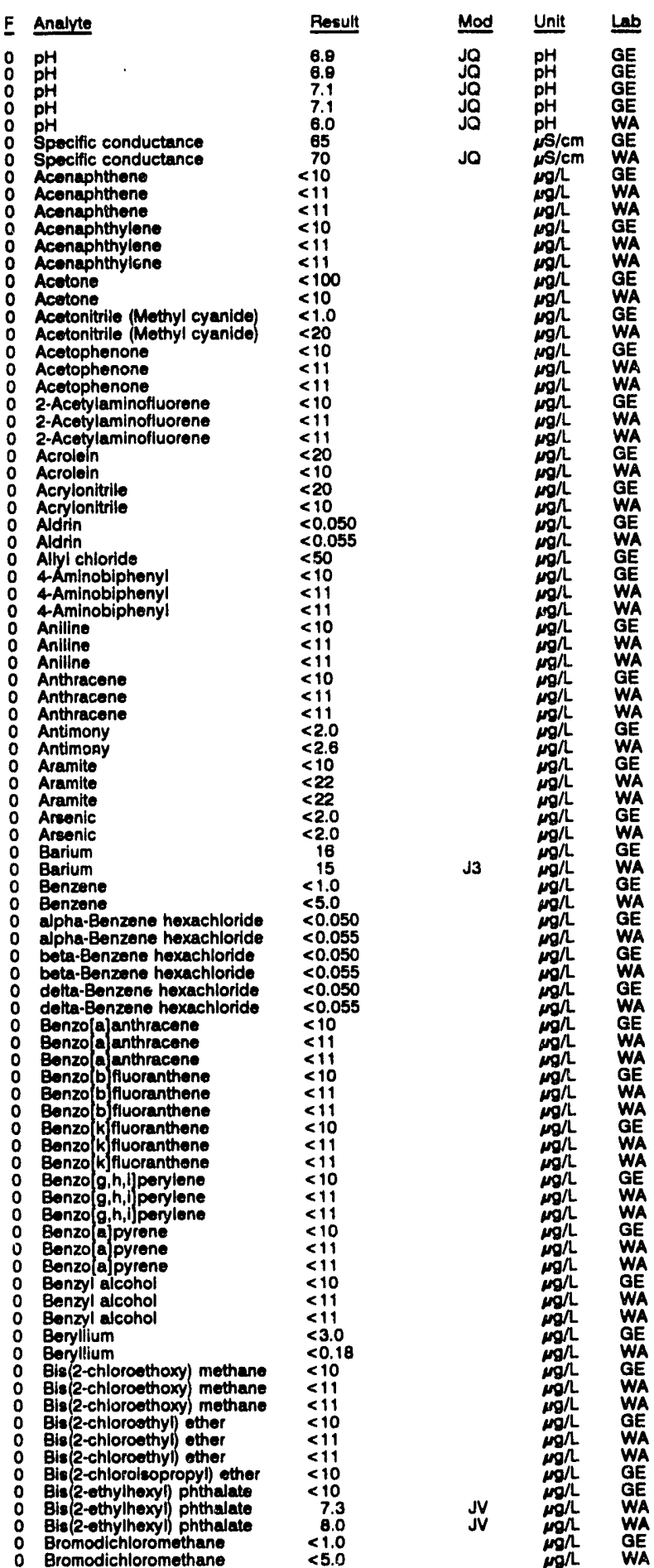

Time: 7:40

PH: 6.0 : $16 \mathrm{mgh}$

Water temperature: $20.7^{\circ} \mathrm{C}$

(1)

(n)

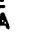


WEL BQX 60 collectod on 07/31/82, laboratory analyees (cont.)

F Anabite

- Bromotorm

Bromomethane

Bromomane

4 Bromophenyl phenyl ther

4 -Bromophenyl phenyl thet

Butylbenzy! phthulate

Butylbenzy/ phthalate

2-ace-8utyl-4, 8-dinitrophonol

2-cec-eutyl-4,8-dinltrophenol

Cadmlum

Cadmium

Calcium

Carbon dieulifide

Carbon trechloride

Carbon tetrachionide

Chlordane

Chloride

4-Chloroaniline

4-Chloroanilline

A-Chloroaniline

Chiorobenzane

Chlorobenzilate

Chlorobenzilate

Chlorobenzilate

para-Chloro-mata-creacol

para-Chloro-meta-creed

Cari-Choro-m

Chloromthan

Chloroethene Minyl chloride)

Chioroethene (Vinyl chloride)

2-Chloroethyl vinyl ether

Chloroform

Chloromethane

2-Chloronaphthaleme

2-Chloronaphthalene

2-Chloronaphtha

2-Chlorophenol

4-Chlorophenyl phenyl other

4-Chlorophenyl phenyl other

Chloropreno

Chioroprens

Chromium

Chromium

Chryeans

Chryen

Cobar

Copper

o-Cresol (2-Methyiphenol)

o-Cresel (2-Methyiphenol)

a-Cresed (2-Methylphenol)

m-Cresol (3-Methylphenol)

m-Cresol (3-Methylphenol)

m-Cresol (3-Methylphenol

p-Cresol 4-Methylpheno

p-Cresel (4-Methylphenol)

Cyanide

0 p,p'-ODD

P,P'DOD

$p, p^{\prime}-D O E$

P,P'-ODT

p,p'-DOT

Bialinte

Diallato

Dibenz $[a, h)$ anthracene

Dibenz a h h anthracone

Dibenzofuran

Dibenzoturan

Dibenzoturan

Dirochoromethane

1,2-Dibromo-3-chloropropane

i. Dibromo-achloroprc

1,2.Dibromoethane

Dibromomethan
$<1.0$

$<5.0$

$<10$

$<10$

$<11$

<1

$<10$

$<55$

$<55$
$<2.0$
$<0.35$

8,220
8,010

$<1.0$

$<1.0$

$<5.0$
$<0.50$
$<0.55$

$<0.55$
2,800
3,000

$\leq 11$

$<10$

$<5.0$

$<10$

$<11$

$<10$

<i1

$<1.0$

1.0

$<10$

$<10$

$<5.0$

$<1.0$

$<1$

$<111$

$<10$

<11

$<10$

$<11$

$<20$

$<20$

$<4.1$

$<10$

$<11$

$<4.0$
$<0.88$
$<4.0$

$<4.0$

$<10$

$x$

$<10$

$<1$

$<10$

$<11$

$\leq 5.0$

$<5.0$
$<0.10$
$<0.11$

$<0.11$
$<0.10$
$<0.11$

$<0.11$

$<0.11$

$<10$

$<11$

$<10$

$<11$

$<10$

$<1.0$

$<5.0$

$<1.0$

$<20$

$<1.0$
$<10$
Unit La

$\mu g / L$ GE

WE

WELL BGX 6D collectod on 07/31/92, laboratory analyees (cont.)

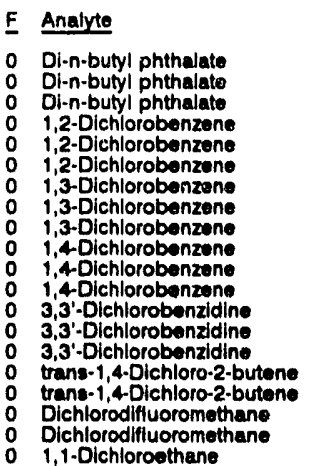

Result

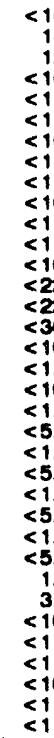

$<10$
14

12
$<10$

$<11$

$<10$

$<11$

$<11$

$<10$

$<22$

$<100$

10

$<1.0$

$<1.0$

$<1.0$

$<5.0$

1,1-Dichloroethylene

trans-1,2-Dichloroethylene

- Dichloromothane

2.4

2,4-Dichlorophenol

2,4-Dichlorophenol

2,6-Dichlorophenol

2,6-Dichlorophenol $<11$

2,4-Dichlorophonoxymcetic acld

1,2-Dichloropropane

o 1,2-Dichloropropane

0
0
0

o trans-1,3-Dichloropropene

0 trans-1,3-Dichloropropene

0 Dieldrin

o Diethyl phthalate

Diethyl phthalate

Diechyl phthala

2,4-Dimethyl phenol

2,4-Dimethyl phenol

2,4-Dimethyl phenol

0 Dimethyl phthalate

o Dimethyl phthalate

Dimethyl phthalate

p.Dimethylaminoazobenzene

4-Dimethylaminoazobenzene

4Dimethylaminoazobenzene

Dimethylbenz (a) anthracene

Dimethylbenz a anthracens

0 3,3'-Dimethylbenzidine

3,3-Dimethylbenzidine

3,3'-Dimethyloonzidino

3,3-Dimethylbenzidino

a,a-Dimethylphenethylamine

a,a-Dimethylphenothylamine

1,3-Dinitrobenzeno

o 1,3-Dinitrobenzene

1,3-Dinitrobanzene

4,6-Dinitro-ortho-cresol

0 2,4-Dinitrophenol

2,4-Dinitrophenol

2,4-Dinitrophenol

2,4-Dinitrotoluene

2,4-Dinitrotoluene

2,4-Dinitrotoluene

2,6-Dinitrotolueno

2,6-Dinitrotoluene

2, Dinthotoluene

Di-n-octyl phthalate

D Di-n-octyl phthalate

1,4-Dloxane

1,4-Dloxane

1,4-Dloxane

Diphenylamine

o Diphenylamine

D Diphenylamine

o Disutfolon

- Endosulfan

o Endosulfan

O Endosulfan II

o Endosulfan sulfate

- Endosulfan sulfiate

O Endrin

$<1.1$
$<2.2$

$<5.0$

$<5.0$

$\leq 1.0$

$<5.0$
$<0.50$
$<0.11$
8.19

$<10$
$<11$

1.4
$<1.4$
$<10$

$>>10$

<il

$\leq 11$

$\leq 10$

$\leq 11$

$\leq 10$

>11

$\leq 10$

$\leq 11$ 
ANALYTICAL RESULTS

WELL. BGX 60 collocted on 07/31/82, laboratory analyses (cont.)

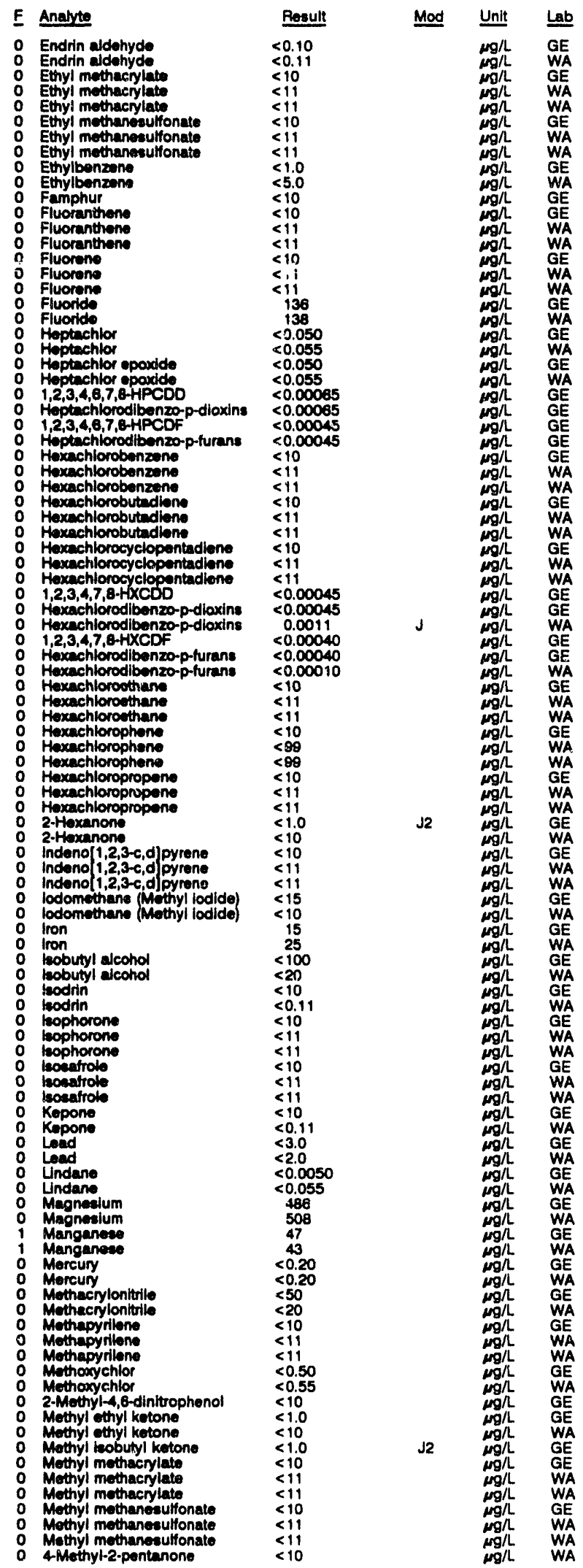

WELL BGX $6 D$ collocted on 07/31/82, laboratory analyese (cont.)

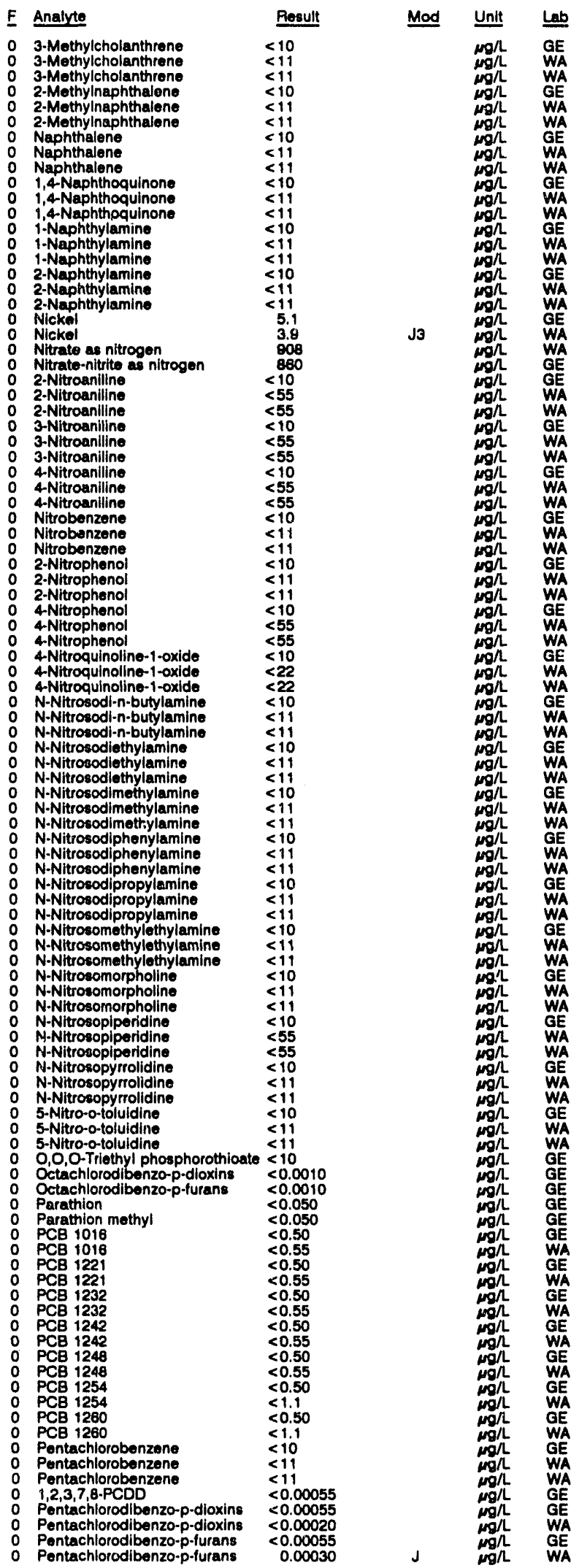


WEL BGX 60 collectod on 07/31/92, laboratory andyees (cont.)

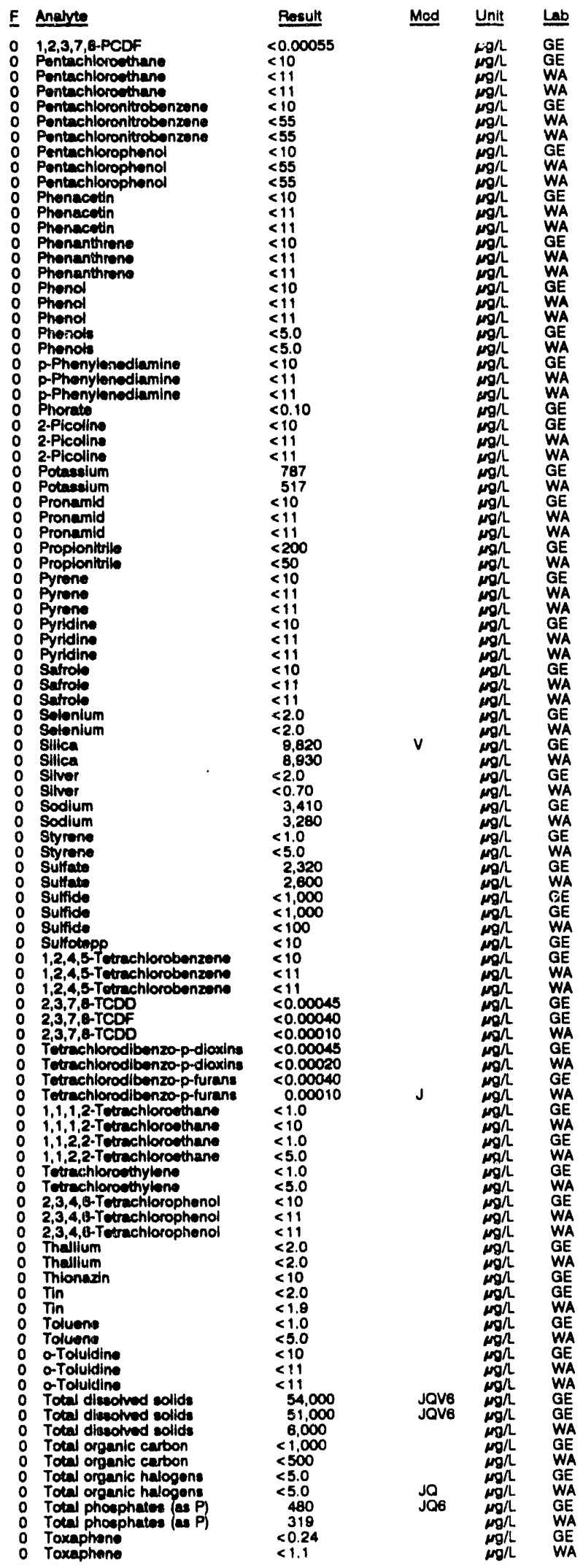

WELL BGX $8 D$ collected on 07/31/82, laboratory analyses (cont)

\begin{tabular}{|c|c|c|c|c|c|}
\hline & Analyte & Result & Mod & Unit & Lab \\
\hline & 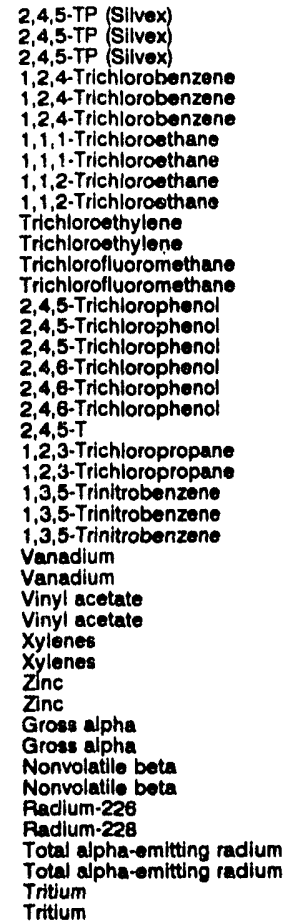 & $\begin{array}{l}<0.090 \\
<0.55 \\
<1.1 \\
<10 \\
<11 \\
<11 \\
<1.0 \\
<5.0 \\
<1.0 \\
<5.0 \\
<1.0 \\
<5.0 \\
2.2 \\
2.1 \\
<10 \\
<55 \\
<55 \\
<10 \\
<11 \\
<11 \\
<0.090 \\
<1.0 \\
<10 \\
<10 \\
<11 \\
<11 \\
<8.0 \\
<0.88 \\
<1.0 \\
<10 \\
<2.0 \\
<5.0 \\
25 \\
29 \\
<2.0 E-09 \\
<6.0 E-10 \\
<2.0 E-09 \\
<7.0 E-10 \\
3.5 E-10 \pm 2.3 E-10 \\
<6.0 E-10 \\
<1.0 E-09 \\
<1.0 E-09 \\
2.8 E-08 \pm 4.0 E-07 \\
2.8 E-08 \pm 6.6 E-07\end{array}$ & J & 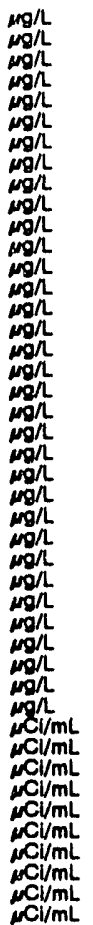 & $\begin{array}{l}G E \\
W A \\
W A \\
G E \\
W A \\
W A \\
G E \\
W A \\
G E \\
W A \\
G E \\
W A \\
G E \\
W A \\
G E \\
W A \\
W A \\
G E \\
W A \\
W A \\
G E \\
G E \\
W A \\
G E \\
W A \\
W A \\
G E \\
W A \\
G E \\
W A \\
G E \\
W A \\
G E \\
W A \\
G E \\
\text { GE } \\
G E \\
T M \\
T M \\
T M \\
G E \\
G E \\
G E \\
T M\end{array}$ \\
\hline
\end{tabular}

WELL BGX 7D

MEASUREMENTS CONDUCTED IN THE FIELO

Sample date: 07/29/92 Time: 15:40

Iraccessibility or mechanical problem prevented semple collection.

WELL BGX 8DR

MEASUREMENTS CONDUCTED IN THE FIELD

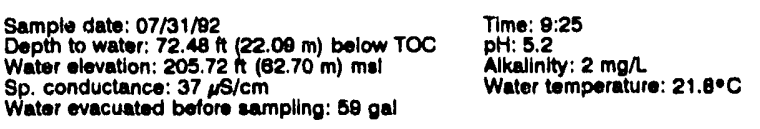

LABORATORY ANALYSES

\begin{tabular}{|c|c|c|c|c|}
\hline Analyte & Rosult & Mod & Unin & Lab \\
\hline 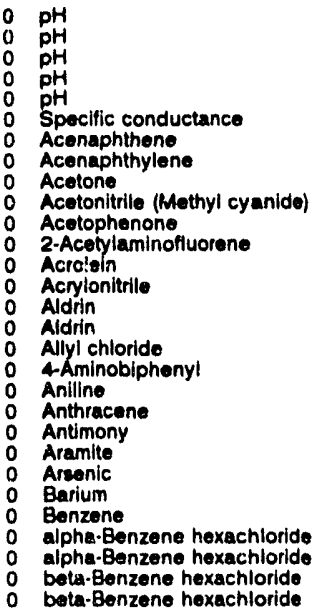 & $\begin{array}{l}6.3 \\
6.4 \\
8.4 \\
6.7 \\
6.4 \\
32 \\
<10 \\
<10 \\
<100 \\
<1.0 \\
<10 \\
<10 \\
<20 \\
<20 \\
<0.050 \\
<0.050 \\
<50 \\
<10 \\
<10 \\
<10 \\
<2.0 \\
<10 \\
<2.0 \\
12 \\
<1.0 \\
<0.050 \\
<0.050 \\
<0.050 \\
<0.050\end{array}$ & $\begin{array}{l}\mathrm{JO} \\
\mathrm{JO} \\
\mathrm{JQ} \\
\mathrm{J} \\
\mathrm{JO}\end{array}$ & 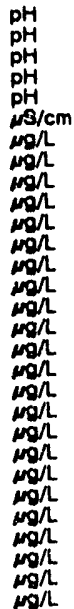 & $\begin{array}{l}\mathrm{GE} \\
\mathrm{GE} \\
\mathrm{GE} \\
\mathrm{GE} \\
\mathrm{GE} \\
\mathrm{GE} \\
\mathrm{GE} \\
\mathrm{GE} \\
\mathrm{GE} \\
\mathrm{GE} \\
\mathrm{GE} \\
\mathrm{GE} \\
\mathrm{GE} \\
\mathrm{GE} \\
\mathrm{GE} \\
\mathrm{GE} \\
\mathrm{GE} \\
\mathrm{GE} \\
\mathrm{GE} \\
\mathrm{GE} \\
\mathrm{GE} \\
\mathrm{GE} \\
\mathrm{GE} \\
\mathrm{GE} \\
\mathrm{GE} \\
\mathrm{GE}\end{array}$ \\
\hline
\end{tabular}


ANALYTICAL RESULTS

WELL BGX BDA colloctod on 07/31/82, laboratory analyses (cont)

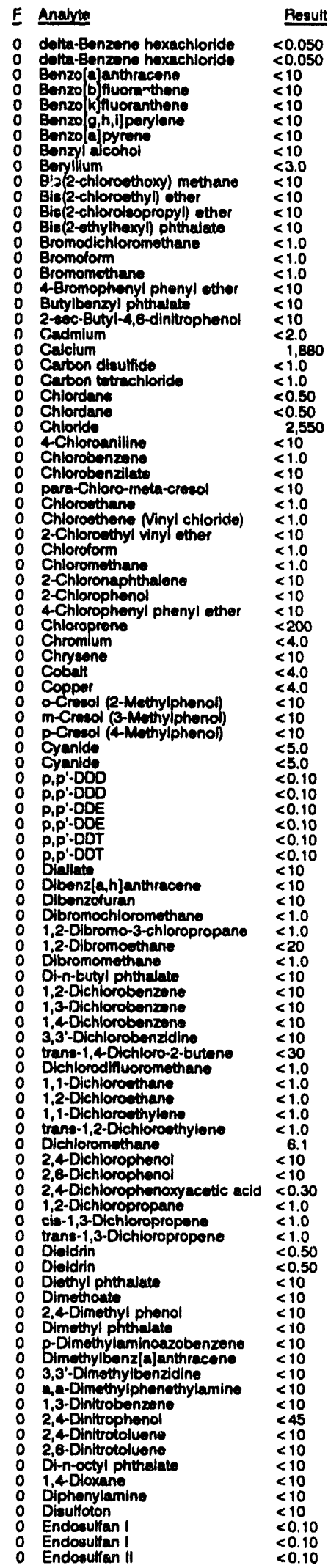

WELL BGX BDR collectod on 07/31/82, laboratory analyees (cont)

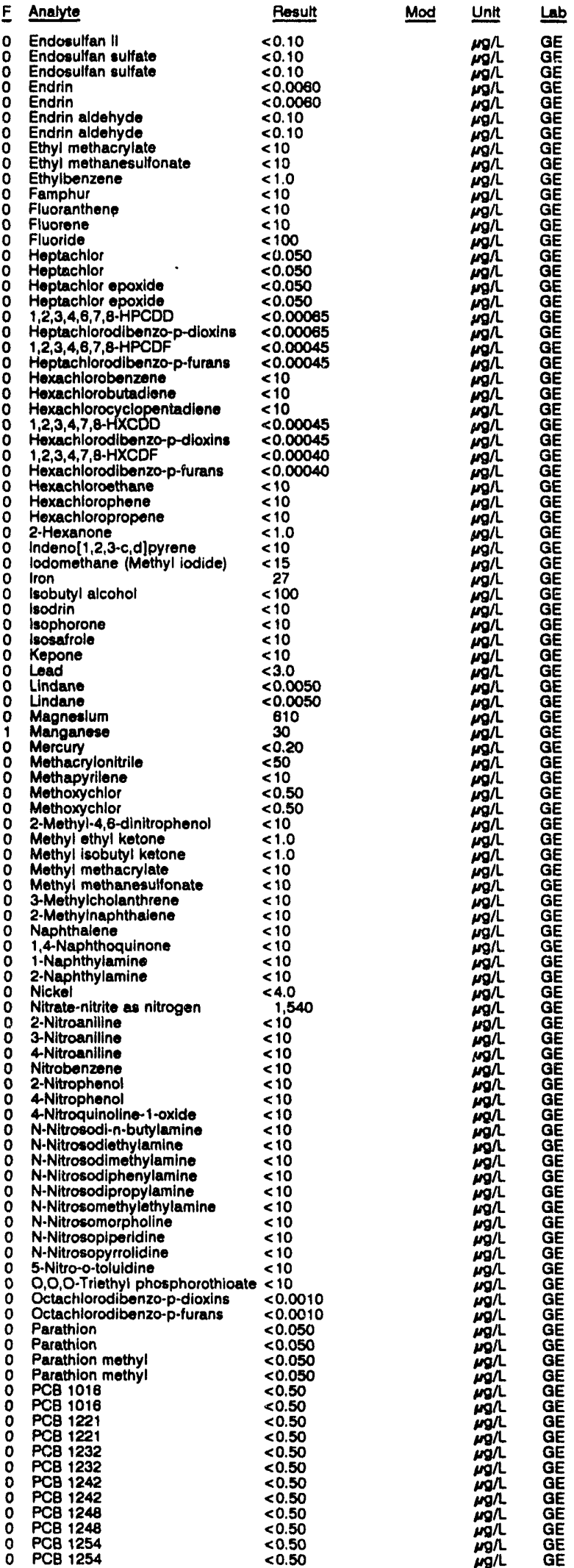


ANALYTICAL RESULTS

WELL BGX 6DA collectod on 07/31/92, laboratory analyees (cont.)

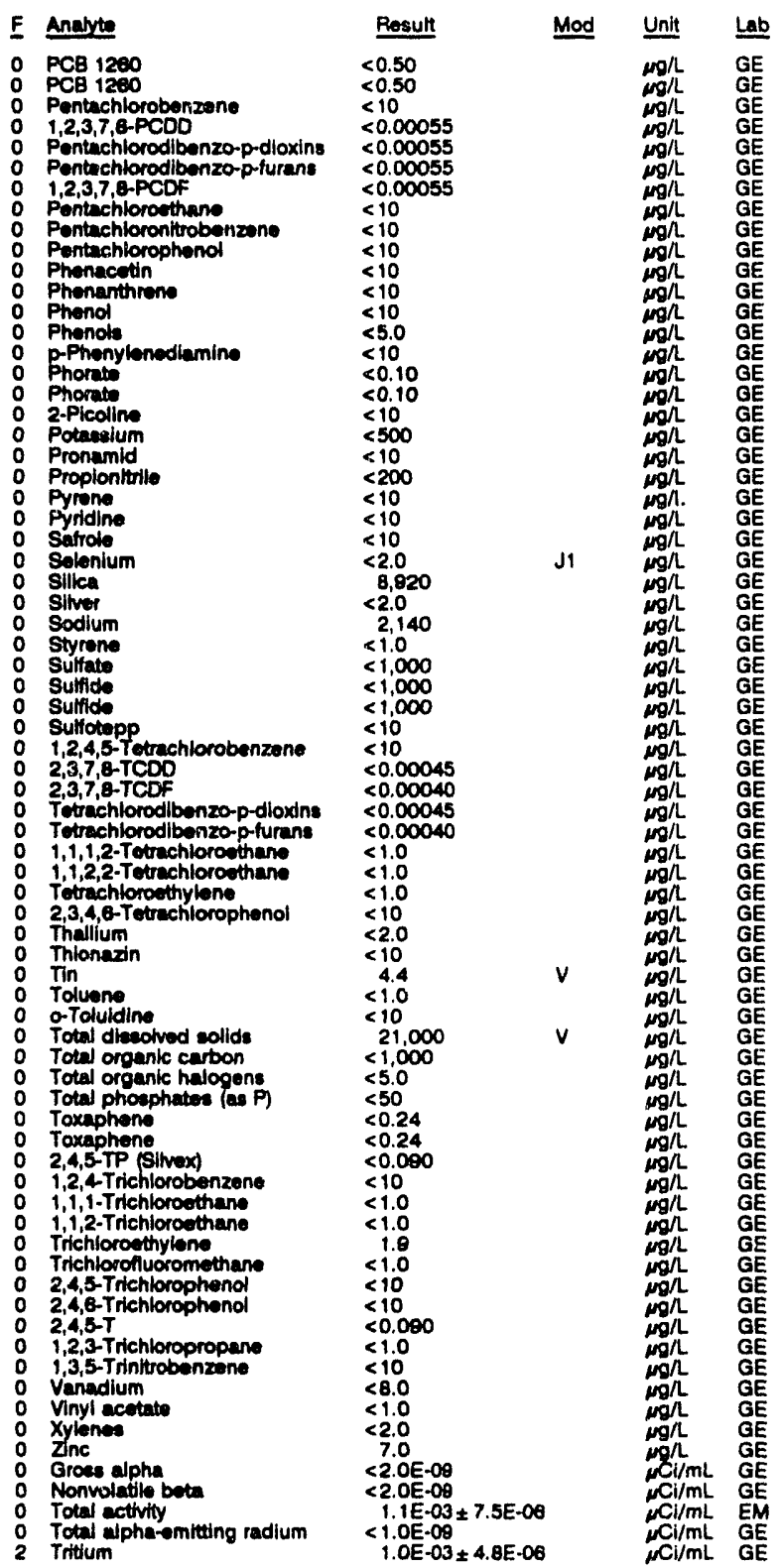

WELL BGX 9D

MEASUREMENTS CONDUCTED IN THE FIELD

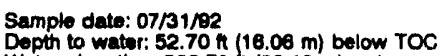

Water elovation: $228.70 \mathrm{~h}(09.1$

Sp. concluctance: $28 \mathrm{\mu s} / \mathrm{cm}$
Wator evacuatiod before eampling: $38 \mathrm{gal}$

LABOPATOFY ANALYSES

\begin{tabular}{|c|c|c|c|c|c|}
\hline$\underline{E}$ & Anelute & Result & Mod & Unit & Lab \\
\hline $\begin{array}{l}0 \\
0 \\
0 \\
0 \\
0 \\
0 \\
0 \\
0\end{array}$ & $\begin{array}{l}\text { pH } \\
\text { pH } \\
\text { pH } \\
\text { pH } \\
\text { pH } \\
\text { Specific conductance } \\
\text { Acenaphthone } \\
\text { Aconaphthylene } \\
\text { Acetone } \\
\text { Acetonitilite (Methyl cyanide) }\end{array}$ & $\begin{array}{l}5.8 \\
5.8 \\
5.8 \\
5.8 \\
5.8 \\
22 \\
<10 \\
<10 \\
<100 \\
<1.0\end{array}$ & $\begin{array}{l}\mathrm{JO} \\
\mathrm{JO} \\
\mathrm{J} O \\
\mathrm{JO} \\
\mathrm{JO} \\
\mathrm{J1} \\
\mathrm{J} 1\end{array}$ & $\begin{array}{l}\mathrm{pH} \\
\mathrm{pH} \\
\mathrm{pH} \\
\mathrm{pH} \\
\mathrm{pH} \\
\mu \mathrm{s} / \mathrm{cm} \\
\mathrm{mg} / \mathrm{L} \\
\mathrm{mg} / \mathrm{L} \\
\mathrm{Ng} / \mathrm{L} \\
\mathrm{mg} / \mathrm{L}\end{array}$ & $\begin{array}{l}\mathrm{GE} \\
\mathrm{GE} \\
\mathrm{GE} \\
\mathrm{GE} \\
\mathrm{GE} \\
\mathrm{GE} \\
\mathrm{GE} \\
\mathrm{GE} \\
\mathrm{GE} \\
\mathrm{GE}\end{array}$ \\
\hline
\end{tabular}

WELL BGX 90 collected on 07/31/92, laboratory analyeses (cont.)

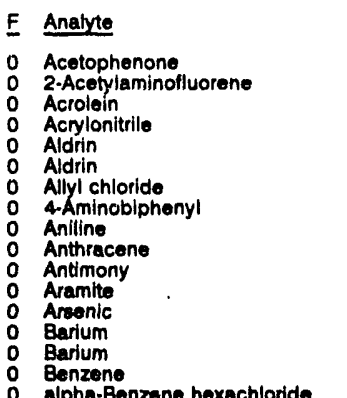

Pesult Mod Unit Lat

$<10$

$<20$

$<0.050$

$<0.050$

$<10$

$<10$
$<10$

$<2.0$

$<10$
$<2.0$
4.9

4.8
4.8
$<1.0$

$<1.0$

alpha-Benzene hexachloride

beta-Benzene hexachloride

beta-Benzene hexachloride

delta-Benzene hoxachloride

Benzo[a]anthracene

Benzo bjfivoranthene

Benzo [kffluoranthene

O Benzolajpyrene

Benzyl aleoho

Borylium

Bis 2-chloroethoxy) methane

Bis 2-chloroethyl) ether

Bis (2-chloroisopropyl) ether

Bis(2-othylhexyl) phthale

0 Bromoform

Bromomethane

Butylibonzyl phthalate

2-sec-Butyl-4,6-dinitrophenol

- Cadmium

Cadmium

O Calclum

0 Carbon disulfide

o Carbon totrachloride

o Chlordane

o Chlordane

o Chloride

o Chlorobenzene

Chiorobenzilate

o para-Chloro-meta-cresol

Chloroethane

O Chloroethene Minyl chloride)

2-Chloroothyl vinyl ether

C Chloroform

Chloromethane

$\begin{array}{ll}0 & \text { 2-Chloronaphthalene } \\ 0 & \text { 2-Chlorophenol }\end{array}$

o Chloroprene

0 Chromium

o Chromium

0 Cobalt

Cobalt

- Copper

o Coppor

o m-Cresol (3-Methylphenol)

o m-Cresol (3-Methylphenol)

o Cyanide

- p.p'-DDD

0 P,p'-DDD

00 P.P.-DDE

0 p.p'-DDE

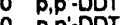

o Biallate

D Dlbenz[a,h]anthracene

O Dlbenzofuran

o Dibromochloromothane

o 1,2-Dibromo-3-chlor

0 1,2-Dibromoethane

o Di-n-butyl phthalate

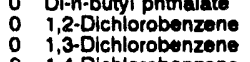

o 1,3-Dichlorobenzene

o 3,3 -Dichlorobonzidine

0 Oichloiodiffuoromethane

- 1.1-Dichloroethane

o 1,2-Dichloroethane

o trans-1,2-Dichloroethylene

O Dichioromethane

0 2,4-Dichlorophenol
o 2,6-Dichlorophenol

\section{$<0.050$}

$<0.050$

$<0.050$

$<10$

$<10$

$<10$

$<10$

$<3.0$

$<3.0$

$<10$

$<10$
$<10$

$<10$
$<1.0$
$<1.0$

$<1.0$

$<10$
$<10$

$<10$
$<10$

$<2.0$
$<2.0$
828

826
828

$<1.0$

$<<0.50$

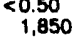

1,850
$<10$
$<1.0$

$<10$

$<10$

$<1.0$

$<1.0$
$<10$
$<1.0$

$<1.0$

$<10$

$<10$

$<200$
$<4.0$

$<4.0$
$<10$

$<10$
$<4.0$
$<4.0$
$<4.0$

$<4.0$

$<10$
$<10$
$<10$

$<10$

$<0.10$

$<0.10$

$<0.10$
$<0.10$

$<0.10$

$<10$
$<10$

$<10$

$<1.0$
$<1.0$

$<1.0$
$<20$
$<1.0$

$<1.0$
$<10$
$<10$
$<10$

$<10$

J1

$<30$
$<1.0$

$<1.0$

$<1.0$

$<1.0$
1.4
$<10$
$<10$ 
ANALYTICAL RESULTS

WELL BGX 90 collocted on 07/31/92, laboratory analyees (cont.)

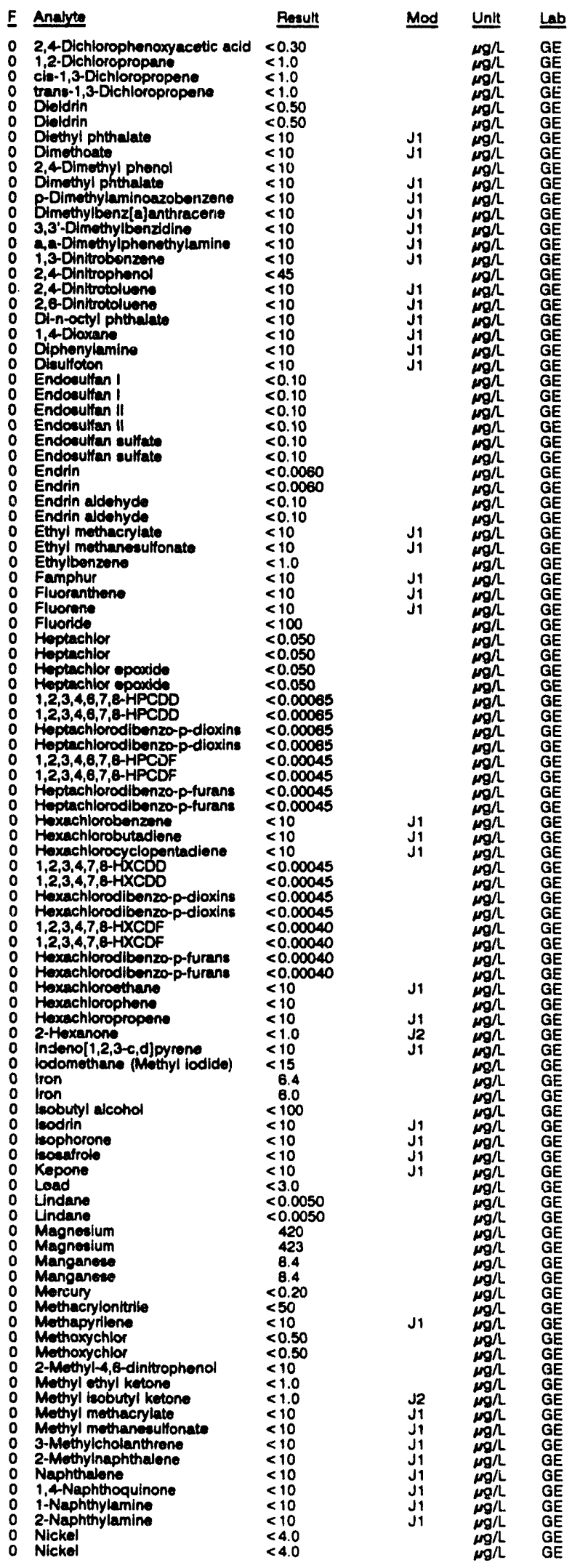

WELL BGX 9D collectod on 07/31/92, laboratory andyees (cont.)

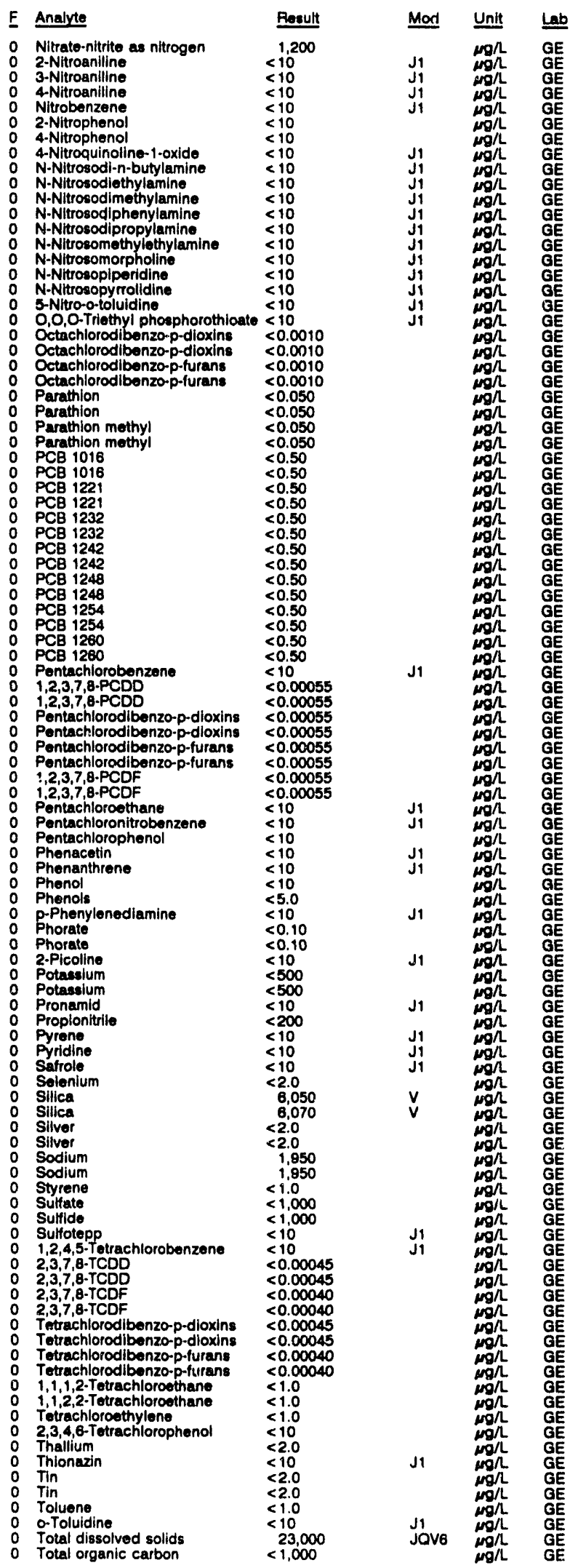


WELL BGX 90 collected on 07/31/92, laboratory analyeen (cont)

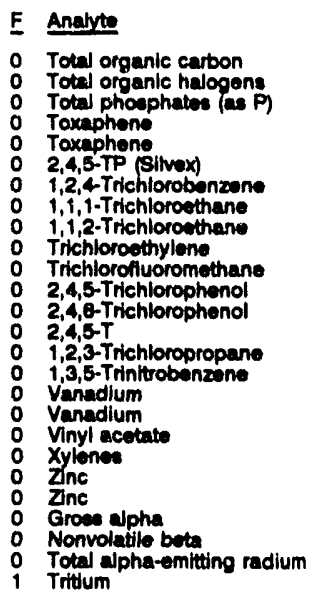

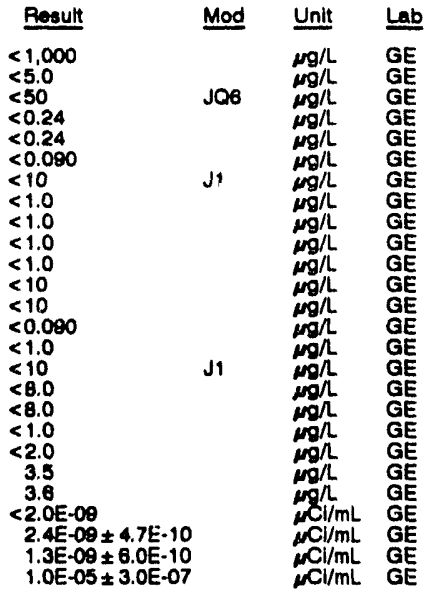

\section{WELL BGX 10D}

MEASUREMENTS CONDUCTED IN THE FIELD

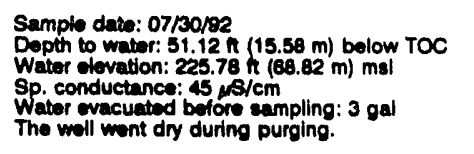

LABORATORY ANALYSES

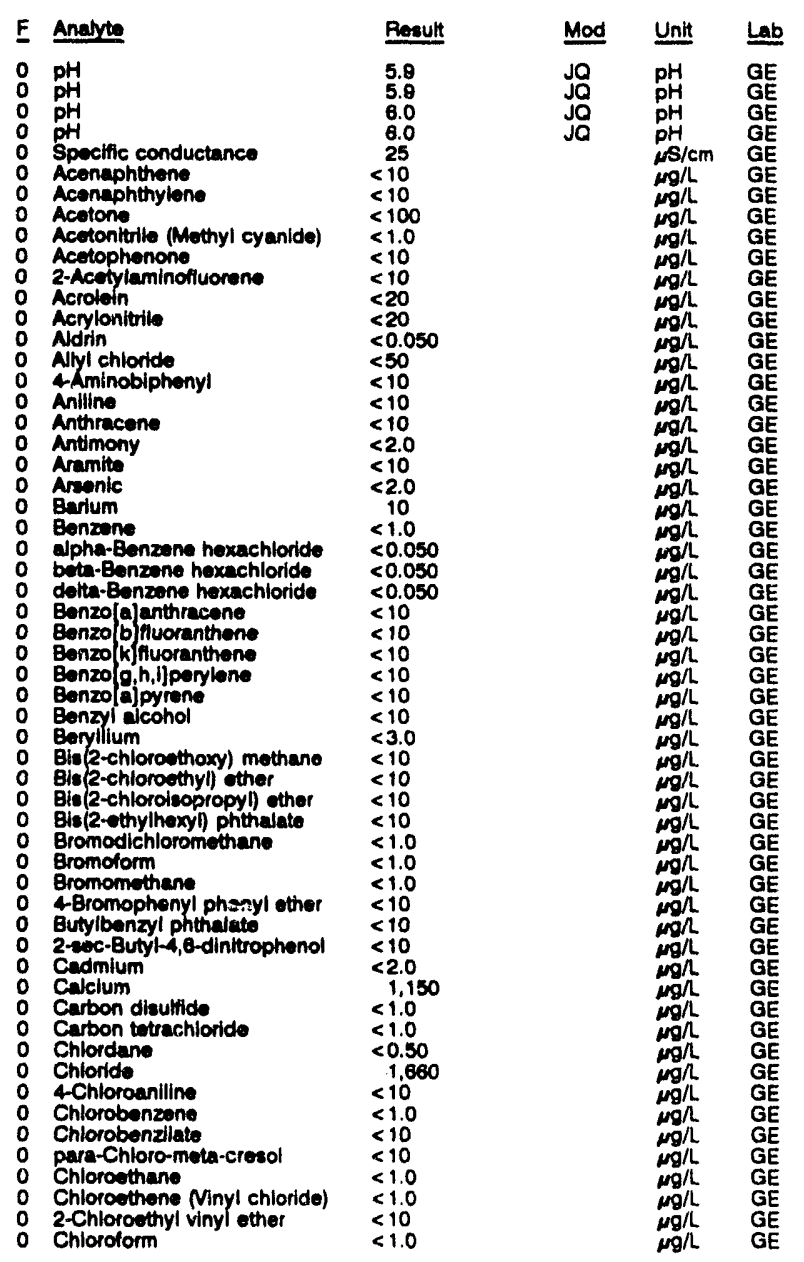

WELL BGX 100 collected on 07/30/92, laboratory analyses (cont.)

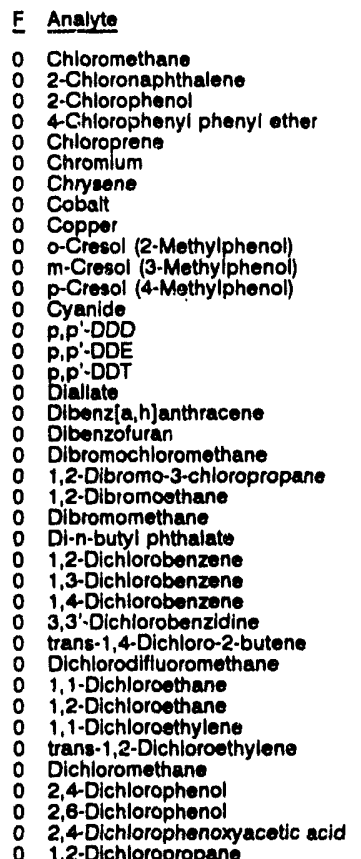

1,2-Dtchloropropano $<1.0$

cis-1,3-Dichloropropeno

trans-1,3-Dichloropropene

Diethyl phthalate

2,4-Dimethyl phenol

p-Dimethylaminaazobenzene

Bimethylibenzina]anthracene

3,3'-Dimethylbenzidine

a,a-Dimethylphenothylamino

1,3-Dinitrobenzene

2,4-Dinitrophenol

2, 2 -Dinitrotoluene

Di-n-octyl phthalate

1,4-Dioxane

Disulfioton

Endosulfan

Endooulfan sulfate

Endrin

Endrin aldehyde

E Ethyl mothanoulfionate

0 Ethylbenzene

Fluoranthene

Fluorene

0 Fluoride

Heptachlor

1,2,3,4,8,7,8-HPCDD

Heptachlorodibenzo-p-dioxins

Heptachlorodibenzo-p-furans

Heptachlorodibenzo-p-

Hexachlorobenzeno.

- Hexachlorocyclopentadiene

$0 \quad 1,2,3,4,7,8-H \times C D D$

0 Hexachlorodibenzo-p-dioxins

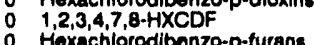

- Hexachloroothane

0 Hexachlorophene

0 Hexachloroprop

indenol $1,2,3-c, d]$ pyrento

- lodomothane (Mathyl lodide)

0 lsobutyi alcohol

- leodrin

0 isosatrole

o Kepone

Load

Lindane

2 Magnesium

0 Mercury
Rosult Mod Unit Lab

$<1.0$

$<10$

$<10$
$<200$

$<4.0$

$<10$
$<4.0$

$<4.0$

$<10$
$<10$

$<10$

$<0.10$

$<0.10$

$<10$

$<10$

$<1.0$

20

$<1.0$
$<10$

10

$<10$
$<10$

(1)

$<1,0$

$\leq 1.0$

$<1.0$

$<1.0$

$<10$

$\underset{\mu g / L}{\mu G} \mathrm{GE}$

GE

GE

$<10$
$<10$

$<10$

$<10$

$<10$

$<10$

$<45$

$<10$

$<10$

$<10$
$<10$
$<10$

$<10$

$<0.10$
$<0.10$

$<0.10$

$<0.10$

$<10$

$<10$

$<1.0$

$<10$
$<10$

$<100$

$<0.050$
$<0.050$

$<0.00065$

$<0.00085$

$<0.00045$

$<10$

$<10$

$<0.00045$

$<0.00045$

$<0.00040$

$<10$
$<10$

$<10$

$<1.0$
$<10$

$<10$
$<15$

6.8
$<100$

$<10$

$<10$
$<10$
$<10$

$<10$
$<3.0$

$<0.0050$

551

59
$<0.20$ 
WELL BGX 10D collected on 07/30/92, laboratory anaiyses (cont)

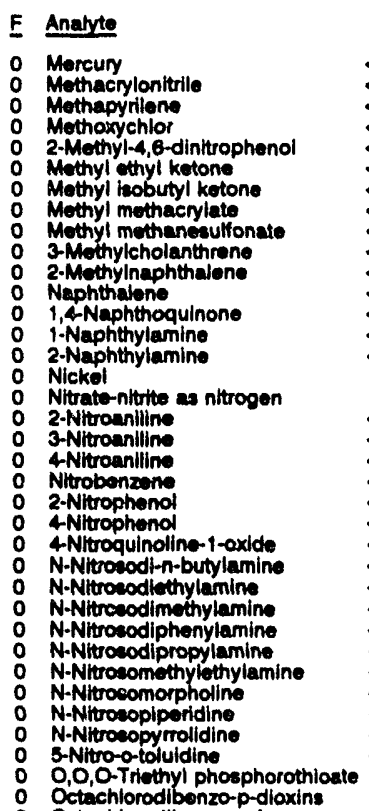

\begin{tabular}{|c|c|c|c|c|}
\hline Rosult & Mod & Unit & Lab & E Analyte \\
\hline $\begin{array}{l}<0.20 \\
<50 \\
<10 \\
<0.50 \\
<10 \\
<1.0 \\
<1.0 \\
<10 \\
110 \\
<10 \\
<10 \\
<10 \\
<10 \\
<10\end{array}$ & 32 & 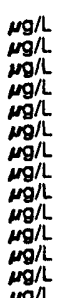 & $\begin{array}{l}G E \\
G E \\
G E \\
G E \\
G E \\
G E \\
G E \\
G E \\
G E \\
G E \\
G E \\
G E \\
G E \\
G E\end{array}$ & $\begin{array}{ll}0 & 2,4,5-\text { Trichlorophenol } \\
0 & 2,4,6 \cdot \text { Trichlorophenol } \\
0 & 2,4,5-T \\
0 & 1,23 . \text { Trichloropropane } \\
0 & 1,3,5-\text { Trinitrobenzene } \\
0 & \text { Vanadium } \\
0 & \text { Vinyl acetate } \\
0 & \text { Xylenes } \\
0 & \text { Zinc } \\
0 & \text { Gross alpha } \\
0 & \text { Nonvolatile beta } \\
0 & \text { Total alpha-emitting radium } \\
1 & \text { Tritium }\end{array}$ \\
\hline
\end{tabular}

WELL BGX 11D

Sp. conductance: $74 \mu \mathrm{S} / \mathrm{cm}$

LABORATORY ANALYSES
WELL BGX 10D collectod on 07/30/82, laboratory analyses (cont.)

Result
$<10$
$<10$
$<0.090$
$<1.0$
$<10$
$<8.0$
$<1.0$
$<2.0$
68
$2.5 E-09 \pm 6.6 \mathrm{E}-10$
$2.2 \mathrm{E}-09 \pm 5.8 \mathrm{E}-10$
$<1.0 \mathrm{E} \cdot 09$
$1.0 \mathrm{E}-05 \pm 5.0 \mathrm{E}-07$

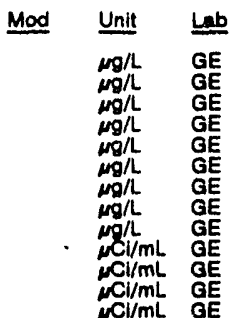

MEASUREMENTS CONDUCTED IN THE FIELD

Sample date: 07/31/82

Depth to water: $40.43 \mathrm{ft}(12.32 \mathrm{~m})$ below TOC

Water elovation: $235.87 \mathrm{ft}(71.89 \mathrm{~m}) \mathrm{msl}$

The mell want dn during pupling: 6 gal

durging:

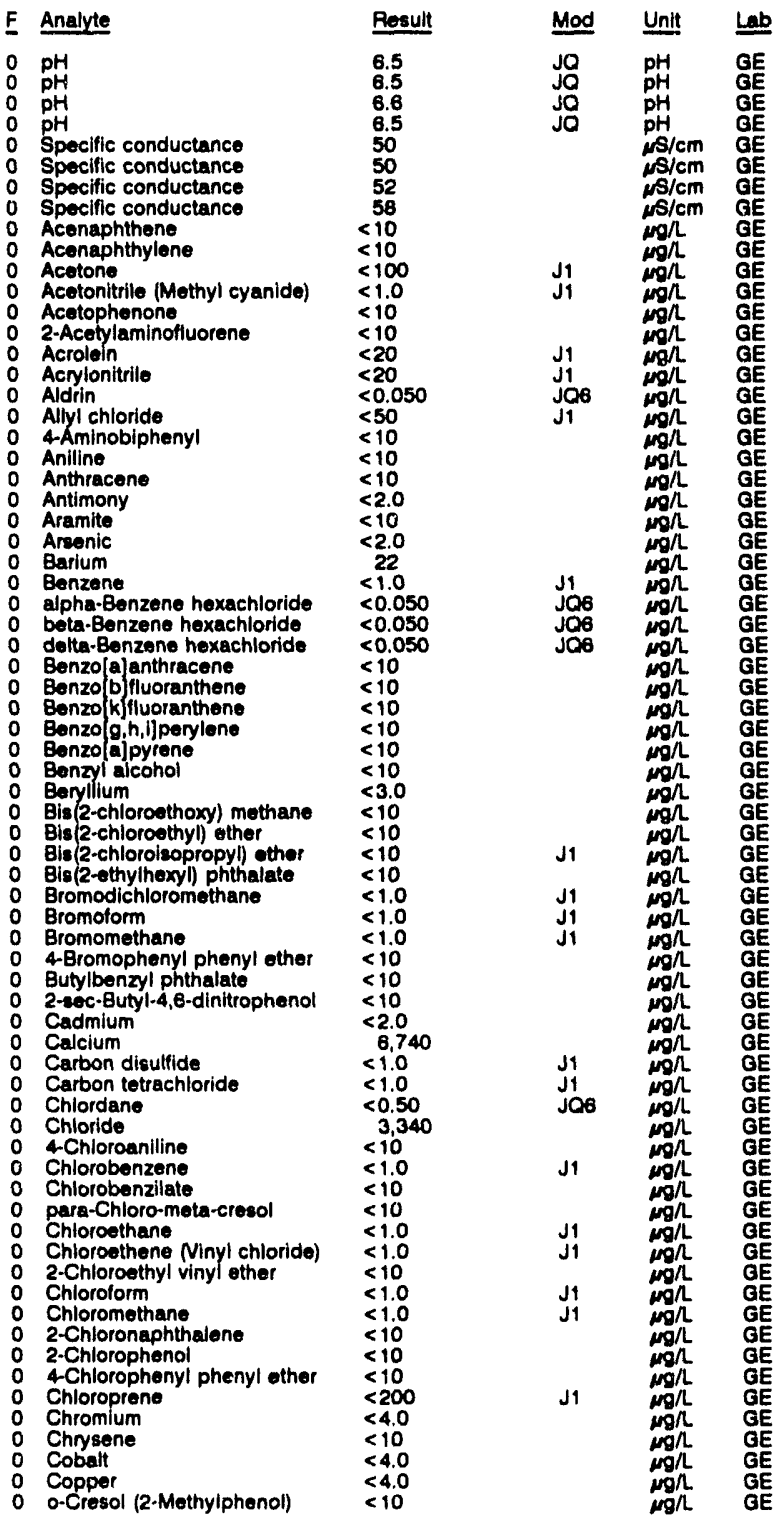

Time: 6:45

pH: 5.7 ikalinty: $15 \mathrm{mgn}$

Water temperature: $21.5^{\circ} \mathrm{C}$ 
WELL BCX 11D collected on 07/31/82, laboratory analyses (cont)

E Anabyte

: m-Crowol (a-Mathylphonol)

Cyanlo

P., POD

B Bilatiats

Dibenzla, h) enthracone

D Dibenzothun
D Dibromochloromethane
0 1,2-Dbromo-3-chloropropane

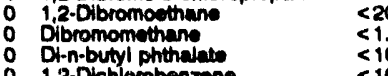

1,2-Dichlorobenzene $<10$

0 1,4-Dichlorobonzene $<10$

o trant-1,4-Dichloro-2-butene

Dichlorodithuoromethane

(1,-Dlodimuoromethan

: i, - Dichlorouthane

: 1,1-Dlehloroethylone

O Dechloromethane

2,4-Dichlorophend

2,4-Dichlorophenoxy acetic acid

1,2-Dichloropropane

o cie-1,3-Dichloropropen

o trane-1,3-Oidrin

Diethyl phthalate

o 2,4-Dimethyl phenol

O Dimethyl phthalate

p-Dimathylaminoazobonzene

3,3'-Dimethylbonzldine

o aimethylphonethy

1,3-Dinitrobenzene

2,4Dinituotoluen

2,e-Dinitrotoluens

1,4-Diaxant

Diphenylamin

O Endowulten I

O Endoeulfan II

O Endomultan

Endrin aldahyde

Ethyl mothacrylate

Ethyl methanesult

Famphur

Fluoranthen

Fluorem

O Fluoride

O Heptachlor

1,2,3,4,6,7,8-HPCDD

o $1,2,3,4,6,7,8-H P C D F-d i a x$

o Heptachlorodibenzo-p-turan

O Hoxuchlorobenzene

Hexuchlorobutadient

o Hexachlorogyclopent

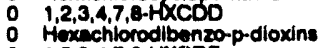

1,2,3,4,7,8-HXCDF-p-doxins

Hexcechlorodibenzo

o Hexachlorosthane

Hexachlorophene

2.Hexinon

indeno[1,2,3-c, d] pyrene

lodomethine (Mrethyl lodido)

Iron

2 leobutyl alcohol

o leodrin

o leosefrole

o Kopone

0 Loed

o Lindane

O Magneaium

O Manganes

Mothacrylonterile

Methecryloniterlo

Methapyribne

2-Mothyl-4,6-dinitropheno

Methyl ethyl ketone

Methyl leobutyl kolon

Methyl mothanosutionate

3-Methylcholanthron
Rosult

$<10$

$<5,0$

$<0.10$

$<0.10$

$<10$

10

-1
0

0

$<10$
$<10$
$<30$

$<10$
$<1.0$

$<1.0$

$<1.0$

$<1.0$
5.8
$<10$

$<10$

$<1.0$

$<1.0$

$<0.50$

$<10$
$<10$

$<10$

$<10$

$<10$
$<10$

$<10$

$<10$

$<10$

$<10$
$<10$

$<10$
$<10$

$<10$

$<0.10$
$<0.10$
$<0.10$

$<0.0060$

$<0.10$

$<10$
$<10$

$<1.0$

$<10$
$<10$

$<10$

$<0.050$

$<0.00085$

$<0.00085$

$<0.00045$

$<10$
$<10$

$<10$
$<0.00045$

$<0.00045$

$<0.00040$
$<0.00040$

$<10$
$<10$

$<10$
$<10$

$<1.0$
$<10$

$<10$
$<15$

$<100$
$<10$
$<10$

$<10$
$<10$

$<3.0$
$<0050$

710
20

$<0.20$
$<50$

$<10$
$<0.50$

$<0.50$
$<10$
$<1.0$
$<1.0$

$<10$

$<10$
$<10$
$<10$

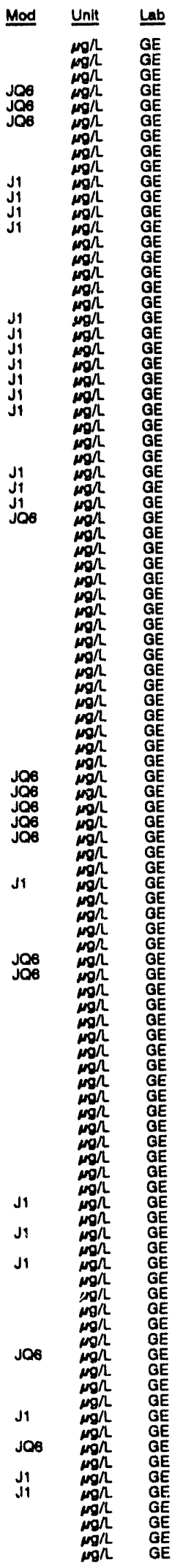

WELL BGX 110 collected on 07/31/82, laboratory analyees (cont.)

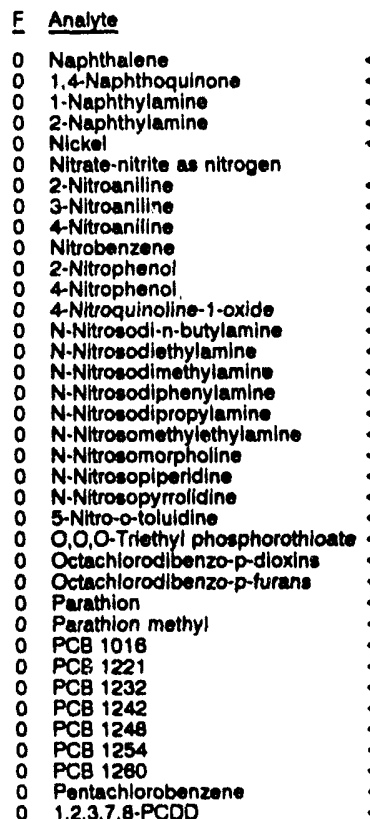

Besult Mod Unit Lيt

$<10$

$<10$

$<4.0$

2,380

$<10$

$<10$

$<10$

10

$<10$

$<10$

$<10$

$<10$

$<0.0010$

$<0.0010$

$<0.050$

$<0.50$

$<0.50$

$<0.50$

$<0.50$

$<10$

Pentachlorodibonzo-p-dioxins $<0.0005$

Pentachlorodibonzo-p-furans $\quad<0.00055$
$1,2,3,7,8-P C D F$

Pentuchioroethano

Pentachloronitrobenzene

Phenacetin

Phenaceln

Phenol

p-Phenylenediamine

Phorate

2.Picoline

Pronamid

Propiontrile

Pyrene

Syridine

Solienium

Sllica

Sodium

Sodium

- Sultato

Suffido

1,2,4,5. Tetrachlorobenzene

$2,3,7,8 . T C D D$
$2,3,8 . T C D E$

Totrachlorodibenzo-p-dloxine

Tetrachlorodibenzo-p-furans

1,1,1,2-Tetrachloroethane

1,1,2,2-Tetrachioroth

2,3,4,6-Tetrachlorophenol

Thallium

Thlonazin

o Tin

$\begin{array}{ll}0 & \text { Toluene } \\ 0 & \text { o.Toluidine }\end{array}$

o Total diseolved solide

Total organic carbon

- Total organic carbon

Tolal organic carbon

Total organic carton

Total organic carbon

o Total organic halogens

o Total organic halogens:

o Total phosphat

2,4,5-TP (Silvex)

o 1,2,4-Trichlorobenzene

o $1,1,1$-Trichloroethane

o $1,1,2$-Trichloroethan

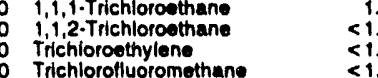

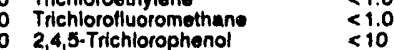

2,4,6-Trichlurophenol

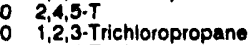

0
0
0 Vanadium
1,3,5-Trinitrobenzene

$<10$

$<10$

$<10$

$<10$

$<5.0$

$<0.10$

$<10$
$<34$
$<10$

$<200$

$<10$

$<10$

7.230
$<2.0$

$<2.00$

$<1.0$

$<1,000$

$<10$

$<0.00045$

$<0.00040$

$<0.00040$

$<1.0$

$<1.0$

$<10$
$<2.0$

3.1
$<1.0$
$<10$

$<10$

41,000
3,810

1,890

3,360
3,490

3,700

$<5.0$

$<5.0$

$<0.24$

$<10$

1.0

$<0.000$

$<0.000$
$<1.0$
$<10$
$<8.0$

$<8.0$

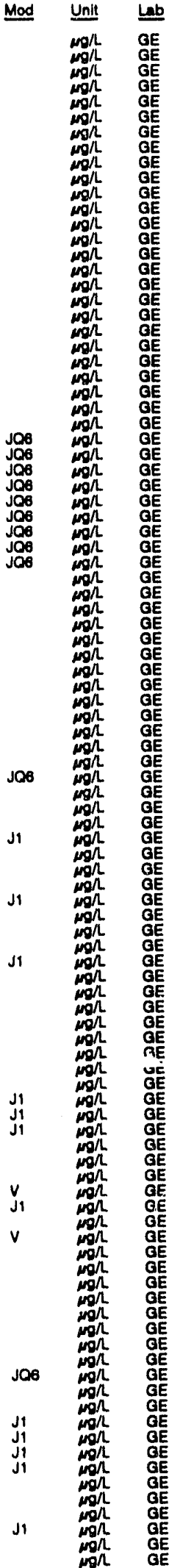


ANALYTICAL RESULTS

WEL BCX 110 collected on 07/31/92, leboratory analyees (cont)

\begin{tabular}{|c|c|c|c|c|c|}
\hline$F$ & Anclyte & Pesult & Mod & Unit & Lab \\
\hline & 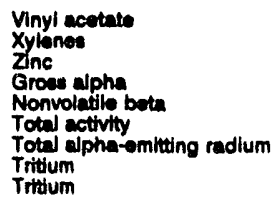 & $\begin{array}{r}<1.0 \\
<2.0 \\
57 \\
8.1 E-09 \pm 2.4 \mathrm{E}-09 \\
6.0 \mathrm{E}-09 \pm 1.8 \mathrm{E}-00 \\
1.0 \mathrm{E}-05 \pm 2.1 \mathrm{E}-00 \\
<1.0 \mathrm{E}-09 \\
1.0 \mathrm{E}-05 \pm 8.0 \mathrm{E}-07 \\
1.8 \mathrm{E}-05 \pm 8.0 \mathrm{E}-07\end{array}$ & $\begin{array}{l}\mathrm{J} 1 \\
\mathrm{~J} 1\end{array}$ & 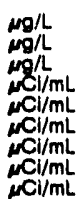 & $\begin{array}{l}\mathrm{GE} \\
\mathrm{GE} \\
\mathrm{GE} \\
\mathrm{GE} \\
\mathrm{GE} \\
\mathrm{EM} \\
\mathrm{GE} \\
\mathrm{GE} \\
\mathrm{GE}\end{array}$ \\
\hline
\end{tabular}

\section{WELL BGX 12C}

MEASUAEMENTS CONDUCTED IN THE FIELD

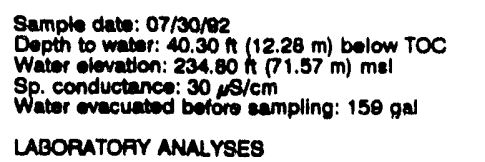

Time: $7: 40$

Alkalinity: $8 \mathrm{~mol}$

Water temperature: $20.5^{\circ} \mathrm{C}$

LABORATOAY ANALYSES

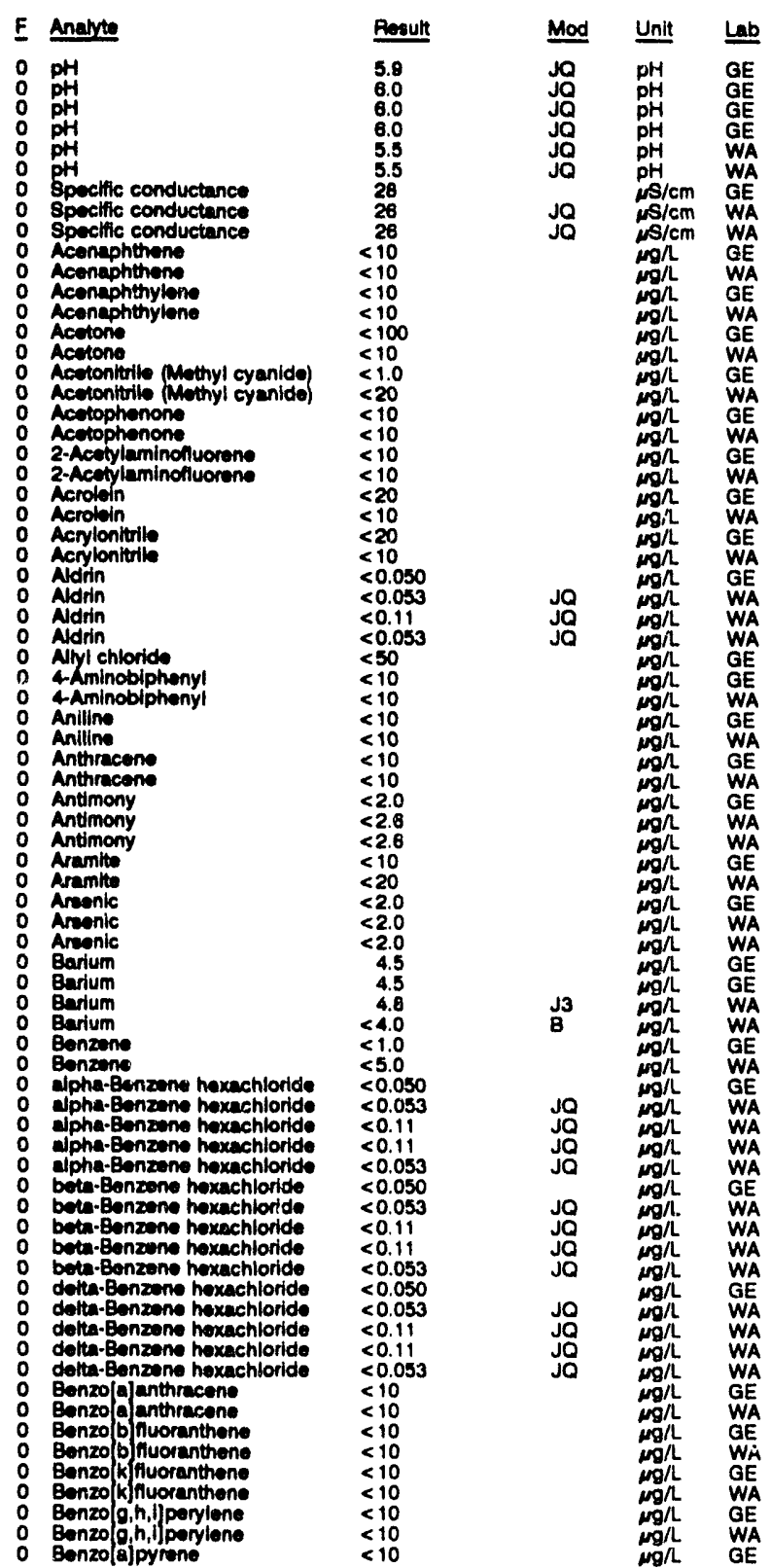

WELL BGX 12C colloctod on 07/30/92, laboratory analyses (cont.)

$\begin{array}{ll}\text { F } & \text { Analyte } \\ 0 & \text { Benzolajpyrene } \\ 0 & \text { Benzyl alcohol } \\ 0 & \text { Benzyl alcohol } \\ 0 & \text { Beryllium } \\ 0 & \text { Beryllium } \\ 0 & \text { Beryllium } \\ 0 & \text { Beryllium } \\ 0 & \text { Bis(2-chloroethoxy) methane } \\ 0 & \text { Bis 2-chloroethoxy) mothane }\end{array}$

Bis 2-chloroethoxy) mothane

Bis 2-chloroethyl) other

Bis(2-chloroisopropyi) ether

Bis(2-ethylhexyl) phthalate

Bis(2-othylhoxyl) phithalato

Bromodichloromethane

Bromotorm

Bromolorm

Bromomethane

4-Bromophonyl phenyl other

4-Bromophenyl phenyl ether

Butylbenzyl phthalate

2-eoc-Butyl-4,6-dinitropheno

2-eec-Butyl-4, 6-dinitropheno

Cadmium

Cadmium

Cadmium

Cadmium

Calclum

Calclum

o Carbon disulfide

- Carbon disulfido

- Carbon tetrachloride

o Chlordane

- Chlordane

O Chlordane

Chlordane

Chloride

4-Chlorouniline

4-Chlorouniline

O Chlorobenzene

o Chlorobenzene

O Chlorobenzilate

o para-Chloro-meta-cresel

para-Chloro-meta-cresol

Chloroothane

- Chloroethane

Chioroethene Ninyl chloride

Chloroethene Ninyl chloride

0 Chloroform

Chloroform

O Chloromethane

Chloromethane
2-Chloronaphthalene

2-Chloronaphthalene

2-Chlorophenol

2-Chlorophenol

4-Chlorophenyl phenyl ether

4 4-Chlorophenyl phenyl other

o Chloroprene

o Chloroprene

o Chloroprene

o Chromium

o Chromium

- Chromium

O Chromium

o Chryeene

0 Cobalt

O Cobalt

O Cobalt

O Cobalt

o Copper

O Copper

O Copper

o O-Cresol (2-Methylphenol)

0
0 0-Cresol (2-Methylphenol)

o m-Cresol (3-Methylphenol)

o m-Cresol (3-Methylphenol

m-Cresol (4-Methylphenol)
0
p-Cresol (4-Methylphenol)

0 Cyanide

0 Cyanido

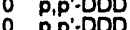

${ }_{0} \quad P^{2}, p^{\prime}-D D D$

O

$\begin{array}{ll}0 & p, p^{\prime} \cdot D D D \\ 0 & p, p^{\prime} \cdot D D E\end{array}$

$<10$

$<10$

$<3.0$

$<0.18$

$<10$

$<100$

$<10$
$\leq 10$
410

$<10$
$<10$

$<1.0$

$<1.0$

$\leq 1.0$

$<10$

$<10$

$<10$

$\leq 10$

$<2.0$

$<2.00$

20
$<0.35$
713

713
712
789
741
710

$<1.0$
$<5.0$

$<1.0$

$<5.0$

$<0.53$

$<1.1$

2,210
2,520

$<10$
$<10$
$<10$

$<1.0$

$<10$

$<100$

$<10$

$<1.0$

$<<1.0$

$<10$

$<5.0$

$<1.0$

$<10$

$<10$

$<10$
$<10$

$\leq 10$

$<20$

$<4.0$

$<4.0$

$<10$

$<4.0$

$<4.0$

$<0.88$

$<4.0$

$<1.1$

$<1,1$

$<10$

$<10$

$<10$

$<5.0$

$<0.10$

$<0.22$

$<0.22$
$<0.11$

$<0.11$

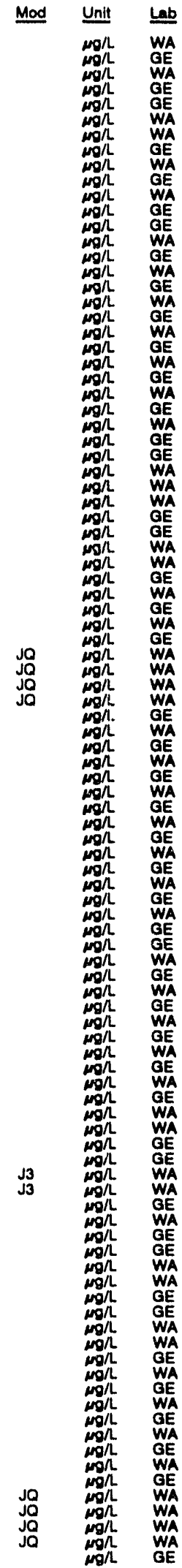


WELL BGX 12C collected on 07/30/92, laboratory analyese (cont)

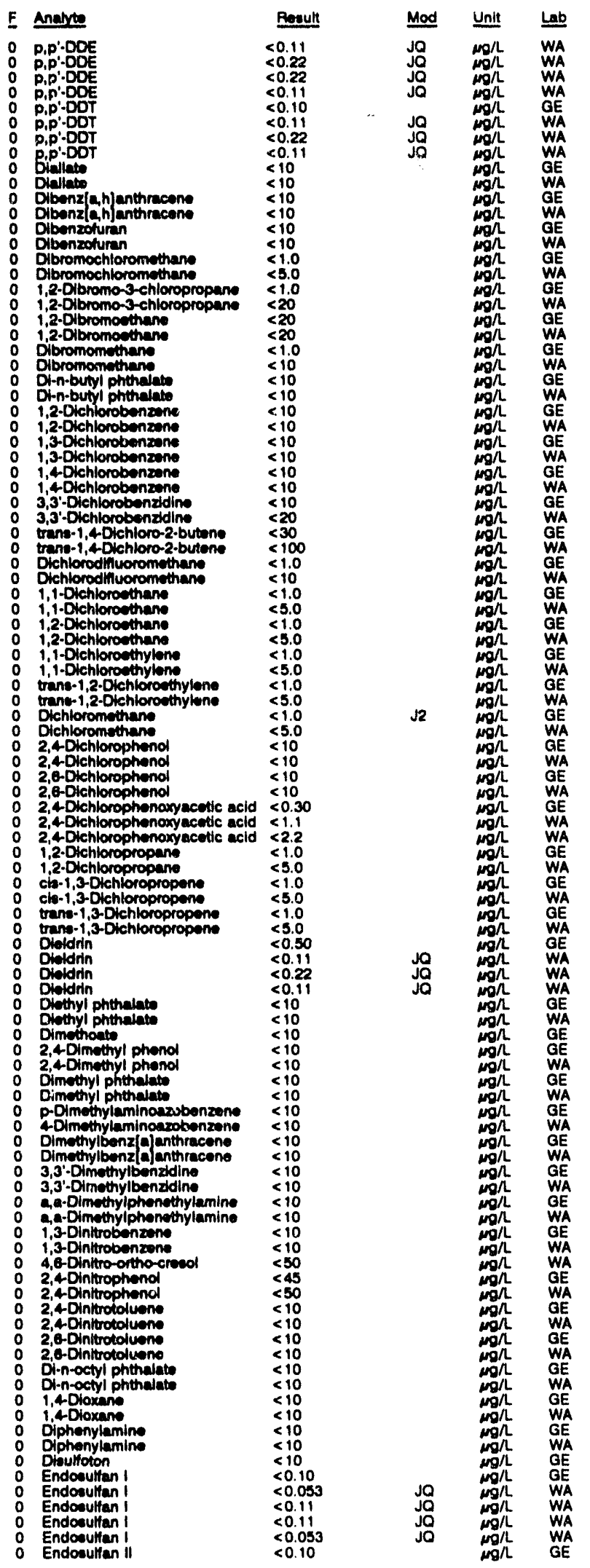

WELL BGX 12C collected on 07/30/82, laboratory analyses (cont.)

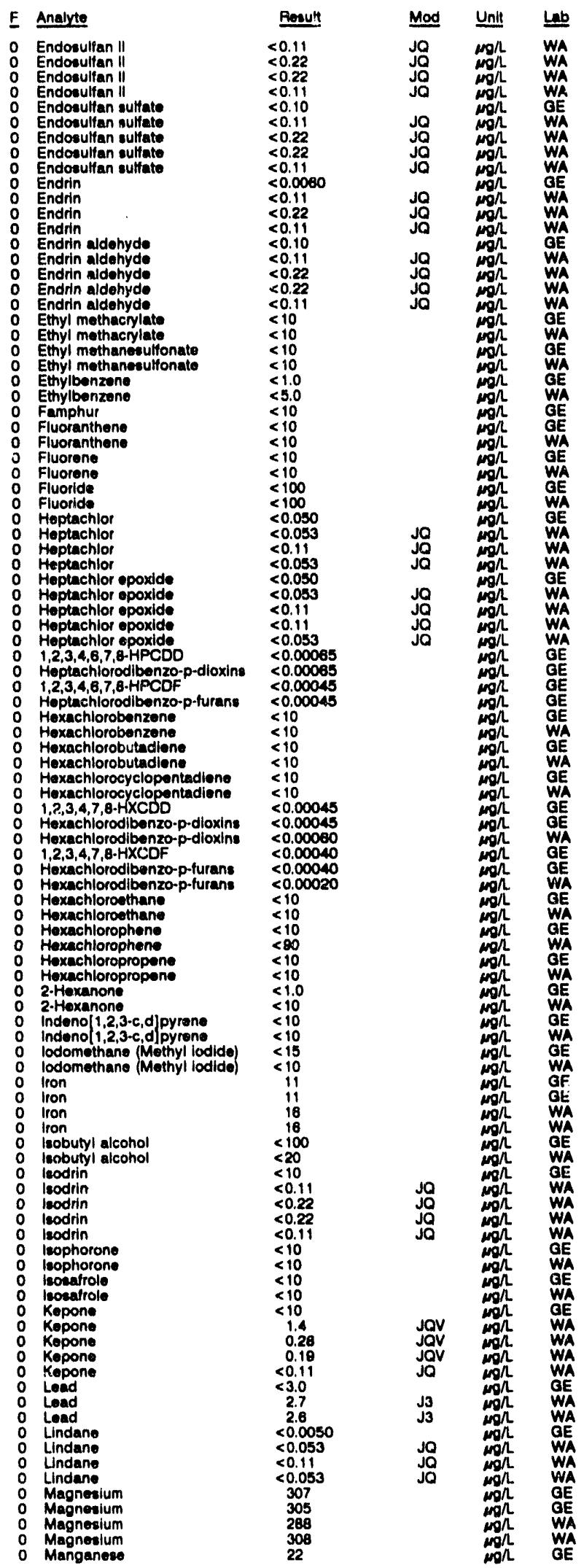


ANALYTICAL RESULTS

WEL. BGX 12C collected on 07/30/92, laboratory analyses (cont)

E Anelyo

O Manganeces

o Manganece

0 Moreury

O Methecrylonitrile

Mrthacylonitril

o Methapyritene

o Mathonychlor

Methanychior

Methasychlor

2-Mothyt-4,6-dinitrophenol

Methyl ethyl ketione

- Methyl ibobutyl ketone

Methyl methecrylato

Muthyl methanceulfonate

4-Awhyl-2-pontanone

3-Methylcholanthrene

3-Awthylcholanthrene

2-Methylnaphthalens

o Nephthalono

1,4-Neshthoquinone

- 1,4-Nephthoquinone

1-Naphthylamino

o 2-Naphthylanine

2-Naphthylamino

0 Nicket

o Nickel

o Nickel

- Nitrate as nitrogen

Nitude-nitstio al nitrogen

2-Nitroaniline

3-Nltroanliline

3-Nltroanilline

4Ntroaniline

o Nitrobenzen

o Nitrobenzane

2-Nitrophenol

2-Nltuophenal

4 Nituophenol

4Ntroquinoline-1-axide

4Nitroquinoline-1-oxdde

N-Nitrocodit-n-butylamine

N-Nitrocodicthylamine

N-Nltroeodiethylamine

N-Nitrosodimithylamino

N-Nitrosodiphemylemine

N-Nitrosodiphenylamine

N-Nitrosodipropylamine

N-Nitrocedipropylamine

N-Nitroemethylethylamine

o N-Nitrosomorpholine

N-Nitrosomorpholin

N-Nitrosopiperldine

N-Nuroeopymoldine

N-Nitrosopyrrolidin

5-Nuro-ofoluidine

5-Nitro o-toluidine

o, o, - riothyl phosphorothloat

$\begin{array}{lll}0 & \text { Octachlorodibenzo-p-dloxins } \quad<0.001 \\ 0 \text { Octachlorodibenzo-p-furans } & <0.0010\end{array}$

0 Parattion methyl

O Paration 1018

P PCB 1016

0 PCB 1018

o PCB 1018

o PCB 1221

0 PCB 1221

PCB 1221

0 PCA 1221

O PCB i232

- PCB 1232

PCA 1232

PCB

PCB 1242

PCB 1242

PCB 1242
PCB 1242

\begin{tabular}{l} 
Result \\
\hline 22 \\
21 \\
22. \\
$<0.20$ \\
$<0.20$ \\
$<50$ \\
$<20$ \\
$<10$ \\
$<10$ \\
$<0.50$ \\
$<0.53$ \\
$<1.1$ \\
$<1.1$ \\
$<0.53$ \\
$<10$
\end{tabular}

$<1.0$

$<10$

$<10$

$<10$

510
$<10$
510

$<10$

$<10$

$<10$

$\leq 10$

$<10$
$<10$
$<10$

$\leqslant 10$

$<10$
$<10$
$<10$

$<10$
$<10$

$\leq 4.0$

$<4.0$

$<3.1$

180

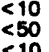

$<10$

$<10$

$<50$

$\leq 10$

$<10$
$<10$
$<10$

$<50$

$<10$

$<10$

$<10$

$<10$

$<100$

$\leq 10$

$<10$

$<10$

$<10$

$<10$

$<10$

$<10$

$<10$

10

$<0.0010$
$<0.0010$

$<0.050$

$<0.50$

$<0.53$
$<1.1$
$<1.1$

$<0.53$
$<0.50$
$<0.53$

$<1.1$

$<0.53$

$<0.53$

$<1.1$

$<0.53$

$<0.50$

$<0.53$

$<1.1$

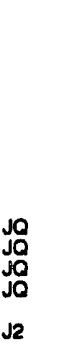

Mod Unit Lub

mon GE

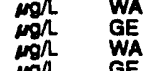

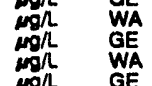

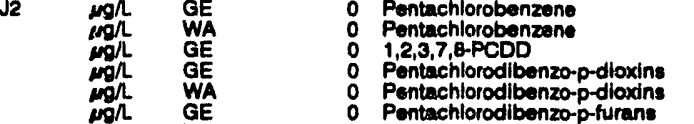

Pentachlorodibenzo-p-furan

Pentachlorodibon

Pentachloroethene

Pentachloroethane

Pentachloronitrobenzene

Pentachlorophenol

Pentachlorophenol

Phenacetin

Phemanthrene

Phenanthrene

Phenol

Phenol

Phenols

Phenols

p-Phonylenediamine

p-Phenylonodiamine

2-Picolline

2-Picoline

2-Picoline

Potaceium

Potassium

Potsasium

Pronamida

Propionitrile

Pyrene

Pyrene

Pyridine

Safrole

Safrole

Selenlum

Selonium

Sillice

silica

Sillica

Sitver

Sitver

Silver

Sodium

Sodium

Sodium

Styrene

Styrene

Sulfate

Sulfate

Sulfide

Sutifide

1,2,4,5-Tetrachlorobenzene

2,3,7,8-TCDD

2,3,7,8-TCD:

Totrachlorodibenzo-p-dioxin:

Tetrachlorodibenzo- diaxine

Tetrachlorodibenzo-p-furans

Tetrachlorodibenzo-p-furans

1,1,1,2-Ietrachloroethane

1,1,1,2-Tetrachloroethane

1,1,2,2-Tetrachloroethan

Totrachloroethylene

2,3,4,6-Tetrachloropheno

2,3,4,6-Tetrachloropheno

Thallum

o Thallium

Regult Mod Unit Lat

$<0.50 \quad$ Jo $\log \Omega$ GE

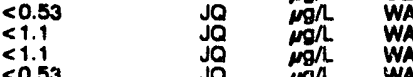

$<0.53$ JO ${ }_{<0.50}$ Mg WA

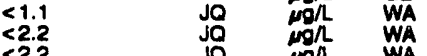

$<1.2$ Ja $\mathrm{mg}^{<1.1} \mathrm{WA}$

$<0.50$

$<2.1$

$<2.2$

$<10$

$<0.00055$

$<0.00055$

mon

$<0.00000 \quad$ mog GE

$<0.00055$ <10

$<10$

$<50$

$<10$

$<50$

$<10$

$<10$

$<10$
$<10$

$<5.0$

$<5.0$

$<5.0$

$<10$

$<0.10$

$<10$

$<500$
$<500$

655
498
$<10$

$<10$

$<200$

$<10$

$<10$

$<10$

$<10$

$<2.0$

$<2.0$

$\begin{array}{llll}12,100 & V & \text { mgl } & \text { GE } \\ 12,100 & V & \text { Ge } \\ 10,800 & & \text { Wh } & \text { WA }\end{array}$

$\begin{array}{r}11,400 \\ \hline\end{array}$

$<2.0$

$<0.70$

$<0.70$

3,8500
3,940

3,840

4,020

$<5.0$

1,620
$<2,500$

$<1,000$

$<100$

$<10$

$<10$

$<0.00045$

$<0.00040$

$<0.0040$

$<0.00045$

$<0.00040$

$<0.00080$

$<1.0$

$<1.0$

$<5.0$

$<5.0$

$<10$
$<10$

$<10$

$<2.0$
$<2.0$
$<2.0$ 
WELL BCX $12 C$ collected on 07/30/82, laboratory analyese (cont)

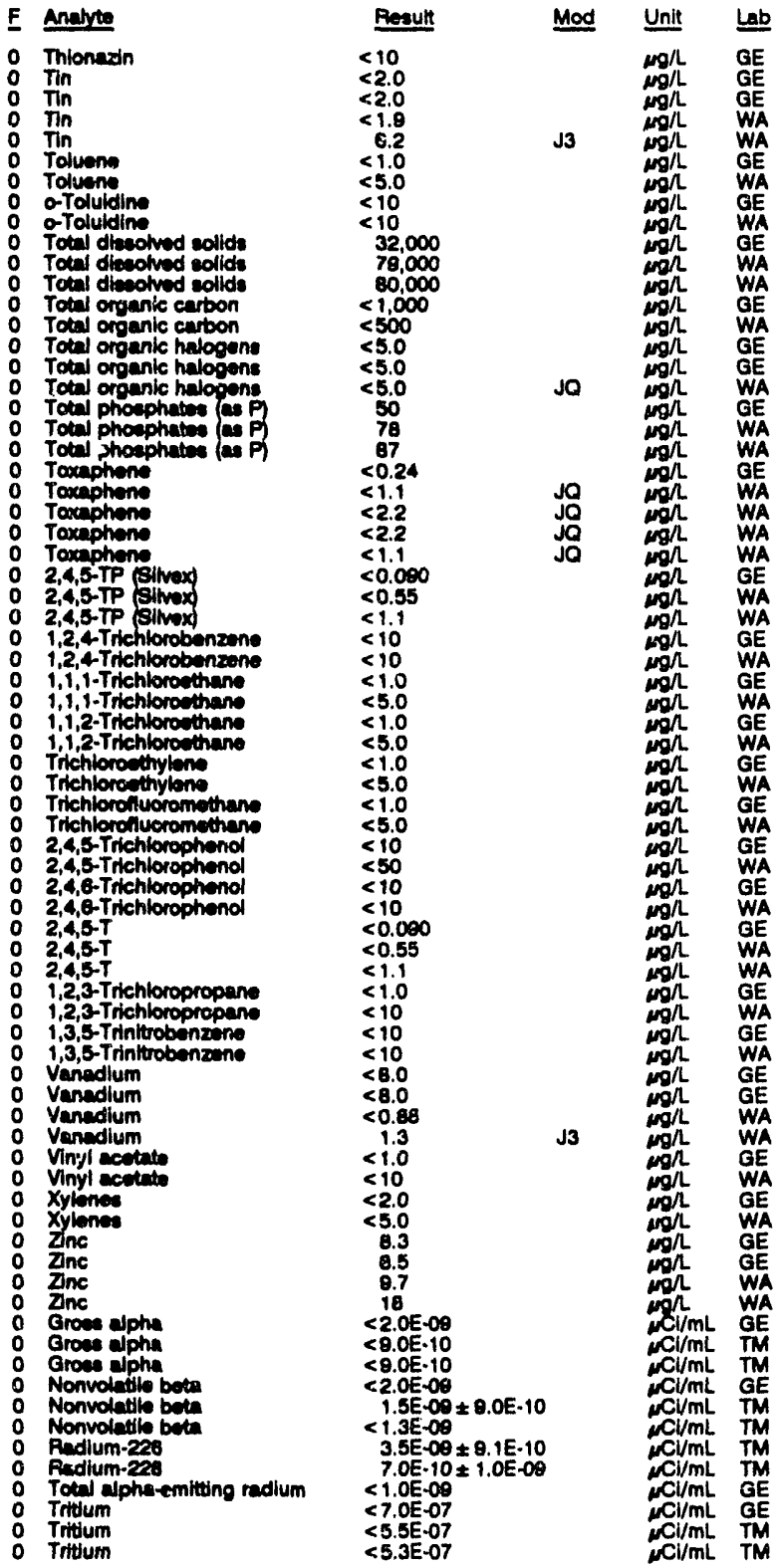

\section{WELL BGX 12C Replicate} MEASUREMENTS CONOUCTED IN THE FIELD

Samplo detas: 07/30/32 Depth to walis: $40.30 \mathrm{ft}(12.28 \mathrm{~m})$ below TOC Water elevation: $234.80 \mathrm{~h}$

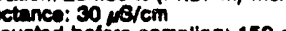

LABORATOPY ANALYSES

\begin{tabular}{|c|c|c|c|c|c|}
\hline E & Analyte & Posult & Mod & Unit & Lab \\
\hline $\begin{array}{l}0 \\
0 \\
0 \\
0 \\
0 \\
0 \\
0 \\
0 \\
0\end{array}$ & $\begin{array}{l}\text { pH } \\
\text { pH } \\
\text { pH } \\
\text { pH } \\
\text { Opecific conductance } \\
\text { Specticic conductance } \\
\text { Acenaphthone } \\
\text { Aconaphthene } \\
\text { Acensphthylone } \\
\text { Acensphthylene }\end{array}$ & $\begin{array}{r}6.0 \\
6.1 \\
6.1 \\
5.8 \\
30 \\
28 \\
<10 \\
<10 \\
<10 \\
<10\end{array}$ & $\begin{array}{l}\text { JO } \\
\text { Jo } \\
\text { JO } \\
\text { JO } \\
\text { Jo }\end{array}$ & $\begin{array}{l}\mathrm{pH} \\
\mathrm{pH} \\
\mathrm{pH} \\
\mathrm{pH} \\
\mathrm{pH} / \mathrm{cm} \\
\mathrm{\mu S} / \mathrm{cm} \\
\mathrm{mgh} \\
\mathrm{mgh} \\
\mathrm{mgh} \\
\mathrm{mgh}\end{array}$ & $\begin{array}{l}\text { GE } \\
G E \\
G E \\
\text { WA } \\
G E \\
\text { WA } \\
\text { GE } \\
\text { WA } \\
\text { GE } \\
\text { WA }\end{array}$ \\
\hline
\end{tabular}

WELL BGX 12C collected on 07/30/92, taboratory analyees (cont)

F Analyte

Acotone

Acelone

Acotone

Acotonitrile (Mothyl cyanide

Acolonitrile Mothyl cyanide

Acetonitrile (Methyl cyanide

Acetonitrite (Methy

Acotophenone

2-Acetylaminofluorent

2-Acetyiaminofluorene

Acrolein

- Acroleln

- Acrolein

Acrylonitrile

Acrylonitrile

Acrylonitrile

o Acrylon

0 Aldrin

- Aldrin

O Alyl chloride

4-Aminobipheny

o Animino

0 Aniline

0 Anthracene

- Anthracene

Antimony

Antimony

o Aramite

0 Aramite

0 Arrenic

O Aratium

O Barium

Bonzono

Bonzane

Benzone enzene hexachloride

alpha-Bonzens hexachtoride

alpha-Benzene hexachloride

apha-Benzene hoxachloride

beta-Benzene hexac

bota-Benzene hexachlorido

beta-Benzene hexachloride

deltz-Banzene hexachloride

delta-Bonzene hexachlonide

dela-Bonzeno hoxachloride

Benzo[ a anthracene

Benzo blunace

Benzolbfivoranthene

Benzo k f fuoranthene

Benzo (k)fluoranthene

Bonzolg,h, , perylone

Benzo $\left.g h_{1}, i\right)$ perylene

Bonzo pyreno

Benzola pyrene

Benzyl alcohol

Benzyl alcoh

Biyllum

Ging

Bise(2-chloroethyl the

Bia (2-chloroisopropyl) ether

Bis 2-othylhoxyl) phithalate

Bromodichlorometharie

Bromodichloromnthane

Bromodichlorometnane

Bromodichloromethane

Bromolorm

Bromolom

Bromolom

Bromomethane

Bromomethen

Bromomethane

Bromomethane

4-Bromophenyl phenyl ether

4-Bromophenyl phenyl the

Butylbenzy! phthalate

Butylbenzyl phthalate 2-ecc-Butyl-4,6-dinitropheno

Cadmium

Cadmium

Calcium

Carbon disulfide

Garbon disulfide

Carbon disulfide

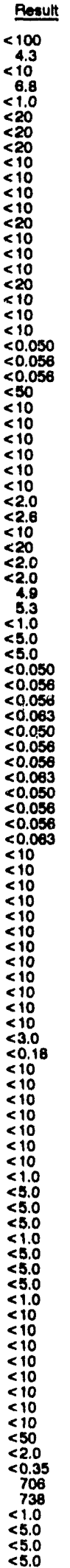

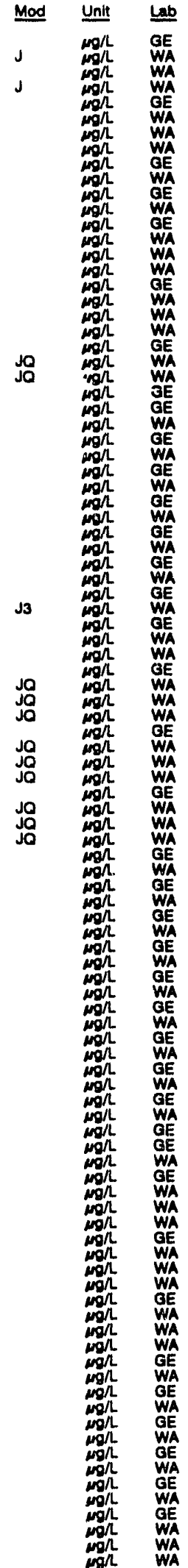


ANALYTICAL RESULTS

WELL BQX $12 C$ colloctod on 07/30/82, laboratory analyses (cont)

E Aneyte

C Carbon totrachionide

O Carbon trachionido

- Carbon tatrechloride

Chlordane

Chlordane

Chloride

Chloride

- 4-Cribroanilin

Chiorobenzens

Chlorobenzon

Chlorobenzalat

para-Chloro-meta-eresol

para-Chloro-mata-cresol

Chlorecthane

Chloroethan

Chloroethan

Chloroethan

Chlorothene Ninyl chloride)

Chlorcethem Ninyl chlorido

Chlorocthene Vinyl chloride

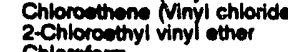

Chloroform

Chioroform

Chtorotorm

Chloromethan

Chloromethan

Chloromethan

2-Choronaphthelone

2-Chloronaphthelen

2-Chlorophenol

4-Chiorophenyl phenyl ther

4 Chlorophenyl phenyl ther

Chloroprene

Chloroprene

Chloroprene

Chloroprene

Chloropren

Chromlum

Chromium

Chryeans

Cobart

Cobalt

Copper

o-Cresol R-Methylphenol

o-Cresel (2-Methylphenol

m-Cresol (3-Methylphenol)

p-Cresol 4 Muthylohenof

p-Cresel (4-Aldhylphenel

Cyanida

o p,p'-DOD

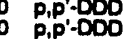

O p,p'-DDO

p.p.po

P,

O P,P'-DDE

P,P'-DDE

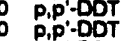

0 p,P'DOT

Ointate

Oibenz;a,h]enthrecene

Dibonz $(a, h)$ enthraceno

Dibenzoturan

Dibromochloromethane

Dibremochloromethane

Dibromochloromethane

1,2-Dibromo-3-chioropropan

1,2-Dibromo-3-chlorepr

1,2-Dibromo-3-chloropropan

1,2-Dibromo-3-chloropropane

1,2-Dibromoethane

1,2-Obromoethan

1,2-Obromoethan

1,2-Dibromoethe

o Dibromomethane

Dibromomethane

Dibromomethane

Di-n-butyl phthalate
$<1.0$

$<5$

$<5.0$

$<0.50$

$<0.58$

2,240
2,510

$<10$

$<1.0$

$<5.0$

$<10$

$<10$

$<10$

$<10$

$<10$

$<10$

$<10$

$<1.0$

$<5.0$

$<1.0$

$<10$
$<10$

$<10$
$<10$

$<10$

$<10$

$<10$

$<200$

$<20$
$<20$

$<20$

$<4.0$
2.5
$<10$

$<10$
$<4.0$

$<0.80$

$<1.1$

$<10$
$<10$
$<10$

$<10$

$<10$
$<5.0$

$<0.10$

$<0.11$

0.1

$<0.13$

$<0.11$

510

$<10$

$<10$
$<10$

$<1.0$

$<5.0$

$<1.0$

$<20$

$<2$
$<20$

$<20$

$<10$

$<10$
$<10$
WELL BGX $12 \mathrm{C}$ collected on 07/30/82, laboratory analyses (cont.)

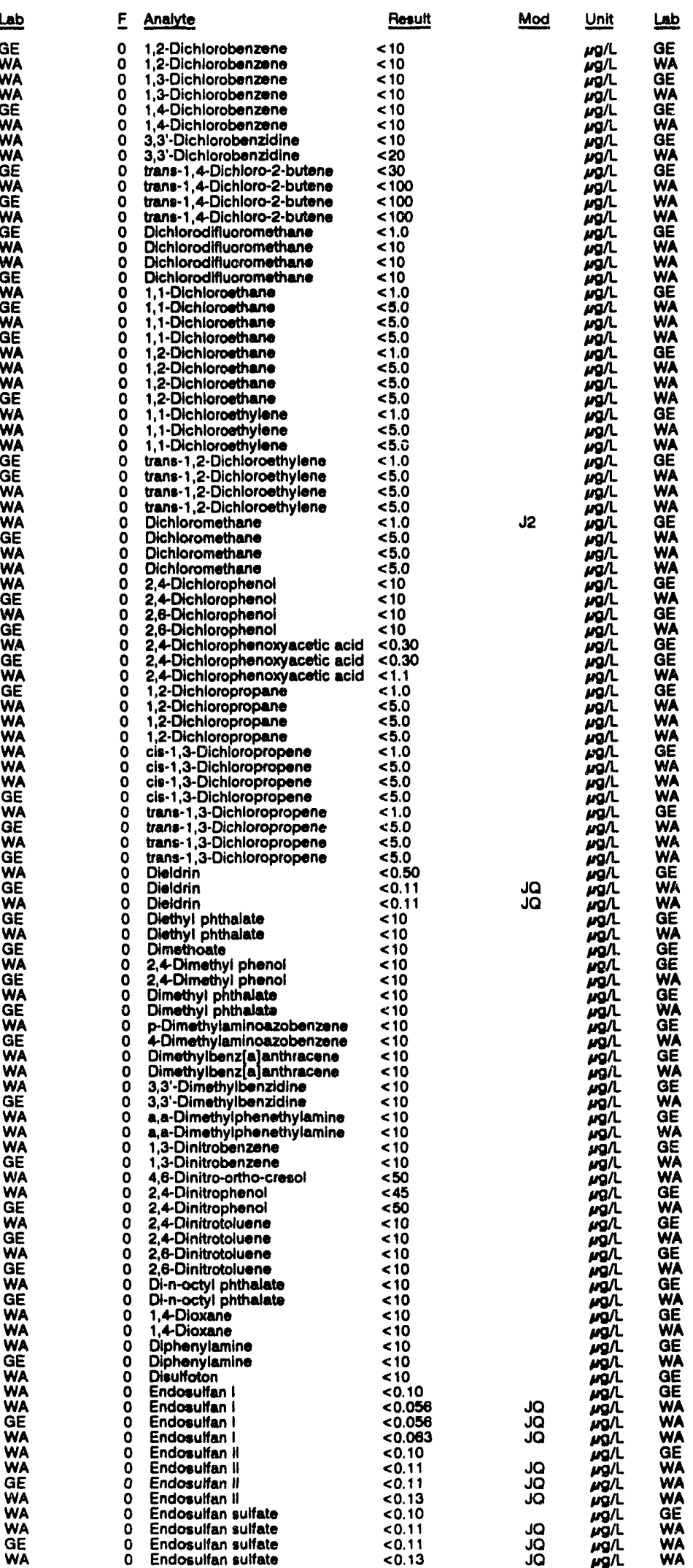

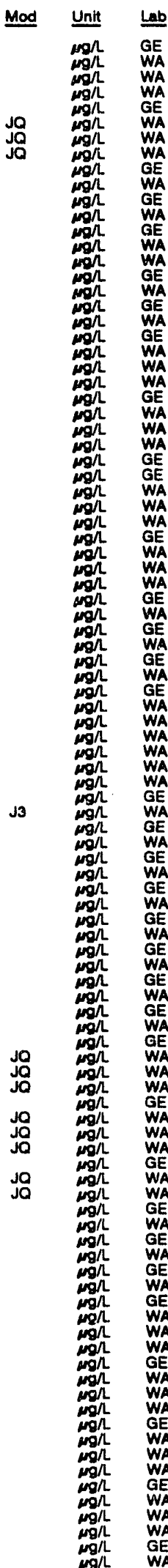


ANALYTICAL RESULTS

WELL BGX 12C collected on 07/30/82, laboratory analyese (cont.)

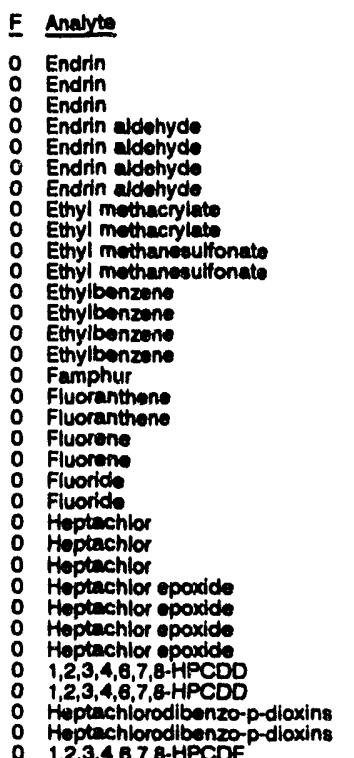

o $1,2,3,4,6,7,8-H P C D F$

1,2,3,4,6,7,8-HPCDF

Hoptachlorodibenzo-p-turans

Hoxachlorobenzente

Hexachlorobutadiene

Haxachlorobutadiene

Hexachlorocyclopentadiene

$1,2,3,4,7,8-1 \times C D D$

Hexpechiorodibenzo-p-diondns

Hoxachlorodibenzo-p-dioxins

$1,2,3,4,7,8+x C D F$

$1,2,3,4,7,8-H X C D F$
Haxachiorodibenzo-p-turan

Hexachlorodibenzo-p-furans

Hexischlorodlbonzo-p-fy

Hexchlorowhan

Hexachlorophene

Hexachlorophene

Hoxachloropropene

2.Hexanone

2-Hoxinon

2.Hexanone

Indeno[1,2,3-c,d]pyren

Indono $[1,2,3-c, d]$ pyrene

lodomethan whethyl lodida)

lodomethane Methyl lodide

lodomethane (Methyl lodide)

Iron

lion

leobutyl alcohol

laobutyl aconol

0 bodrin

boodin

leodrin

leophorone

bophorone

leceatrol

Kopone

Kopone

Kopono

Load

Lindane

Undane

Magnealum

Magnealum

Mangances

Manganoso

Mercury

Methacrylonitrile
$<0.0060$

$<0.11$

$<0.10$

$<0.11$
$<0.11$

(10

$<10$

$<5.0$

5.0

$<10$

$<10$

$<100$

$<100$

s.t.

$<0.058$

$<0.056$

$<0.056$

0.00095

$<0.00085$

$<0.00065$

$<0.00045$

$<0.00045$

$<10$

$<10$

$<10$

$<10$

$<10$

$<0.00045$

$<0.00045$

$<0.00045$

$<0.00040$

$<0.00040$

$<0.00040$

$<0.00040$
$<0.00020$

$<10$

$<10$

$<90$

$<10$

$<10$

$<1.0$

$<10$

$<10$

$<10$

$<15$

$<10$

$<10$

$<10$
8.4
18

$<100$

$<20$
$<20$
$<20$
$<20$

$<20$

$<0.11$

$<0.13$

$<10$
$<10$
$<10$

$<10$
$<10$

$<10$
$<10$
$<10$

$<10.11$

$<0.11$

$<0.13$

$<3.0$
3.2
$<0.0050$

$<0.056$

308
280
22

$<0.20$

$<0.20$

$<50$
$<20$

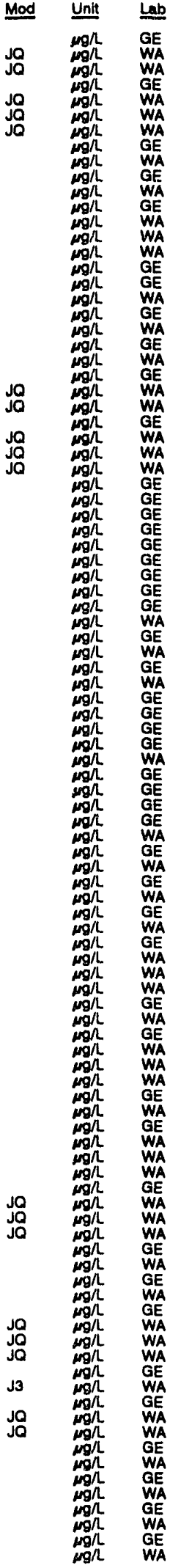

WELL BGX $12 \mathrm{C}$ colloctod on 07/30/82, laboratory analyses (cont.)

\begin{tabular}{|c|c|}
\hline Pescult & Mod \\
\hline $\begin{array}{l}<20 \\
<20 \\
<10 \\
<10 \\
<0.50\end{array}$ & \\
\hline $\begin{array}{l}<0.56 \\
<0.56 \\
<0.63 \\
<10\end{array}$ & $\begin{array}{l}\text { JQ } \\
\text { JQ } \\
\text { JQ }\end{array}$ \\
\hline $\begin{array}{l}<1.0 \\
<10\end{array}$ & $\sqrt{2}$ \\
\hline
\end{tabular}

Methacrylonitrite

Methacrylonitrilo

Methapyrilen

Methoxychlor

Mothoxychlor

Methoxychlor

- 2-Mothyl-4,6-dinitrophenol

o Methyl othyl ketone

Methyl othyl kotone

Methyl ethyl ketone

Mothyl isobutyl kotone

Mothyl methacrylate

Methyl methacrylate

Mothyl methanesulfonate

Methyl methanesulfonato

4 Methyl-2-pentanone

0 4-Methyl-2-pentanone

4-Mothyl-2-pentanone

3.Mothylcholanthreno

D Muthe

2-Methyinaphthaione

0 Naphthalene

O Naphthutene

o 1,4Naphthoquinone

0 1.Naphthylamine

o 1-Naphthylamine

o 2-Naphthylamine

o 2-Naphthylamine

N Nickel

N Nickel

Nitrate as nitrogen

2-Nitroaniline

2-Nitroaniling

3-Nitroaniline

o 3-Nitroaniline

- 4-Nitroaniline

O 4 Nitroaniline

o Nitrobenzene

o 2-Nitropheno

o 2-Nitropheno

o 4Nitropheno

4 Nitropheno

4-Nitroquinoline-1-oxide

4Nitroquinoline-1-oxide

N-Nitrosodi-n-butylamine

N-Nitrosodi-n-butylamino

N-Nitrosodiethylamine

N-Nitrosodimethylamine

N-Nitrosodimethylamine

N-Nitrosodiphenylamine

N-Nitrosodiphenylamine

N-Nitrosodipropylamine

N-Nitrosodipropylamine

o N-Nitrosomethylethylamine

N N-Nitrosomethylethylarmin

N-Nitrosomorpholine

N-Nitrosomorpholine

N-Nitrosopiperidine

N-Nitrosopyrrolidine

N-Nitrosopyrrolidin

5-Nitro-a-toluidine

$<1<10$

Octachlorodibenzo-p-dioxins

Octachlorodibenzo-p-dloxins

Octachlorodibenzo-p-furans

Parathion

- Parathion methyl

0 PCB 1016

0
0 PCB 1016

O PCB 1016

- PCB 1016

PCB 1221

PCB 1221

PCB 1221

PCB 1232

PCB 1242

- PCB 1242

PCB 1242

PCB 1242

PCB 1248

PCB 1248

PCB 1244

PCB 1248

$\begin{array}{lll}0 & \text { PCB } 1254 \\ 0 & \text { PCB } 1254\end{array}$

$<1.0$

$<10$
$<10$

$<10$

$<10$
$<10$

$<10$
$<10$

$<10$

$<10$

$<10$
$<10$

$<10$

$<10$
$<10$

$<10$
$<10$

$<10$
$<10$

$<4.0$

$<3.1$
165

180

$<10$
$<50$

$<10$

$<10$

$<50$

$<10$

$<10$
$<10$

$<50$

$<10$

$<10$

$<10$

$<10$
$<10$

$<10$

$<10$

$<10$
$<10$

$<10$
$<10$

$<10$

$<10$
$<10$

$<50$

10

$<10$
$<10$

$<0.01$

$<0.0010$

$<0.0010$

$<0.050$

$<0.050$

$<0.56$

$<0.56$
$<0.56$
$<0.63$

$<0.63$

$<0.58$

$<0.56$

$<0.50$

0.5

$<0.56$

$<.65$

$<0.50$

$<0.56$

$<0.63$

$<0.56$

$<0.56$

$<0.63$

$<0.50$

wg/L WA

GE

GE

WA 
ANALYTICAL RESULTS

WELL BGX 12C collected on 07/30/92, laboratory analyses (cont.)

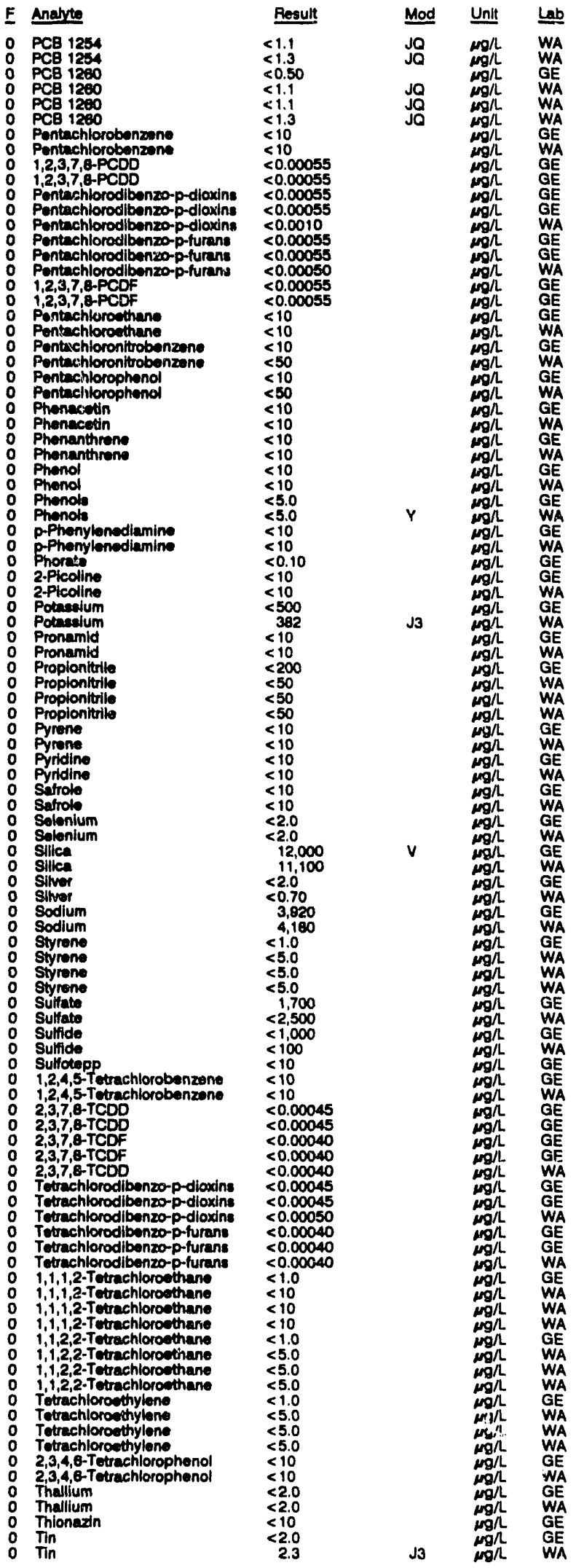

WELL BGX 12C colloctod on 07/30/92, laboratory analyses (cont.)

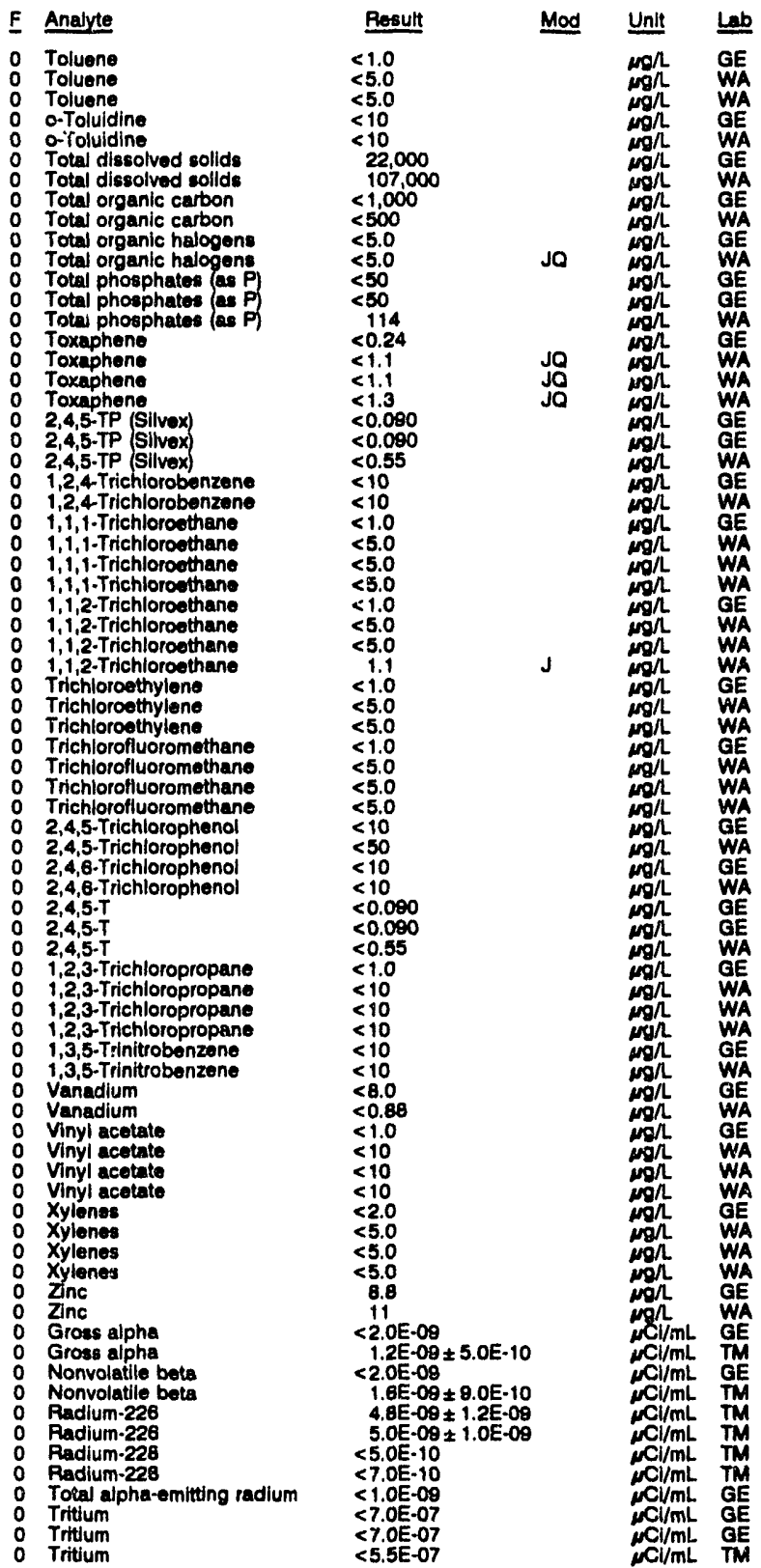

WELL BGX 12D

MEASUREMENTS CONDUCTED IN THE FIELD

\begin{tabular}{|c|c|}
\hline $\begin{array}{l}\text { Sample date: } 07 / 30 / 92 \\
\text { Depth to water: } 35.95 \mathrm{ft}(10.96 \mathrm{~m}) \text { below TOC } \\
\text { Water elevation: } 239.25 \mathrm{ft}(72.92 \mathrm{~m}) \mathrm{mal} \\
\text { Sp. conductance: } 21 \mathrm{fS} / \mathrm{cm} \\
\text { Water evacuated before sampling: } 5 \mathrm{gal}\end{array}$ & $\begin{array}{l}\text { Time: } 8: 35 \\
\text { pH: } 5.0 \\
\text { Alkalinity: } 2 \mathrm{mg} / \mathrm{h} \\
\text { Water temperature: } 20.8^{\circ} \mathrm{C}\end{array}$ \\
\hline
\end{tabular}

LABORATOAY ANALYSES

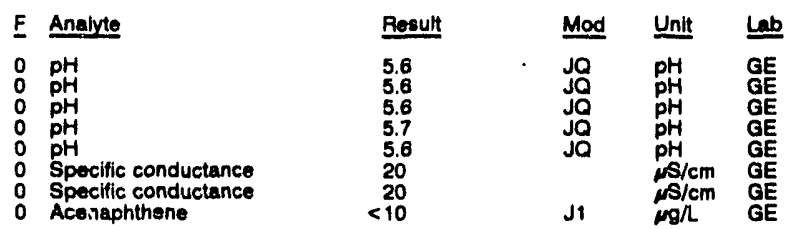


WELL BGX 12D collectad on 07/30/92, laboratory analyses (cont)

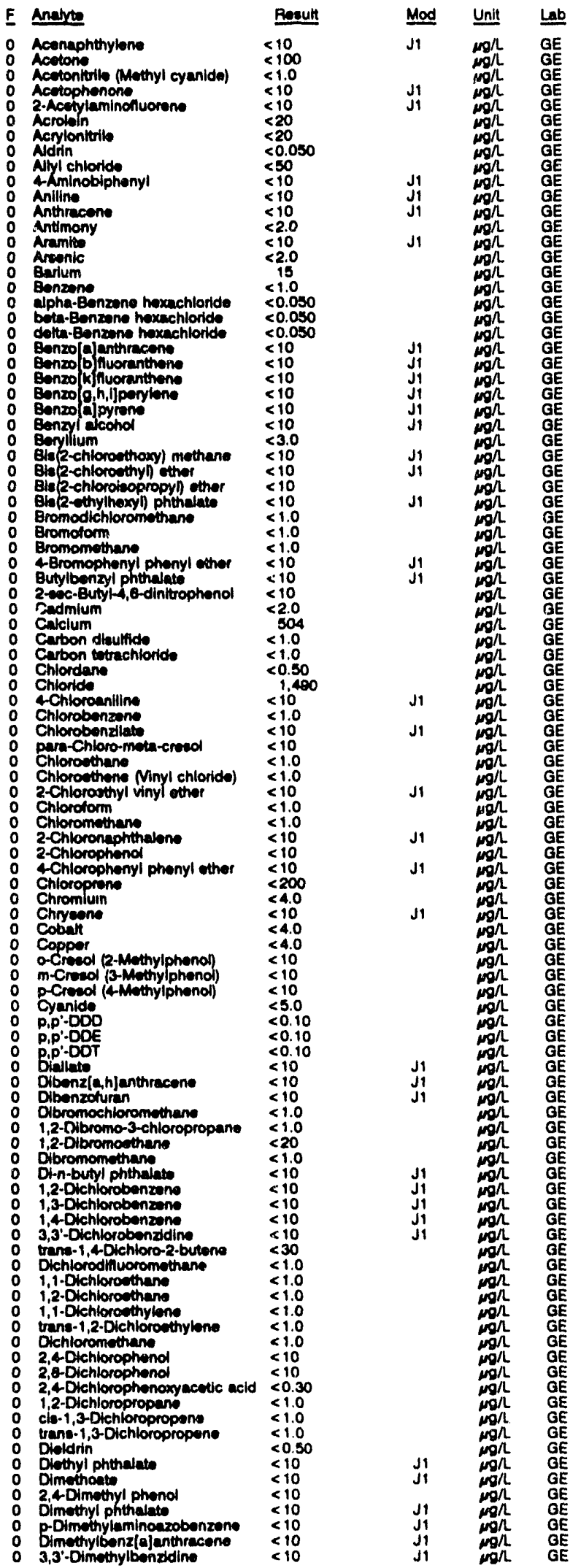

WELL BGX 120 collected on 07/30/92, laboratory analyees (cont)

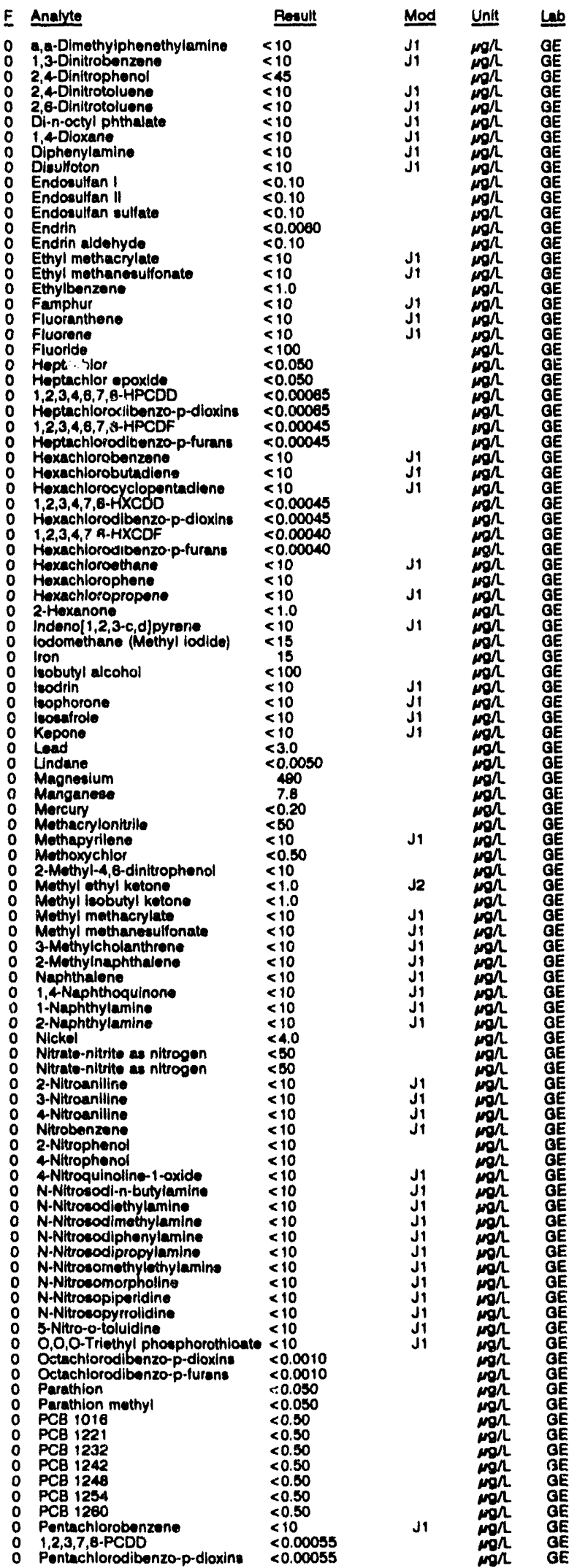


WEUL BGX 120 collected on 07/30/92, laboratory analyses (cont)

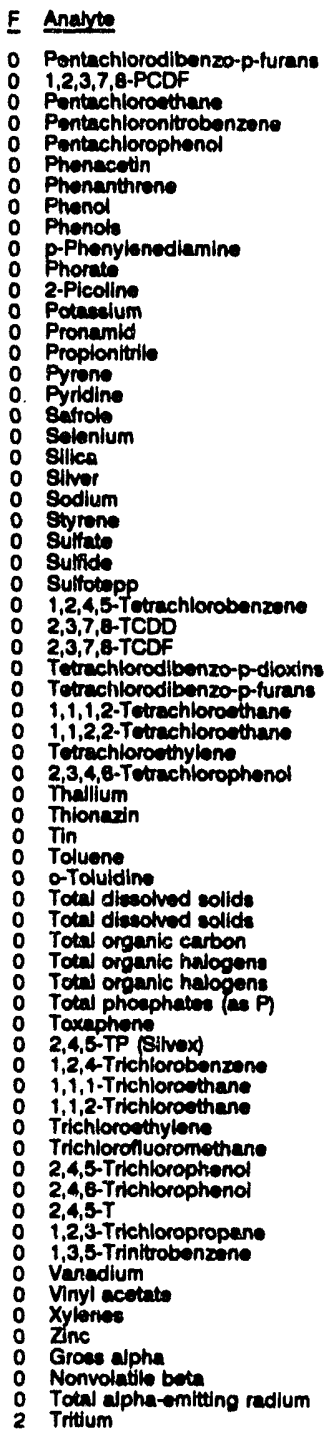

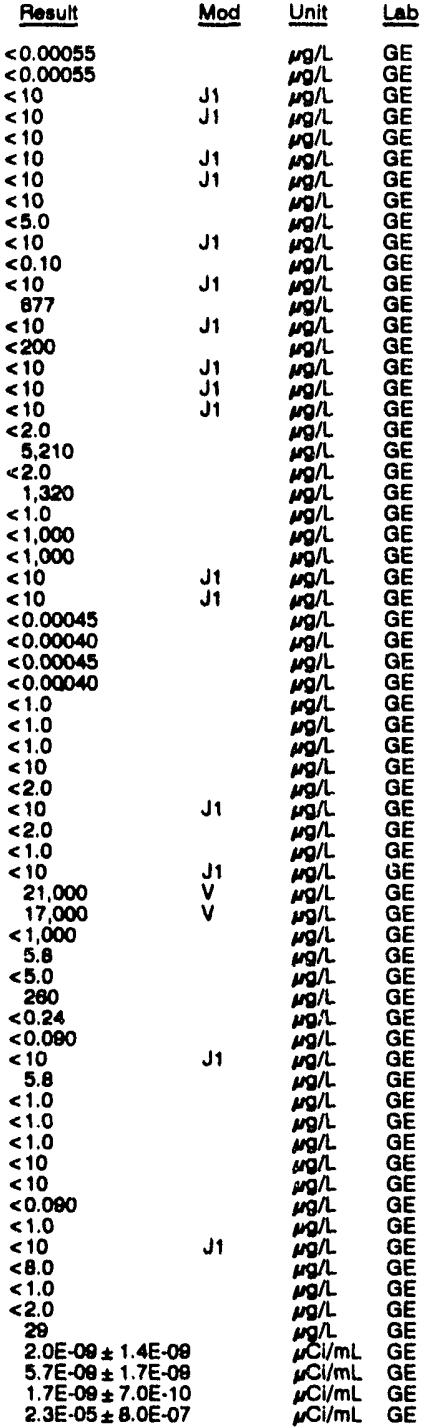

\section{WELL BRD 1}

MEASUREMENTS CONOUCTED IN THE FIELD

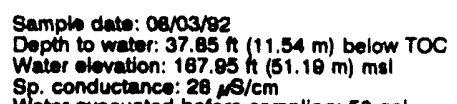

Nkalinity: $1 \mathrm{mg} / \mathrm{m}$

Water evacuated before sampling: $50 \mathrm{gal}$

Water temperature: $22.7^{\circ} \mathrm{C}$

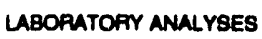

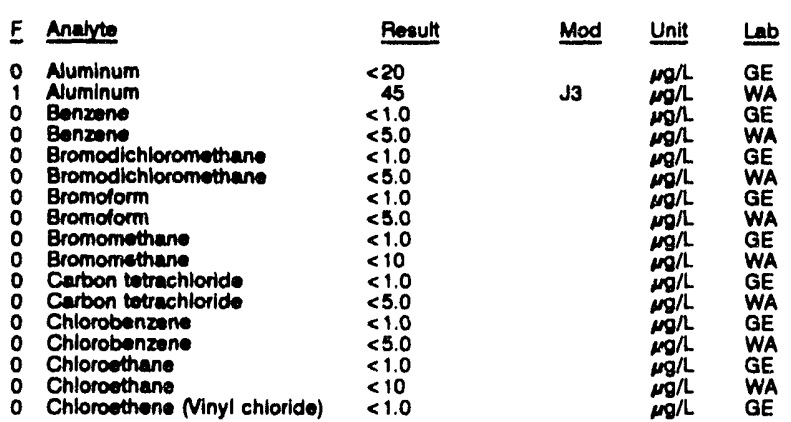

WELL BRD 1 collected on 08/03/82, laboratory analyees (cont.)

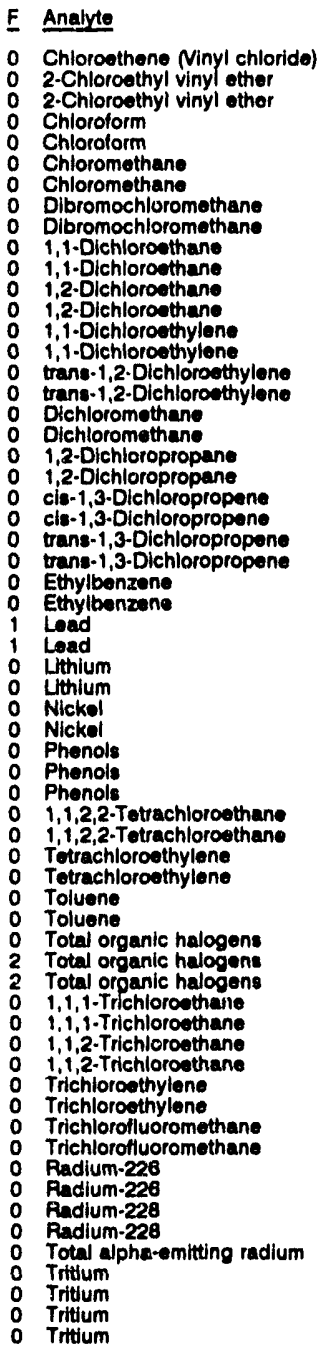

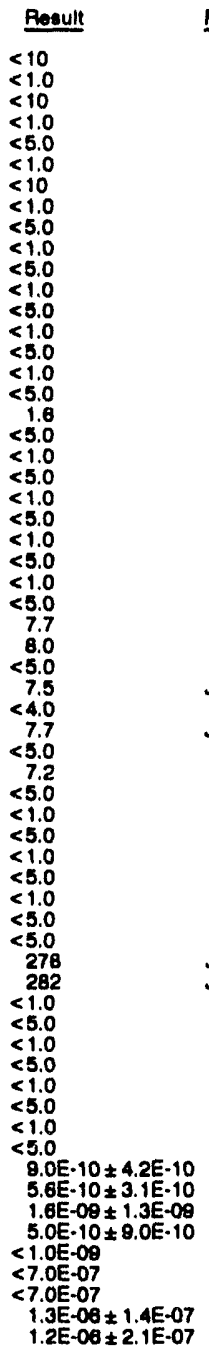

Mod Unit L

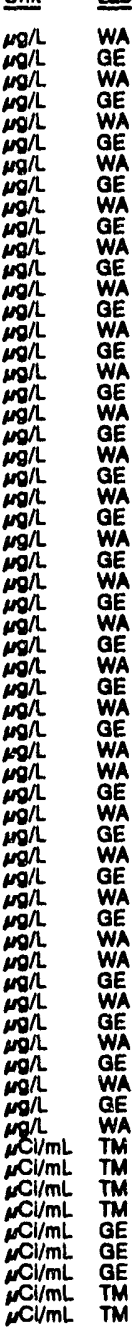

WELL BRD 1 Replicate

MEASUFEMENTS CONDUCTED IN THE FIELD

Sample date: 08/03/92

Dopth to water: $37.85 \mathrm{H}(11.54 \mathrm{~m})$ below TOC

Water elevation: $167.05 \mathrm{ht}$ (51.

Sp. conductance: $28 \mathrm{\mu S} / \mathrm{cm}$

pH: 4.8

Alkalinity: $1 \mathrm{mg} / \mathrm{L}$

LABORATORY ANALYSES

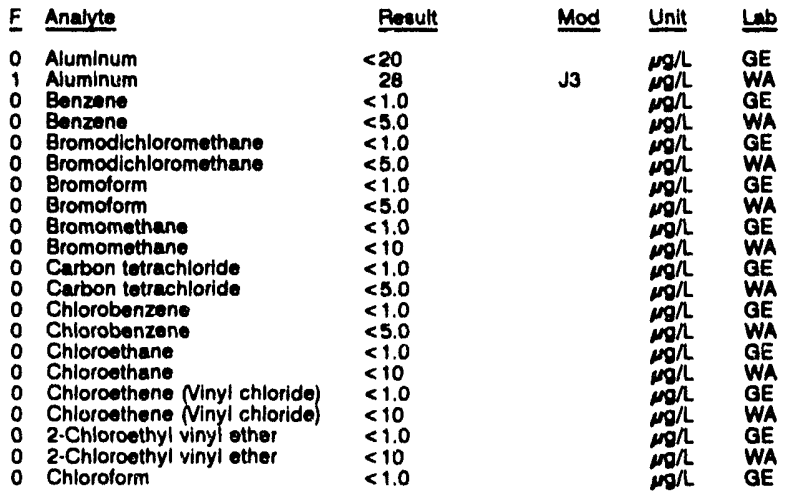


WEL BRD 1 colbetod on 08/03/92, laboratory analyees (cont)

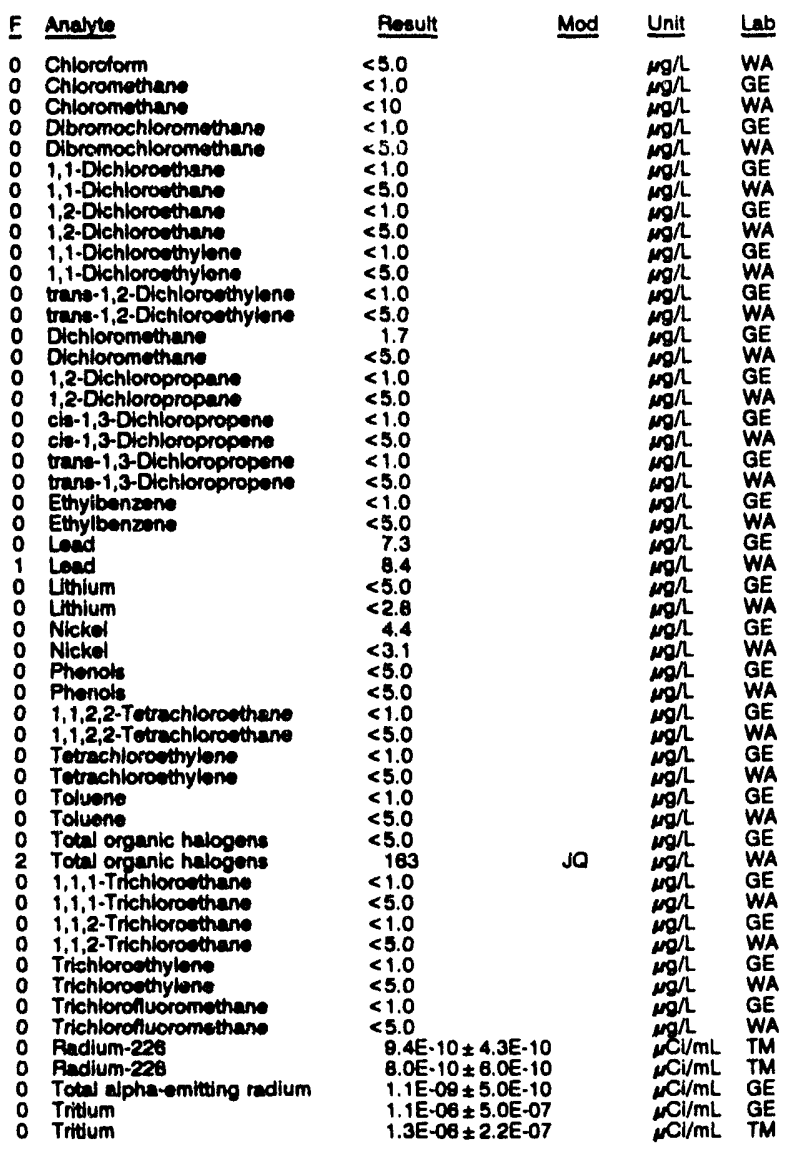

\section{WELL BRD 2}

\section{MEASUREMENTS CONOUCTED IN THE FIELO}

\begin{tabular}{|c|c|c|}
\hline \multicolumn{3}{|c|}{ 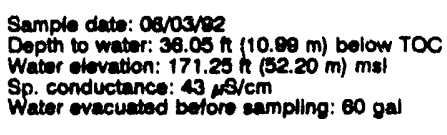 } \\
\hline \multicolumn{3}{|c|}{ LABORATOFY ANALYSES } \\
\hline E & Anaryte & Prosult \\
\hline 0 & 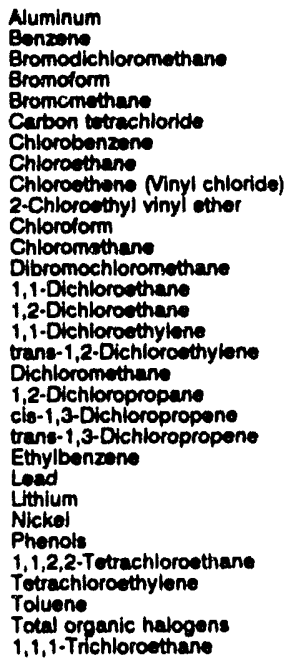 & $\begin{array}{l}<20 \\
<1.0 \\
<1.0 \\
<1.0 \\
<1.0 \\
<1.0 \\
<1.0 \\
<1.0 \\
<1.0 \\
<1.0 \\
<1.0 \\
<1.0 \\
<1.0 \\
<1.0 \\
<1.0 \\
<1.0 \\
<1.0 \\
2.2 \\
<1.0 \\
<1.0 \\
<1.0 \\
<1.0 \\
<13 \\
<5.0 \\
<4.0 \\
<5.0 \\
<1.0 \\
<1.0 \\
<1.0 \\
<5.0 \\
<1.0\end{array}$ \\
\hline
\end{tabular}

WELL BRD 2 collected on 08/03/92, laboratory anslyses (cont.)

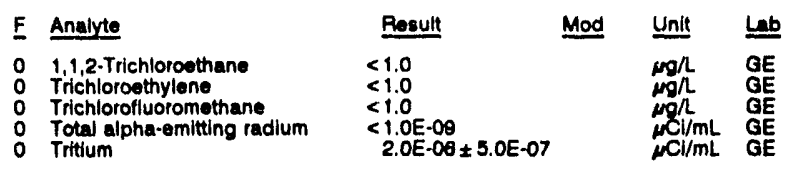

\section{WELL BRD 3}

MEASUREMENTS CONDUCTED IN THE FIELD

\begin{tabular}{|c|c|}
\hline $\begin{array}{l}\text { Sample date: } 08 / 03 / 92 \\
\text { Depth to water: } 51.01 \mathrm{th}(15.55 \mathrm{~m}) \text { bolow TOC } \\
\text { Water elevation: } 168.38 \mathrm{H}(51.63 \mathrm{~m}) \mathrm{ms} \\
\text { Sp. conductance: } 38, \mu \mathrm{s} / \mathrm{cm} \\
\text { Water evacuated bofore sampling: } 7 \mathrm{cal}\end{array}$ & $\begin{array}{l}\text { Time: } 14: 40 \\
\text { pH: } 5.0^{\circ} \\
\text { Alkalinity: } 3 \mathrm{mg} / \mathrm{L} \\
\text { Water temperature: } 23.4^{\circ} \mathrm{C}\end{array}$ \\
\hline
\end{tabular}

The wall went dy during purging.

LABORATORY ANALYSES

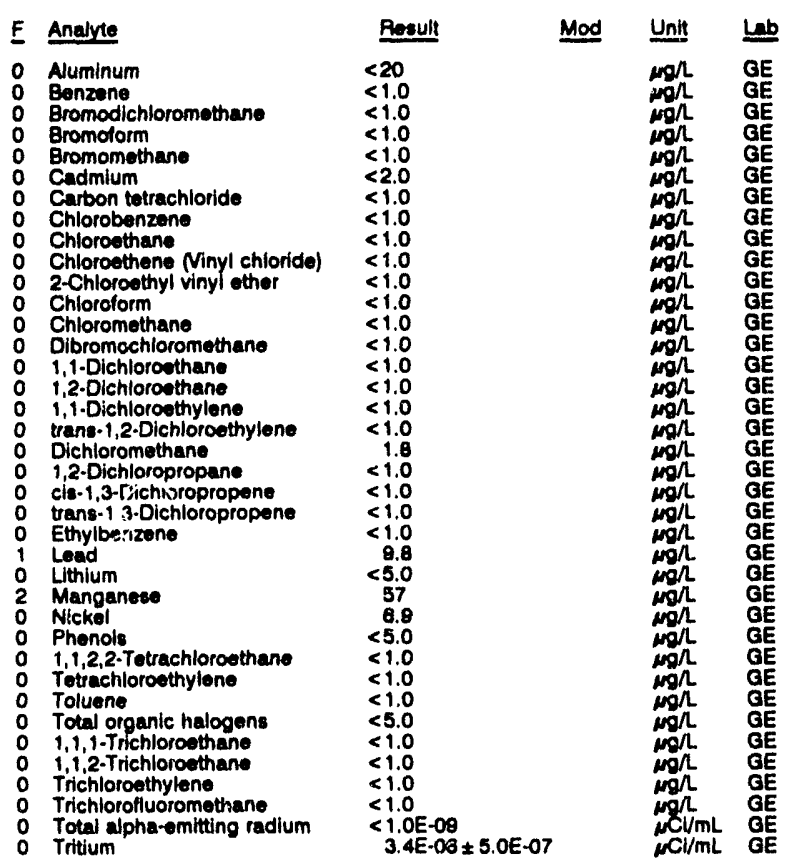

\section{WELL BRD 4}

MEASUREMENTS CONDUCTED IN THE FIELD

Sample date: 08/03/82

Dopth to water: $30.65 \mathrm{ft}(8.34 \mathrm{~m})$ bolow TOC

Water elevation: $167.25 \mathrm{f}(50.98 \mathrm{~m}) \mathrm{mal} \quad$ Akelinity: $0 \mathrm{mg}$

Sp. conductance: $35 \mathrm{\mu S} / \mathrm{cm}$
Water ovacuated before eampling: $100 \mathrm{gal}$

Water tomperature: $22.1 \cdot \mathrm{C}$

LABORATORY ANALYSES

\begin{tabular}{|c|c|c|c|c|}
\hline $\mathbf{F}$ & Analyte & Result & Miod & Unit \\
\hline $\begin{array}{l}0 \\
0 \\
0 \\
0 \\
0 \\
0 \\
0 \\
0 \\
0 \\
0 \\
0 \\
0 \\
0 \\
0 \\
0 \\
0 \\
0\end{array}$ & $\begin{array}{l}\text { Aluminum } \\
\text { Benzene } \\
\text { Bromodichloromethane } \\
\text { Bromolorm } \\
\text { Bromomethane } \\
\text { Carbon tetrachloride } \\
\text { Chlorobenzene } \\
\text { Chloroethane } \\
\text { Chloroethene Ninyl chloride) } \\
\text { 2-Chloroethyl vinyl ether } \\
\text { Chlorolom } \\
\text { Chloromethane } \\
\text { Dibromochloromethane } \\
1,1-\text { Dichloroethane } \\
1,2 \cdot \text { Dichloroethane } \\
1,1-\text { Dichloroethylone } \\
\text { trans-1,2-Dichloroethylene } \\
\text { Dichloromethane } \\
1,2 \cdot \text { Dichloropropane } \\
\text { cis-1,3-Dichloropropene } \\
\text { trans-1,3-Dichloropropene } \\
\text { Ethylbenzene } \\
\text { Load }\end{array}$ & $\begin{array}{r}<20 \\
<1.0 \\
<1.0 \\
<1.0 \\
<1.0 \\
<1.0 \\
<1.0 \\
<1.0 \\
<1.0 \\
<1.0 \\
<1.0 \\
<1.0 \\
<1.0 \\
<1.0 \\
<1.0 \\
<1.0 \\
<1.0 \\
<1.0 \\
<1.0 \\
<1.0 \\
<1.0 \\
<1.0 \\
6.2\end{array}$ & & 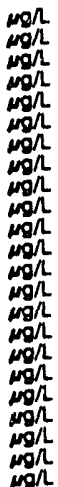 \\
\hline
\end{tabular}


WELL BAD 4 collectiod on 08/03/92, laboratory analysee (cont)

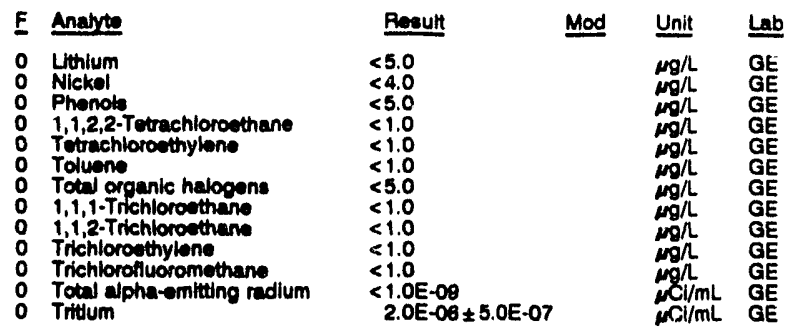

WELL BRD 5D

\begin{tabular}{|c|c|c|c|c|c|}
\hline \multicolumn{6}{|c|}{ MEASUREMENTS CONDUCTED IN THE FIELD } \\
\hline \multicolumn{3}{|c|}{ 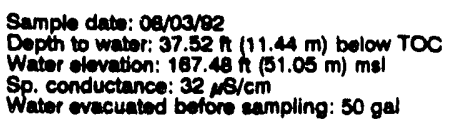 } & \multicolumn{3}{|c|}{$\begin{array}{l}\text { Time: } 13: 40 \\
\text { pH: } 5.6 \\
\text { Alkalinity: } 5 \mathrm{mg} / \\
\text { Water temperature: } 22.6^{\circ} \mathrm{C}\end{array}$} \\
\hline \multicolumn{6}{|c|}{ LABOAATOFY ANALYBES } \\
\hline F & Aneyste & Result & Mod & Unit & Lab \\
\hline $\begin{array}{l}0 \\
0 \\
0 \\
0 \\
0 \\
0 \\
0 \\
0 \\
0 \\
0 \\
0 \\
0 \\
0 \\
0 \\
0 \\
0 \\
0 \\
0 \\
0 \\
0 \\
0 \\
0 \\
0 \\
0 \\
0 \\
0 \\
0 \\
0 \\
0 \\
0 \\
0 \\
0 \\
0 \\
0 \\
0 \\
0 \\
0\end{array}$ & 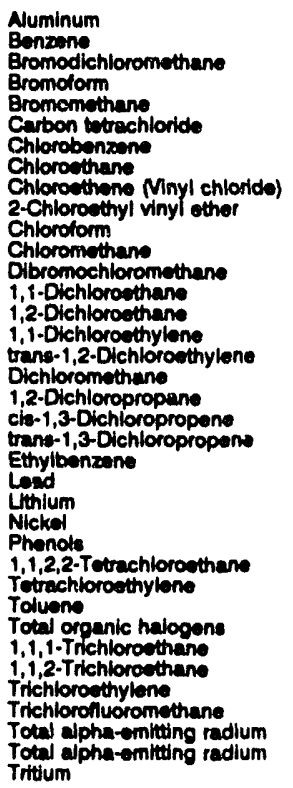 & $\begin{array}{l}<20 \\
<1.0 \\
<1.0 \\
<1.0 \\
<1.0 \\
<1.0 \\
<1.0 \\
<1.0 \\
<1.0 \\
<1.0 \\
<1.0 \\
<1.0 \\
<1.0 \\
<1.0 \\
<1.0 \\
<1.0 \\
<1.0 \\
1.6 \\
<1.0 \\
<1.0 \\
<1.0 \\
<1.0 \\
<3.0 \\
<5.0 \\
<4.0 \\
<5.0 \\
<1.0 \\
<1.0 \\
<1.0 \\
<5.0 \\
<1.0 \\
<1.0 \\
<1.0 \\
<1.0 \\
<1.0 E-00 \\
<1.0 E-09 \\
<7.0 E-07\end{array}$ & & 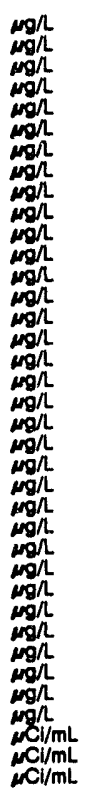 & $\begin{array}{l}\mathrm{GE} \\
\mathrm{GE} \\
\mathrm{GE} \\
\mathrm{GE} \\
\mathrm{GE} \\
\mathrm{GE} \\
\mathrm{GE} \\
\mathrm{GE} \\
\mathrm{GE} \\
\mathrm{GE} \\
\mathrm{GE} \\
\mathrm{GE} \\
\mathrm{GE} \\
\mathrm{GE} \\
\mathrm{GE} \\
\mathrm{GE} \\
\mathrm{GE} \\
\mathrm{GE} \\
\mathrm{GE} \\
\mathrm{GE} \\
\mathrm{GE} \\
\mathrm{GE} \\
\mathrm{GE} \\
\mathrm{GE} \\
\mathrm{GE} \\
\mathrm{GE} \\
\mathrm{GE} \\
\mathrm{GE} \\
\mathrm{GE} \\
\mathrm{GE} \\
\mathrm{GE} \\
\mathrm{GE} \\
\mathrm{GE} \\
\mathrm{GE} \\
\mathrm{GE} \\
\mathrm{GE} \\
\mathrm{GE}\end{array}$ \\
\hline
\end{tabular}

WELL BRR 1D

MEASUREMENTS CONDUCTED IN THE FIELD

\section{Sample date: 08/23/92}

Wopth to water: $77.92 \pi(23.75 \mathrm{~m})$ below TOC

Water elevation: $217.83 \mathrm{~h}(86.44 \mathrm{~m}) \mathrm{msl}$

Sp. conductance: $55 \mathrm{sS} / \mathrm{cm}$

Water oracuated belore sampling: 8 gal

The well went dry during purging.

LABOPATOFY ANALYSES

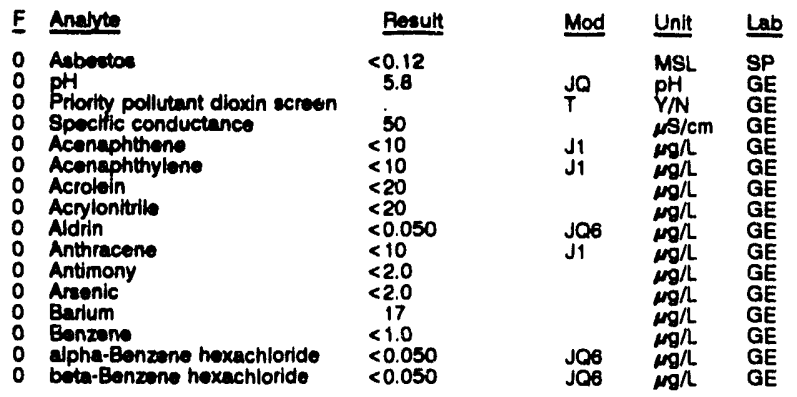

WELL BRR 10 collocted on 08/23/92, laboratory analyees (cont.)

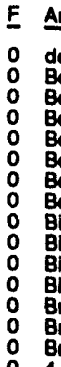

\begin{tabular}{|c|}
\hline 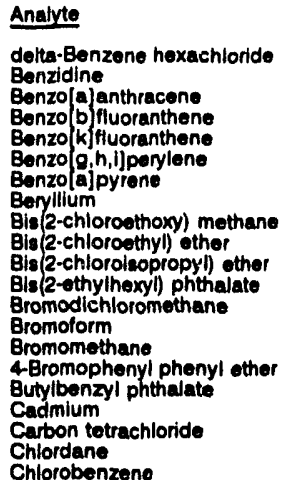 \\
\hline
\end{tabular}

Result

$<0.050$

$<10$

$<10$

$<10$

$<10$

$<10$

$<10$

$<1.0$

$<1.0$

$<1.0$
$<10$
$<10$

$<2.0$

Chlorobenzeno
para-Chloro-meta-cresol

Chloroethane

Chloroethene Ninyl chloride

2-Chloroethyl

Chloroform

2-Chloronaphthene

2-Chlorophenol

4-Chlorophenyl phenyl ether

Chromium

Chrysene

Copper

P,P.:DDD

P,P'-DDE

Gibenz[a, h]anthracene

Dibromochioromethan

Di-n-butyl phthalate

1,2-Dichlorobenzene

1,4-Dichlorobenzene

3,3 -Dichlorobenzidine

1,1-Dichloroethane

1,2-Dichloroethane

i,i-Dichloroethylene

trans-1,2-Dichloroethylene

Dichloromethane

2,4-Dichlorophenol

1,2-Dichloropropane

trans-1,3-Dichloropropene

Dioldrin

Diethyl phthalate

2,40imethyl phenol

2,4-Dinitrophenol

2,4-Dinhtrophenol

2,4-Dinitrotoluene

Di-n-octyl phithalate

1,2-Diphenylhydrazine

Endosultan I

Endosulfan sulfate

Endrin

Endrin aidehyde

Ethylibenzene

Fluoranthen

Fivorene

Heptachlor epoxide

Hexachlorobenzene

Hoxachlorobutadione

Hexachlorocyclopented
Hexachloroothane

Indeno $[1,2,3-c, d]$ pyrene

Iron

0 isophorone

Lead

1 Manganese

Morcury

0 Naphthalene

Nickel

O Nitrobenzene

2-Nitrophenol

4-Nitrophenol
0 N.Nitrosodimethylamine

N-Nitrosodimethylamine

N-Nitrosodiphenylamine

P.Nitrosodip

O PCB 1221

PCB 1232

PCB 1242

PCB 1248
0

$<0.50$

$<10$

$<1.0$ 
WELL BAR 10 collected on Dar23/82, laboratory analyees (cont)

\begin{tabular}{|c|c|c|c|c|c|}
\hline$E$ & Analyte & Resulk & Mod & Unit & Lab \\
\hline & 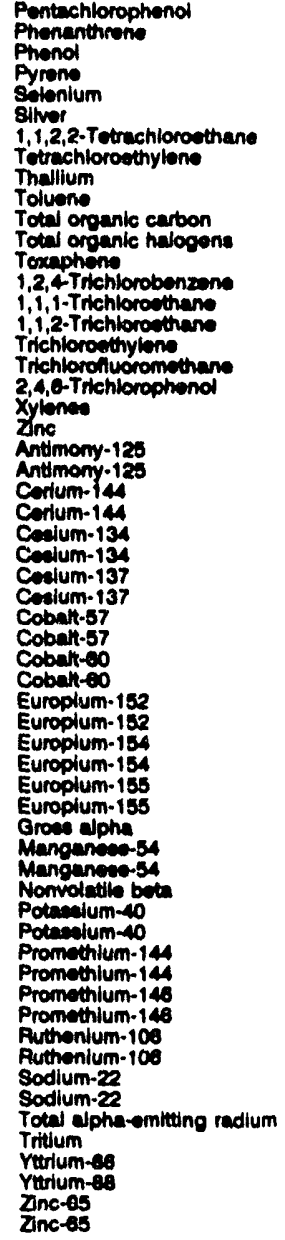 & 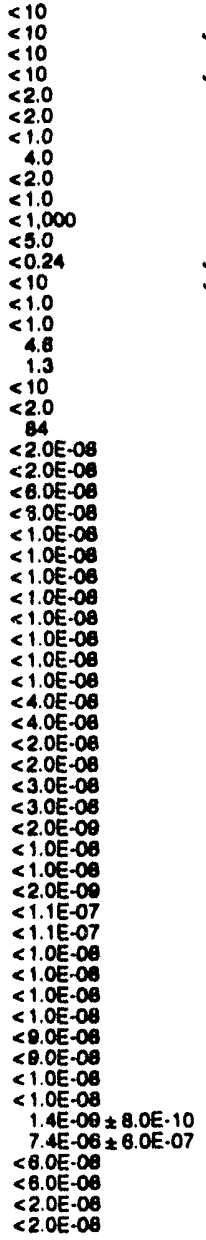 & $\begin{array}{l}\mathrm{JCO} \\
\mathrm{J1}\end{array}$ & 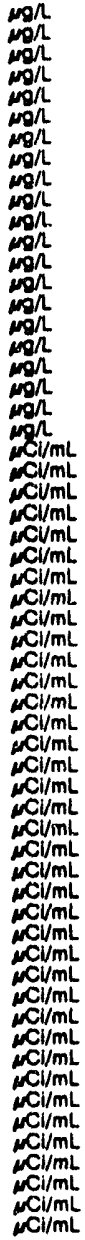 & $\begin{array}{l}G E \\
G E \\
G E \\
G E \\
G E \\
G E \\
G E \\
G E \\
G E \\
G E \\
G E \\
G E \\
G E \\
G E \\
G E \\
G E \\
G E \\
G E \\
G E \\
G E \\
G E \\
G P \\
G P \\
G P \\
G P \\
G P \\
G P \\
G P \\
G P \\
G P \\
G P \\
G P \\
G P \\
G P \\
G P \\
G P \\
G P \\
G P \\
G P \\
G P \\
G E \\
G P \\
G P \\
G E \\
G P \\
G P \\
G P \\
G P \\
G P \\
G P \\
G P \\
G P \\
G P \\
G P \\
G E \\
G E \\
G P \\
G P \\
G P \\
G P\end{array}$ \\
\hline
\end{tabular}

WELL BRR 2D

MEASUREMENTS CONOUCTED IN THE FIELD

sample date: 0aparen

Dopth to watier: $75.32 \mathrm{n}(22.08 \mathrm{~m})$ bolow TOC

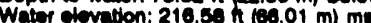

Bp. conductent

Wetore ampling: $12 \mathrm{gal}$

LABORATORY ANALYSES

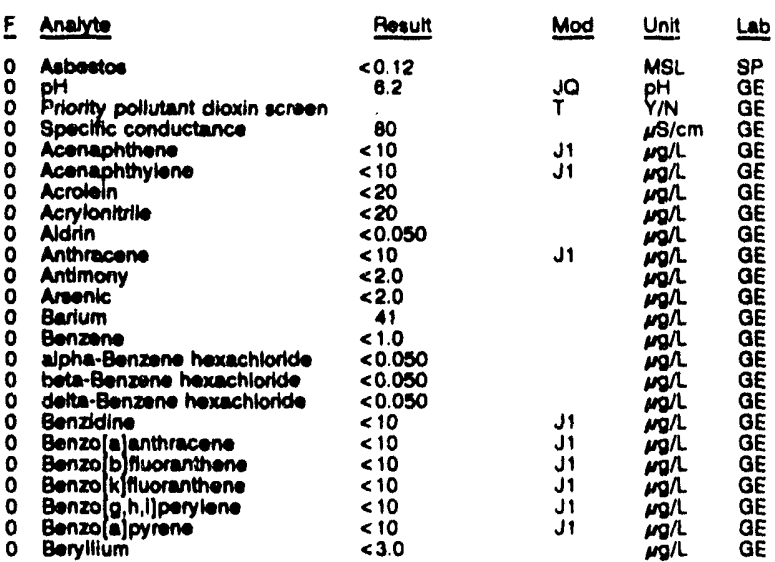

WELL BRA 20 collected on 08/23/92, laboratory analyese (cont.)

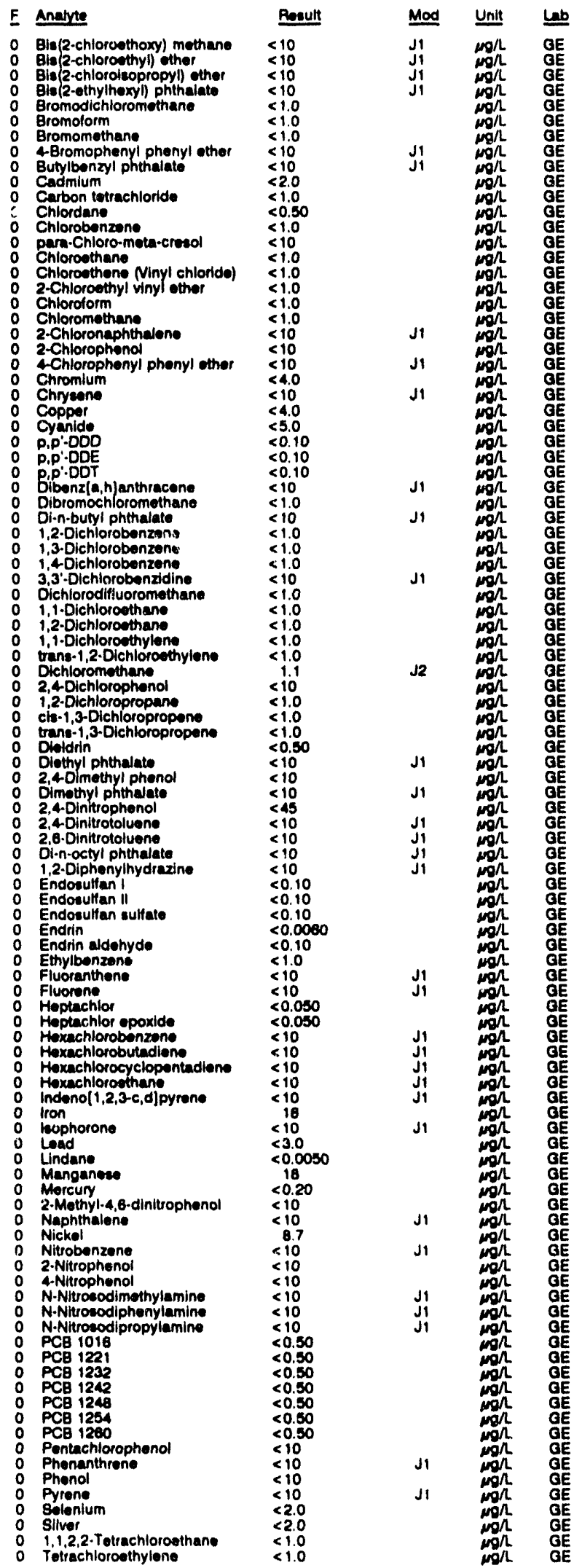


ANALYTICAL RESULTS

WEU B.2A 20 collected on Oar3/02, laboratory analyece (cont)

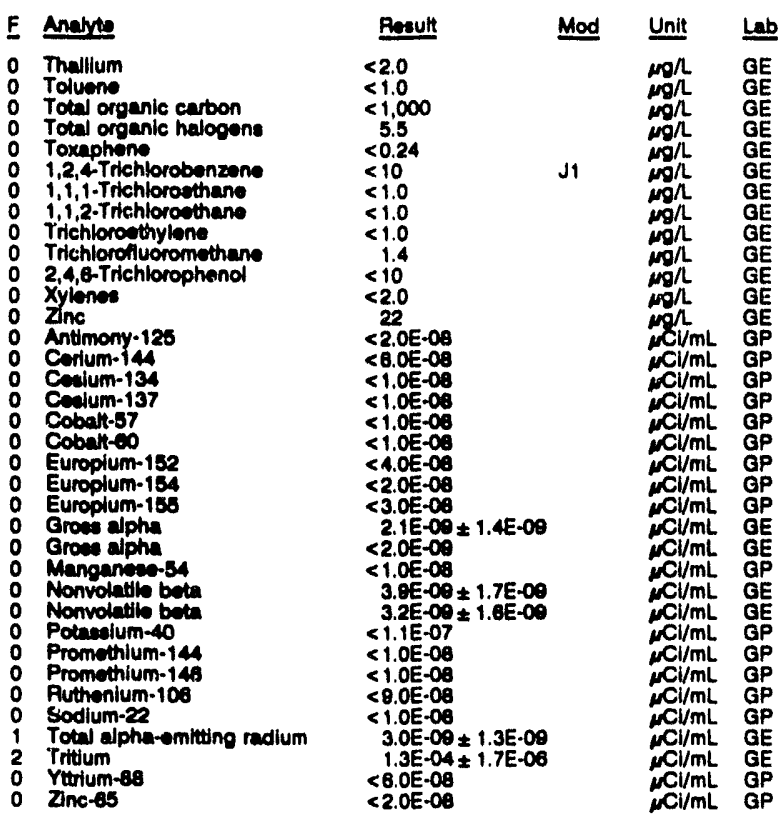

\section{WELL BAR 3D}

\section{MEASUREMENTS CONDUCTED IN THE FIELD}

Depth to water: 75.29 in (22.04 m) below TOC Water elevelton: $216.44 \mathrm{~h}(85.87 \mathrm{~m}) \mathrm{mel}$

Sp. conductance: $144 \mathrm{~m} / \mathrm{cm}$

The well went dy during purging

LABOPATOFY ANALYSES

\begin{tabular}{|c|c|c|c|}
\hline Analyte & Result & Mod & Unit \\
\hline 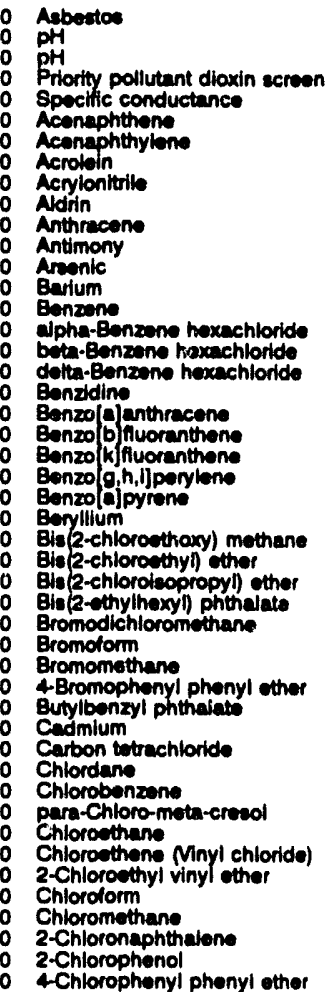 & $\begin{array}{l}<0.12 \\
6.0 \\
5.9 \\
155 \\
<10 \\
<10 \\
<20 \\
<20 \\
<0.050 \\
<10 \\
<2.0 \\
<2.0 \\
37 \\
<1.0 \\
<0.050 \\
<0.050 \\
<0.050 \\
<10 \\
<10 \\
<10 \\
<10 \\
<10 \\
<10 \\
<3.0 \\
<10 \\
<10 \\
<10 \\
<10 \\
<1.0 \\
<1.0 \\
<1.0 \\
<10 \\
<10 \\
<2.0 \\
<1.0 \\
<0.50 \\
<1.0 \\
<10 \\
<1.0 \\
<1.0 \\
<1.0 \\
<1.0 \\
<1.0 \\
<10 \\
<10 \\
<10\end{array}$ & $\begin{array}{l}\mathbf{J 1} \\
\mathbf{J} 1 \\
\mathbf{J} 1 \\
\mathbf{J} 1 \\
\mathbf{J 1} \\
\mathbf{J 1} \\
\mathbf{J 1} \\
\mathbf{J 1} \\
\mathbf{J 1} \\
\mathbf{J 1}\end{array}$ & 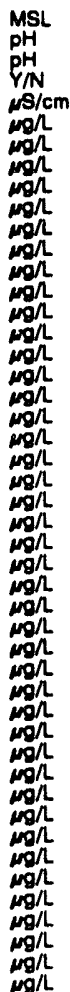 \\
\hline
\end{tabular}

WELL BRR 3D collected on 08/23/92, laboratory analyees (cont)

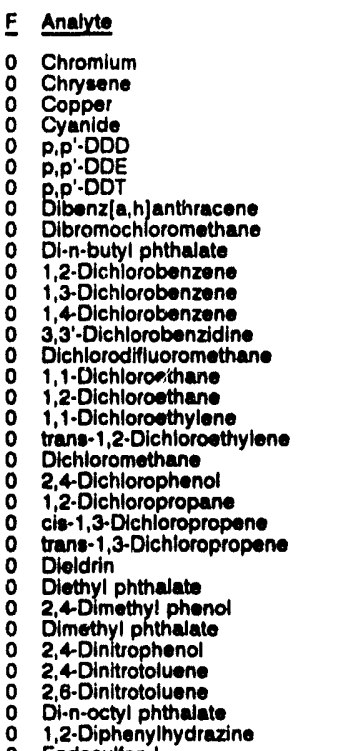

Reautt Mod Unit Lit

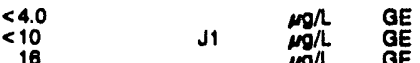
$<5.0$

$<0.10$

$<0.10$

$<10$
$<1.0$
$<10$
$<1.0$

$<1.0$

$<10$

$<1.0$

$<1.0$

$<1.0$

1.6
$<10$
$<1.0$

$<1.0$

$<1.0$
$<0.50$
$<10$

$<10$
$<10$

$<10$
$<10$
$<45$

$<45$

$<10$
$<10$

$<10$
$<10$
$<0.10$

$<0.10$

Endosulfan I

Endosulfan sulfate

Endrin

Endrin aldehyde

Ethylbenzene

Fluorene

Heptachlor epoxide

Haxachlorobenzene

Hexachlorobutadiene

Hexachloroethane

Indeno[1,2,3-c,d]pyrene

Iron

lisophorone

Lead

Manganese

Mercury

2-Mothyl-4,6-dinitrophenol

Naphthai

Nickel

Nitrobenzene

2-Nitropheno

N-Nitrosodimethylamine

N-Nitrosodiphenylamine

N-Nitrosodiphenylamine

PCB 1010

PCB 1221

PCB 1232

P PCB 1242

0 PCB 1248

PCB 1260

Pentuchlorophenol

Phenanthrene

Phenol

Pyrene

Solenium

1,1,2,2-Tetrachloroethane

Totrachloroethylene

Thallium

Total organic carbon

Total organic halogens

Toxaphene

1, 2.Trichlorobenzane

1,1,1-Trichloroethane

1, 1,2-Trichloroethan

Trichlorofluoromothane

2,4,6-Trichlorophanol

Xylonce

Antimony-125

Corlum-144

Coslum-134

Cobalt-57

Cobalt-60

Europium-152

Europlum.154

$<1.0$
$<10$

$<10$
$<0.050$

$<10$

$<10$

$<10$

$<10$
$<10$

$<10$
89
$<10$

89
$<10$
8.6

$<0.0050$

$<0.20$

$<10$
$<10$

44.0

$<10$
$<10$

$<10$
$<10$

$<10$

$<0.50$

$<0.50$

$<0.50$

$<0.50$

$<0.50$

$\leq 10$

$<10$

$<10$
$<2.0$

$<2.0$

$<1.0$
$<1.0$
$<2.0$

$<1,0$

$<1,000$
$<5.0$

$<0.2$

$<10$

$<1.0$
$<1.0$
5.8

$<10$
$<2.0$

$<2.0$

$<2.0 E-08$

$<1.0 E-08$

$<1.0 E-08$

$<1.0 E-08$

$<1.0 E-08$

$<4.0 E-08$
$<2.0 E-08$

$<3.0 E$.08

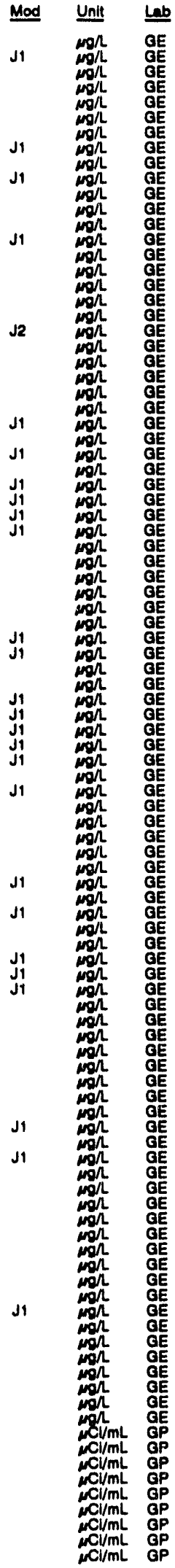


WELL BPA 3D collected on 08/23/92, laboratory analyees (cont.)

\begin{tabular}{|c|c|c|c|c|}
\hline & Anelyte & Result & Unlt & Lab \\
\hline & 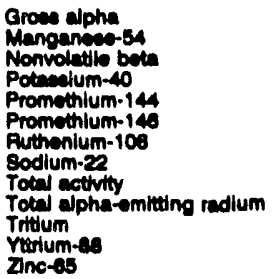 & 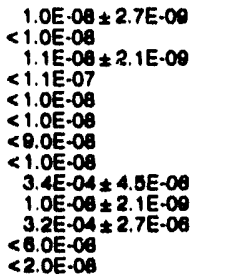 & 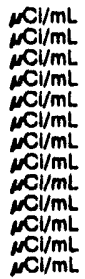 & $\begin{array}{l}G E \\
G P \\
G E \\
G P \\
G P \\
G P \\
G P \\
G P \\
\text { EM } \\
\text { GE } \\
\text { GE } \\
\text { GP } \\
\text { GP }\end{array}$ \\
\hline
\end{tabular}

WELL BRR 4D

MEASUREMENTS CONDUCTED IN THE FIELD

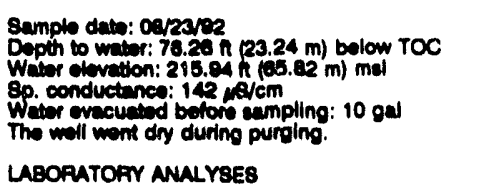

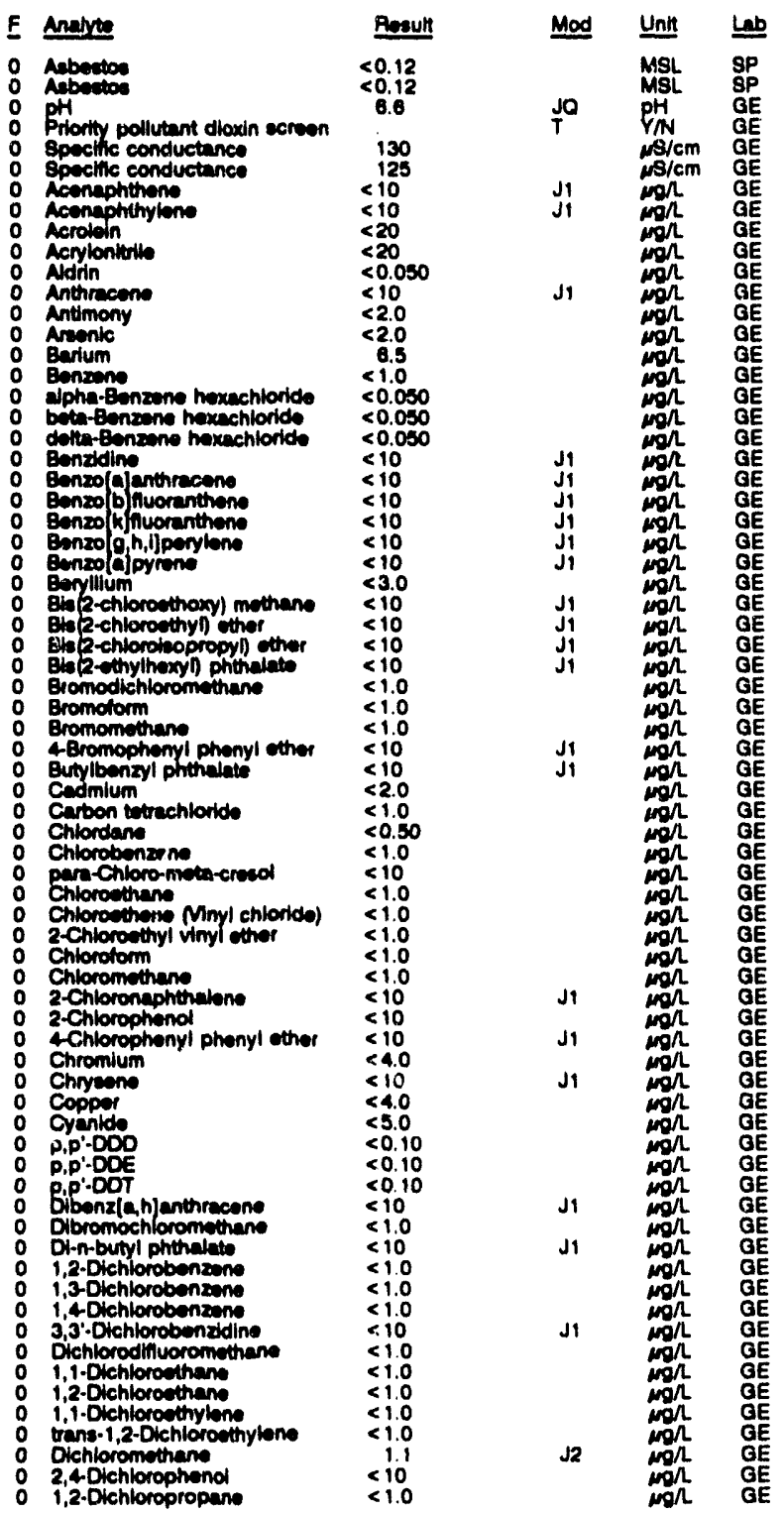

WELL BRA 40 collected on 08/23/92, laboratory analyese (cont.)

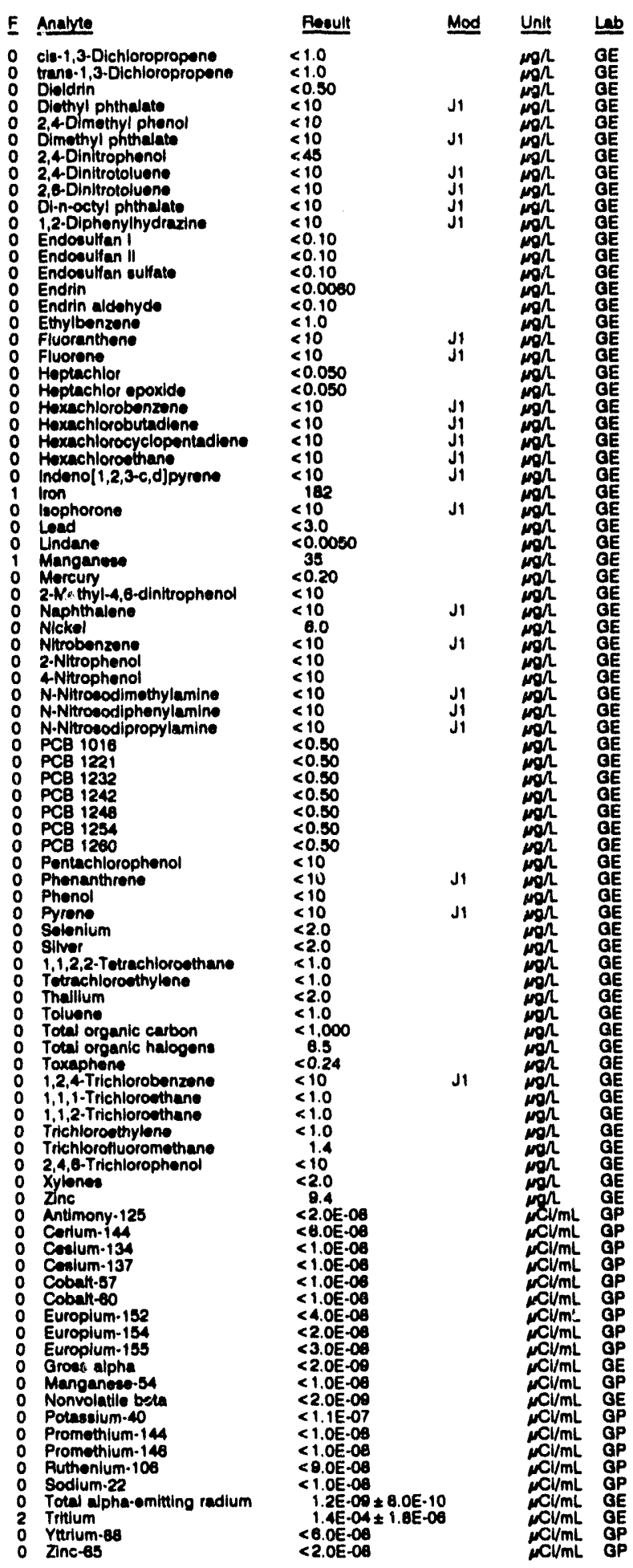


ANALYTICAL RESULTS

WELL BRR 5D

MEASUAREMENTS CONDUCTED IN THE FIELD

Sample detw: 08/23/82

Co $2009 \mathrm{mi}$ below TOC

Wattor olovation: $215.38 \mathrm{hl}(05.71$

Sp. conductance: $06 \mu 8 / \mathrm{cm}$.

Whe well went dy during purging.
The

LABORATOPYY ANALYSES

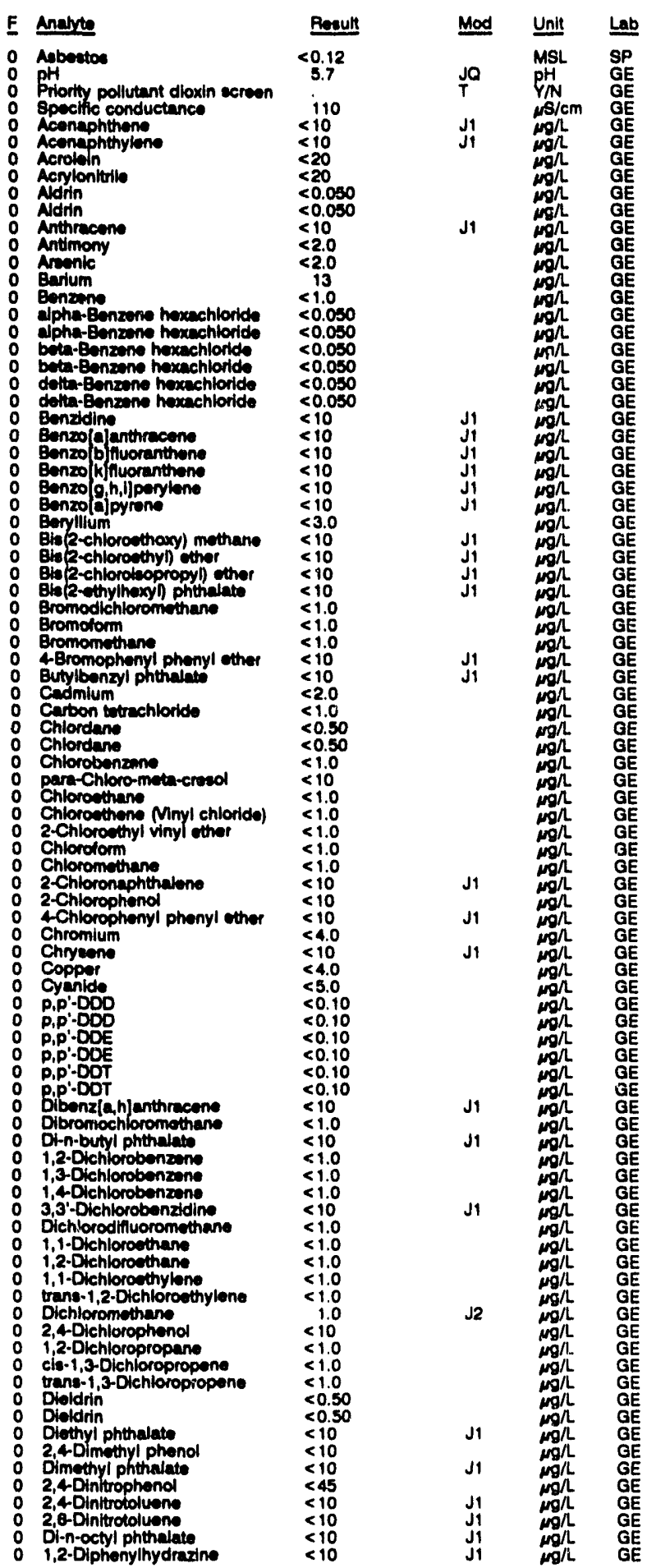

WELL BAR 5D collected on 08/23/92, laboratory analyees (cont.)

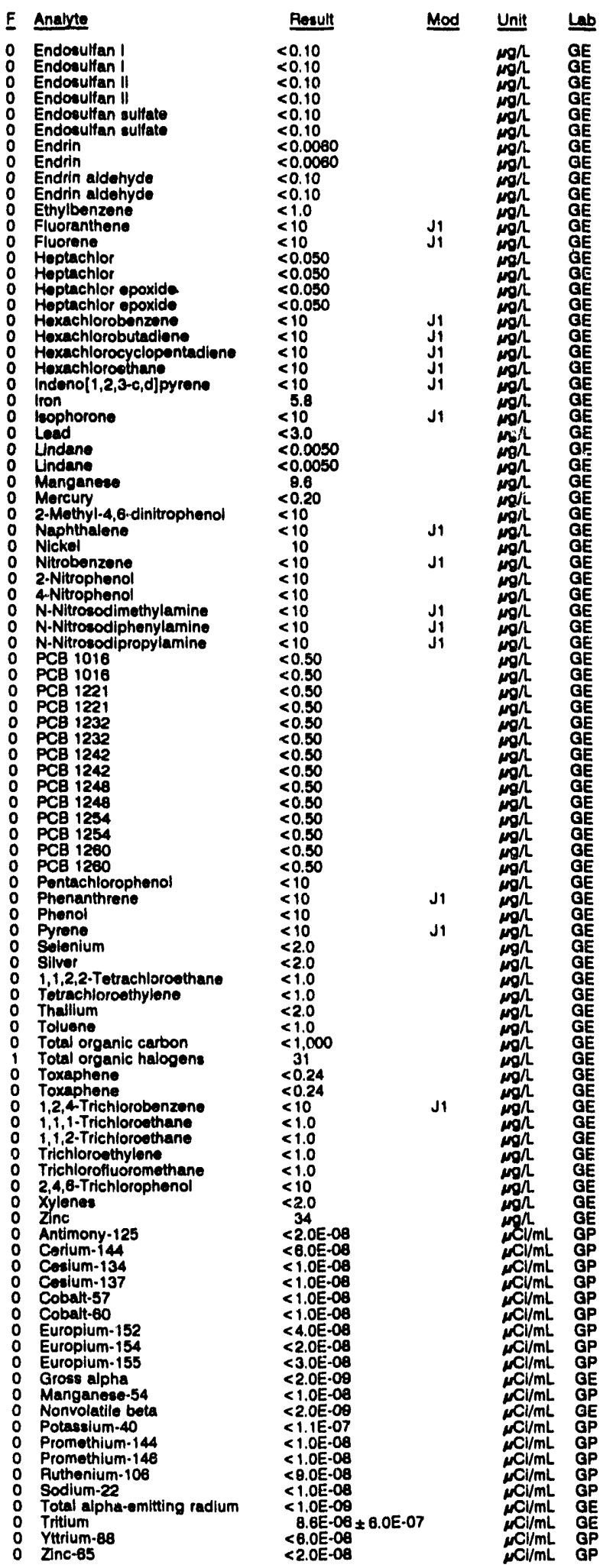


WELL CBR 1D

MEASUREMENTS CONDUCTED IN THE FIELL

Sample data: 07raeper

Depth to mater: 40.45 , $(14,16 \mathrm{~m})$ bolow TOC

Sp. conductence: 28 ,

Whier ovecunted belore sampling: 61 gal

LABORATORY ANALYES

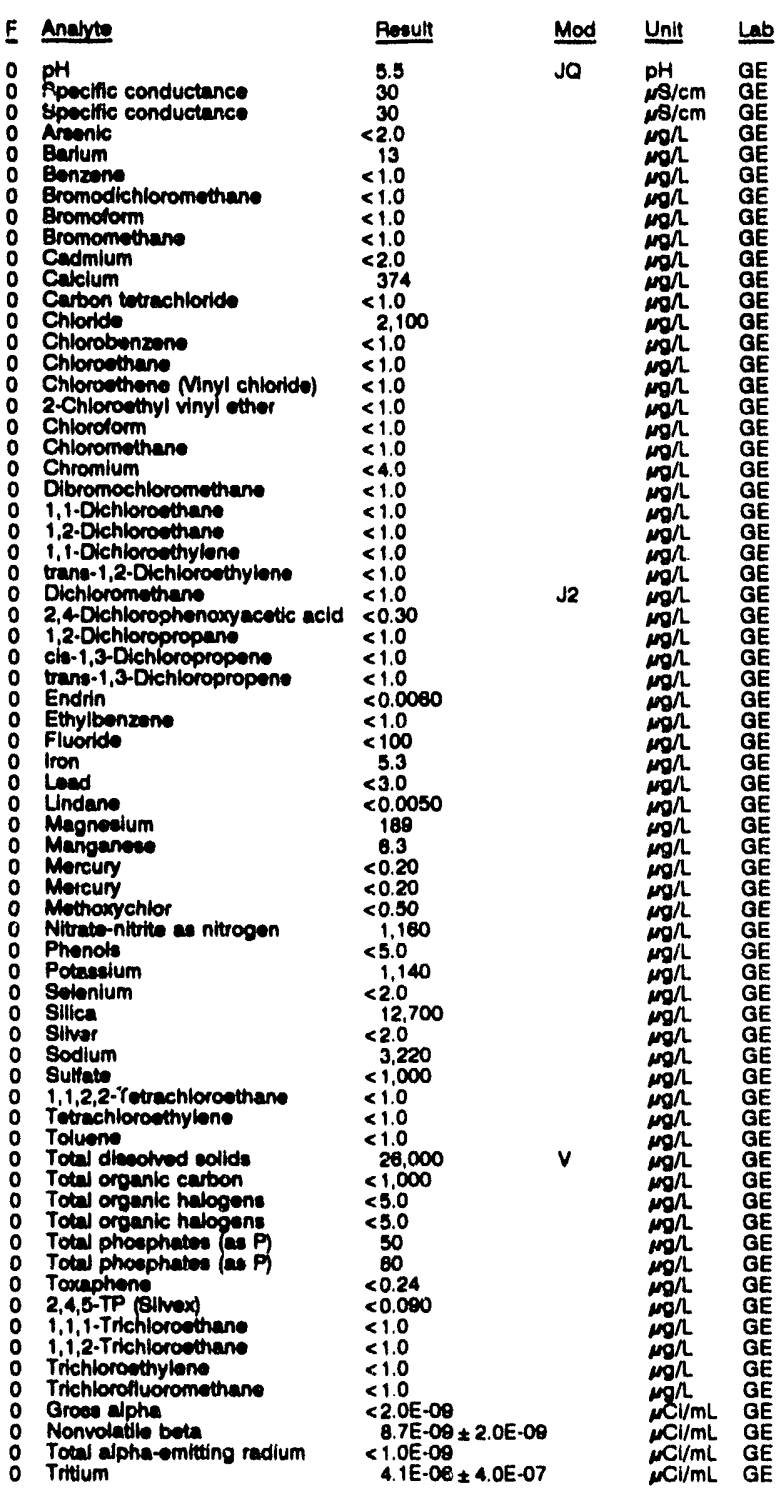

WELL CBR 2D

MEASUREMENTS CONDUCTED IN THE FIELD

Sample date: 08101/02

Depth to watior: $47.25 \mathrm{~h}(14.40 \mathrm{~m})$ below TOC

Wator etevation: $253.05 \mathrm{~h}$

Sp. conductance: $43 \mathrm{~m} \mathrm{~S} / \mathrm{cm}$.

Watef ovecuated before eampling: $52 \mathrm{gal}$

LABOPATORY ANALYBES

\begin{tabular}{|c|c|c|c|}
\hline E Anatyte & Rosult & Mod & Unit \\
\hline $\begin{array}{ll}0 & \mathrm{pH} \\
0 & \mathrm{pH} \\
0 & \mathrm{pH}\end{array}$ & $\begin{array}{l}5.5 \\
5.4 \\
5.4\end{array}$ & $\begin{array}{l}\text { JQ } \\
\text { JQ } \\
\text { JO }\end{array}$ & $\begin{array}{l}\mathrm{pH} \\
\mathrm{pH} \\
\mathrm{pH}\end{array}$ \\
\hline
\end{tabular}

Time: 7:35

Alkalinity: 0 mon

Alkalinity: $0 \mathrm{mgh}$. $20.8^{\circ} \mathrm{C}$

Time: $9: 55$

Akalinity: $2 \mathrm{~mol}$

Water temperature: $22.10 \mathrm{C}$

Lab

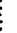

.

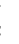

WELL CBR 2D collected on 08/01/82, laboratory analyees (cont.)

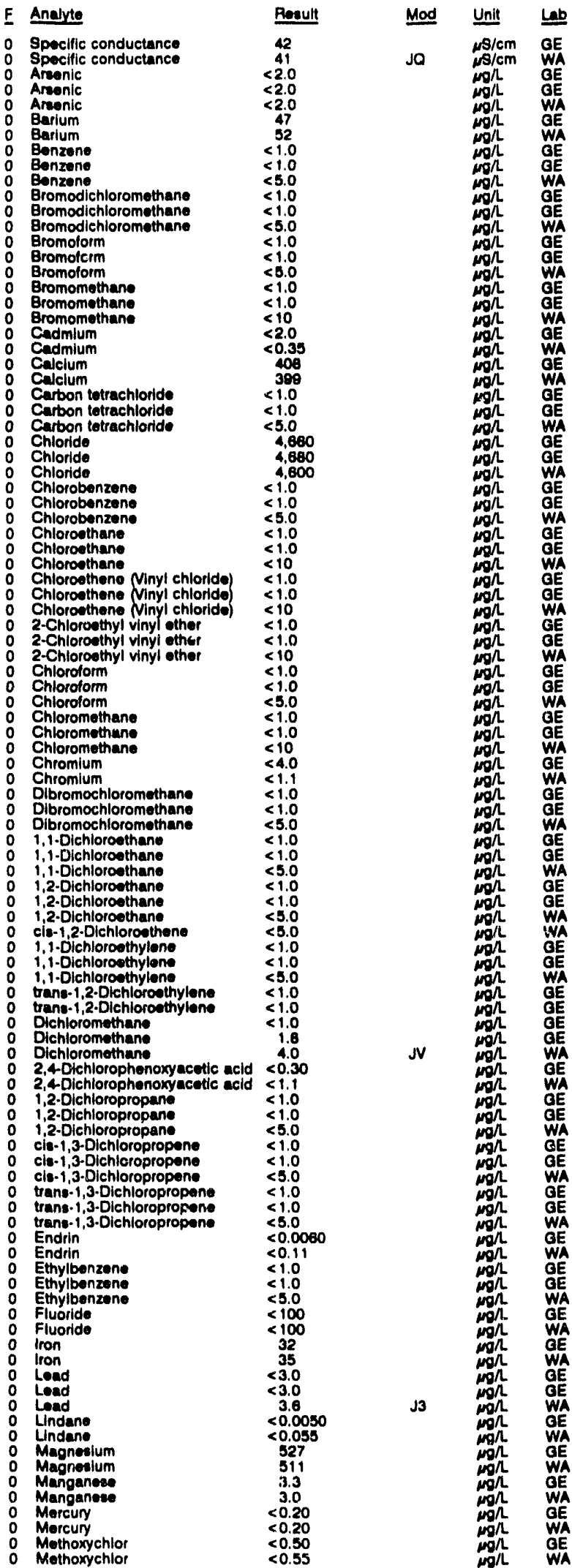


ANALYTICAL RESULTS

WELL CBR 20 collected on 08/01/82, laboratory analyees (cont.)

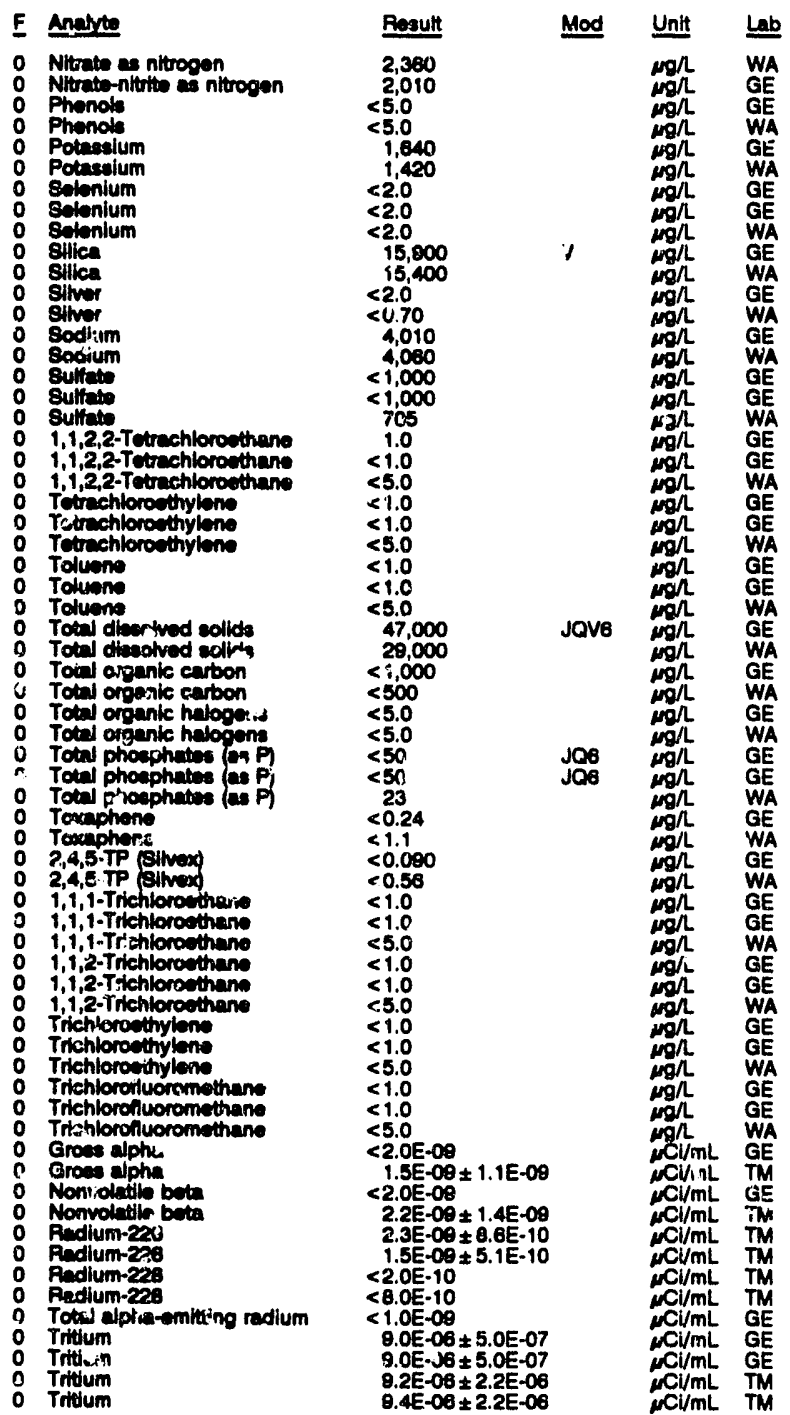

WELL CBR 2D Replicate

MEASIAEMEN IS CONOUCTED IN THE FIELD

Sample tate: 0a101/92

Depth to water: 47.25 is ( $1440 \mathrm{~m}$ ) below TOC

Water elevetion: $253.65 \mathrm{~h}(77.31 \mathrm{~m}) \mathrm{ms}$.

Water ovecuated betors sampling: $52 \mathrm{gal}$

LABORATOFY ANALYSES

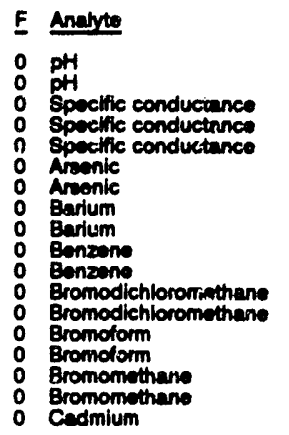

\begin{tabular}{l} 
Peosutt \\
\hline 3.5 \\
5.2 \\
50 \\
44 \\
44 \\
$<2.0$ \\
$<2.0$ \\
51 \\
50 \\
$<1.0$ \\
$<5.0$ \\
$<1.0$ \\
$<5.0$ \\
$<1.0$ \\
$<5.0$ \\
$<1.0$ \\
$<10$ \\
$<2.0$
\end{tabular}

\section{Time: 7:35 \\ Alkalinity: $0 \mathrm{mgh}$ \\ Water temperature: $20.0^{\circ} \mathrm{C}$}

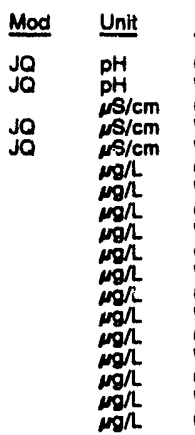

WEL CBR 20 collected on 08/01/92, laboratory analyeec (cont)

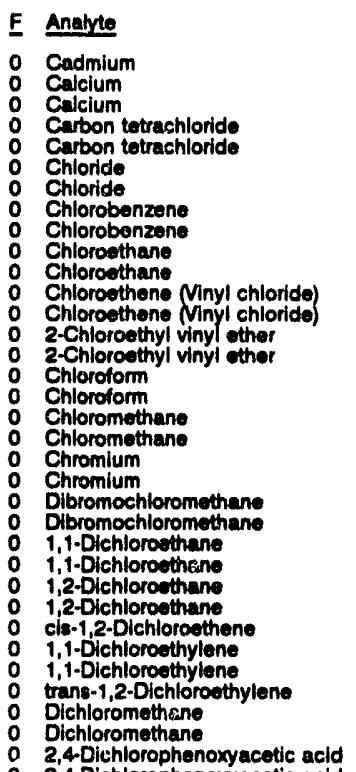

Rosult Mod Lint the

$<0.35$

388
440
$<1.0$

$<1.0$
$<5.0$
1,120

1,120
4,440

$<1.0$

$<1.0$

$<10$

$<1.0$

$<1.0$

$<1.0$

$<5.0$

$<10$

$<4.0$
2.6
$<1.0$

$<1.0$
$<5.0$
$<1.0$

$<5.0$

$<5.0$

$<5.0$

$<5.0$

$<1.0$
1.4
$<5.0$

2,4-Dichlorophenoxyacetic acid $<0.30$

2,4-Oichlorophenoxyacotic acid $<1.1$

1,2-Oichloropropane

- 1 2-Dichloropropane

cis-1,3-Dichloropropens

trane-1,3-Dichloropropen

trane-1,3-Dichioropropene

Endrin

O Ethylbenzene

O Ethylbenzene

O Eluoride

o fivon

o Iron

o Lead

o Lindarw

- Lindane

o Magnesium

- Magnesium

o Manganes:

Mercun

Mercury

Methoxychlor

Methoxychlor

Nitrate as nitrogen

o Nitrate-nittrite nitrogen

Phonots

O Phonols

Potasilum

Selonium

Solenium

o Silice.

o Sllica

o Silver

- Sodlum

Sulfate

Sulfate-Tetrachloroethane

1,1,2,2-Tetrachloroethane

Tetrachloroethylene

T Totrachloresth

Toluene

o Total dissolved sollds

o Total dissolved solids

- Total organic carbon

o Total organic carbon

- Total organic halogens

- Total orgesnic halogens

o Total phosphates (as P)

Toxaphene

o Toxaphene

0 2,4,5-7P (Silvex)

2,4,5-TP (Silvox)

1,1,1-Trichloroethane

1,1,1-Trichloroethane

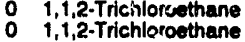

$<1.0$
$<5.0$

$<1.0$

$<5.0$

$<5.0$

$<0.0060$

$<0.11$

$<5.0$

$<100$

39

$<3$

$<0.054$

5408

3.6
3.0

$<0.20$

$\leq 0.20$

$<0.20$

30.50

2,270
1,290

$<5.00$

$<5,000$

1,700
1.400
$<., 400$

$\leq 2.0$

18,700
14.300

$<2,0$

$<0.70$

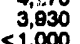

532

51.0

$<1.0$

$\leq 1.0$

$\leq 1.0$

48,000

23,000

1,000
$<500$

$<5.0$

160

23
$<0.24$

$<1.1$

$<0.080$

$<1.0$

$<5.0$

$<1.0$
$<5.0$

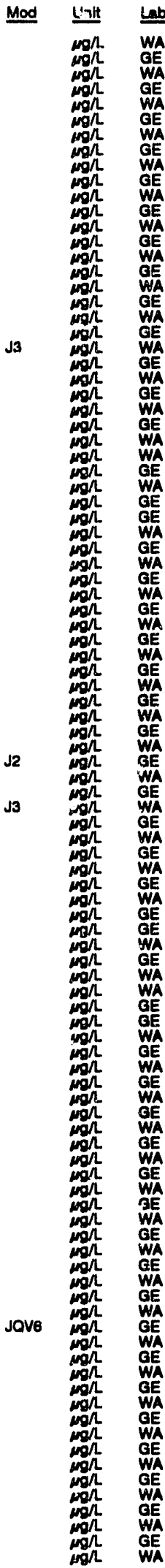


WELL CBR 20 collected on 08/01/92, laboratory analyees (conth)

\begin{tabular}{|c|c|c|c|}
\hline & Analyte & Result & Unit \\
\hline 0 & 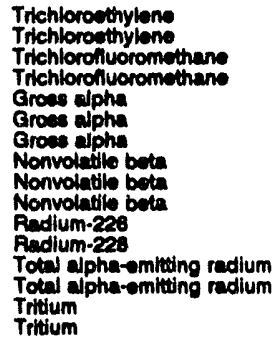 & $\begin{array}{l}<1.0 \\
<5.0 \\
<1.0 \\
<5.0 \\
<2.0 E-09 \\
1.0 E-09 \pm 1.1 E-09 \\
1.3 E-00 \pm 1.0 E-09 \\
2.1 E-09 \pm 3.4 E-10 \\
3.0 E-09 \pm 1.5 E-09 \\
4.4 E-09 \pm 1.7 E-09 \\
8.1 E-10 \pm 3.7 E-10 \\
<3.0 E-10 \\
<1.0 E-09 \\
<1.0 E-09 \\
9.3 E-08 \pm 5.0 E-07 \\
1.1 E-05 \pm 7.8 E-08\end{array}$ & 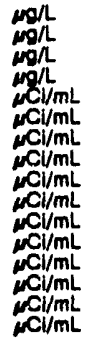 \\
\hline
\end{tabular}

\section{WELL CBR 3D}

MEASUREMENTS CONOUCTEO IN THE FIELD

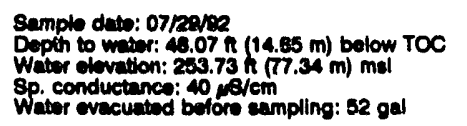

Timo: 10:46

PH: 4.8 . 0 : $\mathrm{man}$

Nkalinity: 0 man $22,4^{\circ} \mathrm{C}$

Weter evecuated before sempling: $52 \mathrm{ge}$

LABORATOAY ANALYSES

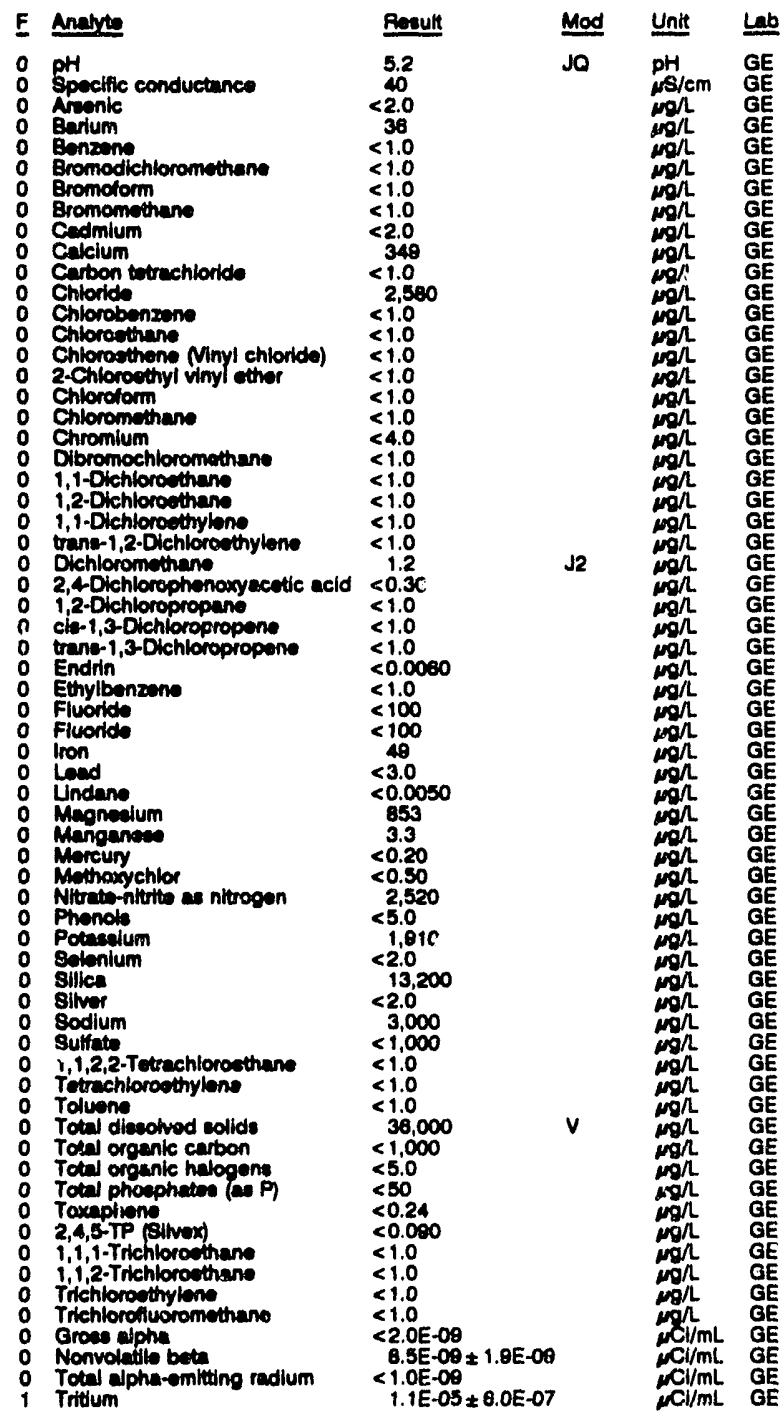

WELL CCB 1

MEASUREMENTS CONDUCTED IN THE FIELD

Sample date: 07/17/82

Depth to water: 51.75 th $(15.77 \mathrm{~m})$ bolow TOC

Water olovation: 228.85 h $(98.14 \mathrm{~m})$ mot

Sp. conductence 28 s

$75 \mathrm{gal}$

PH: 47,00

Alkalinity: $0 \mathrm{mg}$

Wator temperature: $21.6^{\circ} \mathrm{C}$

LABORATORY ANALYSES

\begin{tabular}{|c|c|c|}
\hline E Analute & Besult & Mod \\
\hline
\end{tabular}

WELL CCB 2

MEASUREMENTS CONDUCTEO IN THE FIELD

Sample date: 07/17/92

Delow TOC

Wather olovation: $224.32 \mathrm{~h}(68.37 \mathrm{~m}) \mathrm{mal}$

(2)

PH: 47.

PH: 4.7 in: 0 mon

Water tomporature: $21.80^{\circ} \mathrm{C}$

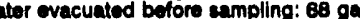

LABOFATORY ANALYSES

\begin{tabular}{|c|c|c|}
\hline Analyze & Resulf & Mod \\
\hline Lead & $<3.0$ & \\
\hline
\end{tabular}

WELL CCB 3

MEASUREMENTS CONDUCTED IN THE FIELD

Sample date: 07/17/92

Depth to wator: 40.36 ft $(12.30 \mathrm{~m})$ bolow TOC Weter elevation: 27.03 h

We conductunce 18 is/cm

TIme: 13:15

Alkailinity: $0 \mathrm{mgh}$

Water ty: molure: $22.00^{\circ} \mathrm{C}$

Water evacuatod before sampling: $58 \mathrm{ged}$

LABORATORY ANALYSES

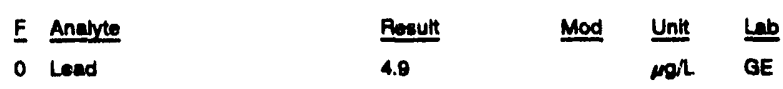

WELL CCB 4

MEASUREMENTS CONDUCTED IN THE FIELD

Sample date: 07/17/82

Dopth to water: $54.50 \mathrm{ft}(18.61 \mathrm{~m})$ bolow TOC

Water olevation: $228.50 \mathrm{Ht}(69.05 \mathrm{~m}) \mathrm{mal}$

So. contuctence. $18.85 / \mathrm{cm}$

mal

Time: 12:55

Alkalinity: $0 \mathrm{mg} / \mathrm{l}$

Water tomperature: $20.8^{\circ} \mathrm{C}$

LABORATORY ANALYSES

\begin{tabular}{|c|c|c|c|}
\hline$E$ Analyte & Result & Mod & Unit \\
\hline : Load & $\begin{array}{l}3.1 \\
3.8\end{array}$ & & $\operatorname{mog}$ \\
\hline
\end{tabular}

\section{WELL CDB 1}

MEASUREMENTS CONDUCTED IN THE FIELD

Sample date: 0Q/18ros

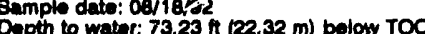

Water to wation: 7.23 . $215.67 \mathrm{ft} .32 \mathrm{~m})$ bolon

Sp. conductance: $83 \mathrm{\mu s} / \mathrm{cm}$ mpling: 14 gal

The woll wont dry during purging.

LABORATORY ANALYSES

\begin{tabular}{|c|c|c|c|c|}
\hline$F$ & Anaryte & Plesulf & Mod & Unit \\
\hline & $\begin{array}{l}\text { Cadmium } \\
\text { lion } \\
\text { Load } \\
\text { Manganeas } \\
\text { Total activity } \\
\text { Tritium }\end{array}$ & $\begin{array}{l}<2.0 \\
228 \\
146 \\
44 \\
5.7 E-05 \\
5.4 E-05\end{array}$ & & 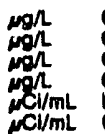 \\
\hline
\end{tabular}


WELL CDB 2

MEASUAEMENTS CONDUCTED IN THE FIELD

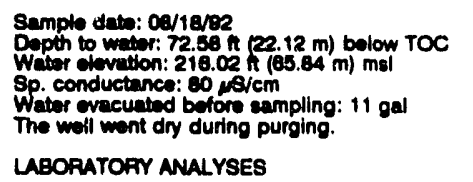

Time: 18:10

PH: 5.3 .30

Water temperature: $24.0^{\circ} \mathrm{C}$

LABOPATOFY ANALYSES

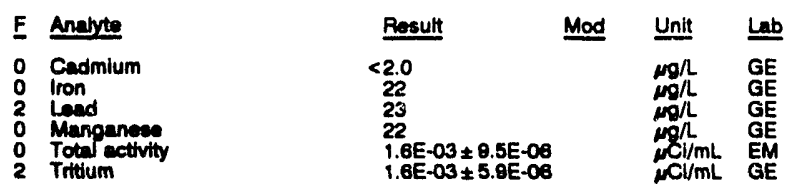

WELL CMP 8

MEASUREMENTS CONDUCTED IN THE FIELD

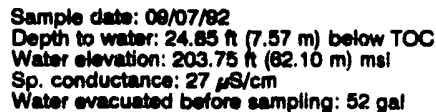

LABORATOAY ANALYYSES

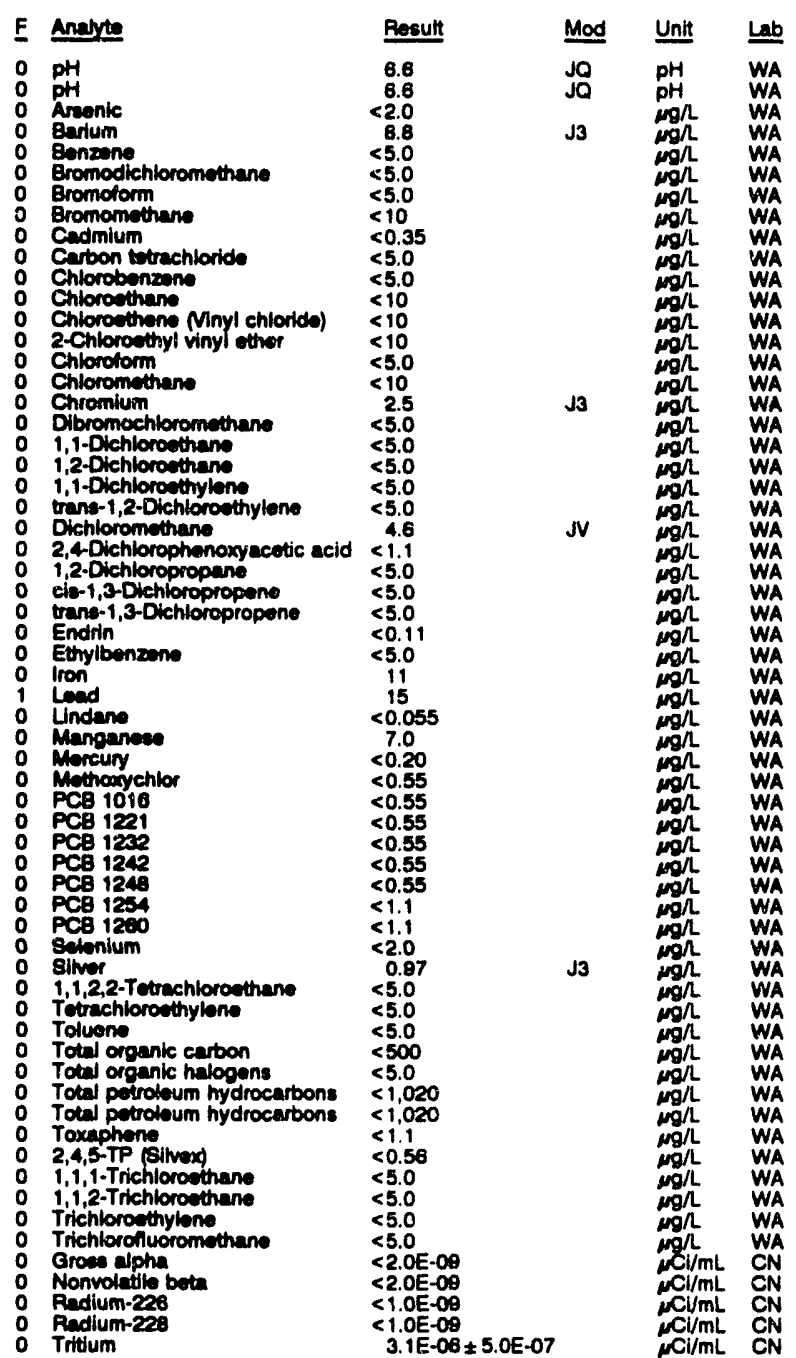

\section{WELL CMP $8 A$}

MEASUREMENTS CONDUCTED IN THE FIELD

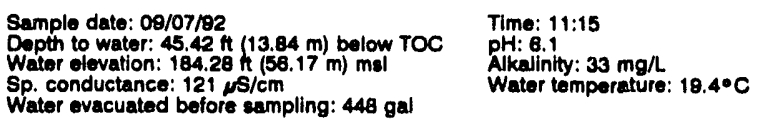

LABORATORY ANALYSES

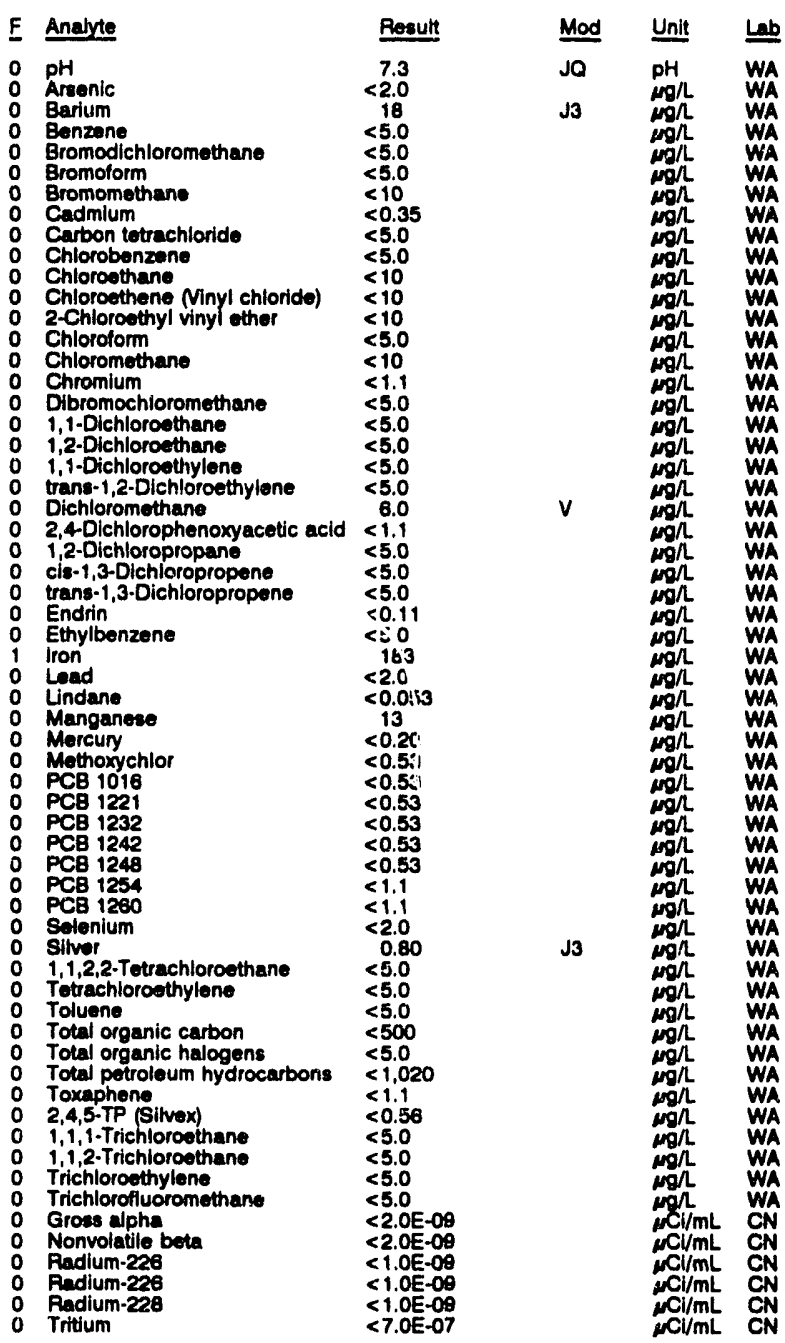

\section{WELL CMP $8 B$}

MEASUREMENTS CONDUCTED IN THE FIELD

\begin{tabular}{|c|c|c|c|c|}
\hline \multirow{2}{*}{\multicolumn{2}{|c|}{ 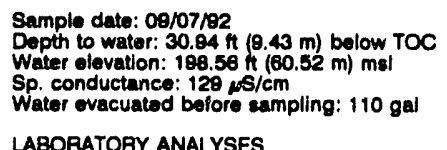 }} & \multicolumn{3}{|c|}{$\begin{array}{l}\text { Time: } 12: 00 \\
\text { pHil: } 8.6 \\
\text { Alkalinity: } 44 \mathrm{mg} h \\
\text { Walter tomperature: } 18.2{ }^{\circ} \mathrm{C}\end{array}$} \\
\hline & & & & \\
\hline Analyte & Result & Mod & Unit & Lab \\
\hline $\begin{array}{ll}0 & \text { pH } \\
0 & \text { Arsenic } \\
0 & \text { Barium } \\
0 & \text { Bonzene } \\
0 & \text { Bromodichioromethane } \\
0 & \text { Bromolorm } \\
0 & \text { Brommothane } \\
0 & \text { Cadmium } \\
0 & \text { Carbon tetrachloride } \\
0 & \text { Chlorobenzene }\end{array}$ & $\begin{array}{l}7.6 \\
<2.0 \\
17 \\
<5.0 \\
<5.0 \\
<5.0 \\
<10 \\
<0.35 \\
<5.0 \\
<5.0\end{array}$ & $\begin{array}{l}\text { JO } \\
\text { J3 }\end{array}$ & 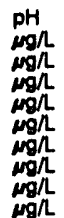 & $\begin{array}{l}\text { WA } \\
\text { WA } \\
\text { WA } \\
\text { WA } \\
\text { WA } \\
\text { WA } \\
\text { WA } \\
\text { WA } \\
\text { WA } \\
\text { WA }\end{array}$ \\
\hline
\end{tabular}


WELL CMP $8 B$ colbeted on 08/07/82, taboratory analyses (cont)

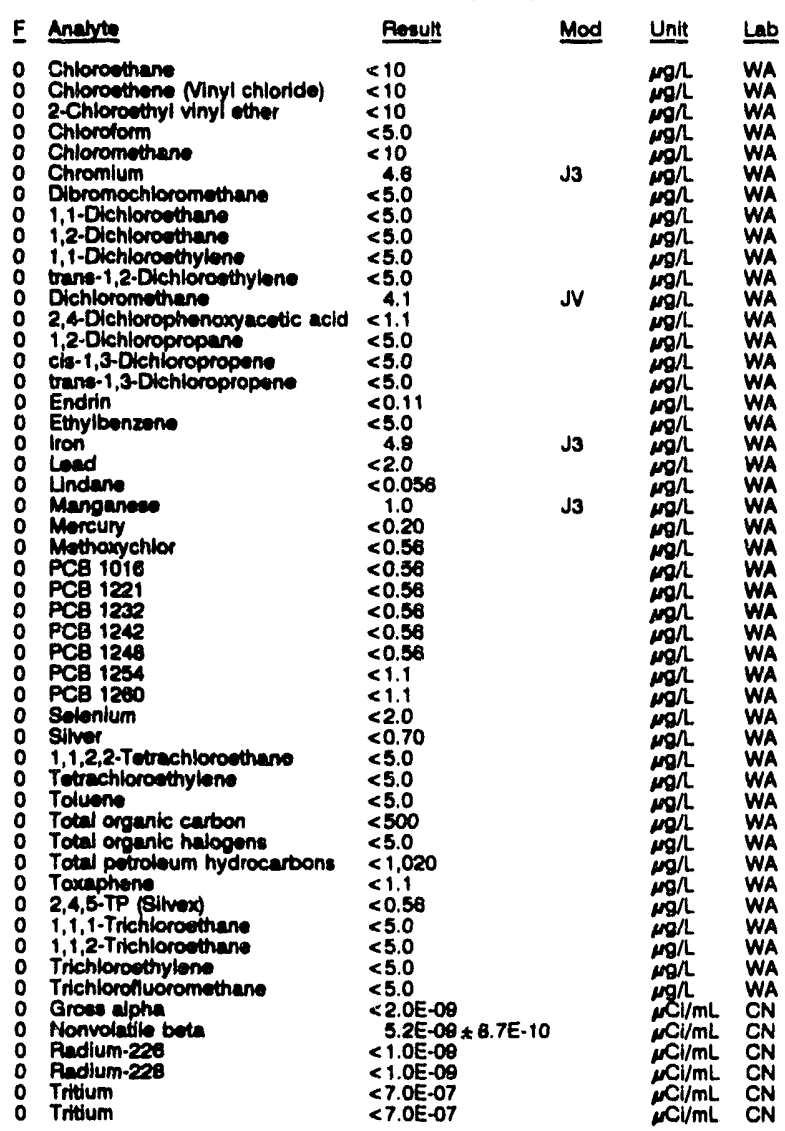

\section{WEL CMP 9B}

MEASUAEMENTS CONOUCTED IN THE FIELD

\section{Sumple dats: 09perep}

Dopth to water: 11899 (t) $(36.57 \mathrm{~m})$ below TOC Whter elovetion: 195.11 ( $150.47 \mathrm{~m})$ mal

Sp. conductance: $170 \mathrm{~s} / \mathrm{cm}$

Witer evacuated betore eampling: $138 \mathrm{gal}$

LABOPATOFY ANALYSES

E Arate

0 pH

o Bartum

O Benzence

Eromodichloromethane

Bromotorm

Cadmium

Carbon trimechlotide

Chlorobenzars

Chlorothane Mnyl chloride)

2-Chioroothyl vinyl ether

Chlordorm.

Chlorometh

Dibromochloromethane

o 1,1-Dichloroethane

o 1,2-Dichloroothane

trans-1,2-Dichloroethylone $<5.0$

2,4-Dichlorophonoxyacetic acid

o 1,2-Dichtoropropane

cis-1,3-Dichioropropene

0 trans-1,3-Diehloropropene

Endrin

Endrin

Iron

Lead

\begin{tabular}{l} 
Result \\
\hline 7.7 \\
$<2.0$ \\
23 \\
$<5.0$ \\
$<5.0$ \\
$<5.0$ \\
$<10$ \\
$<0.35$ \\
$<5.0$ \\
$<5.0$ \\
$<10$ \\
$<10$ \\
$<10$ \\
$<5.0$ \\
$<10$ \\
5.6 \\
$<5.0$ \\
$<5.0$ \\
$<5.0$ \\
$<5.0$ \\
$<5.0$ \\
14 \\
$<1.1$ \\
$<5.0$ \\
$<5.0$ \\
$<5.0$ \\
$<0.11$ \\
$<0.23$ \\
$<5.0$ \\
5.6 \\
$<2.0$ \\
$<0.057$
\end{tabular}

WELL CMP 88 collected on 09/09/82, laboratory analyese (cont.)

\begin{tabular}{|c|c|c|c|}
\hline$F$ & Analyte & Pesult & Unit \\
\hline $\begin{array}{l}0 \\
0 \\
0 \\
0 \\
0 \\
0 \\
0 \\
0 \\
0 \\
0 \\
0 \\
0 \\
0 \\
0 \\
0 \\
0 \\
0\end{array}$ & 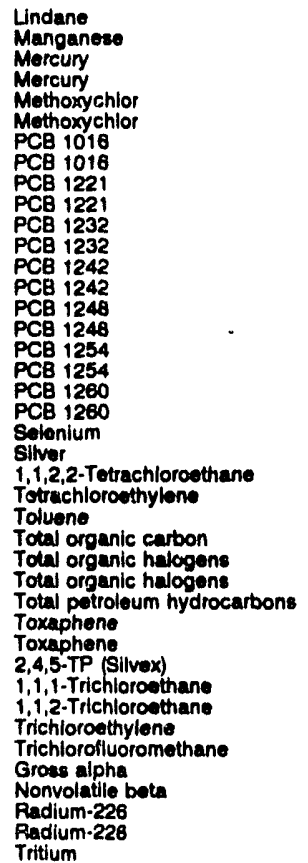 & $\begin{array}{l}<0.11 \\
<0.35 \\
<0.20 \\
<0.20 \\
<0.57 \\
<1.1 \\
<0.57 \\
<1.1 \\
<0.57 \\
<1.1 \\
<0.57 \\
<1.1 \\
<0.57 \\
<1.1 \\
<0.57 \\
<1.1 \\
<1.1 \\
<2.3 \\
<1.1 \\
<2.3 \\
<2.0 \\
<0.70 \\
<5.0 \\
<5.0 \\
<5.0 \\
<500 \\
22 \\
21 \\
<1.020 \\
<1.1 \\
<2.3 \\
<0.56 \\
<5.0 \\
<5.0 \\
<5.0 \\
<5.0 \\
<2.0 E-09 \\
71.2 E-09 \\
<1.0 E-09 \\
<1.0 E-09 \\
<7.0 E-07\end{array}$ & 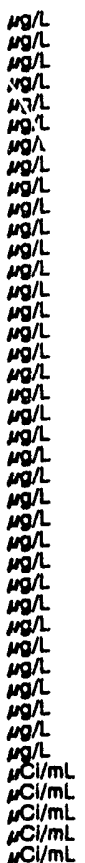 \\
\hline
\end{tabular}

WELL CMP 10

MEASUREMENTS CONDUCTED IN THE FIELO

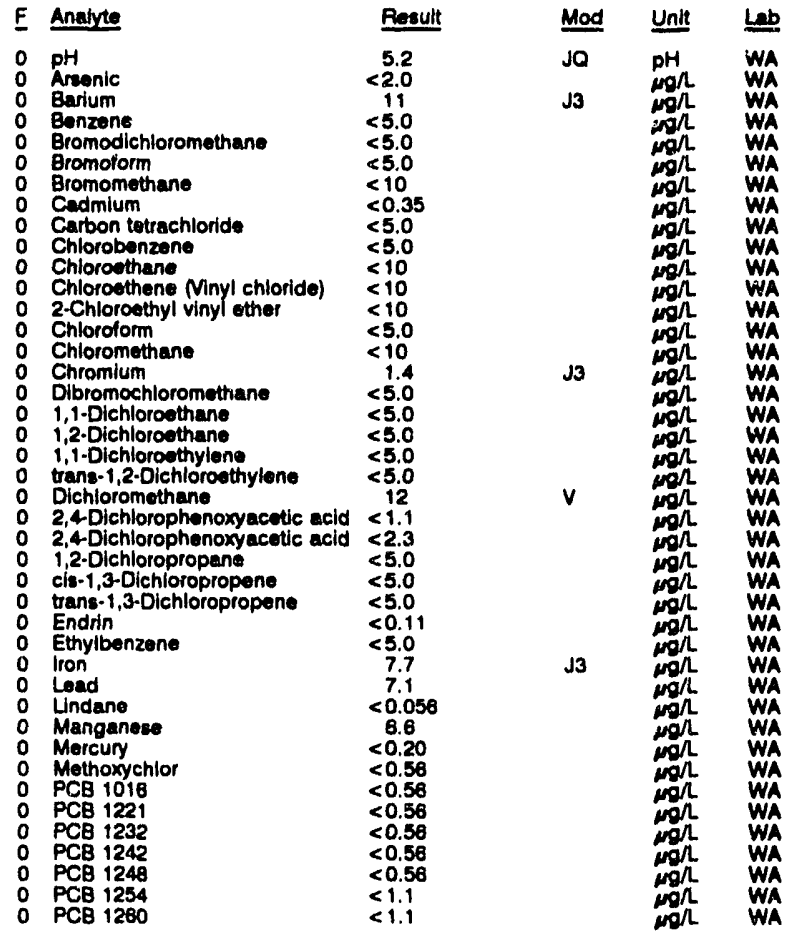

Sample date: $09 / 09 / 92$

Depth to water: $88.97 \mathrm{~h}(27.12 \mathrm{~m})$ below TOC

Water elevation: $221.03 \mathrm{ht}$ (87.8

Water evacuated before sampling: $87 \mathrm{ga}$

LABORATORY ANALYSES

Time: 11:05

Alk: 4.8 : 05

Weter temperature: $20.4^{\circ} \mathrm{C}$

Time: 10:20

pH: 7.0

$67 \mathrm{mgh}$

Water temporature: $20.5^{\circ} \mathrm{C}$

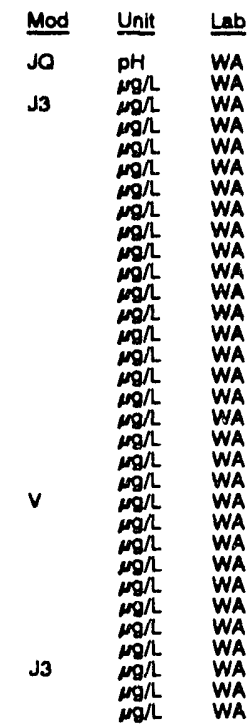

Lab
WA
WA
WA
WA
WA
WA
WA
WA
WA
WA
WA
WA
WA
WA
WA
WA
WA
WA
WA
WA
WA
WA
WA
WA
WA
WA
WA
WA
WA
WA
WA
WA
WA 
ANALYTICAL RESULTS

WELL CMP 10 collected on 00/00/9?, laboratory anelyses (cont.)

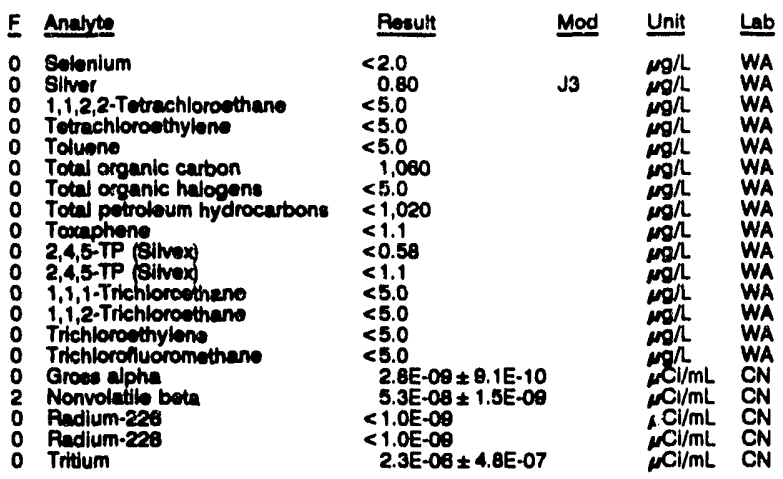

\section{WELL CMP $10 B$}

MEASUREMENTS CCNDUCTED IN THE FIELD

Sample data: $00 / 09 / 92$
Depth to water: $115.40 \mathrm{n}(35.17 \mathrm{~m})$ below TOC
Weter elevation: $185.40 \mathrm{n}(50.56 \mathrm{~m}) \mathrm{msl}$ Sp. conductance: $201 \mu \mathrm{s} / \mathrm{cm}$

W. conductance: $201 \mathrm{H} 8 / \mathrm{cm}$.

LABORATORY ANALYYES

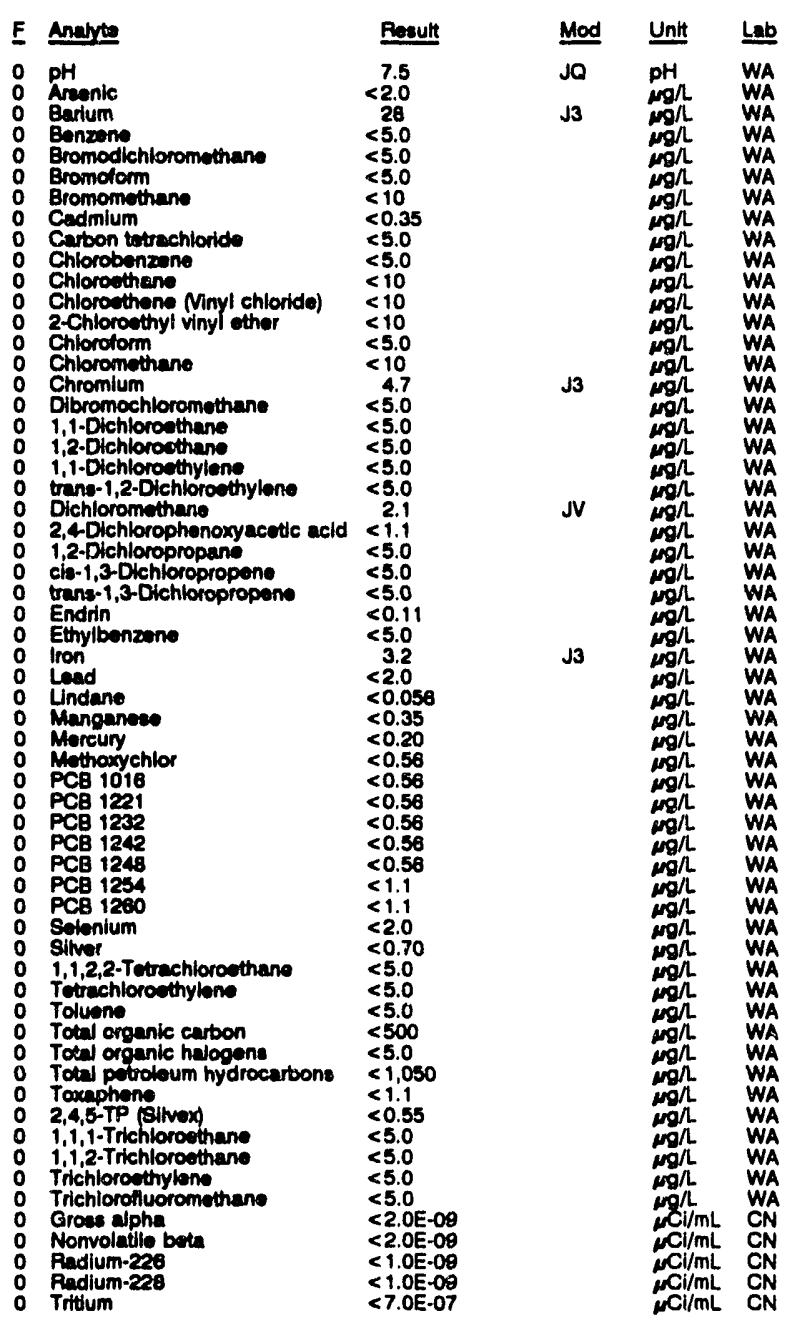

Time; 11:45

AH: 7.4 : $86 \mathrm{mgn}$

Water tomperature: $20.7^{\circ} \mathrm{C}$

\section{WELL CMP 11}

MEASUREMENTS CONDUCTED IN THE FIELD

Sample date: $08 / 10 / 82$

Wopth to water: $98.18 \mathrm{ft}(29.32 \mathrm{~m})$ below TOC

Sp. conductance: $25.31 \mathrm{At}(65.32$

Wator evacuated bofore sampling: $20 \mathrm{gal}$

The well went dry during purging.

LABORATORY ANALYSES

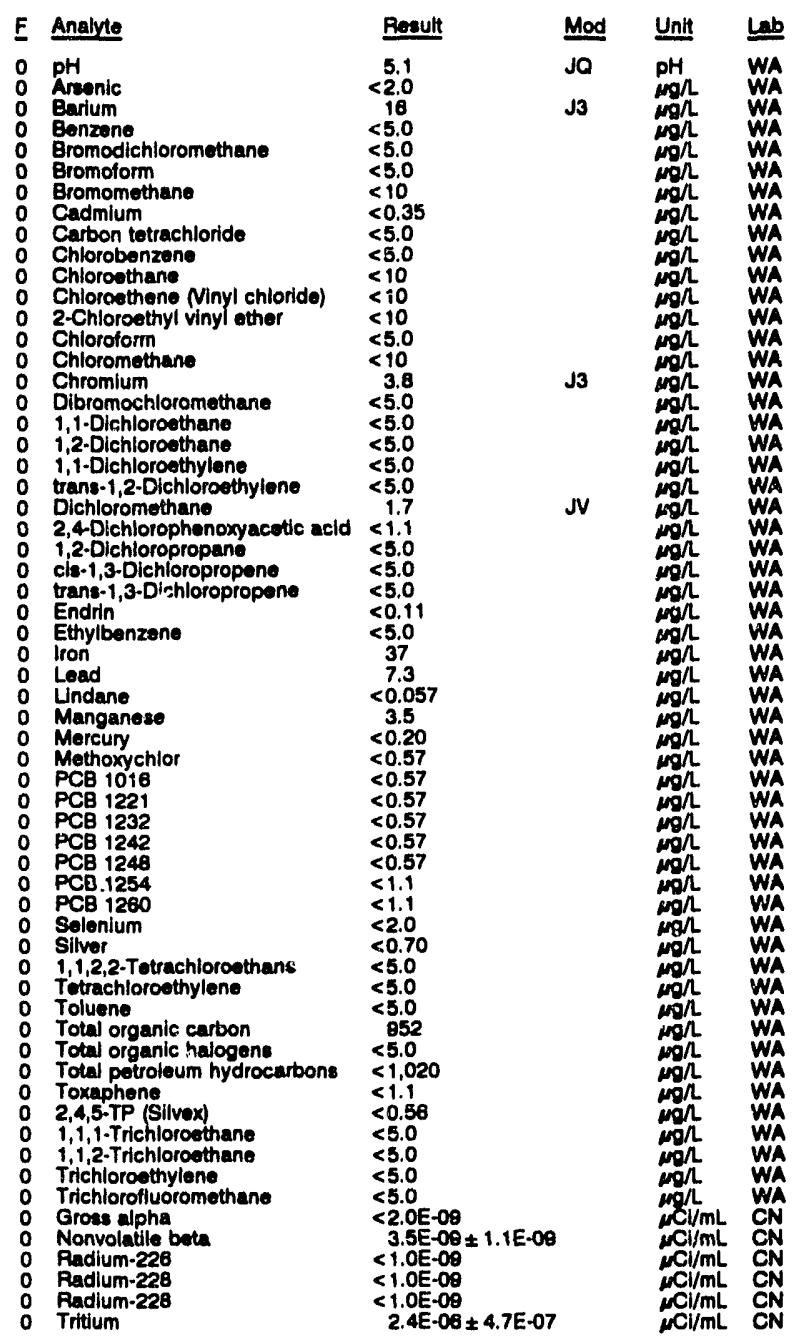

\section{WELL CMP $11 B$}

MEASUREMENTS CONDUCTED IN THE FIELD

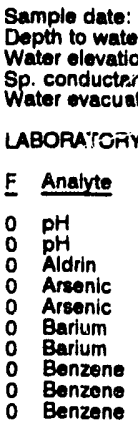


WEUL CMP 118 collected on 00/10/82, laboratory analyses (cont.)

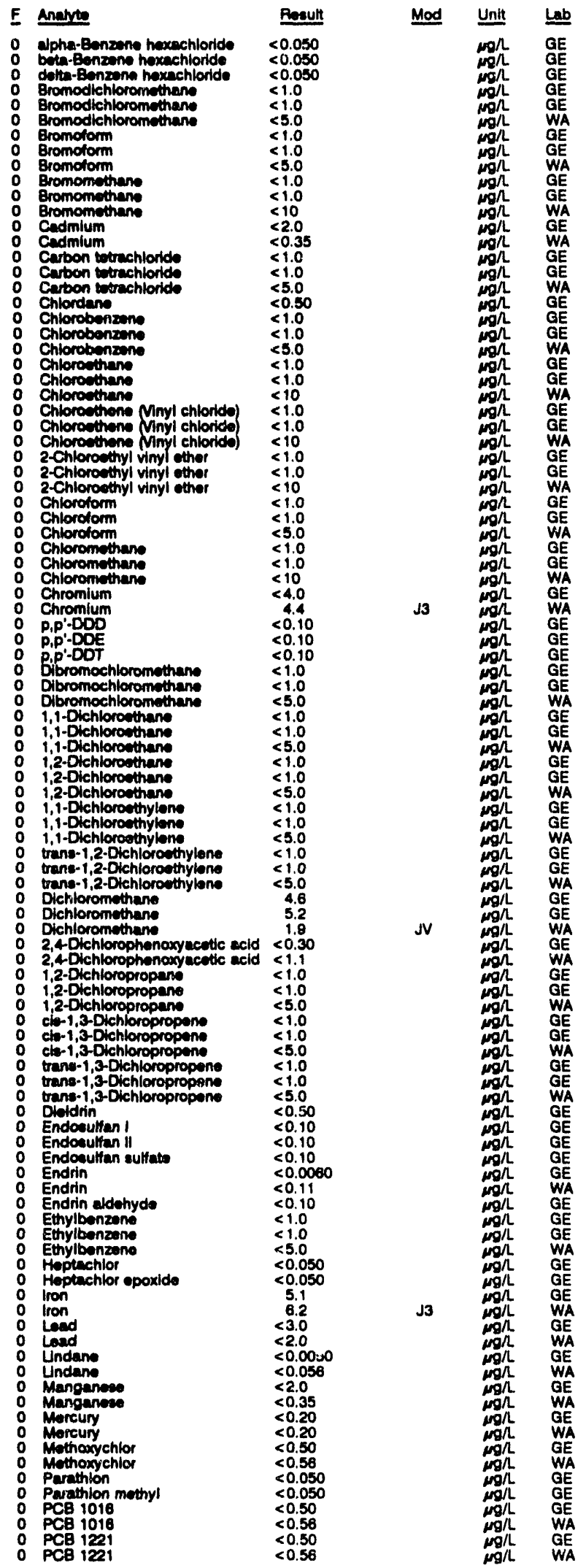

WELL CMP 118 collected on 09/10/92, laboratory analyese (cont)

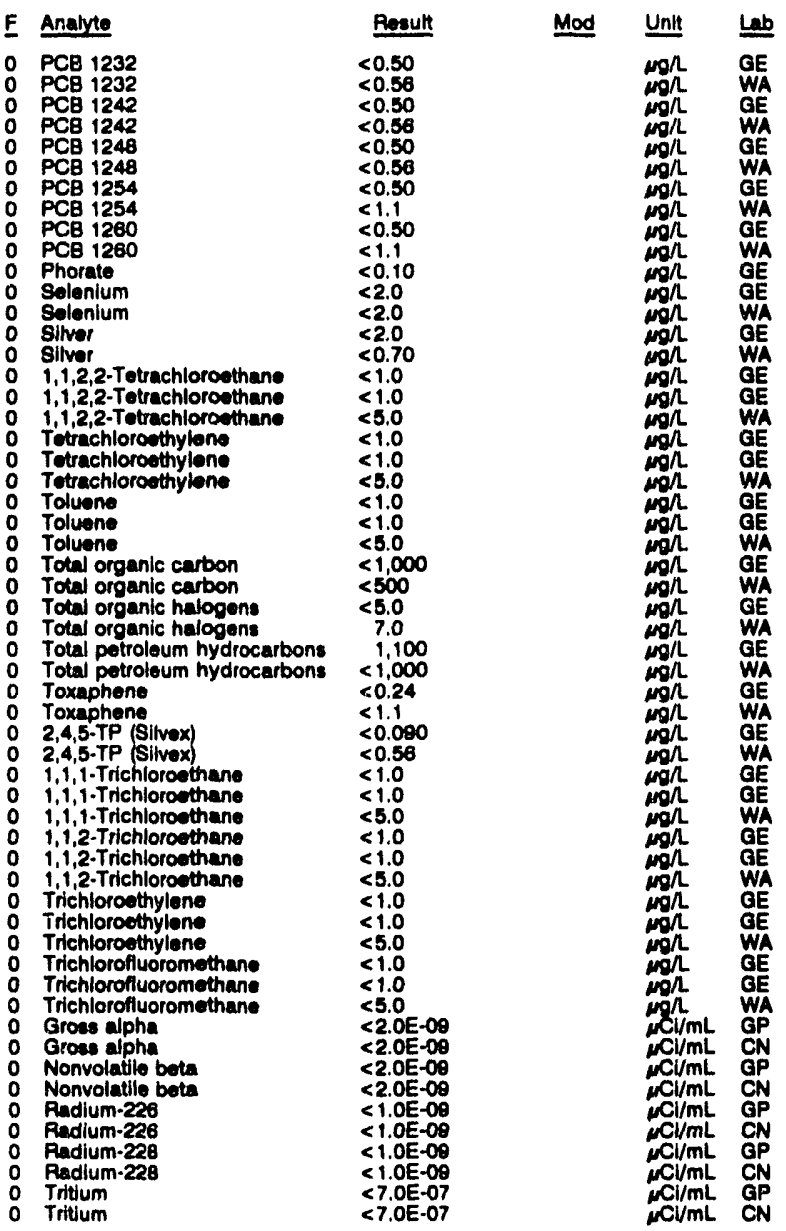

\section{WELL CMP 11B Replicate}

MEASUREMENTS CONOUCTED IN THE FIELO

Sample date: $08 / 10 / 92$

Dopth to water: $114.78 \mathrm{n}(34.98 \mathrm{~m})$ below TOC

Water olovation: $195.44 \mathrm{ft}(50.57 \mathrm{~m}) \mathrm{ma}$

Water ovacuated before sampling: $148 \mathrm{gal}$

LABOPATOAY ANALYSES

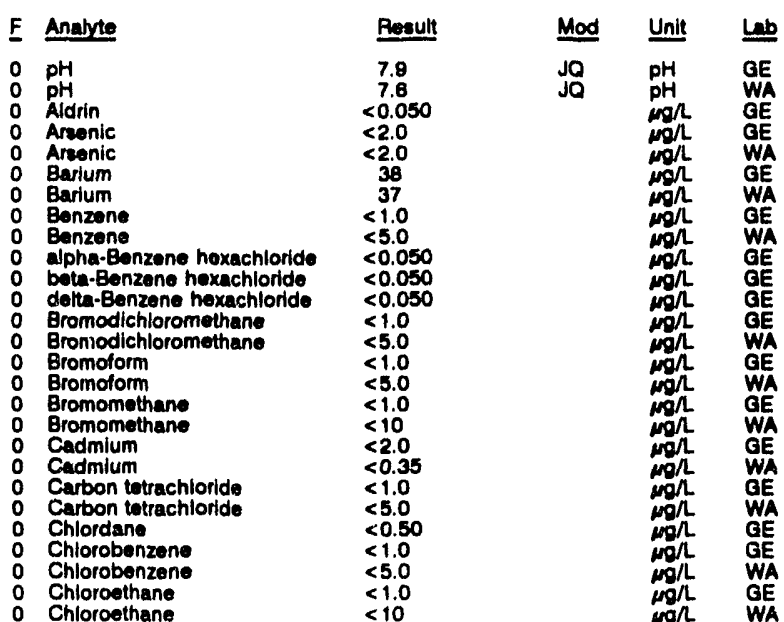


ANALYTICAL RESULTS

WEL CMP 118 colboted on 09/10/92, laboratory analyees (cont.)

\begin{tabular}{|c|c|c|c|c|c|c|}
\hline F Anatyte & Result & Mod & Unit & Lab & E & Analyte \\
\hline 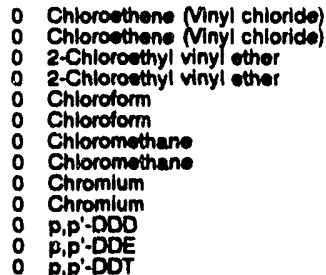 & $\begin{array}{l}<1.0 \\
<10 \\
<1.0 \\
<10 \\
<1.0 \\
<5.0 \\
<1.0 \\
<10 \\
<4.0 \\
4.2 \\
<0.10 \\
<0.10 \\
<0.10\end{array}$ & J3 & 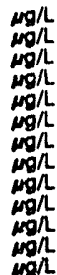 & $\begin{array}{l}G E \\
W A \\
G E \\
W A \\
G E \\
W A \\
G E \\
W A \\
G E \\
W A \\
G E \\
G E \\
G E\end{array}$ & $\begin{array}{l}0 \\
0 \\
0 \\
0 \\
0 \\
0 \\
0 \\
0 \\
0 \\
0 \\
0\end{array}$ & $\begin{array}{l}\text { Trichlorofluoromothane } \\
\text { Gross alpha } \\
\text { Grose aphas } \\
\text { Nonvolatile bota } \\
\text { Nonvolatile bota } \\
\text { Radium-226 } \\
\text { Radium-226 } \\
\text { Radium-228 } \\
\text { Radium-228 } \\
\text { Tritium } \\
\text { Tritium }\end{array}$ \\
\hline
\end{tabular}

WELL CMP 12

MEASUREMENTS CONOUCTED IN THE FIELD

Sample date: 09/09/82

Depth to water: $70.68 \mathrm{~A}(21.54 \mathrm{~m})$ bolow TOC

Water olevation: 212.22 \& $(64.69 \mathrm{~m}) \mathrm{ms}$ )

Sp. conductance: $20 \mathrm{mS} / \mathrm{cm}$

sampling: $49 \mathrm{gal}$

LABORATORY ANALYSES

F Analyte

0 pH

0 Barium

Barium

O Bromodichloromethane

0 Bromoform

- Bromomothane

C Cadmium

- Carbon totrachioride

Chlorobenzene

O Chlorosthene Minyl chloride)

: Chlorosthene Ninyl chloride)

2-Chioroethy

Chloroform

$\begin{array}{ll}0 & \text { Chioromium } \\ 0 & \text { Dibromochloromethane }\end{array}$

1,1-Dichloroethane

o 1,2-Dichloroothane

1,1-Dichloroethylene

trans-1,2-Dichloroet

2,4-Dichlorophenoxyacetic acid

1,2-Dichloropropane

cis-1,3-Dichloropropene

0 trans-1,

O Endrin

Iron

Load

Manganese

Morcury

Methoxychlor

- PCB 1018

PCB 1221

P PCB 1232

PCB 1242

PCB 1254

PCB 1260

Solenlum

1,1,2,2-Tetrachloroethane

Totrach

Toluene

Total organic carbon

Total organic halogens

Toxaphene

2,4,5-TP (Silvex)

o $1,1,1$-Trichloroethane

o 1,1,2-Trichloroethan

2 Trichloroethylente

Grose alpha

Nonvolatile bot

Radium-226

0 Radium-228

Tritium

Pleault
$<5.0$
$<2.0 E-09$
$<2.0 \mathrm{e}-09$
$<2.0 \mathrm{E}-09$
$<2.0 \mathrm{E}-09$
$<1.0 \mathrm{E}-09$
$<1.0 \mathrm{E}-09$
$<1.0 \mathrm{E}-09$
$<1.0 \mathrm{E}-09$
$<7.0 \mathrm{x}-07$
$<7.0 \mathrm{E}-07$

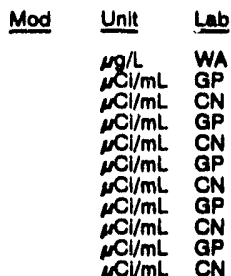

Time: $15: 30$

PH: 4.6

Water temperature: $20.8^{\circ} \mathrm{C}$

-

Rosult

Mod Unit Lnb

5.2

$<2.0$
7.0
$<5.0$
$<5.0$

$<5.0$

$<0.35$

$<5.0$

$<10$
$<10$
$<10$

$<5.0$

$<10$

5.0
$<5.0$

$<5.0$

$<5.0$

$\mathbf{5 . 0}$

$<1.1$
$<5.0$
$<5$

$<5.0$

$<5.0$

$<5.0$

$<0.058$

5.3

$<0.20$

$<0.58$
$<0.58$
$<0.58$

$<0.58$

$<0.58$

$<1.2$

$<2.0$

$<0.70$
$<5.0$

$<5.0$

$<5.0$
$<500$

48

$<1,000$

$<1.2$

$<5.0$

$<5.0$

$<2.0 \mathrm{E}-09$

$<2.0 \mathrm{E}-09$

$<1.0 \mathrm{E}-09$

$<1.0 E-09$

pon WA WA

on WA

$<1,000$

$\begin{array}{ll} & \text { Total petroloum hydrocartons } \\ \text { Toxsphene } & <0.24\end{array}$

Toxaphen

2,4,5-TP Silvor

$<1.1000$

$<0.54$

1,1,1-Trichloroethane

1,1,1-Trichloroethane

1,1,2-Trichloroesthane

rivichloroethylene

Trichloroethylene

$<1.0$

$<1.0$

$<5.0$

$<1.0$

$<5.0$
$<1.0$ 
WELL CMP 12A

MEASUAEEMENTS CONDUCTED IN THE FIELD

Sample dati: 00/00/0R $30.71 \mathrm{~m})$ biow TOC Wopth to water: $100.78 \mathrm{n}(30.71 \mathrm{~m})$ balow

8p. conductance: 173 pe/cm

\section{LABORATOFY ANALYBES}

E Anerto

0 pH

Barlum

Bromodichloromethane

Bromotorm

Cromomn

Gerbon tetrachloride

Chlorobenzans

Chlorothen Mnyl chiordel

2-Chlorothyl vinyl ethes

Chiorolorm

Chloromethene

Chromium

Dibromochloromethane

i, -Okchloroethans

o 1,1-Dichloroethylone

2,4-Dichlorophenomacedte acld

0 1,2-Dichlompropanc

o cla-1,3-Dichloropropone

0 trane-1,

- Ethylbenzone

1 Iron

Indane

2 Manganece

Methonychlor

PCA 1010

P PCB 1221

- PCB 1240

PCB 1246

PCB 1200

o Eebonium

1,1,2,2.Tetrechloroethan

Tetrachloroathylom

Toluena

Total organic carbon

Total petroleum hydrocarbone

Toxaphene.

1,i, Trichlorosthene

Trichiorothyleme

o Trichlorofluoromethene

Nonvoletile beta

Radium-22:

0 Trioum

WELL CMP 12B

MEASUAEMENTS CONDUCTED IN THE FIELO

Sample data: 0epooper

Dopth to wator: $80.00 \mathrm{n}(27.13 \mathrm{~m})$ below TOC Water elevation: 104.co h (60)

Bp. conductance: $103 \mu \mathrm{s} / \mathrm{cm}$.

LABORATORY ANALYYES

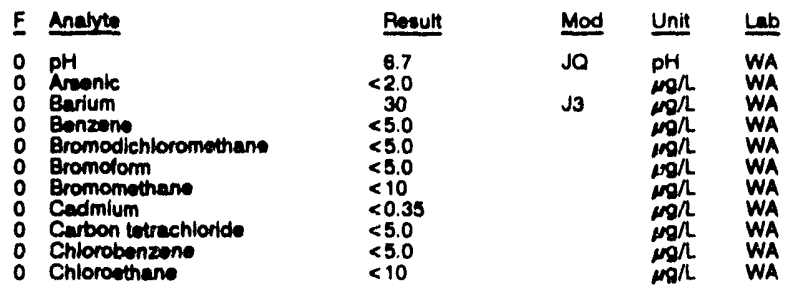

Time: 14:30

pH: 7.3

7. $70 \mathrm{mon}$

Weler tomperature: $19.8 \circ \mathrm{C}$

WA
WA
WA
WA
WA
WA
WA
WA
WA
WELL CMP 128 collected on 00/00/02, laboratory analyeses (cont)

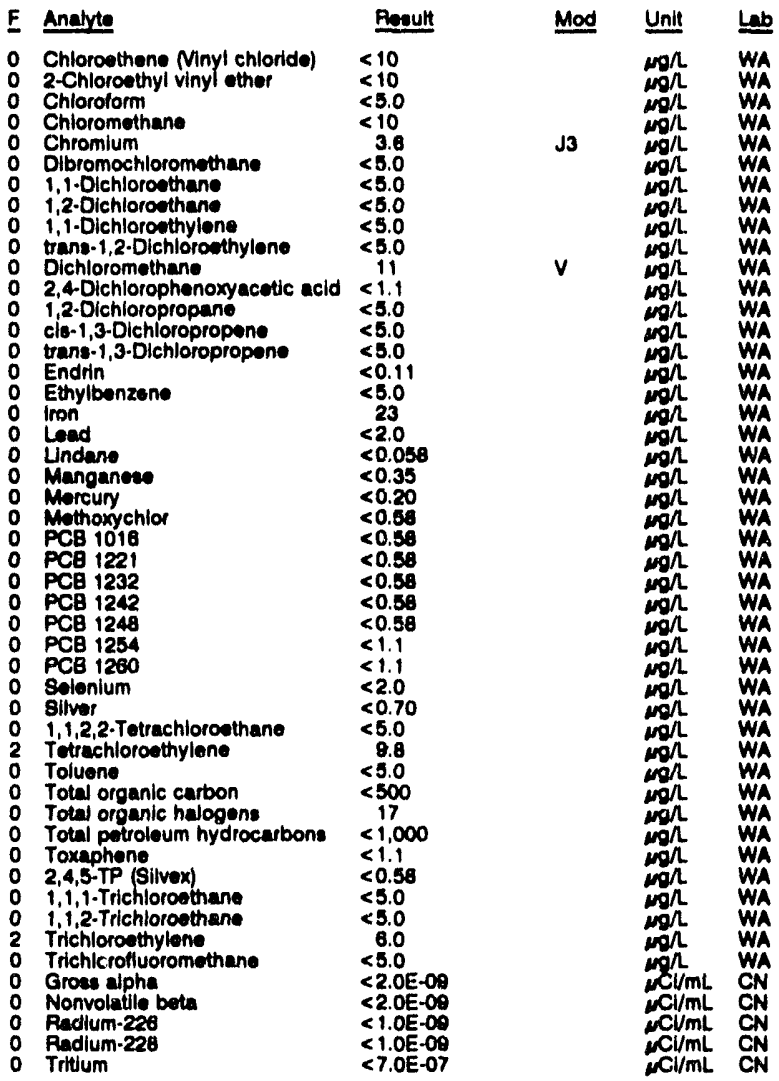

\section{WELLL CMP 13}

MEASUREMENTS CONDUCTED IN THE FIELD

Sample date: 09/10/92

Depth to water: $79.58 \mathrm{ft}(24.28 \mathrm{~m})$ below TOC

Water Govation: $209.62 \mathrm{~h}(83.89 \mathrm{~m}) \mathrm{msl}$

Water evacuated bofore sampling: 8 gal

The well went dry during purging

LABORATOAY ANALYYSES

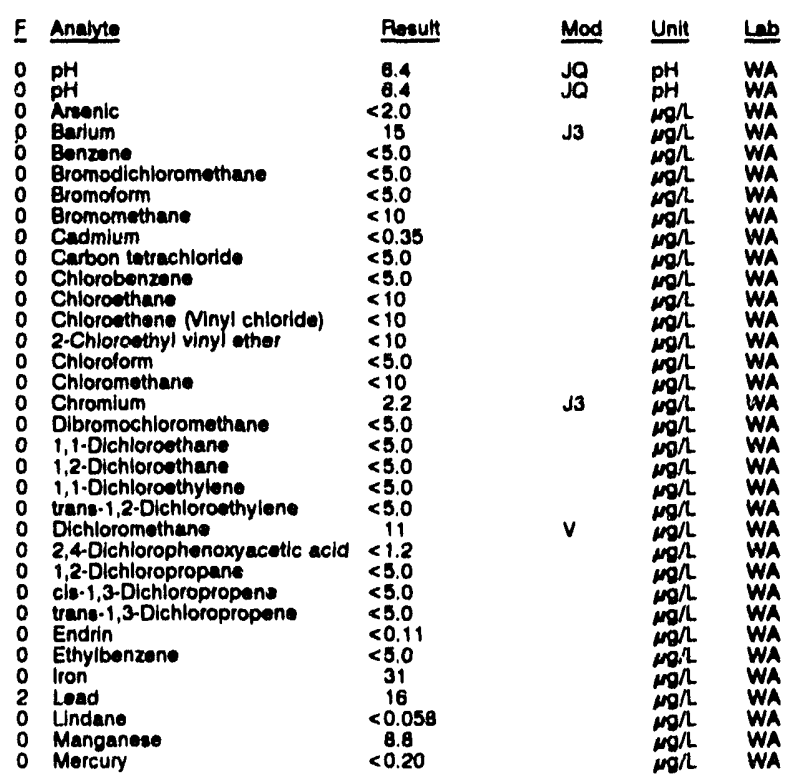

Time: 13:20

pH: 5.8

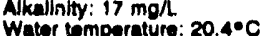


ANALYTICAL RESULTS

WELL CMP 13 collected on 00/10/92, laboratory analyese (cont.)

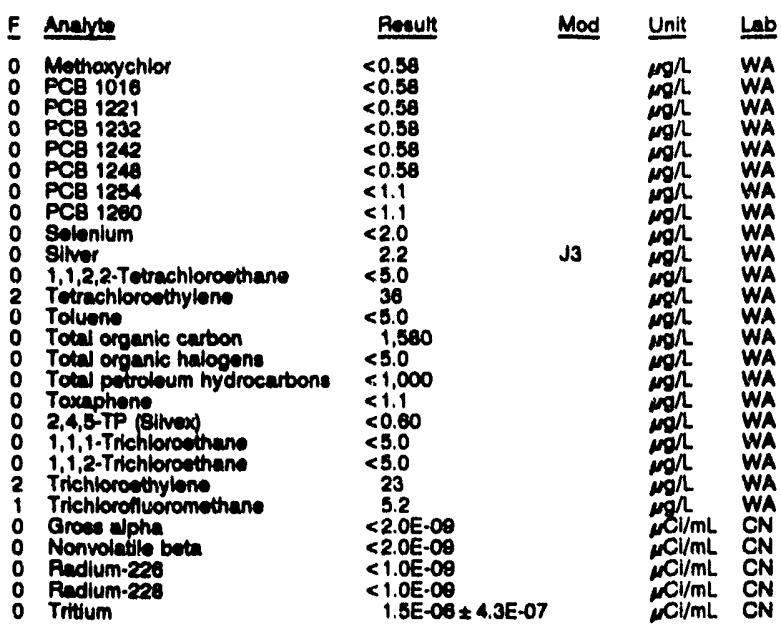

WELL CMP 13B

MEASUREMENTB CONDUCTED IN THE FIELD

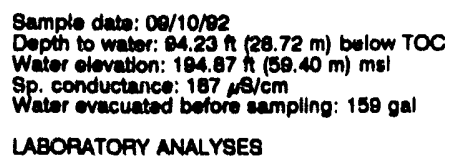

Time: 13:45

pH: 8.5

Alkalinity: $70 \mathrm{mg} / \mathrm{h}$ : $20.4^{\circ} \mathrm{C}$

LABORATORY ANALYSES

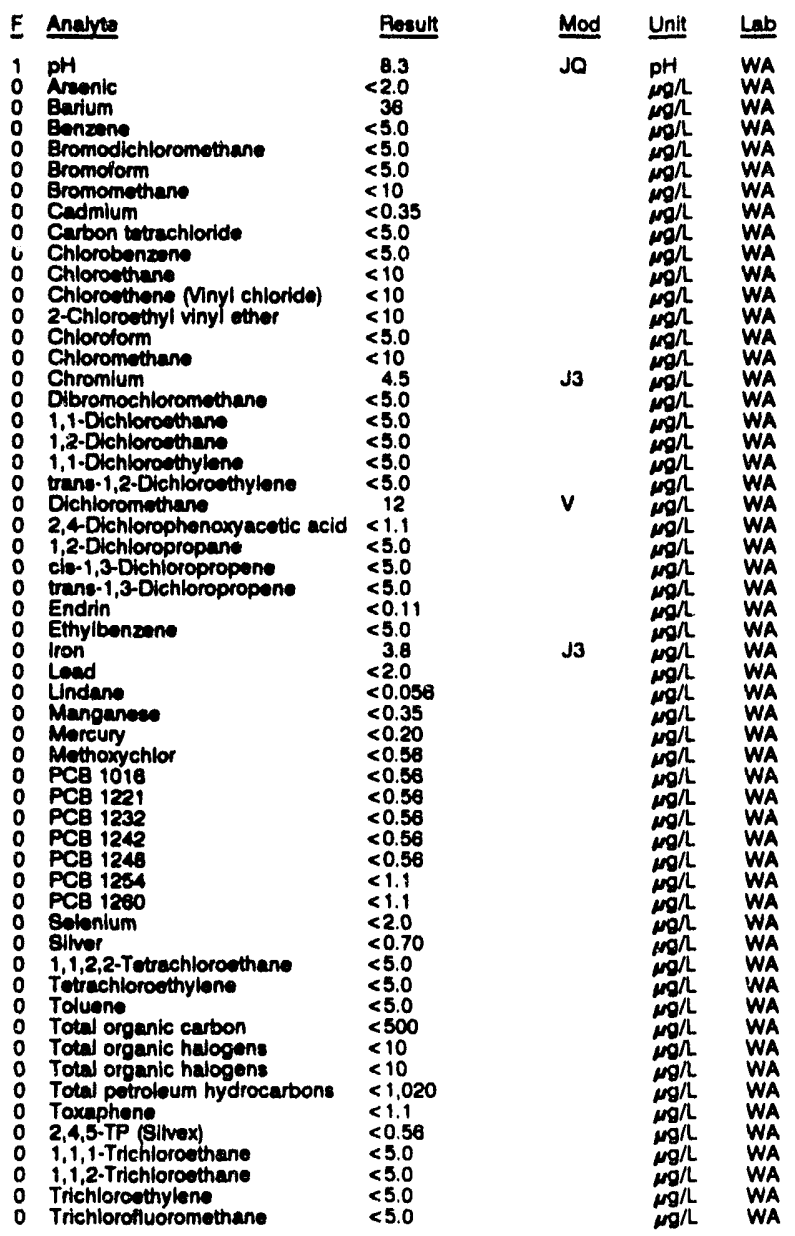

WELL CMP 138 collected on 09/10/92, laboratory analyeen (cont.)

\begin{tabular}{|c|c|c|c|c|}
\hline$\underline{E}$ & Analyte & Result & Mod & Unlt \\
\hline $\begin{array}{l}0 \\
0 \\
0 \\
0\end{array}$ & $\begin{array}{l}\text { Groess alpha } \\
\text { Nonvolatlle bota } \\
\text { Radium-226 } \\
\text { Radium-228 } \\
\text { Tritium }\end{array}$ & $\begin{array}{l}<2.0 \mathrm{E} \cdot 00 \\
<2.0 \mathrm{E} \cdot 00 \\
<1.0 \mathrm{E} \cdot 00 \\
<1.0 \mathrm{E} \cdot 00 \\
<7.0 \mathrm{E}-07\end{array}$ & & 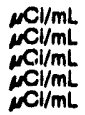 \\
\hline
\end{tabular}

\section{WELL CMP 14B}

MEASUREMENTS CONDUCTED IN THE FIELD

\begin{tabular}{|c|}
\hline $\begin{array}{l}\text { Sample date: } 09 / 11 / 92 \\
\text { Dopth to water: } 69.56 \mathrm{~h}(21.20 \mathrm{~m}) \text { bolow TOC } \\
\text { Wator elovation: } 194.94 \mathrm{~h}(50.42 \mathrm{~m}) \mathrm{mal} \\
\text { Sp. conductance: } 175,13 / \mathrm{cm} \\
\text { Water evacuated botore sampling: } 214 \mathrm{gal}\end{array}$ \\
\hline LABORATORY ANALYSES \\
\hline
\end{tabular}

Time: 10:25

Akalinity: 70 mal Wator tomperature: $18.0^{\circ} \mathrm{C}$

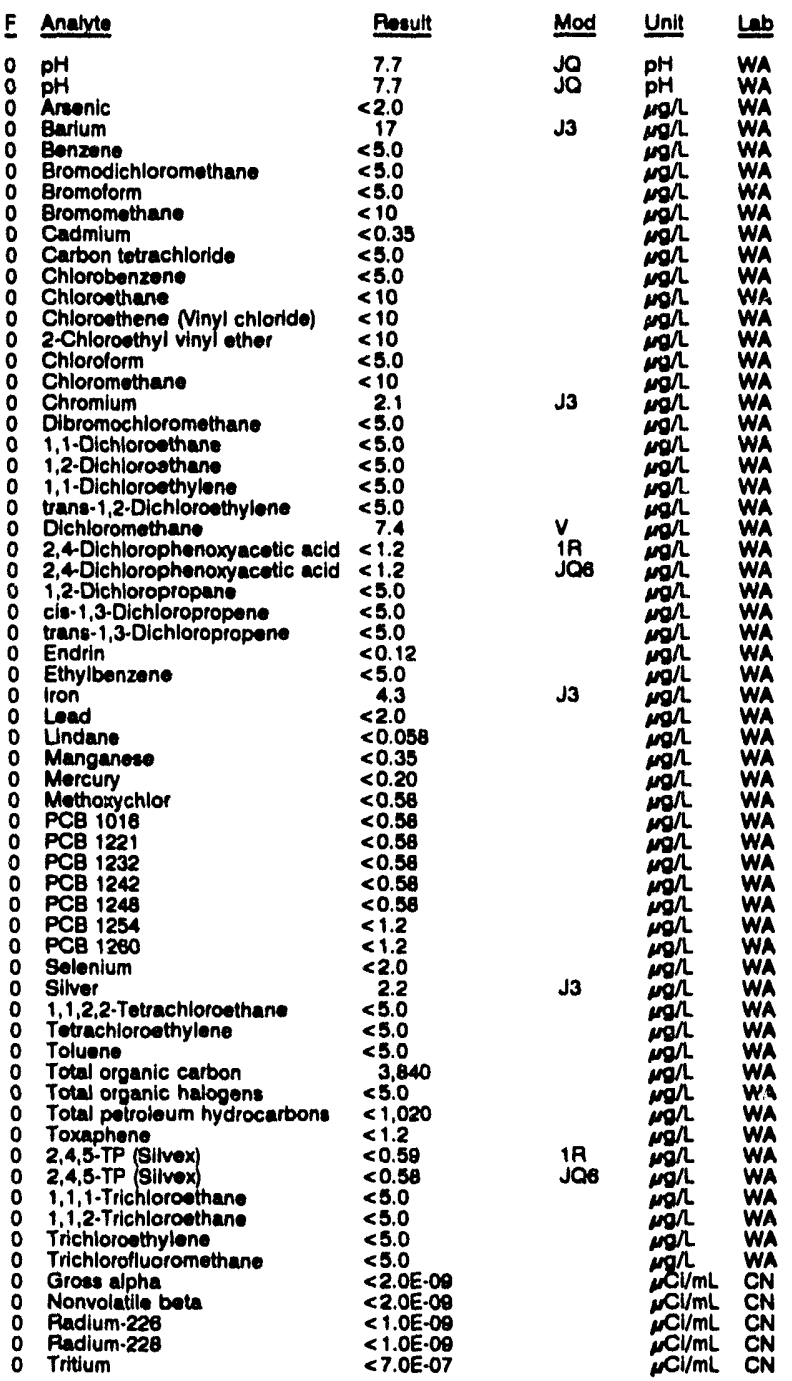


WELL CMP 14C

MEABUREMENTS CONOUCTED IN THE FIELD

8amplo deta: 00/11/20?

Doph to dor: 40.60 . $114.02 \mathrm{~m})$ bolow TOC

aper contution: 215.12 h

8p. conductunca: 17 forcm

LABOFATOAY ANULYBES

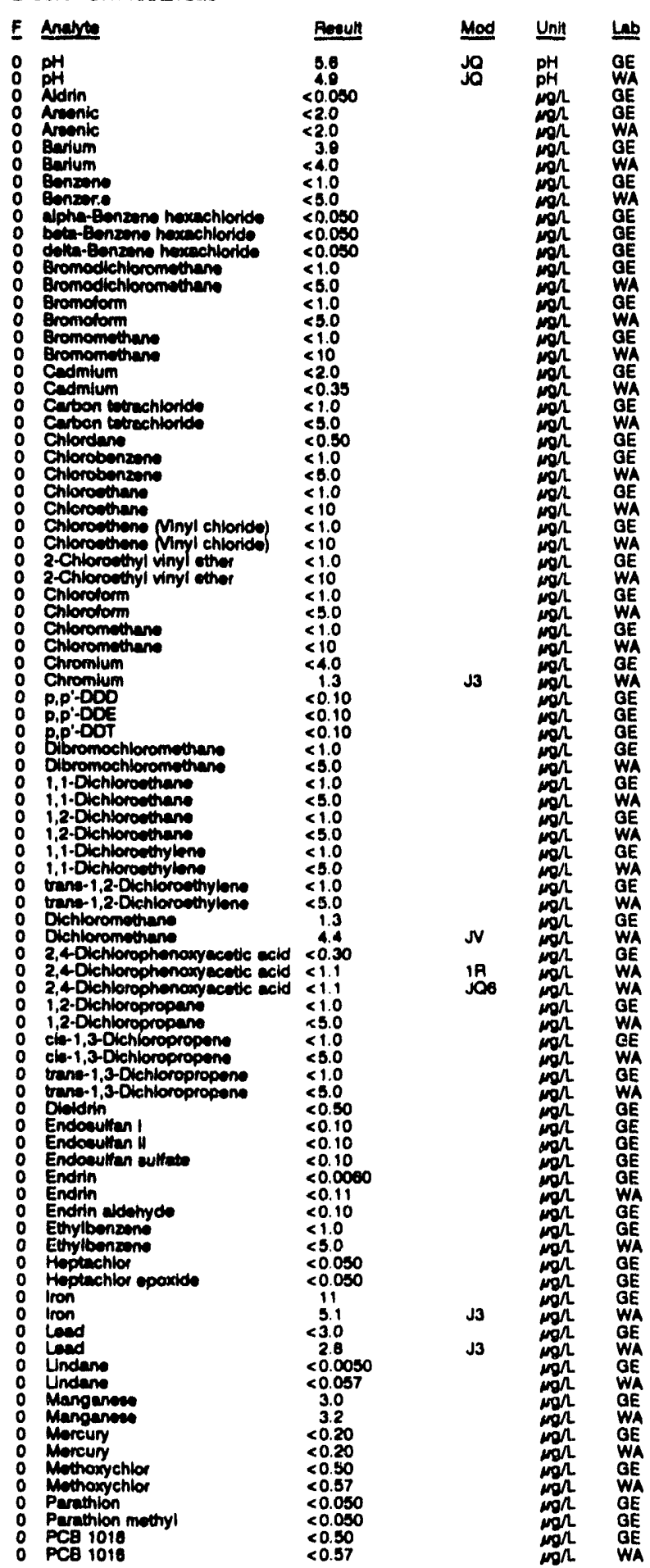

WELL CMP 14C collectod on 00/11/22, laboratory analy soo (cont.)

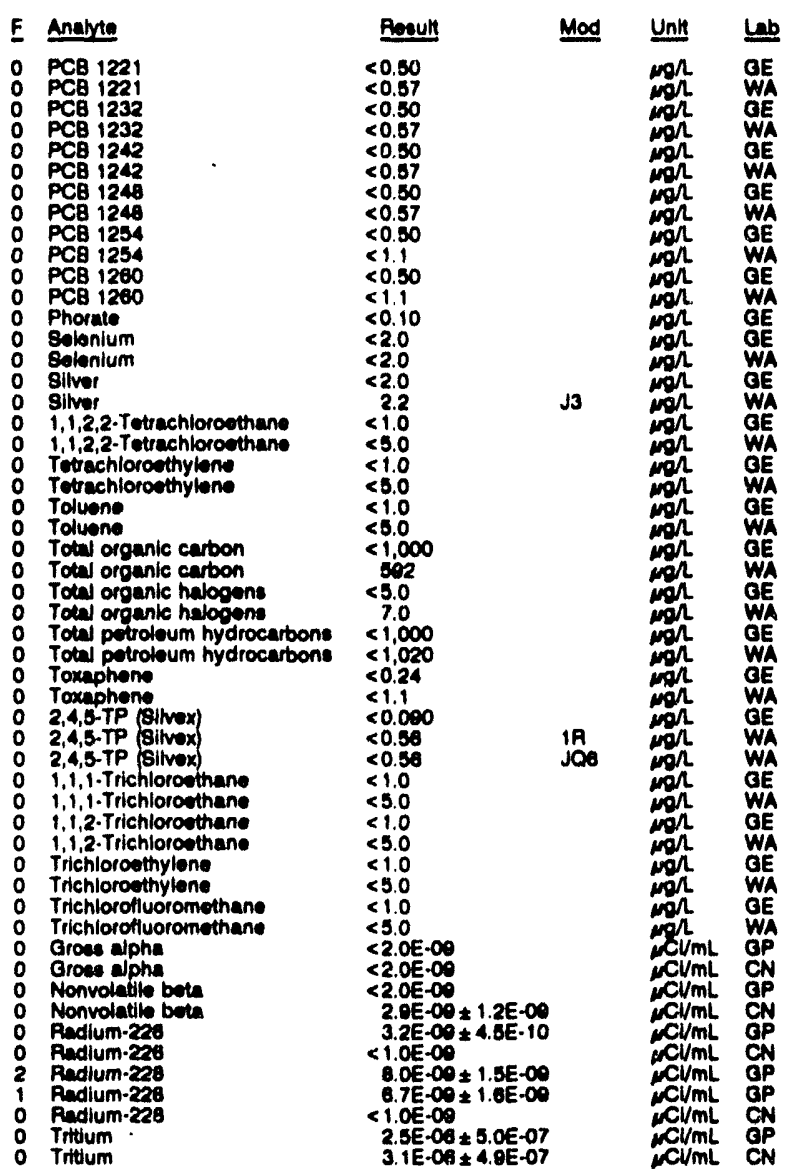

WELL CMP $14 C$ Replicate

MEASUREMENTS CONOUCTEO IN THE FIELD

Sample dato: 09/11/92

Depth to waler: $46.80 \mathrm{n}(14.02 \mathrm{~m})$ bojow TOC

Water olovation: 215.14 ht $1658 \mathrm{se}$

Sp. conductance: 17 Ho/cm

LABOPATOPYY ANALYSES

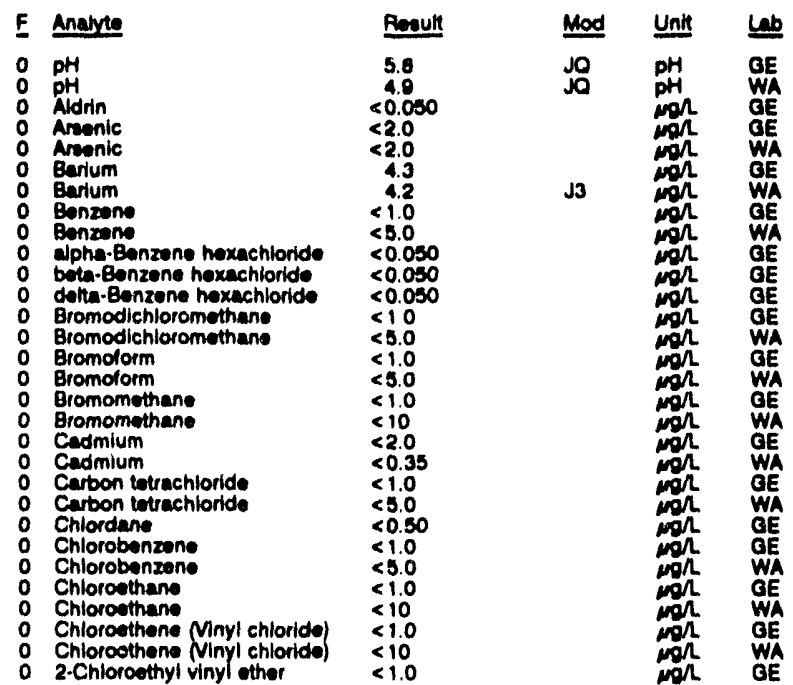


ANALYTICAL RESULTS

WELL CMP 14C collected on CO/11/92, laboratory analyese (cont)

F Anedte

o R-Chloroethyl vinyl ether Chloroform

Chloromethan

Chloromethan

Chromium

p.p.:Dop

P.p'-DOT

Bibromochloromethan

Dibromochloromethan

1,1-Olehloreman

i, Ochlorentian

1,2.Dchlorectinan

o 1,1. Dichlorecthylens

o trane-1,2-Dichloroethyloms

Dichloromethen

2,4-Dichiorophenoury seatic acid

Reault Mod

2,4Dlehiorophenoxyecetic ecid

$<10$
$<1.0$

$<1.0$

$<10$

$<1.1$

$<0.10$

$<0.10$

$<1.0$

$<1.0$

$<5.0$

$<1.0$

$<5.0$

$<1.0$

$<\$ .0$

$<5.0$
$<1.0$

$<1.0$
13
$<0.30$
$<1.1$

$<1.1$

1,2-Oichloropropano

o ci-1,3-Dichlorepropen

ch-1,3-Dichloropropons

trane-1,3-Dlchloropropens

Dioldin'

Endowulten I

Endosultan sultato

Endrin

Endrin aldehydo

Ethylbenzon

Ethylbenzan

o Heptachlor epoxide

0 iron

Iron

0 Lead

o Undane

Menganace

Manganew

Mereury

0 Mercuny

Methowychio

Mothonyentor

Parathion methyl

PCB 1010

PCE 1221

PCE 1221

PCB 1230

PCE 1232

PCS 1242

PCB 1240

PCB 1240

PCA 1254

PCa 1200

Phorets

O Selonium

simer

0 sther

o 1,1,2,2-Tetrechloroethene

1,1,2,2. Trutachiorodinan

Tushlorownylom

o Toluenter

- Total organic carbon

Total organic cartoon

Total organic halogens

Total organic halogena

Total petroleum hydrocarbons

Total petroloum hydrocarbons

Toxaphene

2,45-TP

2,4,5-TP Bivox

2,4,5-TP Binex

1,1.1-Trchloroethane

1,1, Inichlorosthan

1,1,2-Trichtorcentune

Trichloroethylene

$\operatorname{lag}_{\text {Jas }}$

$\operatorname{jag}_{\mathrm{JO}}$

$<0.50$

$<5.0$

$<1.0$

$<5.0$
$<1.0$

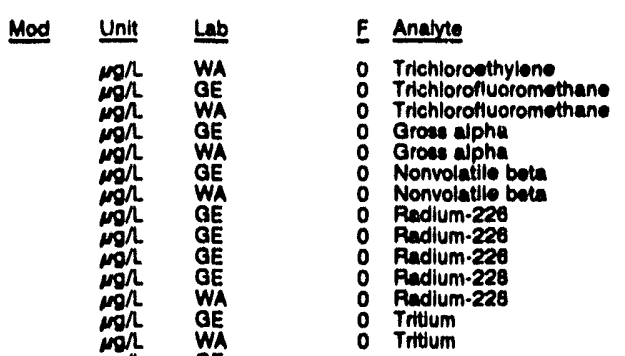

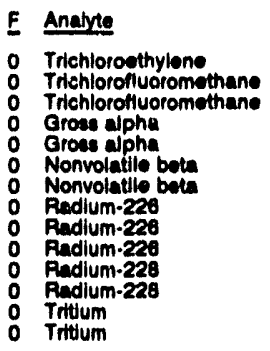

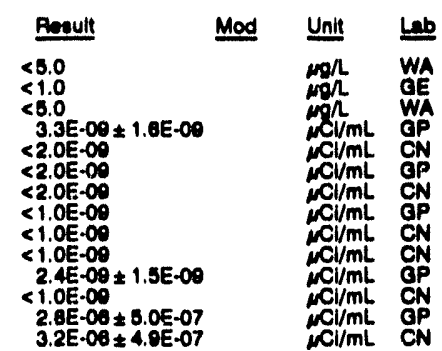

WELL CMP 15A

MEASUREMENTS CONDUCTED IN THE FIELD

sumple date: 09/00/02

Depth to wator: $04.42 \mathrm{n}(28.78 \mathrm{~m})$ below TOC

Water elovation: $182.08 \mathrm{~h}(55.50 \mathrm{~m}) \mathrm{msl}$

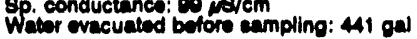

PH: 5.6

pH: 5.6 . $11 \mathrm{mon}$

LABORATOAY ANALYSES

- Iotal organic halogens

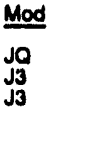

E Analyte

0 pH

o Berium

O Benzeno

O Bromodich

Bromomethane

Cadmium

C Carbon tetrachioride

O Chlorobenzene

Chloroethane

2-Chloroethyl Ninyl chloride

o Chlorotorm

o Chloromethane

- Chromium

o Dibromochloromothane

o 1,1-Dichlorouthane

1,2.Dichlorothan

: 1,1-Dichlorothylone

o Dichicromethan

2,4-Dichlorophenoxy acetic acid

1,2-Dichloropropant

o cib-1,3-Dichloropropens

o trans-1,3-Dichloropropene

0 Endrin

o Ethylbenzene

1 Iron

0 Load

1 Mandane

o Mercury

O PCB 1018

O PCB 122

O PCB 1242

O PCB 1246

P PCE 1280

0 Selenium

O Siver

T,1,2,2-Totrachlorow

0 Toluene

- Totel organic carbon

Total petroleum hydrocarbone

Toxaphens

o 2,4,5-TP (Silvox)

0 1,1,1-Trichloroethane

1,1,2. Trichlorooth

Trichlorofluoromethane

Grows alphe

Nonvolatile bote

Padium-228

Tritium

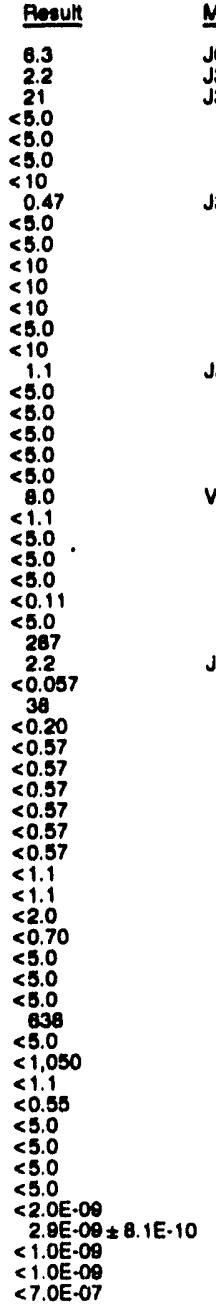

$\sqrt{3}$

Unti Lib

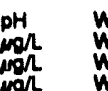

wa

$\operatorname{mon}_{w h} \quad W A$

won WA

won WA

$\operatorname{mog}_{\text {wA }}{ }_{W A}^{W A}$

won WA

$m /$ WA

wan WA

ง3 


\section{WELL CMP 15B}

MEASUREMENTS CONOUCTED IN THE FIELD

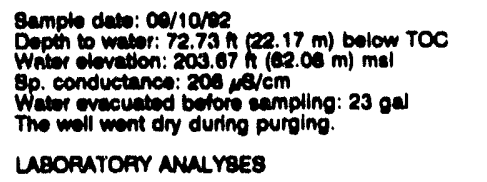

Time: 11:80

PH: 10.8 : $65 \mathrm{mgh}$

Water tomperature: $20.3^{\circ} \mathrm{C}$

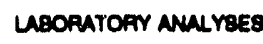

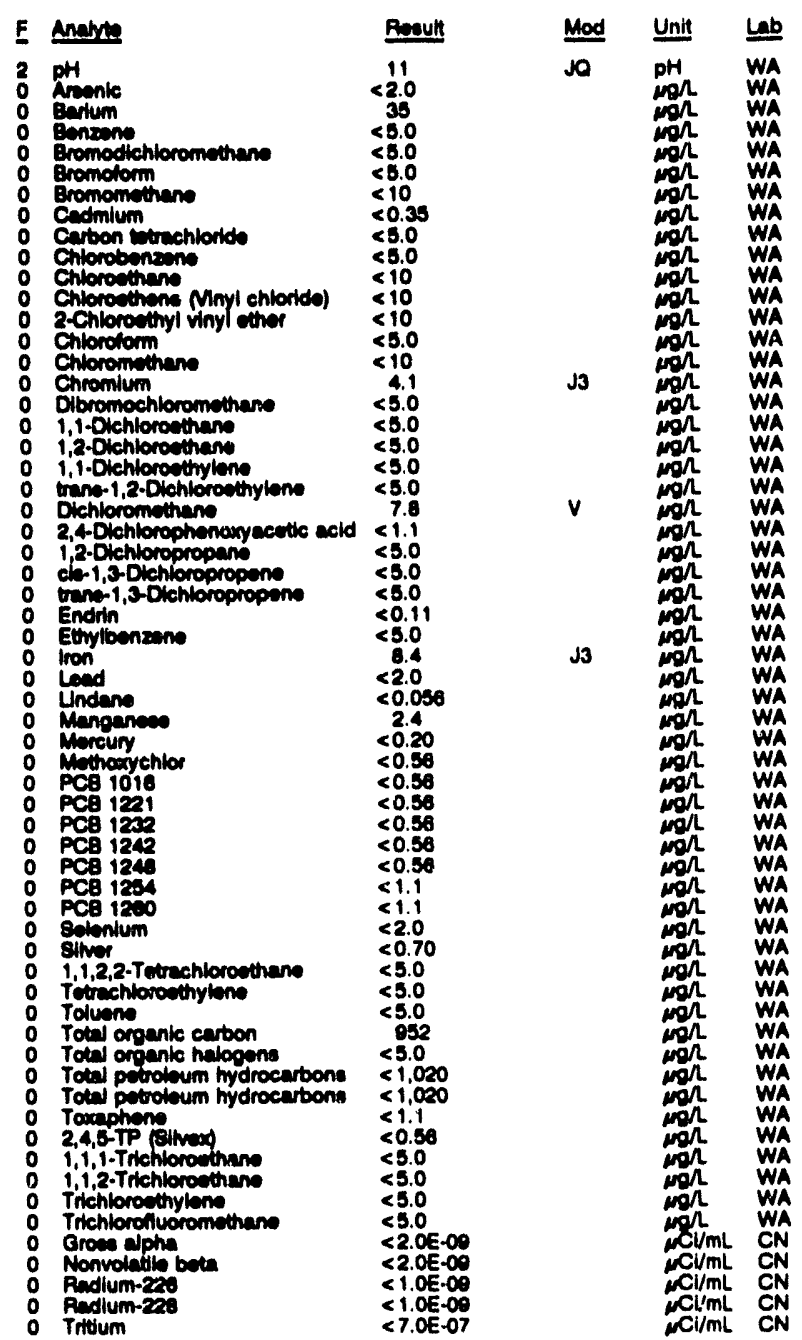

\section{WELL CMP 15C}

MEASUREMENTS CONOUCTED IN THE FIELD

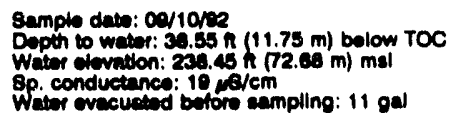

Wilar wecueted betors sampling: 11 gal

The well went dry during purging.

LABOPATOFY ANALYSES

\begin{tabular}{|c|c|c|c|c|}
\hline $\mathbf{F}$ & Analyte & Result & Mod & Unit \\
\hline $\begin{array}{l}0 \\
0 \\
0 \\
0 \\
0 \\
0 \\
0 \\
0 \\
0 \\
0 \\
0\end{array}$ & $\begin{array}{l}\text { pH } \\
\text { Avenke } \\
\text { Barium } \\
\text { Banzane } \\
\text { Bromodichloromethane } \\
\text { Bromolorm } \\
\text { Bromomethen } \\
\text { Cadmium } \\
\text { Carbon } \\
\text { Chlorachloride }\end{array}$ & $\begin{aligned} & 5.6 \\
&<2.0 \\
&<4.0 \\
&<5.0 \\
&<5.0 \\
&<5.0 \\
&<10 \\
&<0.35 \\
&<5.0 \\
&<5.0\end{aligned}$ & 10 & 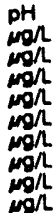 \\
\hline
\end{tabular}

WELL CMP 1BC collected on 00/10/02, laboratory analyees (cont.)

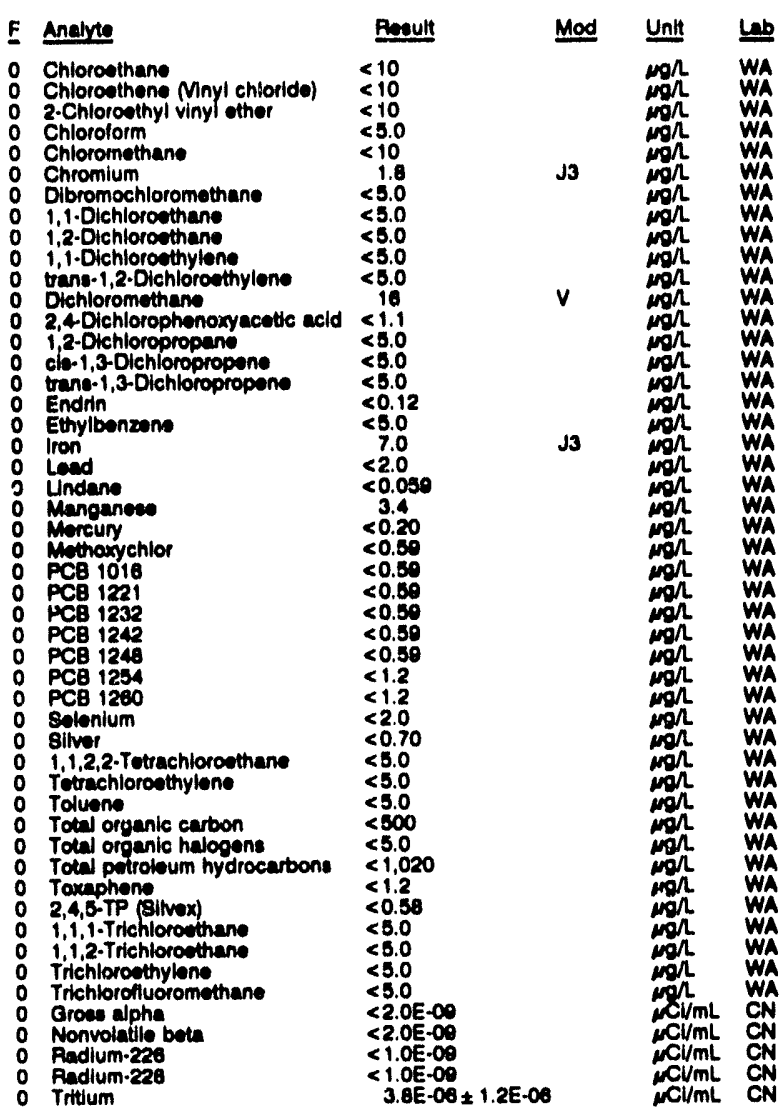

\section{WELL CMP 16B}

MEASUREMENTS CONOUCTED IN THE FIELD

Sample date: 00/00/02

Dopth to water: $122.54 \mathrm{n}(37.35 \mathrm{~m})$ below TOC

Water elevation: $185.18 \mathrm{f}(50.40 \mathrm{~m}) \mathrm{mol}$

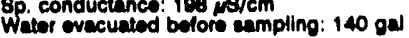

pH: 7.6 . $97 \mathrm{mgh}$

Whalinity: $87 \mathrm{mgh}$, $18.0^{\circ} \mathrm{C}$

LABOPATORY ANALYSES

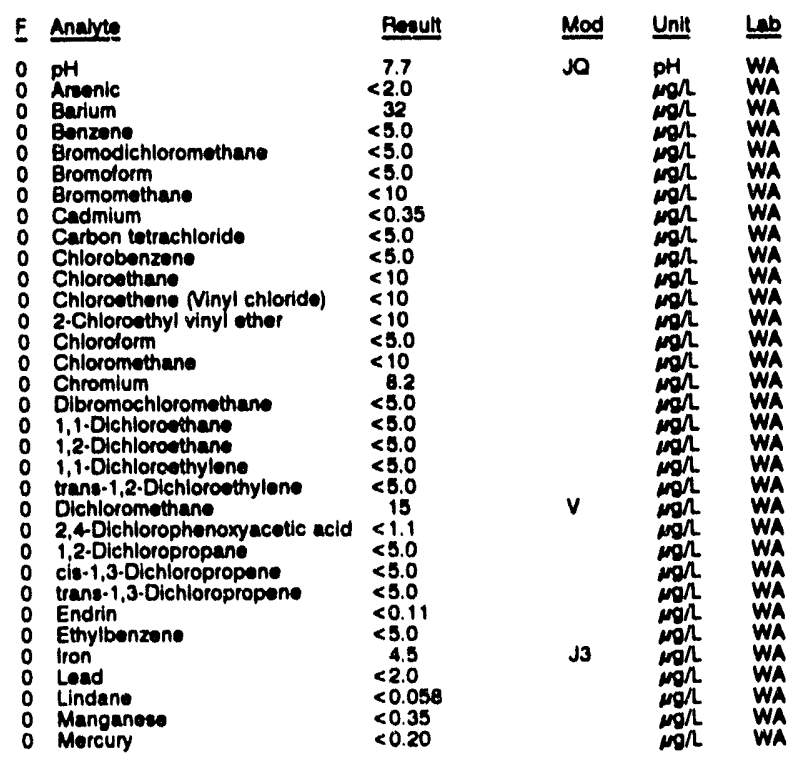


WELL CMP 108 collectod on c0/09/92, laboratory analyees (cont)

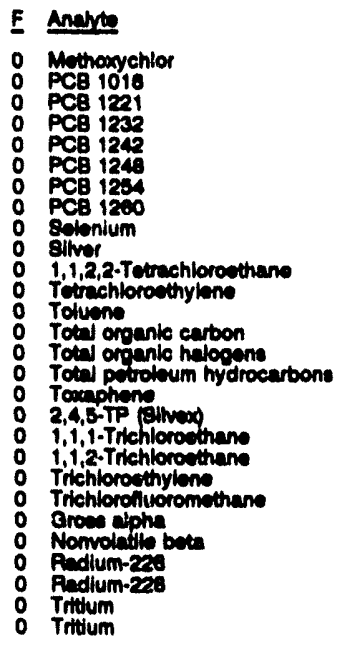

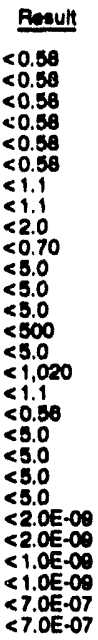

Mod

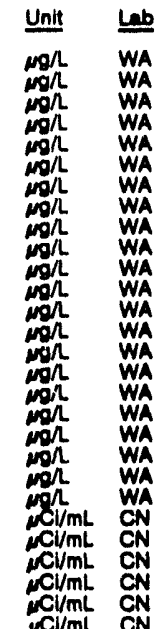

WELL CMP 16C

MEASUREMENTS CONOUCTED IN THE FIELD

Sample deto: covoop

Depth to water: 85.01 it $28.98 \mathrm{~m}$ ) below TOC

Time: 8:35

What clovation: $222.40 \mathrm{~h}(67.82 \mathrm{~m}) \mathrm{mel}$

Ineccesablthy or mechenical problom provented sample collection.

WELL CRP 1

MEASUPEMENTS CONDUCTED IN THE FIELD

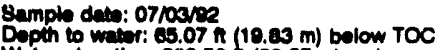

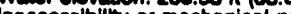

WEU CRP 2

MEABUAREMENTS CONOUCTEO IN THE FIELD

Semple data: 07/03/ce

Depth to water: $70.68 \mathrm{ft}(21.54 \mathrm{~m})$ below TOC

Water elevetion: $208.04 \mathrm{~h}(83.41 \mathrm{~m}) \mathrm{mal}$

ampling: $85 \mathrm{ga}$

Timo: 12:15

pH: 4.8

Alkalinity: $1 \mathrm{~mol}$

Water tomporature: $21.5^{\circ} \mathrm{C}$

LABOPATOFY ANALYSES

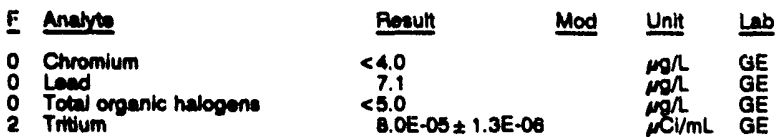

WELL CRP 3

MEASUAEMENTS CONDUCTED IN THE FIELD

Sample data: 07/03/82

Depth to waber: 39.00 R $(17.70 \mathrm{~m})$ below TOC

Water elevetion: $207.74 h(03.32 \mathrm{~m}) \mathrm{ms}$

inacceedbility or mochanical problem prevented sample collection.

WELL CRP 4

MEASUREMENTS CONDUCTED IN THE FIELD

Sample date: $07 / 0392$

Depth to water: $58.41 \mathrm{~h}(17.80 \mathrm{~m})$ below TOC

Water elevetion: $200.29 \mathrm{~h}(83.79 \mathrm{~m}) \mathrm{msl}$

tance: $22 \mu \mathrm{s} / \mathrm{cm}$

pH: 4.8

$1 \mathrm{mgn}$

Wampling: $75 \mathrm{gal}$

LABOAATORY ANALYSES

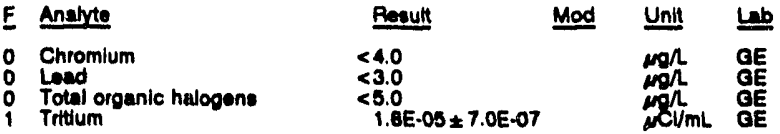

WELL CSA 1

MEASUREMENTS CONDUCTEO IN THE FIELD

gemple date: 07/27/92

Water olevation: 245.67 h $(74.88 \mathrm{~m}) \mathrm{mal}$

Sp. conductance: 47 S/cm

Sp. conductance: 47 Hicm
Watar evacuated betore sampling: $36 \mathrm{gal}$

$\lim _{0,1}: 14: 25$

Alkalinity: $0 \mathrm{mal}$

Water tomperature: $22.0^{\circ} \mathrm{C}$

LABORATOAY ANALYSES

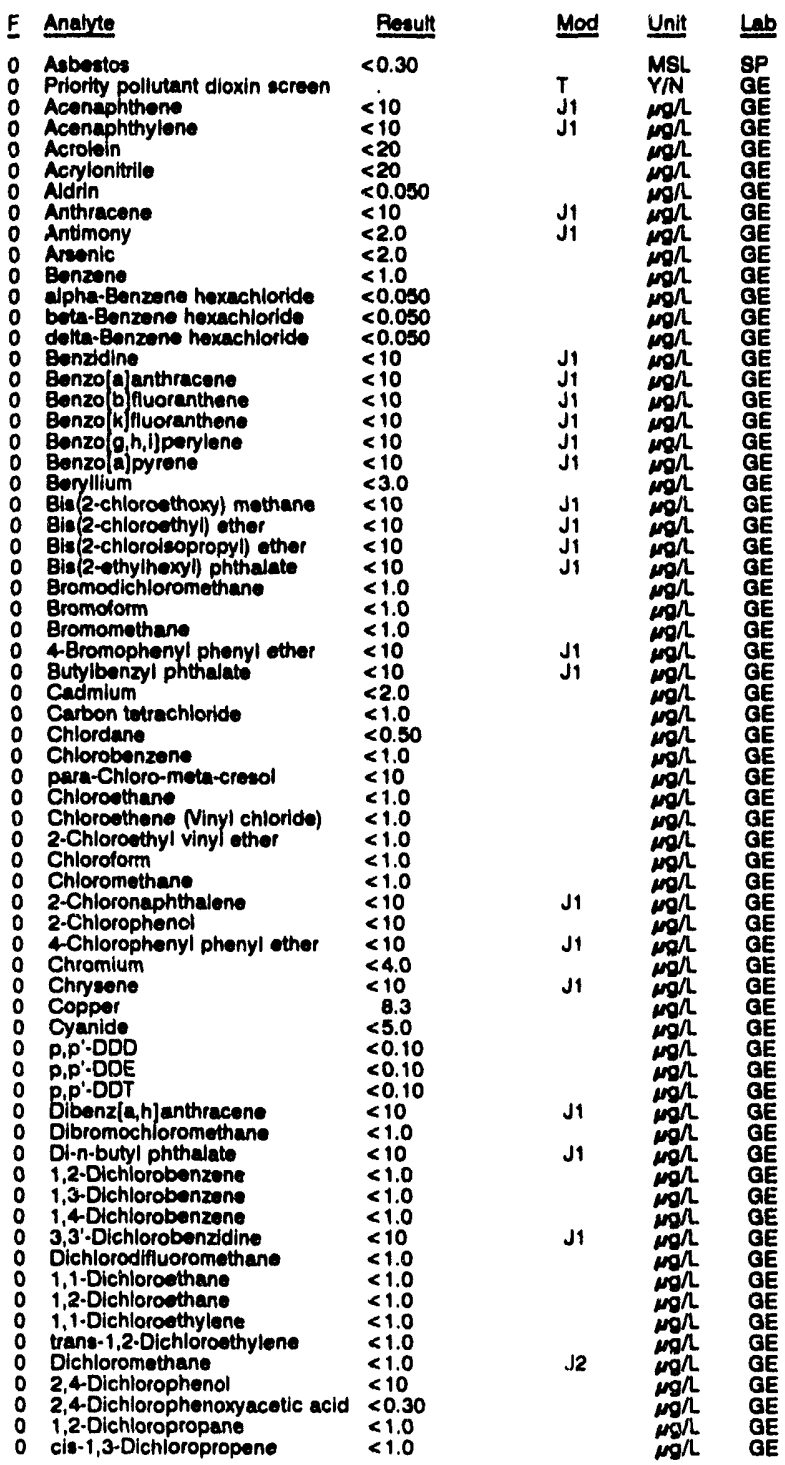


WELL CaA 1 collectod on 07/27/02, laboratory analyses (cont)

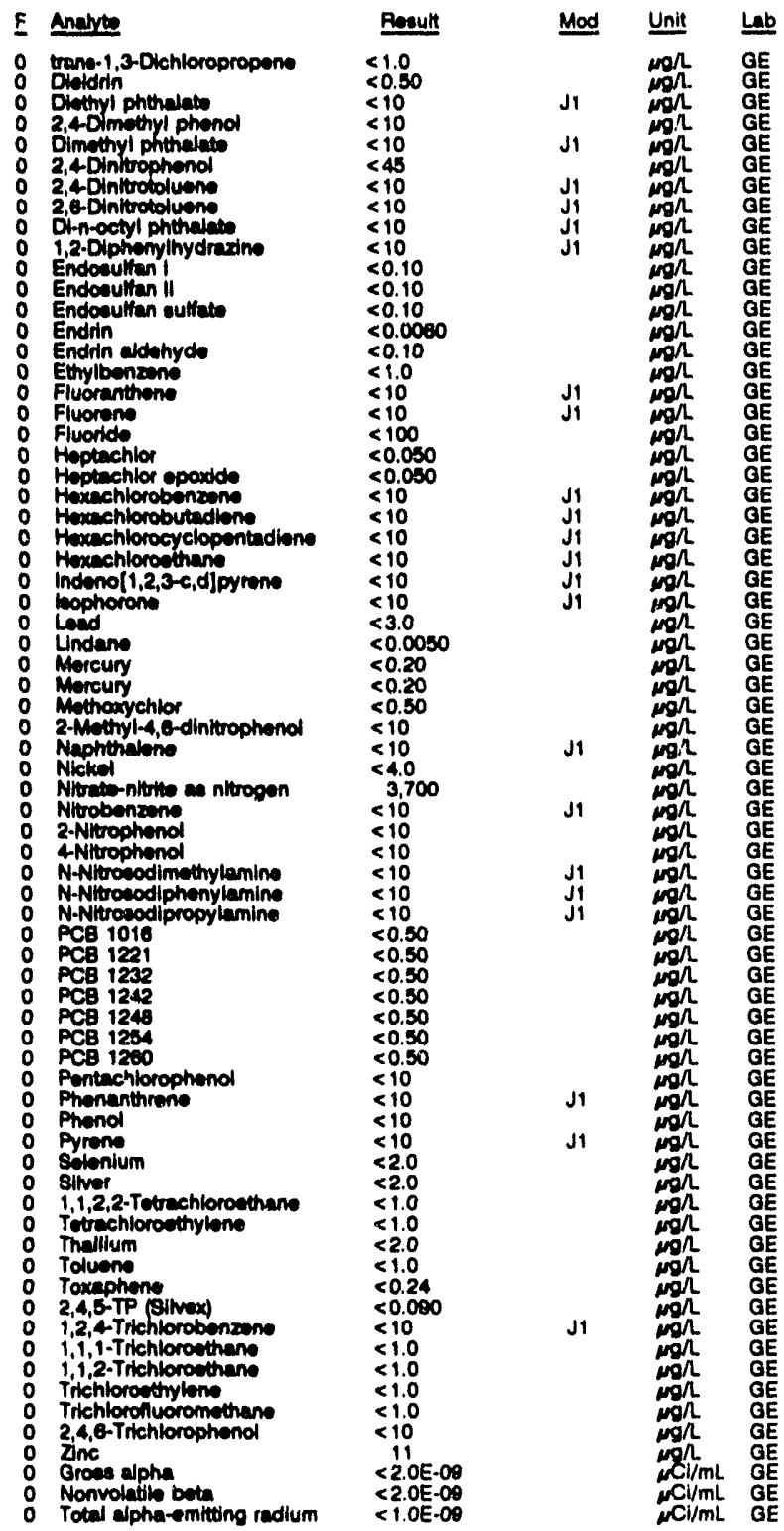

WELL CSA 2

MEABUREMENTS CONOUCTED IN THE FIELD

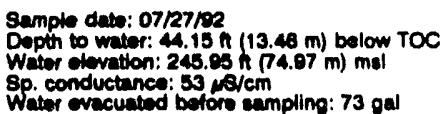

LABORATOPY ANALYEES

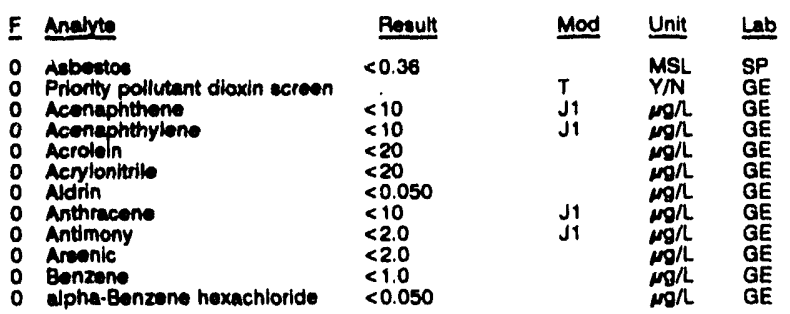

WELL CSA 2 collected on D7/27/82, laboratory analyses (cont.)

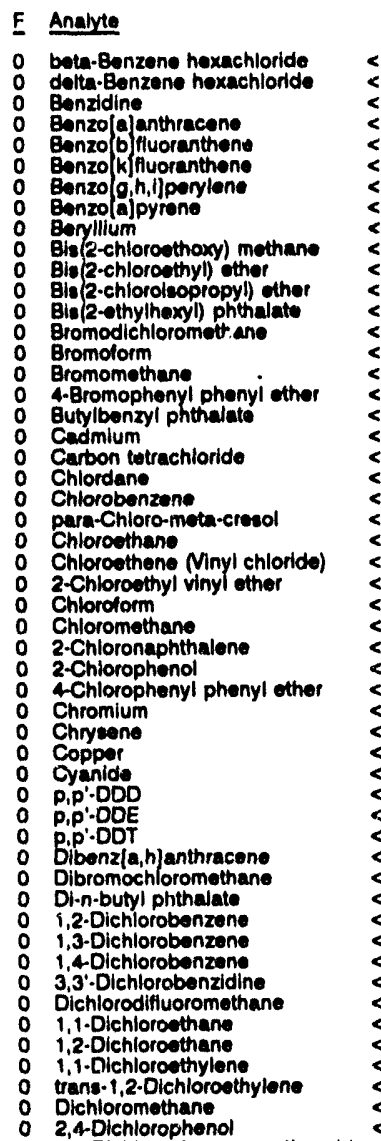

$<0.050$

0.050

$<10$

$<10$

$<10$
$<10$

$<3.0$

$<10$

$<10$

1.0

1.0

10

$<1.0$

1.0

1.0

1.0

$<1.0$

1.0

$<10$
$<10$
$<10$

$<4.0$

4.0

$<5.0$

0.10

10

$<10$

1.0

$<1.0$

1.0

$<1.0$

1.0

$<1.0$

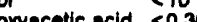

2,4 Dichlomphenonyacolic acld $<0.30$

cis-1,3-Dichloropropen

trans-1,3-Dichloropropene

Dieldrin

Diethyl phthalate

2,4-Dimethyl phenol

Dimethyl phthalato

2,4-Dinitrophenol

2,6-Dinitsotoivene

Di-n-octyl phthalate

1,2-Diphenylhydre

Endosultan II

Endoavilan

Endrin aldehyde

Ethytbenzene

Fluoranthene

Fluorene

Fluoride

Heptachlor epoxide

Hexachlorobenzene

Hoxachlorobutadiene

Hexachlorocyclopenta

indeno $\{1,2,3-c, d\}$ pyrene

leophorone

L Load

Undano

O Mercury

2-Methyl-4,6-dinitrophenol

$\begin{array}{ll}0 & \text { 2-Mothyl-4,6-dit } \\ 0 & \text { Naphthalene } \\ 0 & \text { Niekel }\end{array}$

0 Nitrato-nitrite as nitrogen

- Nitrobenzene

2.Nitrophenol

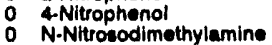

N-Nitrosodiphenylamine

N-Nitrosodipropylamine

PCB 1016

O PCB 1232

O PCB 1232

$<1.0$

$<0.50$

$<10$

$<10$
$<10$
$<45$

$<10$

$<10$

$<10$
$<10$

$<0.10$

$<0.0030$

$<0.10$

$<0.10$

$<10$

$<10$

$<<0.050$

$<10$

$<10$

$<10$
$<10$
$<10$

$<10$
$<3.0$
$<0.00=0$

$<0.20$

$<10$

$<10$
$<4.0$
3.600

3,600
$<10$
$<10$

$<10$

$<10$
$<10$

$<10$
$<0.50$

colos

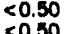

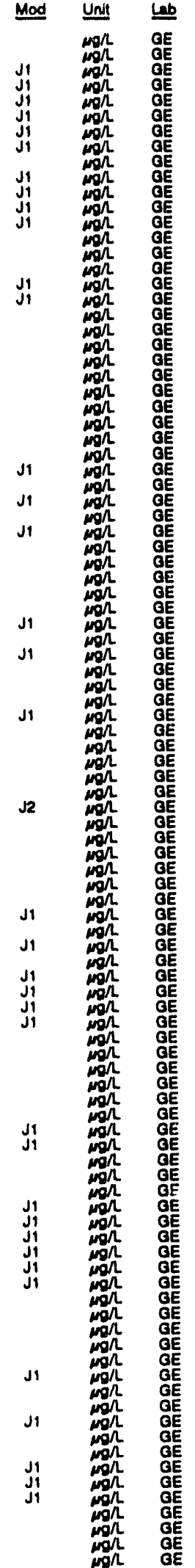


ANALYTICAL RESULTS

WELL CSA 2 collected on 07/27/02, laboratory analyees (cont)

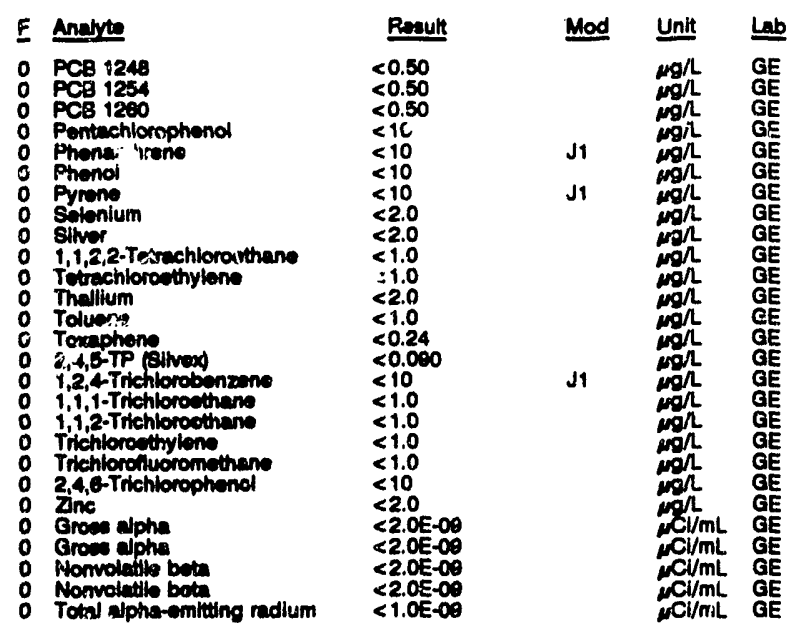

WELL CSA 3

MEABUREMENTS CONDUCTED IN THE FIELD

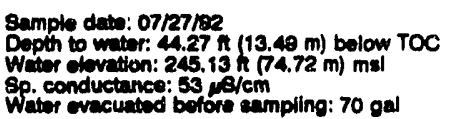

Time: 15:15

pH: 4.9

Alkalinity: $0 \mathrm{mg} / \mathrm{L}$

Water tomperature: $22.5 \circ \mathrm{C}$

LABOPATOFY ANALYSES

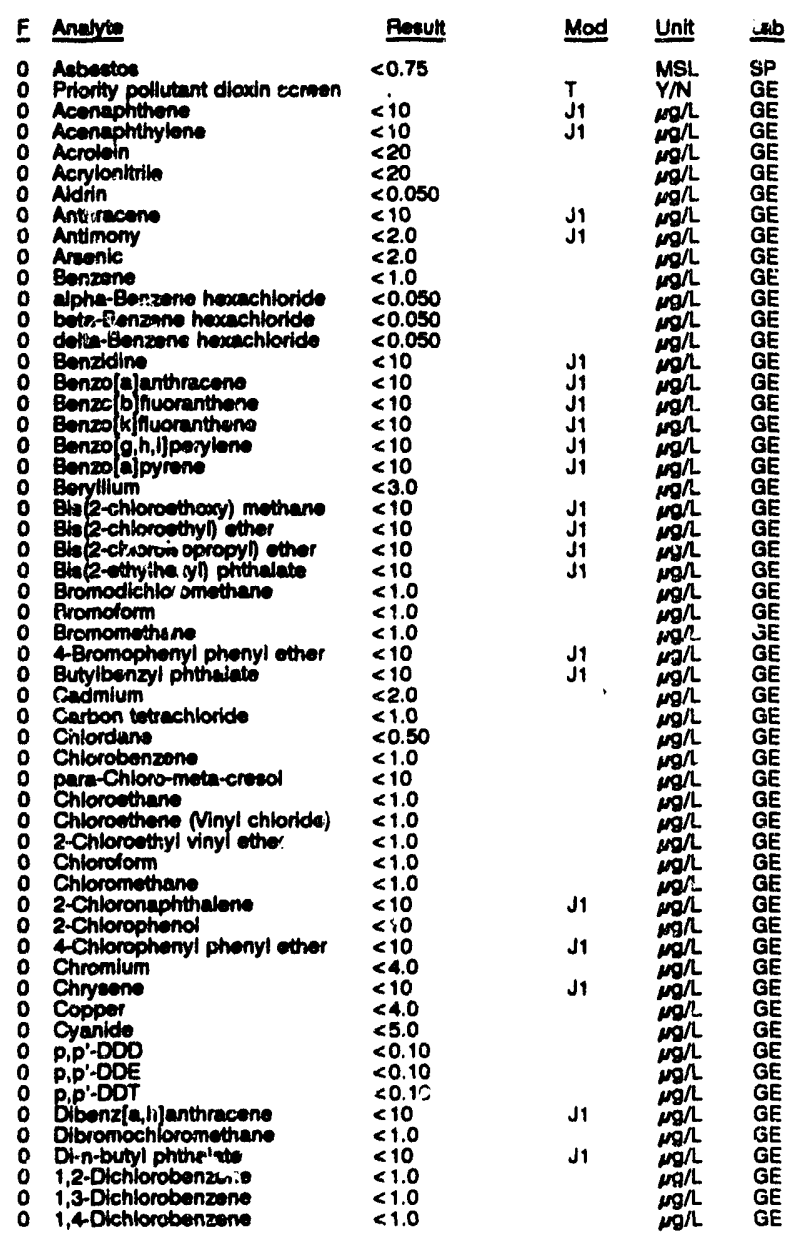

WELL CSA 3 collected on 07/27/92, leboratory analyees (cont.)

\begin{tabular}{|c|c|}
\hline Analyte & Analyte \\
\hline & $\begin{array}{l}\text { 3,3'-Dichlorobinzidine } \\
\text { Oichlorodifiuoromethane } \\
\text { 1,1-Dichloroethane } \\
1,2-\text { Dichloroethane } \\
\text { 1,1-Dichloroethylene } \\
\text { trans-1,2-Dichioroethylerse } \\
\text { Oichloromothane } \\
\text { \& } 4 \text {-Dichlorophenol }\end{array}$ \\
\hline
\end{tabular}

0 \&Dichlorophenol $<$

2,4 Dichlorophenoxyacetic acid $<0.30$
0 1,2-Dichloropropane

1,2-Dichloropropane

O cls-1,3-Dichloropropene
o trane-1,3-Dichloropropene
O Dieldrin

o Diethyl phthalate

2,4-Dimethyl phenol

Dimethyl phthalato

2,4-Dinitrotoluen

2,6-Dinitrotoluene

O Di-n-octyl phthalate

O Endosulfan I

O Endoculfan II

0 Endosulfar

Endrin aldahyde

Ethylbenzene

Fluoranthene

o Fluorene

0 Fluoride

Heptachlor epoxide

- Hoxachlorobenzene

o hexachlorobutadiene

Hexachloroethane

indeno[ $1,2,3-c, d]$ pyreno

o teophoron

0 Lead

o Lindane

M Methoxychlor

2-Methyl-4,6-dinitrophenol

o Naphthaten

O Nickel

O Nitrobenzene

0 2-Nit'uphenol

N-Nitroscodimethylamine

N-Nitrosodiphenylamine

N-Nitrosodipropylamine

PCB 1018

- PCB 1221

- PCB 1242

O PCB 1248

O PCB 1254

o Pentachlorophenol

o Phenanthrente

Phenol

0 Pyrene

o siver

1 1,2,2-Tetrachloroethane

T'trechloroethylent

o Thallum

0 Toluene

0 Toxaphene

2,4,5-TP (Silvox)

1,2,4 Trichlorobenzeno

1,1,1-Trichloroothane

1,1,2-Trichloroethan

Trichioroothylene

: Trichlorofluoromethane

o Zinc

o Nonvolatilo beta

T Total alpha-emitting radium

Reault

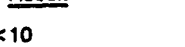

$<1.0$

$<1.0$

$<1.0$

$<1.0$

$<1.0$
$<1.0$
$<0.50$

$\leq 10$

$<10$
$\leq 10$
-45

310

$<>10$

$<10$

$<0.10$

$<0.100$

$<1.0^{<}$

$<10$

$<100$

$<0.050$
$<0.050$

$<0.050$
$<10$
$<10$
$<10$

$<10$
$<10$
$<10$
$<10$

$<10$
$<10$
$<10$

$<10$
$<3.0$

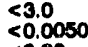

$<0.20$

$<10$

\begin{tabular}{l}
$<10$ \\
$<4.0$ \\
\hline
\end{tabular}

$<4.00$

4,050
$<10$

$<10$
$<10$

$<10$
$<10$

$<10$
$<10$

$<0.50$
$<0.50$
$<0.50$

$<0.50$

$<0.50$

$<0.50$
$<0.50$

$<0.50$

$<10$

$<10$

$<10$
$<10$

$<2.0$

$<2.0$

$<1.0$
$<1.0$

$<2.0$
$<1.0$

$<0.24$

$<10$

$<1.0$

$<1.0$
$<1.0$

1.0

$<10$
2.0

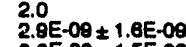

3.3E-09 $01.5 \mathrm{E}-00$

$<1.0 E-09$

Unit Lيa

$\mu \mathrm{g} / \mathrm{L}$ GE

$\mu g / h$ GE

$\mathrm{mgh}$ GE

$\mu g / L$ GE

$\mathrm{wh}$ GE

Total alphn-emitting redium 
WELL CSA 4

MEASUAEMENTS CONOUCTED IN THE FIELD

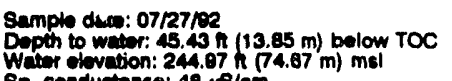

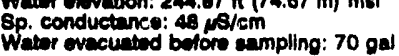

LABOPATOFY ANALYSES

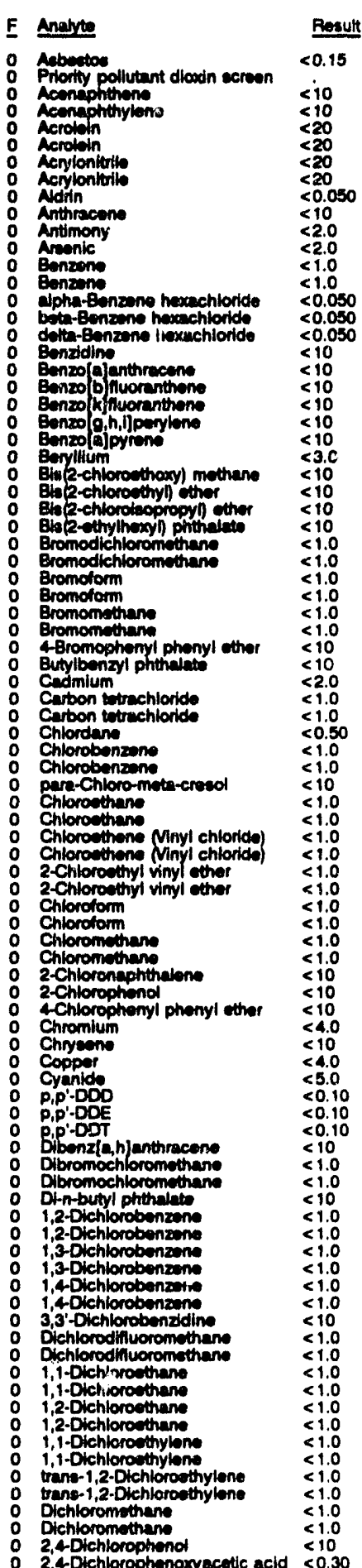

WELL CSA 4 collected on 07/27/92, laboratory analyees (cont.)

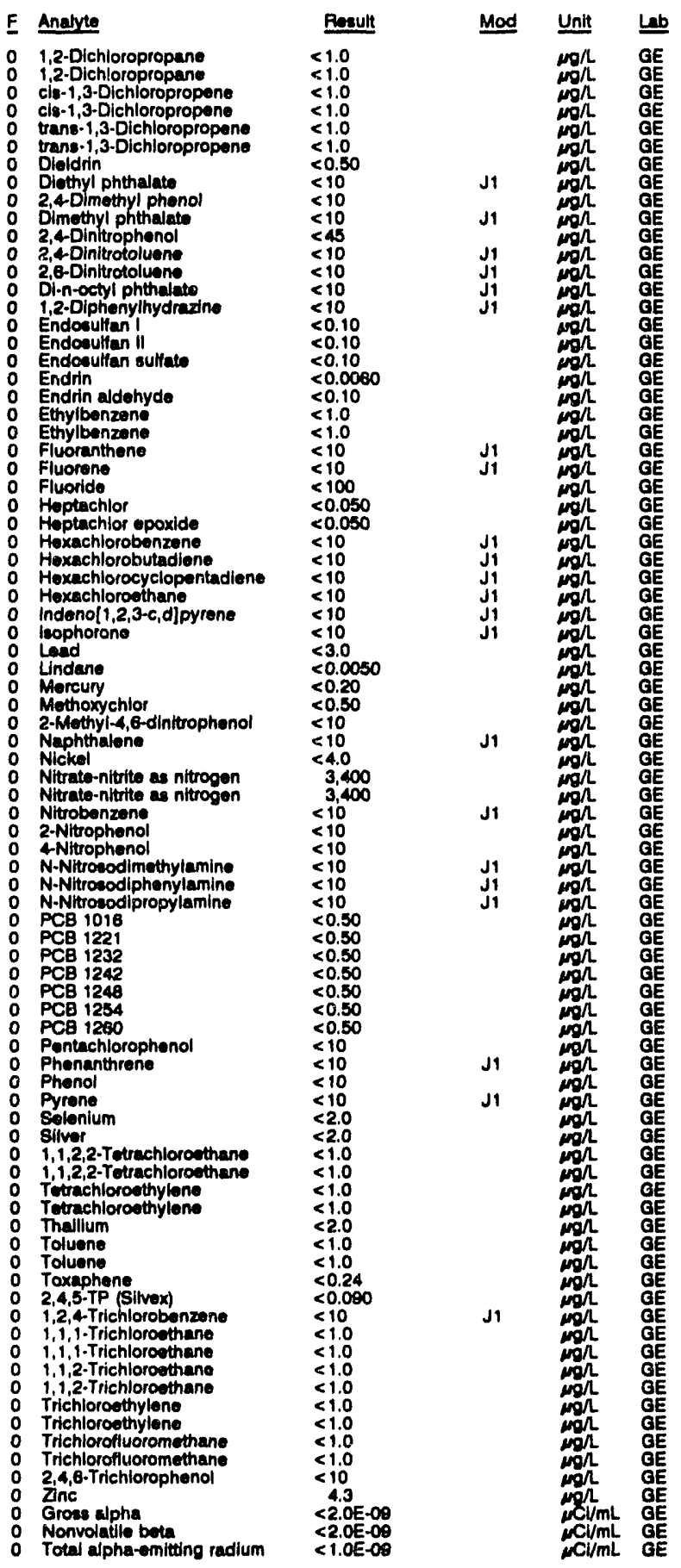


ANALYTICAL RESULTS

\section{WELL CSB 1A}

MEASUREMENTS CONDUCTED IN THE FIELD

\begin{tabular}{|c|c|c|c|c|c|}
\hline & 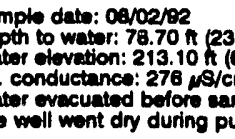 & $\begin{array}{l}\text { ow TOC } \\
\text { gal }\end{array}$ & $\begin{array}{l}\text { Time: } 11: 4 \\
\text { pH: } 7.2 \\
\text { Alkalinity: } \\
\text { Water tem }\end{array}$ & $\begin{array}{l}\mathrm{mg} / \mathrm{h} \\
\text { ture: } 23.2\end{array}$ & \\
\hline & BOAATOFY ANALYSES & & & & \\
\hline E & Analyte & Roeult & Mod & Unit & Lab \\
\hline $\begin{array}{l}0 \\
0 \\
0 \\
0 \\
0 \\
0 \\
0\end{array}$ & 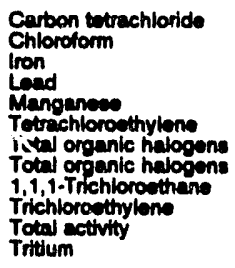 & $\begin{array}{r}<1.0 \\
<1.0 \\
6.6 \\
5.9 \\
1.4 \\
1.5 \\
<5.0 \\
<5.0 \\
<1.0 \\
<1.0 \\
3.5 E-C \\
3.4 E-C\end{array}$ & $\begin{array}{l}08 \\
08\end{array}$ & 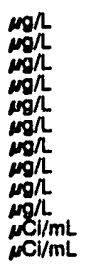 & $\begin{array}{l}\mathrm{GE} \\
\mathrm{GE} \\
\mathrm{GE} \\
\mathrm{GE} \\
\mathrm{GE} \\
\mathrm{GE} \\
\mathrm{GE} \\
\mathrm{GE} \\
\mathrm{GE} \\
\mathrm{GE} \\
\mathrm{EM} \\
\mathrm{GE}\end{array}$ \\
\hline
\end{tabular}

\section{WELL CSB 2A}

MEASUPEMENTS CONDUCTED IN THE FIELD

Sample dato: 08\%1/92

Dopth to water: $72.08 \pi(21.97 \mathrm{~m})$ below TOC

Water eteveation: $212.52 \mathrm{~h}(84.78 \mathrm{~m}) \mathrm{msl}$
inaceedibility or mochanical problom provented sample collection.

\section{WELL CSB 3A}

MEASUAEMENTS CONDUCTED IN THE FIELD

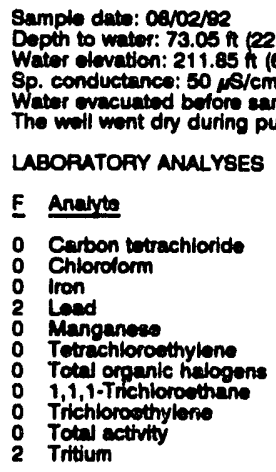

Time: $11: 30$

PH: 5.8 : $8 \mathrm{mgh}$

Water tomperature: $22.11^{\circ} \mathrm{C}$

Weter wecuitad bolore sampling: $18 \mathrm{gal}$

LABORATOFY ANALYSES

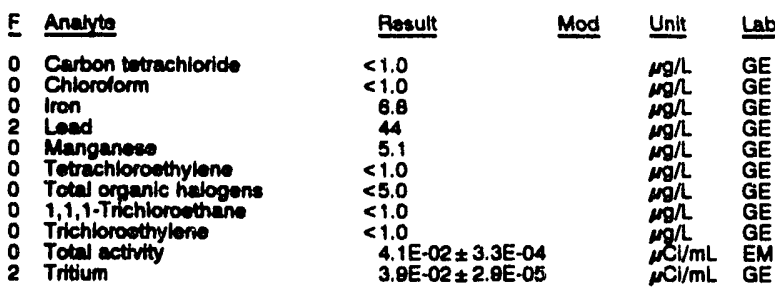

\section{WELL CSB 4A}

\section{MEASUREMENTS CONOUCTED IN THE FIELD}

\section{tamplo date: 0arn?/B2} Jopth to water: $73.35 \mathrm{ft}(22.36 \mathrm{~m})$ below TOC Water elevation: $211.75 \mathrm{~h}(64.54 \mathrm{~m}) \mathrm{msl}$ Water evacuated before sampling: $62 \mathrm{gal}$ LABORATOFY ANALYSES

E Anatyte

Carbon tetrachloride

- Chioroform

O Iron

O Mangan

o Tetrachlorouthylono

- Total organic halogen

o 1,1,1-Trichlorowthane

o Trichloroethylens

2 Total activity
Time: 11:20

Alkalinity: $1 \mathrm{~mol}$

Water tomperature: $23.1^{\circ} \mathrm{C}$

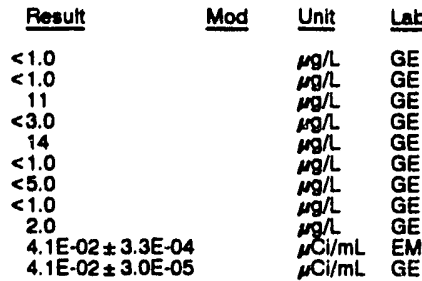

WELL CSB 5A

MEASUREMENTS CONDUCTED IN THE FIELD

Sample date: 08/02/92

Depth to water: $70.99 \mathrm{ft}(21.84 \mathrm{~m})$ bolow TOC

Water elevation: $211.81 \mathrm{ft}(64.56 \mathrm{~m}) \mathrm{mel}$

Sp. conductance: $85 \mathrm{~s} / \mathrm{cm}$

Water evacuated before sampling: $8 \mathrm{gal}$

The well went dry during purging.

LABORATORY ANALYSES

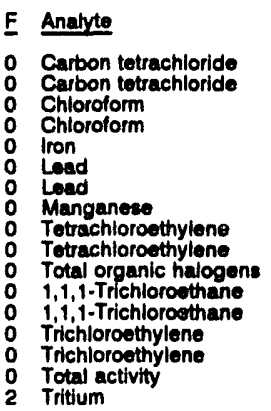

$\begin{aligned} & \text { Result } \\ &<1.0 \\ &<1.0 \\ &<1.0 \\ &<1.0 \\ & 6.1 \\ & 4.7 \\ & 4.5 \\ & 4.8 \\ &<1.0 \\ &<1.0 \\ &<5.0 \\ &<1.0 \\ &<1.0 \\ &<1.0 \\ &<1.0 \\ & 1.1 \mathrm{E}-03 \pm 7.6 \mathrm{E}-08 \\ & 1.0 \mathrm{E}-03 \pm 4.8 \mathrm{E}-06\end{aligned}$

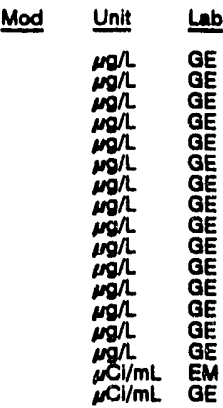

\section{WELL CSB 6A}

MEASUREMENTS CONDUCTED IN THE FIELD

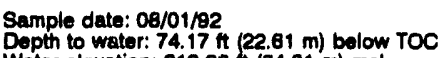

Water elevation: $212.63 \mathrm{ft}(84.81 \mathrm{~m}) \mathrm{ms}$

inaccessibility or mechanical problem prevented sample collection.

\section{WELL CSD 1D}

MEASUREMENTS CONDUCTED IN THE FIELD

Sample date: 07/29/92

Depth to water: $69.22 \mathrm{ft}(21.10 \mathrm{~m})$ below TOC

Water elevation: $246.18 \mathrm{ft}(75.04 \mathrm{~m}) \mathrm{msl}$

Sp. conductance: 27 is/cm

Time: 10:55

Alkalinity: $52 \mathrm{mo}$ Water temperature: $22.8^{\circ} \mathrm{C}$

Whe evacuatod before sampling: $15 \mathrm{gal}$ Whot during purging.

LABORATORY ANALYSES

\begin{tabular}{|c|c|c|c|}
\hline Anajyte & Result & Mod & Unit \\
\hline $\begin{array}{l}\text { Cadmium } \\
\text { Calcium } \\
\text { 2,4-Dichlorophenoxyacetic acld } \\
\text { Diseolved organic carbon } \\
\text { Dissolved organic carbon } \\
\text { Endrin } \\
\text { Iron } \\
\text { Lindane } \\
\text { Magnesium } \\
\text { Mereury } \\
\text { Methoxychlor } \\
\text { Nitrite as nitrogen } \\
\text { Nitrite as nitrogen } \\
\text { Potassium } \\
\text { Silica } \\
\text { Sulfide } \\
\text { Total organic carbon } \\
\text { Total organic halogens } \\
\text { Totat organic halogons } \\
\text { Total petroleum hydrocarbons } \\
\text { Total phosphates (as P) } \\
\text { Toxaphene } \\
2,4,5-T P \text { (Silvex) } \\
\text { Total alpha-emitting radium }\end{array}$ & $\begin{array}{l}<2.0 \\
582 \\
<0.30 \\
<1,000 \\
<1,000 \\
<0.0060 \\
7.5 \\
<0.0050 \\
279 \\
1.1 \\
<0.50 \\
<10 \\
<10 \\
1,450 \\
51,800 \\
<1,000 \\
<1,000 \\
<5.0 \\
<5.0 \\
1,040 \\
50 \\
<0.24 \\
<0.090 \\
<1.0 E-09\end{array}$ & $\begin{array}{l}J 06 \\
J 06 \\
J 06\end{array}$ & 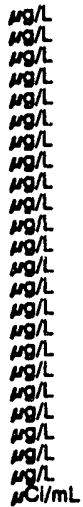 \\
\hline
\end{tabular}

Time: 14:35

Aukalinity: $3 \mathrm{mg} / \mathrm{h}$ Water tomperature: $23.0^{\circ} \mathrm{C}$

$<1.0 E-O B$

MCI/mL GE 
WELL CSD 2D

MEASUREMENTS CONDUCTED IN THE FIELD

\begin{tabular}{|c|c|c|}
\hline & 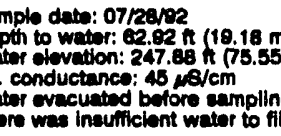 & ow TOC \\
\hline & BOPATOFY ANALYSES & \\
\hline & Analyte & Reault \\
\hline 0 & 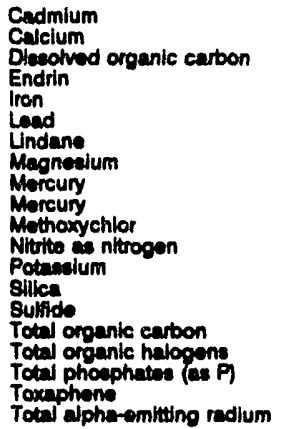 & $\begin{array}{l}<2.0 \\
5153 \\
<1,000 \\
<0.0060 \\
210 \\
8.5 \\
<0.0050 \\
335 \\
<0.20 \\
<0.20 \\
<0.50 \\
<10 \\
1,600 \\
36,500 \\
<1,000 \\
<1,000 \\
<5.0 \\
<50 \\
<0.24 \\
<1.0 \mathrm{E} \\
<1.00\end{array}$ \\
\hline
\end{tabular}

\section{WELL CSD 4D}

MEASUREMENTS CONDUCTED IN THE FIELD

Sample dato: 07/28/92

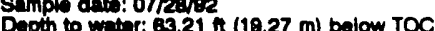

Water elevetion: $245.20 \mathrm{tt}(74.77 \mathrm{ml}$ mst

Sp. conductance: $1177 \mathrm{~s} / \mathrm{cm}$

Water wecuated before sumpling: $18 \mathrm{gat}$

The well went dry during purging.

LABORATOFY ANALYSES

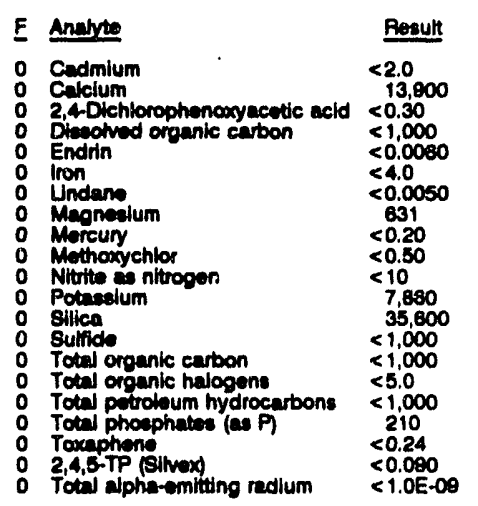

Time: 8:55

PH: 0.5 . $4 \mathrm{mar}$

Water tomperature: $22.7{ }^{\circ} \mathrm{C}$

botties.

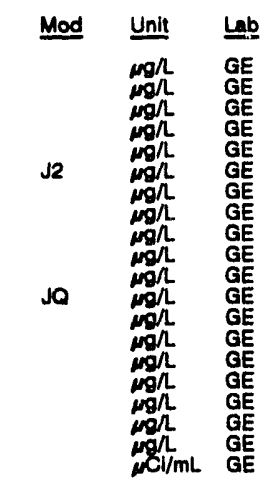

Time: $8: 40$

PH: 10.7 Alkalinity: 76 mol

Water temperature: $22.0^{\circ} \mathrm{C}$

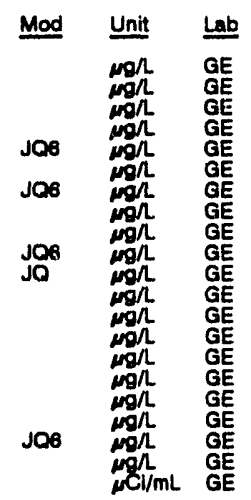

WELL CSD 8D

MEASUREMENTB CONDUCTED IN THE FIELD

Sample datw: 07/27/92

Depth to water: $50.30 \mathrm{~h}(18.10 \mathrm{~m})$ bolow TOC

Water elevation: $244.51 \mathrm{k}$ (7)

Sp. conductance: $33 \mu \mathrm{s} / \mathrm{cm}$.

Water evacuated before eampling: $47 \mathrm{gal}$

LABORATOFY ANALYSES

\begin{tabular}{|c|c|c|}
\hline & Analyte & Rosunt \\
\hline & 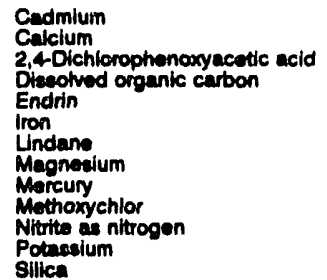 & $\begin{array}{l}<2.0 \\
1,120 \\
<0.30 \\
<1,000 \\
<0.0060 \\
<4.0 \\
<0.0050 \\
366 \\
<0.20 \\
<0.50 \\
<10 \\
804 \\
10,800\end{array}$ \\
\hline
\end{tabular}

pH: 5.3

Alkallinity: $3 \mathrm{mg} /$
Water temperature: $22.8^{\circ} \mathrm{C}$

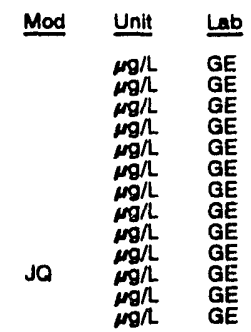

WELL CSD 8D collected on 07/27/92, laboratory analyses (cont)

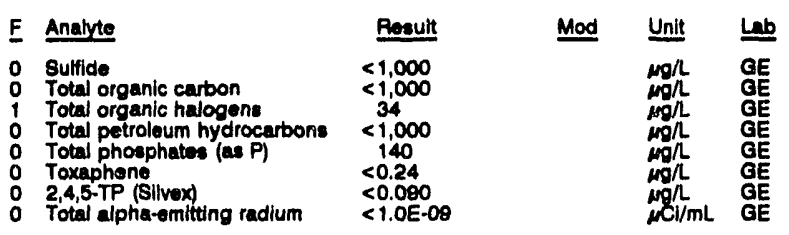

WELLL CSD 9D

MEASUREMENTS CONDUCTED IN THE FIELD

Sample date: $07 / 27 / 92$

Water elevation: $244.49 \mathrm{H}(74.52 \mathrm{~m}) \mathrm{me}$

Water evacuated before rampling: $48 \mathrm{gal}$

LABORATORY ANALYSES

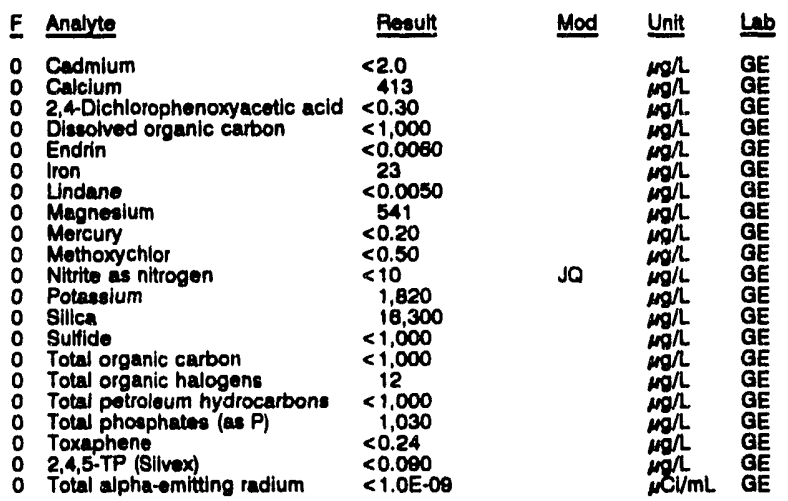

WELL CSD 10D

MEASUREMENTS CONDUCTED IN THE FIELD

Sample date: 07/27/82

Depth to water: $52.48 \mathrm{~h}$ ( $19.00 \mathrm{~m}$ ) below TOC

Water elevation: $244.12 \mathrm{~h}(74.41 \mathrm{~m}) \mathrm{msl}$

Sp. conductance: $35 \mu \mathrm{S} / \mathrm{em}$

Wator ovacuated before sampling: $51 \mathrm{gal}$

LABORATORY ANALYSES

F Analyte

- Cadmium

Posult

$<2.0$

2,4-Dichlorophenoxyacetic acid $<0.30$

Dissotved organic carbon $<1,000$

O Endrin

0 Lindane

Magnesium

Morcury

Methoxychlor

Nitrite as nitro

Sillica

Total organic carton

Total organic halogens

Total potroloum hydrocarbor

Total phosphates (as P)

Toxaphene

Total alphe-emitting radium

$<0.0060$

$<0.0050$

493

$<0.20$

$<0.50$

$<10$

18,200

$<1,000$

$<1,000$

$<1,000$

750
$<0.24$

$<$ < $1.0 \mathrm{OE} .09$

Timo: 10:10

pH: 5.1

Nikalinity: $1 \mathrm{mg} / \mathrm{h}$

Water tomperature: $22,4^{\circ} \mathrm{C}$

imo: 8:45

Alikalinity: $1 \mathrm{mg} / \mathrm{h}$

Water tomperature: $22.6^{\circ} \mathrm{C}$

$\mathrm{CV} / \mathrm{mL}$ G 
ANALYTICAL RESULTS

\section{WELL CSD 11D}

MEASUREMENTS CONDUCTED IN THE FIELD

Sample dats: 07/28/82

Dopth to water: $48.82 \mathrm{f}(14.88 \mathrm{~m})$ below TOC Water elevation: $244.18 \mathrm{ht}$ (7)

Sp. conductanco: $224 \mu \mathrm{s} / \mathrm{cm}$

Water evacuatod before sampling: $13 \mathrm{gal}$

The well went dry during purging.

LABORATOAY ANALYSES

F Analyte

o Cadmium

$\begin{array}{ll}\text { Cadmium } & <2.0 \\ \text { Calcium } & 39,800 \\ 2,4 \text { Dichlorophenaxyacetic acid } & <0.30\end{array}$

Disolved organic carbon $\quad<1,000$

Endrin

Enon

Uindane

Magnealum

Moreury

Mrethoxychlor

Methanychlor

Nitutite es nitrogen

Potaselum

Sillea.

Total organic carbon

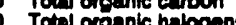

Total prestoum hydrocarto

0 Total phosphates (as P)

o Toxaphen

- 2,4,5-TP (Silvox

Total alpha-emiting radium

$<0.0080$

39
$<0.0050$

$<0.0050$

1.440
$<0.20$

$<0.20$

$<0.50$

$<0.50$

$<10$

1,850
28,700

$<1,000$

$<1,000$

$<5.0$

$<1,000$

820

$<0.24$

$<1.0 \mathrm{E}-09$

\section{WELL CSD 12D}

MEASUREMENTS CONDUCTED IN THE FIELD

Sample date: 07/27/92

Depth to water: $38.71 \mathrm{n}(17.29 \mathrm{~m})$ below TOC

Water elevation: $244.89 \mathrm{ft}(74.8$

Sp. conductance. $34 \mathrm{fs} / \mathrm{cm}$

WABOratomy AMALses

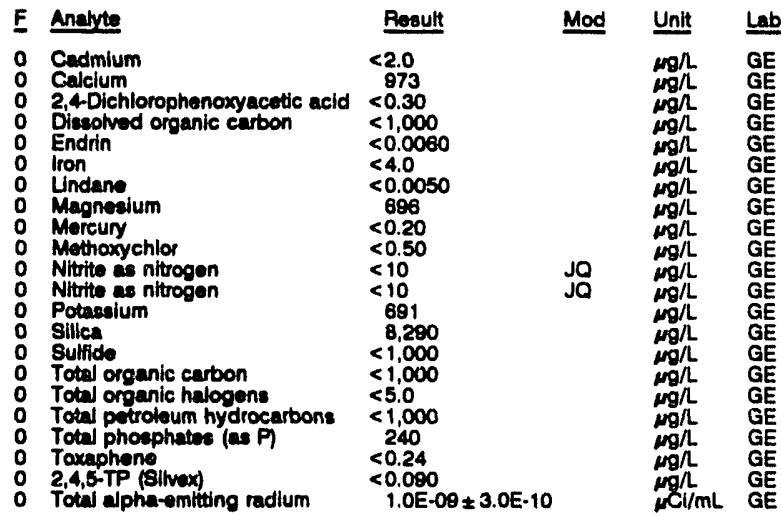

\section{WELL CSD 13D}

MEASUREMENTS CONDUCTED IN THE FIELD

Sample date: 07/29/82

Depth to water: $45.89 \mathrm{ft}(13.89 \mathrm{~m})$ below TOC

Wator elevation: 243.61 h $(74.25 \mathrm{~m}) \mathrm{msl}$

Wator evacuated before sampling: $243 \mathrm{ga}$

LABOPATOPY ANALYSES

\begin{tabular}{|c|c|c|c|c|}
\hline$\underline{F}$ & Analyte & Result & Mod & Unit \\
\hline $\begin{array}{l}2 \\
0 \\
0 \\
0 \\
0\end{array}$ & $\begin{array}{l}\text { Benrene } \\
\text { Bromodichloromethane } \\
\text { Bromoform } \\
\text { Bromomethane } \\
\text { Cadmium }\end{array}$ & $\begin{array}{r}8.7 \\
<1.0 \\
<1.0 \\
<1.0 \\
<2.0\end{array}$ & & $\begin{array}{c}\mathrm{mg} / \mathrm{L} \\
\mathrm{mg} / \mathrm{L} \\
\mathrm{\mu g} / \mathrm{L} \\
\mathrm{\mu g} / \mathrm{L}\end{array}$ \\
\hline
\end{tabular}

WELL CSO 130 collocted on 07/29/82, laboratory analyses (cont)

F Analyte

o Calcium

Carbon tetrachloride

Chlorobenzene

o Chloroethene Ninyl chloride)

2.Chloroethyl vinyl other

Chloroform

Chloromethane

o Dibromochloromethane

o 1,1-Dichlorosthane

1,2-Dichloroethane

1,1-Dichloroethylene
0
trane-1,2-Dichloroethylen

Dichloromothane

2,4-Dichlorophenoxyacetic acl

1,2-Dichloropropane

o cle-1,3-Dichloropropene

trans-1,3-Dichloropropene

0 Endrin

O Ethy

0 Iron

o Lindane

Magnes

Methoxychior

Nitrite as nitrogen

Potassium

O Sulica

${ }_{0}$ Sulfide

1,1,2,2-Tetrachloroethane

Tetrachloroethylene

Toluene

Total organic carbon

- Total organic halogens

Total petroleum hydrocarbon

o Toxaphene

o 2,4,5-TP (Silvex)

o 1,1,1-Trichloroethane

Thloroethene

2 Trichloroethylene

Trichlorofluoromethane

Time: 12.55

PH: 4.8

Alkalinity: $0 \mathrm{mg} / \mathrm{h}$

Water temperature: $22.2^{\circ} \mathrm{C}$

\section{WELL CSO 1}

MEASUREMENTS CONDUCTED IN THE FIELD

Sample date: 07/03/92

Depth to water: $48.75 \mathrm{ft}(14.86 \mathrm{~m})$ bolow TOC

Water elevation: $255.15 \mathrm{~h}$

Sp. conductancs: $35 \mu \mathrm{s} / \mathrm{cm}$

Result Mod Unit Lيb

688

$<1.0$

$<1.0$

$<1.0$

$<1.0$

$<1.0$

$<1.0$

$<1.0$
$<1.0$

$<1.0$
1.3
$<0.30$
$<1.0$

$<1.0$

$<1.0$

$<1,000$

$<0.0060$
$<1.0$
18
$<0.0050$

$<0.0050$

316
$<0.20$

$<0.50$

$<10$

746
10,500

$<1,000$

$<1.0$
3.1

$<1.000$

6.2

$<1,000$
2,210

2,210
$<0.24$

$<1.0$

24

$<1.0$ E-OQ

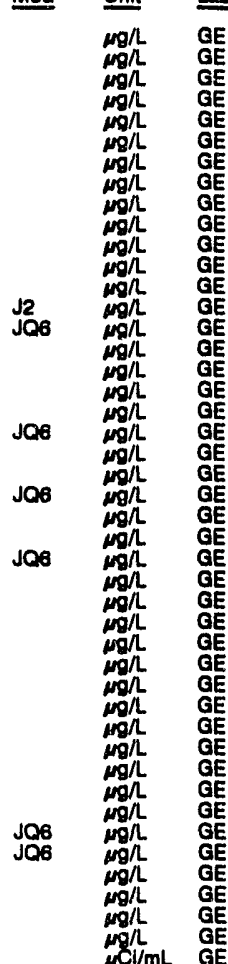

LABORATORY ANALYSES

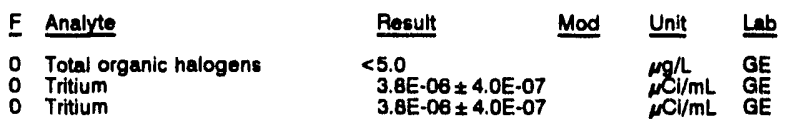

WELL CSO 2

MEASUREMENTS CONDUCTED IN THE FIELD

Sample date: 07/03/92 Depth to water: $46.67 \mathrm{ft}(14.23 \mathrm{~m})$ bolow TOC

Water olevation: $255.23 \mathrm{H}(77$.

Sp. conductance: $35 \mu \mathrm{S} / \mathrm{cm}$

W.

LABORATORY ANALYSES

$\begin{array}{lllll}\text { F Analyte } & \text { Rosult } & \text { Mod } & \text { Unit } & \text { Lab } \\ 0 & \text { Total organic halogens } & <5.0 & & \text { Gg/ } \\ 0 & \text { Tritium } & \text { GE }\end{array}$

Time: $8: 20$

pH: 4.8

Alkalinity: $1 \mathrm{mg} / \mathrm{L}$

o Tritium

\section{Time: $11: 30$}

Alkalinity: $0 \mathrm{mgh}$

Water temperature: $21.3^{\circ} \mathrm{C}$

Time: 11:05

kalinity: $0 \mathrm{mg} / \mathrm{h}$

Water tomperature: $20.8^{\circ} \mathrm{C}$ 


\section{WELL CSR 1 \\ MEASUREMENTS CONDUCTED IN THE FIELD \\ Sample date: 07/29/92 \\ Depth to wator: $15.42 \mathrm{f}(4.70 \mathrm{~m})$ bolow TOC \\ Water elovation: $238.68 \mathrm{ht}(78$ \\ Sp. conductance: 38 $\mathrm{s} / \mathrm{cm}$. \\ LABORATORY ANALYSES \\ E Analute \\ 0 Iron \\ 0 Lead
0 Total organic halogens
0 Groes Spha

Reault
$\begin{aligned} & 48 \\ & 4.7 \\ & <5.0 \\ & <2.0 E \cdot 09\end{aligned}$

\section{WELL CSR 2}

MEASUREMENTS CONDUCTED IN THE FIELD

Sample date: 07/29/92

Depth to water: $31.08 \mathrm{~h}(9.47 \mathrm{~m})$ bolow To
Water elevation: $288.64 \mathrm{~h}(81.27 \mathrm{~m}) \mathrm{msl}$
sp. conductunce

Wator evecuated before sampling: $19 \mathrm{gel}$

The well wont dry during purging.

LABOPATORY ANALYSES

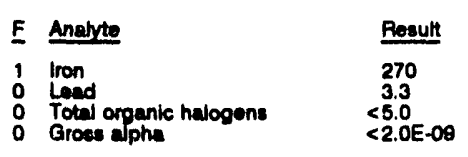

\section{WELL CSR 3}

MEASUREMENTS CONDUCTED IN THE FIELO

Sample date: 07/28/92

Sample data: $07 / 29 / 92$
Depth to water: $27.14 \mathrm{n}(8.27 \mathrm{~m})$ below TOC
Whter elevetion: $258.08 \mathrm{~h}(78.66 \mathrm{~m}) \mathrm{ms}$

Water evacuatad belore sampling; $40 \mathrm{gal}$

The woll went dry during purging.

LABORATORY ANALYSES

F Anabrte

- Iron

0 Load

O Total organic halogen

$$
\begin{array}{r}
68 \\
<3.0 \\
<5.0 \\
<2.06
\end{array}
$$

WELL CSR 4

MEASUREMENTS CONDUCTED IN THE FIELD

Sample date: 07/28/92

Depth to water: $25.10 \mathrm{f}(7.65 \mathrm{~m})$ below TOC

Whter elevation: $250.60 \mathrm{ht}$

Sp. conductance: $24 \mu s / \mathrm{cm}$.
Whater ovecuated before sampling: $58 \mathrm{gal}$

LABORATORY ANALYSES

E Anatyte

- Iron

iron

O Total organic halooen

o Grose alph.

Resutt
12
$<3.0$
$<5.0$
$<2.0 \mathrm{E}-00$

WELL DBP 1

MEASUREMENTS CONDUCTED IN THE FIELD

Sample date: 07/02/82

Wepth to water: $18.78 \mathrm{ft}(5.11 \mathrm{~m})$ below TOC

Water clevation: $116.41 \mathrm{ht}$

.

campling: $68 \mathrm{gat}$

LABORATORY ANALYSES

\begin{tabular}{|c|c|c|c|c|}
\hline$F$ & Analyte & Result & Mod & Unit \\
\hline $\begin{array}{l}0 \\
0 \\
0\end{array}$ & $\begin{array}{l}\text { Iron } \\
\text { Lead } \\
\text { Lead }\end{array}$ & $\begin{array}{r}20 \\
3.1 \\
<3.0 \\
16\end{array}$ & & 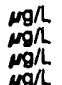 \\
\hline
\end{tabular}

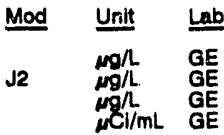

Time: $13: 50$

Alkalinity: $1 \mathrm{mg} / \mathrm{L}$

Alkalinity: $1 \mathrm{mg} / \mathrm{h}$
Water tomperature: $21.80^{\circ} \mathrm{C}$

Time: $14: 1$

Alkalinity: $0 \mathrm{mgl}$

Water temperature: $22.8^{\circ} \mathrm{C}$

Time: $8: 10$

PH: 4.7

Water temperature: $20.9^{\circ} \mathrm{C}$

$\begin{array}{lll}\text { Mod Unit } & \text { Lab } \\ \text { J1 } & \underset{\mathrm{mg} / \mathrm{GE}}{\mathrm{Gg} / \mathrm{GE}} & \mathrm{GE} \\ & \mathrm{Gl} / \mathrm{mL} & \mathrm{GE}\end{array}$

Time: 10:10

pH: 4.3

Alkallity: Omg/ $17.00 \mathrm{C}$
WELL DBP 2

MEASUREMENTS CONDUCTED IN THE FIELD

Sample date: 07/02/82

Depth to water: $9.43 \mathrm{ft}(2.67 \mathrm{~m})$ below TOC

Water olevation: $116.87 \mathrm{At}(35.62 \mathrm{~m}) \mathrm{msl}$

Water ovacuated belore sampling: 85 gal

LABOFATOAY ANALYSES

E Analyte

0 Iron

2 Manganese

Result
$\begin{gathered}117 \\ <3.0 \\ 358\end{gathered}$

\section{Time: $12: 15$}

Alkalinity: $0 \mathrm{mg} / \mathrm{h}$

Water ty: $0 \mathrm{mg} / \mathrm{L}$ : $18.7^{\circ} \mathrm{C}$

\section{WELL DBP 3}

MEASUREMENTS CONDUCTED IN THE FIELD

Sample date: Or/O2/

Depth to water: $8.12 \mathrm{ft}(2.48 \mathrm{~m})$ below TOC

Water elevation: $120.18 \mathrm{ft}(38.83 \mathrm{~m}) \mathrm{msl}$

Alkalinity: $2 \mathrm{molh}$

Water temperature: $18.2^{\circ} \mathrm{C}$

Water evacuated before sampling: $89 \mathrm{gal}$

LABORATORY ANALYSES

\begin{tabular}{|c|c|c|c|}
\hline E Analyte & Result & Mod & Unit \\
\hline $\begin{array}{ll}0 & \text { lron } \\
0 & \text { Lead } \\
0 & \text { Manganose }\end{array}$ & $\begin{array}{r}53 \\
<3.0 \\
16\end{array}$ & & $\underset{m g h}{\operatorname{mog} h}$ \\
\hline
\end{tabular}

\section{WELL DBP 4}

MEASUREMENTS CONDUCTED IN THE FIELD

Sample date: $07 / 02 / 92$

Dopth to water: $6.58 \mathrm{ft}(2.62 \mathrm{~m})$ below TOC

Wp.

Water evacuated before sampling: $88 \mathrm{gal}$

LABORATORY ANALYSES

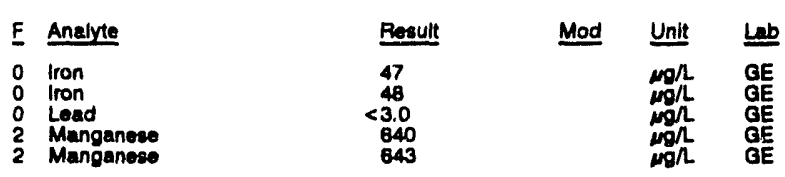

\section{WELL DCB $1 A$}

MEASUREMENTS CONDUCTED IN THE FIELD

Sample date: 07/01/02

Dopth to water: $11.18 \mathrm{ft}(3.41 \mathrm{~m})$ bolow TOC

Water elevation: $115.82 \mathrm{H}(35.33 \mathrm{~m}) \mathrm{mal}$

inacceseibility or mechanical problem prevented sample collection.

\section{WELL DCB 2A}

MEASUREMENTS CONDUCTED IN THE FIELD

Sample date: 07/01/92

Depth to water: $8.57 \mathrm{ft}(2.81 \mathrm{~m})$ bolow TOC

Water olevation: $125.73 \mathrm{ft}(38.32 \mathrm{~m}) \mathrm{ms}$ !

Time: 11:45

pH: 3.6

Water tomperature: $17.8^{\circ} \mathrm{C}$

LABORATORY ANALYSES

\begin{tabular}{|c|c|c|c|c|c|}
\hline$E$ & Analyte & Result & Mod & Unit & ba \\
\hline $\begin{array}{l}1 \\
0 \\
0 \\
0 \\
0\end{array}$ & $\begin{array}{l}\text { Araenic } \\
\text { Cadmium } \\
\text { Chromium } \\
\text { Fluoride } \\
\text { iron } \\
\text { Lead } \\
\text { Manganese } \\
\text { Sulfate } \\
\text { Total organic halogens } \\
\text { Gross alpha } \\
\text { Nonvolatile beta } \\
\text { Total alpha-emitting radlum } \\
\text { Tritium }\end{array}$ & $\begin{array}{l}<2.0 \\
<2.0 \\
<4.0 \\
<100 \\
32 \\
9.7 \\
25 \\
<1.000 \\
<5.0 \\
<2.0 E-09 \\
<2.0 \mathrm{E}-09 \\
<1.0 \mathrm{E}-09 \\
3.6 \mathrm{E}-06 \pm 4.0 \mathrm{E}-07\end{array}$ & $\begin{array}{l}\sqrt{2} \\
\sqrt{2} \\
\sqrt{ } 2\end{array}$ & 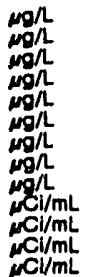 & $\begin{array}{l}G E \\
G E \\
G E \\
G E \\
G E \\
G E \\
G E \\
G E \\
G E \\
G E \\
G E \\
G E \\
G E\end{array}$ \\
\hline
\end{tabular}


WELL DCB 3A

MEASUREMENTS CONDUCTED IN THE FIELD

Sample date: 07/01/82 Depth to water: 11.59 it $(3.53 \mathrm{~m})$ bolow TOC Water olvation: $121.41 \mathrm{~h}$ (37. Water evecuated bofore esmpling: $68 \mathrm{gal}$

LABORATOFY ANALYSES

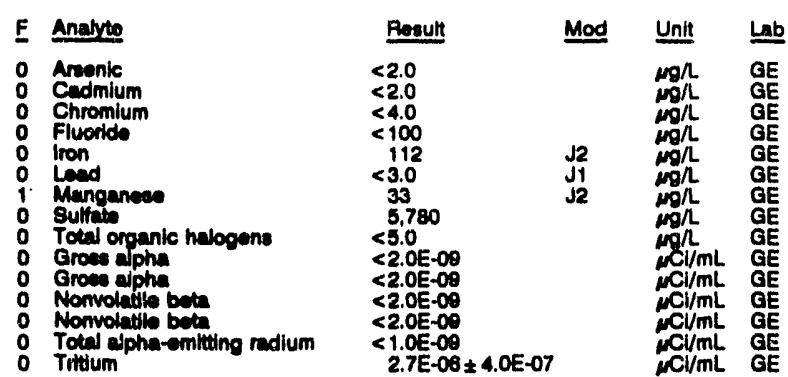

WELL DCB 4A

MEASUREMENTS CONDUCTED IN THE FIELD

Semple date: 07/01/e2

Depth to water: $9.70 \mathrm{~h}(2.86 \mathrm{~m})$ bolow TOC

Water elevation: $110.60 \mathrm{H}(36.52 \mathrm{~m}) \mathrm{msl}$

Sp. conductance: $317 \mu \mathrm{s} / \mathrm{cm}$

Time: $10: 50$

PH: 4.5

Water tomperature: $22.0^{\circ} \mathrm{C}$

LABORATORY ANALYSES

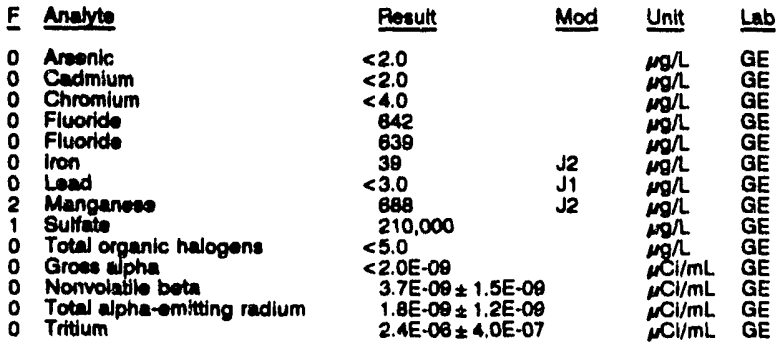

WELL DCB 5A

MEASUREMENTS CONDUCTED IN THE FIELD

Sumple data: 07/01/02 Depth to water: 3.48 (1. $(1.05 \mathrm{~m})$ below TOC Whater wevabion: $118.44 \mathrm{H}(\mathrm{BQ})$

Time: 11:05

pH: 4.8 : $0 \mathrm{mg}$

Water tomperture: $20.4^{\circ} \mathrm{C}$ Water evecuated betore cumpling: $68 \mathrm{gal}$

LABOPATOFY ANALYSES

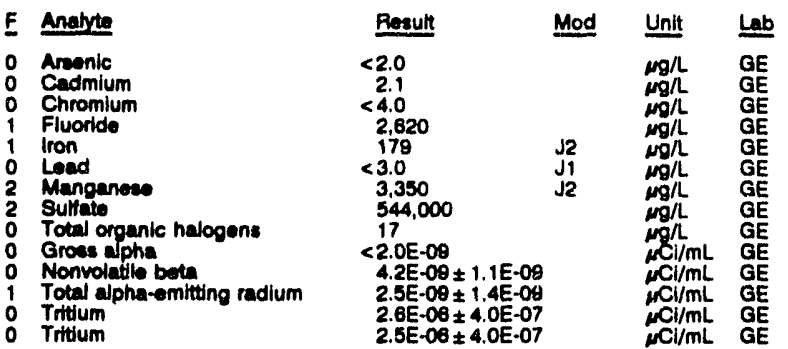

WELL DCB 6

MEASUREMENTS CONDUCTED IN THE FIELO

Sample date: 07/01/92

Depth to water: 13.82 it $(4.24 \mathrm{~m})$ below TOC

Water elevation: $119.27 \mathrm{~h}(36.35 \mathrm{~m}) \mathrm{msl}$

Water ovacuated before eampling: $14 \mathrm{gal}$

The well went dry during purging

LABORATOAY ANALYSES

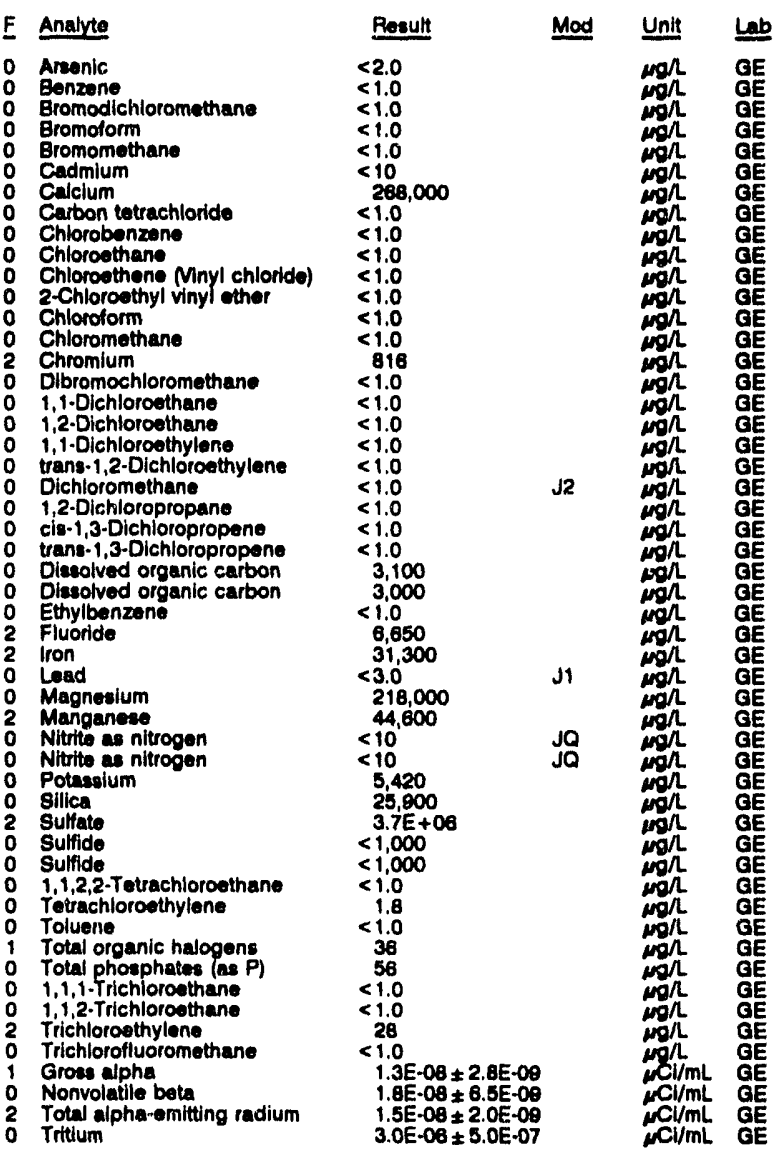

\section{WELL DCB 7}

MEASUREMENTS CONDUGTED IN THE FIELD

Sample date: 07/01/92

$1423 \mathrm{ft}(4.34 \mathrm{~m})$ bolow TOC

Water elevation: $118.57 \mathrm{~h}(36.14 \mathrm{~m}) \mathrm{me}$

Sp. conductance: $4830 \mu \mathrm{S} / \mathrm{cm}$

Water evecuated belore sampling: $28 \mathrm{gal}$

LABORATORY ANALYSES

\begin{tabular}{|c|c|c|c|}
\hline Analyte & Result & Mod & Unit \\
\hline $\begin{array}{l}\text { Arsenic } \\
\text { Benzene } \\
\text { Benzene } \\
\text { Eromodichloromothane } \\
\text { Bromodichloromothane } \\
\text { Bromoform } \\
\text { Bromoform } \\
\text { Bromomethane } \\
\text { Bromomethane } \\
\text { Cadmium } \\
\text { Celclum } \\
\text { Carbon totrachloride } \\
\text { Carbon totrachloride } \\
\text { Chlorobenzene } \\
\text { Chlorobenzene } \\
\text { Chloroothane } \\
\text { Chloroethane } \\
\text { Chlorosthene Ninyl chloride) } \\
\text { Chloroethene (Vinyl chloride) }\end{array}$ & $\begin{array}{l}<2.0 \\
<1.0 \\
<1.0 \\
<1.0 \\
<1.0 \\
<1.0 \\
<1.0 \\
<1.0 \\
<1.0 \\
<20 \\
138,000 \\
<1.0 \\
<1.0 \\
<1.0 \\
<1.0 \\
<1.0 \\
<1.0 \\
<1.0 \\
<1.0\end{array}$ & & 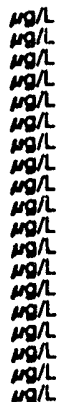 \\
\hline
\end{tabular}

Time: 12:35

PH: 3.8

23.00 C




ANALYTICAL RESULTS

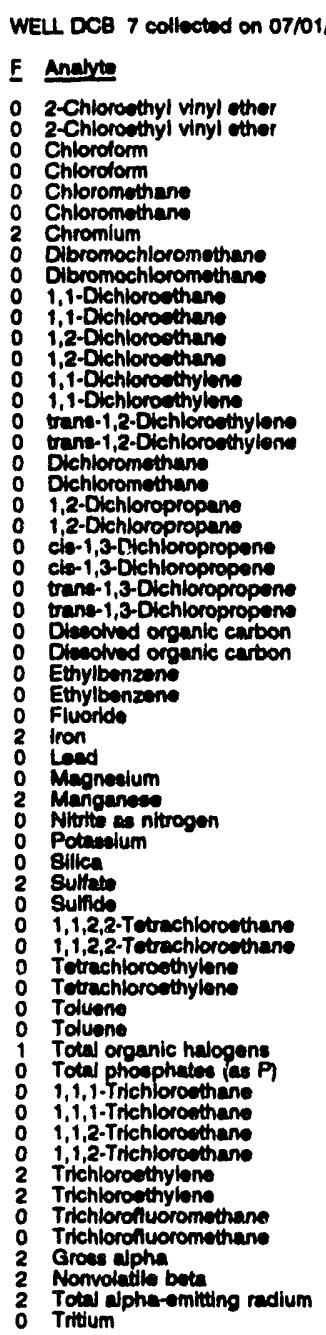

2, Iaboratory analyeses (cont)

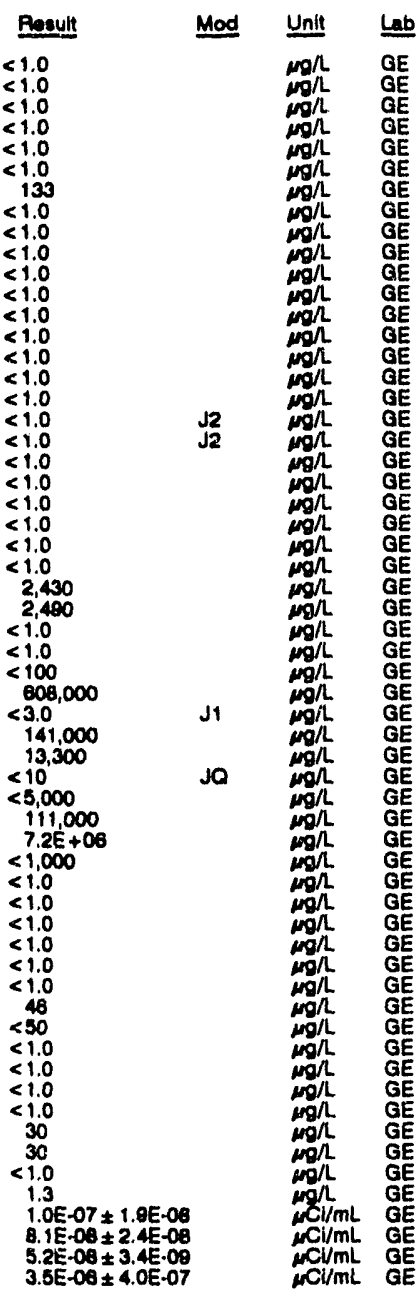

\section{WELL DCB 8}

MEASUREMENTS CONDUCTED IN THE FIELD

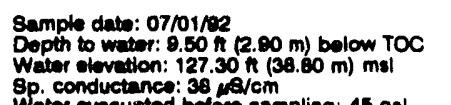

Time: 11:20

Alkalinity: $0 \mathrm{mg} / \mathrm{s}$

Water temperature: $21.4^{\circ} \mathrm{C}$

Water ovecuatod bolore sampling: $45 \mathrm{gal}$

\section{LABOFATOAY ANALYSES}

\begin{tabular}{|c|c|c|c|c|c|}
\hline$F$ & Analyte & Result & Mod & Unit & Lab \\
\hline $\begin{array}{l}0 \\
0 \\
0 \\
0 \\
0 \\
0 \\
0 \\
0 \\
0 \\
0 \\
0 \\
0\end{array}$ & $\begin{array}{l}\text { Areanic } \\
\text { Cadmium } \\
\text { Chromium } \\
\text { Fluoride } \\
\text { ron } \\
\text { Lead } \\
\text { Manganese } \\
\text { Sultato } \\
\text { Total organic halogens } \\
\text { Growe appha } \\
\text { Nonvolatile bota } \\
\text { Total alpha-emiting radium } \\
\text { Tritium }\end{array}$ & $\begin{array}{r}<2.0 \\
<2.0 \\
<4.0 \\
<100 \\
17 \\
<3.0 \\
3.5 \\
1.380 \\
<5.0 \\
4.1 E-09 \pm 8.0 E-10 \\
3.5 E-09 \pm 1.4 E-09 \\
<1.0 E-09 \\
3.1 E-08 \pm 4.0 E-07\end{array}$ & $\begin{array}{l}\sqrt{2} \\
\mathbf{J 1} \\
\sqrt{2}\end{array}$ & 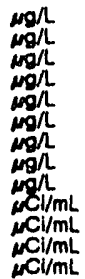 & $\begin{array}{l}\mathrm{GE} \\
\mathrm{GE} \\
\mathrm{GE} \\
\mathrm{GE} \\
\mathrm{GE} \\
\mathrm{GE} \\
\mathrm{GE} \\
\mathrm{GE} \\
\mathrm{GE} \\
\mathrm{GE} \\
\mathrm{GE} \\
\mathrm{GE} \\
\mathrm{GE}\end{array}$ \\
\hline
\end{tabular}

WELL DCB 9

MEASUAEMENTS CONDUCTED IN THE FIELD

Sample date: $07 / 01 / 92$

Depth to water: $7.30 \mathrm{ft}(2.23 \mathrm{~m})$ bolow TOC

Water olevation: $115.00 \mathrm{ft}$ (35.

Sp. conductance: $2090 \mathrm{\mu s} / \mathrm{cm}$.

pH: 3.4

Alkalinity: $0 \mathrm{mg} /$

Water tomperature: $21.3^{\circ} \mathrm{C}$

LABORATORY ANALYSES

\begin{tabular}{|c|c|c|c|}
\hline Analyte & Rosult & Mod & Init \\
\hline $\begin{array}{l}\text { Areonic } \\
\text { Cedmilum } \\
\text { Chromium } \\
\text { Fluoride } \\
\text { Iron } \\
\text { Load } \\
\text { Manganose } \\
\text { Sulfato } \\
\text { Total organic halogens } \\
\text { Total organle halogens } \\
\text { Groes alpha } \\
\text { Nonvolatile beta } \\
\text { Total alpha-emitting radium } \\
\text { Total alpha-emitting radium } \\
\text { Tritum }\end{array}$ & $\begin{array}{l}<2.0 \\
3.4 \\
58 \\
606 \\
30,500 \\
<3.0 \\
35,600 \\
2.8 E+06 \\
33 \\
37 \\
1.6 E-08 \pm 1.7 E-09 \\
9.1 E-00 \pm 2.4 E-09 \\
2.6 E-08 \pm 2.3 E-00 \\
2.3 E-08 \pm 1.7 E-00 \\
2.7 E-08 \pm 4.0 E-07\end{array}$ & $\begin{array}{l}\mathbf{J 2} \\
\mathbf{J 1} \\
\mathrm{J} 2\end{array}$ & 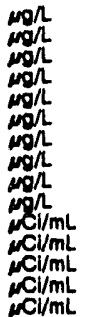 \\
\hline
\end{tabular}

WELL DCB 10

MEASUREMENTS CONDUCTED IN THE FIELD

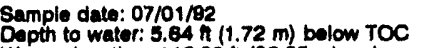

Water elevation: $118.28 \mathrm{~h}(36.05 \mathrm{~m}) \mathrm{msl}$

PH: 2.8

pH: 2.8 . 0 mall

Water tomperature: $24.2 \circ \mathrm{C}$

LABORATORY ANALYSES

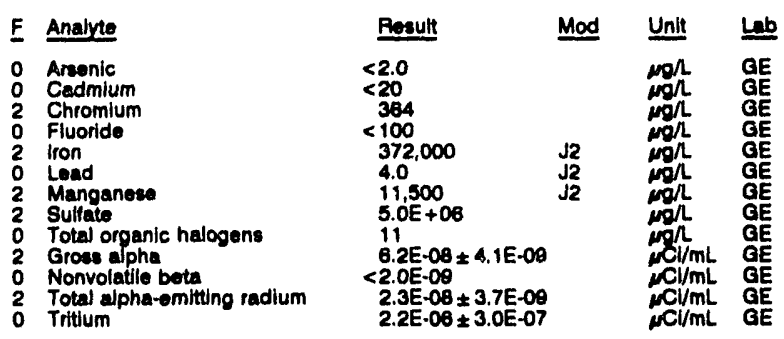

\section{WELL DCB 11}

MEASUAEMENTS CONDUCTED IN THE FIELD

$\begin{array}{ll}\text { Sample date: } 07101 / 02 & \text { Time: } 11: 50 \\ \text { Dopth to water: } 8.53 \mathrm{n}(2.60 \mathrm{~m}) \text { bolow TOC } & \text { pH: } 5.9 \\ \text { Water elevation: } 122.07 \mathrm{ft}(37.21 \mathrm{~m}) \mathrm{mal} & \text { Alkalinity: } 38 \mathrm{mg} / \\ \text { Sp. conductance: } 2680 \mu \mathrm{s} / \mathrm{cm} & \text { Water tomperature: } 22.5 \cdot \mathrm{C} \\ \text { Water ovacuated bofore sampling: } 12 \mathrm{gal} & \end{array}$

Whe woll went ory during purging: $12 \mathrm{gal}$

LABORATORY ANALYSES

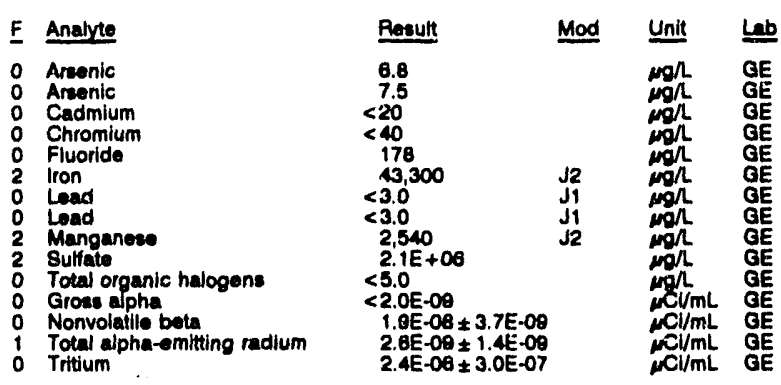


WELL DCB 12

MEABUREMENTS CONDUCTED IN THE FIELD

\begin{tabular}{|c|c|c|c|c|c|}
\hline \multicolumn{3}{|c|}{ 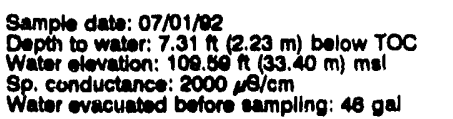 } & \multicolumn{3}{|c|}{$\begin{array}{l}\text { Time: } 9: 25 \\
\text { pH: } 3.7 \\
\text { Alkalinity: } 0 \mathrm{mg} / \mathrm{h} \\
\text { Water temperature: } 18.7^{\circ} \mathrm{C}\end{array}$} \\
\hline \multicolumn{6}{|c|}{ LABORATOFY ANALYBES } \\
\hline E & Aneryte & Reault & Mod & Unit & Lab \\
\hline $\begin{array}{l}0 \\
0 \\
0 \\
0 \\
2 \\
2 \\
0 \\
2 \\
2 \\
0 \\
0 \\
1 \\
0 \\
0\end{array}$ & 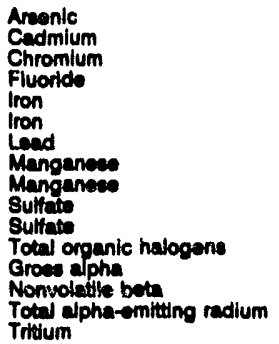 & $\begin{array}{l}<2.0 \\
<2.0 \\
<4.0 \\
184 \\
708 \\
689 \\
<3.0 \\
71 \\
70 \\
47,900 \\
40,800 \\
40 \\
<2.0 E-00 \\
<2.0 E-00 \\
<1.0 E-00 \\
1.3 E-04\end{array}$ & E-06 & 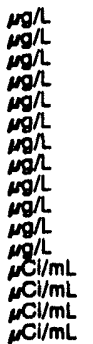 & $\begin{array}{l}\mathrm{GE} \\
\mathrm{GE} \\
\mathrm{GE} \\
\mathrm{GE} \\
\mathrm{GE} \\
\mathrm{GE} \\
\mathrm{GE} \\
\mathrm{GE} \\
\mathrm{GE} \\
\mathrm{GE} \\
\mathrm{GE} \\
\mathrm{GE} \\
\mathrm{GE} \\
\mathrm{GE} \\
\mathrm{GE} \\
\mathrm{GE}\end{array}$ \\
\hline
\end{tabular}

WELL DCB 13

MEASUREMENTS CONDUCTED IN THE FIELD

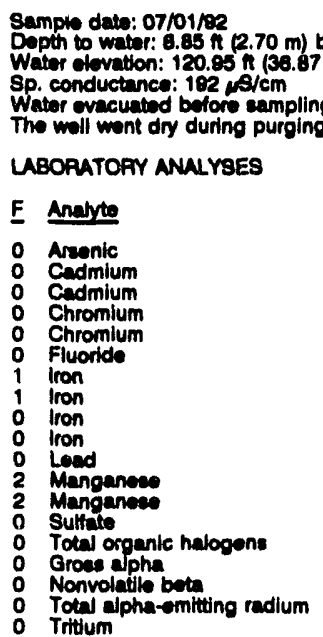

Time: 12:00

PH:

Akalinity: $19 \mathrm{mg} / \mathrm{h}$
Water temperature: $22.0^{\circ} \mathrm{C}$

\section{low TOC}

gal $11 \mathrm{gal}$

\begin{tabular}{|c|c|c|}
\hline Result & Mod & Unit \\
\hline $\begin{array}{l}<2.0 \\
<2.0 \\
<2.0 \\
<4.0 \\
<4.0 \\
140 \\
152 \\
151 \\
142 \\
143 \\
<3.0 \\
341 \\
340 \\
37,000 \\
<5.0 \\
<2.0 \mathrm{E}-09 \\
8.2 \mathrm{E}-09 \pm 1.8 \mathrm{E}-09 \\
<1.0 \mathrm{E}-00 \\
1.6 \mathrm{E}-00 \pm 3.0 \mathrm{E}-07\end{array}$ & $\begin{array}{l}\sqrt{2} \\
\mathrm{~J} 1 \\
\sqrt{ } 2\end{array}$ & 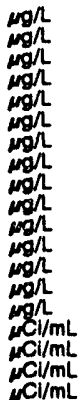 \\
\hline
\end{tabular}

\section{WELL DCB 15}

\section{MEASUREMENTS CONDUCTED IN THE FIELD}

\section{Sample date: 07/01/92}

Depth to water: $14.28 \mathrm{ft}(4.35 \mathrm{~m})$ bolow TOC

Water olevation: 113.34 h (34.

Sp. conductance: $978 \mu \mathrm{s} / \mathrm{cm}$

What orecuated before exmpling: 9 gal

LABORATOFY ANALYEES

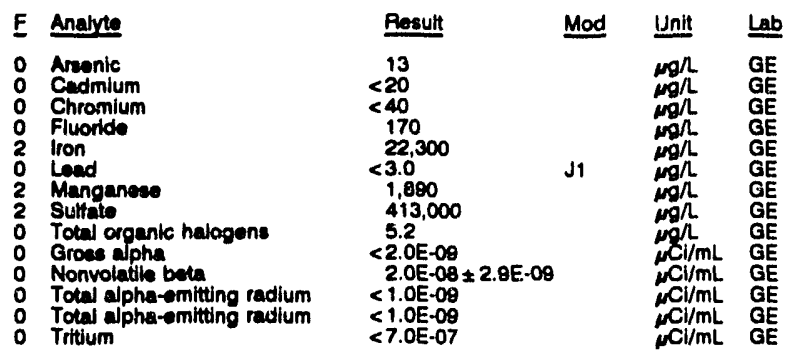

Time: 12:20

Alkalinity: $223 \mathrm{mg} / \mathrm{h}$
Water temperature: $22.0^{\circ} \mathrm{C}$

ab
$G E$
$G E$
$G E$
$G E$
$G E$
$G E$
$G E$
$G E$
$G E$
$G E$
WELL DCB 16

MEASUREMENTS CONDUCTED IN THE FIELD

Sample date: 07/01/92

Dapth to water: $14.54 \mathrm{Ht}(4.43 \mathrm{~m})$ below TOC

Water olovation: 113.38 h $(34.55 \mathrm{~m}) \mathrm{mol}$

Water evacuated befors eampling: $6 \mathrm{gal}$

The woll went dry during purging.

LABORATORY ANALYSES

\begin{tabular}{|c|c|c|c|}
\hline Analyte & Result & Mod & Unit \\
\hline $\begin{array}{l}\text { Arsonic } \\
\text { Arsonic } \\
\text { Cadmium } \\
\text { Chromium } \\
\text { Fluoride } \\
\text { ron } \\
\text { Lead } \\
\text { Lead } \\
\text { Manganese } \\
\text { Sulfate } \\
\text { Total organic halogens } \\
\text { Total organle halogens } \\
\text { Groes alpha } \\
\text { Nonvolatile betin } \\
\text { Total alpha-emitting radium } \\
\text { Tittum }\end{array}$ & $\begin{array}{l}4.3 \\
4.1 \\
<2.0 \\
<4.0 \\
180 \\
6,520 \\
<3.0 \\
<3.0 \\
170 \\
159,000 \\
<5.0 \\
<5.0 \\
<2.0 \mathrm{E}-09 \\
8.5 \mathrm{E}-09 \pm 1.2 \mathrm{E}-00 \\
<1.0 \mathrm{E}-09 \pm 0.00 \\
1.3 \mathrm{E} \cdot 00 \pm 3.0 \mathrm{E}-07\end{array}$ & $\begin{array}{l}\text { J1 } \\
\text { J1 }\end{array}$ & 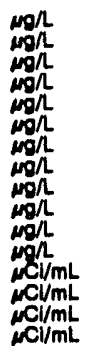 \\
\hline
\end{tabular}

\section{WELL DOB 1}

MEASUREMENTS CONDUCTED IN THE FIELD

Sample date: 07/15/92

Depth to water: $7.11 \mathrm{~h}(2.17 \mathrm{~m})$ below TOC

Water olovation: 144.58 ft (44.

Sp. conductance: $137 \mu \mathrm{s} / \mathrm{cm}$
Water evacuatod before sampling: $78 \mathrm{gal}$

pH: 8.7

Water tomperature: $20.7^{\circ} \mathrm{C}$

LABORATORY ANALYSES

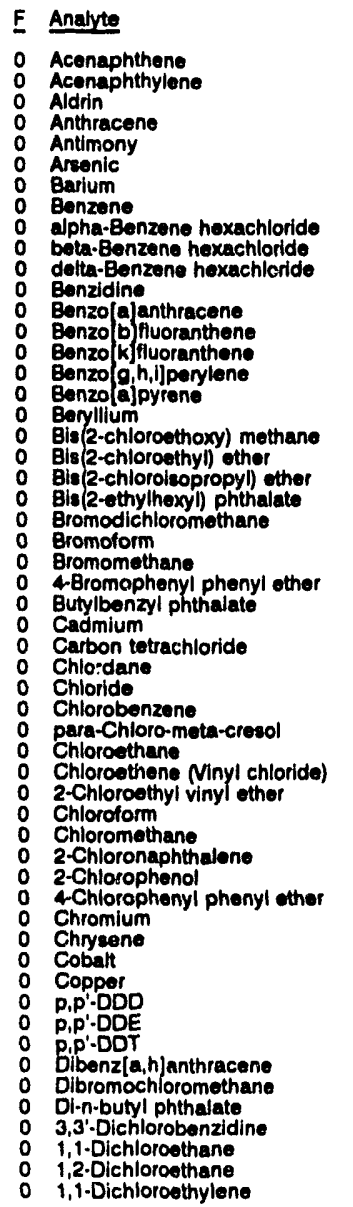

\begin{tabular}{r} 
Pesult \\
\hline 10 \\
$<10$ \\
$<10$ \\
$<10$ \\
$<2.0$ \\
$<2.0$ \\
18 \\
$<1.0$ \\
$<10$ \\
$<10$ \\
$<10$ \\
$<10$ \\
$<10$ \\
$<10$ \\
$<10$ \\
$<10$ \\
$<10$ \\
$<3.0$ \\
$<10$ \\
$<10$ \\
$<10$ \\
$<10$ \\
$<1.0$ \\
$<1.0$ \\
$<1.0$ \\
$<10$ \\
$<10$ \\
$<2.0$ \\
$<1.0$ \\
$<10$ \\
$<1.220$ \\
$<1.0$ \\
$<10$ \\
$<1.0$ \\
$<1.0$ \\
$<1.0$ \\
$<1.0$ \\
$<1.0$ \\
$<10$ \\
$<10$ \\
$<10$ \\
$<4.0$ \\
$<10$ \\
$<4.0$ \\
5.4 \\
$<10$ \\
$<10$ \\
$<10$ \\
$<10$ \\
$<1.0$ \\
$<10$ \\
$<10$ \\
$<1.0$ \\
$<1.0$ \\
$<1.0$
\end{tabular}

Time: 10:45

pH: 6.4

Alkalinity: $48 \mathrm{mon}$

Water tomperature: $21.5 \circ \mathrm{C}$ 
WEL DOB 1 colloctad on 07/15/92, laboratory analyeese (cont.)

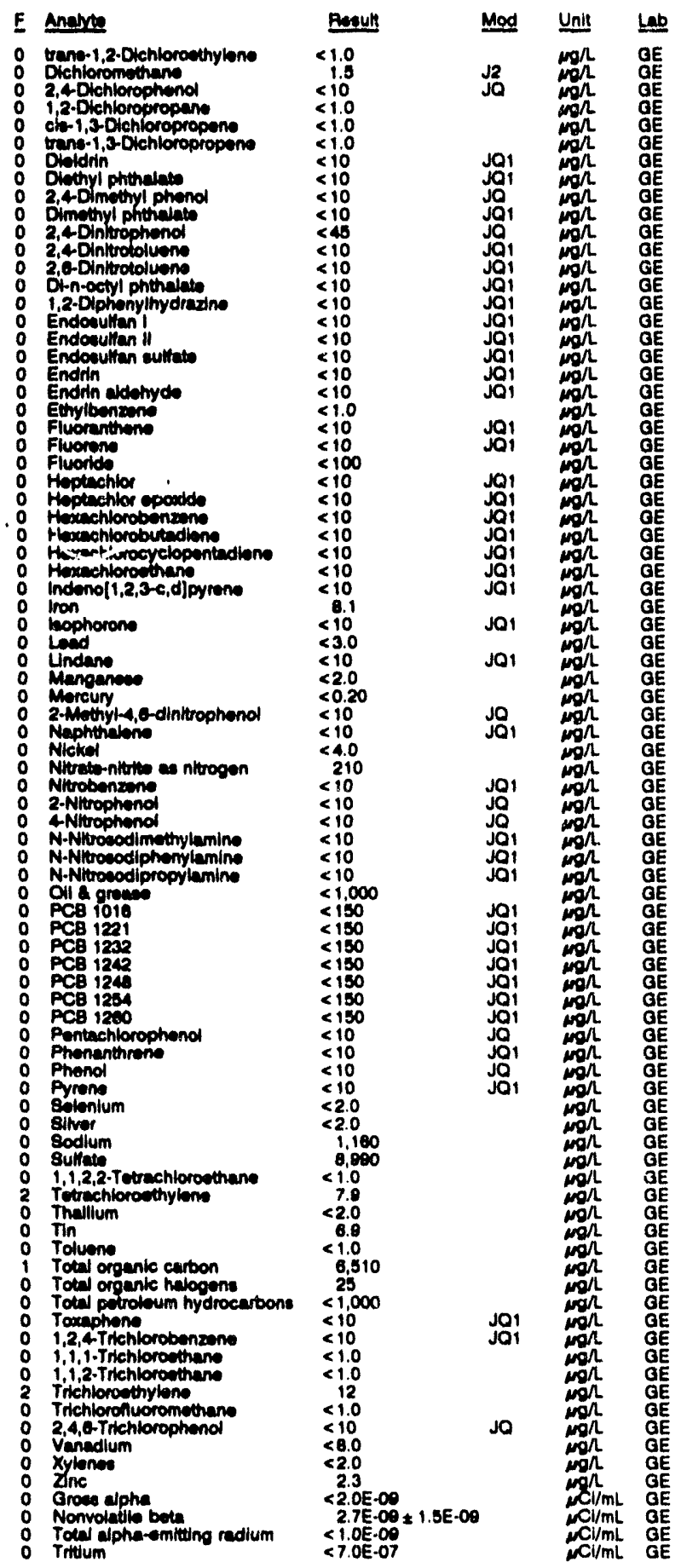

WELL DOB 2

MEASUAEMENTB CONOUCTED IN THE FIELD

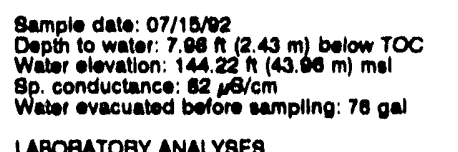

Time: $11: 10$

PH: 8.1 . 2 maln

Water tomperature: $20.8 \circ \mathrm{C}$

LABOFUTORY ANALYBES

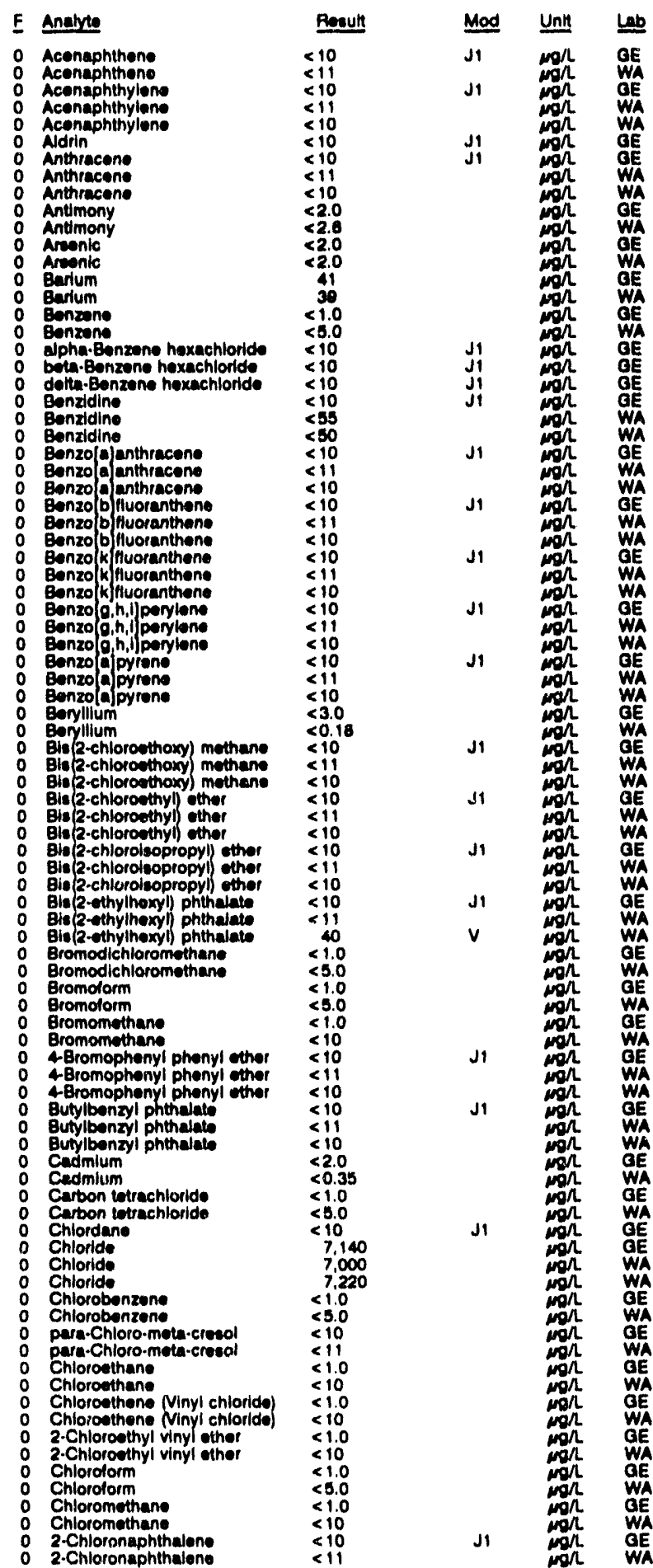


ANALYTICAL RESULTS

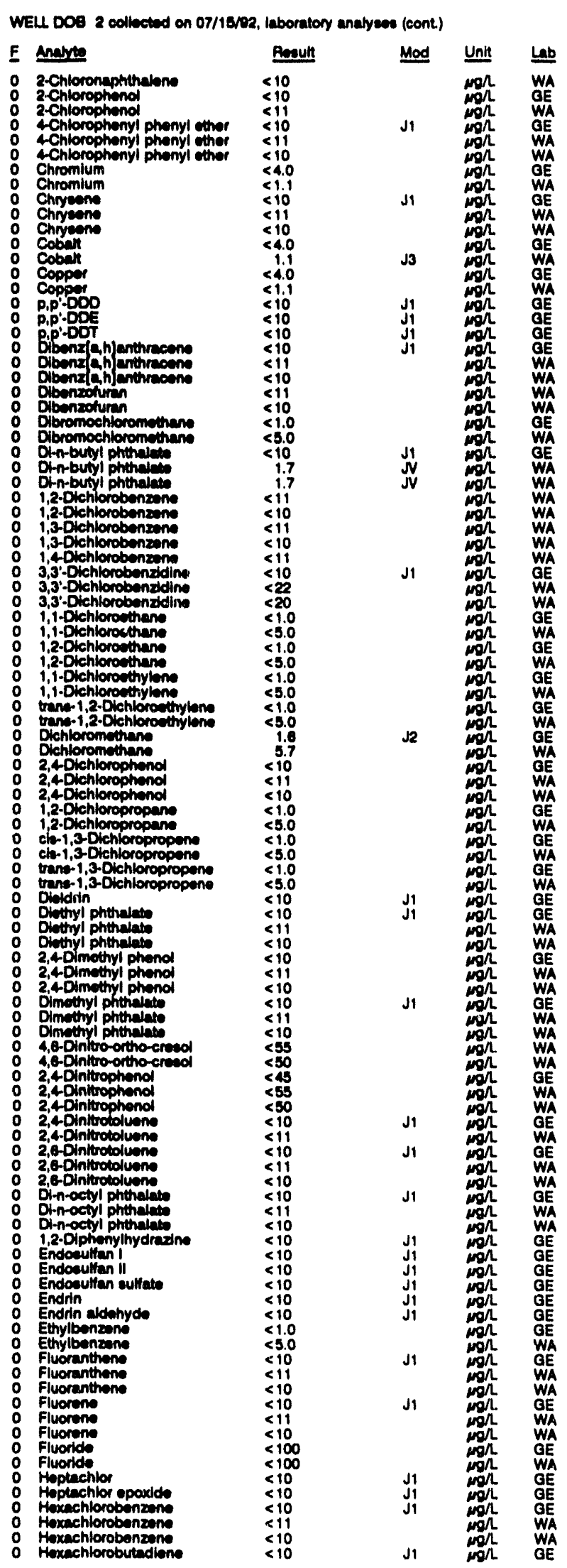

WELL DOB 2 collected on 07/18/92, laboratory analyeses (cont.)

E Anayte Beauh Mod

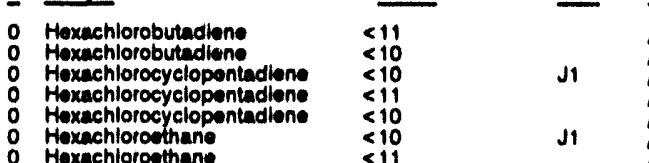

Hoxachlorothan $<11$

o indenol $1,2,3-c, d)$ pyrens

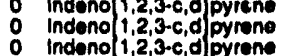

2 indon

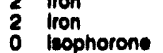

o leophorone

o leophorone

0 Lead

o Undane

o Manganoses

0 Mercun

o Mercury

O Naphthalono

o Naphthalono

0 Naphthalens

O Nickel

O Nlekel

No Nitrate as nitrogen

Nitrate-nitrite as nitrogen

o Nitrobenzene

O Nitrobenzene

- Nltrobenzene

2-Nitrophenol

2-Nitrophenol

4 Nitrophenol

o ANitrophonol

o N-Nitrosodimethylamine

N-Nitrosodimethylamine

O N.Nitrosodimethylamine

O N-Nitrosodiphenylamins

N-Nurosodiphonylamino

N-Nitroesdipropylamine

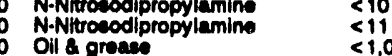

0 Oll groase $<1,000$

O PCB $1016 \quad<150$

PCB 1221
0

PCB 124

o PCB 1248

- PCB 1254

O PCB 1260

Pontachlorophonol

o Phenanthrene

O Phenanthrene

o Phenol

o Phenol

o Pyrono

Pyreno

o Solenium

o silver

0 Silver

Sodium

Oodium

0 Sulfato

O Sulfate

o 1,1,2,2-Tetrachloroethane

1 1,2,2.Tetrachloroothan

o Tetrachlorothylene

0 Thallium

0 Tin

2 Tin

: Toluene

O Total organic carbon

Total organic carbon

2 Total organic halogens

Total organic halogens

Total petroloum hydrocarbons

Total petroleum hydrocarbons

o Toxaphene

o 1,2,4 Trichlorobenzene

o 1,2,4-Trichlorobenzone

1,1,1-Trichloroethane

i, 1, Trichloroethan

1,1,2-Trichloroethane

T 1,1,2-Trichloroethan

$<150$
$\leq 150$
$<150$
$<150$

$<150$

$<150$

$<55$

$\leq 10$

$\leq 10$

$\leqslant 10$

$<10$

$<2.0$

$<0.70$

0.700 war

13,600
13,200

$<1.0$

$<5.0$

$<5.0$

$<2.0$

$<2.0$

32
$<1.8$
$<1.0$

$<1.0$

3,080

22
82
73

$<1,000$

$<010$
$<10$
$<10$

$\leq 10$

$<1.0$

35.0

51.0

$<1.0$

Unt Let

nol WA

WE

GE

$w A$

$w$

GE 
WELL DO8 2 collected on 07/19102, laboratory analyese (cont)

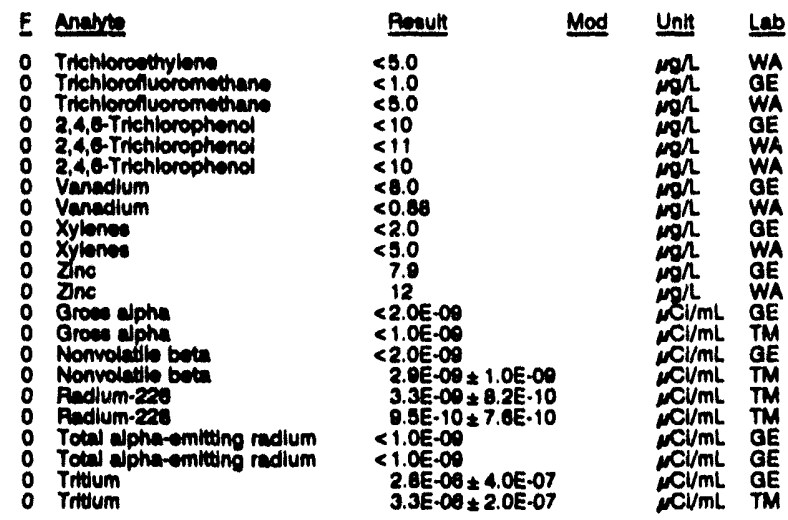

WELL DOB 2 Replicate

MEASUAEEMENTS CONDUCTED IN THE FIELD

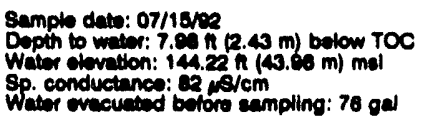

Time: 11:10

PH: Silinity: $2 \mathrm{mgh}$

Water tomperature: $20.8 \cdot \mathrm{C}$

LABOPATOPY ANALYESS

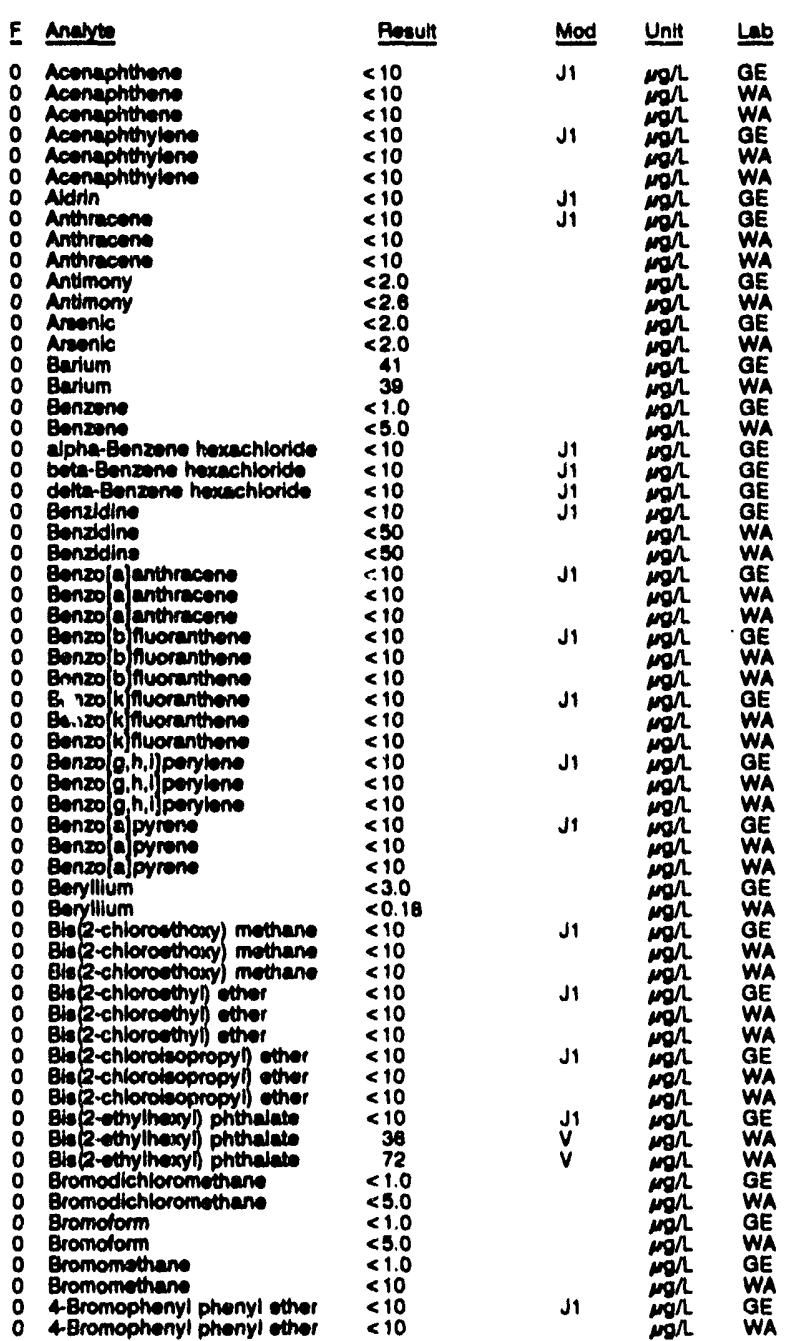

WELL DOB 2 collected on 07/15/92, laboralory analyese (cont)

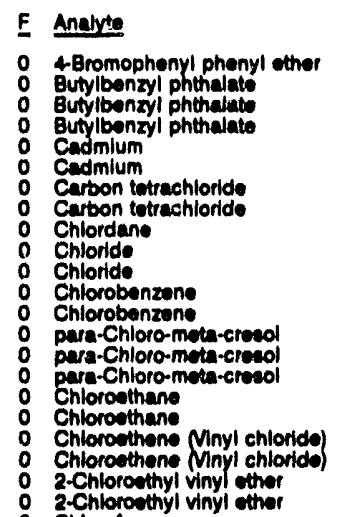

Ronult Mod

Mod Unit Lab

$\leq 10$

$<10$
$\leq 10$

$<2.0$

$<0.39$

$<10$

7,040

$<1.0$

10

$<10$

$\leq 1.0$

$\leq 10$

$<10$

2-Chioroesthyl Why other

Chloodorm

Chloromernthene

Chloromethen:

2.Chloronaphthalone

2-Chloronaphthalons

2-Chloronaphthalene

2-Chlorophonol

2-Chlorophenol

2.Chorophenol

4-Chlorophonyl phenyl ther

4-Chlorophenyl phenyl ether

Chromium

O Chromium

o Chryeone

o Chryeene

Cobart

Copper

- Copper

p,p:DoD

$\begin{array}{lll}0 & p, p \cdot D D E \\ 0 & \text { p.p'-DOT }\end{array}$

Gibenz a hlanthracene

Dibenz e, n enthracone

Dibenz a h h anthracene

Dibenzofuran

Dibromochloromethane

Dibromochloromothan

Di-n-butyl phthalate

Di-n-butyl phthesate

1,2-Oichlorobenzene

i, Dichlorobonzeno

o 1,3-Dichlorobanzene

1,3-Otchlorobenzene

1,4Dichlorobanzene

o 1,4Dichlorobenzene

o 3,3'-Oichlorobenzidine

o 3,3 -Dichlorobenzddine

1,1.Dlchloroethane

1,1-Dichioroethen

: 1,2-Oichloroethane

o 1,1-Dichloroethyleno

o trans-1,2-Dichloroethylene

o trans-1,2-Dichloroethylene

O trans-1,2-Dichloreath

o Dichloromethane

2.4Dichlorophenol
0

2,4-Dichlorophenol

o 1,2 -Dichioropropane

o cle-1,3-Dichloropropene

o cla-1,3-Dichioropropene

o trans-1,3-Dichloropropene

o Dividrin

O Diethyl phthalate

2,4-Dimethyl phenol

2,4Dimothyl phenol

2,4-Dimethyl phenol

o Dimethyl phthalate

D Dimethyl phthalato

0 Dimethyl phthalato

4,6-Dinitro-ortho-creecl

4,6-Dinitro-ortho-cresol

2,4-Diniturophenol

$\begin{array}{ll}\text { 2,4-Dinitrophenol } \\ 0 & \text { 2,4-Dinttrophonol }\end{array}$

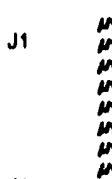

mon wa

WA

WE

GE

WA

$\leq 10$

$<10$
$<10$
$<10$

$<<10$

$<10$

$<10$

$<5.0$

$<1.0$
1.5
1.6

$<10$

$<10$

$<10$

$<10$

$>10$

$<20$

$<5.0$

$<1.0$

$<1.0$

$<5.0$

$<5.0$

1.3
510
5

$<10$

$<1.0$

$<1.0$

$<1.0$

$\leq \leq .0$ 
ANALYTICAL RESULTS

WELL DOB 2 collected on 07/15/202, laboratory analyese (cont)

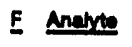

- 2,4-Dinitrotoluene

O 2,4Dinitrotolicene

2,4-Dintrotolueno

2,6-Dinitrotoluen

2,0-Dinitrotoluen

o Dr-n-octyl phthriate

0 Dion-octyl phthalete

1,2-Olphomylhydraine

0 Endoculten I

0 Endowuten eultats

Endinn

Endin aderyyde

Etrulbenasen

o Fluoranthene

o Fluoranthen

0 Fluoren

o Fluoren

F Fivorens

o Fluoride

0 Heptachlor

- Hpptachlor epouda

o Hoxuchlorobenzans

- Haxachiorobienzene

o Hexachlorobutedien

Hexachlorobutadione

Haxachlorebutadiene

Hexehtorocyclopentedien

Hexechlorocyclopentadione

o Hexechlorothan

o Hexachlorethan

indeno:1,2,3-c,d]pyrene

0 indeno $(1,2,3-c, d$ pynen

Iron

ieophorons

o tophorons

0 Loed

0 Lead

o Manganece

Manganese

Moreury

2-Methyl-4,6-dinitrophenol

o Nephthalene

- Naphthabon

N Nickel

N Nitute as nitrogen

Nitrata-nltotto eis nitrogen

Nitrobenzane

Nitrobename

enturain

2. Nitrophenel

2.Nitrophenc

4 Nitrophenol

4 Nitrophene

N-Nitrosodimethylamine

N-Nucoodimethylamine

N-Nitroedimethylamine

N-Nitrocodiphenylemin

N-Nitrosodiphenylamine

$N$-Nitroesodiphenylamine

N-Nitroeodipropylamine

NNitroedipropylamine

N-Nitroecodipropylamine

Oll greace

PCB 1016

PCB 1221

PCB 1232

PCB 1240

PCB 125

Pentachlorophonol

Pentechlorophenol

Pentachlorophenol

Phenanthrens

Phonanthren

Phenol

Phenol

Phonol

Pyrene
WELL DOB 2 collected on 07/15/92, laboratory analyeese (cont.)

\begin{tabular}{|c|c|c|c|}
\hline F Analyte & Result & Mod & Unit \\
\hline 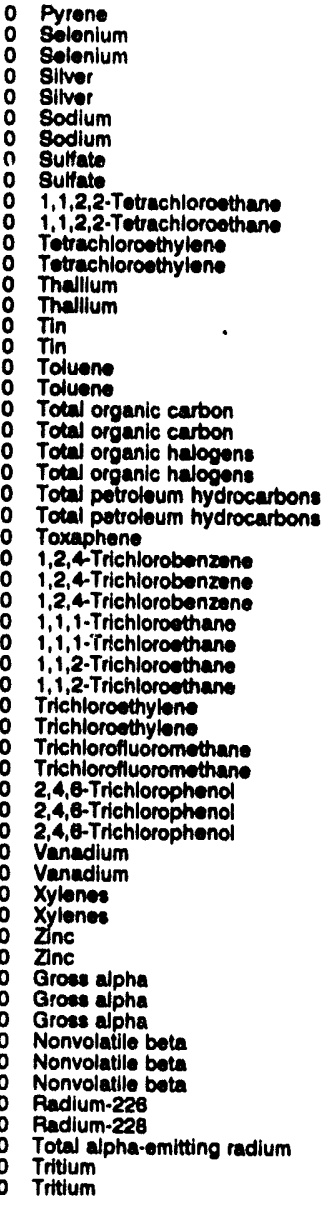 & $\begin{array}{l}<10 \\
<2.0 \\
<2.0 \\
<2.0 \\
<0.70 \\
2,650 \\
2,720 \\
14,400 \\
0.040 \\
<1.0 \\
<5.0 \\
<1.0 \\
<5.0 \\
<2.0 \\
<2.0 \\
<2.0 \\
4.0 \\
<1.0 \\
<5.0 \\
3,430 \\
2,030 \\
22 \\
16 \\
1.370 \\
<460 \\
<10 \\
<10 \\
<10 \\
<10 \\
<1.0 \\
<5.0 \\
<1.0 \\
<5.0 \\
<1.0 \\
<5.0 \\
<1.0 \\
<5.0 \\
<10 \\
<10 \\
<10 \\
<8.0 \\
<0.80 \\
<2.0 \\
<5.0 \\
7.3 \\
12 \\
<2.0 E-09 \\
<2.0 E-09 \\
1.5 E-09 \pm 6.0 E-10 \\
<2.0 E-09 \\
<2.0 E-09 \\
1.0 E-09 \pm 1.3 E-09 \\
2.8 E-09 \pm 7.8 E-10 \\
<1.0 E-09 \\
<1.0 E-09 \\
3.0 E-09 \pm 4.0 E-07 \\
3.5 E-09 \pm 2.7 E-07\end{array}$ & $\begin{array}{l}J \\
J_{1} \\
\mathbf{J} 1\end{array}$ & 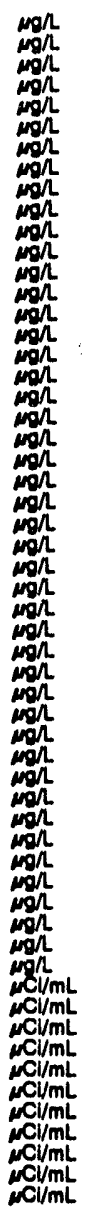 \\
\hline
\end{tabular}

WELL DOB 3

MEASUREMENTS CONDUCTED IN THE FIELD

Sample date: 07/15/82

Water elevation: $144.00 .60 \mathrm{~m})$ bolow TOC

Wator elevation: $144.60 \mathrm{nt}$

F. conductanco: $32 \mu 8 / \mathrm{cm}$.

$\operatorname{Time:}_{\mathrm{pH}: 5} 11: 50$

pH: 5.7

Water temperature: $22.5^{\circ} \mathrm{C}$

LABORATORY ANALYSES

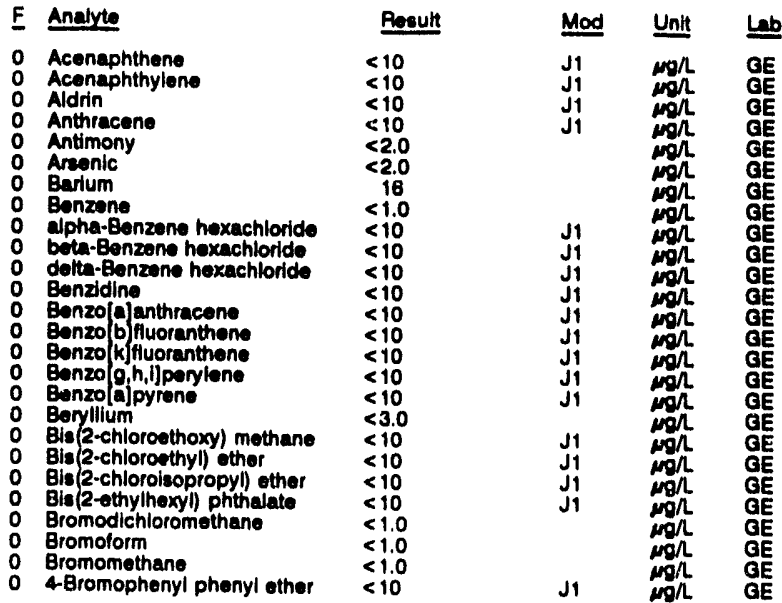


WEL DOB 3 collected on 07/15\%e2, laboratory analyees (cont)

\begin{tabular}{|c|c|c|c|c|c|c|}
\hline E Anchise & Reaul & Mod & Unit & Lي & E & Analyte \\
\hline 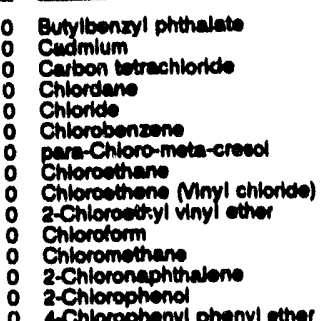 & $\begin{array}{l}<10 \\
<2.0 \\
<1.0 \\
<10 \\
800 \\
<1.0 \\
<10 \\
<1.0 \\
<1.0 \\
<1.0 \\
<1.0 \\
<1.0 \\
<10 \\
<10 \\
<10\end{array}$ & $\begin{array}{l}\text { J1 } \\
\text { J1 }\end{array}$ & 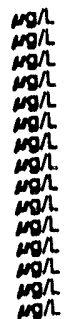 & $\begin{array}{l}G E \\
G E \\
G E \\
G E \\
G E \\
G E \\
G E \\
G E \\
G E \\
G E \\
G E \\
G E \\
G E \\
G E \\
G E\end{array}$ & $\begin{array}{l}0 \\
0 \\
0 \\
0 \\
0 \\
0 \\
0 \\
0 \\
0 \\
0 \\
0 \\
0 \\
0 \\
0\end{array}$ & 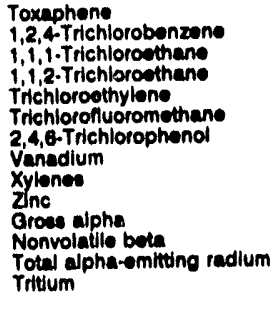 \\
\hline
\end{tabular}

WELL DOB 3 collected on 07/15/02, laboralory analyese (cont.)

\section{WELL DOB 4}

MEASUAEMENTS CONDUCTED IN THE FIELD

sample date: $07 / 19$ :

Demplo date. 07/15/2 $(2.69 \mathrm{~m})$ below TOC Water olovation: $144.18 \mathrm{n}(43.65 \mathrm{~m}) \mathrm{mal}$ Bp. conductance: $61 \mathrm{~s} / \mathrm{cm}$

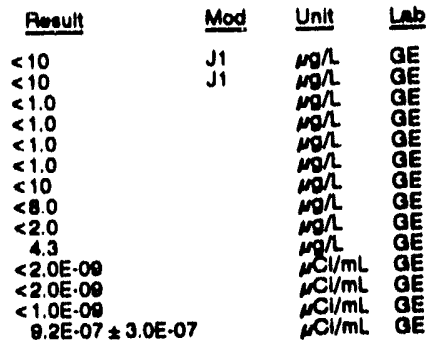

Chromlum

0 Cobat

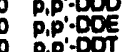

- Bipenzituhjanthracens

o Dhn-butyl phthaled

o 3,3'-Olchlorobenddin

1,1-Okchiorecenteme

: 1,1-Dichlonowtylene

o trane-1,2-Olehioro

o 2,4-Dlchlorophenol

o 1,2-Dichloropropan

ol-1,3-Dichloropropen

Diethyl phthalece

2,4-Dimethyl phence

Dimetryl phithelat

2,4-Dinitrodnluene

2,0-Oinfrotoluens

Di-n-cetyl phthalato

Endooultan 1

Endocaltian sultelo

Endirin

Endrin eldemydo

Fluorentivene

Fluoreno

Fluorkde

Heptachlor epoudde

Haxichlorobenzano

o Hexechlorocyclopentediono

o Hexechlorocthan

0 indeno[1,2,3-c,d]pyrene

iron

leophorone

Undan

Manganea

Marcury

Nephtrabine

Nitrelt-nkite es nitrogen

Nucbernana

2-Nitrophenol

N-Nitrocodimothylamins

N-Nitrocodiphenylamine

N-Nitroeodipropylamine

Oll onace

PCB 1201

PCs 1222

PCB 1242

PCs 1245

PCE 1204

Pentechlorophend

Phenanthrone

Phenol

Extonium

giner

Sodum

8uriet.2. Tetrechloroethane

Tetrachloroethylene

Thallium

Tin

o Total organic carbon

Towl organic halooens

o Total petroleum hydrocarbons

$<10$
$<10$
$<10$

$<1.0$

$<10$

$<1.0$

$<1.0$

1.7
$<10$
$<1.0$

$<1.0$

$<1.0$

$<10$

$<10$

$<10$
$<10$
$<45$

$<45$
$<10$
$<10$

$<10$

$<10$
$<10$

$<10$

$\leq \leq 10$

$<10$

$<10$
$<10$

$<100$

2510

$>10$

$\leq<10$

$<10$

$<28$

$<3.0$

$<10$
$<2.0$
$<20$

$<<10$

$<10$
$<40$
2.50

$<10$

$<10$
$<10$
$<10$

$<10$

$<10$

$<1,000$

$<150$
$<150$

$<150$
$<150$
$<150$

$<150$

$<150$

$<160$
$<10$

$<10$
$<10$

$<10$
$<10$

$<2.0$
$<2.0$

513

5,200
$<1.0$
$<1.0$

$<1.0$

$<2.0$

$<1,000$

LABOAATOAY ANALYSES

\begin{tabular}{|c|c|}
\hline Anulyte & Renul \\
\hline 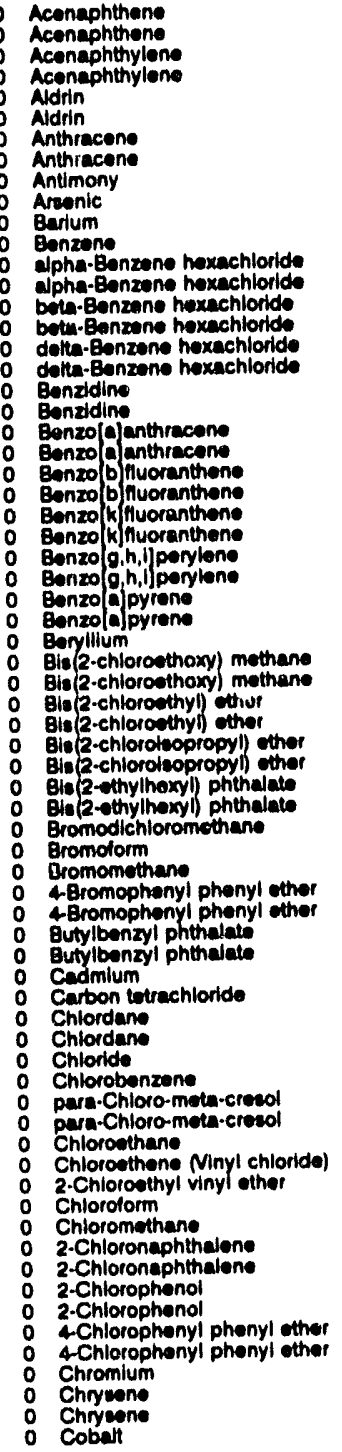 & 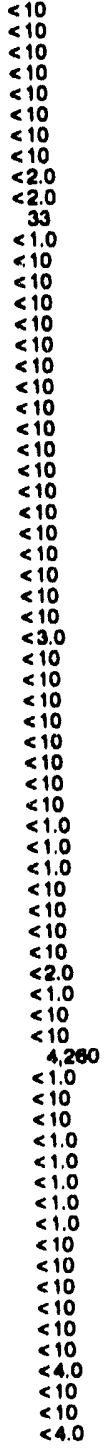 \\
\hline
\end{tabular}

Timo: 10:20

PH: Jilintly: $1 \mathrm{mon}$

Water tomperiture $20.40 \mathrm{C}$

MO GE GE

\begin{tabular}{l}
$<.080$ \\
\hline
\end{tabular}

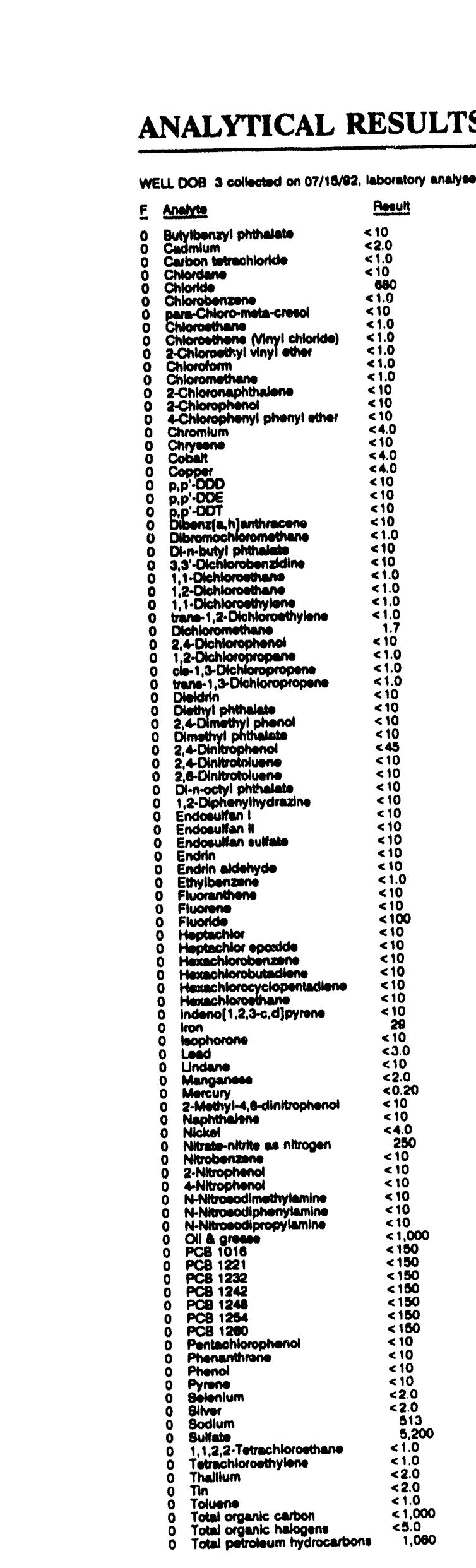


ANALYTICAL RESULTS

Well DOS 4 collectad on 07/15/20, laboratory analyees (cont)

E Aneve

: Coppor

0 P,p'-Dop

p,p-DoE

P.P.DOr

Bibengfa,henthrecene

Obbenza, a jenthrecens

Ditomochloromethan

Din-butyl phralm

3,3. Dichlerobenzidine

3,3'-Dichiorobendin

i, Dichlorosureso

1,1-Dichlorowthylene

Dichionometrien

2,40lehiorophenol

2.40lchionophenot

1,2-0chlorepropen

ci-1,3-0lehioropropeno

Dimition

Dividith

Dintyy phwales

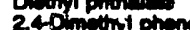

2,4-0imenty phend

Dimethy phinalede

Dimetryl phtraien

2,4-Dinwophend

2,40nisophand

2,40 in

2,0-Dinitrotolume

2, e-Diniveteluen

Dirnoctyl phthelets

1,2-Oiphenythydresing

1,2-0iphenythydradino

Endowenten

Endoevition

Endoncilen it

Endoention wition

Endin

Endih

Endin edomydo

Etmibenzano

Fluorenthens

Fluorenthen

Fivorem

Fluoride

Hopetechior

Hoptechior epoide

Heptimentor eposide

Hepiechlorobenzane

Herochlorobenaens

Hesachionobutiodiense

Hexachlorebutadiens

Herechlorecyctopentedien

Heachionocinane

inderoo: $1,2,3-c, d]$ pyrem

tran

bopision

bophorene

Lead

Undane

o Mangan

2+ketryl-4,8-dintropheno

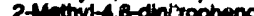

Nephotion

Naphtheien.

Nickel

Nibribritive es nitrooen

Miroberana

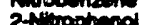

2-Nivophano

aniwophenes

4 Afrophend

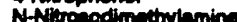

N Nitroectimaty

Nivioding

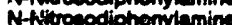

A-Altrocodipropylamine

NNitrocodipropytemine

PCB

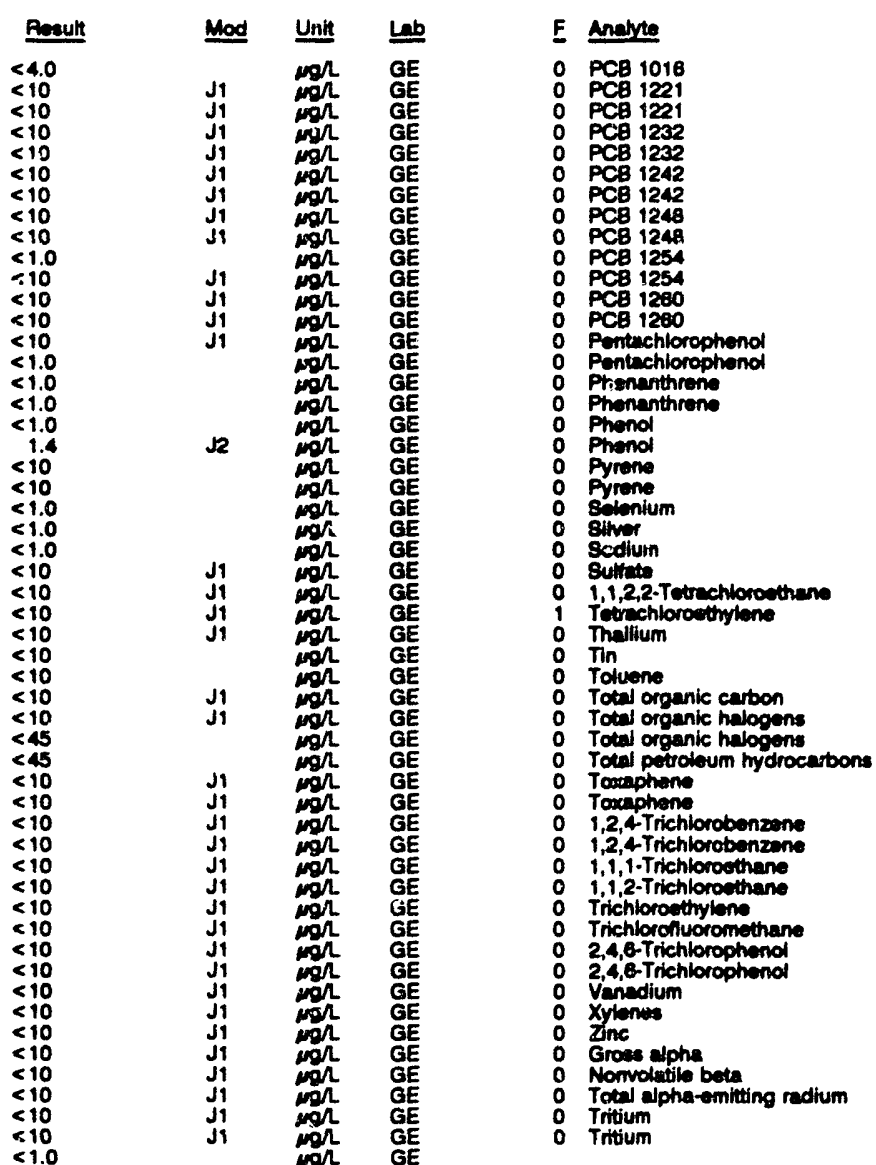

Reautt

$<150$
$<150$

$<150$

$<150$
$<150$

$<150$

$<150$
$<150$

$<150$

$<150$
$<150$

$<150$

$<10$

$<10$
$<10$

$<10$

$<10$

$<10$
$<2.0$

$<2.0$
3.040

7,100

$<1.0$

$<2.0$

$<1,000$

$<5.0$

$<1,000$

$<10$
$<10$

$<10$

$<10$

$<1.0$

$<1.0$

$<1.0$

$<10$

$<8.0$

$<2.0$
2.7

$<2.0 E-\infty$

$<2.0 E-09$

$3.4 E-08 \pm 4.0 E-07$
$3.0 E-00 \pm 4.0 E-07$

Mod Unit Lin

J1 wo/ GE

$\begin{array}{lll}J 1 & \operatorname{mon} \\ J 1 & \cos & \mathrm{GE} \\ \mathrm{J1} & \mathrm{GE}\end{array}$

WELL F 14

MEASUREMENTS CONOUCTED IN THE FIELD

Sumple date: 0eros/ee

Depth to water: $67.50 \mathrm{n}(20.57 \mathrm{~m})$ below TOC

Water elevation: 208.20 h (B3.48

Sp. conductance: $192 \mu \mathrm{B} / \mathrm{cm}$

There ure ineuticiciont weter to fill all

Lhere was inauliciont water

\begin{tabular}{|c|c|c|c|}
\hline E Anclute & Pesult & Hod & Unit \\
\hline 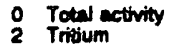 & $\begin{array}{l}\text { 3.5E-O } \\
3.6 E-0\end{array}$ & & CVMLL \\
\hline
\end{tabular}

WELL F 15

MEASUREMENTS CONDUCTED IN THE FIELD

Sample datw: 0a/03/92

Depth to water: $44.13 \mathrm{n}$ (13.45 m) below TOC Time: 7:55

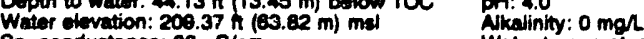

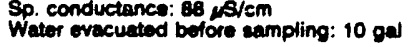

Whatinity: 0 mgh

LABORATOAY ANALYBES

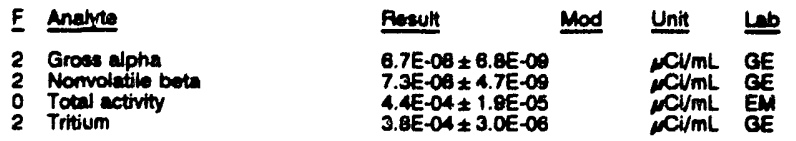


WELL F 16

MEASUREMENTS CONOUCTED IN THE FIELD

Sample dewa: 0003302 Depth to wation: 49.83 ft (14.83 m) betow TOC What clevetion: $207.07 \mathrm{~h}(63.12 \mathrm{~m}) \mathrm{mal}$

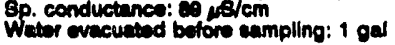

Time: 7:10

PH: 4.4. 0 mor

Water tomperature: $21.0 \circ \mathrm{C}$

LAOORATOFY ANMLYBES

\begin{tabular}{|c|c|c|c|}
\hline F Andrte & Rosult & Mod & Unit \\
\hline $\begin{array}{ll}2 & \text { Groes alphe } \\
2 & \text { Nonvoledite beta } \\
2 & \text { Tritum }\end{array}$ & $\begin{array}{l}\text { S.1E-O } \\
6.0 E-0 \\
0.0 E-0\end{array}$ & & $\underset{\substack{\mathrm{Cl} / / \mathrm{mL} \\
\mathrm{NCl/mL}}}{\mathrm{Cl} / \mathrm{mL}}$ \\
\hline
\end{tabular}

WELL F 17

MEASUAREMENTS CONDUCTED IN THE FIELD

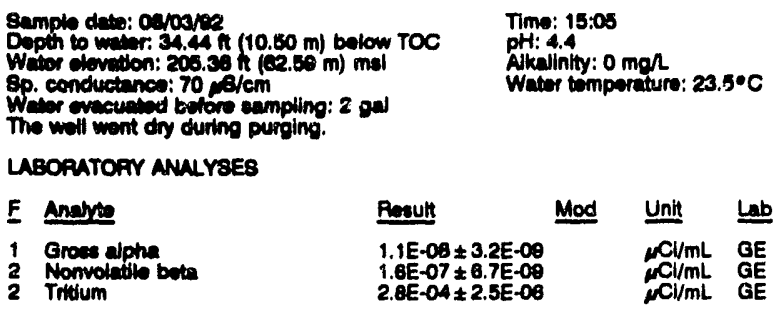

WELL F 25

MEASUREMENTS CONDUCTEE, IN THE FIELD

\begin{tabular}{|c|c|c|c|c|c|}
\hline \multicolumn{3}{|c|}{ 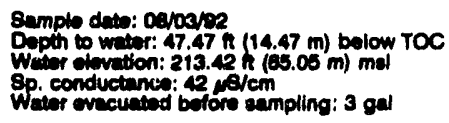 } & \multicolumn{3}{|c|}{$\begin{array}{l}\text { Tima: } 8: 20 \\
\text { pH: } 4.8 \\
\text { Alkalinity: } 0 \text { mgl. } \\
\text { Water tomporature: } 18.8 \circ \mathrm{C}\end{array}$} \\
\hline \multicolumn{6}{|c|}{ LABORATOFY ANALYSES } \\
\hline E & Anche & Result & Mod & Unit & $\underline{L n}$ \\
\hline & $\begin{array}{l}\text { Groes alpha } \\
\text { Nomvolutile beta } \\
\text { Tritum }\end{array}$ & \multicolumn{2}{|c|}{$\begin{array}{l}1.1 E-08 \pm 3.0 E-00 \\
8.3 E=-06 \pm 5.00-00 \\
1.6 E-05 \neq 7.0 E-07\end{array}$} & ACW & $\begin{array}{l}\mathrm{GE} \\
\mathrm{GE} \\
\mathrm{GE}\end{array}$ \\
\hline
\end{tabular}

WELL FAC 3

MEABUAREMENTB CONDUCTED IN THE FIELD

Samplo desto: 0arsoper

Depth to matior: 81.77 in (24.02 m) bolow TOC What devetion: $230.03 \mathrm{~h}(70.11 \mathrm{~m}) \mathrm{mal}$

8p. conductunce: $210 \mathrm{\mu} / \mathrm{cm}$

The ovell went ding during pupling: 8 ga

LAOAATOFY ANALYESS

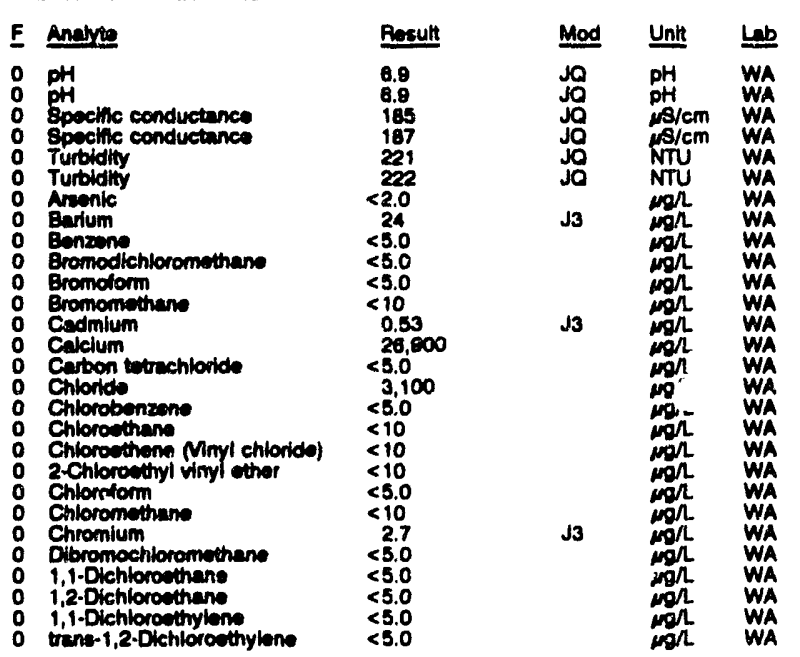

WELL FAC 3 collected on 08/30/92, Iaboratory analyees (cont.)

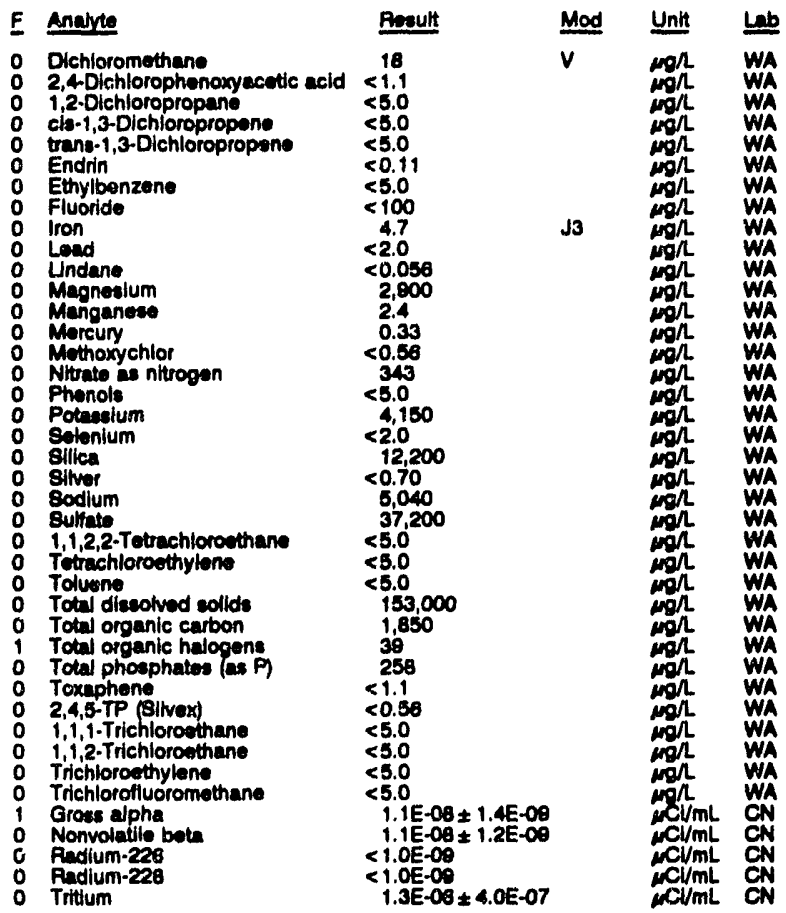

WELL FAC 4

MEASUREMENTS CONDUCTED IN THE FIELD

Sample date: 08j20/82

Depth to water: $80.60 \mathrm{ht}(24.57 \mathrm{~m})$ below TOC

Water olevation: $220.30 \mathrm{~h}(60.69 \mathrm{~m}) \mathrm{mol}$

Whiter wacuated before sempling: 58 gal

PH: 4.6 .

Water tomperture: $22.2 \cdot \mathrm{C}$

LABOPATORY ANALYSES

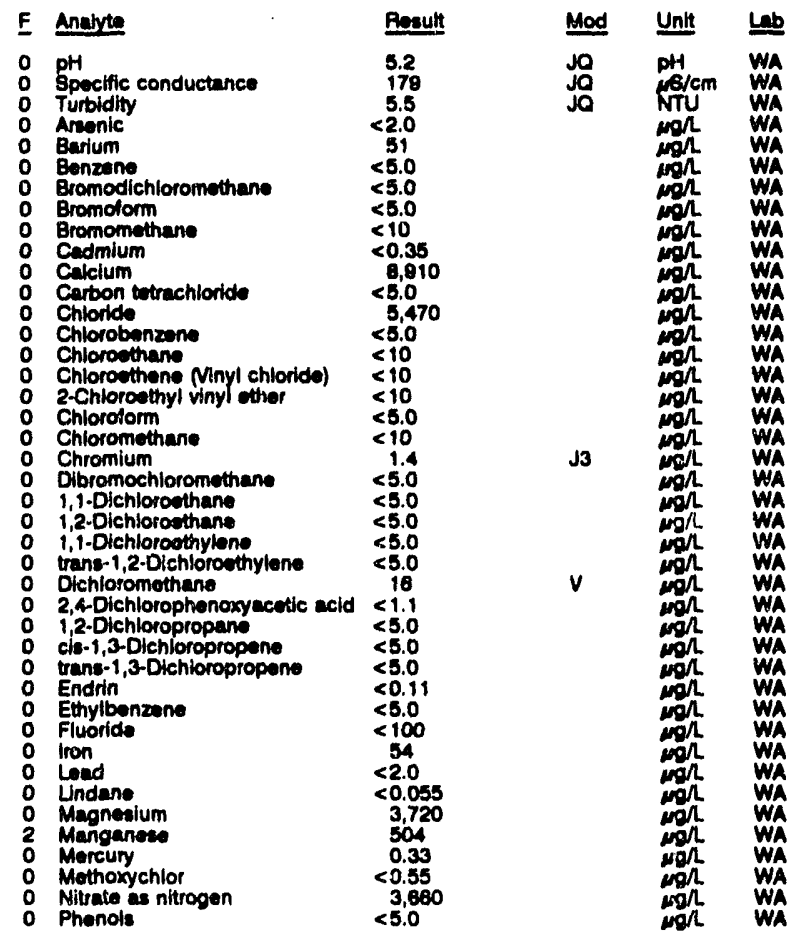


WEL FAC a collectad on 08/29/92, laboratory analyees (cont)

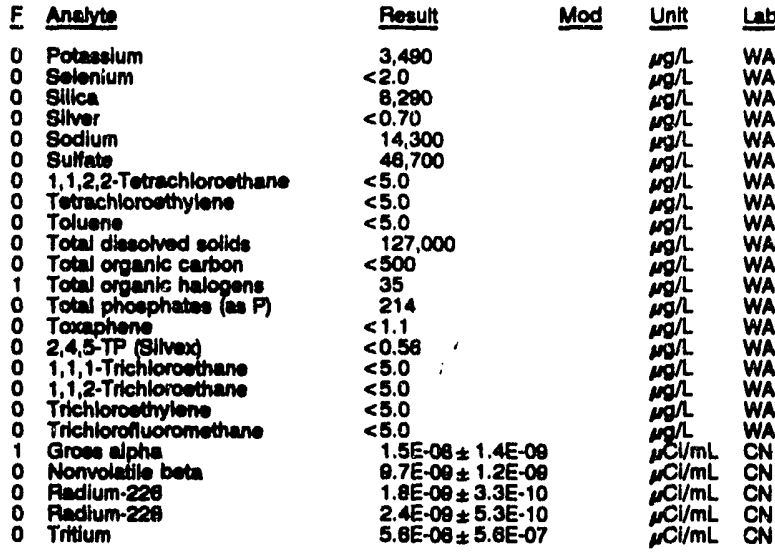

WELL FAC 5

\section{MEASUREMENTS CONDUCTED IN THE FIELL}

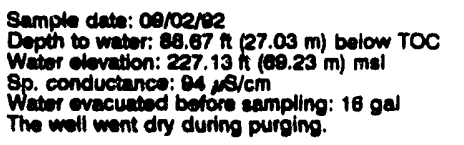

Time: 11:10

Alkalinity: 1 mol

Water temperature: $22.7^{\circ} \mathrm{C}$

LABOPUTORY ANMLYSES

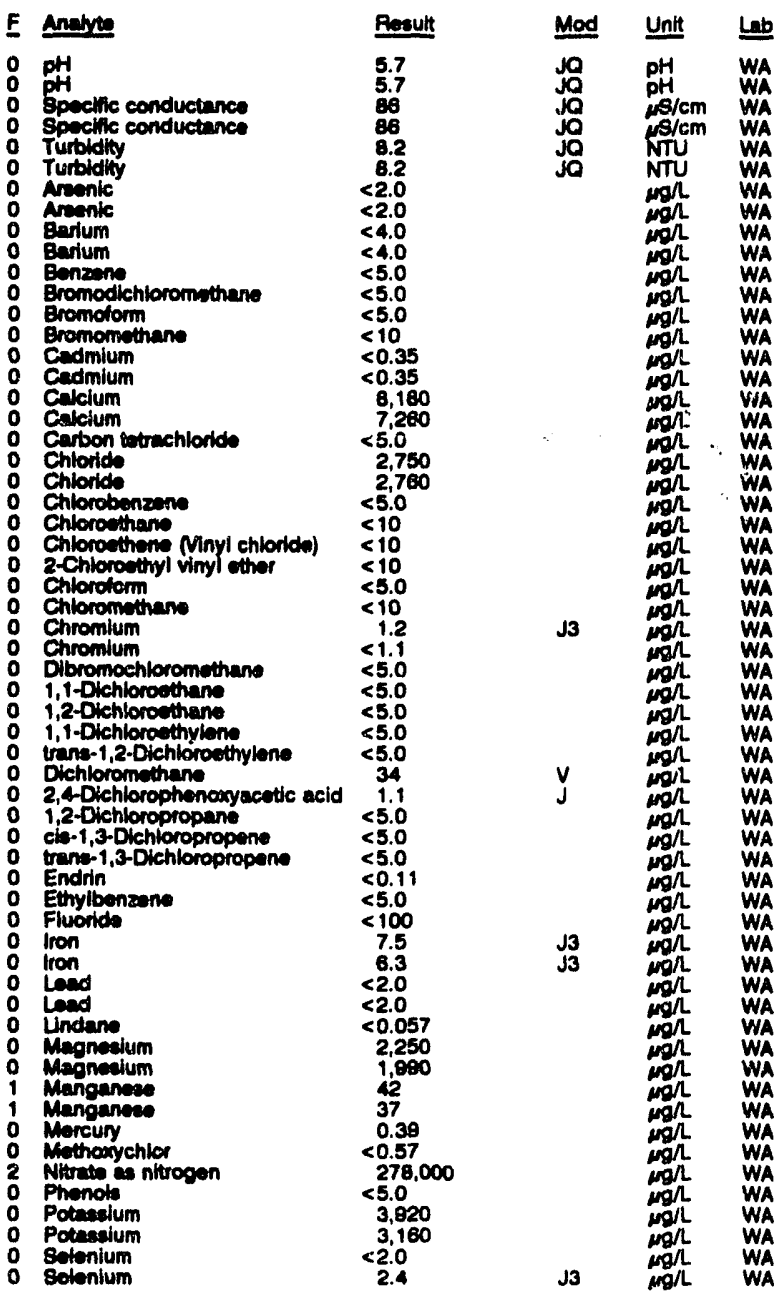

WELL FAC 5 collected on 08/02/92, laboratory analyeen (cont)
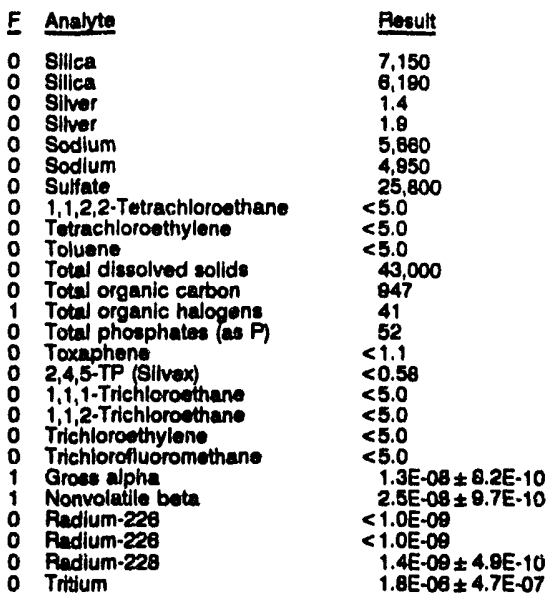

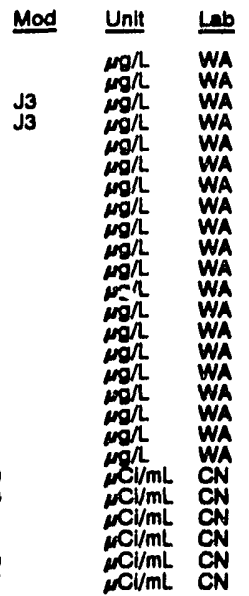

\section{WELL FAC 6}

MEASUAEMENTS CONDUCTED IN THE FIELD

\begin{tabular}{|c|c|}
\hline $\begin{array}{l}\text { Sample date: 08/30/92 } \\
\text { Depth to wator: } 89.62 \mathrm{n}(27.32 \mathrm{~m}) \text { below roc } \\
\text { Water elevation: } 222.88 \mathrm{~h}(87.83 \mathrm{~m}) \mathrm{msl} \\
\text { Sp. conductance: } 75, \mathrm{~s} / \mathrm{cm} \\
\text { Water ovecuated botore sampling: } 10 \mathrm{gal}\end{array}$ & $\begin{array}{l}\text { Time: } 9: 30 \\
\text { pH: } 5.6 \\
\text { Alkalinity: } 5 \mathrm{mg} / \mathrm{L} \\
\text { Water tomperature: } 21.0 \cdot \mathrm{C}\end{array}$ \\
\hline
\end{tabular}

LABORATORY ANALYSES

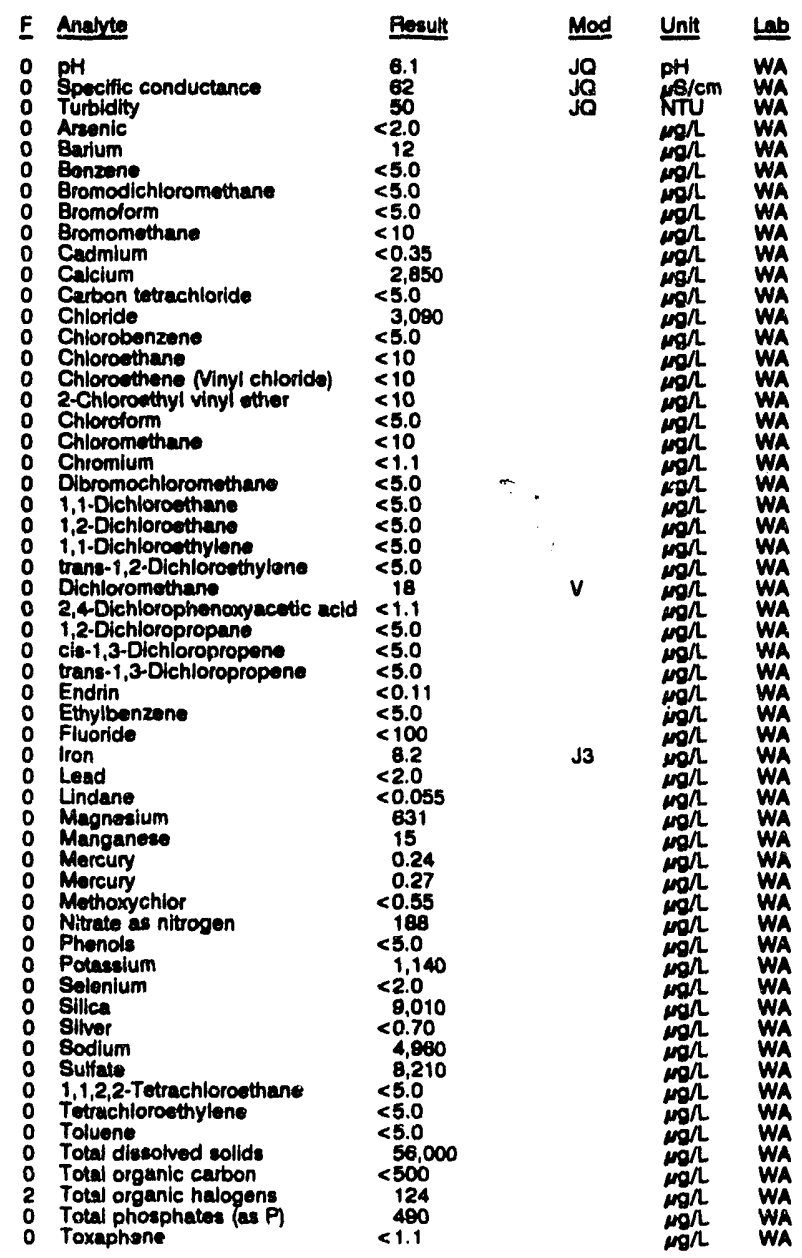


ANALYTICAL RESULTS

WELL FAC 6 collected on 06/30192, laboratory analyses (cont.)

\begin{tabular}{|c|c|c|}
\hline Ansyte & Prenuth & Unit \\
\hline 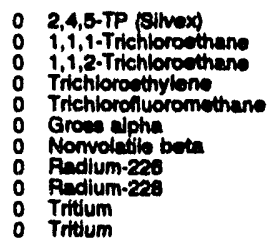 & $\begin{array}{l}<0.55 \\
<5.0 \\
<5.0 \\
<5.0 \\
<5.0 \\
<2.0 E-09 \\
<2.0 E-00 \\
<1.0 E-09 \\
<1.0 E-00 \\
1.5 E-00 \pm 4.4 E-07 \\
2.3 E-00 \pm 4.7 E-07\end{array}$ & 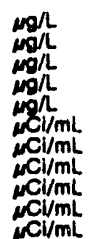 \\
\hline
\end{tabular}

WELL FAC 7

MEASUREMENTB CONDUCTED IN THE FIELD

Sample dato: copearen Wopth to water: 83.46 in $(25.45 \mathrm{~m})$ below TOC Water ellovation: $220.52 \mathrm{~h}(00.05 \mathrm{~m}) \mathrm{mil}$

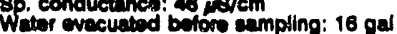
The well went dry during purging.

LABORATOAY ANULYES

\begin{tabular}{|c|c|c|c|c|}
\hline & Anayte & Result & Mod & Unit \\
\hline & 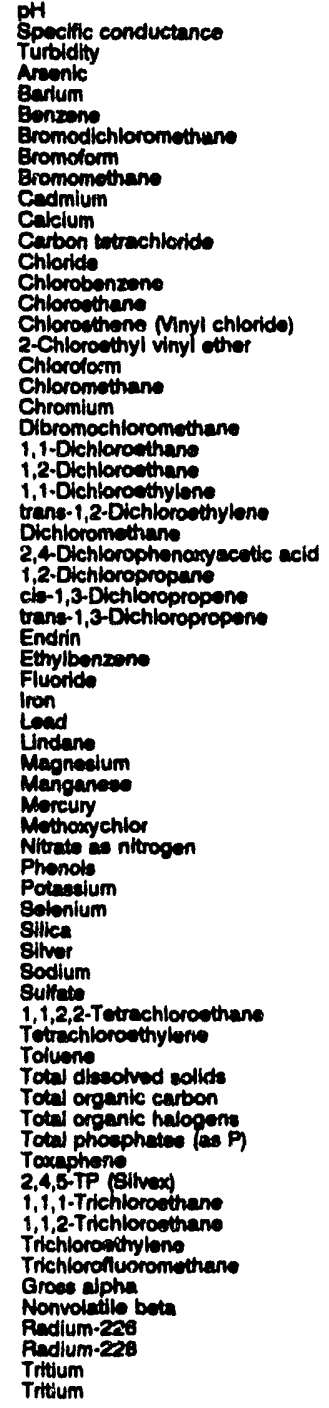 & $\begin{array}{l}5.5 \\
47 \\
6.0 \\
<2.0 \\
5.4 \\
<5.0 \\
<5.0 \\
<5.0 \\
<10 \\
<0.35 \\
5.700 \\
<5.0 \\
2.910 \\
<5.0 \\
<10 \\
<10 \\
<10 \\
<5.0 \\
<10 \\
<1.1 \\
<5.0 \\
<5.0 \\
<5.0 \\
<5.0 \\
<5.0 \\
11 \\
<1.1 \\
<5.0 \\
<5.0 \\
<5.0 \\
<0.11 \\
<5.0 \\
<100 \\
5.8 \\
3.5 \\
<0.057 \\
367 \\
8.2 \\
<0.20 \\
<0.57 \\
77.600 \\
<5.0 \\
11.160 \\
<2.0 \\
7.640 \\
0.78 \\
5.330 \\
5,830 \\
<5.0 \\
<5.0 \\
<5.0 \\
41.000 \\
<500 \\
28 \\
37 \\
<1.1 \\
<0.58 \\
<5.0 \\
<5.0 \\
<5.0 \\
<5.0 \\
<2.0 E-09 \\
<2.0 E-09 \\
1.0 E-09 \pm 2.4 E-10 \\
<1.0 E-09 \\
1.9 E-06 \pm 4.7 E-07 \\
2.4 E-06 \pm A .9 E-07\end{array}$ & $\begin{array}{l}\text { JQ } \\
\text { Jo } \\
\text { JO } \\
\text { J3 }\end{array}$ & 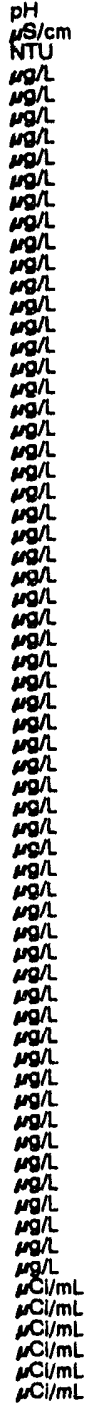 \\
\hline
\end{tabular}

Time: 10:05

Alkalinity: $4 \mathrm{mon}$

Weter temperature: $21.6 \circ \mathrm{C}$

$\stackrel{M}{ } \mathrm{Cl} / \mathrm{mL} \mathrm{CN}$
WELL FAC 8

MEASUREMENTS CONDUCTED IN THE FIELL

Sample date: 09/02/92

Dopth to water: $80.63 \mathrm{~h}(24.68 \mathrm{~m})$ bolow TOC

Water elevation: $230.37 \mathrm{~h}(70.22 \mathrm{~m}) \mathrm{mal}$

Water evacuated before eampling: $32 \mathrm{gal}$

The woll went dry during purging.

LABOFATORY ANALYSES

\begin{tabular}{|c|c|c|c|}
\hline Anatrte & Reault & Mod & Unit \\
\hline 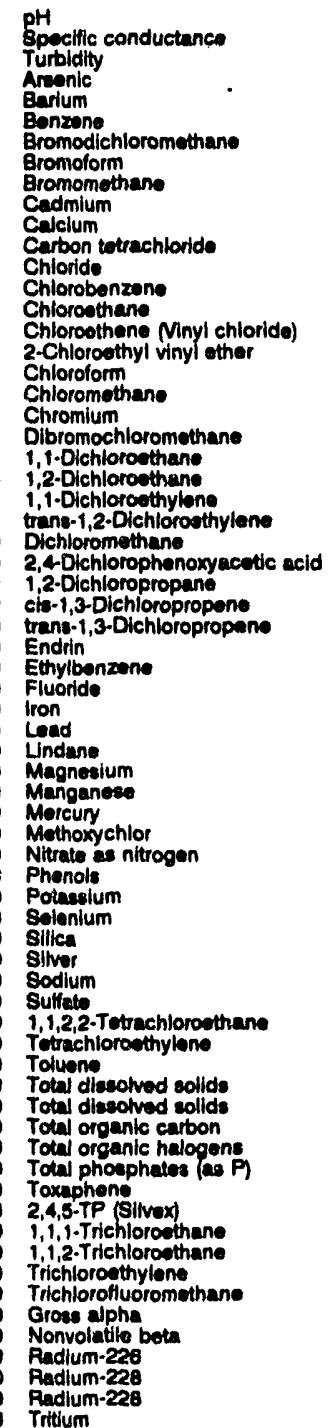 & 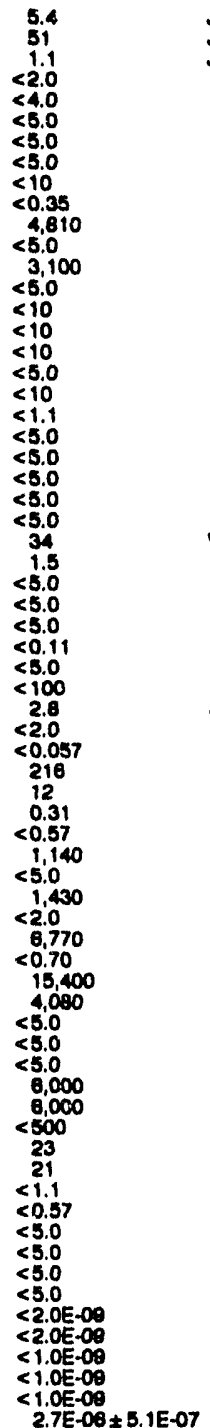 & $\begin{array}{l}\text { Ja } \\
\text { Ja } \\
\text { Ja }\end{array}$ & 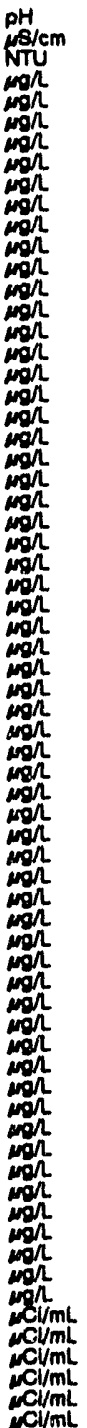 \\
\hline
\end{tabular}

WELL FAL 1

MEASUAEMENTS CONDUCTED IN THE FIELD

Samplo date: 09/22/92

Wator elovation: $220,34 \mathrm{Ht}(67.16 \mathrm{~m}) \mathrm{mal}$

Wator evacuated before sampling: $10 \mathrm{gal}$

The woll went dry during purging.

LABORATOAY ANALYSES

\begin{tabular}{|c|c|c|c|}
\hline E Anajute & Result & Mod & Unit \\
\hline $\begin{array}{ll}0 & \text { pH } \\
0 & \text { Specific conductance } \\
0 & \text { Benzeno }\end{array}$ & $\begin{array}{r}7.5 \\
150 \\
<1.0\end{array}$ & sa & $\begin{array}{l}\mathrm{pH} \\
\mathrm{mg/cm} \\
\mathrm{mol}\end{array}$ \\
\hline
\end{tabular}

\section{Time: 9:05}

Alkalinity: $11 \mathrm{~mol}$

Water tomperature: $21.1 \cdot \mathrm{C}$
Time: $12: 15$

pH: 6.6 .

Water tomporature: $24.3 \circ \mathrm{C}$ 
ANALYTICAL RESULTS

WELL FAL 1 collected on 00/22/82, laboratory analyses (cont)

\begin{tabular}{|c|c|c|}
\hline & Analyte & Reault \\
\hline & 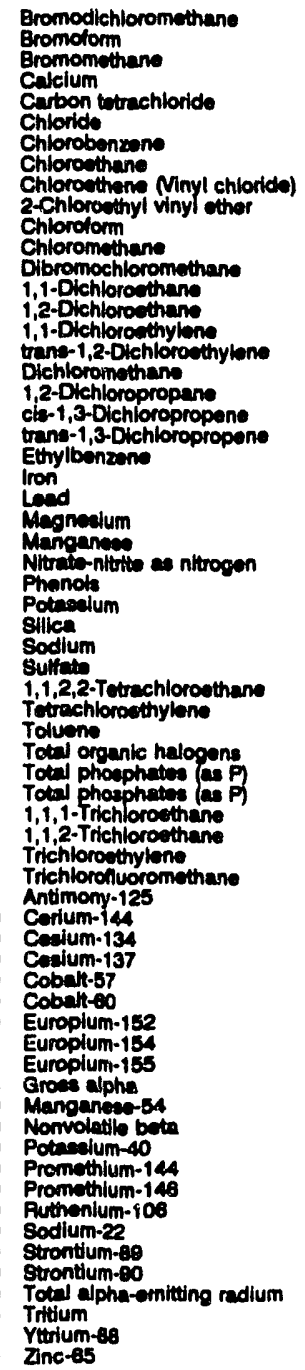 & 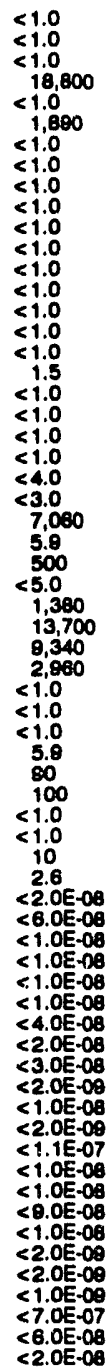 \\
\hline
\end{tabular}

WELL FAL 2

MEASUREMENTS CONDUCTED IN THE FIELD

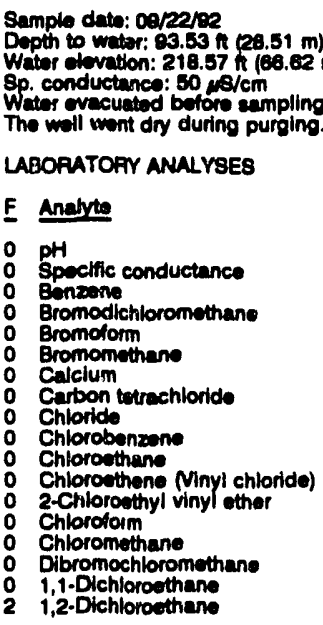

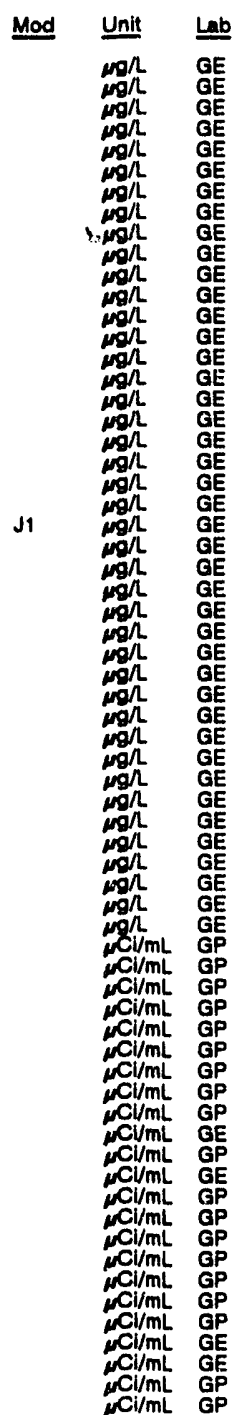

Time: 12:40

Akalinity: $5 \mathrm{mg} / \mathrm{l}$

Water temperature: $24.7^{\circ} \mathrm{C}$

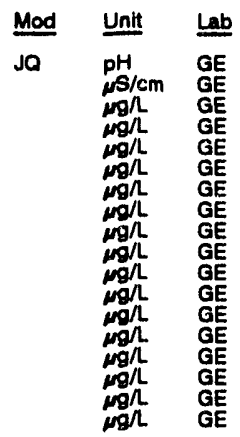

WELL FAL 2 collectod on 09/22/92, laboratory analyees (cont.)

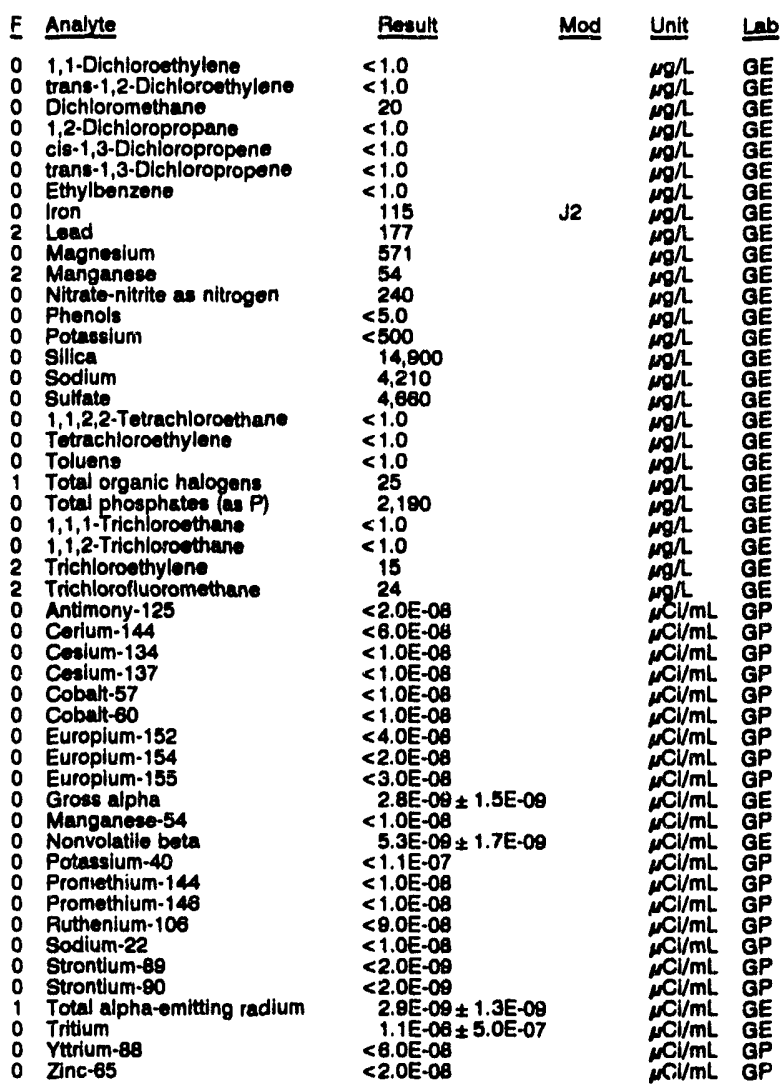

WELL FBP $1 \mathrm{~A}$

MEASUREMENTS CONDUCTED IN THE FIELD

Sample date: 07/19/92

Depth to water: $79.71 \mathrm{ft}(24.30 \mathrm{~m})$ below TOC

Water elevation: $208.18 \mathrm{ht}(63.46$

Sp. conductance: $64 \mu \mathrm{s} / \mathrm{cm}$

Water ovacuated before campling: $122 \mathrm{gal}$

LABORATORY ANALYSES

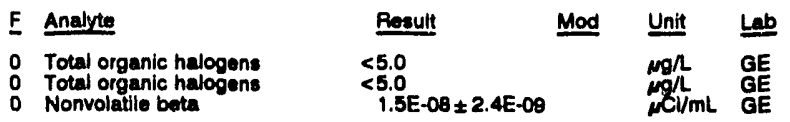

WELL FBP 2A

MEASUREMENTS CONDUCTED IN THE FIELD

\begin{tabular}{|c|c|}
\hline $\begin{array}{l}\text { Sample date: } 07 / 19 / 92 \\
\text { Depth to water: } 95.22 \mathrm{ht}(29.02 \mathrm{~m}) \text { bolow TOC } \\
\text { Water elevation: } 193.89 \mathrm{ht}(59.10 \mathrm{~m}) \mathrm{msl} \\
\text { Sp. conductance: } 92 \mu \mathrm{s} / \mathrm{cm}\end{array}$ & $\begin{array}{l}\text { Time: } 15: 30 \\
\text { pH: } 4.6 \\
\text { Alkalinity: } 0 \mathrm{mg} / \mathrm{h} \\
\text { Water temperature: } 21.2^{\circ} \mathrm{C}\end{array}$ \\
\hline
\end{tabular}

LABORATORY ANALYSES

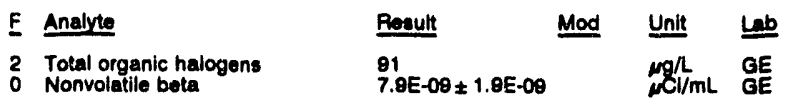


WELL FBP $3 A$

MEASUAEMENTS CONDUCTED IN THE FIELD

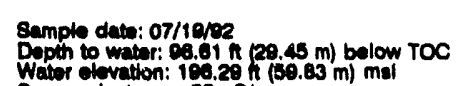

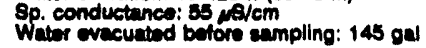

LABORATOFY ANALYBES

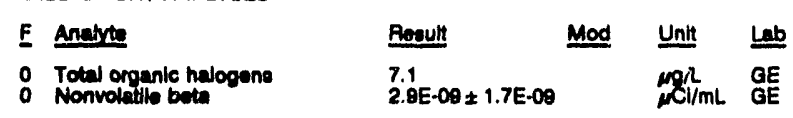

\section{WELL FBP 4}

MEASUREMENTS CONDUCTED IN THE FIELD

\begin{tabular}{|c|c|c|c|c|c|}
\hline \multicolumn{3}{|c|}{ 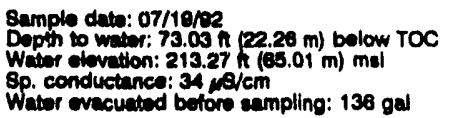 } & \multicolumn{3}{|c|}{$\begin{array}{l}\text { Tima: } 16: 35 \\
\text { pH: } 4.8 \\
\text { Alkalinity: } 0 \mathrm{mg} \Omega \\
\text { Water temporature: } 21.7 \cdot \mathrm{C}\end{array}$} \\
\hline \multicolumn{6}{|c|}{ LABOAATOFY ANALYSES } \\
\hline & Anarte & Result & Mod & $\underline{\text { Unit }}$ & $\underline{\text { Lab }}$ \\
\hline 0 & $\begin{array}{l}\text { Total organic halogens } \\
\text { Nonvolatil beta }\end{array}$ & $\begin{array}{l}<5.0 \\
<2.0 E-0 \theta\end{array}$ & & & $\begin{array}{l}\text { GE } \\
\text { GE }\end{array}$ \\
\hline
\end{tabular}

\section{WELL FCA IN}

MEASUREMENTS CONDUCTED IN THE FIELD

\begin{tabular}{|c|c|}
\hline 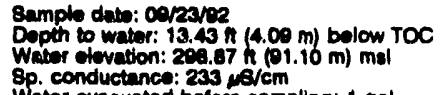 & $\begin{array}{l}\text { Time: } 8: 50 \\
\text { pH: } 7.4 \\
\text { Alkalinity: } 62 \mathrm{mgh} \\
\text { Weter temperature: } 25.0^{\circ} \mathrm{C}\end{array}$ \\
\hline
\end{tabular}
UABORATOFY ANALYSES

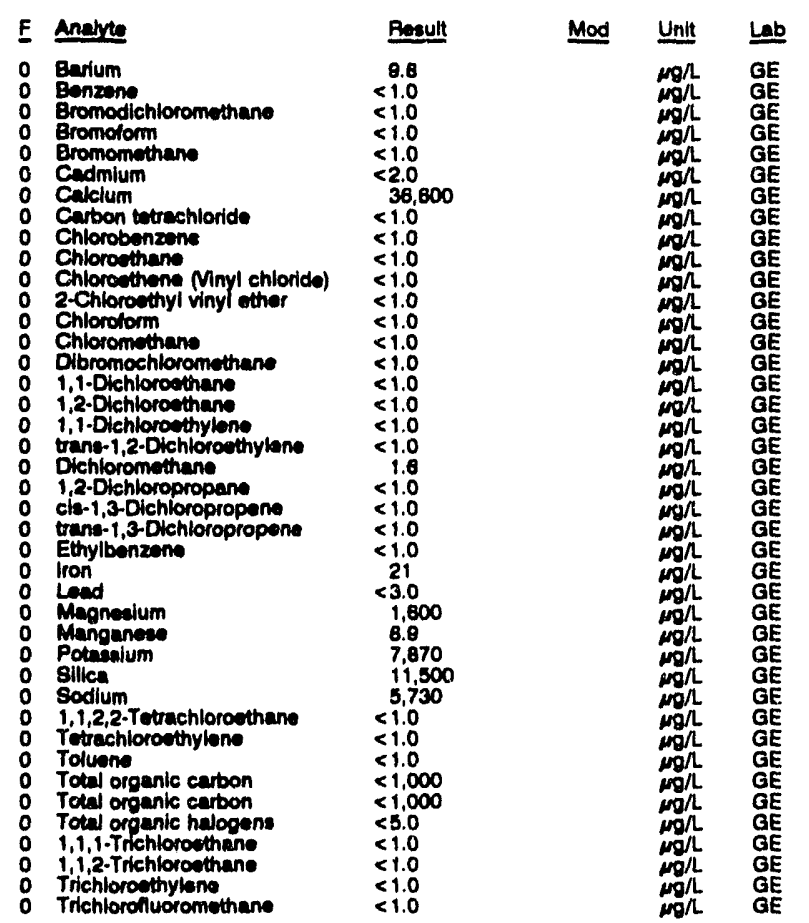

WELL FCA $2 \mathrm{C}$

MEASUREMENTS CONDUCTED IN THE FIELD

Sample date: 09/22/92

Dopth to wime: 14:00

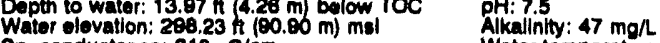

Sp. conductance: $310 \mu \mathrm{s} / \mathrm{cm}$ Water tomporature: $25.70^{\circ} \mathrm{C}$

Wator ovacuated botore zampling: I gal

LABOPATORY ANALYSES

\begin{tabular}{|c|c|c|c|}
\hline Analyte & Rosult & Mod & Unit \\
\hline 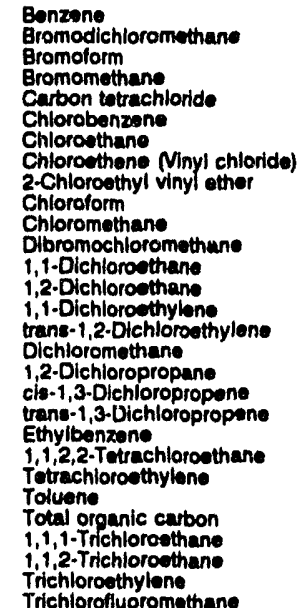 & $\begin{array}{l}<1.0 \\
<1.0 \\
<1.0 \\
<1.0 \\
<1.0 \\
<1.0 \\
<1.0 \\
<1.0 \\
<1.0 \\
<1.0 \\
<1.0 \\
<1.0 \\
<1.0 \\
<1.0 \\
<1.0 \\
<1.0 \\
<1.0 \\
<1.0 \\
<1.0 \\
<1.0 \\
<1.0 \\
<1.0 \\
<1.0 \\
<1.0 \\
5.840 \\
<1.0 \\
<1.0 \\
<1.0\end{array}$ & & 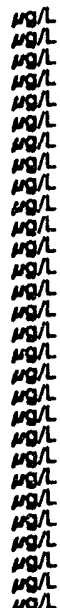 \\
\hline
\end{tabular}

\section{WELL FCA 2D}

MEASUREMENTS CONDUCTED IN THE FIELD

\begin{tabular}{|c|c|}
\hline 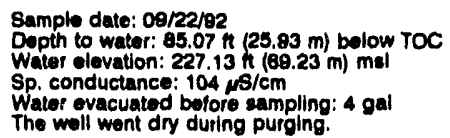 & 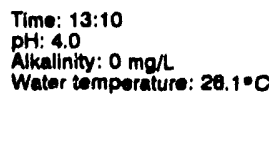 \\
\hline
\end{tabular}

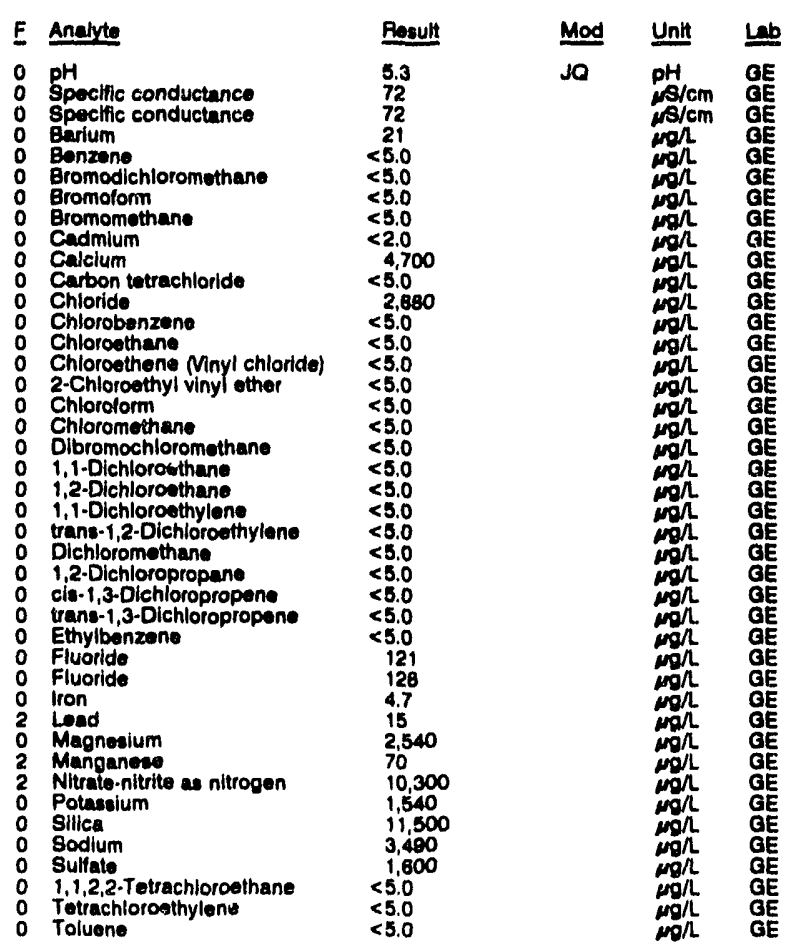


ANALYTICAL RESULTS

WELL FCA 20 collectad on 09/22/82, laboratory analywes (cont.)

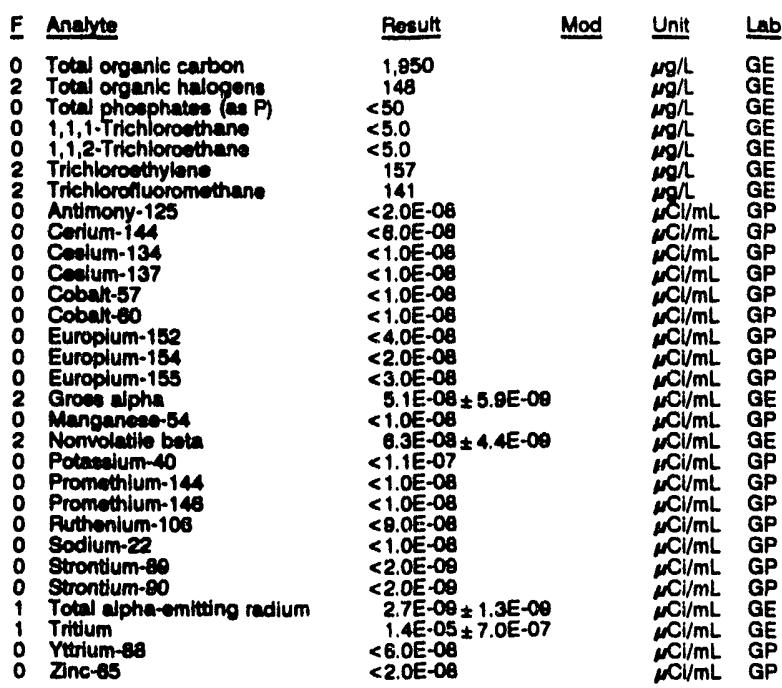

WELL FCA 9B

MEASUAEMENTS CONDUCTED IN THE FIELD

Sample date: 0e/2eree

Time: 16:05

The woll was dry.

WELL FCA 9C

MEASUREMENTS CONOUCTED IN THE FIELD

Sample date: $09 / 21 / 82$
inacceselbility or mechanical problem prevented sample collection.

\section{WELL FCA 9D}

MEASUREMENTS CONDUCTED IN THE FIELD

Sample data:

Dopth to wator: $84.82 \mathrm{~h}(25.89 \mathrm{~m})$ bolow TOC

Water elovation: $228.98 \mathrm{~h}(60.18 \mathrm{~m}) \mathrm{ms}$

W. conductanco: $50 \mathrm{fs} / \mathrm{cm}$

The well went dry during purging: $11 \mathrm{gal}$

LABOPATOFY ANALYSES

\begin{tabular}{|c|c|c|c|c|c|}
\hline$\underline{F}$ & Analyte & Resuit & Mod & Unit & Lab \\
\hline $\begin{array}{l}0 \\
0 \\
0 \\
0 \\
0 \\
0 \\
0 \\
0 \\
0 \\
0 \\
0 \\
0 \\
0 \\
0 \\
0 \\
0 \\
0 \\
0 \\
0\end{array}$ & 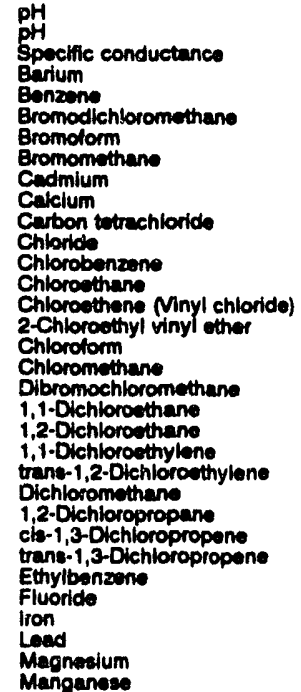 & $\begin{array}{l}5.9 \\
5.8 \\
55 \\
5.2 \\
<1.0 \\
<1.0 \\
<1.0 \\
<1.0 \\
<2.0 \\
738 \\
<1.0 \\
4.850 \\
<1.0 \\
<1.0 \\
<1.0 \\
<1.0 \\
<1.0 \\
<1.0 \\
<1.0 \\
<1.0 \\
<1.0 \\
<1.0 \\
<1.0 \\
1.1 \\
<1.0 \\
<1.0 \\
<1.0 \\
<1.0 \\
<100 \\
16 \\
4.5 \\
304 \\
5.0\end{array}$ & JQ & 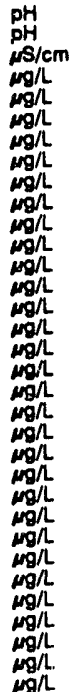 & $\begin{array}{l}\mathrm{GE} \\
\mathrm{GE} \\
\mathrm{GE} \\
\mathrm{GE} \\
\mathrm{GE} \\
\mathrm{GE} \\
\mathrm{GE} \\
\mathrm{GE} \\
\mathrm{GE} \\
\mathrm{GE} \\
\mathrm{GE} \\
\mathrm{GE} \\
\mathrm{GE} \\
\mathrm{GE} \\
\mathrm{GE} \\
\mathrm{GE} \\
\mathrm{GE} \\
\mathrm{GE} \\
\mathrm{GE} \\
\mathrm{GE} \\
\mathrm{GE} \\
\mathrm{GE} \\
\mathrm{GE} \\
\mathrm{GE} \\
\mathrm{GE}\end{array}$ \\
\hline
\end{tabular}

WELL FCA $9 D$ collected on 09/22/92, Iaboratory analyees (cont)

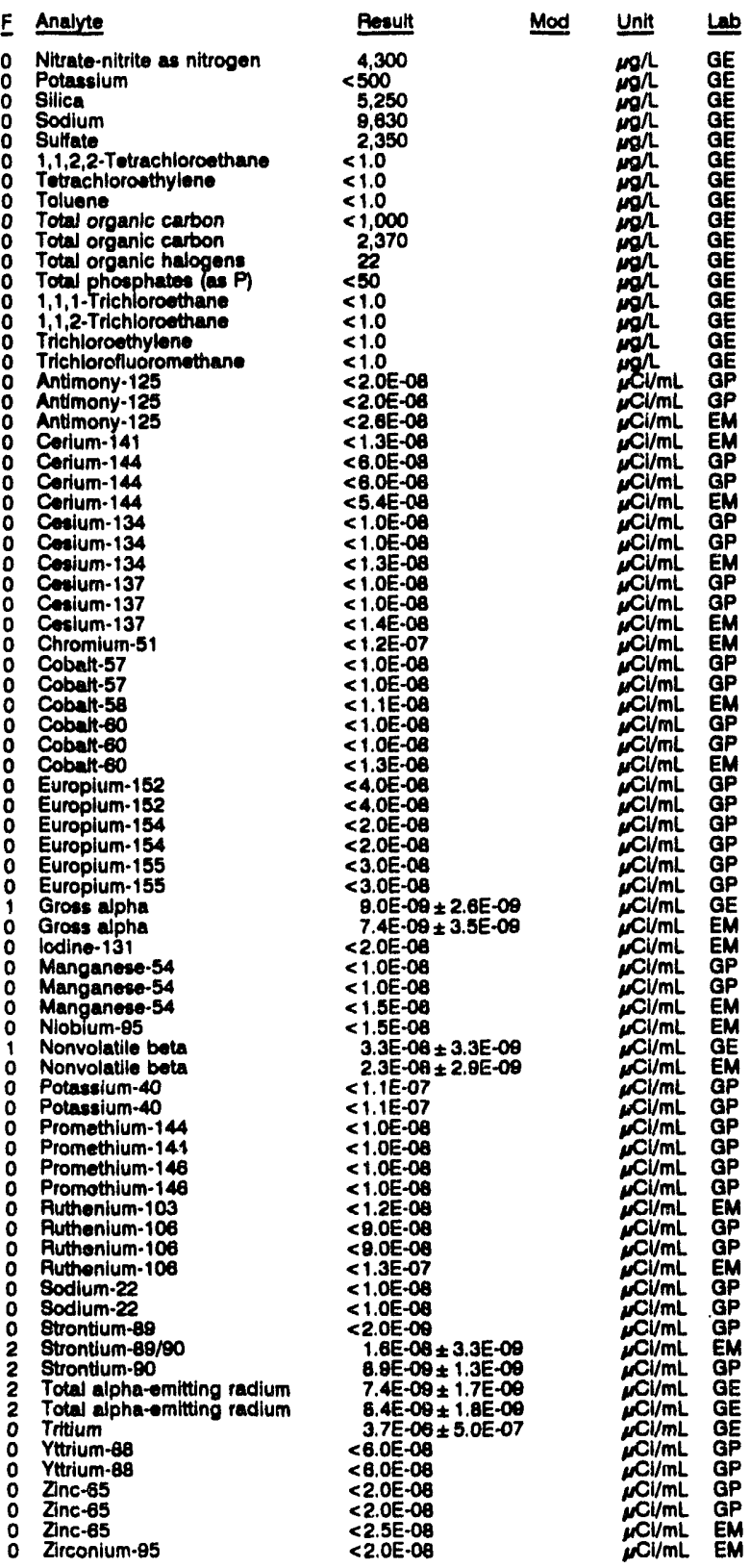

WELL FCA 9DR

MEASUREMENTS CONDUCTED IN THE FIELD

Sample date: 09/22/92 Time: 14:25

Depth to wator: $84.84 \mathrm{ft}(25.88 \mathrm{~m})$ below TOC
inaccessibility of mechanical problem provented sample collection. 
WELL FCA 10A

MEASUAREMENTS CONDUCTED IN THE FIELD

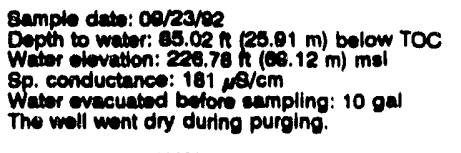

Time: 10:20

Pik: 5.2 ininity: $1 \mathrm{mg} /$

Water temperafure: $24.2^{\circ} \mathrm{C}$

LABORATORY ANALYEES

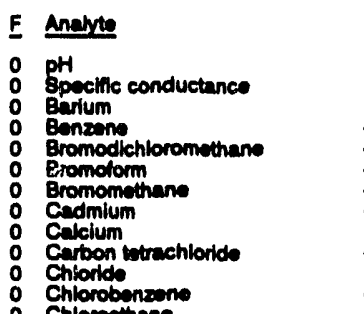

Recult

5.8
200
51
$<1.0$
$<1.0$
$<1.0$
51.0

Mod

Unit Le

Jo

PH/cm $G E$

$\operatorname{mgh}^{\mathrm{mg}} \mathrm{GE}$

$<1.0$

5,280

$<1.720$

Chiorouthene

Chloroethene Minyl chloride)

2-Chloreatry

Chlorom

o trand-1,2-Dichloroethylene

Dichloromethane

1,2-Dichloropropane

o cis-1,3-Dichloropropone

0 Ethylbenzense

0 Fluorido

0 tron

0 Lead

0 Lead

Nitrita-nititio as nitrogen

o Potasealum

: Bllta

O Sodium

i,1,2,2-Tetrachloroethane

Totrechloroethylene

- Toluene

Total organic halogons

0 1,1,1-Trichlorowthane

1,1,2-Triehloroethan

Trichloropthylene

Trichlorofluorom

Cerlum-144

Cealum-137

Cobaliter

Europtum-15?

Europlum-15

Europlum-155

Groes elpha

Manganearsa

Potandum-40

Promethium-14

Promethium-140

Puthenlum-10

Sodium-22

Etrontium-89

Otrontum-e

Strondum-e

Total alpha-emiting radlum

Tritum

Yunc-es

$<1.0$

$<1.0$

$<1.0$

$<1.0$

$<1.0$

$<1.0$

$<1.0$

$<1.0$

$<1.0$

$<1.0$
$<1.0$
$<1.0$

$<1.0$

$<100$

$<3.0$
$<3.0$

4,090

3,080

17,300

12,400
11,200

6,380

$<1.0$
$<1.0$

$<1.180$

$<5.0$

$<1.0$

$<1.0$

$<1.0$

$\angle 2.0 E-08$

$<6.0 E-08$

$<1.00$

$<1.0=00$

$<1.06-00$

$<4.05 .08$

$<2.0 E-06$

$<3.05-00$

$<1.0 \mathrm{E}-09$

$4.2 E-08 \pm 3.7 E-0$

$<1.1 E-07$

$<1.06-08$

$<1.0 E-06$

$<8.0 E-08$

$<1.0 E-00$

$<2.0 E-00$

$<2.0 \mathrm{E}-00$

$<2.0 \mathrm{E}-09$

3.2E-08 $\neq 4.4 E-09$

6.5E-06 $\pm 6.0 \mathrm{E} .07$

$<6.0$ E. 00
$<2.0 \mathrm{E}-00$
Dibromochloromethane

o 1,1-Olchloroethane

1,1-Dichlorosthylene

Total organic carbon

Andimony-12

WELL FCA 10C

MEASUREMENTS CONDUCTED IN THE FIELD

Sample date: 08/21/92

Time: 15:15

The woll was dry.

\section{WELL FCA 10D}

MEASUREMENTS CONDUCTED IN THE FIELD

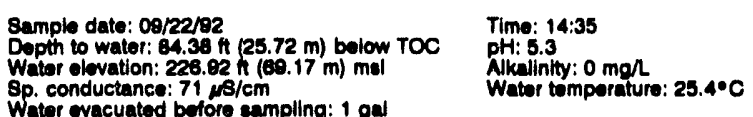

Sp. conductance 71 .

Wator evacuated before enmpling: 1 gar

There wae ineufficient water to fil all or some sampis bottles.

LABORATORY ANALYSES

E Anabte

: $\mathrm{gH}$

o Barlum

B Bromodichloromethane

Bromoform

Bromomothane

Cadmium

Carbon tetrachloride

Chioride

Chiorido

Chlorobenzen

Chloroethene Ninyl chloride)

2-Chloroethyl vinyl ether

Chloroform

Chloromethane

Dibromochloromethane

1,1-Dichloroothan

1,2-Dichloroothane

1,1-Dichloroethylene

Dichioromethene

1,2-Dichloropropans

cis-1,3-Dichloropropene

trang-1,3-Dichloropropen

Ethylbenzen

0 Iron

0 Lead

Magnesium

Nitrationitrite as nitrogen

Potasesium

Silica

Sulfato

Sulfto

1,1,2,2-Tetrachloroethane

Totrachioroathylene

Toluene

Total organic carbon

Total organic halogene

Total phosphateogens

1,1,1.Trichloroethane

1,1,2-Trichloroethan

Trichlorofluoromethen

Tritum

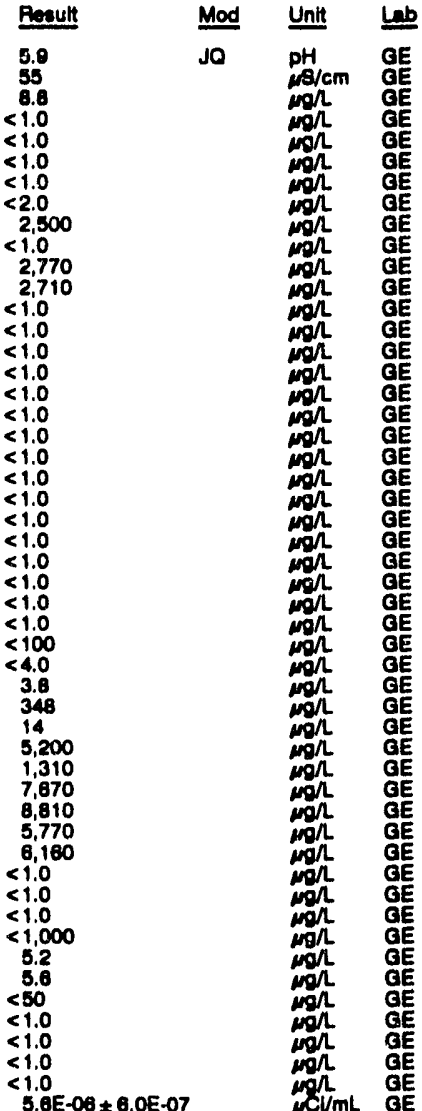

WELL FCA 16A

MEASUAEMENTS CONDUCTED IN THE FIELD

Sumple dato: 09/23/92

Wopth to wator: $85.67 \mathrm{~h}(28.08 \mathrm{~m})$ below TOC

Water olovation: $228.63 \mathrm{ht}(69.0$

Sp. conductance: $61 \mu \mathrm{s} / \mathrm{cm}$

Wator ovacuated bolors ampling: $\theta \mathrm{gal}$

the woll went dry during purging.

LABORATORY ANALYSES

WELL FCA 10B

MEASUREMENTS CONDUCTED IN THE FIELD

Sample date: 0oreres

Time: 16:00

F Anajyte

0 pH

Specific conductance

0 Barlum

Benzene

Bromodichloromethane

Eromoform

Bromomethane

Calcium

\begin{tabular}{l} 
Result \\
\hline 6.0 \\
6.0 \\
65 \\
11 \\
$<1.0$ \\
$<1.0$ \\
$<1.0$ \\
$<1.0$ \\
$<2.0$ \\
2,840
\end{tabular}

Time: 11:05

PH: 5.4

Alkalinity: $5 \mathrm{mg} / \mathrm{L}$

Water tomperature: $28.4^{\circ} \mathrm{C}$

\begin{tabular}{|c|c|}
\hline Mod & Unit \\
\hline JO & 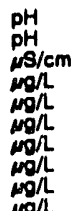 \\
\hline
\end{tabular}


WELL FCA 104 collected on 00/23/92, laboratory analyees (cont.)

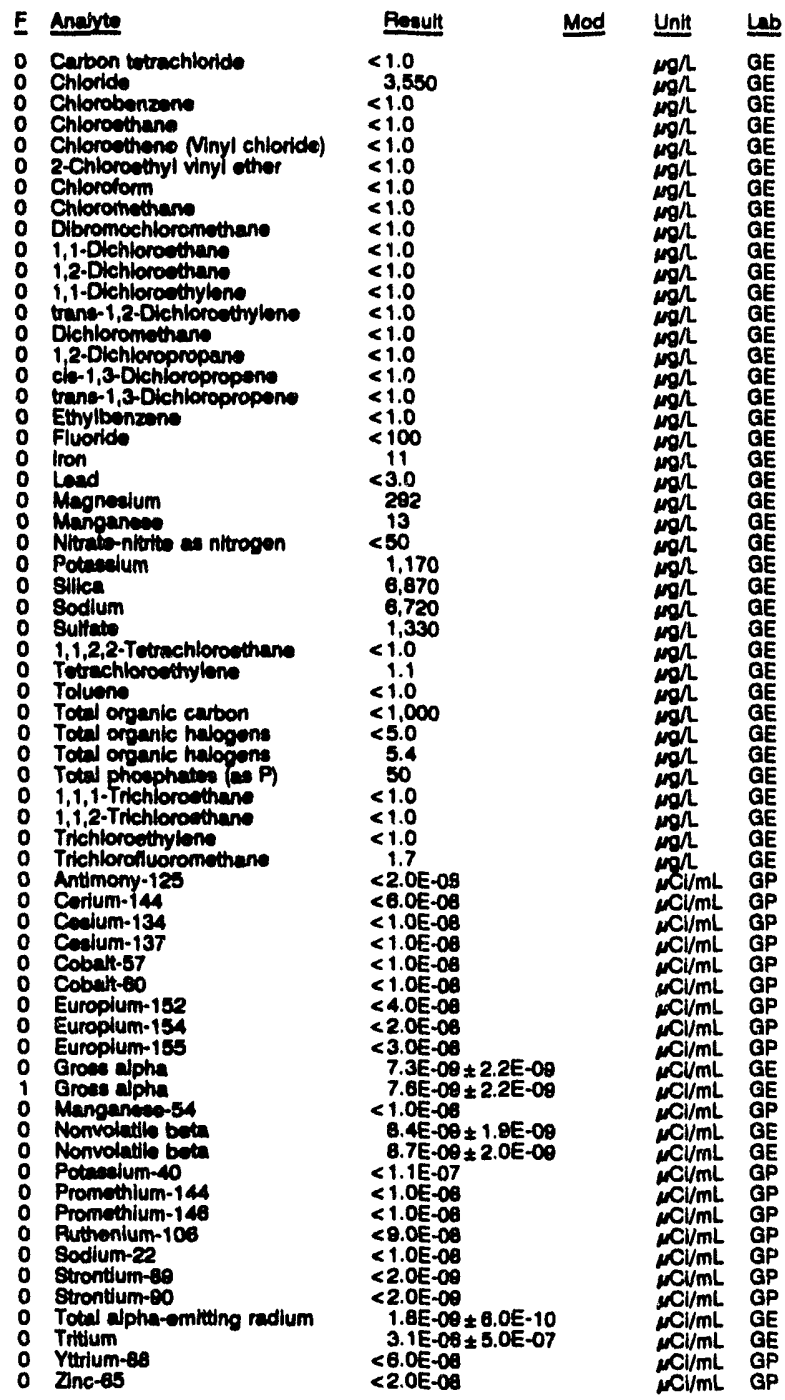

WELL FCA 16B

MEASUREMENTS CONDUCTED IN THE FIELD

\begin{tabular}{|c|c|}
\hline 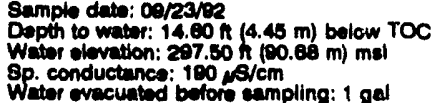 & $\begin{array}{l}\text { Time: } 11: 25 \\
\text { pH: } 8.5 \\
\text { Alkallity: } 61 \mathrm{mg} \Omega \\
\text { Water temperature: } 28.1 \circ \mathrm{C}\end{array}$ \\
\hline
\end{tabular}

Where wacuated insuricient weter to fili all or some semple bottles.

LABORATORY ANALYRES

\begin{tabular}{|c|c|c|c|c|c|}
\hline $\mathbf{F}$ & Analy & Roenult & Mod & Unit & Lab \\
\hline $\begin{array}{l}0 \\
0 \\
0 \\
0 \\
0 \\
1 \\
0 \\
0 \\
0 \\
0 \\
0\end{array}$ & 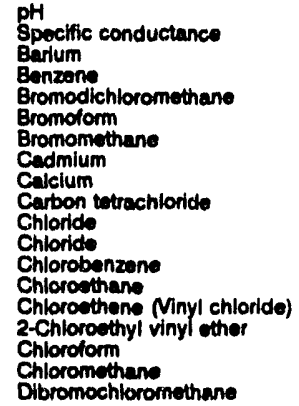 & $\begin{array}{l}6.9 \\
200 \\
68 \\
<1.0 \\
<1.0 \\
<1.0 \\
<1.0 \\
2.9 \\
26,800 \\
<1.0 \\
1.740 \\
1.780 \\
<1.0 \\
<1.0 \\
<1.0 \\
<1.0 \\
<1.0 \\
<1.0 \\
<1.0\end{array}$ & JO & 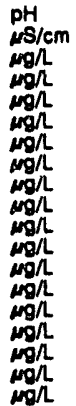 & $\begin{array}{l}\mathrm{GE} \\
\mathrm{GE} \\
\mathrm{GE} \\
\mathrm{GE} \\
\mathrm{GE} \\
\mathrm{GE} \\
\mathrm{GE} \\
\mathrm{GE} \\
\mathrm{GE} \\
\mathrm{GE} \\
\mathrm{GE} \\
\mathrm{GE} \\
\mathrm{GE} \\
\mathrm{GE} \\
\mathrm{GE} \\
\mathrm{GE} \\
\mathrm{GE} \\
\mathrm{GE} \\
\mathrm{GE}\end{array}$ \\
\hline
\end{tabular}

WELL. FCA 188 collectod on 00/23/82, laboratory analyeee (cont.)

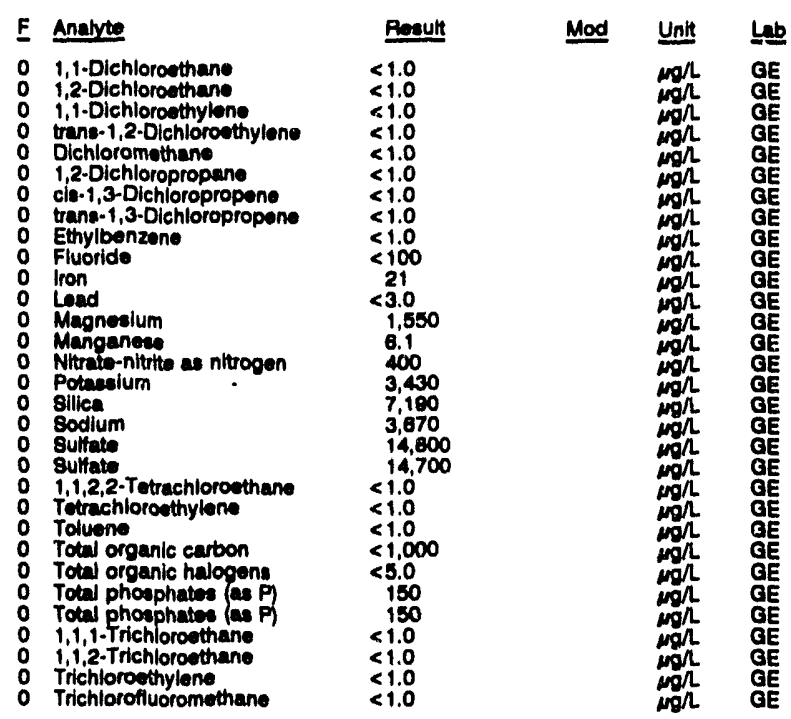

WELL FCA 16D

MEASUREMENTS CONDUCTED IN THE FIELO

Sample date: 00/23/92

Depth to water: $84.18 \mathrm{ft}(25.68 \mathrm{~m})$ below TOC

Water elevation: $226.52 \mathrm{ht}(69.04 \mathrm{~m}) \mathrm{mol}$

Sp. conductanco: $168 \mathrm{\mu s} / \mathrm{cm}$

No water was ovacuatod before sampling.

LABOAATORY ANALYSES

E Anajte

$0 \mathrm{pH}$

Specific conductance

0 Barium

O Bromodichloromethane

Bromolorm

Bromomethane

Cadmium

Carbon totrachlorido

Carbon

Chloride

Chlorobenzene

Chloroothane

Chioroethene Ninyl chlorida) 2-Chloroethyl vinyl other

Chlorotorm

Chloromethane

Dibromochloromoth

1,2-Dichloroethane

1,1-Dichloroothylene

Dichloromethane

1,2-Dichloropropane

o trane-1,3-Dichloropropene

Ethylbenzene

Fluorde

Iron

o Lead

Magneaium

Nitrato-nitrite as nitrogen

Potasslum

silica

Sodium

Suliate

Tetrachloroethyione

Tolvene

Total organic cartoon

Total organic halogen

Total phosphates (as P)

1,1,1-Trichloroethane

1, 2-Trichloroethan

2 Trichloroethylene

O Antimany-125
Tima: $9: 00$

Alkalinity: $10 \mathrm{~mol}$

Water tomporature: $22.8^{\circ} \mathrm{C}$ 
ANALYTICAL RESULTS

\begin{tabular}{|c|c|c|}
\hline Anedre & Result & Unit \\
\hline 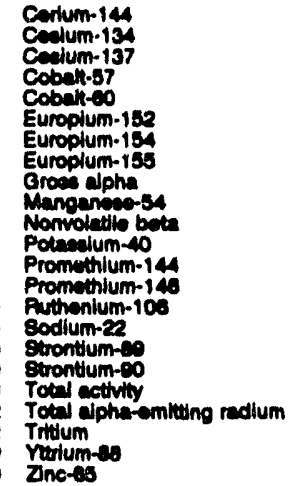 & 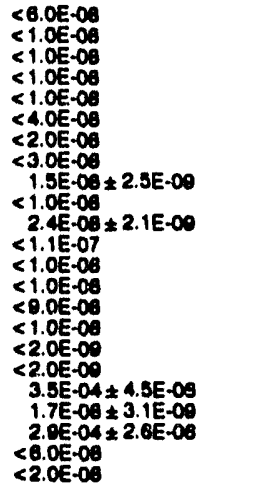 & 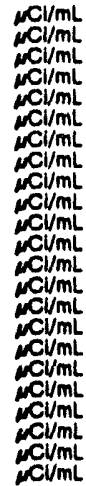 \\
\hline
\end{tabular}

\section{WELL FCA $16 T$}

MEASUAEMENTS CONDUCTED IN THE FIELD

Sample date: oeverpe

Time: 16:35

WELL FCA 19D

MEASUAEMENTS CONDUCTED IN THE FIELD

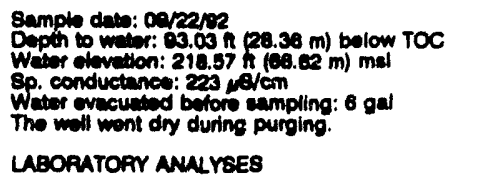

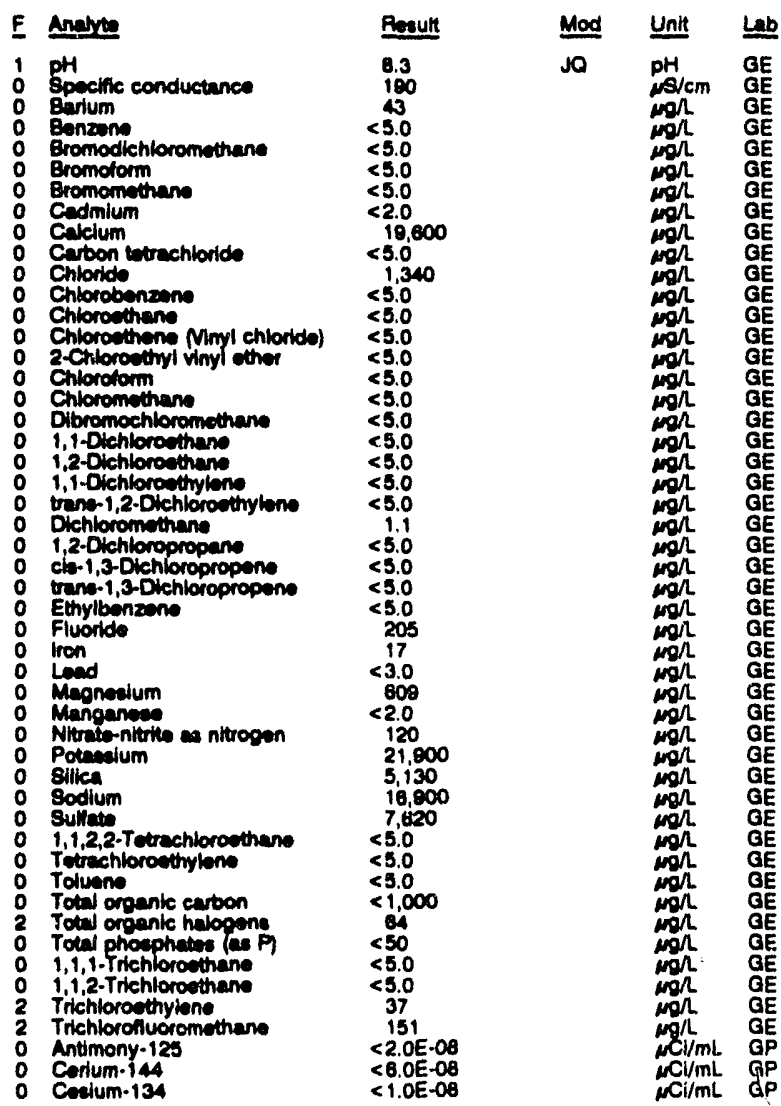

WELL FCA 180 collected on 00/22/82, laboratony analyees (cont)

\begin{tabular}{|c|c|c|c|}
\hline$\underline{F}$ & Anclute & Preauth & Unit \\
\hline $\begin{array}{l}0 \\
0 \\
0 \\
0 \\
0 \\
0 \\
0 \\
0 \\
0 \\
0 \\
0 \\
0 \\
0 \\
0\end{array}$ & 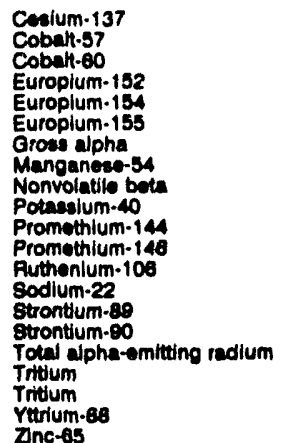 & 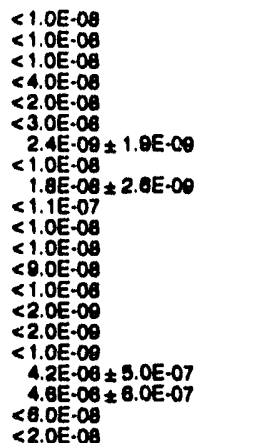 & 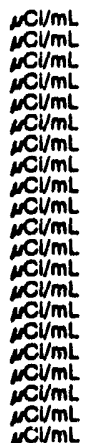 \\
\hline
\end{tabular}

\section{WELL FCB 2}

MEASUREMENTS CONDUCTED IN THE FIELD

Sample date: 0e/27/e2

Depth to waler: 76.61 it $(23.35 \mathrm{~m})$ bolow TOC

Sp. conductanc $230.68 \mathrm{t}$

LABORATORY ANALYYES

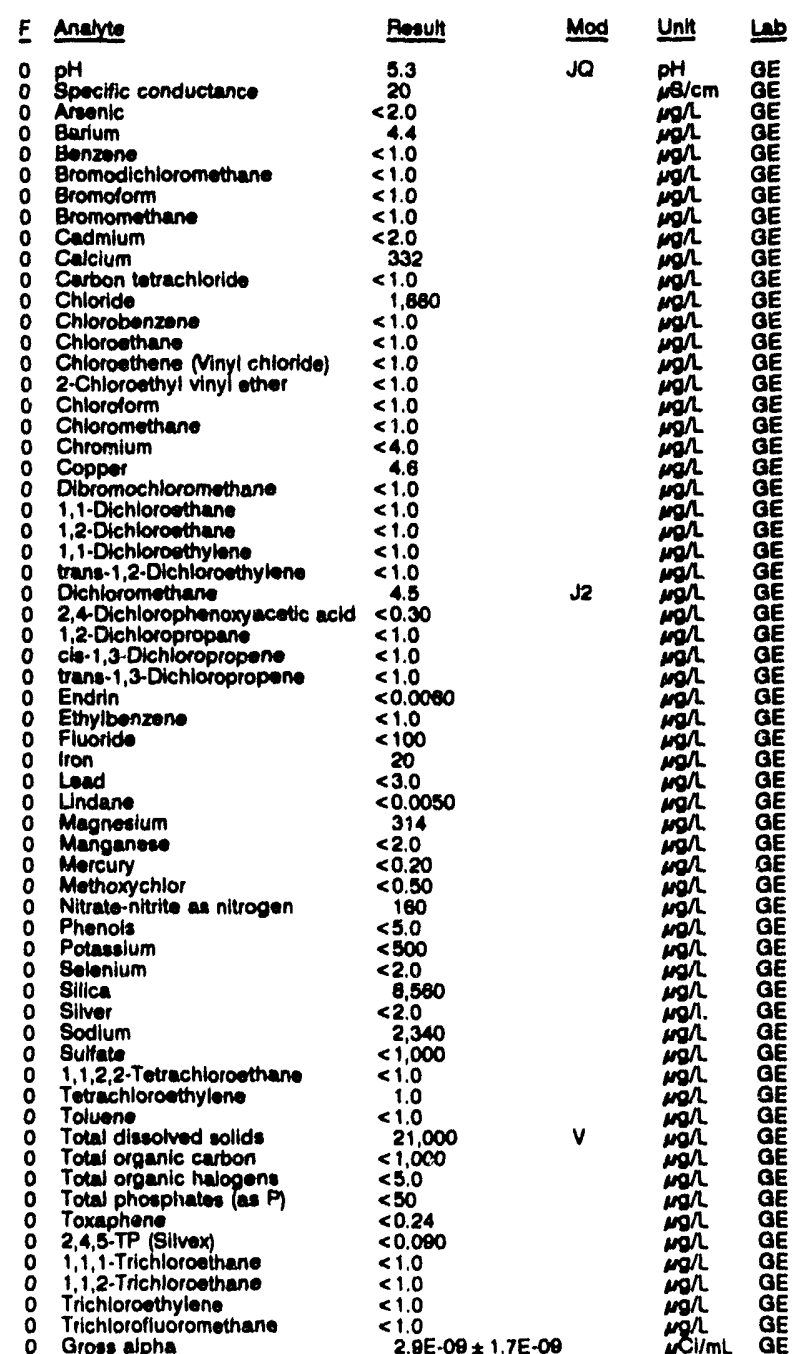


WELL FCB 2 collectied on 0ar27/02, laboratory analyews (cont)

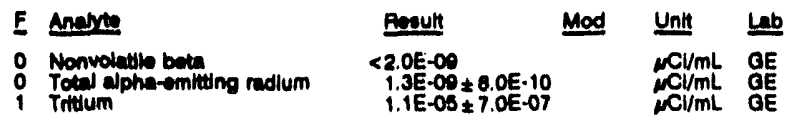

\section{WELL FCB 3}

MEASUAEMENTS CONOUCTED IN THE FIELL

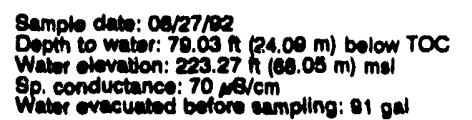

Time: 14:00

Plkalinity: $13 \mathrm{mon}$

Whalinity: $13 \mathrm{mgh}$, $21.00 \mathrm{C}$

\section{LABORATOFY AWALYES}

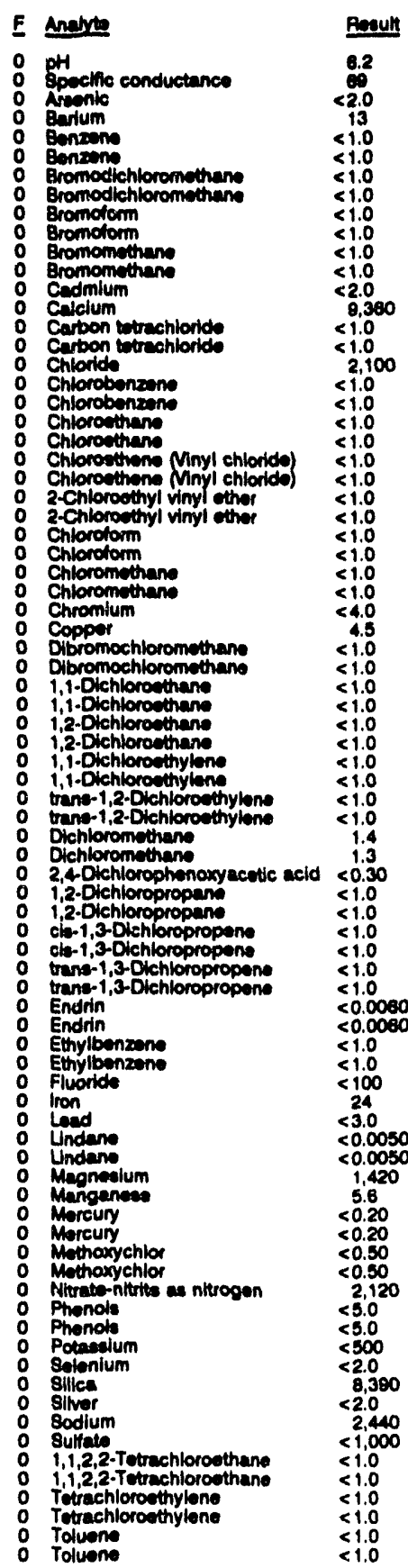

1.0

1.0

1.0

1.0

1.0

4.5

1.0

1.0

1.0

1.4

1.3
$<0.30$
$<1.0$

$<1.0$

0060

(1)

5.8

$<0.20$
$<0.50$
$<0.50$

.0

2,440

1.0

$<1.0$
WELL FCB 3 collected on 0ye7/02, laboratory analyees (cont)

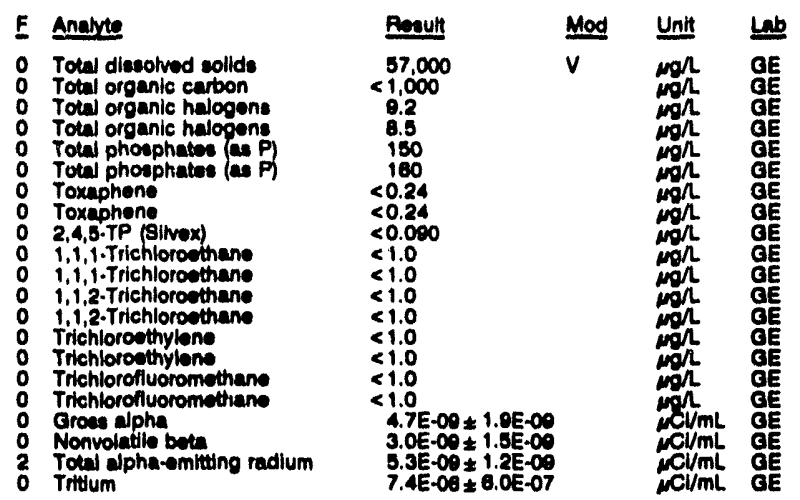

\section{WELL FCB 4}

MEASUREMENTS CONDUCTED IN THE FIELD

Sumple date: 09/22192 Wepth to water: $95.82 \mathrm{~h}(29.21 \mathrm{~m})$ bolow TOC

Sp. conductance: $37 \mathrm{\mu S} / \mathrm{cm}$. The well went dry during purging.

LABORATORY ANALYSES

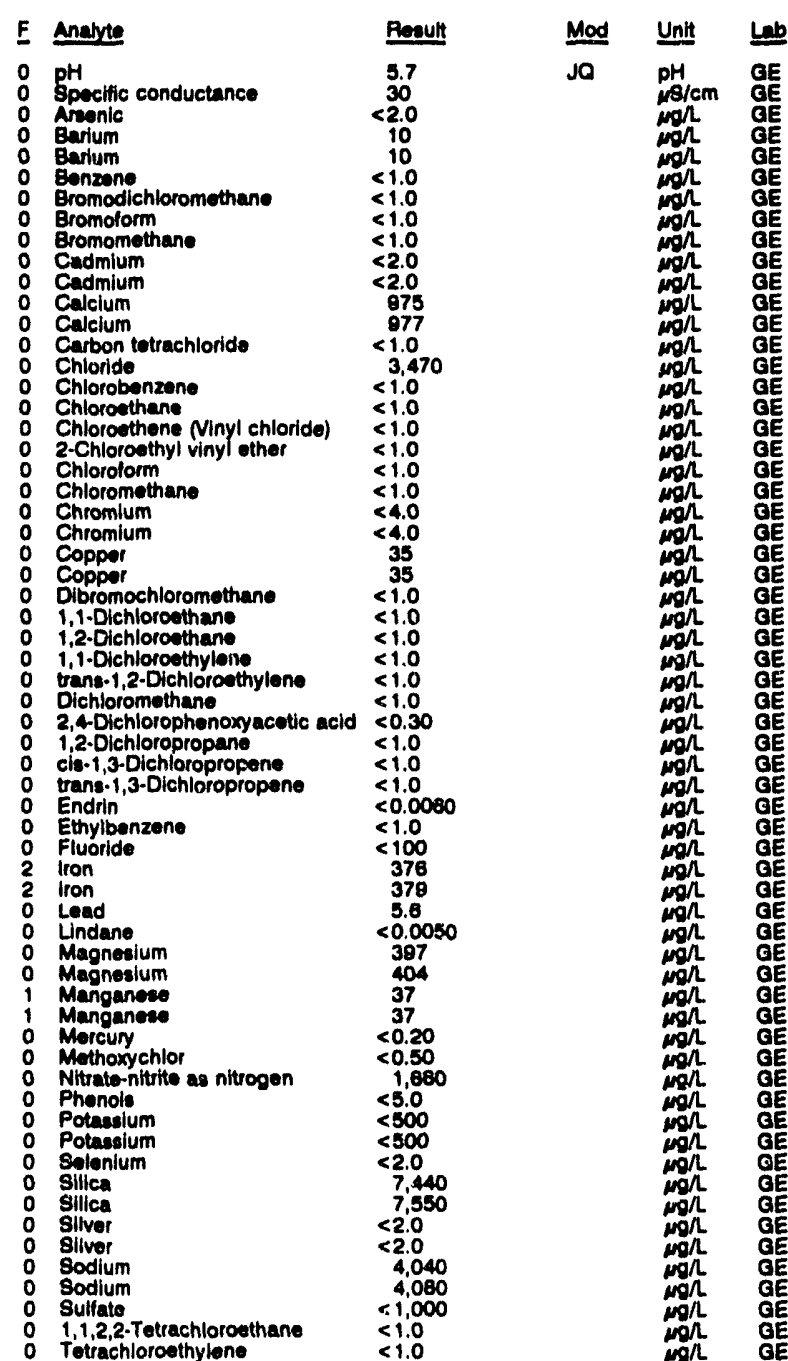

Time: $11: 30$

Alk: 4.9 0 man Water tomperature: $22.2^{\circ} \mathrm{C}$

E




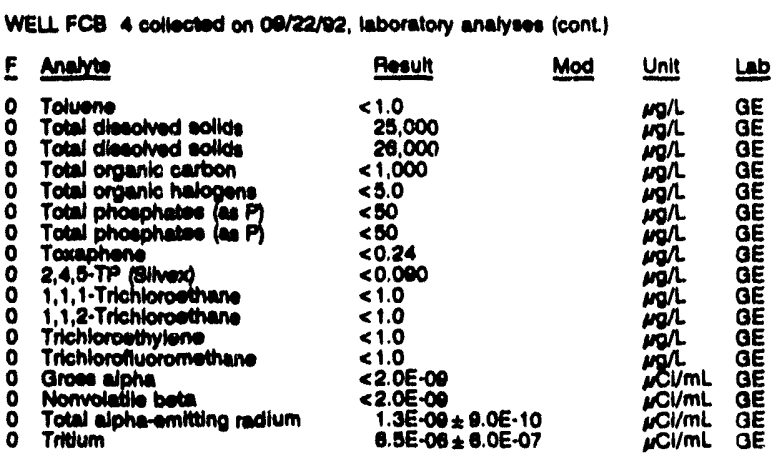

WELL FCB 5

MEASUREMENTS CONOUCTED IN THE FIELD

\begin{tabular}{|c|c|}
\hline 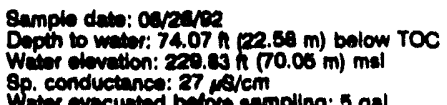 & $\begin{array}{l}\text { Time: } 8: 20 \\
\text { pH: } 4.8 \\
\text { Alkalinity: } 0 \mathrm{mgh} \\
\text { Water tomperiture: } 21.0 \cdot \mathrm{C}\end{array}$ \\
\hline
\end{tabular}

LABORATORY MNAY YES

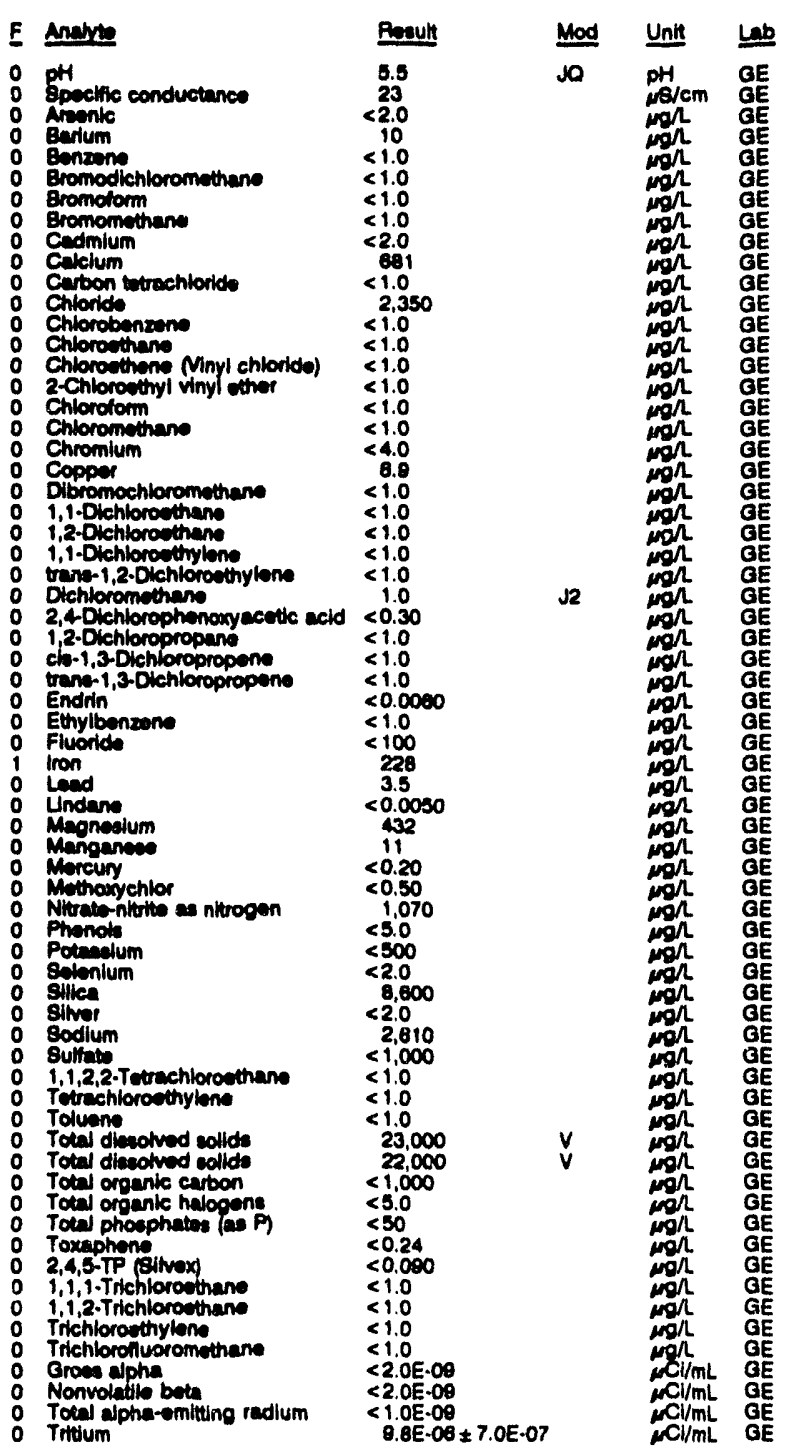

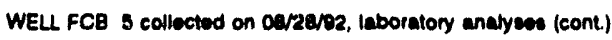

$\frac{E \text { Analyte }}{1 \text { Tritium }} \quad \frac{\text { Peount }}{1.0 E-05 \pm 7.0 E-07} \stackrel{\text { Mod }}{\text { UnClithL }} \frac{\text { Leb }}{\text { GE }}$

WELL FCB 6

MEASUREMENTS CONDUCTED IN THE FIELD

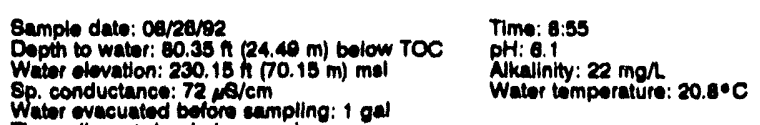
Sp. conductance: $72 \mathrm{\mu s} / \mathrm{cm}$ Who wall went diry during purping: 1 gal

LBOPATORY ANALYBES

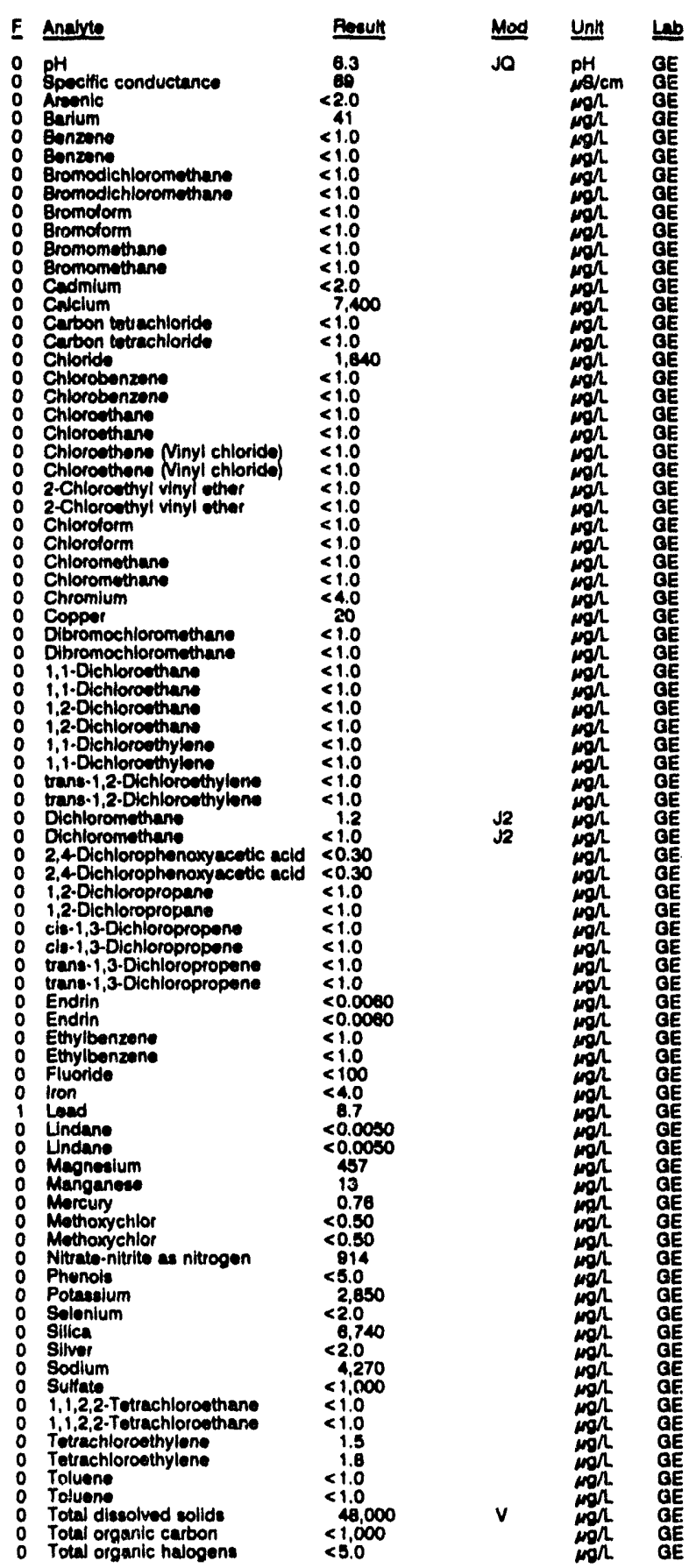


ANALYTICAL RESULTS

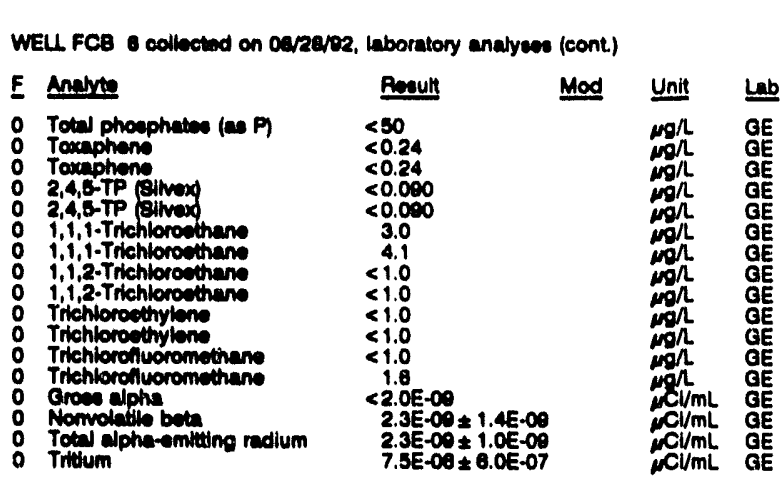

\section{WELL FCB 7}

MEASUREMENTS CONOUCTED IN THE FIELD

Sample dete: 0ave7/ee

Time: 15:00

\section{WELL FET 1D}

MEASUPEMENTS CONDUCTED IN THE FIELD

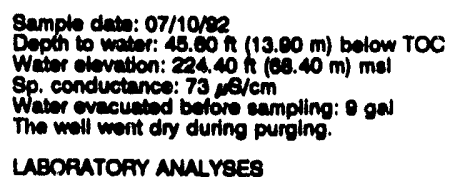

\begin{tabular}{|c|c|c|c|}
\hline F Anarte & Result & Mod & Unit \\
\hline Groee alpha & $<2.0 E-00$ & & $\mathrm{cl} / \mathrm{mL}$ \\
\hline
\end{tabular}

\section{WELL FET 2D}

MEASUREMENTS CONDUCTED IN THE FIELD

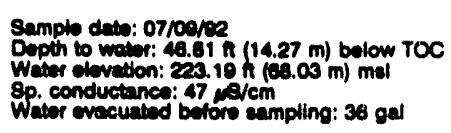

\section{LABORATOFY ANALYSES}

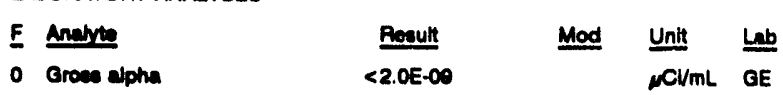

\section{WELL FET 3D}

MEASUREMENTS CONOLCTED IN THE FIELD

Sample date: 07100/pe

Oepth to water: $02.04 \mathrm{~A}$ (18.81 m) below TOC

Water elevation: $223.16 \mathrm{~h} / 69$

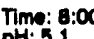

Nhalinity: $1 \mathrm{mar}$

Watine tomperature: $21.3 \circ \mathrm{C}$

$<2.0 E-00$

Time: 12:20

Nkallinity: 0 mor

Weter tomporature: $22.0^{\circ} \mathrm{C}$

LABOPATOFY ANALYSES

\begin{tabular}{|c|c|c|c|}
\hline E Analote & Perult & Mod & Unit \\
\hline 0 Crow alpha & $<2.0 E-00$ & & $\mathrm{cl} / \mathrm{mL}$ \\
\hline
\end{tabular}

\section{WELL FET 4D}

MEASUAEMENTS CONDUCTED IN THE FIELD

Sample date: 07/09/82

Depth to water: $63.32 \mathrm{An}(19.30 \mathrm{~m})$ bolow TOC

Wator elovation: $223.58 \mathrm{~h}(60.15 \mathrm{~m}) \mathrm{met}$

Sp. conductance: $50 \mathrm{~m}^{\mathrm{s} / \mathrm{cm}}$

Wator evacualtod bolore eampling: 47 gal

LABORATORY ANALYSES

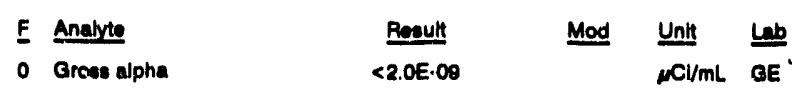

WELL FNB 1

MEASUREMENTS CONDUCTED IN THE FIELL

Sample deve:

Dopth to wator: $71.902 \mathrm{n}(21.04 \mathrm{~m})$ bolow TOC

Wator olevation: $212.31 \mathrm{~h}(84.71 \mathrm{~m}) \mathrm{mal}$

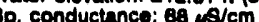

Time: 13:00

pH: 4.8

Water temperature: $22.0^{\circ} \mathrm{C}$

Whter evecuated botors sempling: 02 gal

LABOPATOAY ANALYSES

\begin{tabular}{|c|c|c|c|c|}
\hline Analyte & Recult & Mod & Unit & $\underline{L b}$ \\
\hline 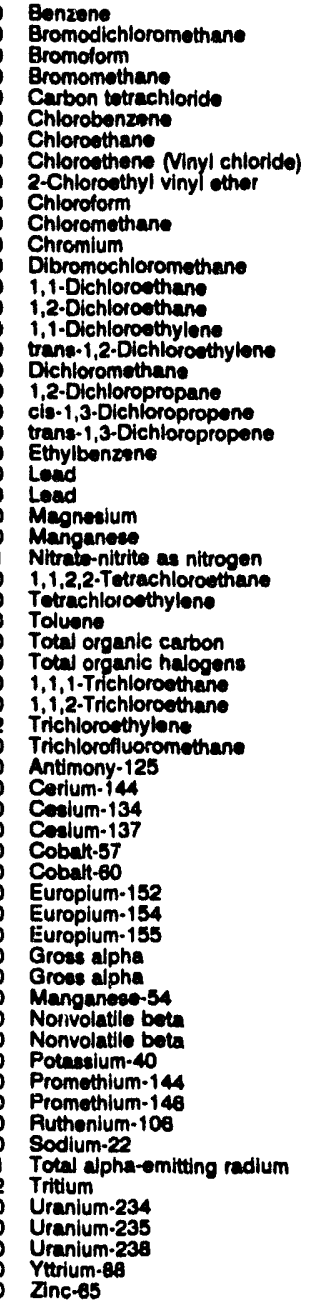 & 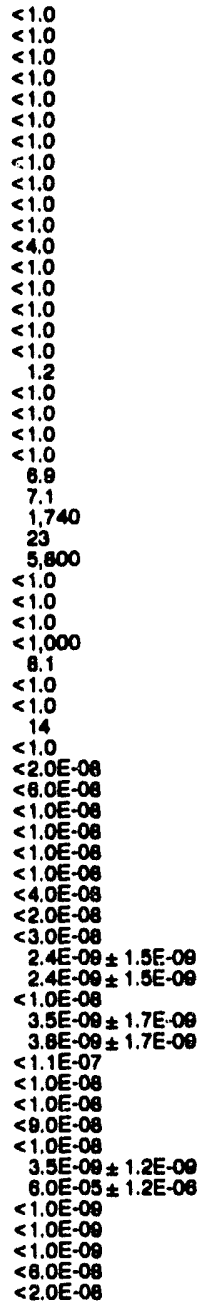 & $\sqrt{2}$ & 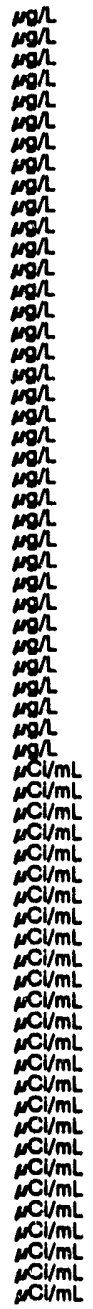 & 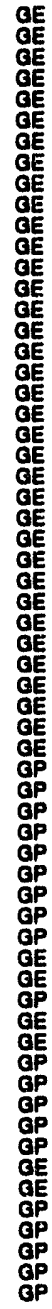 \\
\hline
\end{tabular}




\section{WELL FNB 2}

MEASUAEMAENTS CONOUCTED IN THE FIEL

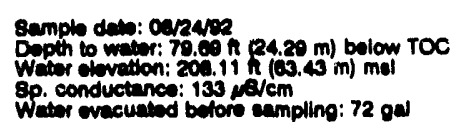

Time: 12:25

pH: 3.8 . 0

Weter tomperature: $21.6^{\circ} \mathrm{C}$

\section{LABORATOFY ANAYYES}

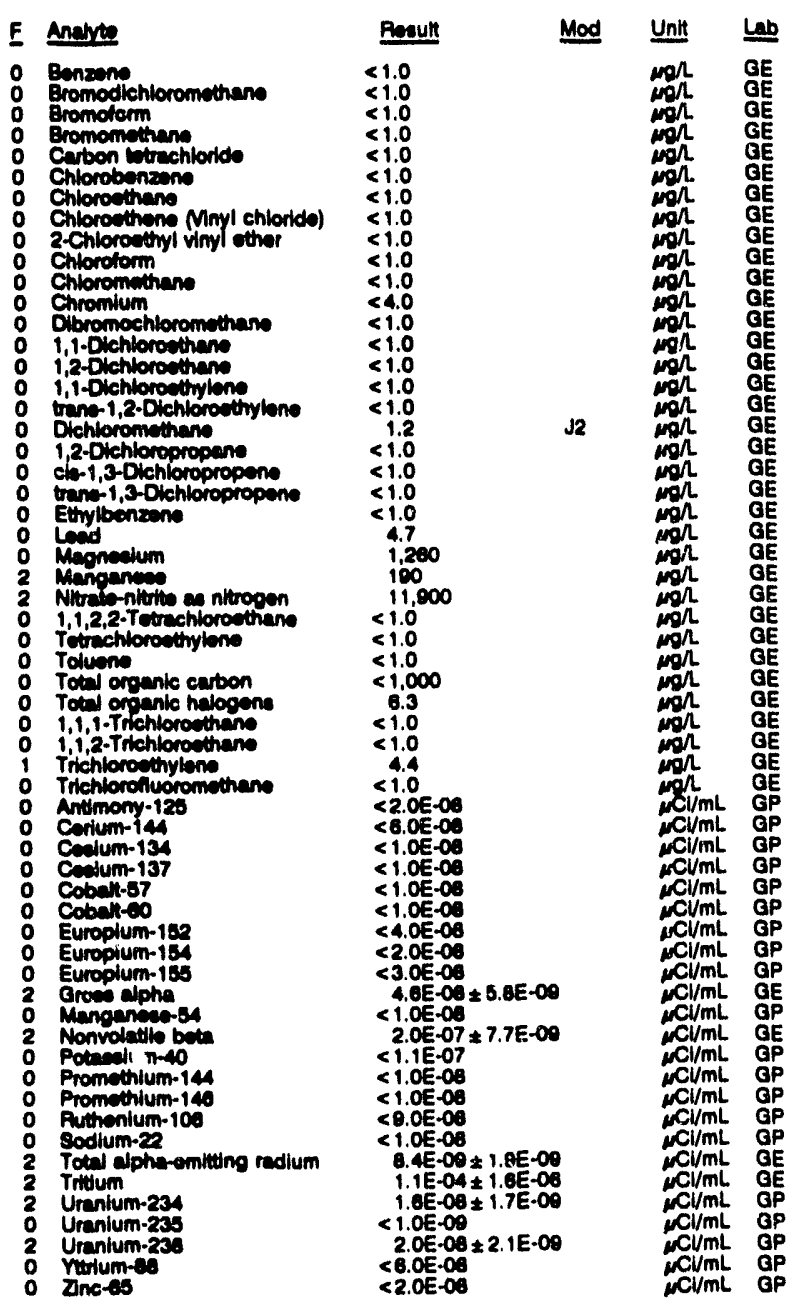

\section{WELL FNB 3}

\section{MEAGUREMENTB CONOUCTED IN THE FIELD}

\begin{tabular}{|c|c|}
\hline 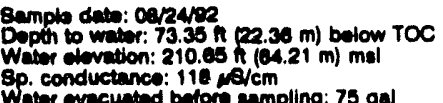 & $\begin{array}{l}\text { Time: } 13.05 \\
\text { pH: } 4.2 \\
\text { Alkatinity: } 0 \mathrm{mgh} \\
\text { Water tomporature: } 21.7 \cdot \mathrm{C}\end{array}$ \\
\hline
\end{tabular}
Water ovecuated betore ampling: $75 \mathrm{gal}$

\section{LABOPATOPY ANALYSES}

\begin{tabular}{|c|c|c|c|c|}
\hline $\boldsymbol{E}$ & Ancrese & Pooult & Mod & Unit \\
\hline $\begin{array}{l}0 \\
0 \\
0 \\
0 \\
0 \\
0 \\
0 \\
0 \\
0 \\
0 \\
0\end{array}$ & 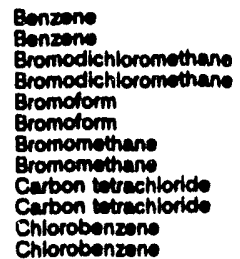 & $\begin{array}{l}<1.0 \\
<1.0 \\
<1.0 \\
<1.0 \\
<1.0 \\
<1.0 \\
<1.0 \\
<1.0 \\
<1.0 \\
<1.0 \\
<1.0 \\
<1.0\end{array}$ & & 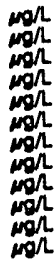 \\
\hline
\end{tabular}

WELL FNE 3 collected on 08/24102, laboratory analyees (cont)

E Analyte

o Chlorosthane

Chloroethan
0 Chlorosthene Minyl chloride)
0 Chloroethen (Vinyl chloride)

2.Chlorosthyl vinyl the

Chlorolorm

- Chorolorm

Chioromethan

Chromlum

O Dibromochloromethane

o Oibromochioromethans

i,i.Dtchloroethune

1,2-Dichloroethan

1,2-Dichloroethan

1,1-Dichioroethyleno

o trens-1,2-Dichloroethylene

o trans-1,2-Dichloroothylene

O Dichloromethans

o Dichloromethane

o cit-1,3-Otchloropropen

o cle-1,3-Dtchloropropen

o trane-1,3-Oichloropropene

O Ethylbonzone

0 Lead

D Magnedium

2 Manganeas

o $1,1,2,2$-Tetrachloroethan

o 1,1,2,2-Tetrachloroethane

Totrachloroethylone

O Toluene

o Total organic carbon

: Total organic carton

1,1, - Tnchlorodthan

1,1,2-Trichlorowthan

1,1,2-Trichloroethan

Trichloroethylons

Trichioroethylone

Trichlorofluoromethane

Antimony-125

Corlum-144

Coslum.134

Cobalt-57

Cobati 60

Europlum-158

Europium-15

Groes alpha

Mangeneas-34

Nonvolatile bet

Promothium-144

Promethlum.149

Ruthenium-100

I Todel alpha-emitung redium

Tritium

o Uranlum-23a

o Uranium-23a

- Uranlum-236

Uranium-235

Uranium-239

- Uranium-239

Yitrlum-e日
1,2-Dichloropropan

Tetrechloroothylene

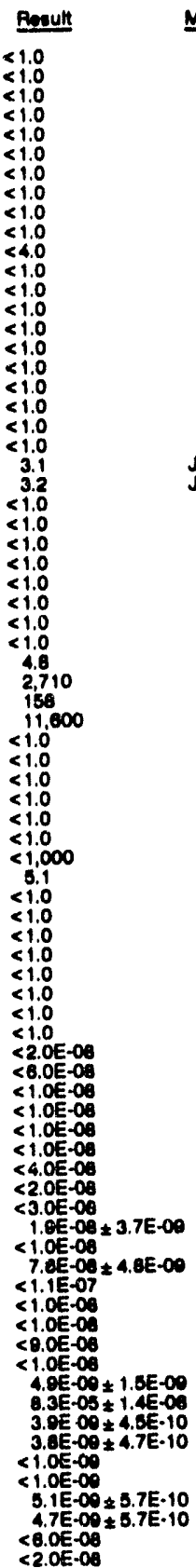

Mod Unit Lab

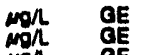

$\operatorname{mon}_{\text {mon }}$ dE

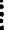

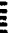

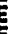$$
\text { E }
$$

更

WELL FNB 4

MEASUREMENTS CONOUCTED IN THE FIELD

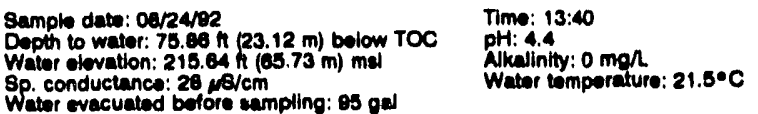

LABOPATORY ANALYSES

\begin{tabular}{|c|c|c|c|}
\hline 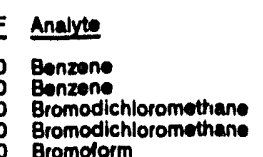 & $\begin{array}{l}\text { Pesult } \\
<1.0 \\
25.0 \\
21.0 \\
55.0 \\
<1.0\end{array}$ & Mod & 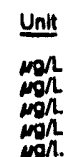 \\
\hline
\end{tabular}


ANALYTICAL RESULTS

WELL FNB a coliected on 0ar2492, taboratory analyees (cont)

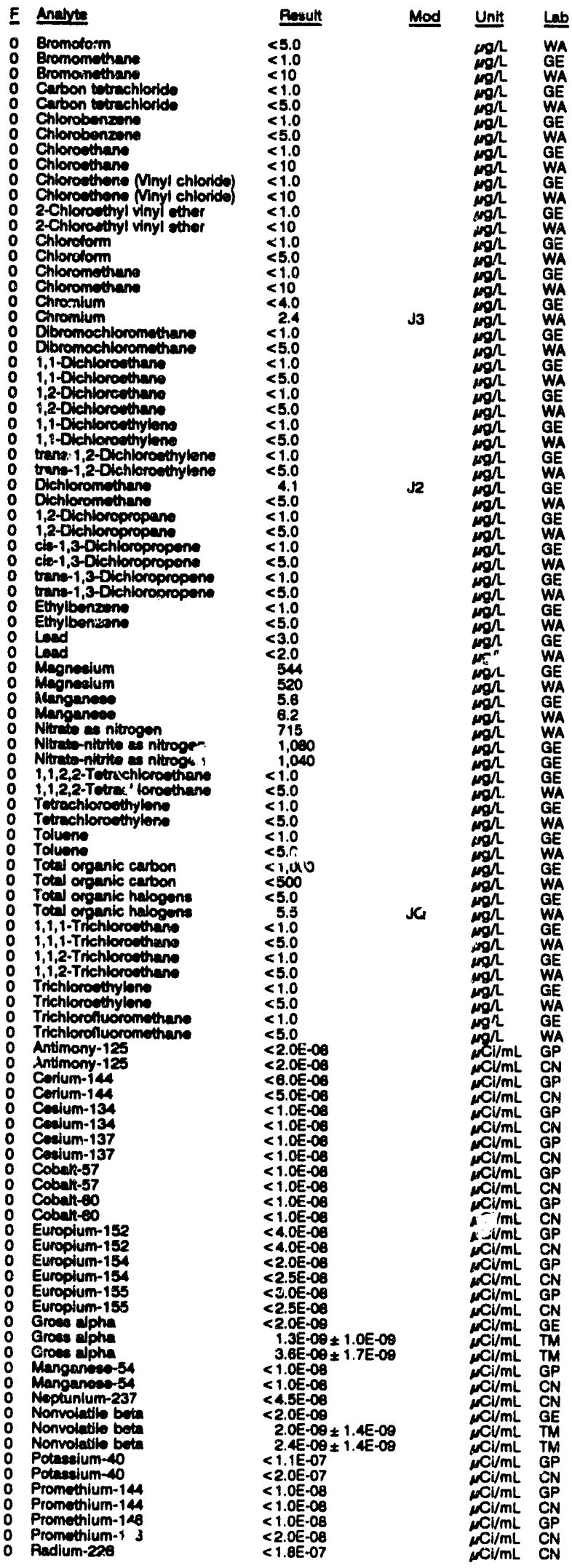

WELL FNB 4 collected on 08/24/82, laboratory analyees (cont.)

$\begin{array}{ll}\text { F } & \text { Analyte } \\ 0 & \text { Redium-228 } \\ 0 & \text { Radium-228 } \\ 0 & \text { Ruthenium-103 } \\ 0 & \text { Ruthenium-108 } \\ 0 & \text { Ruthenium-108 } \\ 0 & \text { Sodium-22 } \\ 0 & \text { Sodium-22 } \\ 0 & \text { Thorium-228 } \\ 0 & \text { Total alpha-emitting radlum } \\ 0 & \text { Trttlum } \\ 0 & \text { Trittum } \\ 0 & \text { Tritum } \\ 0 & \text { Uranium-234 } \\ 0 & \text { Uranium-234 } \\ 0 & \text { Uranium-235 } \\ 0 & \text { Uranium-235 } \\ 0 & \text { Uranium-235 } \\ 0 & \text { Uranium-238 } \\ 0 & \text { Uranium-238 } \\ 0 & \text { Ytrium-88 } \\ 0 & \text { Ytrium-88 } \\ 0 & \text { Znc-65 } \\ 0 & \text { Znc-65 }\end{array}$

Result
$2.0 E-09 \pm 0.1 E-10$
$1.2 E-09 \pm 1.1 E-00$
$<1.0 E-08$
$<0.0 E-08$
$<7.0 E-08$
$<1.0 E-08$
$<1.0 E-08$
$<4.0 E-07$
$1.2 E-09 \pm 7.0 E-10$
$4.0 E-09 \pm 5.0 E-07$
$4.0 E-06 \pm 3.0 E-07$
$5.3 E-06 \pm 3.0 E-07$
$<1.0 E-09$
$<1.0 E-09$
$<1.0 E-09$
$<1.5 E-08$
$<1.0 E-09$
$<1.0 E-09$
$<1.0 E-09$
$<6.0 E-08$
$<1.0 E-08$
$<2.0 E-06$
$<2.0 E-08$

Mod Unit Lي

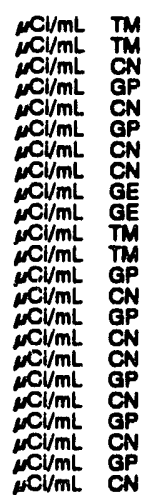

WELL FNB 4 Replicate

MEASLAREMENTS CONDUCTED IN THE FIELD

Sample date: 08/24/02

75.08 (t) $(23.12 \mathrm{~m})$ bolow $\mathrm{roc}$

Water olvation: $215.84 \mathrm{th}(65.73 \mathrm{~m})$ mel

N/kalinity: $0 \mathrm{mg} \Omega$

Water evacuated bolore sampling: $85 \mathrm{gal}$

Water temperature: $21.5^{\circ} \mathrm{C}$

LABORATOPY ANALYSES

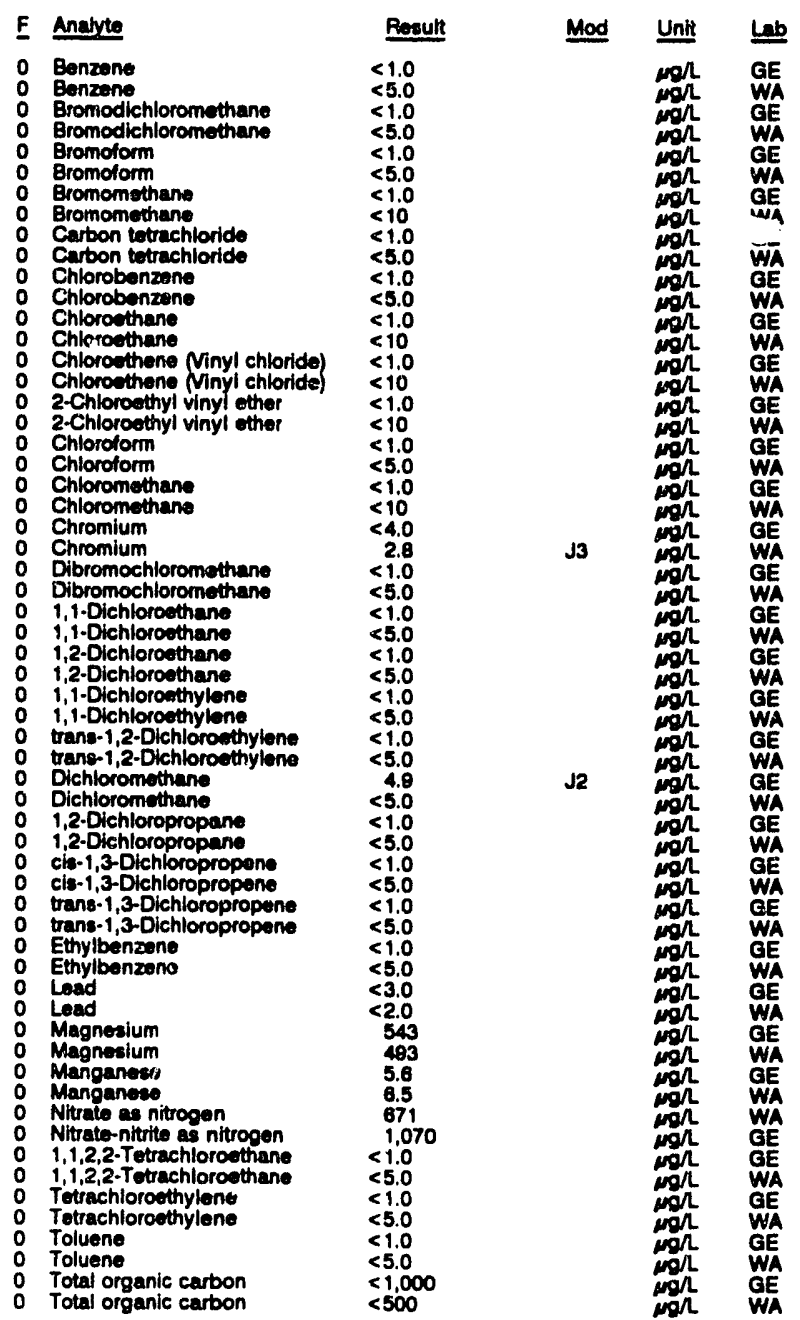


WELL FNB collected on 06/24P2, laboratory analyses (cont)

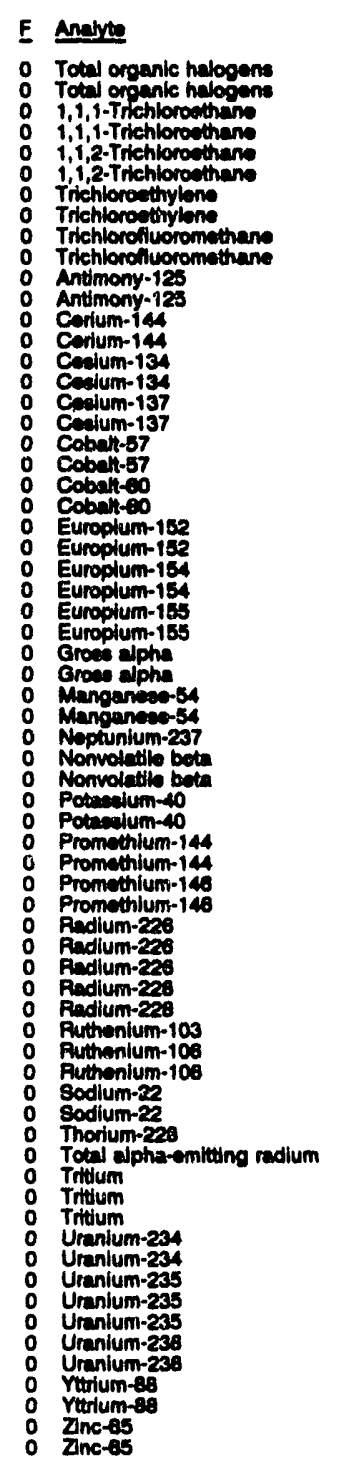

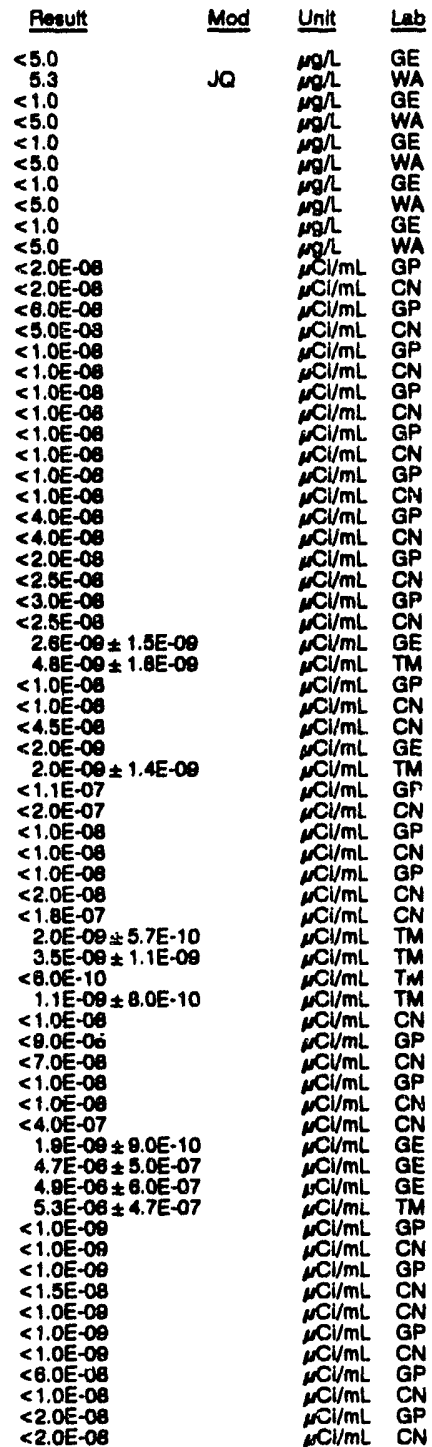

WELL FSB ITA

MEASUREMENTS CONDUCTED IN THE FIELD

Sample date: 07/0aver

WELL FSB ITA

MEASUREMENTS CONDUCTED IN THE FIELD

Sample date: 07/18/2er

Depth to watior: Not envilable

Sp. conductances: 58 is/cm

Water evecueted betore sampling: $800 \mathrm{gal}$

LABORATORY ANALYSES

\begin{tabular}{|c|c|c|c|c|}
\hline F Analyte & Pesult & Mod & Unit & Lab \\
\hline $\begin{array}{ll}0 & \text { py } \\
0 & \text { Epectific conductance } \\
0 & \text { Arenic } \\
0 & \text { Barium } \\
0 & \text { Eenzeno } \\
0 & \text { Benzene }\end{array}$ & $\begin{array}{r}5.5 \\
45 \\
<2.0 \\
15 \\
<1.0 \\
<1.0\end{array}$ & Jo & 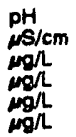 & $\begin{array}{l}\text { GE } \\
G E \\
G E \\
G E \\
G E \\
G E\end{array}$ \\
\hline
\end{tabular}

$\operatorname{Tims:}_{\text {pH: } 5.4} 11: 20$

Alkalinity: $5 \mathrm{mg} /$ Water temperature: $22.5^{\circ} \mathrm{C}$

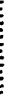

WEL FSB ITA collected on 07/18/92, laboratory analyees (cont.)

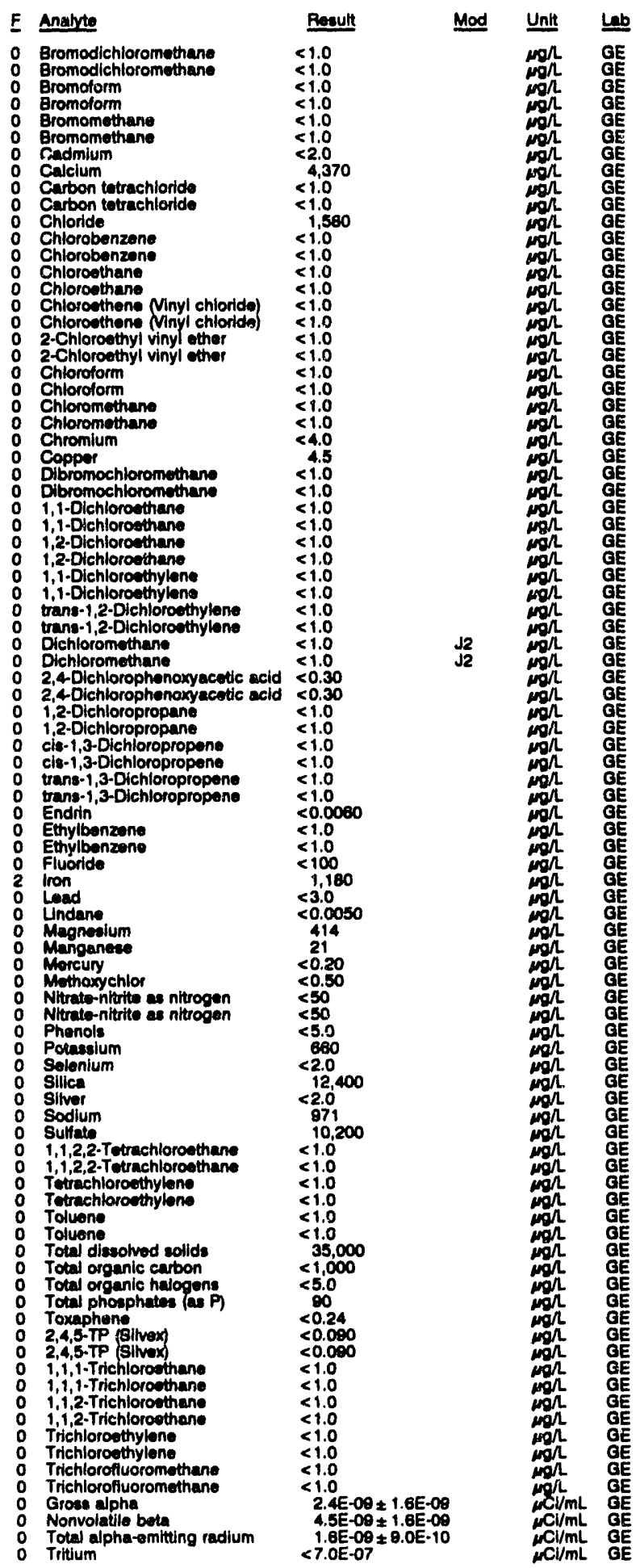


ANALYTICAL RESULTS

WELL FSB 76

MEASUREMENTS CONDUCTED IN THE FIELD

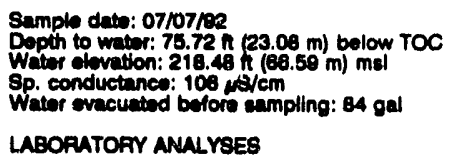

Time: $8: 25$

PH: 4.4 : 0 mon

Water tomperature: $20.1^{\circ} \mathrm{C}$

\section{LABOFUTOFY ANULYSES}
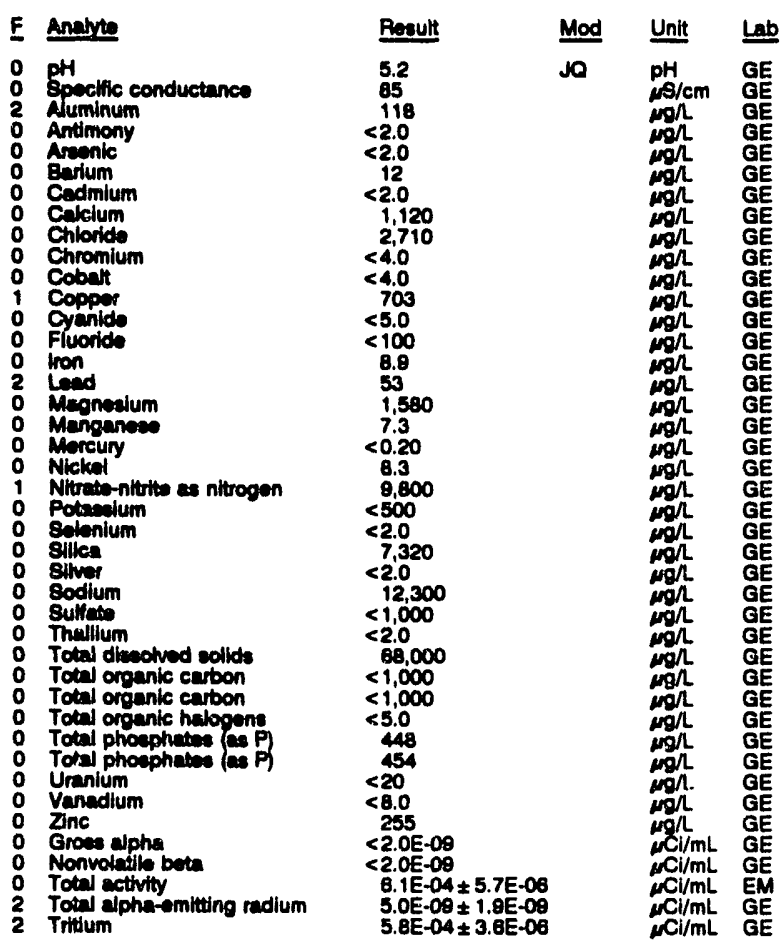

WELL FSB 76A

\section{MEASUREMENTS CONDUCTED IN THE FIELD}

Sampla data: 07/07/pe Depth to weter: 137.88 it $(42.08 \mathrm{~m})$ below TOC Water elevation: $155.82 \mathrm{~h}(147$. Sp. conductance: $133 \mathrm{~ms} / \mathrm{cm}$. Weter evacuated betore eampling: 312 gal LABOPATOFY ANALYSES

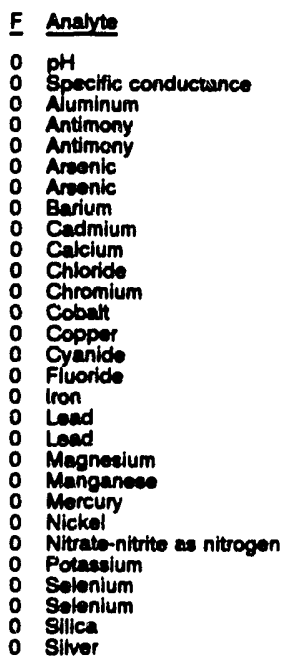

\begin{tabular}{|c|c|c|}
\hline Rosult & Mod & Unit \\
\hline $\begin{array}{c}6.6 \\
120 \\
22 \\
<2.0 \\
<2.0 \\
<2.0 \\
<2.0 \\
28 \\
<2.0 \\
21,100 \\
2,320 \\
<4.0 \\
<4.0 \\
4.5 \\
<5.0 \\
133 \\
<4.0 \\
<3.0 \\
<3.0 \\
643 \\
<2.0 \\
<0.20 \\
<4.0 \\
<50 \\
1.450 \\
<2.0 \\
<2.0 \\
27.000 \\
<2.0\end{array}$ & $\begin{array}{l}\mathrm{J1} \\
\mathrm{J} 1\end{array}$ & 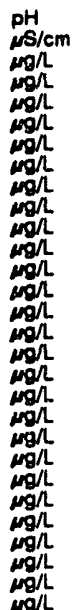 \\
\hline
\end{tabular}

WELL FSB 76A collected on 07/07/82, laboratory analyese (cont)

\begin{tabular}{|c|c|c|c|c|}
\hline$E$ & Analyte & Rosult & Mod & Unit \\
\hline $\begin{array}{l}0 \\
0 \\
0 \\
0 \\
0 \\
0 \\
0 \\
0 \\
0 \\
0 \\
0 \\
0 \\
0 \\
0 \\
0\end{array}$ & 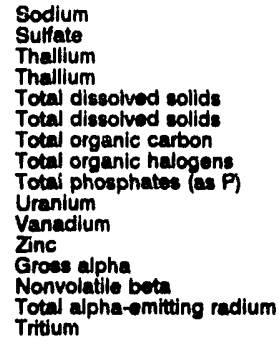 & $\begin{array}{r}2,000 \\
8,050 \\
<2.0 \\
<2.0 \\
85,000 \\
88,000 \\
<1,000 \\
<5.0 \\
370 \\
<20 \\
<8.0 \\
6.3 \\
<2.0 E-09 \\
<2.0 E-09 \\
<1.0 E-09 \\
<7.0 E-07\end{array}$ & & . \\
\hline
\end{tabular}

\section{WELL FSB 76B}

MEASUREMENTS CONDUCTED IN THE FIELD

Sample date: 07/07/92

Depth to water: 141.81 i $(43.22 \mathrm{~m})$ below TOC Wator elovation: $151.00 \mathrm{~h}(46.33 \mathrm{~m}) \mathrm{ms}$ Water evecuated before sampling: $139 \mathrm{gal}$

LABORATORY ANALYSES

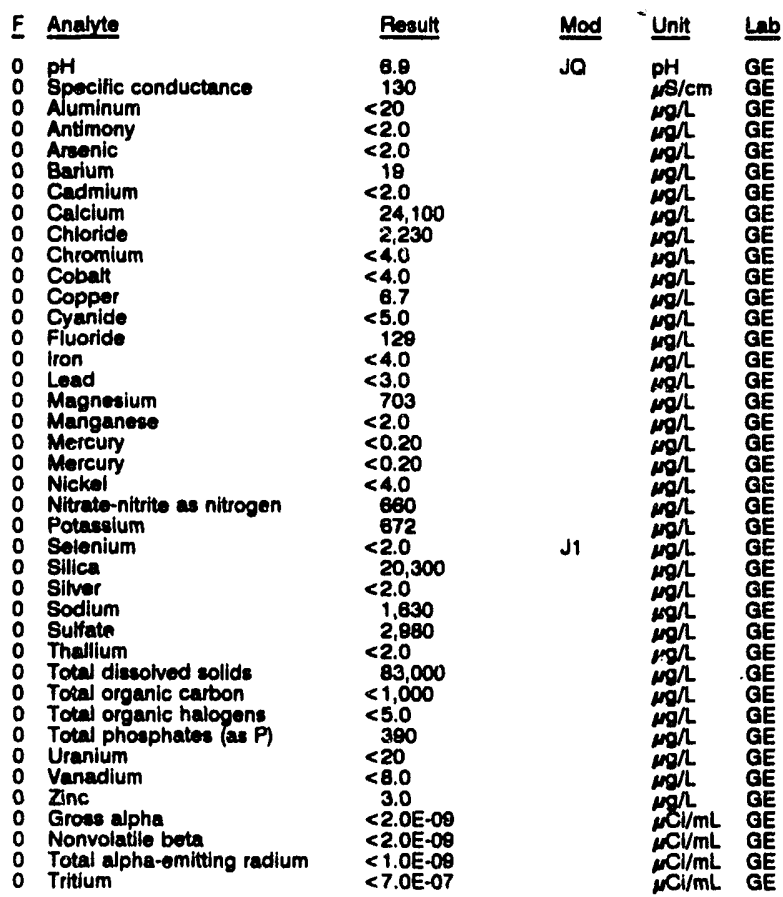

\section{WELL FSB 76C}

MEASUREMENTS CONDUCTED IN THE FIELD

Sample dato: 07/07/92

(2.39 m) below TOC

Wator clevation: $213.57 \mathrm{~h}(85.10 \mathrm{~m}) \mathrm{msl}$

Water evacuated before eampling: $154 \mathrm{gal}$

Time: 8:25

PH: 6.6 : $50 \mathrm{mgn}$

Whater tomporature: $21.4^{\circ} \mathrm{C}$

LABORATORY ANALYSES

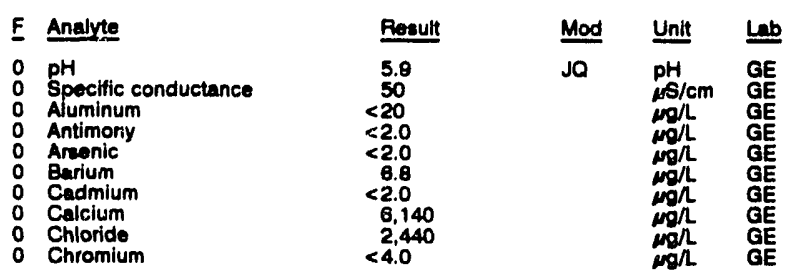




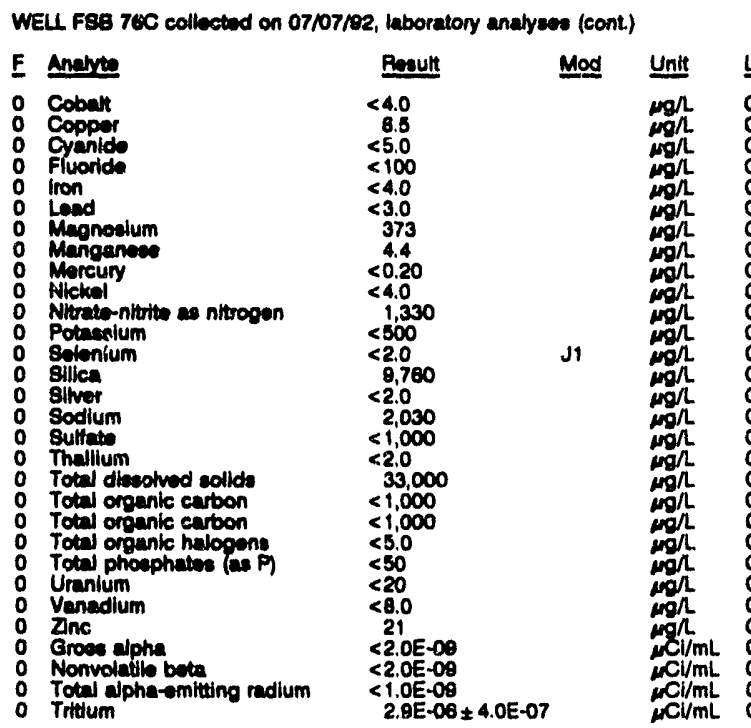

\section{WELL FSB 77}

MEASUAEMENTS CONDUCTED IN THE FIELD

Sample data: 07/00/92 Depth to water: 65.64 ft $(20.01 \mathrm{~m})$ bolow TOC Water elovation: $207.68 \mathrm{~h}(63.30 \mathrm{~m}) \mathrm{mal}$

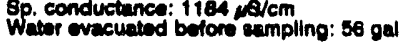

\section{LABOPATOFY ANALYBES}

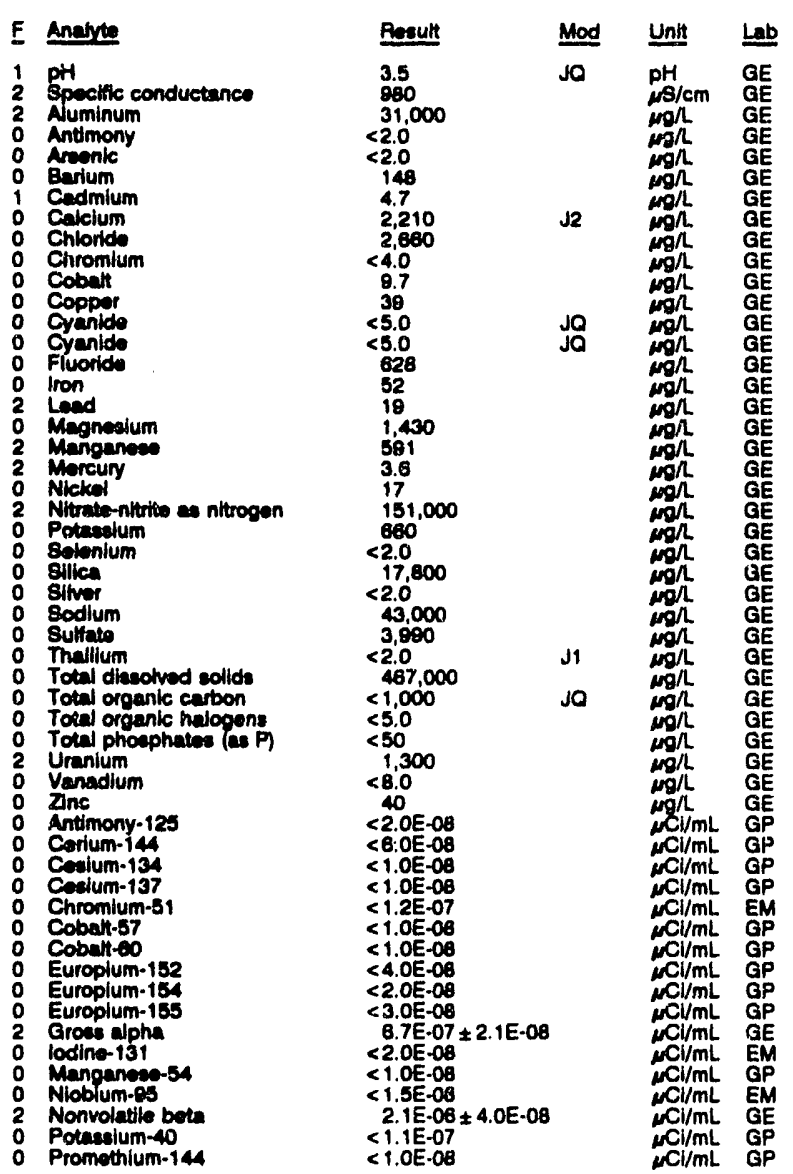

WELL F8B 77 collected on 07/05/92, laboratory analyees (cont.)

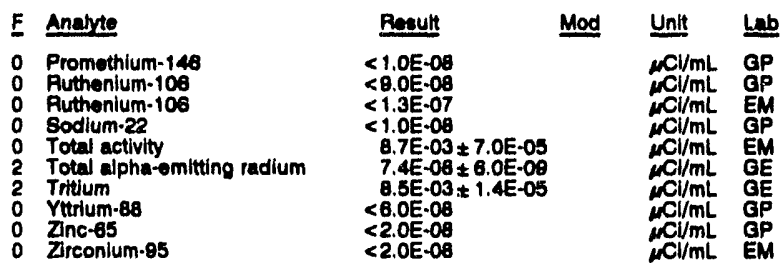

WELL FSB 78

MEASUREMENTS CONDUCTED IN THE FIELD

\begin{tabular}{|c|c|}
\hline $\begin{array}{l}\text { Sample date: } 07105 / 82 \\
\text { Depth to water: } 63.35 \mathrm{ft}(19.31 \mathrm{~m}) \text { below TOC } \\
\text { Water elevation: } 209.25 \mathrm{~h}(83.78 \mathrm{~m}) \mathrm{mal} \\
\text { 8p. conductance: } 2380 \mathrm{\mu} / \mathrm{cm} \\
\text { Whtor evecuatod befor }\end{array}$ & $\begin{array}{l}\text { Time: } 8: 40 \\
\text { pH: } 3.5 \\
\text { Alkalinity: } 0 \mathrm{mgh} \\
\text { Water tomperalure: } 21.8 \cdot \mathrm{C}\end{array}$ \\
\hline
\end{tabular}
LABOFATOAY ANALYSES

\begin{tabular}{|c|c|c|c|}
\hline Analyte & Recult & Mod & Unit \\
\hline 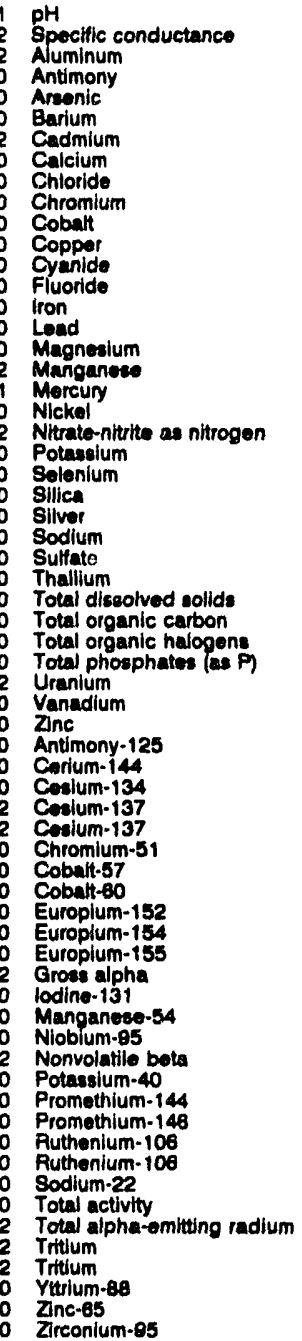 & 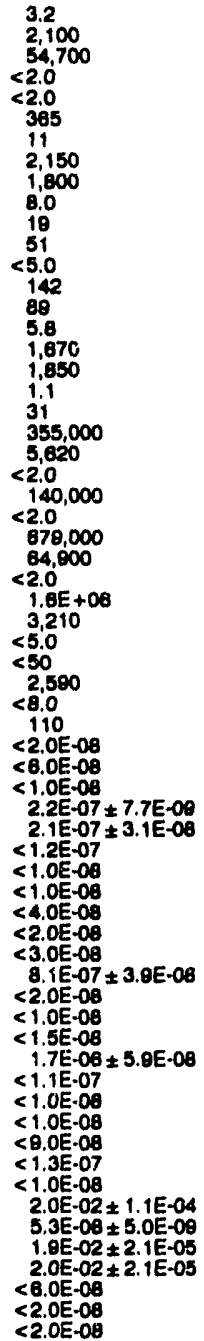 & $\begin{array}{l}\text { J1 } \\
\text { Ja }\end{array}$ & 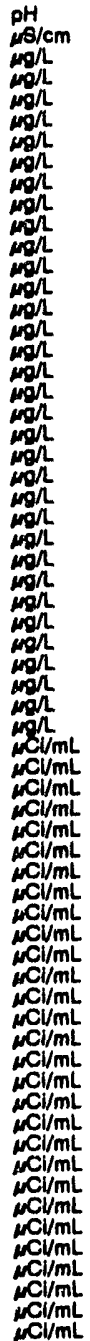 \\
\hline
\end{tabular}


ANALYTICAL RESULTS

\section{WELL FSB 78A}

MEASUPEEMENTS CONOUCTED IN THE FIELD
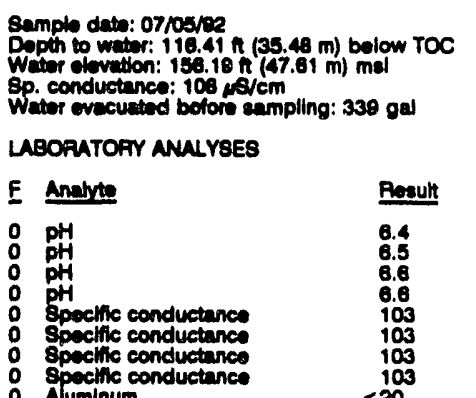

Epecilic conductance

Auminum

Numinum

: Antimony

o Antimony

o Areenic

o Areanic

Arenic

0 Barium

Barium

Cadmium

Cedmium

Cacium

Chionte

Chionde

o Chromium

Chromium

o Cobalt

O Cobalt

Copper

O Copper

Cyanide

o Fluoride

Fluoride

( Fluorido

o iron

0 Iron

0 Lead

0 Lnad

Magnewium

o Magnealum

- Magnexium

Manganeas

Mangeneces

Moreury

Mercury

O Nickel

O Nickel

o Nitrat is nitrogon

0 Nitrate-nititio ea nitrogen

Potancium

Potacium

Selonium

o selonium

Solonium

o Slike.

0 Silica

o sitwer

Sitwer

Sodium

Sodium

o sodlum

O Sultate

S Sulfate

0 Thallium

Thallum

Thallium

Total diseotved solids
WELL FSB 76A colloeted on 07/05/92, laboratory analyeen (cont)
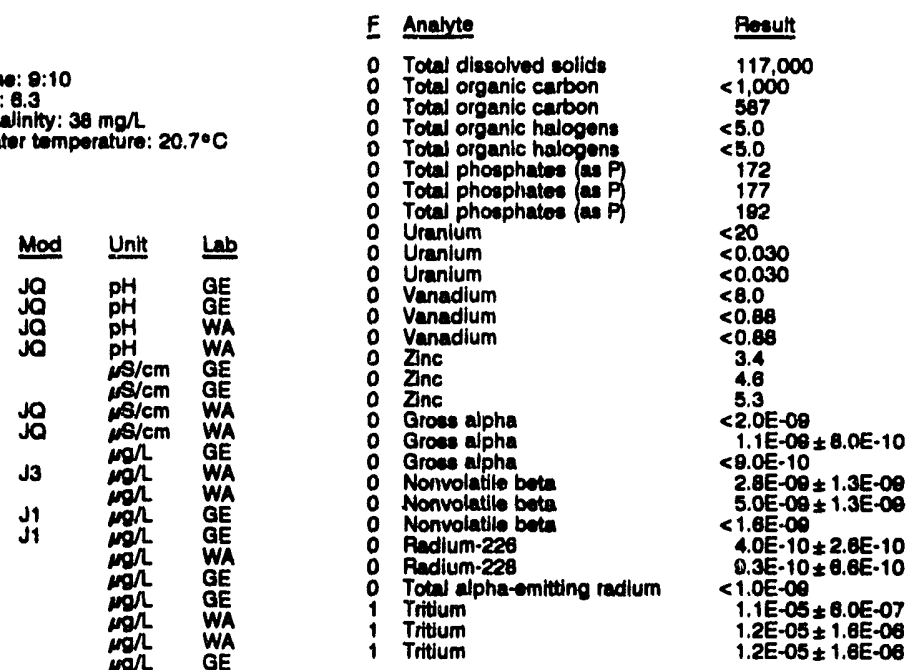

Mod Unit Lub

Time: $9: 10$

PH: 6.3 . $38 \mathrm{mgh}$

Water temperature: $20.7 \circ \mathrm{C}$

$1.2 E-05 \pm 1.6 \mathrm{E}-00$

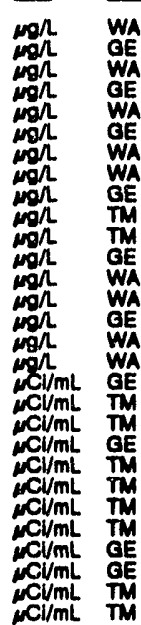

$\mathrm{Cl} / \mathrm{mL} \mathrm{TM}$

WELL FSB 78A Replicate

MEASUREMENTS CONDUCTED IN THE FIELD

Sample dato: 07/05/92

Depth to water: $118.41 \mathrm{Ht}(35.48 \mathrm{~m})$ below TOC

Water elevation: $158.18 \mathrm{~h}(47.81 \mathrm{~m}) \mathrm{msl}$

Wator evacuated bofore sampling: $339 \mathrm{gal}$

LABORATORY ANALYSES

E Anelyte

$\mathrm{O} \mathrm{PH}^{\mathrm{PH}}$

Spectific conductance

Speefific conductance

- Auminumi

Aluminum

Antimony

Arsenic

Barium

Barium

Cadmium

Calcium

Cacium

Chlorida

Chromium

Chromium

: Cobal

Coppor

Coppor

Cyenide

Filuoride

Fluoride

$\begin{array}{lll}0 & \text { Iron } \\ 0 & \text { tron } \\ 0 & \text { Losd } \\ 0 & \text { Load }\end{array}$

Load

Magnesium

Megnosium

Manganece

Mercury

Mercury

Morcuy

Nicke

Nitrate as nitrogen

Nitrate-niturite as nittrogen

Potansium

Potasslum

Solonlum

silica

Silica

Silvor

Sodium

o $\begin{aligned} & \text { Sodium } \\ & 0 \text { Sulfate }\end{aligned}$
Time: $0: 10$

Alkalinity: $38 \mathrm{man}$

Water tomperature: $\mathbf{2 0 . 7} \mathrm{C}$ 
WEL F88 784 collocted on 07/05/92, laboratory analyees (cont)

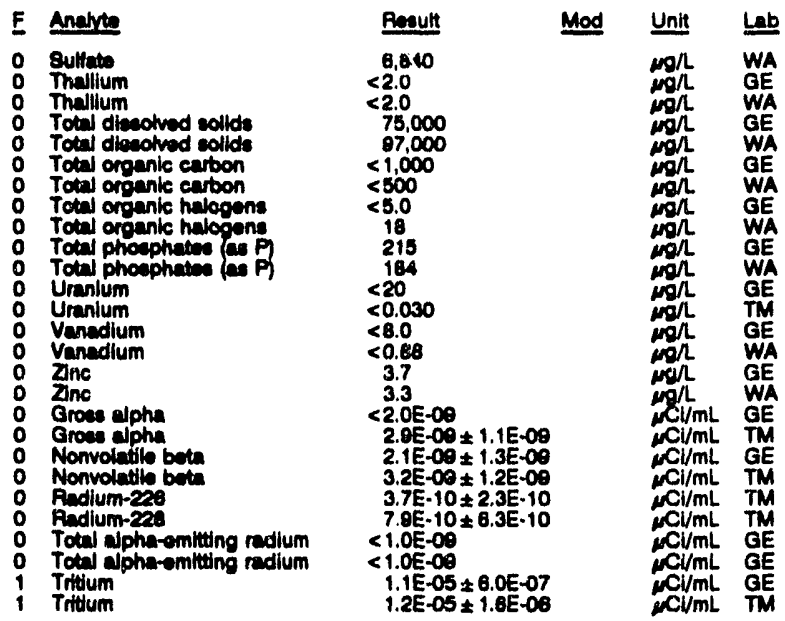

WELL. FSB 78B

MEASUPEMENTS CONDUCTED IN THE FIELD

Sample data: 07/05/02 Depth to watien: $118.22 \mathrm{nt}(38.03 \mathrm{~m})$ below TOC Water elevetion: $154.58 \mathrm{n}(47.12 \mathrm{~m}) \mathrm{ms}$

Time: $8: 20$

Nikalinity: $86 \mathrm{mg} /$ Water tomperature: $20.3^{\circ} \mathrm{C}$

\section{LABOPATORY ANALYSES}

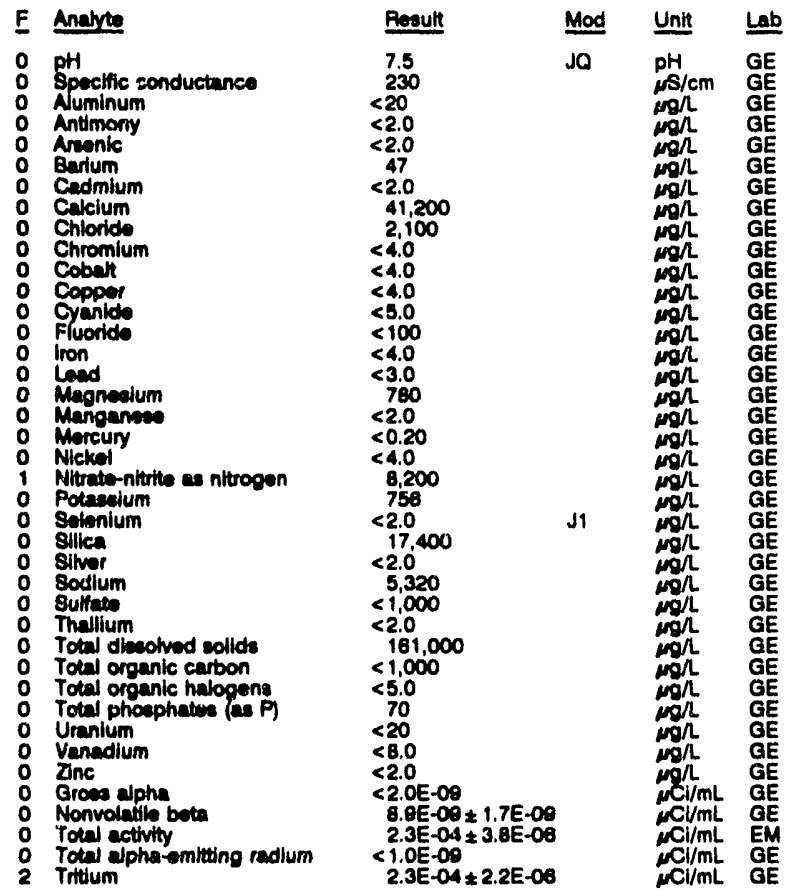

WELL FSB 78C

MEASUREMENTS CONDUCTED IN THE FIELD

Sample date: 07/05/82

Dopth to wator: $64.85 \mathrm{ft}(19.77 \mathrm{~m})$ bolow TOC

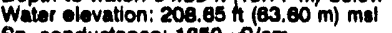

Water evacuated before sempling:

The well went dry during purging: $28 \mathrm{gal}$

LABORATORY ANALYSES

E Analyte

2 Spocitic conductance

2 Aluminum

a Antimile

0 Barium

2 Cadmium

: Callum

0 Chromium

2 Cobalt

O Coppet

0 Fluoride

2 lion

2 Load

2 Manganoes

1 Morcury

2 Nitrato-nitrtito as nitrogen

Gilice

Sirver

Sodium

0 Sulfate

Total dissolved solic

Total organic carbon

o Total organic halogens

Uranium

0 Zanc

0 Antimony-125

O Cerium-144

Cesium-134

Chromium-51

Cobalt-57

0 Cobalt-60

o Europlum-152

o Europlum-155

2 Gross ajph

lodine-131

Manganeee-54

Nonvolatlis both

Potansium-40

Promethium-144

Puthenlum-108

Ruthenium-106

Sodium-22

Totul activty

Total alpha-emitting radium

Tritlum

Yttrium-89

Zirconium-95

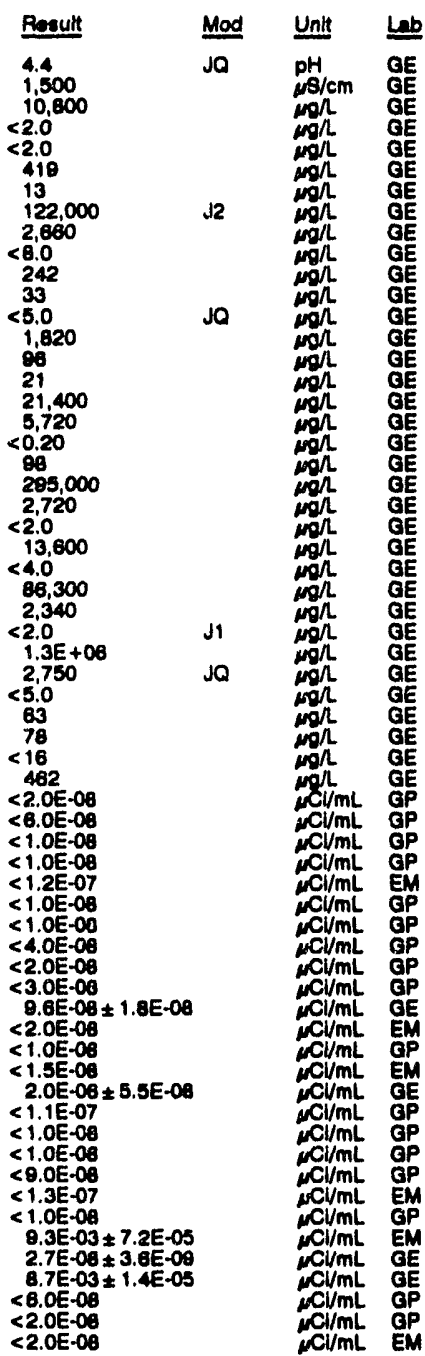

\section{WELL FSB 79}

MEASUREMENTS CONDUCTED IN THE FIELD

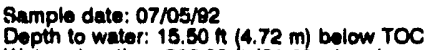
Wapth to wator: $15.50 \mathrm{~h}(4.72 \mathrm{~m})$ bolow $10 \mathrm{c}$

Wp conductance 2 .30

W. conductance:

Tims: 18:35

pH: 3.6 : $0 \mathrm{mon}$

Water tomperature: $22.2{ }^{\circ} \mathrm{C}$

LABORATORY ANALYBES

\begin{tabular}{|c|c|c|c|}
\hline Analyte & Result & Mod & Unit \\
\hline $\begin{array}{l}\text { pH } \\
\text { Spocific conductance } \\
\text { Aluminum } \\
\text { Antimony } \\
\text { Arsenic } \\
\text { Barlum } \\
\text { Cadmlum } \\
\text { Calcium } \\
\text { Chloride }\end{array}$ & $\begin{array}{l}3.5 \\
1,000 \\
41,800 \\
<2.0 \\
<2.0 \\
415 \\
3.6 \\
1,030 \\
1,580\end{array}$ & Ja & 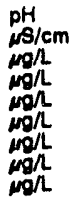 \\
\hline
\end{tabular}


ANALYTICAL RESULTS

WELL FBB 70 collectad on 07/05/92, laboratory analyees (cont)

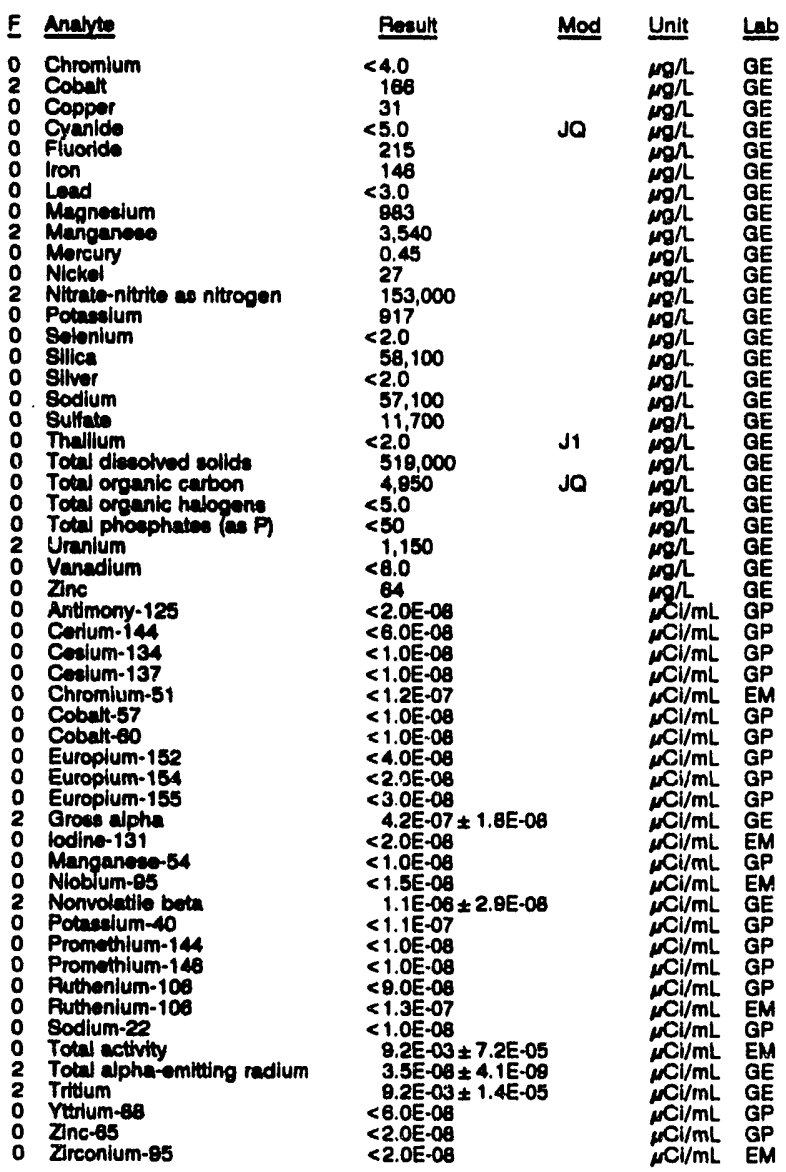

\section{WELL FSB 79A}

\section{MEASUREMENTS CONDUCTED IN THE FIELD}

\section{Sample date: 07/05/e2 \\ Depth a water: 59.97 n (18.28 m) below TOC \\ Whitor ciavation: $158.13 \mathrm{ht}$ (48.24 \\ Watcf evecuated bofore sampling: $388 \mathrm{gal}$}

LABOPATOPY ANALYSES

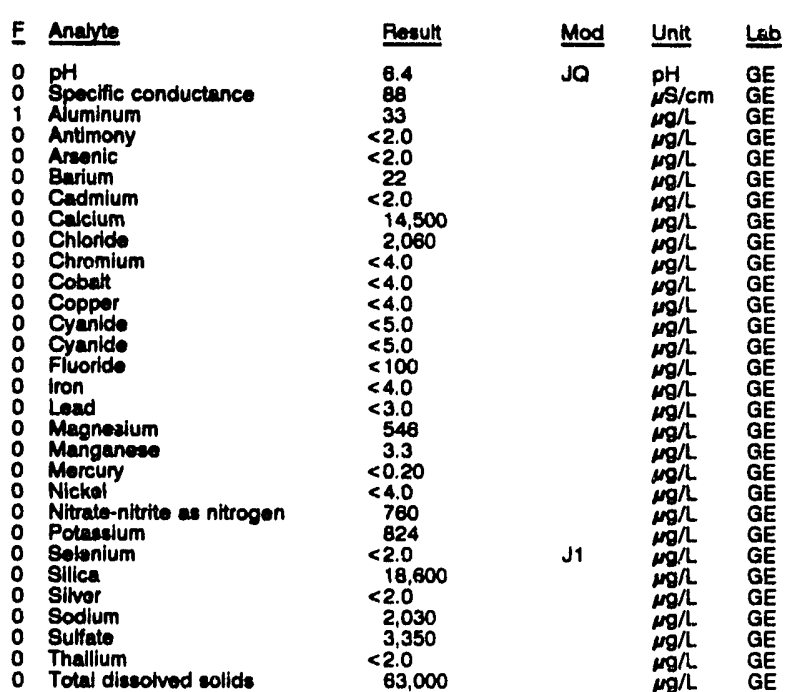

WELLL FSB 79A collected on 07/05/92, laboratory analyese (cont)

\begin{tabular}{|c|c|c|c|}
\hline $\mathbf{E}$ & Analyte & Prosutt & Unit \\
\hline $\begin{array}{l}0 \\
0 \\
0\end{array}$ & $\begin{array}{l}\text { Total organic carbon } \\
\text { Total organic halogens } \\
\text { Total phosphates (as P) } \\
\text { Uranlum } \\
\text { Vanadium } \\
\text { Znc } \\
\text { Gross alpha } \\
\text { Nonvolatio beta } \\
\text { Total alpha-omitting radium } \\
\text { Tritlum }\end{array}$ & $\begin{array}{l}<1.000 \\
<5.0 \\
250 \\
<20 \\
<8.0 \\
<2.0 \\
<2.0 E-09 \\
<2.0 E-09 \\
<1.0 E-09 \\
6.0 E-05 \pm 1.2 E-06\end{array}$ & 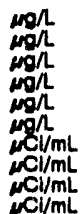 \\
\hline
\end{tabular}

WELL. FSB 79B

MEASUREMENTS CONDUCTEO IN THE FIELD

Sample date: 07/05/92

Time: 15:45

Water elevation: $158.36 \mathrm{tt}(48.27 \mathrm{~m}) \mathrm{msl}$ Alkalinity: $71 \mathrm{mg} / \mathrm{l}$

Sp. conductance: $185 \mathrm{\mu S} / \mathrm{cm}$ Watar tomperature: $22.0^{\circ} \mathrm{C}$

LABOFATORY ANALYSES

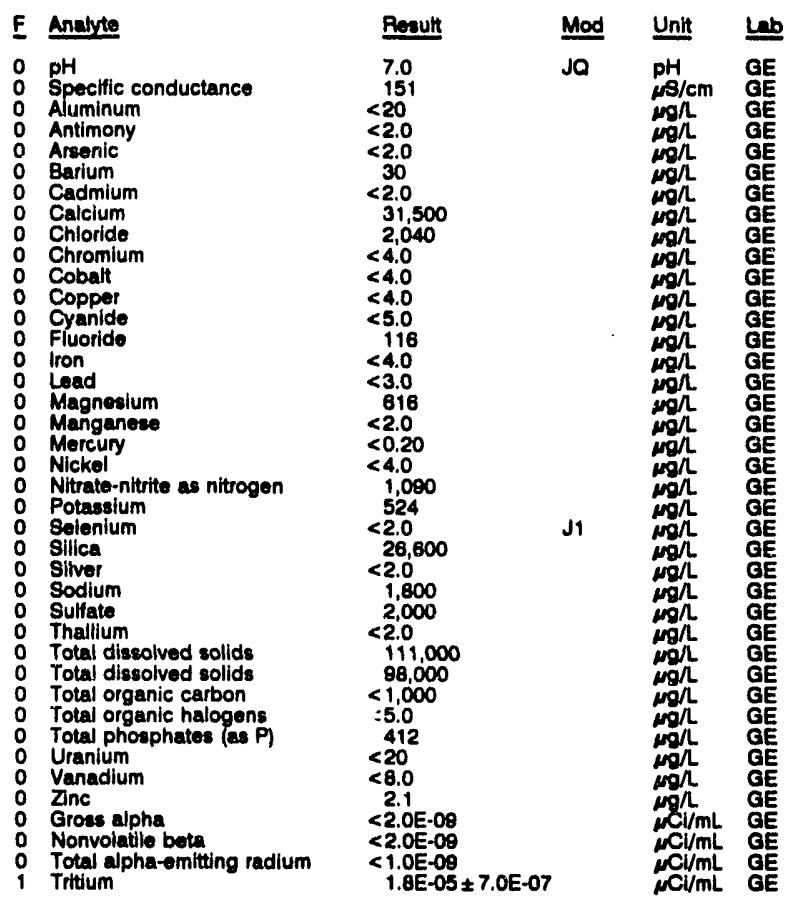

WELL FSB 79C

MEASUREMENTS CONDUCTED IN THE FIELD

Sample date: 07/05/92

Depth to water: $21.31 \mathrm{H}(6.50 \mathrm{~m})$ below TOC

Water elevation: $197.09 \mathrm{ft}(60.07 \mathrm{~m}) \mathrm{msl}$

Sp. conductance: $1305 \mu \mathrm{s} / \mathrm{cm}$

Water evacuated bofore sampling: $212 \mathrm{gal}$

LABOPATORY ANALYSES

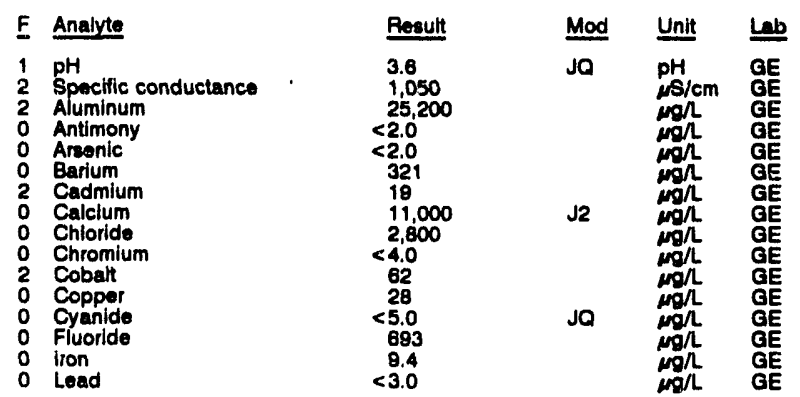


WEL F88 $78 \mathrm{C}$ collected on 07/05/82, laboratory analyses (cont)

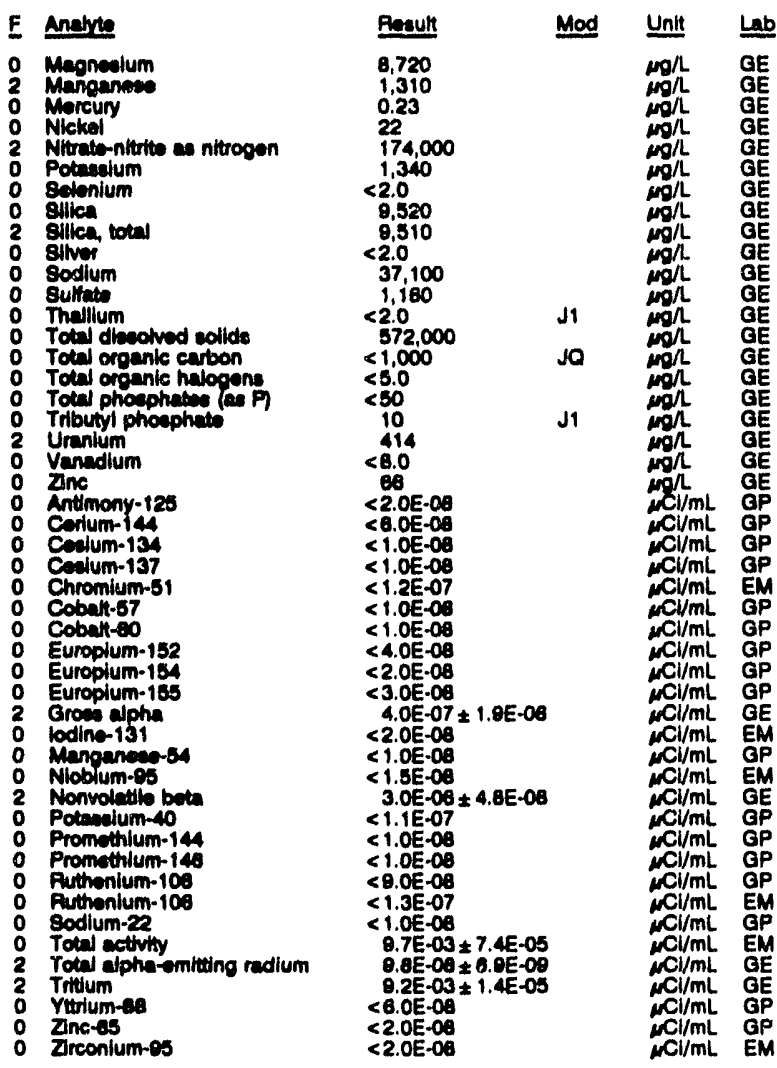

\section{WELL FSB 87A}

MEABUPEMENTS CONDUCTED IN THE FIELD

Sample dela: $07 / 00$ rer

Depth to water: 133.23 n $(40.81 \mathrm{~m})$ below TOC Water elovetion: $154.67 \mathrm{n}(47.11 \mathrm{~m}) \mathrm{mal}$ Sp. conductence: 105 reV/cm

LAOPATOPY ANALYESS

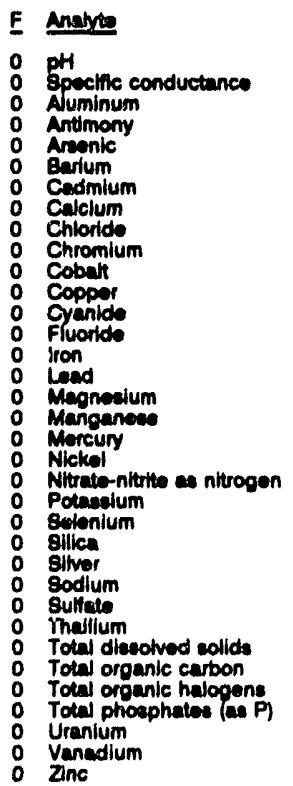

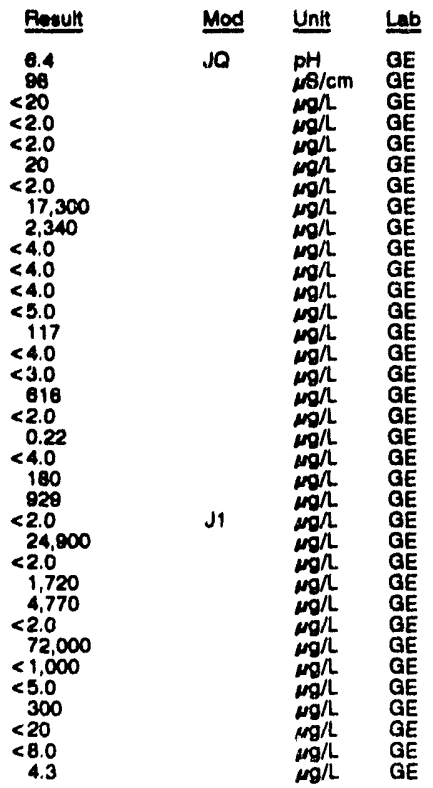

WELL F88 87A collected on 07/08/92, laboratory analyees (cont.)

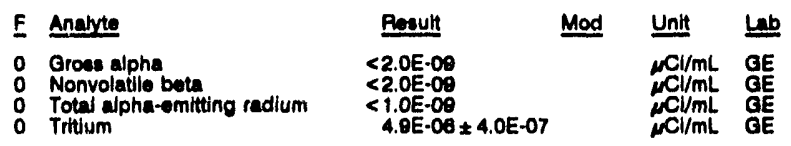

WELL FSB 87B

MEASUREMENTS CONDUCTED IN THE FIELD

Sample date: $07 / 08 / 92$ ( $131.62 \mathrm{~m})$ bolow TOC

Wator elovation; $151.28 \mathrm{ft}(46.11 \mathrm{~m}) \mathrm{mal}$ Alkalinity: $8 \mathrm{mgn}$

Water tomperature: $24.0 \circ \mathrm{C}$ Water evacuated bofore sampling: $161 \mathrm{gal}$

LABORATORY ANALYBES

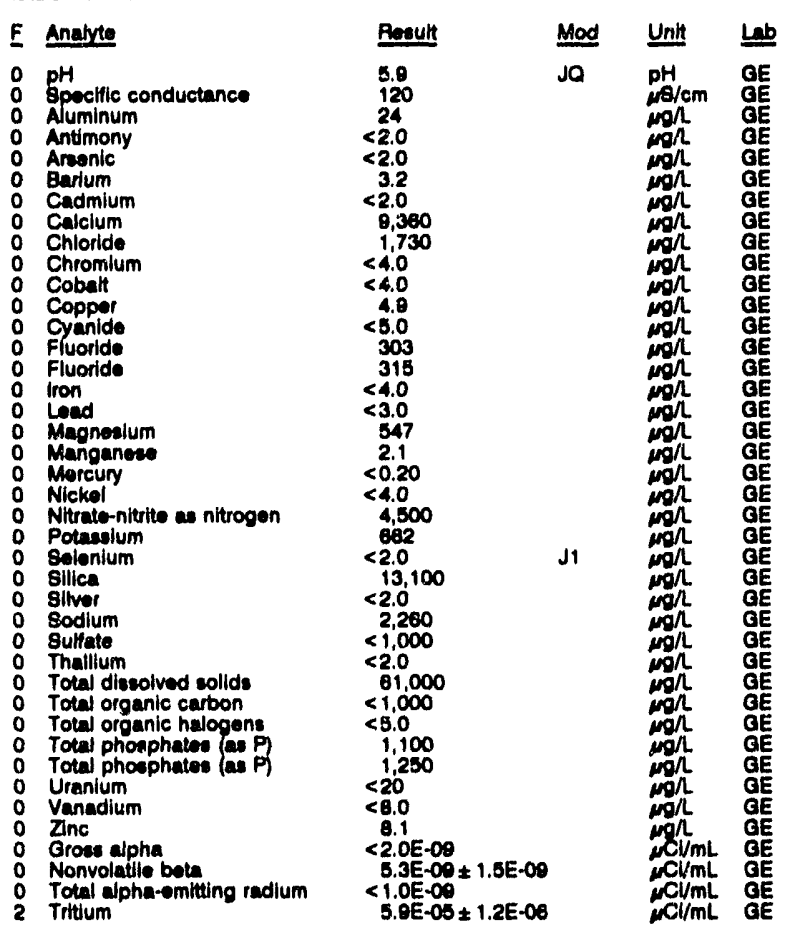

WELL FSB $87 C$

MEABUREMENTS CONDUCTED IN THE FIELD

\begin{tabular}{|c|c|}
\hline 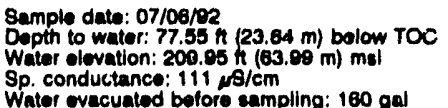 & $\begin{array}{l}\text { Time: } 13: 10 \\
\text { pH: } 5.6: 0 \\
\text { Alkalinity: } 7 \mathrm{mg} / \mathrm{L} \\
\text { Water tomporature: } 23.1 \cdot \mathrm{C}\end{array}$ \\
\hline
\end{tabular}
LABORATORY ANALYSES

$\begin{array}{ll}\text { E } & \text { Analute } \\ 0 & \text { pH } \\ 0 & \text { Spocific conductance } \\ 0 & \text { Aluminum } \\ 0 & \text { Antimony } \\ 0 & \text { Areonic } \\ 0 & \text { Barlum } \\ 0 & \text { Cadmium } \\ 0 & \text { Calclum } \\ 0 & \text { Chloride } \\ 0 & \text { Chromium } \\ 0 & \text { Cobalt } \\ 0 & \text { Copper } \\ 0 & \text { Cyanide } \\ 0 & \text { Fluoride } \\ 0 & \text { Iron } \\ 0 & \text { Lead } \\ 0 & \text { Magnoaium } \\ 0 & \text { Manganese } \\ 0 & \text { Mercury } \\ 0 & \text { Nickel } \\ 2 & \text { Nitrato-nitrito as nitrogen }\end{array}$
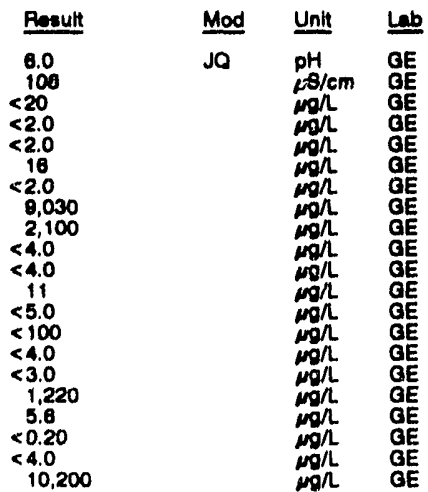
ANALYTICAL RESULTS

WELL F88 87C collectod on 07/00/92, laboratory anelyese (cont).
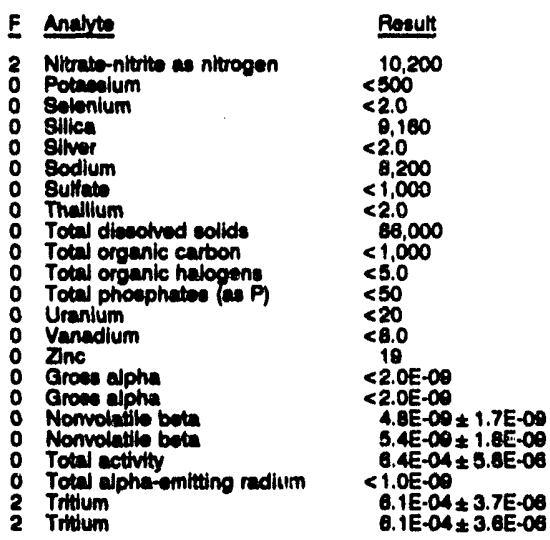

Mod

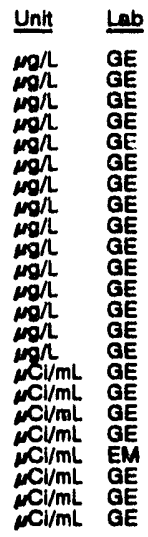

\section{WELL FSB 87D}

\section{MEASUREMENTS CONDUCTED IN THE FIELD}

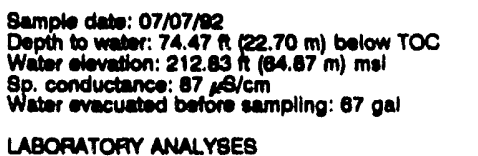

Time: 11:46

PH: A.1 0 mal

Water temperature: $24.8^{\circ} \mathrm{C}$

\section{LABOFATOFY ANALYBES}
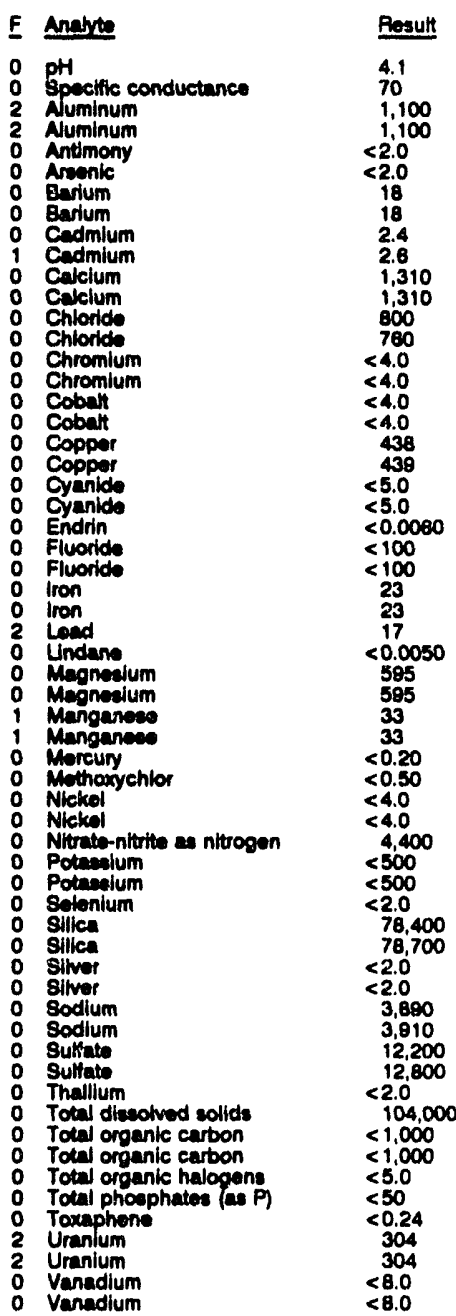

WEL FSB 870 collected on 07/07/02, laboratory analyees (cont)
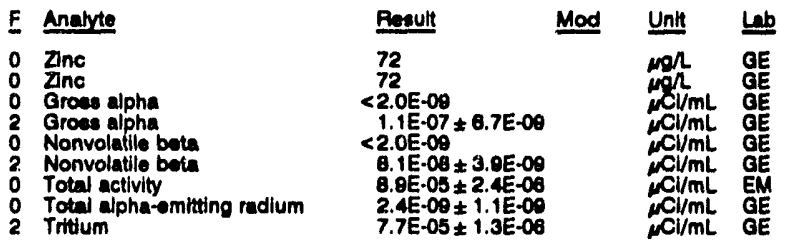

WELL FSB 88C

MEASUREMENTS CONDUCTED IN THE FIELD
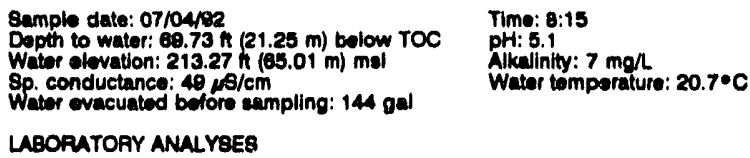

LABORATORY ANALYEES

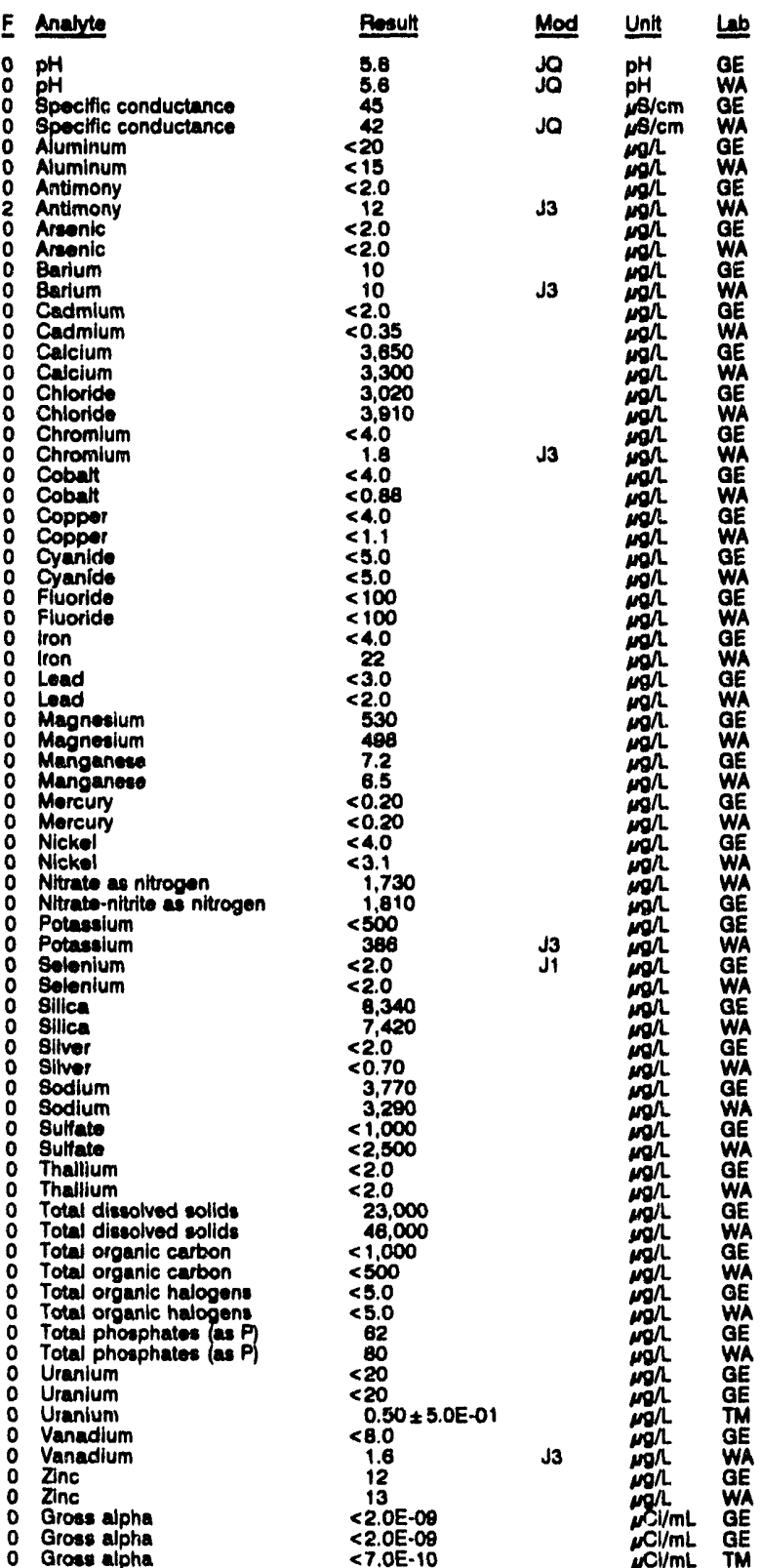




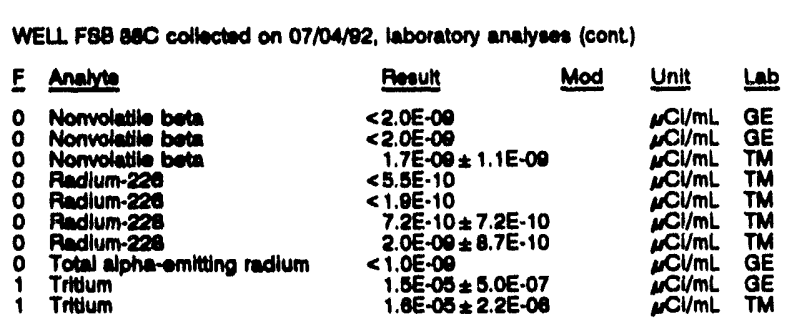

WELL FSB 88C Replicate

\section{MEASUREMENTS CONDUCTED IN THE FIELD}
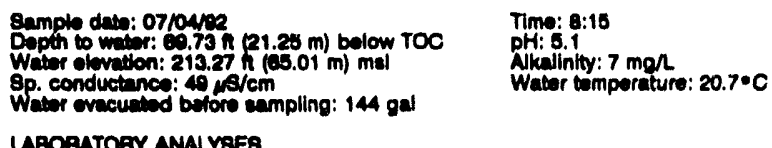

\section{LABORATOAY ANALYSES}

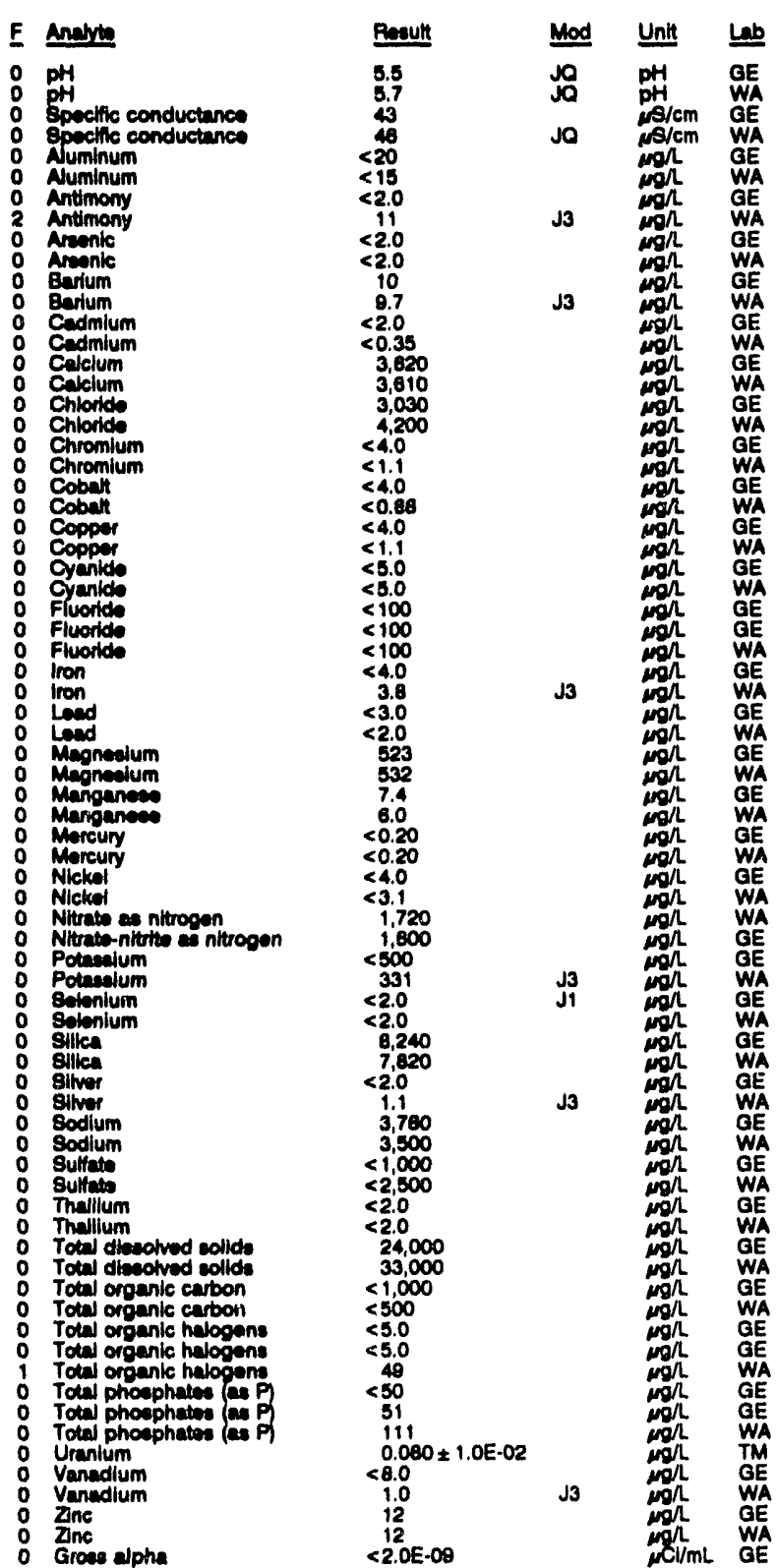

WELL FSB 88C colloctod on 07/0492, laboratory analywer (cont)

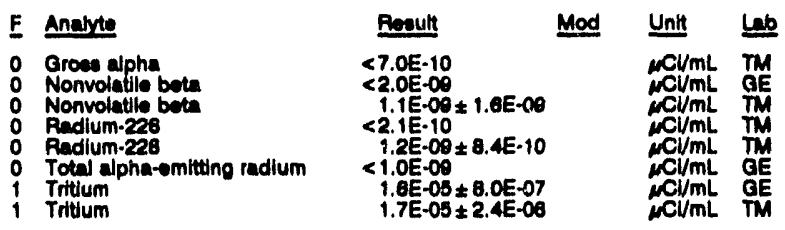

\section{WELL. FSB 88D}

MEASUREMENTS CONDUCTED IN THE FIELD

Sample data: 07/04/02

Dopth to water: $65.40 \mathrm{fh}(10.00 \mathrm{~m})$ bolow TOC

Water clovation: 210.02 h $(00.12 \mathrm{~m}) \mathrm{me}$

8p. conductance: $428 \mathrm{\mu} / \mathrm{cm}$

Wator evacuatiod boforo eampling: $8 \mathrm{gal}$

pH: 4.8 . 8 ikalinity: $8 \mathrm{mgh}$ The woll wont dry during purging.

LABORATOAY ANALYBES

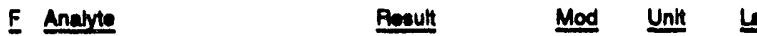

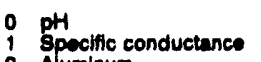

2 Aluminum

Antenic

Aranic

Cadmium

Culcium

Chromium

Cobalt

Coppor

: Cyanldo

iron

2 Lead

2 Manganece

Mercuny

Nitrato-nitrito as nitrogen

Potacedum

Solenium

silver

Sodium

Thallium

Toter diesolvod eollids

- Total organle carbon

Total phosphates (as P)

Uranlum

O Zne

- Antimony-125

Antimony-125

O Corlum. 144

- Cortum-144

Conjum-134

Conium-133

Ceslum. 137

: Chromium-51

O Cobatit.57

- Cobalt-60

Cobart-6

Europlum-152

Europlum-154

Europlum-15a

Europlum-155

O Europlum-165

Gools alph

Mangunewe-54

Nonganneas

Nonvolatio beta

Potasaium-40

Promethium-144

Promoinium-144

Promothium-14

Ruthenium-100

Ruthenium-106

Authonium-109

0 Sodium.22

Sodium-22

Total alph

Yturium-88

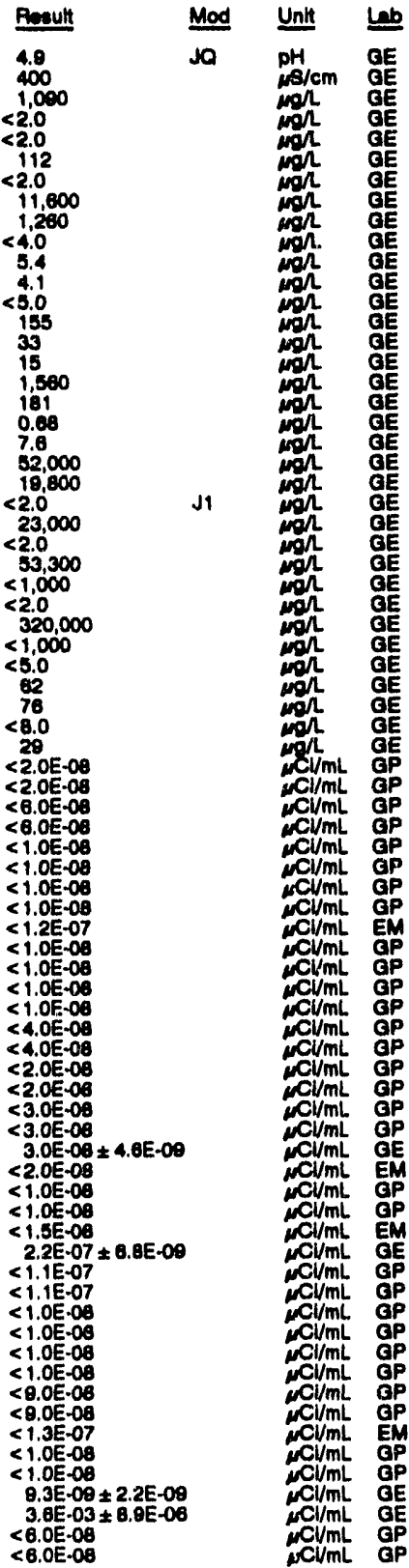


ANALYTICAL RESULTS

WELL FBB ESD colbetod on 07/O4\%2, laboratory analyees (cont)

\begin{tabular}{|c|c|c|c|}
\hline F Analyte & Reault & Mod & Unit \\
\hline $\begin{array}{ll}0 & \text { Zncess } \\
0 & \text { Znces } \\
0 & \text { Zreonlum-es }\end{array}$ & $\begin{array}{l}<2.0 E-09 \\
<2.05-09 \\
<2.0 E-09\end{array}$ & & $\underset{N \mathrm{Cl} / \mathrm{mL}}{\mathrm{Cl} / \mathrm{mL}}$ \\
\hline
\end{tabular}

\section{WELL FSB $89 C$}

MEABUAEMENTS CONOUCTED IN THE FIELD

\begin{tabular}{|c|c|c|c|c|c|}
\hline \multicolumn{3}{|c|}{ 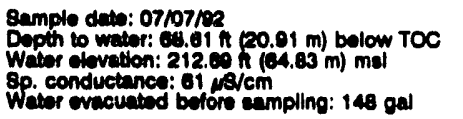 } & \multicolumn{3}{|c|}{$\begin{array}{l}\text { Time: } 14: 40 \\
\text { pH: : } 5.6 \\
\text { Alkelinity: } 10 \mathrm{mgh} \\
\text { Water temperature: } 22.6^{\circ} \mathrm{C}\end{array}$} \\
\hline \multicolumn{6}{|c|}{ LAEORATOFY ANALYEES } \\
\hline & Anerde & Renult & Mod & Unit & $\underline{\mathrm{L}}$ \\
\hline & 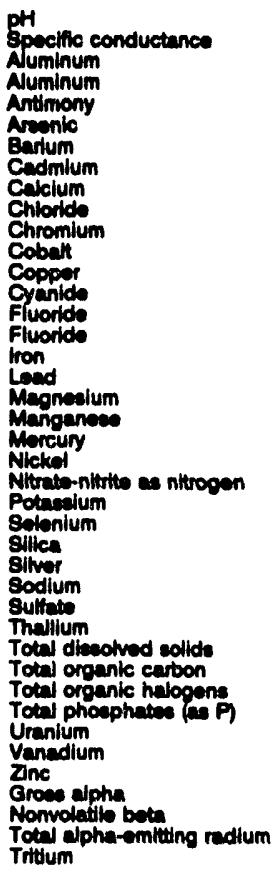 & $\begin{array}{r}5.0 \\
110 \\
305 \\
330 \\
<2.0 \\
<2.0 \\
15 \\
<2.0 \\
6,800 \\
2,870 \\
<4.0 \\
<4.0 \\
9.8 \\
<5.0 \\
<100 \\
<100 \\
<4.0 \\
<3.0 \\
464 \\
14 \\
<0.20 \\
<4.0 \\
<50 \\
<500 \\
<2.0 \\
8,460 \\
<2.0 \\
3,680 \\
<1,000 \\
<2.0 \\
37,000 \\
<1,000 \\
<5.0 \\
<50 \\
<20 \\
<8.0 \\
15 \\
<2.0 E-09 \\
<2.0 E-00 \\
<1.0 E-09 \\
1.7 E-05\end{array}$ & Ja & 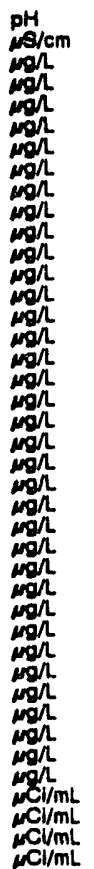 & $\begin{array}{l}\mathrm{GE} \\
\mathrm{GE} \\
\mathrm{GE} \\
\mathrm{GE} \\
\mathrm{GE} \\
\mathrm{GE} \\
\mathrm{GE} \\
\mathrm{GE} \\
\mathrm{GE} \\
\mathrm{GE} \\
\mathrm{GE} \\
\mathrm{GE} \\
\mathrm{GE} \\
\mathrm{GE} \\
\mathrm{GE} \\
\mathrm{GE} \\
\mathrm{GE} \\
\mathrm{GE} \\
\mathrm{GE} \\
\mathrm{GE} \\
\mathrm{GE} \\
\mathrm{GE} \\
\mathrm{GE} \\
\mathrm{GE} \\
\mathrm{GE} \\
\mathrm{GE} \\
\mathrm{GE} \\
\mathrm{GE} \\
\mathrm{GE} \\
\mathrm{GE} \\
\mathrm{GE} \\
\mathrm{GE} \\
\mathrm{GE} \\
\mathrm{GE} \\
\mathrm{GE} \\
\mathrm{GE} \\
\mathrm{GE} \\
\mathrm{GE} \\
\mathrm{GE} \\
\mathrm{GE} \\
\mathrm{GE}\end{array}$ \\
\hline
\end{tabular}

\section{WELL FSB 89D}

MEASUREMENTS CONOUCTED IN THE FIELD

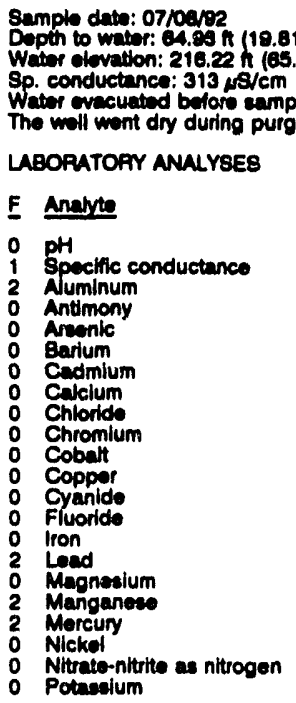

\section{Time: 12:05}

PH: 4.4 ilinity: $0 \mathrm{mon}$

Water tomperature: $24.8^{\circ} \mathrm{C}$

LABOPATOFY ANALYSES

\begin{tabular}{|c|c|c|c|}
\hline E Analyte & Result & Mod & Unit \\
\hline $\begin{array}{l}\text { pH } \\
\text { Specific conductance } \\
\text { Auminum } \\
\text { Antimony } \\
\text { Aveenic } \\
\text { Bartum } \\
\text { Cadmium } \\
\text { Calclum } \\
\text { Chloride } \\
\text { Chromium } \\
\text { Cobalt } \\
\text { Copper } \\
\text { Gyanide } \\
\text { Fluoride } \\
\text { lron } \\
\text { Lead } \\
\text { Magnasium } \\
\text { Manganese } \\
\text { Morcury } \\
\text { Nickel } \\
\text { Nitrato-nitrite as nitrogen } \\
\text { Potaselum }\end{array}$ & $\begin{aligned} & 4.5 \\
& 250 \\
& 3,810 \\
&<2.0 \\
&<2.0 \\
& 56 \\
&<2.0 \\
& 2,820 \\
& 2,790 \\
&<4.0 \\
& 6.5 \\
& 20 \\
&<5.0 \\
& 163 \\
& 88 \\
& 20 \\
& 898 \\
& 189 \\
& 5.1 \\
& 4.5 \\
& 320 \\
& 863\end{aligned}$ & JO & 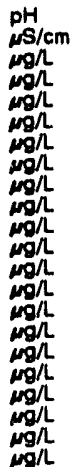 \\
\hline
\end{tabular}

WELL F8B 890 collocted on 07/08/92, laboratory analyese (cont)

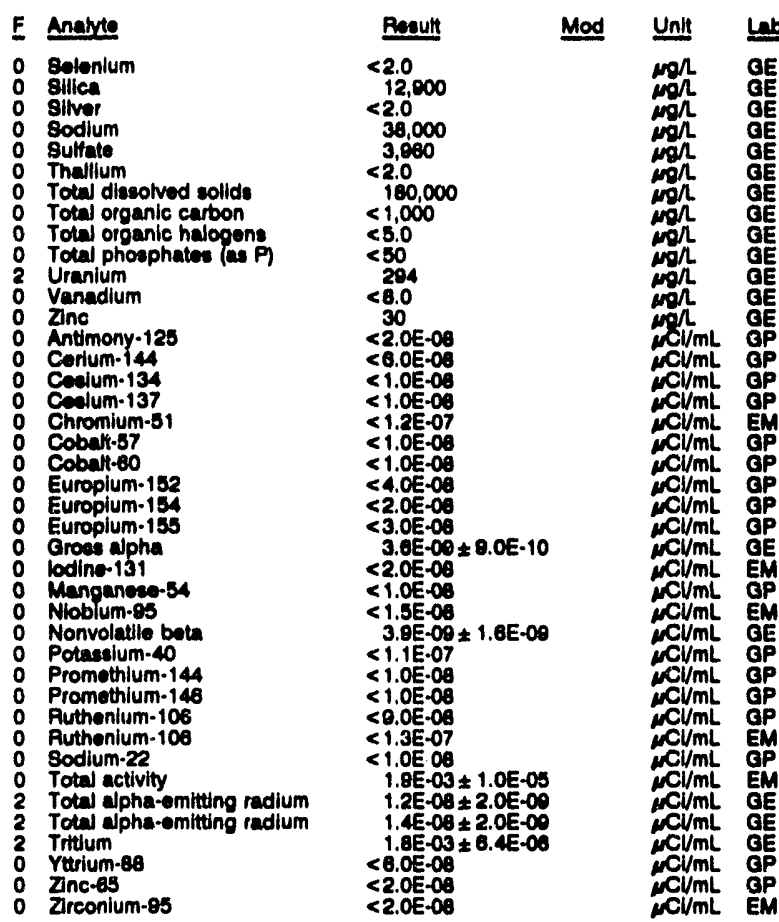

\section{WELL FSB 90C}

\section{MEASUREMENTS CONDUCTED IN THE FIELD}

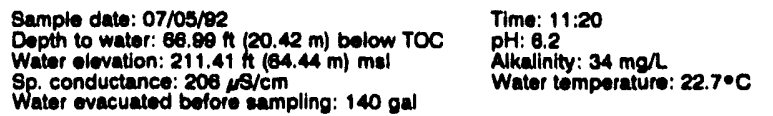

LABOAATOAY ANALYSES

\begin{tabular}{|c|c|c|c|c|c|}
\hline$F$ & Anaryte & Result & $\mathrm{Mod}$ & Unit & Lيb \\
\hline $\begin{array}{l}0 \\
0 \\
0 \\
0 \\
0 \\
0 \\
0 \\
0 \\
0 \\
0 \\
0 \\
0 \\
0 \\
1 \\
0 \\
0 \\
2 \\
0 \\
0 \\
0 \\
0 \\
0 \\
0 \\
0 \\
0\end{array}$ & 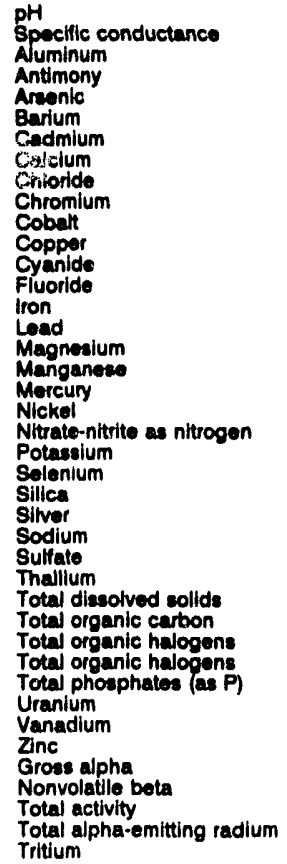 & $\begin{array}{l}6.5 \\
200 \\
68 \\
<2.0 \\
<2.0 \\
46 \\
<2.0 \\
15,800 \\
3,460 \\
<4.0 \\
<4.0 \\
<4.0 \\
<5.0 \\
226 \\
<4.0 \\
<3.0 \\
6,080 \\
28 \\
<0.20 \\
5.9 \\
14,600 \\
1,140 \\
<2.0 \\
8,960 \\
<2.0 \\
12,600 \\
1,220 \\
<2.0 \\
133,000 \\
<1,000 \\
<5.0 \\
<5.0 \\
<50 \\
<20 \\
<8.0 \\
11 \\
2.8 E-09 \pm 8.0 E-10 \\
2.1 E-08 \pm 2.4 E-09 \\
7.3 E-04 \pm 2.3 E-05 \\
<1.0 E-09 \\
7.1 E-04 \pm 3.9 E-06\end{array}$ & Ja & 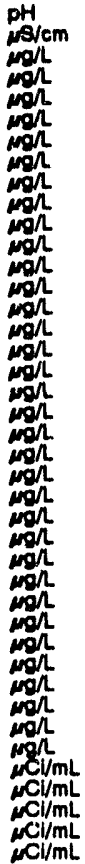 & 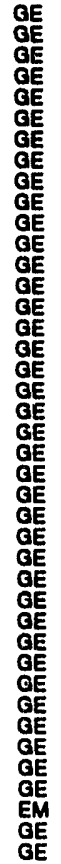 \\
\hline
\end{tabular}


WELL FSB 90D

MEASUAEMENTS CONOUCTED IN THE FIELD
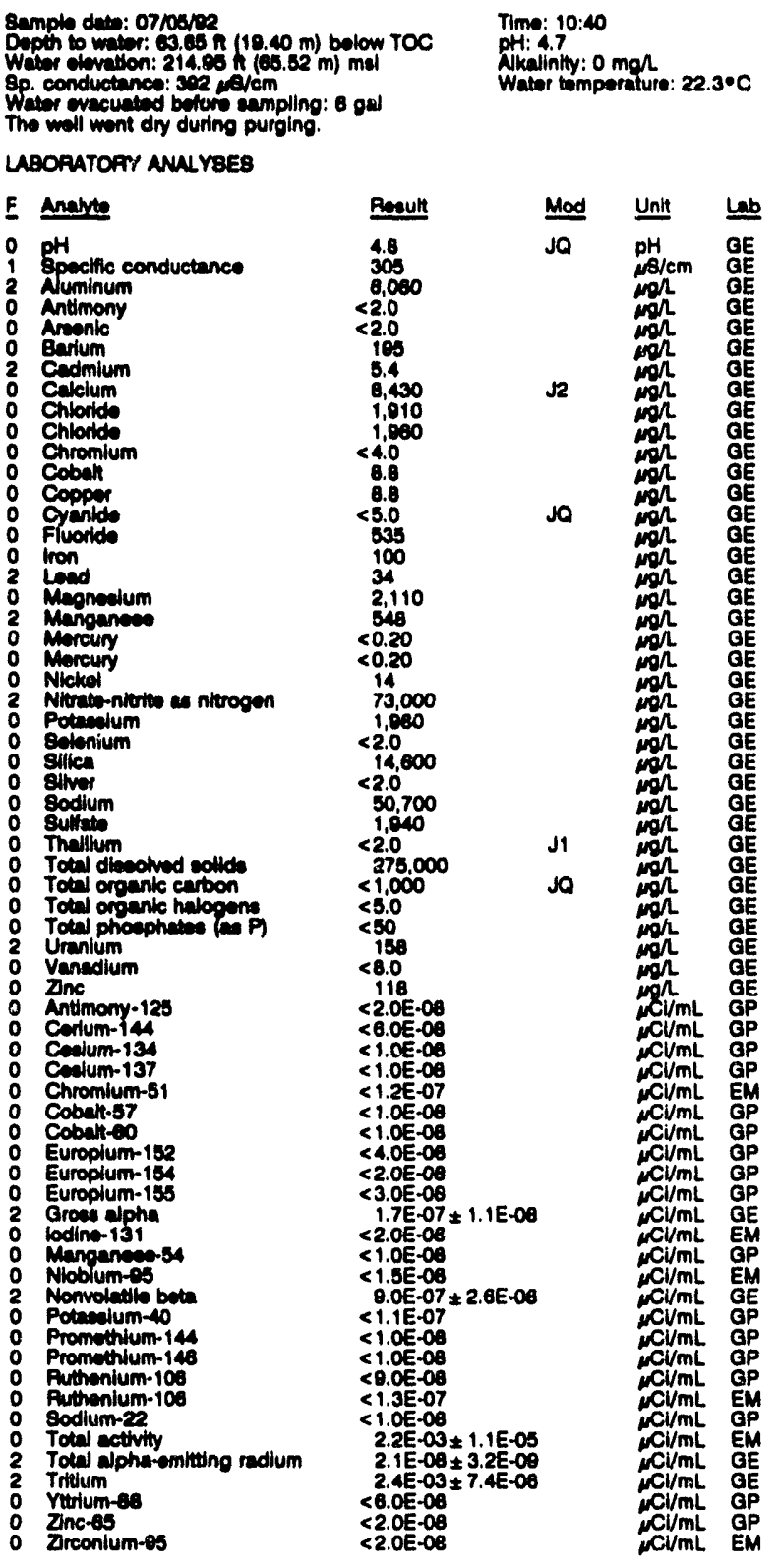

\section{WELL FSB 91C}

MEASUREMENTS CONDUCTED IN THE FIELD

\begin{tabular}{|c|c|c|c|c|c|}
\hline \multicolumn{3}{|c|}{ 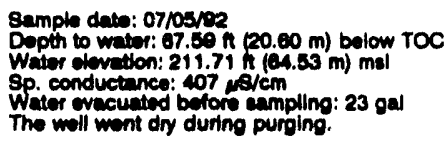 } & \multicolumn{3}{|c|}{$\begin{array}{l}\text { Time: } 10: 00 \\
\text { pht: } 5.2 \\
\text { Alkalinity: } 6 \mathrm{mghl} \\
\text { Water tomperature: } 21.6 \circ \mathrm{C}\end{array}$} \\
\hline \multicolumn{6}{|c|}{ LABOPATOFY ANALY YEES } \\
\hline E & Andres & Peenult & Mod & Unit & $\underline{\text { Lab }}$ \\
\hline & $\begin{array}{l}\text { pH } \\
\text { Spocific conductance } \\
\text { Aluminumi } \\
\text { Antimony } \\
\text { Ansonic } \\
\text { Barluin } \\
\text { Cedmium }\end{array}$ & $\begin{array}{l}5.6 \\
390 \\
1.090 \\
<2.0 \\
<2.0 \\
64 \\
3.1\end{array}$ & Jo & 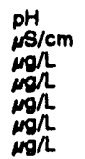 & $\begin{array}{l}G E \\
G E \\
G E \\
G E \\
G E \\
G E \\
G E\end{array}$ \\
\hline
\end{tabular}

WELL F8B $91 \mathrm{C}$ collectiod on 07/08/92, laboratory analyees (cont.)

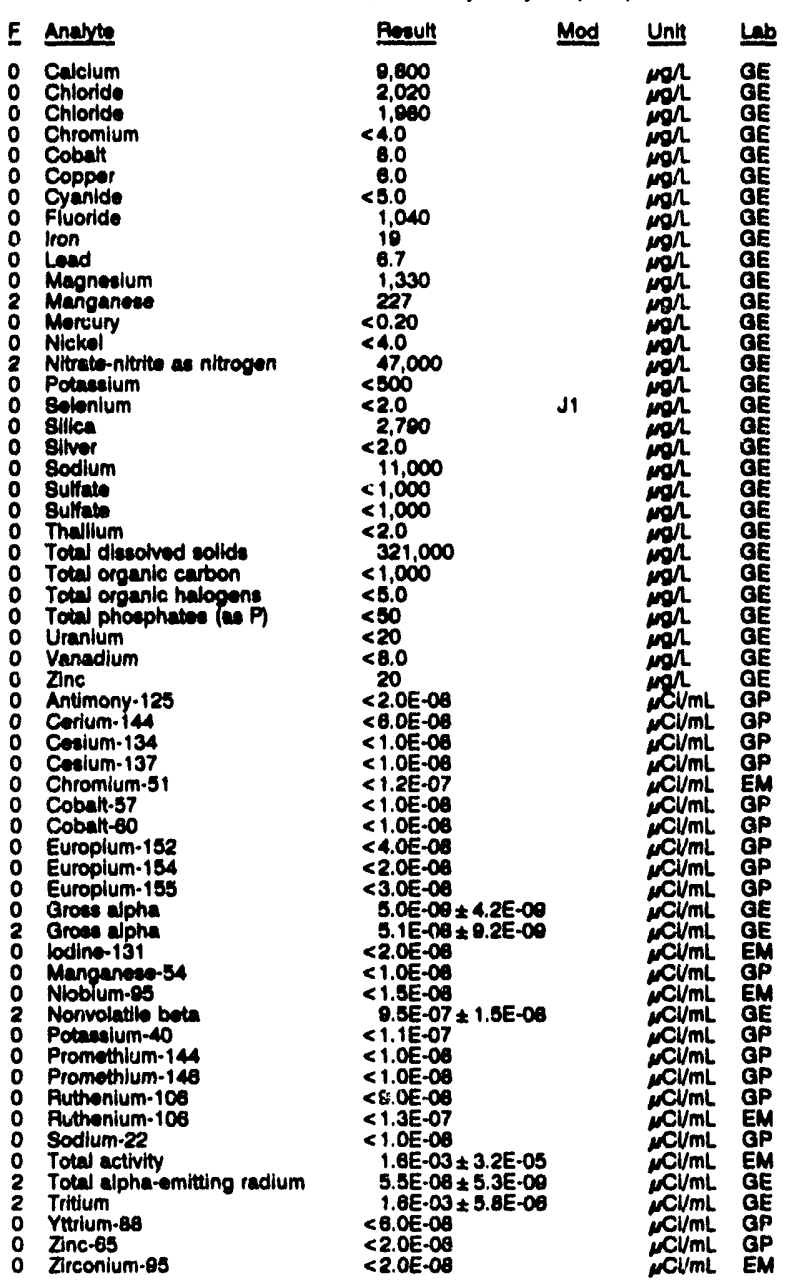

WELL FSB 91D

MEASUREMENTS CONDUCTED IN THE FIELD

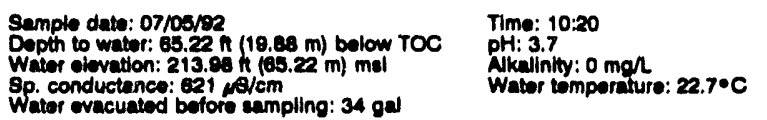

Witer ovacuated bofore sampling: $34 \mathrm{gal}$

LABORATOAY ANALYSES

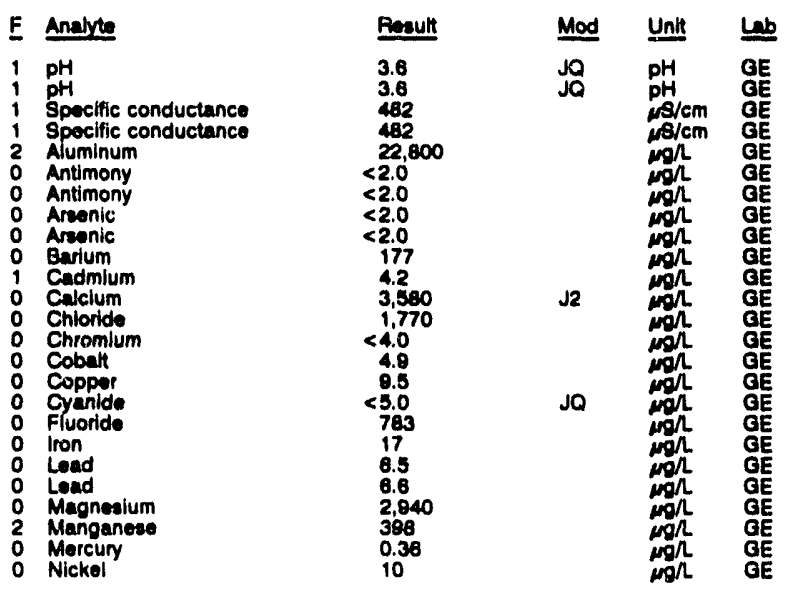


ANALYTICAL RESULTS

WELL F89 910 colbeted on 07/08/02, laboratory analyees (cone)

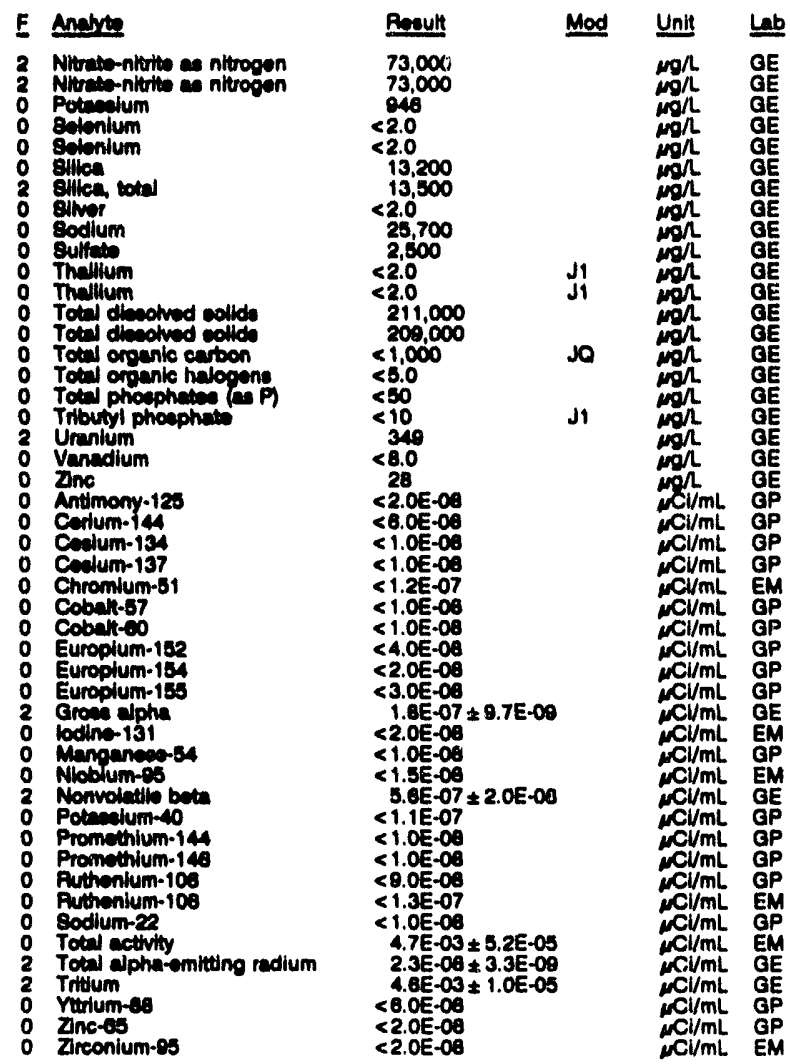

WELL FSB 92D

MEASUREMENTS CONDUCTED IN THE FIELD

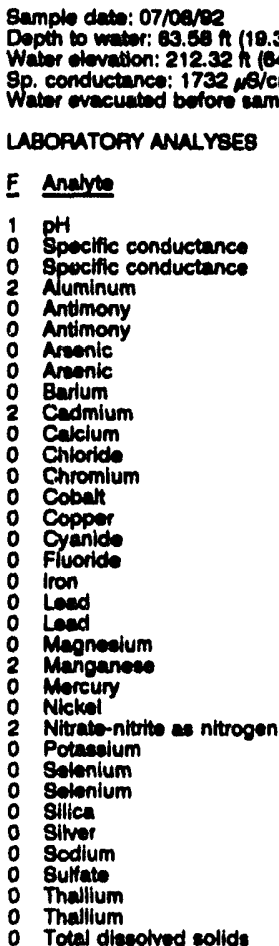

Dopth to watior: $63.68 \mathrm{n}(10.38 \mathrm{~m})$ bolow TOC conductunce: $1732 \mathrm{se/cm}$

LABOATOAY ANALYES

\begin{tabular}{|c|c|c|c|}
\hline Andros & Rosult & Mod & Unit \\
\hline 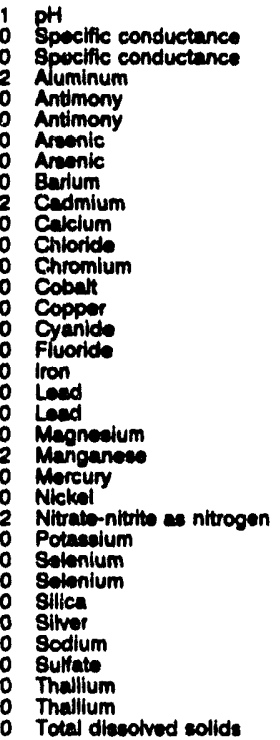 & $\begin{array}{l}3.6 \\
200 \\
200 \\
48,600 \\
<2.0 \\
<2.0 \\
<2.0 \\
<2.0 \\
260 \\
9.5 \\
8,460 \\
3,450 \\
<4.0 \\
8.0 \\
<4.0 \\
<5.0 \\
8.91 \\
16 \\
4.7 \\
4.9 \\
5,800 \\
664 \\
<0.20 \\
20 \\
255,000 \\
1.650 \\
<2.0 \\
<2.0 \\
6,830 \\
<2.0 \\
43.300 \\
2.640 \\
<2.0 \\
<2.0 \\
773,000\end{array}$ & $\begin{array}{l}\mathbf{J 1} \\
\mathbf{J 1} \\
\mathbf{v}\end{array}$ & 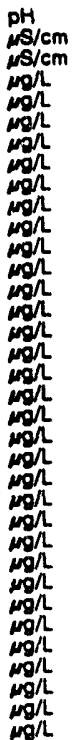 \\
\hline
\end{tabular}

WELL F8B 92D collocted on 07/08/92, laboratory analyese (cont)

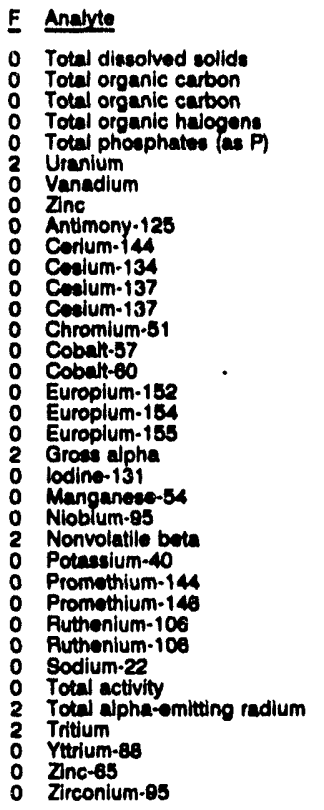

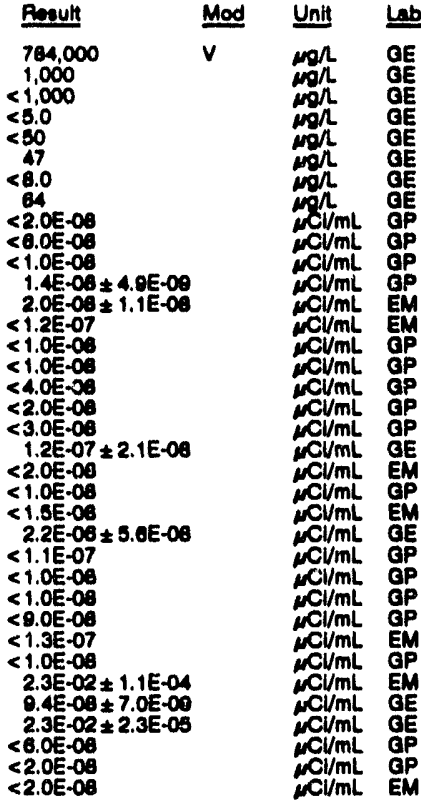

\section{WELL FSB 93C}

MEASUREMENTS CONDUCTED IN THE FIELD

Sample dato: 07/06/92
Depth to water: $68.67 \mathrm{n}(20.32 \mathrm{~m})$ bolow TOC

Water elevation: $209.33 \mathrm{~h}(63.87 \mathrm{~m}) \mathrm{msl}$

pH: 4.9

Water evacuated before sempling: 177 gal

Pater tomporture: $23.0 \circ \mathrm{C}$

LABORATORY ANALYSES

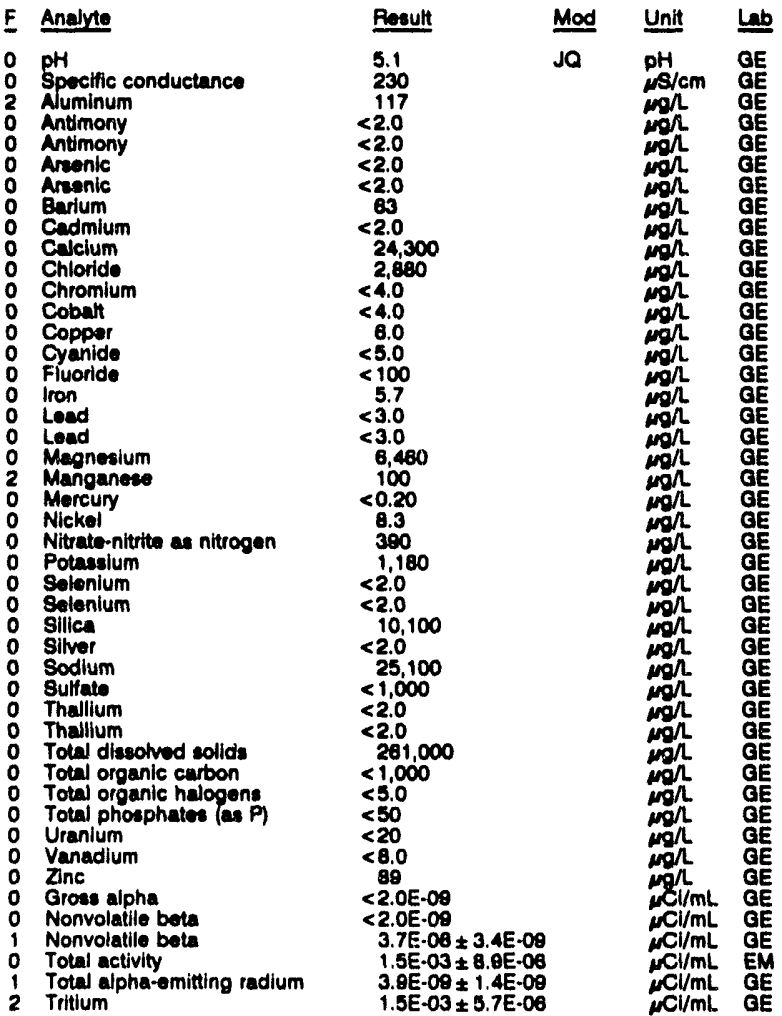


WELL FSB 930

MEAGUAEEMENTS CONDUCTED IN THE FIELD

8amplo dela: 07/0yper

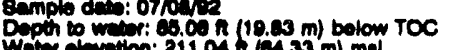
Wow condion: $211.041(04.33 \mathrm{~m}) \mathrm{mal}$

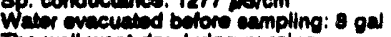
the woll weme diy during purging.

\section{LBORATOFY ANUL YBES}

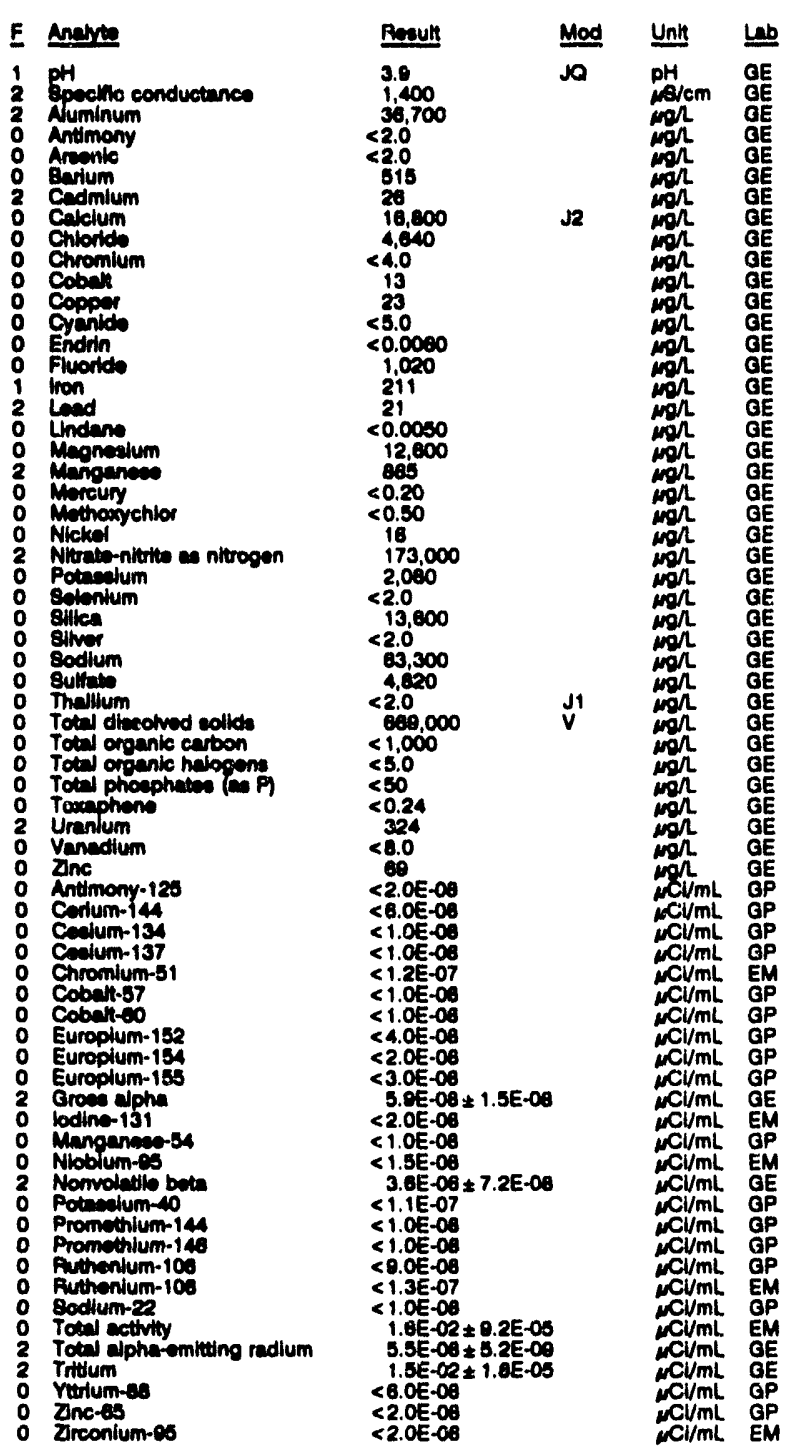

\section{WELL FSB 94C}

MEABUREMENTS CONDUCTED IN THE FIELD

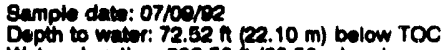

Watar ervetion: 203.86 h $(03.56 \mathrm{~m}) \mathrm{mal}$

Sp. conductance: $1048, \mathrm{~B} / \mathrm{cm}$

The well went dry during puming: $34 \mathrm{ge}$

LABOPATOPY ANALYSES

\begin{tabular}{|c|c|c|c|c|c|}
\hline$\underline{\mathbf{F}}$ & Andres & Rasult & Mod & Unit & Lab \\
\hline $\begin{array}{l}0 \\
2 \\
2 \\
0\end{array}$ & 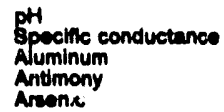 & $\begin{array}{l}4.6 \\
2,020 \\
2,270 \\
2,1 \\
<2.0\end{array}$ & Jo & 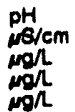 & $\begin{array}{l}\mathrm{GE} \\
\mathrm{dE} \\
\mathrm{GE} \\
\mathrm{GE} \\
\mathrm{GE}\end{array}$ \\
\hline
\end{tabular}

WELL F88 94C collected on 07/00/02, laboratory analyees (cont)

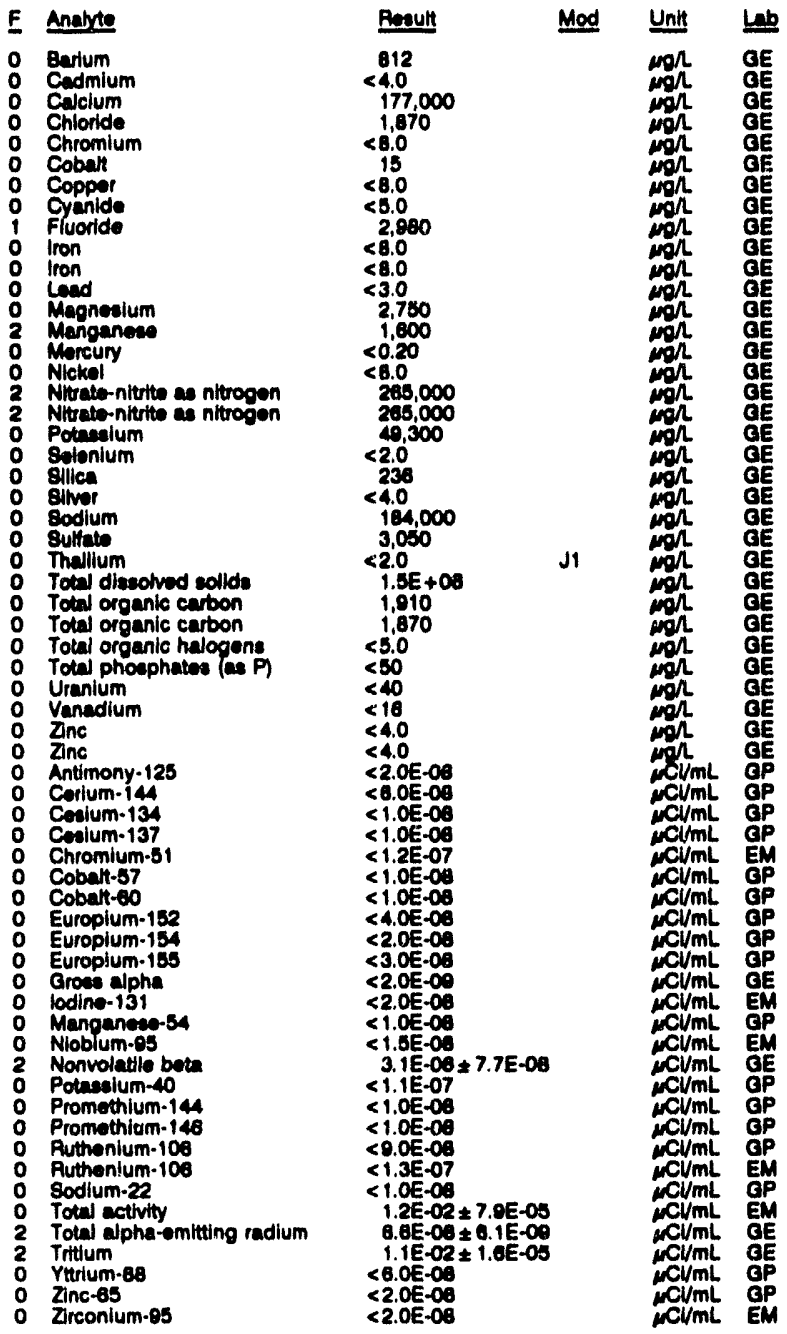

WELL FSB 94DR

MEASUREMENTS CONDUCTED IN THE FIELD

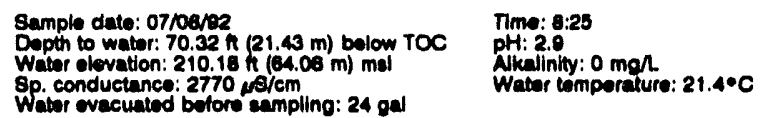

Wibier evacuatod botors eampling: $24 \mathrm{gal}$

LABORATORY ANALYSES

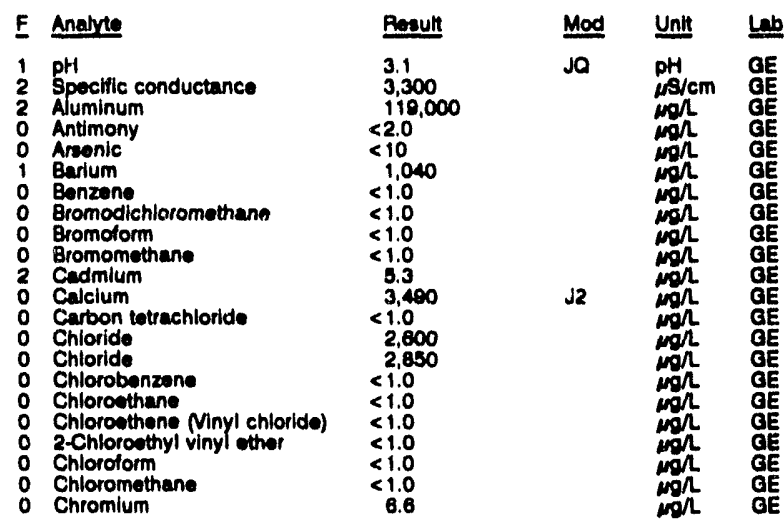




\section{WELL FSB 95DA}

MEASUREMENTS CONDUCTED IN THE FIELL

Sample date: 07/07/ve

Depth to water: 73.76 in $(22.40 \mathrm{~m})$ below TOC

Wp. conductance 210.32 h

Wip. conductances: 2650 ps/cm

LABORATOFY ANALYSES

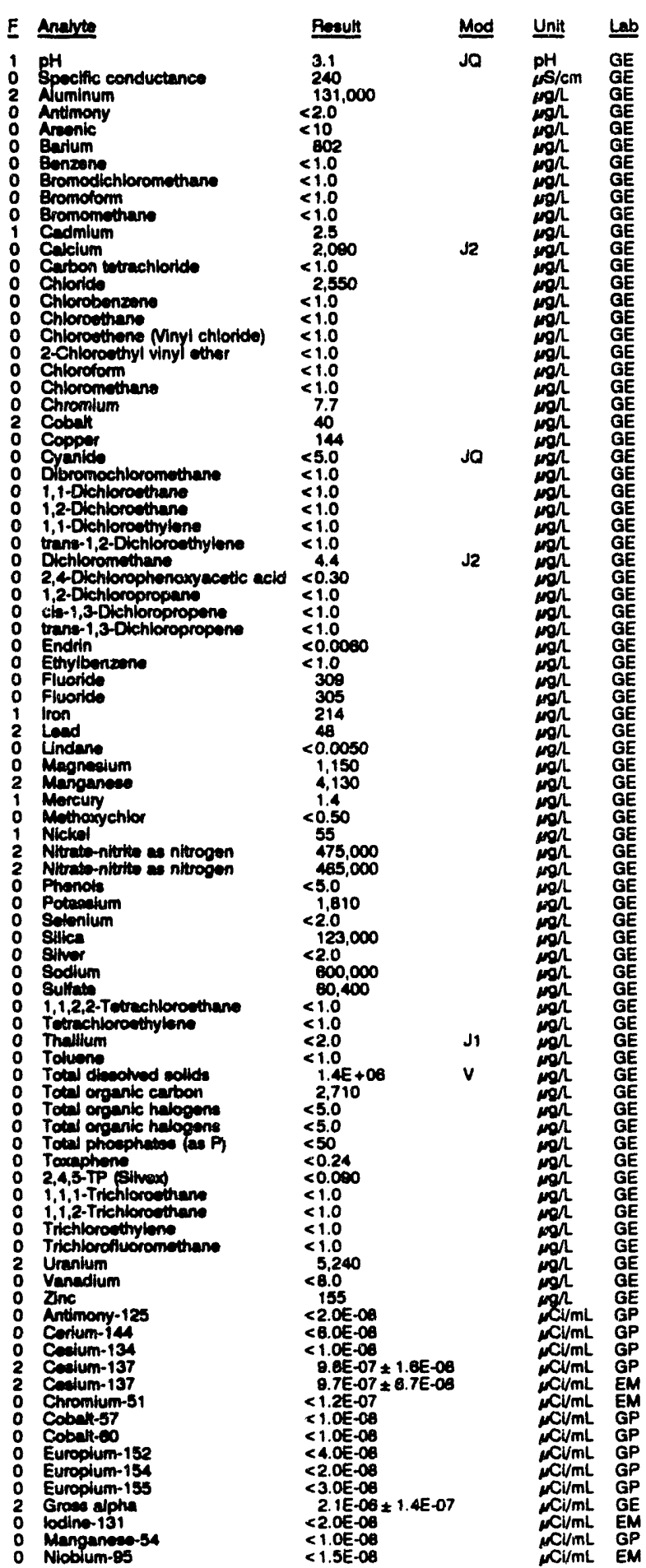

WELL FSB 95DF collected on 07/07/92, laboratory analyses (cont.)

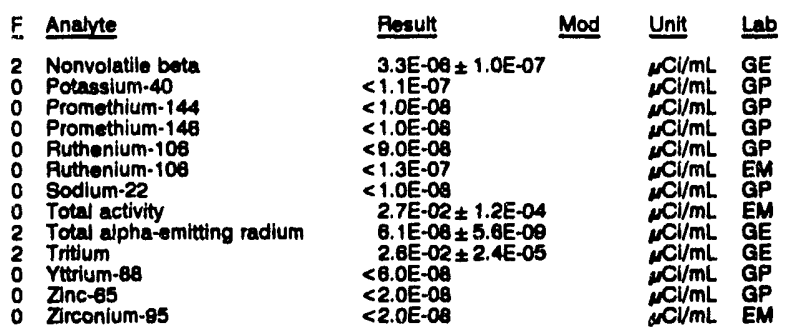

WELL FSB 96AR

MEASUREMENTS CONDUCTED IN THE FIELD

Sample date: 07/07/92

Depth to water: $127.73 \mathrm{Ht}(38.83 \mathrm{~m})$ below TOC

Water elevation: $153.47 \mathrm{~h}(46.78 \mathrm{~m}) \mathrm{ms}$ !

Sp. conductance: $175 \mu \mathrm{s} / \mathrm{cm}$.

PH: 8.8 .8 $77 \mathrm{mgn}$

Whalinity: $77 \mathrm{mgh}$. $22.3^{\circ} \mathrm{C}$

LABORATORY ANALYSES

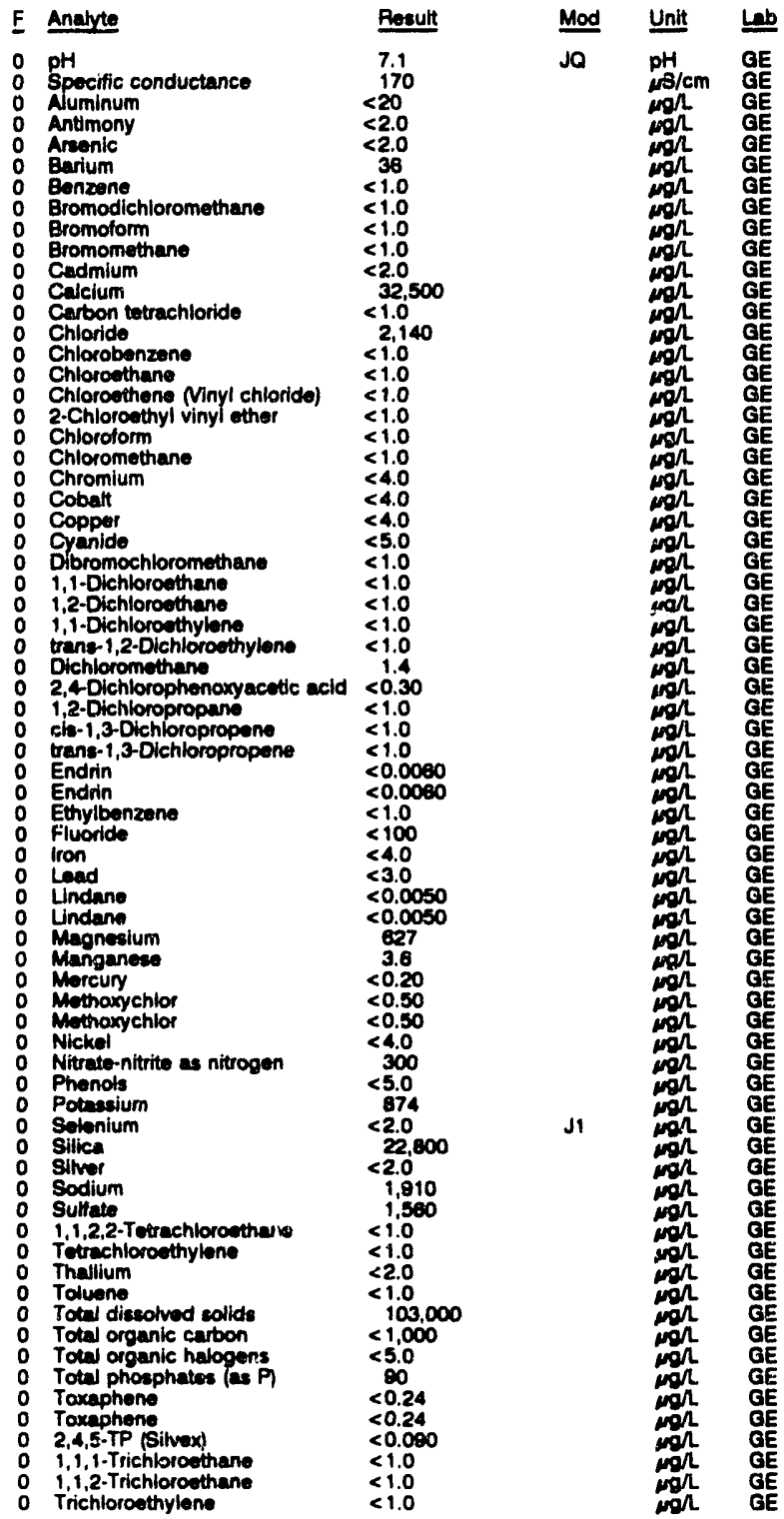


ANALYTICAL RESULTS

WELL FSB EaAP collocted on 07/07/92, laboratory enalyees (cont.)

\begin{tabular}{|c|c|c|c|}
\hline Analyte & Peveult & Mod & Unit \\
\hline $\begin{array}{ll}0 & \text { Trichlorofluoromethane } \\
0 & \text { Uranium } \\
0 & \text { Ventedium } \\
0 & \text { Znc } \\
0 & \text { Groes alpha } \\
0 & \text { Nonvolatilo beta } \\
0 & \text { Totwi alpha-erniting radium } \\
0 & \text { Tritum }\end{array}$ & $\begin{array}{l}<1.0 \\
<20 \\
<6.0 \\
3.1 \\
<2.0 E-09 \\
<2.0 E-09 \\
<1.0 E-09 \\
6.8 E-06 \pm 5.0 E-07\end{array}$ & & 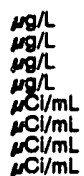 \\
\hline
\end{tabular}

WELL. FSB 97A

MEASUAEMENTS CONOUCTED IN THE FIELD

Sample date: 07/00/02

Depth to water: $133.72 \mathrm{~A}(40.78 \mathrm{~m})$ bolow TOC

Water elevation: $132.38 \mathrm{n}(46.45 \mathrm{~m}) \mathrm{ms}$

Inacceadbility or mechanical problom provented sample collection.

WELL FSB 97C

MEASUREMENTS CONDUCTED IN THE FIELD

Sample dato: 07/0e/ce

Depth to watar: $77.01 \mathrm{ft}(23.47 \mathrm{~m})$ bolow TOC

Water elovation: 200.00 h $(63.73 \mathrm{~m}) \mathrm{msl}$

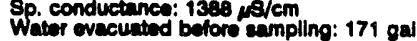

LABOAATOFY ANALYSES

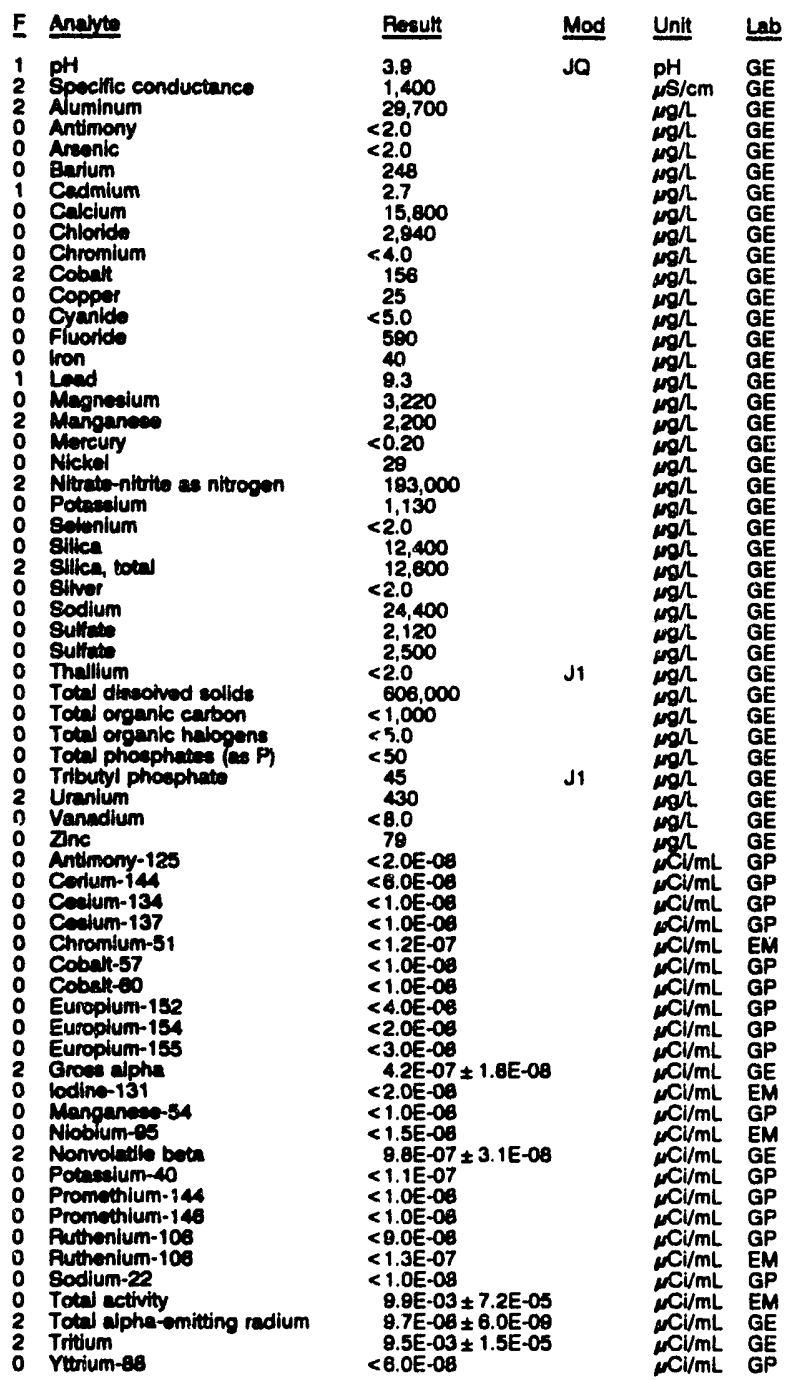

WELL FSB 97C collocted on 07/09/92, laboratory analyees (cont)

\begin{tabular}{|c|c|c|c|}
\hline F Analyte & Pesult & Mod & Unit \\
\hline $\begin{array}{l}0 \\
0 \\
0\end{array}$ & $\begin{array}{l}<2.0 E-08 \\
<2.0 E-08\end{array}$ & & $\stackrel{\mathrm{Cl} / \mathrm{mL}}{\mu \mathrm{Cl} / \mathrm{mL}}$ \\
\hline
\end{tabular}

\section{WELL FSB 97D}

MEASUREMENTS CONDUCTED IN THE FIELD

\begin{tabular}{|c|c|}
\hline 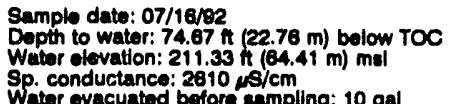 & $\begin{array}{l}\text { Tlme: } 8: 15 \\
\text { pH: } 3.3 \\
\text { Alkallinity: } 0 \text { mgn } \\
\text { Water temperature: } 22.0 \circ \mathrm{C}\end{array}$ \\
\hline
\end{tabular}
The well went dry during purging. $10 \mathrm{ga}$

LABORATORY ANALYBES

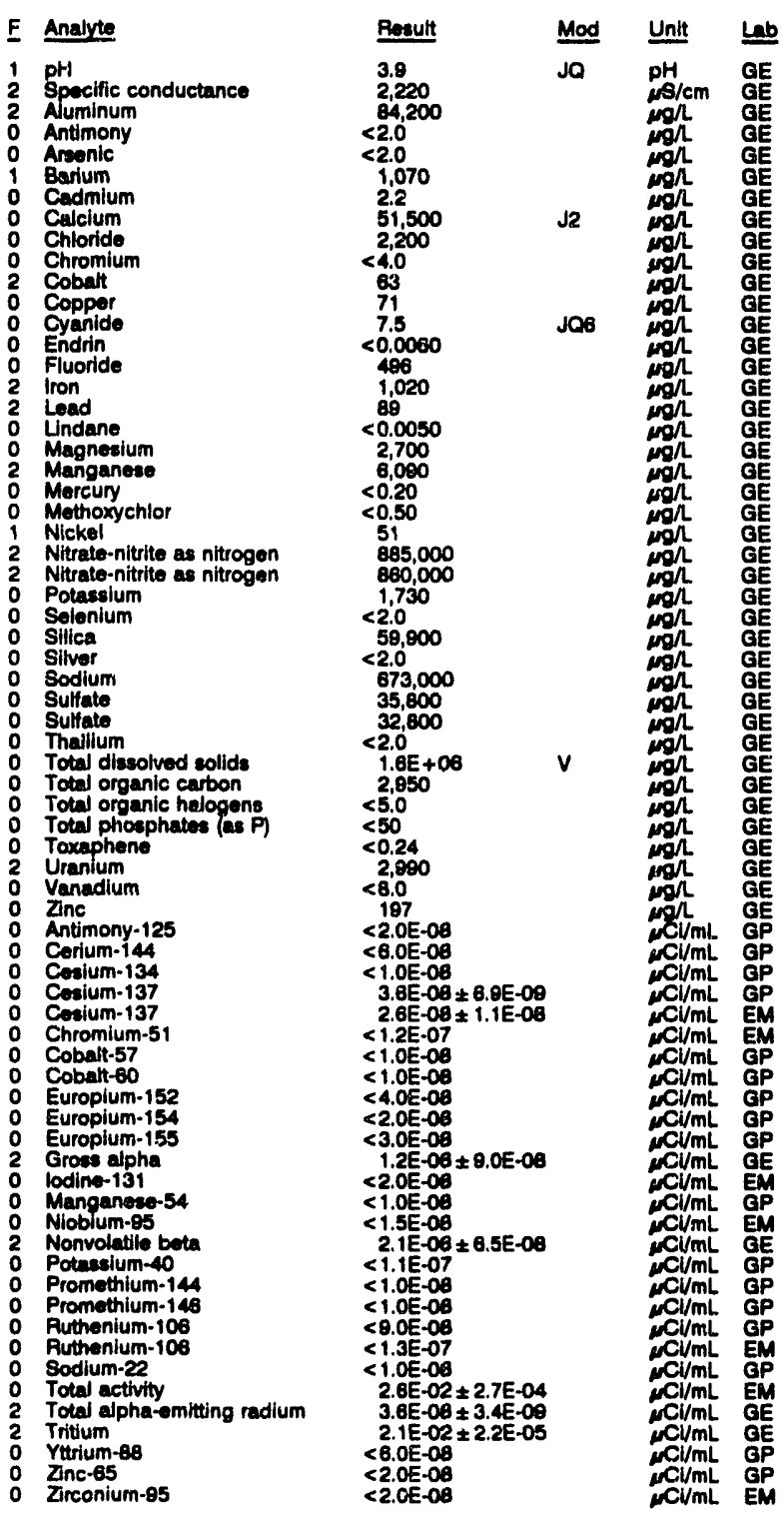


WELL FSB 98AR

MEASUREMENTS CONDUCTED IN THE FIELD

Sample date: 07/10/92

Depth to water: $132.34 \mathrm{n}(40.34 \mathrm{~m})$ below TOC

Water elvevion: $151.68 \mathrm{~h}(46.23 \mathrm{~m}) \mathrm{msl}$

Water oveculted bofors sumpling: $259 \mathrm{gal}$

LABOPATOFY ANALYSES

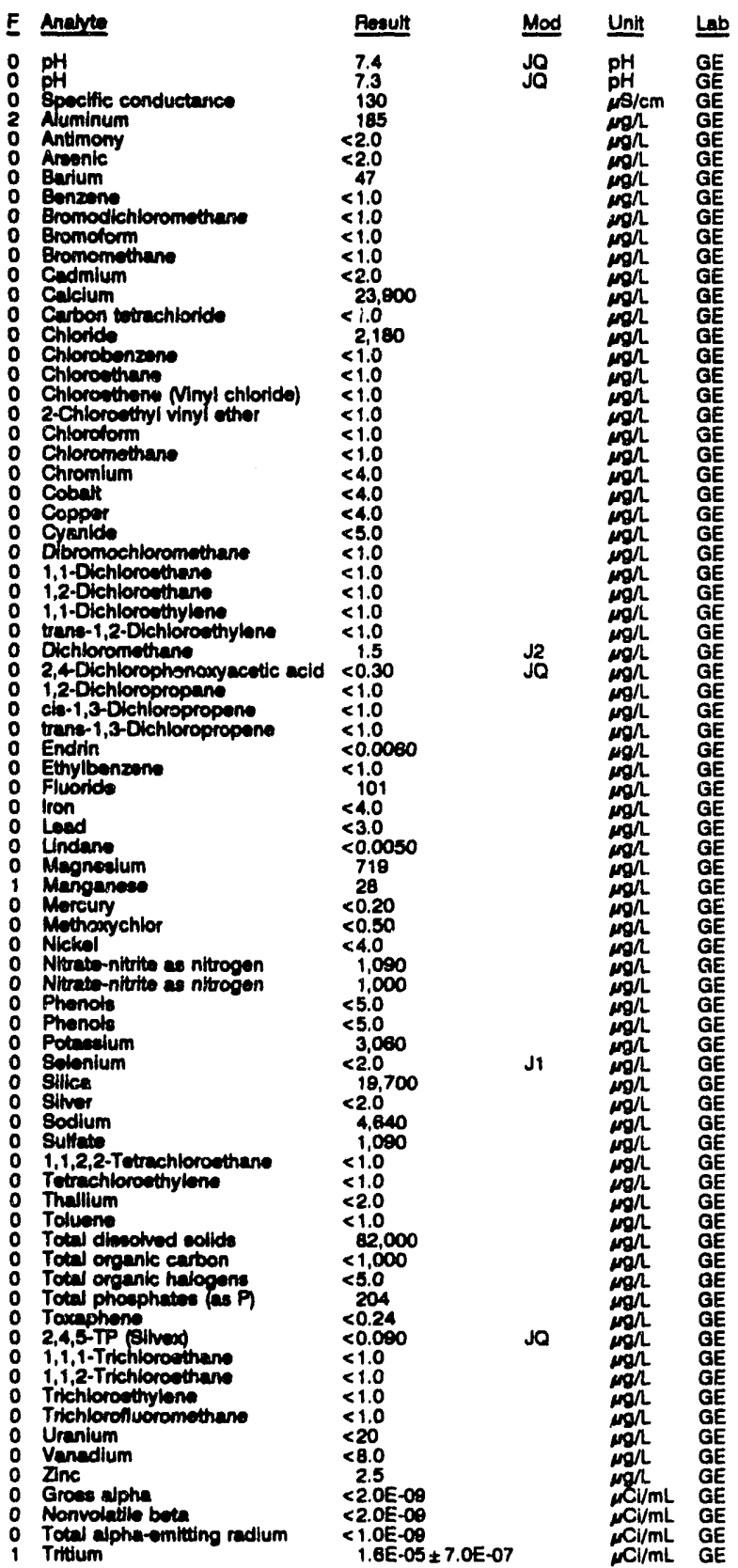

WELL FSB 98C

MEASUREMENTS CONDUCTED IN THE FIELD

Sample date: 07/09/82

Depth to water: $73.65 \mathrm{n}(22.45 \mathrm{~m})$ bolow TOC

Wator olevation: $209.45 \mathrm{ft}(63.84 \mathrm{~m}) \mathrm{ms}$

Water evacuated bofore eampling: 186 gal

LABOPATORY ANALYSES

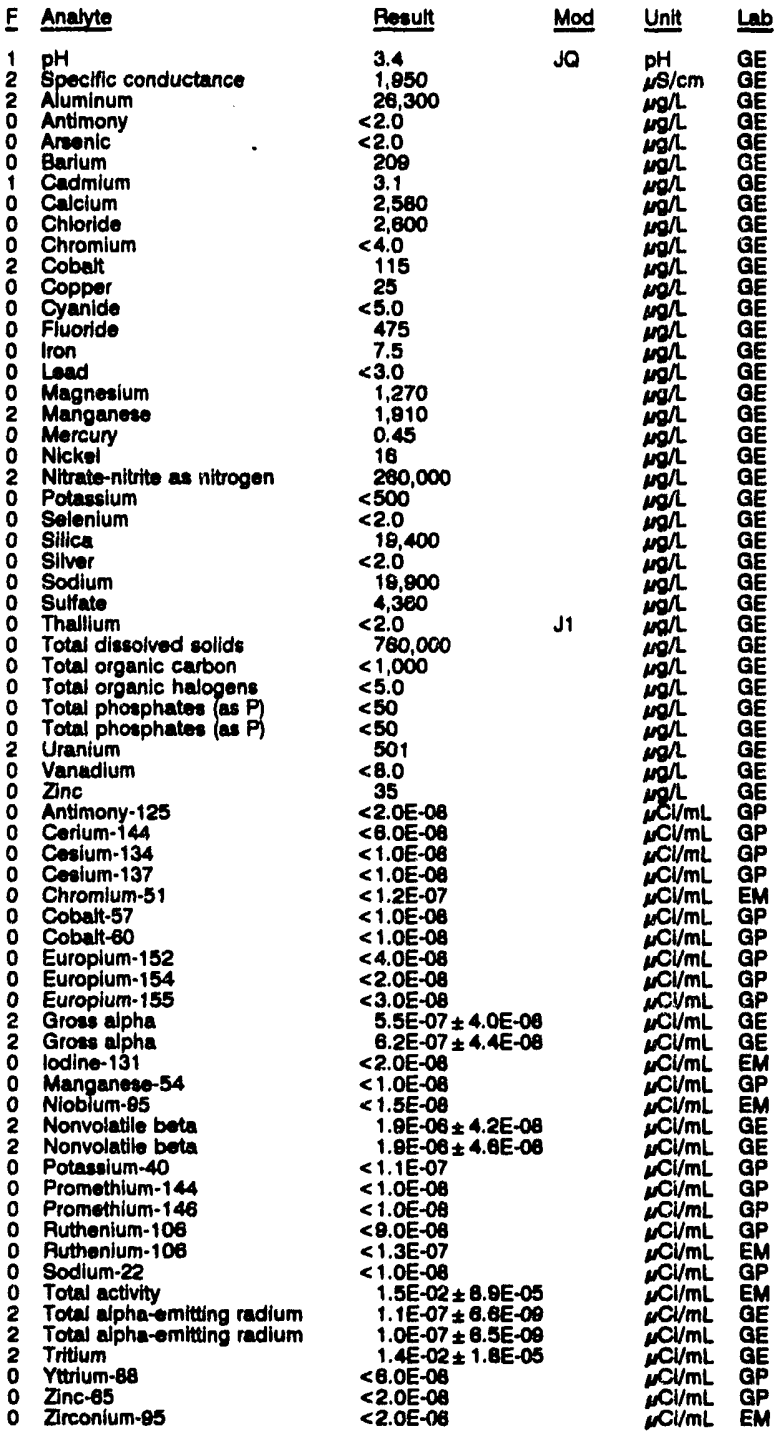

\section{WELL FSB 98D}

MEASUAEMENTS CONDUCTEO IN THE FIELD

Depth to water: 70.65 in $(21.53 \mathrm{~m})$ below TOC

Whter elevation: 212.45 (2) $(84.73$ m) below

Sp. conductance. 1892 is/cm

Time: 13:00

PH: 3.1 : 0 mon

Water temperature: $25.1 \cdot \mathrm{C}$

ducuated before sampling: 18 ge

The well went dry during purging.

LABORATORY ANALYSES

\begin{tabular}{|c|c|c|c|}
\hline E Analyte & Rosult & Mod & Unit \\
\hline $\begin{array}{ll}1 & \text { pH } \\
2 & \text { Specific conductance } \\
2 & \text { Aluminum } \\
0 & \text { Antimony } \\
0 & \text { Areenic }\end{array}$ & $\begin{array}{l}3.7 \\
1,800 \\
48,800 \\
<2.0 \\
<2.0\end{array}$ & Jo & $\begin{array}{l}\mathrm{pH} \\
\operatorname{ms} / \mathrm{cm} \\
\operatorname{mg} / \mathrm{h} \\
\operatorname{mgh} \\
\operatorname{mog}\end{array}$ \\
\hline
\end{tabular}

Time: 8:30

Alkalinity: 0 mor

Water tomperature: $22.0^{\circ} \mathrm{C}$ 
ANALYTICAL RESULTS

WELL FSB OQD collected on 07/10/92, taboratory analyees (cont)

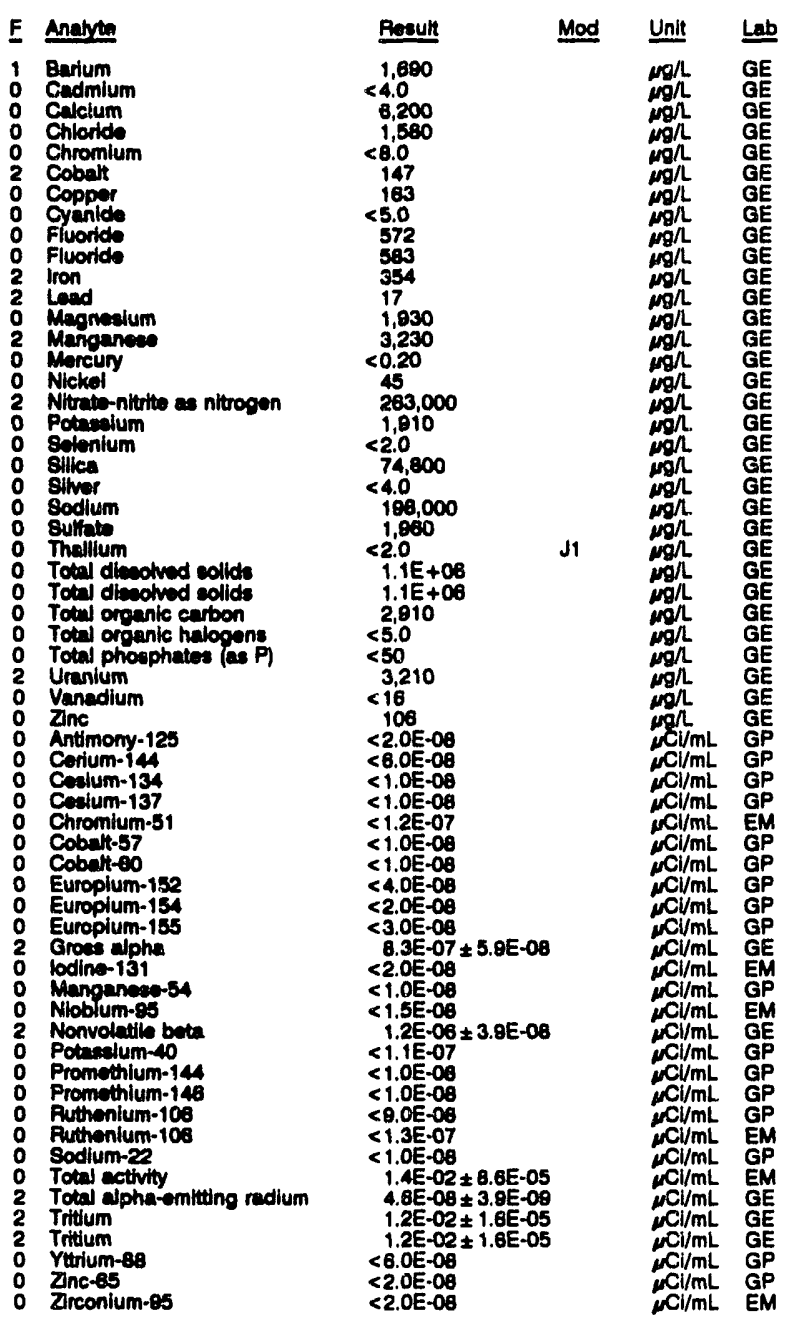

WELL FSB 99A

MEASUREMENTS CONDUCTED IN THE FIELD

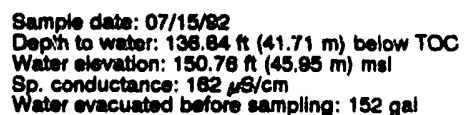

Time: $8: 30$

PH: 8.3 Alkalinity: $57 \mathrm{mg}$

Water tomperature: $20.5^{\circ} \mathrm{C}$ LABORATOAY ANALYSES
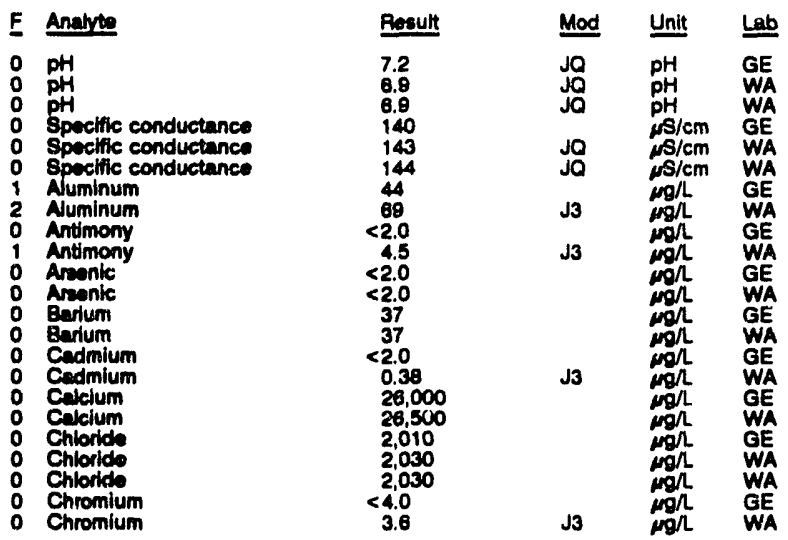

WELL FSB 89A collectod on 07/15/92, laboratory analyses (cont.)

\begin{tabular}{|c|c|c|c|}
\hline Analyte & Result & Mod & Unit \\
\hline 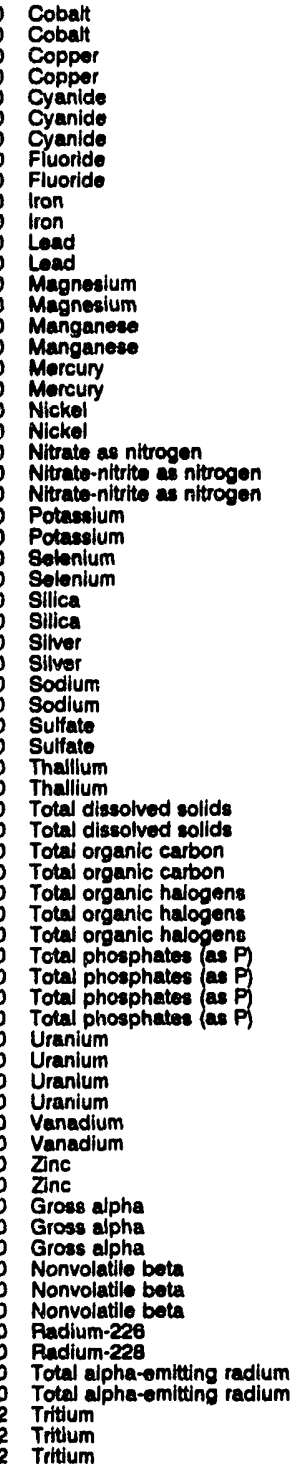 & $\begin{array}{l}<4.0 \\
1.7 \\
<4.0 \\
<1.1 \\
<5.0 \\
<5.0 \\
<5.0 \\
135 \\
128 \\
10 \\
10 \\
<3.0 \\
<2.0 \\
1,170 \\
1,150 \\
6.7 \\
7.5 \\
<0.20 \\
<0.20 \\
<4.0 \\
<3.1 \\
4,000 \\
3,400 \\
3,300 \\
7.45 \\
1,030 \\
<2.0 \\
<2.0 \\
17,000 \\
16,200 \\
<2.0 \\
3.1 \\
3,060 \\
3,190 \\
1,040 \\
<2,500 \\
<2.0 \\
<2.0 \\
104,000 \\
143,000 \\
<1,000 \\
<500 \\
<5.0 \\
<5.0 \\
<5.0 \\
300 \\
331 \\
270 \\
273 \\
<20 \\
<20 \\
0.21 \pm 2.0 E-02 \\
0.21 \pm 2.0 E-02 \\
<8.0 \\
1.3 \\
3.8 \\
5.2 \\
<2.0 E-09 \\
1.0 E-09 \pm 7.0 E-10 \\
1.4 E-09 \pm 7.0 E-10 \\
2.5 E-09 \pm 1.5 E-09 \\
5.3 E-09 \pm 1.2 E-00 \\
4.1 E-09 \pm 1.1 E-09 \\
8.5 E-10 \pm 3.8 E-10 \\
8.5 E-10 \pm 6.8 E-10 \\
<1.0 E-09 \\
<1.0 E .09 \\
1.1 E-04 \pm 1.6 E-00 \\
1.2 E-04 \pm 1.6 E-05 \\
1.1 E-04 \pm 1.5 E-05\end{array}$ & J3 & 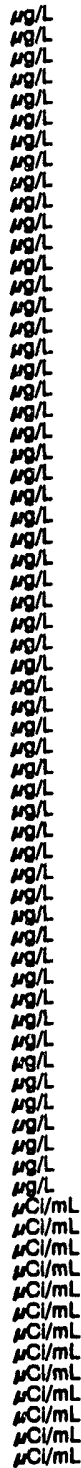 \\
\hline
\end{tabular}

\section{WELL FSB 99A Replicate}

MEASUAEMENTS CONDUCTED IN THE FIELD

Sample date: $07 / 15 / 82$

Depth to water: $136.84 \mathrm{ft}(41.71 \mathrm{~m})$ below TOC

Water elevation: 150.76 h $(45$.

Water evacuated before sampling: $152 \mathrm{gal}$

PH: 8.3

Alkalinity: $57 \mathrm{mg} /$

Water tomperature: $20.5 \circ \mathrm{C}$

LABOPATORY ANALYSES

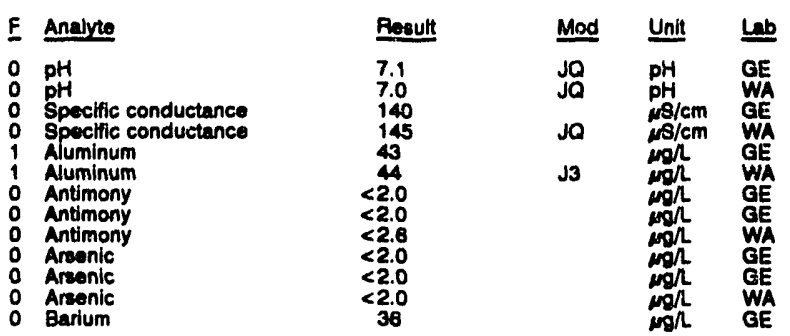


WELL FBg can collectad on 07/15/92, laboratory analyses (cont.)

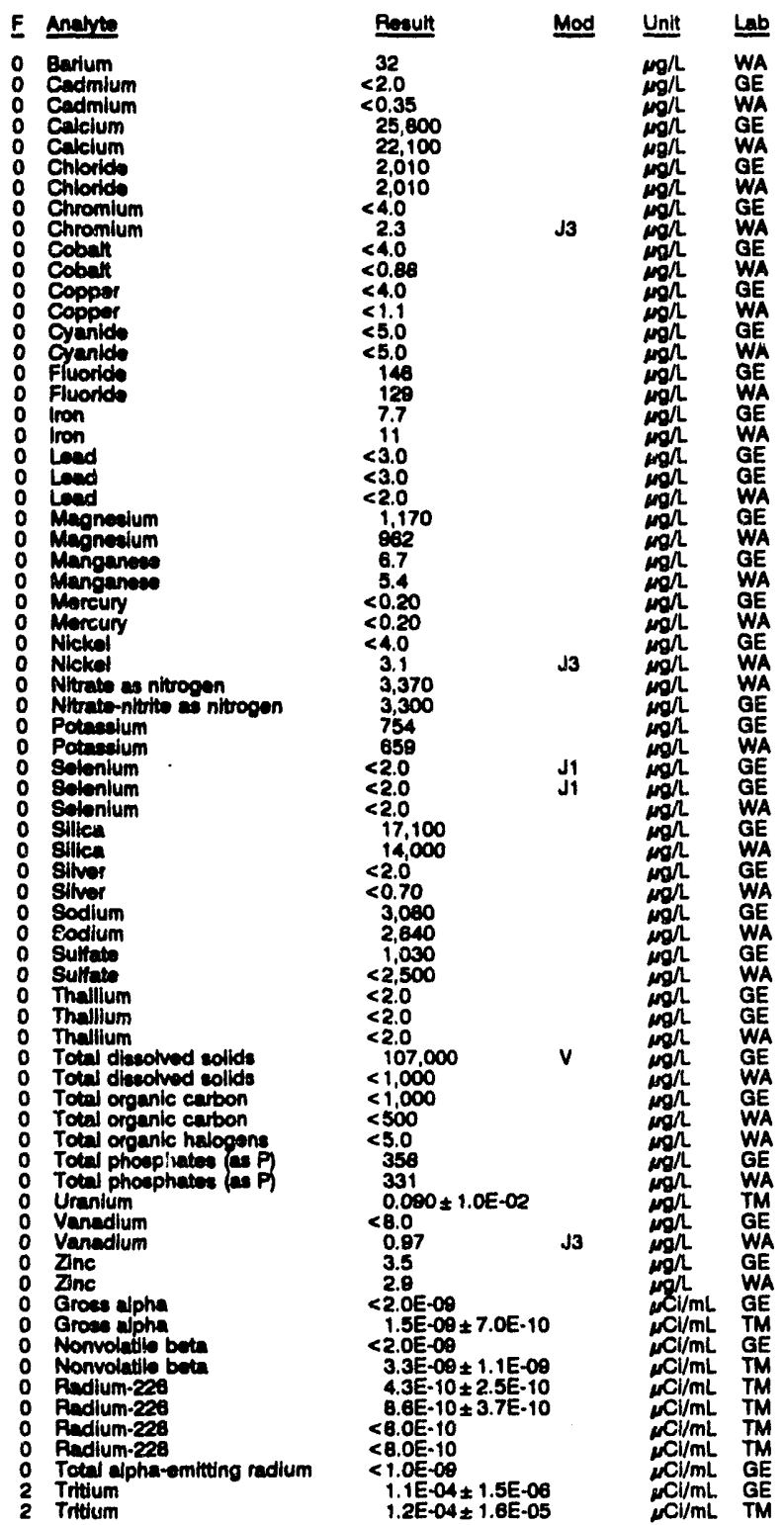

WELL FSB 99C

MEASUREMENTS CONDUCTED IN THE FIELD

Sample date: 07/14/02

Dopth to water: $77.16 \mathrm{ft}(23.52 \mathrm{~m})$ below TOC Water elwation: $210.54 \mathrm{~h} /(84.17$ Sp. conductance: $329 \mathrm{ps} / \mathrm{cm}$.

LABORATOFY ANALYBES

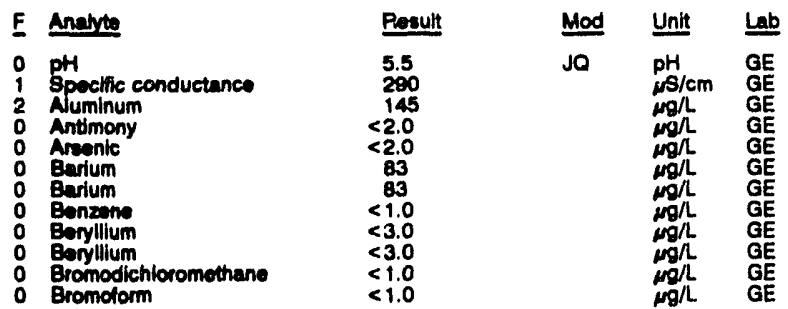

WELL FBB $89 C$ collected on 07/14/92, laboratory analyses (cont.)

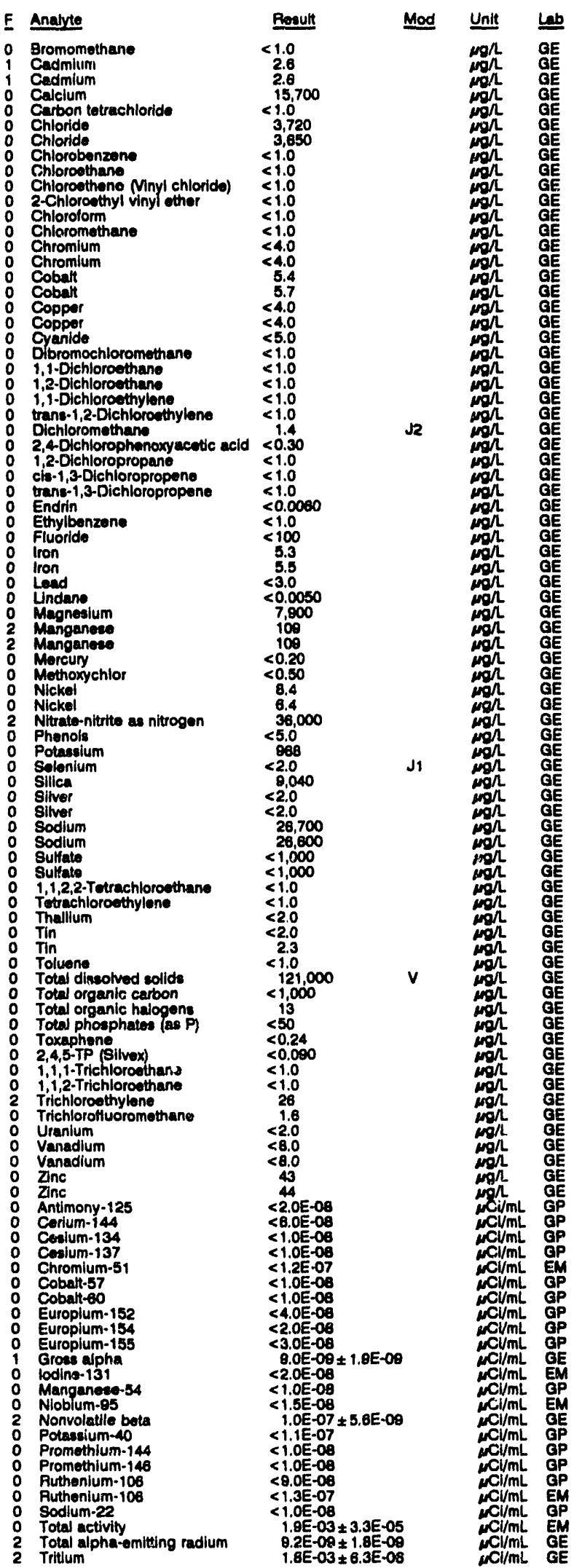


ANALYTICAL RESULTS

WELL Fs8 89 colloctod on 07/14/92, laboratory analywes (cont)

\begin{tabular}{|c|c|c|c|}
\hline E Analyte & Result & Mod & Unit \\
\hline $\begin{array}{ll}0 & \text { Yurium-68 } \\
0 & \text { Znc-es } \\
0 & \text { Zreonlum-es }\end{array}$ & $\begin{array}{l}<8.0 E-08 \\
<2.0 E-08 \\
<2.0 E-08\end{array}$ & & $\begin{array}{l}\mathrm{N} \mathrm{Cl} / \mathrm{mL} \\
\mathrm{N} \mathrm{Cl} / \mathrm{mL} \\
\mathrm{Cl} / \mathrm{mL}\end{array}$ \\
\hline
\end{tabular}

\section{WELL FSB 99D}

MEASUREMENTS CONDUCTED IN THE FIELD

\section{Sample data: 07/14/08}

Depth to water: $73.87 \mathrm{th}$ (22.52 m) below TOC

Water elvation: $213.73 \mathrm{~h}(8 \mathrm{~s}$

Wher

The woll went dry during purging: $7 \mathrm{gad}$

LABOPATOFY ANALYSES

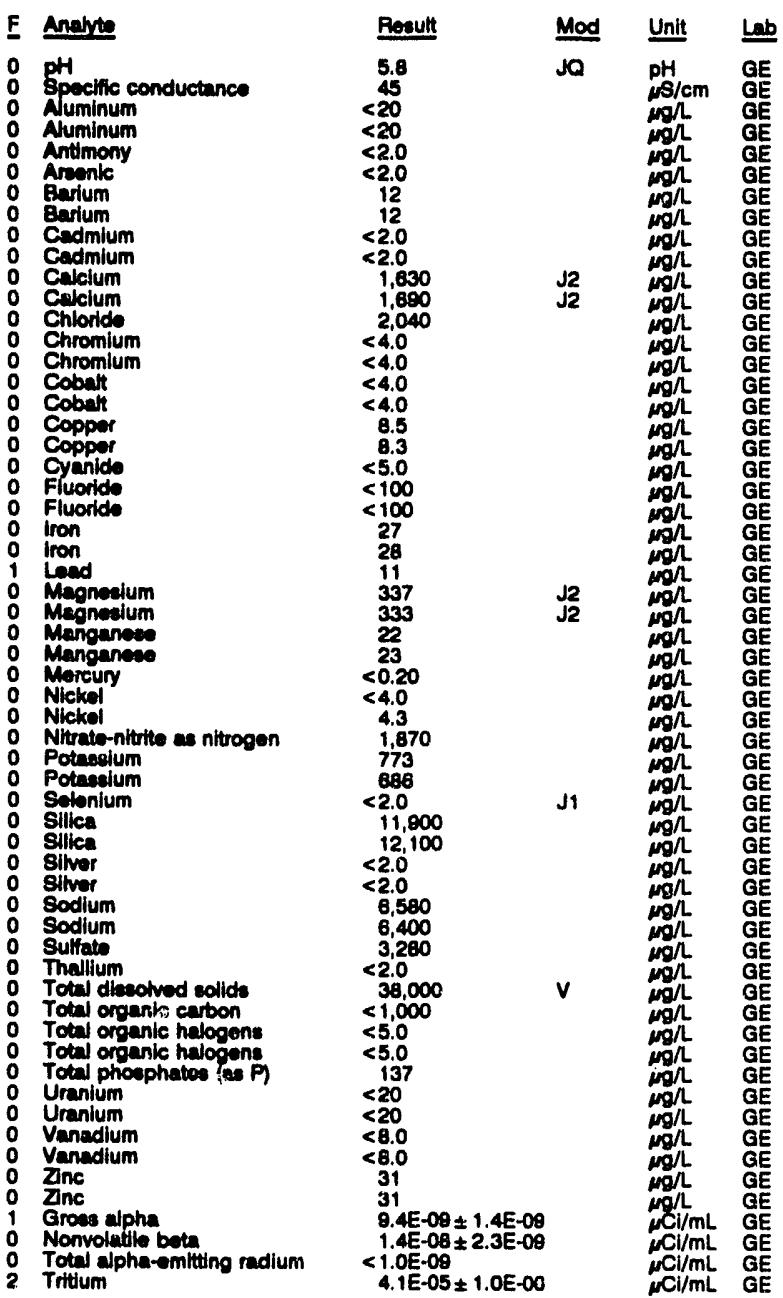

WELL FSB100A

MEASUAEMENTS CONDUCTED IN THE FIELD

Samplo data: 07/10/82 Depth ts water: $134.21 \mathrm{ft}(40.91 \mathrm{~m})$ below TOC Water elovetion: $151.78 \mathrm{f}(48.27 \mathrm{~m}) \mathrm{msl}$ Water evacuated before eampling: $147 \mathrm{gal}$

LABOPATORY ANALYSES

F Analute

$0 \mathrm{pH}$

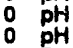

Specific conductance
Time: 14:15

Alkninity: $8 \mathrm{man}$

Water tomperature: $28.1^{\circ} \mathrm{C}$ 
WEL F881004 collected on 07/10/92, laboratony analyses (cont.)

\begin{tabular}{|c|c|c|c|c|}
\hline$E$ & Analyte & Reeult & Unis & $\underline{\underline{b}}$ \\
\hline $\begin{array}{l}0 \\
0 \\
0 \\
0 \\
0 \\
0 \\
0 \\
0 \\
2\end{array}$ & 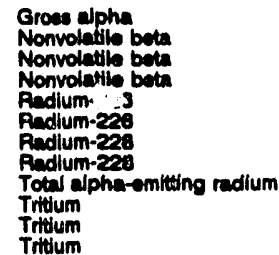 & $\begin{array}{l}1.5 E-09 \pm 8.0 E-10 \\
3.3 E-09 \pm 1.5 E-09 \\
6.4 E-09 \pm 1.2 E-09 \\
8.4 E-09 \pm 1.3 E-09 \\
1.3 E-09 \pm 5.9 E-10 \\
7.3 E-10 \pm 3.3 E-10 \\
2.0 E-09 \pm 1.3 E-00 \\
<7.0 E-10 \\
<1.0 E-09 \\
1.6 E-04 \pm 1.8 E-00 \\
1.6 E-04 \pm 1.3 E-05 \\
1.7 E-04 \pm 1.2 E-05\end{array}$ & 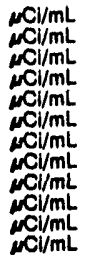 & $\begin{array}{l}\mathrm{TM} \\
\mathrm{GE} \\
\mathrm{TM} \\
\mathrm{TM} \\
\mathrm{TM} \\
\mathrm{TM} \\
\mathrm{TM} \\
\mathrm{TM} \\
\mathrm{GE} \\
\mathrm{GE} \\
\mathrm{TM}\end{array}$ \\
\hline
\end{tabular}

WELL FSB100A Replicate

MEASUREMENTS CONDUCTED IN THE FIELD

Sample date: 07/10/82

Depth to watier: 134.21 it $(40.91 \mathrm{~m})$ below TOC

Weter elevation: $161.70 \mathrm{n} / 48.27$

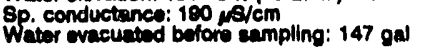

LABOAATOFY ANALSES

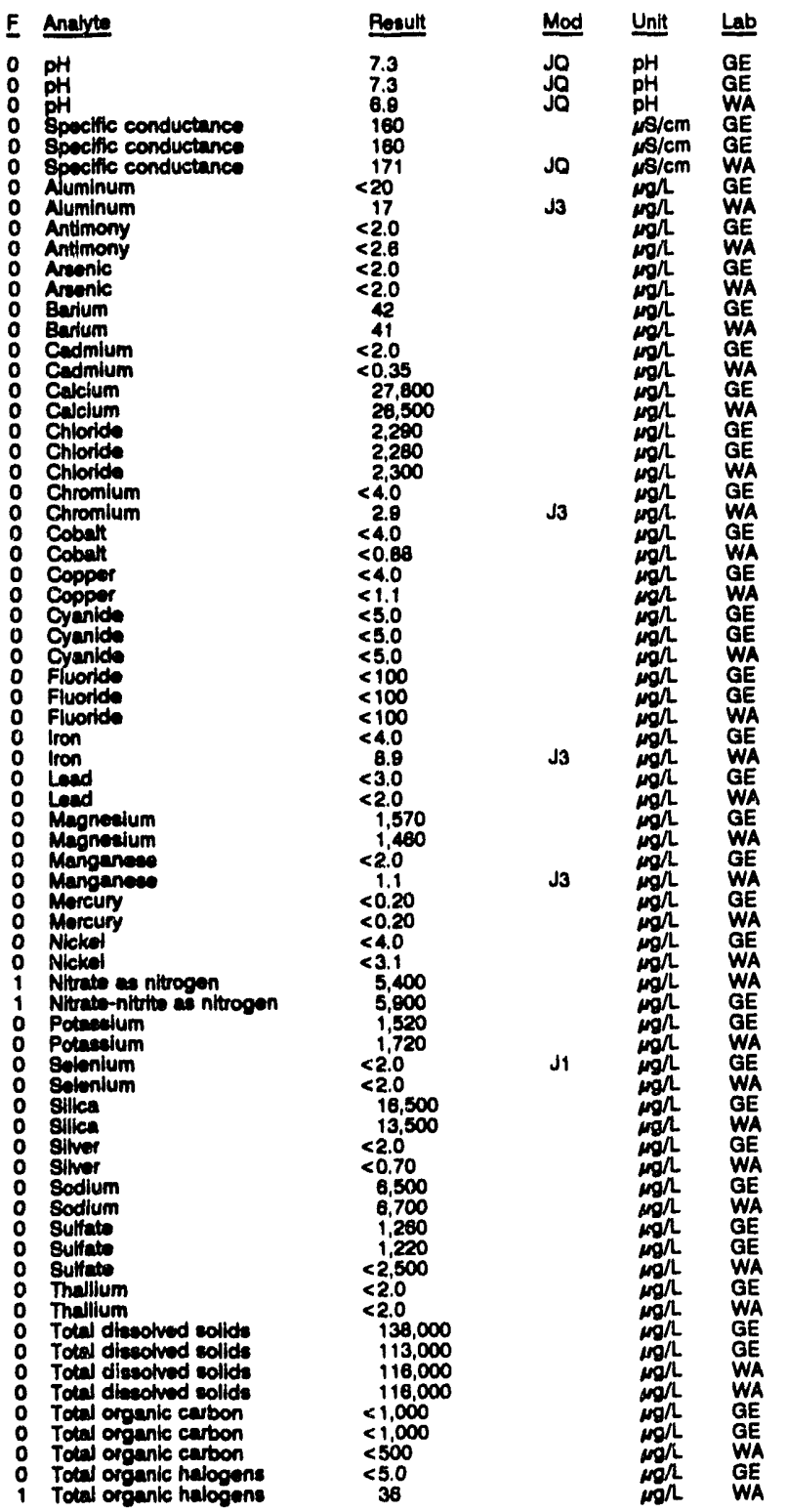

WELL FSB100A collectod on 07/10/92, laboratory analyees (cont.)
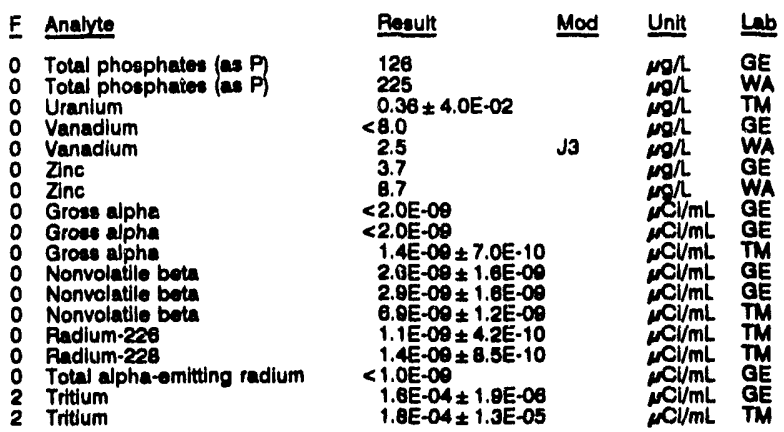

\section{WELL FSB101A}

MEASUREMENTS CONDUCTED IN THE FIELD Sample date: $07 / 08 / 92$
Depth to water: $133.22 \mathrm{ft}(40.61 \mathrm{~m})$ bolow TOC
Water olevation: $151.88 \mathrm{ft}(46.32 \mathrm{~m}) \mathrm{mal}$

Sp. conductance: 164 $1 \mathrm{~S} / \mathrm{cm}$. $155 \mathrm{gal}$

Time: $14: 40$

Alkalinity: $49 \mathrm{mon}$

\section{LABOPATOFY ANALYSES}

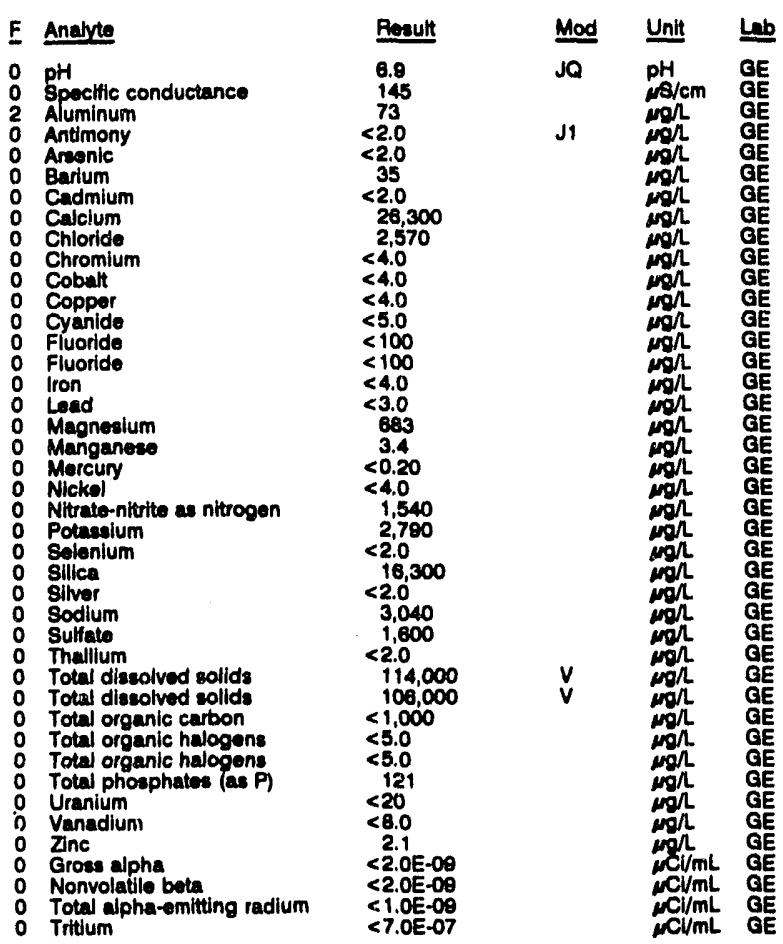

\section{WELL FSB102C}

MEASUREMENTS CONOUCTED IN THE FIELD

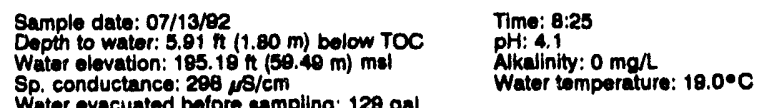
Weter evacuated bofore eampling: $128 \mathrm{gal}$

LABORATORY ANALYSES

\begin{tabular}{|c|c|c|c|c|c|}
\hline$\underline{\mathbf{E}}$ & Analyte & Poosult & Mod & Unit & Lab \\
\hline 0 & $\begin{array}{l}\text { pH } \\
\text { Specific conductance } \\
\text { Aluminum } \\
\text { Antimony } \\
\text { Arsenic } \\
\text { Barlum }\end{array}$ & $\begin{array}{r}4.6 \\
290 \\
710 \\
<2.0 \\
<2.0 \\
80\end{array}$ & Jo & $\begin{array}{l}\mathrm{pH} \\
\mu \mathrm{s} / \mathrm{cm} \\
\operatorname{mgh} \\
\operatorname{mogh} \\
\operatorname{moh} \\
\operatorname{con}\end{array}$ & E \\
\hline
\end{tabular}


ANALYTICAL RESULTS

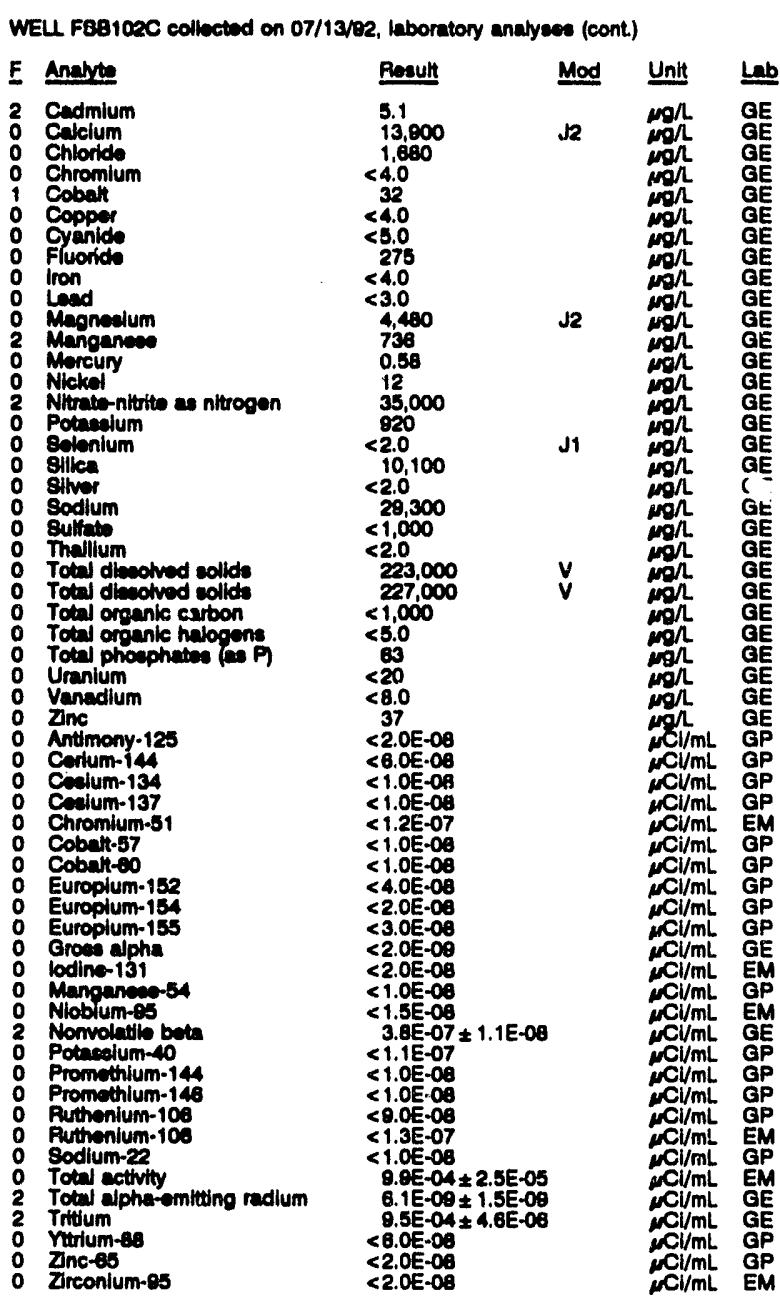

\section{WELL FSB103C}

MEASUREMENTS CONDUCTED IN THE FIELD

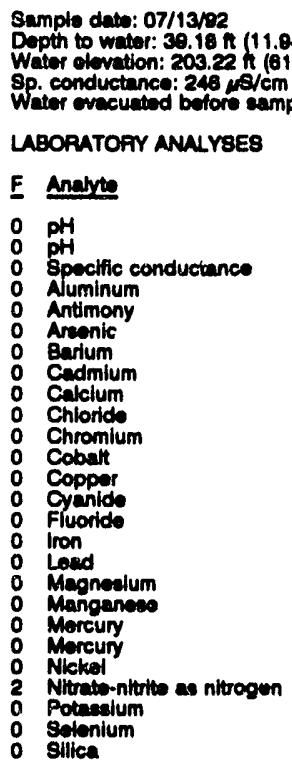

Time: 13:05

PH: 5.4 : 5 molinity: $5 \mathrm{mg}$

Whaler tomperature: $24.0^{\circ} \mathrm{C}$

eampling: $147 \mathrm{gal}$

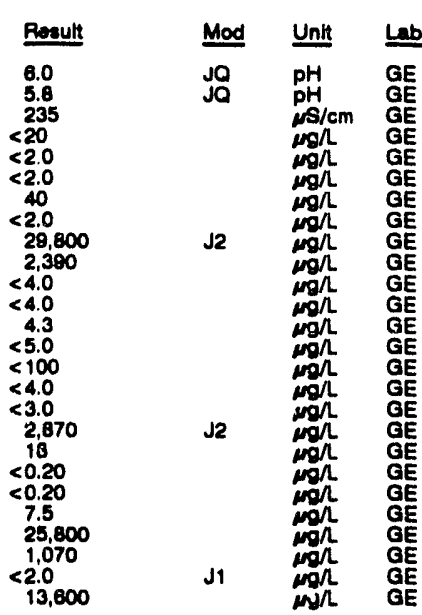

WELL F8B103C collected on 07/13/92, laboratory analyeses (cont)

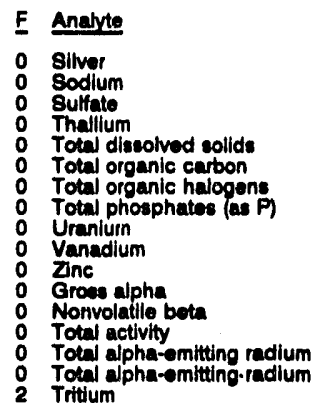

\begin{tabular}{|c|c|c|}
\hline Rosult & Mod & Unit \\
\hline $\begin{array}{l}<2.0 \\
10,100 \\
<1,000 \\
<2.0 \\
210,000 \\
<1,000 \\
<5.0 \\
143 \\
<20 \\
<8.0 \\
30 \\
<2.0 E-09 \\
2.0 E-08 \pm 2.7 E-00 \\
7.3 E-04 \pm 6.3 E-00 \\
<1.0 E-09 \\
<1.0 E-09 \\
8.7 E-04 \pm 3.9 E-08\end{array}$ & v & 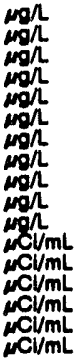 \\
\hline
\end{tabular}

\section{WELL FSB104C}

MEASUREMENTS CONDUCTED IN THE FIELD

8ample date: 07/13/92.
Dopth to water: $17.61 \mathrm{ft}(5.37 \mathrm{~m})$ bolow TOC
Water elevation: $201.40 \mathrm{(81.41} \mathrm{m}) \mathrm{mal}$
Sp. conductance: $400 \mu \mathrm{s} / \mathrm{cm}$
Water evacuated belore sampling: $133 \mathrm{gal}$

Time: 10:45

PH: 4.8 : $0 \mathrm{mon}$

Weter tomperature: $20.4^{\circ} \mathrm{C}$

LABOFATOAY ANALYSES

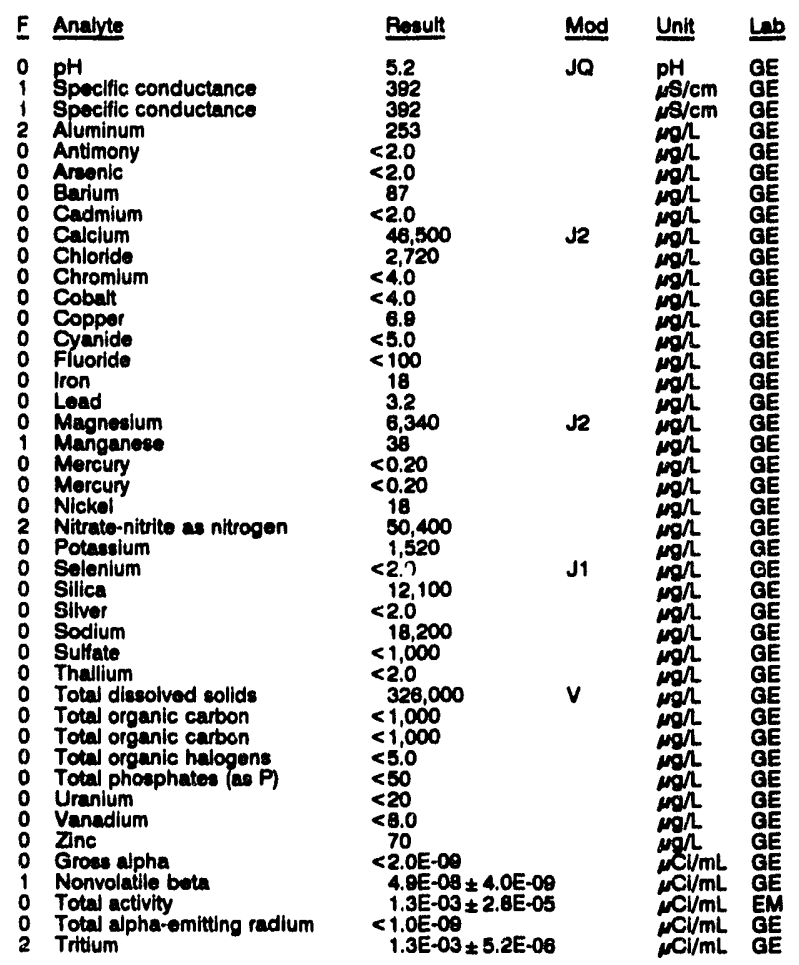

\section{WELL FSB104D}

MEASUREMENTS CONDUCTED IN THE FIELL

\begin{tabular}{|c|c|c|c|c|}
\hline \multicolumn{2}{|c|}{$\begin{array}{l}\text { Sample date: } 07 / 13 / 92 \\
\text { Depth to water: } 14.08 \mathrm{ft}(4.29 \mathrm{~m}) \text { below TOC } \\
\text { Whter elevation: } 205.12 \mathrm{ft}(62.52 \mathrm{~m}) \mathrm{ms} \\
\text { Sp. conductance: } 853 \mu \mathrm{cm} \\
\text { Water evacuated betore sampling: } 39 \mathrm{gal}\end{array}$} & \multicolumn{3}{|c|}{$\begin{array}{l}\text { Time: } 10: 20 \\
\text { pH: } 3.5 \\
\text { Alkalinity: } 0 \mathrm{mg} / \mathrm{L} \\
\text { Water tomperature: } 20.8 \bullet \mathrm{C}\end{array}$} \\
\hline \multicolumn{5}{|l|}{ LABOPATORY ANALYSES } \\
\hline Analye & Reesult & Mod & Unit & Lي \\
\hline $\begin{array}{ll}1 & \text { pH } \\
2 & \text { Bpecific conductance } \\
2 & \text { Aluminum } \\
0 & \text { Antmony } \\
0 & \text { Arsenic } \\
0 & \text { Barium }\end{array}$ & $\begin{array}{l}3.7 \\
920 \\
45,500 \\
<2.0 \\
<2.0 \\
218\end{array}$ & Ja & $\begin{array}{l}\mathrm{pH} \\
\operatorname{mis} / \mathrm{cm} \\
\operatorname{mgh} \\
\operatorname{conh} \\
\operatorname{conh}\end{array}$ & $\begin{array}{l}\mathrm{GE} \\
\mathrm{GE} \\
\mathrm{GE} \\
\mathrm{GE} \\
\mathrm{GE} \\
\mathrm{GE}\end{array}$ \\
\hline
\end{tabular}


WELL F8B1040 collected on 07/13\%2, laboratory analyese (cont)

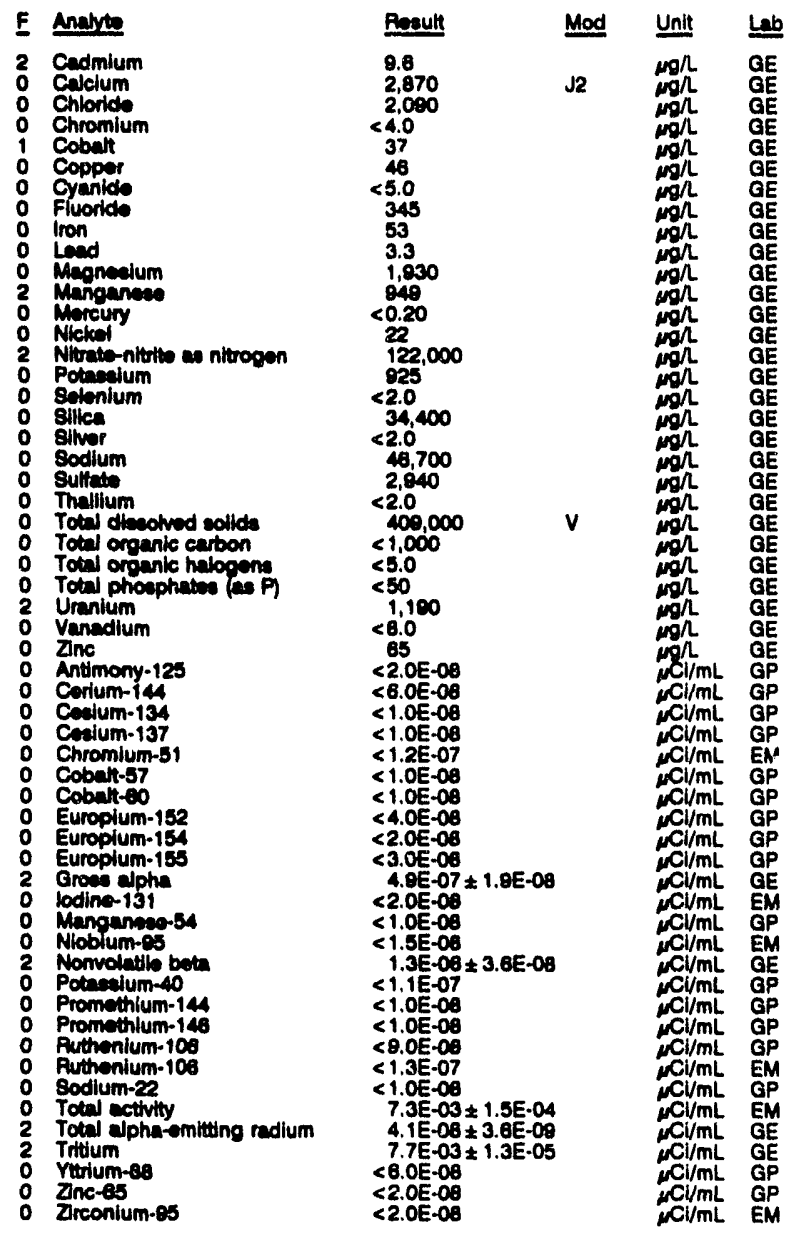

\section{WELL FSB105C}

MEASUREMENTS CONDUCTED IN THE FIELD

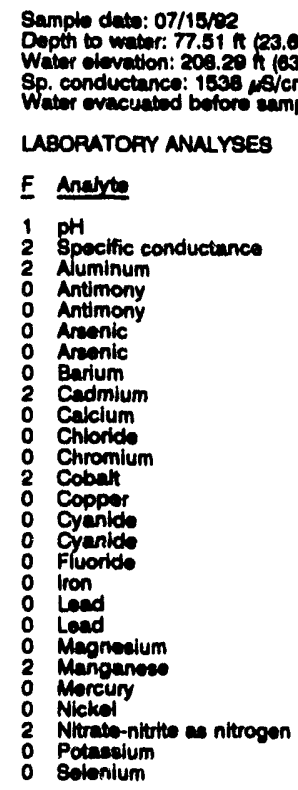

Time: 11:25

PH: 3.3

Water tomperature: $21.7{ }^{\circ} \mathrm{C}$

\section{Water evecunted betore exmpling: 175 gal}

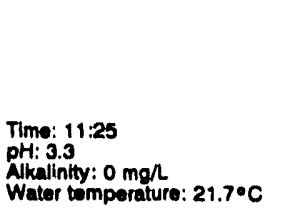

\section{LABORATOAY ANALYSES}

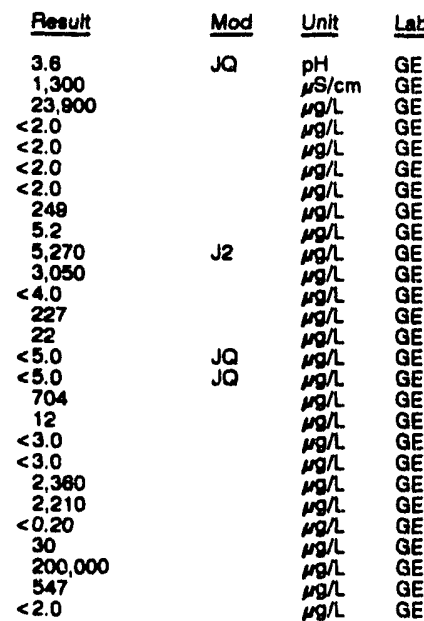

WELL FBB105C collectod on 07/15/92, laboratory analyees (cont)

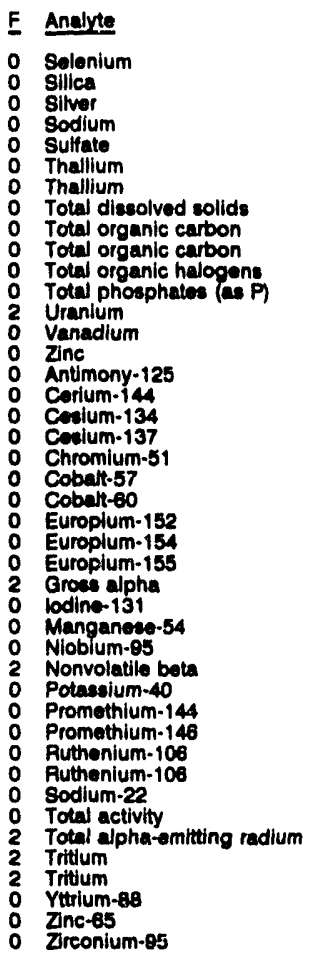

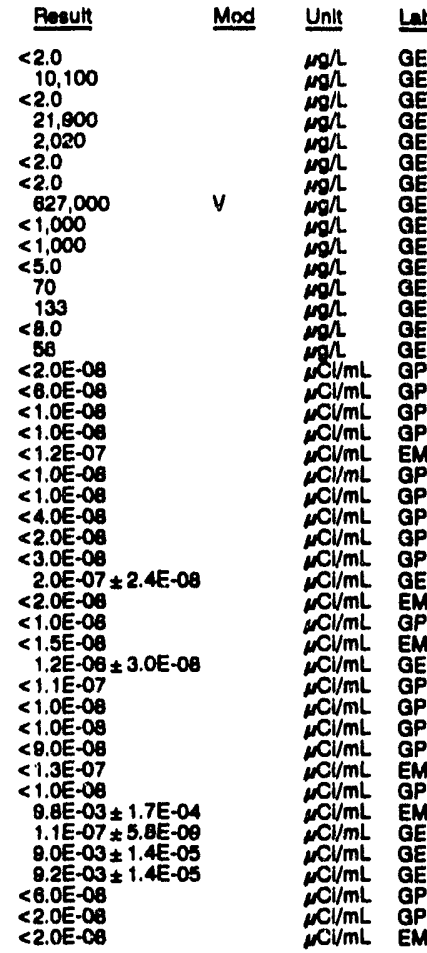

\section{WELL FSB105DR}

MEASUREMENTS CONDUCTED IN THE FIELD

Sample date: 07/15/92

Depth to water: 74.33 it $22.60 \mathrm{~m}$ ) below TOC

mal Alkalinity: $0 \mathrm{mon}$

Water tomperature: $22.1 \cdot \mathrm{C}$

LABORATORY ANALYSES

\begin{tabular}{|c|c|c|c|}
\hline Analyze & Rosult & Mod & Unit \\
\hline 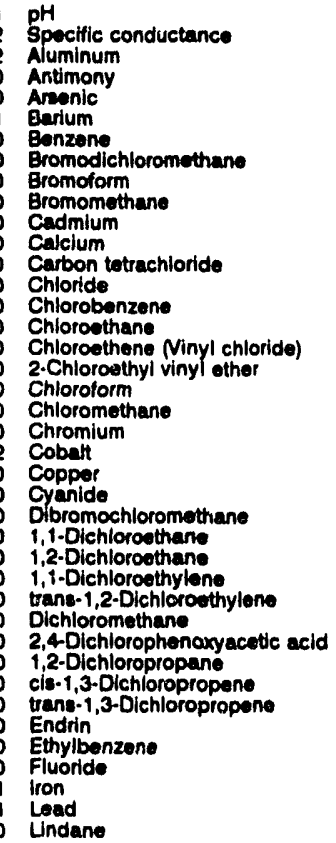 & $\begin{array}{l}3.4 \\
2.720 \\
58,400 \\
<2.0 \\
<2.0 \\
11.120 \\
<1.0 \\
<1.0 \\
<1.0 \\
<1.0 \\
2.2 \\
41.030 \\
<1.0 \\
11.880 \\
<1.0 \\
<1.0 \\
<1.0 \\
<1.0 \\
<1.0 \\
<1.0 \\
4.0 \\
3442 \\
89.0 \\
<5.0 \\
<1.0 \\
<1.0 \\
<1.0 \\
<1.0 \\
<1.0 \\
22.0 \\
<0.30 \\
<1.0 \\
<1.0 \\
<1.0 \\
<0.0000 \\
<1.0 \\
680 \\
209 \\
8.1 \\
<0.0050\end{array}$ & $\begin{array}{l}J_{2} \\
J_{0}\end{array}$ & 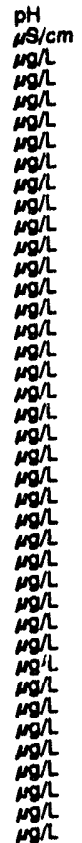 \\
\hline
\end{tabular}


ANALYTICAL RESULTS

WEL F8910SDA collectad on 07/15/92, laboratory analyees (cont.)

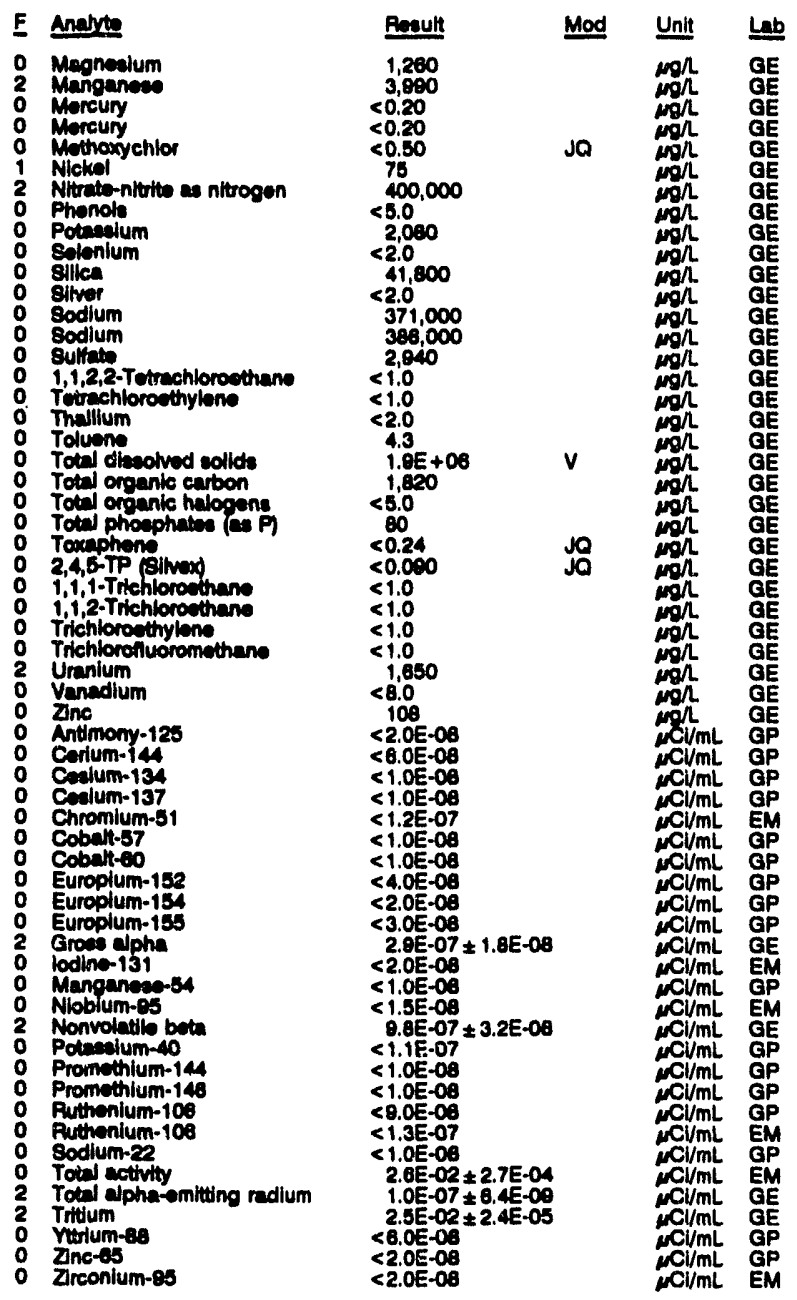

WELL FSB106C

MEASUREMENTS CONDUCTED IN THE FIELD

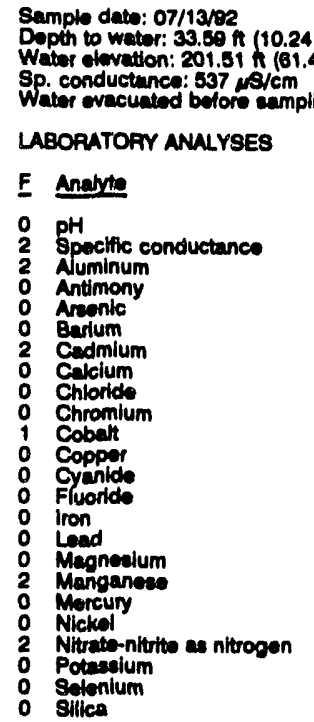

Time: $9: 25$

pH: $\mathbf{5 . 0}$

Water tempergite $20.2^{\circ} \mathrm{C}$

Water evecunted betore exmpling: $120 \mathrm{gal}$

LABORATOFY ANALYSES

\begin{tabular}{|c|c|c|}
\hline Renult & Mod & Unit \\
\hline $\begin{array}{c}5.6 \\
500 \\
1,650 \\
<2.0 \\
<2.0 \\
84 \\
6.1 \\
20,700 \\
3,030 \\
<4.0 \\
31 \\
<4.0 \\
<5.0 \\
395 \\
<4.0 \\
<3.0 \\
3,860 \\
659 \\
<0.20 \\
9.4 \\
75.000 \\
863 \\
<2.0 \\
4,560\end{array}$ & JO & 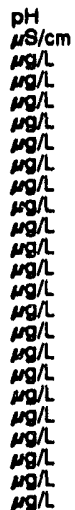 \\
\hline
\end{tabular}

WEL F8B108C collected on 07/13/22, laboratory analyese (cont.)

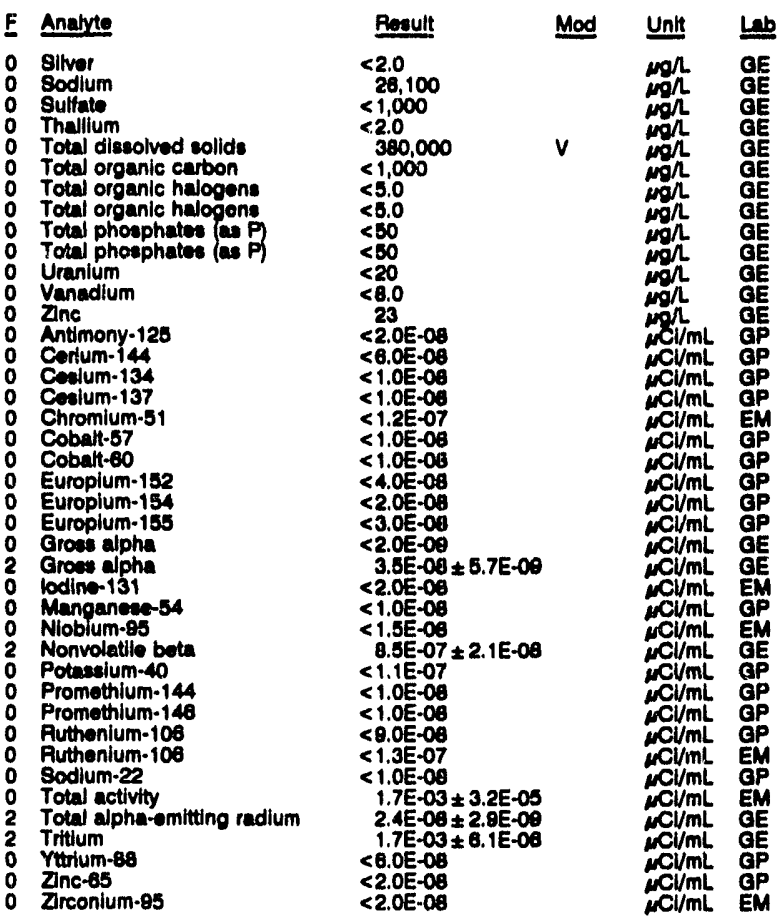

\section{WELL FSB106D}

MEASUAEMENTS CONDUCTED IN THE FIELD

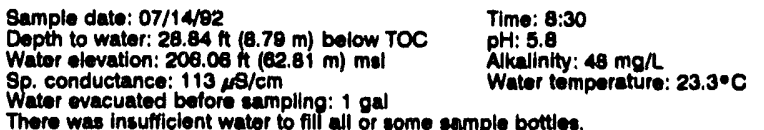

There was insufficient water to fill all or some sample bottice.

LABORATORY ANALYSES

\begin{tabular}{|c|c|c|c|}
\hline Analyte & Rosult & Mod & Unit \\
\hline 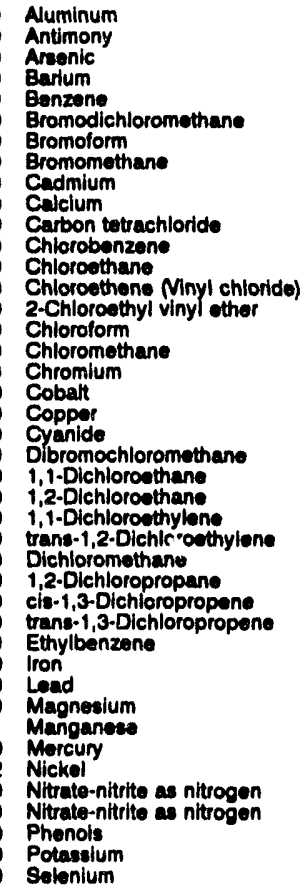 & $\begin{array}{l}<20 \\
<2.0 \\
<2.0 \\
15 \\
<1.0 \\
<1.0 \\
<1.0 \\
<1.0 \\
<2.0 \\
20.800 \\
<1.0 \\
<1.0 \\
<1.0 \\
<1.0 \\
<1.0 \\
<1.0 \\
<1.0 \\
<4.0 \\
<4.0 \\
11 \\
<6.0 \\
<1.0 \\
<1.0 \\
<1.0 \\
<1.0 \\
<1.0 \\
33.2 \\
<1.0 \\
<1.0 \\
<1.0 \\
<1.0 \\
15 \\
<3.0 \\
685 \\
27 \\
<0.20 \\
208 \\
1.140 \\
1.060 \\
<5.0 \\
64.0 \\
<2.0\end{array}$ & J2 & 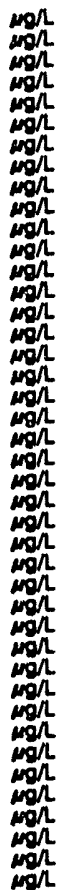 \\
\hline
\end{tabular}


ANALYTICAL RESULTS

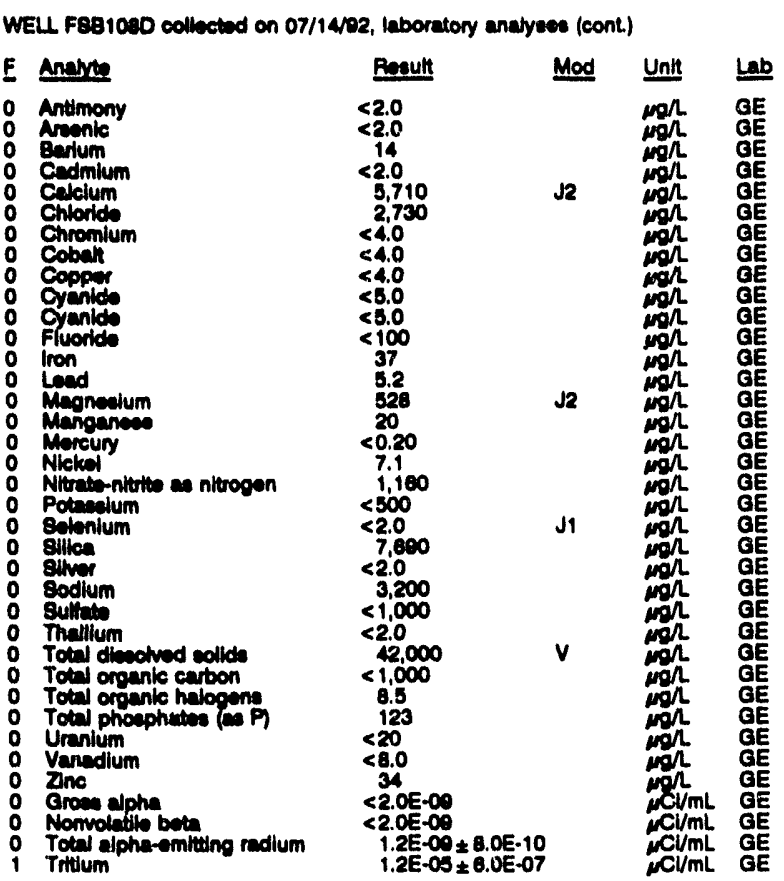

\section{WELL FSB109D}

MEASUREMENTS CONOUCTED IN THE FIELD

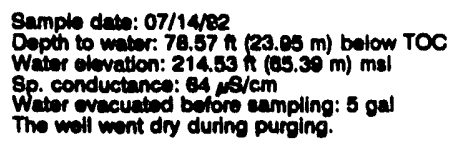

Time: 10:15

PH: 8.0 : $25 \mathrm{mon}$

What tomperature: $21.1^{\circ} \mathrm{C}$

The well went dry during purging.

LABORATOFY ANNLYESS

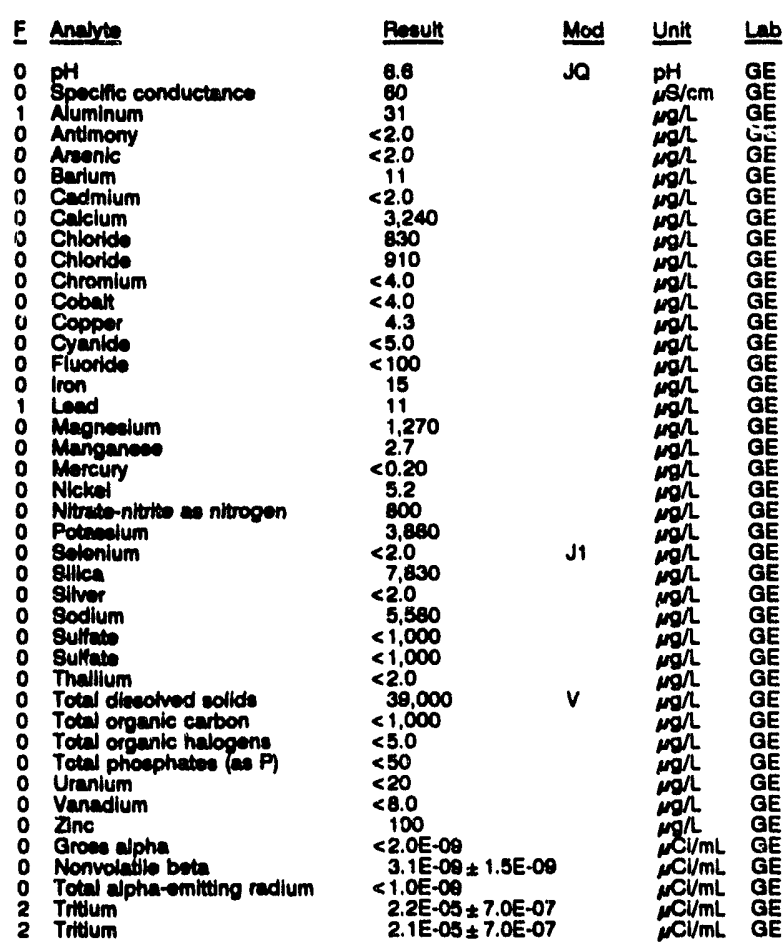

\section{WELL FSB110C}

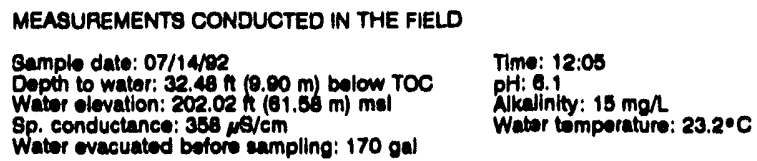

LABOFATOFY AMALYSES

pH
1
Speclfic conductance

Auminum

0 Arsonic

0 Barium

Cadcium

- Chlorido

O Chromlum

O Cobar

Cyanide

0 Fivoride

0 iron

Megnestum

Manganese.

O Mercury

2 Nitrate-nituite as nitrogen

Potacelum

Siliea

Silver

Sodium

Sultitiom

Tothl dissolved solide

Total organic carbon

Total organic halogens

Uranium

o Zine

Antimony-125

Corium-144

Ceslum-134

Chromlum-51

Cobalt:-57

Cobalt.57

Europlum-152

Europlum-184

Europlum-155

Groes alpha

Groses alpha

lodina-131

Manganese-s4

Niobium-05

Nonvolatile beta

Nonvolatile bet

Potasalum-40

Promothium-144

Puthenium-108

Ruthonium-100

Sodlum-22

Tolal actiphary miting redium

2 Trtium

2 Tritum

Ytrolum-88

Zinc-65

Żrconium-95

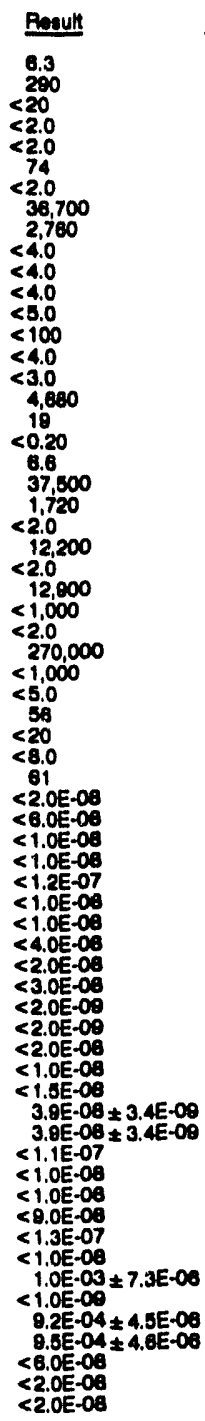

Mod Unt Un

JO ${ }_{\mathrm{NH} / \mathrm{cm}}^{\mathrm{PH}} \mathrm{se}$

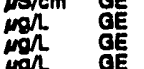

WELL FSB110D

MEASUREMENTS CONDUCTED IN THE FIELD

Sample date: 07/14/92

Depth to water: $28.82 \mathrm{At}(8.78 \mathrm{~m})$ bolow TOC

Water olevation: 205.88 in $(62.68$

Water evacuated bofore sempling: $\mathbf{4 8} \mathrm{gal}$

LABORATOAY ANALYSES

\begin{tabular}{|c|c|c|c|}
\hline Analyte & Posult & Mod & Uiint \\
\hline $\begin{array}{l}\text { pH } \\
\text { pH } \\
\text { Specific conductance } \\
\text { Specific conductance } \\
\text { Aluminum } \\
\text { Antimony }\end{array}$ & $\begin{array}{l}3.4 \\
3.4 \\
1,300 \\
1,250 \\
37,800 \\
<2.0\end{array}$ & Jo & $\begin{array}{l}\mathrm{pH} \\
\mathrm{pH} \\
\mathrm{NS} / \mathrm{cm} \\
\mathrm{N} / \mathrm{cm} \\
\mathrm{wol}\end{array}$ \\
\hline
\end{tabular}


WEU F891 100 collectad on 07/1492, laboratory analyees (cont)

E Aneres

o Antimony

o Arenic

Extum

Cadimium

Chlorido

Chromium

Coppor

Chanide

0 iron

0 Lend

Magnealum

Maseanes

Nithentivite es nivosen

Poteactum

ovonium

o siliea

2 Ellicen, toin

o sodtum

0 Sulves

Sulles

Thallum

o Total dineowed collids

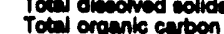

Totel comanic halooen

Tow phophatien (im P)

Tributyl phoephet

Vencen

Zne

Antimony-12:

Cocium-13

Ceclum-137

Chrontum-51

Cobark-67

Europlum-162

Europlum-184

Europlum-15.

Groes atph

Manoanceoses

Nobium-es

Nomolitile bet

Pconatum

Pithenlum-10s

Aythenlum-100

Bodum-2?

Total setrity

Total eloha-eminting medium

Trioum

Znce-6

Zircontum-es
Promentumisas

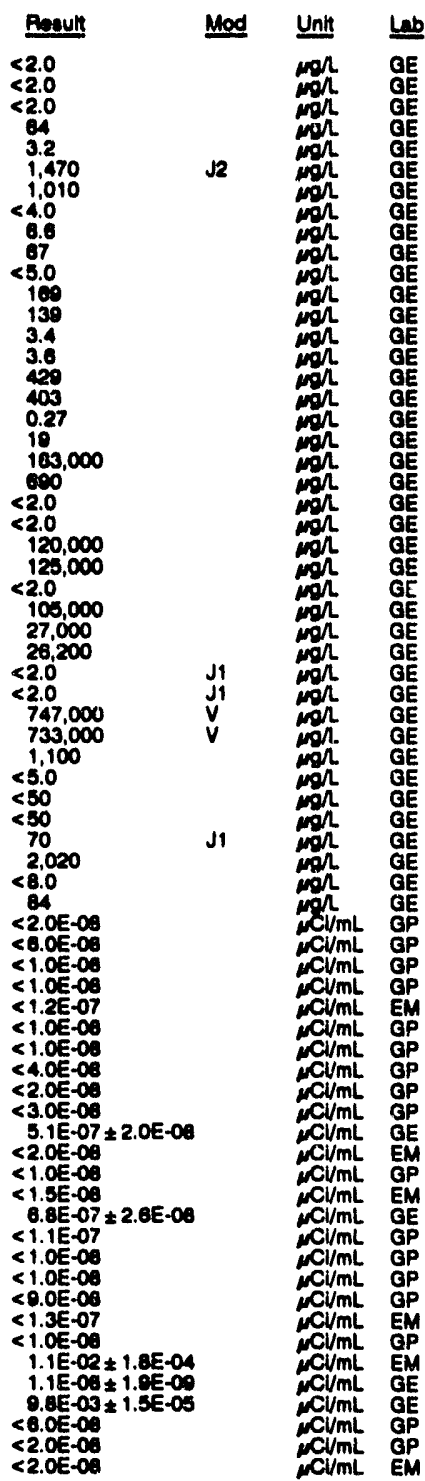

WELL FSB111C

MEASUAEMENTS CONDUCTED IN THE FIELD

Sampio data: 07/10ve

Depth to water: $63.50 \mathrm{ft}$ (18.39 m) below TOC

Watar elevation: 212.71 h $(84.83 \mathrm{~m}) \mathrm{ms}$

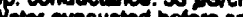

(a) 141

LABORATORY ANALYSES

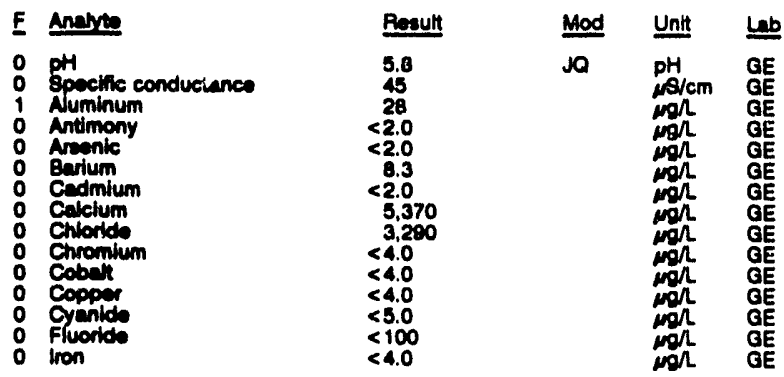

WEL F88111C collected on 07/10/02, laboratory analyewe (cont)

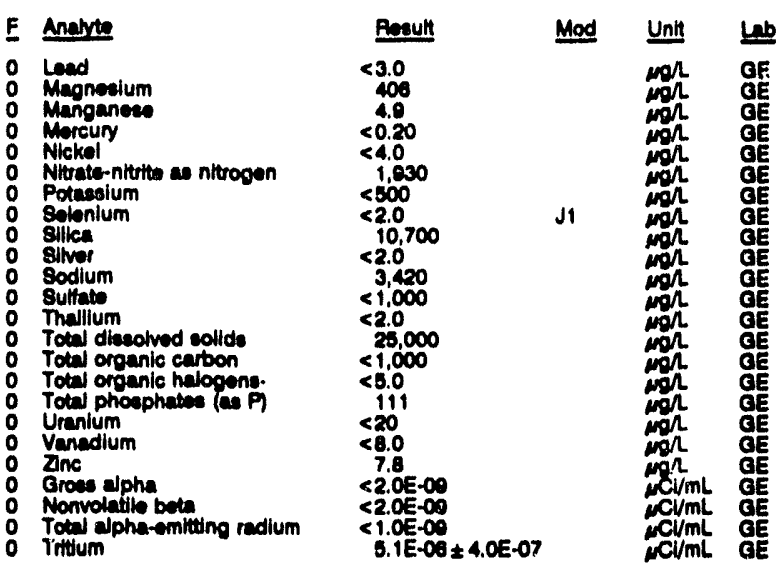

WELL FSB111D

MEASUREMENTS CONOUCTED IN THE FIELD

\begin{tabular}{|c|c|}
\hline $\begin{array}{l}\text { Sample date: } 07 / 10 / 92 \\
\text { Depth to watior: } 60.51 \mathrm{~h}(18.44 \mathrm{~m}) \text { below TOC } \\
\text { Whater elevation: } 216.00 \mathrm{~h}(65.87 \mathrm{~m}) \mathrm{mal} \\
\text { Sp. conductance: } 33 \mu \mathrm{cm} / \mathrm{cm}\end{array}$ & $\begin{array}{l}\text { Time: } 12: 36 \\
\text { pH: } 1.8 \\
\text { Akalinity: } 0 \text { mon } \\
\text { Water tomperature: } 23.5 \cdot \mathrm{C}\end{array}$ \\
\hline
\end{tabular}

LABORATORY ANALYSES

\begin{tabular}{|c|c|c|c|c|}
\hline Anatrte & Aneult & Mod & Unit & Lab \\
\hline 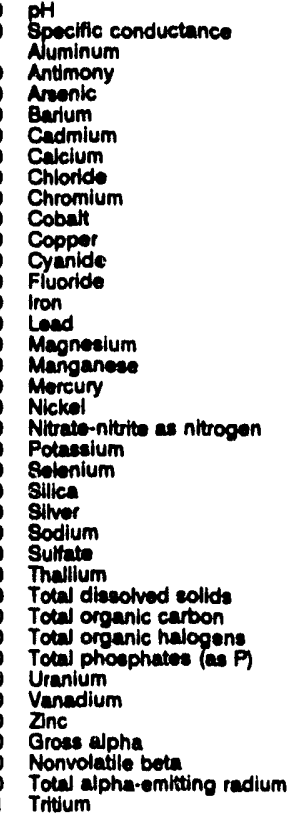 & $\begin{array}{l}5.1 \\
30 \\
33 \\
<2.0 \\
<2.0 \\
11 \\
<2.0 \\
897 \\
2.710 \\
<4.0 \\
<4.0 \\
5.6 \\
<5.0 \\
<100 \\
17 \\
<3.0 \\
671 \\
8.9 \\
<0.20 \\
<4.0 \\
1.170 \\
<500 \\
<2.0 \\
8 ., 020 \\
<2.0 \\
2.840 \\
<1,000 \\
<2.0 \\
24,000 \\
<1.000 \\
<5.0 \\
57 \\
<20 \\
<8.0 \\
13 \\
<2.0 E-09 \\
4.3 E-00 \pm 1.6 E-00 \\
<1.0 E-09 \\
1.2 E-05 \pm 6.0 E-07\end{array}$ & JO & 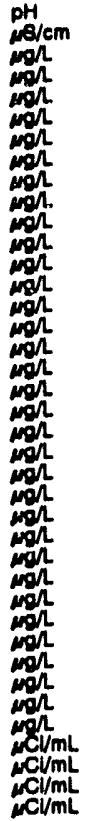 & 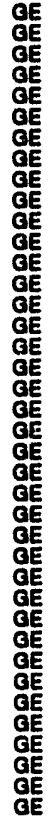 \\
\hline
\end{tabular}

\section{WELL FSB112A}

MEASUREMENTS CONDUCTED IN THE FIELD

Dopth to watier: $76.15 \mathrm{~h}(23.21 \mathrm{~m})$ below TOC

Weter elovation: 15205 (23.

Sp. conductance: 188 is/cm

Water evacuated before sampling: $189 \mathrm{gal}$

PH: 6.8. $43 \mathrm{mgn}$

Water temperature: $18.0^{\circ} \mathrm{C}$

LABORATOFY ANALYSES

\begin{tabular}{|c|c|c|c|}
\hline E Analyte & Rerult & Mod & Untt \\
\hline $\begin{array}{ll}0 & \mathrm{pH} \\
0 & \text { Specific conductance } \\
2 & \text { Aluminum }\end{array}$ & $\begin{array}{l}7.0 \\
130 \\
166\end{array}$ & Jo & $\begin{array}{l}\mathrm{pH} \\
\mathrm{is} / \mathrm{cm} \\
\mathrm{mol}\end{array}$ \\
\hline
\end{tabular}


ANALYTICAL RESULTS

WELL FSB1 12A collected on 07/18/92, laboratory analyeses (cont.)

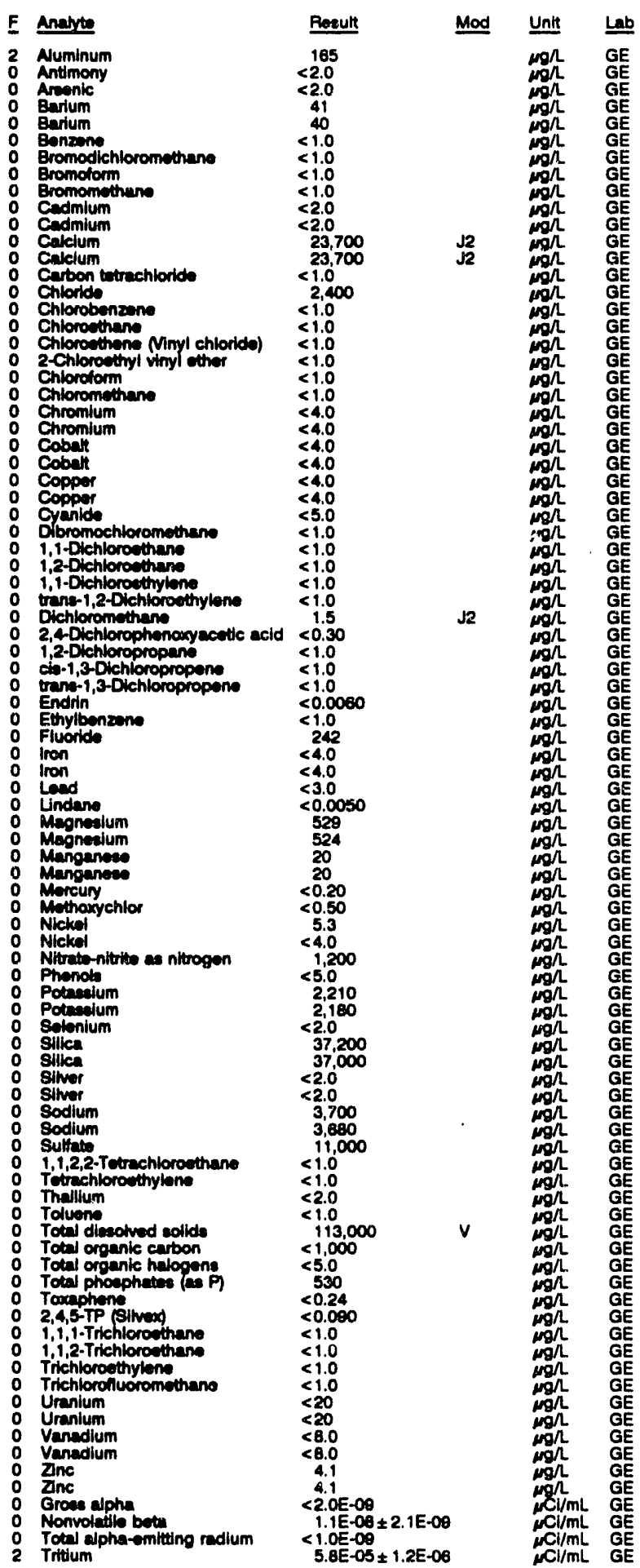

\section{WELL FSB112C}

MEASUREMENTS CONDUCTED IN THE FIELD

Sample date: $07 / 15 / 92$

Wopth to water: $27.01 \mathrm{~h}(8.23 \mathrm{~m})$ bolow TOC

Sp. conductance: 1520

Wator evacuated before sempling: $191 \mathrm{gal}$

Time: 14:30

Alkalinity: $0 \mathrm{mgh}$

Wator tomporefure: $21.4^{\circ} \mathrm{C}$

LABOPATORY ANALYSES

2 2 Spocific conductance

Aluminum

Antimony

Ararium

Barium

Bromodichloromethane

Bromolorm

Bromomethane

Cadmium

Carbon tetrachlorida

Chlorido

Chiorobenzene

Chloroethene Minyl chlorides)

2.Chloroethyl vinyl other

Chloroform

Chloramethane

Chromium

Cobalt

Coppor

Dibromochloromethane

1,1-Dichloroethane

1,2-Dichloroethane

1,1-Dichloroethylene

trans-1,2-Dichloreoth

2,4-Dichlorophenoxyacetic acid

1,2-Dichloropropane

cis-1,3-Dichloropropene

trans-1,3-Dichloropropene

0 Endrin

Ethylbenzene

Iron

Load

Lindane

2 Magnesium

Manganese

O Mercury

Nickel

Nitrato-nitrite as nitrogen

Phenols

Potassium

Solenium

Silver

Sodium

Sulfate

o $1,1,2,2$-Tetrachloroethane

Totrachloroethylene

Thallum

Toluene

Total organic carbon

Total organic halogens

o Total organic halogens

Toxaphene

2,4,5-TP (Silvex)

1,1,1-Trichloroethane

Trichloroethylene

o Trichlorofluoromethane

Uranium

o Zne

Antimony-125

0 Corium-144

o Cosium-134

O Cesium-137

0 Chromium-51

0 Cobalt.57

Europium-152

Europium-154

Europium-155

Groas alpha

lodine-131

Nonvolatile beta

Potasslum-40

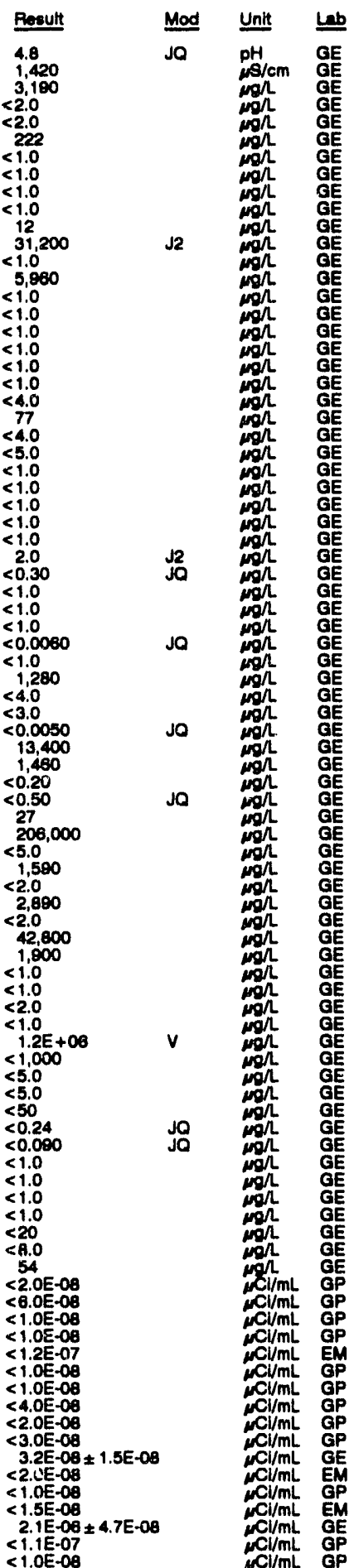


WEL F981 12C collected on 07/15/82, laboratory analyees (cont)

\begin{tabular}{|c|c|c|c|c|}
\hline & Analyte & Rosult & Unit & Lab \\
\hline & 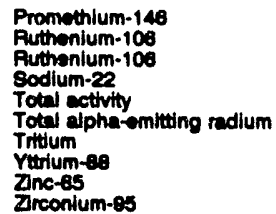 & $\begin{array}{l}<1.0 E-08 \\
<8.0 E-08 \\
<1.3 E-07 \\
<1.0 E-08 \\
7.2 E-03 \pm 6.2 E-05 \\
1.5 E-07 \pm 8.5 E-09 \\
6.6 E-03 \pm 1.2 E-05 \\
<6.0 E-08 \\
<2.0 E-08 \\
<2.0 E-08\end{array}$ & 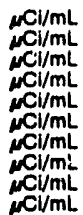 & $\begin{array}{l}\mathrm{GP} \\
\mathrm{GP} \\
\mathrm{EM} \\
\mathrm{GP} \\
\mathrm{EM} \\
\mathrm{GE} \\
\mathrm{GE} \\
\mathrm{GP} \\
\mathrm{GP} \\
\mathrm{EM}\end{array}$ \\
\hline
\end{tabular}

\section{WELL FSB112D}

MEASUREMENTS CONDUCTED IN THE FIELD

Sample date: 07/16/92 Depth to wation: $23.45 \mathrm{ht}(7.15 \mathrm{~m})$ bolow TOC Sp. conductence: $1588, \mathrm{~s} / \mathrm{cm}$

$\prod_{10}: 9: 30$

pH: 3.3 : $0 \mathrm{mgl}$

Water temperature: $18.0^{\circ} \mathrm{C}$

LABORATOFY ANALYSES

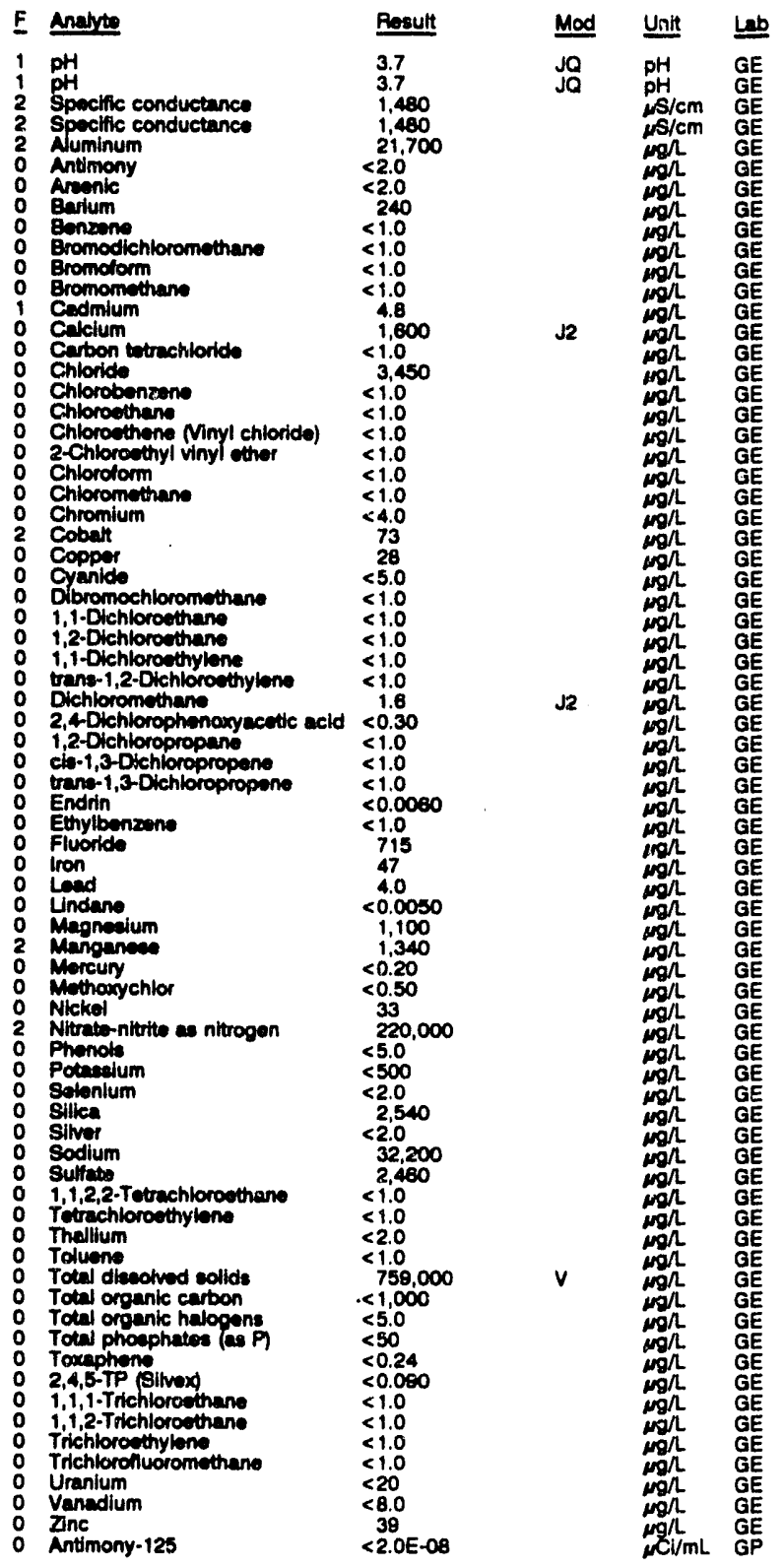

WELL FSB1 12D collocted on 07/16/92, laboratory analyees (cont.)

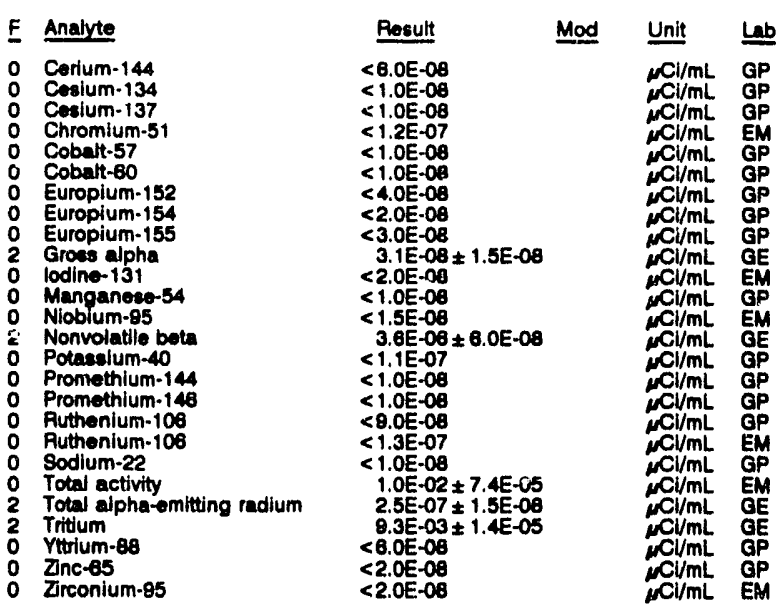

WELL FSB113A

MEASUREMENTS CONDUCTED IN THE FIELD

$\begin{array}{ll}\text { Sample date: } 07 / 0492 & \text { Time: } 12: 40 \\ \text { Depth to water: } 64.45 \mathrm{ft}(19.64 \mathrm{~m}) \text { bolow TOC } & \text { pH: } 11.7 \\ \text { Water olevation: } 158.75 \mathrm{~h}(48.39 \mathrm{~m}) \mathrm{ms} & \text { Alkalinity: } 197 \mathrm{mg} / \\ \text { Sp. conductance. } 772 \mu \mathrm{s} / \mathrm{cm} & \text { Water tomperature: } 22.1 \cdot \mathrm{C} \\ \text { Water ovacuated before sampling: } 204 \mathrm{gal} & \end{array}$

LABORATORY ANALYSES

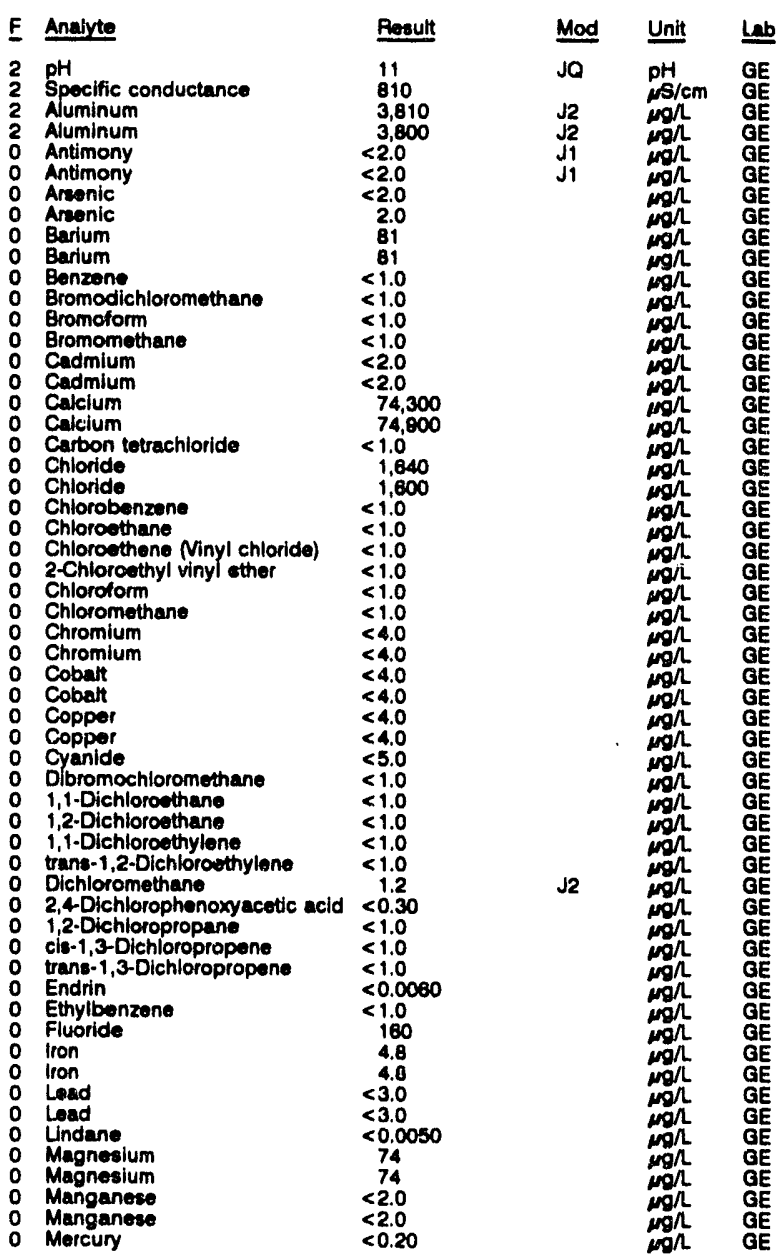


ANALYTICAL RESULTS

WELL FSB1 13A colloctod on 07/04/92, laboratory analyeos (cont)

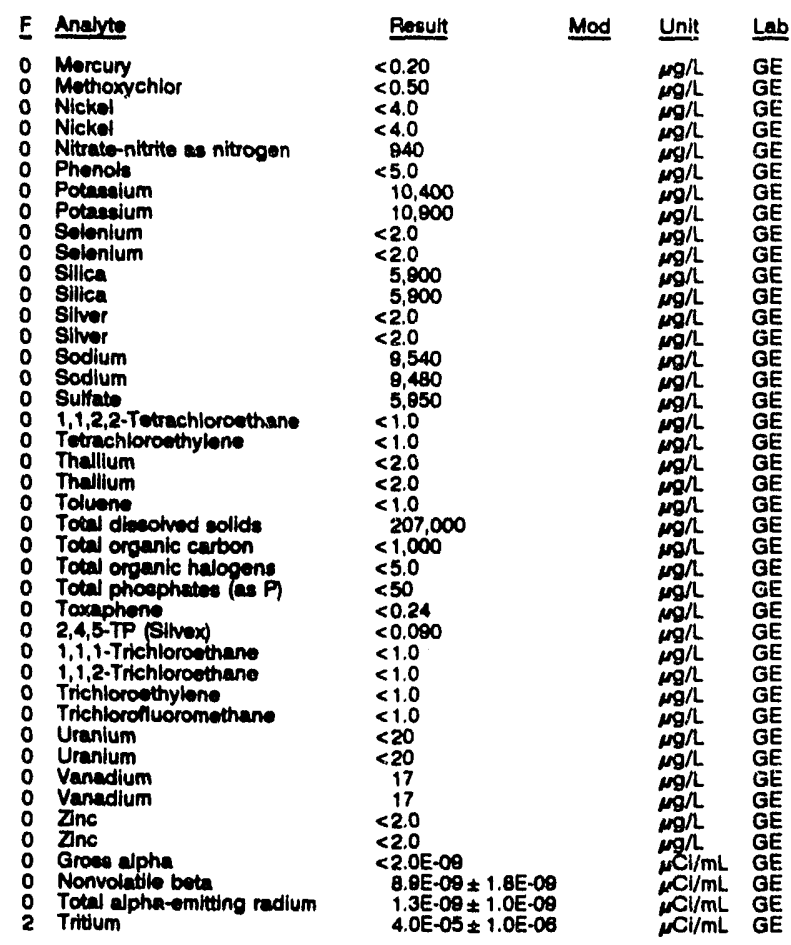

WELL FSB113C

MEASUREMENTS CONDUCTED IN THE FIELD

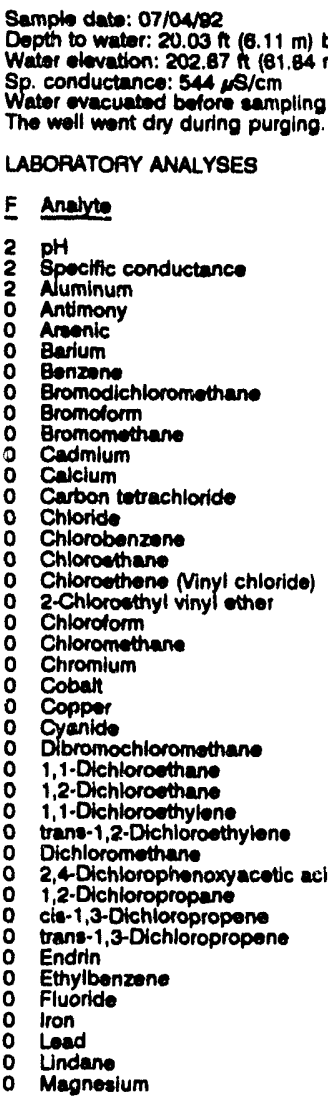

Time: 12:10

PH: 11.7 . $162 \mathrm{mg} / \mathrm{h}$

Aater temperature: $21.3^{\circ} \mathrm{C}$

ing: $28 \mathrm{gal}$

The well went dry during purging

LABORATORY ANALYSES

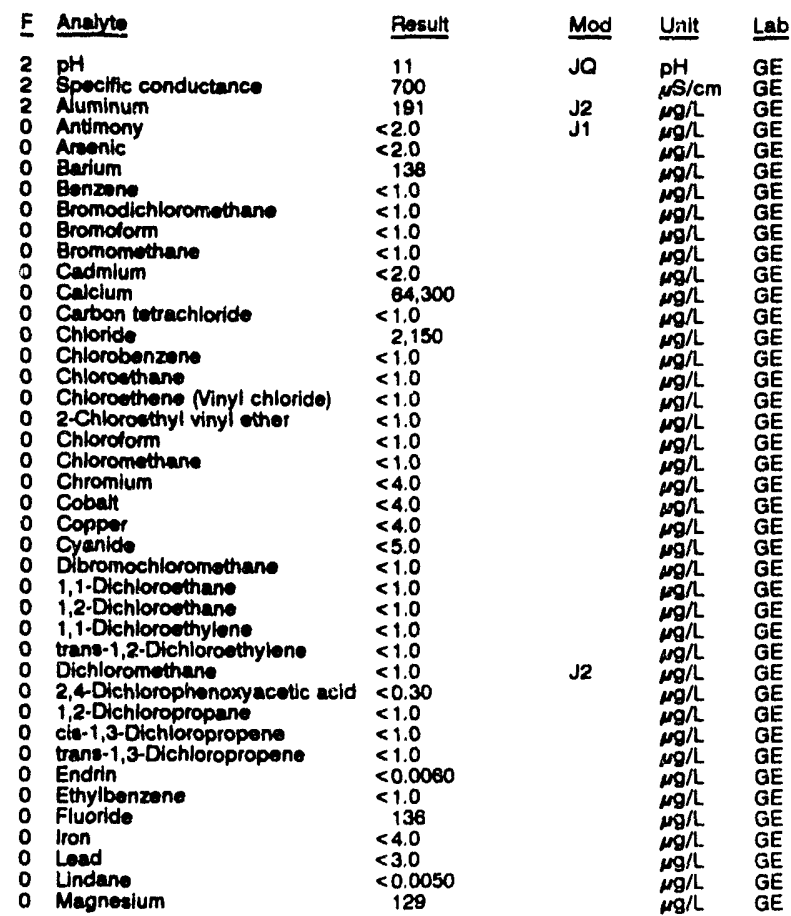

WELL FSB1 13C collected on 07/04/92, laboratory analyeos (cont.)

\begin{tabular}{|c|c|c|c|}
\hline Analyte & Result & Mod & Unit \\
\hline $\begin{array}{l}\text { Mangenese } \\
\text { Mercury } \\
\text { Methoxychlor } \\
\text { Nickel } \\
\text { Nitrate-nitrite as nitrogen } \\
\text { Phenois } \\
\text { Potassium } \\
\text { Solenium } \\
\text { Silica } \\
\text { Sitver } \\
\text { Sodium } \\
\text { Sulfate } \\
1,1,2,2 \text {-Tetrachloroethane } \\
\text { Tetrachloroethylene } \\
\text { Thallium } \\
\text { Toluene } \\
\text { Total dissolved sollds } \\
\text { Total organic carbon } \\
\text { Total organic halogens } \\
\text { Total phosphates (as PI } \\
\text { Toxaphane } \\
2,4,5-T P \text { (Silvex) } \\
\text { 1,1,1-Trchloroethane } \\
\text { 1,1,2-Trichloroethane } \\
\text { Trichloroethylene } \\
\text { Trichiorofluoromethane } \\
\text { Uranlum } \\
\text { Vanadium } \\
\text { Zinc } \\
\text { Gross alpha } \\
\text { Nonvolatile beta } \\
\text { Total alpha-emitting radlum } \\
\text { Tritium }\end{array}$ & $\begin{array}{l}<2.0 \\
<0.20 \\
<0.50 \\
<4.0 \\
3,700 \\
<5.0 \\
1,120 \\
<2.0 \\
6,820 \\
<2.0 \\
7,780 \\
51.550 \\
<1.0 \\
4.1 \\
<2.0 \\
<1.0 \\
164,000 \\
1.050 \\
<5.0 \\
215 \\
<0.24 \\
<0.090 \\
<1.0 \\
<1.0 \\
<1.0 \\
<1.0 \\
<20 \\
<8.0 \\
<2.0 \\
<2.0 E-09 \\
3.2 E-09 \pm 1.4 E-09 \\
<1.0 E-09 \\
5.5 E-05 \pm 1.1 E-06\end{array}$ & & 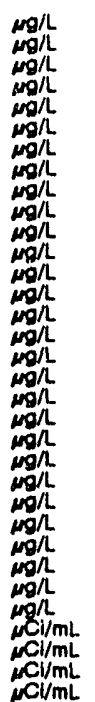 \\
\hline
\end{tabular}

WELL FSB1 13D

MEASUREMENTS CONDUCTED IN THE FIELO

Sample date: 07/04/82 Dopth to water: $15.11 \mathrm{ft}(4.61 \mathrm{~m})$ bolow TOC Wator elovation: $207.39 \mathrm{ht}(03.21 \mathrm{~m}) \mathrm{mst}$

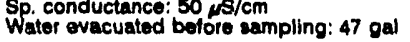

pH: 4.8

Alkalinity: $0 \mathrm{mg} / \mathrm{L}$
Water femperafure: $21.5^{\circ} \mathrm{C}$

LABORATORY ANALYSES

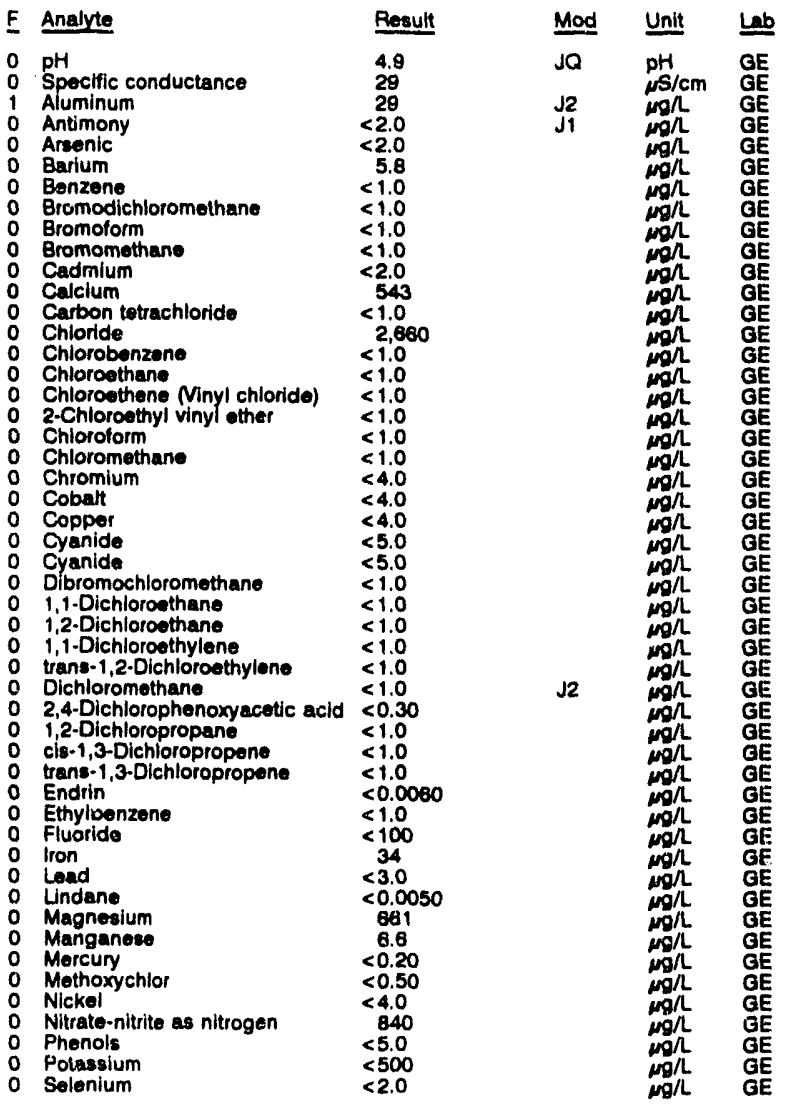




\begin{tabular}{|c|c|c|c|c|}
\hline E & Analyte & Proult & Mod & Unit \\
\hline & 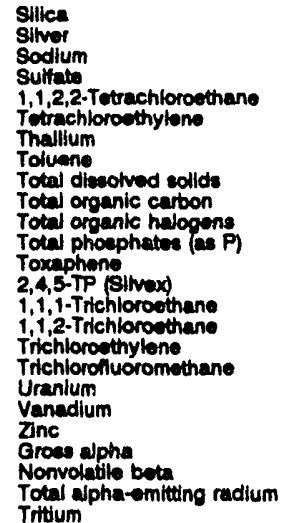 & $\begin{aligned} & 6.490 \\
&<2.0 \\
& 1.070 \\
&<1.000 \\
&<1.0 \\
&<1.0 \\
&<2.0 \\
&<1.0 \\
& 16,000 \\
&<1,000 \\
&<5.0 \\
&<50 \\
&<0.24 \\
&<0.090 \\
&<1.0 \\
&<1.0 \\
&<1.0 \\
&<1.0 \\
&<20 \\
&<8.0 \\
& 5.8 \\
&<2.0 E-09 \\
&<2.0 E-09 \\
&<1.0 E-09 \\
& 1.4 E-05 \pm 6.0 E-07\end{aligned}$ & & 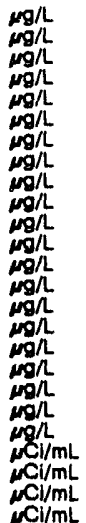 \\
\hline
\end{tabular}

WELL FSB114A

MEASUAEMENTS CONDUCTED IN THE FIELD
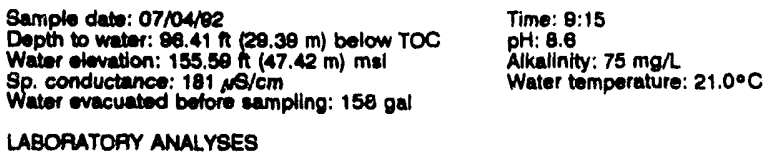

LABORATOPY ANALYSES

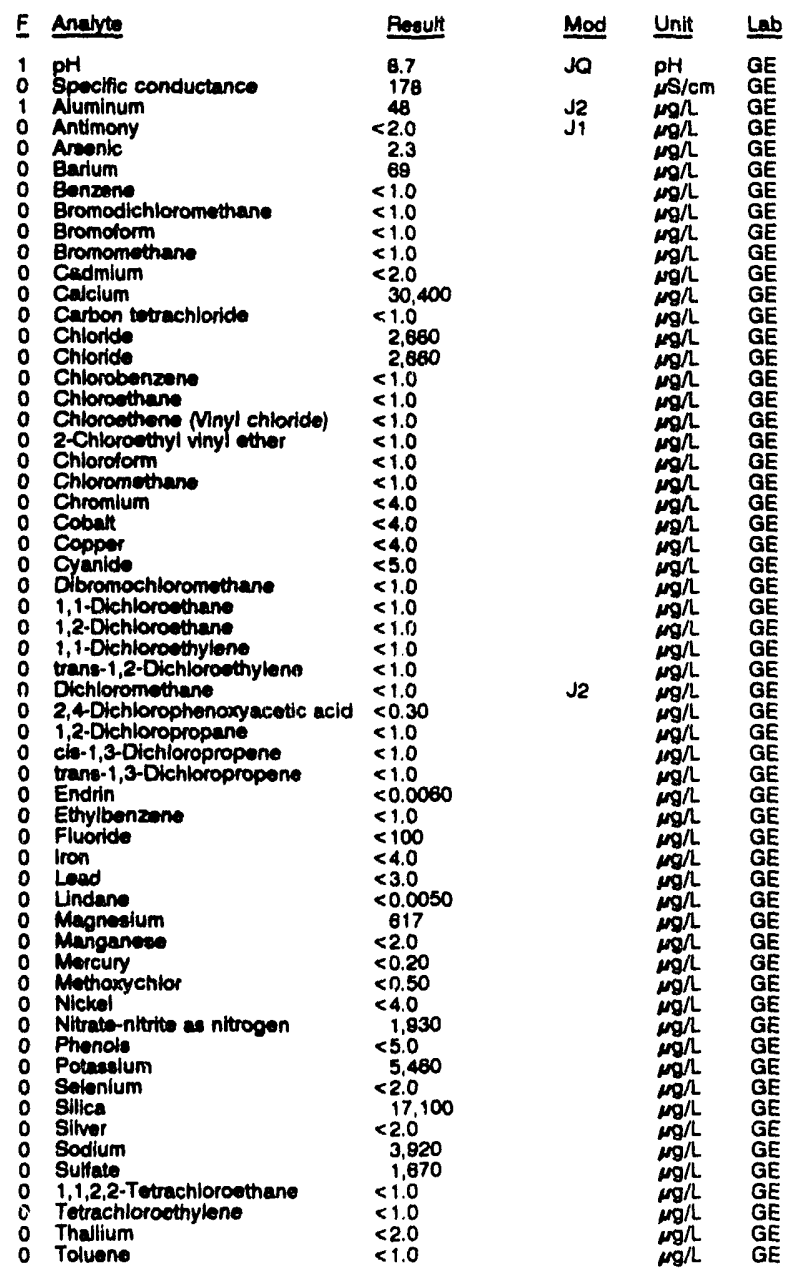

WELL FSB114A colloctod on 07/04/92, laboratory analyses (cont.)

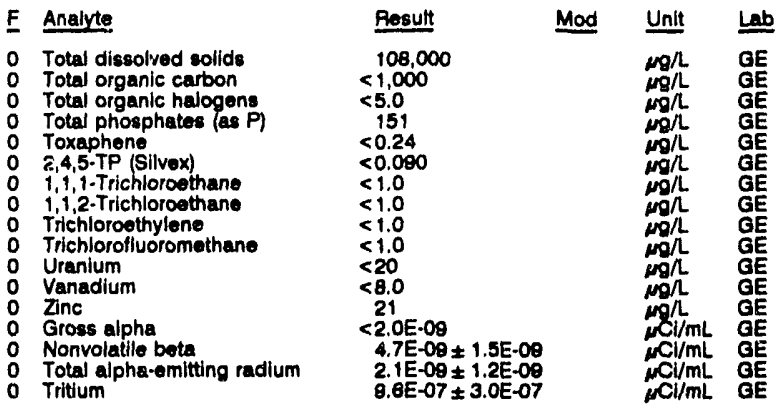

\section{WELL FSB114C}

MEASUREMENTS CONDUCTED IN THE FIELD Sample date: $07 / 04 / 92$
Depth to water: $38.41 \mathrm{tt}(11.71 \mathrm{~m})$ below TOC
Water elevation: $213.79 \mathrm{ft}(65.16 \mathrm{~m}) \mathrm{msl}$ Sp. conductance: $61 \mu \mathrm{S} / \mathrm{cm}$
Water ovacuated before sampling: $146 \mathrm{gal}$

Time: $8: 30$

PH: 5.4 : 0 mall Water tomperature: $20.7^{\circ} \mathrm{C}$

LABORATORY ANALYSES

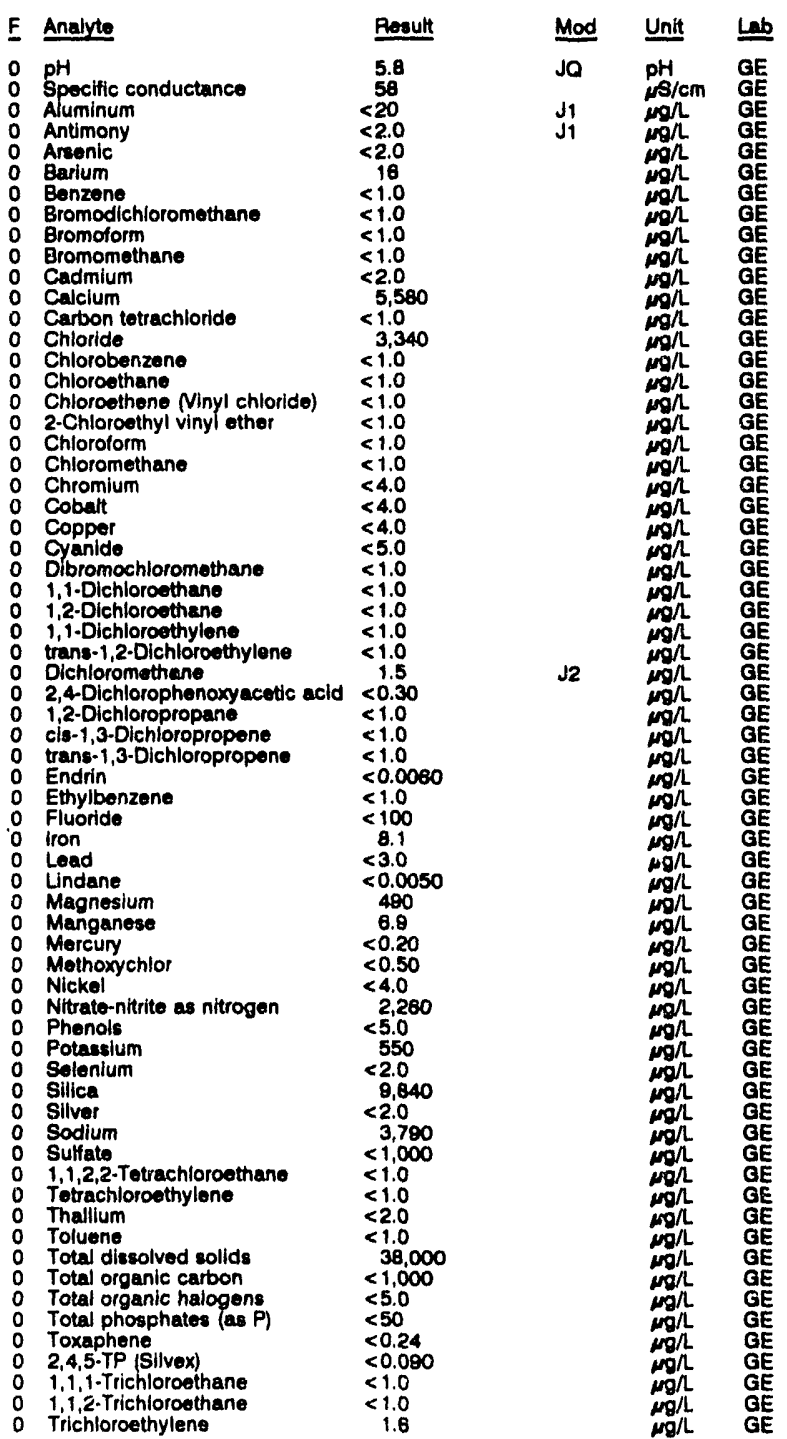


ANALYTICAL RESULTS

WEU FSBI14C collectod on 07/04/82, laboratory analyeos (cont)

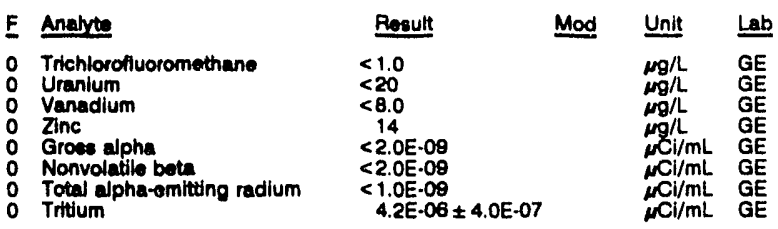

WELL FSB114D

MEASUREMENTS CONDUCTED IN THE FIELD

Sample date: $07 / 0492$
Dopth to water: $35.07 \mathrm{ft}(10.69 \mathrm{~m})$ bolow TOC
Water elevation: $217.13 \mathrm{~h}(68.1 \mathrm{~m}) \mathrm{ms}$
Sp. conductance: $49 \mathrm{~N} / \mathrm{cm}$
Water evacuated bofore sempling: $51 \mathrm{gal}$

LABOAATOFY ANALYSES

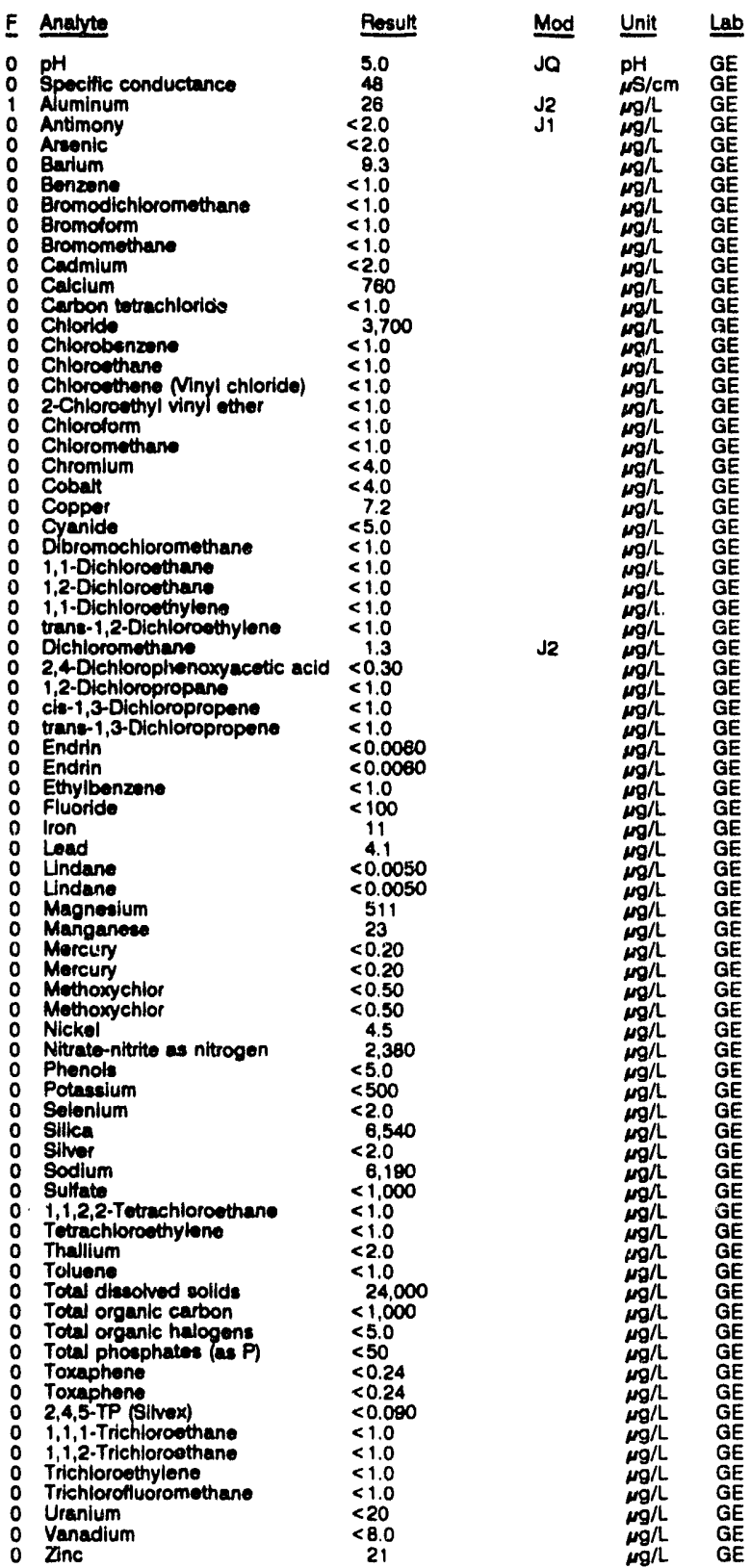

Time: $8: 45$

Alkalinity: $0 \mathrm{mg} / \mathrm{h}$

Waler temperature: $20.8^{\circ} \mathrm{C}$
WELL FSB1 14D collected on 07/04/92, laboratory arialyees (cont.)

\begin{tabular}{|c|c|c|c|c|c|}
\hline & Analyte & Result & Mod & Unit & $\underline{L}$ \\
\hline & $\begin{array}{l}\text { Gross alpha } \\
\text { Nonvolatile beta } \\
\text { Total alpha-emitting radium } \\
\text { Total alpha-emitting radium } \\
\text { Tritium }\end{array}$ & $\begin{array}{l}<2.0 \mathrm{E} \cdot 09 \\
<2.0 \mathrm{E}-09 \\
<1.0 \mathrm{E}-09 \\
<1.0 \mathrm{E}-09 \\
8.3 \mathrm{E}-08 \pm 5.0 \mathrm{E}-07\end{array}$ & & 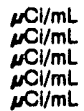 & $\begin{array}{l}\mathrm{GE} \\
\mathrm{GE} \\
\mathrm{GE} \\
\mathrm{GE} \\
\mathrm{GE}\end{array}$ \\
\hline
\end{tabular}

WELL FSB115C

MEASUREMENTS CONDUCTED IN THE FIELD

Sample date: 07/04/92

Depth to water: $23.21 \mathrm{ft}(7.07 \mathrm{~m})$ below TOC

Water elevation: $164.59 \mathrm{ft}(56.28 \mathrm{~m}) \mathrm{msl}$

Sp. conductance: $30 \mathrm{~s} / \mathrm{cm}$

The wacuated before sampling: $12 \mathrm{gal}$

LABORATORY ANALYSES

O $\mathrm{pH}$ Specific conductance

Aluminum

A Antimony

O Arsenic

Barium

B Bromodichloromethane

Bromoform

Bromomethane

Cadmium

Carbon tetrachlorido

Chloride

- Chlornbenzene

- Chloroethane

- Chloroethene (Vinyl chloride)

2-Chloroethyl vinyl ether

C Chloroform

o Chloromethane

- Chromium

O Cobalt

o Dibromochloromethane

o 1,1-Dichloroethane

1, 1-Dichloroothane

1,2-Dichloroethane

o trans-1,2-Dichloroethylene

0 Dichloromethane

2,4-Dichlorophenoxyacetic acid

- 1,2-Dlchloropropane

o cis-1,3-Dichloropropene

0 Endrin

o Ethylbenzene

o Fluoride

o Iron

o Lead

- Magnesium

- Manganese

Mothoxychlor

Nickel

Nitrate-nitrite as nitrogen

Nitrate-nitrite as nitrogen

Phenols

Phenols

Potassium

S Solenium

o Silica

O Silver

Sodium

0 Sulfate

1,1,2,2-Tetrachloroethane

Tetrachloroethylene

Thallium

Total dissolved solids

Total dissolved solids

Total organic cartion

Total organic halogens

Total phosphates (as P)

Toxaphene

2,4,5-TP (Silvex)

1, Trichlorothane

Trichloroethylene

2 Trichlorofluoromethane

Uranium

O Vanadiur

Zinc

- Gross alpha

Nonvolatile beta

$\begin{array}{ll}5.6 & \text { JO } \\ 29 & \text { J1 } \\ <20 & \text { J1 } \\ <2.0 & \end{array}$

$<2.0$

$<1.0$

$<1.0$

$<1.0$

$<2.0$

$<1.360$

1,610

$<1.0$

$<1.0$

$<1.0$

$<1.0$

$<4.0$

$<4.0$

$<5.0$

$<1.0$

(1.0

$<1.0$

$<1.0$

$\begin{aligned} & 1.7 \\ &< 0.30 \\ &< 1.0 \\ &<1.0\end{aligned}$

1.0

$<0.0060$

$<1.0$

$<100$

$<3.0$

$<0.005$

$\begin{aligned} & 308 \\ & 8.0 \\ &< 0.20 \\ &< 0.50\end{aligned}$

$<0.50$
$<4.0$
580
580

580

$<5.0$
$<5.0$
$<2.0$

$<2.0$

$<.0$
2,280
1,920

1,820
$<1,00$

$<1.0$

$<2.0$

$<1.0$
20,000

18,000

$<5.0$

62

$<0.24$

$<1.0$

$<1.0$

$<1.0$

33
$<20$
$<8.0$

$<8.0$

$<2.0 \mathrm{E}-08$

$<2.0 \mathrm{E}-09$

$<1.0 \mathrm{E}-09$

Time: 13:55

Alkalintiy: $3 \mathrm{mg} / \mathrm{L}$

Water temperature: $21.5^{\circ} \mathrm{C}$

o Tritium

9.8E-08 \pm 5.0E-07 


\section{ANALYTICAL RESULTS}

\section{WELL FSB115D}

MEASUREMENTS CONDUCTED IN THE FIELD

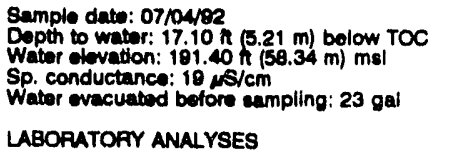

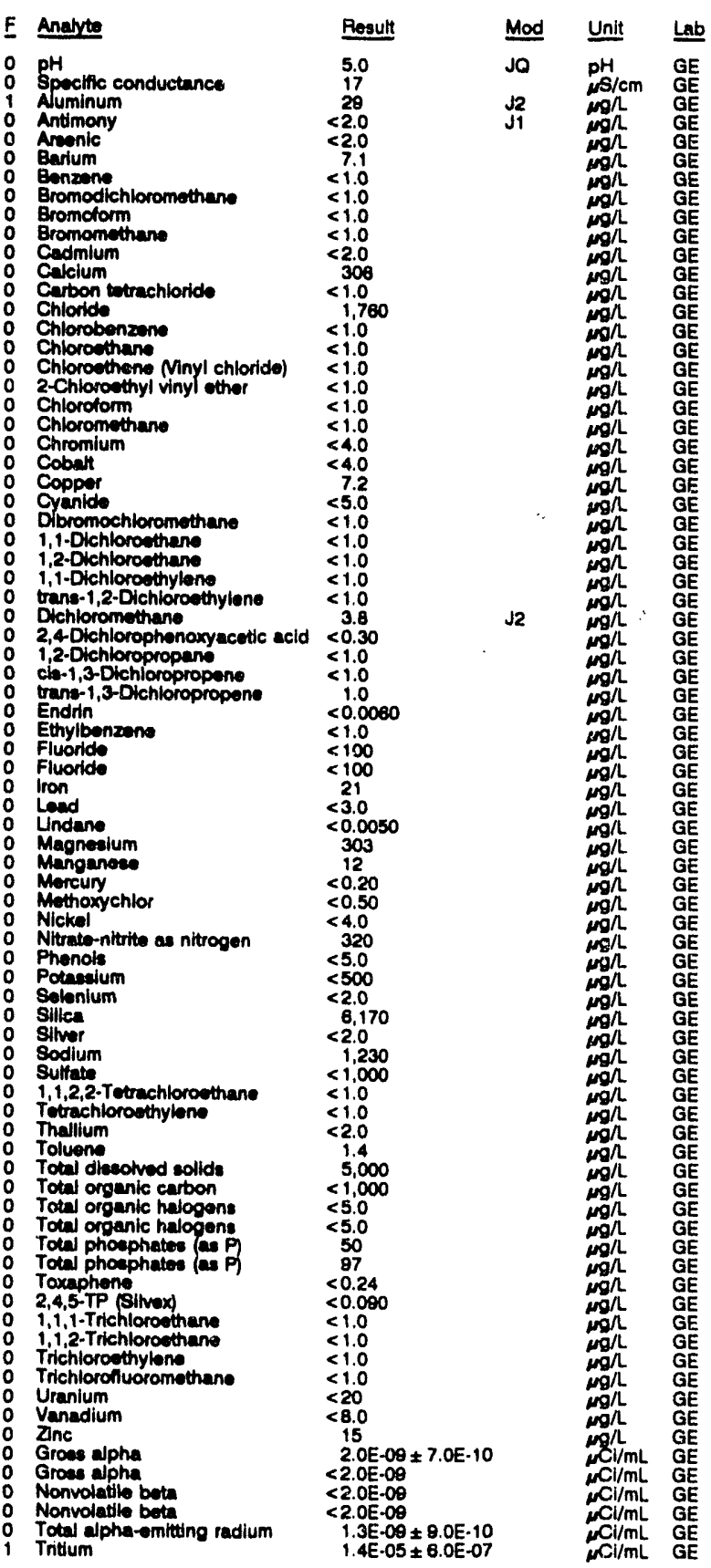

Time: $11: 10$

PH: 4.6 Alkalinity: $1 \mathrm{mg} \Omega$

\section{WELL FSB116C}

MEASUREMENTS CONDUCTED IN THE FIELD

Sample date: 07/04/92

Wator tomperature $20.8 \circ \mathrm{C}$

Depth to water: $12.89 \mathrm{n}(3.83 \mathrm{~m})$ bolow TOC

Sp conductance: $25 \mathrm{~s} / \mathrm{cm}$

Water evacualed before sampling: $78 \mathrm{gal}$

Time: 10:35

AH: 4.8 inginity: $1 \mathrm{man}$

Water temperature: $20.3^{\circ} \mathrm{C}$

LABORATORY ANALYSES

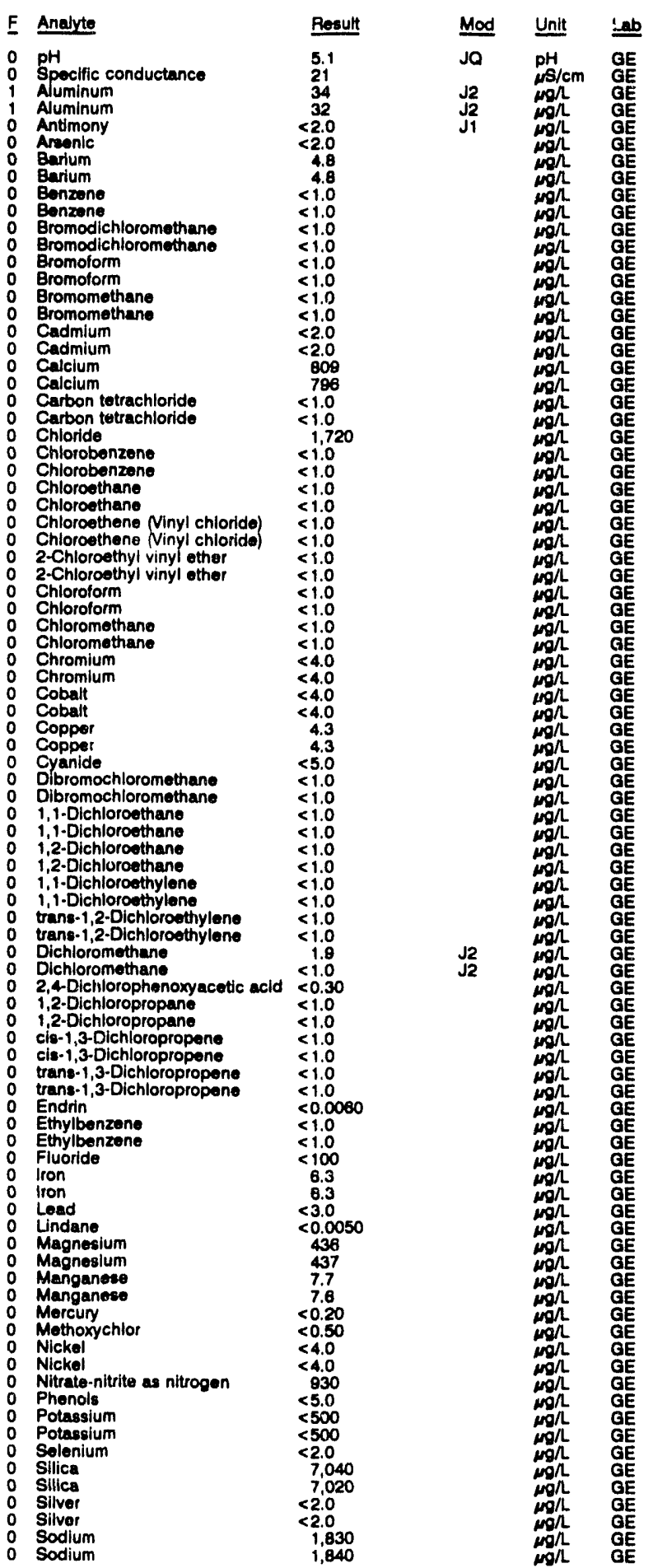


ANALYTICAL RESULTS

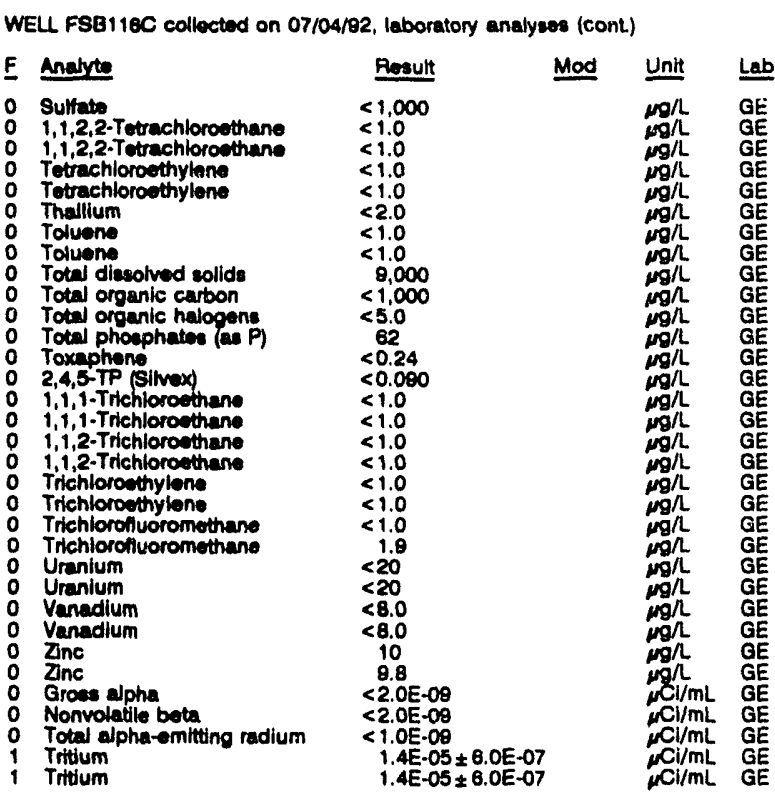

\section{WELL FSB116D}

MEASUREMENTS CONDUCTED IN THE FIELD

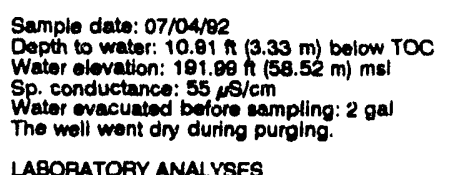

Time: 13:35

pH: 4.8

Alkalinity: $1 \mathrm{mg} h$, $22.8^{\circ} \mathrm{C}$

\section{LABOPATOAY ANALYSES}

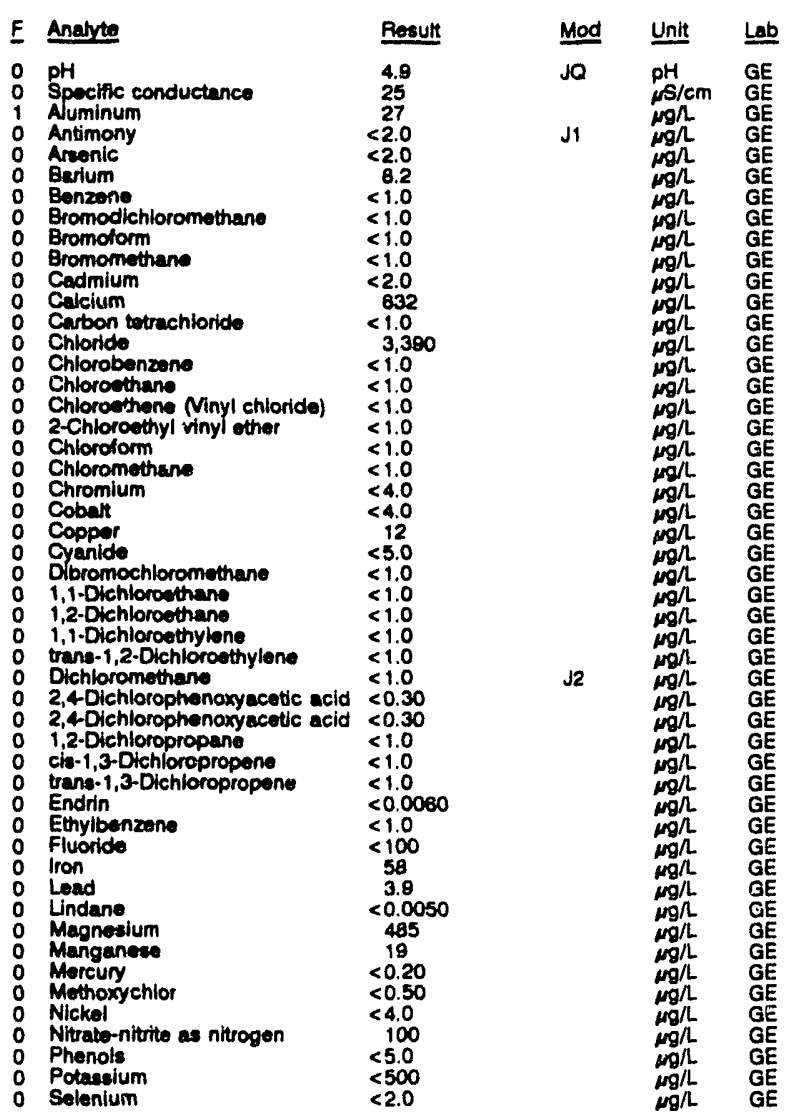

WELL FSB1 16D collocted on 07/04/82, laboratory analyees (cont.)

\begin{tabular}{|c|c|c|c|}
\hline Analyte & Result & Mad & Unit \\
\hline 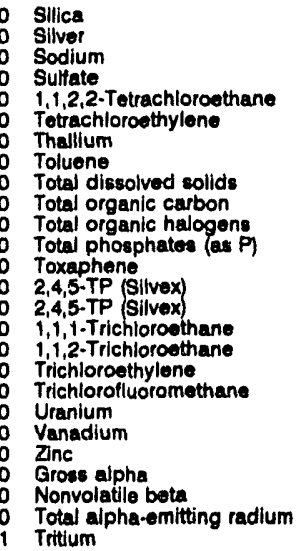 & $\begin{aligned} & 6,320 \\
&<2.0 \\
& 2,250 \\
&<1,000 \\
&<1.0 \\
&<1.0 \\
&<2.0 \\
&<1.0 \\
& 8,000 \\
&<1,000 \\
&<5.0 \\
& 325 \\
&<0.24 \\
&<0.090 \\
&<0.090 \\
&<1.0 \\
&<1.0 \\
&<1.0 \\
&<1.0 \\
&<20 \\
&<8.0 \\
& 48 \\
&<2.0 E-09 \\
&<2.0 E-09 \\
&<1.0 E-09 \\
& 1.5 E-05 \pm 8.0 E-07\end{aligned}$ & & 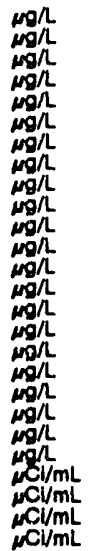 \\
\hline
\end{tabular}

\section{WELL FSB117D}

MEASUREMENTS CONDUCTED IN THE FIELD

$\begin{array}{ll}\text { Sample date: } 07 / 16 / 82 & \text { Time: } 14: 40 \\ \text { Depth to water: } 25.74 \mathrm{ft}(7.85 \mathrm{~m}) \text { below TOC } & \text { pH: } 3.4 \\ \text { Water olevation: } 204.98 \mathrm{ft}(62.47 \mathrm{~m}) \mathrm{msl} & \text { Alkalinity: } 0 \mathrm{mg} / \mathrm{h} \\ \text { Sp. conductance: } 794 \mu \mathrm{s} / \mathrm{cm} & \text { Water tomperature: } 21.0 \circ \mathrm{C} \\ \text { Water ovacuated beforo sampling: } 40 \mathrm{gal} & \end{array}$

LABORATORY ANALYSES

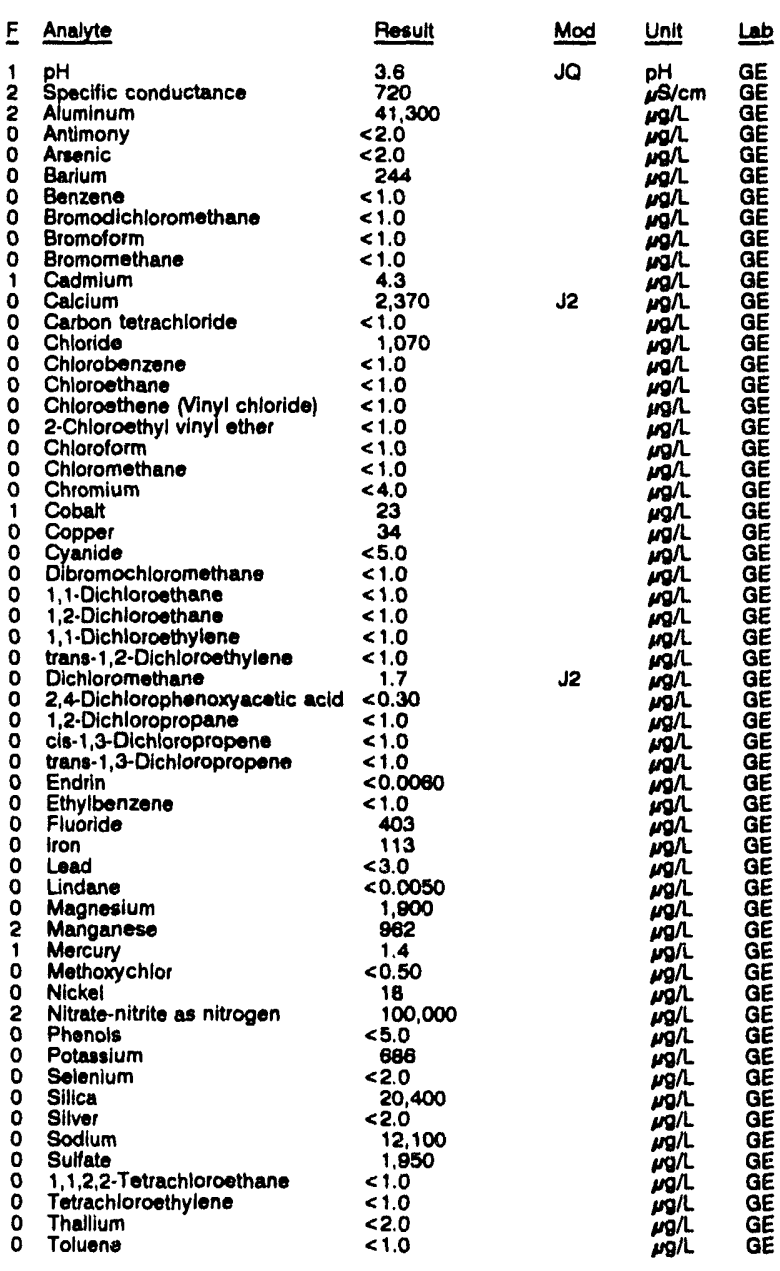


WELL F88117D collected on 07/16/92, laboratory analyees (cont.)

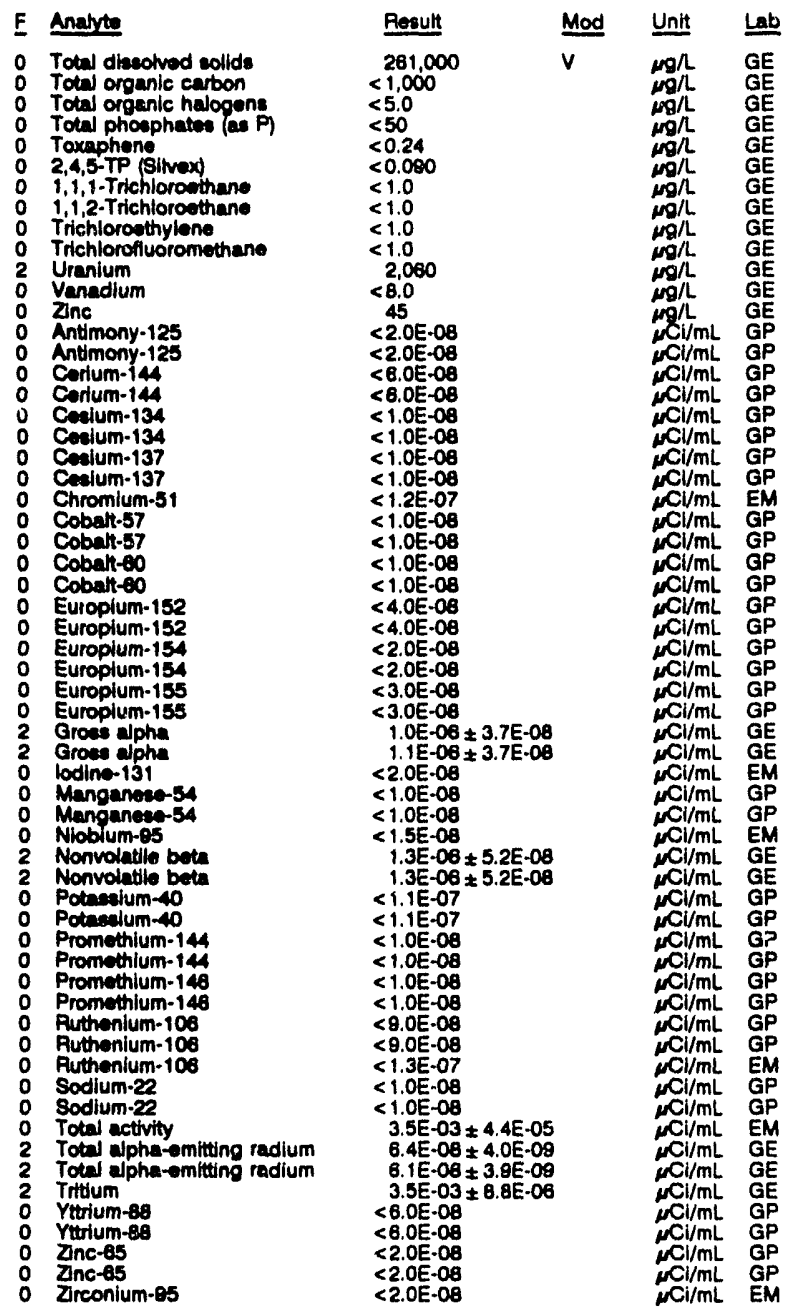

\section{WELL FSB118D}

MEASUREMENTS CONOUCTED IN THE FIELO

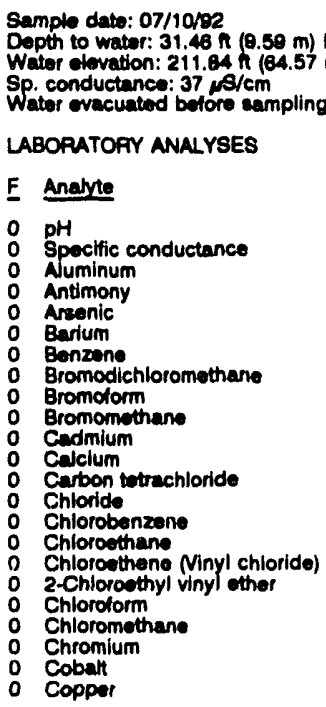

Time: 13:20

PH: 4.8 : $1 \mathrm{mgh}$

Water temperature: $21.0^{\circ} \mathrm{C}$

Mod Unit Lab

\begin{tabular}{l} 
Result \\
\hline 5.2 \\
5.2 \\
$<20$ \\
$<2.0$ \\
$<2.0$ \\
18 \\
$<1.0$ \\
$<1.0$ \\
$<1.0$ \\
$<1.0$ \\
$<2.0$ \\
1.760 \\
$<1.0$ \\
2.840 \\
$<1.0$ \\
$<1.0$ \\
$<1.0$ \\
$<1.0$ \\
$<1.0$ \\
$<1.0$ \\
$<4.0$ \\
$<4.0$ \\
4.2
\end{tabular}

WELL FSB1 18D colloctod on 07/10/82, laboratory analyees (cont.)

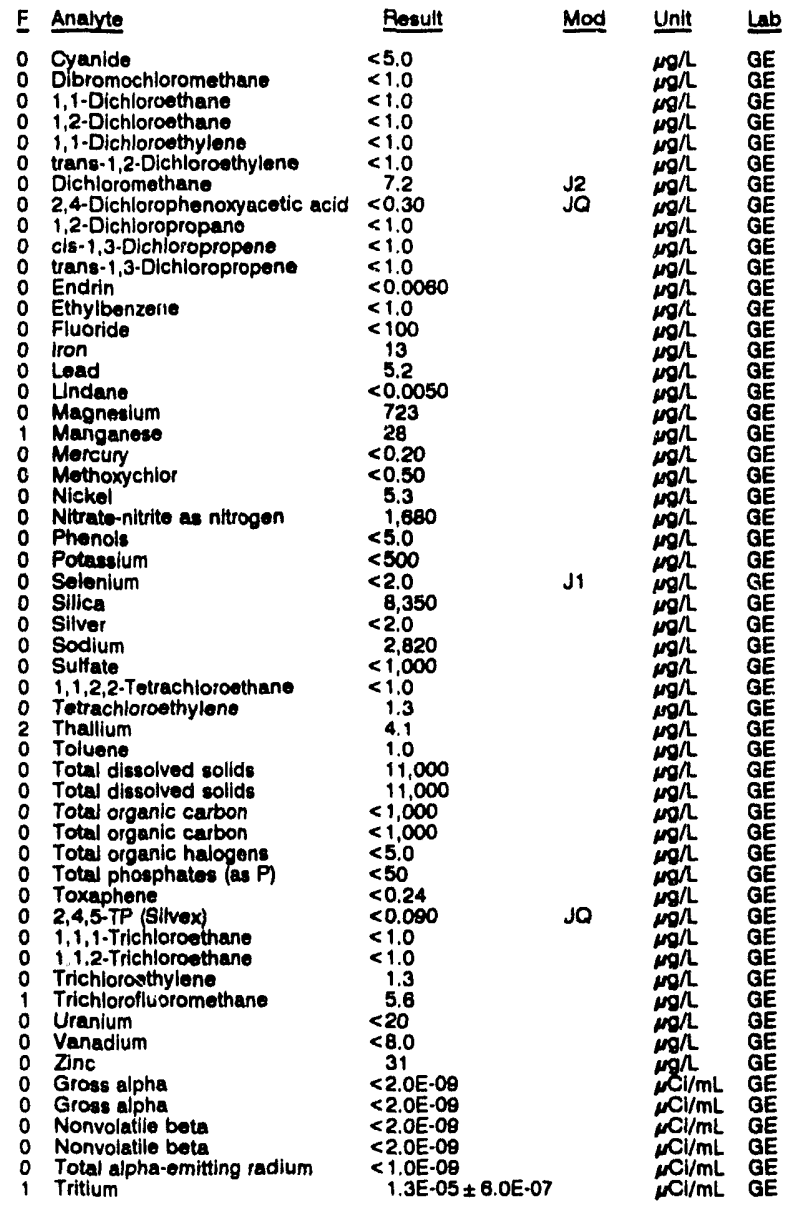

\section{WELL FSB119D}

MEASUAEMENTS CONDUCTED IN THE FIELD

$\begin{array}{ll}\text { Sample date: } 07 / 18 / 92 & \text { Time: } 13: 45 \\ \text { Dopth to wator: } 45.73 \mathrm{~m}(13.84 \mathrm{~m}) \text { below TOC } & \text { pH: } 3.2 \\ \text { Water elevation: } 208.37 \mathrm{ft}(83.51 \mathrm{~m}) \mathrm{msl} & \text { Alkalinity: } 0 \mathrm{mg} / \mathrm{h} \\ \text { Sp. conductance: } 1878 \mu \mathrm{s} / \mathrm{cm} & \text { Water temperature: } 25.1^{\circ} \mathrm{C} \\ \text { Water evacuated before sampling: } 40 \mathrm{gal} & \end{array}$

LABORATOAY ANALYSES

\begin{tabular}{|c|c|c|c|}
\hline Analyte & Rosult & Mod & Unit \\
\hline $\begin{array}{l}\text { pH } \\
\text { Specific conductance } \\
\text { Aluminum } \\
\text { Antimony } \\
\text { Arsenic } \\
\text { Barium } \\
\text { Benzene } \\
\text { Bromodichloromethane } \\
\text { Bromoform } \\
\text { Bromomethane } \\
\text { Cadmium } \\
\text { Caacium } \\
\text { Carbon tetrachloride } \\
\text { Chloride } \\
\text { Chlorobenzene } \\
\text { Chloroethane } \\
\text { Chloroethene Ninyl chloride) } \\
\text { 2-Chloroethyl vinyl ether } \\
\text { Chloroform } \\
\text { Chloromethane } \\
\text { Chromium } \\
\text { Cobalt } \\
\text { Copper } \\
\text { Cyanide } \\
\text { Dibromochloromethane } \\
1,1 \text {-Dichloroethane } \\
1,2 \text {-Dichloroethane } \\
1,1 \text {-Dichloroethylene }\end{array}$ & $\begin{aligned} & 3.5 \\
& 1,620 \\
& 97,400 \\
&<2.0 \\
&<2.0 \\
& 353 \\
&<1.0 \\
&<1.0 \\
&<1.0 \\
&<1.0 \\
& 4.9 \\
& 3,140 \\
&<1.0 \\
& 1,380 \\
&<1.0 \\
&<1.0 \\
&<1.0 \\
&<1.0 \\
&<1.0 \\
&<1.0 \\
&<4.0 \\
& 38 \\
& 52 \\
&<5.0 \\
&<1.0 \\
&<1.0 \\
&<1.0 \\
&<1.0\end{aligned}$ & Ja & 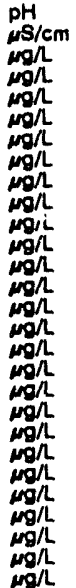 \\
\hline
\end{tabular}


ANALYTICAL RESULTS

WELL FS81 18D collected on 07/16/92, laboratory analyees (cont.)

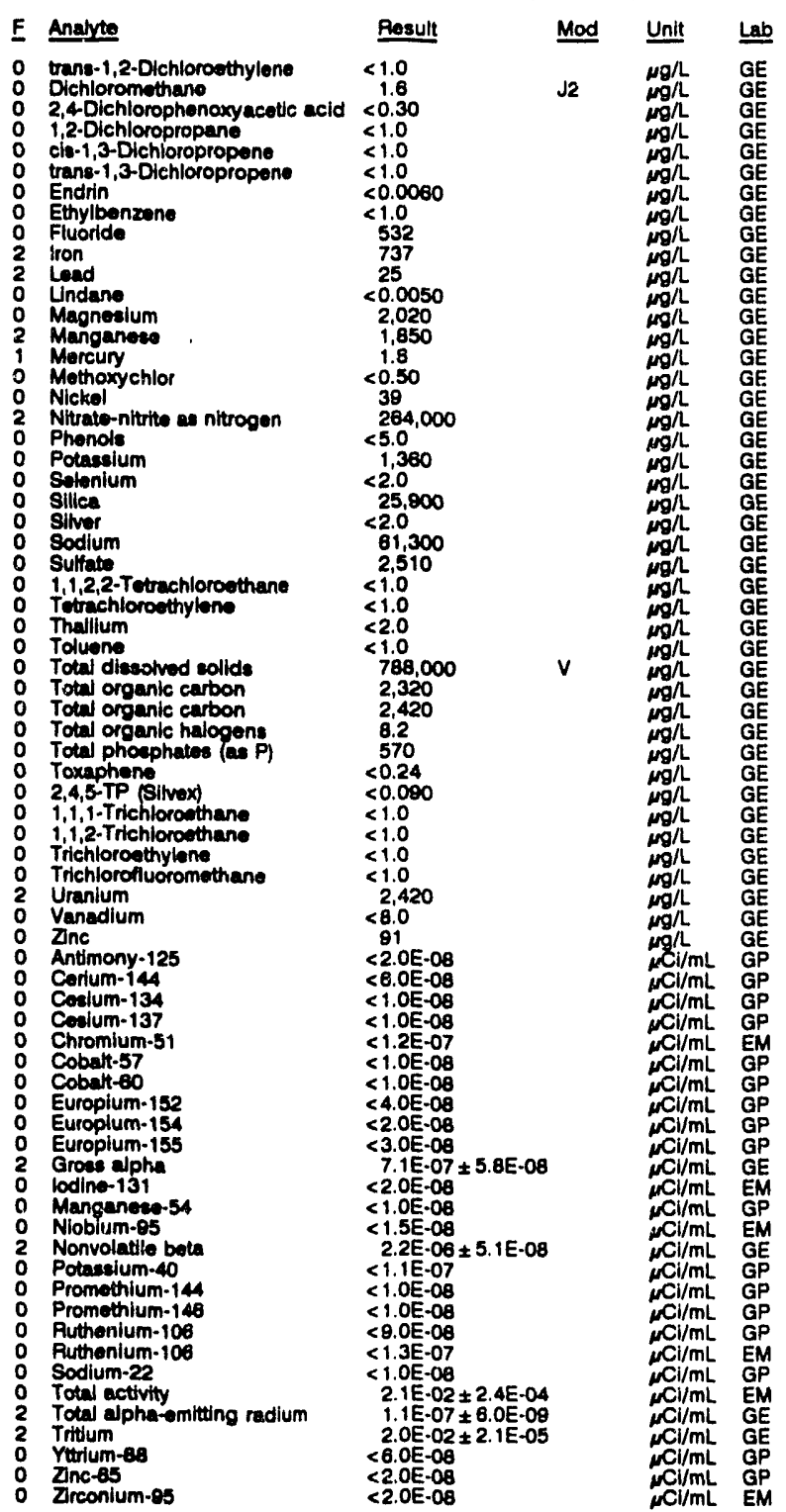

WELL FSB120A

MEASUREMENTS CONDUCTED IN THE FIELD

Depth to wator: $131.89 \mathrm{ft}(40.20 \mathrm{~m})$ below TOC

Water olevation: $148.21 \mathrm{n}(45.17 \mathrm{~m}) \mathrm{msl}$

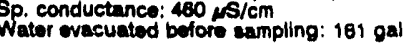

LABOAATOFY ANALYSES

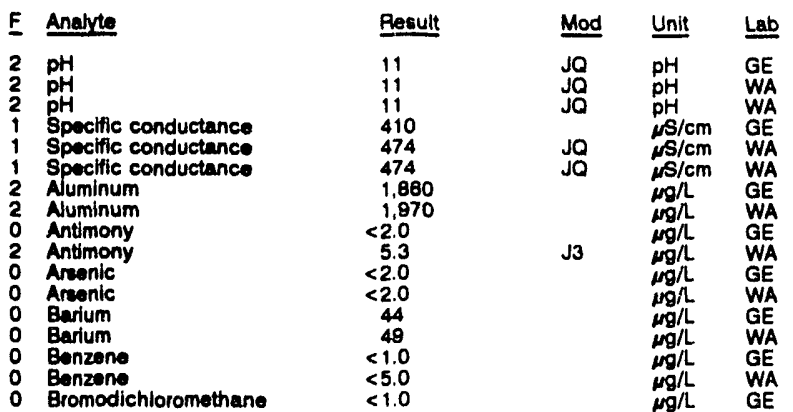

WELL FSB120A collected on 07/19/92, laboratory analyses (cont)

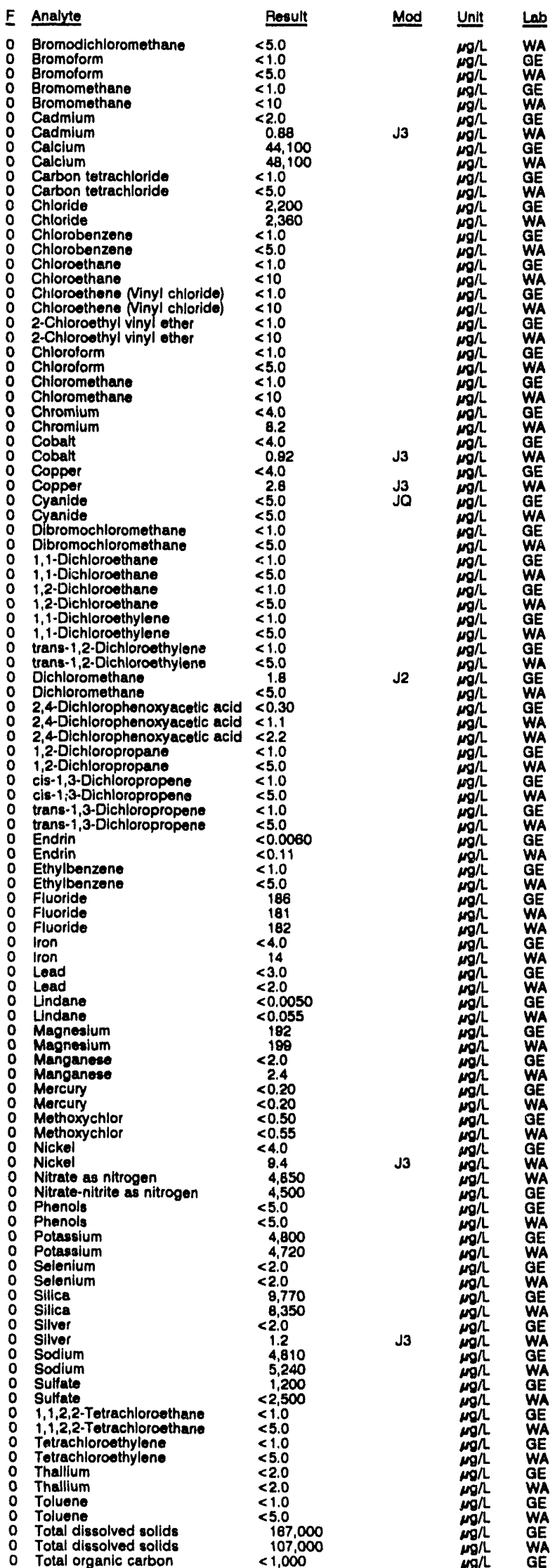


ANALYTICAL RESULTS

WEL FSB120A collected on 07/18/92, laboratory analyees (cont.)

\begin{tabular}{|c|c|c|}
\hline Anayte & Result & Unit \\
\hline 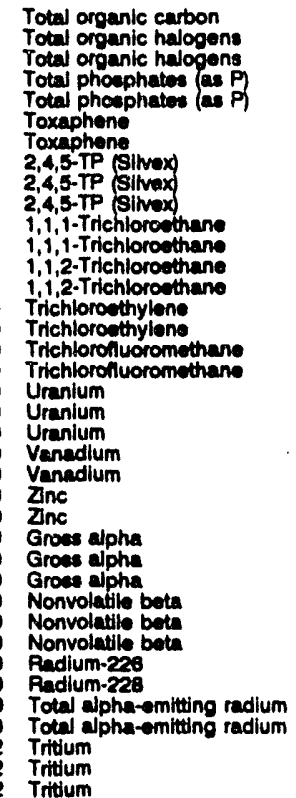 & $\begin{array}{l}<500 \\
<5.0 \\
<5.0 \\
290 \\
250 \\
<0.24 \\
<1.1 \\
<0.090 \\
<0.55 \\
<1.1 \\
<1.0 \\
<5.0 \\
<1.0 \\
<5.0 \\
<1.0 \\
<5.0 \\
<1.0 \\
<5.0 \\
<20 \\
0.13 \\
0.13 \\
<8.0 \\
5.0 \\
<2.0 \\
4.2 \\
<2.0 E-09 \\
2.8 E-09 \pm 1.2 E-00 \\
<2.5 E-09 \\
1.1 E-09 \pm 2.2 E-09 \\
1.4 E-08 \pm 1.5 E-09 \\
1.3 E-08 \pm 1.5 E-09 \\
6.6 E-09 \pm 1.1 E-09 \\
1.3 E-09 \pm 8.0 E-10 \\
1.0 E-09 \pm 8.0 E-10 \\
<1.0 E-09 \\
1.2 E-04 \pm 1.6 E-00 \\
1.2 E-04 \pm 3.7 E-05 \\
1.3 E-04 \pm 3.9 E-05\end{array}$ & 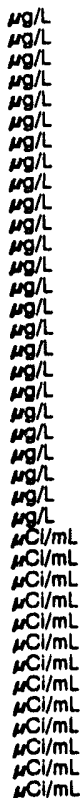 \\
\hline
\end{tabular}

WELL FSB120A Replicate

MEASUREMENTS CONDUCTEO IN THE FIELD

Sample date: 07/19192
Depth to water: $131.69 \mathrm{n}(40.20 \mathrm{~m})$ below TOC
Watter olevation: $148.21 \mathrm{f}(45.17 \mathrm{~m}) \mathrm{msl}$
Sp. conductance: $480 \mu \mathrm{s} / \mathrm{cm}$

Time: 8:35

Alkalinity: $128 \mathrm{mg} / \mathrm{l}$

Water temperature: $20.3^{\circ} \mathrm{C}$

Water evacuated before sampling: $161 \mathrm{gal}$

LABOPATOFY ANALYSES

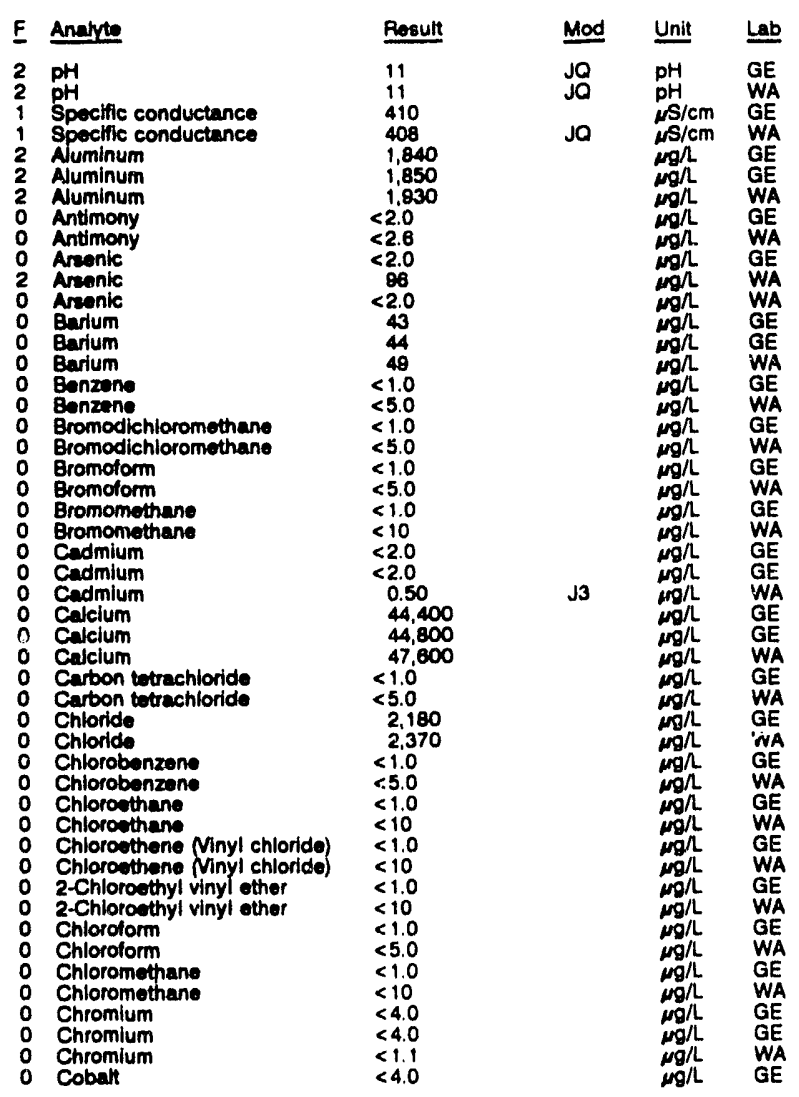

WELL FSB120A colloctod on 07/18/82, laboratory analyses (cont.)

\begin{tabular}{|c|c|}
\hline & Analyte \\
\hline & 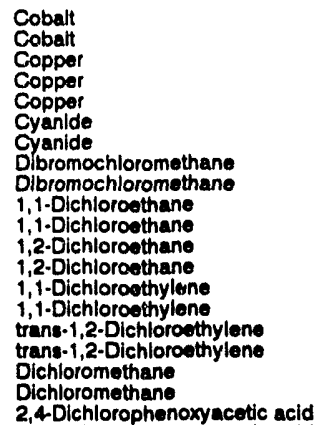 \\
\hline
\end{tabular}

Rosult Mod Unit Lat

$<4.0$

$<4.0$

$<4.0$

$<5.0$

$<5.0$

$<5.0$

$<1.0$

$<1.0$

$<5.0$

$<5.0$

$<1.0$

$<5.0$
1.4
$<5.0$

$<5.0$

2,4-Dichlorophenoxyacetic acld < < $<1$

0 1,2-Dichloropropane

$<1.0$

cis-1,3-Dichloropropene

cia-1,3-Dichloropropene

trans-1,3-Dichloropropene

0 Endrin

0 Endrin

0 Ethylbenzene

0 Ethylbenzene

0 Fluoride

0 Iron

0 Iron

0 Liron

Lead

Lindane

Lindane

Magnesium

Magnesium

Magnesium

Manganese

Manganese

Manganese

Mercury

Mercury

Methoxychlo

Methoxychlor

Methoxychlor

Nickel

Nickel

Nickel as nitrogen

Nitrate-nitrite as nitrogen

Phenols

Phenols

Potassium

Potassium

Potassium

Selenlum

Solenium

Silica

Sillca

Sillica

Silver

Silver

Sodium

Sodium

Sodium

Sulfate

Sulfate $1,1,2,2$-Tetrachloroethane

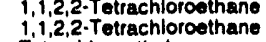

Totrachloroethylene

Tetrachloroethylene

Thallium

Thallium

Toluene

0 Toluene

Total diseolved solids

T Total dissolved solids

Total organic carbon

Total organic halogens

Total organic halogens

0 Total phosphates (as P)

T Total phosphat

Toxaphene

o Toxaphene

Toxaphene

2 2,4,5-TP (Silvex)

2,4,5-TP (Sivex)

$<5.0$

$<5.0$

$<1.0$

$<0.0060$

$<0.0080$ mol GE

$<0.22$

$<1.0$

206

180
$<4.0$

$<4.0$

6.5
$<3.0$

$<2.0$

$<0.0050$

$<0.11$

188

168
$<2.0$
$<2.0$

$<2.0$
3.0
$<0.20$
$<0.20$

$<0.20$
$<0.20$
$<0.50$

$<0.55$

$<1.1$

$<2.2$

$<4.0$
4.2

$<3.1 .090$

4,500
$<5.0$
$<5.0$

$<5.0$

4,640

$<2,450$

$<2.0$

9,660
8,720

8,180
$<2.0$

$<2.0$

$<0.70$

4,740
5,120

$<2,500$

$<1.0$

$<5.0$

$<5.0$

$<2.0$

8.0
$<1.0$
$<5.0$

169,000

94,000
80,000

$<1,000$

$<1,000$
$<500$
$<5.0$

$<5.0$

300

344
$<0.24$

$<2.1$

$<4,3$

$<0.55$

$\mu g / L$ GE

$<1.0$

GE 
ANALYTICAL RESULTS

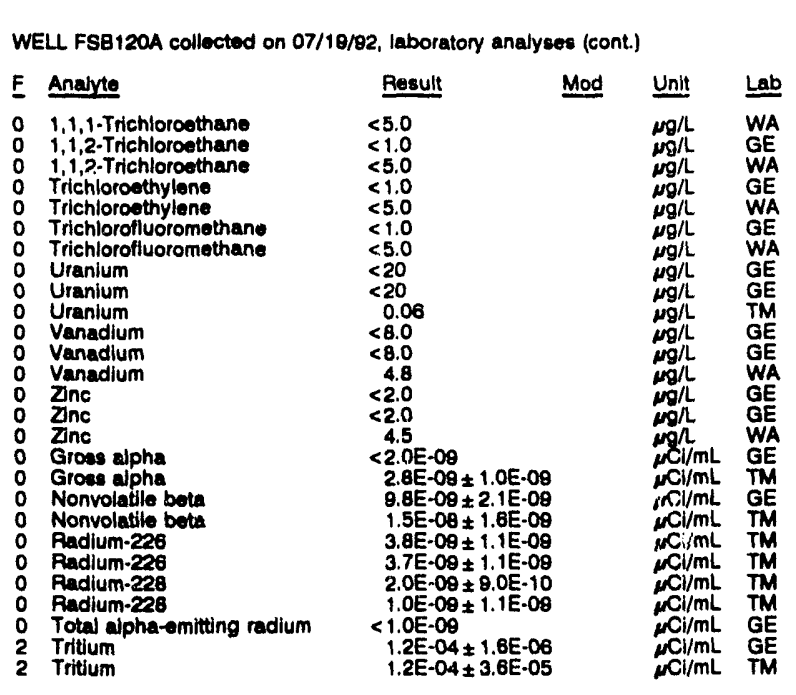

\section{WELL FSB120C}

MEASUMEMENTS CONDUCTED IN THE FIELO
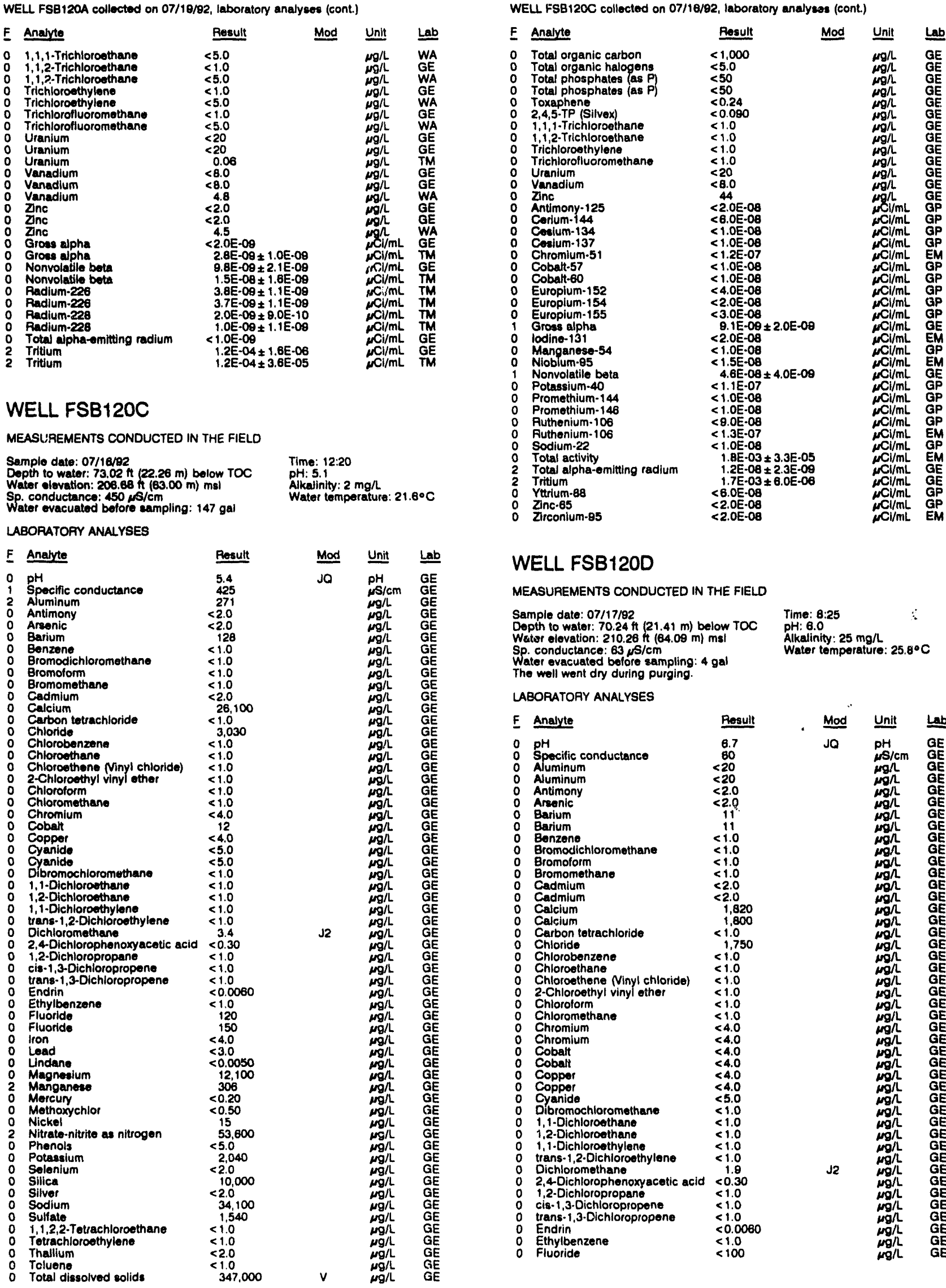

\section{WELL FSB120D}

\section{MEASUREMENTS CONDUCTED IN THE FIELD}

Sample date: 07/17/92

Dopth to water: $70.24 \mathrm{ft}(21.41 \mathrm{~m})$ below TOC

Water elovation: $210.26 \mathrm{ft}(64.09 \mathrm{~m}) \mathrm{msl}$

Sp. conductance: $63, \mathrm{~s} / \mathrm{cm}$

The well went dry during purging.

LABORATORY ANALYSES

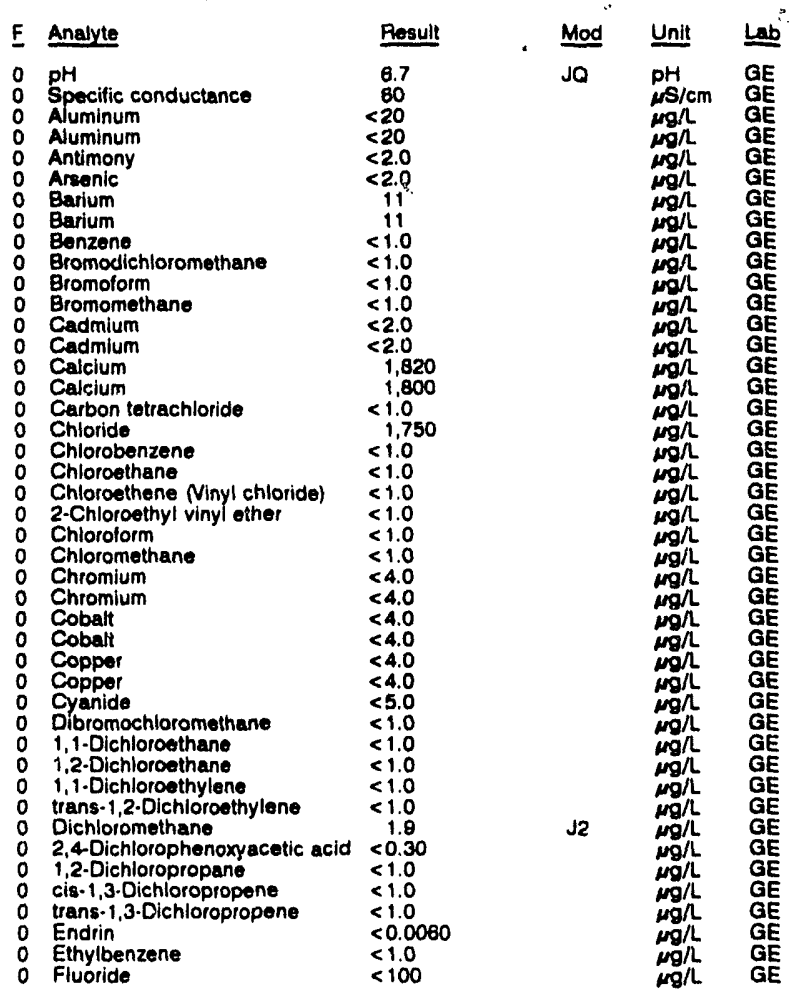

Water evacuated before sampling: $4 \mathrm{gal}$ 
WELL F881200 colbetad on 07/17/02, laboratory analyees (cont)

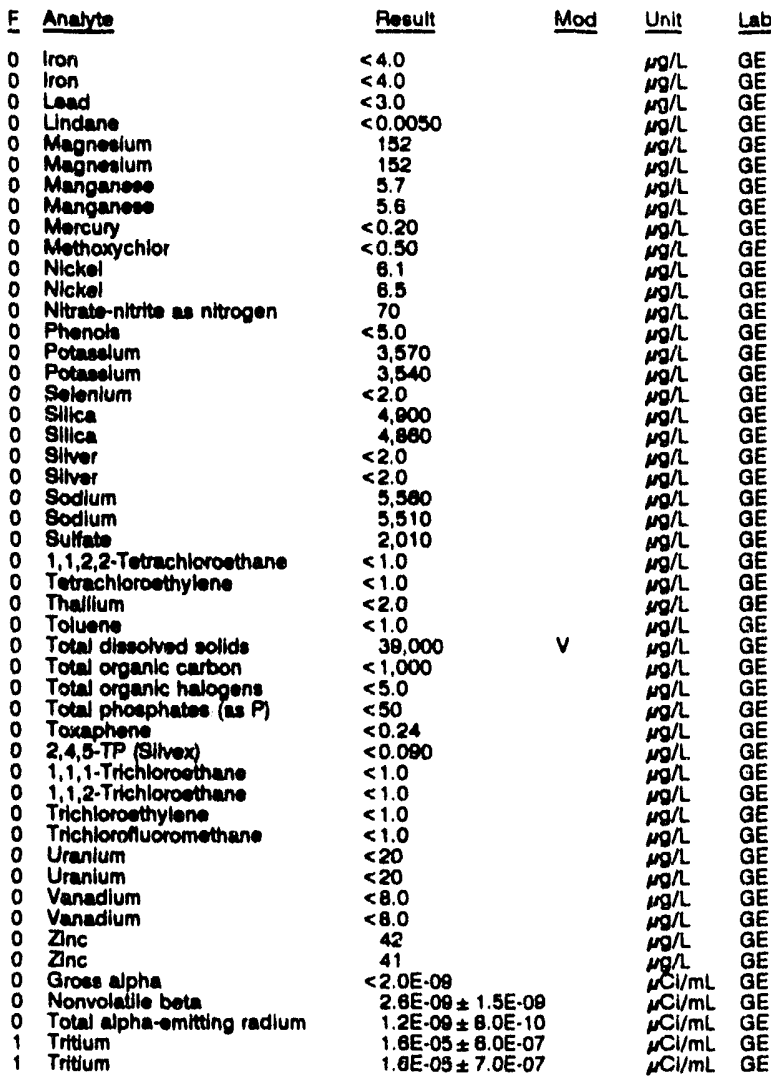

\section{WELL FSB121C}

MEASUREMENTS CONDUCTED IN THE FIELD

\section{Sample date: 07/19/82} Depth to water: 51.68 it $(15.75 \mathrm{~m})$ below TOC Wator elovation: $204.64 \mathrm{~h}(82.44 \mathrm{~m}) \mathrm{msl}$ Water ovacuated bofore sampling: $148 \mathrm{gal}$

LABORATOPY ANALYYES

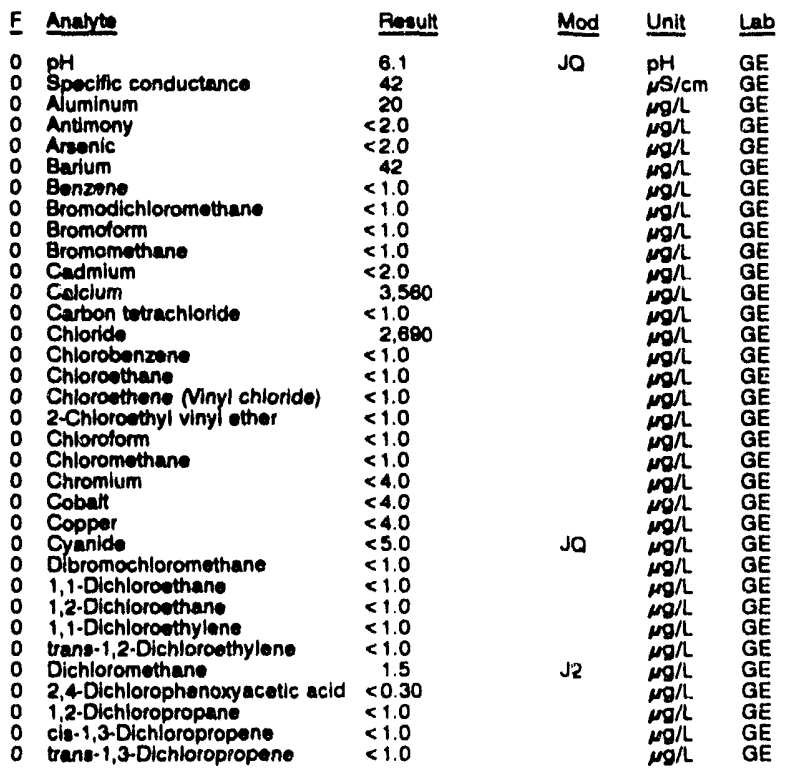

WELL F8B121C collected on 07/18/92, laboratory analyees (cont.)

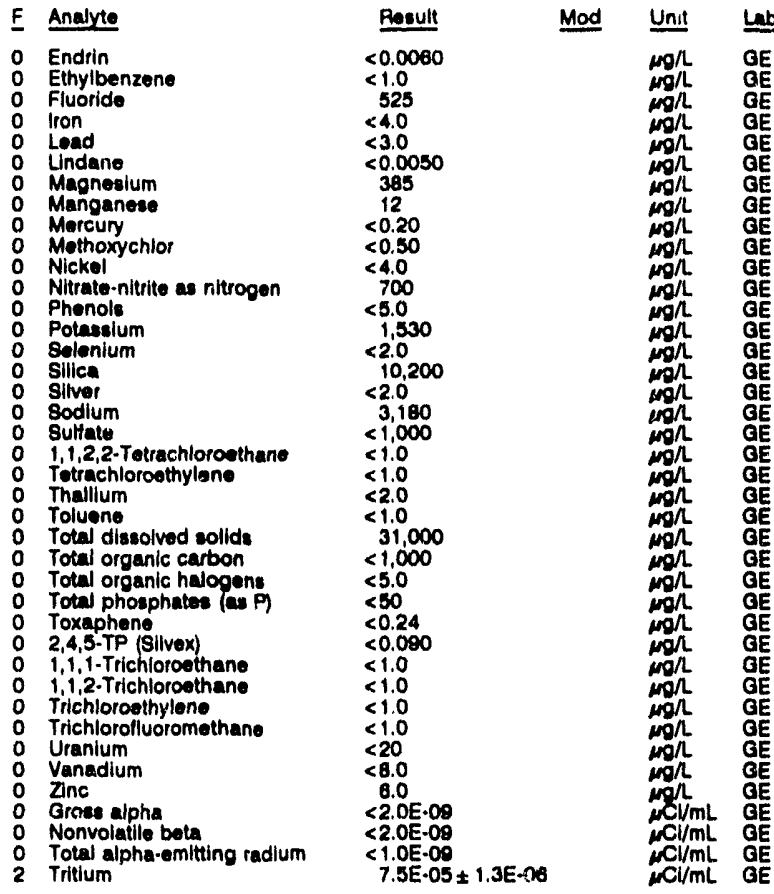

\section{WELL FSB121DR}

MEASUREMENTS CONDUCTED IN THE FIELD

Depth to water: $47.85 \mathrm{n}(14.58 \mathrm{~m})$ bolow TOC

Water elevation: $207.65 \mathrm{~h}(63.29 \mathrm{~m}) \mathrm{msl}$

Sp. conductance: $150 \mathrm{~s} / \mathrm{cm}$

Water ovacuated before earnpling: 8 gal

LABORATORY AIJALYSES

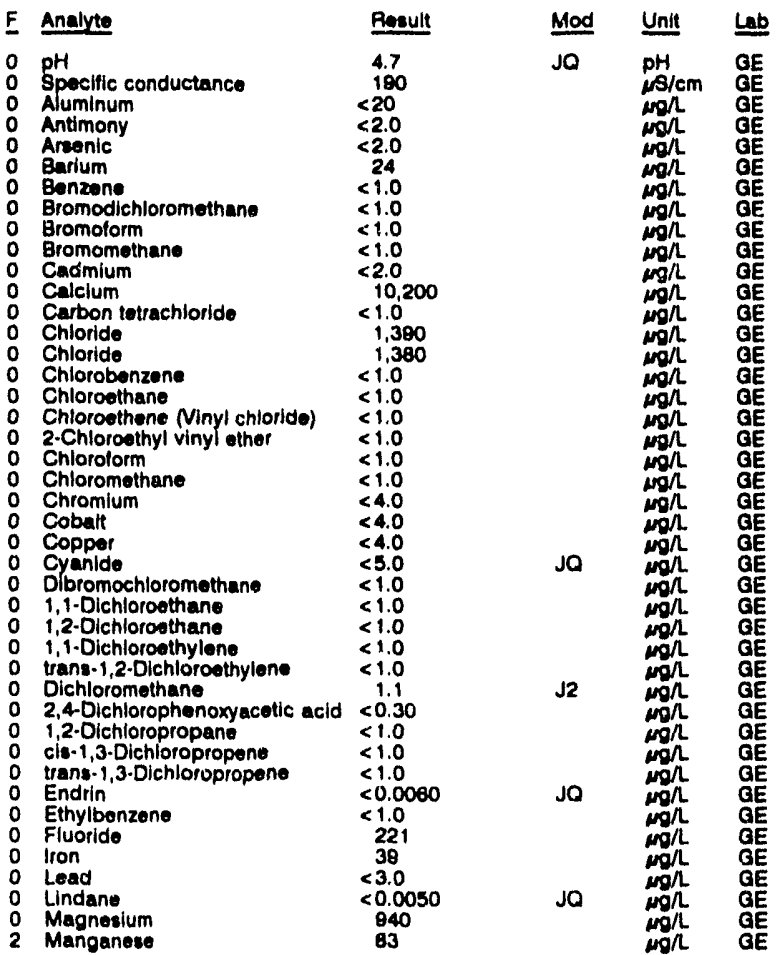


ANALYTICAL RESULTS

WELL FSB121DF collected on 07/18/02, laboratory analyees (cont)

\begin{tabular}{|c|c|c|c|}
\hline Anelote & Reeult & Mod & Unit \\
\hline 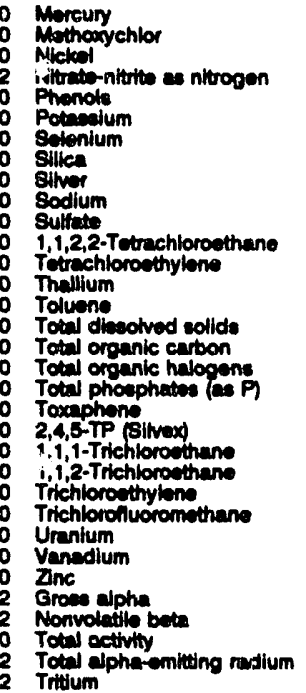 & $\begin{array}{l}<0.20 \\
<0.50 \\
<4.0 \\
25,400 \\
<5.0 \\
8,640 \\
<2.0 \\
8,820 \\
<2.0 \\
18,300 \\
3,690 \\
<1.0 \\
<1.0 \\
<2.0 \\
<1.0 \\
162,000 \\
<1,000 \\
8.0 \\
6,250 \\
<0.24 \\
<0.000 \\
<1.0 \\
<1.0 \\
<1.0 \\
<1.0 \\
<20 \\
<9.0 \\
86 \\
4.0 E-08 \pm 6.1 E-09 \\
1.7 E-07 \pm 7.0 E-09 \\
5.0 E-04 \pm 2.0 E-05 \\
7.5 E-09 \pm 1.8 E-09 \\
4.7 E-04 \pm 3.2 E-08\end{array}$ & Ja & 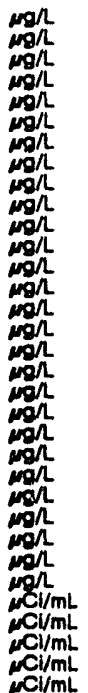 \\
\hline
\end{tabular}

WELL FSB122C

MEASUREMENTS CONOUCTEO IN THE FIELL

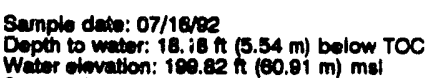
Woder olvvation: $199.82 \mathrm{~h}(100.81 \mathrm{~m}) \mathrm{msl}$

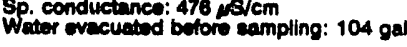

LABORATORY ANALBES

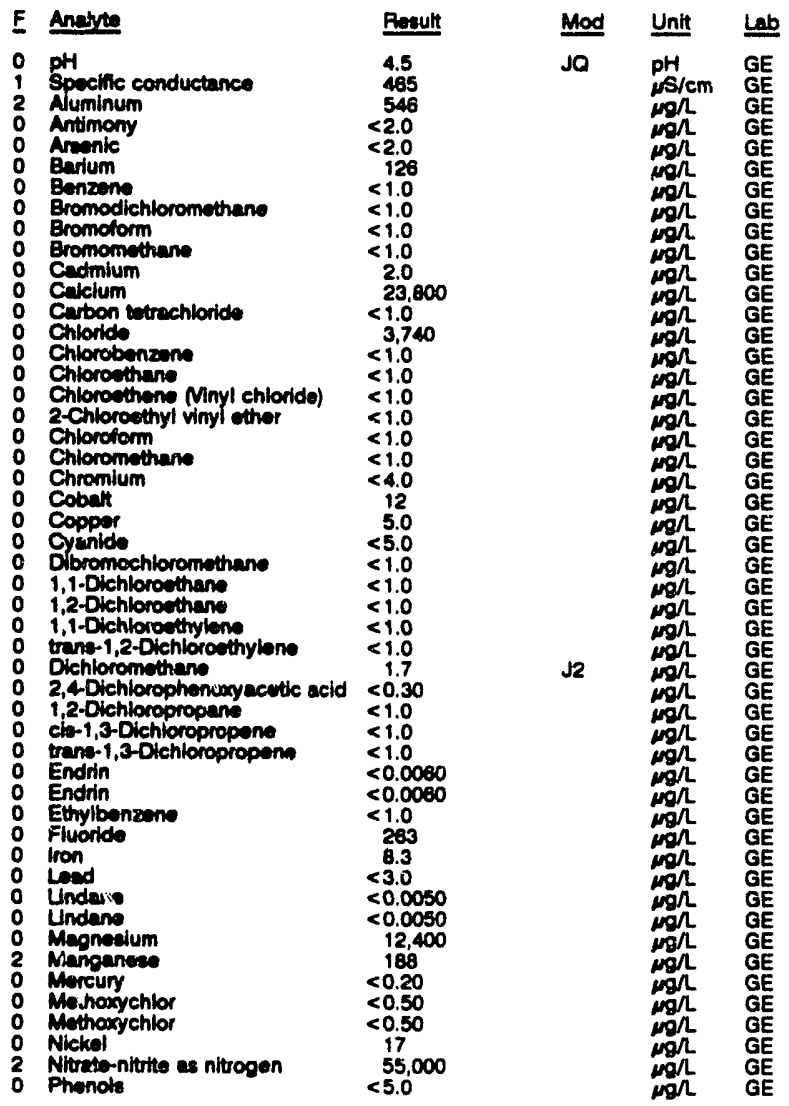

WELL FSB122C colloctod on 07/18/92, laboratory analyses (cont.)

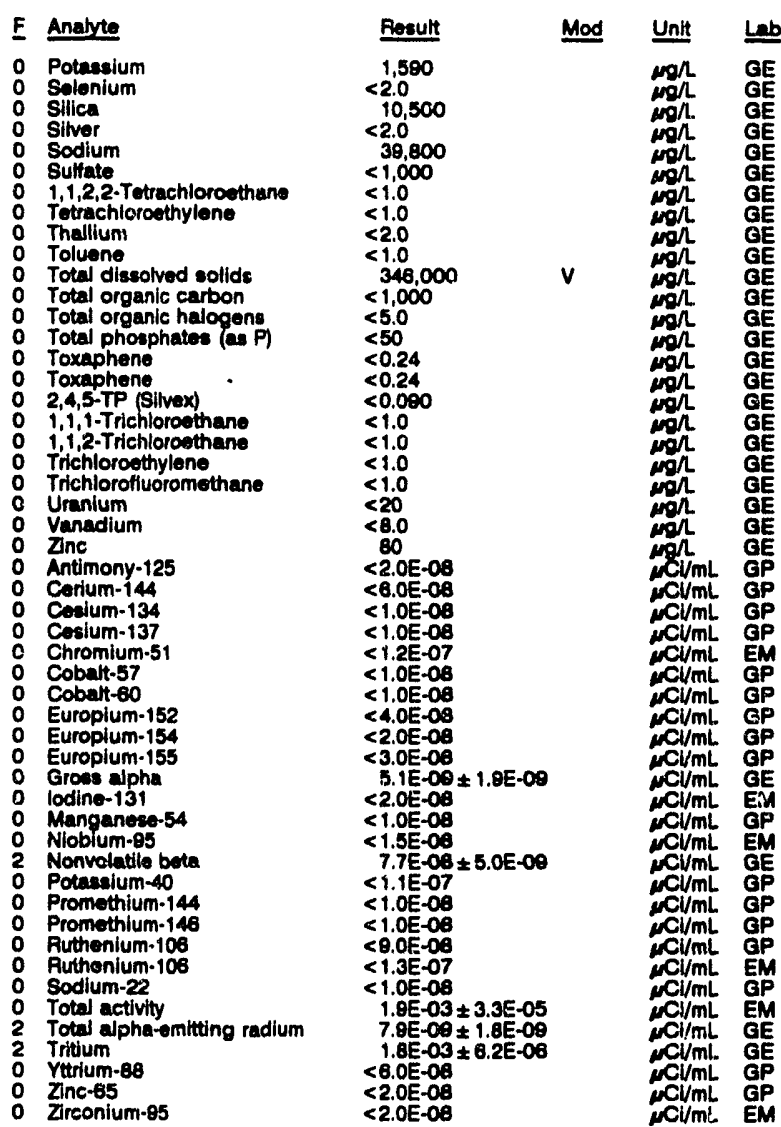

WELL FSB122D

MEASUREMENTS CONDUCTED IN THE FIELO

Sample date: 07/19/92

Depth to water: $13.71 \mathrm{n}(4.18 \mathrm{~m})$ betow TOC

Water elevation: 203.89 it (62.15

Sp. conductance: $100, \mu 8 / \mathrm{cm}$
Water ovacuated before eampling: $45 \mathrm{gal}$

Time: 10:55

PH: 5.1 . $2 \mathrm{mal}$

Water temperature: $20.5^{\circ} \mathrm{C}$

LABOFATOFY ANALYSES

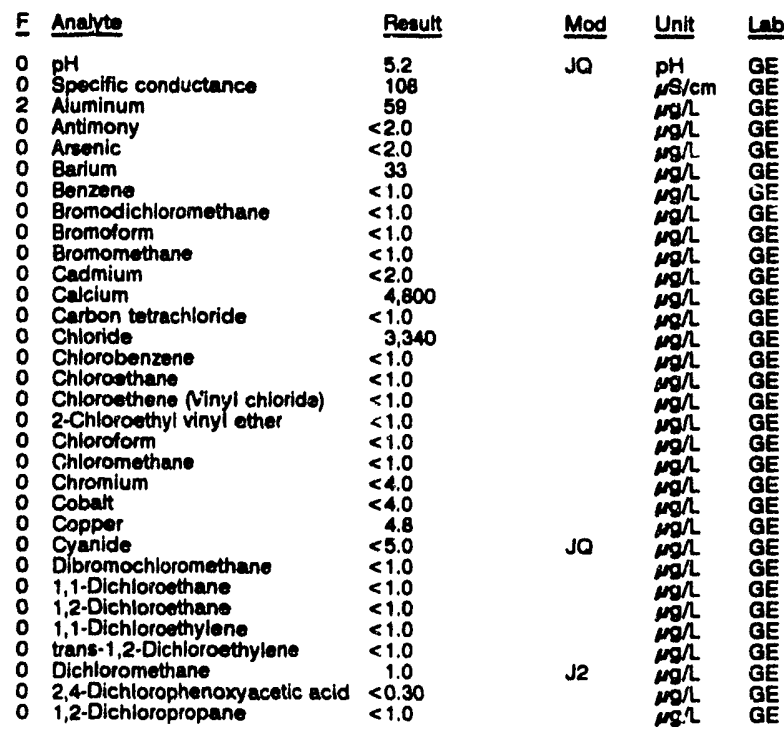


WELL F88122D colletted on 07/18/92, laboratory analyese (cont)

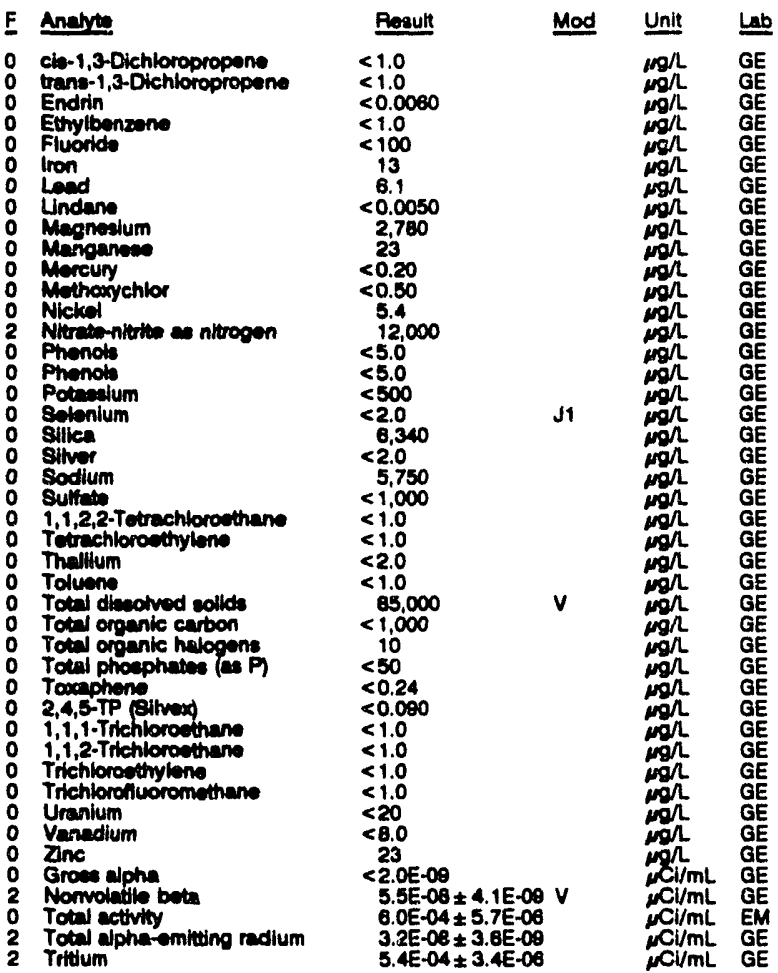

WELL FSB123C

MEASUREMENTS CONDUCTED IN THE FIELD

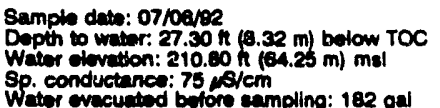

$$
\begin{aligned}
& \text { Tima: } 10: 35 \\
& \text { pH: } 5.6 \\
& \text { Alkalinity: } 13 \mathrm{mg} / \\
& \text { Water temperature: } 20.4{ }^{\circ} \mathrm{C}
\end{aligned}
$$

\begin{tabular}{|c|c|c|c|}
\hline Andyte & Rosult & Mod & Unit \\
\hline 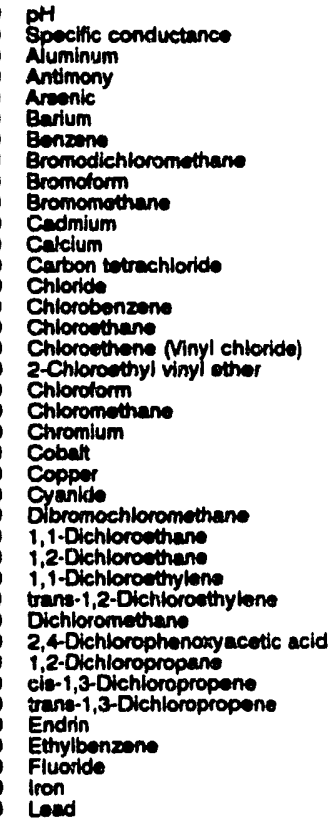 & $\begin{aligned} & 5.8 \\
& 70 \\
& 21 \\
&<2.0 \\
&<2.0 \\
& 17 \\
&<1.0 \\
&<1.0 \\
&<1.0 \\
&<1.0 \\
&<2.0 \\
& 81.460 \\
&<1.0 \\
& 33.890 \\
&<1.0 \\
&<1.0 \\
&<1.0 \\
&<1.0 \\
&<1.0 \\
&<1.0 \\
&<4.0 \\
&<4.0 \\
&<4.0 \\
&<5.0 \\
&<1.0 \\
&<1.0 \\
&<1.0 \\
&<1.0 \\
&<1.0 \\
&<1.0 \\
&<0.30 \\
&<1.0 \\
&<1.0 \\
&<1.0 \\
&<0.0000 \\
&<1.0 \\
&<100 \\
&<4.0 \\
&<3.0\end{aligned}$ & Jo & 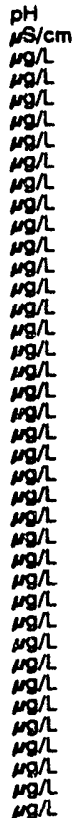 \\
\hline
\end{tabular}
LABOPATOFY ANALYSES
WELL FS8123C collected on 07/06/82, laboratory analyses (cont)

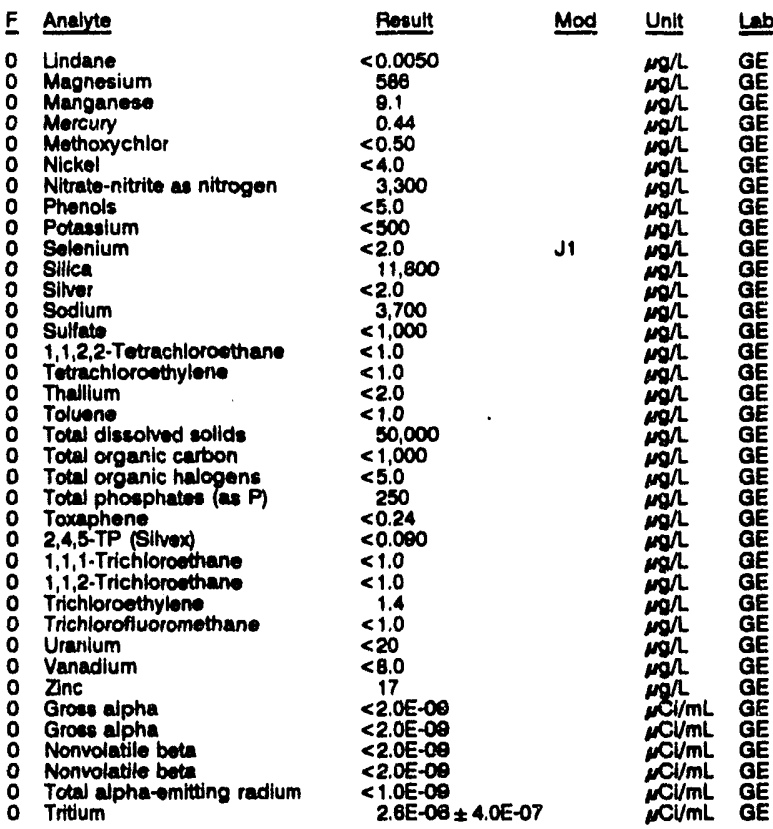

\section{WELL FSB123D}

MEASUREMENTS CONDUCTED IN THE FIELD

Sample dato: 07/08/22

Depth to water: 25.85 it $(7.82 \mathrm{~m})$ below TOC Water elevation: $212.45 \mathrm{ht}(64.76 \mathrm{~m}) \mathrm{msl}$

(a) $42.451 \mathrm{~cm}$

m) mal PH: 4.3 Nikalinity: $0 \mathrm{mg} / \mathrm{h}$

Alkalinity: $0 \mathrm{~mol}$

Water temperature: $20.00 \mathrm{C}$

LABORATOAY ANALYSES

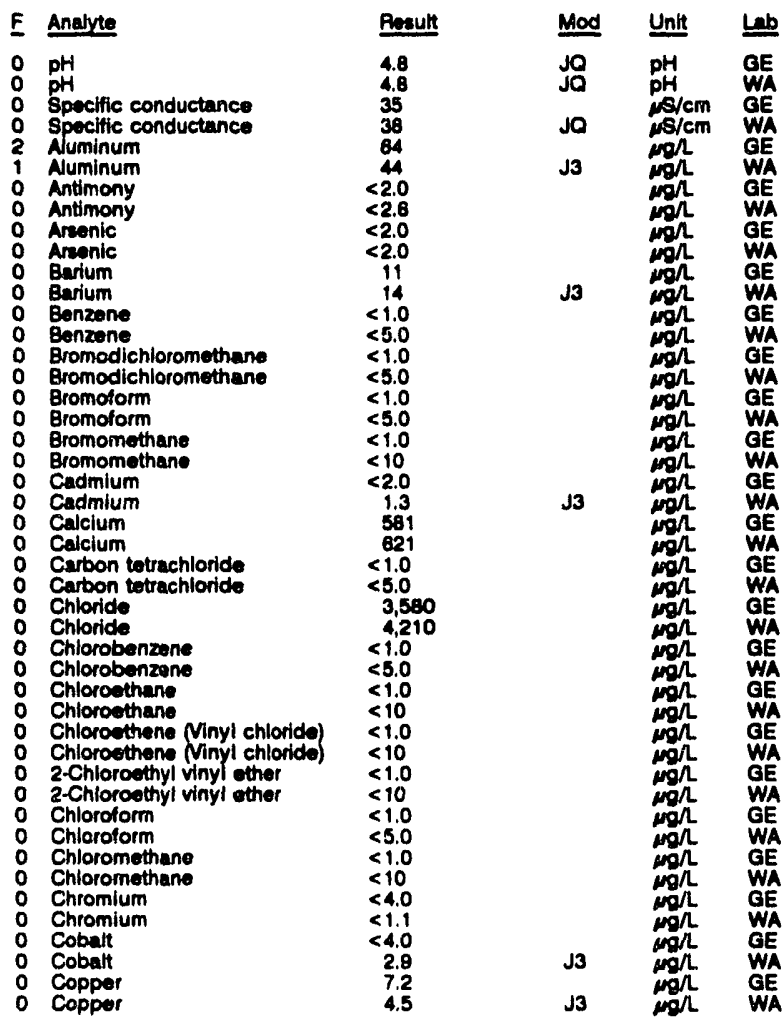


WELL F881230 collected on 07/00/92, laboratory analyees (cont)

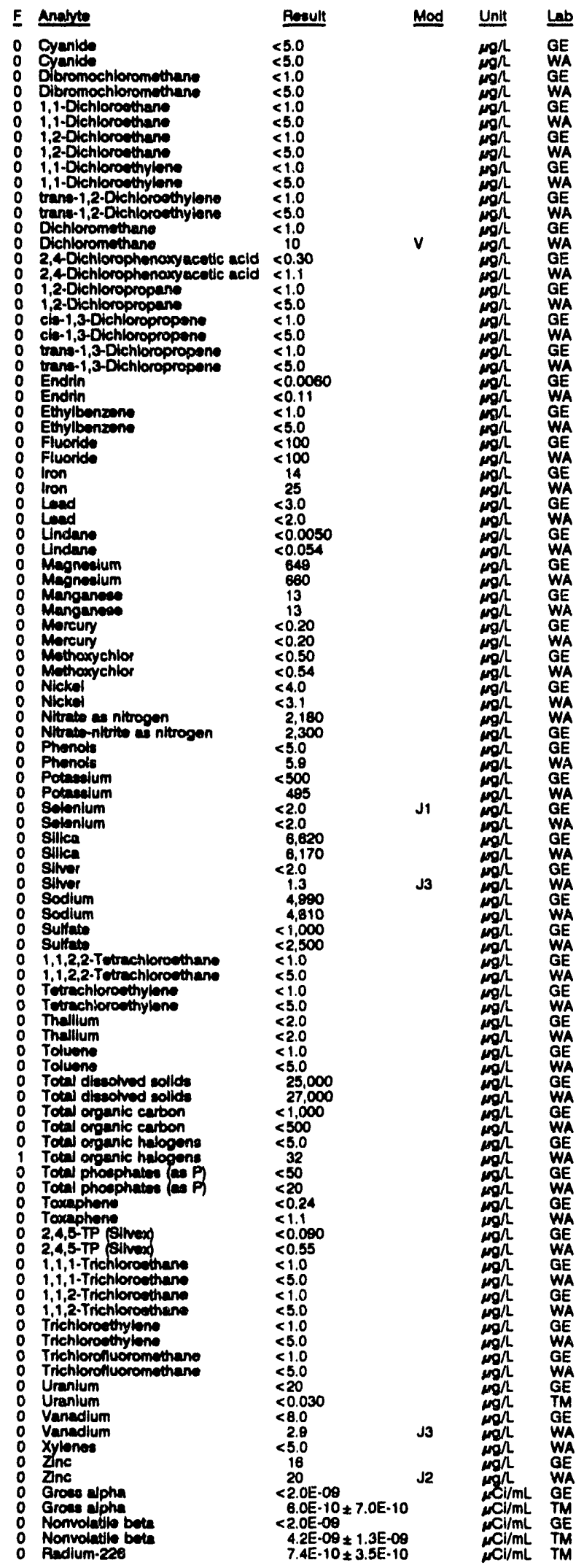

WELL FSB123D collected on 07/08/92, laboratory analyese (cont)

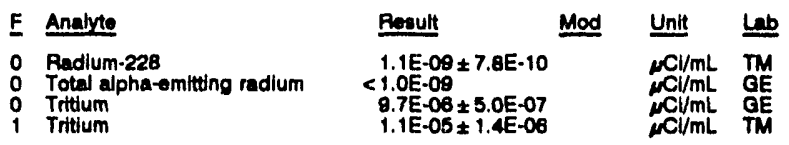

WELL FSB123D Replicate

MEASUREMENTS CONDUCTED IN THE FIELD

Sample date: 07/08/92

Depth to water: $25.65 \mathrm{ft}(7.82 \mathrm{~m})$ below TOC

Water olovation: $212.45 \mathrm{~h}$ (84.7

$(64.76 \mathrm{~m}) \mathrm{mal}$

Alkalinity: 0 man

Water evacuated bofore sampling: $48 \mathrm{gal}$

Water temperature: $20.0 \circ \mathrm{C}$

\begin{abstract}
LABORATORY ANALYSES
\end{abstract}

E Analyte Ressult Mod Unil

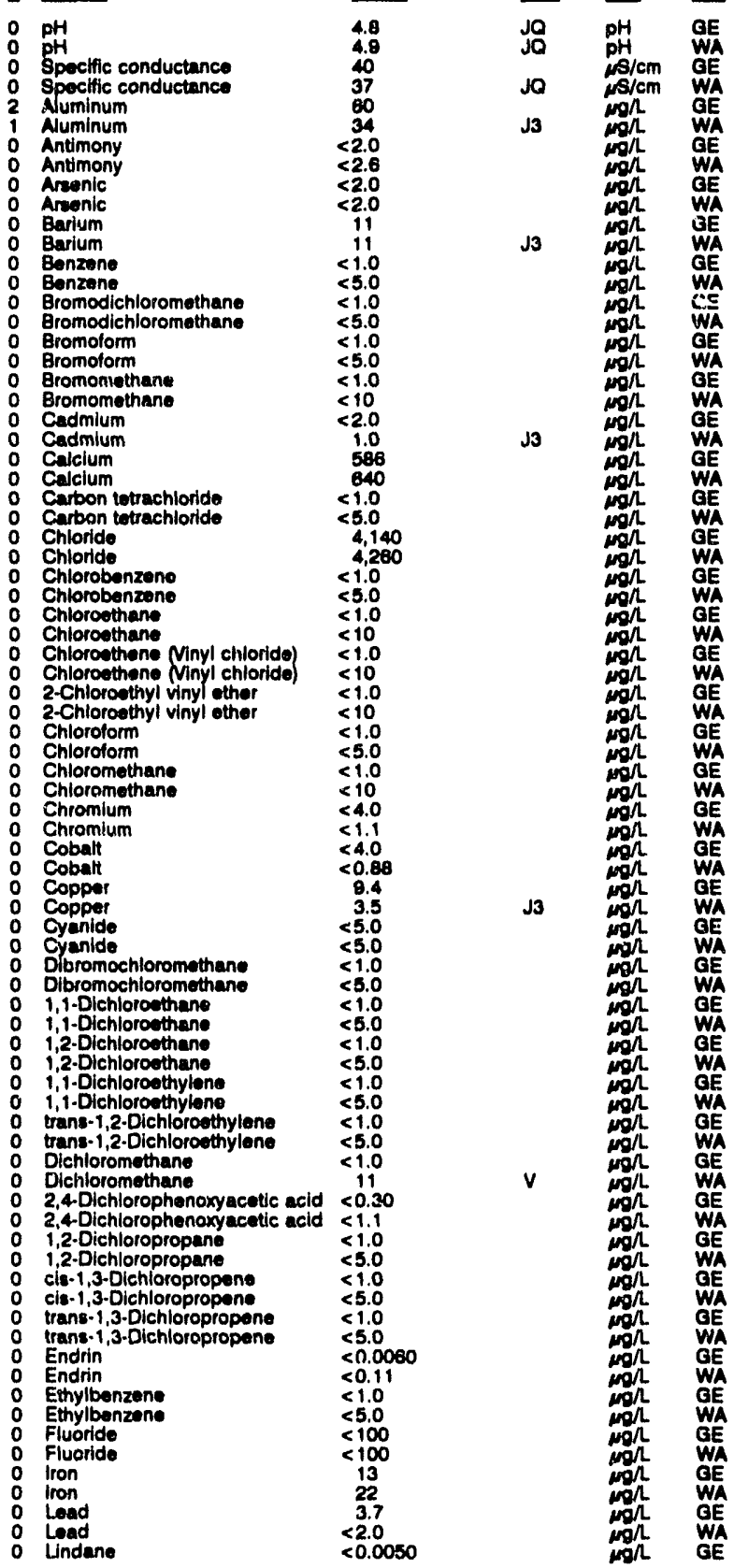


ANALYTICAL RESULTS

WELL F881230 collected on 07/08/82, laboratory enalyees (cont)

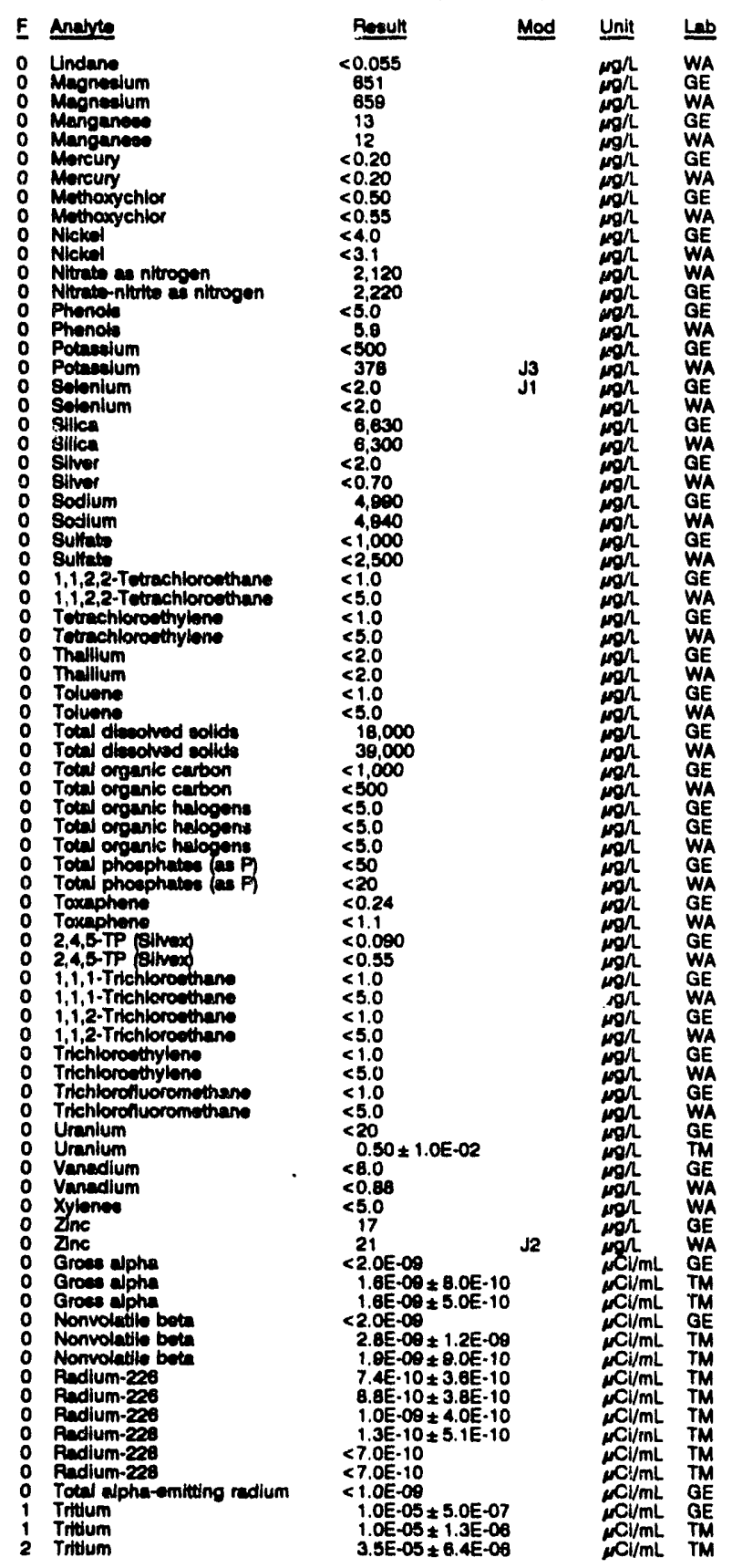

WELL FSL 1D

MEASUREMENTS CONDUCTED IN THE FIELD

Semple date: 00/03/82

Dapth to water: $87.13 \mathrm{n}(28.56 \mathrm{~m})$ below TOC

Sp. conductance: $56 \mathrm{\mu s} / \mathrm{cm}$

LABORATOFY ANALYSES

\begin{tabular}{|c|c|c|c|c|c|}
\hline $\boldsymbol{E}$ & Anarte & Result & Mod & Unit & Lab \\
\hline 0 & $\begin{array}{l}\text { pH } \\
\text { pH } \\
\text { Specific conductanco } \\
\text { Acenaphthone }\end{array}$ & $\begin{array}{r}5.2 \\
5.1 \\
70 \\
<10\end{array}$ & $\begin{array}{l}\text { JQ } \\
\text { JO } \\
\text { JO8 }\end{array}$ & $\begin{array}{l}\mathrm{pH} \\
\mathrm{pH} \\
\mu \mathrm{H} / \mathrm{cm} \\
\mathrm{mg} / \mathrm{L}\end{array}$ & $\begin{array}{l}\mathrm{GE} \\
\mathrm{GE} \\
\mathrm{GE} \\
\mathrm{GE}\end{array}$ \\
\hline
\end{tabular}

Time: $8: 10$

Alkalinity: $4 \mathrm{mg} / \mathrm{h}$ : $22.6^{\circ} \mathrm{C}$
The rentill $7 \mathrm{gol}$

WELL FSL 10 collected on 08/103/82, laboratory analyees (cont)

\begin{tabular}{|c|c|c|}
\hline & Analyte & Pesoult \\
\hline & 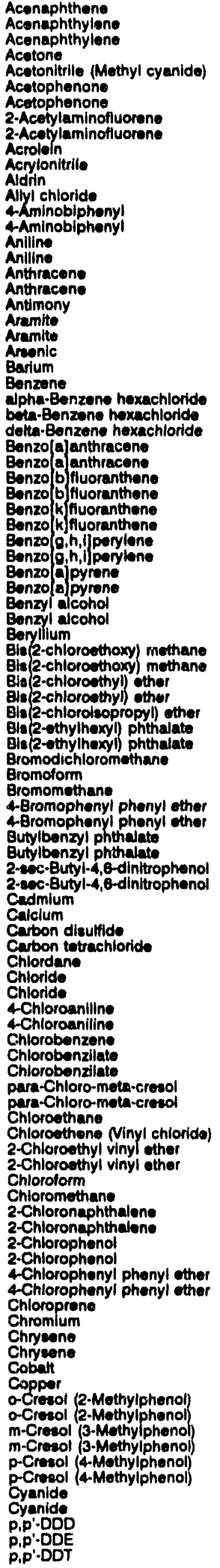 & 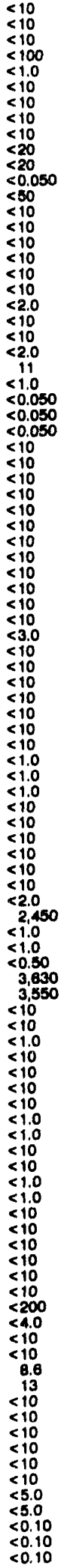 \\
\hline
\end{tabular}

Mod Unit Le

JO $\quad \mu g / L$ GE

JO $\mathrm{mgh}$ GE

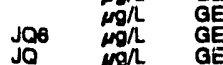

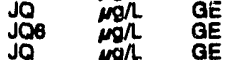

Jos $\operatorname{mogh}$

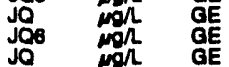

70

Jö

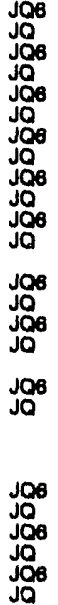

jo

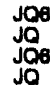

J

soc

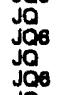

Jo

Jo6

Jo6

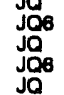

isig 
ANALYTICAL RESULTS

WELL FSL 10 collectod on 09/03/92, laboratory analyeos (cont)

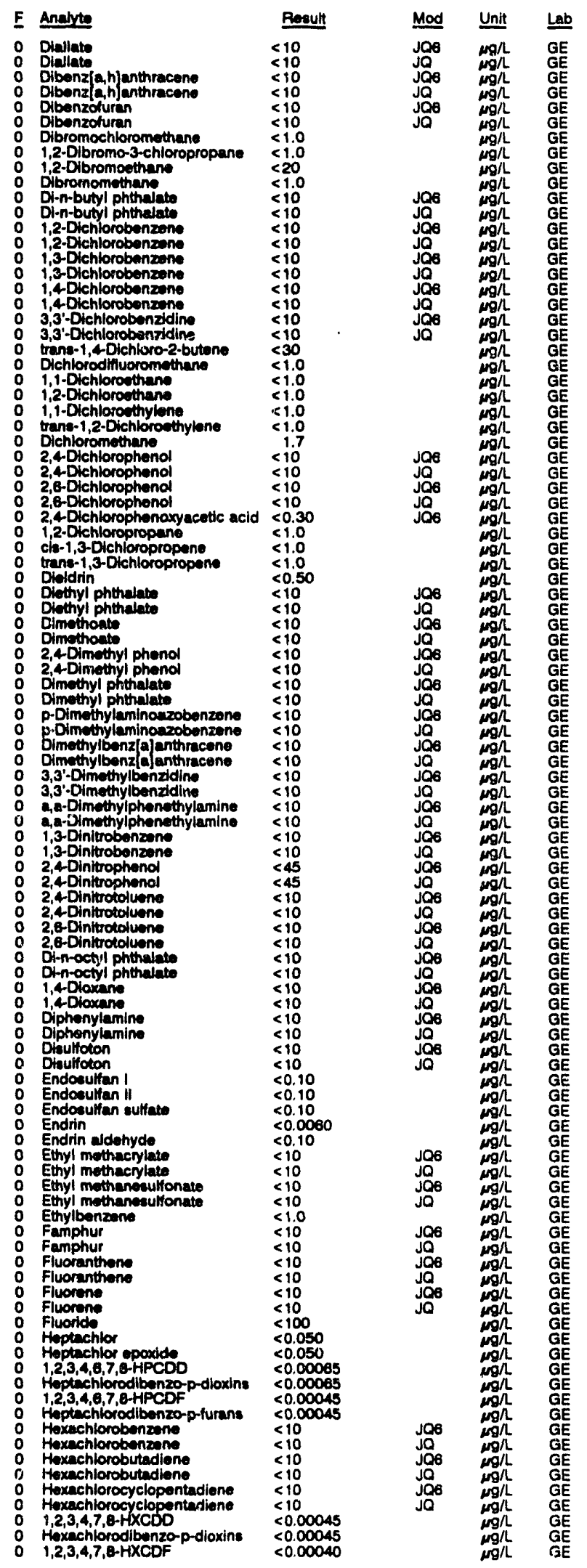

WELLFSL 10 collected on 09/03/92, taboratory analyees (cont.)

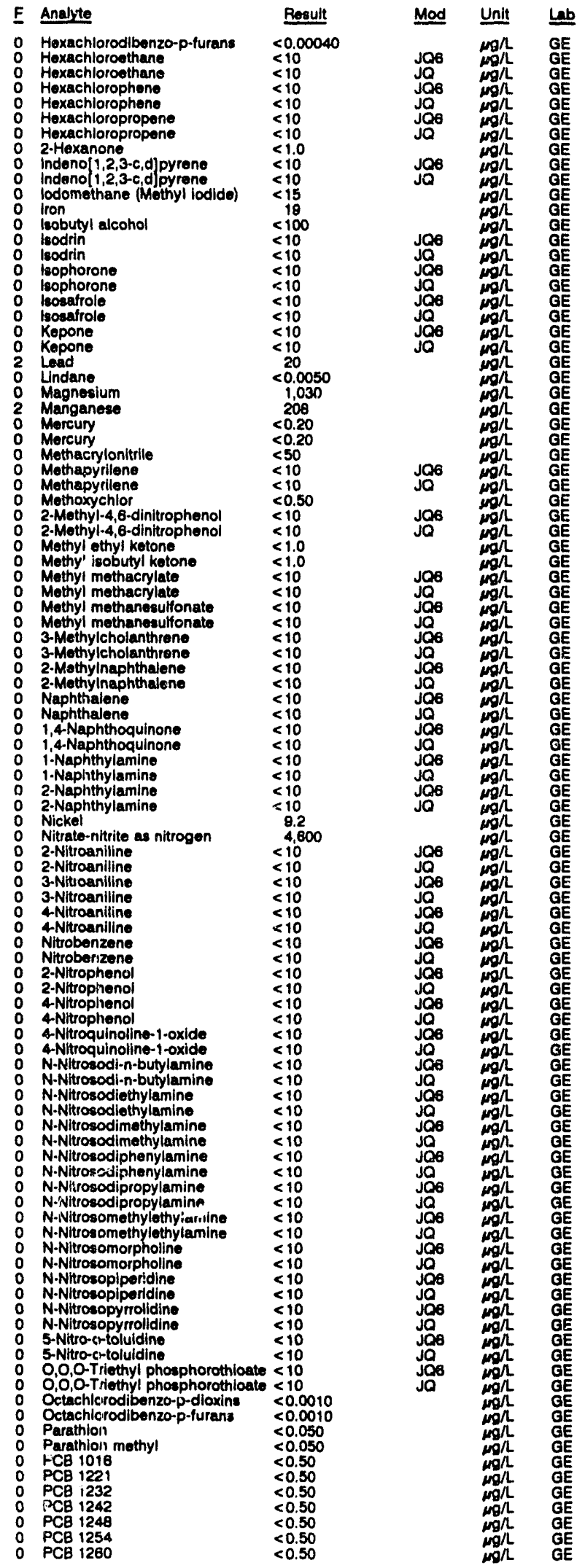


WELL FBL. 10 collected on 09/03/82, laboratory analyees (cont)

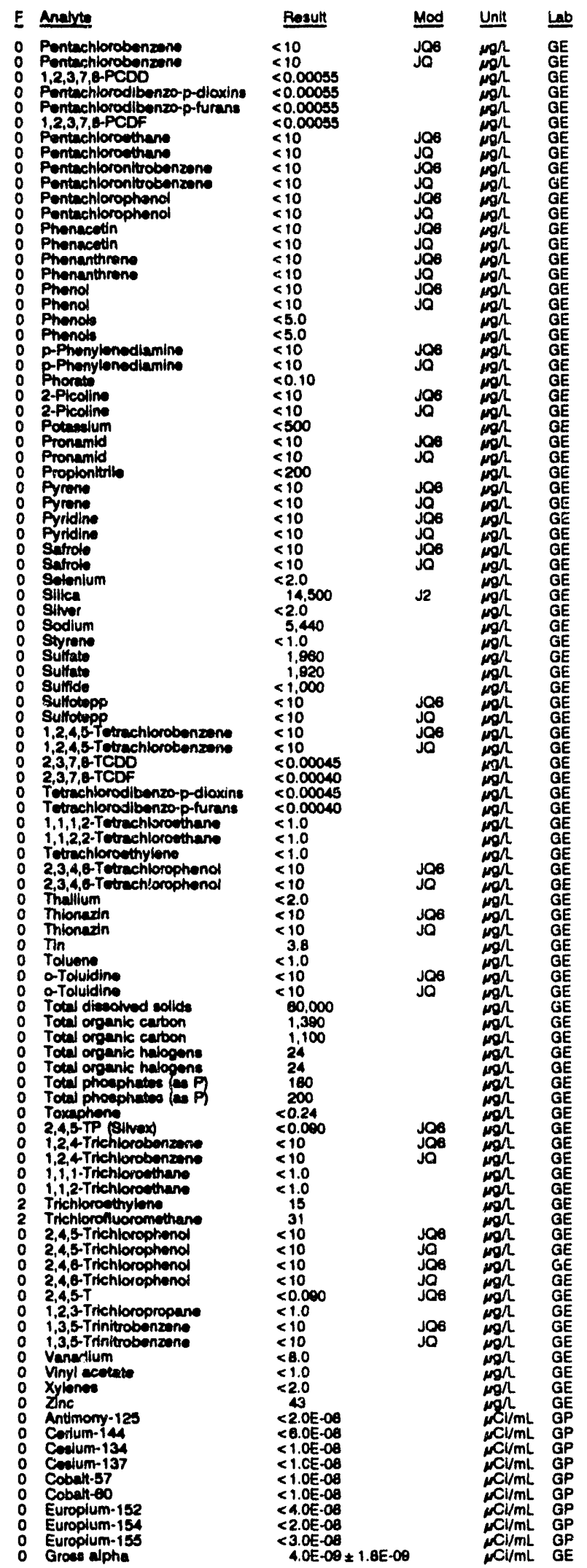

WELL FSL 10 collected on 08/03/82, laboratory analyses (cont.)

\begin{tabular}{|c|c|c|c|c|}
\hline$E$ & Analyte & Result & Unit & Lي \\
\hline $\begin{array}{l}0 \\
0 \\
0 \\
0 \\
0 \\
0 \\
0 \\
0 \\
0 \\
2\end{array}$ & $\begin{array}{l}\text { Manganese-54 } \\
\text { Nonvolatile bota } \\
\text { Potanslum-40 } \\
\text { Promethlum-144 } \\
\text { Promethlum-148 } \\
\text { Puthenium-106 } \\
\text { Sodium-22 } \\
\text { Total activity } \\
\text { Total alpha-emitting radium } \\
\text { Tritium } \\
\text { Yittium-88 } \\
\text { Zinc-65 }\end{array}$ & $\begin{array}{l}<1.0 E-08 \\
5.6 E-09 \pm 1.7 E-00 \\
<1.1 E-07 \\
<1.0 E-08 \\
<1.0 E-08 \\
<0.0 E-08 \\
<1.0 E-08 \\
8.1 E-05 \pm 1.4 E-05 \\
2.2 E-09 \pm 1.1 E-09 \\
5.5 E-05 \pm 1.2 E-00 \\
<6.0 E-08 \\
<2.0 E-08\end{array}$ & 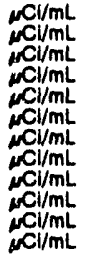 & $\begin{array}{l}G P \\
G E \\
G P \\
G P \\
G P \\
G P \\
G P \\
E M \\
G E \\
G E \\
G P \\
G P\end{array}$ \\
\hline
\end{tabular}

WELL FSL 60

MEASUREMENTS CONDUCTED IN THE FIELD

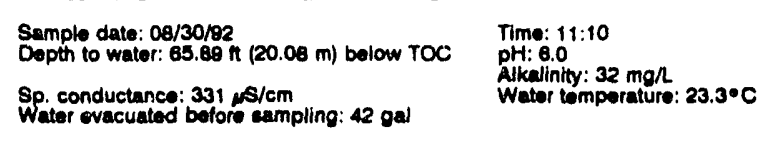
LABORATOFY ANALYSES

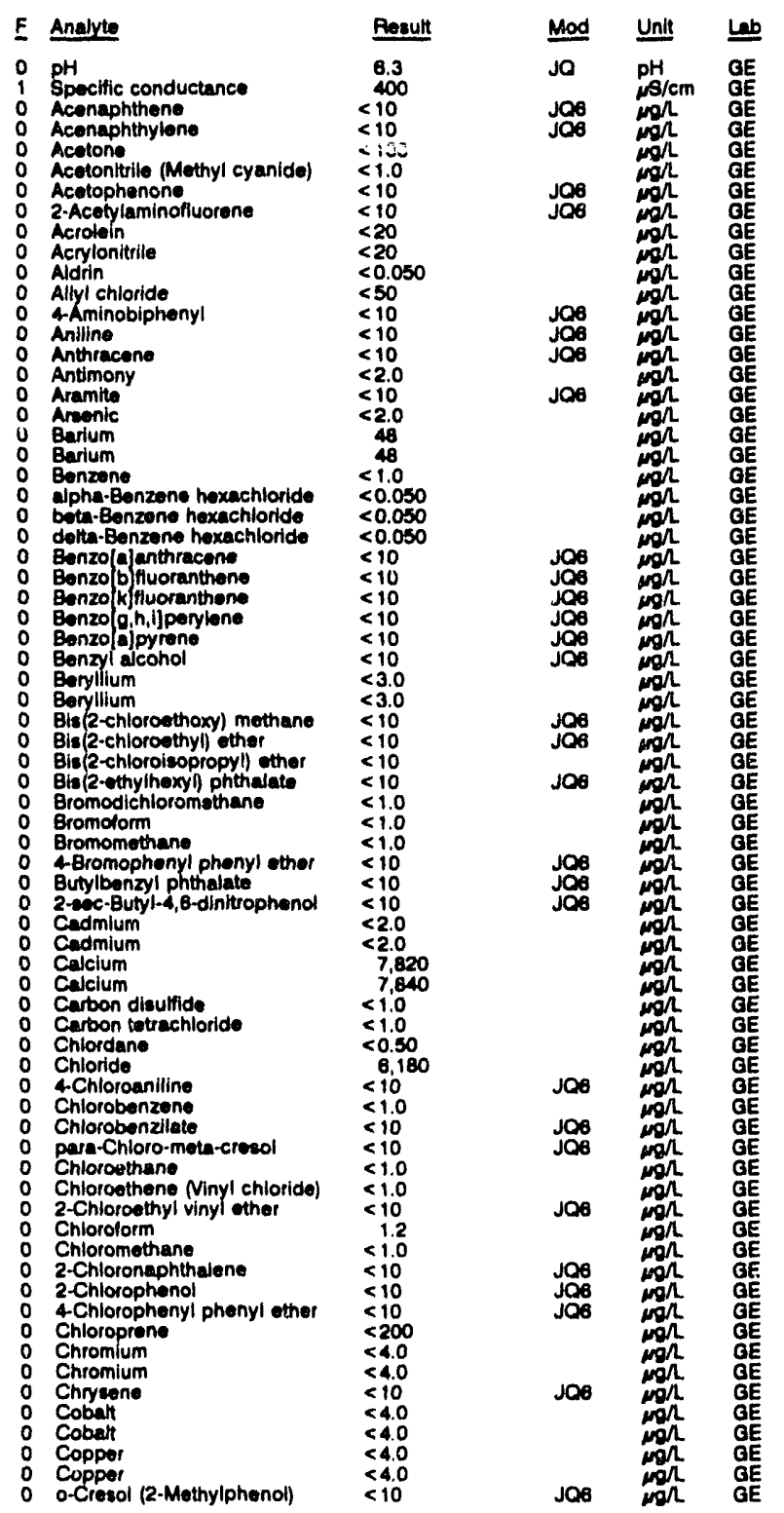


ANALYTICAL RESULTS

WELL FSL $6 D$ collectod on 08/30/92, laboratory analyees (cont.)

D m-Cresol (3-Methylphenol)

p-Cread (4-Methyiphonol)

0 P,p'-DOD

O p.p'-DDE

O Dibenzia,h]anthracene

D Dbenzofuran

D Dibromochloromethane

1,2.Dibromonthane

Dibromomethane

1,2-Olchlorobenzen

o 1,3-Dichlorobenzene

3,3'-Oichlorobenzidin.

0 trans-1,4-Dichloro-2.butene

Dichlorodimuoromethane

o 1,2-Dichlorothane

o 1,1-Dichloroethylene

0 Dichloromethane

2,4-Dichlorophend

2,6-Dichlorophend

2,4-Dichlorophenoxyacetlc acld

1,2-Dichloiopropeno

o cis-1,3-Dichloropropent

0 Deneldrin

O Dinthyl phthalate

2,4-Dimethyl phenol

O Dimethyl phthalate

0 p-Dimethylaminoszobenzene

o 3,3'-Dimethylbenzldine

o a-Dimethylphenethylamine

o 1,3-Dinitrobenzane

o 2,4-Dintrophenot

2,4-Dinitrotoluene

O Di-n-octyl phthalate

1.40koxine

o Diphenylam

o Endosulfan I

O Endosulfan aulfato

- Endrin aldehydo

o Ethyl methecrylate

o Ethylbonzeno

Fluoranthene

0 Fluoride

O Heptachior

O Heptachlor epoxide

o Hoptachiorodibonzo-p-dioxins

o 1,2,3,4,6,7,8-HPCDF

o Heptachlorodlbenzo-p-lura

o Hoxachlorobenzente

o Hexachlorocycloosentadiene

o Hoxachlorocyclopen

O
Hoxachlorodibenzo-p-dioxins
$0 \quad 1,2,3,4,7,6-H X C D F$

o Hoxichlorodibenzo-p-turans

o Hexachlorowthane

o Hoxachloropropen

- 2-ttoxanone

Indeno $[1,2,3-c, d] p y r e n$.

o lodomethare (Mothyl lodide)

o iron

o isobutyl alcohol

o lisobutyl

0 leophorone

o kepantole

o Load

o Magnetium

c Magnesium

Manganese

Manganese

Mothecryloniturite

Methapyrilene

2.Methyl-4,6-dinitropheno

Mothyl ethyl ketone

Mothyl ieobutyl ketone
Posult

$<10$
$<10$
$<5.0$

$<5.0$

$<0.10$
$<0.10$
$<0.10$

$<10$

$<1.0$

$<1.0$

$<20$

$<10$

$<10$

$<10$
$<10$
$<30$

$<1.0$
$<1.0$
$<1.0$

$<1.0$

$<1.0$

$<10$

$<10$
$<0.30$
$<0.30$

$<1.0$

$<1.0$

$<10$

$<10$

$<10$
$<10$

$<10$

$<10$
$<10$
$<10$

$<10$
$<10$

$<45$

$<10$
$<10$

$<10$
$<10$

$<10$
$<10$

$<10$

$<0.10$
$<0.10$

$<0.10$
$<0.0060$

$<10$

$<10$
$<1.0$

$<10$
$<10$

$<10$
$<100$

$<0.050$

$<0.050$

$<0.00085$

$<0.00045$
$<0.00045$

$<10$
$<10$

$<10$

$<0.00045$

$<0.00046$

$<0.00040$

$<10$
$<10$

$<10$

$<1.0$
$<<10$
$<15$

$<15$
12
12
4

12
$<100$
$<10$

$<10$
$<10$
$<10$

$<10$
$<10$
$<3.0$
$<10$

$<3.0$
$<0.0050$

674
677
447

447
448
$<0.20$

$<0.20$
$<50$
$<10$

$<0.50$

$<10$
$<1.0$

Mod
Ja6
JO6
J06
$J 06$
$J 08$

JO6
$J 06$
$J 06$
$J 06$
$J 06$

$\underset{J 06}{J 06}$

$J 06$

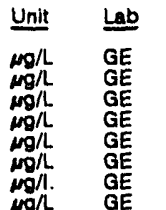

E Analyte

O Mothyl mothacrylate

o 3-Methylcholanthrene

o 2-Methylnaphthalene

- Naphthalene

o 1-Naphthylamine

o 2-Naphthylamine

o Nickel

2 Nickel

0 2-Nitroanlline

4.-Nitroanilline

o Nitrobenzene

2-Nitrophenol

o 4-Nitroquinoline-1-oxide

- N-Nitrosodi-n-butylamine

o N-Nitrosodiethylamine

- N.Nitrosodimethylamine

o N-Nitrosodiphenylamine

N-Nitrosodipropylamine

o N-Nitrosomorpholine

N-Nitrosopiperidine

N-Nhrosopyrrolldine

0 0,0-Triethyl phosphorothioate

- Octachlorodibenzo-p-dioxins

Octachlorodibenzo-p-dioxin

Parathion

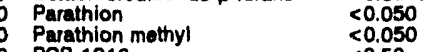

o PCB 1016

O PCB 1221

O PCB 1232

- PCB 1242

0 PCB 1248

P
0 PCB 1254

P Pentachlorobenzene

o Pentachlorodibenzo-p-dioxins

Pentachlorodibenzo-p-furans

1,2,3,7,8-PCDF

Pentachloroethane

Pentachloroniltsobenzene

Pentachlorophen

Phenacetin

0 Phenol

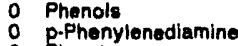

2.Picoline

Potassium

Pronamid

Propionitrile

Pyrene

${ }_{0}$ Pyplidine

o Solonium

Silica

S Silver

Silver

Sodium

Sodium

Styrene

Sulfide

o 1,2,4,5-Tetrachlorobenzene

2,3,7,8-TCDD

2,3,7,8-TCDF

Totrachlorodibenzo-p-dioxins

1,1,1,2-Totrachloroothene

1,1,2,2-Tetrachlorouth

2,3,4,6-Tetrachlorophenol

0 Thallium

Thlonazin

Tin

Tolven

o-Toluidine

Total dissolved solide

Total organic carbon

Totai phosphates (as P)

Toxaphene

2,4,5.TP (Sllvex)

1,2,4-Trichlorobenzen

1,1,1-Trichloroethane

Trichloroethylene

2 Trichlorofluoromethene

$<0.50$

$<0.50$

$<0.50$

$<0.50$
$<0.50$

$<0.00055$

$<0.00055$

$<0.0005$

$<100$

$<<10$

$<10$

$<10$
$<10$

$<0.10$

$<, 670$
2,740

2,10
$<100$

$<<10$

$\leq<10$

$<<10$

10,400
10,400

$<2.0$

57.400
57,200

$<1.0$

8,020
$<1,000$

$<10$

$<0.00045$

$<0.00040$

$<0.00045$

$<0.00040$

$<1.0$

$<1.0$

$<1.0$

$<10$
$<2.0$
$<10$

5.6
5.4

$<1.0$
$<10$

$<10$

$<1,000$

21
$<50$
$<0.24$

$<0.24$

$<0.090$

$<10$

$<1.0$

18
10

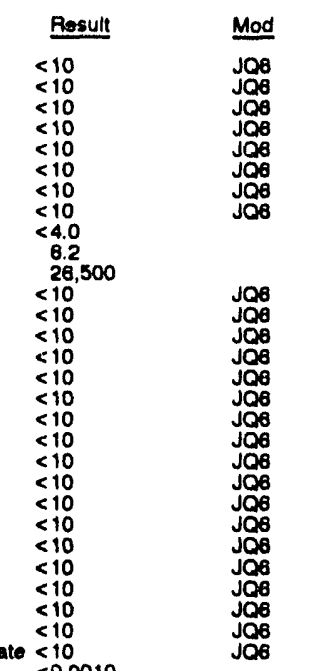

Unit Lea

$\operatorname{mgh} G$

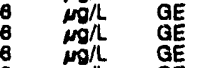

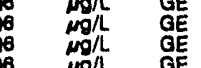

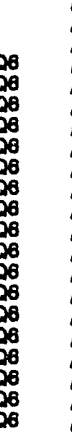

$<10 \quad J a 3$

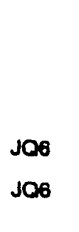

JO6 
WELL FSL 60 collected on 08/30/82, laboratory analyses (cont)

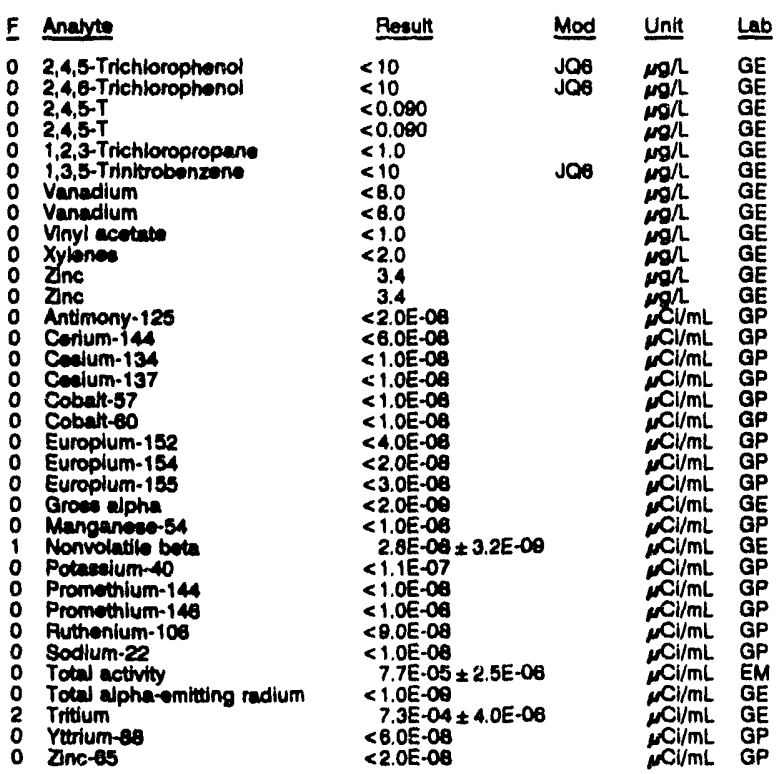

WELL FSL 8D

MEASUAEMENTS CONDUCTED IN THE FIELD

Sample date: 08/30/92 $205 \mathrm{~m}$ below TOC

Time: 12:00 Depth to water: 72.01 n $(21.85$ m) below 100

WELL FSS 10

MEASUREMENTS CONDUCTED IN THE FIELD
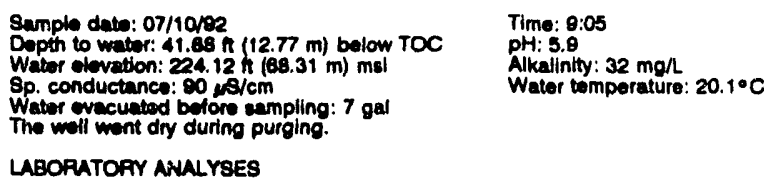

LABOFATOPY ANALYSES

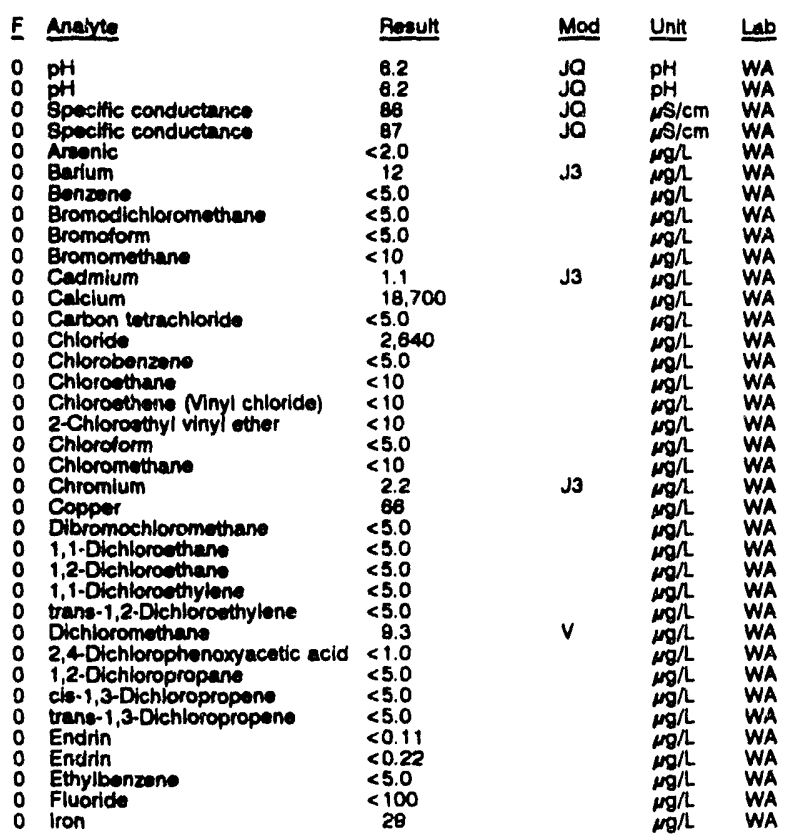

WELL FSS 1D colloctod on 07/10/02, laboratory analyses (cont)

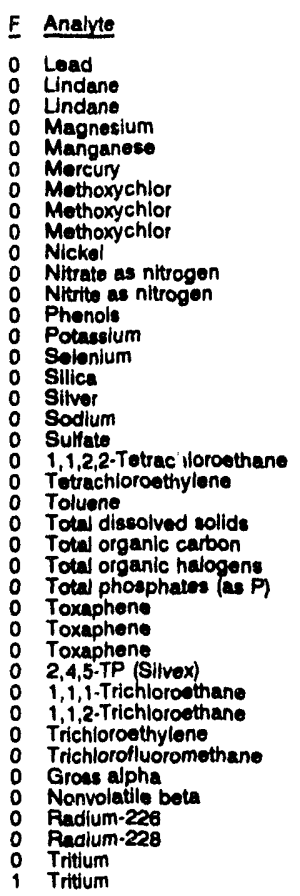

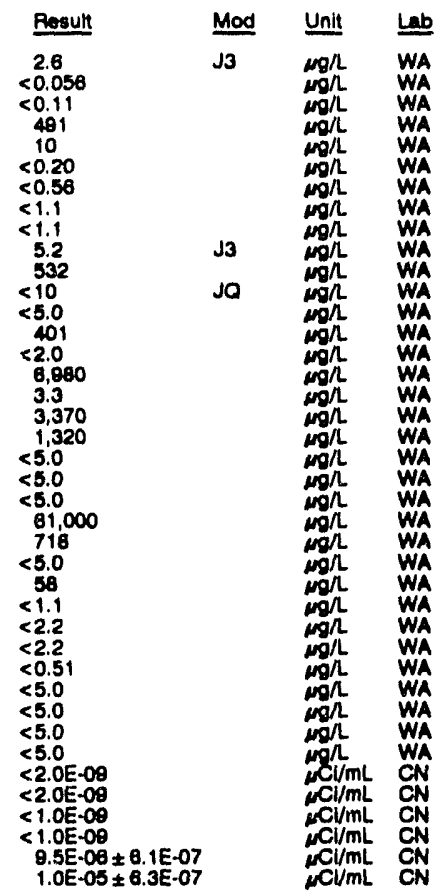

WELL FSS 20

MEASUREMENTS CONDUCTED IN THE FIELD

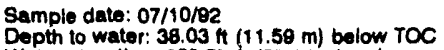

Water elevation: 223.57 h $(68.14 \mathrm{~m}) \mathrm{ms}$

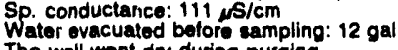

pH: 5.8

Water tomporature: $20.5^{\circ} \mathrm{C}$

LABORATOAY ANALYSES

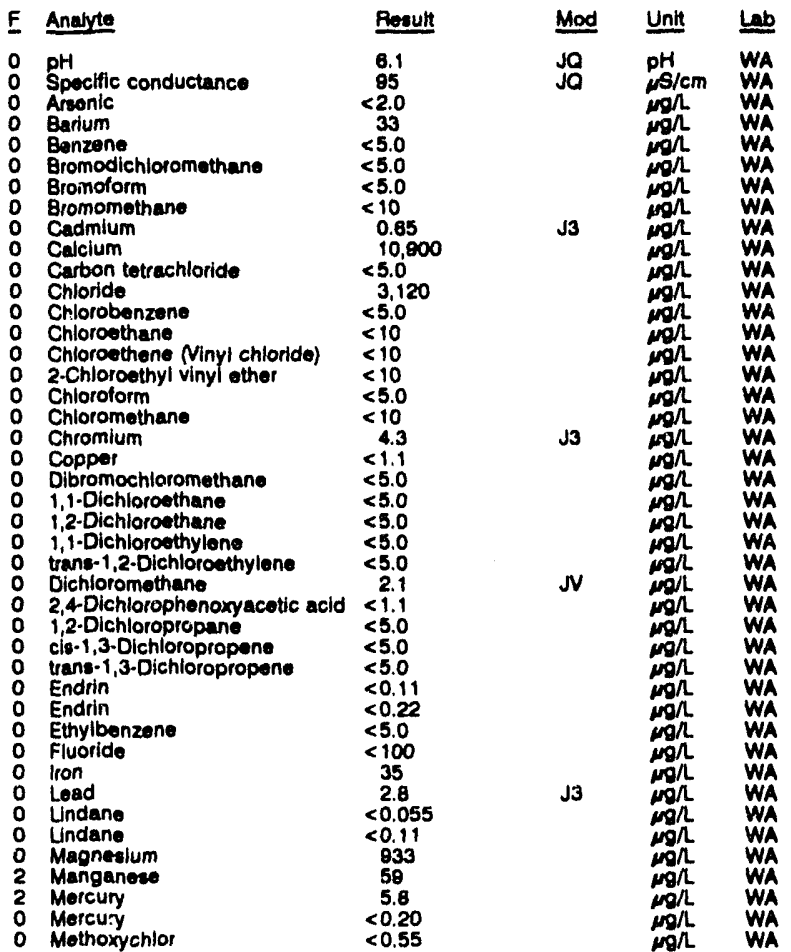


ANALYTICAL RESULTS

WELL FSS 20 collected on 07/10/92, laboratory analyses (cont.)

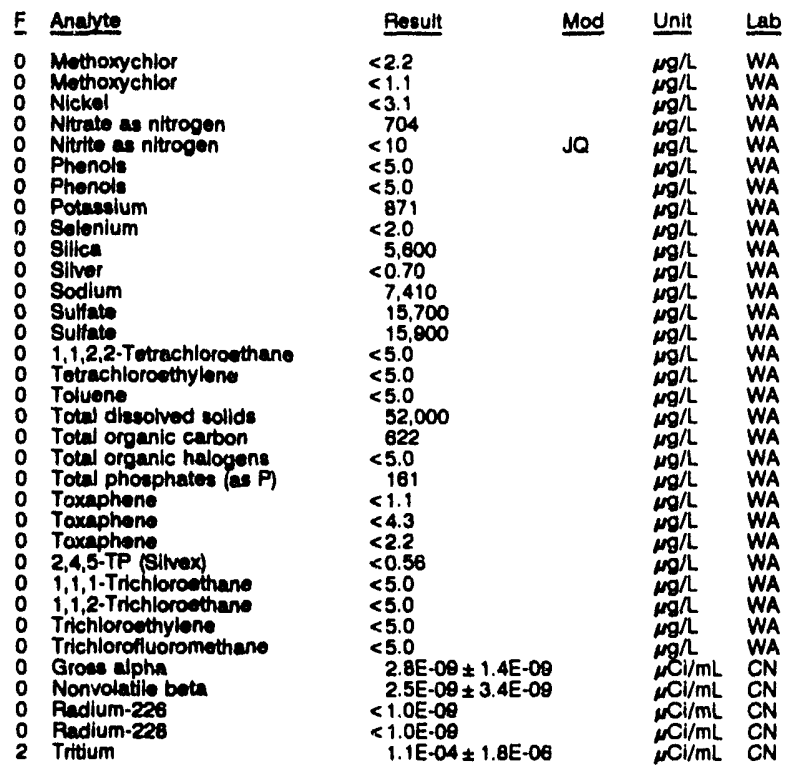

WELL FSS 35

MEASUREMENTS CONDUCTED IN THE FIELL

Sample date: 07/10/92 Dopth to wator: $37.83 \mathrm{ft}(11.53 \mathrm{~m})$ below TOC Watter elovation: 220.37 h $(67$

Sp. conductance: $56 \mu \mathrm{s} / \mathrm{cm}$

The woll went dy during purging: 69

LABORATOFY ANALYSES

E Analyte

$\begin{array}{ll}0 & \text { pH } \\ 0 & \text { Specific conductance } \\ 0 & \text { Arsonic }\end{array}$

Barium

o Bromodiehloromethane

0 Bromoform

Bromomethane

Cadmium

o Calclum

Chlorobenzano

Chloroethene Minyl chloride)

2-Chloroethyl vinyl ether

Chlorotorm

Chloromethene

Chromium

o Copper

1,1-Dichloroethene

1,2-Dichioroethane

o 1,1-Dichlorothylene

trane-1,2-Dichloroet

2,4Dichlorophenoxyacetic acio o 2,4-Dichlorophenoxyecetic acid

o 1,2-Dichloropropane

o cie-1,3-Dichloropropene

0 trane-1,

0 Ethylbenzane

0 Fluoride

2 iron

Iron

2 Lead

Magnealum

Mangane:

Methoxychlor

Nickel

Nickel as nitrogen

Nititu as nitrogen

Phenols

Potablum

Silica

\section{Timo: $8: 1$}

Alkalinity: $1 \mathrm{mg} / \mathrm{l}$

Water temperature: $20.8^{\circ} \mathrm{C}$

$\begin{aligned} & 5.4 \\ & 54 \\ &<2.0 \\ & 17 \\ &<5.0 \\ &<5.0 \\ &<5.0 \\ &<10 \\ & 1.4 \\ & 1.540 \\ &<5.0 \\ & 3.420 \\ &<5.0 \\ &<10 \\ &<10 \\ &<10 \\ &<5.0 \\ &<10\end{aligned}$

$<10$

24
$<5.0$

$<5.0$

$<5.0$

$<5.0$

$<1.1$

$<2.2$

$<5.0$
$<5.0$
$<5.0$
$<0.11$

$<5.0$

$<100$

1,700
1,640

34

$<0.056$
1,220

62

$<0.20$

$<0.56$
5.0
783

763
$<10$

$<10$

675
$<2.0$
6.610

\section{Rosult}

Mod Unit Lab

JO $\quad$ PH $\quad$ WA

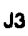

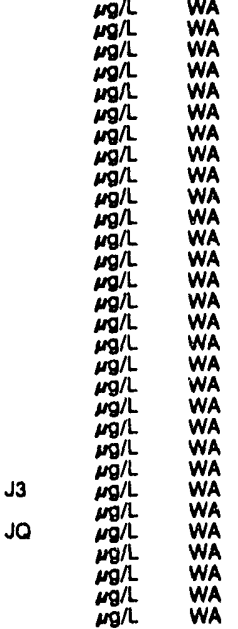

WELL FSS 30 colloctod on $07 / 10 / 82$, laboratory analyees (cont.)

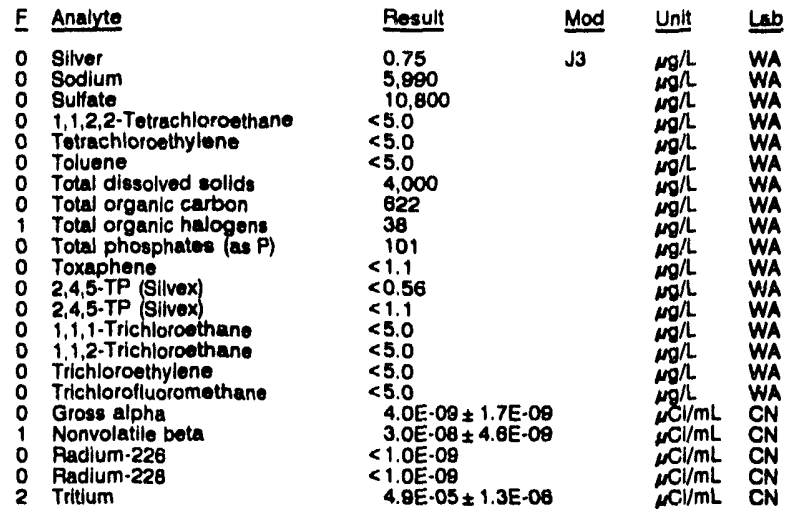

\section{WELL FSS 4D}

MEASUREMENTS CONOUCTEO IN THE FIELD

Sample date: 07/10/92

(10 water: $72.02 \mathrm{th}(21.85 \mathrm{~m})$ below TOC

Water elevation: $219.78 \mathrm{Ht}(68.99 \mathrm{~m}) \mathrm{msl}$

Sp. conductance. 47 .

Time: 8.30

The woll went dy bolore sampling: $13 \mathrm{ga}$

Alkalinity: $0 \mathrm{mg} / \mathrm{l}$

Water temperature: $21.1^{\circ} \mathrm{C}$

LABORATORY ANALYSES

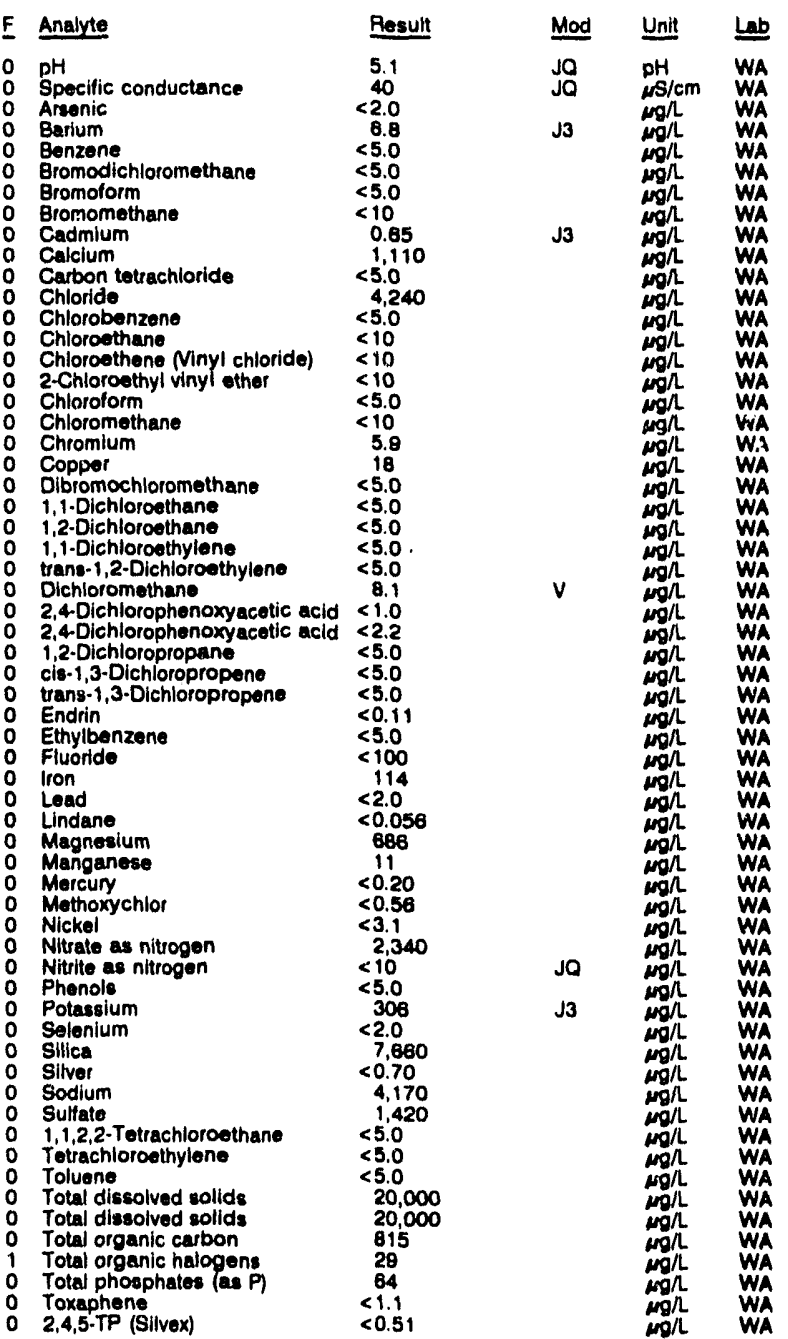


WELL FS9 40 collected on 07/10/82, laboratory analyses (cont.)

\begin{tabular}{|c|c|c|c|c|}
\hline E & Anarte & Result & Mod & Unit \\
\hline & 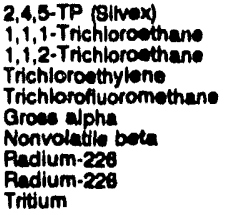 & $\begin{array}{l}<1.1 \\
<5.0 \\
<5.0 \\
1.1 \\
<5.0 \\
<2.0 \mathrm{E}-09 \\
<2.0 \mathrm{E}-09 \\
<1.0 \mathrm{0E} \cdot 00 \\
<1.0 \mathrm{E}-00 \\
5.1 \mathrm{E}-06 \pm 4.8 \mathrm{E}-07\end{array}$ & $\mathrm{~J}$ & 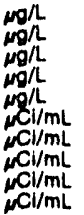 \\
\hline
\end{tabular}

WELL FTF 1

MEASUAEMENTS CONDUCTED IN THE FIELD

Sample dato: 03/2eper Depth to water: $58.00 \mathrm{R}(17.68 \mathrm{~m})$ bolow TOC

Water olevetion: 220.10 h $(89.61 \mathrm{~m}) \mathrm{msl}$

8p. conductenca: $231 \mathrm{~N} / \mathrm{cm}$

Tima: $13: 55$

No water was wecuated before sumpling

Water temperature: $31.8^{\circ} \mathrm{C}$

LABORATOAY ANALYEES

E Ancrate

o Nitrate-niturto as nitrogon

S Sodium

2 Grows alpha

Total elpha-emiting redium

0 Tittum

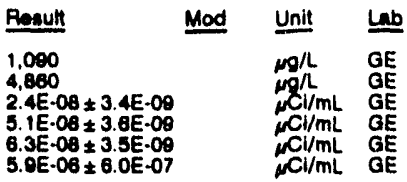

\section{WELL FTF 2}

MEASUPEMENTS CONDUCTED IN THE FIELL

Sample dato: 0arzerpz

Depth to water: $86.00 \mathrm{~h}$ (17.07 m) bolow TOC

Whitor olevation: $225.30 \mathrm{~h}(\mathrm{e8.67} \mathrm{m}) \mathrm{msl}$

Sp. conductence: $71, \mathrm{~s} / \mathrm{cm}$

campling

$\operatorname{Tim}_{\mathrm{pH}: 6.8}$

Water temperature: $28.1 \cdot \mathrm{C}$

LABORATOFY ANALYSES

\begin{tabular}{|c|c|c|c|}
\hline & Analyte & Prosult & Unit \\
\hline & 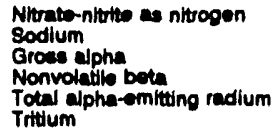 & $\begin{array}{l}130 \\
1,280 \\
1.0 E-08 \pm 3.2 E-09 \\
9.1 E-09 \pm 2.1 E-09 \\
8.5 E-00 \pm 2.0 E-09 \\
8.8 E-07 \pm 5.0 E-07\end{array}$ & 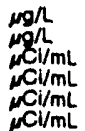 \\
\hline
\end{tabular}

\section{WELL FTF 3}

MEASUREMENTS CONDUCTED IN THE FIELD

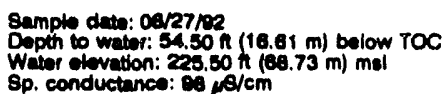

$$
\text { Time: } 12: 45
$$

pH: 5.6

Water elevation: $225.50 \mathrm{~h}(68.73 \mathrm{~m}) \mathrm{m}$

No walis was evecuatidd befors eampling

Water temporature: $33.1{ }^{\bullet} \mathrm{C}$

LABORATOFY ANALYSES

\begin{tabular}{|c|c|c|c|c|}
\hline & Aneryte & Pesult & Unit & Lab \\
\hline & 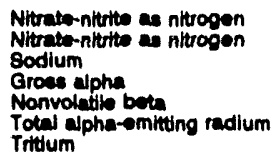 & $\begin{array}{l}102 \\
115 \\
5,020 \\
9.1 E \cdot 09 \pm 2.6 E \cdot 09 \\
1.4 E-00 \pm 2.3 E-09 \\
5.3 E-00 \pm 2.2 E \cdot 09 \\
5.5 E-08 \pm 6.0 E \cdot 07\end{array}$ & 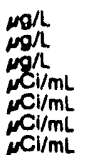 & $\begin{array}{l}\mathrm{GE} \\
\mathrm{GE} \\
\mathrm{GE} \\
\mathrm{GE} \\
\mathrm{GE} \\
\mathrm{GE} \\
\mathrm{GE}\end{array}$ \\
\hline
\end{tabular}

\section{WELL FTF 4}

MEASUREMENTS CONDUCTED IN THE FIELD

\begin{tabular}{|c|c|c|c|c|c|}
\hline \multicolumn{3}{|c|}{ 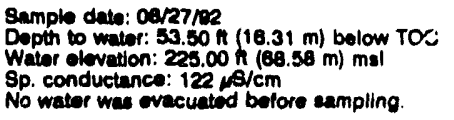 } & \multicolumn{3}{|c|}{$\begin{array}{l}\operatorname{Tims:}_{\mathrm{pH}: 6.1} 12: 30 \\
\end{array}$} \\
\hline \multicolumn{6}{|c|}{ LABORATORY ANALYSES } \\
\hline$\underline{\boldsymbol{F}}$ & Analute & Poeult & Mod & Unit & Lab \\
\hline & $\begin{array}{l}\text { Nitrala-nitutte as nitrogen } \\
\text { Sodium } \\
\text { Groses alpha }\end{array}$ & $\begin{array}{l}2,410 \\
4,310 \\
5.7 \mathrm{E} \cdot 00\end{array}$ & 2E.09 & $\underset{m g / L}{m g / L}$ & $\begin{array}{l}\mathrm{GE} \\
\mathrm{GE} \\
\mathrm{GE}\end{array}$ \\
\hline
\end{tabular}

WELL FIF 4 collected on 08/27/92, laboratory analyeos (cont)

\begin{tabular}{|c|c|c|}
\hline F Analyte & Regutt & Untt \\
\hline $\begin{array}{ll}0 & \text { Nonvolatile bota } \\
1 & \text { Total alpha-emitting radium } \\
0 & \text { Tritium }\end{array}$ & $\begin{array}{l}1.3 \mathrm{E}-08 \pm 2.3 \mathrm{E}-00 \\
4.5 \mathrm{E}-00 \pm 2.8 \mathrm{E}-00 \\
7.0 \mathrm{E}-00 \pm 8.0 \mathrm{E}-07\end{array}$ & $\underset{\substack{\mu \mathrm{Cl} / \mathrm{mL} \\
\mathrm{NCl} / \mathrm{mL}}}{\mathrm{NL}}$ \\
\hline
\end{tabular}

\section{WELL FTF 5}

MEASUAEMENTS CONDUCTED IN THE FIELD

Sample dato: 08mprog

Depth to water: $52.00 \mathrm{~h}(15.85 \mathrm{~m})$ below $\mathrm{TOC}$

Depth to water: $52.00 \mathrm{~h}(15.85 \mathrm{~m})$ bolow

Wator elevation: $225.30 \mathrm{H}(88.67 \mathrm{~m}) \mathrm{mal}$

No water was ovacuatod bolore sampling.

Time: 12:15

$\mathrm{pH}: 8.8$

Water tomperature: $20.1^{\circ} \mathrm{C}$

LABORMTORY ANALYSES

\begin{tabular}{|c|c|c|c|c|}
\hline$E$ & Analyte & Reault & Mod & Untt \\
\hline & $\begin{array}{l}\text { Nitrute-nitrite as nirrogen } \\
\text { Sodium } \\
\text { Grows alpha } \\
\text { Nonvolatile beta } \\
\text { Total alpha-emitting radium } \\
\text { Tritum }\end{array}$ & $\begin{array}{l}1,800 \\
35,400 \\
3.3 E-00 \pm 5.0 E-00 \\
5.2 E-07 \pm 1.1 E-08 \\
1.6 E-00 \pm 4.0 E-09 \\
8.2 E-06 \pm 8.0 E-07\end{array}$ & & 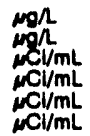 \\
\hline
\end{tabular}

WELL FTF 6

MEASUREMENTS CONOUCTED IN THE FIELL

Sample date: 08/27/92 $16.15 \mathrm{~m}$ below TOC

Water olovation: $225.00 \mathrm{~h}(68.58 \mathrm{~m}) \mathrm{mel}$

8p. conductance: $387 \mathrm{~s} / \mathrm{cm}$

No water was ovacuated before sampling

$\mathrm{pH}: 6.2$

Water temperature: $36.0^{\circ} \mathrm{C}$

LABORATORY ANALYSES

\begin{tabular}{|c|c|c|c|}
\hline & Analyte & Pesoult & Untt \\
\hline $\begin{array}{l}0 \\
2 \\
2\end{array}$ & $\begin{array}{l}\text { Nitrate-nitrite as nitrogen } \\
\text { Sodium } \\
\text { Gross alpha } \\
\text { Nonvolatile bota } \\
\text { Total alpha-emiting radium } \\
\text { Tritium } \\
\text { Tritlum }\end{array}$ & $\begin{array}{l}10,200 \\
71,100 \\
7.8 E-07 \pm 1.0 E-07 \\
1.0 E-05 \pm 2.0 E-07 \\
3.5 E-08 \pm 2.0 E-09 \\
3.2 E-05 \pm 1.0 E-06 \\
3.1 E-05 \pm 8.0 E-07\end{array}$ & 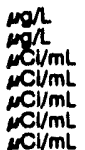 \\
\hline
\end{tabular}

\section{WELL FTF 7}

MEASUREMENTS CONDUCTED IN THE FIELD

Semple date: 08/27/92

m) bolow TOC

Water elevation: $225.00 \mathrm{~h}(88.58 \mathrm{~m}) \mathrm{mal}$

Sp. conductance: $82 \mathrm{\mu s} / \mathrm{cm}$

No water was evacuated bofore sampling

$\operatorname{Tim}_{\mathrm{pH}: 6.3}$ 10:30

LABORATORY ANALYSES

\begin{tabular}{|c|c|c|c|c|}
\hline $\boldsymbol{F}$ & Analyte & Result & Mod & Unit \\
\hline $\begin{array}{l}0 \\
?\end{array}$ & $\begin{array}{l}\text { Nitrate-nitrite as nitrogen } \\
\text { Sodlum } \\
\text { Grows alphe } \\
\text { Nonvolatilo bota } \\
\text { Total alpha-emitting radium } \\
\text { Tritium }\end{array}$ & $\begin{array}{l}<50 \\
1,730 \\
1.2 E-07 \pm 1.3 E-08 \\
2.6 \mathrm{E}-06 \pm 2.8 \mathrm{E} \cdot 08 \\
2.8 \mathrm{E} \cdot 04 \pm 4.8 \mathrm{E} \cdot 00 \\
8.0 \mathrm{E} \cdot 07 \pm 5.0 \mathrm{E}-07\end{array}$ & & 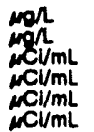 \\
\hline
\end{tabular}

\section{WELL FTF 8}

MEASUREMENTS CONDUCTED IN THE FIELD

Sample date: 08/27/92

Depth to water: $56.80 \mathrm{n}$ (17.22 m) below TOC

Wator elovation: $225.00 \mathrm{~h}(88.68 \mathrm{~m}) \mathrm{mol}$

Sp. conductance: $151 \mathrm{\mu} 8 / \mathrm{cm}$

fore sampling

Time: $10: 19$
pH: 8.1

No wator was ovacualed bel

\begin{tabular}{|c|c|c|c|c|}
\hline$E$ & Analyte & Renult & Unit & $\underline{L} \underline{b}$ \\
\hline 0 & $\begin{array}{l}\text { Nitrato-nitrite as nitrogen } \\
\text { Sodium } \\
\text { Gross alpha } \\
\text { Nonvolatile bota } \\
\text { Total alphu-emitting radium } \\
\text { Tritum }\end{array}$ & $\begin{array}{l}398 \\
2,220 \\
6.3 E-08 \pm 8.3 E \cdot 00 \\
6.0 E-08 \pm 4.4 E \cdot 09 \\
5.0 E \cdot 08 \pm 6.3 E-09 \\
2.2 E-06 \pm 5.0 E \cdot 07\end{array}$ & 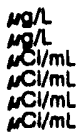 & $\begin{array}{l}\mathrm{GE} \\
\mathrm{GE} \\
\mathrm{GE} \\
\mathrm{GE} \\
\mathrm{GE} \\
\mathrm{GE}\end{array}$ \\
\hline
\end{tabular}


ANALYTICAL RESULTS

\section{WELL FTF 9}

MEASUREMENTS CONDUCTED IN THE FIELLD

Sample date: 0evearer

Depth to water: $48.00 \mathrm{n}$ ( $14.63 \mathrm{~m}$ ) bolow TOC

Water elevation: 223.89 h $(88.24 \mathrm{~m}) \mathrm{ms}$

Sp. conductance: $139 \mathrm{MS} / \mathrm{cm}$

PH: 6.2

Water tomporature: $27.8^{\circ} \mathrm{C}$

LABOPUTOFY ANALYSES

E Analyte

- Nitrato-nitutite as nitrogen

0 Sodium

1 Gross alpha

Nonvolatilo beta

Total elpharemitting redium

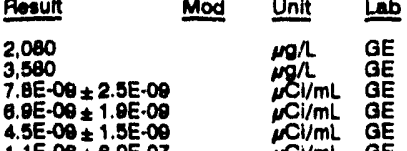

WELL FTF 10

MEASUAREMENTS CONDUCTED IN THE FIELD

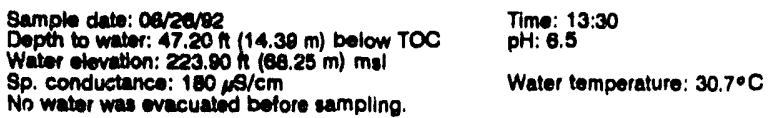

LABORATOFY ANALYSES

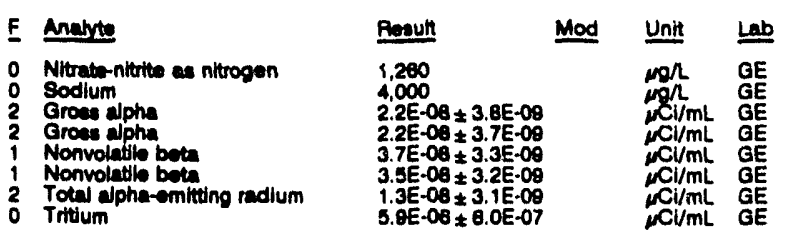

\section{WELL FTF 11}

MEASUREMENTS CONDUCTED IN THE FIELD

\section{Sample date: cerager}

Depth to water: $47.20 \mathrm{~h}(14.39 \mathrm{~m})$ below TOC

Water elevation: $224.00 \mathrm{~h}(68.28 \mathrm{~m}) \mathrm{m}$

Sp. conductunce: $57 \mathrm{~s} / \mathrm{cm}$

$\begin{array}{ll}4.1 \mathrm{E}-00 \pm 8.0 \mathrm{E}-07 & \mu \mathrm{Cl} / \mathrm{mL} \text { GE } \\ \mu \mathrm{Cl} / \mathrm{mL} \text {. } & \end{array}$

LABOPATOFY ANNLYSES

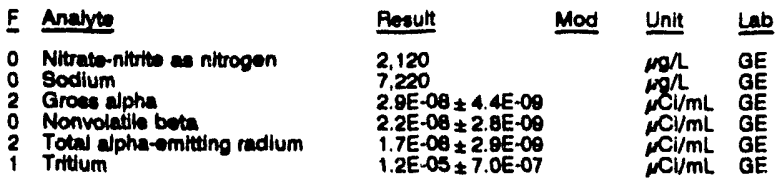

\section{WELL FTF 12}

MEASUAEMENTS CONOUCTED IN THE FIELL

Sample data: 0evarion

Dopth to water: $45.00 \mathrm{~h}(13.72 \mathrm{~m})$ below TOC

Whet to wator: $45.00 \mathrm{~h}(13.72 \mathrm{~m})$ bolow

Water slovation: $22.70 \mathrm{hl}(\mathrm{eq}$

No water was evecuated before eampling.

\section{Time: $13: 00$
pH: 7.2}

Water temperature: $28.3^{\circ} \mathrm{C}$

\section{LABOAMTOAY ANALYSES}

\begin{tabular}{|c|c|c|c|c|}
\hline & Anarye & Pesult & Mod & Unit \\
\hline & 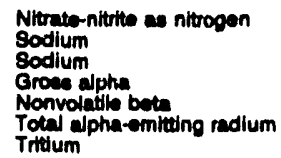 & $\begin{aligned} 1,090 \\
6,000 \\
7,030 \\
<2.0 E-09 \\
1.0 E-00 \\
<1.0 E-09 \\
1.2 E-05 \pm 2.2 E-09 \\
\end{aligned}$ & & 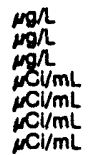 \\
\hline
\end{tabular}

WELL FTF 13

MEASUAEMENTS CONDUCTEO IN THE FIELO

Sample date: 08/28/02

Depth to water: $61.00 \mathrm{ft}(18.59 \mathrm{~m})$ below TOC

Water elovation: $224.80 \mathrm{~h}(68.52 \mathrm{~m}) \mathrm{msi}$

Sp. conductance: $268 \mu \mathrm{s} / \mathrm{cm}$

Time: $10: 30$
DH: 6.6

No water was ovacuatod bofore sampling.

Water temperature: $24.3 \cdot \mathrm{C}$

LABORATORY ANALYSES

\begin{tabular}{|c|c|c|c|}
\hline Analyte & Result & Mod & Unit \\
\hline $\begin{array}{l}\text { Nitrate-nltrite as nitrogen } \\
\text { Sodlum } \\
\text { Groes alpha } \\
\text { Nonvolatilo bota } \\
\text { Total alpha-emitting radium } \\
\text { Trittium }\end{array}$ & $\begin{array}{l}2,460 \\
4,540 \\
5.4 E \cdot 00 \pm 2.3 E-09 \\
8.3 E \cdot 09 \pm 2.1 E-09 \\
7.6 E \cdot 00 \pm 3.2 E-09 \\
7.6 E \cdot 06 \pm 6.0 E-07\end{array}$ & & 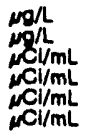 \\
\hline
\end{tabular}

\section{WELL FTF 14}

MEASUREMENTS CONDUCTED IN THE FIELD

Sample date: 08/28/92

TIme: $8: 30$

The woll was dry.

\section{WELL FTF 15}

MEASUREMENTS CONOUCTED IN THE FIELD

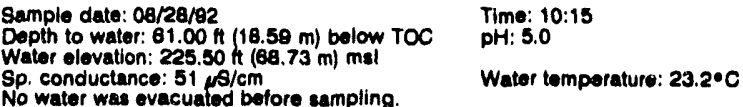

Sp. conductance: $51 \mathrm{~s} / \mathrm{cm}$
No water was evacuated before sampling

LABORATORY ANAL.YSES

\begin{tabular}{|c|c|c|c|}
\hline Analyte & Rosutt & Mod & Unit \\
\hline $\begin{array}{l}\text { Nitrate-nitrite as nitrogen } \\
\text { Nitrate-nitrite as nitrogen } \\
\text { Sodium } \\
\text { Grose alpha } \\
\text { Gross alpha } \\
\text { Nonvolatilo bota } \\
\text { Nonvolatile beta } \\
\text { Total alpha-emitting radium } \\
\text { Total alpha-emitting radium } \\
\text { Tritium }\end{array}$ & $\begin{array}{l}3,650 \\
3,580 \\
4,550 \\
6.5 E \cdot 09 \pm 1.0 E-09 \\
5.4 E \cdot 09 \pm 1.8 E-09 \\
5.7 E-00 \pm 1.8 E-09 \\
5.8 E-00 \pm 1.8 E-09 \\
8.3 E-00 \pm 2.8 E-09 \\
9.7 E-09 \pm 2.8 E-09 \\
8.0 E-08 \pm 6.0 E-07\end{array}$ & & 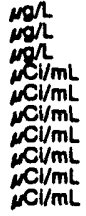 \\
\hline
\end{tabular}

\section{WELL FTF 16}

MEASUREMENTS CONDUCTED IN THE FIELD

Sample dato: 08/28/92
Oepth to water: $64.80 \mathrm{~h}(19.75 \mathrm{~m})$ bolow TOC
PHe: 5.7

Wator elovalon: $223.80 \mathrm{~h}(68.22 \mathrm{~m}) \mathrm{mal}$

No water was ovacuated bofore sanipling

Water tomperature: $25.10^{\circ} \mathrm{C}$

LABOPATORY ANALYSES

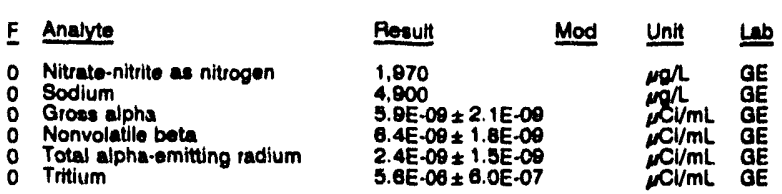

\section{WELL FTF 17}

MEASUREMENTS CONDUCTED IN THE FIELD

\begin{tabular}{|c|c|}
\hline $\begin{array}{l}\text { Imple date: } 08 / 28 / 92 \\
\text { spth to water: } 85.50 \mathrm{n}(18.80\end{array}$ & $\operatorname{Tima:}_{p H: 5.4} 12: 00$ \\
\hline $\begin{array}{l}\text { ter elevation: } 224.10 \mathrm{hl} 168 \\
\text { conductance: } 50 \mathrm{ss} / \mathrm{cm}\end{array}$ & \\
\hline
\end{tabular}

So. conductance: 50 ws/er was ovacuatod before sampling.
No wate

LABOPATORY ANALYSES

E Aralyte

Nitrate-nitrite as nitrogen

Nitrate-nitrite as nitrogen

Sodium

Groses alpha

Nonvolatilo beta

\begin{tabular}{|c|c|c|}
\hline Resull & Mod & Unit \\
\hline $\begin{array}{l}1,940 \\
1,900 \\
5,720 \\
1.1 E-08 \pm 2.7 E-08 \\
6.3 E-08 \pm 1.8 E-00\end{array}$ & & 的 \\
\hline
\end{tabular}


WELL FTF 17 collected on 0e/28/02, laboratory analyees (cont)

\begin{tabular}{|c|c|c|c|}
\hline F Andete & Rosult & Niod & Unit \\
\hline $\begin{array}{l}\text { Total alpha-emitung radi } \\
\text { Thtulum }\end{array}$ & $\begin{array}{l}5.3 E-00 \times 2.1 E-09 \\
5.5 E-06 \pm \theta . C E-07\end{array}$ & & $\underset{\mu \mathrm{Cl} / \mathrm{mL} .}{\mu \mathrm{Cl}}$ \\
\hline
\end{tabular}

\section{WELL FTF 18}

MEASUAEMENTS CONDUCTED IN THE FIELD

\begin{tabular}{|c|c|c|c|c|c|}
\hline \multicolumn{3}{|c|}{ 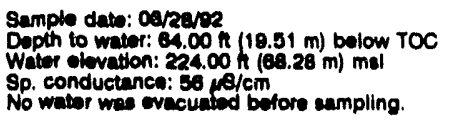 } & $\begin{array}{l}\text { Time: } 12: 1 \\
\text { pH: } 6.0 \\
\text { Water tem }\end{array}$ & rature: 24. & \\
\hline \multicolumn{6}{|c|}{ LABOPATOFY ANALYSES } \\
\hline & Anabte & Result & Mod & Unit & Le \\
\hline & 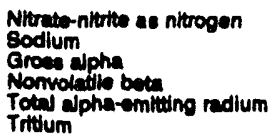 & $\begin{array}{l}2,080 \\
10,000 \\
0.0 E-00 \pm \\
7.1 E-00 \pm \\
4.8 E-00 \pm \\
\theta .2 E-\infty \pm \pm\end{array}$ & $\begin{array}{l}0 . \infty \\
0 .-\infty \\
0.00 \\
0 E-07\end{array}$ & 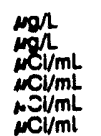 & $\begin{array}{l}\mathrm{GE} \\
\mathrm{GE} \\
\mathrm{GE} \\
\mathrm{GE} \\
\mathrm{GE} \\
\mathrm{GE}\end{array}$ \\
\hline
\end{tabular}

\section{WELL FTF 19}

MEASUAEMENTS CONDUCTED IN THE FIELD

\begin{tabular}{|c|c|c|c|c|c|}
\hline \multicolumn{3}{|c|}{ 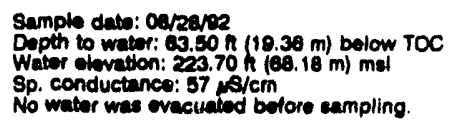 } & \multicolumn{3}{|c|}{$\begin{array}{l}\text { TIme: } 12: 30 \\
\mathrm{pH}: 5.4\end{array}$} \\
\hline \multicolumn{6}{|c|}{ LABOPATOPY ANALYBES } \\
\hline & Andro & Rosult & Mod & Unit & $\underline{\underline{L a b}}$ \\
\hline $\begin{array}{l}0 \\
0 \\
0 \\
0 \\
1 \\
0\end{array}$ & 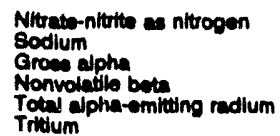 & $\begin{array}{l}2,730 \\
8,630 \\
3.6 E-00 \pm \\
1.15-08 \pm \\
3.7 E-09 \pm \\
7.6 E-08 \pm\end{array}$ & $\begin{array}{l}E-\infty \\
E-09 \\
E-09 \\
E-07\end{array}$ & 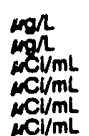 & $\begin{array}{l}\mathrm{GE} \\
\mathrm{GE} \\
\mathrm{GE} \\
\mathrm{GE} \\
\mathrm{GE} \\
\mathrm{GE}\end{array}$ \\
\hline
\end{tabular}

\section{WELL FTF 20}

\section{MEASUREMENTS CONDUCTED IN THE FIELD}

\begin{tabular}{|c|c|c|c|c|c|}
\hline \multicolumn{3}{|c|}{ 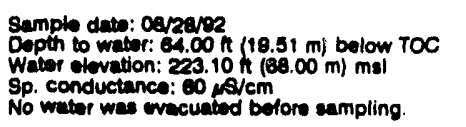 } & \multicolumn{3}{|l|}{$\operatorname{Time:}_{p H: 5.3}^{10: 00}$} \\
\hline \multicolumn{6}{|c|}{ ABOALTOFY ANALYSES } \\
\hline & Analye & Result & Mod & Unit & \\
\hline & 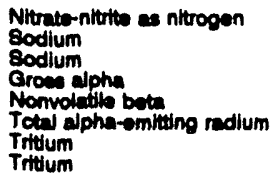 & $\begin{array}{l}1,840 \\
8,240 \\
6,200 \\
8.65-00 \\
6.2 E-00 \\
8.2 E-00 \\
5.7 \mathrm{E}-06 \\
6.0 \mathrm{E}-06\end{array}$ & $\begin{array}{l}E-00 \\
E-09 \\
E-00 \\
E-07 \\
E-07\end{array}$ & 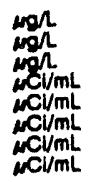 & $\begin{array}{l}\mathrm{GE} \\
\mathrm{GE} \\
\mathrm{GE} \\
\mathrm{GE} \\
\mathrm{GE}\end{array}$ \\
\hline
\end{tabular}

\section{WELL FTF 21}

MEASUREMENTS CONDUCTED IN THE FIELD

Sample dete: cararen

Dopth to water: $84.00 \mathrm{n}(19.51 \mathrm{~m})$ bolow TOC Weter elovation: $223.50 \mathrm{~h}(88.12 \mathrm{~m}) \mathrm{mil}$

No. conductence 4000 sicm

No waler was evecuatiod betore sampling

$\mathrm{H}: 11.2$

Water tomperature: $28.9^{\circ} \mathrm{C}$

LABORATORY ANALYSES

\begin{tabular}{|c|c|c|c|c|c|}
\hline$F$ & Anabrte & Result & Mod & Unit & Lab \\
\hline & $\begin{array}{l}\text { Nitrate-nitrite as nitrogon } \\
\text { Sodium } \\
\text { Grows ajphe } \\
\text { Nonvolatib bets } \\
\text { Total alpha-emitting redium } \\
\text { Tritum }\end{array}$ & $\begin{array}{l}256 \\
36,000 \\
<2.0 E-09 \\
2.0 E-08 \pm 1.9 E-09 \\
2.6 E-09 \pm 1.5 E-09 \\
6.6 E-08 \pm 6.0 E-07\end{array}$ & & 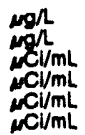 & $\begin{array}{l}\mathrm{GE} \\
\mathrm{GE} \\
\mathrm{GE} \\
\mathrm{GE} \\
\mathrm{GE} \\
\mathrm{GE}\end{array}$ \\
\hline
\end{tabular}

WELL FT:= 22

MEASUREMENTS CONDUCTED IN THE FIELL

Sample date: 08/28/02

Depth to water: $64.00 \mathrm{ft}$ (18.51 m) below TOC

Water elevation: $222.60 \mathrm{H}(87.91 \mathrm{~m}) \mathrm{msl}$

No water was ovacuatod bofore sampling.

Time: $0: 45$

Water temperature: $27.60^{\circ} \mathrm{C}$

LABORATORY ANALYSES

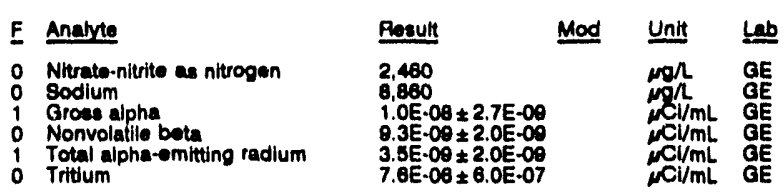

\section{WELL FTF 23}

MEASUREMENTS CONDUCTED IN THE FIELD

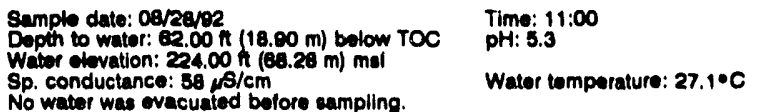

No water was evacuated bofore sampling

LABOPATORY ANALYSES

\begin{tabular}{|c|c|c|c|}
\hline F Analyte & Result & Unt & $\underline{L u b}$ \\
\hline $\begin{array}{ll}0 & \text { Nitrate-nitrite as nitrogen } \\
0 & \text { Sodium } \\
1 & \text { Grost alpha } \\
0 & \text { Nonvolatlle bota } \\
2 & \text { Total alpha-emiting radium } \\
0 & \text { Tritum }\end{array}$ & $\begin{array}{l}3,200 \\
5,030 \\
8.5 E \cdot 00 \pm 2.4 E-09 \\
7.1 E \cdot 00 \pm 1.8 E-09 \\
5.2 E \cdot 09 \pm 2.0 E-09 \\
7.2 E-00 \pm 6.0 E-07\end{array}$ & 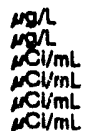 & $\begin{array}{l}\mathrm{GE} \\
\mathrm{GE} \\
\mathrm{GE} \\
\mathrm{GE} \\
\mathrm{GE} \\
\mathrm{GE}\end{array}$ \\
\hline
\end{tabular}

WELL FTF $24 A$

MEASUREMENTS CONDUCTED IN THE FIELD

\begin{tabular}{|c|c|c|c|c|c|}
\hline \multicolumn{3}{|c|}{ 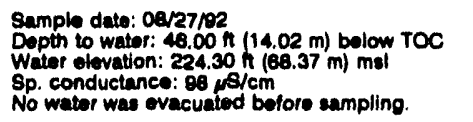 } & \multicolumn{3}{|c|}{$\begin{array}{l}\text { Time: } 13: 15 \\
\text { pH: } 6.4 \\
\text { Water tomperature: } 28.6 \bullet \mathrm{C}\end{array}$} \\
\hline \multicolumn{6}{|c|}{ LABOAATOAY ANALYSES } \\
\hline & Anajyte & Rosult & Mod & Unit & Lab \\
\hline $\begin{array}{l}0 \\
2 \\
2 \\
0 \\
0 \\
2 \\
2 \\
0\end{array}$ & $\begin{array}{l}\text { Nitrate-nitrite as nitrogen } \\
\text { Sodium } \\
\text { Groas alpha } \\
\text { Gross alpha } \\
\text { Nonvolattle bota } \\
\text { Nonvolatile beta } \\
\text { Total alpha-emitting radium } \\
\text { Tritlum }\end{array}$ & $\begin{array}{l}1.910 \\
12,400 \\
2.7 E-06 \pm \\
2.4 E \cdot 08 \pm \\
1.6 E \cdot 08 \pm \\
1.7 E-08 \\
1.0 E-06: \\
7.0 E-08\end{array}$ & $\begin{array}{l} \\
3.9 E-09 \\
3.7 E-09 \\
2.4 E-09 \\
2.4 E-00 \\
2.8 E-09 \\
6.0 E-07\end{array}$ & 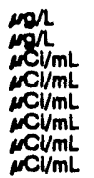 & $\begin{array}{l}G E \\
G E \\
G E \\
G E \\
G E \\
G E \\
G E \\
G E \\
G E\end{array}$ \\
\hline
\end{tabular}

WELL FTF 25A

MEASUREMENTS CONOUCTED IN THE FIELD

Sample dato: 09:a7pa

Depth to whiter: $46.50 \mathrm{Ht}(14.17 \mathrm{~m})$ below TOC

Water olevation: $224.70 \mathrm{~h}(68.49 \mathrm{~m}) \mathrm{msl}$

Sp. conductance 207 .

No water was evacuated before sampling

Water tomperature: $29.1^{\bullet} \mathrm{C}$

LABORATORY ANALYSES

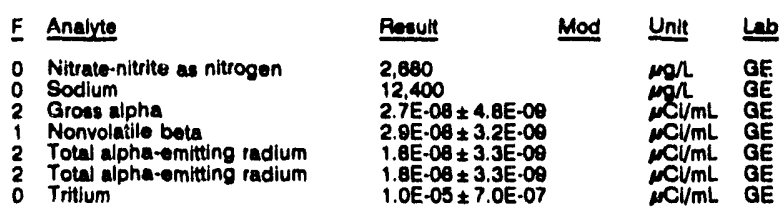


WELL FTF 26

MEASUAEMENTS CONDUCTED IN THE FIELD

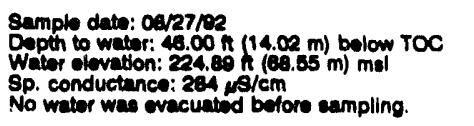
LBOPATOAY ANULYSES

\begin{tabular}{|c|c|c|c|c|c|}
\hline$E$ & Anavese & Reeut & Mod & Unit & $\underline{L a b}$ \\
\hline $\begin{array}{l}1 \\
0 \\
2 \\
2 \\
2 \\
2 \\
2\end{array}$ & 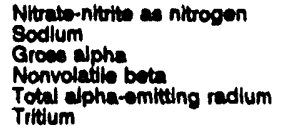 & $\begin{array}{l}3.050 \\
11,600 \\
2.3 E-00 \pm 4.0 E-00 \\
6.7 E-06 \pm 4.7 E-00 \\
2.2 E-06 \pm 3.7 E-00 \\
4.7 E-05 \pm 1.1 E-00\end{array}$ & & 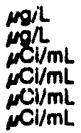 & $\begin{array}{l}G E \\
G E \\
G E \\
G E \\
G E \\
G E\end{array}$ \\
\hline
\end{tabular}

\section{WELL FTF 27}

\section{MEASUREMENTS CONDUCTED IN THE FIELL}

\begin{tabular}{|c|c|c|c|c|c|}
\hline \multicolumn{3}{|c|}{ 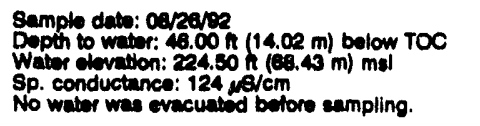 } & \multicolumn{3}{|c|}{$\begin{array}{l}\operatorname{Time:}_{\text {pH: }} 13: 15 \\
\text { PH: }\end{array}$} \\
\hline \multicolumn{6}{|c|}{ LABORATOFY ANALYSES } \\
\hline$\underline{E}$ & Anerte & Renult & Mod & Unit & Lab \\
\hline $\begin{array}{l}0 \\
0 \\
0 \\
0 \\
2 \\
0\end{array}$ & 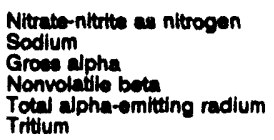 & $\begin{array}{l}1,410 \\
9,700 \\
5.6 E-00_{ \pm} \\
7.1 E-00_{ \pm} \\
7,4 E-00_{ \pm} \\
9.3 E-00_{ \pm}\end{array}$ & $\begin{array}{l}2 E-00 \\
0 E-09 \\
0 E-09 \\
0 E-07\end{array}$ & 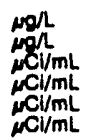 & $\begin{array}{l}\mathrm{GE} \\
\mathrm{GE} \\
\mathrm{GE} \\
\mathrm{GE} \\
\mathrm{GE} \\
\mathrm{GE}\end{array}$ \\
\hline
\end{tabular}

\section{WELL GBW 1}

MEASUREMENTS CONDUCTED IN THE FIELD

Sample dete: 07paros

Depth to watior: 75.78 in $(23.09 \mathrm{~m})$ bolow TOC

Water olovation: $257.84 \mathrm{~h}(78.50 \mathrm{~m}) \mathrm{mol}$

Weter execuated beforem

The will went dry during purging: $17 \mathrm{gal}$

Time: 13:45

$\mathrm{pH}: 6.4$

Water tomperature: $28.4^{\circ} \mathrm{C}$

WELL H 14

MEASUREMENTS CONOUCTED IN THE FIELD

Sample date: cespares

Dopth to wator: $18.57 \mathrm{~h}(5.68 \mathrm{~m})$ bolow TOC

Sp. conductance: $350 \mu \mathrm{s} / \mathrm{cm}$

Water wacuatod bofore sempling: $21 \mathrm{gal}$

LABORATORY ANALYSES

\begin{tabular}{|c|c|c|c|}
\hline Anerve & Result & Mod & Unit \\
\hline $\begin{array}{l}\text { Toted activity } \\
2 \text { Tritium }\end{array}$ & $\begin{array}{l}2.6 \mathrm{E}-0 \\
2.3 \mathrm{E}-0\end{array}$ & & $\stackrel{\mu \mathrm{Cl} / \mathrm{mL}}{\mu \mathrm{Cl} / \mathrm{mL}}$ \\
\hline
\end{tabular}

\section{WELL H 15}

MEASUREMENTS CONDUCTED IN THE FIELD

\begin{tabular}{|c|c|c|c|c|c|}
\hline \multicolumn{3}{|c|}{ 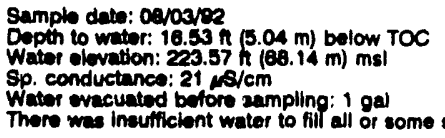 } & \multicolumn{3}{|c|}{$\begin{array}{l}\text { Time: } 18: 10 \\
\text { pH: } 4.7 \\
\text { Alkalinity: } 1 \mathrm{mg} / \mathrm{h} \\
\text { Water temperature: } 29.1 \circ \mathrm{C}\end{array}$} \\
\hline \multicolumn{6}{|c|}{ LABORATOFY ANALYSES } \\
\hline $\boldsymbol{E}$ & Analyte & Result & Mod & Unit & $\underline{\text { Lab }}$ \\
\hline & Trtdum & $1.2 E-0$ & E-07 & $\omega \mathrm{Cl} / \mathrm{mL}$ & GE \\
\hline
\end{tabular}

pH: 4.5

Alkalinity: $0 \mathrm{mgh}$

Water tomperature: $20.8^{\circ} \mathrm{C}$
WELL H 16

MEASUREMENTS CONOUCTED IN THE FIELO

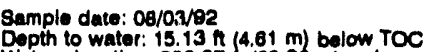

Wath- to water: $15.13 \mathrm{n}(4.61 \mathrm{~m})$ below TOC

Water evacuated before sampling: 13 gal

Alkalinity: $1 \mathrm{mgh} / \mathrm{h}$ : $21.0^{\circ} \mathrm{C}$

LABOPATORY ANALYSES

\begin{tabular}{|c|c|c|c|}
\hline E Analyte & Posuit & Mod & Unit \\
\hline 0 Tritium & 8.0E-06 & & $\mathrm{Cl} / \mathrm{mL}$ \\
\hline
\end{tabular}

WELL H 17 .

MEASUREMENTS CONOUCTED IN THE FIELD

\begin{tabular}{|c|c|}
\hline $\begin{array}{l}\text { Sample date: } 28 / 03 / 92 \\
\text { Depth to water: } 17.17 \mathrm{~h}(5.23 \mathrm{~m}) \text { below TOC } \\
\text { Water elevation: } 220.13 \mathrm{ht}(68.83 \mathrm{~m}) \mathrm{msl} \\
\text { Sp. conductance: } 34 \mu \mathrm{s} / \mathrm{cm}\end{array}$ & $\begin{array}{l}\text { Time: } 15: 55 \\
\text { pH: } 4.6 \\
\text { Nhanlinity: } 1 \text { mon } \\
\text { Water tomporature: } 24.2 \cdot \mathrm{C}\end{array}$ \\
\hline
\end{tabular}

Water evacuated before

Water tomporature: $24.2^{\circ} \mathrm{C}$

There was insufficient water to fill all or some sample bottes.

LALOPATORY ANALYSES

\begin{tabular}{|c|c|c|}
\hline E Analyze & Prosult & Unit \\
\hline $\begin{array}{ll}2 & \text { Gross alpha } \\
0 & \text { Nonvolatile bota } \\
1 & \text { Tritium } \\
1 & \text { Tritium }\end{array}$ & $\begin{array}{l}2.5 E-08 \pm 2.3 E-09 \\
1.1 E-08 \pm 1.6 E-00 \\
1.4 E-05 \pm 7.0 E-07 \\
1.4 E-05 \pm 7.0 E-07\end{array}$ & 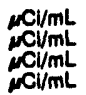 \\
\hline
\end{tabular}

WELLL H 18A

MEASUREMENTS CONDUCTED IN THE FIELD

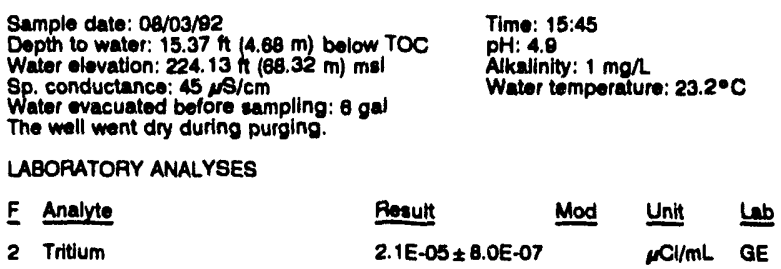

WELL H 19

MEASUREMENTS CONDUCTED IN THE FIELL

Sample date: 08/03/92
The well was dry.

Timo: 8:35

WELL HAC 1

MEASUREMENTS CONDUCTED IN THE FIELD

Sampie date: 08/21/92 Depth to water: 27.24 it $(8.30 \mathrm{~m})$ below TOC Wator elevation: $271.16 \mathrm{~h}$ (82. Water evacuated before eampling: $32 \mathrm{gal}$

Time: 11:00

PH: 5.0

Water temperaiure: $22.0^{\circ} \mathrm{C}$

LABOAATORY ANALYSES

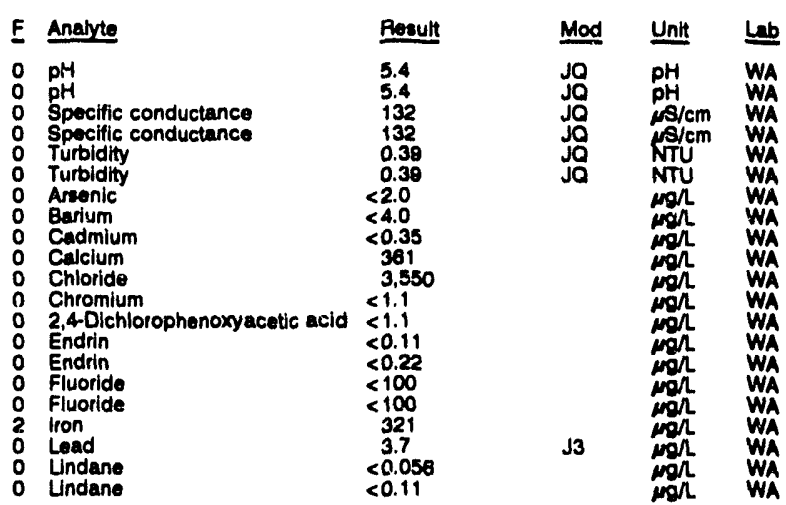


WEU. HAC 1 collectod on 0Q/21/P2, Iaboratory analyses (cont)

\begin{tabular}{|c|c|c|c|c|}
\hline $\boldsymbol{E}$ & Analyte & Result & Mod & Unit \\
\hline $\begin{array}{l}0 \\
0 \\
0 \\
0 \\
0 \\
0 \\
0 \\
0 \\
0 \\
0 \\
0 \\
0 \\
0 \\
0 \\
0 \\
0 \\
0 \\
0 \\
0 \\
0 \\
0 \\
0 \\
0 \\
0 \\
0 \\
0 \\
0 \\
0 \\
0\end{array}$ & 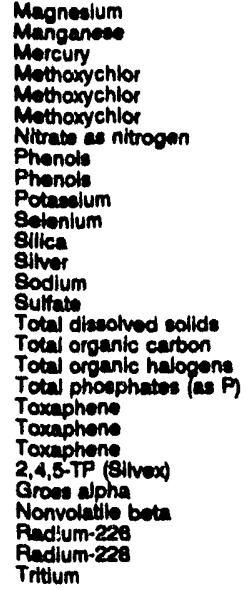 & $\begin{array}{l}179 \\
9.1 \\
<0.20 \\
<0.56 \\
<1.1 \\
<1.1 \\
1.080 \\
<5.0 \\
<5.0 \\
211 \\
2.2 \\
6,300 \\
<0.70 \\
25,200 \\
48,300 \\
30,000 \\
1.110 \\
<5.0 \\
301 \\
<1.1 \\
<2.2 \\
<2.2 \\
<0.58 \\
<2.0 E-09 \\
<2.0 E-09 \\
<1.0 E-09 \\
<1.0 E-09 \\
5.3 E-05 \pm 1.4 E-08\end{array}$ & $\begin{array}{l}\sqrt{3} \\
\sqrt{3}\end{array}$ & 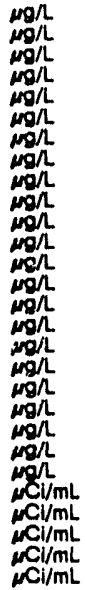 \\
\hline
\end{tabular}

\section{WELL HAC 2}

MEASUREMENTS CONOUCTED IN THE FIELD

\begin{tabular}{|c|c|c|c|c|c|}
\hline & 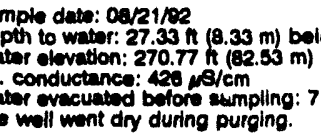 & $\begin{array}{l}\text { TOC } \\
\text { al }\end{array}$ & $\begin{array}{l}\text { Time: } 13 \\
\text { pH: } 5.5 \\
\text { Alkalinity } \\
\text { Water ten }\end{array}$ & $a$ & \\
\hline & BOALTOFY ANALYBES & & & & \\
\hline $\boldsymbol{E}$ & Anatye & Result & Mod & Unit & Lab \\
\hline $\begin{array}{l}1 \\
0 \\
0 \\
0 \\
0 \\
0 \\
0 \\
0 \\
0 \\
0 \\
0 \\
0 \\
0 \\
0 \\
0 \\
0 \\
0 \\
0 \\
0 \\
0 \\
0 \\
0 \\
0 \\
0 \\
0 \\
0 \\
0 \\
0 \\
0 \\
0 \\
0 \\
0 \\
0 \\
0 \\
0 \\
0 \\
0 \\
0 \\
0 \\
0\end{array}$ & 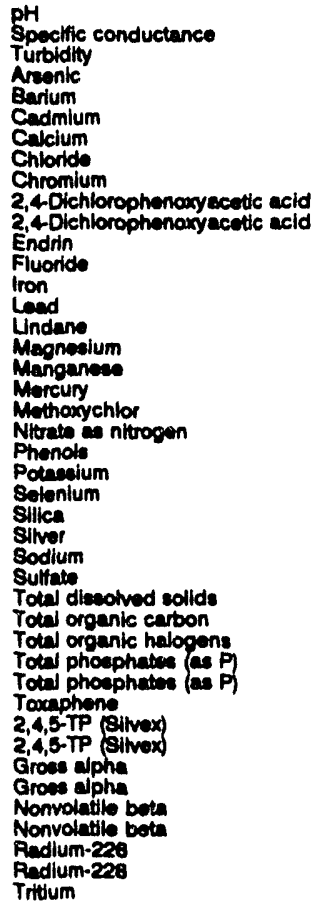 & $\begin{array}{l}5.8 \\
427 \\
8.5 \\
<2.0 \\
5.5 \\
0.92 \\
283 \\
4,400 \\
<1.1 \\
<1.1 \\
<2.2 \\
<0.11 \\
<100 \\
50 \\
<2.0 \\
<0.056 \\
247 \\
11 \\
0.43 \\
<0.58 \\
173 \\
<5.0 \\
<84 \\
2.6 \\
6,370 \\
<0.70 \\
77,700 \\
145,000 \\
201,000 \\
1.010 \\
16 \\
326 \\
339 \\
<1.1 \\
<0.56 \\
<1.1 \\
<2.0 E-09 \\
<2.0 E-09 \\
<2.0 E-09 \\
<2.0 E \cdot 09 \\
<1.0 E-09 \\
<1.0 E-09 \\
3.8 E-05 \\
\end{array}$ & $\begin{array}{l}\mathrm{JO} \\
\mathrm{J} Q \\
\mathrm{JO} \\
\mathrm{J} \\
\mathrm{J3} \\
\mathrm{J3}\end{array}$ & 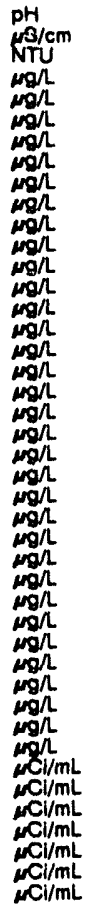 & $\begin{array}{l}\text { WA } \\
\text { WA } \\
\text { WA } \\
\text { WA } \\
\text { WA } \\
\text { WA } \\
\text { WA } \\
\text { WA } \\
\text { WA } \\
\text { WA } \\
\text { WA } \\
\text { WA } \\
\text { WA } \\
\text { WA } \\
\text { WA } \\
\text { WA } \\
\text { WA } \\
\text { WA } \\
\text { WA } \\
\text { WA } \\
\text { WA } \\
\text { WA } \\
\text { WA } \\
\text { WA } \\
\text { WA } \\
\text { WA } \\
\text { WA } \\
\text { WA } \\
\text { WA } \\
\text { WA } \\
\text { WA } \\
\text { WA } \\
\text { WA } \\
\text { WA } \\
\text { WA } \\
\text { WA } \\
\text { CN } \\
\text { CN } \\
\text { CN } \\
\text { CN } \\
\text { CN } \\
\text { CN } \\
\end{array}$ \\
\hline
\end{tabular}

WELL HAC 3

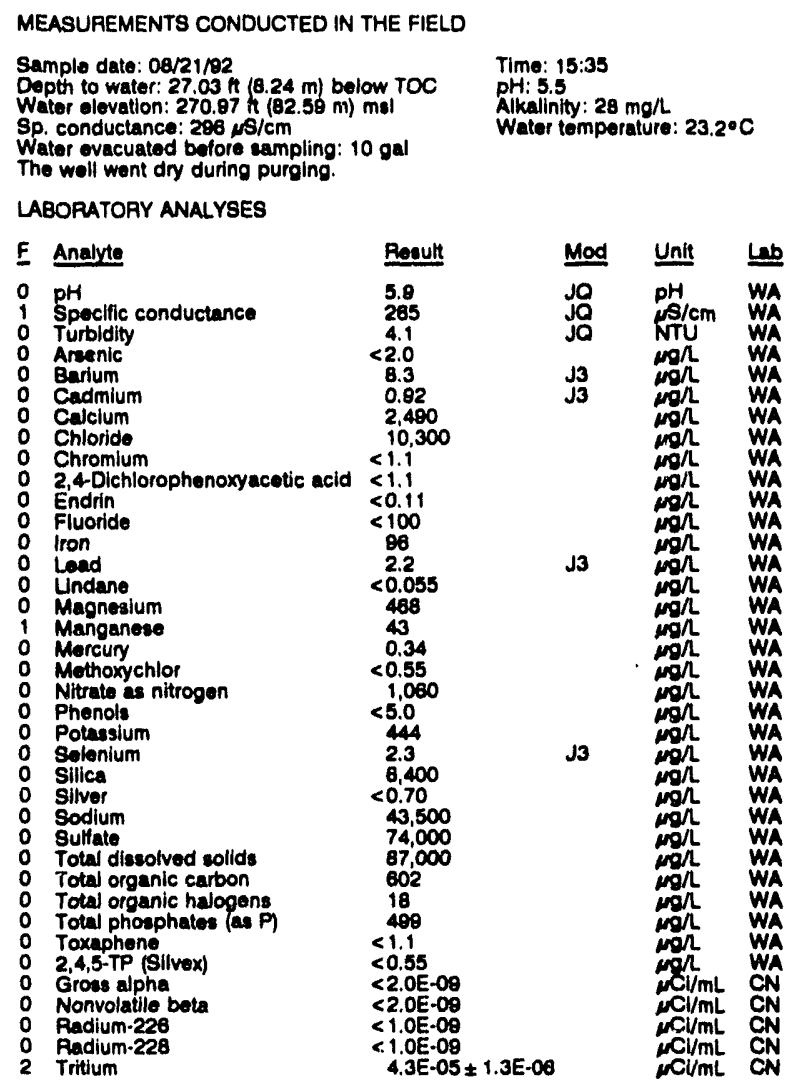

WELL HAC 4

MEASUREMENTS CONDUCTED IN THE FIELD

Dopth to water: $25.53 \mathrm{H}(7.78 \mathrm{~m}$ ) below TOC Water elovation: $271.37 \mathrm{ht}(82.71 \mathrm{~m}) \mathrm{msl}$ Sp. conductance: $36, \mathrm{H} / \mathrm{cm}$
Water ovacuatod before sampling: $45 \mathrm{gol}$ LABORATORY ANALYSES

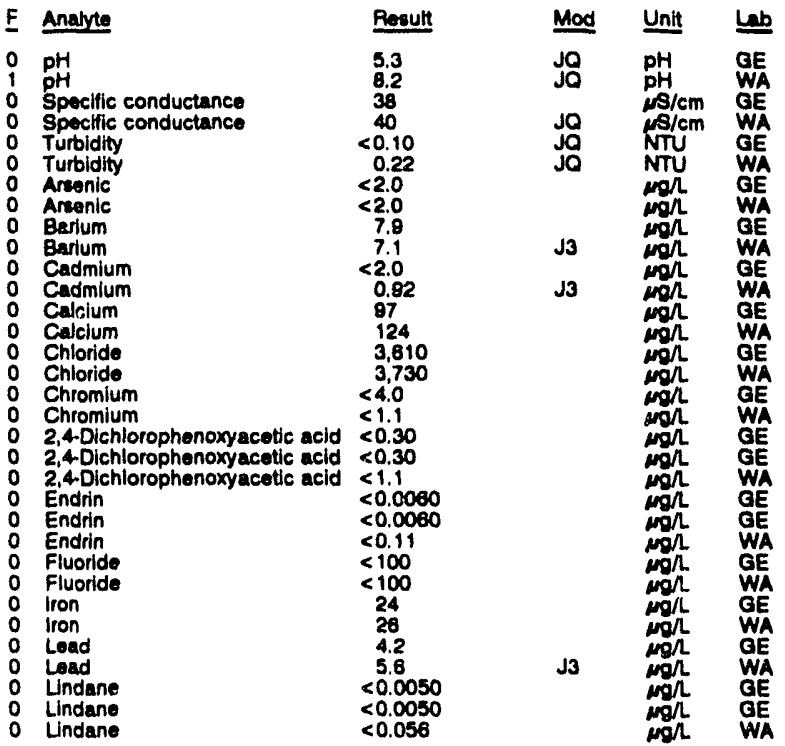


ANALYTICAL RESULTS

WELL HAC 4 collected on 08/21/82, laboratory analveses (cont)

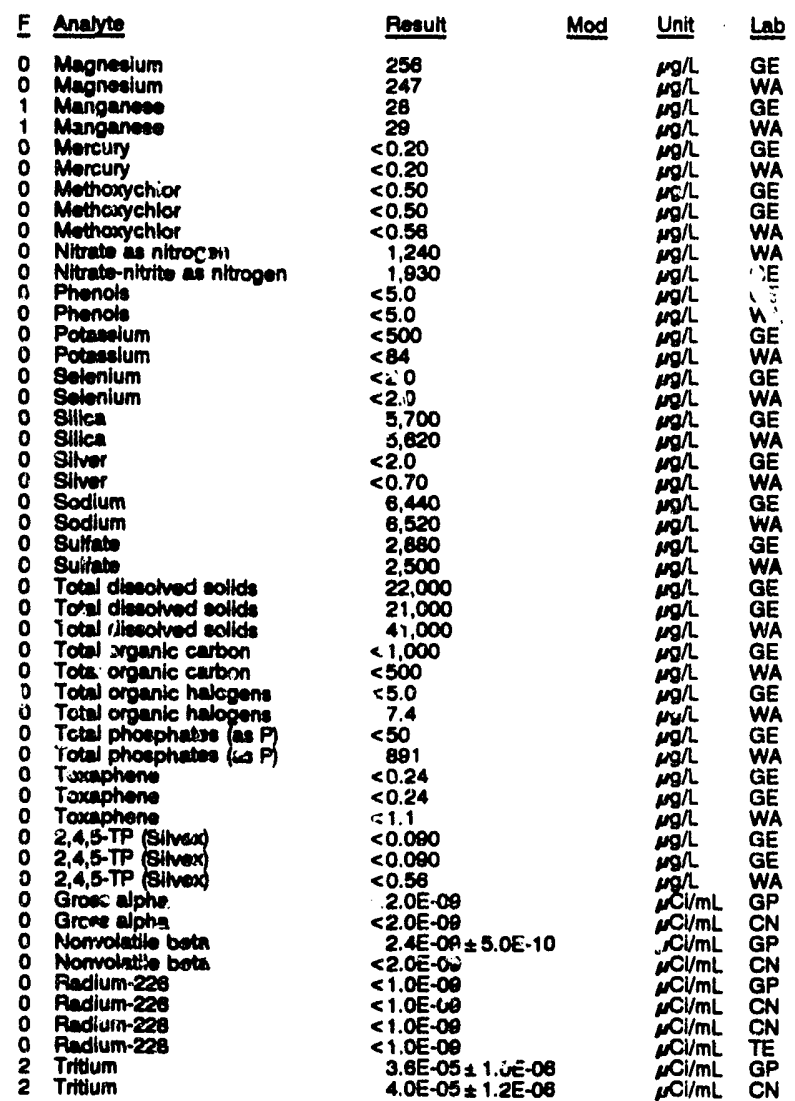

WELL HAC 4 Replicate

MEASUREMENTS CONOUCTED IN THE FIEU)

Sample date: 0.281/82

Depth to walif: $25.53 \%(7.78 \mathrm{~m})$ betciv TOC

Wp. conductinnce: $36 \mathrm{~s}, \mathrm{~s} / \mathrm{cm}$

Water evecuated before empling: $45 \mathrm{gal}$

LABORATORY ANAL YEES

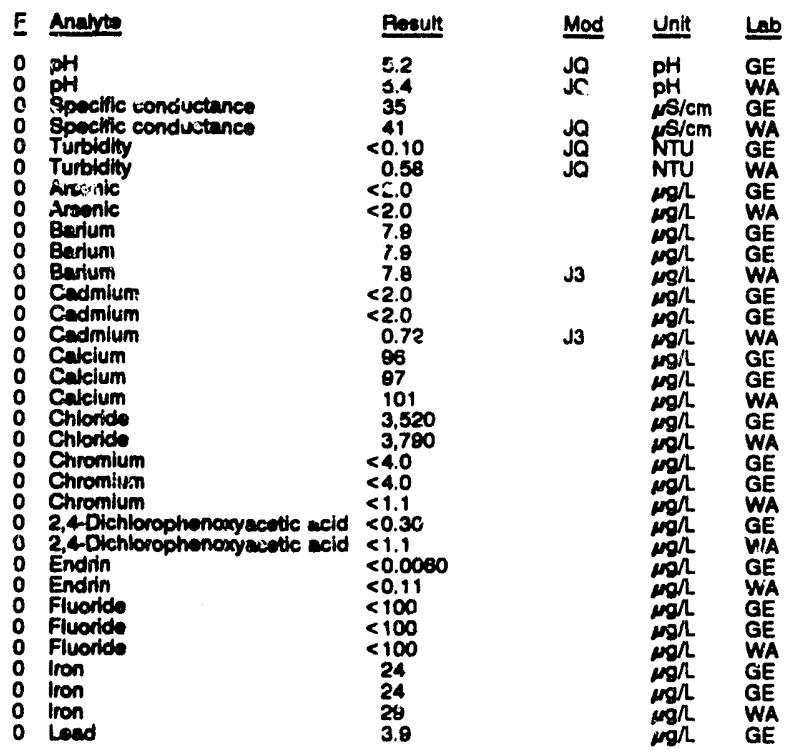

Time: $14: 50$

PH: 4.6

Water temperature: $23.2^{\circ} \mathrm{C}$
WELL HAC 4 collected on 08/21/82, laboratory enalyees (cont.)
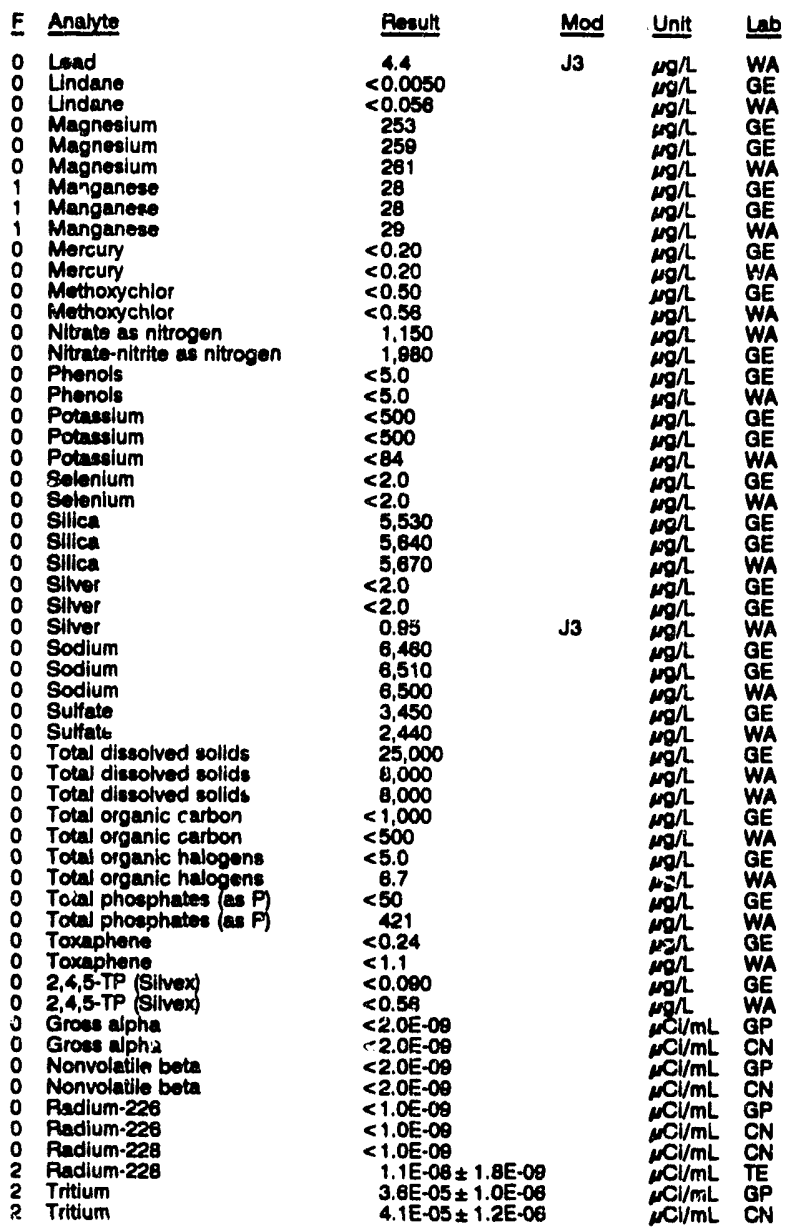

WELL HAP i

MEASUAEMENTS CONDUCTED IN THE FIELD

Sample date: 07/27/82

Dopth to water: $16.86 \mathrm{~h}(5.14 \mathrm{~m})$ below TOC

Water elevation: $272.24 \mathrm{ft}(82.88 \mathrm{~m}) \mathrm{msl}$

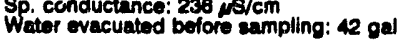

PH: 6.2 :

Water temperature: $21,8 \bullet \mathrm{C}$

WELLL HAP 2

MEASUREMENTS CONCUCTED IN THE FIELD

Sample date: 07/27/02

Depth to water: $18.48 \mathrm{ft}(5.63 \mathrm{~m})$ below roo

Water elevation: $271.44 \mathrm{ft}(62.74 \mathrm{~m}) \mathrm{msl}$

Sp. conductance: $50 \mathrm{~s} / \mathrm{cm}$

TH: 1.8 .

PH: 4.8

Water evacuated before sampling: $73 \mathrm{gal}$ 
WELL HCA 1

MEASUREMENTS CONDUCTED IN THE FIELD

Sample date: 0a/21/ee

Depth to water: $30.25 \mathrm{ft}$ (11.86 m) below TOC

Sp. conduction: $270.73 \mathrm{ht}$ (82

Witer wacleted botors campling: $16 \mathrm{gal}$

The well went dry during purging.

LABORATOFY ANALYSES

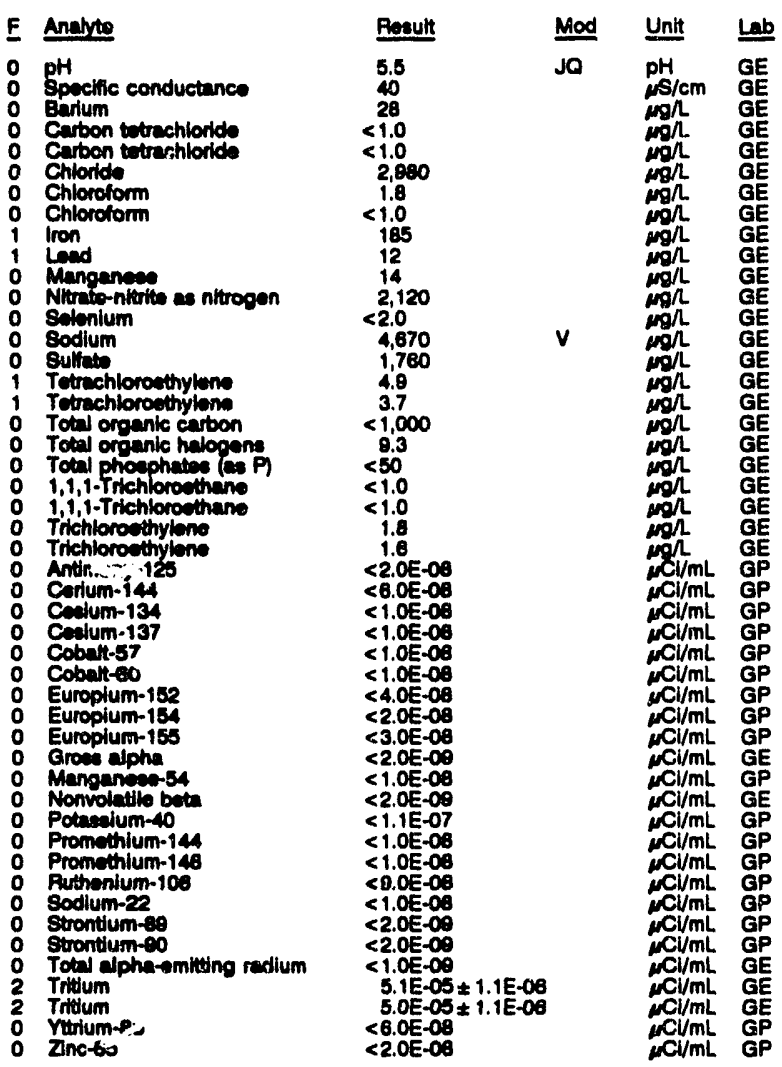

\section{WELL HC:A 2}

MEASUREMENTS CONDUCTED IN THE FIELD

Sample date: 08/21/02 Depth to water: $38.73 \mathrm{n}(11.81 \mathrm{~m})$ below

Watar elevedion: 272.07 h $(82.03 \mathrm{~m}) \mathrm{msl}$

\section{WELL HCA 3}

MEASUREMENTS CONDUCTED IN THE FIELL

Sample date: 0a/21/er

(12 $16 \mathrm{~m})$ bolow TOC

Water olevelton: $270.42 \mathrm{ht}$

Time: $12: 30$

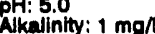

Water temperature: $24.3^{\circ} \mathrm{C}$

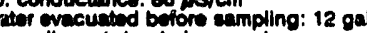

Trie woll went dry during purging.

LABORATOFY ANALY YES

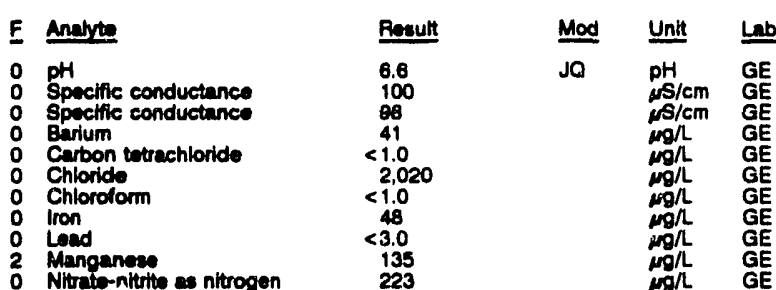

WELL HCA 3 collocted on 08/21/92, laboratory analyees (cont)

F Analyte

0 Solenium

Sodium

Tetrachlorosthylene

Total organic halogen

Total phosphatosens

1,1,1-Trichloroothane

Trichloroethylene

Antimony-125

Antimony-125

o Corium-144

Coslum-134

Ceslum-134

0 Cesium+137

Cobalt-57

0 Cobalt-57

0 Cobalt-60

O Europium-152

Europlum-152

Europlum-15

Europium-155

0 Europium-155

o Groses alph

o Manganese-54

- Nonvolatile bet.

Potasatum-40

Potaselum 40

Promethium-144

Promethlum-146

o Promethium-140

Ruthenium-106

Sodium-22

0 Sodium-22

o Strontium-69

Strontium-80

Total alphe-emitting radium

Tritium

2 Yttum

o Yttrium-68

O Znc-65

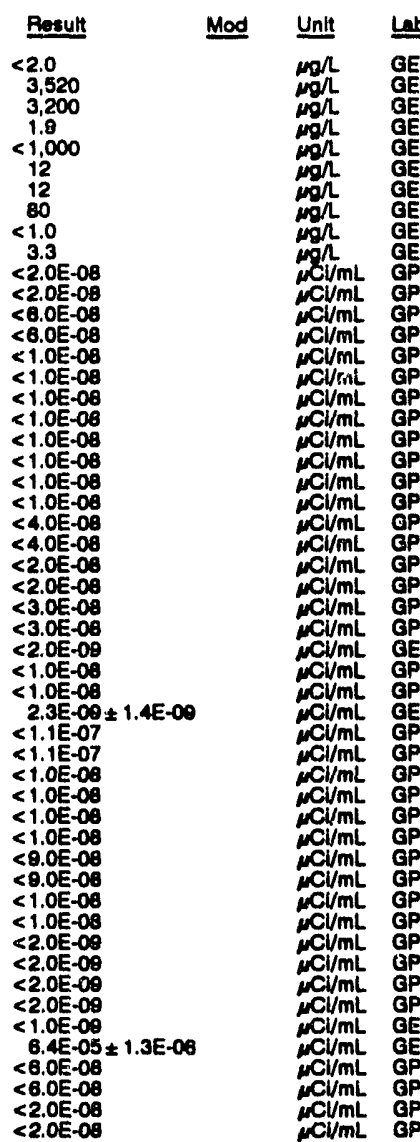

\section{WELL HCA 4}

MEASUREMENTS CONDUCTED IN THE FIELD

Sample dete: 08m

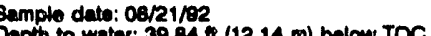
Water elevation: $270.68 \mathrm{ht}(82.86 \mathrm{~m}) \mathrm{msl}$

Ponductance 118 celcm

PH:

Werter

ampling: $21 \mathrm{gal}$

Whter temporature: $24.2^{\circ} \mathrm{C}$

LABORATORY ANALYSES

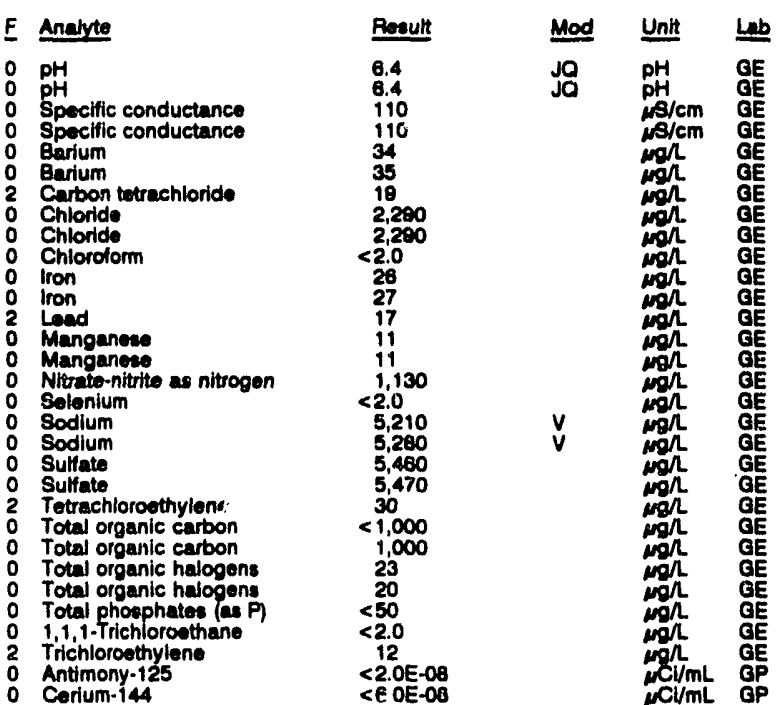


ANALYTICAL RESULTS

WELL MCA 4 collectiad on 06/21/82, laboratory analyses (cont)

\begin{tabular}{|c|c|c|}
\hline Anstyte & Renuth & Unit \\
\hline 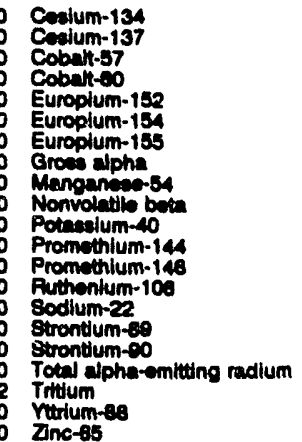 & $\begin{array}{l}<1.0 E-08 \\
<1.0 E-08 \\
<1.0 E-08 \\
<1.0 E-08 \\
<4.0 E-08 \\
<2.0 E-08 \\
<3.0 E-08 \\
3.3 E-09 \pm 1.7 E-09 \\
<1.0 E-08 \\
4.5 E-09 \pm 1.6 E-09 \\
<1.1 E-07 \\
<1.0 E-08 \\
<1.0 E-09 \\
<8.0 E-08 \\
<1.0 E-08 \\
<2.0 E-09 \\
<2.0 E-09 \\
1.6 E-09 \pm 8.0 E-10 \\
4.0 E-09 \pm 1.0 E-08 \\
<8.0 E-08 \\
<2.0 E-08\end{array}$ & 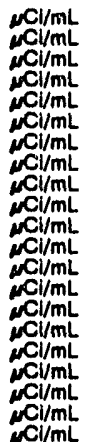 \\
\hline
\end{tabular}

\section{WELL HCB 1}

MEASUREMENTS CONDUCTED IN THE FIELD

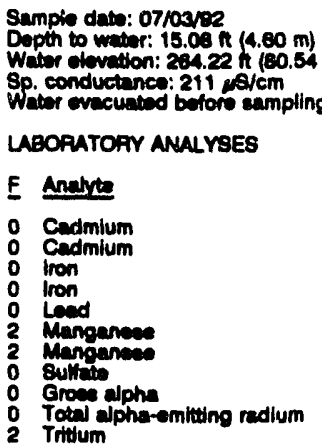

Time: 14:35

PH: 4.7 ilkalinity: $0 \mathrm{mg}$

Water tomporature: $21.3^{\circ} \mathrm{C}$

Weter evecuated befors sampling: $100 \mathrm{gal}$

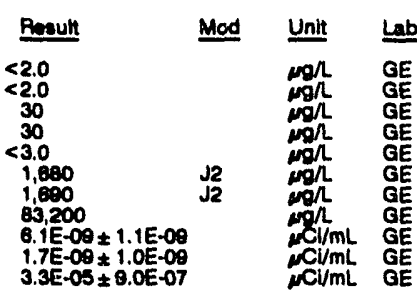

\section{WELL HCB 2}

MEASUAEEMENTS CONDUCTED IN THE FIELD

\begin{tabular}{|c|c|c|c|c|c|}
\hline \multicolumn{3}{|c|}{ 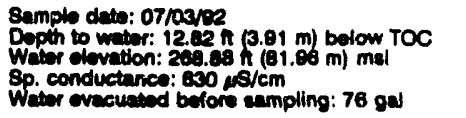 } & \multicolumn{3}{|c|}{$\begin{array}{l}\text { Time: 14:55 } \\
\text { pH: } 3.7 \\
\text { Aknalinity: } 0 \mathrm{mg} \Omega \\
\text { Water tomperature: } 22.4^{\circ} \mathrm{C}\end{array}$} \\
\hline \multicolumn{6}{|c|}{ LABOPATOFY ANALYYES } \\
\hline & Anchte & Reoult & Mod & Unit & \\
\hline & 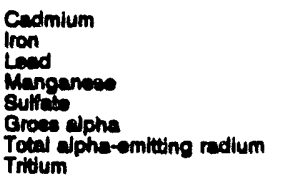 & $\begin{array}{l}<2.0 \\
836 \\
22 \\
1.950 \\
509,000 \\
2.9 E-00 \pm \\
3.8 E-00 \pm \\
2.2 E-05 \pm\end{array}$ & $\begin{array}{c}\text { J2 } \\
E-10 \\
E-07 \\
E-07\end{array}$ & 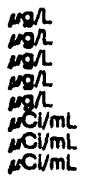 & $\begin{array}{l}\text { GE } \\
\text { GE } \\
\text { GE } \\
\text { GE }\end{array}$ \\
\hline
\end{tabular}

\section{WELL HCB 3}

\section{MEASUAEMENTS CONDUCTED IN THE FIELD}

\begin{tabular}{|c|c|c|c|c|c|}
\hline & 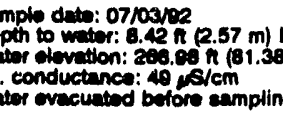 & gal & $\begin{array}{l}\text { Time: 15: } \\
\text { pty: 4.4 } \\
\text { Alkedinity: } \\
\text { Water ton }\end{array}$ & thure: 21. & \\
\hline & BOAATOFY ANALYES & & & & \\
\hline & Anabte & Rosult & Mod & Unit & \\
\hline & $\begin{array}{l}\text { Cadmium } \\
\text { Iron } \\
\text { Lead } \\
\text { Manganese } \\
\text { sulfat } \\
\text { Groes dpha } \\
\text { Total elpha-emitting redium } \\
\text { Tritum }\end{array}$ & $\begin{array}{l}<2.0 \\
21 \\
7.5 \\
8.6 \\
<1,000 \\
<2.0 E-\infty 0 \\
<1.0 E-09 \\
1.8 E-05\end{array}$ & 07 & 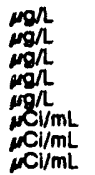 & $\begin{array}{l}\mathrm{GE} \\
\mathrm{GE} \\
\mathrm{GE} \\
\mathrm{GE} \\
\mathrm{GE} \\
\mathrm{GE}\end{array}$ \\
\hline
\end{tabular}

WELL. HCB 4

\begin{tabular}{|c|c|c|c|c|}
\hline \multicolumn{2}{|c|}{$\begin{array}{l}\text { Sample date: } 07 / 03 / 92 \\
\text { Depth to water: } 12.60 \mathrm{~m}(3.84 \mathrm{~m} \text { below TOC } \\
\text { Water olovation: } 265.20 \mathrm{H}(80.83 \mathrm{~m}) \mathrm{mml} \\
\text { Sp. conductance: } 395 \mu \mathrm{s} / \mathrm{cm} \\
\text { Water ovecuated belore sampiling: } 77 \mathrm{gal}\end{array}$} & \multicolumn{3}{|c|}{$\begin{array}{l}\text { Time: } 14: 10 \\
\text { PH: } 4.0 \\
\text { Alkalinity: } 0 \mathrm{mg} / \mathrm{L} \\
\text { Wator tomperature: } 21.7 \cdot \mathrm{C}\end{array}$} \\
\hline \multicolumn{5}{|l|}{ ABOPATORY ANALYSES } \\
\hline Analyze & Reoult & Mod & Unit & Lيb \\
\hline $\begin{array}{l}\text { Cadmium } \\
\text { Chromlum } \\
\text { Fluoride } \\
\text { lron } \\
\text { Lead } \\
\text { Manganese } \\
\text { Sulfate } \\
\text { Sulfate } \\
\text { Gross alpha } \\
\text { Total alpha-emitting radlum } \\
\text { Tritium }\end{array}$ & $\begin{array}{l}<2.0 \\
<4.0 \\
1,020 \\
18 \\
23 \\
387 \\
318,000 \\
322,000 \\
5.7 E-09 \\
2.9 E-09 \\
2.4 E-05\end{array}$ & $\begin{array}{l}.2 E-09 \\
.3 E-09 \\
.0 E-07\end{array}$ & 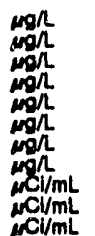 & $\begin{array}{l}\mathrm{GE} \\
\mathrm{GE} \\
\mathrm{GE} \\
\mathrm{GE} \\
\mathrm{GE} \\
\mathrm{GE} \\
\mathrm{GE} \\
\mathrm{GE} \\
\mathrm{GE} \\
\mathrm{GE} \\
\mathrm{GE}\end{array}$ \\
\hline
\end{tabular}

WELL HET 1D

MEASUREMENTS CONDUCTED IN THE FIELD

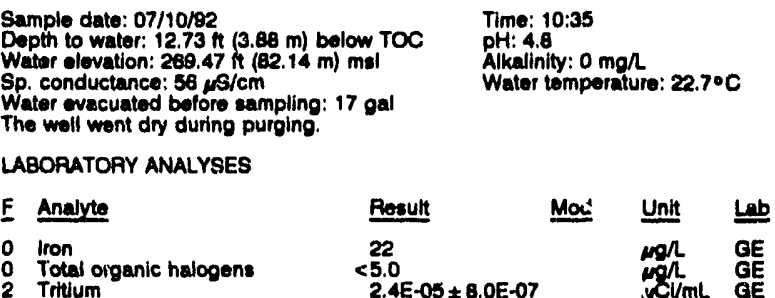

WELL HET 2D

MEASUREMENTS CONDUCTED IN THE FIELD

\begin{tabular}{|c|c|c|c|c|}
\hline \multicolumn{2}{|c|}{$\begin{array}{l}\text { Sample date: } 07 / 10 / 92 \\
\text { Depth to water: } 16.68 \mathrm{ft}(5.14 \mathrm{~m}) \text { below TOC } \\
\text { Water olevation: } 280.04 \mathrm{H}(78.28 \mathrm{~m}) \mathrm{msl} \\
\text { Sp. conductance: } 32 \mu \mathrm{cm} / \mathrm{cm} \\
\text { Water wacuated belore eampling: } 10 \mathrm{gal} \\
\text { The well went dry during purging. }\end{array}$} & \multirow{2}{*}{\multicolumn{3}{|c|}{$\begin{array}{l}\text { Time: } 10: 20 \\
\text { pH: } 3.0 \\
\text { Alkalinity: } 0 \mathrm{mgh} \\
\text { Water temperature: } 21.70 \mathrm{C}\end{array}$}} \\
\hline \multicolumn{2}{|l|}{ LABORATORY ANALYSES } & & & \\
\hline Analyte & Rosult & Mod & Unit & Lي 느 \\
\hline $\begin{array}{ll}0 & \text { Iron } \\
0 & \text { Total organic halogens } \\
2 & \text { Tritium }\end{array}$ & $\begin{array}{l}29 \\
<5.0 \\
3.2 E-0\end{array}$ & $8.0 E-07$ & $\operatorname{mogh}_{\mu \mathrm{LL}}^{\operatorname{mon}}$ & $\begin{array}{l}\text { GE } \\
\text { GE } \\
\text { GE }\end{array}$ \\
\hline
\end{tabular}

WELL HET 3D

MEASUREMENTS CONDUCTED IN THE FIELD

Sample dato: 07/10/8?

Dopth to water: $18.35 \mathrm{th}(4.88 \mathrm{~m})$ below TOC Time: 10:10

Waler olevation: $280.35 \mathrm{f}(78.36 \mathrm{~m}) \mathrm{mbl}$ Alkalinity: $0 \mathrm{mg} \Omega$ Sp. conductance: $29 \mu \mathrm{B} / \mathrm{cm} \quad$ Water temperature: $21.2^{\circ} \mathrm{C}$ Water evacuated betore sampling: $12 \mathrm{gal}$ The woll went dry during purging.

LABOPATOPY ANALYSES

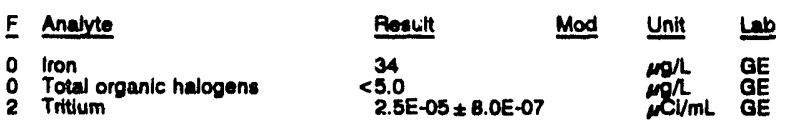


WELL HET 4D

MEASUREMENTS CONDUCTED IN THE FIELL

Sample dats: 07/10/ee

Depth to water: $15.83 \mathrm{n}(4.68 \mathrm{~m} / \mathrm{bol}$ (ow TOC

Water elevation: $260.77 \mathrm{ht} / 7$

We conductance:

The well wont dry during purging.

LABORATOAY ANALYSES

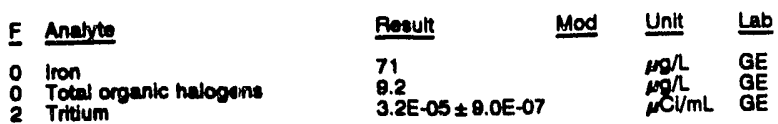

WELL HMD 1D

MEASUAREMENTS CONIJUCTED IN THE FIELD

Sample data: 07/03/9?

Dopth to weter: 34.62 f $(16.65 \mathrm{~m})$ below TOC

Water elevation: 200.88 h 163.

Water ovecuebed bofons eampling: $4 \mathrm{gal}$

Time: $8: 55$

PH: 4.8 : 0 molinity: $0 \mathrm{~mol}$

Whater temperature: $22.3 \circ \mathrm{C}$

The well went dry durlinj purging.

LABORATOFY ANALYSES

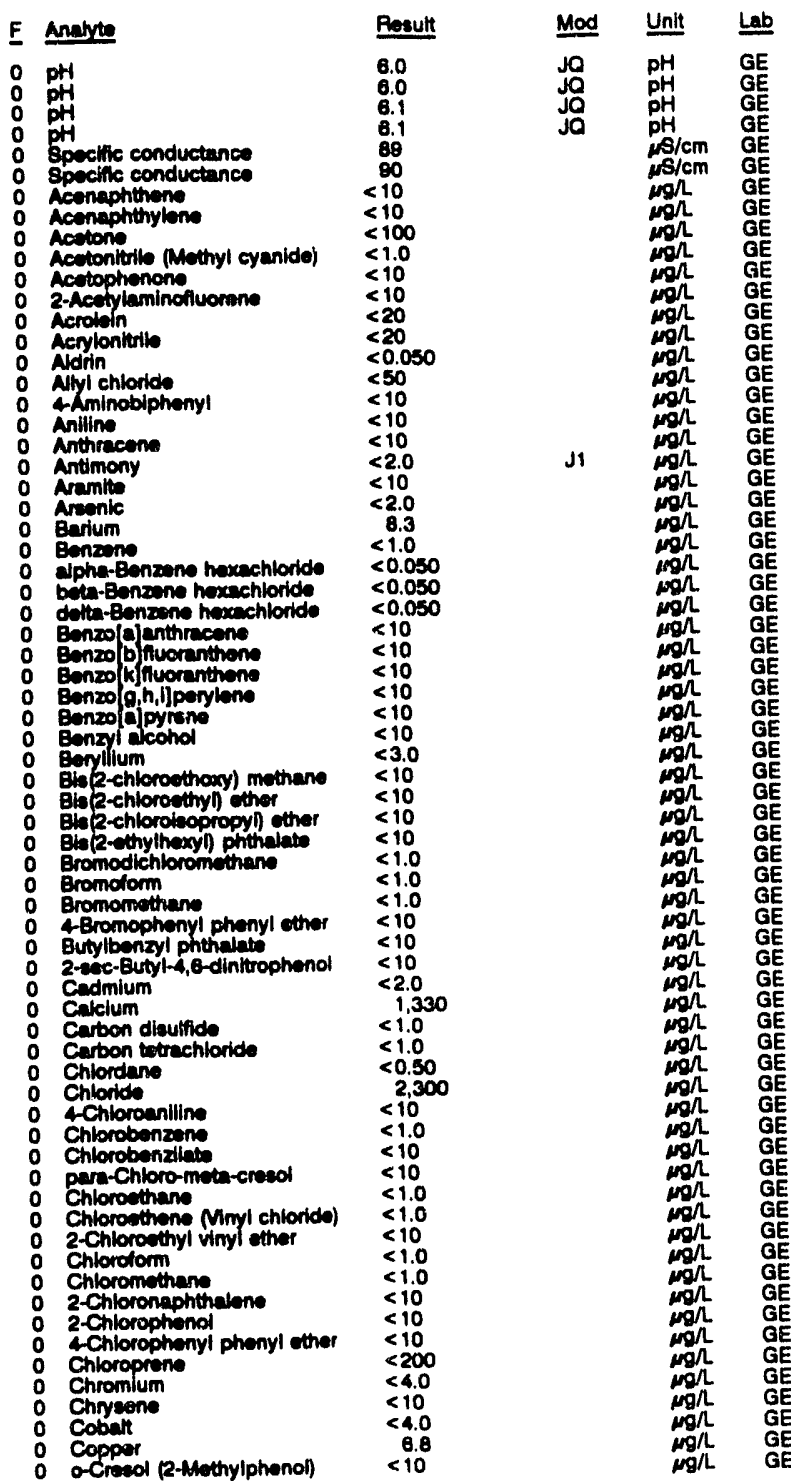

WELL HMD 1D colloctod on 07/03/92, laboratory analyses (cont)

E Analyte

Bequil

m-Crosol (3-Methyiphienoi)

p.Cresol (4-Methylphonol) $<10$

Cyanide

P,P.'DDT

Dibenz $[a, h]$ anthracene

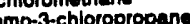

1,2-Dibromoethane

Dibromomethene $<1.0$

Di-n.butyl phthalate $<10$

i,3-Dichlorobenzenene. $<10$

1,4Dichlorobenzene $<10$

3,3-Dichlorobonzidine

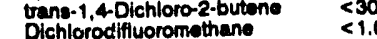

1,1-Dichlorosthene $<1.0$

i, 1.0

1,1-Dichloroethylono $<1.0$

trans-1,2-Dichloroethylone $<1.0$

2.4-Dichlorophonol $<10$

2. 4chlorophenoxyacetic acid $<0.60$

1.2-Dichloropropane

cis-1,3-Dichloropsopene $<1.0$

trans-1,3-Dichloropropene $<1.0$

Dieldrin $>0.50$

$\begin{array}{ll}<10 \\ 0 \text { Dimethoato } & <10\end{array}$

Dimethyl phthalato

p-Dimothylaminouzobonzene

Dimethylbenziajanthracent

3,3-Dimethylbenzidine

1,3-Dintrobenzene

1,3-Dinitrobenzene

2,4-Dinitrotoluene

2,4-Dinitiotoluene

2,6-Dinitrotoluene

1,4-Dioxane

Diphenylamine

Disulfoton

O Endosulfan II

Endosulfan sulfate

O Endrin aldohyde

o Ethyl methacrylate

o Ethyl methanesulfonate

0 Ethylbenzene

Famphur

Fluoranthen

Fluorene

Heptachlor

Heptachior epoxide

$1,2,3,4,6,7,8-H P C D$

Heptachlorodibonzo-p-dioxins

H, $3,4,6,7,8-4$ Con

Hexachlorobenzeno

Hexchlorobutadiene

Hexachlorocyclopentadiene

$1,2,3,4,7,8-H \times C D D$

Hexachlorodibenzo-p-dioxin:

$1,2,3,4,7,8 \cdot H \times C D F-$.

Hoxachlorodibenz

Hexachloroethane

Hexachlorophone

2-Hexanone

Indeno[1,2,3-c,d]pyrene

lodom

o lioobutyl alcohol

a robutyl

leodrin

leophostrole

Kapone

L Lead

Undane

Manganese

M Mercury

Mercury

Methapyrilene

Methoxychlor
2.Methyl-4,6-dinitropheno

2-Methyl-4,6-dinitrophen
Methyl ethyl ketone

Methyl ethyl ketone

Mothyl losutyl koton

Methyl methanesulfonate

O Methyl methunesulfon

$<10$
$<10$

$<10$
$<10$

$<10$
$<10$

$<10$

$<10$

$<10$
$<10$

$<10$

$<0.10$

$<0.10$

$<0.0060$

$<10$

$<10$

$<1.0$

$<10$
$<10$
$<10$

$<10$

$<0.050$

$<0.00065$

$<0.00065$

$<0.00045$

$<10$

$<10$

$<0.00045$

$<0.00045$

0000040

$<10$

$<10$

$<10$

$<10$

$<15$

16
$<<0$
$<10$

$<10$

$<10$
$<10$

$<3.0$

$<0.0050$

231

$<0.20$

$<50$

$<10$
$<0.50$

$<10$

$<1.0$
$<1.0$
$<10$

$<10$
$<10$

$<10$
$<10$

Mod

Unit Let

ugh GE

GE 
ANALYTICAL RESULTS

WELL HMD 10 colloctod on 07/03/82, laboratory analyeses (cont)

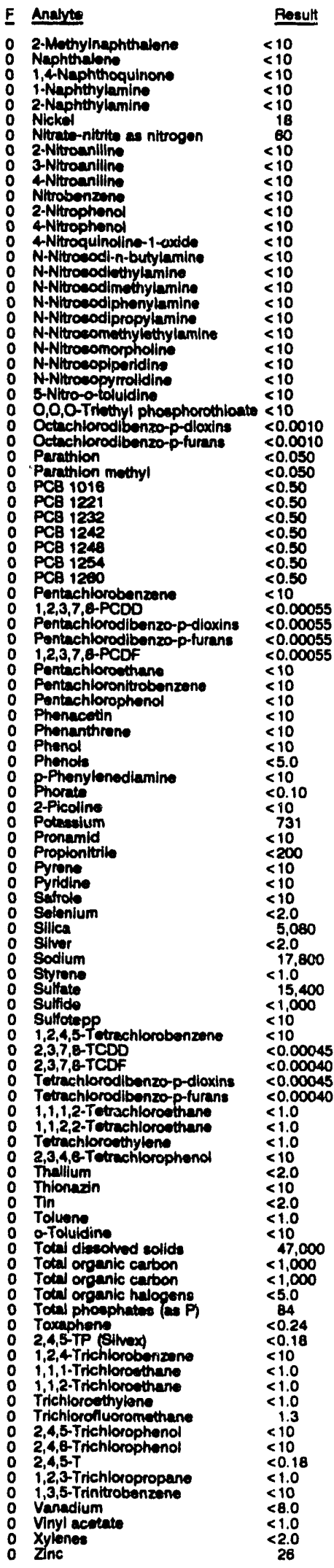

WELL HMD 10 collocted on 07/03/92, laboratory analyses (cont)

\begin{tabular}{|c|c|c|c|}
\hline Anajyte & Resull & Mod & Unit \\
\hline $\begin{array}{l}\text { Groes alpha } \\
\text { Nonvolatile bota } \\
\text { Total alpha-omitting radium } \\
\text { Trtium } \\
\text { Tritum }\end{array}$ & $\begin{array}{l}<2.0 E-09 \\
<2.0 E-09 \\
<1.0 \mathrm{E}-09 \\
1.7 \mathrm{E}-05 \pm 7.0 \mathrm{E}-07 \\
1.7 \mathrm{E}-05 \pm 7.0 \mathrm{E}-07\end{array}$ & & 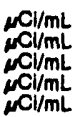 \\
\hline
\end{tabular}

WELL HMD 2D

MEASUREMENTS CONDUCTEO IN THE FIELD

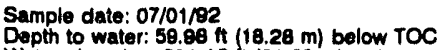

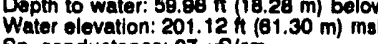
Wator evacuated bofore sampling: $27 \mathrm{gal}$

Time: $8: 45$

Alkalinity: $13 \mathrm{mgn}$

Water temperature: $20.2 \circ \mathrm{C}$

LABORATORY ANALYSES

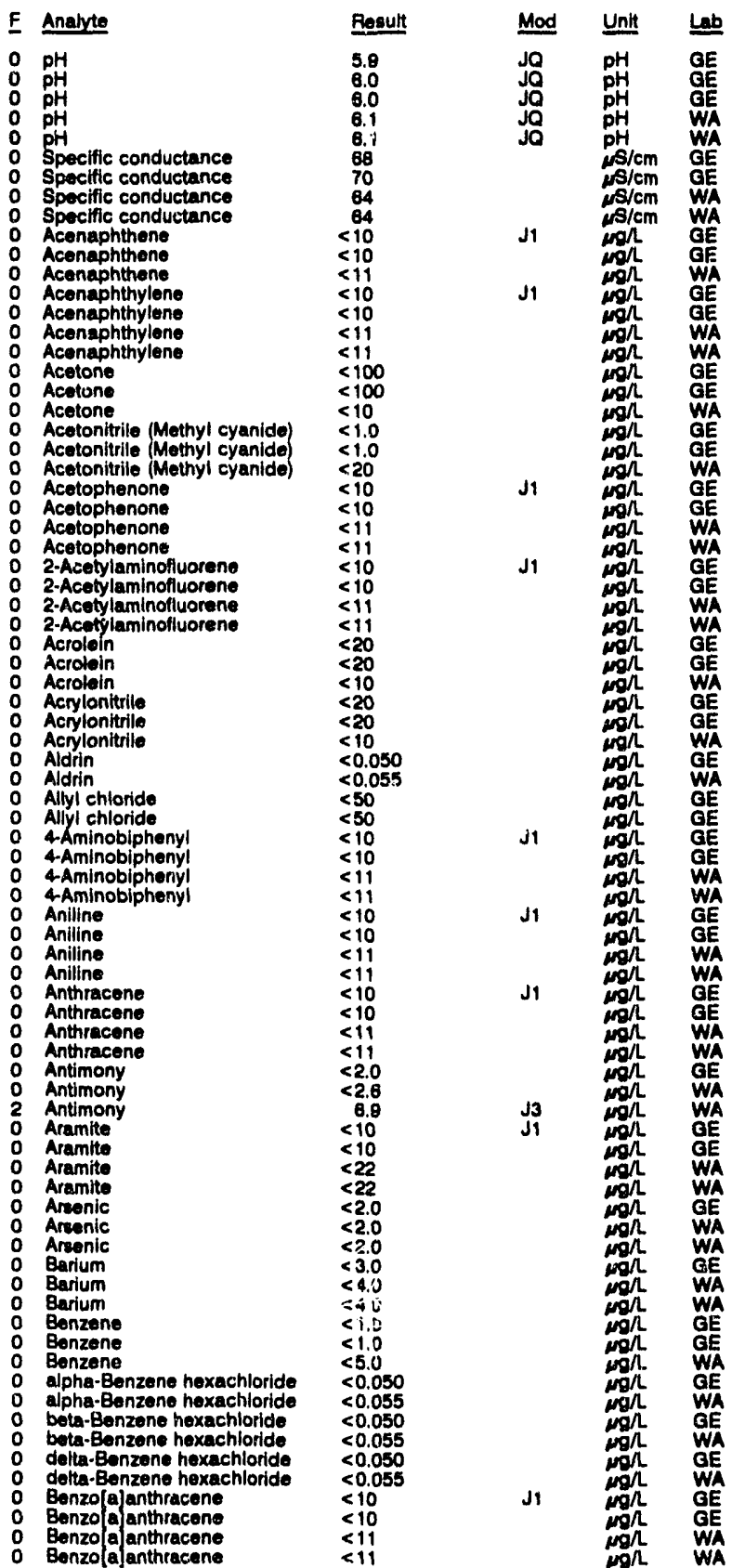


WELL HMD $2 D$ collected on 07/01/82, laboratory analyses (cont)

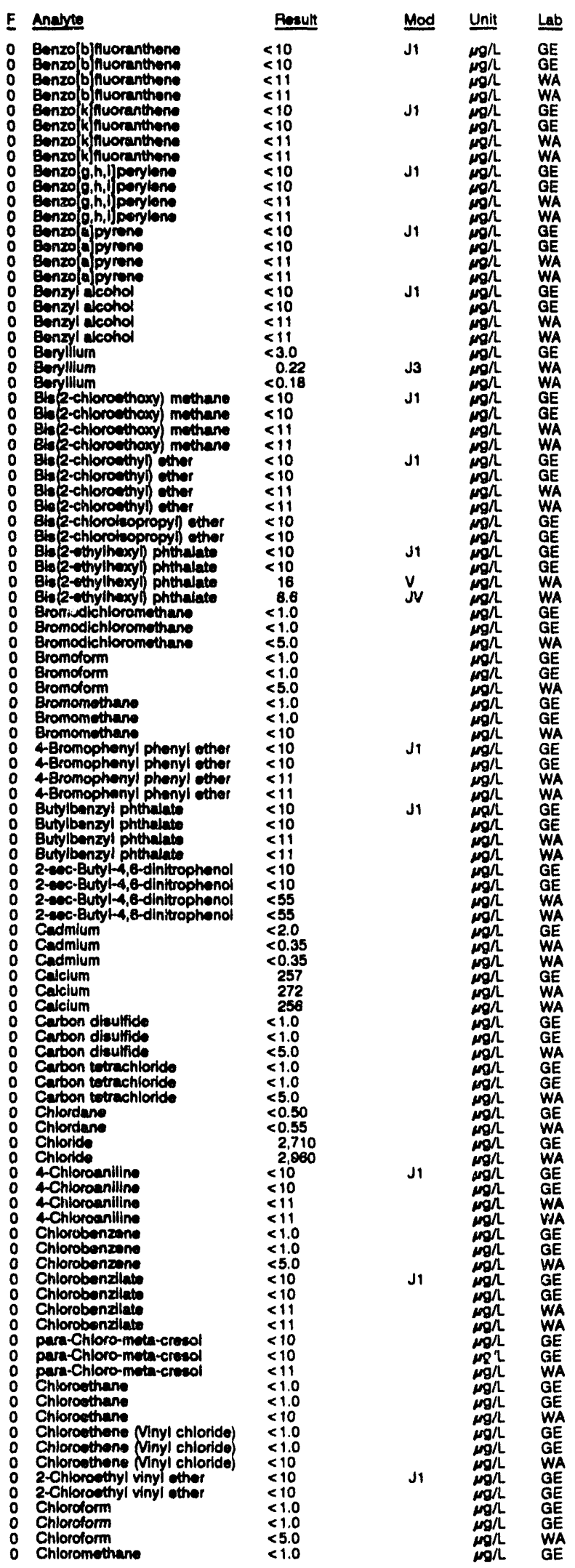

WELL HMD 2D collected on 07/01/92, laboratory analyeses (cont.)

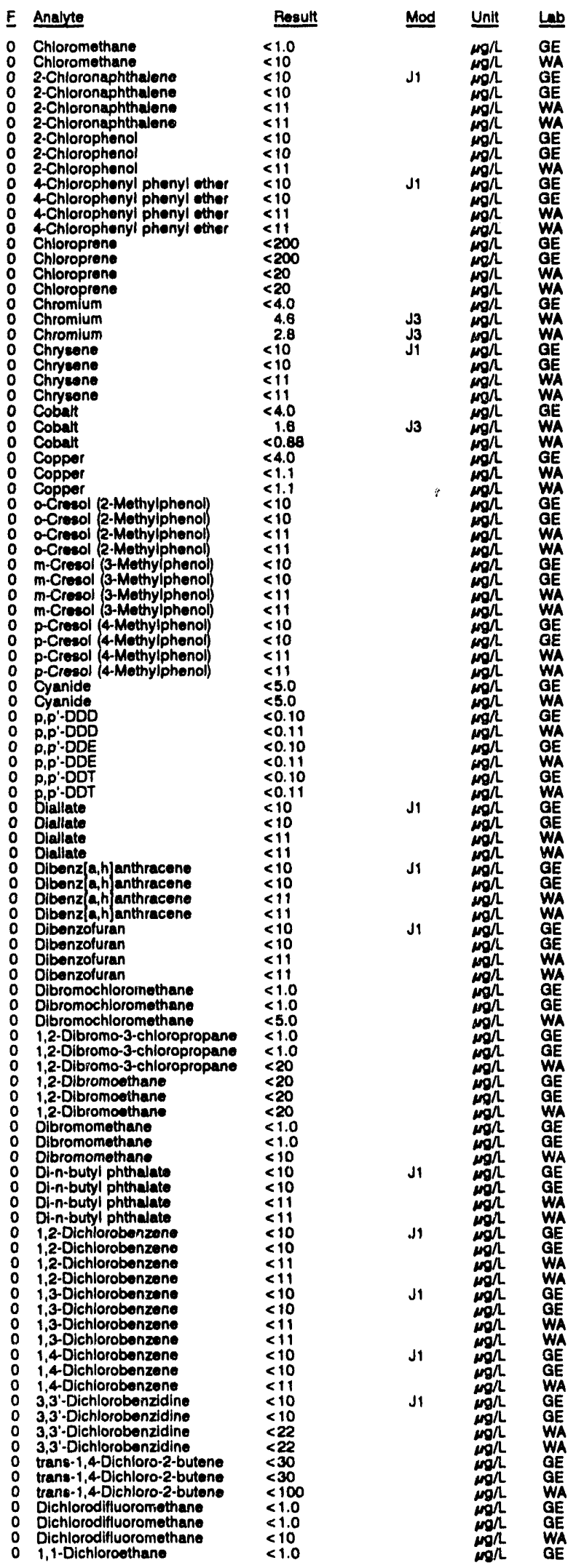


ANALYTICAL RESULTS

WELL HMO 2D collected on 07/01/92, laboratory analyses (cont)

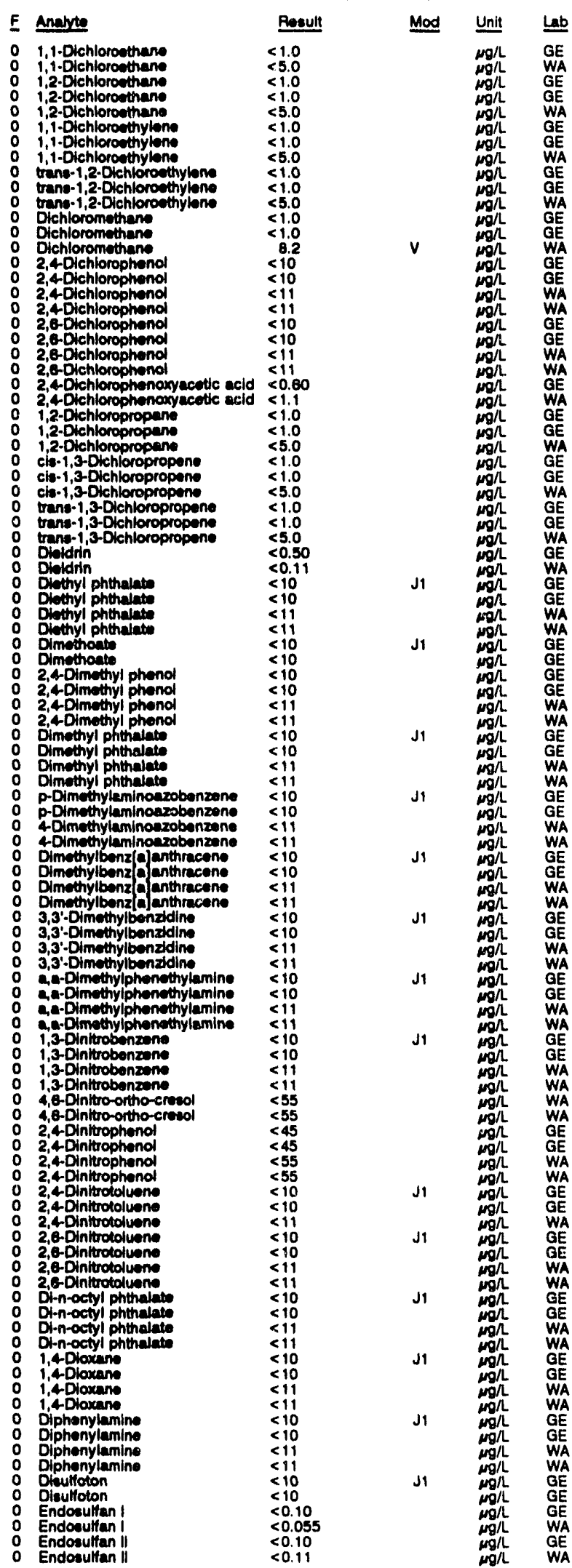

WELL HMD 20 collected on 07/01/92, laboratory analyses (cont)

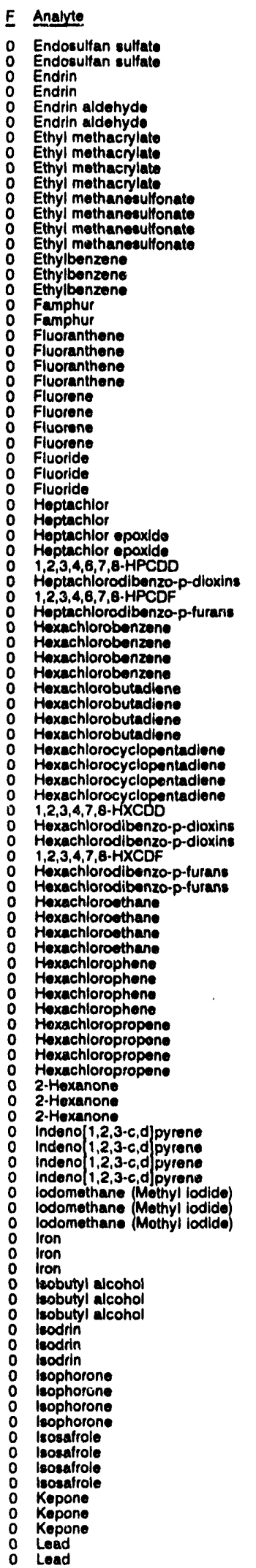

$<0.10$

$<0.0060$

$<0.11$

$<0.11$

$<10$

$<11$

$<10$

$<11$

$<1.0$
$<1.0$

$<5.0$

$<10$

$<10$
$<10$

$<11$

$<10$
$<10$

$<11$

$<100$
$<100$
$<100$
$<0.050$

$<0.050$

$<0.055$

$<0.00085$

$<0.00065$

$<0.00045$

$<10$

$<10$
$<11$

$<11$

$<10$

$<11$

$<10$

$<10$

$<0.00045$

$<0.00045$

$<0.00010$

(

$<0.00040$

$<10$

$<10$
$<11$

$<11$

$<10$

$<89$
$<99$

$<10$

$<11$
$<11$

1.4
$<1.0$

$<10$
$<10$

$<10$

$<11$

$<15$

$<10$

8.2
8.0

$<100$

$<20$
$<10$
$<10$

$<0.11$

$<10$

$\leq 11$

$<10$

$<11$
$<11$

$<10$
$<10$

$<3.0$
Mod Unit Lab

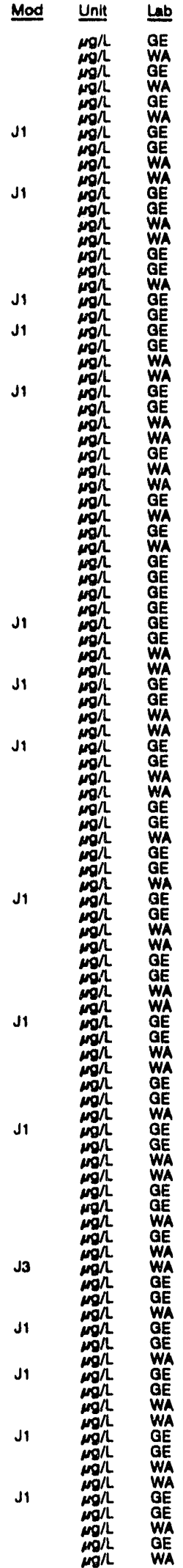


WELL HMO 20 collected on 07/01/92, Iaboration analysese (cont)

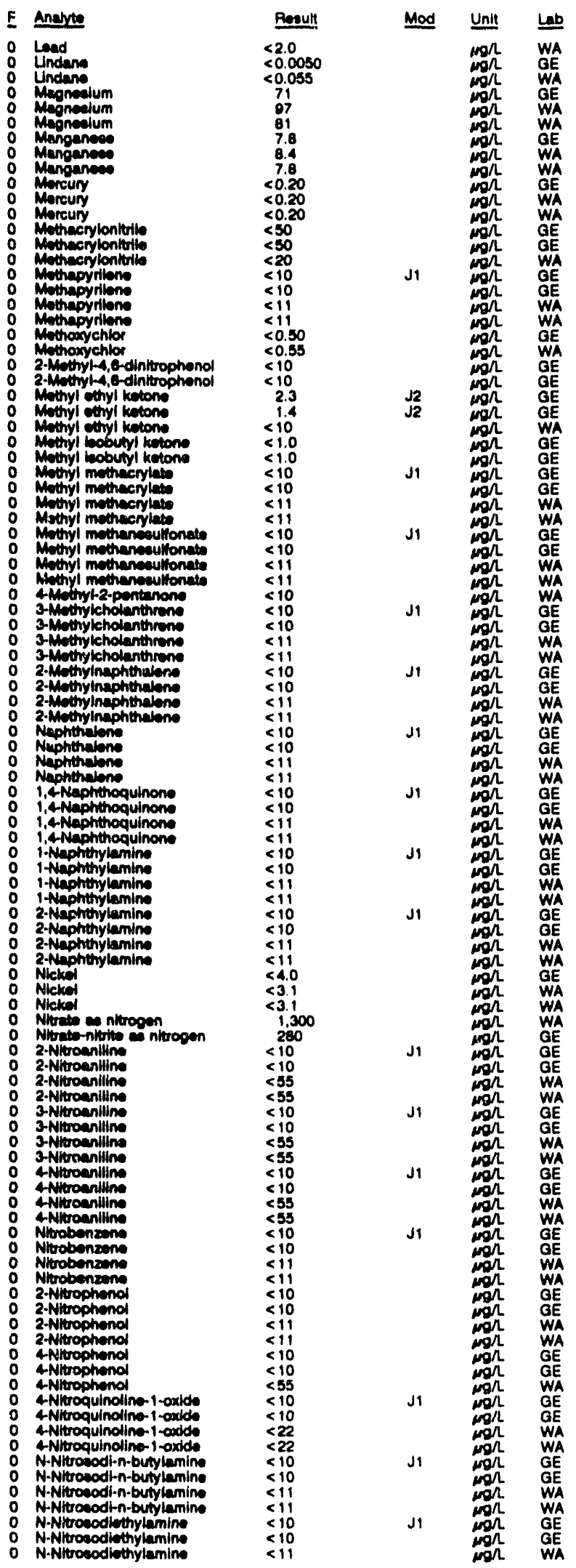

WELL HMO 2D collected on 07/01/92, laboratory analyees (cont.)

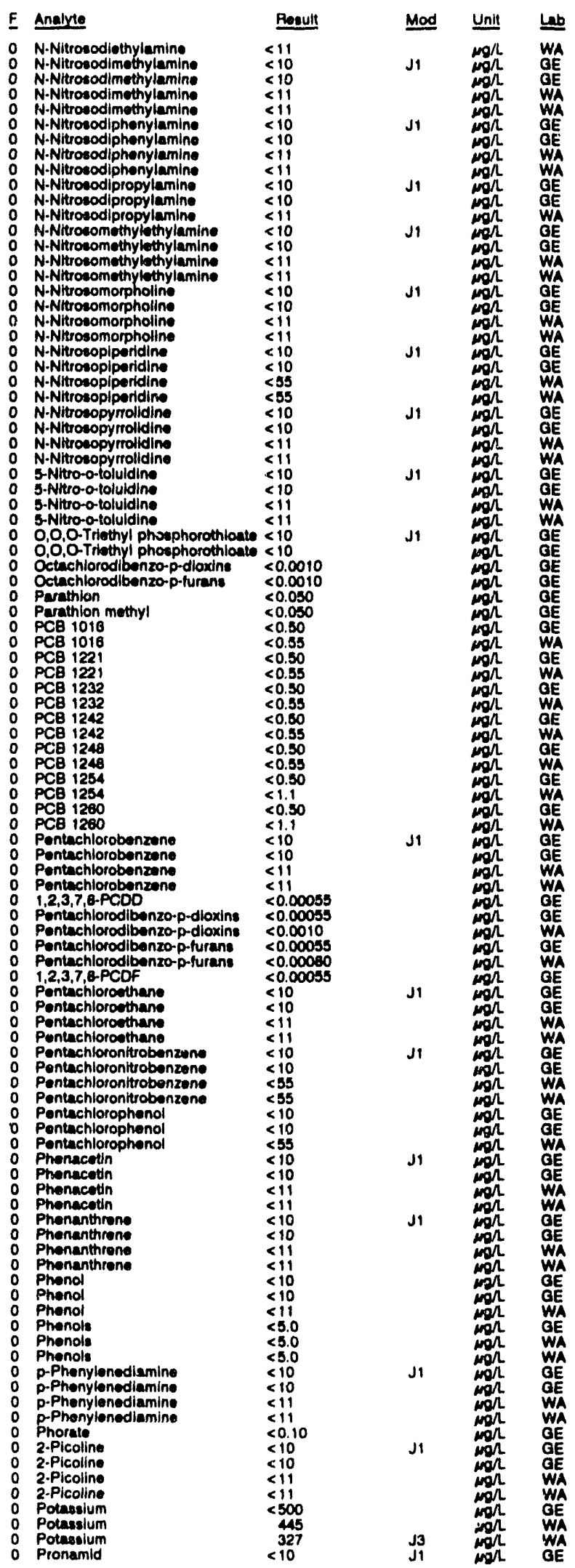


WELL HMD 20 collectiod on 07/01/82, laboratory anadyese (cont)

$E$ Anevte

0 Pronamid

: Pronamid

o Propioniturte

o Proploniturite

O Pyrene

Pyrone

o Pyrndine

o Pyrdine

0 Patroto

O Safrole

o Safrolo

: 8olonium

o Bolonlum

Sllice

sillce

0 Sitwer

0 siker

Sodium

: Sodium

o styone

0 styrom

0 Styrom

: sulato

Oulido

Sultotopp

1,2,4,6-Terechtorobenzene

1,2,4,5-Tetrachlorobonzente

1,2,4,-Ttrachlorobonzzent

2,3,7,0-TCDO

2,3,7,8-TCDF

Totrechlorodibenzo-p-dioxine

Tetrechlorodibenzo-p-dioxine

o Tetrechlorodibenzo-p-furans

Tetrechlorodibonzo-p-turane

o 1,1,1,2-Tetrechlorosthan

o 1,1,1,2-Tetrachloroethane

1,1,1,2-Tetrechlorsthan

o 1, $1,2,2$-Tetrachloromethene

o 1, 1,2,2-Tetrachloroethan

o Tetrachloroethylone

o Tetrechloroethylene

- 2,3,4,-Tetrechlorophenol

2,3,4,0-Tetrechlorophenol

2,3,4,6-Tetrechlorophenol

2,3,4,e-Tetrechlorophenol

Thallum

Thallium

- Thionerin

Thionadín

0 Tin

o $\operatorname{Tin}$

Tolvene

Toluene

Tolueno

O-Toluldin

o-Tolvidine

o-Toluidine

Total diecolved eolide

Total diecolved collide

Total organic carbon

Tota organic carbon

Total organic halogens

T Total organic halogens

Total phosphates (Es P

Total phosphetes (as P)

Taxaphons

2,4,5-TP \&nve

0 2,4,5-TP Binvex)

o 1,2,4-Tichlorobenzene

1,2,4 Trichlorobonzen.

o 1,2,4-Trichlorobenzene

1,1,1-Trichloroethane

1,1,1-Irichlorothan

o 1,1,1-Trichloroethane

1,1,2-Trichloroethane

o 1,1,2-Trichloroethane

$<5.0$

$<1.0$

$<5$

$<10$

$<11$

$<2.0$
$<2.0$
$<2.0$

$<2.0$
$<10$
$<10$
$<2.0$

$<2.0$
$<1.8$
7.5

$<1.0$

$<1.0$

$<10$

$<10$

35,000
65,000

$<1,000$

$<527$

$<5.0$

28
25
55
52

55
52
83

$<0.24$
$<1.1$
$<0.18$
$<0.58$

$<0.58$

$<10$

$<1.0$

$<5.0$

$\therefore .0$

$<1.0$

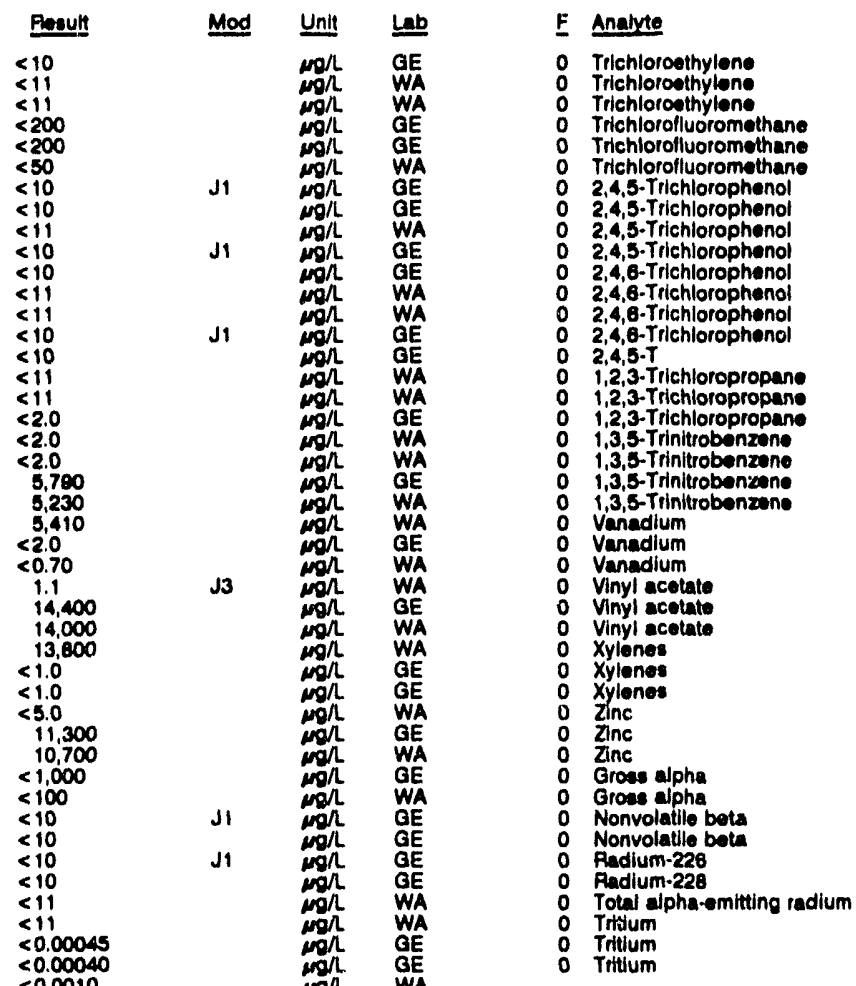

WELL HMD 20 collected on 07/01/82, laboratory analyees (cont)

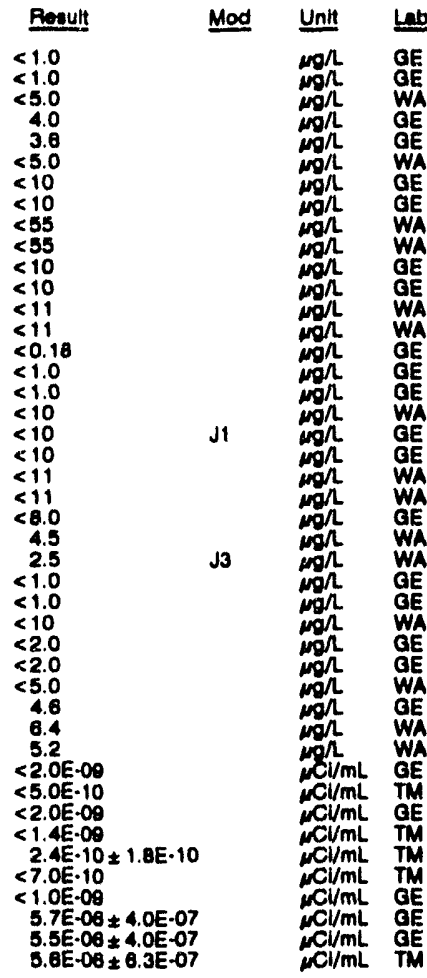

\section{WELL HMD 2D Replicate}

MEASUREMENTS CONOUCTED IN THE FIELD

Sample date: 07/01/02

Dopth to water: $39.98 \mathrm{ft}(18.28 \mathrm{~m})$ below TOC

Water elevation: $201.12 \mathrm{~h}$

Th conductance: 67 s/cm

Water evecuated botore eampling: $27 \mathrm{gal}$

Time: $8: 45$

Alkalinity: $13 \mathrm{mon}$

Water temperature: $20.2^{\circ} \mathrm{C}$

LABORATORY ANALYBES

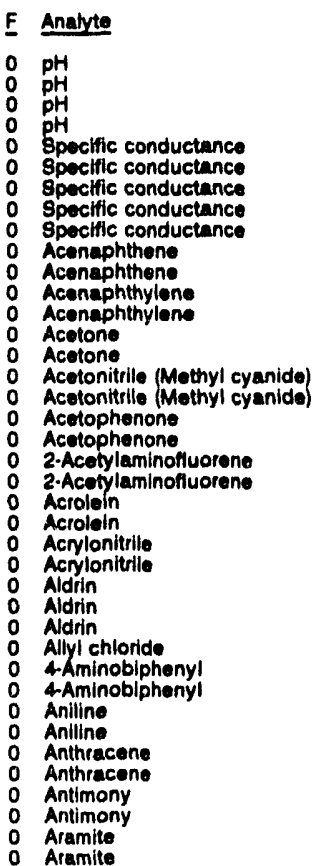

\begin{tabular}{|c|}
\hline $\begin{array}{l}8.0 \\
68.0 \\
8.0 \\
6.1 \\
52 \\
60 \\
63 \\
69 \\
69 \\
63 \\
<10 \\
<11 \\
<10 \\
<11 \\
<100 \\
<10 \\
<1.0 \\
<20 \\
<10 \\
<11 \\
<10 \\
<11 \\
<20 \\
<10 \\
<20 \\
<10 \\
<0.050 \\
<0.05 \\
<0.11 \\
<50 \\
<10 \\
<11 \\
<10 \\
<11 \\
<10 \\
<11 \\
<2.0 \\
<2.6 \\
<10 \\
<22\end{array}$ \\
\hline
\end{tabular}

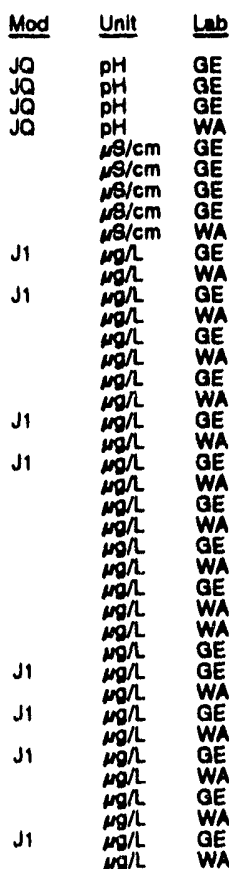


WELL HMD 2D collectad on 07/01/02, laboratory analywes (cont)

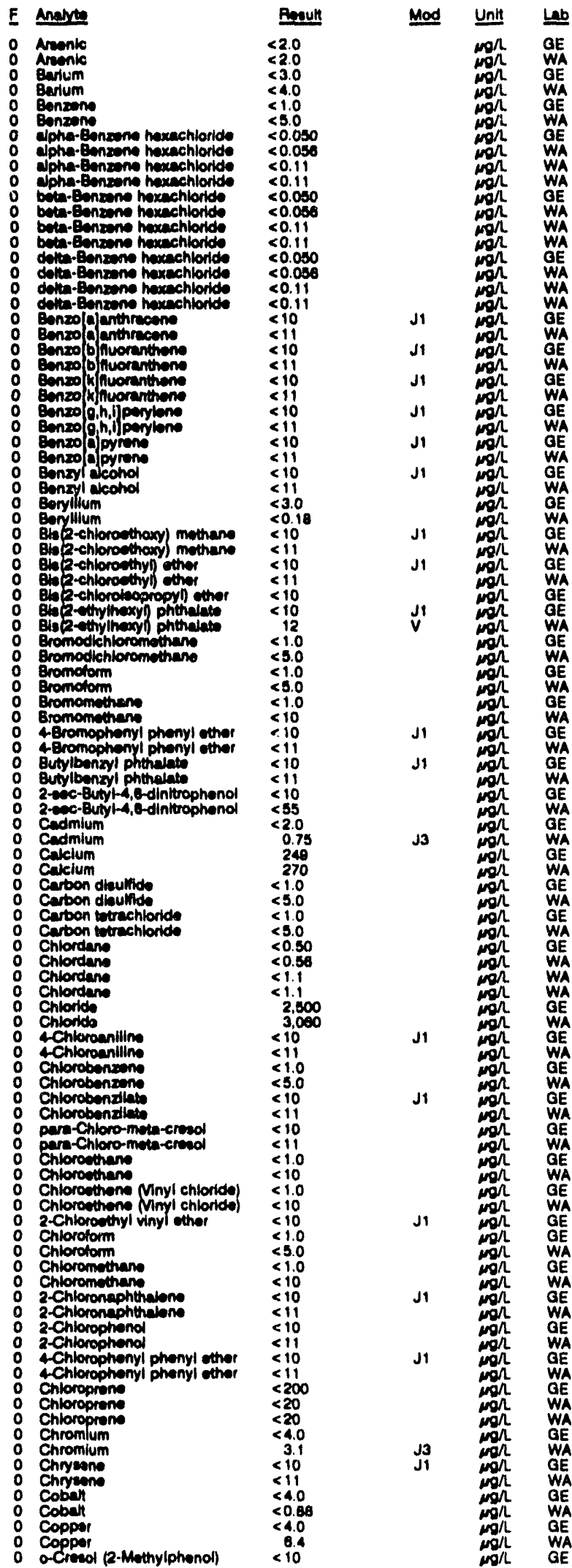

WELL HMD 20 collected on 07/01/02, laboratory analyees (cont)

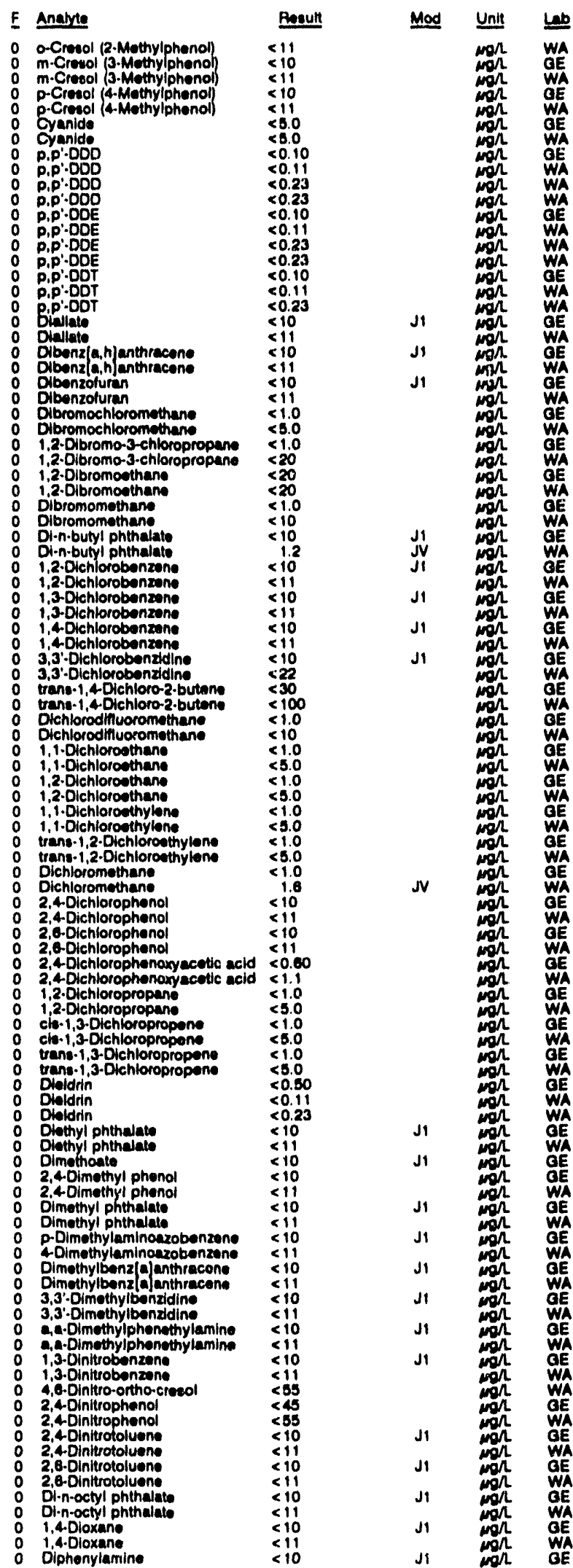


ANALYTICAL RESULTS

WELL HMD 20 collected on 07/01/92, laboratory analyeer (cont)

$E$ Anerve

D Diphenylamine

Endoultian

Endoaculitan

Endowultan I

Endoaulian I

Endosultan I

Endoculian II

Endowultan sultate

Endowultan sultat:

Endrin

Endrin

Endrin

Endrin alohyde

Endrin aldohydo

Ethyl methecrylat

Ethyl methaneaulfonate

Ethylbenzen

Famphur

Fluorenthone

Fluoremente

fluoren

Fluorica

Fluorida.

Hoptechlor

Hoptenchlor

Heptechior epoudd

Hoptachlor epondide

Hoptinchlor epoxida

1,2,3,4,6,7,8-HPCOD

1,2,3,4,6,7,0-HPCDF -doun

Heptachlorodibonzo-p-turans

Hoxachlorobenaense

Maxachlorobutadione

Hexachlorobutedione

Hexuchlorocyelopentidion

$1,2,3,4,7,0+1 \times C 00$

Haxachlorodibenzo-p-dloxina

$1,2,3,4,7,0-4 \times C D$

Hoxachlorodibenzo-p-turens

Hoxechlorodibenzo-p-furans
Hoxachloroethens

Hexachlorophane

Hexachioropropen

2.Haxenom

indeno $[1,2,3-c, d)$ pyren

Indeno $[1,2,3-c, d]$ pyrene

o lodomotran (hithyl lodides

Irun

trobutyl alcohol

bobutyl alcohol

0 boditin

oodrín

0 bodin

o bophorons

g tecentrote

boanfroila

Kopone

Kopon

Kopone

Lead

o Undane

o Undane

Mndan

Magnealum

Manganeas

Mereury

Moreury

Methacryloniturle

Methacrylonitur

Methapyritene

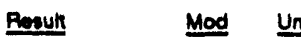

\begin{tabular}{|c|c|}
\hline $\begin{array}{l}<11 \\
<10 \\
<0.10\end{array}$ & Ji \\
\hline
\end{tabular}

$<0.058$

<.j.1.

$\leq 0.10$

$<0.23$

$<0.23$

$<0.10$

$<0.11$
$<0.23$

$<0.0060$

$<0.11$

$<0.10$
$<0.11$
$<0.23$

$<0.23$

$<11$

$<10$

$<11$

$<1.0$

$<10$
$<10$

$<10$

$<11$
$<11$
$<100$

$<100$
$<100$

$<0.050$

$<0.11$

$<0.050$

$<0.11$

$<0.11$

$<0.00005$

$<0.00045$

$<0.0004$
$<10$

$<11$

$<11$

$<10$

$<0.00045$

$<0.00045$

$<0.00020$

$<0.00040$

$<10$
$<11$
$<10$

$<10$

$<10$

$<11$

$<10$

$<10$
$<11$

$<11$

$<10$
11
4.0

4.9
$<100$

$<20$

$<0.11$
$<0.23$
$<0.23$

$<10$
$<11$
$<10$

$<11$

$<0.11$

$<0.23$

$<<.0$

2.5
$<0.0050$

$<0.056$

69
77

7.6
7.8
$<0.20$

$<0.20$

$<50$

$<20$
$<10$
$\underline{L a b}$

WA

WA

WA

WA

GE

WA

GE

WA

WELL HMD 20 collectod on 07/01/82, laboratory analyees (cont.)

E Analyte

- Mothoxychlor

Mothoxychlor

2-Mbthyl-4,8-dintrophonol

- Mothyl othyl kotono

- Mothyl athyl ketone

Mothyl isobutyl kotone

o Mothyl mothecryilate

Methyl mothanceutionate

Methyl methancoultonais

3.Menyl.2-pentanone

3-Methyleholenthreno

2.Mothyinaphthadeno

2.Methylnaphthatone

- Nephthalene

- 1,4 Naphthoquinon

1,4Naphthoquinono

1.Nephthylamino

2.Naphthylamino

2.Nephthylamino

: Nickol

O Nitrate me nitrogen

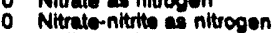

2.Nthoantino

2-Nitroaniling

- 3-Nutroaniline

0 3-Nitroanllino

A Nitroanilino

o Nitrobonzene

Nitrobenzan

2-Nitropheno

2.Nitrophence

4-Nitrophene

ANitrophenol

4-Nitroguinolina-1-oxido

N-Nitrosodil-n-butylamino

N-Nuroeodi-n.butylamine

N-Nitrosodiecthylamine

N.Nitroeodimelamine

N.Nitroeodimethylamin

N-Nhrosodiphenylamin

N-Nitroeodlphenylamine

N-Nitrosodipropylamine

N-Nitrosomethylethylamine

N-Nitrosomorpholine

N.Nitrosolpho

N-Nitrosoplparidine

N-Nitrosopynolidine

N-Nitrosopyrrolidine

5-Nitro-o-toluldine

0,0,0-Triathyl phosphorothloate

Octachlorodibenzo-p-dioxins

Octechlorodibenzo-dioxins

Purathion

Parathion mathyl

- PCB 1016

PCB 1016

PCB 1018

O PCB 1221

PCE 1221

PCB 1221

PCB 1232
0 PCB 1232

PCE 1232

P PCB 1232

PCB 1242
0

PCB 1242

PCA 1248

PCB 1248

P
0 PCB 1248

P PCB 1248

PCB 1234
0

P PCB 1254

P PCB 1254

O PCB 1280

O
PCB 1260
0

P PCB 1260

o Pentachlorobenzene

O Pentachiorobenzen

Reault

$<0.50$

si.j

$\leqslant$ <i.

$<1.0$

$\leqslant 1.0$

$\leq 110$

$\leq 10$

$<10$
$<10$
$<10$

$>11$

311

311

$\leq \leq 11$

311

$>110$

3.40

212

28

$<10 \quad J 1$

$<10-1$

JI 
WEL HMD 20 collected on 07/01/02, laboratory analyeese (cont)

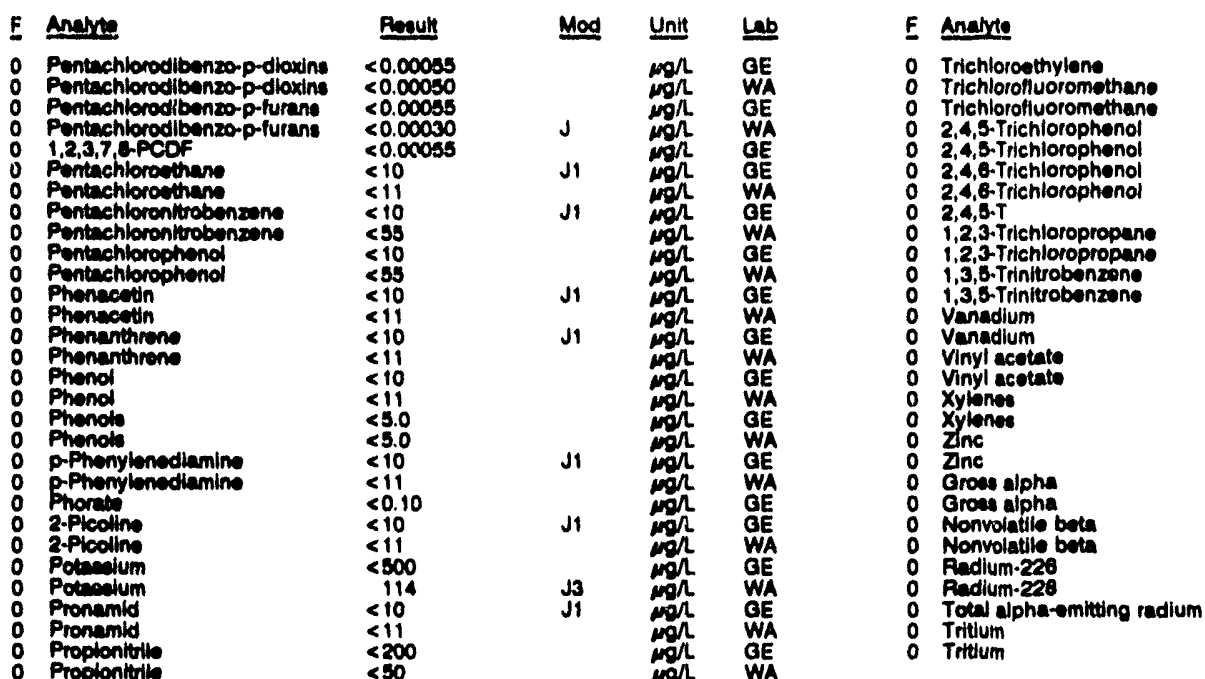

WEL HMD 20 collocted on 07/01/02, laboratory analyeese (cont.)

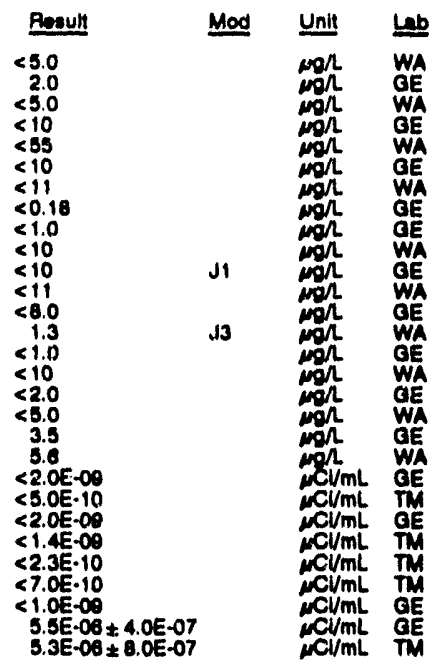

WELL HMD 3D

MEASUREMENTS CONDUCTED IN THE FIELD

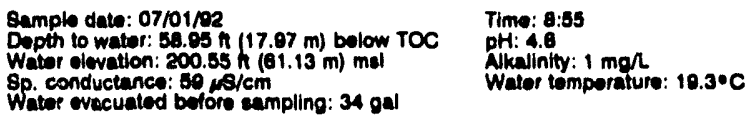

Watar evecuated boforo sempling: $34 \mathrm{gal}$

LAOORATOAY ANALYSES

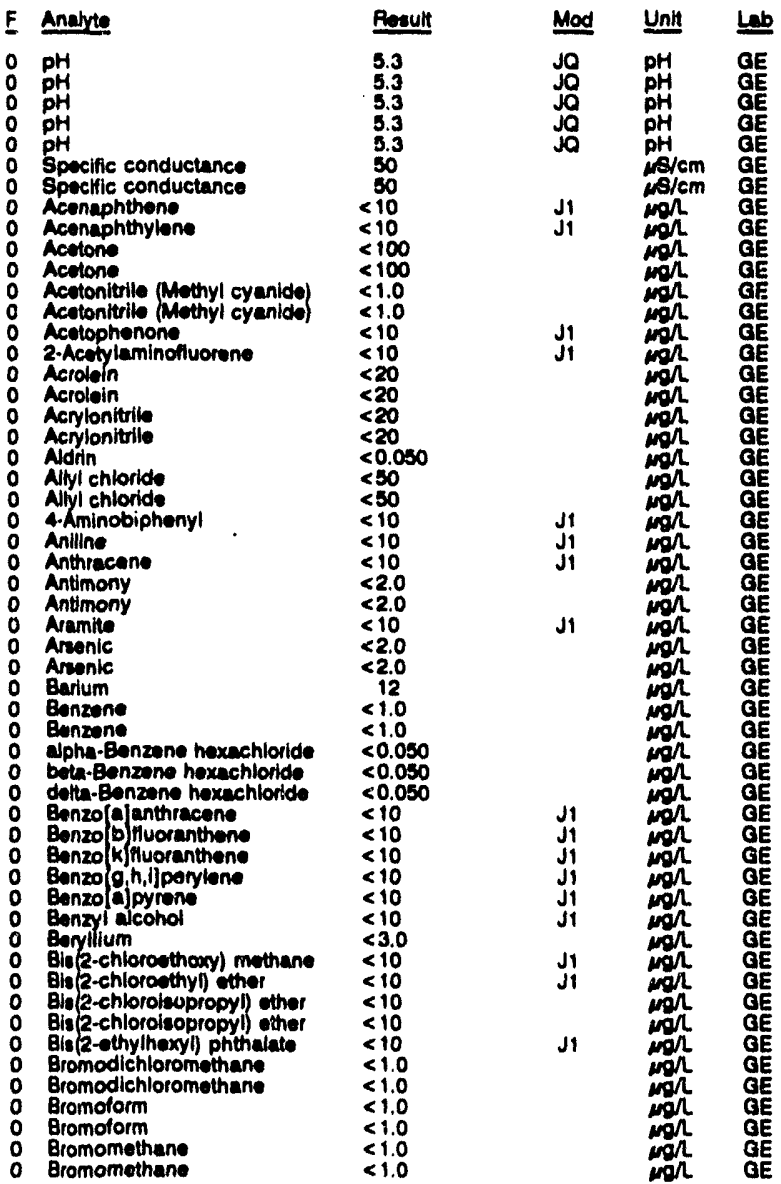


ANALYTICAL RESULTS

WELL HMD 30 collected on 07/01/02, laboratory analyees (cont)

E Anelye

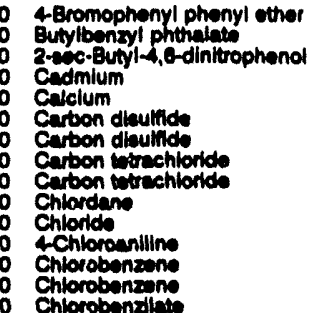

Chiorobonaliate

para-Chloro-mota-creed

Chloredthane

Chloropthene Mnyl chloride)

Chlorowenthen Minyl chloride
2-Chloroethyl vinyl other

Chloroform

Chlorotorm.

Chloromethan

2-Chloronaphthuions

2-Chlorophenol

Chloroprens

Chromium

Cobalt

o Copper

o-creal R.Methylphonol)

p-Creed (4-Methylphenol)

o Cyenids

o p.p.:DOD

(

Dillate

Dibenzigh]anthrecen

Dibromochloromethane

1,2-Otbromo-3-chloropropane

1,2-Dbromo-3-chloropropano

1,2-Otbromoethane

Dibromomethan

o Otbromomethane

1,2-Dlchlorobenzens

o 1,3-Dichlorobenzene

o 1,4-Oichlorobenaan

3,3'-Dichlorobenadin

o trank-1,4-Dichloro-2-butone

o Dichlorodificonomethens

- Dichlorodinuoromethen

o 1,1-Dichlorothane

1,1.Dichloromethen

o 1,2-Dichloromethane

o 1,i-Dichlorothylens

o 1,1-Dichloroethylone

o tene-1,2-Dichloroethylom

o Dichloromethans

O Dichloromethane

2,4Ochlorophend

2 $<10$

1,2-Dehlomemopana

i.

cib-1,3-0ichloropropene

cib-1,3-Dichloropropono

o trens-1,3-Olehloropropene

Dicthyl phthalat

2,40imethyl phono

Dimethyl phthaleto

o p-Oimethylaminoazobonzen

- bimethylbenz(a)anthracen

0 3,3'-Dimethyltonzidine

a-Oimethylphenethylemine

1,3-Dinitrobonzen

2,0-Dinitrotoluen

Di-n-octyl phy

Diphonylamino

- Diphontiton

Endoevulten

- Endosultan sultate

Aeatill

$<10$

$<10$
$<2.0$

1,220

$<1.0$

$<1.0$

$<.500$

$<1.0$

$<10$

$<10$
$<1.0$

$<1.0$

$<1.0$

$<10$
$<1.0$

$<1.0$

$<10$
$<10$

$<10$
$<10$

$<200$
$<200$
$<4.0$

$<4.0$
$<10$
$<4.0$

8.4
$<10$

$<10$
$<10$

$<8.0$

$<.10$
$<0.10$

$<0.10$

$<10$
$<10$

$<1.0$

$<1.0$

$<1.0$

$<20$

$<1.0$

$<10$
$<10$

$<10$

$<10$
$<10$

$<30$

$<1.0$

$<1.0$

$<1.0$

<i.

$<1.0$

$<1.0$

$<1.0$

$<100$

$<1.0$

$<1.0$

$<1.0$

$<\leq 10$

10

$<10$

$<10$

$<10$

$<10$

$<4$

$<10$

$<10$

510
$<10$
510

$<0.10$

$<0.10$
Mod Unit Led

Ji $\mathrm{mg}$ GE

GE

$\mathrm{GE}$

WELL HMD 30 collocted on 07/01/22, laboratory analyses (cont.)

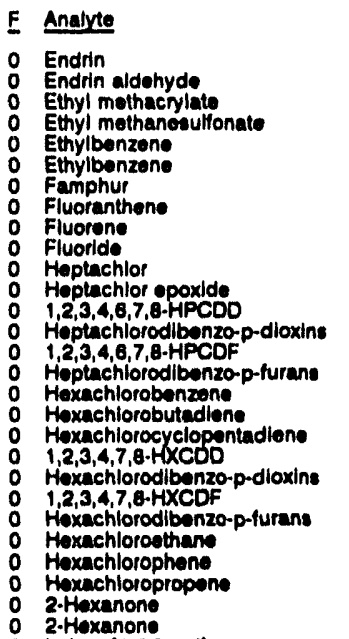

Result
$<0.0080$
$<0.10$
$<10$
$<10$
$<1.0$
$<1.0$
$<10$
$<10$
$<10$
$<100$
$<0.050$
$<0.050$
$<0.00065$
$<0.00065$
$<0.00045$

$<0.0004$

$<10$

$<10$
$<0.00045$

$<0.00045$

$<0.00040$

$<<<10$

$<10$
$<10$
$<10$

$<1.0$

Indeno[ $1,2,3-c, d]$ pyrene

lodomethane (Mothyl lodido)

$\begin{array}{ll}0 & \text { lodom } \\ 0 & \text { Iron }\end{array}$

O lioobutyl alcohol

o leobutyl alcohol

o leodrin

o leophorono

o teosafrole

o Kepone

0 Lead

O Undane

1 Magnesium

1 Manganeas

o Methacrylonitrilo

Mathacrylonituile

O Methapyrilons

2-Mothyl-4,6-dinitrophenol

Mothyl ethyl ketone

Methyl ethyl ketone

Methyl isobutyl ketone

Methyl lsobutyl ketone

o Mothyl methanesulfonate

- 3-Moltylcholanthrene

2.Methylnaphthalene

1,4-Naphthoquinone

T.Naphthylamin

\begin{tabular}{ll}
0 & 2-Naph \\
0 & Niekol \\
\hline
\end{tabular}

0 Nitrato-nitulte as nitrogen

2-Nitroanilline

3-Nitroanilline

ANtroaniline

Nitrobenzene

2.Nitrophond

4 Aitroquinoline-1-oxide

N-Nitrosodl-n-butylainin

N-Nitrosodiethylamine

N-Nitroadimothylamino

N-Nitrosodiphenylamine

N-Nitrosomethylethylamine

N-Nitrosomothylethylam

N-Nitrosomorpholine

N-Nitrosopyrnolidine

5-Nitro-0-tolutidine

0,0,0-Triethyl phosphorothioate

- Octachlorodibonzo-p-dioxint

- Octachlorodibonzo-p-furans

Parathion methyl

PCB 1016

PCB 1221

PCB 1232

PCE 1242

O PCB 1254

- Pentachlorobenzene

o 1,2,3,7,8-PCDD

Pentachlorodibenzo-p-dioxins

1,2,3,7,8-PCDF

Pentachloroethane

O Pentachlorophenol

(n)

$\leq<$

$<15$
$<15$
6.7

$<100$
$<100$

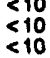

$<10$

3.0

50.040

28

\$5.

$<10$

$<0.50$

1.4
1.0
$<1.0$

$<1.0$

$<1.0$
$<10$
$<10$
$<10$

$<10$

$<10$
$<10$
$<10$

$<10$
$<10$
$<10$

$<10$
$<10$
5.3
470
$<10$
510

sil

$<10$

$\leq \leq 10$

$>110$

$\leq 10$

$\leq 10$

$>110$

$<<10$

$<10$

$\leq 10$

$<0.0010$

$<0.050$
$<0.050$

$<0.50$

$<0.50$

$<0.50$

$<0.50$
$<0.50$

$<0.500$

$<0.50$

$<0.00055$

$<0.00035$

$<0.00055$

$<10$
$<10$
$<10$

Ji

J1

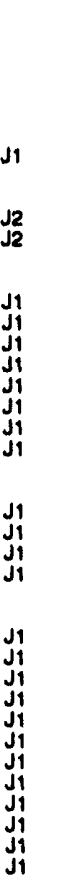

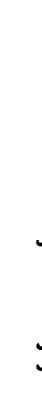

Mod Unit Let

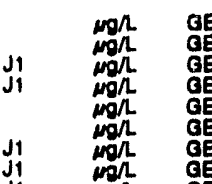

$\frac{L E}{G E}$

E

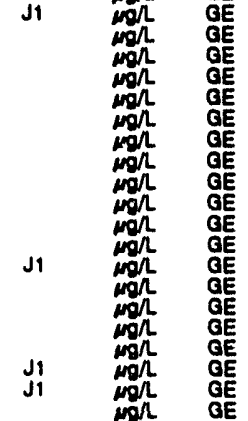


WELL HMO 30 colbetad on 07/01/02, laboratory analyase (cont)

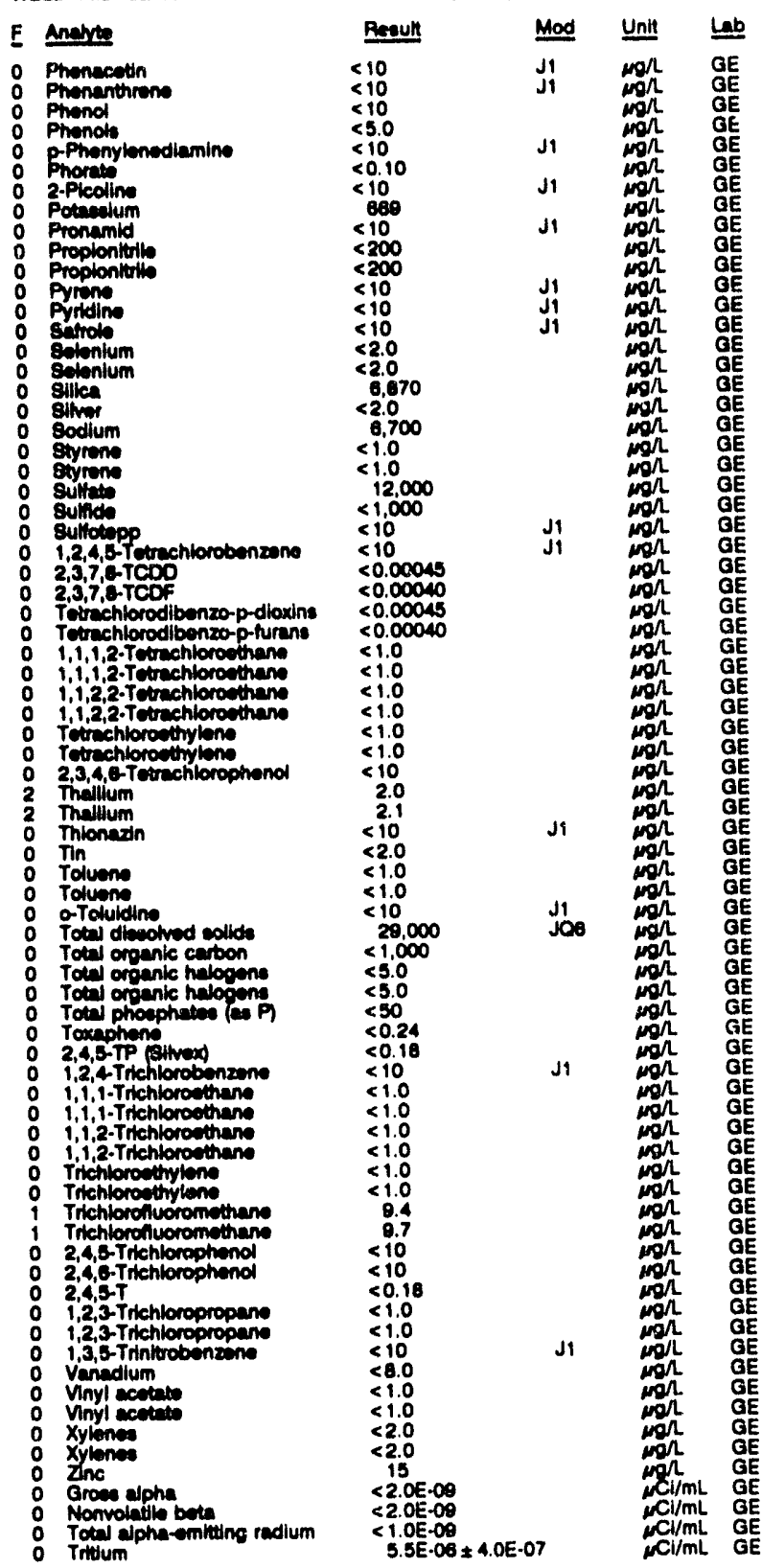

WELL HMD 4D

MEASUREMENTS CONDUCTED IN THE FIELD

8ample date: 07/03/0?

Depth to watier: $80.16 \mathrm{~h}(15.22 \mathrm{~m})$ below TOC

What elevation: $200.74 \mathrm{~h} / 81$

Water evacuated belore cumpling: 6 ge

the well went dry during purging.

LABORATOFY ANALY YES

\begin{tabular}{|c|c|c|c|c|}
\hline F & Anatre & Regult & Mod & Unit \\
\hline $\begin{array}{l}0 \\
0 \\
0 \\
0 \\
0 \\
0 \\
0\end{array}$ & $\begin{array}{l}\text { pH } \\
\text { pH } \\
\text { pH } \\
\text { pH } \\
\text { Epecific conductance } \\
\text { Specific conductance } \\
\text { Acenaphtheno } \\
\text { Acenephthylone }\end{array}$ & $\begin{array}{r}5.4 \\
5.7 \\
5.7 \\
5.7 \\
30 \\
30 \\
<10 \\
<10\end{array}$ & $\begin{array}{l}\text { JO } \\
\text { JO } \\
\text { JO } \\
\text { JO } \\
\text { J1 } \\
\text { J1 }\end{array}$ & $\begin{array}{l}\mathrm{pH} \\
\mathrm{pH} \\
\mathrm{pH} \\
\mathrm{pH} \\
\mathrm{pH} / \mathrm{cm} \\
\mathrm{NS/cm} \\
\mathrm{Ng} / \mathrm{cm} \\
\mathrm{mg} / \mathrm{L}\end{array}$ \\
\hline
\end{tabular}

WELL HMD 40 collected on 07/03/92, laboratory analyeas (cont)

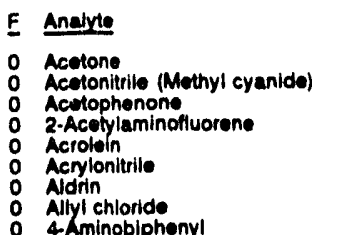

$<100$

$<1.0$

$<10$
$<20$

$<0.050$

4 Aminoblphony

Anthracene

Antimony

0 Arsenic

Barium

Bonzane

dpha.Bonzeno hexachlorido

detta. Banzon hoxachlorlde

Bonzo[a)enthrecons

Benzo b) fluoranthens

Benzo ikffluoranthone

Benzolgh,i]perylone

Benzo, ajpyrene

Bernilium

Bis (2.chioroethony) methene

Bis (2-chloroethyl) other

Bin (2-chloroisopropyll) ether

Bis (2-ethylhexyl) phthalater

Bromodichloromethane

Bromotorm

Bromomethan

4-Bromophenyl phonyl ether

Butylbanzyl phinalate

2-ece-Buty

Calum

Carton disulitide

Carbon tetrachloride

Chlordan

LChloroaniline

Chlorobenzene

Chlorobenzilate

para-Chloro-m

Chloroethane Minyl chloride)

2-Chtoroethyl vinyl ether

Chlorolorm

Chloromethane

2.Chloronaphthal

2.Chlorophenol

4-Chlorophenyl

Chloropren

Chryeon

Cobalt

O-Cper (2-Methylphenol)

m-Cresol (3-Methylphono)

Cyanide

Cyanide

p.p':DOD

P.P.DDE

P,P.DDT

Dibenzla,h]anthraceno

Dibenzofuran

Dibromochloromethane

1,2-Dibromo-3-chloropropane

1,2.Dlbromoethane

Dibromomethene

Di-n-butyl phthalato

1,3-Dichlorobenzene

1,4-Dichlorobenzene

3,3'. Dichlorobenzidine

trans-1,4-Dichloro-2-butan

1,1-Dichloroothan

1,2-Dichlorothane

o $1,1$. Dichloroethylone

o trans-1,2-Dichloroethylene

Dichloromethane

2.4-Dichlorophenol

2,4-Dichlorophenoxyacotic acid $<0.80$

- 1,2-Dichloropropano

o cie-1,3-Dichloropropene

o trana-1,3-Dichloropropene

Dieldrin

Diethyl phthalate

2.4Dimethyl phenol

p.Dimethylaminoazobenzons

Bimethylbenz(a) anthracene

3,3'.Dimethylbenzidine

$<1.0$

$<0.050$

$<0.050$

$<10$

$<10$

$<10$

$<3.0$

$<10$

$<10$

$<1.0$

$<1.0$

$<10$

$<10$

1,000

$<1.0$

$<0.50$

$<10$

$<1.0$

$<10$

$<1,0$

$<10$

$<1.0$

$<10$
$<10$
$<10$

$<10$

$<200$

$<10$

21
$<10$

$<10$

$<10$

550.0

$<0.10$

$<10$

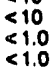

110
510
510

$\$ 10^{\circ}$

$<10$
$<10$

$\leq 10$

$\leq 30$

$\leq 1.0$

$\leq 1.0$

$<1.0$

J2

$<0.60$

$<1.0$
$<1.00$

$<0.50$

$<10$
$<10$
$<10$

$<<10$

$<10$
$\leq 10$
$<10$
Mod Unit Ub

JI mon GE

MO GE

$\begin{array}{lll}j 1 & \mathrm{~m} h & \mathrm{GE}\end{array}$

$<2.0$ J1 $\operatorname{mol}$ GE

$<2.0$ wo ge 
ANALYTICAL RESULTS

WEUL HMD 4D collected on 07/03/92, laboratory analyees (cont.)

F Anerye

o a, - Oimethylphenethytamine 1,3-Oinitrobenzent

2,4Dinitrophenol

2,4-Onitrotolien

Din-octyl phthalato

1,4-Dlocana

Divulfoton

Endowulfin I

Endoaulian II

Endrin

Endrin aldehydo

Ethyl mothanesultonato

Ethylbenzene

Famphur

Fluorense

Fluoride.

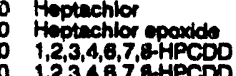

Hipochiorodlbenzo-p-dioxins

Heptechlorodtbenzo-p-dloxins

$1,2,3,4,6,7,8-H F C D F$

Heptachlorodibenzo-p-turens

Heptechlorodibenzo-p-hism

Hexechlorobenzane

Hexechloroguclopentadien

$1,2,3,4,7,0+1 \times 000$

1,2,3,4,7,8-HXCDD

Hexechlorodibenzo-p-dioxing

$1,2,3,4,7,8+1 \times C O F$

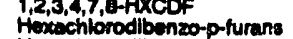

Hoxachlorodibenzo-p-furans

Hexwchloroethane

Hexichloropropene

2.Hexanon

indeno[1,2,3-c,d]pyrone lodom

ecoutyl alcohol

bodin

boentrole

Kepone

Undone

Magnealum

Mangane

Mereury

Nithapyritene

2-Mothyt-4, E-dinitrophenol

Mothyl ethyl ketione

Nethyl bobutyl koton

Methyl methecylato methanstilionato

3-Mothyichotanthrome

2-Methyinaphthalene

Naphthalene

1, Naphthoquirion

1-Naphthylamino

EiNaph

Nitreb-niturtio as nilrogen

2-Nitroanilin

3Nuraniline

Nitrobenzene

2Nitronain

2-Nitropheno

4Nitroquinolino-1-oxide

N-Nitrocodi-n-butylamin

N-Nitroeodimethyming

N-Nitrosodiphemylaming

N-Nitrosodipropylamine

N-Nitroesmothylothyla

N-Nitrosopipopidine

N-Nitrocopprnolidine

$0,0,0$ Trent phoephorothioato

Oetichlorodibenzop-dioxina

Cetrachlorodibenzo-p-dioxina

Octachlorodibenze-p-furums

Octuchlorodibenzo-p-furans

Parethion
PCa 1016

$\begin{array}{ll}<10 & J 1 \\ <10 & J 1 \\ <45 & J 1 \\ <10 & J 1 \\ <10 & J 1 \\ <10 & J 1 \\ <10 & J 1 \\ <10 & J 1 \\ <10 & J 1\end{array}$

$<0.10$

$<0.10$

$<0.0010$

$<0.10$

$<10$

$<1.0$

$<10$

$<100$

$<0.050$

$<0.00065$

$<0.00065$

$<0.00065$

$<0.00045$

$<0.00045$

$<0.00045$

$<0.00045$
$<10$
$<10$

$<10$

$<0.00045$

$<0.00045$

$<0.00045$
$<0.00045$

$<0.00040$

$<0.00040$

$<0.00040$

$<10$

$<10$

$<10$

$<10$

$<10$
$<15$

$<100$

$<10$
$<10$
$<10$

$<10$
$<10$

$<8.80$

47

$<0.20$

$<50$

$<0.50$

$<10$

$<1.0$

$<10$

$<10$

$<10$

$<$

$<10$

5.2
870

$<10$

$<10$

$\leq 10$

$<10$

$<10$

$<10$

$<10$

$<10$

$<10$

$<10$

$<10$

$<10$

$<0.0010$

$<0.0010$

$<0.0010$
$<0.0010$

$<0.050$

$<0.50$

Lab

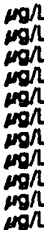

GE

WELL HMD 4D collectod on 07/03/82, laboratory analyees (cont)

E Analyte

O PCB 1221

O PCB 1242

0 PCB 1254

Pontachlorobonzone

1,2,3,7, -PCDD

Pontechlorodibenzo-p dloxing

Ponlachlorodbenzo-p.juxina

Pentachlorodibenzo-p-turane

0 1,2,3,7,8-PCDF

Pentachlorothen

Pentachlorontrtrobenzene

- Pontachlorophono

Phenanthrene

Phenol

o p-Phonylenodiamine

2.Picoline

Dronamid

D Propionitrile

0 Pyrone

Syridine

Solonium

silica

o sodium

S Styrene

0 Sulfide

Sulfide

$1,2,4,5$-Petrachlorobenzene

2,3,7,8-TCDD

2,3,7,8-TCDF

ietrechlorodibenzo-p-dioxins

Tutrachlorodibenzo-p-dioxing

Tetrachlorodibenzo-p-furans

- Tetrachlorodibenzo-p-turans

1,1,1,2-Tetrachloroethane

T, 1,2,2-Tetrachloroethan

o 2,3,4,8-Totrachlorophenol

- Tallum

: Tin

0 Toluone

Total dissolved solids

- Total organic carbon

- Total organic halogons

Toxaphene

o 1,2,4 Trichlorobonzene

: 1,1,1-Trichloroethane

0 Trichloroethylone

- Trichlorofluoromethane

2,4,5-Trichlorophenol

2,4,5-T

o 1,2,3-Trishloropropane

1,3,5-Trinttrobenzene

Vinyl acotote

Xylones

- Zne

G Groas alpha

o Total alpha-emlting radium
Plesult

$<0.50$

$<0.50$

$<0.50$

$<0.50$

$\leqslant 0.00055$

$<0.00055$

$<0.00055$

$<0.00055$

$<0.00055$

$<10$
$<10$
$<10$

$<10$
$<10$
$<10$
$<10$
$<50$

$<5.0$

$<10$

$<10$

$<100$

$<10$

$<10$
$<2.0$

$<2.070$

$<2.0$
1,610

$<1.0$

$<1,000$

$<1,000$

$<10$

$<0.00045$

$<0.00040$

$<0.00040$

$<0.00045$

$<0.00045$

$<0.00040$

$<1.0$
$<1.0$
$<1.0$

$<10$

$<2.0$
$<10$
$<2.0$

$<2.0$
$<1.0$

$<10$

$<1,000$

$<5.0$

$<0.24$

$<10$

$<1.0$

$<1.0$
$<1.0$

$<1.0$
$<10$
$<10$
$<0.18$
$<0.10$

$<0.18$

$<10$

$<8.0$
$<1.0$
$<2.0$

3.0E-09 $7.0 E-10$

4.3E-00 $\pm 1.4 E-09$

$1.3 E-09 \pm 1.0 E-08$
$8.1 E-06 \pm 5.0 E-07$ 
WELL HR3 11

MEASUREMENTS CONDUCTED IN THE FIELD

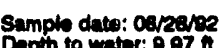

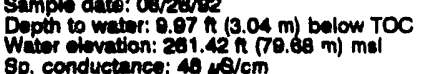

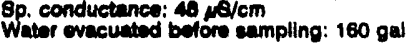
LABORATORY ANALY YSES

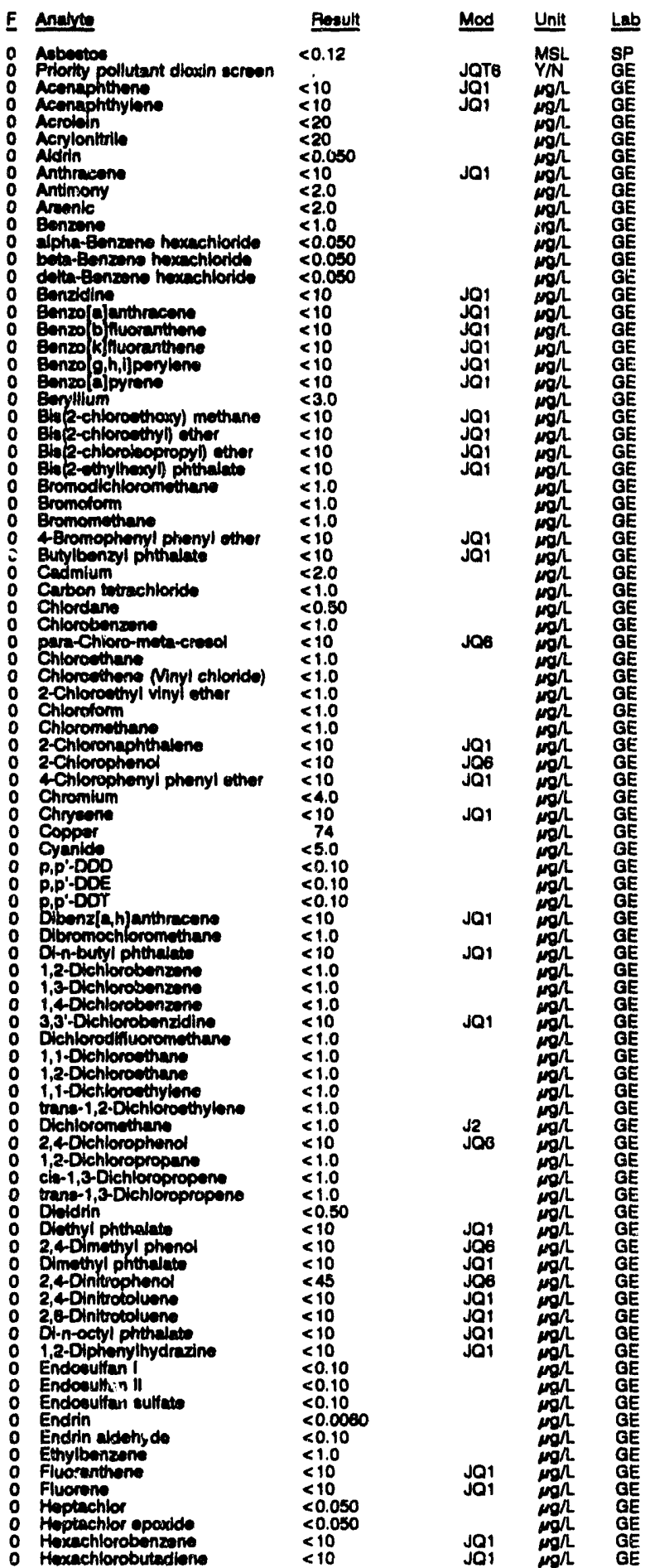

WELL HR3 11 collected on 08/28/82, laboratory analyees (cont)
$E$ Analyte

Time: 13:05

PH: 4.4 : Alkninity: $0 \mathrm{mal}$

Water tomperature: $18.5^{\circ} \mathrm{C}$ o Hoxachlorocyclopentadion

Hoxachloroothane

o indeno[1,2,3-c,d]pyren

o lodine

Lead

o Lindane

D Mercuny

2-Mothyl-4,6-dinitrophenol

0 Naphthalen

Nitrato-nitrite as nitrocon

N Nitutto as nitrogen

- Nitrobenzone

2.Nitrophonol

N-Nitrosodimethylamine

N-Nitrosodiphonylamin

N-Nitrosodipropylamine

PCB 1016

PCB 1232

PCB 1242

P PCB 1254

- Pentachlorophenol

o Phenanthrene

o Phenol

Pyreno

Sitver

Totrachloroethylone

Thallum

Total phonphates (as P)

T Toxaphene

1,2,4-irichlorobenzene

1,1,1-Ttchlorosthane

1,1,2-Trichloroeth

Trichlorofluoromethane

2,4,6-Trichlorophenol

Zinc

Amaricium-241

Americium-24

- Antimony-12s

o Cosium-134

Conlum-137

0 Cobatt-57

- Cobalt-60

D Curium-242

- Curlum-243/244

Curlum-243/24

Europlum-152

Europlum-15.

E Europium-15s

o Manganeas-54

Neptunium-237

Plutonlum-238

o Plutonium-239/240

0 Potansium-40

P Promothium-144

Promethium-146

o Ruthenlum-108

Sodium-22

Thorium-228

o Thorlum-230

Thorium-230

Thorium-232

Total alpha-emitting radium

Tritium

o Uranium-234

Uranium-234

Uranium-235

Uranium-235

Uranlum-238

Uranium-230

Zinc-65 o 1,1,2,2-Tetrachloroothane
Plosult

$<10$
$<10$

$<10$

54
$<10$

4.6
$<0.0050$

3.1
0.32

$<10$
$<10$

$<4.0$

$<10$

$<10$
$<10$

$<10$
$\leq 10$
$<10$
$<10$

$<10$

$<0.50$

$<0.50$

$<0.50$

$<0.50$

$<10$
$<10$
$<10$

$<10$

$<2.0$

$<1.0$

$<1.0$

$<1.0$

$<0.24$

$<10$

$\leq 1.0$

$<1.0$

$<1.0$

8.2

$<1.0 \mathrm{E}-09$

$<1.0 E-09$
$<2.0 E-08$

$<6.0 E-08$

$<$ C OE-O

$<1.0 E-08$

$<1.0 E-08$

$<1.0 E-09$

$<1.0 E-09$

$<1.0$ E-08

$<4.0 E-08$

$<2.0 E-08$
$<3.0 E-08$

$<2.0 E-00$

$<1.0 E-00$

$<1.050$

$<1.0 \mathrm{E}-00$

$<1.0 E-00$

$<1.0 E-09$

<1.10

$<1.0$ E-08

$<9.0 E-08$

$<1.0 E-09$

$<1.0 E-09$

$<1.0 E-109$

$<1.0 E-09$

$1.0 E-09 \pm 7.0 E-10$
$2.0 E-05 \pm 8.0 E-07$

$<1.0 E-09$

$<1.0 \mathrm{E}-00$

$<1.0$ E-00

$<1.0 E-09$

$<1.0 E-09$
$<6.0 E-00$
Mod Unit Le

$\begin{array}{lll}J Q 1 & m / 2 & G E \\ J Q 1 & m g / & G E \\ J Q 1 & m g h & G E \\ J O & m g / & G E\end{array}$

Jดิ

Jat

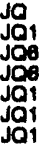

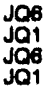

Jai

Ja8 
WELL HR3 13

MEASUREMENTS CONDUCTED IN THE FIELD

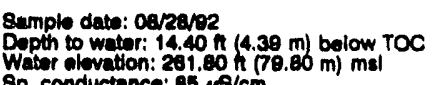
Sp. conductance: $86,18 / \mathrm{cm}$
Water evacuated belore sampling: $149 \mathrm{gal}$

LABOAATOFY ANALYSES

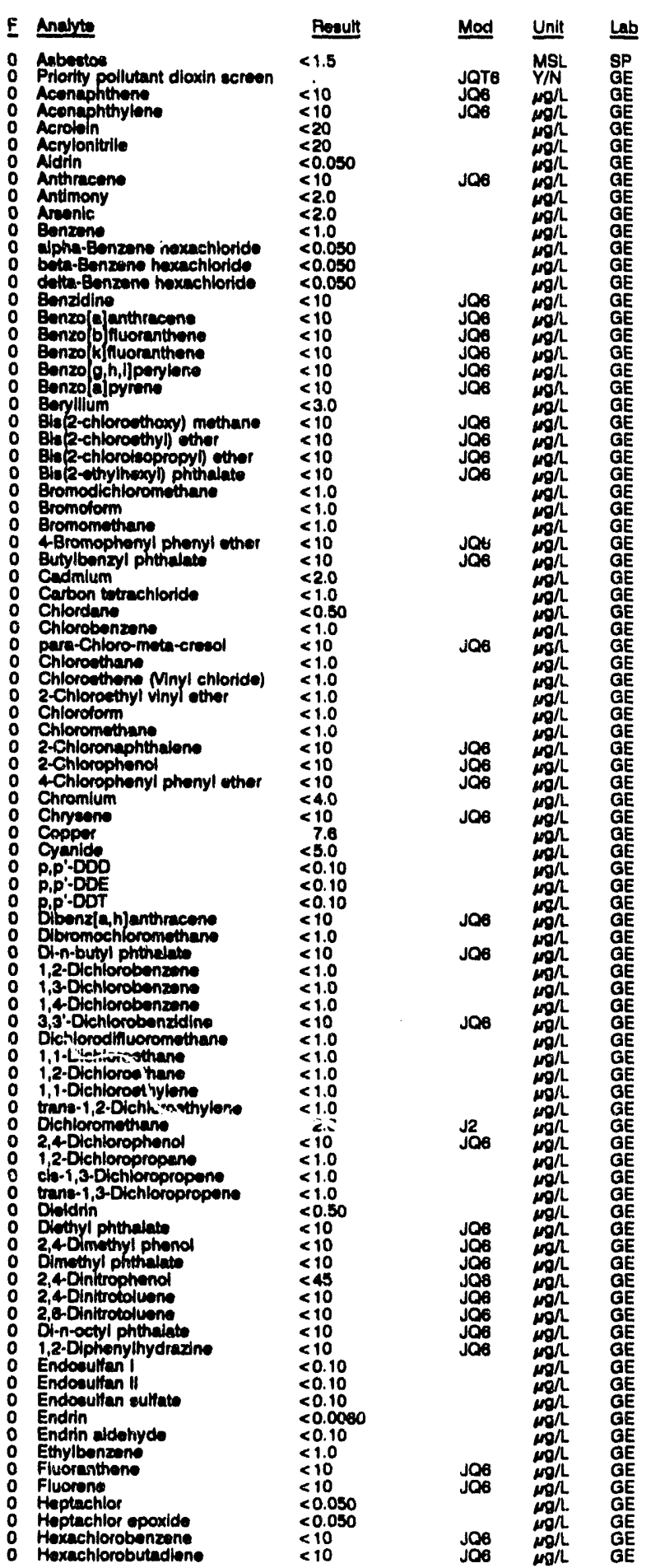

WELL HA3 13 collected on 08/28/92, laboratory analyses (cont.)

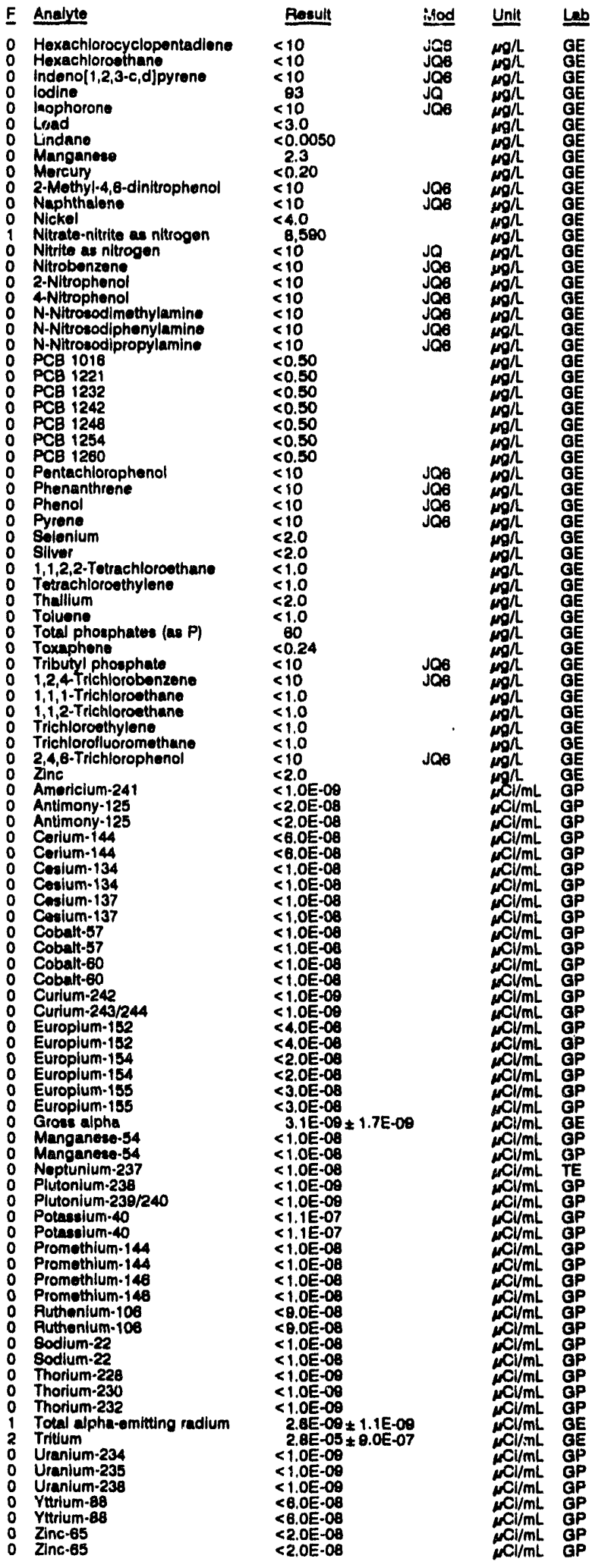


WELL HRB 11

MEASUREMENTS CONDUCTED IN THE FIELD

Samplo dutw: oserage

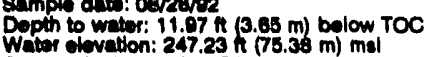

Sp. conductance: 31 $1 \mathrm{~s} / \mathrm{em}$

Water evacuated belore campling: $103 \mathrm{gal}$

LABOPATOAY ANALYSES

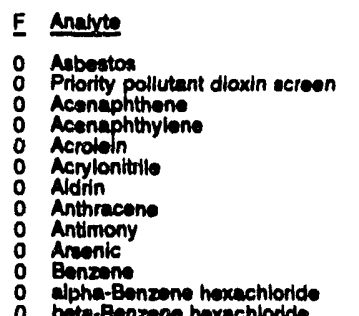

bete-Benzerre hoxachloride

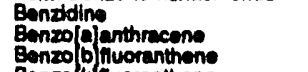

Bonzog knuoranthens

Bonzolidpyrone

Bien (2-entorocthoxy) methane

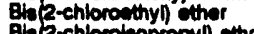

Ble (2-chioroteopropy) the Bromodichiorom phan

Bromotorm

4Bromophenyl phenyl ether

Butylbenzyl phthalate

cadmium

Cepoon futrachiorido

Chlorobenzane

pera-Chloro-mete-cresel

Chiorowtheme Minyl chloride!

2-Chioroethyl vinyl ther

Chlordorm

Chloromethane

2-Chloromaphthe

4-Chlorophenyl phenyl whes

Chromium

Coppor

Cyanide

P.P':DOD

o p,p-DO

- Dbenz (a,n) hanthreceno

Di-n-butyl phthaint

1,2-Dichlorobenzen

o 1,3-Dichlorobenzent

3,3'-Dichlorobenzedino

o Dichlorodilluoromethan

1,1-Dichloreethane

o 1,1-Dichlorowinylene

o tene-1,2-Dichloroethylen

2,4-Dichiorophend

o 1,2-Dichloropropane

cle-1,3-Dichloropropeno

trane-1,3-Dichloropropen

Dioldrín

o Diethyl phthalate

2,4-Dimethyl phenol

D Dimethyl phthalat

2,4-Dinitrotolisen

2,6-Dinitrotoluene

O1-n-cotyl phthalato

1,2-Diphonylhyd

Endowulan II

Endrin

Endrin aldehyde

Elturbenzenen

Fluorene

Hoptachlor

Heptachlor epoxids

Hexuchlorobutediene
Result Mod Unil Lat

$<0.12$

$<10$
$<10$
$<20$

$<0.050$

$<10$

$<2.0$
$<2.0$
$<1.0$

$<0.050$

Time: 11:05

pH: 4.2 . 05

Whter temperature: $21.0^{\circ} \mathrm{C}$

$<0.050$

$<10$

$<10$
$<10$
$<10$

$<10$

$<3.0$

$<10$

$<10$
$<10$
$<10$

$<10$

$<1.0$

$<10$

$<10$
$<2.0$

$<1.0$

$<0.50$

$<10$

$<1.0$

$<1.0$
$<1.0$

$<1.0$

$<10$

$<10$
$<40$

$<4.0$
$<10$

$<10$
122
$<5.0$
$<0.10$

$<0.10$

$<0.10$

$<10$

$<1.0$

$<1.0$

$<1.0$

$<10$

$<1.0$
$<1.0$

$<1.0$

$<1.0$
$<1.0$

1.6

$<10$
$<1.0$
$<1.0$

$<1.0$
$<1.0$
$<0.50$
$<10$

$<10$

$<10$

$<45$

$<10$
$<10$

$<10$

$<10$

$<0.10$

$<0.0060$

$<0.10$

$<1.0$
$<10$

$<10$

$<0.050$

$<0.050$
$<10$

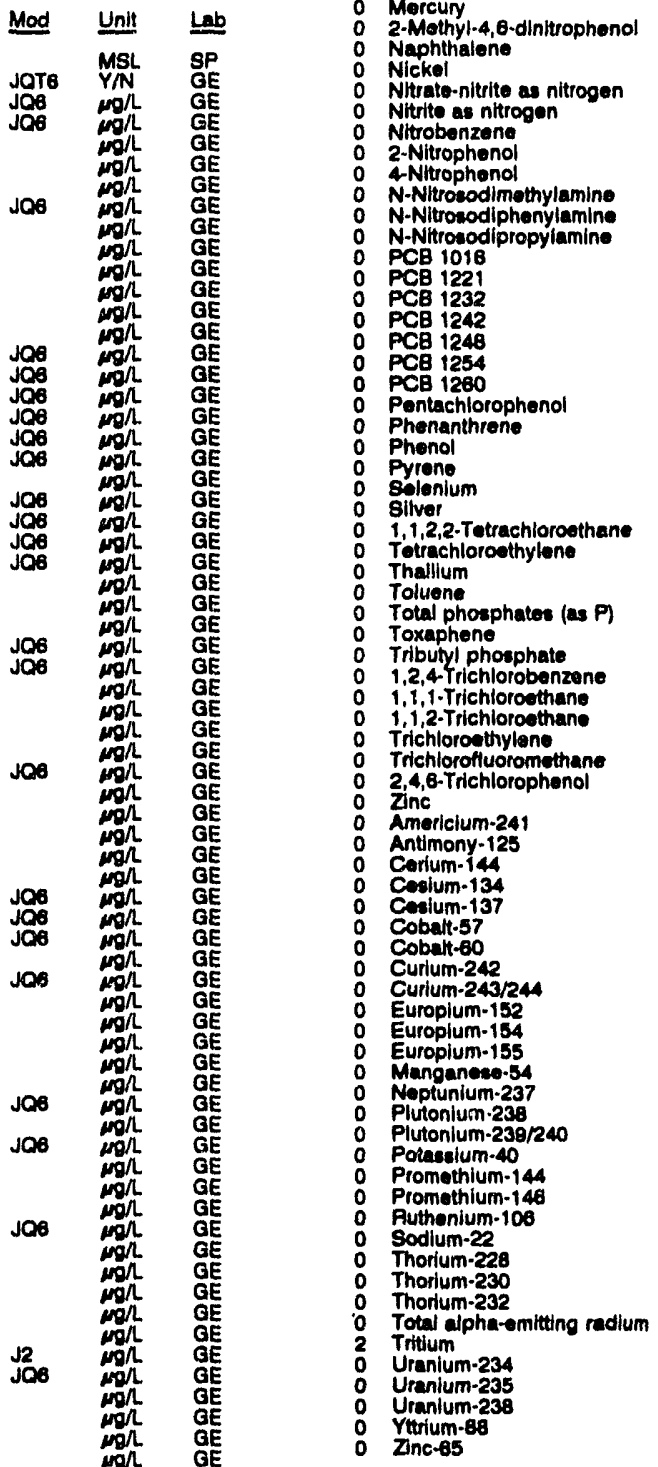

Sample date: 08/28/82

2.2E $-00 \pm 1.0 E-00$
- Analyte

O Hexachlorocyclopentudiono

indeno[1,2,3-c,d]pyren

o lodine

o leophoro

1 Lead

0 Uindane

0 Manganeso

2-Mothyl-4,6-dinitropheno

Nitrale-niturite as nitrogen

Nitrobenzene

Nitrosodipropyiamine

PCB 1254

Pentachloroph

Selonium

1,1,2,2-Totrachloroethan

Thallium

$1,2,4$ Trichlorobenzene 1,1,1. Trichloroethan

Trichlorofluoromethan

arme

Antimony-125

Cosium-134

Cobatt-57

Cobalt-60

Europium-1

Europlum.15s

Plutonlum-239/2

Promethium-144

Promethium-140

Sodium-22

Uranlum-238

Zinc. 65

WELL. HA8 12

MEASUAEMENTS CONDUCTED IN THE FIELD

Depth to water: $17.30 \mathrm{ft}(5.27 \mathrm{~m})$ below TOC

Water olevation: 240.20 h $(73.21 \mathrm{~m}) \mathrm{mal}$

mpling: 89 oa

$<10$
$<10$
$<10$

$<10$

$<8.3$

$<2.0$

$<10$
$<10$

$<4.0$

$<10$

$<10$

$<10$
$<10$

$<10$

$<0.50$

$<0.50$

$<0.50$

$<0.50$

$<10$

$<10$

$<2.0$

$<1.0$

$<2.0$
$<1.0$
$<50$

$<50$

$<10$

$<1.0$

$<1.0$
$<1.0$
$<1.0$

$<10$

0.0
$<1.0 \mathrm{E}-00$

$<2.0 \mathrm{E}-08$

$<6.0 E-08$

$<1.0 \mathrm{E}-0 \mathrm{O}$

$<1.0 E-08$

$<1.0 \mathrm{E}-00$

$<4.0 E-06$

$<2.0 E-08$

$<3.0 E .08$

$<1.0 E-00$

$<1.0 E \cdot 00$

$<1.1 \mathrm{E}-0$

$<1.0 E-08$

$<9.0 E .00$

$<1.0 E-0$

$<1.0 E-09$

$<1.05-00$

$<1.0 E-00$

$<1.0 E-09$

$<2.0 E-08$

Mod Unil

$\mathrm{JOO}$
$\mathrm{J} 00$
$\mathrm{JO6}$
$\mathrm{JO}$

Jas

J06
J06

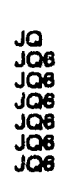

Ja6

108

$\operatorname{con}$ GE

No

$\operatorname{mon}_{\mu \mathrm{G}} \mathrm{GE}$

$\operatorname{mggh}_{\text {mon }} \mathrm{dE}$

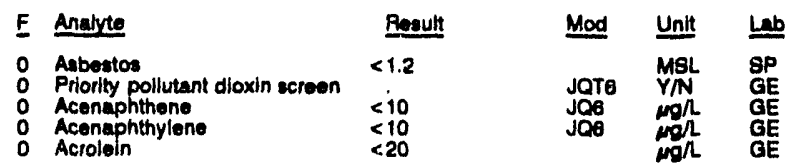


ANALYTICAL RESULTS

WELL HPB 12 collectad on 09/28/82, laboratory analyses (cont)

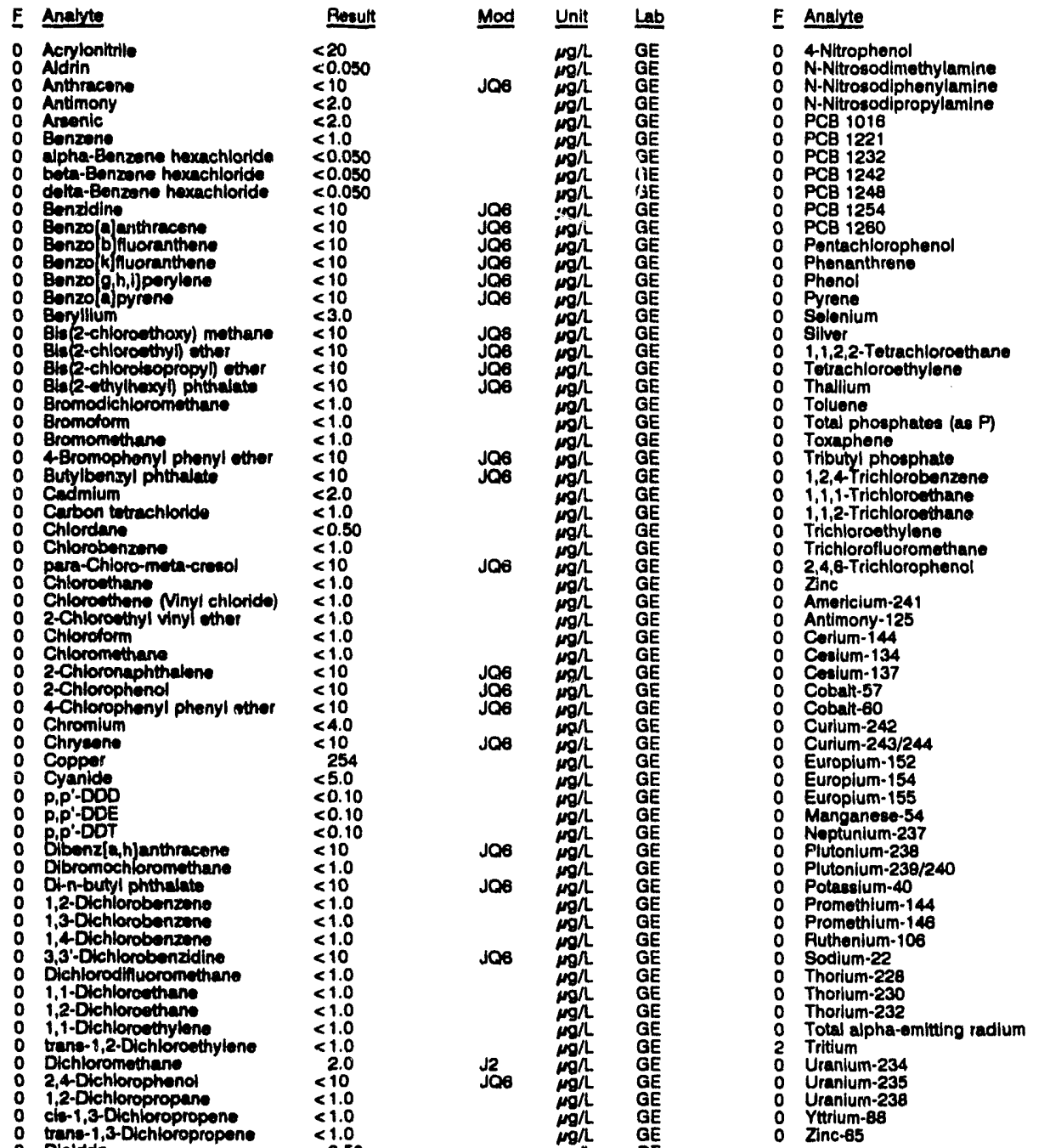

WELL. HRB 12 collocted on 08/28/82, laboratory analyses (cont.)

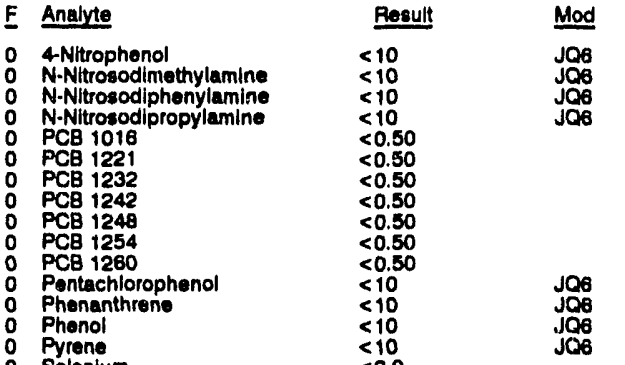

1,1,2,2-Tetrachloroethane

Thallium

Total phosphates (ae P)

1,2,4 Trichlorobenzene

1,1,1-Trichloroethane

Trichiorofluoromethane

Americium-241

Curium-243/24

Manganese-54

Plutonium-238

Plutonium-23日1

Promothium-144

Puthenium-106

Thorium-220

Thorium-230

$<10$
$<2.0$
$<2.0$

$<2.0$

$<2.0$

$<0$

$<10$

$<10$

$<1.0$

$<1.0$

$<23$

$<2.0 \mathrm{E}-08$

$<6.0$ - 08

$<1.0 E-08$

$<1.0 E-08$
$<1.0 E-08$

$<1.0 \mathrm{E}-08$

$<1.0 \mathrm{E}-09$

$<1.0 E-00$
$<4.0 E-08$

$<4.0 E-08$

$<2.0 E-08$
$<3.0 E-08$

$<1.0$ E-OS

$<1.0 \mathrm{E}-09$

$<1.0 E-09$

$<1.1 E-07$

$<1.0 \mathrm{E}-0.09$

(1.OE

$<1.0 \mathrm{E}-00$

$<1.0 E-09$

$<1.0 \mathrm{E}-09$

$<1.0 E-09$

$3.05-05$
$<1.0 E-08$

$<1.0 E-09$

$<1.0 \mathrm{E}-09$

$<6.0 \mathrm{E}-08$

Mod Unit Lab

$\mathrm{JOB}_{\mu \mathrm{N} / \mathrm{GE}}$

$\mathrm{JCB}$

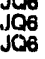

108
100

WELL HR8 13

MEASUREMENTS CONDUCTED IN THE FIELD

Sample date: 08/28/92

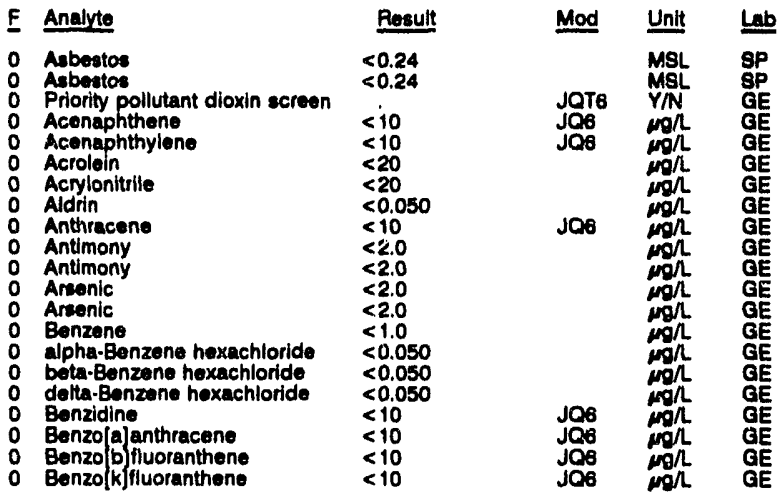

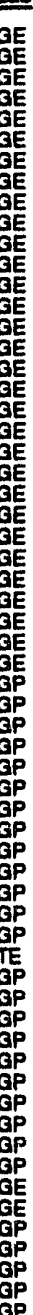

Ci/mL GP
Depth to water: 14.78 it $(4.50 \mathrm{~m}$ ) below TOC

Water elevation: 238.32 t $(72.64 \mathrm{~m}) \mathrm{msl}$

Sp. conductance: $52 \mathrm{\mu S} / \mathrm{cm}$
Water evacuated before sampling: $86 \mathrm{gal}$

LABOPATORY ANALYSEB

Time: 9:50

$0 \mathrm{man}$

Water temperature: $20.6^{\circ} \mathrm{C}$

$<0.10$

$<0.10$

$<10$

$<0.050$

$<0.050$

$<10$

$<10$

$<10$
$<10$

$<118$

20
$<0.0050$

$<2.0$

$<0.20$

$<10$

$<\begin{gathered}<.0 \\ 1,370\end{gathered}$

$<10$

$<10$

$J O 6$
$J O 8$ 


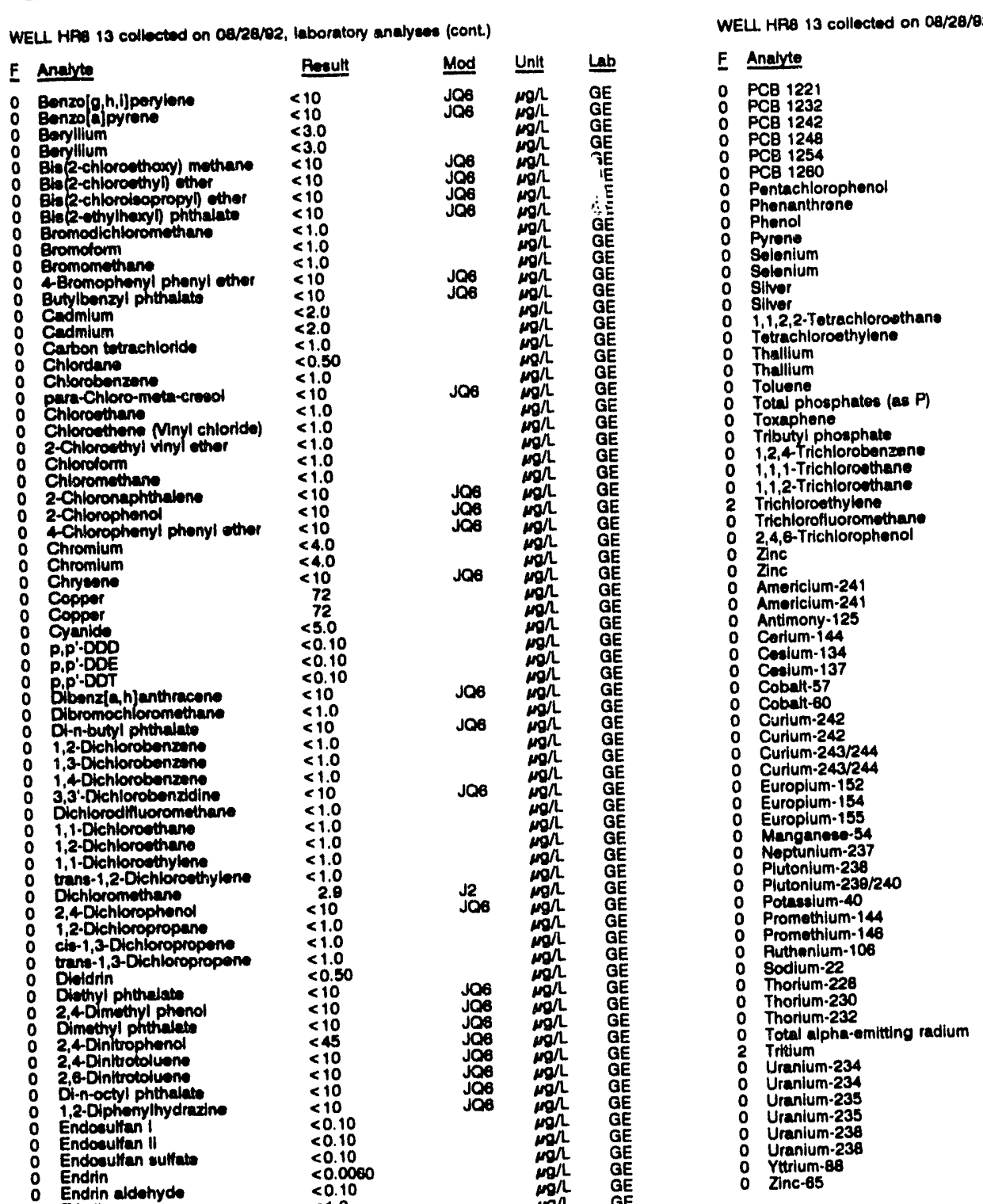

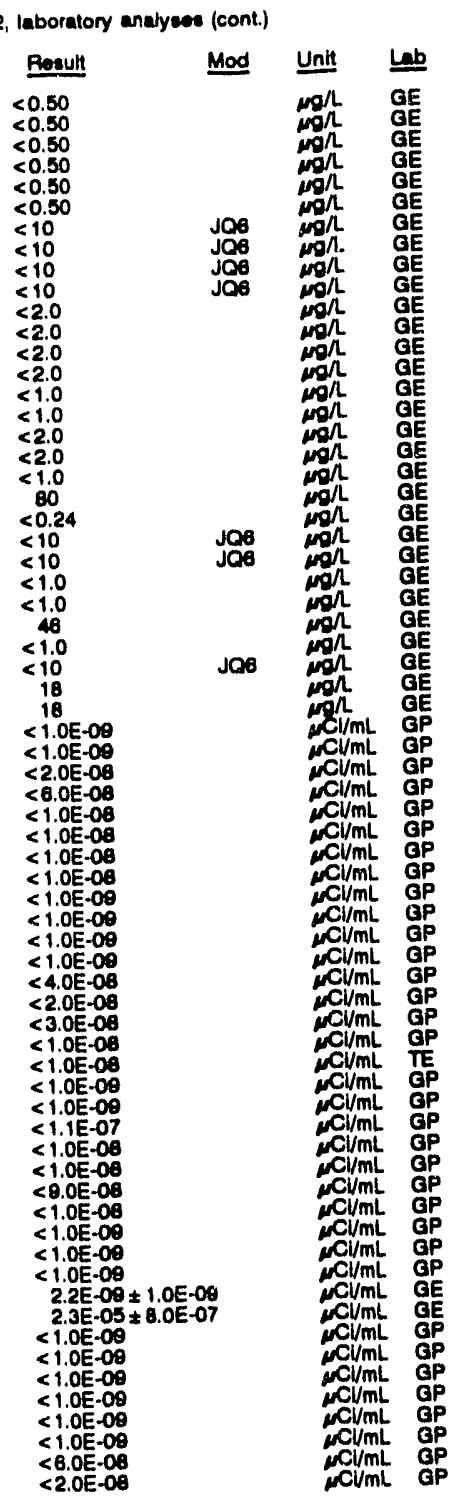

WELL HA8 14

MEASUREMENTS CONDUCTED IN THE FIELD

Sample dute: 08/28/92
Time: 8:25
ineccessiblity or mechanical problem prevented eample collection.

WELL HSB 1TB

MEASUREMENTS CONDUCTED IN THE FIELD

Sample date: 07/06/92

Depth to water: Not avallable

Water olevation: Not avellablo

Sp. Conductance: 44 fs/cm

LABORATORY ANALYSES

\begin{tabular}{|c|c|c|c|c|c|}
\hline$\underline{F}$ & Analyte & Result & Mod & Unit & Lab \\
\hline $\begin{array}{l}0 \\
0\end{array}$ & $\begin{array}{l}\text { pH } \\
\text { Specific conductance } \\
\text { Areenic } \\
\text { Barlum } \\
\text { Benzene } \\
\text { Benzene }\end{array}$ & $\begin{array}{r}4.5 \\
40 \\
<2.0 \\
12 \\
<1.0 \\
<1.0\end{array}$ & JO & 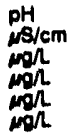 & $\begin{array}{l}\text { GE } \\
\text { GE } \\
\text { GE } \\
\text { GE } \\
\text { GE } \\
\text { GE }\end{array}$ \\
\hline
\end{tabular}


ANALYTICAL RESULTS

WELL HSB 1TB collectod on 07/08/82, laboratory analyees (cont.)

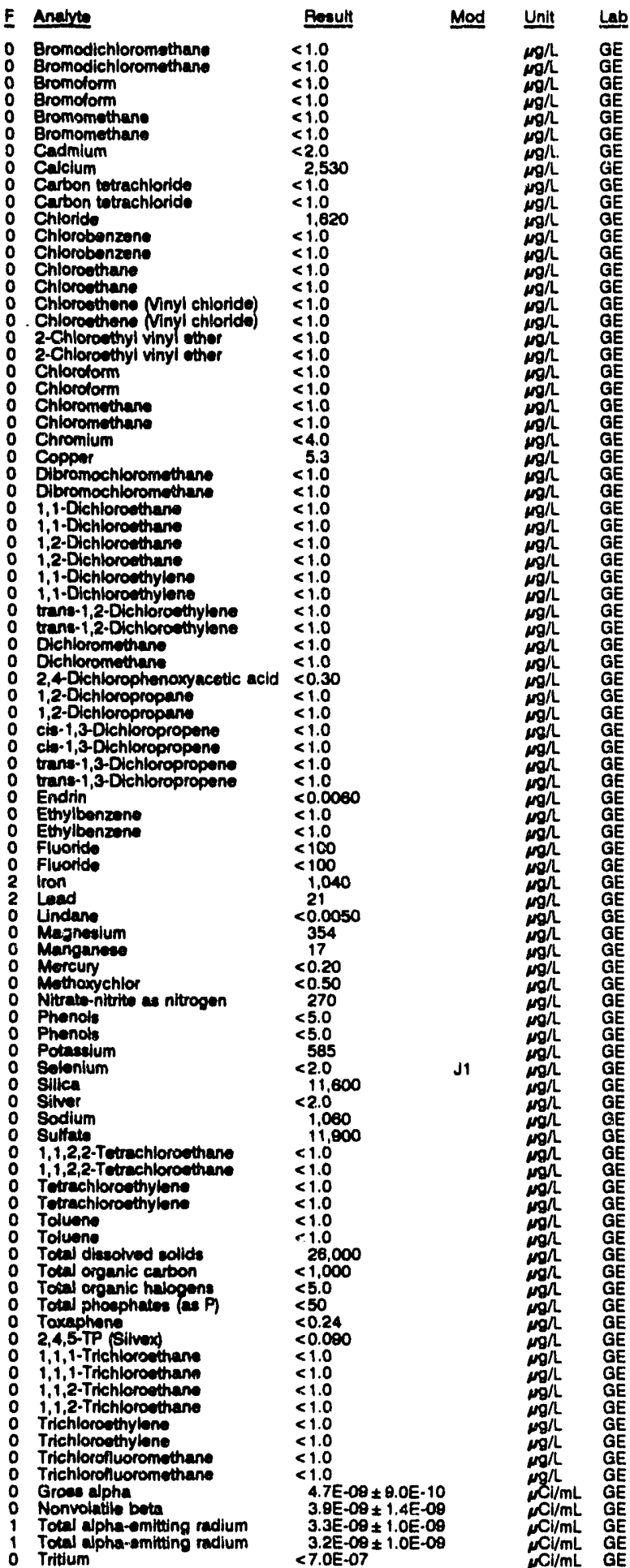

WELL HSB 65

MEASUREMENTS CONDUCTED IN THE FIELD

Sample date: 07/00/02 Depth to water: $39.50 \mathrm{ft}(12.04 \mathrm{~m})$ bolow TOC Wator elevation: $232.50 \mathrm{H}$ (7). Sp. conductance: 44 p $\mathrm{S} / \mathrm{cm}$
Water ovacuated bofore sampling: 53 gal

Time: $11: 10$

PH: 4.6 : 10

LABORATORY ANALYSES

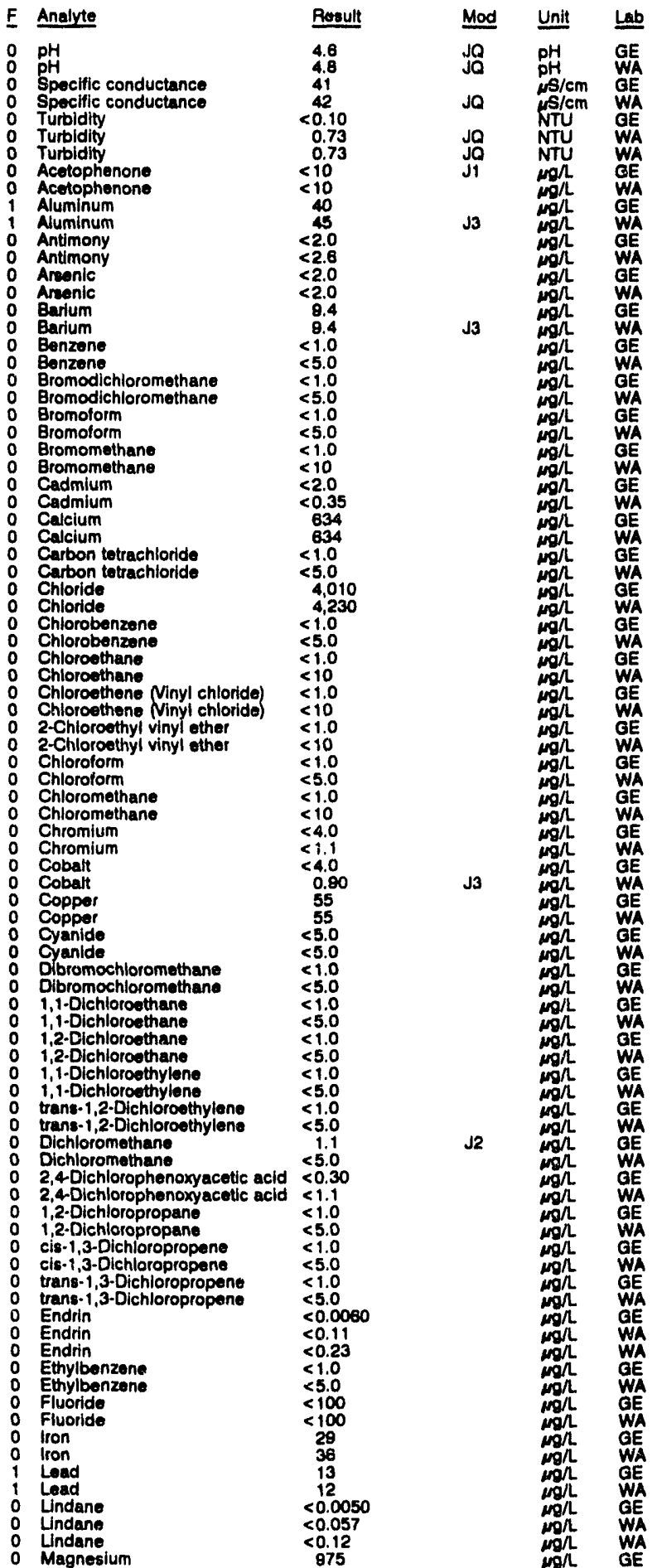


WELL HSB 65 collected on 07/06/92, laboratory analyees (cont.)

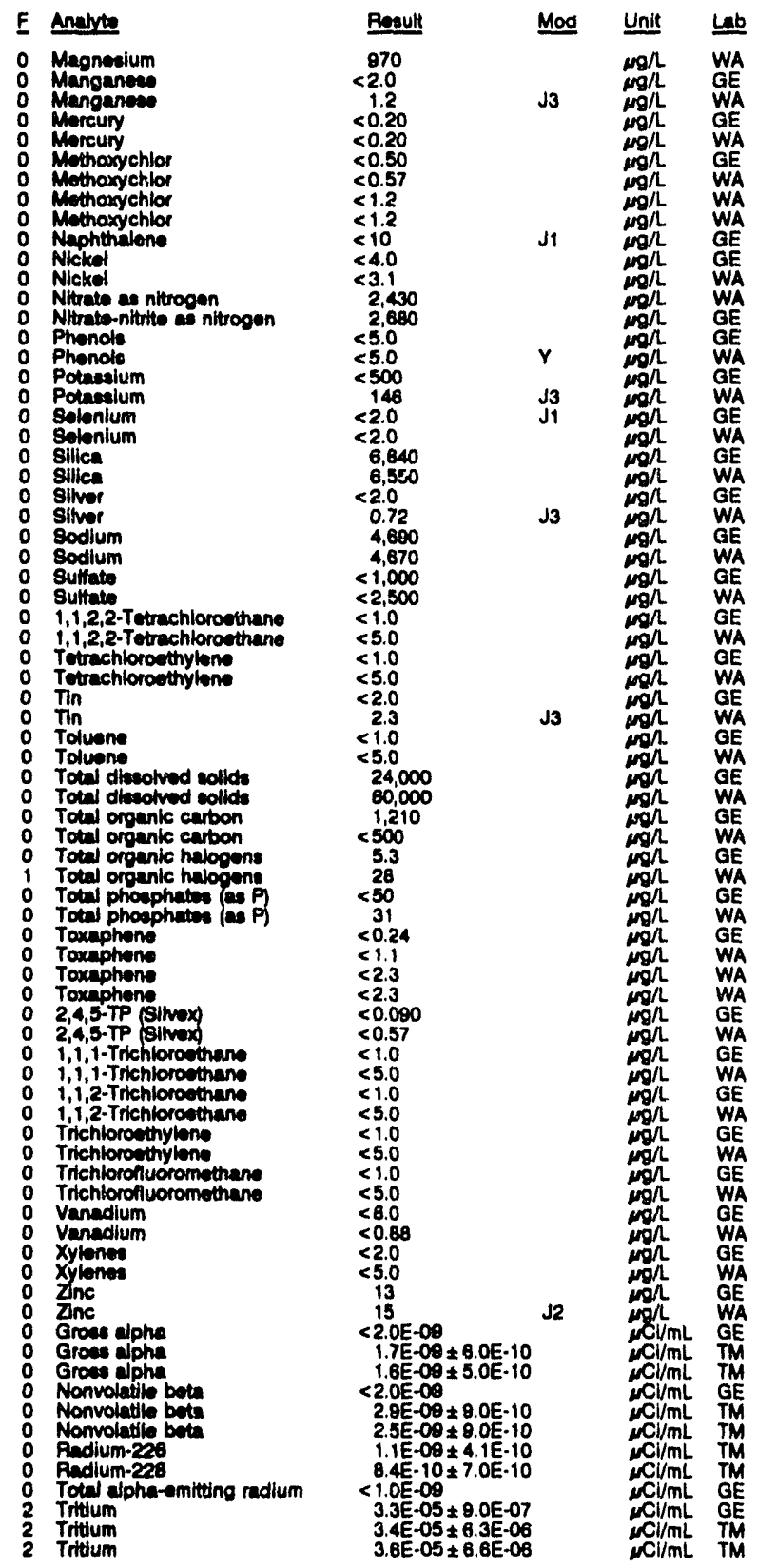

WELL HSB 65 Replicate

MEASUREMENTS CONDUCTED IN THE FIELD

\begin{tabular}{|c|c|c|c|c|c|}
\hline \multicolumn{3}{|c|}{ 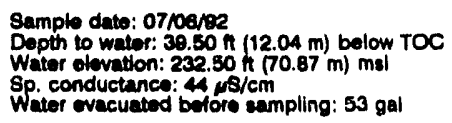 } & \multicolumn{3}{|c|}{$\begin{array}{l}\text { Time: } 11: 10 \\
\text { pH: } 4.6 \\
\text { Alkalinity: } 0 \mathrm{mg} h \\
\text { Water tomperature: } 20.3^{\circ} \mathrm{C}\end{array}$} \\
\hline \multicolumn{6}{|c|}{ LABOPATOFY ANALYSES } \\
\hline$\underline{\mathbf{E}}$ & Analyte & Result & Mod. & Unit & LLab \\
\hline $\begin{array}{l}0 \\
0 \\
0 \\
0 \\
0\end{array}$ & $\begin{array}{l}\text { pH } \\
\text { pH } \\
\text { Spoctific conductance } \\
\text { Speclific conductance } \\
\text { Turbidity } \\
\text { Turbldity } \\
\text { Acetophenon }\end{array}$ & $\begin{array}{c}4.7 \\
4.8 \\
40 \\
42 \\
<0.10 \\
0.55 \\
<10\end{array}$ & $\begin{array}{l}\text { JO } \\
\text { JO } \\
\text { JO } \\
\text { JO }\end{array}$ & $\begin{array}{l}\mathrm{pH} \\
\mathrm{pH} \\
\mathrm{NS} / \mathrm{cm} \\
\mathrm{NS} / \mathrm{cm} \\
\mathrm{NTU} \\
\text { NTU } \\
\mathrm{Nghl}\end{array}$ & $\begin{array}{l}\text { GE } \\
\text { WA } \\
\text { GE } \\
\text { WA } \\
\text { GE } \\
\text { VIA } \\
\text { GE }\end{array}$ \\
\hline
\end{tabular}

WELL HSB 65 collected on 07/08/92, laboratory analyses (cont.)

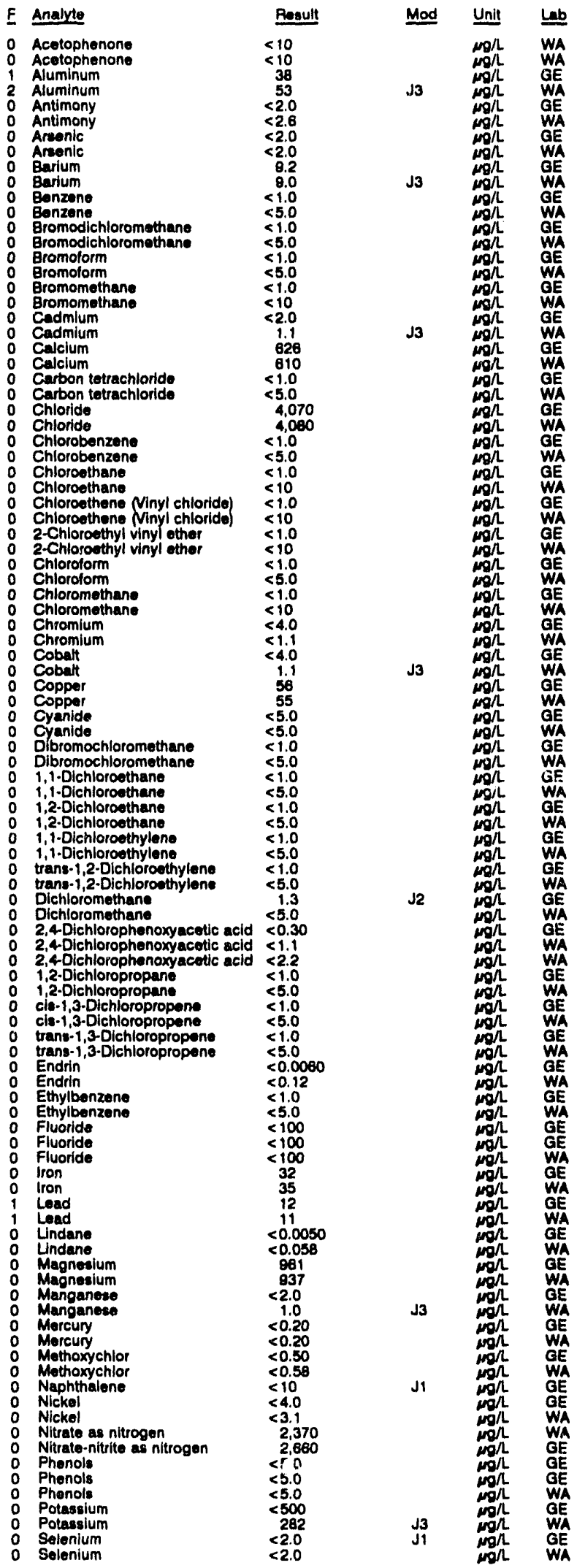


ANALYTICAL RESULTS

WELL HB8 65 collectod on 07/08/92, laboratory analyses (cont.)

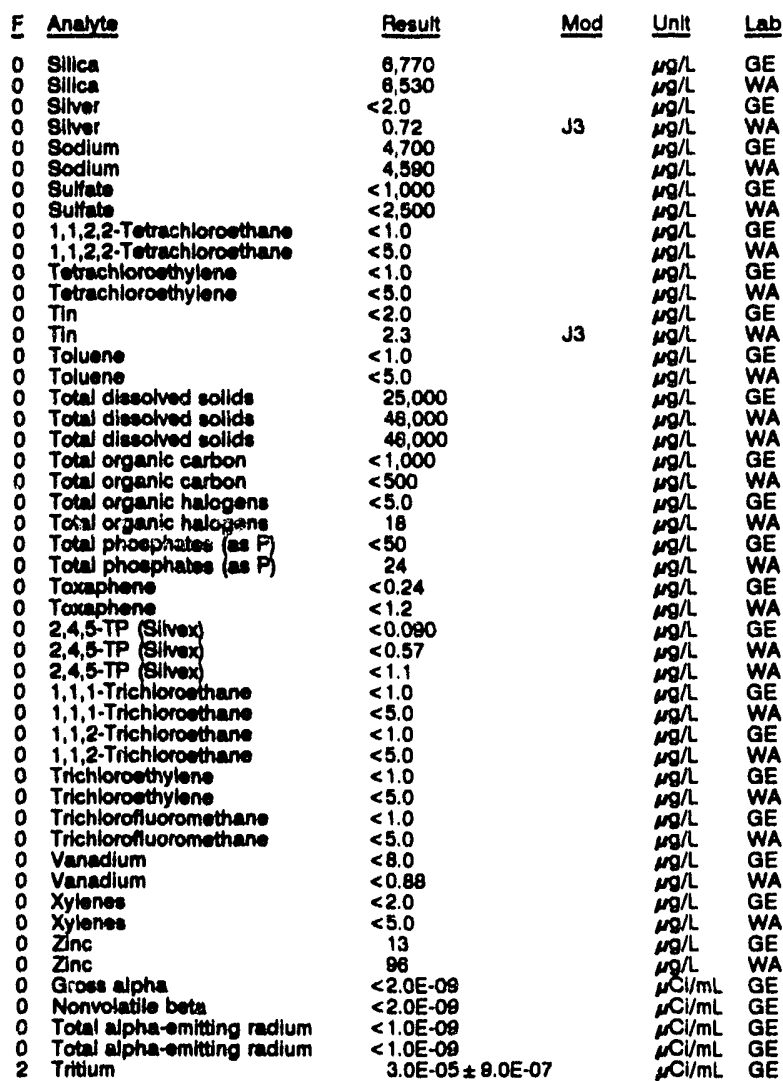

\section{WELL HSB 65A}

MEASUREMENTS CONDUCTED IN THE FIELD

Sample date: 07/08/02 Depth to water: 102.00 n (3t.12 m) bolow TOC Water elevation: 171.51 i $(52.28$ Water evacuated bolore sampling: $286 \mathrm{gal}$

LABOPATOAY ANALYSES

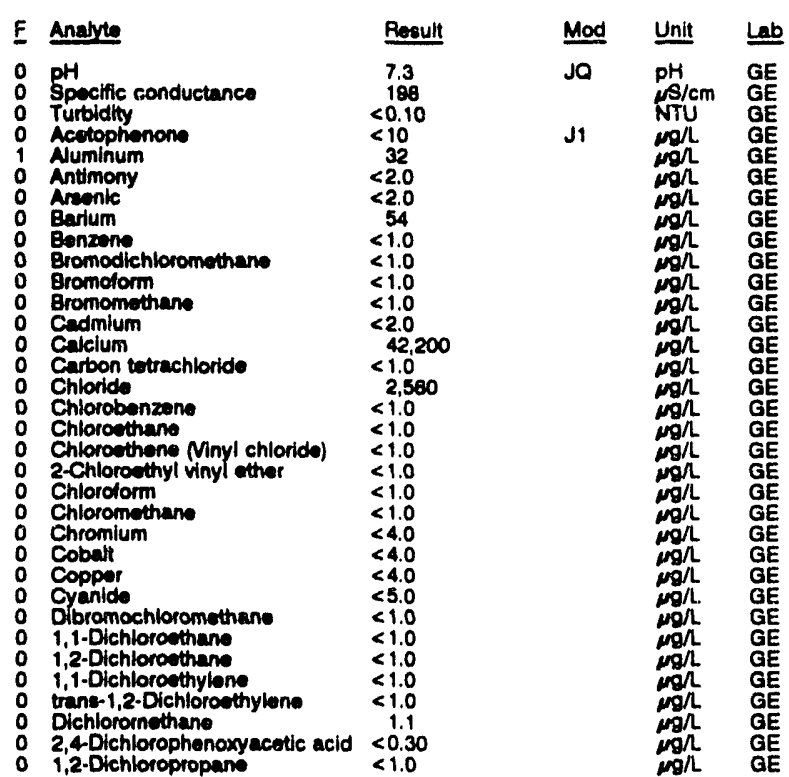

Time: 11:50

Akelinity: $78 \mathrm{mgn}$

Alkalinity: $78 \mathrm{mg} /$. $20.4^{\circ} \mathrm{C}$
WELL HSB 65A collected on 07/08/92, laboratory analyees (cont.)

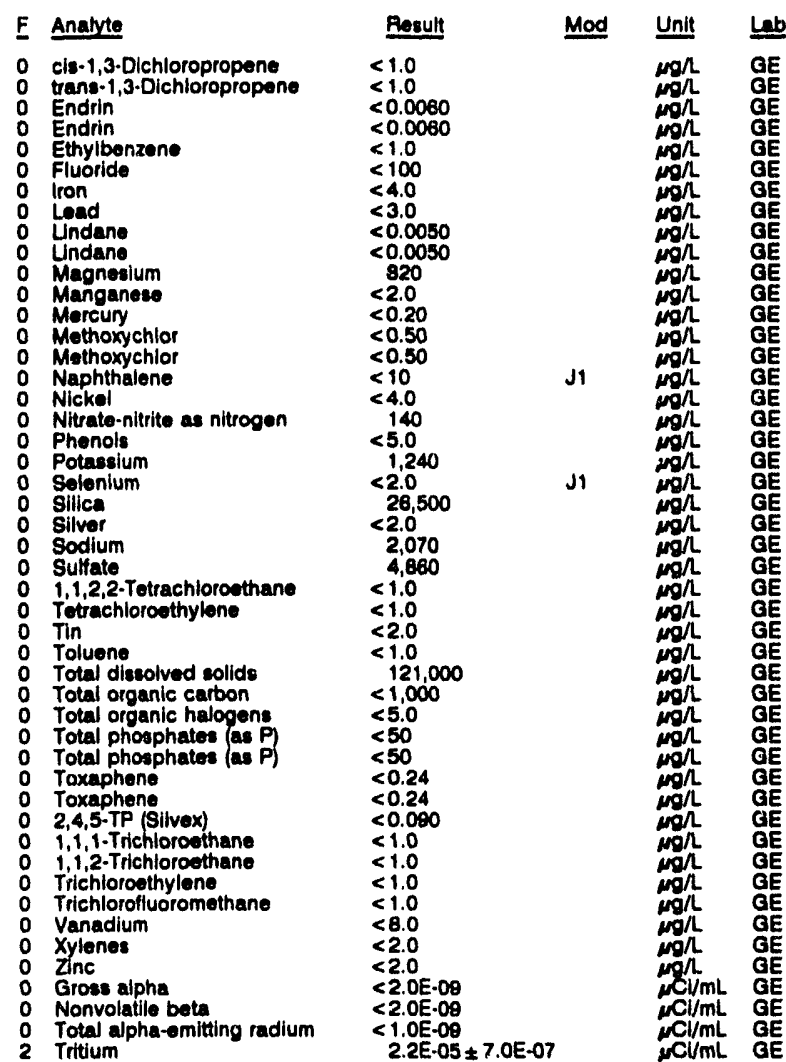

\section{WELL.HSB 65B}

MEASUREMENTS CONDUCTED IN THE FIELD

Sample date: 07/08/92

Depth to water: $48.03 \mathrm{ft}(14.04 \mathrm{~m})$ below TOC

Water olovation: $224.67 \mathrm{~h}(68.48 \mathrm{~m}) \mathrm{msl}$.

Sp. conductance: $208 \mu \mathrm{S} / \mathrm{cm}$.

Time: 10:20

LABORATORY ANALYSES

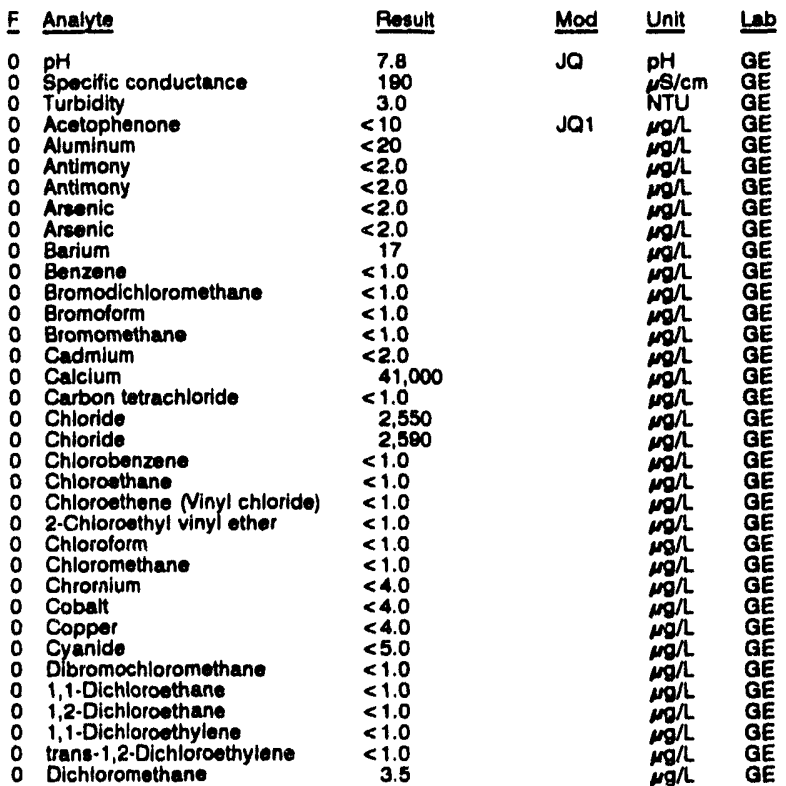


WELL HAB 058 collected on 07/08/02, laboratory analyees (cont)

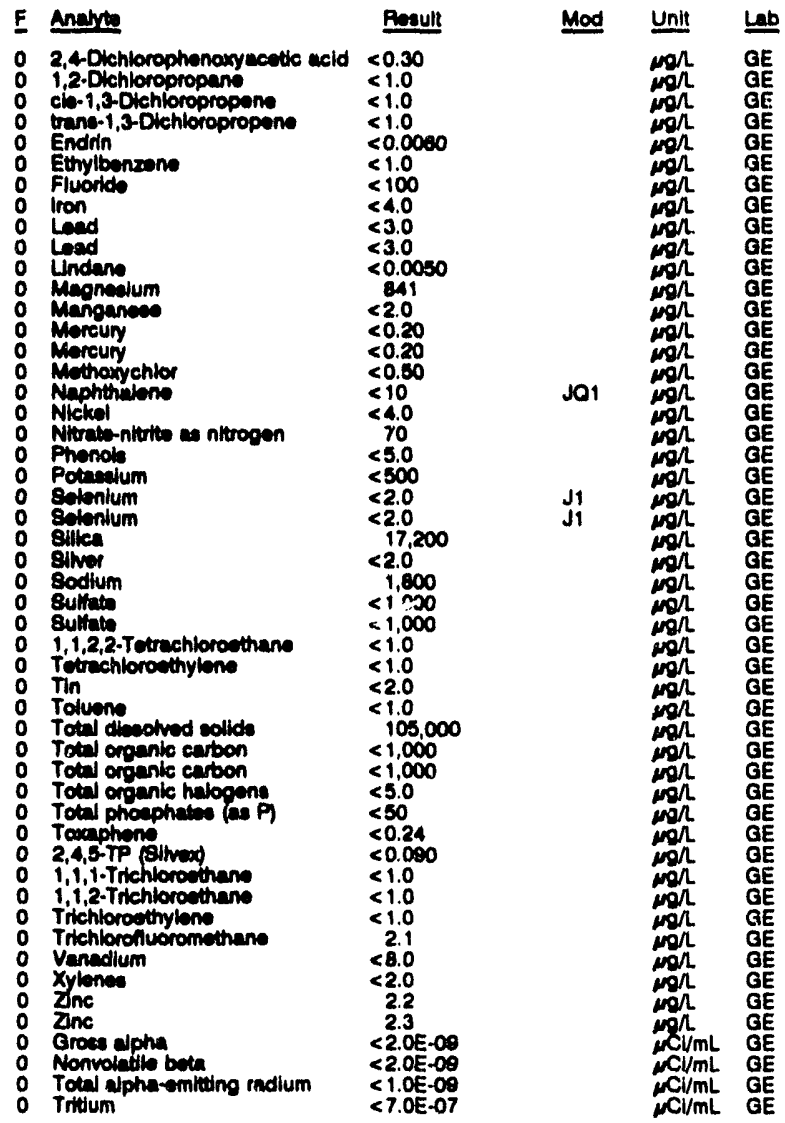

\section{WELL HSB 65C}

MEASUREMENTB CONOUCTEO IN THE FIELD

Bample deta: 0rmare Depth to mater: $40.76 \mathrm{n}(12.42 \mathrm{~m})$ bolow TOC Water elevation: 232.04 ( $(70.07 \mathrm{~m}) \mathrm{mol}$ Woter wecuated betore sampling: $68 \mathrm{gal}$

LABOPATOFY ANALYES

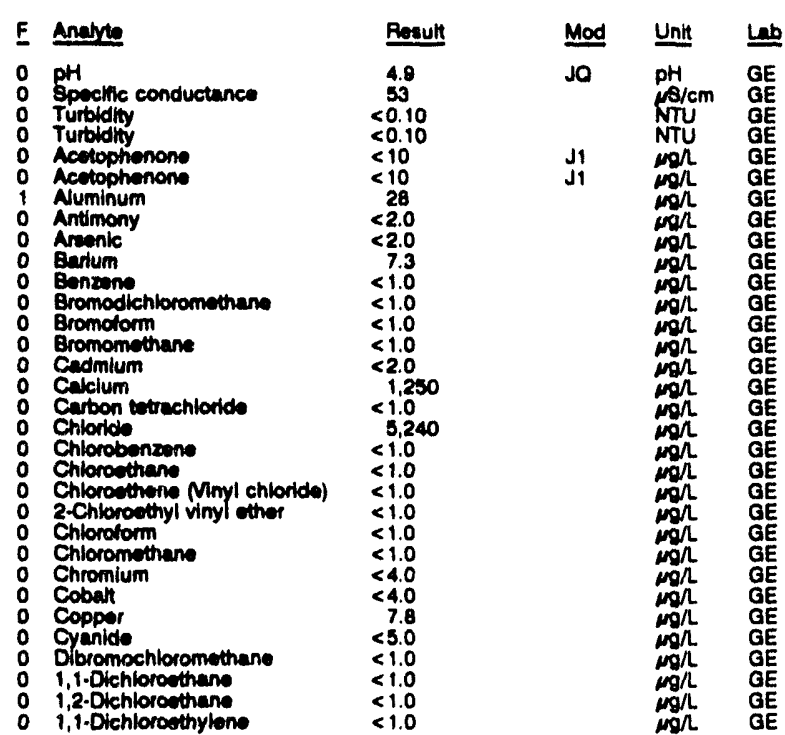

Time: 10:55

PH: 4.7 : $0 \mathrm{mas}$

Water temperature: $20.5 \cdot \mathrm{C}$
WELL HSB 65C collected on 07/00/02, laburatory analyees (cont)

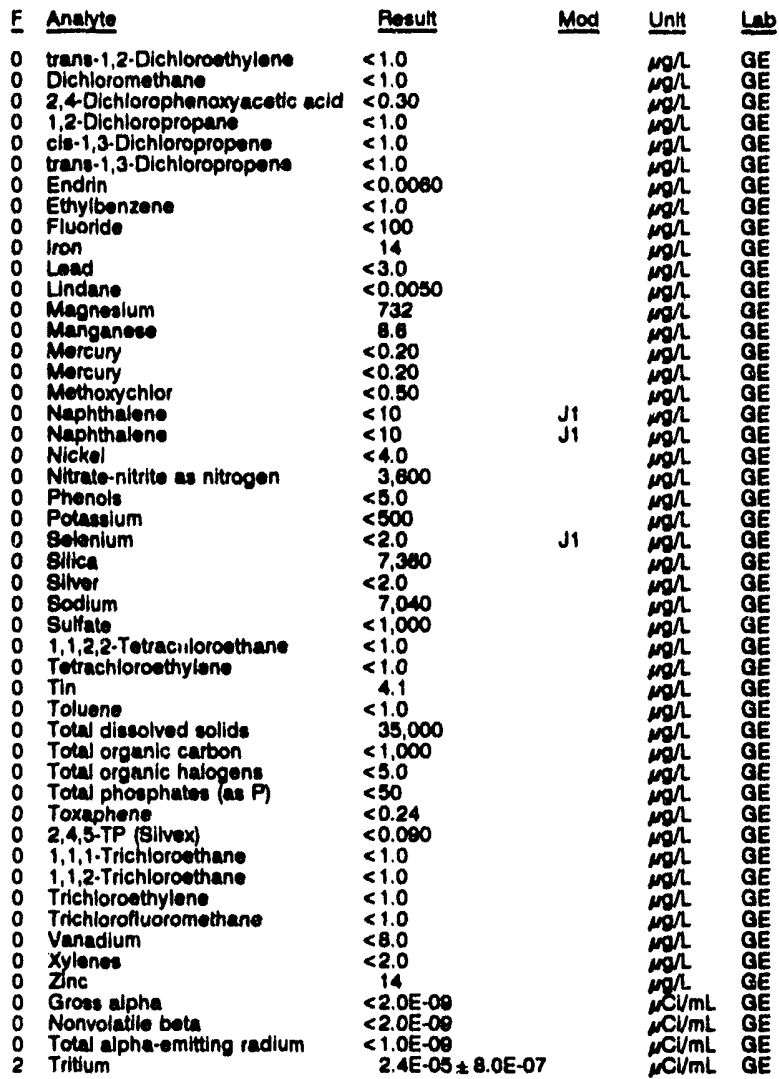

\section{WELL HSB 66}

\section{MEASUREMENTS CONDUCTED IN THE FIELD}

Sanple date: 07/08/22

Depth to water: 55.25 it $(16.64 \mathrm{~m})$ below TOC Walor tovation: $224.05 \mathrm{ht}(80.57 \mathrm{~m}) \mathrm{ms}$ Whitar ovecuated bufors enmpling: $70 \mathrm{gal}$

LABORATOAY ANALYSES

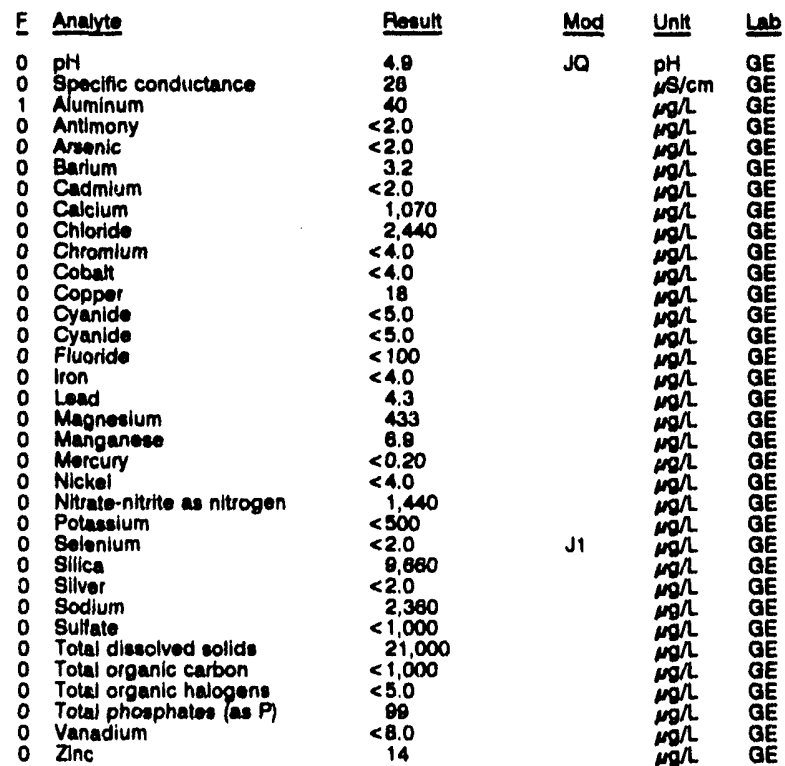




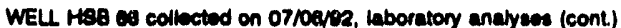

\begin{tabular}{|c|c|c|c|}
\hline Ancyste & Peount & Mod & Unth \\
\hline 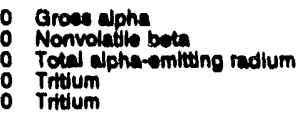 & $\begin{array}{l}<2.0 E-00 \\
<2.0 E-00 \\
1.2 E-00 \pm 0.0 E-10 \\
8.3 E-00 \times 8.0 E-07 \\
8.0 E-00 \pm 8.0 E-07\end{array}$ & & 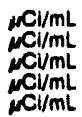 \\
\hline
\end{tabular}

WELL HSB 67

MEABUAEMENTS CONDUCTED IN THE FIELO

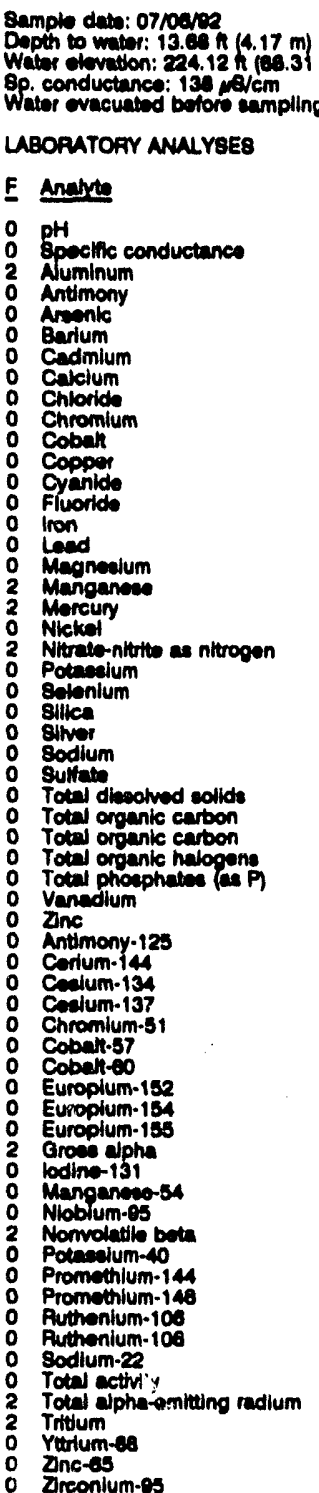

Time: 14:40

PH: 4.1 1 : 0

$$
\text { Water tomporature: } 21.1 \cdot \mathrm{C}
$$$$
\text { mal }
$$

\section{LABORATOFY ANALYSES}

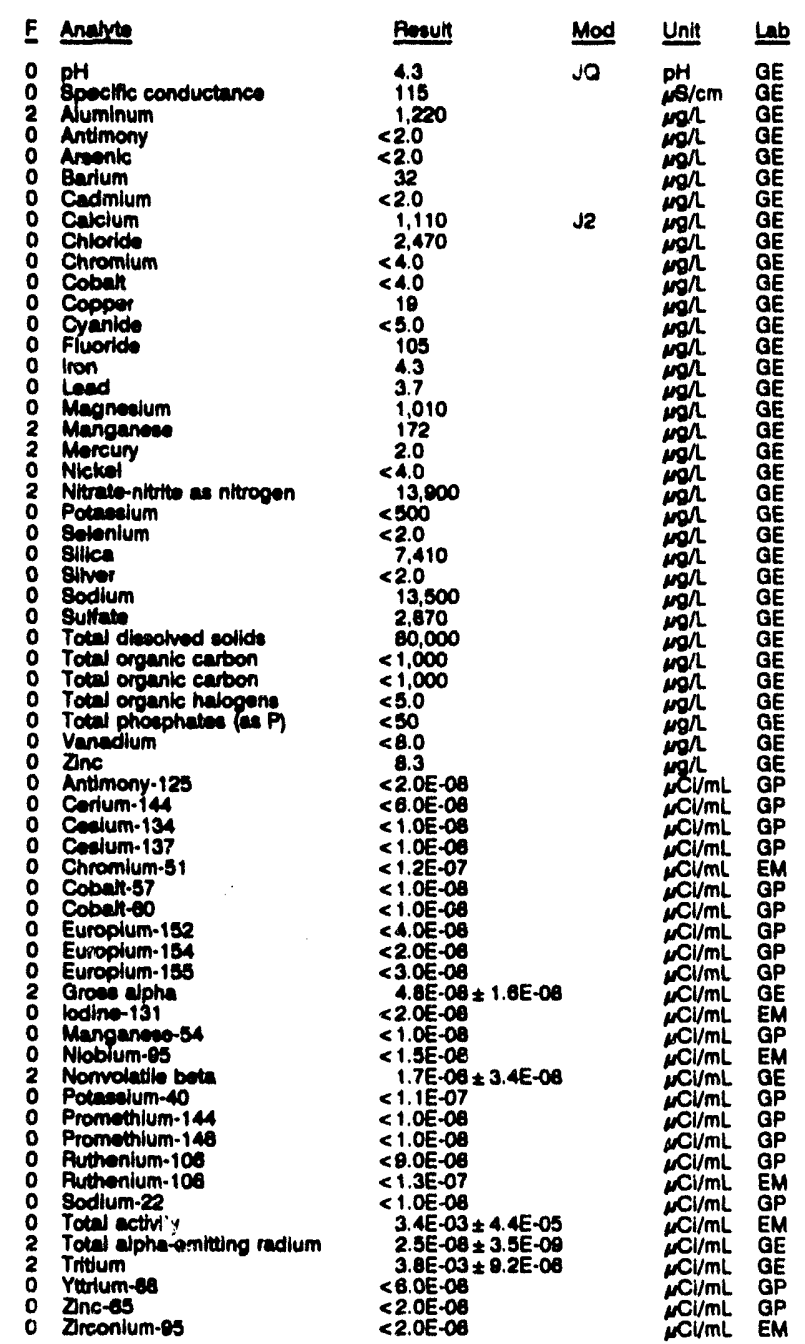

\section{WELL HSB 68}

MEASUREMENTS CONOUCTEO IN THE FIELD

Sample date: 07/01/92

Wopth to wator: $28.87 \mathrm{~h}(8.60 \mathrm{~m})$ below TOC

Water olovation: 221.23 h 107.4

Wheter ovacuated bofore sampling: 21 gal

LABOFATOAY ANALYSES

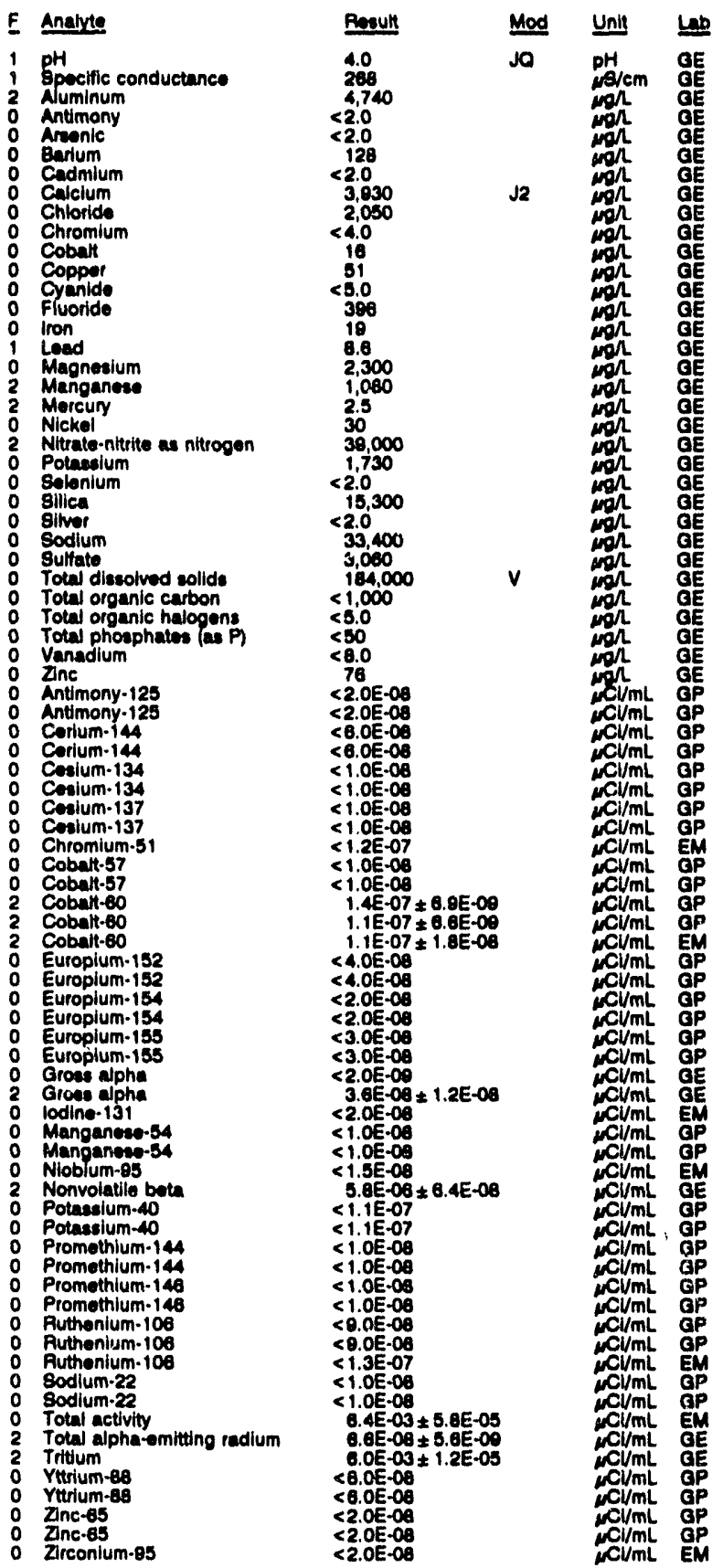




\section{WELL HSB 68A}

MEABUREMENTS CONOUCTEO IN THE FIELD

Eample date: 07/07/pe

Doph to 77,4 , $(23.61 \mathrm{~m})$ balow TOC

Wp condutanc: 171.04 $h$ (o

Whiter wecuatad betore eampiling: 327 gal

LABORATOFY ANALYES

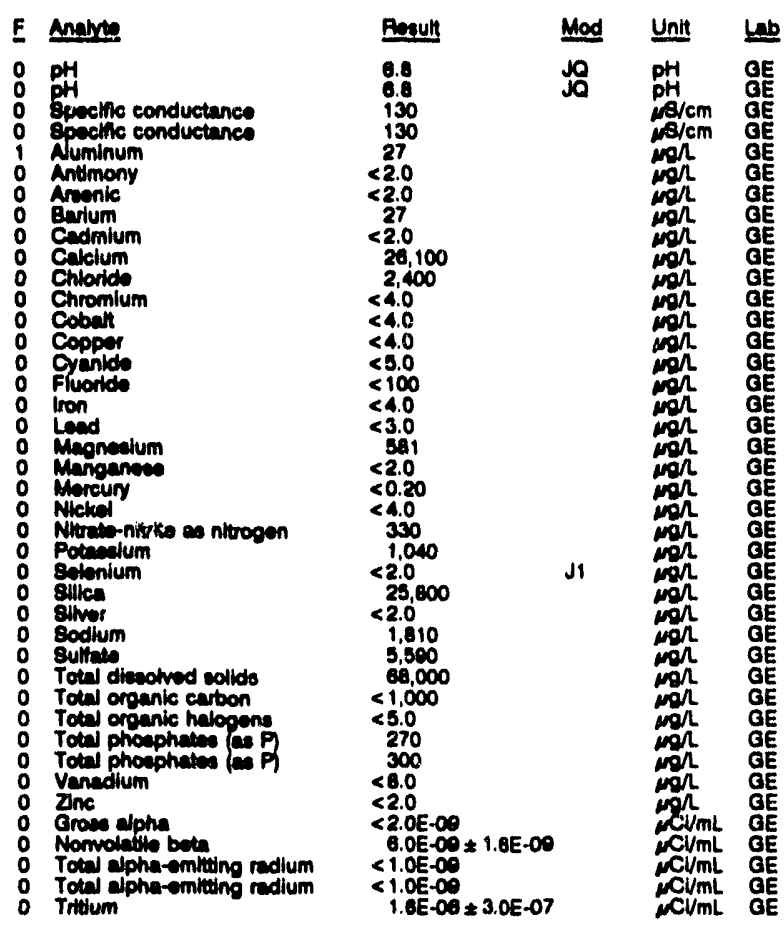

\section{WELL HSB 68B}

MEABUPEMENTS CONOUCTED IN THE FIELD

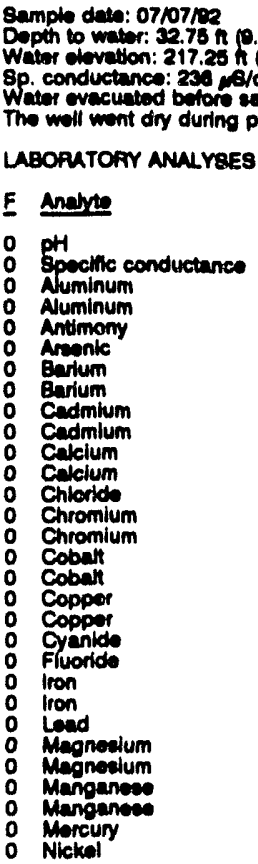

$\begin{array}{ll}\text { m) botow rOC } & \text { Time: } 8: 35 \\ \text { pH: } 7.4 \\ \text { Alkalinity: } 108 \mathrm{mgr} \\ \text { Waller tomperature: } 20.00 \mathrm{C}\end{array}$

Time: 0:20

PH: 6.0 ilinity: $40 \mathrm{mgh}$

Water tomporature: $10.0 \circ \mathrm{C}$
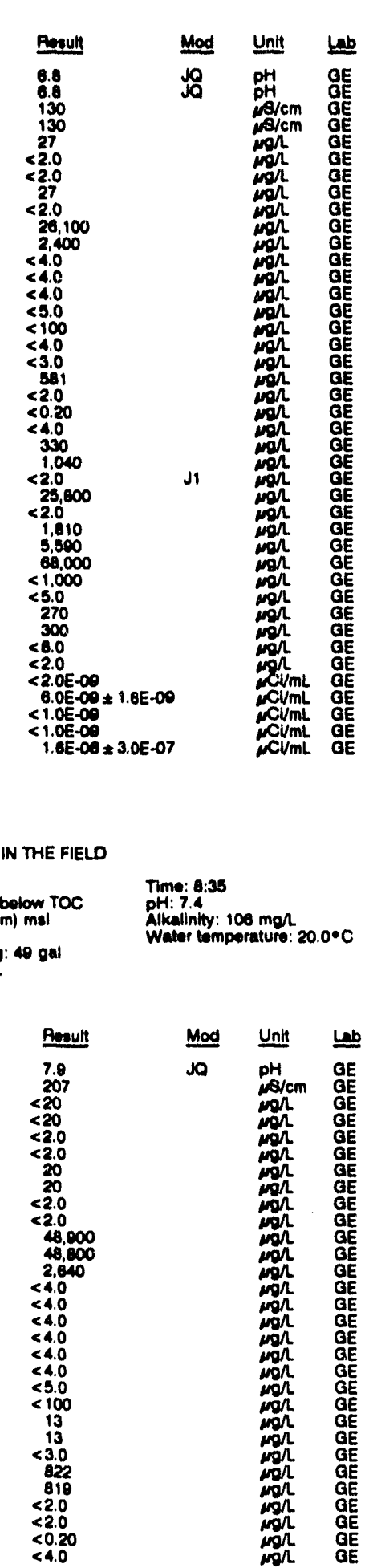

WELL. H88 688 collectod on 07/07/92, laboralory analyees (cont.)

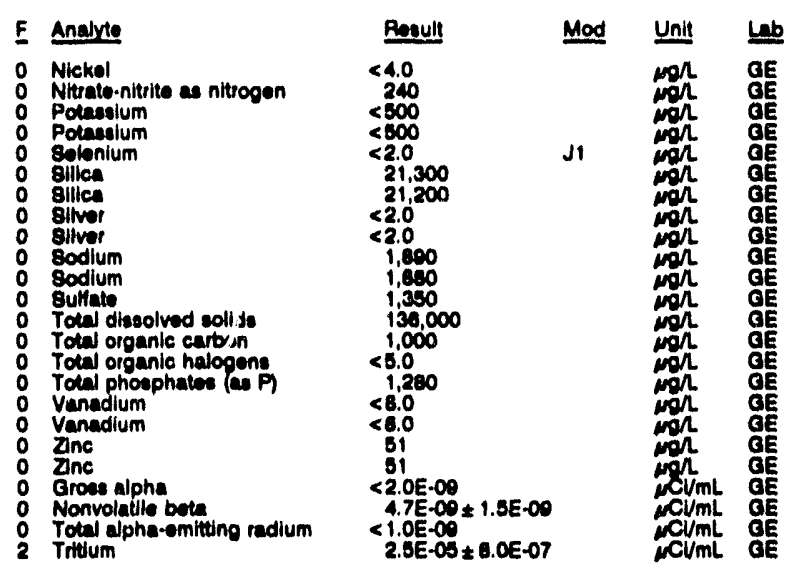

\section{WELL. HSB 68C}

MEASUREMENTS CONDUCTEO IN THE FIELD

\begin{tabular}{|c|c|}
\hline 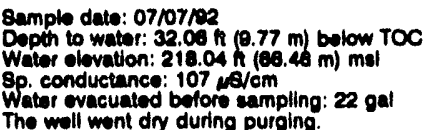 & $\begin{array}{l}\text { Time: } 8: 20 \\
\text { pH: } 0.0 \\
\text { Alkalinity: } 9 \text { mg } / \\
\text { Water tomperaturs: } 20.6^{\circ} \mathrm{C}\end{array}$ \\
\hline
\end{tabular}

LABORATOFY ANALYSES

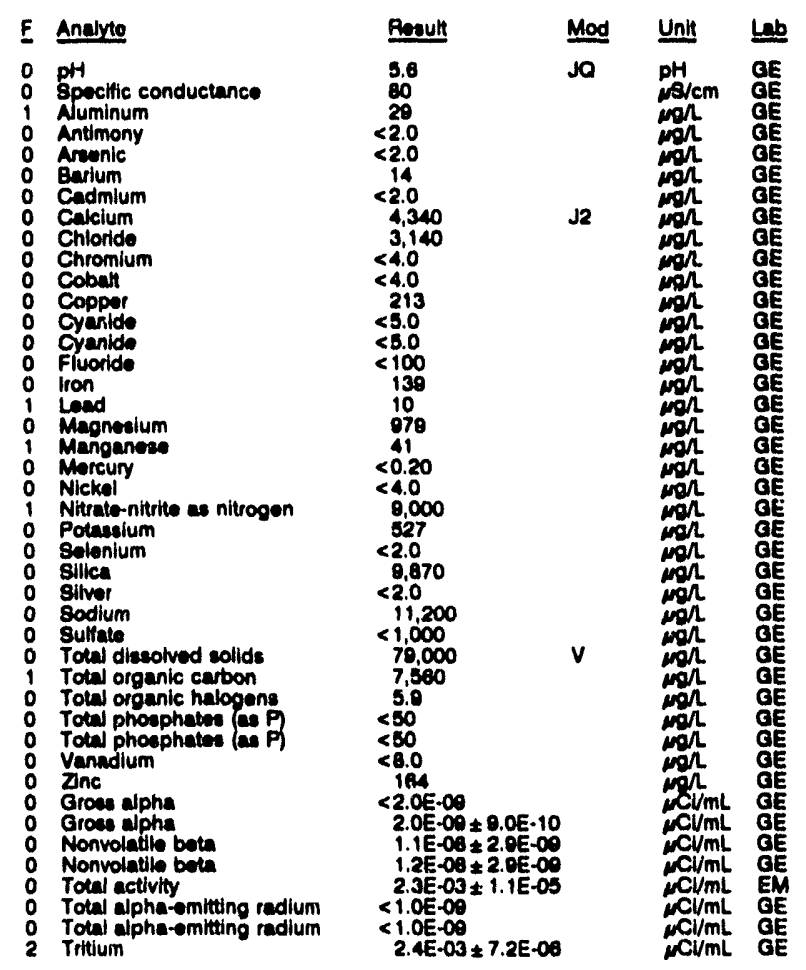


ANALYTICAL RESULTS

WELL HSB 69

MEABUPEMENTS CONDUCTED IN THE FIELD

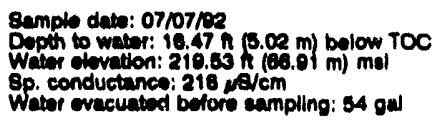
Water evecuated before eampl

E Analyte

1 pH

2 Anuminum

0 Arrenic

0 Barlum

0 Calcium

o Chloride

O Cobatt

- Cobpar

0 Fluorida

o tron

Megnealum

2 Manganea

Mercury

2 Nitratio-nitutio es nitrogen

Potianalum

Silica

0 Biver

O Sodlum

O Todal discolved solids

Tota organic carbon

o Total phosphates (as P)

vanadlum

O Corium-144

o Cesium-13

: Chromium-51

0 Cobalt.57

2 Cobalite

Cobat-eo

Europium-152

Europlum-15.

Groes alphe

lodine-131

Manganeap-sa

Nloblum-8s

Nonvolatile beta

Ponvolatilo betin

Promethium-14a

Promethlum-140

Ruthenlum-108

Podium-2

Toten setwithy

2 Total alpha-emituing radium

Vinc-ses

arconlum-es

19,600

$<2.0$

3,820
86,000

88,000
$<1,000$

8.6

$<300$

62
$<2.0 E-09$

$<2.0 E-09$

$<1.0 E-00$

$<1.2 E-07$

$<4.0 E-00$

$<2.05-08$

$<3.0 E-00$

$<2.06 .08$

$<1.0 F-08$

$<2.06 .00$

$<1,1$ E. 07

$<1.06 .08$

$<8.0 E .08$

$<8.02 .08$

$<1.0 \mathrm{E}-08$

$<6.0 E-06$

$<2.0 E-00$
$<2.0 E-00$

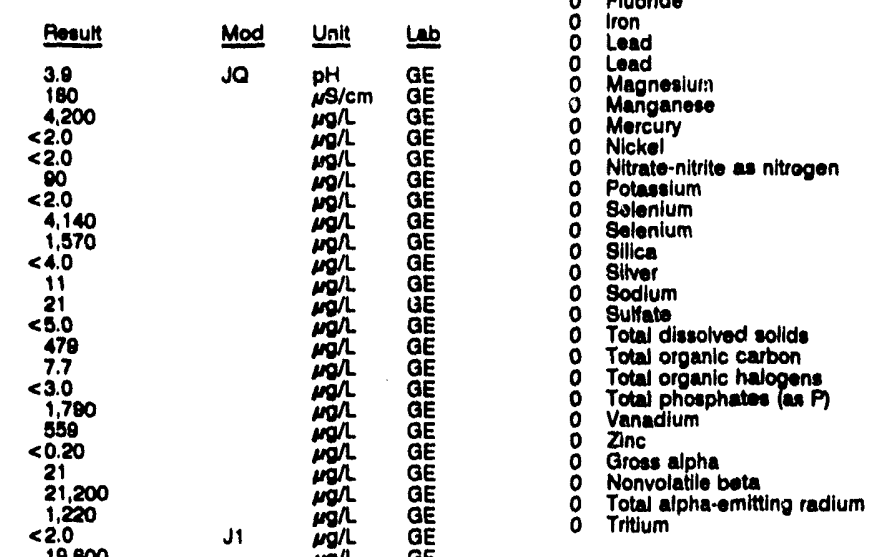

Time: 0:50

Alk: 3.7 ility: $0 \mathrm{mgh}$

Water temporature: $10.8^{\circ} \mathrm{C}$

$1.3 E-07 \pm 1.1 E-08$

1.7E-07 $\pm 2.1 E-0$

$4.3 E-08 \pm 1.1 E-08$

$4.1 E-06 \pm 3.6 E-08$

$7.0 \mathrm{E}-04 \pm 2.3 \mathrm{E}-05$

$7.0 E-04 \pm 2.3 E-05$
7. $3 E-00 \neq 4.2 E-00$
$7.3 E-04 \neq 4.0 E-00$

o Cadmium

o Chlorid

Chromium

Cobalt

Copper

Oranide

Iron

Load

Magnesiurn

Morcury

Nitrate-nitrite as nitrogen

Silice

Sodum

Total dissolved sollds

Total organic carbon

Total phosph

Zinc

Total alpha

WELL HSB 70

Sample date: 07/07/92

Water elevation: $225.25 \mathrm{ht}(68.66 \mathrm{~m}) \mathrm{mal}$

Sp. conductance: $58 \mathrm{\mu s} \mathrm{cm}$

LABORATORY ANALYSES

$E$ Analyte

${ }_{0}^{0} \mathrm{pH}$

Specific conductance

Spocific conductance

Aluminum

Aluminum

Antimony

Antimony

Arsonic

Barium

Barium

Cadmium

- Calcium

Calcium

Chloride

o Chloride

Chromium

0 Cobalt

Cobalt

Copper

WELL HSB 69A collected on 07/07/82, laboratory analyewe (cont)

E Analyte

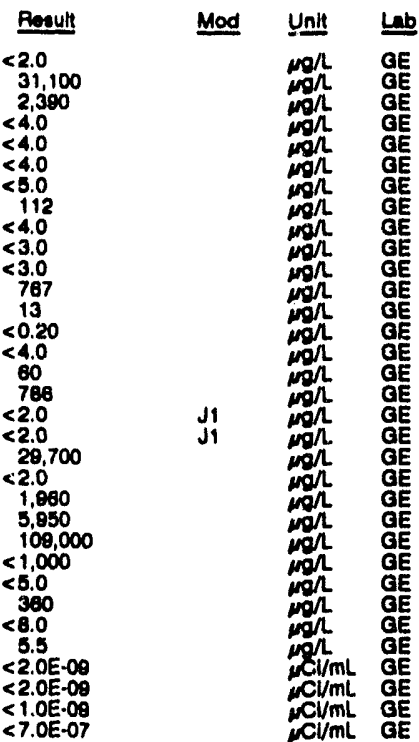

MEASUREMENTS CONDUCTED IN THE FIELO

Depth to water: $17.55 \mathrm{ht}(5.35 \mathrm{~m})$ below TOC

campling: 51 gal

Cyanide

Cyanide

Fluoride

0 Iron

$\begin{array}{ll}0 & \text { iron } \\ 0 & \text { Iron }\end{array}$

2 Lead

0 Magnesium

Magnesium

Manganese

Manganees

Marcury

Mickel

Nickel

Nitrate as nitrogon

Nitrate-nitrite as nitrogen

Potassium

0 Solenium

Selenium

Silica

o Sillca

o Silver

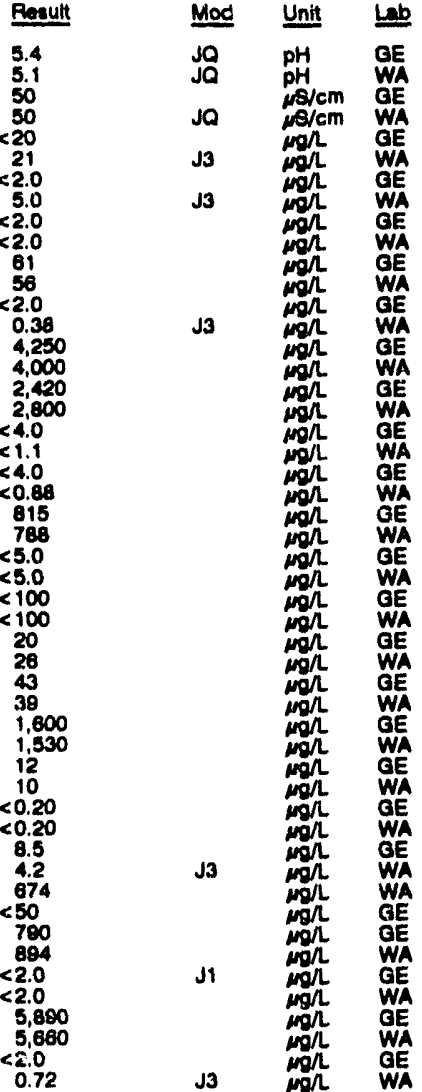


ANALYTICAL RESULTS

WELL H8B 70 collected on 07/07/02, laboratory analyses (cont)

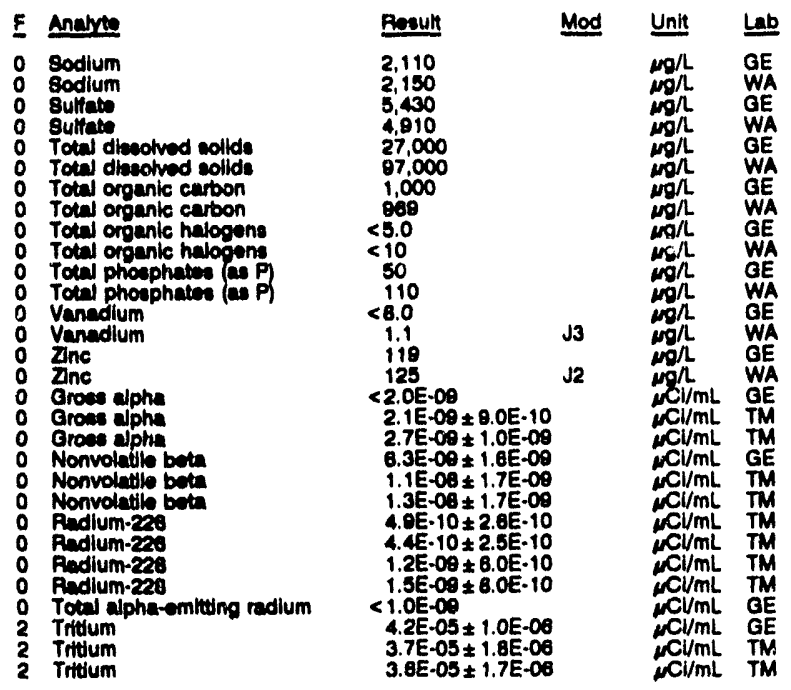

WELL HSB 70 Replicate

\section{MEASUREMENTS CONDUCTED IN THE FIELD}

Sample date: 07/07/pe Dopth to watiof: $17.55 \mathrm{~h}$ (5.35 m) bolow TOC. Sp. conduetance: $50 \mathrm{MS} / \mathrm{cm}$ Witer evecuated before sempling: 51 gal LABORATOFY ANALYSES
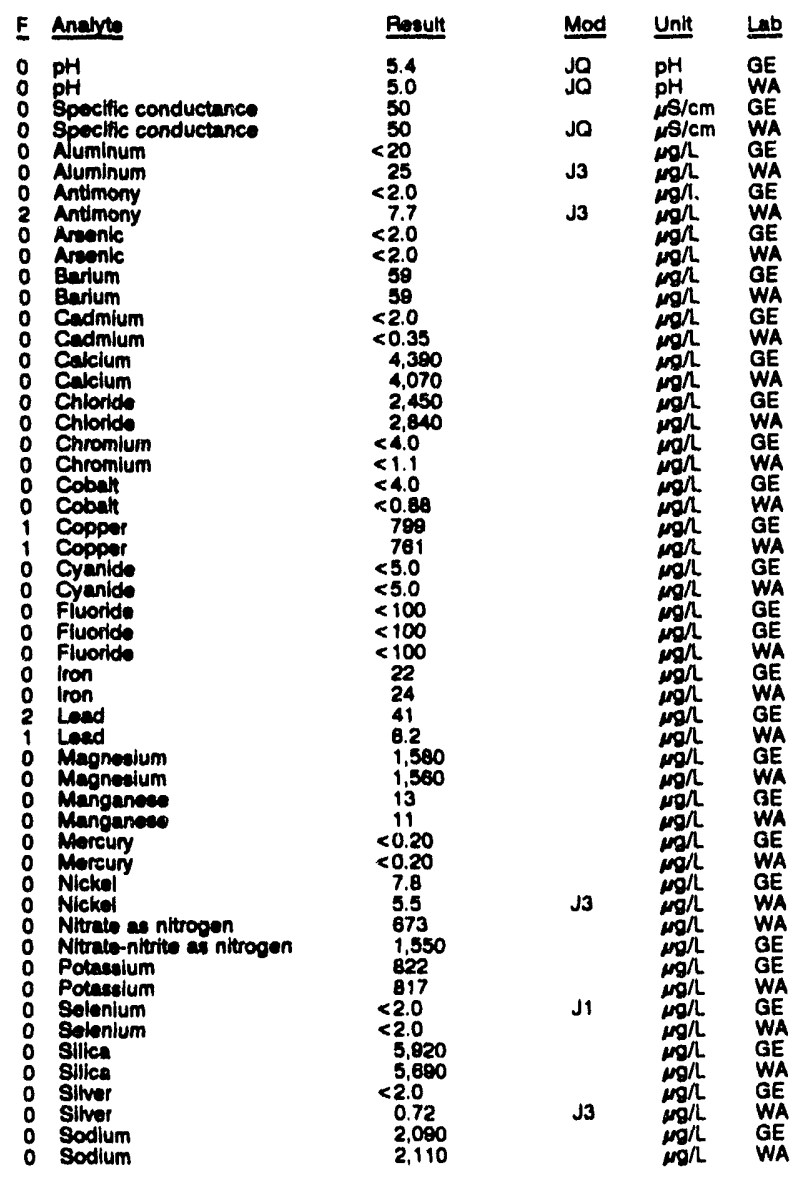

WELL HSB 70 collected on 07/07/82, laboratory analyese (cont.)

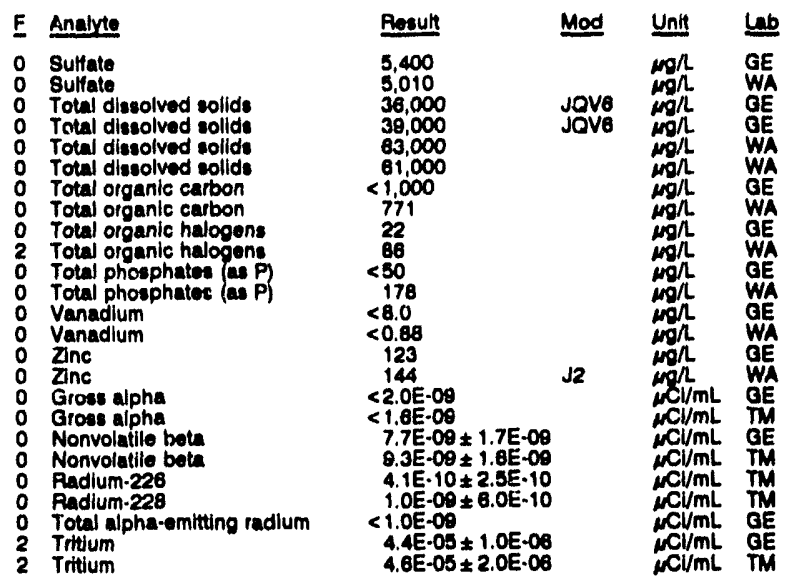

WELL HSB 70C

MEASUAEMENTS CONDUCTED IN THE FIELD

\begin{tabular}{|c|c|}
\hline $\begin{array}{l}\text { Sample date: } 07 / 08 / 82 \\
\text { Depth to water: } 19.21 \mathrm{ht}(5.66 \mathrm{~m}) \text { below TOC } \\
\text { Water elevation: } 223.89 \mathrm{~h}(88.24 \mathrm{~m}) \mathrm{msl} \\
\text { Sp. conductance: } 604 \mu / \mathrm{cm} \\
\text { Water evacuated belore carnpling: } 28 \mathrm{gal}\end{array}$ & $\begin{array}{l}\text { Time: } 8: 30 \\
\text { pH: } 11.8 \\
\text { Alkallinity: } 65 \mathrm{mgn} \\
\text { Water temperature: } 10.0^{\circ} \mathrm{C}\end{array}$ \\
\hline
\end{tabular}

Time: 10:55

pH: 5.1 .

Water temperature: $20.4 \cdot \mathrm{C}$

\section{LABORATORY ANALYBES}

E Analyte Result Mod Unit

PH

o Antimony

0 Arsenic

0 Barium

O Cadmium

C Calcium

Chromium

Cobalt

o Coppor

O Fyanide

o Iron

o Lead

Manganese

Morcury

Nitrate-nitrito as nitrogen

Potassium

Solicnium

Silica

Sodium

Total dissolved solids

Total organic cartion

Total organic halogens

Total phosphates (as PF

Vanadium

Zanc

Antimony-125

Cesium.134

Cesium-134

Chromium-51

Cobult -57

Cobalt-60

Europlum-152

Europium-154

Gross alphe

lodine-131

Manganese-54

Nioblum-95

Nonvolatile bota

Potassium-40

Promethium-144

Promethlum-146

Ruthenium.106

Sodium-22

Total activity

Total alpha-omitting radium

2 Tritium

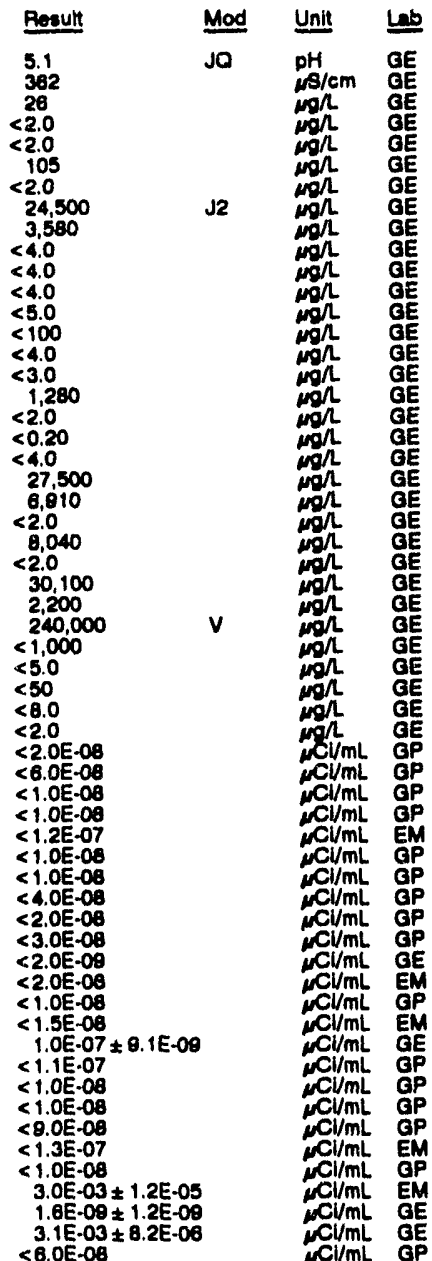


WELL HSB 70C collected on 07/08/92, laboratory analyeses (cont)

\begin{tabular}{|c|c|c|c|}
\hline E Natste & Result & Mod & Unit \\
\hline $\begin{array}{l}0 \\
0 \\
0\end{array}$ & $\begin{array}{l}<2.05-08 \\
<2.0 E-08\end{array}$ & & $\underset{\mu \mathrm{CV} / \mathrm{mL}}{\mu}$ \\
\hline
\end{tabular}

WELL H.SB 71

MEASUREMENTS SONDUCTED IN THE FIELD

Sample date: $07 / 2 a / 02$

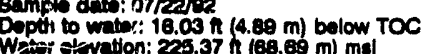

Wation: $225.37 \mathrm{~h}$

Wh. conductance: $24 \mathrm{\mu S} / \mathrm{cm}$.

LABORATOZY ANALYSES

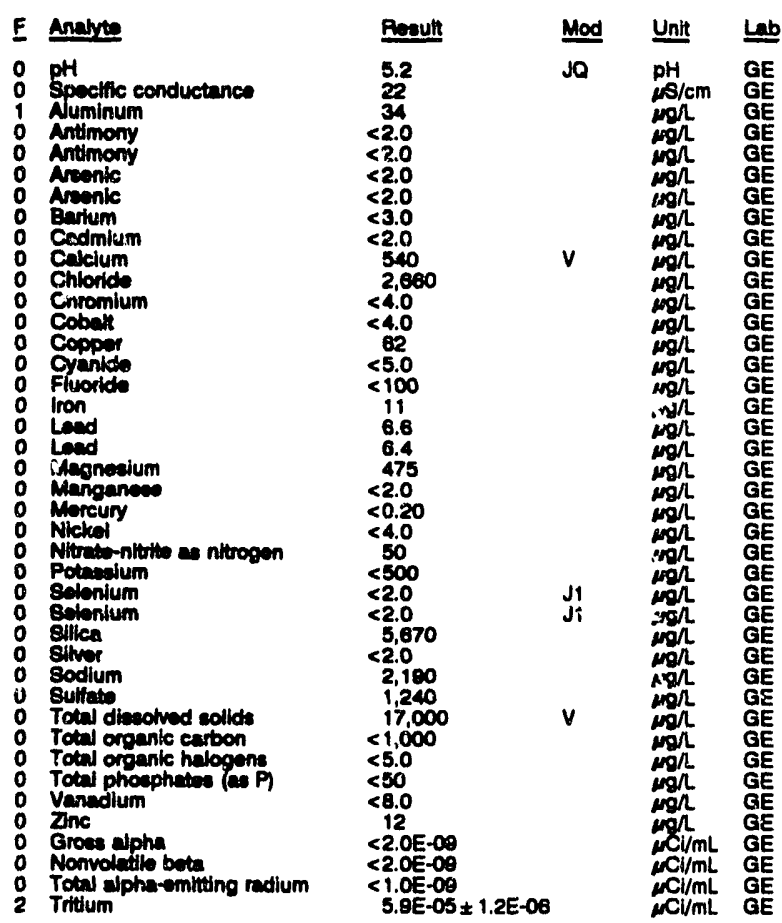

WELL HSB 71C

MEASUPEMENTS CONDUCTED IN THE FIELO

ginnigin dete: 07/23/92 Whith to water: $18.21 \mathrm{~g}(5.55 \mathrm{~m})$ below TOC Wabr envertion: 228.39 h $(69.08$

Water evecuatod before = mpling: $23 \mathrm{gal}$ The well went dry during purging.

LABOAATOAY ANALYSES

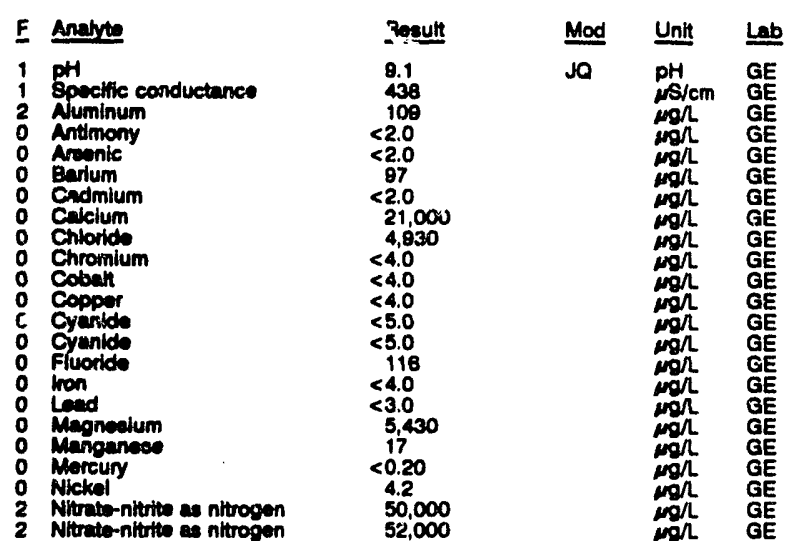

WELL HSB $71 \mathrm{C}$ collected on 07/23/92, laboratory anulyees (cont)

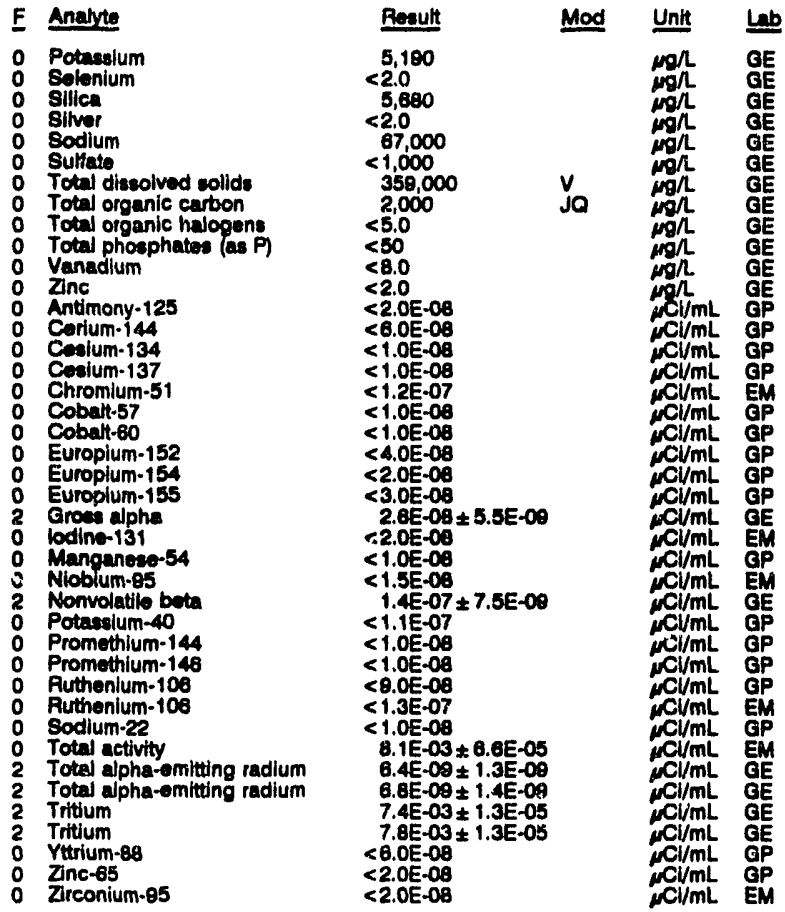

WELL HSB 83A

MEASUREMENTS CONDUCTED IN THE FIELO

Sample date: 07/07/92

Depth to water: $63.86 \mathrm{ft}(18.50 \mathrm{~m})$ bolow TOC

Water elovation: $173.34 \mathrm{th}(52.83 \mathrm{~m}) \mathrm{msi}$

Water evecuated before sampling: $284 \mathrm{gal}$

LABORATOAY ANALYYSES

F Analyte

Specific conductance

Aluminum

Antimony

Arsenic

Barium

Cadmium

Calcium

Chromium

Cobalt

Coppor

Fluoride

Iron

Magnesium

Manganese

Mercury

Nitrato-niturte as nitrogen

Sotasgium

Solica

Sirver

Sodium

Total diesolved solld

Total organic carbon

Total organic halogene

J Total phosphetes (MS PI

o Vanadium

O Zinc

Groas alpha

Nonvolatle bota Total alpha-emitting radium
Trttium
Time: 13:55

pH: 8.6 . $77 \mathrm{mgn}$ Water tomperature: $20.4^{\circ} \mathrm{C}$

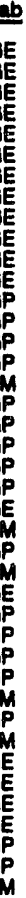

P.




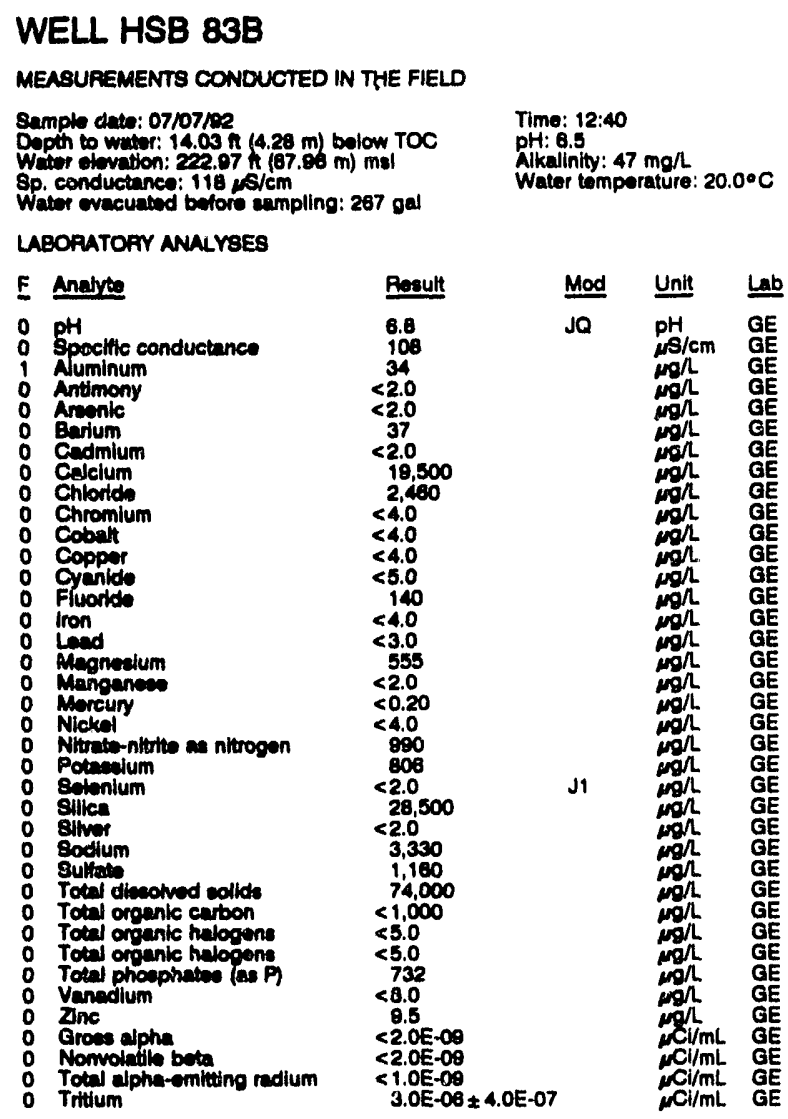

WELL HSB $83 C$

MEASUREMENTS CONDUCTED IN THE FIELD

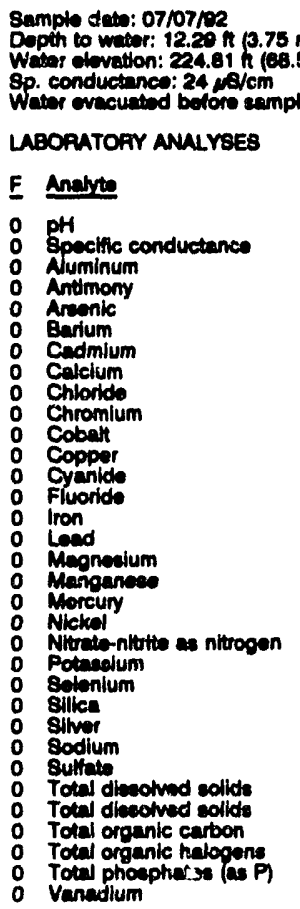

Time: 12:50

$\mathrm{PH}: 5.1$

Alkalinity: $1 \mathrm{mod}$

Water temperature: $18.6^{\circ} \mathrm{C}$
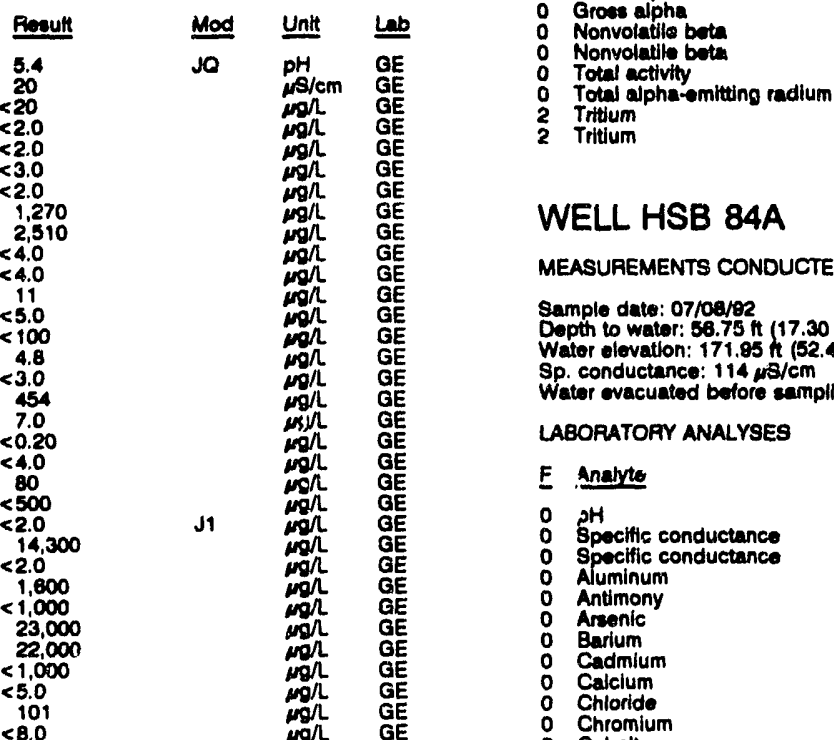

WELL HSB 63C collected on 07/07/82, laboratory analyees (cont.)

\begin{tabular}{|c|c|c|c|}
\hline E Anulyte & Result & Mod & Unit \\
\hline $\begin{array}{ll}0 & \text { Zlnc } \\
0 & \text { Gross alpha } \\
0 & \text { Grose alpha } \\
0 & \text { Nonvolatile beta } \\
0 & \text { Nonvolatile beta } \\
0 & \text { Total alpha-emitting redium } \\
0 & \text { Tritium } \\
0 & \text { Tritium }\end{array}$ & $\begin{array}{rl}11 & 11 \\
<2.0 E-09 \\
<2.0 E-09 \\
<2.0 E-09 \\
<2.0 E-09 \\
<1.0 E-09 \\
8.0 E-07 \pm 3.0 E-07 \\
1.0 E-06 \pm 3.0 E-07\end{array}$ & & 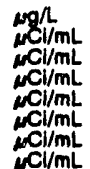 \\
\hline
\end{tabular}

\section{WELL HSB 83D}

MEASUREMENTS CONDUCTED IN THE FIELD

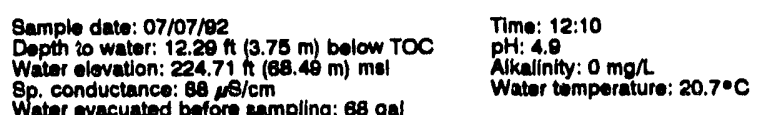
Water evacuated bofore eampling: $68 \mathrm{gal}$

LABORATORY ANALYSES

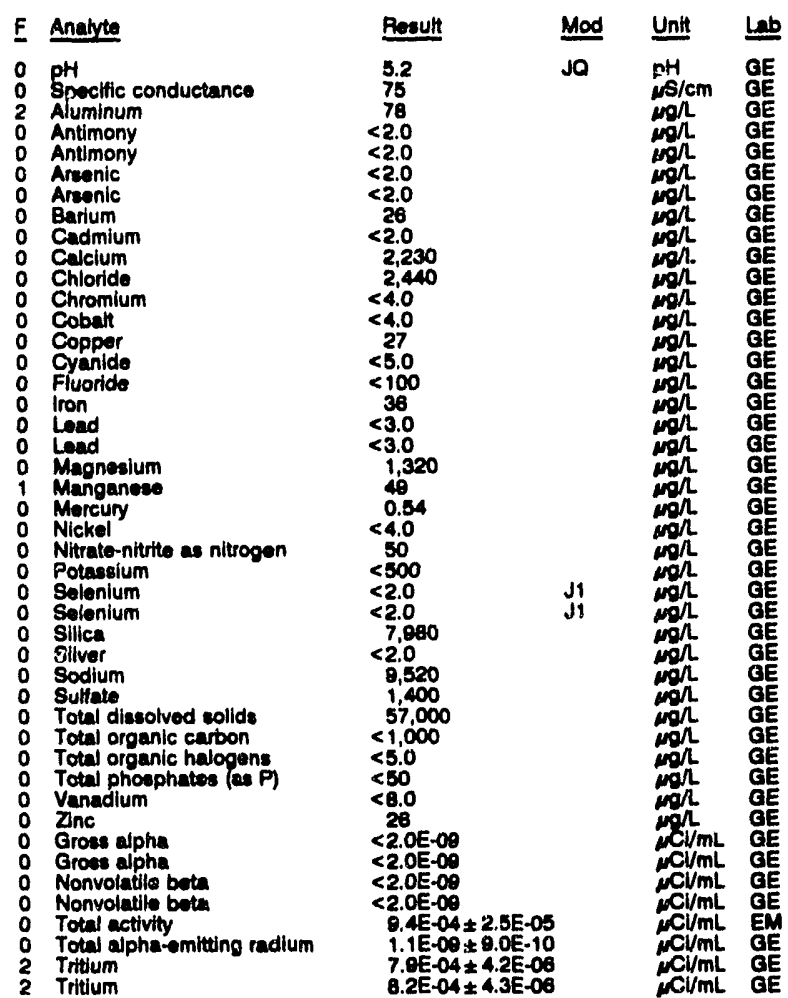

WELL HSB 84A

MEASUREMENTS CONDUCTED IN THE FIELD

\begin{tabular}{|c|c|}
\hline $\begin{array}{l}\text { Sample date: } 07 / 08 / 92 \\
\text { Dopth to water: } 58.75 \mathrm{ft}(17.30 \mathrm{~m}) \text { bolow TOC } \\
\text { Wator olevation: } 171.95 \mathrm{~h}(52.41 \mathrm{~m}) \mathrm{msl} \\
\text { Sp. conductance: } 114 \mathrm{\mu s} / \mathrm{cm}\end{array}$ & $\begin{array}{l}\text { Time: } 8: 55 \\
\text { PH: } 6.4 \\
\text { Alkalinity: } 31 \text { mg/ } \\
\text { Weter tomperature: } 20.00 \mathrm{C}\end{array}$ \\
\hline
\end{tabular}
Water evacuated betore sempling: $281 \mathrm{gal}$ LABORATORY ANALYSES

\begin{tabular}{|c|c|c|c|}
\hline Analyte & Posulk & Mod & Unit \\
\hline $\begin{array}{l}\text { 2H } \\
\text { Spocific conductance } \\
\text { Spoetic conductance } \\
\text { Aluminum } \\
\text { Antimony } \\
\text { Ansenic } \\
\text { Barium } \\
\text { Cadmium } \\
\text { Calcium } \\
\text { Chloride } \\
\text { Chromium } \\
\text { Cobalt } \\
\text { Copper }\end{array}$ & $\begin{array}{r}6.2 \\
102 \\
100 \\
<20 \\
<2.0 \\
3.6 \\
2.0 \\
<2.0 \\
17.700 \\
2,480 \\
<4.0 \\
<4.0 \\
<4.0\end{array}$ & $\begin{array}{l}\text { Jo } \\
\text { J1 }\end{array}$ & 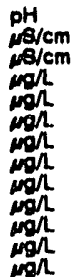 \\
\hline
\end{tabular}


ANALYTICAL RESULTS

WELL HBB eAA collected on 07/08/82, laborntory analyees (cont)

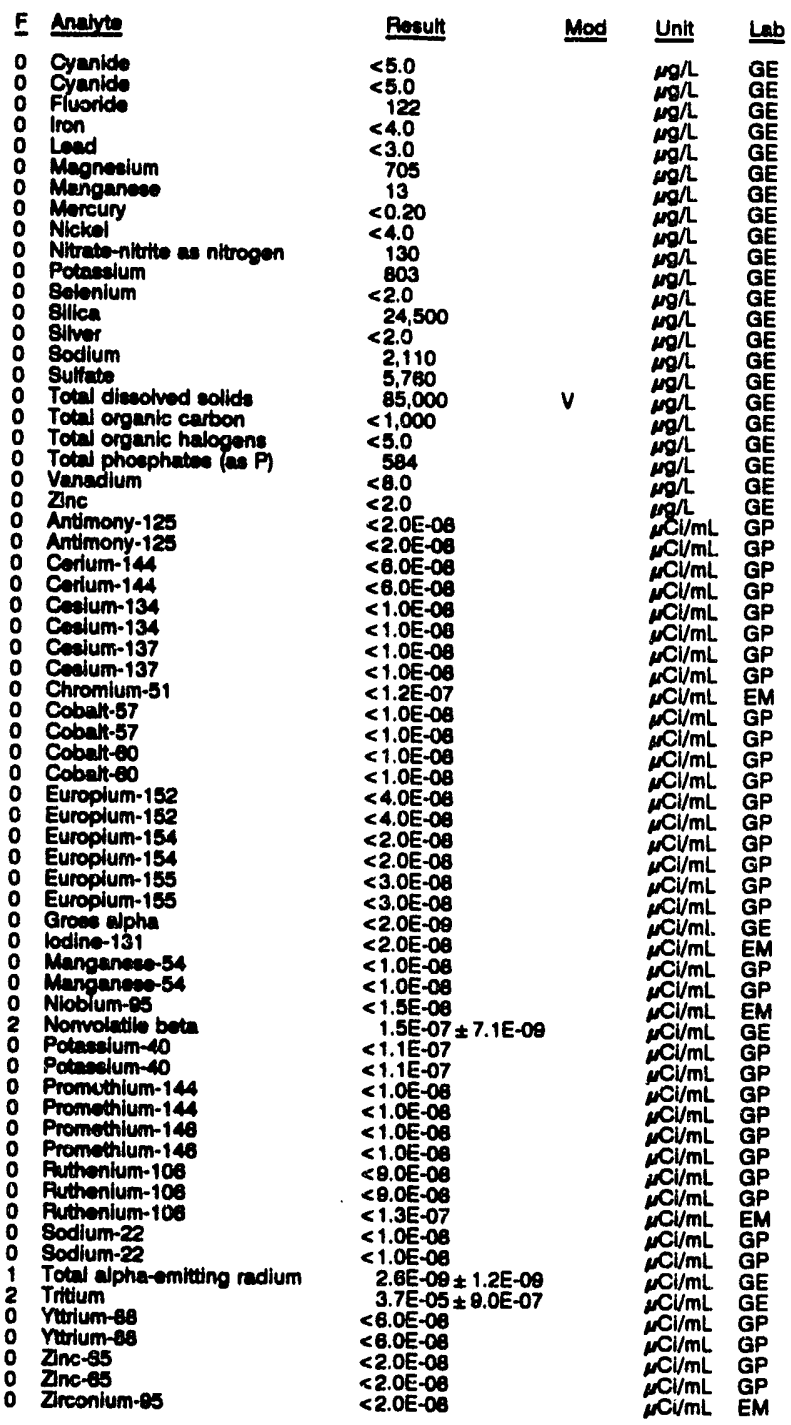

\section{WELL HSB 84B}

MEABUREMENTS CONDUCTED IN THE FIELD

Eample dato: 07/08/er

Dupth to wader: 16.20 it $(5.55 \mathrm{~m})$ bolow TOC

Werter clevation: 210.70 h $(84.22 \mathrm{~m}) \mathrm{msl}$

Sp. conductance: $130 \mathrm{\mu s} / \mathrm{cm}$

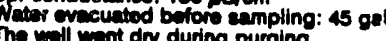

LABORATORY ANALYBES

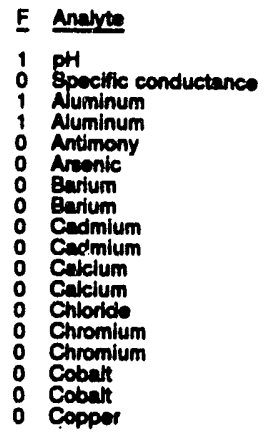

\begin{tabular}{|c|c|c|}
\hline Rosult & Mod & Unit \\
\hline $\begin{aligned} & \theta .3 \\
& 112 \\
& 35 \\
& 35 \\
& 35 \\
&<2.0 \\
&<2.0 \\
& 35 \\
& 35 \\
&<2.0 \\
&<2.0 \\
& 18,400 \\
& 18,400 \\
& 2,440 \\
&<4.0 \\
&<4.0 \\
&<4.0 \\
&<4.0 \\
&<4.0\end{aligned}$ & $\begin{array}{l}\sqrt{2} \\
\sqrt{ } 2\end{array}$ & 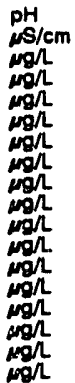 \\
\hline
\end{tabular}

WELL H8B 848 collocted on 07/08/92, laboratory snalyses (cont)

\begin{tabular}{|c|c|c|c|}
\hline Analyte & Rerult & Mod & Unit \\
\hline $\begin{array}{l}\text { Copper } \\
\text { Cyanide } \\
\text { Fluoride } \\
\text { lron } \\
\text { lron } \\
\text { Lead } \\
\text { Magnesium } \\
\text { Magnesium } \\
\text { Manganese } \\
\text { Manganeses } \\
\text { Morcuny } \\
\text { Nickel } \\
\text { Nickel } \\
\text { Nitrate-nitrite as nitrogen } \\
\text { Potassium } \\
\text { Potasslum } \\
\text { Solenlum } \\
\text { Sillica } \\
\text { Sillca } \\
\text { Silver } \\
\text { Silver } \\
\text { Sodium } \\
\text { Sodium } \\
\text { Sulfate } \\
\text { Total dissolved sollds } \\
\text { Total organic carbon } \\
\text { Total organic halogens } \\
\text { Total phosphates (as P) } \\
\text { Vanadlum } \\
\text { Vanadium } \\
\text { Zne } \\
\text { Zine } \\
\text { Grose alpha } \\
\text { Nonvolatile beta } \\
\text { Total alpha-emitting radium } \\
\text { Total alpha-omitting radium } \\
\text { Tritium } \\
\text { Tritium }\end{array}$ & $\begin{array}{l}<4.0 \\
<5.0 \\
<100 \\
<4.0 \\
<4.0 \\
<3.0 \\
240 \\
240 \\
<2.0 \\
<2.0 \\
<0.20 \\
<4.0 \\
<4.0 \\
840 \\
3,100 \\
3,060 \\
<2.0 \\
33,600 \\
33,500 \\
<2.0 \\
<2.0 \\
4,630 \\
4,620 \\
2,870 \\
101,000 \\
<1,000 \\
<5.0 \\
162 \\
<8.0 \\
<8.0 \\
<2.0 \\
<2.0 \\
<2.0 E-00 \\
6.6 E-09 \pm 2.0 E-09 \\
<1.0 E-09 \\
<1.0 E-09 \\
7.5 E-05 \pm 1.3 E-08 \\
7.8 E-05 \pm 1.3 E-08\end{array}$ & v & 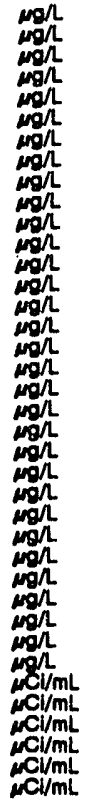 \\
\hline
\end{tabular}

\section{WELL HSB 84C}

MEASUREMENTS CONDUCTED IN THE FIELD

Sample date: 07/0a/82

Depth to water: 15.28 it (4.68 m) below TOC

Water olovation: $213.82 \mathrm{th}(65$

Sp. conductance: $84 \mu \mathrm{s} / \mathrm{cm}$.

The well went dry during purging.

LABORATOFY ANALYSES

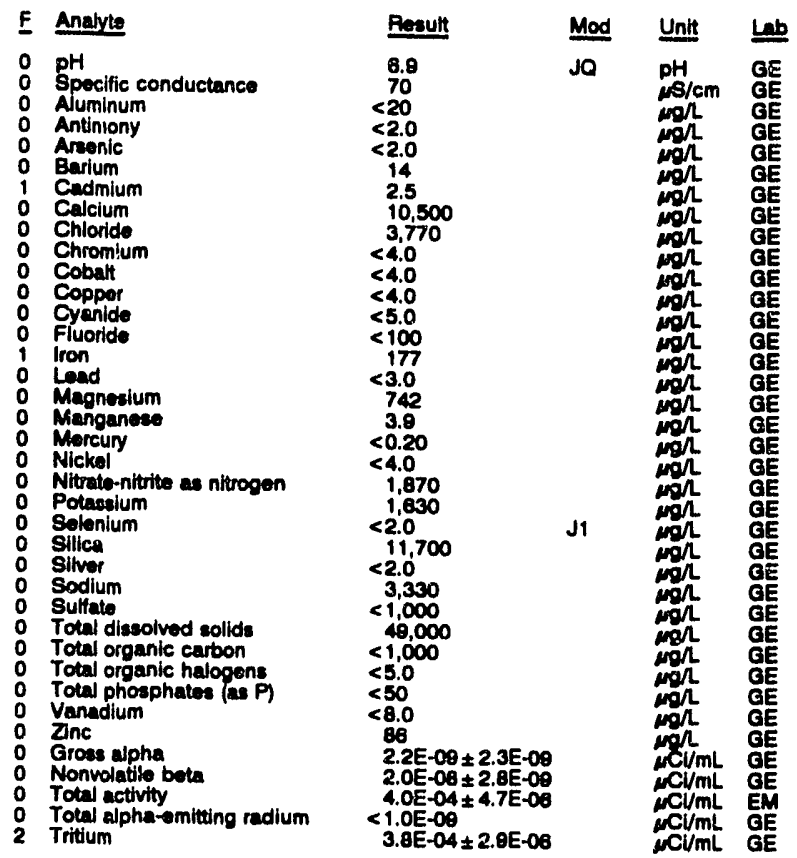


WELL HSB 84D

MEASUREMENTS CONDUCTED IN THE FIELD

Sample dete: 07 nave

Depth to water: 9.85 i $(3.00 \mathrm{~m})$ bolow TOC

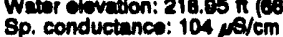

Water evecuated before sampling: 51 gal

LABOFATOFY ANALYSES

$E$ Anabte

$\begin{array}{ll}\text { pH } \\ 2 & \text { Spocific conductance } \\ 2 & \text { Aluminum }\end{array}$

o Antimony

0 Barium

o Cendmium

o Chiorido

- Chromium

O Cobut

0 Copper

0 Fluorle

0 iron

0 Magnealum

2 Mangenea

Moreury

Nitrata-nititite as nitrogen

Nitrate-nituts as nitrogen

Potanalum

selonium

Sinver

0 Sodsum

Total dlacelved collid

Total organic carbon

Total orgenic halogans

Zne

Antimony-125

Corlumin-13

Cecium-137

Chromium-51

Cobatt.57

Cobalte0

Europium-15

Europium-15

Europlum-15

Groes alphe

lodino-131

Mioblum-es

Nonvolatilo beta

Promethium-14s

Promethlum-148

Puthenlum-108

Puthenium-100

Puthonium-10s

Total setivity

Total alpha-omituing radium

Tritium

Yurium-60

Zunce-65

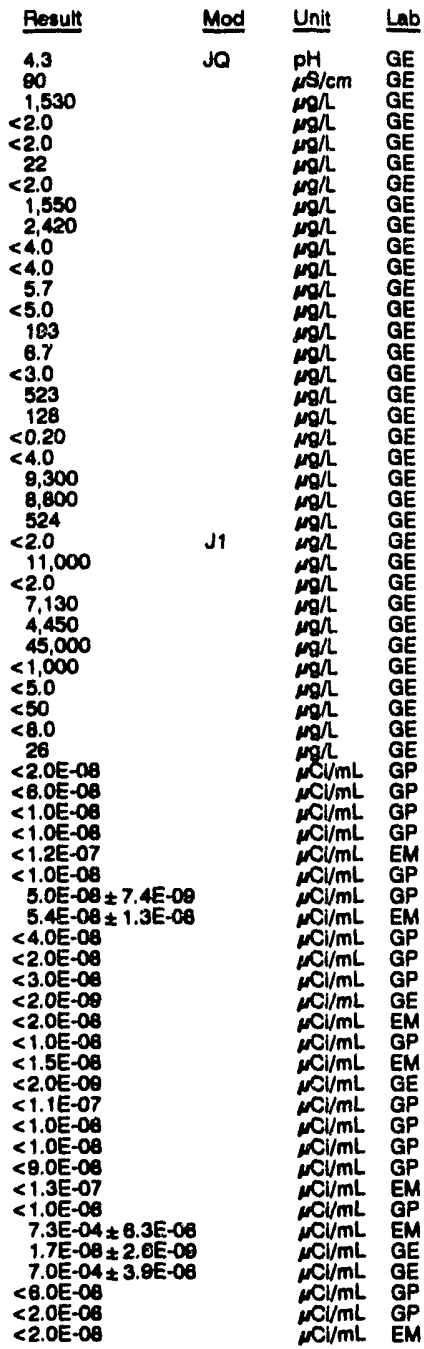

WELL HSB 85A

MEASUREMENTS CONDUCTED IN THE FIELD

Sample deta: 07parge

Depth to watar: 125.32 it $(38.20 \mathrm{~m})$ below TOC

Water olovation: 160.08 if (51)

Time: 8:40

pH: 4.0

Walinity; $0 \mathrm{mg} / \mathrm{L}$

Water temperature: $18.8^{\circ} \mathrm{C}$

Water evecuated before sumpling: $283 \mathrm{gal}$

LABOFATORY ANALYSES

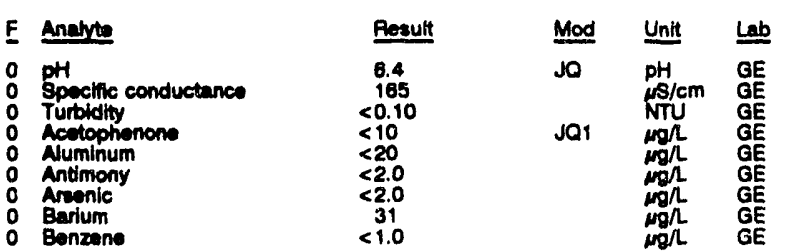

WELL HSB 85A collectod on 07/08/92, laboratory analyees (cont.)

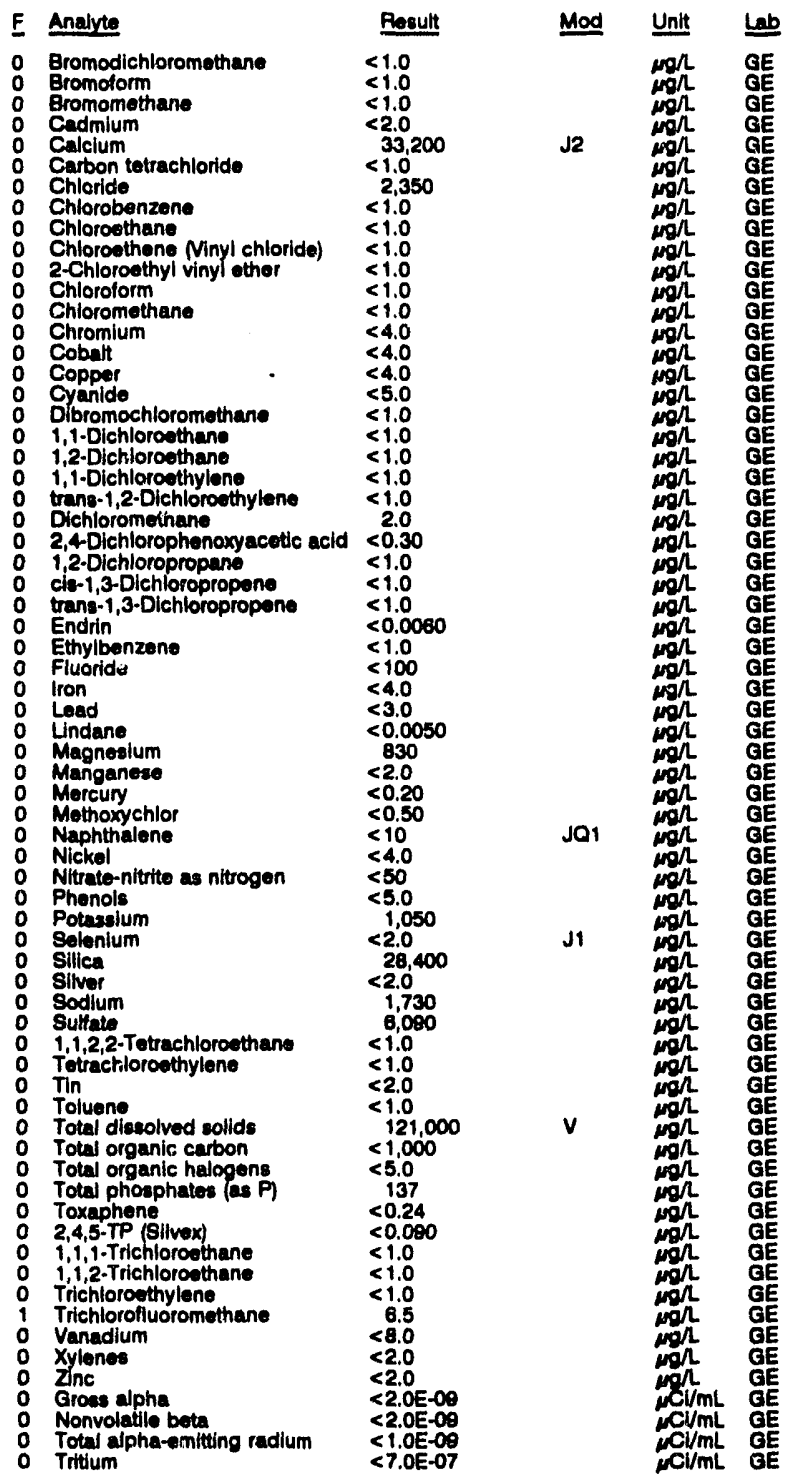

\section{WELL HSB 85B}

MEASUREMENTS CONDUCTED IN THE FIELD

Sample date: 07/00/92

Water evacuated before sampling: $50 \mathrm{gal}$

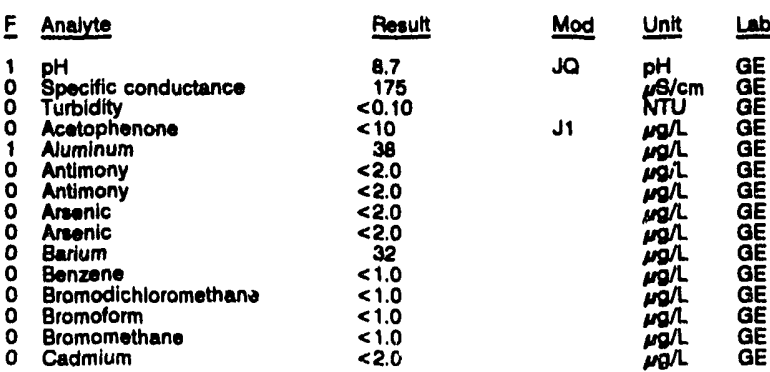

Depth to water: $61.13 \mathrm{ft}(18.63 \mathrm{~m})$ below TOC

Water elevation: 233.37 h $(71.13 \mathrm{~m}) \mathrm{mel}$

Sp. conductance: $513 \mathrm{\mu s} / \mathrm{cm}$

The well went ory during purging.

LABORATORY ANALYSES

Time: 11:35

Alkalinity: $119 \mathrm{mgah}$ Water tomporature: $20.7 \bullet \mathrm{C}$

$83 \mathrm{man}$ Water temperature: $20.3 \circ \mathrm{C}$ 
ANALYTICAL RESULTS

WELL HS8 858 collected on 07/08/92, laboratory analyees (cont)

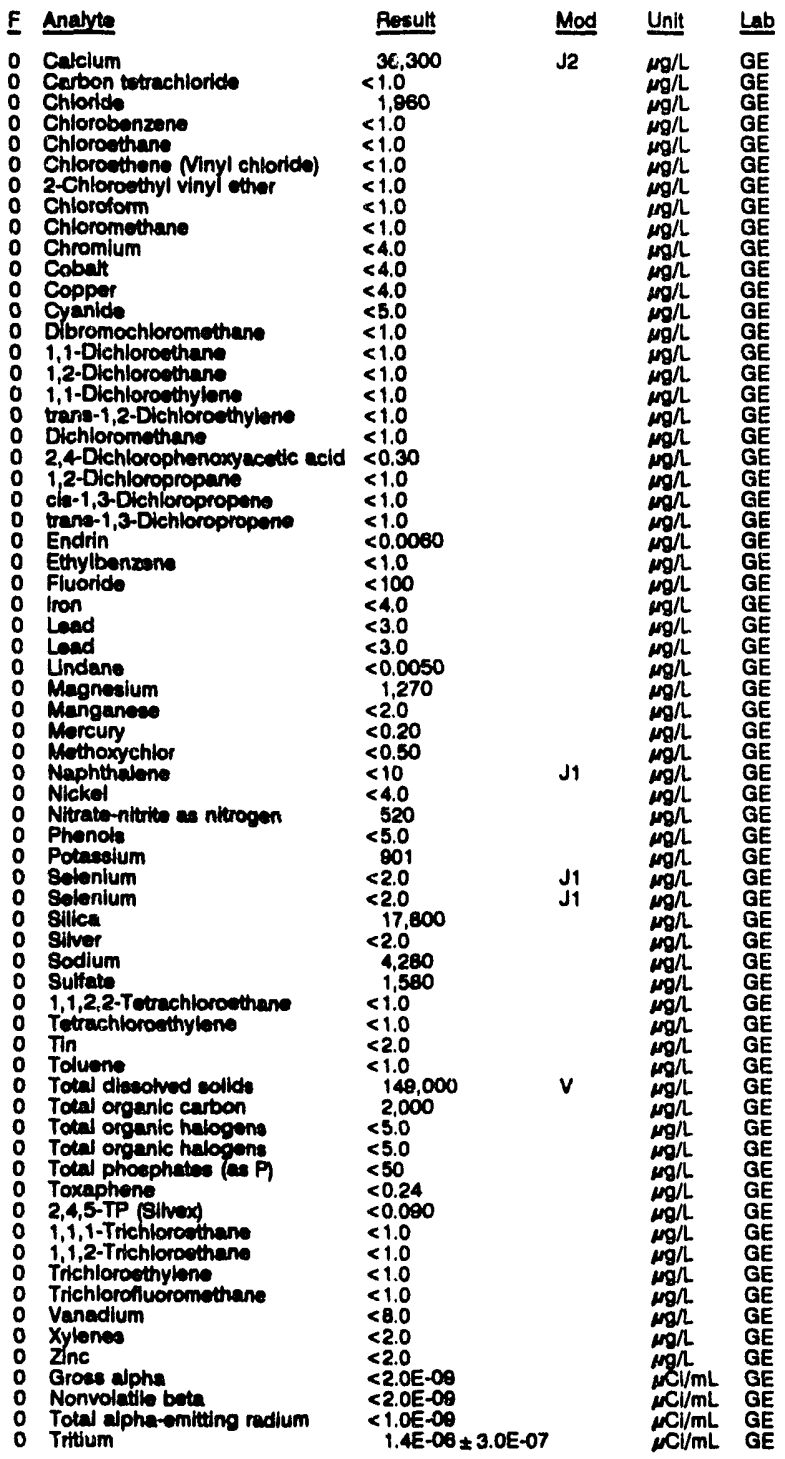

WELL HSB 85C

MEASUREMENTS CONOUCTED IN THE FIELD

Sample date: 07/0a/92

Water elevation: 238.89 ( $(72.84 \mathrm{~m}) \mathrm{ms}$

SPater evectuated bofors eampling: $65 \mathrm{gal}$

LABOPATORY ANNYYSES
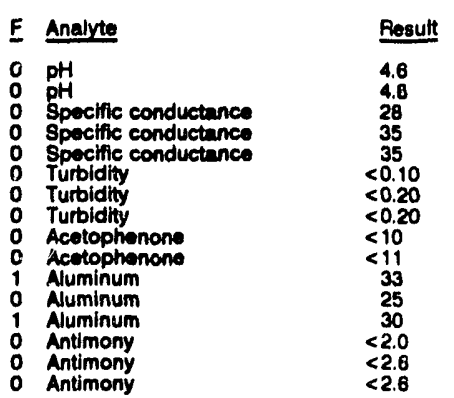

WELL HSB 85C collected on 07/08/92, laboratory analyees (cont.)

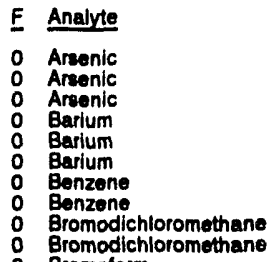

Bromoform

Bromomethan

Bromomethane

Cadmium

Cadmium

Calcium

O Calcium

C Carbon tetrachlorido

Cerbon tetrachloride

Chloride

O Chlorobenzene

Chlorobenzene

Chloroethane

O Chloroethane

o Chloroethene Ninyl chloride)

o Chloroethene Ninyl chloride

o 2-Chloroethyl vinyl other

2-Chloroethyl vinyl ether

- Chloroform

0 Chioromethan

O Chloromethane

o Chromium

o Chromium

0 Cobalt

0 Cobalt

Cobalt

O Copper

Copper

Cyanide

O Dibromochloromethane

o Dibromochloromethane

1,1-Dichioroethane

1,1-Dichloroethane

1,2-Dichloroethane

o 1,1-Dichloroethylene

o 1,1-Dichloroethylene

o trans-1,2-Dichloroethylene

o Dichloromothane

2 Dichloromethane 2,4-Dichlorophenomyacetic acld

o 1,2-Dichloropropane

o 1,2-Dichloropropane

o cis-1,3-Dichloropropene

o cis-1,3-Dichloropropene

o trane-1,3-Dichloropropene

0 trans-1,

O Endrin

0 Ethylbenzene

O Ethylbenzen

o Fluoride

o Iron

0 Iron

: lion

0 Lead

o Lead

0 Lindane

o Magnesium

Magnesium

Magnesium

Manganese

- Manganese

Marcury

Mercury

Mothoxychlor

Methoxychior

Nickel

o Nickel

o Nickel

N Nitrate as nitrogen

Nitrato-nitrite as nitrogen

o Phenols

0
0 Phenols
0 Potassium

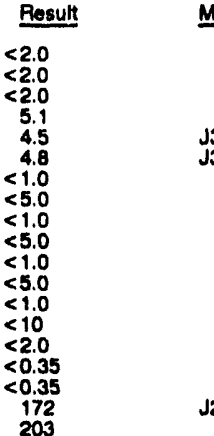

Mod Unit Let

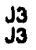

$\sqrt{33}$

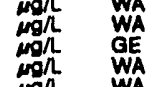

Wa GA

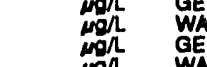

$\sqrt{2}$

$<5.0$

1,980
3,440

$<<1,0$

$\leqslant<.0$

$<10$

$<10$

$<>10$

$\leq 1.0$

$<<1.0$

$<4.0$

$<1.1$

$<4.0$

28

$<10$

$<4.0$
$<3.1$

4.1800
1,920

$<5.0$

$<5.0$
$<500$ 
WELL HSB ASC collected on 07/08/92, laboratory analyees (conL)

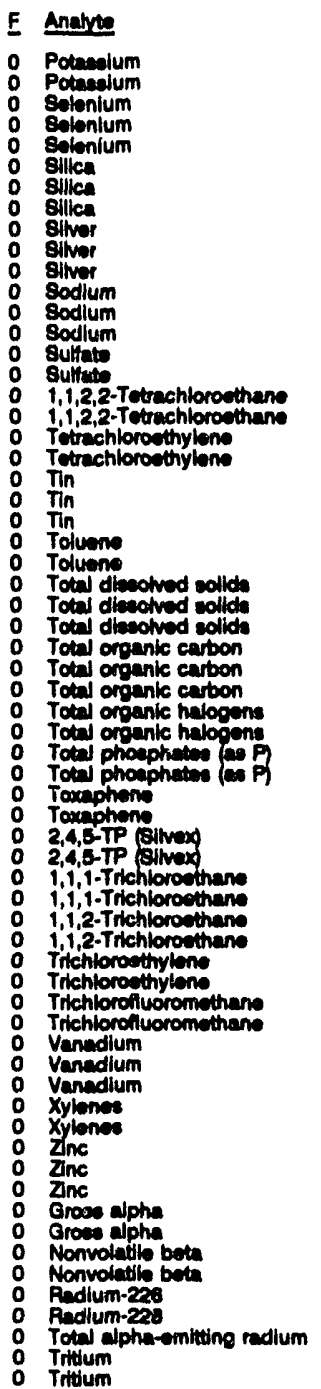

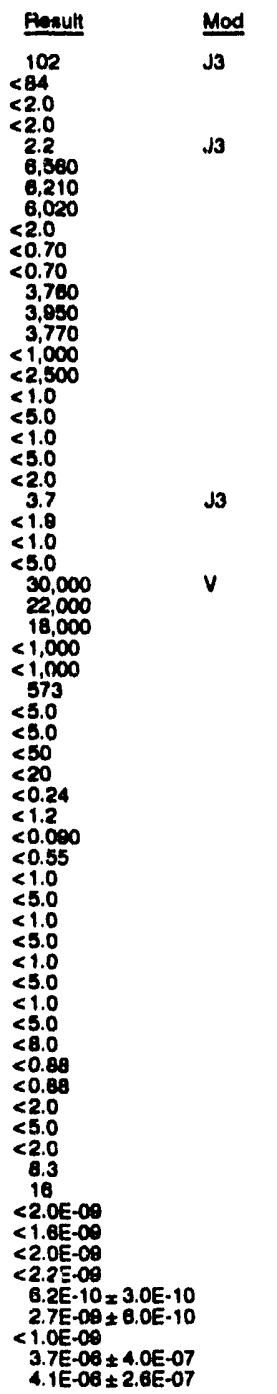

WELL HSB 85C Replicate

\section{MEASUAEMENTS CONDUCTED IN THE FIELD}

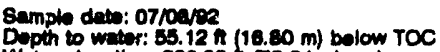
Water Govation: 230.08 ( $h(72.64 \mathrm{~m}) \mathrm{msl}$

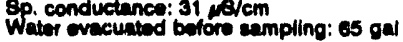

LABOPATOAY ANULYSES
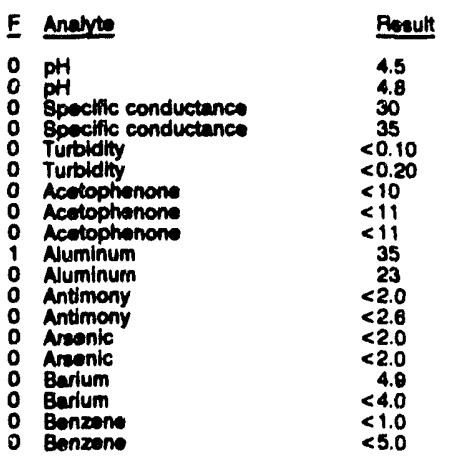

WELL HSB B5C collected on 07/08/92, laboratory analyses (cont)

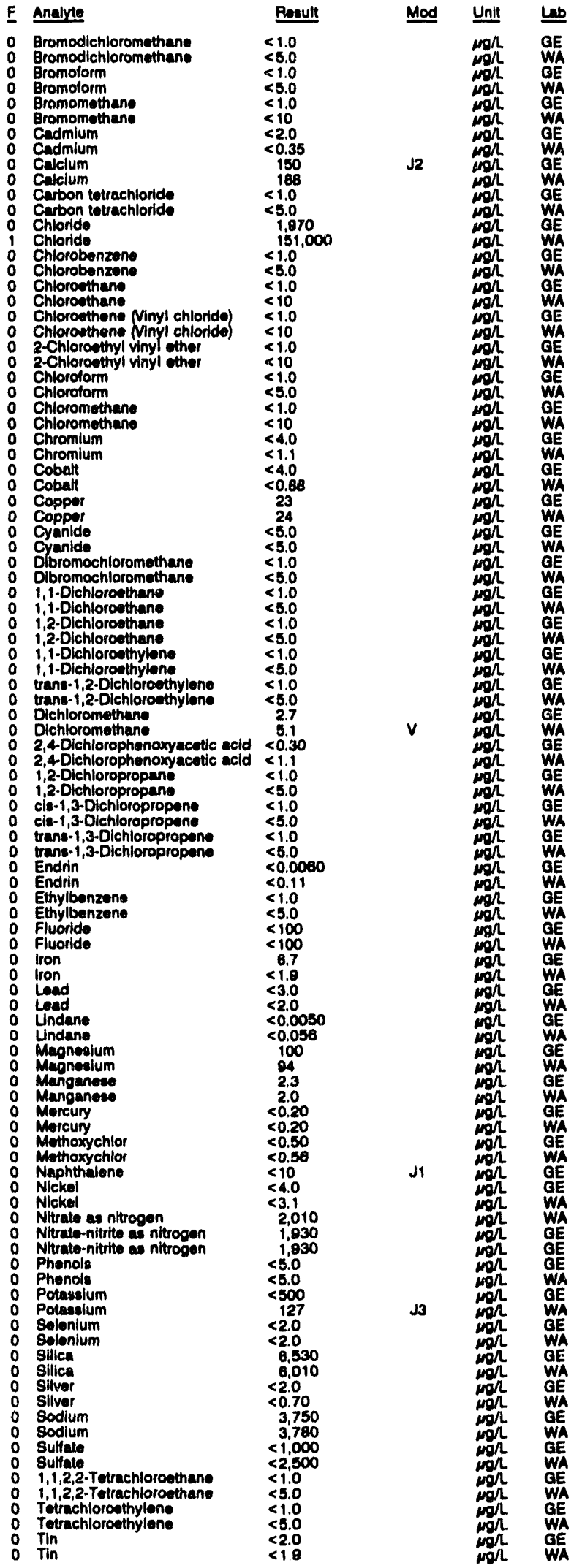


ANALYTICAL RESULTS

WELL HSB asC collectod on 07/08/82, laboratory analyees (cont)

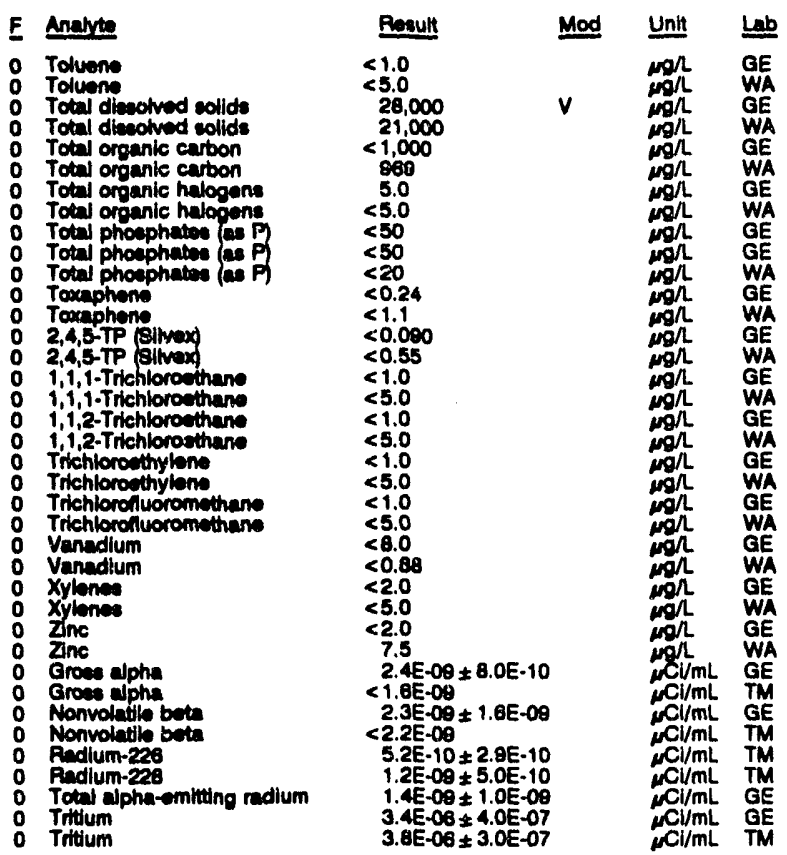

\section{WELL HSB 86A}

MEASUAEEMENTS CONDUCTED IN THE FIELD

\begin{tabular}{|c|c|}
\hline 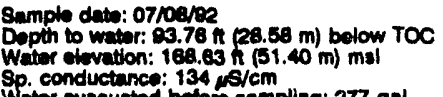 & $\begin{array}{l}\text { Time: } 13: 50 \\
\text { pH: } 6.3 \\
\text { Alkalinity: } 34 \mathrm{mg} / \mathrm{h} \\
\text { Water tomperature: } 20.5^{\circ} \mathrm{C}\end{array}$ \\
\hline
\end{tabular}
Sp. conductance: $134 \mathrm{\mu S/} / \mathrm{cm}$. $277 \mathrm{gal}$

\section{LABOPATOFY ANALLYES}

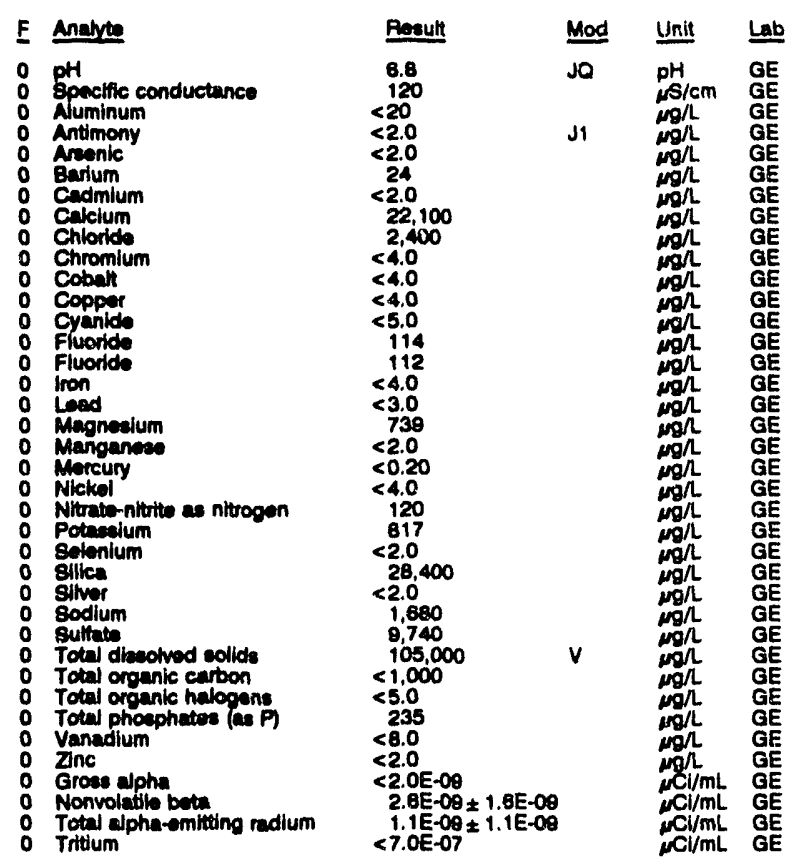

WELL HSB 86B

MEASUREMENTS CONDUCTED IN THE FIELD

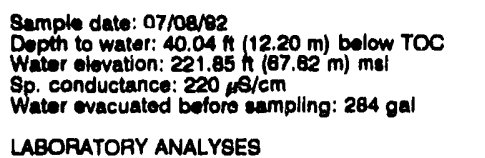

Time: 13:00

PH: 8.8 .

Water temperature: $22.4^{\circ} \mathrm{C}$

LABORATORY ANALYSES

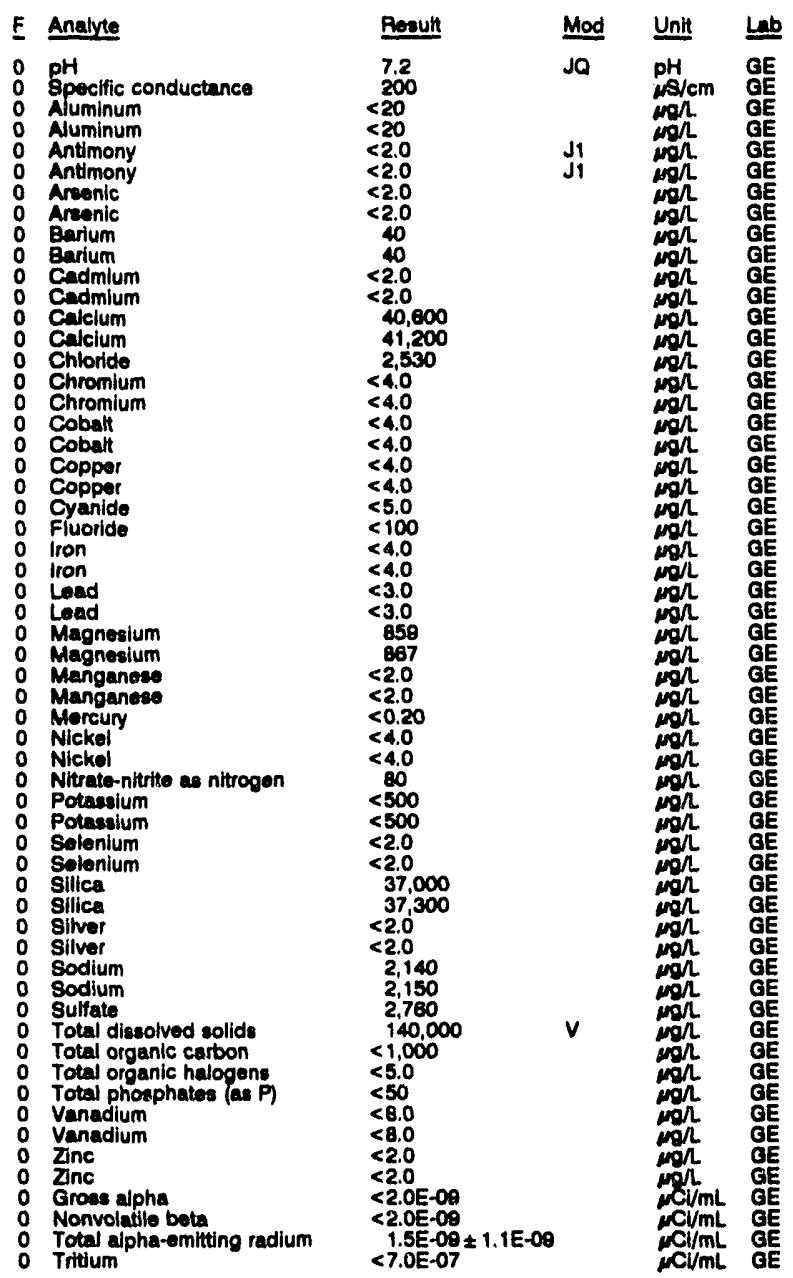

WELL HSB 86C

MEASUREMENTS CONDUCTED IN THE FIELD

Sample date: 07/08/92

Depth to water: $38.85 \mathrm{~A}(11.87 \mathrm{~m})$ below TOC

Water olevation: $223.84 \mathrm{ht}(88.26 \mathrm{~m}) \mathrm{msl}$

Sp. conductance: $404 \mu \mathrm{s} / \mathrm{cm}$
Water ovacuated betore sampling: $91 \mathrm{gal}$

LABORATORY ANALYSES

\begin{tabular}{|c|c|c|c|}
\hline F Anabyte & Result & Mod & Unit \\
\hline $\begin{array}{ll}0 & \text { pH } \\
1 & \text { Spocific conductance } \\
2 & \text { Aluminum } \\
0 & \text { Antimiony } \\
0 & \text { Areonic } \\
0 & \text { Barium } \\
2 & \text { Cadmium } \\
0 & \text { Calcium } \\
0 & \text { Chloride } \\
0 & \text { Chromium } \\
2 & \text { Cobselt } \\
0 & \text { Copper } \\
0 & \text { Cyanide }\end{array}$ & $\begin{array}{r}4.4 \\
400 \\
794 \\
<2.0 \\
<2.0 \\
74 \\
8.3 \\
6,800 \\
2,020 \\
<4.0 \\
43 \\
<4.0 \\
<5.0\end{array}$ & Ja & 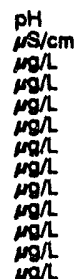 \\
\hline
\end{tabular}


WELL HSB BaC collectad on 07/09/92, laboratory analyese (cont.)

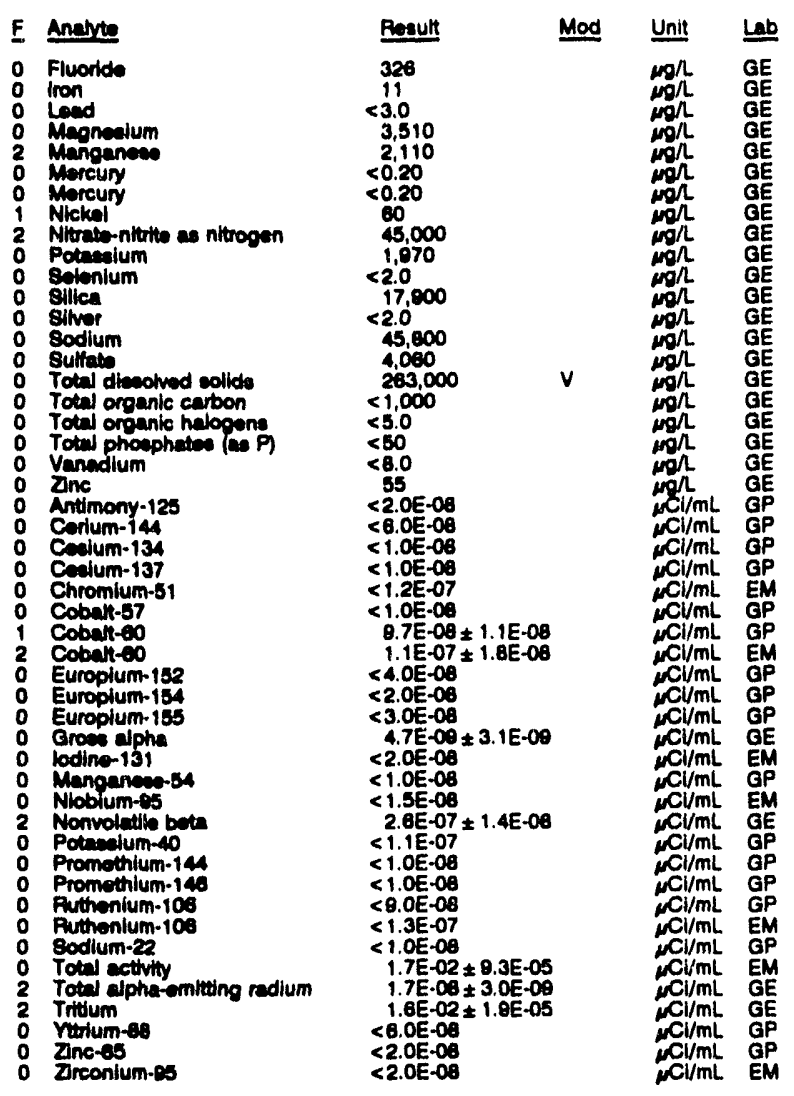

\section{WELL HSB 86D}

MEASUREMENTS CONDUCTED IN THE FIELD

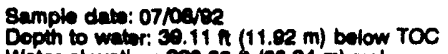
Water olvevation: $223.60 \mathrm{~h}(68.24 \mathrm{~m}) \mathrm{ms}$ W. conductance: 332 rs/cm $15 \mathrm{gal}$

\section{LABORATOFY ANALYES}
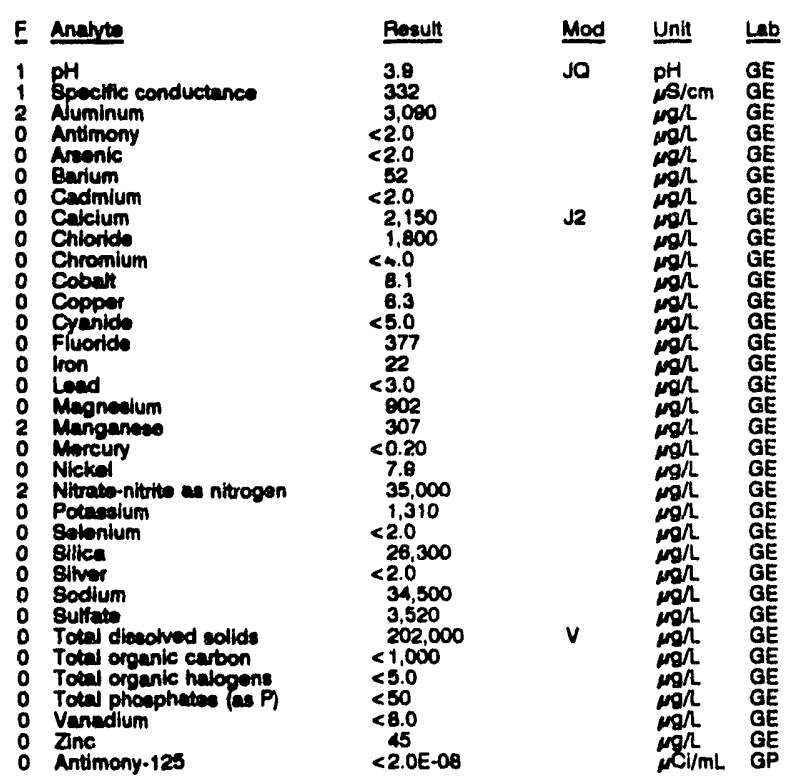

WELL HSB 880 collected on 07/08/92, laboratory analyeese (cont.)

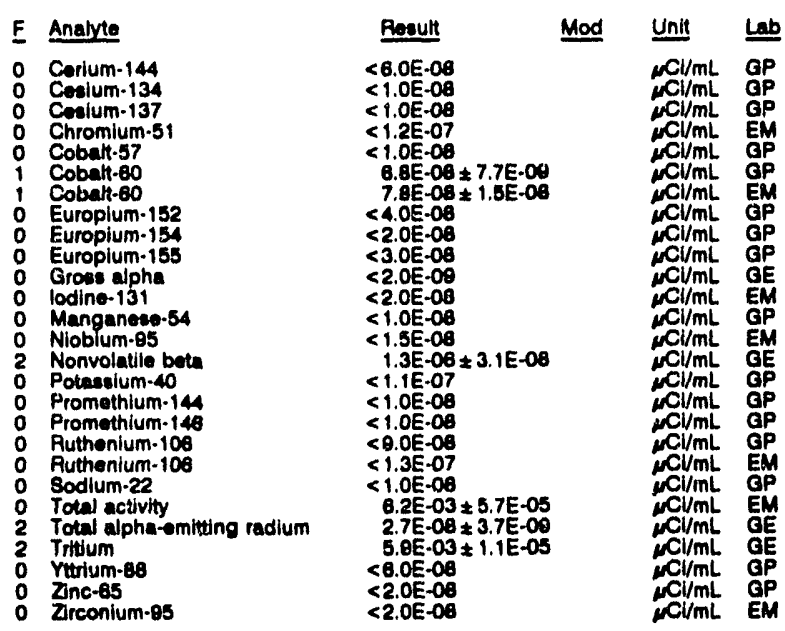

WELL HSB100C

MEASUREMENTS CONDUCTED IN THE FIELD

\begin{tabular}{|c|c|}
\hline $\begin{array}{l}\text { Sample date: } 07 / 08 / 92 \\
\text { Depth to water: } 33.59 \mathrm{H}(10.24 \mathrm{~m}) \text { bolow TOC } \\
\text { Water olevation: } 228.61 \mathrm{Ht}(69.07 \mathrm{~m}) \mathrm{mal} \\
\text { Sp. conductance: } 34 \text {. }\end{array}$ & $\begin{array}{l}\text { Time: } 15: 55 \\
\text { pH: } 5.4 \\
\text { Alkalinity: } 3 \text { mgh } \\
\text { Water tomporature: } 21.5^{\bullet} \mathrm{C}\end{array}$ \\
\hline
\end{tabular}
LABORATORY ANALYSES

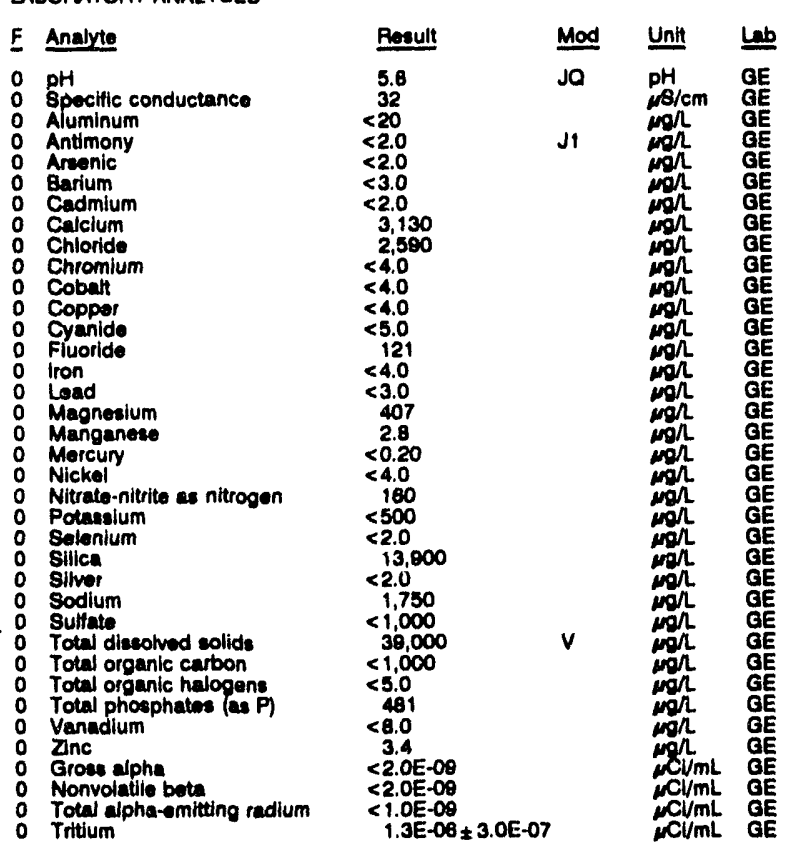

Time: $14: 10$

Whalinity: $0 \mathrm{mgh}$

Water tomperalure: $21.6^{\circ} \mathrm{C}$

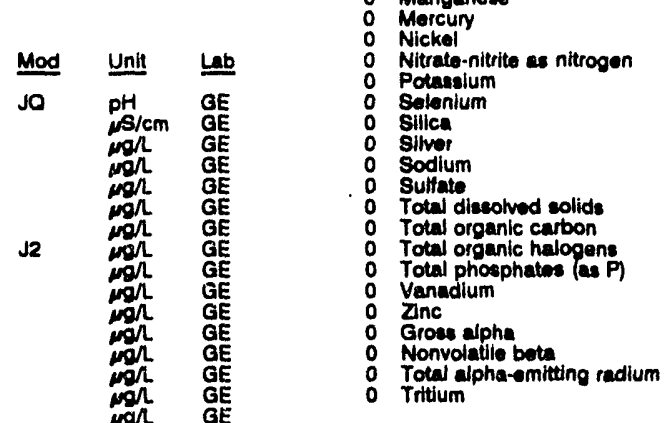


ANALYTICAL RESULTS

WELL HSB100D

MEASUREMENTS CONDLCTED IN THE FIELD

Sample date: $070 \mathrm{per}$

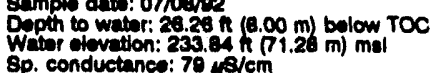

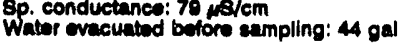
LABOFUTORYY ANALYSES

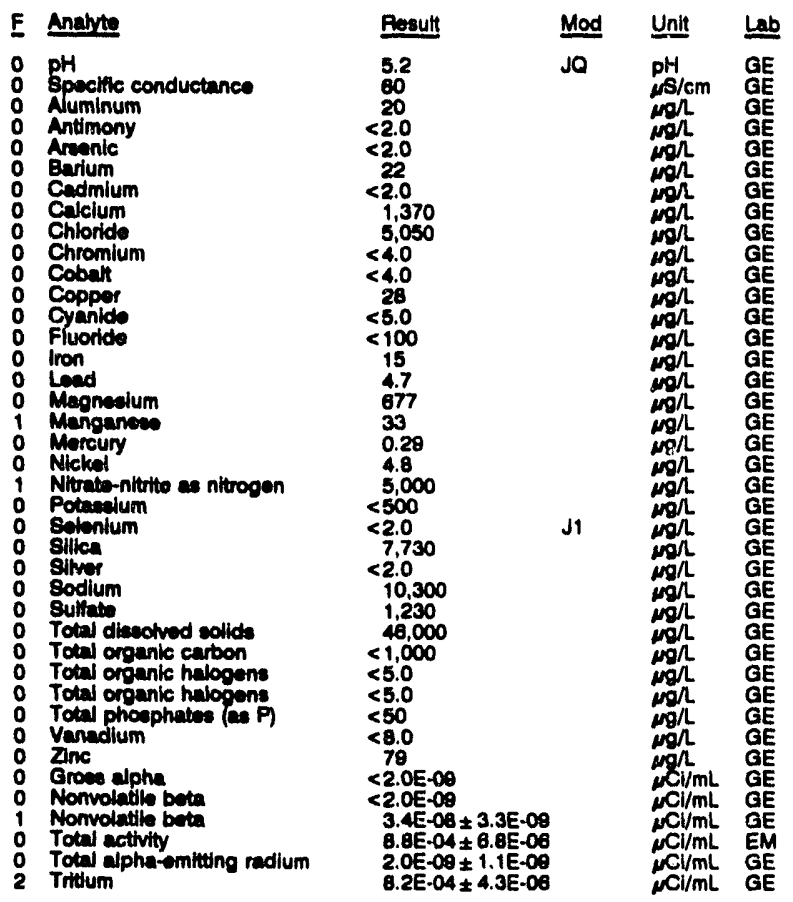

WELL HSB101C

MEABUREMENTS CONDUCTED IN THE FIELD

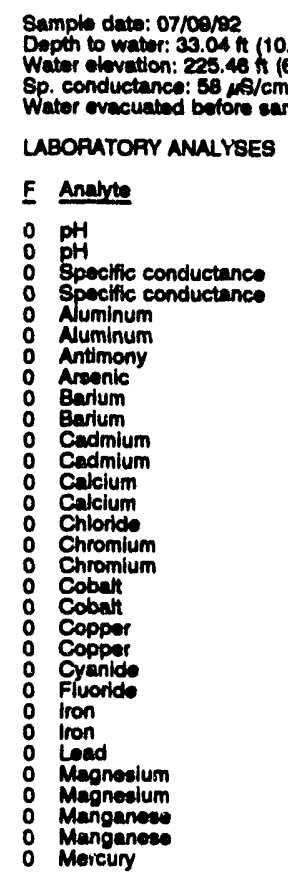

pH: 6.0

Time: $15: 40$

PH: 4.9 . $0 \mathrm{mon}$

Whates tomperture: $22.4^{\circ} \mathrm{C}$

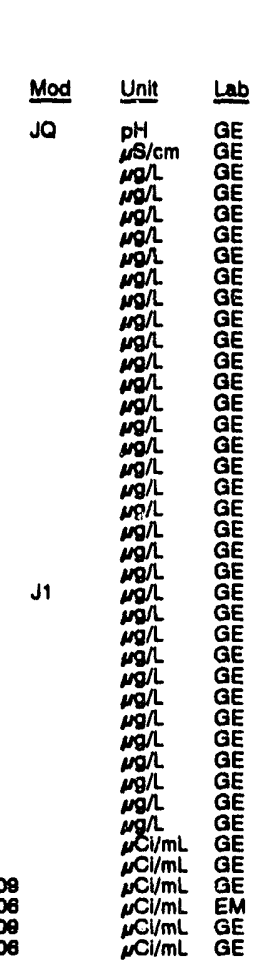

\section{Time: 8:25 \\ Time: $8: 25$
pH: 6.0
Alkalinity: $14 \mathrm{mg} / 2$
Water tomperature: \\ Water tomperature: $20.4^{\circ} \mathrm{C}$

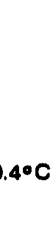

\section{LABOAATOFY ANALYSES}

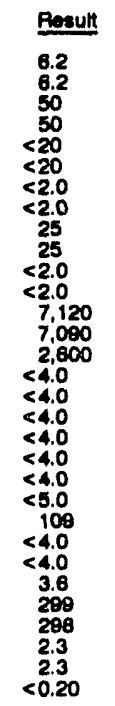

WELL HSB101C colloctod on 07/00/02, laboratory analyees (cont)

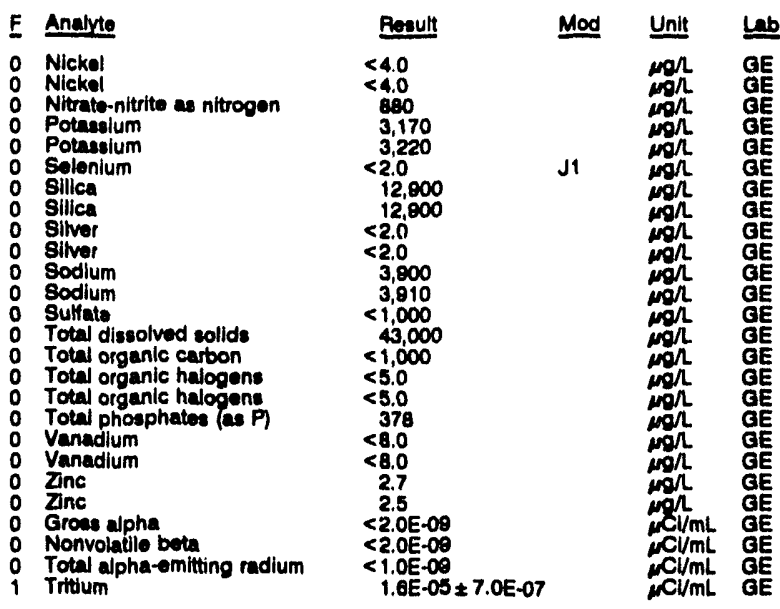

\section{WELL HSB101D}

MEASUREMENTS CONDUCTED IN THE FIELD

\begin{tabular}{|c|c|}
\hline $\begin{array}{l}\text { Sample date: } 07 / 09 / 92 \\
\text { Dopth to water: } 28.02 \mathrm{ht}(8.54 \mathrm{~m}) \text { below TOC } \\
\text { Water elevation: } 230.68 \mathrm{H}(70.31 \mathrm{~m}) \mathrm{msl} \\
\text { Sp. conductancs: } 679 \mathrm{\mu s} / \mathrm{cm} \\
\text { Water evacuated bolore sampling: } 38 \mathrm{gal}\end{array}$ & $\begin{array}{l}\text { Time: 6:05 } \\
\text { pH: } 8.5 \\
\text { Alkalinity: } 157 \mathrm{mg} \Omega \\
\text { Water tomperature: } 21.2 \circ \mathrm{C}\end{array}$ \\
\hline
\end{tabular}

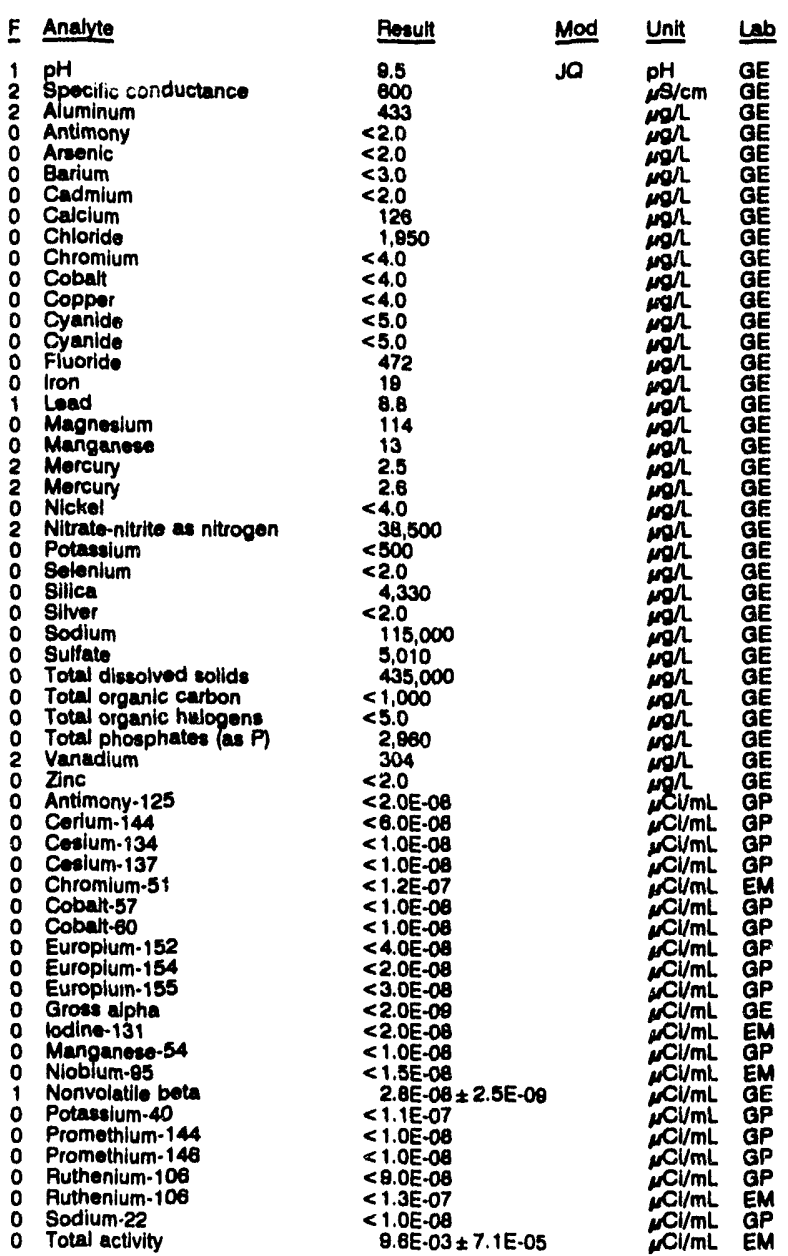


WEL HBQ101D colloctod on 07/09/22, leboratory analyees (cont.)

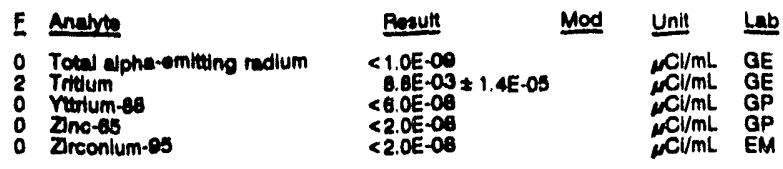

\section{WELL HSB102C}

MEASUAEMENTS CONDUCTED IN THE FIELD

Eample data: 07/0eper Depin to wator: 34.40 h (10.61 m) below TOC Vatse elevation: 224.51 $(64.43 \mathrm{~m}) \mathrm{mml}$ Wiat evecuated bofore sempling: $182 \mathrm{gal}$

LABORATOFY ANAL YSES

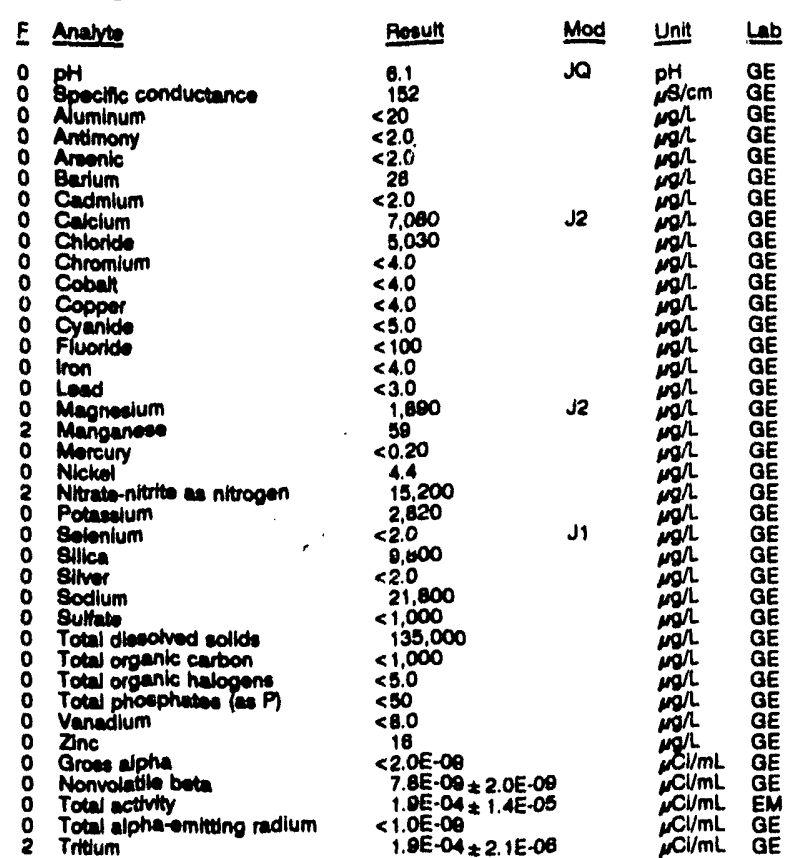

\section{WELL HSB102D}

MEABUREMENTS CONDUCTED IN THE FIELD

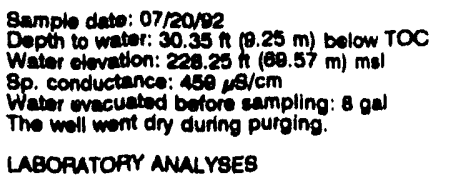

Time: $9: 05$

Alkalinity: $12 \mathrm{mgh}$

Alkalinity: $12 \mathrm{mg} /$ : $20.3^{\circ} \mathrm{C}$
WELL H8B 1020 collectod on 07/20/92, laboratory analyeee (cont.)

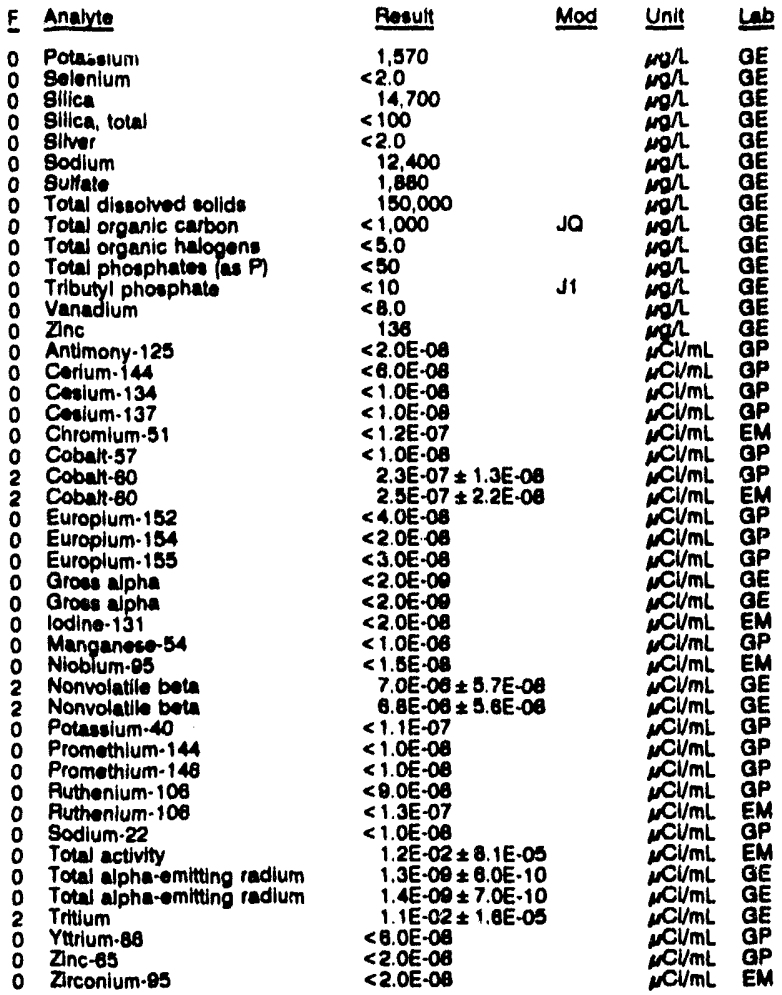

WELL HSB103C

MEASUREMENTS CONDUCTED IN THE FIELD

Sample date: 07/08/02

Depth to water: 23.83 i $(7.28 \mathrm{~m})$ bolow TOC

Water olovation: $223.57 \mathrm{~h}(68.14 \mathrm{~m}) \mathrm{msl}$

Water evacuated before sampling: $169 \mathrm{gal}$

Timo: : 8:55

Alkulinity: 0 mol

Axalnity: 0 mol $20.5 \cdot \mathrm{C}$

LABORATORY ANALYBES

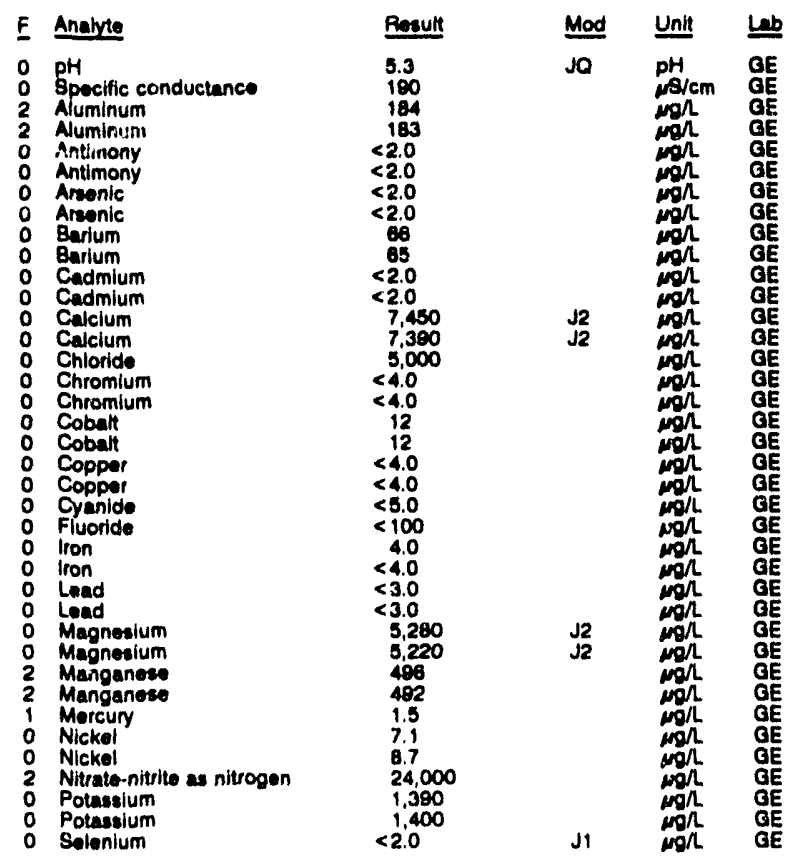


ANALYTICAL RESULTS

\begin{tabular}{|c|c|c|c|}
\hline Anarys & Pesult & Mod & Unit \\
\hline 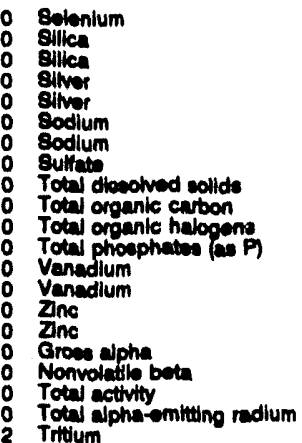 & 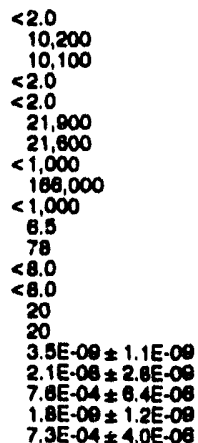 & J1 & 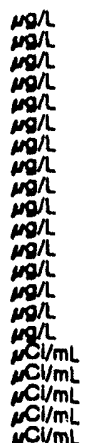 \\
\hline
\end{tabular}

WELL HSB1030 colloctod on 07100/92, laboratory andyeen (cont.)

\begin{tabular}{|c|c|c|c|}
\hline E Analyte & Roeult & Mod & Unt \\
\hline $\begin{array}{ll}0 & \text { Zne-65 } \\
0 & \text { Zirconium-85 }\end{array}$ & $\begin{array}{l}<2.0 E-08 \\
<2.0 E-08\end{array}$ & & N \\
\hline
\end{tabular}

WELL HSB104C

MEASUREMENTS CONDUCTED IN THE FIELD

\begin{tabular}{|c|c|}
\hline $\begin{array}{l}\text { Sample date: } 07 / 109 / 02 \\
\text { Depth to water: } 27.07 \mathrm{~h}(8.25 \mathrm{~m}) \text { below TOC } \\
\text { Water elevation: } 220.83 \mathrm{~h}(67.31 \mathrm{~m}) \mathrm{mal} \\
\text { Sp. conductance: } 176 \mu 8 / \mathrm{cm} \\
\text { Weter evecuated before sempling: } 150 \mathrm{gal}\end{array}$ & $\begin{array}{l}\text { Timo: } 11: 35 \\
\text { pH: } 8.8 \\
\text { Alkulinity: } 43 \text { mgn } \\
\text { Water tomporature: } 20.4 \cdot \mathrm{C}\end{array}$ \\
\hline
\end{tabular}

LABOPATORY ANALYSES

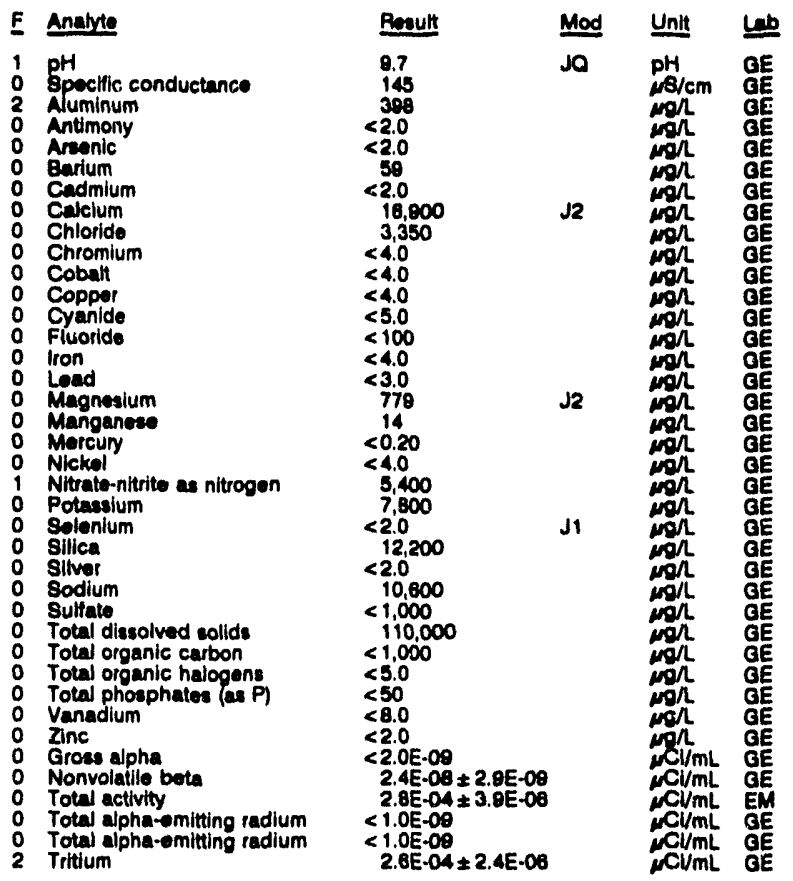

\section{WELL HSB104D}

MEABUAREMENTS CONOUCTEO IN THE FIELO

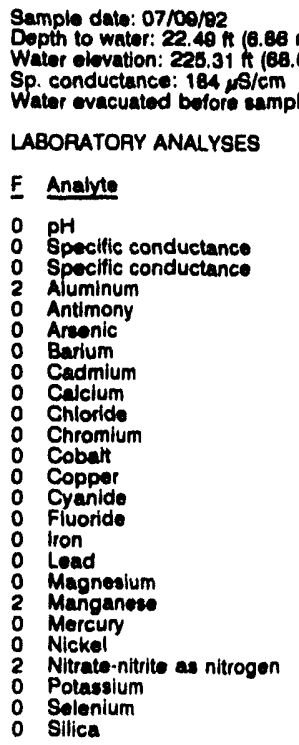

Time: $10: 30$

Alkallinity: $0 \mathrm{mg} /$ Water temperature: $20.8^{\circ} \mathrm{C}$
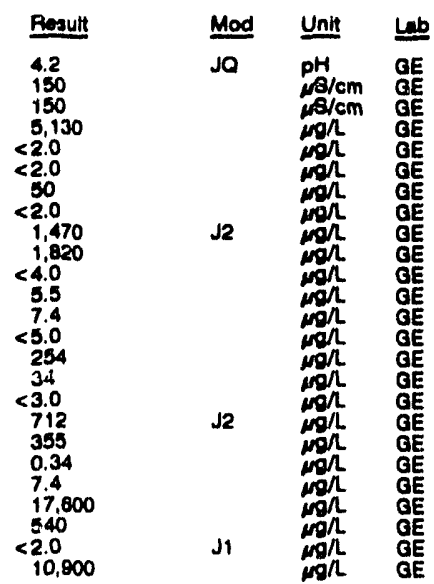

$<$.

4.7E-07 $\pm 8.3 E-00$

$<1.1 E-07$

$<1.0 E-00$

$<1.0 \mathrm{E}-08$

$<8.0 E-08$

$<1.0$-08

$3.5 E-03 \pm 4.3 E-05$

1.2E-08 $\pm 2.0 \mathrm{E}-08$

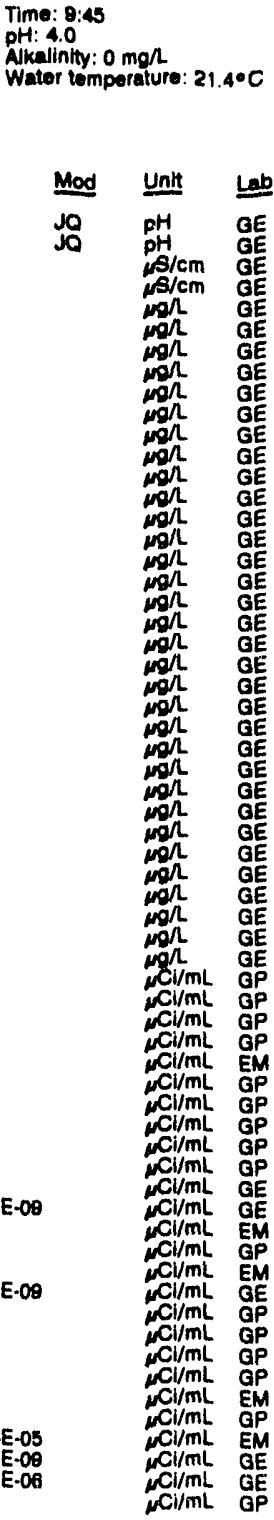
$<6.0 \mathrm{E}-08$ 
WELL H881040 collected on 07/00/02, Iaboratory analyees (cont.)

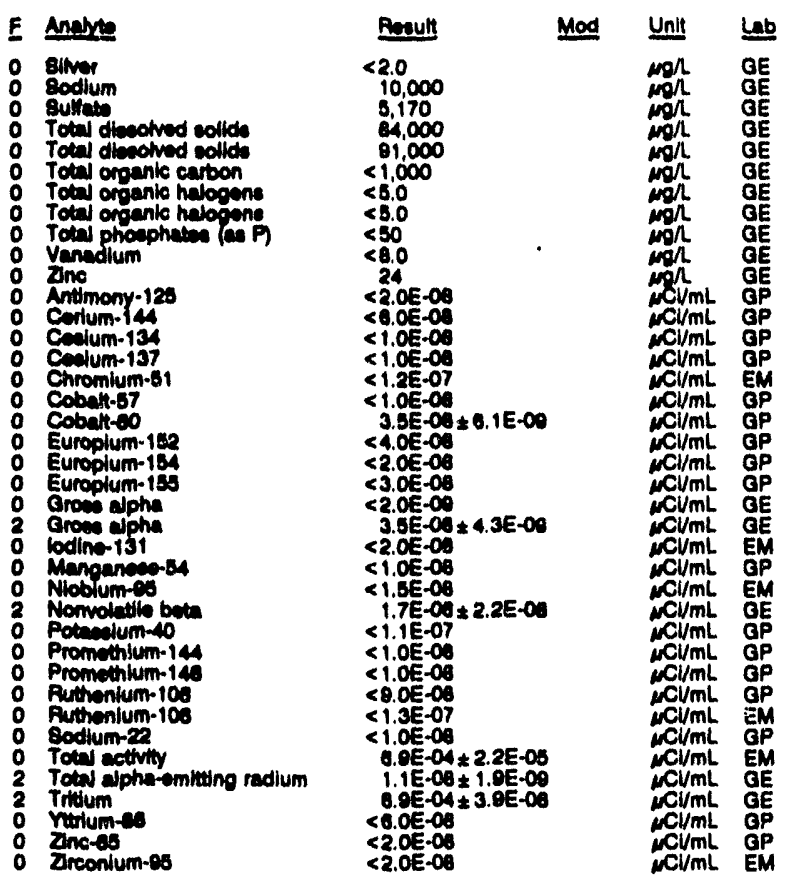

\section{WELL HSB105C}

MEASUAEEMENTS CONOUCTED IN THE FIELD

Sample dats: 07/10\%

Depth to watar: 20.41 it $(9.09 \mathrm{~m})$ bolow TOC

P. conductence $210.60 \mathrm{ht}$

Wiver evecueted betore sampling: $177 \mathrm{gal}$

LABOALTOFY ANALYEE

E Andre

O

: Epacific conduetance

encerife conductance

Epecinic conductence

Auminum

Auminum

Antimony

- Arenic

- Arenis

Barlum

Cndmium

Cadmlum

- calclum

Celcium

Chlorido

Chloride

Chromium

Chromium

Cobar

Copper

Copper

Cyanida

o Fyanide

Fluoride

Iron

- Iron

0 Lead

Lead

Megnedum

- Manganes.

Manganace

Mercury

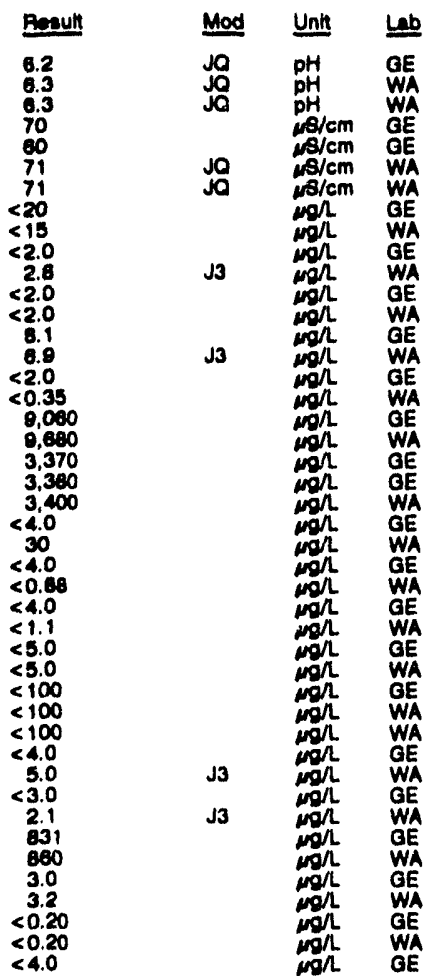

WELL H8B10sC collectod on 07/10/92, laboratory analyese (cont)

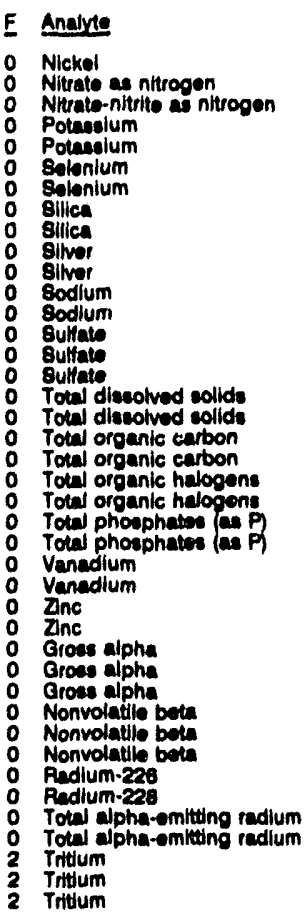

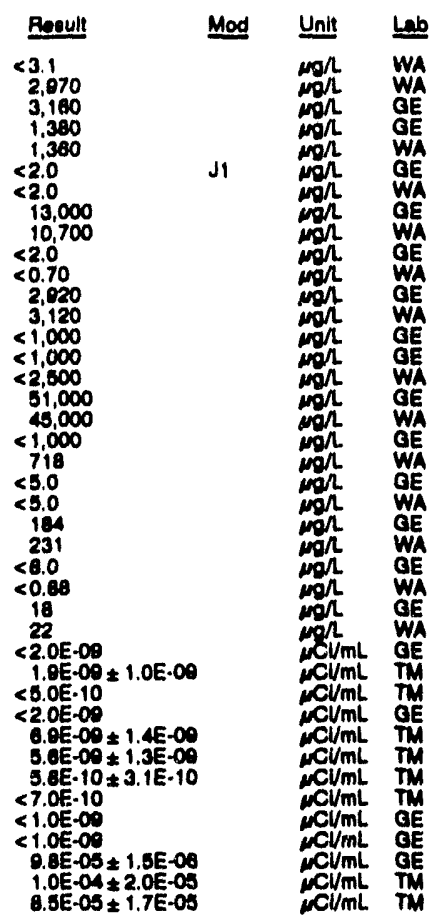

\section{WELL HSB105C Replicate}

MEASUREMENTS CONDUCTED IN THE FIELD

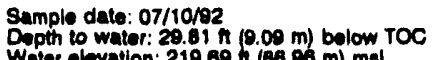

Wator alevation: $219.69 \mathrm{~h}(86.06 \mathrm{~m}) \mathrm{mal}$

Sp. conductance: $148 / \mathrm{cm}$. $177 \mathrm{gal}$

LABOFUTORY ANALYSES
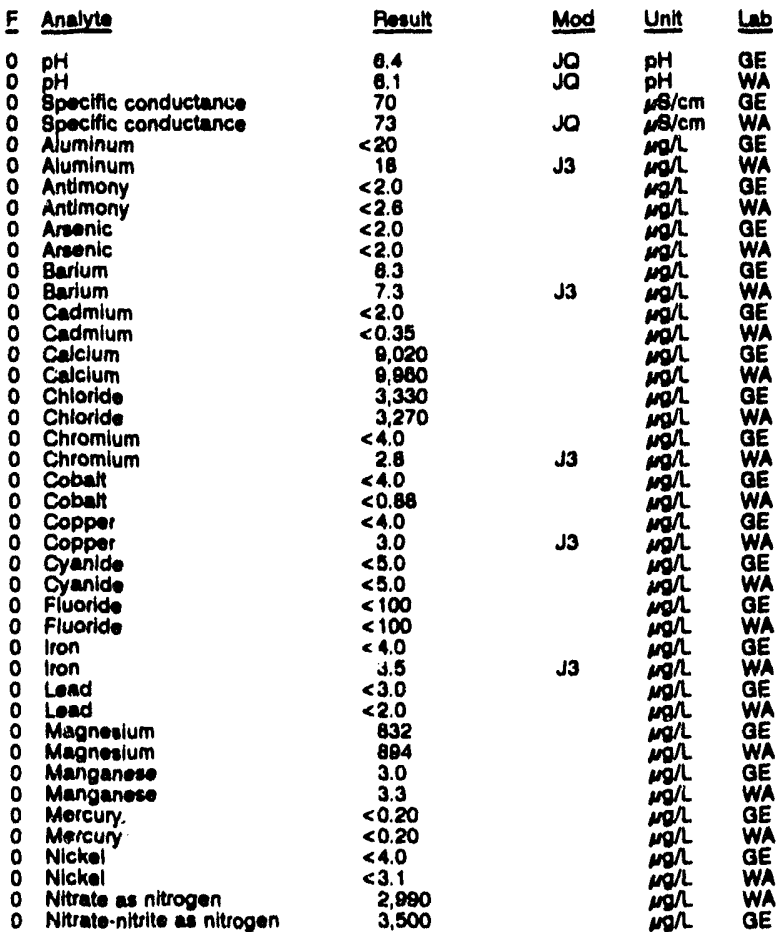
ANALYTICAL RESULTS

WELL H98106C collectad on 07/10/92, laboratory analyeen (cont)

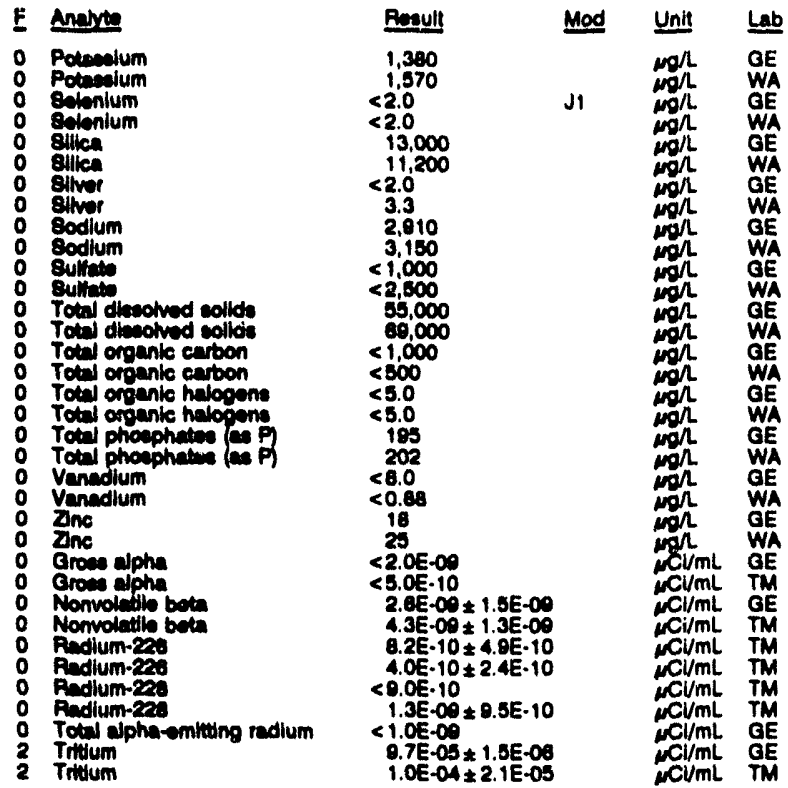

\section{WELL HSB105D}

MEASUREMENTS CONDUCTED IN THE FIELD

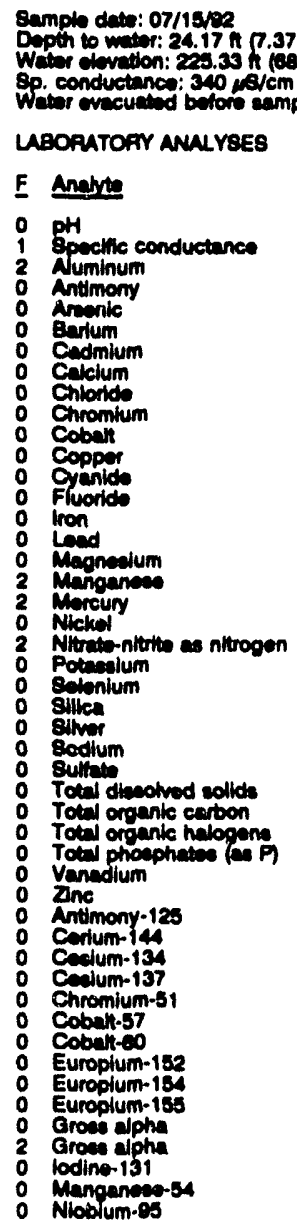

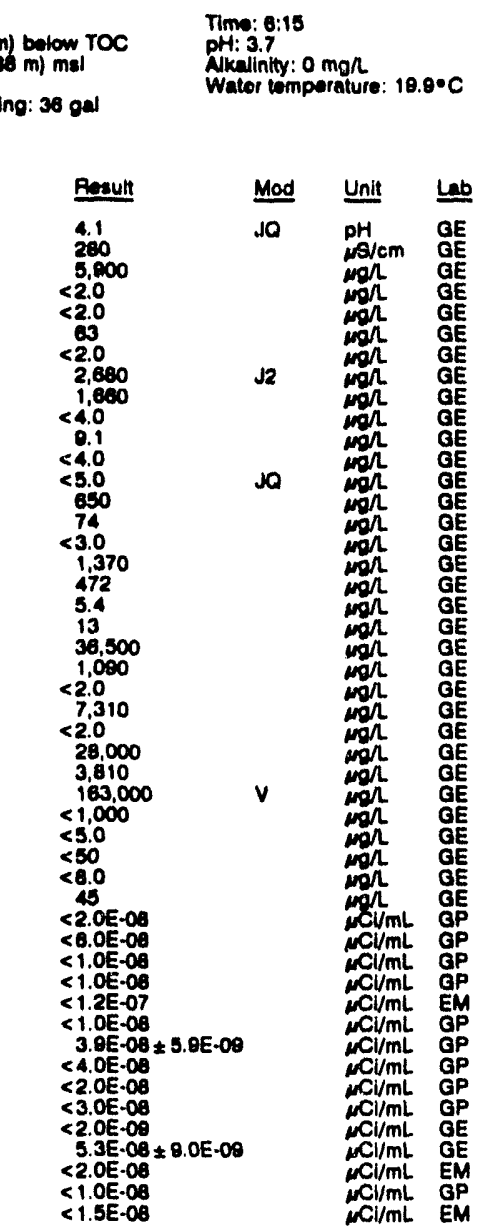

WELL HS81050 colloctod on 07/15/92, laboratory analyees (cont.)

\begin{tabular}{|c|c|c|c|c|}
\hline$F$ & Anabyte & Result & Unit & Lab \\
\hline $\begin{array}{l}0 \\
0 \\
0\end{array}$ & 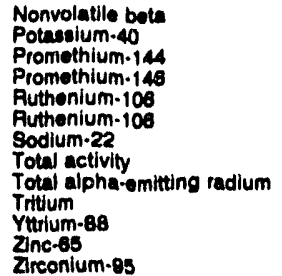 & 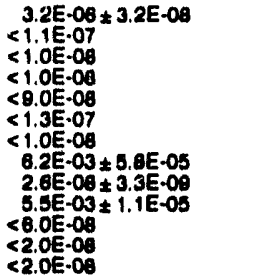 & 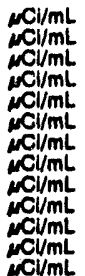 & $\begin{array}{l}G E \\
G P \\
G P \\
G P \\
G P \\
E M \\
G P \\
E M \\
G E \\
G E \\
G P \\
G P \\
E M\end{array}$ \\
\hline
\end{tabular}

WELL HSB106C

MEASUREMENTS CONOUCTED IN THE FIELD

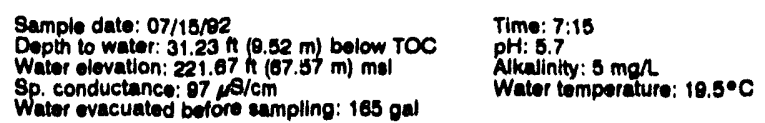

LABOFATOAY ANALYSES

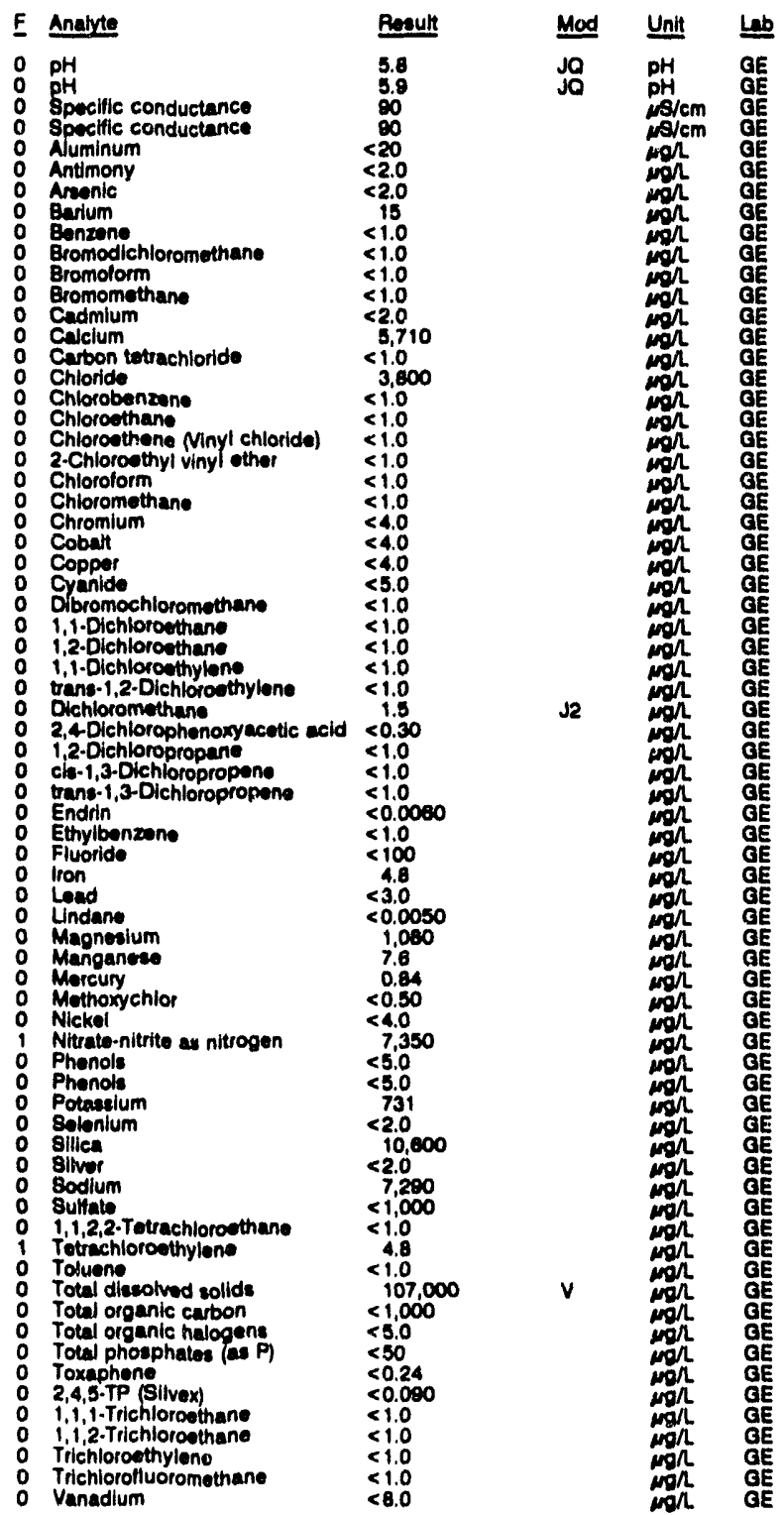




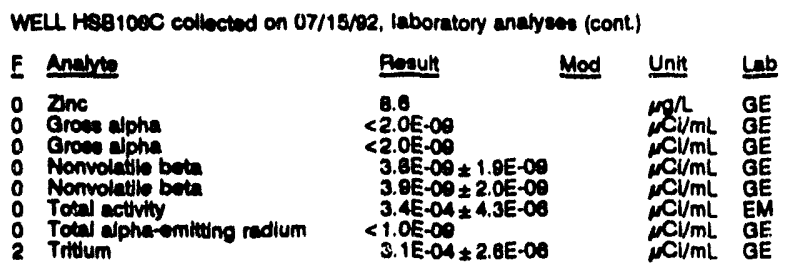

\section{WELL HSB106D}

MEASUREMENTS CONOUCTED IN THE FIELD

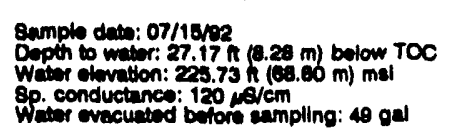

LABOFUTOFY ANULYSES

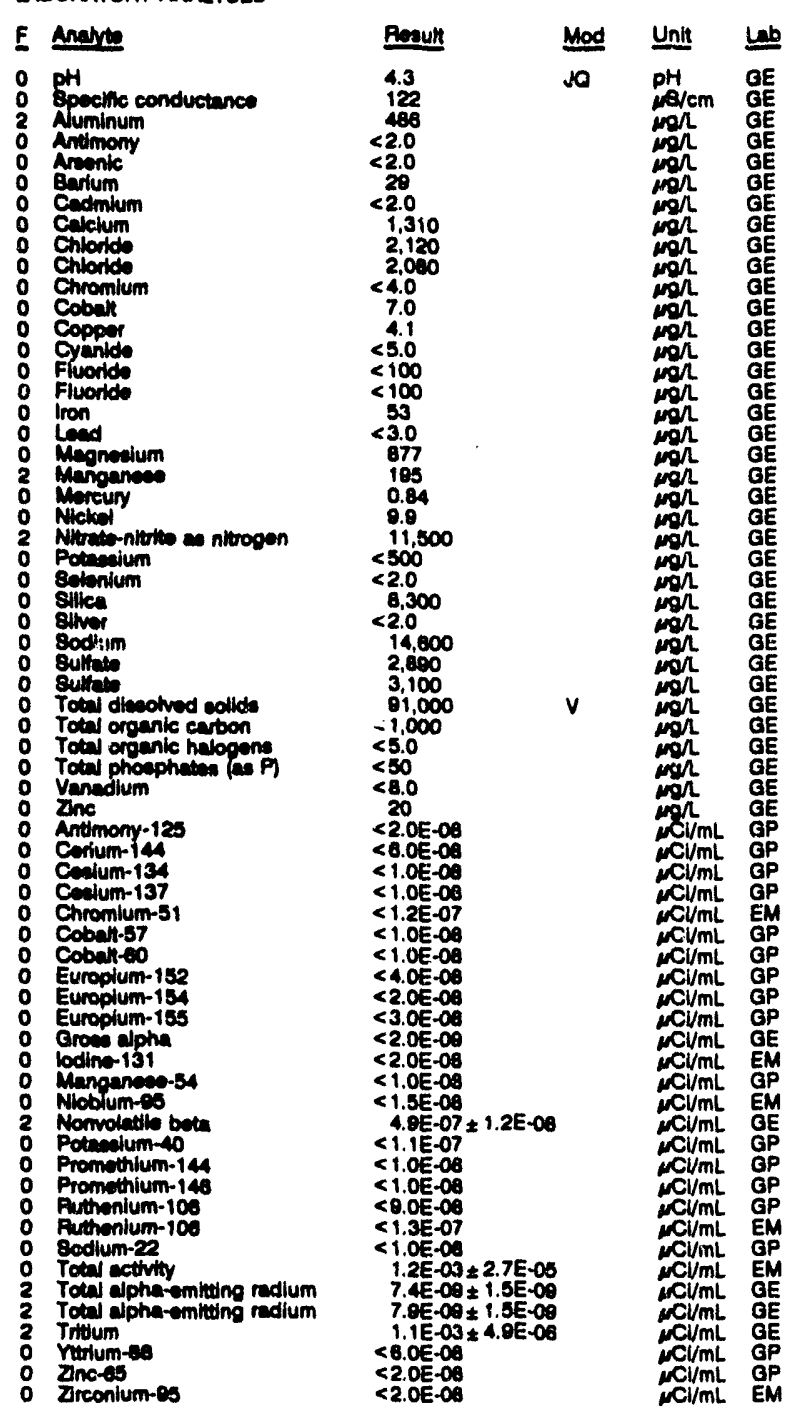

WELL HSB107C

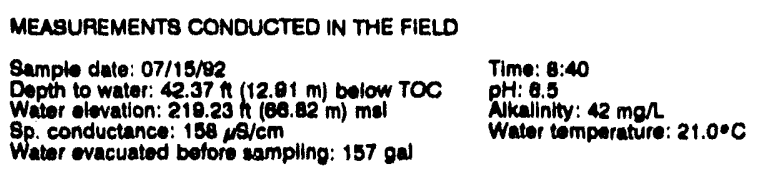

LABOFATORY ANALYSES

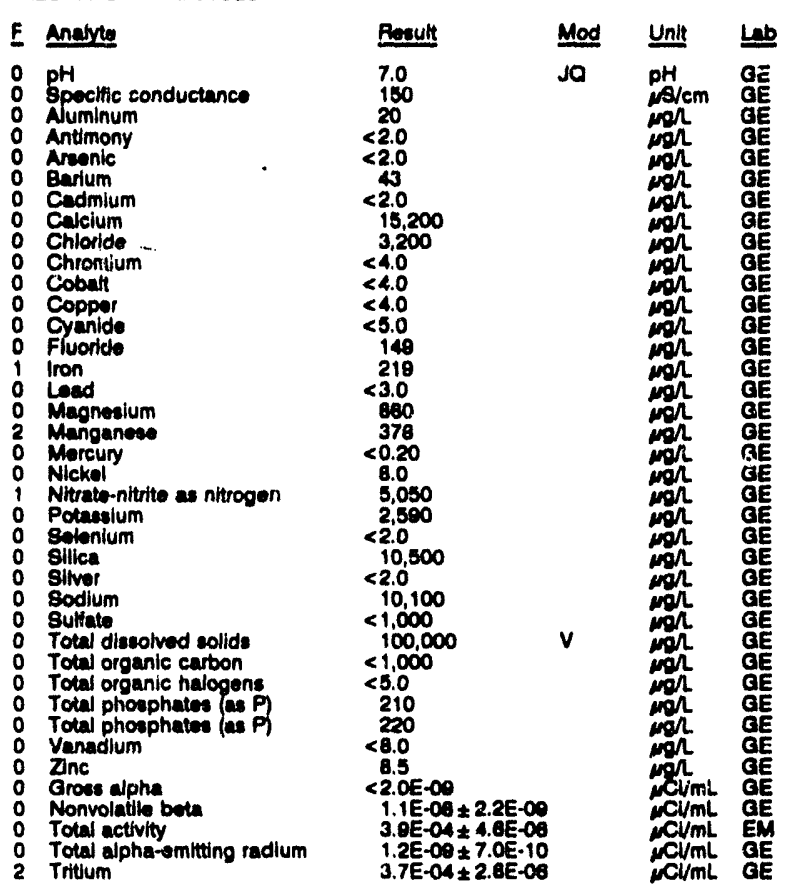

WELL HSB107D

MEASUREMENTS CONDUCTED IN THE FIELD

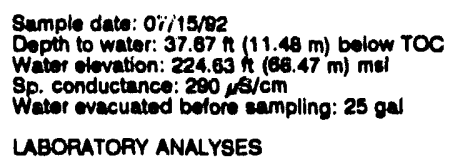

Time: 7:45

pH: 4.6 Water tomporature: $20.4 \cdot \mathrm{C}$ UBOFATORY ANALYSES

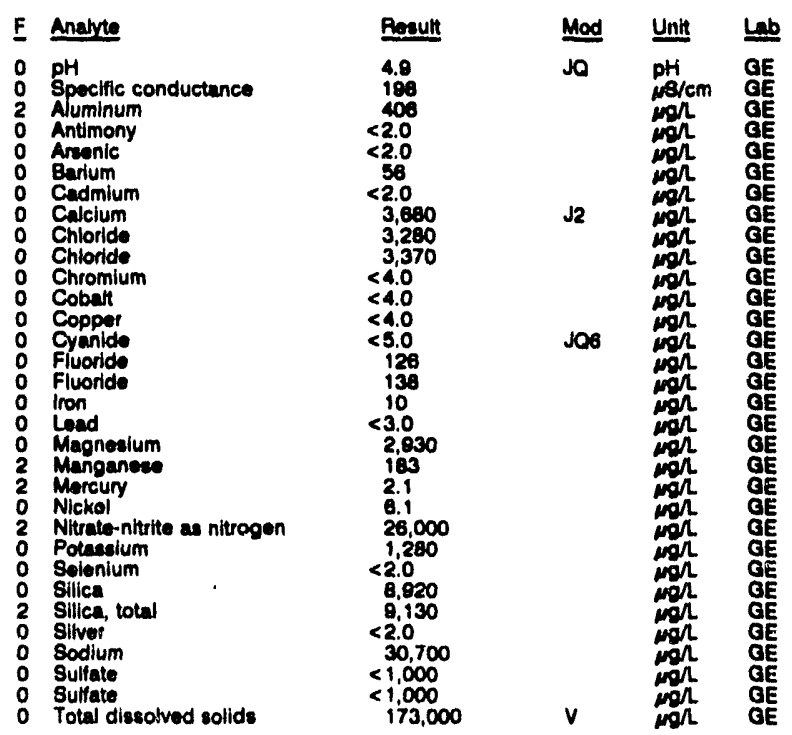


ANALYTICAL RESULTS

WELL HSB1070 collected on 07/15/92, laboratory analyees (cont.)

E Anelyte

Todal organic cation

Total phonichates (as P)

Tributyl phoaphate

- Vansadium

Antimony-125

Corlum-144

Cosium-134

Chromium-51

Cobalt-57

Europlum-154

Groes alph

Manganee-54

Nonvoletile bota

Potadium 40

Promithlum-144

Prominlum-149

Ruthonlum-108

Sodium-202

Tokal activhy

Tritum

Yinces

Jirconium-es
Result

$<1,000$

9.6
$<50$

$<10$

$<2.0 E-08$
$<6.0 E-08$

$<1.0 \mathrm{E}-0.0$

$<1.0 E-08$

$<1.2 E-07$

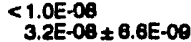

$<4.0 E-08$

$<2.0 E-00$

$<3.0 E-00$

$3.1 E-08 \pm 7.8 E-08$

$<2.0 E-00$

$<1.0 \mathrm{0}-08$

$<1.5 E-068$.

$<1.1 \mathrm{E}-07$

$<1.0=-00$

$<1.0 E-09$

$<9.0 E-09$

$<1.0 E-08$

$1.8 E-09+2.4 E-09$

$<6.06-08$

$<2.0 E-08$
$<2.0 E-08$
3.7E-03 $54.5 E-05$
Europlum-152

Groes alpha

3.3E-03 $\pm 8.5 E-06$

Mod Unit Lab

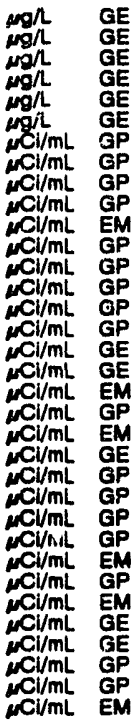

WELL HSB108C

MEASUREMENTS CONOUCTED IN THE FIELD

Sample date 07/15pe

Dopth to water: 47.98 in $(14.62 \mathrm{~m})$ bolow TOC

Wattor olovetion: $218.24 \mathrm{~h}(60.52 \mathrm{~m}) \mathrm{ms}$

$168 \mathrm{~s} / \mathrm{cm}$

pH: 6.7 . $56 \mathrm{mgh}$

Water tomperature: $20.8 \circ \mathrm{C}$

LABOAATOFY ANALYSES

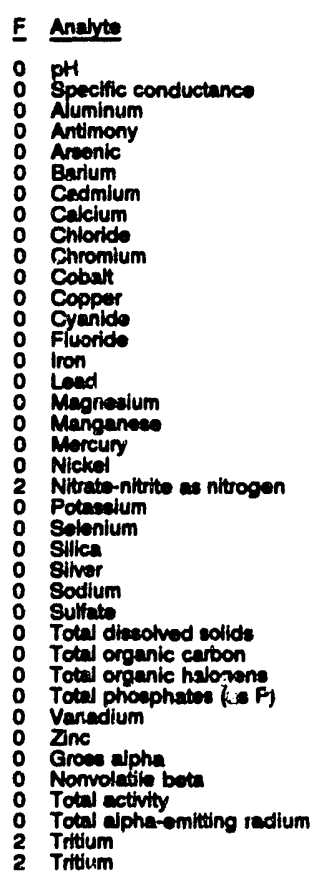

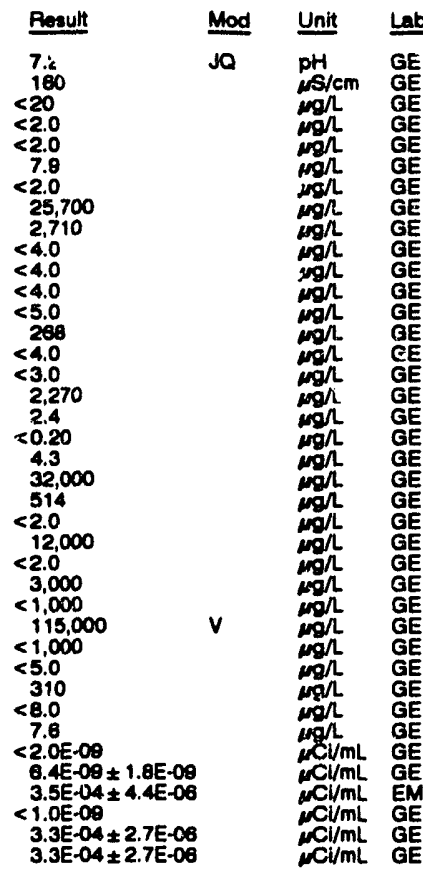

WELL HSB108D

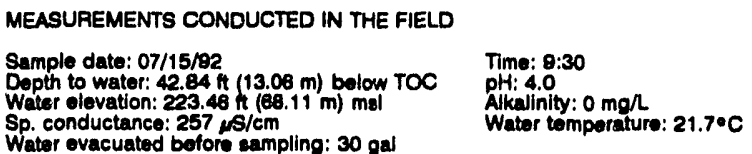

Water ovacuated before eampling: $30 \mathrm{gal}$

LABORATORY ANALYSES

: $\mathrm{pH}$ Spocific conductance

2 Aluminum

0 Ansenic

0 Barium

0 Cadium

Calcium

Chromium

o Cobat

0 Cyanide

Fluorido

Iron

L Load

2 Magnesium

Mercury

Nitrato-nitrite as nitrogen

Potassium

Solenium

Silica

O Siver

: Sodium

Total dissolved solids

Total organic carbon

Total organic halogons

: Total organic halogens

- Vanadium

of Antimony-125

o Corium-144

Cosium-137

Chromium.51

Cobalt-57

Cobalt-60

Europium-152

Europium-154

Europlumi-155

Groes alpho

2 Groes alphe

O Manganezo-54

Nonvolatile bete

Potassium-40

Promethium-144

Promethium-140

Ruthenium-109

Sodium-22

J Total activity

2 Total alpha-emitting radium

2 Tritum

Vitrium-es

Zinc-85

Zirconium-85

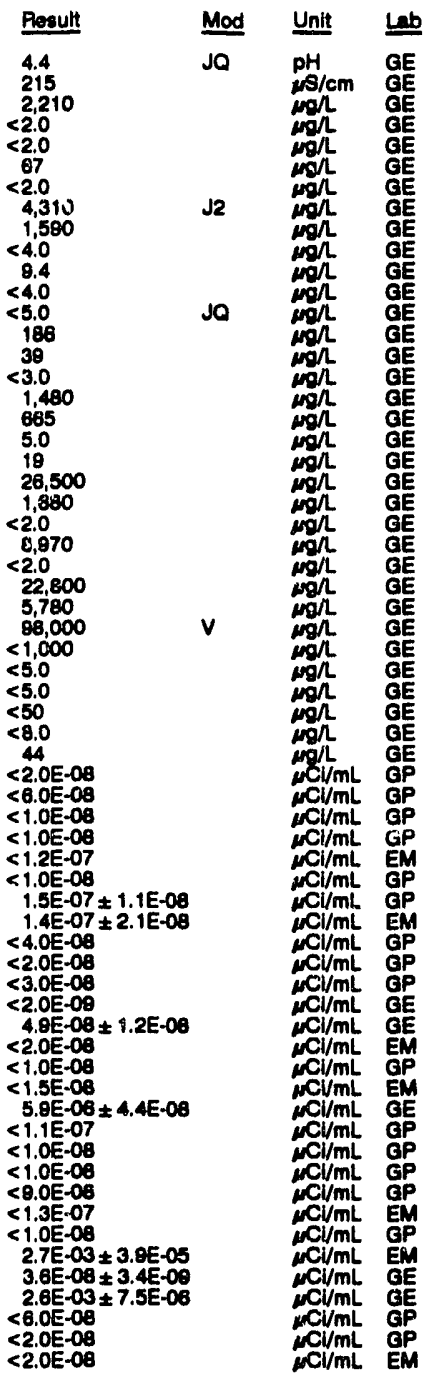

WELL HSB109C

MEASUREMENTS CONOUCTED IN THE FIELD

Sampla date: 07/15/92

Depth to water: $42.83 \mathrm{~h}(13.00 \mathrm{~m})$ below TOC

Water olevation: $218.67 \mathrm{tt}(80.85 \mathrm{~m}) \mathrm{msl}$

Wator ovacuatod before sampling: 132 gal

LABORATOAY ANALYSES

$\begin{array}{ll}\text { E } & \text { Analyte } \\ 0 & \text { pH } \\ 0 & \text { pH } \\ 0 & \text { Spocific conductance } \\ 0 & \text { Aluminum } \\ 0 & \text { Antimony } \\ 0 & \text { Arenic } \\ 0 & \text { Barium } \\ 0 & \text { Cadmium }\end{array}$

Time: 11:10

pH: 5.8

Alkalinity: $12 \mathrm{man}$ Water temperature: $20.5 \cdot \mathrm{C}$

\begin{tabular}{|c|c|c|}
\hline Result & Mod & Unit \\
\hline $\begin{array}{r}8.3 \\
6.3 \\
550 \\
<20 \\
<2.0 \\
<2.0 \\
8.8 \\
<2.0\end{array}$ & Jo & 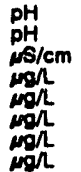 \\
\hline
\end{tabular}




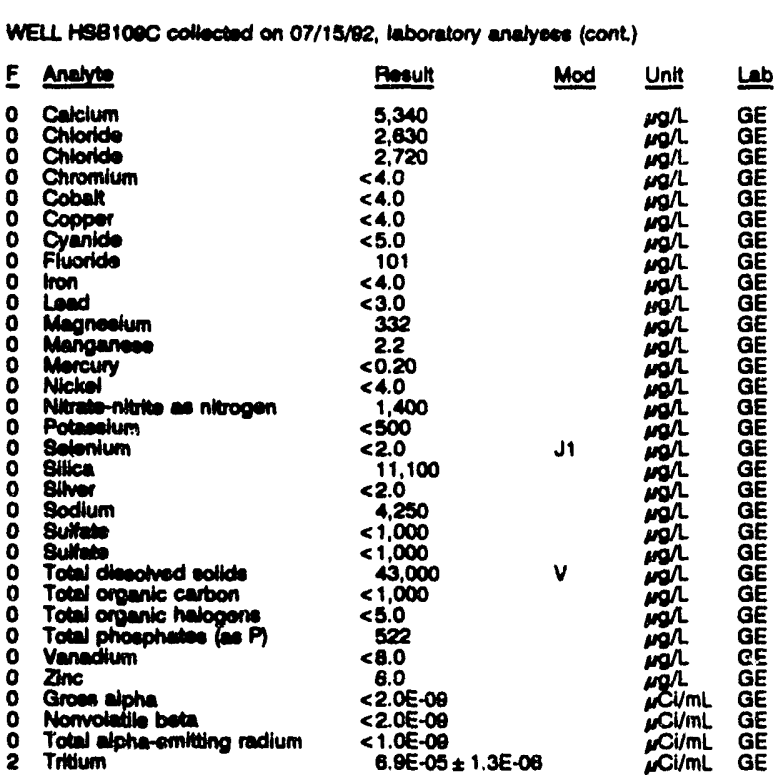

\section{WELL HSB109D}

MEASUREMENTS CONOUCTED IN THE FIELD

Sampie datis: 07/15/er Depth to matr: 30.68 it (11.78 m) bolow TOC Woter clovation: 225.54 h $(87.63 \mathrm{~m}) \mathrm{mel}$ Wistor evecuated befors sempling: 25 gal

LABOAATOFY ANAYYES
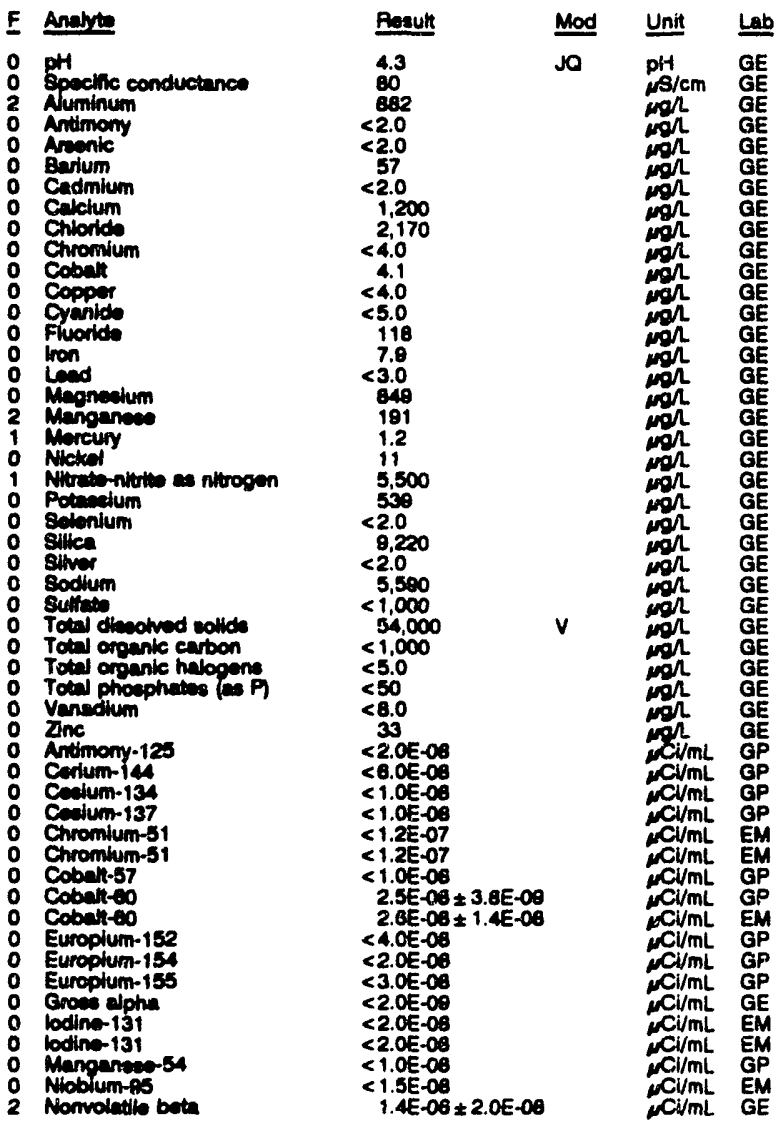

WELL HSB109D collotiod on 07/15/92, laboratory analyees (cont.)

\begin{tabular}{|c|c|c|c|}
\hline Analyte & Result & Mod & Untt \\
\hline 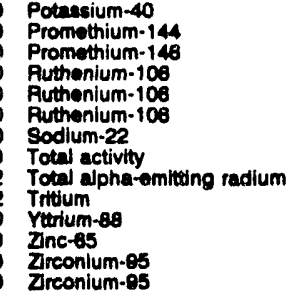 & $\begin{array}{l}<1.1 E-07 \\
<1.0 E-00 \\
<1.0 E-08 \\
<9.0 E-08 \\
<1.3 E-07 \\
<1.3 E-07 \\
<1.0 E-00 \\
3.5 E-04 \pm 4.4 E-06 \\
7.8 E-00 \pm 1.06-09 \\
3.2 E-04 \pm 2.7 E-00 \\
<6.0 E-08 \\
<2.0 E-08 \\
<2.0 E-00 \\
<2.0 E-08\end{array}$ & & 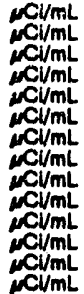 \\
\hline
\end{tabular}

\section{WELL HSB110C}

MEASUPEMENTS CONDUCTED IN THE FIELD

Sumple date: 07/15/382

Dopth to water: $36.67 \mathrm{n}(11.18 \mathrm{~m})$ bolow TOC

8p. conductance: $27.48 / \mathrm{cm}$. $78 \mathrm{~m}) \mathrm{mal}$

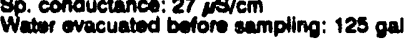

Nhainity: 1 man

ABORATORY ANALYSES

E Analyte

: $\mathrm{PH}$

Aluminum

Antimony

Barium

- Cadmium

Chilorido

o Chromium

O Cobalt

o Copper

o Fluoride

- Iron

o Magneavium

o Manganese

o Mercury

Nitrata-nitrite wa nitrogen

Potaseitum

o selenium

o Silica

o sodlum

O Sulfate

Total diesolved colld

Total organic carbon

Total phoephates (AB P

V Vanadium

O Znc

Grom alphe

Totw alpha-mituing radium

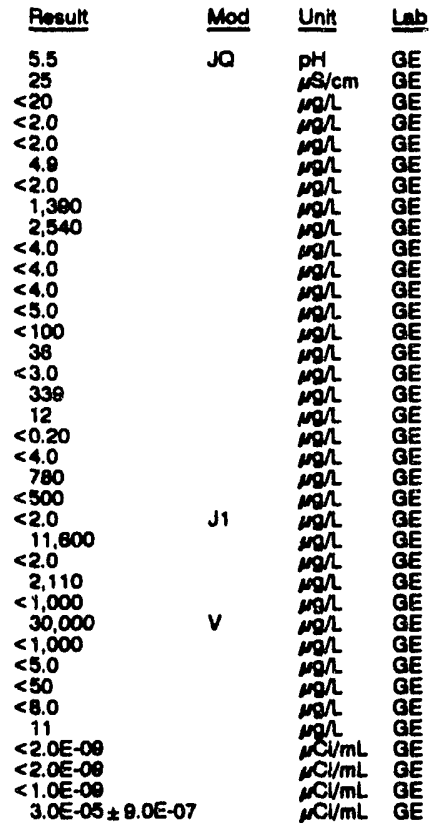

WELL HSB110D

MEASUREMENTS CONDUCTED IN THE FIELD

Sample dato: 07/15/92

Depth to water: 33.68 it $(10.28 \mathrm{~m})$ below TOC

Woter elovation: $221.04 \mathrm{ht}(87.65 \mathrm{~m}) \mathrm{ms}$

Sp. conductance. $80 \mathrm{ra} / \mathrm{cm}$

Pp. conductance: $80 \mathrm{ra} / \mathrm{cm}$
Water evacuated before sampling: $28 \mathrm{gel}$

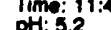

$\mathrm{pH}: 5.2$

water tomport

LABORATORY ANAL.YEES

$\begin{array}{ll}\text { E } & \text { Andrate } \\ 0 & \text { pH } \\ 0 & \text { Spacific conductance } \\ 2 & \text { Aluminum } \\ 0 & \text { Antimony } \\ 0 & \text { Aranic } \\ 0 & \text { Barium } \\ 0 & \text { Cadmium } \\ 0 & \text { Celcium } \\ 0 & \text { Chloride } \\ 0 & \text { Chromium } \\ 0 & \text { Cobalt } \\ 0 & \text { Coppor } \\ 0 & \text { Cyanide } \\ 0 & \text { Fluoride } \\ 0 & \text { Iron }\end{array}$

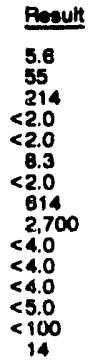

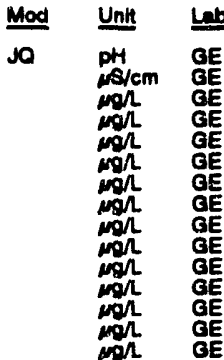


ANALYTICAL RESULTS

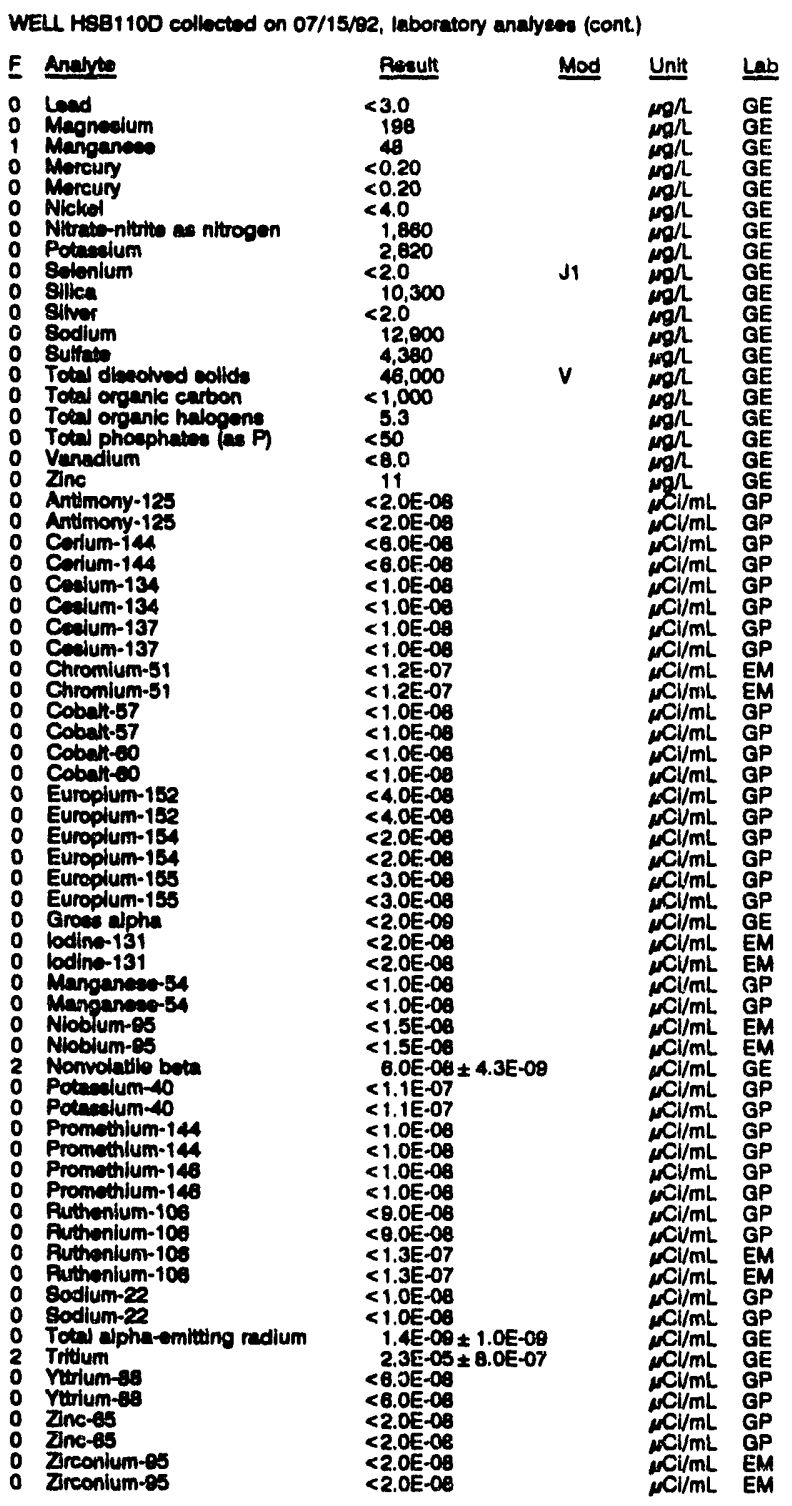

WELL HSB111C
MEASUREMENTS CONDUCTED IN THE FIELD

Sample date: 07/15/02 Depth to water: $35.77 \pi(10.80 \mathrm{~m})$ below TOC So. conductance: $230 \mathrm{ws} / \mathrm{cm}$

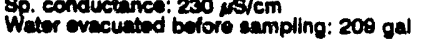

LABOAMTOFY ANALYSES

\begin{tabular}{|c|c|c|c|}
\hline E Aneyse & Result & Mod & Unit \\
\hline 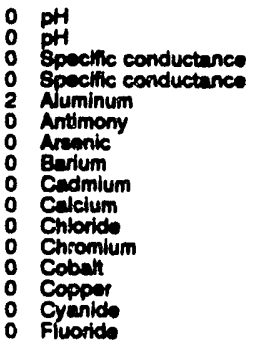 & $\begin{array}{l}5.2 \\
5.2 \\
180 \\
190 \\
140 \\
<2.0 \\
<2.0 \\
23 \\
<2.0 \\
14,300 \\
3,520 \\
<4.0 \\
<4.0 \\
<4.0 \\
<5.0 \\
130\end{array}$ & $\underset{J O}{J 0}$ & 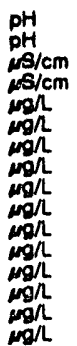 \\
\hline
\end{tabular}

Time: 13:40

Alkalinity: 0 mg/t

Water temperalure: $21.7^{\circ} \mathrm{C}$

Lab
WELL HSB111C collectod on 07/13/82, laboratory analysees (cont.)

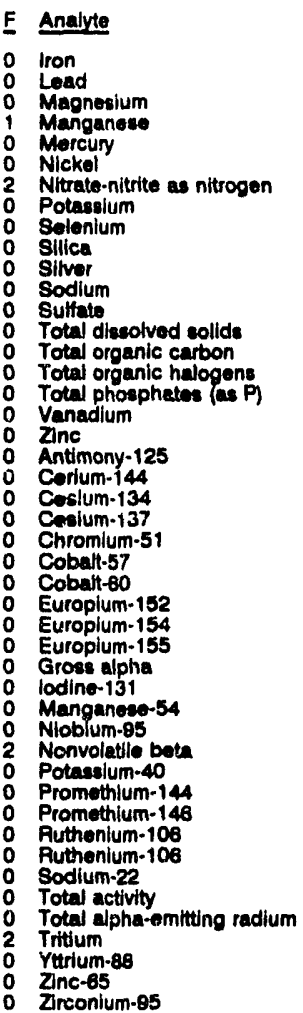

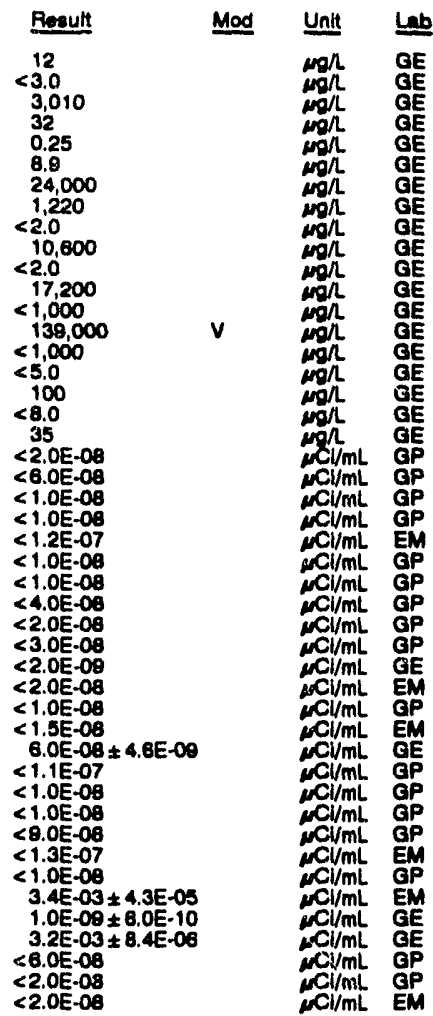

\section{WELL HSB111D}

MEASUREMENTS CONDUCTED IN THE FIELO

\begin{tabular}{|c|c|c|c|}
\hline Analyte & Roeult & $\mathrm{Mod}$ & Unit \\
\hline 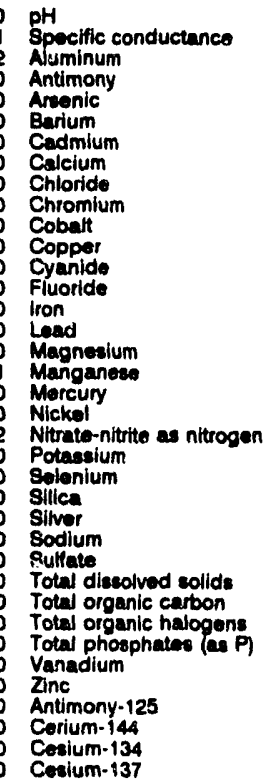 & $\begin{array}{c}5.0 \\
412 \\
185 \\
<2.0 \\
<2.0 \\
40 \\
<2.0 \\
5,350 \\
3,260 \\
<4.0 \\
<4.0 \\
<4.0 \\
<5.0 \\
122 \\
4.4 \\
<3.0 \\
2,370 \\
48 \\
<0.20 \\
5.9 \\
58,000 \\
<500 \\
<2.0 \\
8,670 \\
<2.0 \\
78,100 \\
<1,000 \\
364,000 \\
<1,000 \\
<5.0 \\
50 \\
<8.0 \\
13 \\
<2.0 E-00 \\
<6.0 E-08 \\
<1.0 E-08 \\
<1.0 E-08\end{array}$ & Ja & 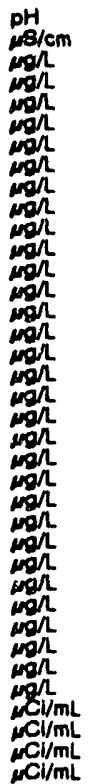 \\
\hline
\end{tabular}

Sample delo: 07/15/92

Depth to water: 34.29 h $(10.45 \mathrm{~m})$ below TOC

Water olevation: $221.71 \mathrm{~h}(67.58 \mathrm{~m}) \mathrm{msl}$

Water evacuated belore sempling: $24 \mathrm{gal}$

LABORATORY ANALYSES

Time: $14: 05$

Akninity: $0 \mathrm{mga}$

Whater tomperture: $21.4^{\circ} \mathrm{C}$

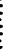

E




\begin{tabular}{|c|c|c|c|c|c|}
\hline E & Anoiste & Renult & Mod & Unit & Lab \\
\hline & 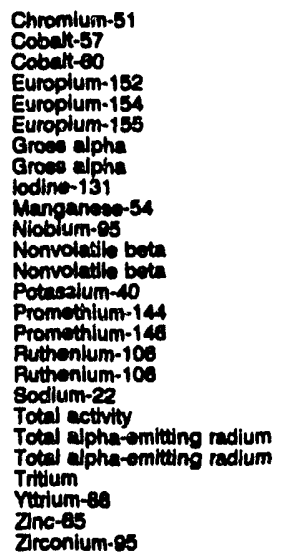 & $\begin{array}{r}<1.2 E-07 \\
<1.0 E-08 \\
<1.0 E-08 \\
<4.0 E-08 \\
<2.0 E-08 \\
<3.0 E-06 \\
6.0 E-09 \pm 3.3 E-09 \\
5.0 E-09 \pm 3.6 E-09 \\
<2.0 E-08 \\
<1.0 E-08 \\
<1.5 E-08 \\
5.4 E-08 \pm 4.9 E-09 \\
6.6 E-08 \pm 5.4 E-08 \\
<1.1 E-07 \\
<1.0 E-06 \\
<1.0 E-08 \\
<9.0 E-08 \\
<1.3 E-07 \\
<1.0 E-08 \\
1.2 E-02 \pm 1.8 E-04 \\
5.5 E-09 \pm 1.3 E-09 \\
6.5 E-09 \pm 1.4 E-09 \\
1.2 E-02 \pm 1.6 E-05 \\
<6.0 E-08 \\
<2.0 E-08 \\
<2.0 E-09\end{array}$ & & 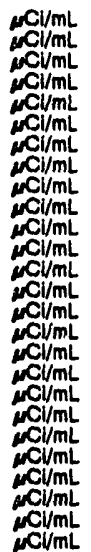 & $\begin{array}{l}\mathrm{EM} \\
\mathrm{GP} \\
\mathrm{GP} \\
\mathrm{GP} \\
\mathrm{GP} \\
\mathrm{GP} \\
\mathrm{GE} \\
\mathrm{GE} \\
\mathrm{EM} \\
\mathrm{GP} \\
\mathrm{EM} \\
\mathrm{GE} \\
\mathrm{GE} \\
\mathrm{GP} \\
\mathrm{GP} \\
\mathrm{GP} \\
\mathrm{GP} \\
\mathrm{EM} \\
\mathrm{GP} \\
\mathrm{EM} \\
\mathrm{GE} \\
\mathrm{GE} \\
\mathrm{GE} \\
\mathrm{GP} \\
\mathrm{GP} \\
\mathrm{EM}\end{array}$ \\
\hline
\end{tabular}

\section{WELL HSB111E}

MEASUREMENTS CONDUCTED IN THE FIELD

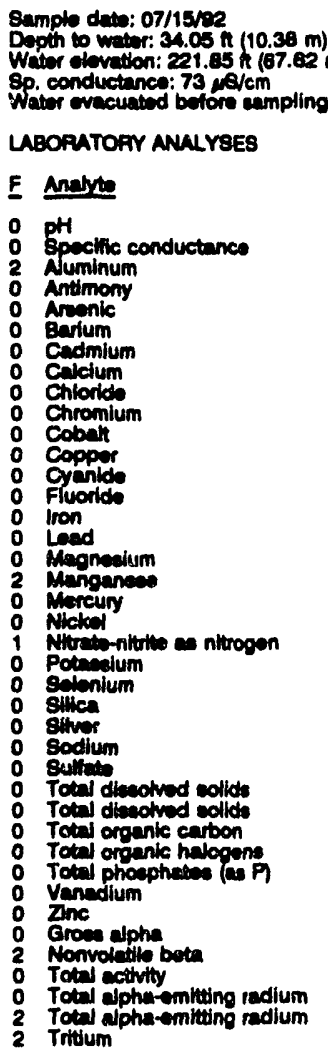

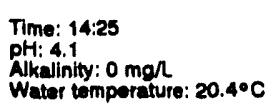

Water temperature: $20.4^{\circ} \mathrm{C}$

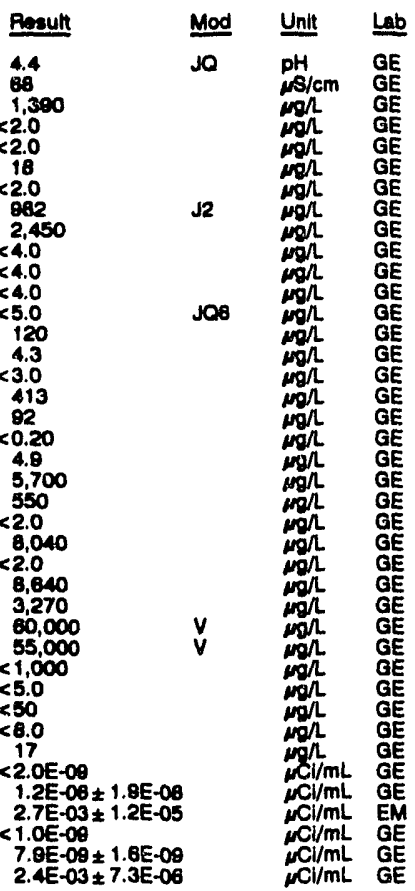

WELL HSB112C

MEASUREMENTS CONOUCTED IN THE FIELD

Sample date: 07/16/92

Dopth to wator: $33.42 \mathrm{ft}(40.18 \mathrm{~m})$ bolow TOC

Wator olevation: 221,48 \& $(67,51$

Sp. conductance: $193 \mathrm{\mu s} / \mathrm{cm}$
Water evecuated betore eampling: $212 \mathrm{gal}$

Yma: 7:45

PH: 6.2 $15 \mathrm{mal}$

Wellinity: $15 \mathrm{mgh}$ : $20.5 \circ 0$

LABOFATOAY ANALYSES

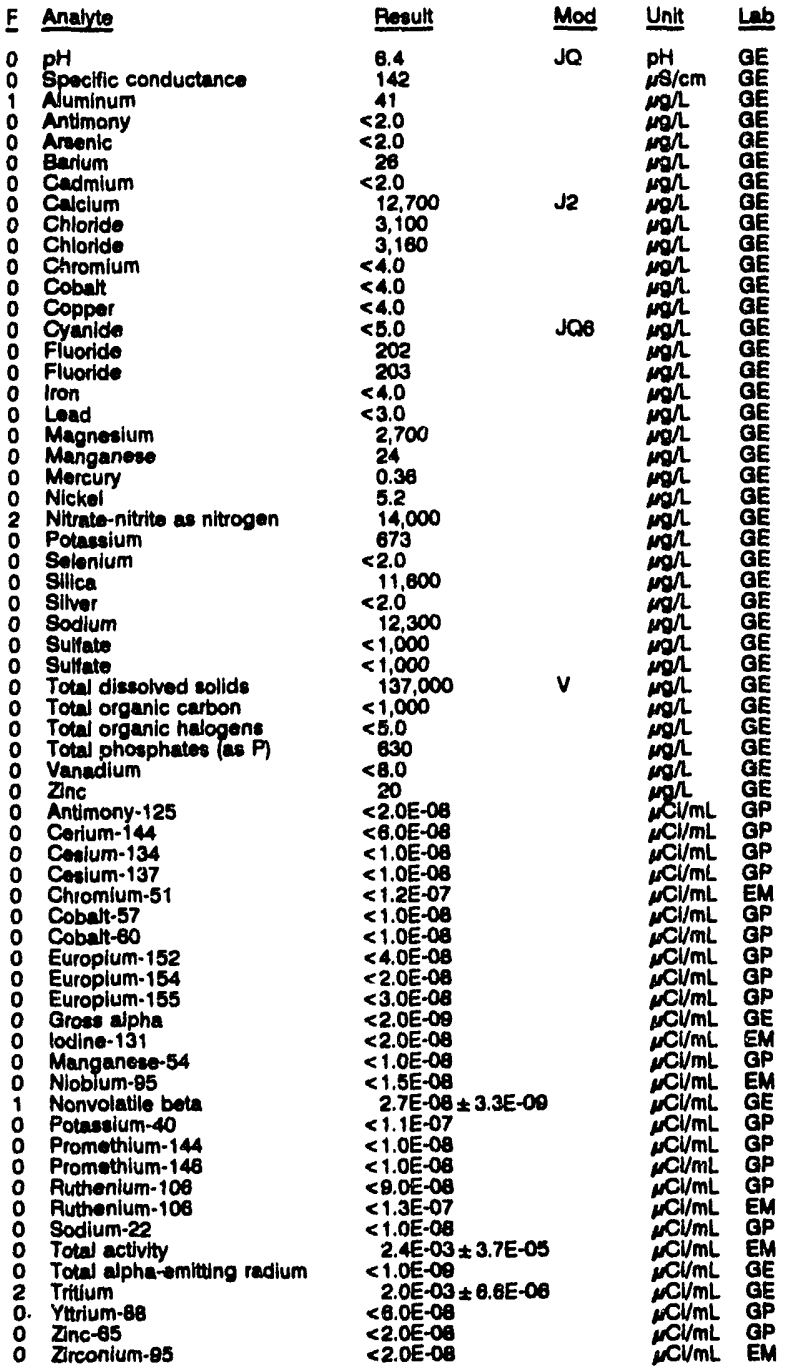

WELL HSB112D

MEASUAEMENTS CONDUCTED IN THE FIELD

Sample date: 07/18/92 20.96

Wopth to water: $32.67 \mathrm{At}(8.86 \mathrm{~m})$ below TOC

Sp. conductance: $435 \mathrm{\mu s} / \mathrm{cm}$
Wator evacuated betore sampling: $80 \mathrm{ges}$

LABOPATORY ANALYSES

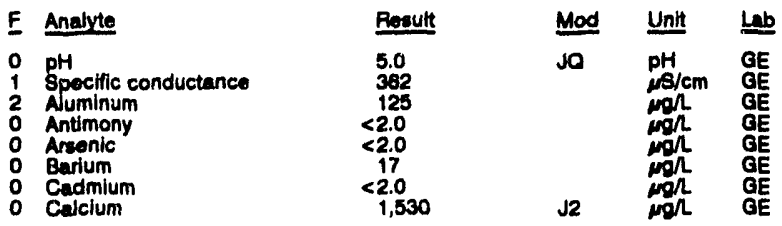


ANALYTICAL RESULTS

WELL HSB1 12D colloctod on 07/18/82, laboratory analyees (cont)

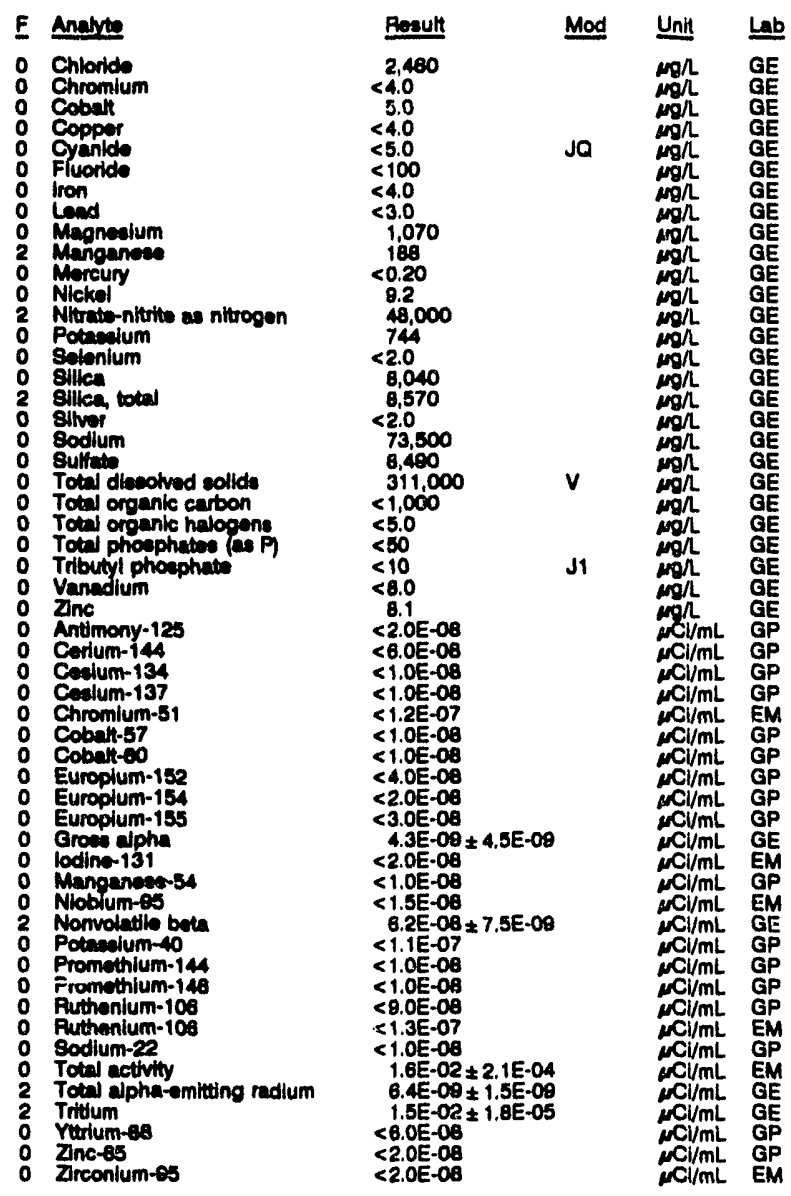

\section{WELL HSB112E}

MEASUAEMENTS CONDUCTED IN THE FIELD

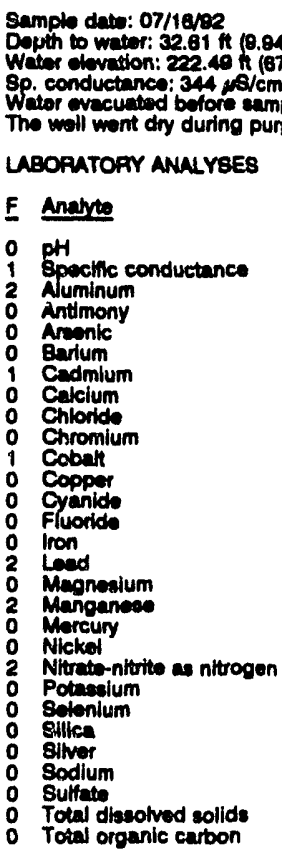

m) bolow TOC $7.82 \mathrm{~m}) \mathrm{mal}$ ling: 2 gal

PH: 5.1 . 0 man

Water temperature: $20.5^{\circ} \mathrm{C}$

Ponutit

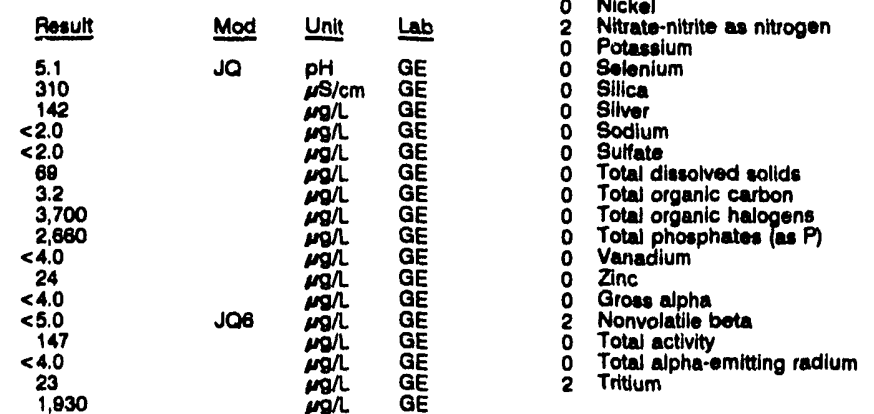
Water elevation: 221.87 t 167.
WELL HSB112E collected on 07/16/92, laboratory analyses (cont)

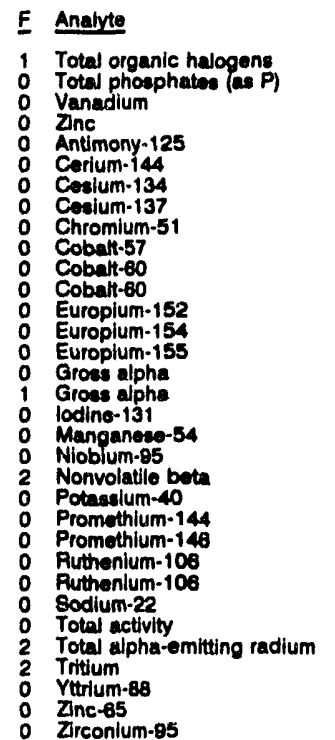

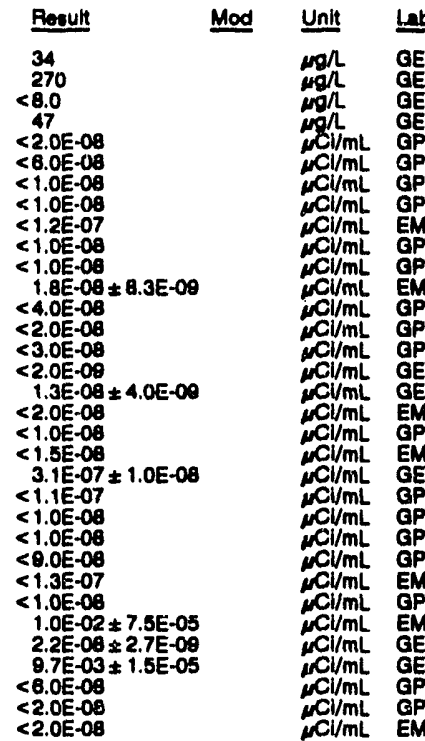

\section{WELL HSB113C}

MEASUREMENTS CONDUCTED IN THE FIELD

Sample deto: 07/16/92 Depth to water: $39.13 \mathrm{th}(11.93 \mathrm{~m})$ below TOC Water evacuated bofore sempling: $184 \mathrm{gal}$ Time: $11: 35$ Alkalinity: $0 \mathrm{mon}$. LABORATORY ANALYSES

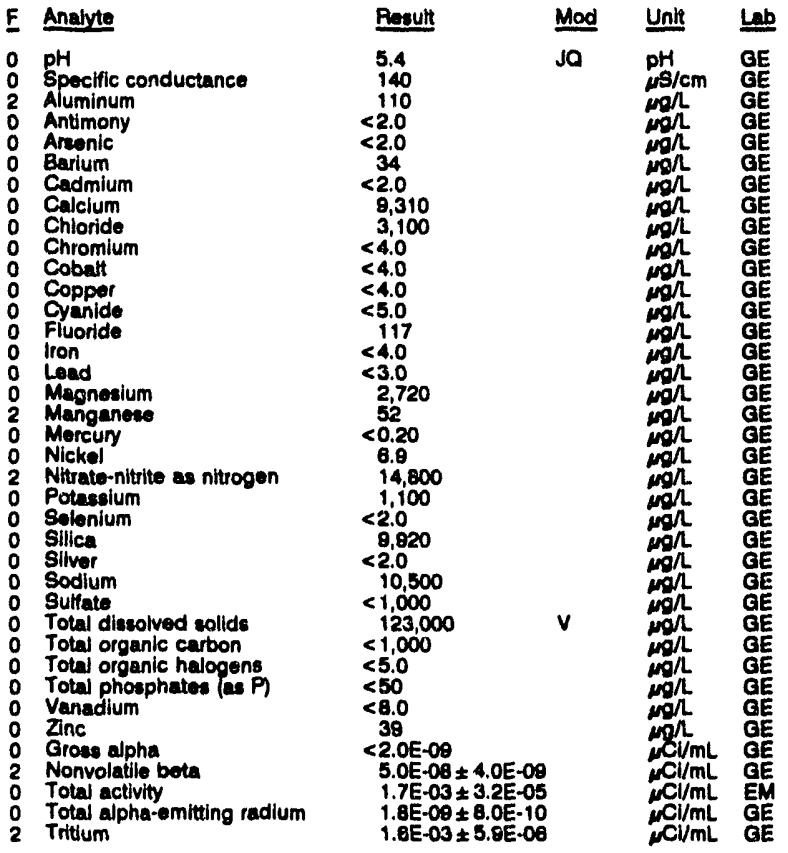


WELL HSB113D

MEASUAEEMENTS CONDUCTED IN THE FIELD

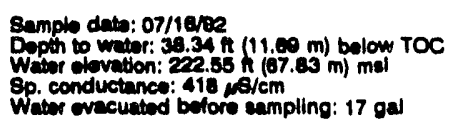

Time: 10:55

PH: 3.5 : $0 \mathrm{mon}$

Water temporefure: $21.5^{\circ} \mathrm{C}$

LABOPATORY ANALYSES

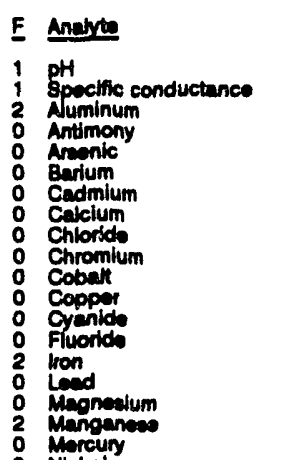

Nickel

Poran

Seienlum

Silica

Sodium

Totel dibectured sollo

Totil dienolved sollds

Totw organic carbon

Totw phosphutes

Total phoephatos fes P

Vanadit

Antimony-125

Antimony-12s

Cerrum-144

Ceclum-134

celum-134

Cesium-137

Coromlum-51

Cobalt.57

Cobatteo

Cobalt-eo

cobalteo

Europlum-152

Europlum-15e

Europlum-15:

Europlum-15s

Groes alpha

Groses elpha

lodina-131

Manganearsa

Nioblum-es

Nonvolatile bot

Potindum-40

Promentum-14

Promethium-144

Promethlum-146

Promethlum-146

Puthenium-10

Puthenium-10

Sodium-22

Sodium-22

rocil activiny minting molium

Total apho-emitung redium

Tritum

Vurium-es

Zinc-es

Zurconium-es

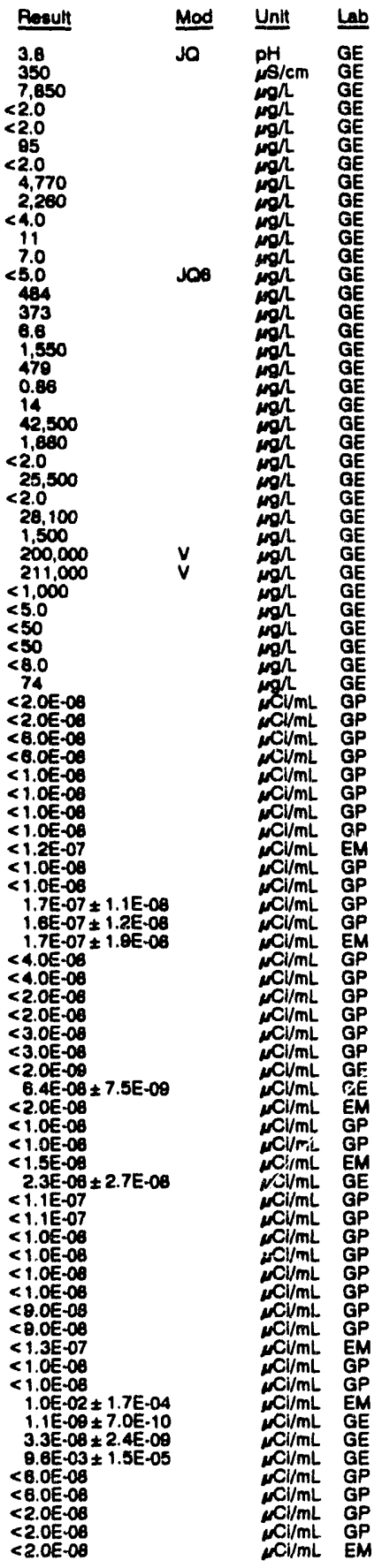

WELL HSB114C

MEASUREMENTS CONDUCTED IN THE FIELO

Sample dato: 07/1982

Depth to water: $40.64 \mathrm{H}(12.39 \mathrm{~m})$ bolow TOC

Wator olevation: 223.16 (68.02 m) ma

Wator evacuated before campling: $89 \mathrm{gal}$

Time: 10:20

Alkulinity: $0 \mathrm{mgh}$

Water tomperture: $21.4^{\circ} \mathrm{C}$

LABOFATORY ANALYSES

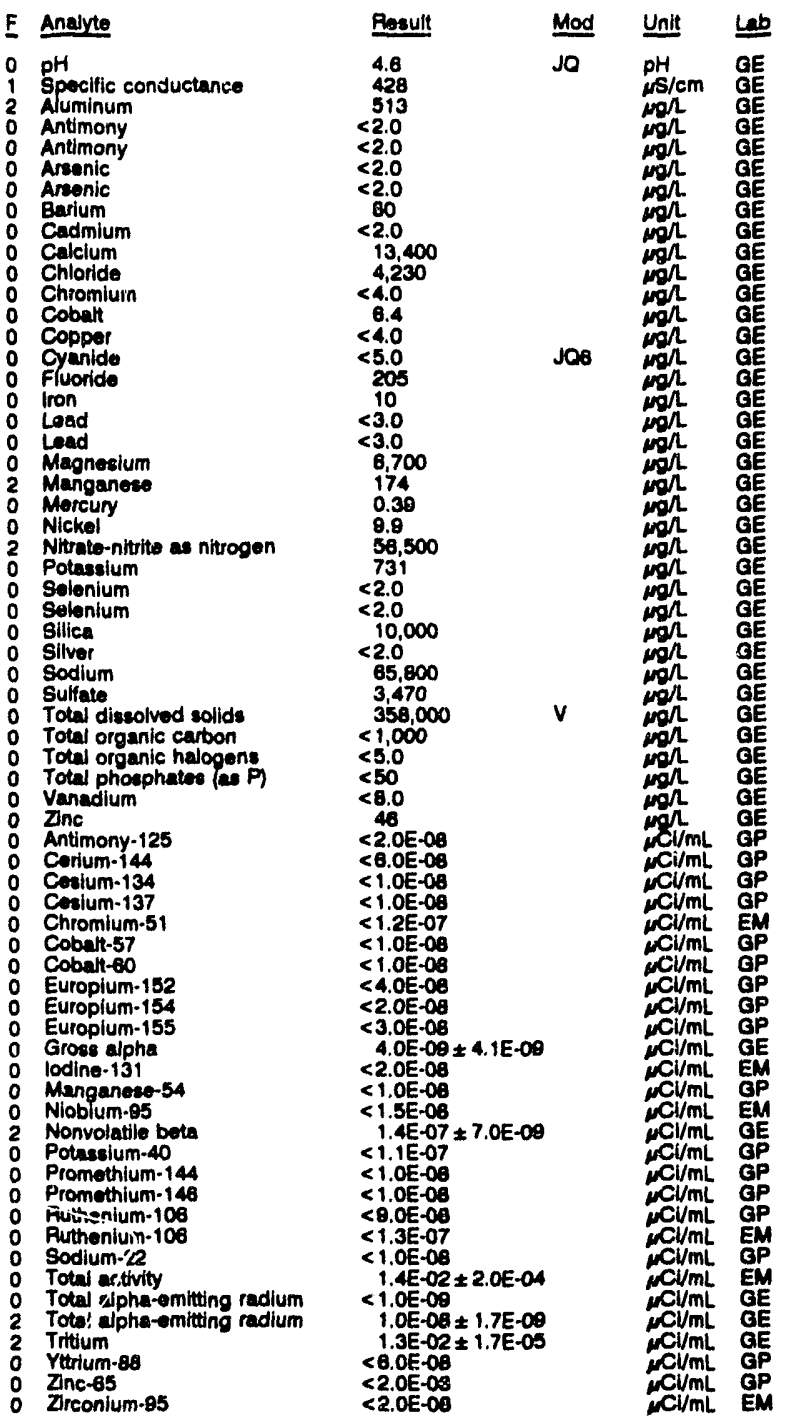

WELL HSB114D

MEASUREMENTS CONDUCTED IN THE FIELD

Sample date: $07 / 18 / 92$

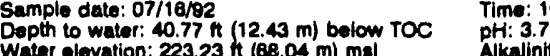

mal Akalinity: $0 \mathrm{mg} / \mathrm{s}$

Witer evacuated bofore eampling: $27 \mathrm{gal}$

Water tomperature: $22.5^{\circ} \mathrm{C}$

LABORATORY ANALYSES

\begin{tabular}{|c|c|c|c|}
\hline E Analyte & Result & Mod & Unit \\
\hline $\begin{array}{ll}1 & \text { pH } \\
0 & \text { Spocific conductance } \\
2 & \text { Aluminum } \\
0 & \text { Antimony } \\
0 & \text { Areonic } \\
0 & \text { Barium }\end{array}$ & $\begin{aligned} & 3.8 \\
& 2.20 \\
& 5,530 \\
&<2.0 \\
&<2.0 \\
& 54\end{aligned}$ & Jo & 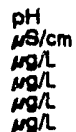 \\
\hline
\end{tabular}


ANALYTICAL RESULTS

WELL HSB1140 collected on 07/16/92, laboratory analyese (cont)

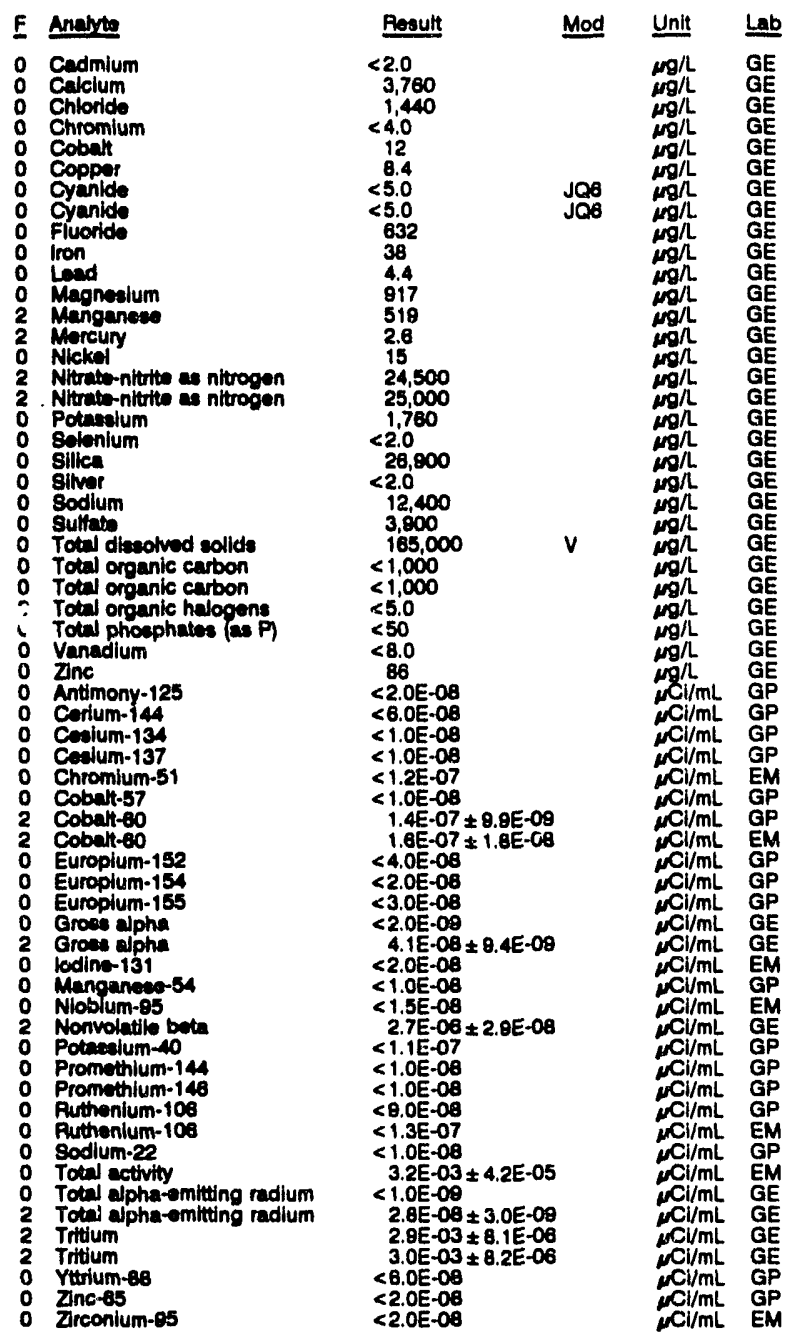

WELL HSB115C

MEASUREMENTS CONDUCTED IN THE FIELD

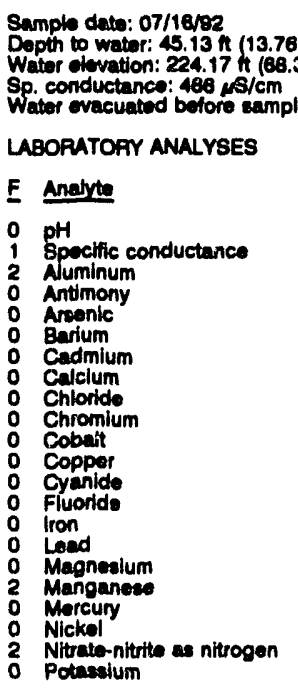

Time: $8: 35$

pH: 8.6

Water tomperature: $21.0^{\circ} \mathrm{C}$

Water evacuated betore eampling: $109 \mathrm{gal}$

LABORATOFY ANALYSES

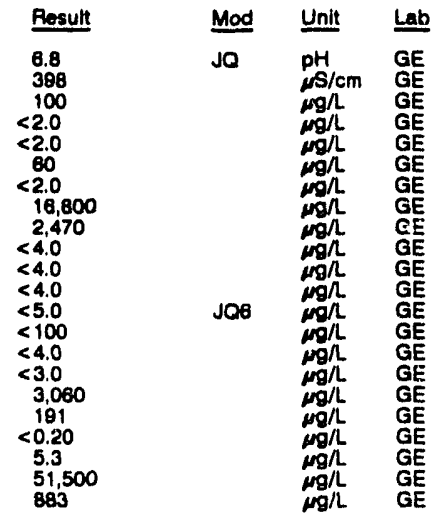

WELL HSB115C colloctod on 07/16/92, laboratory analyees (cont.)

\begin{tabular}{|c|c|c|c|}
\hline Analyte & Result: & Mod & Unit \\
\hline 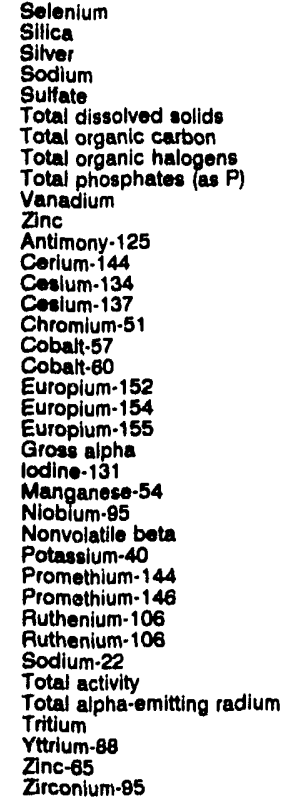 & $\begin{array}{l}<2.0 \\
8,020 \\
<2.0 \\
68,500 \\
4,420 \\
365,000 \\
<1,000 \\
<5.0 \\
<50 \\
<8.0 \\
15 \\
<2.0 \mathrm{E}-08 \\
<6.0 \mathrm{E}-08 \\
<1.0 \mathrm{E}-08 \\
<1.0 \mathrm{E}-08 \\
<1.2 \mathrm{E}-07 \\
<1.0 \mathrm{E}-08 \\
<1.0 \mathrm{E}-08 \\
<4.0 \mathrm{E}-08 \\
<2.0 \mathrm{E}-08 \\
<3.0 \mathrm{E}-08 \\
<2.0 \mathrm{E}-09 \\
<2.0 \mathrm{E}-09 \\
<1.0 \mathrm{E}-08 \\
<1.5 \mathrm{E}-08 \\
1.3 \mathrm{E}-07 \pm 6.7 \mathrm{E}-00 \\
<1.1 \mathrm{E}-07 \\
<1.0 \mathrm{E}-08 \\
<1.0 \mathrm{E}-08 \\
<9.0 \mathrm{E}-08 \\
<1.3 \mathrm{E}-07 \\
<1.0 \mathrm{E}-08 \\
1.5 \mathrm{E}-02 \\
<1.0 \mathrm{E}-09 \\
1.4 \mathrm{E}-02 \\
<6.1 \mathrm{E}-04 \\
<6.0 \mathrm{E}-08 \\
<2.0 \mathrm{E}-08 \\
<2.0 \mathrm{E}-08\end{array}$ & V & 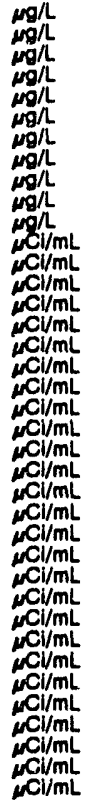 \\
\hline
\end{tabular}

\section{WELL HSB115D}

MEASUREMENTS CONDUCTED IN THE FIELD

$\begin{array}{ll}\text { Sample date: } 07 / 16 / 92 & \text { Time: } 8: 20 \\ \text { Depth to water } 44.80 \mathrm{H}(13.68 \mathrm{~m}) \text { below TOC } & \text { pH: } 3.9 \\ \text { Water olevation: } 224.30 \mathrm{ft}(88.37 \mathrm{~m}) \mathrm{msl} & \text { Alkalinity: } 0 \mathrm{mg} / \mathrm{h} \\ \text { Sp. conductance: } 331 \mu \mathrm{cm} & \text { Water temperature: } 21.4^{\circ} \mathrm{C} \\ \text { Water evacuated bofore sampling: } 4 \mathrm{gal} & \\ \text { The well went dry during purging. } & \end{array}$

LABORATORY ANALYSES

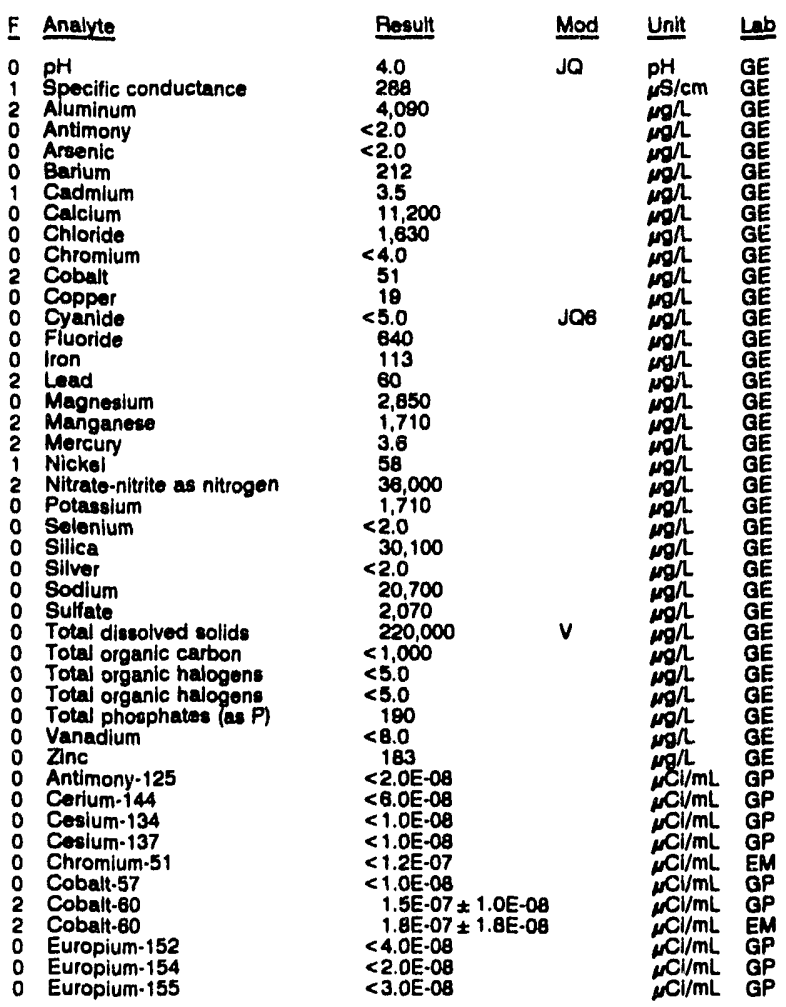


WEL HBB1150 collected on 07/18/92, laboratory analyees (cont)

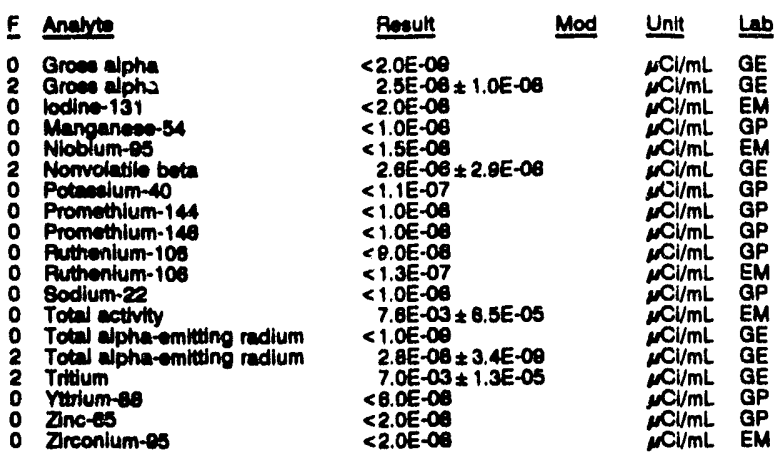

\section{WELL HSB116C}

\section{MEASUREMENTS CONDUCTED IN THE FIELD}

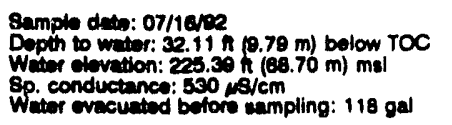

Time: 12:10

pH: 4.7 . $0 \mathrm{man}$

Water temperature: $20.80^{\circ} \mathrm{C}$

LBOFATOFY ANULYSES

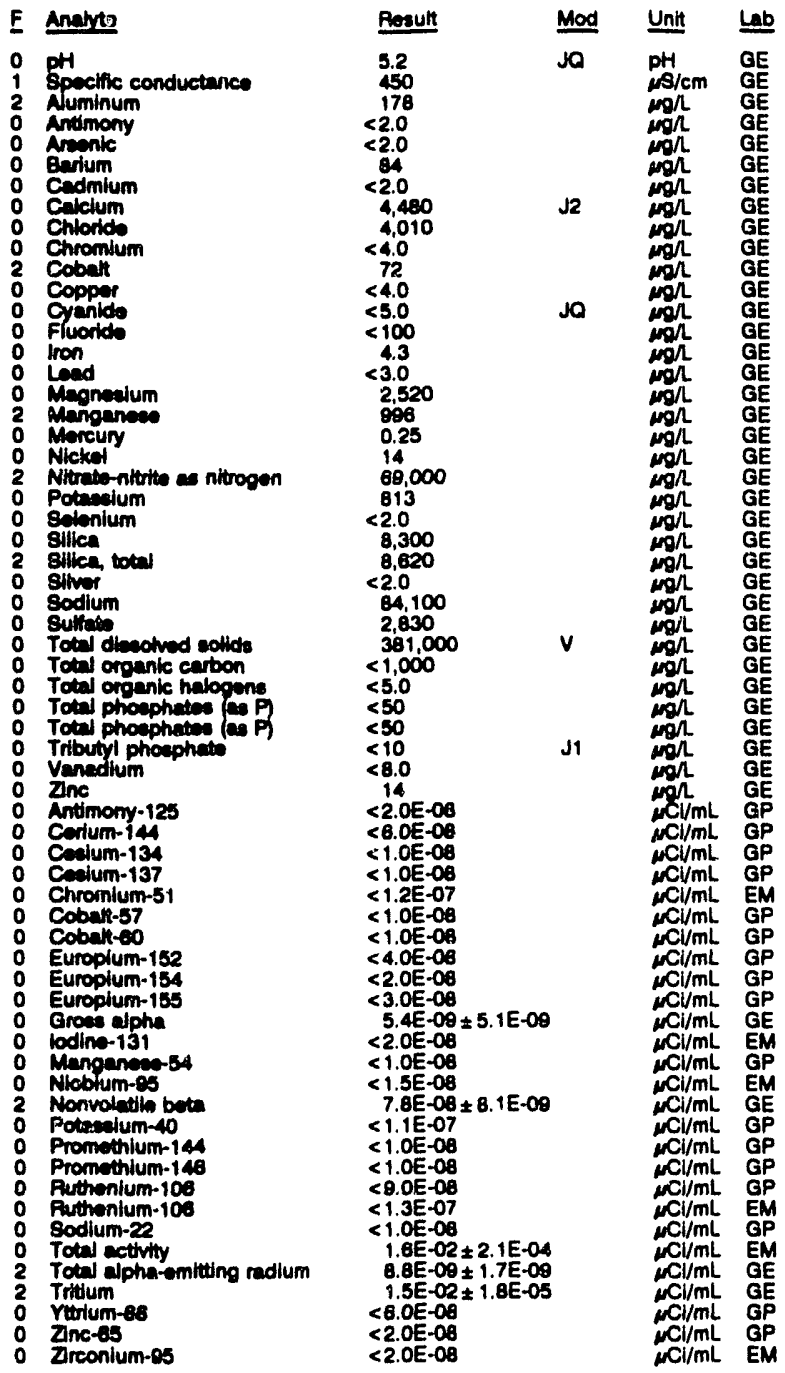

WELL HSB116D

MEASUREMENTS CONDUCTED IN THE FIELD

Sample dato: 07/18/92

Dopth to water: $31.15 \mathrm{~h}(0.40 \mathrm{~m})$ bolow TOC

Wator olevation: $225.85 \mathrm{ht}(68.78 \mathrm{~m}) \mathrm{mal}$

Wator evecuatod bollore sampling: 28 gal

LABOFATORY ANALYSES

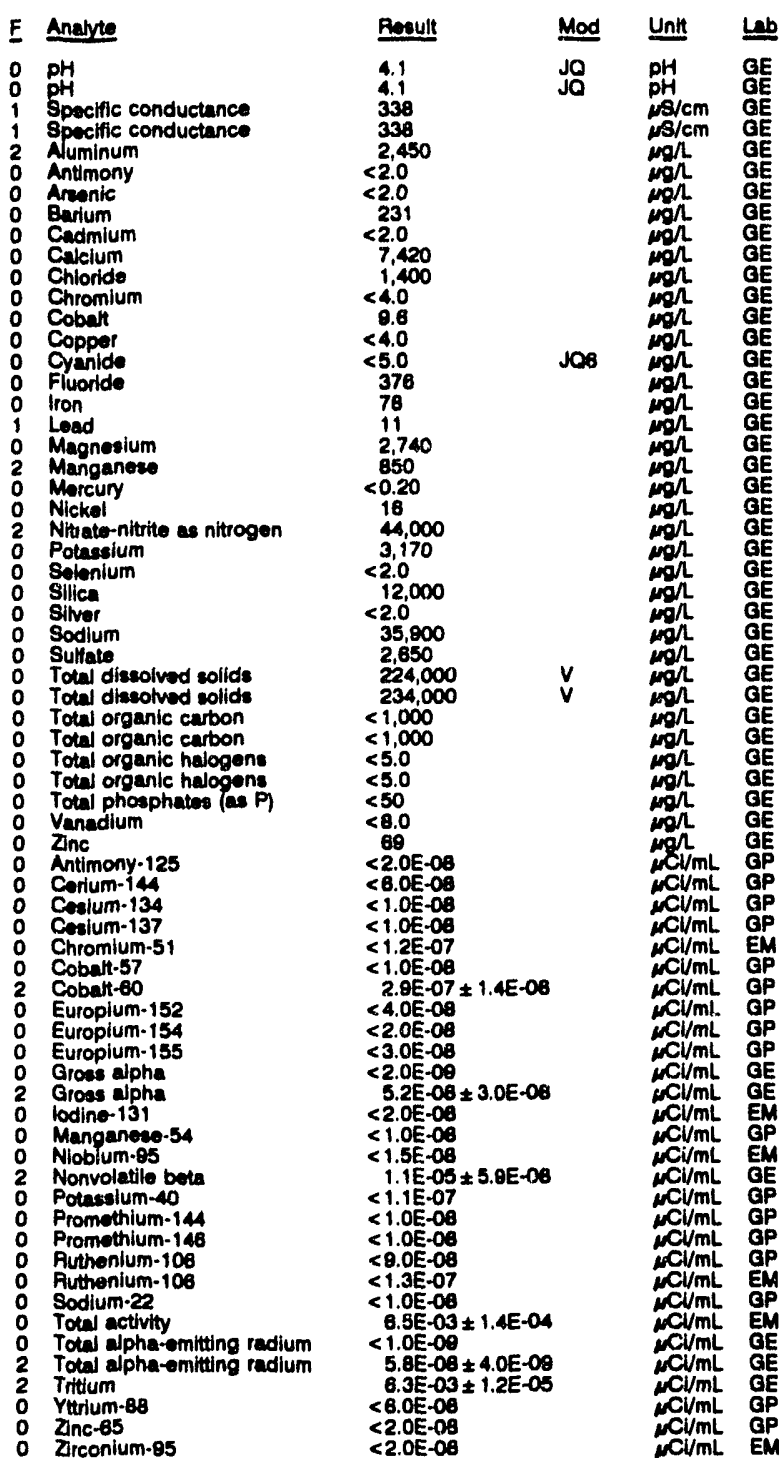

\section{WELL HSB117A}

MEASUREMENTS CONDUCTED IN THE FIELD

Sample date: $07 / 22 / 92$

Depth to water: 69.79 ft $(21.27 \mathrm{~m})$ below TOC

Wattor elovation: $188.51 \mathrm{ft}(50.75 \mathrm{~m}) \mathrm{ms}$

Wator ovacuatod bofore sampling: 216 gal

Time: 12:35

Alknilinity: $0 \mathrm{mgh}$

Wetar temperature: $22.4^{\circ} \mathrm{C}$

LABORATOFY ANALYSES

\begin{tabular}{|c|c|c|c|c|c|}
\hline$E$ & Analyte & Result & Mod & Unit & $\underline{\underline{L} \mathrm{~L}}$ \\
\hline $\begin{array}{l}0 \\
0 \\
0 \\
0\end{array}$ & $\begin{array}{l}\mathrm{pH} \\
\text { Spocific conductance } \\
\text { Aluminum } \\
\text { Antimony }\end{array}$ & $\begin{aligned} & 6.8 \\
& 132 \\
&<20 \\
&< 2.0\end{aligned}$ & JQ & $\begin{array}{l}\mathrm{pH} \\
\mathrm{mg} / \mathrm{cm} \\
\mathrm{mgh}\end{array}$ & $\begin{array}{l}\text { GE } \\
\text { GE } \\
\text { GE } \\
\text { GE }\end{array}$ \\
\hline
\end{tabular}


ANALYTICAL RESULTS

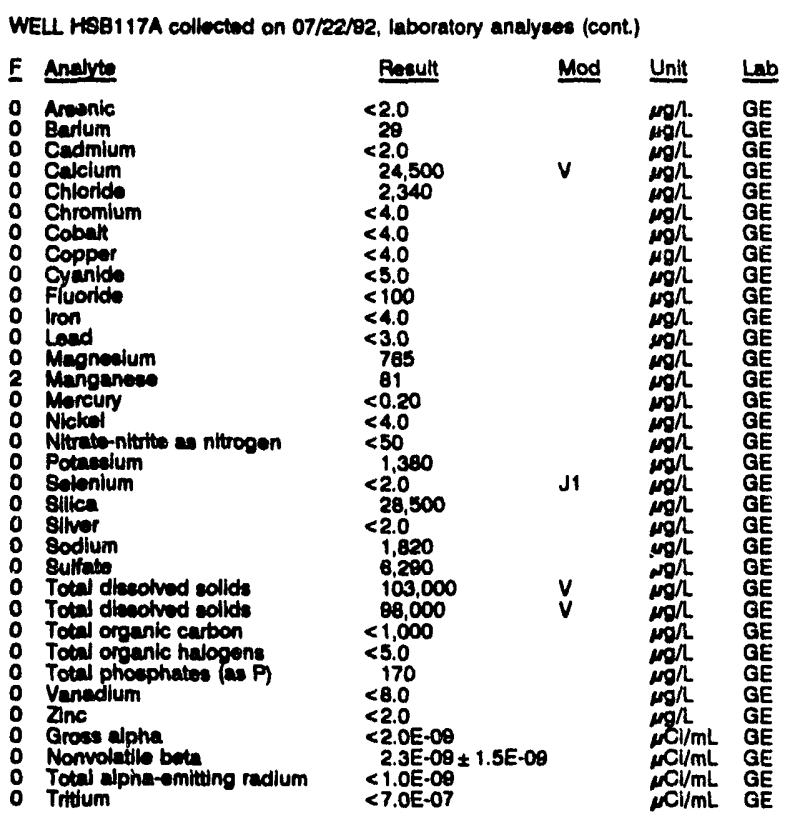

WELL HSB117C

MEASUREMENTS CONDUCTED IN THE FIELL

\begin{tabular}{|c|c|}
\hline 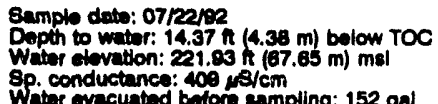 & $\begin{array}{l}\text { Time: } 14: 15 \\
\text { pH: } 4.7 \\
\text { Alkalinity: } 0 \text { mgh } \\
\text { Water tomperature: } 18.5^{\circ} \mathrm{C}\end{array}$ \\
\hline
\end{tabular}

LABORATOFY ANALYSES

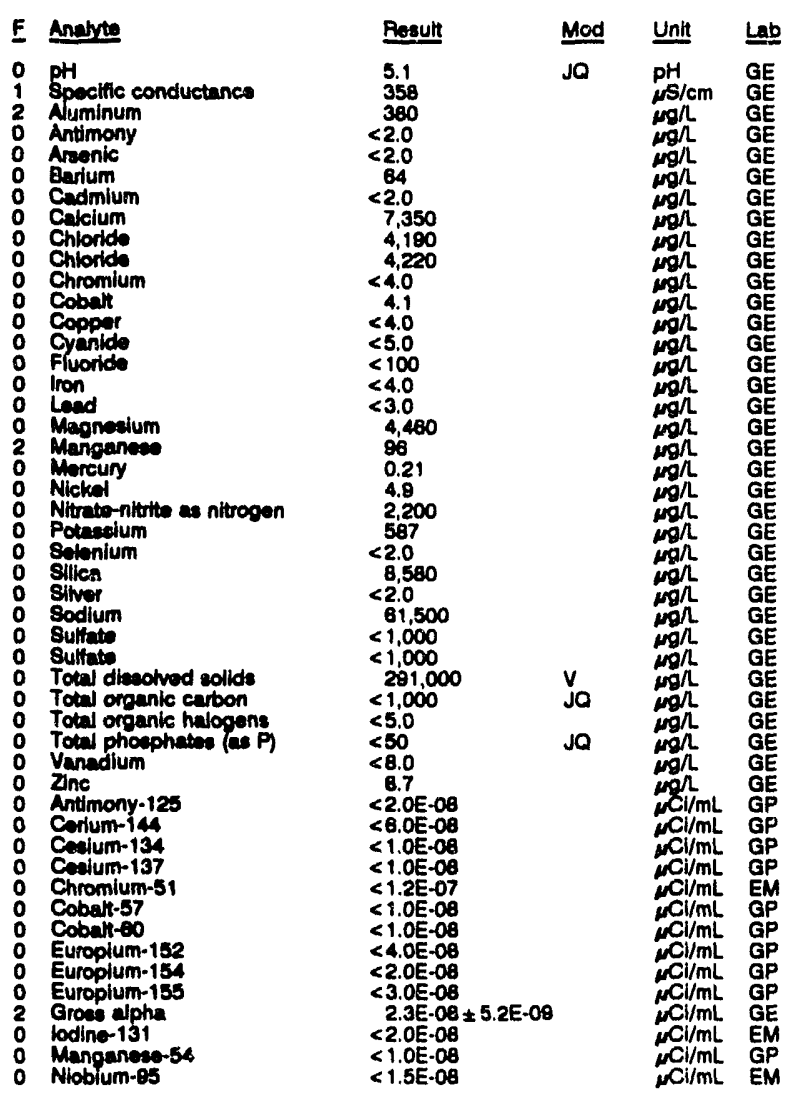

WELL HSB117C collected on 07/22/92, laboratory analyees (cont.)

\begin{tabular}{|c|c|c|c|c|}
\hline F & Analyte & Result & Unit & \\
\hline $\begin{array}{l}2 \\
0 \\
0 \\
0 \\
0 \\
0 \\
0 \\
0 \\
2 \\
2 \\
0 \\
0\end{array}$ & 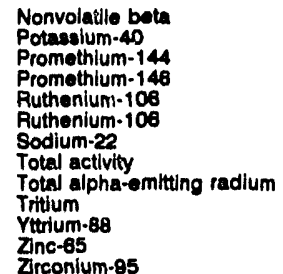 & 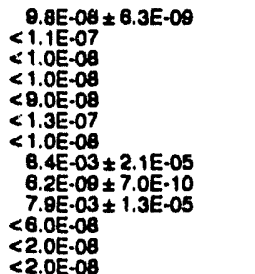 & 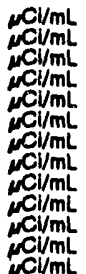 & $\begin{array}{l}G E \\
G P \\
G P \\
G P \\
G P \\
\text { EM } \\
G P \\
\text { EM } \\
G E \\
G E \\
G P \\
G P \\
\text { GM }\end{array}$ \\
\hline
\end{tabular}

WELL HSB117D

MEASUREMENTS CONDUCTED IN THE FIELD

$\begin{array}{ll}\text { Sample date: } 07 / 22 / 92 & \text { Time: } 14: 30 \\ \text { Depph to water: } 11.77 \mathrm{H}(3.58 \mathrm{~m}) \text { below TOC } & \text { PH: } 4.8 \\ \text { Water olovation: } 224.53 \mathrm{H}(68.44 \mathrm{~m}) \mathrm{msl} & \text { Alkwinity: } 0 \mathrm{mgh} \\ \text { Sp. conductance: } 25 \mu \mathrm{sm} & \text { Water tomperature: } 18.4 \circ \mathrm{C} \\ \text { Water evacuated betore sampling: } 67 \mathrm{gal} & \end{array}$
LABORATORY ANALYSES

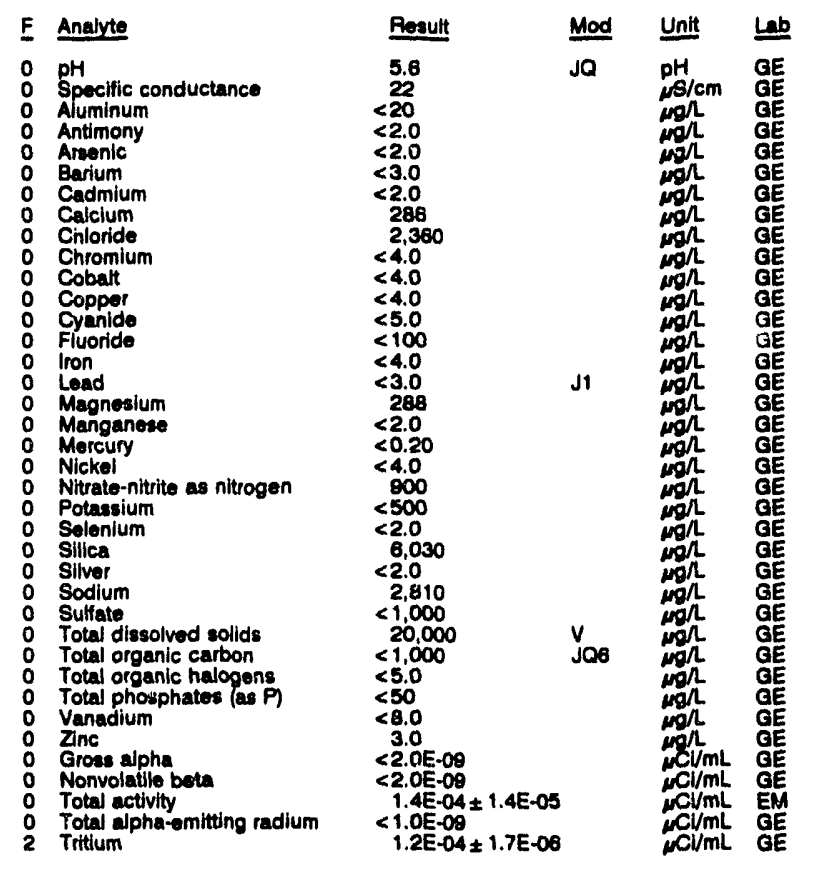

\section{WELL HSB118A}

MEASUREMENTS CONDUCTED IN THE FIELD

$\begin{array}{ll}\text { Sample date: } 07120 / 92 & \text { Time: } 8: 00 \\ \text { Depth to water: } 79.47 \mathrm{ft}(24.22 \mathrm{~m}) \text { below TOC } & \text { pH: } 8.5 \\ \text { Water elevation: } 167.83 \mathrm{Ht}(51.16 \mathrm{~m}) \mathrm{mal} & \text { Alkalinity: } 37 \mathrm{mg} / \\ \text { Sp. conductance: } 250 \mu \mathrm{s} / \mathrm{cm} & \text { Water tomperature: } 19.8 \circ \mathrm{C} \\ \text { Water evacuated bofore campling: } 202 \mathrm{gal} & \end{array}$
LABORATORY ANALYSES

\begin{tabular}{|c|c|c|c|c|}
\hline E Anajyte & Reault & Mod & Unit & La \\
\hline $\begin{array}{ll}0 & \text { pH } \\
0 & \text { Spoctific conductance } \\
0 & \text { Aluminum } \\
0 & \text { Antimony } \\
0 & \text { Aresnic } \\
0 & \text { Barlum } \\
0 & \text { Cadmium } \\
0 & \text { Calclum } \\
0 & \text { Chloride } \\
0 & \text { Chromium } \\
0 & \text { Cobalt } \\
0 & \text { Coppor } \\
0 & \text { Cyanide } \\
0 & \text { Fluoride } \\
0 & \text { iron }\end{array}$ & $\begin{array}{r}6.8 \\
212 \\
<20 \\
<2.0 \\
<2.0 \\
61 \\
<2.0 \\
41.400 \\
2.430 \\
<4.0 \\
<4.0 \\
<4.0 \\
<5.0 \\
136 \\
36\end{array}$ & JO & 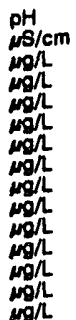 & $\begin{array}{l}\mathrm{GE} \\
\mathrm{GE} \\
\mathrm{GE} \\
\mathrm{dE} \\
\mathrm{GE} \\
\mathrm{dE} \\
\mathrm{dE} \\
\mathrm{GE} \\
\mathrm{GE} \\
\mathrm{GE} \\
\mathrm{GE} \\
\mathrm{GE} \\
\mathrm{GE} \\
\mathrm{GE} \\
\mathrm{GE}\end{array}$ \\
\hline
\end{tabular}




\section{ANALYTICAL RESULTS}

\begin{tabular}{|c|c|c|c|}
\hline E Anerses & Besult & Mod & Unit: \\
\hline 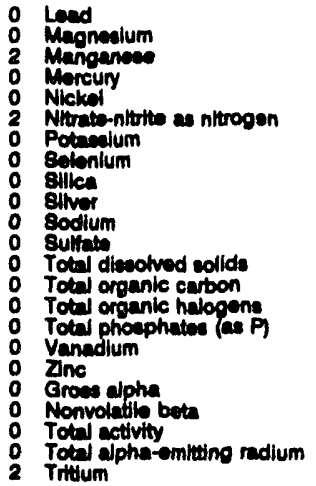 & $\begin{array}{l}<3.0 \\
1,150 \\
57 \\
<0.20 \\
<4.0 \\
13,500 \\
2,050 \\
<2.0 \\
33,400 \\
<2.0 \\
2,080 \\
7,320 \\
217,000 \\
<1,000 \\
<5.0 \\
220 \\
<8.0 \\
<2.0 \\
<2.0 E-09 \\
1.0 E-00 \pm 3.3 E-00 \\
3.0 E-03 \pm 1.3 E-05 \\
1.0 E-00 \pm 4.0 E-10 \\
2.8 E-03 \pm 7.8 E-08\end{array}$ & Jo & 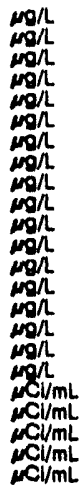 \\
\hline
\end{tabular}

\section{WELL HSB119A}

\begin{tabular}{|c|c|c|c|c|c|}
\hline \multicolumn{6}{|c|}{ MEABUREMENTS CONDUCTED IN THE FIELD } \\
\hline \multicolumn{3}{|c|}{ 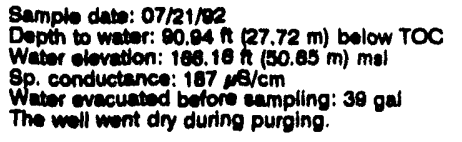 } & \multicolumn{3}{|c|}{$\begin{array}{l}\text { Timo: } 15: 30 \\
\text { pH: } 6.8 \\
\text { Alkalinity: } 62 \mathrm{mgh} \\
\text { Water temperature: } 21.5 \cdot \mathrm{C}\end{array}$} \\
\hline \multicolumn{6}{|c|}{ LABOAMTOFY ANALYES } \\
\hline - & Analyte & Result & Mod & Unit & Lab \\
\hline $\begin{array}{l}0 \\
0 \\
0 \\
0 \\
0 \\
0 \\
0 \\
0 \\
0 \\
0 \\
0 \\
0 \\
0 \\
0 \\
0 \\
0 \\
0 \\
0 \\
0 \\
0 \\
0 \\
0 \\
0 \\
0 \\
2 \\
0 \\
0 \\
0 \\
0 \\
0 \\
0 \\
0 \\
0 \\
0\end{array}$ & 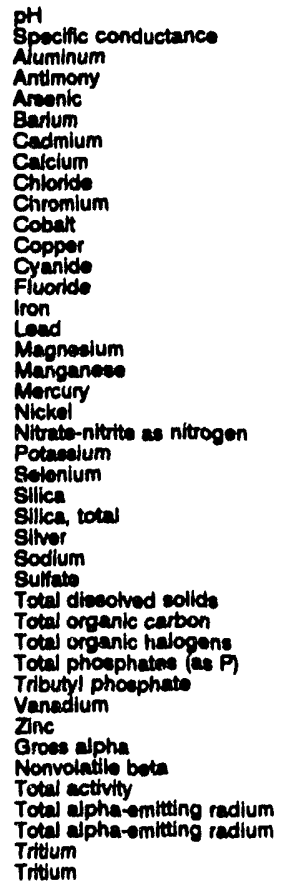 & 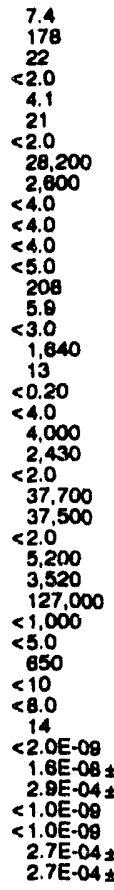 & .06 & 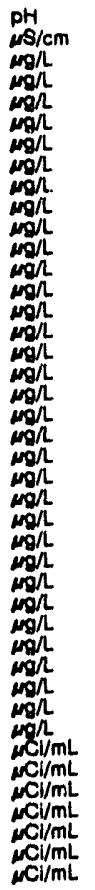 & $\begin{array}{l}\text { GE } \\
\mathrm{GE} \\
\mathrm{GE} \\
\mathrm{GE} \\
\mathrm{GE} \\
\mathrm{GE} \\
\mathrm{GE} \\
\mathrm{GE} \\
\mathrm{GE} \\
\mathrm{GE} \\
\mathrm{GE} \\
\mathrm{GE} \\
\mathrm{GE} \\
\mathrm{GE} \\
\mathrm{GE} \\
\mathrm{GE} \\
\mathrm{GE} \\
\mathrm{GE} \\
\mathrm{GE} \\
\mathrm{GE} \\
\mathrm{GE} \\
\mathrm{GE} \\
\mathrm{GE} \\
\mathrm{GE} \\
\mathrm{GE} \\
\mathrm{GE} \\
\mathrm{GE} \\
\mathrm{GE} \\
\mathrm{GE} \\
\mathrm{GE} \\
\mathrm{GE} \\
\mathrm{GE} \\
\mathrm{GE} \\
\mathrm{GE} \\
\mathrm{GE} \\
\mathrm{GE} \\
\mathrm{GE} \\
\mathrm{GE} \\
\mathrm{GE} \\
\mathrm{GE} \\
\mathrm{GE} \\
\mathrm{GE}\end{array}$ \\
\hline
\end{tabular}

WELL HSB120A

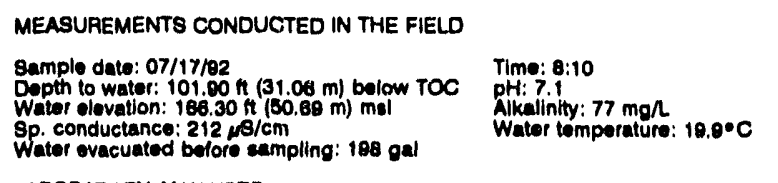

LABOPATOAY ANALYSES

\begin{tabular}{|c|c|c|c|}
\hline 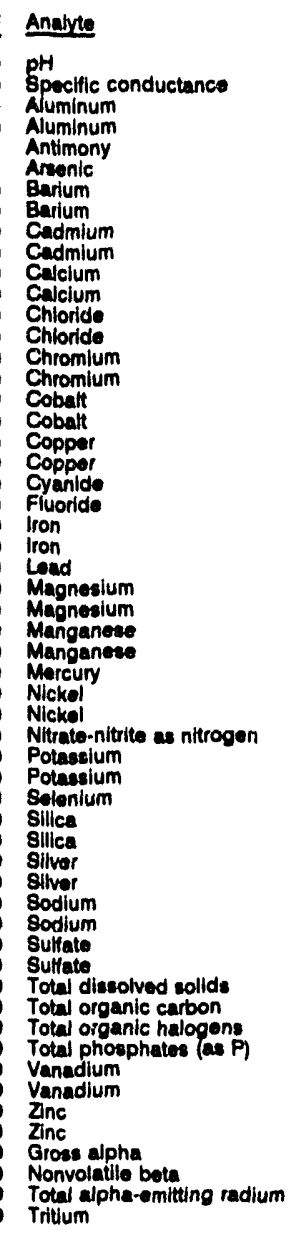 & 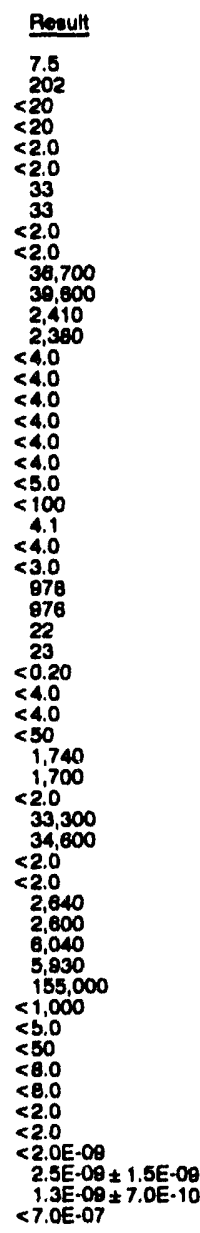 & $\frac{\text { Mod }}{\text { Ja }}$ & 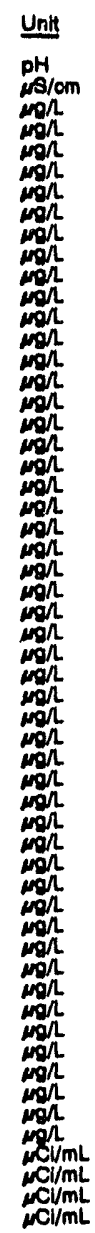 \\
\hline
\end{tabular}

\section{WELL HSB121A}

MEABUREMENTS CONDUCTED IN THE FIELL

Sample dato: 07/17/82 Sample dato: $07 / 17 / 82$
Depth to water: $102.80 \mathrm{H}(31.39 \mathrm{~m})$ below TOC Time: 8:50
pH: 7.0

Wator evacuntod bolore sampling: $210 \mathrm{gal}$

LABORATORY ANALYSES

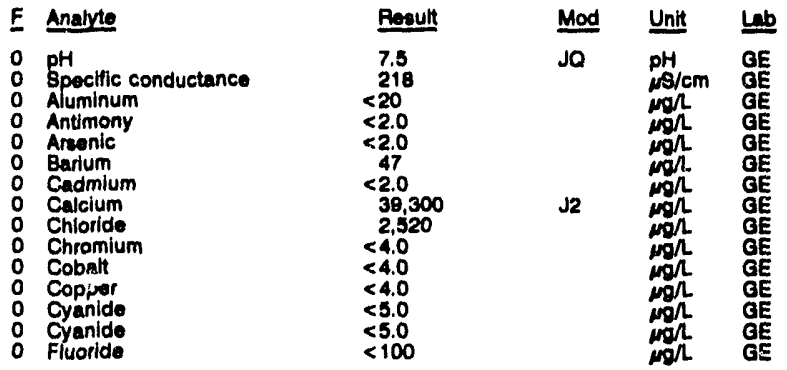


ANALYTICAL RESULTS

WELL HBB121A collocted on 07/17/82, laboratory analysere (cont)

\begin{tabular}{|c|c|c|c|c|}
\hline $\boldsymbol{F}$ & Anayes & Besult & Mod & Unit \\
\hline $\begin{array}{l}0 \\
0 \\
0 \\
0 \\
0 \\
0 \\
0 \\
0 \\
0 \\
0 \\
0 \\
0 \\
0 \\
0 \\
0 \\
0 \\
0 \\
0 \\
0 \\
0 \\
0\end{array}$ & 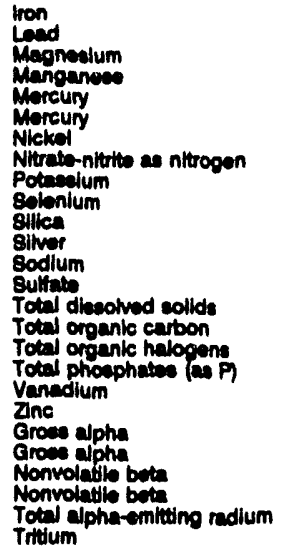 & 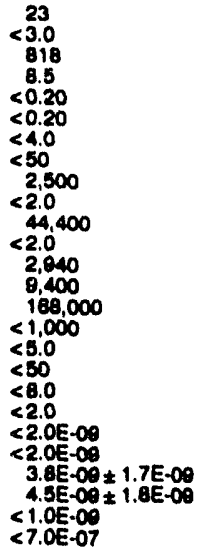 & v & 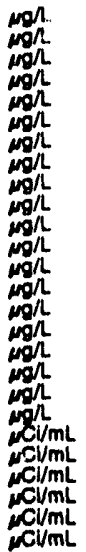 \\
\hline
\end{tabular}

WELL HSB122A

MEASUREMENTS CONDUCTED IN THE FIELD

\begin{tabular}{|c|c|}
\hline 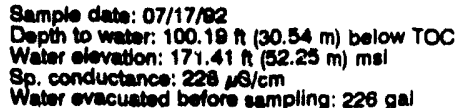 & $\begin{array}{l}\text { Time: } 9: 30 \\
\text { PH: } 6.9 \\
\text { Alkalinity: } 84 \mathrm{mg} / \mathrm{L} \\
\text { Water tomperature: } 18.8 \cdot \mathrm{C}\end{array}$ \\
\hline
\end{tabular}

LABORATORY ANALYSES
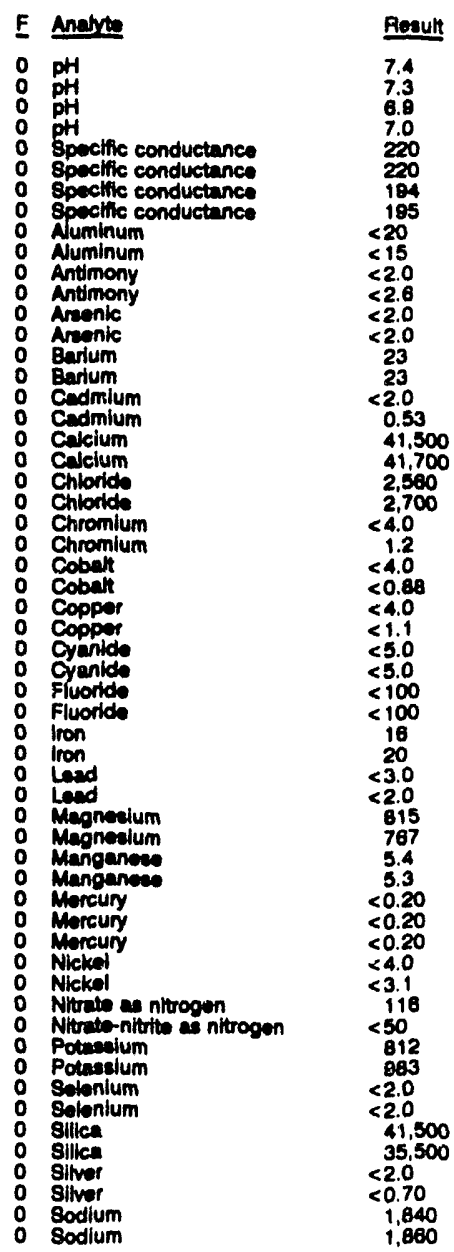

WELL HS9122A collectod on 07/17/92, laboratory analysee (cont)
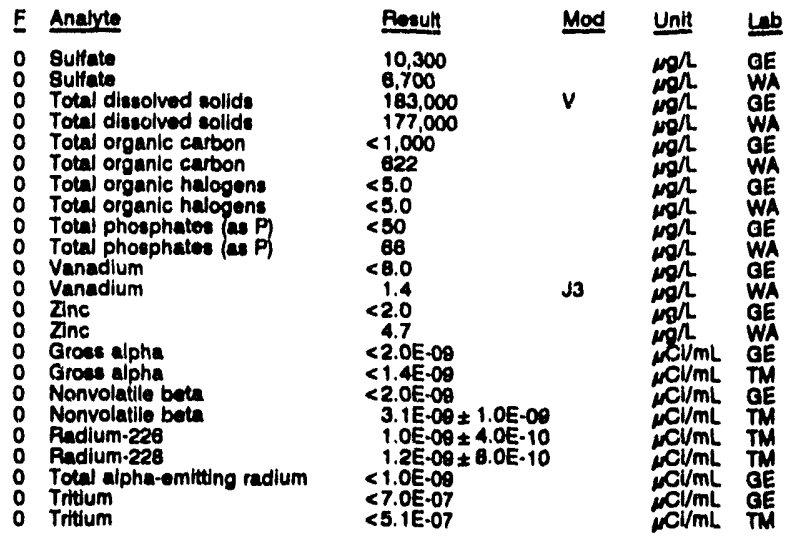

\section{WELL HSB122A Replicate}

MEASUREMENTS CONDUCTED IN THE FIELO

Sample date: 07/17/02

Depth to water: $100.19 \mathrm{nt}(30.54 \mathrm{~m})$ below roc

Water elevation: $171.41 \mathrm{tt} / 52.28$

Water evacuated before sampling: $226 \mathrm{gal}$

Time: $9: 30$

PH: 6.9 alinity: $84 \mathrm{mg} / \mathrm{L}$

Water temperature: $10.0 \times \mathrm{C}$

LABORATORY ANALYSES

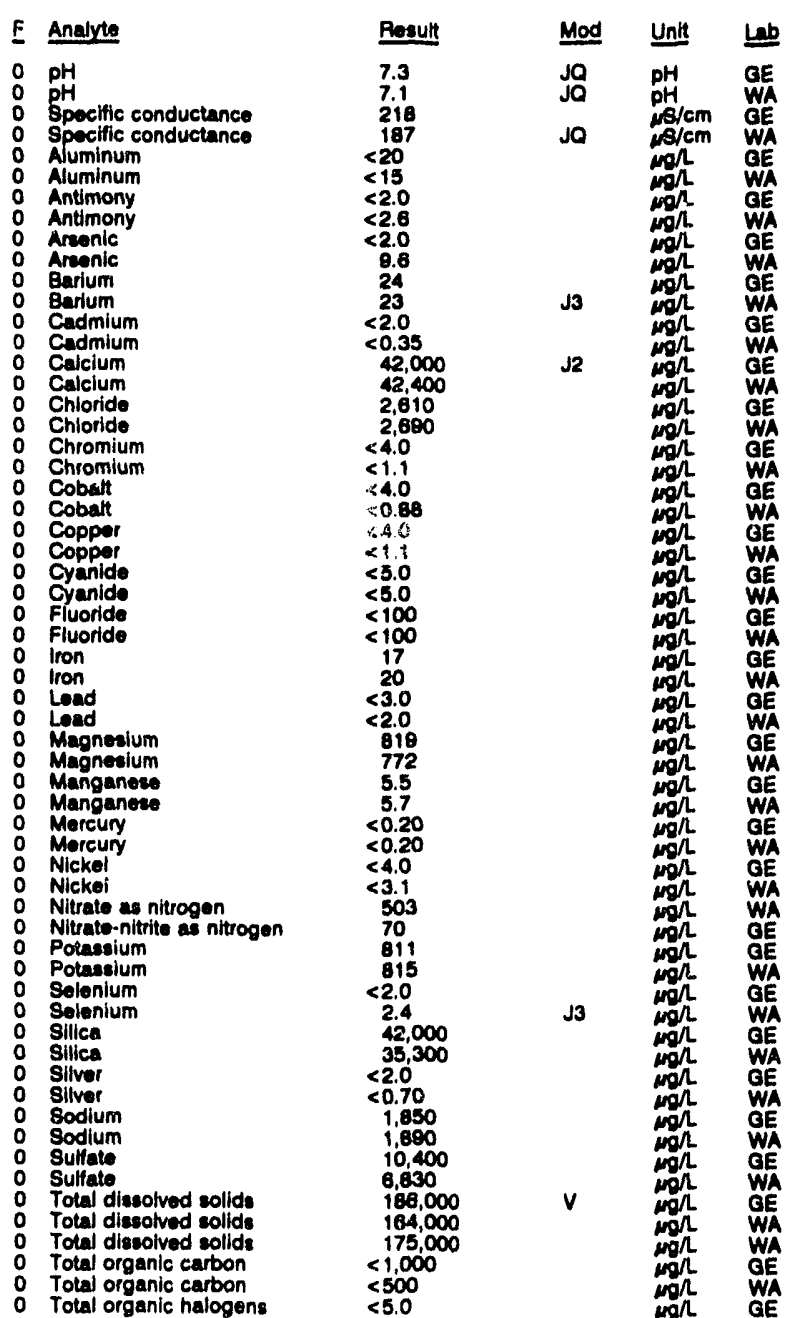




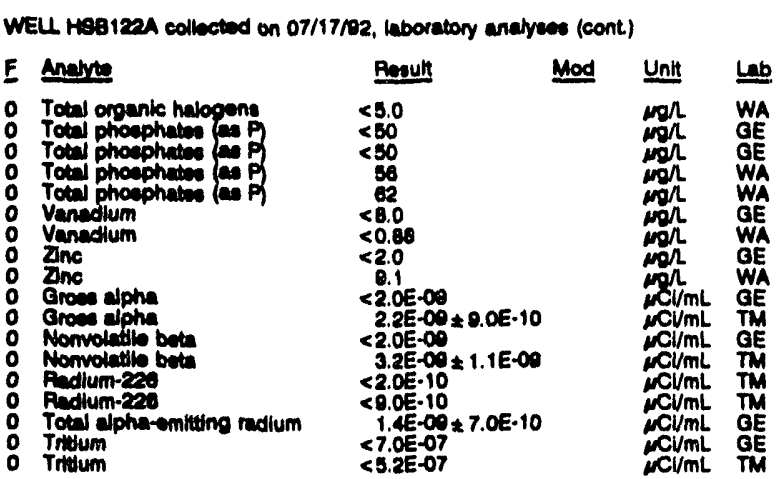

WELL HSB123A

MERSUREMENTS CONDUCTED IN THE FIELD

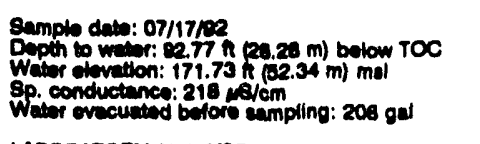

Thmo: 11:25

PH: 8.5 .

Waler tomperature: $20.5 \circ \mathrm{C}$

LABORATOPY ANALYES

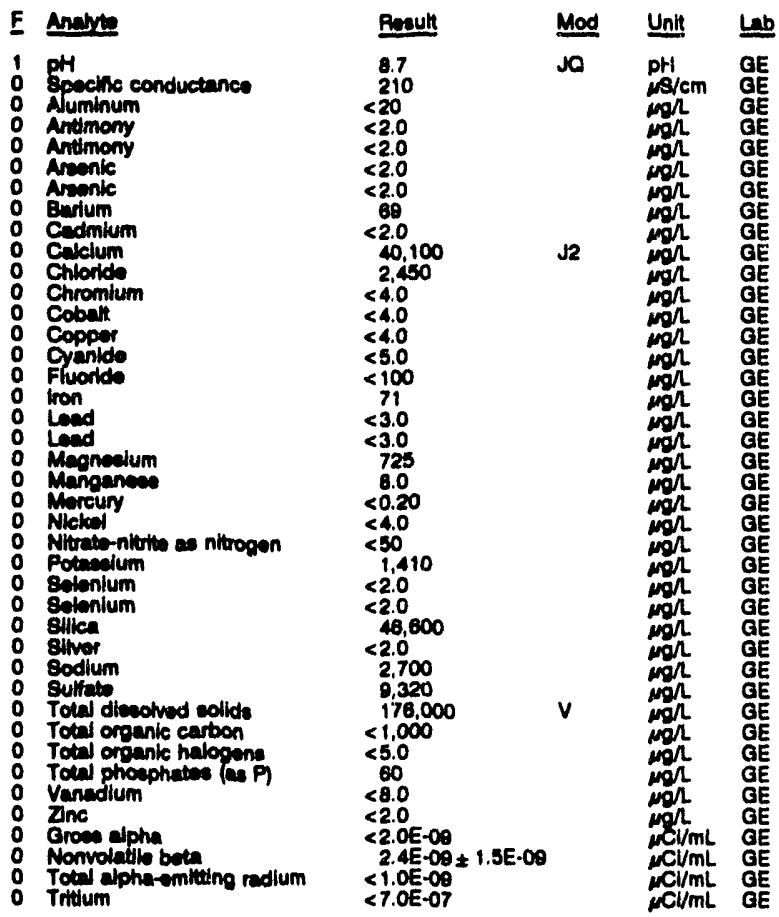

\section{WELL HSB124AR}

MEABUREMENTS CONOUCTED IN THE FIELD

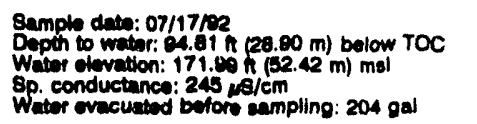

Timo: 11:50

pH: 8.9

Ajkalinity: $60 \mathrm{mg} / \mathrm{L}$. $20.2^{\circ} \mathrm{C}$ Whater ovecuatod before eampling: $204 \mathrm{ga}$

LABORATOPY ANALYRES

\begin{tabular}{|c|c|c|c|c|c|}
\hline $\mathbf{E}$ & Anelyte & Pesun & Mod & Unit & Lab \\
\hline $\begin{array}{l}0 \\
0 \\
0 \\
0 \\
0 \\
0 \\
0\end{array}$ & $\begin{array}{l}\text { gH } \\
\text { Bpocific conductance } \\
\text { Auminum } \\
\text { Antimony } \\
\text { Antimony } \\
\text { Anenic } \\
\text { Arenic }\end{array}$ & $\begin{aligned} & 7.3 \\
& 230 \\
&<20 \\
&<2.0 \\
&<2.0 \\
&<2.0 \\
&<2.0\end{aligned}$ & Jo & 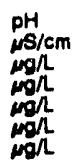 & $\begin{array}{l}\mathrm{GE} \\
\mathrm{GE} \\
\mathrm{GE} \\
\mathrm{GE} \\
\mathrm{GE} \\
\mathrm{GE} \\
\mathrm{GE}\end{array}$ \\
\hline
\end{tabular}

WEL H8B124AR collocted on 07/17/92, laboratory analyees (cont.)

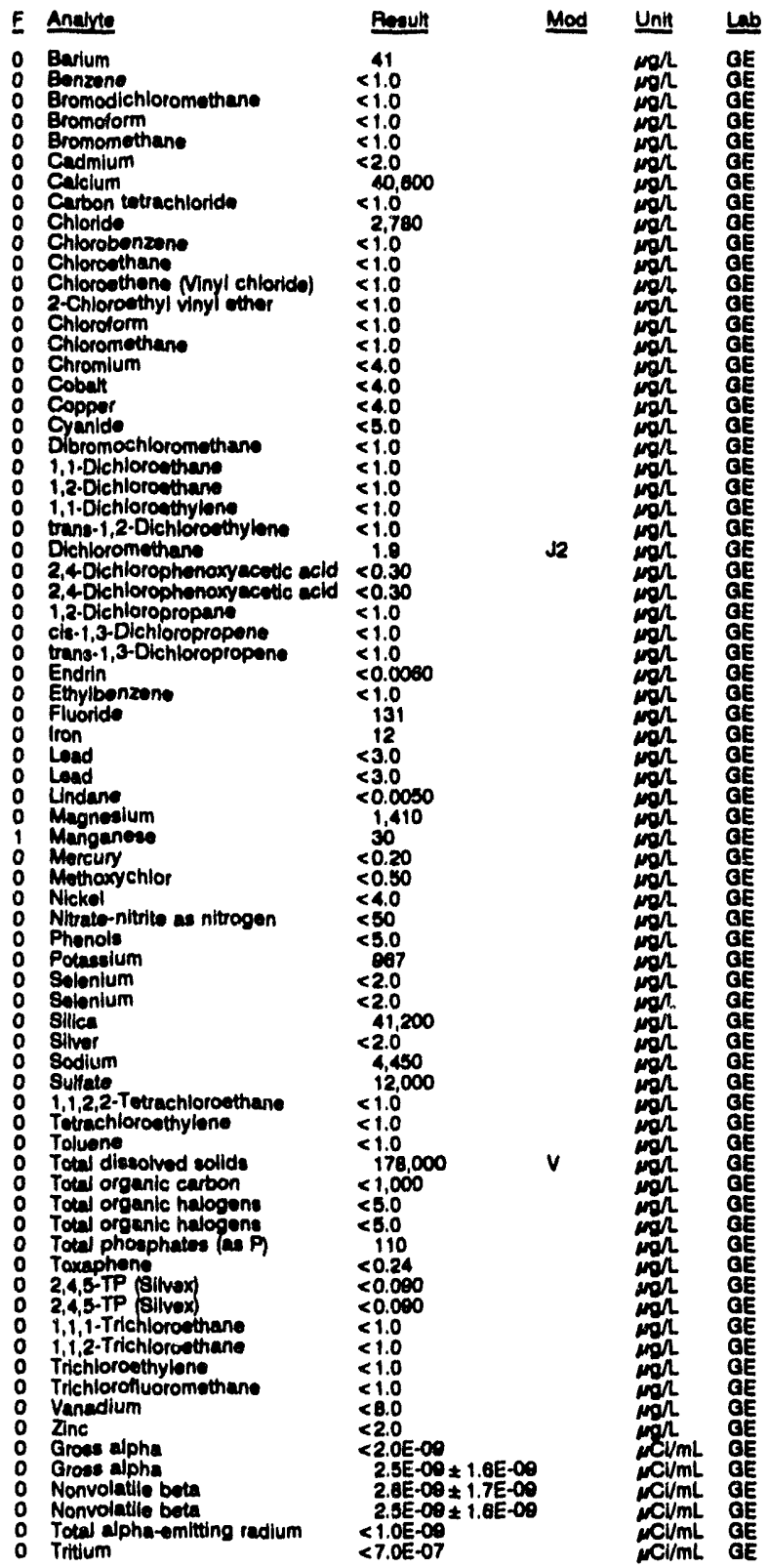

\section{WELL HSB125C}

MEASUREMENTS CONDUCTED IN THE FIELD

Sumple date: 07/20/82

Wopth to wator: $8.42 \pi(2.57 \mathrm{~m})$ bolow TOC

Water slovallon. $223.49(108.12 \mathrm{~m}) \mathrm{mal}$

Water evacuated before sempling: $204 \mathrm{gal}$

LABORATORY ANALYSES

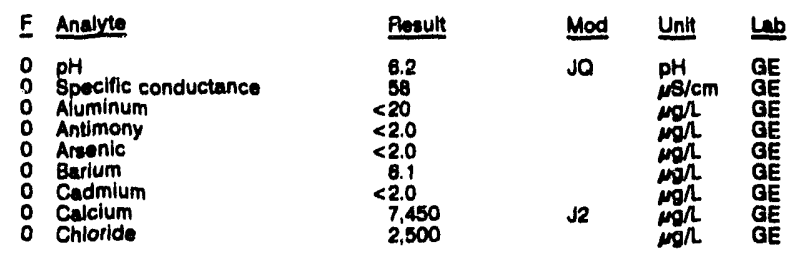


ANALYTICAL RESULTS

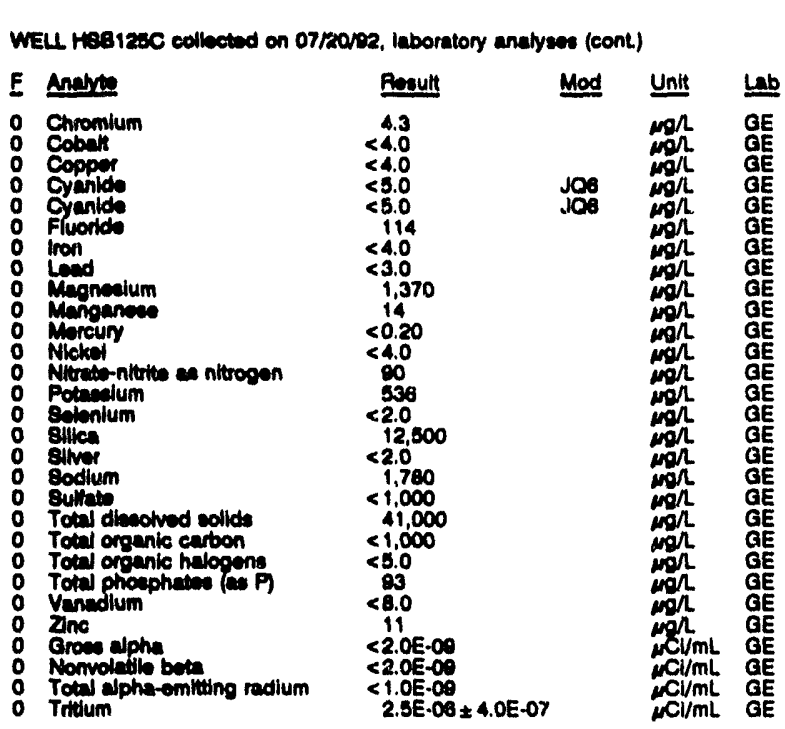

WELL HSB125D

MEASUREMENTS CONDUCTED IN THE FIELD

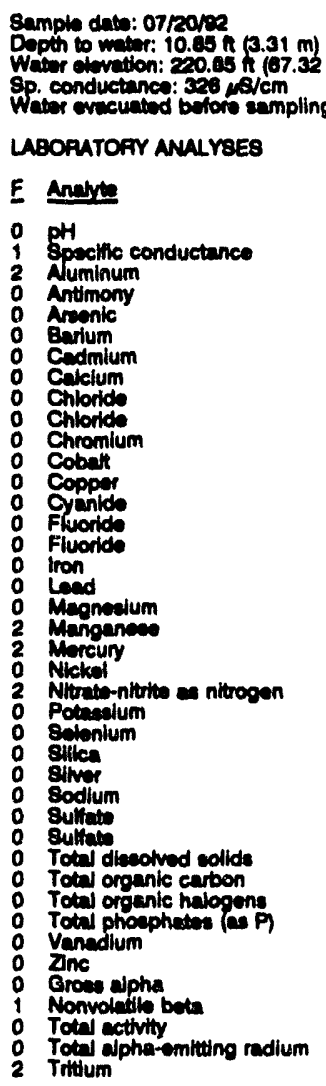

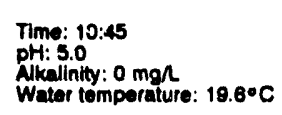

Water tomperature: $19.6^{\circ} \mathrm{C}$

$50 \mathrm{gal}$
$\mathrm{mal}$

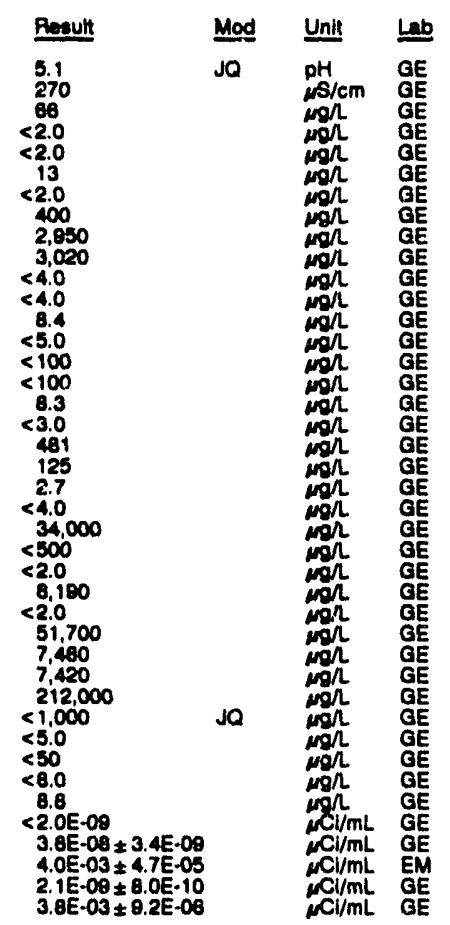

\section{WELL HSB126C}

MEASUREMENTS CONDUCTED IN THE FIELD

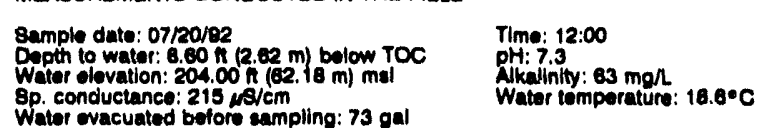

Water wacuated bolors sampling: $73 \mathrm{gal}$

LAOPUTOAY ANALYSES

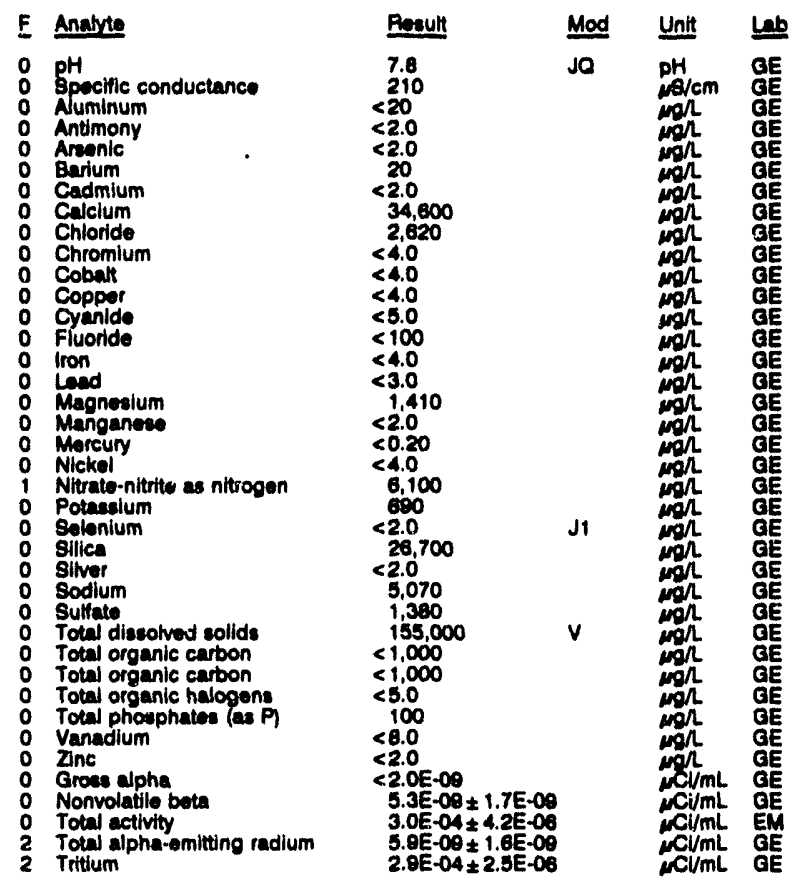

WELL HSB126D

MEASUREMENTS CONDUCTED IN THE FIELL
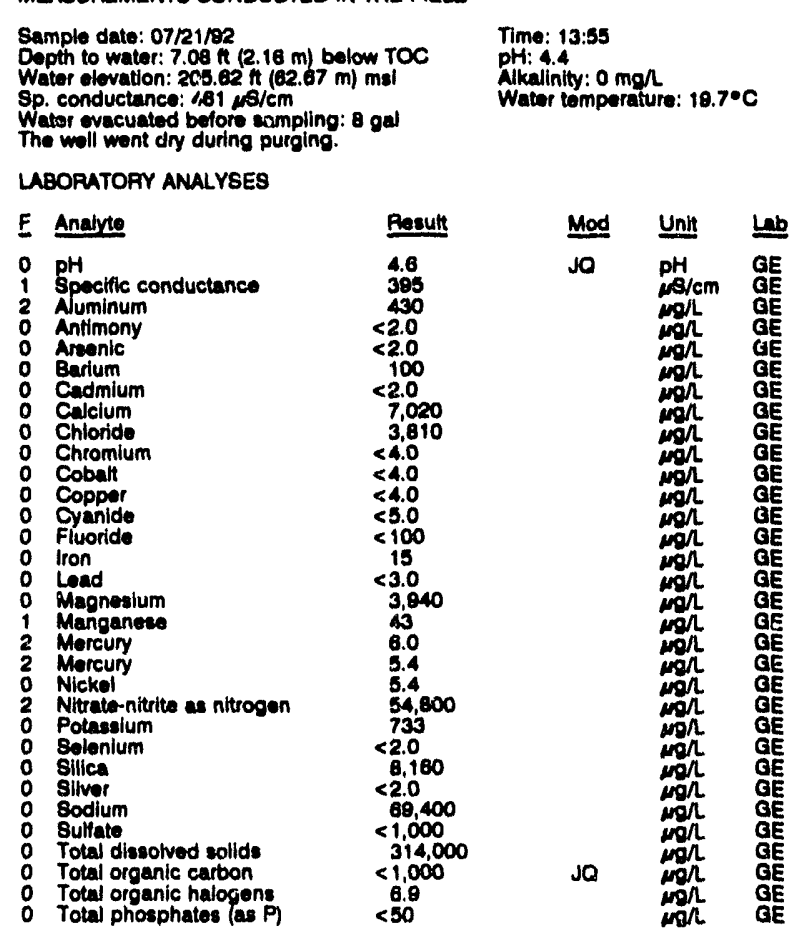

Alkalinity: $0 \mathrm{mg} /$ Wator tomperature: $18.7 \cdot \mathrm{C}$

no: 8 gal

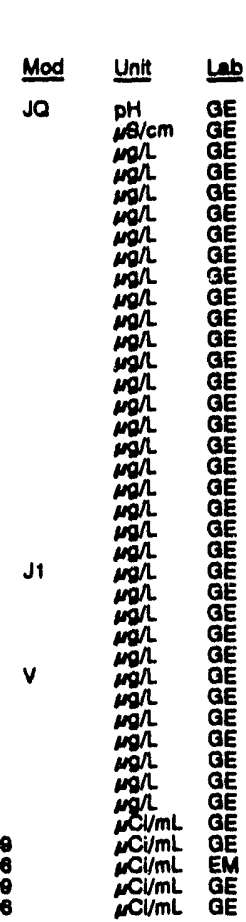

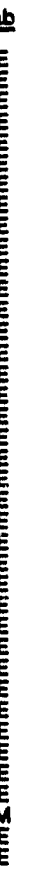

(1)

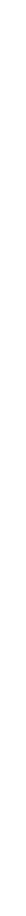




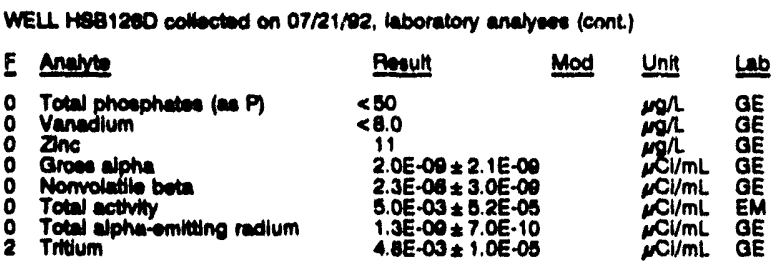

\section{WELL HSB127C}

MEAGUREMENTB CONOUCTED IN THE FIELD

\begin{tabular}{|c|}
\hline 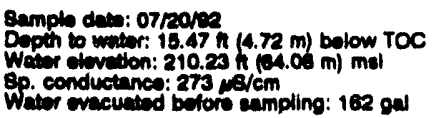 \\
\hline 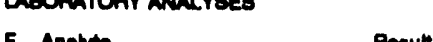 \\
\hline
\end{tabular}

\begin{tabular}{|c|c|c|c|}
\hline andese & Recult & Mod & Unit \\
\hline 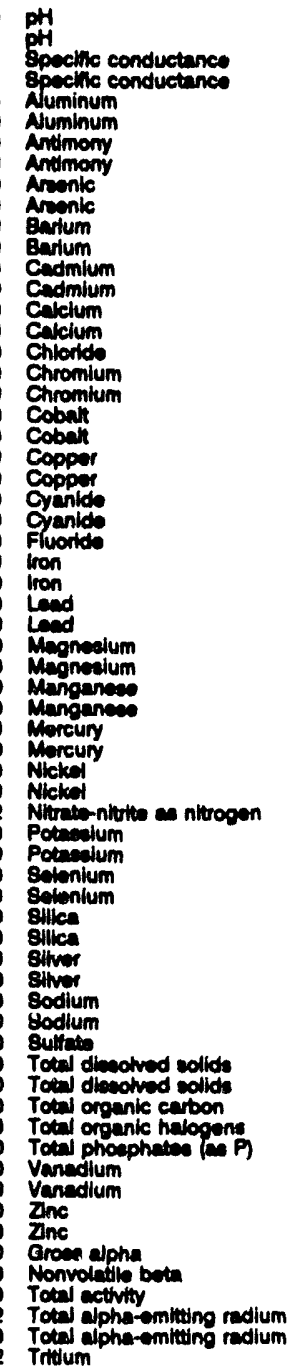 & 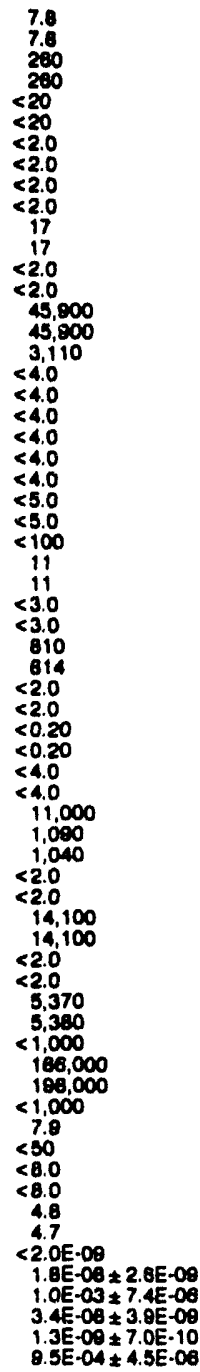 & 政 & 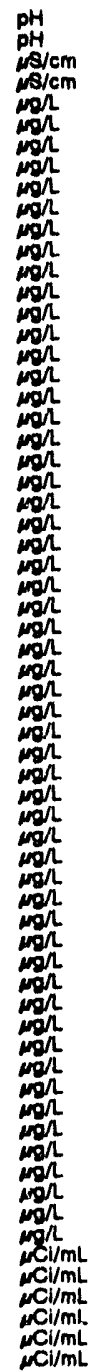 \\
\hline
\end{tabular}

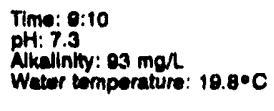

ab

WELL HSB 127D

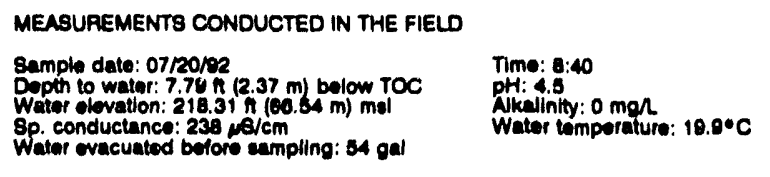

LABORATOAY ANALYYSES

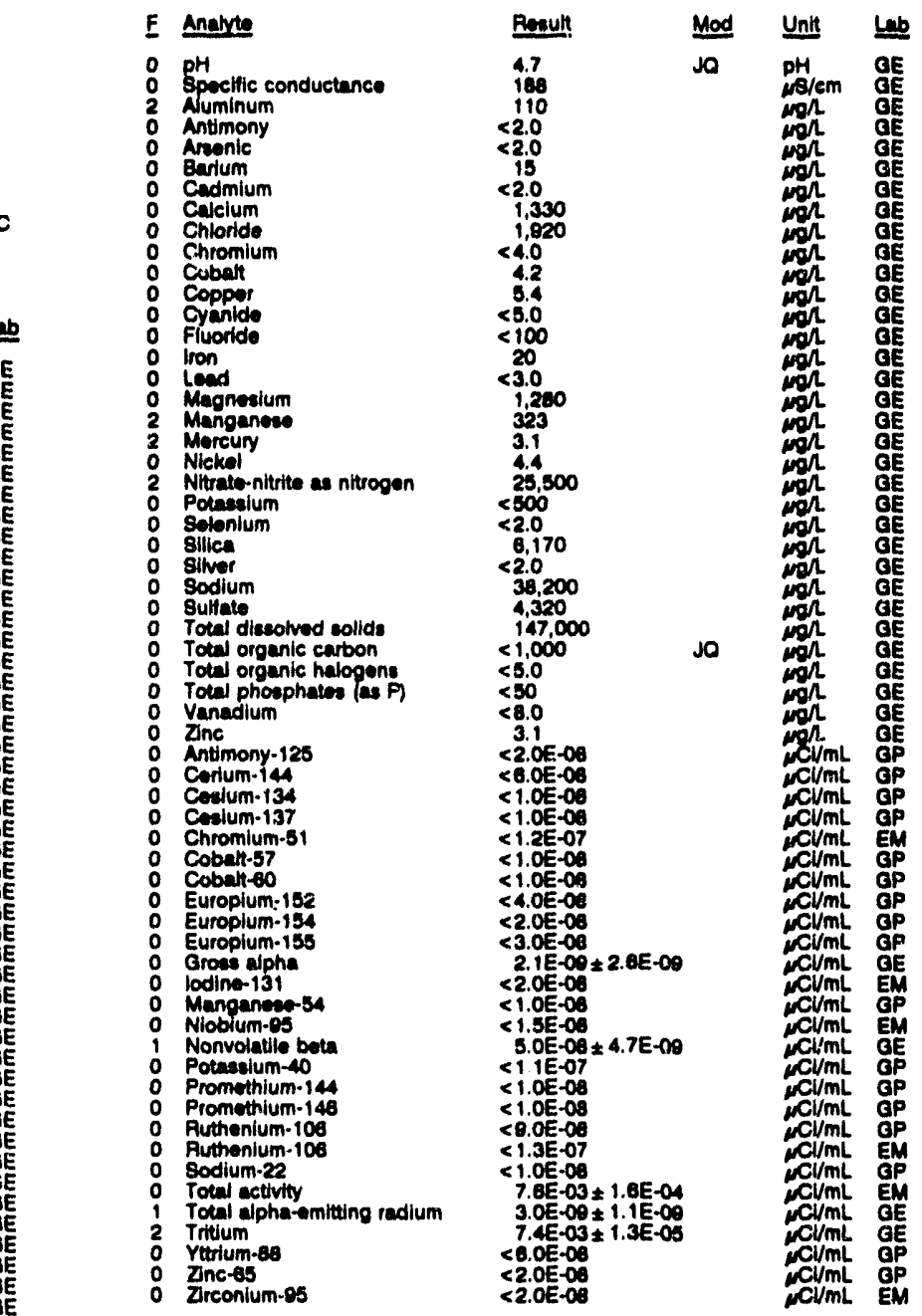

\section{WELL HSB129C}

MEASUREMENTS CONDUCTED IN THE FIELD
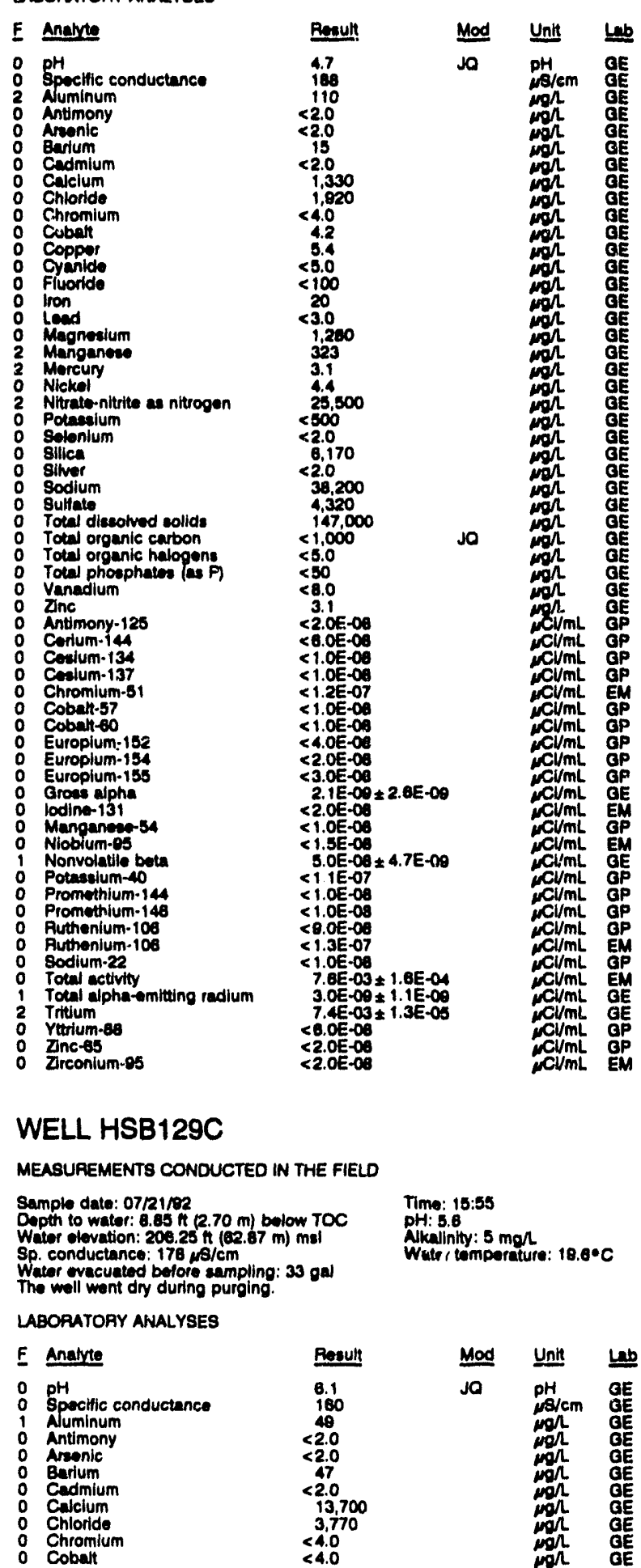
ANALYTICAL RESULTS

WELL HSB128C collected on 07/21/82, labusitirny malyews (cont)

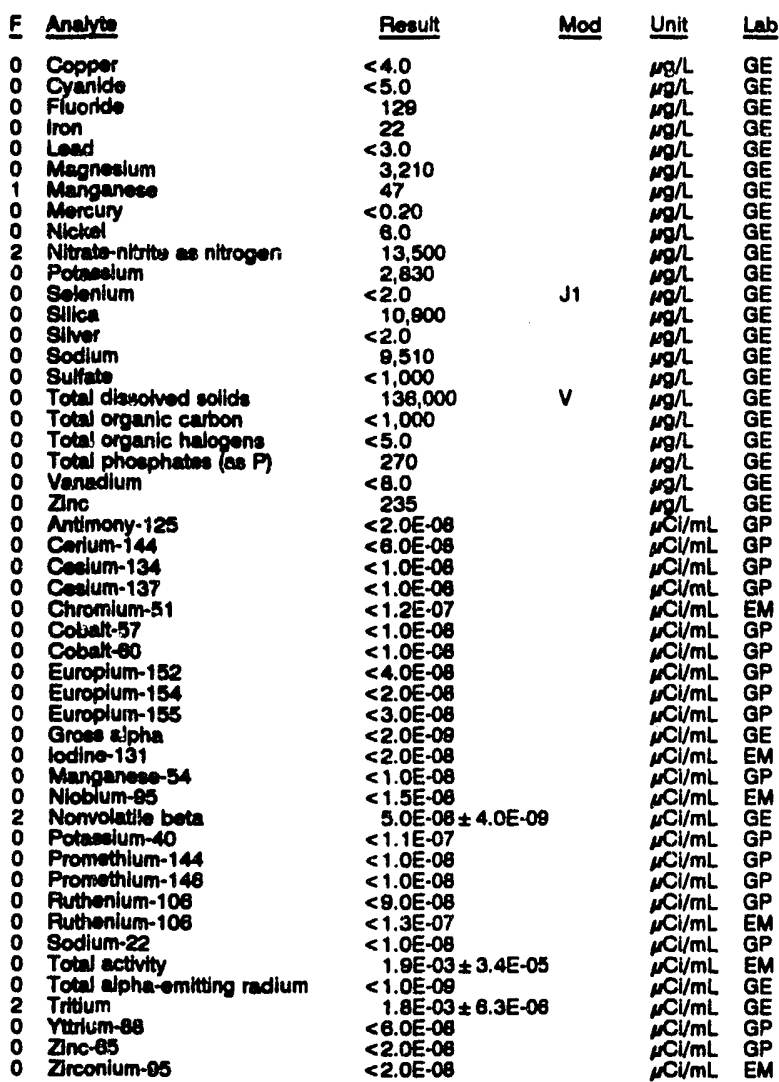

WELL HSB129D

\begin{abstract}
MEASUREMENTS CONDUCTED IN THE FIELD
\end{abstract}
Sample date: 07/21/02

Depth to water: $5.72 \mathrm{f}(1.74 \mathrm{~m})$ bolow TOC

Water elvetion: 200.88 it $(63$.

Sp. conductance: 287 ps/cm

LABOPATOFY ANALYSES

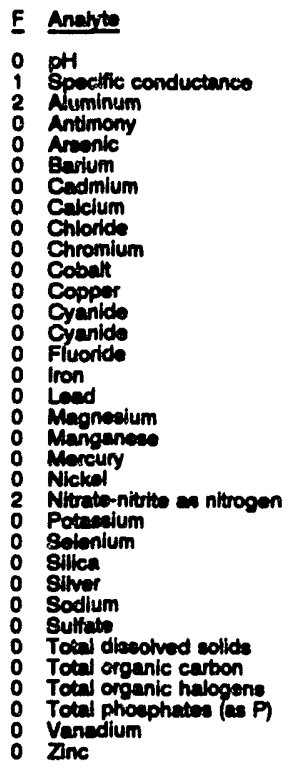

Time: $9: 15$

Alkalinity: $0 \mathrm{mgn}$

Water tomperature: $18.6^{\circ} \mathrm{C}$

\section{F Anabte}

Spectific conductance

Anminany

Anturis

Chlorks

Cobat

Cyanido

Sodium

Total phoesphates (as P)

Zinc

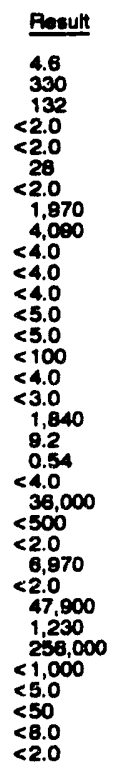

\begin{tabular}{c} 
Pesult \\
\hline 4.6 \\
330 \\
132 \\
$<2.0$ \\
$<2.0$ \\
28 \\
$<2.0$ \\
1,870 \\
4,090 \\
$<4.0$ \\
$<4.0$ \\
$<4.0$ \\
$<5.0$ \\
$<5.0$ \\
$<100$ \\
$<4.0$ \\
$<3.0$ \\
1,840 \\
9.2 \\
0.54 \\
$<4.0$ \\
36,000 \\
$<500$ \\
$<2.0$ \\
6,970 \\
$<2.0$ \\
47,800 \\
1,230 \\
258,000 \\
$<1,000$ \\
$<5.0$ \\
$<50$ \\
$<8.0$ \\
$<2.0$
\end{tabular}

Mod

WEU HS8128D collectod on 07/21/92, laboratory analyses (cont)

\begin{tabular}{|c|c|c|}
\hline Analyte & Rosult & Unit \\
\hline $\begin{array}{l}\text { Antimony-125 } \\
\text { Corium-1444 } \\
\text { Cealum-134 } \\
\text { Cesium-137 } \\
\text { Chromium-51 } \\
\text { Cobalt-57 } \\
\text { Cobalt-60 } \\
\text { Europium-152 } \\
\text { Europlum-154 } \\
\text { Europium-155 } \\
\text { Groas alpha } \\
\text { lodine-131 } \\
\text { Manganees-54 } \\
\text { Nioblum-95 } \\
\text { Nonvolatile bota } \\
\text { Potansium-40 } \\
\text { Promethium-144 } \\
\text { Promethium-146 } \\
\text { Ruthenium-108 } \\
\text { Ruthenium-106 } \\
\text { Sodlum-22 } \\
\text { Total activity } \\
\text { Total alpha-emitting radium } \\
\text { Tritium } \\
\text { Yttrium-68 } \\
\text { Znc-65 } \\
\text { Zirconium-95 }\end{array}$ & $\begin{array}{l}<2.0 E-08 \\
<6.0 E-08 \\
<1.0 \mathrm{E}-08 \\
<1.0 \mathrm{E}-08 \\
<1.2 \mathrm{E}-07 \\
<1.0 \mathrm{E}-08 \\
<1.0 \mathrm{E}-08 \\
<4.0 \mathrm{E}-08 \\
<2.0 \mathrm{E}-06 \\
<3.0 \mathrm{E}-08 \\
4.6 \mathrm{E}-09 \pm 4.0 \mathrm{E}-09 \\
<2.0 \mathrm{E}-08 \\
<1.0 \mathrm{E}-08 \\
<1.5 \mathrm{E}-08 \\
7.1 \mathrm{E}-08 \pm 7.8 \mathrm{E}-00 \\
<1.1 \mathrm{E}-07 \\
<1.0 \mathrm{E}-08 \\
<1.0 \mathrm{E}-08 \\
<8.0 \mathrm{E}-08 \\
<1.3 \mathrm{E}-07 \\
<1.0 \mathrm{E}-08 \\
5.1 \mathrm{E}-03 \pm 5.3 \mathrm{E}-05 \\
1.0 \mathrm{E}-09 \pm 8.0 \mathrm{E}-10 \\
6.3 \mathrm{E}-03 \pm 1.2 \mathrm{E}-05 \\
<6.0 \mathrm{E}-08 \\
<2.0 \mathrm{E}-08 \\
<2.0 \mathrm{E}-08\end{array}$ & 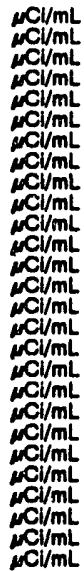 \\
\hline
\end{tabular}

WELL HSB130C

MEASUREMENTS CONDUCTED IN THE FIELD

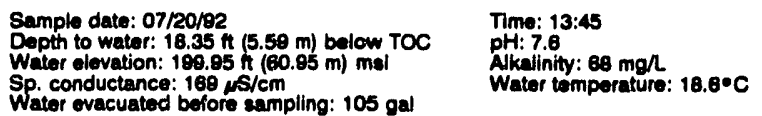

Water evacuated before sampling: $105 \mathrm{gal}$

LABORATORY ANALYSES

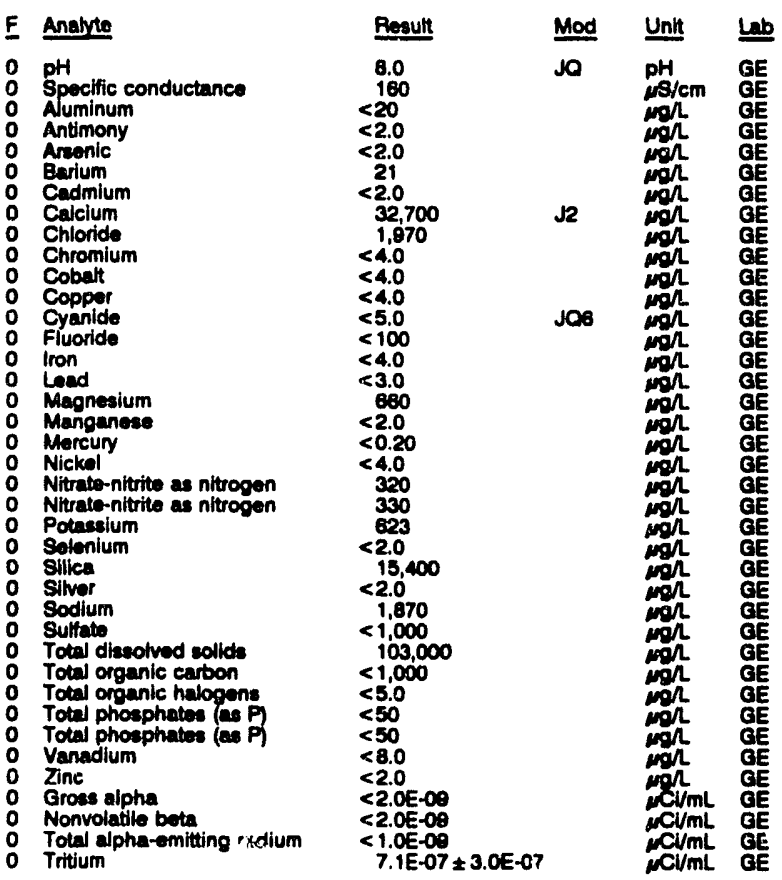


WELL HSB130D

MEAGUAFEMENTS CONDUCTED IN THE FIELD

\begin{tabular}{|c|c|}
\hline 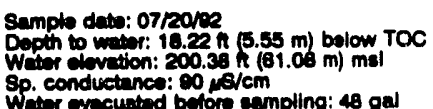 & $\begin{array}{l}\text { Time: } 14: 45 \\
\text { pti: } 8.3 \\
\text { Alknlinity: } 22 \mathrm{mg} / \mathrm{h} \\
\text { Water temperature: } 20.8^{\circ} \mathrm{C}\end{array}$ \\
\hline
\end{tabular}

Weter eyecunted betore sempling: 48 gal

\section{LABOFATORY ANALYSES}

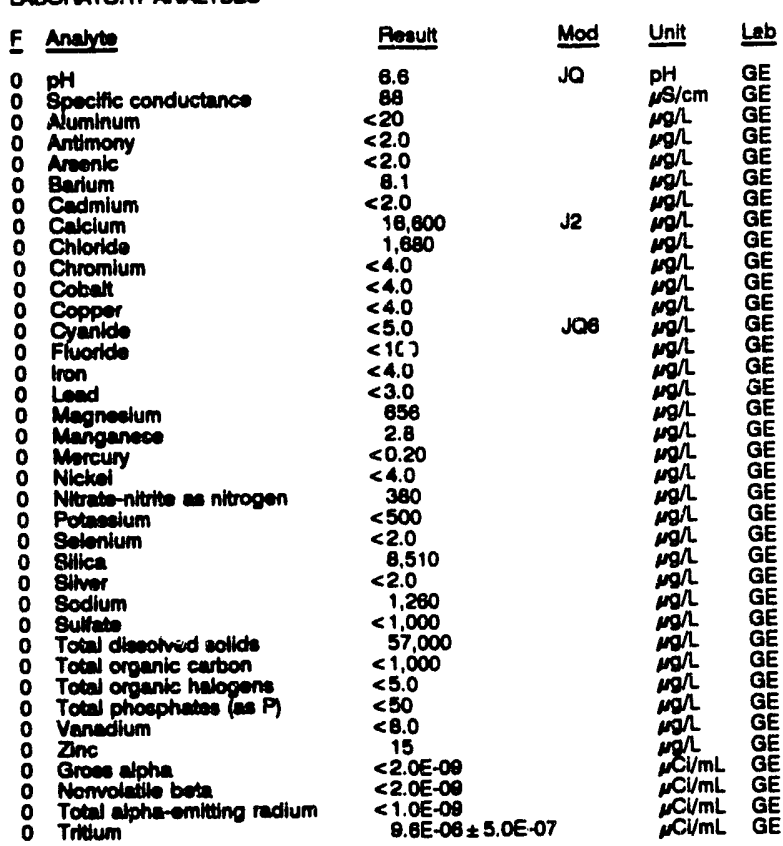

\section{WELL HSB131C}

MEASUPEMENTS CONDUCTED IN THE FIELD

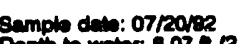

Dopth to water: $8.07 \mathrm{~h}$ (2.46 m) below TOC

Weter civelition: $203.63 \mathrm{f}(02.07 \mathrm{~m}) \mathrm{ms}$

Sp. conductance: 224 r $1 / \mathrm{cm}$. $145 \mathrm{gal}$

LACOATOAY ANALYES

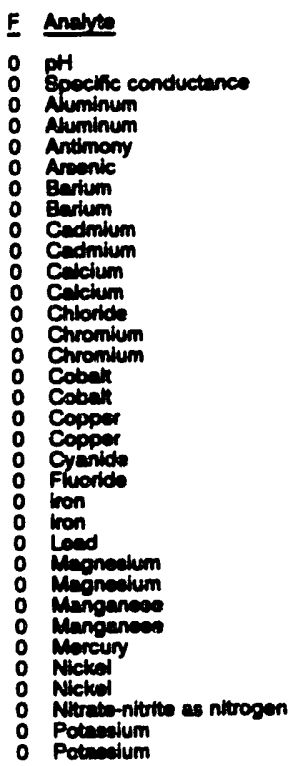

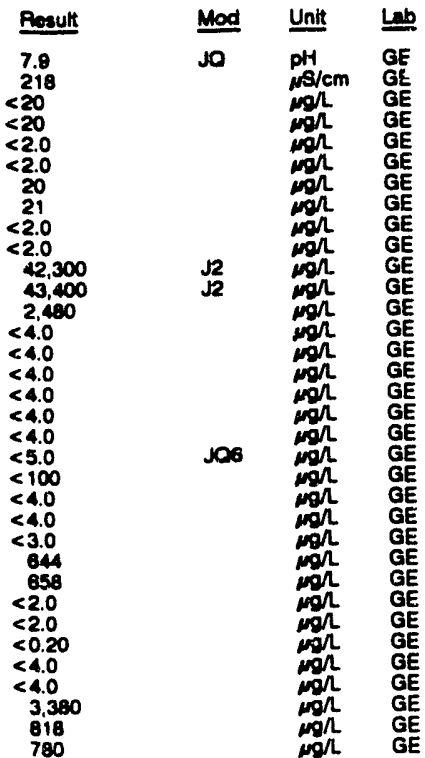

WELL HSB131C collocted on 07/20/92, laboratory analyees (cont)

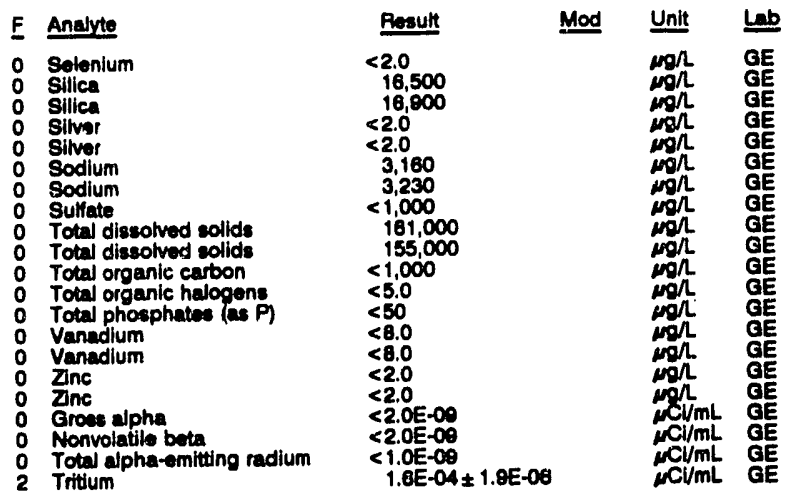

WELL HSB131D

MEASUREMENTS CONDUCTED IN THE FIELD

\begin{tabular}{|c|c|}
\hline $\begin{array}{l}\text { Sample date: } 07 / 20 / 92 \\
\text { Depth to wator: } 6.35 \mathrm{ft}(1.94 \mathrm{~m}) \text { below TOC } \\
\text { Water elevation: } 205.75 \mathrm{n}(62.71 \mathrm{~m}) \mathrm{mal} \\
\text { Sp. conductance: } 25 \mathrm{\mu s} / \mathrm{cm}\end{array}$ & $\begin{array}{l}\text { Time: } 12: 55 \\
\text { pH: } 4.9 \\
\text { Alkalinity: } 0 \text { mg } \Omega \\
\text { Water temperature: } 20.6 \cdot \mathrm{C}\end{array}$ \\
\hline
\end{tabular}

LABORATOFY ANALYSES

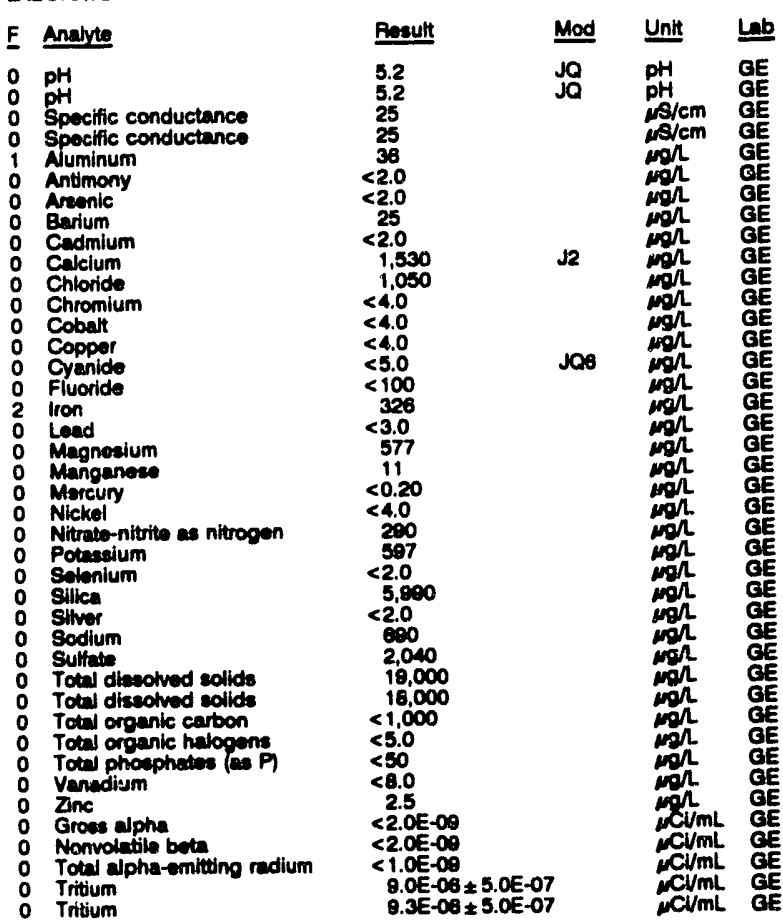

\section{WELL HSB132C}

MEASUREMENTS CONDUCTED IN THE FIELD

Sample dete: 07/240?

Depth to water: $19.07 \mathrm{~h}(5.81 \mathrm{~m})$ belou TOC

Weler elevation: $221.43 \mathrm{ht}(07.40 \mathrm{~m}) \mathrm{mal}$

Sp. conductance: $31, \mathrm{~B} / \mathrm{cm}$

Water evecuated betore eampling: $31 \mathrm{gal}$

The well went dry during purging.

LABOFATOFY ANALYSES

\begin{tabular}{|c|c|c|c|}
\hline F Analyte & Result & Mod & Unit \\
\hline $\begin{array}{ll}0 & \text { pH } \\
0 & \text { Spocific conductance } \\
1 & \text { Aluminum } \\
0 & \text { Antimony }\end{array}$ & $\begin{array}{r}6.0 \\
30 \\
34 \\
<2.0\end{array}$ & Ja & $\begin{array}{l}\mathrm{pH} \\
\mathrm{mS/cm} \\
\mathrm{mgh}\end{array}$ \\
\hline
\end{tabular}


WELL HSB132C collected on 07/24/92, laboratory analyeese (cont.)

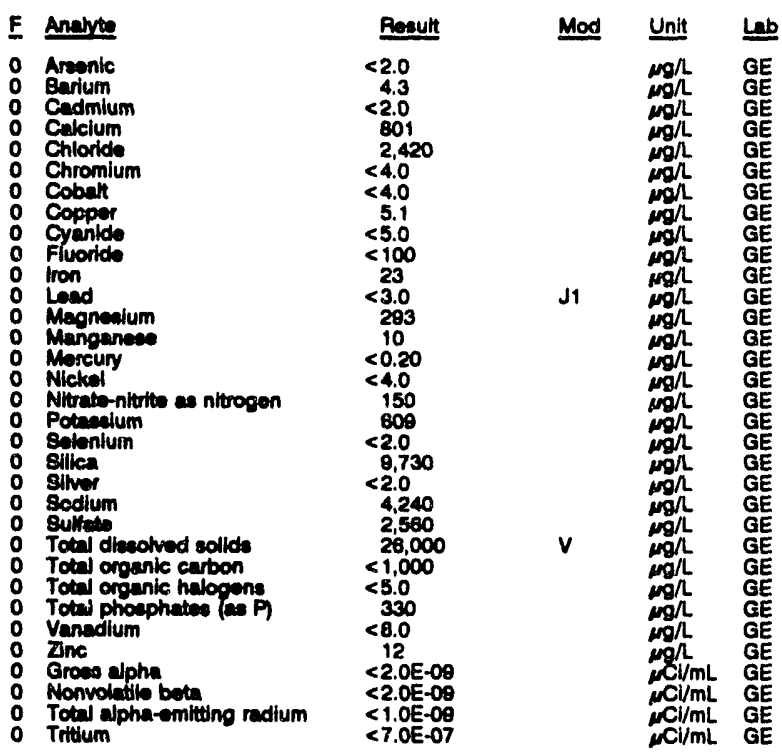

WELL HSB132D

MEASUREMENTS CONDUCTED IN THE FIELD

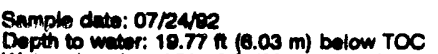

Neter elevelion: 220.03 (t $(07.34 \mathrm{~m}) \mathrm{msl}$

Sp. conductance: $18, \mathrm{~s} / \mathrm{cm}$

Water cvecuetiod before eampling: $7 \mathrm{gal}$

LABOPATORY ANALYSES

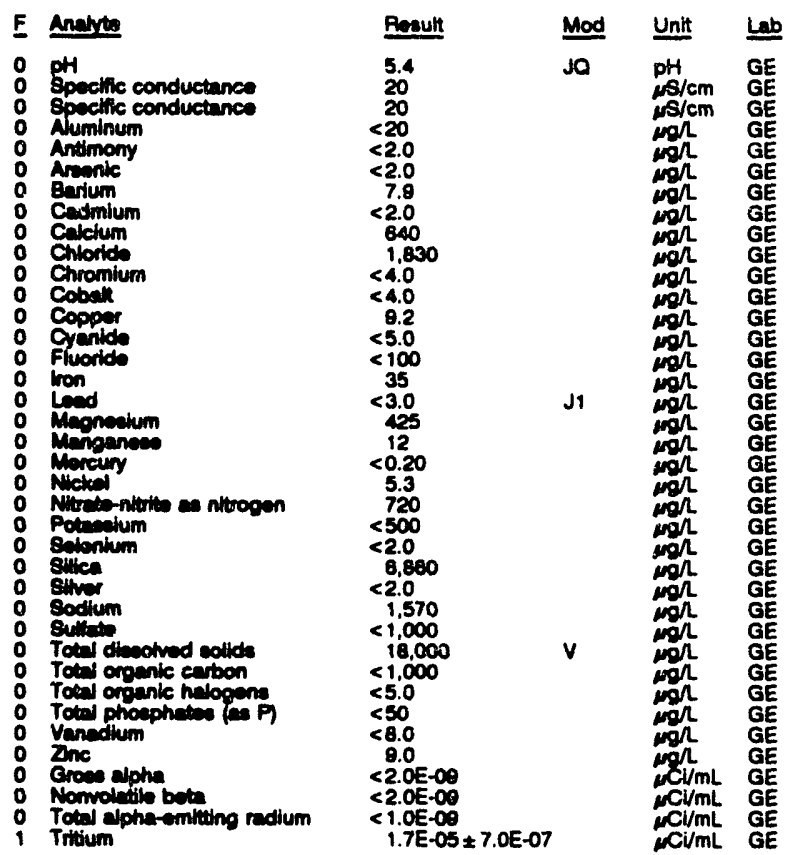

WELL HSB133C

MEASUREMENTS CONDUCTED IN THE FIELD

Sample date: 07/17/92

Depth to water: 25.18 \& $(7.67 \mathrm{~m})$ below TOC

Wo conductance: $230.42 \mathrm{ht}(70.2$

$23 \mathrm{~m}$ ) $\mathrm{msl}$

Water ovacuated before sampling: $150 \mathrm{gal}$

LABORATORY ANALYSES

E Analye

: $\mathrm{pH}$

o Aluminum

Antimony

Aroonic

Garium

Calcium

Chloride

Chromium

Cobalt

Copper

0 Fluoride

o Iron

Magnesium

Manganeas

Nickel

Nitrato-nitrite as nitrogen

Nitrato-nitrite as nitrogen

Potassium

Salenium

Sillea

Sodium

Total dissolved sollds

Total organic carbon

Total organic carbon

Total organic halogene

Total organic halogens

Varadium

Zine

Gross alpha

Nonvolatile beta

Total alphar

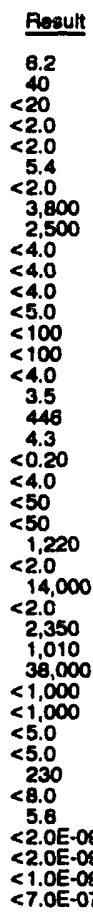

Time: 13:10

Alkalinit $10 \mathrm{mgl}$

Water temperature: $18.9^{\circ} \mathrm{C}$

WELL HSB133D

MEASUREMENTS CONDUCTED IN THE FIELD

Sample date: 07/17/82

Dopth to water: $20.14 \mathrm{ft}(6.14 \mathrm{~m})$ below TOC

Water olovation: $235.18 \mathrm{~h}(71.68 \mathrm{~m}) \mathrm{msl}$

Sp. conductance: $69 \mu \mathrm{s} / \mathrm{cm}$
Water evacuated before sampling: $93 \mathrm{gal}$

LABORATORY ANALYSES

O pH

Specific conductance

Auminum

Arsenic

Barium

Calcium

Chloride

Chromium

Coppar

Cyanide

Iron

Magnesium

Manganes.

Nickely

Nickel

Nitrato-nitrite as nitrogen

Potassium

Solonium

Silica

Sodium

Sulfate

Total diseotved solich

Total organic carbon

Total organic halogen

\begin{tabular}{|c|c|c|}
\hline Result & Mod & Unit \\
\hline $\begin{array}{c}5.8 \\
68 \\
<20 \\
<2.0 \\
<2.0 \\
<3.0 \\
<2.0 \\
1,440 \\
6,070 \\
<4.0 \\
<4.0 \\
<4.0 \\
<5.0 \\
<100 \\
4.7 \\
<3.0 \\
109 \\
3.4 \\
<0.20 \\
<4.0 \\
470 \\
<500 \\
<2.0 \\
6,810 \\
<2.0 \\
10,500 \\
8,660 \\
53,000 \\
<1,000 \\
<5.0\end{array}$ & Jo & 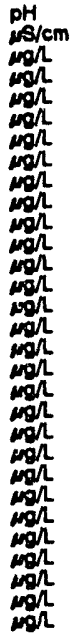 \\
\hline
\end{tabular}

Time: 12:35

Alkalinity: $5 \mathrm{moh}$

Water tomperature: $18.9^{\circ} \mathrm{C}$

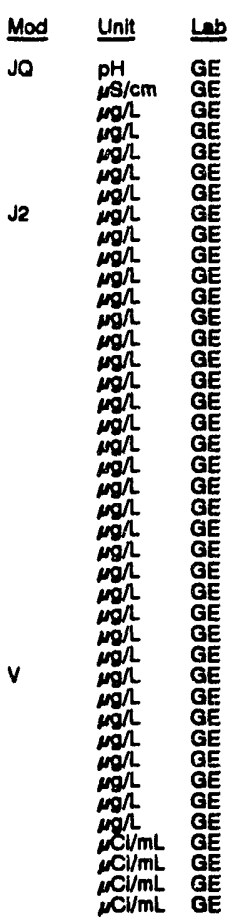

$\frac{}{G E}$
$G E$
$G E$
$G E$
$G E$
$G E$
$G E$
$G E$
$G E$
$G E$
$G E$
$G E$
$G E$
$G E$
$G E$
$G E$
$G E$
$G E$
$G E$
$G E$
$G E$
$G E$
$G E$
$G E$
$G E$
$G E$
$G E$
$G E$
$G E$
$G E$
$G E$
$G E$
$G E$
$G E$
$G E$
$G E$
$G E$
$G E$
$G E$
$G E$

政




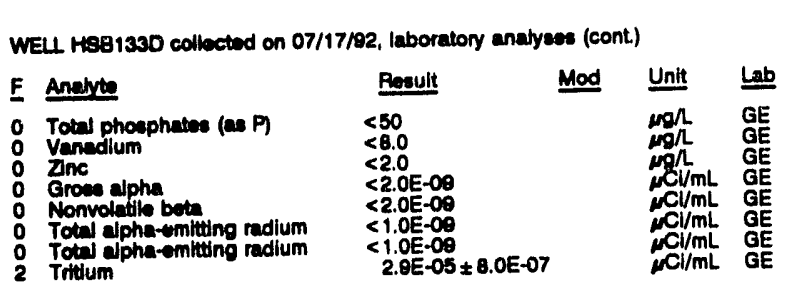

\section{WELL HSB134C}

MEASUREMENTS CONDUCTED IN THE FIELD

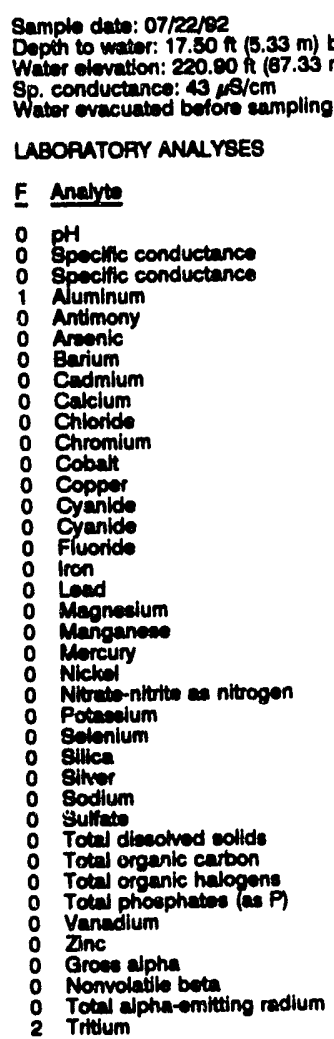

Time: 15:50

PH: 5.4 .450

Water tomperature: $18.4^{\circ} \mathrm{C}$

Wator vacuated before rampling: $188 \mathrm{gal}$

LABORATORY ANALYBES

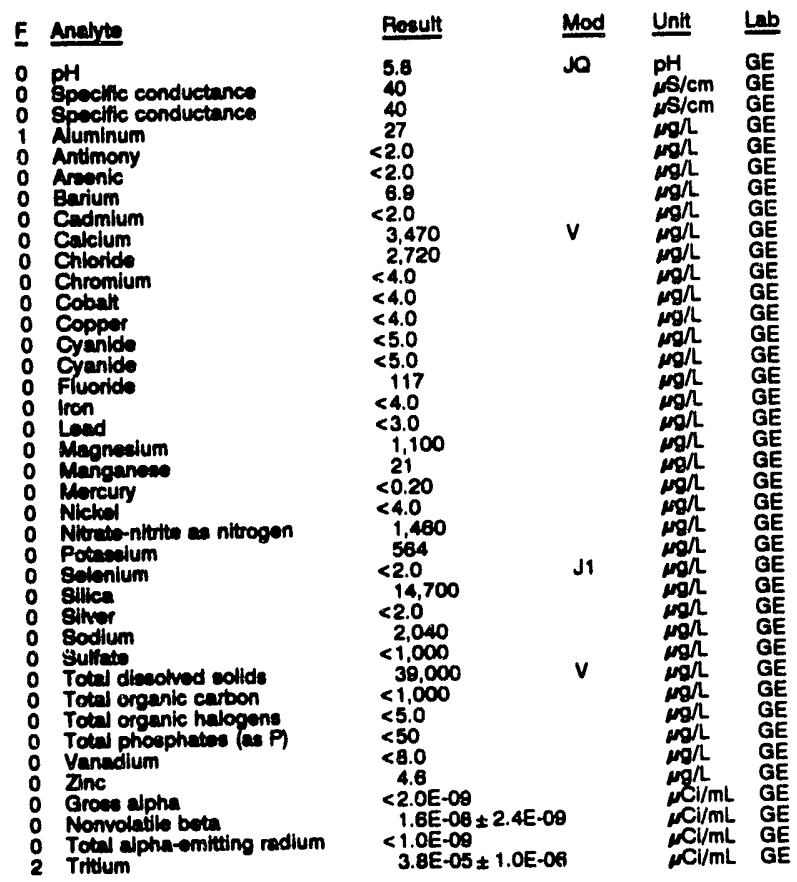

\section{WELL HSB134D}

MEASUREMENTS CONOUCTED IN THE FIELD

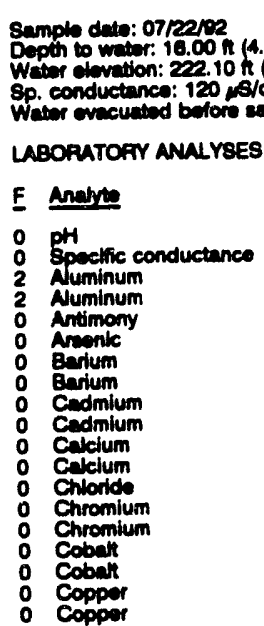

Time: 15:30

pH: 4.2 : $0 \mathrm{man}$

Water temperature: $18.3^{\circ} \mathrm{C}$

43 gal

Mod Unit Lab

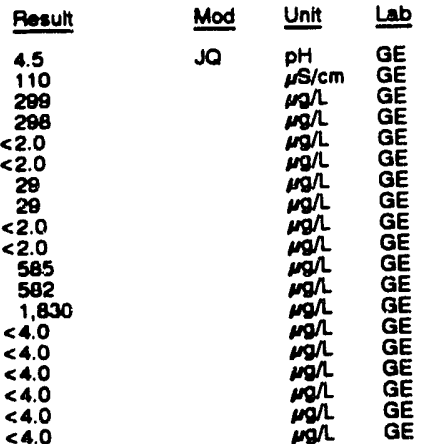

WELL HSB134D collected on 07/22/82, laboratory analyees (cont)

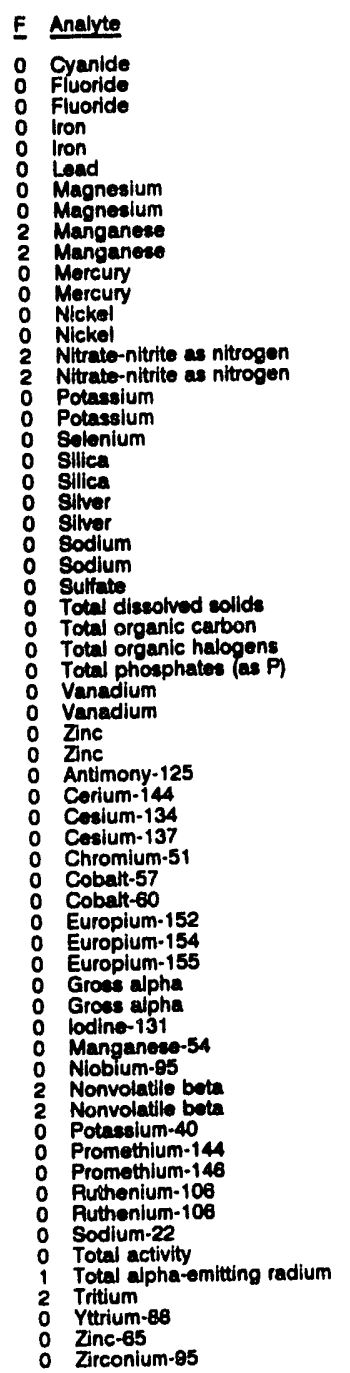

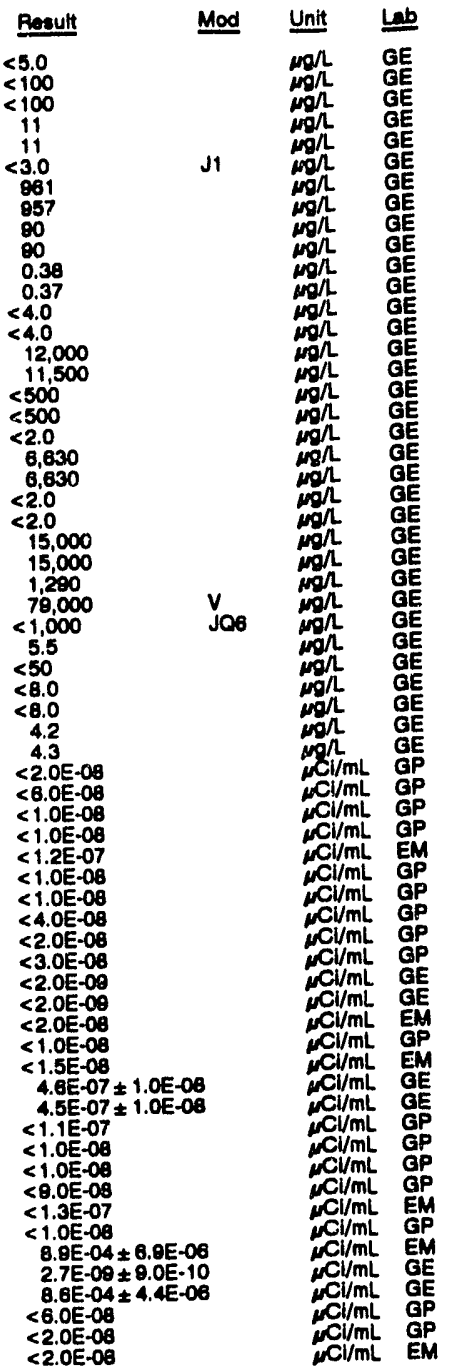

\section{WELL HSB135C}

MEASUREMENTS CONDUCTED IN THE FIELD

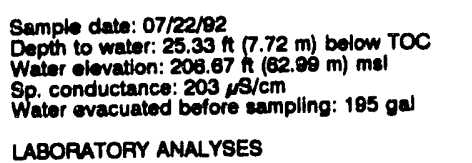

Time: 8:40

pH: 7.5 Alcalintly: $83 \mathrm{mal}$

Whalinity: $93 \mathrm{mg} /$, $19.7 \bullet \mathrm{C}$

LABORATOFY ANALYSES

\begin{tabular}{|c|c|c|c|}
\hline Analyte & Rooult & Mod & Unit \\
\hline $\begin{array}{l}\text { pH } \\
\text { Specific conductance } \\
\text { Aluminum } \\
\text { Antimony } \\
\text { Areenic } \\
\text { Barium } \\
\text { Cadmium } \\
\text { Calcium } \\
\text { Chloride } \\
\text { Chromium } \\
\text { Cobalt } \\
\text { Copper } \\
\text { Cyanide } \\
\text { Fluoride } \\
\text { Iron } \\
\text { Lead } \\
\text { Magnealum } \\
\text { Manganese } \\
\text { Mercury } \\
\text { Nickel }\end{array}$ & $\begin{array}{l}8.0 \\
200 \\
27 \\
<2.0 \\
<2.0 \\
16 \\
<2.0 \\
38.500 \\
2.550 \\
<4.0 \\
<4.0 \\
<4.0 \\
<5.0 \\
3.87 \\
11 \\
<3.0 \\
515 \\
<2.0 \\
<0.20 \\
<4.0\end{array}$ & Jo & 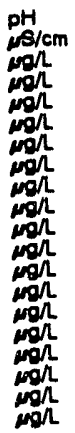 \\
\hline
\end{tabular}


ANALYTICAL RESULTS

WELL HSB135C collected on 07/22/92, laboratory analyses (cont)

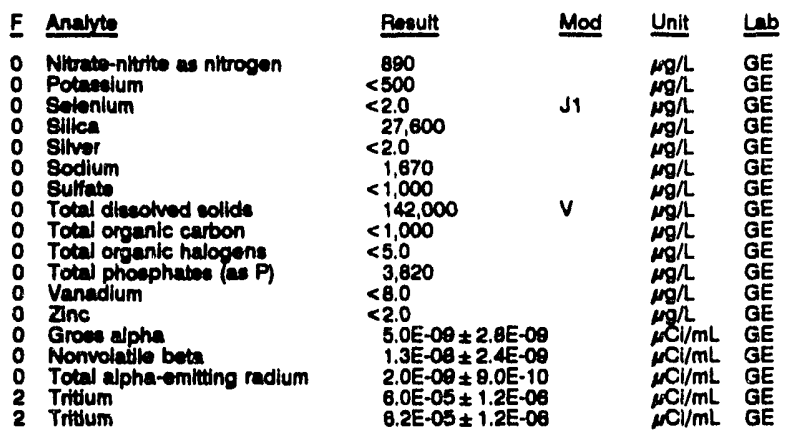

\section{WELL HSB135D}

MEASUREMENTS CONDUCTED IN THE FIELD

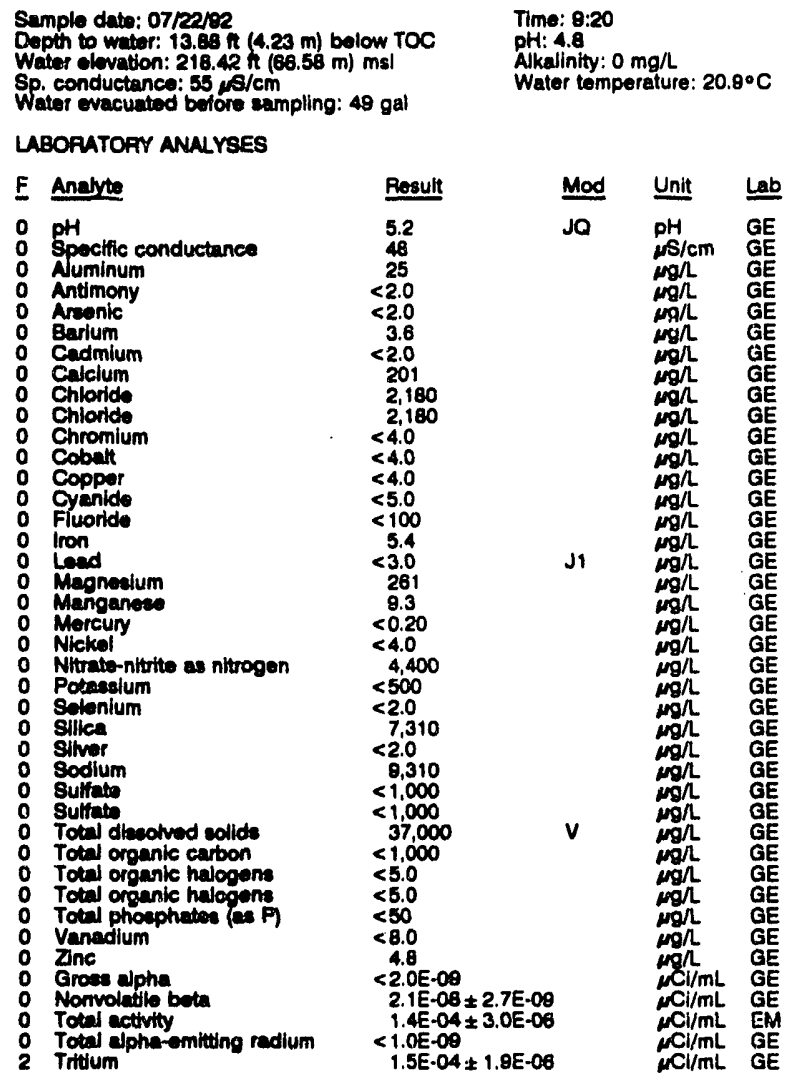

WELL HSB136C

MEASUREMENTS CONDUCTED IN THE FIELD

Sample dati: 07/21/02

Depth to water: $10.31 \mathrm{ft}(3.14 \mathrm{~m})$ below TOC

Waler elevation: $217.80 \mathrm{ht} / 86$.

Wher conductunce: 21 pism $\mathrm{cm}$. $29 \mathrm{gal}$

This woll went dry during purging

LABORATOFY ANALY YES

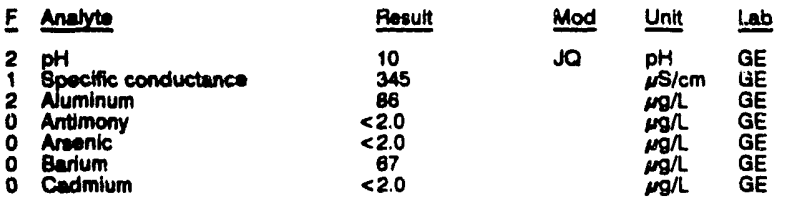

WELL HSB138C collected on 07/21/82, laboratory analyses (cont)

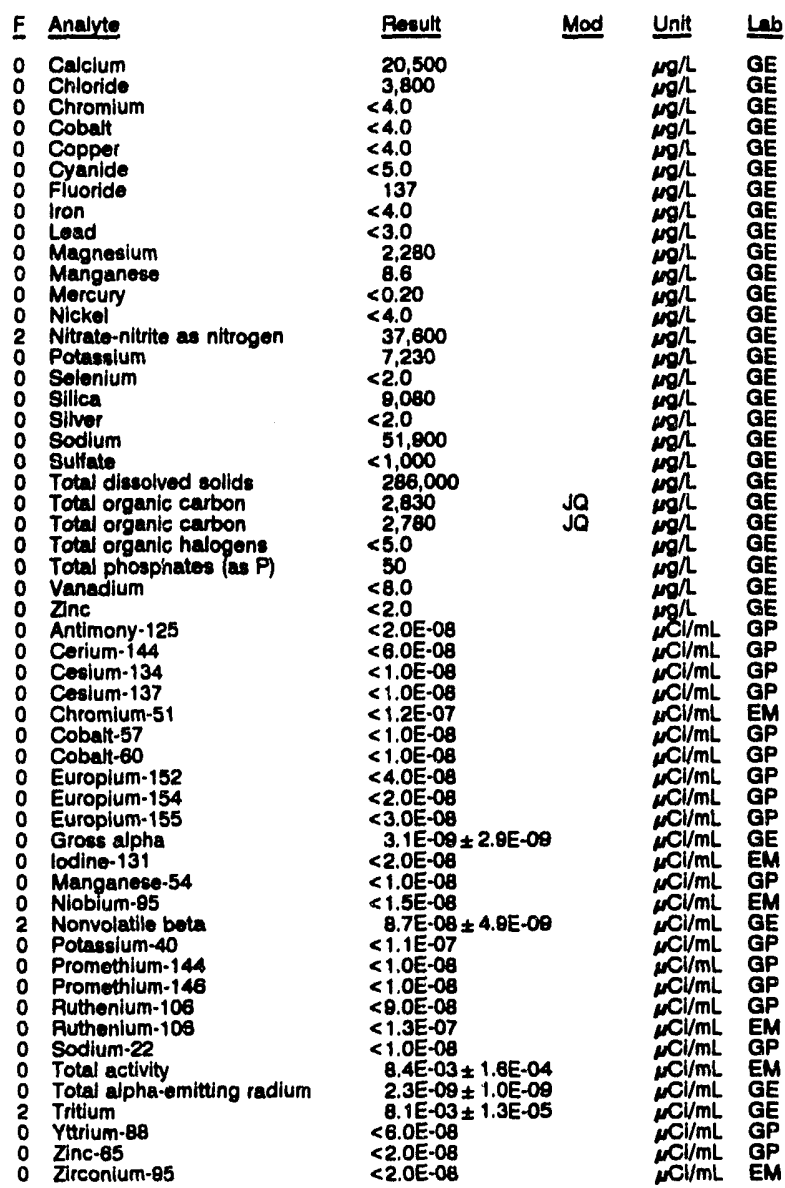

\section{WELL HSB136D}

MEASUREMENTS CONDUCTEO IN THE FIELD

\begin{tabular}{|c|c|}
\hline $\begin{array}{l}\text { Sample date: } 07 / 21 / 92 \\
\text { Depth to water: } 8.80 \mathrm{ft}(2.10 \mathrm{~m}) \text { below TOC } \\
\text { Water elovation: } 221.10 \mathrm{ft}(67.30 \mathrm{~m}) \mathrm{mol} \\
\text { Sp. conductance: } 252 \mu \mathrm{s} / \mathrm{cm}\end{array}$ & $\begin{array}{l}\text { Timo: } 8: 55 \\
\text { pH: } 4.0 \\
\text { Alkalinity: } 0 \mathrm{mg} / \\
\text { Water tomperature: } 18.0^{\circ} \mathrm{C}\end{array}$ \\
\hline
\end{tabular}
LABORATORY ANALYSES

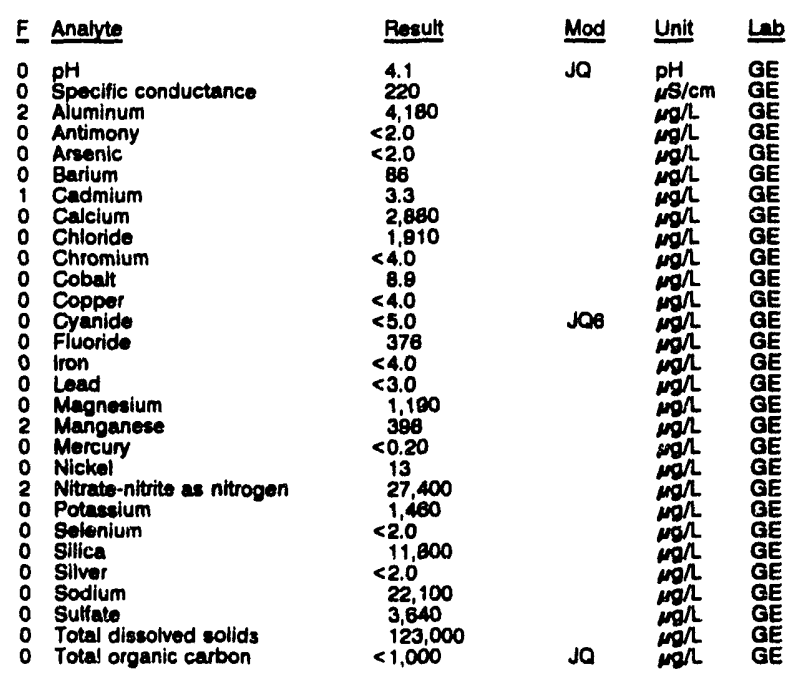


WELL HSB1360 collocted on 07/21/02, laboratory analyees (cont.)

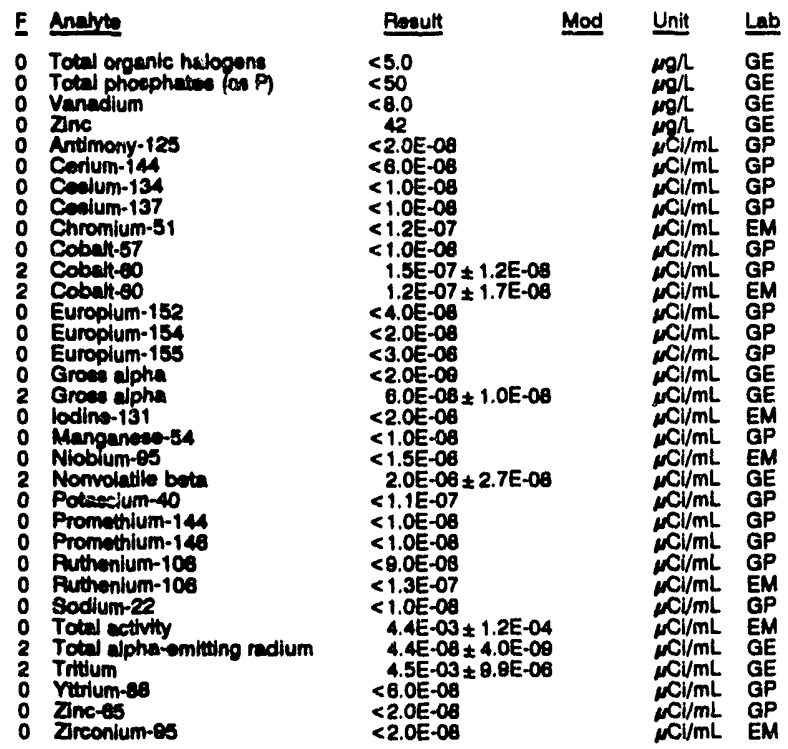

\section{WELL HSB137C}

MEASUAEMENTS CONOUCTED IN THE FIELO

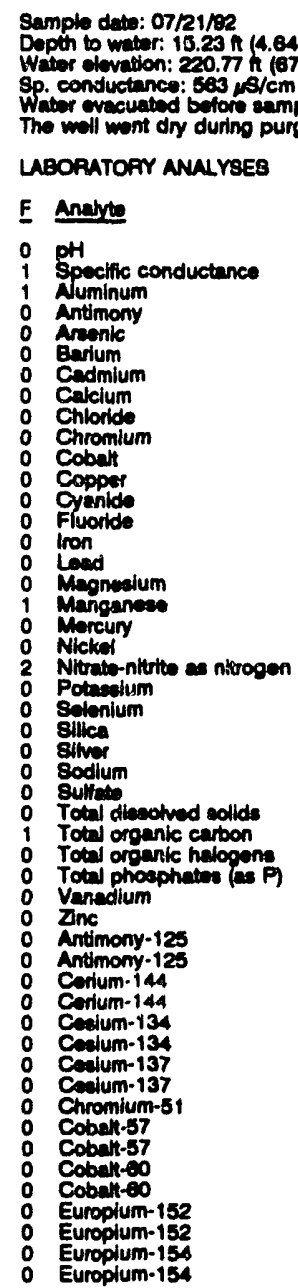

\section{TOC \\ Time: 14:25 \\ pH: 7.4 . $31 \mathrm{mgl}$ \\ Akalinity: $31 \mathrm{mg} / \mathrm{h}: 18.0 \circ \mathrm{C}$}

betore sampling: $28 \mathrm{gal}$

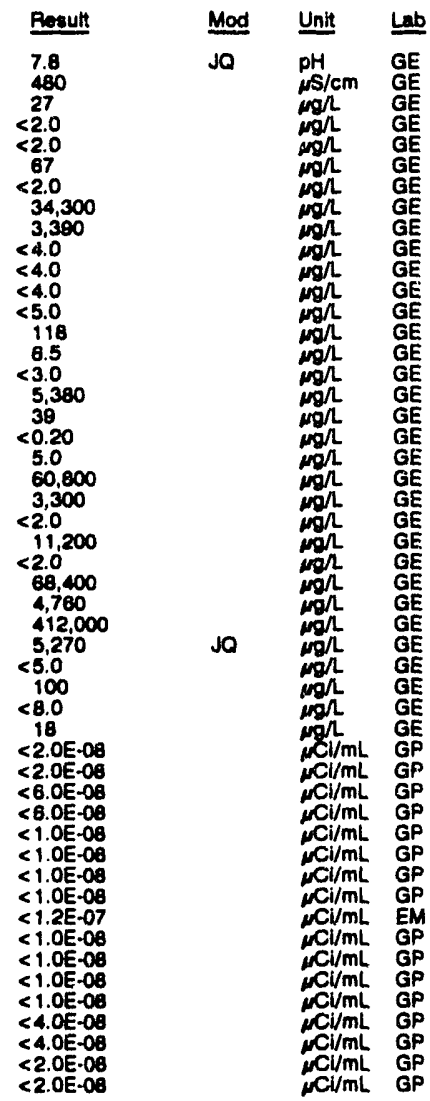

WELL HSB137C collected on 07/21/82, laboratory analyees (cont)

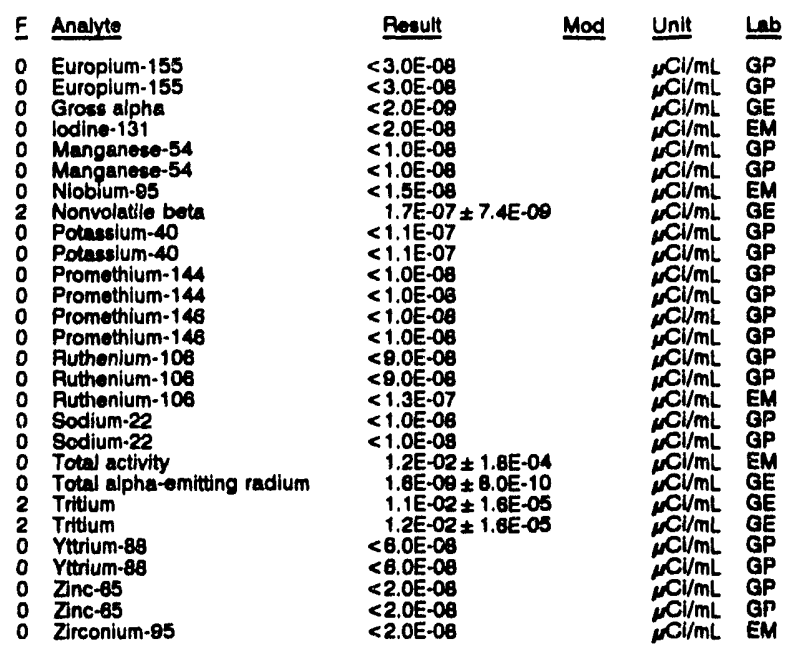

WELL HSB137D

MEASUREMENTS CONDUCTED IN THE FIELD

Sample date: 07/21/92 Depth to water: $13,83 \mathrm{H}(4.25 \mathrm{~m})$ bolow TOC Water elovation: $222.67 \mathrm{~h}(67.87 \mathrm{~m}) \mathrm{msl}$ Bp. conductance: $188 \mathrm{~s} / \mathrm{cm}$ Time: $8: 35$ PH: 4.8 : $0 \mathrm{mgh}$ Water temperature: $16.7^{\circ} \mathrm{C}$ LABORATORY ANALYSES

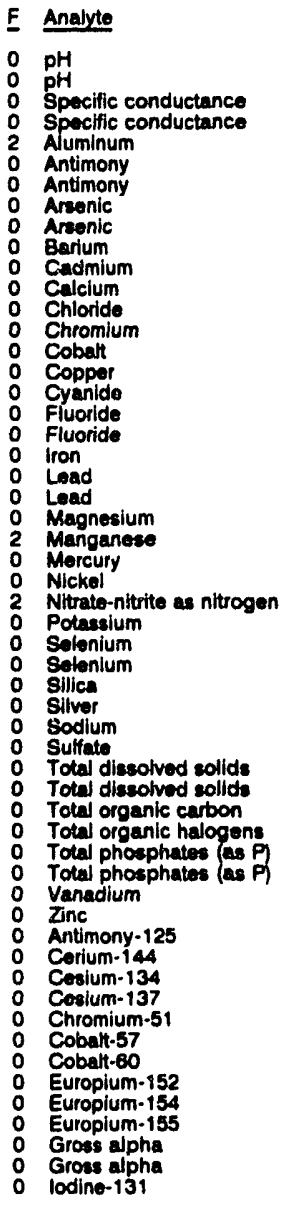

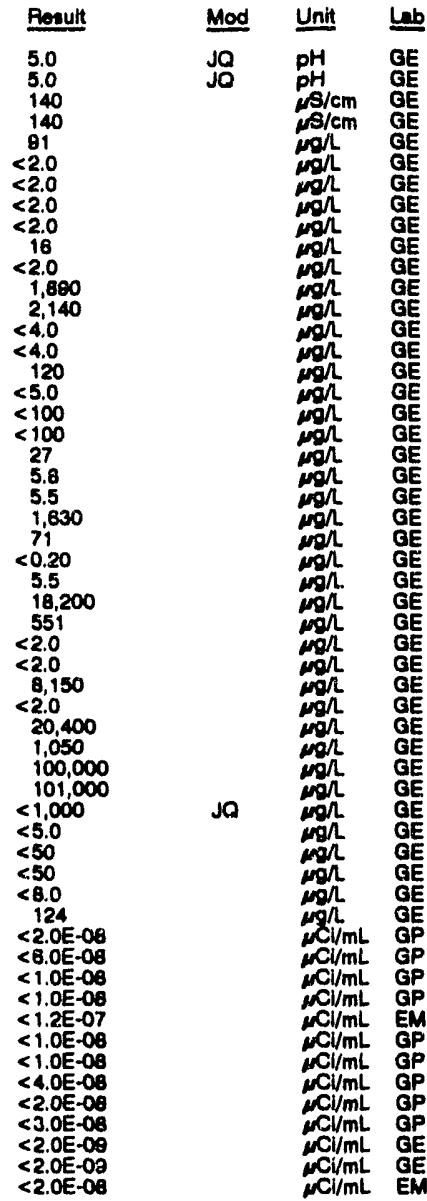


ANALYTICAL RESULTS

\begin{tabular}{|c|c|c|c|}
\hline F Anate & Result & Unit & Lab \\
\hline 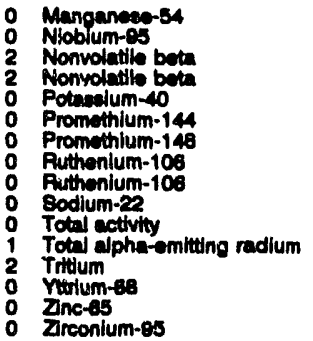 & 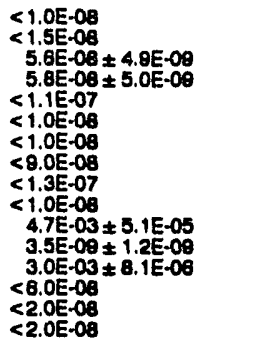 & 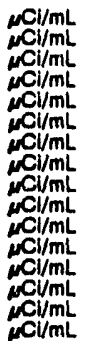 & $\begin{array}{l}\text { GP } \\
\text { EM } \\
\text { GE } \\
\text { GE } \\
\text { GP } \\
\text { GP } \\
\text { GP } \\
\text { GP } \\
\text { EM } \\
\text { GP } \\
\text { EM } \\
\text { GE } \\
\text { GE } \\
\text { GP } \\
\text { GP } \\
\text { EM }\end{array}$ \\
\hline
\end{tabular}

WELL HSB138D

MEASUREMENTS CONDUCTED IN THE FIELD

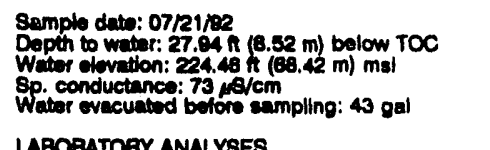

Time: 13:20

PH: 5.2

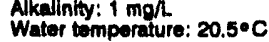

\section{LABORATORY ANALYSES}

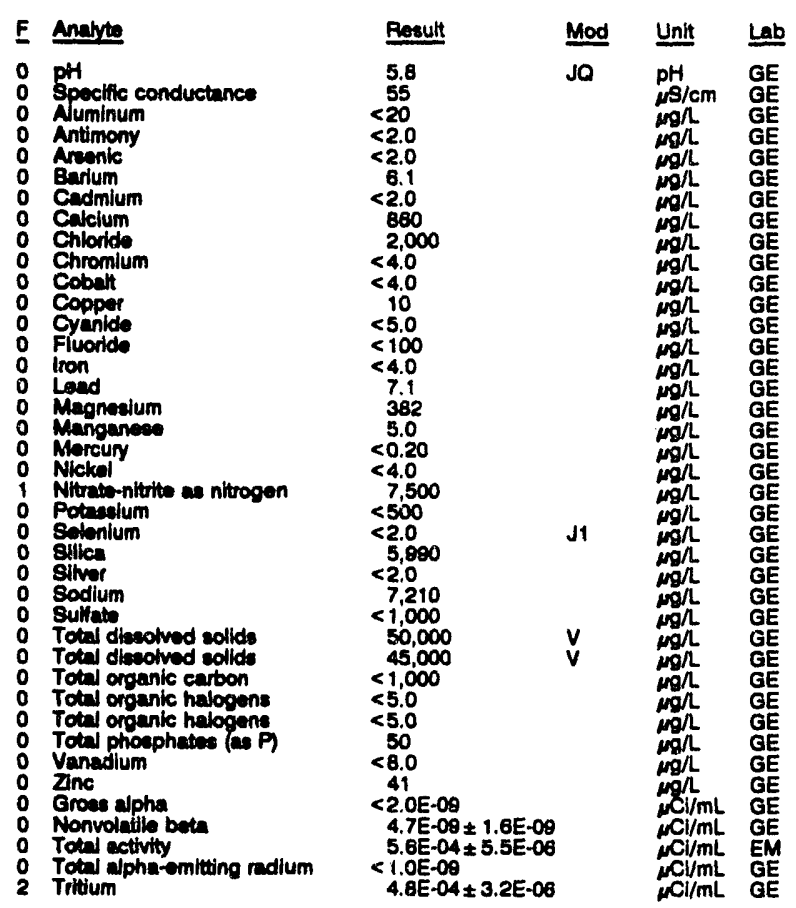

\section{WELL HSB139A}

MEASUREMENTS CONDUCTED IN THE FIELD

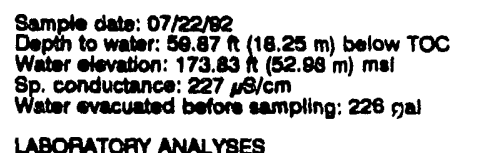

Time: 8:45

Alkalinity: $85 \mathrm{mg} / \mathrm{L}$

Water temperature: $18.3^{\circ} \mathrm{C}$

\section{LABOPATOAY ANALYSES}
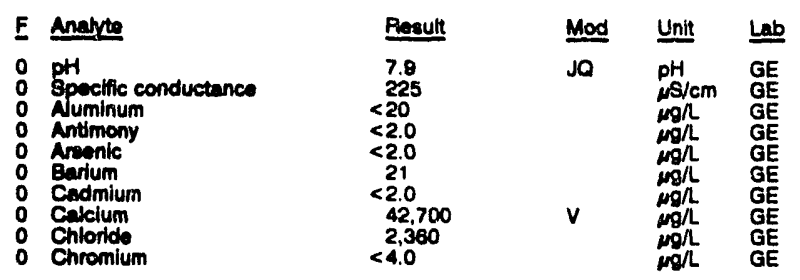

WELL HSB138A collected on 07/22/92, laboratory analyses (cont.)

\begin{tabular}{|c|c|c|c|c|c|}
\hline$\underline{F}$ & Analyte & Result & Mod & Unit & Lab \\
\hline & 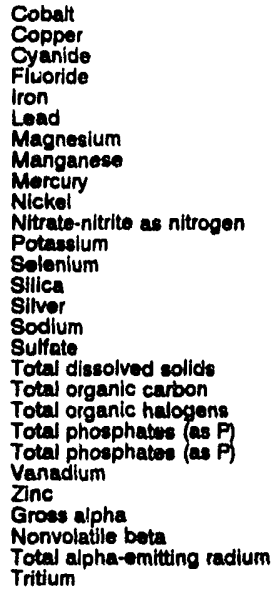 & $\begin{array}{l}<4.0 \\
<4.0 \\
<5.0 \\
<100 \\
<4.0 \\
<3.0 \\
720 \\
4.8 \\
<0.20 \\
<4.0 \\
60 \\
1,700 \\
<2.0 \\
37,300 \\
<2.0 \\
2,590 \\
3,740 \\
139,000 \\
<1,000 \\
<5.0 \\
<50 \\
<50 \\
<8.0 \\
<2.0 \\
<2.0 E-09 \\
8.0 E-09 \\
<1.0 E-09 \\
<7.0 E-07\end{array}$ & J1 & 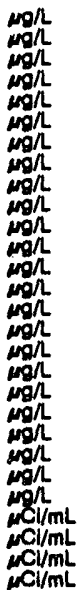 & 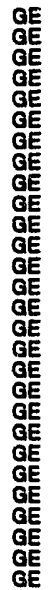 \\
\hline
\end{tabular}

WELL HSB139C

MEASUREMENTS CONDUCTED IN THE FIELD

Sample date: $07 / 22 / 92$

Depth to water: $18.23 \mathrm{ft}(5.89 \mathrm{~m})$ below TOC Time: 18:05

Water elovation: $214.57 \mathrm{Ht}(85.40 \mathrm{~m}) \mathrm{mal} \quad$ Alkalinity: $5 \mathrm{mo} /$

Sp. conductance: $419 \mu \mathrm{s} / \mathrm{cm}$ Water tomperature: $20,4^{\circ} \mathrm{C}$

The well went dry during purging: $28 \mathrm{gal}$

LABORATORY ANALYSES

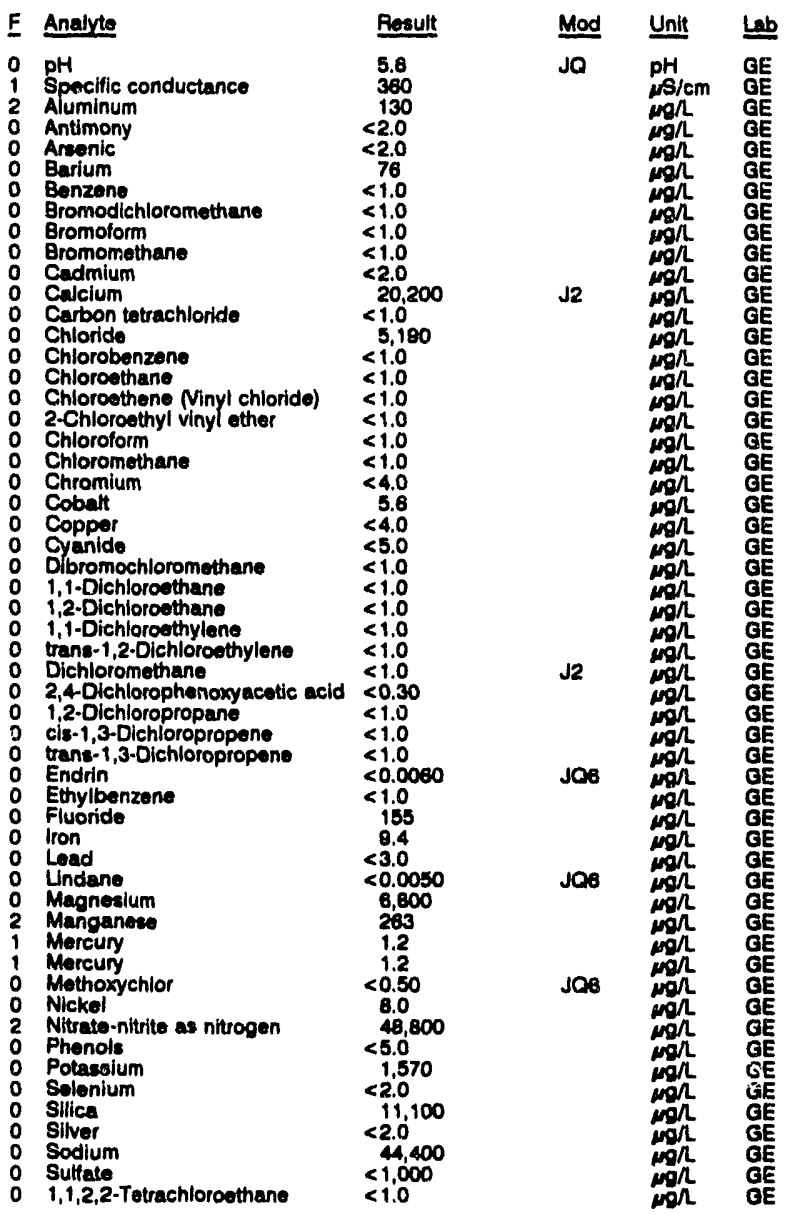




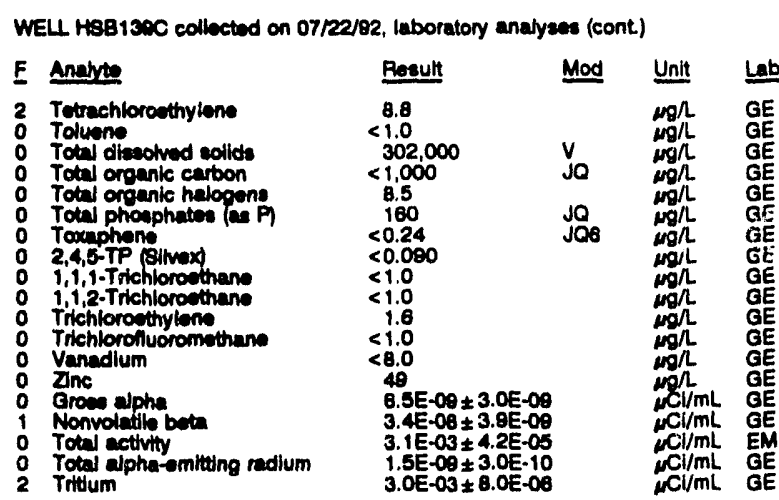

\section{WELL HSB139D}

MEASUREMENTS CONOUCTED IN THE FIELD

\begin{tabular}{|c|c|c|c|c|c|}
\hline & 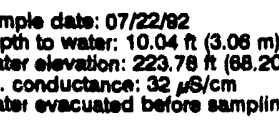 & TOC & $\begin{array}{l}\text { Time: } 8: 2 \\
\text { pH: } 4.7 \\
\text { Alkalinity } \\
\text { Water ter }\end{array}$ & n & \\
\hline & TOPY ANALYSES & & & & \\
\hline & Analyte & Result & Mod & Unit & Lab \\
\hline $\begin{array}{l}0 \\
0 \\
0 \\
0 \\
0 \\
0 \\
0 \\
0 \\
0 \\
0 \\
0 \\
0 \\
0 \\
0 \\
0 \\
0 \\
0 \\
0 \\
0 \\
0 \\
0 \\
0 \\
0 \\
0 \\
0\end{array}$ & 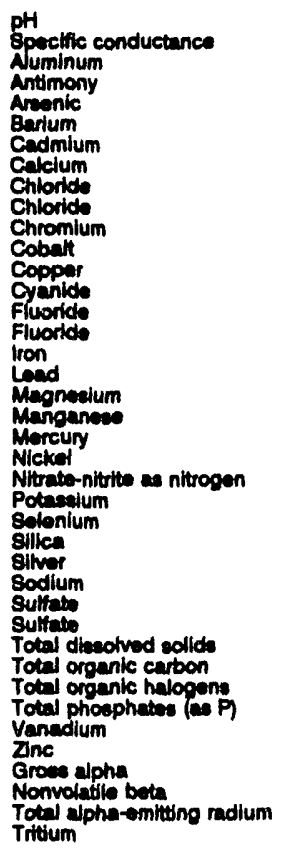 & $\begin{array}{r}4.9 \\
32 \\
36 \\
<2.0 \\
<2.0 \\
8.9 \\
<2.0 \\
1.100 \\
2,680 \\
2,760 \\
<4.0 \\
<4.0 \\
8.3 \\
<5.0 \\
<100 \\
<100 \\
<4.0 \\
<3.0 \\
640 \\
24 \\
<0.20 \\
<4.0 \\
580 \\
<500 \\
<2.0 \\
6.030 \\
<2.0 \\
2.420 \\
1,630 \\
1,650 \\
23.000 \\
<1.000 \\
<5.0 \\
<50 \\
<8.0 \\
52.8 \\
<2.0 E-09 \\
2.5 E-09 \\
<1.0 E-09 \\
1.5 E-05\end{array}$ & 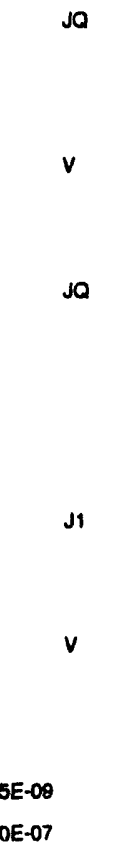 & 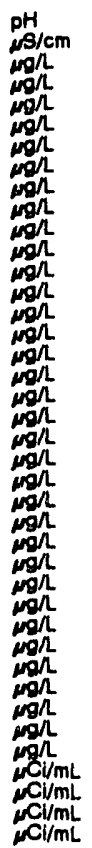 & $\begin{array}{l}\mathrm{GE} \\
\mathrm{GE} \\
\mathrm{GE} \\
\mathrm{GE} \\
\mathrm{GE} \\
\mathrm{GE} \\
\mathrm{GE} \\
\mathrm{GE} \\
\mathrm{GE} \\
\mathrm{GE} \\
\mathrm{GE} \\
\mathrm{GE} \\
\mathrm{GE} \\
\mathrm{GE} \\
\mathrm{GE} \\
\mathrm{GE} \\
\mathrm{GE} \\
\mathrm{GE} \\
\mathrm{GE} \\
\mathrm{GE} \\
\mathrm{GE} \\
\mathrm{GE} \\
\mathrm{GE} \\
\mathrm{GE} \\
\mathrm{GE} \\
\mathrm{GE} \\
\mathrm{GE} \\
\mathrm{GE} \\
\mathrm{GE} \\
\mathrm{GE} \\
\mathrm{GE} \\
\mathrm{GE} \\
\mathrm{GE} \\
\mathrm{GE} \\
\mathrm{GE}\end{array}$ \\
\hline
\end{tabular}

\section{WELL HSB140A}

MEABUREMENTS CONOUCTED IN THE FIELD

Sample data: 07 rearer Depth to waber: $60.35 \mathrm{n}(18.39 \mathrm{~m})$ bolow TOC

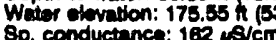

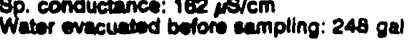
LABORATOFY ANUL YSES

\begin{tabular}{|c|c|c|c|}
\hline E Anats & Result & Mod & Unit \\
\hline 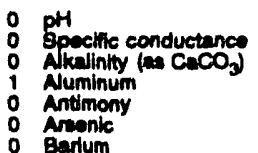 & $\begin{array}{l}7.2 \\
150 \\
63 \\
2.6 \\
<2.0 \\
2.5 \\
48\end{array}$ & $J 0$ & $\begin{array}{l}\mathrm{pH} \\
\operatorname{sis} / \mathrm{cm} \\
\mathrm{mgh} \\
\operatorname{mgh} \\
\operatorname{mgn} \mathrm{m} \\
\operatorname{mgn}\end{array}$ \\
\hline
\end{tabular}

Time: 11:55

Alkalinity: $57 \mathrm{mgh}$ Water temperature: $20.4^{\circ} \mathrm{C}$
WELL. HSB140A collectod on 07/22/82, laboratory analyees (cont)

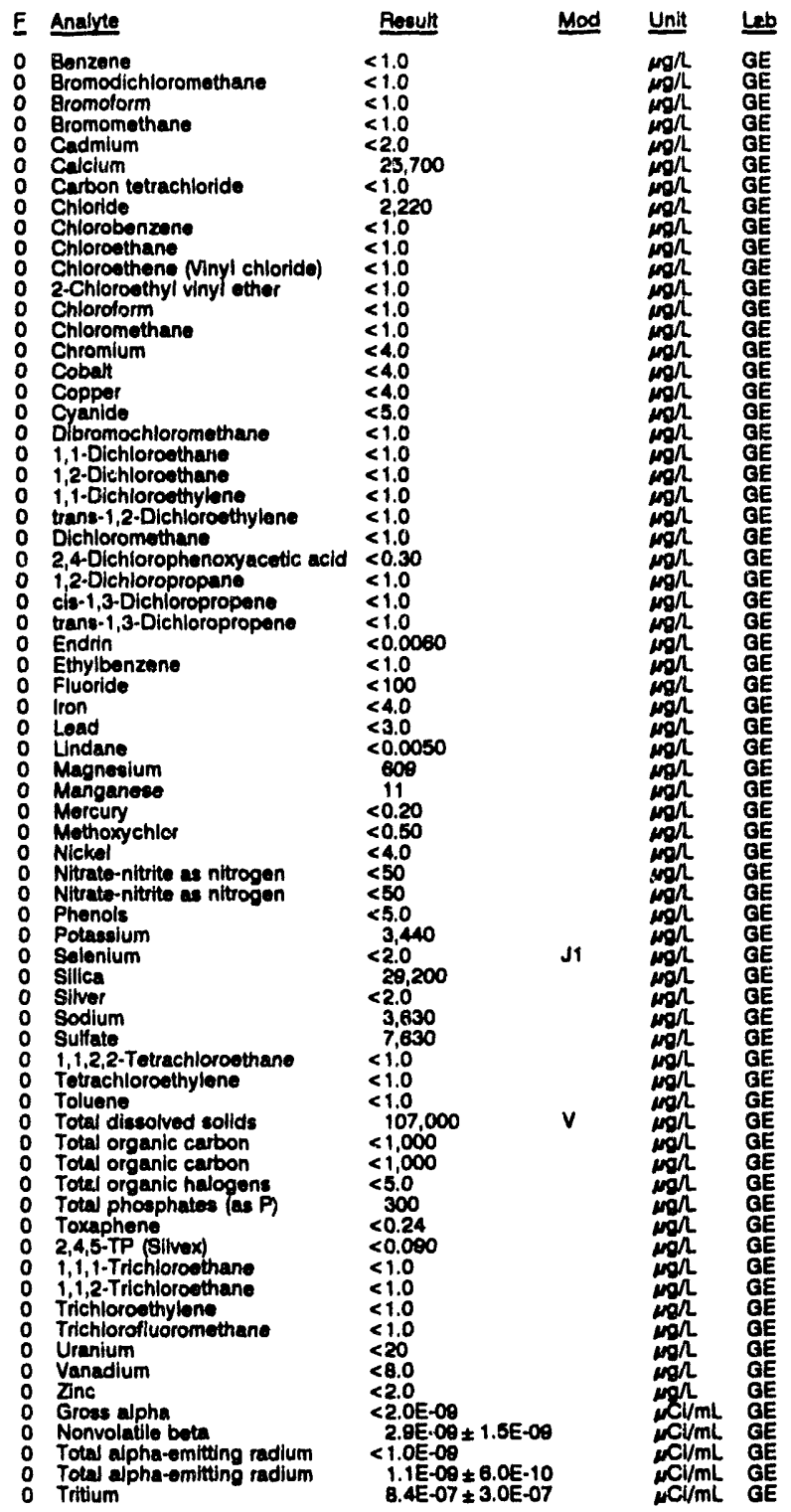

\section{WELL HSB140C}

MEASUREMMENTS CONDUCTED IN THE FIELD

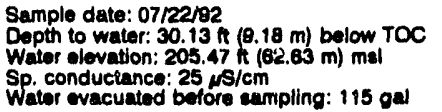

Time: $10: 40$

PH: 5.3 . 3 : 3 malinity: Water tomperature: $20.4^{\circ} \mathrm{C}$

LABOPATORY ANALYSES

Plosult
5.7
5.7
5.4
5.4
22
23
23
23
5.5
$<20$
$<20$
$<15$
$<15$
$<2.0$


ANALYTICAL RESULTS

WELL HBB140C collected on 07/22/82, laboratory analyses (cont)

F Anelyte

: Antimony

0 Antimony

Arsonic

Barium

Barium

Barium

Benzene

Bunzerio

Bromodichloromethane

Bromodichloromethane

Bromoform

Eromotorm

Bromomethane

Cadmium

Cedmlum

Cadmium

Calcium

Calcium

Calcium

Carbon tetrachloride

Carbon tatrachlorido

Chloride

Chloride

Chlorobenzene

Chlorobenziene

Chlorobenzen

Chloroethane

Chlorothene Minyl chloride

Chlorowitiene Vinyl chioride

Chloroction Ninyl chlorida

2.Chloroethyl vinyl ether

2-Chloroethyl vinyl ther

2-Chloroethyl vinyl ther

Chloroform

Chloroform

Chloromethen

Chioromethane

Chloromethan

Chromium

Chromium

Chromium

Cobalt

0 Cobalt

O Cobalt

- Copper

Copper

Copper

Cyanide

Dibromochloromethane

Dibromochloromethane

1.1.Dichlorotthane

i. Dichloromane

1, Ditorochan

1,2-Dichlorothan

1,2-Dichloroethane

1,1-Dichloroethylene

1,1-Dichloromylene

0 trane-1,2-Dichloroethylene

o trane-1,2-Dichloroethylene

Dichloromethane

Dichloromethane

Dichloromethan

2,4Dichlorophenowyacetic acid

2,4-Dichlorophenoxy acetic acid

1,2-Dlchloropropan

1. Dichlopopropen

cie-1,3-Dichionomente

- ela-1,3-Dichloropropene

cib-1,3-Dichloropropene

trana-1,3-Dichloropropene

trans-1,3-Dichloropropon

Endrin'

Endrin

Ethylbenzore

Ethylbenzone

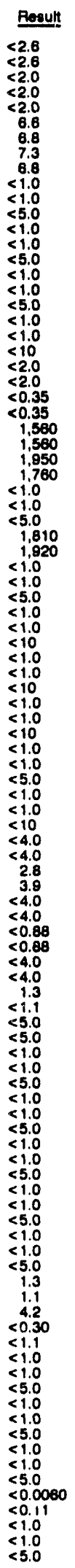

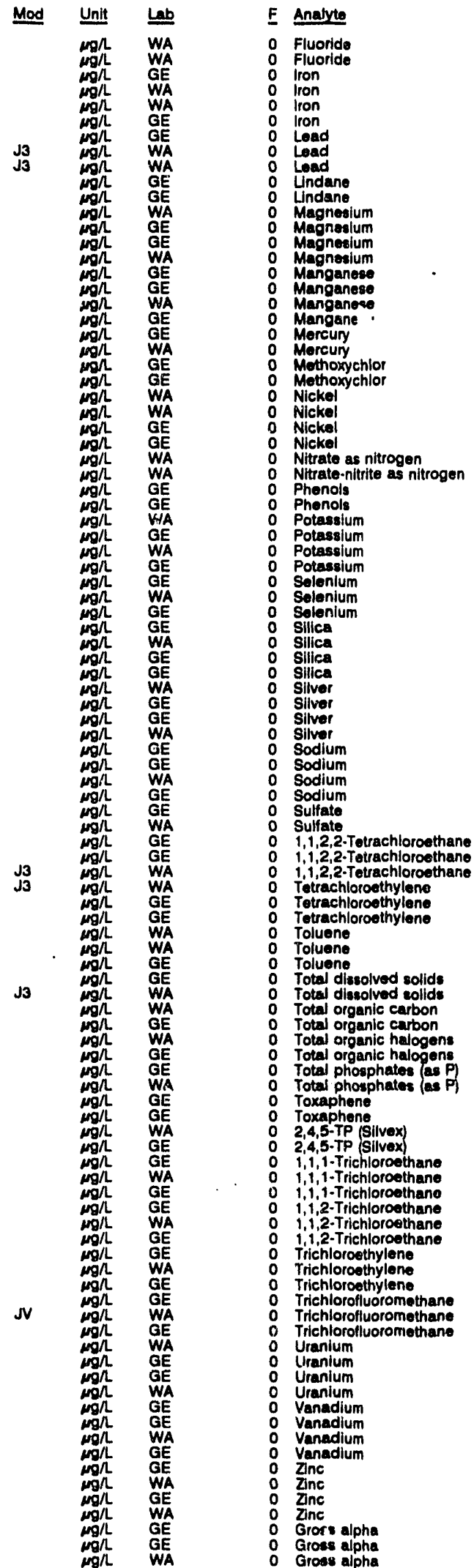

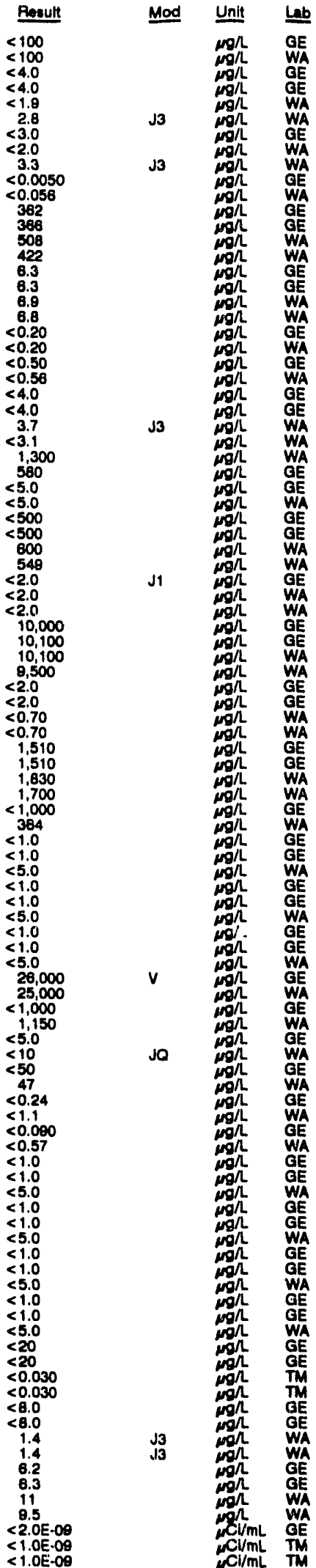


WELL HBB140C collected on 07/22/92, laboratory snalyese (cont.)

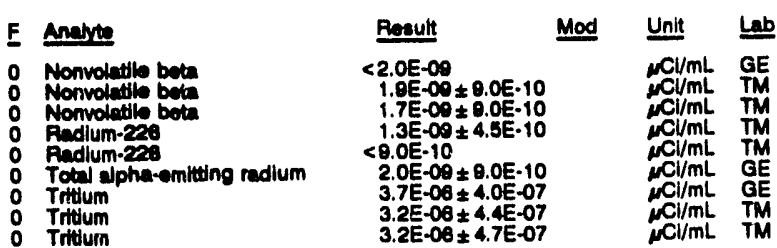

WELL HSB140C Replicate

MEASUAEMENTS CONOUCTED IN THE FIELD

\begin{tabular}{|c|}
\hline 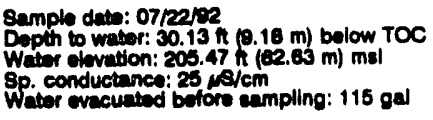 \\
\hline LABORATOAY ANALYSES \\
\hline
\end{tabular}

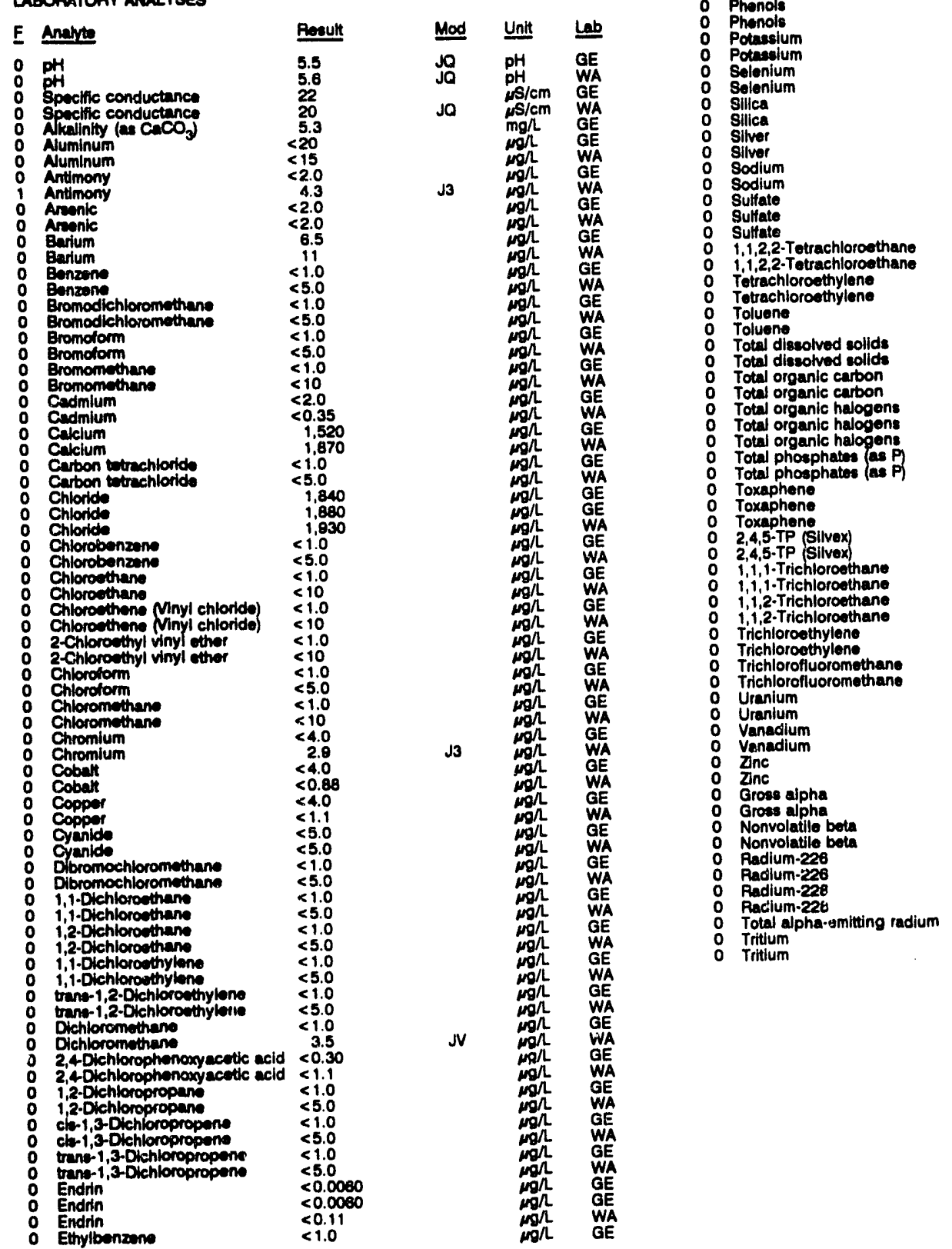

Time: 10:10

Alkalinity: 3 mon

Water temperature: $20.4^{\circ} \mathrm{C}$

LABORATOFY ANULYSES
WEL H8B140C colloctod on 07/22/92, laboratory analyees (cont)

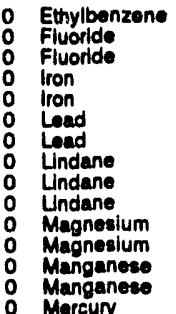

Mercury

O Mercun

Methoxychlor

Methoxychlor

0 Nickol

o Nickel

N Nitrat as nitrogen

Nitrate as nitrogen

Phenols

Porosium

Silles

Sodium

Tetrachloroethan

1,1,2, Tetrachloroethan

Tetrachloroethylene

Toluene

Total diseolved solids

Total dissolved sollds

ooens

Total organic halogons

Total phosphates as P

Toxaphene

5-TP Silvex

$1,1,1$-Trichloroethan

Mod Unt

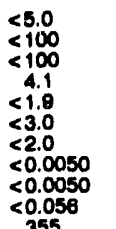

$<0.058$

482

$<0.20$

$<0.20$

$<0.50$

$<0.56$

$<4.0$

$<3.1$

810
$<5.0$

$<5.0$

$<500$

$<2.0$

8,730
8,510

8,510
$<2.0$

$<0.70$

1,680
$<1,000$

$<1,000$
367

$<1.0$

$<5.0$

$<1.0$

$<1.0$

18,000
52,000

$<1,000$

$<500$

$<5.0$
$<5.0$

$<5.0$

25
$<0.24$
$<0.24$

$<0.24$

$<1.1$

$<0.58$

$<1.0$
$<5.0$

$<5.0$
$<1.0$
$<5.0$

$<1.0$

$<5.0$

$<1.0$
$<5.0$

$<20$
$<0.030$
$<0.0$
1.8

1.8
6.4
10

$<2.05 .08$

$<2.0 E-00$

$1.6 E-09 \pm 9.0 E-10$

3.0E-09 $\pm 9.4 E-10$

2.1E-09 $1.7 E-10$

$<8.0 \mathrm{E}-10$

$<1.0 \mathrm{E}-08$

$4.3 E-06 \pm 4.0 E-07$
$3.2 E-00 \pm 4.3 E-07$ 
ANALYTICAL RESULTS

WELL HSB140D

MEASUREMENTS CONDUCTED IN THE FIELD

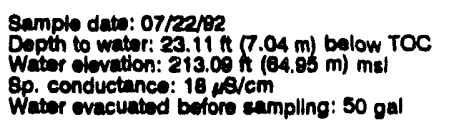

LABOFUTOFY ANALYSES

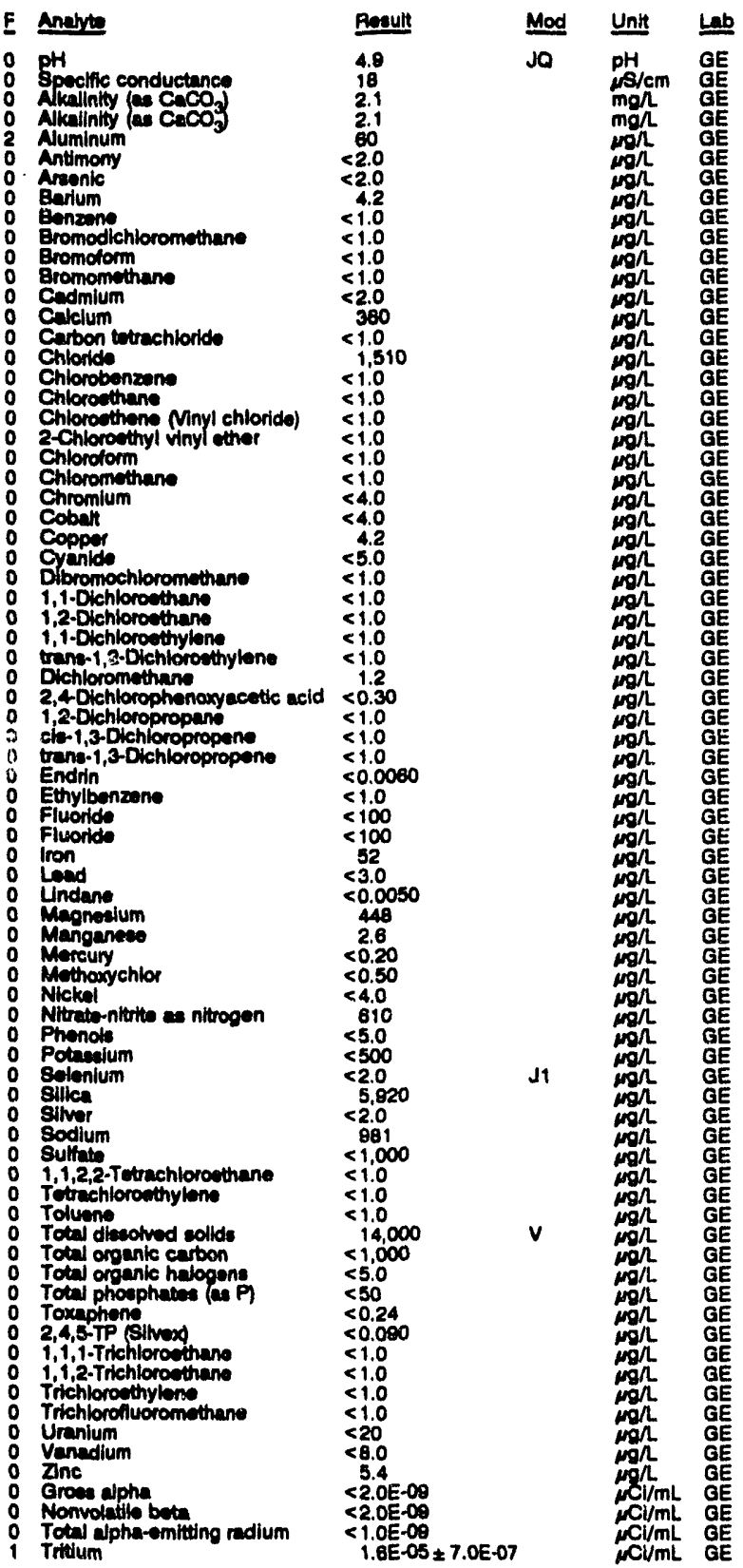

GE

E

.
WELL HSB141A

MEASUREMENTS CONDUCTED IN THE FIELD

Sample date: 07/23/92

Depth to wator: $79.81 \mathrm{At}(24.36 \mathrm{~m})$ bolow TOC

LABORATORY ANALYSES

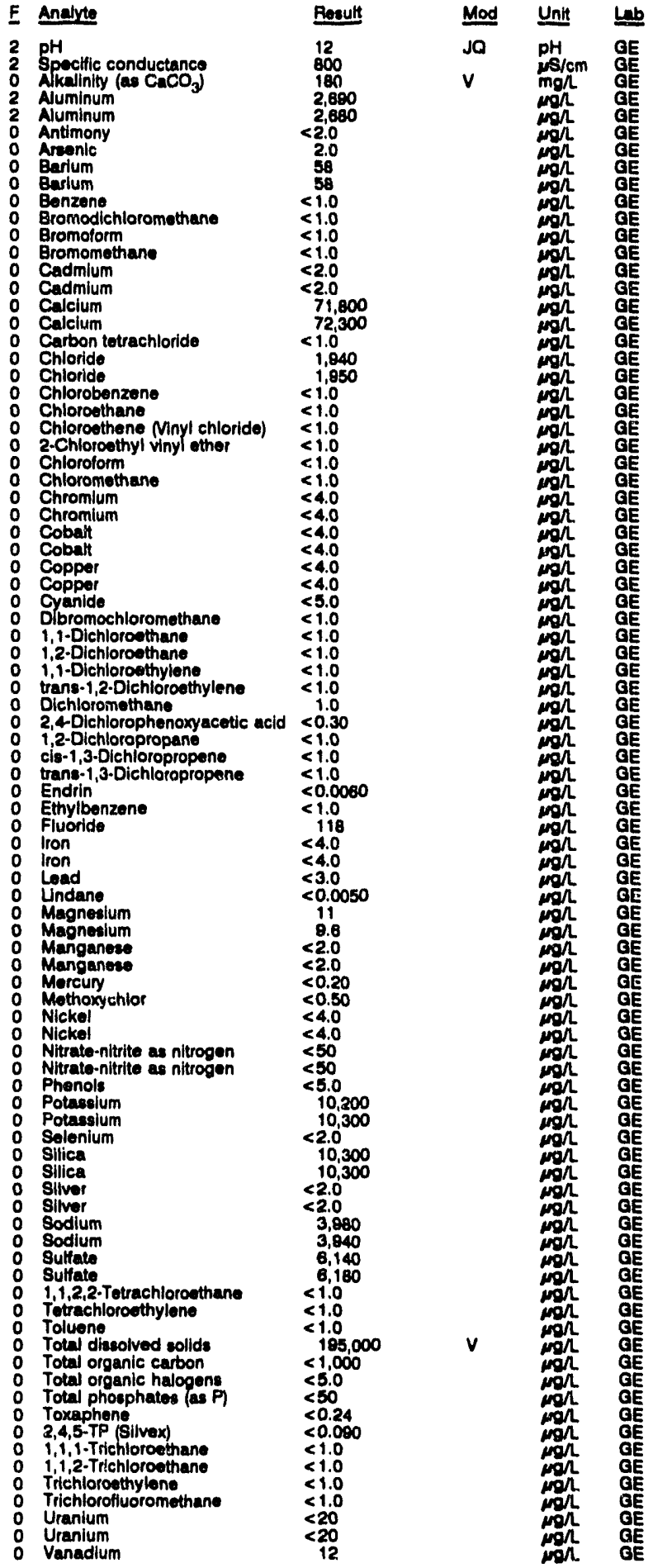

Time: 14:25

PH: 11.3 .3 .250

Water tomperature: $20.7 \circ \mathrm{C}$

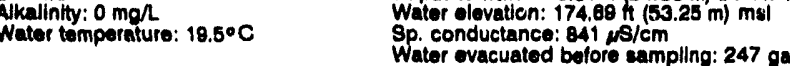

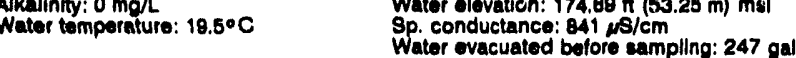


WELL H8B141A collectod on 07/23/92, laboratory analysen (cont)

\begin{tabular}{|c|c|c|c|}
\hline Anetyo & Rerult & Mod & Unit \\
\hline $\begin{array}{ll}0 & \text { Vanedlum } \\
0 & \text { Znce } \\
0 & \text { Znc } \\
0 & \text { Groes dphe } \\
0 & \text { Nonvoledit beti } \\
0 & \text { Total alpha-emiting radium } \\
0 & \text { Tritum }\end{array}$ & $\begin{array}{l}12 \\
2.4 \\
2.4 \\
<2.0 \mathrm{E}-00 \\
7.0 \mathrm{E}-00 \\
<1.0 \mathrm{E} \cdot 00 \\
<7.0 \mathrm{E}-07\end{array}$ & & 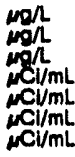 \\
\hline
\end{tabular}

\section{WELL HSB141C}

MEABUAEMENTS CONDUCTED IN THE FIELD
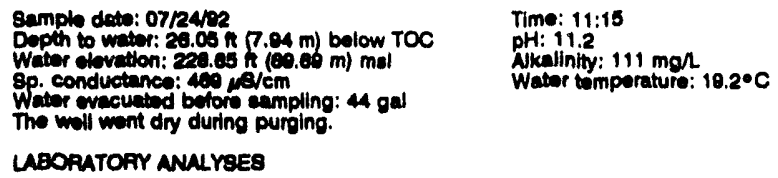

LABOAATOFY ANALYES

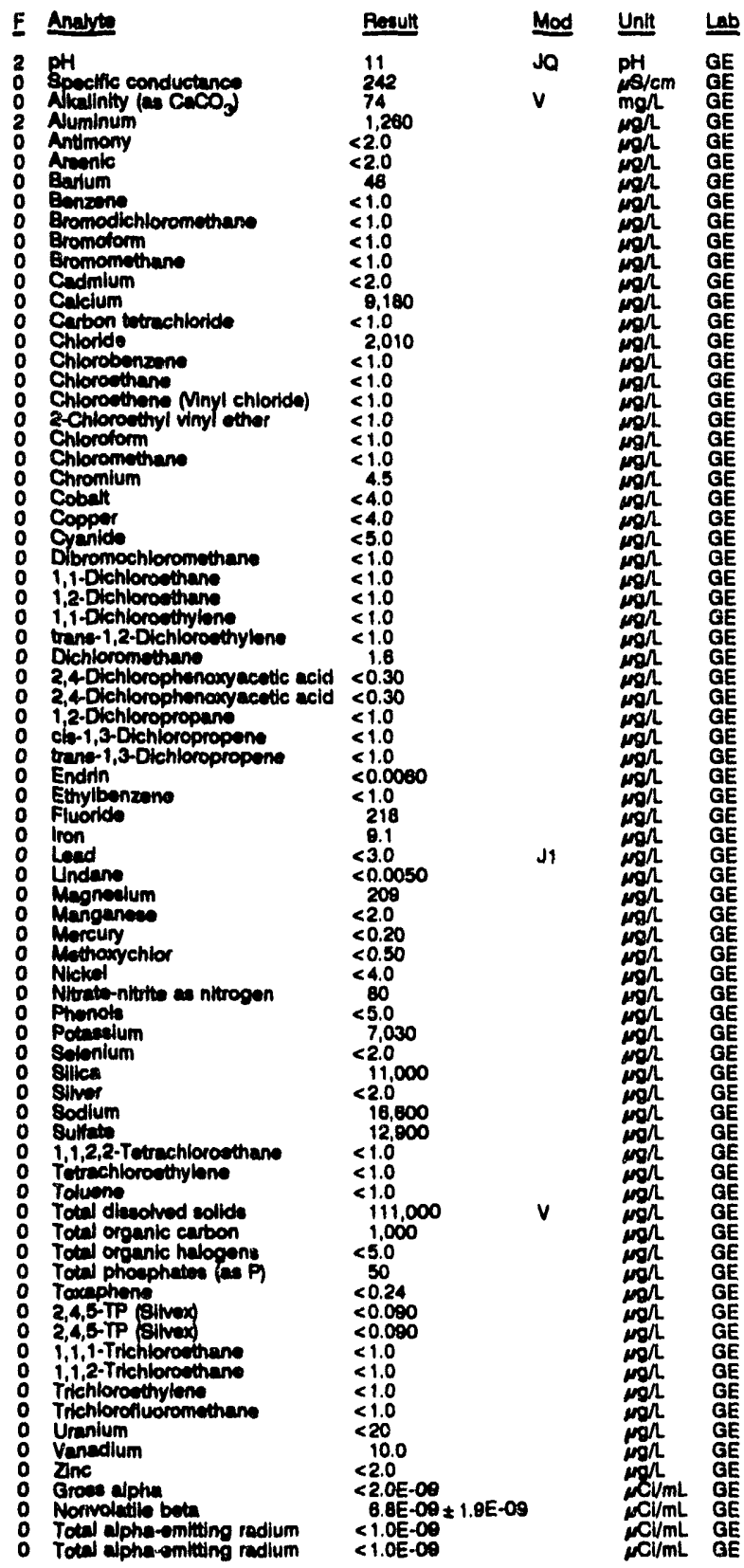

WELL HSB141C collected on 07/24/92, laboratory analyese (cont)

\begin{tabular}{|c|c|c|c|}
\hline E Analyte & Reeult & Mod & Unit \\
\hline 0 Tritlum & $<7.0 E-07$ & & $\mathrm{mCl} / \mathrm{mL}$ \\
\hline
\end{tabular}

WELL HSB141D

UEASUAEMENTS CONDUCTED IN THE FIELO

Sample date: $07 / 24 / 92$
Depth to water: $12.69 \mathrm{ft}(3.87 \mathrm{~m})$ bolow TOC

Water olevation: $242.11 \mathrm{~h}(73.80 \mathrm{~m}) \mathrm{msl}$

Wator tomperature: $10.0^{\circ} \mathrm{C}$

The will went dry during purging: 159

LABOPATOAY ANALYBES

$0 \mathrm{pH}$

Apeclific conductance

Aluminum

1 Auminum

0 Antimony

Barium

Barium

Bromodichloromothane

Bromotorm

Bromomothane

Cadmlum

- Cadmium

- Calclum

O Calcium

Chloride

Chlorlde

Chlorobenzene

Chlorothene Ninyl chloride)

2-Chloroethyl vinyl ether

Chlorotorm

Chloromethane

Chromium

Chromium

Cobalt

O Copper

- Copper

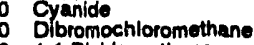

1,1-Dichloroothane

1,2-Dichloroethane

o trans-1,2-Olchlorothyione

Moguit Unit Led

2,4-Dichlorophenoxyacetic acld

1,2.Dichloropropane

cis-1,3-Dichlopopropene

trane-1,3-Dichloropropono

0 Endrin

- Ethylbenzene

o Fluoride

0 Iron

0 iron

o Lead

Magnesium

Magnesium

Manganese

Mangan

Methoxychlor

Nickel

N Nickol

Nitrate-niturite as nitrogen

o Phenols

Potasalum

Potasgium

Selonium

Sillea

Siver

Siver

Sodium

Sodium

Sulfate

1,1,2,2-Tetrachloroethane

T'trachloroethylene

Tolvene

o Total diseolved solio.

- Total organle cartoon

- Total organic halogens

Total phosphates (as P)

Toxaphen:

0
0
0
Time: 11:00

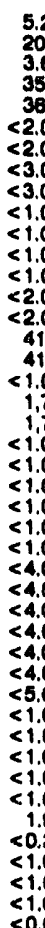

$<0.0060$

$<100$

31
31
$<3.0$

$<0.0050$

322

7.0
7.1

$<0.20$

$<40$

$<4.0$

$<280$

$<00$
$<500$

$<2.0$

5,940
5,860

$<2.0$

$<2.0$
2,070

2,080
1,720

1,780

$<1.0$
$<1.0$

$<1.0$

22,000

$<5.0$
210

180
$<0.24$

$<0.000$

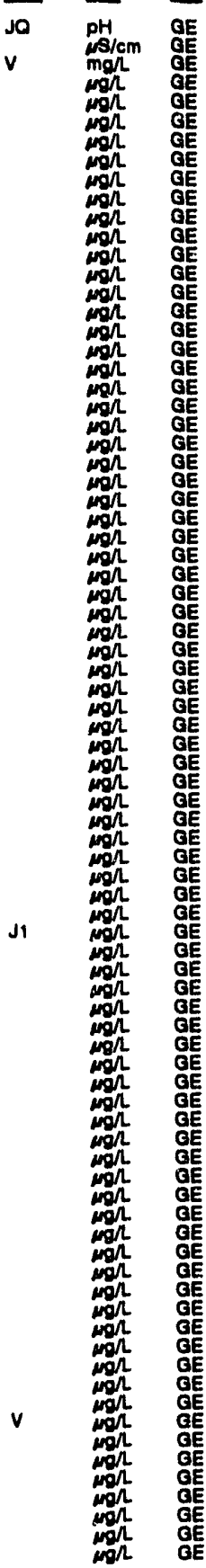


ANALYTICAL RESULTS

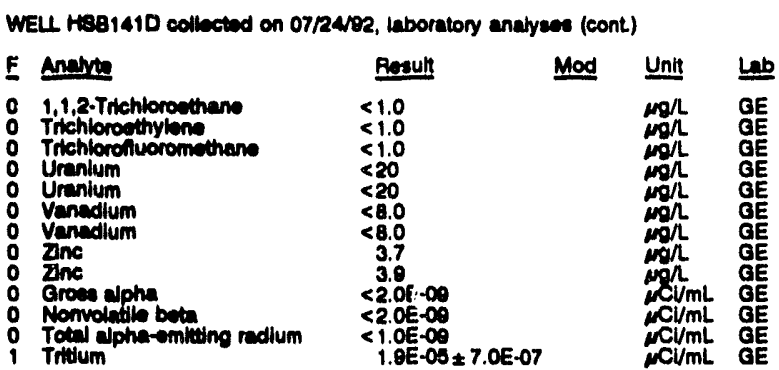

WELL HSB142C

MEASUAREMENTB CONDUCTED IN THE FIELD

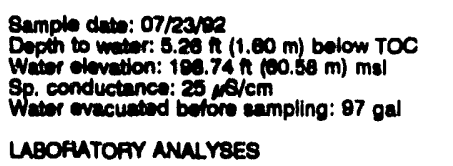

$$
\begin{aligned}
& \text { Time: } 9: 00 \\
& \text { pH: } 5.1 \\
& \text { Alkalinity: } 1 \mathrm{mgn} \\
& \text { Water temperalure: } 18.5^{\circ} \mathrm{C}
\end{aligned}
$$

$E$ Anate

$\therefore$ PH

Specific conductence

Numinum

: Numinum

- Aneonic

D Barium

: Barlum

O Bromodichloromethene

o Bromolorm

c codmlum

C Cedmlum

O Caletum

Carbon utrachioride

O Chtorice

Chtorobenzane

Chloroethene Mryl chloride)

2-Chlorostryl vinyl cther

Chiorofoerm

Chloromethane

Chromium

Chromium

- Cobalt

0 Copper

: Copper

: Olbromochloromethene

1.1.Dehlorouthane

1,i-Dechiorom thy

: tang-1,2-Dichlorothylone

: Dichloromethano

o 1,2-Dichioropropente

o cia-1,3-Dichlomporopone

Enditn

Endrin

0 inon

o rion

0 Lead

: Undane

o Magnealum

- Manoanese

- Mangane.

- Mercuny

O Mrowychlor

Metheryentor

Nickol

Nitrata-niturito es nitrogen

O Phenolo

Potevium

o Potsalum

E Ellen

o Ellea

o Elwer

o sodlum

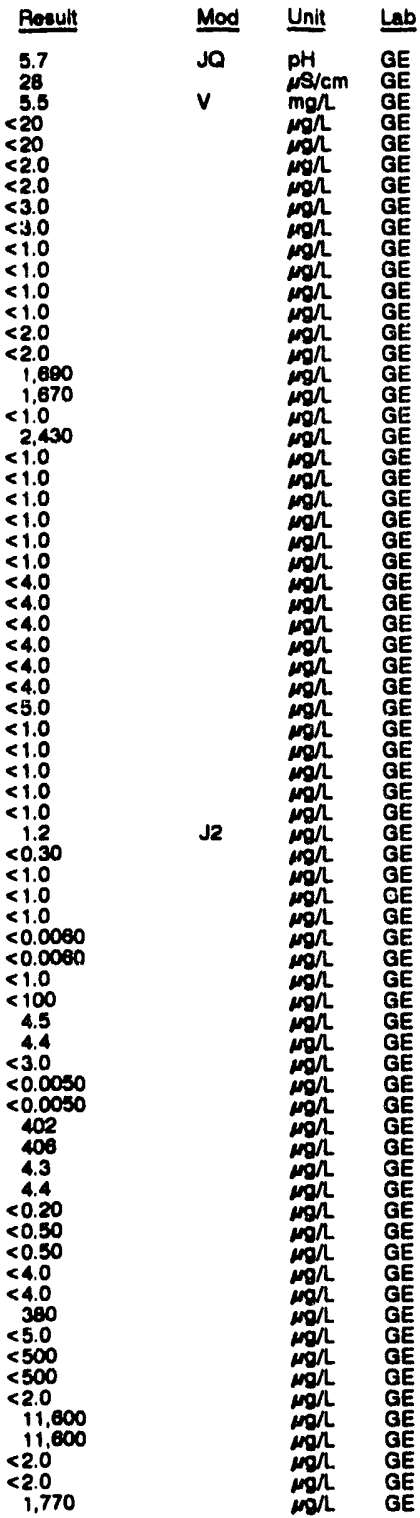

WELL. HSB142C collected on 07/23/92, laboratory analyses (cont)

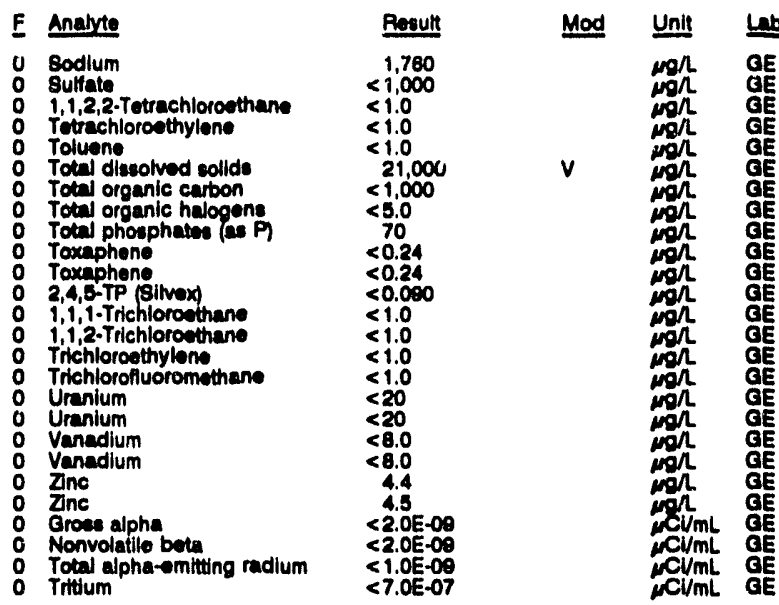

\section{WELL HSB142D}

MEASUREMENTS CONDUCTED IN THE FIELD

Sample date: 07/23/92

(10) TOC

Wator olevation: $188.19 \mathrm{ft}(80.41 \mathrm{~m}) \mathrm{mal}$

Sp. conductance: $46 \mathrm{\mu s} / \mathrm{cm}$.

The well went dry during purging.

LABORATORY ANALYSES

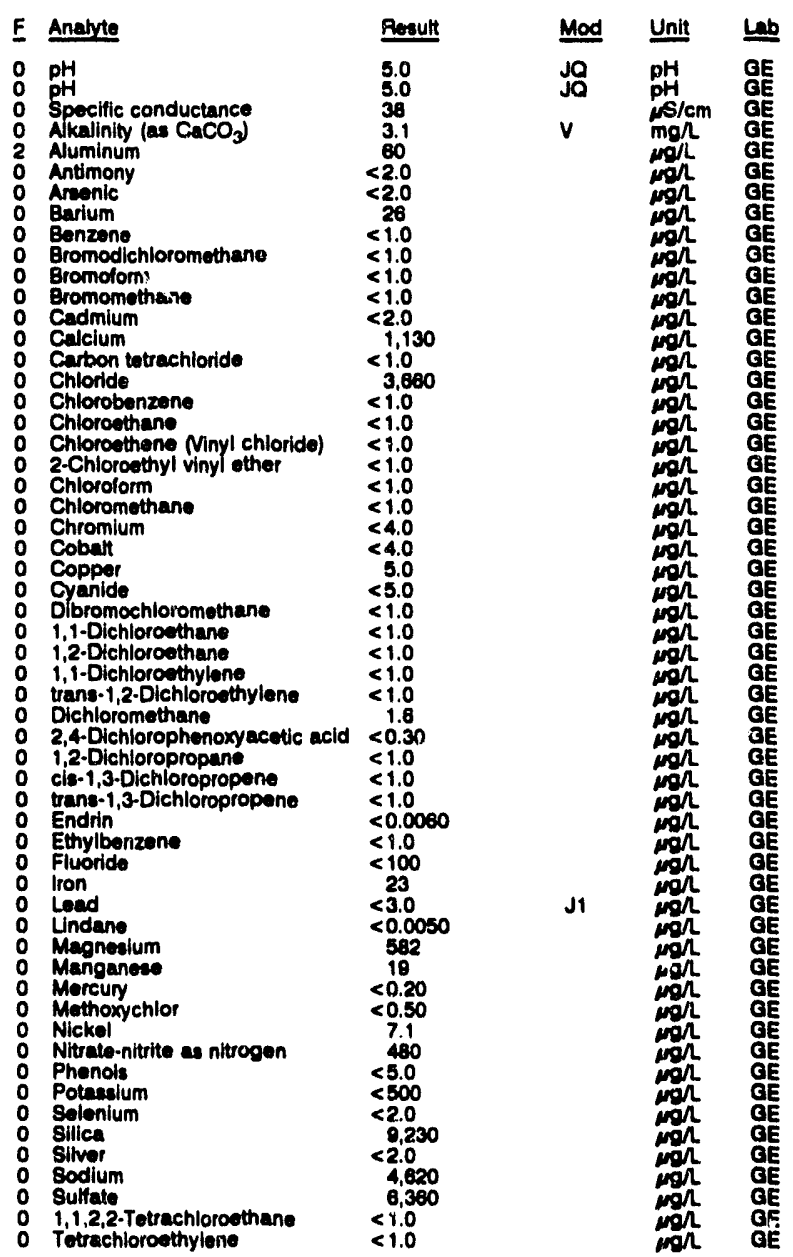




\section{ANALYTICAL RESULTS}

WELL He81480 collected on 07/23/82, laboratory analyees (cont)

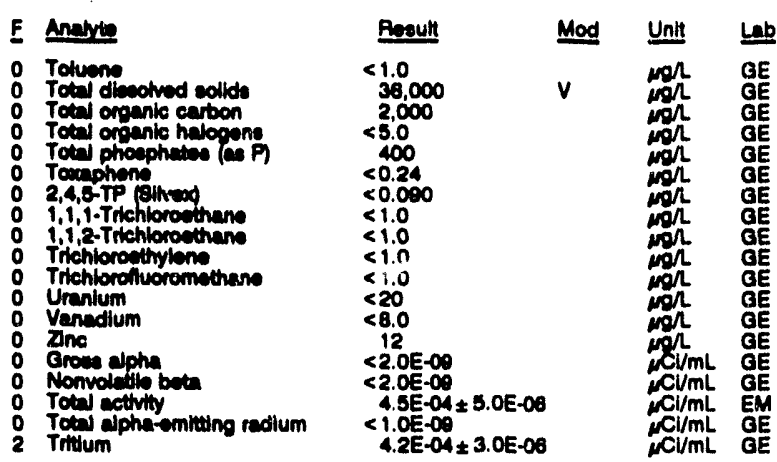

\section{WELL HSB143C}

\section{MEABUREMENTS CONDUCTED IN THE FIELD}

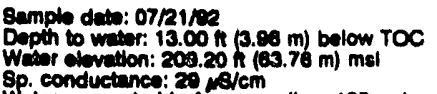

Wiater evecueted betore esmpling: $105 \mathrm{gal}$

\section{LABORATOFY ANALYSES}

\begin{tabular}{|c|c|c|c|}
\hline F Analde & Result & Mod & Unit \\
\hline 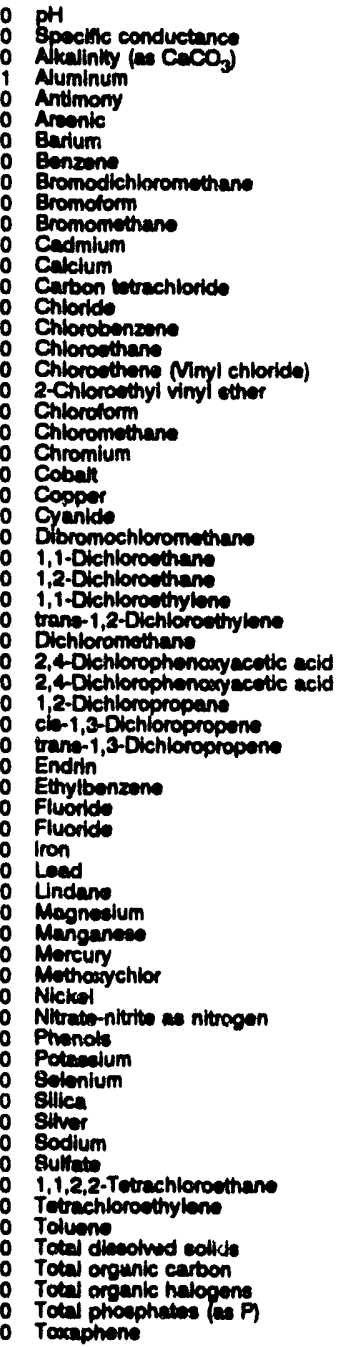 & $\begin{aligned} & 5.3 \\
& 2.3 \\
& 4.8 \\
& 28 \\
&<2.0 \\
&<2.0 \\
& 6.2 \\
&<1.0 \\
&<1.0 \\
&<1.0 \\
&<1.0 \\
&<2.0 \\
& 737 \\
&<1.0 \\
& 2.700 \\
&<1.0 \\
&<1.0 \\
&<1.0 \\
&<1.0 \\
&<1.0 \\
&<1.0 \\
&<4.0 \\
&<4.0 \\
&<4.0 \\
&<5.0 \\
&<1.0 \\
&<1.0 \\
&<1.0 \\
&<1.0 \\
&<1.0 \\
& 1.5 \\
&<0.30 \\
&<0.30 \\
&<1.0 \\
&<1.0 \\
&<1.0 \\
&<0.0060 \\
&<1.0 \\
&<100 \\
&<100 \\
&<4.0 \\
&<3.0 \\
&<0.0050 \\
& 221 \\
& 111 \\
&<0.20 \\
&<0.500 \\
&<4.0 \\
& 47.0 \\
&<5.0 \\
&<500 \\
&<2.0 \\
& 6.780 \\
&<2.0 \\
& 3.2800 \\
&<1.000 \\
&<1.0 \\
&<1.0 \\
&<1.0 \\
& 21.000 \\
&<1.000 \\
&<5.0 \\
&<50 \\
&<0.24\end{aligned}$ & 10 & 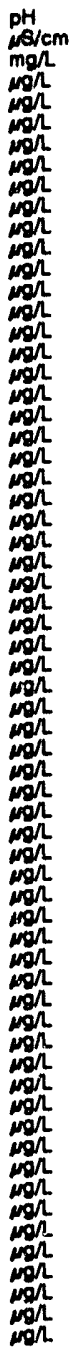 \\
\hline
\end{tabular}

pH: 5.0

Alkalinity: $0 \mathrm{mgh}$ : $20.0 \circ \mathrm{C}$

WELL HSB143C collected on 07/21/92, laboratory analysee (cont.)

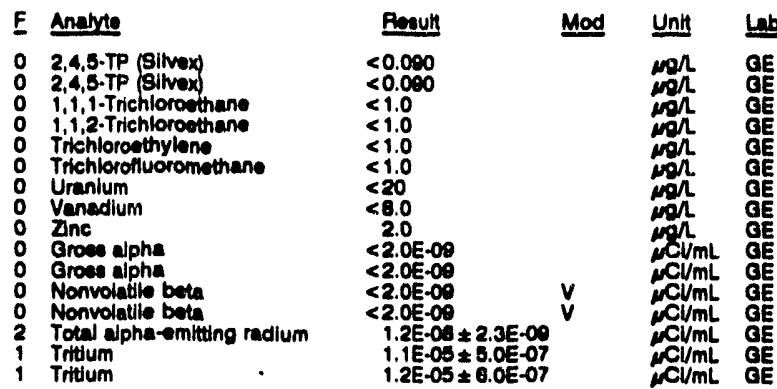

\section{WELL HSB143D}

MEASUREMENTS CONDUCTED IN THE FIELD

Sample date: 07/21/92

Depth to water: 8 . us $n(3.00 \mathrm{~m})$ below TOC

Water elevation: $213.03 \mathrm{H} 104$

Water ovacuated betore sampling: $42 \mathrm{gal}$

LABOFATORY ANALYSES

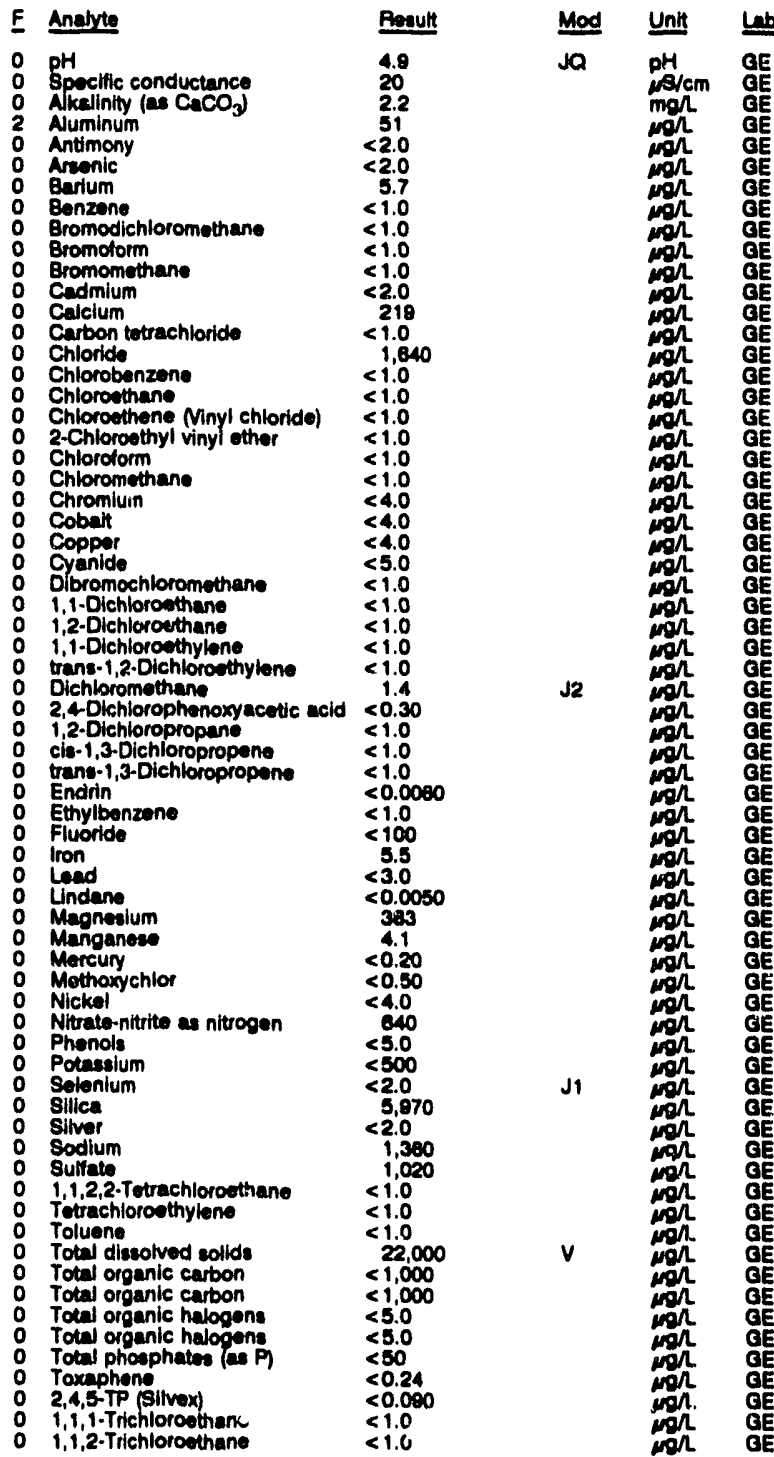

Time: 12:10

pH: 4.5

Nhalinity: $0 \mathrm{man}$

Water temperature: $18.0 \circ \mathrm{C}$ 
ANALYTICAL RESULTS

WELL HS81430 colbeted on 07/21/92, laborutory analyees (cont)

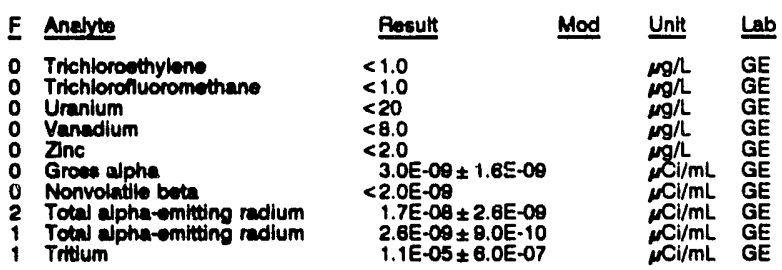

WELL HSB144A

MEASUREMENTS CONDUCTED IN THE FIELD

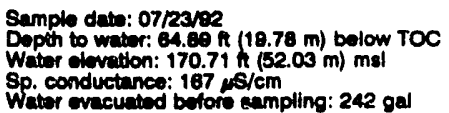

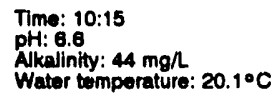

WABOr macuated bofors enat

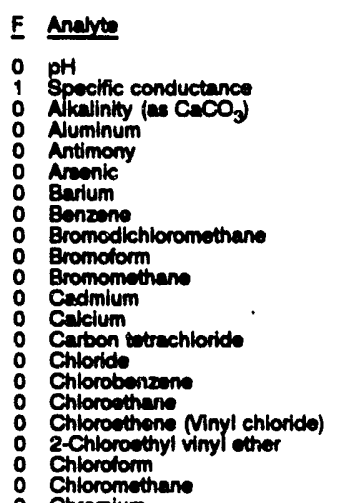

O Cobalt

Copper

O Oibromochloromethane

1,1-Dichlonothane

1,2-Dichloroethane

o trans-1,2-Dichioroethylone

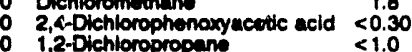

ci-1,3-Dichloropan

o trent-1,3-Dichioropropene

- Endrin

0 Ethylbenzene

o iron

Lindane

o Magnealum

O Morcury

M Mothaxychlor

N Nickel

Nitrato-nitutia as nittrogen

O Phonols

Potacium

0 Silia

o Silver

Sodium

1,1,2,2-Tetrachloroethane

Tetrechloroethylens

Tolwone

Totil diseotved sollds

o Totwl organic carton

- Total phosphates (as P

O Toxaphome

0 2,4,5-TP (Bivex)

1,1,1-Trichloroethan

Trichloroethylene

Trichlorofluoromethane

Uranlum

O Znc

Groses apha

Nonvolatile beta
Total ectivity
Rosult Mod Unit Lab

7.0
310
60

60
$<20$

$<20$
$<2.0$

$<2.0$

$<1.0$

$<1.0$

$<1.0$

$<2.0$

$<1.0$

$<1.0$

$<1.0$

$<1.0$

$<1.0$

$<1.0$ $20.1^{\circ} \mathrm{C}$

$\begin{array}{ll}\mathrm{pH} / & \mathrm{GE} \\ \mathrm{iS} / \mathrm{cm} & \mathrm{G} \\ \mathrm{mg} / \mathrm{h} & \mathrm{G} \\ \mathrm{mg} / \mathrm{L} & \mathrm{G}\end{array}$

$\mu g /$ GE

$\mathrm{mg} / \mathrm{L}$ GE

$\mathrm{mgl}$ GE

so

ge GE

gh GE

$\mathrm{gn}$ GE

$\mathrm{mgh}_{\mathrm{ggh}}^{\mathrm{GE}}$

$<4.0$

$<4.0$

$<1.0$

$<1.0$

$<1.0$

$<1.0$

$<1.0$

$<1.0$

$<0.000$

131

$<4.0$

$<0.0050$

680

$<0.20$

$<0.50$

4.4
1.550

1,550
$<5.0$

2.350
$<2.0$

$<27.600$

5.580
8.470

$<1.0$

$<1.0$

$<1.0000$

$<1,000$

$<50$

$<50$

$<0.000$

$<1.0$

$<1.0$

$<1.0$

$<20$

$<8.0$

$<2.0 E-09$

$6.7 \mathrm{E}-09 \pm 1.9 \mathrm{E}-09$
$1.1 \mathrm{E}-03 \pm 2.7 \mathrm{E}-05$

F Analute

$\begin{array}{ll}0 & \text { Total alpha-emitting radium } \\ 2 & \text { Trtitium }\end{array}$ $\begin{array}{ll}2 & \text { Trtium } \\ 2 & \text { Trtitium }\end{array}$

$1.4 E-09 \pm 6.0 E-10$ $1.1 \mathrm{E}-03 \pm 4.8 \mathrm{E}-06$
$1.0 \mathrm{E}-03 \div 4.7 \mathrm{E}-06$

Mod Unit Lab

WELL HSB145C

MEASUREMENTS CONDUCTED IN THE FIELD

Sample date: 07/23/92

Depth to water: $22.20 \mathrm{~h}(6.77 \mathrm{~m})$ bolow TOC

Water olovation: $213.50 \mathrm{ft}(65.08 \mathrm{~m}) \mathrm{mal}$

Water ovacuated belore sampling: $128 \mathrm{gal}$

Alkalinity: $17 \mathrm{mg} / \mathrm{s}$

Water temperature: $21.0^{\circ} \mathrm{C}$

LABORATORY ANALYSES

$0 \mathrm{pH}$

Specific conductance

Aikalinity (as $\mathrm{CaCO}_{3}$ )

Aluminum

Antimony

Arsonic

Areenic

Barium

Bromodichloromechane

Bromoform

Bromomethane

Cadmium

Carbon tetrachloride

Chloride

Chlorobenzene

Chloroethane

Chlorothene Ninyl chlorida)

2-Chloroethyl vinyl other

Chloroform

Chioromethane

Chromium

Cobart

o Cyanide

Cyanide

Dibromochloromethane

1,1-Dichloroethane

1,2-Dichloroethane

trans-1,2-Dichloroethylene

Dichloromethane

2,4-Dichlorophenoxyacetic acld

1,2-Dichloropropane

o cis-1,3-Dichloropropene

Endrin

Ethylbenzene

Fluoric

0 Lead

L Lead

Lindane

Magnealum

Marcury

Methoxychlor

Nickel

Phate-nitrite se nitrogen

Phenols

Potassium

Solenium

Solenium

Silica

Sitver

O Sodium

S Sulfate

2 Tetrachloroethylene

Tolueno

Total diseolved solids

Total diseolved sollds

- Total organic carbon

Total organic halogens

O Total phosphates (as P)

Toxaphene

2,4,5-TP (Silvex)

o $1,1,1-$ Trichloroethane

1 1,i,2-Trichlorothane

Trichloroethylene

- Trichlorofluoromethane

U Uranium

o Vanad

Gross alpha
2 Nonvolatile beta

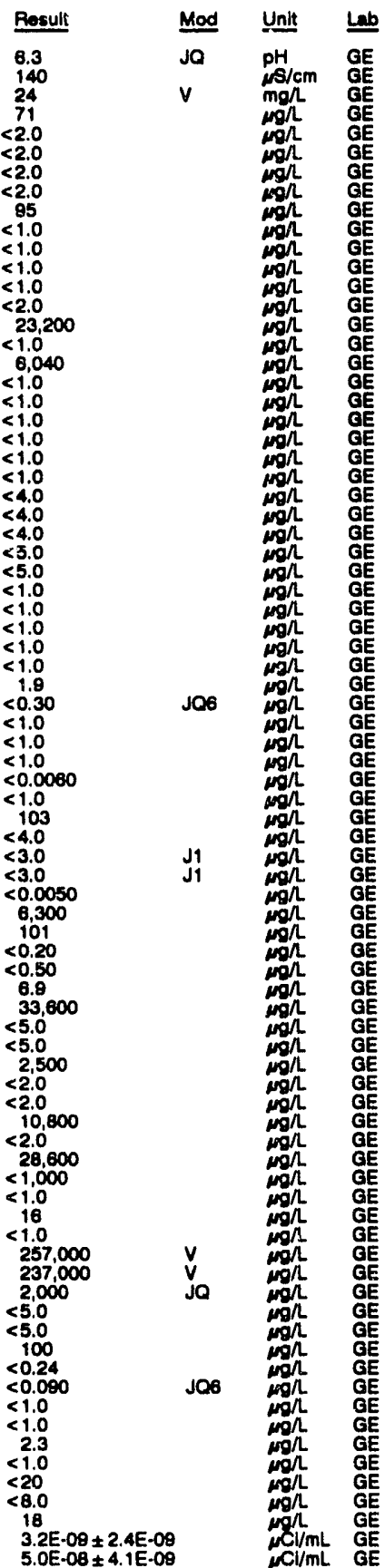


WELL HSB145C collected on 07/23/92, laboraiory analyses (cont.)

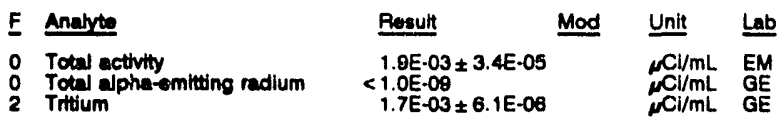

WELL HSB145D

MEASUREMENTS CONDUCTED IN THE FIELD

\begin{tabular}{|c|c|}
\hline 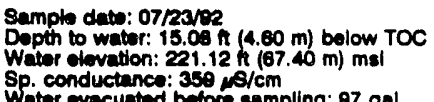 & $\begin{array}{l}\text { Time: } 11: 25 \\
\text { pH: } 5.5 \\
\text { Alkallinity: } 12 \mathrm{mgh} \\
\text { Water tomperature: } 20.1 \circ \mathrm{C}\end{array}$ \\
\hline
\end{tabular}

LABOPATORY ANALYSES

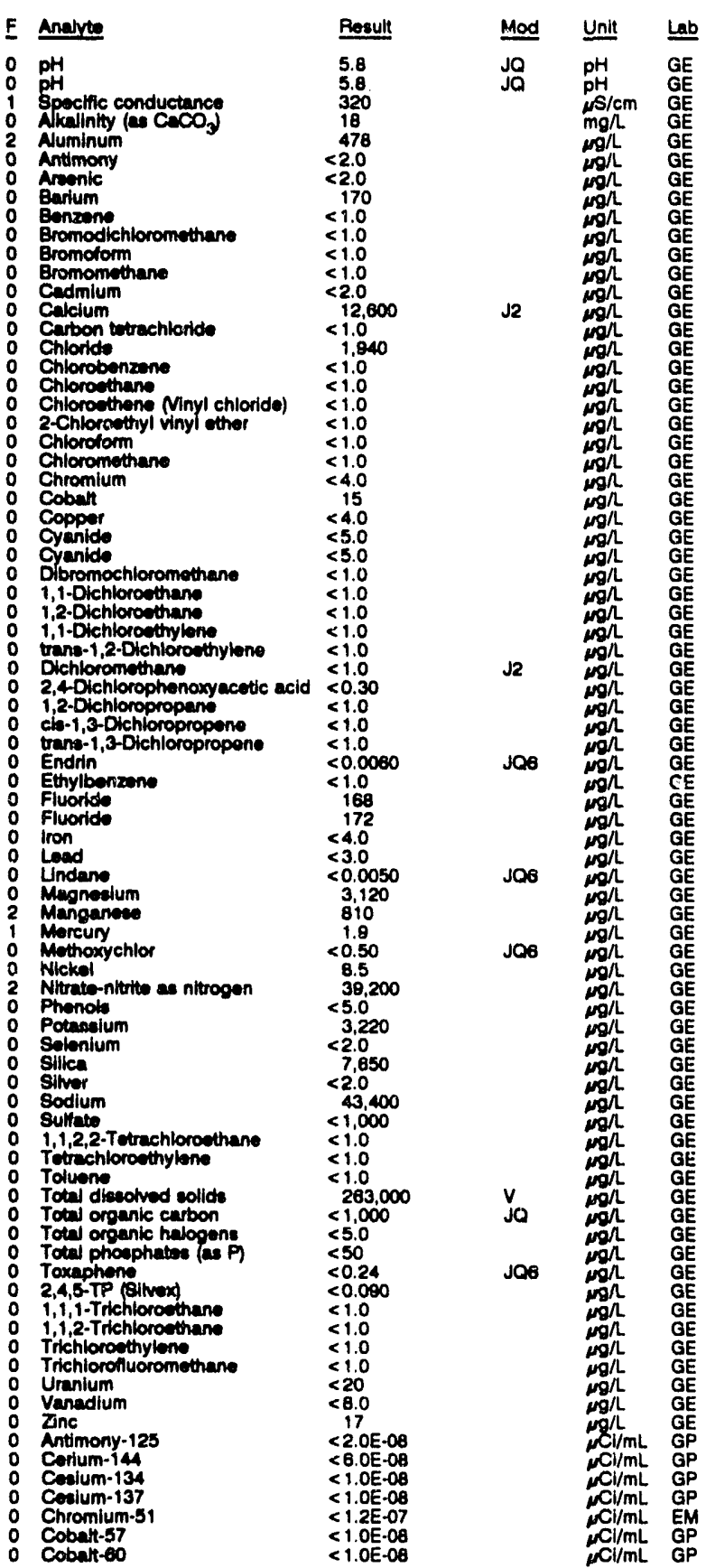

WELL HSB 145D collected on 07/23/92, laboratory analyses (cont.)

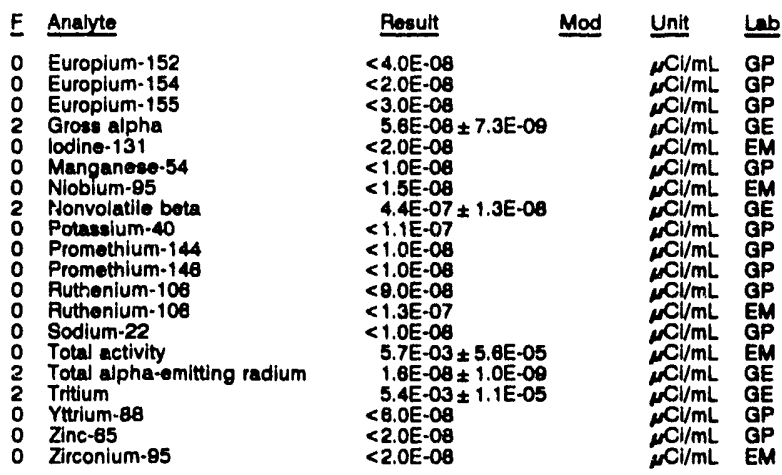

\section{WELL HSB146A}

MEASUREMENTS CONDUCTED IN THE FIELD

Depth to water: $75.81 \mathrm{ft}(23.11 \mathrm{~m})$ below TOC

Water elevation: 175.79 (53.58 m) mol

Wp conduction: 202 (5)

Water evacuated bofore sampling: $238 \mathrm{gal}$

Akalinity: $94 \mathrm{mgn}$

Alkalinity: $94 \mathrm{mg} / \mathrm{h}, 20.5^{\circ} \mathrm{C}$

LABORATORY ANALYSES

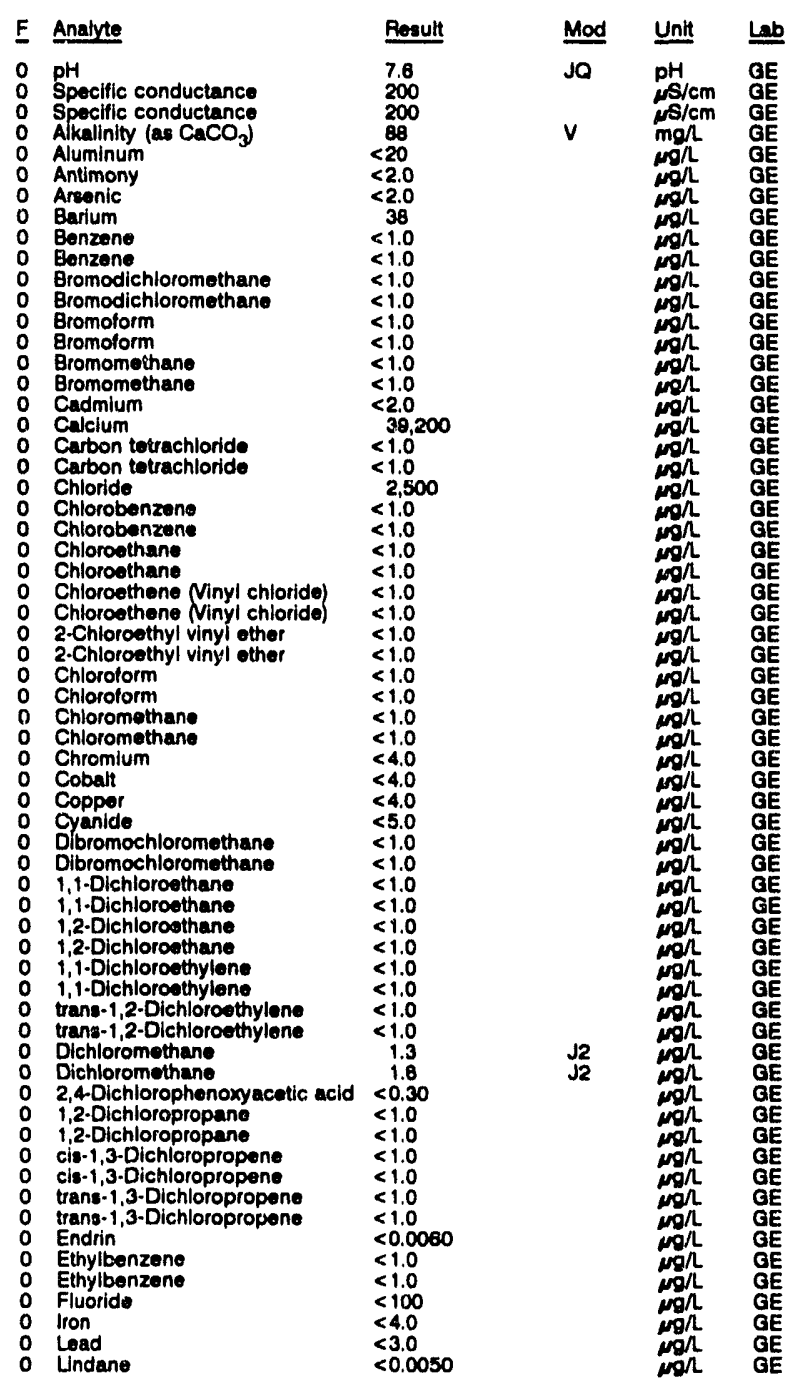


ANALYTICAL RESULTS

WELL HSB146A collected on 07/23/82, laboratory analyses (cont.)

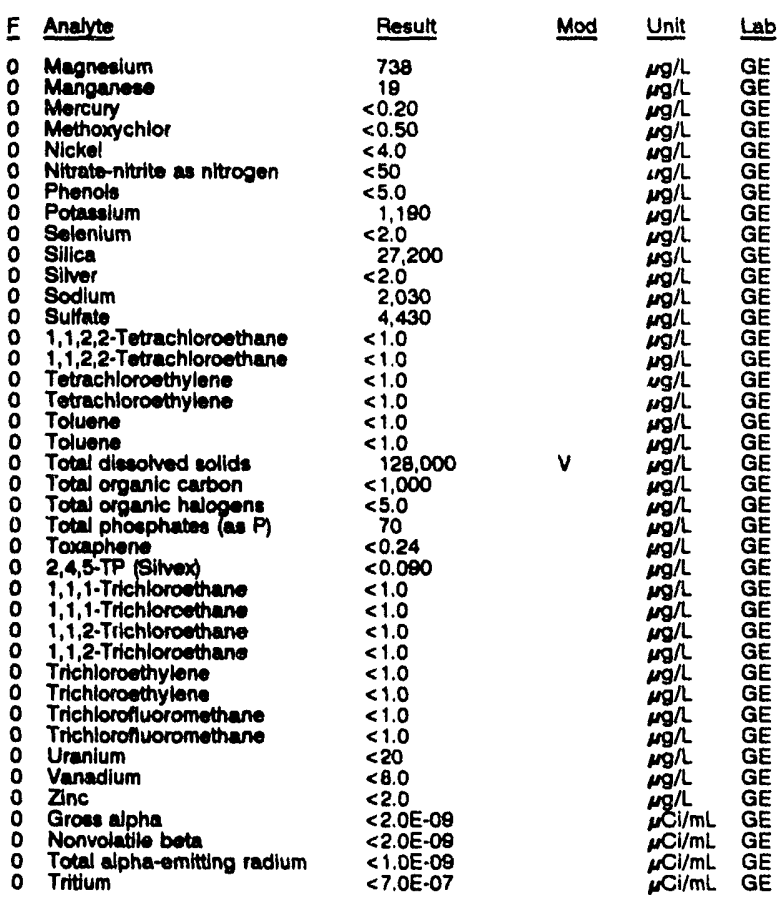

WELL HSB146C

MEASUREMENTS CONDUCTED IN THE FIELD

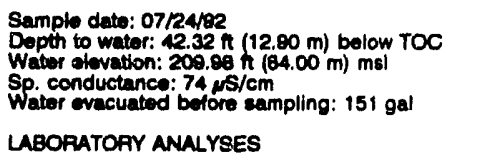

\section{Time: $9: 35$ \\ Alkalinity: $25 \mathrm{mg} / \mathrm{L}$}

Water temperature: $19.1^{\circ} \mathrm{C}$

LABORATORY ANALYSES
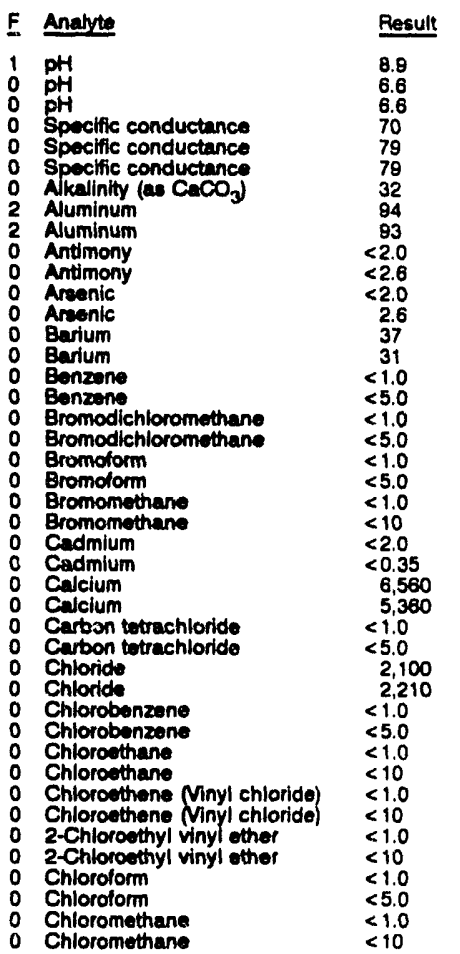

WELL HSB146C collected on 07/24/92, laboratory analyses (cont.)

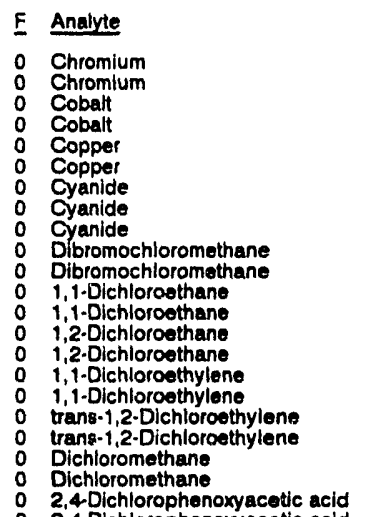

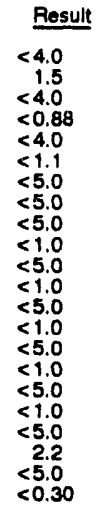

2,4-Dichlorophenoxyacetic acid $<1.1$

2,4 Dichlorophenoxyacetic acid $<2$.

1,2-Dichloropropane

o cis-1,3-Oichloropropene

cis-1,3-Dichloropropene

o trans-1,3-Dichloropropene

0 Endrin

O Ethylbenzene

Ethylbenzen

Fluoride

0 Fluoride

0 Iron

0 Lead

0 Lindane

Lindane

Magnesium

Manganese

Manganes:

0 Mercury

Methoxychlor

Methoxychlo

Nickel

Nitrate as nitrogen

Nitrate as nitrogen
Nitrate-nltrite as nitrogen

Phenols

0 Phenols

0 Potassium

Potassium

Selenium

Sillica

Silica

Silver

0 Sodium

Sodium

Sodium

Sulfate

1,1,2,2-Tetrachloroethane

1,1,2,2-Totrachloroethane

o Tetrachloroethylene

Totrachloroethyleno

Toluene

Total dissolved solids

Total dissotved solids

Total organic carbon

Total organic carbon

- Total organic halogens

- Total organic halogens

Total organic halogens

Total phosphates (as P)

Total phosph

Toxaphene

2,4,5-TP (Silvex)

2,4,5-TP (Silvex)

2,4,5.TP (Silvex)

1,1,1-Trichloroethane

1,1,2-Trichloroethane

1,1,2-Trichloroethane

Trichloroethylene

0 Trichloroethylene

Trichlorofluoromethane

Trichlorofluoromethane

- Uranium

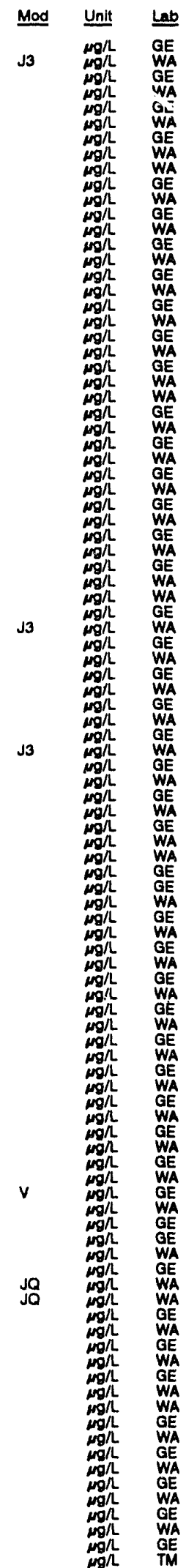


WELL HSB146C collected on 07/24/92, laboratory analyses (cont.)

\begin{tabular}{|c|c|c|c|c|c|}
\hline$\underline{F}$ & Analyte & Prosult & Mod & Unit & Lab \\
\hline $\begin{array}{l}0 \\
0 \\
0\end{array}$ & 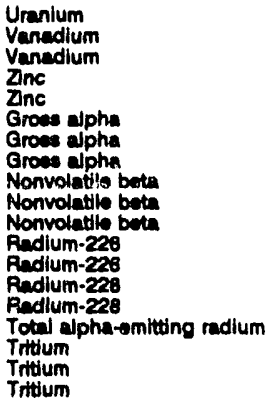 & 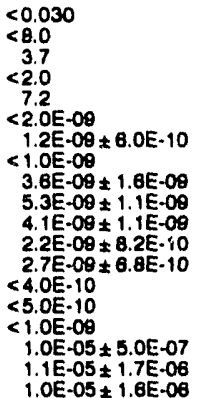 & $\sqrt{3}$ & 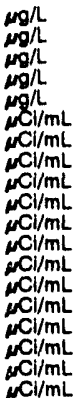 & $\begin{array}{l}T M \\
G E \\
W A \\
G E \\
W A \\
G E \\
G M \\
T M \\
\text { GE } \\
T M \\
T M \\
T M \\
T M \\
T M \\
T M \\
T M \\
G E \\
T M \\
T M\end{array}$ \\
\hline
\end{tabular}

\section{WELL HSB146C Replicate}

MEASUAEMENTS CONDUCTED IN THE FIELD

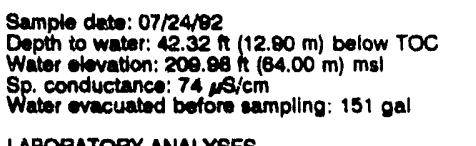

LABORATOPY ANALYSES

\begin{tabular}{|c|c|c|c|c|}
\hline Anclute & Rosult & Mod & Unit & Lab \\
\hline 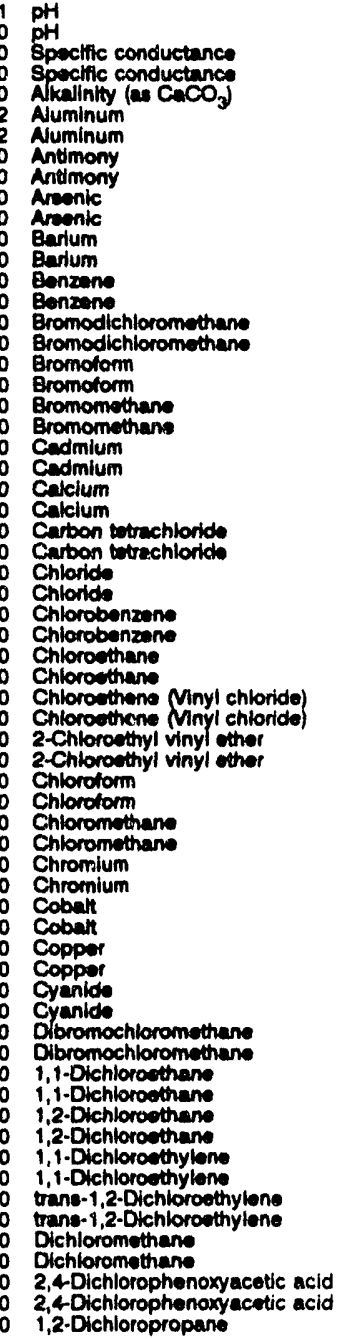 & $\begin{array}{l}8.9 \\
6.9 \\
70 \\
70 \\
35 \\
111 \\
86 \\
<2.0 \\
<2.6 \\
<2.0 \\
<2.0 \\
36 \\
34 \\
<1.0 \\
<5.0 \\
<1.0 \\
<5.0 \\
<1.0 \\
<5.0 \\
<1.0 \\
<10 \\
<2.0 \\
<0.35 \\
6.480 \\
6.060 \\
<1.0 \\
<5.0 \\
2.120 \\
2.220 \\
<1.0 \\
<5.0 \\
<1.0 \\
<10 \\
<1.0 \\
<10 \\
<1.0 \\
<10 \\
<1.0 \\
<5.0 \\
<1.0 \\
<10 \\
<4.0 \\
2.3 \\
<4.0 \\
<0.88 \\
<4.0 \\
<1.1 \\
<5.0 \\
<5.0 \\
<1.0 \\
<5.0 \\
<1.0 \\
<5.0 \\
<1.0 \\
<5.0 \\
<1.0 \\
<5.0 \\
<1.0 \\
<5.0 \\
1.1 \\
<5.0 \\
<0.30 \\
<1.1 \\
<1.0 \\
\end{array}$ & $\begin{array}{l}\mathrm{JQ} \\
\mathrm{JQ} \\
\mathrm{JQ} \\
\mathrm{V}\end{array}$ & 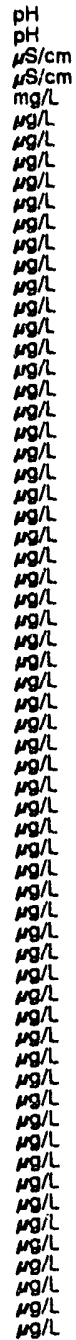 & $\begin{array}{l}G E \\
W A \\
G E \\
W A \\
G E \\
G E \\
W A \\
G E \\
W A \\
W E \\
W A \\
G E \\
W A \\
G E \\
W A \\
G E \\
W A \\
G E \\
W A \\
G E \\
W A \\
G E \\
W A \\
G E \\
W A \\
G E \\
W A \\
G E \\
W A \\
G E \\
W A \\
G E \\
W A \\
G E \\
W A \\
G E \\
W A \\
G E \\
W A \\
G E \\
W A \\
G E \\
W A \\
G E \\
W A \\
G E \\
W A \\
G E \\
W A \\
G E \\
W A \\
G E \\
W A \\
G E \\
W A \\
G E \\
W A \\
G E \\
W A \\
G E \\
W A \\
G E \\
W A \\
G E \\
\text { WA } \\
\text { WA } \\
\text { WA } \\
\text { WA } \\
\text { WA } \\
\text { WA } \\
\text { WA }\end{array}$ \\
\hline
\end{tabular}

WELL HSB148C collected on 07/24/92, laboratory analyees (cont)

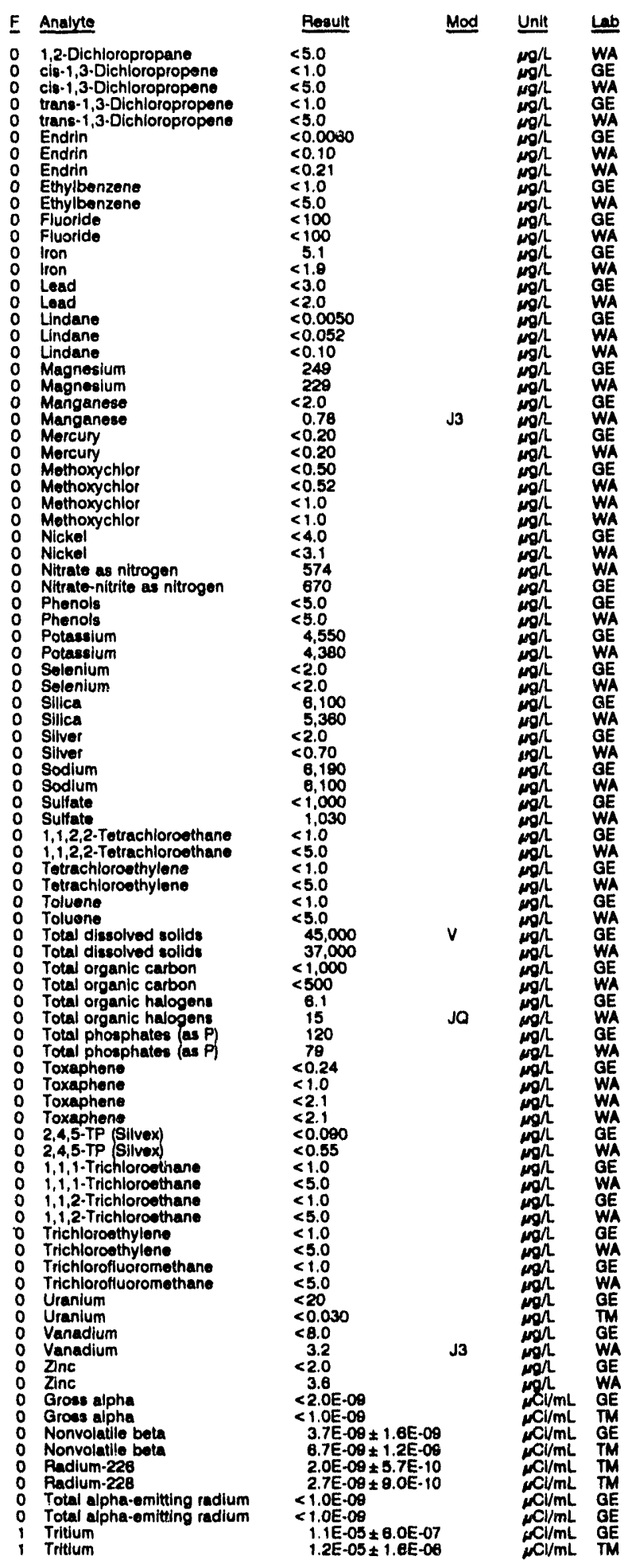


ANALYTICAL RESULTS

WELL HSB146D

MEASUREMENTS CONDUCTED IN THE FIELD

Sample date: 07/24/92

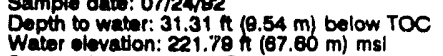

Sp. conductunce: $18 \mathrm{~s} / \mathrm{sm}$

Sp. conductance: $16, \mathrm{~s} / \mathrm{cm}$
Water ovacuated before sampling: $62 \mathrm{gal}$

LABOFATOAY ANALYSES

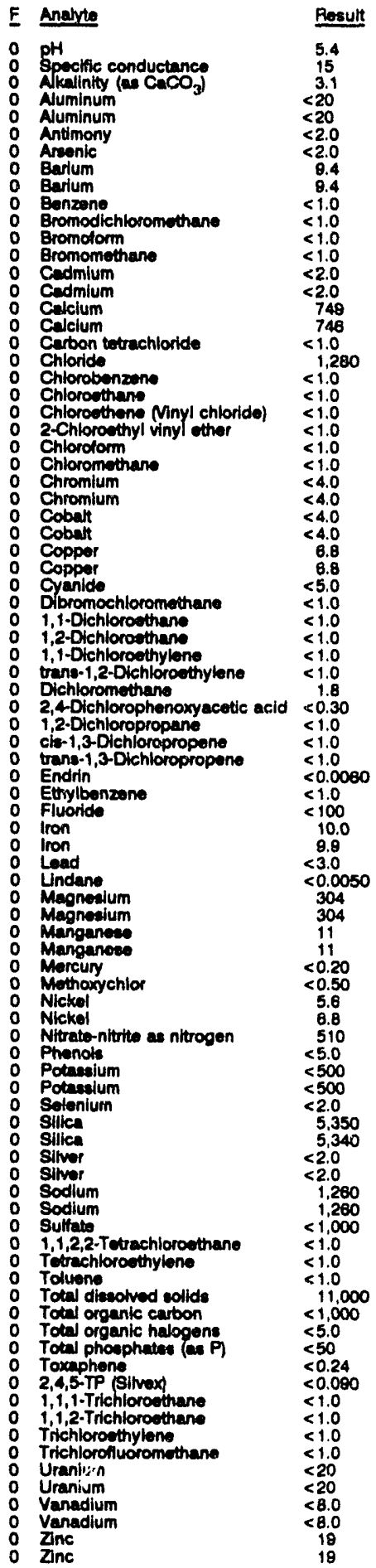

WELL HSB146D collected on 07/24/82, laboratory analyees (cont.)

\begin{tabular}{|c|c|c|c|}
\hline Analyte & Rosult & Mod & Unit \\
\hline $\begin{array}{ll}0 & \text { Gross alpha } \\
0 & \text { Nonvolatile beta } \\
0 & \text { Total alpha-emitting radium } \\
2 & \text { Tritium }\end{array}$ & $\begin{array}{l}<2.0 E-09 \\
<2.0 E-09 \\
<1.0 E-09 \\
2.3 E-05+7.0 E-07\end{array}$ & & $\begin{array}{l}\mu \mathrm{cl} / \mathrm{mL} \\
\mathrm{NCl/mL} \\
\mu \mathrm{Cl} / \mathrm{mL} \\
\mu \mathrm{Cl} / \mathrm{mL}\end{array}$ \\
\hline
\end{tabular}

\section{WELL HSB147D}

MEASUREMENTS CONDUCTED IN THE FIELD

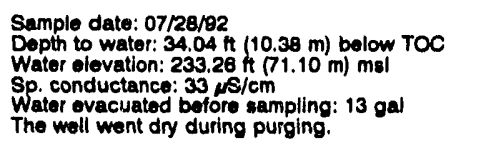

Time: $8: 00$

PH. 5.5 : $2 \mathrm{mgh}$

Water tomperature: $18.1 \circ \mathrm{C}$

LABORATORY ANALYSES

$\begin{array}{ll}0 & \mathrm{pH} \\ 0 & \text { Specific conductance } \\ 0 & \text { Specific conductance }\end{array}$

O Alkalinity (as $\mathrm{CaCO}_{3}$ )

o Aluminum

0 Antimony

0 Arsenic

0 Barium

o Bromodichloromethane

0 Bromoform

o Bromomethane

Cadmium

0 Calcium

0 Carbon tetrachioride

o Chloride

o Chlorobenzene

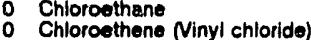

2-Chloroethyl vinyl chlorid

2-Chloroethy

Chloroform

o Chromium

- Cobart

0 Copper

o Cyanide

0 Cyanide

Dibromochloromethane

1,1-Dichloroethane

o 1,2-Dichloroethane

o 1,1-Dichloroethylene

o trans-1,2-Dichloroet

0 Dichloromethane

2,4-Dichlorophenoxy

o cis-1,3-Dichloropropene

trans-1,3-Dichloropropene

o trans-1,3-0

0 Ethylbenzene

o Fluoride

0 Iron

0 Lindane

- Magneslum

Manganeso

Mercury

Methoxychior

Nitrate-nitrite as nitrogen

O Phanols

Solentum

S Silica

0 Silver

o Sodium

o Sulfate

0 Sulfate

0 1,1,2,2-Tetrachioroethane

Tetrachloroethylene

Toluene

Total dissolved solids

Total dissolved solids

Total organic carbon

Total phoschates (as P)

0 Toxaphene

0 2,4,5.TP (Silvex)

1,1,1-Trichloroethane

1,1,2-Trichloroothan

o Trichloroethylene

Trichlorofluoromethane

o Uranium

O Zine

0 Gross alphe

Nonvolatile beta

Total alpha-emitting radium

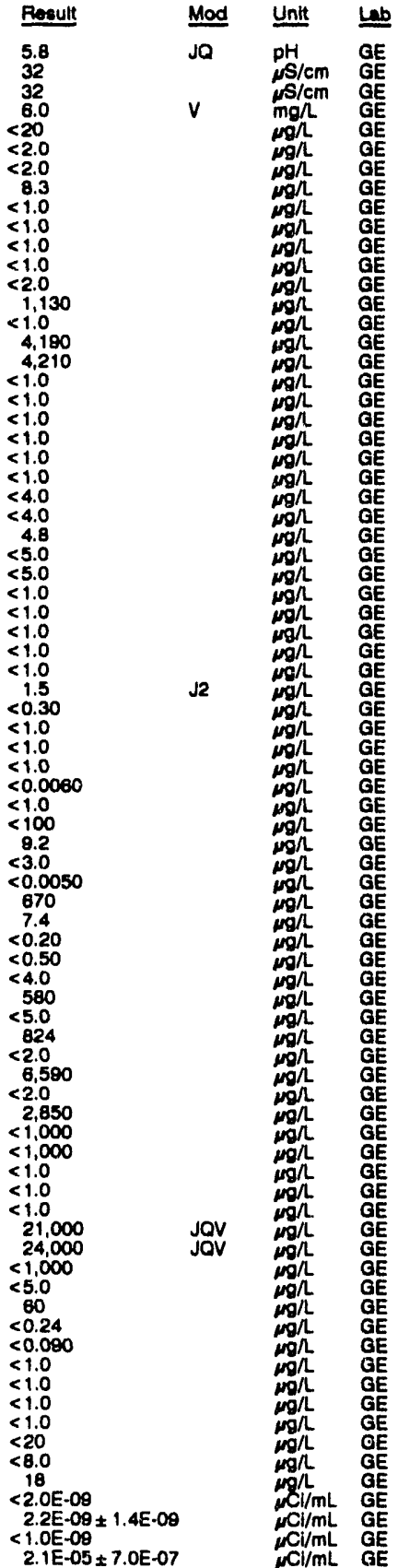


WELL HSB148C

MEASUAEMENTS CONDUCTED IN THE FIELL

Sample data: $07 / 24192$ (15.00 m) bolow TOC

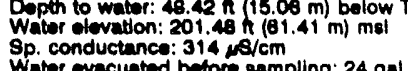

Wator evecuated betora sampling: 24 gat

The woll wont diry during purging.

LABORATORY ANAL YSES

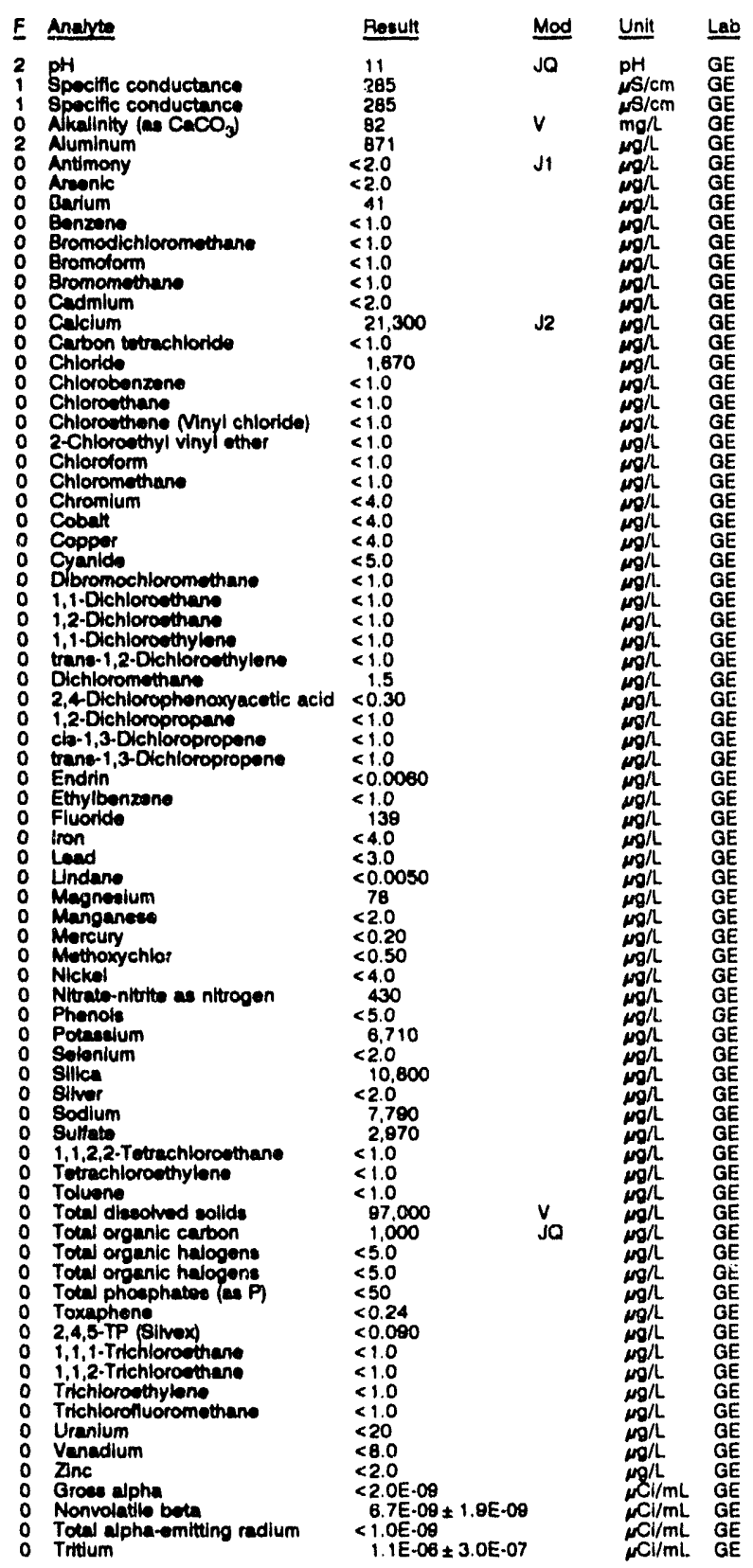

Time: 12:15

AH: 10.8 alinity: $68 \mathrm{mg} / \mathrm{h}$

Water temperature: $18.3^{\circ} \mathrm{C}$
WELL. HSB148D

MEASUREMENTS CONDUCTED IN THE FIELD

Somple date: 07/24/92

Dopth to water: $37.84 \mathrm{ht}(11.53 \mathrm{~m})$ below TOC

Sp. conductanco: $72.26 \mathrm{~h}(\mathrm{~s}, \mathrm{~d}$

Water evacuated bolore campling: 7 gal

The woll went dry Juring purging.

LABORATORY ANALYSES

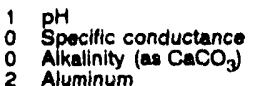

2 Aluminum

0 Antimony

Anonic

Bartum

Barium

Bromodichloromethane

Bromoform

Cadmium

Cadmium

Calelum

Calclum

Carbon totrachlorido

Chloride

Chloroberizene

Chloroethene (Ninyl chlorldo)

2.Chloroothyl vinyl other

Chloroform

Chloromethane
Chromium

Chromium

Cobait

Cobalt

Cobsat

Coppor

Cyanide

Dibromochloromethane

1.1.Dichlorosthane

1,2. Dichloroothane

1,1-Dichlorothylene
trans-1,2-Dichioroethylene

Dichloromethane

noxyacetic acld

2.4.

1,2-Dichloropropane

cin-1,3-Dichloropropene

Endrin

Ethylbenzene

0 Fluoride

lion

0 lron

Lindane

Magnesium

Manganese

Manganese

o Morcury

Methoxychior

Nickel

Nitrate-nitrite as nitrogen

Nitrato-nitrite as nitrogen

Phonols

Potassium

Solenium

Sillica

Silica

Sitver

0 Silver

- Sodium

0 Sodium

Sulfate

1,1,2,2-Tetrachloroethane
0 Totrachloroethylens

Toluene

Total diseolved solide

Total diseolved solide

Total organic carbon

Total phosphates (as P)

Toxaphene

0 2,4,5-TP (Silvox)

2,4,5-TP (Silvex)

i,1,1-Trichloroothane

o $1,1,2$-Trichloroethan

o Trichlorofluoromethane

\begin{tabular}{|c|c|}
\hline \multicolumn{2}{|l|}{ Result } \\
\hline \multicolumn{2}{|r|}{ Jo } \\
\hline $\begin{array}{l}30 \\
396\end{array}$ & $v$ \\
\hline $\begin{array}{r}682 \\
<2.0\end{array}$ & J1 \\
\hline & \\
\hline $\begin{array}{r}10 \\
<1.0\end{array}$ & \\
\hline $\begin{array}{l}<1.0 \\
<1.0 \\
<10\end{array}$ & \\
\hline $\begin{array}{l}<1.0 \\
<2.0\end{array}$ & \\
\hline $\begin{array}{r}16,600 \\
16,600\end{array}$ & $\begin{array}{l}\sqrt{2} \\
\sqrt{2}\end{array}$ \\
\hline
\end{tabular}

$<1.0$

$<1,040$

$<1.0$

$<1.0$

1.1

$<1.0$

$<4.0$

$<4.0$

$<4.0$

$<4.0$

$<1.0$

$<1.0$

$<1.0$

$<0.30$

$<1.0$
$<1.0$

$<1.0000$

$<1.0$

$<100$
$<100$

18
18

$<<0.0050$

$<0.0050$
174
173

173
$<2.0$

2.0

$<0.20$

$<0.50$

$<4.0$

$<50$

$<50$

$<5.0$

1,260
1,250
$<2.0$

$<2.0$

0,640

$<2.0$

2,580
2,550
3,780

3,780

$<1.0$
$<1.0$

$<1.0$

52,000

$<5.6$

$<50$

$<0.04$

$<0.090$

$<1.0$

$<1.0$

$<1.0$
Time: $12: 00$

Alkalinity: $21 \mathrm{mg} /$

Water tomperature: $10.3^{\circ} \mathrm{C}$ 
WEL HSB148D colloctod on 07/24/92, laboratory analyses (cont)

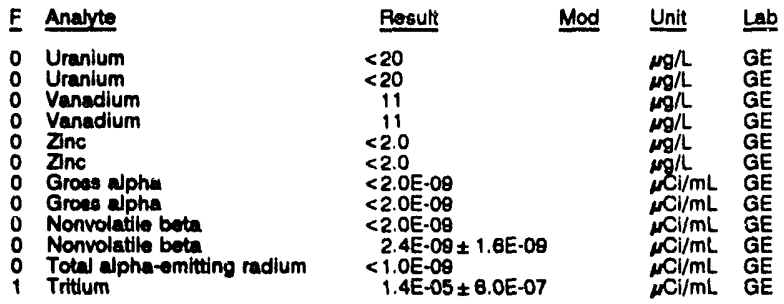

WELL HSB149D

MEASUREMENTS CONDUCTED IN THE FIELD

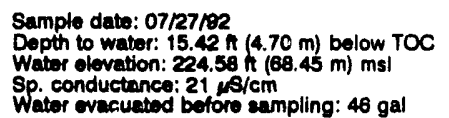

Time: 10:45

Alkalinity: $0 \mathrm{mg} /$

Water temperature: $21.4^{\circ} \mathrm{C}$

LABORATORY ANALYSES

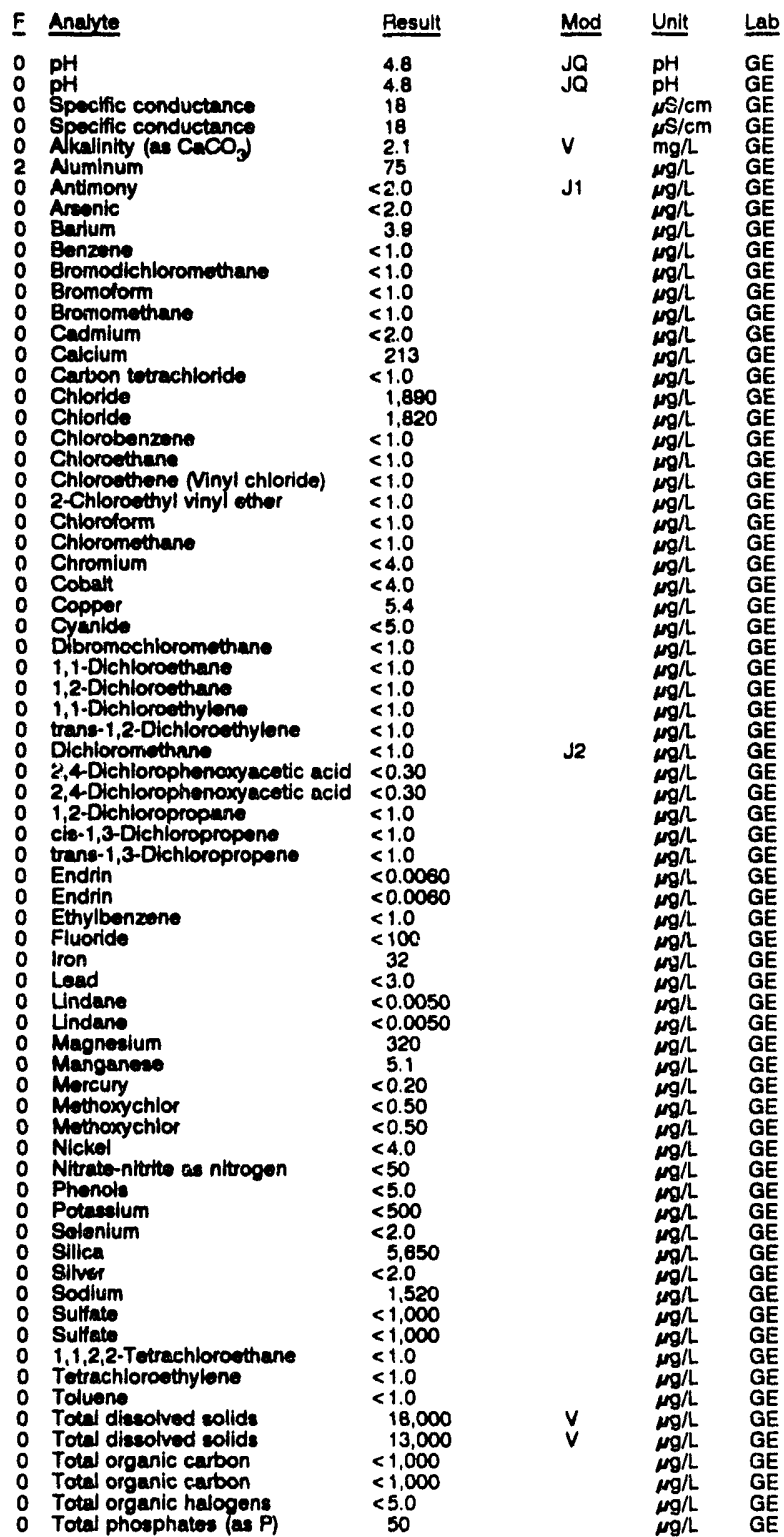

WELL HSB1490 collected on 07/27/82, laboratory analyses (cont.)

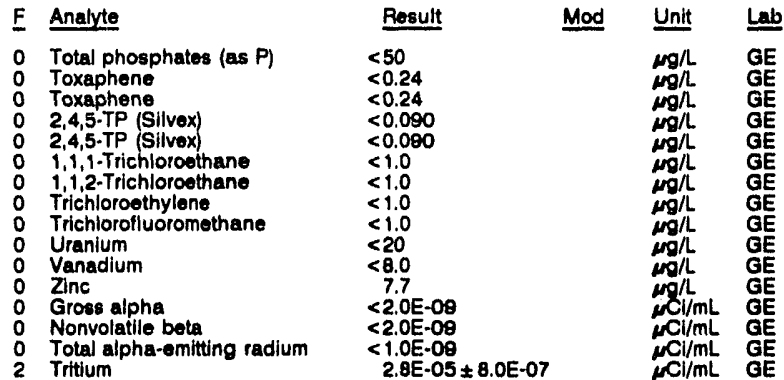

WELL HSB150D

MEASUREMENTS CONDUCTED IN THE FIELD

Sample date: 07/24/82

Depth to water: $9.56 \mathrm{ft}(2.91 \mathrm{~m})$ below TOC

Water olovation: $229.44 \mathrm{tt} / 88$
Sp. conductance: $32, \mathrm{~s} / \mathrm{cm}$

Sp. conductance: $32 \mu \mathrm{s} / \mathrm{cm}$
Water ovacuated before sampling: $59 \mathrm{gal}$

PH: 4.9 Alkalinity: $0 \mathrm{mg} / \mathrm{l}$

Water temperature: $21.0^{\circ} \mathrm{C}$

LABORATORY ANALYSES

F Analyte

$\circ \mathrm{pH}$

Specific conductance

$\begin{array}{l}0 \\ 0\end{array}$ Alkalinity (as $\left.\mathrm{CaCO}_{3}\right)$

1 Aluminum

0 Antimony

Arsenic

o Benzene

0 Bromodichloromethane

Bromomethane

o Cadmium

0 Cadmium

o Carbon tetrachloride

Chloride

0 Chlorobenzene

o Chloroethane

o Chloroethene (Ninyl chloride)

2-Chloroethyl vinyl ether

0 Chloroform

o Chloromethane

Chromium

${ }_{0}$ Cobalt

O Copper

o Dibromochloromethane

Dibromochloromethan

o 1,1 -Dichloroethane

o 1,1-Oichioroethylene

o trans-1,2-Dichloroethylene

o Dichloromethane

0 2,4-Dichlorophenoxyacetic aciod

o 1,2-Dichloropropane

o cis-1,3-Dichloropropene $\quad<1,0$

0 Endrin

Ethylbenzene

Fluoride

Iron

0 Lead

Magnesium

Manganese

Morcury

Methoxychlor

Nickel

Nitrate-nitrite as nitrogen

0 Phonols

Potassium

Selonium

0 Silica

Sodium

Sulfate

$1,1,2,2$-Tetrachloroethane

Tetrachloroethylene

0 Toluene

Total dissolved solids

Total organic carbon

Total organic halogens

Total phosphates (as P)

Toxaphene

2,4,5-TP (Silvex)
$0 \quad 1,1$-Trichloroethane

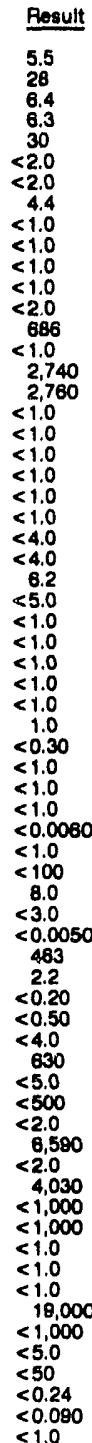

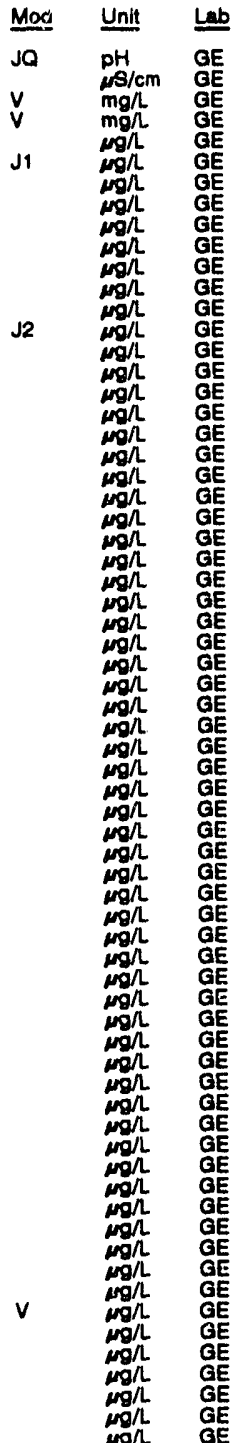


WELL HSB150D collected on 07/24/82, laboratory analyees (cont)

\begin{tabular}{|c|c|c|c|c|}
\hline$\underline{\mathbf{F}}$ & Analyte & Rosult & Mod & Unit \\
\hline $\begin{array}{l}0 \\
0 \\
0 \\
0 \\
0 \\
0 \\
0 \\
0 \\
0\end{array}$ & $\begin{array}{l}\text { 1,1,2-Trichloroethane } \\
\text { Trichloroethylene } \\
\text { Trichlorofluoromethane } \\
\text { Uranium } \\
\text { Vanadium } \\
\text { Zinc } \\
\text { Gros alphe } \\
\text { Nonvolatile beta } \\
\text { Total alpha-emitting radium } \\
\text { Trittium }\end{array}$ & 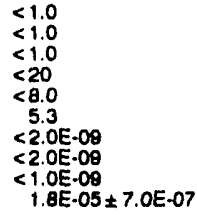 & & 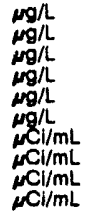 \\
\hline
\end{tabular}

WELL HSB151C

MEASUREMENTS CONDUCTED IN THE FIELD

Sample date: 07/27/02

Dopth to water: $5.04 \mathrm{n}(1.54 \mathrm{~m})$ below TOC

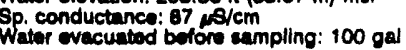

LABOAATOAY ANALYSES

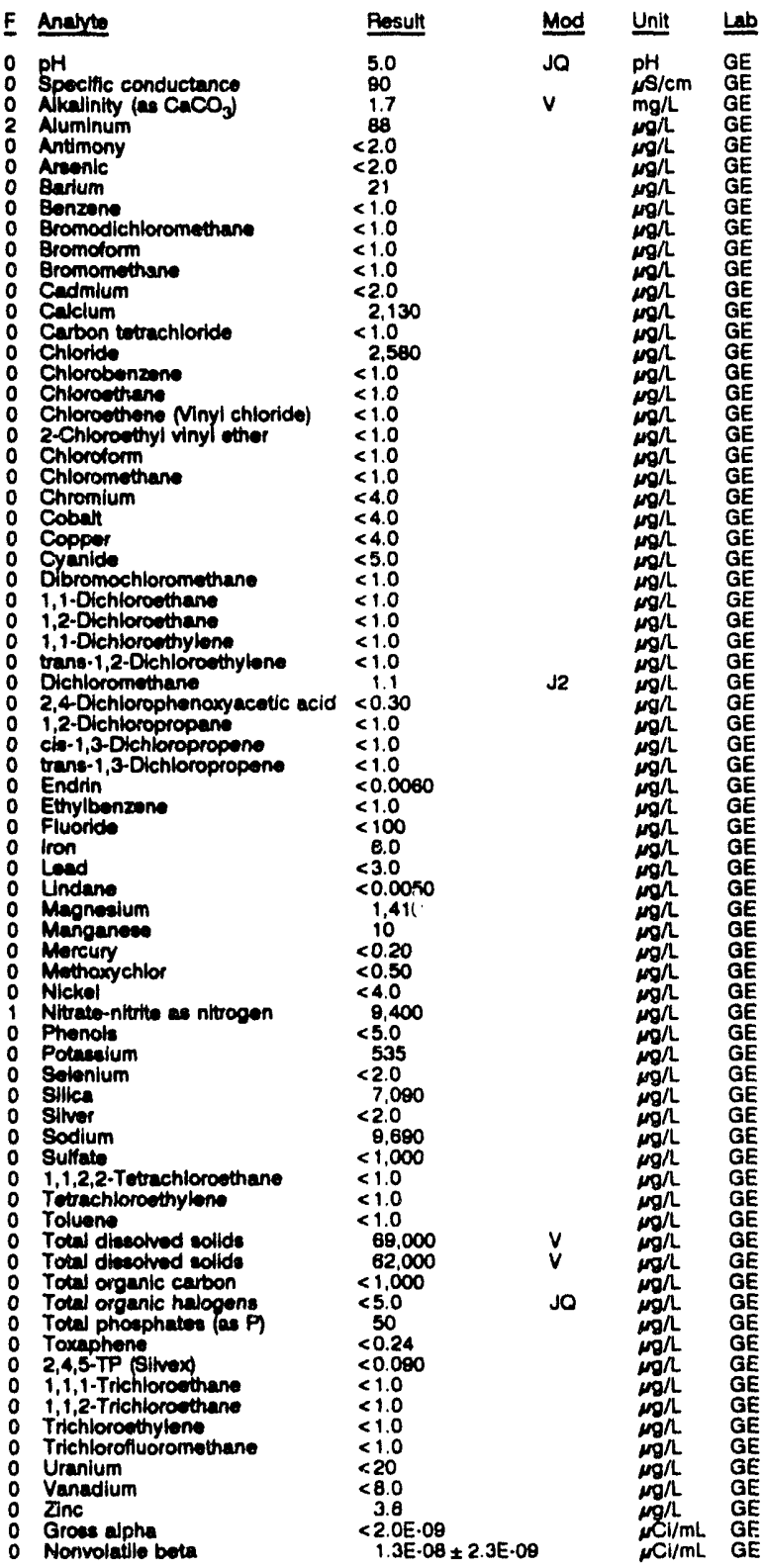

WELL HSB151C colloctod on 07/27/82, laboratory analysee (cont.)

\begin{tabular}{|c|c|c|c|}
\hline Analyte & Plesult & Mod & Unit \\
\hline $\begin{array}{ll}0 & \text { Total activity } \\
0 & \text { Total alpha-omitting radium } \\
0 & \text { Total alpha-omitting radium } \\
2 & \text { Tritum }\end{array}$ & $\begin{array}{l}1.8 E-03 \pm 1.0 E-05 \\
1.1 \mathrm{EE}-00 \pm 5.0 \mathrm{D}-10 \\
1.0 \mathrm{O}-09 \pm 5.0 \mathrm{~T}-10 \\
1.8 \mathrm{E}-03 \pm 6.3 \mathrm{E}-08\end{array}$ & & $\begin{array}{l}\mu \mathrm{Cl} / / \mathrm{mL} \\
\mu \mathrm{Cl} / \mathrm{mL} \\
\mu \mathrm{Cl} / \mathrm{mL} \\
\mu \mathrm{Cl} / \mathrm{mL}\end{array}$ \\
\hline
\end{tabular}

\section{WELL HSB151D}

MEASUREMENTS CONDUCTED IN THE FIELD

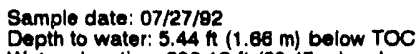

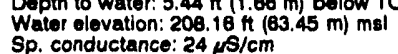

Water ovacuated bofore sampling: $28 \mathrm{gal}$

\section{Time: 8:45}

Alkalinity: $0 \mathrm{mgl}$

Water tomperature: $22,4^{\circ} \mathrm{C}$

Time: $8: 15$

Alkalinity: $0 \mathrm{mg}$

Water tomperature: $20.0^{\circ} \mathrm{C}$

LABORATORY ANALYSES

E Analyte

o pH

A Alkalinity (as $\mathrm{CaCO}_{3}$ )

Aluminum

Antimony

0 Arsenic

0 Barium

Barium

Benzene

Bromodichloromethan

Bromodichloromethane

Bromoform

Bromomethane

Bromomethane

Cadmium

0 Cadmium

O Calcium

Carbon tetrachloride

Carbon terachlorido

Chloride

Chlorobenzene

Cniorobenzene

- Chloroethane

Chloroethane

Chloroothene Ninyl chloride)

Chloroothene Ninyl chlorid

2-Chloroethyl vinyl other

2-Chloroethyl

Chloroform

Chloromethane

Chromium

Chromium

Cobatt

Cobalt

- Copper

- Copper

- Cyanido

- Dibromochloromethane

Dibromochloromethan

1,1-Dichloroethane

1,1 -Dichloroethane

1,2-Dichloroethane

$\begin{array}{ll}1,2-\text { Dichloroethane } \\ 0 & 1,1 \text {-Dichloroethylene }\end{array}$

1,1 . Dichloroethylen

trans-1,2-Dichlorosthylone

trans-1,2-Dichloroethylene

Dichloromethane

Dichloromethane

2,4-Dichlorophenoxyacetic acid

1,2-Dichloropropane

1,2-Oichloropropane

cis-1,3-Dichloropropene

trans-1,3-Dichloropropene

trans-1,3-Dichloropropene

Endrin

Ethylbenzene

Fluoride

0 Iron

o Iron

0 Lead

- Lindane

Magnesium

Mannanium

Manganese

O Mercury

0 Nickel

Nickel
0 Nitrate-nitrite as nitrogon

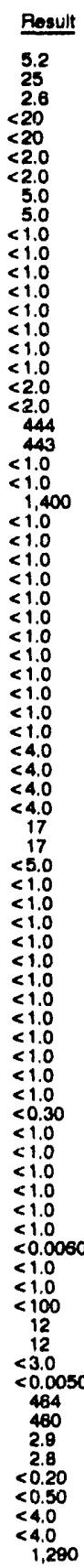


ANALYTICAL RESULTS

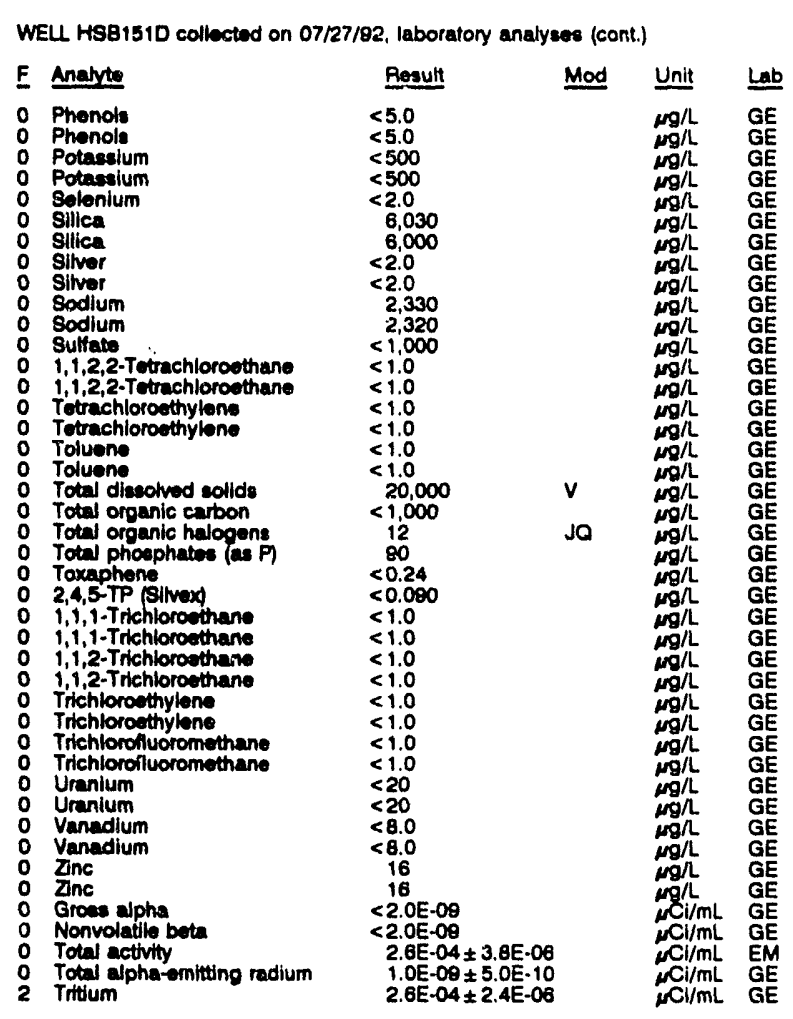

WELL HSB152C

MEASUREMENTS CONDUCTED IN THE FIELD

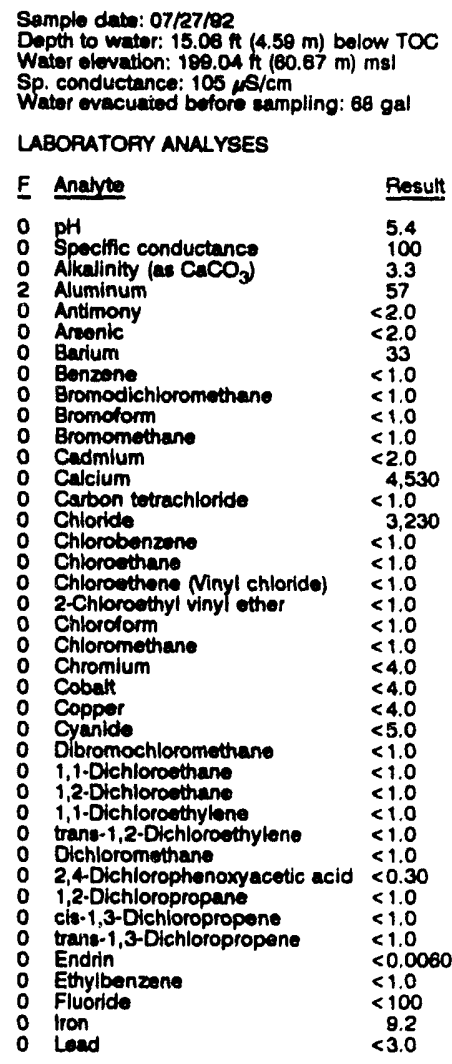

Time: 8:10

Alkalinity: $0 \mathrm{mg} / \mathrm{h}$

Water temperature: $18.7^{\circ} \mathrm{C}$

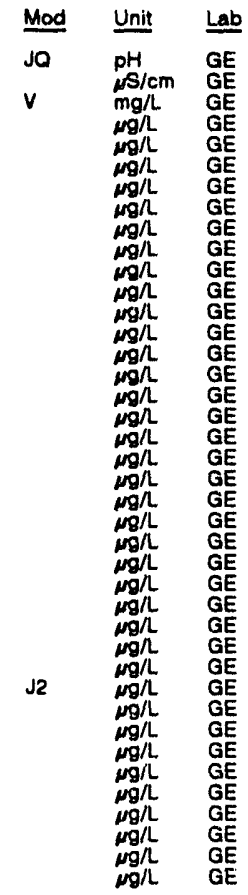

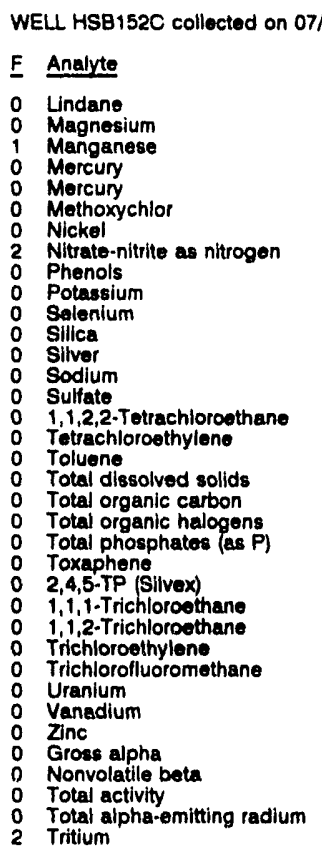
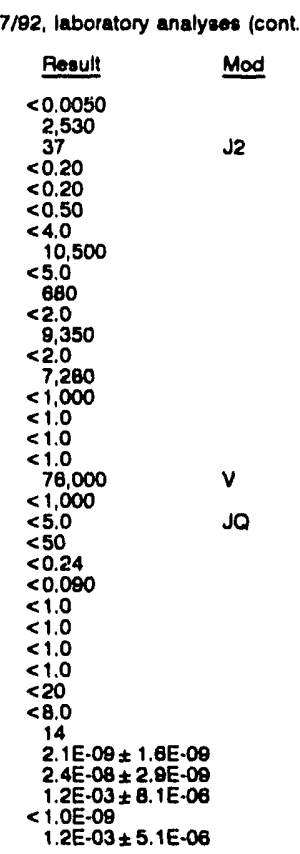

\section{WELL HSB152D}

\section{MEASUREMENTS CONDUCTED IN THE FIELD}

\section{Sample date: 07/27/82}

Depth to water: Not available

Sp. conductance: $35 \mu \mathrm{s} / \mathrm{cm}$

Water evacuated bofors sampling: 4 ge

The well went dry during purging.

LABORATOAY ANALYSES

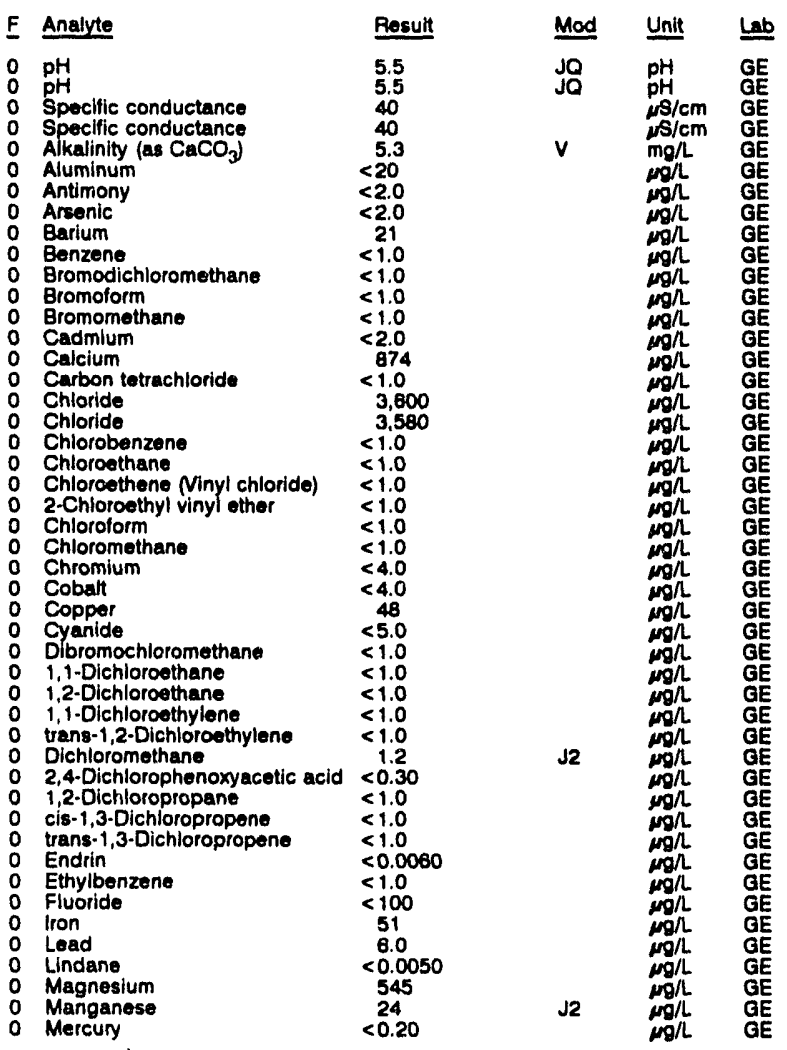

Time: 9:45

Alkalinity: $0 \mathrm{~mol}$

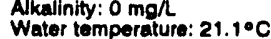

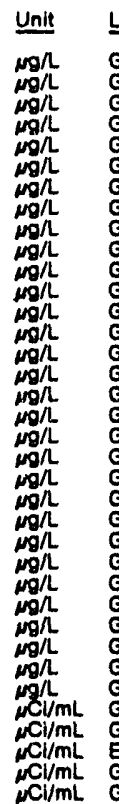

Lab
GE
$G E$
$G E$
$G E$
$G E$
$G E$
$G E$
$G E$
$G E$
$G E$
$G E$
$G E$
$G E$
$G E$
$G E$
$G E$
$G E$
$G E$
$G E$
$G E$
$G E$
$G E$
$G E$
$G E$
$G E$
$G E$
$G E$
$G E$
$G E$
$G E$
$G E$
$G E$
$G E$
$E M$
$G E$
$G E$


ANALYTICAL RESULTS

\begin{tabular}{|c|c|c|c|}
\hline Anayte & Result & Mod & Unit \\
\hline 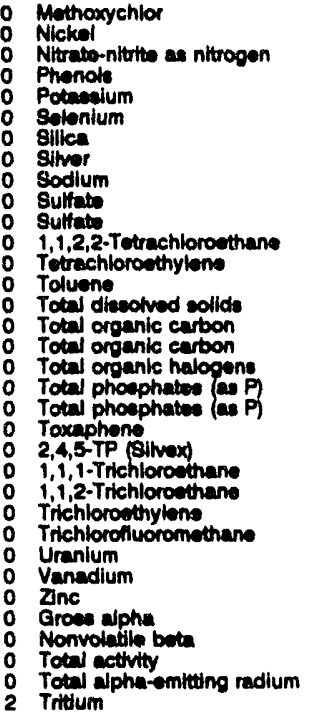 & $\begin{array}{l}<0.50 \\
<4.0 \\
1,170 \\
<5.0 \\
<500 \\
<2.0 \\
5,860 \\
<2.0 \\
4,530 \\
1,150 \\
1,150 \\
<1.0 \\
<1.0 \\
<1.0 \\
33,000 \\
1,300 \\
1,600 \\
25 \\
620 \\
630 \\
<0.24 \\
<0.090 \\
17 \\
<1.0 \\
<1.0 \\
<1.0 \\
<20 \\
<8.0 \\
68 \\
<2.0 E-09 \\
4.7 E-09 \pm 1.6 E-00 \\
1.1 E-04 \pm 3.0 E-06 \\
<1.0 E-09 \\
2.0 E-04 \pm 2.1 E-06\end{array}$ & $\begin{array}{l}v \\
\text { Ja }\end{array}$ & 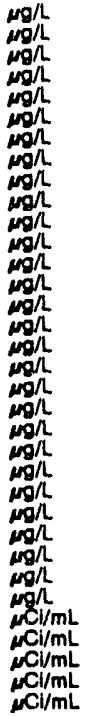 \\
\hline
\end{tabular}

WELL HSL 1D

MEASUREMENTS CONDUCTED IN THE FIELD

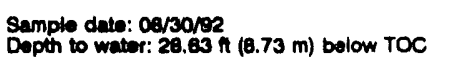

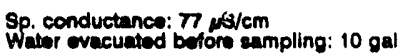

LABOFATORY ANULYSES

\begin{tabular}{|c|c|c|c|c|}
\hline E Analyte & Rosult & Mod & Unit & Lab \\
\hline 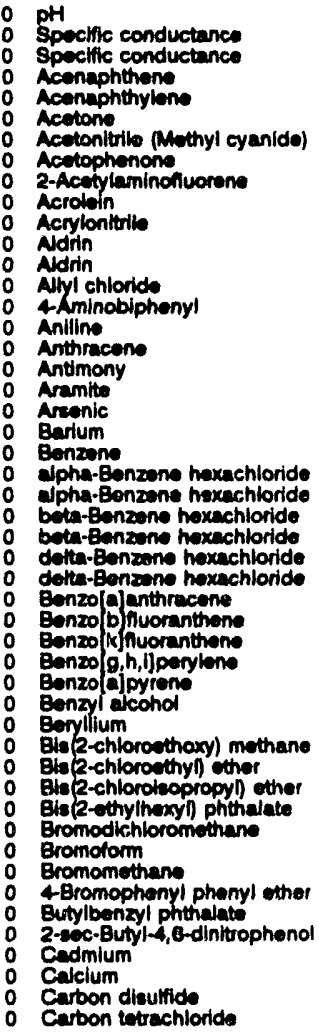 & $\begin{array}{l}5.1 \\
92 \\
92 \\
<10 \\
<10 \\
<100 \\
<1.0 \\
<10 \\
<10 \\
<20 \\
<20 \\
<0.050 \\
<0.050 \\
<50 \\
<10 \\
<10 \\
<10 \\
<2.0 \\
<10 \\
<2.0 \\
41 \\
<1.0 \\
<0.050 \\
<0.050 \\
<0.050 \\
<0.050 \\
<0.050 \\
<0.050 \\
<10 \\
<10 \\
<10 \\
<10 \\
<10 \\
<10 \\
<3.0 \\
<10 \\
<10 \\
<10 \\
<10 \\
<1.0 \\
<1.0 \\
<1.0 \\
<10 \\
<10 \\
<10 \\
<2.0 \\
647 \\
<1.0 \\
<1.0\end{array}$ & $\begin{array}{l}106 \\
J 06 \\
J 06 \\
J 06 \\
J 06 \\
J 06 \\
J 06 \\
J 06 \\
J 06\end{array}$ & 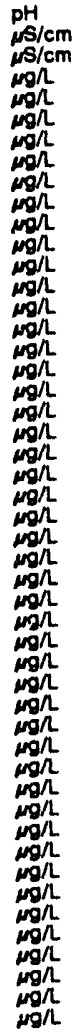 & $\begin{array}{l}\mathrm{GE} \\
\mathrm{GE} \\
\mathrm{GE} \\
\mathrm{GE} \\
\mathrm{GE} \\
\mathrm{GE} \\
\mathrm{GE} \\
\mathrm{GE} \\
\mathrm{GE} \\
\mathrm{GE} \\
\mathrm{GE} \\
\mathrm{GE} \\
\mathrm{GE} \\
\mathrm{GE} \\
\mathrm{GE} \\
\mathrm{GE} \\
\mathrm{GE} \\
\mathrm{GE} \\
\mathrm{GE} \\
\mathrm{GE} \\
\mathrm{GE} \\
\mathrm{GE} \\
\mathrm{GE} \\
\mathrm{GE} \\
\mathrm{GE} \\
\mathrm{GE} \\
\mathrm{GE} \\
\mathrm{GE} \\
\mathrm{GE} \\
\mathrm{GE} \\
\mathrm{GE} \\
\mathrm{GE} \\
\mathrm{GE} \\
\mathrm{GE} \\
\mathrm{GE} \\
\mathrm{GE} \\
\mathrm{GE} \\
\mathrm{GE} \\
\mathrm{GE} \\
\mathrm{GE} \\
\mathrm{GE} \\
\mathrm{GE} \\
\mathrm{GE} \\
\mathrm{GE} \\
\mathrm{GE} \\
\mathrm{GE} \\
\mathrm{GE} \\
\mathrm{GE} \\
\mathrm{GE}\end{array}$ \\
\hline
\end{tabular}

WELL HSL 10 collectod on 08/30/82, laboratory analysere (cont.)

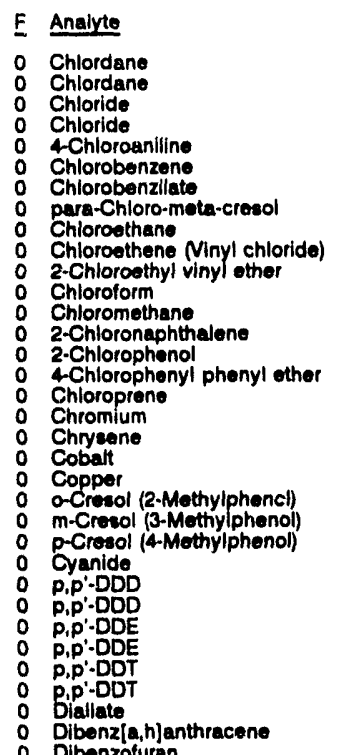

$<0.50 \quad$ Mod Un Unt

3,970
3,980

$<10$

$<1.0$

$<10$

$\leq 1.0$

$<1.0$

$<1.0$

$<10$

$<200$
$<40$

$<10$

$<4.0$

$<10$

$<10$

$<5.10$

$<0.10$

$<0.10$

$<0.10$

$<0.10$

o Dibenzofuran Dibromochloromethane $\quad<1.0$ 1,2-Dibromoothane Dibromomathane

1,2.Dichlorobonzenzeno

1,2-Dichlorobenzeno

1,4-Dichlorobonzeno

3,3-Dichlorobenzzldine

trans-1,40lchloro-2-buten

1,1-Dichloroothane

1,2-Dichloroothane

tans-1,2-Dichloroothylene $<1.0$

2,4-Dichlorophenot

2,6-Dichlorophenol

2,4-Dichlorophenoxy

cis-1,3-Dichloropropene

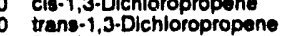

O trans-1,3-Dich

O Dieldrin

Diethyl phthalate

2,4-Dimethyl phenol

Dimethyl phthalate

Dimethylbenz (a)anthracene

3,3'-Dimethylbenzidine

: a, Dimethy iphenethy

2,4-Dinitrophenol

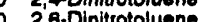

Dil-n-octyl phthalate

1,4-Dioxane

Diphenylamino

- Endosultan 1

o Endosultan I

Endosuttan II

E Endosulfian sultiate

Endosultan sulfate

0 Endrin

Endrin aldehydo

Endrin aldohyde

: Ethyl mothacyiato

- Ethylbenzene

: Famphur

F Fuoranthen

O Fluoride

0 Fluoride

O Heptachlor

o Heptachlor

OHeptachlor epoxide

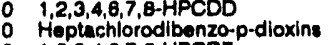

0
0
Heplachlorodibenzo-p.furans

$<10$
$<10$

1.0

$<1.0$

$<1.0$
$<10$
$<10$

$<10$

10

$<30$

$<1.0$
$<1.0$

$<1.0$

$<<10$

$<10$

$<1.0$

$<1.0$

$<0.50$

$<10$

$<10$
$<10$
$<10$

$<10$
$<10$
$<10$
$<10$

$<10$

$<10$

$<45$

$<10$

$<10$

$<10$

$<0.10$

$<0.10$

$<0.10$

$<0.10$

$<0.0000$

$<0.0060$

$<0.10$

$<10$

$<10$

$<1.0$

$<10$
$<10$
$<10$

$<100$
$<100$

$<0.050$

$<0.050$

$<0.050$

$<0.050$

$<0.00065$

$<0.00065$

$<0.00045$

Unit Lab

$\begin{array}{ll}\mu g / L & G E \\ M g h & G E\end{array}$

EE 
ANALYTICAL RESULTS

WELL HSL 1D collected on 08/30/92, laboratory analyees (cont.)

F Anarte

O Hoxachlorobonzene

Hexachlorobutadien

Hexachlorodibenzo-p-dioxins

Hoxachlorodibenzo-p-turans

Hexachloroethane

Hoxechloropropone

indeno[1,2,3-c, d]pyrene

lodomethane (Methyl lodide)

ron

trobutyl alcohol

teophoron

Kopone

Lead

Lindane

Manganese

Morcury

Methacrylonitrile

Methapyrliene

Methoxychlor

2-Methyl-4, o-dinitropheno

Methyl ethyl ketone

Methyl methacrylate

Mothyl methanepulfonate

2.1.h.

Naphthalene

1.4Naphthoquinone

2-Naphthytamin

Nickel

Nitrate-nitrite as nitrogen

2-Nitroaniline

4Nitroanlline

Nitrobenzene

2-Niophenol

4-Nitroquinoline-1-oxide

N-Nitrocodt-n-butytamine

$\mathrm{N}$-Nitrocodiethylemin

N-Nitroeodimothylamino

N-Nitrowodiphenylamino

N-Nitrosodipropylamine

N-Nitrosomorpholine

N-Nitrocoplpendiline

5-Nitrostoluidin

0,0.0-Triethyl phosphorathioate

Octachlorodibenzo-p-dioxins

Octuchlorodibenzo-p.durans

Parathion

- Parathion methy

Parathion methyl

PCB 1018

P PCB 1221

PCB 1221

O PCB 1232

O PCB 1242

O PCB 1242

PCB 1240

PCB 1254

PCB 1280

Pentachlorobonzene

Pentechlorodibenzo-p-dioxins

Pentachtorodibenzo-p-turans

1,2,3,7,8-PCDF

Pentechlorontrobenzene

Pentachlorophenol

Phenacetin

Phenanth

Phenols

P-Phonylonediamine

Phorate

2.Picoline

Potanalum

Pronamid

Proplonituik
$<10$

$<10$

$<0.00045$

$<0.00045$

$<0.00040$

$<10$
$<10$

$<10$

$<1.0$

$<15$
$<4.0$
$<100$
$<10$

$<10$
$<10$
$<10$

$<10$

$<3.0$

$<0.0050$

0.25

0.23
$<50$

$<50$

$<0.50$
$<0.50$

$<10$
$<1.0$
$<1.0$
$<10$

$<10$
$<10$
$<10$
$<10$

$<10$

$<10$
$<10$

$<10$

$<10$

$<.0$
6.240

$<10$

$<10$

$<10$

$<10$
$<10$

$<10$

$<10$

$<10$

$<10$

$<10$
$<10$
$<10$

$<10$

<

$<0.0010$

$<0.050$

$<0.050$

$<0.050$

$<0.50$

$<0.50$

$<0.50$

$<0.50$

$<0.50$

$<0.50$

$<0.50$

$<0.50$

$<0.50$

$<0.50$

$<10$
$<0.00055$
$<0.00055$

$<0.00055$

$<10$

$<10$
$<10$

$<10$
$<10$

$<10$
$<10$

$<10$
$<10$

$<5.0$
$<10$

$<10$

$<0.10$

$<10$

$<10$
$<200$
Mod Unit

JO6
$\mathrm{JOB}$
$\mathrm{JOC}$

$J 06$
$j 06$
$J 06$

Ja8

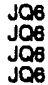

JOS

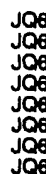

100
100
100
106
100
100
100
100
100
100
100
100
100
100
100
100
100

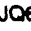

Jo6

$\mathrm{JOS}$
$\mathrm{JO6}$
$\mathrm{JO6}$

Jas

Jo6

Jo6

$J 06$

WELL HSL 1D collectod on 08/30/92, laboratory analyees (cont.)

E Analyte

0 Pyrene

O Syridine

Selenlum

o Silver

Sodium

0 Sulfate

Sulfide

0 1,2,4,5-Potrachlorobenzene

2,3,7,8-TCDO

T Totrachlorodibenzo-p-dioxins

Totrachlorodlibenzo-p-furan

o 1,1,1,2-Totrachloroethane

o 1,1,2,2-Totrachlorooth

2,3,4,6-Tetrachlorophenol

o Thallium

O Tin

Toluene

o Total dissolved eolids

Total dissolved solids

Total organic carbon

Total organic carbon

Total organic halogens

Total organic halogens

Total phosphat

Toxaphene

0 2,4,5.TP (Silvex)

o 1,2,4-Trichlorobenzene

$1,1,1$-Trichloroethane

Tricerchecthe

Trichlorofluoromethane

2,45-Trichlorophenol

2,4,6.Trichlorophenol

0 2,4,5.

1,2,3-Trichloropropane

1,3,5-Trinitrobe

Vinyl acotate

Xylenes

Antimony-125

Cosium-134

Coslum-137

Cobalt.57

Cobalt-60

Europlum-152

Europlum-154

Gross alpha

Manganose-54

Ponvolatile bota

Promethium-14

Promethium-144

Ruthenium-106

Sodium-22

Total activity

Total alpha-emitting radium

Tritium

Zinc-65

Pesult

Mod Unit Lan

$<10$
$<10$
$<10$

$<10$

7,180

$<2.00$

$<\begin{array}{r}2,0 \\ 2,480\end{array}$

$<1,000$

$<10$

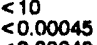

$<0.0004$

$<0.00045$

$<1.0$

$<1.0$

$<10$
$<2.0$

$<2.0$

$<2.0$

$<10$

$\mathbf{5 3}, 000$
$\mathbf{5 4 , 0 0 0}$

54,000
$<1,000$
$<1,000$

$<1,000$

$<5.0$
$<50$

$<0.24$

$<0.24$

$<0.090$

$<1.0$

$<1.0$

$<1.0$

$<10$

$<10$
$<0.090$

$<0.090$
$<1.0$
$<10$
$<8.0$

$<1.0$
$<2.0$

$<2.0$

$<2.0 E-08$
$<6.0 E-08$

$<1.0 \mathrm{E}-\mathrm{OO}$

$<1.0 \mathrm{E} .00$

$<1,0 \mathrm{E}-08$

$<4.0 \mathrm{E}-08$

$<2.0 \mathrm{E}-08$

$<3.0 \mathrm{E}-08$ - $09 \pm 2.1 \mathrm{E}-00$

6.1. $1.09 \pm 2.1 \mathrm{E}-09$

$5.8 E-00 \times 1.7 E-00$

$<1.1 \mathrm{E}-07$

$<1.0 E-08$

$<8.0 E-00$

$<8.0 E-08$

$5.0 \mathrm{E}-05 \pm 2.2 \mathrm{E}-00$

2.3E-09 $\pm 1.2 \mathrm{E}-00$

$<2.0$-08

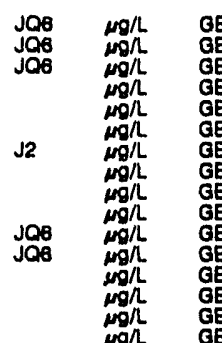

JQ6

Ja8

Jas

$29 h$ GE

WELL HSL 2D

MEASUREMENTS CONDUCTED IN THE FIELD

Sample date: $09 / 01 / 92$

Sp. conductance: $55 \mathrm{~s} / \mathrm{cm}$

Water ovacuated bofore sampling: $11 \mathrm{gal}$

Alkalinity: $0 \mathrm{mg} / \mathrm{L}$

Water temperature: $22.0^{\circ} \mathrm{C}$

LABORATORY ANALYSES

$\circ \mathrm{pH}$

Specific conductance

Acenaphthene

0 Acetone

Acetonitrile (Methyl cyanido)

2-Acetylaminofluorene 
ANALYTICAL RESULTS

WELL HSL 2D collectad on 00/01/92, laboratory analyses (cont.)

$E$ Anente

- 4-Aminobiphenyl

Anilline

Antimony

Aramiti

Arrium

Earum

alpha-Bonzane hexachlorida beta-Banzene haxachloride

delin-Eanzens haxach

Bonzo a anthrincono

Benzolkfluoranthen

Benzo o h,l)perylene

Bonzold pynen

Boryllun

Bia(2-chlorouthayy) mothane

Bit (2-chloropthyl) other

Bis (2-chloroleopropyl) ethar

Bromodichloromethane

Eromotorm

Bromomethane

Butylbenzyl phthalato

Cadmium

Cadmium

Carton disutitido

Carbon totrachloride

Chiondase

AChioroaniline

Chlorobenzane

para-Chloro-meta-cresel

Chlorothane

2-Chloroethyl winyl ether

2-Chloroeth

Chlorolorm

2-Chloronaphtha

\&-Chlorophenyl phenyl ether

Chloroprene

Chromlum

Cobalt

Copper

o-Crecol (2-Mathylphonol)

p-Cresed (4-Methylphenol)

Cyanido

p,p':DDo

p,p'DOE

bialate

Dibenzin h) henthraceno

o Dibromochloromethane

1,2-Dlbromo-3-chloropropane $<1.0$

o Dibromomethane

Ditn-butyl phthalete $<10$

0 1,3-Dichlorobenzene $<10$

o 1,4 Dichlorobenzame $\quad<10$

o 3,3-Oichiorobonzidine $<10$

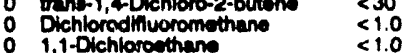

o 1,1-Dichloromethan $<1.0$

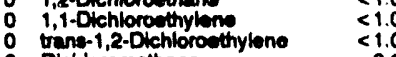

0 Olcliloromethan

2,6-Dichlorophenol $<10$

1,2-Dichloropropant

o cia-1,3-Dlehloropropene $\quad<1.0$

0 trane-1,3-Okchloropropene $<1.0$

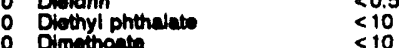

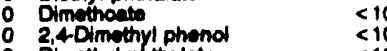

o Dimethyl phthalate

o p-Dimethylaminoezobenzene

$\begin{aligned} & 0 \\ & 0\end{aligned}, 3 \cdot 3^{\circ}$ Dimethylbenzidine

o a-Dimethylphenethylamine

o 1,3-Dinitrobenasne $<10$

2,4-Dinitrophenal <4

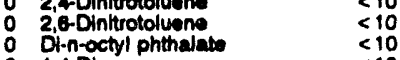

Diphanylam
Disutfoton
Reeult

Mod Unit Le

2.0

2.0
7.6
1.0

0.050

0.050

10

10

$<10$

10

1.0

10

2.0
813
1.0

0.50

1.0

0

1.0
10
1.0

1.0

100

10

4.0

10

.10

0

WELL HSL 2D collected on 08/01/92, laboratory analyeese (cont.)

E Analyte Regult Mod Unit Let

O Endosultan I

Endosultan aulfate $\quad<0.10$

0 Endrin

0 Endrin aldehyde $\quad<0.0060$

0 Ethyl methacrylate $<10$

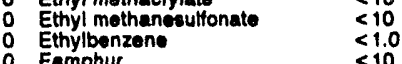

0 Fluoranthene

- Fluorene

0 Fiuoride

Heptachlor $<100$

Heplachlor epoxide $<0.050$

H Hopta, $<0.00065$

o $1,2,3,4,6,7,8 \cdot H$ PCOF

o Heptachlorodibenzo-p-furan

Hoxachlorobonzone

Hexachlorobutadiene

Hoxachlorocyclopent

Hexachlorodibenzo-p-dloxins

1,2,3,4,7,8-HXCDF

Haxachlorodibenzo-p-

Hexachloroethane

Hexachloropropene

2-Hexanone

o lodemo[1,2,3-c,d]pyrene

O Iron

o leodrin

Isophorone

isosafrole

Kepon

Lead

Magnesium

Magnosium

Mercury

Mothacrylonitrile

Mothapyrilene

Methoyychlof

Methyl ethyl ketono

Methyl isobutyl keton

Methyl methacrylate

Mothyl methaneaulionato

2.Methylcholanthreno

Naphthalene

1.4-Naphthoquinone

2-Naphthylamine

Nickol

Nitrato-nitrite as nitrogen

2-Nitroaniline

3-Nitroanilline

4-Nitroanilino

N-Nitrophenol

2-Nitrophenol

4-Nitroquinoline-1-oxide

$N \cdot N$ itrosodi-n-butylamine

N-Nitrosodiethylamine

- N.Nitrosodimethylamine

- N-Nitrosodiphenyiamine

N N-Nitrosodipropylamine

O N-Nitrosomethylethylamin

N-Nitrosomorpholine

N-Nitrosopiperidine

N-Nitrosopyrrolldine

5-Nitro-o-toluidine

Octachlorodibenzo-p-dioxin:

Octachlorodlbonzo-p-dioxin

Perathion

PCs 1016 methy

PCB 1221

P PCB 1232

PCB 1242

PCB 1248

PCB 1254

Pentachlorobenzene

1,2,3,7,8-PCDD

Pentachlorodibenzo-p.lurans

$1,2,3,7,8-P C D F$

Pentachloroothane

Pentachloronitrobenzen

Pentachlorophor

Phenacetin

Phenol

Phenols

p.Phonylenodiamine

$<0.000045$

$<10$
$<10$

$<10$
$<0.00045$

$<0.00045$

$<0.00040$

$<10$
$<10$

$<10$

$<1.0$
$<10$
$<15$
14
$<100$

14
$<100$
$<10$
$<10$

$<10$
$<10$

$<0.0050$

535

$<0.20$

$<50$
$<10$

$<10$
$<0.50$
$<10$

$<1.0$

$<1.0$

$<10$
$<10$

$<10$

$<10$

$<10$
$<10$
$<4.0$

$<4.0$

$<10$

$\leq \leq 10$

$<10$
$<10$

$\leq 10$

$<10$

$<<10$

$<10$
$<10$
$<10$

$<10$
$<10$

$<10$
$<10$

$\leq 10$

$<10$

$<0.0010$

$<<0.050$

$<0.50$

$<0.50$

$<0.50$

$<0.50$

$<0.50$

$<10$
$<0.00055$

$<0.00055$

$<0.00055$

$<10$

$<10$

$<10$
$<10$
$<10$

$<10$
$<10$
$<10$

$<10$
$<5.0$
$<10$ 
ANALYTICAL RESULTS

WELL HSL 20 collectad on 09/01/82, laborafory analyses (cont)

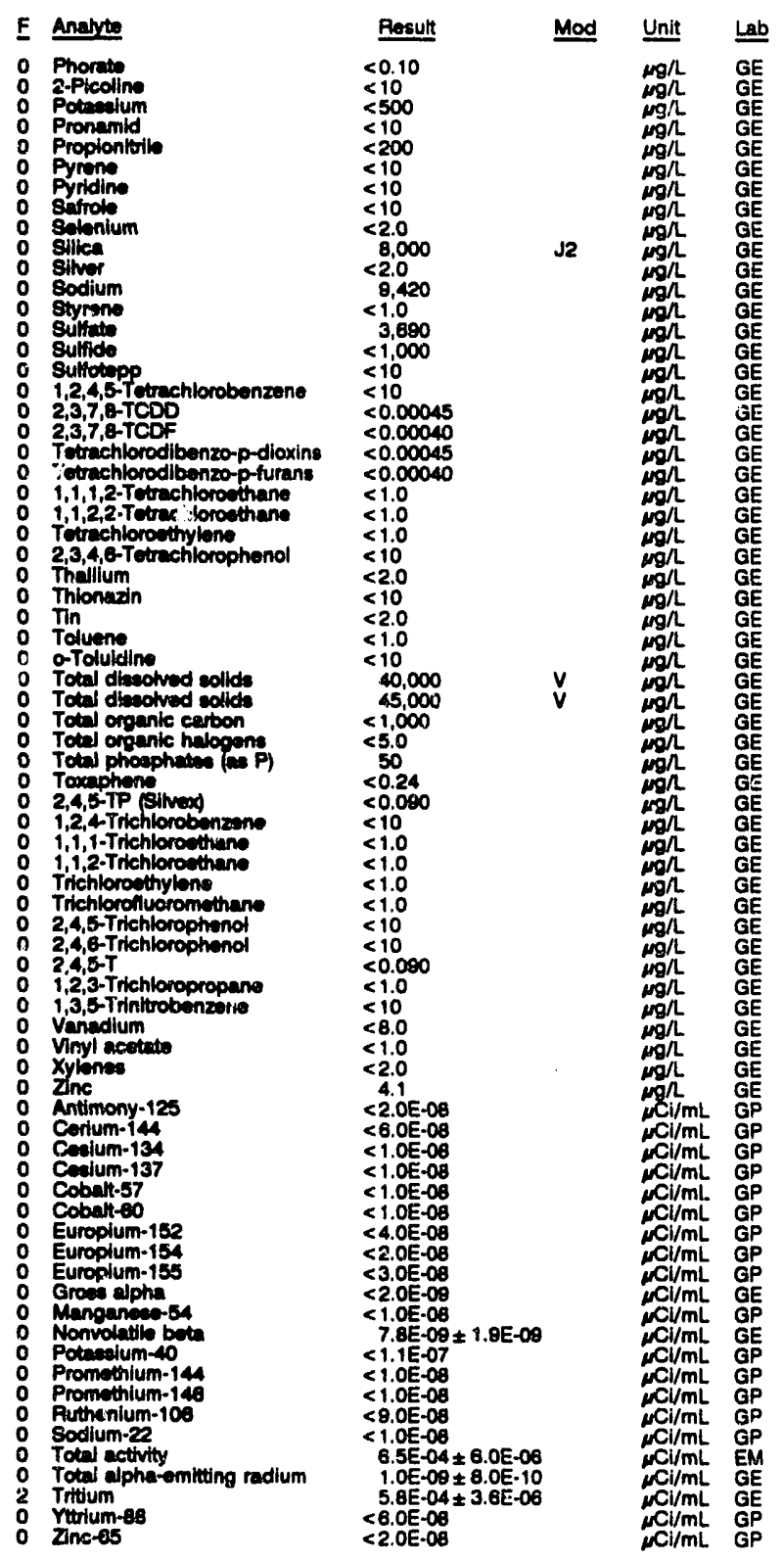

WELL HSL 3D

MEASUREMENTS CONOUCTED IN THE FIELD

Sample date: Ca/01/92

Depth to water: $17.07 \mathrm{n}(5.20 \mathrm{~m})$ below TOC

Time: 10:40

pH: 4.8

Water temperature: $22.1 \cdot \mathrm{C}$

Wator evecuated before sam

\begin{tabular}{|c|c|c|}
\hline & Andycte & Result \\
\hline & $\begin{array}{l}\text { PH } \\
\text { pH } \\
\text { Specific conductance } \\
\text { Specific conductunce } \\
\text { Acenaphthene } \\
\text { Aconaphthylenc } \\
\text { Acetone } \\
\text { Acetonitrile (Mothyl cyanide) } \\
\text { Acetophenone }\end{array}$ & $\begin{array}{l}5.2 \\
5.0 \\
35 \\
35 \\
<10 \\
<10 \\
<100 \\
<1.0 \\
<10 \\
<10\end{array}$ \\
\hline
\end{tabular}

WELL HSL 3D collected on 09/01/92, laboratory analyses (cont.)

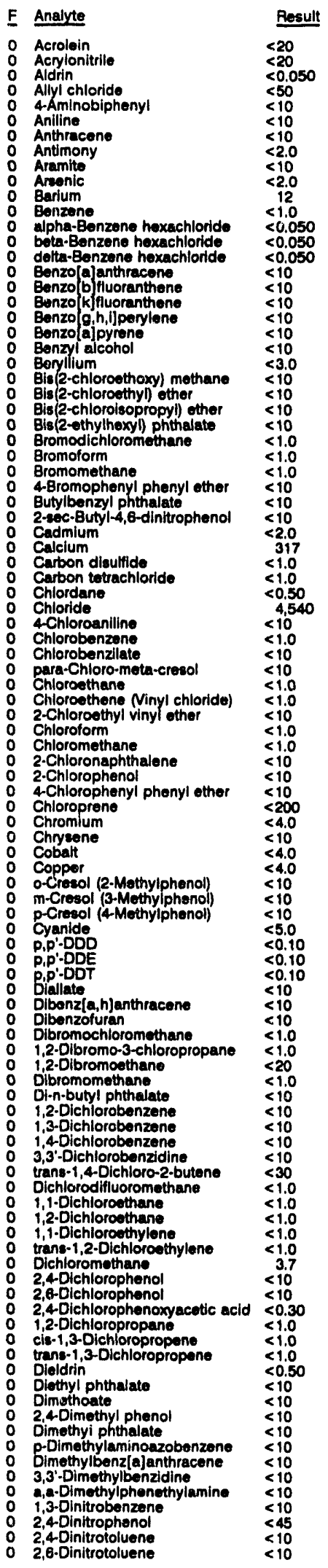

Mod Unit Lab

$\mu g / \mathrm{GE}$

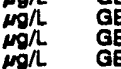

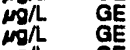

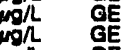

能

gin

GE

on GE

gh GE

gh GE

go $\mathrm{GE}$

on GE

$\mathrm{Ngh}$ GE

$\mu g h$ GE

gin GE

$\operatorname{gon} \Omega$ GE

$\mathrm{mgh}$ GE 
WELL HSL 30 collected on 00/01/92, Iaboratory analyees (cont)

E Aneyte

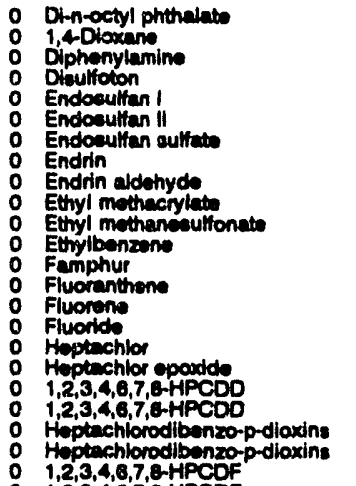

$1,2,3,4,6,7,8-H P C O F$

o Heptachlorodibenzo-p-turans Heptachlorodibenzo-p-furana Hexachlorobonaeno Hexachlorocyclopentindiene $1,2,3,4,7,8-1 \times C D D$

Hexchiorodibenzo-p-dioxins Hexachlorodibenzo-p-dioxin: $1,2,3,4,7,8-1 \times x$ CF

$1,2,3,4,7, \theta+$ - XCDF
Hoxechlorodibenzo-p-turans Hexachlorodibenzo-p-furans Haxachlorosthan Hexcechloropropene

indeno $[1,2,3-c, d] p y r e n e$

lodomethane (M.thyl lodide)

ron

bobuty

bophorone

Kepon

Lead

Undano

Manganece

Morcury

Mothacryionituile

Methapyrilen

2-Awthyla,6-dinitrophenol

Methyl ethyl ketone

Methyl bobutyl ketion

Methyl methaneaultonate

3-Mothylcholanthren

a-Methyinaph

1,4-Naphthoquinone

1-Naphthylamine

Nitrato-nitutto es nituropen

2-Nitroeniline

4Ntroaniline

Nitroberizane

2-Nitrophionol

4t Nrophnol 1 -oxide

N-Nturosoditn-butylamine

N-Nitrocod thyiemine

N-Nitrosodimothylamine

N-Nitrosodiphenylamin

N-Nitrocodipropylamino

N-Nitrocomorpholin

N-Nitrosopyentidine

S-Nitro-atoluiding

0,0,0-Iriethyl phosphorothioat

Octuchlorodibenzo-p-dioxins

Octachlorodibenzo-p-dioxins

octachlorodibenzo-p-uran

Perathion

Parathion methy

PCB 1221

PCB 1232

PCB 124

PCB 1254
$<10$

$<10$

$<0.10$

$<0.10$

$<0.0060$

$<0.10$
$<10$
$<10$

$<10$

$<0.050$

$<0.050$

$<0.00005$

$<0.00065$

$<0,0015$

$<0.00045$

$<0.00045$

$<10$

$<10$

$<0.00045$

$<0.00045$

$<0.00045$

$<0.00040$

$<0.00040$

$<0.00040$

$<10$

$<10$
$<10$

$<1.0$

$<10$
$<15$

$<4.0$

$<100$
$<10$

$<10$
$<10$
5

$<10$
$<10$
$<3.0$

$<3.0$

431
129

$<0.20$

$<10$

$<0.50$

$<10$
$<1.0$

$<1.0$

$<10$

$<10$

$<10$

$<10$

$<10$

$<10$
$<10$
4.2

4.2
1,800

$<10$

$<10$
$<10$

$<10$

$<10$

$<10$

$<10$

$<10$

$<10$

$<10$

$<10$

$<10$

$<10$

$<10$

$<0.0010$

$<0.0010$
$<0.0010$

$<0.0010$

$<0.050$

$<0.50$

$<0.50$

$<0.50$

$<0.50$
$<0.50$

$<0.50$
WELL HSL 3D collected on 09/01/92, laboratory analyees (cont)

F Analyte

PCB 1260
0 Pentachlorobenzene

O 1,2,3,7,8-PCDD

1,2,3,7,8-PCDD

Pentachlorodibonzo-p-dioxins

Pentachlorodibenzo-p-purans

Pentachlorodibenzo-p-furans

1,2,3,7,8-PCDF

Pentachlor

Pentachloronitrobanzene

Pentachlorophenol

Phenacotin

0 Phenol

O Phenols

0 Phorato

2.Picoline

o Potansium

0 Propionitrile

Pyrene

0 Safrole

o Solonium

S Silica

0 Sodium

o Styrene

0 Sulfate

0 Sulfide

0 Sulfotepp

o 1,2,4,5-Potrachlorobenzene

2,3,7,8-TCDD

2 2,3,7,8-TCDD

$2,3,7,8-T C D F$
$0 . T C D F$

0 Tetrachlorodibenzo-p-dioxins

Terrachlorodlbenzo-p-dioxins

Tetrachloroolibonzo-p-furans

1,1,2-Tetrachlopoethane

1,1,2,2-Tetrachioroethane

- Tetrachloroethylone

o 2,3,4,6-Tetrachlorophenol

Thallium

0 Tin

o Toluene

o o-Toluidine

- Total dissolved solids

- Total organic carbon

- Total phosphates (as P)

T Toxaphene

2,4,5.TP (Silvex)

1,2,4-Trichlorobenzene

- 1, Trichlorosthane

Trichions

o Trichlorofluoromethane

2,4,6-Trichlorophenol

0 2,4,5-T

o 1,2,3-Trichioropropane

o 1,3,5.Trinitrobenzene

O Vanadium

o Vinyl acet

X Xylones

Antimony-125

O Corlum-144

O Ceslum-134

o Cobat-57

- Cobati-60

O Europium-152

Europium-154

Europium-155

- Gross alpha

- Manganese-54

0 Potassium -40

0 Promethium-144

Promethium-146

Ruthenium-10

Sodium-22

Total activity

0 Ytrium-8s

0 Zntrium.68

$<0.50$

$<0.00055$

$<0.00055$

$<0.00055$

$<0.00055$

$<0.00055$

$<10$

$<10$

$<10$
$<10$

$<10$
$<10$
$<10$

$<5.0$

$<10$

$<10$

$<10$

$<200$

$<10$
$<10$

$<10$

$<2.0$

$<2.00$

8,210

1.090

$<10$

$<0.00045$

$<0.00045$

$<0.00040$

$<0.00045$

$<0.00045$
$<0.00040$

$<0.00040$

$<1.0$

$<1.0$

$<10$

$<2.0$,

2.1

$<1.0$
$<10$

35,000

$<1,000$
$<5.0$

$<50$

$<0.24$

$<10$

$<1.0$

$<1.0$

$<1.0$

$<10$

$<0.090$

$<10$

$<8.0$

$<1.0$

8.2

$<2.0 E-00$

$<8.0 E-08$
$<1.0 E-08$

$<1.0 \mathrm{E}-0 \mathrm{0}$

$<1.0 E-08$

$<4.0 \mathrm{E}-0 \mathrm{OB}$

$<2.0 \mathrm{E}-0.0$

$<3.0 \mathrm{E}-00$

$3.2 E-09 \pm 1.6 \mathrm{E}-00$

$2.5 E-00 \neq 1.5 E-0 \theta$

$<1.1 E-07$

$<1.0 E-08$

$<1.0 E-08$

$<9.0 E-08$

$<1.0 E-00$

$5.5 E-04 \pm 5.8 E-08$

$2.2 E-09 \pm 1.2 E-00$

$<6.0$ E-08

$<2.0 \mathrm{E}-08$

Mod Unit Lab

mgh GE

$\mathrm{mgh}_{\mathrm{wg}} \mathrm{GE}$

igh GE

$\mu \mathrm{g}$ GE

gh GE

gh $G E$

GE

m GE

won GE

$\operatorname{con}$ GE

mon $G E$

gon GE 
ANALYTICAL RESULTS

WELL HSL 4D

MEASUREMENTS CONDUCTED IN THE FIELD

Sample date: $00 / 00 / 82$
Depth to water: $10.73 \mathrm{n}(3.27 \mathrm{~m})$ bolow TOC
Sp. conductence: $116 \mu \mathrm{s} / \mathrm{cm}$

Wator evacuated before sampling: $15 \mathrm{gal}$ LABORATOFY ANALYSES

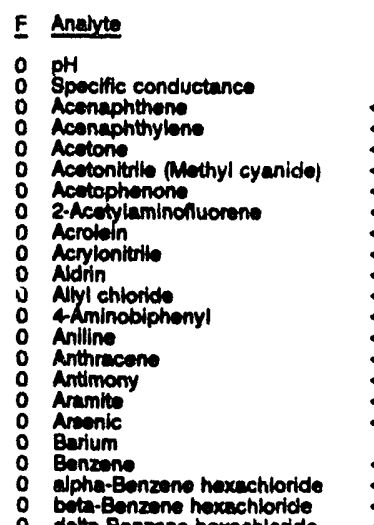

Pesult
5.5
125
$<10$

Time: 14:10

pH: 5.4

Alkalinity: $16 \mathrm{mg} /$

Water tomperature: $24.4^{\circ} \mathrm{C}$

Mod

Unit Let

$<100$

$<1.0$

$<10$

$<20$

0.050

$<10$

$<10$

$<<10$

$<10$

$<40$

$<0.050$

$<0.050$

Bonzo/e anthreceno

Benzo kf puoranthene

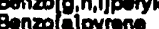

Benzyl acohol

Beryillum

Bis(2-chlorocthoxy) methane

Eia (2-chloroethyn) ether

Bige-chlorolwopropyll ther

Bisenothylhexyly phthald

Bromoform

4-Bromophenyl phenyl ether

Butylbonzyl phthalate

2-ac-Butyld, b-diniturophenol

Cedmium

Carbon diaulfide

Chtordan

\&-Chloroaniline

Chlorobenzano

pare-Chioro-meta-cresol

Chlorethen Minyl chloride

2-Chloroethyl vinyl cher

Chloroform

Chloromerm

2-Chloronaphthalen

2-Chlorophenol

4-Chlorophenyl phenyl ether

Chromium

Chryeene

Cobst

o-Cresol (2-Muthylphonol)

m-Craed (3-Methylphono)

p-crend (4-Methylphonol)

Cyanide

P,p'DDE

P.P'-DOT

Dibenz $[a, h]$

1,2-Dibromo-3-chloropropane 1,2-Dibromoethane

Dirn-butyl phthainte

1,2-Dichiorobenzene

1,3-Dichlorobenzene

1,4-Dlehlorobenzene

3,3'-Dichlorobenzidine

trane-1,4-Dichloro-2-butane

1,1-Dichioroethene

1,2-Dichloroethane

1,1-Dichloroethyione
$<10$

$\leq 10$

$<>10$

10

$<\leq 10$

$<10$

$<10$

$<1.0$

$\leq<10$

$<<10$

$<2.0$

$<1.0$

$<6.50$

$<1.0$

$<10$

$<1.0$

$<1.0$

$<10$

$<1.0$

$<10$

$<10$

$<200$

$<10$

$<4.0$
$<4.0$
$<10$

$<10$

$<10$
$<10$

$<5.0$
$<0.10$
$<0.10$

$<0.10$

$<10$

$<10$

$<1.0$
$<1.0$
$<20$
$<1.0$

$\leq 1.0$

$<10^{\circ}$

$<10$

$<10$
$<10$

$<30$

$<1.0$

$<1.0$
$<1.0$
WELL HSL. 4D collected on 0e/02/82, laboratory analyees (cont.)

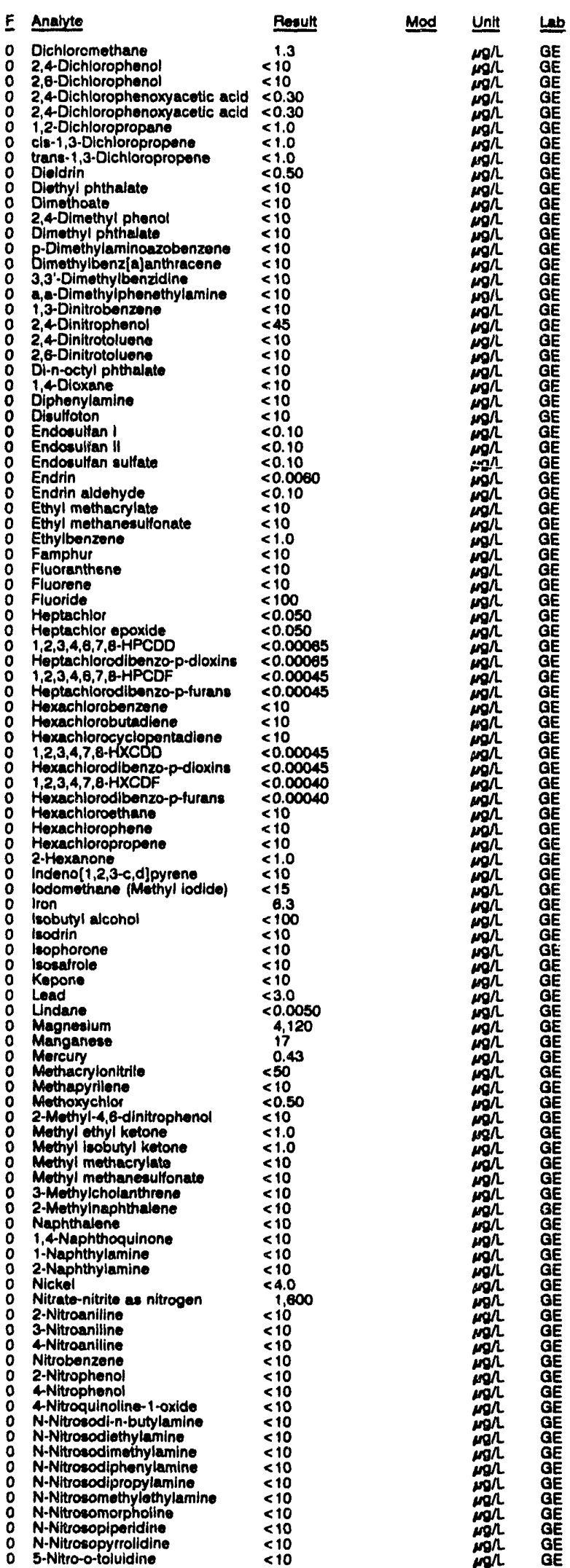


ANALYTICAL RESULTS

WELL HSL 40 collectiod on 09/02/92, laboratory analyees (cont)

$E$ Anewne

- 0,0,0-Tnothyl phosphorothioate

Octachlorodibenzo-p-dioxins

0 Parathion

Parathion methy

PCB 1018

PCB 1232

PCB 1242

PCB 12s4

Pentiachlorobon

Pentiachlorodibenzo-p-dioxins

Pentachloredibenzo-p-turans

Pentachloritan

Pentachlorophenol

Prenaceatin

Phenol

Phonots

Phorate

2-Picolin

Pronamid

Proploniturito

Pyrone

o Sefrole

Silica

Bituer

Eodium

Sultade

Sulfide

Sulfotepp

$2,3,7,8-T C D O$

o $2,3,7,6$-TCDF

T Tetrachlorodibenza-p-dloxins

1,1,1,2-Tetrachloroetffane

o 1,1,2,2-Tetrachloroett

o 2,3,4,6-ietrechlorophionol

o Thuillum

Tin

Toluene

o-Toluldine

o Total dienotved collids

Tot organte colida

Total oroenic halogens.

Total phosphates (of P

- Toxapheno

2,4,5-TP Sinvex

2,4,5-IP Givex

1,1,1-Trichloroethane

Trichloroflyolonemethan

2,4,5-Trichlorophend

2,4,E-T

2,4,5-T Trichloropropan

o 1,3,5-Trinitrobenzene

V Vanedium

o Vylenes

0 Zne

0 Antimony-125

Cotium-144

- Coelum-137

Cobalt.57

o Europlum-152

Europlum-15e

Europlum-15s

Growes alpha

Nonvolatio bete

Potemalum 40

Promethium-144

Ruthenlum-10s

Sodium-22

Total alphe-emitting redium

Tritum

$<0.0010$

$<0.050$

$<0.50$

$<0.50$

$<0.50$

$<0.50$

$<0.50$

$<10$

$<0.00055$

$<0.00055$

$<10$

$<10$

$<10$

$<10$

$<10$

$<10$

$<10$

$<10$

$<200$

$<10$

$<10$

6.680
$<2.0$

3,030
$<1.0$

14,300

$<1,000$

$<10$

$<0.00045$

$<0.00040$
$<0.00045$

$<0.00040$

$<1.0$

$<1,0$

$<10$

$<10$

5.5
$<1.0$

$<10$

78,000
72,000

1,020
$<5,0$

$<5.0$

$<0.24$

$<0.090$

$<10$

$<1.0$

$<1.0$

$<1.0$
$<10$

$<10$

$<0.090$

$<1.0$

$<8.0$

$<8.0$
$<1.0$
$<2.0$

$<2.7$

$<2.0 E-08$
$<8.0 E-08$

$<1.0 E-08$

$<1.0 \mathrm{E}-00$

$<1.0 E .08$

$<4.0 E-08$

$<2.0 E .08$

$<3.0 E .08$

$<2.0 E-09$

$1.0 \mathrm{E}-08$

$<1.1 E-07$

$<1.0 E-00$

$<\mathrm{COE}-08$

$<1.0 E-08$

$1.8 E-05 \pm 1.3 E-05$

1. $8 \mathrm{E}-09 \pm 8.0 \mathrm{E}-10$

2.0E $00 \pm 8.0 \mathrm{E}-10$
1.7E-05 \pm 8.0E -07
Reeult Mod Unit Lob

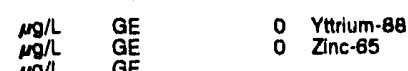

$5.0 \mathrm{E}-08 \pm 4.2 \mathrm{E}-00$

Bervilium

Bromoform

Cand-Buty

- Cadcium

Chlordane

Chioride

Chloroform

Chloroprene

Chromium

Chrysen

Cobalt

p.Cresol

$p, p^{\prime}-D D D$

P.P'-DDE

Bip-DDT

WELL HSL 40 collected on 09/02/92, laboratory analyeses (cont.)

\begin{tabular}{|c|c|c|c|}
\hline Analyte & Posult & Mod & Unit \\
\hline $\begin{array}{l}\text { Yttrium-88 } \\
\text { Zinc-65 }\end{array}$ & $\begin{array}{l}<6.0 E \cdot 08 \\
<2.0 E \cdot 08\end{array}$ & & $\stackrel{\mathrm{Cl} / \mathrm{mL}}{\mathrm{Cl} / \mathrm{mL}}$ \\
\hline
\end{tabular}

WELL HSL 6D

MEASUREMENTS CONDUCTED IN THE FIELD

Sampla date: $09 / 07 / 92$
Dopth to wator: $18.38 \mathrm{it}(5.60 \mathrm{~m})$ bolow TOC

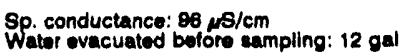

Time: 12:05

Al: 4.1.

Water tomporature: $23.2 \circ \mathrm{C}$

LABORATORY ANALYSES

\begin{tabular}{|c|}
\hline 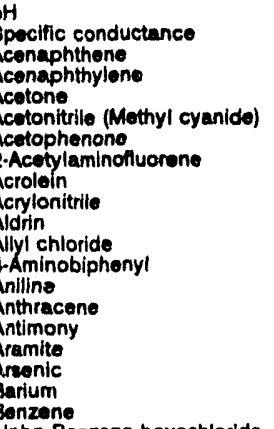 \\
\hline
\end{tabular}

Regutt Mod Unit

delta-Eenzene hexachloride

Benzo[ajanthracene

Benzo b fluoranthene

Benzo g, h, ilporylene

Benzolajpyron

Bis (2-chloroethoxy) methane

Bia 2-chloroethyl) other

Bis (2-ethylhexyl) phthalate

Bromodichloromethane

Bromomethane

4-Bromophenyl phenyl ether

2.ec-Butyl-4,6-dinitrophenol

Carbon disulfide

Carbon tetrachioride

Chlorobenzene

Chlorobenzliato

para-Chloro-mota-cresol

Chloroethene Minyl chiorido)

2-Chloroethyl vinyl ether

Chloromethane

-Chloronaphthalen

4-Chlorophenel phenyl other

o-Cresol (2-Mathylphenol)

m-Cresol (3.Mothy pheno

Dibenz[a,h]anthracene

Dibenzofuran

1.2-Dibromo-3-chioropropane

1,2-Oibromoethan

Di-n-butyl phane

1,2-Dichlorobenzene

1,3-Dichlorobenzene

1,4-Dichlorobenzene

4.4
100
$<10$
$<10$
$<100$
$<1.0$
$<10$
$<10$
$<20$
$<20$
$<0.050$
$<50$
$<10$
$<10$
$<10$
$<2.0$
$<10$
$<2.0$
30
$<1.0$
$<0.050$
$<0.050$
$<0.050$
$<10$
$<10$
$<10$
$<10$
$<10$
$<10$
$<3.0$
$<10$
$<10$
$<10$
$<10$
$<1.0$
$<1.0$
$<1.0$
$<10$
$<10$
$<10$
$<2.0$
$<2.610$
$<1.0$
$<1.0$
$<0.50$
1.550
$<10$
$<1.0$
$<10$
$<10$
$<1.0$
$<1.0$
$<10$
$<1.0$
$<1.0$
$<10$
$<10$
$<10$
$<200$
$<4.0$
$<10$
$<4.0$
$<4.0$
$<10$
$<10$
$<10$
$<5.0$
$<0.10$
$<0.10$
$<0.10$
$<10$
$<10$
$<10$
$<1.0$
$<1.0$
$<20$
$<1.0$
$<110$
$<10$
$<10$
$<10$
$<10$

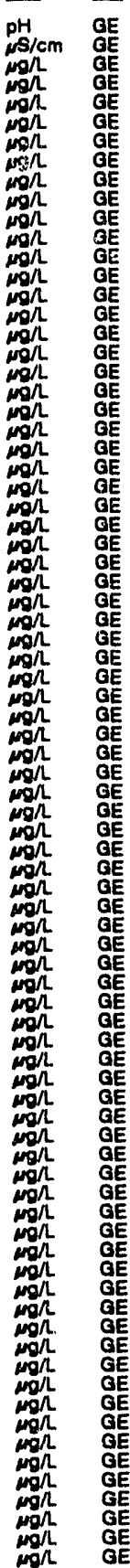


ANALYTICAL RESULTS

WEL HSL 6D collocted on 09/07/82, laboratory analyses (cont)

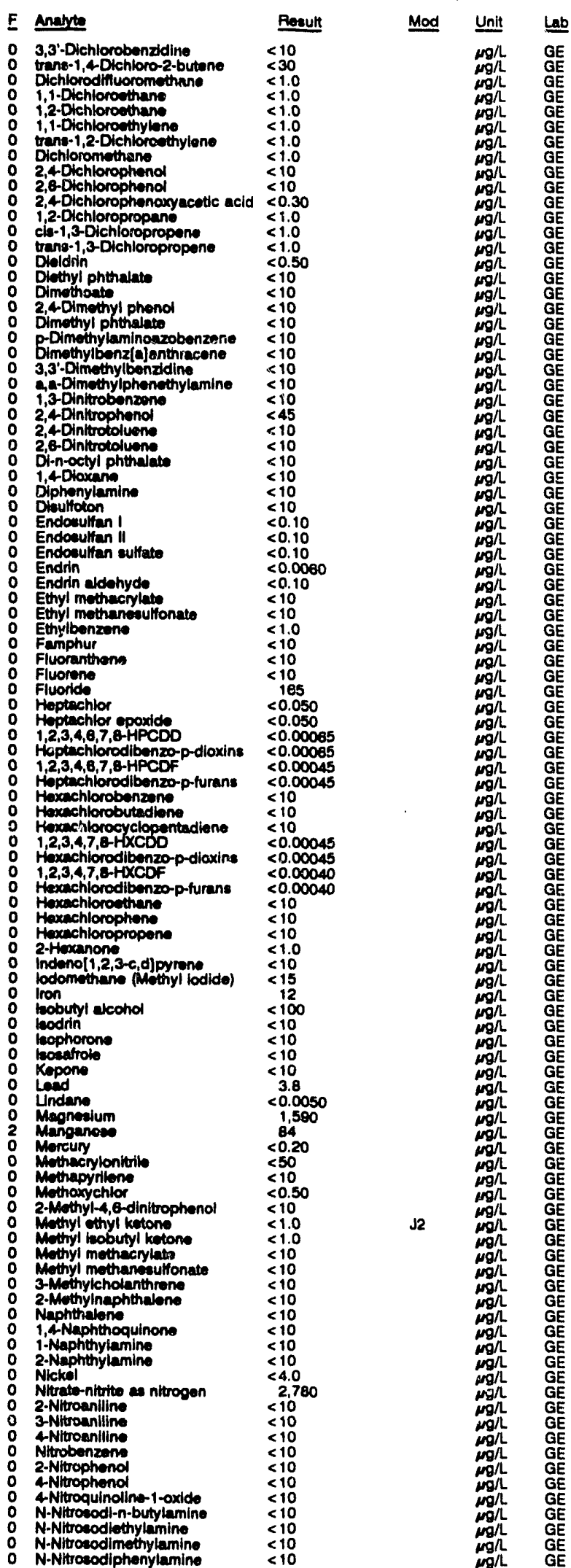

WELL HSL 6D collected on 09/07/82, laboratory analyees (cont)

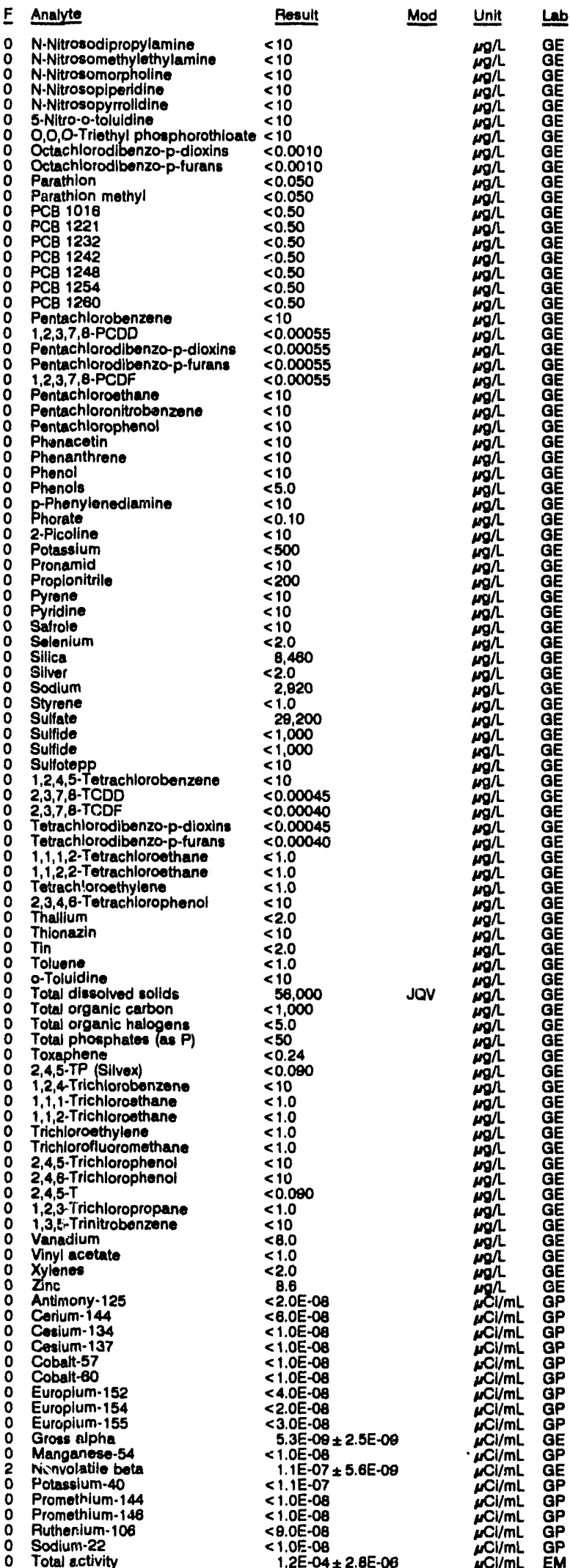


WELL. HSL 6D collected on 09/07/92, laboratory analyses (cont)

\begin{tabular}{|c|c|c|c|c|}
\hline & Anarte & Rosult & Mod & Unit \\
\hline & $\begin{array}{l}\text { Total alpha-emiting radlum } \\
\text { Tritium } \\
\text { Ytrium-88 } \\
\text { Znc-65 }\end{array}$ & $\begin{aligned} 2.7 \mathrm{E}-09 \pm 1.2 \mathrm{E}-09 \\
1.2 \mathrm{E}-04 \pm 1.7 \mathrm{E}-06 \\
<6.0 \mathrm{E}-08 \\
<2.0 \mathrm{E}-08\end{aligned}$ & & 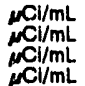 \\
\hline
\end{tabular}

WELL HSL 7D

MEASUREMENTS CONDUCTED IN THE FIELD

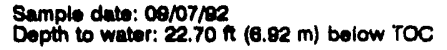

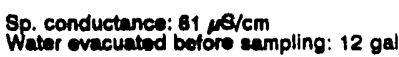

Tima: 11:05

Alkalinity: $7 \mathrm{mg} / \mathrm{L}$

Water tomperature: $22.2^{\circ} \mathrm{C}$

LABOPATORY ANALYBES

E Anabyte

$\begin{array}{ll}0 & \text { pH } \\ 0 & \text { pH }\end{array}$

0 Specific conductance

Speclfic conducter

Acenaphthone

O Acenaphthylone

Acotone

Acetoniterite Methyl cyanide

Acetonitule (Methyl cyanide)

Acetophenon

2-Acetylaminofluorene

2.Acetylaminofluorene

Acrolin

Acrolein

Acrylonitrile

0 Ndin

Alyl chloride

4-Aminobiphenyl

Aniline

Aniline

Anthracen

Antrincen

Antimony

Aramitio

Arenic

Barium

Barium

Benzane

alpha-Benzeno hoxachloride

beta-Benzane hexachloride

dellineonzene hoxechloride

Benzo[a] anthracens

Benzos b fivoranthons

Benzo b filuoranthene

Benzo $k$ flucranthene

Benzo k fluoranthen

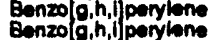

Eenzo g, $h, i$ penyion

Eenzopapyrono

Benzyl alcohol

Benzyl alcoho

Beryllum

Bit (2-chloroethoxy) methene thome mane

Bie(2-chloroethyl) ther

Bis (2-chloroethyl) ether

Bis (2-chlorolsopropyl ether

Bise (2-thylhoxy) phthalate

Bis (2-ethylhoxyl) phthalat

Bromodichloromethan

Bromolorm

Bromotorm

Bromomethan

4 Bromophenyl phenyl other A-Bromophenyl phenyl ther Butylbonzyl phthalat

Butylognzyl phthalato 2-ecc-Butyl-4, 6-dinitrophenol Cadmium

Cadmium

Calcium

Catoon diaulfide

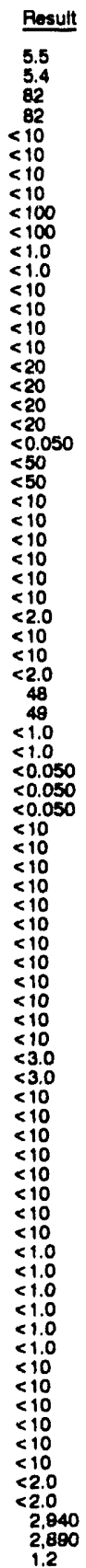

WELL HSL 70 collected on $09 / 07 / 92$, laboratory analyees (cont.)

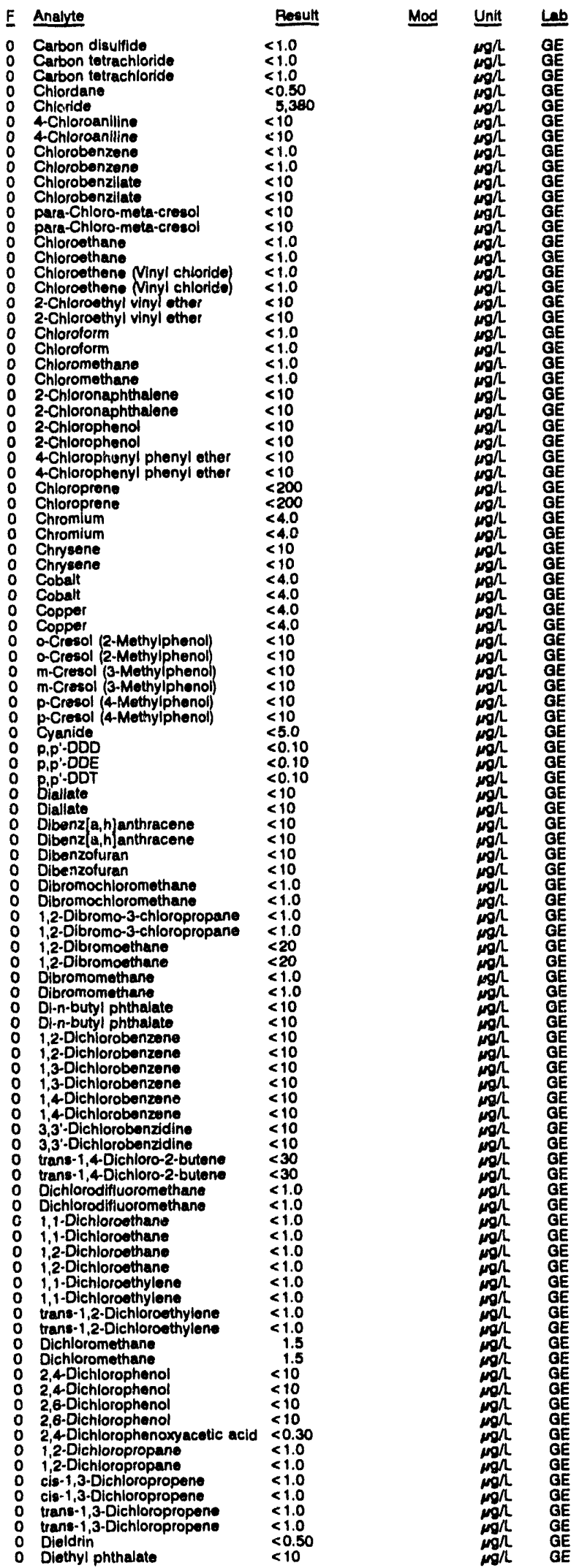


ANALYTICAL RESULTS

WELL MSL 70 collected on 09/07/92, laboratory analyses (cont)

E Analyte

o Diethyl phthalato

o Dimethoate

2,4-Dimethyl phenol

o 2,4-Dimethyl phenol

o Dimethyl phthalatio

o p-Dimothylaminomzobenzene

o p-Dimethyleminomabenzone

D Dimethylbenz (a) anthracene

o 3,3'-Dimethylbonzidine

3,3'-Dimethylbenzdine

a e-Dimethylphenethylamine

o 1,3-Dinltrobonzane

1,3-Dinitrobenzene

2,4-Dinitrophenol

2,4-Dinitrotoluene

2,4-Dintitrotoluene

2,0-Dinitrotoluen

Dt-n-octyl phthalats

o 1,4-Dioxane

o 1 Diphenylamine

Diphenylamine

Disulfoton

Endoaution

- Endosulfan II

O Endosulfan sulfate

Endrin

Endrin aldehydo

Ethyl mothacrylate

Ethyl methaneaultonate

Ethylbenzent

Ethylbenzone

Famphur

Fluoranthene

Fluorent

Fluorene

Fluoride

Heptachlor epordde

Heptachlorodibenzo-p-dioxins

$1,2,3,4,6,7,8-H P C D F$

Hoptachiorodibenzo-p-furans

Hexachlorobonzene

Hexachlorobutadiene

Hexachlorobutadione

Hoxachlorocyclopentadione

Hexachlorocyclopent

Hexachiorodibenzo-p-dioxin

$1,2,3,4,7,8-1 \times C D$

Hexachiorodibenzo-p-furans

Hexachloroethen

Hexachiorophom

Hexachloropropen

2.Hexanon

2. - Hoxanon

indeno[1,2,3-c,d]pyrene

indeno $[1,2,3-c, d$, pyrene

odomathan (Mothyl lodide

lodom

o lion

o inobutyl icoho

0 leobuty

0 bodinn

o bophorone

bocafrole

bovalrole

Kopon

O Kepone

o Lindane

o Magnesium

Magnealum

2 Manganese

Manganese

Mercury

Morcury

Mothacylonitrile
Methapyrilente
Rosult

$<10$

$<10$

$<10$

$<10$

<is

$<10$

$<10$

$<10$
$<10$
$<10$

$<10$

$<45$

$<10$

$<10$

$<10$

$<10$
$<10$

$<10$

$<10$

$<<10$

$<10$

$<0.10$

$<0.10$

$<0.10$

$<10$

$<10$

$<10$

$<1.0$

$<1.0$

$<10$

$<10$

$<10$

$<100$

$<0.050$

$<0.00085$

$<0.00065$

$<0.00045$

$<10$

$\leq 10$

$<10$

$<10$

$<0.00045$

$<0.00045$

$<0.00040$

$<10$

$<10$

$<10$

$<10$

$<10$

$<1.0$

(1)

$<15$

31
31
$<100$
$<100$

$<100$

$<<0$

$<10$

$<10$

$<10$

$<>0$

$<10$

$<0.0050$

1,770
1,760

1,760
277
275

$<0.20$

$<0.20$

$<50$
$<10$
Mod

\section{Unt}

$\mu \quad \mathrm{g} / \mathrm{GE}$

Lab
GE
GE
GE
$G E$

$\mu g$



wogn

mgh $G E$

sg

mog

$\mu g / \mathrm{GE}$

列

酸
WEL HSL 70 collected on 09/07/92, laboratory analyeer (cont)

\begin{tabular}{ll} 
Result & $M$ \\
\cline { 3 - 3 } & $<10$ \\
$<0.50$ \\
$<10$ \\
$<10$ \\
$<1.0$ \\
$<1.0$
\end{tabular}

Mod Unit Leb

2-Mothyl-4,6-dinitrophenol 2-Mothyl-4,8-dinitropheno

Methyl isobutyl ketone

Methyl lisebutyl ketone

Methyl methacryiate

Methyl methanesulfonate

Methyl mothanosulfonate

3-Mothylcholanthrone

2.Methyinaphthalene

2-Methyinaphthalene

Naphthalene

1,4-Naphthoquinone

1,4-Naphthoquinone

1. Naphthylamine

2-Naphthylamine

2-Naph hylamino

Nickol

Nitrate-nitrite as nitrogen

2-Nitroaniline

3. Nitroaniling

3-Nitroaniline

4 -Nitroaniline

4 Nitroaniline

Nitrobenzene

Nitrobenzene

2-Nitrophono

i-Nitropheno

4-Nitropheno

4-Nitroquinoline-1-oxide

4-Nitroquinoline-1-oxide

N-Nhosodi-n-butylamino

N-Nitrosodiethylamine

N-Nitrosodiethylamine

N-Nitrosodimethylamine

N-Nitrosodimethylamine

N-Nitrosodiphenylamine

N-Nitrosodiphenylamine

N-Nitrosodipropylamine

N-Nitrosodipropylamine

N-Nitrosomethylethylamine

N.Nitrosomorpholine

N-Nitrosomorpholine

N-Nirosopiporidino

N-Nitrosopiperidine

N-Nirosopyrtioldine

5-Nitro-o-toluldine

Sitro-0.toluiding $<10$

5.

Octachlorodibenzo-p-dioxine $<0.0010$

Parathion

Parathion methyl

PCB 1221

PCB 1232

PCB 1242

PCB 1254

Pentachlorobenzene

Pontachlorobenzeno

1,2,3,7,8-PCDD Pentachodor

1,2,3,7,8-PCDF

Pentachloroethane

Pentachloronitrobenzene

Pentachloronitrobenzene

Pentachloropheno

Phenacetin

Phenacetin

Phenanthrene

Phenol

Phonol

p-Phenylenediamine

Phorate

2-Picoline

Potassium

Potassium

$\operatorname{mggh}_{\mathrm{mg} / \mathrm{GE}}$

$<1.0$

$<1.0$

$<10$

$<10$

$<10$

$<10$

$<10$

$<10$

$<10$
$<10$

$<10$
$<10$

$<4.0$

2,950
$<10$

$<10$

$<10$

$<10$
$<10$

$<10$

$<10$

$<10$

$<10$

$<10$

$<10$

$<10$

$<10$

$<10$
$<10$
$<10$

$<10$
$<10$
$<10$

$<10$

$<10$
$<10$

$<10$

$<10$

$<10$

$<0.0010$

$<0.050$

$<0.50$

$<0.50$

$<0.50$

$<0.50$

$<0.50$

$<0.50$
$<10$

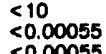

$<0.00055$

$<0.000$

$<10$ 
WELL HSL 7D collected on 09/07/92, laboratory analyses (cont)

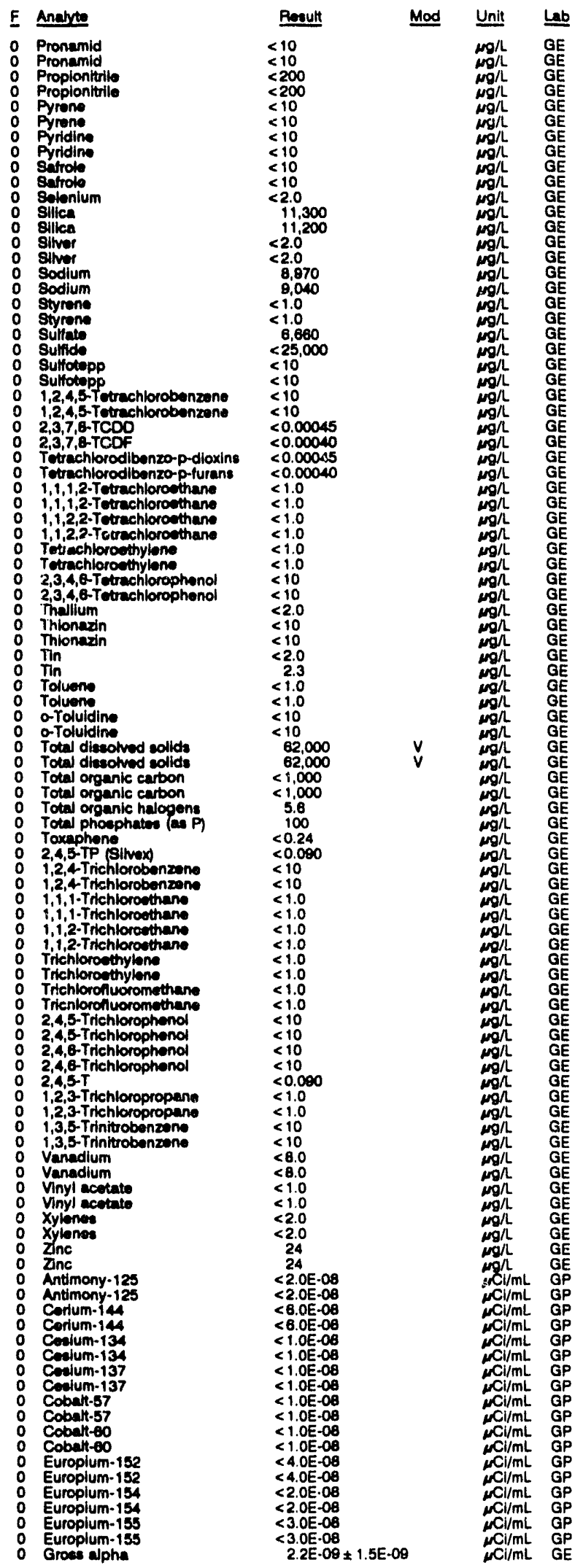

WEL HSL 7D collectod on 09/07/82, laboratory analyees (cont)

\begin{tabular}{|c|c|c|c|c|}
\hline E & Analyte & Result & Unit & Leb \\
\hline $\begin{array}{l}0 \\
0 \\
0 \\
0 \\
0 \\
0 \\
0 \\
0 \\
0 \\
0 \\
0 \\
0 \\
0 \\
0 \\
1 \\
2 \\
0 \\
0 \\
0\end{array}$ & $\begin{array}{l}\text { Manganese-54 } \\
\text { Manganese-54 } \\
\text { Nonvolatile bota } \\
\text { Potassium-40 } \\
\text { Polassium-40 } \\
\text { Promethium-144 } \\
\text { Promethium-144 } \\
\text { Promethium-146 } \\
\text { Promethium-146 } \\
\text { Puthenium-108 } \\
\text { Puthenium-108 } \\
\text { Sodium-22 } \\
\text { Sodium-22 } \\
\text { Total activity } \\
\text { Total alpha-emitting radium } \\
\text { Tritium } \\
\text { Yttrium- } 88 \\
\text { Yttrium-88 } \\
\text { Znc- } 65 \\
\text { Znc-65 }\end{array}$ & 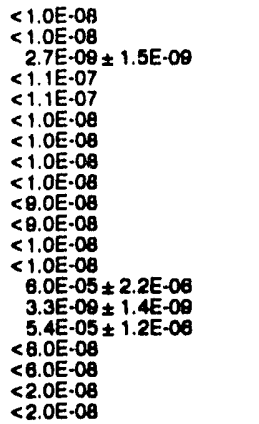 & 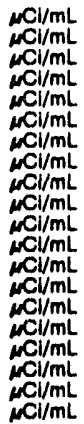 & $\begin{array}{l}G P \\
G P \\
G P \\
G P \\
G P \\
G P \\
G P \\
G P \\
G P \\
G P \\
G P \\
G P \\
G P \\
\text { GM } \\
G E \\
G E \\
G P \\
G P \\
G P \\
G P\end{array}$ \\
\hline
\end{tabular}

WELL HSL 8D

MEASUREMENTS CONDUCTEO IN THE FIELD

Sample date: 09/07/02

Depth to water: $28.86 \mathrm{ft}(8.19 \mathrm{~m})$ below TOC

Sp. conductance: $159 \mu \mathrm{s} / \mathrm{cm}$

PH: 5.4 . $3 \mathrm{mgn}$

Water evacuated bofore sampling: $11 \mathrm{gal}$

Water temperature: $23.0 \circ \mathrm{C}$

LABORATORY ANALYSES

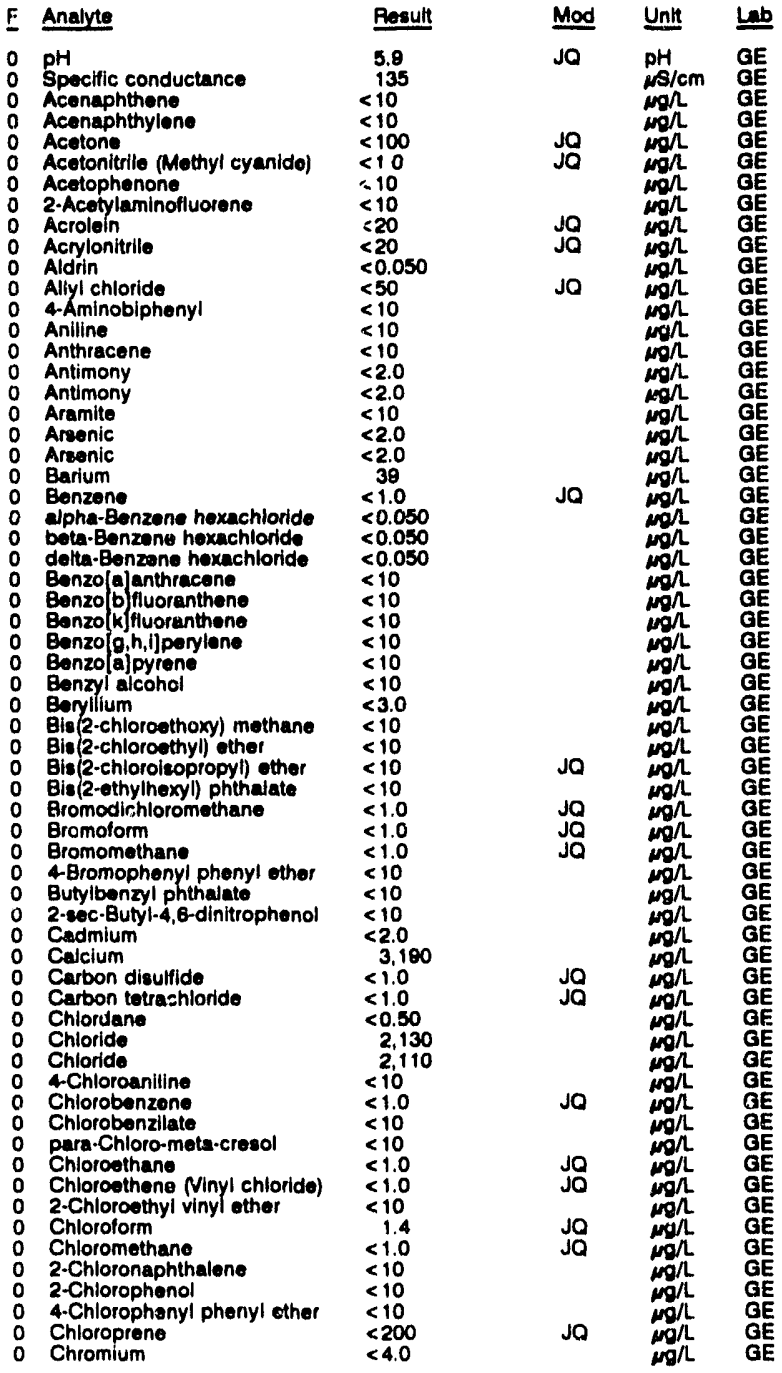


ANALYTICAL RESULTS

WELL HSL 60 collectod on 09/07/92, laboratory analyses (cont.)

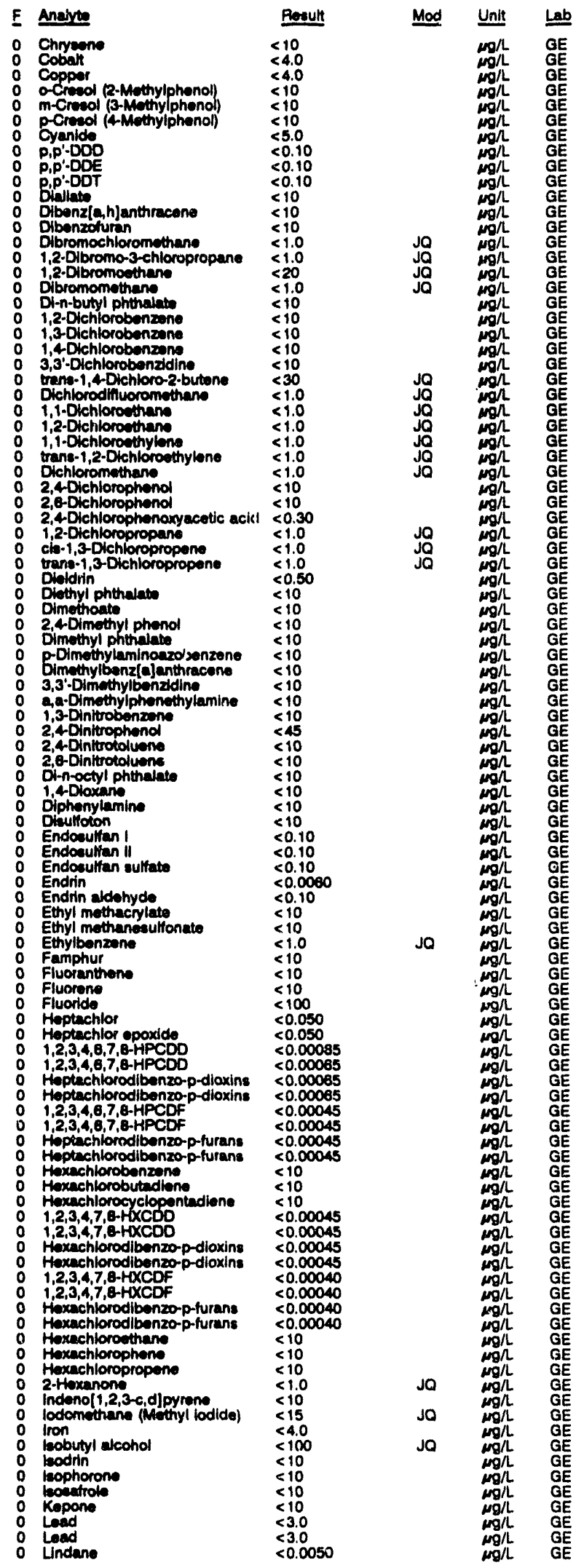

WELL HSL BD collected on $09 / 07 / 92$, laboratory analyses (cont.)

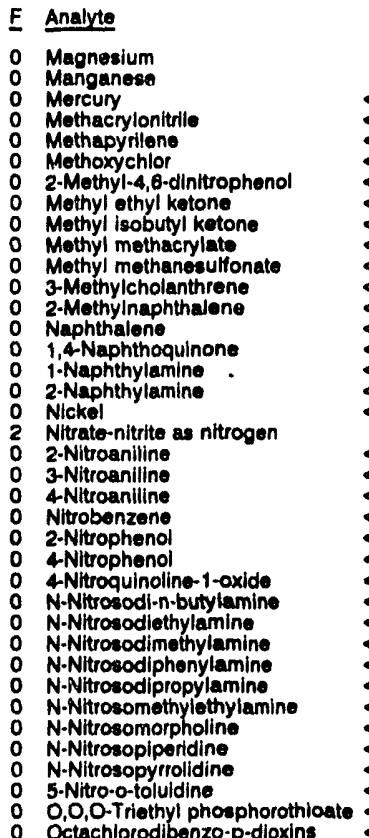

Octachlorodibenzo-p-dioxins

Octachlorodibenzo-p-dioxins

Octachlorodibenzo-p-furans

Parathion mothyl

PCE 1016

PCE 1221

O PCB 1242

O PCB 1248

PCB 1260

Pentachlorobenzene

$\begin{array}{lll}0 & 1,2,3,7,8-P C D D \\ 0 & 1,2,3,7,8-P C D D\end{array}$

Pontachlorodibenzo-p-dioxins

Pentachlorodibenzo-p-dioxins

Pentachlorodibonzo-p-furan

- Pentachlorodibenzo

$\begin{aligned} & 0 \\ & 0\end{aligned}, 2,3,7,8-P C D F$

Pentachloroethane

Pentachloronitrobenzene

Pentachlorophenol

Phenacotin

Phenanthre

Phenol

0
0
0 phenols

0 Phorate

O 2.Picoline

o Pronamid

o Proplonitrite

o Pyridine

Safrole

S

o Silica

O Silver

O Sodium

0 Sulfate

O Sulfato

0 Sulfotepp

1,2,4,5-Tetrachlorobenzen

2,3,7,8-TCDD

$\begin{array}{ll}0 & 2,3,7,8 \cdot T C O D \\ 0 & 2,3,7,8-T C D F\end{array}$

o $2,3,7,8-\mathrm{TCDF}$

o Totrachlorodibsnzo-p-dioxins

o Tetrachlorodibenzo-p-dioxins

o Tetrachlorodibonzo-p-furans

Totrachlorodibenzo-p-furans

1,1,1,2-Tetrachloroethane

Totrachloroothylene

2 3,4,6-Totrachlorophenol

0 Thallium
Result Mod Unit Le

1,850

$<0.20$

$<10$

$<0.50$

$<1.0$
$<1.0$
510

$\leqslant 10$

$<10$

$<10$

$<10$
$<10$

$<10$

$<18,400$

$<10$

$<10$

$<10$
$<10$

$<10$
$<10$

$<10$

$<10$

$<10$

$\leq 10$

$<10$

$<<10$

Mod Unit Leg

GE

$<10$
$<10$

$<<0.00045$

$<0.00045$

$<0.00040$

$<0.00045$

$<0.00040$

$<0.0004$

$<1.0$

$<1.0$
$<10$

$<10$
$<2.0$
$<2.0$ 
WELL HQL 80 colbeted on 09/07/82, laboratory analyees (cont.)

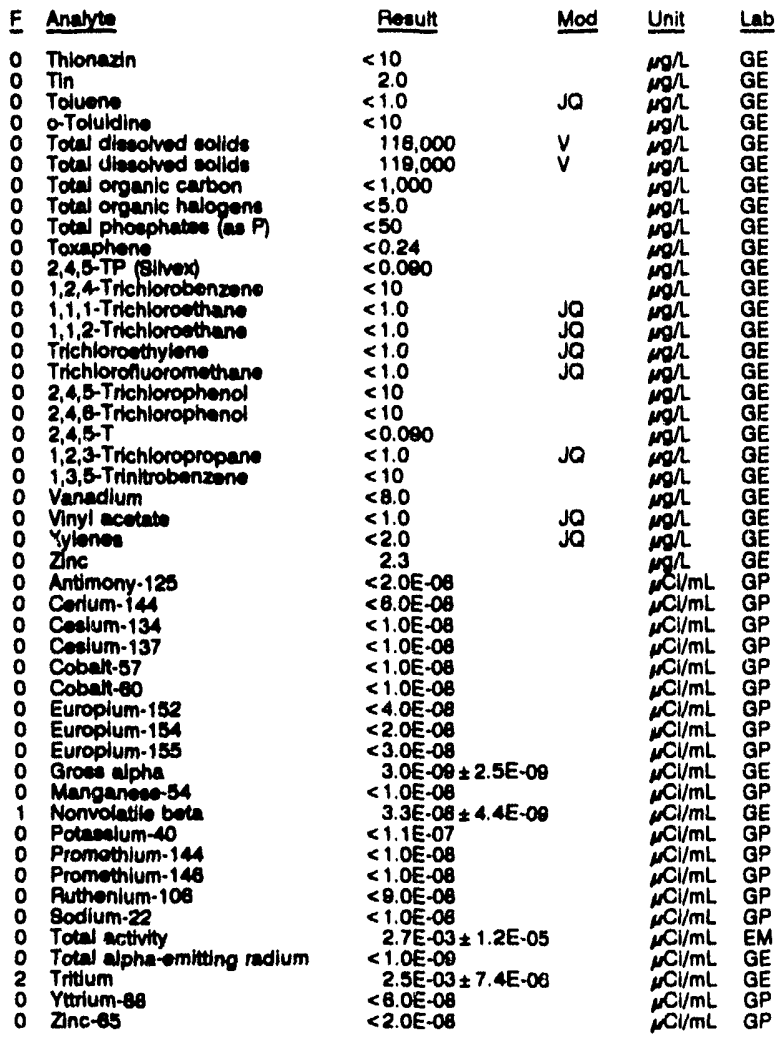

WELL HSS 1D

MEASUREMENTS CONDUCTED IN THE FIELD

Sample date: 07/10/02

Dopth to water: $40.48 \mathrm{n}(12.34 \mathrm{~m})$ below TOC

Sp. conductance: $31 \mathrm{es/ \textrm {cm }}$

Witer evecuatied bofore sampling: 21 gal

The well went dry during purging.

LABORATORY ANALYSES

\begin{tabular}{|c|c|c|c|c|c|}
\hline E & Anabte & Result & Mod & Unit & Lab \\
\hline $\begin{array}{l}0 \\
0 \\
0 \\
0 \\
0 \\
0 \\
0 \\
0 \\
0 \\
0 \\
0 \\
0\end{array}$ & 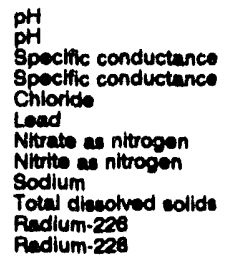 & $\begin{array}{l}5.8 \\
5.8 \\
26 \\
26 \\
1,830 \\
5.6 \\
1,310 \\
<10 \\
1,780 \\
37,000 \\
<1.0 E-09 \\
<1.0 E-09\end{array}$ & $\begin{array}{l}\text { JO } \\
\text { JO } \\
\text { JO } \\
\text { JO } \\
\text { J3 } \\
\text { JO }\end{array}$ & 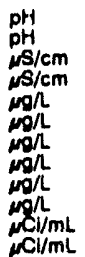 & $\begin{array}{l}\text { WA } \\
\text { WA } \\
\text { WA } \\
\text { WA } \\
\text { WA } \\
\text { WA } \\
\text { WA } \\
\text { WA } \\
\text { WA } \\
\text { WA } \\
\text { CN } \\
\text { CN }\end{array}$ \\
\hline
\end{tabular}

WELL HSS 20

MEASUREMENTS CONOUCTED IN THE FIELD

Sample date: 07,00/92

Depth to water: $35.74 \mathrm{n}(10.89 \mathrm{~m})$ below TOC

Water olvetion: $248.68 \mathrm{~h}$ (81.

Pp. conductunce: $20 \mathrm{\mu s/ \textrm {cm }} .60 \mathrm{~m}) \mathrm{ms}$

Wator ovecuated before eampling: $80 \mathrm{gal}$

LABOFATOFY ANALYSES

\begin{tabular}{|c|c|c|c|c|}
\hline$\underline{F}$ & Analyte & Resull & Mod & Unit \\
\hline $\begin{array}{l}0 \\
0 \\
0 \\
0 \\
0 \\
0 \\
0\end{array}$ & $\begin{array}{l}\text { pH } \\
\text { 8peclfic conductance } \\
\text { 8pectic conductance } \\
\text { Chloride } \\
\text { Chloride } \\
\text { Lead } \\
\text { Nitrate a nitrooen }\end{array}$ & $\begin{array}{l}5.5 \\
28 \\
28 \\
2.770 \\
2.770 \\
<2.0 \\
1,120\end{array}$ & $\begin{array}{l}\mathrm{JO} \\
\mathrm{J} Q \\
\mathrm{JO}\end{array}$ & $\begin{array}{l}\mathrm{pH} \\
\mu \mathrm{s} / \mathrm{cm} \\
\mu \mathrm{S} / \mathrm{cm} \\
\mathrm{mg} / \mathrm{h} \\
\mathrm{mgh} / \mathrm{L} \\
\mathrm{mgh} \\
\mathrm{mg} / \mathrm{L}\end{array}$ \\
\hline
\end{tabular}

WELL HSS 2D collected on 07/09/92, laboratory analyese (cont)

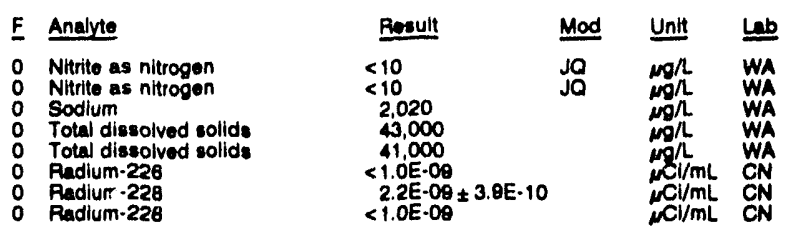

WELL HSS 3D

MEASUAEMENTS CONDUCTED IN THE FIELD

Depth to water: $27.67 \mathrm{ft}(8.43 \mathrm{~m})$ bolow TOC

Water elovation: $282.13 \mathrm{~h}(85.89 \mathrm{~m}) \mathrm{msl}$

Sp. conductance: $28 \mu \mathrm{s} / \mathrm{cm}$

Wator evacuatod bolore anmpling: $18 \mathrm{gal}$

The wall went dry during purging.

LABOFATORY ANALYSES
E Analute

SpH

Chloride

2 Lead

Nitrate as nitrogen

Nitrite as nitrogen

Total dissolved sollds

Radium-226
Radium-228
Time: 11:10

PH: 4.4: 0 mglinity:

Water tomperature: $21.4^{\circ} \mathrm{C}$

\section{WELL HTF 1}

MEASUREMENTS CONDUCTED IN THE FIELO

Sample date: 08/24/92

Depth to water: $7.50 \mathrm{ft}(2.29 \mathrm{~m})$ below TOC

Water olevation: $274.50 \mathrm{Ht}(83$.

No waler was evacuated before sampling.

Time: 10:30

Water temperature: 31.000

LABORATORY ANALYSES

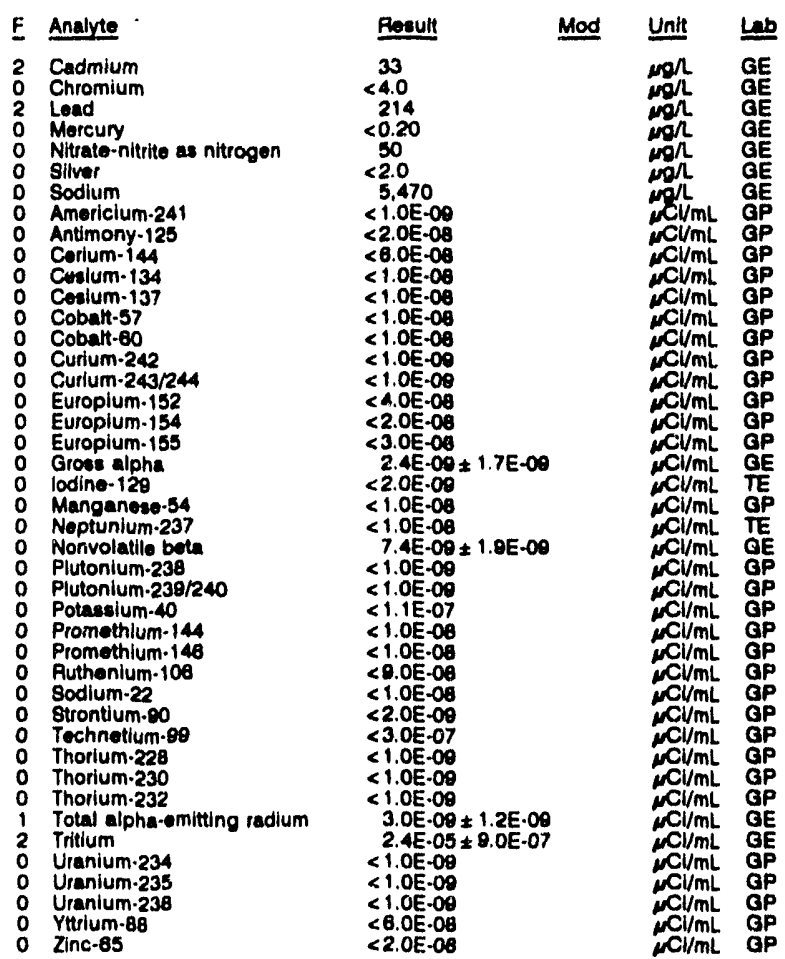


ANALYTICAL RESULTS

WELL HTF 2

MEASUREMENTS CONDUCTED IN THE FIELD

Sample dete: $08 / 2492$
inacceedibility of mechanical problem preventod sample coliection.

\section{WELL HTF 3}

MEASUREMENTS CONDUCTED IN THE FIELL

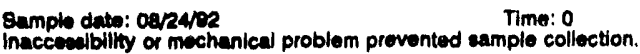

WELL HTF 4

MEABUREMENTS CONDUCTED IN THE FIELD

Sample dato: caraper Time: 0

\section{WELL HTF 5}

MEASUREMENTS CONDUCTED IN THE FIELD

Sample dab: Oarwpe
inaccealbility or mechanical problem provented sample colloction.

Sample dati: Oarwer
inaccealbility or mechanical problem provented sample colloction.

\section{WELL HTF 6}

MEASUREMENTS CONOUCTED IN THE FIELD

Sample date: Daraver Time: 0

Inaccesalblity or mechanical problem provented sample collection

\section{WELL HTF 7}

MEASUREMENTS CONDUCTEO IN THE FIELD

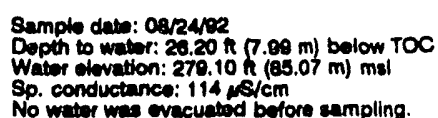

Time: $9: 40$

so. conductance: $114 / \mathrm{s} / \mathrm{cm}$

Water tomperature: $25.2^{\circ} \mathrm{C}$

LABORATOFY ANALYSES

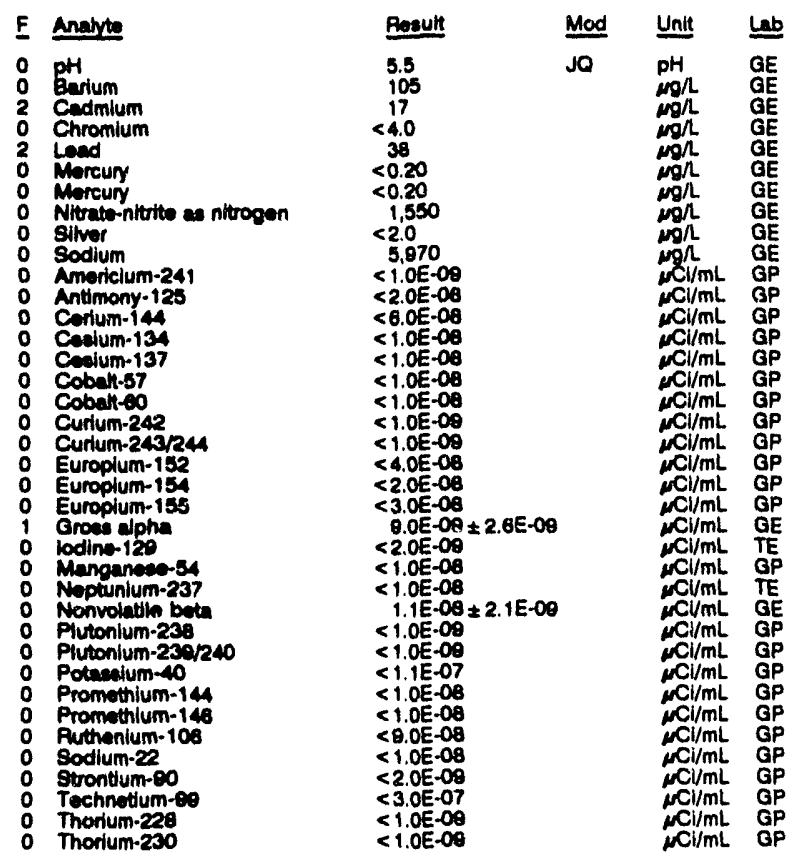

\begin{tabular}{|c|c|c|c|}
\hline Analyte & Resulh & Mod & Unit \\
\hline $\begin{array}{l}\text { Thorium-232 } \\
\text { Total alpha-emitting ractium } \\
\text { Tritium } \\
\text { Tritium } \\
\text { Uranlum-234 } \\
\text { Uranium-235 } \\
\text { Uranium-238 } \\
\text { Yttrium-88 } \\
\text { Znc- } 65\end{array}$ & $\begin{aligned}<1.0 E-09 \\
1.3 \mathrm{E}-08 \pm 2.7 \mathrm{E}-09 \\
1.4 \mathrm{E}-05 \pm 7.0 \mathrm{E}-07 \\
1.3 \mathrm{E}-05 \pm 7.0 \mathrm{E}-07 \\
<1.0 \mathrm{E}-09 \\
<1.0 \mathrm{E}-00 \\
<1.0 \mathrm{E}-00 \\
<6.0 \mathrm{E}-08 \\
<2.0 \mathrm{E}-08\end{aligned}$ & & 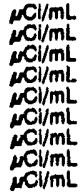 \\
\hline
\end{tabular}

\section{WELL HTF 8}

MEASUREMENTS CONDUCTED IN THE FIELO

Sample date: $08 / 24 / 92$
inacceesibility or mochanical problem prevented sample collection.

\section{WELL HTF 9}

MEASUREMENTS CONDUCTED IN THE FIELD

\begin{tabular}{|c|c|}
\hline $\begin{array}{l}\text { Sample date: 08/21/92 } \\
\text { Depth to water: } 48.50 \mathrm{~h}(14.78 \mathrm{~m}) \text { below TOC } \\
\text { Water elevation: } 275.50 \mathrm{ft}(83.97 \mathrm{~m}) \mathrm{mal}\end{array}$ & $\begin{array}{l}\text { Time: } 10: 20 \\
\text { pH: } 6.3\end{array}$ \\
\hline $\begin{array}{l}\text { Sp. conductance: } 73 \mu \mathrm{s} / \mathrm{cm} \\
\text { No water was ovacuated bofore sampling. }\end{array}$ & erature: $25.7^{\circ} \mathrm{C}$ \\
\hline
\end{tabular}

Sp. conductance: $73 \mu \mathrm{s} / \mathrm{cm}$
No water was ovacuatod bofore sampling.

LABORATORY ANALYSES

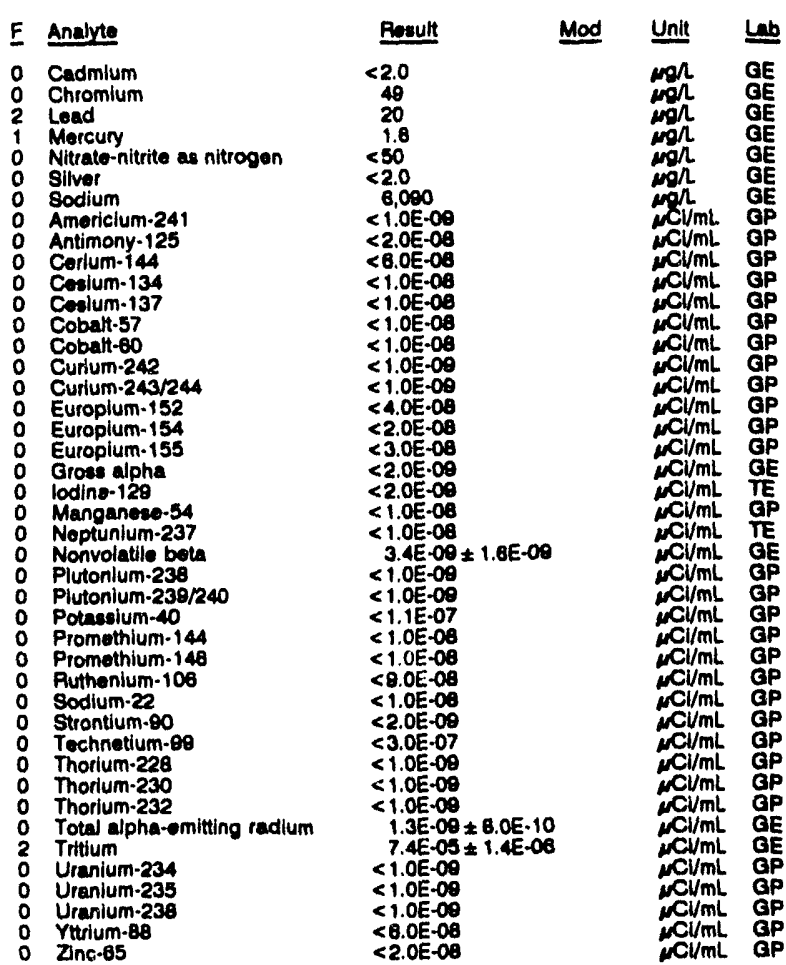

\section{WELL HTF 10}

MEASUREMENTS CONDUCTED IN THE FIELD

Sample date: 08/2192

Depth to water: $47.00 \mathrm{Ht}(14.33 \mathrm{~m})$ below TOC Water elevation: $275.70 \mathrm{~h}(84.03 \mathrm{~m}) \mathrm{ms}$

Sp. conductance: $152 \mathrm{\mu S} / \mathrm{cm}$.

LABOPATOAY ANALYSES

\begin{tabular}{|c|c|c|c|c|}
\hline $\boldsymbol{E}$ & Analyte & Prosult & Mod & Unit \\
\hline $\begin{array}{l}2 \\
0 \\
0\end{array}$ & $\begin{array}{l}\text { Cadmium } \\
\text { Chromium } \\
\text { Lead } \\
\text { Mercury }\end{array}$ & $\begin{array}{c}15 \\
<4.0 \\
3.2 \\
0.32\end{array}$ & & $\begin{array}{c}\operatorname{mon} \Omega \\
\operatorname{mon} h \\
\operatorname{mon}\end{array}$ \\
\hline
\end{tabular}


WEUL MTF 10 collectad on 0Q/21/92, laboratory analyese (cont.)

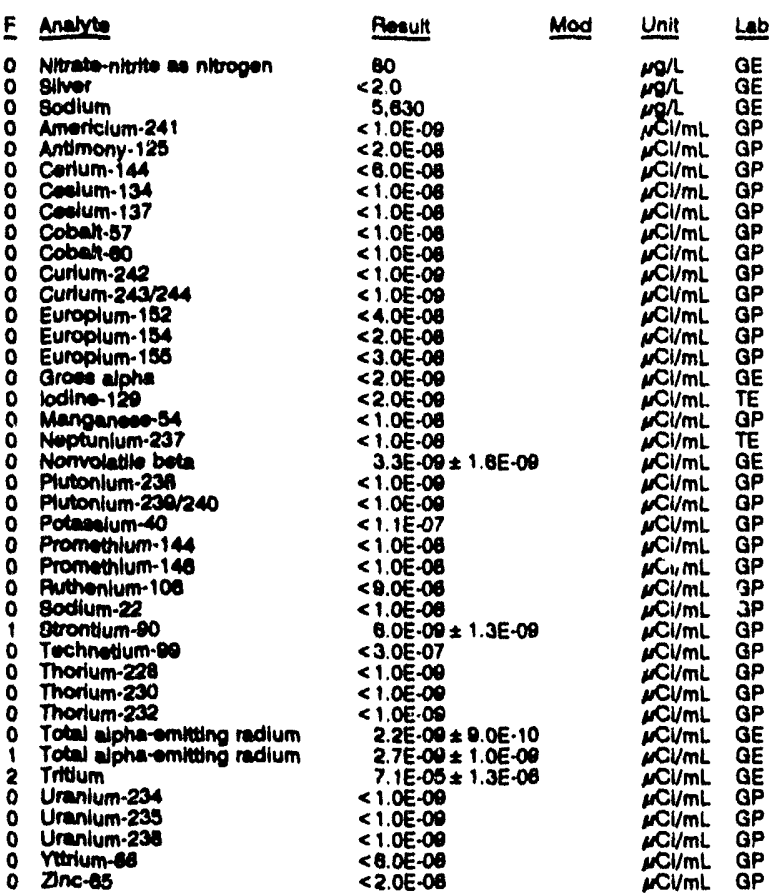

WELL HTF 11
MEASUREMENTS CONDUCTED IN THE FIELD

\section{Sample dato: 0ar21/02}

Depth to water: $40.30 \mathrm{~N}(14.17 \mathrm{~m})$ below TOC Water olovation: $276.30 \mathrm{~h}$ (1)

Sp. conductanca: 22 s/cm

LABOAMTOFY ANALYSES

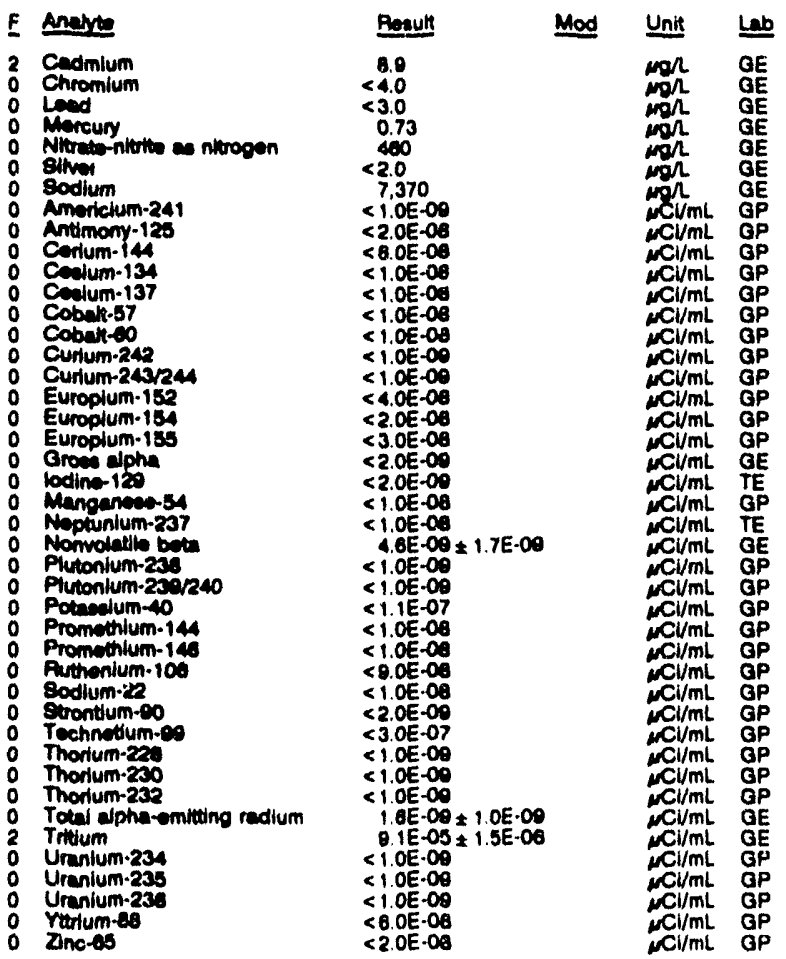

WELL HTF 12

MEASUAEMENTS CONDUCTEO IN THE FIELD

Sample date: 08/21/92

Depth to water: $47.00 \mathrm{ft}(14.33 \mathrm{~m})$ below TOC $\operatorname{Time:}_{\mathrm{pH}: 6.2}$

Water olevation: $275.00 \mathrm{ht}(84.10$

Sp. conductance: $79 \mu \mathrm{s} / \mathrm{cm}$
No wator was ovacuated bolore eampling.

Water temperature: $28.2 \cdot \mathrm{C}$

LABORATORY ANALYBES

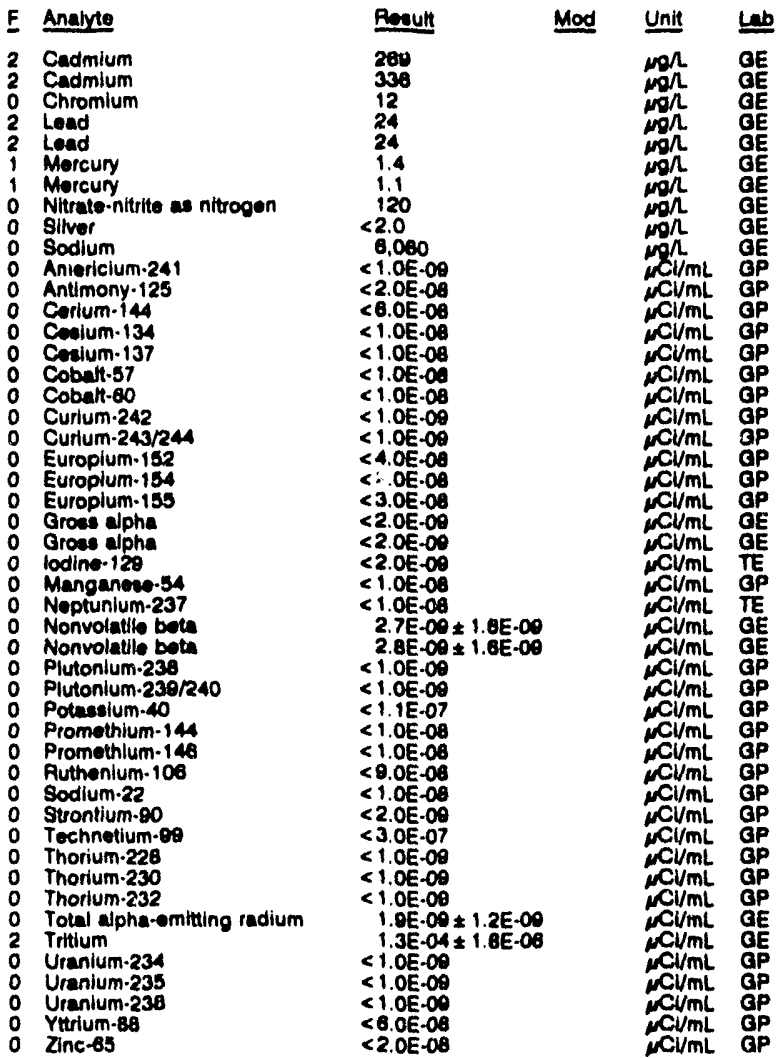

WELL HTF 13

MEASUREMENTS CONOUCTED IN THE FIELD

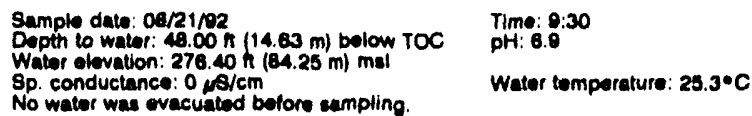

No water was evacuated botore sumpling

LABOPATORY ANALYSES

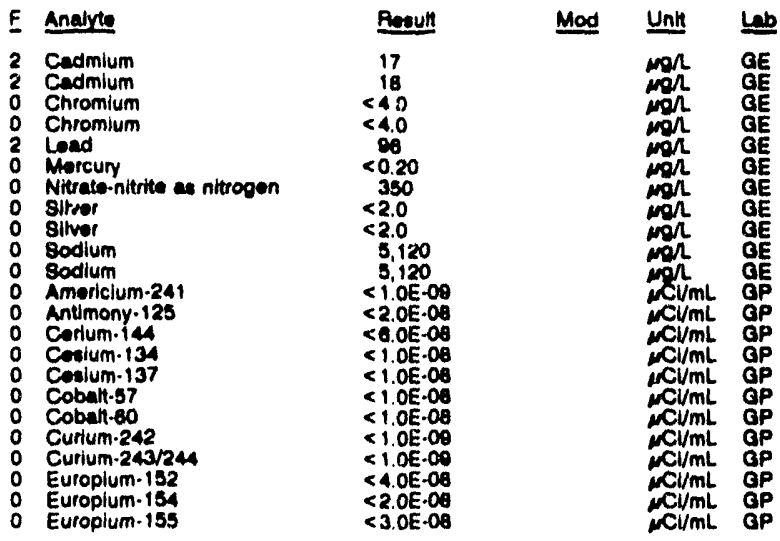


ANALYTICAL RESULTS

WELL HTF 13 collected on 08/21/82, laboratory analyees (cont)

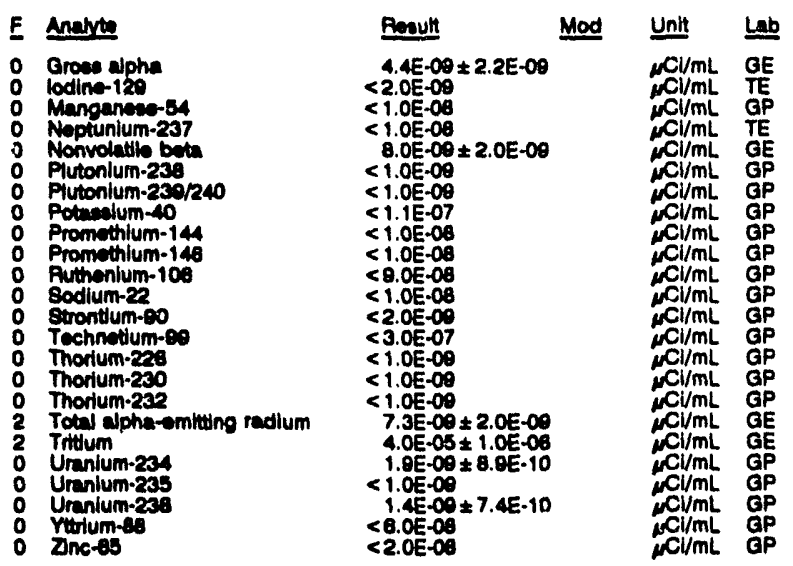

\section{WELL HTF 14}

MEASUREMENTS CONDUCTED IN THE FIELD

\begin{tabular}{|c|c|c|c|c|c|}
\hline \multicolumn{3}{|c|}{ 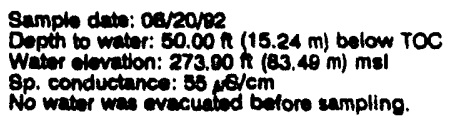 } & \multicolumn{3}{|c|}{$\begin{array}{l}\text { Tlme: } 14: 30 \\
\text { PH: } 5.3 \\
\text { Water temperature: } 28.9 \cdot \mathrm{C}\end{array}$} \\
\hline \multicolumn{6}{|c|}{ LABORATOFY ANALYBES } \\
\hline E & Anave & Rescult & Mod & Unit & $\underline{L a b}$ \\
\hline $\begin{array}{l}0 \\
2 \\
0 \\
0 \\
0 \\
0 \\
0 \\
0 \\
0 \\
0 \\
0 \\
0 \\
0 \\
0 \\
0 \\
0 \\
0 \\
0 \\
0 \\
0 \\
0 \\
0 \\
0 \\
0 \\
0 \\
0 \\
0 \\
0 \\
0 \\
0 \\
0 \\
0 \\
0 \\
0 \\
0 \\
0 \\
2 \\
0 \\
0 \\
0 \\
0 \\
0\end{array}$ & 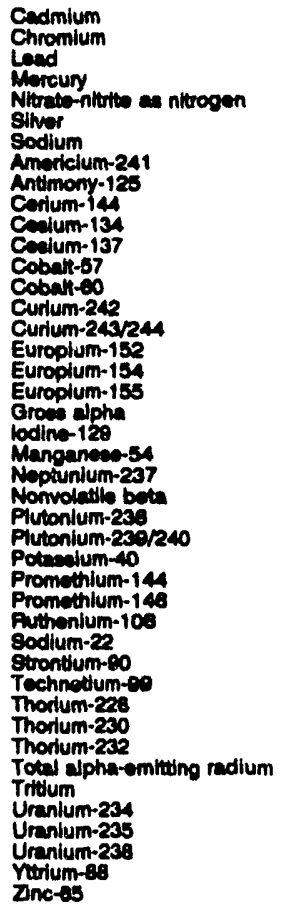 & $\begin{array}{r}27 \\
<A .0 \\
101 \\
0.63 \\
2.080 \\
<2.0 \\
3.350 \\
<1.0 E-0 \\
<2.0 E-0 \\
<8.0 E-0 \\
<1.0 E-0 \\
1.3 E-0 \\
<1.0 E-0 \\
<1.0 E-0 \\
<1.0 E-0 \\
<1.0 E-0 \\
<4.0 E-0 \\
<2.0 E-0 \\
<3.0 E-0 \\
2.4 E-0 \\
<2.0 E-0 \\
<1.0 E-0 \\
<1.0 E-0 \\
1.1 E-0 \\
<1.0 E-0 \\
<1.0 E-0 \\
<1.1 E-0 \\
<1.0 E-0 \\
<1.0 E-0 \\
<8.0 E-0 \\
<1.0 E-0 \\
<2.0 E-0 \\
<3.0 E-0 \\
<1.0 E-0 \\
<1.0 E-0 \\
<1.0 E-0 \\
1.0 E-0 \\
4.4 E-0 \\
<1.0 E-0 \\
<1.0 E-0 \\
<1.0 E-0 \\
<6.0 E-0 \\
<2.0 E-0\end{array}$ & $\begin{array}{l}\text { E-10 } \\
\text { E-06 }\end{array}$ & 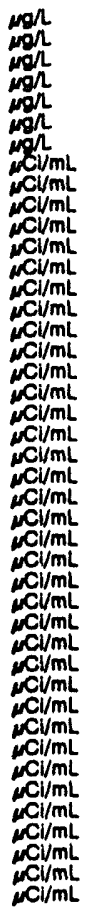 & $\begin{array}{l}G E \\
G E \\
G E \\
G E \\
G E \\
G E \\
G E \\
G P \\
G P \\
G P \\
G P \\
G P \\
G P \\
G P \\
G P \\
G P \\
G P \\
G P \\
G P \\
G E \\
T E \\
G P \\
T E \\
G E \\
G P \\
G P \\
G P \\
G P \\
G P \\
G P \\
G P \\
G P \\
G P \\
G P \\
G P \\
G P \\
G E \\
G E \\
G P \\
G P \\
G P \\
G P \\
G P\end{array}$ \\
\hline
\end{tabular}

WELL HTF 15

MEASUREMENTS CONDUCTED IN THE FIELO

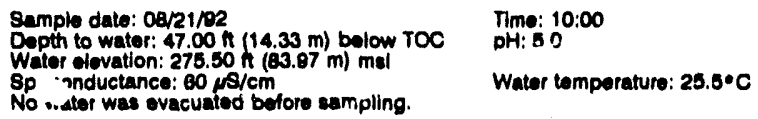

LABORATORY ANALYSES

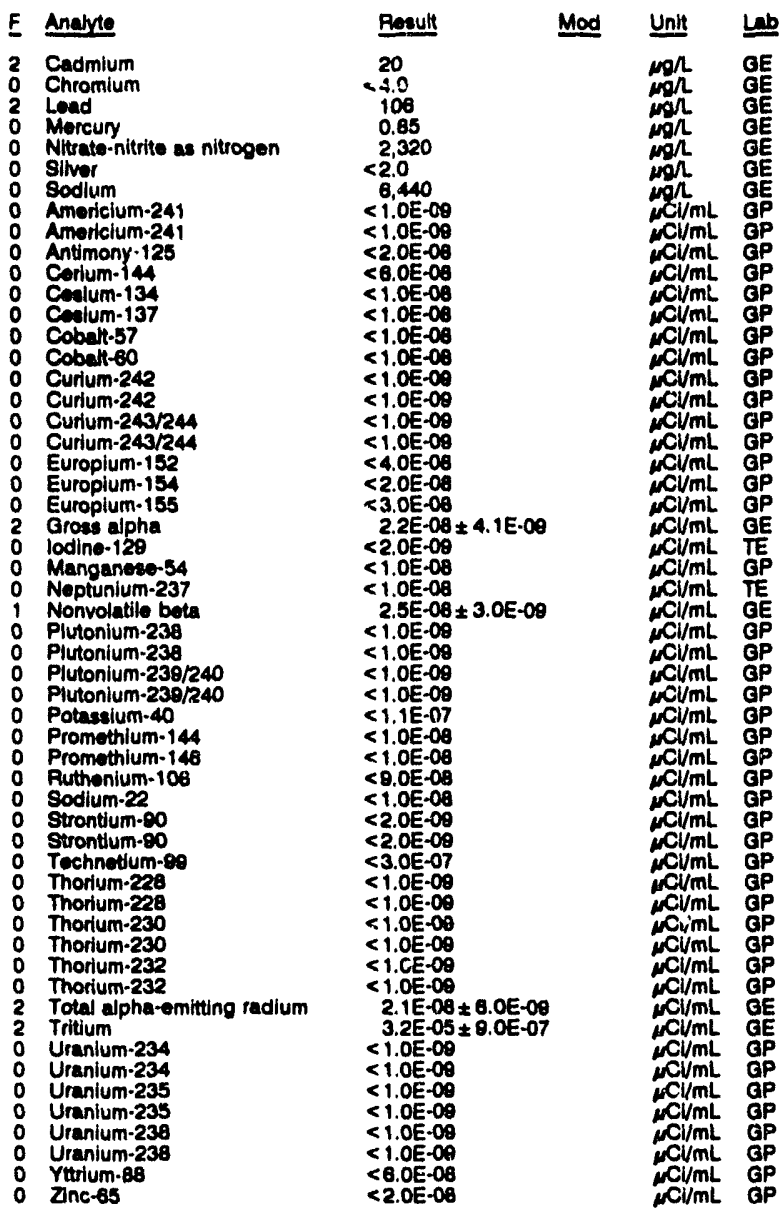

WELL HTF 16

MEASUREMENTS CONDUCTED IN THE FIELD

Sample dato: 08/24/92

Dopth to water: $28.00 \mathrm{Ht}(7.92 \mathrm{~m})$ bolow TOC

Wator olevation: $274.30 \mathrm{~h}(83.81 \mathrm{~m}) \mathrm{mel}$

Sp. conductance: $56 \mu \mathrm{\mu} / \mathrm{cm}$

No water was evacualod before sempling.

LABOPATOAY ANALYSES

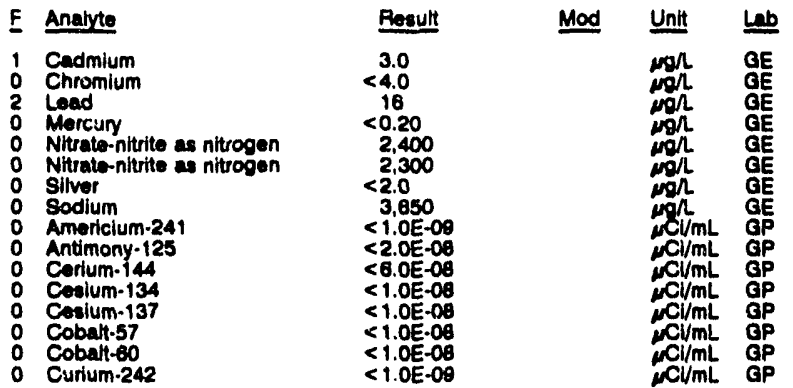


WELL HTF 18 collecteor on 08/24/82, laboratory analyeses (cont)

\begin{tabular}{|c|c|c|c|}
\hline E Andsce & Renult & Unit & Lab \\
\hline 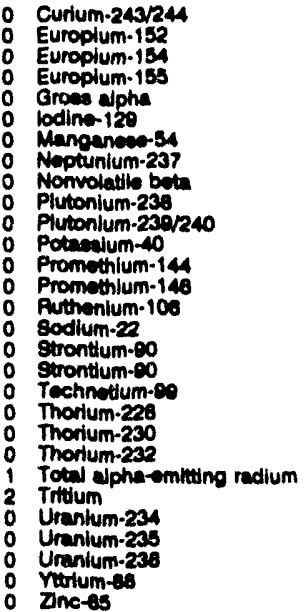 & 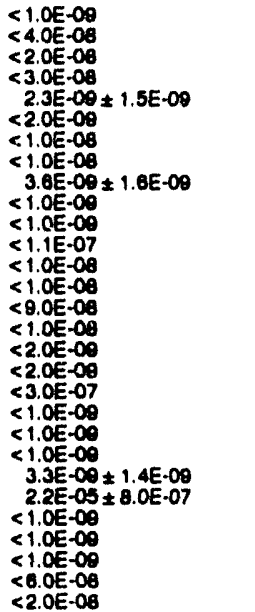 & 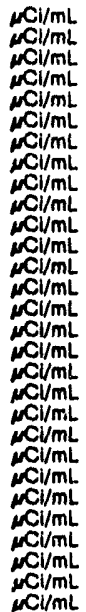 & $\begin{array}{l}G P \\
G P \\
G P \\
G P \\
G E \\
T E \\
G P \\
T E \\
G E \\
G P \\
G P \\
G P \\
G P \\
G P \\
G P \\
G P \\
G P \\
G P \\
G P \\
G P \\
G P \\
G P \\
G E \\
G E \\
G P \\
G P \\
G P \\
G P \\
G P\end{array}$ \\
\hline
\end{tabular}

WELL HTF 17

MEASUREMENTS CONOUCTED IN THE FIELO

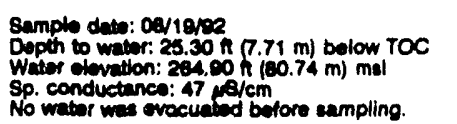

$\operatorname{Time:}_{\text {PH: } 5.1}{ }^{10: 30}$

Sp. conductence: $47 \mathrm{~s} / \mathrm{cm}$

Water temperature: $25.0 \circ \mathrm{C}$

LABOPUTORY ANULYYES

\begin{tabular}{|c|c|c|}
\hline Anate & Result & Unit \\
\hline 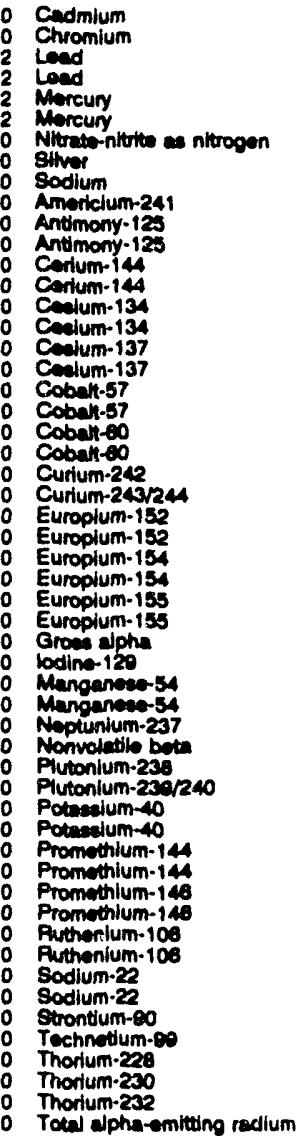 & $\begin{array}{l}2.3 \\
7.4 \\
17 \\
17 \\
2.1 \\
2.1 \\
3.050 \\
<2.0 \\
3.010 \\
<1.0 E-09 \\
<2.0 E-08 \\
<2.0 E-08 \\
<8.0 E-08 \\
<6.0 E-08 \\
<1.0 E-08 \\
<1.0 E-08 \\
<1.0 E-08 \\
<1.0 E-08 \\
<1.0 E-08 \\
<1.0 E-08 \\
<1.0 E-08 \\
<1.0 E-08 \\
<1.0 E-08 \\
<1.0 E-09 \\
<4.0 E-08 \\
<4.0 E-08 \\
<2.0 E-08 \\
<2.0 E-08 \\
<3.0 E-08 \\
<3.0 E-08 \\
2.6 E-09 \pm 1.5 E-09 \\
<2.0 E-09 \\
<1.0 E-08 \\
<1.0 E-08 \\
<1.0 E-08 \\
4.5 E-09 \pm 1.6 E-09 \\
<1.0 E-09 \\
<1.0 E-09 \\
<1.1 E-07 \\
<1.1 E-07 \\
<1.0 E-08 \\
<1.0 E-08 \\
<1.0 E-08 \\
<1.0 E-08 \\
<8.0 E-08 \\
<\theta .0 E-08 \\
<1.0 E-08 \\
<1.0 E-08 \\
<2.0 E-09 \\
<3.0 E-07 \\
<1.0 E-09 \\
<1.0 E-09 \\
<1.0 E-09 \\
1.1 E-09 \pm 5.0 E-10\end{array}$ & 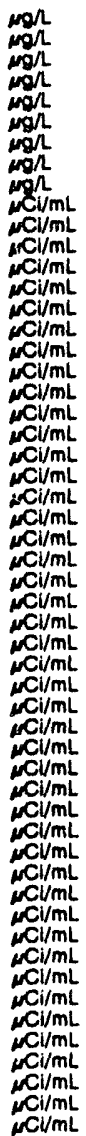 \\
\hline
\end{tabular}

WELL HTF 17 collected on 08/18/02, laboratory analyeese (cont)

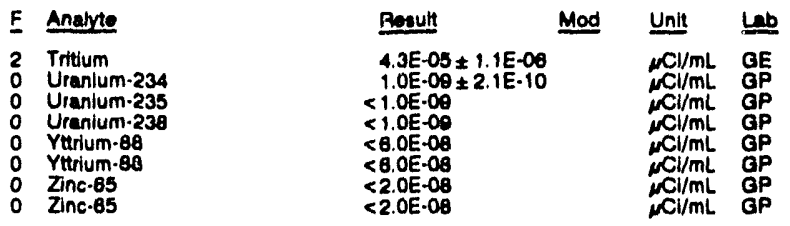

\section{WELL HTF 18}

MEASUREMENTS CONDUCTED IN THE FIELD

\begin{tabular}{|c|c|}
\hline $\begin{array}{l}\text { Sample date: } 08 / 20 / 02 \\
\text { Depth to water: } 50.00 \mathrm{n}(15.24 \mathrm{~m}) \text { below TOC }\end{array}$ & $\prod_{\mathrm{pH}:}: \mathbf{1 4}$ \\
\hline $\begin{array}{l}\text { Sp. conductance: } 60 \mu \mathrm{N} / \mathrm{cm} \\
\text { No water was evacuated before sampling. }\end{array}$ & ature: $28.5^{\circ} \mathrm{C}$ \\
\hline
\end{tabular}

LABORATORY ANALYSES

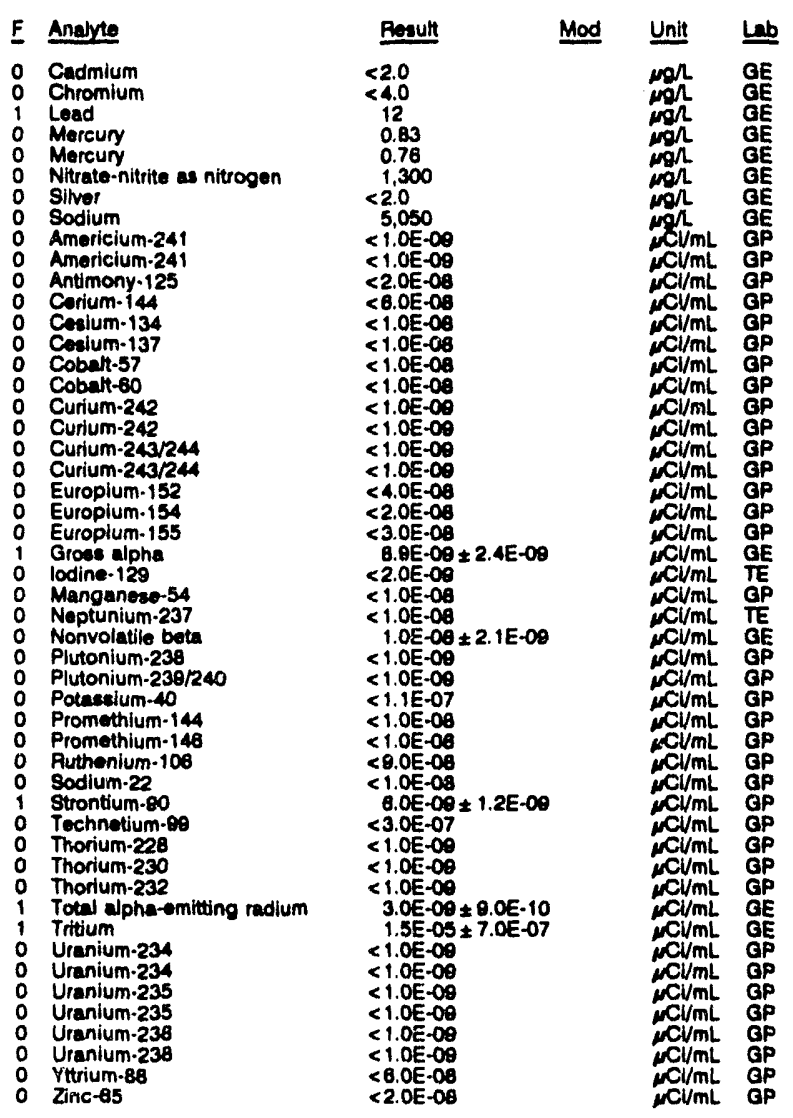

\section{WELL HTF 19}

MEASUREMENTS CONDUCTED IN THE FIELD

Sample date: 08/20/92

Depth to water: $30.80 \mathrm{~h}(16.40 \mathrm{~m})$ bolow TOC
Water elevation: $271.00 \mathrm{~h}(82.80 \mathrm{~m}) \mathrm{ms}$
Sp. conductance: $48.5 \mathrm{~cm}$

Water temperature: $28.5 \circ \mathrm{C}$

No wathe was evecuatisd before campling.

LABORATORY ANALYSES

\begin{tabular}{|c|c|c|c|c|}
\hline$\underline{F}$ & Analyte & Result & Mod & Unit \\
\hline $\begin{array}{l}0 \\
0 \\
0 \\
0 \\
0 \\
0 \\
0 \\
0\end{array}$ & $\begin{array}{l}\text { Cadmium } \\
\text { Chromium } \\
\text { Lead } \\
\text { Lead } \\
\text { Mercury } \\
\text { Nitrate-nitrite as nitrogen } \\
\text { Silver } \\
\text { Sodium }\end{array}$ & $\begin{array}{l}<2.0 \\
<4.0 \\
6.8 \\
7.0 \\
0.23 \\
463 \\
<2.0 \\
2.430\end{array}$ & & 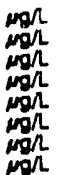 \\
\hline
\end{tabular}


ANALYTICAL RESULTS

WELL HTF 19 collectiod on 08/20/92, laboratory analyses (cont)

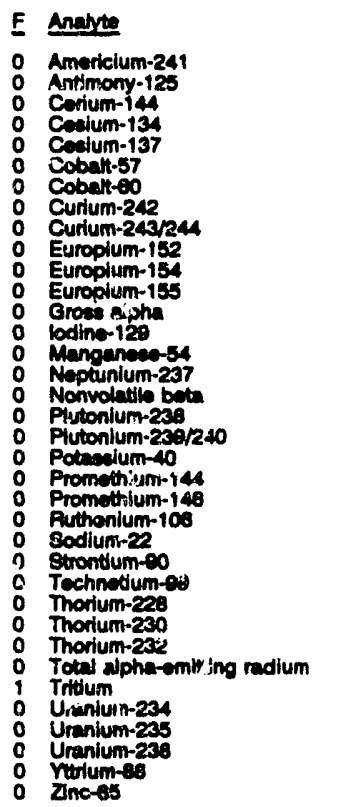

Pensult

$<1.06-00$

$<6.0 \mathrm{E}-0 \mathrm{~B}$

$<1.0 E-08$

$<1.0 \mathrm{E}-08$

$<1.0 E-09$

$<1.05-09$

$<4.06-08$

$<3.02-06$

$3.1 E-09 \pm 1.6 E-09$

$<2.0 E-09$

$<1.00 .08$

$4.1 E-09 \pm 1.3 E-09$

$<1.0 E-09$

$<1.1$ E.07

$<1.0 \mathrm{E}-08$

$<0.05-08$

$<1.0 \mathrm{E}-08$

$<2.0 E-09$

$<1.0 E-00$

$<1.05-\infty$

$<1.05-09$

1. $6 \mathrm{E}-09 \pm 7.0 \mathrm{E}-10$

$<1.05-09$

$<1.0 E-09$

$<6.0$ E- 00

\begin{tabular}{|c|c|}
\hline Mod & Unit \\
\hline & 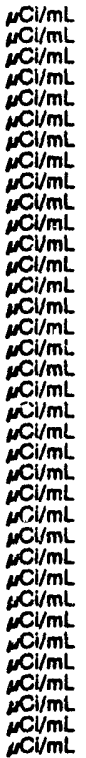 \\
\hline
\end{tabular}

WELL HTF 20

MEASUREMENTS CONDULCTED IN THE FIELD

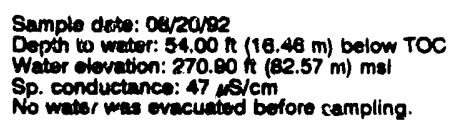

Tims: $13: 00$

PH: 4.9

No water was evecuated before campling

Water temperature: $01.8^{\circ} \mathrm{C}$

LABORATORY ANALYSES

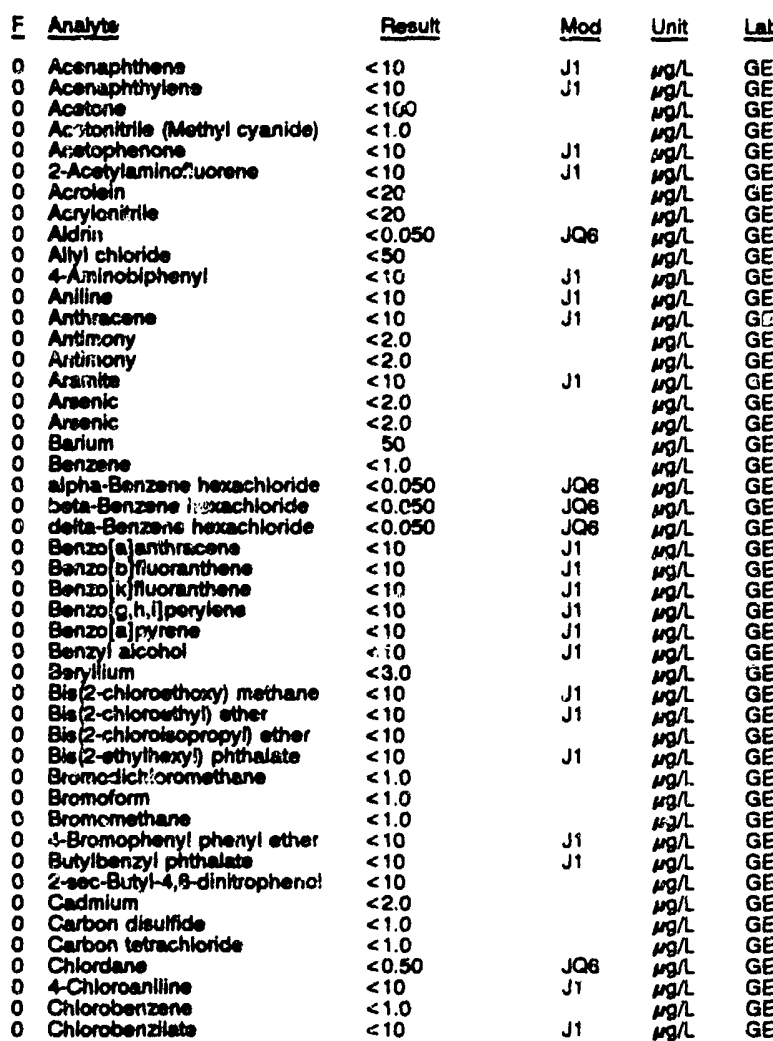

WELL HTF 20 collected on 08/20/82, laboratory analyese (cont.)

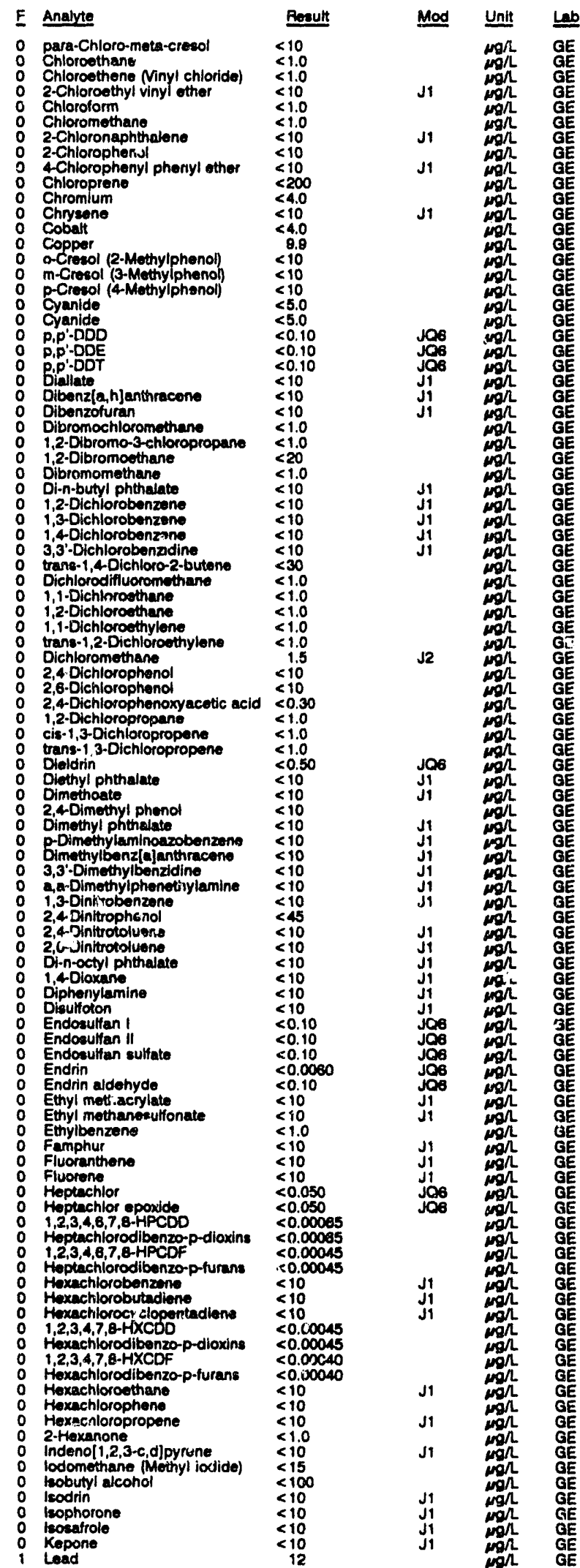


WELL HTF 20 collected on 08/20/92, laboratory analyees (cont)

\begin{tabular}{|c|c|c|c|c|c|c|}
\hline Analyte & Result & Mod & Unit & Lab & $E$ & Analyte \\
\hline 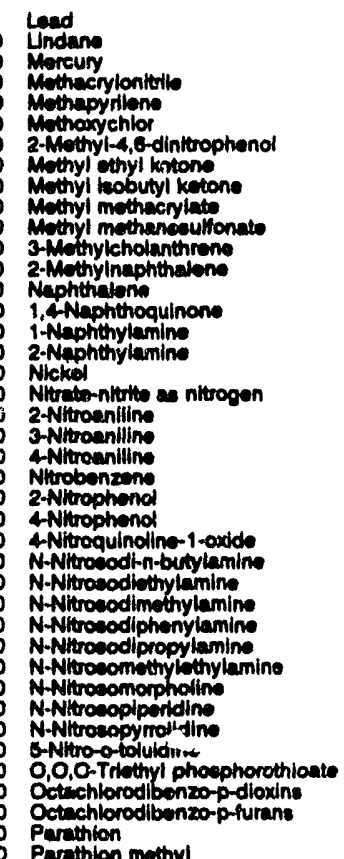 & $\begin{array}{l}13 \\
<0.0050 \\
0.64 \\
<50 \\
<10 \\
<0.50 \\
<10 \\
<1.0 \\
<1.0 \\
<10 \\
<10 \\
<10 \\
<10 \\
<10 \\
<10 \\
<10 \\
<10 \\
10 \\
2,550 \\
<10 \\
<10 \\
<10 \\
<10 \\
<10 \\
<10 \\
<10 \\
<10 \\
<10 \\
<10 \\
<10 \\
<10 \\
<10 \\
<10 \\
<10 \\
<10 \\
<10 \\
<10 \\
<0.0010 \\
<0.0010 \\
<0.050\end{array}$ & 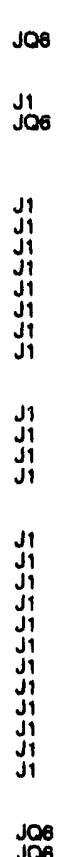 & 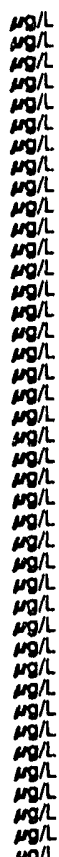 & $\begin{array}{l}G E \\
G E \\
G E \\
G E \\
G E \\
G E \\
G E \\
G E \\
G E \\
G E \\
G E \\
G E \\
G E \\
G E \\
G E \\
G E \\
G E \\
G E \\
G E \\
G E \\
G E \\
G E \\
G E \\
G E \\
G E \\
G E \\
G E \\
G E \\
G E \\
G E \\
G E \\
G E \\
G E \\
G E \\
G E \\
G E \\
G E \\
G E \\
G E\end{array}$ & $\begin{array}{l}0 \\
0 \\
0 \\
0 \\
0 \\
0 \\
0 \\
0 \\
0 \\
0 \\
0 \\
0 \\
0 \\
0 \\
0 \\
0 \\
0 \\
0 \\
0 \\
0 \\
0 \\
0 \\
0 \\
0 \\
0 \\
0 \\
0 \\
0 \\
0 \\
0 \\
0 \\
J \\
0 \\
2 \\
1 \\
0 \\
0 \\
0 \\
0 \\
0\end{array}$ & 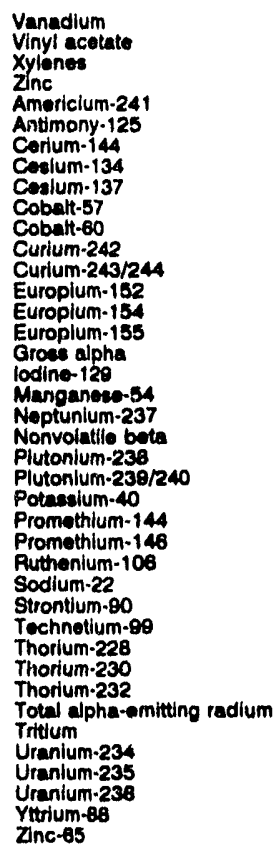 \\
\hline
\end{tabular}

WELL HTF 20 collected on 08/20/82, laboratory analyees (cont.)

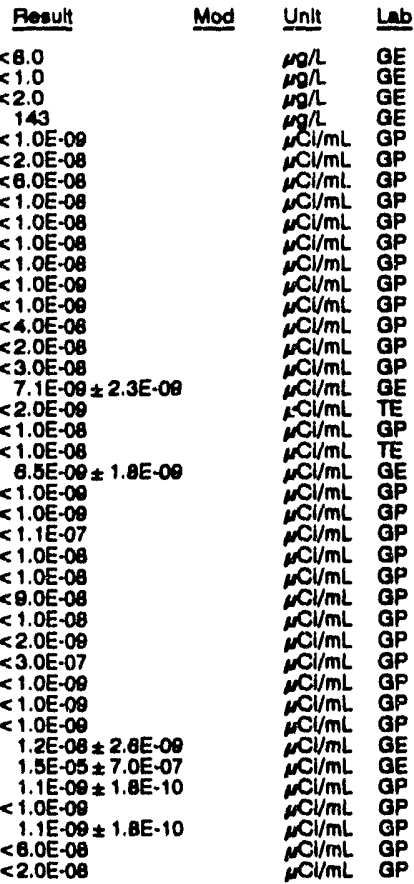

\section{WELL HTF 21}

MEASUREMENTS CONDUCTED IN THE FIELD

Depth to water: $32.00 \mathrm{n}(15.65 \mathrm{~m})$ below TOC

Whtor olovation: $272.70 \mathrm{~h}(83.12 \mathrm{~m}) \mathrm{msl}$

No water was evacuated before campling.

LABORATOAY ANALYSES

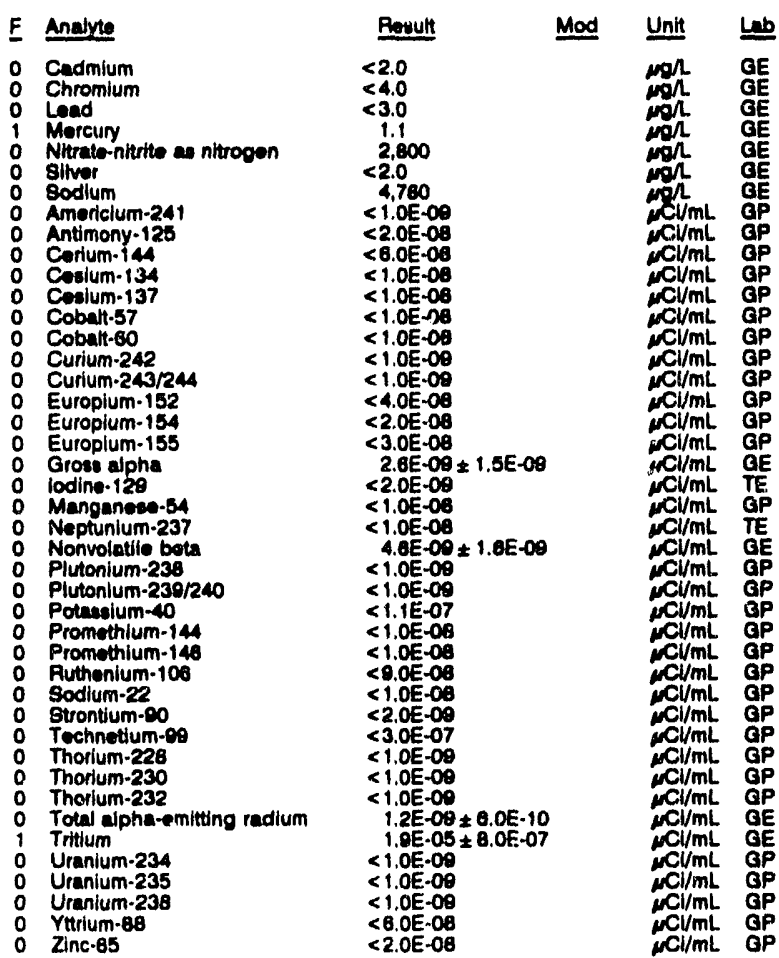


ANALYTICAL RESULTS

WELL. HTF 22

MEASUAEMENTS CONDUCTED IN THE FIELD

Sample data: 00/19pe

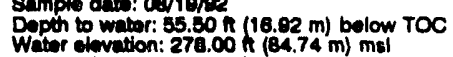
Sp. conductance: $140 \mu \mathrm{s} / \mathrm{cm}$.

LABORATOFY ANALYSES

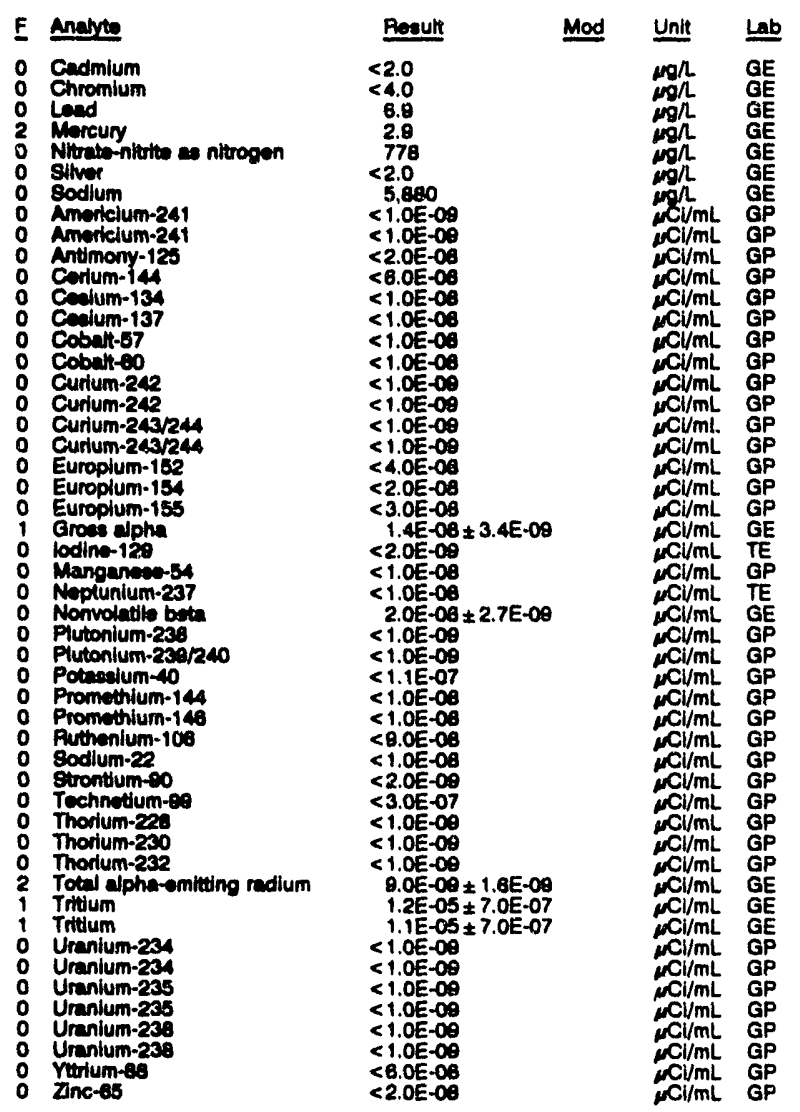

\section{WELL HTF 23}

MEASUREMENTS CONDUCTED IN THE FIELD

\begin{tabular}{|c|c|}
\hline & $\begin{array}{l}\text { date: 08/19/92 } \\
\text { to weito: } 577.40 \mathrm{H} \\
\text { lovetion: } 276.00 \mathrm{~h} \\
\text { nductunce: } 120\end{array}$ \\
\hline & BORATOFY ANALYSES \\
\hline & Analyte \\
\hline & 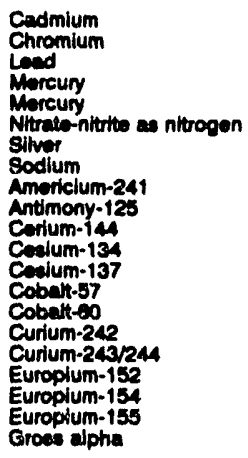 \\
\hline
\end{tabular}

Tima: 12:45

Water tomporature: $30.1{ }^{\circ} \mathrm{C}$

Time: 13:15

Water temperature: $30.5^{\circ} \mathrm{C}$

ab

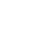

(1)

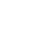

rep

(1)

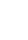

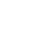

(1)

\section{WELL HTF 24}

MEASUREMENTS CONDUCTED IN THE FIELD $\begin{array}{ll}\text { Sample dete: } 08 / 18 / 92 & \text { Time: } 13: 45 \\ \text { Dopth to water: } 57.00 \mathrm{H}(17.37 \mathrm{~m}) \text { bolow TOC } & \text { pH: } 5.1 \\ \text { Water elevation: } 278.80 \mathrm{Ht}(84.40 \mathrm{~m}) \mathrm{msl} & \text { Water temperature: } 30.3 \circ \mathrm{C} \\ \text { Sp. conductance: } 46 \mathrm{\mu} / \mathrm{cm} & \end{array}$ LABORATORY ANALYSES

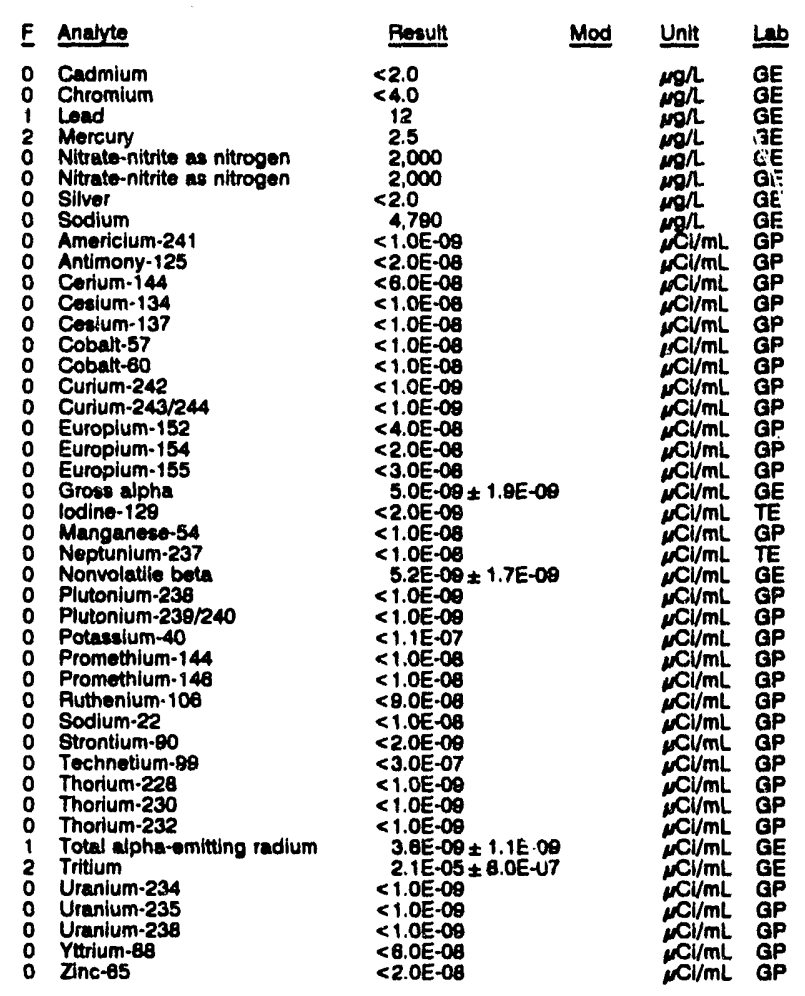




\begin{tabular}{|c|c|c|c|c|c|}
\hline \multicolumn{6}{|c|}{$\begin{array}{l}\text { WELL HTF } 25 \\
\text { MEASUREMENTS CONDUCTTED IN THE FIELD }\end{array}$} \\
\hline \multicolumn{3}{|c|}{ 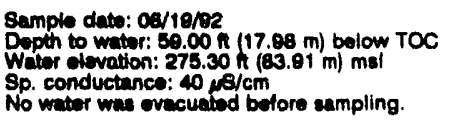 } & \multicolumn{3}{|c|}{$\begin{array}{l}\text { Time: } 14: 15 \\
\text { pH: } 5.2 \\
\text { Water temperature: } 30.8^{\circ} \mathrm{C}\end{array}$} \\
\hline \multicolumn{6}{|c|}{ LABOPATOFY ANALYSES } \\
\hline & Anclete & Result & Mod & Unit & Lab \\
\hline $\begin{array}{l}0 \\
0 \\
0 \\
0 \\
0 \\
0 \\
0 \\
0 \\
0 \\
0 \\
0 \\
0 \\
0 \\
0 \\
0 \\
0 \\
0 \\
0 \\
0 \\
0 \\
0 \\
0 \\
0 \\
0 \\
0 \\
0 \\
0 \\
0 \\
0 \\
0 \\
0 \\
0 \\
0 \\
0 \\
1 \\
0 \\
0 \\
0 \\
0 \\
0\end{array}$ & 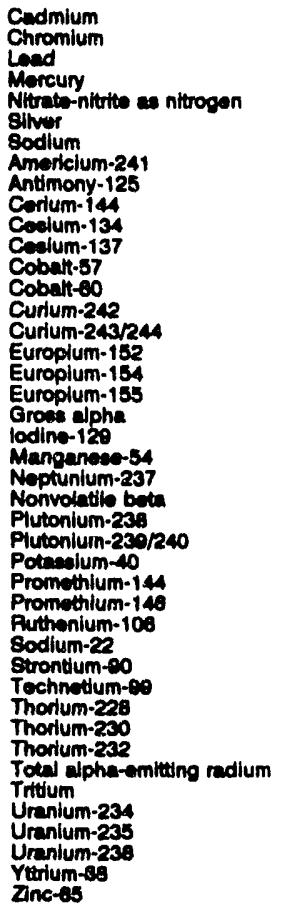 & 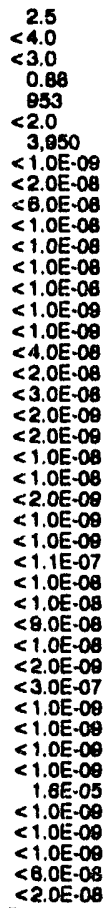 & & 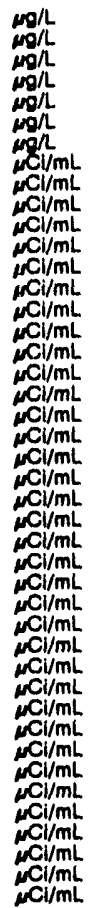 & $\begin{array}{l}G E \\
G E \\
G E \\
G E \\
G E \\
G E \\
G E \\
G P \\
G P \\
G P \\
G P \\
G P \\
G P \\
G P \\
G P \\
G P \\
G P \\
G P \\
G P \\
G E \\
T E \\
G P \\
T E \\
G E \\
G P \\
G P \\
G P \\
G P \\
G P \\
G P \\
G P \\
G P \\
G P \\
G P \\
G P \\
G P \\
G E \\
G E \\
G P \\
G P \\
G P \\
G P \\
G P\end{array}$ \\
\hline
\end{tabular}

WELL HTF 26

MEASUPEEMENTS CONOUCTED IN TME FIELD

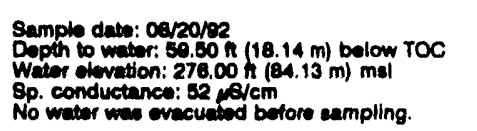

Time: $10: 00$

pH: 5.3

Water temperature: $25.4^{\circ} \mathrm{C}$

\section{LABOAATOPY ANALYRES}

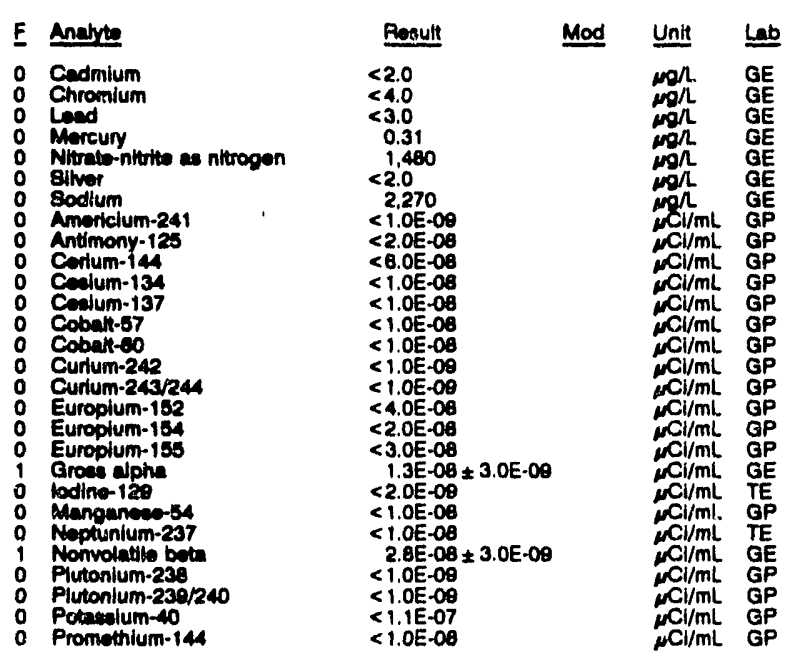

WELL HTF 28 collected on 08/20/92, laboratory analyees (cont.)

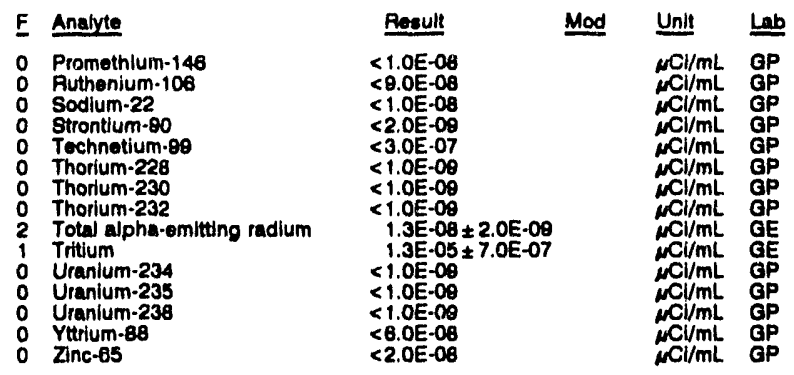

\section{WELL HTF 27}

MEASUREMENTS CONDUCTED IN THE FIELD

Depth to water: $55.50 \mathrm{ft}(16.92 \mathrm{~m})$ below TOC

Water elevation: $277.60 \mathrm{~h}(84.61 \mathrm{~m}) \mathrm{mol}$

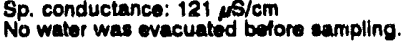

$\operatorname{Tim}_{\mathrm{pH}:} 4.3$

No waler was evecualed betc

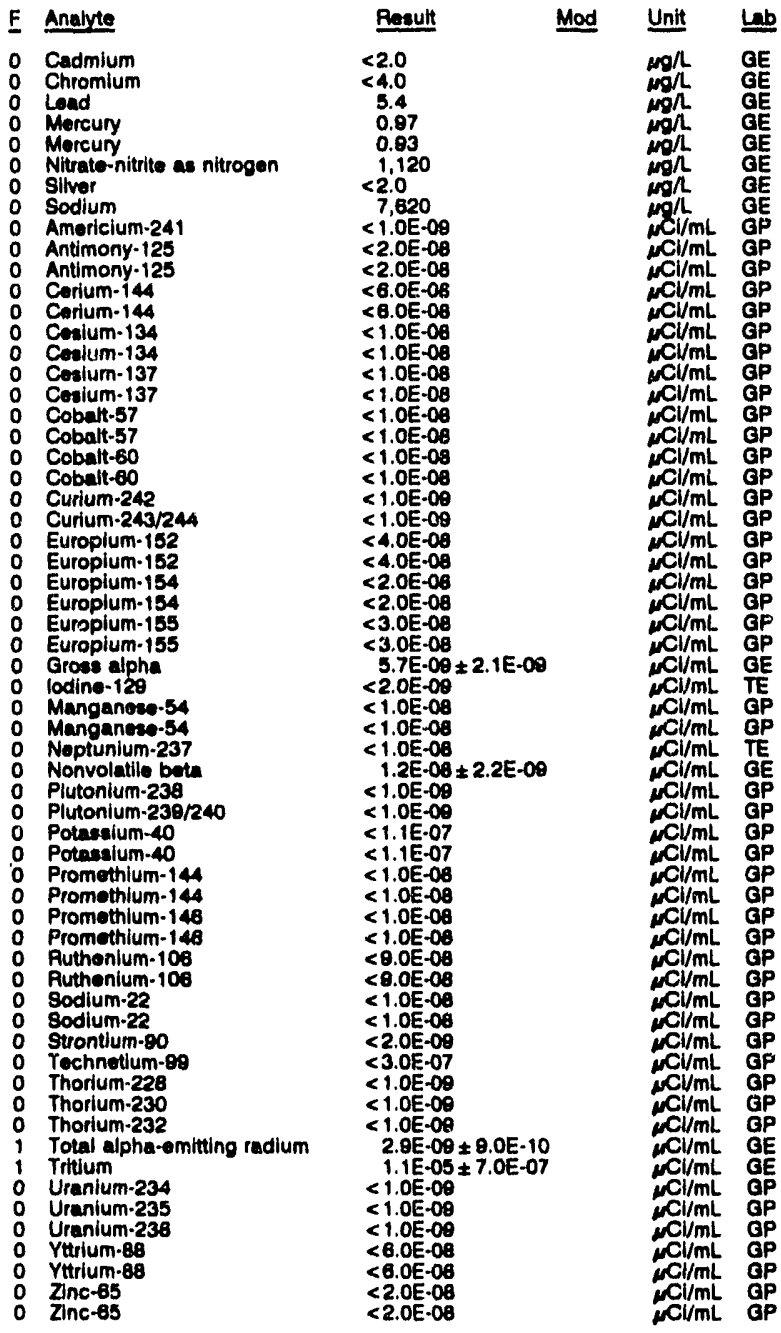


WELL HTF 32

MEASUREMENTS CONDUCTED IN THE FIELD

\begin{tabular}{|c|c|c|c|c|c|}
\hline \multicolumn{3}{|c|}{ 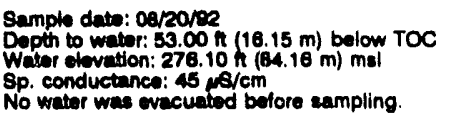 } & \multicolumn{3}{|c|}{$\begin{array}{l}\text { Time: } 10: 40 \\
\text { pH: } 4.8 \\
\text { Water temperature: } 26.5^{\circ} \mathrm{C}\end{array}$} \\
\hline \multicolumn{6}{|c|}{ ABORATOFY ANALYSES } \\
\hline & Anabyte & Resuit & Mod & Unit & Lab \\
\hline & 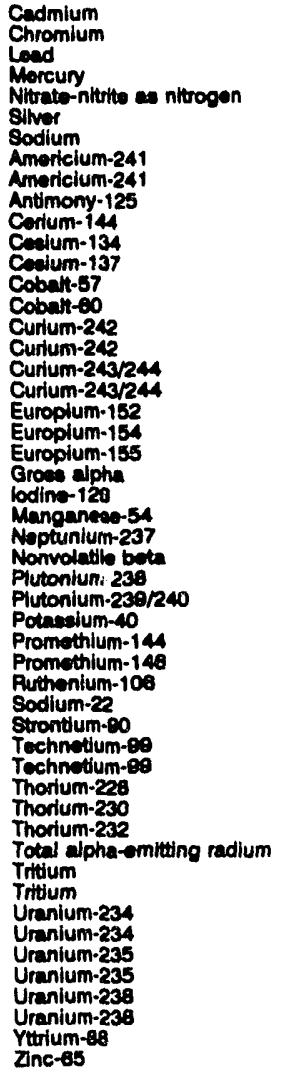 & $\begin{array}{l}<2.0 \\
<4.0 \\
<3.0 \\
2.0 \\
3,350 \\
<2.0 \\
5,430 \\
<1.0 E-09 \\
<1.0 E-09 \\
<2.0 E-08 \\
<8.0 E-08 \\
<1.0 E-09 \\
<1.0 E-08 \\
<1.0 E-09 \\
<1.0 E-08 \\
<1.0 E-09 \\
<1.0 E-09 \\
<1.0 E-09 \\
<1.0 E-09 \\
<4.0 E-08 \\
<2.0 E-08 \\
<3.0 E-08 \\
<2.0 E-09 \\
<2.0 E-09 \\
<1.0 E-09 \\
<1.0 E-08 \\
<2.0 E-09 \\
<1.0 E-09 \\
<1.0 E-09 \\
<1.1 E-07 \\
<1.0 E-08 \\
<1.0 E-08 \\
<\theta .0 E-08 \\
<1.0 E-08 \\
<2.0 E-09 \\
<3.0 E-07 \\
<3.0 E-07 \\
<1.0 E-09 \\
<1.0 E-09 \\
<1.0 E-09 \\
<1.0 E-09 \\
11.1 E-05 \\
110 E-05 \\
<1.0 E-09 \\
<1.0 E-09 \\
<1.0 E-09 \\
<1.0 E-09 \\
<1.0 E-09 \\
<1.0 E-09 \\
<6.0 E-08 \\
<2.0 E-08 \\
\end{array}$ & & 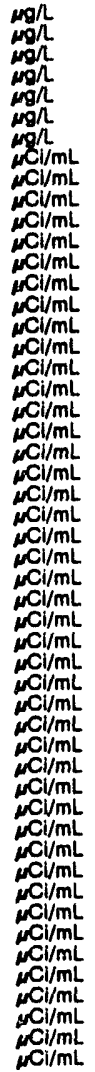 & $\begin{array}{l}\mathrm{GE} \\
\mathrm{GE} \\
\mathrm{GE} \\
\mathrm{GE} \\
\mathrm{GE} \\
\mathrm{GE} \\
\mathrm{GE} \\
\mathrm{GP} \\
\mathrm{GP} \\
\mathrm{GP} \\
\mathrm{GP} \\
\mathrm{GP} \\
\mathrm{GP} \\
\mathrm{GP} \\
\mathrm{GP} \\
\mathrm{GP} \\
\mathrm{GP} \\
\mathrm{GP} \\
\mathrm{GP} \\
\mathrm{GP} \\
\mathrm{GP} \\
\mathrm{GP} \\
\mathrm{GE} \\
\mathrm{TE} \\
\mathrm{GP} \\
\mathrm{TE} \\
\mathrm{GE} \\
\mathrm{GP} \\
\mathrm{GP} \\
\mathrm{GP} \\
\mathrm{GP} \\
\mathrm{GP} \\
\mathrm{GP} \\
\mathrm{GP} \\
\mathrm{GP} \\
\mathrm{GP} \\
\mathrm{GP} \\
\mathrm{GP} \\
\mathrm{GP} \\
\mathrm{GP} \\
\mathrm{GE} \\
\mathrm{GE} \\
\mathrm{GE} \\
\mathrm{GP} \\
\mathrm{GP} \\
\mathrm{GP} \\
\mathrm{GP} \\
\mathrm{GP} \\
\mathrm{GP} \\
\mathrm{GP} \\
\mathrm{GP}\end{array}$ \\
\hline
\end{tabular}

\section{WELL HTF 34}

MEASUREMENTS CONDUCTED IN THE FIELD

Sample date: carzorer
ineccesulbility of mechanical problem prevented sample collection.

Sample date: $08 / 20 / 92$
inecceselbility of mechanical problem prevented sample collection.

\section{WELL HWS 1A}

\section{MEASUREMENTS CONOUCTED IN THE FIELL}

\begin{tabular}{|c|c|c|c|c|}
\hline 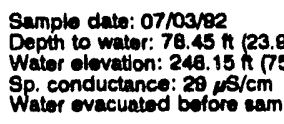 & ow roc & $\begin{array}{l}\text { Time: } 10: 2 \\
\text { pH: } 4.5 \\
\text { Alkalinity: } \\
\text { Water tem }\end{array}$ & ature: & \\
\hline LABOPATOAY ANALYSES & & & & \\
\hline Analyte & Result & Mod & Unit & Lab \\
\hline $\begin{array}{l}0 \text { Load } \\
0 \text { Total organic halogens }\end{array}$ & $\begin{array}{r}6.7 \\
<5.0\end{array}$ & & $\operatorname{mg} / 2$ & SE \\
\hline
\end{tabular}

WELL HWS 2

MEASUREMENTS CONDUCTED IN THE FIELD

Sample date: $07 / 03 / 92$
Depth to water: $78.63 \mathrm{H}(23.38 \mathrm{~m})$ bolow TOC

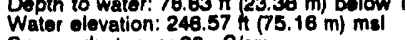

Sp. conductance: $20, \mu \mathrm{S} / \mathrm{cm}$
Water ovacuated belore sampling: 82 gal

LABOFATOAY ANALYSES

\begin{tabular}{|c|c|c|c|}
\hline Analyte & Begult & Mod & Unit \\
\hline $\begin{array}{l}\text { Load } \\
\text { Total organic halogenn } \\
\text { Total organic halogens }\end{array}$ & $\begin{array}{l}<3.0 \\
<5.0 \\
<5.0\end{array}$ & & 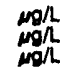 \\
\hline
\end{tabular}

WELL HXB 1

MEASUREMENTS CONDUCTED IN THE FIELD

Sample date: 07/28/92

Dopth to water: $52.25 \mathrm{~h}(15.83 \mathrm{~m})$ below TOC

Wator olevation: $253.85 \mathrm{~h}(77.40 \mathrm{~m}) \mathrm{mad}$

Sp. conductance: $35 \mu 5 / \mathrm{cm}$

Alkalinity: $0 \mathrm{moll}$

Water temporature: $21.8^{\circ} \mathrm{C}$

LABOPATORY ANALYSES

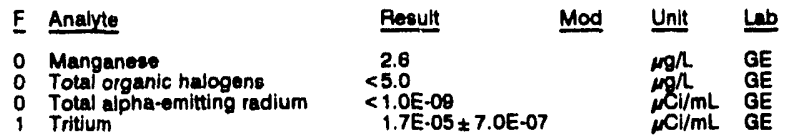

\section{WELL HXB 2}

MEASUREMENTS CONDUCTED IN THE FIELD

Sample deve: $07 / 20$ :

Time: 10:25

Water olovation: $255.35 \mathrm{~h}(77.83 \mathrm{~m}) \mathrm{msl}$ A Alkalinity: $0 \mathrm{mg} / \mathrm{h}$

Water tomporature: $22.3{ }^{\circ} \mathrm{C}$

Water evacuated bofore sampling: 113 gal

LABOFATORY ANALYSES

\begin{tabular}{|c|c|c|c|}
\hline F Analyte & Result & Mod & Unit \\
\hline $\begin{array}{l}0 \text { Manganose } \\
0 \text { Total organic halogens } \\
0 \text { Total alpha-emitting radium } \\
0 \text { Trittum }\end{array}$ & $\begin{array}{l}<2.0 \\
<5.0 \\
<1.0 \mathrm{E}-09 \\
2.5 \mathrm{E}-06\end{array}$ & & 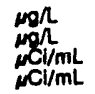 \\
\hline
\end{tabular}

WELL HXB 3

MEASUREMENTS CONDUCTED IN THE FIELD

Sample date: $07 / 28 / 82$

Depth to water: $48.44 \mathrm{ft}(15.07 \mathrm{~m})$ below TOC

Water elevation: $254.78 \mathrm{~h}(77.65 \mathrm{~m}) \mathrm{ms}$

$\operatorname{Time:}_{\text {pH: }}: 8: 40$

Alkalinity: $0 \mathrm{mgh}$

Water tomperature: $21.0^{\circ} \mathrm{C}$

Water ovacuated before sampling: $112 \mathrm{gal}$

LABORATORY ANALYSES

\begin{tabular}{|c|c|c|c|}
\hline Analyte & Rosult & Mod & Unit \\
\hline $\begin{array}{l}\text { Manpanose } \\
\text { Total organic halogens } \\
\text { Total alpha-emitting radium } \\
\text { Tritium }\end{array}$ & $\begin{array}{l}<2.0 \\
<5.0 \\
<1.0 \mathrm{E}-0.0 \\
3.8 \mathrm{E}-0\end{array}$ & & $\underset{\substack{\operatorname{mon} \\
\mu C L / m L}}{\mu C i / m L}$ \\
\hline
\end{tabular}

WELL HXB 4D

MEASUREMENTS CONDUCTED IN THE FIELD

Sumple dete: 07 (28)

Depth to water: $52.10 \mathrm{H}(15.88 \mathrm{~m})$ below TOC

Water elovation: $254.80 \mathrm{ht}(77.69 \mathrm{~m}) \mathrm{msl}$

Water evacuated before sampling: 12 gal

Time: 10:05

PH: 4.8 .

Water tomperature: $21.0^{\circ} \mathrm{C}$

The well went dry during purging.

LABORATORY ANALYSES

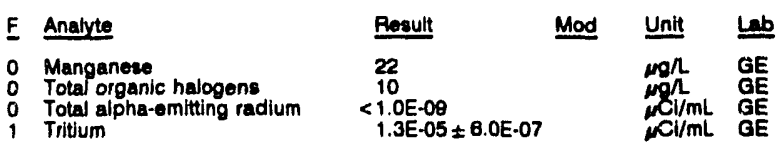


WELL HXB 5D

MEASUREMENTS CONDUCTED IN THE FIELD

Sample dato: 07/28/82

Depth to water: $54.53 \mathrm{n}$ (16.62 m) below TOC

Water olevation: 254.27 i $(77.50 \mathrm{~m}) \mathrm{msl}$

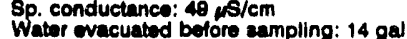

The woll went dry during purging.

LABOPATORY ANALYSES

\begin{tabular}{|c|c|c|c|c|}
\hline $\boldsymbol{F}$ & Analyte & Result & Mod & Unit \\
\hline & $\begin{array}{l}\text { Manganese } \\
\text { Totel organic halogens } \\
\text { Total settutty } \\
\text { Total alpha-emitting redium } \\
\text { Tritium }\end{array}$ & $\begin{array}{l}31 \\
<5.0 \\
1.9 E-04 \pm 3.4 E-06 \\
<1.0 E-09 \\
1.6 E-04 \pm 2.0 E-00\end{array}$ & & 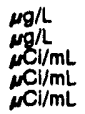 \\
\hline
\end{tabular}

WELL IDB IA

MEASUREMENTS CONDUCTED IN THE FIELD

Sample date: 07/18\%e?

Dopth to wher: 10702 (n) $1203 \mathrm{ml}$ belaw TOC

Whter olvation: 18978 (32.03 m) below

Sp. conductance: $709 \mathrm{~s} / \mathrm{cm}$

Watet wacuated before sampling: $28 \mathrm{gal}$

LABORATOAY ANALYSES

\begin{tabular}{|c|c|c|c|c|}
\hline$\underline{F}$ & Anatyte & Result & Mod & Unit \\
\hline $\begin{array}{l}0 \\
0 \\
0 \\
0 \\
0 \\
0 \\
0\end{array}$ & $\begin{array}{l}\text { 2,4-Dichlorophonoxyacetic acid } \\
\text { Endrin } \\
\text { Iron } \\
\text { Lead } \\
\text { Undane } \\
\text { Methoxychlor } \\
\text { Total organic halogens } \\
\text { Toxaphane } \\
\text { 2,4,5-TP (Bituen) }\end{array}$ & $\begin{array}{l}<0.30 \\
<0.0060 \\
<4.0 \\
<3.0 \\
<0.0050 \\
<0.50 \\
<5.0 \\
<0.24 \\
<0.090\end{array}$ & Jt & 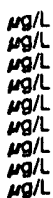 \\
\hline
\end{tabular}

\section{WELL IDB $1 B$}

MEASUREMENTS CONOUCTED IN THE FIELD

Sample dato: 07/18/02

Depth to water: $112.33 n$ (34.24 m) below TOC

Water olovation: $184.87 \mathrm{f}(56.38 \mathrm{~m}) \mathrm{ms}$

Weter evecuated bolore exmpling: $15 \mathrm{gel}$

The well went dry during purging.

LABORATOAY ANALYBES

\begin{tabular}{|c|c|c|c|c|c|}
\hline F & Analyte & Result & Mod & Unit & Lab \\
\hline $\begin{array}{l}0 \\
0 \\
0 \\
0 \\
0 \\
0 \\
0 \\
0 \\
0\end{array}$ & $\begin{array}{l}\text { 2,4-Dichlorophenoxyecetic acid } \\
\text { Endrin } \\
\text { Iron } \\
\text { Lead } \\
\text { Lindane } \\
\text { Methoxychlor } \\
\text { Total organic halogens } \\
\text { Total organic halogens } \\
\text { Toxaphone } \\
\text { 2,4,5-TP (Bituex) }\end{array}$ & $\begin{array}{l}<0.30 \\
<0.0060 \\
14 \\
<3.0 \\
<0.0050 \\
<0.50 \\
<5.0 \\
<5.0 \\
<0.24 \\
<0.080\end{array}$ & $\sqrt{2}$ & 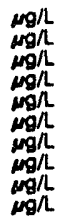 & $\begin{array}{l}\mathrm{GE} \\
\mathrm{GE} \\
\mathrm{GE} \\
\mathrm{GE} \\
\mathrm{GE} \\
\mathrm{GE} \\
\mathrm{GE} \\
\mathrm{GE} \\
\mathrm{GE} \\
\mathrm{GE}\end{array}$ \\
\hline
\end{tabular}

WELL IDB $1 \mathrm{C}$

MEASUREMENTS CONDUCTED IN THE FIELD

Sample date: 07/18/82

Depth to water: $54.50 \mathrm{ft}$ (16.61 m) below TOC Water olevation: $242.70 \mathrm{~h}(73.88 \mathrm{~m}) \mathrm{msl}$

Sp. conductance: $18 \mu \mathrm{s} / \mathrm{cm}$

Time: $8: 15$

pH: 5.5

Alkalinity: $5 \mathrm{mg} / \mathrm{h}$

Water temperature: $22.1^{\circ} \mathrm{C}$

oH: 11.6

Water tomperature: $21.3^{\circ} \mathrm{C}$

pH: 8.0

Alkalinity: $48 \mathrm{mg} / \mathrm{h}$

Water temperature: $21.8 \circ \mathrm{C}$

LABORATOPY ANALYSES

\begin{tabular}{|c|c|c|}
\hline & Analyte & Result \\
\hline & $\begin{array}{l}\text { 2,4-Dichlorophenoxyacetic acid } \\
\text { Endrin } \\
\text { lron } \\
\text { Lead } \\
\text { Lindane } \\
\text { Methoxychlor } \\
\text { Total organlc halogens } \\
\text { Taxaphene } \\
\text { 2,4,5-TP (Silvex) }\end{array}$ & $\begin{array}{l}<0.30 \\
<0.0060 \\
<4.0 \\
<3.0 \\
<0.0050 \\
<0.50 \\
<5.0 \\
<0.24 \\
<0.090\end{array}$ \\
\hline
\end{tabular}

Time: 8:40

pH: 5.0

Alkalinity: $2 \mathrm{mg} / \mathrm{h}$

Water temperature: $19.8^{\circ} \mathrm{C}$
WELLL IDB 2A

MEASUREMENTS CONDUCTED IN THE FIELO

Sample date: 07/18/92

Depth to wator: $115.31 \mathrm{ft}(35.15 \mathrm{~m})$ bolow TOC

Wator olovation: $188.88 \mathrm{~h}$

Water conductance: $62 \mu \mathrm{s} / \mathrm{cm}$.

LABORATORY ANALYSES

\begin{tabular}{lll} 
F Analyte & \multicolumn{1}{c}{ Reault } \\
0 & $2,4-$ Dichlorophenoxyacetic acld & $<0.30$ \\
0 & $<0.0060$ \\
0 & Endrin & 1,010 \\
2 & lon & $<3.0$ \\
0 & Load & $<0.0050$ \\
0 & Lindane & $<0.50$ \\
0 & Methoxychlor & $<5.0$ \\
0 & Total organic halogens & $<0.24$ \\
0 & Toxaphene & $<0.090$ \\
0 & $2,4,5-T P$ (Silvex) &
\end{tabular}

Time: 11:05

pH: 5.8 : $7 \mathrm{mg}$

Alkalinity: $7 \mathrm{mg} /$
Water tomperature: $21.4^{\circ} \mathrm{C}$

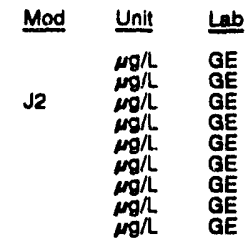

WELL IDB 28

MEASUREMENTS CONOUCTED IN THE FIELD

Depth to water: $128.65 \mathrm{ft}(39.21 \mathrm{~m})$ below TOC

Water evacuated before sampling: $50 \mathrm{gal}$

\begin{tabular}{|c|c|c|c|c|}
\hline$\underline{E}$ & Analyte & Result & Mod & Unit: \\
\hline $\begin{array}{l}0 \\
0 \\
0 \\
2 \\
0 \\
0\end{array}$ & $\begin{array}{l}\text { 2,4-Dichiorophenoxyacetic acid } \\
\text { Endrin } \\
\text { Iron } \\
\text { Lead } \\
\text { Lindane } \\
\text { Methoxychlor }\end{array}$ & $\begin{array}{l}<0.30 \\
<0.0060 \\
<4.0 \\
17 \\
<0.0050 \\
<0.50\end{array}$ & J1 & $\underset{\substack{m g h \\
m g / L}}{m g h}$ \\
\hline
\end{tabular}

Sample date: 07/18/92

Water elevation: $177.05 \mathrm{tt}(53.97 \mathrm{~m}) \mathrm{msl}$

Sp. conductance: $1118 \mu \mathrm{s} / \mathrm{cm}$

The well went dry during purging.

LABORATORY ANALYSES

E Analyte

Result

0 2,4-Dichlorophenoxyacetic acid $<0.30$

0 Endrin

0 Endrin

0 lron

0 Lindane

Lindane

Methoxychlor

Mothoxychlor

Total organic halogen

0 Toxapheno

0 2,4,5-TP (Silvox)

$<0.0060$
$<0.0060$

$<4.0$

4.0
$<0.0050$

$<0.0050$
$<0.0050$

$<0.50$

$<5.0$

$<0.24$

$<0.090$

\section{WELL IDB $2 C$}

MEASUREMENTS CONDUCTED IN THE FIELD

Sample date: 07/18/82

Dopth to water: $66.88 \mathrm{tt}(20.38 \mathrm{~m})$ bolow TOC

Water elevation: $238.54 \mathrm{ht}(73.01 \mathrm{~m}) \mathrm{mgl}$

Water evacuated bofore sampling: 82 gal

LABORATORY ANALYSES

E Anajyte

Besult

o 2,4-Dichlorophenoxyacetic acid $<0.30$

O Endrin

0 lion

Lindane

Methoxychlor

o Total organic halogen

0
0
0

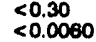

$<4.0$

$<4.0$

$<0.0050$

$<0.50$

$<0.24$

WELL IDB 3

MEASUREMENTS CONDUCTED IN THE FIELD

Sample date: 07/18/92

Depth to water: $84.75 \mathrm{ft}(25.83 \mathrm{~m})$ below TOC

Water olevation: $240.15 \mathrm{ht}(73.20 \mathrm{~m}) \mathrm{msl}$

Water evacuated before sampling: $7 \mathrm{gol}$

The well went dry during purging.

LABORATOPY ANALYSES

\begin{tabular}{|c|c|c|}
\hline $\begin{array}{l}\text { Time: } 14: 35 \\
\text { pH: } 11.6 \\
\text { Alkalinity: } 27 \\
\text { Water tempe }\end{array}$ & ure: 28 & \\
\hline Mod & Unit & \\
\hline J1 & 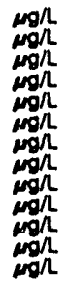 & $\begin{array}{l}\mathrm{GE} \\
\mathrm{GE} \\
\mathrm{GE} \\
\mathrm{GE} \\
\mathrm{GE} \\
\mathrm{GE} \\
\mathrm{GE} \\
\mathrm{GE} \\
\mathrm{GE} \\
\mathrm{GE} \\
\mathrm{GE} \\
\mathrm{GE} \\
\mathrm{GE}\end{array}$ \\
\hline
\end{tabular}

Time: $8: 55$

Alkalinity: $87 \mathrm{mg}$

Water tomperature: $18.6^{\circ} \mathrm{C}$

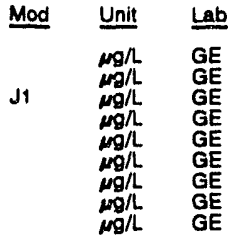

Time: 13:50

$\mathrm{pH}: 11.5$

Alkalinity: $177 \mathrm{mgA}$

\begin{tabular}{|c|}
\hline Unit \\
\hline 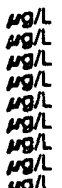 \\
\hline
\end{tabular}

Alkalinity: $177 \mathrm{mg} / \mathrm{L}$ 
WELL 100 3 collectod on 07/18/92, laboratory analyees (cont)

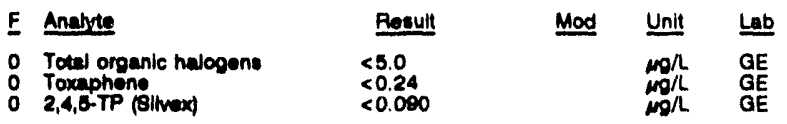

WELL IDB 4

MEASUAREMENTS CONDUCTED IN THE FIELD

Bample date: 07/1892

Depth to water: Not avallable

Water elevation: Not avaliable

Sp. conductance: 42 ws/cm

Whe woll went dy during purging.

LABORATOPY ANALYEES

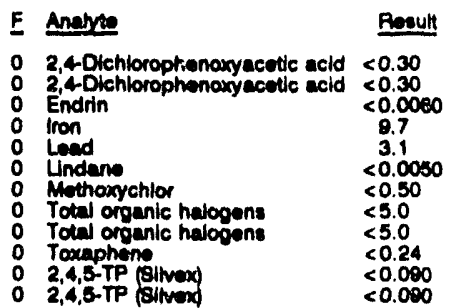

WELL IDB 5

MEASUAEMENTS CONOUCTED IN THE FIELD

Sample dato: 07/18/er

Depth to water: 71.70 i $(21.88 \mathrm{~m})$ bolow TOC

Wator elevation: $280.11 \mathrm{ht}$

Sp. conductance: $73 \mathrm{\mu s} / \mathrm{cm}$

Water ovacuated bofore ampling: $10 \mathrm{gal}$

The woll went dry during purging

LABORATORY ANALY YES

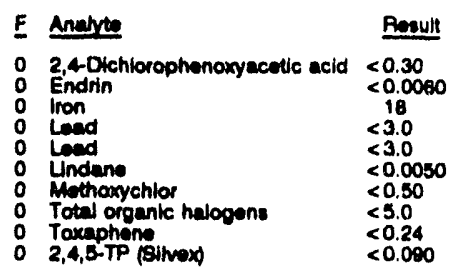

WELL IDB 6

MEASUREMENTS CONDUCTED IN THE FIELD

Sample date: 07/18/2

Dopth to water: $67.40 \mathrm{ft}(17.50 \mathrm{~m})$ below TOC

Water elevation: $201.60 \mathrm{~h}$ (70.7

Sp. conductance: $21 \mathrm{\mu} / \mathrm{cm}$.

Water ovecuated bofors eampling: $55 \mathrm{gal}$

LABORATOAY ANALY YEES

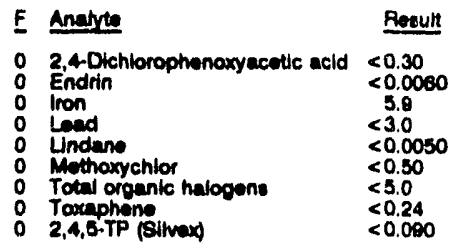

\begin{tabular}{|c|c|c|}
\hline $\begin{array}{l}\text { Time: 14:20 } \\
\text { pH: } 5.6 \\
\text { Alkalinity: } \\
\text { Water tomp }\end{array}$ & gon & \\
\hline Mods & Unit & Lab \\
\hline J2 & 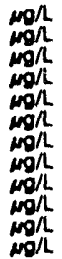 & $\begin{array}{l}\mathrm{GE} \\
\mathrm{GE} \\
\mathrm{GE} \\
\mathrm{GE} \\
\mathrm{GE} \\
\mathrm{GE} \\
\mathrm{GE} \\
\mathrm{GE} \\
\mathrm{GE} \\
\mathrm{GE} \\
\mathrm{GE} \\
\mathrm{GE}\end{array}$ \\
\hline
\end{tabular}

Time: 14:05

PH: 8.4 : $14 \mathrm{mo}$

Water tomperature: $21.4^{\circ} \mathrm{C}$

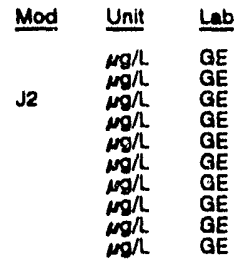

WELL IDB 7

MEASUREMENTS CONDUCTED IN THE FIELD

Sample date: $07 / 18 / 92$

Dopth to water: $52.10 \mathrm{ft}(15.68 \mathrm{~m})$ below TOC

Water olovation: $261.30 \mathrm{~h}(79.65 \mathrm{~m}) \mathrm{mal}$

Sp. conductance: 31 NS/cm
Wator evacuated boforo sumpling: $52 \mathrm{gal}$

LABORATOAY ANALYSES

\begin{tabular}{lll} 
E Analyte & \multicolumn{1}{c}{ Pesult } \\
0 & 2,4 Dichlorophenoxyacetic acid & $<0.30$ \\
0 & $<0.0080$ \\
0 & Endrin & 4.3 \\
0 & lron & $<3.0$ \\
0 & Load & $<0.0050$ \\
0 & Lindane & $<0.50$ \\
0 & Mothoxychilor & $<.0$ \\
0 & Total organlc halogens & $<0.24$ \\
0 & Toxaphene & $<0.090$ \\
0 & $2,4,5 \cdot T P$ (Silvex) &
\end{tabular}

Timo: 12:15

Alkalinity: $0 \mathrm{mg} / \mathrm{L}$

Wator tomporature: $21.0^{\circ} \mathrm{C}$

WELL IDB 8

MEASUREMENTS CONDUCTED IN THE FIELD

Sample date: $07 / 18 / 82$

Water olevation: $240.28 \mathrm{ht}(73.23 \mathrm{ml} \mathrm{mal}$

Sp. conductance: $35 \mathrm{mS} / \mathrm{cm}$. 12 gal

The well went dry during purging

LABORATOAY ANALYSES

$E$ Analyte Rosult

$\begin{array}{ll}0 & 2,4 \text { - Dichlorophenoxyacet } \\ 0 & \text { Endrin } \\ 0 & \text { Endrin } \\ 0 & \text { bon } \\ 0 & \text { Lead } \\ 0 & \text { Lindane } \\ 0 & \text { Lindane } \\ 0 & \text { Mothoxychlor } \\ 0 & \text { Mothoxychlor } \\ 0 & \text { Total organic halogens } \\ 0 & \text { Toxaphene } \\ 0 & \text { Toxaphene } \\ 0 & 2,4,5 \cdot T P \text { (Silvex) }\end{array}$

$<0.30$

WELL IDB 9

MEASUREMENTS CONDUCTED IN THE FIELD

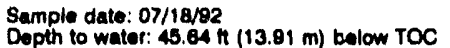

Water elovation: $242.68 \mathrm{~h}(73.80 \mathrm{~m}) \mathrm{mal}$

Sp. conductunce: $148 \mathrm{~s} / \mathrm{cm}$

Water evacuated bolore sampling: 34 gal

The well went dry during purging.

LABOPATORY ANALYSES

\begin{tabular}{|c|c|c|c|}
\hline Analyte & Preault & Mod & Unit \\
\hline $\begin{array}{l}\text { 2,4-Dichlorophanoxyacotic acid } \\
\text { Endrin } \\
\text { Iron } \\
\text { Lead } \\
\text { Undune } \\
\text { Mothoxychlor } \\
\text { Total organic halogens } \\
\text { Toxaphano } \\
2,4,5 \text {-TP (Bilvex) }\end{array}$ & $\begin{array}{l}<0.30 \\
<0.0080 \\
12 \\
<3.0 \\
<0.0050 \\
<0.80 \\
<5.0 \\
<0.24 \\
<0.000\end{array}$ & $\sqrt{2}$ & 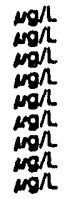 \\
\hline
\end{tabular}

\section{WELL IDB 10}

MEASUAEMENTS CONDUCTED IN THE FIELD

Sample date: 07/1892

Depth to water: $39.42 \mathrm{ft}(12.02 \mathrm{~m})$ bolow TOC Water elovation: $256.38 \mathrm{t}(78.15 \mathrm{~m}) \mathrm{msl}$ $8 \mathrm{p}$. conductance: $34 \mathrm{~s} / \mathrm{cm}$ Water ovacuated botore sampling: $108 \mathrm{gal}$

LABORATOAY ANALYSES

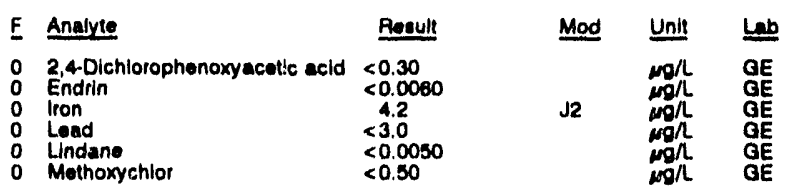

$\operatorname{Time:}_{\mathrm{pH}:}$ 13:35

Alkalinity: $0 \mathrm{mo} / \mathrm{h}$

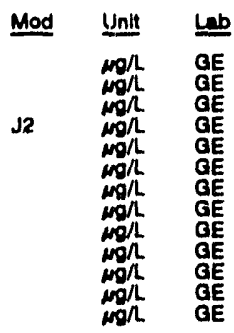

\begin{tabular}{|c|c|c|}
\hline $\begin{array}{l}\text { Time: 14:50 } \\
\text { pH: } 8.6 \\
\text { Alkalinity: } 60 \\
\text { Water tompo }\end{array}$ & olde: 21 & \\
\hline Mod & Unit & Lab \\
\hline$\sqrt{2}$ & 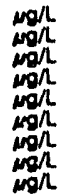 & $\begin{array}{l}\mathrm{GE} \\
\mathrm{GE} \\
\mathrm{GE} \\
\mathrm{GE} \\
\mathrm{GE} \\
\mathrm{GE} \\
\mathrm{GE} \\
\mathrm{GE} \\
\mathrm{GE}\end{array}$ \\
\hline
\end{tabular}

Tima: 12:50

PH: 5.4 . Water tompernture: $21.8 \circ \mathrm{C}$ Water temperalure: $21.5^{\circ} \mathrm{C}$

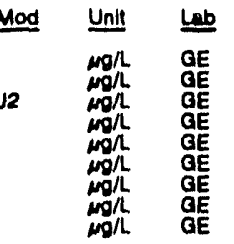

$a b$
$G E$
$G E$
$G E$
$G E$
$G E$
$G E$
$G E$


WELL IDE 10 collected on 07/18/98, laboratory analyese (cont.)

\begin{tabular}{|c|c|c|c|}
\hline E Anaryce & Result & Mod & Unit \\
\hline $\begin{array}{l}0 \text { Total organic halogens } \\
0 \text { Toxaphonne } \\
0 \\
0\end{array}$ & $\begin{array}{l}<5.0 \\
<0.24 \\
<0.090\end{array}$ & & $\operatorname{mog}_{\substack{\mu g / L \\
\mu g / L}}$ \\
\hline
\end{tabular}

WELL IDP 1

MEABUREMENTS CONDUCTED IN THE FIELD

\begin{tabular}{|c|c|c|c|c|c|}
\hline \multicolumn{3}{|c|}{ 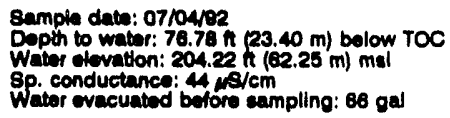 } & \multicolumn{3}{|c|}{$\begin{array}{l}\text { Timo: } 18: 60 \\
\text { pH: } 5.0 \\
\text { Alkalinity: } 1 \mathrm{mg} / \\
\text { Wator tomporalure: } 21.7 \cdot \mathrm{C}\end{array}$} \\
\hline \multicolumn{6}{|c|}{ LABOAMTOPY ANALYSES } \\
\hline E & Analyes & Result & Mod & Unit & \\
\hline $\begin{array}{l}0 \\
0 \\
0 \\
0\end{array}$ & $\begin{array}{l}\text { Iron } \\
\text { Lead } \\
\text { Trittum } \\
\text { Tritium }\end{array}$ & $\begin{array}{l}<4.0 \\
<3.0 \\
2.8 E-08 \\
2.8 E .08\end{array}$ & $\begin{array}{l}\text { OE-07 } \\
\text { OE-07 }\end{array}$ & 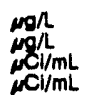 & $\begin{array}{l}\mathrm{GE} \\
\mathrm{GE} \\
\mathrm{GE}\end{array}$ \\
\hline
\end{tabular}

\section{WELL IDP 2}

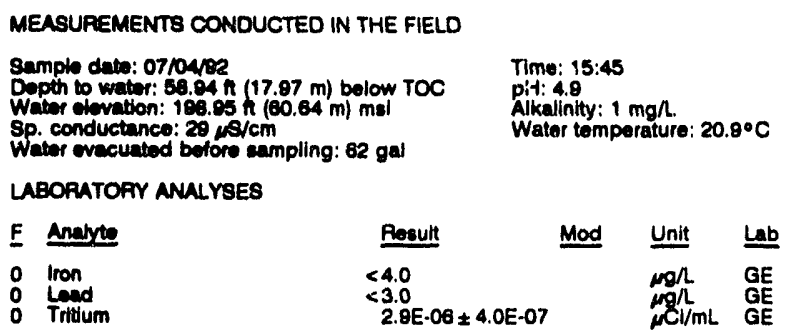

\section{WELL IDP 3A}

MEASUREMENTS CONOUCTED IN THE FIELD

8ampie dato: 07/0s/9e

Depth to water: 118.27 i ( $(35.44 \mathrm{~m}$ ) bolow TOC Water clovation: $187.73 \mathrm{n}(51.12 \mathrm{~m}) \mathrm{msl}$

Watel evecuatod belore sampling: $868 \mathrm{gal}$

LABORATORY ANALYSES

\begin{tabular}{|c|c|c|c|c|}
\hline E Analyte & Prosutt & Mod & Unit & Lab \\
\hline $\begin{array}{ll}2 & \text { iron } \\
0 & \text { Lead } \\
0 & \text { Tritium }\end{array}$ & $\begin{aligned} & 954 \\
&<3.0 \\
&<7.0 E-07\end{aligned}$ & & 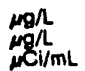 & $\begin{array}{l}\text { GE } \\
\text { GE } \\
\text { GE }\end{array}$ \\
\hline
\end{tabular}

WELL IDP 3B

MEASUREMENTS CONDUCTED IN THE FIELD

Sample date: 07/05/90

Depth to water: 120.87 (t) $(39.67 \mathrm{~m})$ below TOC

Whiter olevation: 157.03 \& $(48.05 \mathrm{~m}) \mathrm{ms}$

Sp. conductance: $161 \mathrm{~s} / \mathrm{cm}$

Witer evacuated before sampling: $163 \mathrm{gal}$

LABORATOAY ANALYSES

\begin{tabular}{|c|c|c|c|c|}
\hline F Anarte & Rosult & Mod & Unit & Lab \\
\hline $\begin{array}{ll}0 & \text { Iron } \\
0 & \text { Leed } \\
0 & \text { Tritium }\end{array}$ & $\begin{array}{l}<4.0 \\
<3.0 \\
<7.0 E .07\end{array}$ & & $\underset{\mu g \Omega}{\mu g h}$ & $\begin{array}{l}\mathrm{GE} \\
\mathrm{GE} \\
\mathrm{GE}\end{array}$ \\
\hline
\end{tabular}

WELL IDP 3C

MEASUREMENTS CONDUCTED IN THE FIELD

Sarnple date: 07/05/82

Depth to water: $82.27 \mathrm{ft}(25.08 \mathrm{~m})$ melow TOC

(25.08 m) bolow TOC

Sp. conductance: $147 \mu \mathrm{s} / \mathrm{cm}$

Water evacuated bofore sampling: $10 \mathrm{gat}$

The well went dry during purging

LABORATORY ANALYSES

\begin{tabular}{|c|c|c|c|}
\hline F Analyte & Presult & Mod & Unit \\
\hline $\begin{array}{ll}0 & \text { lron } \\
0 & \text { Lead } \\
0 & \text { Lead } \\
0 & \text { Tritilum }\end{array}$ & $\begin{array}{l}<4.0 \\
<3.0 \\
<3.0 \\
<7.0 \text { E-07 }\end{array}$ & & 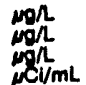 \\
\hline
\end{tabular}

WELL IDP 3D

MEASUREMENTS CONDUCTED IN THE FIELD

Sample date: 07/04/82

TIma: 15:30

The well was dry.

PH. 8.5 $58 \mathrm{mon}$ Water tomporature: $22.4^{\circ} \mathrm{C}$

WELL IDP 4

MEASUREMENTS CONDUCTED IN THE FIELD

Sample date: 07/08/92

Depth to water: 47.58 th $(14.50 \mathrm{~m})$ below TOC

Water olevation: $193.22 \mathrm{~h}(58.89 \mathrm{~m}) \mathrm{ms}$

Sp. conductance: $25 \mu \mathrm{s} / \mathrm{cm}$

Water evacuated before sampling: $4 \mathrm{gal}$

The well went dry during purging.

LABOPATORY ANALYSES

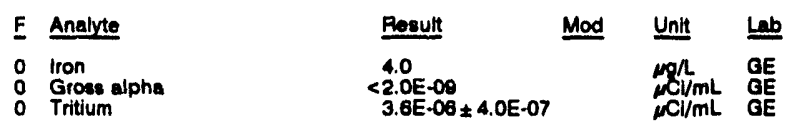

WELL IDP 5

MEASUREMENTS CONDUCTED IN THE FIELD

Sample date: 07/05/92 140

Depth to water: $54.14 \mathrm{ft}(18.50 \mathrm{~m})$ below TOC PH: 5.4

Water elevation: $199.58 \mathrm{~h}(60.83 \mathrm{~m}) \mathrm{msl} \quad$ Alkalinity: $5 \mathrm{mg} / \mathrm{h}$

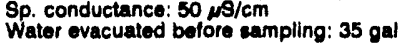

Time: $6: 25$

Nikalinity: $1 \mathrm{mon}$

Water temperature: $18.0^{\circ} \mathrm{C}$

LABORATOAY ANALYSES

F Analyte

0 Iron

0 Load

o Tritium

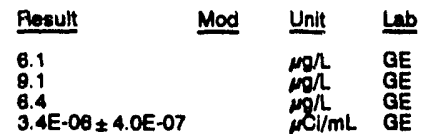

\section{WELL IDP 6}

MEASUREMENTS CONDUCTED IN THE FIELD

Sample date: 07/04/92

Depth to water: $58.98 \mathrm{ft}(17.88 \mathrm{~m})$ below TOC

Water elovation: $202.51 \mathrm{~h}(81.73 \mathrm{~m}) \mathrm{msl}$

Sp. conductance: $50 \mu \mathrm{s} / \mathrm{cm}$.

PH: 5.5

Alkalinity: $4 \mathrm{mon}$

Walor ovacualod boloro sam

E Analyte

o Iron

$\begin{array}{ll}0 & \text { Iron } \\ 0 & \text { Lead } \\ 0 & \text { Tritium }\end{array}$

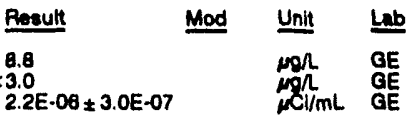




\section{WELL IDP 7}

MEASUAEMENTS CONDUCTED IN THE FIELD

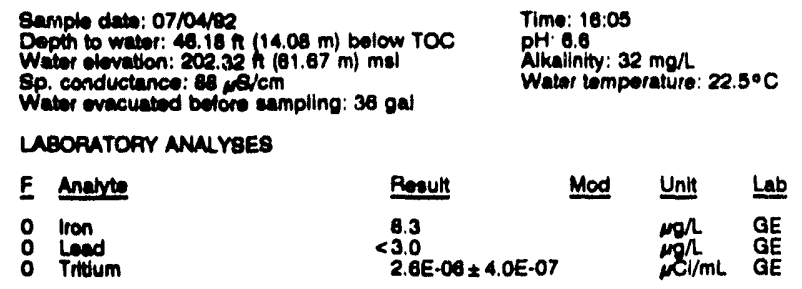

WELL IDP 8

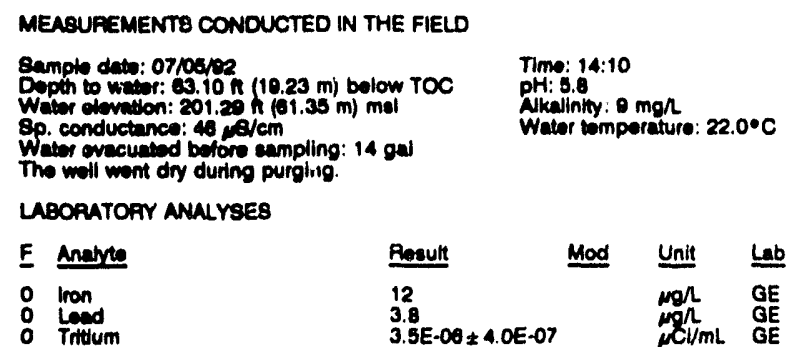

\section{WELL IDP 9}

MEASUREEMENTS CONDUCTED IN THE FIELD

Dopth to dato: 07/04: 67.18 i $n$ (20.48 m) below TOC Water olvetion: $204.71 \mathrm{~h}(62.40 \mathrm{~m}) \mathrm{mal}$ Sp. conductance: $33, \mathrm{~s} / \mathrm{cm}$

The roll want dry durto rampling: $37 \mathrm{gal}$

$\operatorname{Tim}_{\mathrm{PH}: 5.7}:$ 17:05

Alkalinity: $6 \mathrm{mon}$ The woll went dry during purging.

LBOPATOFY ANUL YSES

\begin{tabular}{|c|c|c|c|}
\hline F Aneyte & Rosenth & Mod & $\underline{\text { Unh }}$ \\
\hline $\begin{array}{ll}0 & \text { lron } \\
0 & \text { Leend } \\
\text { Trmium }\end{array}$ & $\begin{array}{c}13 \\
<3.0 \\
2.6 E-\infty 6\end{array}$ & & $\stackrel{\mu g h}{\mu^{2}}$ \\
\hline
\end{tabular}

\section{WELL IDP 10}

MEASUREMENTS CONOUCTED IN THE FIELD

Sample deta: O7/04ver Time: 14:45
The will wei dry.

WELL IDQ 1

MEASUPEMENTS CONOUCTED IN THE FIELL

Samplo deta: O7roerer Time: 18:10

\section{WELL IDQ 2}

MEASUREMENTS CONOUCTED IN THE FIELL

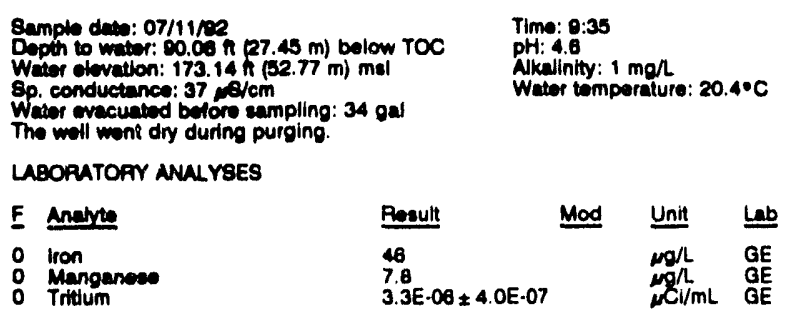

WELL IDQ 3A

MEASUREMENTS CONOUCTED IN THE FIELD

Samplo dato: $07 / 11 / 92$

Dopth to water: $38.85 \mathrm{n}(11.78 \mathrm{~m})$ bolow TOC

Wator alovation: $188.65 \mathrm{~h}(50.80 \mathrm{~m}) \mathrm{mal}$

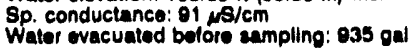

LABOPATOAY ANALYSES

\begin{tabular}{|c|c|c|c|}
\hline E Analyte & Result & Mod & Unit \\
\hline $\begin{array}{ll}2 & \text { Iron } \\
0 & \text { Manganase } \\
0 & \text { Mritium }\end{array}$ & $\begin{array}{c}1.430 \\
14 \\
<7.0 E-07\end{array}$ & & 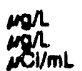 \\
\hline
\end{tabular}

\section{WELL IDQ 3B}

MEASUREMENTS CONDUCTED IN THE FIELD

Sample date: $07 / 11 / 22$ (2)

Dopth to water: 6A. $45 \mathrm{~h}(19.84 \mathrm{~m})$ bolow TOC

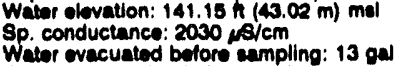

Whe woll went diy during purging.

LABOPATOAY ANALYSES

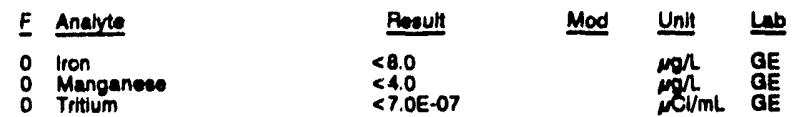

\section{WELL IDQ 3C}

MEASUAEMENTS CONDUCTED IN THE FIELD

Sample date: $07 / 11 / 02$

Dopth to wator: $10.30 \mathrm{n}(12.30 \mathrm{~m})$ bolow TOC

Wator olevation: $160.14 \mathrm{~h}(50.64 \mathrm{~m}) \mathrm{mal}$

Sp. conductance: $25, \mu s / \mathrm{cm}$.

Timo: $0: 20$

Alikininty: $5 \mathrm{moh}$

Weter tomporature: $21.6 \cdot \mathrm{C}$

The well went dry during purging. 12 oal

LABOPATOAY ANALYSES

\begin{tabular}{|c|c|c|c|}
\hline E Anajute & Reaun & Mod & Untr \\
\hline $\begin{array}{ll}0 & \text { Iron } \\
0 & \text { Manganese } \\
0 & \text { Tritium } \\
0 & \text { Tnttium }\end{array}$ & $\begin{array}{l}02 \\
7.4 \\
2.3 E-06 \pm 4.0 E-07 \\
2.1 E-06 \pm 4.0 E-07\end{array}$ & & mon \\
\hline
\end{tabular}

\section{WELL IDQ 4}

MEASUREMENTS CONDUCTED IN THE FIELO

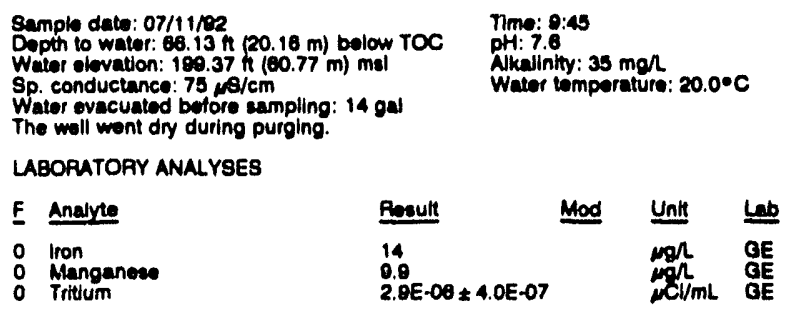

WELL IDQ 5

MEASUAEMENTS CONDUCTED IN THE FIELD

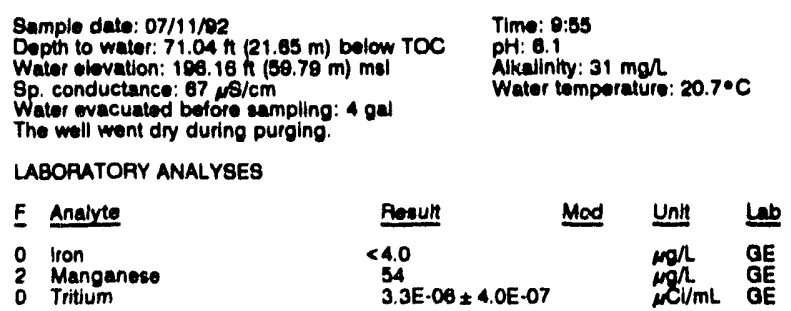


ANALYTICAL RESULTS

WELL IDQ 6

MEASUAEMENTS CONOUCTED IN THE FIELD

8ample deto: 07/11/02 Depth to water: $63.31 \mathrm{~h}(10.30 \mathrm{~m})$ below TOC Water elevation: $104.70 \mathrm{~h}(30.37 \mathrm{~m}) \mathrm{mal}$ 8p. conductance: $124 \mathrm{reV} / \mathrm{cm}$ Whe well wont dry during purging.

LABORATOFY ANALYSES

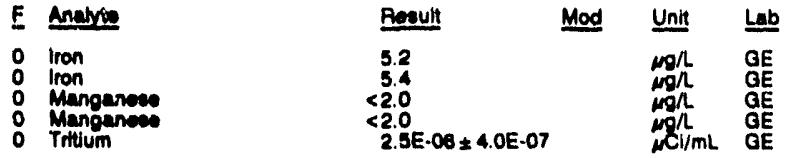

\section{WELL IDQ 7}

MEASUREMENTS CONOUCTEO IN THE FIELD

\begin{tabular}{|c|c|c|c|c|c|}
\hline & 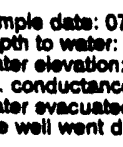 & $\begin{array}{l}\text { low TOC } \\
\text { nal } \\
\text { gal }\end{array}$ & $\begin{array}{l}\text { Time: } 11: 0 \\
\text { prl: } 6.0 \\
\text { Nikdinity: } \\
\text { Water tom }\end{array}$ & $\begin{array}{l}\text { mol } \\
\text { rature: } 21\end{array}$ & $0 \cdot \mathrm{C}$ \\
\hline & BORATOFY & & & & \\
\hline$\underline{E}$ & Andyte & Renut & Mod & Unit & Lab \\
\hline $\begin{array}{l}0 \\
0 \\
0\end{array}$ & $\begin{array}{l}\text { Iron } \\
\text { Manganeas } \\
\text { Tridum }\end{array}$ & $\begin{array}{l}5.5 \\
3.1 \\
2.7 E-08\end{array}$ & E-07 & $\operatorname{mog}_{\mathrm{m} / \mathrm{mL}}$ & $\begin{array}{l}\mathrm{GE} \\
\mathrm{GE} \\
\mathrm{GE}\end{array}$ \\
\hline
\end{tabular}

WELL IDQ 8

MEASUREMENTS CONOUCTED IN THE FIELD

\begin{tabular}{|c|c|c|c|c|c|}
\hline & 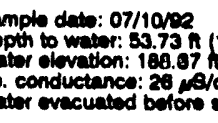 & $\begin{array}{l}\text { low TOC } \\
\text { mal } \\
2 \mathrm{gal}\end{array}$ & $\begin{array}{l}\text { Time: } 15: 10 \\
\text { PH: } 4.6 \\
\text { Alkalinity: } \\
\text { Wator temp }\end{array}$ & ngh & \\
\hline & BOPATOFY ANALYSE & & & & \\
\hline$\underline{\boldsymbol{F}}$ & Anerve & Repult & Mod & Unin & Lab \\
\hline $\begin{array}{l}0 \\
0 \\
0 \\
0 \\
0\end{array}$ & $\begin{array}{l}\text { Iron } \\
\text { Lead } \\
\text { Manganese } \\
\text { Totel organic carbon } \\
\text { Tritum }\end{array}$ & $\begin{array}{c}7.7 \\
6.6 \\
8.5 \\
<1.000 \\
3.5 E-00\end{array}$ & E-07 & 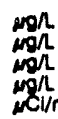 & $\begin{array}{l}\mathrm{GE} \\
\mathrm{GE} \\
\mathrm{GE} \\
\mathrm{GE} \\
\mathrm{GE}\end{array}$ \\
\hline
\end{tabular}

\section{WELL IDQ 9}

MEASUREMENTS CONDUCTED IN THE FIELD

\begin{tabular}{|c|c|c|c|c|c|}
\hline & 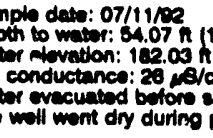 & $\begin{array}{l}\text { gal } \\
\text { gal }\end{array}$ & $\begin{array}{l}\text { Time: } 7: 40 \\
\text { pH: } 5.9 \\
\text { Nkilinity: } \\
\text { Water tom }\end{array}$ & glure: 19 & \\
\hline & SOALTOAY ANALYSES & & & & \\
\hline$E$ & Anarte & Result & Mod & Unit & \\
\hline $\begin{array}{l}0 \\
2 \\
0 \\
0 \\
\end{array}$ & $\begin{array}{l}\text { Iron } \\
\text { Lead } \\
\text { Manpancee } \\
\text { Total organic carbon } \\
\text { Tritum }\end{array}$ & $\begin{array}{r}6.6 \\
28 \\
11 \\
<1.000 \\
3.1 E-08\end{array}$ & .07 & $\operatorname{mogh}_{\operatorname{mon}}^{\operatorname{mon}}$ & $\begin{array}{l}\mathrm{GE} \\
\mathrm{GE} \\
\mathrm{GE} \\
\mathrm{GE}\end{array}$ \\
\hline
\end{tabular}

WELL IDQ 10

MEASUREMENTS CONDUCTED IN THE FIELD

\begin{tabular}{|c|c|c|c|c|c|}
\hline \multicolumn{3}{|c|}{ 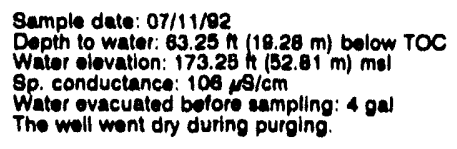 } & \multicolumn{3}{|c|}{$\begin{array}{l}\text { Time: } 7: 55 \\
\text { PH: } 6.8 \\
\text { Allalinity: } 60 \mathrm{mgh} \\
\text { Wator tomporature: } 20.0 \cdot \mathrm{C}\end{array}$} \\
\hline \multicolumn{6}{|c|}{ LABORATOAY ANALYSES } \\
\hline$\underline{\mathbf{F}}$ & Analyte & Reeult & Mod & Unit & $\underline{\underline{L u}}$ \\
\hline $\begin{array}{l}0 \\
0 \\
0\end{array}$ & $\begin{array}{l}\text { Iron } \\
\text { Manganese } \\
\text { Tritium }\end{array}$ & $\begin{array}{l}<4.0 \\
4.1 \\
3.5 E .08\end{array}$ & $1.0 E \cdot 07$ & $\operatorname{mog}_{1 / m L}$ & $\begin{array}{l}\mathrm{gE} \\
\mathrm{dE} \\
\mathrm{dE}\end{array}$ \\
\hline
\end{tabular}

WELL IDQ 11

MEASUREMENTS CONDUCTED IN THE FIELD

Sumple date: 07/10/02 Timo: 15:35

inacceesibility of mechanical problem provented sample collection.

WELL IDQ 12

MEASUREMENTS CONDUCTED IN THE FIELD

\begin{tabular}{|c|c|}
\hline $\begin{array}{l}\text { Sample date: } 07 / 11 / 92 \\
\text { Depth to water: } 54.94 \mathrm{ng}(16.75 \mathrm{~m}) \text { bolow TOC } \\
\text { Water olovation: } 187.26 \mathrm{~h}(57.08 \mathrm{~m}) \mathrm{mel} \\
\text { Sp. conductance: } 37 \mathrm{Ng} / \mathrm{cm} \\
\text { Water evacuated botore sampling: } 58 \mathrm{ogl}\end{array}$ & $\begin{array}{l}\text { Time: } 10: 45 \\
\text { pH: } 5.1 \\
\text { Alkalinity: } 2 \mathrm{mgh} \\
\text { Water temperature: } 21.3 \cdot \mathrm{C}\end{array}$ \\
\hline
\end{tabular}

LABOPATOAY ANALYSES

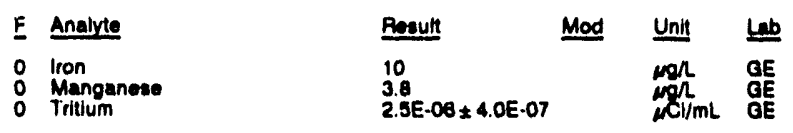

WELL K 301P

MEASUREMENTS CONDUCTED IN TME FIELD

\begin{tabular}{|c|c|c|c|c|c|}
\hline \multicolumn{3}{|c|}{$\begin{array}{l}\text { Sample date: } 07 / 19 / 92 \\
\text { Dopth to water: } 57.31 \mathrm{Ht}(17.47 \mathrm{~m}) \text { below TOC } \\
\text { Wator elevation: } 205.00 \mathrm{ht}(62.70 \mathrm{~m}) \mathrm{msl} \\
\text { Sp. conductance: } 58, \mathrm{~s} / \mathrm{cm} \\
\text { Water ovacuatod bolore sampling: } 7 \mathrm{gal}\end{array}$} & \multicolumn{3}{|c|}{$\begin{array}{l}\text { Timo: } 11: 53 \\
\text { pH: } 5.7 \\
\text { Alkalinity: } 12 \text { mon } \\
\text { Water tomparature: } 23.6^{\circ} \mathrm{C}\end{array}$} \\
\hline \multicolumn{6}{|c|}{ LABOFATORY ANALYBES } \\
\hline$\underline{F}$ & Analyte & Result & Mod & Unit & $\underline{\underline{L n}}$ \\
\hline $\begin{array}{l}0 \\
0 \\
0 \\
0 \\
2 \\
2\end{array}$ & $\begin{array}{l}\text { Cadmium } \\
\text { Total organic halogens } \\
\text { Gross alpha } \\
\text { Nonvolatile bota } \\
\text { Tritium } \\
\text { Tritium }\end{array}$ & $\begin{array}{l}<2.0 \\
<5.0 \\
6.7 \mathrm{E}-10 \pm \\
7.3 \mathrm{E}-10 \pm \\
3.0 \mathrm{E} \cdot 05 \pm \\
3.1 \mathrm{E}-05 \pm\end{array}$ & $\begin{array}{l}1.2 E-\infty \\
.0 E \cdot 10 \\
.0 E-07 \\
1.4 E-00\end{array}$ & 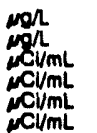 & $\begin{array}{l}\text { GE } \\
\text { QE } \\
\text { EM } \\
\text { QE } \\
\text { EM }\end{array}$ \\
\hline
\end{tabular}

\section{WELL KAB 1}

MEASUREMENTS CONOUCTED IN THE FIELD

\begin{tabular}{|c|c|c|c|c|c|}
\hline \multicolumn{3}{|c|}{$\begin{array}{l}\text { Sample date: } 07 / 18 / 92 \\
\text { Depth to water: } 61.34 \mathrm{n}(18.70 \mathrm{~m}) \text { bolow TOC } \\
\text { Water olevation: } 204.68 \mathrm{~h}(82.38 \mathrm{~m}) \mathrm{mal} \\
\text { Sp. conductance: } 284 \text { s } 1 / \mathrm{cm} \\
\text { Water wacunted bolore sampling: } 14 \mathrm{gal} \\
\text { The woll wont dry during purging. }\end{array}$} & \multicolumn{3}{|c|}{ 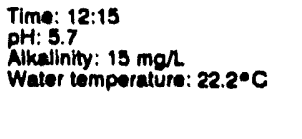 } \\
\hline \multicolumn{6}{|c|}{ LABORATORY ANALYSES } \\
\hline$\underline{\mathbf{F}}$ & Anatyte & Parull & Mod & Unit & $\underline{\underline{L u b}}$ \\
\hline $\begin{array}{l}2 \\
2 \\
0 \\
2\end{array}$ & $\begin{array}{l}\text { Iron } \\
\text { Manganese } \\
\text { Total organic halogens } \\
\text { Total alpha-emitting radium }\end{array}$ & $\begin{array}{r}3.350 \\
471 \\
<5.0 \\
8.4 E-00\end{array}$ & $1.6 \mathrm{E}-00$ & $\operatorname{mog}_{\substack{n \\
\cos ^{\prime} / \mathrm{mL}}}$ & $\begin{array}{l}\text { GE } \\
\mathrm{GE} \\
\mathrm{GE} \\
\mathrm{GE}\end{array}$ \\
\hline
\end{tabular}


WELL KAB 2

MEABUAREMENTS CONOUCTED IN THE FIELD

Sample dato: 07/10102

Depth to water: $33.24 \mathrm{~h}(16.44 \mathrm{~m})$ balow TOC

Whor olevation: $200.70 \mathrm{~h}$ i

P. conductence: 80 m $\mathrm{s} / \mathrm{cm}$.

The rer wecuaced

LABOPATOFY ANALYBES

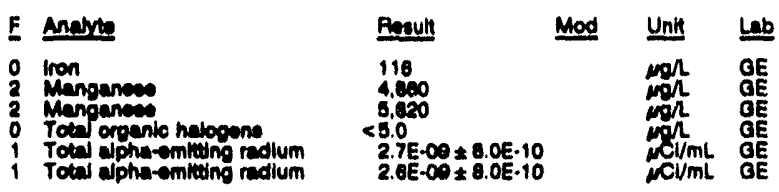

WELL KAB 3

MEASUAEMENTS CONOUCTED IN THE FIELD

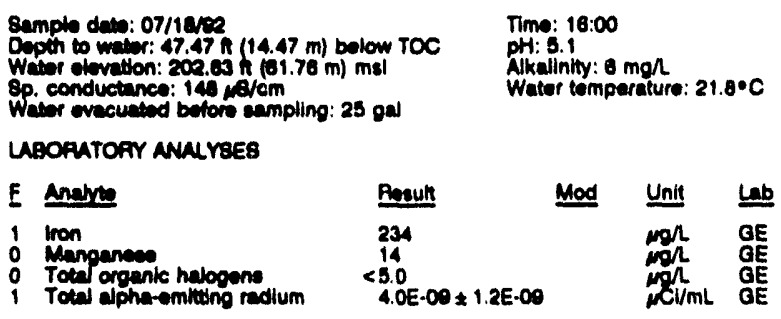

WELL KAB 4

MEABUREMENTS CONDUCTED IN THE FIELD

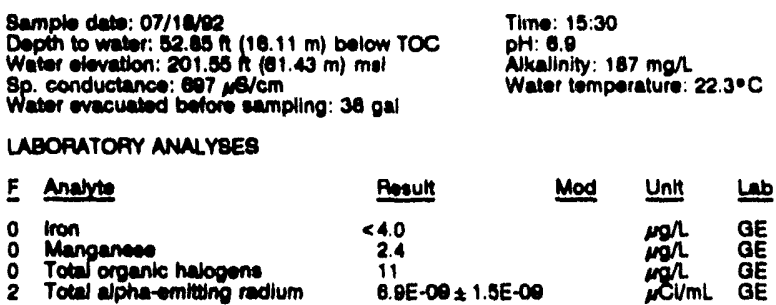

WELL KAC 1

MEASUREMENTS CONDUCTED IN THE FIELO

Sample dem oupipe

Depth to wation: $47.41 \mathrm{~h}(14.45 \mathrm{~m})$ bolow TOC

Webrolovation: $210.50 \mathrm{~h}(106.63 \mathrm{~m}) \mathrm{mal}$

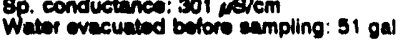

Time: $12: 30$

PH: 8.7 .

Whiter tomperture: $22.7 \cdot \mathrm{C}$

usoputory A Nu Yeses

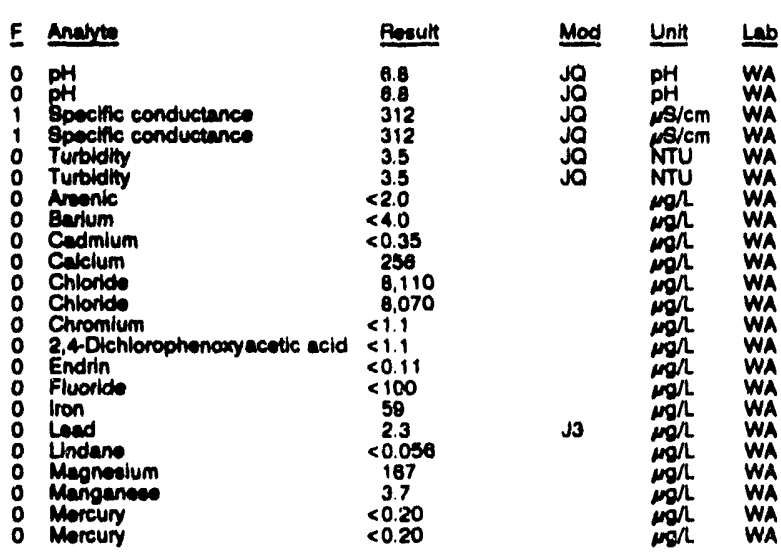

WELL KAC 1 collected on 08/01/02, laboralory analyees (cont.)

\begin{tabular}{|c|c|c|c|}
\hline Analyte & Posult & Mod & Unit \\
\hline 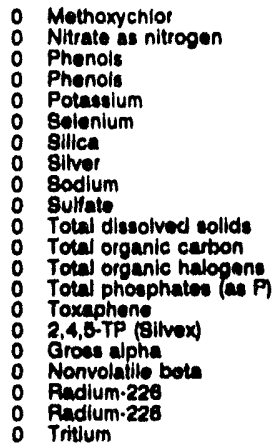 & 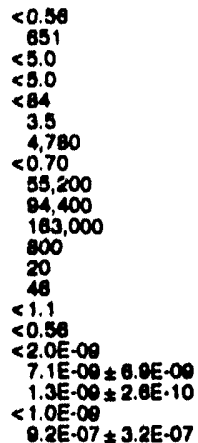 & Jo & 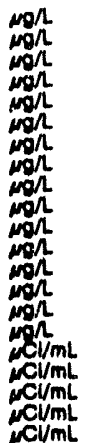 \\
\hline
\end{tabular}

\section{WELL KAC 2}

MEASUREMENTS CONOUCTED IN THE FIELD

\begin{tabular}{|c|c|}
\hline 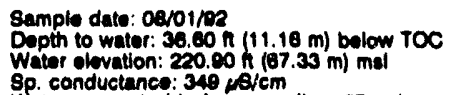 & $\begin{array}{l}\text { Time: } 10.25 \\
\text { PH: } 6.1 \\
\text { Nikalinity: } 61 \mathrm{mg} \Omega \\
\text { Water tomparaturs: } 22.0 \circ \mathrm{C}\end{array}$ \\
\hline
\end{tabular}

Water ovacuated batore sampling: 67 oe

LABORATORY ANALYSES

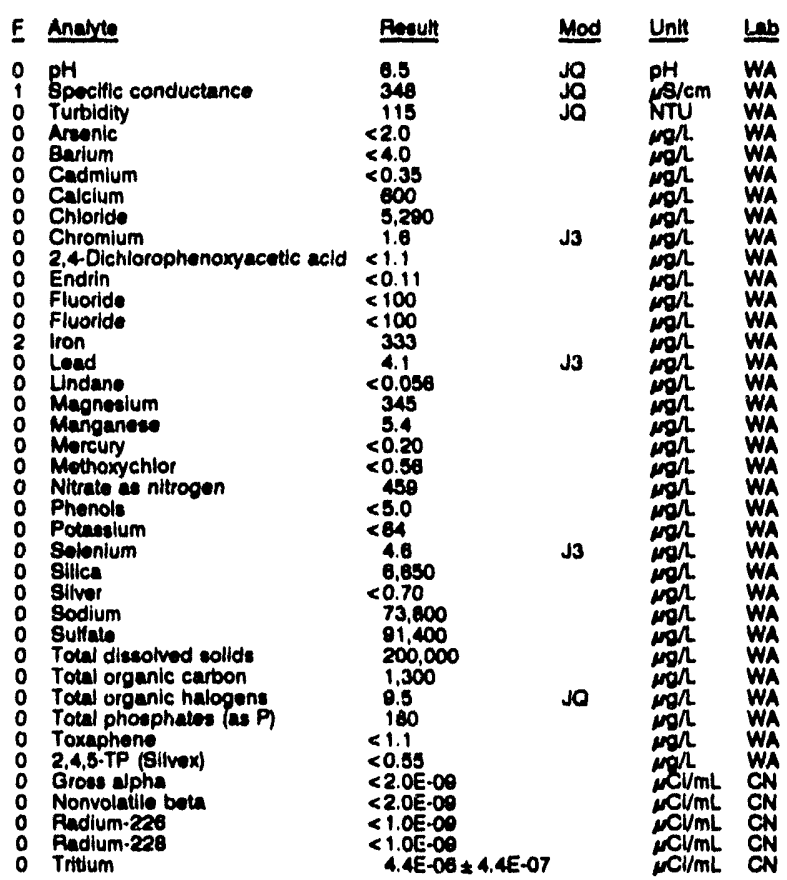

\section{WELL KAC 3}

MEASUREMENTS CONDUCTED IN THE FIELO

Sample date: carpip?

Depth to water: $36.85 \mathrm{f}$ (11.17 m) bolow TOC

Water to watevation: $221.15 \mathrm{~h}(07.41 \mathrm{~m}) \mathrm{msl}$

Sp. conductance 40 istem

Whter evecuated before eampling: 67 gel

LABORATORY ANALYSES

\begin{tabular}{|c|c|c|c|}
\hline Analyte & Rosult & Mod & Unit \\
\hline $\begin{array}{l}\text { pH } \\
\text { 8pecilic conductance } \\
\text { Turbidity } \\
\text { Areonic } \\
\text { Earlum } \\
\text { Cadmium }\end{array}$ & $\begin{array}{r}6.6 \\
357 \\
0.41 \\
<2.0 \\
7.8 \\
<0.35\end{array}$ & $\begin{array}{l}\text { JQ } \\
\text { JO } \\
\text { JO } \\
\text { J3 }\end{array}$ & $\begin{array}{l}\mathrm{pH} \\
\mathrm{NH} / \mathrm{cm} \\
\mathrm{NT} \\
\operatorname{mon} \\
\operatorname{mon}\end{array}$ \\
\hline
\end{tabular}


ANALYTICAL RESULTS

WEL KAO 3 collected on 0a/01/92, leboratory anayeen (cont)

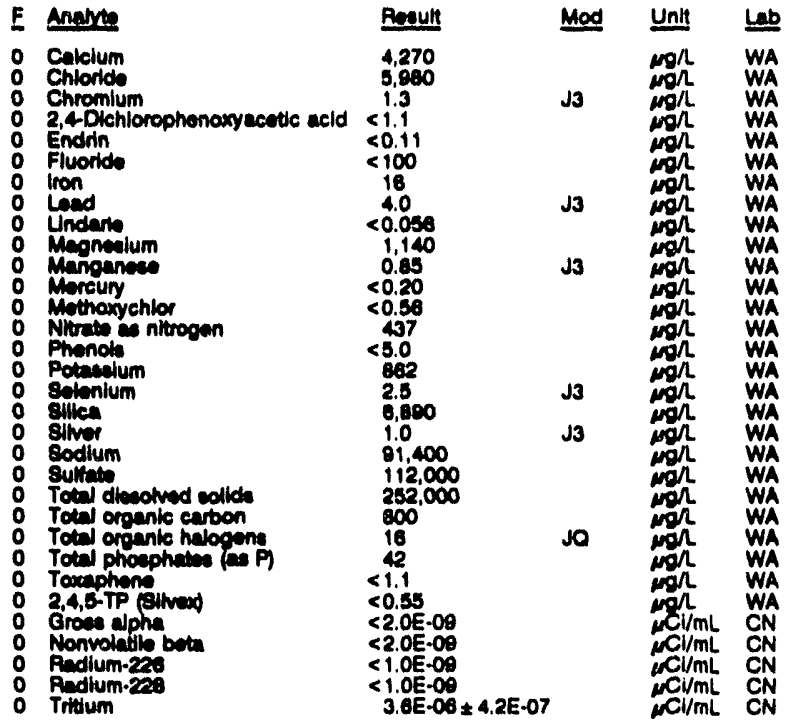

WELL KAC 4.

MEABUAEMENTS CONDUCTED IN THE FIELD

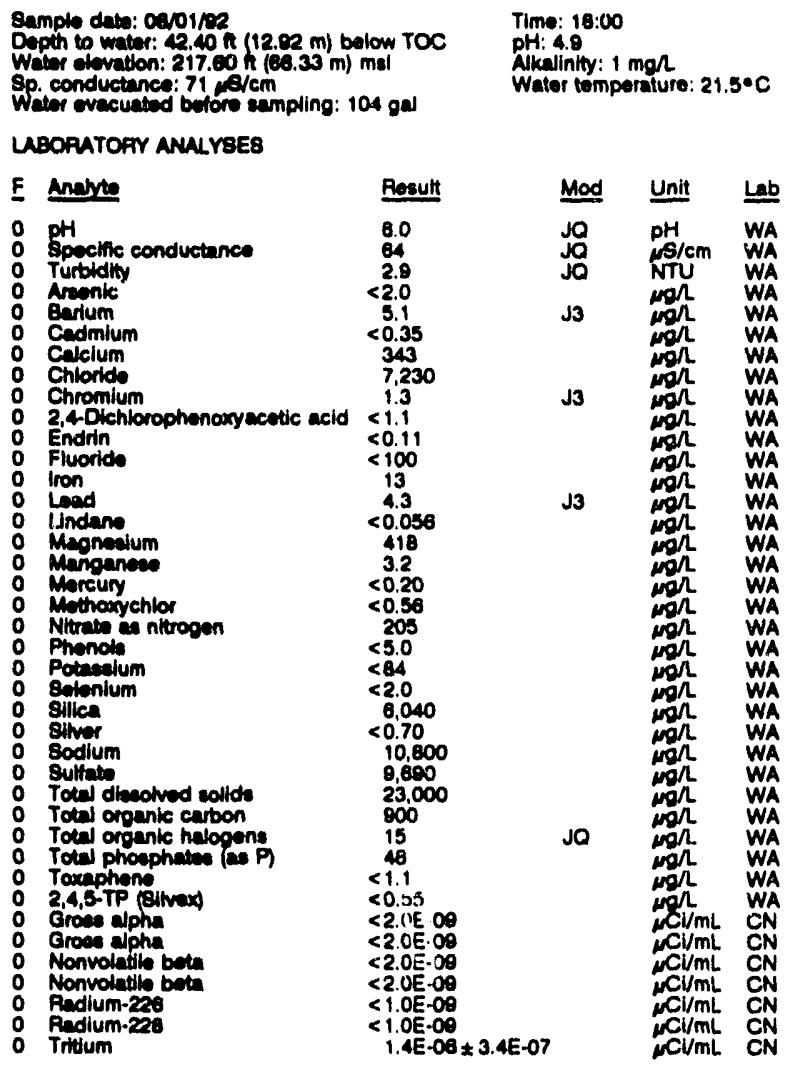

WELL KAC 5

MEASUAEMENTS CONDUCTED IN THE FIELD

Sample date: 08/01/02 Depth to water: $38.05 \mathrm{~h}(11.80 \mathrm{~m})$ bolow TOC We. Wator ovacuatod botore sampling: 44 gel LAORATORY ANALYBES

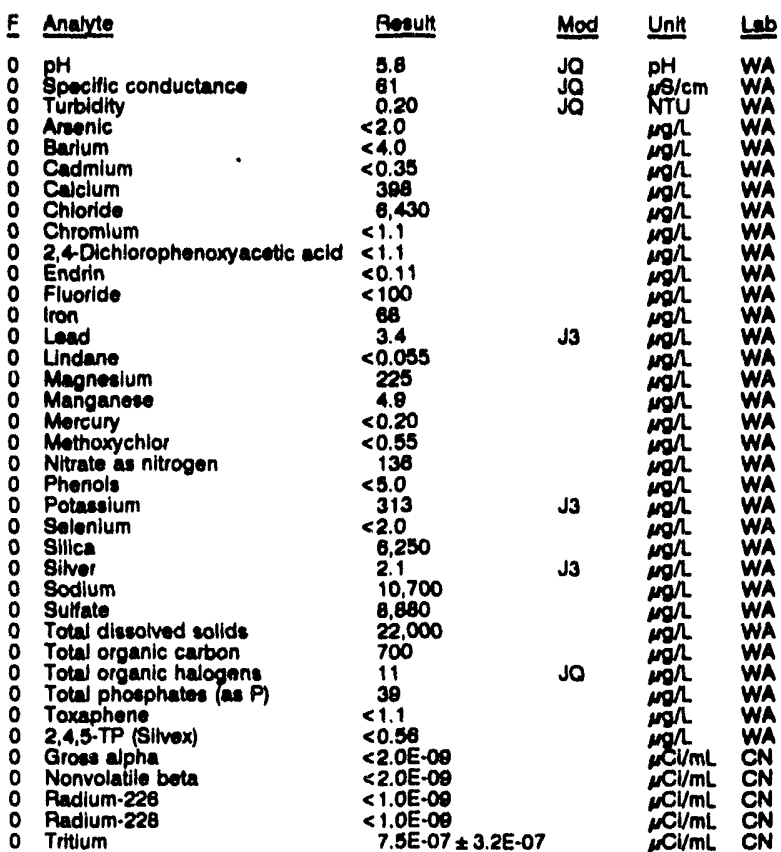

WELL KAC 6

MEASUREMENTS CONDUCTED IN THE FIELD

Sample date: $08 / 02 / 02$

Depth to water: 38.08 i $(11.61 \mathrm{~m})$ bolow TOC Water elevation: $220.91 \mathrm{~h}(67.33 \mathrm{~m}) \mathrm{mal}$ W. conductance: : 87 fs/cm the well went dry during purging.

LABOPATORY ANALYSES

\begin{tabular}{|c|c|c|c|}
\hline Analyte & Result & Mod & Unit \\
\hline 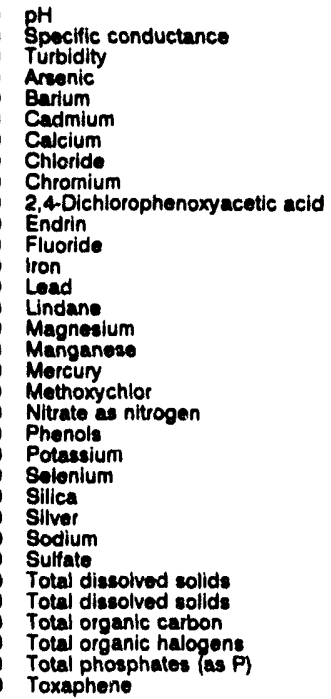 & $\begin{array}{l}5.7 \\
8.7 \\
25 \\
<2.0 \\
5.3 \\
<0.35 \\
318 \\
6,570 \\
1.3 \\
<1.1 \\
<0.11 \\
<100 \\
103 \\
5.3 \\
<0.055 \\
269 \\
6.0 \\
<0.20 \\
<0.55 \\
131 \\
<5.0 \\
338 \\
<2.0 \\
6,680 \\
1.8 \\
14,200 \\
18,500 \\
40,000 \\
45,000 \\
<B 00 \\
16 \\
67 \\
<1.1\end{array}$ & $\begin{array}{l}\mathrm{JO} \\
\mathrm{JO} \\
\mathrm{JO} \\
\mathrm{J3}\end{array}$ & 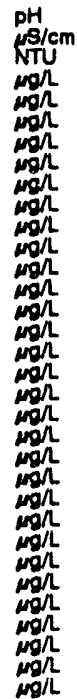 \\
\hline
\end{tabular}


WELL Kac 1 collected on 0a/02/92, laboralory analyees (cont.)

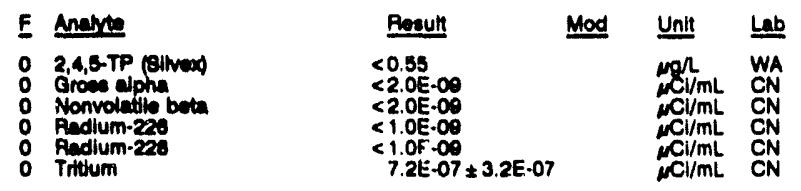

WELL KAC 7

MEABUPEMAENTS CONOUCTED IN THE FIELD

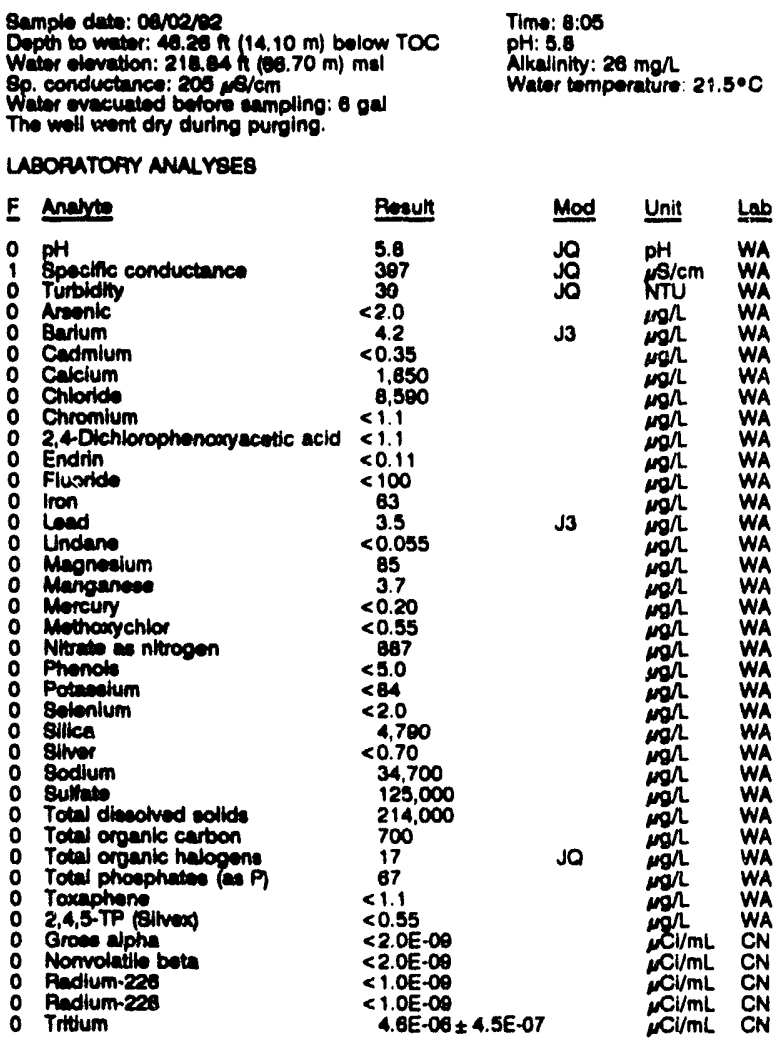

WELL KAC 8

MEABUREMENTS CONDUCTED IN THE FIELD

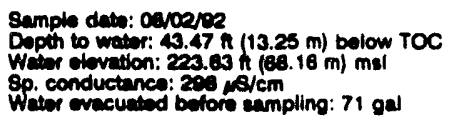

Time: $9: 15$
pH: 5.5

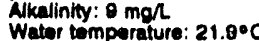

LABOAATOFY ANALYSES

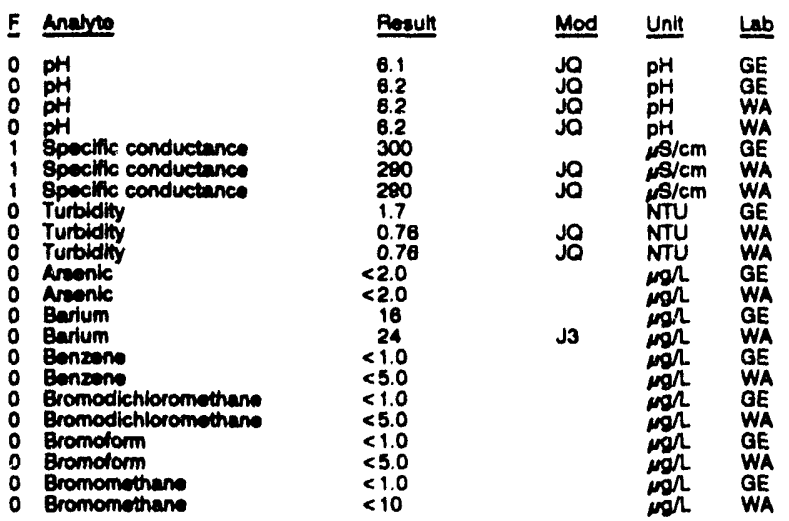

WELL KAC 8 collected on 08/02/92, laboratory analyees (cont)

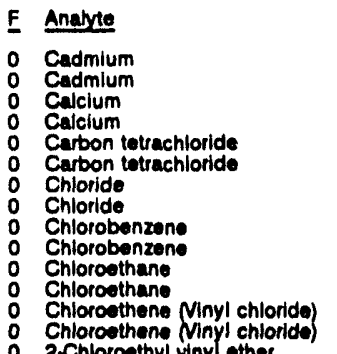

Chlorodthene Ninyl chlorido

2-Chloroethyl vinyl ther

Chlorotorm

Chloroform

Chloromethane

Chlorometh

Chromium

Dibromochloromethane

Dibromochloromethan

1,1-Oichloroethane

(1. Dichlorosthane

1,2-Oichlorowthan

1,1-Dichlorosthylene

o 1,1-Dichlorouthylene

trans-1,2-Dichloroethylene

Dichloromothane

Dichloromethane

Dichloromethane
2,4 Oichlorophenoxyacetic acid $<0.30$
$<0.30$

2,4-Dichlorophenoxyacetic acid <1.

1,2-Dichloropropane

1,2-Dichloropropano

cis-1,3-Dichtoropropene

o cir-1,3-Dichloropropene

o trume-1,3-Dichloroplopene

trans:1,3-

Endrin

O Endrin

O Ethylbenzene

E Ethylbenzent

0 Fluoride

0 iron

o Iron

0
0
0

0 Lead

0 Lead

o Lindane

O Lindane

o Magnesium

Magnesium

Manganose

Manganese

Mercun

Methoxychlor

Methoxychios

Methoxychlor

Methoxychlor

Nitrate as nitrogen

Nitrate-nitrite as nitrogen
Nitrate-nitrite as nitrogen

Phenols

Phenols

P Phenols

Potassium

0 Solenium

S selenium

o Silica

o Silica

o Silver

Sodium

Sodium

Sulfate

- Sulfate

1,1,2,2-Tetrachloroethane

1,1,2,2-Tetrachloroethane

Tetrachlorothylens

Tolvene

Toluene

Total diseolved sollds

Tolal orsolved sollas

Total organic carton

Total organic carbon

Total organic halogens

- Total phosphates las P
$<2.0$

1,600

$<1.0$

$<5.0$

8,740
$<1.0$
$<5.0$

$<1.0$

$<1.0$

$<10$

$<1.0$

2.3
2.2
$<1.0$

$<10$

$<4.0$
$<1.7$
$<1.0$

$<1.0$

$<5.0$

$<1.0$

$<10$

$<5.0$

$<1.0$

$<5.0$

$<1.0$
$<5.0$

$<1.0$

$<1.0$

$<0.0060$

$<0.11$

30.23

7.00
5100
$<100$
1100

$<100$

125
132
132

$<3.0$

$<0.0050$

$<0.056$

743
783

783
35
36

36

$<0.20$

$<0.50$

$<.36$

$<i .1$

525
270
270

270
550
$<50$
5.0

55.0

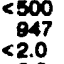

$<2.0$
$<2.0$
$<2$

6.740
6,880

6,6
$<2.0$
1.7

52,400
49,300

103,000
100,000

$<1.0$

$<5.0$

$<1.0$

$<5.0$
$<1.0$

$<5.0$

168,000
180,000

$<1,000$

$<1,000$

896
5.2
$<5.0$

2,000

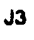

Mod Unit Let

won GE

WE 
ANALYTICAL RESULTS

WELL KAC 8 collectad on 08/02/92, laboratory analyces (cont)

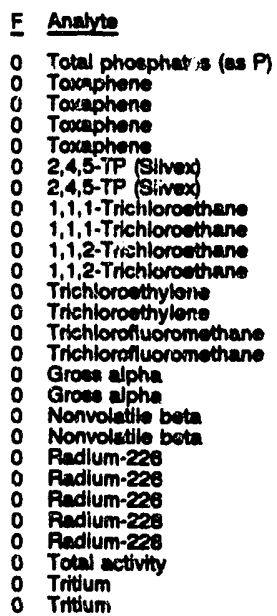

\begin{tabular}{|c|c|}
\hline Result & Mod \\
\hline $\begin{aligned} & 34 \\
&<0.24 \\
&<1.1 \\
&<2.3 \\
&<2.3 \\
&<0.090 \\
&<0.56 \\
&<1.0 \\
&<5.0 \\
&<1.0 \\
&<5.0 \\
&<1.0 \\
&<5.0 \\
&<1.6 \\
&<5.0 \\
&<2.0 E-09 \\
&<2.05 \cdot 00 \\
& 3.2 E-09 \pm 1.6 E-08 \\
&<2.0 E-09 \\
&<1.0 E-09 \\
&<1.0 E-09 \\
&<1.0 E-\infty 9 \\
& 1.9 E-09 \pm 8.6 E-10 \\
&<1.0 E-\infty 9 \\
& 2.5 E-09 \pm 1.2 E-06 \\
& 1.7 E-06 \pm 5.0 E-07 \\
&<7.0 E-07\end{aligned}$ & JQ \\
\hline
\end{tabular}

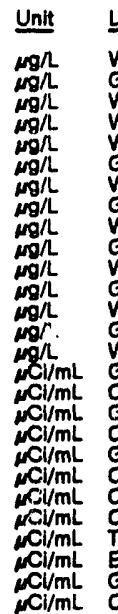

WELL KAC \& Replicate

MEASUREMENTS CONDUCTED IN THE FIELD

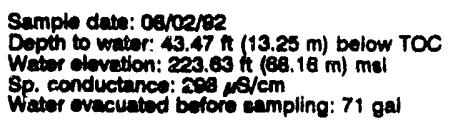

Time: $8: 15$

AHkalinity: $9 \mathrm{mon}$

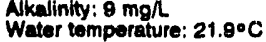

LABORATORYY ANALYSSES

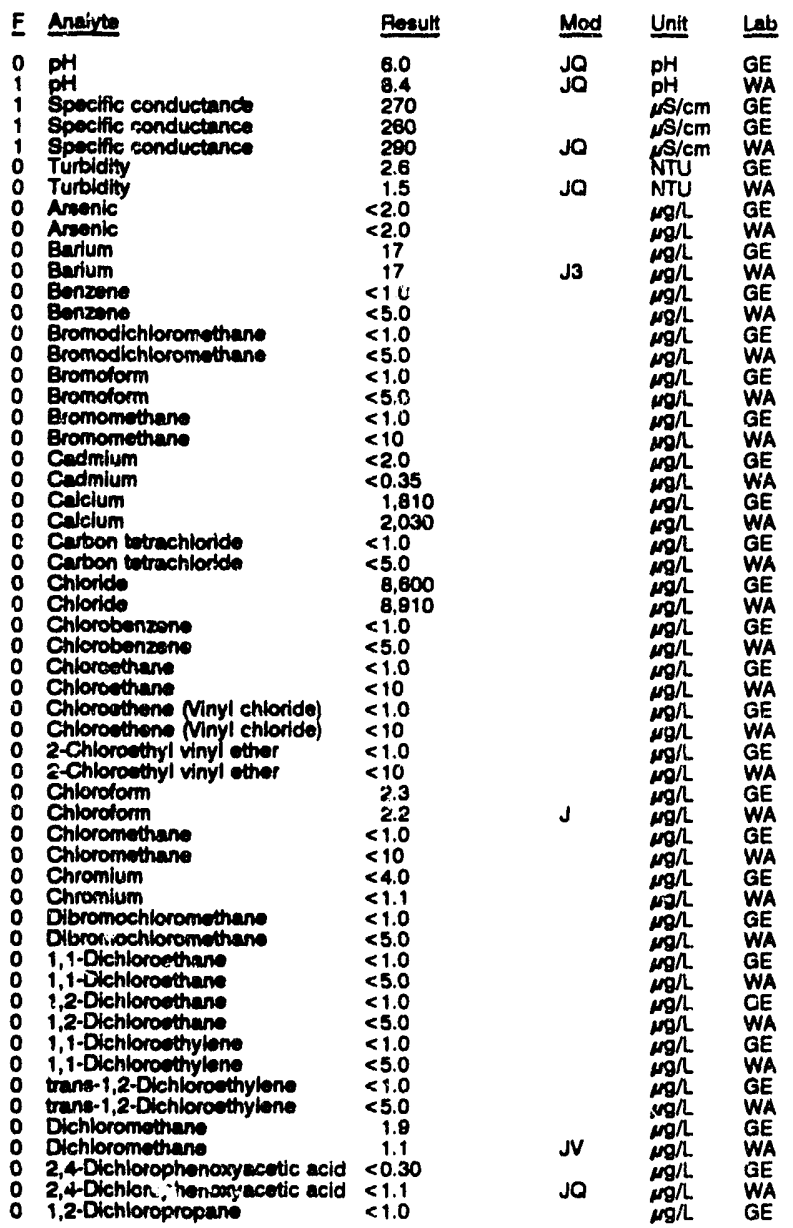

WELL KAC 8 collected on 08/02/82, laboratory analyees (cont)

\begin{tabular}{|c|c|c|c|c|}
\hline Analyte & Rosult & Mod & Unit & Lيb \\
\hline 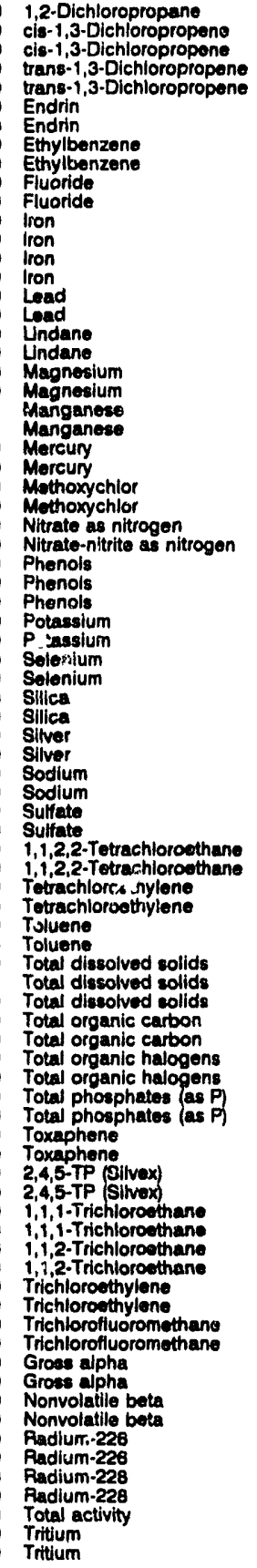 & 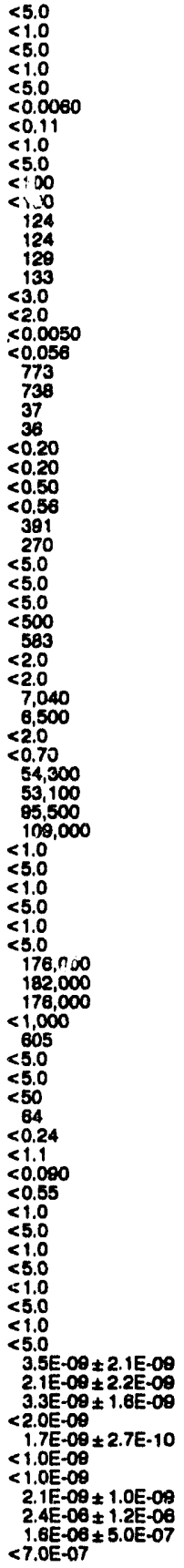 & $\begin{array}{l}\mathbf{J 3} \\
\mathbf{d 1}\end{array}$ & 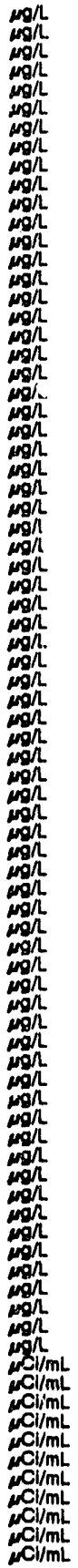 & 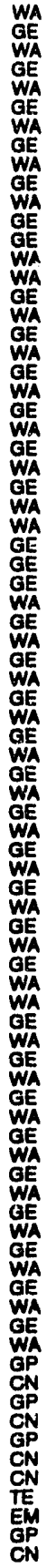 \\
\hline
\end{tabular}


WELL KAC 9

MEASUREMENTS CONDUCTEO IN THE FIELD

Sample date: oaverper

Depth to water: $46.47 \mathrm{n}$ (14.77 m) below TOC

Wath chevition: 213.73 h $(65.18$

Wetor evecuated betore eampling: $61 \mathrm{gal}$

LABORATOFY ANALYSES

E Anatute

$1 \mathrm{pH}$

Specticic conductance

Turbidity

Amenic

Barium

Bromodichloromethane

Bromotorm

Bromomethan

Calcium

Carbon tetrechloride

Chloride

Chlorobenzene

Chlorouthene Mmyl chloride)

2-Chloroethyl vinyl ether

Chiorolorm

Chloromethane

Droinochloromethane

1,1-Dichlorosthan

1,2-Dichloroethan

trans-1,2-Dichloroettrylane

Dichioromethan

4-Dichlorophenoryecetic acid

2,4-Dichiorophe

1,2 -Dichloropropane

trane-3ichloropropene

Endr:"

Ethrjibenzane

Fuonido

Iron

Lead

Magneatum

Mercuny

Mothayschlor

Nitrate as nitrogen

Phends

Potacelum

Selenium

Silca

Sodium

sulfatio

1,2,2.Tetrachloroethane

Tetruchioroethylone

Total dianolved solios

Tota organic carbon

Total phoephetes (as P

Toxaphene

2,4,5-TP Sinvex)

2,4,5-Trichloroethen

1,1, - Thichlorocthan

Trichloroesthylen

Trichlonofluoromethane

Groess elpha

Rendium-28:

Aadium-22a

Totw activity

Tritium

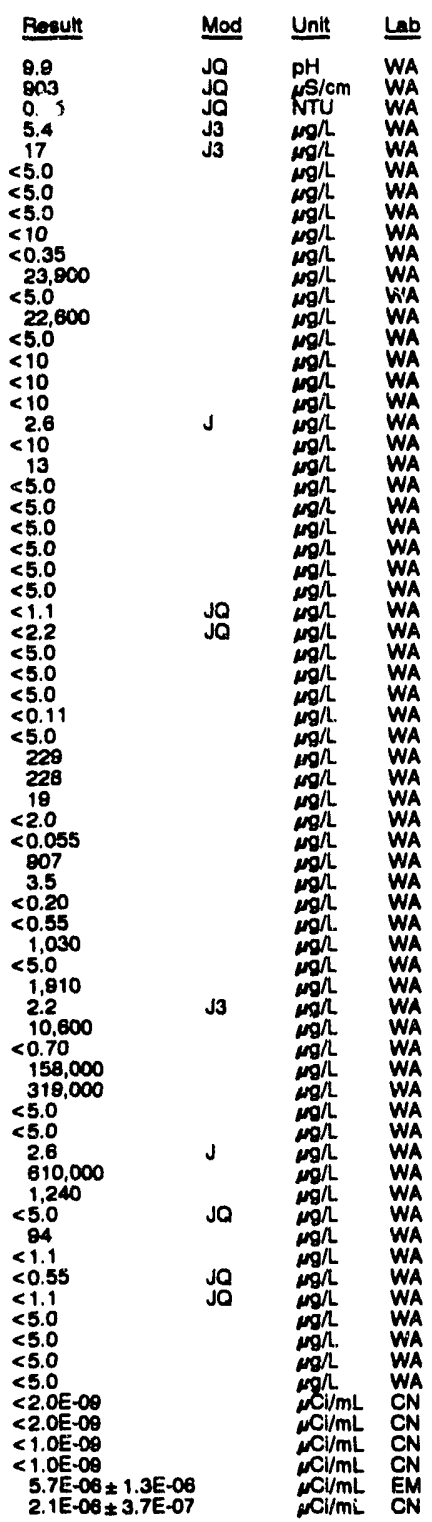

Time: 10:30

Alkalinity: $128 \mathrm{mg} / \mathrm{h}$

Water tomperature: $21.7^{\circ} \mathrm{C}$
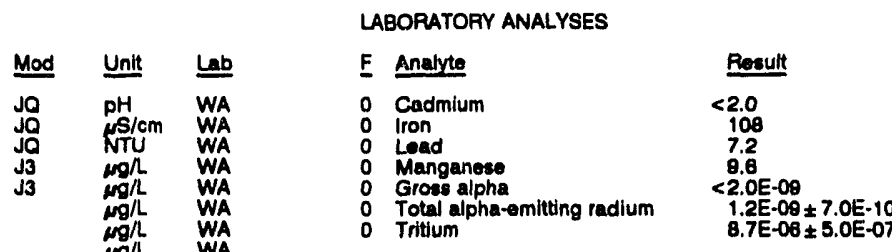

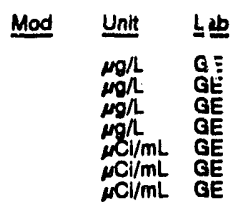

WELL KCB 2

MEASUREMENTS CONDUCTED IN THE FIELD

Sample date: $07 / 16 / 92$

Depth to water: $50.08 \mathrm{ft}(15.26 \mathrm{~m})$ bolow TOC

Water elevation: $204.32 \mathrm{k}$ (62.

Sp. conductance: $62 \mu \mathrm{s} / \mathrm{cm}$
Water evacuated bofore sampling: $44 \mathrm{gal}$

LABOPATOAY ANALYSES

E Analyte

- Cadmium

1 Iron

o Manganese

0 Sulfate

0 Sulfate

- Gross alpha

Total alpha-emitting radium

0 Tritium

\section{WELL KCB 3}

MEASUREMENTS CONDUCTED IN THE FIELD

Depth to water: $45.43 \mathrm{ft}(13.85 \mathrm{~m})$ below TOC

Depth to water: $45.43 \mathrm{ft}(13.85 \mathrm{~m})$ beiow

Wp. conductance 628 .

Water ovacuated belore sampling: $48 \mathrm{gal}$

LABORATOAY ANALYSES

\begin{tabular}{|c|c|c|c|}
\hline & Analyte & Reosult & Unit \\
\hline & $\begin{array}{l}\text { Cadmium } \\
\text { lron } \\
\text { Lead } \\
\text { Manganese } \\
\text { Sulfate } \\
\text { Gross alpha } \\
\text { Total slpha-omitting radium } \\
\text { Tritium }\end{array}$ & $\begin{array}{l}<2.0 \\
84 \\
4.4 \\
1.210 \\
448,000 \\
1.1 E-08 \pm 2.7 E-09 \\
1.1 E-08 \pm 2.0 E-09 \\
6.8 E-06 \pm 5.0 E-07\end{array}$ & 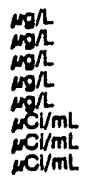 \\
\hline
\end{tabular}

WELL KCB 4

MEASUREMENTS CONDUCTED IN THE FIELD

Sample date: 07/16/20

inaccessibility or mechanical problem provented sample collection.

\section{WELL KDB 1}

MEASUREMENTS CONDUCTED IN THE FIELD

Sample date: 08\%7/0

Depth to water: $64.18 \mathrm{it}(19.56 \mathrm{~m})$ below TOC

Water elevation: $208.94 \mathrm{tt}(63.69 \mathrm{~m}) \mathrm{msl}$

Sp conductance: 112 (s/cm

Time: 15:00

Alkalinity: $0 \mathrm{mg} / \mathrm{s}$

Water tomperature: $22.1^{\circ} \mathrm{C}$

Aler tempernture: $22.5^{\circ} \mathrm{C}$

Water evacuated before sampling: $18 \mathrm{gal}$

The woll went dry during purging.

LABORATORY ANALYSES

\begin{tabular}{|c|c|c|c|}
\hline F Analyte & Result & $\mathrm{Mod}$ & Unit \\
\hline $\begin{array}{ll}0 & \text { Cadmium } \\
0 & \text { Cadmium } \\
2 & \text { Lead }\end{array}$ & $\begin{array}{l}<2.0 \\
<2.0 \\
80\end{array}$ & & $\operatorname{mog}_{n}$ \\
\hline
\end{tabular}


WELL KRB 17D

MEASUREMENTS CONDUCTED IN THE FIELD

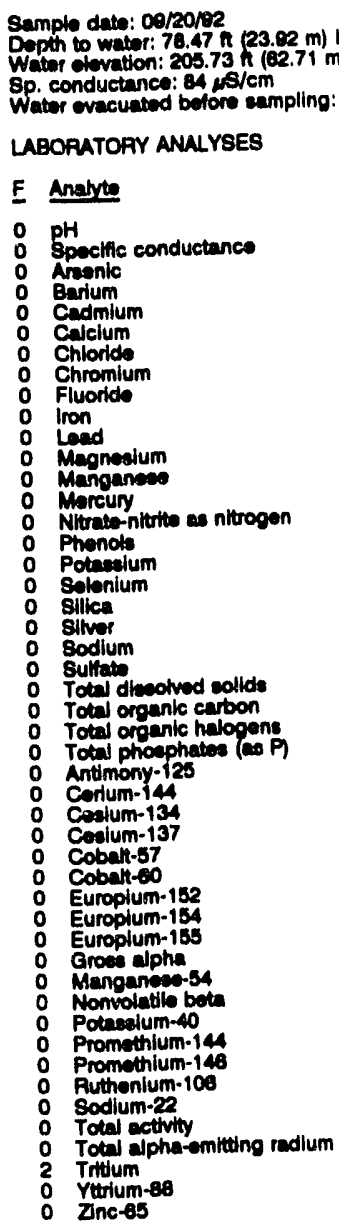

$<500$
$<2.0$

$<2.0$

56,000
$<1,000$

$<1,000$

$<5.0$
Time: 10:05

PH: 5.8 : $21 \mathrm{mg} / \mathrm{h}$

Alkalinity: $21 \mathrm{mg} / \mathrm{h}: 21.3^{\circ} \mathrm{C}$

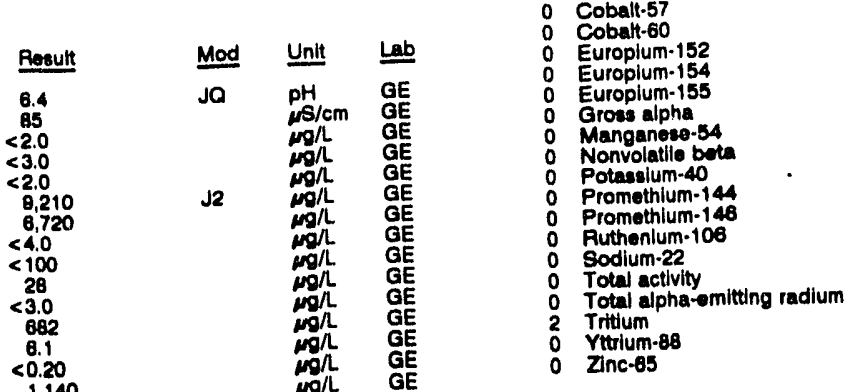

WELL KRB 180 collectod on 09/20/82, laboratory analyees (cont.)

\begin{tabular}{|c|c|}
\hline & Analyte \\
\hline $\begin{array}{l}0 \\
0\end{array}$ & 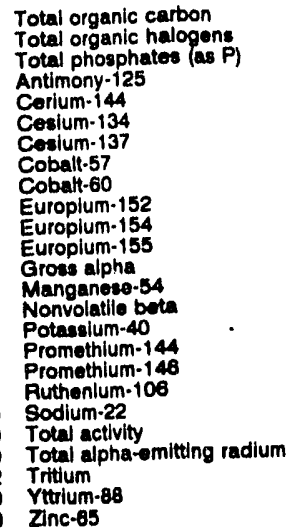 \\
\hline
\end{tabular}

\begin{tabular}{l} 
Roenult \\
\hline 1,610 \\
$<5.0$ \\
60 \\
$<2.0 E-08$ \\
$<6.0 E-08$ \\
$<1.0 E-08$ \\
$<1.0 E-08$ \\
$<1.0 E-08$ \\
$<1.0 E-08$ \\
$<4.0 E-08$ \\
$<2.0 E-08$ \\
$<3.0 E-08$ \\
$<2.0 E-09$ \\
$<1.0 E-08$ \\
$2.5 E-09 \pm 1.4 E-09$ \\
$<1.1 E-07$ \\
$<1.0 E-08$ \\
$<1.0 E-08$ \\
$<8.0 E-08$ \\
$<1.0 E-08$ \\
$7.6 E-04 \pm 2.4 E-05$ \\
$1.7 E-09 \pm 1.1 E-09$ \\
$7.8 E-04 \pm 4.2 E-08$ \\
$<6.0 E-08$ \\
$<2.0 E-08$
\end{tabular}

Mod . Unit Lab

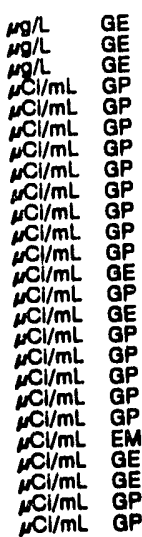

WELL KRB 19D

MEASUREMENTS CONDUCTED IN THE FIELD

Sample date: 09/20/92 Depth to water: $78.28 \mathrm{it}(23.86 \mathrm{~m})$ below
Whater olevation: $203.42 \mathrm{~h}(62.00 \mathrm{~m}) \mathrm{msl}$ Water elevation: $203.42 \mathrm{ht}(62$.

Time: 14:30

100
$<2.0 E-08$

$<1.0 E-08$

$<1.0 E-09$

$<1,0 \mathrm{E}-08$

$<4.0 \mathrm{E}-08$

$<2.0 E-08$

$<2.0 \mathrm{E} .09$

$<2.0 \mathrm{CE} .08$

$<2.0 E-09$

$<1.0 \mathrm{C}-08$

$<1.0 E-08$

$<8.0 \mathrm{E}-08$

$<1.0 E-08$ - $4.1 E=4.8 E-05$

$4.1 E-03 \pm 4.8 E-05$
$<1.0 E-09$

$4.1 E-03$

$<6.0 E-08$
$<2.0 E-08$

Witer evacuated bofore eampling: $11 \mathrm{ga}$

The well went dry during purging.

LABORATORY ANALYSES

\begin{tabular}{|c|c|}
\hline & Analyte \\
\hline 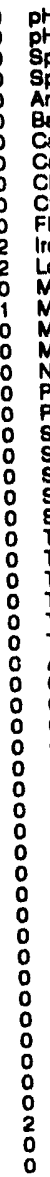 & 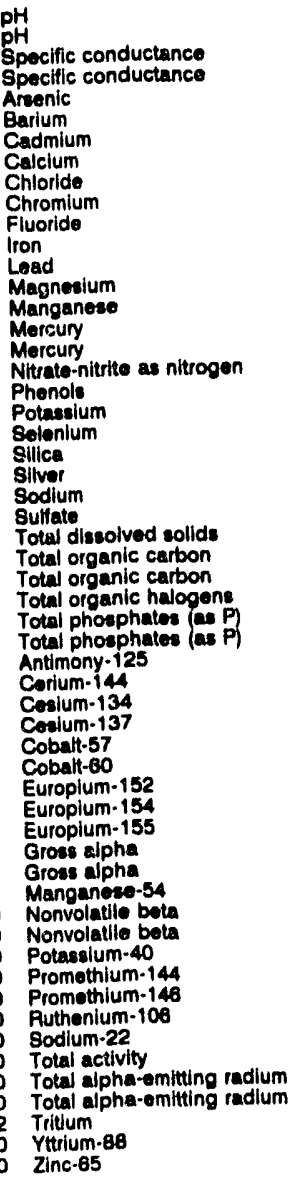 \\
\hline
\end{tabular}

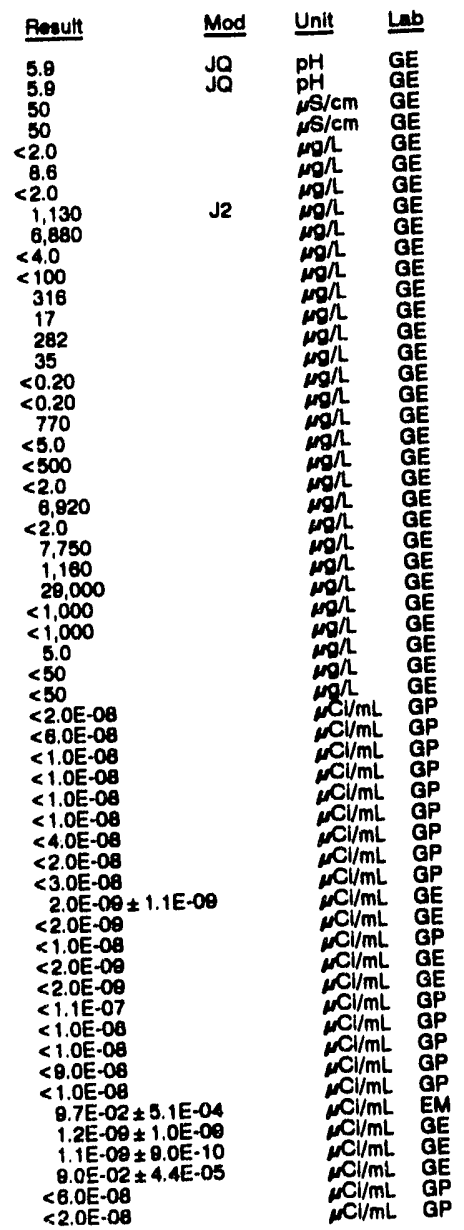


WELL KRP 1

MEASUREMENTS CONDUCTED IN THE FIELD

Sumple date: 07/17/02

Dopth to water: 44.23 . $(13.48 \mathrm{~m})$ below TOC

Welor olovaton: $219.66 \mathrm{~h}(68.95 \mathrm{~m}) \mathrm{ms}$

Wator evacuated before eampling: $33 \mathrm{gal}$

LABOPATORY ANALYSES

\begin{tabular}{|c|c|c|c|}
\hline F Analyte & Result & Mod & Li.nt! \\
\hline $\begin{array}{ll}0 & \text { Iron } \\
1 & \text { Lead } \\
0 & \text { Manganese } \\
0 & \text { Total organic halogons }\end{array}$ & $\begin{array}{c}131 \\
13 \\
19 \\
<5.0\end{array}$ & $\mathrm{~J} 2$ & $\begin{array}{c}\mu g / L \\
\mu g / L \\
\mu g / L \\
\mu g / L\end{array}$ \\
\hline
\end{tabular}

\section{WELL KRP 2}

MEASUREMENTS CONOUCTEO IN THE FIELD

Sample date: 07/17/92

(11.00 m) below TOC

(2)

Wator ovacuatod betore sempling: $55 \mathrm{gal}$

LABORATOFY ANUL YSES

\begin{tabular}{|c|c|}
\hline F Anaryte & Result \\
\hline $\begin{array}{ll}0 & \text { Iron } \\
0 & \text { lron } \\
2 & \text { Lead } \\
0 & \text { Manganeas } \\
0 & \text { Manpaneas } \\
0 & \text { Total organic halogens }\end{array}$ & $\begin{array}{r}11 \\
11 \\
28 \\
5.2 \\
5.2 \\
<5.0\end{array}$ \\
\hline
\end{tabular}

\section{WELL KRP 3}

MEASUREMENTS CONDUCTED IN THE FIELD

\section{Sample date: 07/17/0 \\ Depth to water: $33.33 \mathrm{~m}$ (10.22 m) below TOC \\ Water elevation: $220.97 \mathrm{~h}(87.35 \mathrm{~m}) \mathrm{ms}$}

Water ovacuated before cumpling: $35 \mathrm{gal}$

LABOFATOFY ANALYSES

\begin{tabular}{|c|c|}
\hline Anabute & Rosult \\
\hline $\begin{array}{ll}0 & \text { lion } \\
2 & \text { Load } \\
1 & \text { Lead } \\
2 & \text { Manpaneas } \\
0 & \text { Total organic halogens }\end{array}$ & $\begin{array}{l}113 \\
15 \\
15 \\
52 \\
<5.0\end{array}$ \\
\hline
\end{tabular}

WELL KRP 4

MEASUREMENTS CONOUCTED IN THE FIELD

Sample date: 07/17/9e

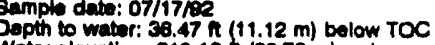
Watter olevation: 218.13 ( $(86.78 \mathrm{~m}) \mathrm{ms}$

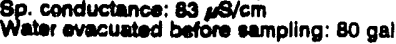

LABORATOPY ANALYES

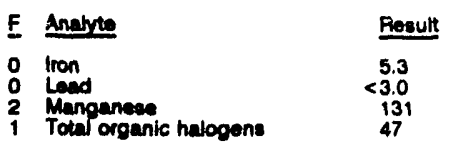

Time: 7:45

PH: 4.3

Weter temperature: $20.70 \mathrm{C}$

Time: 8:05

Alkalinity: $1 \mathrm{mgh}$

Water temperature: $20.3^{\circ} \mathrm{C}$

\begin{tabular}{|c|c|}
\hline $\mathrm{Mod}$ & Unit \\
\hline $\begin{array}{l}\mathrm{J} 2 \\
\mathrm{~J} 2\end{array}$ & $\begin{array}{l}\mu g / \\
\mu g / \\
\mu g / \\
\mu g / L \\
\mu g h \\
\mu g / L\end{array}$ \\
\hline
\end{tabular}

Time: 8:25

Alkallinity: $0 \mathrm{mg} / \mathrm{h}$

Water temperature: $20.0^{\circ} \mathrm{C}$

\begin{tabular}{|c|c|}
\hline Mod & Unit \\
\hline J2 & $\begin{array}{l}m g / h \\
\mu g h / \\
\mu g / L \\
\mu g h \\
\mu h /\end{array}$ \\
\hline
\end{tabular}

Timo: 8:45

pH: 4.7

Alkalinity: $0 \mathrm{mg} /$

Water tomperature: $20.5 \circ \mathrm{C}$

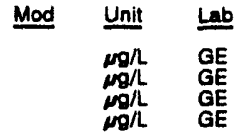

WELL KSB 1

MEASUREMENTS CONDUCTED IN THE FIELD

Dopth to water: $62.44 \mathrm{ft}(19.03 \mathrm{~m})$ bolow TOC

Water elevation: 204.95 \& $(62.47 \mathrm{~m}) \mathrm{mal}$

Water evacuated before sampling: $77 \mathrm{gal}$

LABORATORY ANALYSES

\begin{tabular}{|c|c|c|c|}
\hline F Analyte & Remoult & Mod & Unit \\
\hline $\begin{array}{ll}0 & \text { Cadmium } \\
0 & \text { Total organic halogens } \\
0 & \text { Grous alpha } \\
0 & \text { Nonvolatile beta } \\
2 & \text { Tritium } \\
2 & \text { Tritum }\end{array}$ & $\begin{array}{l}<2.0 \\
6.5 \\
1.4 E-09 \pm 1.1 E-09 \\
2.1 E-09 \pm 8.4 E-10 \\
2.8 E-03 \pm 7.7 E-00 \\
2.6 E-03 \pm 1.2 E-05\end{array}$ & & 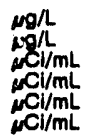 \\
\hline
\end{tabular}

WELL KSB 2

MEASUREMENTS CONDUCTED IN THE FIELO

\begin{tabular}{|c|c|}
\hline $\begin{array}{l}\text { Semple date: } 07 / 19 / 92 \\
\text { Dopth to water: } 60.86 \mathrm{H}(18.55 \mathrm{~m}) \text { below TOC } \\
\text { Water olevation: } 204.64 \mathrm{ht}(62.47 \mathrm{~m}) \mathrm{ms} \\
\text { Sp. conductance: } 35 \mu \mathrm{s} / \mathrm{cm}\end{array}$ & $\begin{array}{l}\text { Time: } 13: 45 \\
\text { pH: } 4.4 \\
\text { Alkallinity: } 0 \mathrm{mg} / \\
\text { Water temperature: } 22.0^{\circ} \mathrm{C}\end{array}$ \\
\hline
\end{tabular}

Time: 13:20

PH: 4.8

$23.6^{\circ} \mathrm{C}$

LABORATORY ANALYSES

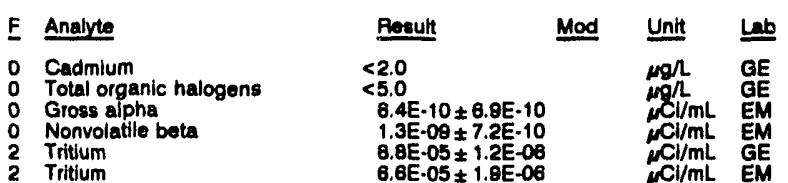

WELL KSB 3

MEASUREMENTS CONDUCTED IN THE FIELO

$\begin{array}{ll}\text { Sample date: } 07 / 19 / 92 & \text { Time: } 14: 10 \\ \text { Depth to water: } 57.15 \mathrm{ft}(17.42 \mathrm{~m}) \text { below TOC } & \text { pH: } 4.4 \\ \text { Water olevation: } 204.35 \mathrm{H}(62.29 \mathrm{~m}) \mathrm{msl} & \text { Alkalinity: } 0 \mathrm{mg} / \\ \text { Sp. conductance: } 37 \mu \mathrm{s} / \mathrm{cm} & \text { Water temperature: } 22.6^{\circ} \mathrm{C} \\ \text { Water evacuated betore sampling: } 81 \mathrm{gal} & \end{array}$

Water evacuated betore sampling: $81 \mathrm{gal}$

LABOPATORY ANALYSES

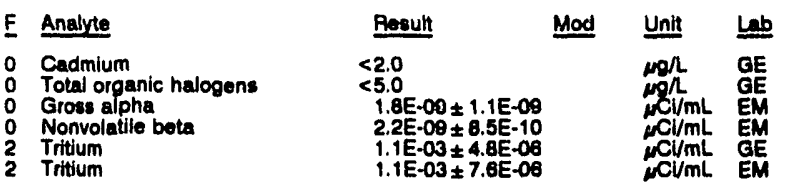

\section{WELL KSB 4A}

MEASUREMENTS CONDUCTED IN THE FIELD

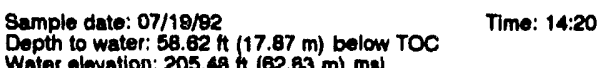

Inaccessibility or mochanical problem provented sample collection.

WELL KSB 4A

MEASUREMENTS CONOUCTED IN THE FIELD

\begin{tabular}{|c|c|}
\hline $\begin{array}{l}\text { Sample dato: 08/31/92 } \\
\text { Depth to water: } 58.97 \mathrm{ft}(17.87 \mathrm{~m}) \text { bolow TOC } \\
\text { Water elevation: } 205.13 \mathrm{ht}(82.52 \mathrm{~m}) \mathrm{msl} \\
\text { Sp. conductance: } 31 \text { is/cm } \\
\text { Water ovacuated betore sampling: } 93 \mathrm{gal}\end{array}$ & $\begin{array}{l}\text { Time: } 15: 25 \\
\text { pH: } 4.6 \\
\text { Alkalinity: } 0 \mathrm{mg} \Omega \\
\text { Water temperature: } 22.9^{\circ} \mathrm{C}\end{array}$ \\
\hline
\end{tabular}

Water ovacuated betoro sampling: 83 gal

LABORATORY ANALYSES

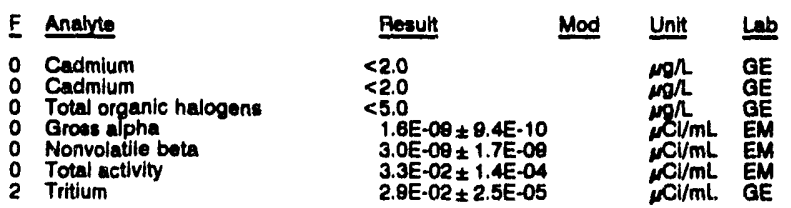


WELL K8B \&A colbeted on 08/31/92, laboratory analyses (cont)

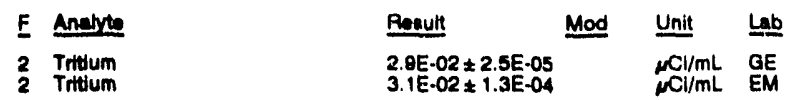

WELL KSM 1D

MEASUREMENTS CONDUCTED IN THE FIELO Depth to water: $64.11 \mathrm{n}$ (19.54 m) bolow roc Water olovation: 208.28 h (83.

Time: 14:10 Wher wacuatiad before sampling: $10 \mathrm{gal}$

Alkalinity: $11 \mathrm{mg} / \mathrm{h}$ Water tomperature: $23.0^{\circ} \mathrm{C}$ The well went dry during purging.

LABORATOAY ANALYES

\begin{tabular}{|c|c|c|c|}
\hline Anabte & Ronult & Mod & Unit \\
\hline Tritium & 0.4E. O & & $\mu \mathrm{Cl} / \mathrm{mL}$ \\
\hline
\end{tabular}

\section{WELL KSM 1D}

MEASUREMENTS CONDUCTED IN THE FIELD

\begin{tabular}{|c|c|}
\hline 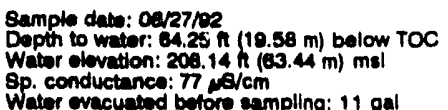 & $\begin{array}{l}\text { Time: } 11: 20 \\
\text { pH: } 5.7^{\text {Alkalinity: } 18 \mathrm{mg} / \mathrm{h}} \\
\text { Water tomperature: } 24.2^{\circ} \mathrm{C}\end{array}$ \\
\hline
\end{tabular}
The well went dry during purging: 11 gal

LABOAROFY ANALYSES

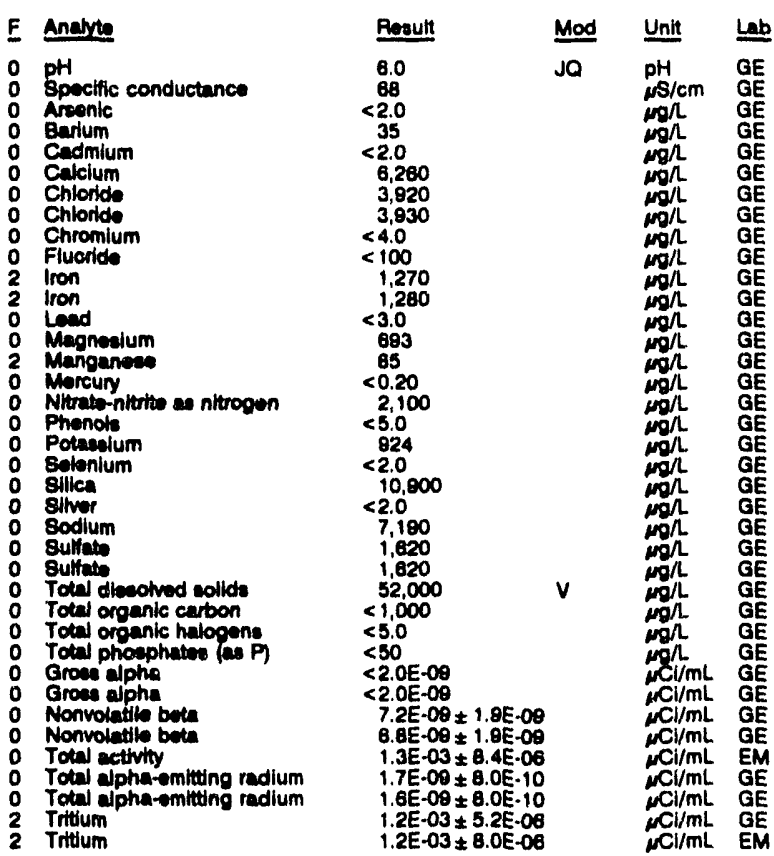

WELL KSM 1D

MEASUREMENTS CONOUCTEO IN THE FIELD

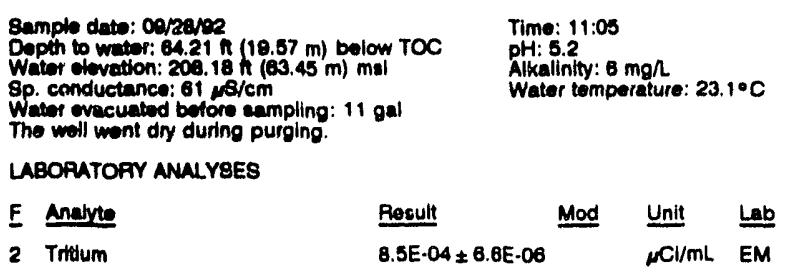

WELL KSS 1D

MEASUREMENTS CONDUCTED IN THE FIELLD

Sample date: 08/01/92

Depth to water: $54.32 \mathrm{H}(16.56 \mathrm{~m})$ below TOC

Water olevation: $175.48 \mathrm{ht}$

Thell went dy during purging: $15 \mathrm{get}$

LABORATORY ANALYSES

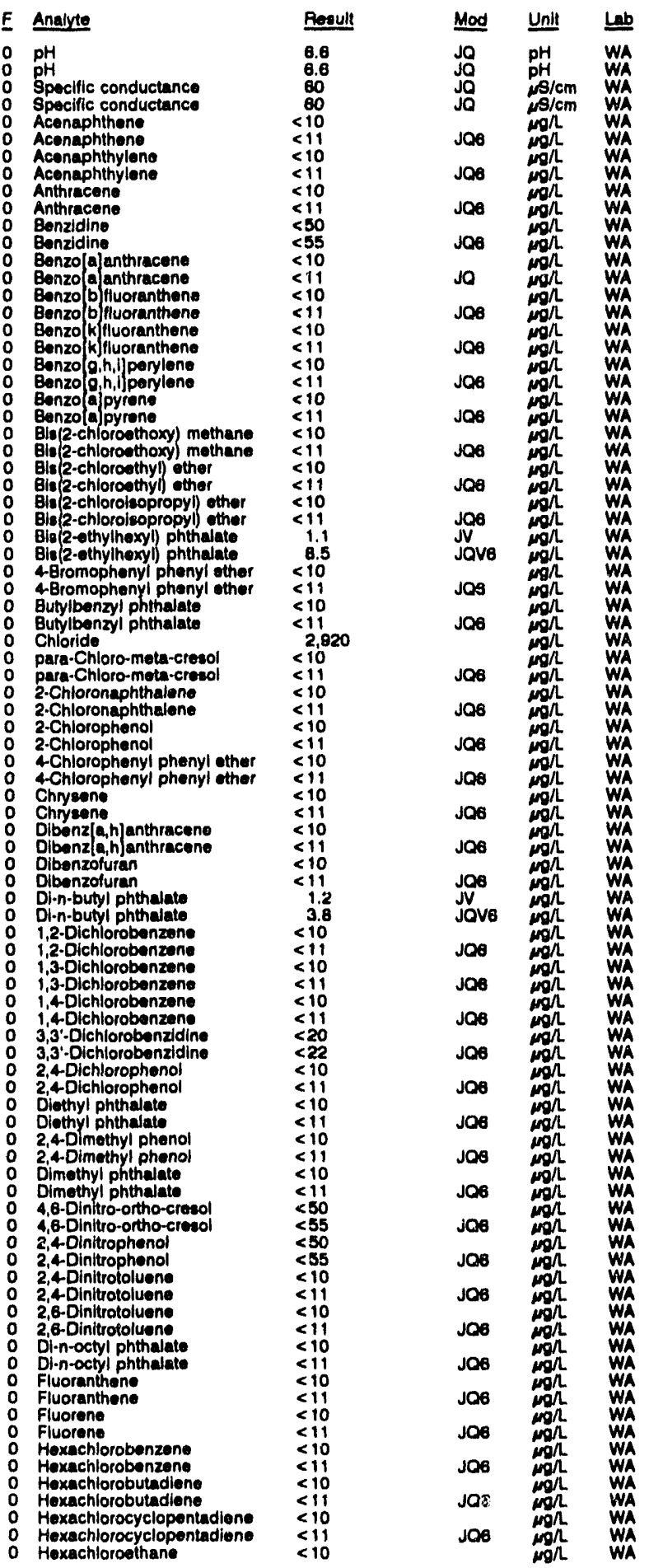

Time: 15:30

Alkallinity: $21 \mathrm{mo} / \mathrm{L}$

Water temperature: $213^{\circ} \mathrm{C}$ 
ANALYTICAL RESULTS

WELL KSS 1D collocted on 08/01/92, laboratory analyses (cont.)

\begin{tabular}{|c|c|c|c|}
\hline Analyte & Pesult & Mod & Unit \\
\hline 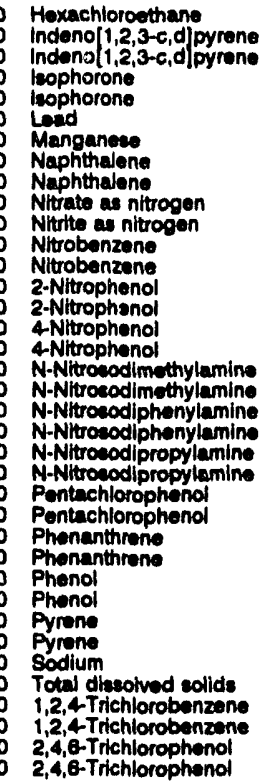 & $\begin{array}{l}<11 \\
<10 \\
<11 \\
<10 \\
<11 \\
<2.0 \\
5.5 \\
<10 \\
<11 \\
585 \\
<10 \\
<10 \\
<11 \\
<10 \\
<11 \\
<50 \\
<55 \\
<10 \\
<11 \\
<10 \\
<11 \\
<10 \\
<11 \\
<50 \\
<55 \\
<10 \\
<11 \\
<10 \\
<11 \\
<10 \\
<11 \\
2,490 \\
23,00 \\
310,000 \\
<11 \\
<11 \\
<10 \\
<11\end{array}$ & 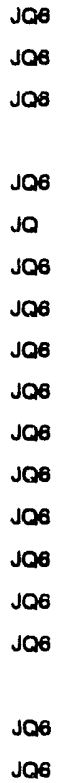 & 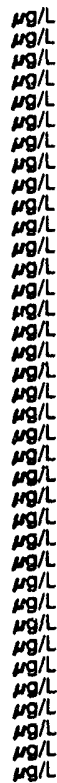 \\
\hline
\end{tabular}

WELL KSS 2D

MEASUREMENTS CONDUCTED IN THE FIELD

\begin{tabular}{|c|c|c|c|c|c|}
\hline \multicolumn{3}{|c|}{ 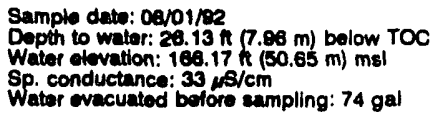 } & \multicolumn{3}{|c|}{$\begin{array}{l}\text { Time: } 14: 50 \\
\text { pH: } 5.3 .3 \\
\text { Alkalinity: } 5 \text { mg/h } \\
\text { Water temperature: } 20.5^{\circ} \mathrm{C}\end{array}$} \\
\hline \multicolumn{6}{|c|}{ LABORATORY ANALYSES } \\
\hline$\underline{F}$ & Anabyte & Pesult & Mod & Unit & Lab \\
\hline 0 & 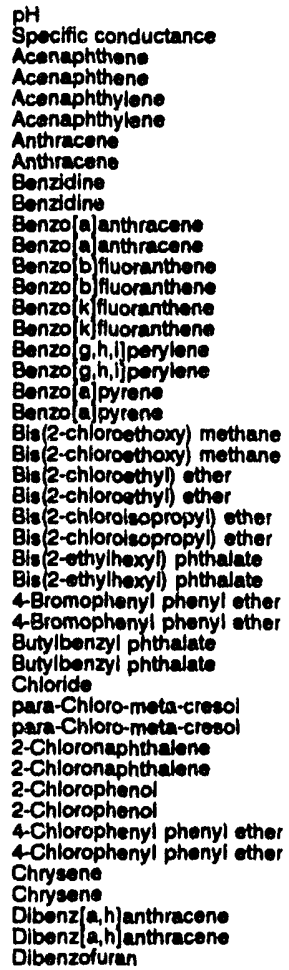 & $\begin{aligned} & 6.2 \\
& 27 \\
&<10 \\
&<11 \\
&<10 \\
&<11 \\
&<10 \\
&<11 \\
&<50 \\
&<55 \\
&<10 \\
&<11 \\
&<10 \\
&<11 \\
&<10 \\
&<11 \\
&<10 \\
&<11 \\
&<10 \\
&<11 \\
&<10 \\
&<11 \\
&<10 \\
&<11 \\
&<10 \\
&<11 \\
& 2.1 \\
& 6.6 \\
&<10 \\
&<11 \\
&<10 \\
&<11 \\
& 2,210 \\
&<10 \\
&<11 \\
&<10 \\
&<11 \\
&<10 \\
&<11 \\
&<10 \\
&<11 \\
&<10 \\
&<11 \\
&<10 \\
&<11 \\
&<10\end{aligned}$ & 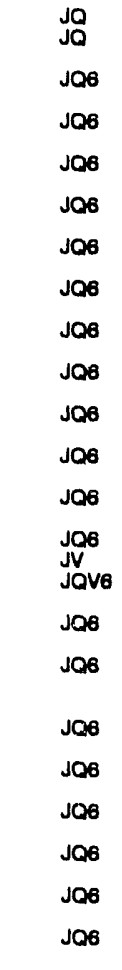 & 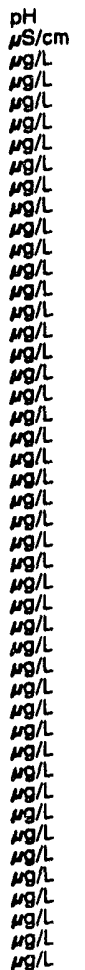 & $\begin{array}{l}\text { WA } \\
\text { WA } \\
\text { WA } \\
\text { WA } \\
\text { WA } \\
\text { WA } \\
\text { WA } \\
\text { WA } \\
\text { WA } \\
\text { WA } \\
\text { WA } \\
\text { WA } \\
\text { WA } \\
\text { WA } \\
\text { WA } \\
\text { WA } \\
\text { WA } \\
\text { WA } \\
\text { WA } \\
\text { WA } \\
\text { WA } \\
\text { WA } \\
\text { WA } \\
\text { WA } \\
\text { WA } \\
\text { WA } \\
\text { WA } \\
\text { WA } \\
\text { WA } \\
\text { WA } \\
\text { WA } \\
\text { WA } \\
\text { WA } \\
\text { WA } \\
\text { WA } \\
\text { WA } \\
\text { WA } \\
\text { WA } \\
\text { WA } \\
\text { WA } \\
\text { WA } \\
\text { WA } \\
\text { WA } \\
\text { WA } \\
\text { WA } \\
\text { WA }\end{array}$ \\
\hline
\end{tabular}

WELL. KSS 20 collocted on $08 / 01 / 82$, laboratory analyees (cont.)

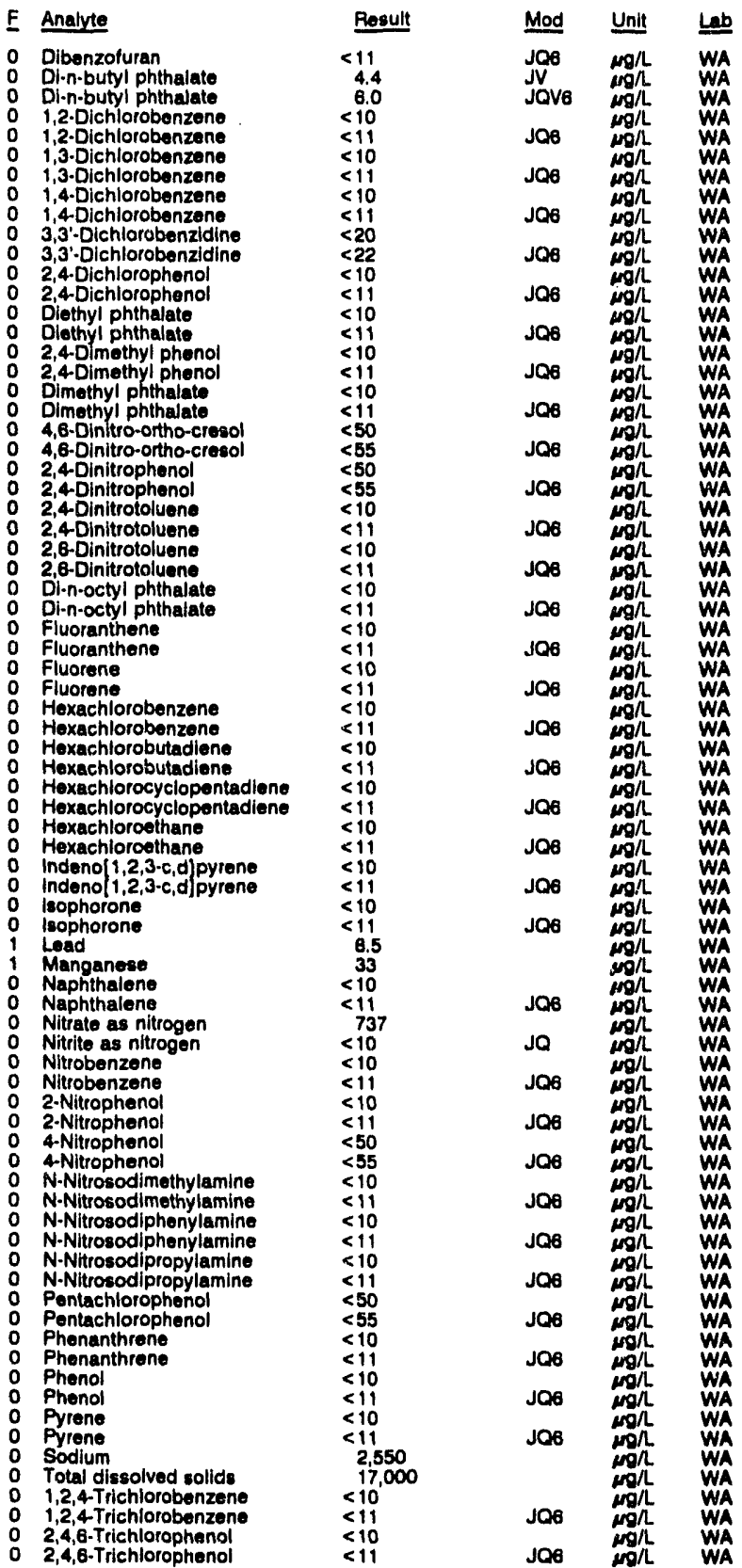

\section{WELL KSS 3D}

MEASUREMENTS CONDUCTED IN THE FIELD

Sample date: 08/01/92

Depth to water: $19.52 \mathrm{ft}(5.95 \mathrm{~m})$ below TOC Water elevation: $165.68 \mathrm{ht}(50.50 \mathrm{~m}) \mathrm{mst}$

Sp. conductance: $32 \mathrm{~s} / \mathrm{cm}$

Water evacuated before sampling: $69 \mathrm{gal}$

LABORATORY ANALYSES

\begin{tabular}{|c|c|c|c|}
\hline E Analyte & Result & Mod & Unit \\
\hline $\begin{array}{ll}\text { D } & \text { pH } \\
0 & \text { Specific conductance } \\
0 & \text { Acenaphthene } \\
0 & \text { Acenaphthylene } \\
0 & \text { Anthracene } \\
0 & \text { Benzidine }\end{array}$ & $\begin{array}{r}6.2 \\
31 \\
<10 \\
<10 \\
<10 \\
<50\end{array}$ & $\begin{array}{l}\mathrm{J} Q \\
\mathrm{~J}\end{array}$ & $\begin{array}{l}\mathrm{pH} \\
\mathrm{m} / \mathrm{cm} \\
\mathrm{mgh} \\
\mathrm{mgh} / \mathrm{L} \\
\mathrm{mg} / \mathrm{L}\end{array}$ \\
\hline
\end{tabular}

Time: $15: 10$

Alkalinity: $8 \mathrm{mo}$ Water temperafure: $20.6^{\circ} \mathrm{C}$ 
WELL KSS 3D colbetad on 08/01/92, laboratory analyees (cont.)

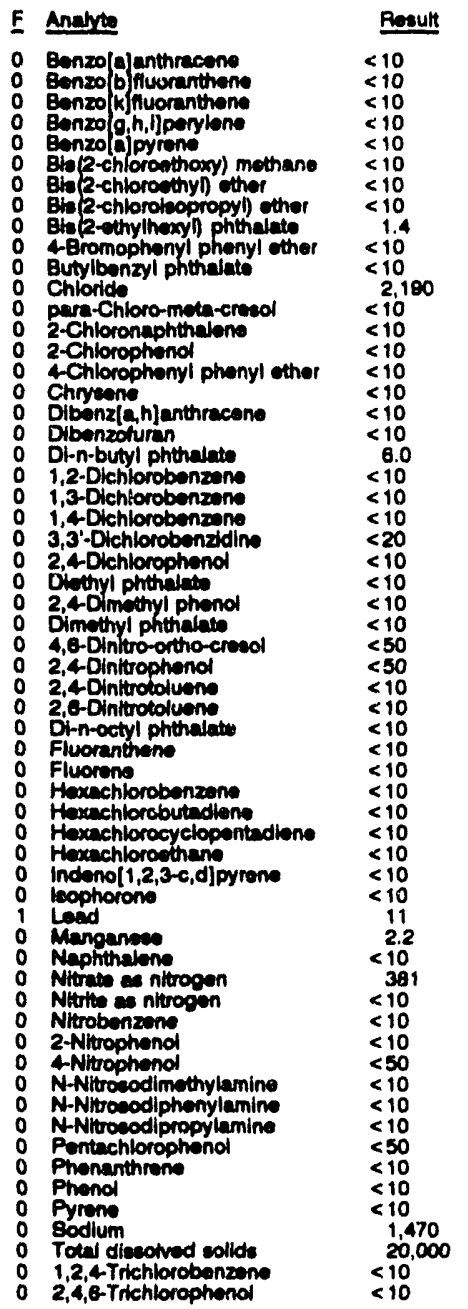

WELL LAC 1

MEASUREMENTS CONDUCTED IN THE FIELD

Sample date: 0av1/02

Depth to water: $20.71 \mathrm{f}(6.31 \mathrm{~m})$ bolow TOC Water tovation: 217.40 h $(09.20 \mathrm{~m}) \mathrm{msl}$ Sp. conductance: 28 is/cm

LABORATORY ANALYBES

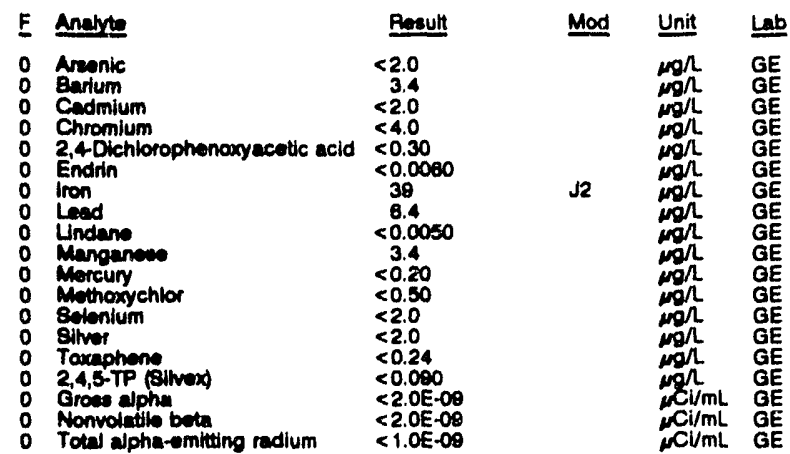

Tima: 10.

Water temperafure: $22.00 \mathrm{C}$
WELL LAC 2

MEASUREMENTS CONDUCTED IN THE FIELD

Sumple date: 08/01/02

Depth to water: $22.30 \mathrm{ft}(6.80 \mathrm{~m})$ below TOC

Water elevation: $217.00 \mathrm{ft}$

Alkelinity: $0 \mathrm{mg}$

Water tomperature: $22.8^{\circ} \mathrm{C}$

LABORATORY ANALYSES

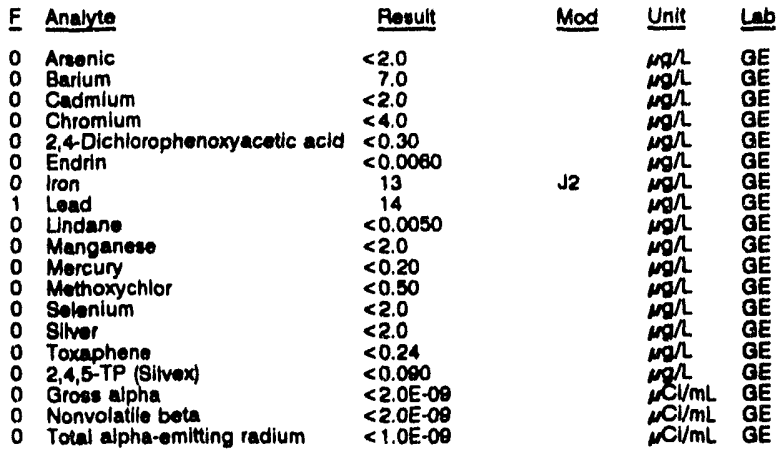

\section{WELL LAC 3}

MEASUREMENTS CONDUCTED IN THE FIELD

Sample date: 08/01/82

Wepth to water: $20.22 \mathrm{n}(6.16 \mathrm{~m})$ below TOC

Water elevation: $217.58 \mathrm{ft}(66.32 \mathrm{~m}) \mathrm{msl}$

Wator evacuatod before rampling: 71 gal

LABORATORY ANALYSES

\begin{tabular}{|c|c|c|c|c|}
\hline$F$ & Analyte & Result & Mod & Unit \\
\hline $\begin{array}{l}0 \\
0 \\
0 \\
0 \\
0 \\
0 \\
0 \\
0 \\
0 \\
0 \\
0 \\
0 \\
0 \\
0 \\
0 \\
0 \\
0 \\
0\end{array}$ & 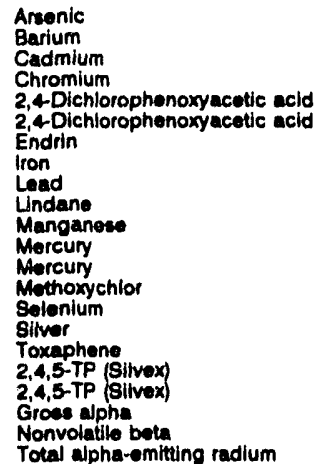 & $\begin{array}{l}<2.0 \\
<3.0 \\
<2.0 \\
<4.0 \\
<0.30 \\
<0.30 \\
<0.0060 \\
17 \\
<3.0 \\
<0.0050 \\
<2.0 \\
<0.20 \\
<0.20 \\
<0.50 \\
<2.0 \\
<2.0 \\
<0.24 \\
<0.090 \\
<0.090 \\
<2.0 E-09 \\
<2.0 E-09 \\
<1.0 E-09\end{array}$ & J2 & 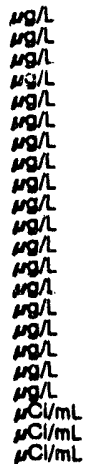 \\
\hline
\end{tabular}

WELL LAC 4

MEASUREMENTS CONDUCTED IN THE FIELD

Semple date: 08/01/92.

Depth to water: $18.45 \mathrm{At}(5.83 \mathrm{~m})$ bolow TOC

Water elevation: $217.65 \mathrm{~h}(68.34 \mathrm{~m}) \mathrm{mul}$

Water evacuated before sampling: $85 \mathrm{gal}$

LABOFATORY ANALYSES

\begin{tabular}{|c|c|c|c|}
\hline Analyte & Prosult & Mod & Unith \\
\hline $\begin{array}{l}\text { Arsenic } \\
\text { Arzonic } \\
\text { Areonic } \\
\text { Barium } \\
\text { Barium } \\
\text { Cadmium } \\
\text { Cadmlum } \\
\text { Chromium } \\
\text { Chromium } \\
\text { 2,4Dichlorophenoxyacetic acid } \\
\text { 2,4-Dichlorophenoxyacetic acid } \\
\text { Endrin } \\
\text { Endrin }\end{array}$ & $\begin{array}{l}<2.0 \\
<2.0 \\
<2.0 \\
<3.0 \\
<4.0 \\
<2.0 \\
<0.35 \\
<4.0 \\
1.8 \\
<0.30 \\
<1.1 \\
<0.0060 \\
<0.11\end{array}$ & $\mathbf{J 3}$ & 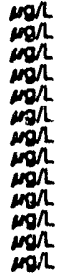 \\
\hline
\end{tabular}

Time: $0: 35$

Alkalinity: $78 \mathrm{~mol}$

Water tomperature: $224^{\circ} \mathrm{C}$

$M C l / m L$ GE
Time: 10:30

PH: 6.1 : 37 man

Alkalinity: $37 \mathrm{mgh}$. 20

b


WELL LAC \& collectad on 08/01/82, laboratory analyees (cont.)

\section{E Anclyte}

0 Iron

0 Lead

0 Lead

O Lindane

Manganease

Mercury

Mercuny

Mothoxychlor

Sotenium

Selonium

Silver

S Silver

Toxaphene

2,4,5-TP silwox)

Groas alph

Nomolutite bet

Nonvolatile bet

Redium-228

Radium-228

Radium-228

Radium-228

Toted alpha-amitting radium

Regult
$<4.0$
20
$<3.0$
$<3.0$
$<2.0$
$<0.0050$
$<0.053$
$<2.0$
0.63
$<0.20$
$<0.20$
$<0.50$
$<0.53$
$<2.0$
$<2.0$
$<2.0$
$<2.0$
$<0.70$
$<0.24$
$<1.1$
$<0.090$
$<0.55$
$<2.0 E-09$
$<8.0 E-10$
$3.5 E-09 \pm 1.6 E-00$
$1.6 E-09 \pm 1.4 E-00$
$<6.4 E-10$
$1.2 E-09 \pm 2.8 E-09$
$1.3 E-09 \pm 1.3 E-09$
$1.4 E-09 \pm 1.4 E-09$
$<1.0 E-09$

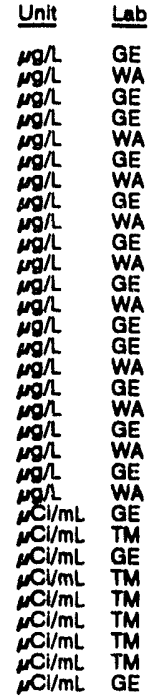

WELL LAC 4 Replicate

MEASUREMENTS CONDUCTED IN THE FIELD

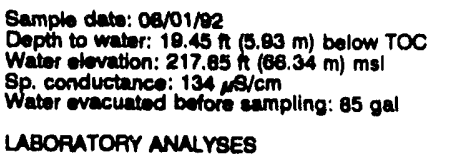

Water temporature: $21.7^{\circ} \mathrm{C}$

LABORATORY ANALYESS

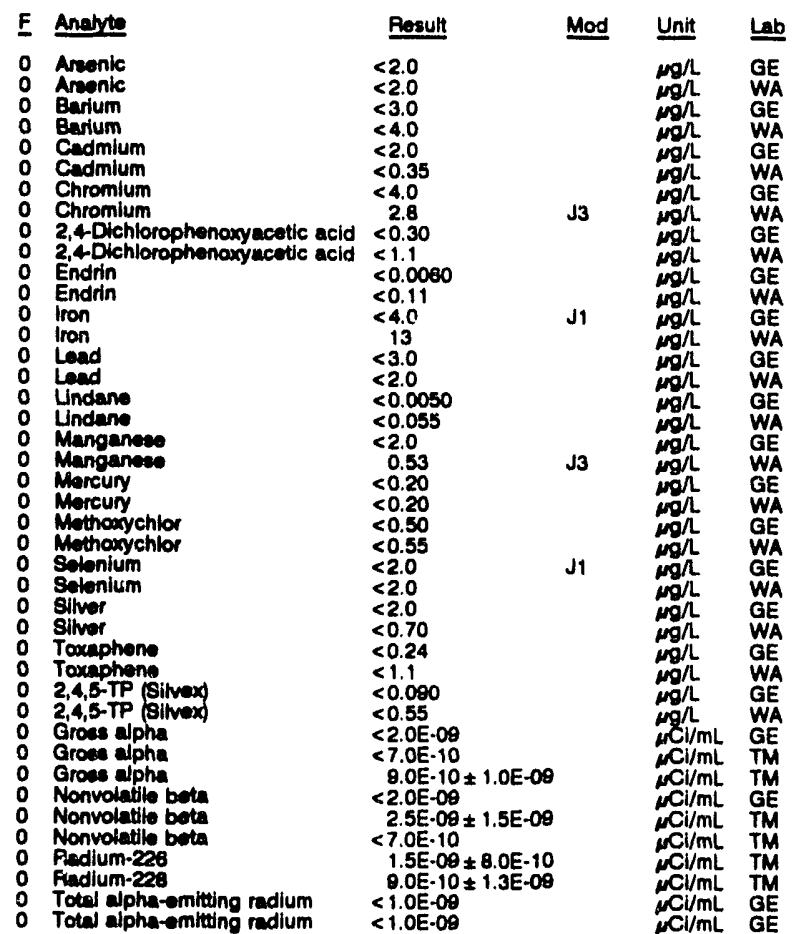

WELL LAW 10

MEASUAEMENTS CONDUCTED IN THE FIELD

Sample date: 08/01/92

Dopth to water: $41.41 \mathrm{ft}(12.82 \mathrm{~m})$ below TOC

Sp. conductance: $79.98 / \mathrm{cm}$

Water evacuated before sampling: $446 \mathrm{gal}$

Alkalinity: $18 \mathrm{mg} / \mathrm{h}$, $21.2^{\circ} \mathrm{C}$

LABORATORY ANALYSES

E Anajyte

$0 \mathrm{pH}$

Specific conductance

o Acenaphthene

Anthracene

Arranic

Bartum

apha-Benzene hoxachlorido

beta.Benzene hoxachloride

Benzolajanthracene $<10$

B <10

- Benzo kffluoranthene $<10$

O Bnzo

Benzo g, h, il perylen

Bia(2-chloroethoxy) mothane

Bis 2-chloroethyl) ether

Bis (2-chloroisopropyl) ether

4-Bromophenyl phenyl ether

Butylbenzyl phthalate

Cadmium

Calcium

Chlordane

para-Chloro-meta-cresol

2-Chloronaphthalene

4Chiorophenyl phenyl ether

Chromium

O Chrysene

P,P':DDD

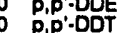

- Bibenzla,h]anthracene

D Di-n-butyl phthalate

2,4-Dichlorophenol

0 Dieldrin

0 Diethyl phthalate

0 2,4-Dimethyl phenol

Dimethyl phthalate

2,4-Dinitrophonol

2,4-Dinitrotoluene

o 2,6-Dinitrotoluene

1,2-Diphenylhydrazine

o Endosulfan!

O Endosulfan II

- Endosulfan sulfate

- Endrin

- Endrin aldehydo

o Fluoranthene

o Fluorene

F Fluoride

Heptachlor

Hexachlorobenzene

o Hexachlorobutadiene.

o Hexachlorocyclopentadiene

Hoxachloroethane

Indeno[1,2,3-c,d]pyrene

0 isophorone

o Lead

o Lindarie

1 Magneaium

1 Manganeso

2-Methyl-4,6-dinitrophenol

Nitrate-nitrite as nitrogen

o Nitrobenzene

2-Nitrophenol

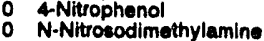

N-Nitrosodiphenylamine

N-Nitrosodipropylamine

O PCB 1016

O PCB 1232

O PCB 1242

O PCB 1248

PCB 1250

- Pontachlorophenol

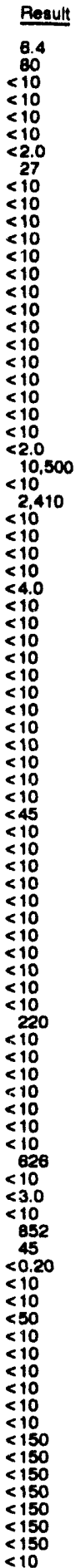

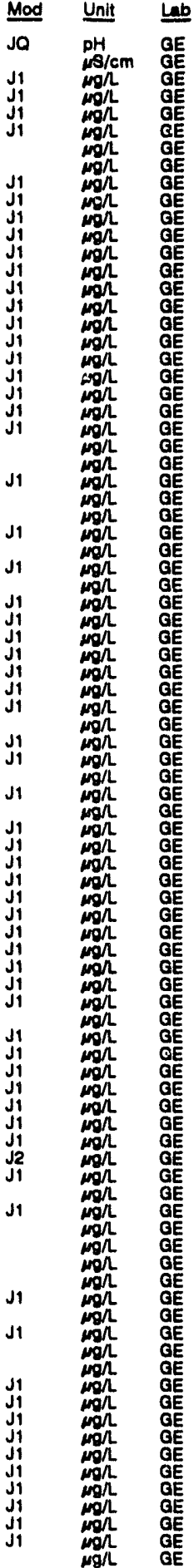




\section{ANALYTICAL RESULTS}

WELL LAW 10 collectad on 08/01/92, laboratory analyees (cont)

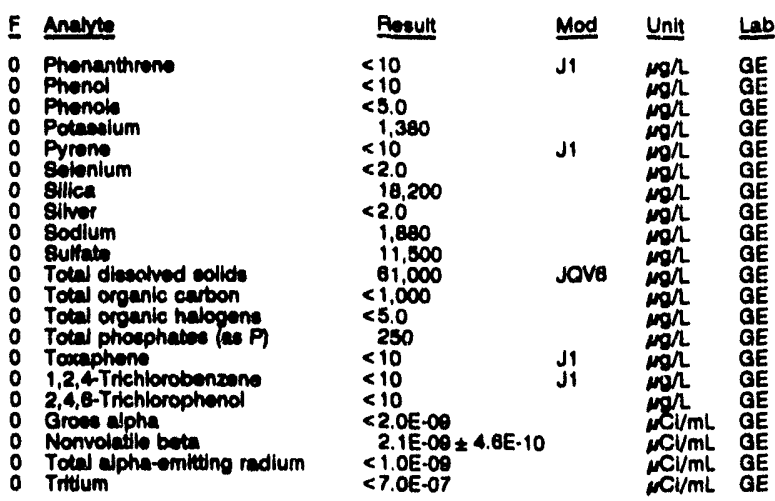

WELL LAW 2B

MEASUREMENTS CONOUCTED INI THE FIELD

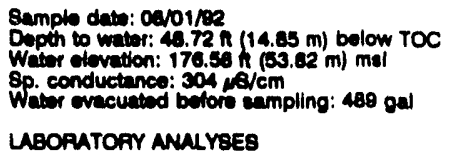

Time: 13:15

PH: 11.0

Water temperature: $22.1 \bullet \mathrm{C}$

LAORATORY ANALYEES

\begin{tabular}{|c|c|c|c|}
\hline Anerse & Result & Mod & Unit \\
\hline 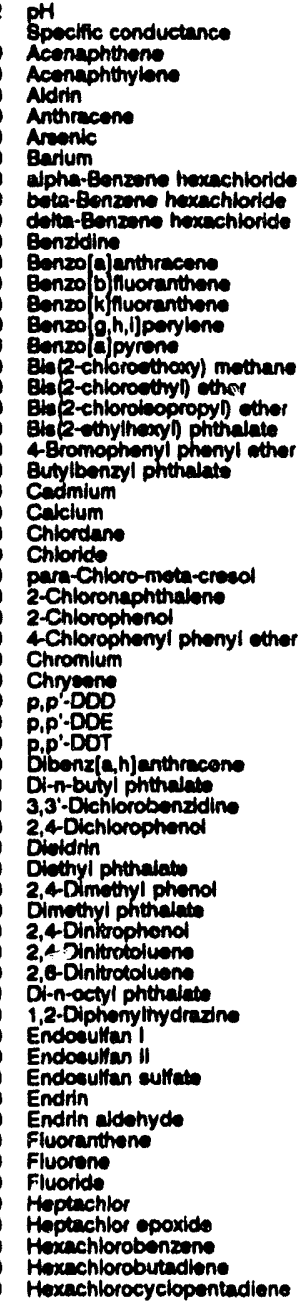 & $\begin{aligned} & 11 \\
& 2190 \\
&<10 \\
&<10 \\
&<10 \\
&<10 \\
&<2.0 \\
& 87 \\
&<10 \\
&<10 \\
&<10 \\
&<10 \\
&<10 \\
&<10 \\
&<10 \\
&<10 \\
&<10 \\
&<10 \\
&<10 \\
&<10 \\
&<10 \\
&<10 \\
&<10 \\
&<2.0 \\
& 53,800 \\
&<10 \\
& 2,180 \\
&<10 \\
&<10 \\
&<10 \\
&<10 \\
&<4.0 \\
&<10 \\
&<10 \\
&<10 \\
&<10 \\
&<10 \\
&<10 \\
&<10 \\
&<10 \\
&<10 \\
&<10 \\
&<10 \\
&<10 \\
&<45 \\
&<10 \\
&<10 \\
&<10 \\
&<10 \\
&<10 \\
&<10 \\
&<10 \\
&<10 \\
&<10 \\
&<10 \\
&<10 \\
&<10 \\
& 186 \\
&<10 \\
&<10 \\
&<10 \\
&<10 \\
&<10 \\
&<10\end{aligned}$ & Jo & 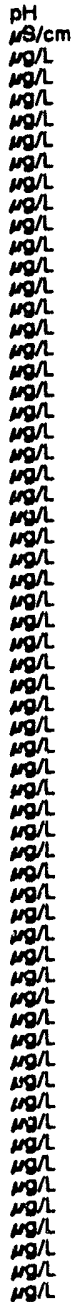 \\
\hline
\end{tabular}

WELL LAW 28 collected on 08/01/02, taboratory analyese (cont.)

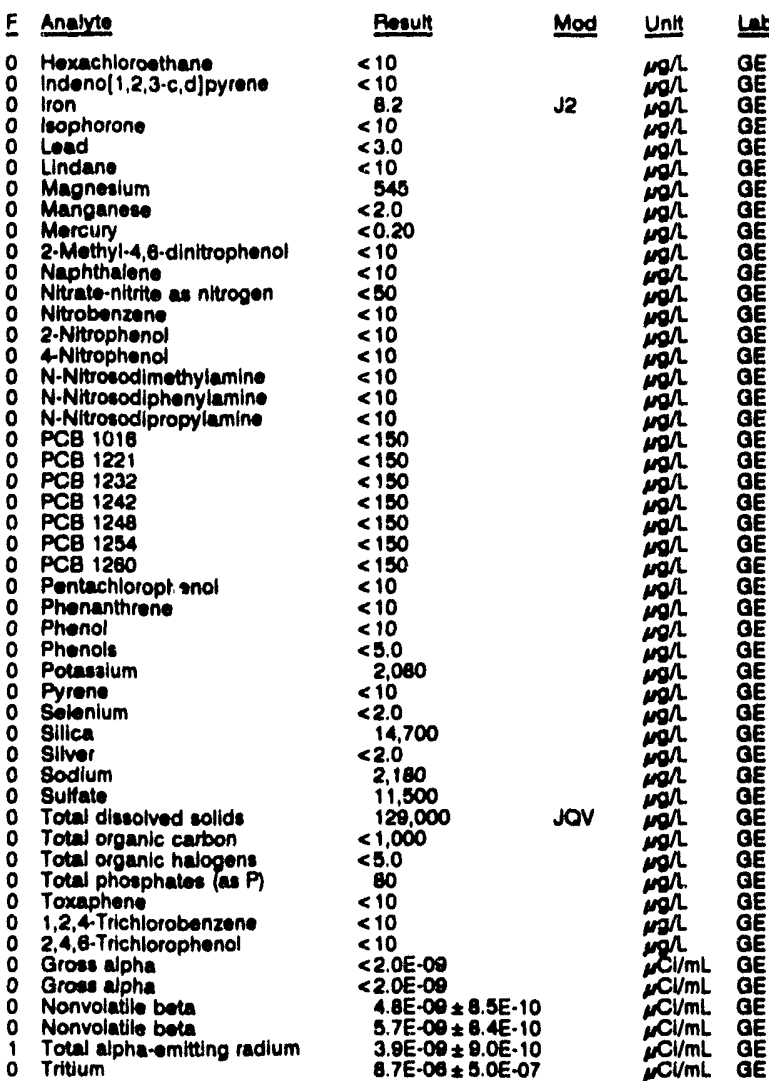

\section{WELL LAW 3B}

MEASUREMENTS CONDUCTED IN THE FIELD
Sample dete: 0 spor

Depth to water: 70.02 it $(21.34 \mathrm{~m})$ below TOC Wator elovation: $178.38 \mathrm{~h}(54.37 \mathrm{~m}) \mathrm{msl}$

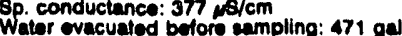
LABORATORY ANALYSES

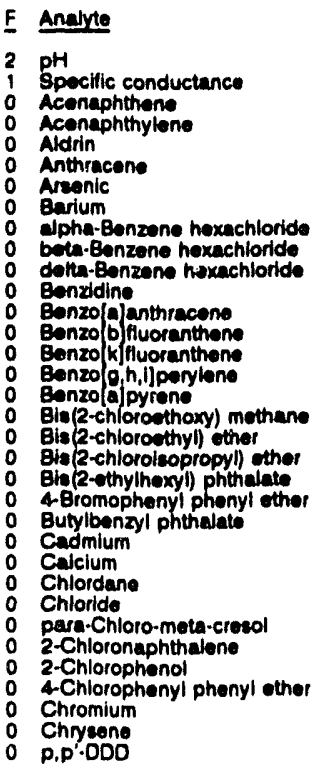

Time: 11:55

PH: 10.8. $183 \mathrm{mgh}$ Nhalinity: $183 \mathrm{mg} / 2.000$

\begin{tabular}{|c|c|c|}
\hline Result & Mod & Unth \\
\hline $\begin{aligned} & 11 \\
& 330 \\
& 310 \\
&<10 \\
&<10 \\
&<10 \\
&<10 \\
& 4.6 \\
& 89 \\
&<10 \\
&<10 \\
&<10 \\
&<10 \\
&<10 \\
&<10 \\
&<10 \\
&<10 \\
&<10 \\
&<10 \\
&<10 \\
&<10 \\
&<10 \\
&<10 \\
&<10 \\
&<2.0 \\
& 58,600 \\
&<10 \\
& 2,140 \\
&<10 \\
&<10 \\
&<10 \\
&<10 \\
&<4.0 \\
&<10 \\
&<10\end{aligned}$ & $\begin{array}{l}\mathbf{J 1} \\
\mathbf{J 1} \\
\mathbf{J 1} \\
\mathbf{J 1} \\
\mathbf{J 1} \\
\mathbf{J 1} \\
\mathbf{J 1} \\
\mathbf{J 1} \\
\mathbf{J 1} \\
\mathbf{J 1} \\
\mathbf{J 1} \\
\mathbf{J 1} \\
\mathbf{J 1} \\
\mathbf{J 1} \\
\mathbf{J 1} \\
\mathbf{J 1} \\
\\
\mathbf{J 1}\end{array}$ & 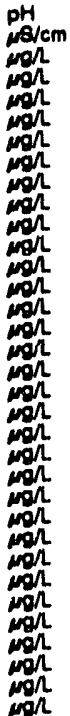 \\
\hline
\end{tabular}


WELL LAW 39 collected on 0er01/22, laboratory anayeer (cont)

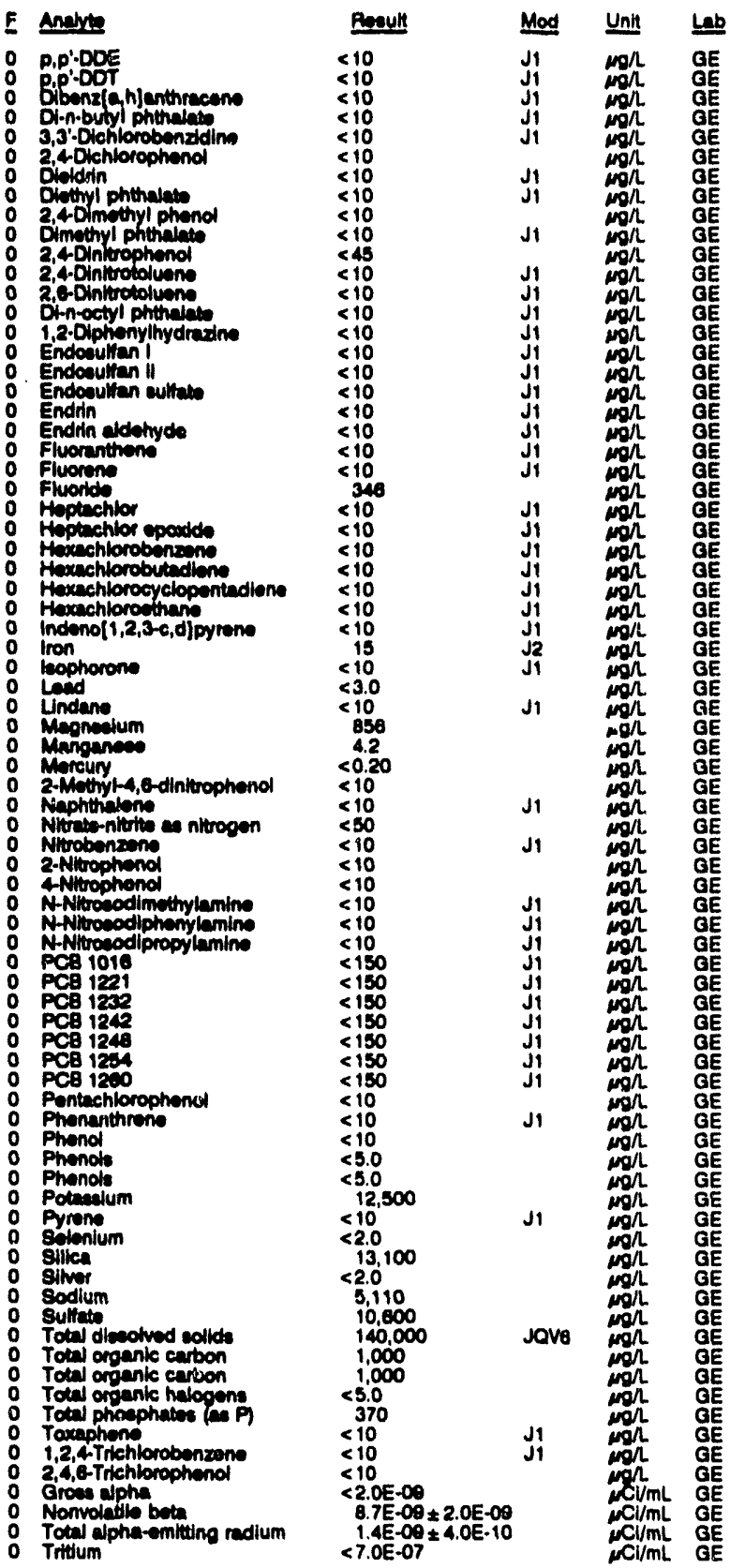

WELL LAW 3C

MEASUAEMENTS CONDUCTED IN THE FIELD

\begin{tabular}{|c|c|c|c|c|}
\hline \multicolumn{2}{|c|}{ 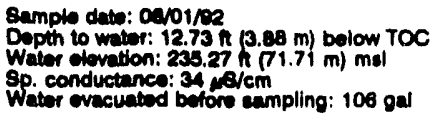 } & \multicolumn{3}{|c|}{$\begin{array}{l}\text { Time: } 11: 05 \\
\text { pH: } 4.8 \\
\text { Nikalinity: } 0 \mathrm{mg} / \\
\text { Wator tomperafure: } 22.8^{\circ} \mathrm{C}\end{array}$} \\
\hline \multicolumn{5}{|l|}{ LABOPATOFY ANALYEES } \\
\hline Anante & Pesult & Mod & Unit & Lab \\
\hline $\begin{array}{ll}0 & \text { pH } \\
0 & \text { pH } \\
0 & \text { Epeclific conductance } \\
0 & \text { Bpecific conductance } \\
0 & \text { Acentephthone } \\
0 & \text { Acenophthylen }\end{array}$ & $\begin{array}{r}5.8 \\
5.7 \\
35 \\
35 \\
<10 \\
<10\end{array}$ & $\begin{array}{l}\text { Jo } \\
\text { Jo }\end{array}$ & 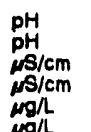 & $\begin{array}{l}G E \\
G E \\
G E \\
G E \\
G E \\
G E\end{array}$ \\
\hline
\end{tabular}

WELL LAW 3C collocted on 08/01/02, leboratory analyeee (cont.)

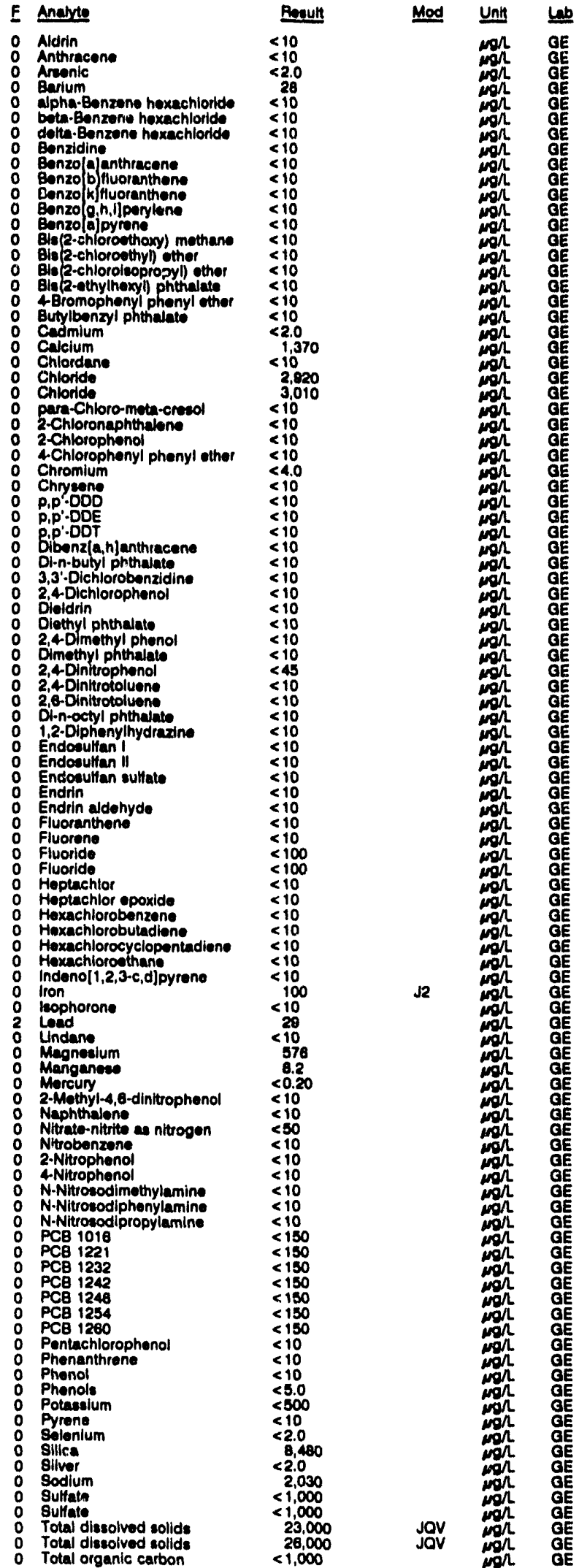


WELL LAW 3C collectad on Oavo1/92, laboratory analyees (cont.)

\begin{tabular}{|c|c|c|c|c|}
\hline & Anste & Resur & Unin & b \\
\hline $\begin{array}{l}0 \\
0 \\
0 \\
0 \\
0\end{array}$ & 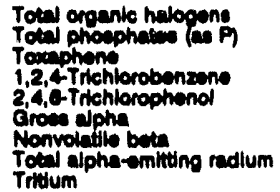 & $\begin{array}{l}<5.0 \\
120 \\
<10 \\
<10 \\
<10 \\
<2.05-00 \\
<2.0 E-00 \\
<1.0 E-00 \\
2.0 E-00 \pm 4.0 E-07\end{array}$ & 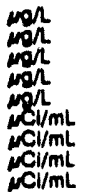 & $\begin{array}{l}\text { OE } \\
\text { QE } \\
\text { QE } \\
\text { GE } \\
\text { GE } \\
\text { GE } \\
\text { GE } \\
\text { GE }\end{array}$ \\
\hline
\end{tabular}

WELL LCO 1

MEASUREMENTS CONOIJCTEO IN THE FIELD

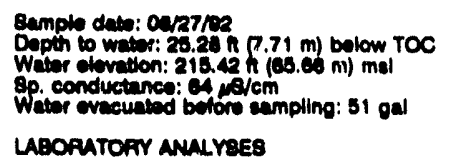

Time: 9:15

PH: 0.4 . 7 inity: $7 \mathrm{~mol}$

Waber tomporature: $20.0 \cdot \mathrm{C}$

LABOAATOFI ANALYRES

E Anate

: Epecilite conductance O Acenaphtion

o Addin

o Anthrecene

: Avanic

O Eavium

Upha-Eenzane hoxechloride

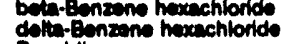

Eonzos onturicens.

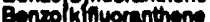

Eenzolo, h,il)perylen

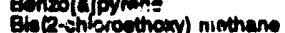

Eiv (2-chioreathy) ther

Bhe 2-ehloroinopropyll etter

Bb (R-thylhexyin phthalat

Eromodichion

Eromoiorm

4 Bromophomyl phenyl ethet Butylbenzyl phthelato

Cedmium

Chlordar

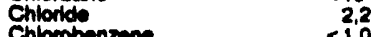

pera-Chloro-mutu-creed $<10$

Cniorouthan 41

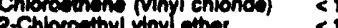

Chlordorm $<1.0$

D-Chioromohthalens $<1.0$

2-Chlorephend $<10$

4Chlorophenyl phenyl ether

Chromlum

p.p.oog

p.p.op

Bibenzla, n)anthreceno

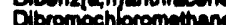

Di-n-butyl phthuides

3,3'-Ovehlorobendidin

1, 1-Olchloreothane

1,1.Dichlorecthyion

trane-1,2-Dichloroethylene

Dichloromethane

2,4Okchlorophenot

cib-1,3-Dichloropropene

thane-1,3-Dichlorepropone

Diethyl phthatale

2,40imethyt phenol

2,4-Dinturophend

2,4 inlugphonol

2,0-Diniturotoluen

Di-n-octyl phthalato

1,2-Diphonylhydrasine

Endosulten I

Endosultan II

Endouultan sultato

Endrin aldohydo
WELL LCO 1 collected on 0Q/27/02, laboralory analyeese (cont.)

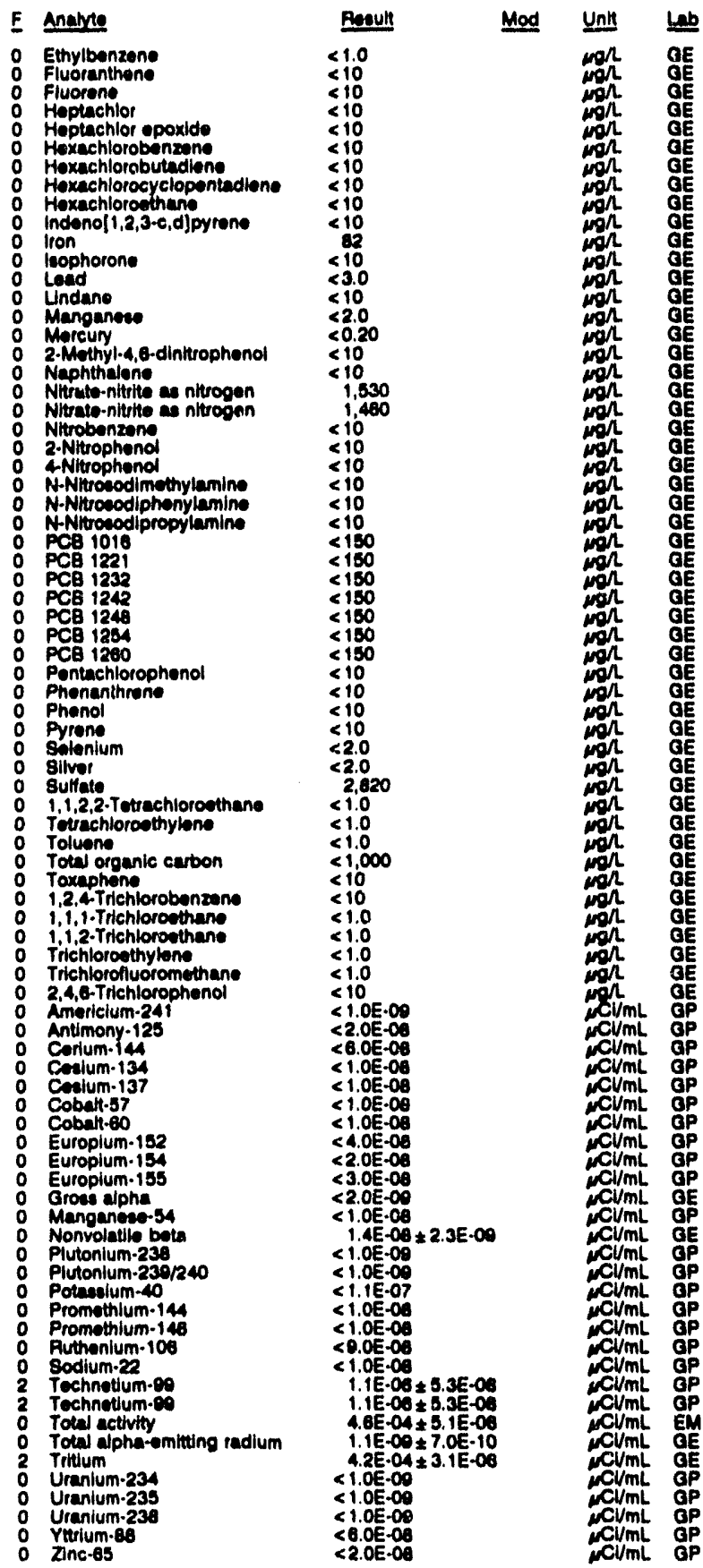


ANALYTICAL RESULTS

WELL LCO 2

MEABUREMENTS CONOUCTED IN THE FIELD

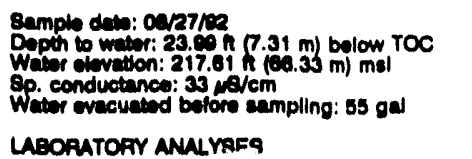

Time: 11:45

PH: 41 1 0 man

Water temperature: $22.4^{\circ} \mathrm{C}$

E Anevite

: EH
: Epecilic conductence
: Epelife conductanco

Acemaphiturions

Adirn

Anthrecen

Bunivo

Benzon:

dphafEenzane hexachlorldo

bein-Eenzano havehlorids

Eenadino

Eenzolajenthraceno

Eenzo k huorantiene

Eonzol e h,ilpentiono

Einzechlorecthouy) mothen

Bie (2-chlorod thyt) wher

En (2-chloreloopropyll ether Expotich

Eromotorm

4-Bromophemyl phenyl ther

Euromoph

Cedintum

Caroon intract

Chiorids

Chlorobenaens

pey-Chioro-meta-creed

Chlorowano Minl chlorida)

2-Chloroathyl vinyl ether

Chiondorm

2-Chomenthenther

2 Chlorophen

4Chlorophenyl phenyl ether

Chrornitum

P.p.Doo

p,p'-DoE

Bibenziah] anthrecen

Dibromochloromithan

3.3.-Dichtorobendelin

1,1-Dichloroethen

1,2-Dichloroptian

tiane-1,2-Dichionoethylene

Dichioromethane

1,2-Dichloropropen

chili-bichioropropens

Dialdin

Dithyl phthaled

Oimelmethyl phenol

2,40introphenol

2,e-Oinitrotolume

1,2-Diphenylhydratine

1,2-Diphenylhydraino

Endawulian I

Endoaulten sulfedo

Endin

Endinn aldehyde

Fluorenthen

Fluorene

Keptachlor epoudide

Hexachlorobenzan

Hexichlorobutadien

Hoxechloropten

Indeno[1,2,3-c,d]pyrene

bophorone

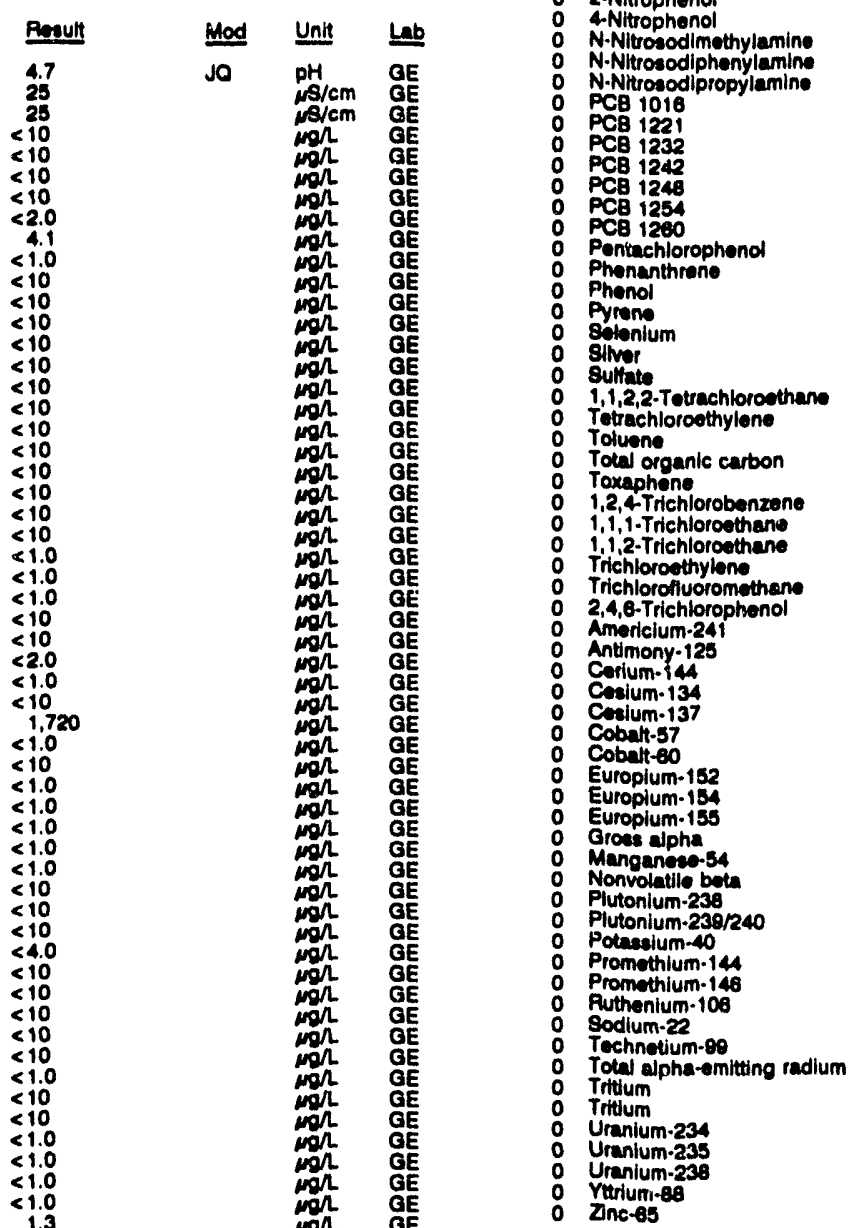

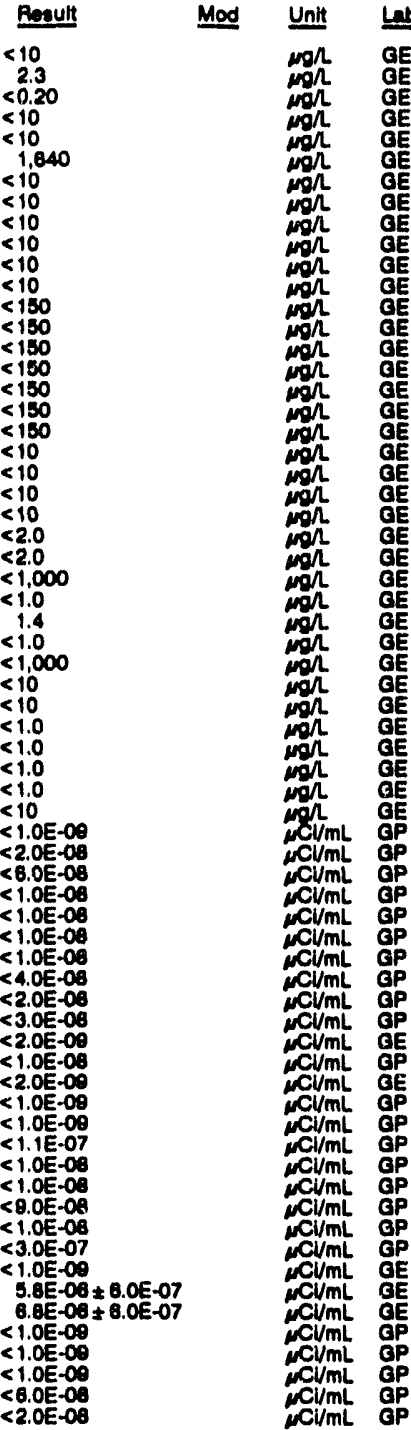

WELLL LCO 3

MEASUREMENTS CONDUCTED IN THE FIELD

Sample date: 08/27/02

Depth to water: 24.25 it $(7.39 \mathrm{~m})$ bolow TOC

Water olevation: $217.15 \mathrm{~h}(\mathrm{Bg}$.

Sp. conductance: $234 \mu \mathrm{s} / \mathrm{cm}$.

Waler wrecuated bolors sam

E Analyte

$0 \mathrm{PH}$

0

Specific conductance

Specific conductance

Spactific conductance

Acenaphthene

Acenaphthylone

Aconeph

Anthracen

Anthracene

Anthracene

0 Arsenic
Time: 10:00

PH: 7.4 Alinity: $88 \mathrm{mon}$

Water tomperature: $20.8 \circ \mathrm{C}$

\begin{tabular}{|c|c|c|}
\hline Reount & Mod & Unit \\
\hline $\begin{array}{l}7.7 \\
7.6 \\
7.6\end{array}$ & $\begin{array}{l}\text { Ja } \\
\text { Ja } \\
\text { JO }\end{array}$ & $\begin{array}{l}\mathrm{pH} \\
\mathrm{pH} \\
\mathrm{pH}\end{array}$ \\
\hline $\begin{array}{r}201 \\
201 \\
<10\end{array}$ & $\begin{array}{l}\text { JQ } \\
\text { Ja } \\
\text { J1 }\end{array}$ & $\begin{array}{l}\mathrm{m} / \mathrm{cm} \\
\mathrm{M} / \mathrm{cm} \\
\mathrm{mol}\end{array}$ \\
\hline $\begin{array}{l}<10 \\
<11 \\
<11\end{array}$ & J1 & $\operatorname{mon}^{2}$ \\
\hline $\begin{array}{l}<10 \\
<10 \\
<11 \\
<11 \\
<2.0 \\
<2.0\end{array}$ & $\begin{array}{l}\text { J1 } \\
\text { J1 }\end{array}$ & $\begin{array}{l}\operatorname{mon} \\
\operatorname{mon} \\
\operatorname{mon} \\
\operatorname{mon}^{2} \\
\operatorname{mon}\end{array}$ \\
\hline
\end{tabular}


WELL LCO 3 collected on 0Q/27/92, laboratory analycen (cont)

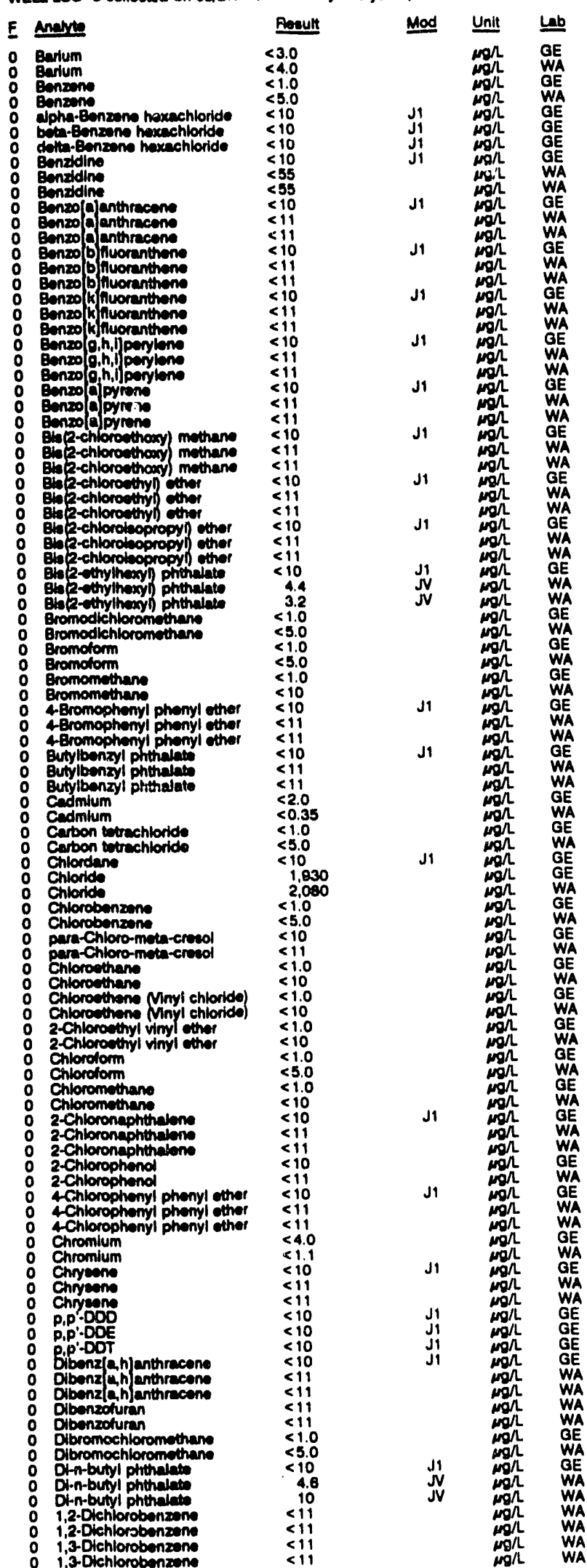

WELL LCO 3 collectod on 06/27/02, laboratory analyees (cont.)

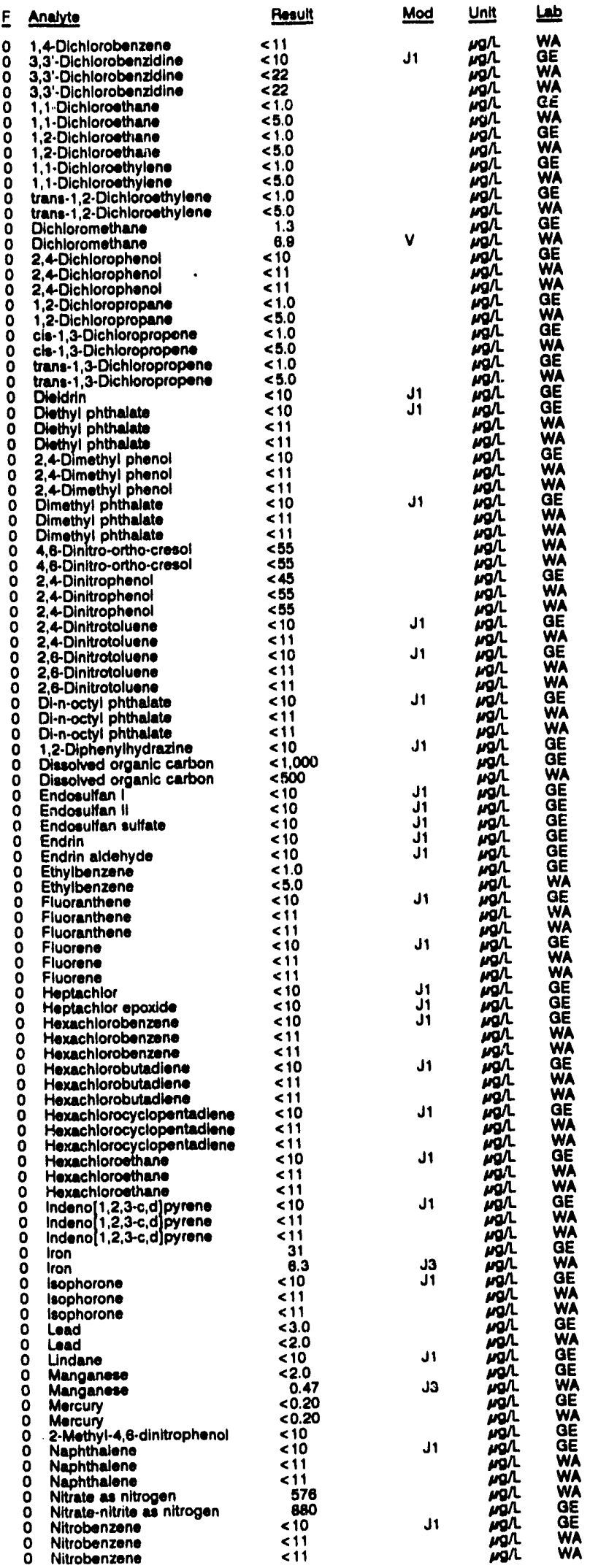


WELL LCO 3 collectod on 08/27/92, laboratory analyees (cont)

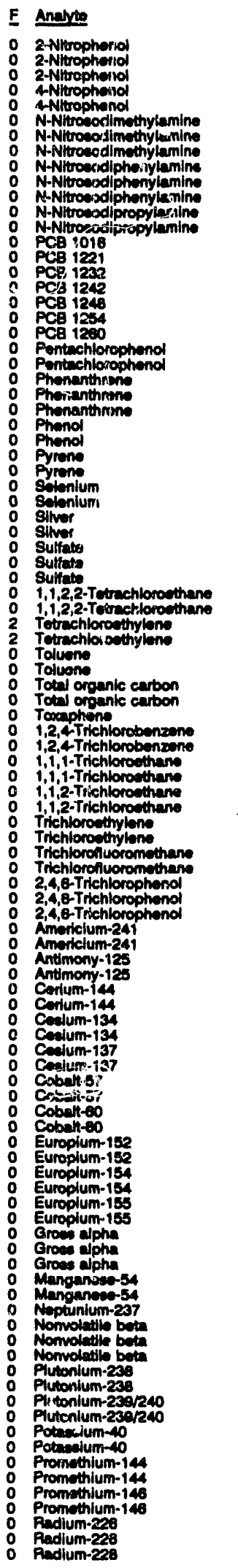

$<\begin{array}{cc}<1.0 \\ <5.0\end{array}$

8.3
$<1.0$

$<<.000$

$<500$

$<10$

$\leq 11.0$

$<1.0$

$<5.0$

$<5.0$

$<1.0$

$<10$

$<11$

$<1.06-09$

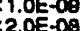

$<2.0 E-0.0$

$<8.0 E-09$

$<1.0 \mathrm{E}-09$

$<1.0 E-08$

$<1.0 E-08$

$<1 \mathrm{OE}-08$

$<1.0 E-08$

$<1.0 E-08$

$<1.2 E-08$

$<4.0 E-08$

$<2.0 E-08$

$<2.5 E-08$

$<2.5 E-08$

$<2.5 E-08$

$1.6 E-09 \pm 1.6 E-09$
$2.3 E-00 \pm 2.0 E-09$

$2.0 E-08$
$<1.0 E-08$

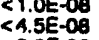

2.5E-09 $2.09 \pm 1.5 E-30$

$2.5 E-09 \pm 1.5 E-20$

$<1.0 \mathrm{E}-09$

$<1.0 E-09$

$<1.0 \mathrm{E}-00$

$1.1 \mathrm{E}-07$
$<2.5 \mathrm{E}-07$

$<1.0$ E-08

$\checkmark 1.0 E-08$

$<1.0 E-08$

$<2.2 E-07$

$<1.8 E-10$
$<5.0 E-10$

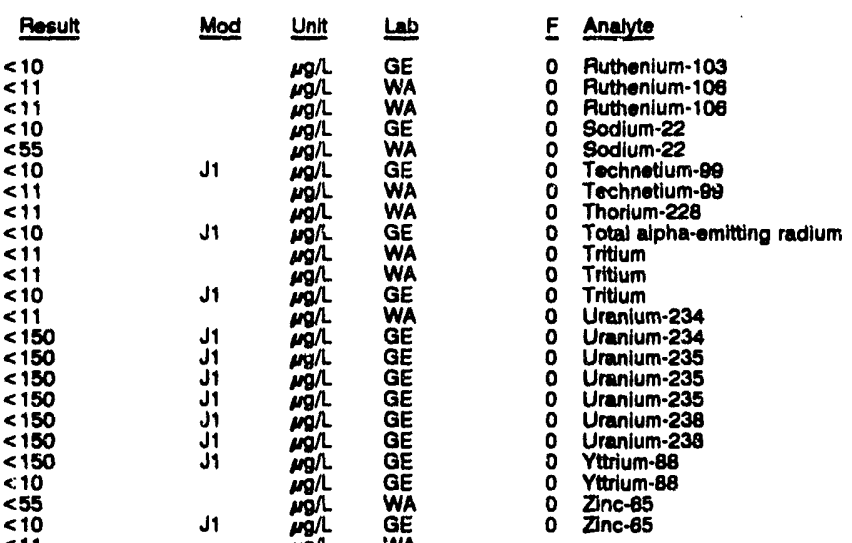

\begin{tabular}{|c|c|c|c|c|}
\hline $\mathbf{E}$ & Analyte & Posult & Mad & Unit \\
\hline $\begin{array}{l}0 \\
0 \\
0 \\
0 \\
0 \\
0 \\
0 \\
0 \\
0 \\
0 \\
0 \\
0 \\
0 \\
0 \\
0 \\
0 \\
0 \\
0 \\
0\end{array}$ & 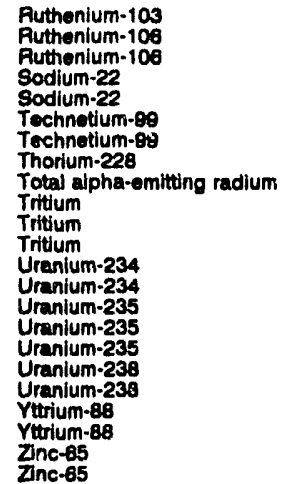 & $\begin{array}{l}<1.0 E-08 \\
<8.0 E-08 \\
<8.0 E-08 \\
<1.0 E-08 \\
<1.0 E-08 \\
<3.0 E-07 \\
<3.0 E-07 \\
<4.0 E-07 \\
<1.0 E-09 \\
<7.0 E-07 \\
5.0 E-08 \pm 0.3 E-07 \\
5.2 E-09 \pm 1.2 E-03 \\
<1.0 E-09 \\
<1.0 E-09 \\
<1.0 E-09 \\
<1.5 E-08 \\
<1.0 E-09 \\
<1.0 E-09 \\
<1.0 E-09 \\
<6.0 E-08 \\
<1.0 E-08 \\
<2.0 E-08 \\
<2.3 E-08\end{array}$ & & 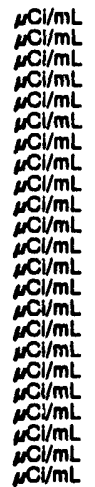 \\
\hline
\end{tabular}

\begin{tabular}{|c|c|c|c|c|}
\hline $\mathbf{E}$ & Analyte & Rosult & Mad & Unit \\
\hline $\begin{array}{l}0 \\
0 \\
0 \\
0 \\
0 \\
0\end{array}$ & 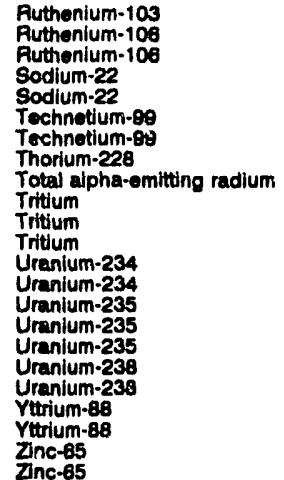 & $\begin{array}{r}<1.0 E-08 \\
<\theta .0 E-08 \\
<8.0 E-08 \\
<1.0 E-08 \\
<1.0 E-08 \\
<3.0 E-07 \\
<3.0 E-07 \\
<4.0 E-07 \\
<1.0 E-09 \\
<7.0 E-07 \\
5.0 E-08 \pm 0.3 E-07 \\
5.2 E-09 \pm 1.2 E-00 \\
<1.0 E-09 \\
<1.0 E-09 \\
<1.0 E-09 \\
<1.5 E-08 \\
<1.0 E-09 \\
<1.0 E-09 \\
<1.0 E-09 \\
<6.0 E-08 \\
<1.0 E-08 \\
<2.0 E-08 \\
<2.3 E-08\end{array}$ & & 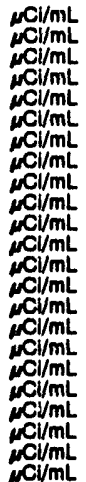 \\
\hline
\end{tabular}

WELL LCO 3 Replicate

MEASUREMENTS CONDUCTED IN THE FIELD

Sample dato: 08/27/92

Depth to water: $24.25 \mathrm{ft}(7.38 \mathrm{~m})$ below TOC

Water olevation: $217.15 \mathrm{ft}(68.18$

Sp. Conductance: $234 \mu \mathrm{s} / \mathrm{cm}$
Wator ovacuated before rampling: $55 \mathrm{gal}$

LABOPATORY ANALYSES

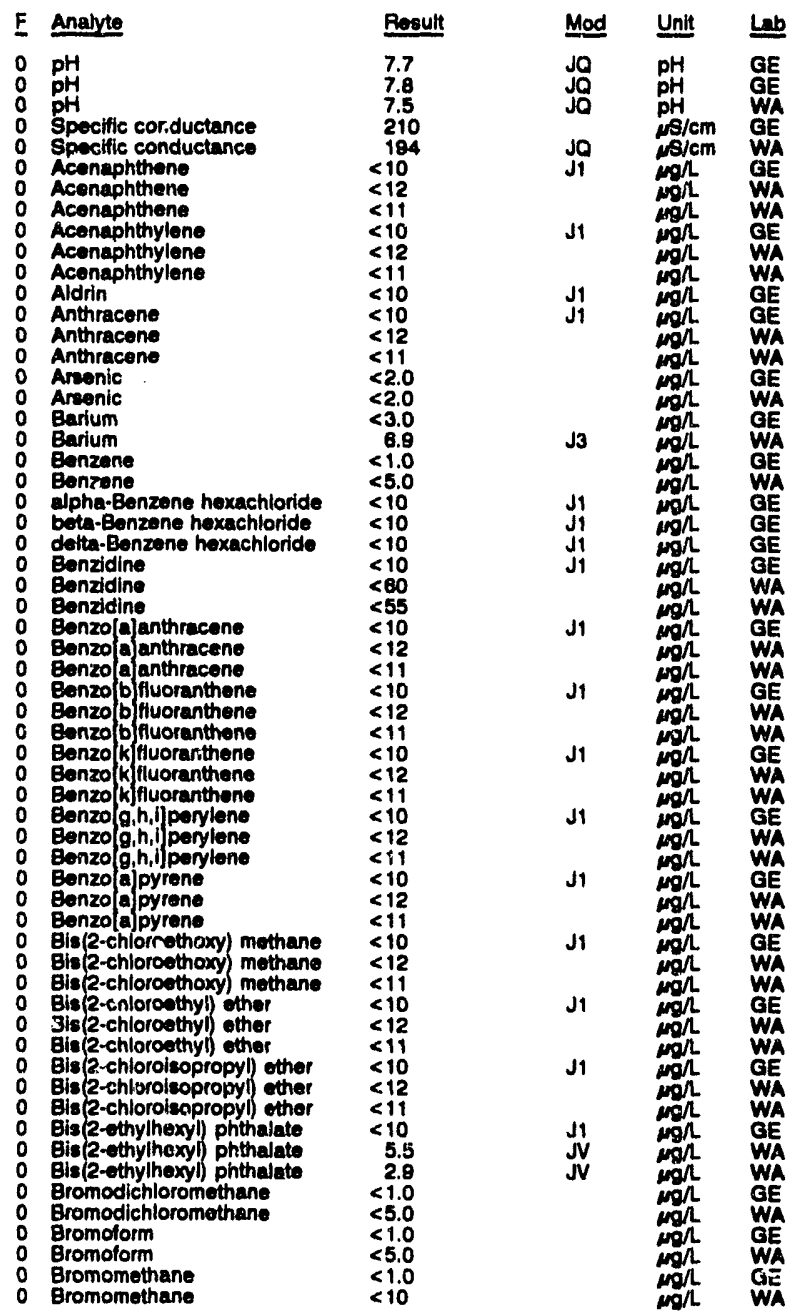

Time: 10:00

Alkalinity: $88 \mathrm{mon}$ Water tomporature: $20.8{ }^{\circ} \mathrm{C}$
Bromomethane 
WELL LCO a collectod on 0Q/27/82, laboratory analyees (cont)

$E$ Anayte

O Eromophenyl phenyl other

4Eromophenyl phenyl etther

Butylbenzyyl phthalate

Butylbonzyl phthalate

Cadmium

Curbon trachlonde

Chiordans

Chloride

Chloride

Chlorido

Chiorobenzene

pare-Chloro-minta-cresel

para-Chloro-meta-creed

Chloroethane

Chlorethon Mnyl chloride)

Chloroetivent Mnyl chloride

2-Chloroothyl vinyl ether

Chioroform

Chionotorm

Chloromethane

Chloromethane

2.Chloromaphthelono

2-Chloronephtha

2-Chlorophenol

\&-Chlorophenyl phenyl ether

4-Chlorophenyl phonyl ther

yl phenyl ther

Chromlum

Chryeene

Chryeane

Chryen

P,P'-DOE

0 ppo-ot

Gibenz[a, h]anthrecone

Dibonz a, $h$ esthracene

Dibenzofuren

Dibromochloromethane

Dibromochloromethane

Di-n-butyl phothalat.

Di-n-butyl phthalate

Di-n-butyl phothalete

1,2-Dichlorobenzinzene

1,3-Dichiorobenzene

1,3-Dichlorobenzene

1,4-Dichlorobenzane

3,3'-Dichlorobenzidine

- 3,3'-Ochlorobenzddino

3,3'-Oichlorobenaddin

o 1,1-Dichloroethan

o 1,2-Dichloromina

o 1,2-Dichlorowthen

1,1-Dichlorosthylens

trane-1,2-Dichloroethylone

trene-1,2-Oichloro thylone

Dehloromethano

2,40ichiorophend

2,4Dichlorophenol

2,40ichlorophenol

1,2-Dchlorophonol

1,2-Dichloropropan

cle-1,3-Olchloropropeno

ch-1,3-Dichloropropone

twank-1,3-Dichloropropene

Dieldrin

Dethyl phthelat

Driny phralato

2.40 methyl phenol

2,4-Dimethyl phond

Dimelmyt phone

Dimethyl phtheleto

Dimethyl phithalato

4,0-Oinitro-ortho-eresol

2,4-Dinturophence

2,4-Dintropheno

2,4-Diniturophesel

$$
\text { Beount }
$$

$<10$

$<11$

$<12$

$<2.0$

$<1.0$
$<5.0$

1,800
1,670

1,670

$<1.0$

$<10$
$<11$
$<11$

$\leqslant 1.0$

$<10$

$<1.0$

$<1.0$

$\leq 1.0$

$\$ 5.0$

$<10$

$<10$
$<12$

$<11$

$<<12$

$<19$

$<12$

$<11$
$<1.0$
$<1.1$
$<10$

$<10$
$<12$
$<12$

$<10$

$<10$

$<10$

$<12$

$<12$

$<11$

$<5.0$

$<10$
12
8.8
$<12$
$<12$

$\leq 11$

$\leq 12$

$\leq 12$

$<110$

$<22$

$<5.0$

$<1.0$

$<s .0$

$\leq \leq .0$

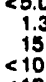

$<<12$

$<1.0$

$<\leq$

$\leq 5.0$

$<5.0$

$<10$
$<10$
2.2

2.2
$\leq 11$
$<10$
$<1$

$\leq 12$

$<10$

$<12$

$<60$

$<45$

$<60$
Mod Unit

J1 $\mathrm{mg} / \mathrm{GE}$

J1 $m$ No/L WE

WA

WA

WA

政

2,4-Dinitrotoluene

0 2,4D

2,8-Dinitrotoluene

o 2,6-Dinitrotoluene

o Di-n-octyl phthalate

- Di-n-octyl phthalate

o 1,2-Diphenylhydrazine

o Diseolved organic carbon

- Diseolved organic carbon

o Endosultan !

Endosurtan II

0 Endrin

o Endrin aldehyde

O Ethylbanzeno

F Ethylbenzens

o Fluoranthene

F Fluoranthone

o Fluorene

o Fluorene

O Foptechlor

o Heptachior epoxide

- Hexachlorobonzene

- Hoxachlorobanzene

o Hoxachlorobenzene

Hexachlorobutadlene

Hoxachlorobutadiene

Hoxachlorobutadione

H Hexechlorocyclopentadione

Hoxachlorocyelopentedione

o Hexachlorosthune

Hoxachloroothane

Hexachlorithane

indeno: $1,2,3-c, d)$ pyrene

indeno $1,2,3-c, d$ pyrene

o iron

o reophorons

b leophorone

Lead

o Lead

o Manganewe

Mangan

Mercuny

2.Methyl.4,6-dinitrophenol

O Nuphthialone

O Naphthalene

O Naphthalene

Nitrate as nitrogon

Nitrobenzene

Nhrobanzono

Titrophonol

2.Nitropheno

2-Nituopheno

4Nitrophenol

4Nitropheno

initrophene

N.Nitrosodimethylamins

N-Nltrocodimethylamino

N N-Nhroeodimothylamine

N-Nitrocodiphenylamine

N.Nirosodphonylamine

N-Nirosodphenylamine

N-Nitroecdipropylamine

N.Nirosodpropylaming

O PCB 1018

P PCB 1016

PCB 1232

PCB 1242

0
0 PCB 1248

PCE 280

Pont hlorophenol

Pentachlorophenol

Phonanthrene

Phonanthron

o Phonol

0 Phenol

0 Phenol

Pyrene

0 Pyrene

o selenium

$\begin{array}{ll}0 & \text { Selenium } \\ 0 & \text { Silver }\end{array}$ laboratory analyese (cont)

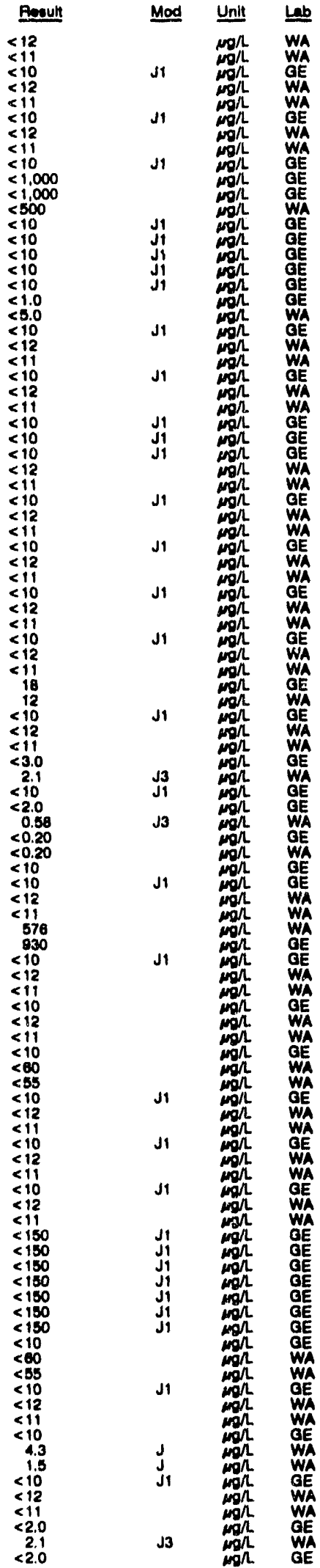


WELL LCO 3 collected on 08/27/92, laboratory analyses (cont)

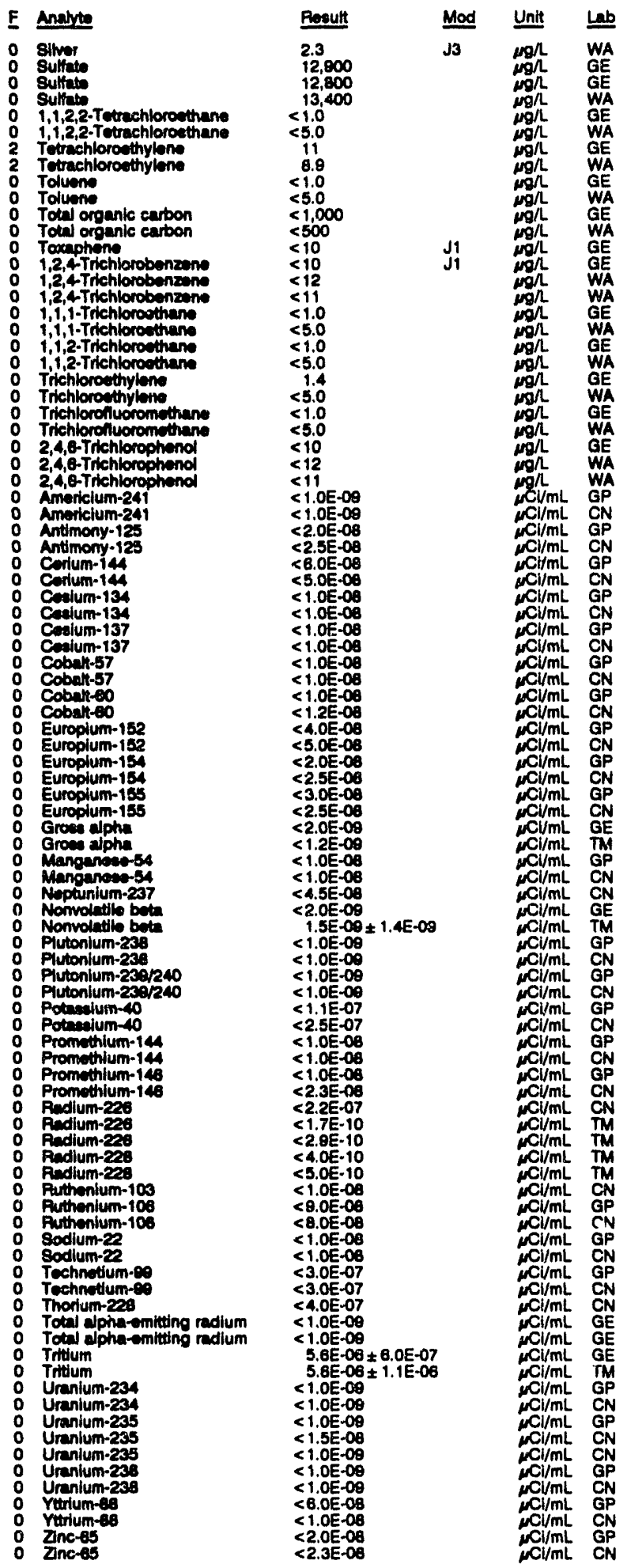

WELL LCO 4

MEASUREMENTS CONDUCTED IN THE FIELD

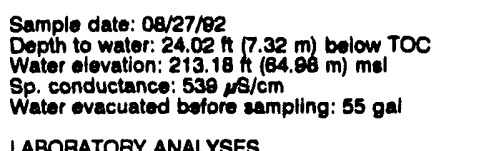

Time: 11:10

Alkalinity: $1 \mathrm{mg} /$

Water tomperature: $21.4{ }^{\circ} \mathrm{C}$

\section{LABORATOAY ANALYSES}

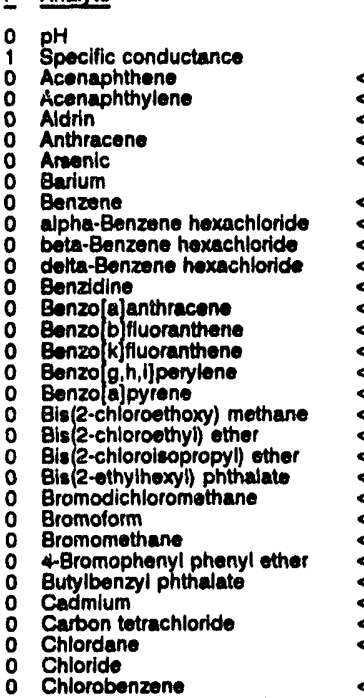

Result $\quad$ Mod Unt

para-Chloro-meta-cresol

Choroothane Ninyl chloride)

2-Chloroethyl vinyl ether

2-Chioroothy

Chorotorm

2-Chlorenaphe

2-Chorophanol

4-Chlorophenyl phenyl ether

Chromium

O Chrysene

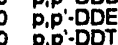

Pip'-DDT

Dibromochioromethane

Di-n-butyl phanalate

1. Dichloroethane

1, Dichloroethan

1, 1 -

trans-1,2-Dichloroethylene

Oichloromethane

2,4-Dichlorophonol

1,2-Dichloropropane

trans-1,3-Dichloropropene

Dieldrin

Diethyl phthalato

2,4 Dimethyl phenol

2,4-Dinturopienal

2,4 - inituopinenta

2,6.Dinitrololuene

Oi-n-octyl phthatate

1,2-Diphenyithydrazine

Dissolved organic carbon

Endosulfan I

Endoesulfan sulfato

Endrin

Endrin aldehyde

Ethylbonzone

Fluorene

Hoptachlor epoxide

Hexachorobenzeno.

Hoxachlorocyclopentadiene

Hexachlorowthane

Indonol1,2,3-c,dipyreno

Iron

5.5
480
$<10$
$<10$
$<10$
$<10$
$<2.0$

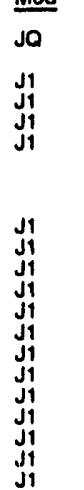

PH GE

7.0
7.2

$\leq 10$

$<10$

$<10$

$<10$
$<10$

$<10$

$<10$

$<10$

$<1.0$

$<10 \quad$

J1

800

$<1,0$

$<1.0$

$<1.0$

$<10$

$<10$

$<4.0$
$<10$
$<10$

$<10$

$<10$

$<1.0$

$<10$

$<10$

$<1.0$
$<1.0$
$<1.0$
1.2

1.2
$<10$
$<1.0$

$<1.0$

$<1.0$

$<10$

$<10$

$<45$

$<10$

$<1,000$

$<10$

$<10$

$<10$

2.6
$<10$

$<10$

$<10$

$<10$

$<10$
$<10$

isophoron

Lindane 
WEUL LCO \& collected on 08/27/92, laboratory andyses (cont)

\begin{tabular}{|c|c|c|c|c|c|}
\hline$E$ & Anelyte & Result & Mod & Unit & Lab \\
\hline & 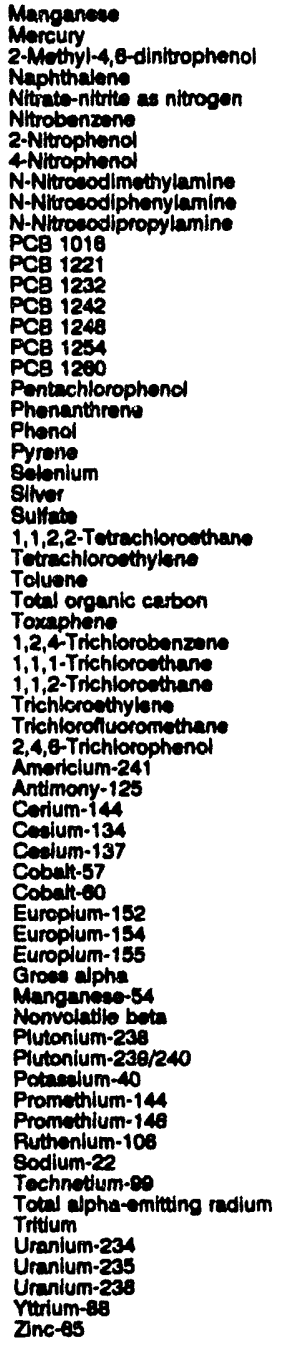 & 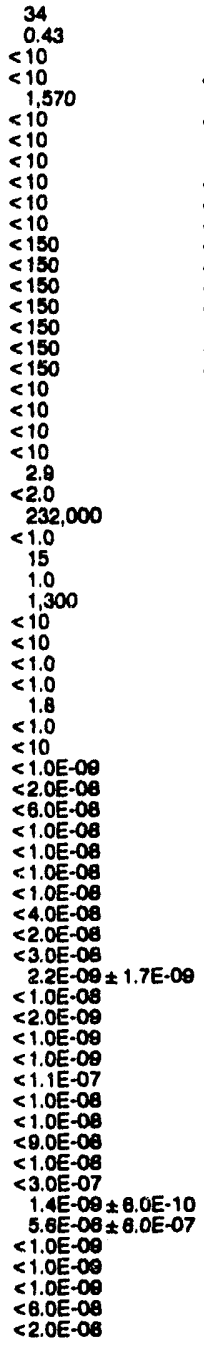 & $\begin{array}{l}\mathbf{J 1} \\
\mathbf{J} 1 \\
\mathbf{J 1} \\
\mathbf{J 1} \\
\mathbf{J 1} \\
\mathbf{J 1} \\
\mathbf{J 1} \\
\mathbf{J 1} \\
\mathbf{J 1} \\
\mathbf{J 1} \\
\mathbf{J 1} \\
\mathbf{J 1}\end{array}$ & 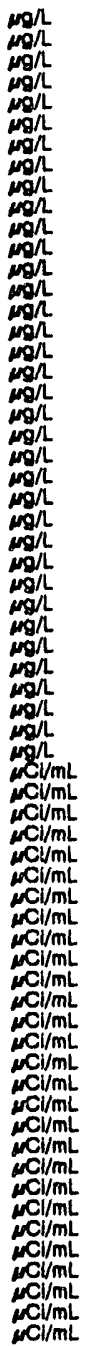 & $\begin{array}{l}G E \\
G E \\
G E \\
G E \\
G E \\
G E \\
G E \\
G E \\
G E \\
G E \\
G E \\
G E \\
G E \\
G E \\
G E \\
G E \\
G E \\
G E \\
G E \\
G E \\
G E \\
G E \\
G E \\
G E \\
G E \\
G E \\
G E \\
G E \\
G E \\
G E \\
G E \\
G E \\
G E \\
G E \\
G E \\
G E \\
G E \\
G E \\
G P \\
G P \\
G P \\
G P \\
G P \\
G P \\
G P \\
G P \\
G P \\
G P \\
G E \\
G P \\
G E \\
G P \\
G P \\
G P \\
G P \\
G P \\
G P \\
G P \\
G P \\
G E \\
G E \\
G P \\
G P \\
G P \\
G P \\
G P \\
G P\end{array}$ \\
\hline
\end{tabular}

WELL LDB 1

\begin{tabular}{|c|c|c|c|c|c|}
\hline \multicolumn{6}{|c|}{ MEASUREMENTS CONDUCTED IN THE FIELD } \\
\hline \multicolumn{3}{|c|}{ 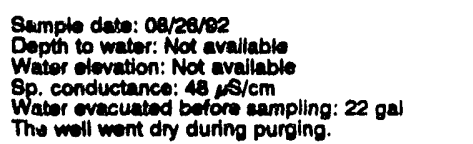 } & \multicolumn{3}{|c|}{$\begin{array}{l}\text { Time: } 14: 35 \\
\text { pH: } 4.7 \\
\text { Alkalinity: } 0 \mathrm{mg} / \mathrm{h} \\
\text { Water tomperature: } 24.7^{\circ} \mathrm{C}\end{array}$} \\
\hline \multicolumn{6}{|c|}{ LABOAATOPY ANALYSES } \\
\hline E & Aneryte & Recult & Mod & Unit & Lab \\
\hline $\begin{array}{l}2 \\
0 \\
0 \\
0\end{array}$ & $\begin{array}{l}\text { Lead } \\
\text { Total organic halogens } \\
\text { Trtifum } \\
\text { Trtium }\end{array}$ & $\begin{array}{l}52 \\
19 \\
7.7 E-08 \pm 6 \\
7.7 E-06 \pm 6\end{array}$ & $\begin{array}{l}\text { OE-07 } \\
\text { OE-07 }\end{array}$ & $\underset{m \mathrm{mi} / \mathrm{mL}}{\mathrm{m} / \mathrm{L}}$ & $\begin{array}{l}\mathrm{GE} \\
\mathrm{GE} \\
\mathrm{GE} \\
\mathrm{GE}\end{array}$ \\
\hline
\end{tabular}

WELL LDB 2

MEASUREMENTS CONDUCTED IN THE FIELO

Sample date: 08/26/82

Depth to water: Not avallable

Water elevation: Not available

Whater evacuated betore sempling: $22 \mathrm{gal}$

The well went dry during purging.

LABORATORY ANALYSES

\begin{tabular}{|c|c|c|c|}
\hline E Analyte & Roeult & Mod & Unit \\
\hline $\begin{array}{l}2 \text { Lead } \\
2 \text { Total organic halogens } \\
0 \text { Trittum }\end{array}$ & $\begin{array}{l}18 \\
52 \\
4.6 E-0\end{array}$ & & 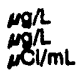 \\
\hline
\end{tabular}

WELL LFW 6

MEASUREMENTS CONDUCTED IN THE FIELD

$\begin{array}{ll}\text { Sample date: } 08 / 25 / 92 & \text { Time: } 10: 45 \\ \text { Depth to water: } 16.50 \mathrm{ft}(3.03 \mathrm{~m}) \text { below TOC } & \text { PH: } 5.2 \\ \text { Water elevation: } 155.20 \mathrm{ft}(47.31 \mathrm{~m}) \mathrm{mal} & \text { Alkalinity: } 18 \mathrm{mg} / \mathrm{h} \\ \text { Sp. conductance: } 89 \mu \mathrm{s} / \mathrm{cm} & \text { Water tomporature: } 21.5 \circ \mathrm{C} \\ \text { Water ovacuated before sampling: } 37 \mathrm{gal} & \end{array}$

LABORATORY ANALYSES

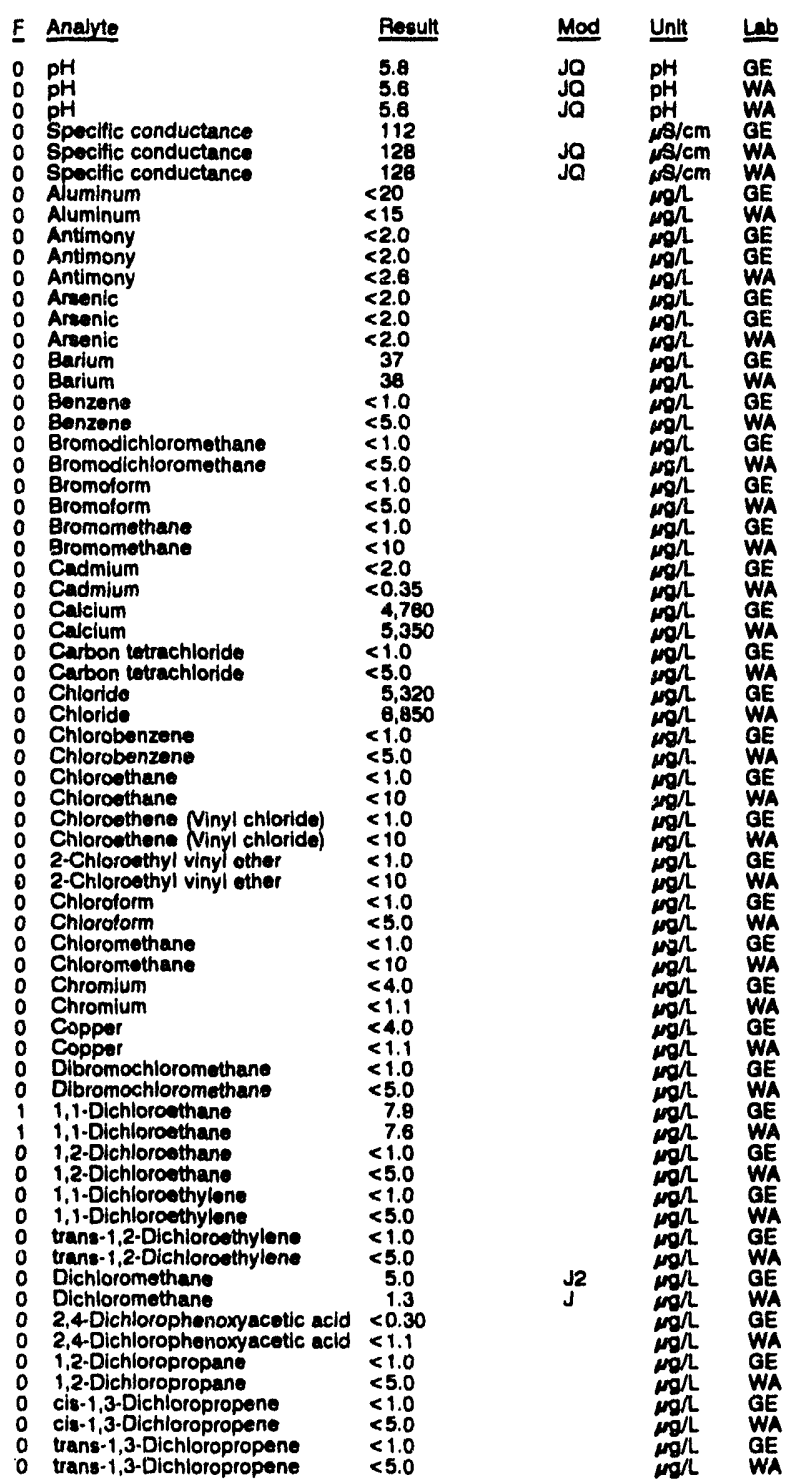


ANALYTICAL RESULTS

WEUL LFW 6 coliected on 08/25/92, laboratory analyses (cont)

E Anarte

Endin

Endrin

0 Fluoride

0 Fivorido

$\begin{array}{ll}2 & \text { Iron } \\ 2 & \text { Iron } \\ 0 & \end{array}$

0 Lend

o Lundan

o Undane

is Megnealum

Manganewe

Manganeco

Mopeury

Methonyetion

Nethosychior

Nitrate as nitrogen

Nirecho-nilute en nitrogen

Phenole

Phonots

: Potenelum

0 Potanalum

setentum

setonium

Sillea

- simor

sinver

Sodium

Sullute

$1,1,2,2-$ Totrachloroethane

1,1,2,2-Terechioroethan

Tetrachlorocthylions

Toluene

Tolueno

- Totil organic carbon

Toit organic carbon

2 Total organic haloom

Total organic halogens

Toxaphone

Tocaphon

o 2,4,5-TP Silvex

1,1,1-Trichlorothen

1,1,1-Trichloroethen

1,1,2-Trichloroethan

Trichioroethylon

Inchloroethyleme

Trichloronluoromothan

Vanadlum

Vanedlum

Groes alpha

Nomolattle bota

Nonvolatile bota

Radlum-22a

Radlum-22:

Radium-20

T Truum
$<0.0060$

$<0.11$

$<5.0$

$<100$

9,680
10,300

$<3.0$

$<2.00$

$<0.056$

4.870
5,080

30

$<0.20$

$<0.20$

$<0.50$

$<0.56$

$<3.1$

323

306
$<5.0$
$<50$

$<5.0$

$<5$.

851
$<2.0$
$<2.0$

$<2.0$

8,360
8,220

$<2.70$

2,680

2,820
4,840
5,610

$<1.0$

$<5.0$
$<1.0$

$<5.0$

$<5.0$

2,370
2,000

1,800

59

118
$<0.24$
$<1.1$

$<0.090$

$<0.56$

$<1.0$

$<1.0$

$<5.0$

$<1.0$

$<1.0$
$<5.0$

$<8.0$

$<.68 .09 \pm 2.2 E-00$

$2.8 E-00+8.9 E-10$

3.4E-09 $01.8 E-10$

4.3E-09 4.1E-10

$<1.00-09$

$3.8 E-09 \pm 1.3 E-09$

$3.1 E-09 \pm 6.5 E-10$
$1.7 E-00 \pm 5.0 E-07$
Mod Unit La

ergh GE

0 Aluminum

$\therefore$ Antmony

: Areonic

Barlum

o Benzene

Bonzene

Bromodichloromothan

Bromodichloromethane

Bromolorm

Bromolorm

Bromomethane

Bromomethane

: Cadmium

Calcium

Calclum

Carbon totrachioride

Carbon totrachiorido

Chloride

Chloride

Chlorobenzene

Chlorobonzene

C Chlorobenzene

Chloroethane

Chloroethane

CChloroethane

Chlorosthene Minyl chloride

Chiorosthene Miny chloride

2.Chiorcethyl vinyl other

2-Chloroethyl vinyl ether

Chloroform

Chloroform

Chloromethane

Chloromethane

Chloromethen

Chromium

Chromium

copper

Dibromochloromethane

Dibromochloromothane

1 1.-Dichloroethane

1.1-Dichloroothane

1,i-Oichloroethane

1,2-Dichloroethene

1,2-Dichiorosthane

1,2-Dichlorodthene

1, - Dichloroethylone

i, 1-Dichloroethylione

trans-1,2-Dichloroethylene

trans. - .2-Dichloroethylone

Dens-1,2-Dichioroethylene

Dichloromethane

Dichloromethene

2,40ichlorophenoxyacetic acid

2,4-Dichlorophenowectic acid

1,2-Dichloropropane

1,2-Oichloropropane

1,2-Dichloropropane

cis-1,3-Dichloropropene

cis-1,3-Dichioropropone

tans-1,3-Dichloropropene

trans-1,3-Dichloropropene

trans-1,3.Dichloropropene

Endrin

Ethylbenzene

Ethylbenzene

Fluoride

2 Fluorido

2 Iron

2 Lron

Lead

Lindane

Undane

Magnesium

Manganese

Mercury

Mercury

Methoxychlor

\begin{tabular}{|c|c|c|c|}
\hline Andyce & Bosult & Mod & Unit \\
\hline & $\begin{array}{l}5.8 \\
5.6\end{array}$ & $\begin{array}{l}\text { JQ } \\
\text { JQ }\end{array}$ & pH \\
\hline $\begin{array}{l}\text { Spocticic conductunce } \\
\text { Auminum }\end{array}$ & $<20$ & Ja & $\begin{array}{l}\mu \mathrm{N} / \mathrm{cm} \\
\mathrm{Ng} / \mathrm{m}\end{array}$ \\
\hline
\end{tabular}

laboratory analyeses (cont.)

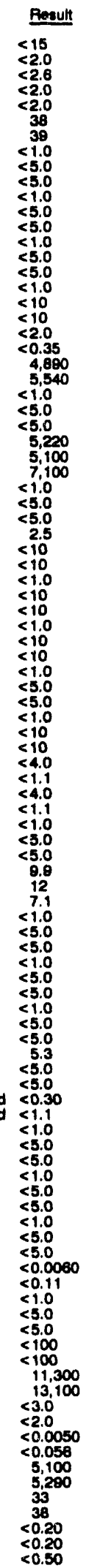

Unit Lo

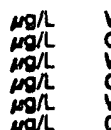

WA 


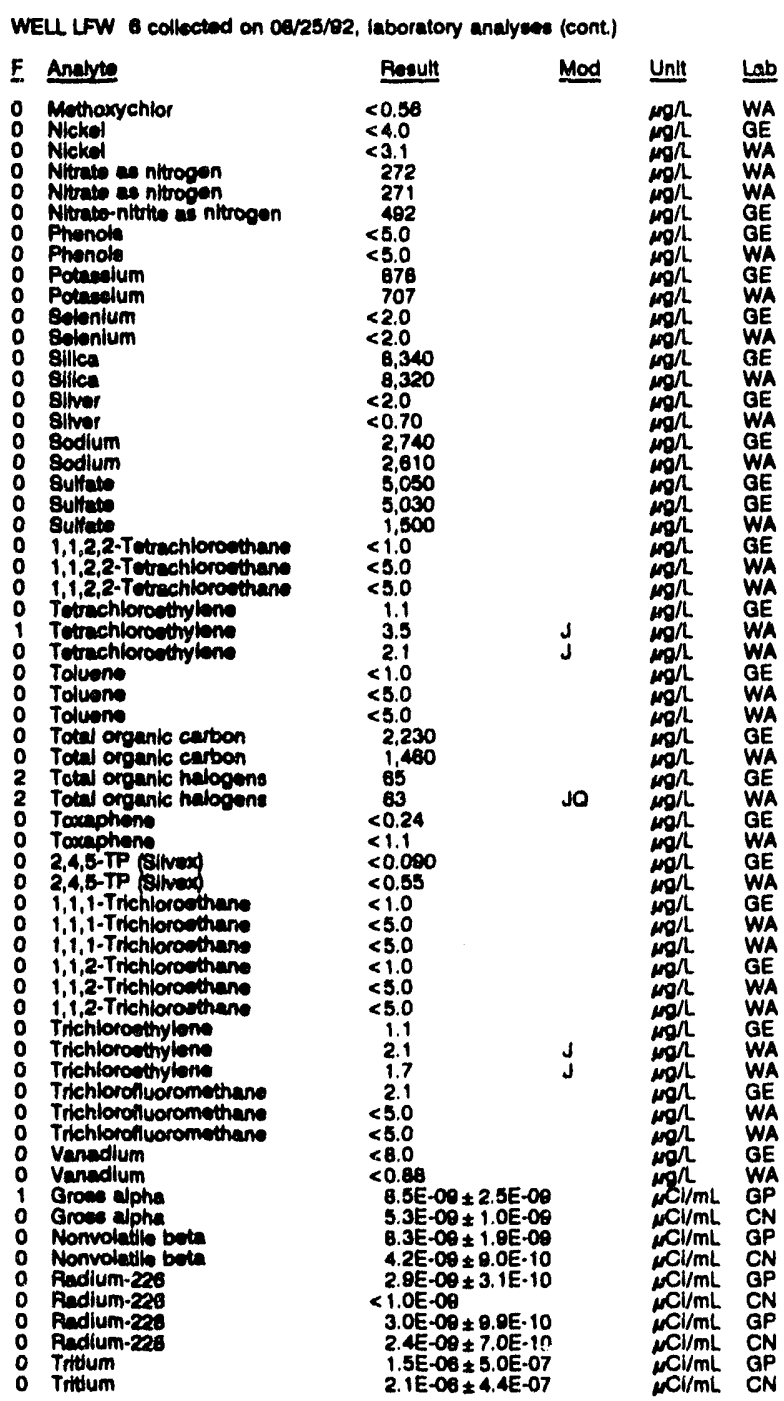

WELL LFW 7

MEASUREMENTS CONDUCTED IN THE FIELD

Sample dato: 0a/2s/or

Depth to water: $18.03 \mathrm{n}(5.50 \mathrm{~m})$ below TOC

Water elovation: $153.17 \mathrm{~h}(48.69 \mathrm{~m}) \mathrm{mal}$
inacceealbility or mochanical problem prevented sample collection.

WELL LFW 8

MEASUREMENTS CONDUCTED IN THE FIELD

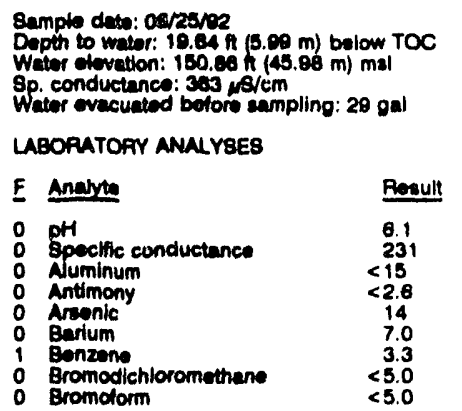

Time: 9:55

pH: 8.4 .4 $153 \mathrm{mg} /$

Water tomperature: $20.3^{\circ} \mathrm{C}$

(29 gal

LABOPATOFY ANALYRES

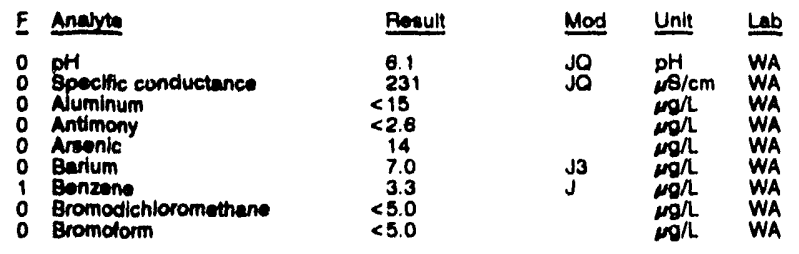

WELL LFW 8 collocted on 06/25/82, laboratory analyees (cont.)

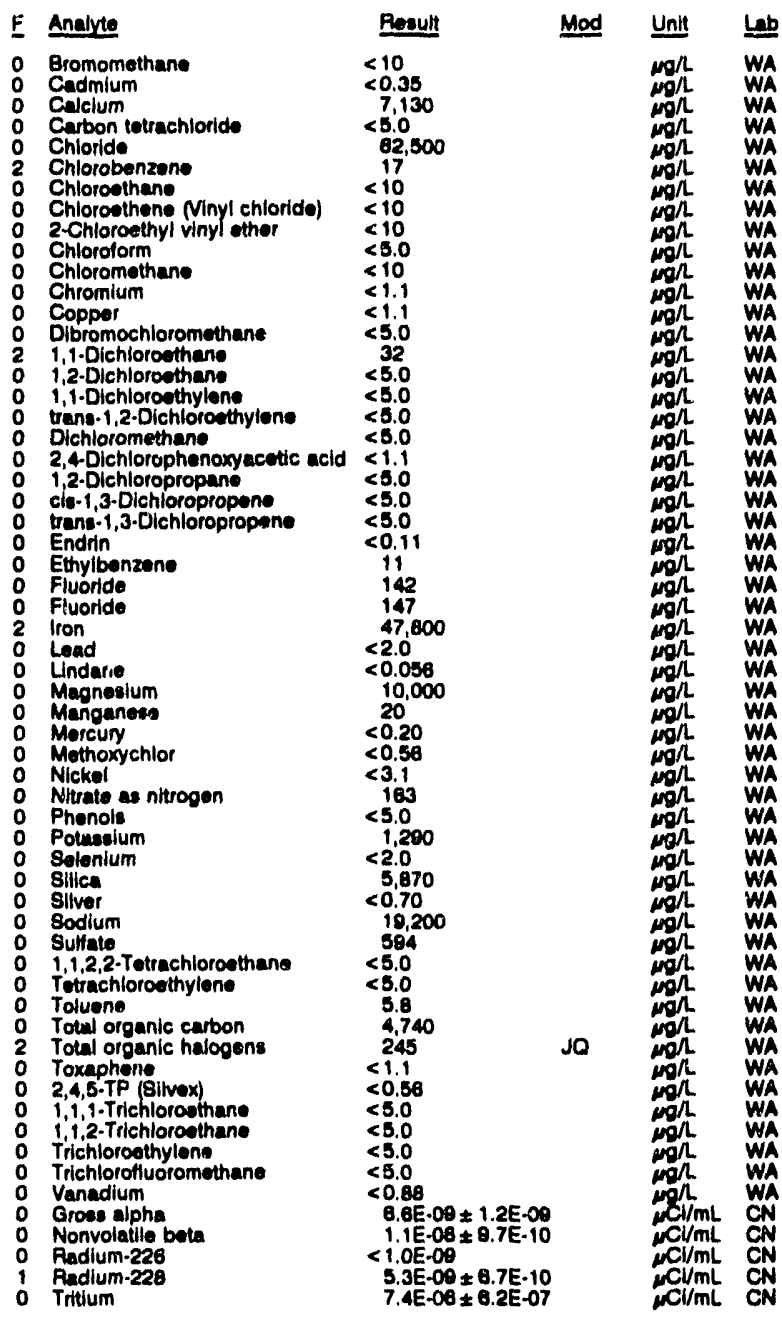

WELL LFW 10A

MEASUREMENTS CONDUCTED IN THE FIELD

8umple date: 08/24/82

Depth to water: $22.28 \mathrm{~h}(6.78 \mathrm{~m})$ bolow TOC

Water olovation: $153.24 \mathrm{ht}(46.71 \mathrm{~m}) \mathrm{mal}$

Sp. conductance: $435 \mu \mathrm{s} / \mathrm{cm}$

Wator evacuated before sampling: 63 gal

LABORATOAY ANALYSES

\begin{tabular}{|c|c|c|c|c|}
\hline$E$ & Analye & Result & Mod & Unit \\
\hline $\begin{array}{l}0 \\
0 \\
1 \\
1 \\
0 \\
0 \\
0 \\
0 \\
1 \\
0 \\
0 \\
0 \\
0 \\
0 \\
0 \\
0 \\
0\end{array}$ & $\begin{array}{l}\text { pH } \\
\text { pH } \\
\text { Specific conductance } \\
\text { Specific conductance } \\
\text { Aluminum } \\
\text { Antimony } \\
\text { Areenic } \\
\text { Barium } \\
\text { Benzene } \\
\text { Bromodichloromethane } \\
\text { Bromoform } \\
\text { Bromomethane } \\
\text { Cadmium } \\
\text { Calclum } \\
\text { Carbon tetrachloride } \\
\text { Chloride } \\
\text { Chlorobenzene } \\
\text { Chloroethane } \\
\text { Chlorosthene Ninyl chloride) } \\
\text { 2-Chlorosthyl vinyi ether } \\
\text { Chloroform } \\
\text { Chloromethane } \\
\text { Chromlum }\end{array}$ & $\begin{array}{r}5.9 \\
5.9 \\
331 \\
331 \\
<15 \\
<2.6 \\
5.2 \\
13 \\
4.1 \\
4.1 \\
<5.0 \\
<5.0 \\
<10 \\
<0.35 \\
10.700 \\
<5.0 \\
29.000 \\
<5.0 \\
<10 \\
<10 \\
<10 \\
<5.0 \\
<10 \\
42\end{array}$ & $\begin{array}{l}\sqrt{J Q} \\
\text { Ja } \\
\mathrm{J} \\
\mathrm{J} Q \\
\mathrm{~J} \\
\mathrm{J3} \\
\mathrm{J}\end{array}$ & 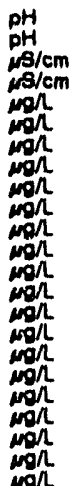 \\
\hline
\end{tabular}


ANALYTICAL RESULTS

WELL LFW 10A colloctod on 08/24/82, laboratory analyees (cont)

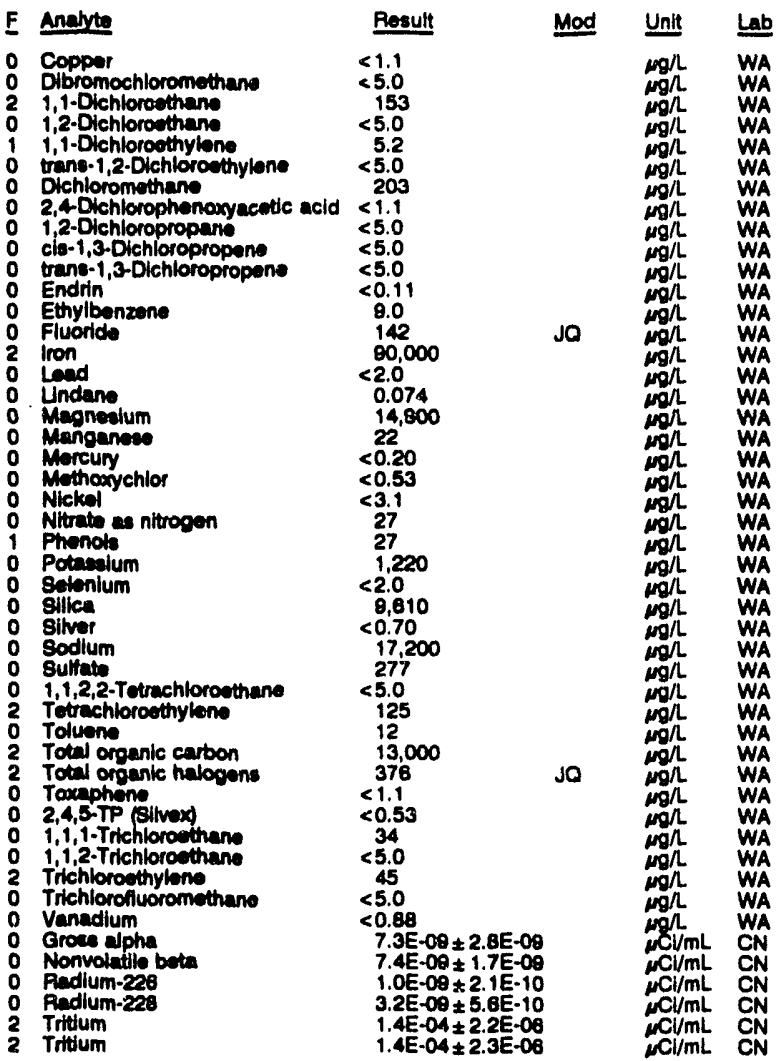

WELL LFW 16

MEASUREMENTS CONDUCTED IN THE FIELD

Semple date: 0ar24/82

Depth to water: 22.69 in $(6.91 \mathrm{~m})$ below TOC Water elovation: 158.14 ( $(47.59 \mathrm{~m}) \mathrm{ms}$. Wh. conductance: $36 \mathrm{HS} / \mathrm{cm}$.

LABOFATOFY ANALYSES

\begin{tabular}{|c|c|c|c|}
\hline Analyte & Result & Mod & Unit \\
\hline 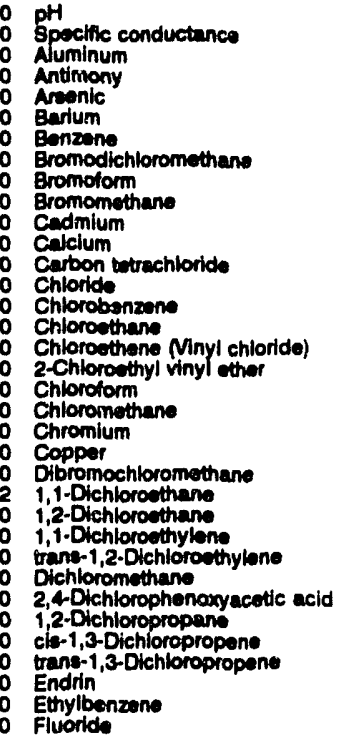 & $\begin{array}{l}5.1 \\
41 \\
<15 \\
<2.6 \\
<2.0 \\
14 \\
<5.0 \\
<5.0 \\
<5.0 \\
<10 \\
<0.35 \\
1.950 \\
<5.0 \\
3.240 \\
<5.0 \\
<10 \\
<10 \\
<10 \\
<5.0 \\
<10 \\
\theta .0 \\
1.2 \\
<5.0 \\
32.0 \\
<5.0 \\
<5.0 \\
<5.0 \\
14 \\
<1.1 \\
<5.0 \\
<5.0 \\
<5.0 \\
<0.11 \\
<5.0 \\
<100\end{array}$ & טم Jo & 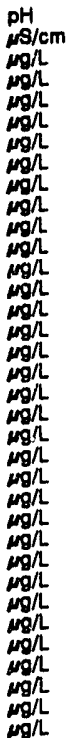 \\
\hline
\end{tabular}

WELL LFW 16 collected on 08/24/82, laboratory analyses (cont)

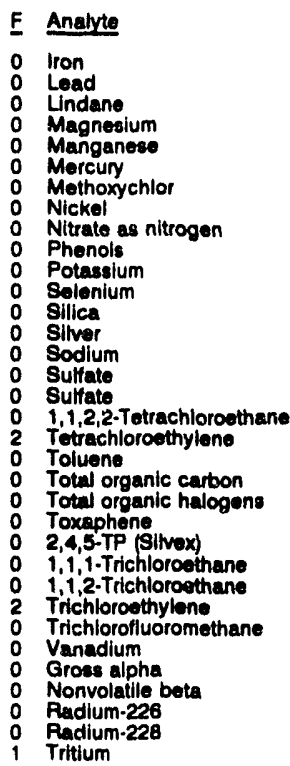

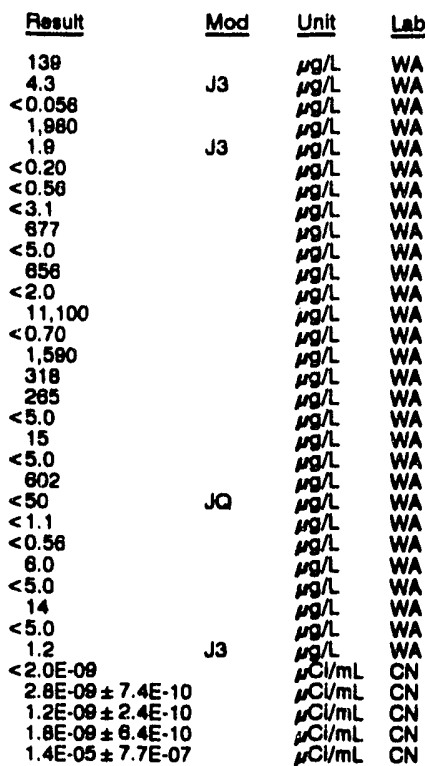

\section{WELL LFW 17}

MEASUREMENTS CONDUCTEU IN THE FIELD

Sample date: 08/25/82

Depth to water: $22.18 \mathrm{~h}(6.76 \mathrm{~m})$ below TOC

Water elevation: $155.62 \mathrm{~h}(47.43$

Water evacuated volore sampling: 71 gat

LABORATORY ANALYSES

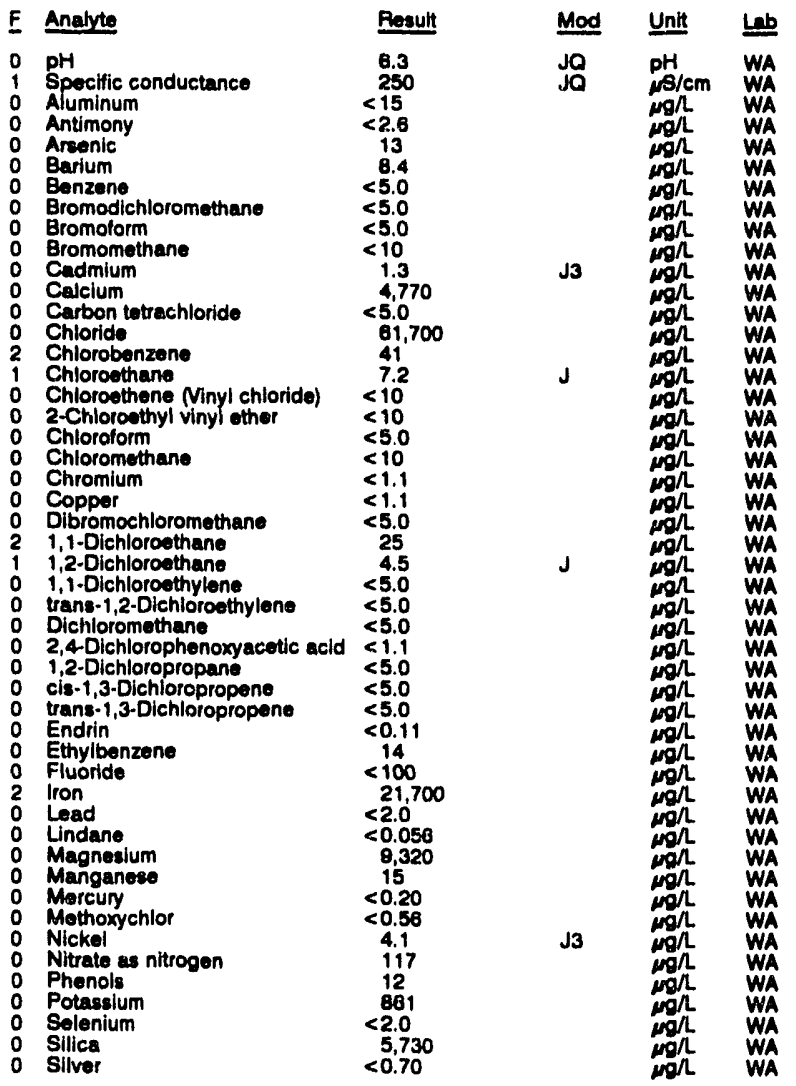

Time: 8:25

PH: 8.3 : $86 \mathrm{mal}$

Water temperature: $19.7 \circ \mathrm{C}$
PH: 4.8

Al: 4.8
Watinity: $0 \mathrm{mg} / \mathrm{h}$
Water tomperature: $21.3^{\circ} \mathrm{C}$

WA

.




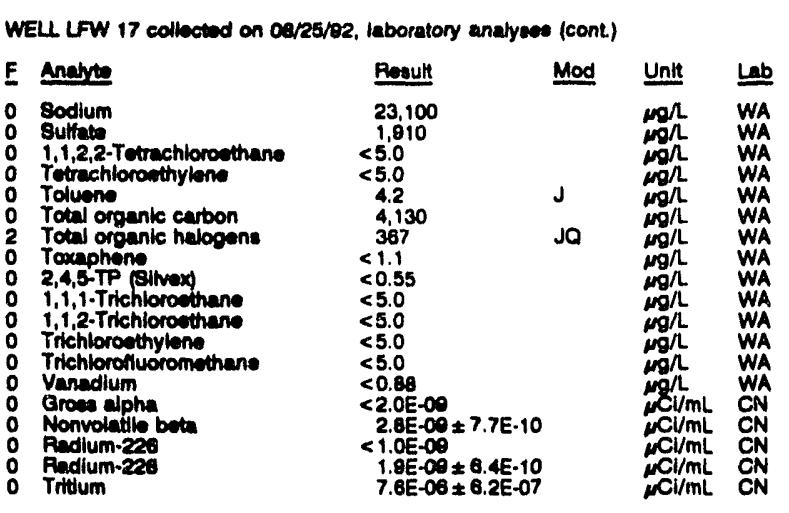

WELL LFW 18

MEASUPEMENTS CONDUCTED IN THE FIELD
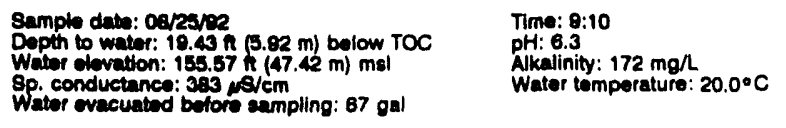

LABOPATOFY AMULYSES

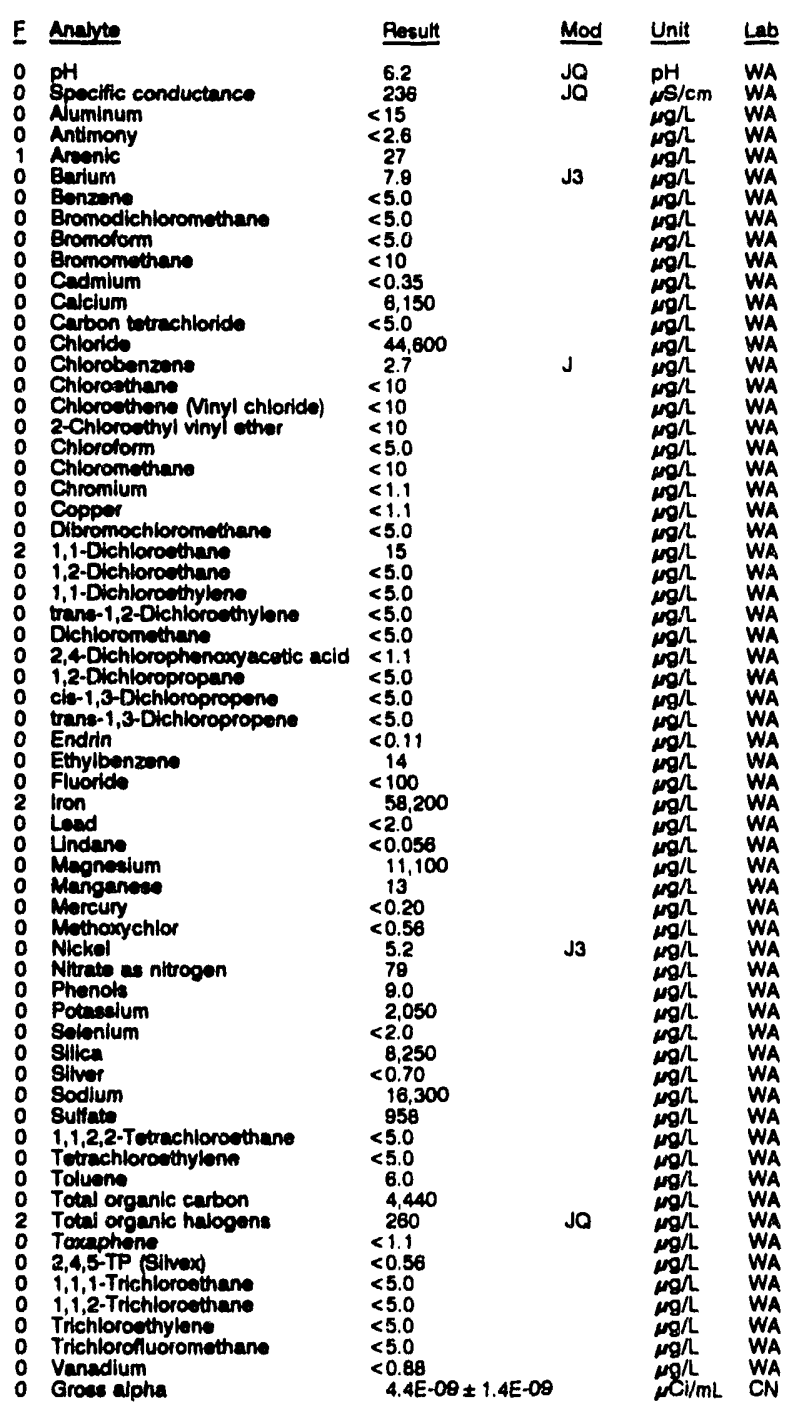

WELL LFW 18 collectod on 08/25/82, laboratory analyees (cont)

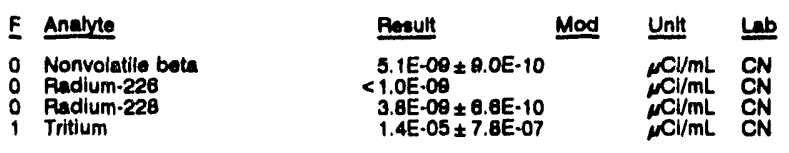

WELL LFW 19

MEASUREMENTS CONDUCTED IN THE FIELD

\begin{tabular}{|c|c|}
\hline 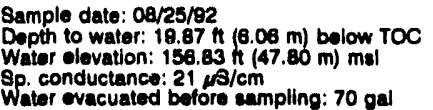 & $\begin{array}{l}\text { Time: } 12: 05 \\
\text { pH: } 1.05 \\
\text { Alkalinity: } 0 \text { mgh } \\
\text { Wator tomporalure: } 20.4 \cdot \mathrm{C}\end{array}$ \\
\hline
\end{tabular}

LABOPATORY ANALYSES

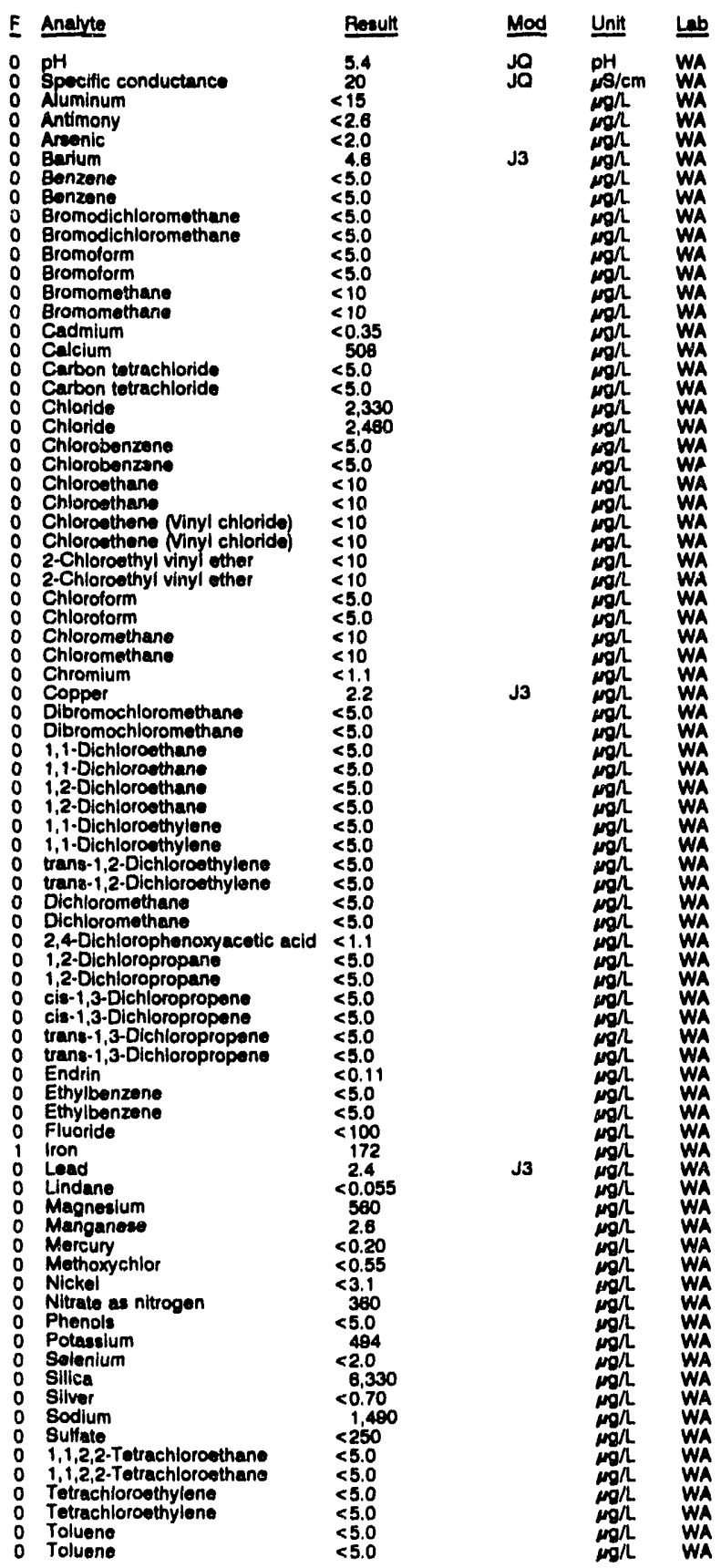


ANALYTICAL RESULTS

WEL LFW 19 collected on 06/25/82, laboratory analyees (cont.)

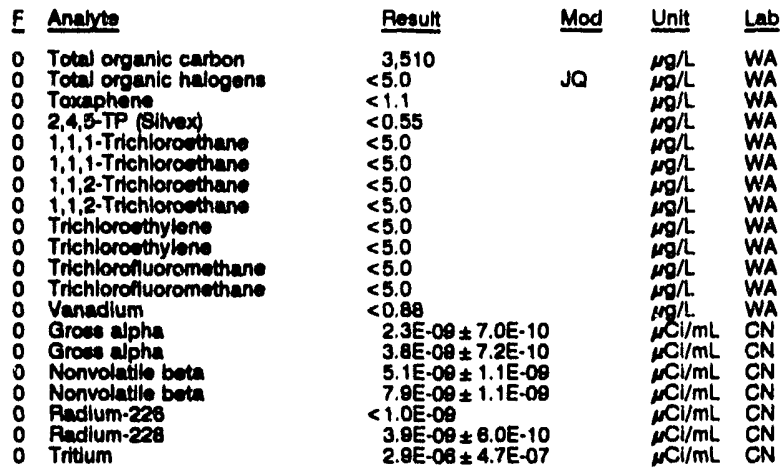

\section{WELL LFW 20}

MEASUREMENTS CONDUCTED IN THE FIELD

Sample dato: 08/2492

Time: 14:00

Whter elevation: $180.04 \mathrm{~h}(48.78 \mathrm{~m}) \mathrm{msl}$

inaccessibility or mechanical problem prevented sample collection.

WELL LFW 21

MEASUREMENTS CONDUCTED IN THE FIELD

\begin{tabular}{|c|c|}
\hline \\
\hline & 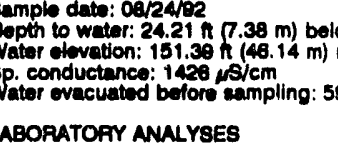 \\
\hline & Anulyts \\
\hline & 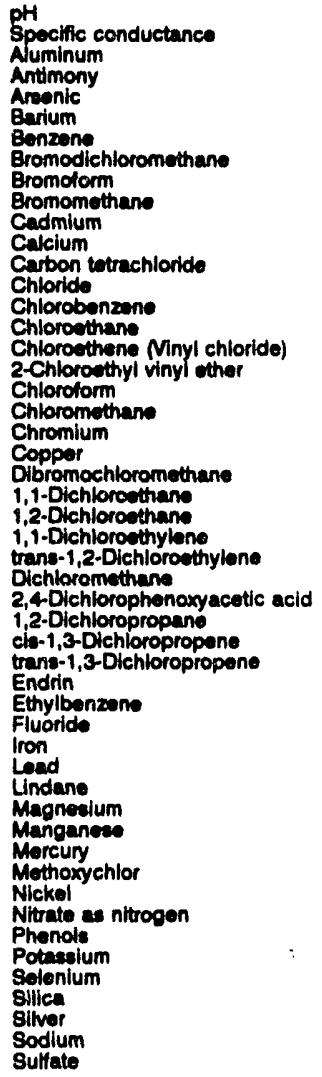 \\
\hline
\end{tabular}

Time: 12:50

Alkalinity: $273 \mathrm{mg} / \mathrm{h}$

Water temperature: $22.2^{\circ} \mathrm{C}$

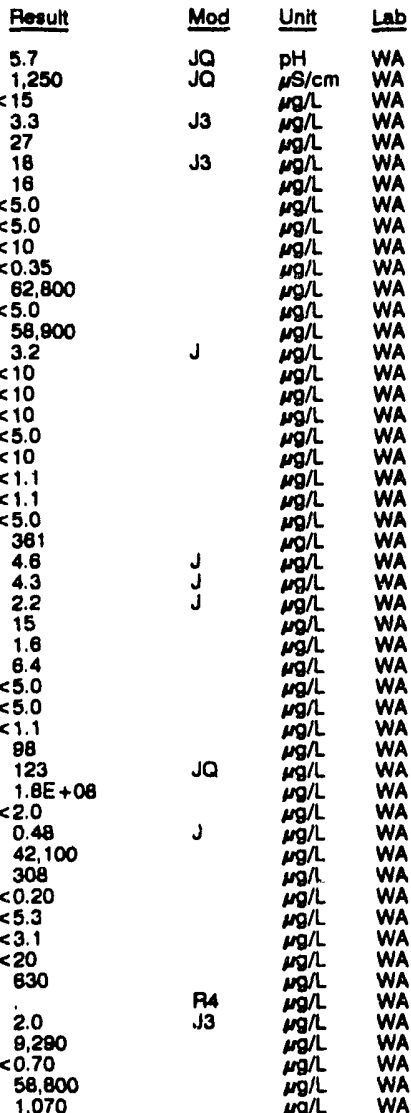

WELL LFW 21 collected on 08/24/82, laboratory annlyees (cont)

\begin{tabular}{|c|c|c|c|c|}
\hline & Analyte & Renult & Mod & Unit \\
\hline $\begin{array}{l}0 \\
2 \\
2 \\
0 \\
0 \\
0 \\
0 \\
0 \\
2 \\
0 \\
0 \\
0\end{array}$ & $\begin{array}{l}\text { 1,1,2,2-Totrachloroethane } \\
\text { Totrachloroethylene } \\
\text { Toluene } \\
\text { Total organic carbon } \\
\text { Total organic halogens } \\
\text { Toxaphene } \\
2,4,5-T P \text { (Silvex) } \\
1,1,1 \cdot \text { Trichloroethane } \\
\text { 1,1,2-Trichloroethane } \\
\text { Trichloroethylone } \\
\text { Trichlorofluoromethane } \\
\text { Vanadlium } \\
\text { Groas alpha } \\
\text { Nonvolatile beta } \\
\text { Radium-228 } \\
\text { Radium-228 } \\
\text { Tritium }\end{array}$ & $\begin{array}{l}<5.0 \\
10 \\
387 \\
516,000 \\
504 \\
<11 \\
<0.53 \\
4.5 \\
<5.0 \\
24 \\
<5.0 \\
<0.88 \\
<8.0 E-09 \\
<5.3 E-09 \\
2.2 E-09 \pm 3.4 E-10 \\
2.9 E-09 \pm 5.9 E-10 \\
1.7 E-05 \pm 8.5 E-07\end{array}$ & JO & 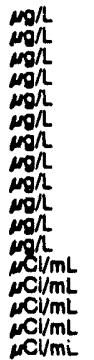 \\
\hline
\end{tabular}

\section{WELLL LFW 22}

MEASUREMENTS CONDUCTED IN THE FIELD

Sample date: 08/24/92

Depth to water: $21.90 \mathrm{ft}(8.70 \mathrm{~m})$ bolow TOC

Water elevation: 132.21 h 146

Timo: 11.5

Water evacuated before sampling: $78 \mathrm{gel}$

allity: $333 \mathrm{mgh}$

Water temperature: $21.1 \circ \mathrm{C}$

LABORATORY ANALYSES

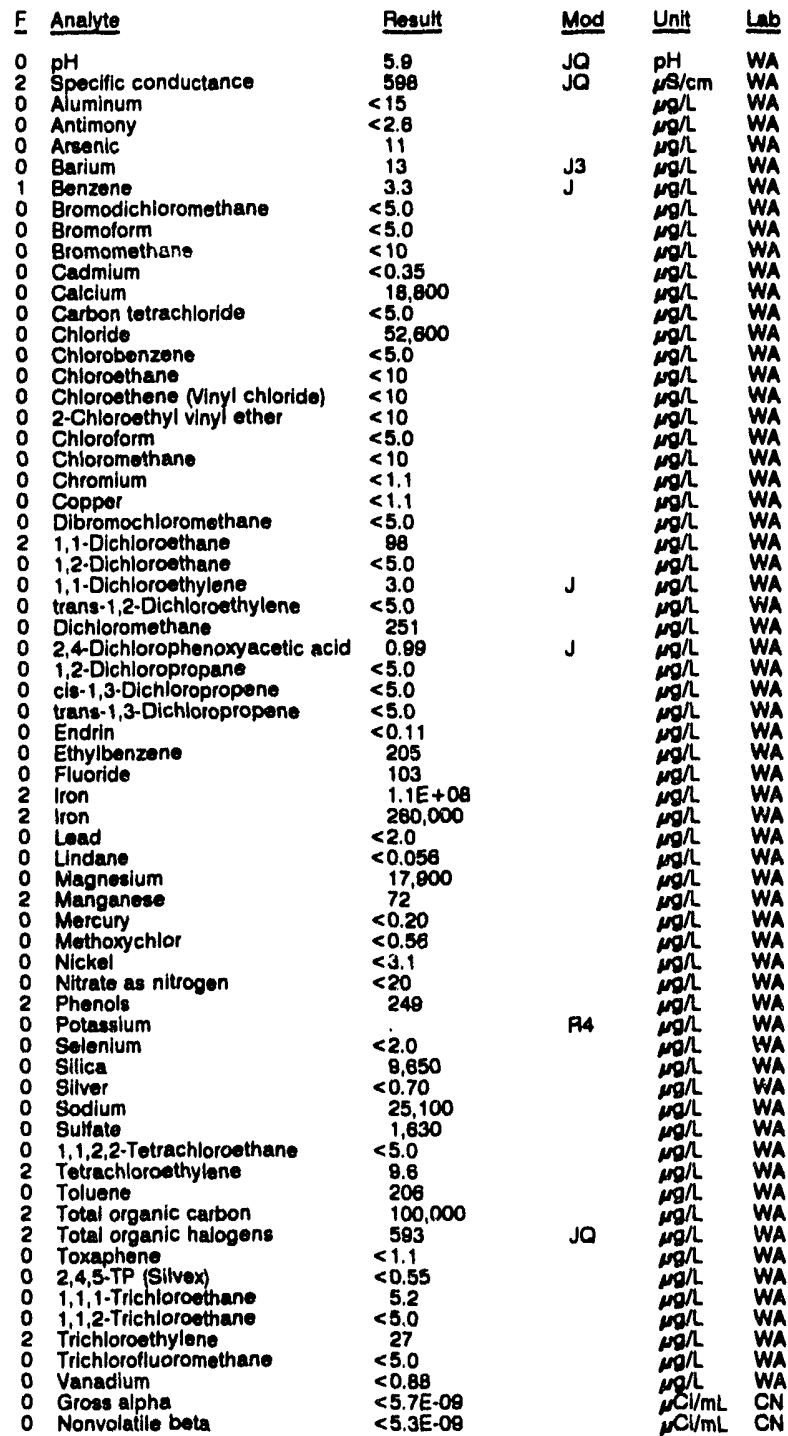


WELL LFW 22 collected on 04/24/92, laboratory analyeen (cont)

\begin{tabular}{|c|c|c|c|}
\hline Analyte & Boeulk & Mod & Unit \\
\hline $\begin{array}{l}0 \text { Pedium-220 } \\
0 \\
0 \text { Pedlum-220 } \\
0\end{array}$ & $\begin{array}{l}1.1 \mathrm{E}-\infty \\
2.3 \mathrm{E}-\infty \\
6.6 \mathrm{E}-\infty\end{array}$ & & 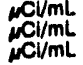 \\
\hline
\end{tabular}

\section{WELL LFW 23}

MEASUREMENTS CONOUCTED IN THE FIELD

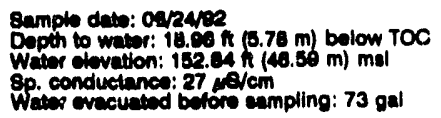

Time: 11:15

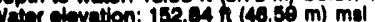

8p. conductance: 27 pe/cm

LABOAATOFY ANALYEES

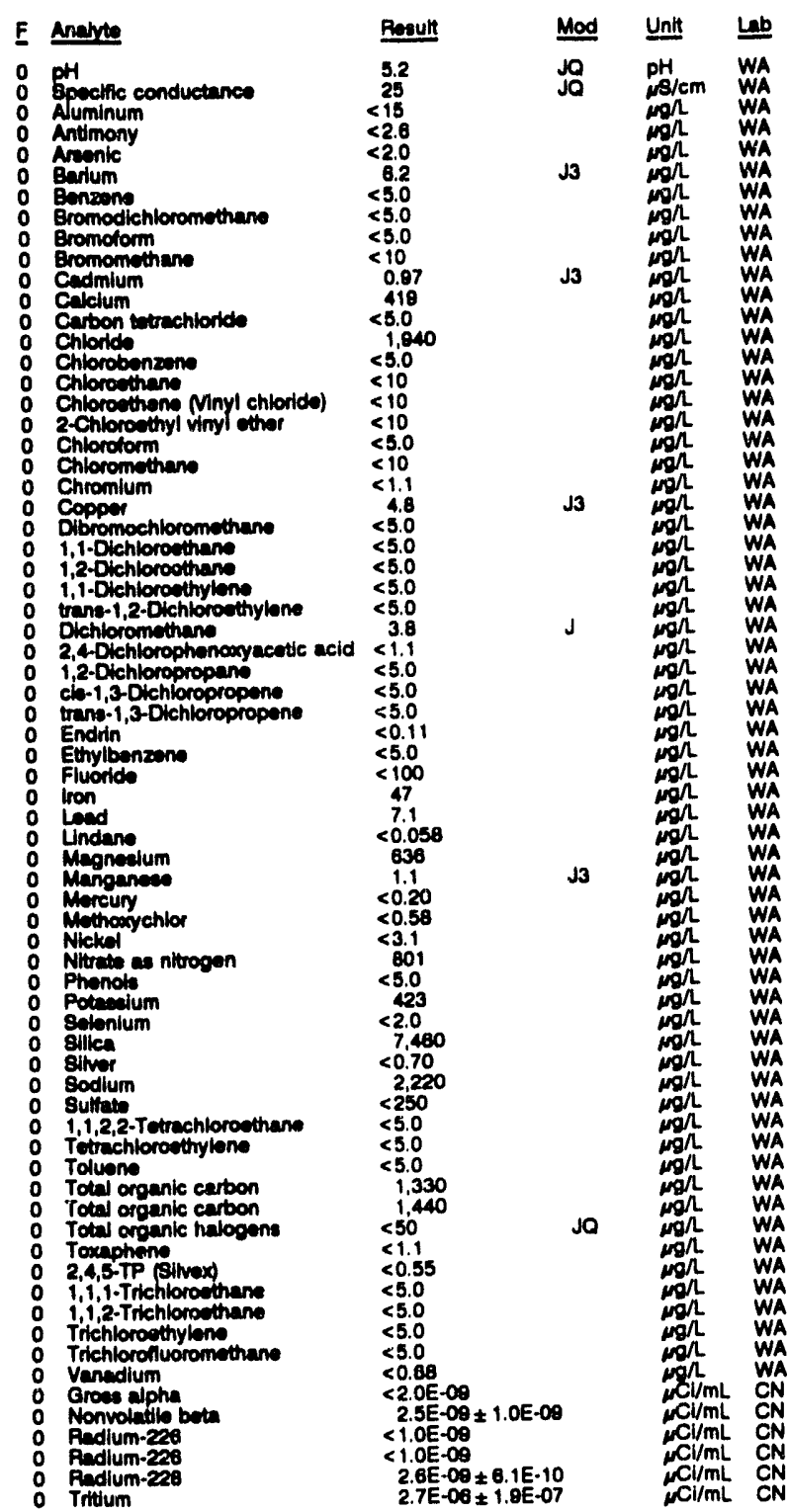

\section{WELL LFW 24}

MEASUREMENTS CONDUCTED IN THE FIELD

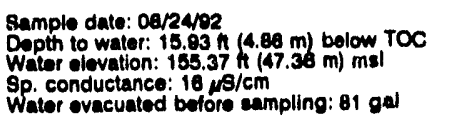

Time: 10:20

PH: 4.7

Water tomperafure: $20.2 \cdot \mathrm{C}$
LABOFUTORY ANALYSES

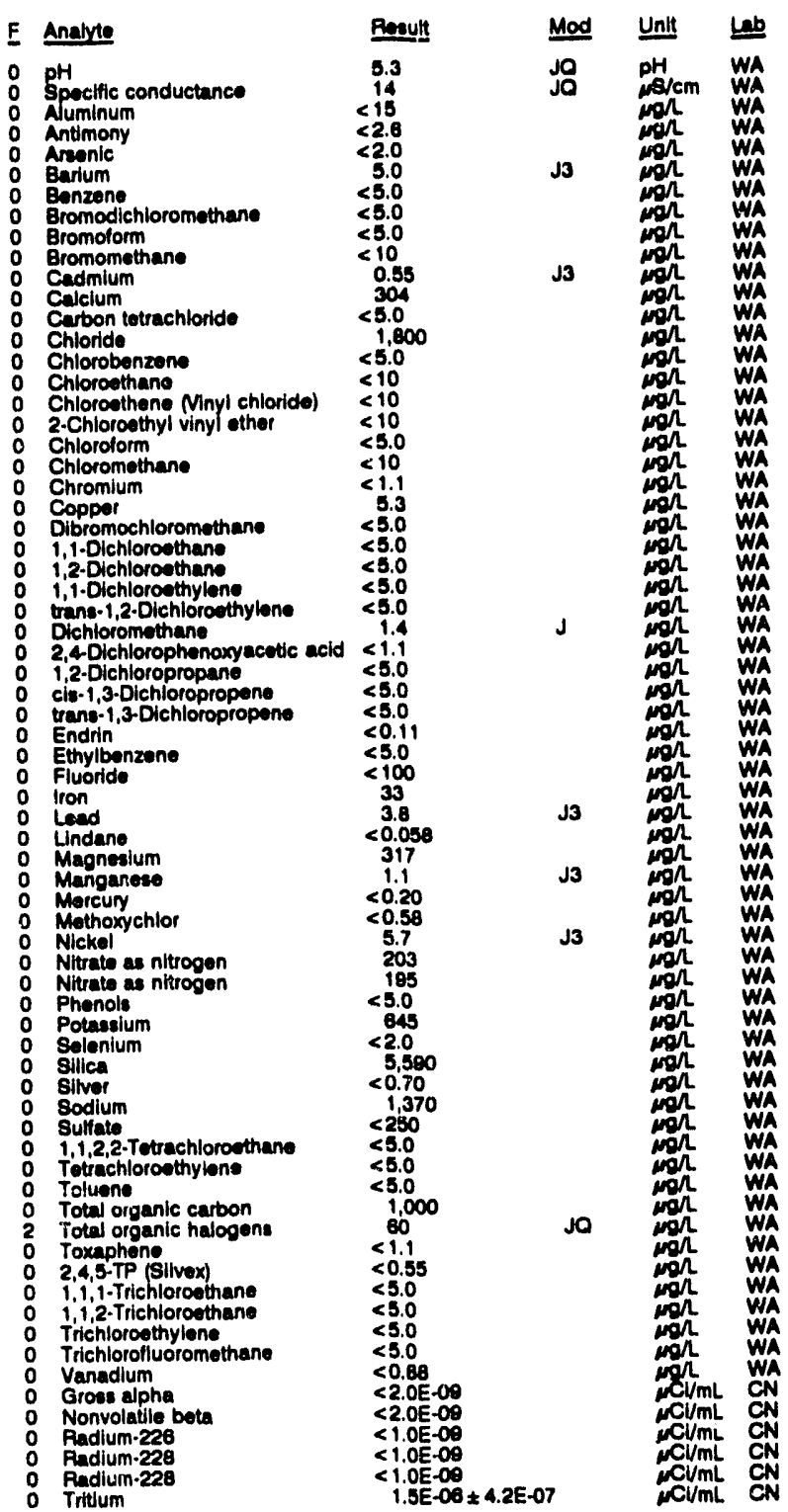




\section{WELL LFW 25}

MEABUPEMMENTS CONDUCTED IN THE FIELD

Sample dato: 00/31/02 Depth to watio: 17.05 . $18.20 \mathrm{~m})$ bolow TOC 8p. conductunce: $10 \mathrm{res} / \mathrm{cm}$ Waber ovecuetod betoro campling: 80 gal LABOPATOAY ANULYRES

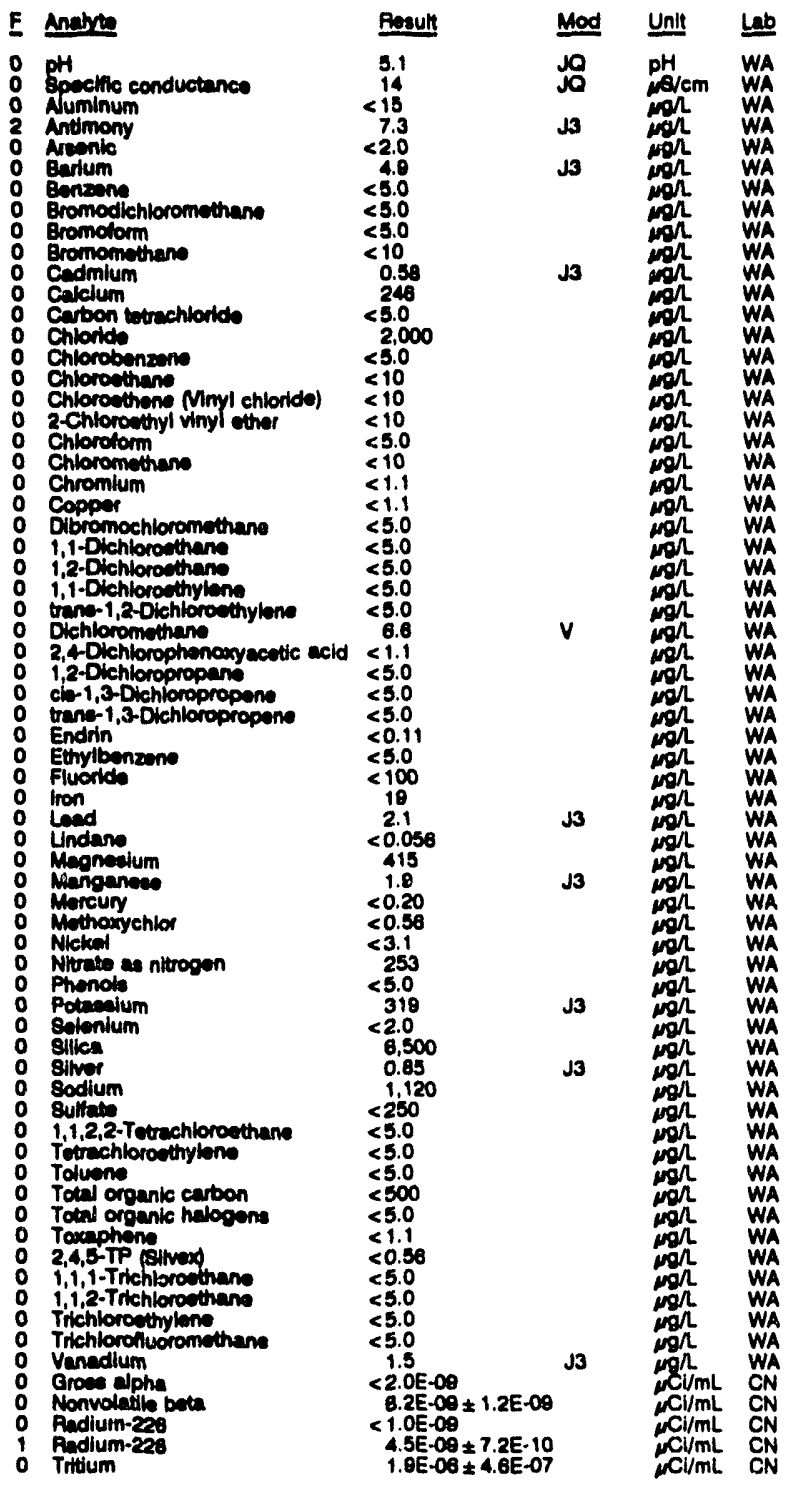

\section{WELL LFW 26}

\section{MEASUAREMENTS CONOUCTED IN THE FIELD}

\begin{tabular}{|c|c|c|c|c|}
\hline \multirow{2}{*}{\multicolumn{2}{|c|}{ 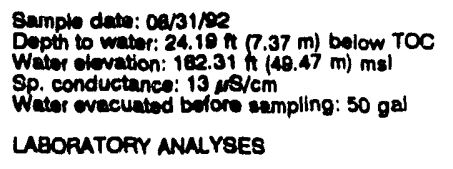 }} & \multicolumn{3}{|c|}{$\begin{array}{l}\text { Time: } 13: 15 \\
\text { pH: } 4.7 .7 \\
\text { Nklinity: } 0 \mathrm{mg} / \mathrm{L} \\
\text { Water tomperature: } 20.1^{\circ} \mathrm{C}\end{array}$} \\
\hline & & & & \\
\hline E Anasute & Plosult & Mod & Unit & Lab \\
\hline $\begin{array}{ll}0 & p H \\
0 & p H \\
0 & \text { Specific conductance }\end{array}$ & $\begin{array}{l}5.2 \\
5.2 \\
11\end{array}$ & $\begin{array}{l}\text { Jo } \\
\text { Jo } \\
\text { Jo }\end{array}$ & $\underset{\substack{p H \\
\mathrm{pH} / \mathrm{cm}}}{\mathrm{pH}}$ & $\begin{array}{l}\text { WA } \\
\text { WA } \\
\text { WA }\end{array}$ \\
\hline
\end{tabular}

WELL LFW 28 collected on 08/31/02, laboratory enalyeoe (cont)

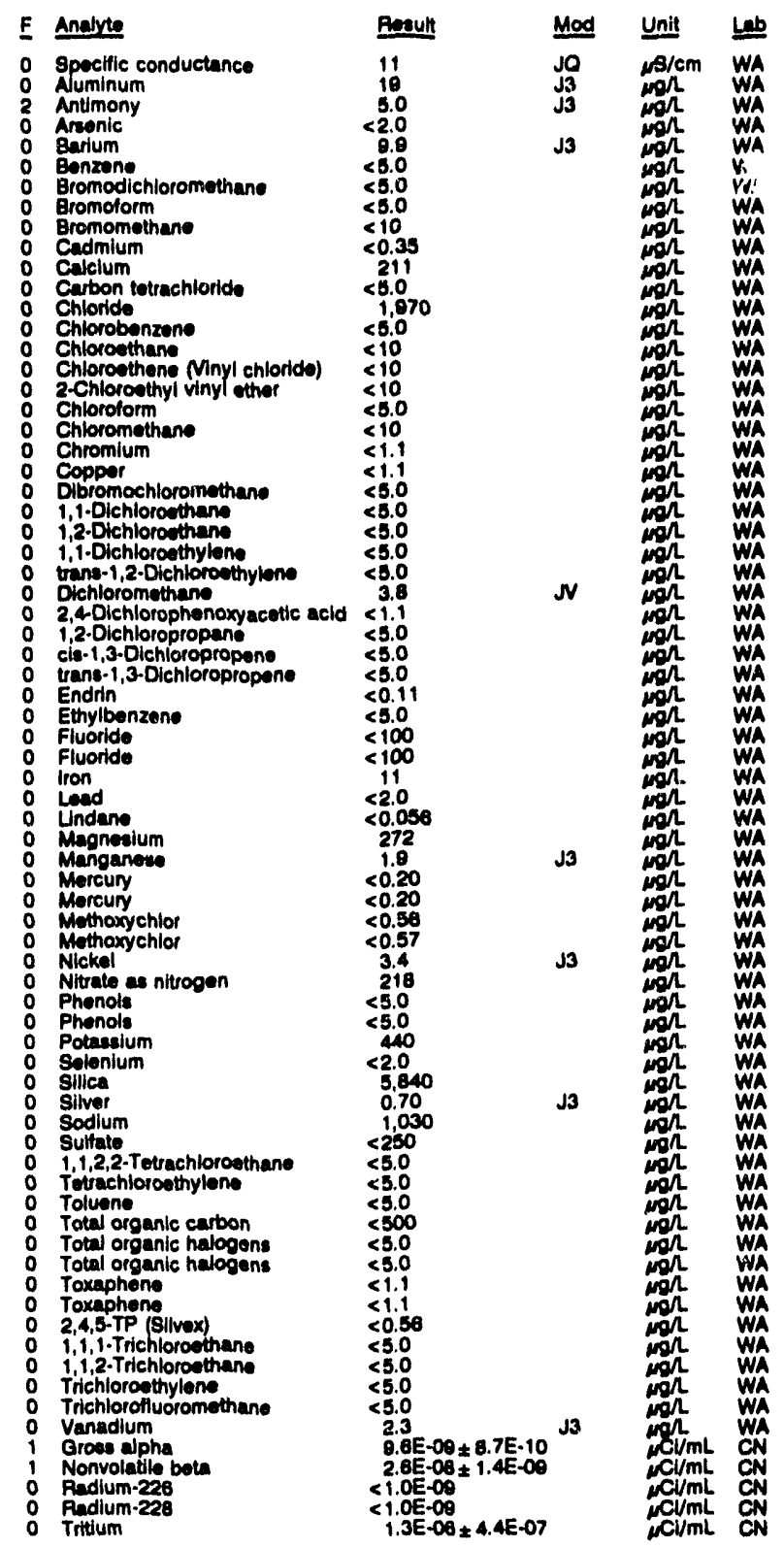

\section{WELL LFW 27}

MEASUAEMENTS CONDUCTED IN THE FIELD

\begin{tabular}{|c|c|c|c|c|c|}
\hline \multicolumn{3}{|c|}{ 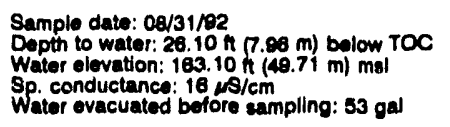 } & \multicolumn{3}{|c|}{$\begin{array}{l}\text { Time: } 12: 50 \\
\text { pH: } 4.7 \\
\text { Alkalinity: } 0 \mathrm{mg} / \mathrm{h} \\
\text { Water tomperature: } 20.00^{\circ} \mathrm{C}\end{array}$} \\
\hline \multicolumn{6}{|c|}{ LABOPATOAY ANALYSES } \\
\hline E & Analute & Rosult & Mod & Unit & Lي \\
\hline $\begin{array}{l}0 \\
0 \\
0 \\
0 \\
0 \\
0 \\
0 \\
0 \\
0 \\
0\end{array}$ & $\begin{array}{l}\text { pH } \\
\text { Specific conductance } \\
\text { Aluminum } \\
\text { Antimony } \\
\text { Areonic } \\
\text { Barlum } \\
\text { Bonzene } \\
\text { Bromodichloromethane } \\
\text { Bromolorm } \\
\text { Bromomethen }\end{array}$ & $\begin{aligned} & 5.3 \\
& 12 \\
&<15 \\
&<2.6 \\
&<2.0 \\
&<2.4 \\
& 4.4 \\
&<5.0 \\
&<5.0 \\
&<5.0 \\
&<10\end{aligned}$ & Ja & 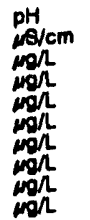 & $\begin{array}{l}\text { WA } \\
\text { WA } \\
\text { WA } \\
\text { WA } \\
\text { WA } \\
\text { WA } \\
\text { WA } \\
\text { WA }\end{array}$ \\
\hline
\end{tabular}




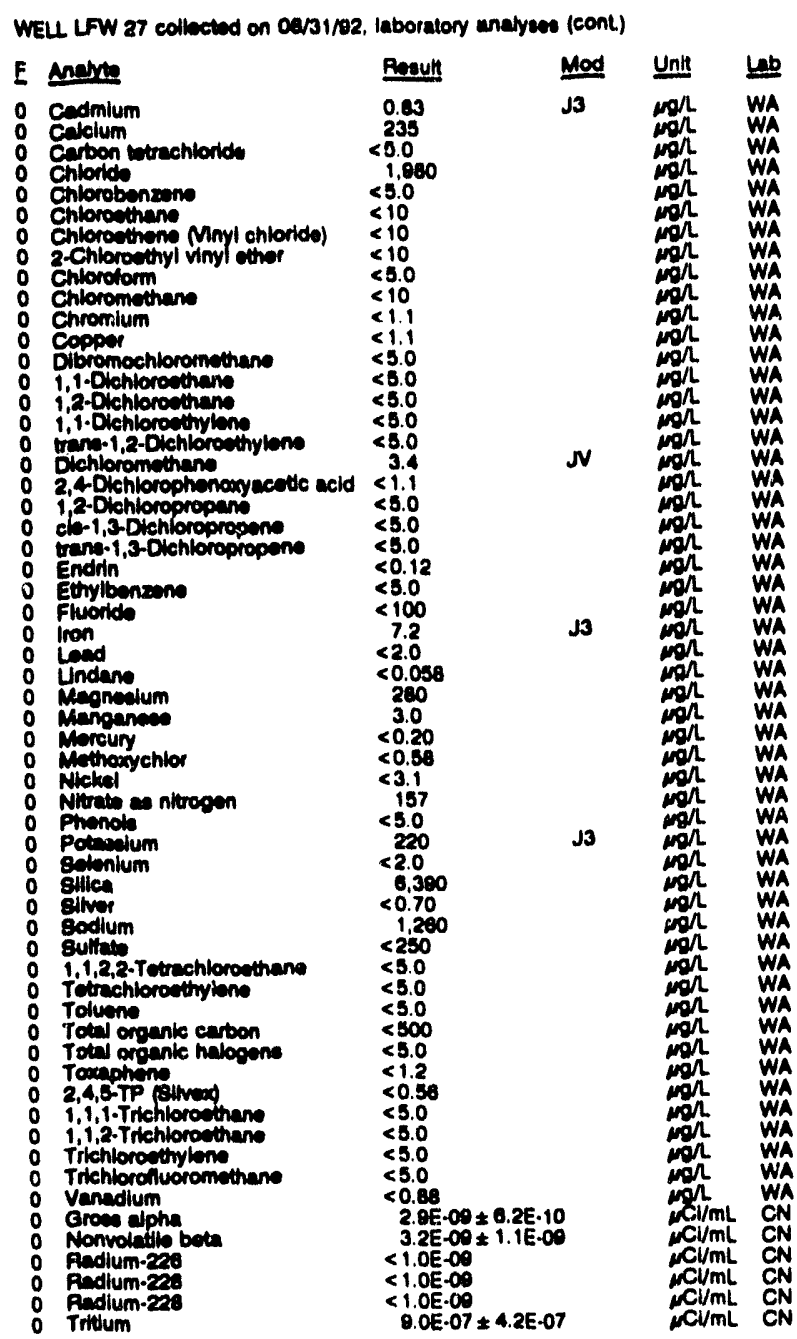

WELL LFW 28

MEASUAEMENTS CONDUCTED IN THE FIELD

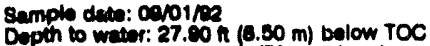

Weich tovation: 184.60 ht

Wheres

the well went dry during purging.

LABORATCTY ANALYRES

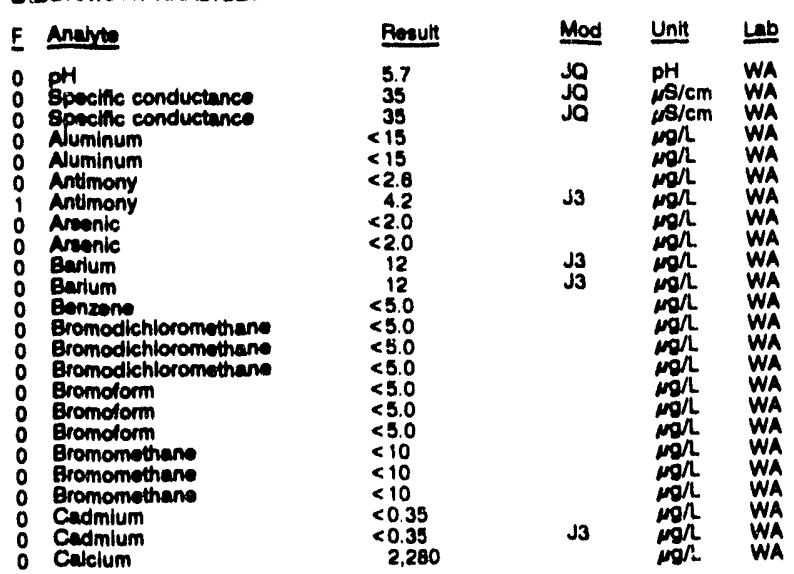

WELL LFW 28 collected on 00/01/22, laboralory analyese (cont)

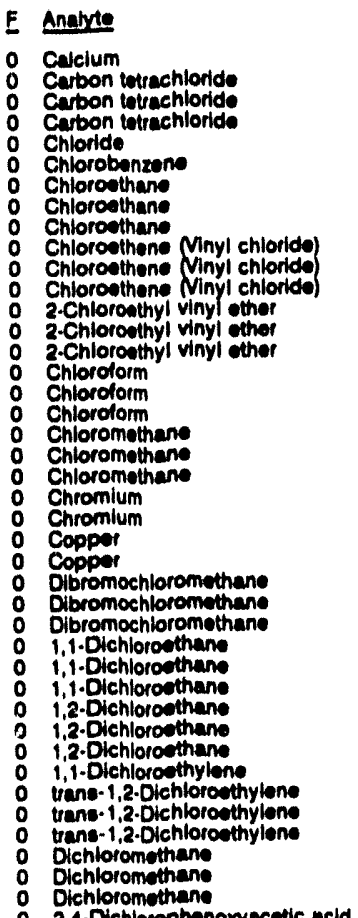



Reault Mod Unit Leb

2,350

$<6.0$

1,020

10

$<10$

$\leqslant 10$

$<10$

$<10$

10

5.0

10

$<1.1$

2.1
3.9
3.0

(5.0

$<5.0$

$<5.0$

2.4-Dichlorophonoxyecostc uclo yacotic acid $<2$

i. Dichloropropant

1.2-Dichloropropane

cib-1,3-Dichloropropane

cte-1.3-2ichloropropeno

cie-1,3-Dichloropropono

teens-1,3.Dichloropropene

tense-1,3.Dichloropropene

Uana-1,

Ethylbonzone

Ethylbonzone

Efuoride

Fluorido

iron

lion

Loed

Magneium

Megneslum

Mangannoese

Manganose

Mercuny

Methoxyentar

Nickol

Nitrate as nitrogon

Phonols

P Phonolis

: Potanasilum

solenlum

solonium

0 sillica

o siliva

: Silvor

o Sodium

o sodium

o sulfato

- 1,1,2,2. Totrachlorosthane

- i,1,2,2.Totrachloroeth

Tetrachloroothylene

Tetrachiorosthylone

Totrachloroethyione

Toluono

Total organic carbon

Total organic halogens

2,4,5.TP (Silvox)

1,1,1. Trichloroethan

1,1,1.Trichloroethane 
ANALYTICAL RESULTS

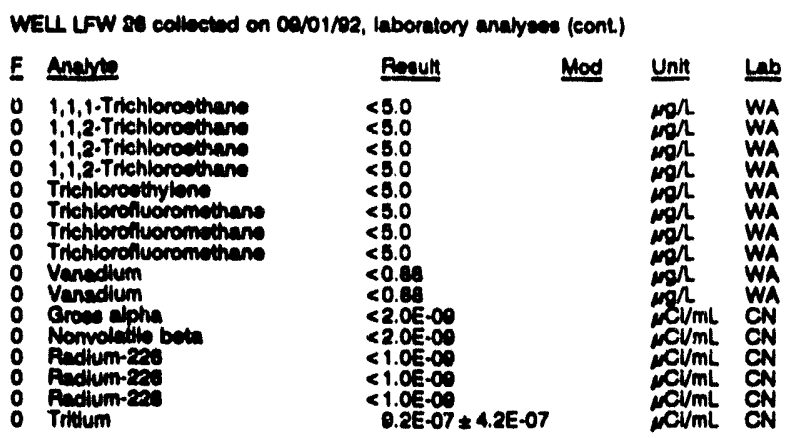

\section{WELL LFW 29}

MEAGUAREMENTS CONOUCTEO IN THE FIELL

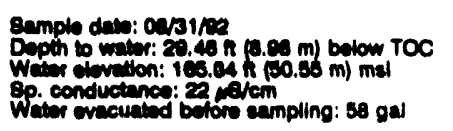

Tims: 11:45

PHallining: $0 \mathrm{man}$

Whalinity: O mon

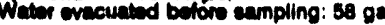

\section{LABORATOPY ANALYES}

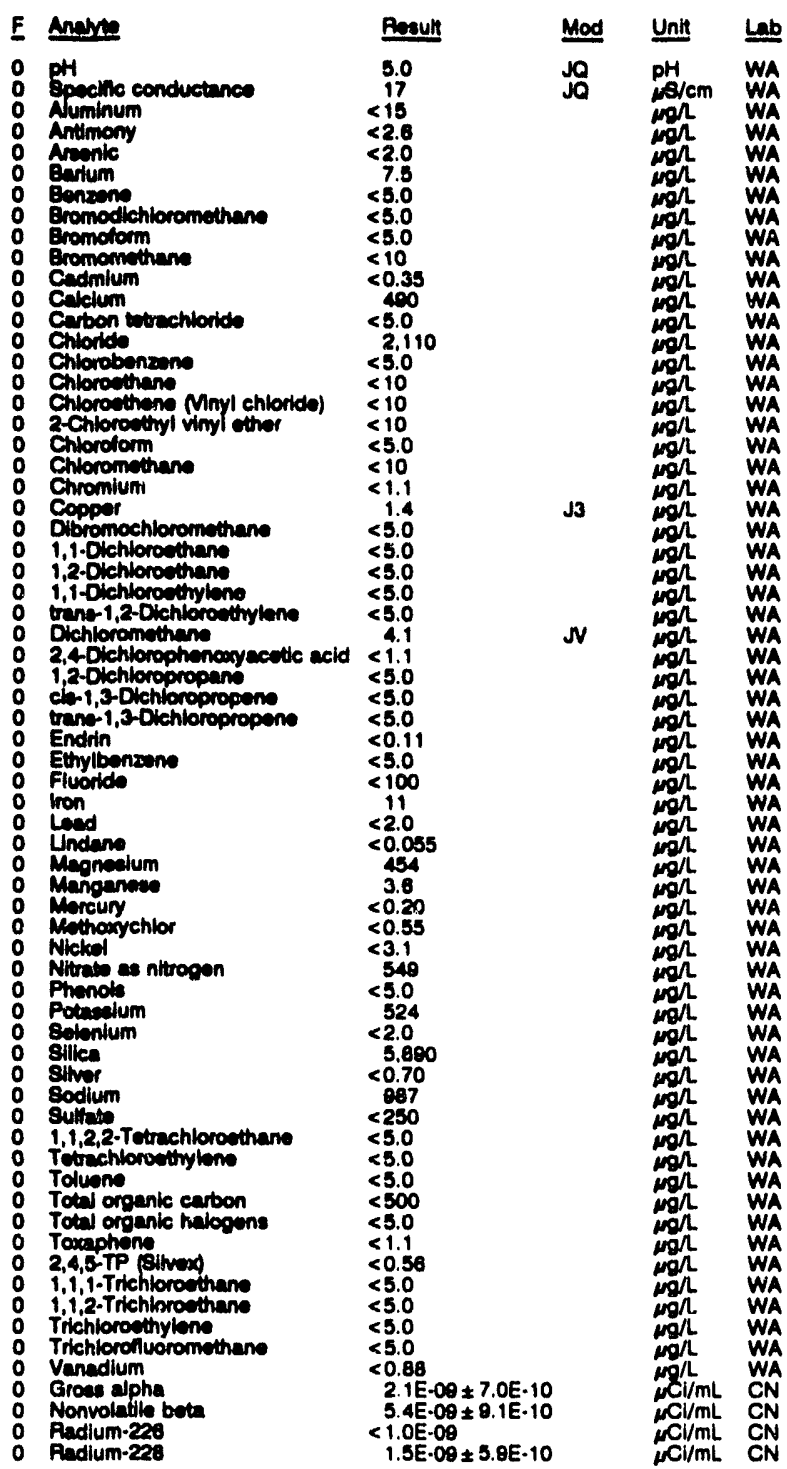

WELL LFW 29 collected on 08/31/02, laboratory analywee (cont)

\begin{tabular}{|c|c|c|c|}
\hline E Anatrte & Renult & Mod & Unit \\
\hline 0 Tritlum & $1.7 \mathrm{E}-\mathrm{O}$ & & $\mathrm{CV} / \mathrm{mL}$ \\
\hline
\end{tabular}

\section{WELL LFW 30}

MEASUREMENTS CONDUCTED IN THE FIELO

Sample date: 0arsipe

Depth to water: $4.15 \mathrm{~h}(13.48 \mathrm{~m})$ bolow TOC

Watof olevatlon: $105.85 \mathrm{~h}$ ( $(50.85 \mathrm{~m}) \mathrm{mal}$

Wicor ovecuatod bofóro empling: 23 gal

DH: 20.00

Aktalinity: 0 man

LABORATORY ANMLYSES

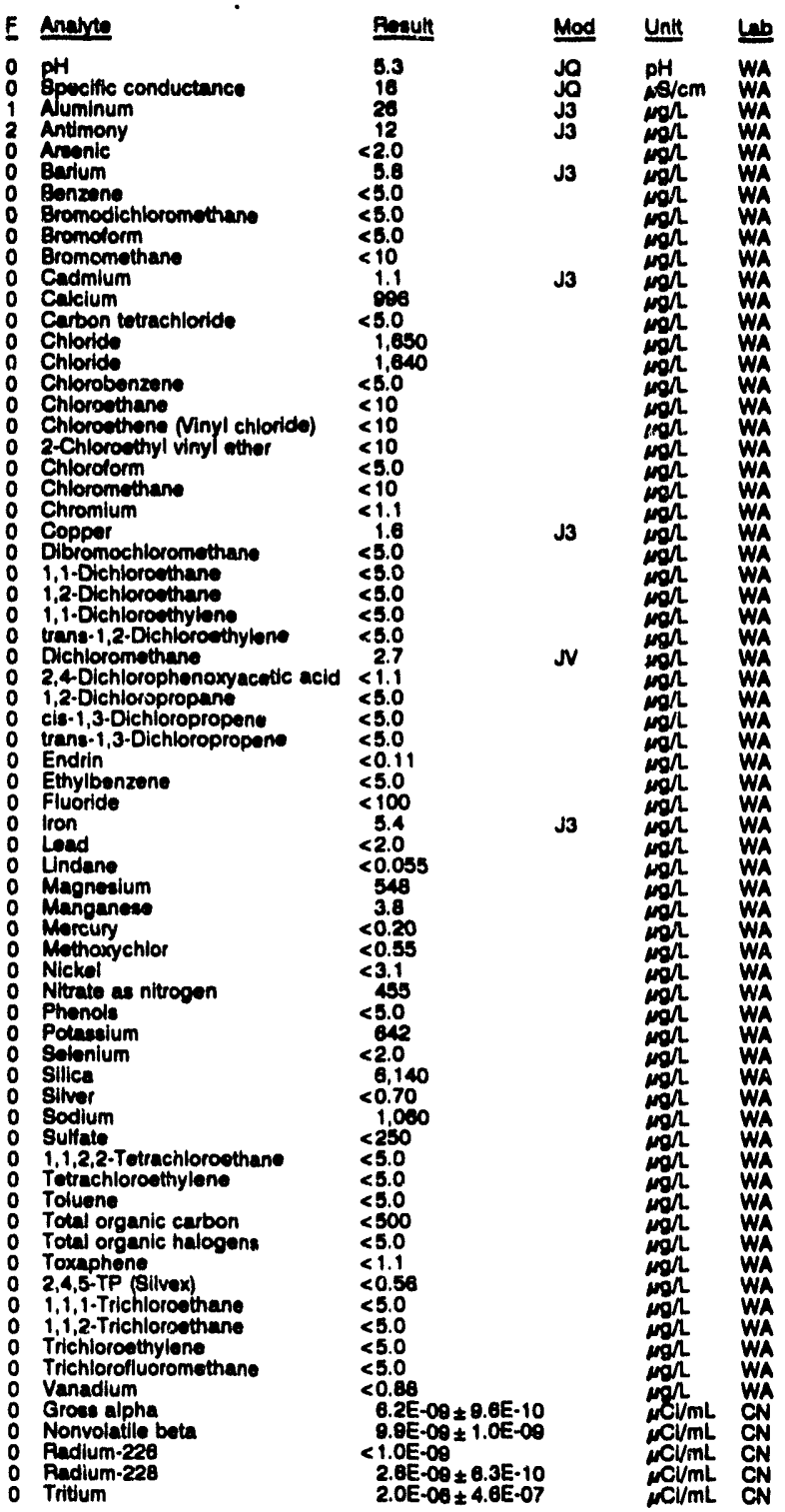




\section{WELL LFW 31}

MEABUREMENTI CONDUCTED IN THE FIELD

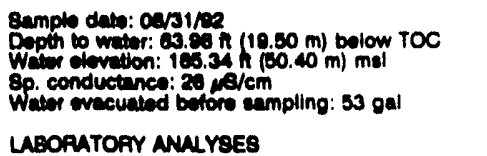

\author{
Time: 10:30 \\ Nhallinity: $0 \mathrm{mg} / \mathrm{s}$ \\ Water tomperalure: $18.9^{\circ} \mathrm{C}$
}

E Anerse

: $\mathrm{pH}$

Spectile conductance

A uminum

Amenic

Barium

Bromodichloromothane

Bromotorm

Eromomuthane

Cedmium

carton wochiondo

Chlorldo

Chiorobenzane

Chlorowthans

Chloroethene Mayl chloride

Chioriorm

Chioromethan

Chrominn

Olbpenochloromothane

1,1-Dichlorowhene

1,2-Dichlorowtram

o trent-1,2-Dichlorometrylene

o Dichloromethen

2,4-Olehtorophenoxyecetic acld

1,2-Olchioroprepens.

ci-1,3-Dichioropropene

ren-1,3-Dichloropropen

- Enylibename

0 iron

0 Lend

o Undano

Mernanee

Mereury

Mrenowyentor

Nickal

Nitrate en nitrogen

Potioneium

gerenlum

Sillea

Simer

Sodium

sulate

1,1,2,2-Tetrachloroethane

Toluechion

5.4
20
$<15$
4.7
$<2.0$
44.8
$<5.0$
$<5.0$
$<5.0$
$<10$
0.75
505
$<5.0$
2.81
$<5.0$
$<10$
$<10$
$<10$
$<5.0$
$<10$
$<1.1$
15
$<5.0$
$<5.0$
$<5.0$
$<5.0$
$<5.0$
3.9
$<1.1$
$<5.0$
$<5.0$
$<5.0$
$<0.1$
$<5.0$
$<100$
6.0
$<2.0$

Tolven organic carbon

Totel organic halogene

Toxaphons

2,4,8-TP Bum

1,1.1-Trichlorosthen

$1,1,2-$ Trichlorcethen

Trichlorofluoromethene

venedium

Grow alpha.

Nonvolatile be

Padum-zzes

Trotum

\section{WELL LFW 32}

MEASUREMENTS CONDUCTED IN THE FIELD

Sample date: 08/31/92

Depth to water: $60.35 \mathrm{An}(18.39 \mathrm{mi})$ below TOC

Wator elevation: $163.35 \mathrm{~h}$

$40.79 \mathrm{~m}) \mathrm{mal}$

Watet ovacuated before eampling: $\mathbf{5 0} \mathrm{gal}$

LABORATORY ANALYSES

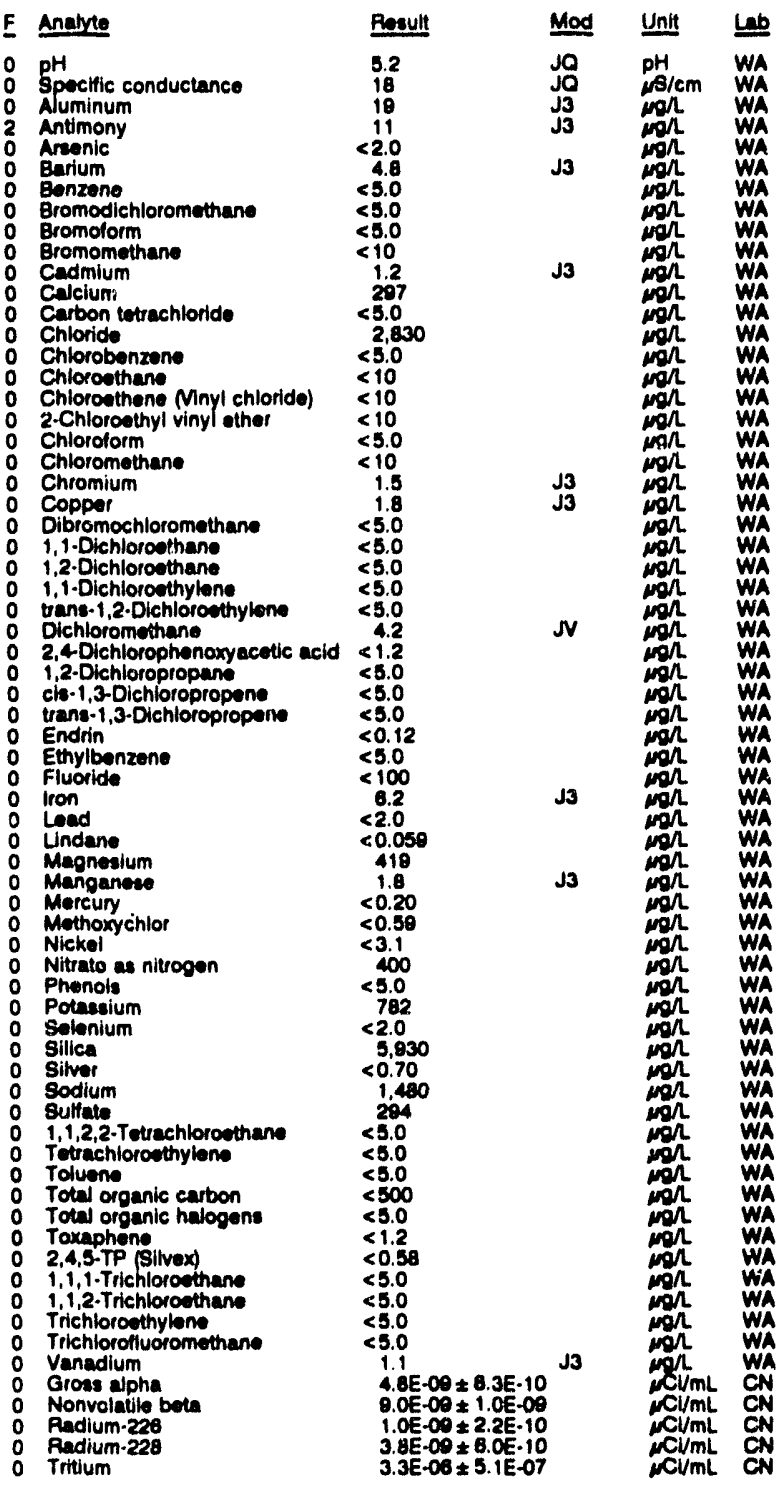

\section{WELL LFW 33}

MEASUAEMENTS CONDUCTED IN THE FIELD

Sample date: 06/31/92 Water olevation: $162.00 \mathrm{~h}(40.36 \mathrm{~m}) \mathrm{mal}$

Sp. conductence: 20 is/cm

PH: 4.7
Alkalinity: $0 \mathrm{mgr}$

Alkalinity: $0 \mathrm{mgh}$

Weter evecuated betore sampling: $46 \mathrm{gal}$

LABORATOAY ANALYSES

\begin{tabular}{|c|c|c|c|}
\hline F Analyte & Rosult & Mod & Unit \\
\hline $\begin{array}{ll}0 & \text { pH } \\
0 & \text { Specific conductance } \\
0 & \text { Aluminum }\end{array}$ & $\begin{array}{r}5.2 \\
16 \\
<15\end{array}$ & $\begin{array}{l}\mathrm{JQ} \\
\mathrm{JO}\end{array}$ & $\begin{array}{l}\mathrm{pH} \\
\mathrm{NS/ \textrm {cm }} \\
\mathrm{NO} \Omega\end{array}$ \\
\hline
\end{tabular}


ANALYTICAL RESULTS

WELL LFW 33 collocted on 08/31/82, laboratory analyees (cont)

\begin{tabular}{|c|c|c|c|}
\hline Anderte & Result: & Mod & Init \\
\hline 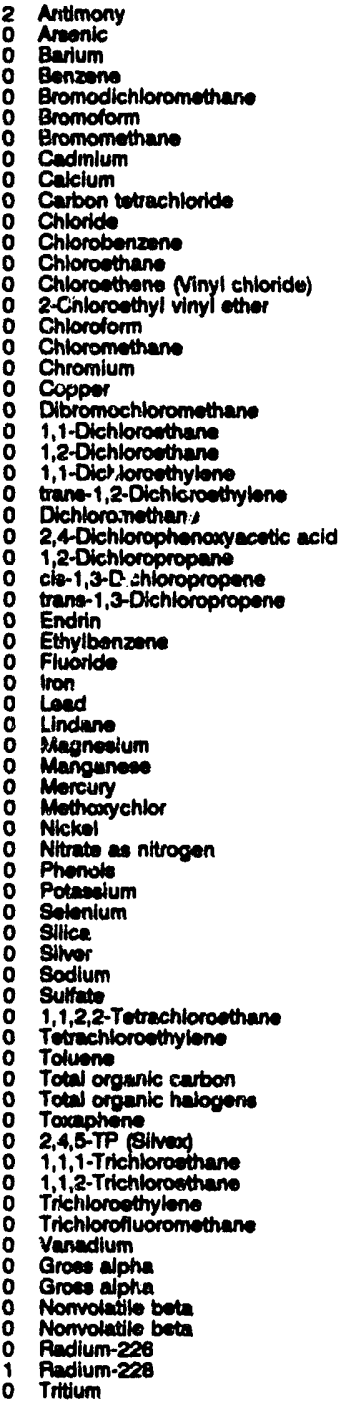 & $\begin{array}{l}8.4 \\
<2.0 \\
<4.0 \\
<5.0 \\
<5.0 \\
<5.0 \\
<10 \\
0.38 \\
284 \\
<5.0 \\
2.420 \\
<5.0 \\
<10 \\
<10 \\
<10 \\
<5.0 \\
<10 \\
<1.1 \\
1.2 \\
<5.0 \\
<5.0 \\
<5.0 \\
<5.0 \\
<5.0 \\
14 \\
<1.1 \\
<5.0 \\
<5.0 \\
<5.0 \\
<0.11 \\
<5.0 \\
<100 \\
7.6 \\
2.0 \\
<0.056 \\
340 \\
1.2 \\
<0.20 \\
<0.58 \\
<3.1 \\
311 \\
<5.0 \\
643 \\
<2.0 \\
60.210 \\
<0.70 \\
1.480 \\
55.1 \\
<5.0 \\
<5.0 \\
<5.0 \\
<500 \\
<5.0 \\
<1.1 \\
<0.58 \\
<5.0 \\
<5.0 \\
<5.0 \\
<5.0 \\
0.88 \\
2.4 E-09 \pm 7.3 E-10 \\
4.4 E-09 \pm 8.9 E-10 \\
3.8 E-09 \pm 9.2 E-10 \\
5.6 E-09 \pm 1.1 E-09 \\
1.8 E-09 \pm 2.8 E-10 \\
4.6 E-09 \pm 6.7 E-10 \\
3.2 E-08 \pm 5.0 E-07\end{array}$ & $\begin{array}{l}\mathbf{J 3} \\
\mathbf{J 3}\end{array}$ & 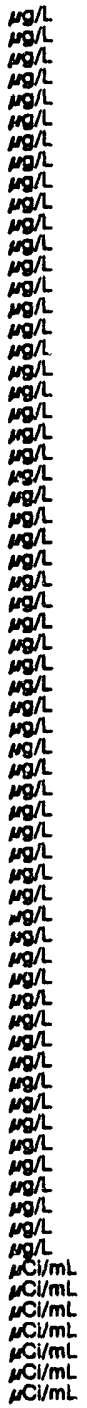 \\
\hline
\end{tabular}

WELL LFW 34

MEASUREMENTS CONDUCTED IN THE FIELD

Sample dato: 0Q/31/82 Depth to weter: $40.38 \mathrm{nt}(12.30 \mathrm{~m})$ bolow TOC Water covation: 160.84 h ( 40. Sp. conductance: 23 ps/cm

Wever evecuatiod betore sam

\begin{tabular}{|c|c|c|c|}
\hline Anclyts & Result & Mod & Unit \\
\hline 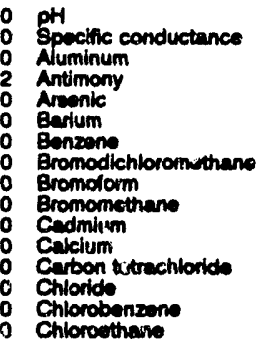 & $\begin{array}{r}5.3 \\
16 \\
21 \\
5.2 \\
<2.0 \\
<4.0 \\
<5.0 \\
<5.0 \\
<5.0 \\
<10 \\
1.1 \\
360 \\
<5.0 \\
2.780 \\
<5.0 \\
<10\end{array}$ & $\begin{array}{l}1 Q \\
j a \\
J 3 \\
J 3\end{array}$ & 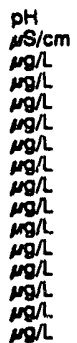 \\
\hline
\end{tabular}

Time: $8: 35$

Akalinity: $0 \mathrm{mon}$

Water temperature: $18.8^{\circ} \mathrm{C}$
WELL LFW 34 collected on 08/31/92, laboratory analyees (cont.)

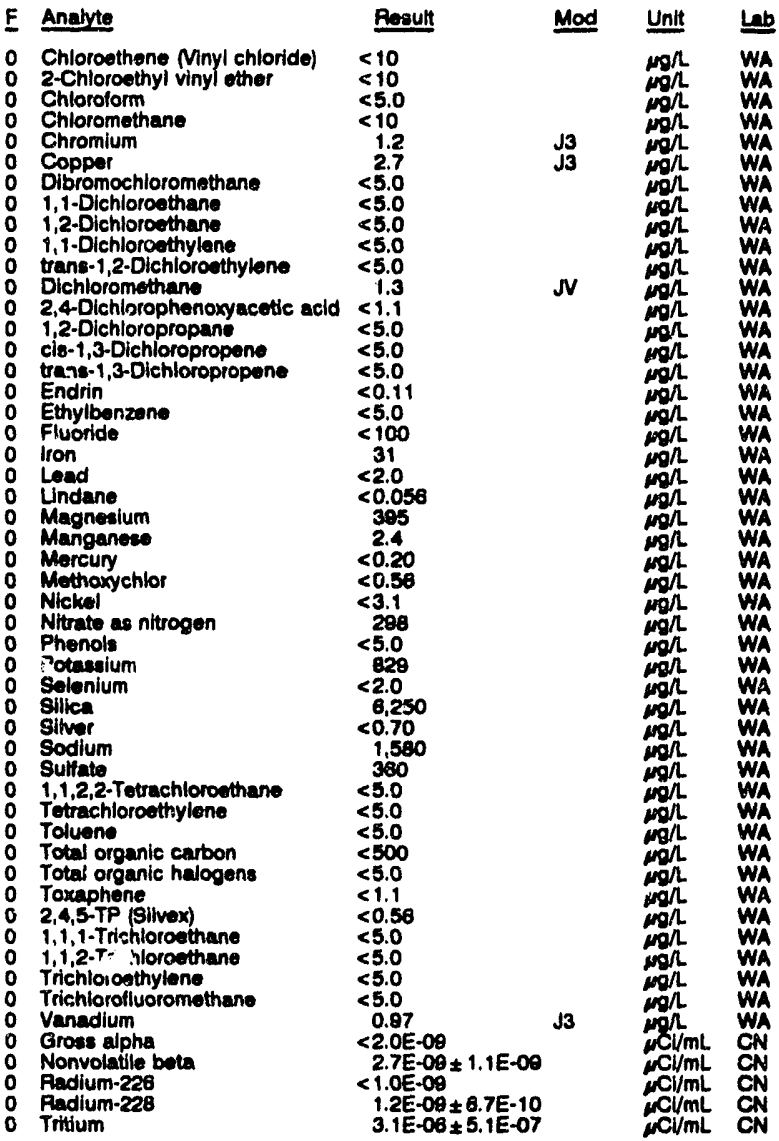

\section{WELL LFW 35}

MEASUREMENTS CONDUCTED IN THE FIELD

Samplo dats: 09/01/92

Cupth to water: $24.04 \mathrm{ft}(33 \mathrm{mI}$ below TOC

Water olevation: $158.68 \mathrm{~h}(48.66 \mathrm{~m}) \mathrm{mol}$

Sp. conductance: $33 \mu \mathrm{s} / \mathrm{cm}$.

LABORATOAY ANALYSES

\begin{tabular}{|c|c|}
\hline Anatyte & Progult \\
\hline 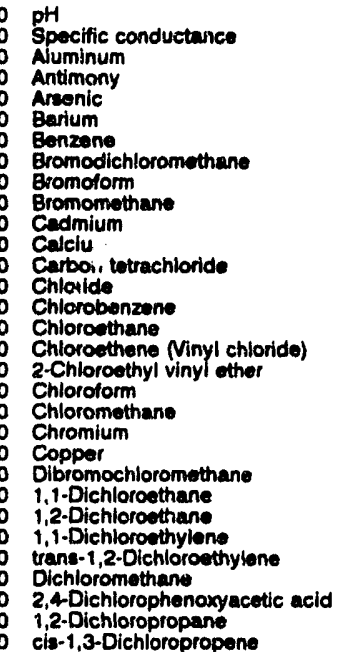 & $\begin{array}{r}5.2 \\
28 \\
<15 \\
<2.8 \\
<2.0 \\
6.3 \\
<5.0 \\
<5.0 \\
<5.0 \\
<10 \\
<0.35 \\
380 \\
<5.0 \\
2.720 \\
<5.0 \\
<10 \\
<10 \\
<10 \\
<5.0 \\
<10 \\
<1.1 \\
<1.1 \\
<5.0 \\
<5.0 \\
<5.0 \\
<5.0 \\
<5.0 \\
<5.0 \\
<1.1 \\
<5.0 \\
<5.0\end{array}$ \\
\hline
\end{tabular}

\section{Time: 8:05}

Alkalinity: $1 \mathrm{~mol}$

Water tempernture: $20.4 \cdot \mathrm{C}$

cis-1,3-Dichloropropent 


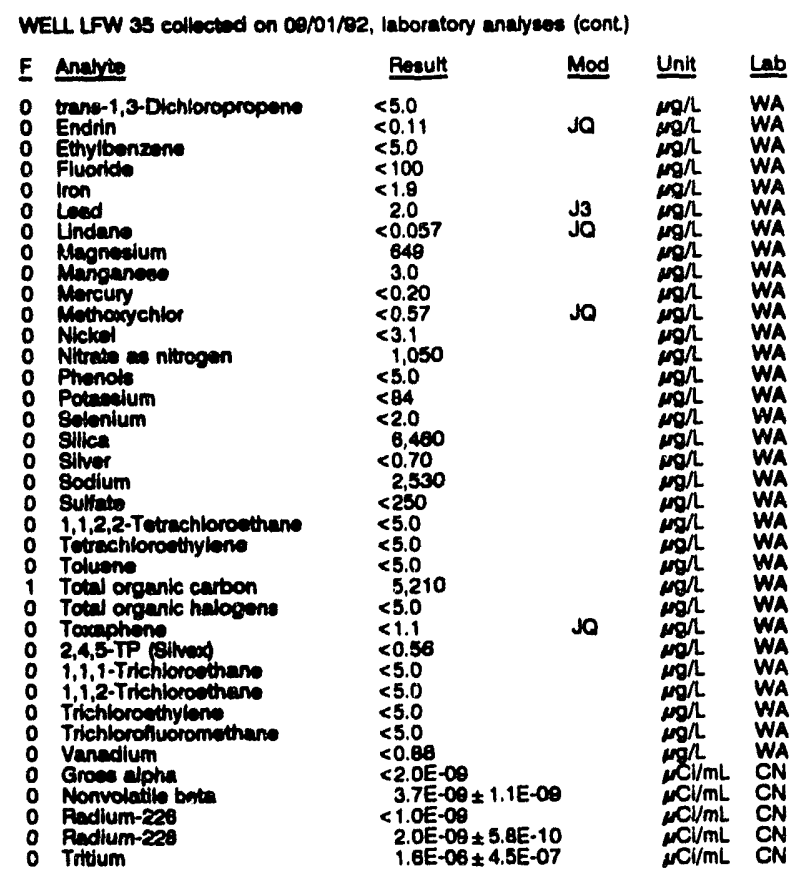

\section{WELL LFW 36}

MEASUAEMENTS CONOUCTED IN THE FIELD

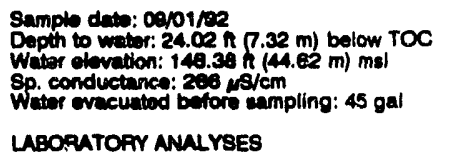

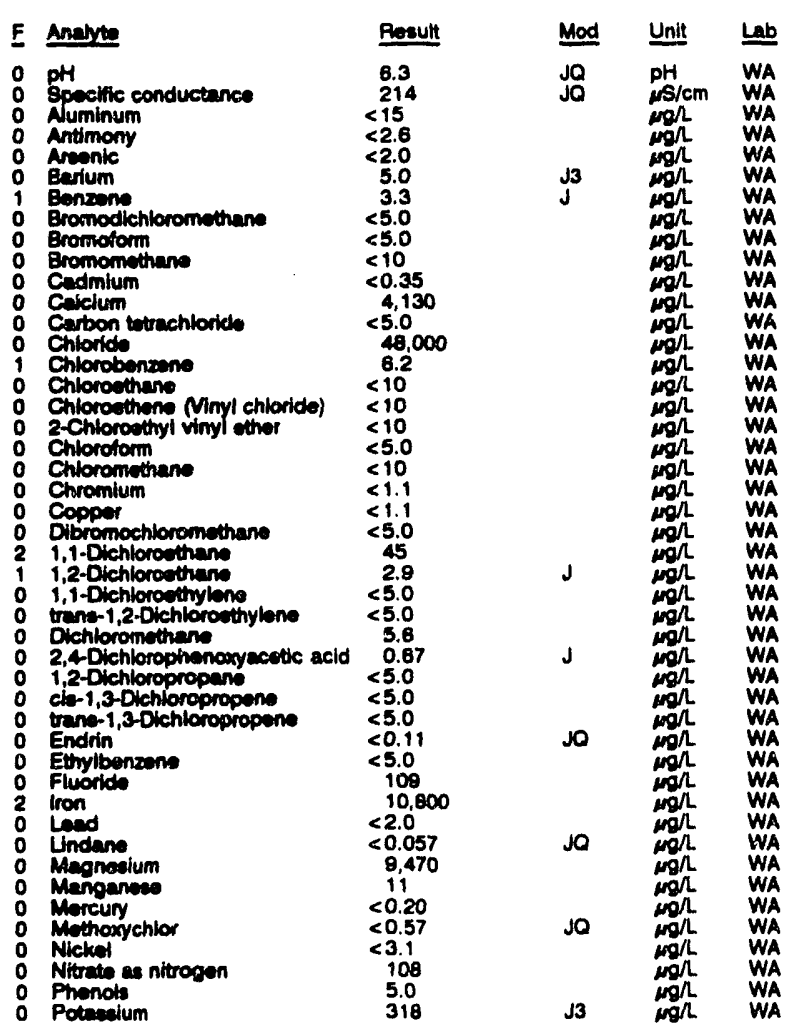

WELL LFW 38 collectod on CE, D1/82, laboratory anayeses (cont)

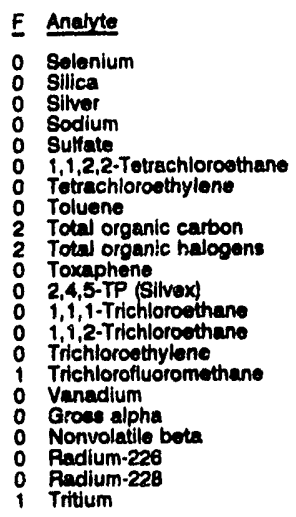

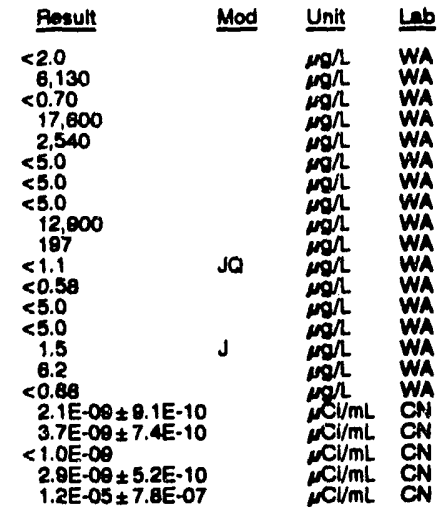

\section{WELL LFW 37}

MEASUREMENTS CONDUCTED IN THE FIELD

\begin{tabular}{|c|}
\hline $\begin{array}{l}\text { Sample date: } 09 / 01 / 92 \\
\text { Dopth to water: } 26.55 \mathrm{ft}(8.09 \mathrm{~m}) \text { bolow TOC } \\
\text { Water elovation: } 143.35 \mathrm{ht}(43.69 \mathrm{~m}) \mathrm{mal} \\
\text { Sp. conductance: } 153 \mu \mathrm{s} / \mathrm{cm} \\
\text { Water evacuated betore sampling: } 36 \mathrm{gal}\end{array}$ \\
\hline ABOFAIOHY ANALYSES \\
\hline
\end{tabular}

$$
\begin{aligned}
& \text { TIme: } 13: 20 \\
& \text { pH: } 5.1 \\
& \text { Alkalinity: } 8 \mathrm{mg} / \\
& \text { Water temporature: } 20.8 \circ \mathrm{C}
\end{aligned}
$$

LABORATOAY ANALYSES

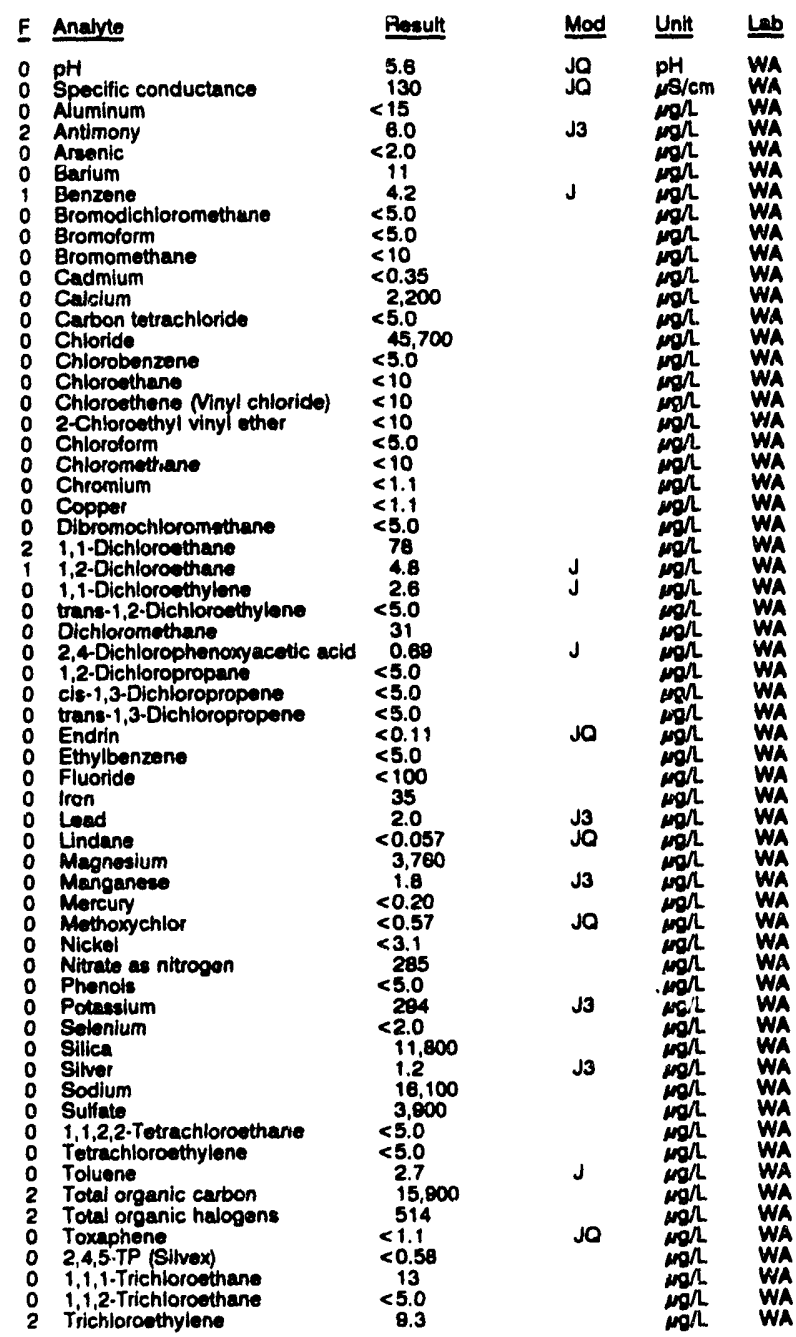


ANALYTICAL RESULTS

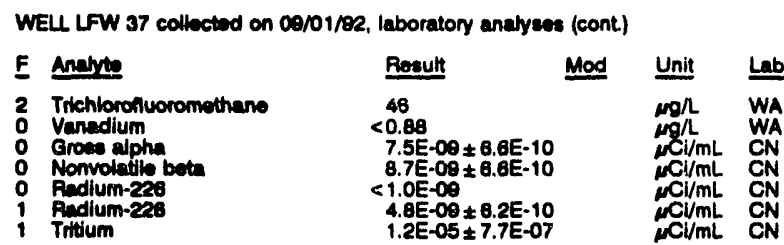

\section{WELL LFW 38}

MEASUREMENTS CONDUCTED IN THE FIELD

Sample date: 00/01/82

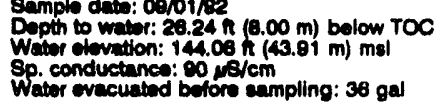

LABOPATOPY ANALYSES

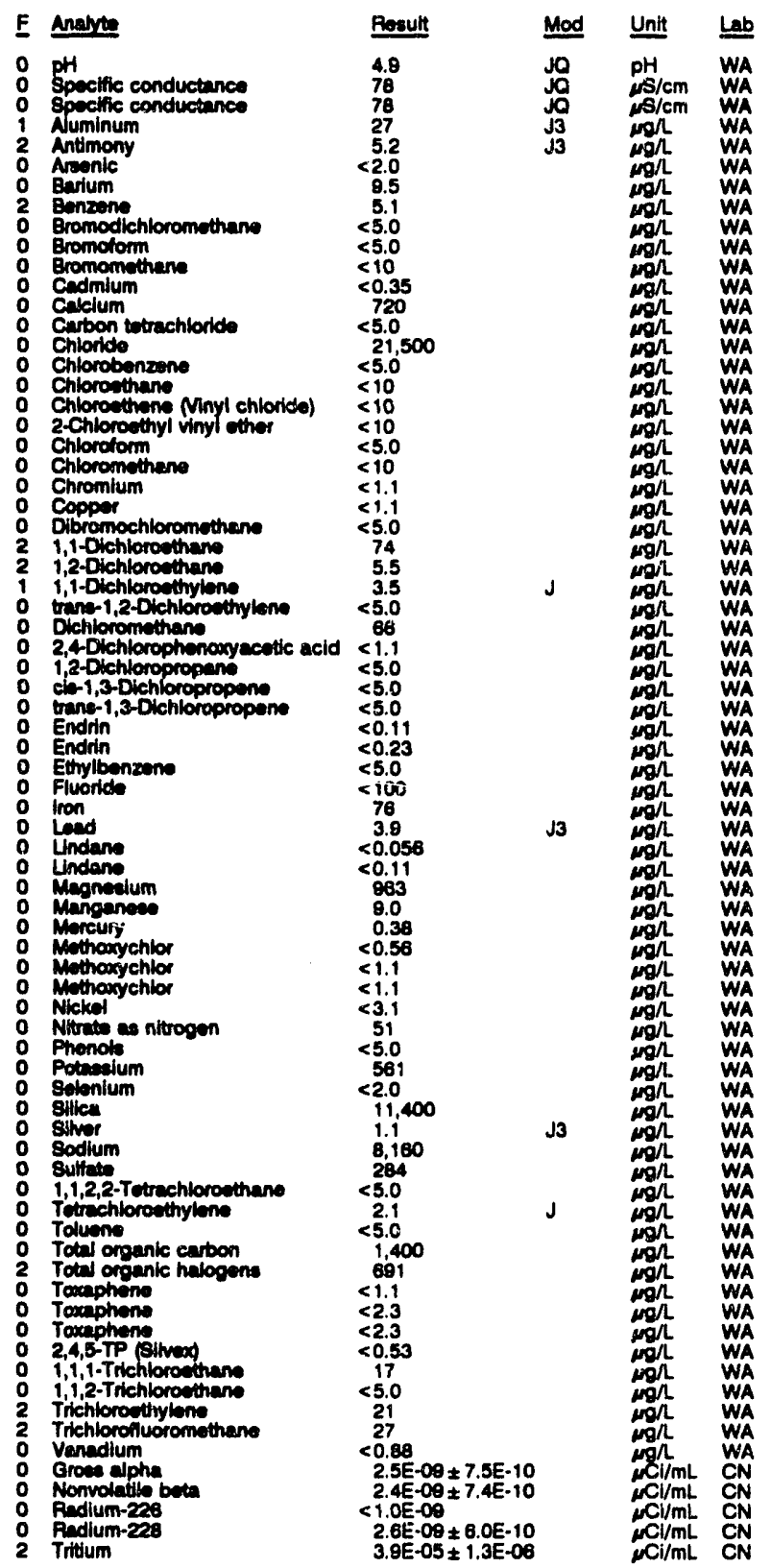

\section{WELL LFW 39}

MEASUREMENTS CONDUCTED IN THE FIELD

\begin{tabular}{|c|c|}
\hline $\begin{array}{l}\text { Sample date: } 09 / 01 / 82 \\
\text { Depth to water: } 27.22 \mathrm{ft}(8.30 \mathrm{~m}) \text { below TOC } \\
\text { Water elevation: } 144.18 \mathrm{ft}(43.85 \mathrm{~m}) \mathrm{msl} \\
\text { Sp. conductance: } 32 \mu \mathrm{\mu s} / \mathrm{cm} \\
\text { Water evacuated belore sampling: } 34 \mathrm{gal}\end{array}$ & $\begin{array}{l}\text { Time: } 12: 00 \\
\text { pH: } 4.5 \\
\text { Alkalinity: } 0 \text { mgn } \\
\text { Water temperature: } 21.3^{\circ} \mathrm{C}\end{array}$ \\
\hline
\end{tabular}
Water evecuated before sampling: $34 \mathrm{gal}$ LABORATORY ANALYSES

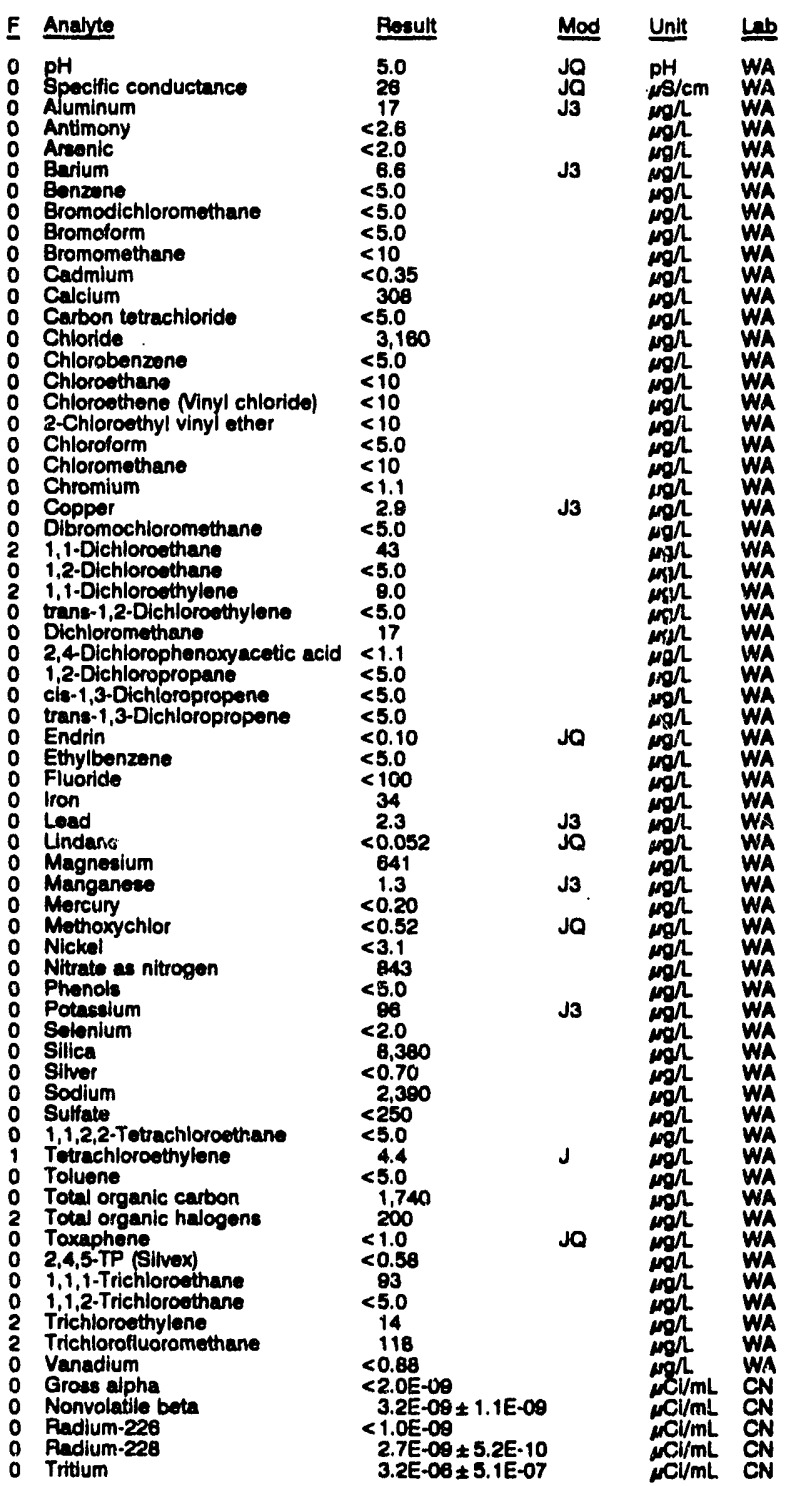

\section{WELL LFW 40}

MEASUREMENTS CONDUCTED IN THE FIELD

\begin{tabular}{|c|c|c|c|c|c|}
\hline \multicolumn{3}{|c|}{$\begin{array}{l}\text { Sample date: } 09 / 01 / 92 \\
\text { Depth to water: } 27.06 \mathrm{ht}(8.25 \mathrm{~m}) \text { below TOC } \\
\text { Wator elevation: } 143.84 \mathrm{ft}(43.87 \mathrm{~m}) \mathrm{msl} \\
\text { Sp. conductence: } 94 \mathrm{ps} / \mathrm{cm} \\
\text { Wator evacuated before sampling: } 33 \mathrm{gal}\end{array}$} & \multicolumn{3}{|c|}{$\begin{array}{l}\text { Time: } 11: 05 \\
\text { pH: } 5.7 \\
\text { Alkalinity: } 20 \mathrm{mghl} \\
\text { Water temperaure: } 20.2 \cdot \mathrm{C}\end{array}$} \\
\hline \multicolumn{6}{|c|}{ LABORATORY ANALYSES } \\
\hline $\boldsymbol{F}$ & Analyte & Prosulf & Mod & Unit & Lي \\
\hline & $\begin{array}{l}\text { pH } \\
\text { Specific conductance } \\
\text { Aluminum }\end{array}$ & $\begin{array}{r}6.0 \\
46 \\
<15\end{array}$ & Jo & $\underset{\mathrm{mS} / \mathrm{cm}}{\mathrm{pH}}$ & $\begin{array}{l}\text { WA } \\
\text { WA } \\
\text { WA }\end{array}$ \\
\hline
\end{tabular}


WELL LFW 40 collected on 00/01/92, laboratory analyses (cont.)

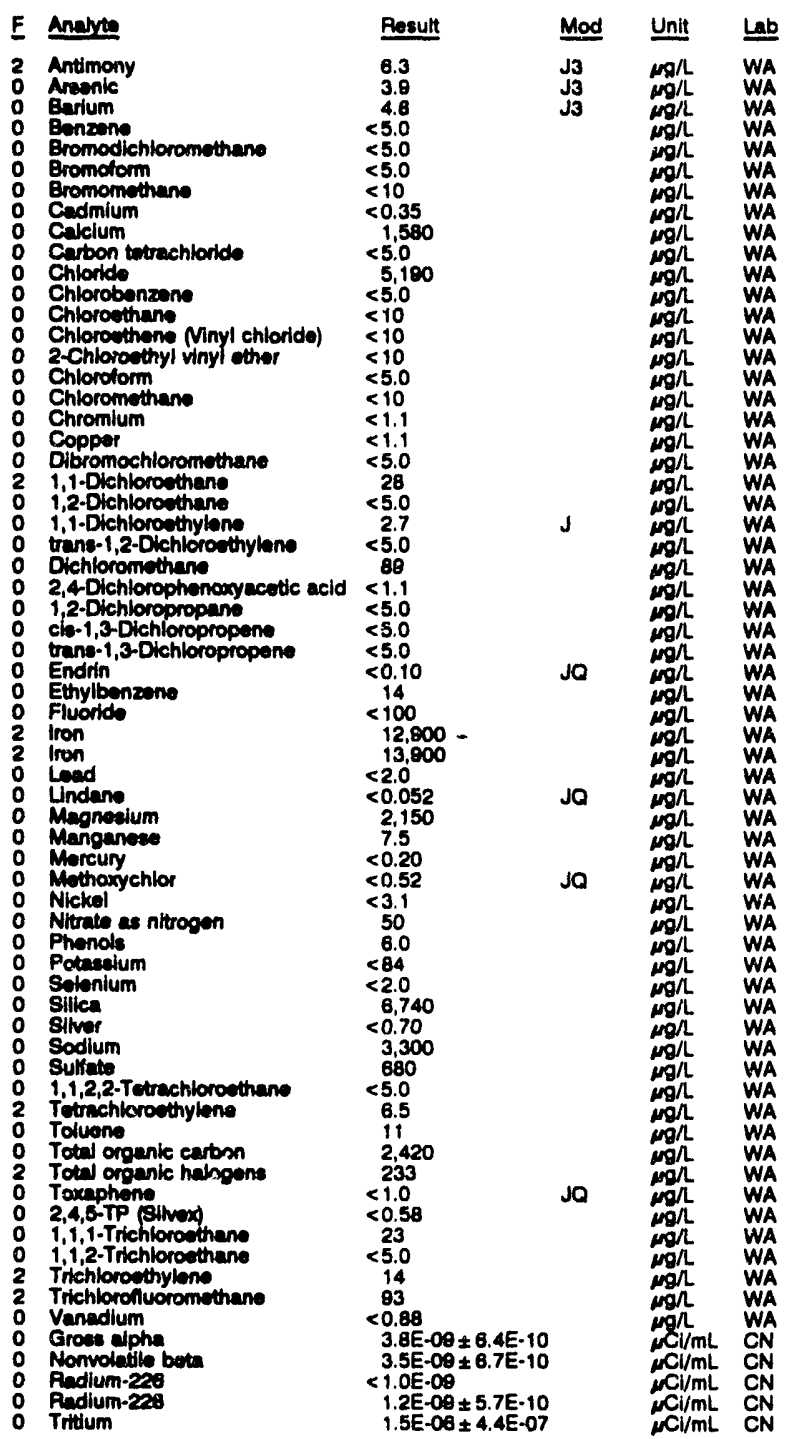

WELL LFW 41

MEASUREMENTS CONDUCTED IN THE FIELD

Sample dato: 08/01/0e

Dopth to wator: 23.00 n $(7.62$ m) below TOC

Wator elevation: $145.50 \mathrm{~h}$ (4

Sp. conductance: 16 \% $1 / \mathrm{cm}$.

LABORATOFY ANALYSES

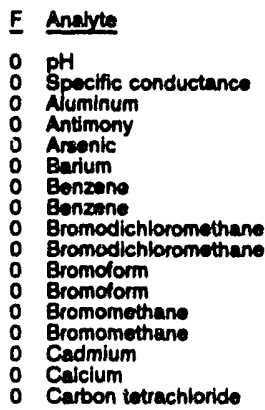

\begin{tabular}{l}
\multicolumn{1}{r}{ Result } \\
\hline 5.6 \\
12 \\
12 \\
$<2.6$ \\
$<2.6$ \\
$<2.0$ \\
$<4.0$ \\
$<5.0$ \\
$<5.0$ \\
$<5.0$ \\
$<5.0$ \\
$<5.0$ \\
$<5.0$ \\
$<10$ \\
$<10$ \\
$<0.35$ \\
240 \\
$<5.0$
\end{tabular}

WELL LFW 4 i coliected on 09/01/92, laboratory analyees (cont.)

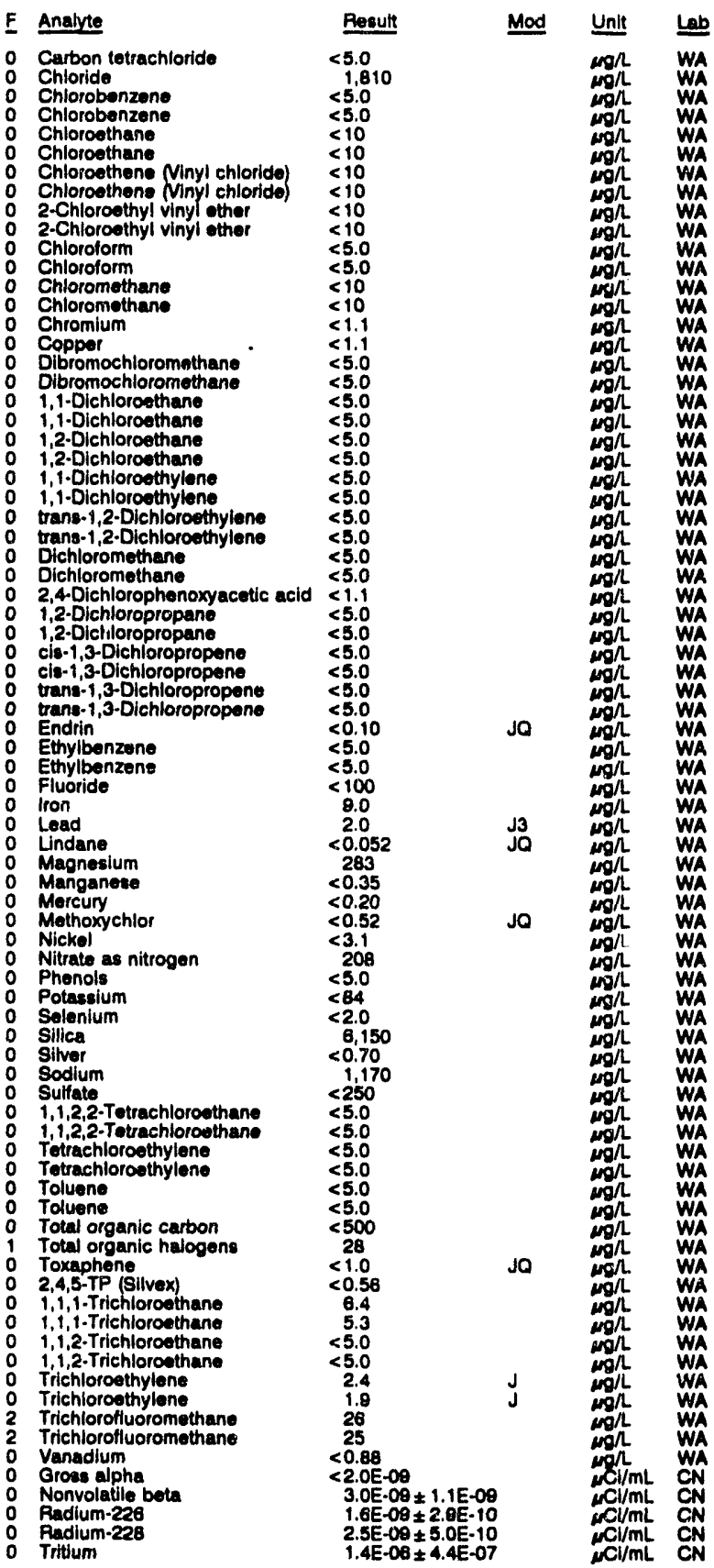

\section{WELL LFW 42}

MEASUREMENTS CONDUCTED IN THE FIELD

Sample date: 09/01/92 Time: 0:50

Dopth to water: $22.28 \mathrm{Ht}(6.79 \mathrm{~m})$ bolow TOC PH: 4.8

Sp. conductance: $18 \mu \mathrm{s} / \mathrm{cm}$ Water temperature: $19.7{ }^{\circ} \mathrm{C}$

Water evacuated bolore sampling: $46 \mathrm{ga}$

LABORATORY ANALYSES

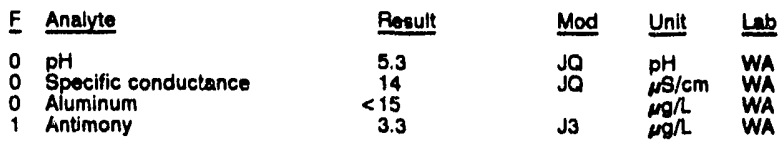


ANALYTICAL RESULTS

WELL LFW 42 collected on 00/01/92, laboratory analyese (cont)

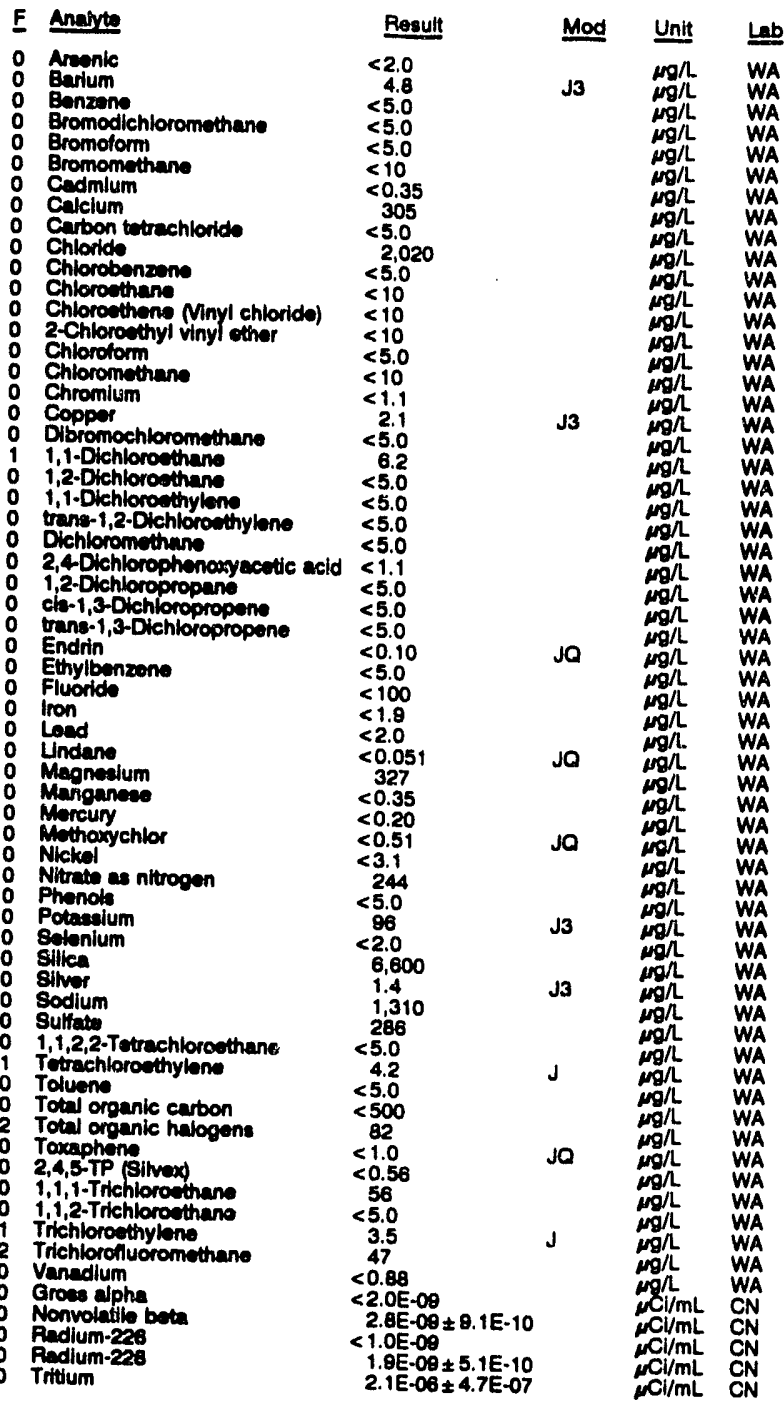

\section{WELL LFW 43B}

MEASUREMENTS CONDUCTED IN THE FIELD

Sample date: 00/02502

Wopth to water: $37.00 \mathrm{n}(11.28 \mathrm{~m})$ below TOC

Sp. conduction: $188.00 \mathrm{~h}$ (50.

Water evacunted before sampling: $200 \mathrm{gal}$

LABORATORY ANALYSES

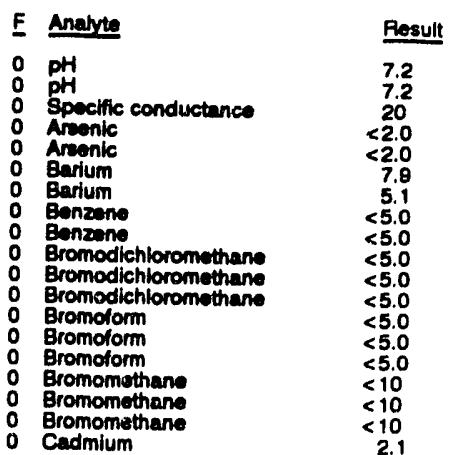

Time: 1425

PH: 5.6

Water temperature: $19.5^{\circ} \mathrm{C}$

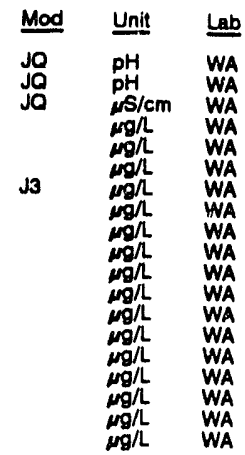

WELL LFW 438 colloctod on 09/08/92, laboraton analyses (cont)

E Analyte

0 Cadmlum

: Calclum

o Carbon tetrachloride

Carbon tetrachloride

- Carbon tetrachloride

0 Chlorido

: Chlorobenzene

o Chloroethane

o Chloroethane

O Chloroethane

: Chloroethene Ninyl chloride)

Chloroothone Ninyl chloride

2-Chiornene Minyl chloride

2-Chloroethyl vinyl other

2.Chloroethyl vinyl other

Chloroform

Chloroform

Chloromethane

Chloromethane

Chromium

Chromium

Dibromochioromethane

Dibromochloromethane

Dibromochloromethane

1,1.Dichloroethane

o i.1.Dichloroethane

o 1,2.Dichloroestrane

o 1,2-Dichloroethane

: 1, 2-Dichloroethane

o i,i-Dichloroethylene

trans-1,2-Dichlorcethylene

trans-1,2-Dichloroethylene

: trans-1,2-Dichloroethy

- Dichloromethane

o Dichloromethane

2,4-Dichlorophenoxyacetic acid

1,2-Dichloropropane

1,2-Dlchloropropane

o cis-1,3-Dichloropane

o cis-1,3-Dichloropropene

cis-1,3-Dichloropropene

o trans-1,3-Dichloropropene

trans-1,3-Dichloropropene

O Endrin

0 Endrin

Ethylbenzene

O Ethylbenzene

Fluoride

iron

Lead

Load

Lindane

O Magnesium

Magnesium

Manganose

Manganese

Morsury

Mercury

Methoxychlor

Nitrate as nitrogen

Phenols
Phenols

Polassium

Potassium

Selenium

o Solenium

S Silica

o Silvor

siver

sodium

Sulfate

Sulfato

$1,1,2,2$-Tetrachloroethane

1,1,2,2-Tetrachloroothane

$1,1,2,2$-Tetrachloroethan

Tetrachloroethylone

Tetrachloroethylene

Toluene

Total dissolved solids

Total organic carbon

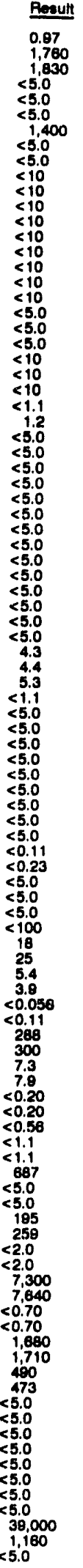

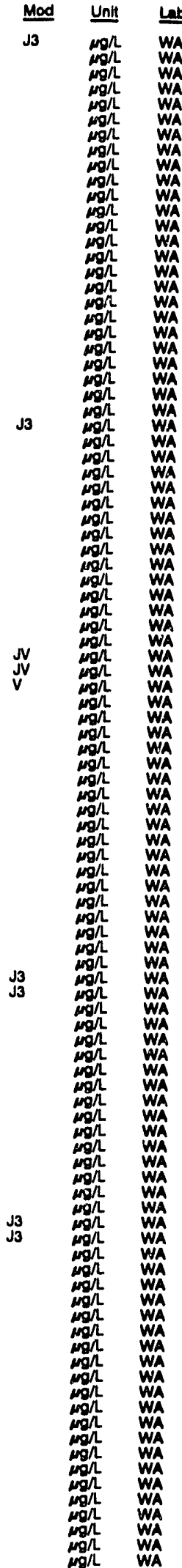


ANALYTICAL RESULTS

WELL LFW 438 collected on 00/08/92, laboratory analyese (cont)

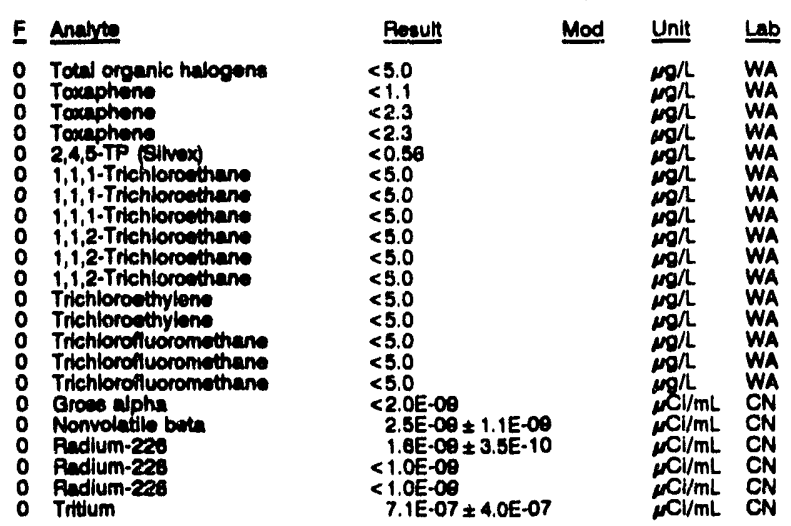

\section{WELL LFW 43C}

\section{MEASUREMENTS CONDUCTED IN THE FIELD}

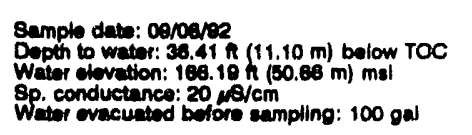

Time: 14:30

PH: 5.1 Alkalinity: 1 mon

Water tomperature: $20.2^{\circ} \mathrm{C}$

LABOAATOFY ANALYSES

\begin{tabular}{|c|c|c|c|c|c|}
\hline F & Anarde & Rosult & Mod & Unit & $\underline{L}$ \\
\hline & 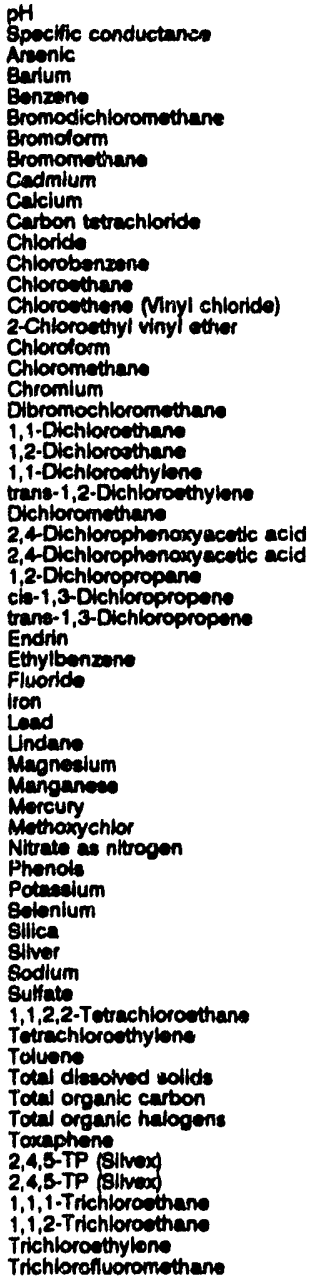 & $\begin{aligned} 6.4 \\
14 \\
<2.0 \\
6.2 \\
<5.0 \\
<5.0 \\
<5.0 \\
<10 \\
0.60 \\
987 \\
<5.0 \\
1.310 \\
<5.0 \\
<10 \\
<10 \\
<10 \\
<5.0 \\
<10 \\
<1.1 \\
<5.0 \\
<5.0 \\
<5.0 \\
<5.0 \\
<5.0 \\
3.2 \\
<1.1 \\
<2.2 \\
<5.0 \\
<5.0 \\
<5.0 \\
<0.11 \\
<5.0 \\
<100 \\
5.8 \\
<2.0 \\
<0.056 \\
362 \\
4.5 \\
<0.20 \\
<0.56 \\
278 \\
<5.0 \\
248 \\
<2.0 \\
55890 \\
<0.70 \\
670 \\
286 \\
<5.0 \\
<5.0 \\
<5.0 \\
36.000 \\
638 \\
<5.0 \\
<1.1 \\
<0.55 \\
<1.1 \\
<5.0 \\
<5.0 \\
<5.0 \\
<5.0 \\
<5\end{aligned}$ & $\begin{array}{l}\text { JO } \\
\text { JO } \\
\text { J3 }\end{array}$ & 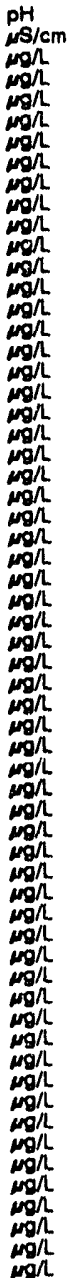 & $\begin{array}{l}\text { WA } \\
\text { WA } \\
\text { WA } \\
\text { WA } \\
\text { WA } \\
\text { WA } \\
\text { WA } \\
\text { WA } \\
\text { WA } \\
\text { WA } \\
\text { WA } \\
\text { WA } \\
\text { WA } \\
\text { WA } \\
\text { WA } \\
\text { WA } \\
\text { WA } \\
\text { WA } \\
\text { WA } \\
\text { WA } \\
\text { WA } \\
\text { WA } \\
\text { WA } \\
\text { WA } \\
\text { WA } \\
\text { WA } \\
\text { WA } \\
\text { WA } \\
\text { WA } \\
\text { WA } \\
\text { WA } \\
\text { WA } \\
\text { WA } \\
\text { WA } \\
\text { WA } \\
\text { WA } \\
\text { WA } \\
\text { WA } \\
\text { WA } \\
\text { WA } \\
\text { WA } \\
\text { WA } \\
\text { WA } \\
\text { WA } \\
\text { WA } \\
\text { WA } \\
\text { WA } \\
\text { WA } \\
\text { WA } \\
\text { WA } \\
\text { WA } \\
\text { WA } \\
\text { WA } \\
\text { WA } \\
\text { WA } \\
\text { WA } \\
\text { WA } \\
\text { WA } \\
\text { WA } \\
\text { WA } \\
\text { WA }\end{array}$ \\
\hline
\end{tabular}

WELL LFW 43 C collected on 09/08/82, laboratory analyses (cont.)

\begin{tabular}{|c|c|c|c|}
\hline E Analyte & Rosult & Mod & Unit \\
\hline $\begin{array}{ll}0 & \text { Gross alpha } \\
0 & \text { Nonvolatile bota } \\
0 & \text { Radium-228 } \\
0 & \text { Radlum-228 } \\
0 & \text { Tritlum }\end{array}$ & $\begin{array}{l}<2.0 \mathrm{E}-09 \\
<2.0 \mathrm{E}-09 \\
<1.0 \mathrm{E}-00 \\
<1.0 \mathrm{E}-09 \\
1.6 \mathrm{E}-00 \neq 4.2 \mathrm{E}-07\end{array}$ & & 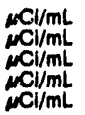 \\
\hline
\end{tabular}

\section{WELL LFW 43D}

\section{MEASUREMENTS CONDUCTED IN THE FIELD}

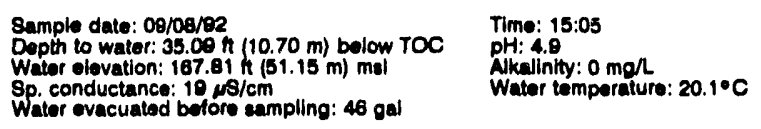

LABORATORY ANALYSES

F Analyte Besult Mod Unit

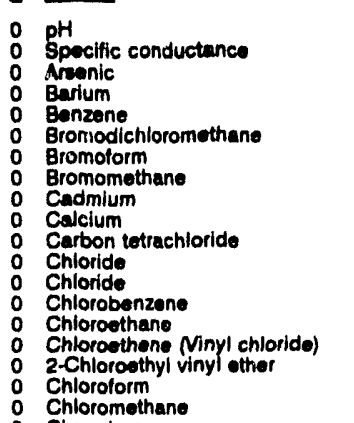

Chloromothane

o Dibromochloromathane

o 1,1 -Dichloroothane

o 1,1-Dichloroethylane

o trans-1,2-Dichloroethylene

O Dichioromethane

o 1,2 -Dichloropropane

o cis-1,3-Dichloropropene

Endrin

Ethylbenzene $<0.1$

o Fluoride

0 Fluoride

lion

0 Lead

o Magneaium

O Manganese

Mercury

Nitrate as nitrogen

o Phenois

0 Potansium

0 Selenium

0
0
0

- Sodium

Sulfato

o T,1,2,2. Tetrachloroethan

o Toluene

o Total dissolved collds

o Total organic carbon

o Total organic halogene

o Toxaphene

o 2,4,5-TP (Silvex)

o 1,1,1-Trichlorosthane

o 1,1,2-Trichloroethan

o richlorosthylone

Trichlorofluorom

Gross alpha

Radium-226

O Radium-22:

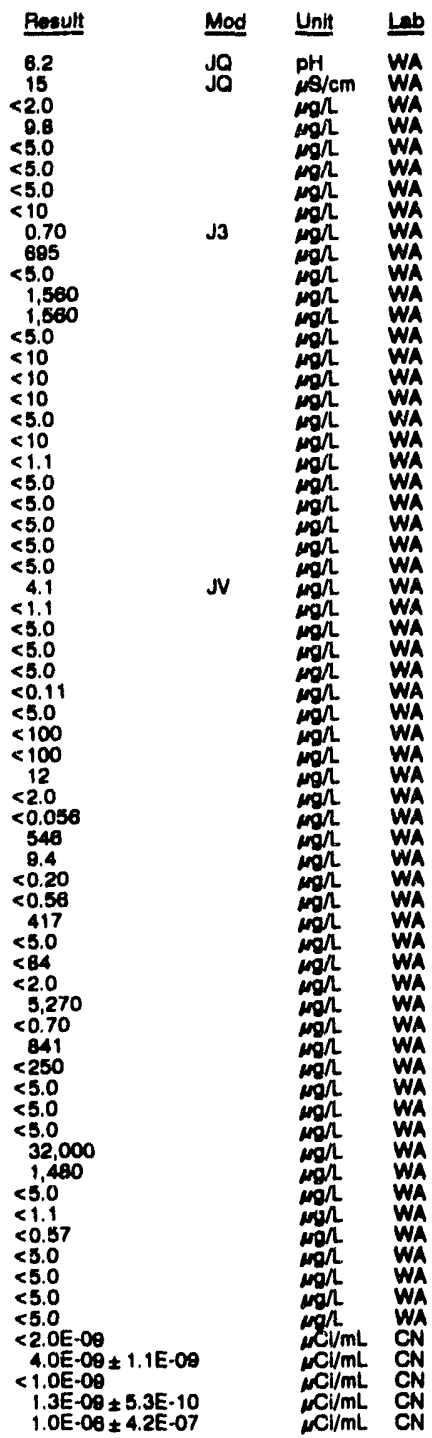


WELL LFW 44D

MEASUREMENTS CONDUCTED IN THE FIELD

Sample date: 08/0a/er

Depth to water: 15.12 (1) $4.61 \mathrm{~m}$ ) below TOC

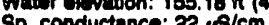

Sp. conductance: $22 \mu s / \mathrm{cm}$
Water evacuated betore sampling: $41 \mathrm{gal}$

LABORATOFY ANALYEES

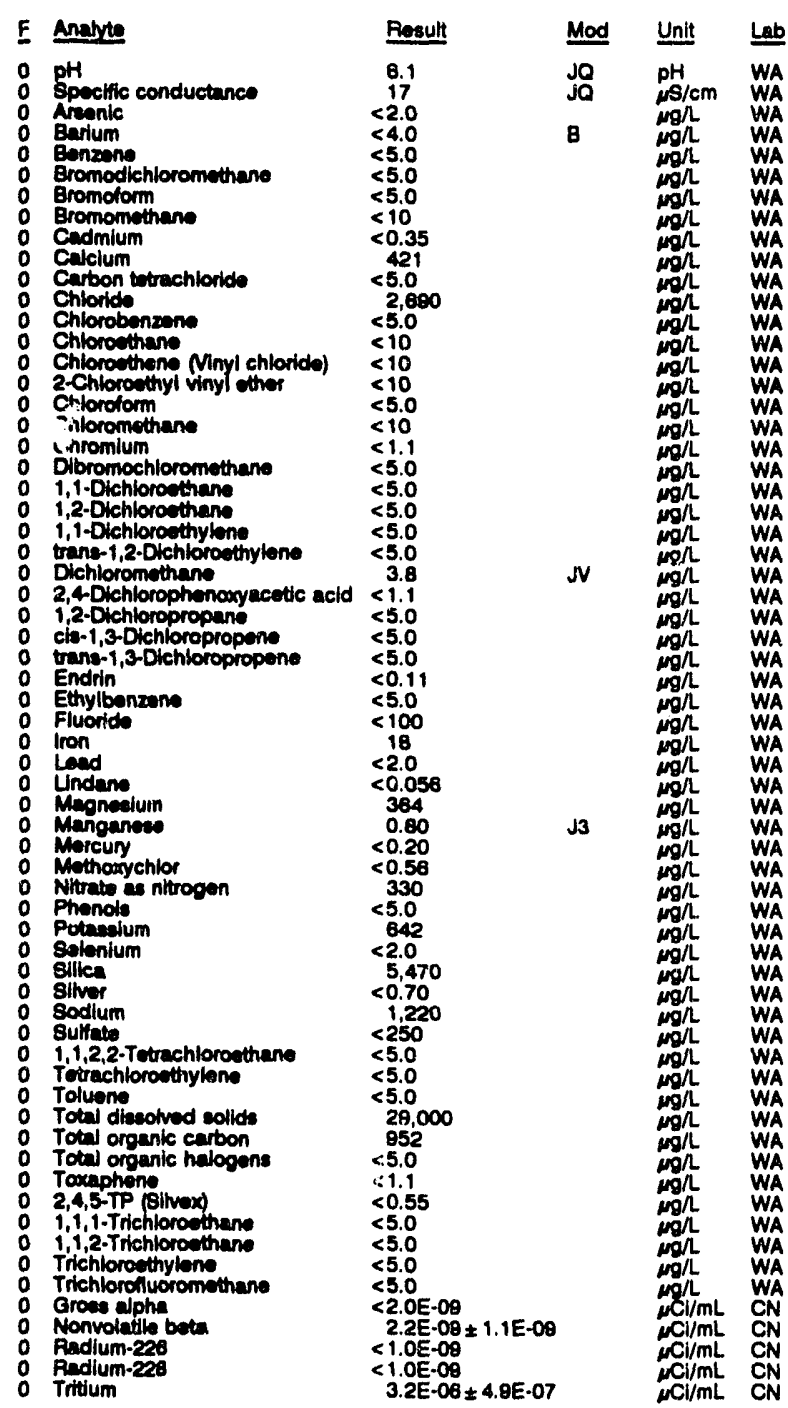

\section{WELL LFW 45D}

MEASUREMENTS CONDUCTED IN THE FIELD

Sample date: $09100 \mathrm{re}$

Depth to water: 13.78 . $14.20 \mathrm{~m}$ ) bolow TOC

Water to water: 13.78 ilevation: 152.51

Sp. conductance: 22 . $8 / \mathrm{cm}$

Water evacuated before sempling: $47 \mathrm{gal}$

LABOPATOFY ANALYSES

\begin{tabular}{|c|c|c|c|c|c|}
\hline$\underline{E}$ & Analute & Result & Mod & Unit & Lab \\
\hline $\begin{array}{l}0 \\
0 \\
0 \\
0 \\
0 \\
0 \\
0\end{array}$ & $\begin{array}{l}\text { pH } \\
\text { Specific conductance } \\
\text { Areenic } \\
\text { Barium } \\
\text { Bonzone } \\
\text { Bromodichloromethane } \\
\text { Eromoform }\end{array}$ & $\begin{array}{r}6.1 \\
17 \\
<2.0 \\
4.2 \\
<5.0 \\
<5.0 \\
<5.0\end{array}$ & $\begin{array}{l}J Q \\
J Q \\
J 3\end{array}$ & $\begin{array}{l}\mathrm{pH} \\
\mu \mathrm{N} / \mathrm{cm} \\
\mathrm{mg} / \mathrm{L} \\
\mathrm{\mu g} / \mathrm{L} \\
\mathrm{mg} / \mathrm{L} \\
\mathrm{Mg} / \mathrm{L} \\
\mathrm{mg} / \mathrm{L}\end{array}$ & $\begin{array}{l}\text { WA } \\
\text { WA } \\
\text { WA } \\
\text { WA } \\
\text { WA } \\
\text { WA } \\
\text { WA }\end{array}$ \\
\hline
\end{tabular}

WELL LFW 45D collected on 06/08/92, laboratory analyese (cont.)

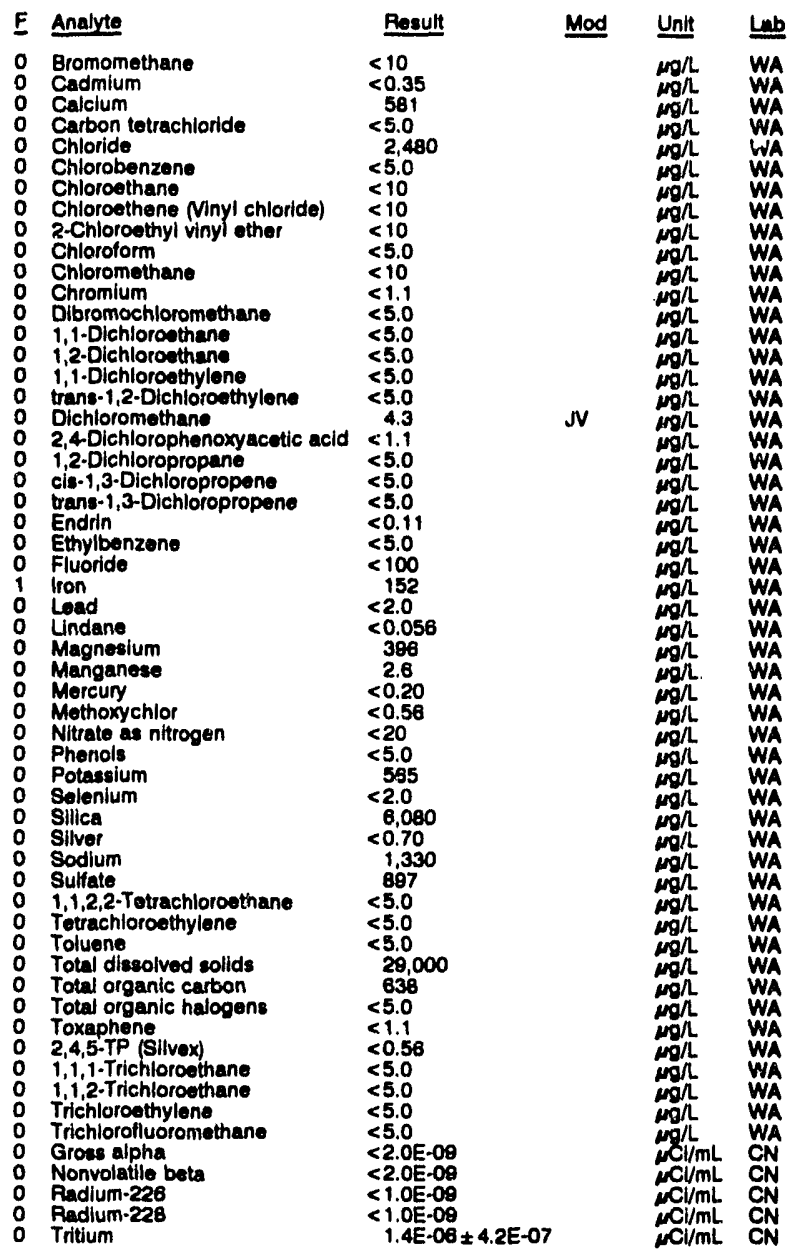

\section{WELL LFW 46D}

MEASUREMENTS CONDUCTED IN THE FIELD

\begin{tabular}{|c|c|}
\hline $\begin{array}{l}\text { Sample date: 09/08/92 } \\
\text { Dopth to water: } 13.87 \mathrm{~h}(4.23 \mathrm{~m}) \text { below TOC } \\
\text { Water olovation: } 151.23 \mathrm{H}(46.10 \mathrm{~m}) \mathrm{mol} \\
\text { Sp. conductance: } 104 \mu \mathrm{sm} \\
\text { Water evacuated bolore eampling: } 37 \mathrm{gal}\end{array}$ & $\begin{array}{l}\text { Time: } 12: 05 \\
\text { pH: } 5.3 \\
\text { Alkalinity: } 3 \mathrm{mg} / \mathrm{h} \\
\text { Water temperature: } 21.0^{\circ} \mathrm{C}\end{array}$ \\
\hline
\end{tabular}

LABORATORY ANALYYES

\begin{tabular}{|c|c|c|c|c|c|}
\hline$E$ & Analyte & Rosult & Mod & Unit & $\underline{L b}$ \\
\hline $\begin{array}{l}0 \\
0 \\
0 \\
0 \\
0 \\
0\end{array}$ & $\begin{array}{l}\text { pH } \\
\text { Specific conductance } \\
\text { Araenic } \\
\text { Barium } \\
\text { Bonzene } \\
\text { Bromodichloromethane } \\
\text { Bromolorm } \\
\text { Bromomethane } \\
\text { Cadmium } \\
\text { Calcium } \\
\text { Carbon tetrachloride } \\
\text { Chloride } \\
\text { Chlorobenzene } \\
\text { Chloroethane } \\
\text { Chloroethene Ninyl chioride) } \\
\text { 2-Chloroethyl vinyl ether } \\
\text { Chloroform } \\
\text { Chloromethane } \\
\text { Chromium } \\
\text { Dibromochioromethane } \\
\text { 1,1-Dichloroethane } \\
\text { 1,2-Dichloroothane } \\
\text { 1,1-Dichloroethylene } \\
\text { trang-1,2-Dichloroethylene } \\
\text { Dichloromethane } \\
\text { 2,4-Dichlorophenoxyacetic acid }\end{array}$ & $\begin{array}{r}5.3 \\
82 \\
<2.0 \\
11 \\
11 \\
<5.0 \\
<5.0 \\
<5.0 \\
<10 \\
<0.35 \\
7.910 \\
<5.0 \\
2,160 \\
<5.0 \\
<10 \\
<10 \\
<10 \\
<5.0 \\
<10 \\
<1.1 \\
<5.0 \\
<5.0 \\
<5.0 \\
<5.0 \\
<5.0 \\
3.1 \\
<1.1\end{array}$ & $\begin{array}{l}\text { JO } \\
\text { JO } \\
\text { J3 }\end{array}$ & 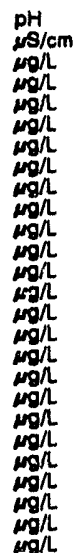 & $\begin{array}{l}\text { WA } \\
\text { WA } \\
\text { WA } \\
\text { WA } \\
\text { WA } \\
\text { WA } \\
\text { WA } \\
\text { WA } \\
\text { WA } \\
\text { WA } \\
\text { WA } \\
\text { WA } \\
\text { WA } \\
\text { WA } \\
\text { WA } \\
\text { WA } \\
\text { WA } \\
\text { Wh }\end{array}$ \\
\hline
\end{tabular}


WELL LFW 480 collected on 00/08/92, laboratory analyses (cont)

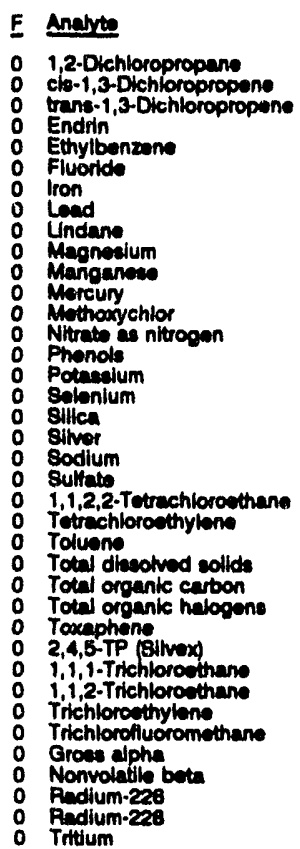

\begin{tabular}{l} 
Resuh \\
\hline 5.0 \\
$<5.0$ \\
$<5.0$ \\
$<0.11$ \\
$<5.0$ \\
$<100$ \\
38 \\
$<2.0$ \\
$<0.055$ \\
3.550 \\
3.6 \\
$<0.20$ \\
$<0.55$ \\
332 \\
$<5.0$ \\
1.030 \\
$<2.0$ \\
5.740 \\
$<0.70$ \\
1.150 \\
28,400 \\
$<5.0$ \\
$<5.0$ \\
$<5.0$ \\
77,000 \\
743 \\
$<5.0$ \\
$<1.1$ \\
$<0.56$ \\
$<5.0$ \\
$<5.0$ \\
$<5.0$ \\
$<5.0$ \\
$<2.0 E-09$ \\
$4.4 E-09 \pm 6.7 E-10$ \\
$<1.0 E-09$ \\
$2.1 E-09 \pm 7.0 E-10$ \\
$1.7 E-06 \pm 4.3 E-07$
\end{tabular}

\begin{tabular}{|c|}
\hline $\mathrm{m}$ \\
\hline
\end{tabular}

WELL LFW 47C

MEASUREMENTS CONDUCTED IN THE FIELD

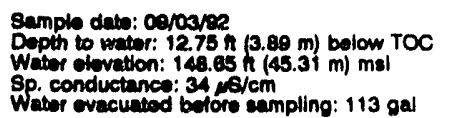

\section{Time: 10:40}

pH: 5.2

Water temperature: $18.8^{\circ} \mathrm{C}$ LABOPATOFY ANALYSES

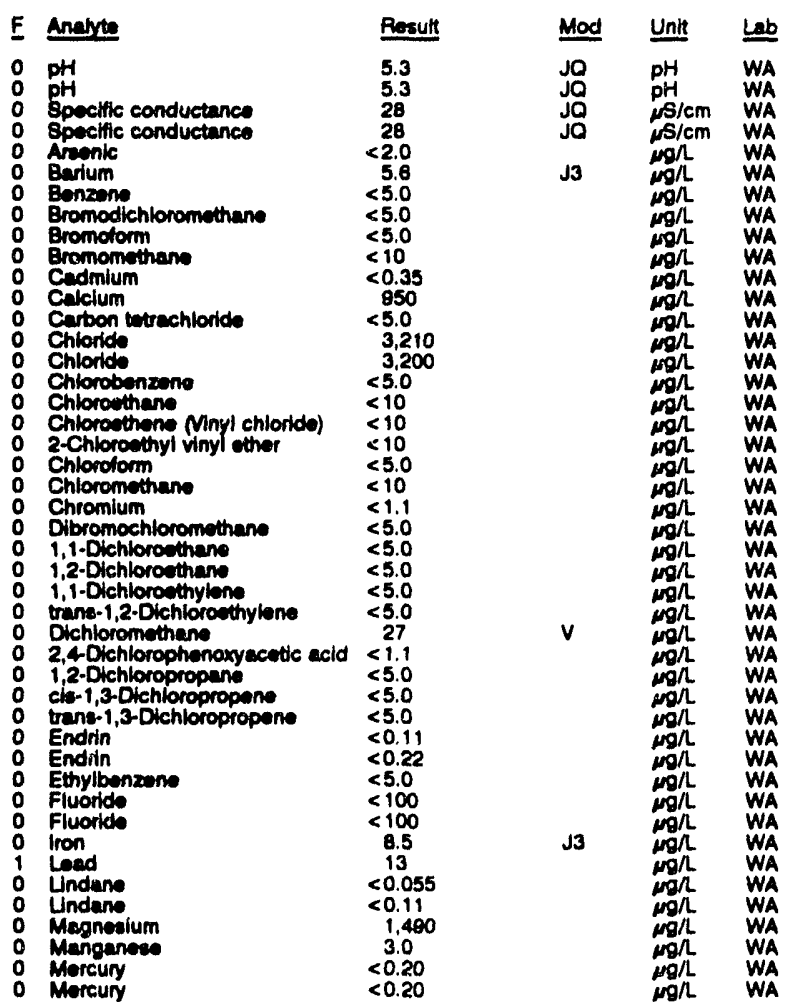

WELL LFW $47 \mathrm{C}$ collected on 09/03/82, laboratory analyses (cont.)

\begin{tabular}{|c|c|c|c|c|}
\hline Analyte & Result & Mod & Unit & Lي \\
\hline 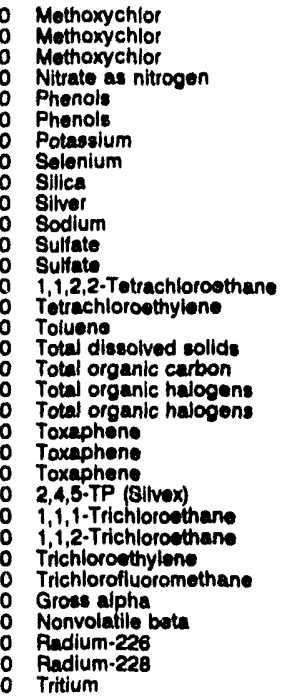 & $\begin{array}{l}<0.55 \\
<1.1 \\
<1.1 \\
287 \\
<5.0 \\
<5.0 \\
431 \\
<2.0 \\
6.480 \\
1.4 \\
2.160 \\
599 \\
576 \\
<5.0 \\
<5.0 \\
<5.0 \\
12.000 \\
<500 \\
16 \\
17 \\
<1.1 \\
<2.2 \\
<2.2 \\
<0.55 \\
<5.0 \\
<5.0 \\
<5.0 \\
<5.0 \\
<2.0 E-09 \\
1.5 E-08 \pm 1.0 E-00 \\
<1.0 E-09 \\
1.0 E-09 \pm 4.8 E-10 \\
2.8 E-06 \pm 5.1 E-07\end{array}$ & J3 & 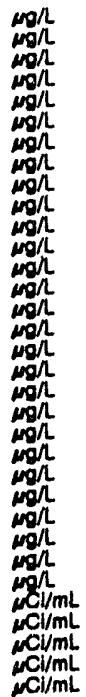 & $\begin{array}{l}\text { WA } \\
\text { WA } \\
\text { WA } \\
\text { WA } \\
\text { WA } \\
\text { WA } \\
\text { WA } \\
\text { WA } \\
\text { WA } \\
\text { WA } \\
\text { WA } \\
\text { WA } \\
\text { WA } \\
\text { WA } \\
\text { WA } \\
\text { WA } \\
\text { WA } \\
\text { WA } \\
\text { WA } \\
\text { WA } \\
\text { WA } \\
\text { WA } \\
\text { WA } \\
\text { WA } \\
\text { WA } \\
\text { WA } \\
\text { CN } \\
\text { CN } \\
\text { CN } \\
\text { CN } \\
\text { CN }\end{array}$ \\
\hline
\end{tabular}

\section{WELL LFW 47D}

MEASUREMENTS CONDUCTED IN THE FIELD

Sample date: 09/03/92

Depth to water: $12.54 \mathrm{ft}(3.82 \mathrm{~m})$ below TOC

Water olevation: $149.16 \mathrm{hl}(45.44$

Watar evacuated before eampling: $37 \mathrm{gal}$

$\lim ^{2}$. $10: 20$

PH: 5.0 Alkalinity: $1 \mathrm{mon}$

Water tomporature: $21.0^{\circ} \mathrm{C}$

LABORATORY ANALYSES

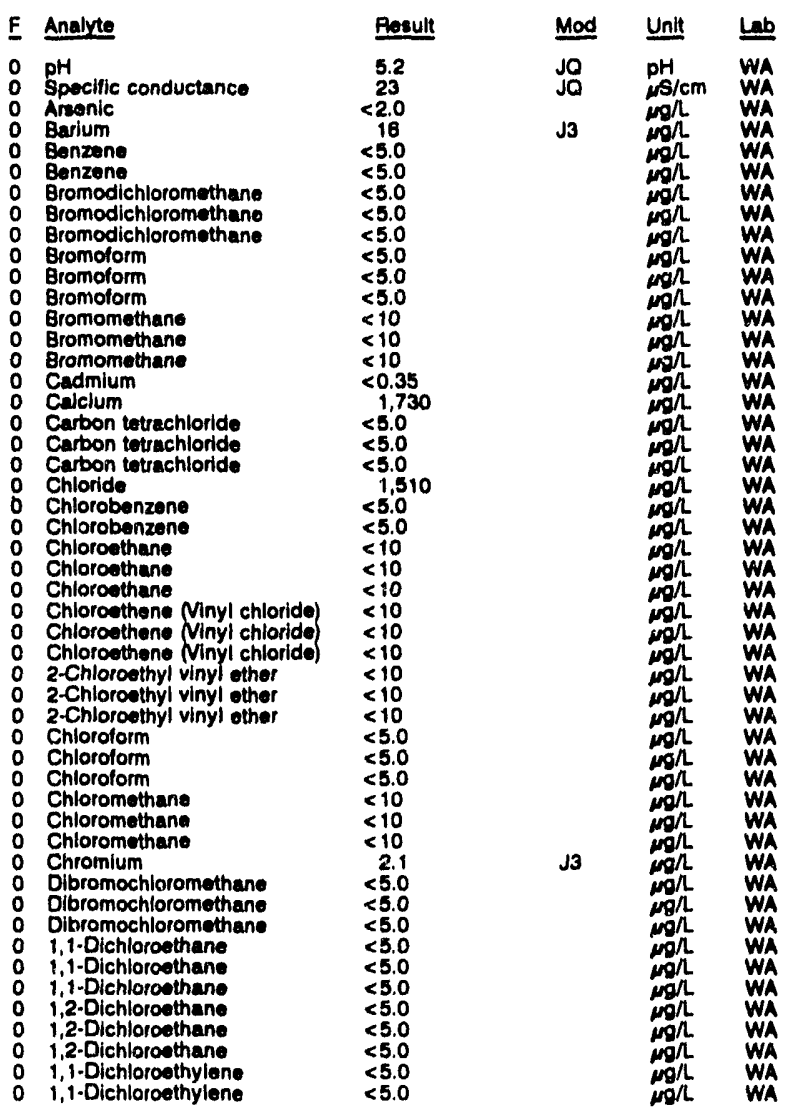


WEL LFW 470 colbetod on 09/03/82, laboratory analyses (cont.)

E Anavte

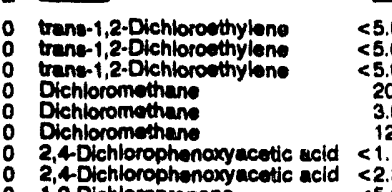

1.2-Dichloropropane

1,2-Dichloropropane

ch-1,3-Diehloropropene

ch-1,3-Dichloropropen

trane-1,3-Dichloropropene

trane-1,3-Dichloropropene

trane-1

Ethylbonzen

Ethylbonzans

Fluoride

Iron

Lindane

Magnewum

Mangun

Methoxychlor

Nitrate as nitrogen

Potenelum

Solenlum

Sillea

Sodium

$1,1,2,2$-Tetrachloroethane

$1,1,2,2-1$ rrachlorome

$1,1,2,2$-Tetrechloroethane

Tetrechloroethylone

Tetrechloroethylene

Toluene

Totel discolved eolids

Total organic carbon

Toxaphene

2,4,5-TP Silvox

1,1,1-Trichloroethan

1,1,1-Trichlorothane

1,1,1-Trichloroethane

1,1,2-Trichloroethane

1,1,2.Trichloroethen

Tirichloroethyleno

Trichloroethyiane

Trichloroiluoromethane

Trichlorolluoromethan

Groes alpha

Nonvoladie bat

Padium-22

o Trtium
Rosult Mod Unt

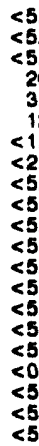

$<5.0$

$<5.0$

3.8

$<2.3$
$<5.0$

$<5.0$

$<5.0$

$<5.0$

$<5.0$

$<5.0$

$<0.11$

55.0
$<5.0$
55.0

$<5.0$
$<100$

20
21
$<0.055$

$<28$
3.5

3.5
$<0.20$

223
$<5.0$

$<5.0$

$<, 0$
4,880

2.3
1.010

4,600

$<5.0$

$<5.0$

$<5.0$

$<5.0$
$<5.0$

$<.000$
8,000

$<500$

5.5
$<1.1$

$<0.57$

$<1.1$

$<5.0$

$<5.0$

$<5.0$

$<5.0$

$<5.0$

$<5.0$

$<5.0$

$<5.0$

$7.0 \mathrm{E}-09 \pm 1.1 \mathrm{E}-00$

$<1.0 \mathrm{E}-09$

1. 1 E-09 0 +4.4E-07

jv

J3
Mod Unil Leo



\section{WELL LFW 48C}

MEASUREMENTS CONDUCTED IN THE FIELD

Sample date: 00/03/92

Depth to water: $20.52 \mathrm{~h}(6.25 \mathrm{~m})$ bolow TOC Water oilevation: $148.78 \mathrm{~h}$ (45.3

Water evacuated botoro sampling: $123 \mathrm{gal}$

LABORATOFY ANALYSES

\begin{tabular}{|c|c|c|}
\hline & Anaryte & Result \\
\hline 0 & $\begin{array}{l}\text { pH } \\
\text { Specific conductince } \\
\text { Apeonic } \\
\text { Barium } \\
\text { Eenzene } \\
\text { Bromodichloromethane } \\
\text { Bromolorm } \\
\text { Bromomethane } \\
\text { Cadmilum } \\
\text { Calclum } \\
\text { Curbon tetrachloride } \\
\text { Chlorlde } \\
\text { Chlorobenzene } \\
\text { Chloroethane } \\
\text { Chiloroethene Minyl chloride) } \\
\text { 2-Chlorosthyl vinyl ether }\end{array}$ & $\begin{aligned} & 5.2 \\
& 15 \\
&<2.0 \\
& 9.1 \\
&<5.0 \\
&<5.0 \\
&<5.0 \\
&<10 \\
&<0.35 \\
& 927 \\
&<5.0 \\
& 2.040 \\
&<5.0 \\
&<10 \\
&<10 \\
&<10\end{aligned}$ \\
\hline
\end{tabular}

Time: 9:40

PH: 5.4

Water temperature: $18.3^{\circ} \mathrm{C}$

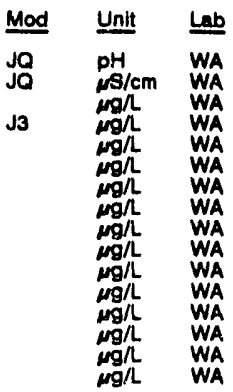

WELL LFW 48C collected on 09/03/92, laboratory analyees (cont)

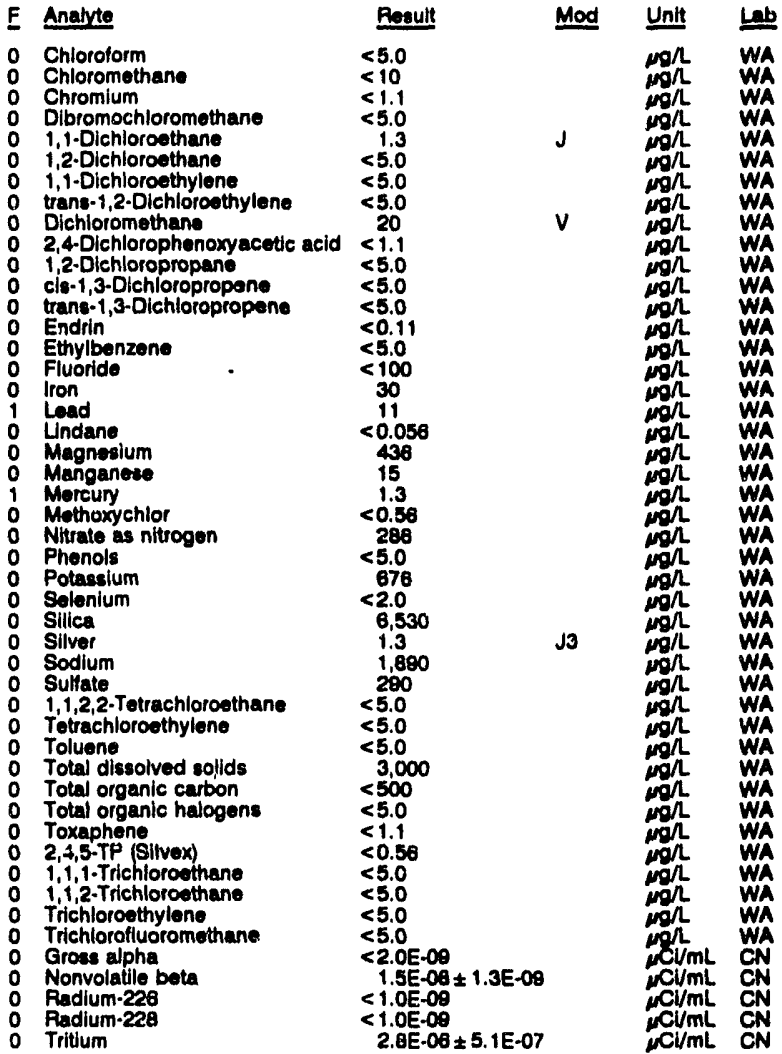

\section{WELL LFW 48D}

MEASUAEMENTS CONDUCTED IN THE FIELD

Sample date: $09 / 03 / 92$

Water olevation: $149.15 \mathrm{tt}(45.46 \mathrm{~m}) \mathrm{msl}$

Water evacuated bolore sampling: $37 \mathrm{gal}$

Time: 8:10

Alkalinity: $173 \mathrm{mgh}$

Alkalinity: $173 \mathrm{mgh}$

LABORATORY ANALYSES

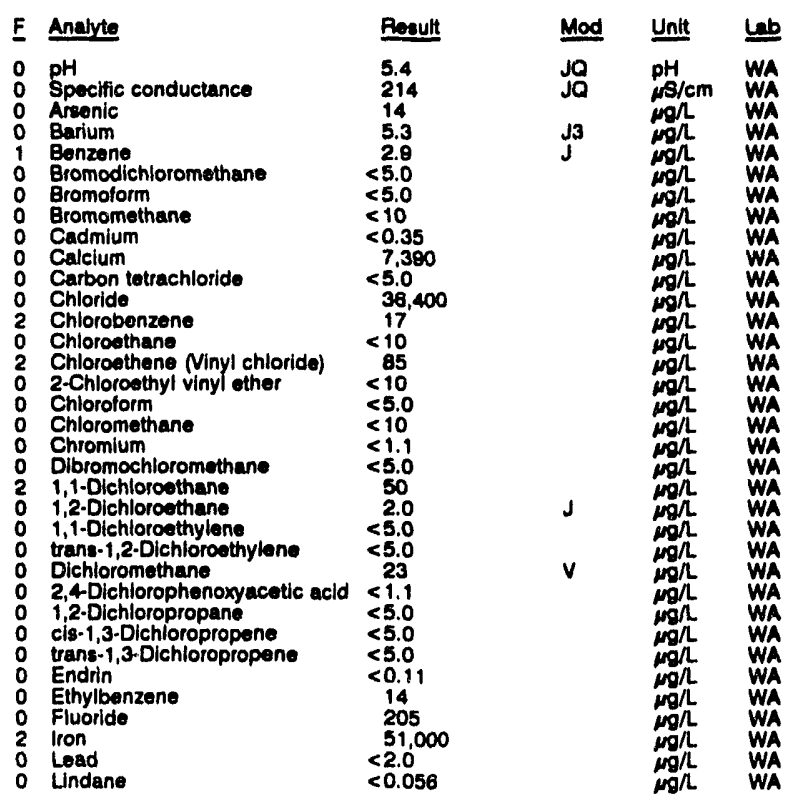




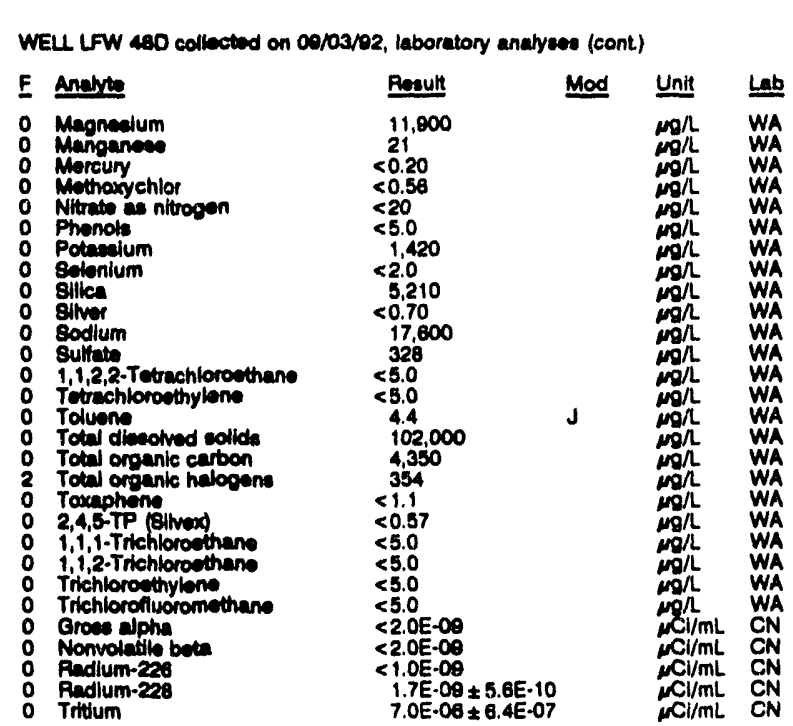

\section{WELL LFW 55C}

MEASUREMENTS CONDUCTED IN THE FIELD

Sample data: 00/03/92 Oepth to water: $0.63 \mathrm{~h}(2.94 \mathrm{~m})$ below TOC
Whter slovation: $140.77 \mathrm{~h}(44.74 \mathrm{~m}) \mathrm{msl}$ Sp. conductanco: $20 \mathrm{~s} / \mathrm{cm}$

Water evacuatiod betore cempling: 130 gal

LABORUTOPY MNALYSES

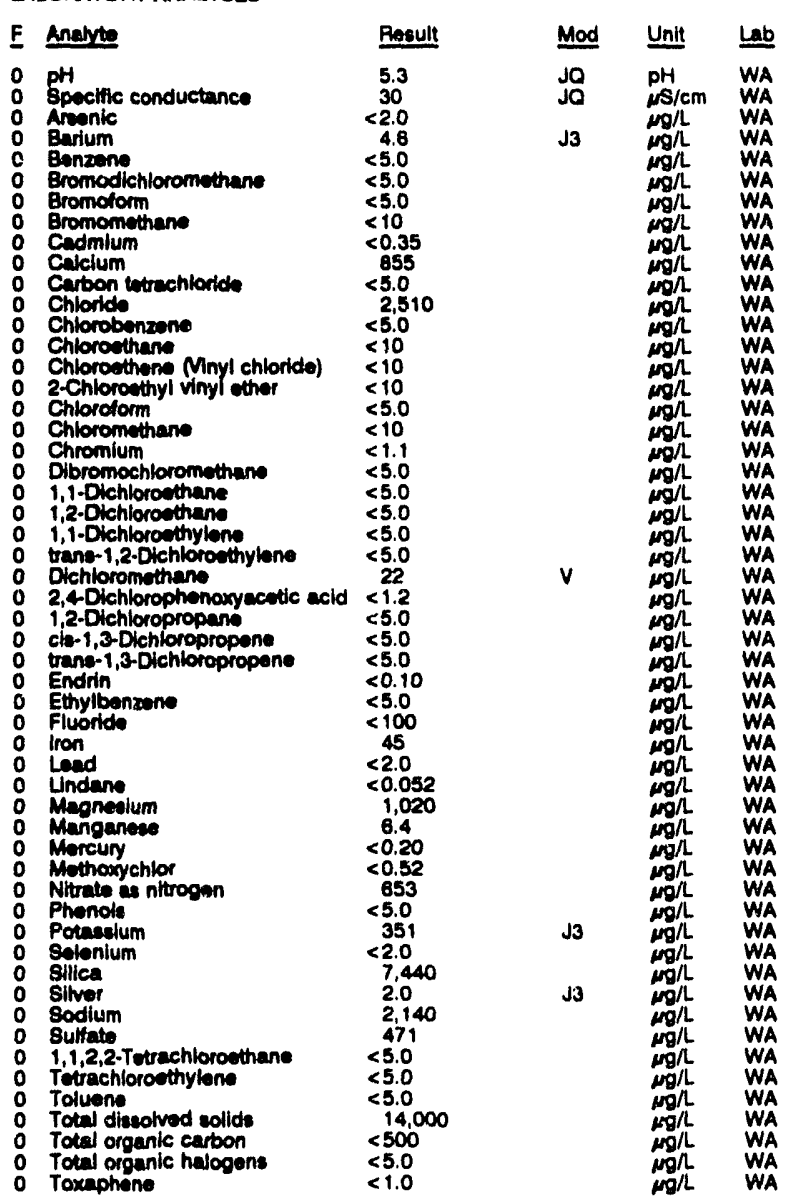

Time: 13:40

Al: 5.1 itin: $1 \mathrm{mg}$

Water tomperature: $19.8^{\circ} \mathrm{C}$
WELL LFW S5C collected on 09/03/92, laboratory analyser (cont)

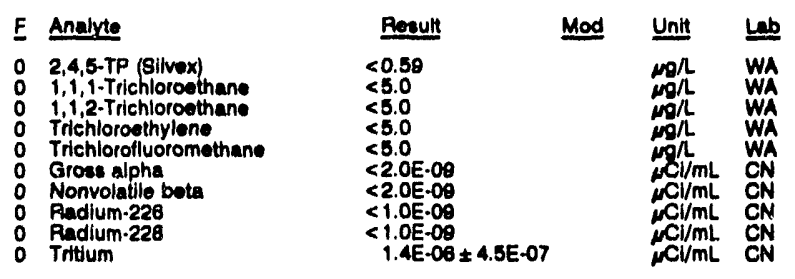

WELL LFW 55D

MEASUREMENTS CONDUCTED IN THE FIELD

\begin{tabular}{|c|c|}
\hline $\begin{array}{l}\text { 8ample date: } 09 / 03 / 92 \\
\text { Depth to wator: } 8.62 \mathrm{H}(2.63 \mathrm{~m}) \text { bolow TOC } \\
\text { Water olevation: } 146.78 \mathrm{ft}(44.74 \mathrm{~m}) \mathrm{mal} \\
\text { Sp. conductance: } 29 \mathrm{\mu s} / \mathrm{cm} \\
\text { Water evacuated betore sampling: } 67 \mathrm{gal}\end{array}$ & $\begin{array}{l}\text { Time: } 13: 15 \\
\text { pH: } 4.8 \\
\text { Alkelinity: } 0 \text { mgn } \\
\text { Water tomperature: } 20.5^{\circ} \mathrm{C}\end{array}$ \\
\hline
\end{tabular}
LABORATORY ANALYSES

\begin{tabular}{|c|c|c|c|c|c|}
\hline 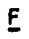 & Analyte & Reoult & Mod & Unit & $\underline{\underline{L}}$ \\
\hline & 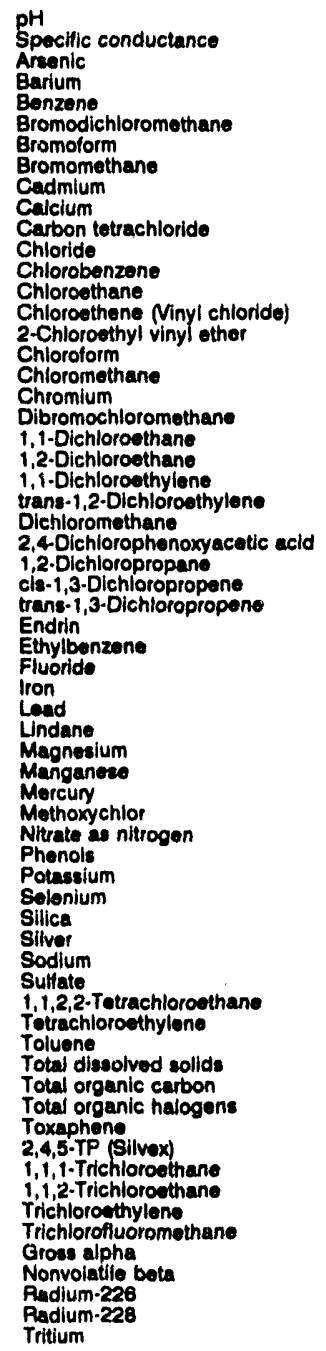 & $\begin{array}{l}5.1 \\
23 \\
<2.0 \\
8.8 \\
<5.0 \\
<5.0 \\
<5.0 \\
<10 \\
<0.35 \\
1.070 \\
<5.0 \\
2.480 \\
<5.0 \\
<10 \\
<10 \\
<10 \\
<5.0 \\
<10 \\
<1.1 \\
<5.0 \\
<5.0 \\
<5.0 \\
<5.0 \\
<5.0 \\
5.0 \\
<1.1 \\
<5.0 \\
<5.0 \\
<5.0 \\
<0.11 \\
<5.0 \\
<100 \\
147 \\
3.0 \\
<0.054 \\
813 \\
8.8 \\
<0.20 \\
<0.54 \\
<20 \\
<5.0 \\
704 \\
<2.0 \\
55,730 \\
11.4 \\
1,370 \\
3.270 \\
<5.0 \\
<5.0 \\
<5.0 \\
11.000 \\
720 \\
<5.0 \\
<1.1 \\
<0.56 \\
<5.0 \\
<5.0 \\
<5.0 \\
<5.0 \\
<2.0 E-09 \\
3.1 E-09 \\
<1.0 E-09 \\
<1.0 E-09 \\
2.3 E-06 \pm 4.8 E-07\end{array}$ & $\begin{array}{l}\text { JO } \\
\text { JO } \\
\text { J3 }\end{array}$ & 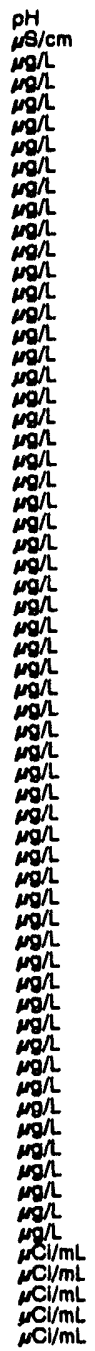 & $\begin{array}{l}\text { WA } \\
\text { WA } \\
\text { WA } \\
W A \\
W A \\
W A \\
\text { WA } \\
\text { WA } \\
\text { WA } \\
\text { WA } \\
\text { WA } \\
\text { WA } \\
\text { WA } \\
\text { WA } \\
\text { WA } \\
\text { WA } \\
\text { WA } \\
\text { WA } \\
\text { WA } \\
\text { WA } \\
\text { WA } \\
\text { WA } \\
\text { WA } \\
\text { WA } \\
\text { WA } \\
\text { WA } \\
\text { WA } \\
\text { WA } \\
\text { WA } \\
\text { WA } \\
\text { WA } \\
\text { WA } \\
\text { WA } \\
\text { WA } \\
\text { WA } \\
\text { WA } \\
\text { WA } \\
\text { WA } \\
\text { WA } \\
\text { WA } \\
\text { WA } \\
\text { WA } \\
\text { WA } \\
\text { WA } \\
\text { WA } \\
\text { WA } \\
\text { WA } \\
\text { WA } \\
\text { WA } \\
\text { WA } \\
\text { WA } \\
\text { WA } \\
\text { WA } \\
\text { WA } \\
\text { WA } \\
\text { WA } \\
\text { WA } \\
\text { WA } \\
\text { CN } \\
\text { CN } \\
\text { CN } \\
\text { CN } \\
\text { CN } \\
\end{array}$ \\
\hline
\end{tabular}

Alkalinity: 0 mgn
Water tomperature: $20.5^{\circ} \mathrm{C}$

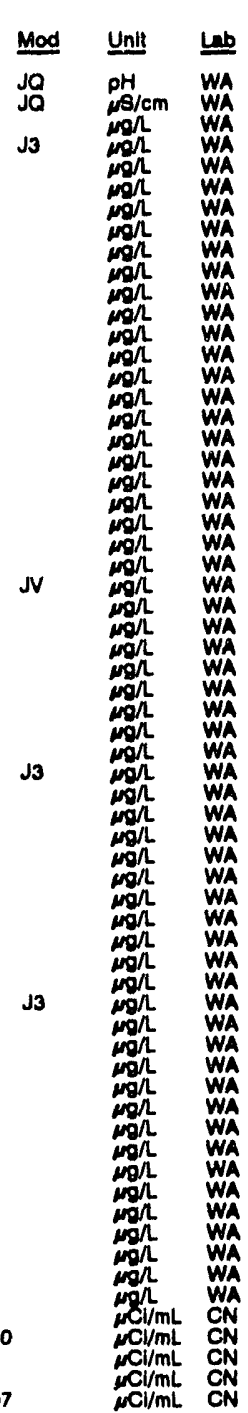


ANALYTICAL RESULTS

WELL LFW 56D

MEASUREMENTS CONDUCTED IN THE FIELD

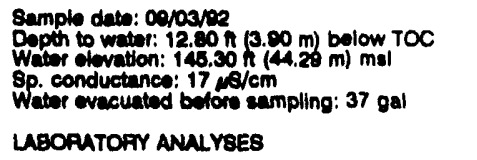

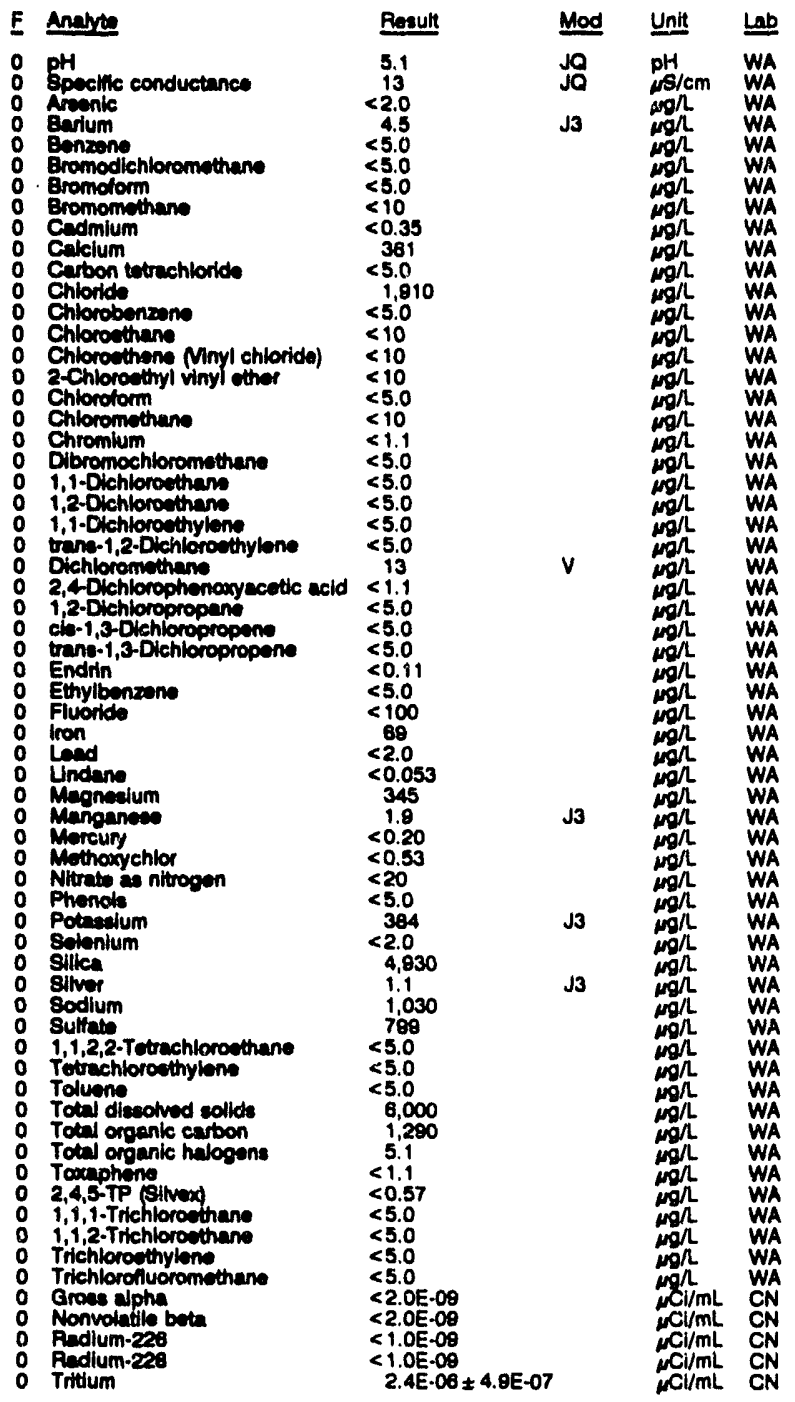

\section{WELL LFW 57B}

MEASUREMENTS CONDUCTED IN THE FIELD

Sample date: 09/03/00

Depth to water: $21.73 \mathrm{~h}(6.62 \mathrm{~m})$ below TOC

Wettor elevation: 143.87 t $(43.76 \mathrm{~m}) \mathrm{msl}$

Sp. conductence: $81 \mathrm{~s} / \mathrm{cm}$.

Water ovecuntad belors sampling: $188 \mathrm{gal}$

LABORATOFY ANALYSES

\begin{tabular}{|c|c|c|c|}
\hline F Anarte & Result & Mod & Unit \\
\hline $\begin{array}{ll}0 & \text { pH } \\
0 & \text { Specific conductance } \\
0 & \text { Ameenic } \\
0 & \text { Earium } \\
0 & \text { Benzeno } \\
0 & \text { Bromodichloromethane } \\
0 & \text { Bromoform }\end{array}$ & $\begin{array}{r}4.7 \\
48 \\
<2.0 \\
6.7 \\
<5.0 \\
<5.0 \\
<5.0\end{array}$ & $\begin{array}{l}\mathrm{JO} \\
\mathrm{J} \\
\mathrm{J}\end{array}$ & $\begin{array}{l}\mathrm{pH} \\
\mu \mathrm{S} / \mathrm{cm} \\
\mathrm{mg} / \mathrm{L} \\
\mathrm{mg} / \mathrm{L} \\
\mathrm{mg} / \mathrm{L} \\
\mathrm{mg} / \mathrm{L}\end{array}$ \\
\hline
\end{tabular}

WELL LFW 578 colloctod on 09/03/02, Laboratory analyees (cont)

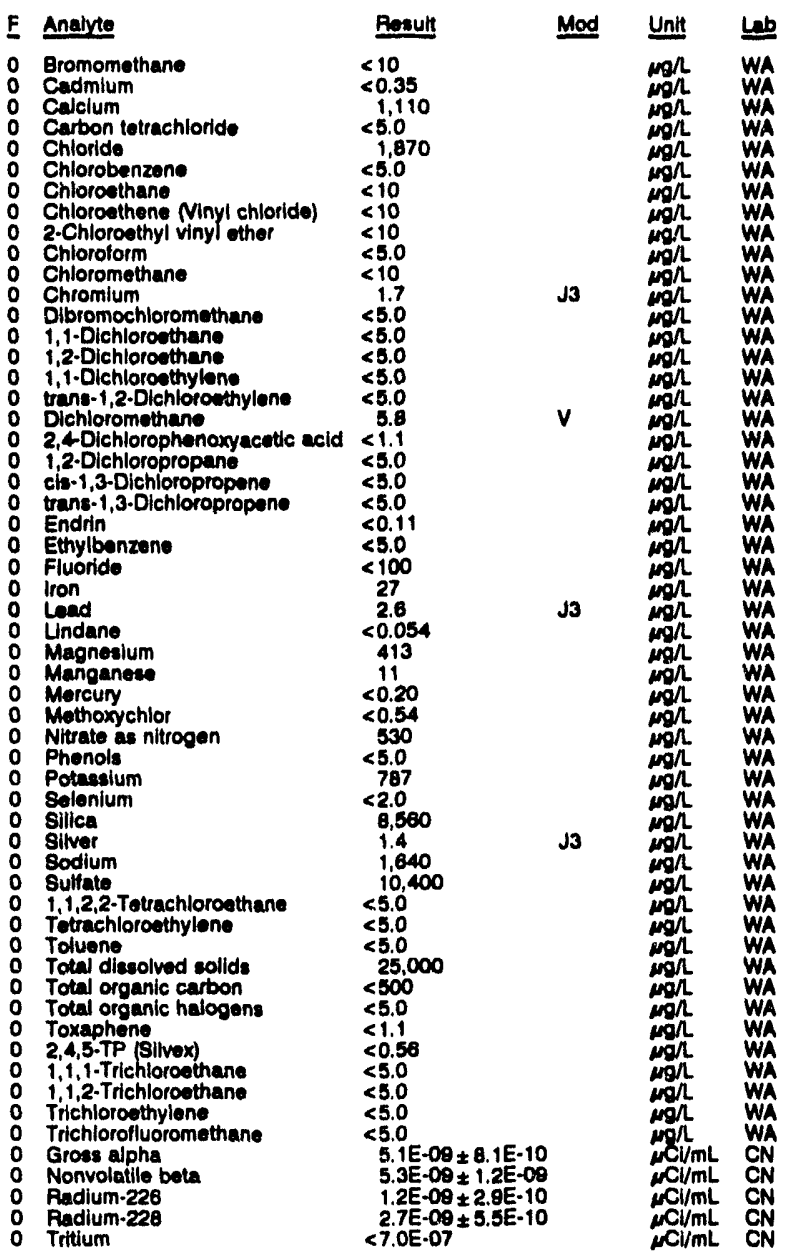

WELL LFW 57C

MEASUREMENTS CONDUCTED IN THE FIELD

\begin{tabular}{|c|c|c|c|c|c|}
\hline \multicolumn{3}{|c|}{$\begin{array}{l}\text { Sample date: } 08 / 03 / 92 \\
\text { Dopth to water: } 21.25 \mathrm{Ht}(6.48 \mathrm{~m}) \text { below roc } \\
\text { Water olovation: } 143.75 \mathrm{ht}(43.82 \mathrm{~m}) \mathrm{mol} \\
\text { Sp. conductance: } 30 \text { लs/cm } \\
\text { Water evacuated before sempling: } 84 \mathrm{gal}\end{array}$} & \multicolumn{3}{|c|}{$\begin{array}{l}\text { Time: } 11: 30 \\
\text { pH: } 4.8 \\
\text { Alkalinity: } 1 \mathrm{mg} / \mathrm{h} \\
\text { Water temperature: } 18.7 \bullet \mathrm{C}\end{array}$} \\
\hline \multicolumn{6}{|c|}{ LABORATORY ANALYSES } \\
\hline $\mathbf{E}$ & Analyte & Result & Mod & Unit & $\underline{L a b}$ \\
\hline $\begin{array}{l}0 \\
0 \\
0 \\
0 \\
0 \\
0 \\
0 \\
0 \\
0 \\
0\end{array}$ & $\begin{array}{l}\text { pH } \\
\text { Specific conductance } \\
\text { Arsenic } \\
\text { Barium } \\
\text { Benzene } \\
\text { Bromodichloromethane } \\
\text { Bromoform } \\
\text { Bromomethane } \\
\text { Cadmium } \\
\text { Calcium } \\
\text { Carbon tetrachloride } \\
\text { Chloride } \\
\text { Chlorobenzene } \\
\text { Chloroethane } \\
\text { Chloroethene Mnyl chloride) } \\
\text { 2-Chloroethyl vinyl ether } \\
\text { Chloroform } \\
\text { Chloromethane } \\
\text { Chromium } \\
\text { Dibromochloromethane } \\
1,1 \text {-Dichloroethane } \\
1,2 \text {-Dichloroethane } \\
\text { 1,1-Dichloroethylene } \\
\text { tians-1,2-Dichloroethylene } \\
\text { Dichloromethane } \\
2,4 \text {-Dichlorophenoxyacetic acid }\end{array}$ & $\begin{array}{r}5.0 \\
24 \\
<2.0 \\
8.3 \\
<5.0 \\
<5.0 \\
<5.0 \\
<10 \\
<0.35 \\
1.020 \\
<5.0 \\
2550 \\
<5.0 \\
<10 \\
<10 \\
<10 \\
<5.0 \\
<10 \\
2.0 \\
<5.0 \\
<5.0 \\
<5.0 \\
<5.0 \\
<5.0 \\
7.6 \\
<1.1\end{array}$ & Jo & 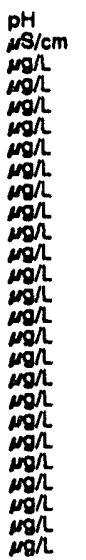 & $\begin{array}{l}\text { WA } \\
\text { WA } \\
\text { WA } \\
\text { WA } \\
\text { WA } \\
\text { WA } \\
\text { WA } \\
\text { WA } \\
\text { WA } \\
\text { WA } \\
\text { WA } \\
\text { WA } \\
\text { WA } \\
\text { WA } \\
\text { WA } \\
\text { WA } \\
\text { WA } \\
\text { WA } \\
\text { WA } \\
\text { WA } \\
\text { WA } \\
\text { WA }\end{array}$ \\
\hline
\end{tabular}


WELL LFW S7C colloctod on 00/03/82, laboratory andyaces (cont)

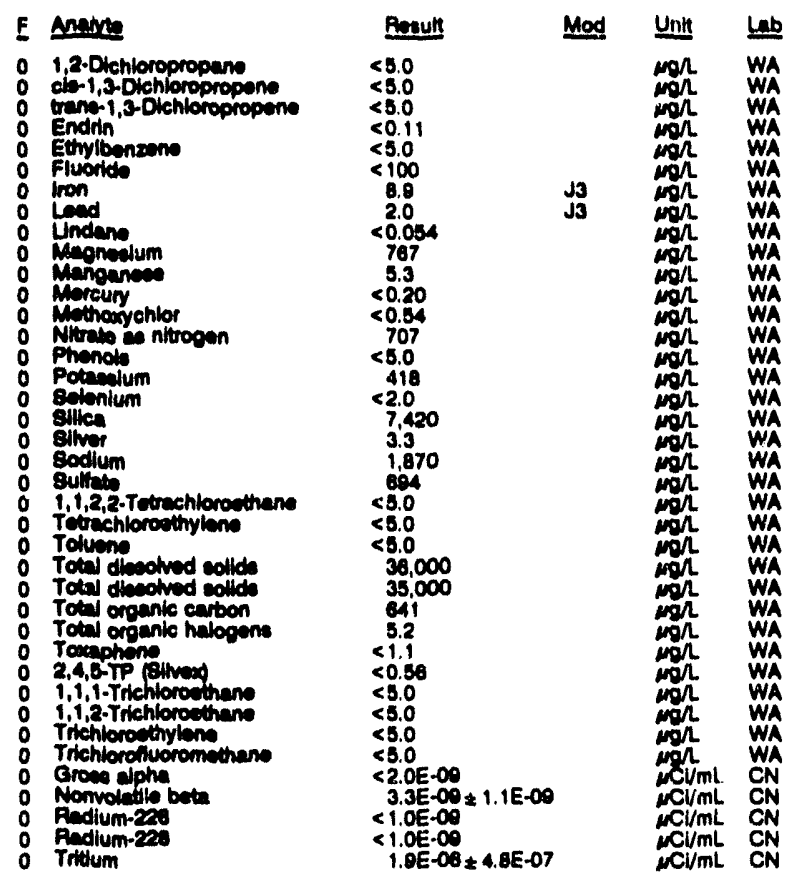

\section{WELL LFW 57D}

MEASUAEMENTS CONOUCTED IN THE FIELD

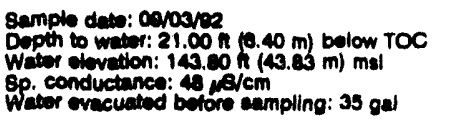

LABORATOFY ANAL YrES

\begin{tabular}{|c|c|c|c|}
\hline Aneste & Posulk & Mod & Unit \\
\hline 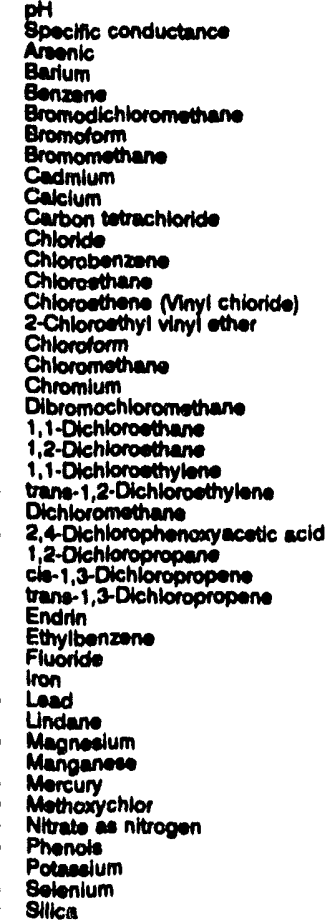 & $\begin{array}{r}5.2 \\
40 \\
<2.0 \\
6.1 \\
<5.0 \\
<5.0 \\
<5.0 \\
<10 \\
<0.35 \\
1,090 \\
<5.0 \\
5,600 \\
<5.0 \\
<10 \\
<10 \\
<10 \\
<5.0 \\
<10 \\
<1.1 \\
<5.0 \\
27 \\
<5.0 \\
<5.0 \\
<5.0 \\
3.8 \\
<1.1 \\
<5.0 \\
<5.0 \\
<5.0 \\
<0.10 \\
<5.0 \\
<100 \\
21 \\
2.8 \\
<0.052 \\
11.810 \\
11 \\
<0.20 \\
<0.52 \\
261 \\
<5.0 \\
227 \\
<2.0 \\
4.860\end{array}$ & $\begin{array}{l}\text { Jo } \\
\text { JO } \\
\text { J3 }\end{array}$ & 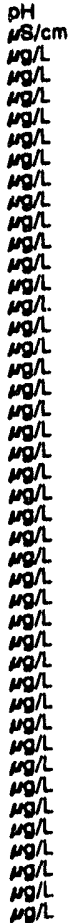 \\
\hline
\end{tabular}

WELL LFW 570 collectod on 09/03/22, laboratory analyees (cont)

\begin{tabular}{|c|c|c|c|c|c|}
\hline E & Anatyte & Besun & Mod & Unt & Lab \\
\hline $\begin{array}{l}0 \\
0 \\
0\end{array}$ & 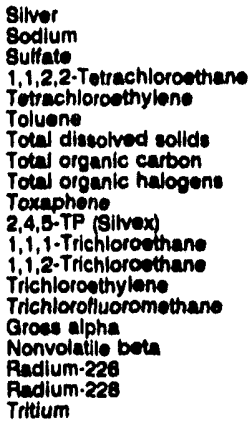 & $\begin{array}{l}1.9 \\
4,840 \\
1,110 \\
<8.0 \\
<5.0 \\
<5.0 \\
25,000 \\
1.770 \\
60 \\
<1.0 \\
<0.50 \\
<5.0 \\
<8.0 \\
<5.0 \\
<5.0 \\
<2.05-00 \\
2.05 .00 \\
<1.0 E \cdot 00 \\
<1.0 E-00 \\
2.6 E-08\end{array}$ & J3 & & $\begin{array}{l}\text { WA } \\
\text { WA } \\
\text { WA } \\
\text { WA } \\
\text { WA } \\
\text { WA } \\
\text { WA } \\
\text { WA } \\
\text { WA } \\
\text { WA } \\
\text { WA } \\
\text { WA } \\
\text { CN } \\
\text { CN } \\
\text { CN } \\
\text { CN }\end{array}$ \\
\hline
\end{tabular}

\section{WELL LFW 58D}

MEABUREMENTS CONDUCTED IN THE FIELL

Sample date: cosourez

Depth to water: $28.02 n(7.81 \mathrm{~m})$ bolow TOC

Water elevation: $141.08 \mathrm{~h}(43.26 \mathrm{~m}) \mathrm{mal}$

Sp. conductance: $79 \mu^{\mathrm{s} / \mathrm{cm}}$.

Time: 10:10

PH: 4.7

Water tomperature: $19.6^{\circ} \mathrm{C}$

LABORATORY ANALYSES

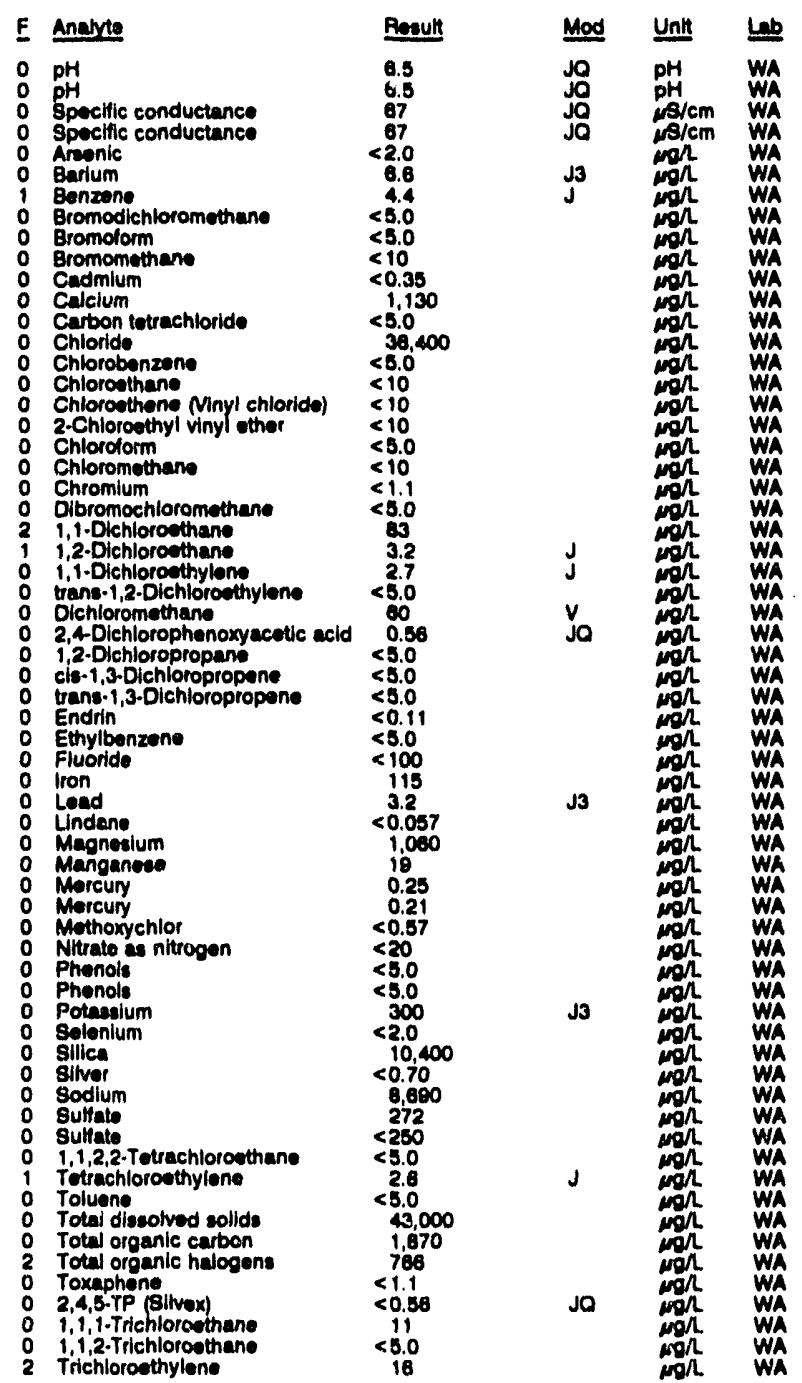


ANALYTICAL RESULTS

\begin{tabular}{|c|c|c|c|}
\hline E Ansis & Benuk & Mod & Unit \\
\hline 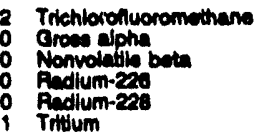 & $\begin{aligned} & 80 \\
&<2.0 E-00 \\
& 2.0 E-00 \\
& 21.0 E-09 \\
&<1.0 E .09-10 \\
&<1.0 E \cdot 00 \\
& 1.0 E-05 \neq 7.3 E-07\end{aligned}$ & & 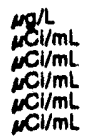 \\
\hline
\end{tabular}

\section{WELL LFW 59B}

MEABUREMENTS CONDUCTED IN THE FIELD

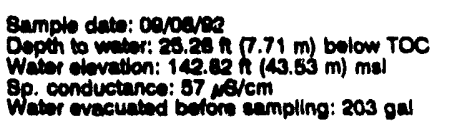
Wp. conductance: $07 \mathrm{fs} / \mathrm{cm}$.

\section{LABOPATOFY ANALYEES}

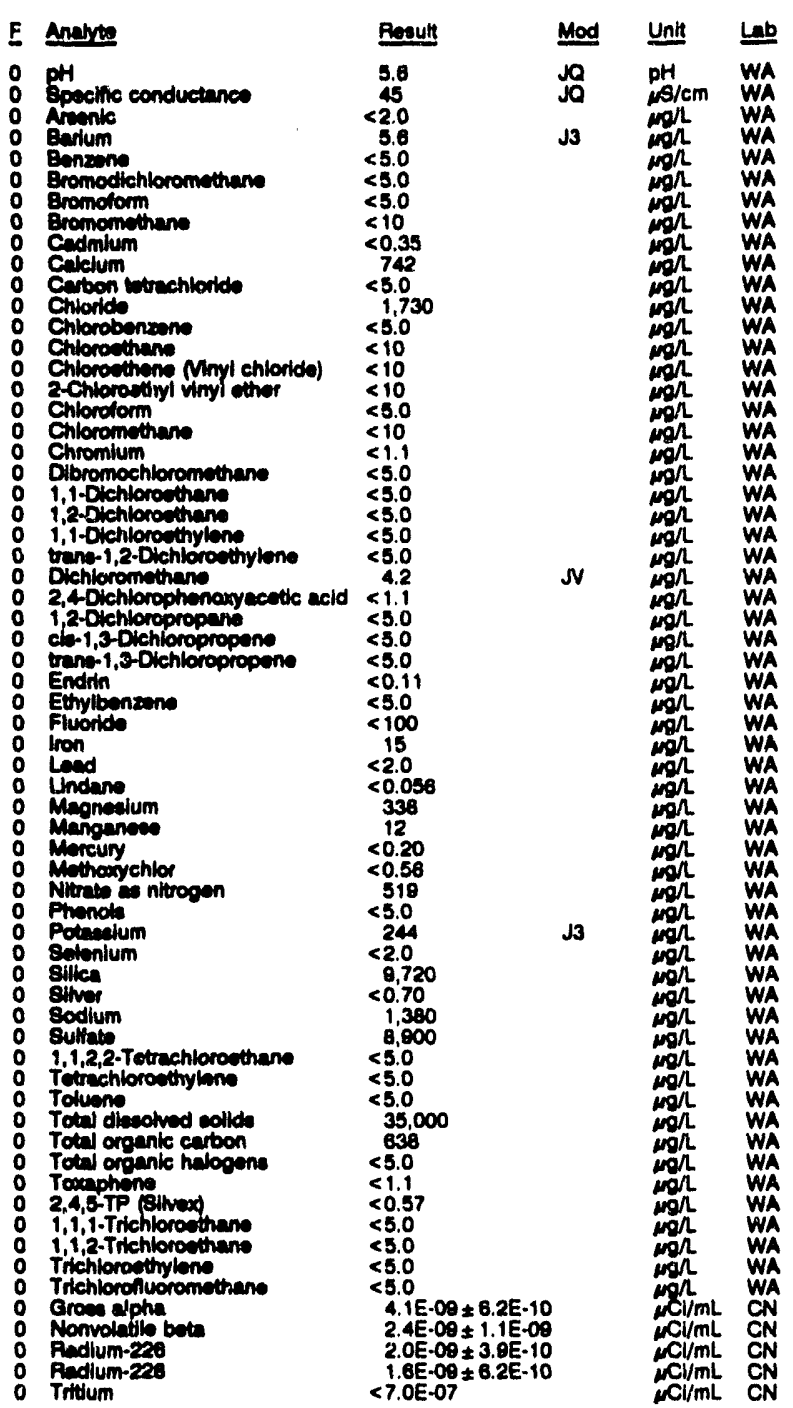

WELL LFW 59C

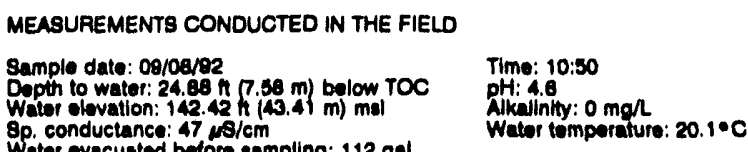

8p. conductance: $47,88 / \mathrm{cm}$

Water evacuated betore sampling: $112 \mathrm{gal}$

LABORATOAY ANALYSES

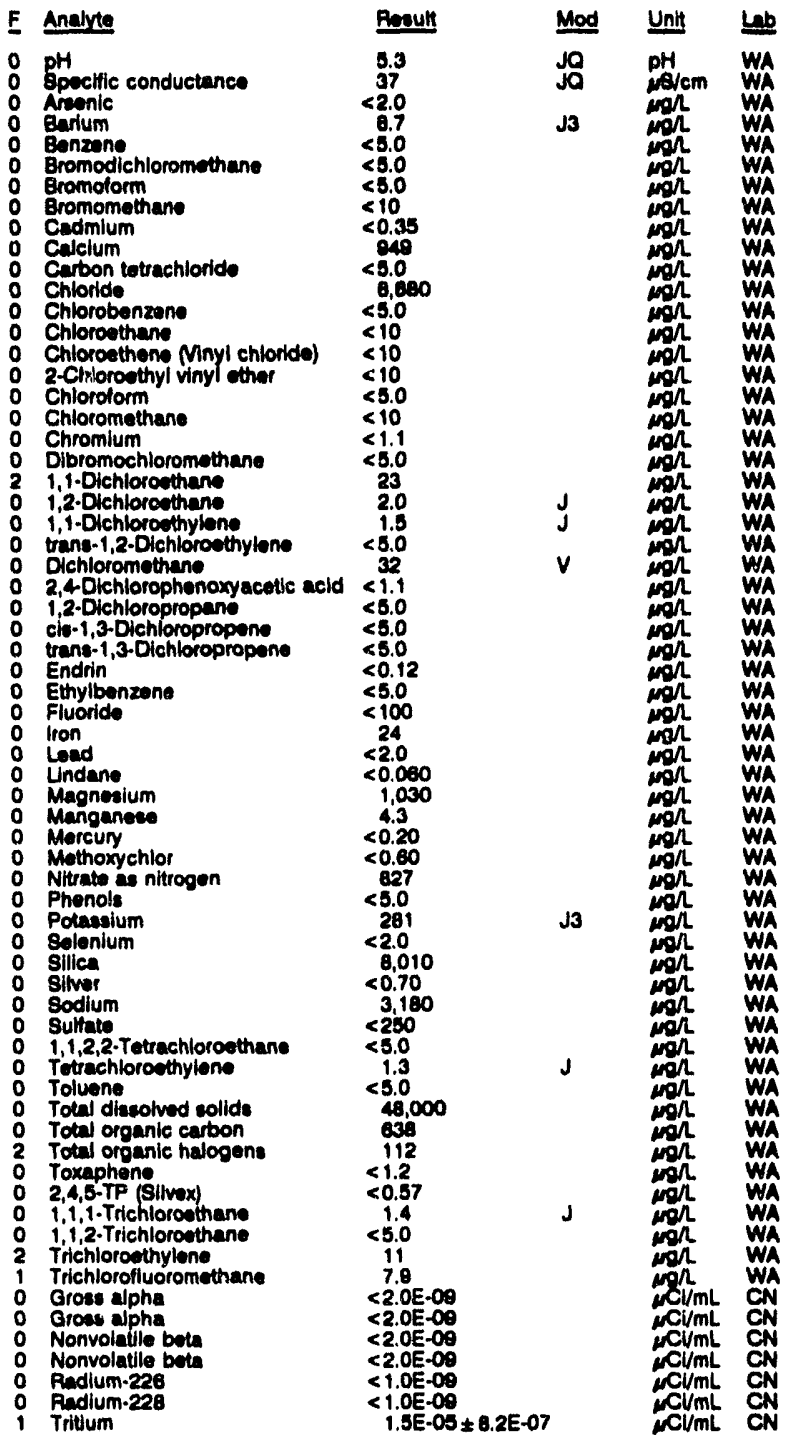

\section{WELL LFW 59D}

MEASUREMENTS CONDUCTED IN THE FIELD

Sample dato: $09 / 0492$
Depth to water: $24.32 \mathrm{n}(7.41 \mathrm{~m})$ below TOC
Water elevation: $143.28 \mathrm{~h}(43.67 \mathrm{~m}) \mathrm{mal}$

Waler elovation: $143.28 \mathrm{ht}(43$.

Spetor evecuated before sampling: $37 \mathrm{gal}$

LABORATOAY ANALYSES

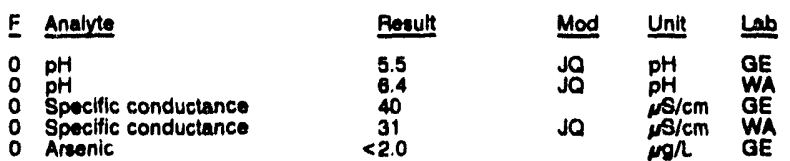

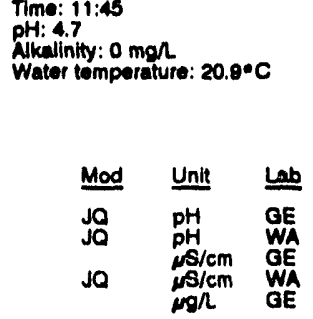


ANALYTICAL RESULTS

WELL LWW se0 colbetiod on 00/0492, laboratory analyees (cont.)

\begin{tabular}{|c|c|c|c|c|}
\hline Androte & Rosult & $\mathrm{Mod}$ & Unit & Lab \\
\hline 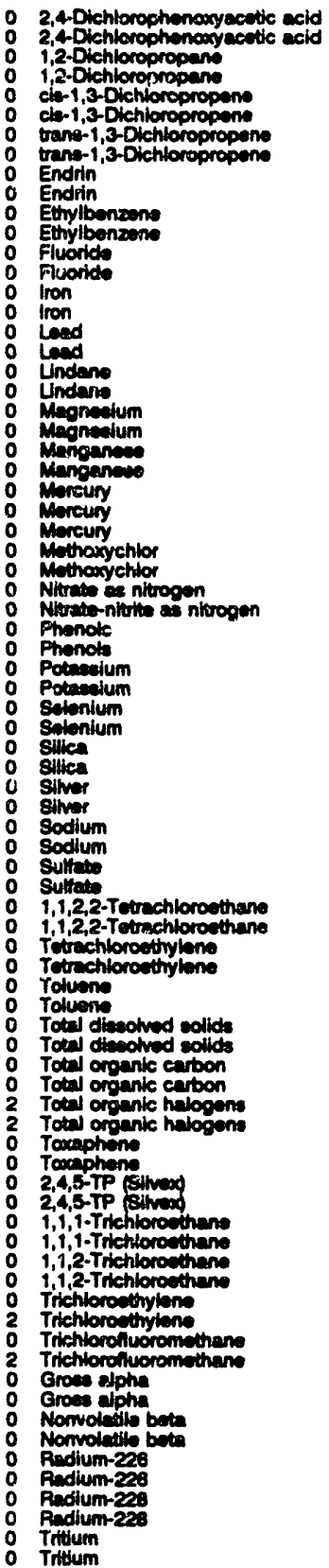 & 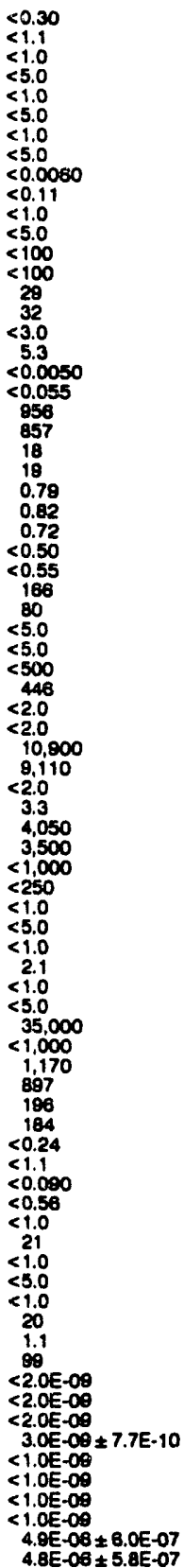 & $\underset{\mathrm{JQB}}{\mathrm{JOB}}$ & 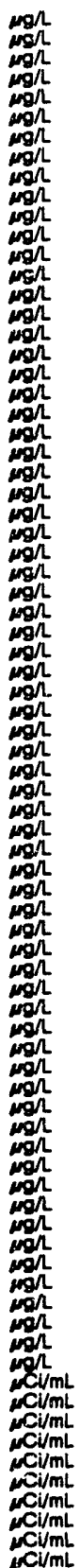 & $\begin{array}{l}G E \\
W A \\
\text { GE } \\
W A \\
G E \\
W A \\
G E \\
W A \\
G E \\
W A \\
G E \\
W A \\
G E \\
W A \\
G E \\
W A \\
G E \\
W A \\
G E \\
W A \\
G E \\
W A \\
G E \\
W A \\
G E \\
G E \\
W A \\
G E \\
W A \\
W A \\
G E \\
G E \\
W A \\
G E \\
W A \\
G E \\
W A \\
G E \\
W A \\
G E \\
W A \\
G E \\
W A \\
G E \\
W A \\
G E \\
W A \\
G E \\
W A \\
G E \\
W A \\
G E \\
W A \\
G E\end{array}$ \\
\hline
\end{tabular}

\section{WELL LFW 60D}

MEASUREMENTS CONOUCTED IN THE FIELD

Sample dete: coveree

Depth to water: $18.78 \mathrm{n}(0.72 \mathrm{~m})$ below TOC

Water clovetion: 138.32 h (4

Sp. conductance: 18 ps/cm

Water wacusted belore enpling: 11 gal

LABORATOFY ANALYSES

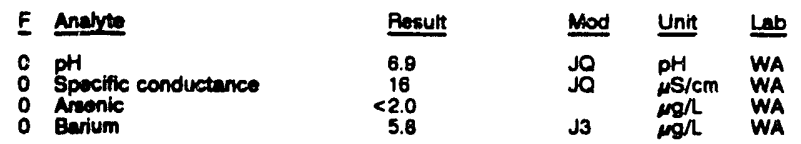

WELL LFW 60D collectod on 09/04/92, laboratory analyees (cont.)

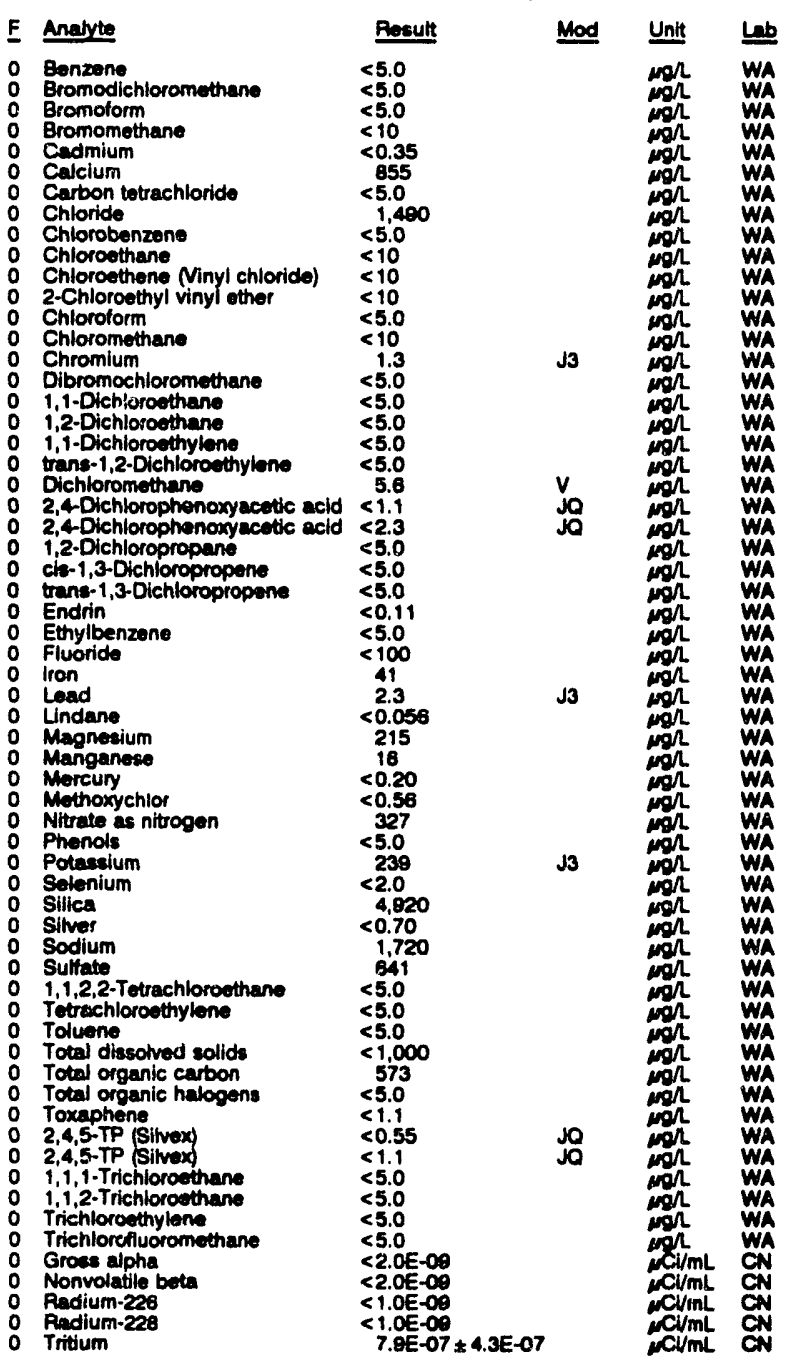

WELL LFW 61C

MEASUREMENTS CONDUCTED IN THE FIELD

Sample date: 00/08/92

Depth to water: $26.41 \mathrm{ft}(8.05 \mathrm{~m})$ below TOC

Water elevation: 141.60 \&

Sp. conductance: $63 \mu \mathrm{s} / \mathrm{cm}$.

Time: 8:50

pH: 5.8

Nkalinity: $18 \mathrm{man}$

Water temperature: $19.5^{\circ} \mathrm{C}$

LABORATORY ANALYSES

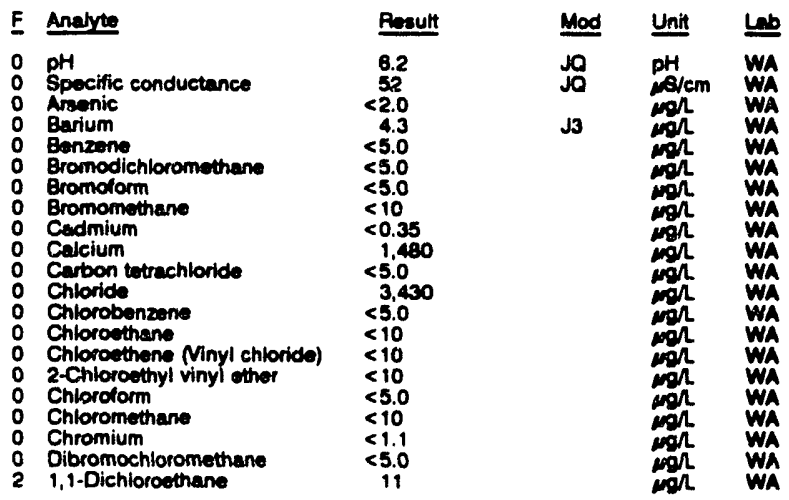




\section{ANALYTICAL RESULTS}

WELL LFW O1C collected on 09/08/92, laboratory analyeese (cont)

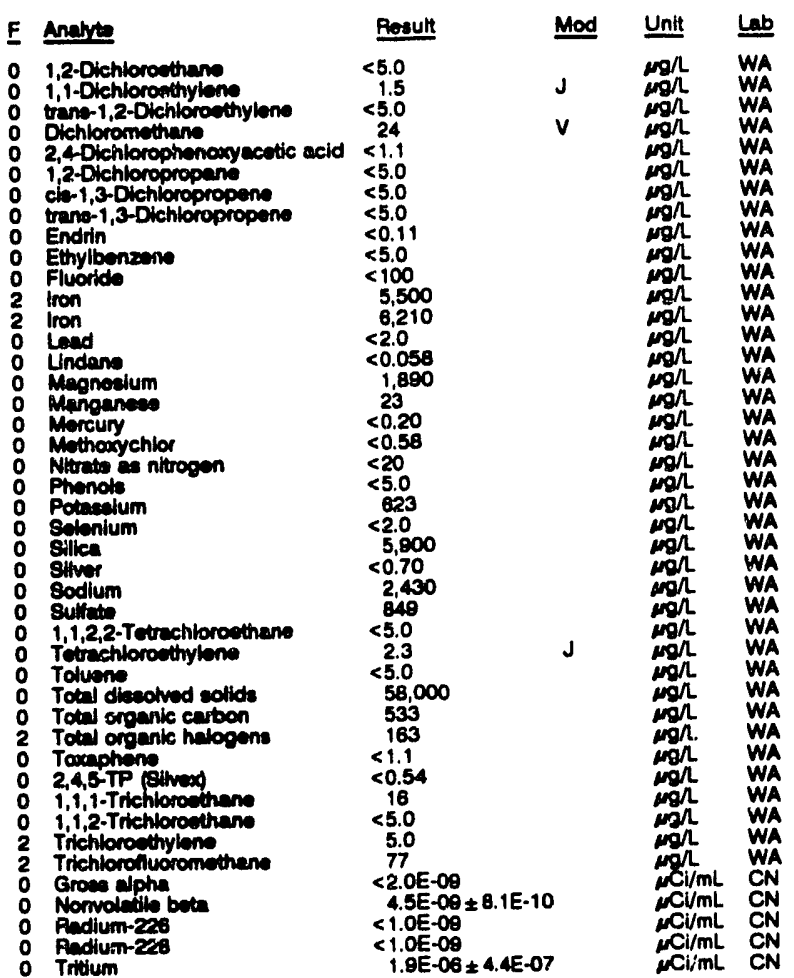

\section{WELL LFW 61D}

MEASUREMENTS CONDUCTED IN THE FIELD

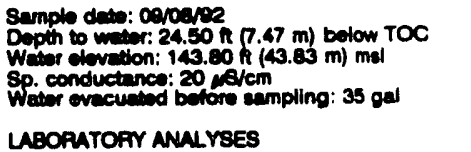

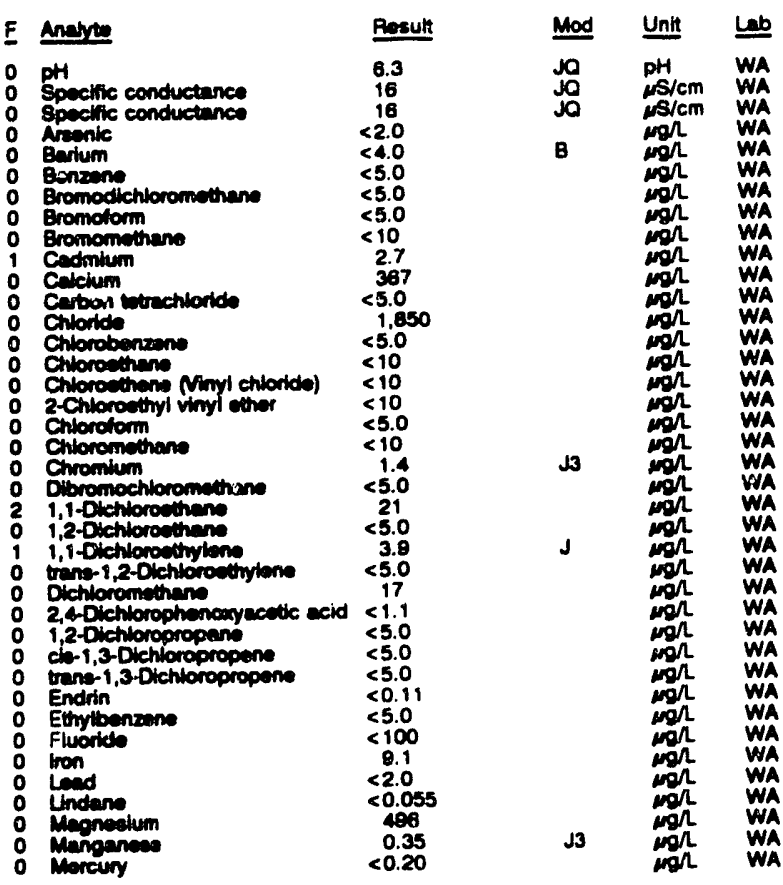

WELL LFW 610 collected on 09/08/92, laboratory analyees (cont)

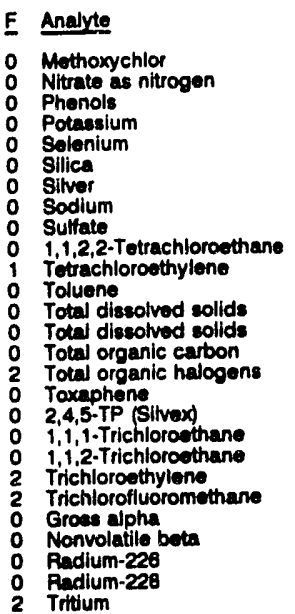

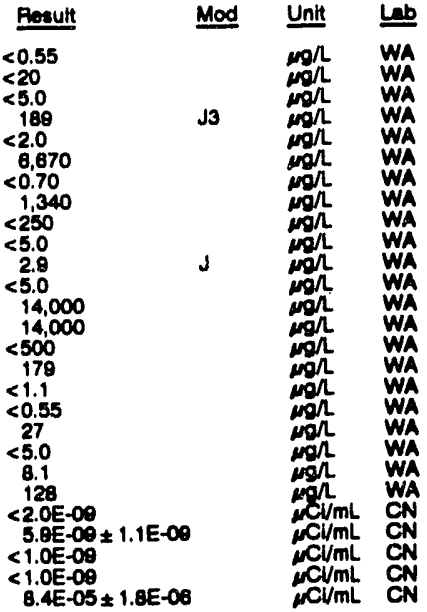

\section{WELL LFW 62B}

MEASUREMENTS CONDUCTED IN THE FIELD

Sumple date: $09 / 08 / 92$

Depth to water: 22.73 it $(0.23 \mathrm{~m})$ bolow TOC

Water elevation: 142.17 it $(43.3$

Sp. conductanco: $38 \mathrm{rS} / \mathrm{cm}$.

PH: 4.4 . $0 \mathrm{mgn}$

Water temperafure: $18.0^{\circ} \mathrm{C}$

LABOPATORY ANALYSES

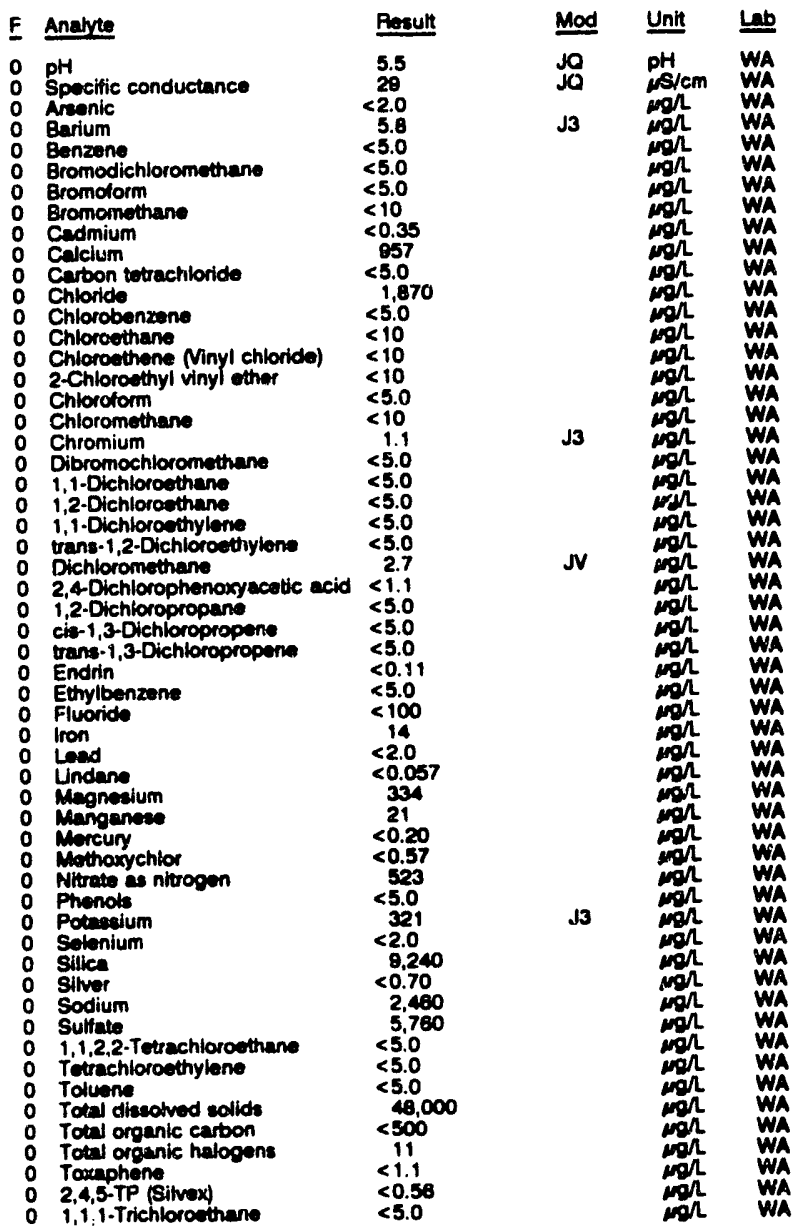


ANALYTICAL RESULTS

WELL LFW 628 collectiod on 00/08/92, laboratory analyees (cont'

\begin{tabular}{|c|c|c|}
\hline F Analyte & Pesult & Unit \\
\hline 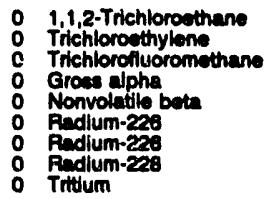 & $\begin{array}{l}<5.0 \\
<5.0 \\
<5.0 \\
6.0 E-00 \pm 8.1 E-10 \\
1.2 E-00 \pm 1.2 E-00 \\
1.8 E-00 \pm 4.0 E-10 \\
3.0 E-00 \pm 5.3 E-10 \\
1.4 E-00 \pm 5.1 E-10 \\
<7.0 E-07=10\end{array}$ & 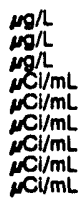 \\
\hline
\end{tabular}

\section{WELL LFW 62C}

MEASUREMENTS CONDUCTED IN THE FIEL

Sample date: 0e/0erez Depth to watior: $22.70 \mathrm{n}(6.95 \mathrm{~m})$ below TOC Sp. conductance: $35 \mathrm{\mu S} / \mathrm{cm}$ Witar ovecuated bafore sampling: 81 gal LAOPATOFY ANALYES

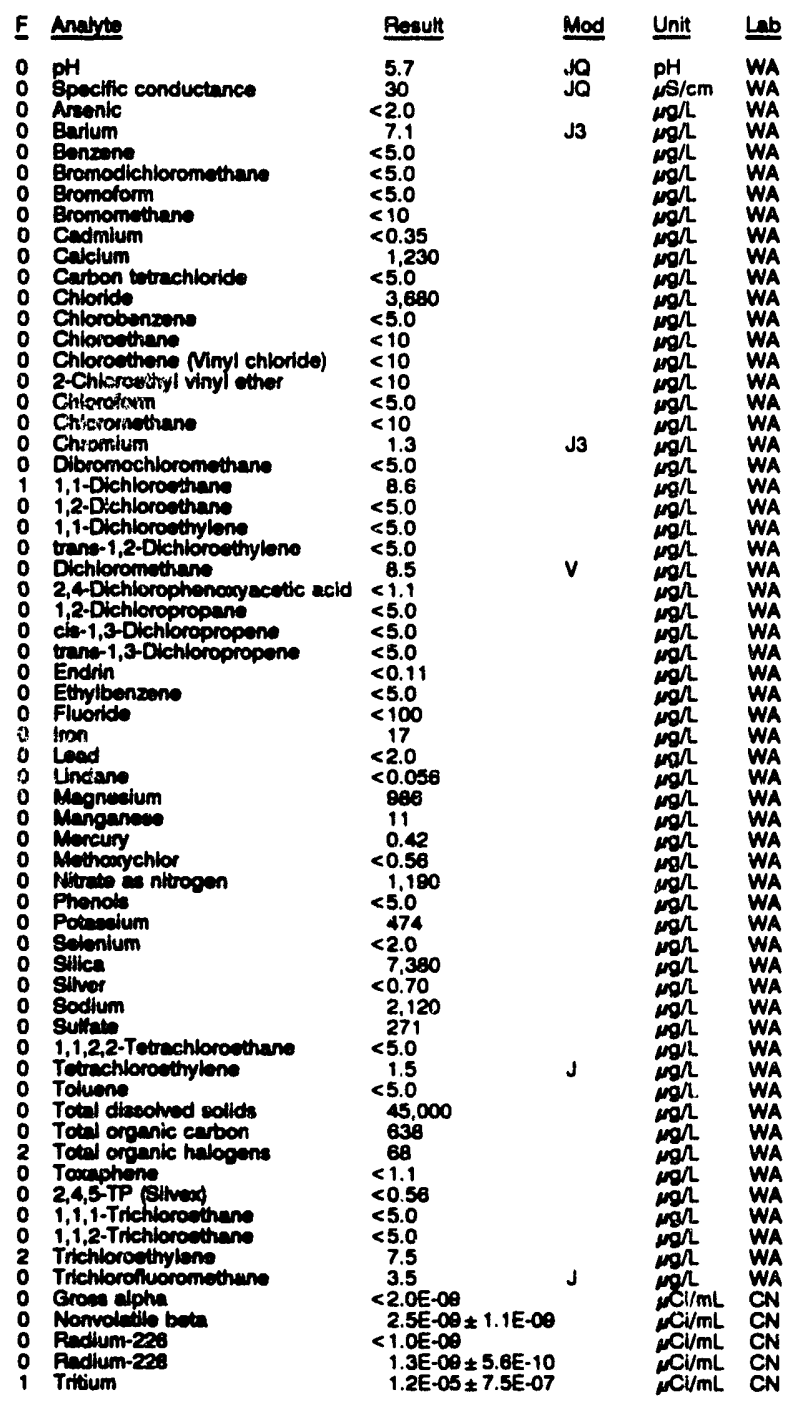

\section{WELL LFW 62D}

MEASUREMENTS CONDUCTED IN THE FIELD

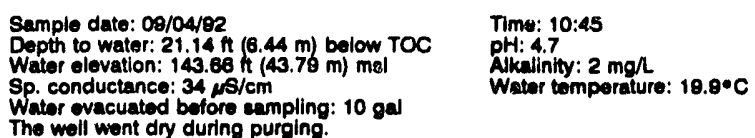
The well went dry during purging.

LABORATORY ANALYSES

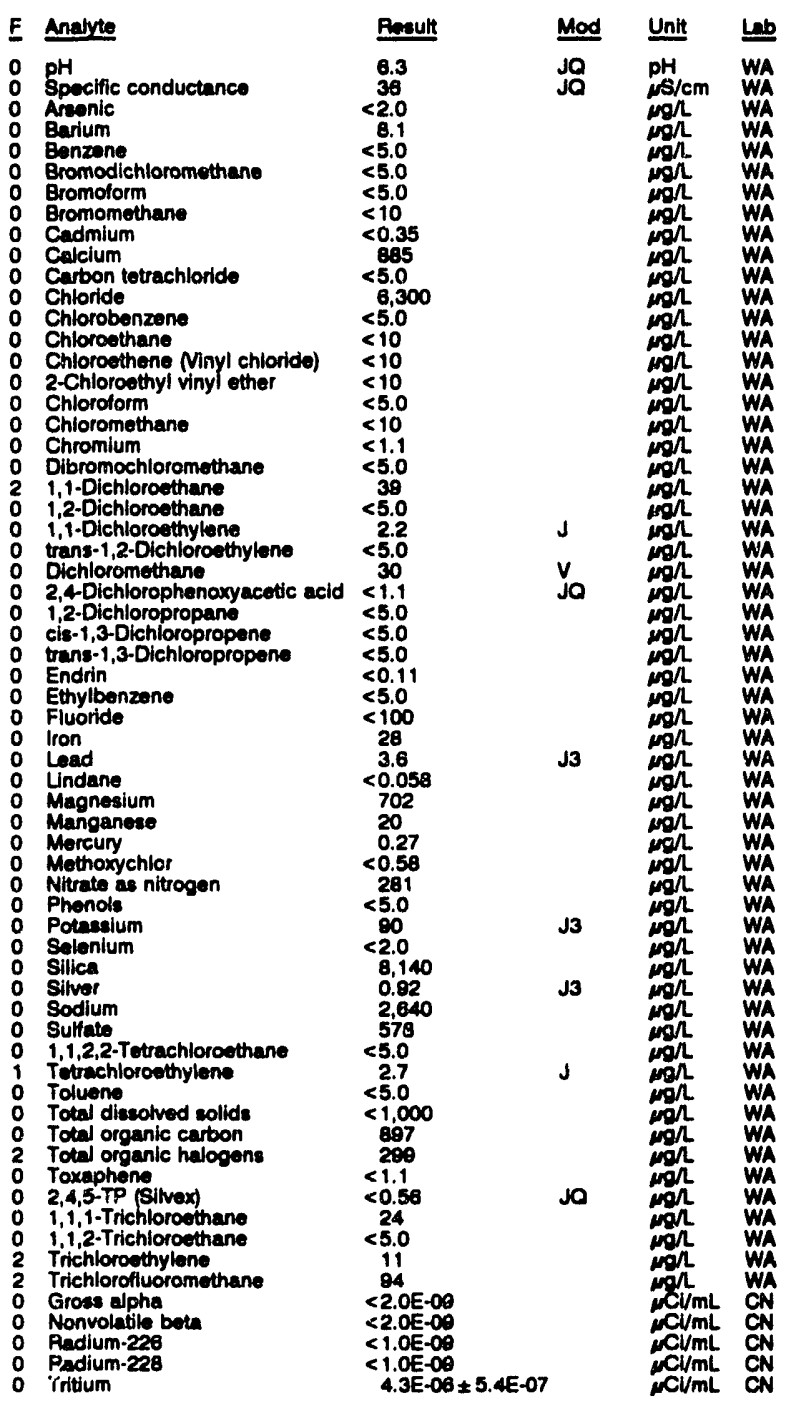

WELL LRP 1

MEASUAEMENTS CONDUCTED IN THE FIELD

Sample date: 07/03/92

Dopth to water: $42.15 \mathrm{H}(12.85 \mathrm{~m})$ below TOC

Water elovation: $210.75 \mathrm{~h}(84.24 \mathrm{~m}) \mathrm{mal}$

Sp. conductance: $24 \mu \mathrm{S} / \mathrm{cm}$.

LABORATOAY ANALYSES
$E$ Analyze
Pesult
Mod Unit Leb
0 Load
7.4
woh GE

Time: 13:30

Nkalinity: $0 \mathrm{mgh}$

Water temperature: $21.1 \cdot \mathrm{C}$ 
WELL LRP 2

MEABUAEMENTS CONDUCTED IN THE FIELD

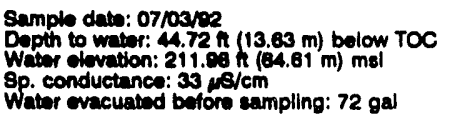
LABOPUTORY ANML YSES

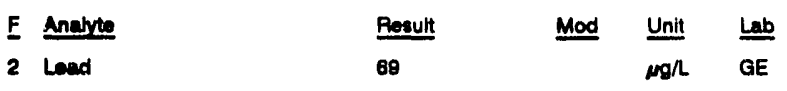

WELL LRP 3

MEASUREMENTS CONOUCTED IN THE FIELD
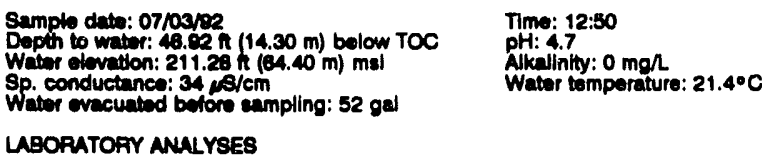

Alkalinity: $0 \mathrm{mon}$

Water tomperature: $21.4^{\circ} \mathrm{C}$

LABORATOFY ANALYSES

\begin{tabular}{|c|c|c|c|}
\hline F Analute & Rosult & Mod & Unit \\
\hline 2 Lead & 17 & & $\mu / L$ \\
\hline
\end{tabular}

WELL LRP 4

MEASUREMENTS CONDUCTED IN THE FIELD

Sumple deto: 07 Map

Depth to water: $45.13 \mathrm{n}(13.78 \mathrm{~m})$ below TOC

Wathe of ovation: $210.47 \mathrm{~h}(34.15 \mathrm{~m}) \mathrm{msl}$

8p. conductence: 20 is/cm

Time: 13:45

Alkalinity: 1 mon

Water temperature: $21.4^{\circ} \mathrm{C}$

Watus evecuated before eampling: $88 \mathrm{gal}$

LABORATOAY ANALYSES

\begin{tabular}{|c|c|c|c|}
\hline E Analute & Result & Mod & Unit \\
\hline Lead & $<3.0$ & & $\mathrm{~mol}$ \\
\hline
\end{tabular}

WELL LSB 1

MEASUREMENTS CONOUCTED IN THE FIELD

Sample detar ceramen

Depth to whtor: $21.07 \mathrm{~h}(8.42 \mathrm{~m})$ below TOC Wepth to water: $21.07 \mathrm{~h}(3.42 \mathrm{~m})$ below Toc Sp. conductance: $23 \mathrm{~s} / \mathrm{cm}$. 50 get LAEORATOFY AMALYES

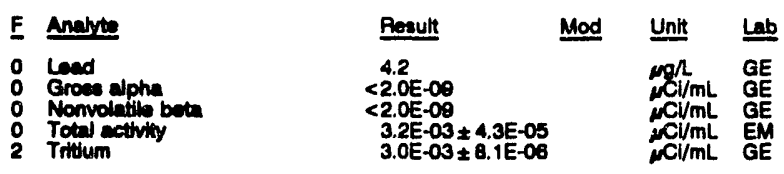

WELL LSB 2

MEASUREMENTS CONOUCTEO IN THE FIELD

\begin{tabular}{|c|c|c|c|c|c|}
\hline \multicolumn{3}{|c|}{ 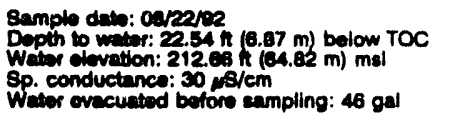 } & \multicolumn{3}{|c|}{$\begin{array}{l}\text { Time: } 13: 05 \\
\text { pH: } 4.3 \\
\text { Alkalinity: } 0 \mathrm{mg} / \\
\text { Water temperature: } 23.6^{\circ} \mathrm{C}\end{array}$} \\
\hline \multicolumn{6}{|c|}{ LABORATOPY ANALYSES } \\
\hline $\boldsymbol{F}$ & Aneste & Result & Mod & Unit & Lab \\
\hline & $\begin{array}{l}\text { Lead } \\
\text { Groes alphn } \\
\text { Nonvolatil beta } \\
\text { Tittium }\end{array}$ & $\begin{aligned} 9.5 \\
<2.0 \mathrm{E}-00 \\
<2.0 \mathrm{E}-00 \\
4.3 \mathrm{E}-0 \mathrm{0}\end{aligned}$ & DE-07 & 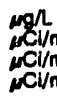 & $\begin{array}{l}\mathrm{GE} \\
\mathrm{GE} \\
\mathrm{GE} \\
\mathrm{GE}\end{array}$ \\
\hline
\end{tabular}

Time: 13:15

Akalinity: $0 \mathrm{mon}$

Water temperature: $21.0^{\circ} \mathrm{C}$

Time: 12:20

PH: 4.6 inity: $0 \mathrm{mgh}$

Water temperafure: $21.4^{\circ} \mathrm{C}$
WELL LSB 3

MEASUREMENTS CONDUCTED IN THE FIELD

$\begin{array}{ll}\text { Sample date: } 08 / 22 / 92 & \text { Time: } 13: 50 \\ \text { Depth to water: } 17.31 \mathrm{Ht}(5.28 \mathrm{~m}) \text { below TOC } & \text { pH: } 4.6 \\ \text { Water elevation: } 219.09 \mathrm{Ht}(68.78 \mathrm{~m}) \mathrm{ms} & \text { Alkalinity: } 0 \mathrm{mg} / \mathrm{L} \\ \text { Sp. conductance: } 20 \mu \mathrm{cm} / \mathrm{cm} & \text { Water temperature: } 22.7 \circ \mathrm{C} \\ \text { Water evacuated before sampling: } 59 \mathrm{gal} & \end{array}$

\begin{tabular}{|c|c|c|c|}
\hline Analyte & Result & Mod & Unit \\
\hline $\begin{array}{l}\text { Load } \\
\text { Groas alpha } \\
\text { Nonvolatile beta } \\
\text { Tritium }\end{array}$ & $\begin{array}{l}r .5 \\
<2.0 \mathrm{E}-09 \\
<2.0 \mathrm{0}-09 \\
1.0 \mathrm{E}-05 \pm 7.0 \mathrm{DE}-07\end{array}$ & & 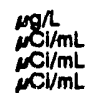 \\
\hline
\end{tabular}

WELL LSB 4

MEASUREMENTS CONDUCTED IN THE FIELD

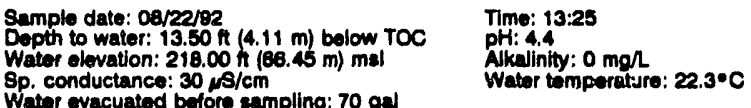

Sp. conductance: $30 \mu \mathrm{s} / \mathrm{cm}$

Water evacuated before sampling: $70 \mathrm{gal}$

LABORATORY ANALYSES

\begin{tabular}{|c|c|c|c|}
\hline F Analyte & Rosult & Mod & Unit \\
\hline $\begin{array}{ll}0 & \text { Load } \\
0 & \text { Groas alpha } \\
0 & \text { Nonvolapilie bota } \\
0 & \text { Total activity } \\
2 & \text { Tritium }\end{array}$ & $\begin{array}{l}6.0 \\
<2.0 E-09 \\
<2.0 \mathrm{E}-09 \\
2.4 \mathrm{E}-03 \pm 3.8 \mathrm{EE}-05 \\
2.3 \mathrm{E}-03 \pm 7.0 \mathrm{0E}-06\end{array}$ & & 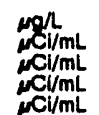 \\
\hline
\end{tabular}

WELL MCB 2

MEASUREMENTS CONDUCTED IN THE FIELD

Sample date: 07/27/92

Water olevation: $223.37 \mathrm{ft}(68.08 \mathrm{~m}) \mathrm{mal}$

Sp. conductance: $28 \mu \mathrm{s} / \mathrm{cm}$

Water evacuated before sampling: $16 \mathrm{gal}$

pH: 5.8

Alkalinity: $6 \mathrm{mg}$.

Water temperature: $20.6^{\circ} \mathrm{C}$

LABORATORY ANALYSES

F Analyce

- Aluminum

Benzene

Bromoform

Bromomethane

Carbon tetrachloride

Chlorobenzene

Chloroethane

Chloroethene Minyl chloride)

2-Chloroethyl vinyl ether

Chloroform

Chloromethane

Dibromochloromethane

1,1-Dichloroethene

1,2-Dichloroethane

1,1-Dichloroethylene

Dichloromethane

1,2-Dichloropropano

cis-1,3-Dichloropropene

trans-1,3-Dichloropene

Ethylbenzone

Load

Lithium

Manganese

Mercury

Nickol

1,1,2,2-Tetrachloroethan

Tetrach

Toluene

1,1,1-Trichloroethene

i,1,2-Trichloroeth

Trichlorofluorome

Groess alpha

Nonvolatile bete

Total alpha-emiting radium

Total apha-emitting radium

Tritium

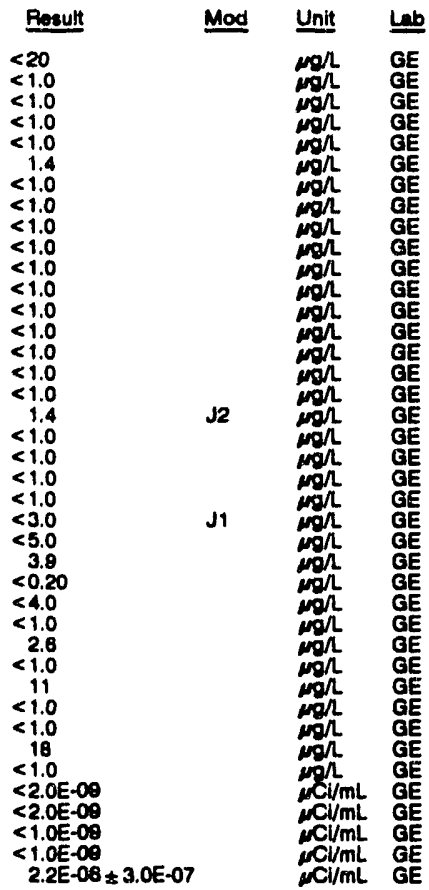


ANALYTICAL RESULTS

WELL MCB 4

MEASUREMENTS CONDUCTED IN THE FIELD

Sample date: 07/27/82 Dpth to water: $126.81 \mathrm{n}(38.85 \mathrm{~m})$ bolow TOC Sp. conductance: $14 \mu 8 / \mathrm{cm}$

Water evacuated bufore eampling: $13 \mathrm{gal}$ The woll went dry during purging.

LABORATOFY ANALYES

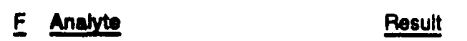

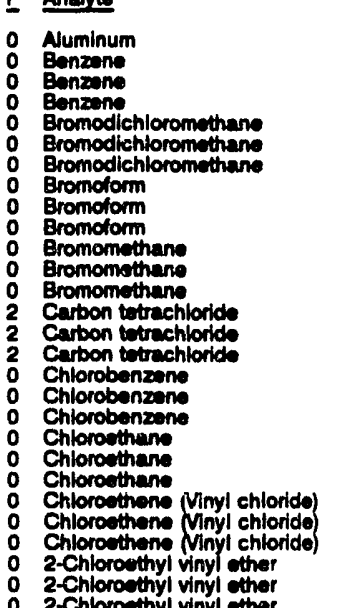

2-Chloroethyl vinyl ether

Chloroform

Chloroform

Chloromethane

Chloromethane

Dibromochloromethane

Dibromochloromethane

Dibromochloromethan

1,1-Dichlorowthan

1,1-Dichlorothen

1,1-Dichloroethane

o 1,2-Dichloroethane

1,2-Dichloroethane

1,1-Dichloroethylene

1,1-Dichlorosthylene

- trans-1,2-Otchloroethylene

trane-1,2-Dichloroethylene

Dichloromethan

Dichloromethan

1,2-Dichloropropane

1,2-Dichloropropane

1,2-Dichloropropane

cla-1,3-Dichloropropene

o ci-1,3-Dichloropropene

trans-1,3-Dichloropropene

o trane-1,3-Dichloropropene

trans-1,3-Dichloropropene

o Ethylbenzene

Ethylbonzone

Lead

Lithium

O Manganea

1,1,2,2-Tetrachloroethane

1,1,2,2-Tetrachloroethane

1,1,2,2-Tetrachloroethane

Tetruchloroethylome

Tetrechloroethylion

o Tolven

o Tolwene

2 Total organic halogens

1,1,1-Tilehloroethene

o 1,1,1-Trichlorothen

o i,1,1-Trichloromenthe

o 1,1,2-Trichtorothere

o 1,1,2-Trichlorowethare

o 1,1,2-Triehloroethan

2 Trichloroethylone

Trichlorosthylene
Trichioroethylene
WELL MCB 4 collectod on 07/27/92, taboratory analyese (cont)

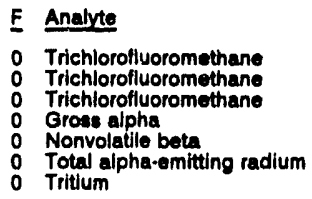

\begin{tabular}{|c|c|c|}
\hline Rosult & Mod & Unit \\
\hline $\begin{array}{l}<5.0 \\
<5.0 \\
<5.0 \\
2.7 E-09 \pm 1.5 E-09 \\
2.6 E-09 \pm 1.5 E-09 \\
1.7 E-09 \pm 7.0 E-10\end{array}$ & & 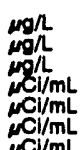 \\
\hline
\end{tabular}

WELL MCB 5

MEASUREMENTS CONDUCTED IN THE FIELD

Sample date: 08/13/82

Depth to water: $115.01 \mathrm{ft}(35.06 \mathrm{~m})$ below TOC

Water elovation: 224.59 it 168.44

Sp. conductance: $47 \mathrm{\mu s} / \mathrm{cm}$. $40 \mathrm{~m}$ mol

PH: 6.8 : $18 \mathrm{mg}$

Alkalinity: $18 \mathrm{mgh}$. $22.1 \circ \mathrm{C}$

LABORATORY ANALYSES

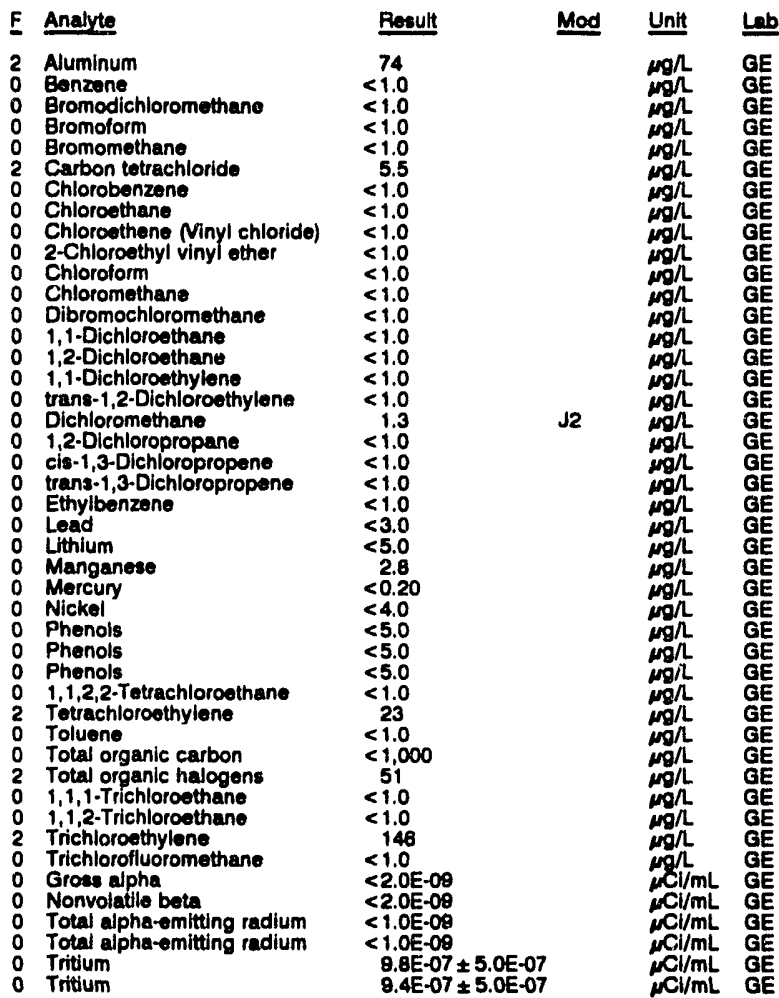

WELL MCB 5C

MEASUREMENTS CONDUCTED IN THE FIELD

Sample date: 08/14/92

Depth te water: $144.45 \mathrm{n}(44.03 \mathrm{~m})$ below TOC

Water olevation: $194.65 \mathrm{ft}(59.33 \mathrm{~m}) \mathrm{msl}$

Water evacuatod before sampling: $14 \mathrm{gal}$

Water tomperature: $18.8^{\circ} \mathrm{C}$

The well went dry during purging.

LABORATORY ANALYSES

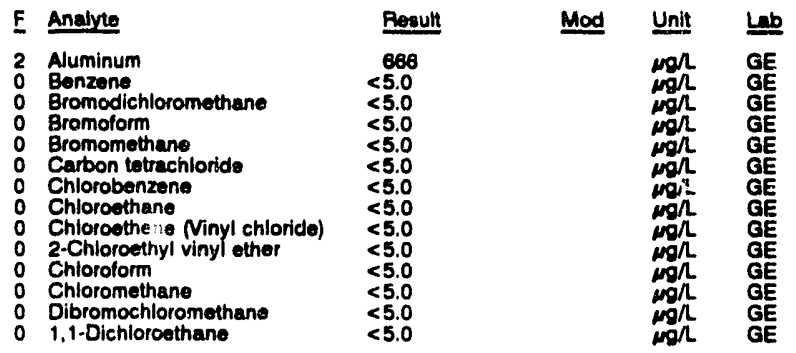


WELL MCE SC collocted on OQ/1492, Iaboratory analycese (cont)

\begin{tabular}{|c|c|c|c|c|}
\hline$F$ & Analyte & Bosult & Mod & Unit \\
\hline $\begin{array}{l}0 \\
0 \\
2 \\
0 \\
0 \\
0 \\
0 \\
0 \\
0 \\
2 \\
0 \\
2 \\
2 \\
0 \\
0 \\
0 \\
2\end{array}$ & 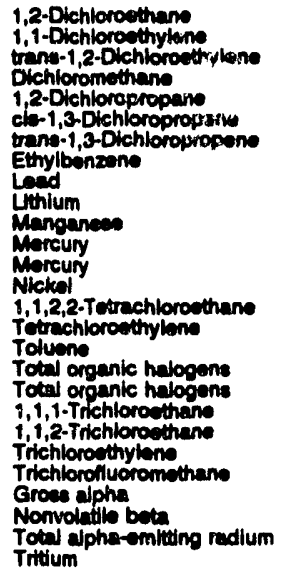 & $\begin{array}{l}<5.0 \\
<5.0 \\
<5.0 \\
17 \\
<5.0 \\
<5.0 \\
<5.0 \\
<5.0 \\
<3.0 \\
610 \\
<2.0 \\
<0.20 \\
<0.20 \\
<4.0 \\
<5.0 \\
24 \\
43 \\
89 \\
93 \\
<5.0 \\
<5.0 \\
134 \\
<5.0 \\
3.7 E-09 \pm 1.2 E-00 \\
4.7 E-08 \pm 1.8 E-00 \\
3.1 E-09 \pm 5.0 E-10 \\
<7.0 E-07\end{array}$ & $\sqrt{2}$ & 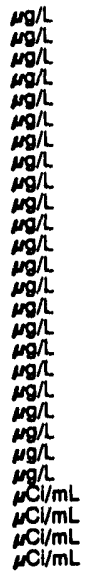 \\
\hline
\end{tabular}

WELL MCB 6

MEASUREMENTS CONDUCTED IN THE FIELD

Sample date: 07/27/me

Depth to water: $113.15 \mathrm{ft}(34.49 \mathrm{~m})$ below TOC

Water elevation: $218.95 \mathrm{n}(68.74 \mathrm{~m}) \mathrm{mal}$

Sp. conductance: $31 \mathrm{~N} / \mathrm{cm}$

Whater wacuated before eampling: 6 gal

$\mathrm{pH}: 8.5$

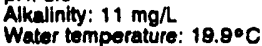

LABOPATOFY ANALYES

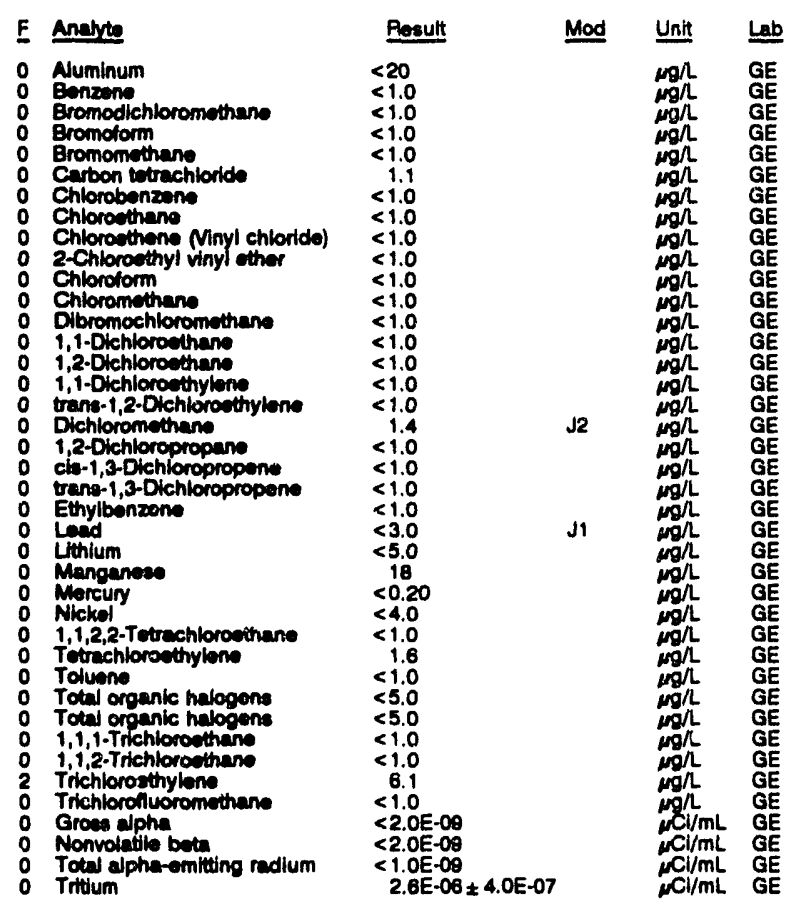

\section{WELL MCB 6C}

MEASUREMENTS CONDUCTED IN THE FIELD

Sample date: 07/28/92

Dopth to water: 138.68 in $(41.86 \mathrm{~m})$ bolow TOC

mil: 6.3

Akalinity: $18 \mathrm{mg} / \mathrm{h}$

Water wacuated bofore eampling: $80 \mathrm{gal}$

LABORATORY ANALYSES

E Analyte

1 Aluminum

Benzene

Bromodichloromethene

Bromolorm

Carbon totracehtoride

Chlorobenzene

Chorothane

2-Chloroethyl vinyl ether

Chloroform

O Chloromothane

1,1-Dichloroethene

1,2-Dichlorosthane

trans-1,2-Dichloroethylene

1,2-Dichloropropane

trans-1,3-Dichloropropene

Ethylbenzene

Lead

I Manganeso

0 Nickol

1,1,2,2-Tetrachlorcethane

Totrachloroethylene

Toluene

Total organic halogene

1,1,1-Trichloroethane

1,1,2.Trichloroethan

Trichlorofluoromethane

0 Gross ulpha

Nonvolatile bet

Total alpha-emitting radium

Total alpha-emitting radium

$\begin{aligned} & \text { Result } \\ & 32 \\ &<1.0 \\ &<1.0 \\ &<1.0 \\ &<1.0 \\ &<1.0 \\ &<1.0 \\ &<1.0 \\ &<1.0 \\ &<1.0 \\ &<1.0 \\ &<1.0 \\ &<1.0 \\ &<1.0 \\ &<1.0 \\ &<1.0 \\ &<1.0 \\ & 1.2 \\ &<1.0 \\ &<1.0 \\ &<1.0 \\ &<1.0 \\ &<3.0 \\ & 5.4 \\ & 260 \\ &<0.20 \\ &<4.0 \\ &<1.0 \\ &<1.0 \\ &<1.0 \\ &<5.0 \\ &<1.0 \\ &<1.0 \\ & 11.4 \\ &<1.0 \\ &<2.0 E-09 \\ & 2.0 E-09 \pm 1.5 E-09 \\ &<1.0 E-09 \\ &<1.0 E-09 \\ &<7.0 E-07 \\ &\end{aligned}$

Mod Unit

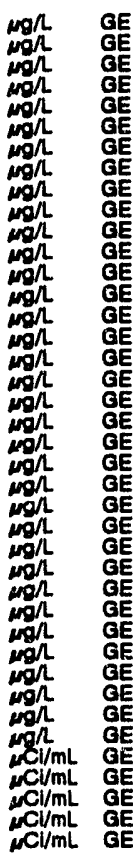

WELL MCB 7C

MEASUREMENTS CONDUCTED IN THE FIELD

Sample date: 08/14/92 $\mathrm{H}(43.81 \mathrm{~m})$ bolow TOC

Water elevation: $193.86 \mathrm{ft}(58.12 \mathrm{~m}) \mathrm{ms}$.

Sp. conductance: $3040 \mu \mathrm{s} / \mathrm{cm}$

Water evacuatod before sampling: $14 \mathrm{gal}$
The woll went dry during purging.

LABORATORY ANALYSES

\begin{tabular}{|c|c|c|c|c|}
\hline \multicolumn{5}{|l|}{ LABORATORY ANALYSES } \\
\hline E Analyte & Bosult & Mod & Unit & Lي \\
\hline 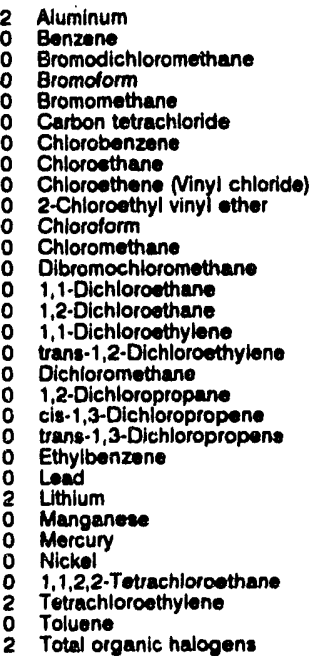 & $\begin{aligned} & 4.600 \\
&<1.0 \\
&<1.0 \\
&<1.0 \\
&<1.0 \\
&<1.0 \\
&<1.0 \\
&<1.0 \\
&<1.0 \\
&<1.0 \\
&<1.0 \\
&<1.0 \\
&<1.0 \\
&<1.0 \\
&<1.0 \\
&<1.0 \\
&<1.0 \\
& 1.4 \\
&<1.0 \\
&<1.0 \\
&<1.0 \\
&<1.0 \\
& 4.4 \\
& 1.5 \\
&<6.0 \\
&<0.20 \\
&<1.2 \\
&<1.0 \\
& 27 \\
&<1.0 \\
& 54\end{aligned}$ & & 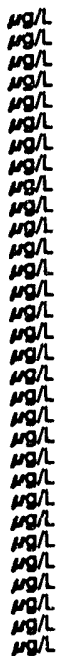 & $\begin{array}{l}G E \\
G E \\
G E \\
G E \\
G E \\
G E \\
G E \\
G E \\
G E \\
G E \\
G E \\
G E \\
G E \\
G E \\
G E \\
G E \\
G E \\
G E \\
G E \\
G E \\
G E \\
G E \\
G E \\
G E \\
G E \\
G E \\
G E \\
G E \\
G E \\
G E \\
G E\end{array}$ \\
\hline
\end{tabular}

Time: $7: 40$

PH: 12.0 . 755 mon Alkalinity: $755 \mathrm{mg} /$. $10.5^{\circ} \mathrm{C}$ 
WELL MCB 7C colloctad on 08/14/92, laboratory analyses (cont.)

\begin{tabular}{|c|c|c|c|c|}
\hline $\mathbf{E}$ & Anatyte & Pesult & Mod & Unit \\
\hline $\begin{array}{l}0 \\
2 \\
0 \\
0 \\
0 \\
0\end{array}$ & $\begin{array}{l}\text { 1,1,1-Trichloroethane } \\
\text { 1,1,2-Trichloroethan } \\
\text { Trichloroethylene } \\
\text { Trichlorofluoromethane } \\
\text { Groes dpha } \\
\text { Nonvolatile beta } \\
\text { Total alpha-emitting radium } \\
\text { Total alpha-emitting radium } \\
\text { Trittum }\end{array}$ & $\begin{aligned}<1.0 \\
<1.0 \\
82 \\
<1.0 \\
3.5 E-09 \pm 1.1 E-09 \\
5.0 E-09 \pm 1.1 E-09 \\
1.6 E-09 \pm 5.0 E-10 \\
1.4 E-09 \pm 5.0 \mathrm{E}-10 \\
1.9 \mathrm{E}-00 \pm 5.0 \mathrm{E}-07\end{aligned}$ & & 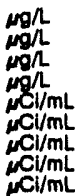 \\
\hline
\end{tabular}

WELL MGA 36

MEASUREMENTS CONDUCTED IN THE FIELD

Semple date: 07/27/92

Time: 12:15

The woll wa: dry.

\section{WELL MGC 9}

MEASUREMENTS CONDUCTED IN THE FIELD

\begin{tabular}{|c|c|c|c|c|c|}
\hline \multicolumn{3}{|c|}{$\begin{array}{l}\text { Sample date: } 07 / 27 / 92 \\
\text { Dopth to wator: } 54.00 \mathrm{ft}(16.48 \mathrm{~m}) \text { below TOC } \\
\text { Water elevation: } 230.10 \mathrm{~h}(70.14 \mathrm{~m}) \mathrm{msl} \\
\text { Sp. conductance: } 204 \mathrm{~s} / \mathrm{cm} \\
\text { No water was evacuated before sampling. }\end{array}$} & \multicolumn{3}{|c|}{$\begin{array}{l}\text { Time: } 10: 30 \\
\text { pH: } 5.3\end{array}$} \\
\hline \multicolumn{6}{|c|}{ LABORATOFY ANALYSES } \\
\hline- & Analyte & Result & Mod & Unit & \\
\hline $\begin{array}{l}0 \\
0 \\
0 \\
2\end{array}$ & $\begin{array}{l}\text { Grons apha } \\
\text { Nonvoladile beta } \\
\text { Total activity } \\
\text { Trittum }\end{array}$ & $\begin{array}{l}5.9 \mathrm{E}-09 \\
8.6 \mathrm{E}-09 \\
2.1 \mathrm{E}-02 \\
2.1 \mathrm{E}-02\end{array}$ & $\begin{array}{l}=-09 \\
=-09 \\
=-04 \\
=-05 \\
=-05\end{array}$ & $\begin{array}{c}\mathrm{Cl} / \mathrm{mL} \\
\mathrm{Cl} / \mathrm{mL} \\
\mathrm{Cl} / \mathrm{mL} \\
\mathrm{Cl} / \mathrm{mL}\end{array}$ & \\
\hline
\end{tabular}

\section{WEUL MGC 11}

MEASUREMENTS CONDUCTEO IN THE FIELO

Sample dats: 07/27/12

Time: 10:45

The woll was dry.

WELL MGC 19

MEASUREMENTS CONOUCTED IN THE FIELD

\begin{tabular}{|c|c|c|c|c|c|}
\hline \multicolumn{3}{|c|}{ 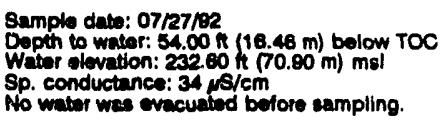 } & \multicolumn{3}{|c|}{$\begin{array}{l}\text { Time: } 13: 55 \\
\text { pH: } 5.1\end{array}$} \\
\hline \multicolumn{6}{|c|}{ MBOAATOFY ANALYSES } \\
\hline & Analyte & Rosult & Mod & Unit & \\
\hline & $\begin{array}{l}\text { Groes alpha } \\
\text { Nonvolatile beta } \\
\text { Tritum }\end{array}$ & $\begin{array}{l}1.2 E-0 \\
1.7 E-0 \\
8.0 E-0\end{array}$ & $\begin{array}{l}2 E \cdot 09 \\
5 E \cdot 09 \\
4 E-06\end{array}$ & $\underset{\substack{\omega \\
\mathrm{N} \mathrm{Cl} / \mathrm{mL} \\
\mathrm{NCi} / \mathrm{mL}}}{\mathrm{m}}$ & \\
\hline
\end{tabular}

WELL MGC 23

MEASUREMENTS CONDUCTED IN THE FIELD

Sample date: 07/27/82 Time: 13:25

The well was dry.

WELL MGC 32

MEASUREMENTS CONDUCTED IN THE FIELD

Semple date: 07/27/02

The well wes dry.
WELL MGC 36

MEASUAEMENTS CONDUCTED IN THE FIELD

Sample date: $07 / 27 / 02$

Depth to water: 61.00 $\mathrm{ft}(18.59 \mathrm{~m})$ below TOC

Water elevation: $235.60 \mathrm{H}(\mathbf{7 1 . 8 1} \mathrm{m}) \mathrm{ms}$

No water was ovacuated belore sampling.

Water temperature: $22.5^{\circ} \mathrm{C}$

LABORATORY ANALYSES

\begin{tabular}{|c|c|c|c|}
\hline Analyte & Plesult & Mod & Unlt \\
\hline $\begin{array}{ll}1 & \text { Groses alpha } \\
0 & \text { Nonvolatilo beta } \\
0 & \text { Total activity } \\
2 & \text { Tritlum }\end{array}$ & $\begin{array}{l}1.2 \mathrm{E}-0 \\
1.5 \mathrm{E}-0 \\
1.8 \mathrm{E}-0 \\
1.8 \mathrm{E}-0\end{array}$ & & $\begin{array}{l}\mathrm{NCl/mL} \\
\mathrm{NCl/mL} \\
\mathrm{N} \mathrm{Cl/mL} \\
\mathrm{NCl} / \mathrm{mL}\end{array}$ \\
\hline
\end{tabular}

\section{WELL MGE 9}

MEASUREMENTS CONDUCTED IN THE FIELD

$\begin{array}{ll}\text { Sample date: } 07 / 27 / 92 & \text { Time: } 14: 35 \\ \text { Depth to water: } 54.70 \mathrm{Ht}(16.67 \mathrm{~m}) \text { below TOC } & \text { pH:5.8 } \\ \text { Water elevation: } 228.80 \mathrm{~h}(69.77 \mathrm{~m}) \mathrm{msl} & \text { Water temperature: } 24.6^{\circ} \mathrm{C} \\ \text { Sp. conductance: } 81 \mu \mathrm{s} / \mathrm{cm} & \end{array}$

So. conductance: $81 \mu \mathrm{s} / \mathrm{cm}$

Water temperafure: $24.6^{\circ} \mathrm{C}$

LABORATORY ANALYSES

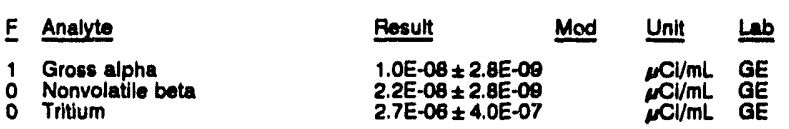

WELL MGE 21

MEASUREMENTS CONDUCTED IN THE FIELD

Sample date: 07/27/92 Time: 13:40

WELL MGE 30

MEASUAEMENTS CONDUCTED IN THE FIELD

Sample date: 07/27/92 Time: 13:35

The well was dry.

\section{WELL MGE 34}

MEASUREMENTS CONDUCTEO IN THE FIELD

Sample dato: 07/27/92

Time: $13: 00$

The well was $d r y$.

WELL MGG 15

MEASUREMENTS CONDUCTED IN THE FIELD

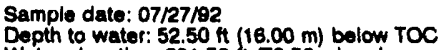

Water elevation: $231.50 \mathrm{~h}(70.56 \mathrm{~m}) \mathrm{ms}$

Sp. conductance: $60 \mu \mathrm{s} / \mathrm{cm}$

No water was evacuated before sampling.

Time: 14:20

Water temperature: $24.0^{\circ} \mathrm{C}$

LABORATORY ANALYSES

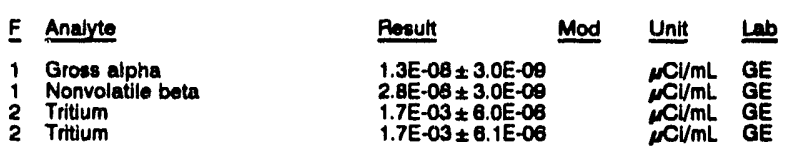


WELL MGG 19

MEASUREMENTS CONDUCTED IN THE FIELD

Sample dete: 07/27/9

Depth to wait: $34.00 \mathrm{n}(16.46 \mathrm{~m})$ below TOC

Whiter etevation: $220.00 \mathrm{t}(68.68 \mathrm{~m}) \mathrm{ms}$

Sp. conductance: 169 s/cm

Time: 14:10

Water temperature: $23.2^{\circ} \mathrm{C}$

LABORATOFY ANALYSES

\begin{tabular}{|c|c|c|c|}
\hline E Anarde & Rosult & Mod & Unit \\
\hline $\begin{array}{l}\text { Crose alpha } \\
0 \text { Nonvolatile beta } \\
\text { Trttum }\end{array}$ & $\begin{array}{l}2.8 E-0 \\
4.9 E-0 \\
8.8 E-0\end{array}$ & & $\underset{\mu \mathrm{cl} / / \mathrm{mL}}{\mathrm{\mu Cl} / \mathrm{mL}}$ \\
\hline
\end{tabular}

WELL MGG 23

MEASUREMENTS CONDUCTED IN THE FIELD

Sample date: 07/27/e

Time: 13:45

The well was dry.

\section{WELL MGG 28}

MEASUAEMENTS CONDUCTED IN THE FIELD

Sample date: 07/27/92

Water: $40.00 \mathrm{ft}(12.18 \mathrm{~m})$ below TOC

Weter elevation: $238.50 \mathrm{~h}(72.00 \mathrm{~m}) \mathrm{ms}$

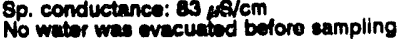

Time; 12

Water temperature: $24.0^{\circ} \mathrm{C}$

LABORATORY ANALYSES

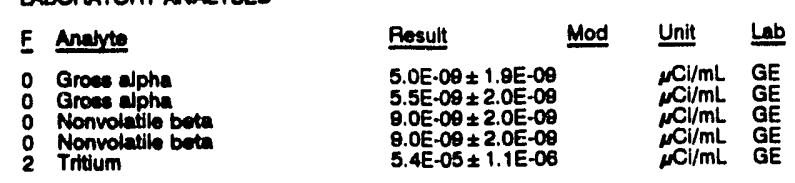

\section{WELL MGG 36}

MEASUREMENTS CONDUCTED IN THE FIELD

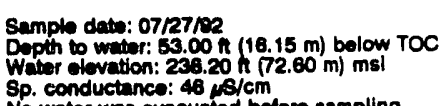

\section{Time: 12:35}

Time:

Wator temperature: $22.6^{\circ} \mathrm{C}$

No water was evecuatied before sampling

LABOPATOPY ANALYSES

\begin{tabular}{|c|c|c|}
\hline Analy te & Rosult & Unit \\
\hline $\begin{array}{l}\text { Grow alpha } \\
\text { Groes alpha } \\
\text { Nonvolatio bata } \\
\text { Nonvolatil beta } \\
\text { Totid ectivity } \\
\text { Tritium }\end{array}$ & $\begin{array}{l}4.4 E-08 \pm 6.0 E-09 \\
4.2 E-08 \pm 3.9 E-09 \\
3.5 E-08 \pm 4.2 E-09 \\
3.1 E-08 \pm 2.8 E-09 \\
3.2 E-02 \pm 2.9 E-04 \\
2.7 E-02 \pm 2.4 E-05\end{array}$ & 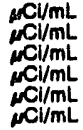 \\
\hline
\end{tabular}

WELL MSB 1B

MEASUREMENTS CONDUCTED IN THE FIELD

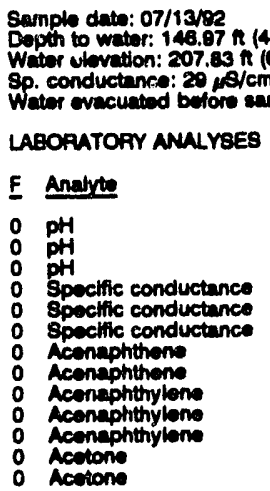

Tlme: 10:0

PH: 5.2 . $2 \mathrm{~mol}$

Water temperature: $21.4^{\circ} \mathrm{C}$
WELL MSB 18 collected on 07/13/92, laboratory analyees (cont)

E Analyte

Acetone

Acotonitrile (Methyl cyanide)

Acotonitrile Mothyl cyanido

Acotonitrile (Methyl cyanide)

Acotophenone

Acetophenone

Acetophenone

2-Acetylaminofluoren

2-Acetylaminofluoreno

Acrolein

Acrolein

Acrolein

Acrolein

o Acrylonitrile

o Acrylonitrile

Acrylonitrilo

Adrin

Allyl chloride

Alyl chloride

Alyl chiorido

Alyl chloride

Alyl chloride

Aluminum

Aluminum

4-Aminobipheny

Anlline

Anlline

Anthrecene

Anthracene

Anthracene

Antimony

Antimony

Aramito

Aramite

Aramito

Arrenic

Arronic

Barlum

Benzene

Benzene

Benzene

alpha-Benzene hexachloride

beta-Benzene hexachloride

beta-Benzeno hoxachloride

delta-Benzene hoxachloride

delta-Benzene hoxach

Benzo a anthracene

Bonzo a anthracene

Eenzo b fluorunthene

Enzo buchanthon

Benzo b fluoranthene

Benzo fluoranthene

Enzo $k$ fuoranthen

Eenzo k fluoranthene

Benzolc acid

Benzoic acid

Benzo[g,h,i]perylene

Benzo g, hi, perylene

Benzo g, hil)perylen

Benzo ajpyrens

Benzola pyrene

Benzola pyren

Bonzyl acchol

Benzyl alcohol

Bonzyl alcoho

Beryllium

Bis (2-chloroethoxy) methane

Bis 2-chloroethoxy methane

Bis(2-chlorouthoxy) math

Bis (2-chloroethyl) ether

Bis (2-chloroethyl) other

Bis(2-chloroizopropyl) ether

Bis (2-chloroleopropyl) ther

Bis (2-chlorotsopropyl) ether

Bis (2-ethylhexyl) phthalate

Bis(2-ethylhexy) phthalate

Bis(2-ethylhoxyl) phthalalo

Bromodichloromethane

Eromodichloromethane

Bromodichloromethane

Bromodichloromethane

Bromotorm

Bromolarm

Bromoform

Bromomethane

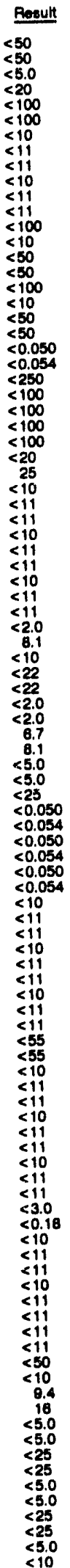

Mod Unit Lab
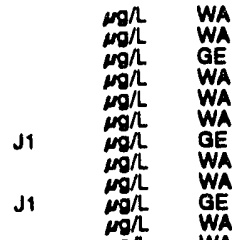

$\operatorname{mog}_{\operatorname{mog}}$

E

WA

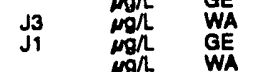

J1

Ji

$\mathfrak{J}_{\mathfrak{3}}$

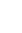

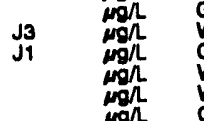

WA 
ANALYTICAL RESULTS

WELL M88 18 collectad on 07/13/92, laboratory analyses (cont.)

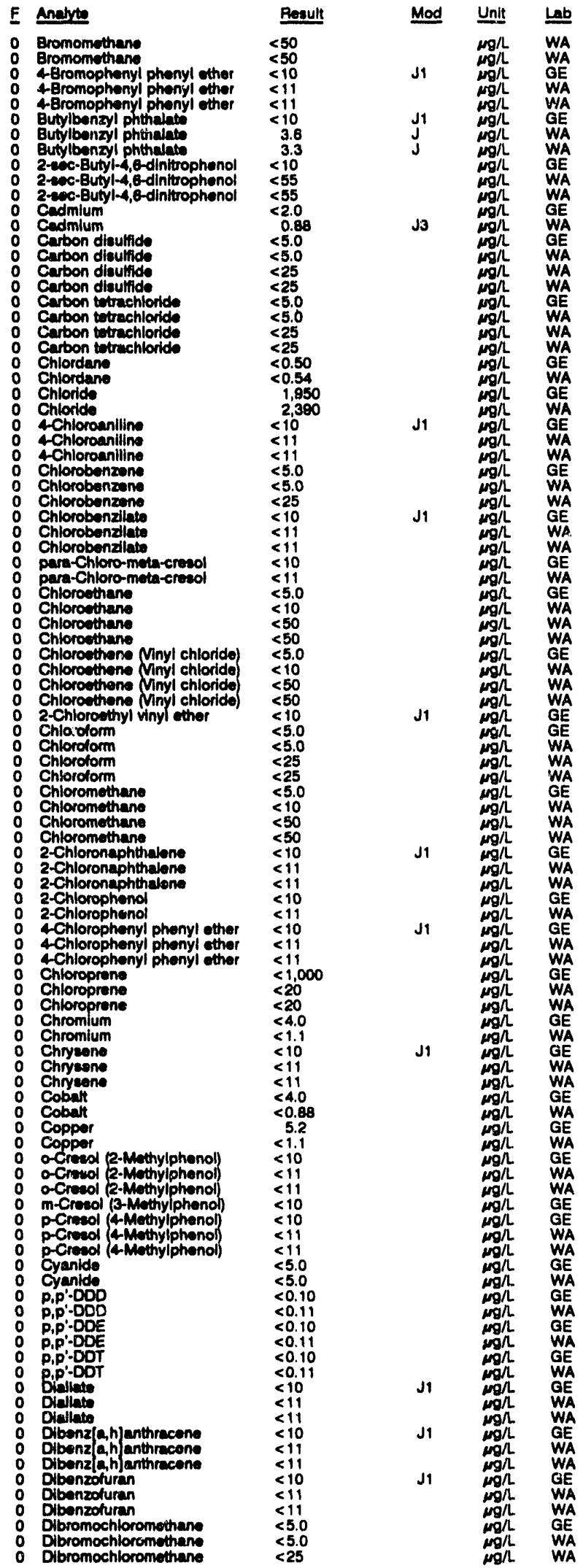

WELL MSB 18 collected on 07/13/92, laboratory analyaes (cont)

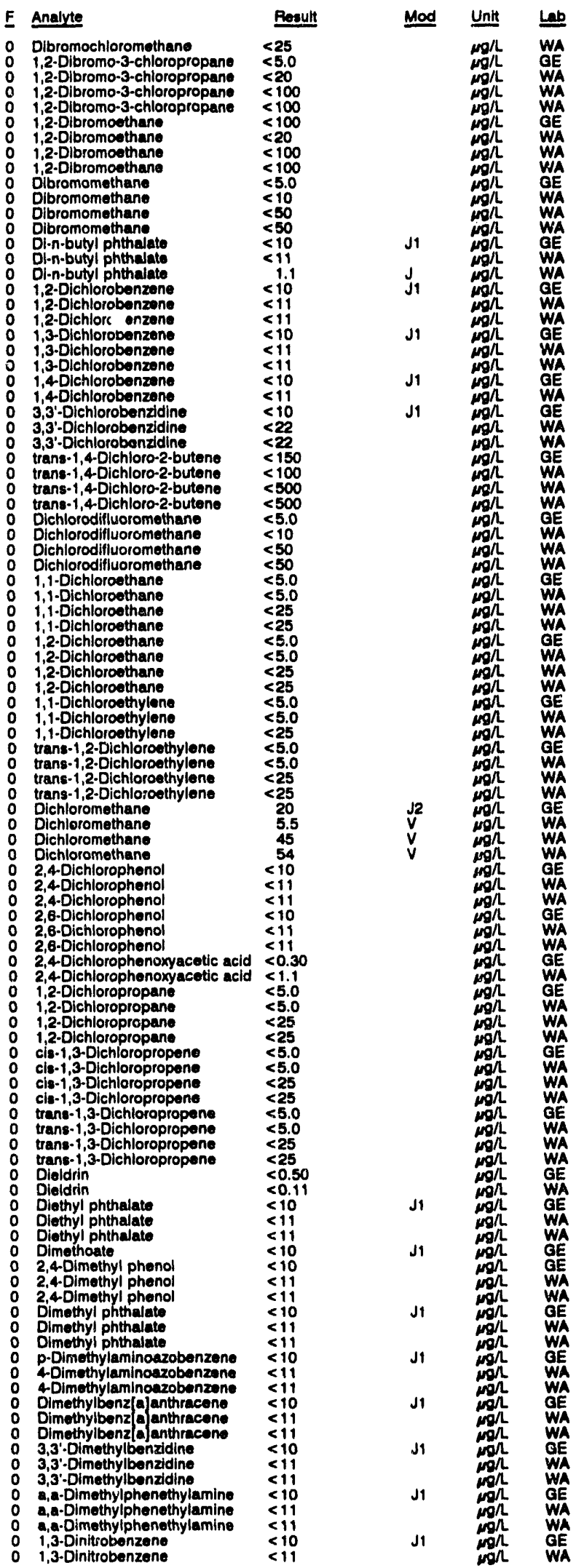


WELL MSB 1B collectad on 07/13/82, laboratory analyeses (cont)

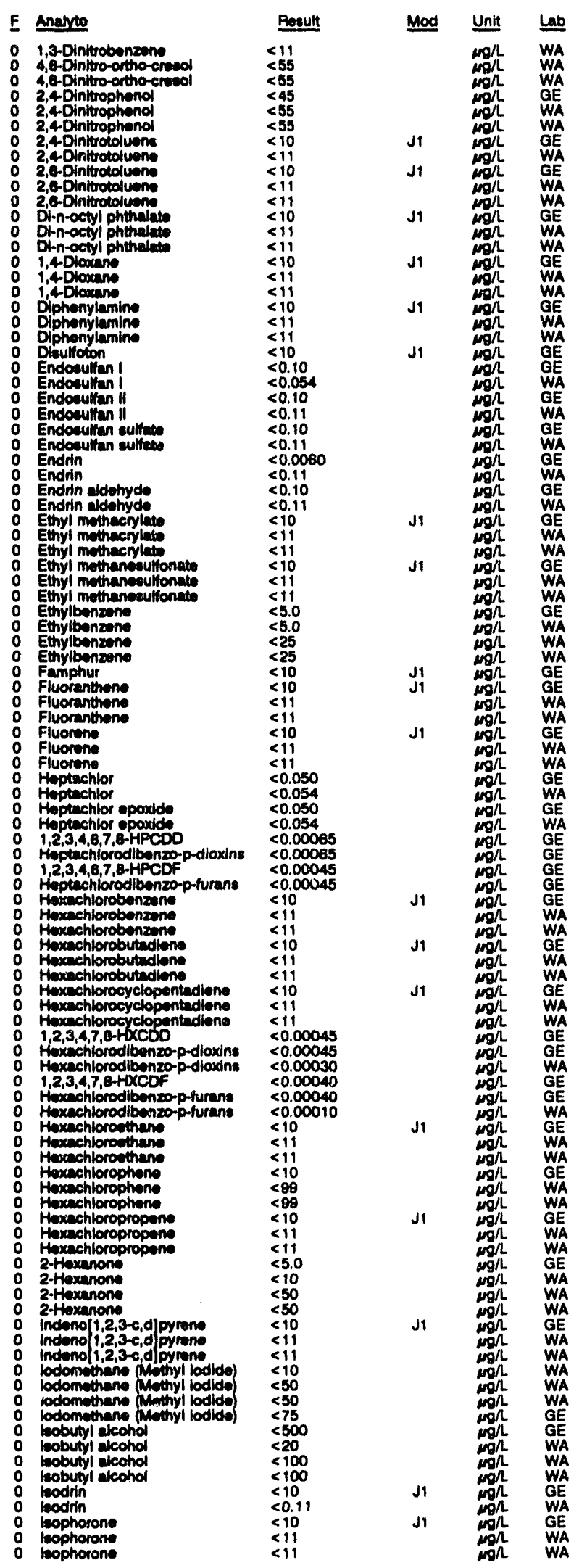

WELL MSB 18 collected on 07/13/82, laboratory analyses (cont.)

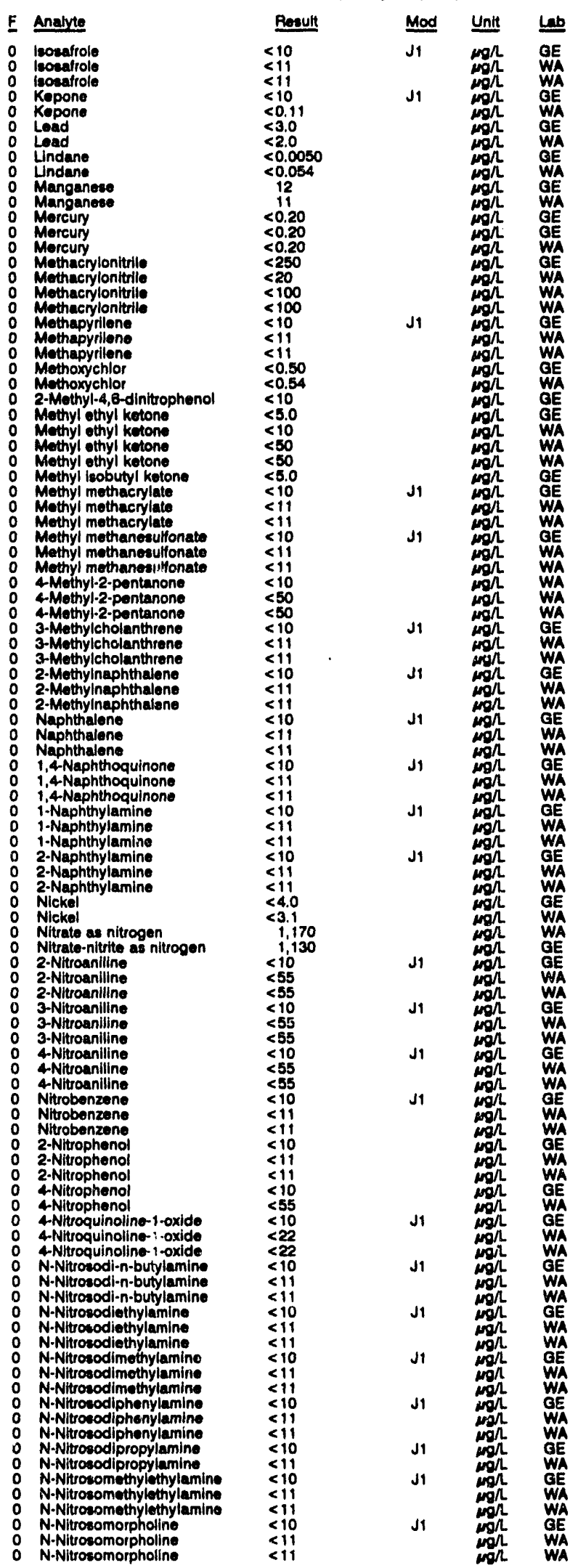


WEL MBB 1B collected on 07/13/92, laboratory analyese (cont.)

E Anaryte

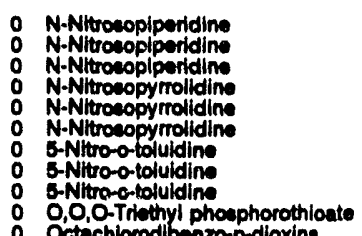

Octechiorodibenzo-p-furans

Parathion methy

PCB 1016

PCB 1221

O PCB 1232

PCB 1242

PCB 1248

PCE 1254

O PCB 1280

Pentachlorobenzene
0 Pentachlorobenzene
0 Pentachlorobenzene
0
0

Pentachlorodibenzo-p-dioxins

Pentachlorodibenzo-p-turans

$1,2,3,7,8-P C O F$

Pentachloroethane

Pentachloroethane

Pentrachlorenitrobanzene

Pentachlorenltrobenzene

Pontachloropheno

Prienchioutin

Pronacetin

Phenanthren

Phenanthrone

Phenol

Phonol

Phenote

Phenols

p-Phonyienediamine

p.Phenylenediamine

Phorate

2.Picoline

2.Plcoline

Pronamid

Pronamid

Proplonitrile

Proptonituile

Proplonitur

Pyreme

Pyndine

0 Pyndin

safrole

Safrole

Selonium

soleni

Siver

Sodlum

Sodium

Styrene

Styrene

gtyrene

Sulfate

Sulfate

Sulfide

Sulfido

1,2,4,5-tutrachlorobenzene

crechlorobenzan.

1,2,4,5ertrach

2,3,7,8-TCD

$2,3,7,8-T C D D$ \begin{tabular}{l}
\multicolumn{1}{r}{ Aeqult } \\
\multicolumn{1}{r}{10} \\
$<55$ \\
$<55$ \\
$<10$ \\
$<11$ \\
$<11$ \\
$<10$ \\
$<11$ \\
$<11$ \\
$<10$ \\
$<0.00$
\end{tabular}

$<0.0010$

$<0.050$

$<0.50$

$<0.50$

$<0.54$

$<0.54$

$<0.50$

$<0.50$

$<0.50$

$<1.1$

$<0.30$

$<10$

$<11$

$<0.00055$

$<0.00060$

$<0.00050$

$<0.0050$

$<10$

$\leq 11$

$<110$

$<10$
$<55$
$<55$

$<10$

$<10$

$<11$

$\leq 11$

$\leq 10$

$\leq 11$

$<110$

$<5.0$

$<5.0$

$\leq \leq 11$

$<11$

$<10$

$<11$

$<11$

$<11,000$

$<50$

$<250$

$<>10$

$<10$

$\leq 11$

$\leq 10$

$<11$

$<2.0$

$<0.70$

2,210
2,180
25

$<5.0$

$<5.0$
$<25$
$<25$

$<1,000$

$<250$

$<1,000$

$<100$

$<10$

$<11$

$<0.00040$

Mod Unit Lab

Lab

政

WE

WA

WE

GE

GE

WE

WA

GE

WE

WA

WA

$\mathrm{GE}$

WA

GE

WA

WE

WE

WE

GE

WA

WA

WA

GE

E

WA
WA
$G E$

WA

GE

WA

WA

GE

WE

WA

GE

GE

GE

WA
GE
WA
WA

WA
WA
GE
WA

WA

GE

GE

WELL MSB 18 collocted on 07/13/92, laboratory analyees (cont.)

E Analyte

o Tetrachlorodibenzo-p-dioxins

Tetrachlorodibenzo-p-dioxins

Tetrachlorodibenzo-p.jurans

Trectrachlorosthane

$1,1,1,2$-Tetrachlorothane

$1,1,1,2$ - Tetrachloroothane

1, 2. Tetrachloroethane

$1,1,2,2$ - Totrachloroethane

1,1,2. Tetrachlorothane

Totrachloroethylene

Tetrachlorosthylone

Tetrachloroethylone

2,3,4,6-Tetrachloropheno

2,3,4,6-Tetrachloropheno

2,3,4,6-Tetrachloropheno

Thallium

Tin

Toluene

Toluene

Tolvene

o-Toluidine

o.Toluldine

Total organic carbon

Total organic carton

Total organic halogens

Total organic halogens

Total phosphates as P

Total phosphates (as P

Toxaphene

2,4,5.TP (Silvox)

1,2,4-Trichlorobenzen

1,2,4-Trichlorobenzene

1,1,1-Trichloroethane

1,1,1-Trichloroethane

1,1,1-Trichloroethane

1,1,2-Trichloroethane

$1,1,2$-Trichloroothane

1,1,2-Trichloroothane

Trichloroothylene

Trichloroethylen

Trichloroethylene

Trichlorofluoromethane

Trichlorofluoromethane

Trichiorofluoromethane

2,4.5-Trichlorophenol

2,4,5-Trichlorophene

2,4,5-Trichloropheno

2,4,8-Inchloropheno

2,4,8-Trichlorophenol

$2,4,6$. The

1,2,3-Trichloropropane

1,2,3-Trichl fopropano

1,2,3.Trichloropropane

1,3,5.Trinitrobenzene

1,3-Trinitrobenzen

Uranium

Uranium

Vanadium

Vinyl acetate

Vinyl acetate

Vinyl acetate

Xylenes

Xylones

Xylones

Zinc

Gross alphe

Nonvolatilo beta

Nonvolatile beta

Radium-226

Padlum-22

Radium-228
Total alpha-omitting radium

Penult

$<0.00045$

$<0.00060$

$<0.00050$

$<5.0$

$<10$

$<50$

$<5.0$

$<25$
$<25$
$<5$

$<5.0$

$<25$

$<11$

$<2.0$

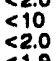

$<1.8$

$<5.0$

$<25$
$<10$

$\leq 111$

$\leq 1,000$

185

$<50$

$<20$

$<0.24$

$<1.1$

$<10$

$<11$

$<5.0$

$<5.0$

$<5.0$
$<25$
$<25$

$<25$

464
447

$<5.0$

$<25$

$<25$

$<55$

$<11$

$<11.00$

$<5.0$

$<10$

$<50$

$<50$

$\leq 11$

$<20$

$<0.030$

$<0.88$

$<>10$

$<50$ 
WELL MSB 1B Replicate

MEASUREMENTS CONOUCTED IN THE FIELD

Eample date: 07/139e
Dopth to watof: $148.07 \mathrm{~h}(44.80 \mathrm{~m})$ bolow TOC
Whter elevedion: $207.63 \mathrm{~h}(03.38 \mathrm{~m}) \mathrm{mal}$

8p. conductunce: $20 \mathrm{~s} / \mathrm{cm}$

Water evacuated before eampling: $183 \mathrm{gal}$

\section{LABORATOAY ANALYSES}

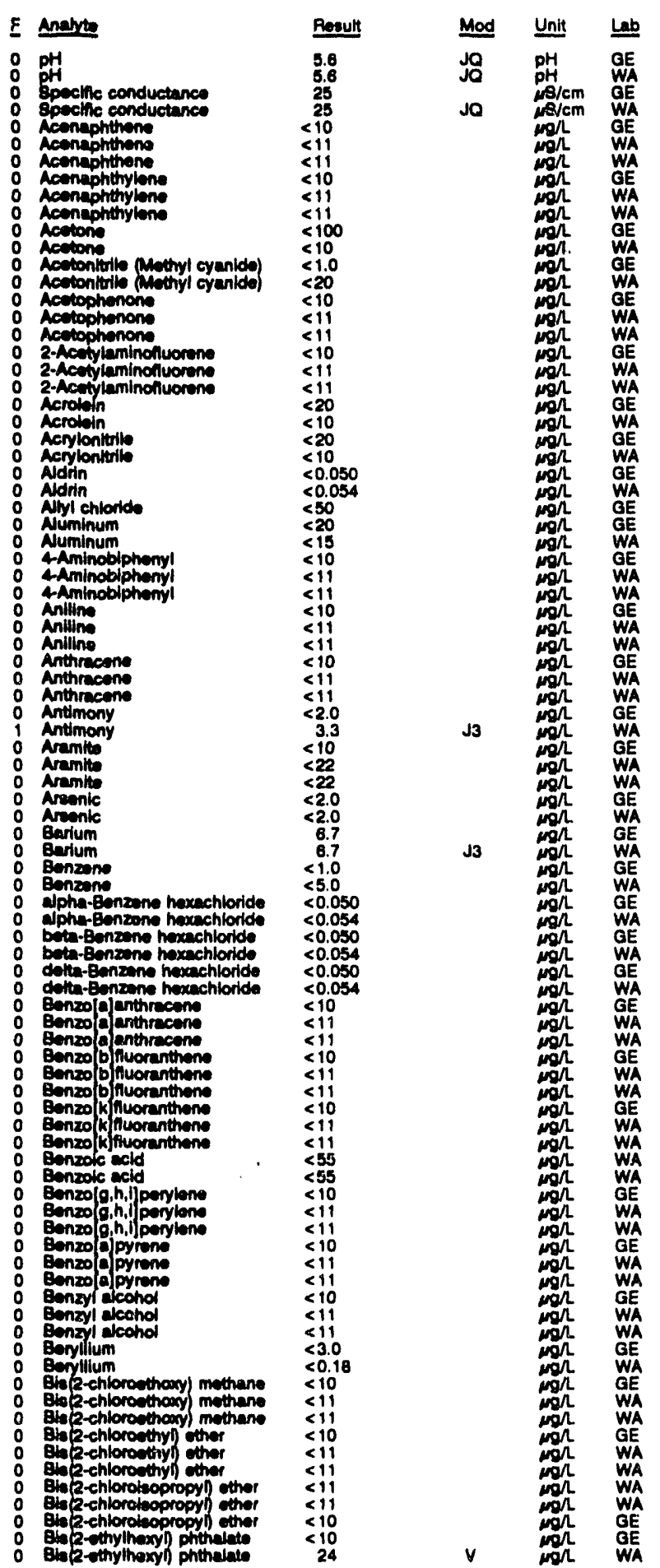

Time: 10:00

PH: 5.22

Water tomporature: $21.4^{\circ} \mathrm{C}$

WELL MSB 1B collected on 07/13/92, laboratory analyees (cont)

\section{E Analyte}

- Bis(2-ethylhoxyl) phthalate

Bromodichloromethane

Bromolorm

Bromolorm

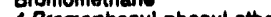

4. Bromophonyl phenyl ther

4 Bromophenyl phonyl ether

Butylbonzy! phthalatio

Butylbonzyl phthalate

2-ecec-Butyl-4, o-dintitrophenol

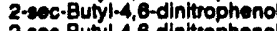

2-ecc-Butyl-4, 6-dinitrophon

Cadmium

Carbon disulfido

Carbon totrachioride

Carbon tetrachlorido

Chlordane

Chlordane

Chloride

of Chloroanlline

4-Chloroanliline

- Chlorobenzene

- Chlorobenzene

C Chlorobenzilate

Chlorobenzilate

para-Chloro-meta-cresol

para-Chioro-mota-creso

parn-Chloro-mata-creed

Chlorthe

Chloroetthene Minyl chloride)

Chloroettenene Vinyl chloride)

2-Chlorotethyl vinyl other

Chioroform

Chioromethen

Chloromethane

2.Chloronaphthalene

2-Chloronaphthaleno

2.Chloronaphth

2-Chloropheno

2-Chlorophenol

aChlorophenyl phenyl ether

4-Chlorophenyl phenyl thet

o Chloroprene

Chloroprene

Chloroprene

Chromium

- Chryeone

- Chrysento

Chreono

Cobalt

Cobatit

Copper

O-Cresol (2-Mothylphenol

o-Cresol 2-Methylphene

m-Creal 13 -Mothy pheno

p-Cresol (4-Methylphono

p-Cresol 4 Methylpheno

p-Crecol (4Methylphond)

0 Cyanida

$0 y$ Cynide
p.p.DoD

p.p.pon

P,P:DOE

p,p-DDE

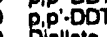

Oiallate

Diallaio

Dibonz (a,h) anthracone

Qibenz a,n anturacono

Dibenzofurar

Dibonzofuran

Dibenzofuran

o Dibromochloromethane

o 1,2-Dibromo-3-6illoropropane

1,2-Dibromo-3-chloropropane

1,2-Dibromoethane

Dibromomethane

Dibromomethane

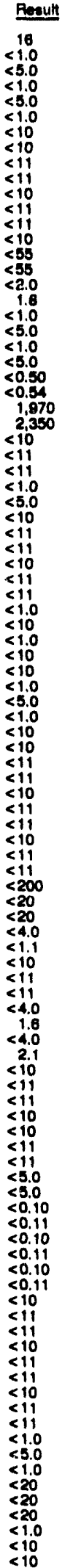

J3

Mod Unit La

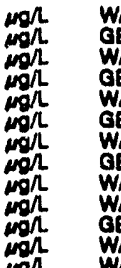

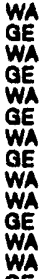

WA

WA

WA 
ANALYTICAL RESULTS

WELL MBB 18 collectod on 07/13/92, laboratory analyees (cont.)

$F$ Andeste

: O-n-butyl phthelate

1,2-Dchlorabenzene

1,2-0chlorobenzene

1,2-Dichlorobenzene

: 1, Dichorobenzen

1,3-Ochlorobenzane

- itichhorobonzens

1,40 Dchlorobenzene

3,3'-Dichlorobonzadino

: 3,3-Dichiorobenziding

o tank-1,40chioro-2-bution

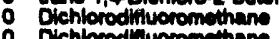

- Dichorodiluoromethan

i,i.Dichionowthen

: 1,2-Dichlowothane

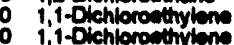

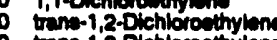

trent-1,2-Dichloroethylion

D Dehiorometran

o 2,4Oichtorophenat

2,4Dichlorophence

2, o-Dchlorophene

2,0-Dichiorophene

2.0-Dichlorophenol

onyacede aeld $<1$

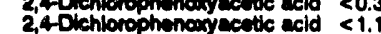

1,2-Dichloropropane

elo-1,3-Dichloropropene

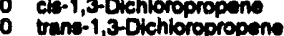

o tranti-1,3-Dichloropropenene

o Dieldrin

Dildrín

Diethyl phthelate

Dithyl phtheloto

- Dimethont

2,4Dimathyl phenol

2,4-Dimetyyl phend

Dimethy phenes

Dimothy photholate

D-Dimuthilaminonzobonzane

4 Oimethylaminoasobenzene

4Dimethylaminoazobonzone

Oimethylbenźajenthrucene

- Dimethytbenz A entriacano

- Dimethyibenzia anthracene

: 3,3.-Dimmotylbonzdine

o 3,3'-Dimothylbenzidino

an-Dimethylphenethylamine

a.-Dimethylphonethylamine

1.3.-Ointitrobonzom

i

- 4,-Dintroo-ontio-creser

4,6-OIntitro-ortho-crees

2,4Dintroptional

2,4-Dinitiophenol

2.4Dintrophenal

- 2,4Dintrotoluen

2,4Dinitrotoliven

2,6-Dintirotoluem

2,8-Dintitodoluom

Din-octyl phthalate

Din-octyl phthalede

o 1,4Dlovens

1,4-Dloxan

i,4-Diocena

Ophonytamine

Dphenylamin

Divulitotion

Endocultan!

Endosulfan II

Endowultan sulfat

eavlan sultet

0 Endrin

O Endrin aldohydo

Endrin aldotiydo
Bescult

$<11$

$<11$
$<10$
$<11$

$<11$

$<11$

$\leq 10$

$\leq 11$

$<22$

$<22$
$<30$
$<100$

$<100$

$<10$

$<1.0$

$<5.0$

$<5.0$

$<1.0$
$<5.0$
1.7

$<.0$

$<11$

$<11$
$<10$
$<11$

$<11$

$<1.0$

$<5.0$

$<5.0$

$<1.0$

$<0.50$

$<0.11$

$<11$

$<11$

$<1$

$<11$

$<11$

$\leq 11$

$<1$

$<10$

$<11$

$<1$

$<11$

$<1$

$<10$

$<11$

$<55$

$<55$

$<45$
$<55$
$<55$

10

$<11$

$<10$

$<11$

$<11$

$<11$

$<11$

$<11$
$<10$
$<11$

$<11$

$<10$

$<0.10$

$<0.10$

$<0.11$

$<0.11$

$<0.11$

$<0.10$
$<0.11$

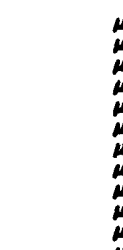

Mod U

mg/ WA

WA

WA

WE

WE

WA

WE

WE

GE

GE

WA

\begin{tabular}{|c|}
\hline 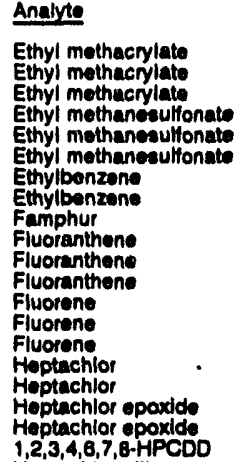 \\
\hline
\end{tabular}

Besult

$<10$
$<11$

$<11$

$<10$
$<11$
$<11$

$<1.0$
$<5.0$

$<10$

$<11$

$<11$

$<11$
$<11$

$<0.050$

$<0.050$

O Heptuchiorodibonzo-p-dioxins

1,2,3,4,6,7,8-HPCDF-dtur Heptachloroditibenzo-p Hexachlorobenzene

Hoxachlorobenzeno

Hexachlorobututadione

Hexachlorocyclopentadiene Hexachlorocyclopontadione

Hoxuchlorocyclopon

Hexachiorodibenzo-p-dioxins

Hexachlorodibenzo-p

Hexachlorodibenzo-p.turans Hexachlorodibonzo-p-turana Hexachloroethane

Hexachloroethane

Hoxachloroethane

Hexachlorophene

Hexachlorophene

Hexachloropropene

Hexachloropropeno

2-Hexanone

2-Hexanone

indeno $[1,2,3-c, d]$ pyrene

Indonol $1,2,3-c, d$ pyrene

Indenol 1,2,3-c,dpyrene

lodomethano (Mothyl lodide)

lodomethans a linthy

lsobutyl alcoho

roodinn

leophorone

leophorone

laceatrole

leosafrole

Kopone

Kopono

Lead

Lindane

Manganese

Merguny

Morcury

Mothacylonitrile

Mothacrylonitrile

Methapyrilen

Methapyrilien

Mothoxychlor

Methoxychlor

2-Mothyl-4,6-dinitrophono

Mothyl othyl ketone

Mothyl isobutuly kotone

Mothyl methacrylate

Methyl methacrylate

Mothyl mothacrylate

Methyl mothanosullonate

Mothyl methanceutilonate

4-Metmothanosunona

3-Methyicholanthrene

3-Mothylcholanthrene

3-Mothyleholenthrene

2.Mothyinaphthalone
2.-Mrethyinaphithalone

2-Mothy naphthalone

Naphthatepe

Naphthalone

\section{$<0.00065$}

$<0.00045$

$<0.0004$

$<10$
$<11$
$<11$

$<11$

$<10$

$\leq 11$

$<11$

$<11.00043$

$<0.0004$

$<0.00020$
$<0.00040$

$<0.00040$

$<10$

$<11$

$<10$

$<89$
$<10$

$<10$
$<11$
$<11$

$\leq 11.0$

$<10$
$<10$

$\leq 11$

$<10$
$<15$

$<100$

$<10$

$<0.11$

$<1$

$<10$
$<11$
$<11$ 
WELL MBS 18 coslected on 07/13/92, laboratory enalyeese (cont)

\section{E Anerat}

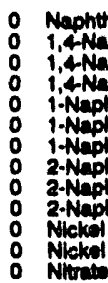

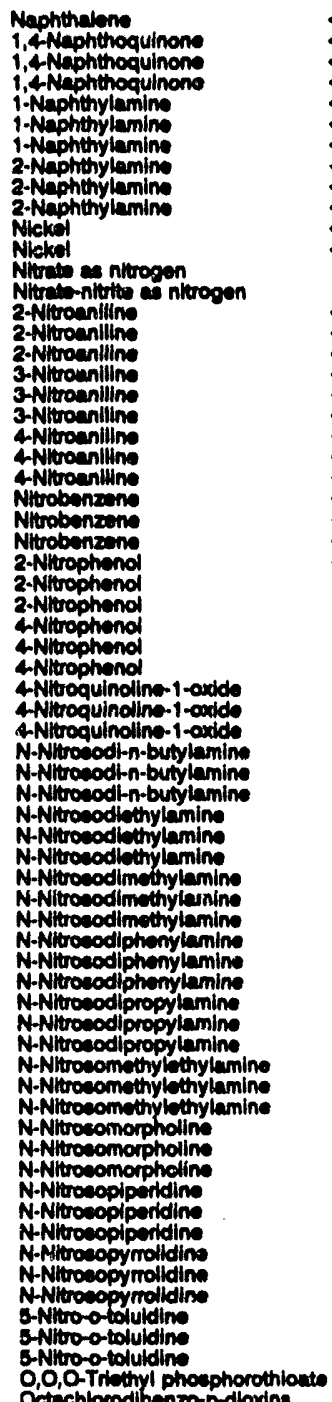

0,0,0-Triethyl phouphorothlo

Oetechlorodibenzo-p-furan

Parnthion

Parathion methyl

PCB 1016

PCB 1221

PCA 1202

PCB 1232

PCs 1242

PCB 1248

PCB 1248

PCB 1234

PCB 1200

P Pentachlorobenzene

Pentachlorobonzan

Pontachloroben

Pentichlorodibenzo-p-dloxin

Pentechlorodibenzo-p-dioxin

Pentuchlorodibenzo-p-furans

Pentachiorodibenzo-p-furane

1,2,3,7,0-PCDF

Pentiachloreethan

Pentachlorathanes

Pentuchloredthan

Pentachloronlitobonzame

Pentechloronlurobinzame

Pentichloronituoben:

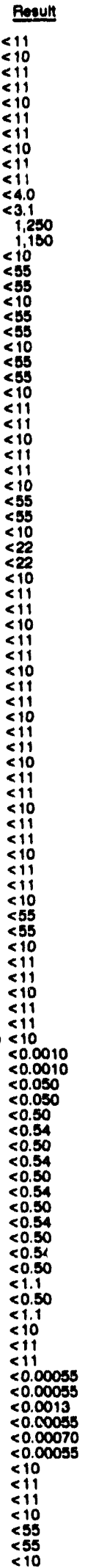

WELL MSB 18 collected on 07/13/92, laboratory analyees (cont.)

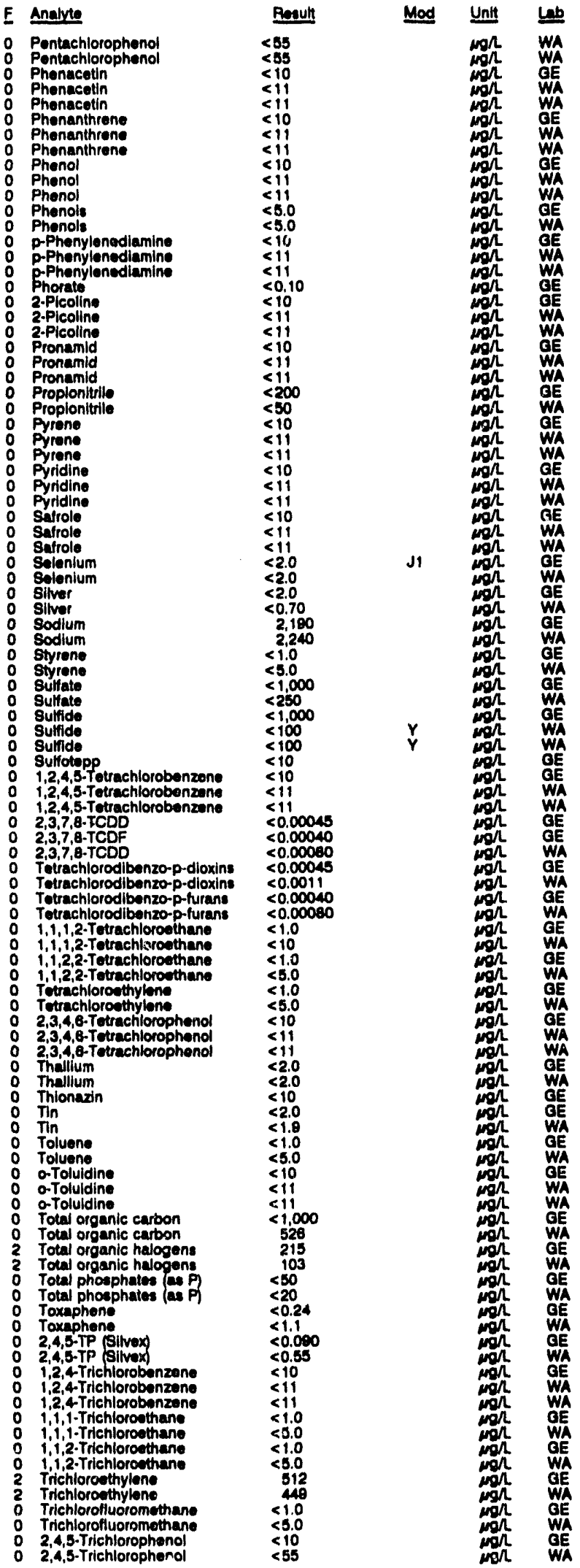


WELL MSB 18 colloctod on 07/13/92, laboratory analyses (cont),

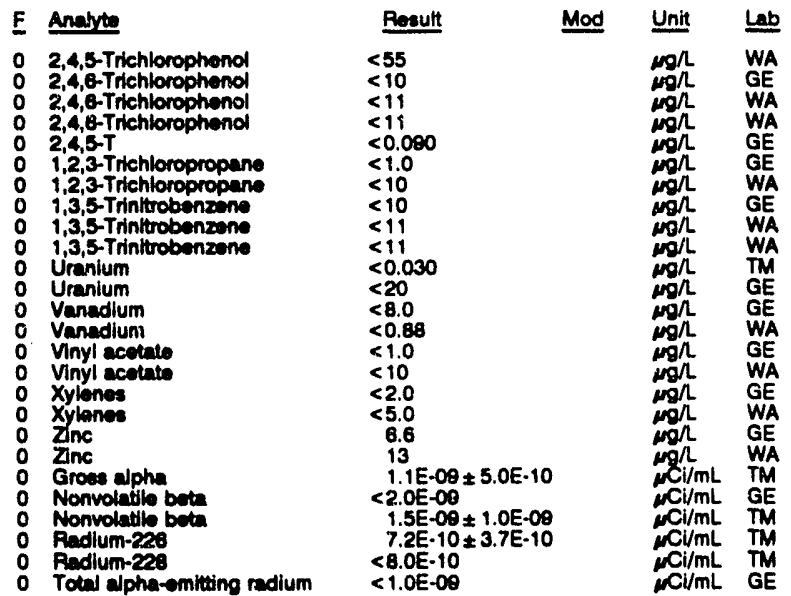

WELL MSB 1C

MEASUREMENTS CONDUCTED IN THE FIELD

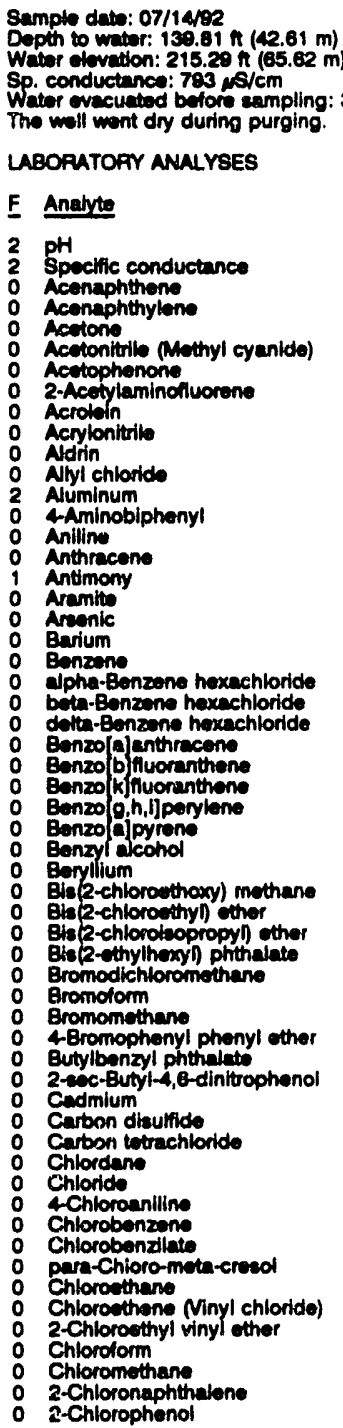

\section{low TOC \\ PH: 11.5 \\ PH: 11.50 \\ Water tomperature: $20.1{ }^{\circ} \mathrm{C}$}

LABORATORY ANALYSES

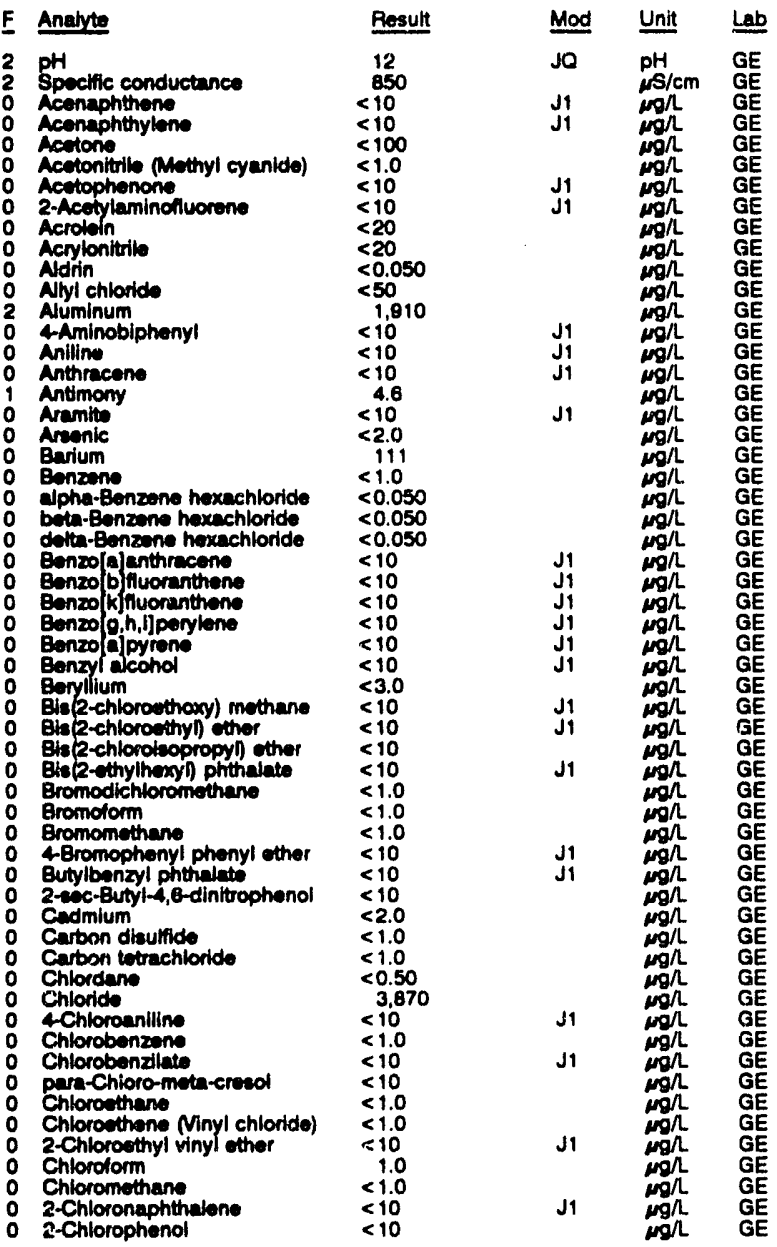

WEL MSB 1C colloctod on 07/14/82, laboratory analyees (eont)

\begin{tabular}{|c|}
\hline 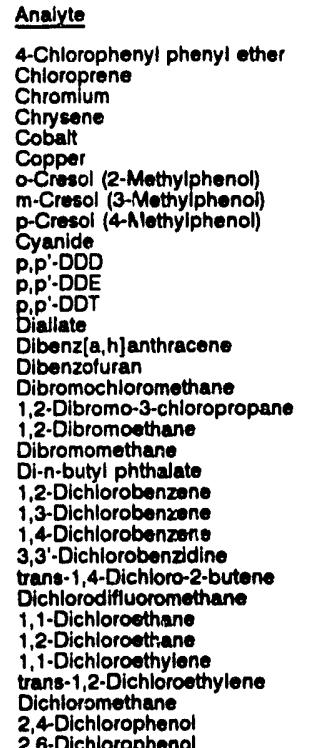 \\
\hline
\end{tabular}

Prosuit Mod Unit Lub

$<10$

$<4.0$

$<4.0$

$<4.0$

10

$<10$

$<0.10$

$<0.10$

$<10$

$<10$

$<1.0$

$<1.0$

$<1.0$

$<10$

$<10$

$<10$

30

1.0

$<1.0$

$<1.0$

2.2
$<10$

2,6-Dichlorophonol $<10.30$

1.2-Dichlorophenoxyacetic acido < < 1.30

cis-1,3-Dichloropropene $<1.0$

$\begin{array}{ll}0 & \text { trans-1,3-Dichloropropere } \\ 0 & <0.50\end{array}$

Diothyl phthalate $<10$

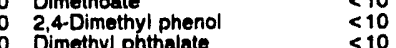

p-Dimethylaminoazobenzene $<10$

3.3'-Dimethylbenzidine $<10$

o a, Dimethylphenethylamine $<10$

1,3-Dinitrobenzene $<10$

< $<10$

2.,6-Dinitrotoluene $<10$

$\begin{array}{ll}<10 \\ 0 \text { Di-n-octyl phthalate } & <10\end{array}$

Diphenylamine $<10$

Disulfoton

- Endosulfan 1

- Endosulfan I

: Endrin

o Ethyl methacrylate

: Ethyl methanosulfionate

Ethylbenzene

O Famphur

F Fluoranthene

- Fiuorene

Heptachlor epoxide

$1,2,3,4,6,7,8-H P C D D$

Heptachiorodibenzo-p-dioxins

1,2,3,4,6,7,8-HPCDF-

Heptachlorodibenzo-p

Hexachlorobenzene

Hexachlorobutadione

1,2,3,4,7,8-HXCDD

$1,2,3,4,7,8-H \times C D D$
Hexachlorodibenzo-p-dioxins

作

Hexachiorodibenzo-p

Hexachloroothane

Hexachloropropene

2.Hexanone

Indeno $1,2,3-\epsilon$, d)pyrene

todomethane (Methyl iodide)

isobutyl alcohol

lisodrin

isophorone

isosafrole

Kepone

L Lead

Manganese

Mercun

Methacrylonitrile

Mothapyrilene

2-Methyl-4,6-dinitrophenol

Methyl ethyl ketone

Mothyl ethyl ketone

$<10$

$<0.10$

$<0.0060$

$<10$

$<10$

$<1.0$
$<10$
$<10$

$<10$

$<0.050$

0.00065

$<0.00065$

$<0.00045$

$<10$

$<10$

$<0.00045$

$<0.00045$

$<0.00040$

$<0.00040$
$<10$
$<10$

$<10$

$<1.0$

$<10$
$<15$
$<100$

$<<100$

$<10$
$<10$

$<10$
$<10$

$<3.0$

$<2.0$

$<50$

$<10$

$<0.50$
$<10$

$<10$
$<1.0$
$<1.0$

N1 $\operatorname{mon}_{\mathrm{mg} \Omega} \mathrm{GE}$

J1

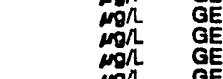

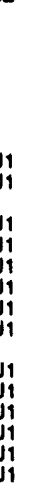

J1
J1
J1
J1

GE

$$
\text { . }
$$

.

$$
\text { . }
$$


WELL MSB IC coliected on 07/14/92, laboratory analyees (cont)

O Methyl methacrylate

Why methanesulfonate

2-Methylcholanthrene

Naphthalene

1, -Naphtroquinon

1-Naphthylamine

2-Naph

Nitrate-nitutie as nitrogen

2-Nitroanilime

4Nitroaniline

Nitrobenzane

2-Nutuopheno

4-Nitroquinoline-1-oxide

N-Nitrocodi-n-butylamine

N.Nitrocodiethylamine

N-Nitrosodimethylamino

N-Nitrocodiphenylamine

N-Nitrosodipropylamine

N-Nitrocomethylethylamine

N-Nitromomorpholine

N-Nitroeopynolidine

5-Niroepyriolidin

-Nltro-o-tolutdine

Octechlorodibenzo-p-dioxins

Oetachlorodibenzo-p-turans

Parathion

Parathion methyl

PCB 1016

PCB 1232

PCB 1242

PCB 1248

PCE 1200

Pentachlorobenzen

1,2,3,7,8-PCDO

Pentachlorodibenzo-p-dloxins

Pentachlorodib

Pentiachloroethane

Pentachloronitrobenzene

Pentachlorophenol

Phenacetin

Phenanthrene

Phenol

p-Phenylonediamine

2-Picoline

2-Picoline

Proplonitrilo

Pyrene

0 Safrole

Selenium

Silver

Sodium

Styrene

Sulfate

sulnde

1,2,4,5-Tetrechlorobenzen

2,3,7,8-TCDO

Tetrachlorodibenzo-p-dloxins

Tutrachlorodibonzo-p-furen

1,1,1,2-Tetrachlorowthane

1,1,2,2-Tetrachloroeth

2,3,4,8-Tetrachiorophenol

Thallum

Thion

Toluen

o-Toluidine

Total organic halogens

Totw phomphates

2,4,5-TP (sivex)

1,2,4-Trichlorobenzen

1,1,2-Trichloroethane

Trichloroethylene

Trichlordivoromane

$2,4,5-T$ rehlorophond

$2,4,5-T$

$1,2,3$-Trichloropropan

1,3,5-Trinittrobenzane

U Uranium

Vinyl acetate

Zylene:

Mod
$J 1$
$J 1$
$J 1$
$J 1$
$J 1$
$J 1$
$J 1$
$J 1$
J1
$J 1$
$J 1$
$J 1$

$J 1$
$J 1$
$J 1$
$J 1$
$J 1$
$J 1$
$J 1$
$J 1$
$J 1$
$J 1$
$J 1$
$J 1$

$<10$
$<10$

$<10$

$<10$
$<10$

$<<10$

$<10$

$<4.0$

$<10^{\circ}$

$<10$

$<10$

$<10$

$<10$

$<10$

$<10$

$<10$

$<10$

$<10$

$<10$
$<10$
$<10$

$<0.0010$

$<0.050$

$<0.050$

$<0.50$

$<0.50$

$<0.50$
$<0.50$
$<0.50$

$<0.50$

$<0.00055$

$<0.00055$

$<0.00055$

$<10$
$<10$

$<10$

$<10$

$<10$
$<10$

$<10$
$<5.0$

$<5.0$
$<10$
$<0.10$
$<10$

$<10$

$<200$

$<10$

$<10$
$<10$
$<2.0$

$<2.0$
$<2.0$

$<\begin{aligned} & 48,900 \\ & <1.0\end{aligned}$

$<1.000$

$<10$
$<10$

$<0.00045$

$<0.00045$

$<0.00040$

$<1.0$
$<1.0$

$<1.0$
326

$<10$

4.3
$<10$

$<2.0$

$<10$

$<1,000$

195
$<50$

$<0.24$

$<10$

$<1.0$

$<1.0$

$<1.0$

$<10$

$<0.090$

$<1.0$

$<10$
$<20$

14
$<1.0$
$<2.0$

$<2.0$
$<2.0$

Lab

WELL MSB 1C collected on 07/14/82, laboratory analyses (cont.)

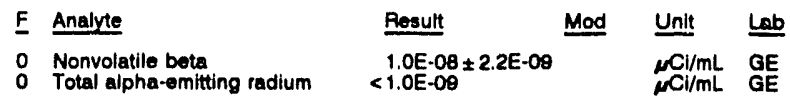

WELL MSB 1CC

MEASUREMENTS CONDUCTED IN THE FIELD

Samplo date: 07/14/92

Wepth to water: $137.89 \mathrm{H}(42.03 \mathrm{~m})$ botow TOC

Water olovation: $217.01 \mathrm{H}(88.15$

We. conductance: $181 \mu \mathrm{s} / \mathrm{cm}$

The well went dry during purging.

LABORATORY ANALYSES

F Analyte

0 pH

Specific conductance

Acenaphthene

0 Acotone

Acetonitrile (Methyl cyanide)

Acotophenone

2-Acetylaminofluorene

Acrolein

Acrylonitrile

o Allyl chloride

4-Aminobiphenyl

Anilline

Anthracene

Antimony

Aramito

Arenic

Barium

alpha-Benzene hexachloride

beta-Benzene hoxachloride

delta-Benzene hoxachloride

Benzo b fluoranthene

Benzo $k$ kf fluoranthene

Benzo $g, h, i j p e r y l o n$

Benzyl alcohol

0 Beryllium

Bis(2-chlorosthoxy) mothane

Bis (2-chloroethyl) ether

Bis (2-chloroisopropyl) ether

Bis(2-ethylhexyl) phthalate

Bromodich

Bromotorm

4-Bromophenyl phenyl ether

Butylbenzy! phthalato

2-soc-Buty

Cadmium disulfid

Carbon disulide

- Chlordane

Chloride

4-Chloroaniline

Chlorobenzene

Chlorobenzilate

para-Chloro-meta-cresol

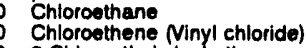

2-Chloroethyl vinyl ether

Chioroform

Chloromethane

2.Chloronaphthalon

2-Chlorophenol
0 4-Chlorophenyl phenyl other

- Chromium

Chrysen

Cobalt

O-Cresol (2-Mothylphonol)

m-Cresol (3-Methyiphenol)

p-Cresol (4-Methylphanol)

- Cyanide

0 p,p'-DOD

p,p'-DDE

P.p'-DD

Dibenz $(a, h)$ anthracene

Dibenzofuran

Dibromochloromethane

o 1,2-Dibromo-3-chloropropane

1,2-Dibromoethane

Di-n-butyl phthalate

1,2-Dichlorobenzene

1,4-Dichlorobenzene
6.8

$<10$

$\leq \leq 100$

$<100$

$<10$

$<10$
$<20$

$<20$

$<50$

$<20$

$<10$

$<2.0$

$<10$

30
$<1.0$

$<0.050$

$<0.050$
$<0.050$

$<10$

$<10$

$<10$

$<10$

$<3.0$

$<10$

$<10$

$<1.0$

$<1.0$

$<10$

$<10$

$<10$

$<1.0$

$<0.50$

3,430
$<10$

$<1.0$

$<10$

$<1.0$

$<1.0$

$<1.0$

$<1.0$

$<10$

$<10$
$<10$

$<200$

$<4.0$

$<4.0$

8.8
$<10$

$<10$
$<10$

$<10$

$<5.0$
$<0.10$
$<0.10$
$<0.10$
$<10$

$<10$

$<10$

$\leq 1.0$

$<1.0$
$<20$

$<1.0$

$<10$

$<10$
$<10$
$<10$
Time: 7:10

Alkalinity: $10 \mathrm{mg} /$ Water tomperature: $18.8^{\circ} \mathrm{C}$ 
ANALYTICAL RESULTS

WELL MSB 1 CC colisetod on 07/14/92, laboratory analyees (cont)

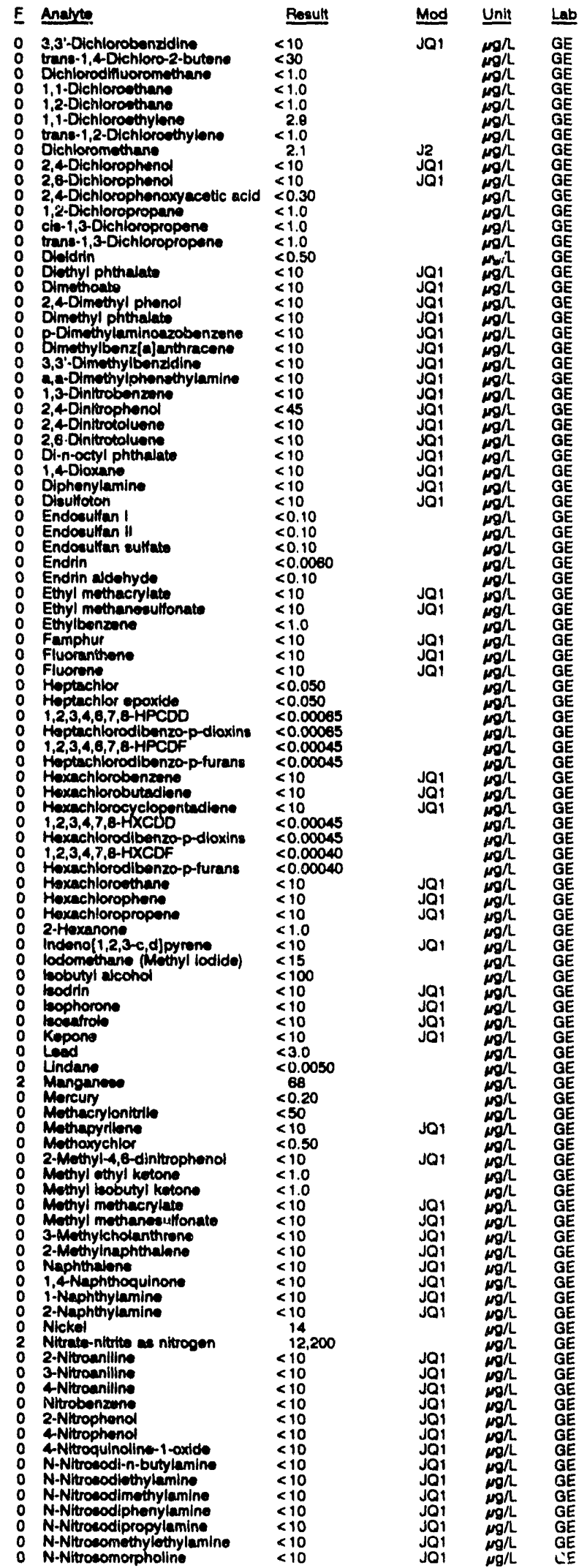

WELL MSB 1CC collected on 07/14/82, laboratory analyees (cont)

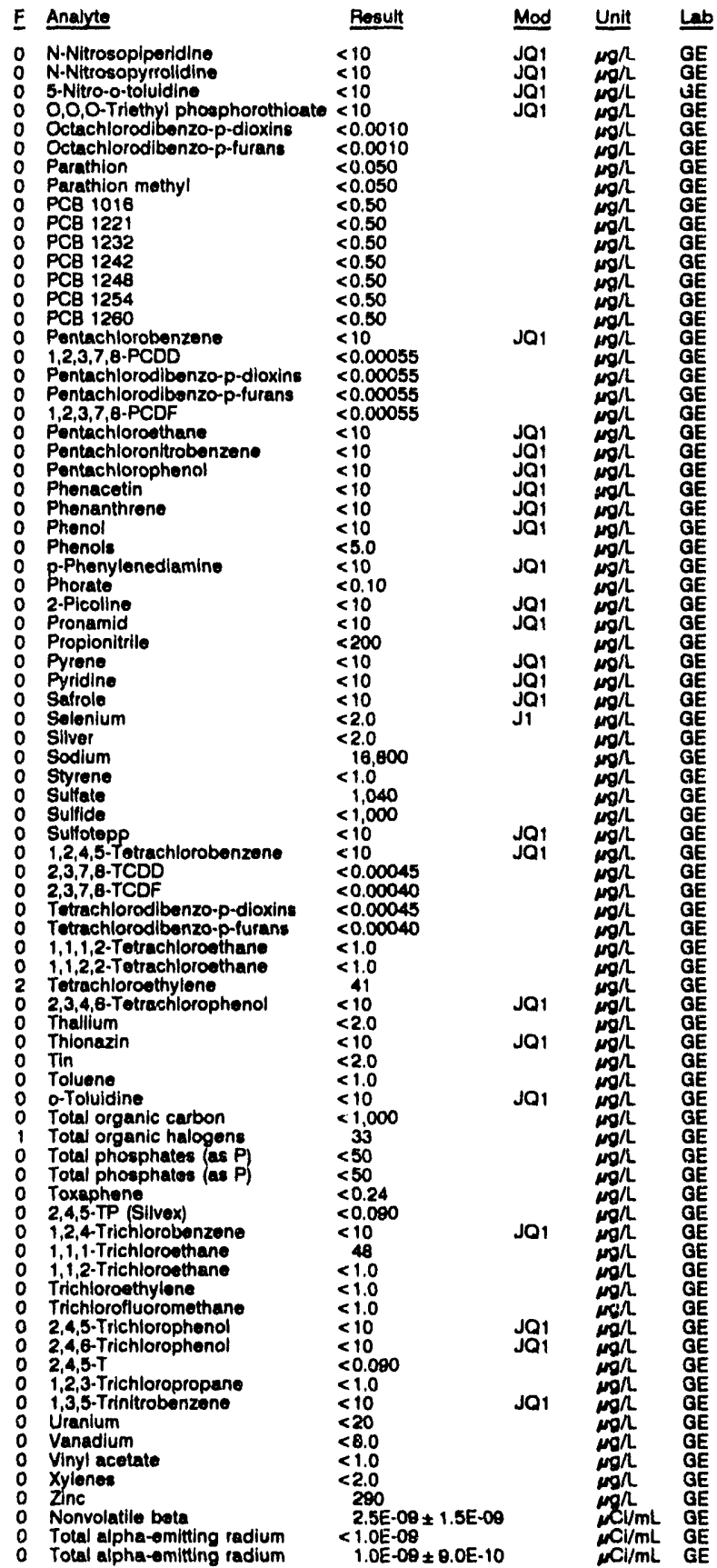

WELL MSB $1 D$

MEASUREMENTS CONDUCTED IN THE FIELD

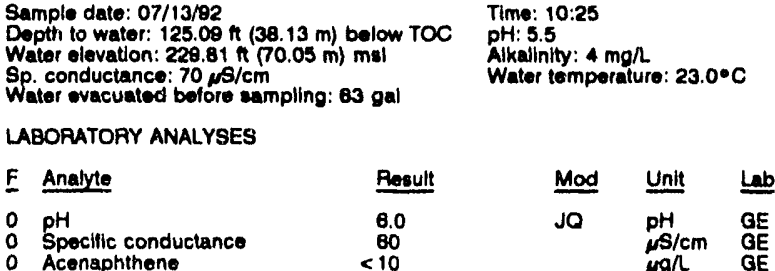


WELL MSB 10 collectiod on 07/13/92, laboratory analyses (cont)

E Anajo

o Aconaphthylone

o Acatonituile (Mothyl cyanide)

o Acetophonon

o Acroliln

Acrylon

o Alyi chloride

4Aminoblphionyl

Anthracene

o Antimony

A Aramite

Areanic

Bonzense

alpha-Benzone hoxachloride

bota-Benzone hoxachloride

Benzo| jejthracens

Benzo/b) fluoranthene

Benzolo,h,l]perylane

Benzo a.j, lpyene

Benzyl dechol

Bia (2-chlonothoxy) methane

Bia (2-chloroethyn the

Bise(2-chloroleopropyl) wher

Bin(2-thylhoxyl) phthala

Bromoform

Bromomethans

2-ec-Butyl-4, B-dinituophenol

Cadmium

Cadimium disulfido

Curbon totruchioride

Chlordene

A-Chloronitine

Chiorobenzene

chlorobenzlate

Chloroethan

Chlorosthene Minyl chloride)

2-Chloroethyl vinyl ther

Chlorolorm

Chloromethane

2-Chloronaphthat

2-Chlorophend
4Choroptienyl phenyl ether
Chloroprene

o Chromlum

Chryeente

0 Cobalt

Coppor

o-cread (2-Methylphenol)

o m-Cresol (3-Methylphenol)

Cyanide

0 p.p'-DOD

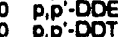

biling

Dibenzingienthrecene

D Dibenzofuran

1,2-Dibromo-3-chioropropante

1,2-Dibromothen

1,2-Dibromothan

Di-n-butyl phthalate

1,2-Dichlorobenzene

o 1,3-Dichlorobenzen

3,3'-Dichlorobenzidine

trane-1,4-Dichloro-2-buten

Dichlorodifluoromethane

1,1-Dichloroethane

1,2-Dichloroethane

o 1,1-Dichloroethylone

o Dichioromethane

2,4-Dichlorophend

2,4Dichiorophenoryacetic aciol

1,2-Dichloropropan

cia-1,3-Dichloropropene
0 tans-1,3-Dichloropropene

o Diethyl phthalate

Dimethoats

2,4-Dimethyl phonol

o D-Dimethylaminoazobenzeno

3,3'-Dimethyibenzidine
Result Mod

$<10$
$<100$

$<1.0$

$<10$

$<20$

$<0.050$

$<50$
$<20$
$<10$

$<10$

$<10$

$<2.0$

$<10$
$<2.0$
14

$<1.0$

$<0.050$

$<0.050$
$<0.050$

$<10$

$<10$
$<10$

$<10$

$<10$

$<30$

$<10$

$<10$
$<10$

$<10$

1.0

$<1.0$

$<10$

$<10$

$<1.0$
$<1.0$
$<0.50$

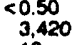

$<10$
$<1.0$

$<10$
$<10$

$<1.0$

$<1.0$
$<10$

$<10$
$<1.0$

$<1.0$

$<10$
$<10$

$<10$
$<200$
$<4.0$
$<10$

$<10$
$<4.0$

$<4.0$

$<10$
$<10$

$<10$

$<5.0$
$<0.10$

0.10

10

$<1.0$

$<1.0$

$<20$
$<1.0$

$<1.0$

$<10$

$<10$
$<10$

$<10$

$<30$
$<1.0$
$<1.0$
$<1.0$

$<1.0$

$<1.0$

$<.0$
2.0

$<10$
$<0.30$
$<1.0$

$<1.0$
$<1.0$

$<1.0$

$<10$

$<10$
$<10$

$<10$
$<10$

$<10$
$<10$

Mod Unit Lo

$m /$ GE

$\mathrm{GE}$

GE

GE

GE

GE

跣

跣

西

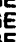

WELL MSB 10 collocted on 07/13/82, laborati iry analyese (cont)

F Analyte Besult Mod Unit Leb

a a-Dimethylphenethylamine $<$

1,3-Dinitrobenzene $<10$

$\begin{array}{lll}0 & 2,4 \text {-Dinitrophenol } & <45 \\ 0 & 2,4 \text { Dinitrotoluene } & <10\end{array}$

$\begin{array}{ll}2,6-\text { Dinitrotoluen: } & <10 \\ 0 \text { Di-n-octyl phthalate } & <10\end{array}$

i,

O Diphenylamine

O Disulfoton

E Endosulfan I

$<0.10$

$<0.10$

0 Endrin aldehydo $\quad<0.10$

0 Ethyl mothacrylate $<10$

E Ethyl methanesultonate $<10$

0 Heptachlor

Heptachlor epoxide $\quad<0.050$

$<0.00065$

0 Heptachlorodibenzo-p-dioxins $<0.00065$

$1,2,3,4,8,7,8$-HPCDF $<0.00045$

Heptachlorodibenzo-p-furans <0.000

0 Hexachlorobutadiene $\quad<10$

0 Hexachlorocyclopentadiene $<10$

1,2,3,4,7,8-HxCDD $<0.00045$

0 Hexachlorodibonzo-p-dloxins $\quad<0.00045$

0 Hexachlorodibenzo-p-furans $<0.0004$

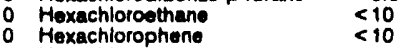

Hexachloropropene

2.Hexanono

Indeno[1,2,3-c,d]pyrene

$\begin{array}{ll}0 & <15 \\ 0 & <100 \\ \text { lsobutyl alcohol } & <10\end{array}$

sodrin

isosafrole

Kepone

Load

Undane

1 Manganeso

O Morcury

Methapyrilene

Mothoxychlor

2-Methyl-4,6-dinitropheno

Methyl ethyi kotone

Methyl methacrylate

Methyl methanesulfonate

3-Methylcholanthrene

2-Methylnaphthalone

Naphthalene

1,4-Naphthoquinone

1-Naphthylamine

Nicke

Nitrato-nitrite as nitrogen

2-Nitroaniline

3-Nitroaniline

4-Nitroaniline

2Nitroptenen

2-Nitrophenol

4-Nitroquinoline-1-oxide

N.Nirogulnalne-1-oxide

N-Nitrosodiethylamine

N-Nitrosodimethyleming

N-Nitrosodiphenylamin

N-Nitrosodipropylamine

N.Nitrosomethylethylami

N-Nitrosomorpholine

N-Nitrosoplperidine

N-Nitrosopyrrolidine
5-Nitro-o-toluldine

O,0,0-inothyl phosphorothicate

actachlorodibenzo-p-dioxins

Parathion

Parathion methy

PCB 1016

PCB 1232

PCB 1248

PCB 1254

O PCB 1260

$1,2,3,7,8-P C D D$

o Pontachlorodibenzo-p-dioxins

Pentachlorodibenzo-p-furane

1,2,3,7,8-PCDF

Pentachlorosthane

$<10$
$<10$
$<10$

1.0

$<10$

$<10$

$<3.0$

$<6$

$<0.20$

$<50$
$<10$

$<0.50$

$<10$

$<1.0$
$<1.0$

$<10$

$<10$

$<10$

$<10$

$<<10$

$<10$

$<4.000$

$<10$

$<10$
$<10$
$<10$

$<10$ 
ANALYTICAL RESULTS

WELL MSB 10 collected on 07/13/92, laboratory analyses (cont)

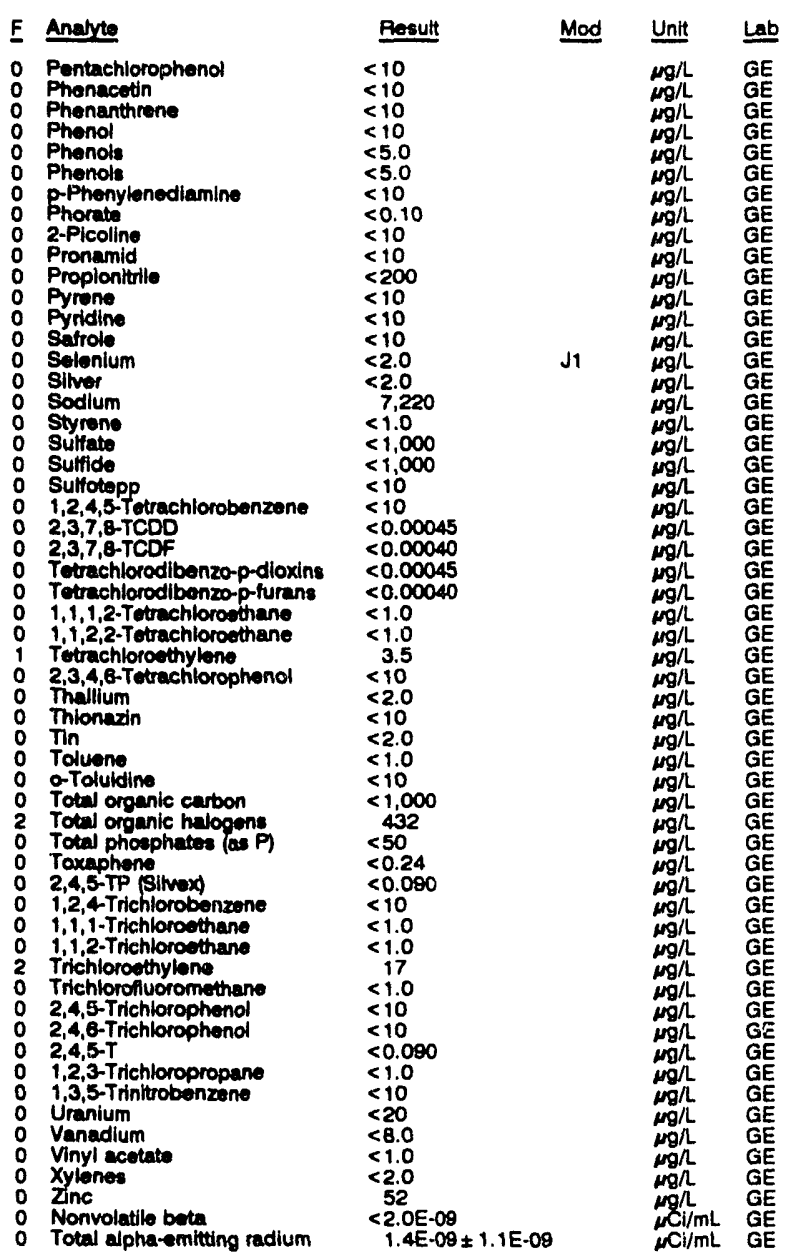

WELL MSB 2B

MEASUREMENTS CONOUCTED IN THE FIELD

Sample date: 08/12/er

Depth to water: $144.95 \mathrm{n}(44.18 \mathrm{~m})$ below TOC

Water elevation: $209.65 \mathrm{r}(83.80 \mathrm{~m}) \mathrm{ms}$

Sp. conductance: $2580 \mathrm{~ms} / \mathrm{cm}$. $39 \mathrm{gal}$

The well went dry during purging.

LABOHATOFY ANALYSES

2 PH 2 Specific conductance

Acenaphthene

Acenaphthene

Acenaphthylone

Acenaphth

Acotone

Acetophenon

Acetophenone

2-Acetylaminofluorene

Acrotein

Acrylonituile

Altyl chloride

Aluminum

4-Aminobipheny!

Anlline

Anthracent

Anthracene

Antimony

Aramito
Time: $8: 00$

Alkalinity: $500 \mathrm{~mol}$

Water temperature: $22.0^{\circ} \mathrm{C}$

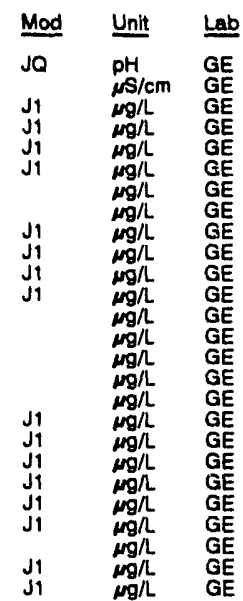

WELL MSB 28 collocted on 08/12/92, laboratory analyses (cont.)

E Analyte Reguis Mod Unit Let

$\begin{array}{lll}0 & \text { Arsenic } \\ 0 & \text { Barlum } \\ 0 & \text { Benzene } & <\end{array}$

o Benzene

beta-Benzeno haxachloride

delta-Benzene haxachloride $<0.050$

Benzo[a]anthracene $<10$

0 Benzob) fluoranthene $\quad<10$

0 Benzolbffluoranthene $\quad<10$

0 Benzolk fluoranthene $\quad<10$

Benzo (k)fluoranthene $\quad<10$

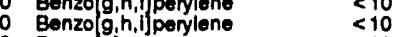

O Benzolajpyrene

Benzola]pyrene

Benzyl alcohol

O Benzyl alcoh

0 Bis(2-chloroethoxy) methane

Bis 2-chlorothoxy mothene

Bis 2-chloroothyll other

Bis 2-chloroothyl other

Bis 2-chloroisopropyly ther

Bis 2-othylhexyl) phthalate

Bis (2-ethylhexyl) phthalato

Bromodichloromethane

O Bromoform

Bromomethane

4-Bromophenyl phenyl ether

4-Bromophenyl phenyl ether

Butylbenzyl phthalate

2-sec-Butyl-4,6-dinitrophenol 2-sec-Butyl-4,6-dinitrophenol
2-sec-Butyl-4,6-dinitrophenol 2-sec-Butyl-4

Carbon disulfide

Carbon tetrachloride

Chlordane

4-Chloroaniline

4-Chloroanlline

0 Chlorobenzene

Chlorobenzilate

para-Chloro-meta-creso

para-Chloro-mete

Chioroethene (Vinyl chloride)

2.Chloroethyl vinyl ether

2-Chloroethy

o Chioroform

C Chloromethane

2-Chloronaphthalene

2-Chloronaphthalen

2-Chlorophenol

4-Chlorophenyl phenyl ether

Chloroprene

Chromium

Chrysene

Chrysene

o Cobat

Copper

o-Cresol (2-Methylphenol

m-Cresol (3-Mothylpheno

m-Cresol (3-Methy'phenol)

p-Cresol (4-Methylphenol)

p-Cresol (4-Methylphenol) $<10$

Cyanide $<5.0$

P.P-DDE <0.10

$\begin{array}{ll}\text { P.P.DDT } & <0.10 \\ \text { P.P. } & <0.10\end{array}$

Diallato

Diallate

Dibenzla, h] anthracene

Oibenzofuran

Dibenzofuran

Dibromochloromethane

1,2-Dibromo-3-chloro

1,2-Dibromoethane

Di-n-butyl phthalate

Di-n-butyl phthalate

1-n-butyl phthalate

1,2-Dichlorobenzene

1,3-Dichlorobenzene

1,3-Dichlorobenzene

1,4-Dichlorobenzene

1,4-Dichlorobenzene

3,3'-Dichlorobenzidine

trans-1,4-Dichloro-2-butene

Dichlorodifluoromethane

1,1-Dichloroethane
$2.0 \quad \mathrm{\mu g} / \mathrm{L}$ GE

10
10
10
10
10
10
10

$<10$
$<10$
$<10$

$<3.0$

$<10$
$<10$
$<10$

$<10$

$<250$
$<10$

$<10$
$<25$

$<25$

$<10$

$<10$
$<10$

$<>10$

$<2.0$
$<25$
$<25$

$<0.50$

$<10$
$<10$

$<25$

$<10$
$<10$
$<10$

$<25$
$<25$
$<10$

$<10$
$<25$
$<25$

$<10$
$<10$

$<10$
$<10$

$<10$
$<10$

$<5,000$

$<10$
$<10$

$<4.0$
4.2

$<10$

$<10$

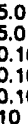

$<10$
$<10$

$<10$
$<10$

$<10$

$<25$

$<500$

$<10$
$<10$

$<10$
$<10$

$<10$

$<10$
$<10$

$<10$

$<10$

$>750$
$<25$
$<25$

$<25$
$<25$ 
WELL MSB 2B collocted on 08/12/92, laboratory analyees (cont)

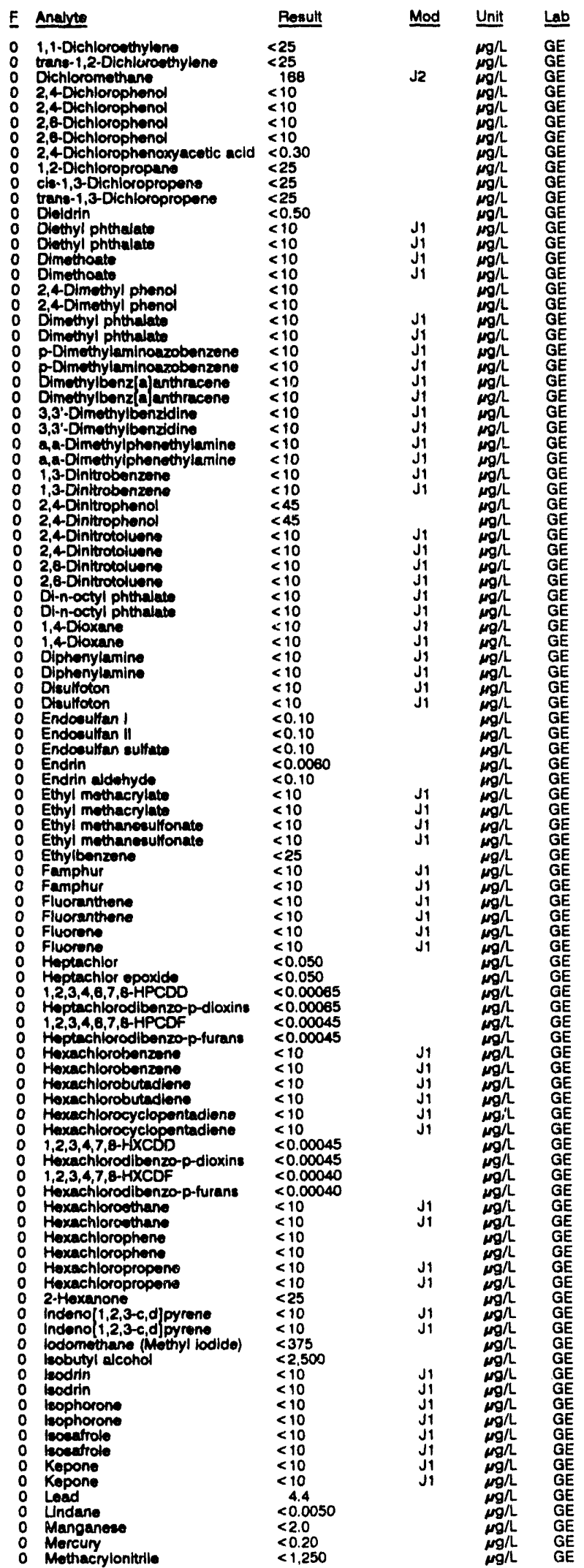

WELL MSB 28 colloctod on 08/12/82, laboratory analyses (cont.)

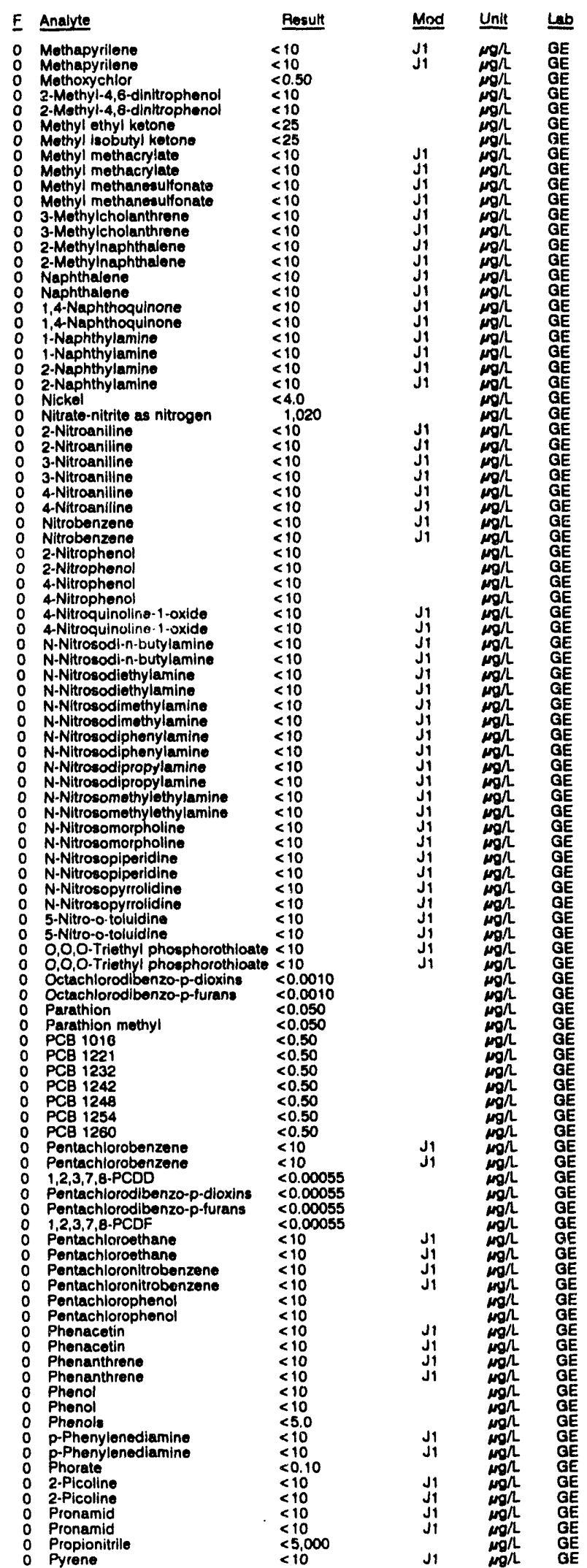


ANALYTICAL RESULTS

WELL MSB 2B collectod on 08/12/92, laboratory analyses (cont.)

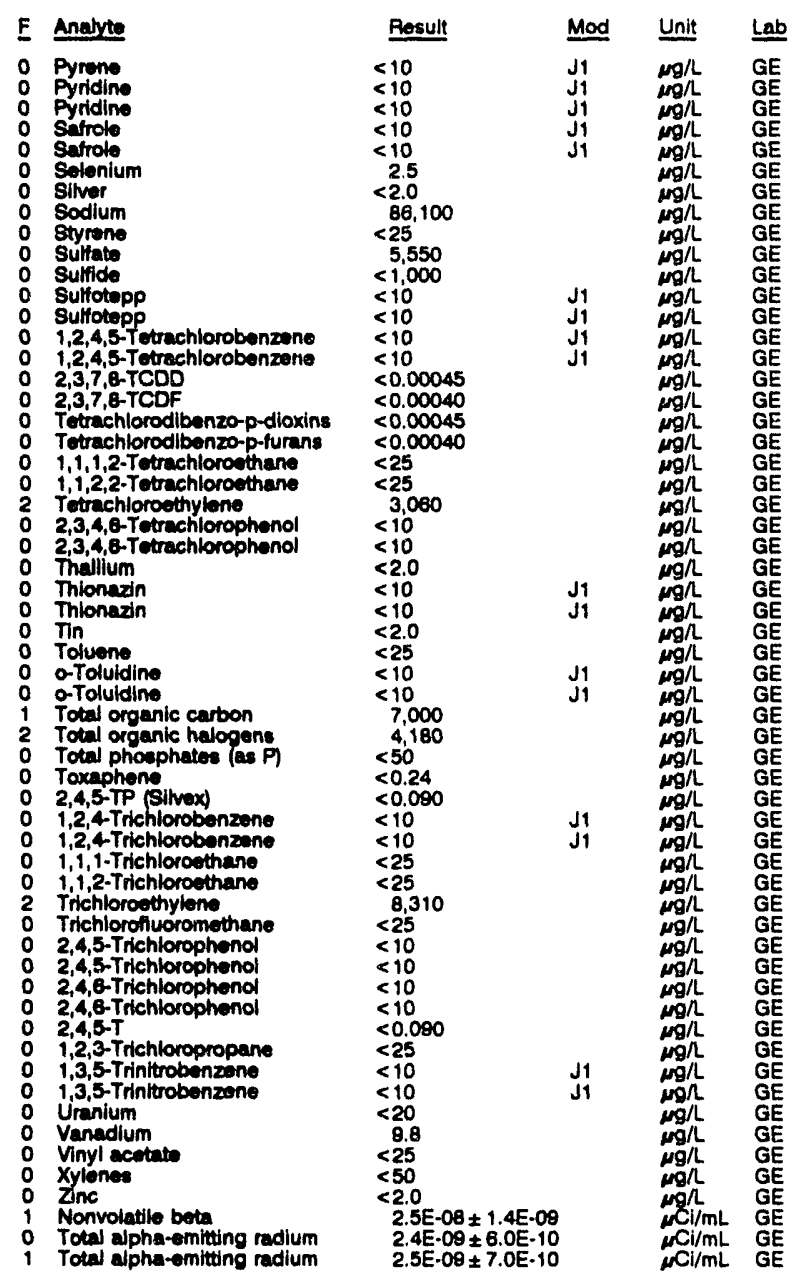

WELL MSB 2C

MEASUREMENTS CONOUCTED IN THE FIELD

\begin{tabular}{|c|c|c|c|c|c|}
\hline \multicolumn{3}{|c|}{ 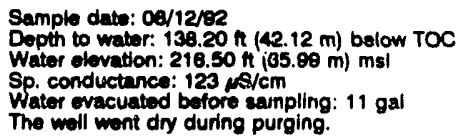 } & \multicolumn{3}{|c|}{$\begin{array}{l}\text { Time: } 9: 20 \\
\text { pH: } 11.7 \\
\text { Alkalinity: } 250 \mathrm{mg} / \mathrm{L} \\
\text { Water temperature: } 22.0^{\circ} \mathrm{C}\end{array}$} \\
\hline \multicolumn{6}{|c|}{ LABOPATOFY ANALYSES } \\
\hline $\mathbf{F}$ & Analyte & Result & Mod & Unit & Lab \\
\hline $\begin{array}{l}2 \\
0 \\
0 \\
0 \\
0 \\
0 \\
0 \\
0 \\
0 \\
0\end{array}$ & 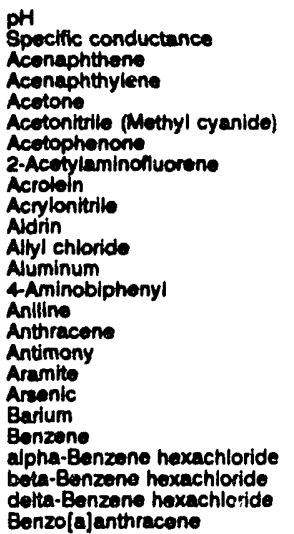 & $\begin{array}{l}12 \\
1,200 \\
<10 \\
<10 \\
<100,000 \\
<1,000 \\
<10 \\
<10 \\
<20,000 \\
<20,000 \\
<0.050 \\
<50,000 \\
2,330 \\
<10 \\
<10 \\
<10 \\
<2.0 \\
<10 \\
<2.0 \\
93 \\
<1,000 \\
<0.050 \\
<0.050 \\
<0.050 \\
<10\end{array}$ & $\begin{array}{l}J 1 \\
J 1 \\
J 1 \\
\text { J1 }\end{array}$ & $\begin{array}{l}p H \\
\mu S / c m \\
\mu g / L \\
\mu g / L \\
\mu g / L \\
\mu g / L \\
\mu g / L \\
\mu g / h \\
\mu g / L \\
\mu g / L \\
\mu g / L \\
\mu g / L \\
\mu g / L \\
\mu g / L \\
\mu g / L \\
\mu g / L \\
\mu g / L \\
\mu g / L \\
\mu g / L \\
\mu g / L \\
\mu g / L \\
\mu g / L \\
\mu g / L \\
\mu g / L \\
\mu g / L\end{array}$ & $\begin{array}{l}\mathrm{GE} \\
\mathrm{GE} \\
\mathrm{GE} \\
\mathrm{GE} \\
\mathrm{GE} \\
\mathrm{GE} \\
\mathrm{GE} \\
\mathrm{GE} \\
\mathrm{GE} \\
\mathrm{GE} \\
\mathrm{GE} \\
\mathrm{GE} \\
\mathrm{GE} \\
\mathrm{GE} \\
\mathrm{GE} \\
\mathrm{GE} \\
\mathrm{GE} \\
\mathrm{GE} \\
\mathrm{GE} \\
\mathrm{GE} \\
\mathrm{GE} \\
\mathrm{GE} \\
\mathrm{GE} \\
\mathrm{GE} \\
\mathrm{GE}\end{array}$ \\
\hline
\end{tabular}

WELL MSB 2C collected on 08/12/82, laboratory analyses (cont.)

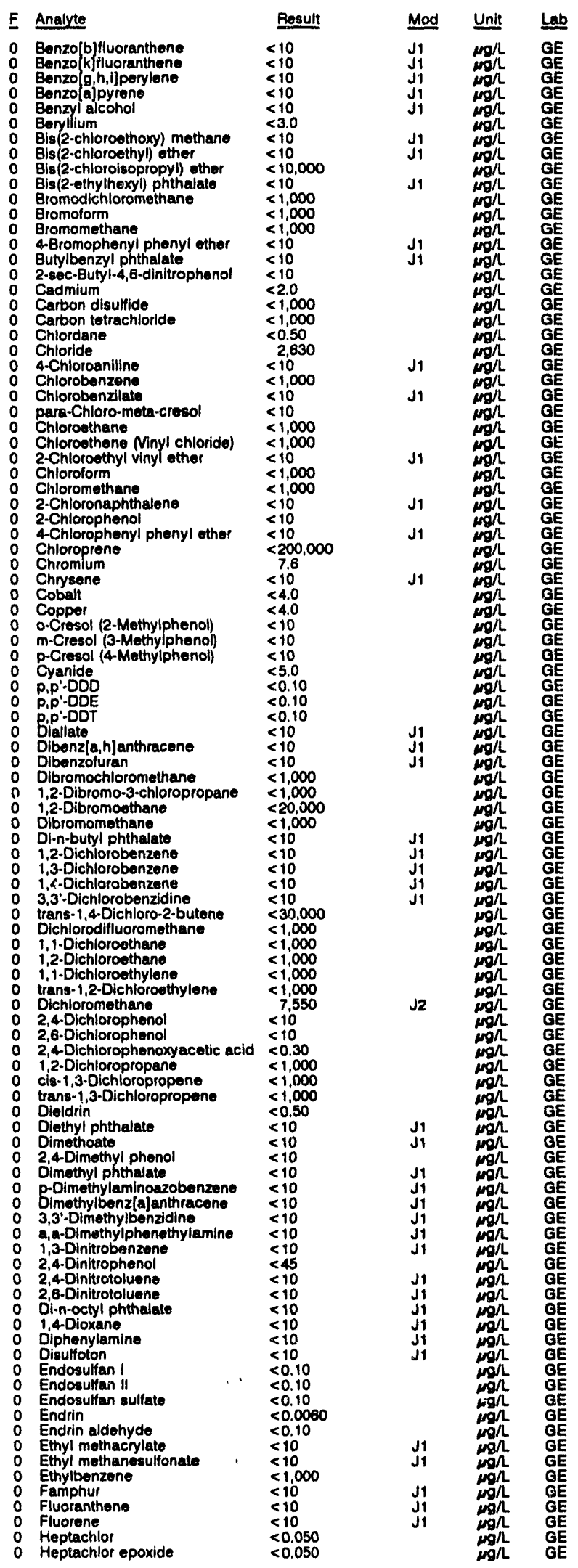


WELL MSB 2C collected on 08/12/92, laboratory analyees (cont)

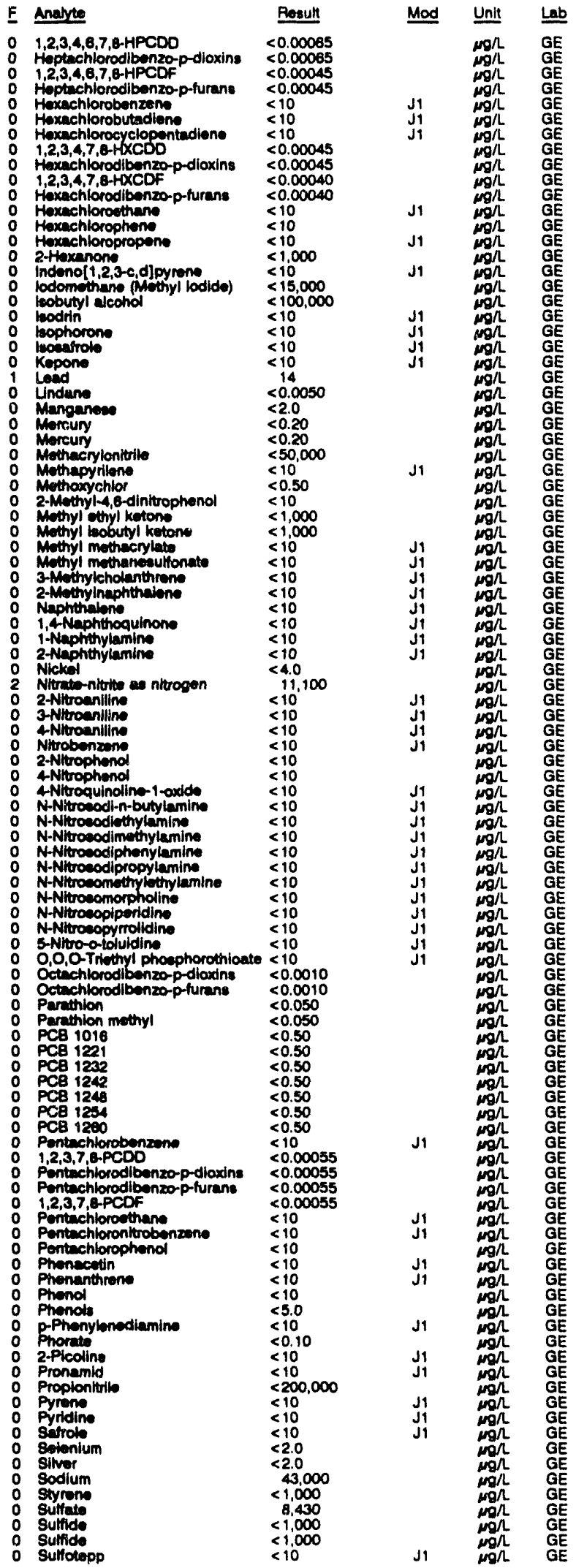

WELL MSB $2 C$ collected on 08/12/92, laboratory analyses (cont)

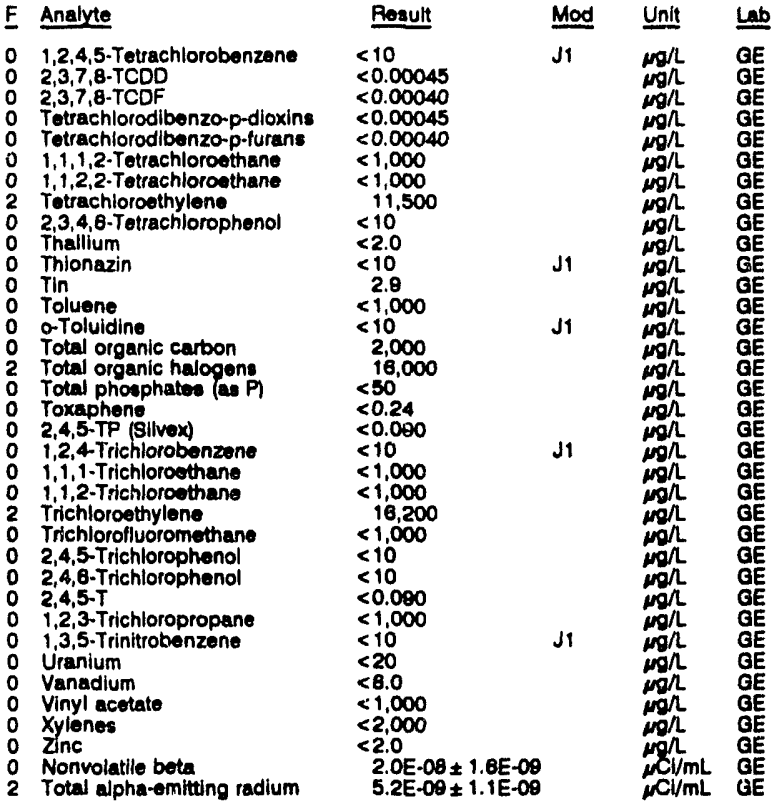

\section{WELL MSB 2D}

MEASUREMENTS CONDUCTED IN THE FIELD

Dopth to wator: $123.48 \mathrm{~h}(37.84 \mathrm{~m})$ below TOC Wator tovevalion: $230.32 \mathrm{~A}$ (7)

Water evacuated before sampling: 51 gal

PH: $4:$ :

Alkalinity: $0 \mathrm{man}$

Water temperature: $21.6^{\circ} \mathrm{C}$

LABORATORY ANALYSES

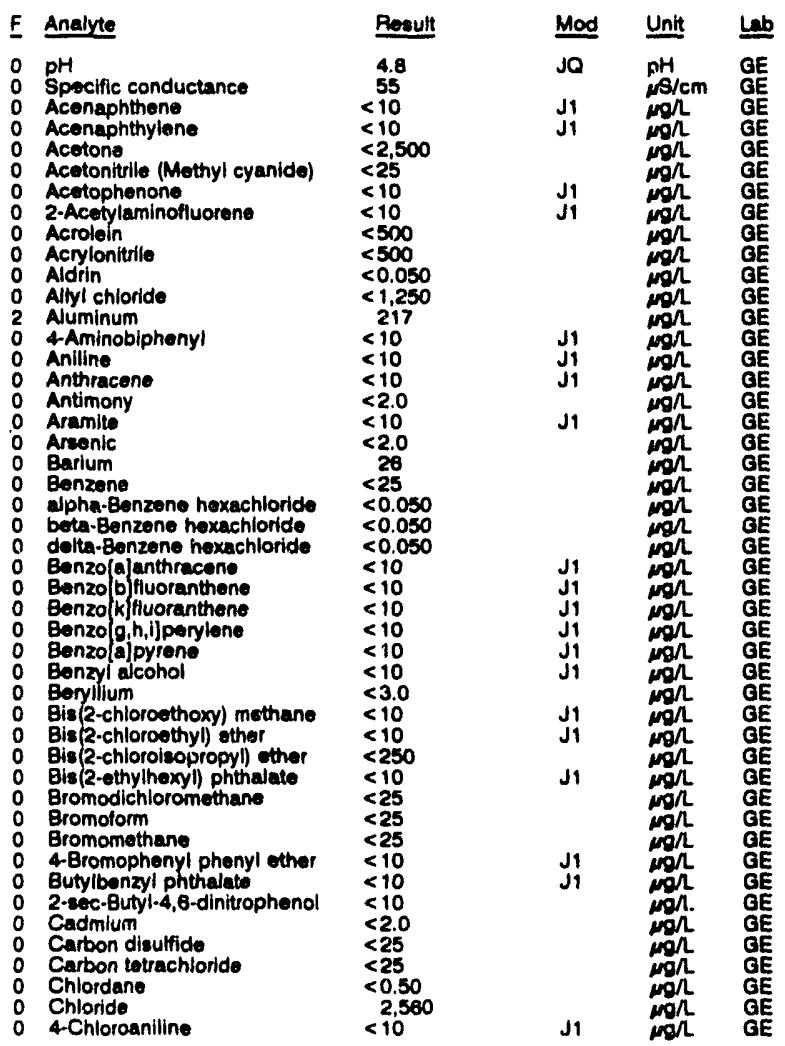


ANALYTICAL RESULTS

WELL MSB 20 collected on 07/09/92, laboratory analyses (cont.)

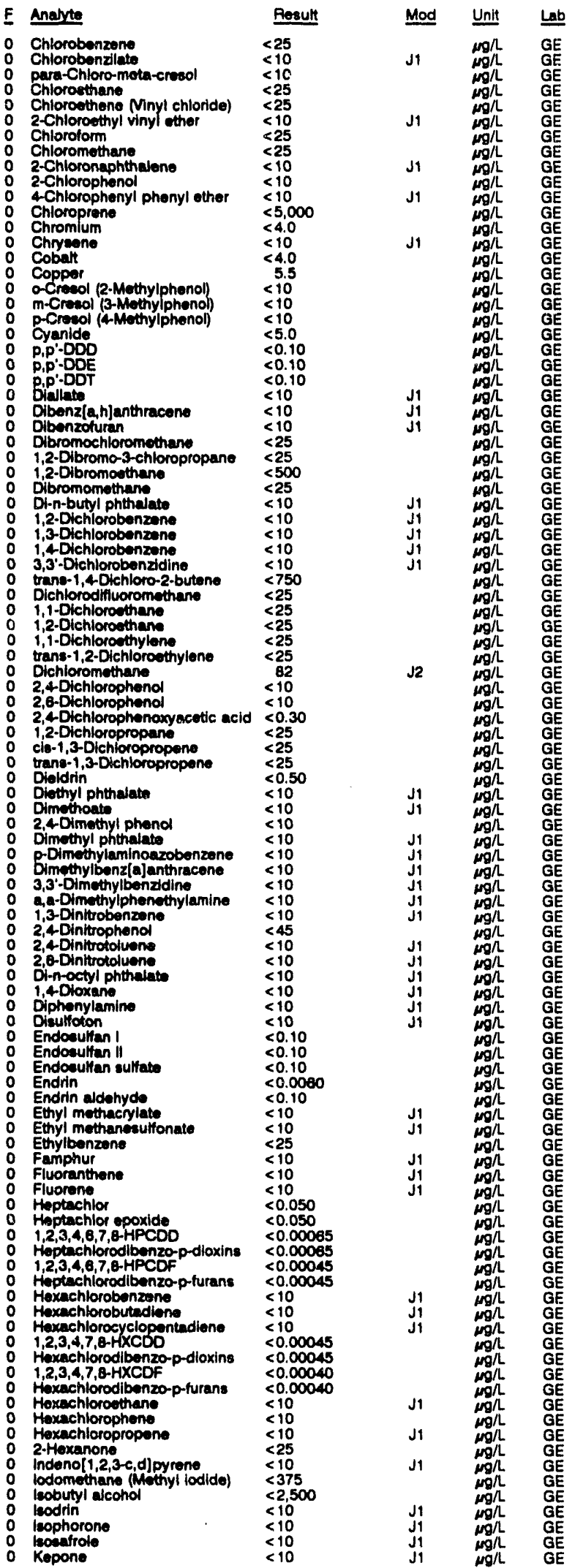

WELL MSB 2D collected on 07/09/92, laboratory analyses (cont.)

F Analyte Result Mod

\begin{tabular}{|c|}
\hline $\begin{array}{l}\text { Lead } \\
\text { Lindane } \\
\text { Manganese } \\
\text { Morcury } \\
\text { Mercury } \\
\text { Methacrylonitrile } \\
\text { Mothapyrilene } \\
\text { Methoxychlor } \\
\text { 2-Methyl-4,6-dinitrophenol } \\
\text { Methyl ethyl ketone } \\
\text { Methyl isobutyl ketone } \\
\text { Methyl methacrylate } \\
\text { Mothyl methanesulfonate } \\
\text { 3-Mothylcholanthrene } \\
\text { 2-Methylnaphthaiene } \\
\text { Naphthalene } \\
\text { 1.4-Naphthoquinone } \\
\text { 1-Naphthylamine } \\
\text { 2-Naphthylamine }\end{array}$ \\
\hline
\end{tabular}

$<3.0$
$<0.0050$
31

31
$<0.20$

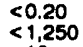

$<100$

$<25$

$<25$

$<10$
$<10$
$<10$
$<10$
$<10$

$<10$
$<10$
$<10$

$<10$
$<10$
$<10$
$<4.0$
5.400

Nickol

2-Nitroaniline

3-Nitroaniline

Nitrobenzene

2-Nitrophenol

4 Nitrophenol

A-Nitroquinoline-1-oxide

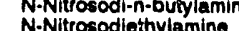

N-Nitrosodiethylamine

N-Nitrosodiphenylamine

N-Nitrosodipropylamine

N-Nitrosomethylethylamine

N-Nitrosomorpholine

N-Nitrosopiperidine

N-Nitrosopyrrolidine

5-Nitro-0-toluidine

0,0,0-Triethyl phosphorothioate

Octachlorodibenzo-p-dioxins $<0.0010$

Parathion methyl

P PCB 1016

0 PCB 1221

PCB 1232

0
0

0 PCE 1254

Pentachlorobenzene

o Pentachlorobenzen

o Pentachlorodibenzo-p-dioxins

Pentachlorodibenzo-p-turans

1,2,3,7,6.PCDF

Pentachloroethane

Pentechloronitrobenzen

Pentachlorophenol

- Phenacetin

o Phenanth

Phenol

P.Phenylenediamine

0 Phorate

o 2-Picoline

o Proptonitrile

0 Pyrsne

O Pyridine

0 Selenium

O Silver

Sodium

0 Styrene

0 Sulfide

0 Sulfotepp

1,2,4,5-Tetrach

$\begin{array}{lll}0 & 2,3,7,8-T C D D \\ 0 & 2,3,7,8-T C D F\end{array}$

Tetrachlorodibenzo-p-dioxins

Tetrachlorodibenzo-p-furans

o 1,1,1,2-Tetrachloroethane

1,1,2,2-Totrachloroothane

2 Tetrachloroothylene

o Thallum

0 Tin

$\begin{array}{ll}0 & \text { Toluene } \\ 0 & \text { o-Toluidine }\end{array}$

o Total organic carbon

2 Total organic halogens

o Total phosphates as P

0 Toxaphene

2,4,5-TP (Silvex)

o $1,1,1$-Trichloroothane

0 1,1,2-Trichloroothane

$<10$
$<10$
$<10$
$<10$

$<>10$

$<10$

$<10$

$<0.10$

$<10$
$<10$
$<5,000$

$<5,000$

$<10$

$<10$
$<2.0$

$<2.0$

2,860
$<25$

$<1,000$

$<1,000$
$<10$

$<100045$

$<0.00040$

$<0.0004$

$<25$
$<25$
870

$<10$

$<2.0$

$<10$
$<2.0$

$<25$
$<10$

$<1,000$

$\begin{array}{r}303 \\ <50 \\ \hline 50\end{array}$

$<50$
$<0.24$

$<0.090$

$<10$
$<25$

$<25$

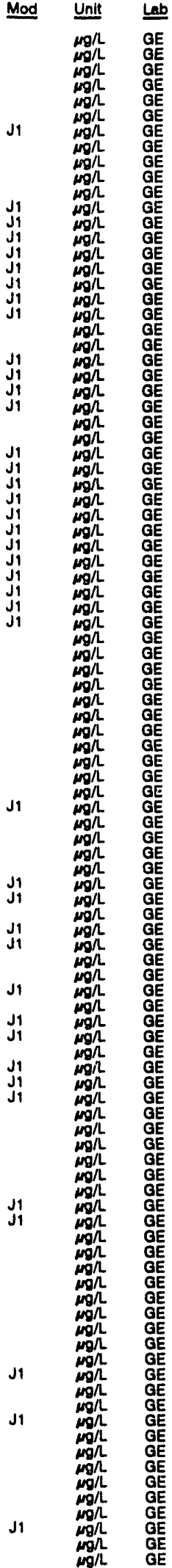


WELL MSB 2D collected on 07/09/92, laboratory analyses (cont.)

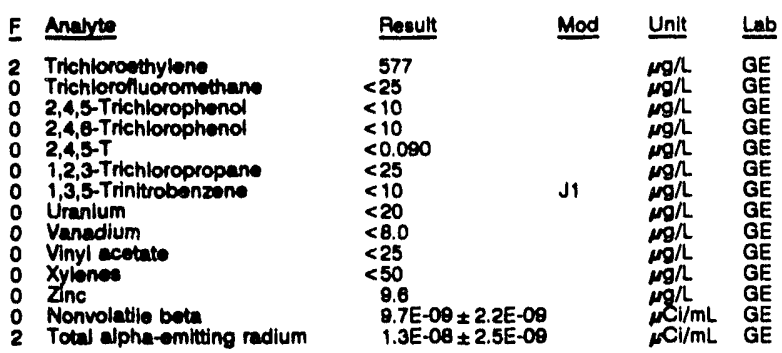

WELL MSB 3B

MEASUREMENTS CONDUCTED IN THE FIELD

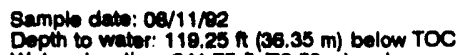
Wathe to wation: 118.25 A $(38.35 \mathrm{~m})$ below Witer evacuatiod betore sampling: $264 \mathrm{gal}$

LABORATORY ANNLYSES

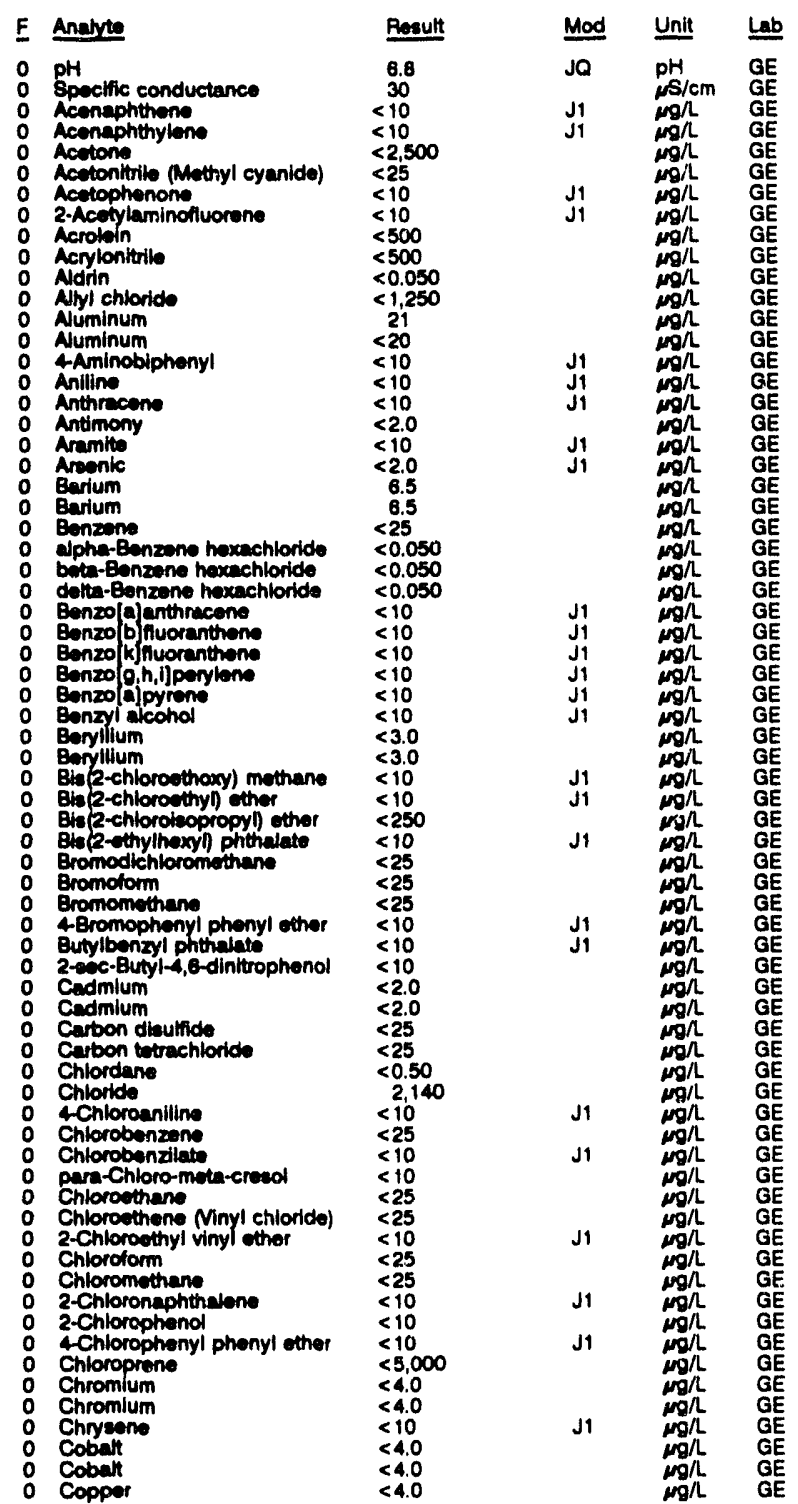

WELL MSB 38 collected on 08/11/82, laboratory analyses (cont.)

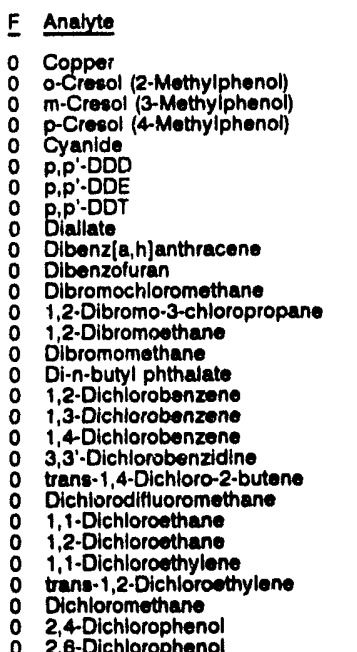

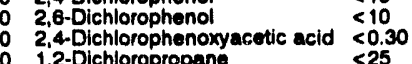
1,2-Dichloropropane 0
0
0 trans-1,3-Dichloropropene D Dieldrin 2,4-Dimethy! phenol o p-Oimethytaminoazobenzene O bimethylbenz(a)anthracene 0 3,3'-Dimethylbenzidine 0 a-Dimethylphenethylamine 0 1,3-Dinitrobenzene 2,4-Dinitrophenol 2,4-Dinitrotoluene 2,6-Dinitrotoluene O Di-n-octyl phthe

O Diptionylamine

0 Disulfoton

O Endosulfan I

O Endosulian II

0 Endrin

0 Endrin aldohyde

E Ethyl methacrylate

0 Ethylbenzene

o Famphur

Fluoranthene

Fluorene

O Heptachlor epoxide

o $1,2,3,4,6,7,8-H P C D D$

Heptachlorodibonzo-

Heptachlorodibenzo-p-furans

Hexachlorobenzene

Hexachlorobutadiene

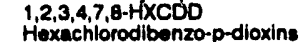

Hoxachlorodibenzo-

1,2,3,4,7,8-HXCDF

Hexachloroothane

Hexachlorophene

2-Hexanone

Indeno[1,2,3-c,d]pyrene

lodomethane (Methyl lodide)

Isobutyl

isophorone

S rosatrole

Kepone

Lindane

Manganese

Manganeso

Methacrylonitrile

Methapyriten

2-Mothyl-4,6-dinitrophenol

Methyl ethyl ketone

Mothyl bobutyl ketone

Mothy! mothanesulfonato

3-Methylcholanthrene

2.Methylnaphthalene
Result

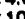

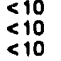

$\leq 5,0$

$<0$

$<10$

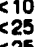

$<500$

$<25$
$\leq 10$
$<10$

$<10$
$<10$
10

$<10$

$<730$

2

<25

$<25$

210
$<0.30$
$<25$
$<25$
$<250$

$<250$

$<10$
$<10$

$\leq \leq 10$

$<10$

$<\leq 10$

$\leq 10$

$\leq 10$

$\leq 10$

$<<10$

$<10$

$<10$

$<0.10$

$<0.10$

(

$<0.10$

$<10$

$<25$

$<10$

$<10$

$<0.050$

$<0.00005$

$<0.00045$

$<0.00045$

$<10$

$<10$

$<0.00045$

$<0.00045$

$<0.00040$

$<10$

$<10$

$<10$

$<375$
$<2,500$

$<10$

$<10$

$<10$

$<0.0050$

11
11

$<0.20$

$<1,250$
$<10$

$<0.50$

$<10$
$<25$

$<25$
$<25$

$<10$
$<10$

$<10$
$<10$

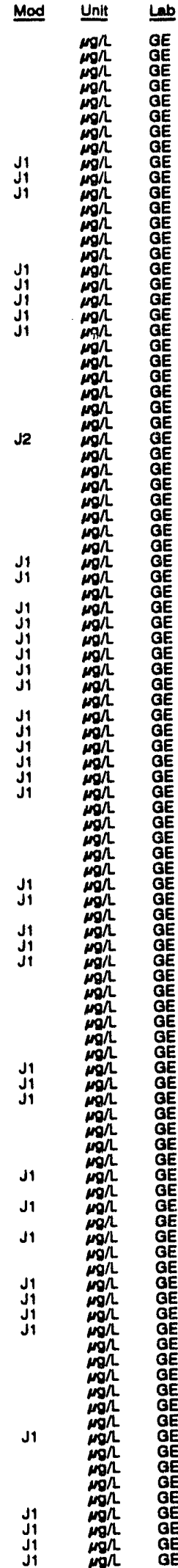


WELL MSB 38 collected on 08/11/92, laboratory analyees (cont.)

E Analyte

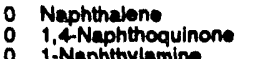

o 1-Naphthylamin

0 Nickel

o Nitrate-nitrite as nitrogen

2-Nitroaniline

4 Nitroanlline

Nitrobenzene

2-Nitropheno

o 4Nitroquinoline-1-oxide

o N-Nitrocodi-n-butylamine

N-Nitrosodiet thyt

. N-Nitrocodimethylamine

N-Nitrosodiphonylamine

N-Nitroeomethylethylamine

N-Nhosomorpholin

N-Nitrosopymolidin

S10 $<10$

O,O,o rithyl phoephorcthioate

Octachlorodibenzo-p-dioxins

Parathion

O Parethion methyl

P
0

PCB 1232

PCB 1242

PCE 1248

PCB 1200

Pentachiorobenzom

Pentechlorodibenzo-p-dioxins

Pentachlorodibenzo-p-furans

1,2,3,7,8-PCDF

Pentachloroethane

Pentachloronltrobenzene

Pentachloropheno:

Phonacedtin

Phenol

Phenols

p-Phonylenediamine

Phorate

2.Picoline

Propionitrile

Propiontento

Pyridine

Sarrolu

Siver

Sitver

Sodium

Sodium

Styrene

Sulifide

Sulfide

Sultotiapp

2, 2,4,7,8-TCDD

2,3,7,8-TCDF

Teirichlorodlbenzo-dlaxin

1,1,1,2-Tetrachloroethane

$1,1,2,2$. Trechlorothan

2 Tetrechloroethylene

2,3,4,6-T

Thionarin

Tin

Tin

Tolvene

O-Toluidine

Total organic carbon

Total organic halogens

Toxaphene

1,2,4-Trichiorobenzene

1,1,1-Trichloroethane

1,1,2-Trichloroethen

Trichioroethylone

2,4,5-Trichiorophenol

2,4,8-Trichloropheno

2,4,5-T

1,2,3-Trichloropropan

1,3,5-Trinitrobenzene

Uranium

0 Vanedium

0 Vanadium
$<10$

$<10$
$<10$

$<4.0$

$<4.0$

$<10$

$<10$

$<10$

$<10$

$<10$

$<10$

$<10$

$<10$

$<10$

10

$<10$
$<10$

$<0.0010$

$<0.050$

$<0.50$

$<0.50$
$<0.50$

$<0.50$

$<0.50$

$<0.50$

$<0.00055$

$<0.000055$

$<0.00055$

$<10$

$<10$

$<10$

$<10$
$<10$

$<10$

$<5.0$

$<10$

$<10$
$<10$

$<100$

$<10$
$<10$

$<10$
$<10$

$<10$
$<2.0$
$<2.0$

$<2.0$

2,340
2,350

$<25$

$<1,000$

$<1,000$

$<10$

$<<0.00045$

0.00040

$<0.00045$

$<25$
$<25$

$<25$
34
$<10$
$<2.0$

$<2.0$
$<10$
$<2.0$

$<2.0$

$<25$

$<1000$

6.32
$<50$

$<0.24$

$<10$
$<25$
$<25$

1,280

$<25$

$<10$

$<0.080$

$<25$

$<10$

$<20$
$<20$
$<8.0$
$<8.0$

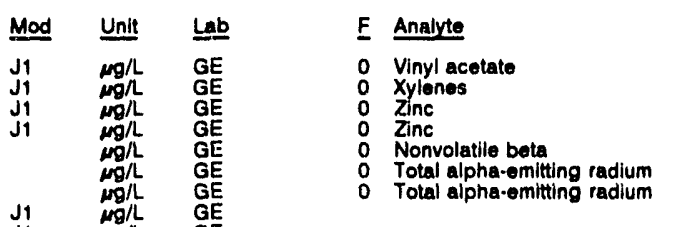

WELL MSB 3B collected on 08/11/82, laboratory analyees (cont.)

WELL MSB 3C

MEASUREMENTS CONDUCTED IN THE FIELD

Sample date: 08/12/82

Dopth to water: 142.83 (tt $(43.47 \mathrm{~m})$ below TOC

Water elovation: $218.17 \mathrm{t}(66.50 \mathrm{~m}) \mathrm{mel}$

Sp. conductance: 2820 ms/c

Water ovacuatod bolore sampling: $17 \mathrm{gal}$

Rosult Mod

$<25$

$<50$
5.4
5.0

$<2.0 E-0 \%$

$1.0 E-09 \pm 4.0 E \cdot 10$

Mod Unit Leb

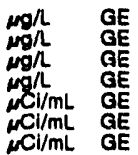

LABORATORY ANALYSES

2 Spectic conductance

Acenaphthene

Acetone

Acetonitrile (Methyl cyanide)

Acetophenone

2-Acetylaminofluorene

Acrolein

0 Acrylonit

0 Aldrin

Aluminum

4-Aminobiphenyl

Aniline

Anthracene

Aramite

Aremite

Areenic

alpha-Banzene hexachloride

beta.Benzene hexachloride

delta-Benzene hexachlorido

Benzo[a]anthracene

Benzo b) fluoranthene

Benzo kjfluoranthene

Benzo g, h, il) perylene

Benzolappyren

Benzyl alcoh

Bis (2-chloroethoxy) methane

Bis (2-chloroethyl) ether

Bis (2-chloroothyl) ethef
Bis (2-chloroisopropyl) ether

Bis(2-ethylhexyl) phthelate

Bromodichloromethan

Bromoform

4-Bromophenyl phenyl ether

Butylbenzyl phthalate

2-sec-Buty

Cadmium

Carbon disulfide

Carbon tetrach

Chlordane

A.Chloroaniline

4-Chloroaniline

Chlorobenzene

para-Chloro-meta-cresol

Chioroethane

Chloroethene Ninyl chloridel

2.Chloroethyl vinyl other

Chloroform

Chloromethan

2-Chloronaphthalene

2-Chlorophenol
4-Chlorophenyl phenyl ether

Chloroprene

Chromium

Chryeon

o-Cresol (2-Methyiphenol)

m-Cresol (3-Methylphenol)

p-Cresol (4-Mothylphenol)

Cyanide

P,P'-ODD

P,p'-DDE

Diallate

Dibenz[a,h]anthracene

Dibenzofuran

Dibromochioromethane

1,2-Dibromo-3-chloropro
Time: $7: 50$

Alkalinity: $881 \mathrm{mon}$
Water tomperafure: $21.3^{\circ} \mathrm{C}$

GE


WELL M8B 3C collected on 08/12/92, laboratory analyees (cont.)

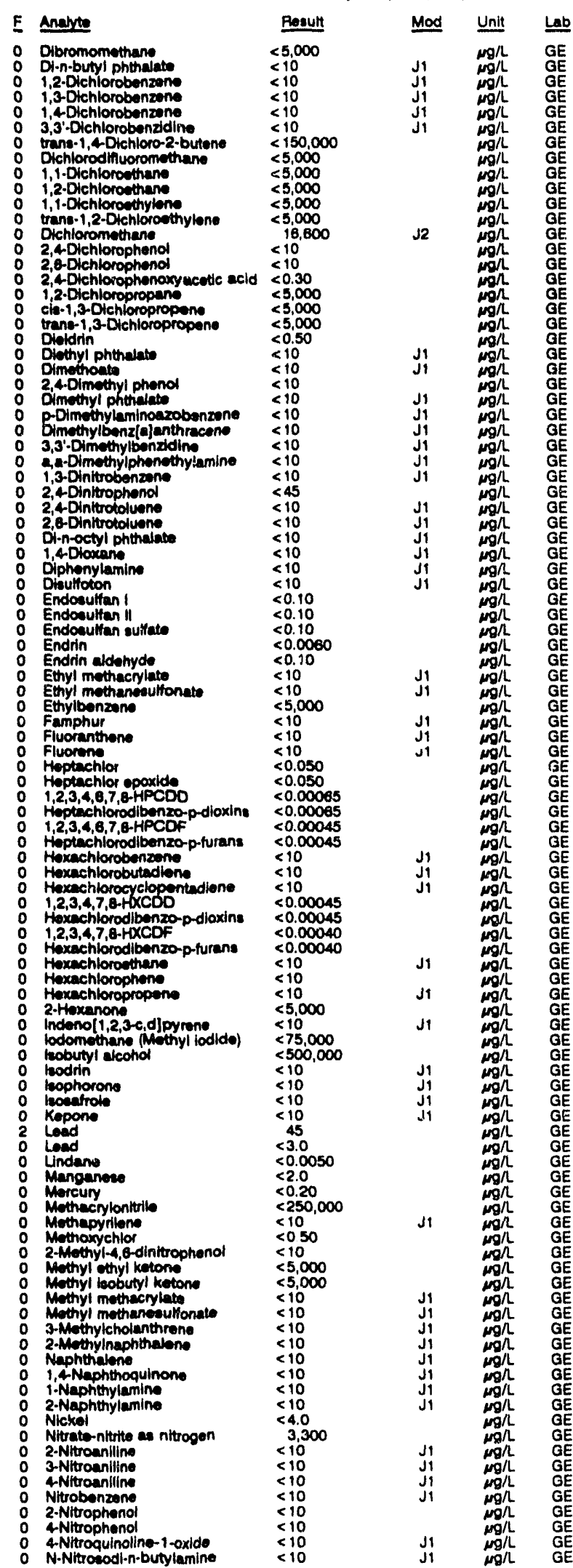

WELL MSB 3C collocted on 08/12/92, laboratory analyese (cont.)

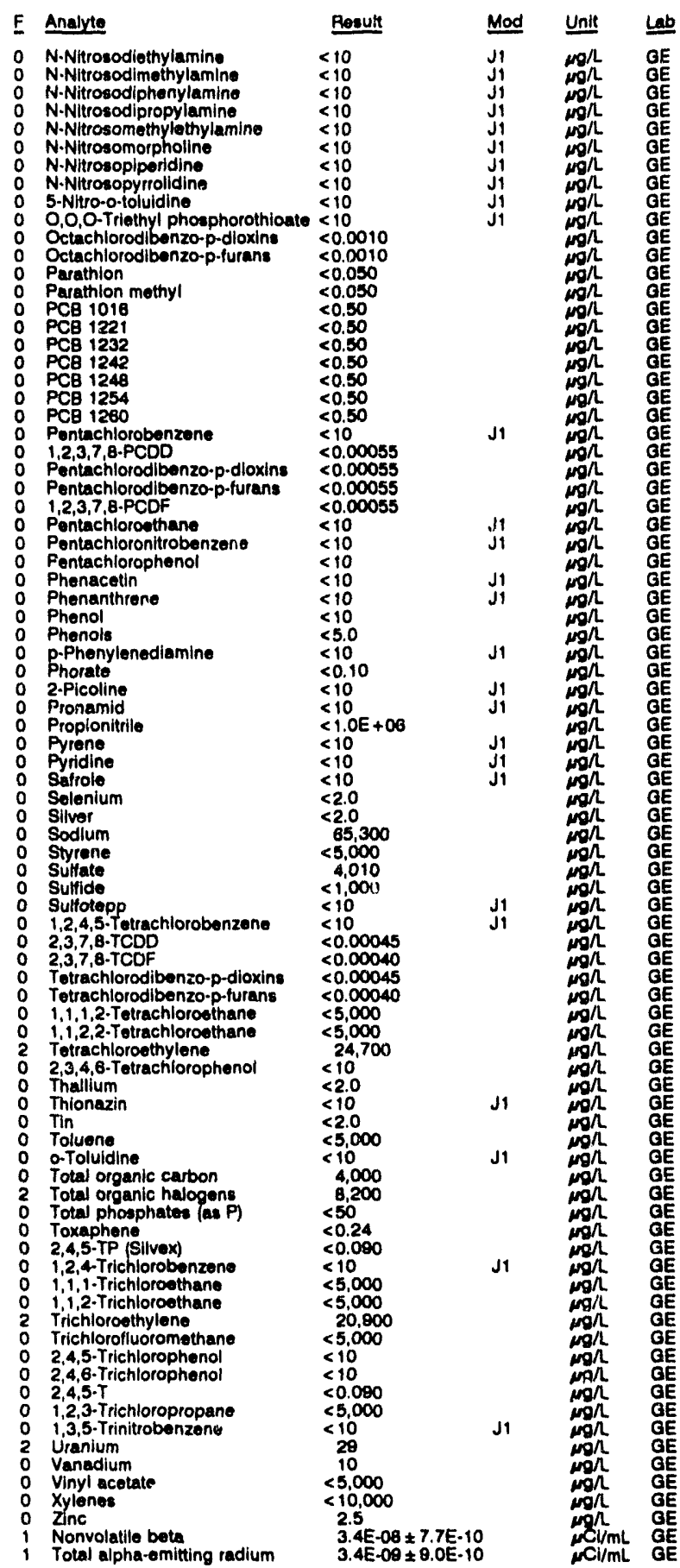

WELL MSB 3D

MEASUREMENTS CONDUCTED IN THE FIELD

Sample date: 08/11/92 Time: 7:30

Depth to water: $129.80 \mathrm{H}(38.59 \mathrm{~m})$ below TOC

inaccessibility or mechanical problem prevented sample collection. 
ANALYTICAL RESULTS

WELL MSB 4B

MEASUREMENTS CONOUCTED IN THE FIELD

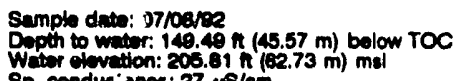
Sp. conducin ince: $27 \mu \mathrm{s} / \mathrm{cm}$ Wetor ovecueted botore cempling: $177 \mathrm{gal}$

LABORATOFY ANAL YSES

E Anave

: $\mathrm{pH}$ Spectific conductance

o Aconaphthylone

O Acettoniturile (Methyl cyanide)

2.Acophlanoninofluorene

Acrololn

o Acrylont

Nlyl chloride

0 AAminobiphenyl

Anilino

Antimony

Aramite

Barium

alpha-Benzene hoxechloride beta-Benzone noxachloride deltin-Benzame hoxachiofide

Bonzoj: ienthracens

Benzo/b) nuoranthene

Benzo/k huoranthone

Benzo/g,h,l]pentiono

Benzol acohol

Boryllium

Bis 2-chloroethocy) methane

Bia (2-chloroleoveropyl) ether

Brome

Bromotion

4 Bromophenyl phenyl ether

2-ece-Butyl-4,e-dintropheno

Cadmium

Carbon dieulfide

Carbon tortect

Chlorido

4Chloroanilino

Chlorebenzene

para-Chioro-mota-creseal

Chloroettione Minyl chloride 2-Chiorothyl viny chor

Chlorelorm

Chloromethar

2-Chloronephthelen

2-Chiorophenol

4-Chlorophenyl pirenyl ether

Chromium

Chryeon

Cobart

o-cresal R-Methyiphenol

m-Crevol (B-Awethylphend)

p-Cread (4-Methylphenol) $<10$

P,p'-DDt

Bupiod

Dibenz $[a, h] a n t h r a c e n$

Dibenzoturan

Dibromochloromothane

1,2-Dibromouthan

Dibromompthane

1,2-Dichlorobens sene

1,4 pintoromane

3,3'-Olchlorobendine

trans-1,4-Dichloro-2-butene

Dichlorodinlioromethan

1,1-Dichlorowthen

1,1-Dchlorethen

trant-1,2-Dichloroethylene

4.5
$<2$
$<10$
$<10$
$<2,500$
$<25$
$<10$
$<10$
$<500$
$<500$

Time: 13:25

Hik: 4.8 .8. 0.9

Water temperature: $21.7^{\circ} \mathrm{C}$

$<1,250$

$<20$

$<10$

$<10$

$<10$

$<2.0$

$<25$

$<0.050$
$<0.050$

$<10$

$<10$

$<10$

$<10$

$<3.0$

$<10$
$<10$

$<250$

$<25$

$<25$

$<10$

$<2.0$

$<25$
$<0.50$

$<0.50$

$<10$
$<25$

$<10$
$<10$

$<25$
$<25$
$<10$
$<25$

$<25$

$<10$
$<10$

$<10$
$<5,000$

$<4.0$
$<10$

$<4.0$

$<10$

$<10$
$<5.0$

$<0.10$

$<0.10$

$<10$

$<10$
$<25$

$<25$

$<500$
$<25$

$<10$
$<10$
$<10$

$<10$

$<10$
$<10$
$<750$

$<750$

$<25$
$<25$
$<25$

$<25$
WELL MSB 4B collected on 07/08/82, laboratory analyees (cont)

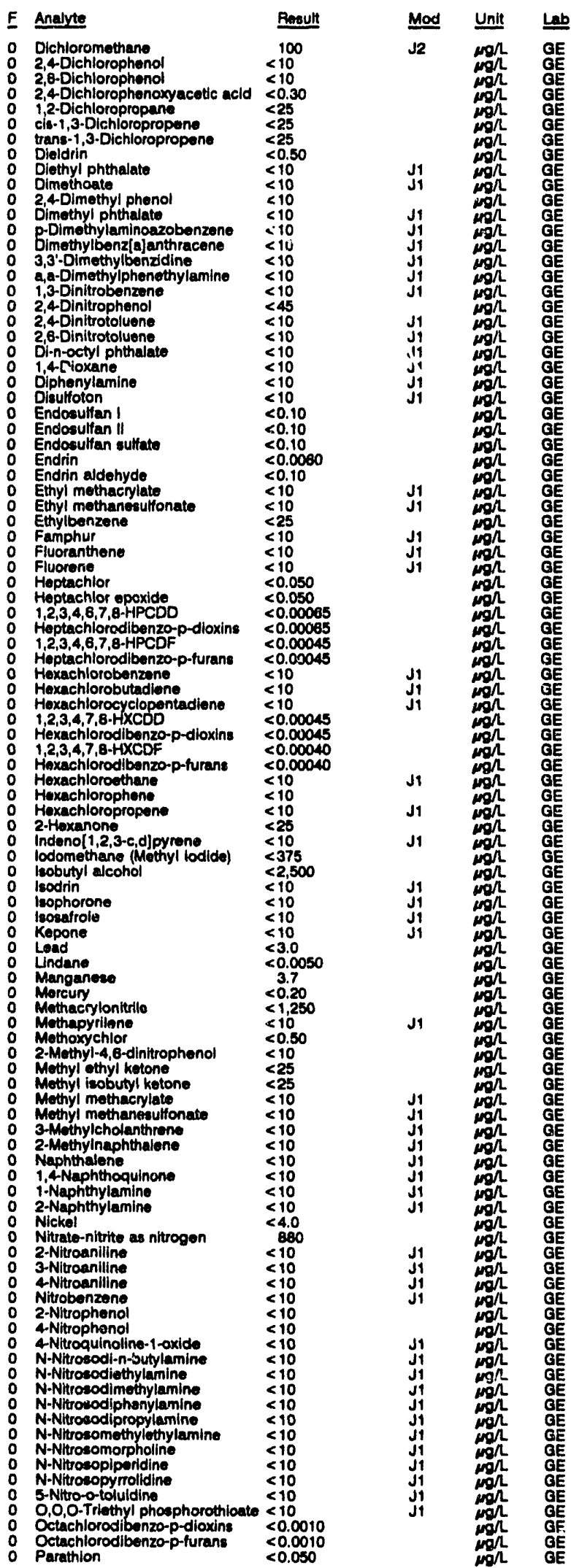


WELL MSB 48 collected on 07/08/92, laboratory analyese (cone)

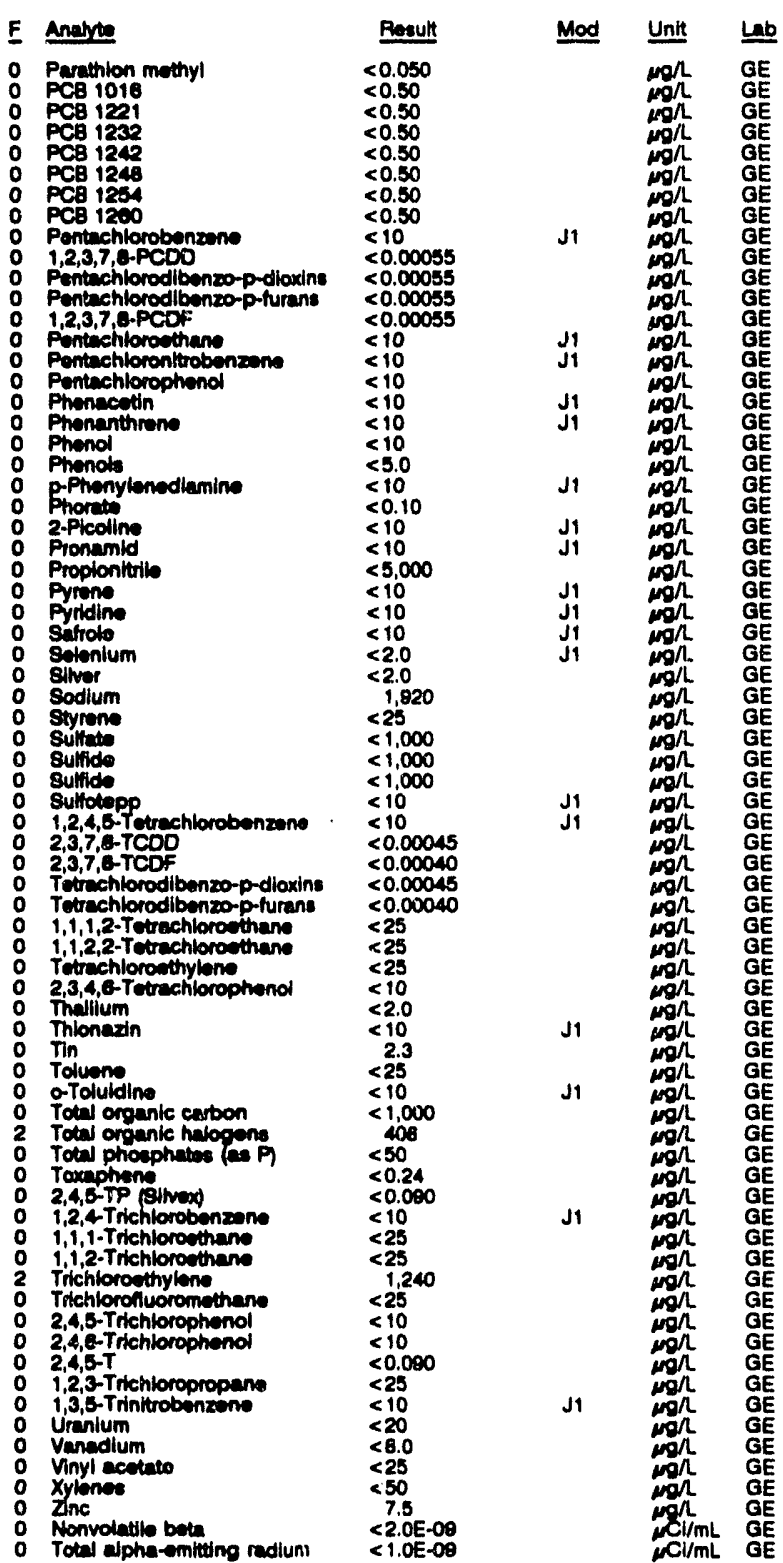

WELL MSB 4C

MEASUREMENTS CONDUCTED IN THE FIELD

\section{Sample data: 08/12/02}

Dopte to water. $141.02 \mathrm{n}(43.17 \mathrm{~m})$ below TOC

Water olovation: 213.50 it (As

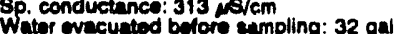

Whe well went dry during purging

LABOAATORY ANALYSES

\begin{tabular}{|c|c|c|c|c|}
\hline$F$ & Anatrote & Result & Mod & Unit \\
\hline $\begin{array}{l}2 \\
1 \\
0 \\
0 \\
0 \\
0 \\
0 \\
0 \\
0\end{array}$ & 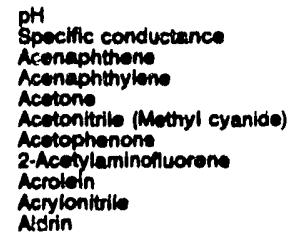 & $\begin{aligned} & 11 \\
& 270 \\
&< 10 \\
&< 10 \\
&< 10,000 \\
&< 100 \\
&< 10 \\
&<10 \\
&<2,000 \\
&<2,000 \\
&<0.050\end{aligned}$ & $\begin{array}{l}\text { Ja } \\
\text { J1 } \\
\text { J1 } \\
\text { J1 } \\
\mathbf{J 1}\end{array}$ & 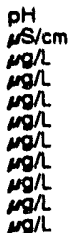 \\
\hline
\end{tabular}

WELL MSB 4C collectod on 08/12/92, laboratory analyees (cont.)

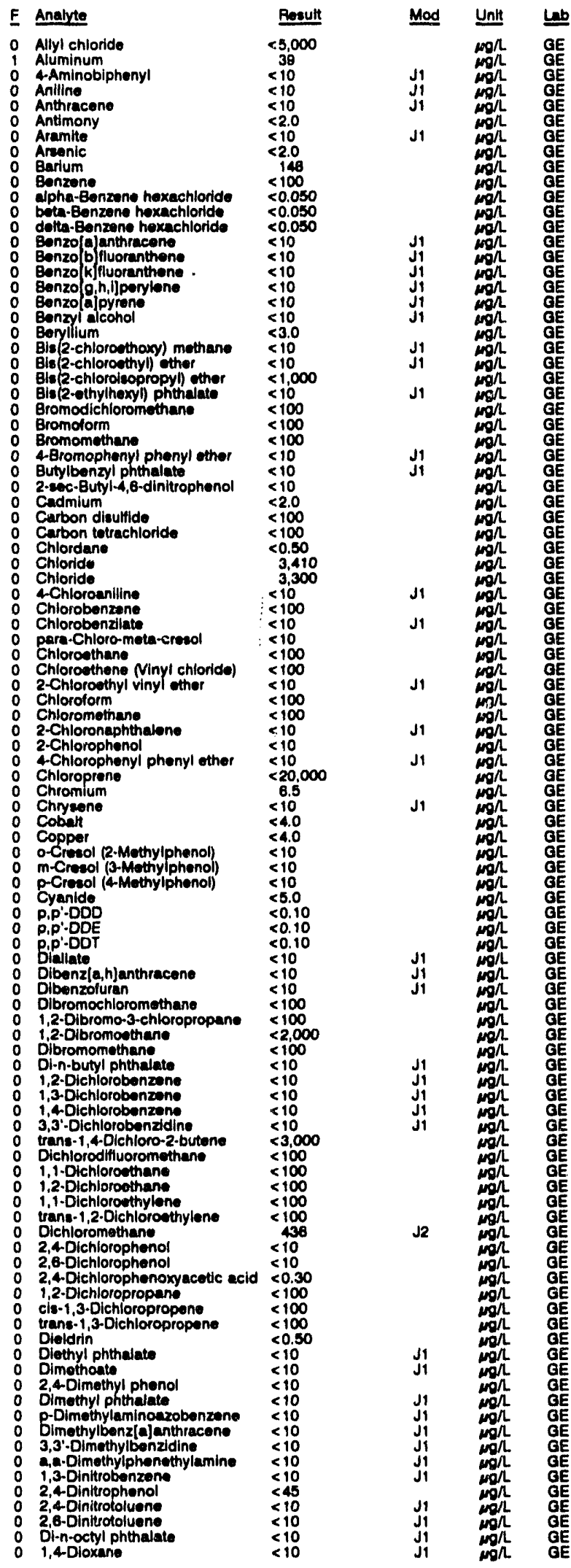


ANALYTICAL RESULTS

WELL MSB \&C colbetiod on 08/12/92, laboratory analyeos (cont)

E Andyte

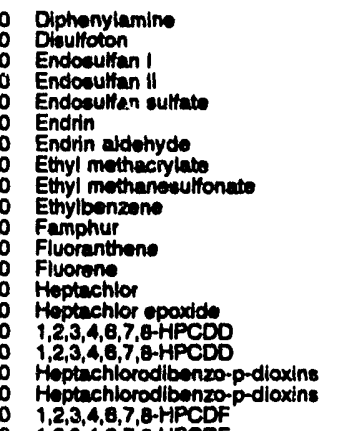

1,2,3,4,8,7,8-HPCDF

H Heptechlorodibenzo-p-turans

Hoptachlorodibenzo-p-furan:

Hexachlorobutedien

Hexachlorogyclopentadiene

$1,2,3,4,7,8-1 \times C D O$

Hexachlorodibonzo-p-dloxine

$1,2,3,4,7,8-H \times C D F$

Hixachlorodibenzo-p-furans

Hexechlorodibenzo-p-furans

Hoxachloroethente

Hoxachlorophene

$2+$ tibxanone

Indono $[1,2,3-c, d] p y r e n$ e

lodomethane (Methyl lodide)

leodrin

bophorone

reanfrone

Kapon

L Lindane

Mercury

Methecryionitrite

Mothapyritone

2-Methyl-4,6-dinitrophenol

Methyl ethyl ketone

Methyl bobutyl keton

Mathyl methanesulfonate

3-Methyicholanthrone

Naphitistene

1,4-Naphthoquinone

1-Naphthylamine

Nickel

Nitrata-nilutite as nitrogen

2-Nitroaniline

4 Nitroanilline

Nitrobenzene

2-Nitrophene

4-Nitroquinolino-1-axide

N-Nitroeodion-butylamin

N-Nitroesdiethylamine

N-Nitrosodimethylamine

N-Nitrosodiphenylamine

N-Nitrocomedthylethylamine

N-Nitrocomorpholine

N-Nitrosopyrrolidine

S-Nitro-o-toluldino

Octuchlorodibenza-p

Octachlorodibenzo-p-dioxins

Octachlorodibenzo-p-dioxins

Oetachlorodibenzo-p-furans

Parathion

Paration methyl

PCB 1232

PCB 1242

PCB 125

PCB 1260

Pentachlcrobonzen

, 2,3,7,8-PCOD

Pentachlorodibenzo-p-dioxins
$<10$

$<0.10$

$<0.10$

$<0.0000$

$<0.10$

$<10$

$<10$

$<10$
$<10$

$<0.050$

$<0.050$

$<0.00005$

$<0.00065$

$<0.00065$

0.00045

$<0.00045$

$<10$

$<10$

$<0.00045$

$<0.00045$

$<0.00045$

$<0.00045$
$<0.00040$

$<0.00040$

$<0.00040$

$<10$

$<10$

$<<100$

$<10$

$<1,500$

$<10^{\circ}$

$<10$
$<10$
$<10$

$<10$
$<3.0$
$<0.0050$

$<0.0050$

$<2.0$

$<5,000$

$<10$

$<10$

$<100$
$<100$

$<10$
$<10$

$<10$
$<10$

$<10$
$<10$

$<10$

$<10$
$<10$

$<4.0$

15,300
$<10$

$<10$

$<10$
$<10$

$<10$
$<10$

$\leq 10$

$<<10$

$<10$

$<10$

$<10$

$<10$

10

(10

$<0.0010$

$<0.0010$

$<0.0010$

$<0.050$
$<0.050$

$<0.50$

$<0.50$

$<0.50$

$<0.50$
$<0.50$

$<0.50$

$<0.00055$

$<0.00055$
$<0.00055$

Mod Unit Lab

GE

Ji

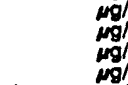

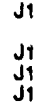

J

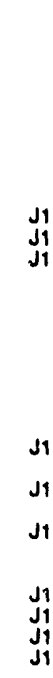

WELL MSB 4 C collectod on 08/12/82, laboratory analyses (cont.)

F Analyte

- Pentachlorodibenzo-p-dioxins

o Pentachlorodibenzo-p-furans

$\begin{array}{ll}0 & 1,2,3,7,6 \cdot P C D F \\ 0 & 1,2,3,7,8 \cdot P C D F\end{array}$

0 Pentachloroothane

- Pentachloronitrobenzene

O Pentachloropheno

O Phenol

o Phorate

o 2.Picoline

D Propionitrile

o Pyrene

o Safrole

o Silver

o Sodium

o Sulfate

O Sulfate

O Sulfide

1,2,4,5-Tetrachlorobenzene

$2,3,7,6-\mathrm{TCD}$

2,3,7,8-TCDD

2,3,7,8-TCDF

-

Tetrachlorodibenzo-p-dioxin

Tetrachlorodibenzo-p-dioxin

Terrachlorodibenzo-p-furans

1,1,1,2-Tetrachloroethane

1,1,2,2-Tetrachloroethan

2
0
0

o Thallum

o Thionarin

Toluene

o-Toluidine

Total organic carbon

2 Total organic halogens

0 Toxaphene

o 2,4,5-TP (Silvox)

- 1,2,4-Trichlorobenzene

o 1,1,1-Trichloroethane

o 1,1,2-Trichloroethane

2 Trichioroethylene

Trichlorofluoromethane

2,4,5-Trichlorophenol

$\begin{array}{ll}0 & 2,4,6-T \\ 0 & 2,4,5-T \\ & 1,3,3\end{array}$

o 1,2,3-Trichloropropane

o 1,3,5.Trinitrobenzene

- Úranium

Vanadium

o Xylenos

0 Zinc

i Notal alpha-emitting radium

Besult

$<0.00055$

$<0.00055$

$<0.00055$

$<10$
$<10$

$<10$

$<10$

$<10$

$<5.0$

$<0.10$

$<10$

$<20,000$

$<10$

$<10$
$<2.0$

14,200

14,200
$<100$

$<1,000$
$<1,000$

$<1,000$

$<10$

$<0.00045$

$<0.00045$

$<0.00040$

$<0.00045$

$<0.00040$

$<0.00040$

$<100$

4,510

$<10$

$<2.0$

2.8
$<100$

$<100$

2,000
4,900

$<<0$

$<0.090$

$<10$
$<100$

$<100$

6,580
$<100$

$<100$

<10

$<100$

$<100$

$<10$
$<20$
$<8.0$
$<100$
$<200$

$<200$

$<2.0$

$1.2 E-08 \pm 5.4 E-10$

$3.0 E-00 \pm 8.0 E-10$
Mod Unit Lab

$\operatorname{mog}_{\operatorname{mon}} G E$

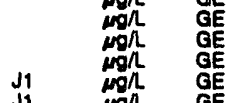

$J_{1}$ m

WELL MSB 4D

MEASUREMENTS CONDUCTED IN THE FIELD

Sample date: 07/08/92

Depth to water: $126.81 \mathrm{th}(38.65 \mathrm{~m})$ bolow TOC

Water elevation: $228.79 \mathrm{H}(69.74 \mathrm{~m}) \mathrm{msl}$

Water evacuated before sampling: $52 \mathrm{gal}$

LABORATORY ANALYSES

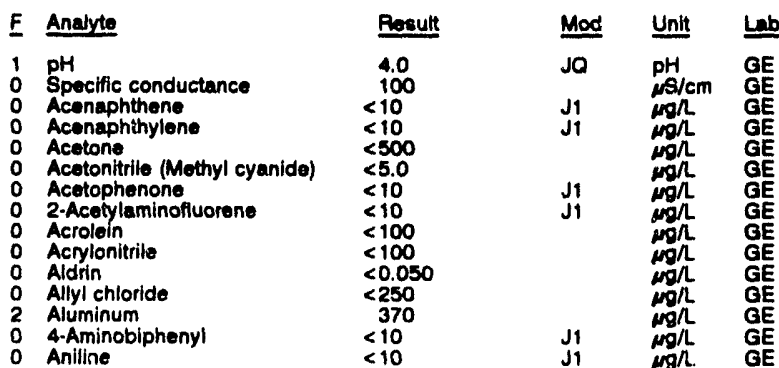

Time: 13:10

Alkalinity: $0 \mathrm{mon}$

Water temperature: $22.0^{\circ} \mathrm{C}$ 
ANALYTICAL RESULTS

WELL MSB 40 collected on 07/08/92, loboratory analyees (cont.)

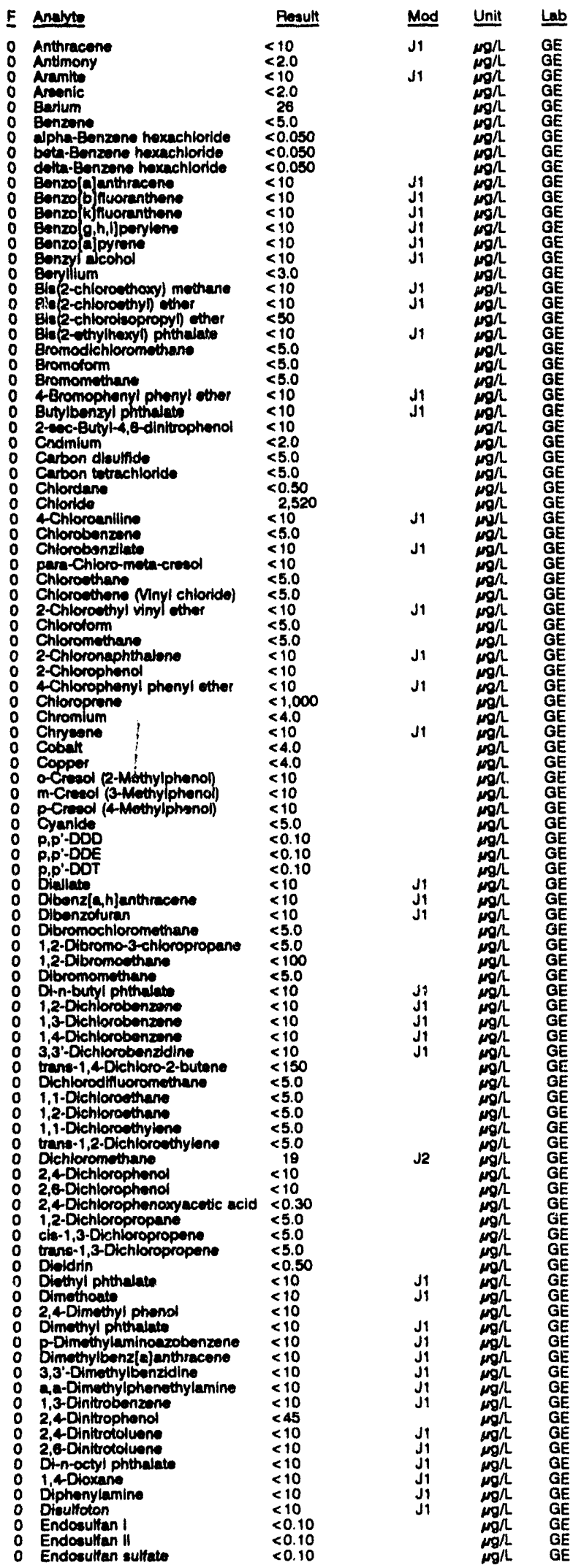

WELL MSB 4D collected on 07/08/92, laboratory analyees (cont.)

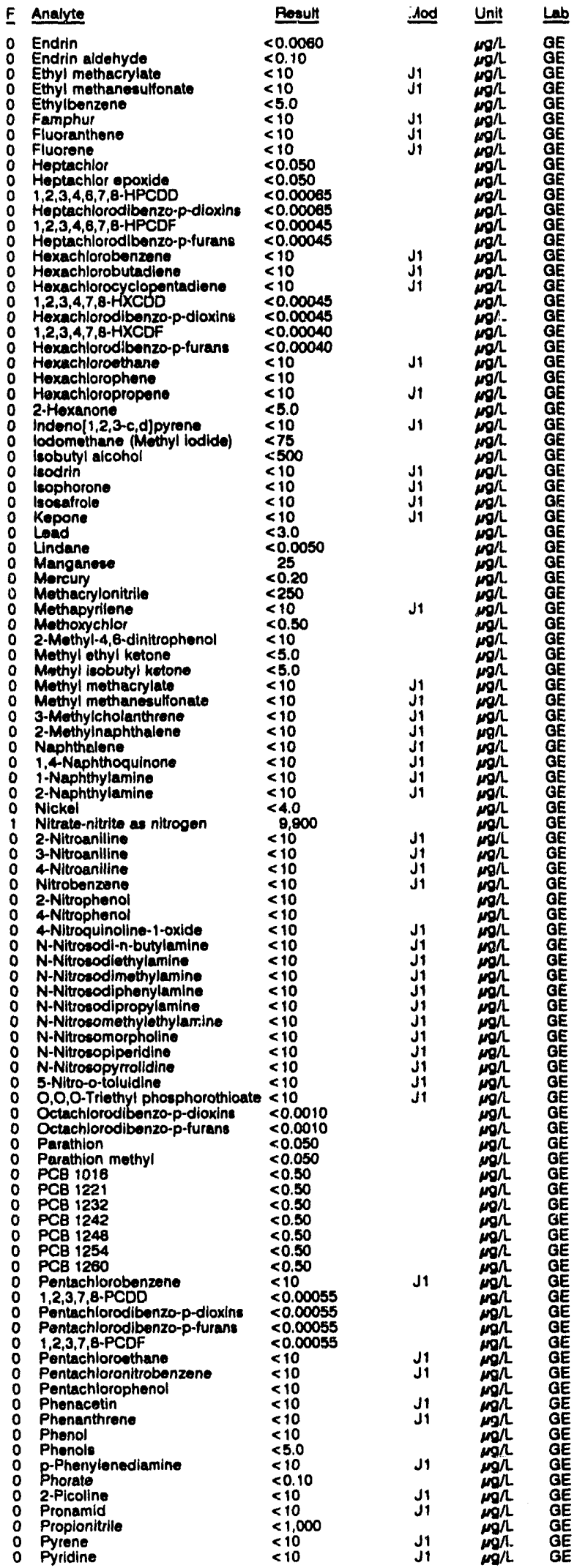


WELL. MSB 4D collected on 07/08/82, laboratory analyees (cont.)

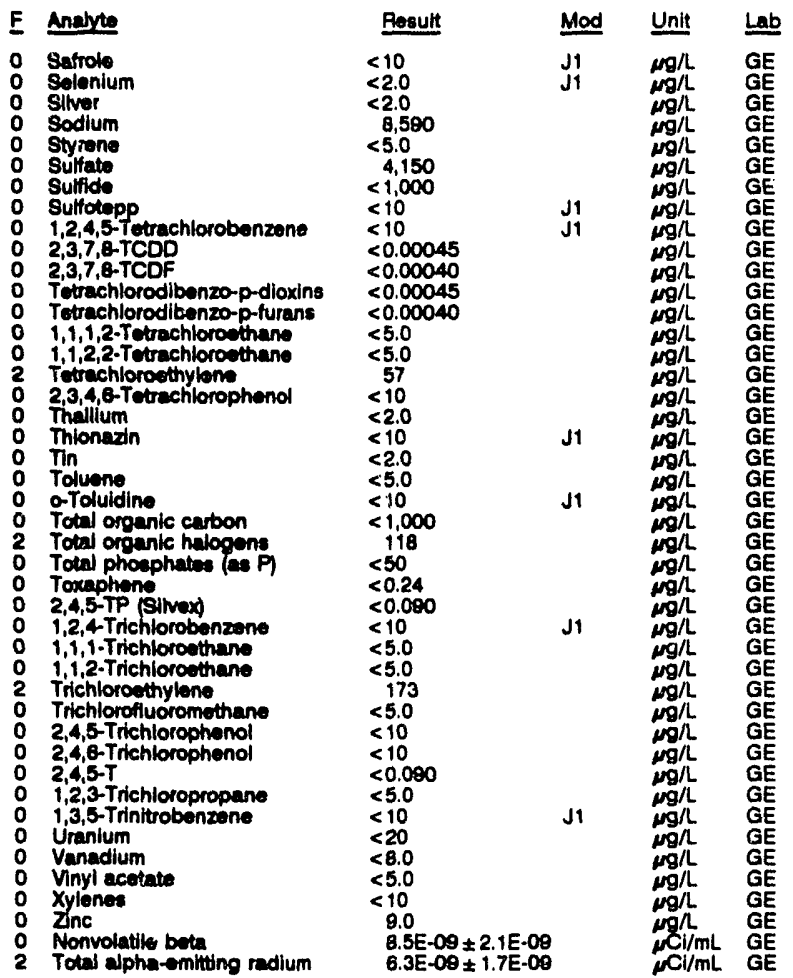

WELL MSB 5A

MEASUREMENTS CONDUCTED IN THE FIELD

\section{Sample datu: 07/00/82}

Depth to water: $117.10 \mathrm{At}(35.72 \mathrm{~m})$ below TOC Water elevation: $227.41 \mathrm{Ht}(69.32 \mathrm{~m}) \mathrm{msl}$

Sp. conductance: 37 $3 \mathrm{~S} / \mathrm{cm}$.

LABOPATOPY ANALYSES

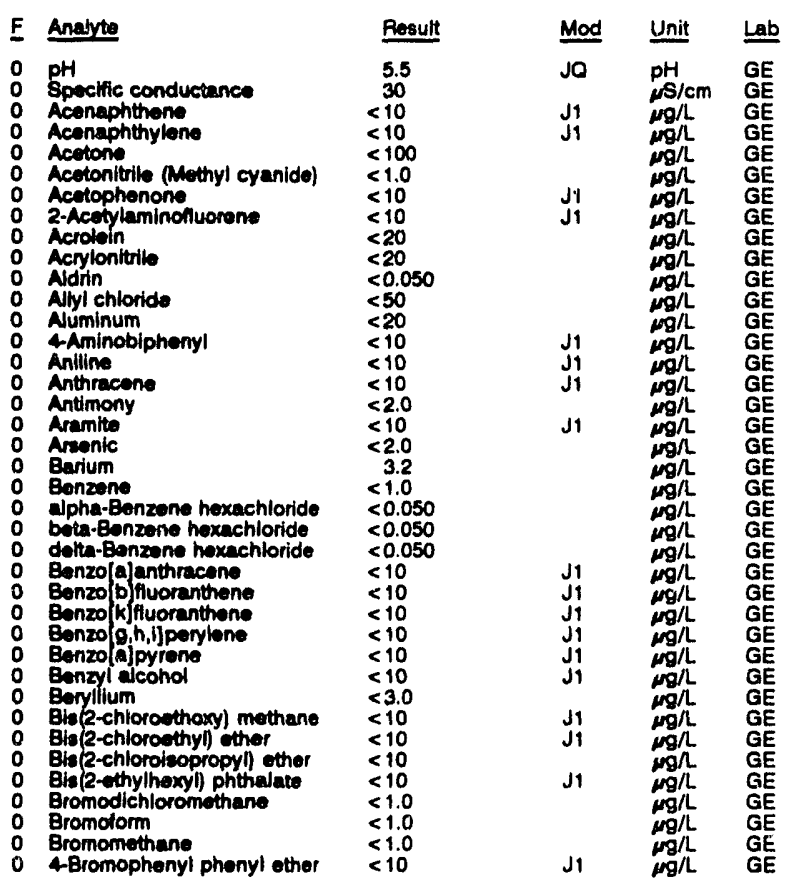

WELL MSB 5A collocted on 07/09/92, laboratory analyees (cont.)

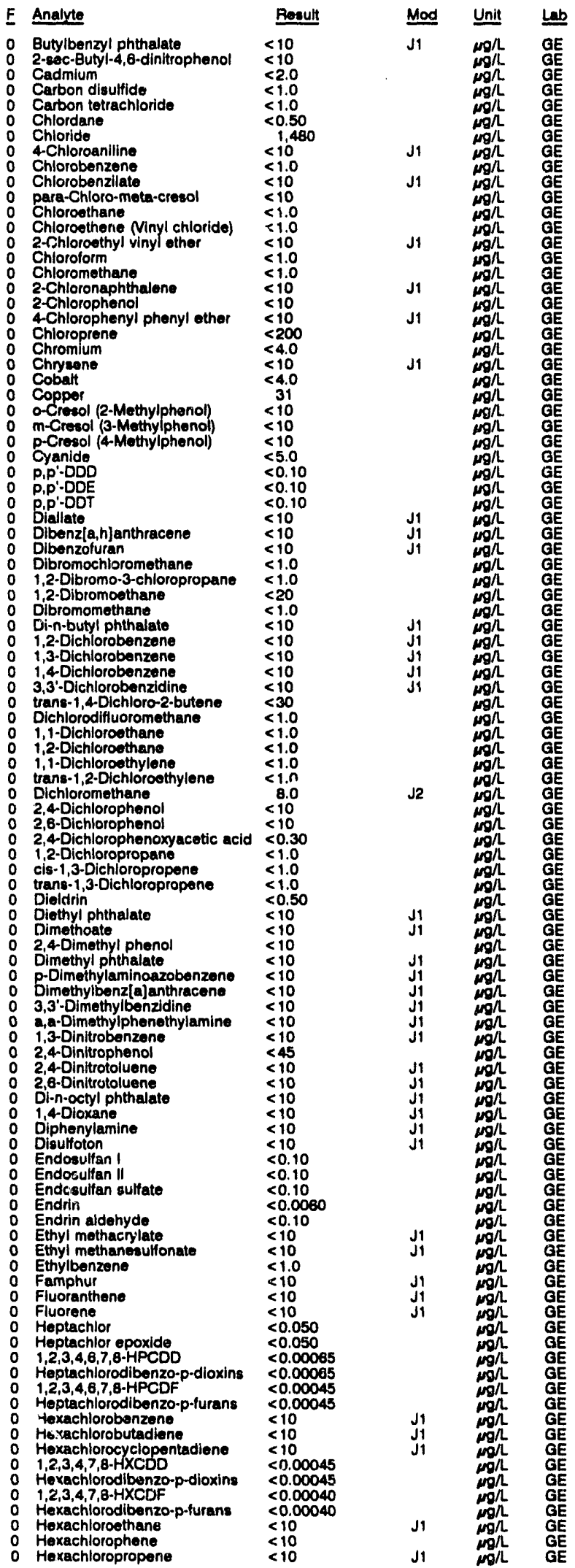


WELL MSB SA collectad on 07/09/82, laboratory analyses (cont.)

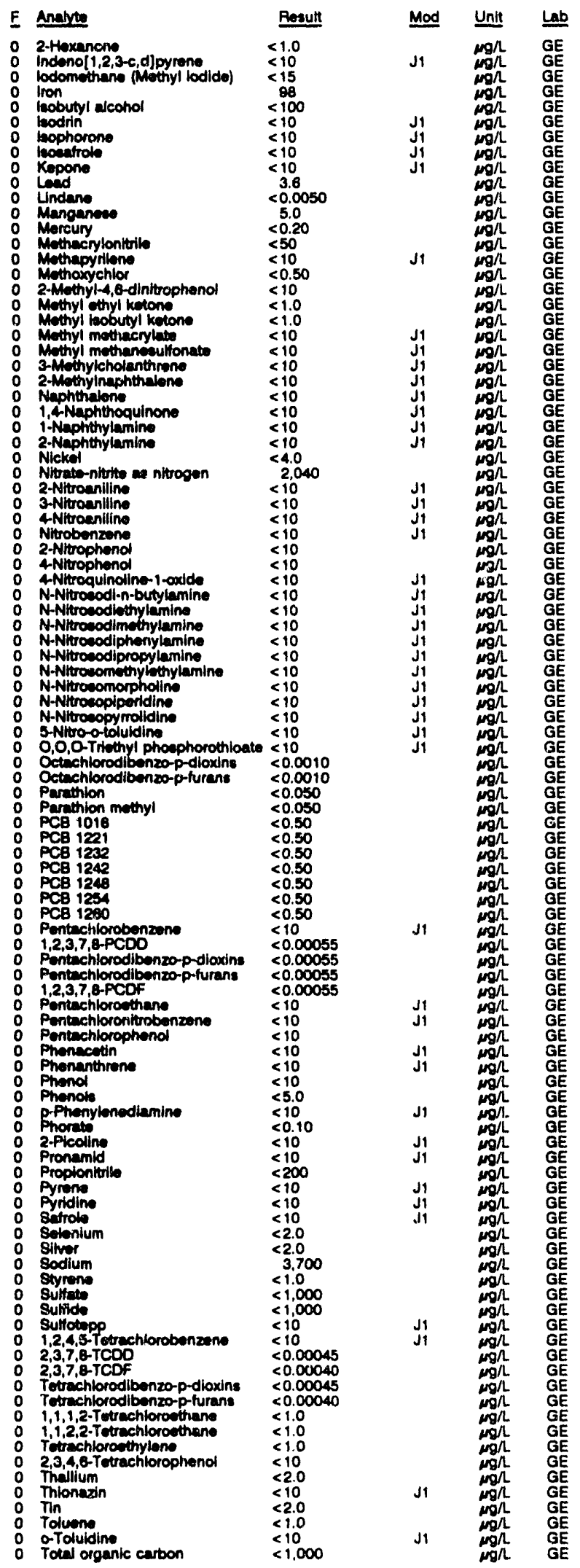

WELL MSB 5A collectod on 07/00/92, laboratory analyees (cont)

\begin{tabular}{|c|c|c|c|}
\hline Analyte & Result & Mod & Unit \\
\hline 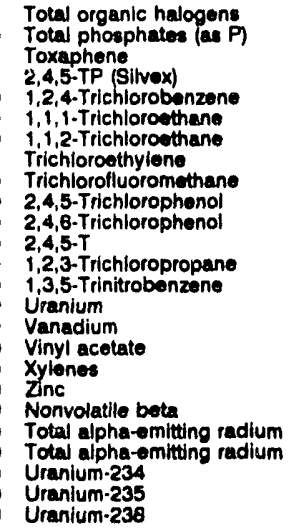 & $\begin{array}{l}<5.0 \\
<50 \\
<0.24 \\
<0.090 \\
<10 \\
<1.0 \\
<1.0 \\
<1.0 \\
<1.0 \\
<10 \\
<10 \\
<0.000 \\
<1.0 \\
<10 \\
<20 \\
<8.0 \\
<1.0 \\
<2.0 \\
23 \\
2.3 E-09 \pm 1.8 E-09 \\
<1.0 E-09 \\
<1.0 E-09 \\
<1.0 E-09 \\
<1.0 E-09 \\
<1.0 E-09\end{array}$ & J1 & 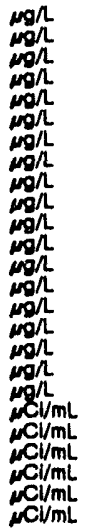 \\
\hline
\end{tabular}

WELL MSB 5B

MEASUREMENTS CONDUCTED IN THE FIELD

Sample date: 07/09/92

Sample date: $07 / 09 / 92 \mathrm{nt}(42.12 \mathrm{~m})$ below TOC THe: $13: 00$

Wp. conduction: $207.30 \mathrm{ft}(63.19$

pH: 5.1

Water evacuated before sampling: $188 \mathrm{gel}$

Whaller ty: $2 \mathrm{mg} / \mathrm{h}$ : $21.00 \mathrm{C}$

LABORATOFY ANALYSES

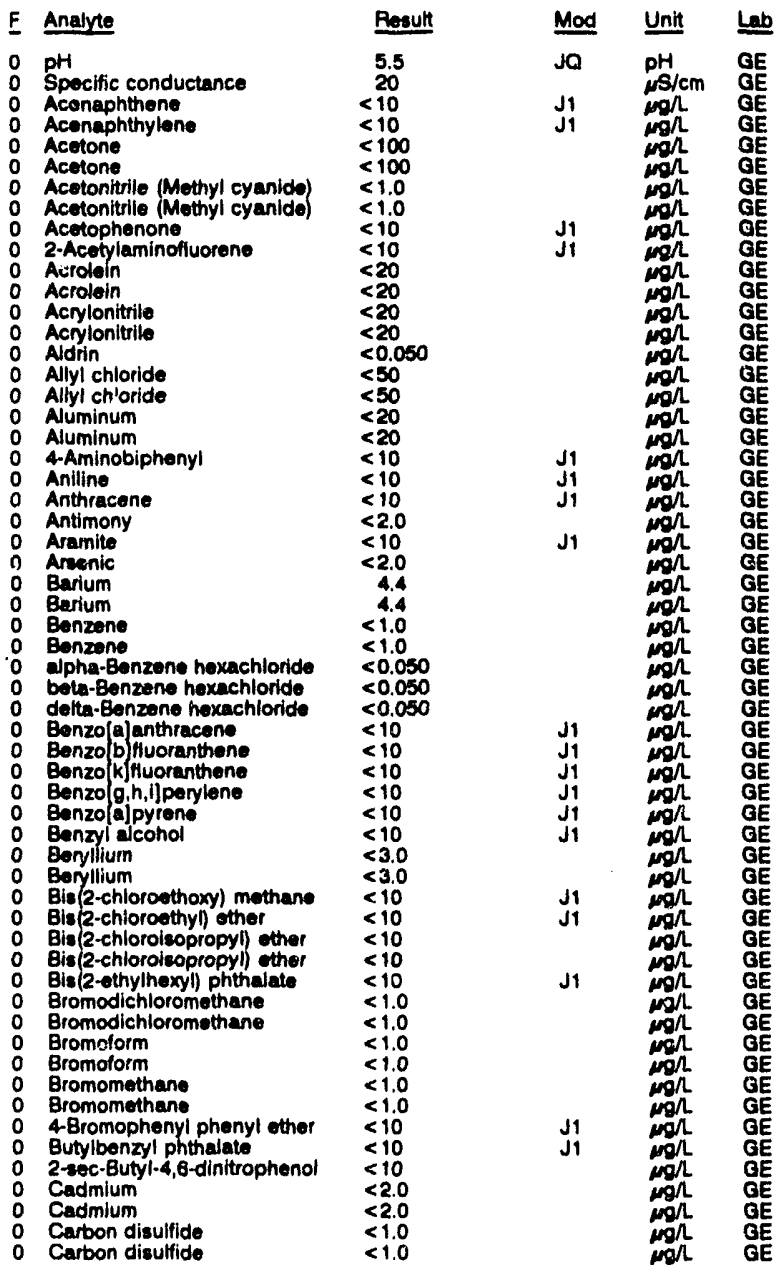


ANALYTICAL RESULTS

WELL M8B SB collectod on 07/09/82, laboratory analyees (cont.)

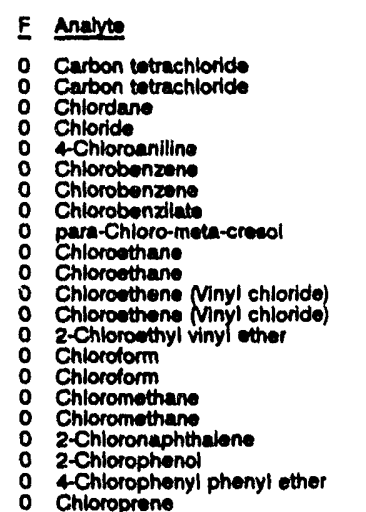

Chloroprene

Chromium

Chromium

Chryeano

Cobat

0 Coppes

Oopper

m-Cresol (3-Methylpheno)

P.P'-DDD

p,p'-DOE

Bip-Dote

Dibenz [a,h]anthracene

Dibromochioromethane

1,

1,2.

1,2-Dbromoethano

Dibromomethane

Dibromomethane

Or-n-butyl phthalate

1,2-Olchlorobenzene

1,3 -Dichlorobenzente

1,4'-Dichlorobenzene

trane-1,4-Dichloro-2-butene

trane-1,4-Dichloro-2-buterse

Dichlorodifluoromethane

1,1-Oichlorothane

1,1-Dichloroethane

1,2-Dichloroethene

1,2-Dichloroethane

1,1-Dichloroethyliono

trans-1,2-Oichloroethylene

trane-1,2-Dichloroethylono

Dichloromethane

2,4-Dichiorophenol

2,8-Oichiorophionol

1,2.Dichloropronane

1,2-Dichlocopropan

cle-1,3-Oichloropropene

trane-1,3-Dichloropropan

trane-1,3-Dichloropropene

Diethyl phthalate

2,4-Dimethyl phenol

p-Oimethylaminoazobenzene

bimethylbenzlalenthrecene

3,3'-Dimethylbenzidine

a.-Dimethylphonethylamine

1,3-Dinitrobanzene

2,4-Dinitrophenol

2,4-Dinitrotoluene

2,6-Dinitrotolume

1,4Dloxine

Diphenylamine

Endiosulten

Endosultan II

Endosulfan sulfato

Endrin

Endrin aldohyde

Ethyl methacrylate
$<1.0$

$<0.50$

$<1.0$
$<1.0$

$<10$

$<10$

$<1.0$

$<1.0$

$<10$

$<1.0$

$<1.0$

$<1.0$

$<10$
$<10$

$<10$

$<200$

$<4.0$

$<10$

$<4.0$

$<4.0$

$<10$

$<10$
$<10$

$<5.0$

$<0.10$

$<10$

$<<10$

$<1.0$

$<1.0$

$<1.0$

$<20$

$<1.0$

$<1.0$

$<10$
$<10$
$<10$

$<10$

$<10$

$<30$

$<1.0$

$<1.0$

$<1.0$

$<1.0$

$<1.0$

$<1.0$

$<1.0$

$<10$

$<10$

$<1.0$

$<1.0$

$<1.0$

$<<1.0$

$<0.50$
$<10$
$<10$
$<10$

$<10$

$<10$

$<<10$

$<10$
$<10$

$<10$

$<10$
$<10$

$<10$

$<10$
$<10$
$<10$

$<0.10$

$<0.10$
$<0.10$

$<0.0060$

$<0.10$
$<10$
J1

11

J1

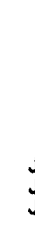

J1
J1
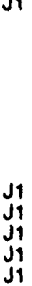

J1

Mod Unit

$\operatorname{mgn}_{\mu \mathrm{g}} \mathrm{h}$

GE

GE

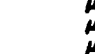

Ji ${ }_{j 1}$

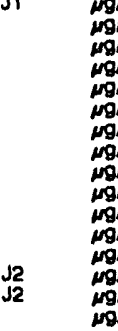

E Analyte

o Ethylbenzene

O Famphur

Fluoranthene
Fluorene

O Heptachlor

Heptachlor epoxide

Heptachlorodibenzo-p-dioxin

1,2,3,4,6,7,8-HPCDF
Heptachlorodibenzo-p-furane

Hexachlorobenzene

Hexachlorocyclopentadione

$1,2,3,4,7,8-\mathrm{HXCOO}$

Hexachlorodibenzo-p-dloxins
$1,2,3,4,7,8$-HXCDF
0 Hexachlorodibenzo-p-furans

Hexachloroethane

Rexachlorophene

2.Hoxanone

indeno[1,2,3-c,d]pyren

lodomethane (Methyl lodide)

lodomethane (Mothyl lodide)

bobutyl alcohol

loobutyl alcohol

o lsodin

isceafrole

0 Kepone

Lead

O Manganese

Manganere

Morcury

Mothacrylonitrite

Methoxychlo

2-Methyl-4,6-dinitrophenol

Methyl ethyl ketone
Methyl othyl ketone

Mothyl isobutyl ketone

Mothyl isobutyl ketone

Methyl methanesulfonato

3-Mothylcholanthrene

2-Methyinaphthalene

1,4Naphthoquinone
1,Naphthe

1-Naphthylamine

2-Naphthylamine

Nickol

Nickel

2-Nitroanlline

4-Nitroaniline

Nitrobenzene

2-Nitropheno

4-Nitrophenol

4Nitroquinoline-1-oxide

N-Nitroeodi-n-butylamin

N-Nitrosodiethylamine

N-Nitrosodimethylamine

N-Nitrosodipropylamine

N-Nitrosomethylethylemine

N-Nitrosomorpholine

N-Nitrosopiperidine

N-Nitrosopyrolidine

5-Nitro-o-toluidine

$<10$

Octachlorodibenzo-p-dioxins

Octachlorodibnzo-p-dloxins

Parathion

PCB 1016

PCB 1221

0
0 PCB 1242

PCB 1248

O
0

Pentachlorobenzene

1,2,3,7,8-PCDD

Pentachlorodibenzo-p-dioxins

Pentachlorodiben

o Pentachloroethane

Pentachloronitrobenzene

Pentachlorophenol

Phenacetin

o Phenantir

O Phenols

P
0 p-Phenols
p-Plenediamine

$<10$

$<10$

$<10$

$<10$
$<10$

$<15$

$<10$
$<10$

$<>10$

$<<10$

Result

$<1.0$

$<0.050$

$<0.00065$

$<0.0004$

$<10$

$<0.00045$

$<0.00045$

$<0.000040$

$<10$

$\leq 1.0$

$<1.0$

$<15$
$<100$
$<100$

$<100$

$<10$
$<3.0$

$<3.0050$

\begin{tabular}{l}
6.0 \\
6.0 \\
\hline
\end{tabular}

$<0.20$

$<50$
$<10$
$<0.50$

$<0.50$

$<1.0$

$<1.0$
$<1.0$

$<10$

$<10$
$<10$

$<10$
$<10$

$<4.0$

420
$<10$

$<10$
$<10$

$<10$
$<10$

$<10$
$<10$

$<10$
$<10$

$<10$
$<10$
$<10$

$<10$

$<10$

$<10$

$<10$

$<0.0010$

$<0.0010$
$<0.050$

$<0.50$

$<0.50$

$<0.50$

$<0.50$

$<0.50$

$<0.0005$

$<0.00055$

$<0.00055$
$<0.00055$

$<10$

$<10$

$<10$

$<10$

$<5.0$ 
ANALYTICAL RESULTS

\begin{tabular}{|c|c|c|c|c|}
\hline E Anarte & Result & Mod & Unit & Lab \\
\hline 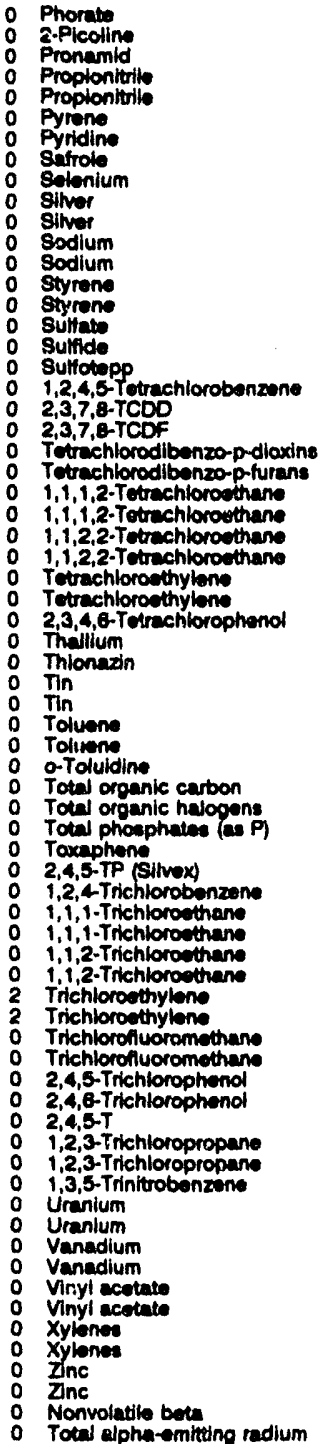 & $\begin{array}{l}<0.10 \\
<10 \\
<10 \\
<200 \\
<200 \\
<10 \\
<10 \\
<10 \\
<2.0 \\
<2.0 \\
<2.0 \\
1.700 \\
1.080 \\
<1.0 \\
<1.0 \\
<1.000 \\
<1.000 \\
<10 \\
<10 \\
<0.00045 \\
<0.00040 \\
<0.00045 \\
<0.00040 \\
<1.0 \\
<1.0 \\
<1.0 \\
<1.0 \\
<1.0 \\
<1.0 \\
<10 \\
<2.0 \\
<10 \\
<2.0 \\
<2.0 \\
<1.0 \\
<1.0 \\
<10 \\
<1,000 \\
10 \\
<50 \\
<0.24 \\
<0.090 \\
<10 \\
<1.0 \\
<1.0 \\
<1.0 \\
<1.0 \\
25 \\
288 \\
<1.0 \\
<1.0 \\
<10 \\
<10 \\
<0.080 \\
<1.0 \\
<1.0 \\
<10 \\
<20 \\
<20 \\
<8.0 \\
<8.0 \\
<1.0 \\
<1.0 \\
<2.0 \\
<2.0 \\
8.0 \\
82.7 \\
<1.0 E-09 \\
<1.0 E-09\end{array}$ & $\begin{array}{l}j 1 \\
j 1 \\
j 1\end{array}$ & 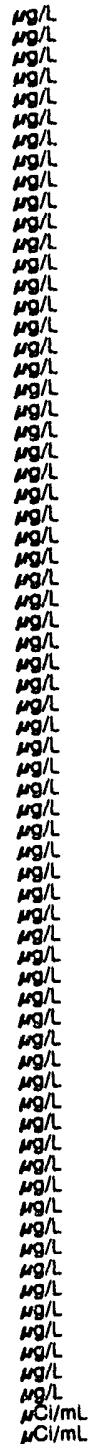 & $\begin{array}{l}G E \\
G E \\
G E \\
G E \\
G E \\
G E \\
G E \\
G E \\
G E \\
G E \\
G E \\
G E \\
G E \\
G E \\
G E \\
G E \\
G E \\
G E \\
G E \\
G E \\
G E \\
G E \\
G E \\
G E \\
G E \\
G E \\
G E \\
G E \\
G E \\
G E \\
G E \\
G E \\
G E \\
G E \\
G E \\
G E \\
G E \\
G E \\
G E \\
G E \\
G E \\
G E \\
G E \\
G E \\
G E \\
G E \\
G E \\
G E \\
G E \\
G E \\
G E \\
G E \\
G E \\
G E \\
G E \\
G E \\
G E \\
G E \\
G E \\
G E \\
G E \\
G E \\
G E \\
G E \\
G E \\
G \\
G \\
G \\
G \\
G\end{array}$ \\
\hline
\end{tabular}

WELL MSB 5C

MEASUREMENTS CONDUCTED IN TME FIELD

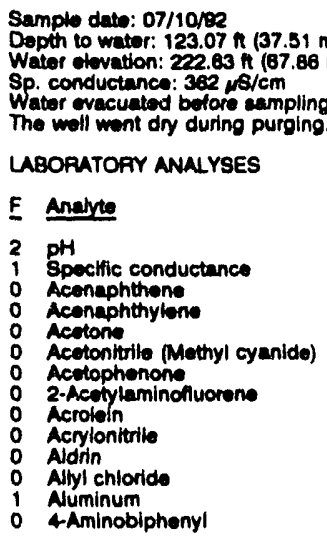

\section{Time: $7: 30$}

Alkalinity: 86 mant

Waler tempsrature: $20.0^{\circ} \mathrm{C}$
WELL MSB 5C collectod on 07/10/82, laboratory analyees (cont.)

E Analyte

: Anliline

Antimony

Areonic

Barlum

alpha.Benzene hexachloride

bota-Benzene hoxachloride

dotra-Bonzeno hoxachlondo
Benzo

Benzolb) fluoranthene

Benzo $k$ kffluoranthene

Benzo g, h.ljperyione

Benzolajpyreno

Bonzyl alcohol

Boryllium

Bis(2-chloroett yi) ether

Bis (2-chloroisupropyl) other

Bla (2-othylhoxyl) phthal

Bromoform

Bromomethane

4-Bromophenyl phenyl ether

2-exc-Butyl-4, 6-dinitrophenol

Cadmium

Carbon disulfide

Carbon iotracho

Chlordane

4-Chloroaniline

Chlorobenzone

para-Chloro-mota-cresol

Chloroothane

Chloroethene Ninyl chloride)

2-Chloroethyl vinyl ether

Chloroform

2-Chioronaphthalene

2-Chlorophenal

4-Chlorophenyl phenyl ether

Chloroprene

Chryesno

Chryeon
Cobatt
Coppor

o-Cresol (2-Mothylphenol)

m-Crosol (3-Methyiphonol)

p-Cresol (

$\begin{array}{lll}0 & \text { P.p. } \\ 0 . D D D \\ 0.0 D E\end{array}$

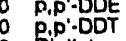

Dibonz $(\mathrm{a}, \mathrm{h}$ ) anthracens

Dibenzoturan

12.0inomothane.

1,2-Dibromoothane

Oibromomothane
Olin-butyl phthalate

1.2.Dichlorobenzene

1,3-Dichlorobenzene

1,4'-Dichlorobenzene

trans-1,4-Oichloro-2-butene

Dichlorodifivoromethane

1,1-Dichloroothane

1,2-Dichloroethane

2 1,1-Dichlorocthylene

Dichloromethane

2,4-Dichlorophenol
0 2,6-Dichlorophenol

2,6-Dichlorophonol <1 $<10$

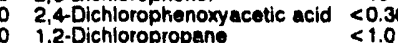

cis-1,3-Diopropane

$\begin{array}{lll}0 & \text { cis-1,3-Dichloropropene } & <1.0 \\ 0 & \text { trans-1,3-Dichloropropeno } & <1.0\end{array}$

$<0.50$

o Dimethote

2,4-Dimethyl phenol
0
0
0

: Bimethylbenzinalanthracene

3,3'-Dimethylbenzidine

a,a.Dimothylphenothylamine

1, Dintuobenzente

(2, Dinitroluen

o 2, B.Dinitrotoluene

Di-n-octyl phthalate

1,4-Dioxane

o Diphenylam

O Endosiltan I
$<10$

$<10$

$<1.0$

$<0.050$

$<0.050$

$<10$

$<10$

$<10$
$<10$
$<3.0$
$<10$

$<3.0$
$<10$
$<10$

$<10$

$<1.0$

$<1.0$

$<10$

$<10$

$<1.0$

$<0.50$

$<1.0$

$<10$

$<10$
$<1.0$

$<1.0$

$<10$

$<200$

$<4.0$
$<10$

$<4.0$

$<10$

$<5.0$

$<0.10$

$<10$

$<10$

$<1.0$

$<1.0$
$<10$

$<10$
$<10$

$<10$
$<10$

$<30$

$<1.0$

$<1.0$

<1.0 J2

(1)

$<10$

$<10$
$<10$

$<10$
$<10$

$<10$
$<10$

$<10 \quad \mathrm{JI}$

$<10$

$<10$

$<10$
$<10$

$<10$
$<0.10$

$<0.10$
$<0.10$
Mod Unit La

$J 1$ N⿴囗十 $\quad$ GE

J1

J1

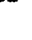

J1

$j 1$
$j 1$
$j 1$
$j 1$
$J 1$
$J 1$
$j 1$
$j 1$
$j 1$
$j 1$ 
ANALYTICAL RESULTS

WELL MSB SC colloctod on 07/10/82, laboratory analyees (cont)

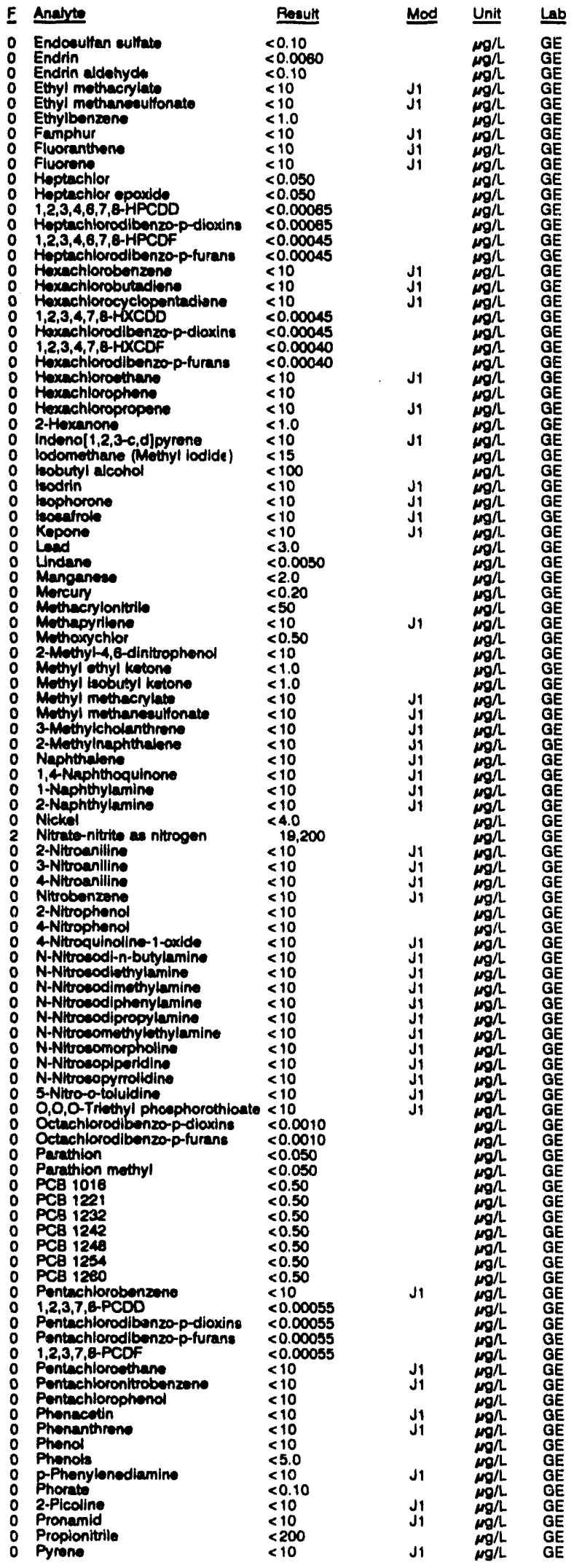

WELL MSB 5C collected on 07/10/82, Iaboratory analyees (cont)

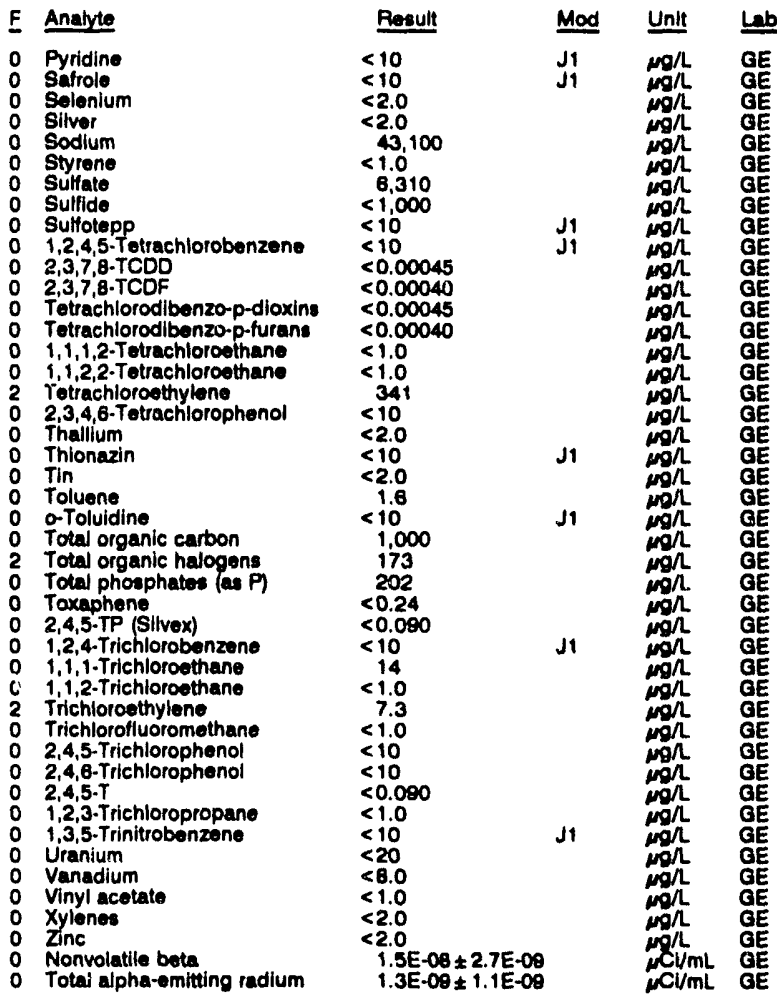

WELL MSB 6A

MEASUREMENTS CONDUCTED IN THE FIELO

\begin{tabular}{|c|c|}
\hline $\begin{array}{l}\text { Sample date: } 07 / 09 / 92 \\
\text { Depth to water: } 117.03 \mathrm{~h}(35.67 \mathrm{~m}) \text { bolow TOC } \\
\text { Water elevation: } 226.87 \mathrm{ft}(89.15 \mathrm{~m}) \mathrm{ms} \\
\text { Sp. conductunce: } 38 \mu \mathrm{s} / \mathrm{cm}\end{array}$ & $\begin{array}{l}\text { Time: } 13: 35 \\
\text { pH: } 5.0 \\
\text { Alkalinity: } 3 \mathrm{mg} / \\
\text { Water temperature: } 21.2^{\circ} \mathrm{C}\end{array}$ \\
\hline
\end{tabular}

LABOPATORY ANALYSES

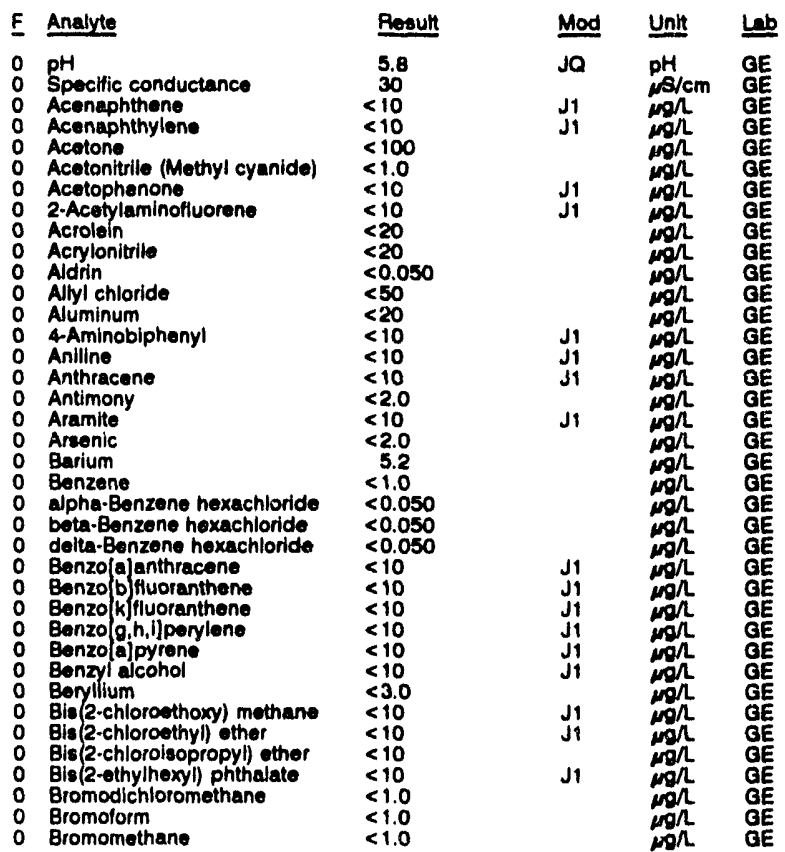


WELL MSB aA collocted on 07/00/92, laboratory analyees (cont)

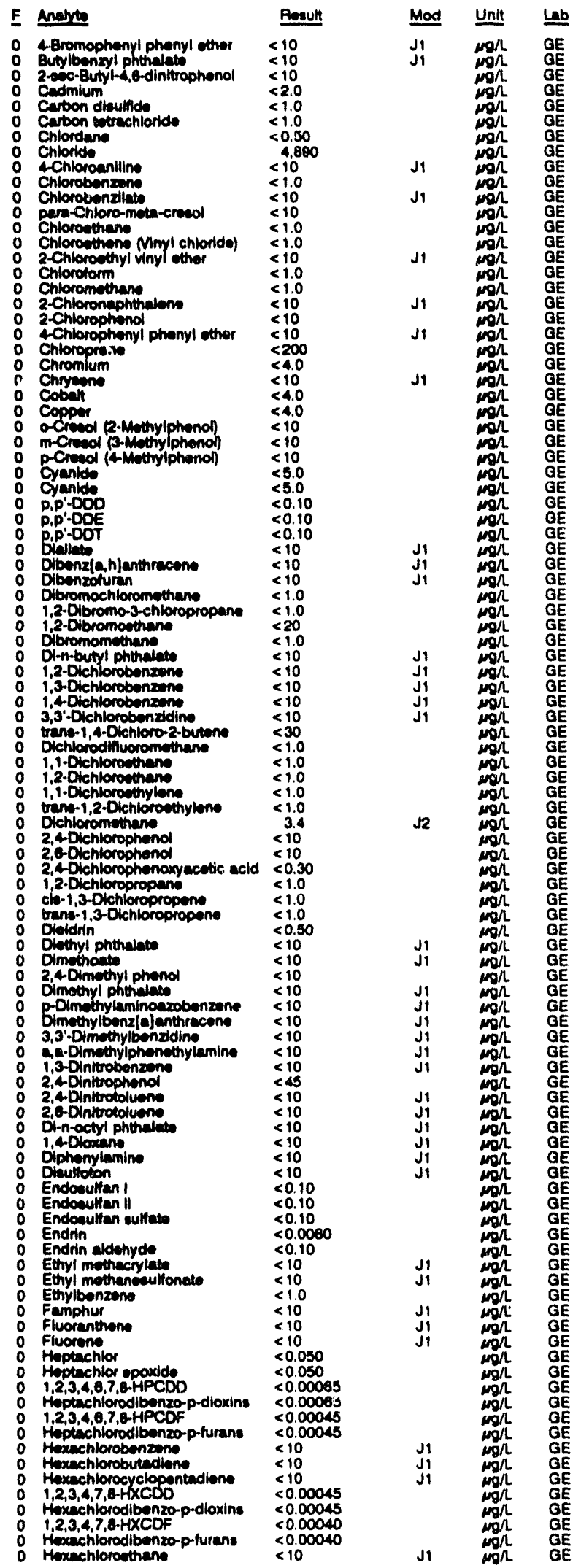

WELL MSB BA collected on 07/09/92, laboratory analyees (cont.)

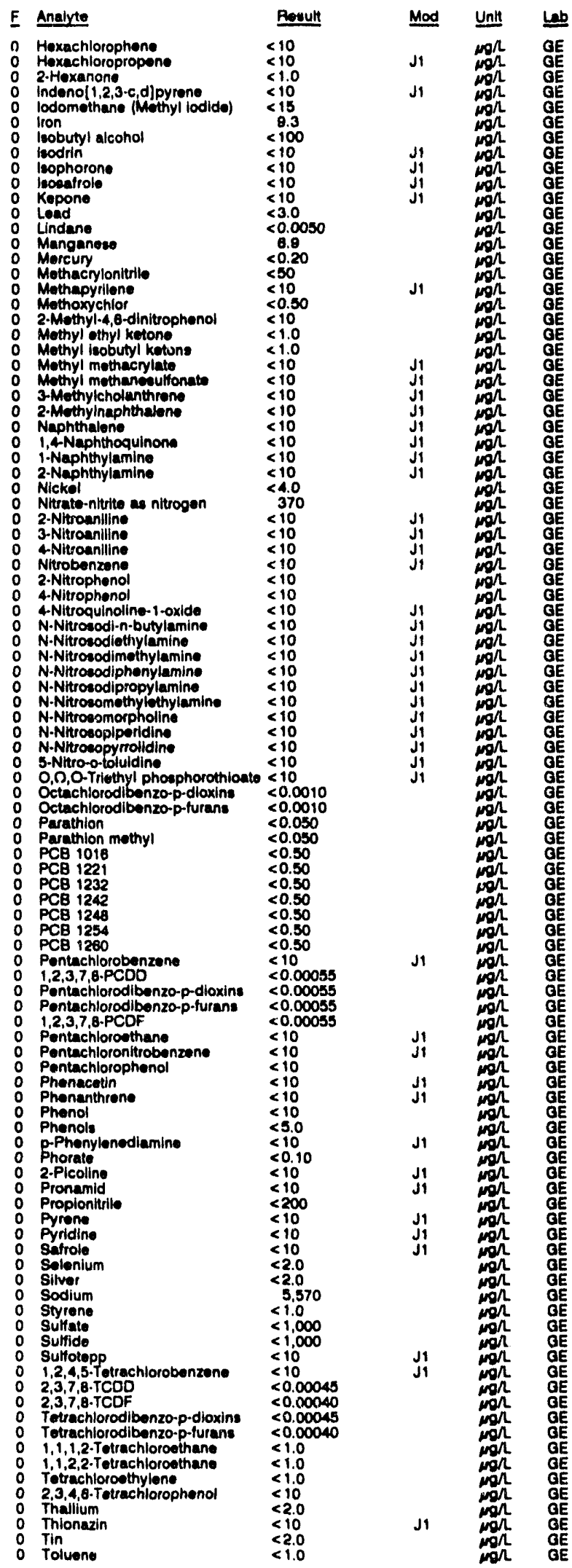


ANALYTICAL RESULTS

WELL MSB aA collocted on 07/09/92, laboratory analyees (cont)

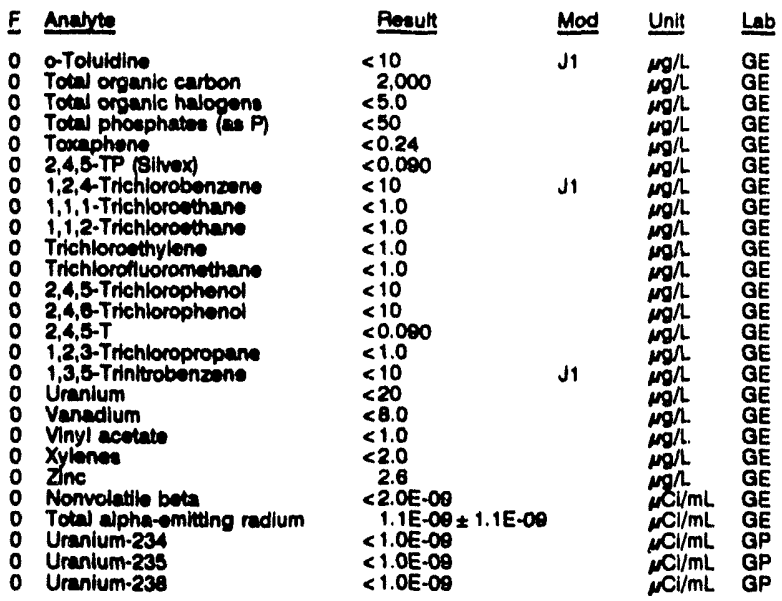

\section{WELL MSB 6B}

MEASUREMENTS CONOUCTED IN THE FIELD

Sample date: 0\%/18/92 $131.87 \mathrm{~m}$ ) bolow TOC Water olevation: $207.04 \mathrm{f}(03.38 \mathrm{~m}) \mathrm{msl}$

Sp. conductance: $41 \mathrm{~s} / \mathrm{cm}$

Witer ovecuated betore sempling: $216 \mathrm{gal}$

Tlme: $12: 00$
pH: 5.8

Alkalinity: $7 \mathrm{mgh}$

Water temporature: $21.4^{\circ} \mathrm{C}$

LAOFATORY ANALYSES

\begin{tabular}{|c|c|}
\hline Analyto & Uu \\
\hline 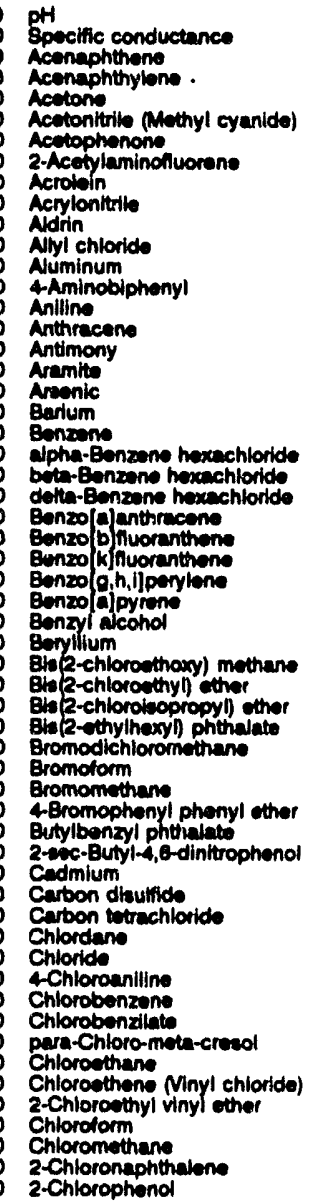 & $\begin{array}{l}6.1 \\
42 \\
<10 \\
<10 \\
<2,500 \\
<25 \\
<10 \\
<10 \\
<500 \\
<500 \\
<0.050 \\
<1,250 \\
21 \\
<10 \\
<10 \\
<10 \\
<2.0 \\
<10 \\
<2.0 \\
222 \\
<25 \\
<0.050 \\
<0.050 \\
<0.050 \\
<10 \\
<10 \\
<10 \\
<10 \\
<10 \\
<10 \\
<3.0 \\
<10 \\
<10 \\
<250 \\
<10 \\
<25 \\
<25 \\
<25 \\
<10 \\
<10 \\
<10 \\
<2.0 \\
<25 \\
<25 \\
<0.50 \\
1,820 \\
<10 \\
<25 \\
<10 \\
<10 \\
<25 \\
<25 \\
<10 \\
<25 \\
<25 \\
<10 \\
<10\end{array}$ \\
\hline
\end{tabular}

WELL MSB 68 collected on OQ/18/92, laboratory analyees (cont)

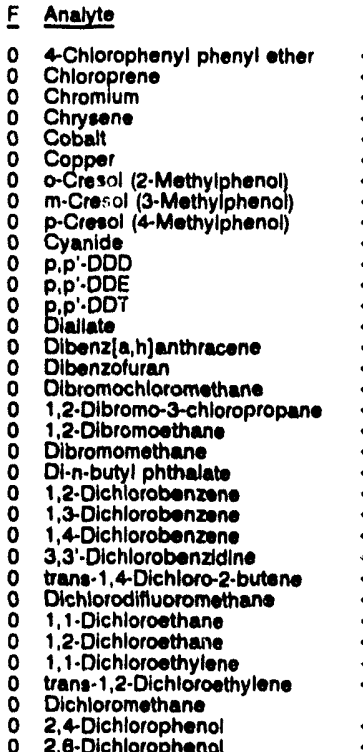

2, 6.Dichlorophenol $<10$

1,2-Diehloropropane

cis-1,3-Dichloropropone $<25$

trans-1,3-Dichloropropene $<25$

$\begin{array}{ll}\text { Dieldrin } & <0.50 \\ \text { Dlethyl phthalato } & <10\end{array}$

2,4-Dimethy! phenol

D-Dimethylaminoazobenzene

Bimethylbenzifajanthracene

3,3'. Dimethylbenzidine

a, a.Dimethylphenethylamine

1,3-Dinitrobenzen

2,4-Dinitrophenol

2.4-Dinitrotoluene

Di-n-octyl phthalate

1,4-Dioxane

Diphonylamin

Disulfoton

Endosulfan !

Endosulfan sulfate

Endosulta

Endrin aldehyde

Ethyl mothacrylate

Ethyl mothanesulfonate

Ethylbenzene

Famphur

Fluoranthene

Fluoreno

Heptachlor opoxide

1,2,3,4,6,7,8-HPCDD

Heptachlorodibanzo-p-dioxins $1,2,3,4,6,7,8 \cdot$ HPCDF

Heptachlorodibenzo-p-turans

Hexachlorobutadien.

Hexachlorocyclopentadiene

$1,2,3,4,7,8+H \times C D D$

Hexuchlorodlbenzo-p-dioxin:

$1,2,3,4,7,6 \cdot H \times C O F$

Hoxachlorodibenzo-p.turan

Hoxachloroethune

Hoxachiorophene

2-Hexanione

indeno[1,2,3-c,d]pyrene

lodomethane (Mothyl lodide)

leobutyl alcohol

loodrin

teophorone

locarrolo

Kepono

Lead

Manganese

Mercury

Methacrylonitrile

Mothapyrilene

Methoxychlor

2-Mothyl-4,6-dinitrophenol

Methyl ethyl ketone
Regut
$<10$
$<5,000$
$<4.0$
$<10$
$<4.0$
$<4.0$
$<10$
$<10$
$<10$
$<5.0$
$<0.10$
$<0.10$
$<0.10$
$<10$
$<10$
$<10$
$<25$
$<25$
$<500$
$<25$
$<10$
$<10$
$<10$
$<10$
$<10$
$<750$
$<25$
$<25$
$<25$
$<25$
$<25$
$<68$
$<10$
$<10$

J1 Unit L

(

J1 $\mathrm{mg}^{\mathrm{GO}} \mathrm{GE}$

4.0

10
5.0

25
68
10
10
0.30
25
25
25
0.50
10

$<10$
$<10$

$<10$
$<10$

$<10$

$<10$

$<10$
$<45$

$<45$
$<10$
$<10$

$<10$

$<10$
$<10$

$<10$

$<0.10$
$<0.10$

$<0.10$

$<0.0060$

$<10$

$<10$

$<10$

$<10$

$<0.050$

$<0.050$

$<0.00085$

$<0.00045$

$<0.00045$

$<10$

$<10$

$<0.00045$

$<0.00045$

$<0.00040$

$<10$

$<10$

$<10$

$<10$

$<375$

$<10$

$<10$

$<10$
$<10$

$<3.0$

$<0.0050$
B.2

$<0.20$

$<1,250$
$<10$

$<0.50$

$<25$
$<25$ 
WELL MSB 68 collectiod on OQ/18/92, laboratory analysee (cont)

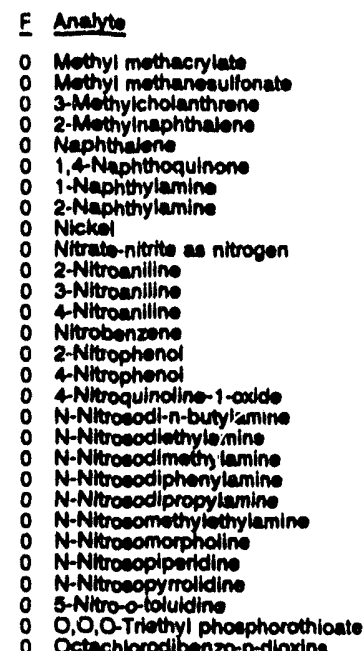

(1)

$<10$
$<10$

$<10$
$<10$
$<10$

$<10$

$<10$

$<10$

2,160

$\leq 10$

$<10$

$<10$

10

$<10$

10

$<10$

$<10$

$<10$

10

$0,0,0$ - Trethyl phouphorothioat

Octachiorodibenzo-p-di

Parathion methyl

PCB 1016

PCB 1221

PCA 1240

PCB 1234

PCB 1200

Pentachlorobenzan

Pentechlorodibonzo-p-dioxing

Pentachlorodibenzo-p-turane

$1,2,3,7,0$-PCOF

Pentechioroethane

Pentachloronitroben

Phenecefin

Phomantin

Phenol

P-Phenylenediamin

Phoradi

2-Picoline

Propionitrila

Pyrone

Pyrdin

sarrobium

Silver

Sodium

Surene

Butindo

8ullotepp

2,2,4,5-TCtrachio

Tetrechlorodibenzo-p-dioxine

Tetrachlorodibenzo-p-furan

i, 1,2,2-Tetrechlorowthan

Tetrechlorvethylions

2,3,4,6-Tutrechlorophenol

Thallum

Tin

O Toluen

o O-Toluldine

Total organic halogens

Total phosph

2,4,5-TP (Bivex)

$1,2,4-$ Trichiorobenzon

1,1,1-Trichloroethan

1,1,2-Trichioroethen

Trichlorofluoromethane

2,4,5-Trichlorophend

$2,4,5$

1,2,3-Trichloropropene

1,3,5.Trinitrobenzene

U Uranlum

Vanadlum

O Vyyl acestat

O Zylones

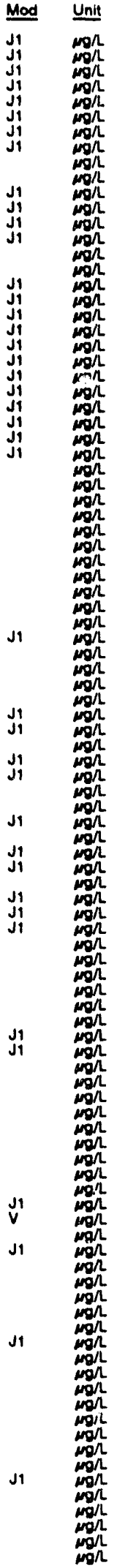

WELL MSB 68 collocted on 08/18/92, laboratory analyees (cont)

\begin{tabular}{|c|c|c|c|}
\hline Analyte & Benulf & Mod & Unit \\
\hline $\begin{array}{l}\text { Nonvolatilo bota } \\
\text { Total alpha-emitting radium }\end{array}$ & $\begin{array}{l}2.4 E \text {. } \\
2.1 E \text {. }\end{array}$ & & $\stackrel{\mu \mathrm{Cl} / \mathrm{m}}{\mu \mathrm{Cl} / \mathrm{m}}$ \\
\hline
\end{tabular}

WELL MSB 6C

MEASUREMENTS CONDUCTED IN THE FIELD

Sample date: 07/10/02

Depth to water: $121.18 \mathrm{n}(39.23 \mathrm{~m})$ bolow TOC

Wator olevation: $223.04 \mathrm{n}(87.08 \mathrm{~m}) \mathrm{mal}$

Water evacuated before ceampling: $18 \mathrm{gal}$

pH. 0.3

The woll went dy durte purging.

Water tomperature: $18.7{ }^{\circ} \mathrm{C}$

LABORATORY ANALYSES

2 Specific conductance

Aconaphthene

Acetone

Acatonitrile (Methyl cyanido)

2-Acotylaminofluorene

Acrotein

Acrylonitilo

Aldyl chloride

- Aluminum

4Aminobiphenyl

Anthiecene

Antimony

Antimon

Aramite

0 Arsenic

Aarium

- Benzene

Jpha-Benzene hoxachloride

beta-Benzene hexachloride

delta-Benzene hoxachloride

Benzo ajenthracono

Benzo kfluoranthene

Benzo o.h.ilperyiene

Benzolujpyreno

Benzylulcoho

Boryilium

Bis(2-chloroethoxy) methane

Bis (2-chloroothyl) other

Eis 2-chlorolespropyl) ether

Bis(2-olhylhoxyl) phthalato

Bromoform

4-Bromophenyl phonyl ther

Butylbonzyl phtheinto

2-ecc-8utyl-4,8-dinitsophonol

Cedmium

Carbon disulficio

Carton totrachioride

Chlordane

\&Chloroaniline

Chlorobenzen

Chlorobenzilat

para-Chloro-meta-creesl

Chiorosthane

Chloroothone Ninyl chloride)

2.Chloroethy

Chlorolorm

2.Chloronaphthalent

2.Chiorophenol

4-Chlorophenyl phenyl ether

O Chloroprent

Chromium

: Chryean

Cosar

O-Cresel (2-Methylphenol)

m-Cresol (3-Mothylpheno)

p-Cresol (4-Mothyiphenol)

Cyanido

P,P'-Dop

P,P-ODE

Bip'Dor

Dibenzia,h]anthracene

Dlbenzoturan

o Dibromochloromethane

1,2-Dibromo-3-chloropropane

Di-n-butyl phthal

1,2-Dichlorobenzene

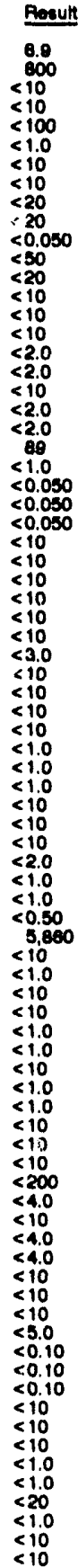

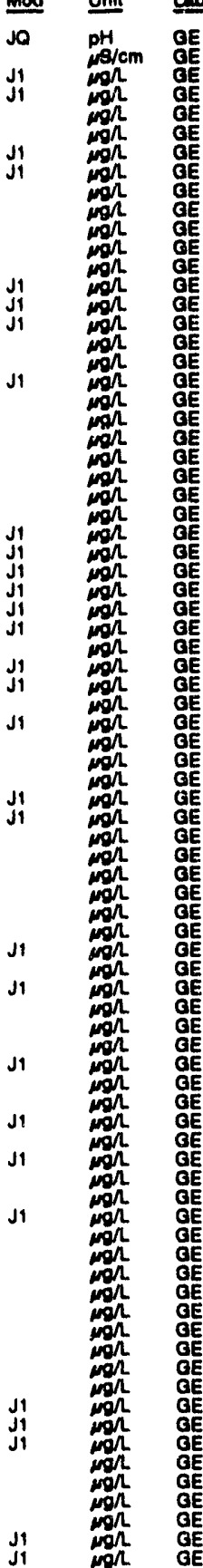


ANALYTICAL RESULTS

WELL MSB \&C collocted on 07/10/92, laboratory analyees (cont)

E Anayte

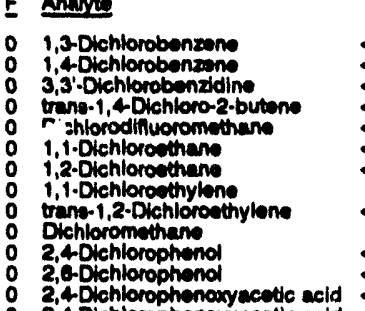

2.4 Dichlorophonoryacedic acld $<0.30$

1, 2-Olchioropropente

ch-1,3-Dichloropropene

Dididinin

Diethyl phthelat

2,4-Oimothyl phond

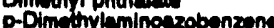

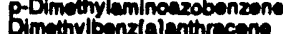

3,3'-OImethylbenzidins

a. Olmethylphenethylumine

2, 4 - Dinurobenzen

2.4-Dinitrotoluen

Din-octyl phthelat

1.4-Dlaxens

Diphenylamin

Endocultan

Endowultan II

Endoasulian

Endrin Evdin ahyde

Endrin aldohydo

Ethyl methanesultionate

Ethylbonaen

Fluorenth

Fluoreno

Heptachlor

$1,2,3,4,6,7,8-H P C D O$

Heptachloredibonzo-p-dioxine

Heptechlorodibenzo-p-turan

Haxachlorobonazm

Haxchlorobutadiens

Hoxchlorogyclopent

Hemchlorodibenzo-p-dloxins

Hexuchlorodibenzo-p-turane

Hedechlorowthans

Hexcentorophone

2. Hexenono

indeno[1,2,3-e, d]pyrene

bobutyl alcohol

coodin

bophofrole

Kopone

Lead

Undan

Mangane.

Marcun

Methecryioniturite

Methapynions

2-Mrisych or

Methyl ethyl ketone

Motyl mothecrytets

Methyl methaneaulfonate

3-Minylcholentirien

Maphthatons

1,4Nephthoquinone

1. Nephthytamino

Nicket

Nituata-nititis as nitrogen

2-Nitroanilime

4-Nitroanilin

HNroenilin

2-Nitrophenol

4Nitrophenol

4Nitroquinoline-1-oxdde

N-Nitrosodj-n-butylamino

N-Nitrocodiethylamin
$<10$

$<10$

$<1.0$

$<1.0$

3.0
$<1.0$

$<10$

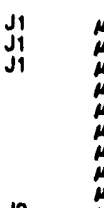

J2

$<1.0$
$<1.0$

$<1.0$
$<0.50$

$<10$

$<10$
$<10$

$<10$

$<10$
$<10$
$<10$

$<10$

$<10$
$<10$
$<45$
$<10$

$<10$

$<10$
$\leq 10$
$\leq 10$

$\leq \leq 10$

$<10$

$<0.10$

$<0.10$

$<0.10$

$<10$

$<10$

$<1.0$

510
510
510
$<10$

$<10$

$<0.050$

$<0.00085$

$<0.00045$

$<0.00045$

$<10$

$<10$

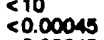

$<0.00045$

$<0.00040$

$<10$

$<10$
$<10$

$<10$

$<1.0$
$<15$

$<15$

$<10$

$<10$
$<10$

$<10$

$<3.0$

$<0.0050$

$<0.20$

$<50$
$<10$
$<10$

$<0.50$

$<10$

$<1.0$

$<10$
$<10$
$<10$

$<10$
$<10$
$<10$

$<10$
$<10$

$<10$
$<10$
$\leq 10$

$\leqslant 10$

$<10$

80,000

$<\leq 10$

$<10$

$\leq 10$

$<<10$

$<10$

$\leq 10$

$<10$
$<10$
WELL MSB 6C collected on 07/10/92, laboratory analywes (cont.)

Result

Mod Unit Le

0 N-Nitrosodiphenylamine

$<10$

N.Nitrosomethylethylamine $<10$

A trosomorpholine

N.Nitrosopiperidine

N-Nitrosopyrrolldino

5.Nitro-0.toluldine

$0,0,0$-Tlethyl phosphorothionte

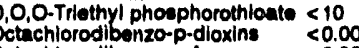

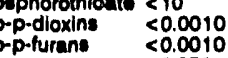

Parathion

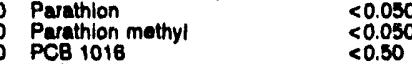

PCB 1018

0 PCE 1232

PCB 1240

PCB 1254
0 PCB 1260

Pentachlorobenzano

1,2,3,7,8.PCDD

Pentachlorodibanzo-p-dioxins

Pentachlorodibenze

Pentachloroer

Pentachloronltrobenzene

Pentachlorophenol

Phenacetin

Phenol

Phenols

p-Phenylonediamine

Phorate

2.Plcoline

Propionitrile

Pyrene

Salrote

Selenium

Silver

Sodium

Styrene

Sulfide

Suffotepp

1,2,4,5-Totrach

2,3,8-TCDF

Tetrachlorodibenzo-p-dioxins

Tetrachlorodibenzo-p-furans

1,1,1,2-Tetrachlorosthan

Titrachloroethylene

2,3,4.6-Tetrachioropheno

Thallium

Thallium

Tin

Tolvone

Total organic carbon

Total organic halogens

Tolal phospha

2,4,5-TP (Sivex)

2,4,5-TP (Silvex)

1, - Trichlorobenzene

1,1,2-Trichloroethan

2 Trichloroothylene

Trichlorofluoromothane

2,4,5-Trichlorophenol

2,4,6-Trichlorophenol

$2,4,5-T$

1,2,3:Trichloropropane

o 1,3,5-Trinitrobenzene

Venadium

Vinyl acotat

0 Xylenes

Nonvolatile beta

Total alpha-emitting radium
$<10$

$<0.50$

$<0.50$

$<0.50$

$<0.50$

$<0.00055$

$<0.00055$

$<0.00055$

$<10$

$<10$

$<10$

$<10$
$<10$

$<10$

$<5.0$
$<0.10$

$<10$

$<10$

$<200$

$<10$

$<10$
$<10$
$<2.0$
$<2.0$
$<2.0$

129,000

$<1.0$

$<\begin{array}{r}1,440 \\ <1,000\end{array}$

$<10$

$<0.00045$

$<0.00040$

$<0.00045$

$<1.0$

$<1.0$

$<10$

$<2.0$

$<2.0$

$<10$

$<10$

$<1,000$

9.6
$<50$
$<5.24$

$<<0.24$

$<0.000$

$<10$

4.0
$<1.0$

$<.0$
6.6

$<1.0$

$<10$
$<10$

$<0.090$

$<0.080$

$<1.0$

$<20$

$<<8.0$

$<2.0$

21 $7.1 E-08 \pm 9.5 E-09$
$\theta .4 E-0 \theta \pm 2.0 E-00$

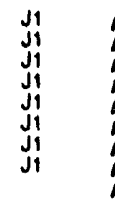

$\operatorname{mon}_{\text {mon }} \mathrm{GE}$

GE

E

政

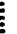

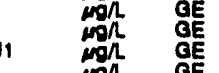

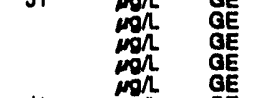

J1 跑 dE

J1

J1 $\mathrm{mgh} G$

$\begin{array}{ll}J 1 & \operatorname{mon} \\ j 1 & G E \\ \operatorname{mon} & G E\end{array}$

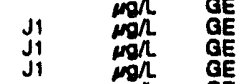

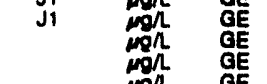


WELL MSB 7A

MEASUREMENTS CONDUCTED IN THE FIELD

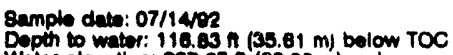
Wator oflevation: $227.67 \mathrm{n}(60.30 \mathrm{~m}) \mathrm{msi}$

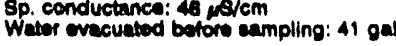

LABOFATOAY ANALYSESS

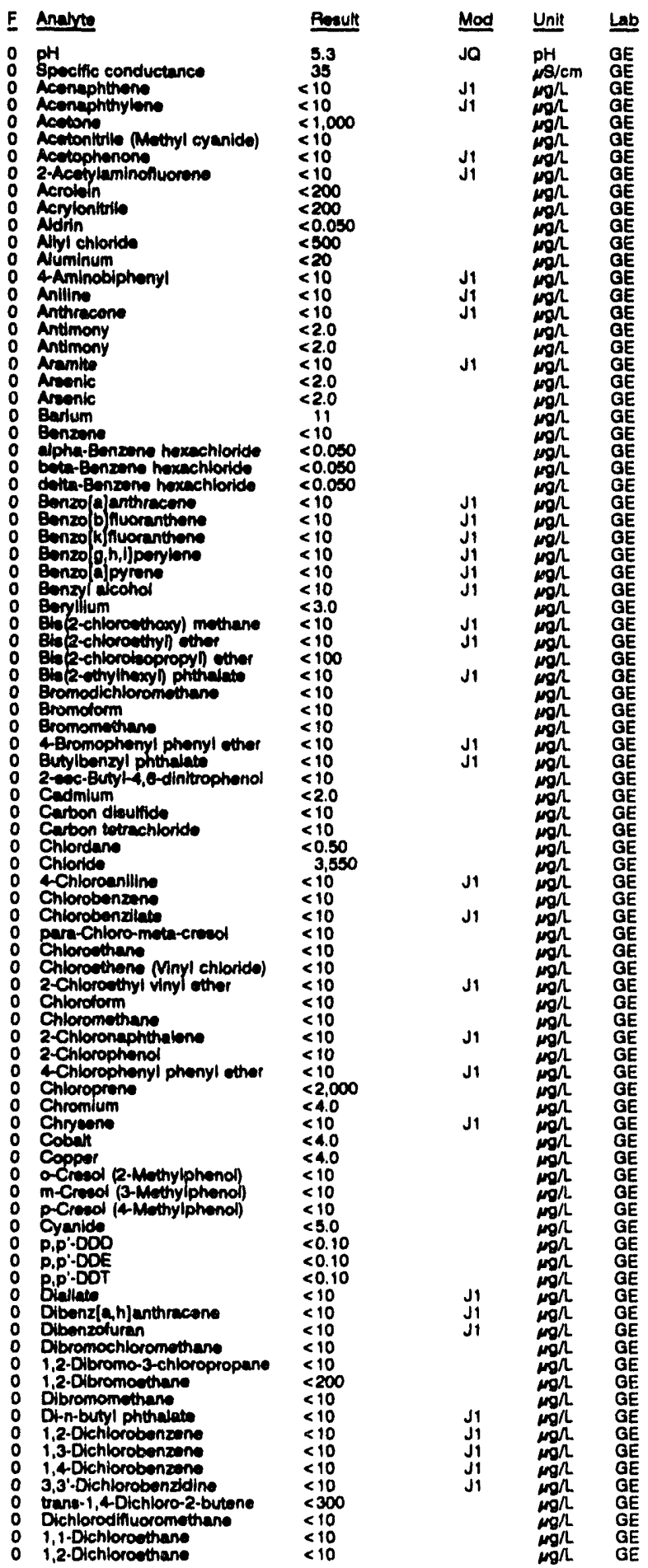

WELL MSB 7A collectiod on 07/14/82, laboratory analyeer (cont)

Time: 8:45

AH: S.1.1 1 mor

Waler tomporature: $20.00^{\circ} \mathrm{C}$

0 1,1.Dichloronthylono

Itand-1,2-Dichlorosthylono

2,4-Dichlorophenol

1,2-Dichlorophenoxyacetic acld $<0.30$

cise-1,

o trans-1,3-Dichloropropene

$<0.50$

0 Diethyl phthalate $<10$

0 2,4-Dimothyl phonol $<10$

- p-Dimathylaminaazobonzene

Dimethylibenz (a) anthrecono

a, 3 - Dimethylbenzldine

$<10$

2,4.Dintrophonol

2,4 Dinurolueno

Di-n-octyl phthelate

1,4Dioxano

O Oiphenylamino

Oisultioton

Endosulfan

Endosulfan eutfate

Endrin

Endrin aldohyde

: Ethyl mothacrylate

E Ethyl mothaneactio

Famphur

- Fluorenten

Heptachlor

Heptachlor opoxide

a d

Heptachlorodibenzo-pod

Heptachiorodibenzo-p-turans

Hoxachlorobonzene

Hexachlorocyclopentiadione

$1,2,3,4,7,8-H \times C D D$

Hoxuchlorodibenzo-p-dioxine

$1,2,3,4,7,8$-HXCDF
Hexachlorodibenzo-p-turans

Hexachlorosthane

Hexachlorophene.

2-Hexanone

indeno $(1,2,3-c$, d) pyrene

lodomethane (Methyl lodide)

leobutyl alcohol

leophorone

Irosufrole

Kopono

Load

Load

Manganoese

Mercury

Methacrylonitrile

Methapyrilente

2-Methyl-4,8-dinitrophenol

Me-Mothyy-4, is-dinitioph

Mothyl isobutyl keton

Methyl mothanesulfonate

3-Methylcholanthrene

2-Mothylnaphthalone

Naphthalene

1.4Naphthoquinone

i- Naphithylamine

2.Naphthylamine

Nitrate-nitrito as nitrogon

2.Nitroanline

antroanilino

Nitrobenzene

2.Nitrophenol

4 Nitropheno

4-Nitroquinoline-1-oxide

N-Nitrosodi-n-butylamino

N.Nitrosodiothylamino

N.Nitrocodimethylamino

N-Nitrosodiphonylamine

N-N.Ntrososomotipropylamino

N-Nitrosomothy lothy

N.Nitrosomorpholine

N-Nitrosopyrrolidine

5.Nitro-o-toluidine
$<10$

40
42

$<0.30$
$<10$

象

10

$<10$
$<10$
$<10$
$<45$

$<45$

$<10$

$<10$
$<10$

$<0$
$<0.10$
$<0.10$
$<0.10$
$<0.006$

0.0060

$<10$

10

10

$<10$

$<10$

$<0.050$

$<0.00065$

$<0.00045$

$<0.00045$

$<10$
$<10$

$<10$
$<0.00045$

$<0.00045$

$<0.00040$

$<10$

$<10$
$<10$

$<10$
$<10$
$<130$
4.5

4.5
$<1,000$

$<10$
$<10$

$<\leq 10$

$<\leq 3.0$

$<0.0050$

$<0.0050$
19
$<0.20$
$<500$

$<10$
$<0.50$

$<10$
$<\leq 10$
$<10$

$\leq 10$

$<10$
$<10$
$\leq 10$

10
210
$<10$
$<10$

510
$<10$
510

$<10$
$<10$
$<10$

$<4.0$

$\begin{aligned} & 1.00 \\ & \leq 10 \\ & \leq 10 \\ &<10 \\ &<10\end{aligned}$

310

$<10$
$<10$
$\leq \leq 10$

$<10$
$<10$
$<10$

$<10$

$<10$

$<<10$

$<10$
$<10$
$<10$

$<10$
$<10$
Mod Unt Len

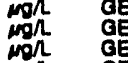

$\operatorname{mon}_{\operatorname{mon}} \mathrm{GE}$ 
ANALYTICAL RESULTS

WELL MSB 7A collected on 07/14/92, laboraton, analyees (cont.)

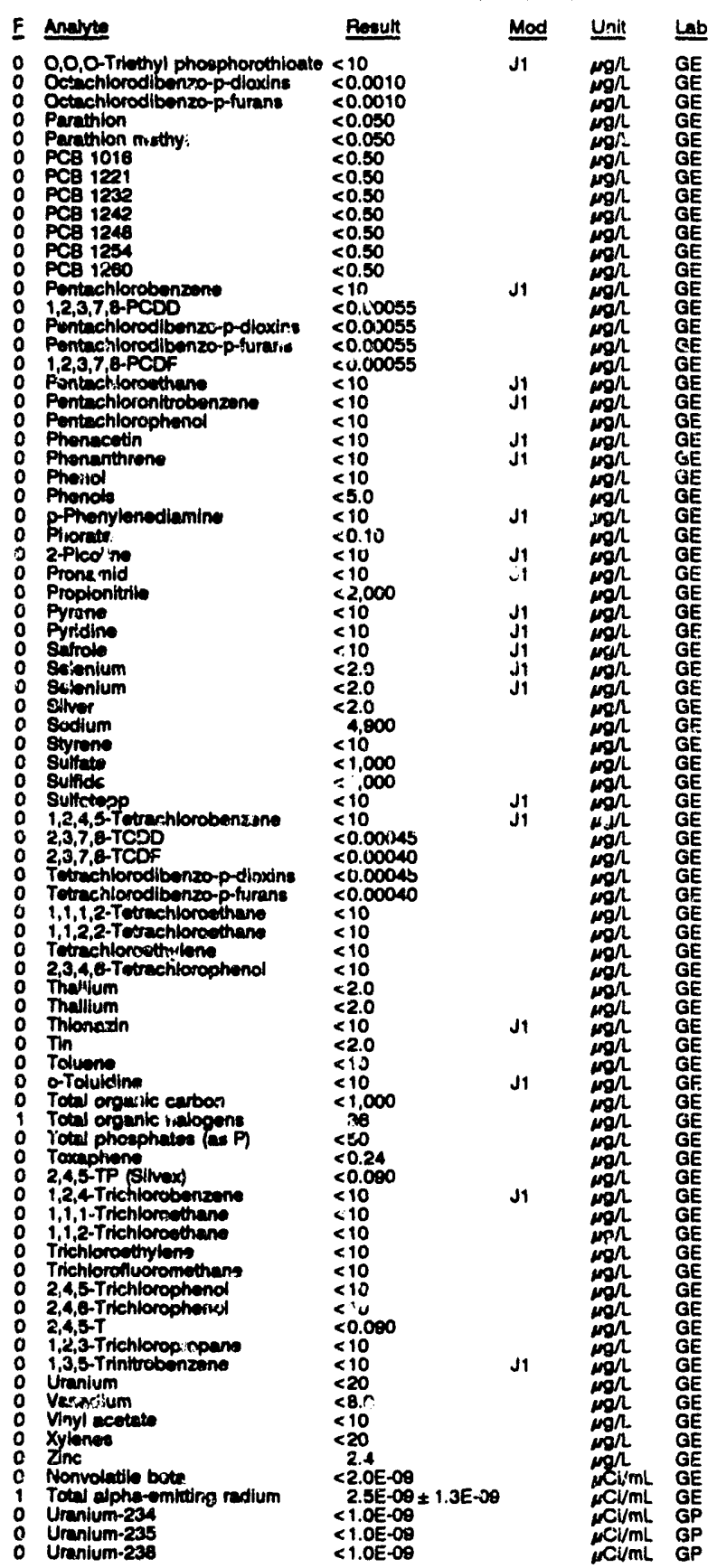

WELL. MSB 7B

MEASUREMENTS CONDUCTED IN THE FIELD

Sample dete: 07/14/9e Dopth to water: $137.00 n$ (4. $07 \mathrm{~m}$ ) below TOC Weter elevation: 205.51 2 (62.05 m) mel Waber ovecuatiod butors sampling: $42 \mathrm{gal}$ the well went dry during purging.

LABOPATOAY ANALYSES

\begin{tabular}{|c|c|c|c|c|}
\hline E Anatyte & Rosult & Mod & Unit & Lab \\
\hline $\begin{array}{ll}2 & \text { pH } \\
1 & \text { Speclific conductance } \\
0 & \text { Acenaphthene }\end{array}$ & $\begin{array}{r}11 \\
300 \\
<10\end{array}$ & $\begin{array}{l}\text { JO } \\
\text { J1 }\end{array}$ & $\begin{array}{l}\mathrm{pH} \\
\mathrm{mS} / \mathrm{cm} \\
\mathrm{mg} / \mathrm{L}\end{array}$ & $\begin{array}{l}\mathrm{GE} \\
\mathrm{GE} \\
\mathrm{GE}\end{array}$ \\
\hline
\end{tabular}

WELL MSB $7 B$ collected on 07/14/82, laboratory analyees (cont)

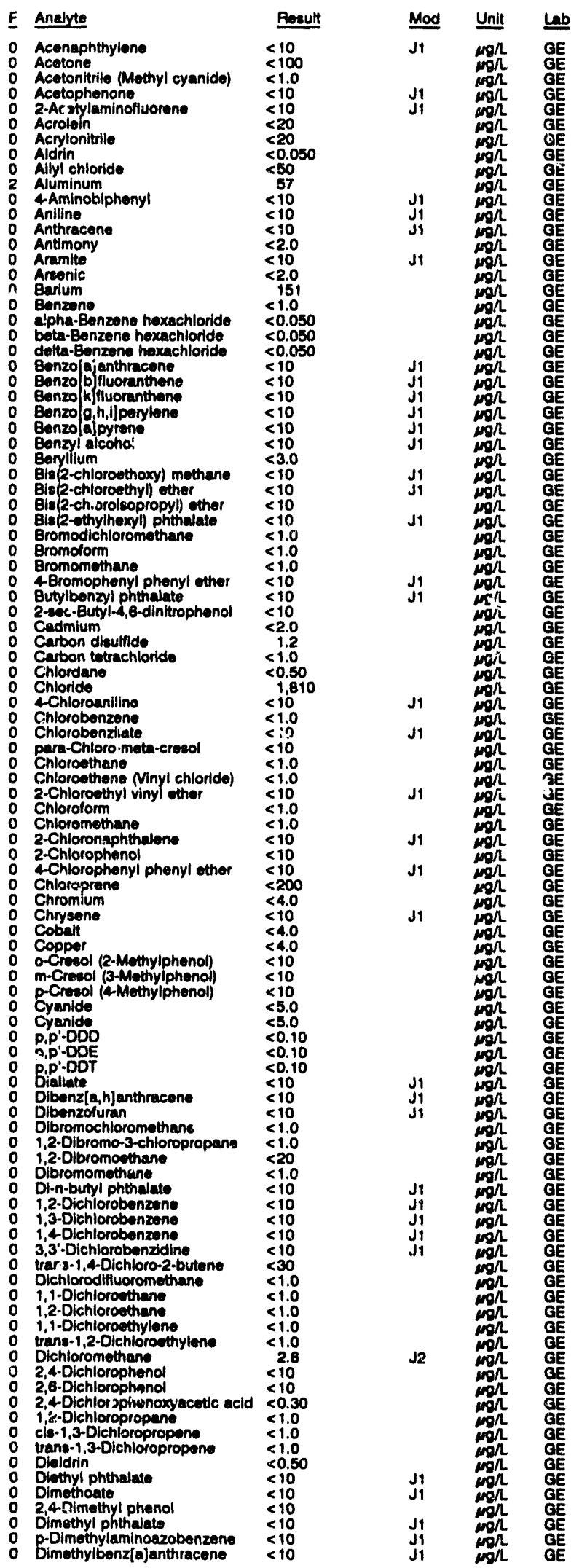


WELL MSB 78 collectod on 07/14/92, laboratory analyees (cont.)

$F$ Andyte

3,3'-Oimethylbenzidine

a,-Dimethylphenethylamine

1,3-Dinturobonzon

2,4-Onitroteluon

Di-n-octyl phthalate

O Diphenylamine

Diaulitotion

Endowilian 1

Endoaulian sultate

Endrin

Endinn aldohydo

Ethyl methanesulfonate

Ethylbenzeme

Fluoranthene

Fluorene

Heotachior epardede

1,2,3,4,6,7,0-HPCDD

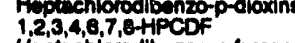

Hoptachiorodibenzo-p-furane

Hexachlorobenzene

Hexachlorocyelopen

$1,2,3,4,7,8-4 \times C D D$-dioxins

$1,2,3,4,7,8-10 \times C D$

Hixichiorodibenzo-p-turans

Hexcechloroethen

Hexechloropiopene

indeno $[1,2,3-c, 0]$ pyrene

laobutyl alcohol

leodrin

hophorone

Kepone

Lind

Undanse

Mercury

Methacrylonititis

Methoxychlo

2-Muthyl-4,6-dinitrophenol

Motinyl ethyl ke ine

Methyl methecnitate

Methyl methan sultones

2-Mnthylinaphthiterie

Naphthialens

iNaphosuroquinm

Nickel

Nitratio-nitutio as nitrogen

3-Nitroanilin

4Nitroanilline

Nitrobenzane

2-Nitrophona

4Nitroquinoline-1-oxide

N-Nitrosodi-n-butylemin

N-Nitrocod athylamino

N-Nitrosodiphenylamin

N-Nitroedodipropylumina

N-Nitroeomorpholine

N-Nitrosoplpertiline

N-Nltroespyrrolidin

5-Niro-o-toluldina $<10$

$0,0,0$ - rnithyl phoephorothionte $<10$

octectionso-p-dioxins $<0.0010$

0 Perathion methy

PCB 1016

PCB 122

0 PCB 1242

PCE 125

PCB 1260

Pentachlorobenzene

$1,2,3,7,6-P C D O$

Pentachlorodibenzo-p-dioxins

Pe,2,3,7,8-PCof

\section{Ansult \\ Mod Unit}

$<10$

$<10$

$<10$

$<10$

$<10$
$<10$

$<10$
$<10$
$<0.10$
$<0.10$

$<0.10$

$<0.0080$

$<0.10$

$<10$
$<10$

$<10$

$<10$

0.050

$<0.00085$

$<0.00065$

0.00045

$<10$
$<10$

$<0.00045$

$<0.00045$

$<0.00040$

$<10$
$<10$

$<10$

$<1.0$
$<10$

$<15$

$<100$
$<10$
$<10$

$<10$
$<10$
$<10$

$<3.0$
$<0.0050$

$<2.0$

$<50$
$<10$

$<0.50$

$<1,0$

$<10$

$<10$
$<10$

$<10$

$<10$

$<10$

$<4.0$

870
$<10$

$<10$

$<10$
$<10$
$<10$

$<10$

$<10$
$<10$

$<10$
$<10$
$<10$
$<10$

$<10$

$<10$

$<10$

410

$<0.0010$
$<0.0010$

$<0.050$

$<0.50$

$<0.50$

$<0.50$

$<0.50$

$<0.50$

$<10$

$<0.00055$

$<0.00055$

$<0.00055$

$<0.0005$

J1
J1
J1
J1
J1
J1
J1
J1
J1

跣

Leb

ga

GE

GE

WELL MSB 78 collocted on 07/14/92, laboratory analyees (cont.)

\begin{tabular}{|c|c|c|c|}
\hline 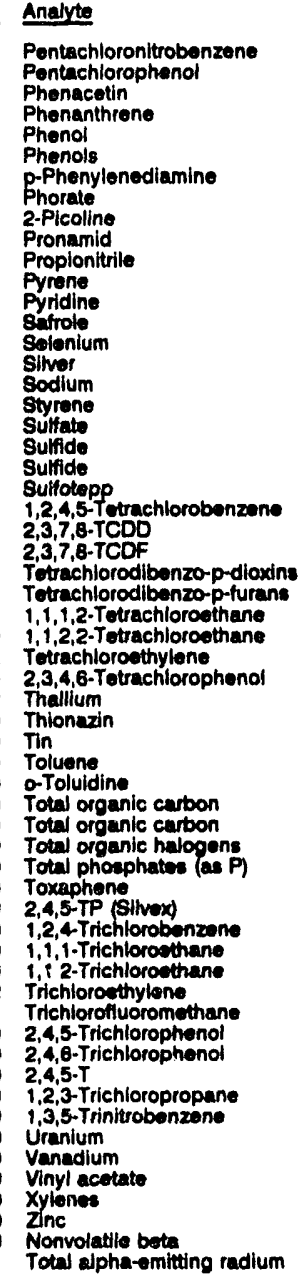 & 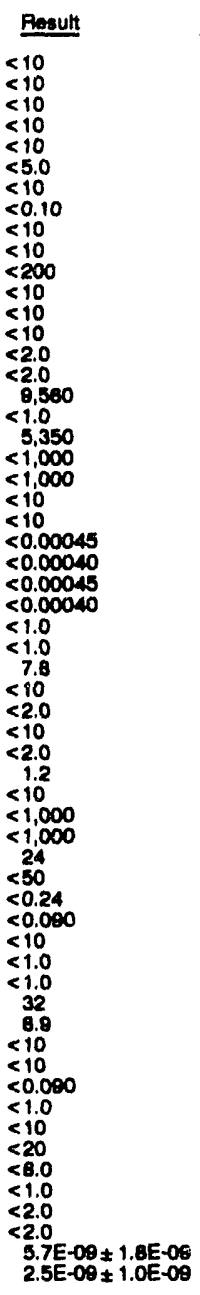 & $\mathrm{Mox}$ & 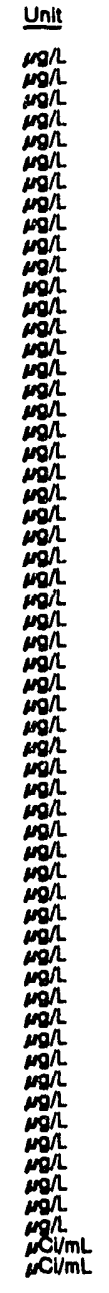 \\
\hline
\end{tabular}

\section{WELL MSB 7C}

MEASUREMENTS CONDUCTED IN THE FIELD

Depth to water: $122.77 \mathrm{At}(37.42 \mathrm{~m})$ below TOC

Water elevation: $221.83 \mathrm{H}(67.81 \mathrm{~m}) \mathrm{mal}$

Water ovacuated belore sampling: $15 \mathrm{gal}$

The well went dry during purging.

LABORATORY ANALYSES

\begin{tabular}{|c|c|c|c|c|}
\hline F & Analyte & Pesult & Mod & Unit \\
\hline $\begin{array}{l}0 \\
0 \\
0 \\
0 \\
0 \\
0 \\
0 \\
0 \\
0 \\
0 \\
0 \\
0 \\
0 \\
0\end{array}$ & $\begin{array}{l}\text { phi } \\
\text { Specific conductance } \\
\text { Acenaphthene } \\
\text { Acenaphthylene } \\
\text { Acetone } \\
\text { Acetonitrile (Methyl cyanide) } \\
\text { Acetophenone } \\
\text { 2-Acetylaminoflumene } \\
\text { Acrolein } \\
\text { Acrylonitrile } \\
\text { Aldrin } \\
\text { Allyl chloride } \\
\text { Aluminum } \\
\text { A Aminoblphenyl } \\
\text { Anilline } \\
\text { Anthracene } \\
\text { Antimony } \\
\text { Aramite } \\
\text { Arsenic } \\
\text { Barium } \\
\text { Benzene } \\
\text { alpha-Benzene hexachlorido } \\
\text { beta-Benzene hexachloride } \\
\text { delta-Benzene hexachloride }\end{array}$ & $\begin{array}{l}6.4 \\
410 \\
<10 \\
<10 \\
<100 \\
<1.0 \\
<10 \\
<10 \\
<20 \\
<20 \\
<0.050 \\
<50 \\
<20 \\
<10 \\
<10 \\
<10 \\
<2.0 \\
<10 \\
<2.0 \\
54 \\
<1.0 \\
<0.050 \\
<0.050 \\
<0.050\end{array}$ & $\begin{array}{l}\text { JO } \\
\text { J1 } \\
\text { J1 } \\
\text { J1 } \\
\text { J1 }\end{array}$ & 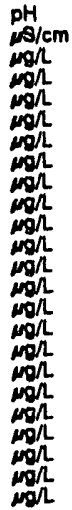 \\
\hline
\end{tabular}


ANALYTICAL RESULTS

WELL MS8 7C collected on 07/1482, laboratory analyees (cont.)

F Anelyte

: Benzo|ajenthrocone

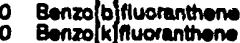

Benzo g, hiljpontione

Benzoldpyrone

: Berlilium

o Bla (2-chlorowthyin other

Biag-chloroleopropyl) ether

Bromodichioromethano

Bromotorm

CEromephonyl phenyl ether

2-acc-Buty|-4, Q-dintrophonol

Carbon disulfice

Corton the

Chlorldo

LChloroenillime

Chlorobonzenzilato

pern-Chioro-meth-eresed

Chlorobthene Mnyl chloride)

2-Chloroethyl vinyl other

Chlorotorm

Chloromothano

2-Chloropophonthol

4Chlorophenyl phenyl ether Chloroprins

Chryeene

o Cobalt

o o-cresol (2-Methylpitenol)

m-Creal (3-Muthylphenof

: Cyanide

O P,p'-DOD

: P,p':DOE

and

- Dibenz[a,h]anthracene

0 Olbenzoturan

1,2-Obromo-3-chioropropane

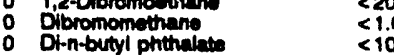

o 1,2-Dichiorobename $<10$

o 1,3-Dichlorobenzen

0 3,3'-Dichlorobenzidine $\quad<1$

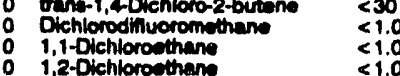

i) 1,1 -Dichloroethylens

trana-1,2-0lehiorom

2,4-Dichlorophenol

2,8-Oichlorophenol

2,4-Dichlorophenoxy acetic acid

o 2,4Dichlorophenoxyacetic acid <0

1,2-Dichloropropane

$\begin{array}{lll}0 & \text { cis-1,3-Dichloropropene } & <1.0 \\ 0 & \text { tana-1,3-Dichloropropene } & <1.0\end{array}$

O Oldorin $<0.50$

O Olethyl phthalate $<10$

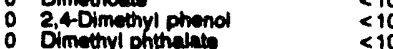

o p-Dimethylaminanzobonzene $<10$

D bimptrylbenziajanthracens $<10$

0 3,3'-Oimethylloenzdine

1,3-Dinitrobenzens

2,6-Dinitrotolueno

DA-n-octyl phthalati

o Diphenylamino

Disulfoton

o Endocultan!

o Endosurfan sulfato

Endrin

O Endrin aldehydo

: Ethyl methacrylato

O Ethylbenzene

F Femphur

o Fluoranthene

\section{Result}

$<10$

10

$<10$
$<10$

$<<.0$

$<10$

$<10$
$<1.0$

$<1.0$

10

$<10$
$<10$
$<2.0$

$<2.0$
$<1.0$

0.50
5.040

$<10$
$<1.0$

$<10$

1.0

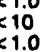

1.0

$<10$
$<200$
$<4.0$

$<10$

$<10$

10

$<5.0$
$<5.0$

10
10

(1)

0

10
10
10
10
1.0
1.0
80
1.0

$<.0$
2.2

10

$<0.30$

1.0

0
0
0
0
0
0
0
0

$<10$
$<10$
$<10$

$<10$
$<45$
$<10$

$<10$

$<10$
$<10$

$<10$
$<10$

$<0.10$

$<0.10$

$<0.0060$

$<10$

$<10$
$<1.0$

$<10$
$<10$

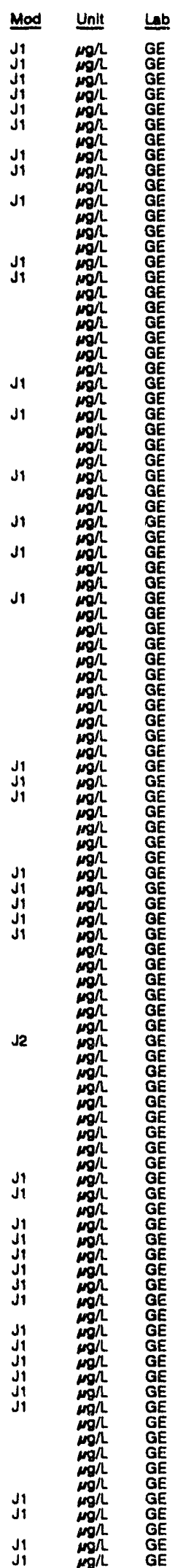

WEL MSB 7C collected on 07/14/82, laboratory analysee (cont.)

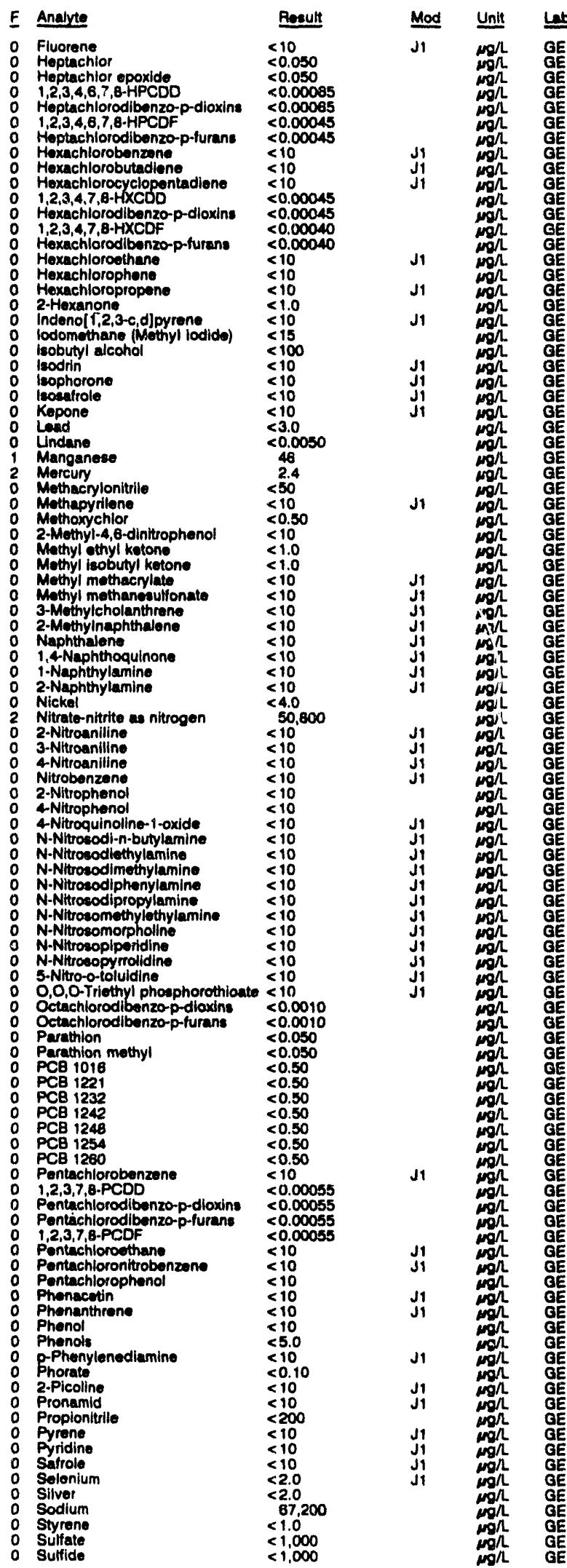


WELL MSB 7C collected on 07/14/92, laboratory analyses (cont.)

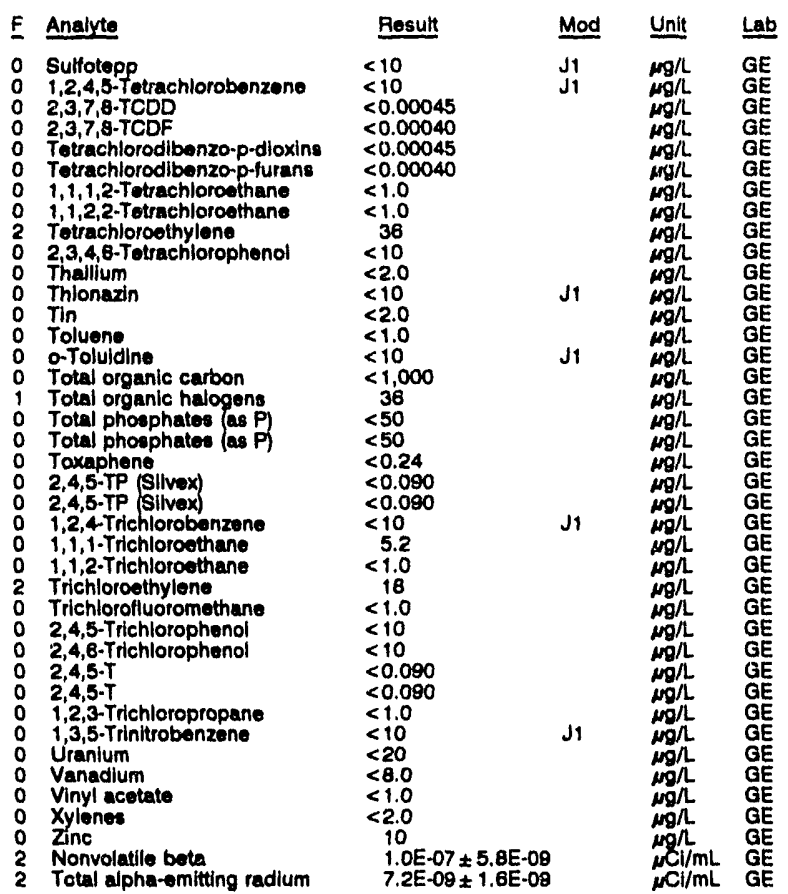

\section{WELL MSB 8A}

MEASUAEMENTS CONDUCTED IN THE FIELD

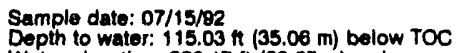
Water elevation: $229.17 \mathrm{~A}(69.85 \mathrm{~m}) \mathrm{ms}$ p. conductance: $70 \mu \mathrm{S} / \mathrm{cm}$

Water ovacuated bofore sampling: $54 \mathrm{gal}$

LABORATORY ANALYSES

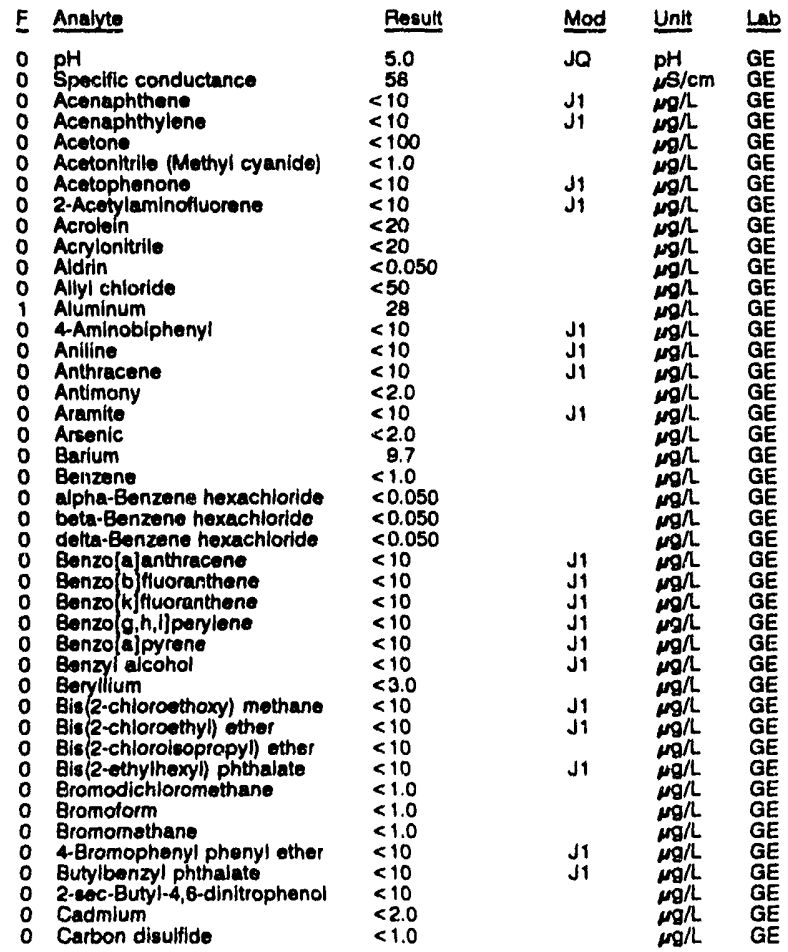

WELL MSB BA collocted on 07/15/92, laboratory analyoes (cont.)

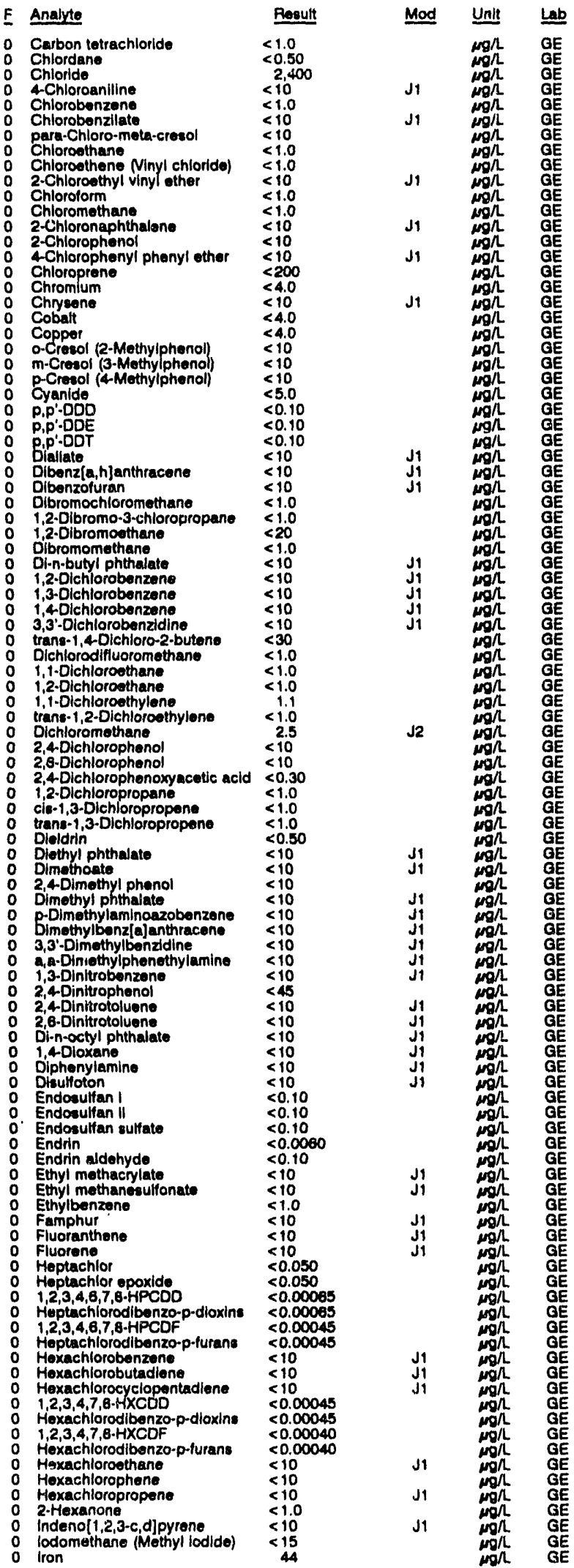


WELL MSB BA collectod on 07/15/92, laboratory analyses (cont.:

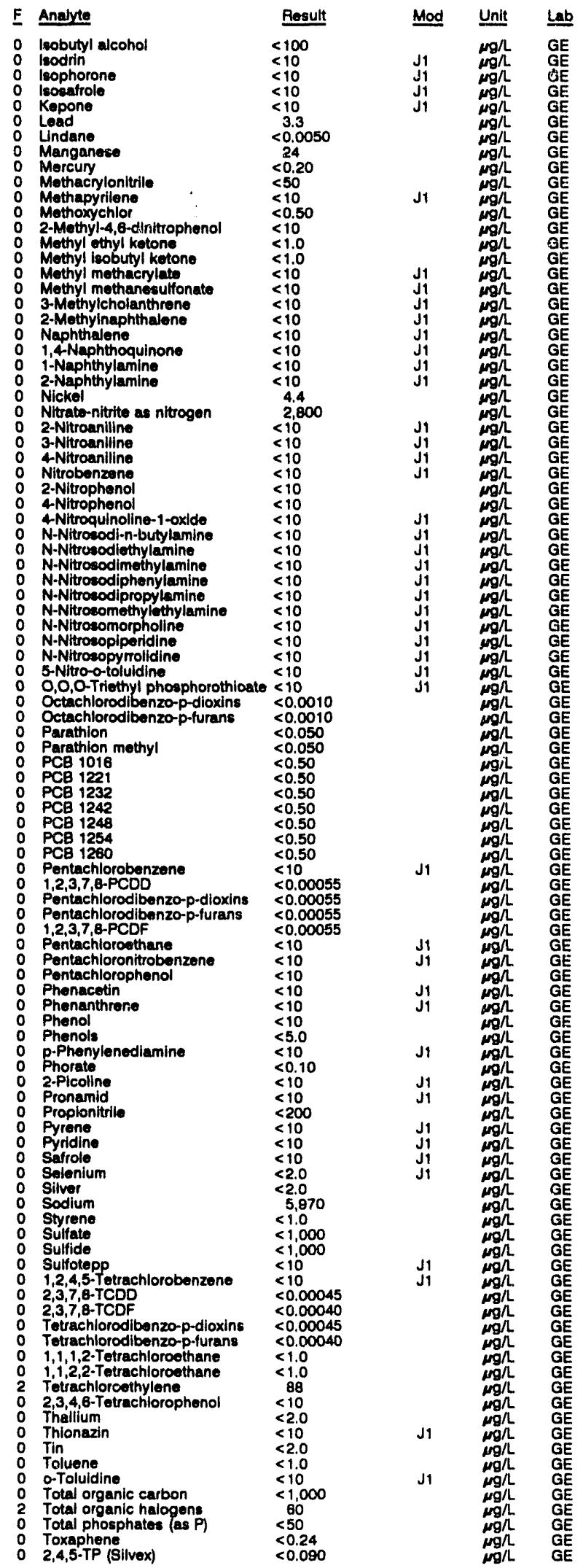

WELL MSB BA collected on 07/15/92, laboraton analyees (cont.)
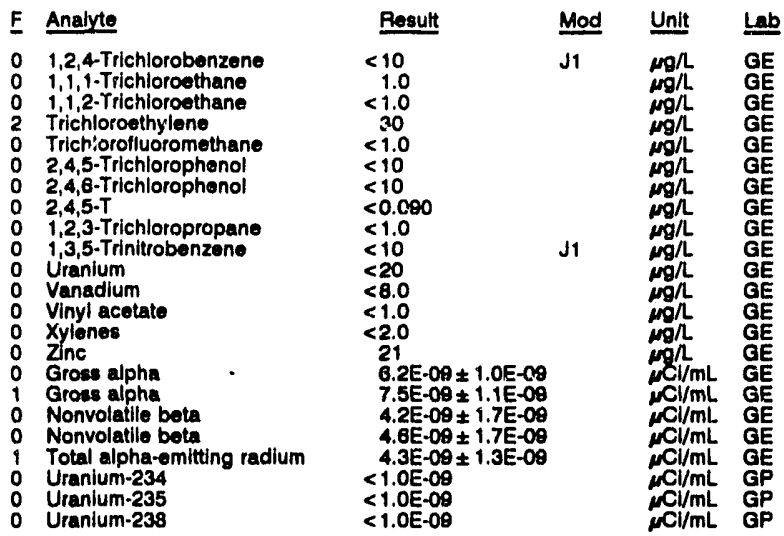

\section{WELL MSB 8B}

\section{MEASUREMENTS CONDUCTED IN THE FIELD}

Sample date: 07/15/92 Depth to water: $136.28 \mathrm{ft}(41.54 \mathrm{~m})$ bolow TOC Water olevation: $207.62 \mathrm{ft}(83.28 \mathrm{~m}) \mathrm{msl}$ Water evacuated before sampling: $161 \mathrm{gal}$

Time: $8: 15$

Hik: 5.1. 1 man

Water temperature: $18.7^{\circ} \mathrm{C}$

LABORATOAY ANALYSES

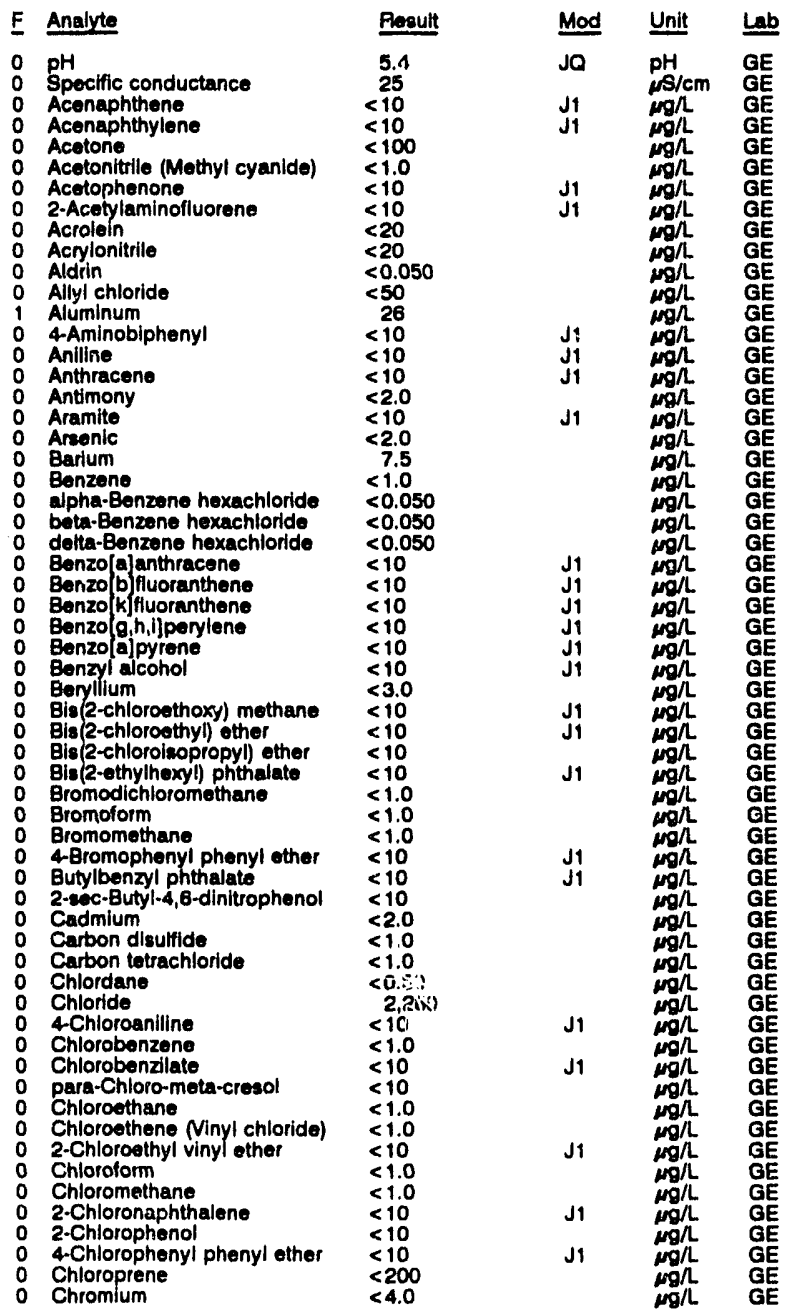


WELL MSB $8 B$ collected on 07/15/92, laboratory analyses (cont.)

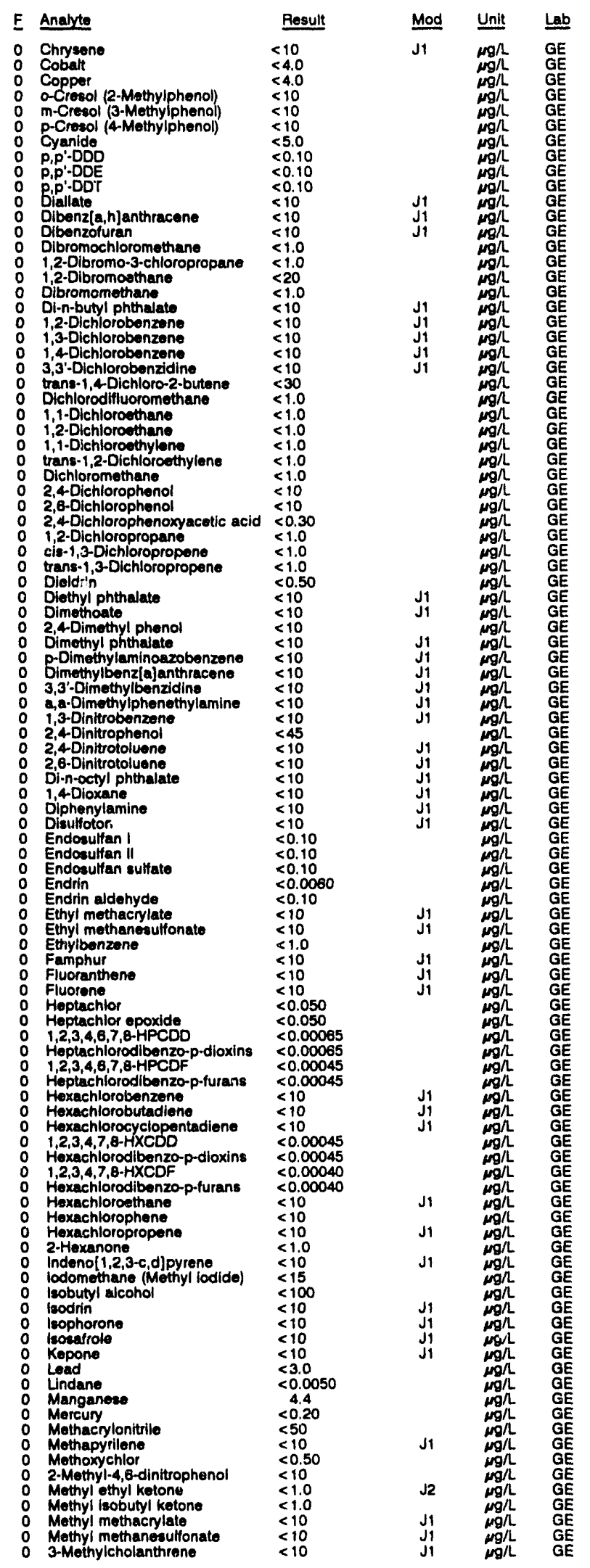

WELL MSB 8B collected on 07/15/92, laboratory analyses (cont.)

E Analyte Result

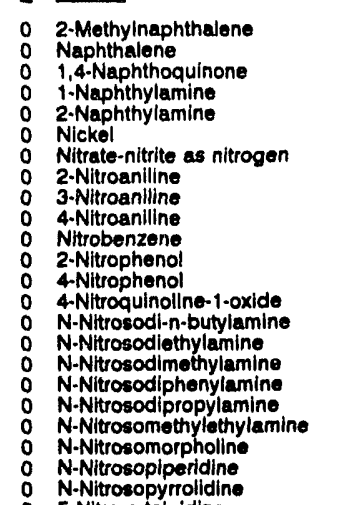

<

5-Nltro-o-toluidine $<10$ - 10

O,0,0-Triethyl phosphorothioate $<10$

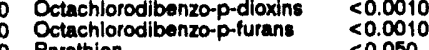

Parathion

Parathion methyl

PCB 1221

PCB 1232

PCB 1248

PCB 1254

PCB 1260

$1,2,3,7,8 \cdot P C D D$

Pentachlorodibenzo-p-dioxins

Pentachlorodibenzo-p-furans

$1,2,3,7,8 \cdot P C D F$

Pentachloroethane

Pentachlorophenol

Phenanthrene

Phenol

0 Phenols

$\begin{array}{ll}0 & \text { Phenols } \\ 0 & \text { p.Phenylenediamine } \\ 0 & \text { Phorate } \\ 0 & \text { Picoline }\end{array}$

2-Picoline

O Propionitrile

O Pyrone

$\begin{array}{ll}0 & \text { Pyridine } \\ 0 & \text { Safrole } \\ 0 & \text { Selentum }\end{array}$

o Selenium

S Sodium

Sodium

0 Sulfate

Sulfotopp

1,2,4,5-Totrachlorot

$\begin{array}{ll}0 & 2,3,7,8-T C D D \\ 0 & 2,3,7,8-T C D F\end{array}$

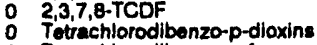

Totrachlorodibenzo-p-furans

o $1,1,1,2-$ Tetrachloroethane

o Tetrachloroethylene

$\begin{array}{ll}0 & 2,3,4,6-T \\ 0 & \text { Thallium }\end{array}$

O Thionazin

Tin

o Toluone

O Total organic carbon

T Total organic halogens

0 Total phosphates

o 2,4,5-TP (Silvex)

o 1,2,4-Trichlorobenzene

o 1,1,1-Trichloroethane

$\begin{array}{ll}0 & 1,1,2-\text { Trichloroethane } \\ 2 & \text { Trichloroethylene }\end{array}$

Trichlorofluoromethane

2,4,5-Trichlorophenol

o 2,4,5-T

o 1,3,5-Trinitrobenzene

o Uranium

O Vanadium

X Xylenes

Nonvolatile beta
0 Total alpha-emitting radium

$<10$

$<10$

780
$<10$

$<10$
$<10$
$<10$

10

$<10$

$<10$
$<10$

10

$<10$
$<10$

10

10

0.001
0.001
0.050
0.050

$<0.50$

$<0.50$

$<0.50$

$<0.50$

$<0.50$

$<10.00055$

$<0.00055$

$<0.00055$

$<0.00055$

$<10$

$<10$

$<10$

$<10$

$<10$
$<5.0$
$<10$
$<0.10$

$<10$
$<10$
$<200$
$<10$

$<10$

$<10$

$<10$
$<2.0$
$<2.0$

$<2.040$

1,940
$<1.0$
$<1,000$

$<1,000$
$<1,000$

$<10$

$<10$
$<0.00045$

$<0.00040$

$<0.00045$

$<1.0$

$<1.0$
2.2
$<10$

2.2
$<10$
$<20$

$<2.0$
$<10$
$<2.0$

$<2.0$
$<1.0$
$<10$

$<1,000$

11
$<50$

$<0.24$

$<10$
$<1.0$

$<1.0$

19
$<1.0$

$<10$
$<10$

$<0.090$

$<1.0$
$<10$

$<20$

$<8.0$

$<1.0$
$<2.0$

$<2.0 E-09$

Mod Unit Lab

$\begin{array}{ll}\mu g / & G E \\ \mu g h & G E\end{array}$

$\mu g$ GE

$\mu \mathrm{m} / \mathrm{L}$ GE

GE

$g /$ GE

$g /$ GE

gn GE

g, GE

GE

GE

GE

E


WELL MSB $8 C$

MEASUREMENTS CONDUCTED IN THE FIELD

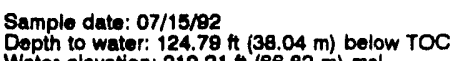
Dopth to water: $124.79 \mathrm{ht}(38.04 \mathrm{~m})$ below
Water olovation: $219.21 \mathrm{th}(68.82 \mathrm{~m}) \mathrm{msl}$
Sp. conductance: $194 \mathrm{~s} / \mathrm{sm}$ Water evacuated before sampling: $73 \mathrm{gal}$

LABORATORY ANALYSES

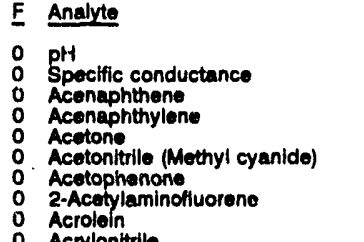

Result Mod Unit Lab

Acrylon

Aldrin

2 Allyl chlorido

2 Aluminum

Aniline

Anthracene

Antimony

o Aramite

O Arsonic

0 Barium

o Benzene

alpha-Benzene hoxachloride

beta-Benzene hexachloride

Benzolajanthracene

Benzo (k) fluoranthene

Benzo $g, h, i]$ perylene

Benzo(ajpyrene

o Benzyl alco

Beryllum

Bis 2-chloroethyl) ether

Bis (2-chloroisopropyl) other

Bie(2-ethylhexyl) phthalat

Bromodich

Bromomethane

4-Bromophenyl phenyl ether

2-sec-Butyl-4,6-dinitrophenol Cadmium

Carbon dieulitide

Carbon tetrachioride $\quad<5.0$

O Chlordan

0 Chloride

4 Chloraaniline

- Chlorobenzeno

para-Chioro-meta-cresol

Chioroethane

Chloroethene Minyl chloride)

2-Chloroeth

Chloromethan

2-Chloronaphthalent

2. Chlorophenot

4-Chlorophenyl phenyl ether

Chloroprene

o Chryeene

O Cobalt

Copper

o a-Cresol (2-Mothylphenol)

m-Cresol (3-Methylphenol)

Cyanide

0 p, p -000

0 P,

O Bialiate

Dibenz[a,h]anth

Dibenzofuran racene

Dibromochloromethane

1,2-Dibromo-3-chloropropane

1,2-Dibromoethan

Di-n-bumethano

1,-n-butyl phthalato

1,2-Dichlorobenzene

1,4Dichlorobenzene

3,3'-Dichlorobenzidine

trans-1,4-Dichloro-2-buten

1,1-Dichloroethane
Time: 7:40

Alkalinity: $1 \mathrm{mo} / \mathrm{t}$

Water temperature: $19.3^{\circ} \mathrm{C}$

Mod Unit Lab

5.3

$<10$
$<10$

$<500$

$<10$

$<100$

$<0.050$

$<250$

$<10$

$<10$

$<2.0$

$<2.0$

$<5.0$

$<0.050$

$<0.050$

$<10$

$<10$

$<10$

$<10$

$<10$

$<50$

$<5.0$

$<5.0$

$<10$

.

$<.50$
4,270

4,300
$<10$

$<5.0$

$<10$

$<5.0$

$<10$

$<5.0$
$<5.0$

$<10$

$<10$
$<10$

$<1,000$

$<4.0$

$<4.0$

$<10$

$<10$

$<5.0$

$<0.10$

$<0.10$

$<10$

$<10$

$<5.0$

$<100$

$<10$

$<10$

$<10$

$<10$

$<5.0$
WELL MSB BC colloctod on 07/15/92, laboratory analyses (cont)

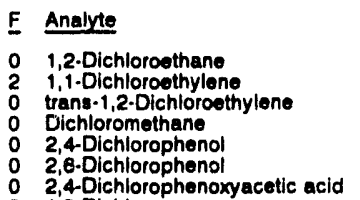

$\begin{aligned} & r \text { Pesut } \\ &<5.0 \\ & 28 \\ &<5.0 \\ & 23 \\ &<10 \\ &<10 \\ &<0.30 \\ &<5.0\end{aligned}$

$\begin{array}{ll}\text { 1,2-Dichloropropane } & <5.0 \\ \text { cis:1,3-Dichloropropene } & <5.0 \\ & <50\end{array}$

$\begin{array}{ll}\text { trans-1,3-Dichloropropene } & <5.0 \\ & <0.50\end{array}$

Diethyl phthalate

2,4Dimethyl phenol

Dimothyl phthalate

D.Dimethylaminoazobenzeno

3,3'-Dimethylbonzzldina

3,3-Dimethylbonzidine $\quad<10$

1,3. Dinitrobenzent

2,4-Dinitrophenol

2,4Dintrotoluene

Di-n-octyl phthaiate

1,4-Dioxane

Oiphenylam

Endosultan

Endosulfan sulfate

Endrin

Endrin aldehyde

Ethyl methanesulfonato

Ethylbenzene

Fluoranthene

Fluorene

Hoptachlor

Heptachlor apoxide

Heptachlorodibenzo-p-dioxins

$1,2,3,4,8,7,8$-HPCDF

Hoptachlorodibenzo-p-turans

Hexachloratadione

Hexachlorocyclopentadiene

1,2,3,4,7,8-HXCDD

Hexachlorodibenzo-p-dioxins

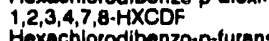

Hexachlorodibenzo-p

Hexachlorosthane

Hexachloropropeno

2-Hexanone

Indeno $[1,2,3-c, d] p y r e n e$

lodomethane (Methyl lodide)

isodin

o leophorone

Tesarrole

Load

Lead

Lindane

Mortury

Methacrylonitrile

Mothapyrilone

2-Methyl-4,6-dinitrophenol

Methyl ethyl kotone

Muthyl isobutyl ketone

Methyl mothacrylato

3-Methylcholanthrene

2-Mothylnaphthalon

14 Nophthogund

1. Naphthoquinon

2-Naphthylamine

Nickel

Nitrate-nitrite as nitrogen

2-Nitroaniline

4 Nitroaniline

Nitrobanzeno

2-Nitropheno

4-Nitroquinoline-1-oxide

N-Nitrosodi-n-butylamin

N-Nitrosodiethylamine

N-Nitrosodimethylamine

N-Nitrosodipropylamine

N-Nitrosomorpholine

N-Nitrosomorpholine

N-Nitrosopyrrolidine

5-Nitro-o-tolutine
$<10$

$<10$

$<10$

$<10$

$<10$

10

$<10$

$<10$

$<10$

$<0.10$

$<0.10$

$<0.0060$

$<10$

$<5.0$

$<10$

$<10$

$<0.050$

$<0.050$

$<0.00065$

$<0.00045$

$<10$

$<10$

$<0.00045$

$<0.00045$

$<0.00040$

$<10$
$<10$

$<10$

$<5.0$

$<10$

$<500$

$<10$

$<10$

$<3.0$

$<0.0050$

$<222$

$<250$

$<10.50$

$<10$

$<5.0$

$<10$

$<10$
$<10$

$<10$

$<10$

$<10$

18,000

$<10$
$<10$

$<10$

$<10$

$<10$

$<10$

$<10$

$<10$

$<10$

$<10$
$<10$

$<10$
$<10$
$<10$

$<10$
$<10$
J!

$\mathrm{J}$
$\mathrm{J} 1$
$\mathrm{~J} 1$
$\mathrm{~J} 1$
$\mathrm{~J} 1$
$\mathrm{~J} 1$
$\mathrm{~J} 1$
$\mathrm{~J} 1$
$\mathrm{~J} 1$
$\mathrm{~J} 1$
$\mathrm{~J} 1$

J1
J1
J1

Ji

J

Mod Unit Lab

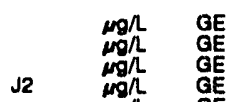

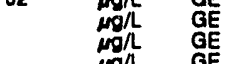

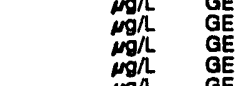


WELL MSB BC collected on 07/15/82, laboratory analyses (cont)

\begin{tabular}{|c|c|c|c|}
\hline Analyte & Result & Mod & Unit \\
\hline 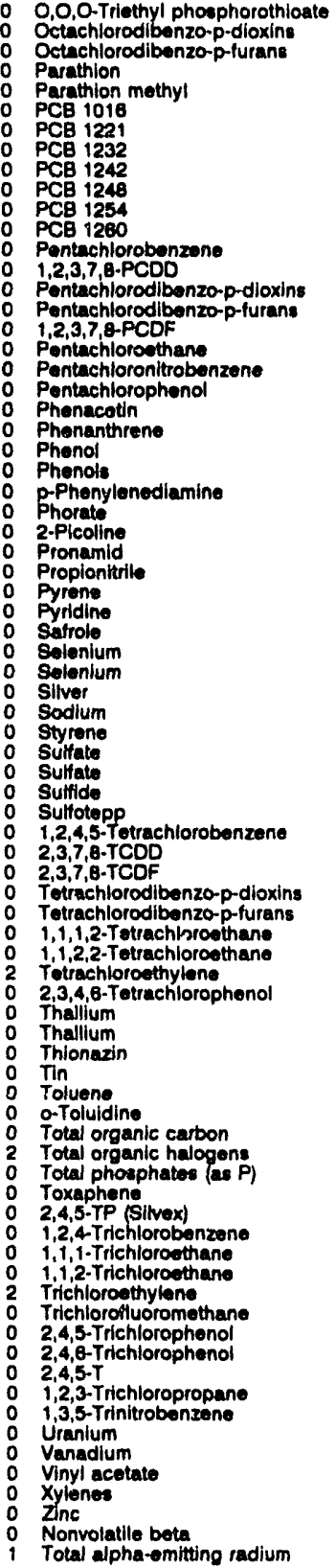 & $\begin{array}{l}<10 \\
<0.0010 \\
<0.0010 \\
<0.050 \\
<0.050 \\
<0.50 \\
<0.50 \\
<0.50 \\
<0.50 \\
<0.50 \\
<0.50 \\
<0.50 \\
<10 \\
<0.00055 \\
<0.00055 \\
<0.00055 \\
<0.00055 \\
<10 \\
<10 \\
<10 \\
<10 \\
<10 \\
<10 \\
<5.0 \\
<10 \\
<0.10 \\
<10 \\
<10 \\
<1.000 \\
<10 \\
<10 \\
<10 \\
<2.0 \\
<2.0 \\
<2.0 \\
15,500 \\
<5.0 \\
1,500 \\
1.480 \\
<1.000 \\
<10 \\
<10 \\
<0.00045 \\
<0.00040 \\
<0.00045 \\
<0.00040 \\
<5.0 \\
<5.0 \\
177 \\
<10 \\
<2.0 \\
<2.0 \\
<10 \\
<2.0 \\
<5.0 \\
<10 \\
<1.000 \\
85 \\
<50 \\
<0.24 \\
<0.090 \\
<10 \\
18 \\
<5.0 \\
68 \\
<5.0 \\
<10 \\
<10 \\
<0.090 \\
<5.0 \\
<10 \\
<20 \\
<8.0 \\
<5.0 \\
<10 \\
8.3 \\
8.1 \mathrm{E}-09 \pm 1.9 \mathrm{EE} \cdot 0 \\
3.5 \mathrm{E} \cdot 09 \pm 1.2 \mathrm{E}-0\end{array}$ & $\begin{array}{l}\mathrm{J1} \\
\mathrm{J1} \\
\mathrm{J} 1 \\
\mathrm{J1} \\
\mathrm{J1} \\
\mathrm{J} 1 \\
\mathrm{~J} 1 \\
\mathrm{~J} 1\end{array}$ & 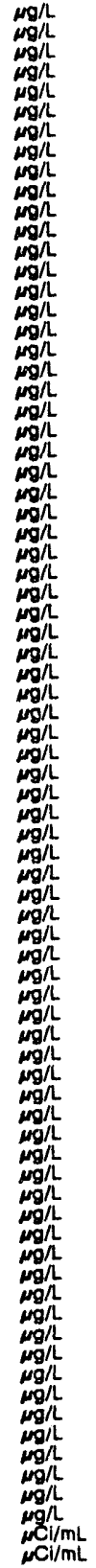 \\
\hline
\end{tabular}

WELL MSB 9A

MEASUREMENTS CONDUCTED IN THE FIELD

Sample date: $08 / 18 / 92$ H $(45.73 \mathrm{~m})$ below TOC

Water elovation: $209.37 \mathrm{~h}(63.82 \mathrm{~m}) \mathrm{ms}$

Sp. conductance: $31, \mathrm{NS} / \mathrm{cm}$
Water ovacuated bolore sampling: $185 \mathrm{gal}$

LABORATORY ANALYSES

\begin{tabular}{|c|c|c|c|}
\hline F Analyte & Result & Mod & Unit \\
\hline $\begin{array}{ll}0 & \text { pH } \\
0 & \text { Specific conductance } \\
0 & \text { Aluminum } \\
0 & \text { Arsenic } \\
0 & \text { Arsenic }\end{array}$ & $\begin{array}{r}6.3 \\
40 \\
<20 \\
<2.0 \\
<2.0\end{array}$ & JO & $\begin{array}{l}\mathrm{pH} \\
\mathrm{mS} / \mathrm{cm} \\
\mathrm{mg} / \mathrm{h} \\
\mathrm{mg} / \mathrm{L} \\
\mathrm{mg} / \mathrm{L}\end{array}$ \\
\hline
\end{tabular}

WELL MSB 9A collected on 08/18/92, laboratory analyses (cont.)

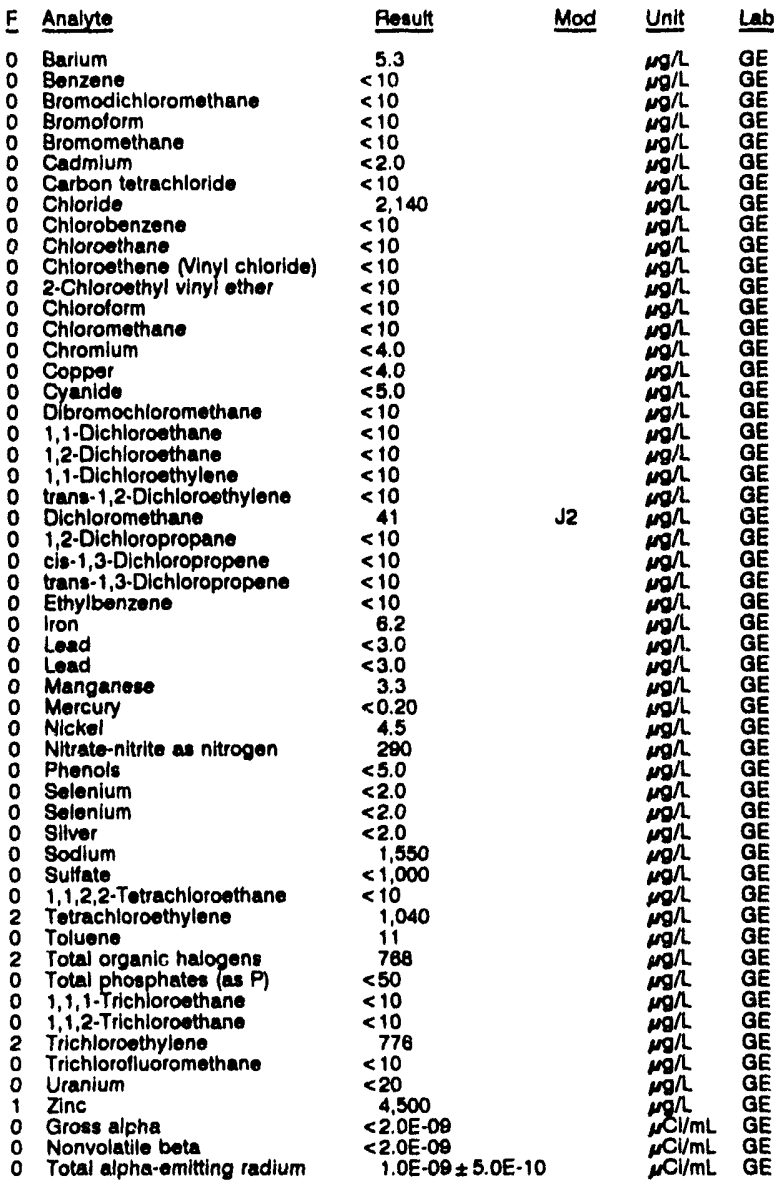

\section{WELL MSB 9B}

\section{MEASUREMENTS CONDUCTED IN THE FIELO}

Sample date: 08/18/92 Time: 8:25

Dopth to water: $130.78 \mathrm{H}(39.86 \mathrm{~m})$ below TOC PH: 8.2
Whater elevation: $228.82 \mathrm{t}(88.75 \mathrm{~m}) \mathrm{mal}$
Alkalinity: $14 \mathrm{mg} / \mathrm{l}$

Sp. conductance: $204 \mathrm{\mu S} / \mathrm{cm}$ Water temperature: $20.0{ }^{\circ} \mathrm{C}$

Water evacuated bofore sampling: 8 gal

The well went dry during purging

LABORATORY ANALYSES

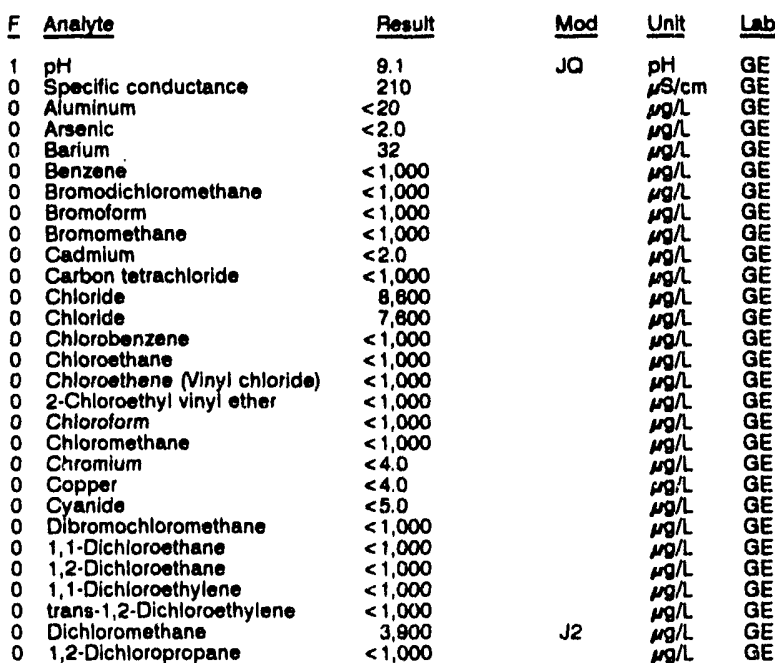


ANALYTICAL RESULTS

WELL MSB 88 collocted on 08/18/82, laboratory analyses (cont)

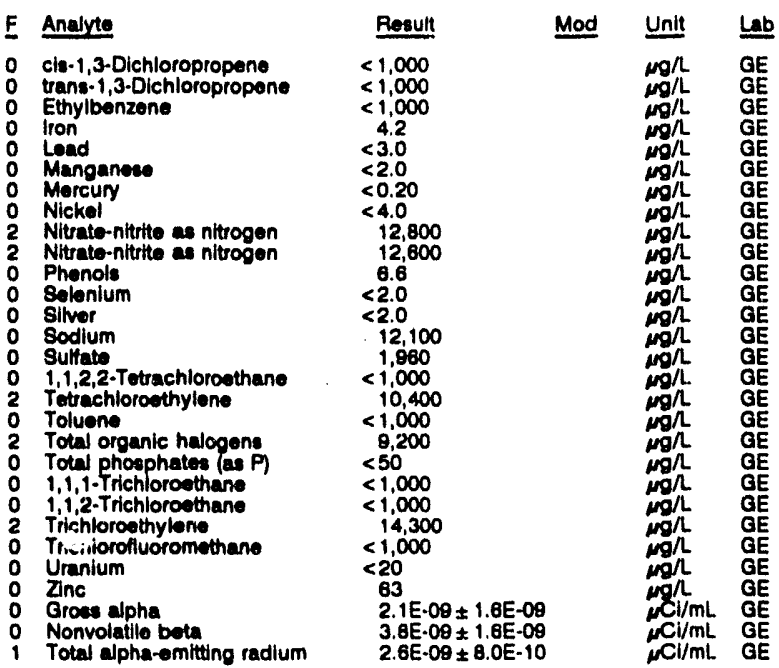

WELL MSB 9C

MEASUREMENTS CONDUCTED IN THE FIELD

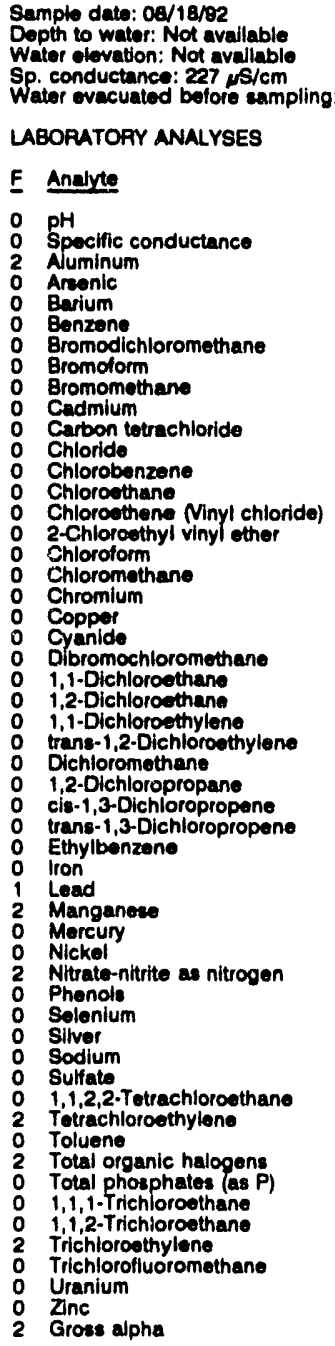

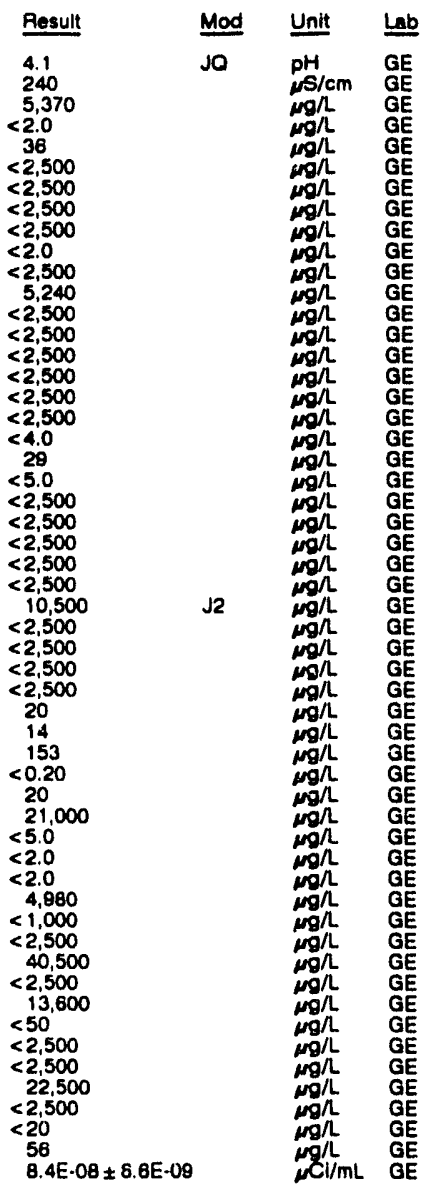

WELL MSB $\theta C$ collected on 08/18/82, laboratory analyees (cont)

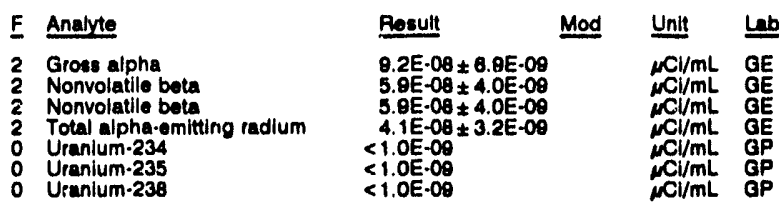

WELL MSB 10A

MEASUREMENTS CONOUCTED IN THE FIELD

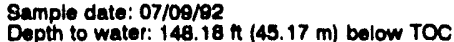

Water elevation: $208.82 \mathrm{ft}(\mathbf{6 3 . 0 4} \mathrm{m}) \mathrm{mel}$

Water evacuated before sampling: $233 \mathrm{gal}$

LABORATORY ANALYSES

E Anabrto

$0 \mathrm{pH}$

Specific conductance

Aluminum

0 Arsenic

Denzene

B Bromodichloromethane

Bromomethane

Cadmium

Chloridochloride

Chlorobenzen

Chloroethane

Chloroethene (Vinyl chloride)

2-Chloroethyl vinyl ether

Chlorotorm

o Chloromethane

Chromium

Copper

o Dybromochloromethane

1,1-Dichloroethane

o i, Dichloroethane

1,2-Dichlorosthano

o trans-1,2-Dichloroethylene

o Dichloromethane

o 1,2-Dichloropropane

o cis-1,3-Dichloropropene

o trani-1,3-Dichloropropeno

o Ethylbenzene

o Iron

0 Manganeso

0 Mercuny

o Nickol

o Nitrate-nitrite as nitrogen

Phonols

Selenium

0 Sodium

o Sultato

Suliate -Tetrachloroethane

1 Tetrachloroethylene

0 Toluene

- Total organic halogens

- Total phosphates (as P)

o 1,1,1. Trichloroethane

0 1,1,2-Trichloroethan

2 Trichloroethylene

o Trichloroftuoromethan

- Uranium

0 Zinc

- Gross alpha

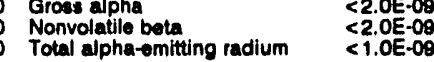

$\operatorname{Tim}_{\mathrm{PH}}: 8.8$

Alkalinity: $2 \mathrm{mg} /$ Water temperalure: $20.2^{\circ} \mathrm{C}$

\begin{tabular}{|c|c|c|}
\hline $\begin{aligned} & 5.5 \\
& 20 \\
&<20 \\
&<2.0 \\
& 4.3 \\
&<1.0 \\
&<1.0 \\
&<1.0 \\
&<1.0 \\
&<2.0 \\
&<1.0 \\
& 2.040 \\
&<1.0 \\
&<1.0 \\
&<1.0 \\
&<1.0 \\
&<1.0 \\
&<1.0 \\
&<4.0 \\
&<4.0 \\
&<5.0 \\
&<1.0 \\
&<1.0 \\
&<1.0 \\
&<1.0 \\
&<1.0 \\
& 3.4 \\
&<1.0 \\
&<1.0 \\
&<1.0 \\
&<1.0 \\
&<4.0 \\
&<3.0 \\
&<2.0 \\
&<0.20 \\
&<4.0 \\
& 310 \\
&<5.0 \\
&<2.0 \\
&<2.0 \\
&<1.480 \\
&<1.000 \\
&<1.0 \\
& 21.9 \\
&<1.0 \\
&<11 \\
&<50 \\
&<1.0 \\
&<1.0 \\
& 18 \\
&<1.0 \\
&<20 \\
& 43 \\
&<2.0 E .09 \\
&<2.0 E-09 \\
&<1.0 E-09\end{aligned}$ & JO & 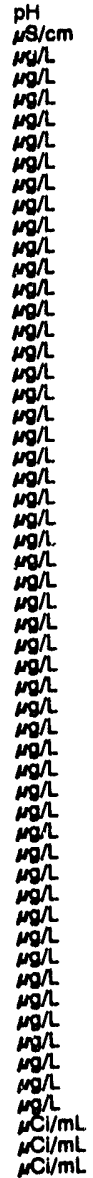 \\
\hline
\end{tabular}

WELL MSB 10B

MEASUREMENTS CONDUCTED IN THE FIELD

Depth to water: $145.45 \mathrm{ft}(44.33 \mathrm{~m})$ below TOC Water elevation: $209.25 \mathrm{tt}(63.78 \mathrm{~m}) \mathrm{ms}$

PH: 4.4 Alkalinity: $0 \mathrm{mg} / \mathrm{h}$

Alkalinity: $0 \mathrm{mg} / \mathrm{h}$

Water ovacuated before sampling: $157 \mathrm{gat}$

LABORATORY ANALYSES

\begin{tabular}{|c|c|c|c|}
\hline F Analyte & Result & Mod & Unit \\
\hline 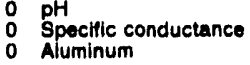 & $\begin{array}{r}5.0 \\
38 \\
<20\end{array}$ & JO & $\begin{array}{l}\mathrm{pH} \\
\mathrm{\mu S} / \mathrm{cm} \\
\mathrm{\mu g} / \mathrm{L}\end{array}$ \\
\hline
\end{tabular}


ANALYTICAL RESULTS

\begin{tabular}{|c|c|c|c|c|c|}
\hline & Anatyte & Result & Mod & Unit & Lab \\
\hline & 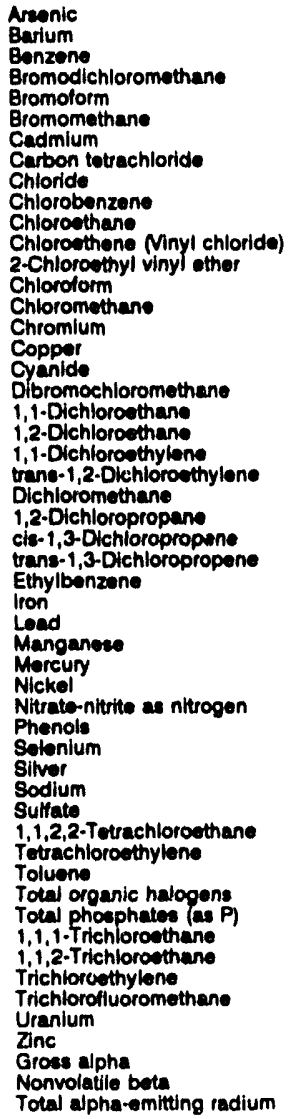 & $\begin{array}{l}<2.0 \\
11 \\
<1.0 \\
<1.0 \\
<1.0 \\
<1.0 \\
<2.0 \\
<1.0 \\
2.020 \\
<1.0 \\
<1.0 \\
<1.0 \\
<1.0 \\
<1.0 \\
<1.0 \\
<4.0 \\
<4.0 \\
<5.0 \\
<1.0 \\
<1.0 \\
<1.0 \\
<1.0 \\
<1.0 \\
1.4 \\
<1.0 \\
<1.0 \\
<1.0 \\
<1.0 \\
<4.0 \\
<3.0 \\
51.3 \\
<0.20 \\
<4.0 \\
<50 \\
<5.0 \\
<2.0 \\
<2.0 \\
2.540 \\
81.170 \\
<1.0 \\
<1.0 \\
<1.0 \\
<5.0 \\
<50 \\
<1.0 \\
<1.0 \\
2.2 \\
<1.0 \\
<20 \\
118 \\
<2.0 E-09 \\
<2.0 E-09 \\
<1.0 E-09\end{array}$ & J2 & 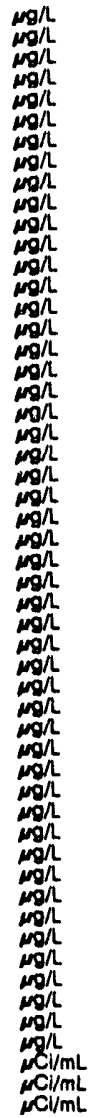 & $\begin{array}{l}G E \\
G E \\
G E \\
G E \\
G E \\
G E \\
G E \\
G E \\
G E \\
G E \\
G E \\
G E \\
G E \\
G E \\
G E \\
G E \\
G E \\
G E \\
G E \\
G E \\
G E \\
G E \\
G E \\
G E \\
G E \\
G E \\
G E \\
G E \\
G E \\
G E \\
G E \\
G E \\
G E \\
G E \\
G E \\
G E \\
G E \\
G E \\
G E \\
G E \\
G E \\
G E \\
G E \\
G E \\
G E \\
G E \\
G E \\
G E \\
G E \\
G E \\
G E \\
G E \\
G E\end{array}$ \\
\hline
\end{tabular}

WEL MSB $10 \mathrm{C}$ collocted on 08/14/92, laboralory analyeee (cont.)

\begin{tabular}{|c|c|c|c|}
\hline Analyte & Pesult & Mod & Unit \\
\hline 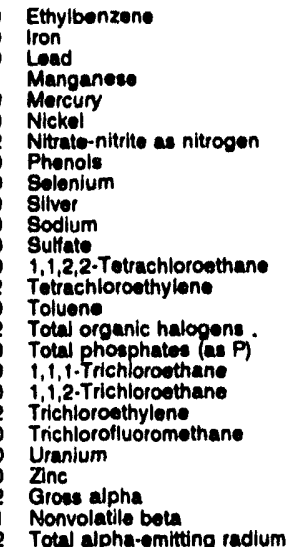 & $\begin{array}{l}<5,000 \\
<4.0 \\
<3.0 \\
29 \\
<0.20 \\
<4.0 \\
20,000 \\
<5.0 \\
<2.0 \\
<2.0 \\
11,200 \\
<1,000 \\
<5,000 \\
71,000 \\
<5,000 \\
17,400 \\
<50 \\
<5,000 \\
<5,000 \\
42,000 \\
<5,000 \\
<20 \\
<2.0 \\
3.8 E-00 \pm 5.5 E \cdot 00 \\
2.0 E-08 \pm 3.2 E-00 \\
1.6 E-08 \pm 2.2 E-00\end{array}$ & & 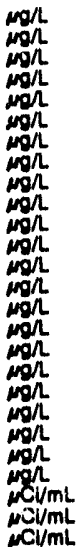 \\
\hline
\end{tabular}

WELL MSB 11A

MEASUREMENTS CONDUCTED IN THE FIELD

Sample date: 07/09/92 Dopth to water: $153.82 \mathrm{~A}(48.68 \mathrm{~m})$ balow TOC Water elevation: $211.0 \mathrm{~A} /(84.34 \mathrm{~m}) \mathrm{msl}$

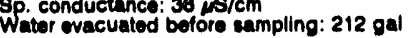
Time: $7: 45$ Alkalinity: $8 \mathrm{mon}$ Water tomperature: $19.8 \cdot \mathrm{C}$ LABORATOAY ANALYSES

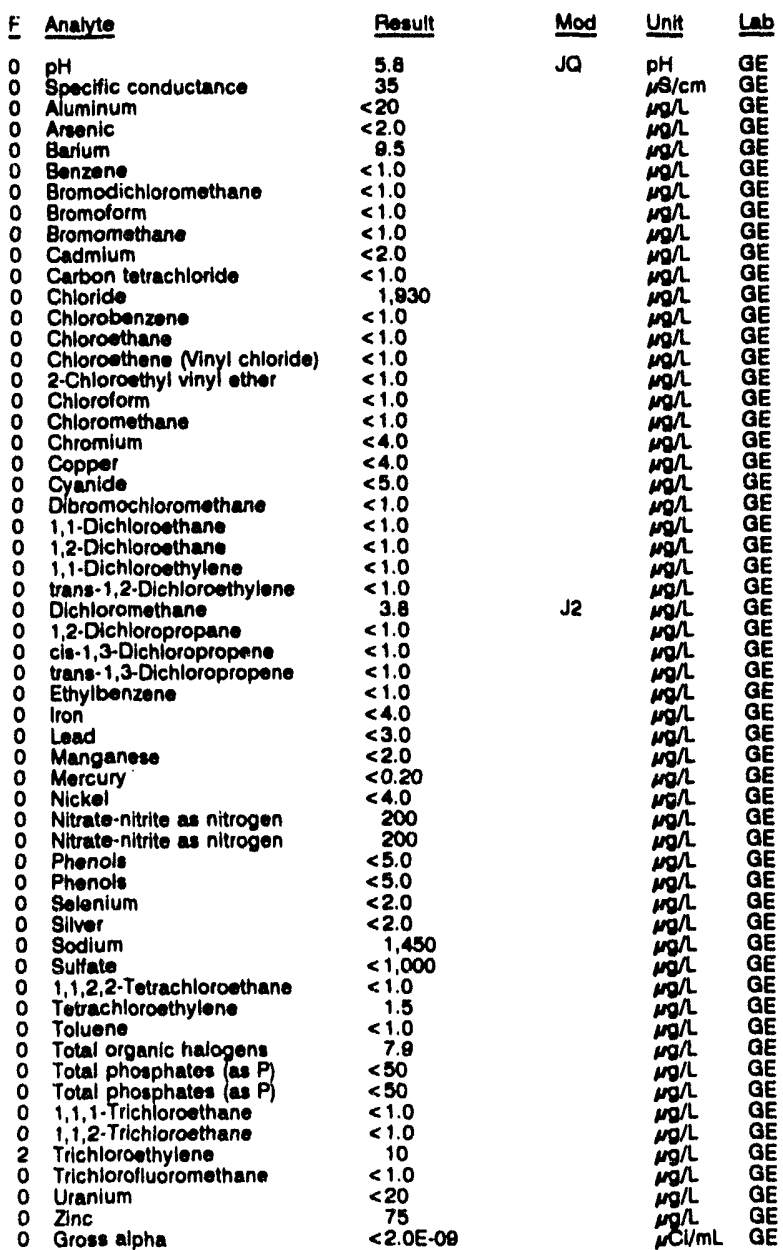

E

\section{WELL MSB 10C}

MEASUREMENTS CONDUCTED IN THE FIELD

Sample date: 08/14/92
Depth to water: 128.22 it $(30.08 \mathrm{~m})$ below TOC Depth to water: $128.22 \mathrm{Ht}(39.08 \mathrm{~m})$ below Sp. conductance: $305 \mu \mathrm{s} / \mathrm{cm}$
Wator evacuated botore eampling: $58 \mathrm{gal}$

\section{LABOPATOAY ANALYSES}

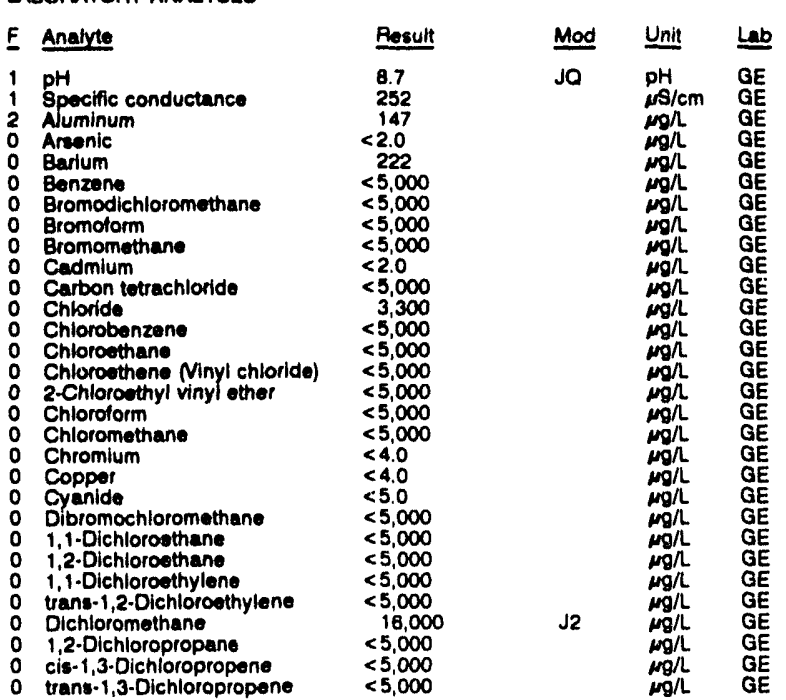

Time: 14:35

Alk: 9.4 : $98 \mathrm{mon}$

Water temperature: $20.2^{\circ} \mathrm{C}$

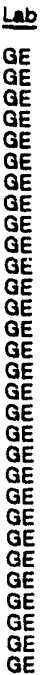


ANALYTICAL RESULTS

WELL MSB 11 A collocted on 07/09/82, laboratory analyees (cont.)

\begin{tabular}{|c|c|c|c|}
\hline E Analute & Result & Mod & Unit \\
\hline $\begin{array}{l}\text { Nonvolatile beta } \\
\text { Total alpha-emitting radium }\end{array}$ & $\begin{array}{l}<2.0 E \cdot 00 \\
<1.0 E \cdot 0 \theta\end{array}$ & & $\underset{\mathrm{MCl} / \mathrm{mL}}{\mathrm{C} \mathrm{mL}}$ \\
\hline
\end{tabular}

WELLL MSB $11 B$

MEASUAEMENTS CONDUCTED IN THE FIELD

Sample dato: $07 / 08 / 92$
Depth to water: $148.08 \mathrm{n}(45.41 \mathrm{~m})$ below TOC
Wator olevation: $215.82 \mathrm{At}(85.78 \mathrm{~m}) \mathrm{ms}$

Sp. conductance: $28 \mathrm{\mu g} / \mathrm{cm}$
What wacuated bofore sampling: $144 \mathrm{gal}$

LABOPATOFY ANALYSES

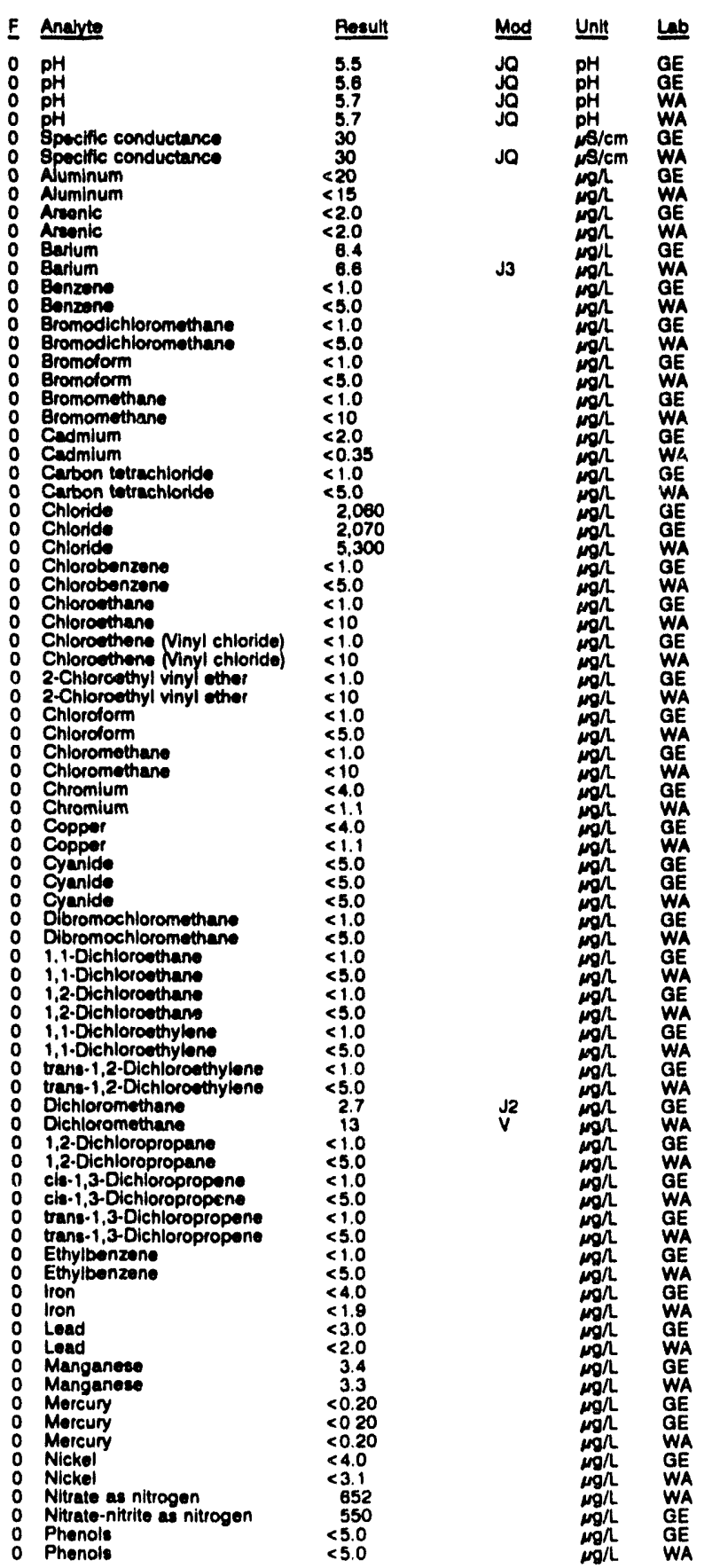

WELL MSB 11 B collectod on 07/00/92, laboratory andyees (cont.)

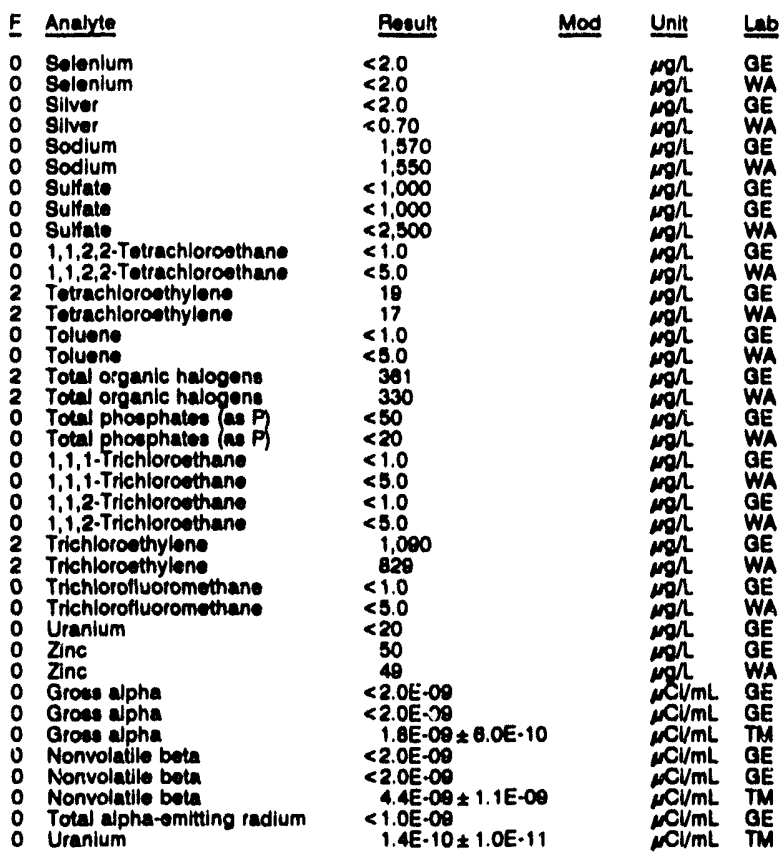

WELL MSB 11B Replicate

MEASUAEMENTS CONDUCTED IN THE FIELL

Sample dete: 07/09/92

Depth to water: $148.08 \mathrm{n}(45.41 \mathrm{~m})$ below TOC

Water elovation: 215.62 N 18.7

Water evacuated belore sampling: $144 \mathrm{gal}$

pH: 5.0

in: $2 \mathrm{mon}$

ABORATORY ANALYSES

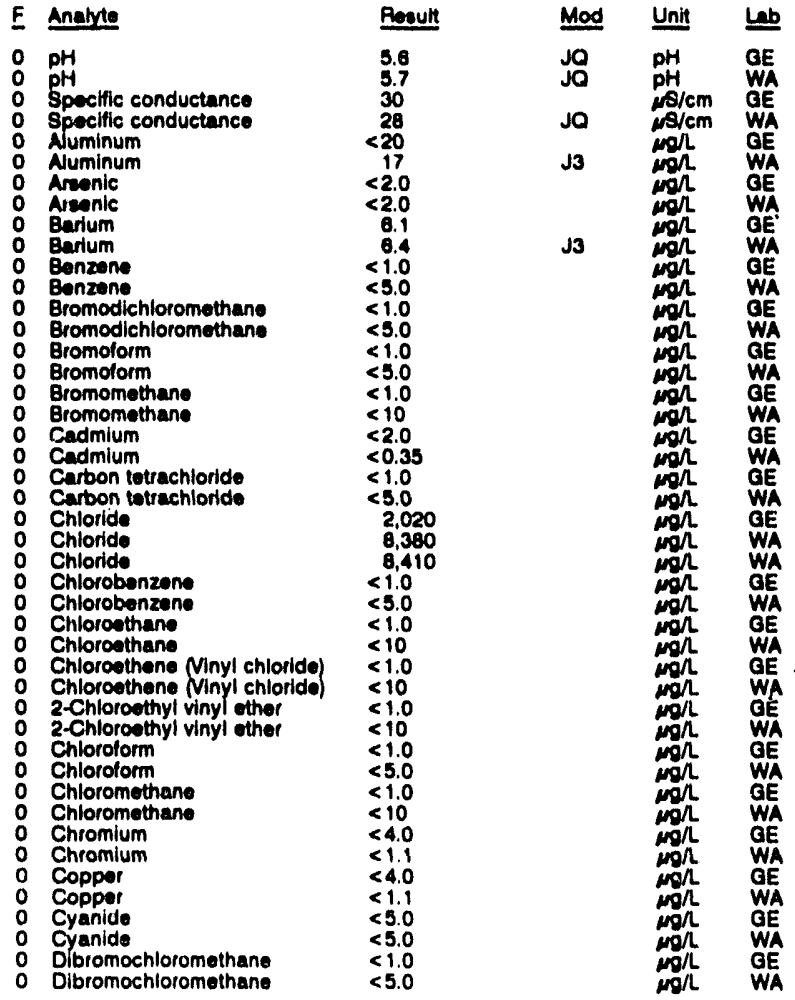


WELL MSB 118 collected on 07/08/92, laboratory analyees (cont.)

\begin{tabular}{|c|c|c|c|c|c|}
\hline & Analyte & Renult & Mod & Unif & Lab \\
\hline $\begin{array}{l}2 \\
0 \\
0 \\
0 \\
0\end{array}$ & 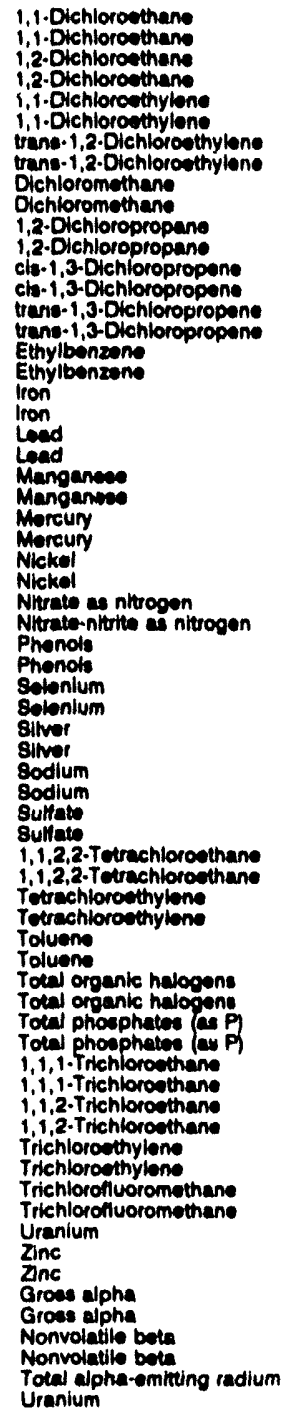 & 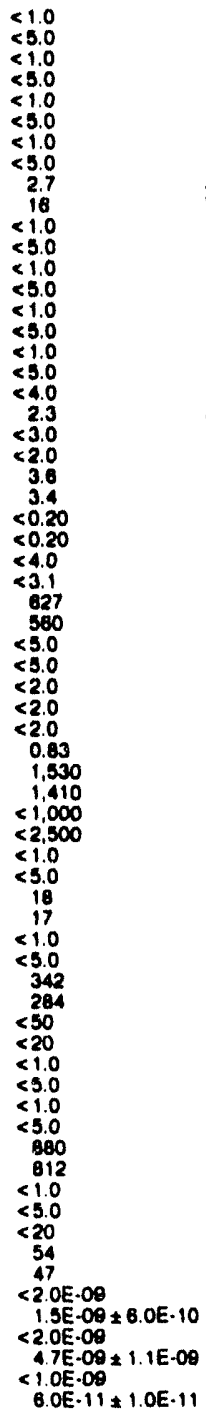 & $\underset{v}{\sqrt{2}}$ & 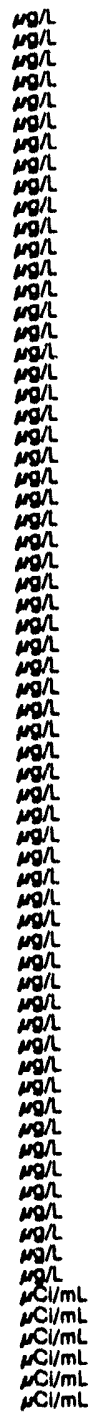 & 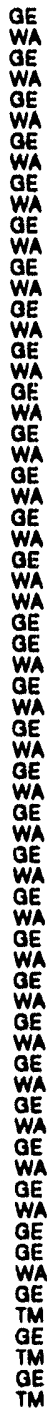 \\
\hline
\end{tabular}

WELL MSB 11C

MEASUREMENTS CONDUCTED IN THE FIELD

Sample dato: 00/11/82 Depth to wator: $148.87 \mathrm{n}(44.80 \mathrm{~m})$ bolow TOC
Water olevation: $217.03 \mathrm{n}(88.43 \mathrm{~m}) \mathrm{msl}$ Water evecuated belore eampling: $106 \mathrm{gal}$

LABOMATORY ANALYSES

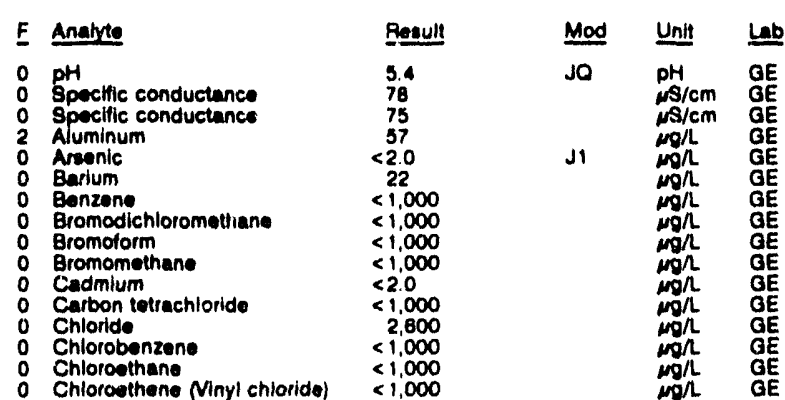

WELL M8B $11 \mathrm{C}$ collocted on $08 / 11 / 92$, laboratory analyese (cont)

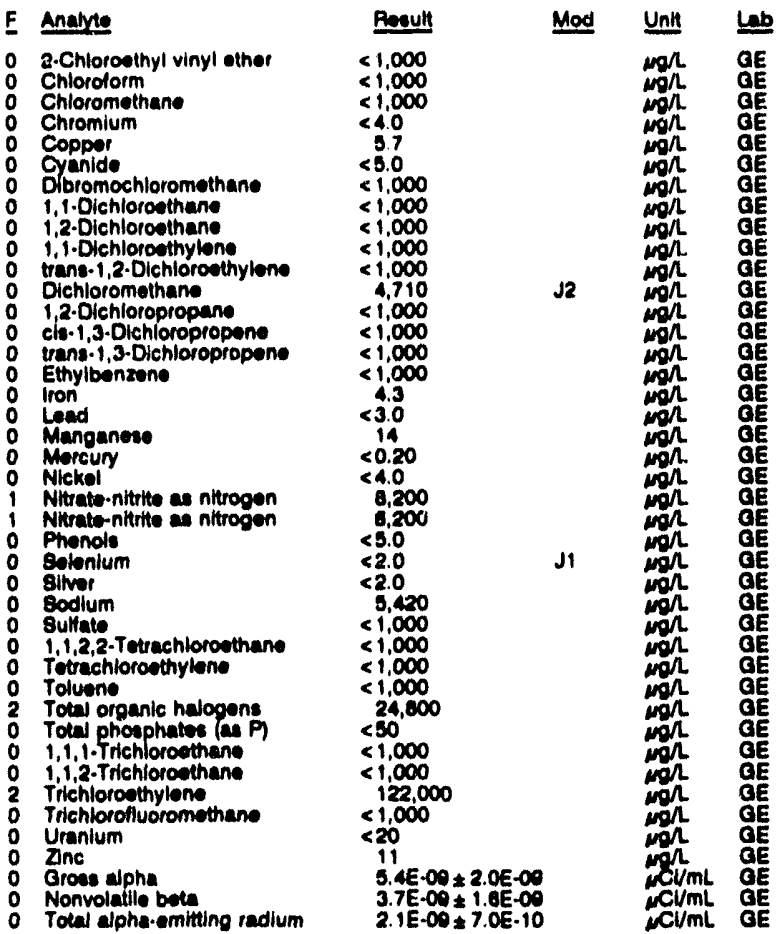

WELL MSB 11D

MEASUAEMENTS CONDUCTED IN THE FIELD

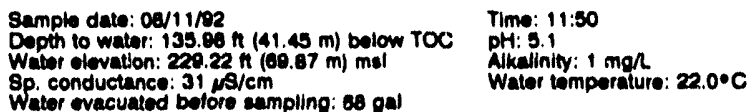

Witer evacuated bolore sumpling: 60 gal

LABORATOAY ANALYSES

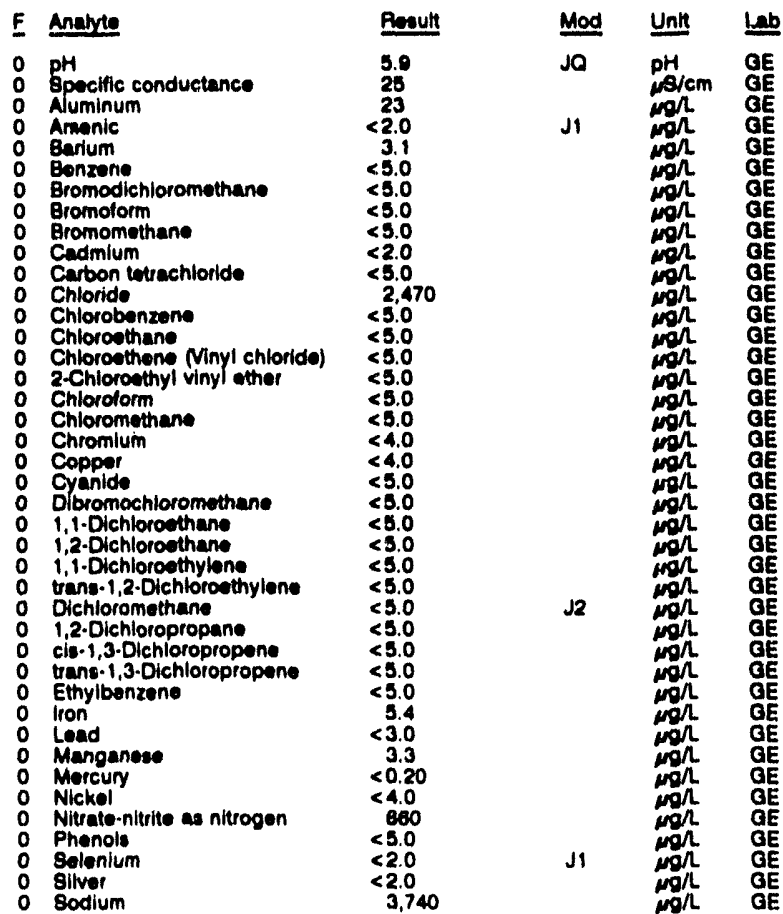


ANALYTICAL RESULTS

WELL M88 110 collected on 08/11/92, laboratory analyees (cont.)

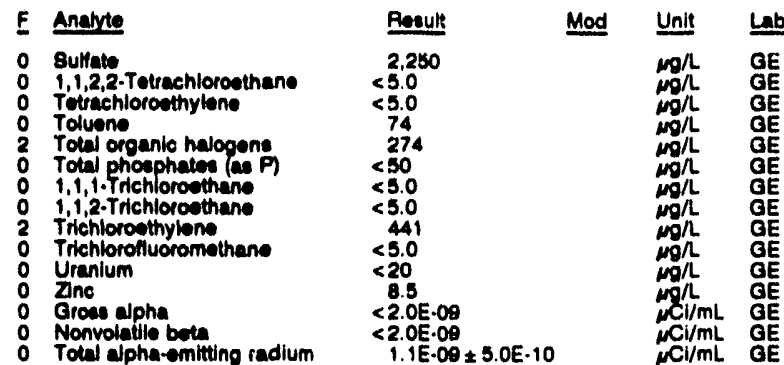

WELL MSB 11E

MEABUAEMENTS CONDUCTEO IN THE FIELD

Sample dats: 07/00102

(37.84 m) bolow TOC

Water olevation: $241.08 \mathrm{n}(73.48 \mathrm{~m}) \mathrm{ms}$

inaccesalbility of mochanical problem prevented sample collection.

WELL MSB 11F

MEASUAEMENTS CONDUCTED IN THE FIELD

8ample date: $08 / 11 / 02$

Depth to water: Not avallable

Wator olevation: Not avallablo

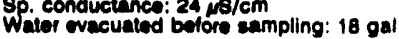

LABORATORY ANALYSES

\begin{tabular}{|c|c|c|c|}
\hline Analyte & Result & Mod & Unit \\
\hline 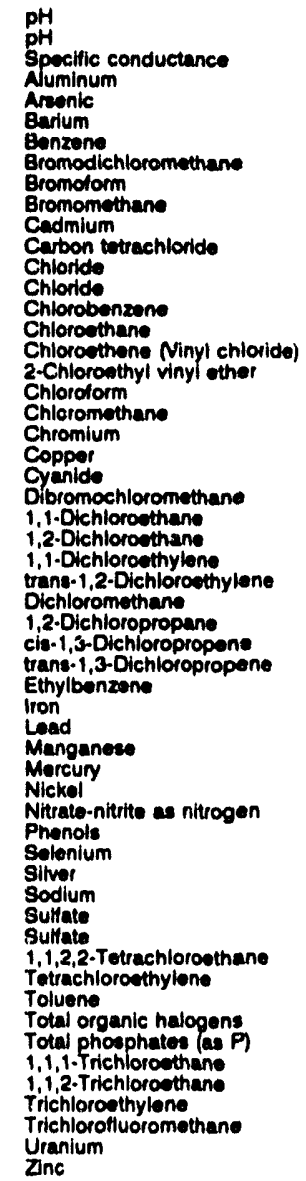 & $\begin{aligned} & 5.2 \\
& 5.2 \\
& 25 \\
& 81 \\
&<2.0 \\
& 3.8 \\
&<1.0 \\
&<1.0 \\
&<1.0 \\
&<1.0 \\
&<2.0 \\
&<1.0 \\
& 2.630 \\
& 2.830 \\
&<1.0 \\
&<1.0 \\
&<1.0 \\
&<1.0 \\
&<1.0 \\
&<1.0 \\
&<4.0 \\
& 7.0 \\
&<5.0 \\
&<1.0 \\
&<1.0 \\
&<1.0 \\
&<1.0 \\
&<1.0 \\
&<1.0 \\
&<1.0 \\
&<1.0 \\
&<1.0 \\
&<1.0 \\
& 42 \\
&<3.0 \\
& 6.7 \\
&<0.20 \\
& 5.6 \\
& 900 \\
&<3.0 \\
&<2.0 \\
&<2.0 \\
& 2.340 \\
&<1.000 \\
&<1.000 \\
&<1.0 \\
& 1195 \\
&<1.0 \\
& 373 \\
& 550 \\
&<1.0 \\
&<1.0 \\
& 810 \\
&<1.0 \\
&<20 \\
& 115 \\
&<\end{aligned}$ & $\begin{array}{l}\text { JQ } \\
\text { JO } \\
\text { J1 }\end{array}$ & 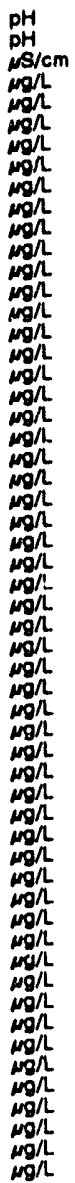 \\
\hline
\end{tabular}

WELL MSB $11 \mathrm{~F}$ collocted on 08/11/02, laboratory analyees (cont)

\begin{tabular}{|c|c|c|}
\hline E Analute & Reault & Unit \\
\hline $\begin{array}{ll}1 & \text { Gross alpha } \\
0 & \text { Grose alpha } \\
0 & \text { Nonvolatile bota } \\
0 & \text { Nonvolatile bota } \\
2 & \text { Total alpha.emilting radium }\end{array}$ & $\begin{array}{l}7.6 E \cdot 09 \neq 2.1 E \cdot 09 \\
6.8 E \cdot 00 \neq 2.0 E-09 \\
4.2 E \cdot 09 \neq 1.7 E-09 \\
4.6 E \cdot 00 \neq 1.7 E \cdot 00 \\
6.7 E \cdot 00 \neq 1.4 E \cdot 00\end{array}$ & $\underset{\substack{\mathrm{Cl} / / \mathrm{mL} \\
\mathrm{Cl} / \mathrm{mL} \\
\mathrm{Cl} / \mathrm{mL}}}{\mathrm{Cl} / \mathrm{mL}}$ \\
\hline
\end{tabular}

WELL MSB 12A

MEASUREMENTS CONDUCTED IN THE FIELO

Sample dato: 08/18/92

Depth to water: $140.67 \mathrm{H}(42.88 \mathrm{~m})$ below TOC

Water elovation: $207.13 \mathrm{H}(83.13 \mathrm{~m}) \mathrm{ms}$

Witor evacuated bolore sempling: $239 \mathrm{gal}$

LABORATORY ANALYSES

E Anarte

O $\mathrm{pH}$ pecific conductance

o Aluminum

0 Areanic

0 Earium

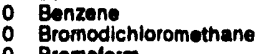

o Bromoform

- Cadmium

- Carbon totrachloride

O Chlorido

o Chlorobenzene

o Chloroothene Minyl chloride

2-Chloroethyl vinyl other

Chlorolorm

Chloromethane

Chromium

0 Copper

o Cyanide

o 1,1-Dichloroethane

1,2.Dichloroethane

0 1,1-Dichloroethylene
o trang-1,2.Dichloroethylene

0
0
0

o 1,2-Dichloropropane

0
0
trans-1,3-Dichloropropene

o Ethylbenzene

0 Iron

o Manganese

- Morcuny

Nickel

o Nitrale-nitrite as nitrogen

o Phenols

S Selenium

0 Sodium

o Sulfate

0 Sulfate

o $1,1,2,2$.Tetrachloroethane

2 Tetrachloroethylene

2 Total organic halogene

0 Total phosphates (as P)

o 1,1,1.Trichlorosthane

2 Trichlorothylene

o Trichlorofluoromothane

o Uranium

o Zinc

o Grose alphe

Nonvolatile bota

Total alpha-emitting radium

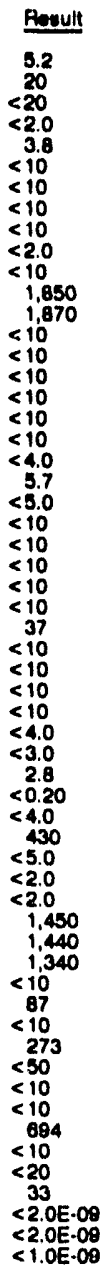

Time: 11:20

Alkalinity: $0 \mathrm{mg} /$

Water temperature: $18.5^{\circ} \mathrm{C}$

WELL MSB 12B

MEASUREMENTS CONDUCTED IN THE FIELD

Dopth to water: $131.60 \mathrm{n}(40.11 \mathrm{~m})$ below TOC Water elovation: $216.80 \mathrm{H}(86.08 \mathrm{~m}) \mathrm{ms}$

Sp conduction: $216.80 \mathrm{H}(88.08$

Water evacuated bofore sampling: $159 \mathrm{gal}$

LABORATORY ANALYSES

\begin{tabular}{|c|c|c|c|}
\hline E Analyte & Result & Mod & Unit \\
\hline $\begin{array}{ll}0 & \mathrm{pH} \\
0 & \text { Specific conductance } \\
1 & \text { Aluminum }\end{array}$ & $\begin{array}{l}4.9 \\
120 \\
50\end{array}$ & Jo & $\begin{array}{l}\mathrm{pH} \\
\mathrm{NS} / \mathrm{cm} \\
\mathrm{mg} / \mathrm{L}\end{array}$ \\
\hline
\end{tabular}

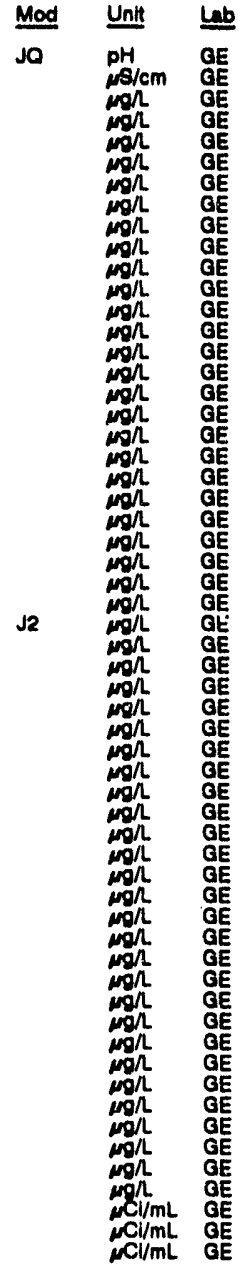

Time: 11:00

PH: 4.5

Alkalinity: $0 \mathrm{mg} /$. $18.6^{\circ} \mathrm{C}$ 
WELL MBB 128 collected on 08/18/92, laboratory analyees (cont)

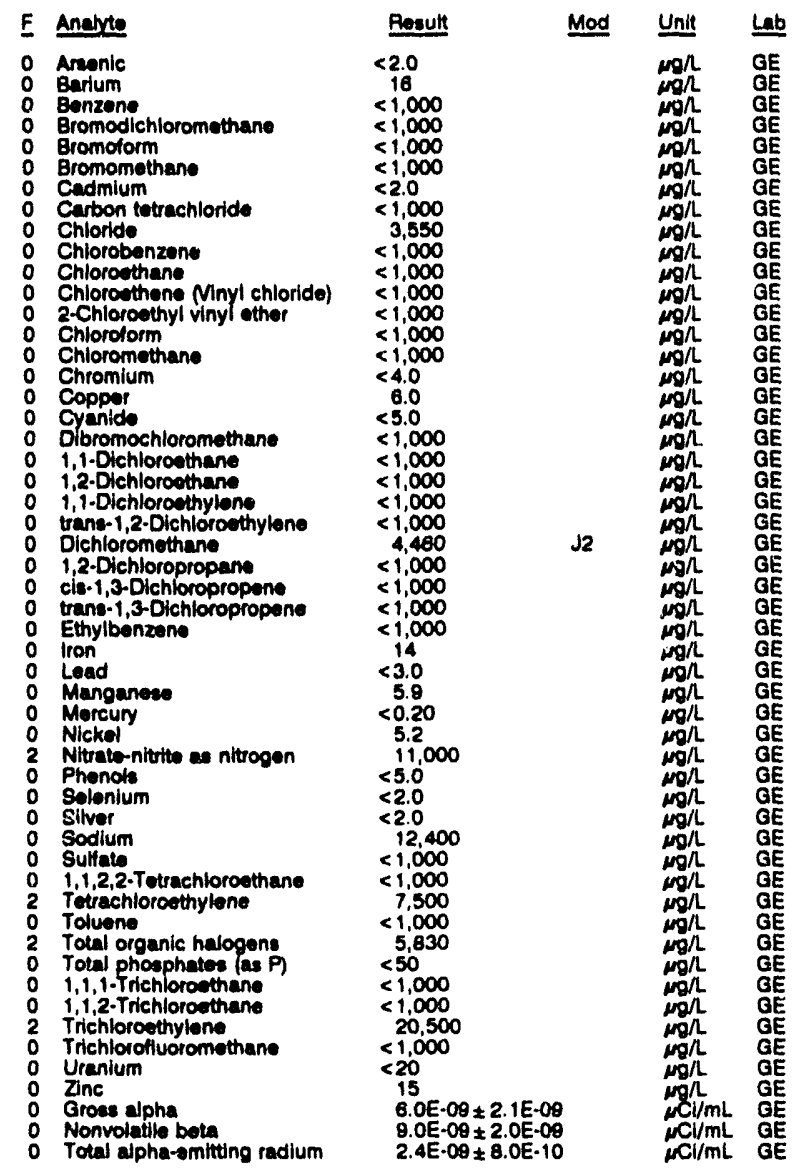

WELL MSB $12 C$

MEASUREMENTS CONDUCTED IN THE FIELD

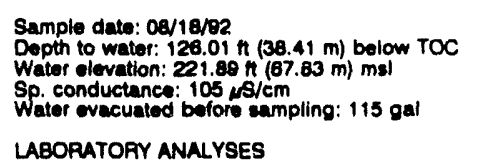

Time: 10:20

PH: 4.8 : $0 \mathrm{mg} /$

Water temperature: $19.2^{\circ} \mathrm{C}$

LABORATORY ANALYSES

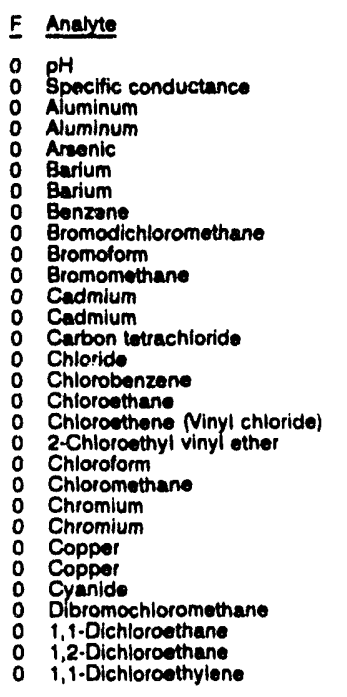

\begin{tabular}{l} 
Result \\
\hline 5.2 \\
120 \\
21 \\
$<20$ \\
$<2.0$ \\
24 \\
24 \\
$<5,000$ \\
$<5,000$ \\
$<5,000$ \\
$<5,000$ \\
$<2.0$ \\
$<2.0$ \\
$<5,000$ \\
3,560 \\
$<5,000$ \\
$<5,000$ \\
$<5,000$ \\
$<5,000$ \\
$<5,000$ \\
$<5,000$ \\
$<4.0$ \\
$<4.0$ \\
$<4.0$ \\
$<4.0$ \\
$<5.0$ \\
$<5,000$ \\
$<5,000$ \\
$<5,000$ \\
$<5,000$
\end{tabular}

WELL MSB 12 C collectod on 08/18/92, laboratory analyees (cont.)

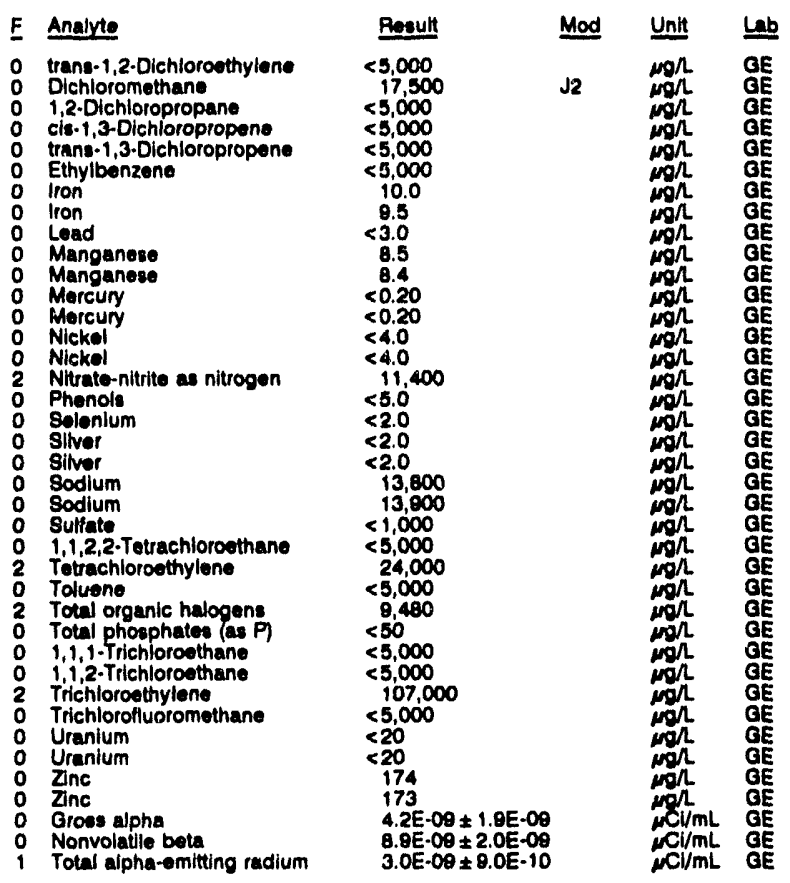

WELL MSB 12D

MEASUREMENTS CONOUCTED IN THE FIELD

Sample date: $07 / 20 / 82$

Time: 8:50

The woll was dry.

WELL MSB 12TA

MEASUREMENTS CONDUCTED IN THE FIELD

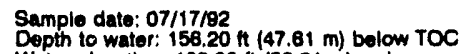
Depth to water: $156.20 \mathrm{ft}(47.61 \mathrm{~m})$ below
Water elevation: $192.30 \mathrm{ft}(58.61 \mathrm{~m}) \mathrm{msl}$ Water elevation: $192.30 \mathrm{H} /(58.81 \mathrm{~m}$ ) mal
Water evactunce: $32 \mu \mathrm{\mu S} / \mathrm{cm}$
Wated before sampling: $803 \mathrm{gal}$

Alkalinity: $11 \mathrm{mo} / \mathrm{h}$ LABORATORY ANALYSES

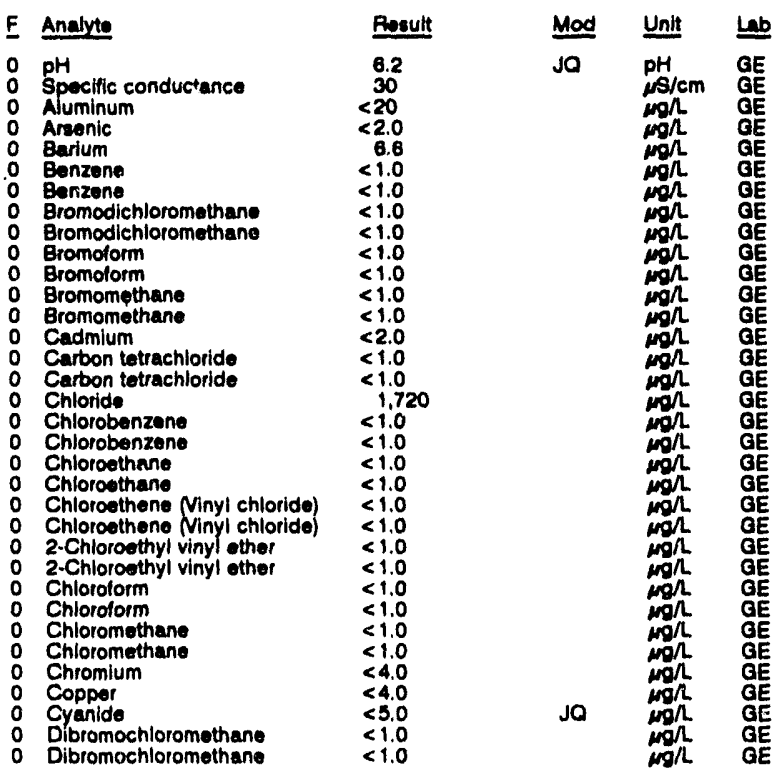


ANALYTICAL RESULTS

WELL MSB 12TA collorted on 07/17/82, laboratory analy3es (cont)

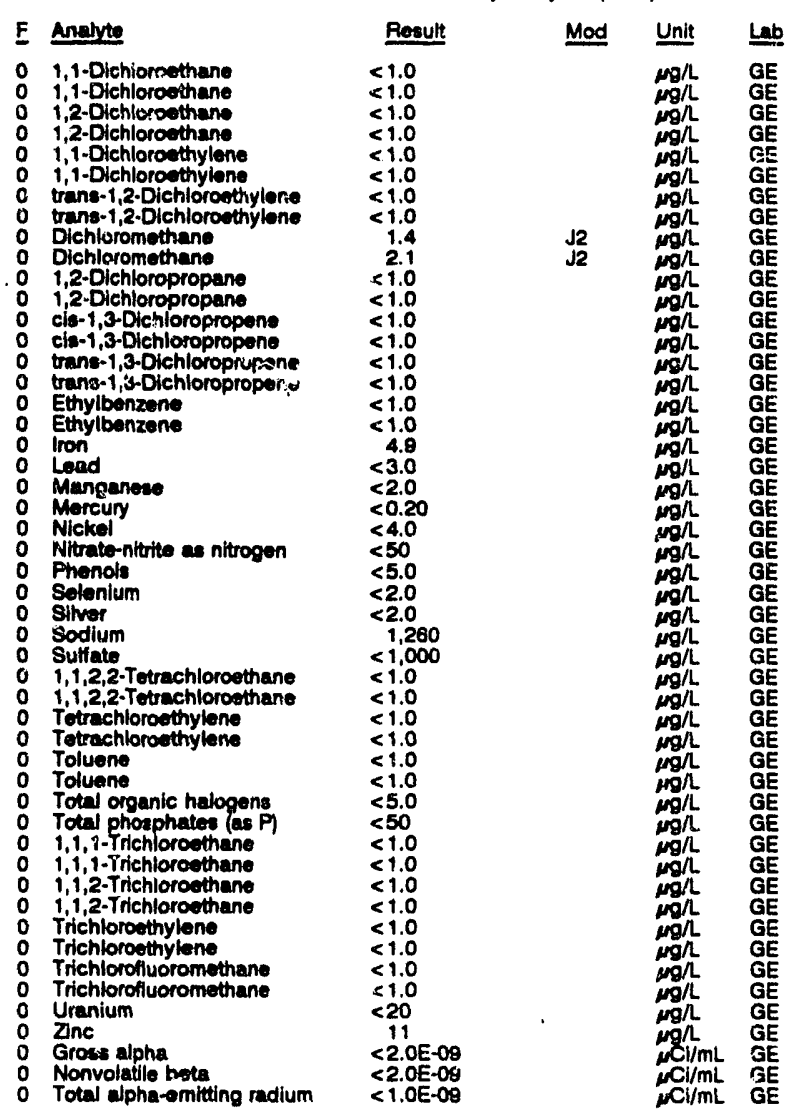

WELL MSB 12TB

MEASUREMENTS CONDUCTED IN THF FIELC Sample date: $07 / 17 / 92$
Depth to water: 156.38 \# $(47.68 \mathrm{~m})$ below TOC Depth to water: $156.36 \mathrm{H}(47.68 \mathrm{~m})$ below TOC
Water olevation: $182.54 \mathrm{n}(58.68 \mathrm{~m}) \mathrm{mst}$

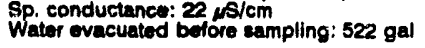

\section{LABORATOAY ANALYSES}

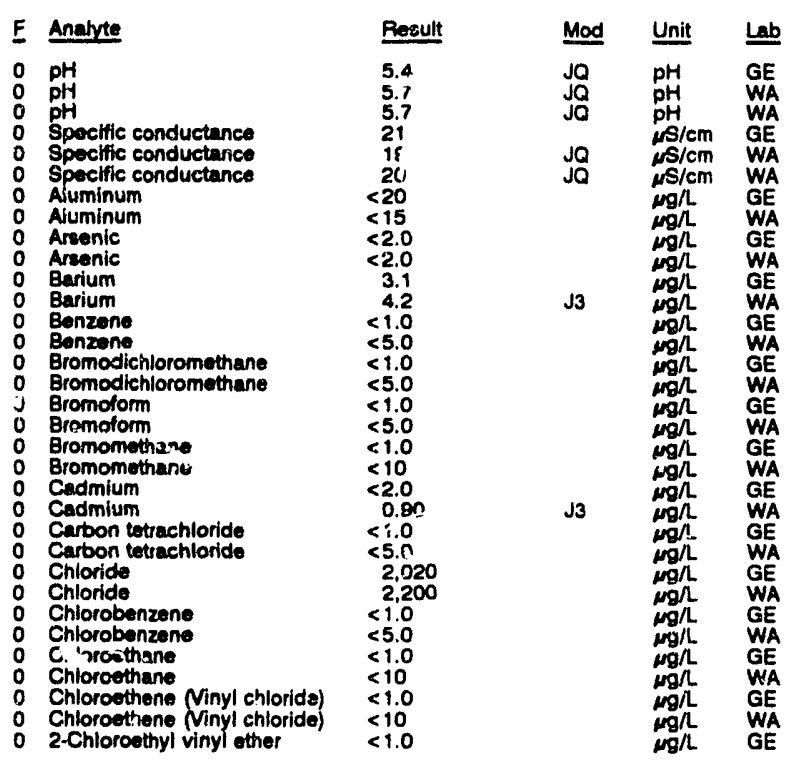

WELL MSB 12TB collected on 07/17/92, laboratory analyses (cont.)

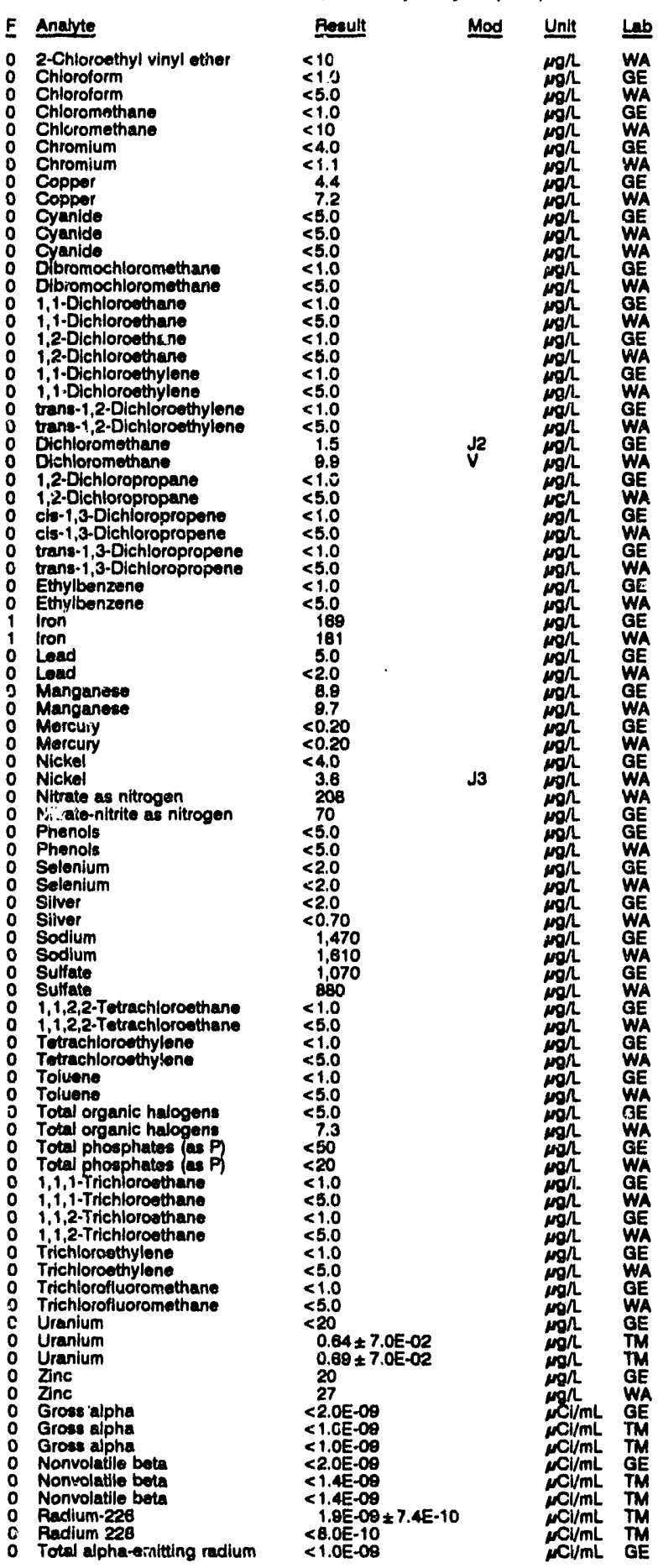


WELL MSB 12TB Replicate

MEASUREMENTS CONDUCTED IN THE FIELD

Sample date: 07/17/92

Depth to wator: 156.36 H. $(47.86 \mathrm{~m})$ below TOC

Wator olevation: 182.54 it $(58.69$

Sp. conductanco: $22, \mathrm{~s} / \mathrm{cm}$.

LABORATOPYY ANALYSES

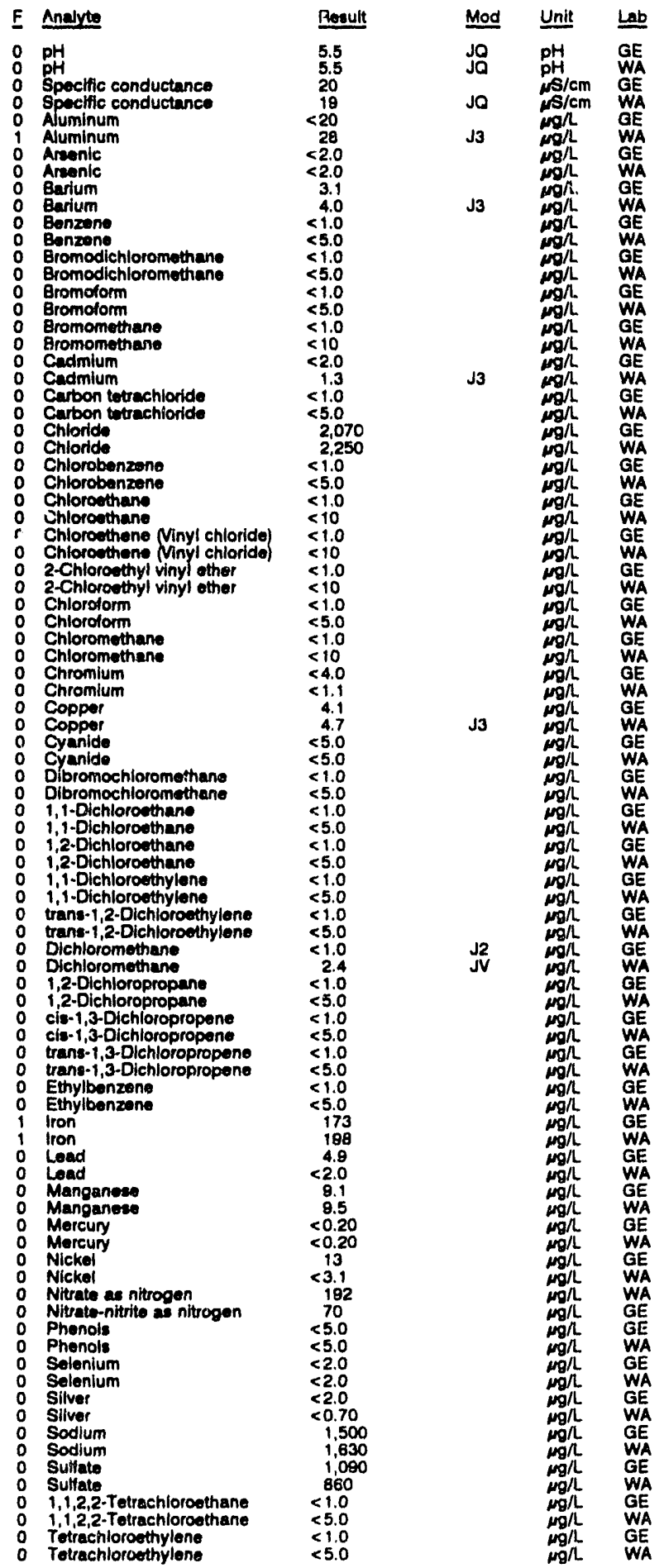

WELL MSE $12 T 8$ collected on 07/17/92, labotatory analyees (cont.)

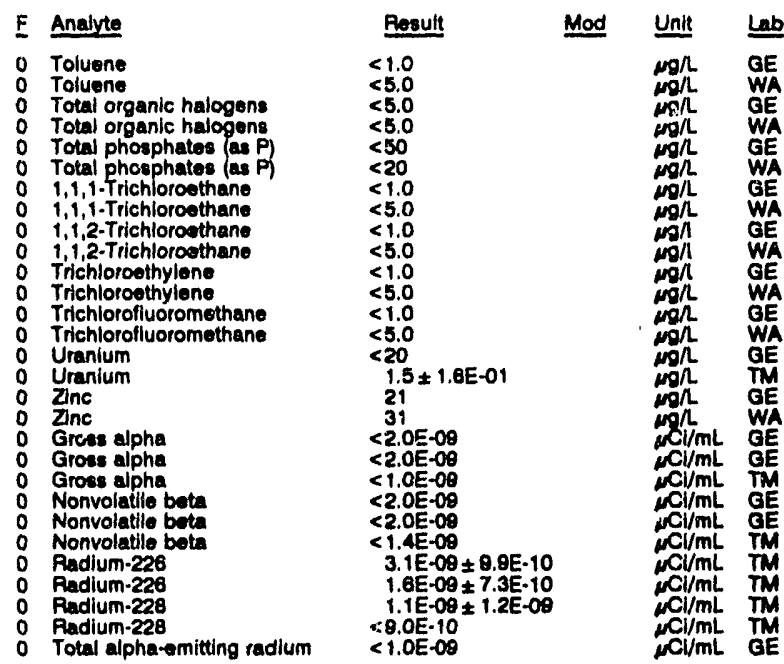

\section{WELL MSB 13A}

MEASUREMENTS CONDUCTED IN THE FIELD

Sample date: 07/10/82

Dopth to water: 140.01 it $142.68 \mathrm{ml}$ below TOC

Water sievation: $205.18 \mathrm{it}(82.54 \mathrm{~m}) \mathrm{msl}$

Sp. conductance: $23, \mathrm{~s} / \mathrm{cm}$ paling: 228 gal

LABOPATORY ANALYSES

$E$ Analyze Reoult Mod Unit

: $\mathrm{Pp}$ Specific conductance

o Aconaphthene.

- Acenaphthylene

- Acotone

Acetonitrile (Methyl cyenide)

Acotophenone
2.Acentlaminofluorene

Acrolein

: Acrylon

Allyl chloride

Aluminum

Anlline

Anthracene

Antimony

Aramite

Barium

Benzene

apha-Benzene hexachlorlde

a pha-Benzeno hexachloride

beta-Bonzene hexachlorido

beta-Benzene hexachlorido

deftu-Benzene hexachloride

dolta. Benzene hexachioidd

Bonzo| a anthracono

Benzo b fluoranthene

Benzo hilperyene

Benzo aj pyrene

Benzyl alcohol

Bentlium

Bis (2-chloroethoxy) methane

Bis (2-chloroethyl) ethor

Bis 2-chloroleopropyl) ther Ela (2-ethylhexyl) phthajalo

Bromodichlom

rromotorm

4 Bromophenyl phenyl other

2-coc-Butyl-4,6-dinitrophenot

Cadmium

Carbon dizulfide

Carbon totrachloride

Chlordane

Chlordane

Chloride

4-Chloroanilline

Chlorobenzene
Time: 7:05

Alkalinity: $0 \mathrm{mg} /$

Water tomperature: $18.80^{\circ} \mathrm{C}$

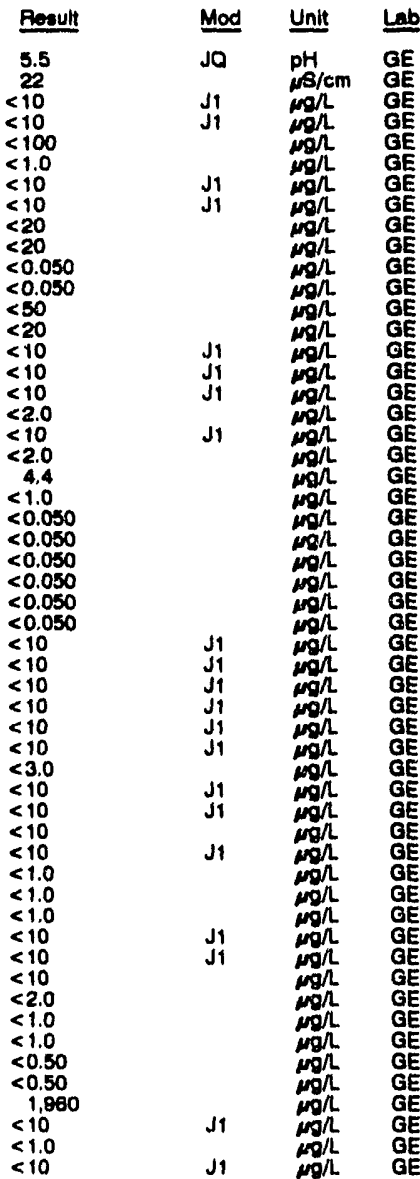


ANALYTICAL RESULTS

WELL MSB 13A collected on 07/10/92, laboratory analyses (cont.)

E Analye

0 para-Chloro-mete-cresol

o Chloroethene (Ninyl chloride)

2 2-Chioroethyl vinyl ether

Chloroform

o 2-Chloronaphthalene

4-Chlorophentil phenyl ether

Chromium

0 Cobsat

Copper

o-Cresol (2-Methylphenol)

m-Cresol (3-Mothylphenol)

0 Cyanlde

0 P,P'-DDD

0 p.p'-DDE

0 P,P'-DDE

$\begin{array}{lll}0 & \text { p,p'-DDT } \\ 0 & \text { p,p'-DDT }\end{array}$

0 Biallate

Dibenzla,h]anthracene

1,2-Dibromo-3-chloropropane

o 1,2-Dibromoethane

D Dibromomethane

o 1,2 -Dichlorobenzene

1,4-Dichlorobenzene

trans-1,4-Dichloro-2-butene

Dichlorodifluoromethane

1,2-Dichloroethane

1,1-Dichioroethylone

trans-1,2-Dichloroothylene

Dichloromethane

2,4-Dichlorophenol

2,4-Dichlorophenol

1,2.Dichloropropane

cis-1,3-Dichloropre

trane-1,3-Dichloropropene

Dieldrin

Diethyl phthalate

Dimothoate

2,4-Dimethyl phonol

Dimethyl phthalate

p-Oimethylaminouzobenzene

3,3'-Dimethylbenzidino

a,a-Dimethylphenethylamine

1,3-Dinitrobonzane

2,4-Dinitrotoluen

2,e-Dinitrotoluene

Di-n-octyl phthalate

1,4-Dioxane

O Dir ulifingn

Endosulfan I

Endosuttan

Endosultan

Endoculfan sulta

Endosultan sulfate

E Endrin

Endrin aldehydo

Endrin aldehyde

Ethyl methanesulfonate

O Ethylbenzene

Famphur

Fluoranthen

Fluorene

Heptachior

Heptachlor epoxide

Heptachlor epoxide

Heptachlorodibenzo-p-dioxins

$1,2,3,4,6,7,8-H P C D F$
0 Heptachlorodibenzo-p-furans

Hexachlorobenzene

Hoxachlorobutadiene

Hexachlorocyclopent

Hexachlorodibenzo-p-dioxins

$1,2,3,4,7,8-H X C D F$

Hexachlorodibenzo-p-furans

Hexschloroethane
Result Mod Unit Lab

$<10$

$<1.0$

$<10$

$<1.0$

$<10$
$<10$
$<10$

$<10$

$<4.0$

$<4.0$

$<4.0$

$<10$

$<10$

$<0.10$

$<0.10$

$<0.1$

$<0.10$

$<10$

1.0

$<10$

$<10$

$<30$
$<1.0$
$<1.0$
$<1.0$

$<1.0$

$<1.0$
$<1.0$

$<10$

$<0.30$

$<1.0$

$<1.0$
$<0.50$
$<0.50$

$<10$

$<10$

$<10$

$<10$

$<10$
$<10$
$<10$

$<10$
$<10$

$<45$

$<10$
$<10$

$<10$

$<10$
$<10$

0.10

$<0.10$

$<0$

$<0.16$

$<0.0060$

$<0.10$

$<0.10$

$<10$
$<10$

$<+0$

$<10$

$<0.050$

$<0.050$

$<0.00065$

$<0.00045$
$<0.00045$

$<0.0004$
$<10$
$<10$

$<10$
$<0.00045$

$<0.00045$

$<0.00040$
$<0.00040$

$<10$
$<10$ $\mu g / L \quad G E$

J1

$\mathrm{J}$
$\mathrm{J} 1$
$\mathrm{~J} 1$

J1

J1
J1
J1
J1
J1

J
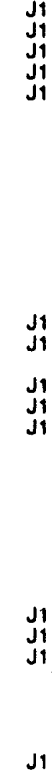

WELL MSB 13A collected on 07/10/82, laboratory analyees (cont.)

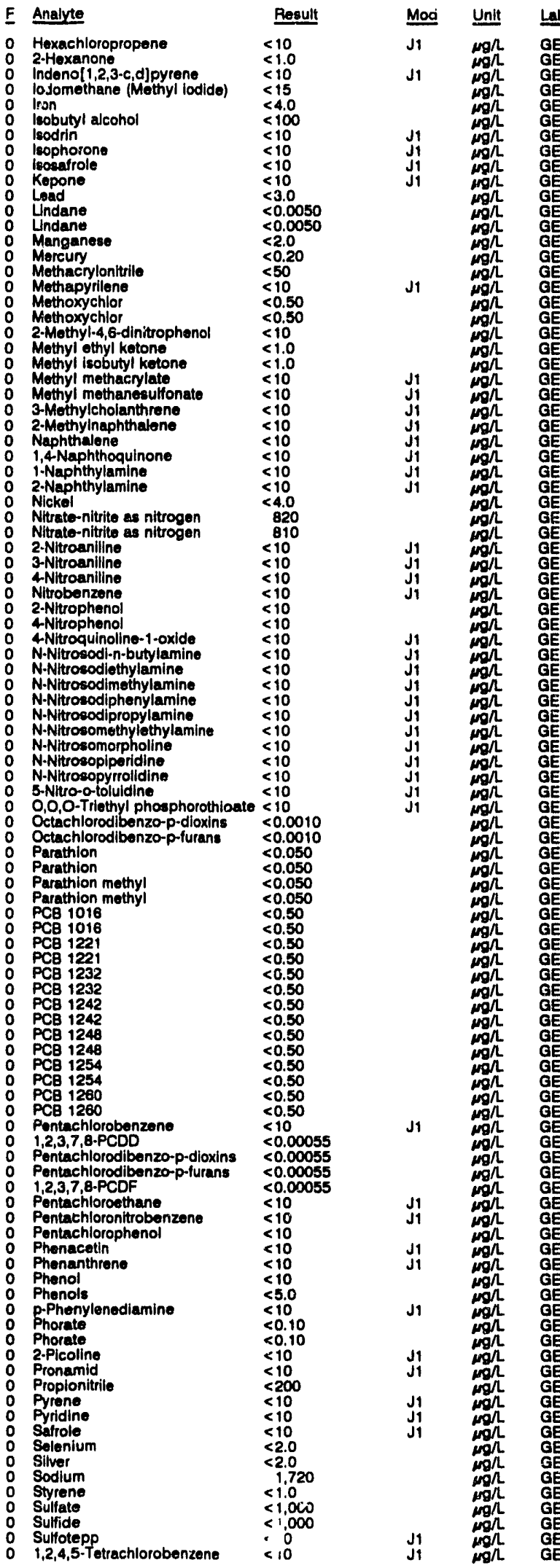


WEL MSB $13 A$ collected on 07/10/92, laboratory analysers (cont.)

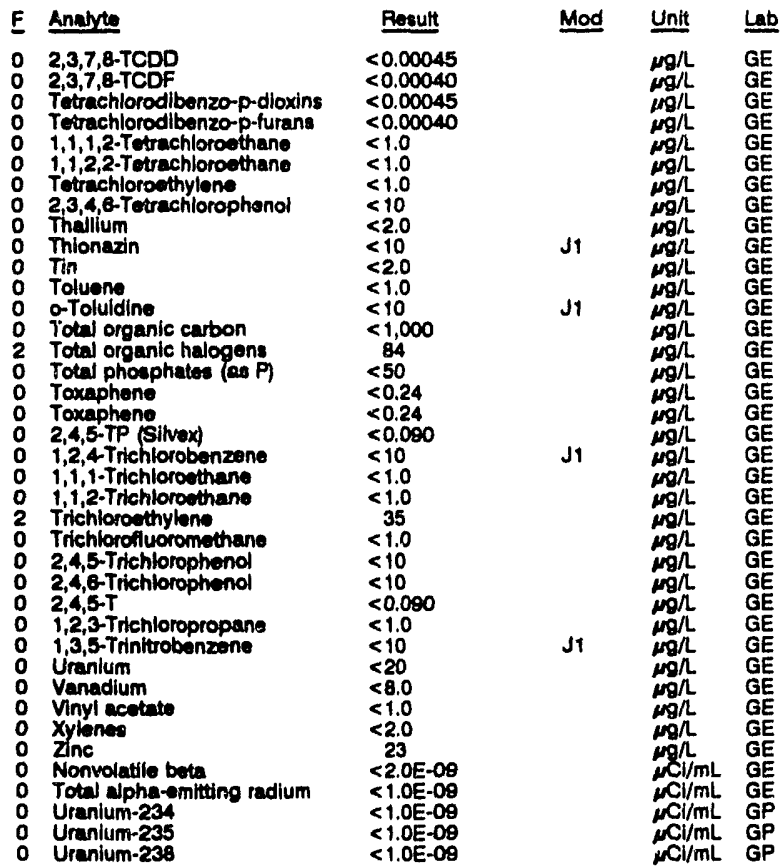

\section{WELL MSB 13B}

MEASUREMENTS CONDUCTED IN THE FIELD

Sample date: 08/20/92

Depth to water: $154.52 \mathrm{t}(47.10 \mathrm{~m})$ below TOC

Water elevation: 191.08 it (58.24

Tho: 13.10

Alkallinity: $154 \mathrm{mgh}$

What tompergture: $20.7 \circ \mathrm{C}$

There was insufficient water to fill all or some sample bottles.

LABORATOPY ANALYSES

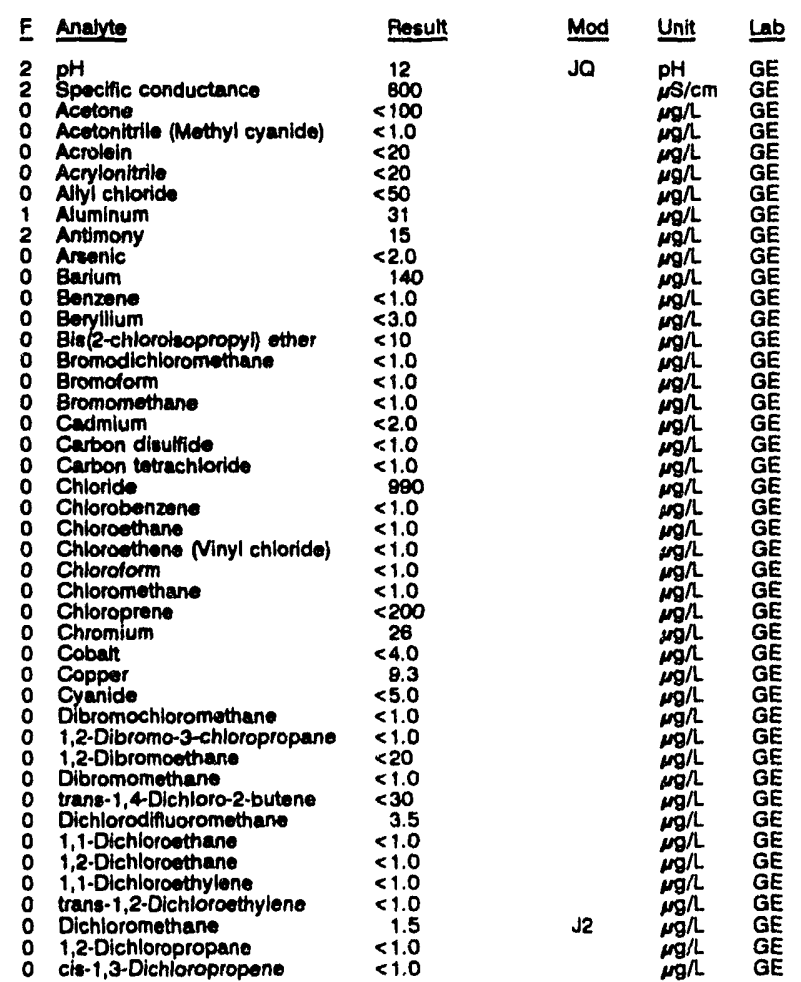
cis-1,3-Dichloropropene
WELL MSB 138 collected on 08/20/92, laboratory analyees (cont.)

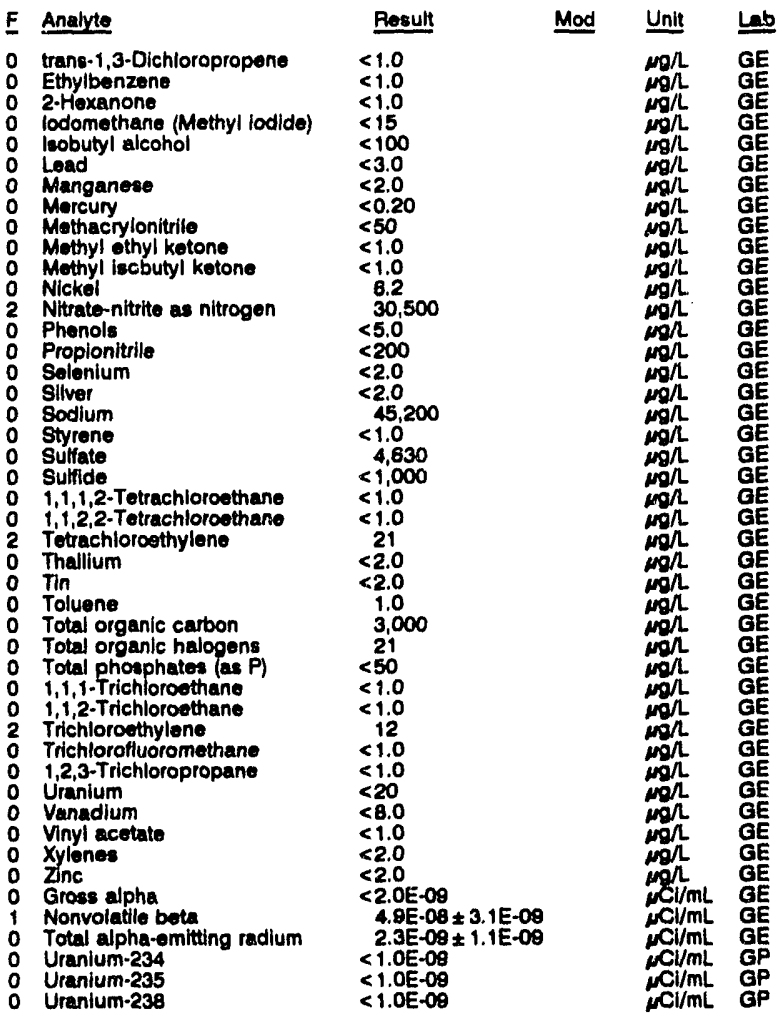

WELL MSB 13CC

MEASUREMENTS CONDUCTED IN THE FIELD
Sample date: 07/10/92

Depth to water: $123.38 \mathrm{ft}(37.61 \mathrm{~m})$ bolow TOC

Water evacuated before sampling: 15 gel

The woll went dry during purging.

LABORATORY ANALYSES

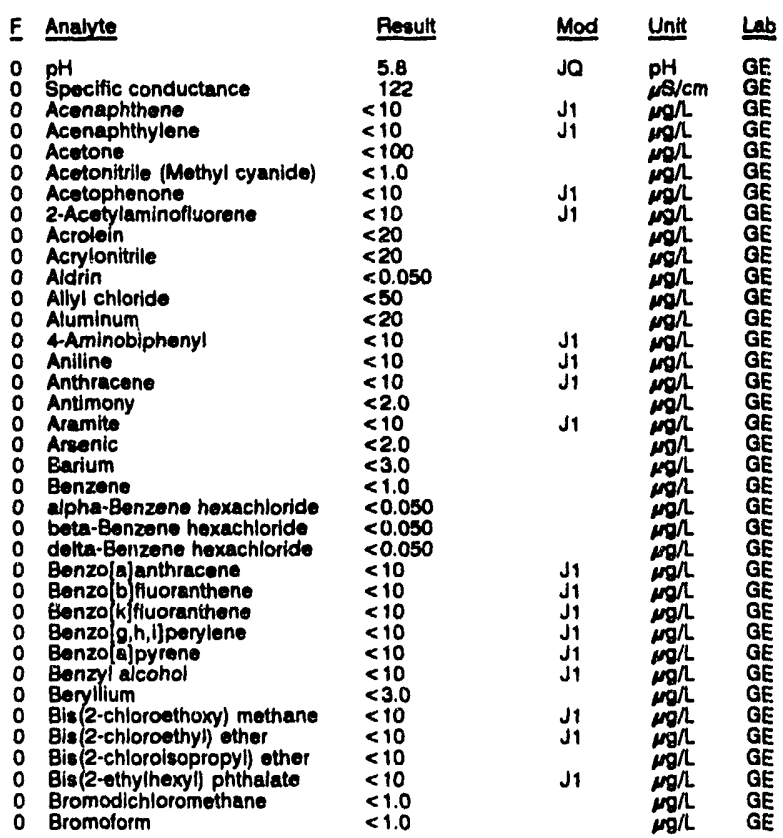

Time: 6.55

PHkalinity: $4 \mathrm{mgh}$

Alkalinity: $4 \mathrm{mg} / \mathrm{h}$
Water elevation: $223.52 \mathrm{ft}(88.13 \mathrm{~m}) \mathrm{ms}$

E

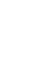


ANALYTICAL RESULTS

WELL MSB 13CC collected on 07/10/82, laboratory analyees (cont.)

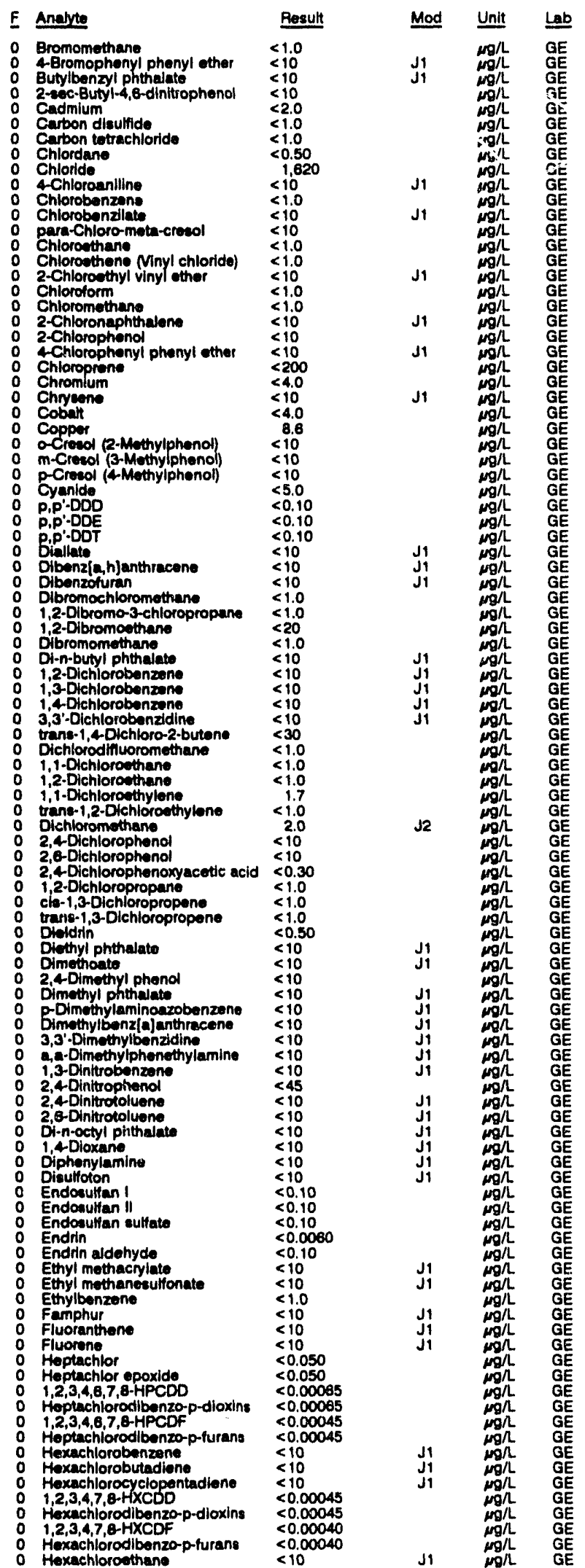

WELL MSB 13CC collected on 07/10/82, laboratory analymes (cont)

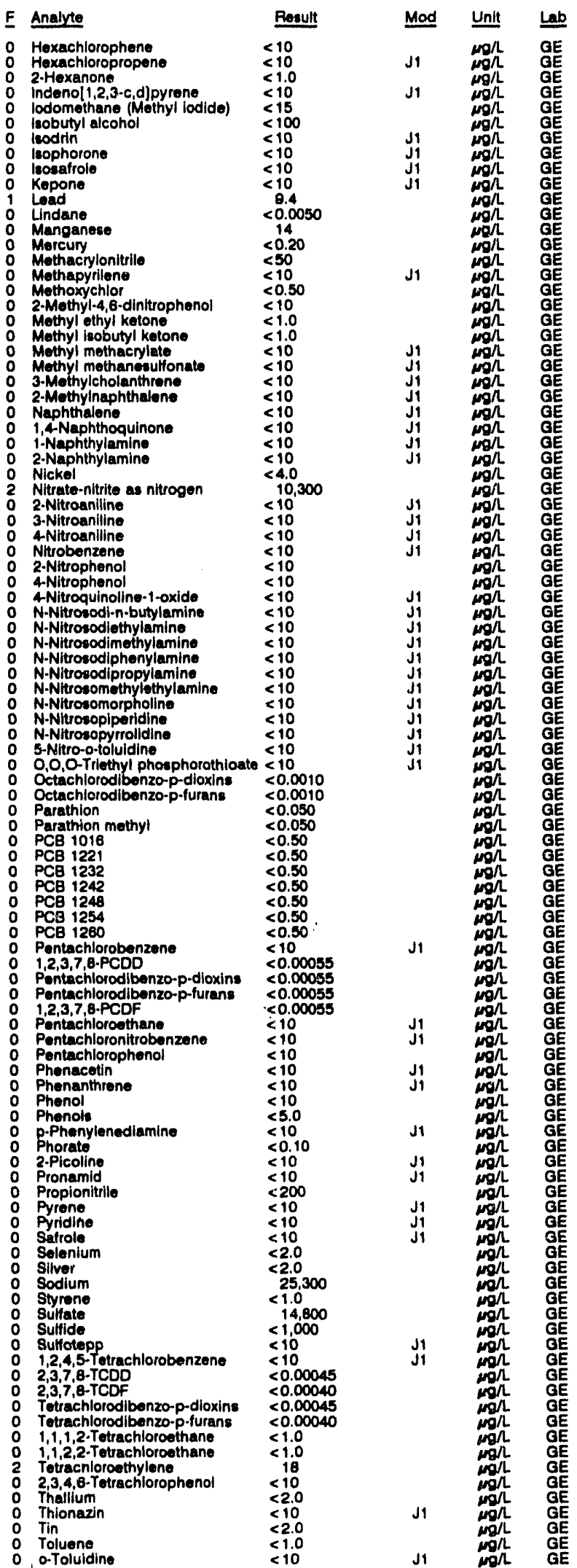


ANALYTICAL RESULTS

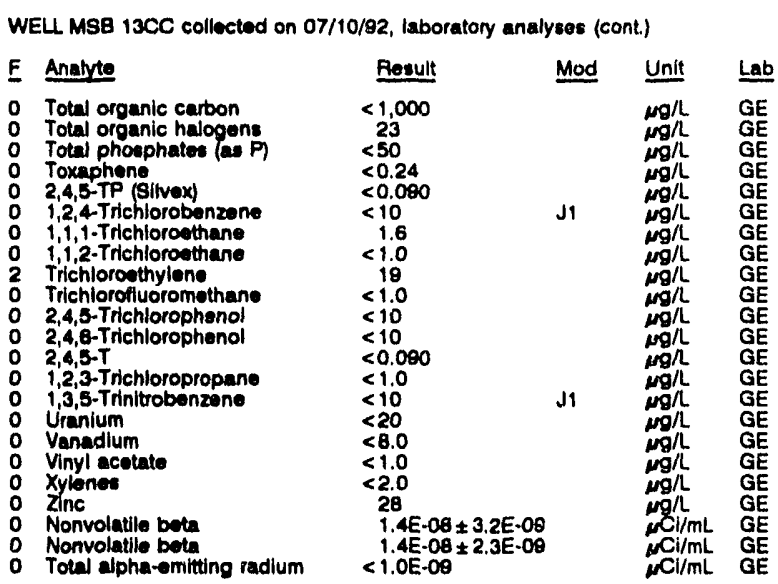

WELL MSB 13D

MEASUREMENTS CONDUCTED IN THE FIELD

\begin{tabular}{|c|c|}
\hline $\begin{array}{l}\text { Sample date: } 07 / 10 / 92 \\
\text { Oepth to water: } 120.39 \mathrm{f}(38.69 \mathrm{~m}) \text { below TOC } \\
\text { Water olovation: } 227.34 \mathrm{ft}(69.28 \mathrm{~m}) \mathrm{msl} \\
\text { Sp. conductance: } 412 \mu \mathrm{s} / \mathrm{cm} \\
\text { Wator ovacuated belore eampling: } 12 \mathrm{gal}\end{array}$ & $\begin{array}{l}\text { Time: } 6: 35 \\
\text { pH: } 6.1 \\
\text { Alkalinity: } 56 \mathrm{mg} / \mathrm{h} \\
\text { Water temperature: } 20.2^{\circ} \mathrm{C}\end{array}$ \\
\hline
\end{tabular}

LABORATOAY ANALYSES

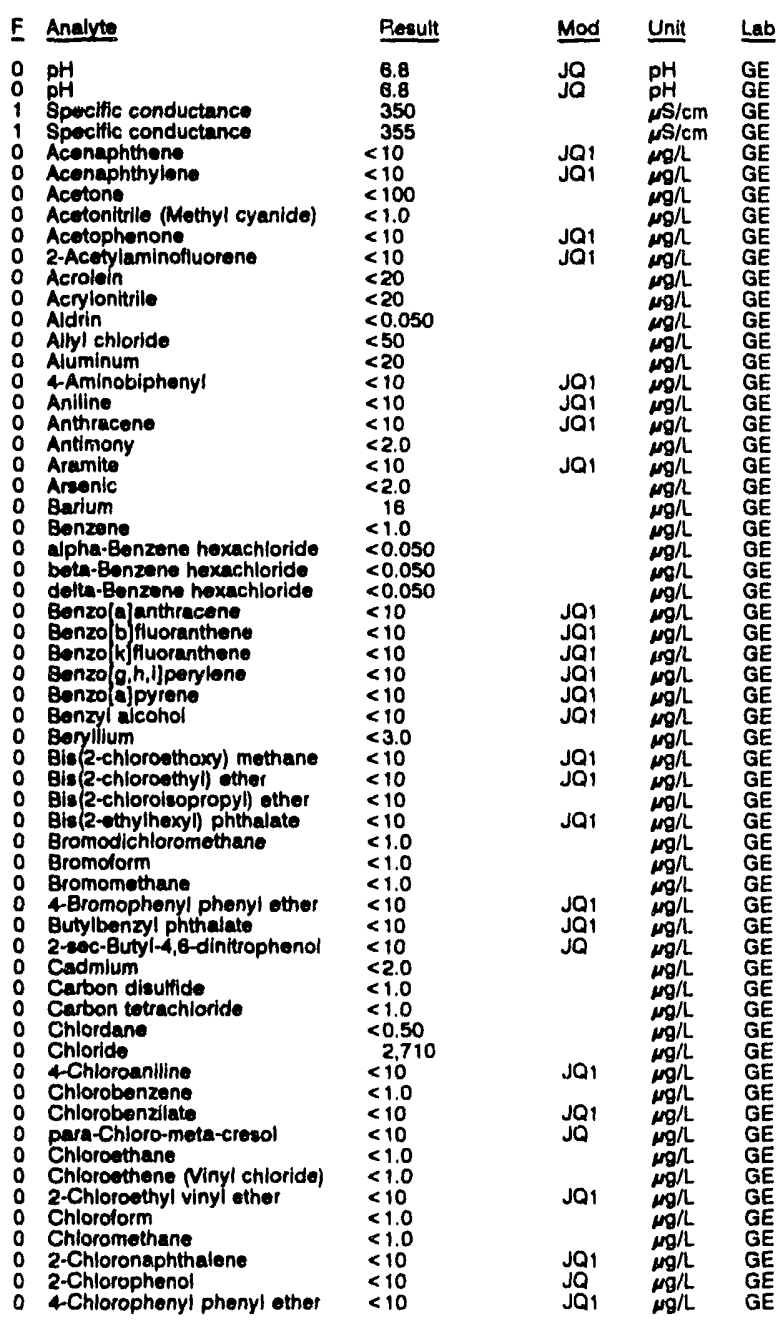

WELL MSB 13D collected on 07/10/82, laboratory analyses (cont.)

\begin{tabular}{|c|c|}
\hline & Analyte \\
\hline & $\begin{array}{l}\text { Chloropreno } \\
\text { Chromlum } \\
\text { Chrysene } \\
\text { Cobait } \\
\text { Copper } \\
\text { o-Ciesol (2-Methylphenol) } \\
\text { m-Cresol (3-Methylphenol) } \\
\text { p-Cresol (4-Methylphenol) } \\
\text { Cyanide } \\
\text { p.p'.DDD } \\
\text { p.p'-DDE } \\
\text { p.p'-DDT } \\
\text { Diallate } \\
\text { Dibenzla,h]anthracene } \\
\text { Dibenzofuran } \\
\text { Dibromochloromethane }\end{array}$ \\
\hline
\end{tabular}

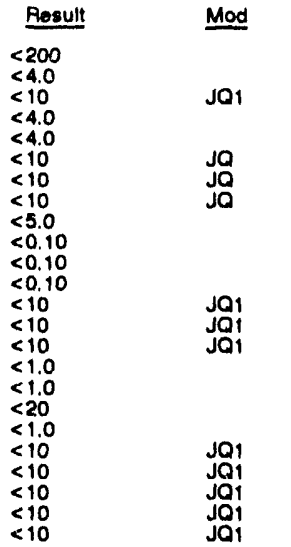

Unit Lag

$\underset{\mu g / h}{\mathrm{GE}}$

GE

GE

1,2-Dibromo-3-chloropropane

1,2.Dlbromosthane

Dibromomethane

1,2.Dichlorobenzene

1,3-Dichlorobenzene

3,3'-Dichlorobenzidine

trans-1, 4-Dichloro-2-butene

Dichlorodifluoromethane

1,1-Dichloroethane

1 i.1.Dichloroethylene

trans-1,2-Dichloroethylen

Dichloromethane

2,4-Dichlorophenol

2,6.Dlchlorophenol

2,4-Dichlorophenoxyacetic acid

1,2.Dichloropropane

cis.1,3-Dlchloropropene

trana-1,3-Dichloropropene

o Diethyl phthaiato

0 Dimethoate

2,4-Dimethy! pheno

o p-Dimethylaminoazobenzene

Dimethylbenz; a) anthracene

3,3'.Dimethylbenzidine

a.a.Dimethylphenethyla

1,3-Dinitrobenzene

2,4-Dinitrophenol

2,4-Dinitrotoluene

Di-n-octyl phthalate

o 1.4-Dioxane

Diphenylamin

Disulfoton

Endosulfan II

Endosulfan sulfate

Endrin

Endrin aldehyde

Ethyl methacrylate

Ethylbenzene

Famphur

Fluoranthen

Fluoreno

Heptachlor

1,2,3,4,6,7,8-HPCOD

$1,2,3,4,6,7,6$-HPCDO

Heptachlorodibonzo-p-dioxin

$1,2,3,4,6,7,8-H P C D F$

$1,2,3,4,6,7,8-H P C D F$
0 Heptachlorodibenzo-p-furans

Hoptachlorodibenzo-p-furans

Hexachlorobenzeno

Hexachlorobutadiene

Hexachlorocyclopen

$1,2,3,4,7,8-H \times C D O$
$1,2,3,4,7,8-H \times C O O$

Hexachlorodibenzo-p-dioxins

- Hexachlorodibenzo-p-dioxin

$0 \quad 1,2,3,4,7,8 \cdot H X C D F$

$1,2,3,4,7, B \cdot H X C D F$

Hexachlorodibenzo-p-furans

Hexachloroethane

Hexachlorophene

Hexachloropropene

2-Hexanone

o Indeno[1,2,3-c, d]pyrene

o lobutyl alcohol

0 Isodin

isophorone

0 Isosafroie

o Linad

o Manganese

$<10$

$<10$

$<10$

$<10$

$<0.10$
$<0.10$
$<0.10$

$<0.0060$

$<10$

$<10$
$<1.0$
$<10$

$<10$
$<10$

$<10$

$<0.050$

$<0.00065$

$<0.00065$

$<0.00085$

$<0.00045$

$<0.00045$

$<<0.00045$

$<10$
$<10$

$<10$

$<0.00045$

$<0.00045$

$<0.00045$

$<0.00040$

$<0.00040$

$<0.00040$

$<10$

$<10$

$<1.0$

$<10$
$<15$

$<15$
$<100$

$<100$

$<10$

$<10$
$<10$
$<3.0$

$<0.0050$

7.1 
ANALYTICAL RESULTS

WELL MSB 130 collected on 07/10/92, laboratory analyses (cont.)

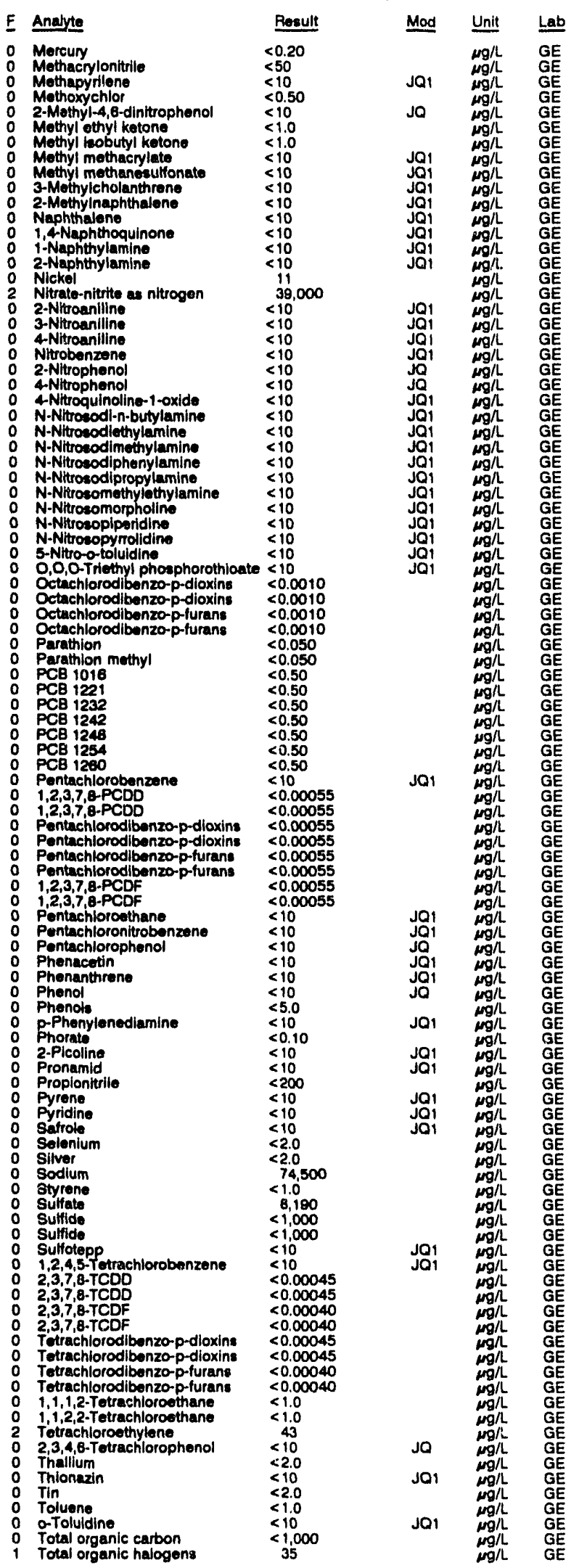

WELL MSB 13D collected on 07/10/82, laboratory analyses (cont.)

\begin{tabular}{|c|c|c|c|c|c|}
\hline $\mathbf{F}$ & Analyte & Result & Mod & Unit & ئ \\
\hline & 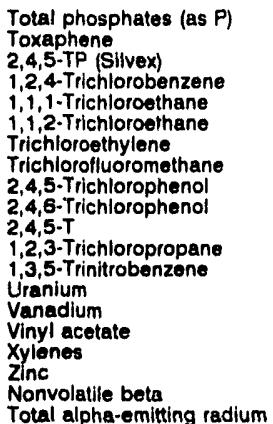 & $\begin{array}{l}<50 \\
<0.24 \\
<0.090 \\
<10 \\
8.6 \\
<1.0 \\
38 \\
<1.0 \\
<10 \\
<10 \\
<0.090 \\
<1.0 \\
<10 \\
<20 \\
<8.0 \\
<1.0 \\
<2.0 \\
35 \\
7.8 E-09 \pm 1.9 E-09 \\
<1.0 E-09\end{array}$ & $\begin{array}{l}\text { Jo } \\
\text { Ja } \\
\text { JO1 }\end{array}$ & 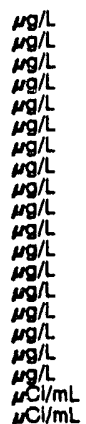 & $\begin{array}{l}\mathrm{GE} \\
\mathrm{GE} \\
\mathrm{GE} \\
\mathrm{GE} \\
\mathrm{GE} \\
\mathrm{GE} \\
\mathrm{GE} \\
\mathrm{GE} \\
\mathrm{GE} \\
\mathrm{GE} \\
\mathrm{GE} \\
\mathrm{GE} \\
\mathrm{GE} \\
\mathrm{GE}\end{array}$ \\
\hline
\end{tabular}

\section{WELL MSB 14A}

MEASUREMENTS CONDUCTED IN THE FIELD

$\begin{array}{ll}\text { Sample date: } 08 / 14 / 92 & \text { Time: } 9: 00 \\ \text { Depth to water: } 133.86 \mathrm{ft}(40.80 \mathrm{~m}) \text { below TOC } & \text { pH: } 4.6 \\ \text { Water olevation: } 214.44 \mathrm{Ht}(65.36 \mathrm{~m}) \mathrm{msl} & \text { Alkalinity: } 0 \mathrm{mg} / \mathrm{h} \\ \text { Sp. conductance: } 185 \mu \mathrm{s} / \mathrm{cm} & \text { Water temperature: } 20.0 \circ \mathrm{C} \\ \text { Water evacuated before sampling: } 184 \mathrm{gal} & \end{array}$
LABORATORY ANALYSES

E Analyte Result Mod

$\begin{array}{ll}0 & \text { pH } \\ 0 & \text { Specific conductance } \\ 2 & \text { Aluminum } \\ 0 & \text { Arrenic } \\ 0 & \text { Barium } \\ 0 & \text { Benzene } \\ 0 & \text { Bromodichloromethane } \\ 0 & \text { Bromolorm } \\ 0 & \text { Bromomethane } \\ 0 & \text { Cadmium } \\ 0 & \text { Carbon totrachloride } \\ 0 & \text { Chloride } \\ 0 & \text { Chlorobenzene } \\ 0 & \text { Chloroethane } \\ 0 & \text { Chloroethene Ninyl chloride) } \\ 0 & 2 . \text { Chloroethyl vinyl ether } \\ 0 & \text { Chloroform } \\ 0 & \text { Chlomiun }\end{array}$

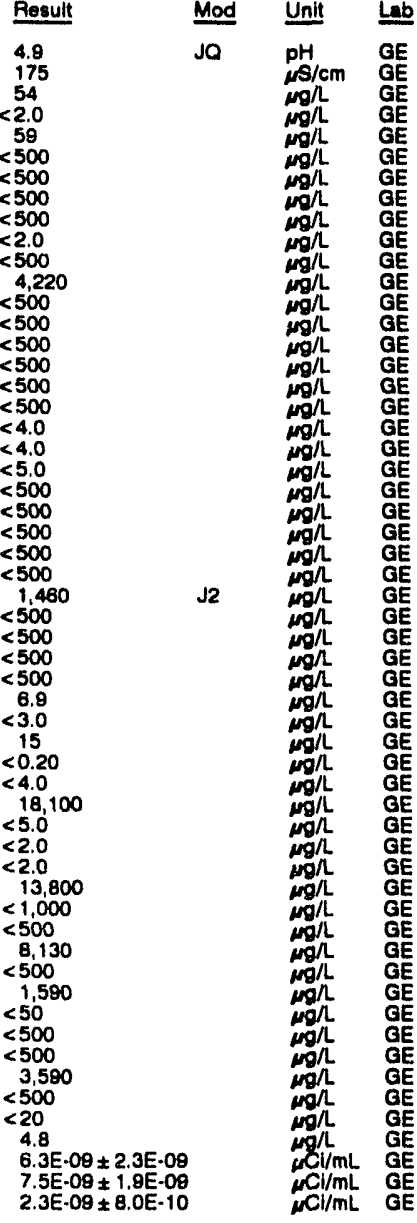


WELL MSB 14B

MEASUREMENTS CONDUCTED IN THE FIELD

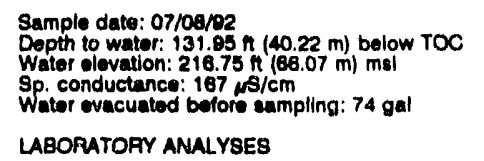

LABOPATORY ANALYSES

F Analyte

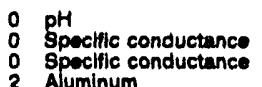

2 Apuminum

2 Aluminum

Bartum

Barlum

Benzen

Bromodichloromethane

Bromodichloromethan

Bromotorm

Bromolorm

Bromomethane

Cadmium

Camium

Carbon totrachlorlde

Carbon tetrechloride

Chloride

Chlorobanzene

Chloroethane

Chloroethane

Chlorotthene Ninyl chloride

2-Chloroethyl vinyl ether

Chioroform

Chloromethane

Chloromethane

Chromium

Chromium

Copper

Copper

Oybromochloromethane

Dibromochloromethan

1,1-Dichloroethene

1,2-Dichloroethane

1,2-Dichloroethane

1,1-Dichloroethylene

trans-1,2-Dichloronthylene
trans-1,2-Dichloroethylene

Dichloromethane

Dichloremethane

1,2-Dichloropropant

cis-1,3-Dichloropropene

clo-1,3 Dichloropropeno

trans-1,3-Dichloropropeno

Ethylbonzono

Iron

Iron

Lead

Manganease

Manganeso

Mercun

Nicke

Nitrato-nititie as nitrogen

Phonols

Selenium
Silver

Sitver

Sodium

Sodium

Sulfate -Tetrachloroethan

1,1,2,2-Totrachloroethan

Ti,2,2-Totrachioroeth
Tetrachioroethylene
Tetrachloroethylene

Toluene

Tolue organic halogen

Total phoaphates las $P$

1.1,1-Trichloroethane

$1,1,1$-Trichloroethane

$1,1,2$-Trichloroothane

Trichloroethyiene

Trichloroethylene

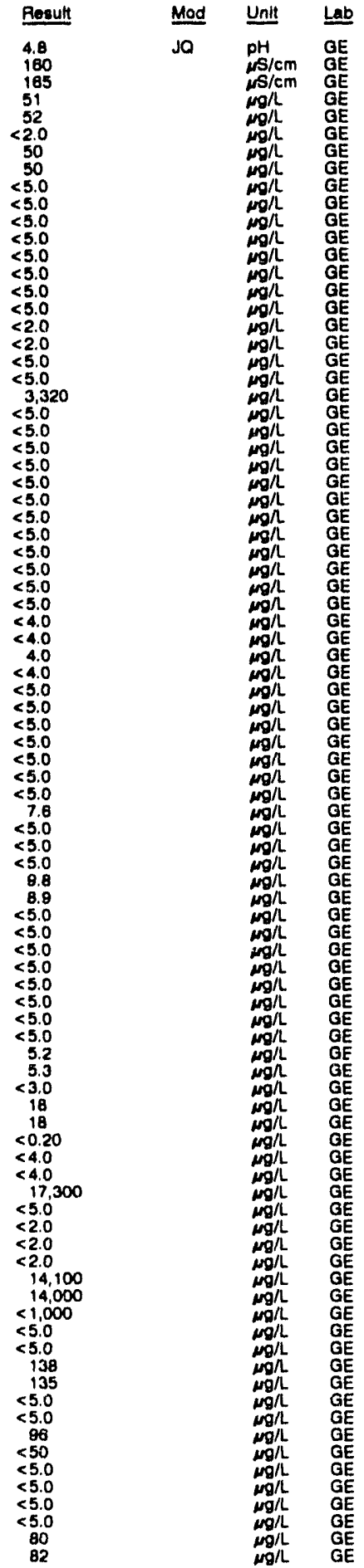

WELL MSB 148 collected on 07/08/92, laboratory analyces (cont.)

$E$ Analyze

Time: 14:20

Alkalinity: $0 \mathrm{mg} / \mathrm{h}$

Water tomperalure: $22.2{ }^{\circ} \mathrm{C}$

o Trichlorofluoromethane

Trichlorofluoromethane

o Uranium

O Zinc

o Zine

O Gross alpha

Nonvolatile bota
Total alpha-emitting radium

\begin{tabular}{|c|c|c|}
\hline Aesult & Mod & Untt \\
\hline $\begin{array}{l}<5.0 \\
<5.0 \\
<20 \\
<20 \\
22 \\
22 \\
5.3 \mathrm{E} \cdot 00 \pm 2.3 \mathrm{E}-00 \\
4.6 \mathrm{E}-09 \pm 1.6 \mathrm{E}-09 \\
3.0 \mathrm{E}-09 \pm 1.5 \mathrm{E}-09\end{array}$ & & 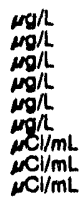 \\
\hline
\end{tabular}

WELL MSB 14C

MEASUREMENTS CONOUCTED IN THE FIELD

Sample date: 07/08/92

Depth to water: Not avallable

Water elevation: Not available

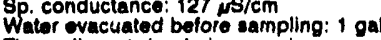

The well went dry during purging.

LABOAATORY ANALYSES

E Analyte

$0 \mathrm{pH}$

Specific conductance

1 Aluminum

Barium

Benzene

Bromodichloromethane

Bromolorm

Bromomethane

Cadmium

Carbon tetrachloride

Chlorobenzene

Chloroethene (Ninyl chloride)

2-Chloroethyl vinyl ether

Chlorotorm

Chloromethane

Chromium

Copper

Dibromochloromethane

1,1.Dichloroothane

1,2-Dichloroethane

$1,1$. Dichloroothylens
trans-1,2-Dichioroethylene

Dichioromethane

1,2-Dichloropropano

cis-1,3-Dichloropropene

Trans-1,3-Dich

Iron

0 Manganese

o Morcury

Nickel

Nitrate-nitrite as nitrogen

Phenols
Solenium

Silver

Sodium

O Sulfate Totrachloroethane

Totisechorothyon

- Toluene

- Total organic halogens

o Total phosphates (as P)

1,1,1-Trichloroethane

1,1,2-Trichloroethane

o Trichloroethylene

o Trichlorolliv

Uranium

2inc

2 Gross alpha

2 Total alpha-omitting radium

Total alpha-emitting radium

Uranium-234

Uranium-235

0 Uranium-238

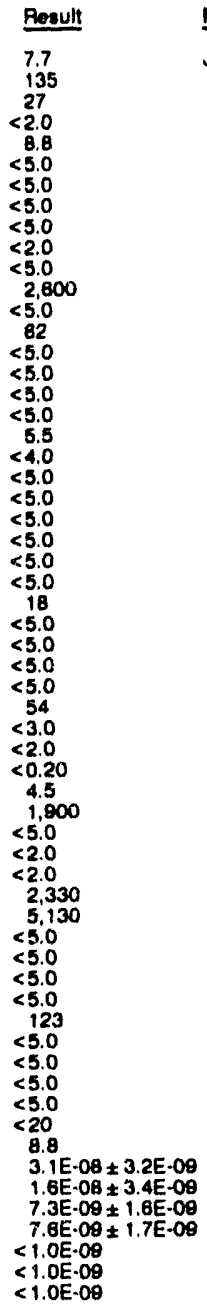

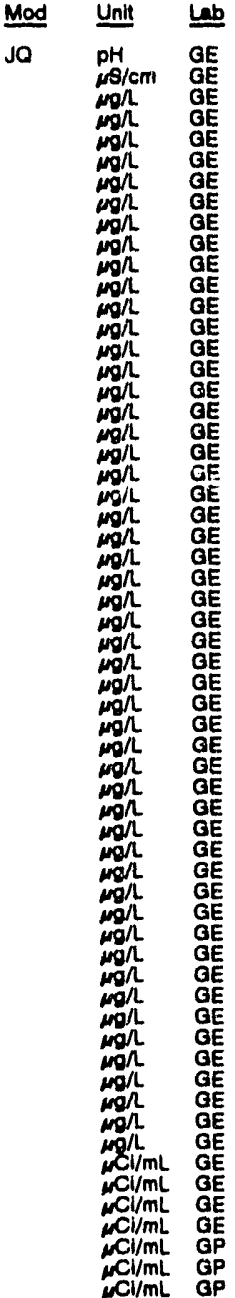


ANALYTICAL RESULTS

WELL MSB 15A

MEASUREMENTS CONDUCTED IN THE FIELO

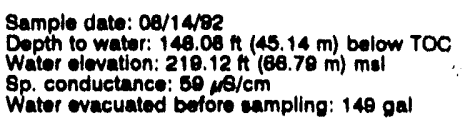

LABORATORY ANALYSES

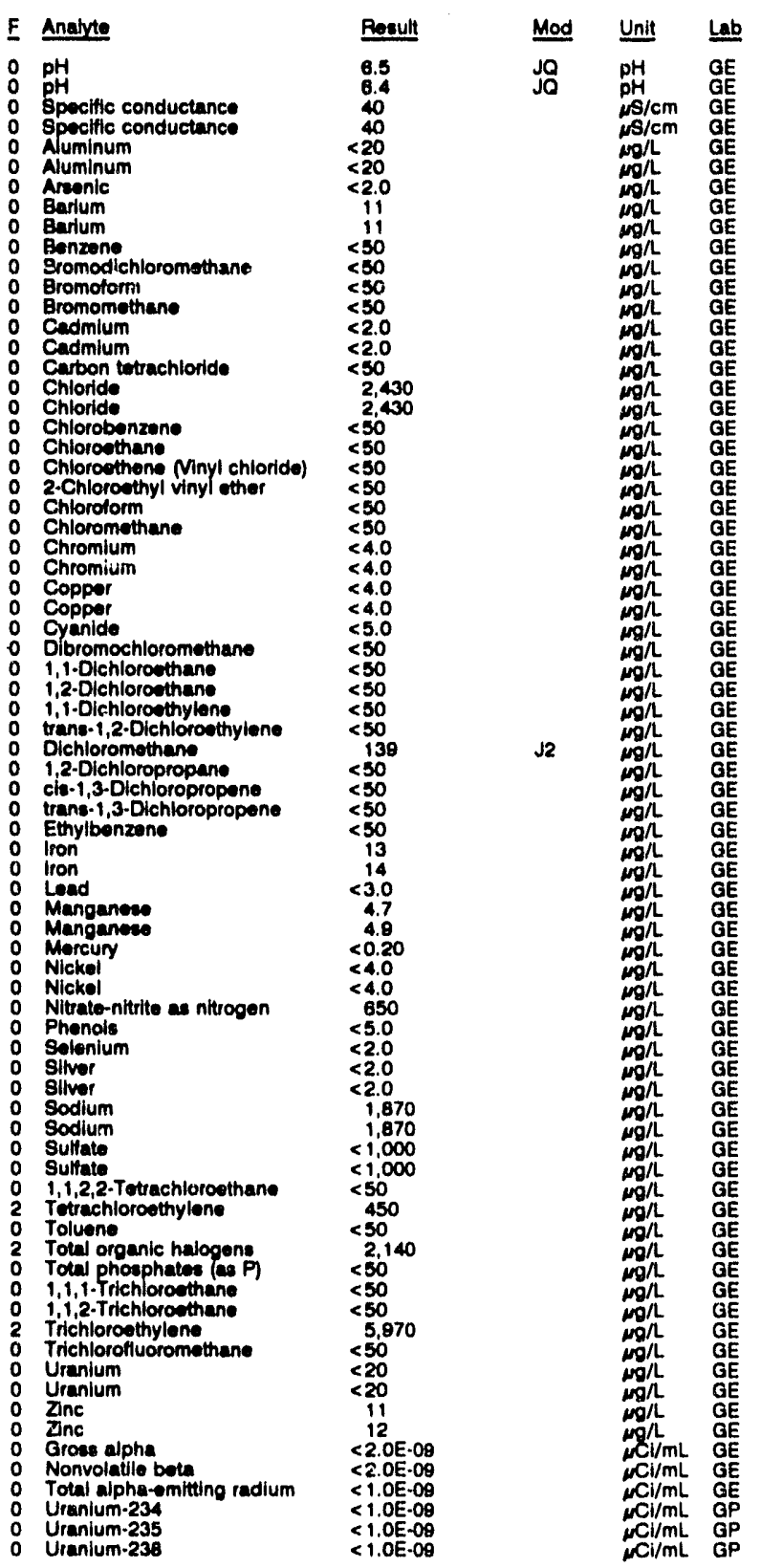

\section{WELL MSB 15AA}

MEASUAEMENTS CONDUCTED IN THE FIELD

Sample date: 07/08/92

Depth to water: $155.53 \mathrm{~h}(47.41 \mathrm{~m})$ below TOC

Water elovation: 213.97 \& 185

8p. conductance: $27 \mathrm{~s} / \mathrm{cm}$

Water evacuated betore sampling: $187 \mathrm{gal}$

LABORATORY ANALYSES

\begin{tabular}{|c|c|c|c|}
\hline Analyte & Result & Mod & Unit \\
\hline $\begin{array}{l}\text { Cadmlum } \\
\text { Carbon totrachloride } \\
\text { Chloroform } \\
\text { lron } \\
\text { Lead } \\
\text { Manganese } \\
\text { Morcury } \\
\text { Nitrale-nitrite as nitrogen } \\
\text { Phenols } \\
\text { Phenols } \\
\text { Tetrachloroethylene } \\
\text { Total organic carbon } \\
\text { Total organic halogens } \\
\text { 1,1,1-Trichloroethane } \\
\text { Trichloroethylone } \\
\text { Groes alpha } \\
\text { Nonvolatile beta } \\
\text { Total alpha-emitting radium } \\
\text { Trttlum }\end{array}$ & $\begin{array}{l}<2.0 \\
<2.0 \\
<2.0 \\
<4.0 \\
<3.0 \\
<2.0 \\
<0.20 \\
00 \\
<5.0 \\
<5.0 \\
7.4 \\
<1.000 \\
72 \\
<2.0 \\
177 \\
<2.0 \mathrm{E}-09 \\
<2.0 \mathrm{E}-09 \\
<1.0 \mathrm{E} \cdot 09 \\
<7.0 \mathrm{E}-07\end{array}$ & & 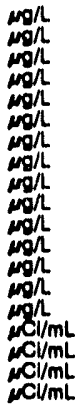 \\
\hline
\end{tabular}

\section{WELL MSB 15C}

MEASUREMENTS CONDUCTED IN THE FIELD

Depth to water: 122.94 in $(37.47 \mathrm{~m})$ below TOC Water elovation: $243.68 \mathrm{ft}(74.27 \mathrm{~m}) \mathrm{msl}$ Sp. conductance: $22 \mu \mathrm{S} / \mathrm{cm}$

pling: 1 gal

Time: $12: 10$

Alkalinity: $6 \mathrm{moll}$

Water temperalure: $21.7^{\circ} \mathrm{C}$

LABORATORY ANALYSES

\begin{tabular}{|c|c|c|c|}
\hline Analyte & Result & Mod & Unit \\
\hline 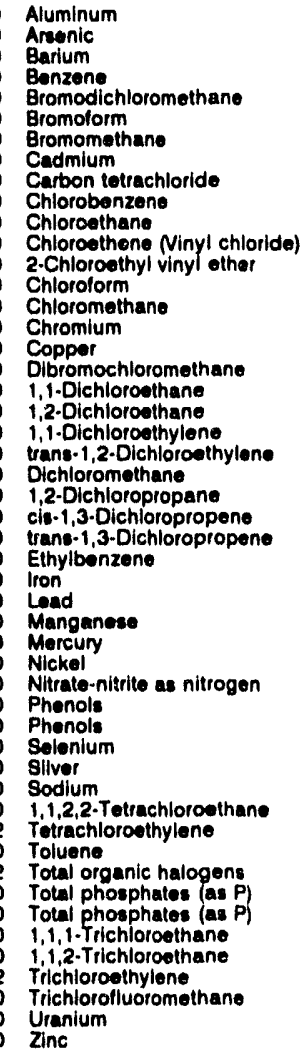 & $\begin{array}{l}<20 \\
<2.0 \\
4.0 \\
<50 \\
<50 \\
<50 \\
<50 \\
<2.0 \\
<50 \\
<50 \\
<50 \\
<50 \\
<50 \\
<50 \\
<50 \\
<4.0 \\
<4.0 \\
<50 \\
<50 \\
<50 \\
<50 \\
<50 \\
192 \\
<50 \\
<50 \\
<50 \\
<50 \\
5.1 \\
<3.0 \\
2.0 \\
<0.20 \\
<4.0 \\
475 \\
<5.0 \\
<5.0 \\
<2.0 \\
<2.0 \\
2,450 \\
<50 \\
6,600 \\
<50 \\
2.750 \\
4,710 \\
4,620 \\
<50 \\
<50 \\
7.710 \\
<50 \\
<20 \\
8.8 \\
\end{array}$ & J2 & 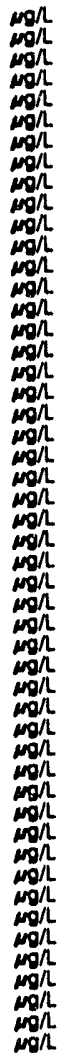 \\
\hline
\end{tabular}


WELL MSB 15D

MEASUREMENTS CONDUCTED IN THE FIELD

Sample date: 08/21/02

Dopth to wator: 137.72 n $(41.08 \mathrm{~m})$ below TOC Water olevation: $231.00 \mathrm{n}(70.43 \mathrm{~m}) \mathrm{mal}$ Sp. conductance: $28, \mathrm{~s} / \mathrm{cm}$.

The well went dry during purging.

LABORATOFY ANALYSES

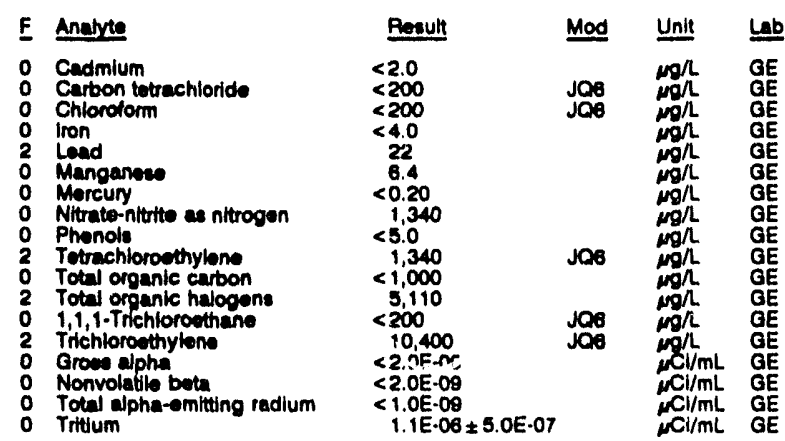

\section{WELL MSB 16A}

MEASUREMENTS CONDUCTED IN THE FIELD

Sample dale: 08/14/92

Depth to water: $146.38 \mathrm{n}(45.23 \mathrm{~m})$ below TOC Water elevation: 218.32 ft 168.54

Wa. conductance: 38 ps/cm

LABORATORY ANALYSES

\begin{tabular}{|c|c|c|c|c|c|}
\hline & Anaryte & Result & Mod & Unit & Lab \\
\hline & 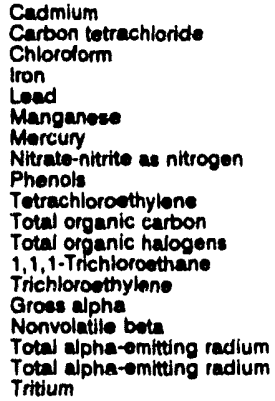 & $\begin{array}{l}<2.0 \\
<50 \\
<50 \\
23 \\
<3.0 \\
2.2 \\
2.2 \\
<0.20 \\
1,440 \\
<5.0 \\
735 \\
<1,000 \\
5,900 \\
<50 \\
4,100 \\
<2.0 E-09 \\
<2.0 E-09 \\
<1,0 E \cdot 09 \\
<1.0 E-09 \\
1.2 E-06 \pm 5.0 E \cdot 07\end{array}$ & $\begin{array}{l}106 \\
\mathrm{JO6} \\
\mathrm{J} 06\end{array}$ & 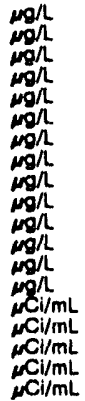 & $\begin{array}{l}G E \\
G E \\
G E \\
G E \\
G E \\
G E \\
G E \\
G E \\
G E \\
G E \\
G E \\
G E \\
G E \\
G E \\
G E \\
G E \\
G E \\
G E \\
G E\end{array}$ \\
\hline
\end{tabular}

\section{WELL MSB 16C}

MEASUREMENTS CONDUCTED IN THE FIELD

Sample deto: Oanipe

Depth to water: 137.04 it ( $41.77 \mathrm{~m}$ ) below TOC Dopth to wator: $137.04 \mathrm{~h}(141.77 \mathrm{~m})$ below
Wates olovation: $220.56 \mathrm{~h}(69.87 \mathrm{~m}) \mathrm{ms}$
So. conductance: $85, \mathrm{~s} / \mathrm{cm}$

Time: 7:55

pH: 5.0

Alkalinity: $1 \mathrm{mg} / \mathrm{h}$

Water tomperature: $20.8^{\circ} \mathrm{C}$

Water evacuated bofore sampling: 3 gal

The well went dry during purging

LABOFATOFY ANALYSES

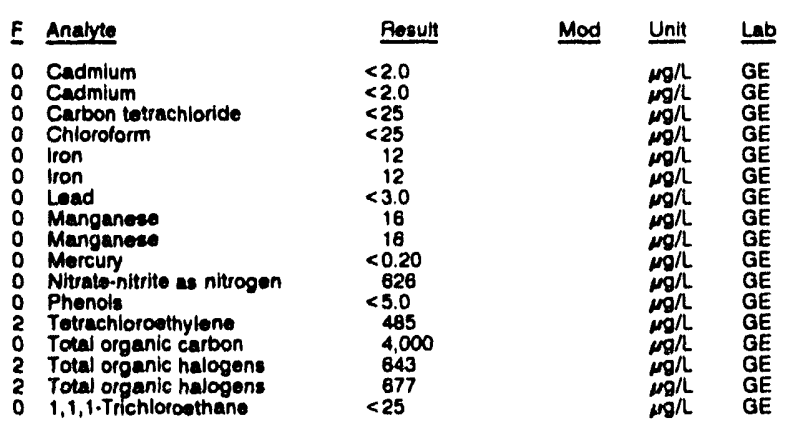

WELL MSB $16 \mathrm{C}$ collected on 00/21/82, laboratory analyenes (cont.)

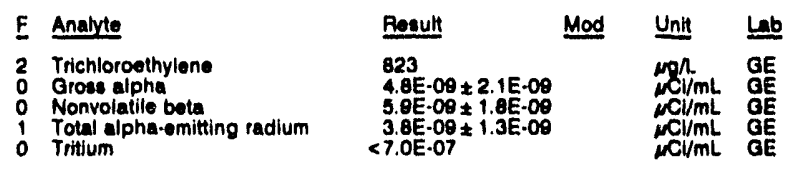

\section{WELL MSB 17A}

MEASUREMENTS CONDUCTED IN THE FIELD

\begin{tabular}{|c|c|}
\hline 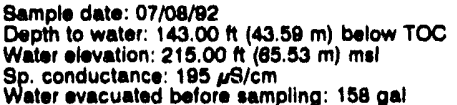 & $\begin{array}{l}\text { Tima: } 12: 50 \\
\text { pH: } 4.8 \\
\text { Alkalinity: } 0 \text { mo/ } \\
\text { Water tomporature: } 21.8 \cdot \mathrm{C}\end{array}$ \\
\hline
\end{tabular}
Wator ovacuated bofore sampling: $158 \mathrm{gal}$

LABORATORY ANALYSES

\begin{tabular}{|c|c|c|c|c|c|}
\hline$\underline{E}$ & Analyte & Besult & Mod & Unit & $\underline{L b}$ \\
\hline $\begin{array}{l}2 \\
0 \\
0 \\
0 \\
0 \\
0 \\
0 \\
0 \\
0 \\
0 \\
0 \\
0 \\
2 \\
0 \\
0 \\
0 \\
0 \\
0 \\
0 \\
2 \\
0 \\
2 \\
2 \\
0 \\
0 \\
0 \\
2 \\
0 \\
0 \\
0 \\
0\end{array}$ & 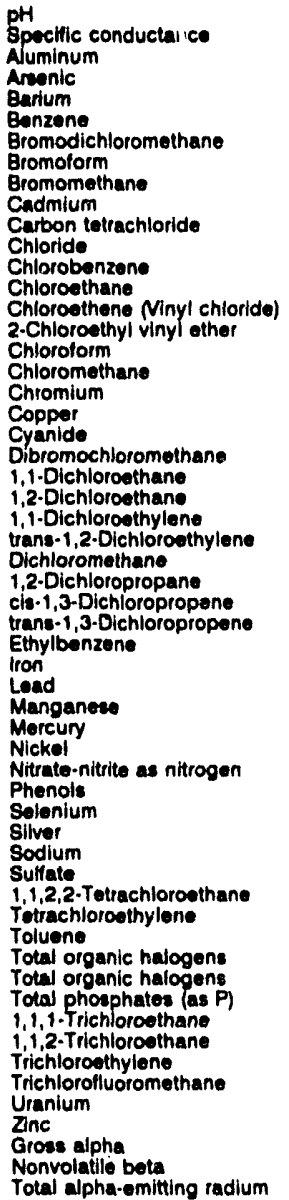 & 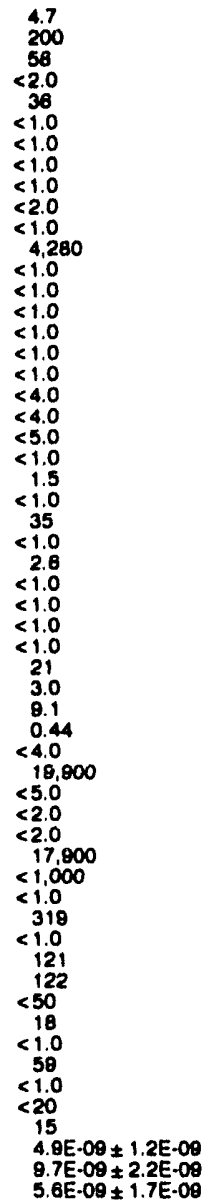 & Jo & 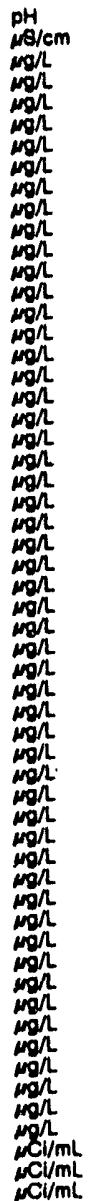 & 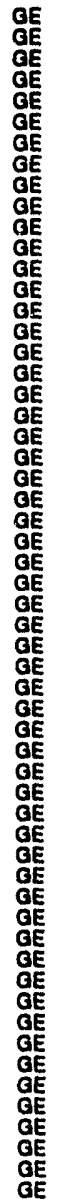 \\
\hline
\end{tabular}

WELL MSB 17B

MEASUREMENTS CONDUCTED IN THE FIELD

\begin{tabular}{|c|c|c|c|c|c|}
\hline \multicolumn{3}{|c|}{$\begin{array}{l}\text { Sample date: } 08 / 14 / 92 \\
\text { Dopth to water: } 132.96 \mathrm{ht}(40.53 \mathrm{~m}) \text { below TOC } \\
\text { Water clevation: } 224.94 \mathrm{H}(68.58 \mathrm{~m}) \mathrm{msl} \\
\text { Sp. conductance: } 114 \mathrm{NS} / \mathrm{cm} \\
\text { Water evacuated before sampling: } 105 \mathrm{gal}\end{array}$} & \multicolumn{3}{|c|}{$\begin{array}{l}\text { Time: } 14: 00 \\
\text { pH: } 4.5 \\
\text { Alkalinity: } 0 \mathrm{mg} / \mathrm{h} \\
\text { Water temperalure: } 20.0^{\circ} \mathrm{C}\end{array}$} \\
\hline \multicolumn{6}{|c|}{ LABORAYORY ANALYSES } \\
\hline $\mathbf{E}$ & Analyte & Result & Mod & Unit & Lab \\
\hline & $\begin{array}{l}\text { pH } \\
\text { Spocific conductance } \\
\text { Aluminum } \\
\text { Arsenic }\end{array}$ & $\begin{array}{r}5.0 \\
110 \\
115 \\
<2.0\end{array}$ & JO & $\underset{\substack{\mathrm{PH} \\
\mathrm{NO} / \mathrm{cm}}}{\cos \Omega}$ & $\begin{array}{l}\mathrm{GE} \\
\mathrm{GE} \\
\mathrm{GE} \\
\mathrm{GE}\end{array}$ \\
\hline
\end{tabular}


WELL MSB 178 collectind on 08/14/92, laboratory analyses (cont.)

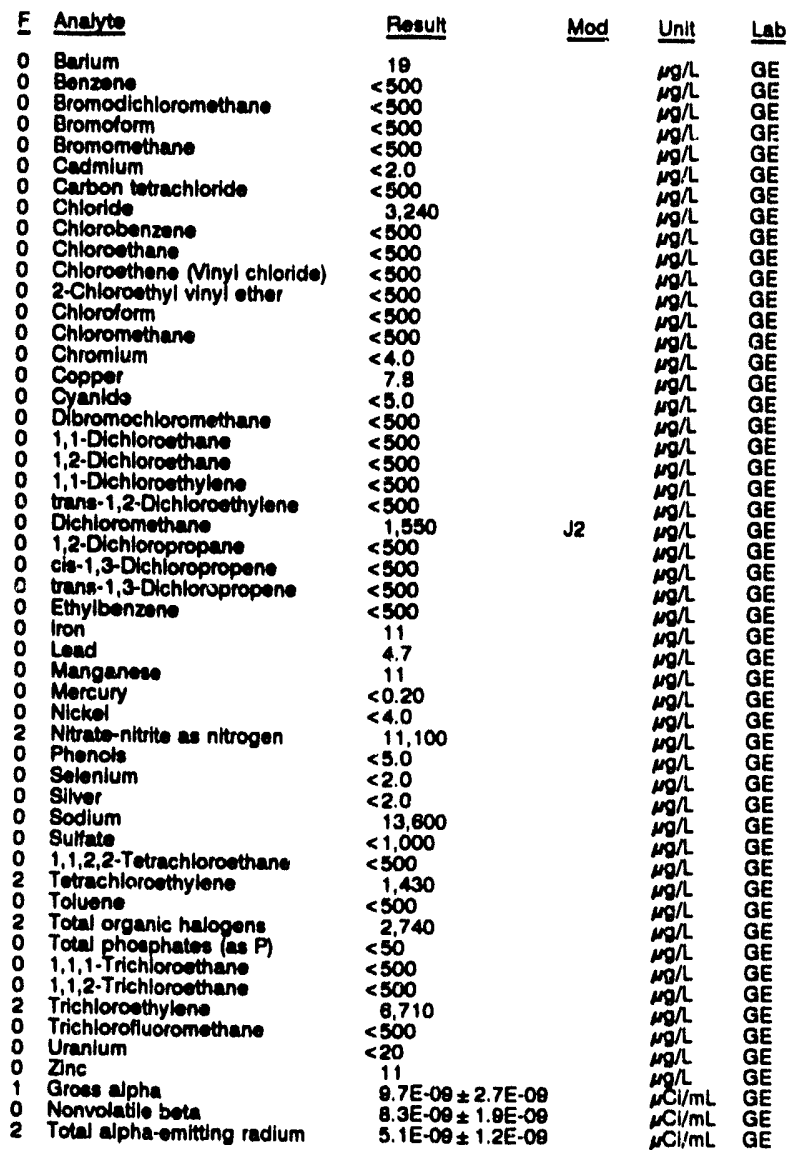

\section{WELL MSB 17BB}

MEASUREMENTS CONDUCTED IN THE FIELD

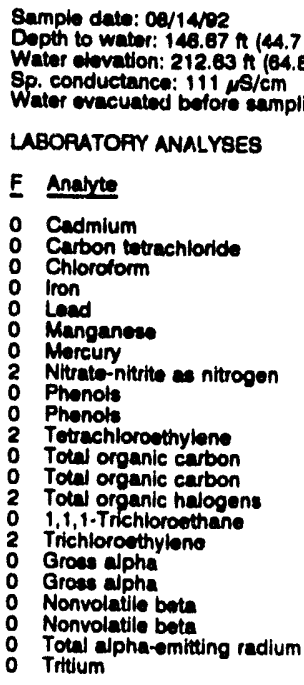

Time: 14:15

Plkalinity: $3 \mathrm{mo/h}$

Water temporature: $20.0^{\circ} \mathrm{C}$

\section{LABORATOFY ANALYSES}

\begin{tabular}{|c|c|c|c|}
\hline F Anatrte & Ressult & Mod & Unit \\
\hline 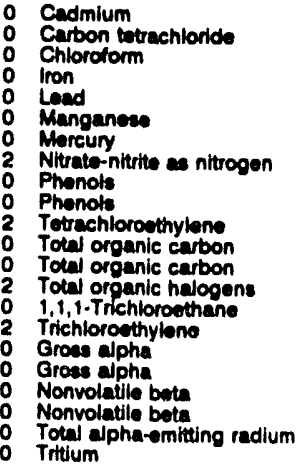 & $\begin{array}{l}<2.0 \\
<50 \\
<50 \\
<4.0 \\
<3.0 \\
12 \\
<0.20 \\
11,000 \\
<5.0 \\
<5.0 \\
585 \\
<1,000 \\
<1,000 \\
511 \\
<50 \\
1,400 \\
2.7 E-09 \pm 1.6 E-09 \\
2.4 E-09 \pm 1.5 E-09 \\
5.1 E-09 \pm 1.6 E-09 \\
4.7 E-09 \pm 1.8 E-09 \\
1.7 E \cdot 09 \pm 7.0 E-10 \\
<7.0 E \cdot 07\end{array}$ & $\begin{array}{l}\mathrm{J} 96 \\
\mathrm{~J} 06\end{array}$ & 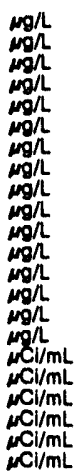 \\
\hline
\end{tabular}

WELL MSB 17C

MEASUREMENTS CONDUCTED IN THE FIELD

Sample date: 07/08/92

Timo: 12:25

The woll was dry.

WELL MSB 17D

MEASUREMENTS CONDUCTED IN THE FIELD

Sumple dato: 07/08/92

Depth to water: $133.36 \mathrm{H}(40.65 \mathrm{~m})$ below TOC

Water elevation: $226.64 \mathrm{ht}$

Sp. conductance: $35 \mu 8 / \mathrm{cm}$

Wator evacuatod before sampling: $35 \mathrm{gal}$

LABORATOAY ANALYSES

E Anabite

o Cadmlum

Carton tetrachloride

o Iron

o lion

o Manganese

Moneury

Nitrate-nitrite as nitrogen

Nitrate-nitsite as nitrogen

o Phenols

o Tetrachloroethylene

o Total organic carbon

Total organic carbon

Total organic halogens

O 1,1,1.Trichloroethan

Trichioroethyiens

Gross alph

o Nonvolatile bota

Nonvolatile beta

Total elpha-emitting radium

0 Tritium

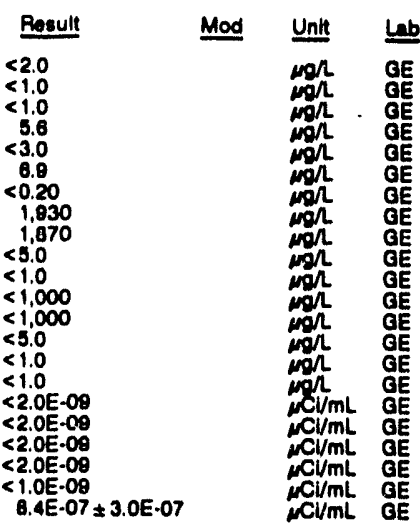

WELL MSB 18A

MEASUREMENTS CONDUCTED IN THE FIELO

Sample date: 07/08/92

Depth to water: $129.83 \mathrm{ft}(39.57 \mathrm{~m})$ below TOC Water elevation: $210.37 \mathrm{n}(64.12 \mathrm{~m}) \mathrm{ma}$ Wator evacuated betore sampling: $139 \mathrm{gal}$

PH: 4.5

Alkalinity: $0 \mathrm{~mol}$

Water temperaturs: $21.3^{\circ} \mathrm{C}$

LABOPATORY ANALYSES

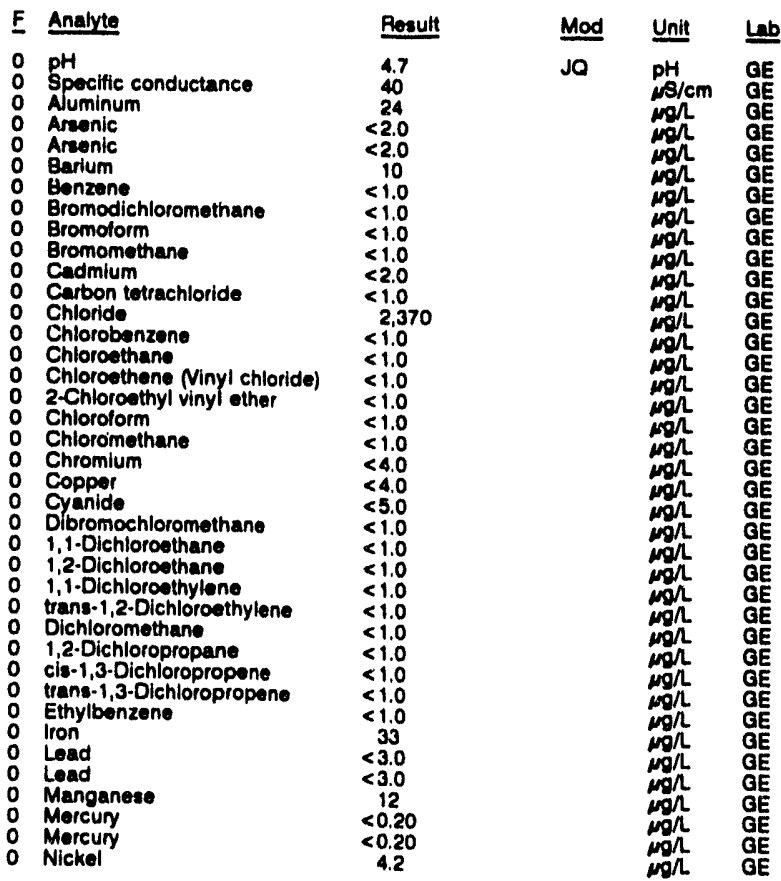




\begin{tabular}{|c|c|c|c|c|c|}
\hline & Anardo & Broult & Mod & Unit & Lab \\
\hline $\begin{array}{l}0 \\
0 \\
0 \\
0 \\
0 \\
0 \\
0 \\
0 \\
0 \\
0 \\
0 \\
0 \\
0 \\
0 \\
0 \\
0 \\
0 \\
0 \\
0 \\
0\end{array}$ & 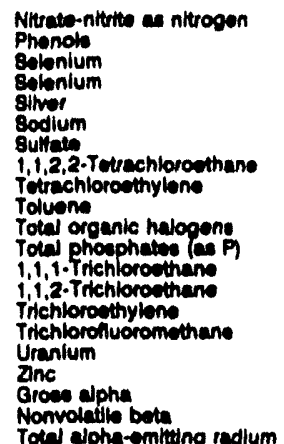 & $\begin{array}{l}2,500 \\
<50 \\
<2.0 \\
<2.0 \\
<2.0 \\
2.570 \\
<1.000 \\
<1.0 \\
<1.0 \\
<1.0 \\
10 \\
<50 \\
<1.0 \\
<1.0 \\
<1.0 \\
<1.0 \\
<20 \\
5.4 \\
<2.0 E-00 \\
<2.0 E-00 \\
<1.0 E-00\end{array}$ & & 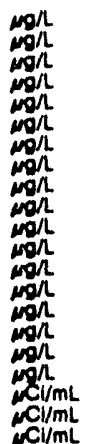 & $\begin{array}{l}G E \\
G E \\
G E \\
G E \\
G E \\
G E \\
G E \\
G E \\
G E \\
G E \\
G E \\
G E \\
G E \\
G E \\
G E \\
G E \\
G E \\
G E \\
G E \\
G E \\
G E\end{array}$ \\
\hline
\end{tabular}

\section{WELL MSB 18B}

MEAGUAEMENTS CONOUCTED IN THE FIELL

\begin{tabular}{|c|c|c|c|c|c|}
\hline & 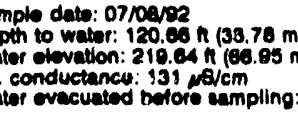 & TOC & $\begin{array}{l}\text { Time: 15: } \\
\text { pH: } 5.1 \\
\text { Alkalinity: } \\
\text { Water ten }\end{array}$ & $n$ & \\
\hline & BOPATOAY ANALYSES & & & & \\
\hline$\underline{E}$ & Anclute & Reault: & Mod & Unit & Leb \\
\hline & 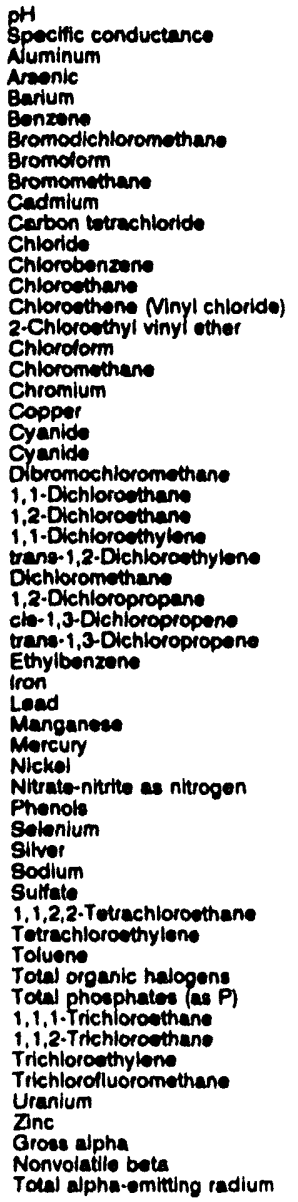 & $\begin{array}{r}5.2 \\
132 \\
28 \\
<2.0 \\
27 \\
<1.0 \\
<1.0 \\
<1.0 \\
<1.0 \\
<2.0 \\
<1.0 \\
4.200 \\
<1.0 \\
<1.0 \\
<1.0 \\
<1.0 \\
<1.0 \\
<1.0 \\
<4.0 \\
<4.0 \\
<5.0 \\
<5.0 \\
<1.0 \\
<1.0 \\
<1.0 \\
8.4 \\
<1.0 \\
1.0 \\
<1.0 \\
<1.0 \\
<1.0 \\
<1.0 \\
38 \\
<3.0 \\
25 \\
<0.20 \\
<4.0 \\
11.200 \\
<5.0 \\
<2.0 \\
<2.0 \\
13.300 \\
<1.000 \\
<1.0 \\
34.0 \\
<1.0 \\
<5.0 \\
<50 \\
4.0 \\
<1.0 \\
112 \\
4.1 \\
<20 \\
29 \\
<2.0 E-09 \\
8.6 E .09 \\
2.0 E .09 \\
\end{array}$ & jo & 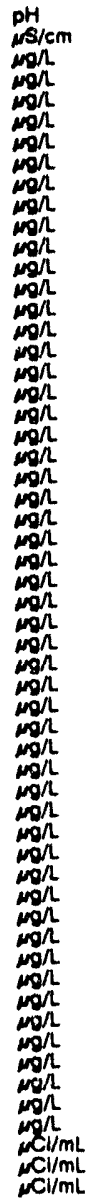 & $\begin{array}{l}G E \\
G E \\
G E \\
G E \\
G E \\
G E \\
G E \\
G E \\
G E \\
G E \\
G E \\
G E \\
G E \\
G E \\
G E \\
G E \\
G E \\
G E \\
G E \\
G E \\
G E \\
G E \\
G E \\
G E \\
G E \\
G E \\
G E \\
G E \\
G E \\
G E \\
G E \\
G E \\
G E \\
G E \\
G E \\
G E \\
G E \\
G E \\
G E \\
G E \\
G E \\
G E \\
G E \\
G E \\
G E \\
G E \\
G E \\
G E \\
G E \\
G E \\
G E \\
G E \\
G E \\
G E \\
G E \\
G E \\
G E\end{array}$ \\
\hline
\end{tabular}

WELL MSB 18C

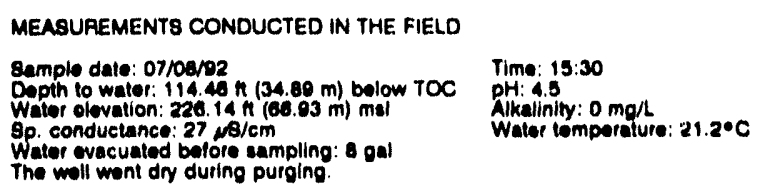

LABOFATOPY ANALYSES

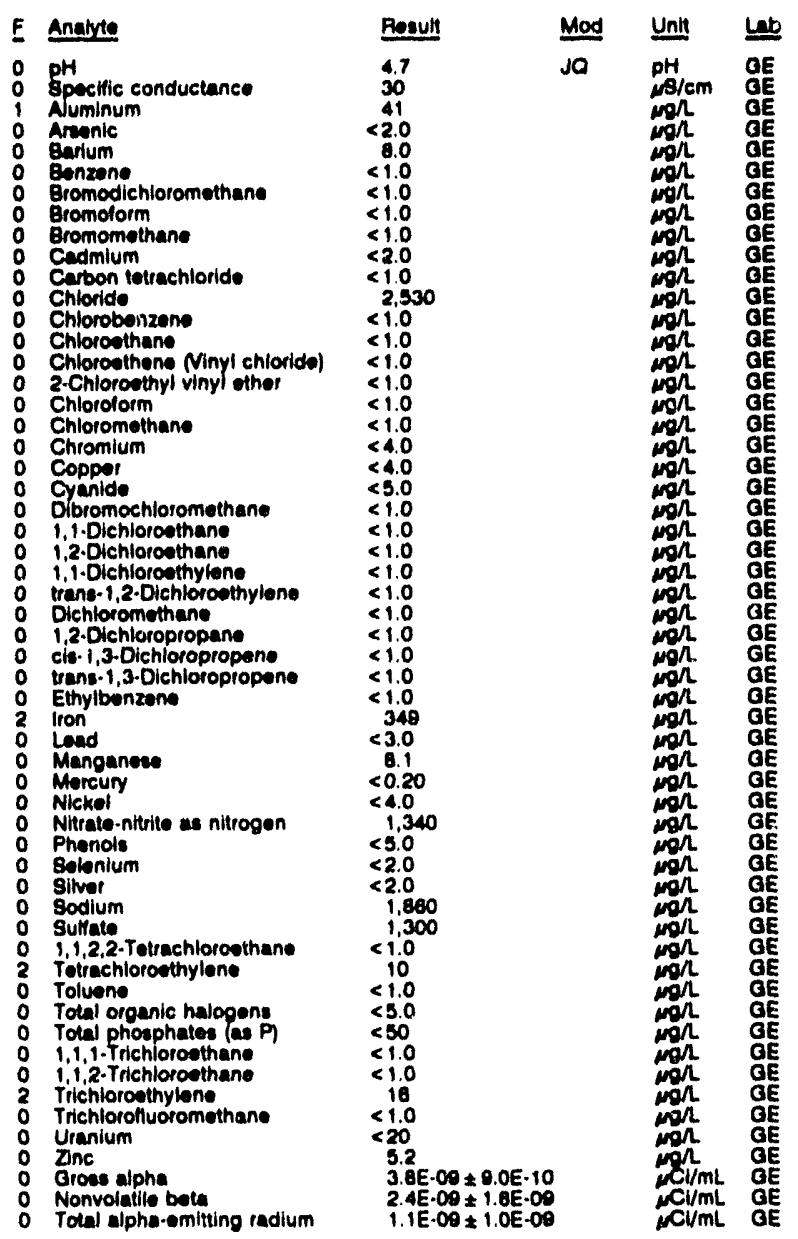

WELL MSB 19A

MEASUREMENTS CONOUCTED IN THE FIELO

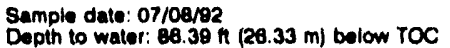

Wator olovation: 213.11 h $184.90 \mathrm{~m}) \mathrm{ms}$.

Sp. Conductance: $28 \mu \mathrm{s} / \mathrm{cm}$
Walor evacuatod bolore ampling: $25 \theta \mathrm{gal}$

PH: $: 070$

Alkalinity: $1 \mathrm{mo} /$

Water temporature: $18.7^{\circ} \mathrm{C}$

LABORATORY ANALYSES

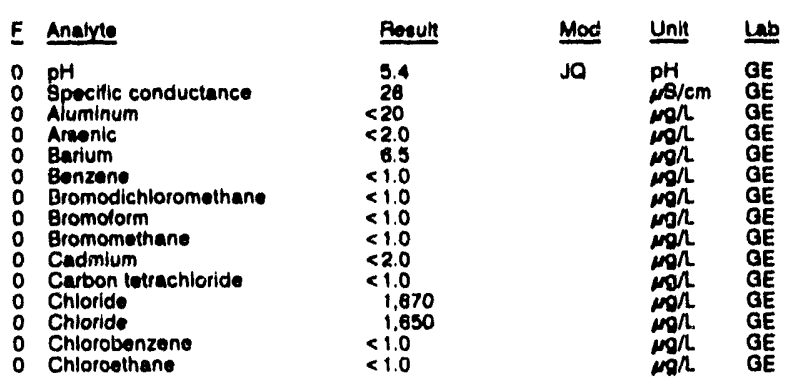


ANALYTICAL RESULTS

WELL MB8 18 A colloctod on 07/08/02, laboratory analyses (cont)

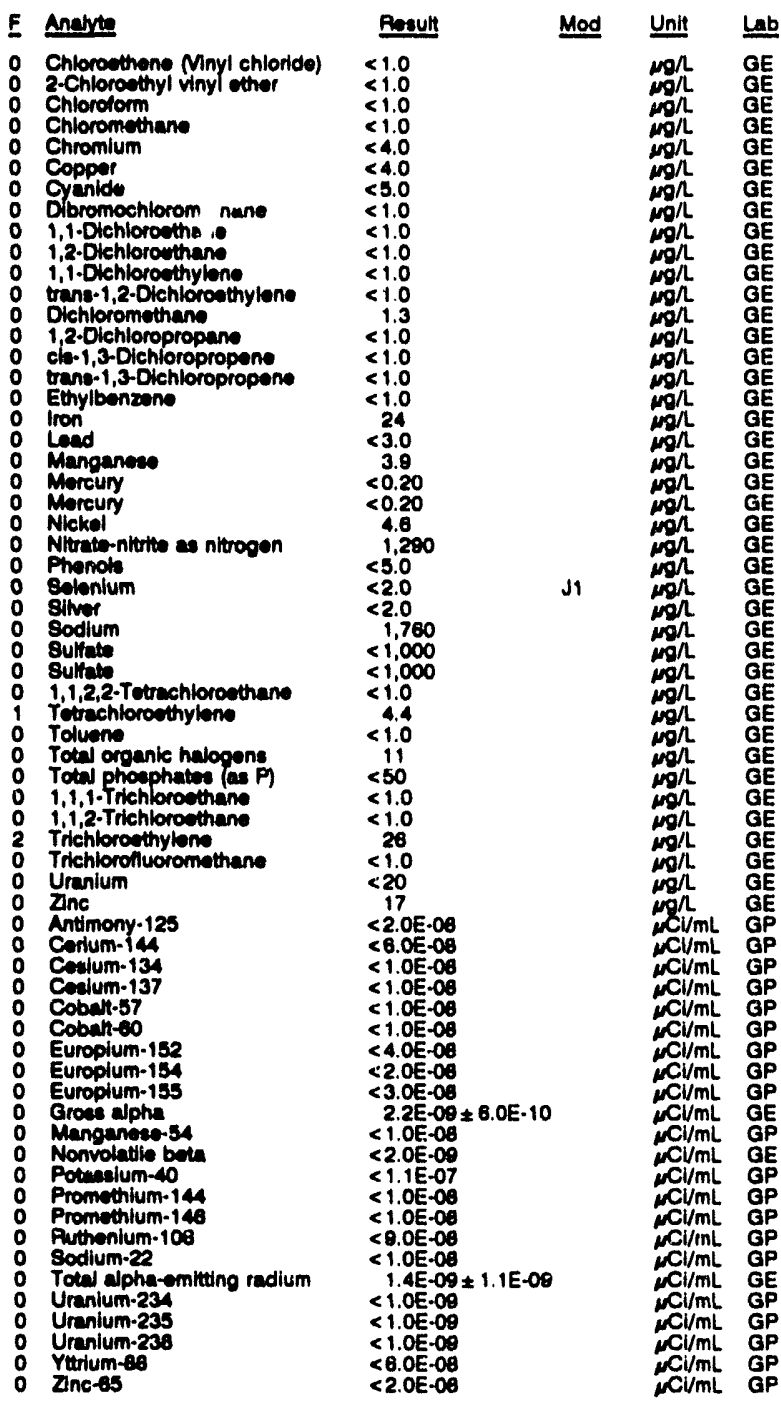

WELL MSB 19B

MEASUAEMENTS CONDUCTED IN THE FIELD

\begin{tabular}{|c|c|c|c|c|c|}
\hline \multicolumn{3}{|c|}{ 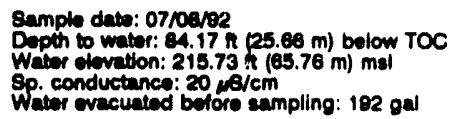 } & \multicolumn{3}{|c|}{$\begin{array}{l}\text { Time: } 7: 20 \\
\text { pH: } 4.4 \\
\text { Alkalinity: } 0 \mathrm{mgh} \\
\text { Water temperature: } 19.0 \circ \mathrm{C}\end{array}$} \\
\hline \multicolumn{6}{|c|}{ LABORATOFY ANALYSES } \\
\hline$E$ & Anave & Result & Mod & Unit & Lab \\
\hline $\begin{array}{l}0 \\
0 \\
0 \\
0 \\
0 \\
0 \\
0 \\
0 \\
0 \\
0 \\
0 \\
0 \\
0 \\
0 \\
0 \\
0 \\
0 \\
0 \\
0\end{array}$ & $\begin{array}{l}\text { pH } \\
\text { pH } \\
\text { 8pecific conductance } \\
\text { Spocific conductance } \\
\text { Aluminum } \\
\text { Aluminum } \\
\text { Areanic } \\
\text { Arronic } \\
\text { Barlum } \\
\text { Barium } \\
\text { Benzene } \\
\text { Benzone } \\
\text { Bromodichlorornethane } \\
\text { Bromodichloromethane } \\
\text { Bromolorm } \\
\text { Bromolorm } \\
\text { Bromomethane } \\
\text { Bromomethane } \\
\text { Cadmium }\end{array}$ & $\begin{array}{r}5.2 \\
5.2 \\
20 \\
18 \\
<20 \\
23 \\
<2.0 \\
<2.0 \\
4.3 \\
4.2 \\
<1.0 \\
<5.0 \\
<1.0 \\
<5.0 \\
<1.0 \\
<5.0 \\
<1.0 \\
<10 \\
<2.0\end{array}$ & $\begin{array}{l}\text { JQ } \\
\text { JO }\end{array}$ & 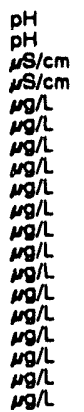 & $\begin{array}{l}G E \\
W A \\
\text { GE } \\
W A \\
G E \\
W A \\
\text { GE } \\
W A \\
G E \\
W A \\
G E \\
W A \\
\text { GE } \\
W A \\
G E \\
\text { WA } \\
G E \\
W A \\
G E\end{array}$ \\
\hline
\end{tabular}

WELL MSB 198 collected on 07/08/92, laboratory analyese (cont)

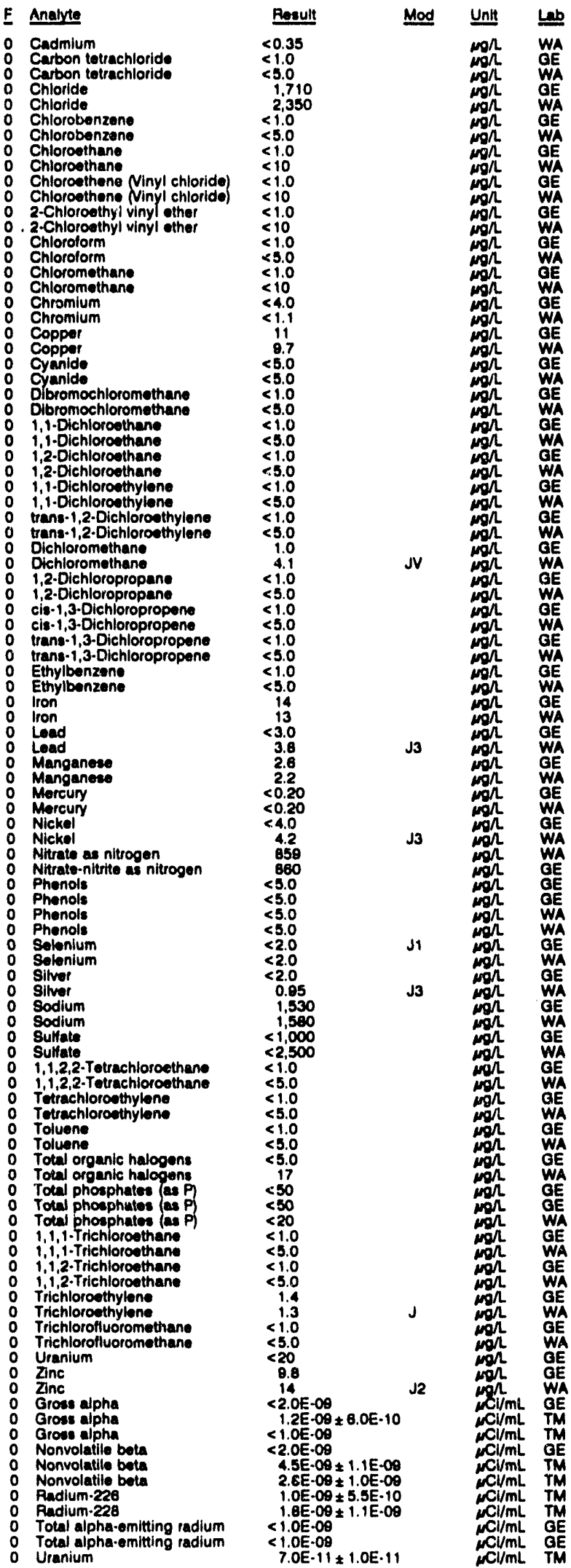


WELL M88 108 colloctod on 07/08/82, laboratory analyses (cont).

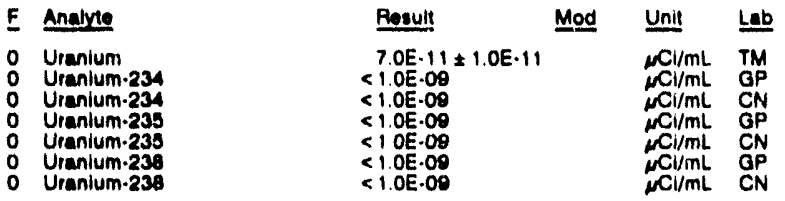

\section{WELL MSB 19B Replicate}

MEASUAEMENTS CONDUCTED IN THE FIELD

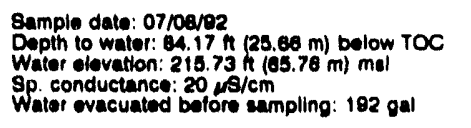

rime: 7:20

pH: $4: 4$

Alkalinity: $0 \mathrm{mg} /$

Water tomperalure: $19.0^{\circ} \mathrm{C}$

LABOPUTORY ANALYSES

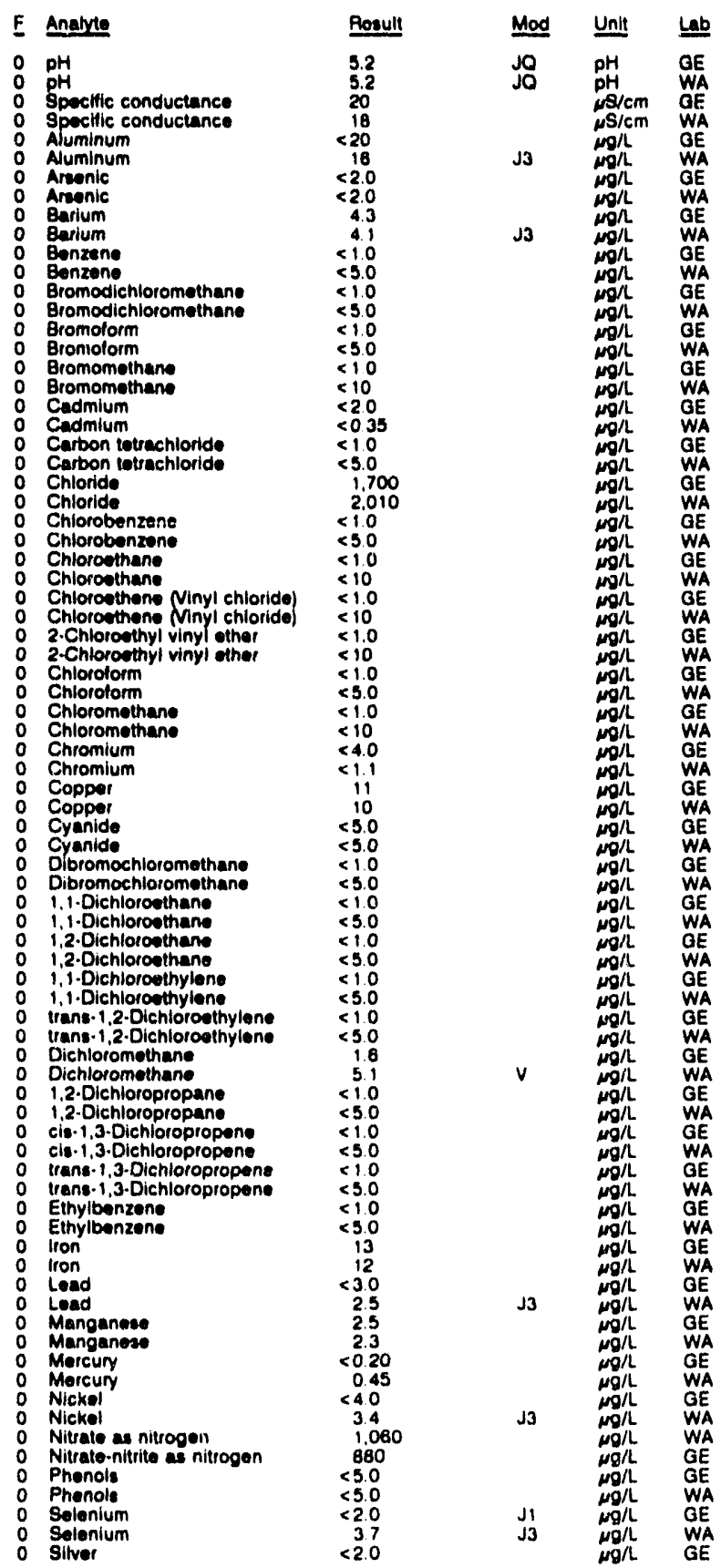

WELL MSB 198 collected on 07/08/92, laboratory analyese (cont.)

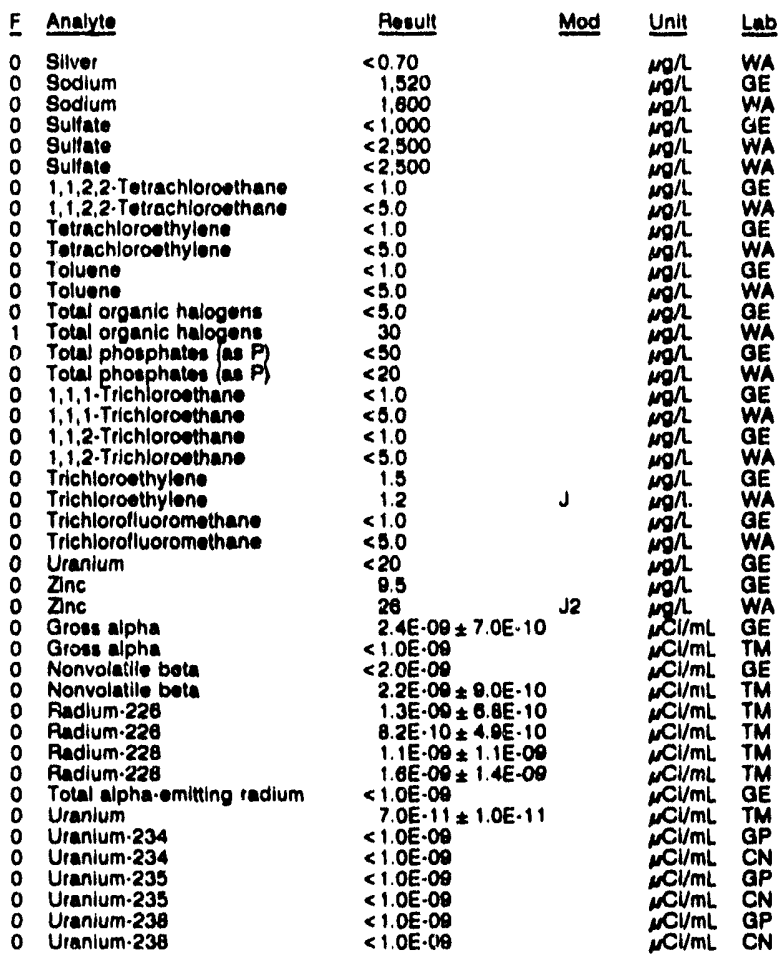

WELL MSB 19C

MEASUREMENTS CONDUCTED IN THE FIELD

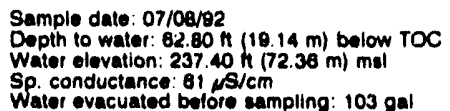

Time: $0: 00$

PH: 4.7 Water tomporature: $18.7^{\circ} \mathrm{C}$ LABOPATORY ANALYSES

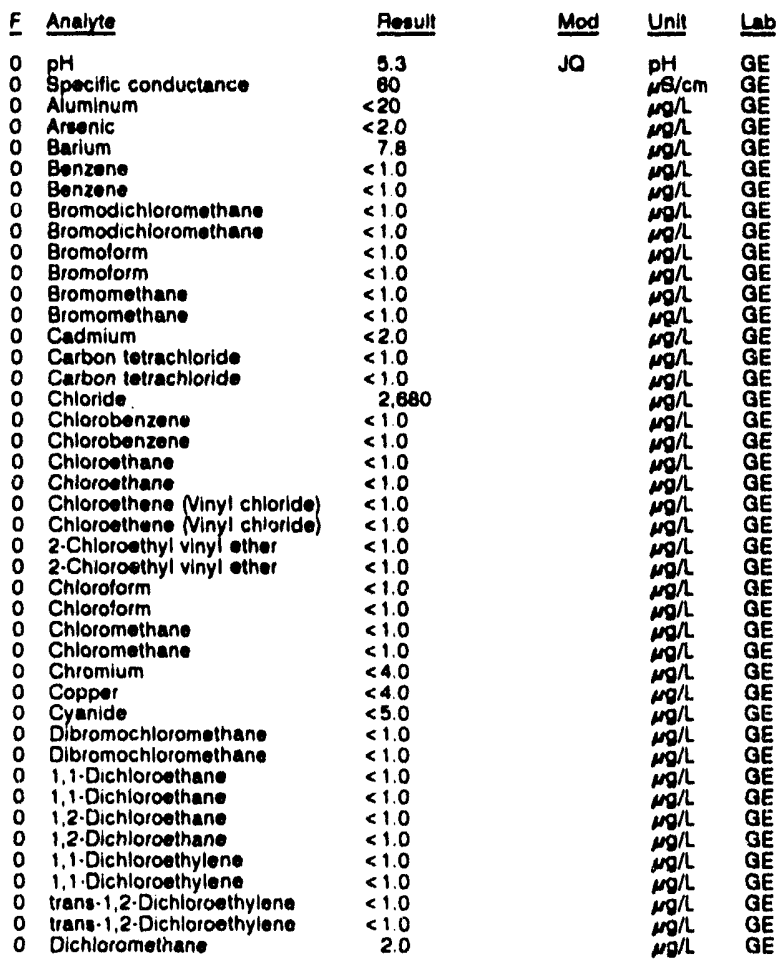


ANALYTICAL RESULTS

WELL MSB 18C collected on 07/08/92, laboratory analyese (cont)

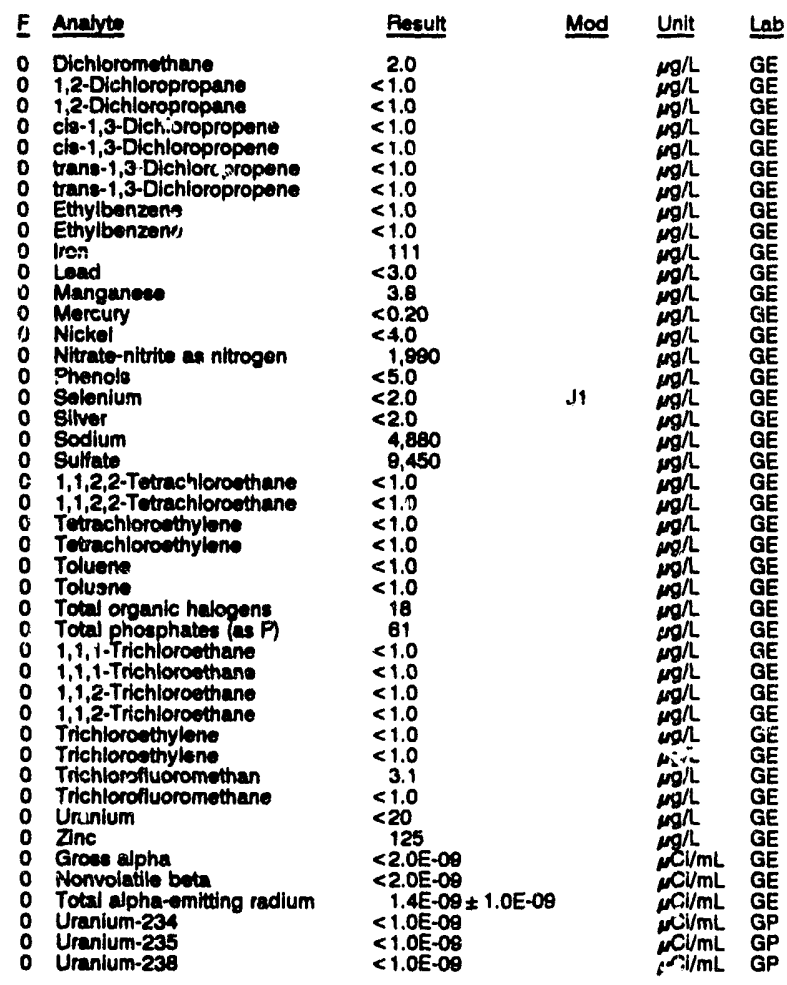

WELL MSB 20A

MEASUREMENTS CONDUCTED IN THE FIELO

8ample deto: 08/14/92

Dopth to water: $138.89 \mathrm{~h}(41.68 \mathrm{~m})$ below TOC Water elevation: $217.32 \mathrm{ft}(68.24 \mathrm{~m}) \mathrm{msl}$

Wiet evacuated before sampling: $160 \mathrm{gal}$

LABORATORY ANALYSES

\begin{tabular}{|c|c|}
\hline Analyte & Rosuit \\
\hline 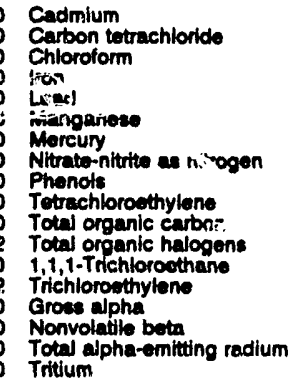 & $\begin{array}{l}<2.0 \\
<50 \\
<50 \\
13 \\
<3.0 \\
4.0 \\
<0.20 \\
1,200 \\
<5.0 \\
<50 \\
<1,000 \\
347 \\
<50 \\
1,230 \\
<2.0 E-08 \\
<2.0 E-08 \\
<1.0 E-08\end{array}$ \\
\hline
\end{tabular}

$$
\begin{aligned}
& \text { Tme: } 13: 25 \\
& \text { pH: } 5.2 \\
& \text { Alkalinity: } 2 \text { mgh. } \\
& \text { Water temperature: } 20.2^{\circ} \mathrm{C}
\end{aligned}
$$

\section{WELL MSB 20C}

MEASUREMENTS CONDUCTED IN THE FIELD

Sample date: 07/22/92

Depth to water: $127.81 \mathrm{ft}(38.98 \mathrm{~m})$ below TOC

Water elovation: 225.40 in $(68.73 \mathrm{~m}) \mathrm{msl}$

Water evacuated belors sampling: $10 \mathrm{gal}$

\begin{tabular}{|c|c|c|c|c|}
\hline$\underline{E}$ & Anabute & Result & Mod & Unit \\
\hline $\begin{array}{l}0 \\
0 \\
0 \\
0\end{array}$ & $\begin{array}{l}\text { Cadmium } \\
\text { Carbon totrachloride } \\
\text { Carbon tetrachloride } \\
\text { Chloroform }\end{array}$ & $\begin{array}{l}<2.0 \\
<1.0 \\
<1.0 \\
<1.0\end{array}$ & & $\underset{m g h}{\operatorname{mg} \Omega} \operatorname{sh}$ \\
\hline
\end{tabular}

The ril wellod bolorio canpling:

LABORATOAY ANALYSES
WELL MSB 20C colloctod on 07/22/82, laboratory analysese (cont.)

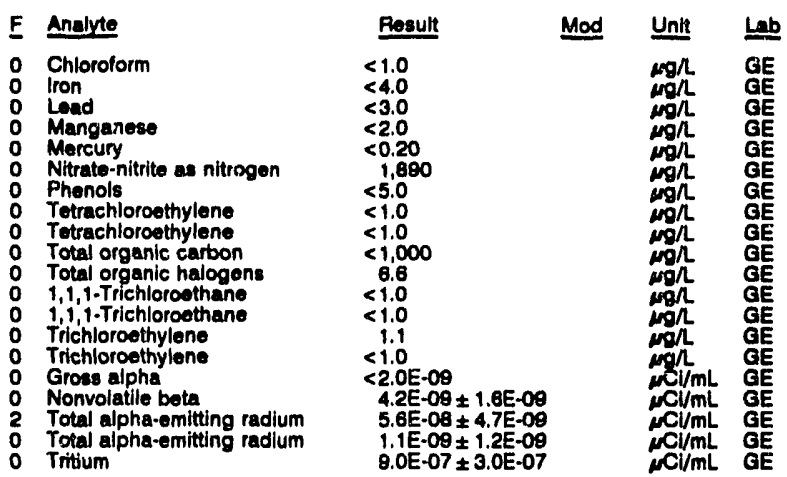

WELL MSB 21A

MEASUREMENTS CONDUCTED IN THE FIELD Sample date: $07 / 22 / 92$ (t $(40.96 \mathrm{~m})$ below TOC Water elevation: $218.03 \mathrm{ft}(66.76 \mathrm{~m}) \mathrm{msl}$

Water evacuated bofore sampling: $231 \mathrm{gal}$

Time: $10: 3$

PH: 5.1 Water temperature: $20.8^{\circ} \mathrm{C}$ LABORATORY ANALYSES

\section{E Analyte}

Result

Specific conductance

Aluminum

Anseric

Bromodichloromethane

Bromoform

Bromomethan

Carbon tetrachloride

Carbon toun

Chlorobenzene

Chloroethane

2-Croethene Ninyl chlor

Chloroform

- Chloromethane

Chromium

Copper

Dibromochloromethane

1,1-Dichloroethane

1, Dichlorothylen

o trans-1,2-Dichloroethylene

Dichloromethane

1,2-Dichloropropane

trans-1,3-Dichloropropene

- Ethylbenzene

0 Iron

Manganese

Mercury

Nitrato-nitrite as nitrogen

Nitrate-nitrite as nitrogen

Phenols

Solonium

Sodiur

Sulfat

1,1,2,2-Totrachloroethan

Tetrachloroethylene

Toluene

Total organic haiogens

Total phosphates as

1,1,1-Trichoroethane

1,1,2-Trichioroeth

Trichiorofluoromethane

Uranium

Zinc

Nonvolatile beta

Total alpha-emltting radium

Total alpha-omitting radium

Uranium-234

Uranium-238

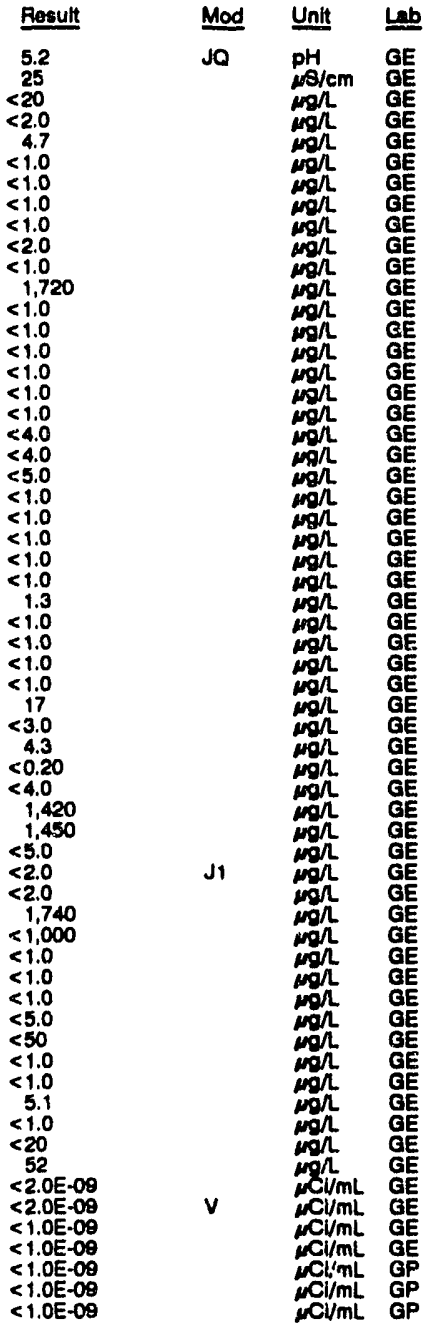




\section{WELL MSB 21B}

MEASUREMENTS CONDUCTED IN THE FIELD

Sample date: 07/22/92

Depth to water: $135.27 \mathrm{k}(41.23 \mathrm{~m})$ below TOC

Sp. conductanco: $33 \mu \mathrm{s} / \mathrm{cm}$

Water evacuatod betore eampling: $203 \mathrm{gal}$

LABORATOAY ANALYSES

\begin{tabular}{|c|c|c|}
\hline & Analyte & lesult \\
\hline & 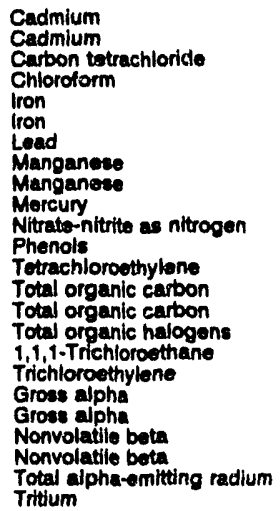 & $\begin{array}{c}<2.0 \\
<2.0 \\
<10 \\
<10 \\
<4.0 \\
<4.0 \\
<3.0 \\
3.4 \\
3.4 \\
<0.20 \\
810 \\
<5.0 \\
<10 \\
<1,000 \\
<1,000 \\
820 \\
<10\end{array}$ \\
\hline
\end{tabular}

\section{WELL MSB 21C}

MEASUREMENTS CONDUCTED IN THE FIELD

Sample date: $07 / 22 / 92$ fis $(38.34 \mathrm{~m})$ below TOC Dopph to water: $125.80 \mathrm{ft}(38.34 \mathrm{~m})$ below
Wator olovation: $227.60 \mathrm{ft}(63.37 \mathrm{~m}) \mathrm{msl}$ Water evacuatod befora sampling: 42 gal

UBORATORY ANALYSES

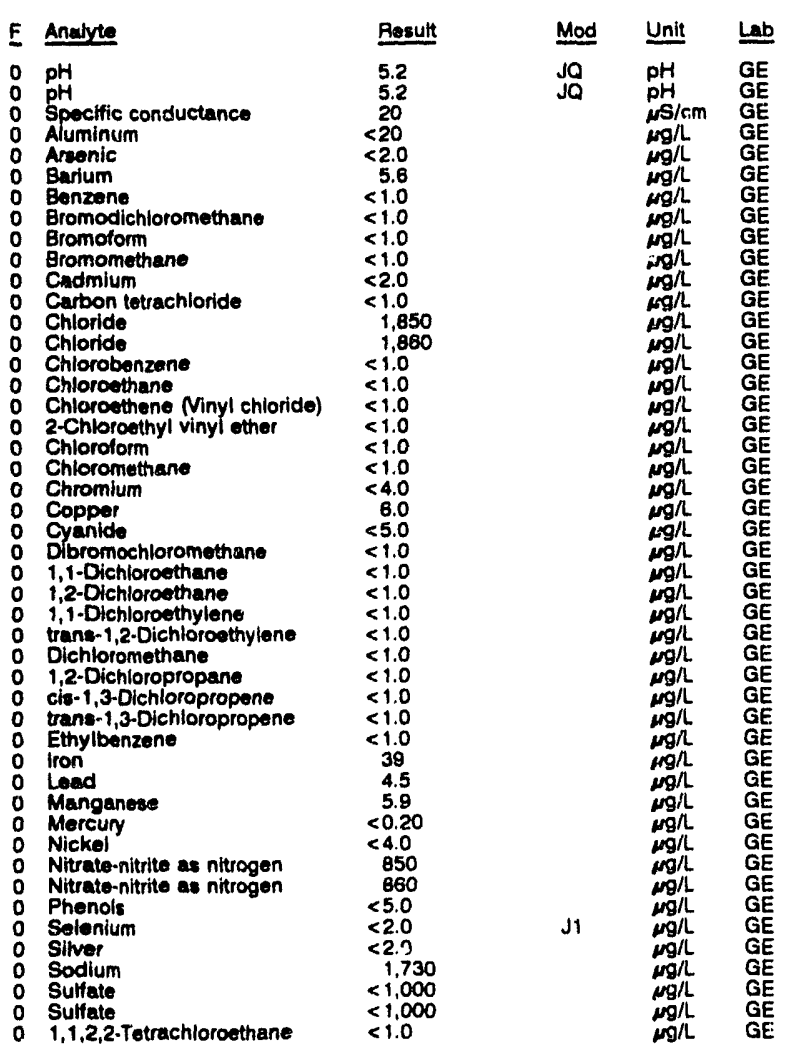

Time: 10:45

Alkalinity: $1 \mathrm{mg} /$

Water tompergture: $21.0^{\circ} \mathrm{C}$

Time: $10: 20$

Water temperature: $21.7 \circ \mathrm{C}$

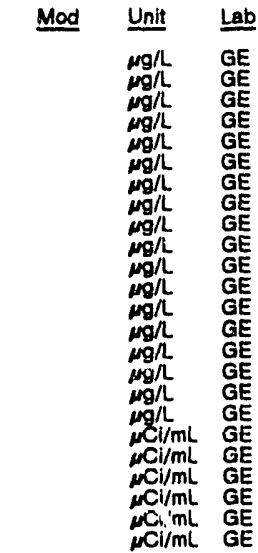

WELL MSB 21C collectod on 07/22/82, laboratory analyses (cont.)

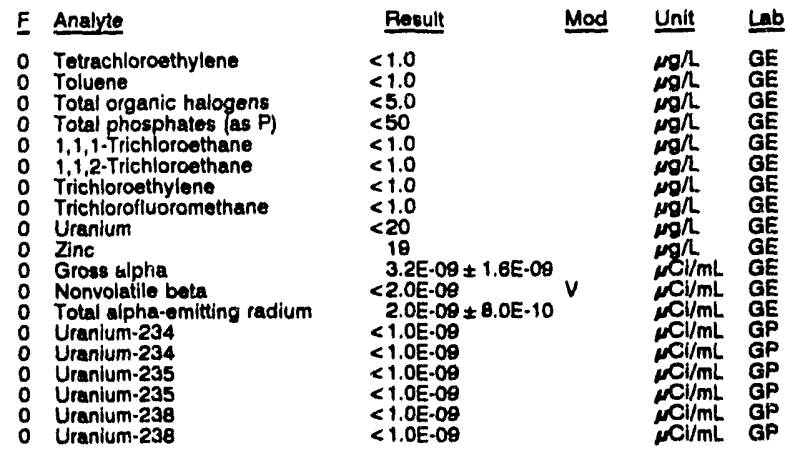

WELL MSB 21TA

MEASUREMENTS CONOUCTED IN THE FIELD

$\begin{array}{ll}\text { Sample date: } 07 / 17 / 82 & \text { Time: } 14: 30 \\ \text { Depth to water: } 160.18 \mathrm{Ht}(48.82 \mathrm{~m}) \text { below TOC } & \text { pH: } 5.8 \\ \text { Water olevation: } 194.52 \mathrm{ft}(58.29 \mathrm{~m}) \mathrm{msl} & \text { Alkalinity: } 10 \mathrm{mg} / \mathrm{h} \\ \text { Sp. conductance: } 56 \mu \mathrm{fS} / \mathrm{cm} & \text { Wator temperature: } 20.7 \cdot \mathrm{C} \\ \text { Water ovacuated betore sampling: } 481 \mathrm{gal} & \end{array}$

LABOFATORY ANALYSES

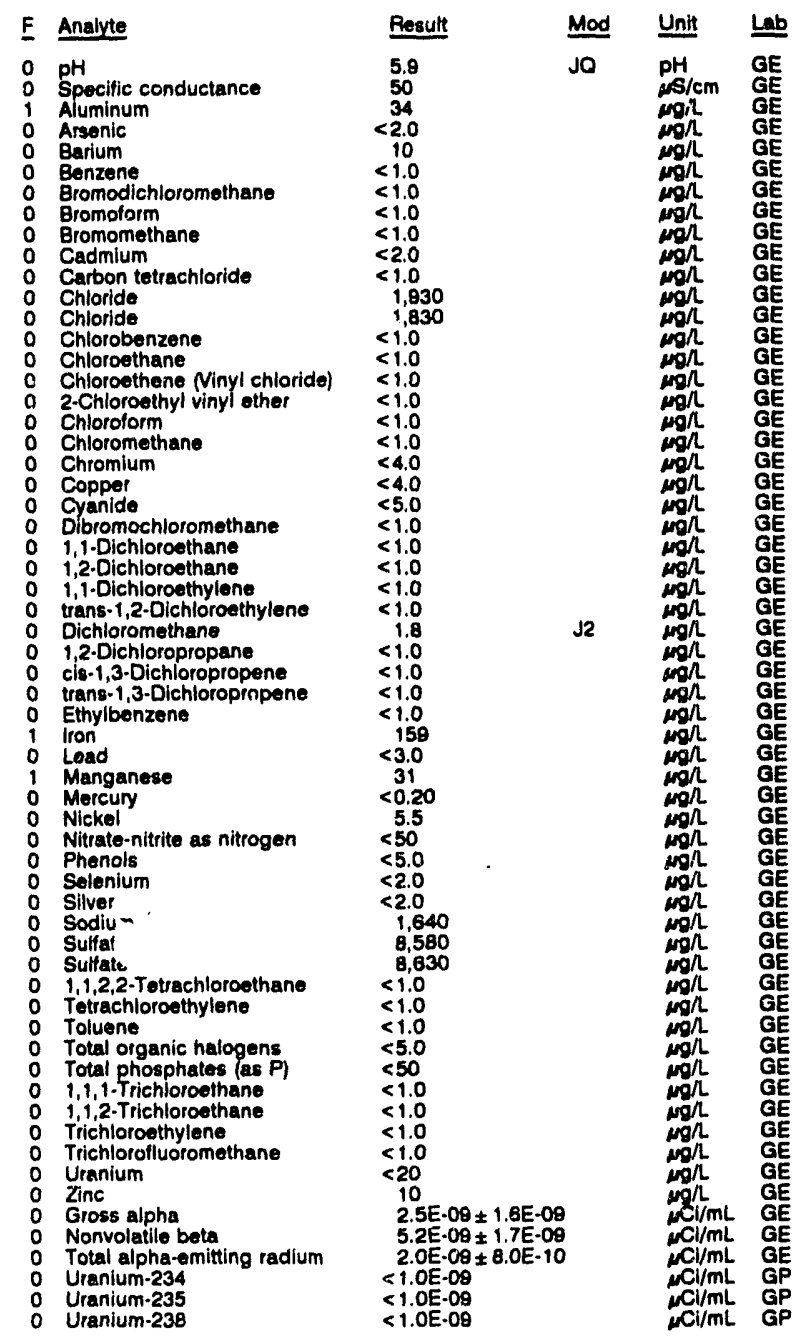

Analyte

Spocific con

Arsonic

Bromodichloromethane

Bromolom

Cadmium

Chloride

Chlorot

Chloroform

Chloromethan

Copper

Dibromochloromethane

1,
trans-1,2-Dichloroethylene

1,2.Dichloropropano

trans-1, - Dichloroprnpene

Ethylbenzene

1 Manganeso

Selenium

Silver

0 Sulfa

11,

Terachloroethylene

0 Toluene

Total organic halogens

1,1,1.Trichloroethano

- Trichlorofluoromethan

- Gross alpha

Total alpha-emiting radium

- Uranium-23日

$<1.0 \mathrm{E} .00$

E

b

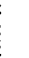

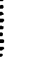

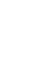


ANALYTICAL RESULTS

WELL MSB 22

MEASUREMENTS CONDUCTED IN THE FIELD

Sample date: $08 / 11 / 82$

The well was $\mathrm{dry}$.

Time: 7:20

\section{WELL MSB 23}

MEASUREMENTS CONDUCTED IN THE FIELD

Sample date: $08 / 13 / 82$
The well was dry.

Time: 8:25

\section{WELL MSB 23B}

MEASUREMENTS CONDUCTED IN THE FIELD

Sample date: 08/13/92

Depth to water: $148.68 \mathrm{~h}(45.32 \mathrm{~m})$ below TOC

Sp. conductioncs: $32.02 \mathrm{ft}(67 \mathrm{~cm}$

(a)

LABOALTOAY ANALYSES

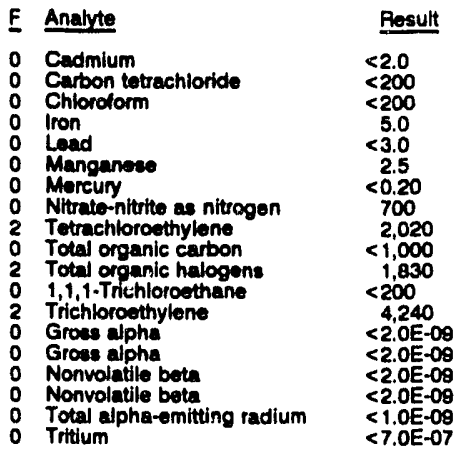

WELL MSB 23TA

MEASUREMENTS CONDUCTED IN THE FIELD

Sample date: 02/13/92

Depth to water: $170.55 \mathrm{~h}(51.98 \mathrm{~m})$ below TOC

Water elevetion: $202.35 \mathrm{ft}(61.68 \mathrm{~m}) \mathrm{msl}$

Water evecuated belore eampling: $372 \mathrm{gal}$

LABORATORY ANALYSES

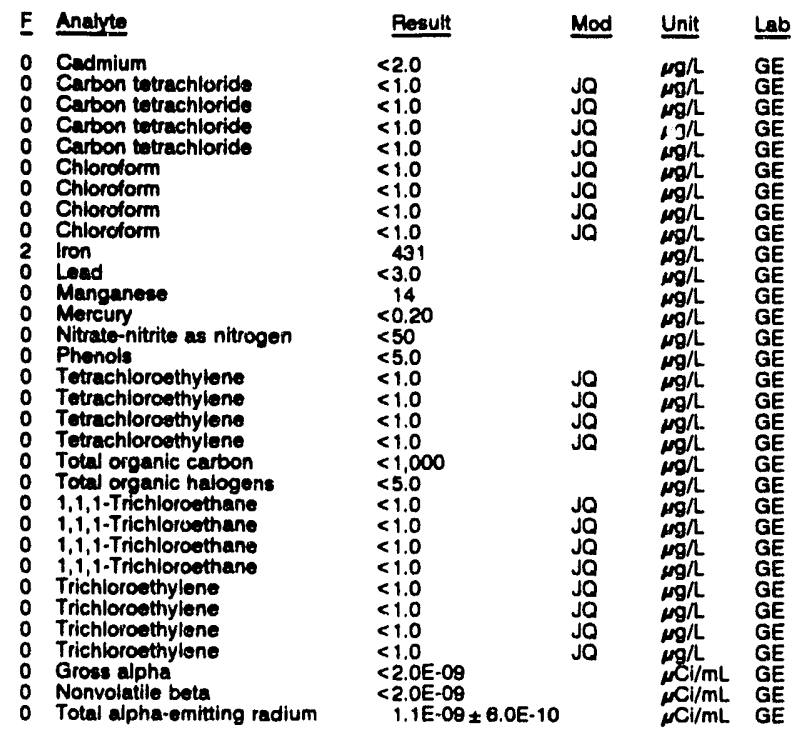

Yime: 10:45

pH: 4.8 .

Water temperature: $21.4^{\circ} \mathrm{C}$
WELL. MSB 23TA collected on 08/13/92, laboratory analyeses (cont.)

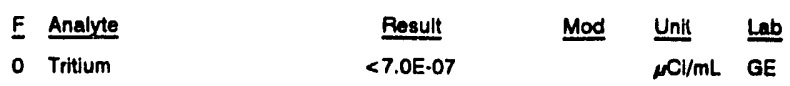

\section{WELL MSB 24}

MEASUREMENTS CONDUCTED IN THE FIELD

Sample date: 08/13/92

Depth to water: 14409 th $(43.92 \mathrm{~m})$ below TOC

Water olevation: $236.11 \mathrm{ft}(71.87 \mathrm{~m}) \mathrm{msl}$
Sp. conductance: $80 \mathrm{~s} / \mathrm{cm}$

Wator evacuated before sampling: $7 \mathrm{gal}$

The well went dry during purging.

LABORATORY ANALYSES

\begin{tabular}{|c|c|c|c|}
\hline Analyte & Result & Unit & Lي \\
\hline $\begin{array}{l}\text { Cadmium } \\
\text { Cadmium } \\
\text { lron } \\
\text { lron } \\
\text { Lead } \\
\text { Lead } \\
\text { Manganese } \\
\text { Manganese } \\
\text { Mercuny } \\
\text { Mercury } \\
\text { Nitrate-nitrite as nitrogen } \\
\text { Nitrate-nitrite as nitrogen } \\
\text { Phenols } \\
\text { Total organic carbon } \\
\text { Total organic halogens } \\
\text { Gross apha } \\
\text { Nonvolatile beta } \\
\text { Total alpha-emitting radium } \\
\text { Tritium }\end{array}$ & $\begin{array}{l}<2.0 \\
<2.0 \\
26 \\
26 \\
<3.0 \\
<3.0 \\
<2.0 \\
<2.0 \\
<0.20 \\
<0.20 \\
2,280 \\
2,240 \\
<5.0 \\
<1,000 \\
5,400 \\
<2.0 \mathrm{E}-09 \\
<2.0 \mathrm{E}-09 \\
<1.0 \mathrm{E}-09 \\
1.4 \mathrm{E}-06 \pm 5.0 \mathrm{E}-07\end{array}$ & 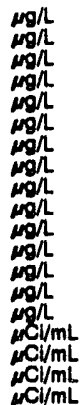 & $\begin{array}{l}\mathrm{GE} \\
\mathrm{GE} \\
\mathrm{GE} \\
\mathrm{GE} \\
\mathrm{GE} \\
\mathrm{GE} \\
\mathrm{GE} \\
\mathrm{GE} \\
\mathrm{GE} \\
\mathrm{GE} \\
\mathrm{GE} \\
\mathrm{GE} \\
\mathrm{GE}\end{array}$ \\
\hline
\end{tabular}

\section{WELL MSB 24A}

MEASUREMENTS CONDUCTED IN THE FIELD

Sample date: $08 / 13 / 92$ Time: 8:55

Depth to water: $155.43 \mathrm{ft}(47.38 \mathrm{~m})$ below TOC

Water elevation: $226.17 \mathrm{H}(68.94 \mathrm{~m}) \mathrm{ms}$ i

inaccessibility or mechanical problem prevented sample collection.

\section{WELLL MSB 25}

MEASUREMENTS CONDUCTED IN THE FIELD

Sample date: 08/13/92

Time: 11:15

The well was dry.

WELL MSB 25A

MEASUREMENTS CONDUCTED IN THE FIELD

\begin{tabular}{|c|c|}
\hline $\begin{array}{l}\text { Sample date: } 08 / 13 / 92 \\
\text { Depth to water: } 150.70 \mathrm{ft}(45.83 \mathrm{~m}) \text { below TOC } \\
\text { Water elevation: } 215.70 \mathrm{ft}(65.75 \mathrm{~m}) \mathrm{msl} \\
\text { Sp. conductance: } 31 \mu \mathrm{S} / \mathrm{cm}\end{array}$ & $\begin{array}{l}\text { Time: } 11: 40 \\
\text { pH: } 4.7 \\
\text { Alkalinity: } 0 \text { mgl. } \\
\text { Water temperature: } 22.7 \cdot \mathrm{C}\end{array}$ \\
\hline
\end{tabular}

LABOAATORY ANALYSES

\begin{tabular}{|c|c|c|c|c|c|}
\hline$F$ & Analyte & Result & Mod & Unit & Lab \\
\hline & $\begin{array}{l}\text { Cadmlum } \\
\text { Carbon tetrachloride } \\
\text { Chloroform } \\
\text { Iron } \\
\text { Lead } \\
\text { Manganese } \\
\text { Mercury } \\
\text { Mercury } \\
\text { Nitrate-nitrite as nitrogen } \\
\text { Phenols } \\
\text { Tetrachloroethylene } \\
\text { Total organic carbon } \\
\text { Total organic carbon } \\
\text { Total organic halogens } \\
\text { 1,1, -Trichloroethane } \\
\text { Trichloroethylene } \\
\text { Gross alpha } \\
\text { Nonvolatile beta } \\
\text { Total alpha-emitting radium } \\
\text { Tritium }\end{array}$ & $\begin{aligned}<2.0 \\
<50 \\
<50 \\
6.3 \\
3.1 \\
<2.0 \\
<0.20 \\
<0.20 \\
1,750 \\
<5.0 \\
365 \\
<1.000 \\
<1.000 \\
1.130 \\
<50 \\
2,020 \\
2.1 E-09 \pm 1.4 E-09 \\
2.0 E-09 \pm 1.4 E-09 \\
<1.0 E-09 \pm 1.09-07 \\
1.5 E-06 \pm 5.0 E-07\end{aligned}$ & JO J & 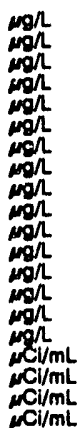 & $\begin{array}{l}G E \\
G E \\
G E \\
G E \\
G E \\
G E \\
G E \\
G E \\
G E \\
G E \\
G E \\
G E \\
G E \\
G E \\
G E \\
G E \\
G E \\
G E \\
G E \\
G E\end{array}$ \\
\hline
\end{tabular}


WELL MSB 26

MEASUREMENTS CONDUCTED IN THE FIELD

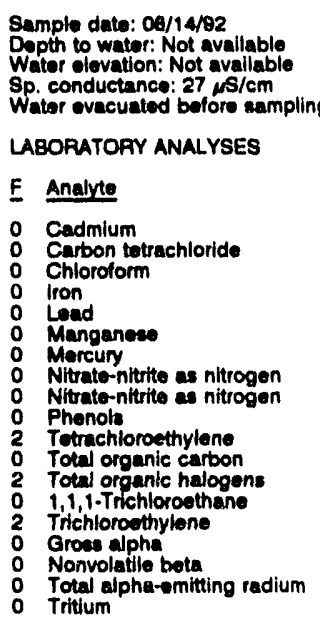

31 gal
Time: 11:55

Alkalinity: $1 \mathrm{mg} / \mathrm{h}$

Water tomperature: $21.2^{\circ} \mathrm{C}$

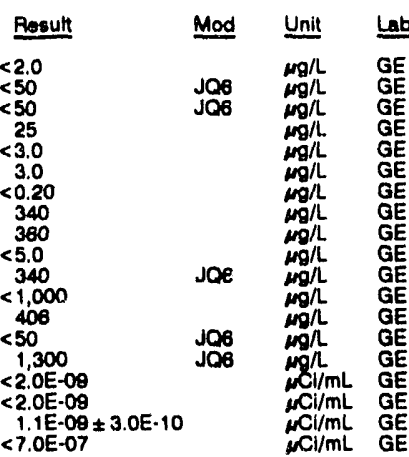

\section{WELL MSB 26A}

MEASUREMENTS CONDUCTED IN THE FIELD

Sample date: 08/14/92

Depth to water: $137.88 \mathrm{H}$ (42.03 m) below TOC

Water elevation: $223.01 \mathrm{~h}$ (67.

Water evacuated before sampling: $141 \mathrm{gal}$

LABORATORY ANALYSES

F Analyte

- Cadmium

o Iron

O Manganese

Morcury

Phenola

Total oroanic halogens

Grose alpha

Tonvolatile beta

Tritium

\begin{tabular}{l}
\multicolumn{1}{r}{ Result } \\
\hline 2.0 \\
$<4.0$ \\
$<3.0$ \\
$<2.0$ \\
$<0.20$ \\
320 \\
$<5.0$ \\
$<1,000$ \\
481 \\
$<2.0 \mathrm{E}-09$ \\
$<2.0 \mathrm{E}-09$ \\
$<1.0 \mathrm{E}-09$ \\
$<7.0 \mathrm{E}-07$
\end{tabular}

\section{WELL MSB 26B}

MEASUREMENTS CONDUCTED IN THE FIELD

Sample date: 08/04/92

Wepth to watar: 144.75 ft (44.12 m) below TOC

Water elovation: $218.45 \mathrm{H}$ (68.

Water evacuated bolore sampling: $226 \mathrm{gal}$

LABORATOAY ANALYSES

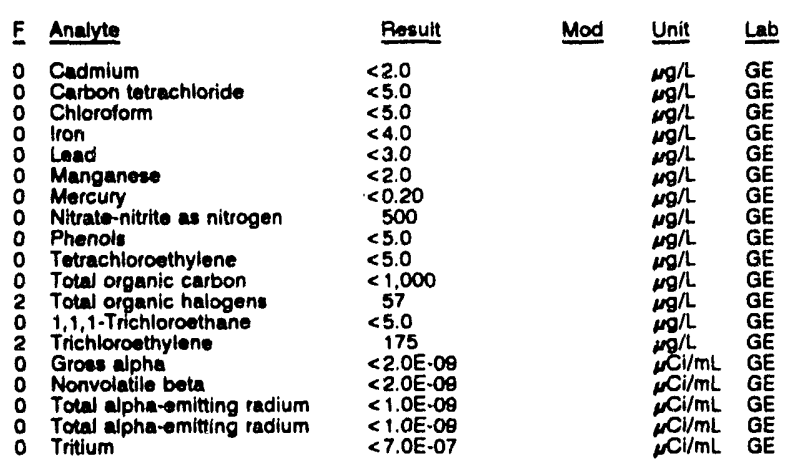

WELL MSB 27

MEASUAEMENTS CONDUCTED IN THE FIELL

Sample date: 08/05/82

Depth to water: $137.09 \mathrm{H}(41.78 \mathrm{~m})$ bolow TOC

Water elevation: 238.41 it (7

LABORATORY ANALYSES

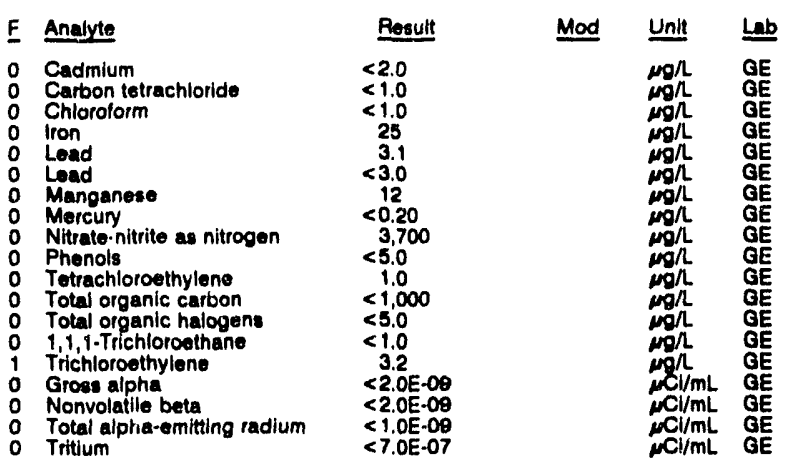

WELL MSB 27A

MEASUREMENTS CONDUCTED IN THE FIELD

Sample date: $08 / 11 / 92$ (t) $(44.65 \mathrm{~m})$ below TOC

Water elevation: $228.72 \mathrm{ft}(69.71 \mathrm{~m}) \mathrm{ms}$

Inaccessibility or mechanical problem prevented sample collection.

WELL MSB 27B

MEASUREMENTS CONDUCTED IN THE FIELD

Sample date: 08/05/82

Depth to water: 152.31 in $(46.42 \mathrm{~m})$ bolow TOC Water elevation: $224.48 \mathrm{ft}(88.43 \mathrm{~m}) \mathrm{ms}$

Water evacuated before sampling: $158 \mathrm{gal}$

LABORATORY ANALYSES

F Analyte

- Cadmium

Carbon tetrachloride

Chioroform

o lion

L Lead

Manganese

Nitrate-nitrite as nitrogen

Phenols

Tetrachioroethylene

Total organic carbon

Total organic halogens

1,1,1-Trichloroethen

Groses alpha

Gross alpha

Nonvolatile bota

Nonvolatilo beta $\quad<2.0 E-00$

Total alpha-emitting radium $<2.0 E-09$

Time: 10:50

pH: 5.0 . $1 \mathrm{mon}$

Alkalinity: $1 \mathrm{mg} /$. $200 \mathrm{C}$

\section{WELL MSB 27TA}

MEASUAEMENTS CONDUCTED IN THE FIELD

Sample date: $08 / 05 / 92 \mathrm{~h}(53.40 \mathrm{~m})$ below TOC

Water elevation: $201.41 \mathrm{ft}(61.38 \mathrm{~m})$ ins

Sp. conductance: $25 \mathrm{ss} / \mathrm{cm}$

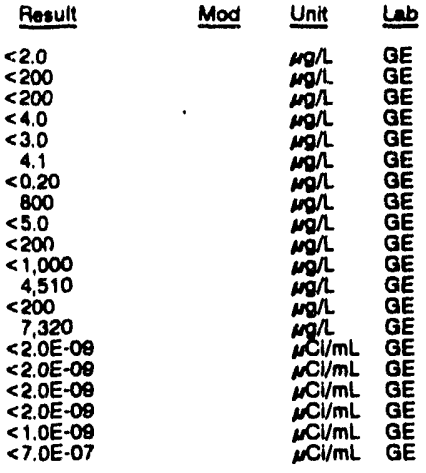

Water evacuated before sampling: $396 \mathrm{gal}$

LABORATORY ANALYSES

\begin{tabular}{|c|c|c|c|}
\hline E Analyte & Result & Mod & Unit \\
\hline $\begin{array}{ll}\text { O Cadmium } \\
0 & \text { Cadmium } \\
0 & \text { Carbon tetrachloride }\end{array}$ & $\begin{array}{l}<2.0 \\
<2.0 \\
<1.0\end{array}$ & & $\cos$ \\
\hline
\end{tabular}


WELL MSE $27 T$ A colloctod on 08/05/92, laboratory analyses (cont.)

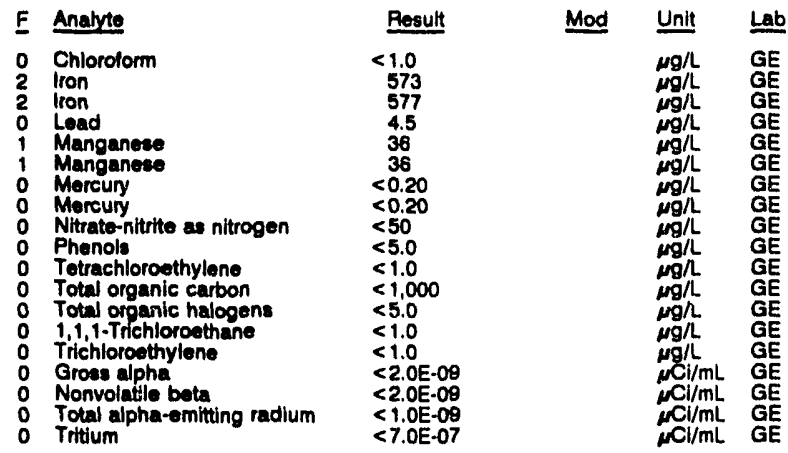

WELL MSB 28

MEASUREMENTS CONDUCTED IN THE FIELD

Sample date: 08/0492 Water atovation: $229.61 \mathrm{ft}(89.89 \mathrm{~m}) \mathrm{msl}$

conductance: $73.6 \mathrm{~s} / \mathrm{cm}$

$\mathrm{pH}: 6.7$

(n) $41 \mathrm{mg} / \mathrm{L}$

Water temperature: $22.1^{\circ} \mathrm{C}$

Water evacunted belore sampling: 50 gai

LABORATOAY ANALYSES

\begin{tabular}{|c|c|c|}
\hline Anabrte & Rosult & Unit \\
\hline $\begin{array}{l}\text { Cadmium } \\
\text { Carbon tetrachloride } \\
\text { Chioroform } \\
\text { ron } \\
\text { Lead } \\
\text { Manganese } \\
\text { Mercury } \\
\text { Nltrate-nitrite as nitrogen } \\
\text { Phenols } \\
\text { Phenole } \\
\text { Tetrachloroethylene } \\
\text { Total organic Carbon } \\
\text { Total organic halogens } \\
\text { 1,11. Thenloroetthane } \\
\text { Trichloroethylene } \\
\text { Groes alpha } \\
\text { Nonvolatlle beta } \\
\text { Total alpha-emitting radium } \\
\text { Trittum }\end{array}$ & $\begin{array}{l}<2.0 \\
<1.0 \\
<1.0 \\
7.0 \\
<3.0 \\
3.2 \\
<0.20 \\
1.00 \\
<5.0 \\
<5.0 \\
<1.0 \\
<1.000 \\
<5.0 \\
<1.0 \\
<1.0 \\
<2.0 E-08 \\
3.0 E \cdot 09 \pm 1.5 E-00 \\
<1.0 E-09 \\
8.1 E-07 \pm 5.0 E-07\end{array}$ & 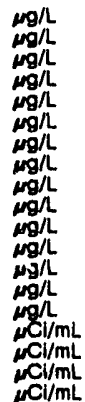 \\
\hline
\end{tabular}

WELL MSB 28A

MEASUREMENTS CONDUCTED IN THE FIELO

Depth to water: $131.50 \mathrm{~h}(40.08 \mathrm{~m})$ below TOC Water to wavation: $222.70 \mathrm{ft}(67.88 \mathrm{~m}) \mathrm{msl}$ So conductance. 12 (cm Water evacuated before sampling: $208 \mathrm{gal}$

Time: $8: 50$

Alkalinity: $0 \mathrm{mg} / \mathrm{h}$

Weter temperature: $18.8^{\circ} \mathrm{C}$

LABORATORY ANALYSES

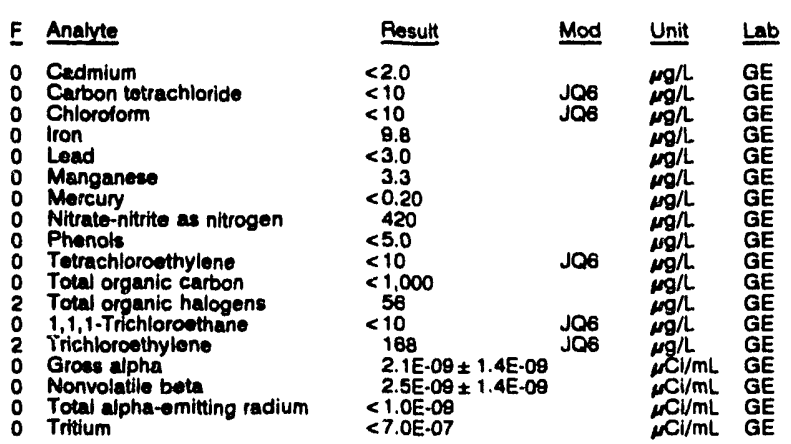

WELL MSB 29A

MEASUREMENTS CONDUCTED IN THE FIELD

Sample date: 07/26/82

Depth to water: $145.25 \mathrm{Ht}(44.27 \mathrm{~m})$ bolow TOC

Wator elevation: $220.15 \mathrm{~h}(67.10 \mathrm{~m}) \mathrm{ms}$

Water evacuated before sampling: $268 \mathrm{gal}$

LABORATORY ANALYSES

\begin{tabular}{|c|c|c|c|}
\hline Analyte & Result & Mod & Unit \\
\hline $\begin{array}{l}\text { pH } \\
\text { Spocific conductance } \\
\text { Areonic } \\
\text { Barlum } \\
\text { Cadmium } \\
\text { Chloride } \\
\text { Chromium } \\
\text { Copper } \\
\text { lron } \\
\text { Lead } \\
\text { Manganese } \\
\text { Morcury } \\
\text { Niakel } \\
\text { Nitrate-nitrite us nitrogen } \\
\text { Phenols } \\
\text { Solonlum } \\
\text { Silver } \\
\text { Sodium } \\
\text { Sulfate } \\
\text { Total organic carbon } \\
\text { Total organic halogens } \\
\text { Total phosphates (as P) } \\
\text { Zinc } \\
\text { Nonvolatile betta } \\
\text { Total alpha-emitting radium } \\
\text { Total alpha-emitting radium } \\
\text { Uranium-234 } \\
\text { Uranium-234 } \\
\text { Uranium-235 } \\
\text { Uranium-235 } \\
\text { Uranium-238 } \\
\text { Uranium-238 }\end{array}$ & $\begin{array}{l}6.4 \\
45 \\
<2.0 \\
20 \\
<2.0 \\
1,470 \\
<4.0 \\
<4.0 \\
40 \\
<3.0 \\
20 \\
<0.20 \\
<4.0 \\
780 \\
<5.0 \\
<2.0 \\
<2.0 \\
1,670 \\
4,320 \\
6.000 \\
<5.0 \\
<50 \\
11 \\
<2.0 E-09 \\
1.2 E-08 \neq 1.9 E-09 \\
1.1 E-09 \neq 8.0 E-10 \\
<1.0 E \cdot 09 \\
<1.0 E-09 \\
<1.0 E-09 \\
<1.0 E-09 \\
<1.0 E-09 \\
<1.0 E \cdot 09\end{array}$ & JO & 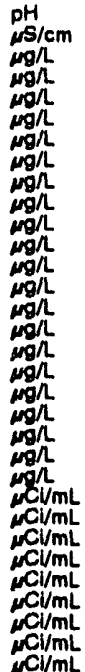 \\
\hline
\end{tabular}

WELL MSB 29B

MEASUREMENTS CONDUCTED IN THE FIELD

Sample date: 07/26/92

Depth to water: $140.52 \mathrm{~h}(42.83 \mathrm{~m})$ below TOC

Water elovation: $224.68 \mathrm{ft}(68.4$

Sp. conductance: $35 \mu \mathrm{s} / \mathrm{cm}$
Water evacuated before sampling: $202 \mathrm{gal}$

pH: 4.5

LABOPATORY ANALYSES

\begin{tabular}{|c|c|c|c|}
\hline Analyte & Result & Mod & Unit \\
\hline $\begin{array}{l}\text { pH } \\
\text { Specific conductance } \\
\text { Arsenic } \\
\text { Garium } \\
\text { Cudmium } \\
\text { Chloride } \\
\text { Chromium } \\
\text { Copper } \\
\text { lron } \\
\text { Lead } \\
\text { Manganese } \\
\text { Mercury } \\
\text { Nickel } \\
\text { Nitrate-nitrite as nitrogen } \\
\text { Phenols } \\
\text { Selenium } \\
\text { Silver } \\
\text { Sodium } \\
\text { Sulfate } \\
\text { Total organic carbon } \\
\text { Total organic halogens } \\
\text { Total phosphates gas P) } \\
\text { Total phosphates (as P) } \\
\text { Zinc } \\
\text { Nonvolatile bota } \\
\text { Total alpho-emitting radium } \\
\text { Uranium-234 } \\
\text { Uranium-235 } \\
\text { Uranium-238 }\end{array}$ & 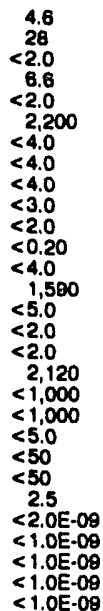 & Jo & 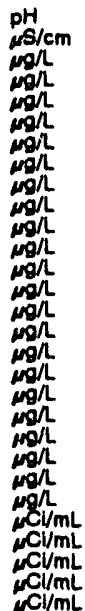 \\
\hline
\end{tabular}


WELL MSB 29C

MEASUREMENTS CONDUCTED IN THE FIELD

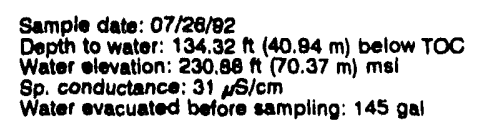
Water ovacuated before sampling: $145 \mathrm{gal}$

LABORATORY ANALYSES

\begin{tabular}{|c|c|c|c|c|c|}
\hline$F$ & Anabite & Result & Mod & Unit & Lab \\
\hline & $\begin{array}{l}\text { pH } \\
\text { Spectfic conductance } \\
\text { Arsenic } \\
\text { Barium } \\
\text { Cadmium } \\
\text { Chloride } \\
\text { Cliromium } \\
\text { Copper } \\
\text { Iron } \\
\text { Loed } \\
\text { Manganese } \\
\text { Morcury } \\
\text { Nickel } \\
\text { Nitralo-nitrite as nitrogen } \\
\text { Phonols } \\
\text { Solonium } \\
\text { Silver } \\
\text { Sodium } \\
\text { Sulfate } \\
\text { Total organic carbon } \\
\text { Total organic halogens } \\
\text { Total phosphates (as P) } \\
\text { Zinc } \\
\text { Nonvolatile beta } \\
\text { Total alphe-emitting radium } \\
\text { Uranlum-234 } \\
\text { Uranium-235 } \\
\text { Uranium-238 }\end{array}$ & $\begin{aligned} & 4.9 \\
& 28 \\
&<2.0 \\
& 5.6 \\
&<2.0 \\
& 1,050 \\
&<4.0 \\
&<4.0 \\
&<4.0 \\
&<3.0 \\
& 2.7 \\
&<0.20 \\
&<4.0 \\
& 1.600 \\
&<5.0 \\
&<2.0 \\
&<2.0 \\
& 2.080 \\
&<1,000 \\
&<1.000 \\
&<5.0 \\
&<50 \\
& 7.1 \\
& 3.7 E-09 \pm 1.6 E-09 \\
& 1.3 E-09 \pm 6.0 E-10 \\
&<1.0 E-09 \\
&<1.0 E-09 \\
&<1.0 E-09\end{aligned}$ & J & 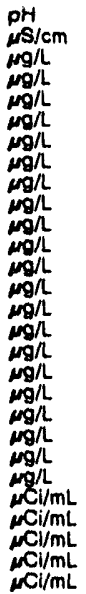 & $\begin{array}{l}\mathrm{GE} \\
\mathrm{GE} \\
\mathrm{GE} \\
\mathrm{GE} \\
\mathrm{GE} \\
\mathrm{GE} \\
\mathrm{GE} \\
\mathrm{GE} \\
\mathrm{GE} \\
\mathrm{GE} \\
\mathrm{GE} \\
\mathrm{GE} \\
\mathrm{GE} \\
\mathrm{GE} \\
\mathrm{GE} \\
\mathrm{GE} \\
\mathrm{GE} \\
\mathrm{GE} \\
\mathrm{GE} \\
\mathrm{GE} \\
\mathrm{GE} \\
\mathrm{GE} \\
\mathrm{GE} \\
\mathrm{GE} \\
\mathrm{GE} \\
\mathrm{GP} \\
\mathrm{GP} \\
\mathrm{GP}\end{array}$ \\
\hline
\end{tabular}

\section{WELL MSB 29D}

MEASUREMENTS CONDUCTED IN THE FIELD

Sample date: $07 / 28 / 92$
Depth to water: $132.15 \mathrm{H}(40.28 \mathrm{~m})$ below TOC
Water olovation: $232.95 \mathrm{n}(71.00 \mathrm{~m}) \mathrm{msl}$
Sp. conductance: $34 \mu \mathrm{s} / \mathrm{cm}$
Water evacuatod belore sampling: $63 \mathrm{gal}$

Time: 12:05

AH: 4.6 : $0 \mathrm{mgl}$

Water temperature: $22.1^{\circ} \mathrm{C}$

LABORATORY ANALYSES

\begin{tabular}{|c|c|c|c|c|}
\hline Analyte & Result & Mod & Unit & Lab \\
\hline $\begin{array}{l}\text { pH } \\
\text { Specific conductance } \\
\text { Areonic } \\
\text { Barium } \\
\text { Cadmium } \\
\text { Chloride } \\
\text { Chromium } \\
\text { Copper } \\
\text { Iron } \\
\text { Lead } \\
\text { Manganese } \\
\text { Morcuny } \\
\text { Nickel } \\
\text { Nitrato-nitrite as nitrogen } \\
\text { Phenols } \\
\text { Solenium } \\
\text { Silver } \\
\text { Sodium } \\
\text { Sulfato } \\
\text { Total organic carbon } \\
\text { Total organic halogens } \\
\text { Total phosphates (as P) } \\
\text { Zinc } \\
\text { Nonvolatile beta } \\
\text { Total alpha-emitting redium } \\
\text { Uranium-234 } \\
\text { Uranium-235 } \\
\text { Uranium-238 }\end{array}$ & $\begin{array}{c}4.7 \\
28 \\
<2.0 \\
6.6 \\
<2.0 \\
2.500 \\
<4.0 \\
7.5 \\
29 \\
6.4 \\
2.6 \\
<0.20 \\
<4.0 \\
1.520 \\
<5.0 \\
<2.0 \\
<2.0 \\
2.740 \\
1.220 \\
<1,000 \\
<5.0 \\
<50 \\
<2.0 \\
9.2 E-09 \pm 2.0 E-09 \\
7.6 E-09 \pm 1.5 E-09 \\
<1.0 E-09 \\
<1.0 E \cdot 08 \\
<1.0 E-09\end{array}$ & 10 & 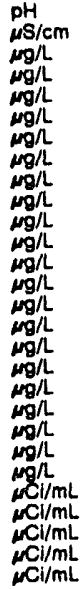 & $\begin{array}{l}\mathrm{GE} \\
\mathrm{GE} \\
\mathrm{GE} \\
\mathrm{GE} \\
\mathrm{GE} \\
\mathrm{GE} \\
\mathrm{GE} \\
\mathrm{GE} \\
\mathrm{GE} \\
\mathrm{GE} \\
\mathrm{GE} \\
\mathrm{GE} \\
\mathrm{GE} \\
\mathrm{GE} \\
\mathrm{GE} \\
\mathrm{GE} \\
\mathrm{GE} \\
\mathrm{GE} \\
\mathrm{GE} \\
\mathrm{GE} \\
\mathrm{GE} \\
\mathrm{GE} \\
\mathrm{GE} \\
\mathrm{GE} \\
\mathrm{GE}\end{array}$ \\
\hline
\end{tabular}

WELL. MSB 29TA

MEASUREMENTS CONDUCTED IN THE FIELO

Sample date: 07/26/92

Depth to water: 152.61 it $(48.52 \mathrm{~m})$ below TOC

Water slovation: $212.59 \mathrm{Ht}(84.80 \mathrm{~m}) \mathrm{mal}$

Water evacuated belore sampling: $400 \mathrm{gal}$

LABORATORY ANALYSES

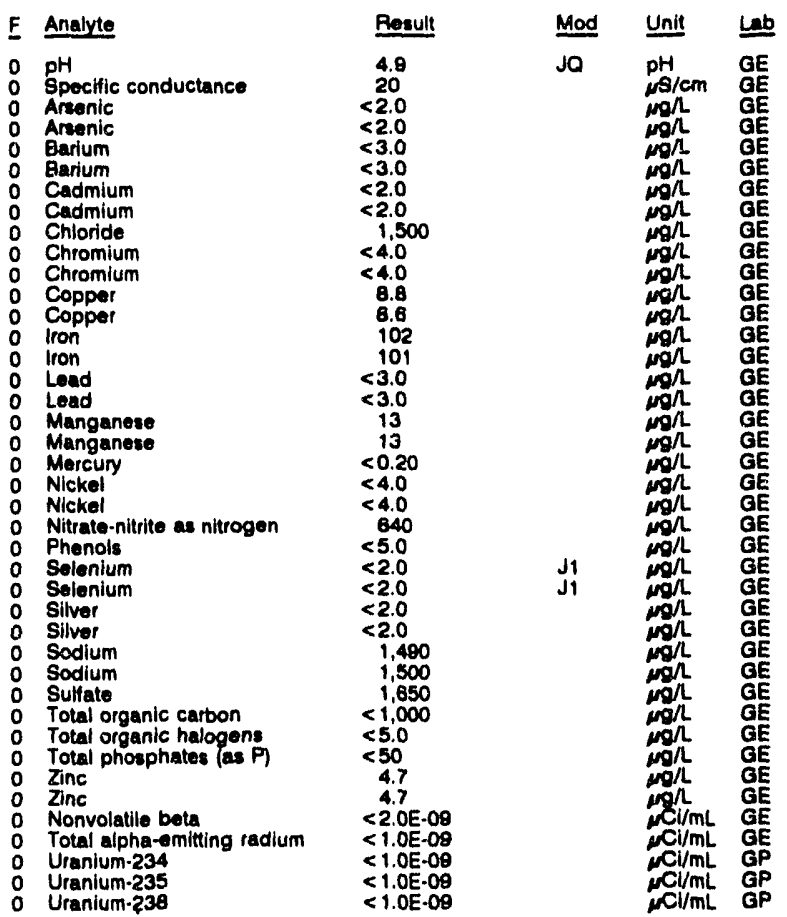

\section{WELL MSB 30A}

MEASUREMENTS CONDUCTED IN THE FIELD

Sample date: 08/0482

Depth to wator: 150.04 (t) $(47.58 \mathrm{~m})$ man

Sp. conductance: 56.58

Time: 11:55

Alkalinity: $0 \mathrm{~mol}$

Whater temperature: $22.00^{\circ} \mathrm{C}$

Water evacuated before sampling: $451 \mathrm{gal}$

LABORATORY ANALYSES

\begin{tabular}{|c|c|c|c|c|}
\hline$F$ & Analyte & Resoult & $\mathrm{Mod}$ & Unit \\
\hline & $\begin{array}{l}\text { Cadmium } \\
\text { Cadmium } \\
\text { Carbon totrachloride } \\
\text { Chioroform } \\
\text { rron } \\
\text { lron } \\
\text { Lead } \\
\text { Manganese } \\
\text { Manganese } \\
\text { Mercury } \\
\text { Nitrate-nitrite as nitrogen } \\
\text { Nitrate-nitrite as nittogen } \\
\text { Phenols } \\
\text { Tetrachloroethylene } \\
\text { Total organic carbon } \\
\text { Total organic halogens } \\
\text { 1,1.1-Trichloroethane } \\
\text { Trichloroethylene } \\
\text { Gross alpha } \\
\text { Nonvolatile beta } \\
\text { Total alpha-emitting radium } \\
\text { Tritium }\end{array}$ & $\begin{array}{l}<2.0 \\
<2.0 \\
<1.0 \\
<1.0 \\
20 \\
20 \\
<3.0 \\
14 \\
14 \\
<0.20 \\
<50 \\
<50 \\
<5.0 \\
<1.0 \\
<1.000 \\
<5.0 \\
<1.0 \\
<1.0 \\
<2.0 E-09 \\
2.3 E-09 \pm 1.4 E-0 \\
<1.0 E-09 \\
<7.0 E-07\end{array}$ & & 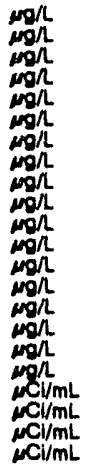 \\
\hline
\end{tabular}


ANALYTICAL RESULTS

WELL MSB 3OAA

MEASUREMENTS CONDUCTED IN THE FIELD

Sample date: 08/05/92

Depth to water: $129.12 \mathrm{ft}(39.38 \mathrm{~m})$ below TOC

Water olevation: $223.46 \mathrm{ft}$

Water ovacuated belore sampling: 77 gal

The woll went dry during purging.

LABORATORY ANALYYSES

\begin{tabular}{|c|c|c|c|c|c|}
\hline$\underline{F}$ & Analyte & Result & Mod & Unit & Lab \\
\hline $\begin{array}{l}2 \\
0 \\
0 \\
0 \\
0\end{array}$ & 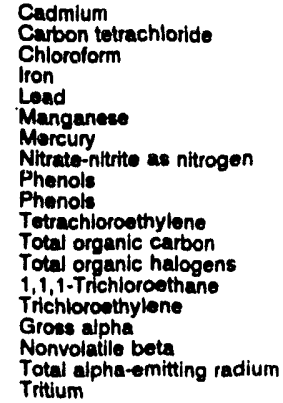 & $\begin{array}{l}<2.0 \\
<1.0 \\
<1.0 \\
4.680 \\
<3.0 \\
86 \\
<0.20 \\
<50 \\
<5.0 \\
<5.0 \\
<1.0 \\
1.040 \\
<5.0 \\
<1.0 \\
<1.0 \\
<2.0 \mathrm{E}-09 \\
4.1 \mathrm{E}-09 \pm 4.1 \mathrm{E} \cdot 10 \\
<1.0 \mathrm{E}-09 \\
<7.0 \mathrm{E}-07\end{array}$ & & 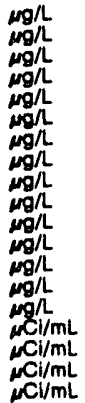 & $\begin{array}{l}\mathrm{GE} \\
\mathrm{GE} \\
\mathrm{GE} \\
\mathrm{GE} \\
\mathrm{GE} \\
\mathrm{GE} \\
\mathrm{GE} \\
\mathrm{GE} \\
\mathrm{GE} \\
\mathrm{GE} \\
\mathrm{GE} \\
\mathrm{GE} \\
\mathrm{GE}\end{array}$ \\
\hline
\end{tabular}

\section{WELL MSB 30B}

MEASUREMENTS CONDUCTED IN THE FIELD

Depth to water: $128.62 \mathrm{~A}(39.20 \mathrm{~m})$ below TOC

Wator lovation: $224.48 \mathrm{ft}(68.42 \mathrm{~m}) \mathrm{msl}$

Water evacuated before sampling: $263 \mathrm{gal}$

LABORATOAY ANALYSES

\begin{tabular}{|c|c|c|c|c|}
\hline Analyte & Result & Mod & Unit & Lab \\
\hline $\begin{array}{l}\text { Cadmium } \\
\text { Carbon tetrachloride } \\
\text { Chloroform } \\
\text { Iron } \\
\text { Lead } \\
\text { Manganese } \\
\text { Mercury } \\
\text { Nitrate-nitrite as nitrogen } \\
\text { Phenols } \\
\text { Phonols } \\
\text { Tetrachloroethylene } \\
\text { Total organic carton } \\
\text { Total organic halogens } \\
1,1,1 \text {-Trichloroethane } \\
\text { Trichloroethylene } \\
\text { Groes alpha } \\
\text { Nonvolatile beta } \\
\text { Total alpha-emitting radium } \\
\text { Tritium }\end{array}$ & $\begin{aligned}<2.0 \\
<1.0 \\
<1.0 \\
5.2 \\
3.8 \\
8.8 \\
<0.20 \\
50 \\
<5.0 \\
<5.0 \\
<1.0 \\
<1.000 \\
<5.0 \\
<1.0 \\
<1.0 \\
<2.0 \mathrm{E}-00 \\
<2.0 \mathrm{E}-09 \\
<1.0 \mathrm{E}-09 \\
<7.0 \mathrm{E}-07\end{aligned}$ & & 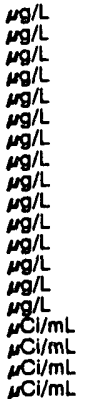 & $\begin{array}{l}\mathrm{GE} \\
\mathrm{GE} \\
\mathrm{GE} \\
\mathrm{GE} \\
\mathrm{GE} \\
\mathrm{GE} \\
\mathrm{GE} \\
\mathrm{GE} \\
\mathrm{GE} \\
\mathrm{GE} \\
\mathrm{GE} \\
\mathrm{GE} \\
\mathrm{GE} \\
\mathrm{GE} \\
\mathrm{GE} \\
\mathrm{GE} \\
\mathrm{GE} \\
\mathrm{GE} \\
\mathrm{GE}\end{array}$ \\
\hline
\end{tabular}

\section{WELL MSB 30C}

MEASUREMENTS CONDUCTED IN THE FIELD

Sample date: 08/04/92

Depth to water: $123.68 \mathrm{ft}(37.70 \mathrm{~m})$ below TOC Water elevation: $231.22 \mathrm{~A}(70.48 \mathrm{~m}) \mathrm{ms}$

Sp. conductance: $17 \mathrm{\mu S} / \mathrm{cm}$
Water evacuated before sampling: $38 \mathrm{gal}$

LABORATORY ANALYSES

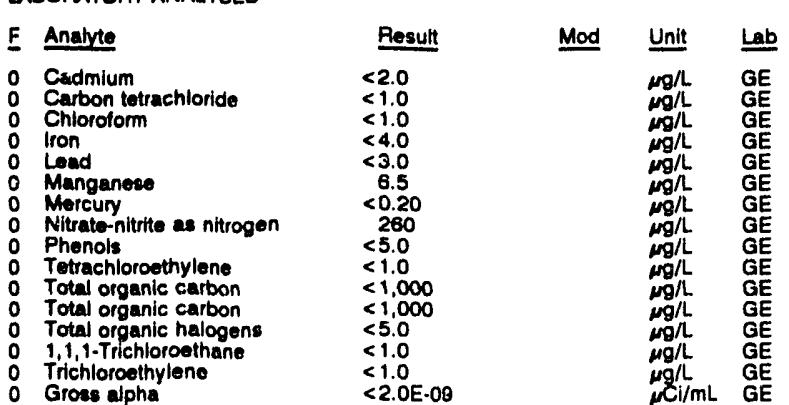

WEL MSB 30 C collected on 08/04/92, laboratory analyses (cont.)

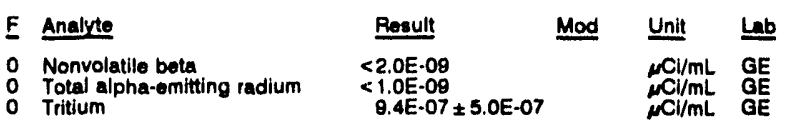

\section{WELL MSB 30CC}

MEASUREMENTS CONDUCTED IN THE FIELD

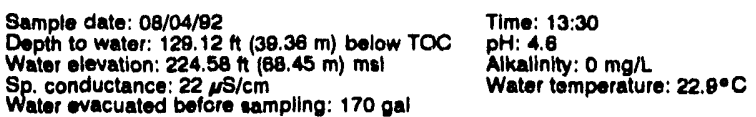

Sater conductance: $22 \mathrm{\mu S} / \mathrm{cm}$.

LABORATORY ANALYSES

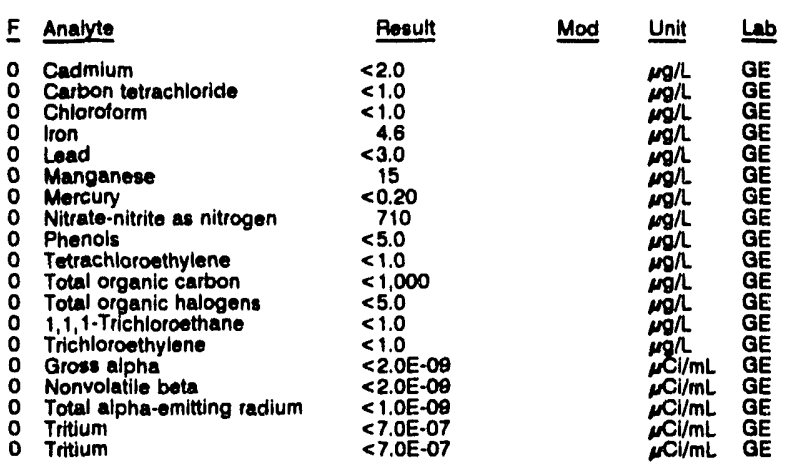

WELL MSB $31 \mathrm{~A}$

MEASUREMENTS CONDUCTED IN THE FIELD Sample date: 08/04/92
Depth to water: $149.31 \mathrm{tt}(45.51 \mathrm{~m})$ below TOC
Water olovation: $197.89 \mathrm{H}(60.32 \mathrm{~m}) \mathrm{ms}$ )

Water evacuated before sampling: $488 \mathrm{gal}$

pH: 5.0 . 0.09

Alkalinity: $0 \mathrm{mg} / \mathrm{L}$ : $22,6^{\circ} \mathrm{C}$

LABORATORY ANALYSES

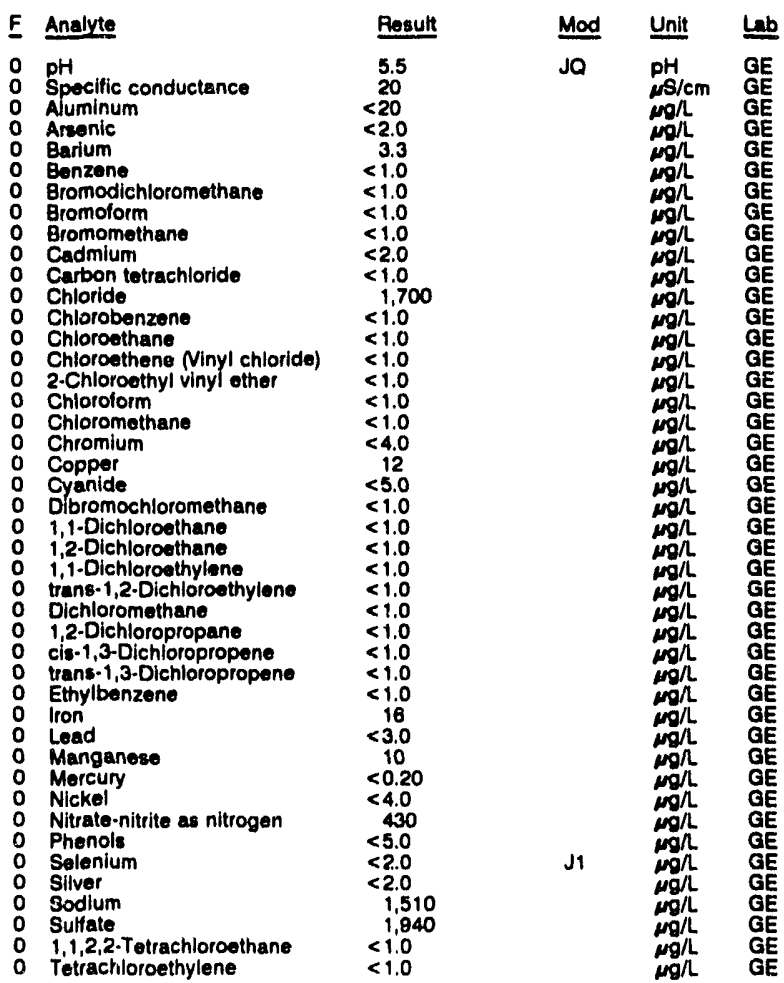


ANALYTICAL RESULTS

\begin{tabular}{|c|c|c|c|}
\hline Analyte & Rosult & Mod & Unit \\
\hline 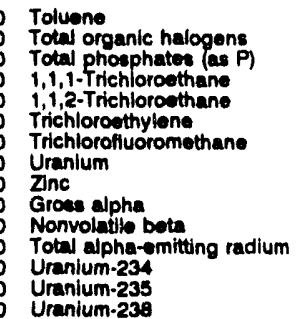 & $\begin{array}{l}<1.0 \\
<5.0 \\
<50 \\
<1.0 \\
<1.0 \\
<1.0 \\
<1.0 \\
<20 \\
10 \\
<2.0 E-09 \\
<2.0 E-09 \\
<1.0 E-09 \\
<1.0 E-09 \\
<1.0 E-09 \\
<1.0 E-00\end{array}$ & & 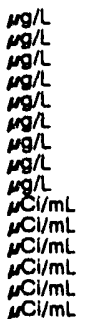 \\
\hline
\end{tabular}

WELL MSB 31B

MEASUREMENTS CONDUCTED IN THE FIELO

Sample date: 06/04/92

Depth to watior: $135.37 n(41.26 \mathrm{~m})$ below TOC Water etovation: $212.13 \mathrm{n}(84.68 \mathrm{~m}) \mathrm{mal}$ Sp. conductence: $37 \mathrm{~m} / \mathrm{cm}$

Water evecuatod before sampling: $157 \mathrm{gal}$

LABORATOAY ANALYSES

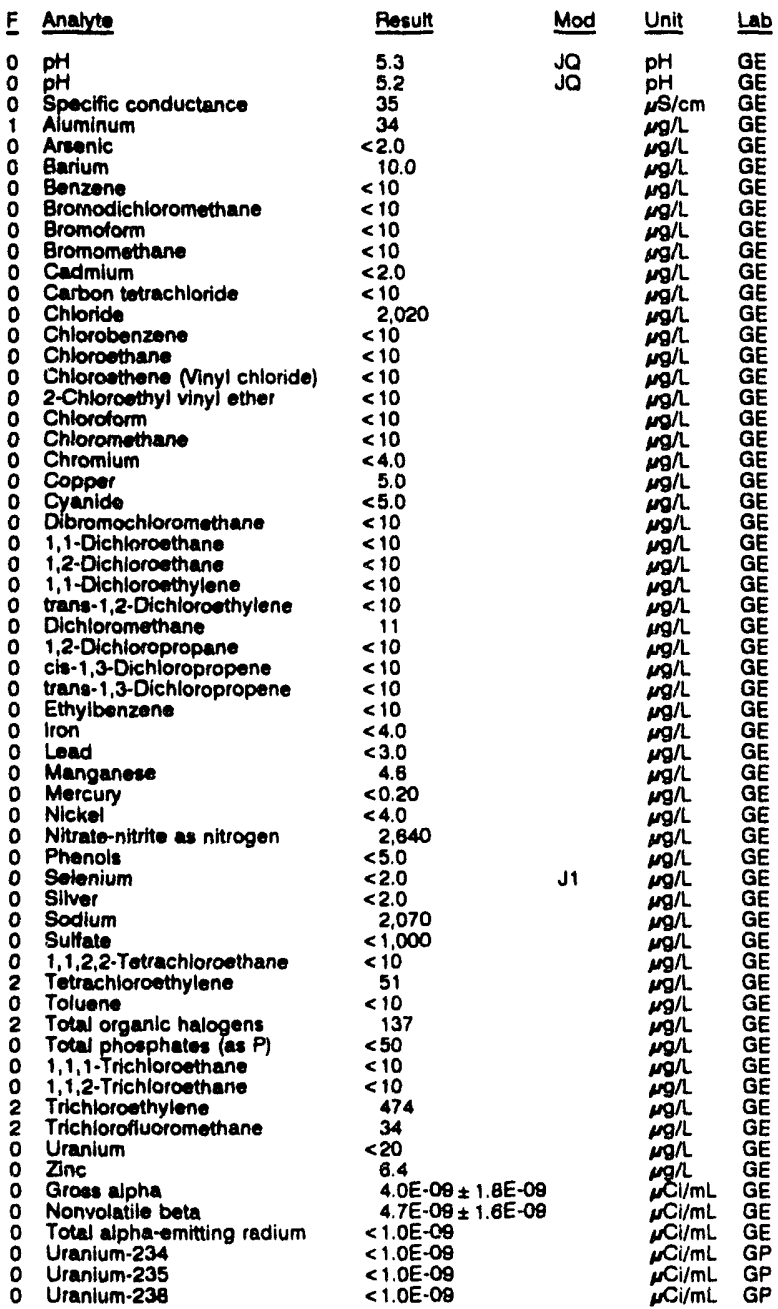

WELL MSB 31C

MEASUREMENTS CONOUCTED IN THE FIELD

Sample date: 08/17/92

Depth to water: $113.83 \mathrm{H}(34.70 \mathrm{~m})$ below TOC Water elevation: $233.47 \mathrm{ft}(71.16 \mathrm{~m}) \mathrm{ms}$ Water evacuated bofore sampling: $46 \mathrm{gol}$

LABORATORY ANALYSES

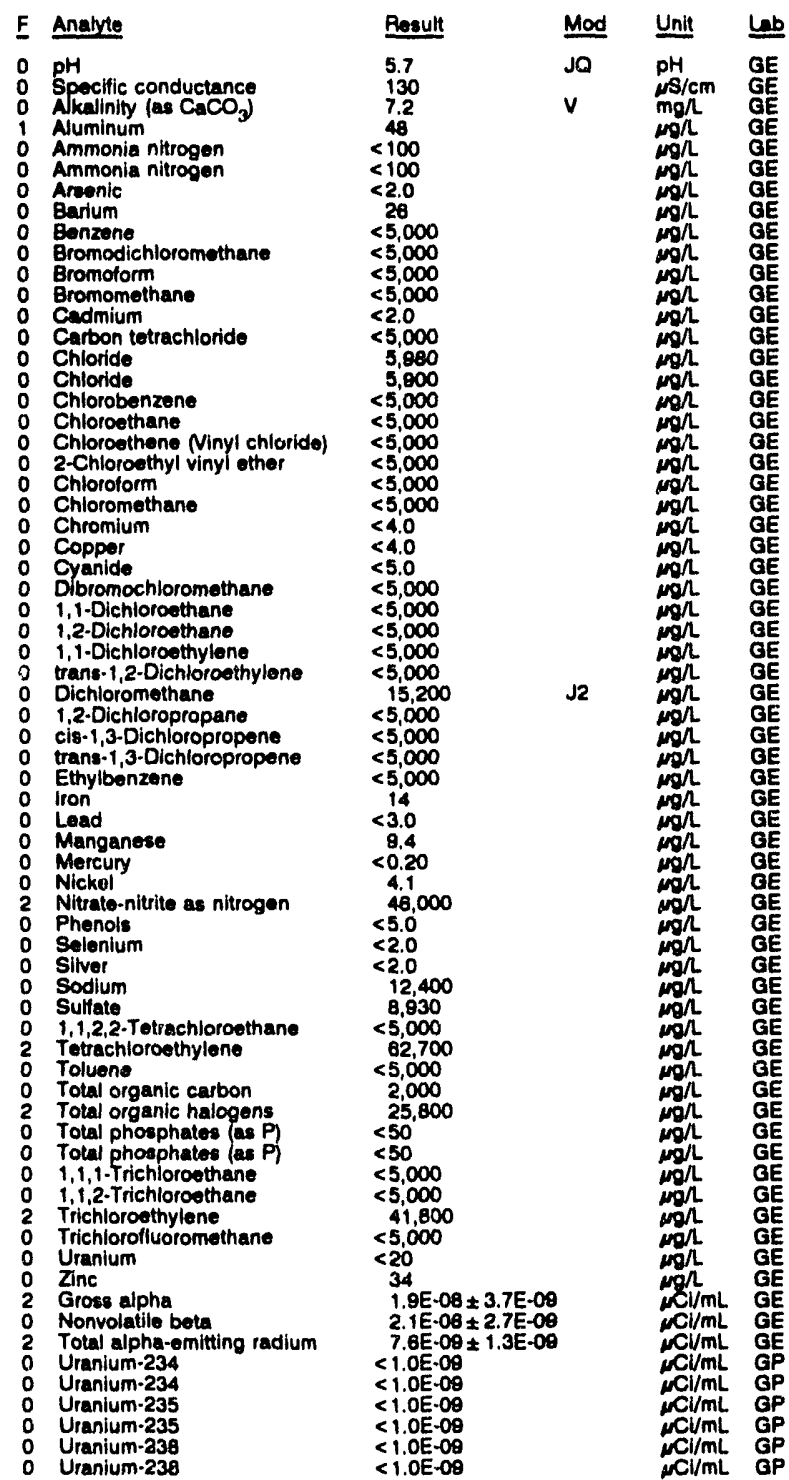

WELL MSB 31CC

MEASUAEMEINTS CONOUCTED IN THE FIELD

\begin{tabular}{|c|c|c|c|c|c|}
\hline \multicolumn{3}{|c|}{$\begin{array}{l}\text { Sample date: } 08 / 04 / 82 \\
\text { Depth to water: } 135.17 \mathrm{ft}(41.20 \mathrm{~m}) \text { bolow TOC } \\
\text { Water olovation: } 213.63 \mathrm{~h}(65.12 \mathrm{~m}) \mathrm{msl} \\
\text { Sp. conductance: } 54 \mu \mathrm{s} / \mathrm{cm} \\
\text { Water ovacuated before sampling: } 88 \mathrm{gal}\end{array}$} & \multicolumn{3}{|c|}{$\begin{array}{l}\text { Time: } 14: 50 \\
\text { pH: } 5.8 \\
\text { Alkalinity: } 5 \mathrm{mgh} \\
\text { Water temperature: } 22.7 \circ \mathrm{C}\end{array}$} \\
\hline \multicolumn{6}{|c|}{ LABORATORY ANALYSES } \\
\hline & Analyte & Result & Mod & Unit & Lab \\
\hline & $\begin{array}{l}\text { Cadmium } \\
\text { Carbon tetrachioride } \\
\text { Chloroform }\end{array}$ & $\begin{array}{l}<2.0 \\
<5.0 \\
<5.0\end{array}$ & & $\underset{m g h}{\operatorname{mg} \Omega}$ & $\begin{array}{l}\text { GE } \\
\text { GE } \\
\text { GE }\end{array}$ \\
\hline
\end{tabular}


WELL MSB 31CC collocted on 08/04/92, laboratory analyses (cont.)

\begin{tabular}{|c|c|c|c|}
\hline $\boldsymbol{E}$ & Analute & Rosult & Unit \\
\hline $\begin{array}{l}0 \\
0 \\
0 \\
0 \\
0 \\
2 \\
0 \\
0 \\
2 \\
2 \\
0 \\
0 \\
2 \\
0 \\
0 \\
0\end{array}$ & $\begin{array}{l}\text { Iron } \\
\text { Lead } \\
\text { Manganese } \\
\text { Mercury } \\
\text { Nitrate-nitrite at nitrogen } \\
\text { Phenole } \\
\text { Totrachloroethylene } \\
\text { Total organic carbon } \\
\text { Total organic carbon } \\
\text { Total organic halogons } \\
\text { Total organic halogens } \\
1,1,1 \text {-Trichloroethane } \\
\text { Trichloroethylene } \\
\text { Groes alpha } \\
\text { Nonvolatile beta } \\
\text { Total alpha-emitting radium } \\
\text { Trtium }\end{array}$ & $\begin{array}{l}12 \\
<3.0 \\
7.8 \\
<0.20 \\
2,040 \\
<5.0 \\
13 \\
<1,000 \\
<1,000 \\
177 \\
180 \\
<5.0 \\
412 \\
<2.0 \mathrm{E}-09 \\
2.8 \mathrm{E}-09 \\
<1.0 \mathrm{E}-09 \\
<7.0 \mathrm{E}-07\end{array}$ & 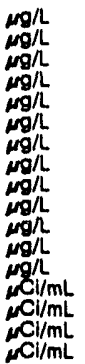 \\
\hline
\end{tabular}

\section{WELL MSB 32}

MEASUAEMENTS CONDUCTED IN THE FIELD

Sample date: 07/08/82

Water olevation: $224.25 \mathrm{~h}(88.35 \mathrm{~m}) \mathrm{msl}$

Sp. conductance: $27 \mu \mathrm{s} / \mathrm{cm}$

Time: $8: 30$

pH: 4.8

Alkainity: $1 \mathrm{mg} / \mathrm{h}$

LABORATORY ANALYSES

\begin{tabular}{|c|c|c|c|}
\hline Analyte & Result & Mod & Unit \\
\hline $\begin{array}{l}\text { Cadmium } \\
\text { Carbon tetrachloride } \\
\text { Chloroform } \\
\text { Iron } \\
\text { Lead } \\
\text { Manganese } \\
\text { Mercury } \\
\text { Nitrate-nitrite as nitrogen } \\
\text { Tetrachloroethylene } \\
\text { Total organic carbon } \\
\text { Total organic carbon } \\
\text { Total orpanic halogens } \\
1,1,1-\text { Trichloroethane } \\
\text { Trichloroothyiene } \\
\text { Gross alpha } \\
\text { Nonvolatile beta } \\
\text { Total alpha-emitting radium } \\
\text { Tritium }\end{array}$ & $\begin{array}{l}<2.0 \\
<1.0 \\
<1.0 \\
15 \\
<3.0 \\
<2.0 \\
<0.20 \\
670 \\
14 \\
<1,000 \\
<1,000 \\
<5.0 \\
<1.0 \\
64 \\
<2.0 \mathrm{E}-09 \\
<2.0 \mathrm{E}-09 \\
<1.0 \mathrm{E}-09 \\
<7.0 \mathrm{E}-07\end{array}$ & & 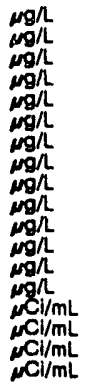 \\
\hline
\end{tabular}

WELL MSB 33

MEASUREMENTS CONDUCTED IN THE FIELD

Sample date: 07/07/82

Depth to water: $37.50 \mathrm{ft}(11.43 \mathrm{~m})$ below TOC

Wator glovation: $219.10 \mathrm{H}(68.78 \mathrm{~m}) \mathrm{ma}$

Sp. conductance: $64 \mu \mathrm{s} / \mathrm{cm}$
Water evacuatod beforo sampling: $32 \mathrm{gal}$

LABORATORY ANALYSES

\begin{tabular}{|c|c|c|c|c|}
\hline 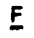 & Anabute & Result & Mod & Unit \\
\hline 0 & $\begin{array}{l}\text { Cadmium } \\
\text { Iron } \\
\text { Lead } \\
\text { Manganese } \\
\text { Mercury } \\
\text { Nitrato-nitrtte as nitrogen } \\
\text { Phenole } \\
\text { Total organic carbon } \\
\text { Total organic halogens } \\
\text { Groase alpha } \\
\text { Nonvolatile beta } \\
\text { Total alpha-emitting radium } \\
\text { Trittum }\end{array}$ & $\begin{array}{l}<2.0 \\
60 \\
<3.0 \\
<2.0 \\
<0.20 \\
4,800 \\
<5.0 \\
<1,000 \\
14 \\
<2.0 \mathrm{E}-09 \\
<2.0 \mathrm{E}-09 \\
1.7 \mathrm{E}-09 \pm 1.0 \mathrm{E}-08 \\
<7.0 \mathrm{E}-07\end{array}$ & & 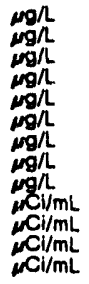 \\
\hline
\end{tabular}

WELL MSB 33A

MEASUAEMENTS CONDUCTED IN THE FIELD

Depth to water: $51.31 \mathrm{ht}(15.64 \mathrm{~m})$ below TOC

Water olevation; $204.09 \mathrm{~h}(62.21 \mathrm{~m}) \mathrm{mal}$

Water evacuated belore sampling: $314 \mathrm{gal}$

LABORATOAY ANALYSES

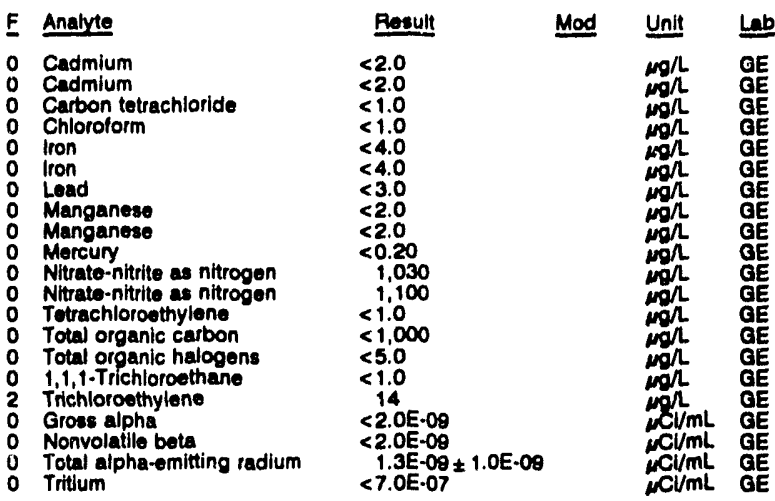

\section{WELL MSB 33B}

MEASUREMENTS CONDUCTED IN THE FIELD

Sample date: $07107 / 92$

Depth to wator: 47.88 it $(14.59 \mathrm{~m})$ below TOC

Water elevation: $207.32 \mathrm{ft}(63.10 \mathrm{~m}) \mathrm{ms}$

pling: $223 \mathrm{gal}$

Time: 10:55

Alkalinity: $1 \mathrm{mon}$

Water tomperature: $21.3^{\circ} \mathrm{C}$

LABORATOAY ANALYSES

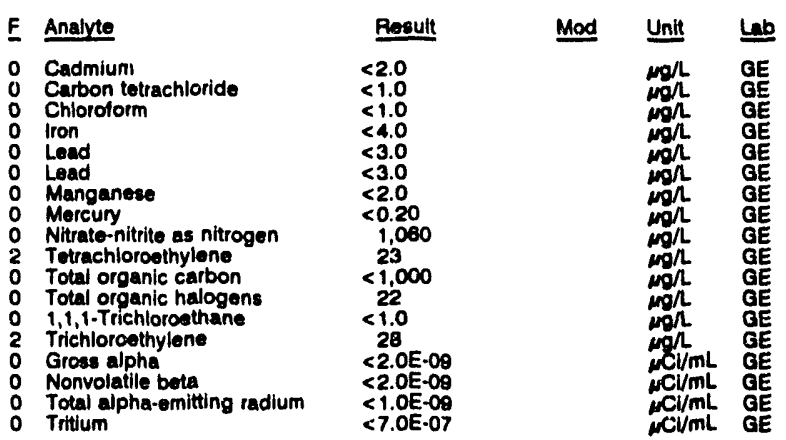

\section{WELL MSB 33C}

MEASUREMENTS CONDUCTED IN THE FIELO

Depth to water: $45.16 \mathrm{ft}(13.76 \mathrm{~m})$ below TOC

Wopth to water: $45.18 \mathrm{~h}(13.76 \mathrm{~m})$ bolow
Water elevation: $210.14 \mathrm{~h}(64.05 \mathrm{~m}) \mathrm{msi}$
Sp. conductance: $44,5 \mathrm{~cm}$

Time: 10:25

A. 5.22101

Water temporature: $22.0 \circ \mathrm{C}$

Water ovacuated before sampling: $113 \mathrm{gal}$

LABORATORY ANALYSES

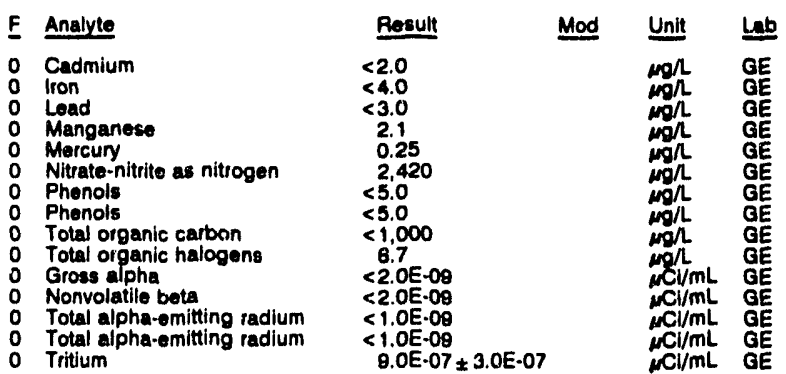




\section{ANALYTICAL RESULTS}

WELL MSB 33TA

MEASUREMENTS CONDUCTED IN THE FIELD

Sample dats: 07/07/02

Dopth to water: 61.29 in $(18.68 \mathrm{~m})$ below TOC

Water olevation: 194.21 ht (59.2

W. conductanco: 24 rolcm

LABOFATOFY ANALYSES

\begin{tabular}{|c|c|c|}
\hline & Analyte & Renult \\
\hline & 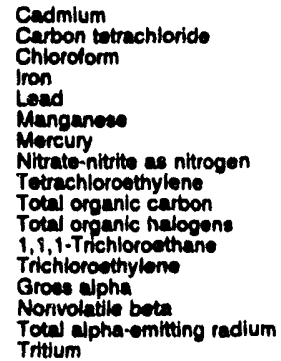 & $\begin{array}{l}<2.0 \\
<1.0 \\
<1.0 \\
7.4 \\
5.6 \\
54 \\
<0.20 \\
430 \\
<1.0 \\
<1.000 \\
12 \\
<1.0 \\
<1.0 \\
<2.0 E-09 \\
<2.0 E-09 \\
<1.0 E-09 \\
<7.0 E-07\end{array}$ \\
\hline
\end{tabular}

\section{WELL MSB 34A}

MEASUREMENTS CONDUCTED IN THE FIELD

Sample date: 08/17/92

Depth to water: $165.40 \mathrm{ft}(50.41 \mathrm{~m})$ below TOC Wator olovation: $217.80 \mathrm{ft}(66.38 \mathrm{~m}) \mathrm{ms}$

Water ovacuated bofore sampling: $274 \mathrm{gal}$

LABOPATORY ANALYSES

\begin{tabular}{|c|c|c|c|c|}
\hline E Analyte & Rese:!t & Mod & Unit & Lab \\
\hline 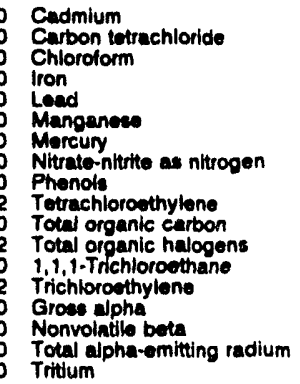 & $\begin{array}{l}<2.0 \\
<100 \\
<100 \\
<4.0 \\
<3.0 \\
3.8 \\
<0.20 \\
1,280 \\
<5.0 \\
210 \\
<1,000 \\
995 \\
<100 \\
3,600 \\
<2.0 \mathrm{E}-09 \\
<2.0 \mathrm{E}-09 \\
<1.0 \mathrm{E}-09 \\
<7.0 \mathrm{E}-07\end{array}$ & $\begin{array}{l}\text { JO } \\
\text { JO }\end{array}$ & 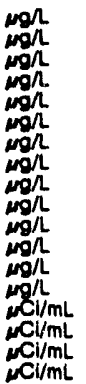 & $\begin{array}{l}\mathrm{GE} \\
\mathrm{GE} \\
\mathrm{GE} \\
\mathrm{GE} \\
\mathrm{GE} \\
\mathrm{GE} \\
\mathrm{GE} \\
\mathrm{GE} \\
\mathrm{GE} \\
\mathrm{GE} \\
\mathrm{GE} \\
\mathrm{GE} \\
\mathrm{GE} \\
\mathrm{GE} \\
\mathrm{GE} \\
\mathrm{GE} \\
\mathrm{GE} \\
\mathrm{GE}\end{array}$ \\
\hline
\end{tabular}

\section{WELL MSB 34B}

MEASUREMENTS CONDUCTED IN THE FIELD

Sampla date: 08/17/92

(157.47 $\mathrm{h}(48.00 \mathrm{~m})$ below roc

Water elevation: $225.63 \mathrm{tt}(88.77 \mathrm{~m}) \mathrm{mew}$

Sp. conductance: $14 \mathrm{~s} / \mathrm{cm}$.

Water ovecuated before sampling: $76 \mathrm{gal}$

LABOFATOAY ANALYSES

\begin{tabular}{|c|c|c|c|c|}
\hline & Analyte & Result & Mod & Unit \\
\hline & $\begin{array}{l}\text { Cadmium } \\
\text { lron } \\
\text { Lead } \\
\text { Manganese } \\
\text { Mercuny } \\
\text { Nitrate-nitrite as nitrogen } \\
\text { Phenols } \\
\text { Total Organic carbon } \\
\text { Total organic halogens } \\
\text { Groes alph } \\
\text { Groses apha } \\
\text { Nonvolatile beta } \\
\text { Nonvolatile bota } \\
\text { Total alpha-omitting radium } \\
\text { Tritium }\end{array}$ & $\begin{array}{l}<2.0 \\
<4.0 \\
<3.0 \\
3.0 \\
<0.20 \\
1.100 \\
<5.0 \\
<1,000 \\
35 \\
2.2 E-09 \pm 1.4 E-09 \\
2.2 E-09 \pm 1.4 \mathrm{E} \cdot 00 \\
2.5 \mathrm{E}-09 \pm 1.6 \mathrm{E}-09 \\
2.7 \mathrm{E}-09 \pm 1.6 \mathrm{E}-00 \\
1.0 \mathrm{E}-09 \pm 5.0 \mathrm{E}-10 \\
<7.0 \mathrm{E}-07\end{array}$ & & 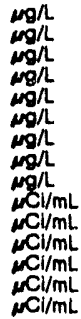 \\
\hline
\end{tabular}

Time: 14:20

Alkalinity: $0 \mathrm{~mol}$

Water temporature: $21.0^{\circ} \mathrm{C}$

Time: 13:

Alkalinity: $1 \mathrm{mgh}$

Water tempergture: $21.20 \mathrm{C}$
WELL MSB 34C

MEASURF MENTS CONDUCTED IN THE FIELD

Semple date: 08/09/92 190.24 m) below TOC

Water elevation: $231.50 \mathrm{~h}(70.58 \mathrm{~m}) \mathrm{mal}$

Whet ovacuated bofore eampling: $28 \mathrm{gal}$

LABORATORY ANALYSES

\begin{tabular}{|c|c|c|c|c|}
\hline$F$ & Analyte & Result & Unt & et \\
\hline & 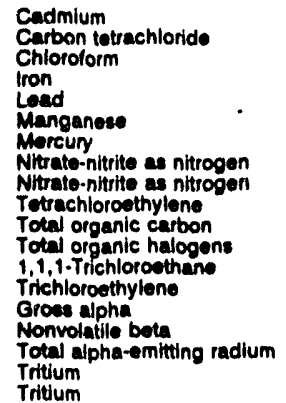 & $\begin{array}{l}<2.0 \\
<5.0 \\
<5.0 \\
5.7 \\
12 \\
8.1 \\
<0.20 \\
2,080 \\
2,040 \\
35 \\
<1,000 \\
74.0 \\
<5.0 \\
102 \\
5.1 E-09 \pm 8.6 E-10 \\
4.4 E-00 \pm 7.2 E-10 \\
3.5 E-09 \pm 8.0 E-10 \\
<7.0 E-07=8.07 \\
<7.0 E .07\end{array}$ & 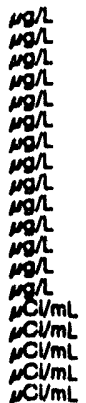 & $\begin{array}{l}\text { QE } \\
\text { GE } \\
\text { QE } \\
\text { QE } \\
\text { QE } \\
\text { QE } \\
\text { QE } \\
\text { QE }\end{array}$ \\
\hline
\end{tabular}

\section{WELL MSB 34TA}

MEASUREMENTS CONDUCTED IN THE FIELD

Sample date: 08/09/92

Depth to water: $179.83 \mathrm{~h}(54.81 \mathrm{~m})$ below TOC

Sp. conductionc: $202.87 \mathrm{ht}(61.7$

Water evacuated belore sampling: $801 \mathrm{gal}$

LABORATOAY ANALYSES

\begin{tabular}{|c|c|c|c|}
\hline E Analyte & Rosult & Mod & Unh \\
\hline $\begin{array}{l}\text { Cadmlum } \\
\text { Carbon totrachloride } \\
\text { Chlorolorm } \\
\text { lron } \\
\text { Lead } \\
\text { Manganese } \\
\text { Mercury } \\
\text { Nitrate-nitrite as nitrogen } \\
\text { Tetrachloroethylene } \\
\text { Total organic carbon } \\
\text { Total organic halogens } \\
\text { 1,11. Trichloroethane } \\
\text { Trichloroethylene } \\
\text { Grose alpha } \\
\text { Nonvolatile beta } \\
\text { Total alpha-emitting radium } \\
\text { Tritium }\end{array}$ & $\begin{array}{l}<2.0 \\
<1.0 \\
<1.0 \\
285 \\
<3.0 \\
114 \\
<0.20 \\
300 \\
<1.0 \\
<1.000 \\
<5.0 \\
<1.0 \\
<1.0 \\
<2.0 E-09 \\
<2.0 E-09 \\
<1.0 E-09 \\
<7.0 E-07\end{array}$ & & mon \\
\hline
\end{tabular}

\section{WELL MSB 34TB}

MEASUREMENTS CONDUCTED IN THE FIELD

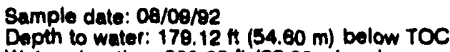

Water elevation: $203.68 \mathrm{~h}(62.08 \mathrm{~m}) \mathrm{mal}$

Sp. conductance: $38 \mathrm{~s} / \mathrm{cm}$

Water ovacuated before campling: 382 gai

Time: 16:35

Alkalinity: 0 molt

Water temperature: $22.80 \mathrm{C}$

LABORATORY ANALYSES

\begin{tabular}{|c|c|c|c|}
\hline E Analyce & Rosuln & Mod & Unit \\
\hline $\begin{array}{ll}0 & \text { Cadmium } \\
0 & \text { Carbon totrachloride } \\
0 & \text { Chlorolorm } \\
2 & \text { lron } \\
1 & \text { Lead } \\
0 & \text { Manganese } \\
0 & \text { Mercury } \\
0 & \text { Nitrate-nitrite as nitrogen } \\
0 & \text { Tetrachloroothylene } \\
0 & \text { Total organic carbon } \\
0 & \text { Total organic carbon } \\
0 & \text { Total organic halogens } \\
0 & 1,1,1 \text {-Trichloroethane } \\
0 & \text { Trichlorosthylene } \\
0 & \text { Groes alpha } \\
0 & \text { Nonvolatile beta } \\
0 & \text { Total alpha-emitting radium } \\
0 & \text { Tritium }\end{array}$ & $\begin{array}{l}<2.0 \\
<1.0 \\
<1.0 \\
310 \\
7.6 \\
11 \\
<0.20 \\
270 \\
<1.0 \\
<1.000 \\
<1,000 \\
<5.0 \\
<1.0 \\
<1.0 \\
<2.0 E-09 \\
<2.0 E-09 \\
<1.0 E-09 \\
<7.0 E-07\end{array}$ & & 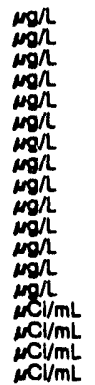 \\
\hline
\end{tabular}

Alkulinity: $0 \mathrm{mon}$

Whater temperature: $21.5 \circ 0$

Akalinity: $1 \mathrm{mgh}$ Watef tomperture: $23.3^{\circ} \mathrm{C}$

$M \mathrm{C} / \mathrm{mL}$
$\mathrm{Cl} / \mathrm{mL}$ GE
Time: $17: 30$ 
WELL MSB 35A

MEASUREMENTS CONDUCTED IN THE FIELD

Sample data: 08/04/02

Dopth to wator: $134.02 \mathrm{~h}(41,2 \mathrm{~m})$ below TOC Wator covation: $216.16 \mathrm{~h}$.

Wator ovacuatod boforo sampling: $238 \mathrm{gal}$

LABOPATORY ANALYSES

\begin{tabular}{|c|c|}
\hline Anabyte & Pesult \\
\hline 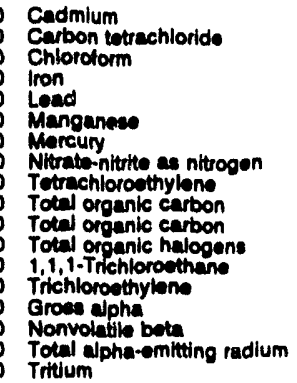 & $\begin{array}{l}<2.0 \\
<1.0 \\
<1.0 \\
5.00 \\
<3.0 \\
2.6 \\
<0.20 \\
1.110 \\
<1.0 \\
<1,000 \\
<1.000 \\
<5.0 \\
<1.0 \\
1.0 \\
<2.0 E-09 \\
<2.0 E-00 \\
<1.0 E-09 \\
<7.0 E-07\end{array}$ \\
\hline
\end{tabular}

\section{WELL MSB 35B}

MEASUREMENTS CONDUCTED IN THE FIELD

Sample date: 08/04/92

Depit to wator: 132.65 n $(40.43 \mathrm{~m})$ below TOC Water elovation: $210.15 \mathrm{n}$ (68.8

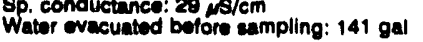

LABOPATOAY ANALYBES

E Anelyte

- Cadmium

Carbon tetrachloride

Chiorotorm

0 Iron

0 Manganese

Mercury

Nitrato-nitrite as nitrogen

Tetrachloroethylene

Total organic halogens

1,1,1-Trichloroethane

Trichlorosthylene

Grows alpha

Groes alpha

Nonvolatile beta

Total alpha-emitting radium

\begin{tabular}{|c|}
\hline Resul \\
\hline $\begin{array}{l}<2.0 \\
<1.0 \\
<1.0 \\
111 \\
<3.0 \\
<2.0 \\
<0.20 \\
180 \\
<5.0 \\
<1.0 \\
<1.000 \\
<5.0 \\
<1.0 \\
<1.0 \\
<2.0 E \\
<2.0 E\end{array}$ \\
\hline
\end{tabular}

WELL MSB 35D

MEASUREMENTS CONDUCTED IN THE FIELD

Sample date: 08/04/82

The woll was dry.

Time: 7:45

WELL MSB 35TA

MEASUREMENTS CONDUCTED IN THE FIELD

Sample date: 08/04/82

Depth to water: $149.33 \mathrm{n}(45.52 \mathrm{~m})$ below TOC

Wator elevation: 201.07 it $(61$

Wator evecunced before

LABORATOAY ANALYSES

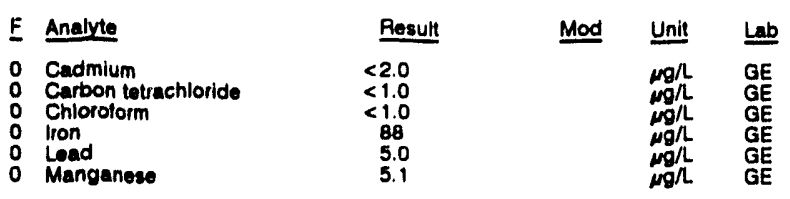

Time: 8:40

Alkalinity: $7 \mathrm{mgn}$

Whter temperitur: $20.9^{\circ} \mathrm{C}$

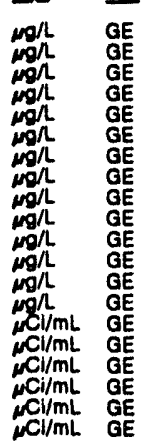

Time: $6: 50$

Alkalinity: $0 \mathrm{mgn}$

Water temperature: $20.5^{\circ} \mathrm{C}$
WELL MSB 35TA collected on 08/04/92, laboratory analyses (cont.)

\begin{tabular}{|c|c|c|c|}
\hline E Analyte & Result & Mod & Unit \\
\hline $\begin{array}{ll}0 & \text { Mercury } \\
0 & \text { Nitrate-nitrite as nitrogen } \\
0 & \text { Tetrachlorosthylone } \\
0 & \text { Total organic carbon } \\
0 & \text { Total organic halogons } \\
0 & 1,1,1 . \text { Trichloroethane } \\
0 & \text { Trichloroethylone } \\
0 & \text { Gross alpha } \\
0 & \text { Nonvolatile bota } \\
0 & \text { Total alpha-emitting radium } \\
0 & \text { Tritium }\end{array}$ & $\begin{aligned} &< 0.20 \\
& 330 \\
&<1.0 \\
&<1.000 \\
&<5.0 \\
&<1.0 \\
&<1.0 \\
&<2.0 \mathrm{E} \cdot 09 \\
&<2.0 \mathrm{E} \cdot 09 \\
&<1.0 \mathrm{E} \cdot 09 \\
&<7.0 \mathrm{E} \cdot 07\end{aligned}$ & & 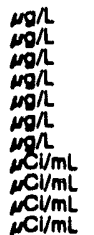 \\
\hline
\end{tabular}

WELL MSB 36A

MEASUAEMENTS CONDUCTED IN THE FIELO

\begin{tabular}{|c|c|}
\hline $\begin{array}{l}\text { Sample date: } 07 / 24 / 92 \\
\text { Depth to water: } 131.54 \mathrm{~h}(40.09 \mathrm{~m}) \text { below TOC } \\
\text { Water elevation: } 209.06 \mathrm{H}(63.72 \mathrm{~m}) \mathrm{mal} \\
\text { Sp. conductance: } 45, \mathrm{~s} / \mathrm{cm} \\
\text { Witer evecuated bolore sampling: } 87 \mathrm{gal}\end{array}$ & $\begin{array}{l}\text { Time: } 4: 30 \\
\text { pH: } 4.4 \\
\text { Alkalinity: } 0 \mathrm{mgh} \\
\text { Water temporature: } 19.6 \cdot \mathrm{C}\end{array}$ \\
\hline
\end{tabular}

The wall went dry during purging.

LABORATORY ANALYSES

\begin{tabular}{|c|c|c|c|}
\hline Anabute & Result & Mod & Unit \\
\hline 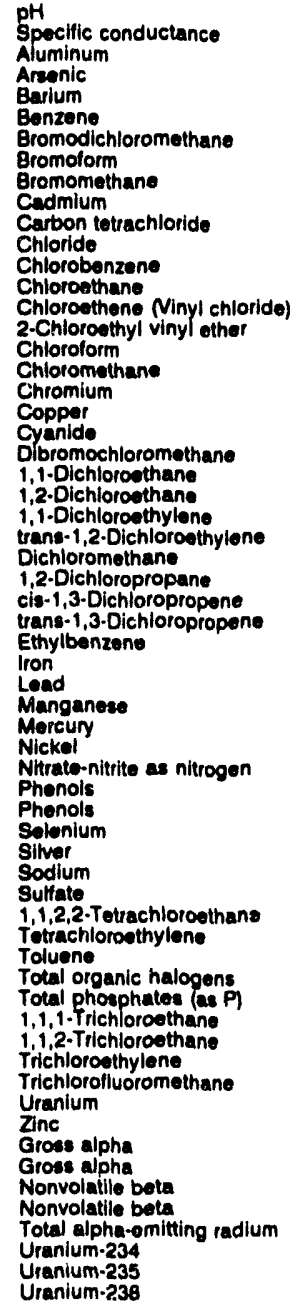 & 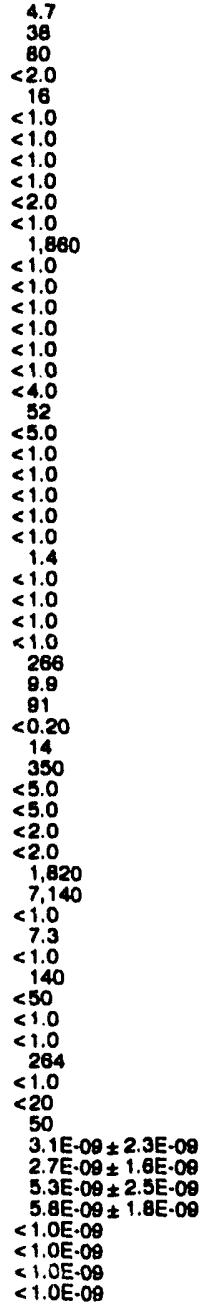 & Jo & 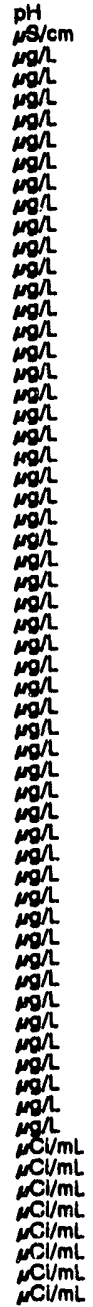 \\
\hline
\end{tabular}

E




\section{WELL MSB 36B}

MEASUAEMENTS CONOUCTED IN THE FIELD

Bample date: 0es/17/02

Dopth to wator: $126.65 \mathrm{H}(38.80 \mathrm{~m})$ bolow TOC Water elevation: 214.05 \& 185.24

Sp. conductance: $220 \mathrm{wS} / \mathrm{cm}$. $144 \mathrm{gal}$

LABORATOFY ANALYSES

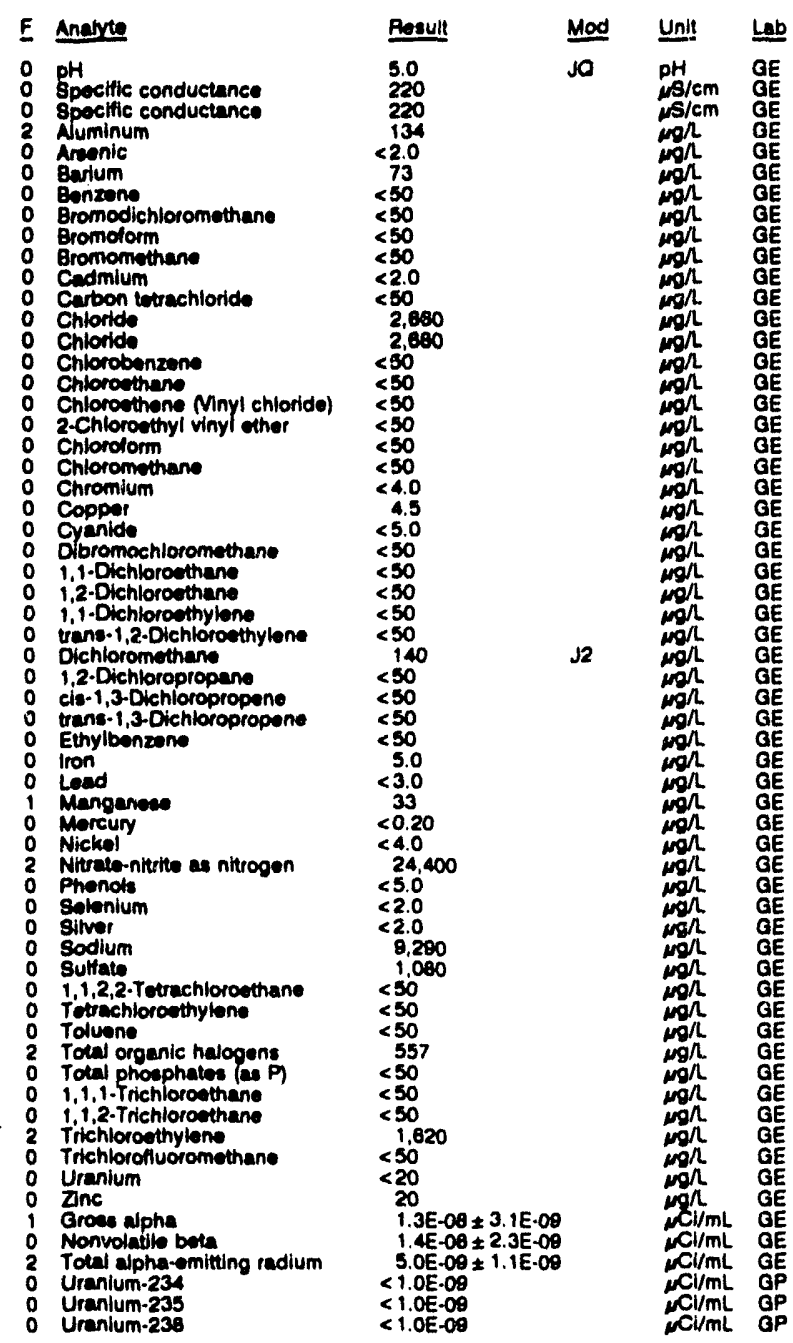

\section{WELL MSB 36C}

MEASUREMENTS CONDUCTED IN THE FIELO

Sample date: 07/24/92

(3)

Weter elevation: $213.59 \mathrm{n}(85.10 \mathrm{~m}) \mathrm{ms}$ )

So. conductance: $30 \mathrm{mS} / \mathrm{cm}$

Water ovacuated belore sampling: $64 \mathrm{gal}$

LABORATOAY ANALYSES

\begin{tabular}{|c|c|c|c|c|}
\hline F Analyte & Result & Mod & Unit & Lab \\
\hline $\begin{array}{ll}0 & \text { pH } \\
0 & \text { Specific conductance } \\
1 & \text { Aluminum } \\
0 & \text { Areenic } \\
0 & \text { Burium } \\
0 & \text { Benzene } \\
0 & \text { Bromodichloromethane } \\
0 & \text { Bromoform } \\
0 & \text { Bromomethane } \\
0 & \text { Cadmium }\end{array}$ & $\begin{array}{r}5.1 \\
28 \\
26 \\
<2.0 \\
6.8 \\
<5.0 \\
<5.0 \\
<5.0 \\
<5.0 \\
<2.0\end{array}$ & Jo & 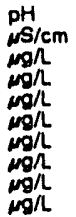 & $\begin{array}{l}\mathrm{GE} \\
\mathrm{GE} \\
\mathrm{GE} \\
\mathrm{GE} \\
\mathrm{GE} \\
\mathrm{GE} \\
\mathrm{GE} \\
\mathrm{GE} \\
\mathrm{GE} \\
\mathrm{GE}\end{array}$ \\
\hline
\end{tabular}

WELL MSB 38C collocted on 07/24/92, laboratory analyaer (cont.)

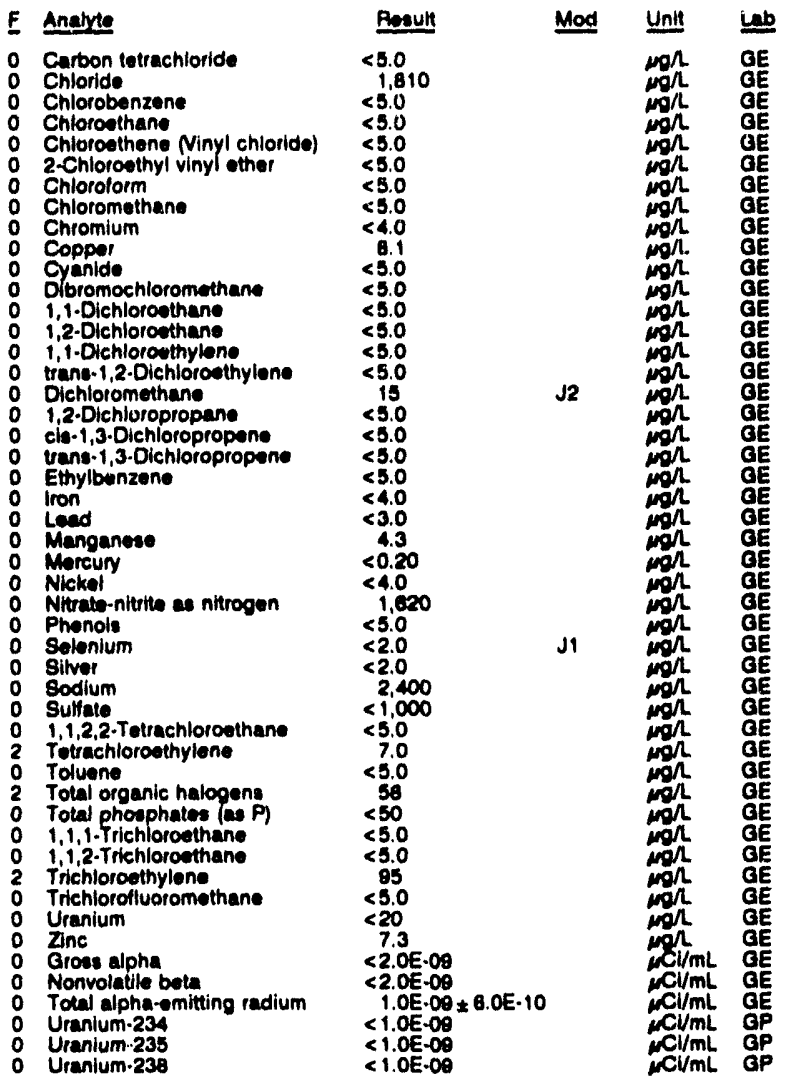

\section{WELL MSB 36D}

MEASUREMENTS CONDUCTED IN THE FIELD

Sample date: 07/24/92 3 (32.11 m) below TOC

Weter olevation; $236.16 \mathrm{n}(71.08 \mathrm{~m}) \mathrm{ms}$

Sp. conductance: $56 \mu \mathrm{s} / \mathrm{cm}$

PH: 8.3
Alkalinity: $21 \mathrm{moh}$

Water temperature: $22.3 \circ \mathrm{C}$

Water evacuated bofore sampling: 4 gel

LABORATOAY ANALYSES

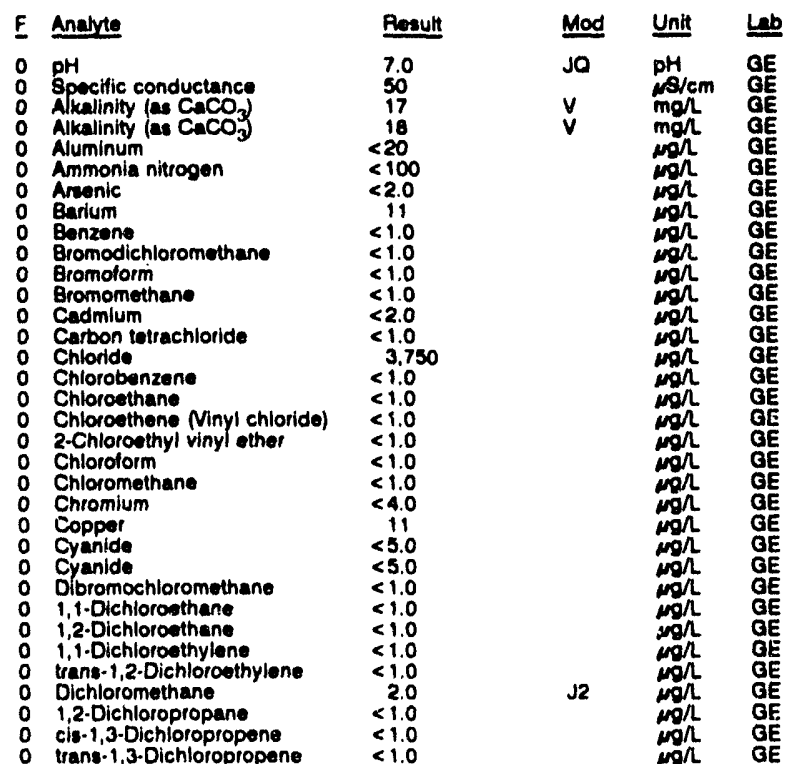


ANALYTICAL RESULTS

WELL MS8 3a0 collected on 07/24/92, laboratory analyese (cont.)

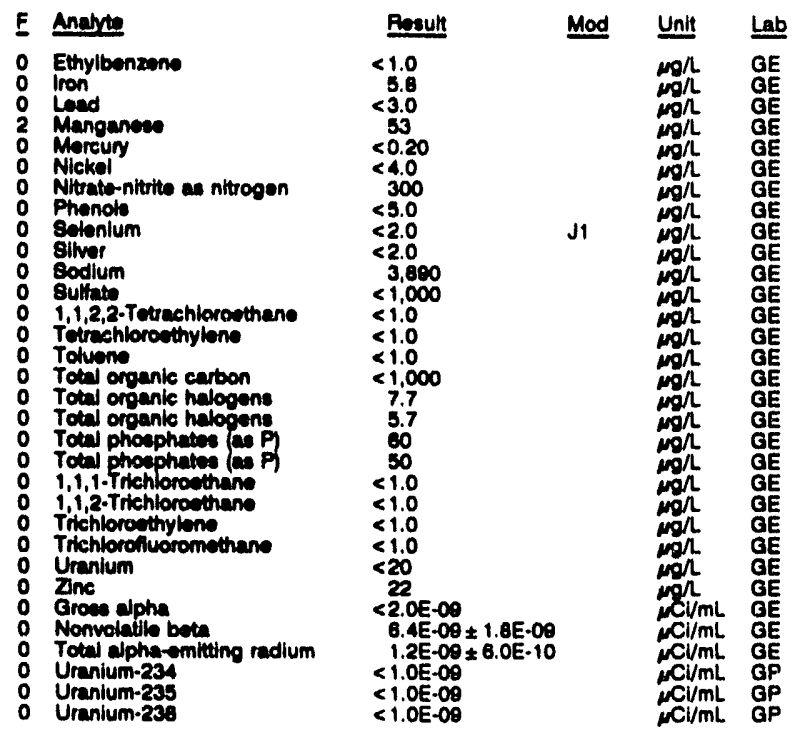

\section{WELL MSB 36TA}

MEASUREMENTS CONOUCTED IN THE FIELD

Sample dats: 07/24102

Depth to water: 146.00 it $(44.32 \mathrm{~m})$ below roC Water elevation: $104.54 \mathrm{n}(59.30 \mathrm{~m}) \mathrm{mal}$

Sp. conductance: 22 pl/cm

LABORATOAY ANALYES

\begin{tabular}{|c|c|c|c|}
\hline Anarts & Result & Mod & Unit \\
\hline 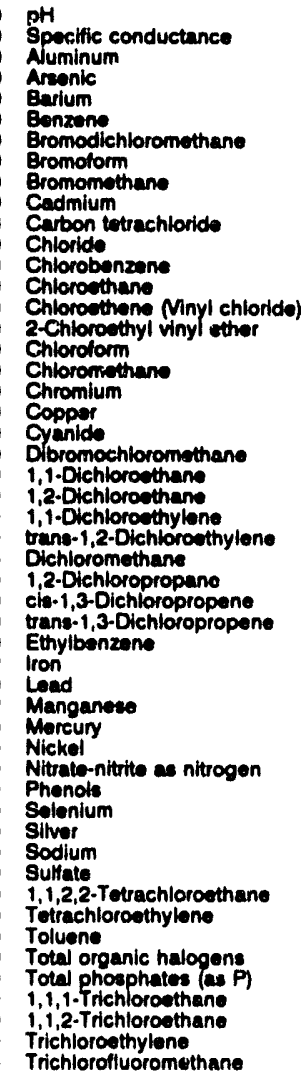 & $\begin{array}{r}5.3 \\
22 \\
<20 \\
<2.0 \\
5.6 \\
<1.0 \\
<1.0 \\
<1.0 \\
<1.0 \\
<2.0 \\
<1.0 \\
1.800 \\
<1.0 \\
<1.0 \\
<1.0 \\
<1.0 \\
<1.0 \\
<1.0 \\
<4.0 \\
6.9 \\
<5.0 \\
<1.0 \\
<1.0 \\
<1.0 \\
<1.0 \\
<1.0 \\
1.5 \\
<1.0 \\
<1.0 \\
<1.0 \\
<1.0 \\
845 \\
5.3 \\
58 \\
<0.20 \\
<4.0 \\
<50 \\
<5.0 \\
<2.0 \\
<2.0 \\
1.490 \\
2.500 \\
<1.0 \\
<1.0 \\
<1.0 \\
<5.0 \\
51.0 \\
<1.0 \\
<1.0 \\
<1.0 \\
<1.0\end{array}$ & JO & 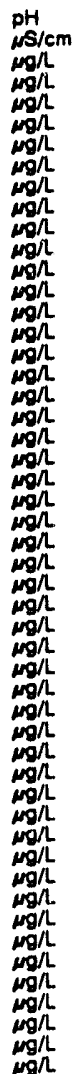 \\
\hline
\end{tabular}

WELL MSB 38TA collected on 07/24/92, laboratory analyees (cont.)

\begin{tabular}{|c|c|c|c|c|}
\hline F Anabyte & Result & Mod & Unit & Le \\
\hline $\begin{array}{ll}0 & \text { Uranium } \\
0 & \text { Zinc } \\
0 & \text { Groas alpha } \\
0 & \text { Nonvolatile bota } \\
0 & \text { Total alpha-emitting radium } \\
0 & \text { Uranium-234 } \\
0 & \text { Uranium-235 } \\
0 & \text { Uranium-238 }\end{array}$ & $\begin{array}{l}<20 \\
2.7 \\
<2.0 E-09 \\
<2.0 E-09 \\
<1.0 E-09 \\
<1.0 E-09 \\
<1.0 E-09 \\
<1.0 E-09\end{array}$ & & 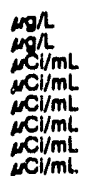 & $\begin{array}{l}G E \\
G E \\
G E \\
G E \\
G E \\
G P \\
G P \\
G P\end{array}$ \\
\hline
\end{tabular}

WELL MSB 37A

MEASUREMENTS CONDUCTED IN THE FIELD

Sample date: 08/09/82

Dopth to water: $174.79 \mathrm{n}(69.28 \mathrm{~m})$ bolow TOC

Water elevation: $208.31 \mathrm{n}(63.49 \mathrm{~m}) \mathrm{mal}$

8p. conductance: $64 \mathrm{~m} 8 / \mathrm{cm}$ anpling: 73 gal

Time: 10:10

PH: 6.0 : $10 \mathrm{mal}$

Whe well went dry during purging

LABORATOAY ANALYSES
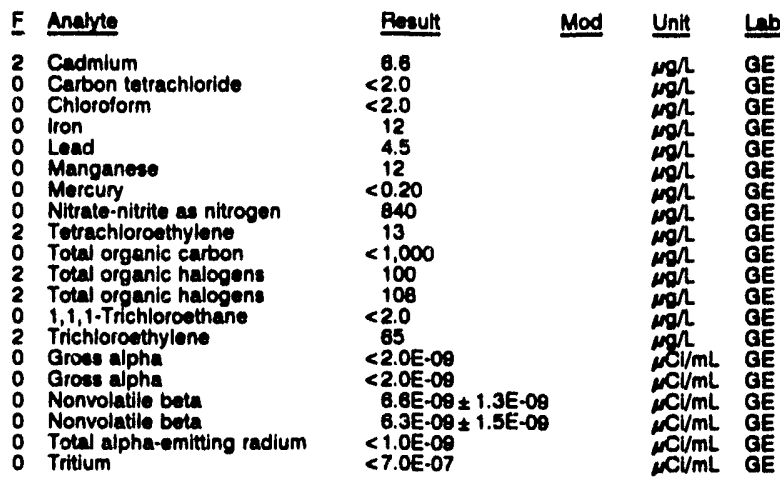

\section{WELL MSB 37B}

MEASUREMENTS CONDUCTED IN THE FIELD

Sample date: 08/08/92

183.09 ft $(49.71 \mathrm{~m})$ below TOC

Walt onation: $218.71 \mathrm{ft}(60$.

.

LABORATORY ANALYSES

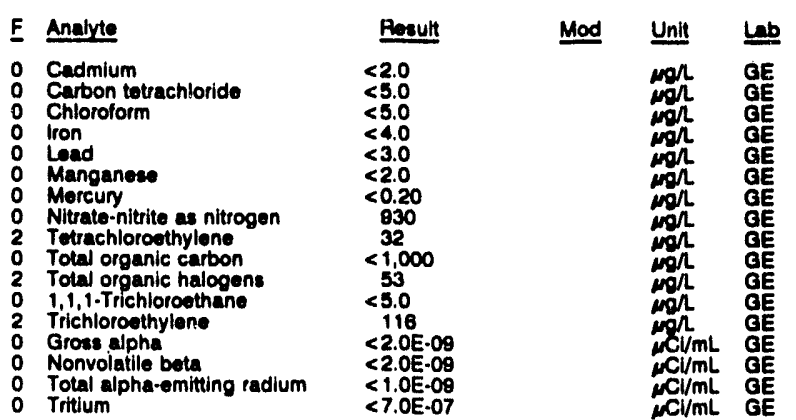

\section{WELL MSB 37C}

MEASUREMENTS CONOUCTED IN THE FIELD

Sample date: 08/08/92

Depth to water: $154.33 \mathrm{ft}(47.10 \mathrm{~m})$ below TOC Water elevation: $228.57 \mathrm{H}(68.67 \mathrm{~m}) \mathrm{ms}$ ) Sp. conductance: $37 \mathrm{\mu S} / \mathrm{cm}$

Time: $14: 15$
pH: 5.6

PH: 5.6

Water ovacuated bolore sampling: $138 \mathrm{gal}$

Water tomperalure: $22.2^{\circ} \mathrm{C}$

LABORATORY ANALYSES

\begin{tabular}{|c|c|c|c|}
\hline F Analyte & Rosult & Mod & Unlt \\
\hline $\begin{array}{ll}0 & \text { Cadmium } \\
0 & \text { Cadmium } \\
0 & \text { Iron } \\
0 & \text { iron }\end{array}$ & $\begin{array}{r}<2.0 \\
<2.0 \\
5.9 \\
4.9\end{array}$ & & $\underset{m o l}{m / L}$ \\
\hline
\end{tabular}




\section{ANALYTICAL RESULTS}

WELL MB8 $37 \mathrm{C}$ collectod on 0e/0a/92, laboratory analyses (cont.)

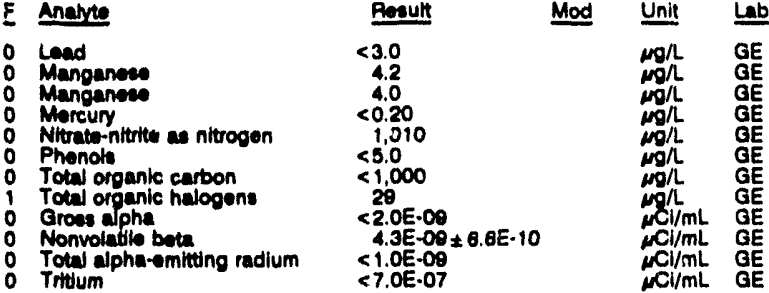

WELL MSB 37D

MEASUREMENTS CONDUCTED IN THE FIELD

Sample data: 08/09/02

Depth to water: $151.45 \mathrm{f}(46.16 \mathrm{~m})$ below TOC

Water tovation: 231.35 it $(70.52 \mathrm{~m}) \mathrm{ms}$

inaccesability or mechanical problem prevented sample collection.

WELL MSB 3TTA

MEASUREMENTS CONDUCTED IN THE FIELD

Sample dato: 0ar12

Depth to wathr: 174.28 n $(53.12 \mathrm{~m})$ below TOC Wator elevetion: $208.12 \mathrm{~A}(83.44 \mathrm{~m}) \mathrm{msl}$

Timo. 14:05

PH: 4.8 : $1 \mathrm{malin}$

Water temperature: $22.0^{\circ} \mathrm{C}$

Weter avecunted before sampling: $498 \mathrm{gal}$

LABOPATORY ANALYSES

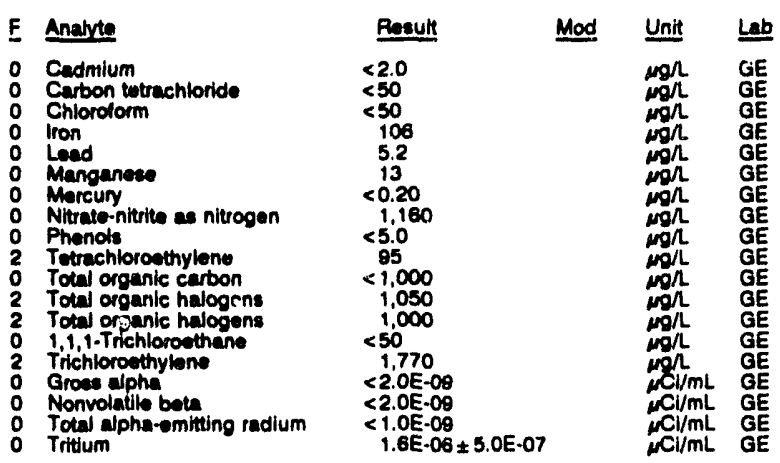

\section{WELL MSB 38B}

MEASUREMENTS CONDUCTED IN THE FIELD

Sample date: 08/17/92

$144.47 \mathrm{~h}(44.03 \mathrm{~m})$ below TOC

Water elevation: $212.13 \mathrm{ft}(64$.

Weter evecuated betore sampling: $191 \mathrm{gal}$

LABOPATORY ANALYSES

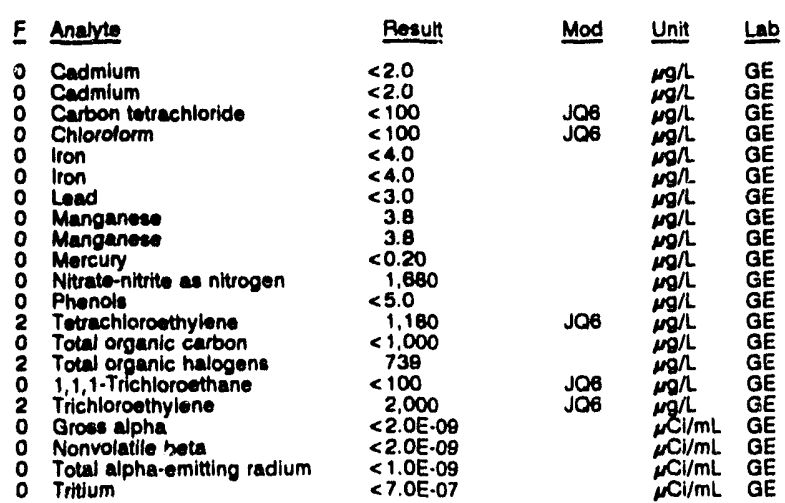

WELL MSB 38C

MEASUREMENTS CONDUCTED IN THE FIELD

Depth to water: $141.20 \mathrm{n}(43.04 \mathrm{~m})$ below TOC

Wator olevation: $215.10 \mathrm{H}(85.58 \mathrm{~m}) \mathrm{mal}$

Bp. conductance 48 r $/ \mathrm{cm}$

Water evacuated belore sampling: $140 \mathrm{gal}$

LABORATORY ANALYSES

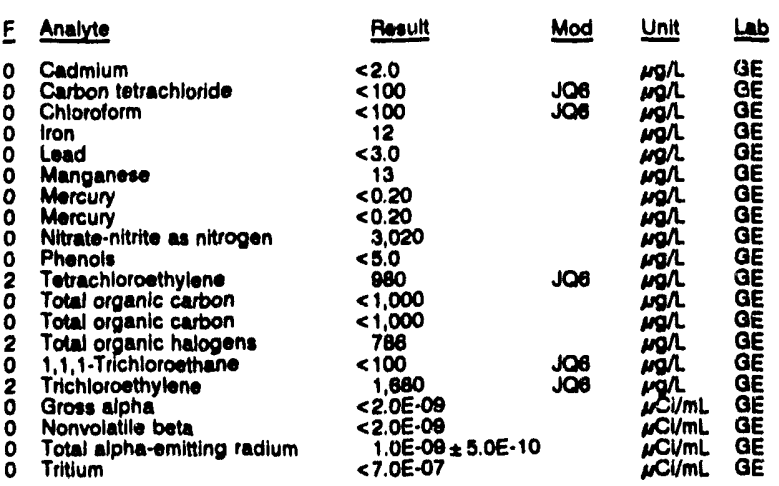

WELL MSB 38D

MEASUREMENTS CONDUCTED IN THE FIELD

Sample date: 08/08/92 Time: 14:45

28.03 $\mathrm{n}(38.41 \mathrm{~m}) \mathrm{mol}$

The wall went dry before sampling begen.

WELL MSB 38TA

MEASUAREMENTS CONOUCTED IN THE FIELD

Sample date: $08 / 08 / 92$ n $(48.94 \mathrm{~m})$ below TOC

Water elevation: $196.13 \mathrm{ft}(59.78 \mathrm{~m}) \mathrm{msl}$

Water evacuated betore sampling: $447 \mathrm{gal}$

Time: $11: 10$

Alknlinity: $8 \mathrm{mg} / \mathrm{h}$

Water temperature: $20.0 \circ \mathrm{C}$

LABORATORY ANALYSES

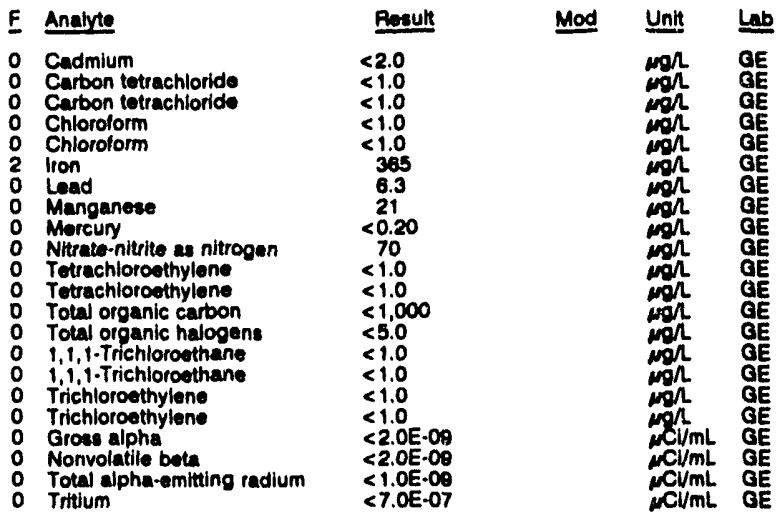


ANALYTICAL RESULTS

WELL MSB 39A

MEASUREMENTS CONDUCTED IN THE FIELD

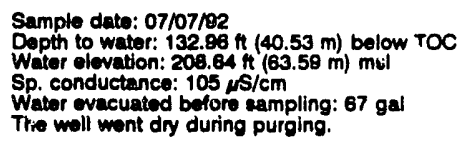

LABORATORY ANALYSES

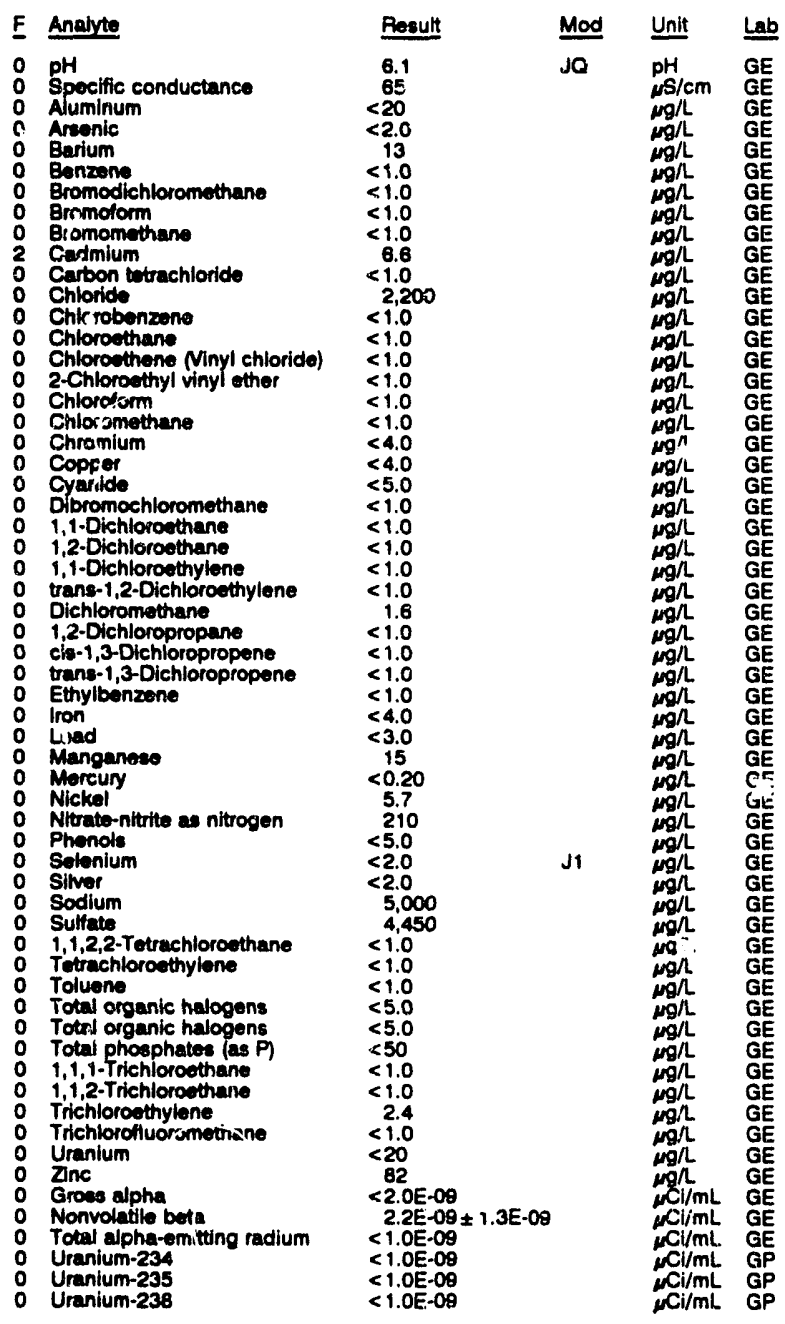

\section{WELL MSB 39B}

MEASUREMENTS CONDUCTED IN THE FIELD

\section{Sample date: $07 / 07 / 92$ in $(39.76 \mathrm{~m})$ below TOC Water olevation: $211.38 \mathrm{f}(64.42 \mathrm{~m}) \mathrm{msl}$ \\ Sp. conductance: $216 \mathrm{~s} / \mathrm{cm}$ \\ Water evacuated before sempling: $174 \mathrm{gal}$}

LABORATOAY ANALYSES

\begin{tabular}{|c|c|c|c|c|c|}
\hline$\underline{F}$ & Analyte & Result & Mod & Unit & $\underline{L a b}$ \\
\hline $\begin{array}{l}0 \\
0 \\
2 \\
2 \\
0 \\
0 \\
0 \\
0 \\
0 \\
0 \\
0\end{array}$ & $\begin{array}{l}\text { pH } \\
\text { Specific conductance } \\
\text { Aluminum } \\
\text { Aluminum } \\
\text { Arenic } \\
\text { Arsenic } \\
\text { Barium } \\
\text { Barium } \\
\text { Benzene } \\
\text { Bromodichloromethane } \\
\text { Bromoform }\end{array}$ & $\begin{array}{r}4.6 \\
208 \\
78 \\
79 \\
<2.0 \\
<2.0 \\
44 \\
44 \\
<5.0 \\
<5.0 \\
<5.0\end{array}$ & JO & 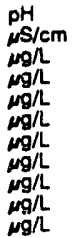 & $\begin{array}{l}\mathrm{GE} \\
\mathrm{GE} \\
\mathrm{GE} \\
\mathrm{GE} \\
\mathrm{GE} \\
\mathrm{GE} \\
\mathrm{GE} \\
\mathrm{GE} \\
\mathrm{GE} \\
\mathrm{GE} \\
\mathrm{GE}\end{array}$ \\
\hline
\end{tabular}

Time: 8:05

PH: 4.2

Water temperature: $18.4^{\circ} \mathrm{C}$
WELL MSB 38 B colloctod on 07/07/82, laboratory analyses (cont.)

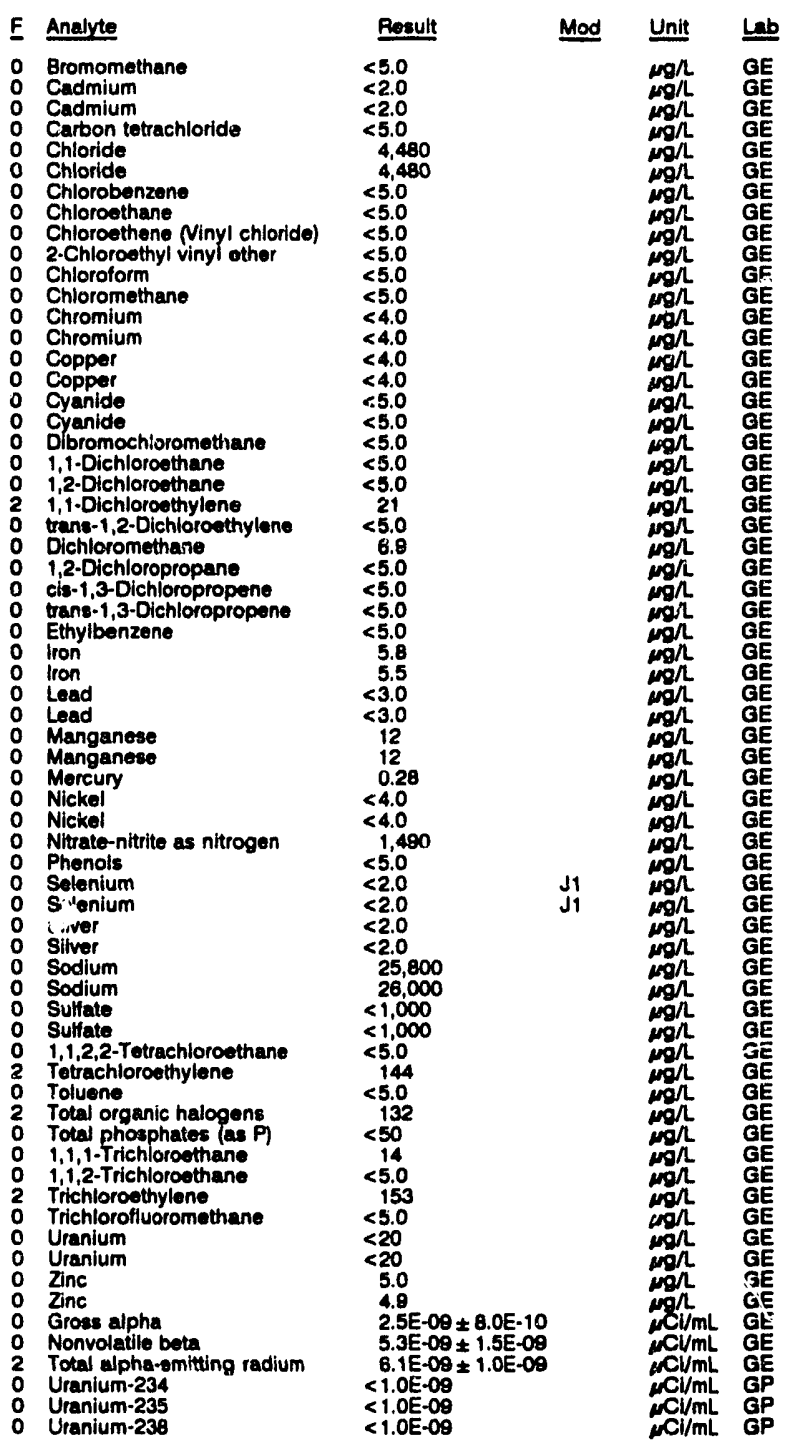

WELL MSB 39C

MEASUREMENTS CONDUCTED IN THE FIELD

Sample date: 07/07/92 $39.59 \mathrm{~m})$ below TOC

Water elevation: $214.80 \mathrm{ft}(65.50 \mathrm{~m}) \mathrm{msl}$

Sp. conductance: $44 \mathrm{~S} / \mathrm{cm}$

Pfi: 4.1
Alkalinity: $0 \mathrm{mg} /$

Alkalinity: $0 \mathrm{mg} / \mathrm{L}$

LABOAATORY ANALYSES

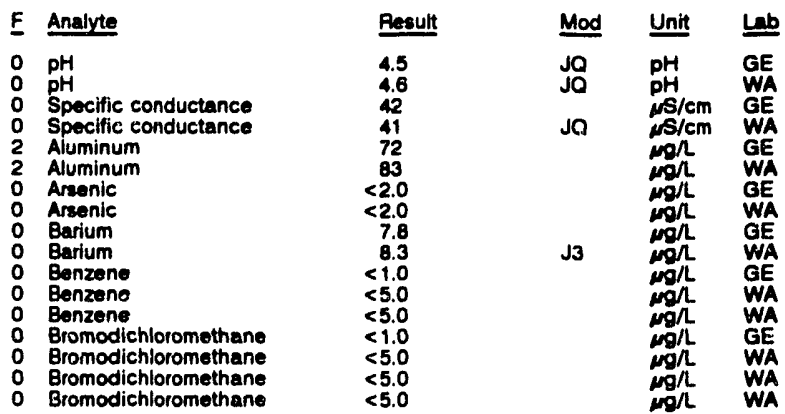


ANALYTICAL RESULTS

WEL MSB 38C colloctod on 07/07/82, laboratory analyeas (cont.)

E Anatrte

- Bromolorm

Bromolorm

0 Bromolorm

Bromomethane

Bromomethane

Bromomethene

Cadmium

Carbon totrachloride

Carbon tetrachloride

Carbon tetrachloride

Carbon totrechioride

Chloride

Chiorobonzene

Chlorobenzene

Chlorabenzane

Chioroethane

Chloroethane

Chloroethene Ninyl chioride

Chloroettene Vinyl chloride

Chioroethene Vinyl chioride

Chioroethene Ninyl chloride

2-Chloroethyl vinyl ether

2-Chloroethyl vinyl other

2-Chloroethyl vinyl other

Chloroform

Chloroform

Chloroform

Chloromethane

o Chloromethane

Chloromethane

Chromium

Chromium

Copper

0 Eyanido

O Cyanide

Dibromochloromethan

Dibromochloromethane

Dibromochloromethane

1,1-Dichloroethane

1,i-Oichlorosthane

o 1,i-Dichloroethane

1,2-Dichloroethane

1,2.Dichloroethane

1,2.Dichloroothane

1,1-Dichioroethylene

1,1.Dichloroethylene

$1,1-D i c h l o r o s t h y l e n e$
trans-1,2-Dichloroethylene

trans-1,2-Dichloroethylene

trans-1,2-Dichloroethylene
trans-1,2-Dichloroethylene

trans-1,2-Dichloreeth
Dichloromethane

Dichloromethane

Dichloromethane

Dichloromethane

1.2-Dichloropropane

1,2-Dichloropropane

1,2-Dichloropropane

1,2-Dichloropropane

eis-1,3-Dichloropropene

cis-1,3-Dichloropropene

trans-1,3-Dichioropropene

trans-1,3-Dichloropropene

trans-1,3-Dichloropropene
trans-1,3-Dichioropropene

Ethylbenzene

Ethylbenzene

Ethylbenzene

$\begin{array}{ll}0 & \text { lion } \\ 0 & \text { Iron }\end{array}$

0 Load

Manganea

O Manganese

Mercuny

Norcury

Nichel

Nitrate as nitrogen

Nitrato-nitrite es nitrogen

Phenols

Phenols

$<1.0$

$<5.0$

$<5.0$

$<10$

$<<10$

$<2.0$
$<0.35$

$<1.0$

$<5.0$
$<5.0$

2.300

2.580

$<5.0$

$<5.0$

$<10$

$<10$

$<1.0$

$<10$
$<10$

$<10$

$<1.0$

$<10$
$<10$

$<10$

$<1.0$
$<5.0$

$<5.0$

$<5.0$
$<1.0$

$<10$

$<10$

$<4.0$

$<4.0$

$<1.1$

$<5.0$

$<1.0$

$<5.0$

$<5.0$

$<1.0$

$<5.0$

$<1.0$

$<5.0$

$<5.0$

$<1.0$
$<5.0$

$<5.0$

$<5.0$

$<5.0$

$<5.0$

1.7
12
10

$<1.0$
$<5.0$

$<5.0$
$<5.0$

$<1.0$

$<5.0$

$<5.0$

$<1.0$
$<5.0$

$<5.0$

$<1.0$

$<5.0$

$<5.0$
4.7

3.3
$<3.0$
$<2.0$

$<.1$
6.5
5.5

$<0.20$
$<0.20$

$<4.0$

3.840
$<50$

$<50$
$<5.0$

$<5.0$
$<5.0$
Mod Unit Lيb

wg/ GE

WA

GE

WA

GE

GE

WA

WA

GE

WA

GE

\begin{tabular}{|c|c|c|c|}
\hline 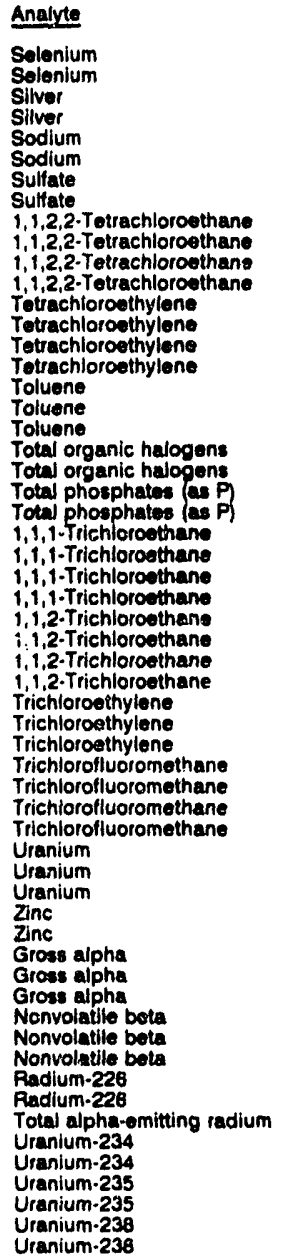 & 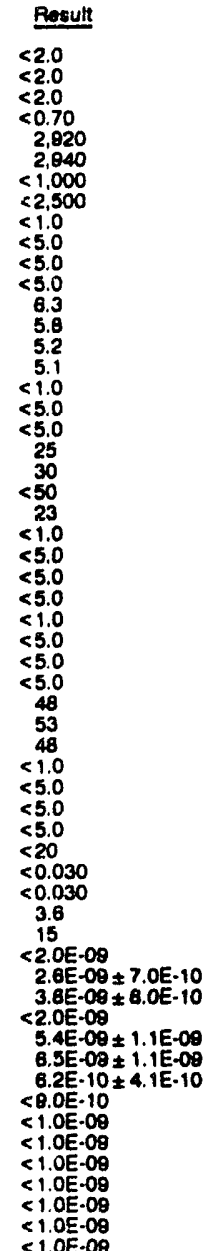 & $\frac{\text { Mod }}{J 1}$ & 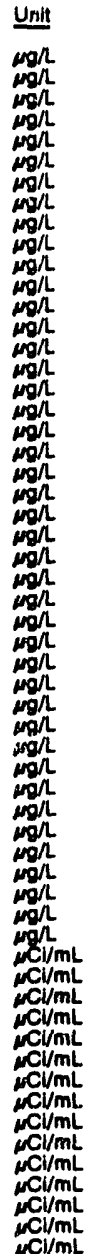 \\
\hline
\end{tabular}

WELL MSB 39C Replicate

MEASUREMENTS CONDUCTED IN THE FIELD

Sample date: 07/07/92

Depth to water: $128.60 \mathrm{~h}(38.58 \mathrm{~m})$ below TOC

Water olevation: $214.00 \mathrm{ft}(05.5$

We. conductance. 4 rst $\mathrm{cm}$.

Time: 7:20

pH: 4.1 Alkalinity: $0 \mathrm{mg}$

Water temperature: $19.4^{\circ} \mathrm{C}$

LABORATOAY ANALYSES

$\begin{array}{ll}\text { F } & \text { Analyte } \\ 0 & \text { pH } \\ 0 & \text { pH } \\ 0 & \text { pH } \\ 0 & \text { Specific conductance } \\ 0 & \text { Specific conductance } \\ 0 & \text { Specific conductance } \\ 2 & \text { Aluminum } \\ 2 & \text { Aluminum } \\ 0 & \text { Arsenic } \\ 0 & \text { Arenic } \\ 0 & \text { Barium } \\ 0 & \text { Barium } \\ 0 & \text { Benzene } \\ 0 & \text { Benzene } \\ 0 & \text { Bromodichloromethnne } \\ 0 & \text { Bromodichloromethane } \\ 0 & \text { Bromolorin } \\ 0 & \text { Bromolorm } \\ 0 & \text { Bromomethane } \\ 0 & \text { Bromomethane } \\ 0 & \text { Cadmium } \\ 0 & \text { Cadmium } \\ 0 & \text { Carbon tetrachloride } \\ 0 & \text { Carbon tetrachloride } \\ 0 & \text { Chloride } \\ 0 & \text { Chloride } \\ 0 & \text { Chloride } \\ 0 & \text { Chlorobenzene }\end{array}$
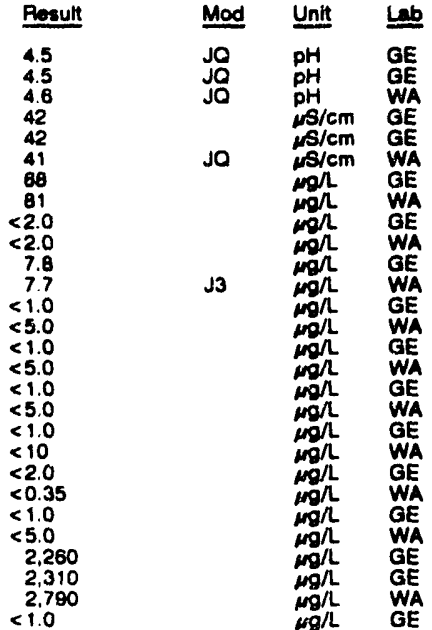
ANALYTICAL RESULTS

WELL MSB 30 C collectod on 07/07/92, laboratory analyese (cont.)

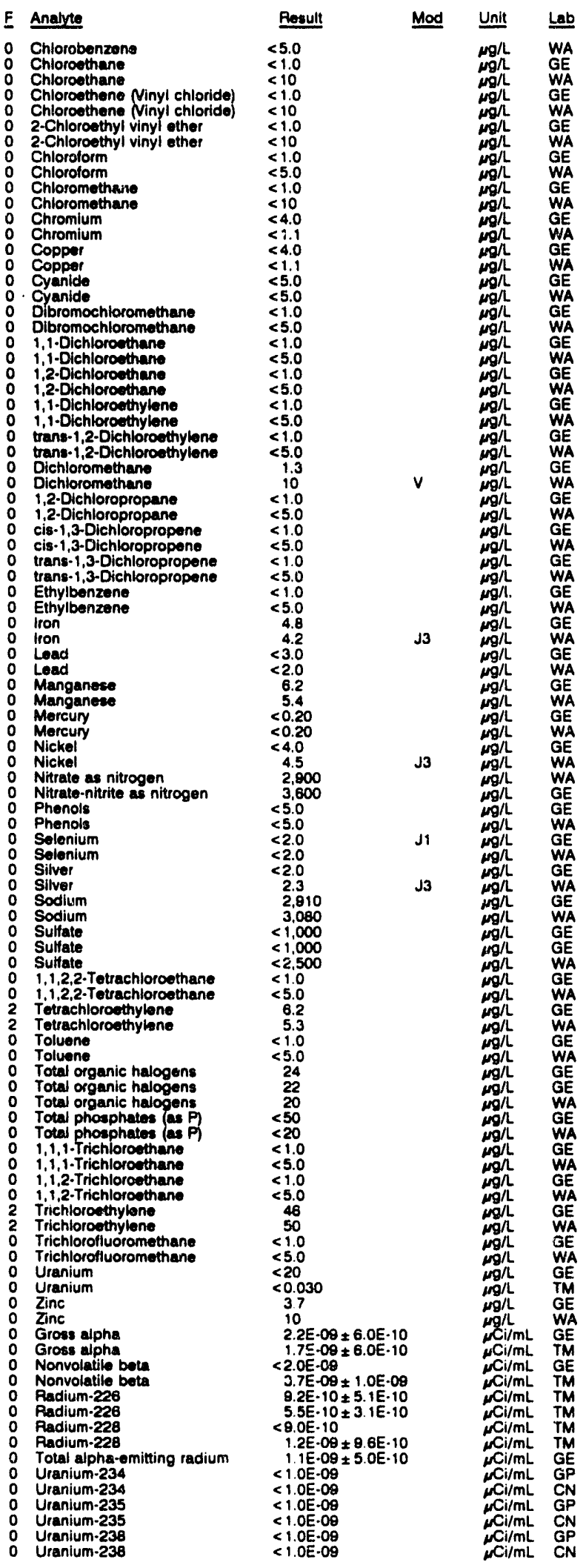

WELL MSB 39D

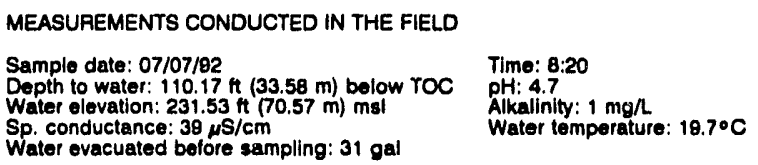

LABORATORY ANALYSES

E Analyte

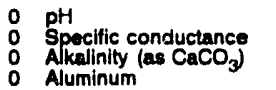

$\begin{array}{ll}0 & \text { Aluminum } \\ 0 & \text { Ammonia nitrogen } \\ 0 & \text { Arsenic }\end{array}$

: Arsonic

o Barlum

Bromodichloromethane
0 Bromoform

Bromomethan

Carbon tetrachloride

o Chioride

O Chlorobenzene

Chloroethane

2.Chloroethyl vinyl other

0 Chlorolorm

- Chloromethane

- Chromiun

0 Copper

0 Cyanide

Dibromochloromethane

1, - Dichloroethane

1,2-Dichloroothane

0
0
0

D Dichloromethane

1,2-Dichloropropane

cois-1,3-Dichloropropene

O Ethylbenzene

0 iron

o Manganese

o Mercury

Nickel

2 Nitrate-nitrite as nitrogen

Phenols

: Selenium

: Silvor

: Sodium

o $1,1,2,2$-Tetrachloroethane

o Totrachloroethylene

0 Toluene

- Total organic carbon

- Total organic halogens

- Total phosphates (as P)

o 1,1,1.Trichlorosthane

- 1,1,2-Trichloroethan

o Trichloroethylene

- Uranium

0 Zinc

- Gross alphe

- Gross sipha

Nonvolatile bots

O Nonvoiatile bota

- Total alpha-emitting radium

- Uranium-234

O Uranium-235

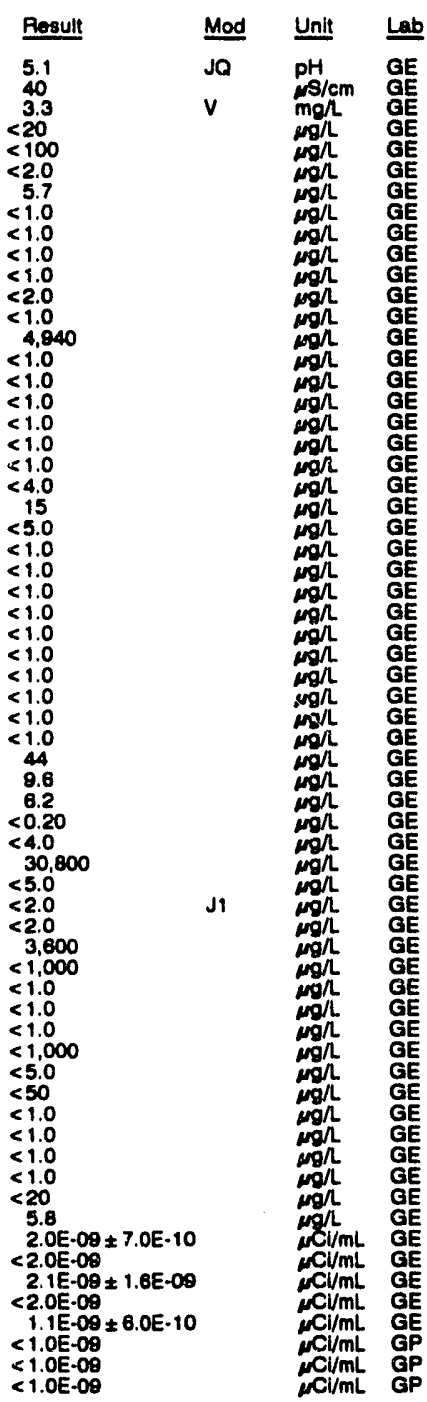

WELL' MSB 39TA

MEASUREMENTS CONDUCTED IN THE FIELD

Sample date: 07/07/92

Depth to weter: $146.58 \mathrm{ft}(45.28 \mathrm{~m})$ bolow TOC

Water alevation: $193.22 \mathrm{ft}(58.89 \mathrm{~m}) \mathrm{ms}$

Sp. conductance: $18 \mathrm{rS} / \mathrm{cm}$

PH: 4.4
Alkalinity: $0 \mathrm{mg} / \mathrm{h}$

Alkalinity: $0 \mathrm{mg} / \mathrm{l}$

LABORATORY ANALYSES

\begin{tabular}{|c|c|c|c|}
\hline Analyte & Fesult & Mad & Unit \\
\hline $\begin{array}{l}\text { pH } \\
\text { Specific conductance } \\
\text { Aluminum } \\
\text { Arsenic } \\
\text { Barium } \\
\text { Benzene } \\
\text { Bromodichloromethane }\end{array}$ & $\begin{array}{r}4.9 \\
20 \\
<20 \\
<2.0 \\
3.0 \\
<1.0 \\
<1.0\end{array}$ & JO & $\begin{array}{l}\operatorname{pH} \\
\operatorname{mS} / \mathrm{cm} \\
\operatorname{cog} / \mathrm{h} \\
\operatorname{cog} \Omega \\
\operatorname{cog} / L \\
\operatorname{cog} /\end{array}$ \\
\hline
\end{tabular}


WELL MSB 30TA collocted on 07/07/02, laboratory analyses (cont.)

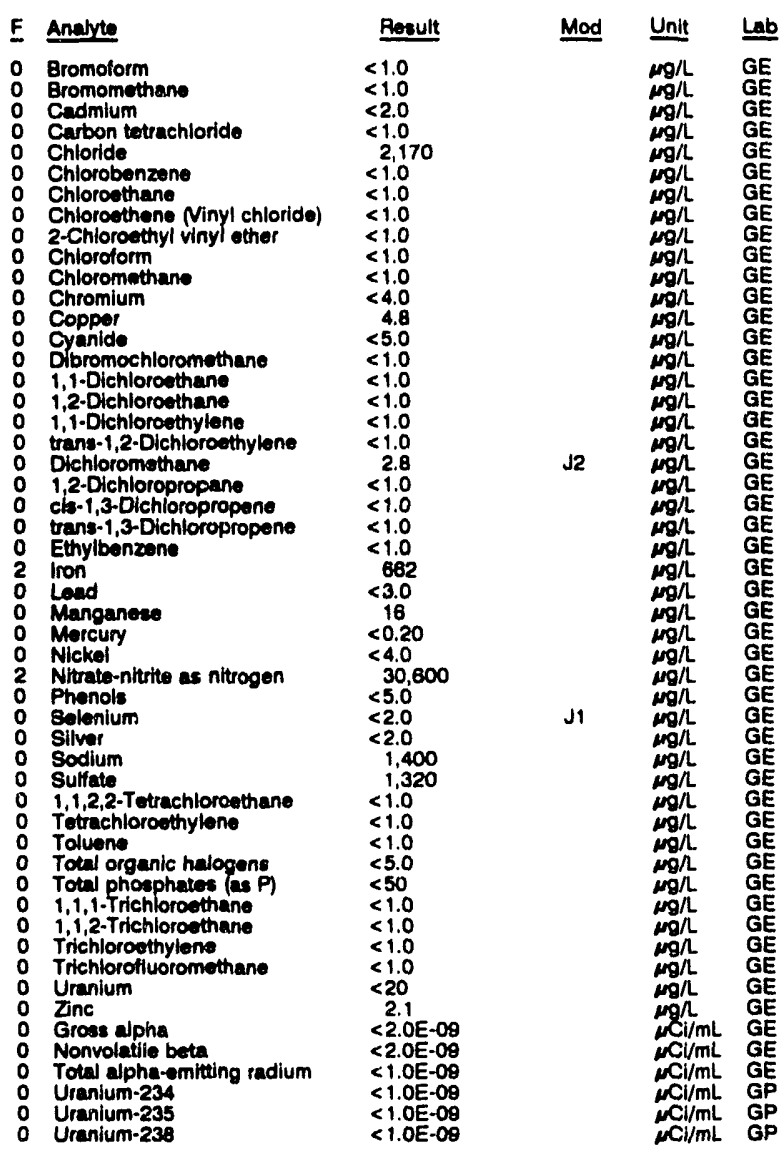

\section{WELL MSB 40A}

MEASUAEMENTS CONDUCTED IN THE FIELL

$$
\text { Sample dato: 07/24/82 }
$$

Depth to water: 119.04 it $(38.25 \mathrm{~m})$ bolom TOC Water elevetion: 202.26 (181.85 m) msl

Sp. conductunce: $48 \mathrm{~s} / \mathrm{cm}$ Water evecuated before sampling: $237 \mathrm{gal}$

LABORATOAY ANALYSES

\begin{tabular}{|c|c|c|c|c|c|}
\hline $\mathbf{E}$ & Anabyte & Result & Mod & Unit & Lab \\
\hline & $\begin{array}{l}\text { pH } \\
\text { Specific conductance } \\
\text { Aluminum } \\
\text { Ansenic } \\
\text { Barium } \\
\text { Bonzene } \\
\text { Bromodichloromethane } \\
\text { Bromoform } \\
\text { Bromomethane } \\
\text { Cedmium } \\
\text { Carbon tetrachloride } \\
\text { Chioride } \\
\text { Chlorobenzene } \\
\text { Chloroettrane } \\
\text { Chioroethene Ninyl chloride) } \\
\text { 2-Chloroethyl vinyl ether } \\
\text { Chlorotorm } \\
\text { Chloromethene } \\
\text { Chromium } \\
\text { Copper } \\
\text { Cyanide } \\
\text { Dibromochloromethane } \\
\text { 1,1-Dichloroethane } \\
\text { 1,2-Dichloroethane } \\
\text { 1,1-Dichloroethylene } \\
\text { trans-1,2-Oichloroethylene } \\
\text { Dichloromethane } \\
\text { 1,2-Dichloropropane } \\
\text { cis-1,3-Dichloropropene } \\
\text { trans-1,3-Dichloropropene } \\
\text { Ethylbenzene }\end{array}$ & $\begin{array}{l}4.7 \\
50 \\
64 \\
<2.0 \\
1.0 \\
<1.0 \\
<1.0 \\
<1.0 \\
<1.0 \\
<2.0 \\
<1.0 \\
2.070 \\
<1.0 \\
<1.0 \\
<1.0 \\
<1.0 \\
<1.0 \\
<1.0 \\
<4.0 \\
<4.0 \\
<5.0 \\
<1.0 \\
<1.0 \\
<1.0 \\
<1.0 \\
<1.0 \\
1.9 \\
<1.0 \\
<1.0 \\
<1.0 \\
<1.0\end{array}$ & JQ & 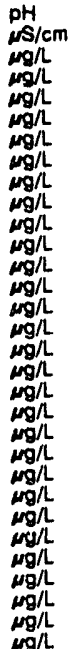 & $\begin{array}{l}\mathrm{GE} \\
\mathrm{GE} \\
\mathrm{GE} \\
\mathrm{GE} \\
\mathrm{GE} \\
\mathrm{GE} \\
\mathrm{GE} \\
\mathrm{GE} \\
\mathrm{GE} \\
\mathrm{GE} \\
\mathrm{GE} \\
\mathrm{GE} \\
\mathrm{GE} \\
\mathrm{GE} \\
\mathrm{GE} \\
\mathrm{GE} \\
\mathrm{GE} \\
\mathrm{GE} \\
\mathrm{GE} \\
\mathrm{GE} \\
\mathrm{GE} \\
\mathrm{GE} \\
\mathrm{GE} \\
\mathrm{GE} \\
\mathrm{GE} \\
\mathrm{GE} \\
\mathrm{GE} \\
\mathrm{GE} \\
\mathrm{GE} \\
\mathrm{GE} \\
\mathrm{GE}\end{array}$ \\
\hline
\end{tabular}

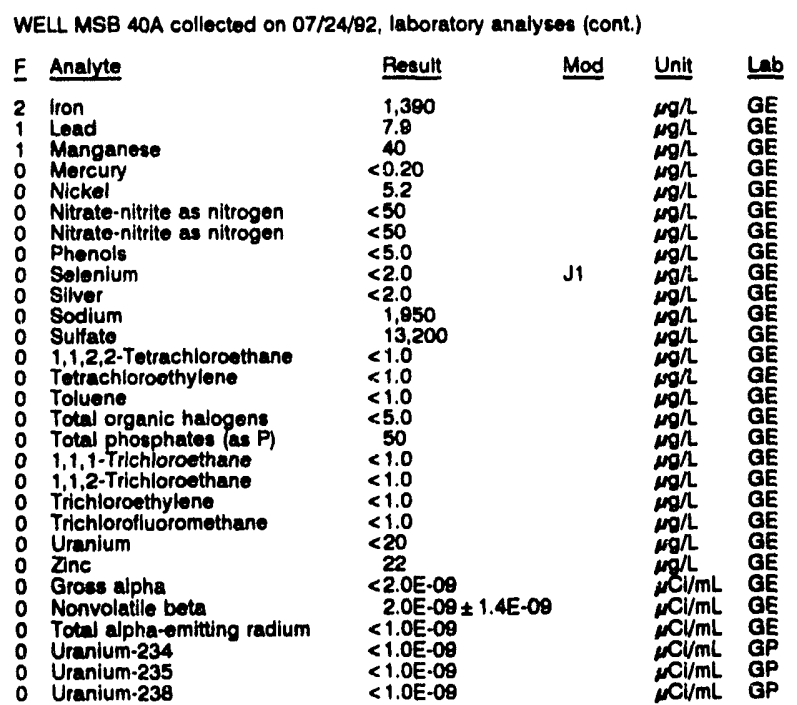

WELL MSB 40B

MEASUREMENTS CONDUCTED IN THE FIELD

Sample date: 08/20/92 Dopth to water: $117.20 \mathrm{H}(35.72 \mathrm{~m})$ bolow TOC (1) Water evacuated before sampling: $142 \mathrm{gal}$ Alkalinity: $1 \mathrm{mg} /$, $22.00 \mathrm{C}$

LABORATORY ANALYSES

\begin{tabular}{|c|c|c|c|}
\hline Analyte & Result & Mod & $\underline{\text { Unit }}$ \\
\hline 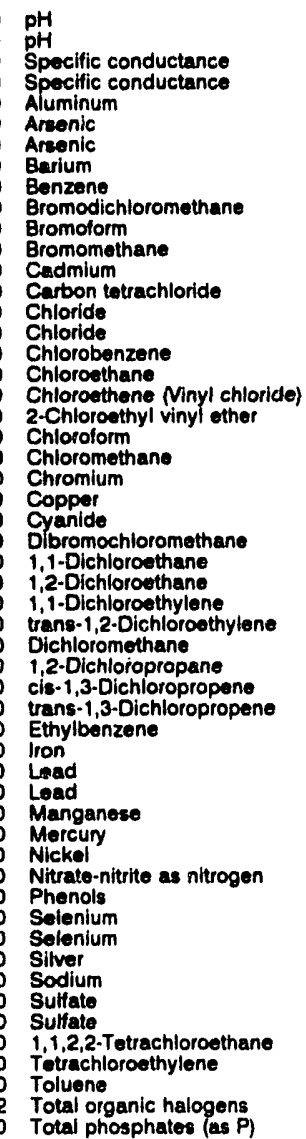 & 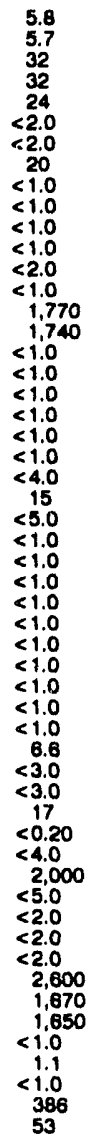 & $\begin{array}{l}\text { Jo } \\
\text { Jo }\end{array}$ & 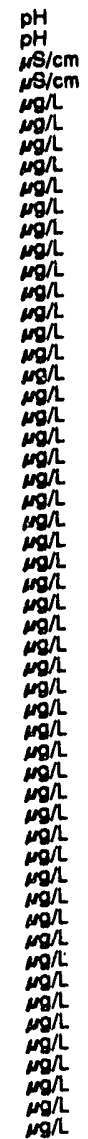 \\
\hline
\end{tabular}


ANALYTICAL RESULTS

WELL MSB 408 collocted on 08/20/92, laboratory analyses (cont.)

\begin{tabular}{|c|c|c|c|c|}
\hline Analyte & Rosult & Mod & Unit & Lab \\
\hline $\begin{array}{l}1,1,1-\text { Trichloroethane } \\
1,1,2-\text { Trichloroethane } \\
\text { Trichloroothylene } \\
\text { Trichlorotluoromothane } \\
\text { Uranium } \\
\text { Zinc } \\
\text { Grose alpha } \\
\text { Nonvolatilo beta } \\
\text { Total alpha-emitting radium } \\
\text { Uranlum-234 } \\
\text { Uranium-235 } \\
\text { Uranium-238 }\end{array}$ & $\begin{array}{l}<1.0 \\
1.5 \\
1,310 \\
<1.0 \\
<20 \\
24 \\
<2.0 \mathrm{E}-09 \\
<2.0 \mathrm{E} \cdot 09 \\
2.2 \mathrm{E}-09 \pm 1.1 \mathrm{E}-09 \\
<1.0 \mathrm{E}-09 \\
<1.0 \mathrm{E}-09 \\
<1.0 \mathrm{E} \cdot 09\end{array}$ & & 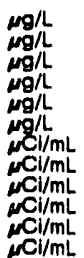 & $\begin{array}{l}\mathrm{GE} \\
\mathrm{GE} \\
\mathrm{GE} \\
\mathrm{GE} \\
\mathrm{GE} \\
\mathrm{GE} \\
\mathrm{GE} \\
\mathrm{GE} \\
\mathrm{GE} \\
\mathrm{GP} \\
\mathrm{GP} \\
\mathrm{GP}\end{array}$ \\
\hline
\end{tabular}

\section{WELL MSB 40C}

MEASUREMENTS CONDUCTED IN THE FIELD

Sample date: 07/24/92

Depth to water: $117.23 \mathrm{ft}(35.73 \mathrm{~m})$ below TOC

Water elevation: $204.87 \mathrm{Ht}(62.4 \mathrm{~s}$

Sp. conductance: $72 \mu \mathrm{s} / \mathrm{cm} .45 \mathrm{~m}$ ) $\mathrm{msl}$

Walor ovacuatod botore sampling: $8 \mathrm{gal}$

The well went ory during purging.

LABOFATOFY ANALYSES

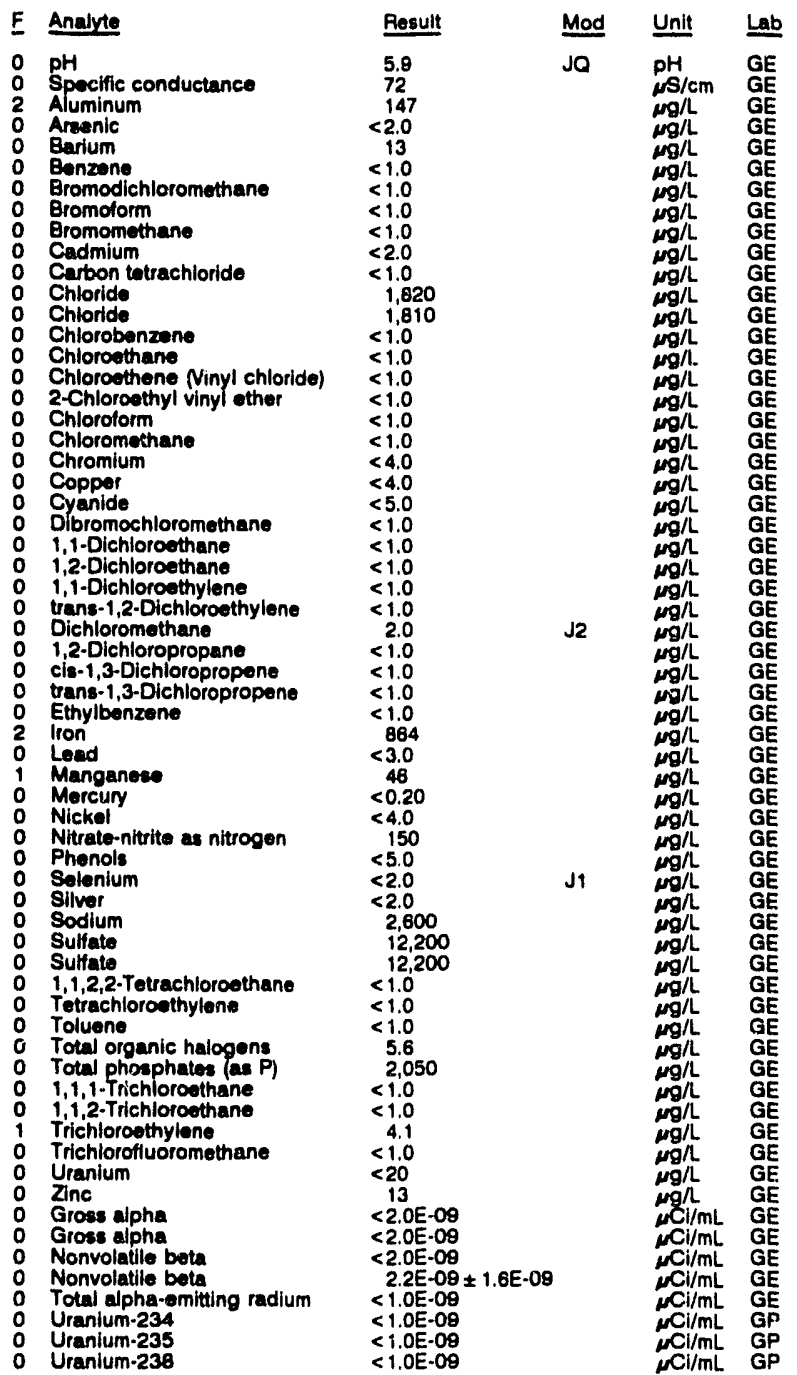

pH: 5.6

Alkalinity: $8 \mathrm{mg} / \mathrm{h}$

Water temperature: $21.4^{\circ} \mathrm{C}$

\section{WELL MSB 40D}

MEASUAEMENTS CONDUCTED IN THE FIELD

Sample date: 07/24/92 2903 Time: 2:50

Water elovation: $227.68 \mathrm{tt}(69.39 \mathrm{~m}) \mathrm{mm}$

Inaccessibility or mechanical problem prevented sample collection.

WELL MSB 40TA

MEASUREMENTS CONDUCTED IN THE FIELD

Sample date: 07/24/92

Depth to water: $131.54 \mathrm{At}(40.09 \mathrm{~m})$ bolow TOC

Water olovation: 189.26 ft (57.68

Sp. conductance: $27 \mu \mathrm{S} / \mathrm{cm}$

Water ovacuated before sampling: $\mathbf{4 3 0} \mathrm{gal}$

LABORATORY ANALYSES

E Analyte

: $\mathrm{pH}$

Specific conductance

O Spectitic conductance

o Aluminum

o Arsenic

0 Arrenic

0 Barium

Bromodichloromethane

o Bromoform

O Eromomethane

C Cadmium

Carbon tetrachioride

Chloride

Chlorobenzene

Chloroethene Ninyl chloride)

2-Chloroethyl vinyl ether

2-Chloroethy

o Chloroform

o Chromium

- Copper

O Cyanide

o Dibrornochloromethane

o 1,1-Dichloroethane

o 1,2-Dichloroethane

o trans-1,2-Dichloroethylene

Dichloromethane

o 1,2-Dichloropropane

o cis-1,3-Dichloropropene

trans-1,3-Dichloropropene

Ethylbenzene

2 Iron

0 Lead

Manganese

- Mercury

0 Mercury

Nlckel

Phenols

Solenium

Selenium

S Silver

Sodium

Sulfate

T,1,2,2-Totrachloroothan

0 Tetrach

Toluene

Total organic halogens

Total phosphates (as P)

1.1, r-Trichioroothan

1,1,2-Trichlorooth

Trichlorofluoromethane

Uranium

- Zine

O Gross alpha

$\begin{array}{ll}<2.0 E-09 \\ 0 \text { Nonvolatile beta } & <2.0 E-09\end{array}$

Uranium-234

$\begin{array}{ll}<1.0 E-09 \\ 0 \text { Uranium-235 } & <1.0 \mathrm{E}-09\end{array}$

Alkalinity: $2 \mathrm{mg} / \mathrm{h}$

Water temperature: $20.1^{\circ} \mathrm{C}$

0 Uranium.238 $<1.0 \mathrm{E} .09$

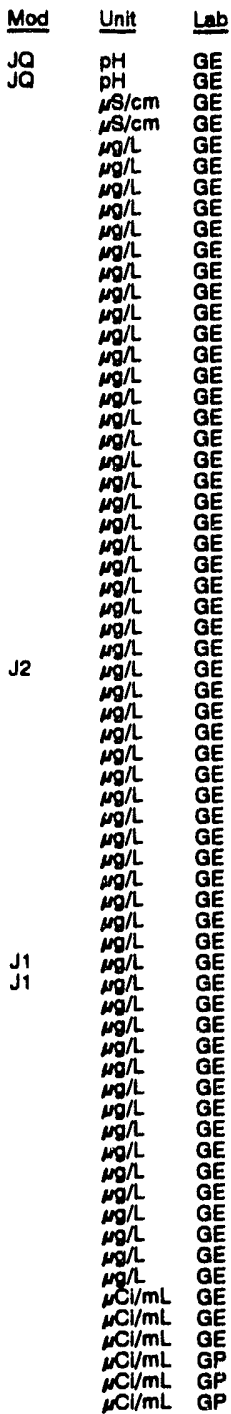


WELL MSB 41A

MEASUREMENTS CONDUCTED IN THE FIELD

\begin{tabular}{|c|c|c|c|c|c|}
\hline \multicolumn{3}{|c|}{ 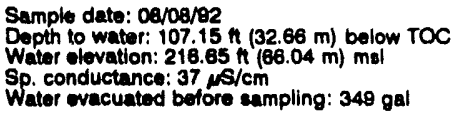 } & \multicolumn{3}{|c|}{$\begin{array}{l}\text { Time: } 11: 30 \\
\text { pH: } 5.6 \\
\text { Alkalinity: } 4 \mathrm{mgh} \\
\text { Water temperature: } 21.2^{\circ} \mathrm{C}\end{array}$} \\
\hline \multicolumn{6}{|c|}{ ABORATOAY ANALYSES } \\
\hline & Analyte & Result & Mod & Unit & Let \\
\hline & 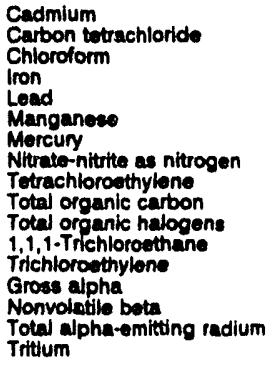 & $\begin{array}{l}<2.0 \\
<1.0 \\
<1.0 \\
<4.0 \\
<3.0 \\
3.5 \\
<0.20 \\
1.460 \\
1.8 \\
<1,000 \\
<5.0 \\
<1.0 \\
<1.0 \\
4.0 \mathrm{E}-0 \\
3.7 \mathrm{E}-0 \\
1.08 \\
<7.0 \mathrm{E}-0\end{array}$ & & 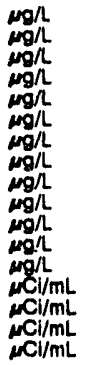 & $\begin{array}{l}G E \\
G E \\
G E \\
G E \\
G E \\
G E \\
G E \\
G E \\
G E \\
G E \\
G E \\
G E \\
G E \\
G E \\
G E \\
G E \\
G E\end{array}$ \\
\hline
\end{tabular}

\section{WELL MSB 41B}

MEASUREMENTS CONDUCTED IN THE FIELD

\begin{tabular}{|c|c|c|c|c|c|}
\hline \multicolumn{3}{|c|}{ 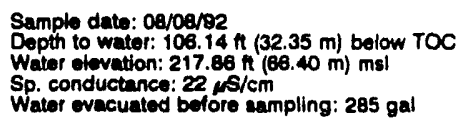 } & \multicolumn{3}{|c|}{$\begin{array}{l}\text { Time: } 12: 15 \\
\text { pH: } 5.2 \\
\text { Alkalinity: } 1 \mathrm{mg} \Omega \\
\text { Water temperature: } 22.2^{\circ} \mathrm{C}\end{array}$} \\
\hline \multicolumn{6}{|c|}{ LABORATOFY ANALYSES } \\
\hline $\mathbf{F}$ & Anaryte & Rosult & Mod & Unit & Lab \\
\hline $\begin{array}{l}0 \\
0 \\
0 \\
0 \\
0 \\
0 \\
0 \\
0 \\
2 \\
0 \\
0 \\
0\end{array}$ & $\begin{array}{l}\text { Cadmium } \\
\text { Carbon tetrachloride } \\
\text { Chlorolorm } \\
\text { lron } \\
\text { Lead } \\
\text { Manganese } \\
\text { Mercury } \\
\text { Mercury } \\
\text { Nitrate-nitrite as nitrogen } \\
\text { Totrachlorowthylene } \\
\text { Total organtc carbon } \\
\text { Total organic hajogens } \\
\text { 1,1,1.Trichioroethane } \\
\text { Trichloroethylene } \\
\text { Groes alpha } \\
\text { Nonvolatile beta } \\
\text { Total alpha-emitting radium } \\
\text { Total aipha-emiting radium } \\
\text { Tritium }\end{array}$ & $\begin{array}{l}<2.0 \\
<1.0 \\
<1.0 \\
<4.0 \\
<3.0 \\
<2.0 \\
<0.20 \\
<0.20 \\
1.180 \\
8.0 \\
<1.000 \\
5.2 \\
<1.0 \\
2.1 \\
<2.0 \mathrm{E}-09 \\
2.0 \mathrm{E}-09 \pm \\
<1.0 \mathrm{E}-09 \\
<1.0 \mathrm{E}-09 \\
<7.0 \mathrm{E}-07\end{array}$ & & 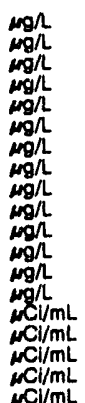 & $\begin{array}{l}\mathrm{GE} \\
\mathrm{GE} \\
\mathrm{GE} \\
\mathrm{GE} \\
\mathrm{GE} \\
\mathrm{GE} \\
\mathrm{GE} \\
\mathrm{GE} \\
\mathrm{GE} \\
\mathrm{GE} \\
\mathrm{GE} \\
\mathrm{GE} \\
\mathrm{GE} \\
\mathrm{GE} \\
\mathrm{GE} \\
\mathrm{GE} \\
\mathrm{GE} \\
\mathrm{GE}\end{array}$ \\
\hline
\end{tabular}

WELL MSB 41C

MEASUREMENTS CONDUCTED IN THE FIELD

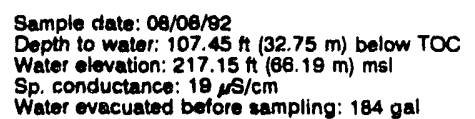

Time: 12:45

PH: 4.8 Alkalinity: $1 \mathrm{mgh}$

Water temperature: $21.6^{\circ} \mathrm{C}$

LABORATORY ANALYSES

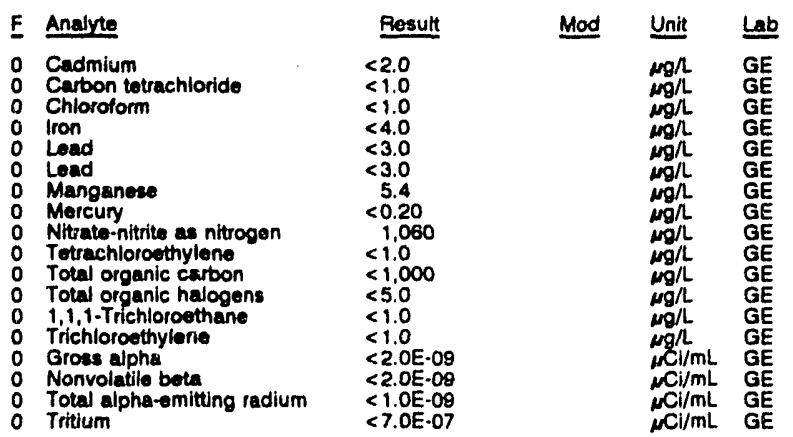

WELL MSB 41D

MEASUREMENTS CONDUCTED IN THE FIELD

\begin{tabular}{|c|c|}
\hline $\begin{array}{l}\text { Sample date: } 08 / 08 / 92 \\
\text { Depth to water: Not avallable } \\
\text { Water elovation: Not available } \\
\text { Sp. conductance: } 22 \text { } 25 / \mathrm{cm} \\
\text { Water evacuated before sampling: } 1 \mathrm{gal}\end{array}$ & $\begin{array}{l}\text { Time: } 9: 45 \\
\text { pH: } 5.4 \\
\text { Alkalinity: } 4 \mathrm{mg} / \mathrm{h} \\
\text { Water temperature: } 23.6^{\circ} \mathrm{C}\end{array}$ \\
\hline
\end{tabular}

Water evacuated before sampling: $1 \mathrm{gal}$

The well went dry during purging.

LABORATORY ANALYYSES

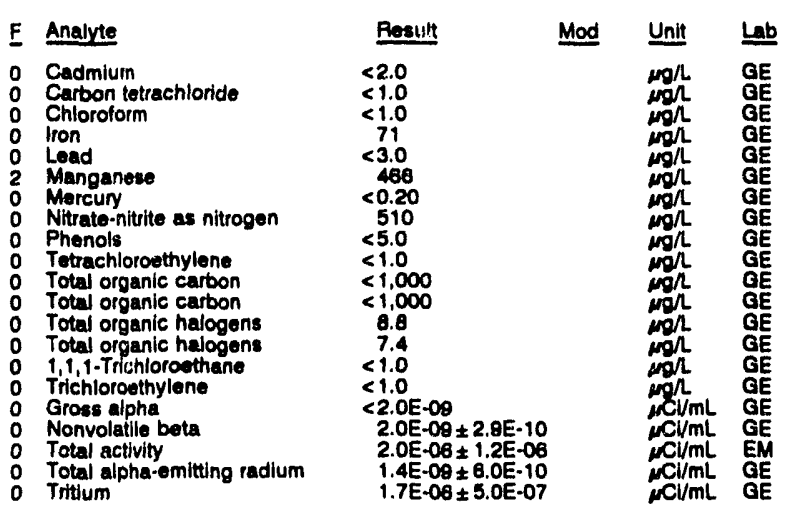

WELL MSB 41TA

MEASUREMENTS CONDUCTED IN THE FIELD

\begin{tabular}{|c|c|c|c|c|c|}
\hline \multicolumn{3}{|c|}{$\begin{array}{l}\text { Sample date: } 08 / 08 / 92 \\
\text { Depth to water: } 117.63 \mathrm{ft}(35.85 \mathrm{~m}) \text { below TOC } \\
\text { Water elevation: } 206.07 \mathrm{ft}(62.81 \mathrm{~m}) \mathrm{msl} \\
\text { Sp. conductance: } 22 \mu \mathrm{s} / \mathrm{cm} \\
\text { Water evacuated bofore sampling: } 487 \mathrm{gal}\end{array}$} & \multicolumn{3}{|c|}{$\begin{array}{l}\text { Time: } 12: 20 \\
\text { pH: } 5.0 \\
\text { Alkalinity: } 0 \mathrm{mg} / \mathrm{h} \\
\text { Water tomperature: } 22.3^{\circ} \mathrm{C}\end{array}$} \\
\hline \multicolumn{6}{|c|}{ LABORATORY ANALYSES } \\
\hline$F$ & Analyze & Result & Mod & Unit & $\underline{L a b}$ \\
\hline $\begin{array}{l}0 \\
0 \\
0 \\
0 \\
0 \\
0 \\
0 \\
0 \\
0 \\
0 \\
0 \\
0 \\
0 \\
0 \\
0 \\
0 \\
0 \\
0\end{array}$ & $\begin{array}{l}\text { Cadmium } \\
\text { Carbon totrachloride } \\
\text { Chloroform } \\
\text { lron } \\
\text { Lead } \\
\text { Mangunese } \\
\text { Mereury } \\
\text { Nitrate-nitrite as nitrogen } \\
\text { Tetrachloroethylene } \\
\text { Total organic carbon } \\
\text { Total organic halogens } \\
1,1,1 . \text { Trichloroethane } \\
\text { Trichlorethylene } \\
\text { Gross alpha } \\
\text { Nonvolatle beta } \\
\text { Total alpha-emitting radium } \\
\text { Tritium }\end{array}$ & $\begin{array}{l}<2.0 \\
<1.0 \\
<1.0 \\
132 \\
5.9 \\
33 \\
<0.20 \\
880 \\
<1.0 \\
<1.000 \\
<5.0 \\
<1.0 \\
<1.0 \\
<2.0 \mathrm{E}-09 \\
<2.0 \mathrm{E}-09 \\
<1.0 \mathrm{E}-09 \\
<7.0 \mathrm{E}-07\end{array}$ & & 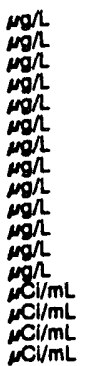 & $\begin{array}{l}G E \\
G E \\
G E \\
G E \\
G E \\
G E \\
G E \\
G E \\
G E \\
G E \\
G E \\
G E \\
G E \\
G E \\
G E \\
G E \\
G E \\
G E\end{array}$ \\
\hline
\end{tabular}

WELL MSB 42A

MEASUAEMENTS CONDUCTED IN THE FIELD

Semple date: 08/20/92

Depth to water: $157.70 \mathrm{At}(49.07 \mathrm{~m})$ below TOC Water slevation: $218.90 \mathrm{it}(88.72 \mathrm{~m}) \mathrm{ms}$ )

Sp. conductance: $25 \mu \mathrm{s} / \mathrm{cm}$

$1.7 \mathrm{E}-00 \pm 5.0 \mathrm{E}-07 \quad \mathrm{NC} / \mathrm{mL}$ GE

Wator ovacuated bofore sampling: $246 \mathrm{gal}$

LABORATORY ANALYSES

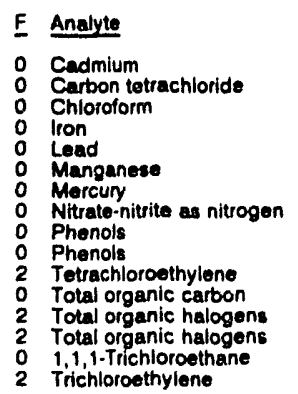

Pesult
$<2.0$
$<25$
$<25$
$<25$
42.0
43.0
4.6
1.20
1.100
$<5.0$
$<5.0$
205
$<1,000$
461
452
$<25$
868

Time: 10:35

pH: 5.0

Alkalinity: $0 \mathrm{mg} / \mathrm{h}$

Water temperature: $21.4^{\circ} \mathrm{C}$

Result
$<2.0$
$<25$
$<25$
42
$<3.0$
4.6
$<0.20$
1.100
$<5.0$
$<5.0$
205
$<1.000$
461
452
$<25$
868

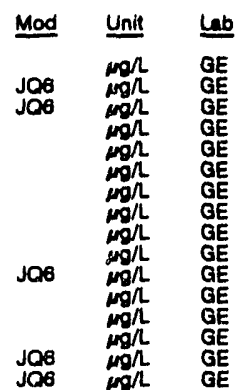


ANALYTICAL RESULTS

WELL MSB 42A colloctad on 08/20/92, laboratory analyses (cont.)

\begin{tabular}{|c|c|c|c|}
\hline Analyte & Result & Mod & Unit \\
\hline $\begin{array}{l}\text { Grose alpha } \\
\text { Nonvolatille beta } \\
\text { Total alpha-emitting radium } \\
\text { Trittium }\end{array}$ & $\begin{array}{l}<2.0 E-09 \\
<2.0 E-09 \\
<1.0 E-09 \\
<7.0 E-07\end{array}$ & & 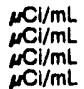 \\
\hline
\end{tabular}

WELL MSB 42B

MEASUREMENTS CONDUCTED IN THE FIELD
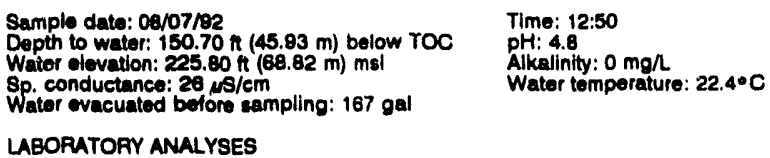

LABORATORY ANALYSES

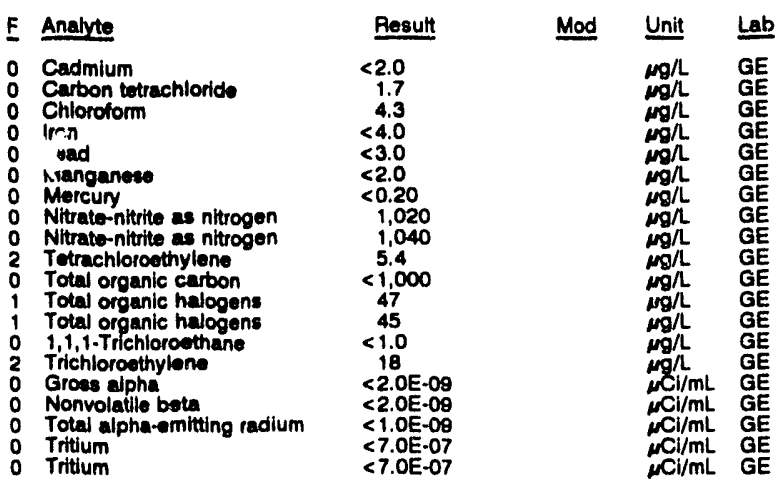

\section{WELL MSB 42C}

MEASUAEMENTS CONDUCTED IN THE FIELD

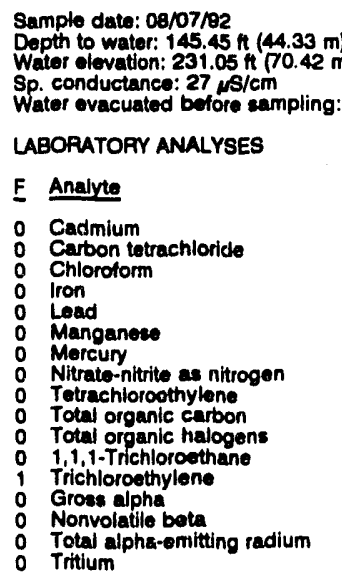

Time: 13:05

PH: 5.2

Water temperature: $22.0^{\circ} \mathrm{C}$

\section{LABOPATORY ANALYSES}

\section{WELL MSB 42D}

MEASUAEMENTS CONDUCTED IN THE FIELD

Sample date: 08/07/92

Wepth to water: $144.08 \mathrm{At}(\mathbf{4 3 . 9 1} \mathrm{m})$ below TOC

Water olevation: $232.44 \mathrm{tt}(70.85 \mathrm{~m}) \mathrm{ms}$

inaccessibility or mechanical problem prevented sample collection.

WELL MSB 42TA

MEASUAEMENTS CONDUCTED IN THE FIELD

Sample date: 08/07/92

Depth to water: $170.65 \mathrm{Ht}(52.01 \mathrm{~m})$ below TOC Water olovation: $206.05 \mathrm{Ht}(62.80 \mathrm{~m}) \mathrm{mal}$ Sp. conductance: $10 \mu \mathrm{\mu} / \mathrm{cm}$
Water ovacuated before sampling: $\mathbf{4 3 0} \mathrm{gal}$ LABORATORY ANALYSES

F Analyte

- Cadmium

o Chloroform

o Iron

0 Lead

O Manganese

Mercuny

Nitrate-nitrite as nitrogen

2 Tetrachloroethylene

Total organic carbon

Total organic carbon

Total organic halogens

2 1,i.1. Trichloroethan

2 Trichloroethylen

o Nonvolatile beta

Total alpha-emitting radium

Tritium

\section{WELL MSB 43A}

MEASUREMENTS CONDUCTED IN THE FIELD

Sample date: $07 / 20 / 92 \mathrm{H}$ (39.23 m) below TOC Depth to water: $128.72 \mathrm{ft}(39.23 \mathrm{~m})$ below
Water elevation: $229.18 \mathrm{ft}(69.85 \mathrm{~m}) \mathrm{msl}$
Sp conductance: 22 Water evacuated before sampling: $244 \mathrm{gal}$

\section{LABOPATORY ANALYSES}

$\begin{array}{ll}\text { E } & \text { Analyte } \\ 0 & \text { pH } \\ 0 & \text { Specific conductance } \\ 0 & \text { Arsenic } \\ 0 & \text { Barium } \\ 0 & \text { Cadmium } \\ 0 & \text { Chloride } \\ 0 & \text { Chromium } \\ 0 & \text { Copper } \\ 0 & \text { Iron } \\ 0 & \text { Lead } \\ 0 & \text { Manganese } \\ 0 & \text { Mercuny } \\ 0 & \text { Nickel } \\ 0 & \text { Nitrate-nitrite as nitrogen } \\ 0 & \text { Phenols } \\ 0 & \text { Selenium } \\ 0 & \text { Silver } \\ 0 & \text { Sodium } \\ 0 & \text { Sulfate } \\ 0 & \text { Total organic carbon } \\ 0 & \text { Total organic halogens } \\ 0 & \text { Total phosphates las Py } \\ 0 & \text { Zinc } \\ 0 & \text { Nonvolatile beta } \\ 0 & \text { Total alpha-emitting radium } \\ 0 & \text { Uranium-234 } \\ 0 & \text { Uranium -235 } \\ 0 & \text { Uranium-238 }\end{array}$

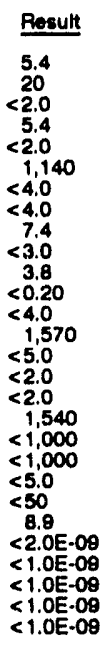

\section{WELL. MSB 43B}

MEASUREMENTS CONDUCTED IN THE FIELD

Sample date: 07/20/92

Depth to water: $128.02 \mathrm{At}(39.02 \mathrm{~m})$ below TOC Water olevation: $229.88 \mathrm{ft}(70.10 \mathrm{~m}) \mathrm{msl}$ Sp. conductance: $28 \mu \mathrm{s} / \mathrm{cm}$. LABORATORY ANALYSES

\begin{tabular}{|c|c|c|c|}
\hline E Analyte & Result & Mod & Unit \\
\hline $\begin{array}{ll}0 & \text { pH } \\
0 & \text { Specific conductance } \\
0 & \text { Arsenic } \\
0 & \text { Barium } \\
0 & \text { Cadmium } \\
0 & \text { Chloride } \\
0 & \text { Chromium } \\
0 & \text { Copper }\end{array}$ & $\begin{aligned} & 5.0 \\
& 25 \\
&<2.0 \\
&<3.0 \\
&<2.0 \\
& 1.460 \\
&<4.0 \\
&<4.0\end{aligned}$ & JO & 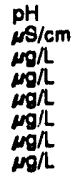 \\
\hline
\end{tabular}

\author{
Time: 13:35 \\ Alkalinity: $1 \mathrm{mg} / \mathrm{h}$ \\ Water tomporature: $22.4^{\circ} \mathrm{C}$
}

PH: $5,1.05$

Alkalinity: $1 \mathrm{mgh}$

Water tomperature: $21.1^{\circ} \mathrm{C}$

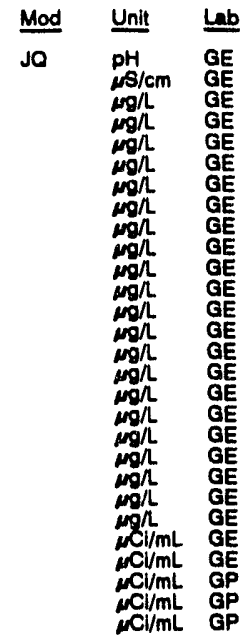

Time: 15:55

pH: 4.4 : 0 mgl

Water temperature: $22.1^{\circ} \mathrm{C}$ 
ANALYTICAL RESULTS

WELL MSB 438 collected on 07/20/92, laboratory analyees (cont.)

\begin{tabular}{|c|c|c|c|}
\hline$\underline{F}$ & Anabyte & Result & Unit \\
\hline $\begin{array}{l}0 \\
0 \\
0 \\
0 \\
0 \\
0 \\
0 \\
0\end{array}$ & $\begin{array}{l}\text { Iron } \\
\text { Load } \\
\text { Manganese } \\
\text { Mercury } \\
\text { Nickel } \\
\text { Nitrate-nitrite as nitrogen } \\
\text { Phenols } \\
\text { Solenlum } \\
\text { Silver } \\
\text { Sodium } \\
\text { Sulfate } \\
\text { Total organic carbon } \\
\text { Total organic carbon } \\
\text { Total organic halogena } \\
\text { Total phoaphatee (as P) } \\
\text { Zinc } \\
\text { Nonvolatile beta } \\
\text { Total alpha-emitting radium } \\
\text { Uranlum-234 } \\
\text { Uranium-235 } \\
\text { Uranium-238 }\end{array}$ & $\begin{array}{l}<4.0 \\
<3.0 \\
2.0 \\
<0.20 \\
<4.0 \\
1.670 \\
<5.0 \\
<2.0 \\
<2.0 \\
1,880 \\
<1,000 \\
<1,000 \\
<1,000 \\
<5.0 \\
<50 \\
7.6 \\
<2.0 E-09 \\
1.5 E-09 \pm 8.0 E-10 \\
<1.0 E-09 \\
<1.0 E-09 \\
<1.0 E-09\end{array}$ & $\begin{array}{l}\mu g / L \\
\mu g / L \\
\mu g / L \\
\mu g / L \\
\mu g / L \\
\mu g / L \\
\mu g / L \\
\mu g / L \\
\mu g / L \\
\mu g / L \\
\mu g / L \\
\mu g / L \\
\mu g / L \\
\mu g / L \\
\mu g / L \\
\mu g / L \\
\mu C l / m L \\
\mu C l / m L \\
\mu C l / m L \\
\mu C i / m L \\
\mu C l / m L\end{array}$ \\
\hline
\end{tabular}

\section{WELL MSB 43D}

MEASUREMENTS CONDUCTED IN THE FIELD

$\begin{array}{ll}\text { Sample date: } 07 / 20 / 92 & \text { Time: } 16: 10 \\ \text { Depth to water: } 126.40 \mathrm{n}(38.53 \mathrm{~m}) \text { below TOC } & \text { pH: } 4.6 \\ \text { Watter elovation: } 231.10 \mathrm{f}(70.44 \mathrm{~m}) \mathrm{msl} & \text { Alkalinity: } 0 \mathrm{mg} / \mathrm{L} \\ \text { Sp. conductance: } 23 \mu \mathrm{S} / \mathrm{cm} & \text { Water temperature: } 20.5^{\circ} \mathrm{C} \\ \text { Water evacuated bofore sampling: } 79 \mathrm{gal} & \end{array}$

LABORATORY ANALYSES

E Analyte

0 pH

0 pH

Specific conductance

Specific conductance

Areonic

Areenic

Barium

O Barium

Cadmium

Cadmium

Cadmium

Chloride

Chloride

Chiorido

Chromium

Chromium

Copper

Copper

Iron

iron

- Iron

0 Lead

Lead

Manganees

Manganese

Manganese

Mercury

Mercuny

Nickel

Nickol

Nitrate as nitrogen

Nitrate-nitrite os nitrogen

Phenols

Phonols

Selonium

Selenium

Silver

Silver

Sodium

Sodium

Sodium

Sulfato

Sufte

Total organic carbon

Total organic carbon

Total organic halogens

Total organic halogens

Total organic halogens

Total phosphates as P

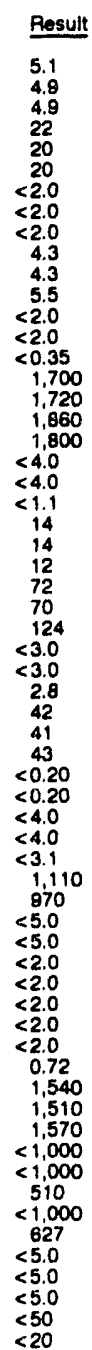

Specific conductance

Arsenic

0 Barlum

Barlum

Cadmium

Cadmium

Chloride

Chromium

Chromium

Copper

Iron

Iron

0 Lead

Manganese

Manganes

Mercury

Mercury

Nickel

Nitrate as nitrogen

Nitrate-nitrite as nitrogen

Nitrato-nitrite as nitrogon

Phenols

Selenium

Selenium

Silver

Sodium

Sodium

Sulfate

Total organic carbon

Total organic carbon

Tola organic halogons

Total phosphates (es P)

Total phosphates as P

Zinc

Groses alphe

Nonvolatile beta

Nonvolatile beta

Nonvolatile beta

Radium-228

Radium-226

Radium-228

Total alpha-emitting radium

Uranium-234

Uranium-23

Uranium-234

Uranium-235

Uranium-235

Uranium-23 es (cont.)

\begin{tabular}{|c|c|c|}
\hline Rosult & Mod & Unit \\
\hline $\begin{aligned} & 8.7 \\
& 9.7 \\
& 12 \\
&<1.0 \mathrm{E}-09 \\
&<1.0 \mathrm{E} \cdot 09 \\
&<2.0 \mathrm{E} \cdot 09 \\
&<1.4 \mathrm{E} \cdot 09 \\
&<1.4 \mathrm{E} \cdot 09 \\
& 2.8 \mathrm{E} \cdot 09 \pm 9.2 \mathrm{E} \cdot 10 \\
&<\mathrm{B} .0 \mathrm{E}-10 \\
&<1.0 \mathrm{E}-09 \\
&<1.0 \mathrm{E} \cdot 09 \\
&<1.0 \mathrm{E} \cdot 09 \\
&<1.0 \mathrm{E} \cdot 09 \\
&<1.0 \mathrm{E} \cdot 09 \\
&<1.0 \mathrm{E}-09 \\
&<1.0 \mathrm{E} \cdot 09 \\
&<1.0 \mathrm{E} \cdot 09\end{aligned}$ & & 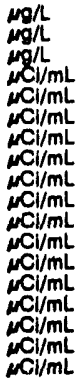 \\
\hline
\end{tabular}

\section{Replicate}

IN THE FIELL

16:10

Alkalinity: $0 \mathrm{mo} / \mathrm{h}$ Water temperature: $20.5^{\circ} \mathrm{C}$

$$
\text { }
$$


ANALYTICAL RESULTS

WEL MSB 430 collocted on 07/20/82, laboratory analyses (cont.)

\begin{tabular}{|c|c|c|c|}
\hline E Analyte & Rosult & Mod & Unit \\
\hline 0 Uranium-238 & $<1.0 E-09$ & & $\mu \mathrm{Ci} / \mathrm{mL}$ \\
\hline
\end{tabular}

\section{WELLL MSB 43TA}

MEASUAEMENTS CONDUCTED IN THE FIELD

Sample date: $07 / 20 / 92 \mathrm{H}(46.82 \mathrm{~m})$ balow TOC Depth to water: $153.62 \mathrm{ft}(46.82 \mathrm{~m})$ balow TOC
Water elevation: $203.88 \mathrm{ft}(62.17 \mathrm{~m}) \mathrm{msl}$ Sp. conductance: 18 $\mathrm{s} / \mathrm{cm}$
Water evacuated bofore eampling: $438 \mathrm{gal}$ LABORATORY ANALYSES

\begin{tabular}{|c|c|c|c|c|c|}
\hline$\underline{F}$ & Analyte & Result & Mod & Unit & Lab \\
\hline $\begin{array}{l}0 \\
0 \\
0 \\
0 \\
0 \\
0 \\
0 \\
0 \\
0\end{array}$ & $\begin{array}{l}\text { pH } \\
\text { Specific corductance } \\
\text { Aneonic } \\
\text { Barium } \\
\text { Cedmium } \\
\text { Chloride } \\
\text { Chromium } \\
\text { Copper } \\
\text { Iron } \\
\text { Lead } \\
\text { Manganese } \\
\text { Morcury } \\
\text { Mercury } \\
\text { Nickel } \\
\text { Nitrate-nitrite ae nitrogen } \\
\text { Phenols } \\
\text { Selonium } \\
\text { Silver } \\
\text { Sodium } \\
\text { Sulitate } \\
\text { Total organic carton } \\
\text { Total organic halogens } \\
\text { Total organic halogens } \\
\text { Total phosphates (as P) } \\
\text { Znc } \\
\text { Nonvolatlla beta } \\
\text { Total alpha-emitting radium } \\
\text { Uranium-234 } \\
\text { Uranium-235 } \\
\text { Uranium-23s }\end{array}$ & $\begin{aligned} & 5.0 \\
& 20 \\
&<2.0 \\
&<3.0 \\
&<2.0 \\
& 1,900 \\
&<4.0 \\
& 5.8 \\
& 351 \\
& 8.2 \\
& 31 \\
&<0.20 \\
&<0.20 \\
&<4.0 \\
& 100 \\
&<5.0 \\
&<2.0 \\
&<2.0 \\
& 1,400 \\
& 1.020 \\
&<1.000 \\
&<5.0 \\
&<5.0 \\
&<50 \\
& 2.1 \\
&<2.0 \mathrm{E}-09 \\
&<1.0 \mathrm{E}-09 \\
&<1.0 \mathrm{E}-09 \\
&<1.0 \mathrm{E}-09 \\
&<1.0 \mathrm{E}-09\end{aligned}$ & $J Q$ & 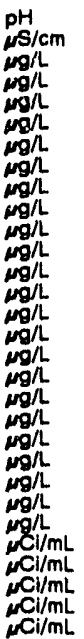 & $\begin{array}{l}\mathrm{GE} \\
\mathrm{GE} \\
\mathrm{GE} \\
\mathrm{GE} \\
\mathrm{GE} \\
\mathrm{GE} \\
\mathrm{GE} \\
\mathrm{GE} \\
\mathrm{GE} \\
\mathrm{GE} \\
\mathrm{GE} \\
\mathrm{GE} \\
\mathrm{GE} \\
\mathrm{GE} \\
\mathrm{GE} \\
\mathrm{GE} \\
\mathrm{GE} \\
\mathrm{GE} \\
\mathrm{GE} \\
\mathrm{GE} \\
\mathrm{GE} \\
\mathrm{GE} \\
\mathrm{GE} \\
\mathrm{GE} \\
\mathrm{GE} \\
\mathrm{GE} \\
\mathrm{GE} \\
\mathrm{GP} \\
\mathrm{GP} \\
\mathrm{GP}\end{array}$ \\
\hline
\end{tabular}

\section{WELL MSB 44A}

MEASUREMENTS CONDUCTED IN THE FIELD

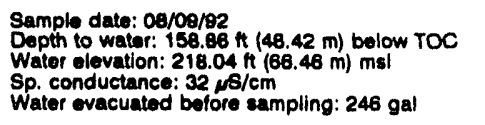

Time: $18: 45$

Alkalinity: $0 \mathrm{mg}$

Water temperature: $21.5^{\circ} \mathrm{C}$

$\mu \mathrm{Ci} / \mathrm{mL}$ GP

Time: 11:05

PH: 5.1 Alkalinity: $1 \mathrm{mg} / \mathrm{h}$

Waler temperature: $22.3^{\circ} \mathrm{C}$

LABORATORY ANALYSES

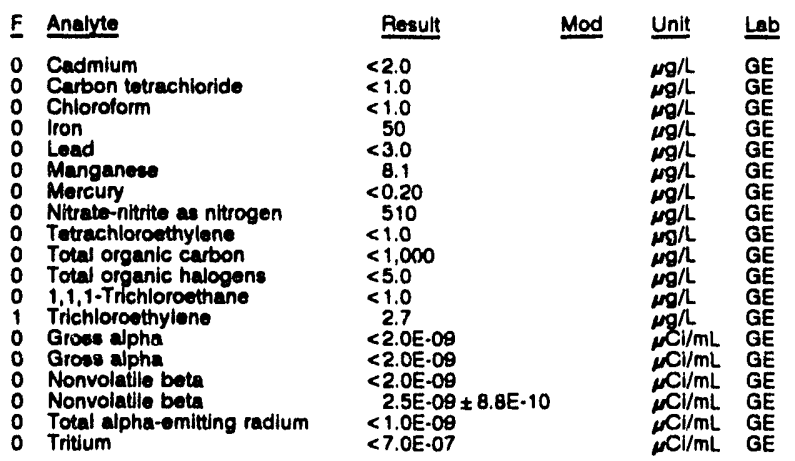

WELL MSB 44B

MEASUREMENTS CONDUCTED IN THE FIELD

Sample date: 08/09/92

Depth to water: $152.41 \mathrm{~h}(46.48 \mathrm{~m})$ below TOC

Sp. conductance: $44.68 \mathrm{~cm}$

Water evacuated before sampling: $133 \mathrm{gal}$

LABORATORY ANALYSES

\begin{tabular}{|c|c|c|c|c|}
\hline Analyie & Pesult & Mod & Unit & Lab \\
\hline $\begin{array}{l}\text { Cadmium } \\
\text { Carbon tetrachloride } \\
\text { Chloroform } \\
\text { Iron } \\
\text { Load } \\
\text { Manganese } \\
\text { Morcury } \\
\text { Mercury } \\
\text { Nitrate-nitrite as nitrogen } \\
\text { Tetrachloroethylene } \\
\text { Total organic carbon } \\
\text { Total organic halogens } \\
\text { 1,1,1-Trichloroothane } \\
\text { Trichloroethylene } \\
\text { Gross alpha } \\
\text { Nonvolatile beta } \\
\text { Total alpha-emitting radium } \\
\text { Tritium }\end{array}$ & $\begin{aligned}<2.0 \\
<1.0 \\
<1.0 \\
6.1 \\
<3.0 \\
3.0 \\
<0.20 \\
<0.20 \\
100 \\
<1.0 \\
<1.000 \\
<5.0 \\
<1.0 \\
<1.0 \\
<2.0 \mathrm{E}-09 \\
<2.0 \mathrm{E}-09 \\
<1.0 \mathrm{E} \cdot 09 \\
<7.0 \mathrm{E}-07\end{aligned}$ & & 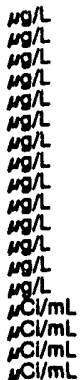 & $\begin{array}{l}\mathrm{GE} \\
\mathrm{GE} \\
\mathrm{GE} \\
\mathrm{GE} \\
\mathrm{GE} \\
\mathrm{dE} \\
\mathrm{GE} \\
\mathrm{gE} \\
\mathrm{GE} \\
\mathrm{GE} \\
\mathrm{GE} \\
\mathrm{GE} \\
\mathrm{GE} \\
\mathrm{GE} \\
\mathrm{GE} \\
\mathrm{GE} \\
\mathrm{GE} \\
\mathrm{GE}\end{array}$ \\
\hline
\end{tabular}

\section{WELL MSB 44C}

MEASUREMENTS CONDUCTED IN THE FIELD

Sample date: 08/0日9:

Depth to water: $142.69 \mathrm{ft}(43.49 \mathrm{~m})$ below TOC

Water olovation: $235.21 \mathrm{ft}(71.69 \mathrm{~m}) \mathrm{msl}$

Water evacuated before sampling: $4 \mathrm{gal}$

LABORATORY ANALYSES

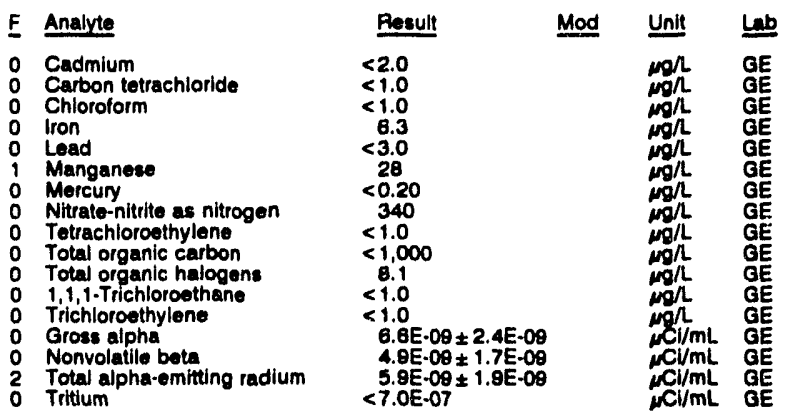

WELL MSB 45A

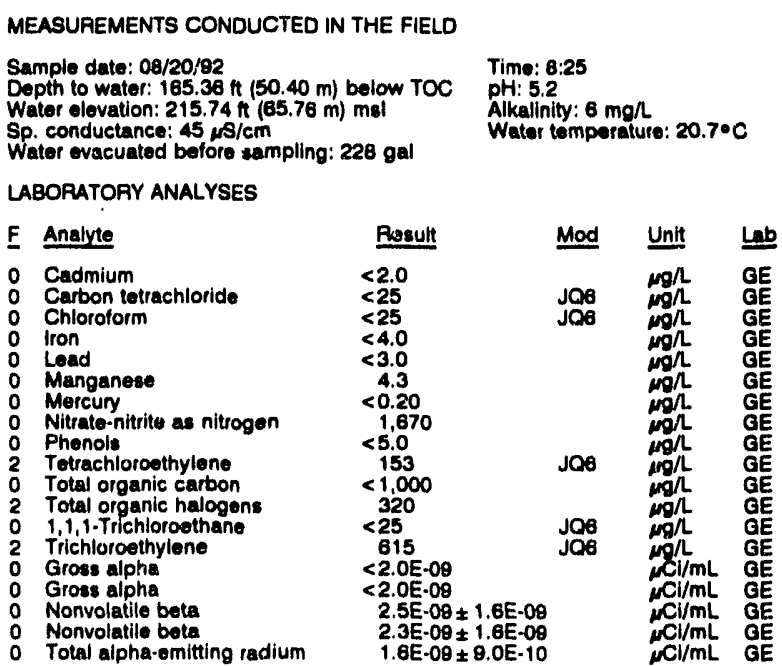




\begin{tabular}{|c|c|c|c|c|c|}
\hline$\underline{E}$ & Anajute & Result & Mod & Unit & \\
\hline $\begin{array}{l}0 \\
0\end{array}$ & $\begin{array}{l}\text { Total alpha-omiting radium } \\
\text { Tritium }\end{array}$ & $\begin{array}{r}2.0 \mathrm{E} \cdot 09 \\
<7.0 \mathrm{E} \cdot 07\end{array}$ & 10 & $\underset{\mu \mathrm{Cl} / \mathrm{mL}}{\mu \mathrm{Cl} / \mathrm{mL}}$ & $\begin{array}{l}\mathrm{GE} \\
\mathrm{GE}\end{array}$ \\
\hline \multicolumn{6}{|c|}{ WELL MSB 45B } \\
\hline \multicolumn{6}{|c|}{ MEASUREMENTS CONDUCTED IN THE FIELD } \\
\hline \multicolumn{3}{|c|}{$\begin{array}{l}\text { Sample date: } 08 / 10 / 92 \\
\text { Depth to wator: } 188.00 \mathrm{n}(47.38 \mathrm{~m}) \text { below TOC } \\
\text { Wator olovation: } 225.01 \mathrm{~h}(88.58 \mathrm{~m}) \mathrm{mal} \\
\text { Sp. conductance: } 39,18 / \mathrm{cm} \\
\text { Water wacuated before eampling: } 119 \mathrm{gal}\end{array}$} & \multicolumn{3}{|c|}{$\begin{array}{l}\text { Time: } 11: 30 \\
\text { pH: } 4.0^{\circ} \\
\text { Alkalinity: } 1 \mathrm{mg} / \mathrm{L} \\
\text { Water tomperature: } 22.3^{\circ} \mathrm{C}\end{array}$} \\
\hline \multicolumn{6}{|c|}{ LABOFUTOFY ANALYSES } \\
\hline $\mathbf{E}$ & Anulyte & Result & Mod & Unit & 느 \\
\hline $\begin{array}{l}0 \\
0 \\
0 \\
0 \\
0 \\
0 \\
0 \\
0 \\
0 \\
0 \\
0 \\
0 \\
0 \\
0 \\
0 \\
0\end{array}$ & 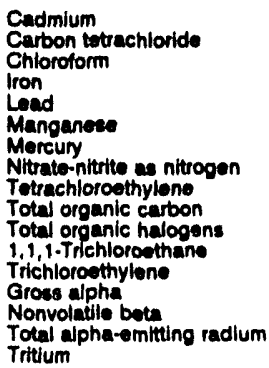 & $\begin{array}{l}<2.0 \\
<1.0 \\
<1.0 \\
47 \\
<3.0 \\
<2.0 \\
<0.20 \\
170 \\
<1.0 \\
<1.000 \\
<5.0 \\
<1.0 \\
<1.0 \\
<2.0 E \cdot 09 \\
<2.0 E .09 \\
<1.0 E-09 \\
<7.0 E-07\end{array}$ & & 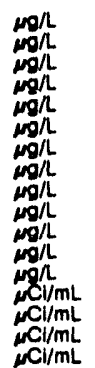 & $\begin{array}{l}G E \\
G E \\
G E \\
G E \\
G E \\
G E \\
G E \\
G E \\
G E \\
G E \\
G E \\
G E \\
G E \\
G E \\
G E\end{array}$ \\
\hline
\end{tabular}

\section{WELL MSB 45C}

MEASUREMENTS CONDUCTED IN THE FIELD

Sample date: 08/10/82

The woll was dy.

\section{WELL MSB 46A}

MEASUREMENTS CONDUCTED IN THE FIELD

\begin{tabular}{|c|c|c|c|c|c|}
\hline & 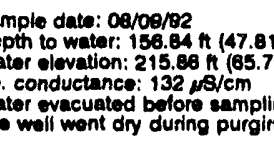 & $\begin{array}{l}\text { glow TOC } \\
\text { mel } \\
\text { gal }\end{array}$ & $\begin{array}{l}\text { Time: } 12 \\
\text { pH: } 9.2 \\
\text { Alkalinity } \\
\text { Watei te }\end{array}$ & $g / L$. & \\
\hline & BORATORY ANALYSES & & & & \\
\hline$\underline{F}$ & Analyte & Result & Mod & Unit & \\
\hline & $\begin{array}{l}\text { Cadmium } \\
\text { Carbon totrachloride } \\
\text { Chloroform } \\
\text { lron } \\
\text { Loed } \\
\text { Manganewe } \\
\text { Morrury } \\
\text { Nitrate-nitrite as nitrogen } \\
\text { Tetrachloroethylens } \\
\text { Total organic carbon } \\
\text { Total organic halogens } \\
\text { 1,1,1-Trichloroetthane } \\
\text { Trichloroethylane } \\
\text { Grose alpha } \\
\text { Nonvolatlie beta } \\
\text { Total alpha-emitting radium } \\
\text { Tritium }\end{array}$ & $\begin{array}{l}<2.0 \\
<1.0 \\
<1.0 \\
8.6 \\
<3.0 \\
<2.0 \\
<0.20 \\
<50 \\
<1.0 \\
<1.000 \\
6.0 \\
<1.0 \\
<1.0 \\
<2.0 \mathrm{E} \cdot 08 \\
1.0 \mathrm{E}-08 \pm \\
<1.0 \mathrm{E} \cdot 09 \\
<7.0 \mathrm{E} \cdot 07\end{array}$ & & 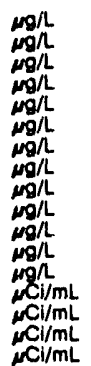 & $\begin{array}{l}\mathrm{GE} \\
\mathrm{GE} \\
\mathrm{GE} \\
\mathrm{GE} \\
\mathrm{GE} \\
\mathrm{GE} \\
\mathrm{GE} \\
\mathrm{GE} \\
\mathrm{GE} \\
\mathrm{GE} \\
\mathrm{GE} \\
\mathrm{GE} \\
\mathrm{GE} \\
\mathrm{GE} \\
\mathrm{GE}\end{array}$ \\
\hline
\end{tabular}

\section{WELL MSB 46B}

MEASUREMENTS CONDUCTED IN THE FIELD

Sample date: 08/09/92

Depth to water: Not evallable

Water elevation: Not availablo

Water ovacuated before sampling: $112 \mathrm{gol}$

LABORATORY ANALYSES

\begin{tabular}{|c|c|c|c|c|}
\hline$\underline{F}$ & Analyte & Rosult & Mod & Unit \\
\hline 0 & $\begin{array}{l}\text { Cadmium } \\
\text { Cadmium } \\
\text { Carbon totrachloride }\end{array}$ & $\begin{array}{l}<2.0 \\
<2.0 \\
<1.0\end{array}$ & & $\begin{array}{l}\mu g / L \\
\mu g / L \\
\mu g / L\end{array}$ \\
\hline
\end{tabular}

Time: 11:10

Time: 11

WELL MSB 488 collected on 08/09/02, laboratory analyees (cont.)

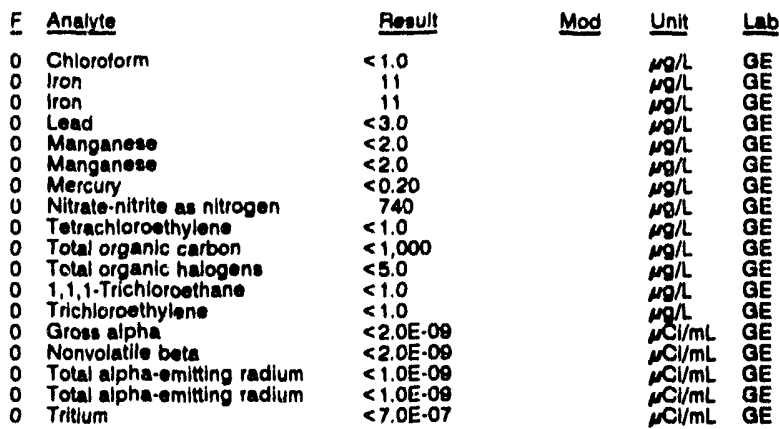

\section{WELL MSB 46C}

MEASUREMENTS CONDUCTED IN THE FIELD

Sample date: 08/09/82

Depth to wator: $131.80 \mathrm{~h}(40.20 \mathrm{~m})$ below TOC Water elevation: $240.90 \mathrm{~h}(73.43 \mathrm{~m}) \mathrm{msl}$ Water evacuated botore sampling: 3 gal

Time: 12:55

pH: 5.4

Alxalinity: $2 \mathrm{mg} / \mathrm{L}$

LABORATORY ANALYSES

\begin{tabular}{|c|c|c|c|}
\hline Analyte & Result & Mad & Unil \\
\hline $\begin{array}{l}\text { Cadmlum } \\
\text { Carbon totrachloride } \\
\text { Chloroform } \\
\text { rron } \\
\text { Load } \\
\text { Manganese } \\
\text { Morcury } \\
\text { Nitrate-nitrite as nitrogen } \\
\text { Phenols } \\
\text { Phonols } \\
\text { Totrachloroethylene } \\
\text { Total organic carbon } \\
\text { Total organic halogens } \\
\text { 1,1,1.Trichloroethane } \\
\text { Trichloroethylene } \\
\text { Gross alpha } \\
\text { Gross alpha } \\
\text { Nonvolatile bota } \\
\text { Nonvolatilo beta } \\
\text { Total alpha-emitting radium } \\
\text { Tritium }\end{array}$ & $\begin{array}{l}<2.0 \\
6.1 \\
<1.0 \\
28 \\
<3.0 \\
3.8 \\
<0.20 \\
2.720 \\
<5.0 \\
<5.0 \\
<1.0 \\
6,860 \\
10 \\
<1.0 \\
<1.0 \\
<2.0 E-09 \\
1.5 E-08 \pm 2.0 E-00 \\
2.1 E-08 \pm 1.4 E-00 \\
1.5 E-08 \pm 1.0 E-09 \\
1.2 E-09 \pm 0.0 E-10 \\
1.2 E-08 \pm 5.0 E-07\end{array}$ & & 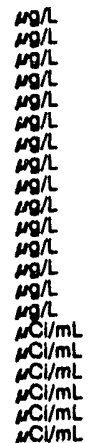 \\
\hline
\end{tabular}

\section{WELL MSB 47B}

MEASUPEMENTS CONDUCTED IN THE FIELD

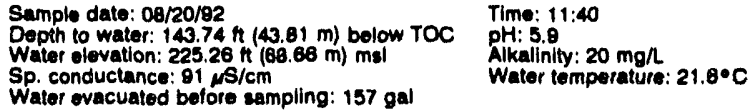

Wator evacuated before sampling: $157 \mathrm{gal}$

LABORATORY ANALYSES

\begin{tabular}{|c|c|c|c|}
\hline Analyte & Result & Mod & nit \\
\hline $\begin{array}{l}\text { Cadmium } \\
\text { Carbon totrachloride } \\
\text { Chloroform } \\
\text { lron } \\
\text { Lead } \\
\text { Manganese } \\
\text { Morcury } \\
\text { Nitrate.niltrite as nitrogen } \\
\text { Phenuls } \\
\text { Totrachloroethylene } \\
\text { Total organic carbon } \\
\text { Total organic carbon } \\
\text { Total organic haiogens } \\
\text { 1,1, Trichlorothane } \\
\text { Trichloroethylent } \\
\text { Gross alpha } \\
\text { Nonvolatile beta } \\
\text { Total alpha-emitting radium } \\
\text { Tritium }\end{array}$ & $\begin{array}{l}<2.0 \\
<100 \\
<100 \\
<4.0 \\
<3.0 \\
7.9 \\
<0.20 \\
3,350 \\
<5.0 \\
<100 \\
<1,000 \\
<1,000 \\
1,010 \\
<100 \\
2,060 \\
4.5 E-09 \pm 8.0 E-10 \\
5.5 E \cdot 09 \pm 7.8 E-10 \\
2.1 E \cdot 09 \pm 1.1 E-09 \\
4.6 E \cdot 06 \pm 5.0 E \cdot 07\end{array}$ & $\begin{array}{l}J Q 6 \\
\text { JQO }\end{array}$ & 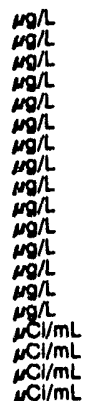 \\
\hline
\end{tabular}

Time: 12:2

pH: 5.3

Alkalinity: $3 \mathrm{mg} / \mathrm{h}$ : $22.7^{\circ} \mathrm{C}$

Tritium

E


ANALYTICAL RESULTS

WELL MSB 47BB

MEASUAEMENTS CONDUCTED IN THE FIELD

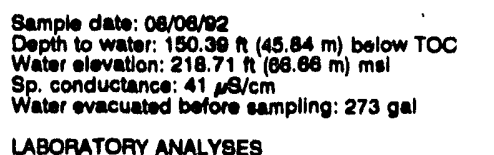

F Anayte

: pH

O Aluminum

o Areanic

O Barlum

O Bromodichloromothane

Bromoiorm

Bromomethane

o Caleium

Carbon tetrachloride

0 Chloride

o Chlorobenzene

Chloroethane

Chlorocthene Minyl chloride)

2.Chloroethyl vinyl ether

Chloroform

Chloromethane

Copper

Cyanide

Dibromochloromethane

1,1-Dichloroethane

1,4-Dichlophan.

trane-1,2-Dichloroethylene

Dichioromethane

cis-1,3-Dichloropropen

trane-1,3-Dichloropropen

Ethylbenzene

Fluoride

iron

Load

Magnesium

Mercun

Nitrato-nitrite es nitrogen

Phenols

Potnagium

Sillea

Situer

Sodium

1,1,2,2-Tetrachioroethane

Totruchloroethylone

Toluene

Total dissolved solids

Total organic carbon

Total organic carbon

Total oreanic halogens

1,1,1-Trichlorcethane

1,1,2-Trichloroethen

Trichlorofluoromethane

Uranium

Zine

Groes alpha

Total alpha-emitting radium

Peeuit

5.0
42
23
$<2.0$
30
$<1.0$
$<1.0$
$<1.0$

$<1.0$
$<1.0$

4,410

$<1.0$

1,620
$<1.0$

$<1.0$

$<1.0$

$<1.0$

$<1.0$

$<4.0$

$<5.0$

$<1.0$

$<1.0$

$<1.0$

$<1.0$
1.8
$<1.0$

$<1.0$

$<1.0$
$<1.0$

$<1.0$

$<100$
$<100$

7.9
$<3.0$
236

236
3.7
$<0.20$

$<0.20$

$<4.0$
1.180
$<5.0$

$<5.00$

$<2.0$

$<2.0$

3,000
$<1,000$

$<1.0$

$<1.0$

42,000
$<1,000$

$<1,000$
$<1,000$

6.6

$<50$

$<1.0$
$<1.0$

26
2.0

$<1.0$

$<20$

$<2.0 \mathrm{E}-09$

$<1.0 \mathrm{C}-\mathrm{O}$

o Tritum
Time: 13:20

PH: 6.2 Alkalinity: $13 \mathrm{mg} / \mathrm{L}$

Water temperature: $20.8 \circ \mathrm{C}$

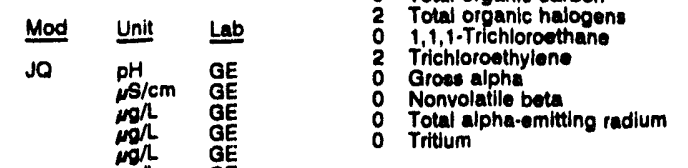

o Manganese

o Morcury

Nitrate-nitrite as nitrogen

Phenols

Tetrachloroethylene

Total organio hatoon

Groes alph

Trttum

WELL MSB 47C collected on 08/20/92, laboratory anulyese (cont.)

$E$ Anatrie

0 Lead

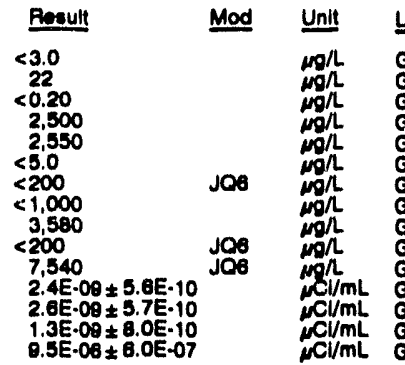

WELL MSB 47D

MEASUREMENTS CONDUCTED IN THE FIELO

Sample date: 08/06/92

Depth to water; $135.27 \mathrm{ht}(41.23 \mathrm{~m})$ below TOC

Watar elevation: $233.83 \mathrm{~A}(71.30 \mathrm{~m}) \mathrm{mal}$

Bp. conductance: $65 \mathrm{mS} / \mathrm{cm}$

Time: $12: 55$

PH: 4.7

Wator tomporalure: $20.5^{\circ} \mathrm{C}$

LABORATOAY ANALYSES

\begin{tabular}{|c|c|c|c|c|}
\hline$F$ & Analyte & Result & Unit & $a b$ \\
\hline $\begin{array}{l}0 \\
0 \\
0 \\
0\end{array}$ & $\begin{array}{l}\text { Cadmium } \\
\text { Carbon totrachloride } \\
\text { Chloroform } \\
\text { Iron } \\
\text { Lead } \\
\text { Manganese } \\
\text { Mercury } \\
\text { Nitrate-nitrite as nitrogen } \\
\text { Totrachloroethylene } \\
\text { Total organic carton } \\
\text { Total organic halogens } \\
1,1,1-\text { Trichloroethane } \\
\text { Trichloroethylene } \\
\text { Gross alpha } \\
\text { Gross alpha } \\
\text { Nonvolatile beta } \\
\text { Nonvolatile bota } \\
\text { Total alpha-emitting radium } \\
\text { Tritium }\end{array}$ & 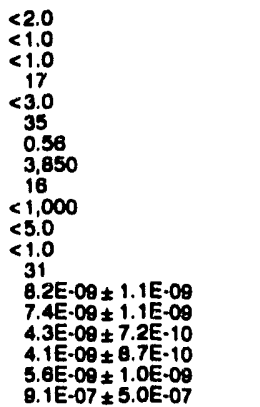 & 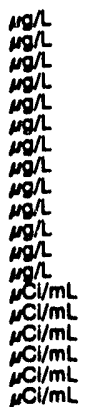 & $\begin{array}{l}\mathrm{GE} \\
\mathrm{GE} \\
\mathrm{GE} \\
\mathrm{GE} \\
\mathrm{GE} \\
\mathrm{GE} \\
\mathrm{GE} \\
\mathrm{GE} \\
\mathrm{GE} \\
\mathrm{GE} \\
\mathrm{GE} \\
\mathrm{GE} \\
\mathrm{GE} \\
\mathrm{GE} \\
\mathrm{GE} \\
\mathrm{GE} \\
\mathrm{GE} \\
\mathrm{GE} \\
\mathrm{GE}\end{array}$ \\
\hline
\end{tabular}

WELL MSB 47TA

MEASUAEMENTS CONDUCTED IN THE FIELD

Sample date: 08/20/92 Depth to water: $132.24 \mathrm{~h}(46.40 \mathrm{~m})$ below TOC Wator elovation: $216.78 \mathrm{t}(68.07 \mathrm{~m})$ il1:1

Water evacuatod bolore sampling: 497 as!

LABORATORY ANALYSES

F Analyte

- Ceodmium

0 Cadmium

o Chloroform

Iron

tron

Load

Manganere

Manganees

Morcury

Nitrate-nitrite as nitrogen

Phenols

Tetrachloroethylene

Total organic carbon

2 Total organic halogen

Total organic halogen

2 Trichloroethylene

Gross alpha

Nonvolatile beta

Total alpha-emitting radium

o Tritium

\begin{tabular}{|c|c|c|c|}
\hline F Anajyte & Rosult & Mod & Unit \\
\hline $\begin{array}{ll}0 & \text { Cadmium } \\
0 & \text { Carbon tetrachloride } \\
0 & \text { Chloroform } \\
0 & \text { lron } \\
0 & \text { Laad }\end{array}$ & $\begin{array}{l}<2.0 \\
<200 \\
<200 \\
<4.0 \\
<3.0\end{array}$ & $\begin{array}{l}J 08 \\
J 06\end{array}$ & 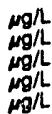 \\
\hline
\end{tabular}

pH: 5.6 : $9 \mathrm{mg}$

Alkalinity: $9 \mathrm{mg} / \mathrm{h}$
Water temperature: $20.8^{\circ} \mathrm{C}$
Time: 12:45

Alkalinity: $0 \mathrm{mon}$ Water temperature: $21.3^{\circ} \mathrm{C}$

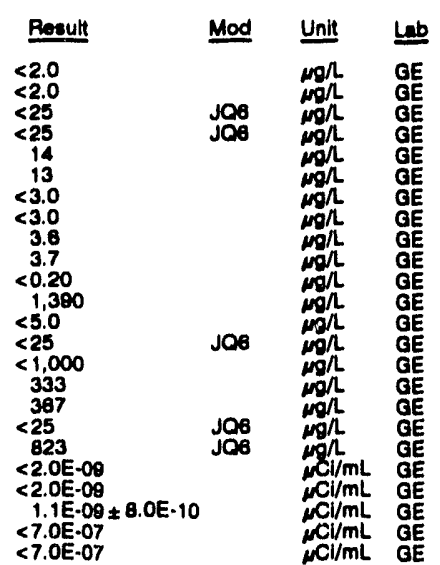


WELL MSB 48A

MEASUREMENTS CONDUCTED IN THE FIELD

Sample date: $07 / 25 / 92$
Oepth to wation: $139.10 \mathrm{~h}(42.40 \mathrm{~m})$ bolow TOC
Whtor olovation: $223.10 \mathrm{ft}(8 . .00 \mathrm{~m}) \mathrm{mal}$ Wabier elevation: $223.10 \mathrm{ft} / 09$

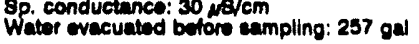

LABORATOFY ANALYEES

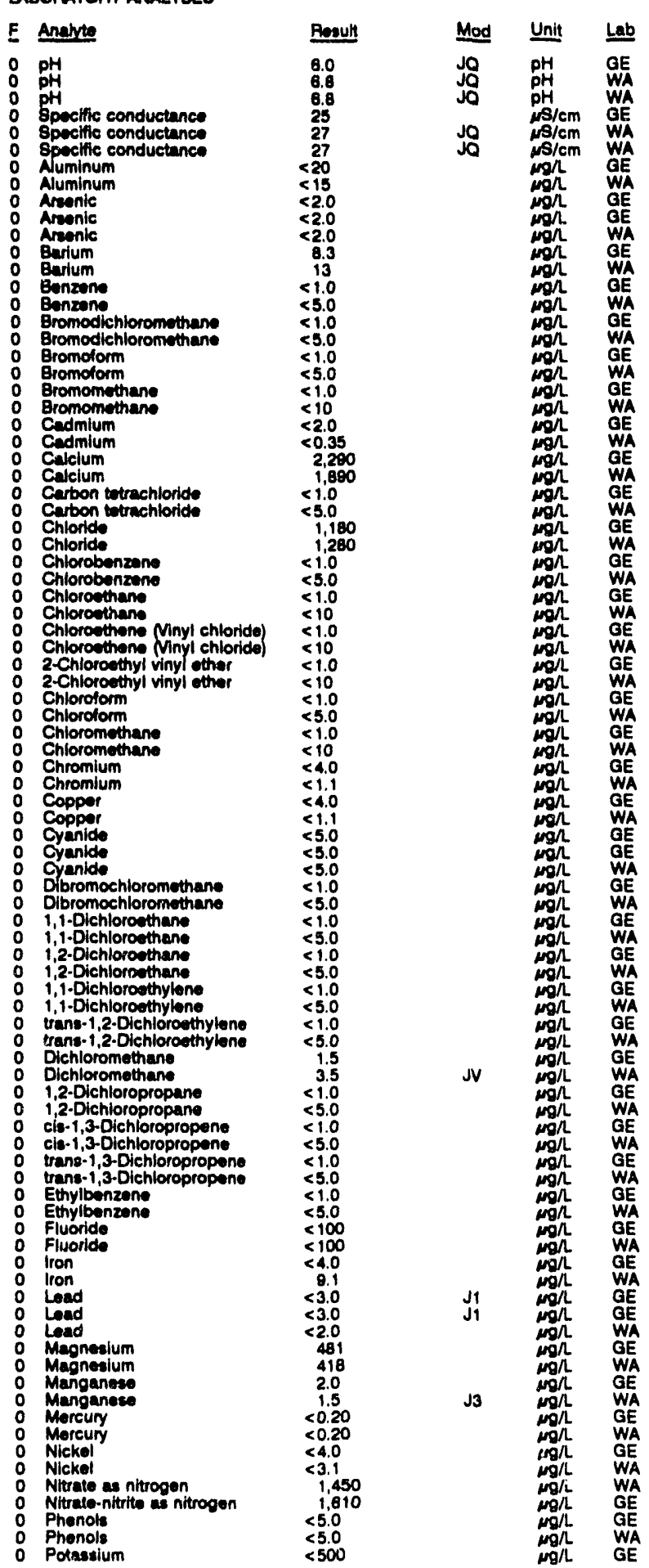

WELL MSB 484 collected on 07/25/92, laboratory analyese (cont.)

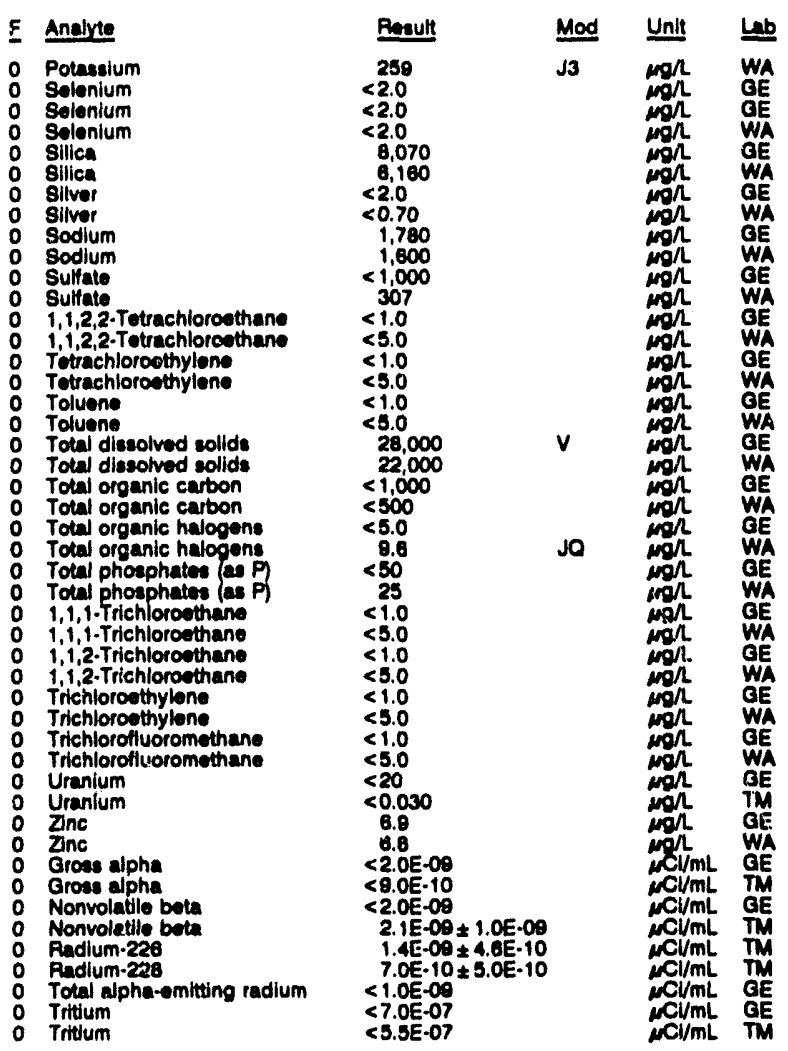

WELL MSB 48A Replicate

MEASUAEMENTS CONDUCTED IN THE FIELD

Sample date: 07/25/92

Depth to water: $139.10 \mathrm{~h}(42.40 \mathrm{~m})$ below TOC

Water elevation: $223.10 \mathrm{Ht}$ (68.0

Water evacuated bofore eampling: $257 \mathrm{gal}$

$\operatorname{Time:}_{\mathrm{pH}: 5} \mathbf{5 . 7}$

PH: 5.7 : $3 \mathrm{mg}$

Water temperature: $22.4 \circ \mathrm{C}$

LABORATORY ANALYSES

$\begin{array}{ll}\text { F } & \text { Analyte } \\ 0 & \text { pH } \\ 0 & \text { pH } \\ 0 & \text { Specific conductance } \\ 0 & \text { Spectilic conductance } \\ 0 & \text { Aluminum } \\ 0 & \text { Aluminum } \\ 0 & \text { Arsenic } \\ 0 & \text { Arsenic } \\ 0 & \text { Barium } \\ 0 & \text { Barium } \\ 0 & \text { Benzene } \\ 0 & \text { Benzene } \\ 0 & \text { Bromodichloromethane } \\ 0 & \text { Eromodichloromethane } \\ 0 & \text { Bromoform } \\ 0 & \text { Bromolorm } \\ 0 & \text { Bromomethane } \\ 0 & \text { Bromomothane } \\ 0 & \text { Cadmium } \\ 0 & \text { Cadmium } \\ 0 & \text { Calclum } \\ 0 & \text { Calclum } \\ 0 & \text { Carbon tetrachioride } \\ 0 & \text { Carbon tetrachloride } \\ 0 & \text { Chloride } \\ 0 & \text { Chloride } \\ 0 & \text { Chlorobenzene } \\ 0 & \text { Chlorobenzene } \\ 0 & \text { Chloroethane } \\ 0 & \text { Chloroethane } \\ 0 & \text { Chloroethene Minyl chloride) } \\ 0 & \text { Chloroethene (Vinyl chloride) } \\ 0 & 2 \text {-Chlorothyl vinyl ether } \\ 0 & 2 \text {-Chloroethyl vinyl ether } \\ 0 & \text { Chlorolorm } \\ 0 & \text { Chloroform } \\ & \end{array}$
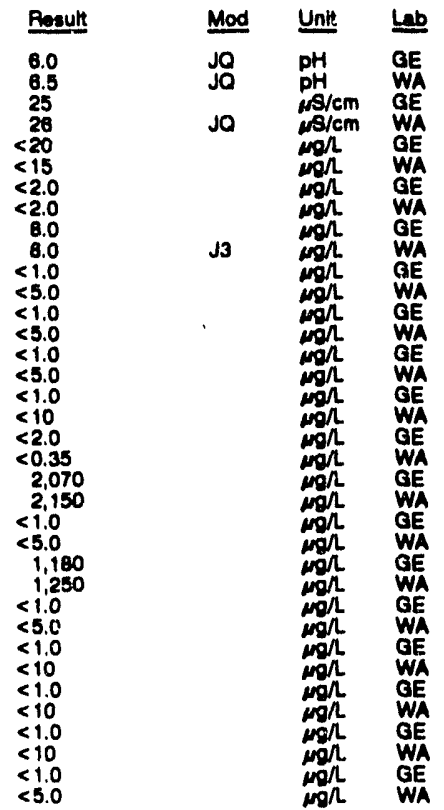
WELL M88 48A collocted on 07/25/92, laboratory analyses (cont)

E Aneyte

: Chloromethane

- Chromium

Coppor

Copper

O Cyanido

Obromochloromothane

1,1-Dichloromethen

1,1-Olchloroethane

1,2.Dichlorocthane

o 1,1-Dichlorosthylune

o trans.1,2-Dichloromthylene

trano-1,2-Dichioroethylene

Dichloromethane

1,2-Dichloropropane

1,2-Dichloropropano

cio-1,2-Dichloropropent

o thane-1,3-Dichopropone

o trans-1,3-Dichloropropene

O Ethylbonzene

o Fluoride.

Fluoride

: Iron

Lion

0 Load

- Magnoalum

- Magnealum

Manganese

Morcury

Morcuny

Nickal

Nitrate as nitrogon

Nitrata-niturtite as nitrogen

Nitrato-nitritto as nitrogen

Phonols

Phonolis

Potreasium

solienium

solonium

S Sllicen

o silver

silvor

o Sodium

Sodium

Sulfate

1,1,2,2-Tetrechloroethane

i Ietrechlorosthylone

- Totrachloroenthylons

- Toluen

Total discolved wollde

- Total discolved sollda

Total organic carbon

Toel oganic carbon

Total organic halogens

: Total phosphation (Es P)

O Total phosphates (as P)

1,1.Trichlorothane

i, T. Trichlorothane

i,i, Trichlorothane

Trichloroethylene

- Trichlorofluoromethane

o Trichlofolfuoromethane

o Uranlum

Uranium

Zine

Groses alphe

Gross alphe

Grose alphe

Nonvolatilio bett.

Nonvolatilio beth

Nonvolatilie beta

Radium-226

Total alpha-emitting radium

Tritium

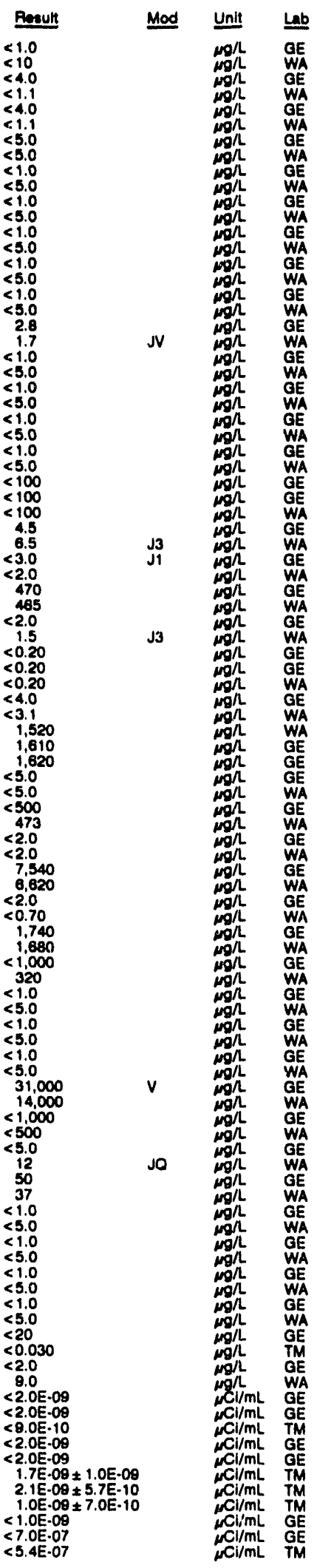

WELL MSB 48B

MEASUREMENTS CONDUCTEO IN THE FIELD

Sample data: 08/20/92

Depth to water: $137.73 \mathrm{H}(41.20 \mathrm{~m})$ below TOC

Wator olovation: $224.17 \mathrm{f}(88.33 \mathrm{~m}) \mathrm{mal}$

Wator ovacuated bofore sampling: $184 \mathrm{gal}$

LABORATORY ANALYSES

F Analyze

o $\mathrm{Sp}$ Pecific conductance

Aluminum

Breenic

Barium

Bromodichloromethane

o Bromomethane

Cadmium

Calcium

Carbon totrachloride

Chlorlde

Chlorobenzene

Chloroethene Minyl chloride)

2-Chloroethyl vinyl other

Chloroform

Chloromethane

Chromium

Copper

Cyanide

Dibromochloromethane

1,1.Dichloroethane

1,1.Diechloroethylene

trans-1,2-Dichloroethylene

Dichioromethene

1,2-Dichloropropane

trans-1,3-Dichloropropene

Ethylbenzene

Fluoride

Iron

Magnosium

Manganose

Mercury

Nitrato-nitrite as nitrogen

Phenols

Potaselum

solica

silver

Sodium

o $1,1,2,2$-Totrachloroethane

Totrechloroethylone

Toluene

Total dissolved solide

Total organic carbon

2 Total organic halogens

Total phosphates (as $P$

1,1,1. Trichlorosthane

T, 1,2-Trichlorothan

Trichlorofluoromethane

o Uranium

Grose alpha

- Nonvolatile beta

Total alpha-emitting radium

Time: $0: 30$

PH: 5.7

Water tomperalure: $20.5 \cdot \mathrm{C}$

WELL MSB 48C

MEASUREMENTS CONOUCTED IN THE FIELD

Sample date: $07 / 25 / 92$

Water elevation: $224.00 \mathrm{H}(28.55 \mathrm{~m}) \mathrm{mel}$

Sp. conductance: $53 \mu 8 / \mathrm{cm}$

Aceult Mod Unit Let

$<20$

$<2.0$

$<1.0$

$<1.0$

3,200
$<1.0$

$<1,0$

$<1.0$

$<1.0$

$\leq 1.0$

$<4.0$

$<4.0$

$<5.0$

$<1.0$

$<1.0$

$<1.0$
$<1.0$

1.1
$<1.0$
$<1.0$

$<1.0$

$<1.0$

$<100$

$<3.0$
802
3.1

3.1
$<4.20$

1,850

$<5.0$
523

$<2.0$

$<2.0$
2,570

$<1,000$

$<1.0$

31,000

$<1,000$

$<50$

$<1.0$

204
$<1.0$

$<20$

3.8
$<2.0 E-09$

$<2.0 \mathrm{E} \cdot 09$

$2.2 E .09 \pm 1.1 E .09$

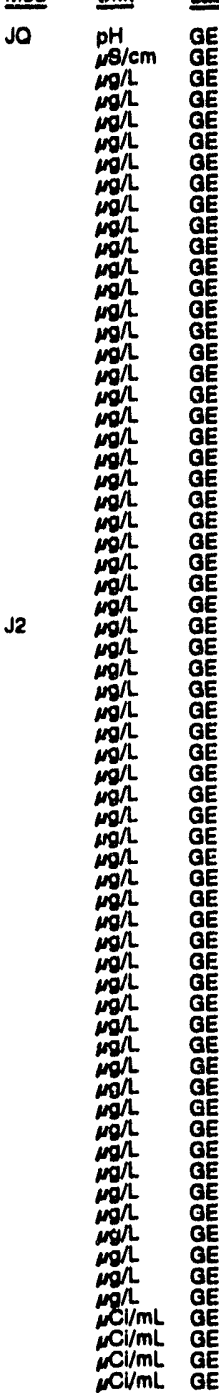

Water evacuated betore sampling: 133 gel

Time: 13:20

PH: 6.3 11 mon

Wator tomperature: $22.4{ }^{\circ} \mathrm{C}$

LABOPATORY ANALYSES

\begin{tabular}{|c|c|c|c|}
\hline E Analyte & Rosult & Mod & Unit \\
\hline $\begin{array}{ll}0 & \text { Cadmium } \\
0 & \text { Carbon tetrachloride } \\
0 & \text { Chloroform } \\
0 & \text { lron } \\
0 & \text { Lead } \\
0 & \text { Manganose }\end{array}$ & $\begin{aligned}<2.0 \\
<1.0 \\
<1.0 \\
<4.0 \\
<3.0 \\
5.4\end{aligned}$ & JI & 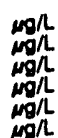 \\
\hline
\end{tabular}




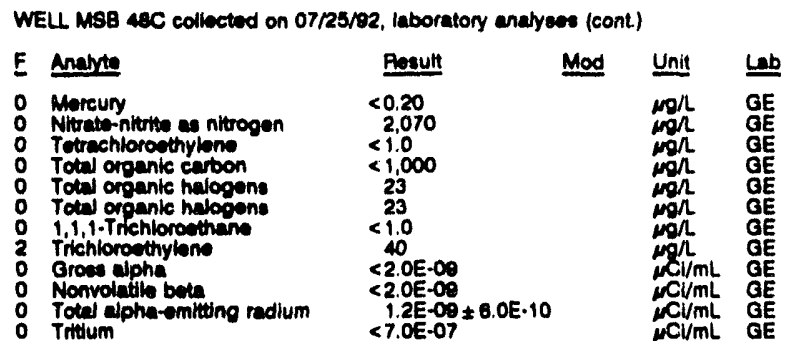

\section{WELL MSB 48D}

\begin{tabular}{|c|c|c|c|c|c|}
\hline \multicolumn{6}{|c|}{ MEASUREMENTS CONDUCTED IN THE FIELD } \\
\hline \multicolumn{3}{|c|}{ 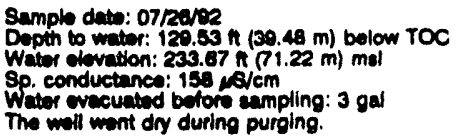 } & \multicolumn{3}{|c|}{$\begin{array}{l}\text { Time: } 10: 35 \\
\text { pH: } 9.0 \\
\text { Akalinity: } 71 \mathrm{mgh} \\
\text { Water tomporature: } 22.8 \cdot \mathrm{C}\end{array}$} \\
\hline \multicolumn{6}{|c|}{ LABORITOPY ANALYSES } \\
\hline & nelyte & Result & Mod & Unit & \\
\hline & 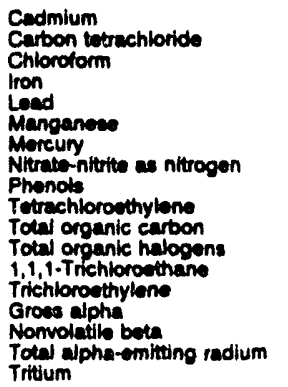 & $\begin{array}{l}<2.0 \\
<1.0 \\
<1.0 \\
<4.0 \\
<3.0 \\
2.7 \\
<0.20 \\
80 \\
<5.0 \\
<1.0 \\
<1.000 \\
<5.0 \\
<1.0 \\
<1.0 \\
<2.0 \mathrm{E}-09 \\
6.0 \mathrm{p}-09 \pm \\
<1.0 \mathrm{E}-09 \\
1.5 \mathrm{E}-06 \pm\end{array}$ & EE.07 & 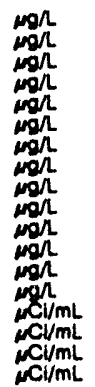 & $\begin{array}{l}\mathrm{GE} \\
\mathrm{GE} \\
\mathrm{GE} \\
\mathrm{GE} \\
\mathrm{GE} \\
\mathrm{GE} \\
\mathrm{GE} \\
\mathrm{GE} \\
\mathrm{GE} \\
\mathrm{GE} \\
\mathrm{GE} \\
\mathrm{GE} \\
\mathrm{GE} \\
\mathrm{GE} \\
\mathrm{GE} \\
\mathrm{GE} \\
\mathrm{GE} \\
\mathrm{GE}\end{array}$ \\
\hline
\end{tabular}

\section{WELL MSB 48TA}

MEASUREMENTS CONDUCTED IN THE FIELD

\begin{tabular}{|c|c|c|c|c|}
\hline \multicolumn{2}{|c|}{ 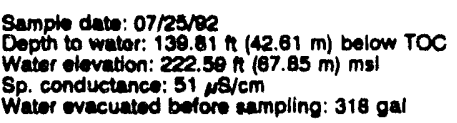 } & \multicolumn{3}{|c|}{$\begin{array}{l}\text { Time: } 13: 00 \\
\text { pH: } 6.7 \\
\text { Alkalinity: } 18 \mathrm{mgh} \\
\text { Water temperature: } 21.7 \cdot \mathrm{C}\end{array}$} \\
\hline \multicolumn{5}{|l|}{ LABOAMTOFY ANALYSES } \\
\hline Anable & Rosult & Mod & Unit & $\underline{\underline{L a b}}$ \\
\hline 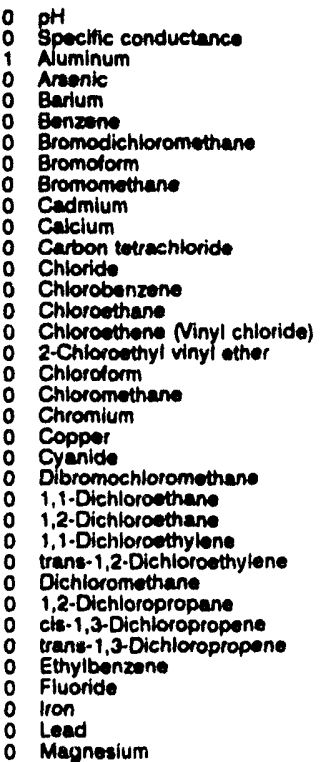 & $\begin{array}{r}7.0 \\
45 \\
33 \\
<2.0 \\
8.1 \\
<1.0 \\
<1.0 \\
<1.0 \\
<1.0 \\
<2.0 \\
6.730 \\
<1.0 \\
1.310 \\
<1.0 \\
<1.0 \\
<1.0 \\
<1.0 \\
<1.0 \\
<1.0 \\
<4.0 \\
<4.0 \\
<5.0 \\
<1.0 \\
<1.0 \\
<1.0 \\
<1.0 \\
<1.0 \\
2.5 \\
<1.0 \\
<1.0 \\
<1.0 \\
<1.0 \\
<100 \\
26 \\
<3.0 \\
437\end{array}$ & م & 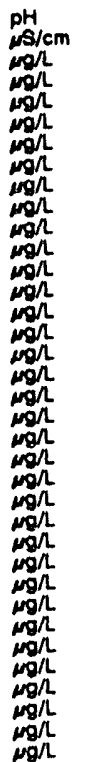 & $\begin{array}{l}G E \\
G E \\
G E \\
G E \\
G E \\
G E \\
G E \\
G E \\
G E \\
G E \\
G E \\
G E \\
G E \\
G E \\
G E \\
G E \\
G E \\
G E \\
G E \\
G E \\
G E \\
G E \\
G E \\
G E \\
G E \\
G E \\
G E \\
G E \\
G E \\
G E \\
G E \\
G E \\
G E \\
G E\end{array}$ \\
\hline
\end{tabular}

Magnesium 437
WELL MSB 48TA collectod on 07/25/92, laboratory analyees (cont)

\begin{tabular}{|c|c|c|c|}
\hline 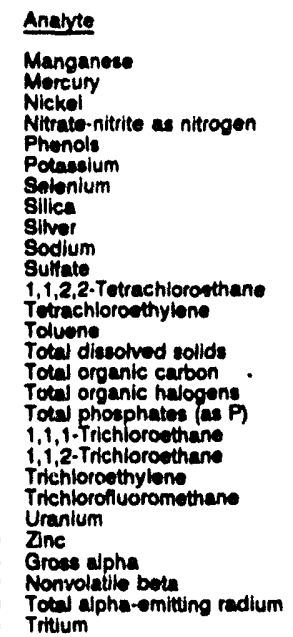 & 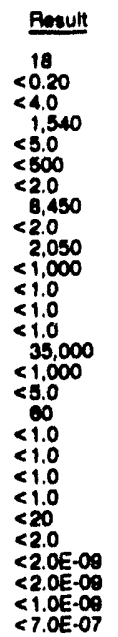 & $\operatorname{Mod}$ & Unit \\
\hline
\end{tabular}

WELL MSB 49A

MEASUREMENTS CONOUCTED IN THE FIELD

Sample dato: 00/08/82

Depth to wator: $137.69 \mathrm{n}(42.03 \mathrm{~m})$ bolow TOC Wator olovation: $197.51 \mathrm{~h}(80.20 \mathrm{~m}) \mathrm{msl}$

Sp. conductance: $29, \mathrm{~s} / \mathrm{cm}$. 20 ing: 327 gal

PH: A.8

Whinity: 0 mor

Weicr evecuated betors ant

\begin{tabular}{|c|}
\hline 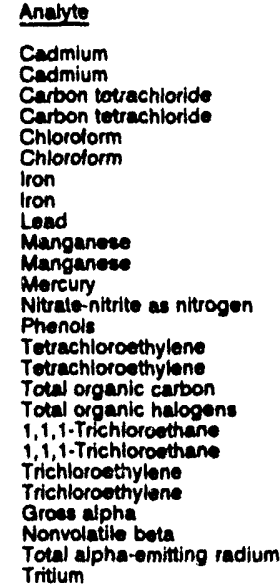 \\
\hline
\end{tabular}

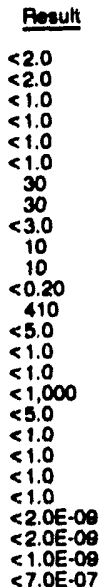

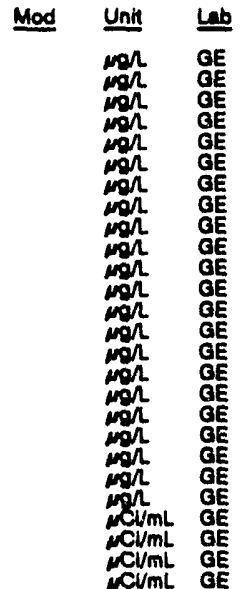

WELL MSB 49B

MEASUREMENTS CONDUCTED IN THE FIELD

Samplo data: 08/06/92

Depth to wator: 131.29 h $(40.02 \mathrm{~m})$ bolow TOC Wetter olevation: $203.51 \mathrm{t}(\mathbf{2} 2.03 \mathrm{~m}) \mathrm{msl}$ W. conductance: $74 \mu \mathrm{s} / \mathrm{cm}$

Water evacuatod beforo rampling: $244 \mathrm{gal}$

LABOFATOAY ANALYSES

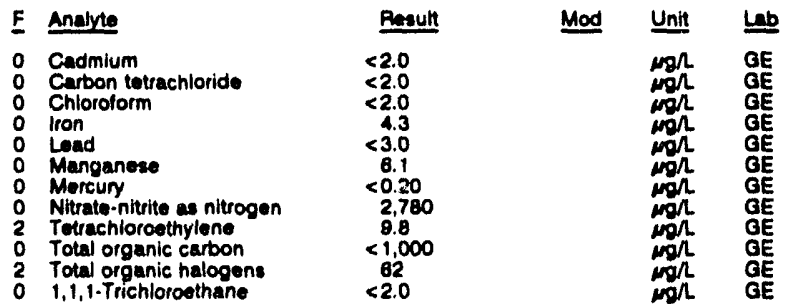

Time: 10:30

pH: 6.4 .490 .96 Water tomperature: $20.8 \cdot \mathrm{C}$
E 
ANALYTICAL RESULTS

WELL MSB 408 colbettod on 08/08/82, laboratory analyses (cont)

\begin{tabular}{|c|c|c|c|}
\hline E Analyte & Result & Mod & Unit \\
\hline $\begin{array}{ll}2 & \text { Trichloroethylene } \\
0 & \text { Grose alpha } \\
0 & \text { Nonvolatilo beta } \\
0 & \text { Total alpha-emitting radium } \\
0 & \text { Tritium }\end{array}$ & $\begin{array}{l}171 \\
<2.0 E-09 \\
2.8 E-09 \pm 5.5 E-10 \\
<1.0 E-00 \\
<7.0 E-07\end{array}$ & & 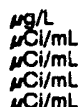 \\
\hline
\end{tabular}

WELL MSB 49D

\begin{tabular}{|c|c|c|c|c|}
\hline \multicolumn{2}{|c|}{ 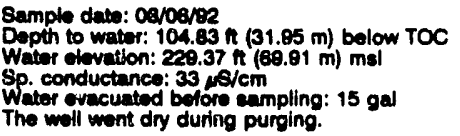 } & \multicolumn{3}{|c|}{$\begin{array}{l}\text { Time: } 16: 15 \\
\text { pH: } 5.5 \\
\text { Alkalinity: } 4 \mathrm{mg} h \\
\text { Water temperature: } 20.0^{\circ} \mathrm{C}\end{array}$} \\
\hline \multicolumn{5}{|l|}{ LABORATOFY ANALYSES } \\
\hline Anabute & Rosult & Mod & Unit & $\underline{\text { Lab }}$ \\
\hline 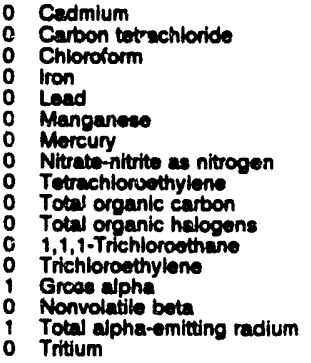 & $\begin{array}{l}<2.0 \\
<1.0 \\
<1.0 \\
58 \\
<3.0 \\
7.2 \\
<0.20 \\
870 \\
<1.0 \\
<1.000 \\
<5.0 \\
<1.0 \\
<1.0 \\
1.0 \mathrm{E}-08 \\
7.4 \mathrm{E}-09 \\
2.7 \mathrm{E}-09 \\
1.1 \mathrm{E}-00\end{array}$ & $\begin{array}{l}6 E-09 \\
9 E-09 \\
0 E-10 \\
0 E-07\end{array}$ & 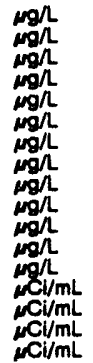 & $\begin{array}{l}\mathrm{GE} \\
\mathrm{GE} \\
\mathrm{GE} \\
\mathrm{GE} \\
\mathrm{GE} \\
\mathrm{GE} \\
\mathrm{GE} \\
\mathrm{GE} \\
\mathrm{GE} \\
\mathrm{GE} \\
\mathrm{GE} \\
\mathrm{GE} \\
\mathrm{GE} \\
\mathrm{GE} \\
\mathrm{GE} \\
\mathrm{GE} \\
\mathrm{GE}\end{array}$ \\
\hline
\end{tabular}

\section{WELL MSB 50B}

\section{MEASUREMENTS CONDUCTED IN THE FIELD}

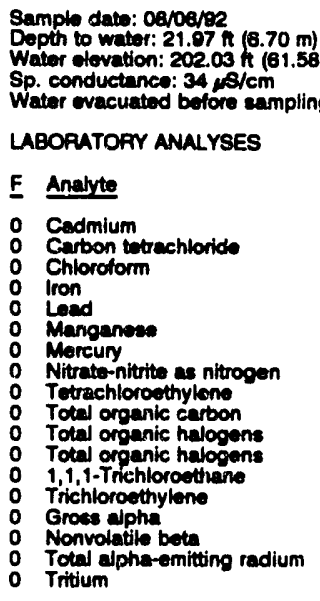

Time: 8:35

PH: 5.5

Water temperature: $19.4^{\circ} \mathrm{C}$

Water vacuated bofore sampling: $139 \mathrm{gal}$

Result
$<2.0$
$<1.0$
$<1.0$
4.0
$<3.0$
4.7
$<0.20$
1.110
$<1.0$
$<1.000$
21
19
$<1.0$
$<1.0$
$<2.0 E-09$
$2.4 E-09 \pm 1.4 E-09$
$<1.0 E-09$
$8.7 E-07 \pm 5.0 E-07$

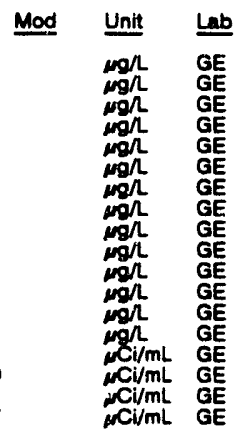

\section{WELL MSB 50D}

MEASUREMENTS CONDUCTED IN THE FIELD

Sample date: 0eroarge

Depth to water: $21.47 \mathrm{n}(6.54 \mathrm{~m})$ below TOC

Water olevation: 202.03 h (61.

Sp. conductance: $74 \mathrm{~s} / \mathrm{cm}$

LABORATOFY ANALYSES

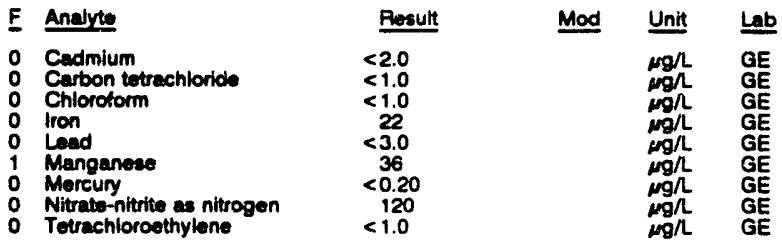

WELL MSB 50D collected on 08/06/82, laboratory analyees (cont)

\begin{tabular}{|c|c|c|c|c|}
\hline$F$ & Analyte & Pesult & Mod & Inin \\
\hline & $\begin{array}{l}\text { Total organic carbon } \\
\text { Total organic halogens } \\
\text { ot } 1,1 \text {-Trichloroethane } \\
\text { Trichloroethylene } \\
\text { Gross alpha } \\
\text { Nonvolatile beta } \\
\text { Total alpha-emitting radium } \\
\text { Total alpha-emiting radium } \\
\text { Tritium }\end{array}$ & $\begin{array}{l}1,000 \\
<5.0 \\
<1.0 \\
<1.0 \\
<2.0 E-09 \\
<2.0 E-09 \\
<1.0 E-09 \\
<1.0 E-09 \\
7.2 E-07 \pm 5.0 E-07\end{array}$ & & 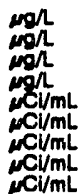 \\
\hline
\end{tabular}

\section{WELL MSB 51B}

MEASUREMENTS CONDUCTED IN THE FIELO

Sample date: 08/08/02

Depth to water: $59.77 \mathrm{ft}(18.22 \mathrm{~m})$ below TOC

Water olovation: $203.73 \mathrm{Ht}(62$

Sp. conductance: $31 \mu \mathrm{s} / \mathrm{cm} .10 \mathrm{~m}) \mathrm{ms} \mid$

Time: $7: 45$

Ak: 5.8 : $6 \mathrm{mgl}$

Water temperature: $18.6^{\circ} \mathrm{C}$

LABOAATOAY ANALYSES

\begin{tabular}{|c|c|c|c|}
\hline Analyte & Result & Unit & Lat \\
\hline $\begin{array}{ll}0 & \text { Cadmium } \\
0 & \text { Carbon tetrachloride } \\
0 & \text { Carbon totrachloride } \\
0 & \text { Chloroform } \\
0 & \text { Chloroform } \\
0 & \text { Iron } \\
0 & \text { Lead } \\
0 & \text { Lead } \\
0 & \text { Manganese } \\
0 & \text { Morcury } \\
0 & \text { Nitrate-nitrite as nitrogen } \\
0 & \text { Tetrechloroethylene } \\
0 & \text { Tetrachloroethylene } \\
0 & \text { Total organic carton } \\
0 & \text { Total organic carbon } \\
0 & \text { Total organic halogens } \\
0 & \text { 1,1,1-Trichloroethane } \\
0 & 1,1,1-T r i c h l o r o e t h a n e \\
0 & \text { Trichloroethylene } \\
0 & \text { Trichloroethylene } \\
0 & \text { Gross alpha } \\
0 & \text { Nonvolatile beta } \\
0 & \text { Total alpha-emitting radium } \\
0 & \text { Trittum }\end{array}$ & $\begin{aligned}<2.0 \\
<1.0 \\
<1.0 \\
<1.0 \\
<1.0 \\
<4.0 \\
<3.0 \\
<3.0 \\
3.5 \\
<0.20 \\
330 \\
<1.0 \\
<1.0 \\
<1.000 \\
<1.000 \\
<5.0 \\
<1.0 \\
<1.0 \\
<1.0 \\
<1.0 \\
<2.0 E-09 \\
2.5 E-09 \pm 1.4 E-09 \\
<1.0 E-09 \\
1.2 E-08 \pm 5.0 E-07\end{aligned}$ & 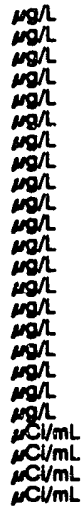 & $\begin{array}{l}\mathrm{GE} \\
\mathrm{GE} \\
\mathrm{GE} \\
\mathrm{GE} \\
\mathrm{GE} \\
\mathrm{GE} \\
\mathrm{GE} \\
\mathrm{GE} \\
\mathrm{GE} \\
\mathrm{GE} \\
\mathrm{GE} \\
\mathrm{GE} \\
\mathrm{GE} \\
\mathrm{GE} \\
\mathrm{GE} \\
\mathrm{GE} \\
\mathrm{GE} \\
\mathrm{GE} \\
\mathrm{GE} \\
\mathrm{GE} \\
\mathrm{GE}\end{array}$ \\
\hline
\end{tabular}

\section{WELL MSB 51D}

MEASUPEMENTS CONDUCTED IN THE FIELD

Sample dato: 07/28/92

Depth to water: $51.76 \mathrm{~h}(15.78 \mathrm{~m})$ below TOC

Water elevation: $210.74 \mathrm{tt}$

Sp. conductance: $42 \mu \mathrm{S} / \mathrm{cm}$

Water evacuated before sampling: $8 \mathrm{ge}$

The well went dry during purging.

LABORATOFY ANALYSES

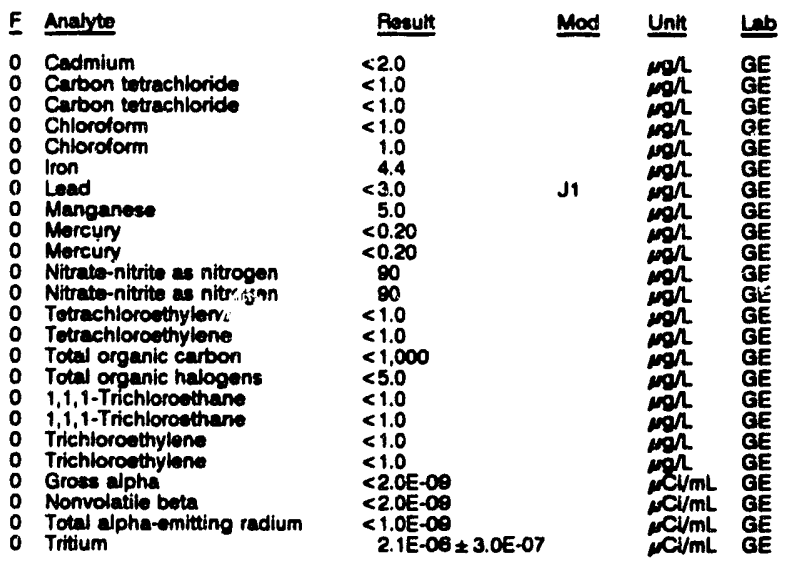


WELL MSB 52B

MEASUREMENTS CONDUCTED IN THE FIELD

Sample data: 08:08/92

Depth to water: $103.32 \mathrm{n}(31.48 \mathrm{~m})$ below TOC

Sp. conductunce: $34 . \mathrm{s} / \mathrm{cm}$

Sp. conductunce: 54 is/cm

UBORATOFY ANALYSES

\begin{tabular}{|c|c|c|c|c|c|}
\hline $\boldsymbol{F}$ & Analyte & Pesult & Mod & Unit & Lab \\
\hline $\begin{array}{l}0 \\
0 \\
0 \\
0 \\
0 \\
0 \\
0 \\
0 \\
0 \\
2 \\
0 \\
0 \\
0 \\
0 \\
2 \\
0 \\
0 \\
0 \\
0\end{array}$ & 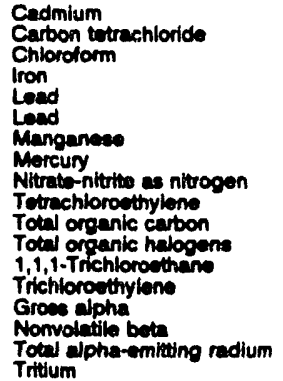 & $\begin{array}{l}<2.0 \\
<1.0 \\
<1.0 \\
<4.0 \\
<3.0 \\
<3.0 \\
5.5 \\
<0.20 \\
1.170 \\
7.4 \\
<1.000 \\
5.1 \\
<1.0 \\
5.6 \\
<2.0 E-00 \\
<2.0 E-09 \\
<1.0 \mathrm{E}-09 \\
<7.0 \mathrm{E}-07\end{array}$ & & 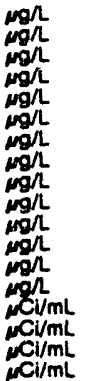 & $\begin{array}{l}\mathrm{GE} \\
\mathrm{GE} \\
\mathrm{GE} \\
\mathrm{GE} \\
\mathrm{GE} \\
\mathrm{GE} \\
\mathrm{GE} \\
\mathrm{GE} \\
\mathrm{GE} \\
\mathrm{GE} \\
\mathrm{GE} \\
\mathrm{GE} \\
\mathrm{GE} \\
\mathrm{GE} \\
\mathrm{GE} \\
\mathrm{GE} \\
\mathrm{GE} \\
\mathrm{GE}\end{array}$ \\
\hline
\end{tabular}

\section{WELL MSB 52D}

MEASUREMENTS CONOUCTED IN THE FIELD

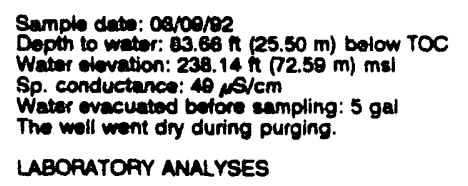

$\operatorname{Tim}_{0 \rightarrow 0}: 20$

Alkalinity: $2 \mathrm{mg} / \mathrm{l}$

Water temperature: $20.7^{\circ} \mathrm{C}$

LABORATORY ANALYSES

\begin{tabular}{|c|c|c|c|}
\hline$F$ & Analute & Rosult & Unit \\
\hline $\begin{array}{l}0 \\
0 \\
0 \\
0 \\
0 \\
0 \\
0 \\
0 \\
0 \\
0 \\
0 \\
0 \\
0 \\
0 \\
0 \\
0\end{array}$ & 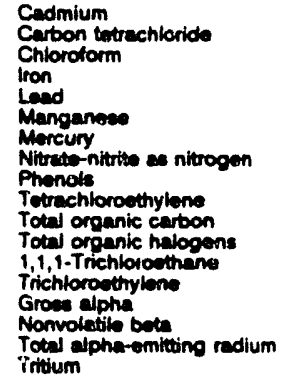 & $\begin{array}{l}<2.0 \\
<1.0 \\
1.4 \\
3.5 \\
<3.0 \\
5.5 \\
<0.20 \\
230 \\
<5.0 \\
<1.0 \\
<1.000 \\
<5.0 \\
<1.0 \\
<1.0 \\
<2.0 E-00 \\
<2.0 E-00 \\
<1.0 E-00 \\
1.7 E-08 \pm 5.0 E-07\end{array}$ & 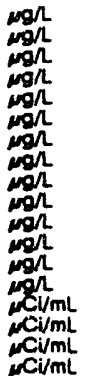 \\
\hline
\end{tabular}

\section{WELL MSB 53B}

MEASUREMENTS CONDUCTED IN THE FIELD

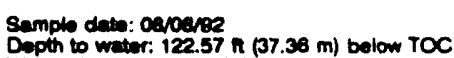
Watter olevation: $222.03 n(67.68 \mathrm{~m}) \mathrm{ms}$

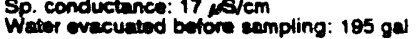

Time: 13:20

Alkadinity: $13 \mathrm{mg} / \mathrm{l}$

Water tomperature: $22.2^{\circ} \mathrm{C}$

LABOPATOFY ANALYSES

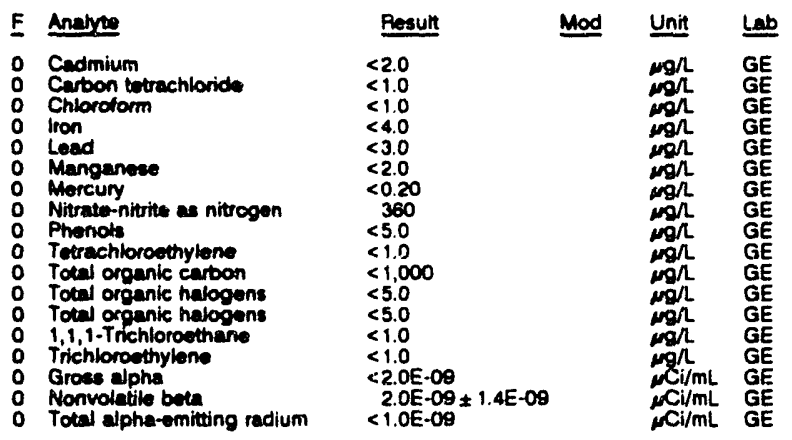

WELL MSB 53B collected on 08/08/92, laboratory analyses (cont.)

\begin{tabular}{|c|c|c|c|}
\hline F Analyte & Result & Mod & Unit \\
\hline 0 Tritium & $<7.0$ E-07 & & $\mu \mathrm{Cl} / \mathrm{mL}$ \\
\hline
\end{tabular}

\section{WELL MSB 53C}

MEASUAT:MENTS CONDUCTED IN THE FIELD

Sample date: 08/08/92

Dopth to water: $122.77 \mathrm{n}(37.42 \mathrm{~m})$ below TOC Water elevation: $222.73 \mathrm{~h}(67.89 \mathrm{~m}) \mathrm{msl}$

Water ovecuated before sampling: $81 \mathrm{gal}$

Tho: 0.35

Nhalinity: $1 \mathrm{man}$

ABORATORY ANALYSES

\begin{tabular}{|c|c|c|c|}
\hline Analyte & Result & Mod & Unit \\
\hline 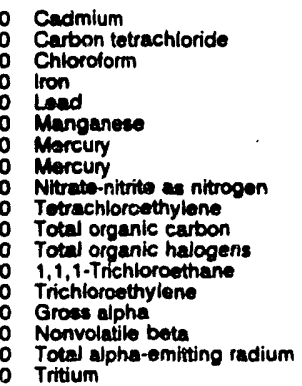 & $\begin{array}{l}<2.0 \\
<1.0 \\
<1.0 \\
<4.0 \\
<3.0 \\
3.3 \\
<0.20 \\
<0.20 \\
580 \\
1.4 \\
<1.000 \\
<5.0 \\
<1.0 \\
2.3 \\
<2.0 E-09 \\
<2.0 E-09 \\
<1.0 E-09 \\
<7.0 E-07\end{array}$ & & \\
\hline
\end{tabular}

\section{WELL MSB 53D}

MEASUREMENTS CONDUCTED IN THE FIELD

Sample date: 08108/92

Wepth to water: $111.38 \mathrm{At}(33.95 \mathrm{~m})$ below TOC

So. conductance: $22 \mathrm{~s} / \mathrm{cm}$ Wheter evacuated before sampling: $27 \mathrm{gal}$

Time:
pH: 5.1

Alkalinity: $0 \mathrm{~mol}$

Water temperature: $21.1^{\circ} \mathrm{C}$

LABORATORY ANALYSES

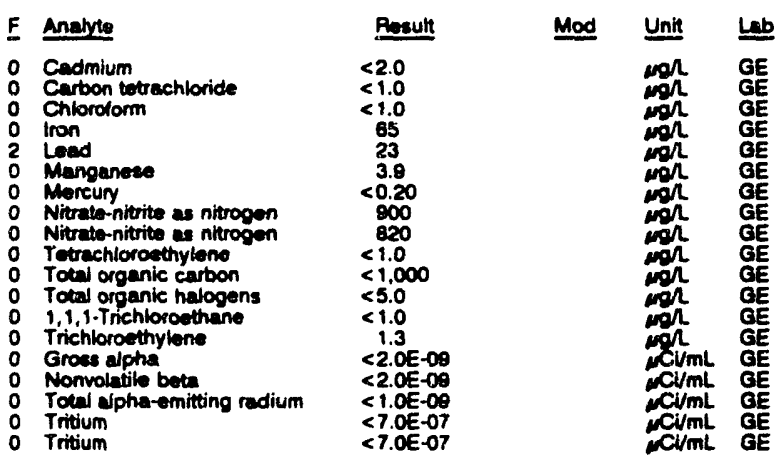

WELL MSB 54B

MEASUREMENTS CONDUCTED IN THE FIELD

Sample date: 07/25/82

Depth to waten: $151.00 \mathrm{n}(46.03 \mathrm{~m})$ below TOC

Water elevation: $222.70 \mathrm{~h}(67.88 \mathrm{~m}) \mathrm{mal}$ Alkalinity: $4 \mathrm{mgh}$

Sp. conductance: $26 \mu \mathrm{s} / \mathrm{cm}$.

LABOARTOFY ANALYSES

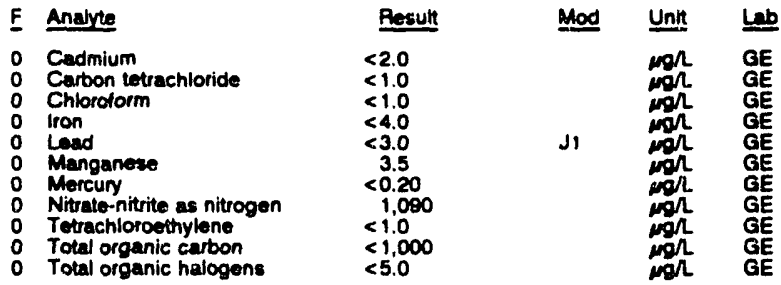


ANALYTICAL RESULTS

WELL MSB 548 collectod on 07/25/92, taboratory analyses (cont.)

\begin{tabular}{|c|c|c|c|c|c|}
\hline $\boldsymbol{F}$ & Analyte & Plosult & Mod & Unit & Lab \\
\hline $\begin{array}{l}0 \\
0 \\
0 \\
0 \\
0\end{array}$ & $\begin{array}{l}\text { 1,1,1-Trichloroethane } \\
\text { Trichloroethylene } \\
\text { Groes alpha } \\
\text { Nonvolatile beta } \\
\text { Total alpha-emitting radium } \\
\text { Trittum }\end{array}$ & $\begin{array}{l}<1.0 \\
<1.0 \\
<2.0 E-09 \\
<2.0 E-09 \\
<1.0 \mathrm{E}-09 \\
<7.0 \mathrm{E}-07\end{array}$ & & 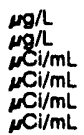 & $\begin{array}{l}\mathrm{GE} \\
\mathrm{GE} \\
\mathrm{GE} \\
\mathrm{GE} \\
\mathrm{GE} \\
\mathrm{GE}\end{array}$ \\
\hline
\end{tabular}

WELL MSB 54C

MEASUREMENTS CONDUCTED IN THE FIELD

Sample dato: 07/25/92

Depth to water: $148.66 \mathrm{ft}(44.70 \mathrm{~m})$ below TOC

Water olevation: 227.04 ft $(80.2$

conductance: $24 \mu \mathrm{s} / \mathrm{cm}$

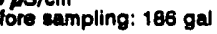

Time: 14:45

PH: 10.1 . $50 \mathrm{mgl}$

Alkalinity: $50 \mathrm{mg} / \mathrm{h}$ : $22.3^{\circ} \mathrm{C}$

LABOFATORY ANALYSES

\begin{tabular}{|c|c|c|c|c|c|}
\hline$\underline{F}$ & Anelyte & Result & Mod & Unit & Lab \\
\hline $\begin{array}{l}0 \\
0\end{array}$ & $\begin{array}{l}\text { Cadmium } \\
\text { Carbon totrachloride } \\
\text { Chloroform } \\
\text { lron } \\
\text { Lead } \\
\text { Manganese } \\
\text { Morcury } \\
\text { Nitrate-nitrite as nitrogen } \\
\text { Tetrachloroethylene } \\
\text { Total organic carbon } \\
\text { Total orgunic halogens } \\
1,1,1-T \text { Trichloroethane } \\
\text { Trichloroethylene } \\
\text { Grose alpha } \\
\text { Nonvolatile beta } \\
\text { Total alpha-emituing radium } \\
\text { Total alpha-emitting radium } \\
\text { Tritium }\end{array}$ & $\begin{array}{l}<2.0 \\
<1.0 \\
<1.0 \\
<4.0 \\
<3.0 \\
<2.0 \\
<0.20 \\
1.390 \\
<1.0 \\
<1.000 \\
<5.0 \\
<1.0 \\
<1.0 \\
2.6 \mathrm{E}-09 \pm 1.0 \mathrm{E}-09 \\
2.8 \mathrm{E}-09 \pm 1.5 \mathrm{E}-09 \\
1.0 \mathrm{E}-09 \pm 6.0 \mathrm{E}-10 \\
<1.0 \mathrm{E}-09 \\
<7.0 \mathrm{E}-07\end{array}$ & J1 & 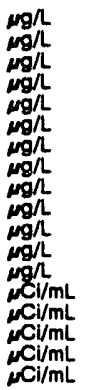 & $\begin{array}{l}\mathrm{GE} \\
\mathrm{GE} \\
\mathrm{GE} \\
\mathrm{GE} \\
\mathrm{GE} \\
\mathrm{GE} \\
\mathrm{GE} \\
\mathrm{GE} \\
\mathrm{GE} \\
\mathrm{GE} \\
\mathrm{GE} \\
\mathrm{GE} \\
\mathrm{GE} \\
\mathrm{GE} \\
\mathrm{GE} \\
\mathrm{GE} \\
\mathrm{GE} \\
\mathrm{GE}\end{array}$ \\
\hline
\end{tabular}

WELL MSB 54D

MEASUREMENTS CONDUCTED IN THE FIELD

Sample date: 07/25/92

Depth to water: $139.91 \mathrm{n}(42.85 \mathrm{~m})$ below TOC

Water olevation: $234.09 \mathrm{n}$ (

Sp. conductance: $27 \mu \mathrm{m} / \mathrm{cm}$
Water evacuated before sampling: $28 \mathrm{gal}$

LABORATORY ANALYSES

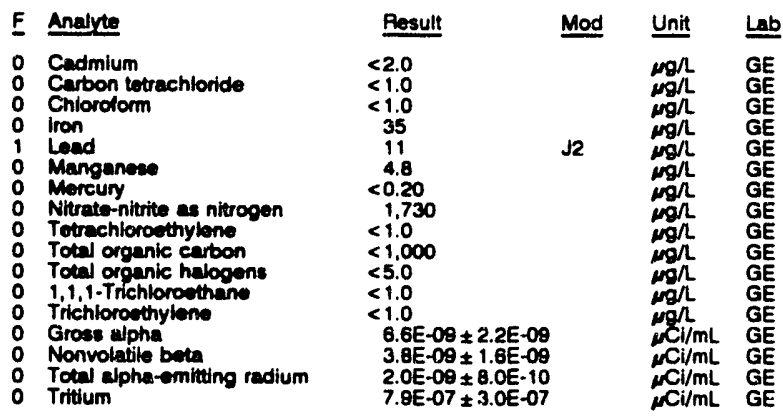

WELL MSB 54TA

MEASUREMENTS CONDUCTED IN THE FIELD

Sample date: 07/25/92 $146.79 \mathrm{~m}$ ) below TOC

Water elevation: $220.28 \mathrm{n}(87.14 \mathrm{~m}) \mathrm{ms}$

Sp. conductance: 45 s $5 / \mathrm{cm}$

Water evacuated before sampling: $380 \mathrm{gal}$

LABORATORY ANALYSES

\begin{tabular}{|c|c|c|c|}
\hline F Analyte & Result & Mod & Unit \\
\hline $\begin{array}{ll}0 & \text { Cadmium } \\
0 & \text { Carbon tetrachloride } \\
0 & \text { Chlorotorm } \\
0 & \text { ron } \\
0 & \text { Lead } \\
0 & \text { Manganese } \\
0 & \text { Mercury } \\
0 & \text { Nitrate-nitrite as nitrogen }\end{array}$ & $\begin{array}{l}<2.0 \\
<1.0 \\
<1.0 \\
<4.0 \\
<3.0 \\
3.3 \\
<0.20 \\
1.040\end{array}$ & $J \mathbf{J}$ & 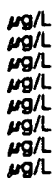 \\
\hline
\end{tabular}

WELL MSB 54TA collected on 07/25/82, laboratory analyese (cont.)

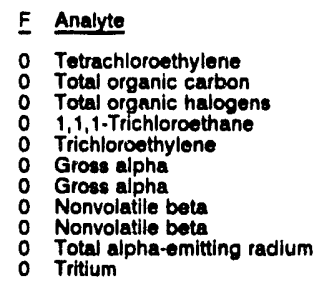

Rosult
$<1.0$
$<1,000$
$<5.0$
$<1.0$
$<1.0$
$<2.0 \mathrm{E}-09$
$<2.0 \mathrm{E}-09$
$<2.0 \mathrm{E}-09$
$<2.0 \mathrm{E} \cdot 09$
$<1.0 \mathrm{E} \cdot 09$
$<7.0 \mathrm{E}-07$

\begin{tabular}{|c|c|}
\hline Mod & Unit \\
\hline & 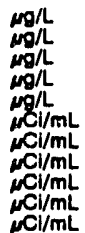 \\
\hline
\end{tabular}

\section{WELL MSB 55B}

MEASUREMENTS CONDUCTED IN THE FIELD

Depth to water: $147.07 \mathrm{ft}(44.83 \mathrm{~m})$ below TOC Water elevation: $221.83 \mathrm{k}(\mathbf{8 7 . 6 1 \mathrm { m } ) \mathrm { msl }}$ Wator ovacuated before sampling: $183 \mathrm{gal}$

Time: 15:50

Alkalinity: $0 \mathrm{mg} /$ Water ovacuated before sampling: $193 \mathrm{gal}$

Water temperature: $22.80^{\circ} \mathrm{C}$

LABORATORY ANALYSES

\begin{tabular}{|c|c|c|c|}
\hline Analyte & Ressult & $M \infty d$ & Unit \\
\hline 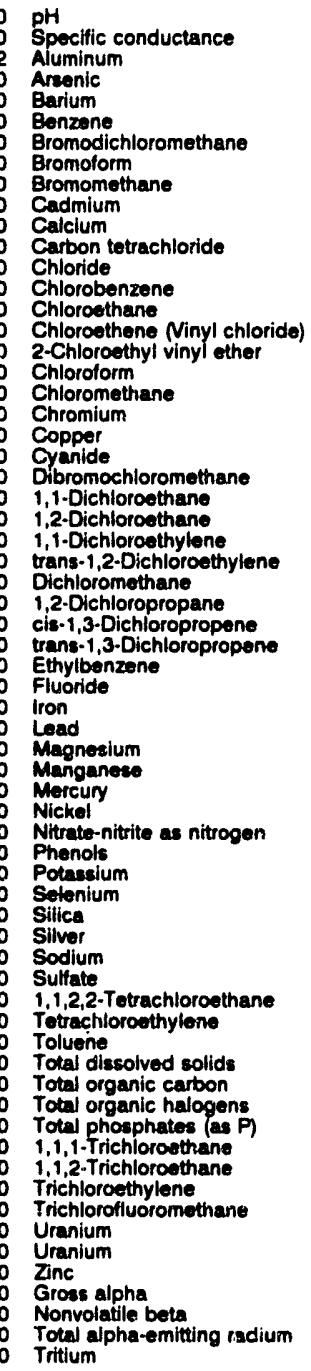 & 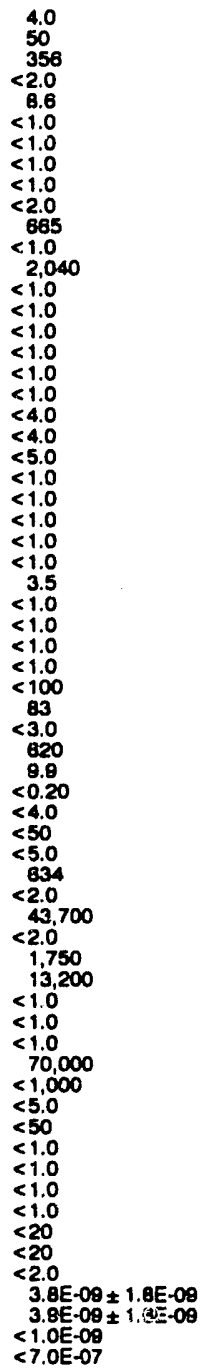 & jo & 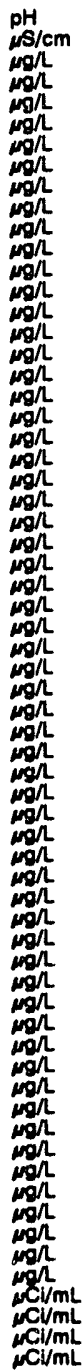 \\
\hline
\end{tabular}


WELL MSB 55C

MEASUREMENTS CONDUCTED IN THE FIELD

Sumple dato: 07/25/82

Depth to water: $140.31 \mathrm{n}(42.77 \mathrm{~m})$ below TOC

Wator olovation: $229.19 \mathrm{~A} /(89.8 \mathrm{c}$

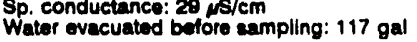

LABORATORY ANALYSES

\begin{tabular}{|c|c|c|c|c|c|}
\hline$\underline{E}$ & Analyte & Result & Mod & Unit & Lab \\
\hline $\begin{array}{l}0 \\
0 \\
0 \\
0 \\
0 \\
0 \\
0 \\
0 \\
0 \\
0 \\
0 \\
0 \\
0 \\
0 \\
0 \\
0 \\
0\end{array}$ & $\begin{array}{l}\text { Cadmium } \\
\text { Carbon tetrachloride } \\
\text { Chloroform } \\
\text { Iron } \\
\text { Lead } \\
\text { Manganese } \\
\text { Mercury } \\
\text { Nitrate-nitrite as nitrogen } \\
\text { Phenols } \\
\text { Tetrachloroethylene } \\
\text { Total organic carbon } \\
\text { Total organic carbon } \\
\text { Total organic hatogens } \\
\text { 1,1,1-Trichloroethane } \\
\text { Trichloroethyiene } \\
\text { Gross alpha } \\
\text { Nonvoliatile beta } \\
\text { Total alpha-emitting radium } \\
\text { Trittium } \\
\text { Tritlum }\end{array}$ & $\begin{array}{l}<2.0 \\
<1.0 \\
<1.0 \\
6.7 \\
<3.0 \\
6.4 \\
<0.20 \\
1.310 \\
<5.0 \\
<1.0 \\
<1,000 \\
<1.000 \\
<5.0 \\
<1.0 \\
<1.0 \\
<2.0 E-09 \\
<2.0 E-09 \\
<1.0 E-09 \\
<7.0 E-07 \\
<7.0 E-07\end{array}$ & d1 & 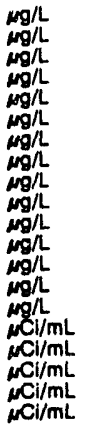 & $\begin{array}{l}\mathrm{GE} \\
\mathrm{GE} \\
\mathrm{GE} \\
\mathrm{GE} \\
\mathrm{GE} \\
\mathrm{GE} \\
\mathrm{GE} \\
\mathrm{GE} \\
\mathrm{GE} \\
\mathrm{GE} \\
\mathrm{GE} \\
\mathrm{GE} \\
\mathrm{GE} \\
\mathrm{GE} \\
\mathrm{GE} \\
\mathrm{GE} \\
\mathrm{GE} \\
\mathrm{GE} \\
\mathrm{GE} \\
\mathrm{GE}\end{array}$ \\
\hline
\end{tabular}

\section{WELL MSB 55D}

MEASUREMENTS CONDUCTED IN THE FIELD

Sample date: 07/25/92

(4) Water elevation: $234.20 \mathrm{H}(71.39 \mathrm{~m}) \mathrm{msl}$

Sp. conductance: 28 s/cm

Water evecuated before sampling: $26 \mathrm{gal}$

LABOAATOAY ANALYSES

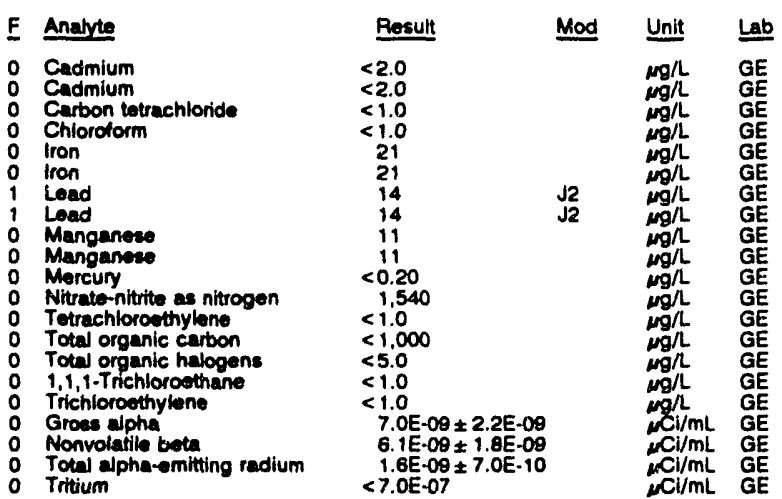

\section{WELL MSB 55HC}

MEASUREMENTS CONDUCTED IN THE FIELD

\section{Sample date: De/20/82}

Depth to water: 135.65 ft $(41.35 \mathrm{~m})$ below TOC

Water elevation: $233.15 \mathrm{H}(71.06$

Sp. conductance: $180 \mathrm{\mu s} / \mathrm{cm}$

Wher wacuated betore sampling: $10 \mathrm{gat}$

Time: 18:05

Alkalinity: $1 \mathrm{moh}$

Water temporaturn: $21.8^{\circ} \mathrm{C}$

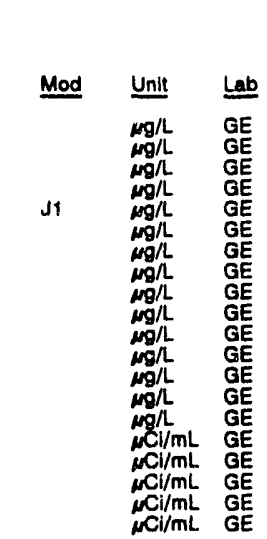

Time: 18:25

PH: 4.9 . 1 malinity: $1 \mathrm{mgh}$

Water temperature: $21.4^{\circ} \mathrm{C}$

LABORMTORY ANALYSES

\begin{tabular}{|c|c|c|c|c|c|}
\hline$\underline{\boldsymbol{F}}$ & Anarte & Result & Mod & Unit & Lab \\
\hline $\begin{array}{l}2 \\
0 \\
2 \\
2 \\
0 \\
0 \\
0 \\
0 \\
0 \\
0 \\
0 \\
0\end{array}$ & $\begin{array}{l}\text { pH } \\
\text { Specific conductance } \\
\text { Aluminum } \\
\text { Aluminum } \\
\text { Arsenic } \\
\text { Barium } \\
\text { Barium } \\
\text { Banzene } \\
\text { Bromodichloromethane } \\
\text { Bromotorm } \\
\text { Bromomethane } \\
\text { Cadmium } \\
\text { Cadmium }\end{array}$ & $\begin{aligned} & 11 \\
& 220 \\
& 208 \\
& 207 \\
&<2.0 \\
& 197 \\
& 197 \\
&<1.0 \\
&<1.0 \\
&<1.0 \\
&<1.0 \\
&<2.0 \\
&<2.0\end{aligned}$ & Jo & 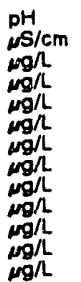 & $\begin{array}{l}\mathrm{GE} \\
\mathrm{GE} \\
\mathrm{GE} \\
\mathrm{GE} \\
\mathrm{GE} \\
\mathrm{GE} \\
\mathrm{GE} \\
\mathrm{GE} \\
\mathrm{GE} \\
\mathrm{GE} \\
\mathrm{GE} \\
\mathrm{GE} \\
\mathrm{GE}\end{array}$ \\
\hline
\end{tabular}

Alkalinity: $61 \mathrm{mg} / \mathrm{L}$
WELL MSB 55HC collected on 08/20/82, laboratory analyees (cont.)

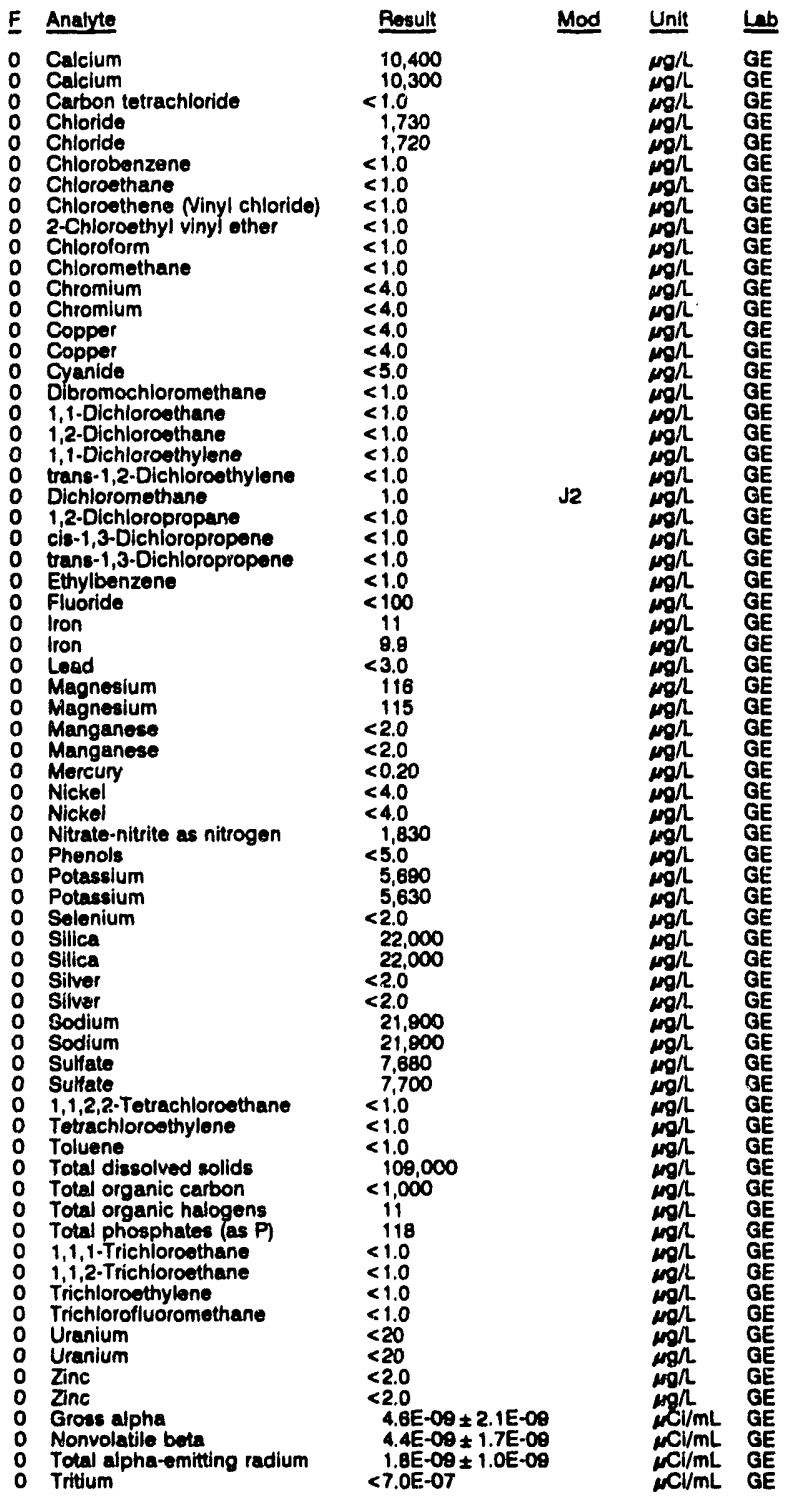

WELL MSB 55TA

MEASUREMENTS CONDUCTED IN THE FIELD

Sample date: 07/25/82 Depth to water: $154.73 \mathrm{ft}(47.16 \mathrm{~m})$ below TOC Water elevation: $214.07 \mathrm{ft}(65.25 \mathrm{~m}) \mathrm{msl}$ Sp. conductance: $25 \mu \mathrm{s} / \mathrm{cm}$. LABORATOPY ANALYSES
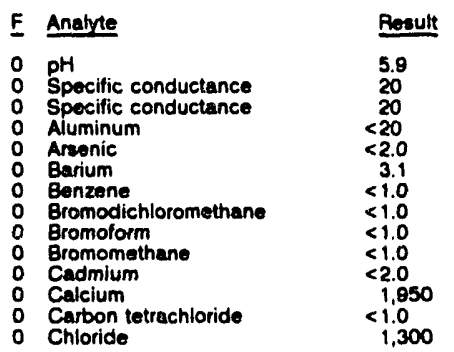

Time: 16:15

pH: 5.3 Water temperature: $21.8{ }^{\circ} \mathrm{C}$ 1,300 
WELL MSB 55TA colloctod on 07/25/82, laboratory analyses (cont.)

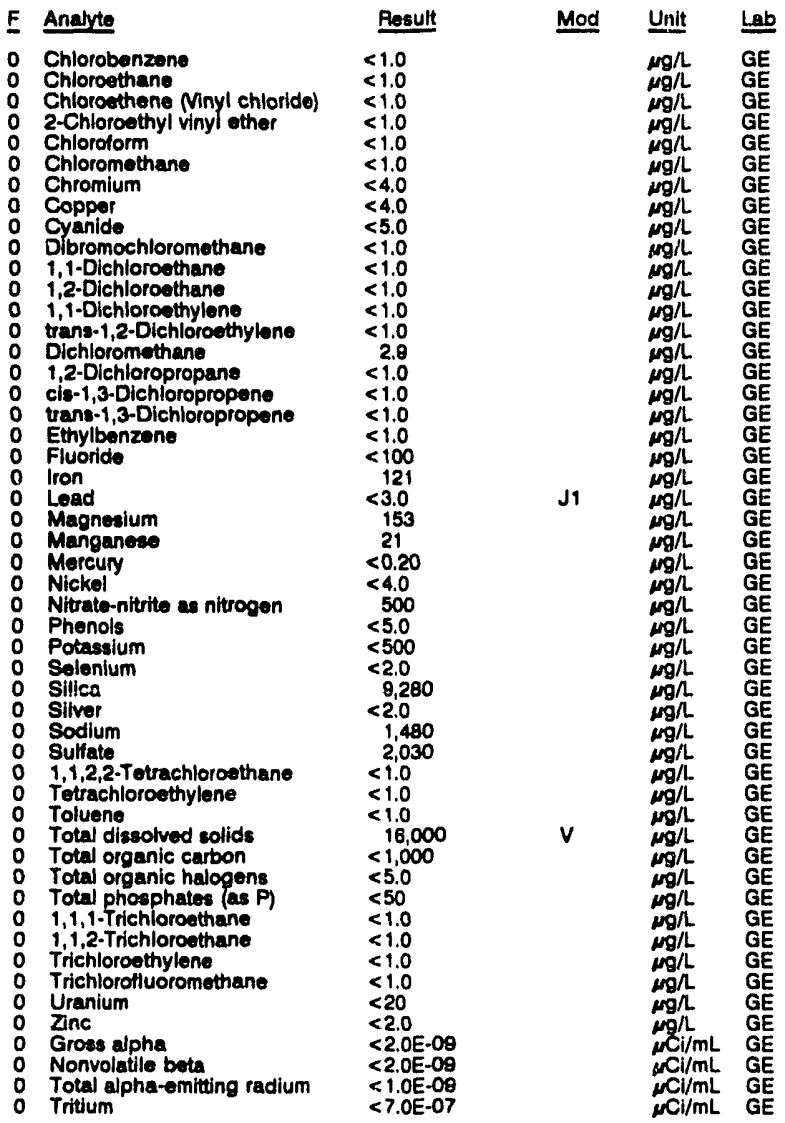

\section{WELL MSB 56D}

MEASUAEMENTS CONDUCTED IN THE FIELD

Depth to water: $58.82 \mathrm{~h}(17.93 \mathrm{~m})$ below TOC Water elevation: $220.98 \mathrm{ht}(67.38 \mathrm{~m}) \mathrm{msl}$

Water evecuated bofore sampling: $26 \mathrm{gal}$

LABORATORY ANALYSES

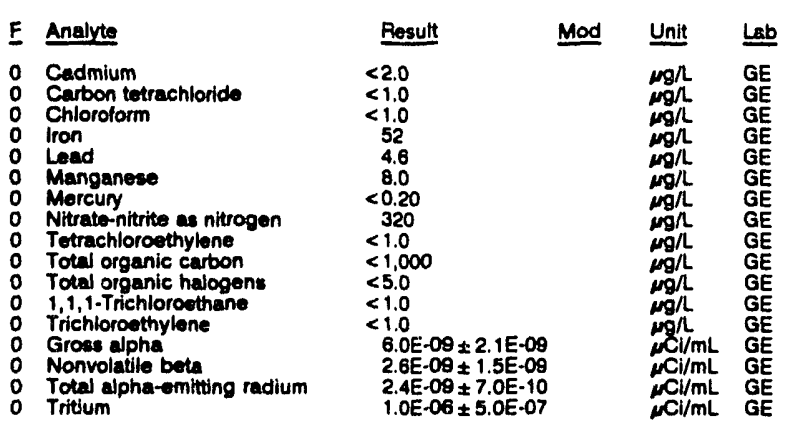

WELL MSB 57D

MEASUREMENTS CONDUCTED IN THE FIELD

Sample date: 07/28/82

Dopth to water: 125.29 h $(38.19 \mathrm{~m})$ below TOC

Water olevalion: $230.91 \mathrm{t}(70.38 \mathrm{~m}) \mathrm{ms}$

Water evacuated before sampling: $15 \mathrm{gal}$

The well went dry during purging.

LABORATORY ANALYSES

$E$ Analyte

O $\mathrm{pH}_{\mathrm{pH}}$

Specific conductance

Acenap conductanc

- Acenaphthylene

Acetonitrile (Methyl cyanide)

Acetophenone

2-Acotylam

Ocrylonitrito

0 Acrylon

Allyy chloride

4.Aminobiphenyl

Aniline

Anthracene

Antimony

Aramite

- Arsenic

o Barium

Bonzene

beta.Benzene hexach

beta-Benzene hexachloride

Belta-Bonzene hexach

Benzo a anthracene

Benzo kj fluorantrene

Benzo g hilperylene

Benzola]pyrene

Benzyl aicohol

Bis (2-chloroethoxy) methane

Bis (2-chioroethyl) ether

eiss 2-chloroisopropyl) ether

Bis(2-ethythexyl) phthalate

Bromodich

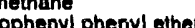

phenyl pheriyl ether

2-sec-Butyl-4,6-dinitrophenol

2-sec-Buty

Carbon disulfide

Carbon tetrachloride

Chlordane

Chloride

4.Chloroaniline

Chlorobenzene

Chiorobenzilate

para-Chloro-mo

Chloroethene Ninyl chloride)

Chloroethene Ninyl chlorido)
2-Chloroethyl vinyl other

2-Chloroeth

Chloroform

2-Chloronaphthalen

2-Chlorophenol

4-Chlorophenyl phenyl ether

Chloroprene

Chromium

Chrysene

Cobalt

Copper

m-Cresol (3-Methylphenol)

p-Cresol (4-Methylpheno)

C.P.ODO

P.P.PDDE

P.P.:DDT

Dilallate

Dibenz[a,h]anthracene

Dibenzofuran

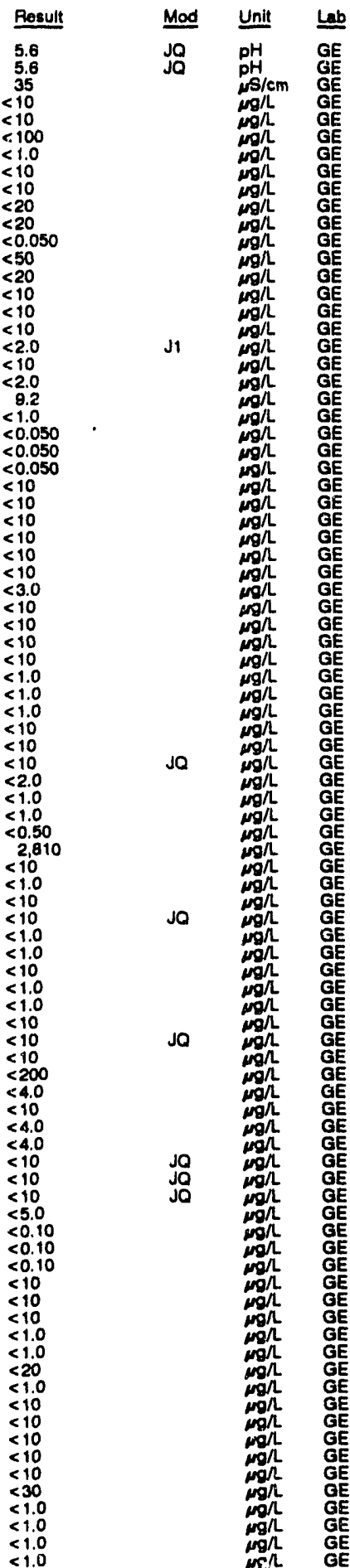

Time: 7:10

Alkalinity: $2 \mathrm{mg} / \mathrm{L}$

Water temperature: $21.2^{\circ} \mathrm{C}$ 1,2-Dibromoethane

Di-n-butyl phthalate

1,2-Dichiorobenzene

1,3-Dichlorobenzene

1,4-Dichlorobenzene

trans-1,4-Dichloro-2-butene

0 Dichlorodifluoremethane

1,1-Dichloroethane

i, Dichloroethyle
$<1.0$ 
WELL MSB $57 C$ collectod on 07/28/82, laboratory analyees (cont.)

\section{E Analyte}

- trans-1,2-Dichlorowit vione

$\begin{array}{ll}0 & \text { Dichloromethans } \\ 0 & 2,4-\text { Dichlorophena! } \\ 0 & 2,6 \text {-Dichlorophsind }\end{array}$

2,4-Dichlorophenoxyacotic acid

1,2-Dichloropropane

trans-1,3-Dichloropropene

Dibldirin

Diethyl phthalate

2,4-Dimethyl phenol

Dimethyl phthaiate

p-Dimethylaminaezobenzene

bimethylbenz[a]anthracene

3,3-Dimethylbenzidine

1,3-Dintrobenzene

2,4-Dinitrophenol

2,4-Dinftrotoluene

Di-n-octyl phthalate

1,4-Diaxane

Oiphonylam

Endosultan I

Endosultian I

Endoesulfan sulfate

Endrín

Endrin aldehyde

Ethyl methacrylate

Ethylbenzene

Famphur

Fluoranthen

Fluorene

Heptachior

Heptachlorodibonzo-p-dioxins

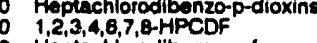

Haptachiorodibenzo-p-turans

Hexachlorobenzene

Hexachlorobyclodiene

$1,2,3,4,7,8-H \times C D D$

Hexachlorodibenzo-p-dioxins

$1,2,3,4,7,8-H X C D F$
Hexachlorodibenzo-p-furans

Hexachloroethane

Hoxachlorophene
Hexachloropropene
2.Hexanone

Indeno[1,2,3-c,d]pyrene

lodomethane (Methyl lodide)

leobutyl alcohol

teodrin

toosafrote

Kepone

Load

1 Manganere

Mercury

Methacrylonitril

Methapyrilen

2-Methyl-4,6-dinitrophenol

Methyl ethyl ketone

Mothyl twobutyl keton

Methyl methacrylate

3-Methyicholanthrene

2-Methylinaphthalone

1.4Naphthoquinone

i-Nephthylamine

2. Naphthylamino

Nickel

Nitrato-nitrite as nikrogen

2-Nitroaniline

3-Nitroaniline

Nitrobenzene

2-Nitrophena

4Nittophonol

4-Nitroquinoline-1-oxide

N-Nhtrosodi-n-butylamin

N-Ntrosodiothylamine

N-Nitrocodiphenylamine

N-Nitrosodipropylamine

N-Nitrosomethylethylamine

N-Nitrosomorpholine

N-Nitrosopiperidine

N-Nitroeopyrrolidine

O,O,O-Triathyl phosphorothioat

Octuchlorodibenzo-p-dioxins

Rosule

$<1.0$

1.2
$<10$
$<10$

$<0.30$

$<1.0$

$<1.0$

$<0.50$

$<10$

$<10$

$<10$

$<10$

$<10$

$<10$

$<45$
$<10$

$<10$

$<10$

$<10$

$<0.10$

$<0.10$

$<0.10$

$<10$

$<10$

$<1.0$

$<10$

$<.050$

$<0.00065$

$<0.00045$

$<0.00045$

$<10$
$<10$

$<0.00045$

$<0.00045$

$<0.00040$

$<10$
$<10$

$<10$

$<10$
$<10$

$<15$

$<100$

$<10$
$<10$

$<10$

$<10$

$<0.0050$

$<0.20$

$<50$
$<10$

$<0.50$

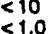

$<1.0$

$<10$

$<10$

$<10$

$<10$
$<10$

$<10$
$<10$

$<10$
$<4.0$

$<.0$
2,380

2,3
$<10$

$<10$
$<10$

$<10$

$<10$

$<10$
$<10$
$<10$

$<10$

$<10$

$<10$

$<10$

$<10$

$<10$
$<10$

$<10$

$<10$

$<10$
$<0.0010$

$<0.0010$
$<0.0010$
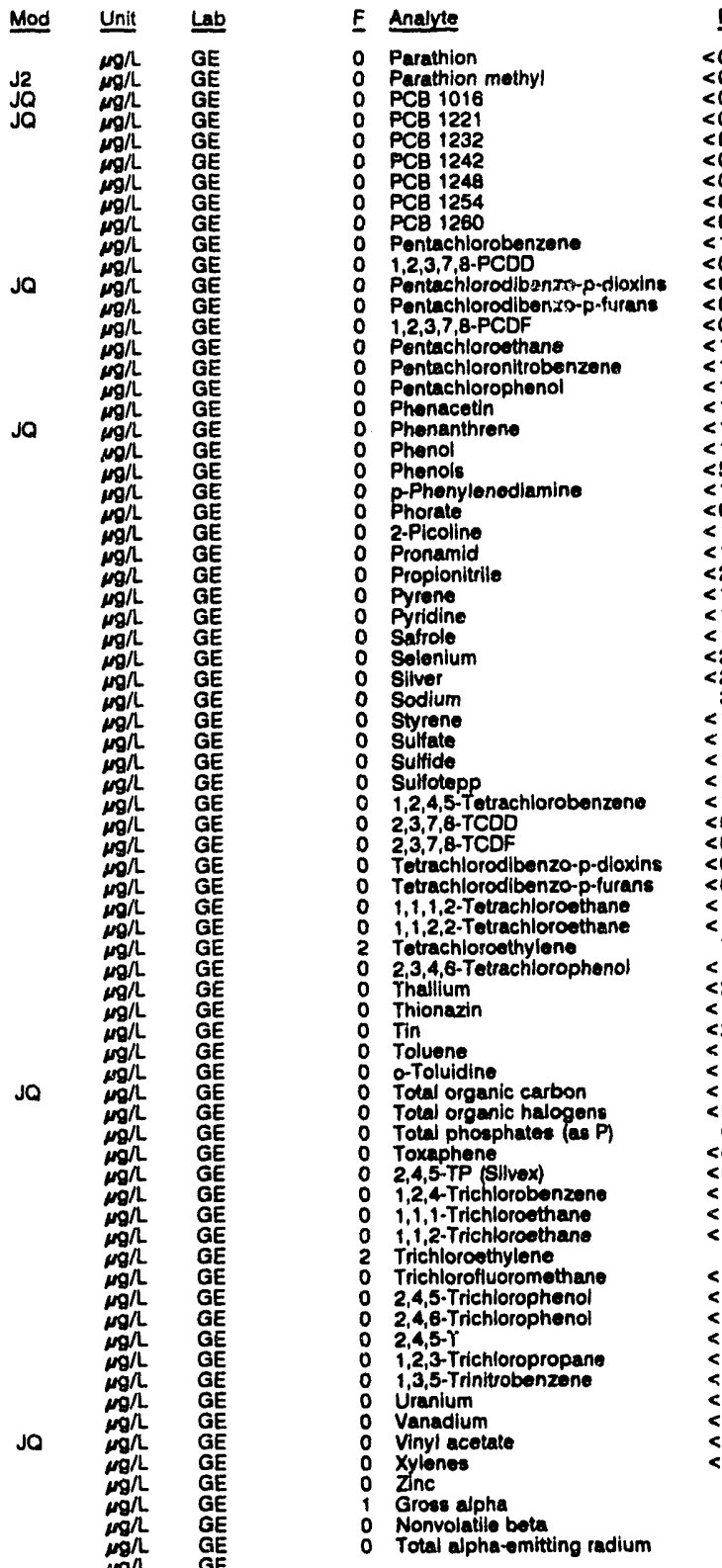

$<0.050$

$<0.50$

$<0.50$

$<0.50$

$<0.50$

$<0.50$
$<10$

$<0.00055$

$<0.00055$

$<0.0005$
$<10$
$<10$

$<10$
$<10$

$<10$
$<10$
$<10$

$<10$
$<10$
$<5.0$
$<10$

$<0.10$

$<10$
$<10$

$<200$

$<10$
$<10$

$<10$
$<2.0$

$<2.0$

3,520
$<1.0$
$<1.000$

$<1,000$

$<10$

$<0.00045$

$<0.00040$

$<0.00045$

$<0.00040$
$<1.0$
$<1.0$

7.4
$<10$

$<10$
$<2.0$

$<10$

$<2.0$
$<1.0$
$<10$

$<1,000$

65.0

$<0.24$

$<10$

$<1.0$

14

$<1.0$

$<0.090$

$<1.0$

$<10$

$<6.0$

$<2.0$

$9.3 \mathrm{E}-09 \pm 2.5 \mathrm{E}-09$

$6.2 E-09 \pm 1.8 E-00$

Mod Unit Lab

wo/h GE

\section{WELL MSB 58D}

MEASUREMENTS CONDUCTED IN THE FIELD

Sample date: 08/18/92 3139 m bolow TOC

Water elovation: $230.83 \mathrm{t}(70.38 \mathrm{~m}) \mathrm{mel}$

Sp. conductanco: $22 \mathrm{\mu s} / \mathrm{cm}$

Water ovacuatod belore sampling: $10 \mathrm{gal}$

The well went dry during purging.

LABORATORY ANALYSES

\begin{tabular}{|c|c|c|c|c|}
\hline$\underline{F}$ & Analyze & Result & Mod & Unitt \\
\hline $\begin{array}{l}0 \\
0\end{array}$ & $\begin{array}{l}\text { pH } \\
\text { pH } \\
\text { Specific conductance } \\
\text { Acenaphthene } \\
\text { Acenaphthylene } \\
\text { Acetone } \\
\text { Acetonitille (Methyl cyanide) } \\
\text { Acetophenone } \\
\text { 2-Acelylaminofluorene } \\
\text { Acrolein }\end{array}$ & $\begin{aligned} & 5.4 \\
& 5.4 \\
& 30 \\
& 310 \\
&<10 \\
&<10 \\
&<10,000 \\
&<100 \\
&<10 \\
&<10 \\
&<2,000\end{aligned}$ & $\begin{array}{l}\text { JQ } \\
\text { JQ } \\
\text { J1 } \\
\text { J1 } \\
\text { J1 }\end{array}$ & 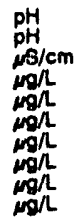 \\
\hline
\end{tabular}


ANALYTICAL RESULTS

WEU MSB 58D collectod on 08/18/92, taboratory analyses (cont.)

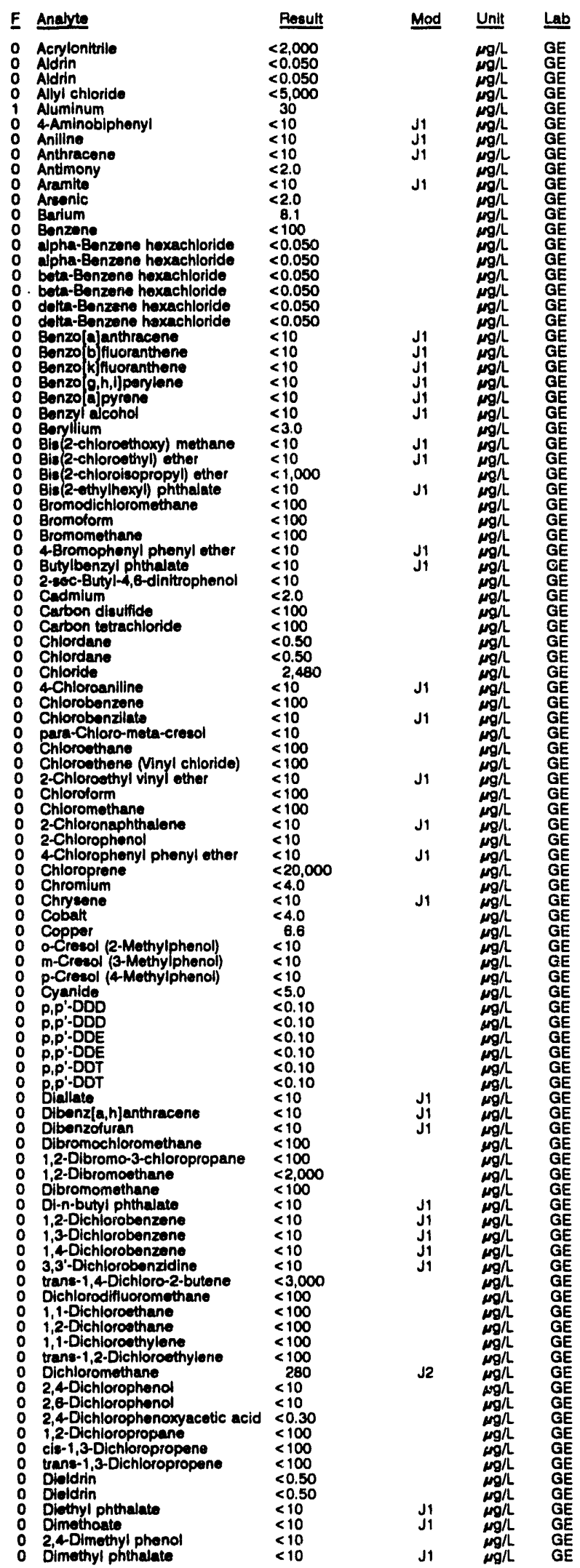

WELL MSE 58D colloctod on 08/18/92, laboratory analyeos (cont.)

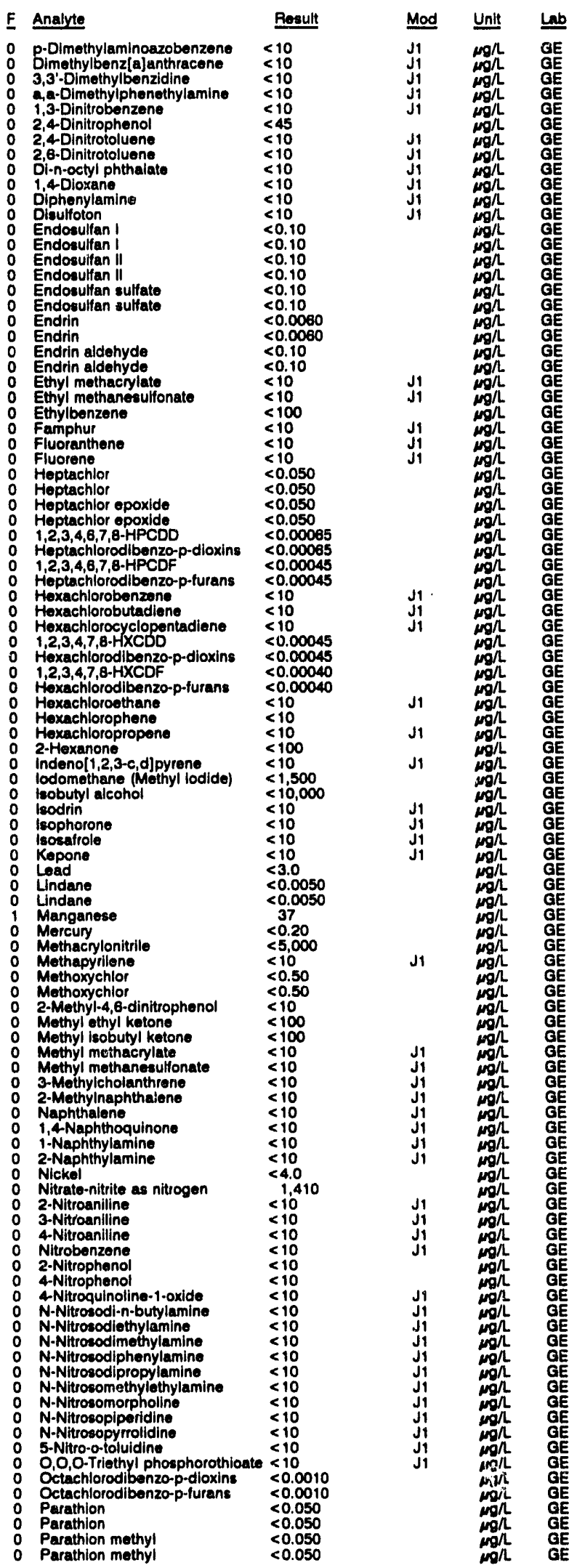


WELL MSB 58D collectod on 08/18/82, laboratory analyses (cont.)

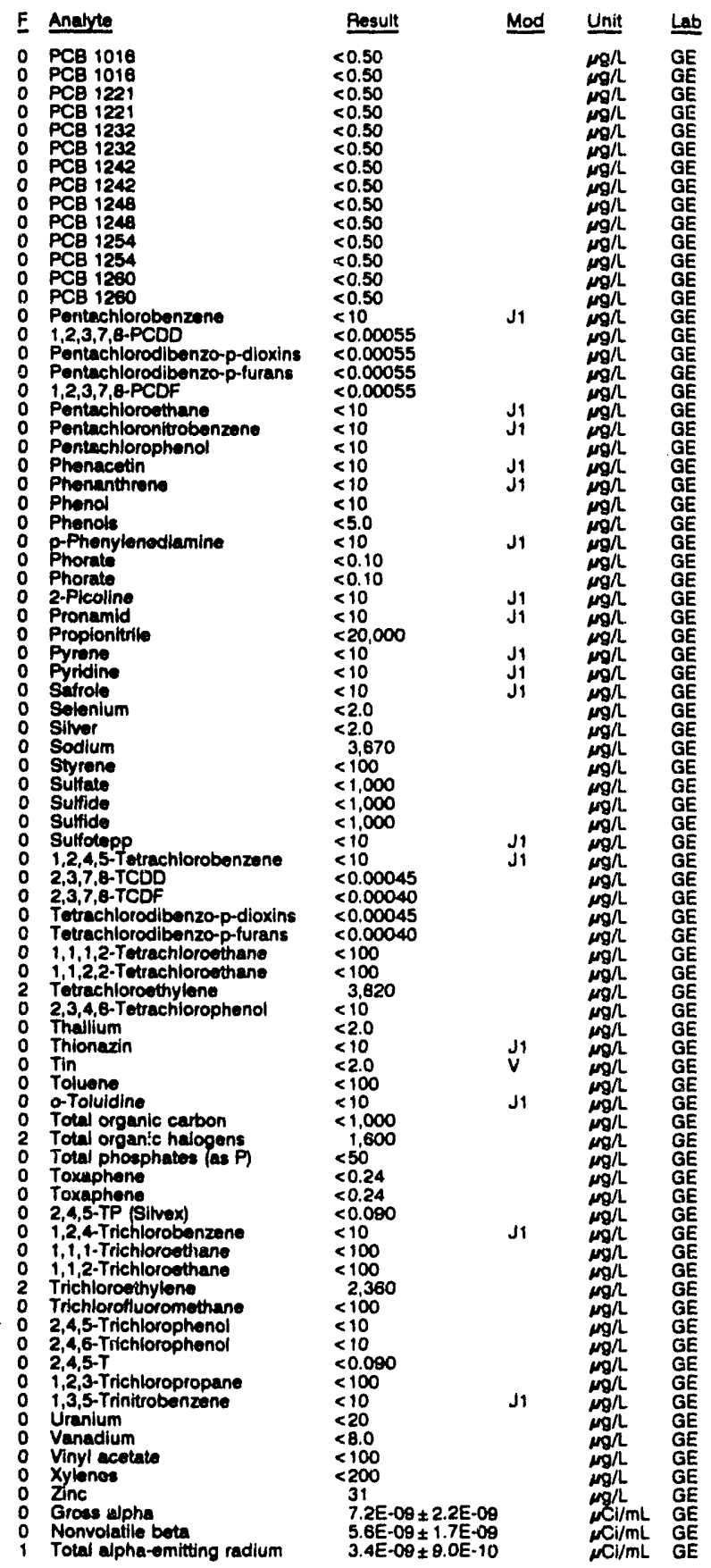

WELL MSB 59D

MEASUREMENTS CONDUCTED IN THE FIELD

Sample date: 08/21/92

Depth to water: $130.11 \mathrm{~h}(39.66 \mathrm{~m})$ bolow TOC Water elevation: $228.18 \mathrm{H}(68.88 \mathrm{~m}) \mathrm{msl}$ Water evacuated betore sampling: 51 gal

LABORATORY ANALYSES

$\begin{array}{ll}0 & \text { pH } \\ 0 & \text { Specific conductance } \\ 0 & \text { Acenaphthene } \\ 0 & \text { Acenaphthylene } \\ 0 & \text { Acetone }\end{array}$

Acetonitrile (Methyl cyanide)

2-Acetylaminofluorene

Acrolein

Acrylonitrile

Allyl chloride

Aluminum

Aniline

Anthracene

Antimony

Aramite

Arsenic

beta-Benzene hexachloride

delta-Bonzene hexachlorlde

Benzo b) fluoranthene

Benzo/k fluoranthene

Benzolo hil perylene

Benzo(a)pyrene

Benzyl alcoho

Beryllium

Bis(2-chloroethoxy) methane

Bis (2-chloroethyl) ether

Bis(2-chloroisopropyl) ether

Bis (2-ethylhexyl) phthalde

Bromoform

Bromomethane

4-Bromophenyl phenyl ether

2-sec-Butyi-4,6-dinitrophenol

Carbon disulfide

Carbon tetrachioride

Chlordane

Chloride

4-Chloroaniline

Chlorobenzene

para-Chloro-meta-cresol

Chiorosthene Minyl chloride) 2-Chloroethyl vinyl other

Chloroform

Chloromethane

2-Chloronaphtha

2-Chlorophenol
4-Chiorophenyl phenyl ether Chloroprene

Chromium

Cobalt

Copper

o-Cresol (2-Methylphenol)

m-Cresol (3-Methylphenol)

Cyanide.

Cyanide

p,p'-DDE

p.p'-DDT

biallato

Dibenz $[a, h]$ anthracene

Dibenzofuran

1, Dromochloromethane

1, Dibromo chlor

Dibromomethane

1,-Dichlorthaiate

1,3-Dichlorobenzene

1,4-Dichlorobenzene

3,3'Dichlorobenzidine

trans-1,4-Dichloro-2-butene

Dichlorodifluoromethane

1,1-Dichioroethane

i, - Dichloroethane

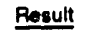

5.7
65
$<10$
$<10$

$<10$
$<500,000$

$<500,000$
$<5,000$
$<10$
$<10$

$<100,000$

$<100,000$

$<0.050$
$<250,000$

77
$<10$

$<10$
$<10$
$<10$

$<10$
$<2.0$

$<10$
$<2.0$

27
$<5,000$

$<0.050$

$<0.050$
$<0.050$

$<10$
$<10$
$<10$

$<10$
$<10$
$<10$

$<10$

$<3.0$
$<10$
$<10$
$<50,000$

$<10$
$<50,000$

$<10$

$<5,000$
$<5,000$

$<5,000$

$<10$
$<10$

$<10$
$<10$
$<2.0$

$<2.0$
$<5,000$

$<5,000$
$<0.50$

$<.50$
$<10$
$<10$

$<5,000$

$<10$

$<5,000$

$<5,000$
$<5,000$

$<10$
$<5,000$

$<5,000$

$<10$
$<10$

$<10$

$<1.0 E+06$

$<4.0$
$<10$
$<4.0$
16

16
$<10$

$<10$
$<10$

$<10$
$<10$
$<50$

$<5.0$

$<0.10$
$<0.10$

$<0.10$

$<10$

$<10$

$<5,000$

$<5,000$
$<100,000$

$<5,000$

$<10$

$<10$
$<10$

$<10$
$<10$
$<10$

$<10$
$<150,000$

$<5,000$

$<5,000$

$<5,000$
$<5,000$
Time: $8: 35$

Alkalinity: $4 \mathrm{mgh}$

Water temperafu: $20.7^{\circ} \mathrm{C}$ 
ANALYTICAL RESULTS

WELL MSB 500 colloctod on 08/21/82, laboratory analyses (cont.)

$\begin{array}{lll}0 & \text { trane-1,2-Dichloroethylene } & <5,000 \\ 0 & \text { Dichloromethane } & 10,000 \\ 0 & 2,4 \text {-Dichlorophenol } & <10 \\ 0 & 2,6 \text {-Dichlorophenol } & <10 \\ 0 & 2,4 \text {-Dichlorophenoxyacetic acid } & <0.30 \\ 0 & \text { 1,2-Dichloropropane } & <5,000\end{array}$

cis-1,3-Dichloropropene

Diethyl phthalate

Dimothoate

Dimethyl phthalate

D-Dimethylaminaszobenzene

3,3'-Dimethylbenzidine

a, oimethylphenethylainine

1,3-Dinitrobonzene

2,4-Dinitrophenol

2,6-Dinitrotoluene

Dirn-octyl phthalate

1,4-Dioxane

Diaulfoton

Endosulfar I

Endosulfan sultate

Endrin

Endrin aldehydo

Ethyl methacrylate

Ethyl mothanesulfonate

Ethylbenzene

Fluoranthene

Fluorene

Heptachlor

1,2,3,4,6,7,8-HPCDD
Heptachlorodibenzo-p-dioxins

Heptachlorodibenzo-p-dioxin

Heptachlorodibenzo-p-turans

Hexachlorobenzene

Hexachlorocyclopentadiene

1,2,3,4,7,8-HXCDD

Hexachiorodibenzo-p-dioxins

$1,2,3,4,7,8-H X C D F$
Hexachlorodibenzo-p-furans

Hexachloroethane

Hexachlorophene

Hexachloroprop

indeno[1,2,3-c,d]pyrene

lodomethane (Methyl lodide)

isodrín

lsophorone

kocafrola

Kepon

Lindane

Manganeese

Morcury

Mothacrylonitrile

Methapyrilens

Methoxychior

2-Methyl-4,8-dinitrophenol

Methyl ethyl ketone

Methyl loobutyl ketone

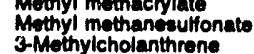

2-Methylnaphthalene

Naphthalene

1,4Naphthoquinone

1-Naphthylamine

Niekel

Nitrato-nitrite as nitrogen

2-Nitroaniline

3-Nitroaniline

4-Nitroanilin

Nitrobenzene

2-Nitrophenol

4-Nitrophenol

4.Nuroquinoline-1-oxide

N-Nitroadi-n-butylamin

N-Nitrosodiethylamine

N.Nitrosodiphenylamine

N-Nitrosodipropylamine

N-Nitrosomethylethylamine

N-Nitrosomorpholine

N.Nitrosopiperidine

N.Nitrosopyrrolldine

$<10$

$0,0,0$-Triethyl phosphorothioate $<10$

$\begin{array}{ll}\text { Octachlorodibenzo-p-dioxins } & <0.0010 \\ \text { Octachlorodibenzo-p.furane } & <0.0010\end{array}$
5,000

$<, 000$
10,000

10

$<5,000$

$<5,000$

$<10$

$<10$

$<10$

$<10$

$<10$
$<10$

$<10$

$<10$

$<10$

$<10$

$<10$

$<0.10$
$<0.10$
$<0.10$

$<0.0080$

$<<10$

$<10$

$<5,000$

$<10$

$<10$
$<0.050$

$<0.00085$

$<0.00065$

$<0.00045$

$<10$

$<10$

$<0.00045$

$<0.00045$
$<0.00040$

$<0.00040$

$<0.00040$
$<10$
$<10$

$<10$

$<5,000$
$<10$

$<10,000$

$<500,000$
$<10$
$<10$

$<10$
$<10$

$<10$
$<10$
4.5

$<0.0050$

112
$<0.20$

$<250,000$

$<10$
$<0.50$

$<10$

$<5,000$
$<5,000$

10
$<10$

$<10$
$<10$
$<10$

$<10$
$<10$

$<10$
$<10$

$<10$
$<10$

$<10$
6.8
4.800

4,600

$<10$

$<10$
$<10$

$<10$
$<10$

$<10$
$<10$

$<10$
$<10$

$<10$

$<10$

$<10$

$<10$

10

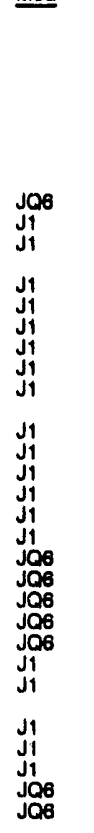

Lab

$\mathrm{GE}$

GE

GE

E

GE

GE

WELL MSB 59D collected on 08/21/82, laboratory analyees (cont.)

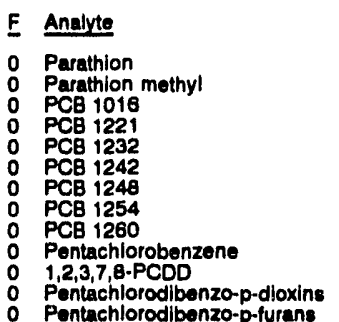

Result

$<0.050$

$<0.050$

$<0.50$

$<0.50$
$<0.50$
$<0.50$

$<<.50$

$<0.50$

$<10.00055$

$<0.00055$

$<0.00055$

0 Pentachlorodibenzc

o Pentachloroothane

o Pentachlorophenol

Phone glin

o Phenol

p-Phenylenediamine

O Phorate

2 2-Picoline

o Propionitrile

o Pyrene

0 Safrole

0 Selenium

0 Silver

- Styrene

o Sulfate

0 Sulfotopp

1,2,4,5-Tetrachlorobenzene

2,3,7,8-TCDD

0 Tetrachlorodibenzo-p-dioxine

- Tetrachlorodibenzo-p-furans

1, 1,1,2-Tetrachloroethane

0
2
0
0

Thallium

o Thionaz

0 Toluene

o-Toluidine

T Total organic carbon

2 Total organic halogens

o Toxaphene

$\begin{array}{ll}0 & 2,4,5-T P \\ 0 & 1,2,4-T \text { Trichlorobe } \\ 0 & 1,1,1 \text {-Trichloroenzene }\end{array}$

o 1,1,1-Trichloroethane

2 Trichloroethylene

2 Trichlorofluoromethane

o 2,4,5-Trichlorophenol

0 2,4,6-Trich

$\begin{array}{ll}0 & 2,4,5-T \\ 0 & 1,3,5-\text { Trichloropropane } \\ 0 & \end{array}$

o Úranlum

V Vinyl acetate

o Xylenes

Z Zne

O Gross alphe

o Nonviliti

Nonvolatile beta

o Total alpha-emitting radium

$<10$

$<10$

$<10$
$<10$
$<10$

$<10$

$<10$
$<0.10$

$<0.10$
$<10$
$<10$

$<1.0 E+06$

$<10$

$<10$
$<10$

$<2.0$

6,370

$<5,000$
$<1,000$

$<1,000$

$<10$

$<10$
$<0.00045$

$<0.00040$

$<0.00045$
$<0.00040$

$<5,000$

101,000

$<10$
$<2.0$

$<2.0$
$<10$
$<2.0$

$<2.0$

$<100$

$<1,000$
40,200

$<50$

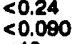

$<10$

$<5,000$

24,500

$<5,000$

$<10$
$<10$

$<0.000$

$<5,000$

$<10$
$<20$

$<8.0$

$<5,000$
$<10,000$

55

2.4E-09 $\pm 7.3 E-10$

2.3E- $09 \div 6.0 E-10$

$4.7 \mathrm{E}-09 \pm 8.1 \mathrm{E}-10$

$5.1 \mathrm{E}-09 \pm 8.5 \mathrm{E}-10$
$2.0 \mathrm{E}-09 \pm 1.0 \mathrm{E}-09$

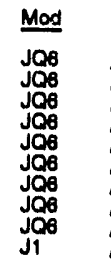

Unit Lي

$\mu g / L \quad G E$

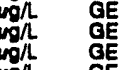

WELI MSB 600

MEASUREMENTS CONDUCTED IN THE FIELD

Sample dato: 07/26/92

Depth to water: $124.79 \mathrm{ht}(38.04 \mathrm{~m})$ below TOC

Water elevation: 229.71 \& $(70.02 \mathrm{~m}) \mathrm{me}$

Water wacuatod bofore sampling: $15 \mathrm{gal}$

pH: 5.5

Alkalinity: $6 \mathrm{mgh}$ 
WEL M98 60D colls tod on 07/28/82, laboratory analyses (cont.)

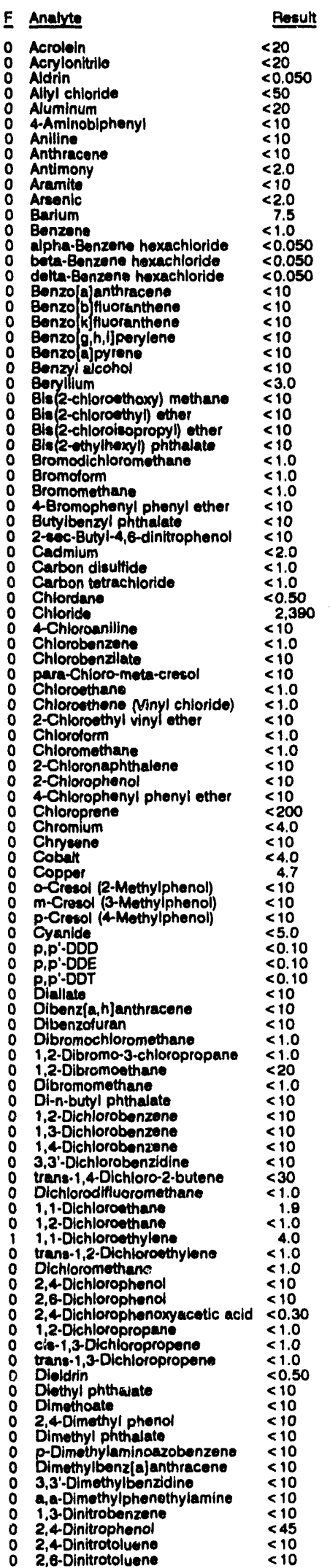

Mod Unit Lab

$\mu / L$ GE

GE

$\begin{array}{ll}\mu g / L & G E \\ \mu g / L & G E\end{array}$

WELL. MSB 60D collected on 07/26/92, laboratory analyses (cont.)

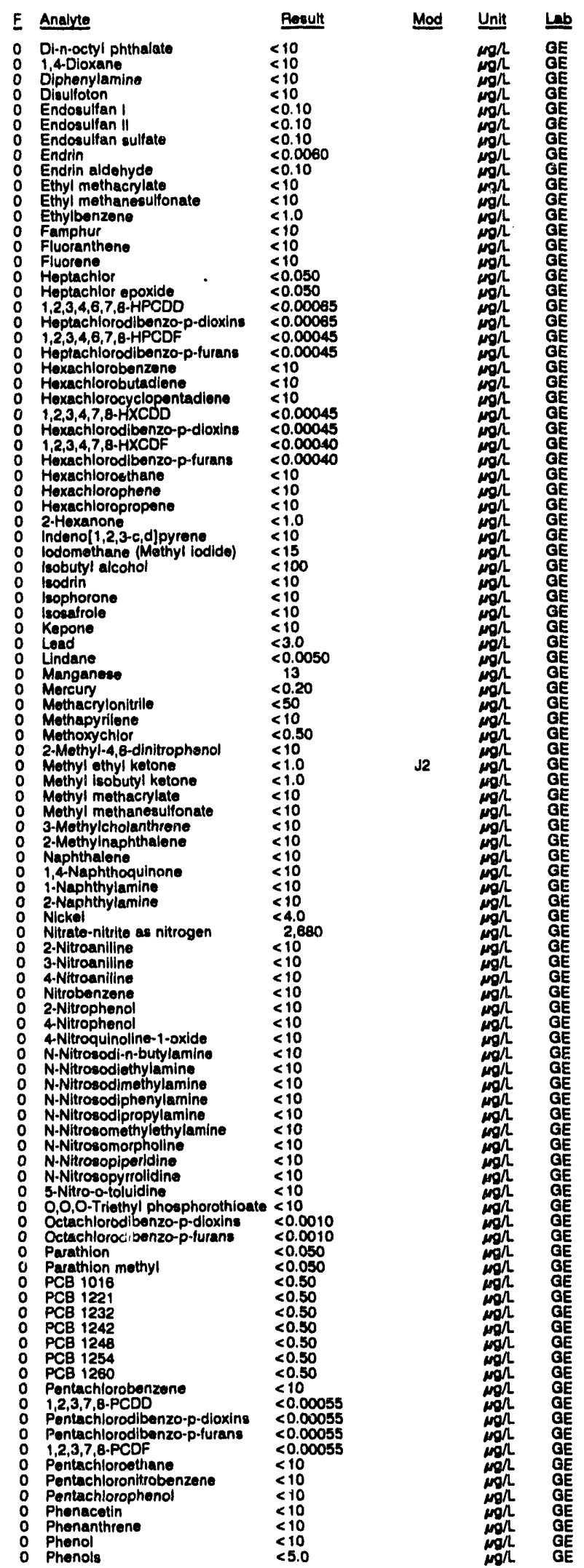


WELL MSB 800 collocted on 07/26/92, laboratory analyses (cont)

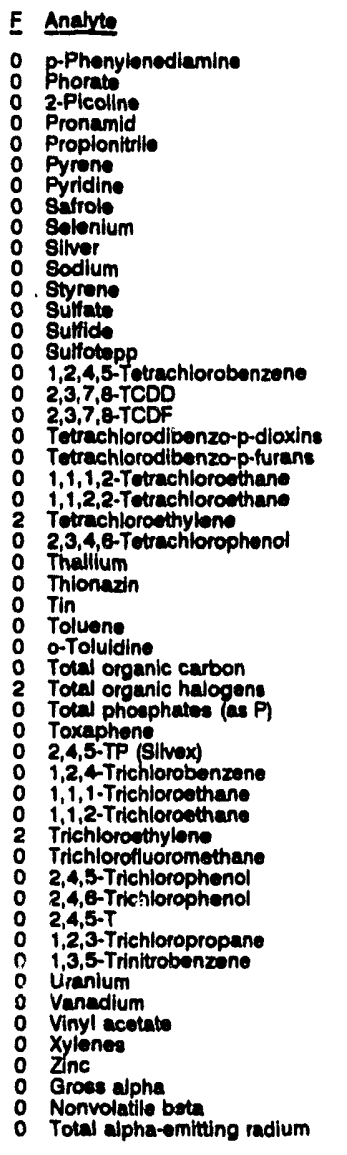

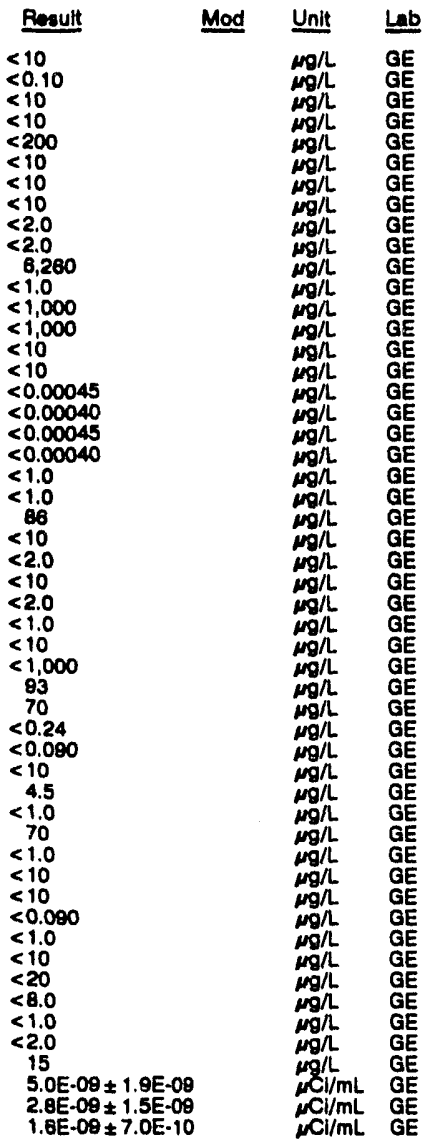

\section{WELL MSB 61C}

\section{MEASUREMENTS CONDUCTED IN THE FIELO}

Bample date: 08/08/a2 Depth to water: $04.55 \mathrm{ft}(28.82 \mathrm{~m}$ ) below TOC Wator elevation: $223.05 \mathrm{ht}(67.89 \mathrm{~m}) \mathrm{msl}$ Water evecunted before eampling: $127 \mathrm{gal}$

Time: $8: 15$
pH: 5.0

PH: 5.0 . $1 \mathrm{mon}$

Water temperature: $19.8^{\circ} \mathrm{C}$

LABORATORY ANALYSES

\begin{tabular}{|c|c|c|c|c|}
\hline & Analyte & Result & Unit & Lab \\
\hline $\begin{array}{l}0 \\
0 \\
0 \\
0 \\
0 \\
0 \\
0\end{array}$ & $\begin{array}{l}\text { Cadmium } \\
\text { Carbon totrachloride } \\
\text { Chloroform } \\
\text { Iron } \\
\text { Load } \\
\text { Manganese } \\
\text { Mercury } \\
\text { Nitrate-nitrite as nitrogen } \\
\text { Totrachloroethylene } \\
\text { Total organic carbon } \\
\text { Total organic carbon } \\
\text { Total organic halogens } \\
1,1,1 \text {-Trichloroethane } \\
\text { Trichloroethylene } \\
\text { Groas alpha } \\
\text { Nonvolatile beta } \\
\text { Total alpha-emitting radium } \\
\text { Tritium }\end{array}$ & $\begin{aligned}<2.0 \\
<1.0 \\
<1.0 \\
<4.0 \\
<3.0 \\
<2.0 \\
<0.20 \\
720 \\
<1.0 \\
<1.000 \\
<1.000 \\
<5.0 \\
<1.0 \\
<1.0 \\
2.5 E \cdot 09 \pm 1.5 E-09 \\
3.6 E-09 \pm 1.5 E-09 \\
<1.0 E \cdot 09 \\
1.8 E \cdot 06 \pm 5.0 E-07\end{aligned}$ & 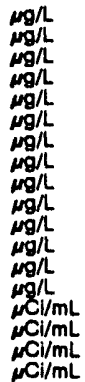 & $\begin{array}{l}\mathrm{GE} \\
\mathrm{GE} \\
\mathrm{GE} \\
\mathrm{GE} \\
\mathrm{GE} \\
\mathrm{GE} \\
\mathrm{GE} \\
\mathrm{GE} \\
\mathrm{GE} \\
\mathrm{GE} \\
\mathrm{GE} \\
\mathrm{GE} \\
\mathrm{GE} \\
\mathrm{GE} \\
\mathrm{GE} \\
\mathrm{GE} \\
\mathrm{GE} \\
\mathrm{GE}\end{array}$ \\
\hline
\end{tabular}

WELL MSB 61D

MEASUREMENTS CONDUCTEO IN THE FIELD

Sample date: 08/00/82

Dopth to water: $02.74 \mathrm{fh}(28.27 \mathrm{~m})$ bolow TOC

Water olovation: $225.38 \mathrm{kt}(68.60 \mathrm{~m}) \mathrm{mal}$

Sp. Conductance: 25, fs/cm
Whater wacuated bolore sampling: $\theta$ gal

The woll went dry during purging.

LABORATORY ANALYSES

\begin{tabular}{|c|c|c|c|}
\hline Analyte & Bosult & Mod & Unit \\
\hline 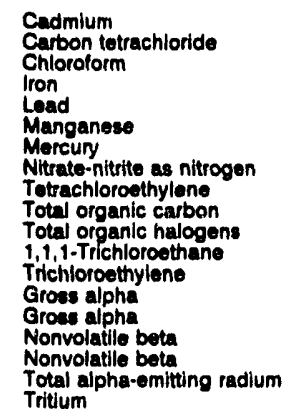 & $\begin{array}{l}<2.0 \\
<1.0 \\
<1.0 \\
36 \\
5.6 \\
2.3 \\
<0.20 \\
460 \\
<1.0 \\
<1.000 \\
<5.0 \\
<1.0 \\
<1.0 \\
2.2 E-09 \pm 1.4 E-09 \\
2.16-09 \pm 1.4 E-00 \\
<2.0 E-09 \\
<2.0 E \cdot .09 \\
<1.0609 \\
0.2 E-07 \pm 5.0 E-07\end{array}$ & & 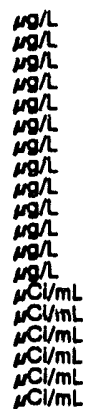 \\
\hline
\end{tabular}

\section{WELL MSB 62B}

MEASUREMENTS CONDUCTED IN THE FIELD

Depth to waler: $141.67 \mathrm{ft}(43.18 \mathrm{~m})$ below TOC Water elevation: $207.43 \mathrm{H}(83.23 \mathrm{~m}) \mathrm{msl}$ Sp. conductance: 24 $2 \mathrm{~s} / \mathrm{cm}$
Water evacuated bolore sampling: $187 \mathrm{gal}$

Time: $0: 50$

pH: 5.3 . 20

Water tomperature: $20.4{ }^{\circ} \mathrm{C}$

LABORATOAY ANALYSES

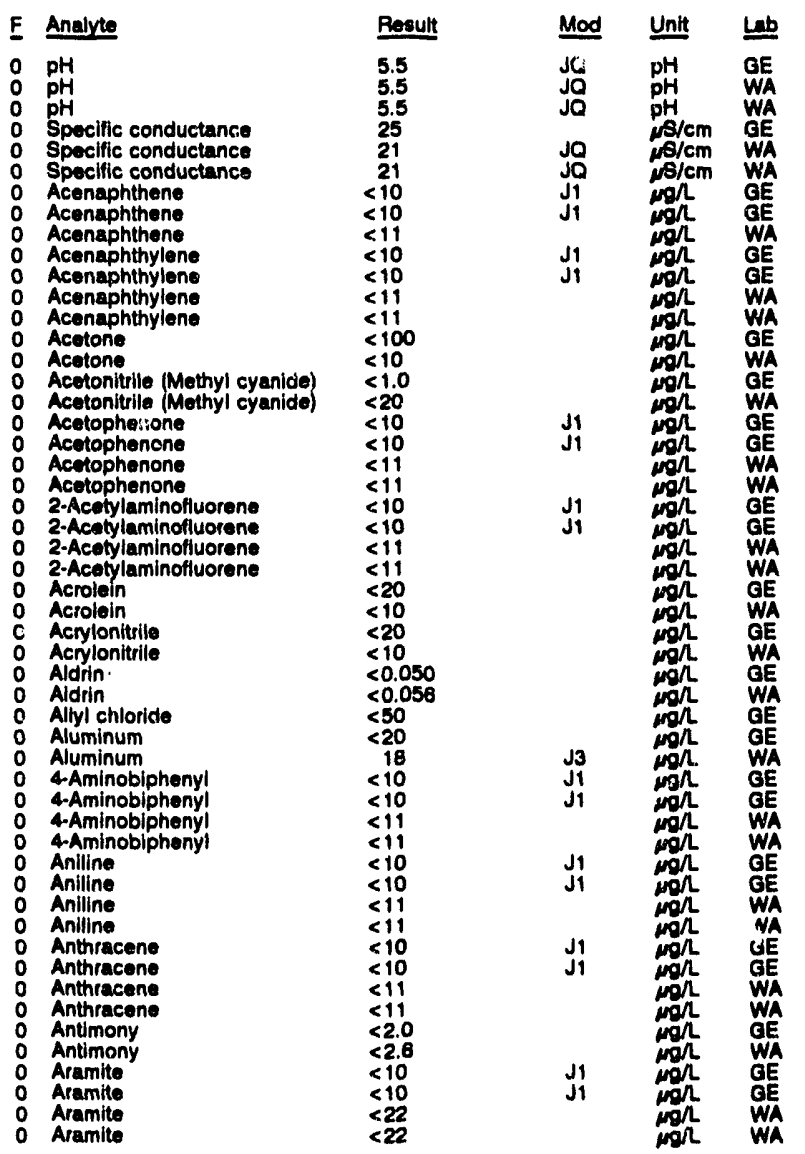


ANALYTICAL RESULTS

WELL M88 628 colloctod an 07/21/82, laboratory analyese (cont)

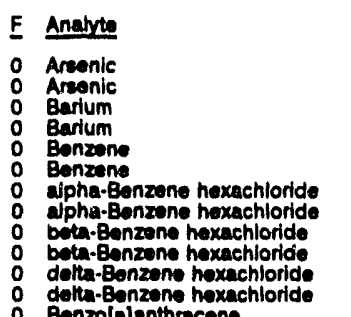

Bonzola anthrecone

Bonzo anthraceno

Bonzo e enthracene

Banzo b. fuoranthens

Eenzo b) fuoranthone

Benzo b) fluoranthen:

Benzo K f nuoranthene

Bonzo k fuormentione

Benzo

Eonzo g,hilporylone

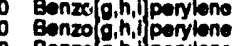

o Benzo ${ }^{2}$, il perylone

Benzo D pyrone

Bonzo pyrone

Benzo pyrone

Bonzy acohol

Benzyl alcohol

Bonzul alcohol

Beryllium

Bily -chloroethoxy methane

Bia 2-chlorosthoxy methene

Bis 2-chloroothoxy methane

Bis (2-chloroethoxy) mothan

Bis 2-chioroethyl) other

Bis 2-chloroethyl) ether

Bis 2-chloroethyll ther

Bis (2-chloroleopropy) ether

Bis (2-athylnoxyl) phthalate

Bis (2. Ethylhexyl) phthalate

Bis (2-ethylnexy) phthalate

Bromodichloromethane

Bromodichloromethane

Gromolorm

Bromomethane

Bromomethane

4Bromophenyl phenyl ether

Eromophonyl phenyl other

4 Bromophenyl phenyl ther

-Bromophenyl phenyl other

Butylbenzi phthalato

Butylbenzyl phthalate

2utylbenzyl phthalate

2-ecc-Butyl-4, b-dinttrophono

2-ecc-Butyl-4,6-dinittophenol

2-eec-Butyl-4,6-dinitropheno

Cadmium

Cadmium

Carbon disulfide

Carbon totrachloride

Carbon totrach

Chiordane

Chioride

Chioride

\&Choroaniline

4-Chloroaniline

4-Chloroaniline

Chlorobanzene

Chiorobenzene

Chlorobenzilate

Chlorobenzilate

Chiorobenzilate

para-Chioro-meta-cresol

para-Chloro-meta-crese

para-Chloro-meta-creas

Chloroethene

Chloroethone Ninyl chloride) Chloroethene Ninyl chloride 2-Chloroethyl vinyl ther
2-Chloroothyl vinyl ether Chlordorm
Result

$<2.0$
$<2.0$
7.7

8.7
81.1
$<5.0$

$<5.0$

$<0.050$

$<0.050$

$<0.050$

$<0.050$
$<10$
$<10$

Mod Unit

Lab

$<10$
$<11$
$<11$

$<11$

$<10$
$<11$
$<11$

$<10$

$<10$
$<11$
$<11$

$<11$
$<10$
$<10$

$<10$

$<11$

$<10$
$<10$

$<11$

$>10$

$<10$
$<11$
$<11$

$<3.0$

$<10$

$<11$

$<11$

$<10$
$<10$
$<11$

$<11$

$\leq 10$

$<10$
$<10$
8.0

8.0
11
$<1.0$

$<5.0$

$<5.0$

$<1.0$
$<10$
$<10$

$<10$

$<10$

$\leq$

$<10$
$<11$

$<10$

$<10$

$<55$

$<2.0$

$<1.0$

$<1.0$

$<5.50$

1,880
37,300

31,300
$<10$
$<10$

$<10$

$<11$ <

$<5.0$

$<10$

$<11$

$<10$

$<1$

$<1.0$

$<1.0$

$<10$

$<10$
$<1.0$

$<1.0$
$<5.0$

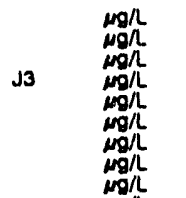

GE

WE

WA
WELL MSB 82B collected on 07/21/82, laboratory analyese (cont.)

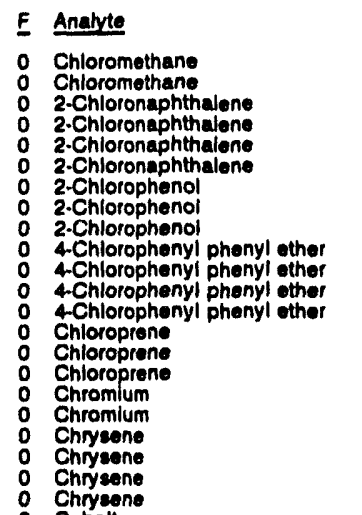

Besult

Mod Unit Leb

$<1.0$

$<10$

$<11$

$<10$

$<11$

$<10$

$<200$

$<20$

$<4.0$

$<10 \quad J 1$

Cobalt

Cobalt

Copper

o-Cosol (2-Mothylphenol

o-Cresol 2-Methyiphonol

a-Crosol 2-Mothylphenol

0.Cresol (2-Mothylphenol

m-Crosol (3-Mothylphono

m-Cresol (3-Mothylphenol

m.Cresol (3-Mathylphenol)

m-Cresol (3-Mothyiphenol)

p-Crosol 4-Methypheno:

p-Crosol (4-Mothylphenol)
p-Cresol (4-Methylphenol)

Cyanido

Cyanido

P,P':DOD

P,P'Dod

P,P.:DOE

P.P'-DOT
P,P.DDT

Dialate

Diallate
Diallate

Dibbonz[a, h] anthracane

Dibenz $(a, n)$ anthracene

Dibenza a, n anthracene

Dibenz a,h anthracene

Dibenzoluran

Dibenzofuran

Dibenzofuran

Dibenzofuran

1,2-Dibromo-3-chloropropane

1,2-Obromo-3-chloropropane

1,2-Dibromoothane

1,2-Dibromosthane

Obromomothane

Di-n.butyl phantalate

Di-n-butyl phehalate

Di-n.butyl phthalato

Di-n-butyl phthalate

1,2-Dichlorobonzente

1,2-Dichlorobenzene

1,2-Dichlorobonzen:

o i, J-Dichlorobenzene

1,3-Dichiorobenzene

- 1,3-Dichlorobenzene

1,3-Dichlorobenzeno

1,4Dichlorobonzente

o i,4-Dichlorobenzenene

o 3,3'.Dlchlorobnenzidine

o $3,3^{\prime}$. Dichlorobonzidine

3
0
0

trans-1,4-0ichloro-2-butene

0 trans-1,4-Dichloro-2.butene

o Oichlorodifluoromethane

o 1.1. Dichloroothane

o 1,1.Dichloroothane

o 1,2-Dichloror hane

o 1,1-Dichloroothylene

- 1,1-Dichloroethylene
o trens-1,2-Dichloroethylene

trans-1,2-Dichlofoethylene
0 trans-1,2-Dichloloethylene

o Oichloromethane

O Dichlorominane

o 2,4-Dichlorophenol

$<10$

$\leq 11$

$<10$

$\leq 11$

$<10$

$\leq 11$

$<5.0$

$<0.10$

$<0.10$

$<0.10$
$<0.11$

$<10$

$\leq 11$

$<11$

$\leq 10$

$<11$

$<11$

$\leq 1.0$

$<5.0$

$<1.0$

$<20$

$<1.0$

$<10$

2.3
2.4
$<10$

$<10$

$<i 1$

$<10$

$<10$

$<10$

$<10$

$<10$

$<22$

$<30$

$<100$ 
ANALYTICAL RESULTS

WELL MSB 228 colbeted on 07/21/82, laboratory analyees (cont.)

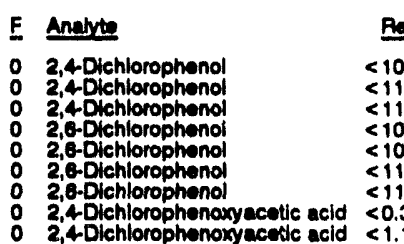

1,2.Dichloropropan

cis-1,3-Dichloropropen

cks-1,3-Dichloropropene

trans-1,3-Dichloropropene

Dleldrin

Diethyl phthrulate

Diethyl phthalato

Diethyl phthalate

Oiminoalo

2,4-Dimathyl phanol

2,4-Dimethyl phenol

2,4-Dimethyl phenol

2,4-Dimethy phenol

Dimothyl phthalate

Dimethyl phthalate

D-Dimethylaminoerobenzene

p-Dimethylaminoszobonzene

4Dimethylaminaszobenzene

4Dimethylaminoazobenzene

Dimethylbenz a anthracene

Dimethylbenz a enthracene

0 3,3'-Dimethylbenzidine

3,3'-Dimethylbenzidine

3,3'-Dimethylbenzidin

o a. Dimethylphonethylamine

a,a-Oimethylphenethylamino

a.Dimethylphenethylamine

o 1,3-Dinitrobenzane

1,3-Dinitrobenzene

: 1,3-Diniturobenzente

o 4,6-Oinitro-ortho-cresol

2,4-Dintrophenol

2,4Dinitrophenol

2,4-Dinitrophenal

2,-Dinitrophenol

2,4 initrotoluene

2,4-Dinitrotoluene

2,4-Dinitrotoluene

2,6-Dintrotoluen

2,6-Dinitrotoluene

2,0-Dinitrotoluene

Di-n-octyl phithalate

Di-n-octyl phthalate

o Di-n-octyl phthalate

o Di-n-octyl phthalat

1,40loxane

1,4-Dioxano

D Diphenylanine

D Diphenylamine

o Diphenylamine

o Oiphenylamine

Disulfoton

Disulfoton

Endoaulian

- Endoeulfan II

- Endosulfan II

o Endosulfan sulfate

O Endrin

- Endrin

O Endrin aldehyde

Ethyl methacrylate

Ethyl mothacrylato

Ethyl methacrylat

o Ethyl methanesulfonate

Ethyl mothanesulfonat

Ethyl mothanesulfonate

Ethyl mothaneaulfonate

Ethylbenzano

o Famphup

$<10$
$<11$
$<11$
$<10$
$<10$
$<11$

$<1.1$

$<1.0$

$<1.0$

$<1.0$

$<0.50$

$<0.11$

$<10$

$\leq 11$

$<10$
$<10$
$<10$

$<10$

$<10$

511

$<10$
$<10$

(11)

$<10$

$\leq 1$

$<11$
$<10$

$<10$

<11

$<10$

$<11$

$<10$

$<10$
$<10$
$\leq 11$

$\leq 11$

$\leq 10$

$<10$

$<11$

$<55$

$<45$

$<55$

$<10$

$<10$
$\leq 11$
$\leq 10$

$<10$
$<10$
$<11$
$<11$

$<10$

$<10$

$<11$

$<10$

<10

$<11$

$<10$

<11

$\leq 10$

$<10$

$<0.10$

$<0.10$

$<0.10$

$<0.11$

$<0.0060$

$<0.10$

$<0.11$

$<10$
$<10$
$<11$

$<11$

211

$<11$
$<1.0$

$<1.0$
$<5.0$

$<10$
$<10$

\section{Mod Unil}

GE

${ }_{\mu g / L}$

GE

WA

WE

WE

WA

GE

WE

GE

WA

E

EA

WA
WELL. M9B 628 collected on 07/21/82, laboratory analyses (cont.)

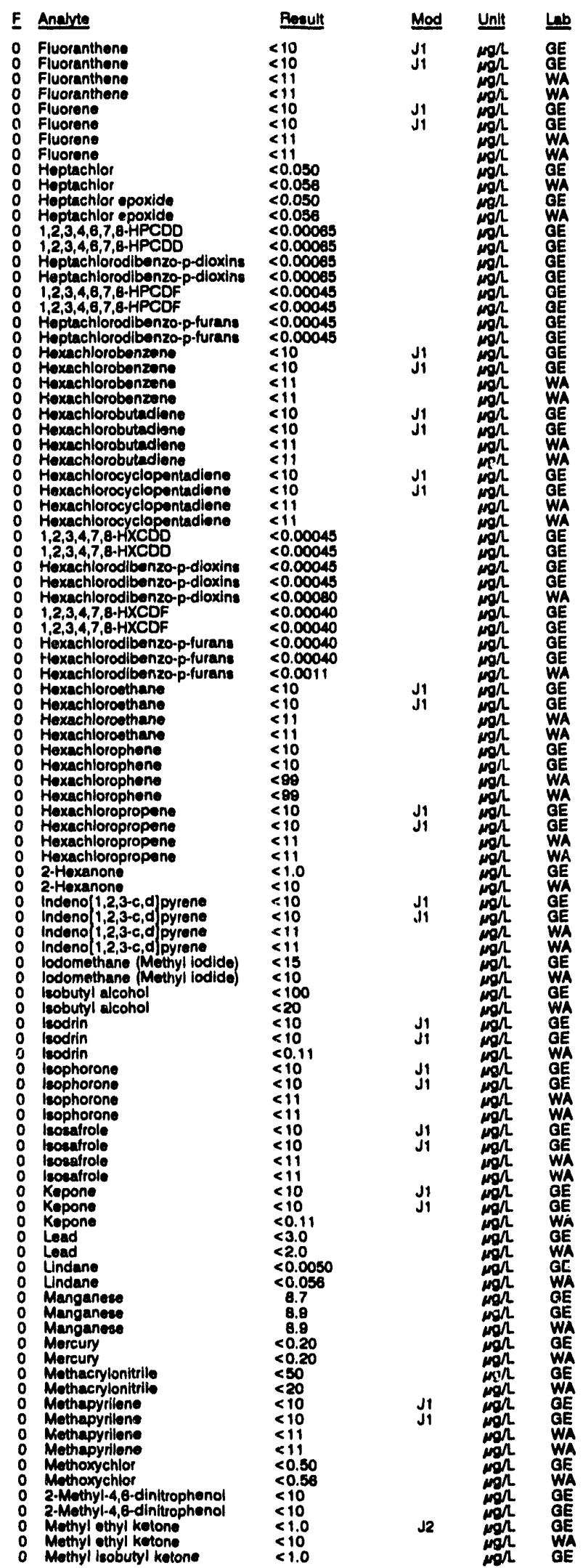


WELL MBB E2B collested on 07/21/82, laboratory analyees (cont.)

E Anate

O Methyl mothecrylato

o Methyl methecylinte

Mothyl methanewilitionate

Methyl mothaneaulfonate

Methyl methanesulfonato

Minyl methaneaulfonate

4-Mothyl-2-pentanone

3.Mnylcholanthren

3-Nothylcholanthren

3-Nethylcholanthrone

2-Methylnaphthalen

2-Nethylnaphthalone

Naphthalens

Naphthalone

Nephthalen

1,4Naphthoquinone

1,4Naphthoquinone

1,4Nephthoquinon

i-Nephithylamine

1. Naphthylamino

1.Naphthylamine

1-Naphthylamino

2-Naphthylamine

2-Naphthylamine

2-Naphthyiamine

Nickel

Nickol

Nitrate as nitrogen

2-Nitroaniline

2.Nitroaniline

2-Nuroanilino

2-Nhroaniline

3-Nuroaniline

3-Nitroaniline

3-Ntroanniline

4Nitroaniline

4 Nitroaniline

4-Nitroanlitine

Nitrobenzone

Nitrobenzene

Nitrobenzene

Nitrobenzane

2-Nitrophingl

2.Nutrophonol

2-Nitrophenol

ANtrophenel

4Nitropheno

4. Nitroquinoline-1-axide

\&Nitroquinolina-1-axide

4-Nitroquinoline-1-axide

4-Nitroquinolino-1-oxide

N-Nitroedodi-n-butylamine

N-Nltroesdi-n-butylemine

$N$-Nitrosodi-n-butylamine

N-Nitrosodiethylamine

N-Nitrosodiethylamino

N-Nitrosodiethylamine

N-Nitroeodimethyiamine

N-Nitrocodimethylamine

$\mathrm{N}$-Nitrocodimethylamine

N-Nitrosodimethylamine

N-Nitroesdiphenylamine

N-Nitroesodiphenylamine

N-Nitroeodiphenylarnine

N-Nitrocodiphanylamine

N-Nitrocodipropylemine

N-Nitrocodipropylamine

N-Nitrosomethylethylemine

N-Nitrosomethylethylamine

N-Nitrocoinethylethylamine

N-Nitrocomethylethylamin

N-Nitroeomorphollne

N-Nitroeomorpholine

N-Nitrosomorpholine

N-Nitrosopiperidine

N-Nitrosopiperidine

N-Nitroeoplperidine

N-Nitroesoplporidine

N-Nitroespyrrolidine

N-Nitrocopyrrolldine

N-Nitrocopynolidine
Beoult

$<10$
$<10$

$<11$

$<10$
$<10$

$<11$

$<10$

$<11$

$\leq 10$

$\leq 110$

$\leq 11$

$\leq 110$

$\leq 11$

$\leq 10$

$\leq 11$

$<10$

$\leq 10$

$\leq 11$

$\leq 10$

$<11$

$<4.0$

$<3.18$

$<50$

$\leq 10$

$\sum_{<55}$

$<10$

$<55$

$<10$

$<\leq 5$

$<5$

$<10$

¿11

$<10$

$\leq 11$

$<10$

$<5$

$<10$

(22

10

10

$\leq 11$

$<10$

III

$\leq 10$

$\leq 10$

sil

$<10$

$>10$

311

$\leq 11$

110
510

\11

$\leqslant 10$

$5<5$

$<55$

$<10$
$<10$

$<11$

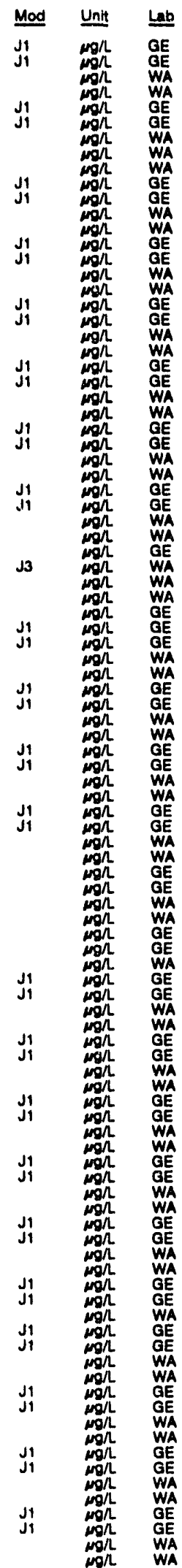

WELL MSB 628 collected on 07/21/92, laboratory analyees (cont.)

E Analyte Besult Mod Unit Let

5-Nitro-0.toluidine $\quad<10 \quad \mathrm{J1}$ mog $\mathrm{GE}$

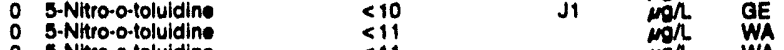

0 OO. Trethyl phosphorothioate

ond

o Octachlorodibonzo-p-dioxina $<0.0010$

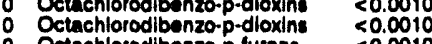

Octachlorodibenzo-p-furane $<0.0010$

Parathion $<0.050$

0 Parathion methyl $<0.050$

- PCB 1018

PCB 1016
0

PCB 1221

: PCB 1232

- PCB 1242

P PCB 1248

- PCB 1248

- PCB 1254

PCE 1254

PCB 1200

- Pentachlorobenzene

- Pentachlorobenzene

o Pentachlorobenzene

1,2,3,

$1,2,3,7,8$-PCDO

Pentechlodibenzo-p-dioxins <0.00055

Pontachlorodibenzo-p.dioxine <0.0005s

Pentachiorodibonzo-p-dioxing <0.0033

o Pentachlorodibanzo-p-p-turens $<0.00055$

Pentachlorodibenzo-p-turens

0 1,2,3,7,8.PCDF

o Pentachloroethane

o Pentachlorosthane

o Pontachloroothane

- Pentachloroethane

Pentactiloronitrobenzene

Pentachloronitrobenzene

Pentachioronitrobenzene

Pentachloronitrobenzen

- Pentuchlorophono

Pentachloropheno

- Prenacetin

O Phenacotin

Phonacetin

Phenacetin

Phenanthrene

Phenanthrene

0 Phenol

o Phenol

o Phenol

Phenole

Phenols

p-Phenylenediamine

o p-Phonylenediamine

o p-Phenylenedlamine

o Phorate

o 2-Picoline

2-Picolino

2.Picoline

Pronamid

o Pronamid

Pronamid

Propionitrite

o Propionititrile

o Propion

0 Pyrene

0 Pyrene

- Pyridine

- Pyridine

o Pyridine

O Safrote

o Safrole

$\begin{array}{ll}0 & \text { Safrole } \\ 0 & \text { Safrole }\end{array}$

Selenium

0 Silver

0 Silver

Sodium

Sodium

0

Sulfate

$<0.0025$

mon wa

$<10$

$<10$

$<11$

$<10$

$<10$

$<55$

$<10$

$<10$

$<55$

$<10$

$<11$

$<11$

$<10$

$<11$

$\leq 11$

$<10$

$<11$

$<5.0$

$<10$

$<10$
$<11$
$<11$
$<0.10$

$<10$

$<10$

$<11$

$<10$

$<11$

$<200$

$<10$

$<10$

$<11$

$<10$

$<11$

$<10$

$<11$

$<2.0$

$<2.0$

$<0.70$

$<1.0$

$<5.00$

1,090
1,100

J1

$\operatorname{mog}_{\substack{\operatorname{mon} \\ \operatorname{mogh}}}$

on

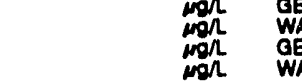


ANALYTICAL RESULTS

WELL MSB 628 collectind on 07/21/92, laboratory analyses (cont.)

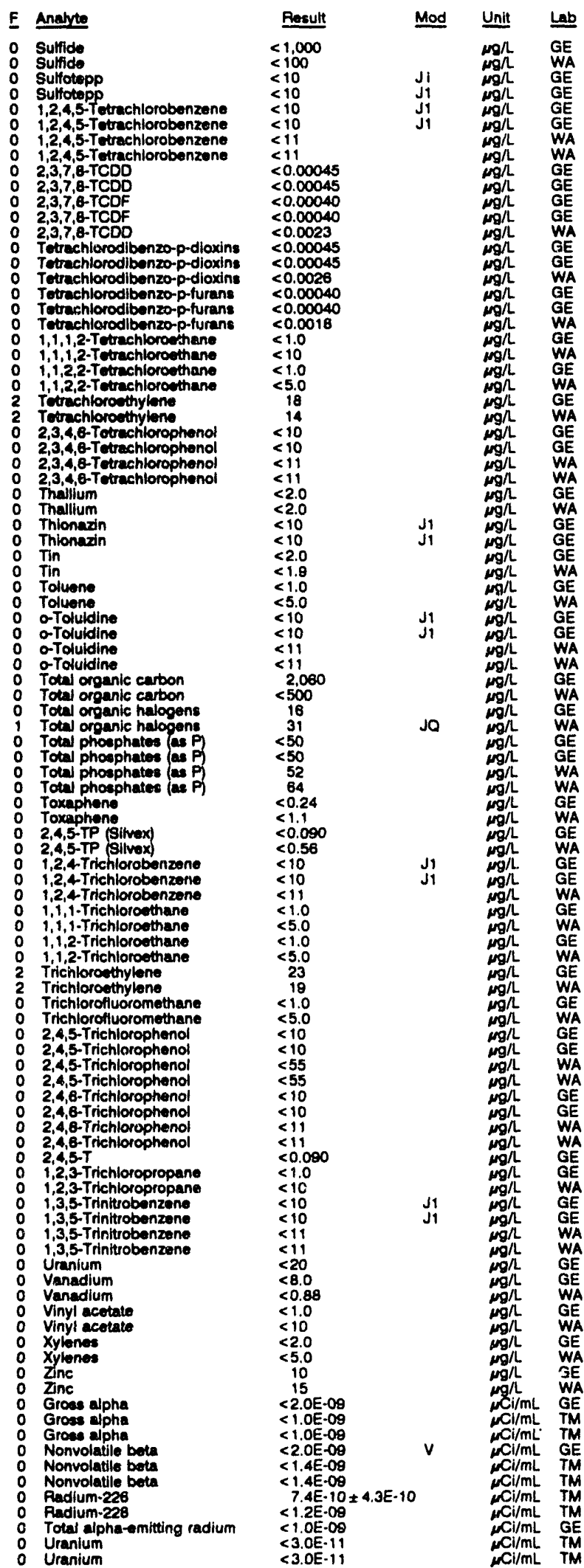

WELL MSB 62B Replicate

MEASUREMENTS CONDUCTED IN THE FIELD

Sample date: $07 / 21 / 82$

Depth to water: $141.87 \mathrm{H}(43.18 \mathrm{~m})$ below TOC

Sp. conductance: $24.43 \mathrm{t}(6 \mathrm{~s})$

Water evacuated before sampling: $187 \mathrm{gal}$

PH: 5.1 Alkalinity: $4 \mathrm{mg} /$

Water temperature: $21.4^{\circ} \mathrm{C}$

LABORATORY ANALYSES

$E$ Analyte

0 pH

Specific conductance

- Acenaphthene

Acenaphthene

Acconaphthene

Acenaphthylene

Acenaphthylene

Acetone

Acetonitrile (Methyl cyanide

Acetonitrile (Methyl cyanide)

- Acetophenone

- Acetophenone

2-Acotylaminofluorene

2.Acotylaminofluorene

2-Acotylaminofluorene

Acrolein

Acrylonitrile

Acrylonitrile

Aldrin

Allyl chloride

Aluminum

4-Aminobipheny

4.Aminobinobienyeny!

An Aniline

Anilino

Anilino

Anthracene

Anthracene

Antimony

Antimony

Aramite

Aramite

Aramite

Arsenic

Barium

Benzene

Benzene

alpha-Benzene hexachloride

ajpha-Benzene hexachioride

beta-Benzene hexachloride

beta-Benzene hexachloride

dofta-Bonzene hexachloride

delta-Benzene hexachloride

Benzola anthracene

Benzo a anthracen

Benzo a anthracene

Benzol fifluoranthene

Benzo buoranthene

Benzo bfluoranthene

Benzo fuoranthene

Benzo Kf fluoranthene

Benzolg hilporytene

Benzog,hil perylene

Benzol hiljperytene

Benzo a pyrene

Benzola pyrene

Esnzolapyrene

Benzyl alcoho

Benzyl alcohol

Beryllium

Bis(2.chloroethoxy) methane

Bis (2-chloroethoxy) methane

Bis 2-chloroethoyy) methane

Bis(2-chloroothyl) other

Bis (2-chlorosthy) other

Bis (2-chloroethyll ether

Bis (2-chloroisopropyl) other

Bis (2-ethylhexyl) phthalate

Bis 2-ethythexyl) phthalate

Bis(2-ethylhexyl) phthaist

Bromodichloromethane

Bromodichlorom
Bromoform

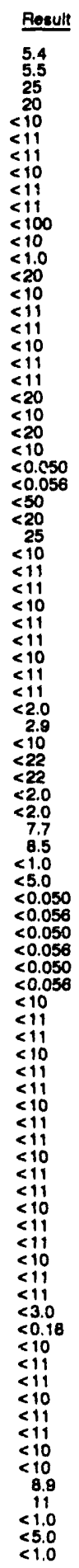

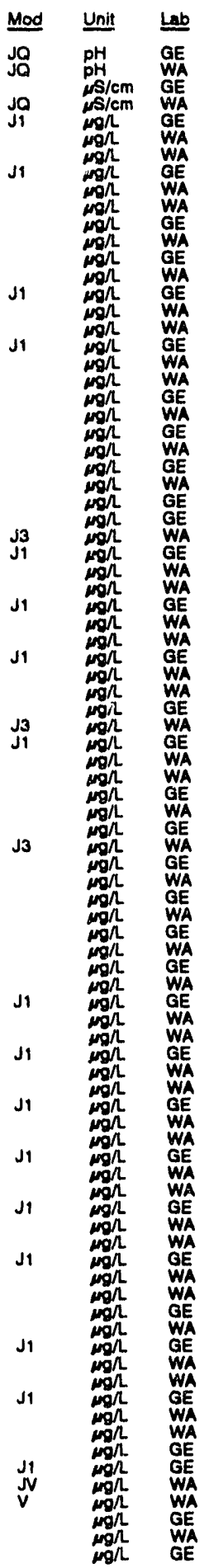


WEUL MSB 628 coliected on 07/21/82, laboratory analyees (cont.)

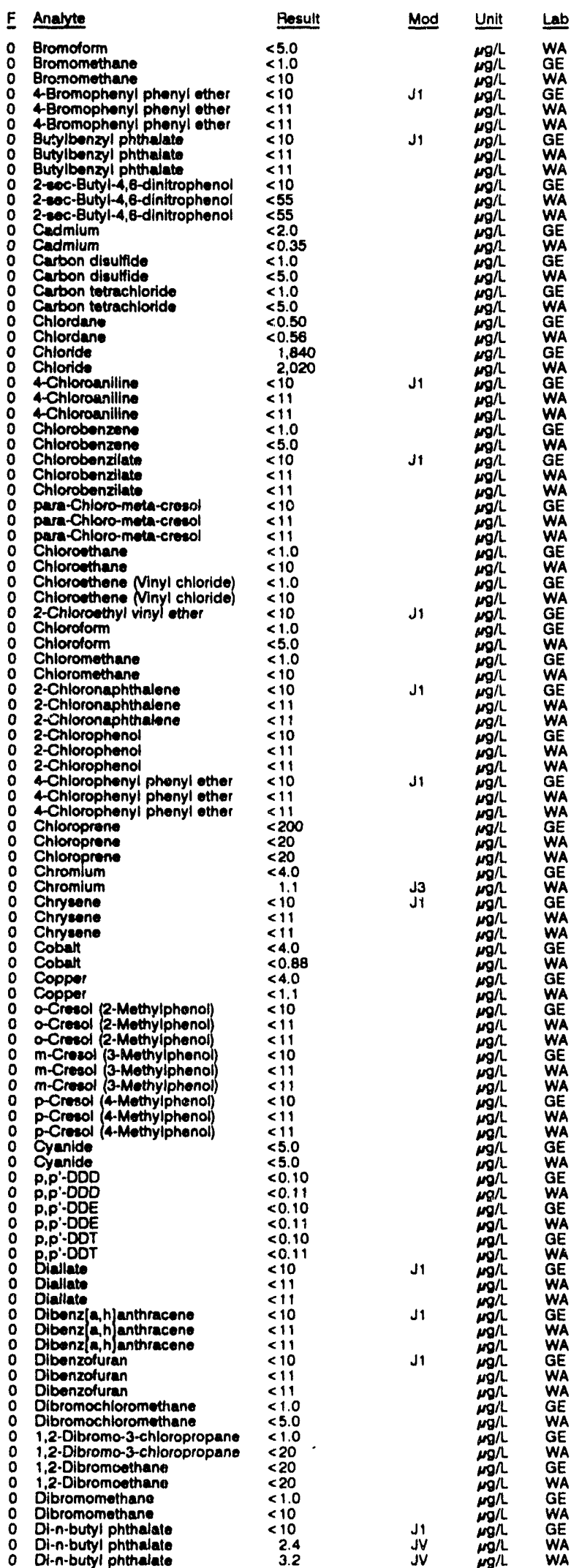

WELL MSB 628 collected on 07/21/82, laboratory anelyses (cont.)

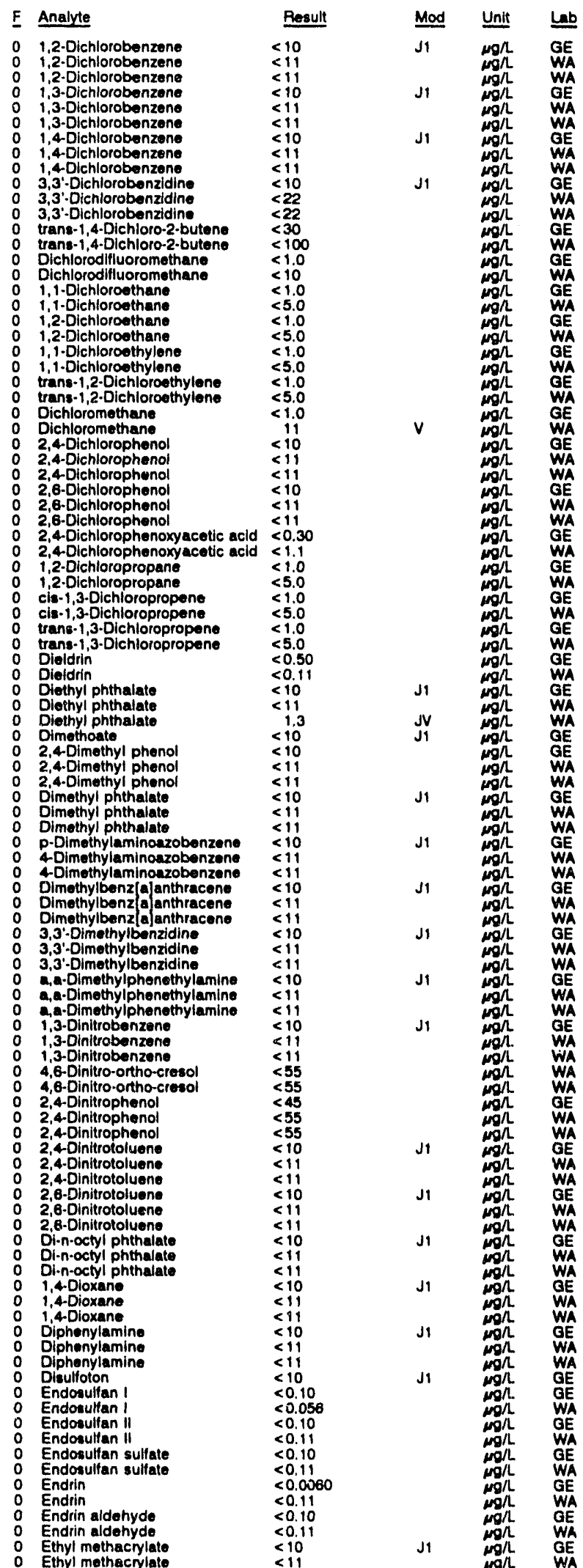


ANALYTICAL RESULTS

WELL MSB 628 collected on 07/21/92, laboratory analyses (cont.)

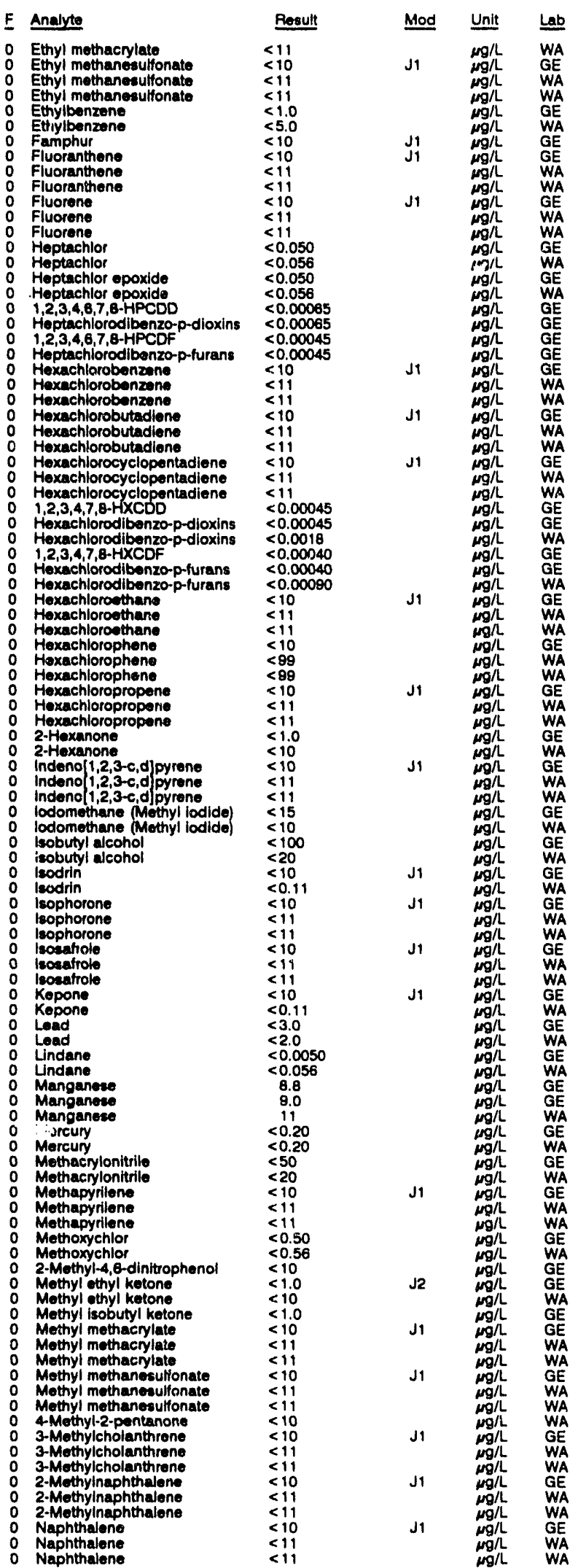

WELL MSB 628 collected on 07/21/82, laboratory analyses (cont.)

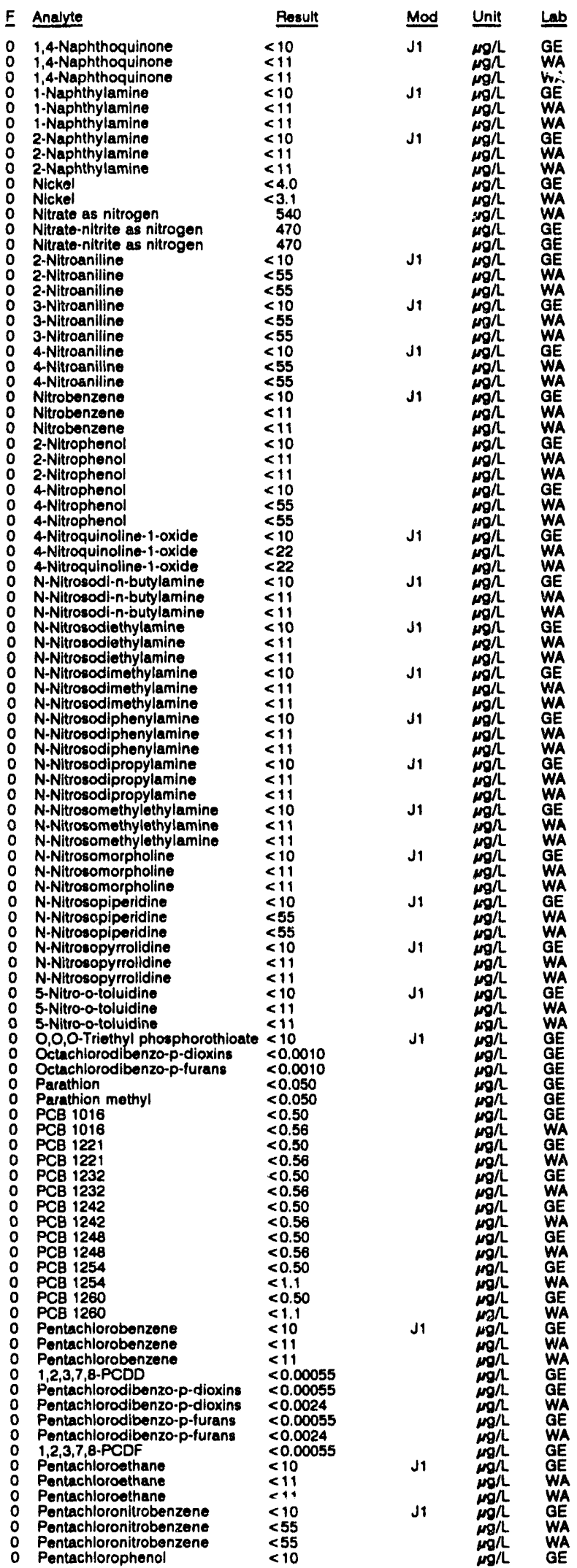


WELL MSB 628 collocted on 07/21/82, laboratory analyses (cont.)

\begin{tabular}{|c|c|c|c|c|c|c|}
\hline F Analyte & Result & Mod & Unit & $\underline{\mathrm{Lab}}$ & $E$ & Analyte \\
\hline $\begin{array}{ll}0 & \text { Pentachlorophenol } \\
0 & \text { Pentachlorophenol } \\
0 & \text { Phenacetin } \\
0 & \text { Phenacetin } \\
0 & \text { Phenacetin } \\
0 & \text { Phenanthrene } \\
0 & \text { Phenanthrene } \\
0 & \text { Phenanthrene } \\
0 & \text { Phencl } \\
0 & \text { Phenol } \\
0 & \text { Phenol } \\
0 & \text { Phenole } \\
0 & \text { Phenole } \\
0 & \text { p-Phenylenediamine } \\
0 & \text { p-Phenylenediamine } \\
0 & \text { p-Phenylenediamine } \\
0 & \text { Phorate } \\
0 & 2-\text { Plcoline } \\
0 & 2 \text { Picoline } \\
0 & 2-\text { Picoline } \\
0 & \text { Pronamid } \\
0 & \text { Pronamid } \\
0 & \text { Pronamid } \\
0 & \text { Propionitrile } \\
0 & \text { Propionitrile } \\
0 & \text { Pyrene } \\
0 & \text { Pyrene } \\
0 & \text { Pyrene } \\
0 & \text { Pyridine } \\
0 & \text { Pyridine }\end{array}$ & $\begin{array}{l}<55 \\
<55 \\
<10 \\
<11 \\
<11 \\
<10 \\
<11 \\
<11 \\
<10 \\
<11 \\
<11 \\
<5.0 \\
<5.0 \\
<10 \\
<11 \\
<11 \\
<0.10 \\
<10 \\
<11 \\
<11 \\
<10 \\
<11 \\
<11 \\
<200 \\
<50 \\
<10 \\
<11 \\
<11 \\
<10 \\
<11\end{array}$ & $\begin{array}{ll}J_{1} \\
J_{1}\end{array}$ & 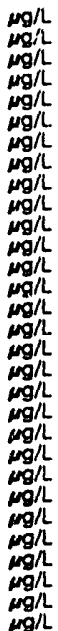 & 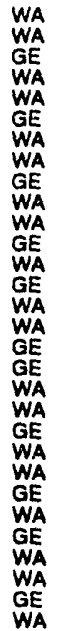 & $\begin{array}{l}0 \\
0 \\
0 \\
0 \\
0 \\
0 \\
0 \\
0 \\
0 \\
0 \\
0 \\
0 \\
0 \\
0 \\
0 \\
0 \\
0 \\
0 \\
0 \\
0 \\
0 \\
0 \\
0 \\
0 \\
0 \\
0 \\
0 \\
0 \\
0\end{array}$ & $\begin{array}{l}\text { 2,4,6-Trichlorophenol } \\
2,4,6-\text { Trichlorophenol } \\
2,4,6-\text { Trichlorophenol } \\
2,4,5-T \\
1,3-\text { Trichloropropane } \\
1,2,3-\text { Trichloropropane } \\
1,3,5-\text { Trinitrobenzene } \\
1,3,5-\text { Trinitrobenzene } \\
\text { 1,3,5-Trinitrobenzene } \\
\text { Uranium } \\
\text { Vanadium } \\
\text { Vanadlum } \\
\text { Vinyl acetate } \\
\text { Vinyl acistate } \\
\text { Xylenes } \\
\text { Xylones } \\
\text { Zinc } \\
\text { Zinc } \\
\text { Groes alpha } \\
\text { Gross alpha } \\
\text { Nonvolatile beta } \\
\text { Nonvolatile beta } \\
\text { Radium-226 } \\
\text { Radium-226 } \\
\text { Radium-228 } \\
\text { Radium-228 } \\
\text { Total alpha-emitting radium } \\
\text { Total alpha-emitting radium } \\
\text { Uranium }\end{array}$ \\
\hline
\end{tabular}

WELL MSB 628 collected on 07/21/82, laboratory analyses (cont)

\section{WELL MSB $62 C$}

MSASUREMENTS CONDUCTED IN THE FIELD

Sample date: 07/21/82 $\mathrm{n}(38.58 \mathrm{~m})$ bolow TOC Depth to water: $128.58 \mathrm{H}(38.58 \mathrm{~m})$ below
Water olevation: $222.52 \mathrm{H}(67.82 \mathrm{~m}) \mathrm{msl}$ Water evacuated before sampling: $148 \mathrm{gal}$

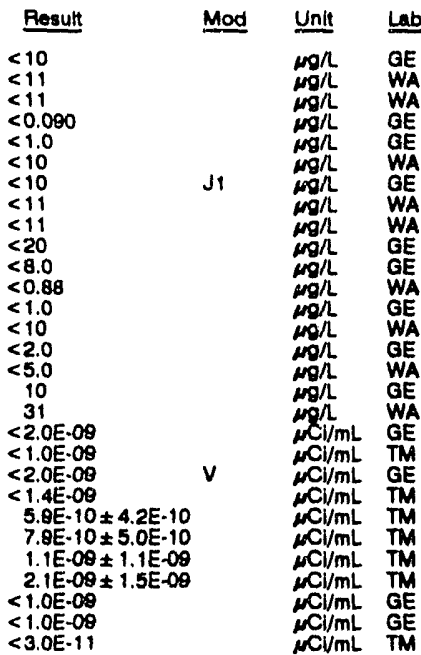

$<11$

Solonium

Silver

Sodium

Styrene

Styrene

Sulfate

Sulfide

$1,2,4,5$-Tetrachiorobenzene $1,2,4,5$-Tetrachiorobenzene 2,3,7,8-TCOD

2,3,7,8-TCDF

Tetrachlorodibenzo-p-dioxin Tetrachlorodibenzo-p-dioxins Tetrachlorodibenzo-p-furans

$1,1,1,2$-Tetrachioroethane

$1,1,1,2-$ Tetrachlorosthane

$1,1,2,2$-Tetrachlorcethne

Tetrachloroethylene

2,3,4,6-Tetrachlorophenol

$2,3,4,8$-Tetrachlorophenol

2,3,4,0-rotrachlorophenol

Thallium

Thionazin

$\operatorname{Tin}$

Toluene

a-Toluldin

a-Tolvidine

Total organic carbon

Total organic carbon

Total organic halogens

Total organic halogens

Total phosphates (as P)

Toxaphen:

Toxaphene

2,4,5-TP (Silvex)

1,2,4-Trich!nrobenzene

1,2,4-Trichlorobenzene

1, 1, 1-Trichloroethane

1,1,1-Trichloroethane

1,1,2-Trichloroethane

1,1,2-Trichloroethan

Trichloroethylene

Trichlorofiuoromethane

Trichloroluoromethan

2,4,5-Trichloropheno

2,4,5-Trichlorophenol
$<2.0$
$<2.0$
$<0.70$

2,090
2,270

$<1.0$
$<5.0$

1,060
1,080

$<1,000$

$<100$

$<1$

$<11$

$<0.00045$

$<0.00040$

$<0.00045$

$<0.002540$

$<0.0023$

$<1.0$
$<10$

$<1.0$

18
15
$<10$

$<10$
$<11$

$<11$
$<2.0$

$<2.0$
$<10$

$<2.0$
2.4

$<.4$
$<1.0$
$<5.0$

$<5.0$
$<10$
$<11$
$<11$
$<1,000$

$<1,000$
$<500$

$<500$
19
31
$<50$

$<5$
25
$<0.24$

$<0.24$

$<0.090$

$<0.55$

$<11$

$<1.0$

$<1.0$

$<5.0$
24

24
19

$<5.0$

$<10$
$<55$
LABORATORY ANALYSES

\begin{tabular}{|c|c|c|c|c|}
\hline Analyte & Pesult & Mod & $\underline{U_{\text {nit }}}$ & Lab \\
\hline 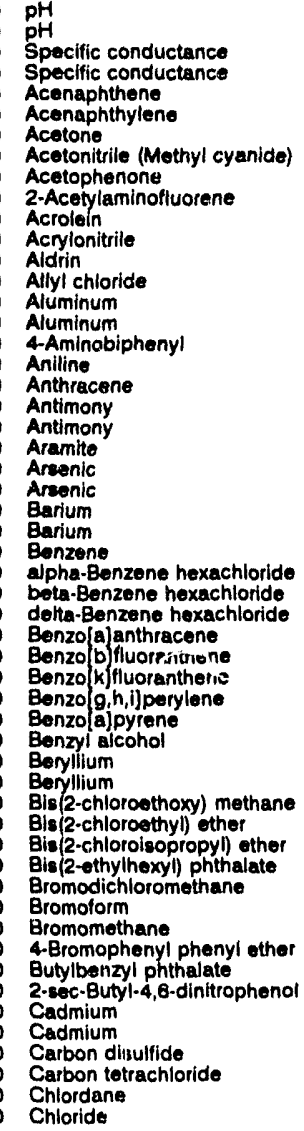 & $\begin{aligned} & 5.4 \\
& 5.4 \\
& 240 \\
& 240 \\
&<10 \\
&<10 \\
&<100 \\
&<1.0 \\
&<10 \\
&<10 \\
&<20 \\
&<20 \\
&<0.050 \\
&<50 \\
&<20 \\
&<20 \\
&<10 \\
&<10 \\
&<10 \\
&<2.0 \\
&<2.0 \\
&<10 \\
&<2.0 \\
&<2.0 \\
& 39 \\
& 39 \\
&<1.0 \\
&<0.050 \\
&<0.050 \\
&<0.050 \\
&<10 \\
&<10 \\
&<10 \\
&<10 \\
&<10 \\
&<10 \\
&<3.0 \\
&<3.0 \\
&<10 \\
&<10 \\
&<10 \\
&<10 \\
&<1.0 \\
&<1.0 \\
&<1.0 \\
&<10 \\
&<10 \\
&<10 \\
&<2.0 \\
&<2.0 \\
&<1.0 \\
&<1.0 \\
&<0.50 \\
& 4.150\end{aligned}$ & $\begin{array}{l}\mathrm{J1} \\
\mathrm{d} 1 \\
\mathrm{~d} 1 \\
\mathrm{d1} \\
\mathrm{d1} \\
\mathrm{d} 1\end{array}$ & 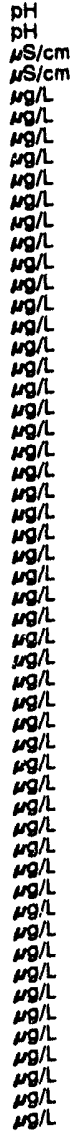 & $\begin{array}{l}G E \\
G E \\
G E \\
G E \\
G E \\
G E \\
G E \\
G E \\
G E \\
G E \\
G E \\
G E \\
G E \\
G E \\
G E \\
G E \\
G E \\
G E \\
G E \\
G E \\
G E \\
G E \\
G E \\
G E \\
G E \\
G E \\
G E \\
G E \\
G E \\
G E \\
G E \\
G E \\
G E \\
G E \\
G E \\
G E \\
G E \\
G E \\
G E \\
G E \\
G E \\
G E \\
G E \\
G E \\
G E \\
G E \\
G E \\
G E \\
G E \\
G E \\
G E \\
G E \\
G E \\
G E \\
G E\end{array}$ \\
\hline
\end{tabular}


ANALYTICAL RESULTS

WELL MSB $62 C$ coliected on 07/21/82, laboratory analyses (cont.)

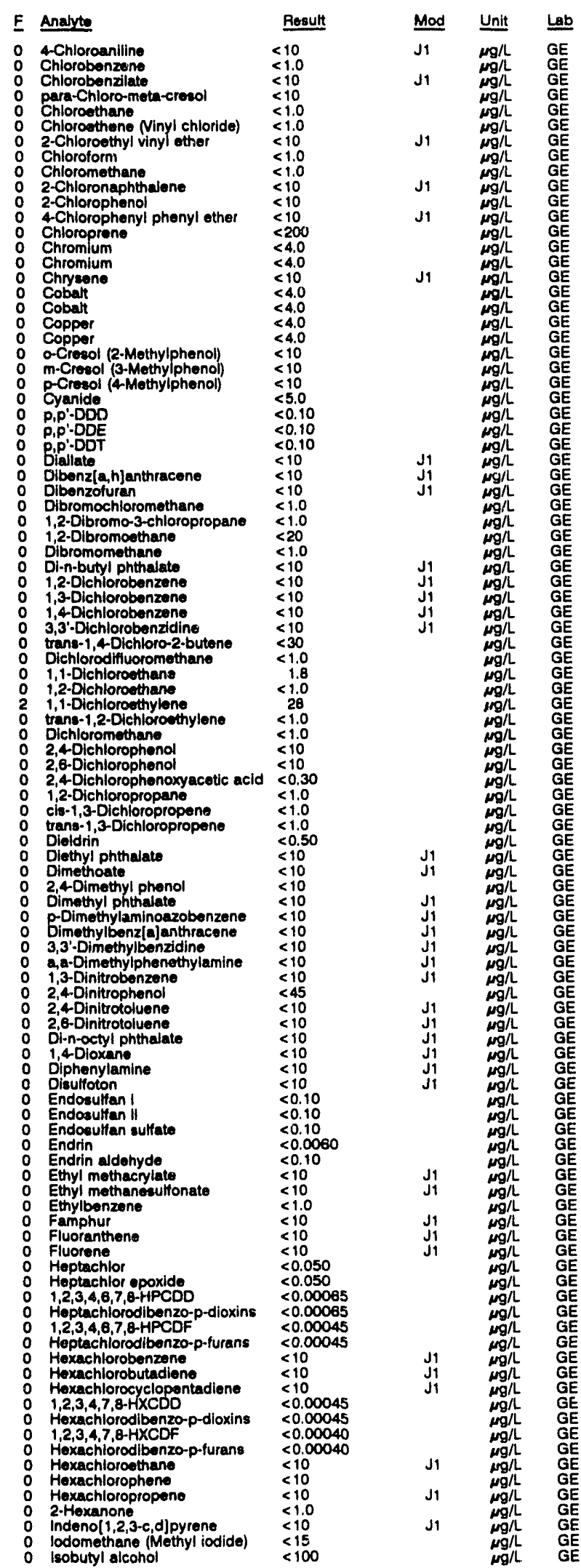

WELL MSB 62C collected on 07/21/92, laboratory analyses (cont.)

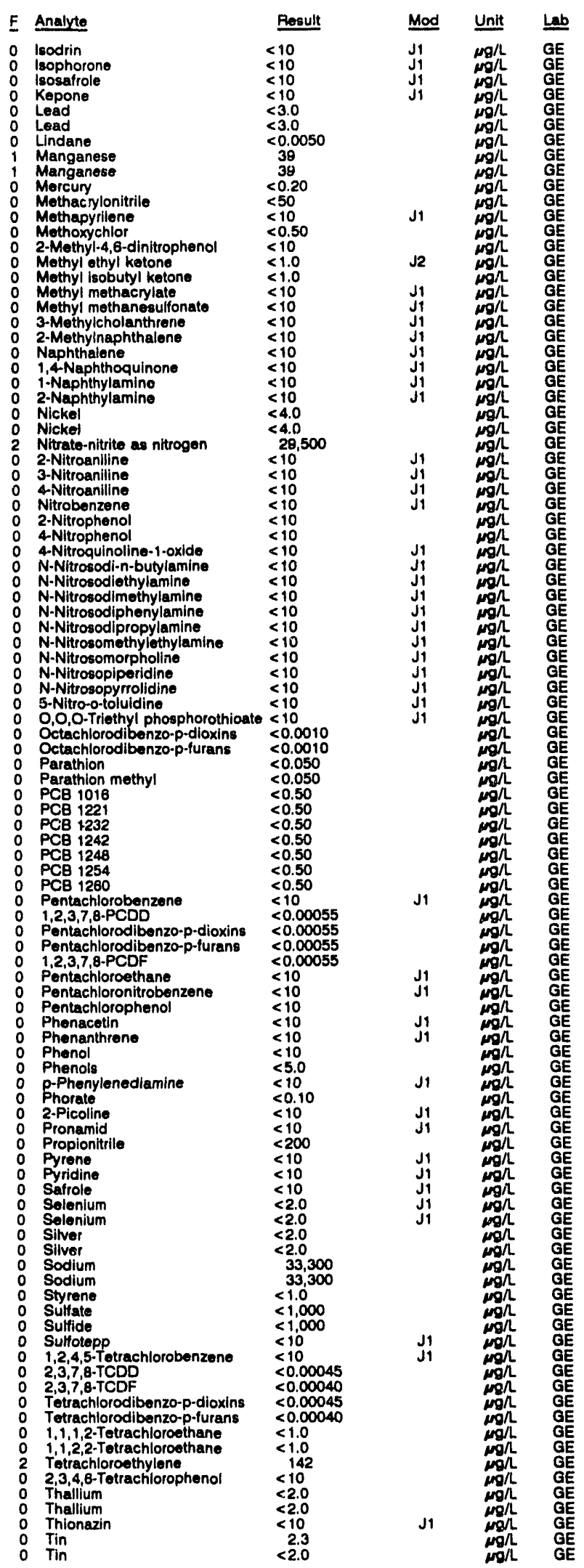


ANALYTICAL RESULTS

WELL MSB 62C collected on 07/21/92, laboratory analyses (cont.)

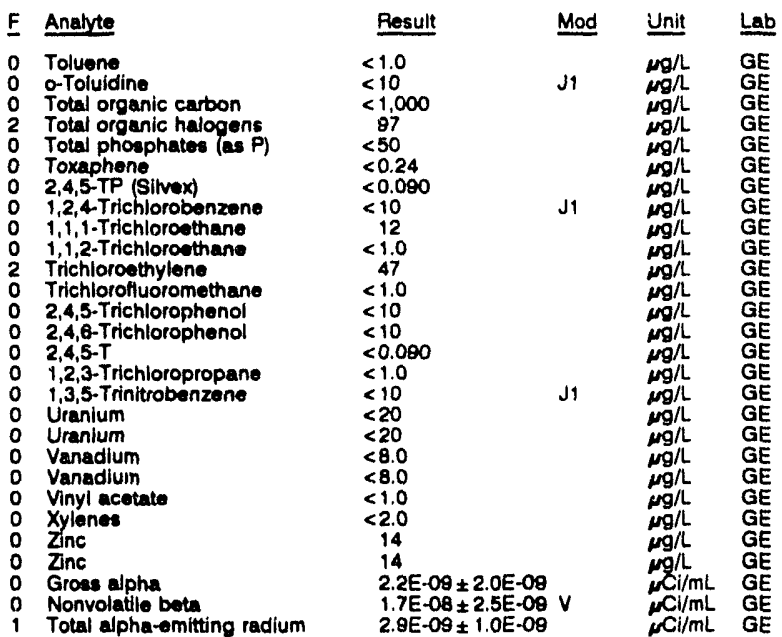

WELL MSB 62D

MEASUREMENTS CONDUCTED IN THE FIELD

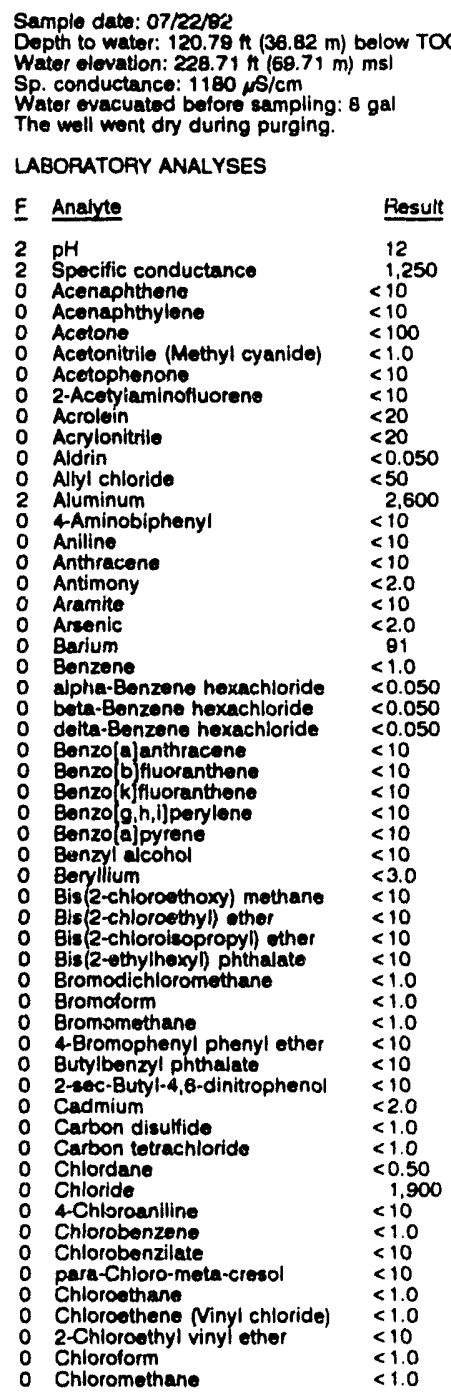

Time: 7:45

pH: 11,8 : $253 \mathrm{mg}$

Water temperature: $20.1^{\circ} \mathrm{C}$

1,250

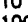

$<10$
$<20$

0.050

2,600

91

1.050

$<0.050$

150

10

$<10$

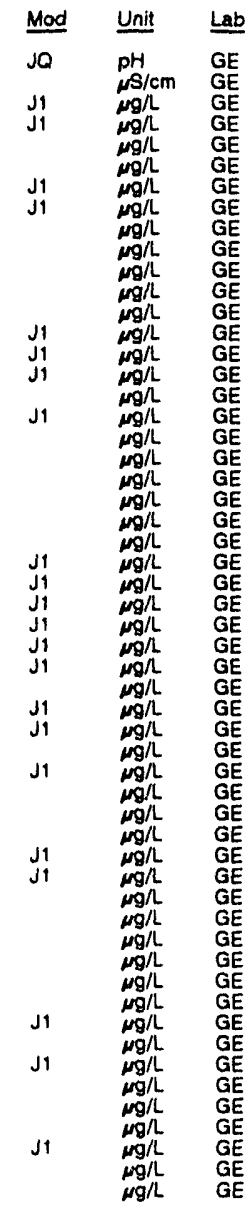

WELL MSB 620 collected on 07/22/82, laboratory analyses (cont.)

Result

2-Chloronaphthalen

4-Chlorophenol

- Chloropren

Chromium

Chrysen

Copper

0-Cresol (2-Methylphenol)

m-Cresol (3-Methylpheno)

p-Cresol (4-Methylphenol)

Cyanide

P,P.DDE

$p, p^{\prime} \cdot D D T$

Dialiate

Dibenzofuran

Dibromochloromethane

1,2-Dibromoethane

Di-n-butyl phthalate

1,2-Dichlorobenzene

1,3-Dichlorobenzene

1,4-Dichlorobenzene

trans-1,4-Dichloro-2-butene

Dichlorodifluoromethane

1,1-Dichloroethane

1,2.Dichloroethane

trans-1,2-Dichloroethyiene

Dichloromethane

2,4-Dichlorophenol

2,4-Dichlorophenoxyacotic acid $<0.30$

1,2-Dichloropropane

cis-1,3-Dichloropropene

trans-1,3-DI

Diethyl phthalate

Dimethoate

2,4-Dimethyl phenol

p-Dimethylaminoazobenzene

Dimethylbenz[a]anthraceno

3,3 - Dimethylbenzidine

1,3-Dinitrobenzene

2,4-Dinitrophenol

2,4-Dinitrotoluene

Di-n-octyl phthalate

1,4-Dioxane

O Diphenylamin

O Endosulfan

Endosulfan

Endosulfan sulfate

Endrin

- Endrin aldehyde

E Ethyl mothacrylate

Ethylbenzene

0 Famphur

Fluoranthen

O Fluorene

Heptachior epoxide

Heptachlorodibenzo-p-dioxins $<0.00065$

$\begin{array}{ll}1,2,3,4,6,7,6-H P C D F & <0.00045 \\ 0 & <0.00045\end{array}$

Hexachlorobenzene

Hexachlorobutadiene

Hexachlorocyclopentadiene

o $1,2,3,4,7,8: H \times C D D$

O Hexachlorodibenzo-p-dioxins

$1,2,3,4,7,8-H X C D F$
Hexachiorodibenzo-p-furans

Hexachloroethane

Hexachloropropene

2.Hexanone

indeno $[1,2,3-c, d] p y r e n \theta$

o lodomethane (Methyl iodide)

isobutyl alcohol

Isodin

lsophorone

Kepone

Load

o Lindane

Manganese

Mercuny

Methacrylonitrile

Methapyrilen
$<10$

$<200$

$<10$

$<4.0$

$<10$

5.10

$<0.10$

$<1.0$

$<1.0$

$<1.0$

$<10$
$<10$

$<10$

(

$<1.0$

$<1.0$

$<0.30$

$<1.0$

$<10$
$<10$

$<10$

$<<$

$<10$

$<10$

$<45$

$<10$
$<10$

$<10$

$<0.10$

$<0.10$

$<0.0080$

$<<10$

$<10$

$<1.0$

$<10$

$<10$

$<0.00045$

$<0.00040$

$<0.00040$

$<10$

$<10$

$<1.0$

$<15$

$<<100$

$<10$

$<10$

$<3.0$

$<2.0$

$<0.20$

$<0.20$

$<50$
$<10$

$<0.50$
JI$$
\text { J }
$$$$
\begin{aligned}
& \mathrm{J} 1 \\
& \mathrm{J1} \\
& \mathrm{J} 1 \\
& \mathrm{~J} 1 \\
& \mathrm{J1}
\end{aligned}
$$

Mod Unit La

$J 1$ Mgh GE

J1 $\mu g / h$

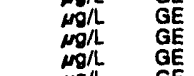

$\mathrm{GE}$ EE 
ANALYTICAL RESULTS

WELL MSB 62D collocted on 07/22/82, laboratory analyses (cont.)

E Analyte

o 2-Methyl-4,6-dinitrophenol

Methyl ethyl ketone

Mothyl isobutyl koton

O Mothyl methanesulfonate

- 3-Mothylcholanthrene

o 2-Methylnaphth thene

o 1,4-Naphthoquinone

1.Naphthylamine

o Nickel

Nitrato-nitrite as nitrogen

2-Nitroanilline

4-Nitroaniline

Nitrobenzene

2-Nitropheno

4 Nituphonol 1 - xide

4-Nitroquinolino-1-oxide

N-Nitrosodi-n-butylami

N-Nitrosodiethylamine

N-Nitrocodiphenylamine

N-Nitrocodipropylamine

N-Nitrosomethylethylam

N-Nitrosopiperidine

N-Nitrosopyrrolidine

5-Nitro-o-toluidin

0,0,0.Triethyl phosphorothioate

Octachlorodibenzo-p-dioxins

Octachlorodibenzo-p-furans

Parathion methyl

PCB 1016

PCB 1221

PCB 1242

PCB 1248

PCB 1254

Pontachlorobonzen

Pentachlorodibenzo-p-dioxins

Pentachlorodibenzo-p-furans

1,2,3,7,6-PCDF

Pentachloroethane

Pentachlorophenol

Phenacetin

Phenanth

Phenol

o p-Phenylenediamine

Phorate

2-Picoline

Propionitrile

Pyrene

Pyridine

Solenium

0 Silver

O Sodium

0 Styrene

Sulfide

Sulfide

o $1,2,4,5$-Tetrachlorobenzene

2,3,7,8-TCDD

Tetrachlorodibenzo-p-dioxins

Tetrachlorodibenzo-p-furans

- 1,1,1,2-Tetrachloroethane

o 1, 1,2,2-Tetrachloroethan

2 Tetrachloroethylene

Thallium

o Thionazin

Tin

Toluene

O O-Toluidine

2 Total organic halogens

Total phosphates (as P)

o Toxaphene

1,2,4-Trichlorobenzente

$1,1,1$-Trichloroethane

1,1,2-Trichloroethan

2 Trichloroethylone

o Trichlorofluoromethane

2,4,5-Trichloropheno

2,4,6-Trichloropheno

0 2,4,5-T

o 1,2,3-Trichloropropan

o 1,3,5-Trinitrobenzene

$<10$

5,900

$<10$

$<10$

$<10$

$<10$

$<10$
$<10$

$<10$

$<10$

$<10$

$<10$

$<10$

$<10$

$<10$

$<0.0010$
$<0.0010$

$<0.050$

$<0.050$
$<0.50$
$<0.50$
$<0.50$

$<0.50$

$<0.50$

$<0.50$

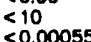

$<0.00055$

$<0.00055$

$<10$

$<10$
$<10$

$<10$
$<10$
$<10$

$<10$
$<10$

$<5.0$
$<10$
$<0.10$
$<10$

$<10$
$<10$

$<200$
$<10$
$<10$

$<10$
$<10$

$<10$
$<2.0$
$<2.0$

$<2.0$

$<1.0$
13,400

13,400
$<1,000$

$<1,000$

$<10$

$<10.00045$

$<0.00040$

$<0.00040$

$<0.0004$
$<1.0$
$<1.0$

$<1.0$
199
$<10$

$<10$
$<2.0$

$<10$

$<2.0$

2.9
$<10$
1,240

1,240
$<1,000$

176

$<0.24$

$<10$

$<10$
17

$<1.0$
74
$<1.0$

74
$<1.0$
$<10$

$<10$

$<0.090$
$<1.0$

$<1.0$
$<10$

\begin{tabular}{|c|c|c|c|c|c|}
\hline Result & Mod & Unit & Lab & $\underline{E}$ & Analyte \\
\hline $\begin{array}{r}<10 \\
1.8 \\
1<1.0 \\
<10 \\
<10 \\
<10 \\
<10 \\
<10\end{array}$ & $\begin{array}{l}\mathrm{J} 2 \\
\mathrm{~J} 1 \\
\mathrm{~J} 1 \\
\mathrm{~J} 1 \\
\mathrm{~J} 1 \\
\mathrm{~J} 1\end{array}$ & $\begin{array}{l}\mu g / L \\
\mu g / L \\
\mu g / L \\
\mu g / L \\
\mu g / L \\
\mu g / L \\
\mu g / L \\
\mu g / L\end{array}$ & $\begin{array}{l}\mathrm{GE} \\
\mathrm{GE} \\
\mathrm{GE} \\
\mathrm{GE} \\
\mathrm{GE} \\
\mathrm{GE} \\
\mathrm{GE} \\
\mathrm{GE}\end{array}$ & $\begin{array}{l}0 \\
0 \\
0 \\
0 \\
0 \\
0 \\
0 \\
0\end{array}$ & $\begin{array}{l}\text { Uranium } \\
\text { Vanadium } \\
\text { Vinyl acetate } \\
\text { Xylenes } \\
\text { Zine } \\
\text { Gross alpha } \\
\text { Nonvolatile beta } \\
\text { Total alpha-emitting radium }\end{array}$ \\
\hline
\end{tabular}

WELL MSB 620 collected on 07/22/92, laboratory analyses (cont.)

WELL MSB 63B

MEASUREMENTS CONDUCTEO IN THE FIELD

Sample date: $07 / 22 / 92$ (t) $(42.43 \mathrm{~m})$ below TOC Wato elevation: $207.80 \mathrm{ft}(83.34 \mathrm{~m}) \mathrm{msl}$ Water ovacuated before sampling: $188 \mathrm{gal}$

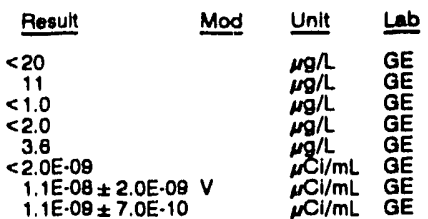

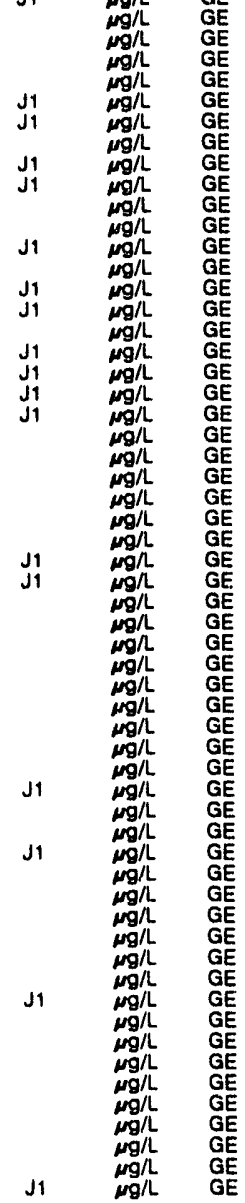

LABORATORY ANALYSES

F Analyte Result $\mathrm{Mod}$

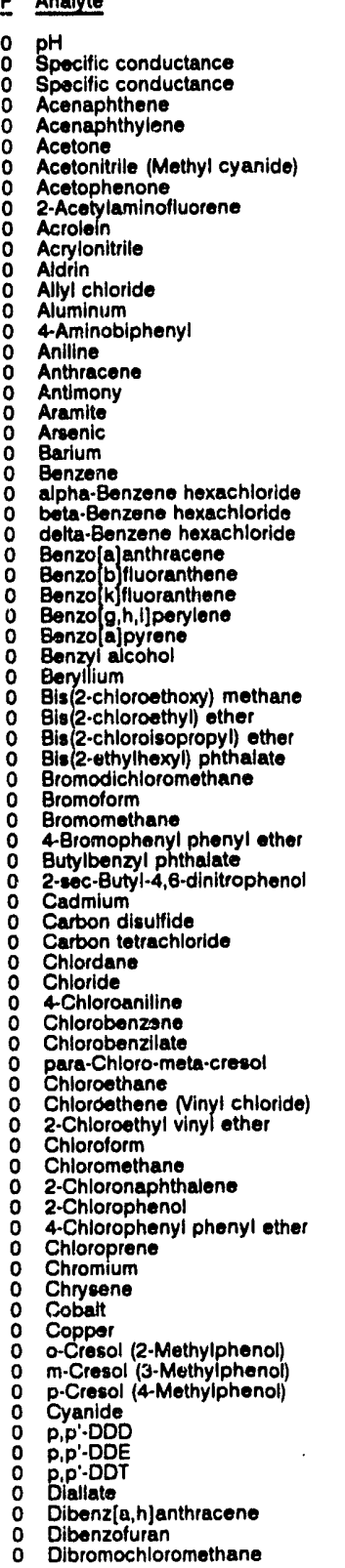

\begin{tabular}{l} 
Result \\
\hline 5.3 \\
22 \\
22 \\
22 \\
$<10$ \\
$<10$ \\
$<100$ \\
$<1.0$ \\
$<10$ \\
$<10$ \\
$<20$ \\
$<20$ \\
$<0.050$ \\
$<50$ \\
$<20$ \\
$<10$ \\
$<10$ \\
$<10$ \\
$<2.0$ \\
$<10$ \\
$<2.0$ \\
5.7 \\
$<1.0$ \\
$<0.050$ \\
$<0.050$ \\
$<0.050$ \\
$<10$ \\
$<10$ \\
$<10$ \\
$<10$ \\
$<10$ \\
$<10$ \\
$<10$ \\
$<3.0$ \\
$<10$ \\
$<10$ \\
$<10$ \\
$<10$ \\
$<10$ \\
$<1.0$ \\
$<1.0$ \\
$<1.0$ \\
$<10$ \\
$<10$ \\
$<10$ \\
$<2.0$ \\
$<1.0$ \\
$<1.0$ \\
$<0.50$ \\
$<1,000$ \\
$<10$ \\
$<1.0$ \\
$<10$ \\
$<10$ \\
$<1.0$ \\
$<1.0$ \\
$<10$ \\
$<1.0$ \\
$<1.0$ \\
$<10$ \\
$<10$ \\
$<10$ \\
$<200$ \\
$<4.0$ \\
$<10$ \\
$<4.0$ \\
$<4.0$ \\
$<10$ \\
$<10$ \\
$<10$ \\
$<5.0$ \\
$<0.10$ \\
$<0.10$ \\
$<0.10$ \\
$<10$ \\
$<10$ \\
$<10$ \\
$<1.0$ \\
$<1.0$ \\
\end{tabular}

Time: 11:40

AH: 5.1 : $0 \mathrm{mg}$

Water temperature: $21.1^{\circ} \mathrm{C}$

Mod Unit Lut

10

1.0

20

50

$<2.0$

0.050

050

3.0

10

1.0

$<10$

1,800
$<10$

$<10$

$<1.0$

1.0

$<10$
$<200$

10

$<10$

0.10

0.10

$<10$
$<10$

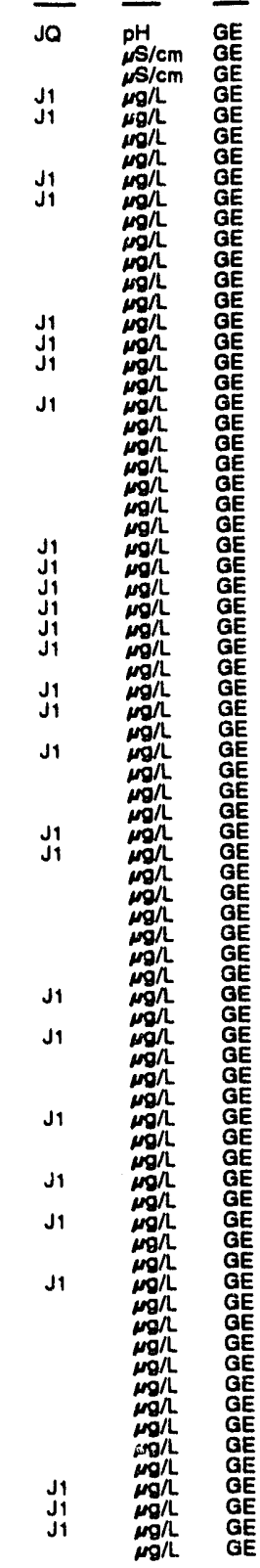


WELL MSB 638 collocted on 07/22/92, laboratory analyses (cont.)

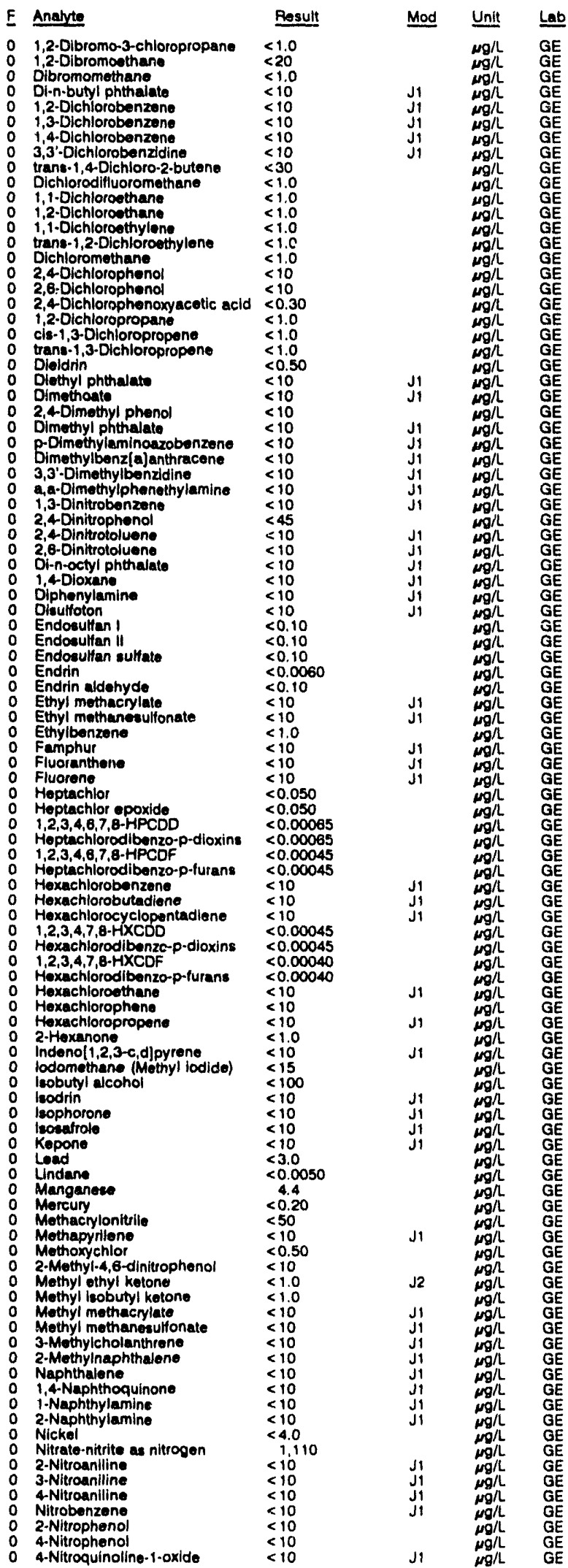

WELL. MSB 63B collected on 07/22/82, laboratory analyees (cont)

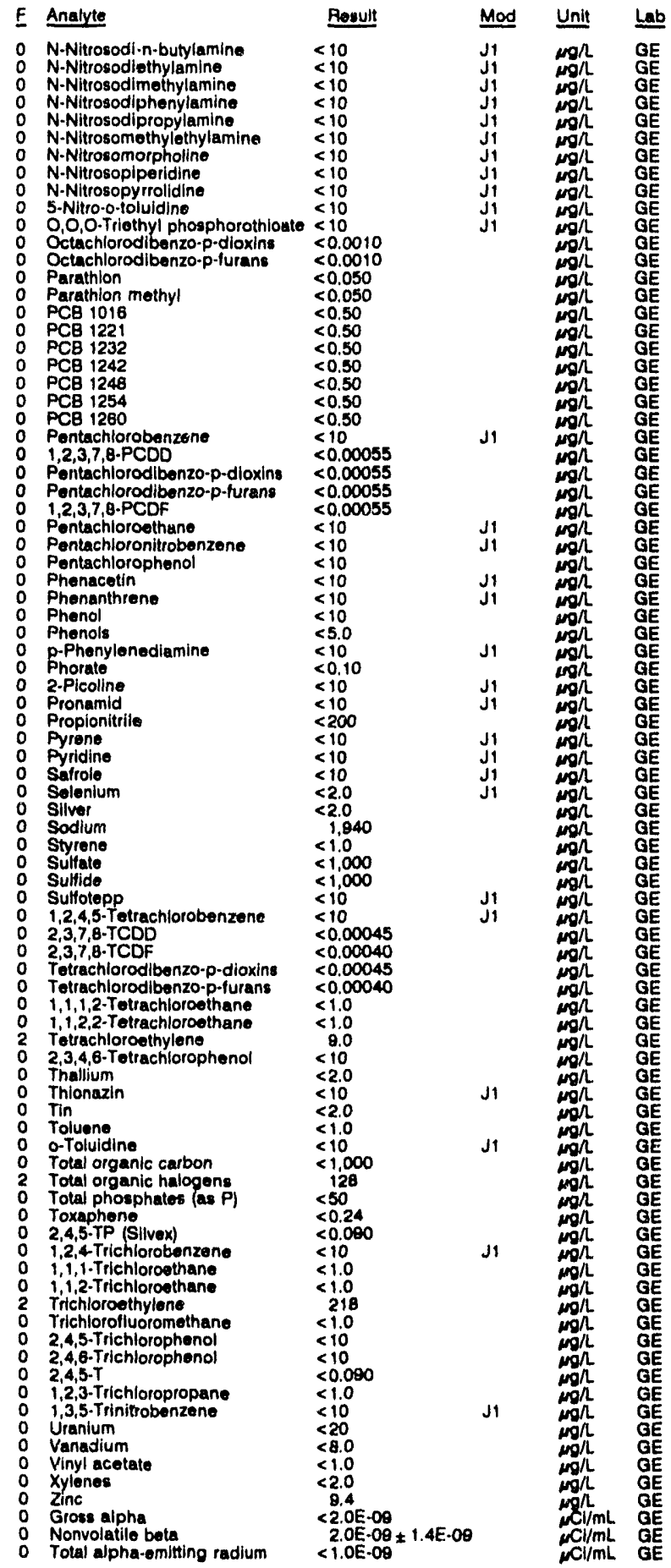


ANALYTICAL RESULTS

WELL MSB 63C

MEASUREMENTS CONDUCTED IN THE FIELD

Sample dato: 07/22/92

Depth to water: $127.51 \mathrm{ht}(38.87 \mathrm{~m})$ below TOC

Water olevation: 219.59 it $(68$

Sp. conductance: $53 \mu \mathrm{s} / \mathrm{cm}$
Water evacuated before sampling: 79 ga

LABORATORY ANALYSES

E Analyte

0 Ppecific conductance

o Acenaphthene

Acenaphthene

Acenaphthylene

Acetone

Acetonitrile (Methyl cyanide)

Acetophenone

2-Acetylaminofluorene

2.Acotylaminofluoren

Acrylonitrile

Allyi chloride

Aluminum

4-Aminobiphenyl

Aniline

Anthracene

Anthracene

Antimony

Aramite

Arsonic

Barlum

alpha-Benzene hexachloride

beta-Benzene hexachloride

detta-Benzerie hexachloride

Benzo[a) anthracene

Benzola anthraceno

Benzo/b) fluoranthene

Eonzo b] fluoranthene

Eonzo kfluoranthene

Benzo k filuoranthene

Benzo g, $h, 1$ perylene

Benzo a)pyrene

Bonzyl ajcohol

Benzyl alcohol

Beryllium

Bis(2-chloroechoxy) mothane

Bis (2-chloroethoxy) methane Bis (2-chloroethyl) other

Bis(2-chloroisopropyl) other

Bis(2-ethylhexyl) phthalate

Bis(2-ethylhexyl) phthalate

Bromodich

Bromomethane

4-Bromophenyl phenyl ether

Butylbonzyl phthalate

Butyon

2-rec-Butyl-4,8-dinitrophenol

Cadmium

Carbon disutfico

Carbon tetrachlorido

Chlordano

4-Chloroaniline

4-Chioroaniline

Chlorobenzene

O Chlorobenzilate

para-Chloro-meta-cresol

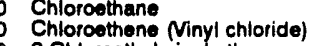

2-Chloroethyl vinyl ether

Chloroform

Chloroform

2-Chloronaphthalene

2-Chloronaphthai

4-Chlorophenyl phenyl ether

o 4-Chlorophenyl phenyl ether

o Chloroprene

o Chromium

Chrysene

Chrysen

Copper

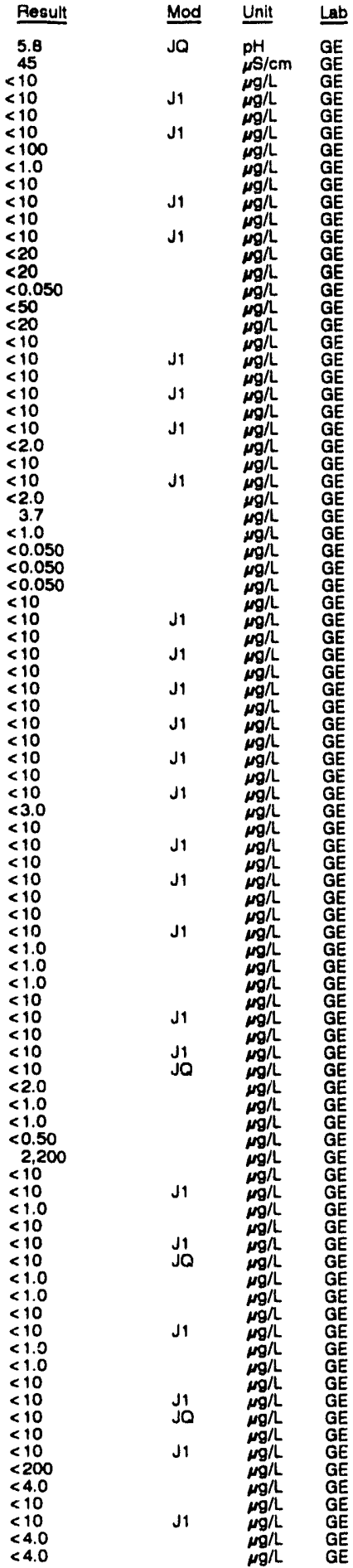

Water temperature: $21.4^{\circ} \mathrm{C}$

WELL MSB 63C collected on 07/22/82, laboratory analyses (cont.)

$E$ Analyte

Time: 11:50

PH: 5.3

o 0-Cresol (2-Methyiphenol)

m-Cresol (3-Methylphenol)

Cyanide

Cyanide

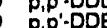

0 P,P.DDT

0 Diallate

Dibenz $[a, h]$ anthracene

Dibenz $[a, h]$ anthracene

Dibenzofuran

Dibromochloromethane

1,2-Dibromo-3-chloropropane

1,2-Dibromoethan

Di-n-butyl phthalate

Di-n-butyl phthalate

1,2-Dichlorobenzene

1,2.Dichlorobenzene

, 3-Dichlorobenzene

1,4 -Dichlorobenzene

1,4 Dichlorobenzene

3,3'-Dichlorobenzidine

3,3-Dichlorobenzidine

Dichlorodifluoromethane

1,1-Dichloroethane

1,2-Dichloroethane

trans-1,2-Dichloroethylene

Dichloromethane

2,4-Dichlorophenol

ryacetic acid

1,2-Dichioropropane

cis-1,3-Dichloropropene

trans-1,3-Dichloropropene

Dieldrin

Diethyl phthalate

Dimethoate

2,4-Dimethyl phenol

Dimethyl phthalate

p-Dimethylaminoazobenzene

p-Dimethylaminoazobenzene

Dimethylbenz [ajanthracene

Dimethylbenz (a) anthrace

o 3,3'-Dimethylbenzidine

3,3'-Dimethylbenzidine

a,a-Dimethylphenethylamine

a,a-Dimethylphenethy

1,3-Dinitrobenzene

2,4-Dinitrophenol

2,4.Dinitrotoluene

2,4-Dinitrotoluene

2,6-Dinitrotoluene

Di-n-octyl phthalate

o Di-n-octyl phthajate

0 1,4-Dioxane

1,4-Diexane

0 Diphenylamine

o Disulfoton

- Endosulfan I

O Endosulfan sulfate

0 Endrin

o Endrin aldehyde

0 Ethyl methacylate

Ethyl methacrylate

o Ethyl methanesulfonate

Ethyl methanesulfonate

o Ethylbenzen

o Famphur

O Famphur

o Fluoranthene

Fluoranthen

Fluorene

Heptachlor

- Heptachlor epoxide

Hoptachlorodibenzo-p-dioxin

Heptachlorodibenzo-p-dioxin

Heptachi, dibenzo-p-furans

Hexachlorobenzene

Hexachlorobenzene

Hexachlorobutadiene

Hexachlorobutadiene

Hexachlorocyclopentadiene
Result

Mod Unit Lab

$<$

$<10$
$<10$

$<10$

$<0.10$

$<0.10$

$<10$
$<10$

$<10$
$<10$

$<10$

$<10$

$<20$

$<10$

$<10$
$<10$

$<10$

$<10$

$<10$
$<10$

$<10$

$<10$
$<30$

$<1.0$

$<1.0$

$<1.0$

$<1.0$

$<10$

$<0.30$

$<1.0$

$<0.50$

$<10$
$<10$

$<10$

510
$<10$

$<10$

$<10$

$<10$

$<10$

$<10$

$<10$

$<10$
$<45$
$\leq 10$
$\leq 10$

$<10$

$<<0$

$<<10$

$<10$
$<10$

$<10$

$<10$

$<10$
$<0.10$

$<0.10$

$<0.0080$

$<0.10$

$<10$

$<<10$

$<1.0$

$<10$

$<<10$

$<10$

$<10$
$<0.050$

$<0.050$

$<0.00065$

$<0.00045$

$<10$

$<10$

$<10$
$<10$
$<10$

$<10$
$<10$
$<10$

GE 
ANALYTICAL RESULTS

WELL MSB 63 C collocted on 07/22/92, laboratory analyses (cont.)

F Analyte

o 1,2,3,4,7,8-HXCDD

Hexachlorodlbenzo-p-dioxins

Hexachiorodibenzo-p-furans

Hexachlorosthane

Hexachloroethane

Hexachloropropent

2.Hexachloropropo

indeno $[1,2,3-c, d)$ pyrene

lodomothane (Mithyl iodide)

leobutyl alcoho

leodrin

Isophorone

lsophorone

lsosatrole

Kepone

Kepone

Lindane

Mercuny

Methacrylonitrile

Methapyrilene

Mothapynien

2-Methyl-4,6-dinitrophenol

Mothyl ethyl ketone

Methyl methacrylate

Methyl methacrylate

Mothyl methanesulfonate

Methyl methanesulfonato

3-Mothylcholantiren

3-Mothylcholantiren

2.Methyinaphthaiene

Naphthalene

i, Nephthoquinone

1,4Naphthoquinone

1.Naphthylamine

2-Naphthylaming

2-Naphthylamine

Nitrato-nitrite as nitrogen

2.Nitroaniline

3-Nuroaniline

3-Nitroaniline

4Nttroaniline

4Nitroaniline

Nitrobenzene

Nitrobenzent

4 Nitrophenol

4-Nitroquinoline-1-oxido

N.Nitroed nibutylamine

Nithomino

N.Nitroesodiethylamine

N-Nitrosodimethylamine

N-Nitrosodimethylamine

N-Nitrosodiphenylamine

N-Nitroaodiphenylamine

N-Nitroesodipropylamine

N-Nitrosomethylethyiamine

N.Nitrosomethylethylamine

N-Nitrosomorpholine

N.Nramorpholine

N-Nitrospiporidine

N-Nitrosopyrrolldine

N-Nitrosopyrrolldine

5-Nitro-o-toluidine

o,0,0-I riethyl phosphorothioate $<10$

0,0,0-rinothyl phosphorothioal

Oclachlorodibanzo-p-dioxins $<0.0010$

$<0.0010$

Parathion methyl $<0.050$

PCB $1018<0.50$

PCB 1221

O PCB 1242

O $\mathrm{PCB} 1248$

O PCB 1254

O PCB 1260

Pontachlorobenzene

Pentachlorobenzen

Pentachlorodibenzo-p-dioxins

Plosult

$<0.00045$

$<0.00040$

$<10$

$<10$
$<10$
$<10$

$<10$

$<10$
$<10$

$<15$
$<100$

$<10$
$<10$

$<10$

$<10$
$<10$

$<10$
$<3.0$

6.0

$<0.20$

$<10$
$<10$

$<10$
$<10$

$<1.0$

$<10$

$<10$

$<10$

$<10$

$<10$

$<10$
$<10$

$<10$

$<10$

3,080

$<10$

$<10$

$<10$

$<10$

$<<10$

$<10$
$<10$

$<10$

$<10$

$<10$

$<10$

$<10$

$<10$

$<10$
$<10$

$<10$

$<10$

10

0
0.0010

$<0.050$
$<0.50$

$<0.50$

$<0.50$
$<0.50$

$<0.50$

$<0.50$

$<10$

$<0.00055$ $\mu g / L$

GE

GE

J

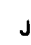

J1

J1

J1

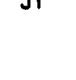

31

JQ

J1

J1

J

J1

J

J

J

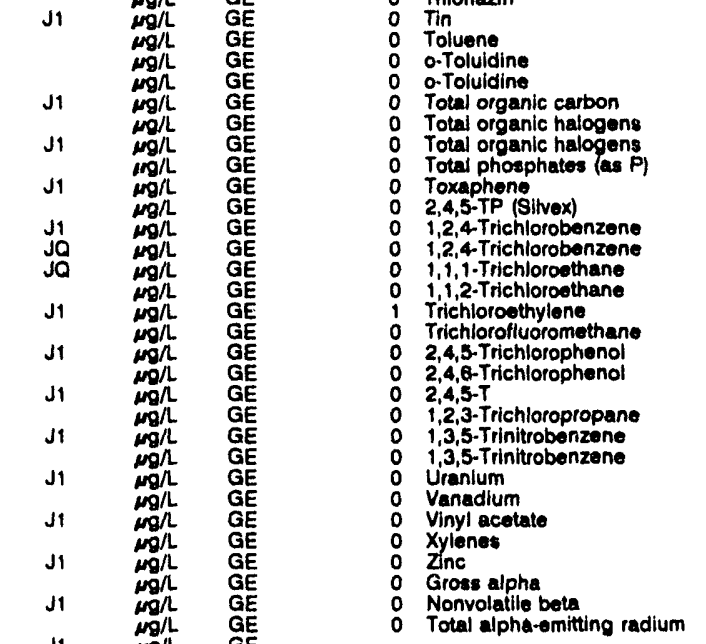

WELL MSB 63D

MEASUREMENTS CONDUCTED IN THE FIELD

Sample date: 07/23/92

Depth to water: $117.84 \mathrm{ft}(35.92 \mathrm{~m})$ below TOC

Water elevation: $228.86 \mathrm{ft}(68.78 \mathrm{~m}) \mathrm{msl}$

Sp. conductance: $81 \mu \mathrm{s} / \mathrm{cm}$

Water ovacuated before sampling: $\theta$ gal

LABORATORY ANALYSES

\begin{tabular}{|c|c|c|c|c|}
\hline F Analyte & Result & Mod & Unit & $\underline{L a b}$ \\
\hline $\begin{array}{ll}0 & \text { pH } \\
0 & \text { Specific conductance } \\
0 & \text { Acenaphthene } \\
0 & \text { Acenaphthylene } \\
0 & \text { Acetone }\end{array}$ & $\begin{array}{r}5.5 \\
98 \\
<10 \\
<10 \\
<100\end{array}$ & $\begin{array}{l}\text { Ja } \\
\text { J1 }\end{array}$ & $\begin{array}{l}\mathrm{pH} \\
\mu \mathrm{s} / \mathrm{cm} \\
\mathrm{mg} / \mathrm{L} \\
\mu g / L \\
\mu g / L\end{array}$ & $\begin{array}{l}\text { GE } \\
G E \\
G E \\
G E \\
G E\end{array}$ \\
\hline
\end{tabular}

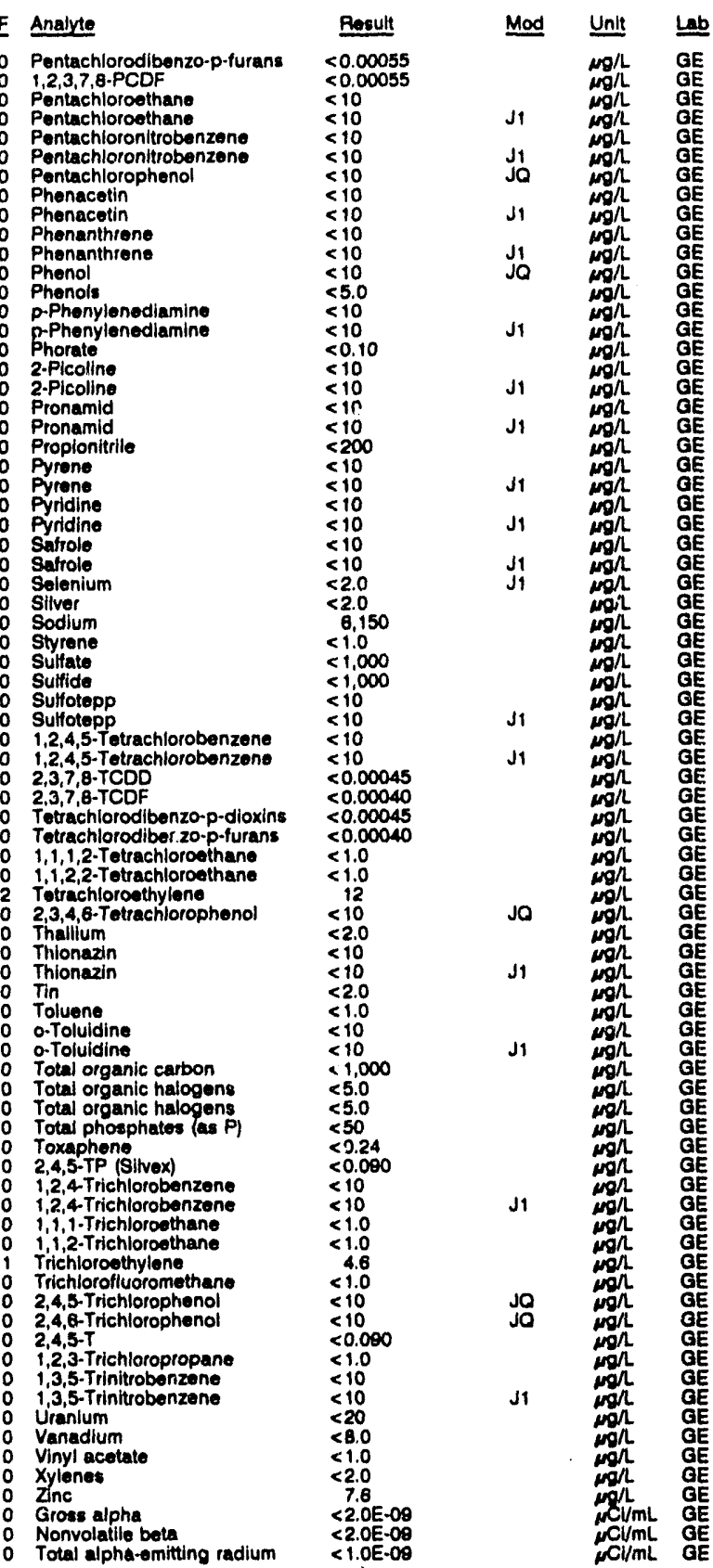

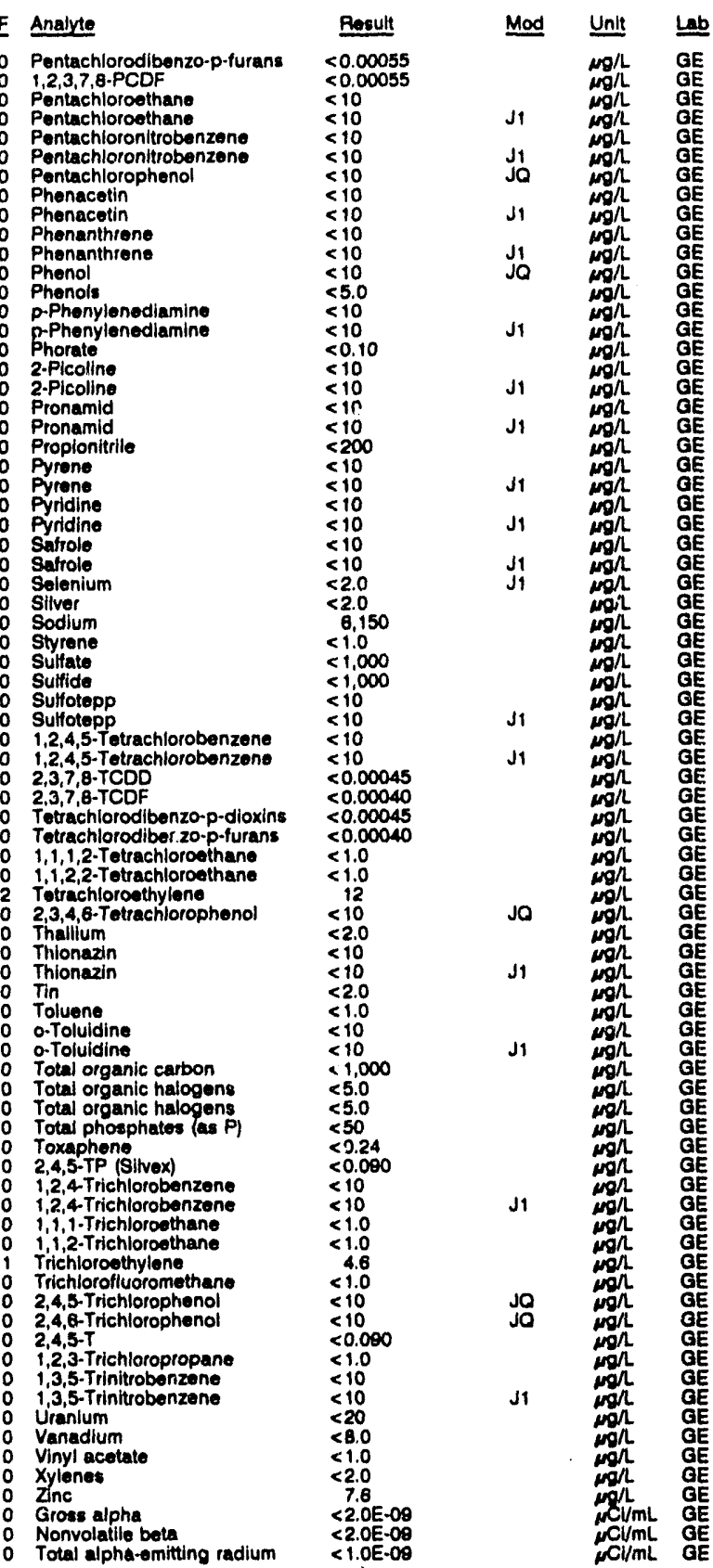

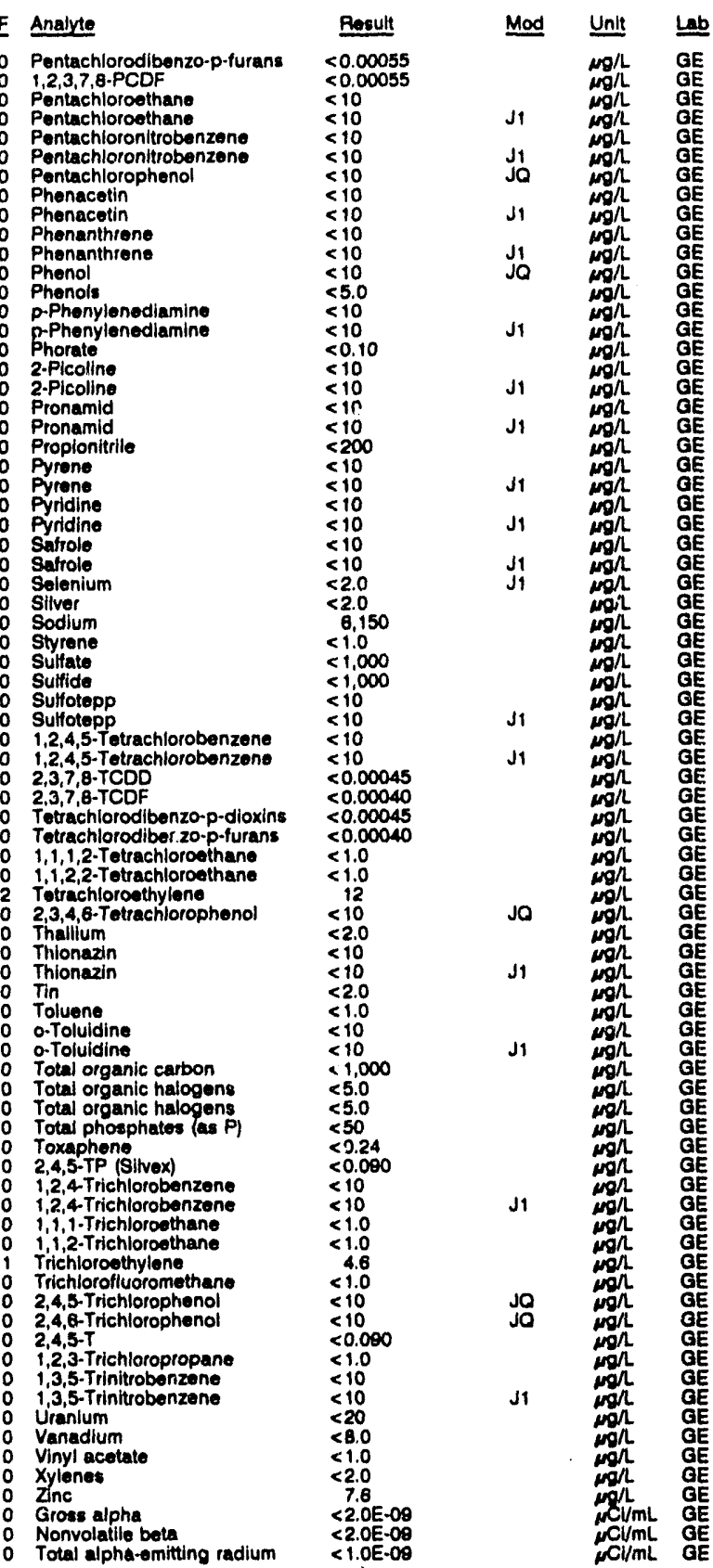

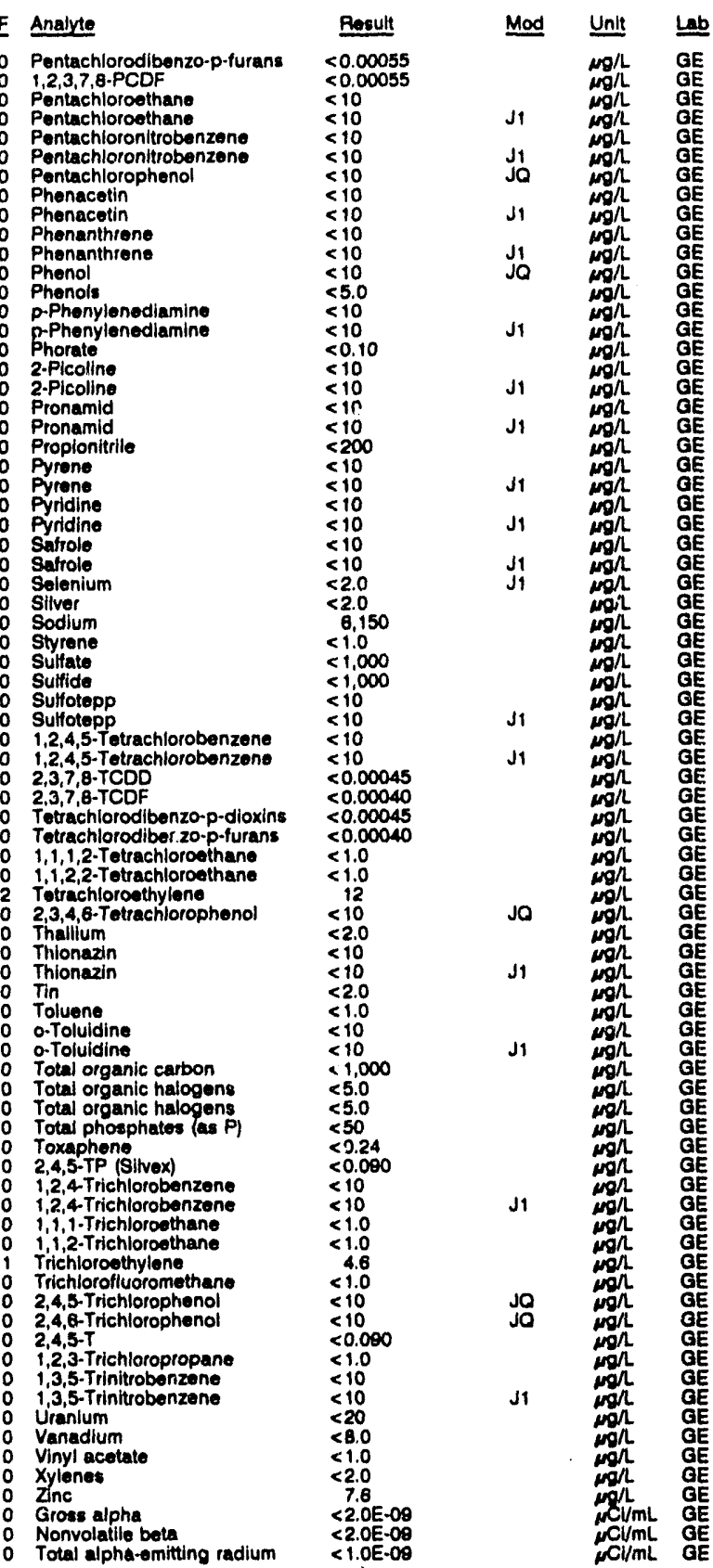

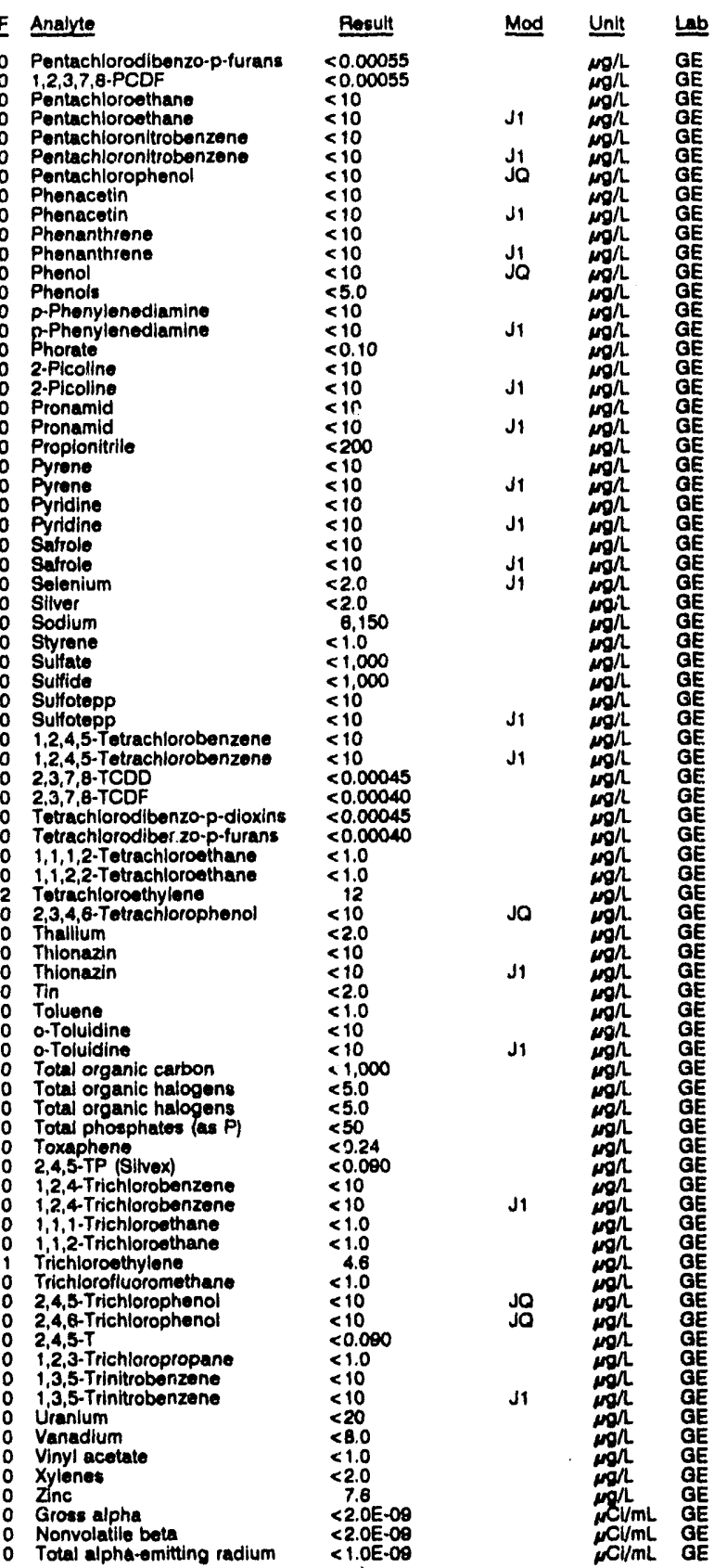

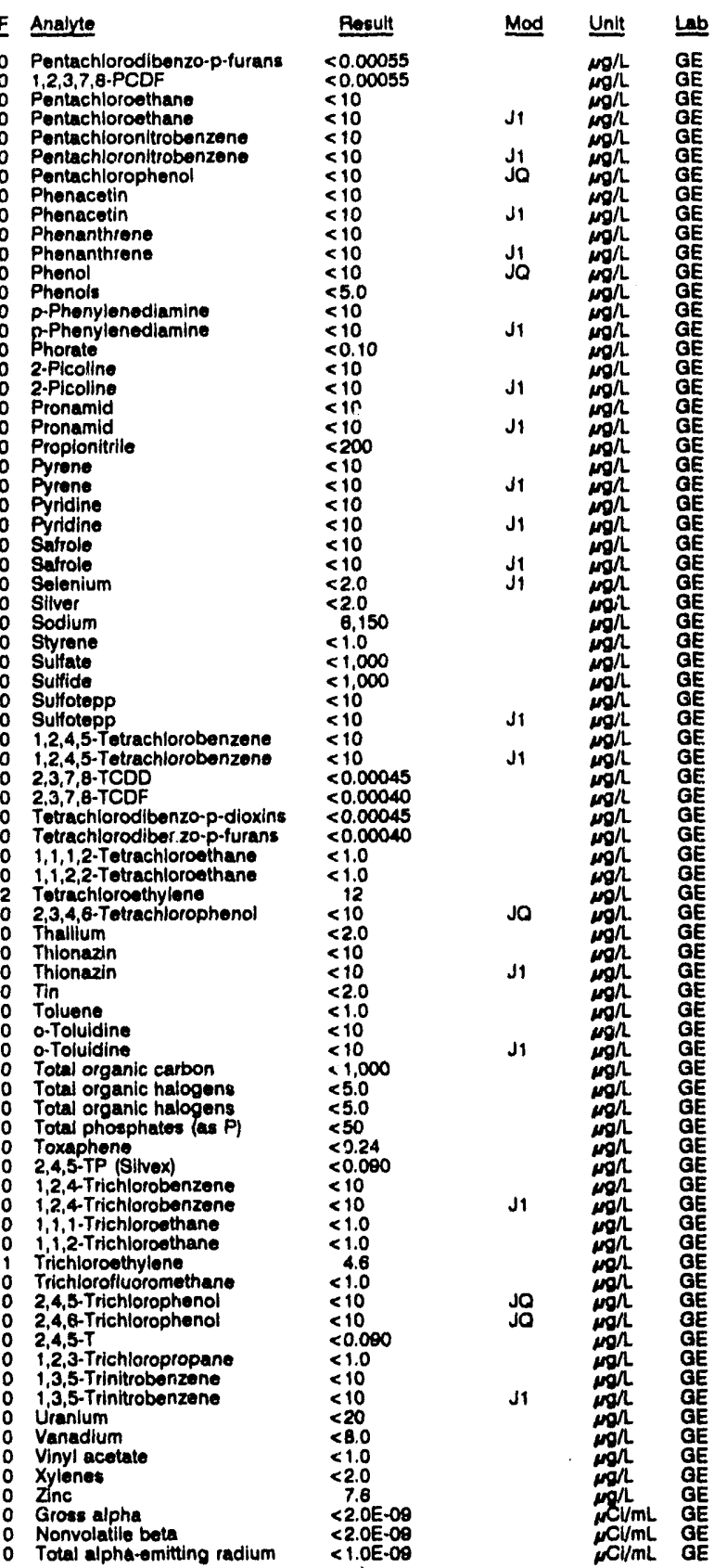

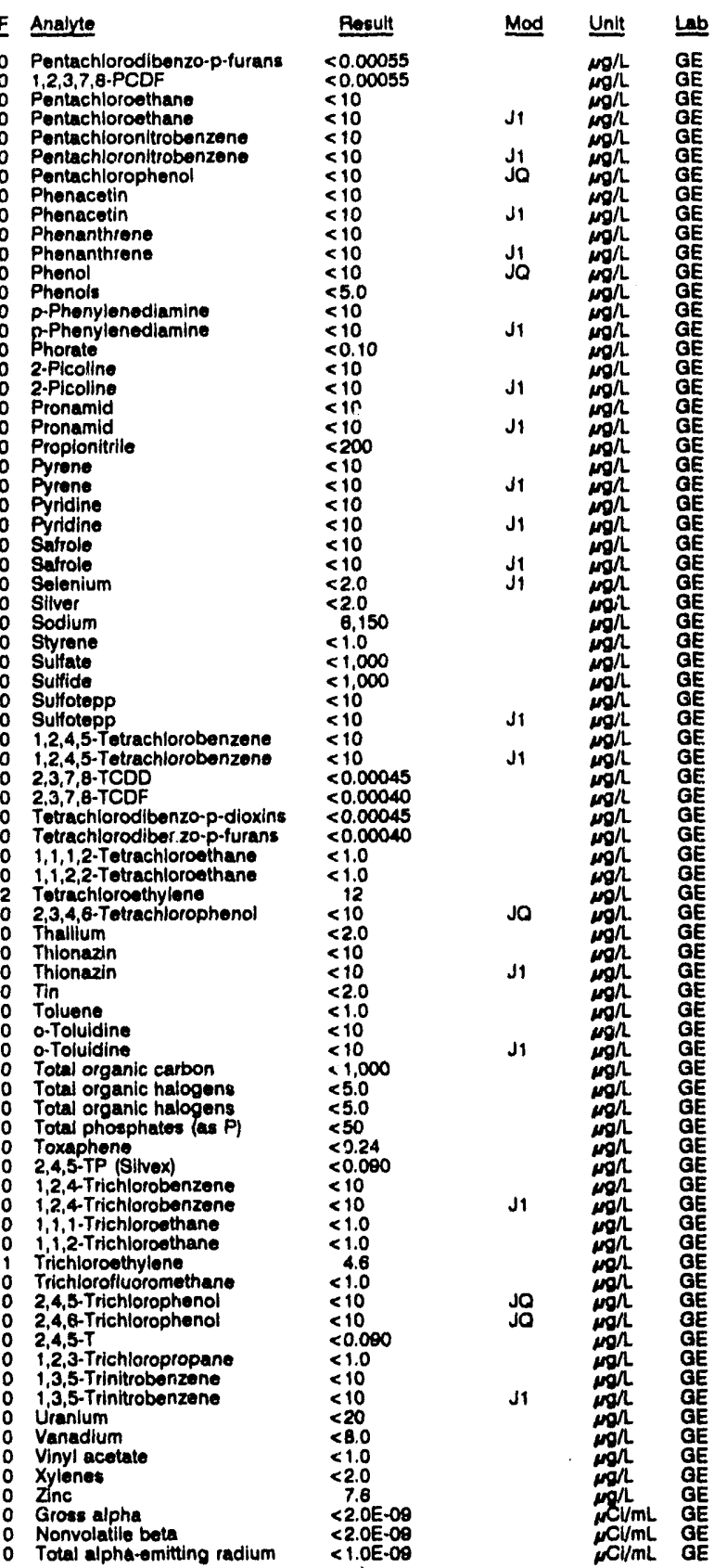

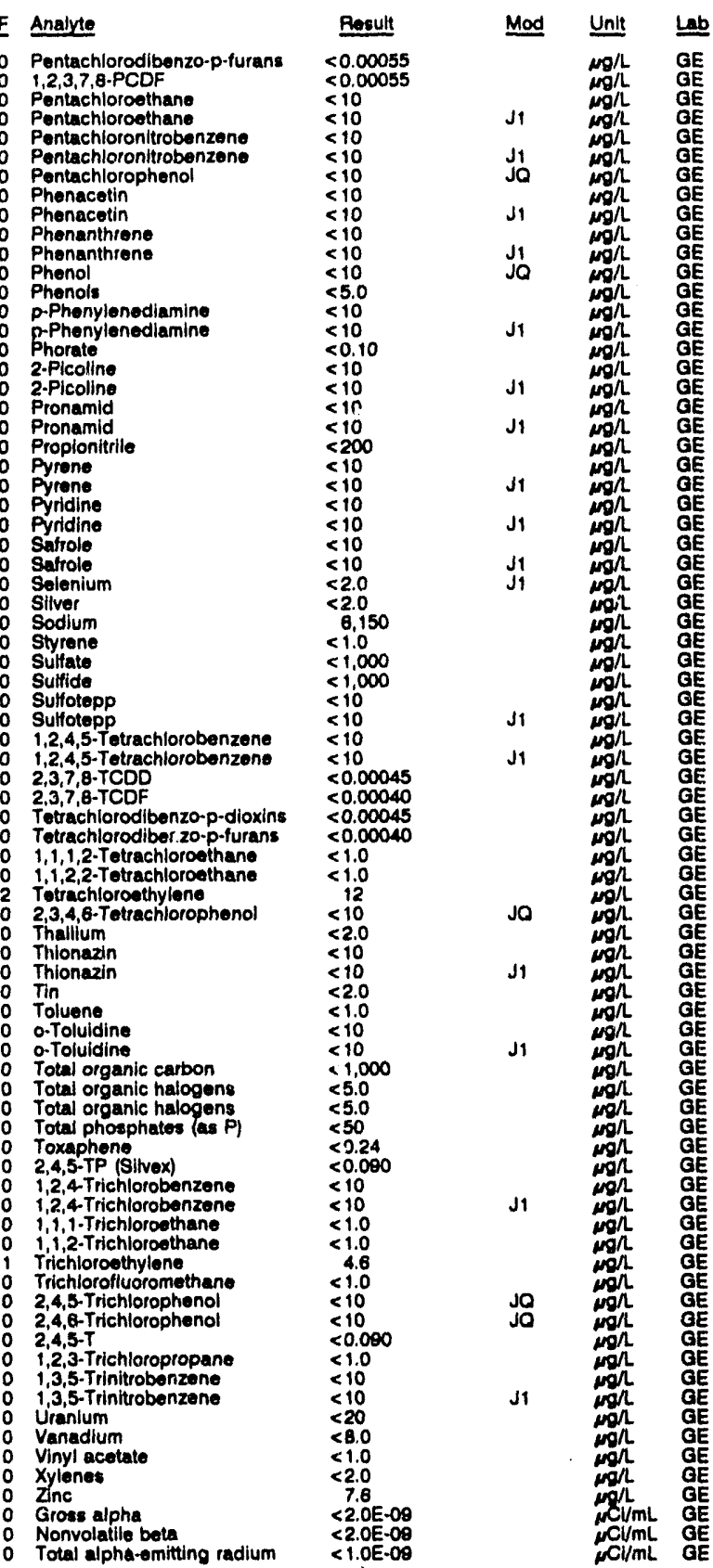

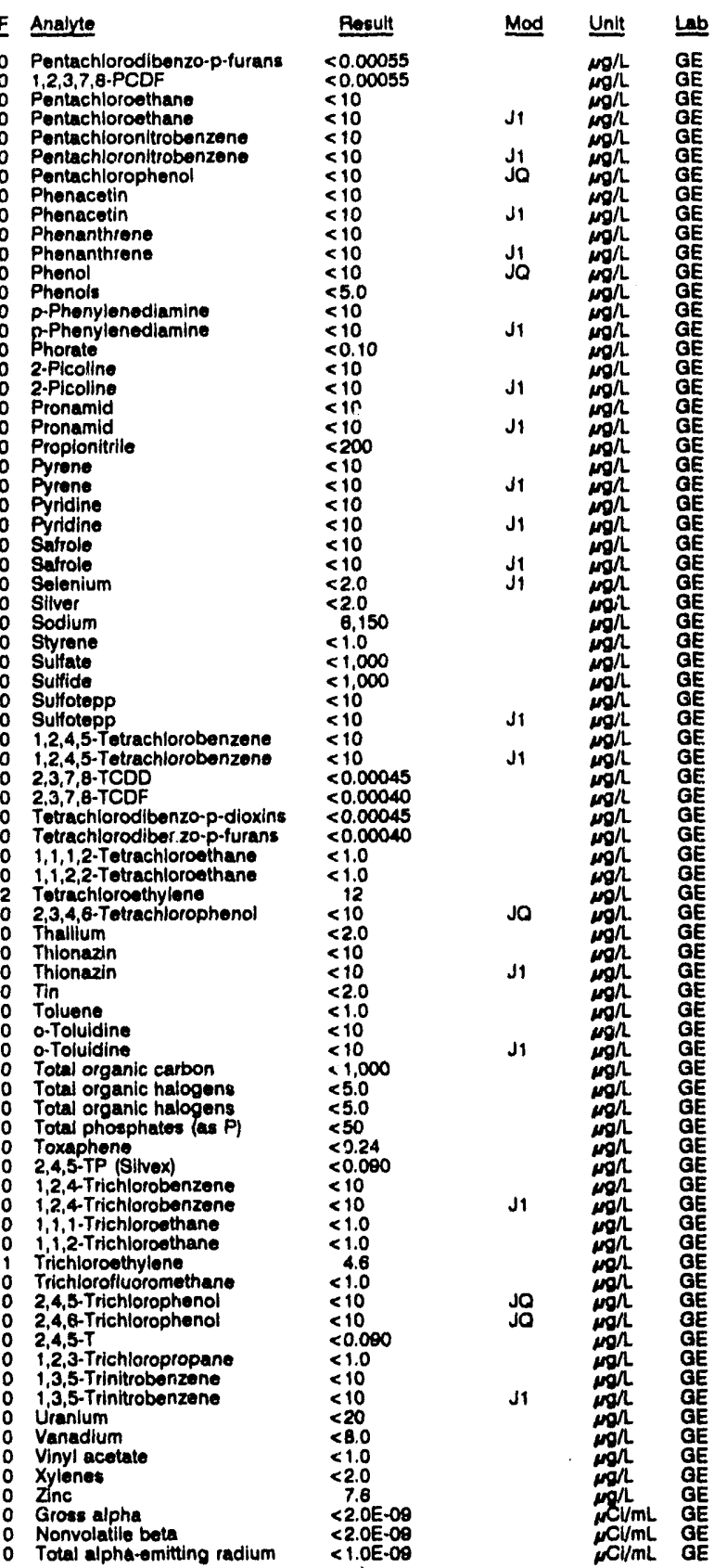

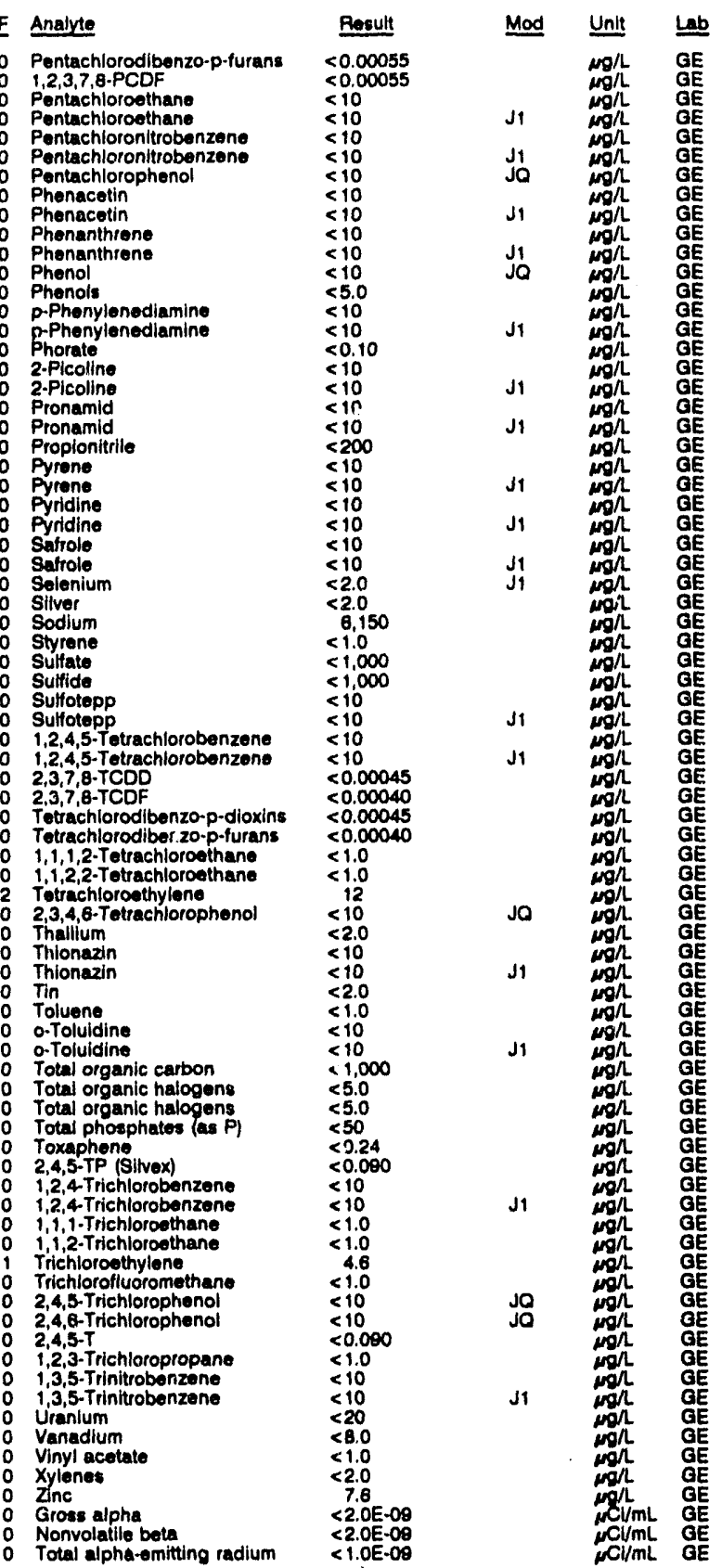

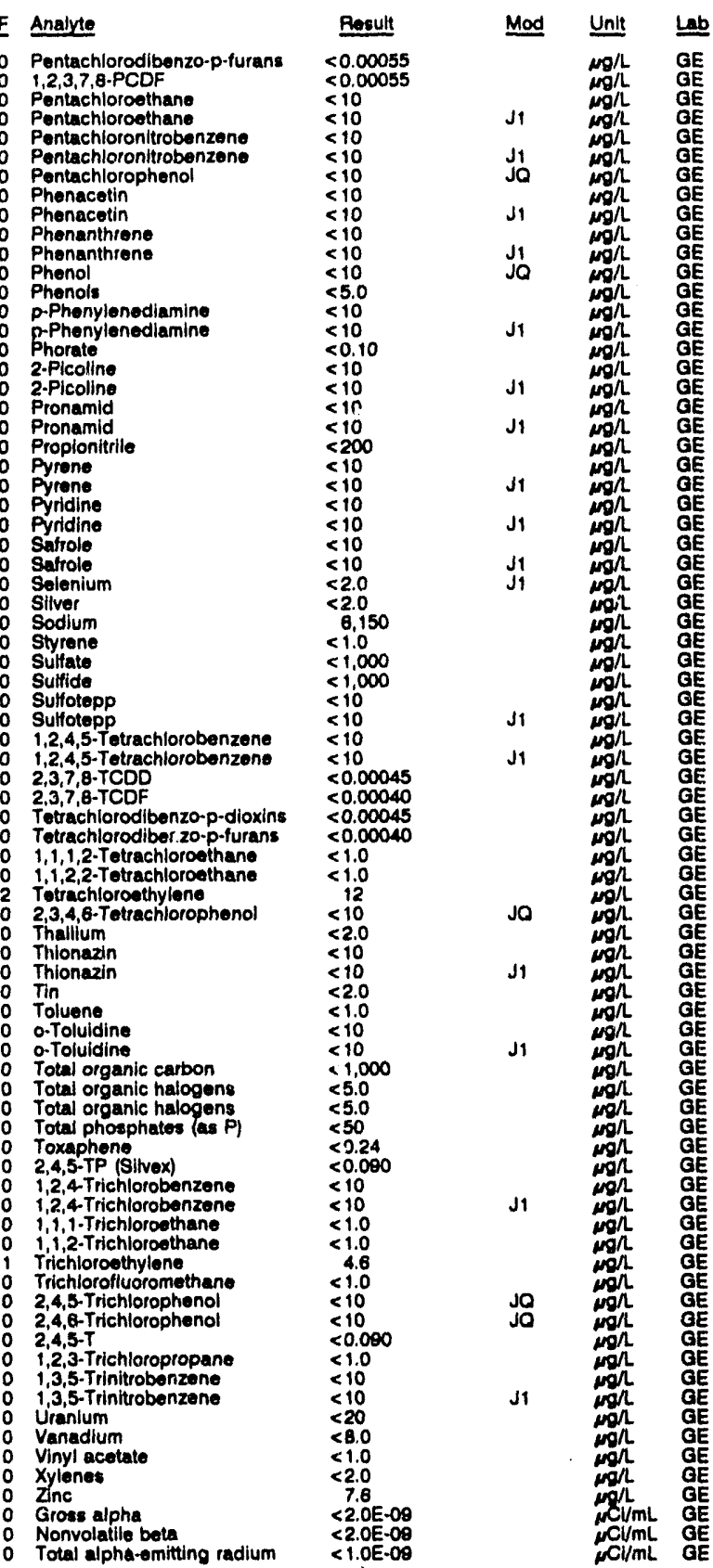

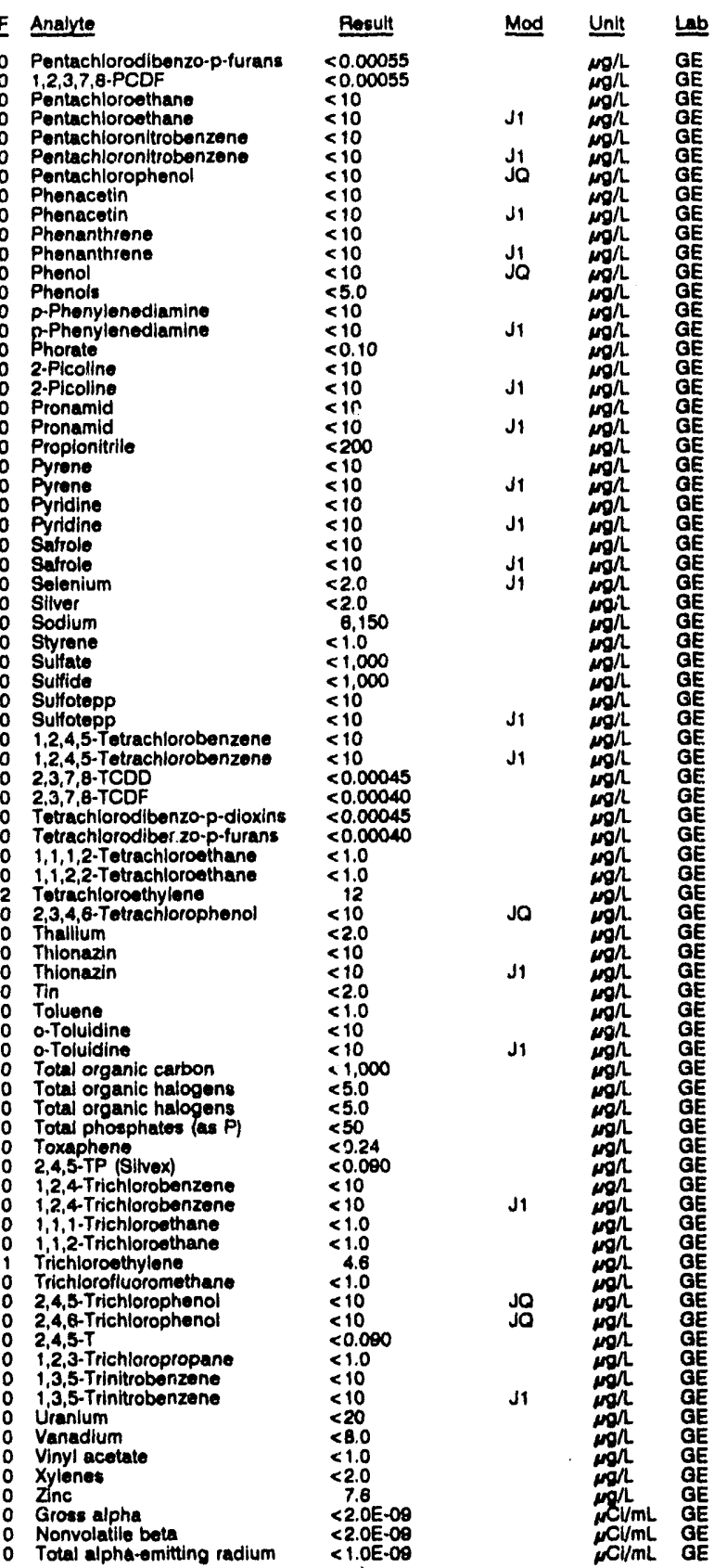

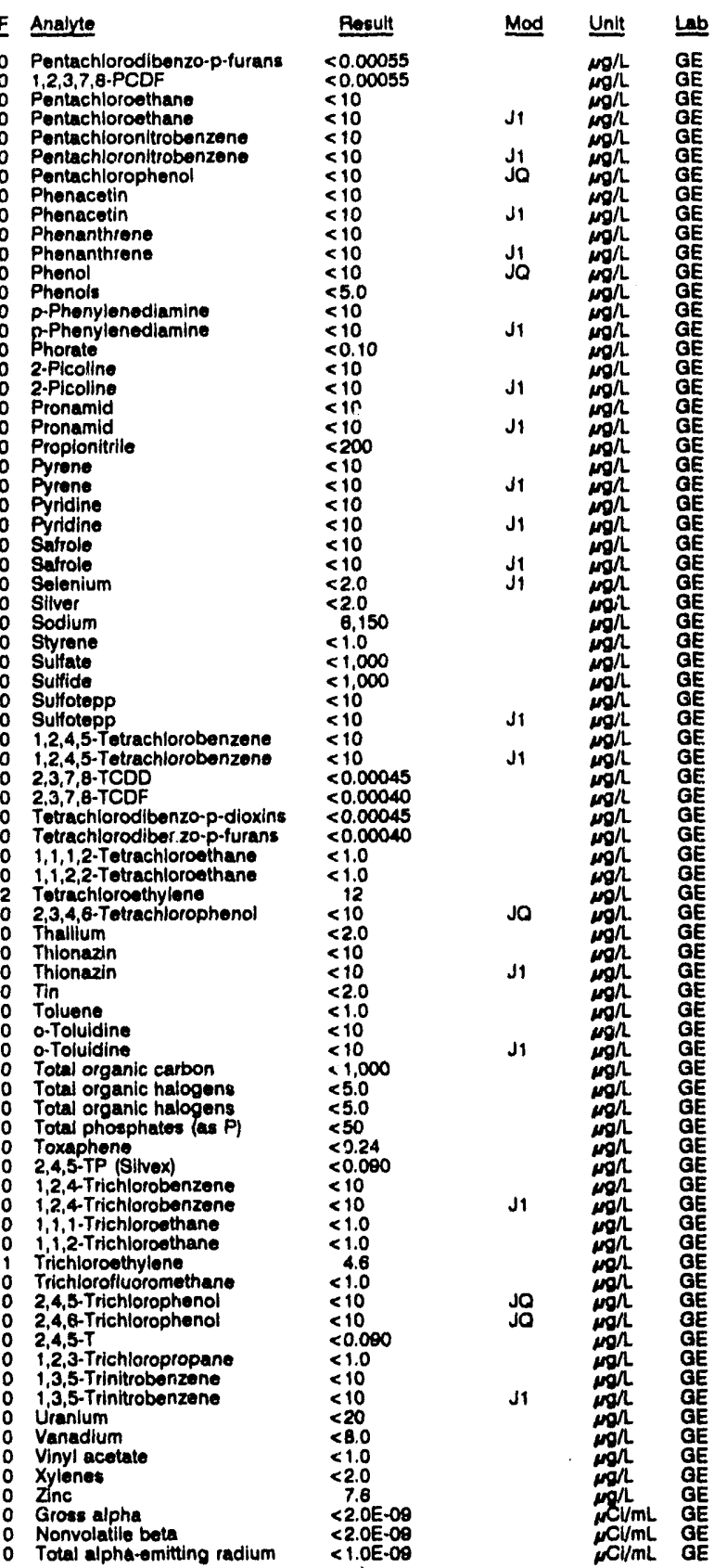

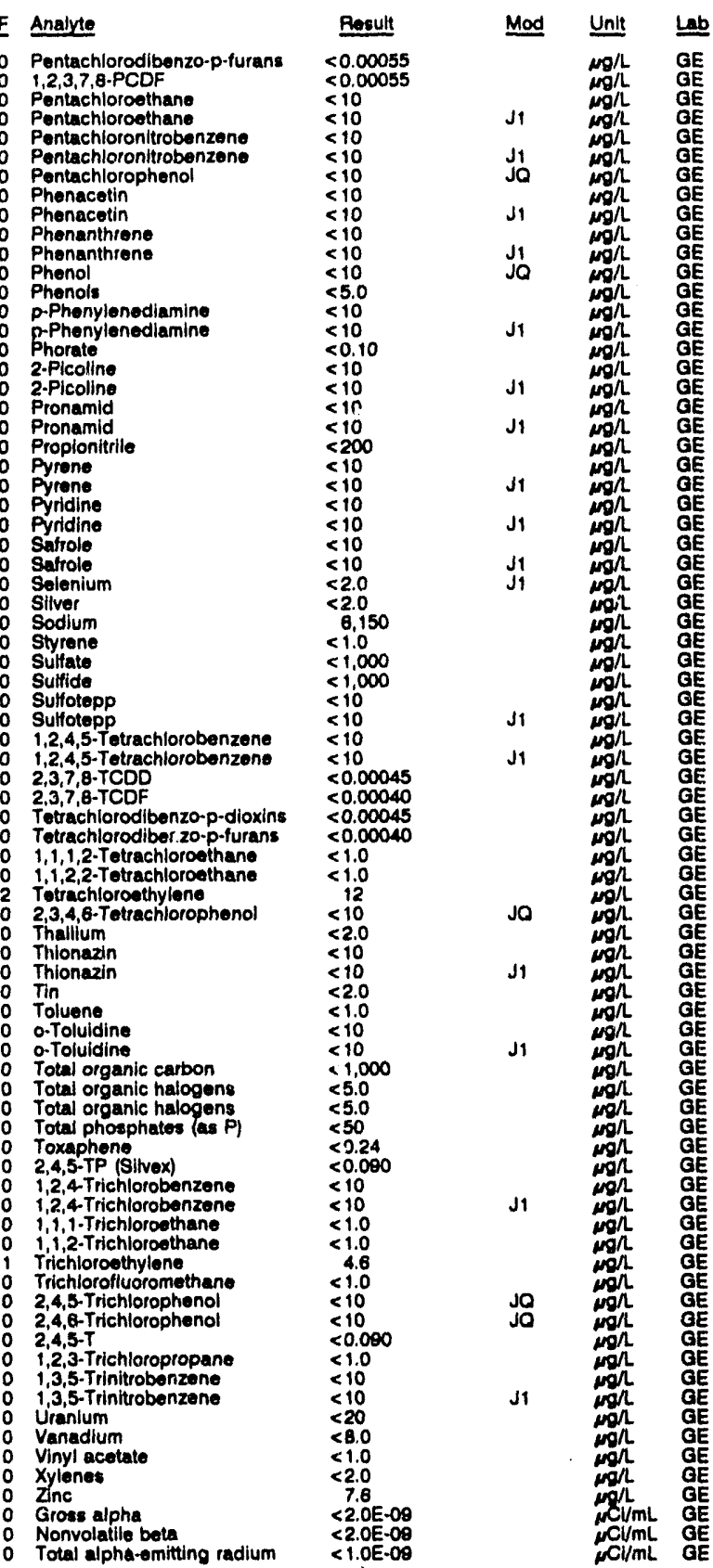

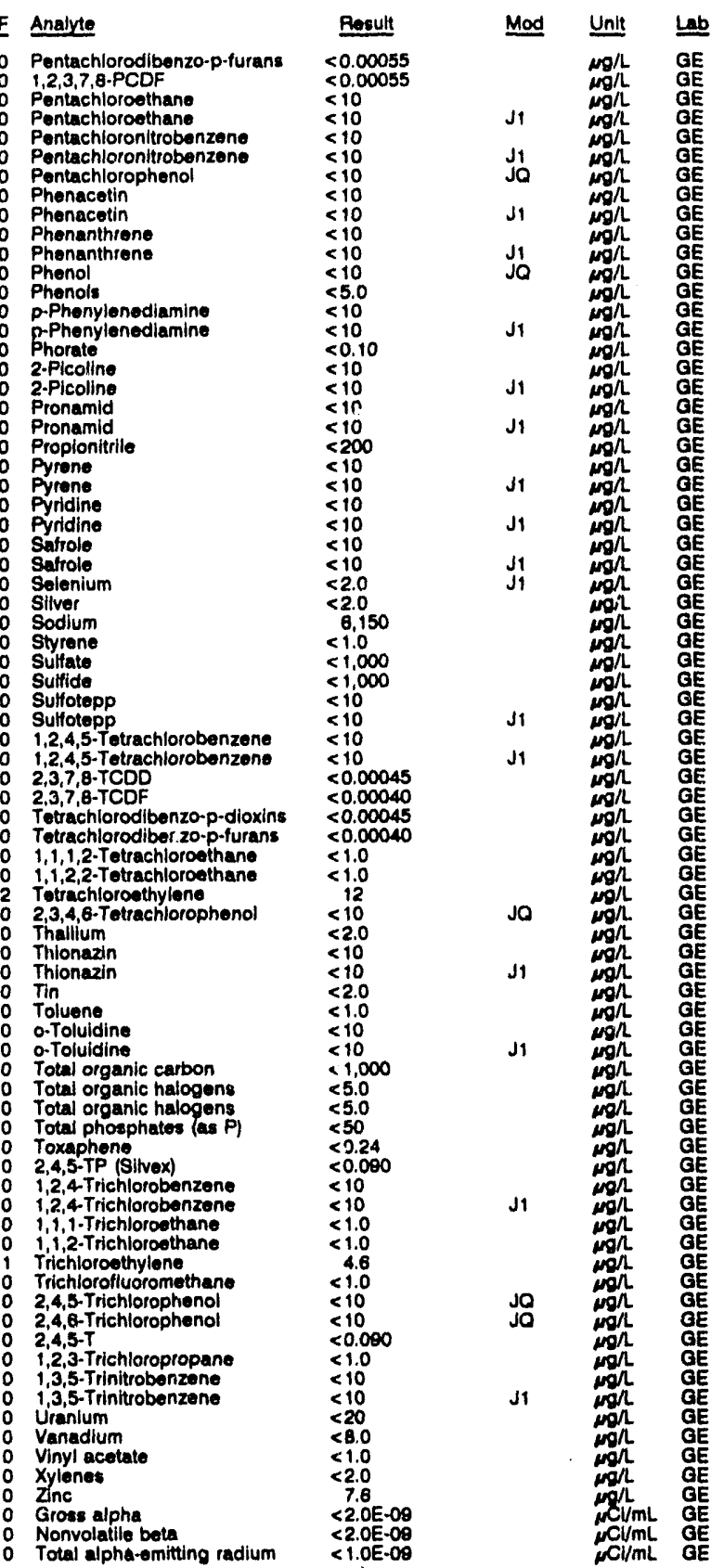

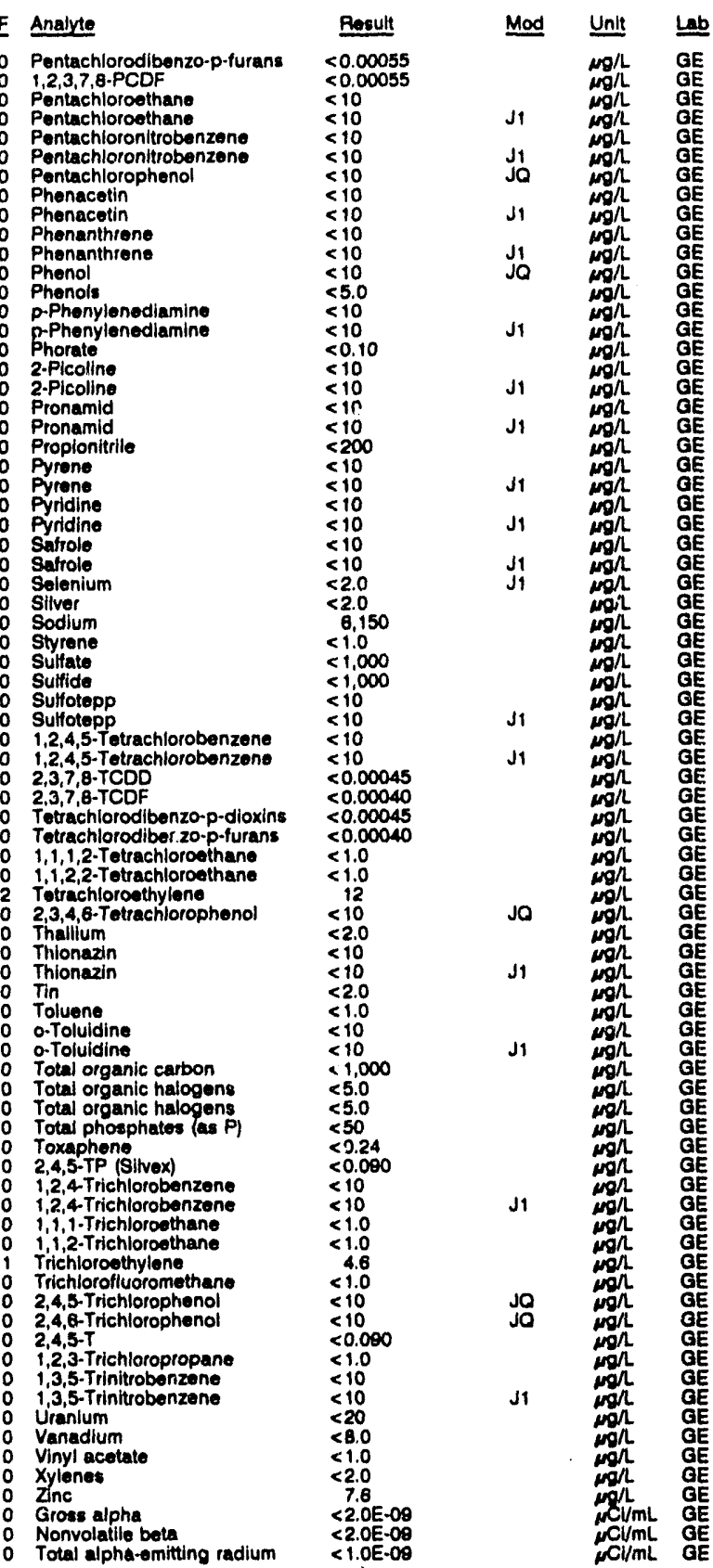

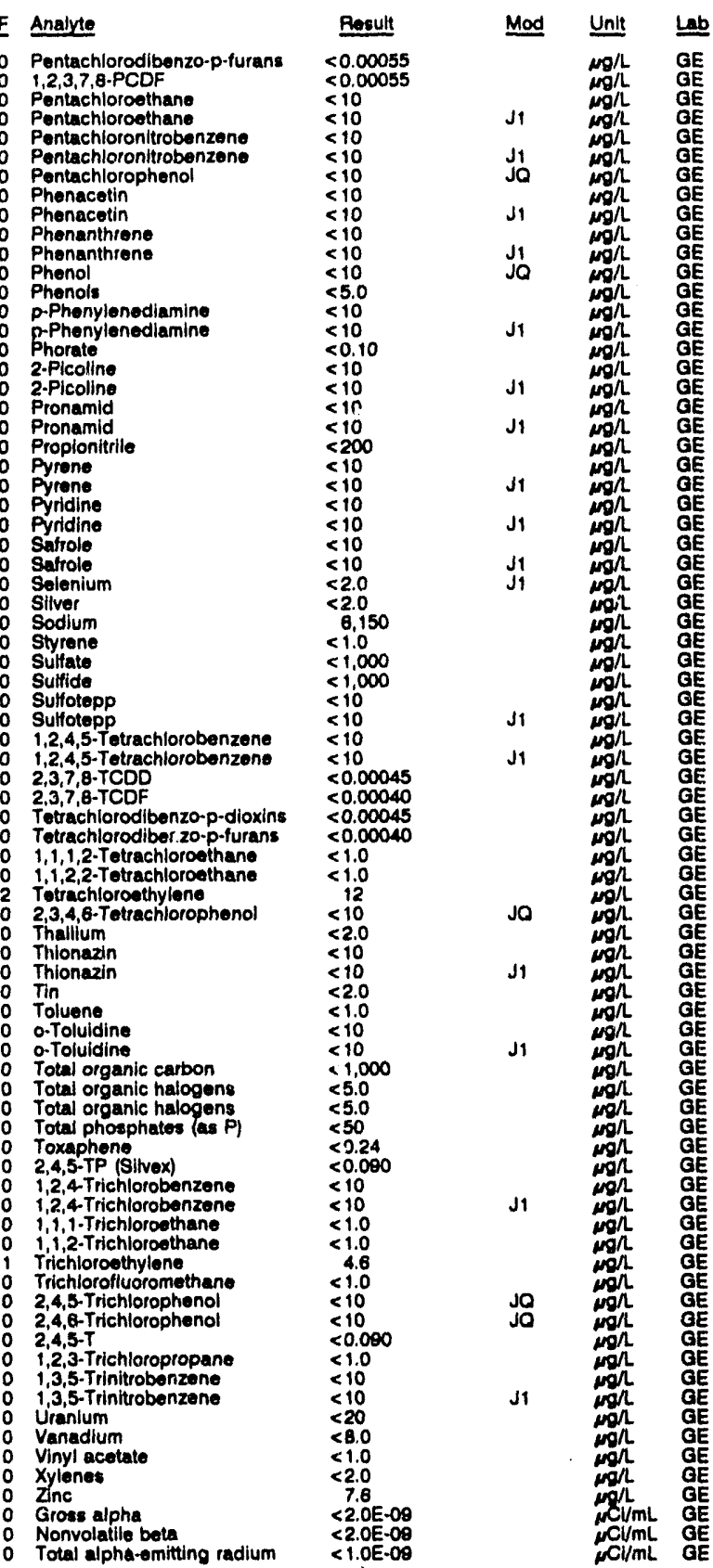

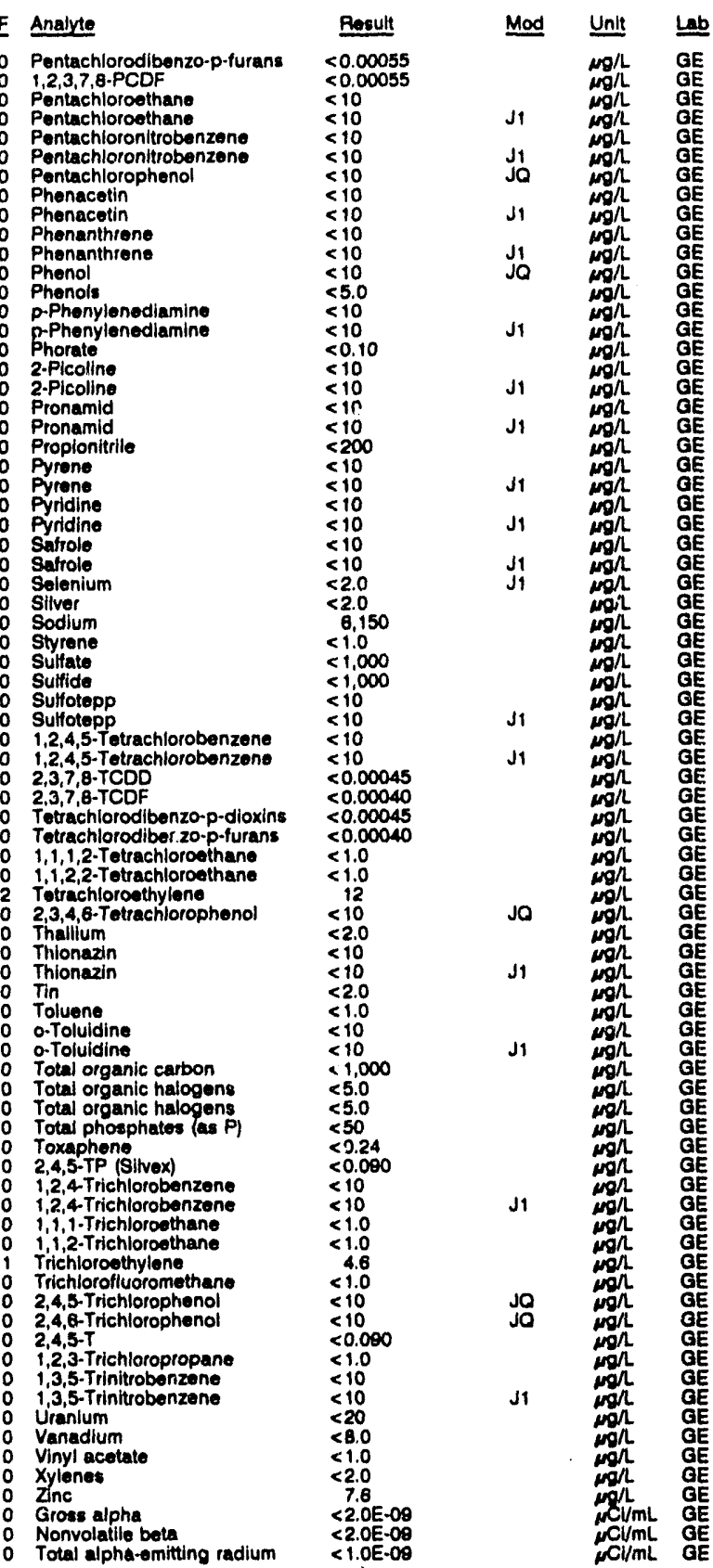

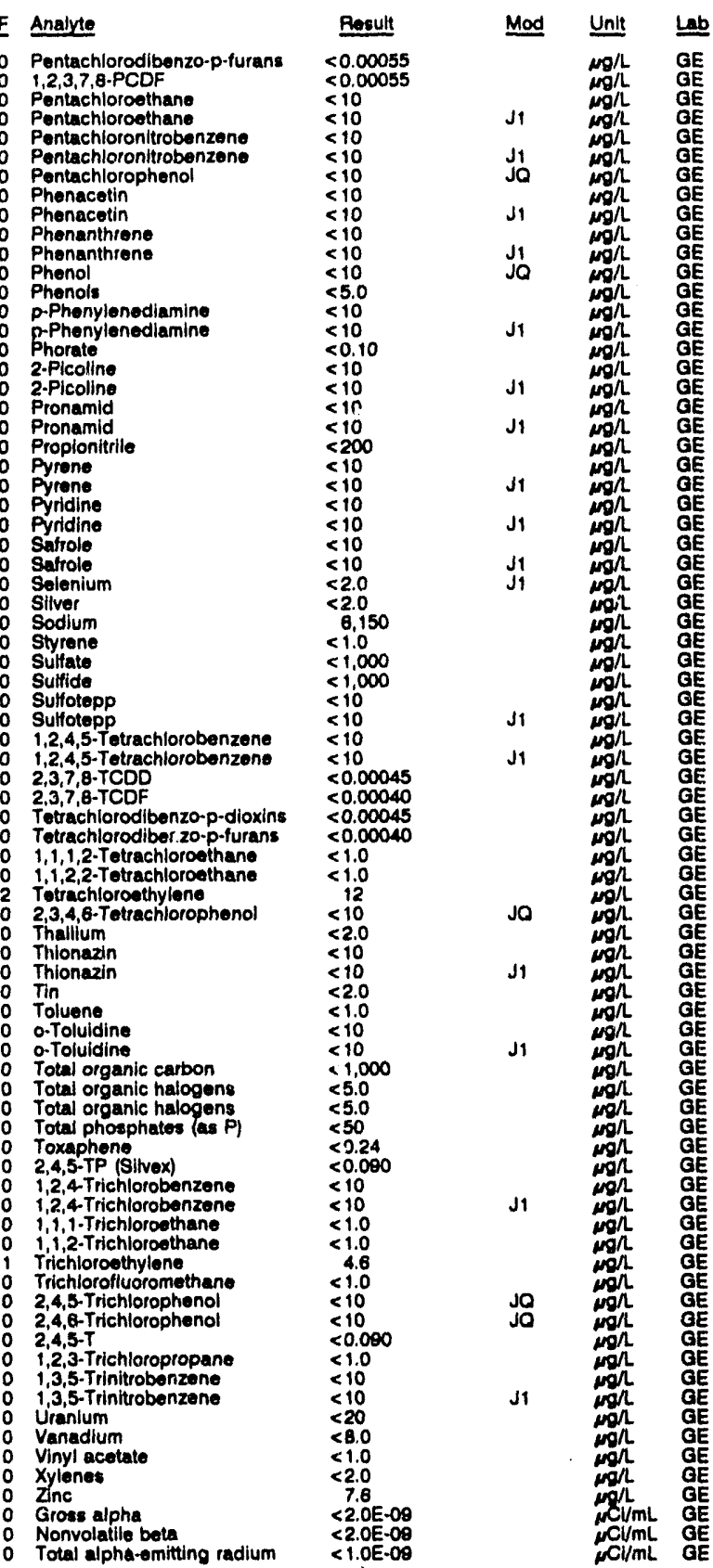

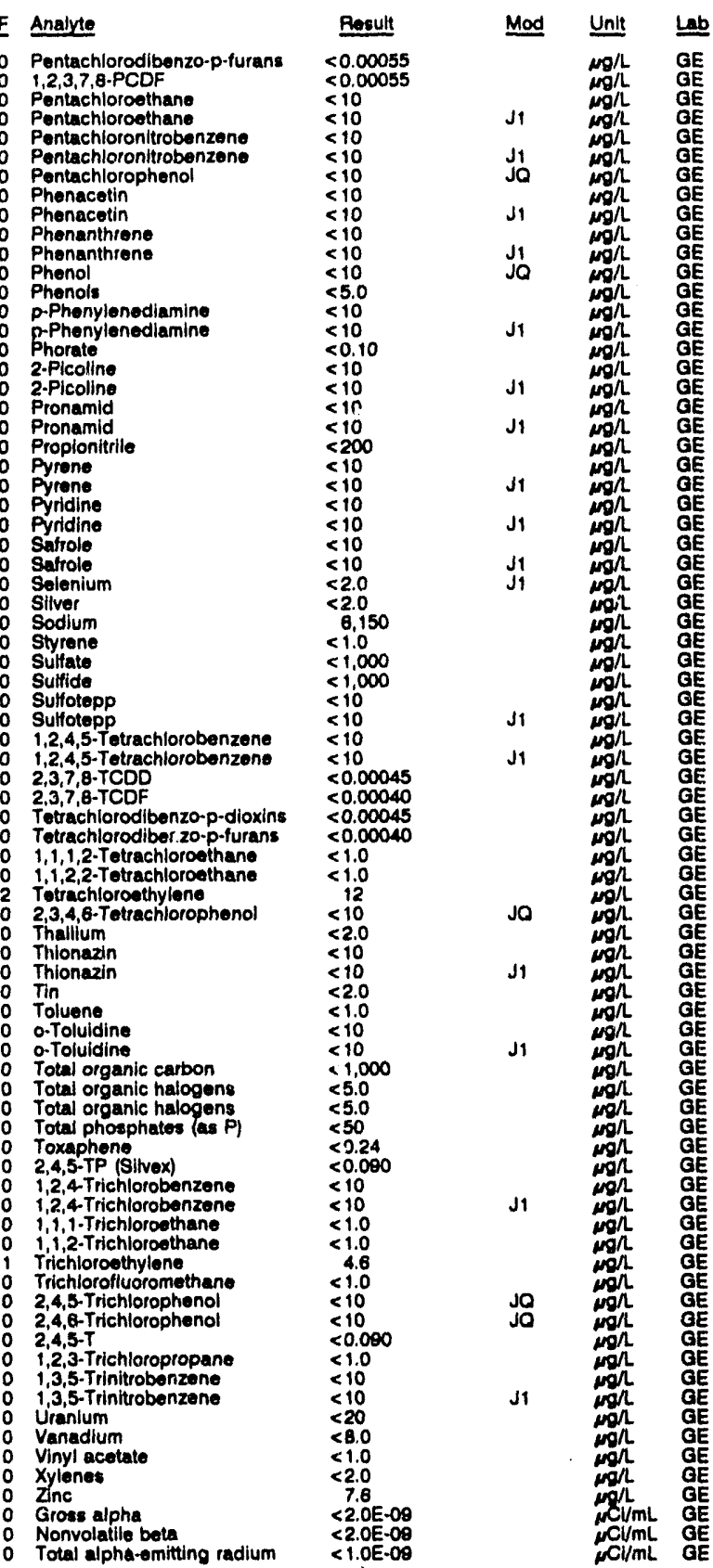

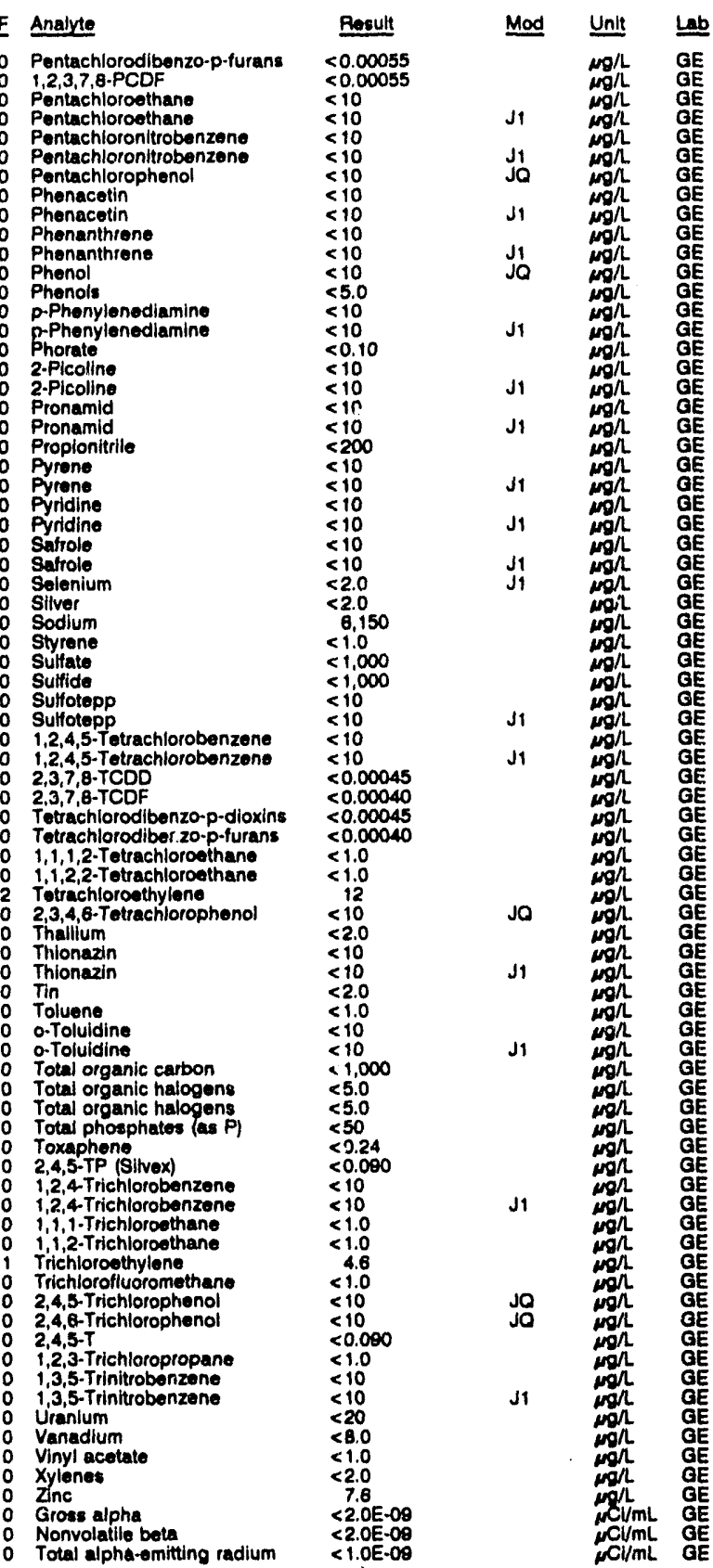

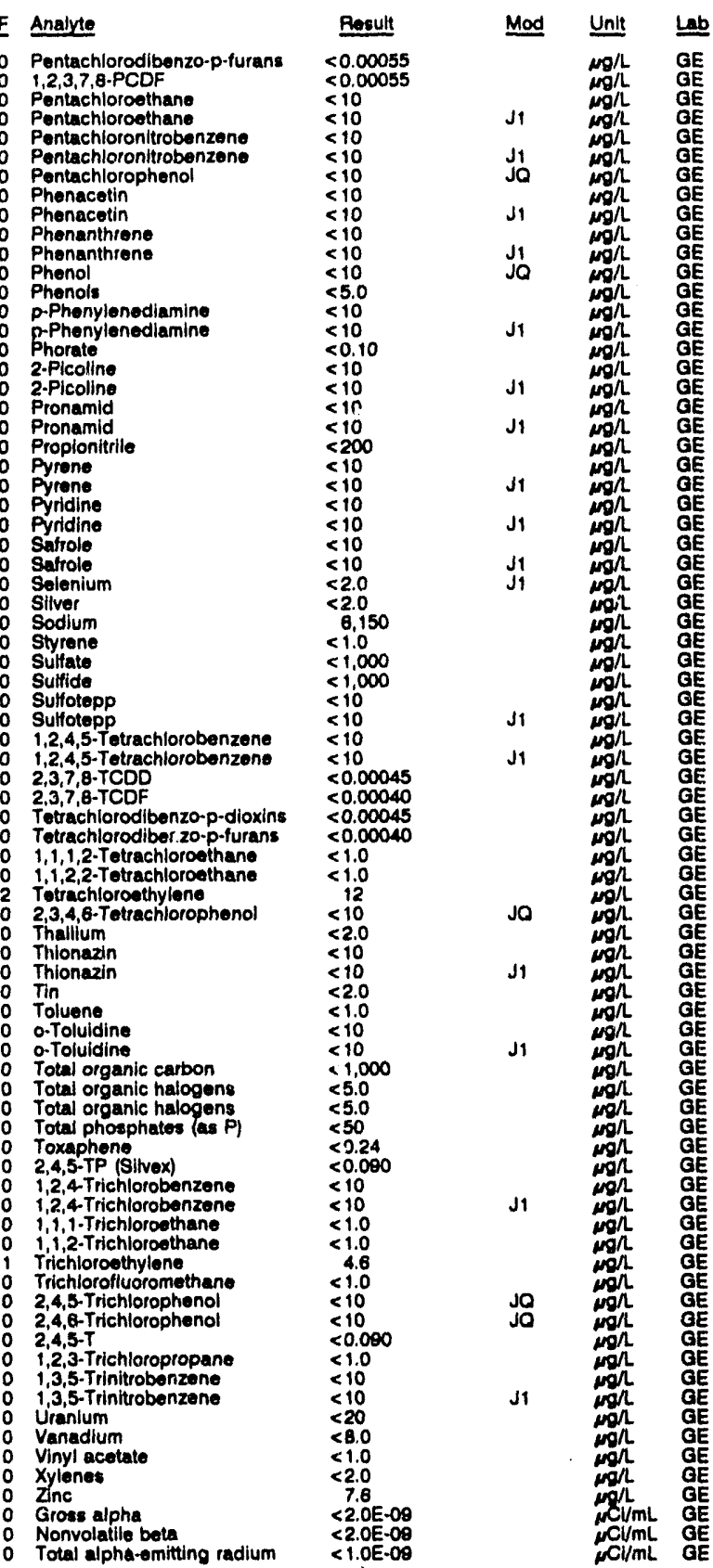

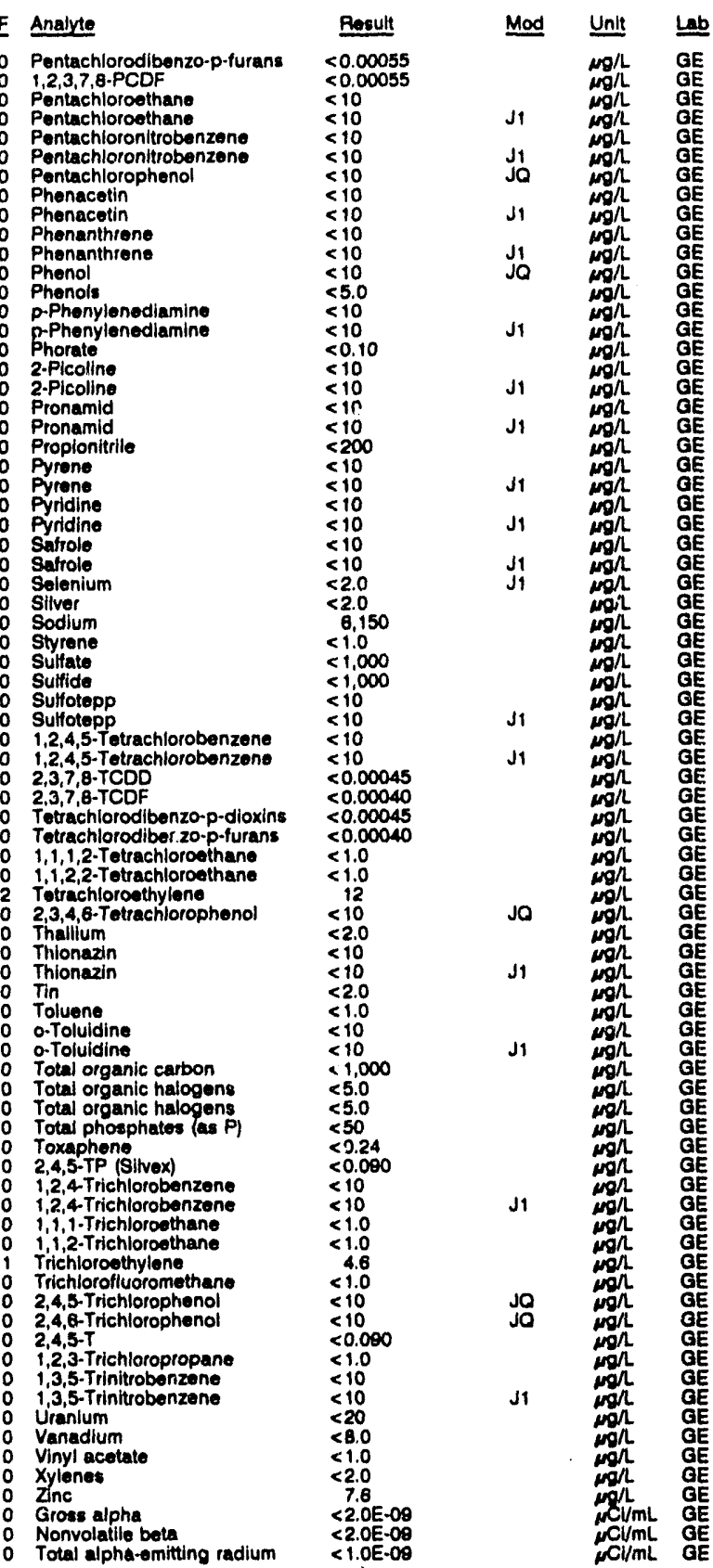

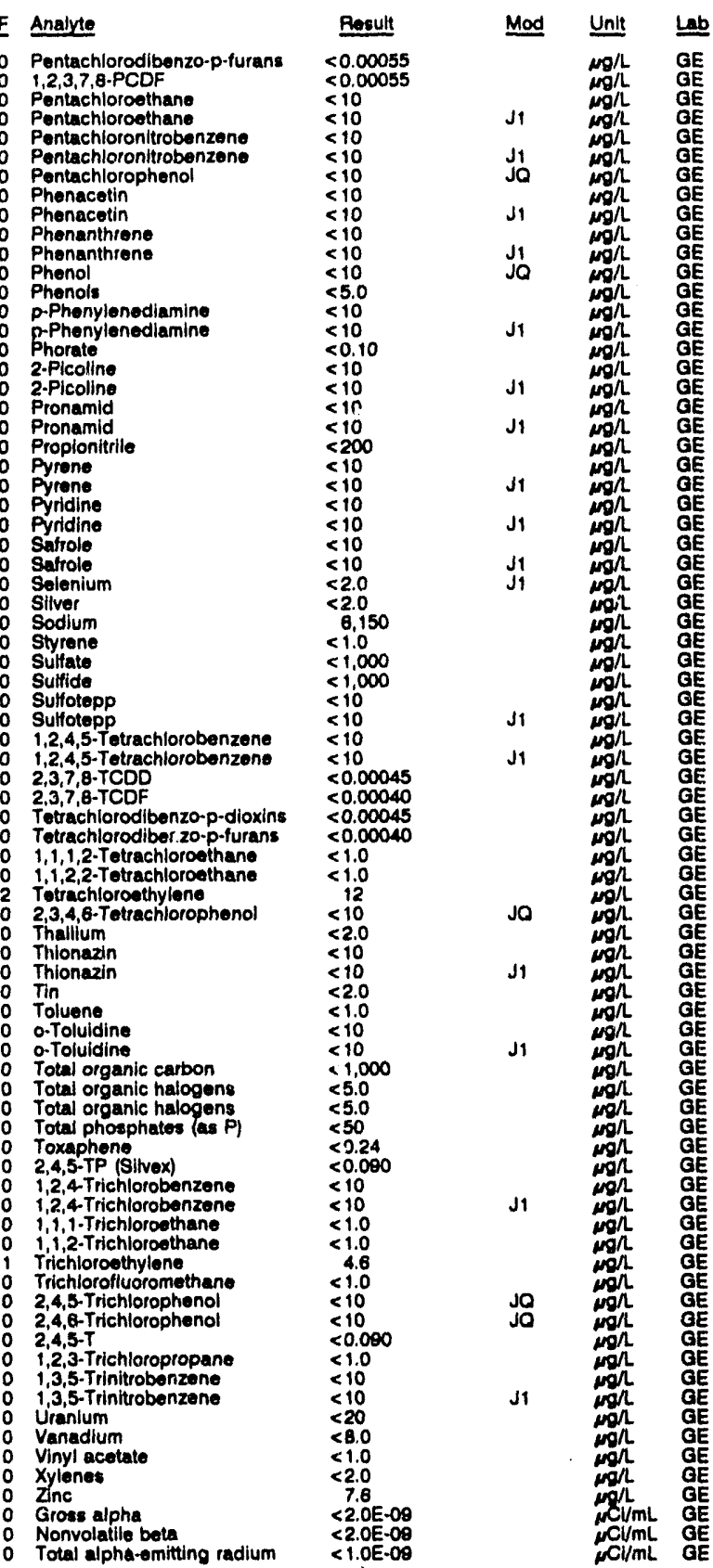

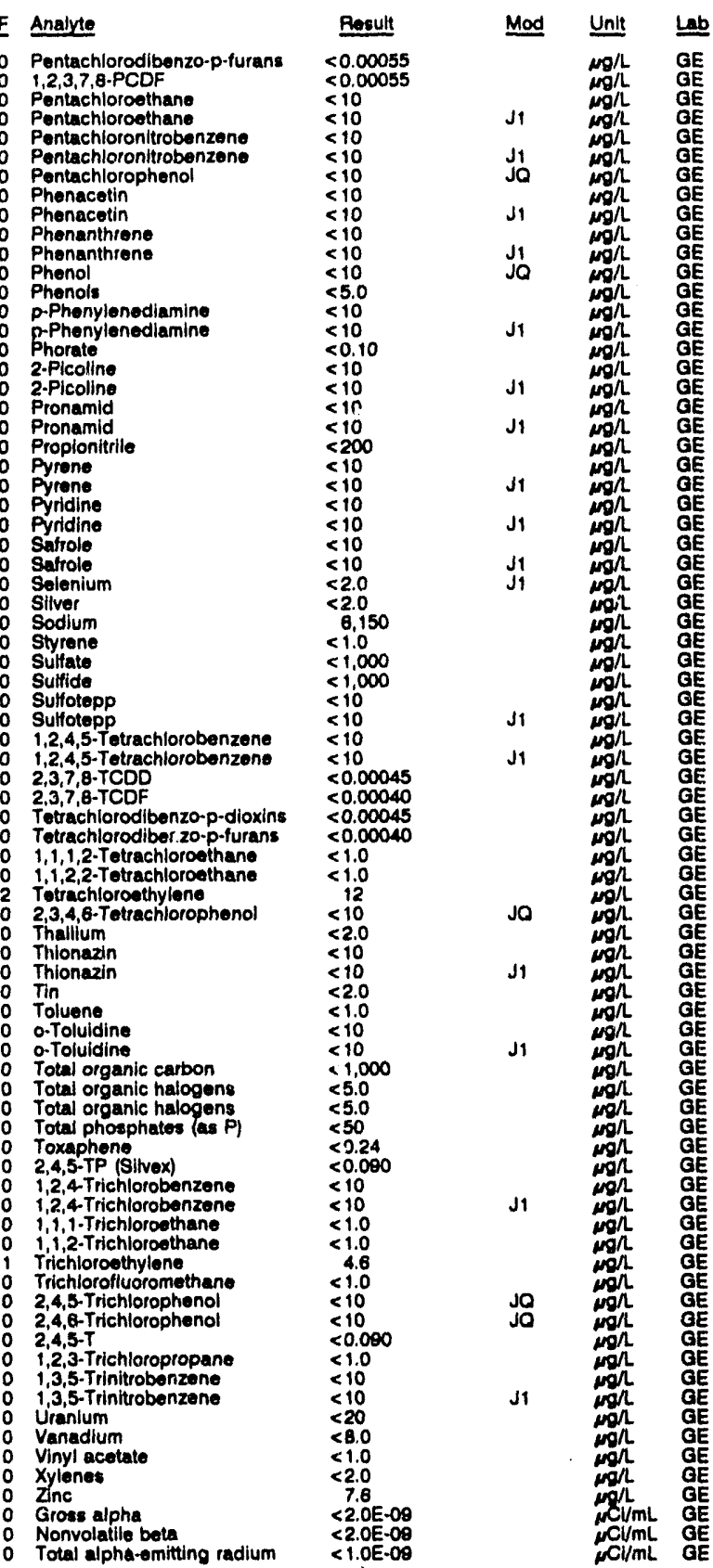

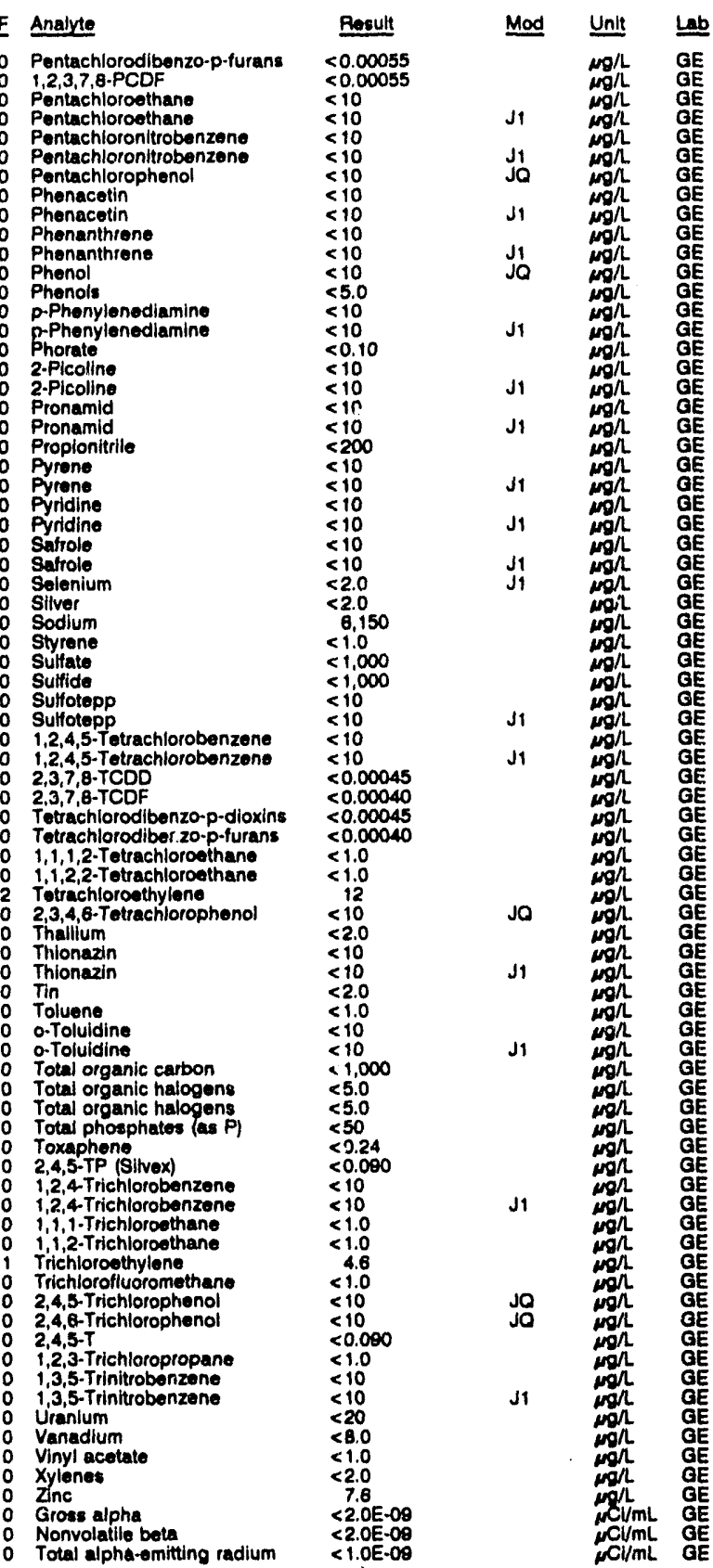

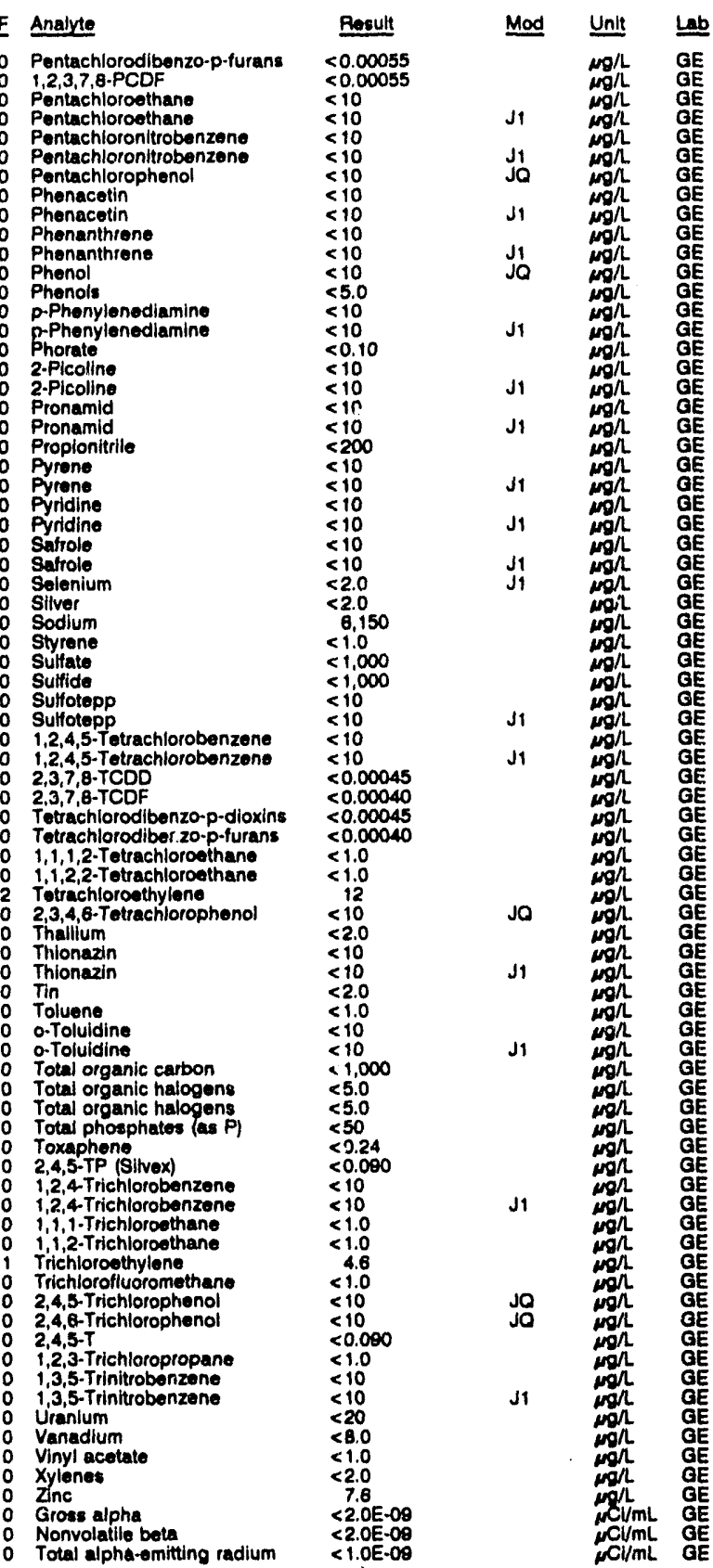

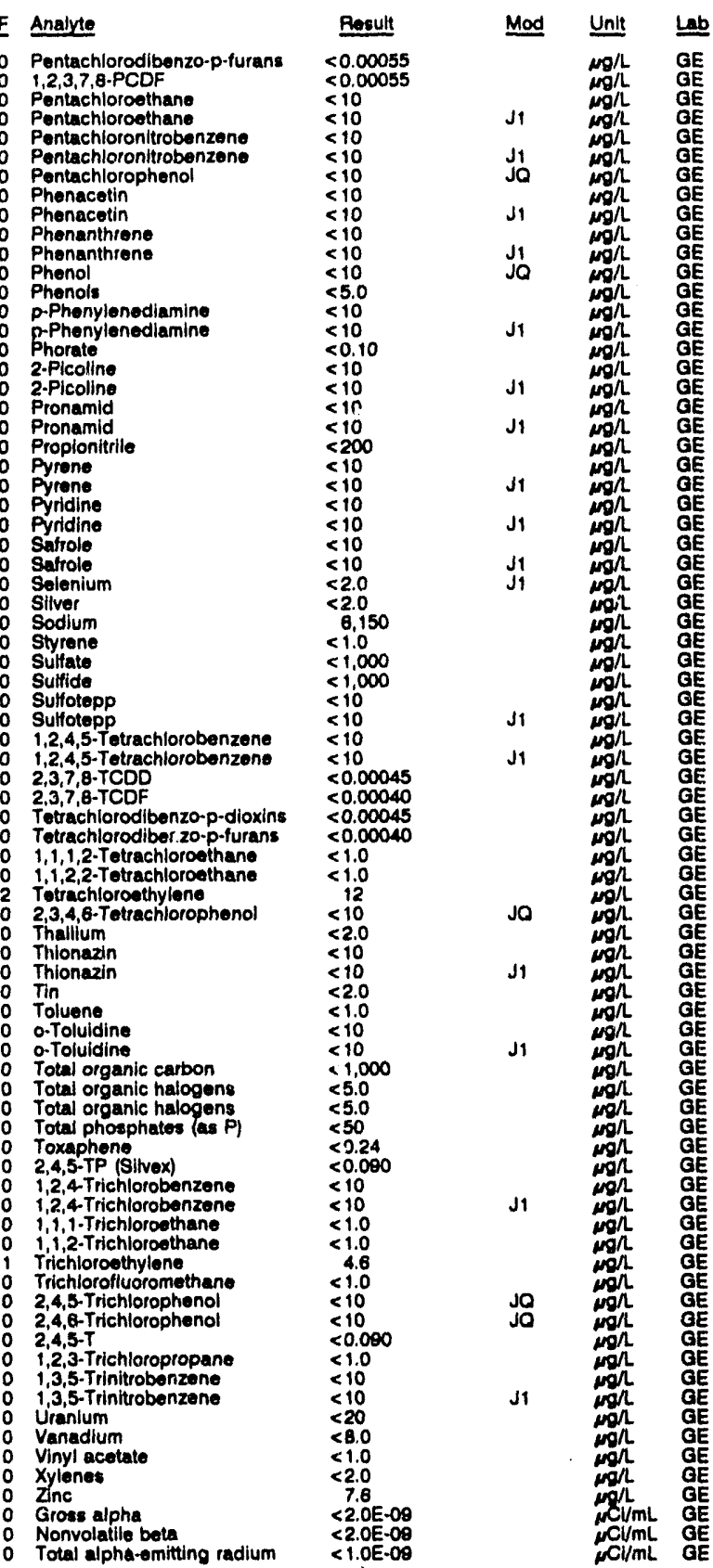

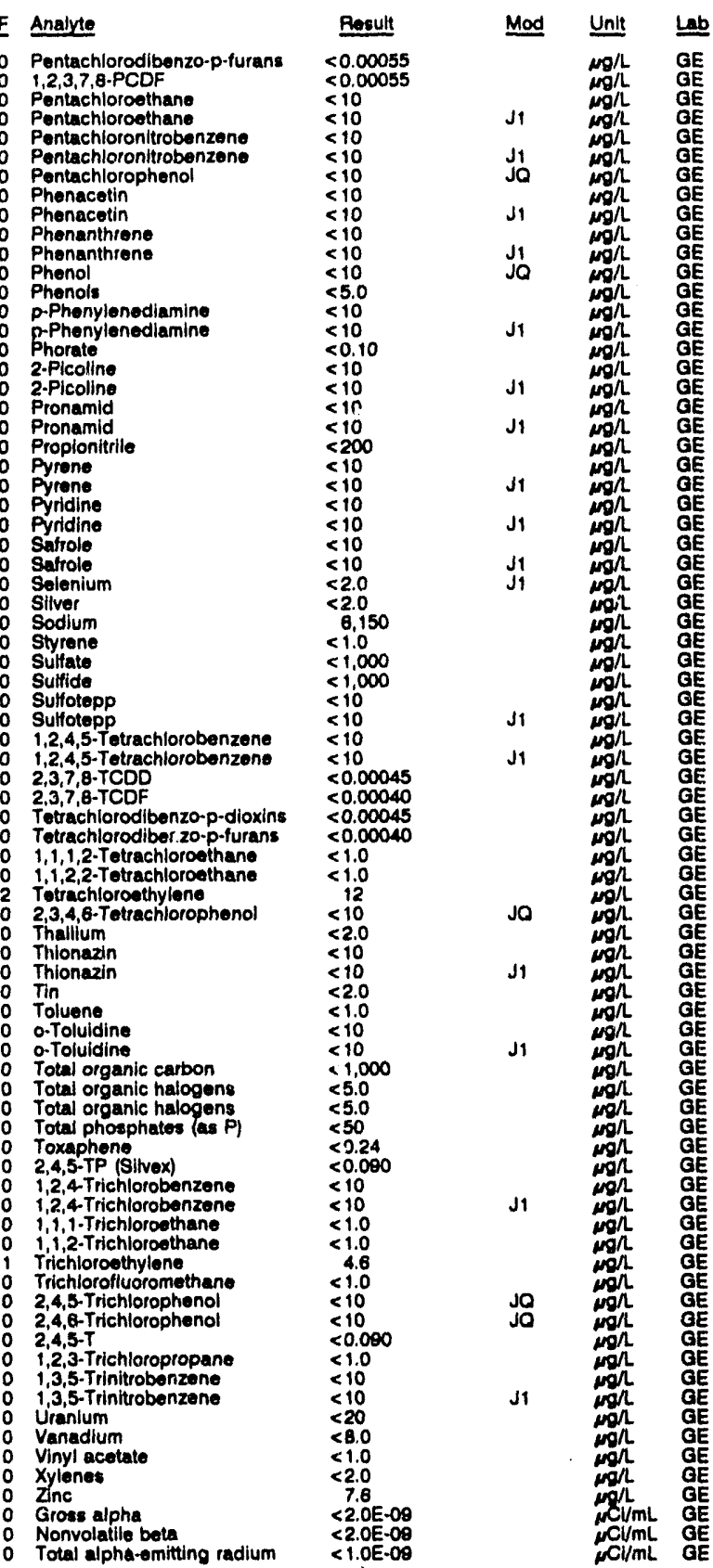

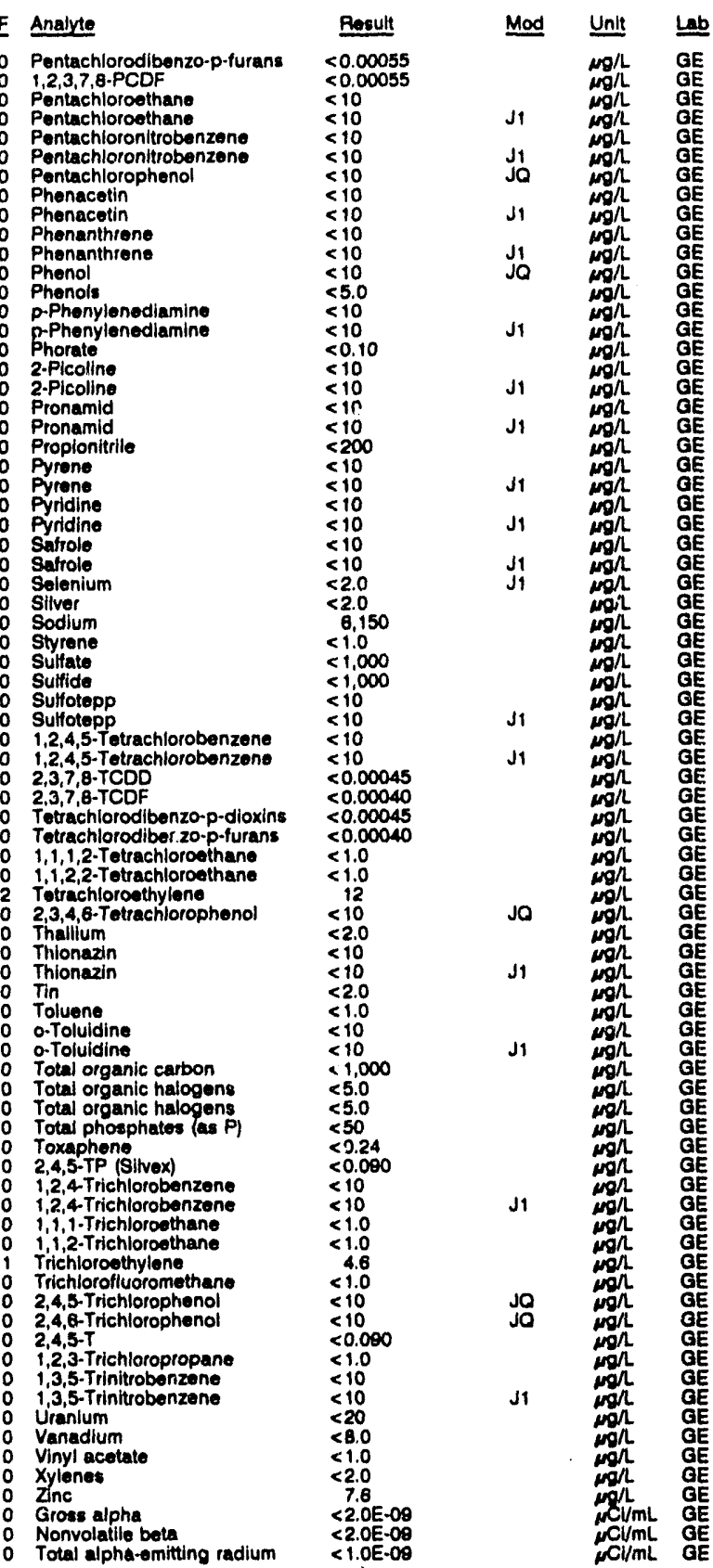

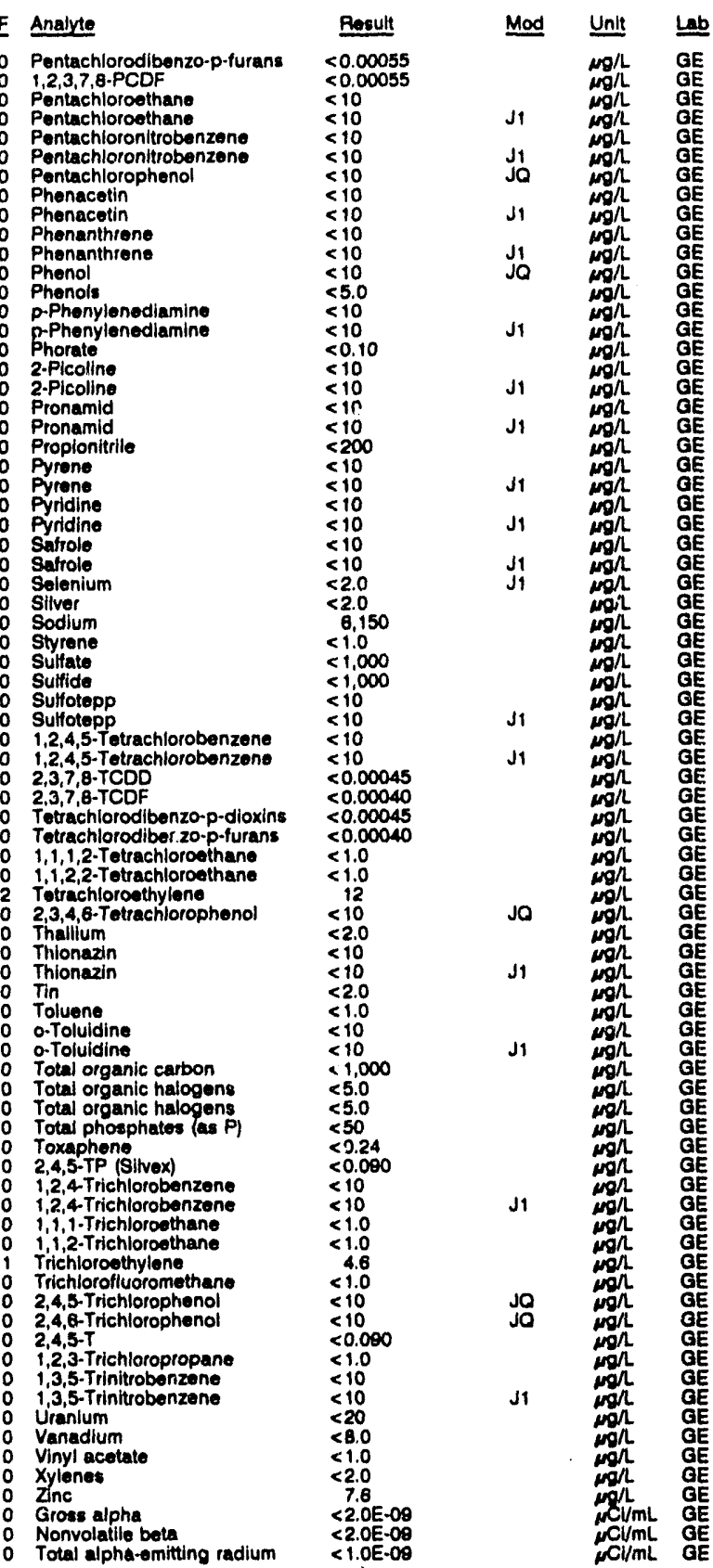

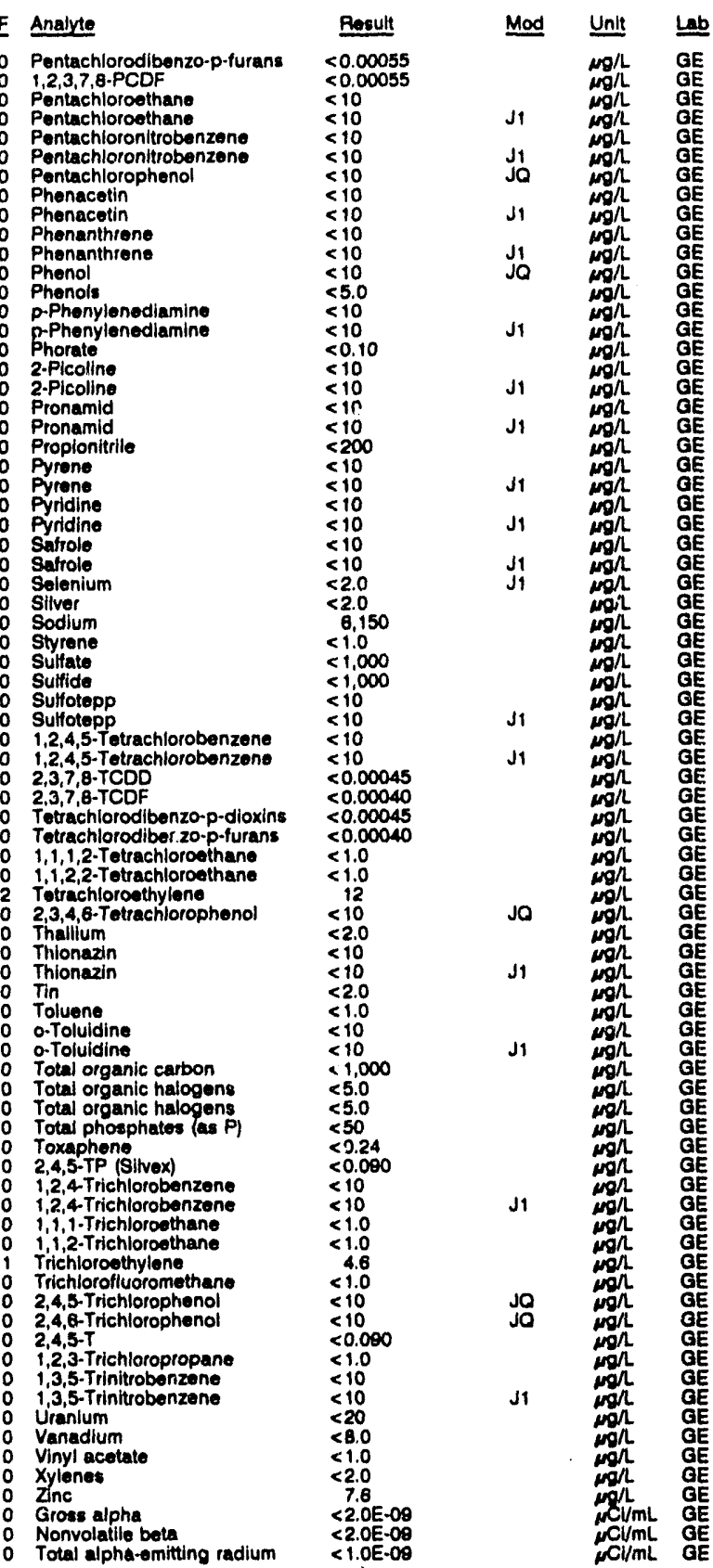

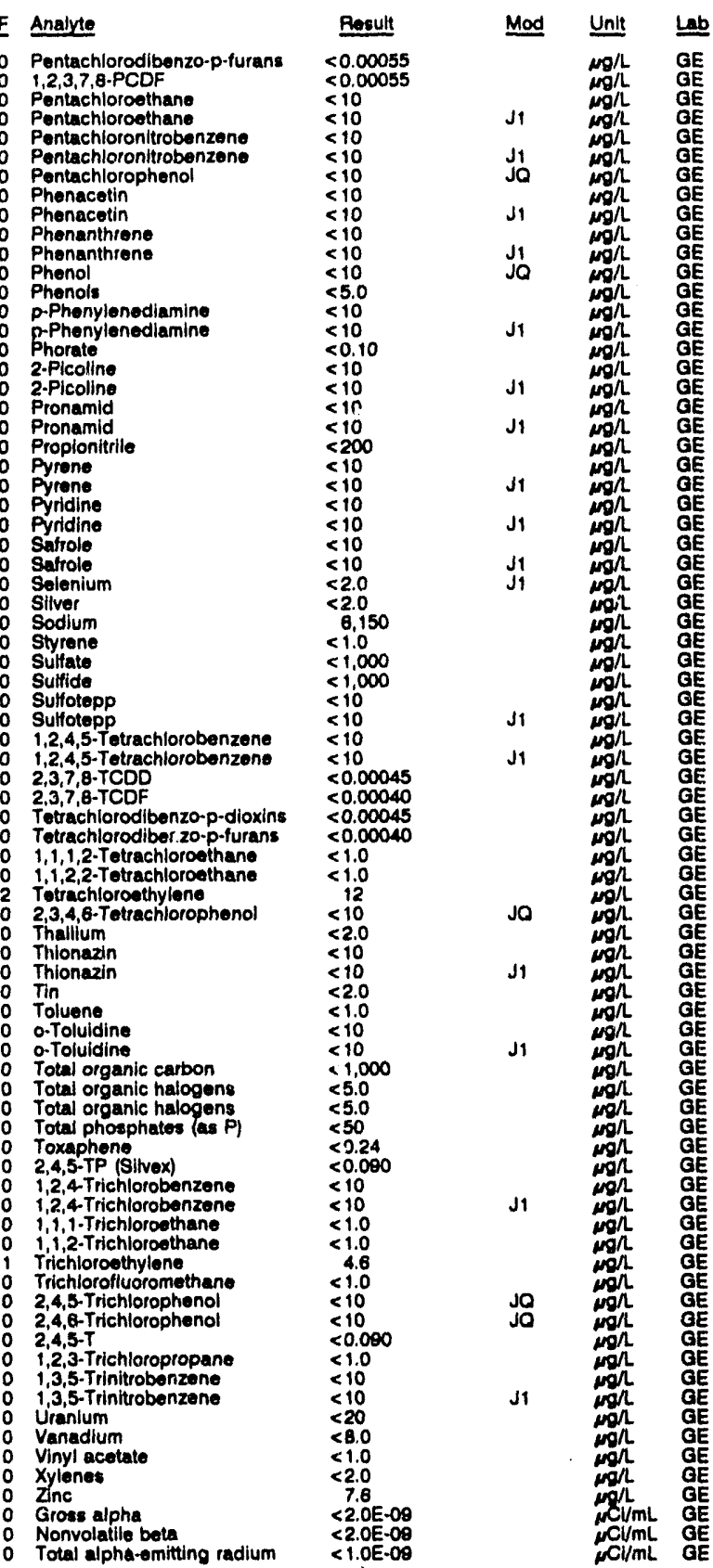

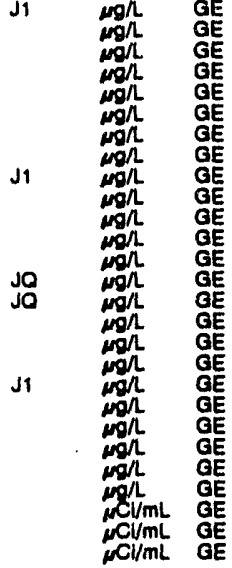


ANALYTICAL RESULTS

WELL MSB 630 coliected on 07/23/82, laboratory analyses (cont.)

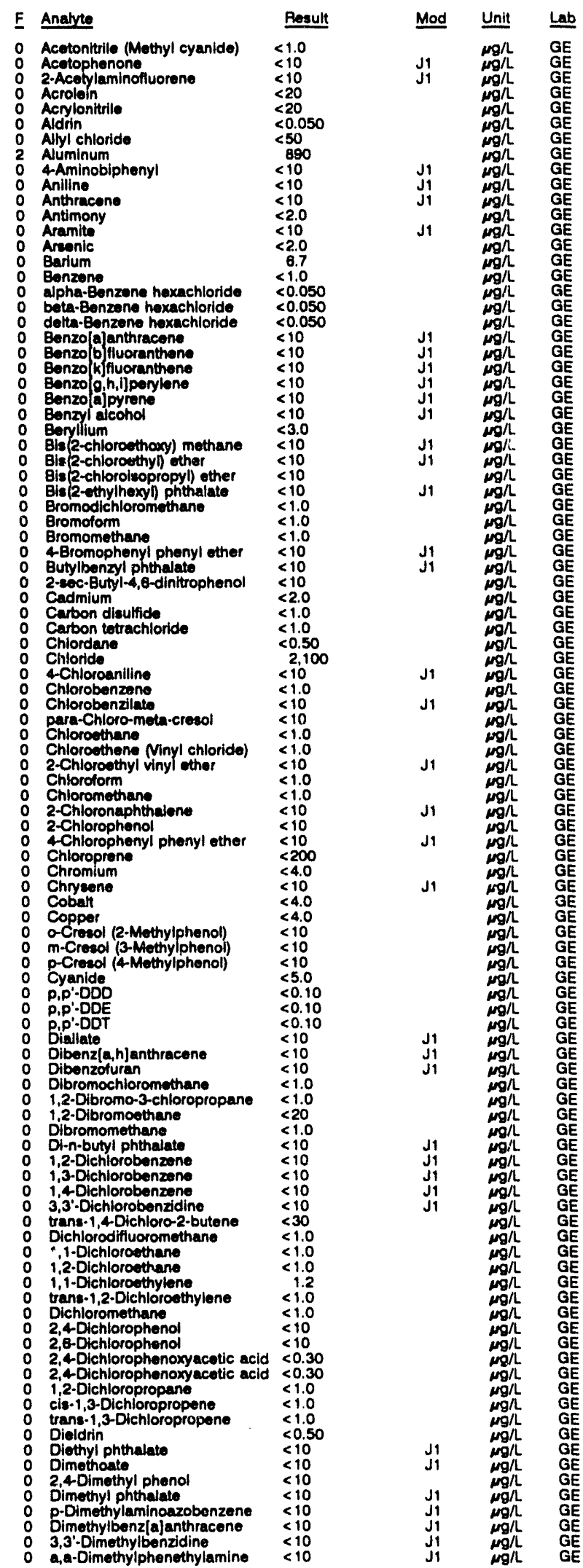

WELL MSB 63D collected on 07/23/82, laboratory analyees (cont.)

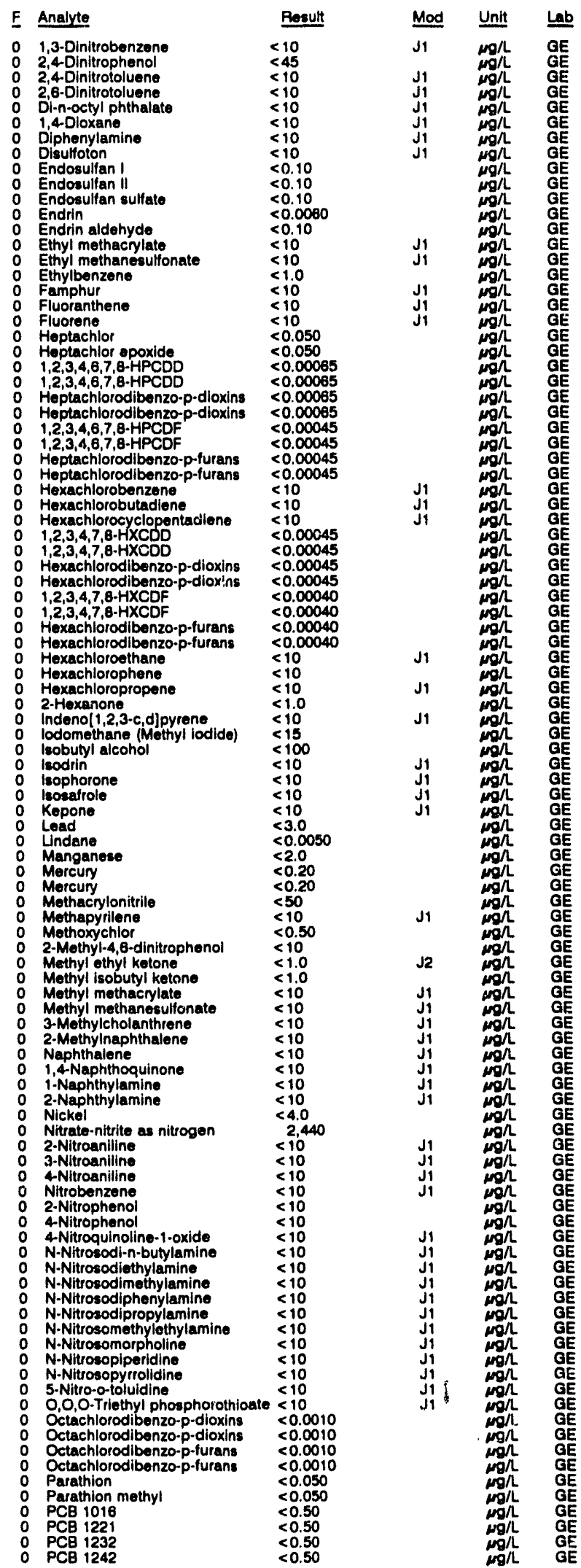


ANALYTICAL RESULTS

WELL MSE 63D collected on 07/23/92, laboratory analyses (cont.)

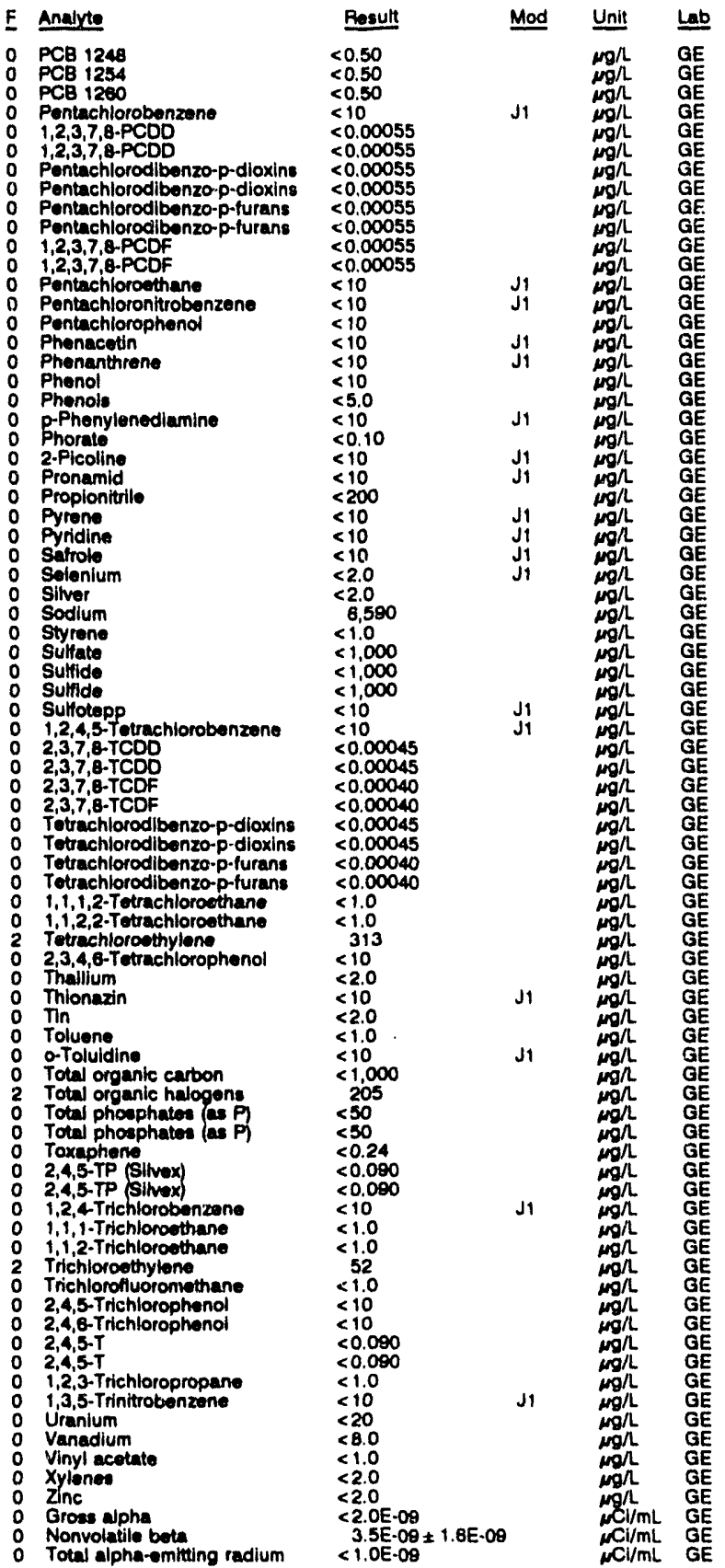

WELL MSB 64B

MEASUREMENTS CONDUCTED IN THE FIELD

Sample date: 08/21/92 Dopth to water: $140.82 \mathrm{H}(42.85 \mathrm{~m})$ below TOC
Water elevation: $207.78 \mathrm{n}(63.33 \mathrm{~m}) \mathrm{msl}$ Water evacuated before sampling: $231 \mathrm{gal}$

LABOPATORY ANALYSES

\begin{tabular}{|c|c|c|c|}
\hline E Analyte & Result & Mod & Unit \\
\hline $\begin{array}{ll}0 & \mathrm{pH} \\
0 & \mathrm{pH} \\
0 & \text { Specific conductance }\end{array}$ & $\begin{array}{r}6.0 \\
6.0 \\
50\end{array}$ & JO & $\begin{array}{l}\mathrm{pH} \\
\mathrm{pH} \\
\mu \mathrm{S} / \mathrm{cm}\end{array}$ \\
\hline
\end{tabular}

WELL MSB 648 collected on 08/21/82, laboratory analyees (cont.)

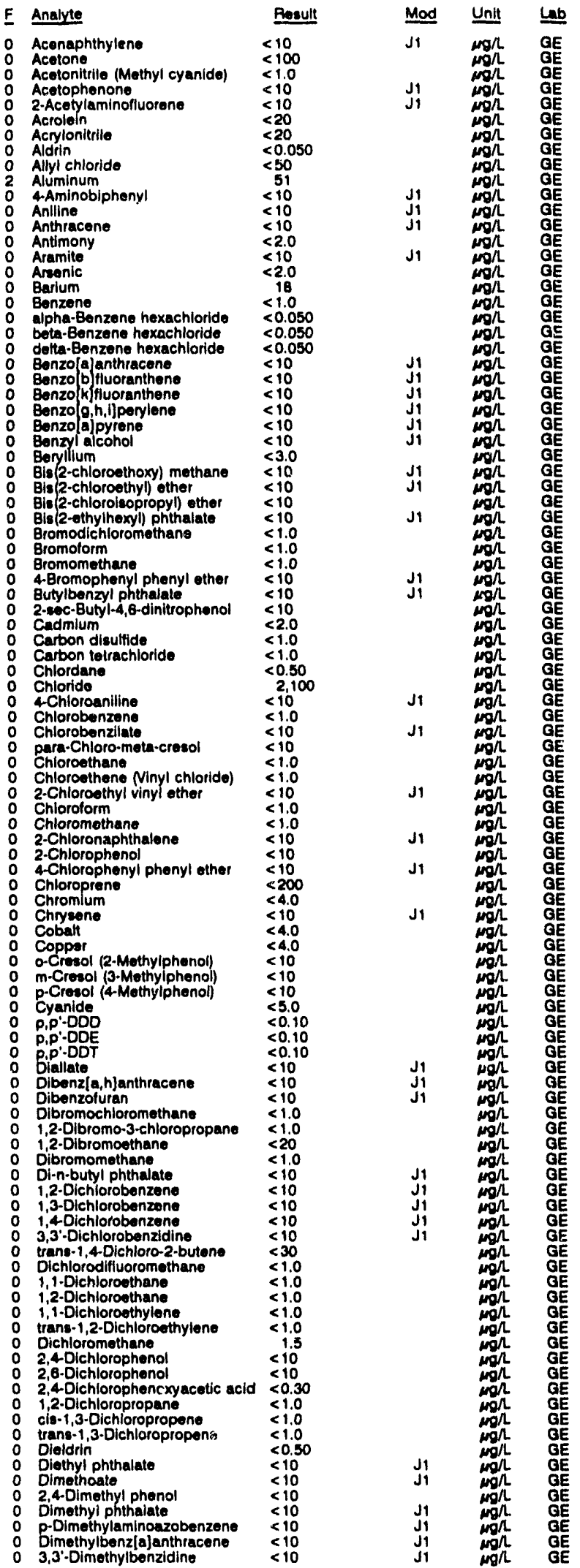


ANALYTICAL RESULTS

WELL MSB 648 collected on 08/21/82, laboratory analyeses (cont)

F Analyte

o a.a-Dimethylnhenethylamine

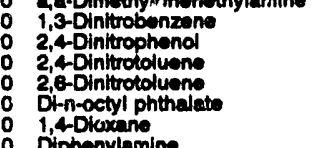

$1,4-010$

Disulfoton

O Endowulfan I

Endoevilfan sulfate

Endrin

Endrin aldehyde

Ethyl mothanesulfonate

Ethylbonzenn

Fluorenthene

Fluorene

Hoptachlor

1,2,3,4,6,7,8-HPCDD

o Heptachlorcodibenzo-p-dioxins

o Hoptachloradibenzo-p-furans

o Hexachlorobenterobutadiene

- Hexachlorocyclopentadiene

1,2,3,4,7,8-HxCDD
o
Hoxxachlorodlibenzo-p-dioxins

Hexochlorodibenzo-p-furans

Hexachloroethane

o Hoxachlorophone

o Hexachloropropene

2-Haxanone

Indeno[1,2,3-c,d]pyrene

lodomothane (Methyl lodide)

leobutyl alcohol

reodrin

leophorone

Kepone

O Lead

o Manganese

0 Mercury

Methacryloniterts

Meinapyriene

2-Methyl-4, 8-dinitrophenol

Methyl ethyl ketone

Methyl bobutyl ketone

Methyl methacylate

3-Methylcholanthren

2-Methyinaph

1,4Naphthoquinone

i-Naphthylamin

2-Naphth

Nitrato-nitrite as nitrogen

2-Nitroaniline

3-Nitroanlline

Nitrobenzene

2-Nitrophenol

4Nitroquinoline-1-oxide

N-Nitrocodi-n-butylamin

N-Nitrosodiethylamine

N-Nitrocodimethylamine

N-Nitrocodiphenylamine

N-Nitrosomethylethylamine

N-Nitrosomorphoiline

N-Nitrosopynolldine

5-Nitro-o-tuludine

O O. O-Triethyl phosphorothicate $<10$

Octachlorodibenzo-p-diaxins $<0.0010$

Octachlorodibenzo-p-furans $\quad<0.001$

Parathion methy! $\quad<0.050$

PCB $1016 \quad<0.50$

PCB 1232

P $P$ CB 1242

PCB 1254

Pentachiorobenzene

$1,2,3,7,6-P C D O$

Pentachlorodibenzo-p-dioxins

Pentachlorodibenzo-p-furans

$1,2,3,7,8-P C D F$

Pentachloroniturbenzen
$<10$

$<15$
$<10$

$<10$

$<10$
$<10$

$<0.10$

$<0.0060$

$<10$

$<1.0$

$<10$

$<0.050$

.00065

$<0.000045$

$=0.00045$

$<10$

$<0.00045$

$<0.00045$

$<0.00040$

$<10$

$<10$

$<10$
$<15$

$<100$

$<10$
$<10$

$<3.0$

7.6

$<50$
$<10$

$<0.50$

$<1.0$

$<10$

$<10$

$<10$
$<10$

$<10$
$<10$

$<4.000$

3,200
$<10$
$<10$

$<10$

$<10$

$<10$

$<10$

$<10$

<

$<11.50$

$<0.50$

$<0.50$

$<0.00055$

$<0.00055$

$<0.00055$

$<10$
$<10$

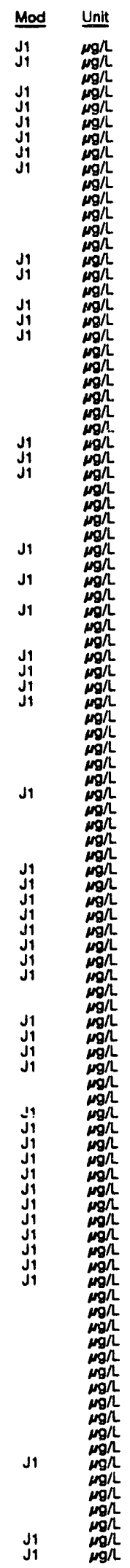

WELL MSB 648 collected on 08/21/82, laboratory analyeos (cont)

F Analyte

o Pentachlorophenol

Phenacetin

o Phenol

p-Phonylenedlamine

0 Phorate

2-Picoline

Propionizrile

0 Pyrene

o Pyridine

o selonium

sllver

- Sodium

o Styrone

0 Sulfide

0 Sulfide

Sulfotepp

0 $2,3,4,5-1$ - etrach

Tox

- Tetrachlorodibenzo-p-furans

o 1,1,1,2-Tetrachlorosthane

- 1, i,2,2-Tetrachloroethan

2 Totrachlorothylene

$2,3,4,6-T$

Thlonazin

0 Tin

: Toluene

Total organic carbon

2 Total organic halogens

: Total phosphato

2,4.5-TP (Silvex)

1,2,4-Trichlorobenzene

D i, Trichloroethene

2 Trichloroethylene

Trichlorofluoromethane

2,4,5-Trichlorophenol

2,4,6-Tricht

1,2,3-Trichloropropane

1,3,5-Trinitrobenzene

Vinyl acetate

Xylones

o Zine

Total alpha-omitting radium

Result
<10
$<10$
$<10$
$<10$
$<5.0$
$<10$
$<0.10$
$<10$
$<10$
$<200$
$<10$
$<10$
$<10$
$<2.0$
$<2.0$
55.040
$<1.0$
$<1.000$
$<1.000$
$<1.000$
$<10$
$<10$
$<0.00045$
$<0.00040$
$<0.00045$
$<0.00040$
$<1.0$
$<1.0$
61
$<10$
$<2.0$
$<10$
$<2.0$
$<1.0$
$<10$
$<1.000$
976
$<50$
$<0.24$
$<0.090$
$<10$
$<1.0$
1.1
21.440
$<1.0$
$<10$
$<10$
$<0.000$
$<1.0$
$<10$
$<20$
$<8.0$
$<1.0$
$<2.0$
12
$<2.00-08$
$<2.0 E-08$
$<1.0 E-08$

Mod Unit Le

J1 ${ }_{\text {Ji }}^{\mu g / h}$ GE

J1 $\operatorname{mog}_{\substack{\operatorname{mg} \Omega \\ \operatorname{mg} \Omega}} \mathrm{GE}$

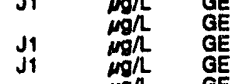

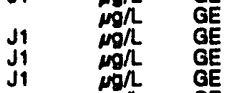

WELL MSB 64C

MEASUREMENTS CONDUCTED IN THE FIELD

Sample date: 07/25/92

Sp.

Water ovacuated before sampling: $120 \mathrm{gal}$

pH: 4.5

Alkalinity: $0 \mathrm{mg} / \mathrm{h}$

Water temperature: $212^{\circ} \mathrm{C}$

LABOPATORY ANALYSES

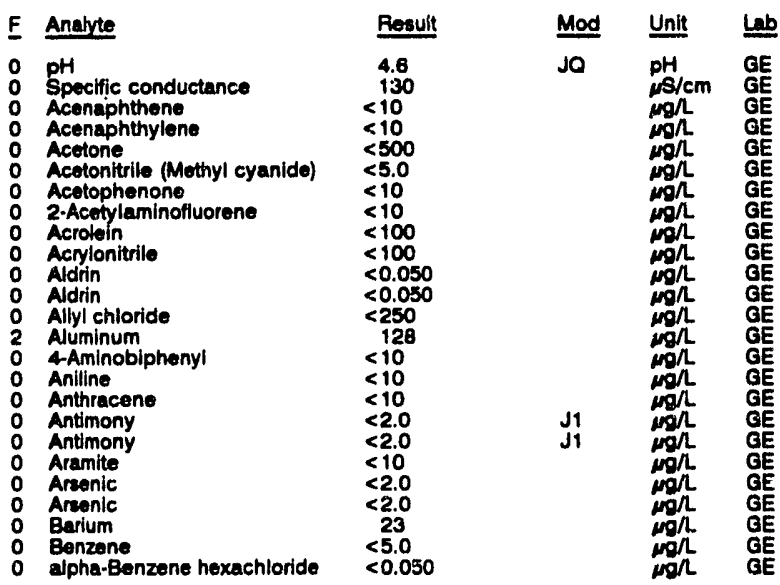


ANALYTICAL RESULTS

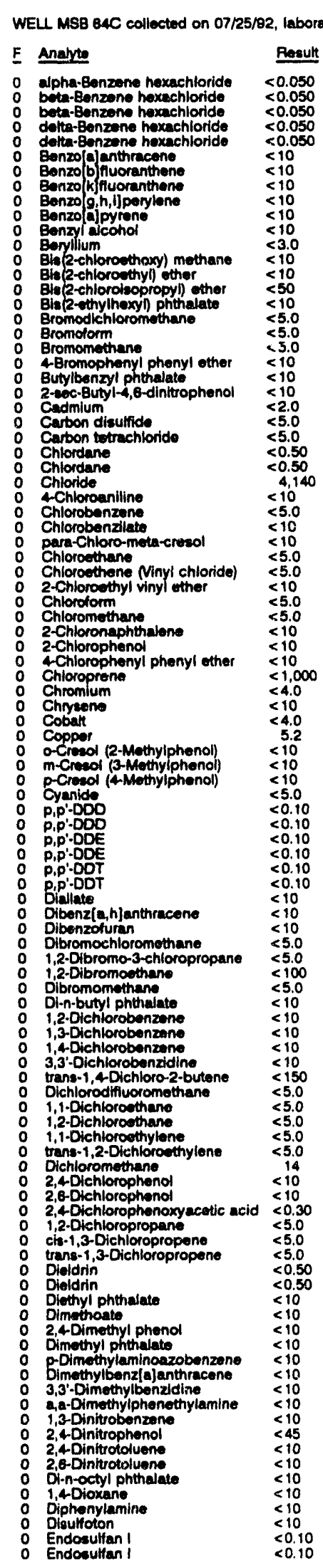

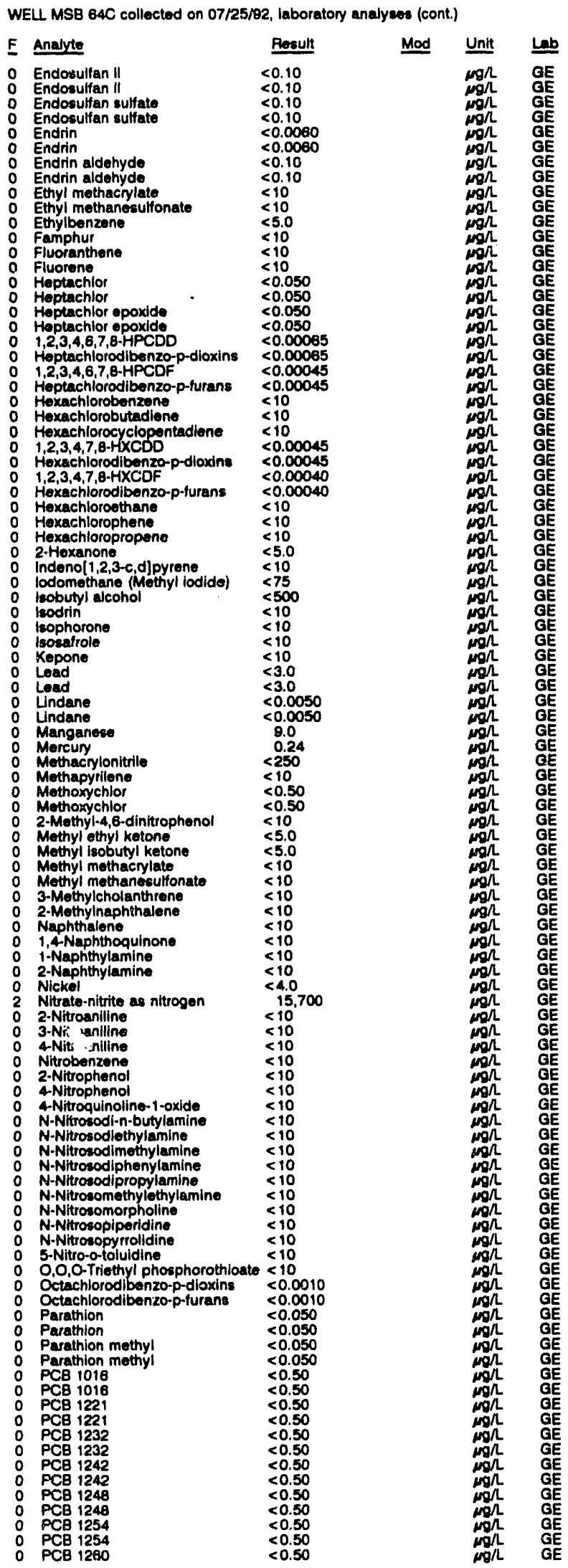


ANALYTICAL RESULTS

WELL MSB 64C collected on 07/25/92, laboratory analyses (cont.)

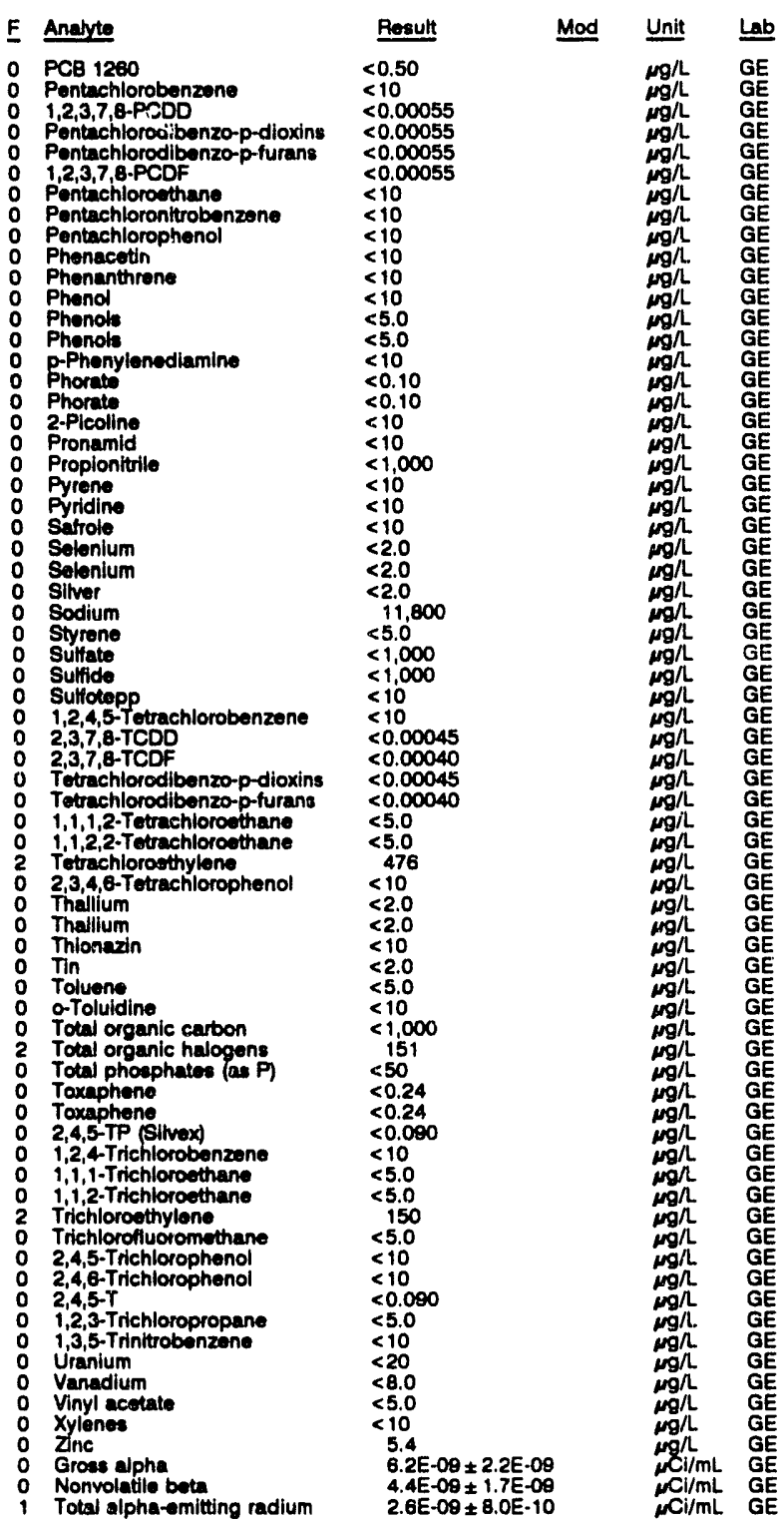

WELL MSB 64D

MEASUREMENTS CONDUCTED IN THE FIELD

Sample date: 07/25/92

Dopth to water: $121.87 \mathrm{ft}(37.15 \mathrm{~m})$ below TOC

Water elevation: 227.13 it (69.23

Sp. conductance: $206 \mu \mathrm{s} / \mathrm{cm}$

Water evacuatod before eampling: $44 \mathrm{gal}$

LABORATORY ANALYSES

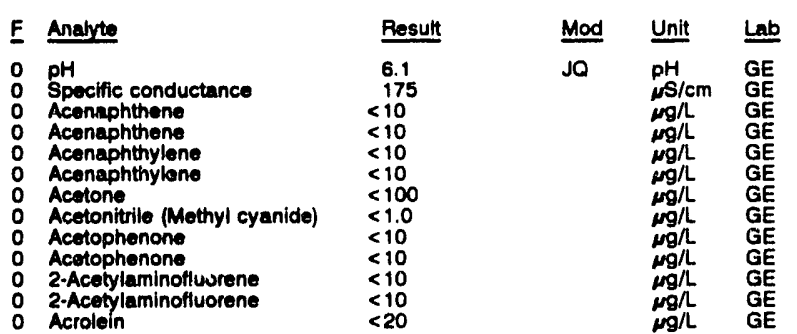

WELL. MSB 64D collocted on 07/25/92, laboratory analyses (cont.)

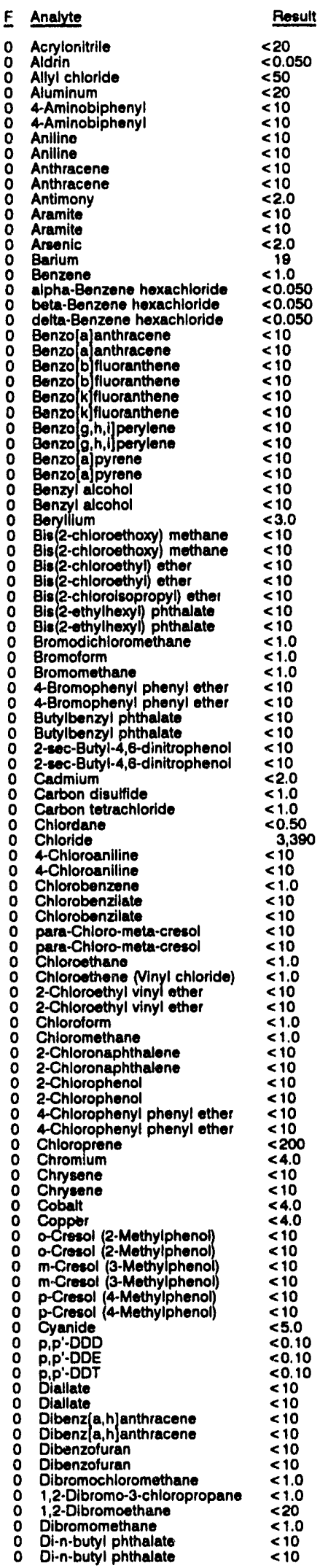

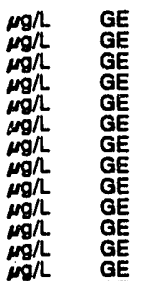


ANALYTICAL RESULTS

WELL MSB 640 collectud on 07/25/92, laboratory analyees (cont)

\section{E Anajyte}

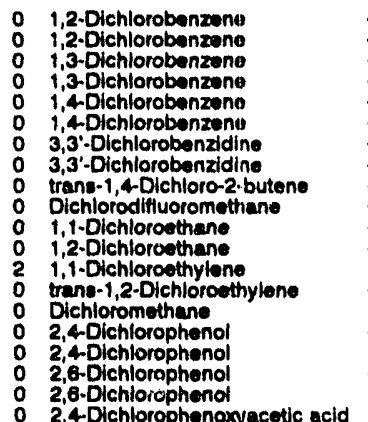

Peoult Mod Unit

2,4Dichlorophenoxyacetic acid 4

1,2-Dichloropropand

cie-1,3-Dichloropropene

Diolorin

Dithyl phthalate

Diethyl phth

Dimethoate

2,4-Dimethyl phenol

2,40imethyl phen

Dimethyl phthalat

p-Dimethylaminoazobenzene

bimmethybanz

Dimethylbenz a anthracene

3,3'-Dimethylbenzldine

a,a-Dimethylphenethylamine

a,a-Dimethylphenethylamine

1,3-Dinturobenzen

1,3-Dintrobenzane

2,4-Dinitrotoluene

2,6.Dinitrotoluene

2,0-Dinitrotoluene

O Oi-n-octyl phthalate

1,4-Diaxan

1,4-Dioxane

o Diphenylamine

Disulfoton

Diculfoton

Endosultan I

Endosultan sulfate

Endrin

$<10$
$<10$

$<10$

$<10$

$<10$
$<10$

$<30$

$<1.0$

$<1.0$

$<1.0$

21
$<1.0$
1.0

$<10$

$<10$
$<10$
$<10$

$<0.30$

$<1.0$

Endrin aldohydo

Ethyl methacrylate

Ethyl mothanesulfonate

Ethyl mothanesulfonato

Ethylbenzone

Famphur

Fluoranthene

Fluorene

Fivoreno

Heptachlor epoxide

1,2,3,4,6,7,8-HPCDD
Hoptachlorodibenzo-p-dioxin:

$1,2,3,4,6,7,8-H P C D F$

Hoptachlorodibonzo-p-furans

Hoxachlorobanzano

Hoxachlorobonzeno

Hexechlorobutadiene

Hexachlorocyclopentadiene

1,2,3,4,7,8-HXCDD

Hexachlorodlbenzo-p-dioxins

1,2,3,4,7,8-HXCDF
Hexachiorodibenzo-p-furans

Hexachloroethane

Hoxachloroethane

Hoxachlorophene

Herachorophono

Hexachloropropene

2. Hexnnone

Indeno $[1,2,3-c, d]$ pyrene

lodomethane (Methy
leobutyl alcohol
Mod Unit Lab

E Analyte

GE 0 lsodrin

0 lsoodin

o leophorone

isosafrole

Kopone

0 Kepon

Lead

Manganeso

Moreury

Mothacrylonitril

Mothapyrliene

Mothoxychlo

2-Mothyl-4,6-dinitropheno

2-Mothyl-4,6-dinitroph

Methy inglo

Mothyl methecryiate

Methyl mothacrylate

Mothyl methanesulfonate

Mothyl methanesulfonate

3-Methylcholanthrene

2-Mothylnaphthulene

2-Methylnaph

Naphthalene

0 1,4-Naphthoquinone

1.-Naphthylamin

2. Naphthylamine

2-Naphthylamin

Nickol

Nitrate-nitrite as nitrogen

2-Nitroaniline

2-Nitroaniline

3-Nitroaniline

3.Nitroaniline

4-Nitroaniline

4-Nitroaniline

Nitrobenzene

2-Nitropheno

2-Nitrophenol

4-Nitrophenol

4-Nitrophen

4-Nitroquinoline-1.oxide

4-Nitroquinoline-1-oxide

N-Nitrosodi-n-butylamine

N-Nitrosodi-n-butylamine

N-Nitrosodiethylamine

N-Nitrocodimethylamin

N-Nitrosodimethylamine

N. Nitrodiphedamin

N-Nitrosodiphenylamino

N-Nitrosodipropylamino

N-Nitrosodipropylamine

N-Nitrosomethytethylamine

N-Nitrosomethylethylamine

N-Nitrosomorpholine

$N$-Nitrosomorpholine

N-Nitrosopiperidine

N.Nitrosopyrroliding

N.Nitrosopyrrolidine

N-Nitrosepyrrolidin

5-Nitro-o-toluidine

phorothionte $<10$

Octachlorodibenzo-p-dioxins

Octachlorodibenzo-p-dioxins $<0.0010$
Octachlorodibenzo-p.turans

Parathion

Parathion mothyl

PCB 1016

PCB 1221

PCB 1232

PCB 1242

PCB 1254

PCB 1260

Pentachlorobenzene

$1,2,3,7,6 . P C D D$

Pentachlorodibenzo-p-dioxin

Pentachlorodibenzo-p-furans

$1,2,3,7,8-P C D F$

Pentachloroethane

Pentachloronitrobenzene

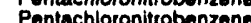

Pentachlorophenol

Pentachlorophenol

Phonacetin

Phenacetin
Phenanthrene yses (cont.)

$<<10$

$<<10$

$<10$

$<10$

$<3.0$

18

$<50$

$<10$

$<0.50$

$<10$

$<1.0$

$<10$

$<10$

$<10$

$<10$

$<10$

$<10$
$<10$

$<10$

$<10$

44.0

$<10$
$<10$

$<10$
$<10$
$<10$

$<10$
$<10$
$<10$

$<10$

$<10$

410

$<10$
$<10$
5

$\begin{aligned} &< 10 \\ &<10 \\ &<10\end{aligned}$

10

$<10$
$<10$
$<10$

510
510

$<10$

$<10$
$<10$

$<<10$

$<10$

$\leq 10$

$<0.050$

$<0.50$

$<0.50$

$<0.50$
$<0.50$
$<0.50$

$<0.50$

$\leq 10$

$<0.00055$

$<0.00055$

$<0.00055$

$<10$

$<<$

$\leq \leq 10$

$<10$
$<10$

$<10$
$<10$
$<10$

$<10$
$<10$
Jnit Let

$\mu g /$ GE

$\operatorname{mg}_{\mu, ~} \mathrm{GE}$



GE

mg

㹺

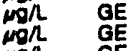

นog GE

ugh gE

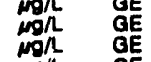

as

mol Ge

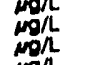





${ }_{\mu g h} \mathrm{gE}$

mon

wog

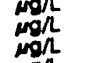

Noh GE

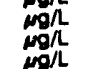

尛

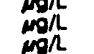

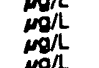

man

moh

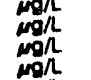

(

sis



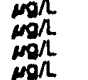


ANALYTICAL RESULTS

WELL MSB 64D collected on 07/25/92, laboratory analyses (cont.)

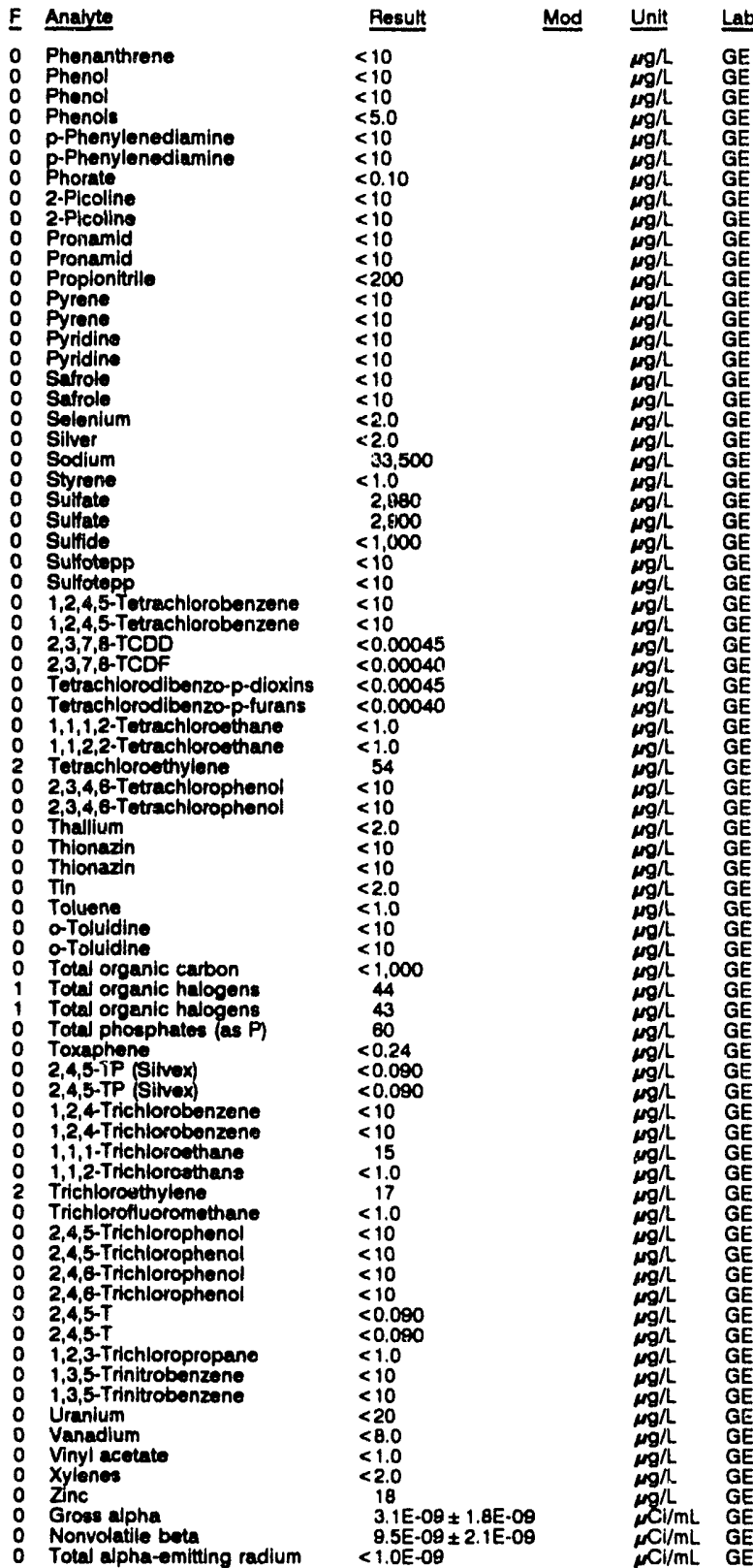

\section{WELL MSB 65D}

\section{MEASUREMENTS CONDUCTED IN THE FIELD}

Sample date: 08/10/92

Depth to water: 118.38 tt $(35.47 \mathrm{~m})$ below TOC

Water olevation: $233.12 \mathrm{t}(71.06 \mathrm{~m}) \mathrm{ms}$

Sp. conductance: $37 \mu 3 / \mathrm{cm}$

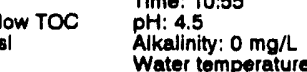

Alkalinity: $0 \mathrm{mg} / \mathrm{L}$

Water temperature: $22.7^{\circ} \mathrm{C}$

LABORATORY ANALYSES

\begin{tabular}{|c|c|c|c|c|}
\hline E & Analyte & Result & Mod & Unit \\
\hline $\begin{array}{l}0 \\
0 \\
0 \\
0\end{array}$ & $\begin{array}{l}\text { Cadmium } \\
\text { Carbon totrachloride } \\
\text { Chloroform } \\
\text { Iron } \\
\text { Lead } \\
\text { Manganese } \\
\text { Mercury } \\
\text { Mercury }\end{array}$ & $\begin{aligned}<2.0 \\
<1.0 \\
1.2 \\
5.1 \\
<3.0 \\
1.4 \\
<0.20 \\
<0.20\end{aligned}$ & & 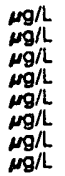 \\
\hline
\end{tabular}

WELL MSB 650 collocted on 08/10/92, laboratory analyses (cont.)

\begin{tabular}{|c|c|c|c|}
\hline Analyte & Rosult & Mod & Unit \\
\hline $\begin{array}{l}\text { Nitrate-nitrite as nitrogen } \\
\text { Phenols } \\
\text { Totrachloroethylene } \\
\text { Total organic carbon } \\
\text { Total organic halogens } \\
1,1 \text {-Trichloroethane } \\
\text { Trichloroethylene } \\
\text { Gross alpha } \\
\text { Nonvolatile bota } \\
\text { Total olpha-emitting radium } \\
\text { Tritium }\end{array}$ & $\begin{aligned} & 1,960 \\
&<5.0<1.0 \\
&< 1,000 \\
&<5.0 \\
&<1.0 \\
&<1.0 \\
& 7.6 \mathrm{E}-09 \pm 2.3 \mathrm{E}-09 \\
& 3.7 \mathrm{E}-09 \pm 1.6 \mathrm{E}-00 \\
& 3.4 \mathrm{E}-09 \pm 8.0 \mathrm{E}-10 \\
& 1.3 \mathrm{E}-06 \pm 5.0 \mathrm{E}-07\end{aligned}$ & & 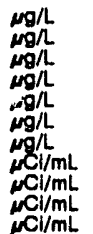 \\
\hline
\end{tabular}

WELL MSB 66B

MEASUAEMENTS CONDUCTED IN THE FIELD

$\begin{array}{ll}\text { Sample date: } 08 / 09 / 92 & \text { Time: } 14: 00 \\ \text { Depth to water: } 163.20 \mathrm{ft}(49.74 \mathrm{~m}) \text { bolow TOC } & \text { pH: } 10.4 \\ \text { Water elevation: } 220.30 \mathrm{ft}(67.15 \mathrm{~m}) \mathrm{mal} & \text { Alkalinity: } 61 \mathrm{mg} \Omega \\ \text { Sp. conductance: } 128 \mu \mathrm{s} / \mathrm{cm} & \text { Water temperature: } 23.8^{\circ} \mathrm{C} \\ \text { Wator ovacuated bofore sampling: } 263 \mathrm{gal} & \end{array}$

LABORATORY ANALYSES

\begin{tabular}{|c|c|c|c|}
\hline Analyte & Result & Unit & Lab \\
\hline $\begin{array}{l}\text { Cadmium } \\
\text { Carbon tetrachloride } \\
\text { Chloroform } \\
\text { Iron } \\
\text { Lead } \\
\text { Manganese } \\
\text { Mercury } \\
\text { Nitrate-nitrite as nitrogen } \\
\text { Phonols } \\
\text { Tetrachloroethylene } \\
\text { Total organic carton } \\
\text { Total organtc halogens } \\
\text { 1,1,1-Trichloroethane } \\
\text { Trichloroethylene } \\
\text { Gross alpha } \\
\text { Nonvolatile beta } \\
\text { Total alpha-emilting radium } \\
\text { Tritium }\end{array}$ & $\begin{array}{l}<2.0 \\
<1.0 \\
<1.0 \\
6.0 \\
<3.0 \\
<2.0 \\
<0.20 \\
1.190 \\
<5.0 \\
6.8 \\
<1.000 \\
11 \\
<1.0 \\
18 \\
<2.0 E-09 \\
2.6 E-09 \pm 1.5 E-09 \\
1.2 E-09 \pm 5.0 E-10 \\
<7.0 E-07\end{array}$ & 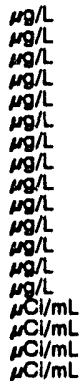 & $\begin{array}{l}\mathrm{GE} \\
\mathrm{GE} \\
\mathrm{GE} \\
\mathrm{GE} \\
\mathrm{GE} \\
\mathrm{GE} \\
\mathrm{GE} \\
\mathrm{GE} \\
\mathrm{GE} \\
\mathrm{GE} \\
\mathrm{GE} \\
\mathrm{GE} \\
\mathrm{GE} \\
\mathrm{GE} \\
\mathrm{GE} \\
\mathrm{GE} \\
\mathrm{GE}\end{array}$ \\
\hline
\end{tabular}

WELL MSB 66C

MEASUREMENTS CONDUCTED IN THE FIELD

Depth to water: 154.12 i $(46.88 \mathrm{~m})$ below TOC Water olevetion: $229.38 \mathrm{ft}(69.92 \mathrm{~m}) \mathrm{msl}$ Water evacuated before sampling: $168 \mathrm{gal}$

Time: $14: 30$

pH: 5.5

Water temperature: $22.5^{\circ} \mathrm{C}$

LABORATORY ANALYSES

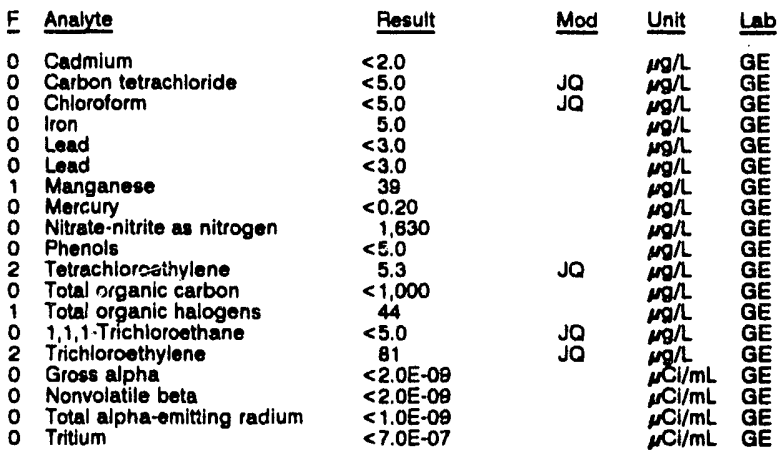

WELL MSB 66D

MEASUREMENTS CONDUCTED IN THE FIELD

Sample date: 08/09/92

Depith to water: $152.39 \mathrm{Ht}(46.45 \mathrm{~m})$ below TOC

Inaccessiblity or mechanical problem provented sample collection. 


\section{WELL MSB 66TA}

MEASUREMENTS CONDUCTEO IN THE FIELD

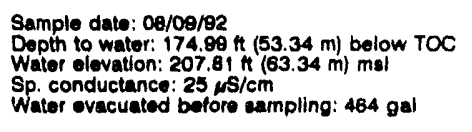
LABORATORY ANALYSES

\begin{tabular}{|c|c|c|}
\hline & Analyte & Pesult \\
\hline $\begin{array}{l}0 \\
0\end{array}$ & 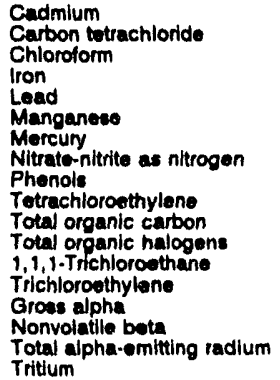 & $\begin{array}{l}<2.0 \\
<1.0 \\
<1.0 \\
44.1 \\
<3.0 \\
8.0 \\
<0.20 \\
740 \\
<5.0 \\
3.0 \\
<1.000 \\
<5.0 \\
<1.0 \\
1.6 \\
<2.0 E-09 \\
<2.0 E-09 \\
<1.0 E-09 \\
<7.0 E-07\end{array}$ \\
\hline
\end{tabular}

\section{WELL MSB 67B}

MEASUREMENTS CONOUCTED IN THE FIELD

Sample date: 08/07/92

Depth to water: $145.78 \mathrm{n}(44.43 \mathrm{~m})$ below TOC Water elevation: 218.34 t 168

Water evacuatod before sampling: $234 \mathrm{gal}$

LABORATORY ANALYSES

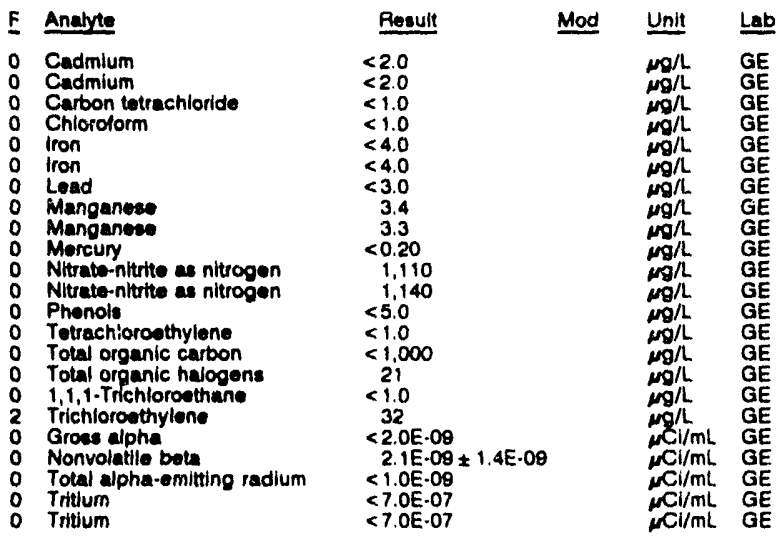

\section{WELL MSB 67C}

MEASUREMENTS CONDUCTED IN THE FIELO Sample date: 08/07/02 Depth to water: $139.00 \mathrm{~h}(42.08 \mathrm{~m})$ below TOC Water olovalion: $228.80 \mathrm{~h}$

Sp. Conductance: $16 \mu \mathrm{s} / \mathrm{cm}$ LABORATORY ANALYSES

\begin{tabular}{|c|c|c|c|c|}
\hline$E$ & Analyte & Pesull & Mod & Unit \\
\hline $\begin{array}{l}0 \\
0 \\
0 \\
0 \\
0 \\
0 \\
0 \\
0 \\
0 \\
0 \\
0 \\
0\end{array}$ & $\begin{array}{l}\text { Cadmium } \\
\text { Carbon totrachloride } \\
\text { Chloroform } \\
\text { lion } \\
\text { Load } \\
\text { Manganese } \\
\text { Mercury } \\
\text { Mercury } \\
\text { Nitrate-nitrite as nitrogen } \\
\text { Phenole } \\
\text { Totrachloroethylone } \\
\text { Total organic carbon } \\
\text { Total organic halogens }\end{array}$ & $\begin{array}{l}<2.0 \\
<5.0 \\
<5.0 \\
8.7 \\
<3.0 \\
12 \\
<0.20 \\
<0.20 \\
1.810 \\
<5.0 \\
<5.0 \\
<1.000 \\
13\end{array}$ & $\begin{array}{l}\text { JO } \\
\text { JO }\end{array}$ & 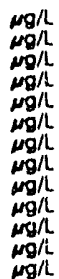 \\
\hline
\end{tabular}

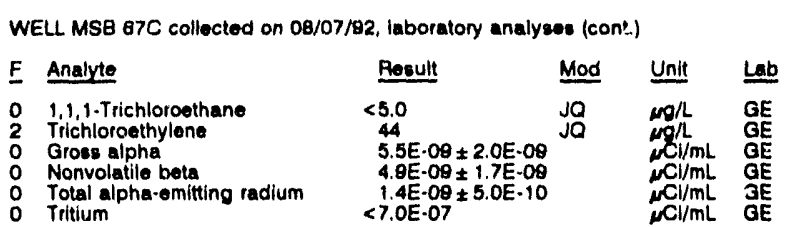

WELL MSB 67D

MEASUREMENTS CONDUCTED IN THE FIELD

Sample date: 08/13/82

Depth to waler: $132.45 \mathrm{n}(40.37 \mathrm{~m})$ below TOC Water olovation: $232.55 \mathrm{k}(70.88 \mathrm{~m}) \mathrm{msl}$ Water ovacuated bofore sampling: $29 \mathrm{gal}$

Alkalinity: $13 \mathrm{mgh}$ Alkalinity: $13 \mathrm{mgh}$ : $21.3 \circ \mathrm{C}$

LABORATORY ANALYSES

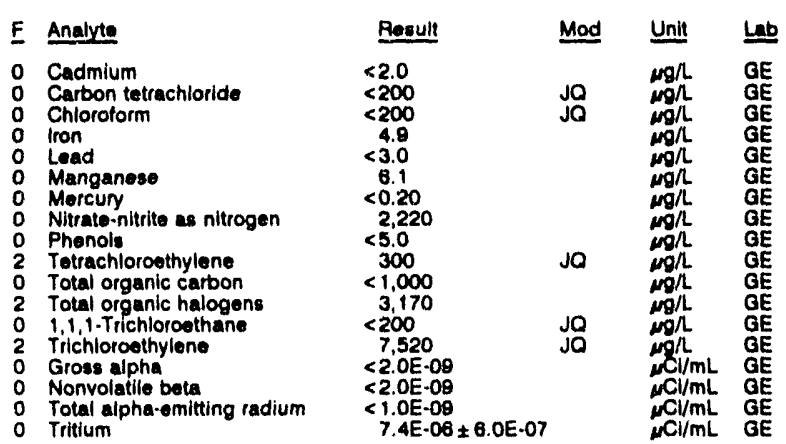

WELL MSB $68 B$

MEASUREMENTS CONDUCTED IN THE FIELD

Sample date: 08/07/92

Depth to water: 137.19 it (41.82 m) bolow TOC

Wator elevation: $218.71 \mathrm{Ht}(66.87 \mathrm{~m}) \mathrm{mal}$ Wator evacualed boloro sampling: $240 \mathrm{gal}$

PH: 4.9 : $1 \mathrm{~mol}$

Water tomperature: 20.000

LABORATORY ANALYSES

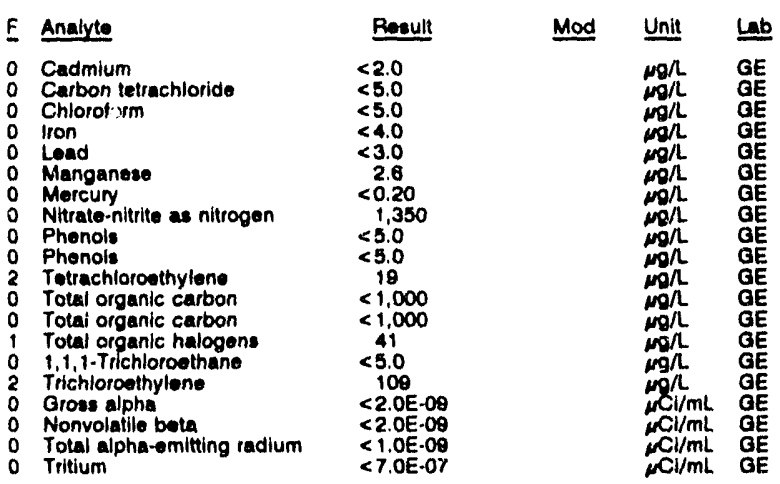

\section{WELL MSB 68C}

MEASUREMENTS CONDUCTED IN THE FIELD

Sample date: $08 / 13 / 92 \mathrm{n}(40.16 \mathrm{~m})$ below TOC Time: $7: 40$

Water eievation: $224.85 \mathrm{n}(88.57 \mathrm{~m}) \mathrm{ms} \quad$ Alkalinity: $0 \mathrm{mg}$

Sp. conductance: $30 \mu \mathrm{N} / \mathrm{cm}$
Wator evacuated botore sampling: $152 \mathrm{gal}$
Water temperature: $20.3^{\circ} \mathrm{C}$

LABORATORY ANALYSES

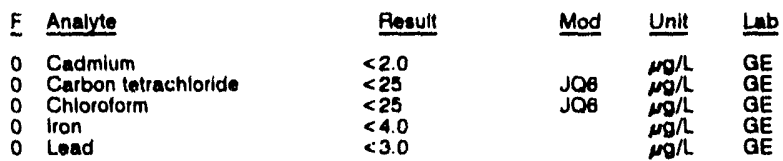




\begin{tabular}{|c|c|c|c|c|c|}
\hline$\underline{F}$ & Analyce & Result & Mod & Unit & $\underline{\text { Lab }}$ \\
\hline $\begin{array}{l}0 \\
0 \\
0 \\
0 \\
0 \\
2 \\
0 \\
2 \\
0 \\
0 \\
0\end{array}$ & $\begin{array}{l}\text { Manganese } \\
\text { Mercury } \\
\text { Nitrate-nitrite as nitrogen } \\
\text { Phenols } \\
\text { Tetrachloroethylene } \\
\text { Total orgenic carbon } \\
\text { Total organic halogenc } \\
1,1,1-\text { Trichloroethane } \\
\text { Trichioroethylone } \\
\text { Gross elpha } \\
\text { Nonvolatlle beta } \\
\text { Total alpha-emitting radium } \\
\text { Tritium }\end{array}$ & $\begin{aligned} & 4.4 \\
&< 0.20 \\
& 1.740 \\
&<5.0 \\
&<25 \\
&<1.000 \\
& 395 \\
&<25 \\
& 740 \\
& 2.9 \mathrm{E}-09 \pm 1.5 \mathrm{E}-09 \\
& 5.7 \mathrm{E}-09 \pm 1.3 \mathrm{E}-09 \\
& 1.4 \mathrm{E}-09 \pm 8.0 \mathrm{E}-10 \\
& 3.5 \mathrm{E}-06 \pm 5.0 \mathrm{E}-07\end{aligned}$ & $\begin{array}{l}J 06 \\
\text { JO6 } \\
\text { JOB }\end{array}$ & $\begin{array}{c}\mu g / L \\
\mu g / L \\
\mu g / L \\
\mu g / L \\
\mu g / L \\
\mu g / L \\
\mu g / L \\
\mu g / L \\
\mu g / L \\
\mu C l / m L \\
\mu C l / m L \\
\mu C l / m L \\
\mu C l / m L\end{array}$ & $\begin{array}{l}\mathrm{GE} \\
\mathrm{GE} \\
\mathrm{GE} \\
\mathrm{GE} \\
\mathrm{GE} \\
\mathrm{GE} \\
\mathrm{GE}\end{array}$ \\
\hline
\end{tabular}

\section{WELL MSB 68D}

MEASUREMENTS CONDUCTED IN THE FIELD

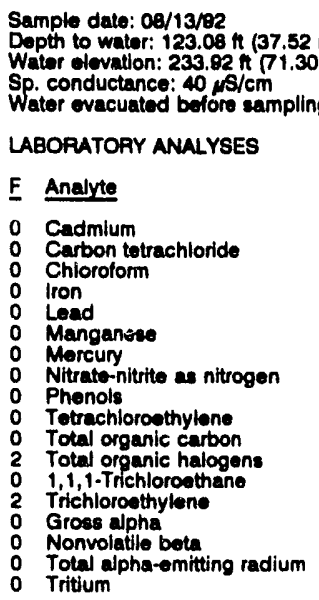

Time: 7:25

Alkalinity: $1 \mathrm{mon}$

Water temperature: $20.3^{\circ} \mathrm{C}$ Water ovacuated before sampling: $35 \mathrm{gal}$

\section{LABOPATORY ANALYSES}

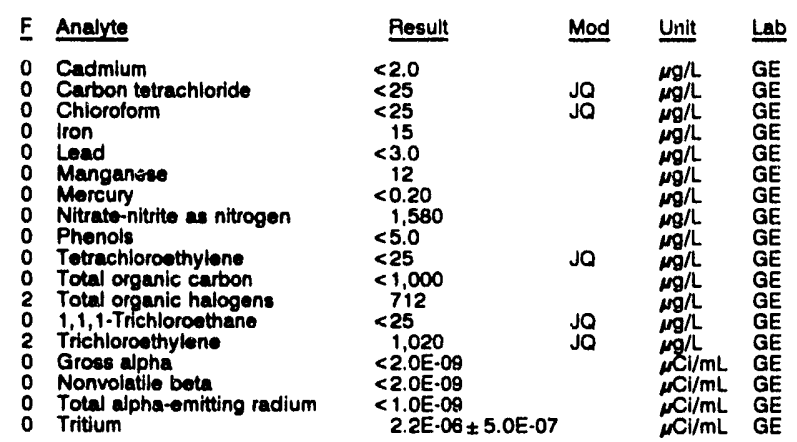

\section{WELL MSB 69B}

MEASUREMENTS CONDUCTED IN THE FIELD

Sample date: 0 s/07/g

Depth to water: $160.27 \mathrm{~h}(48.85 \mathrm{~m})$ below TOC

Wepth to water: $180.27 \mathrm{~h}(48.85 \mathrm{~m})$ below

Plkalinity: $12 \mathrm{mg} / \mathrm{L}$

Water temperature: $22.2^{\circ} \mathrm{C}$

Water evacuated bofore sampling: $214 \mathrm{gal}$

\section{LABORATORY ANALYSES}

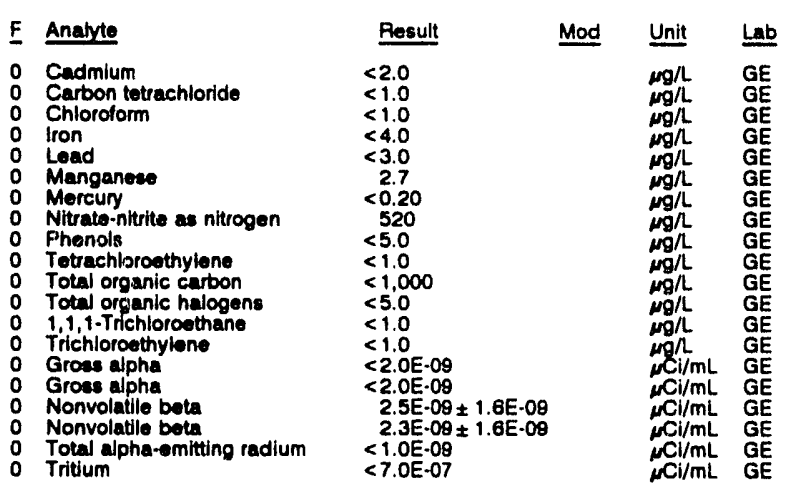

WELL MSB 69C

\begin{tabular}{|c|c|c|c|c|c|}
\hline \multicolumn{3}{|c|}{$\begin{array}{l}\text { Sample date: } 08 / 07 / 82 \\
\text { Depth to water: } 154.12 \mathrm{~h}(46.98 \mathrm{~m}) \text { below TOC } \\
\text { Water olevation: } 227.68 \mathrm{H}(69.40 \mathrm{~m}) \mathrm{msl} \\
\text { Sp. conductance: } 55 \mu \mathrm{NS} / \mathrm{cm} \\
\text { Water ovacuated before sampling: } 33 \mathrm{gal} \\
\text { The well went dry during purging. }\end{array}$} & \multicolumn{3}{|c|}{$\begin{array}{l}\text { Time: } 15: 55 \\
\text { pH: } 5.9^{-1} \\
\text { Alkalinity: } 11 \mathrm{mg} / \mathrm{L} \\
\text { Water temperature: } 22.2^{\circ} \mathrm{C}\end{array}$} \\
\hline \multicolumn{6}{|c|}{ LABORATORY ANALYSES } \\
\hline$E$ & Analyte & Result & Mod & Unit & $\underline{\underline{L}}$ \\
\hline & $\begin{array}{l}\text { Cadmium } \\
\text { Carbon totrachlorlde } \\
\text { Chloroform } \\
\text { lron } \\
\text { Lead } \\
\text { Manganese } \\
\text { Mercury } \\
\text { Nitrate-nitrite as nitrogen } \\
\text { Phenols } \\
\text { Totrachloroethylene } \\
\text { Total organic carbon } \\
\text { Total organic halogens } \\
1,1,1 \text {-Trichloroethane } \\
\text { Trichloroethylene } \\
\text { Gross alpha } \\
\text { Nonvolatile beta } \\
\text { Total alpha-emilting radium } \\
\text { Tritium }\end{array}$ & $\begin{array}{l}<2.0 \\
<5.0 \\
<5.0 \\
24 \\
<3.0 \\
20 \\
<0.20 \\
2.700 \\
<5.0 \\
<5.0 \\
<1,000 \\
82 \\
<5.0 \\
148 \\
3.3 \mathrm{E}-00 \\
3.0 \mathrm{E}-09 \\
<1.0 \mathrm{E}-09 \\
<7.0 \mathrm{E}-07\end{array}$ & $\begin{aligned} E-\infty \\
E-\infty \theta\end{aligned}$ & 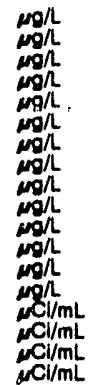 & $\begin{array}{l}\mathrm{GE} \\
\mathrm{GE} \\
\mathrm{GE} \\
\mathrm{GE} \\
\mathrm{GE} \\
\mathrm{GE} \\
\mathrm{GE} \\
\mathrm{GE} \\
\mathrm{GE} \\
\mathrm{GE} \\
\mathrm{GE} \\
\mathrm{GE} \\
\mathrm{GE} \\
\mathrm{GE} \\
\mathrm{GE} \\
\mathrm{GE} \\
\mathrm{GE} \\
\mathrm{GE}\end{array}$ \\
\hline
\end{tabular}

WELL MSB 69D

\begin{tabular}{|c|c|c|c|c|c|}
\hline \multicolumn{6}{|c|}{ MEASUREMENTS CONDUCTED IN THE FIELD } \\
\hline \multicolumn{3}{|c|}{$\begin{array}{l}\text { Sample date: } 08 / 07 / 82 \\
\text { Depth to water: } 148.33 \mathrm{ft}(45.21 \mathrm{~m}) \text { below TOC } \\
\text { Water olevation: } 233.87 \mathrm{ft}(71.28 \mathrm{~m}) \mathrm{msl} \\
\text { Sp. conductance: } 26 \mu \mathrm{s} / \mathrm{cm} \\
\text { Water evacuated before sampling: } 35 \mathrm{gal}\end{array}$} & \multicolumn{3}{|c|}{$\begin{array}{l}\text { Time: } 14: 10 \\
\text { pH: } 4.7 \\
\text { Alkalinity: } 0 \mathrm{mg} / \mathrm{h} \text {. } 22.6^{\circ} \mathrm{C} \\
\text { Water temperature: }\end{array}$} \\
\hline \multicolumn{6}{|c|}{ LABORATORY ANALYSES } \\
\hline$\underline{F}$ & Analyte & Result & Mod & Unit & Lab \\
\hline $\begin{array}{l}0 \\
0 \\
0 \\
0 \\
0 \\
0 \\
0 \\
0\end{array}$ & $\begin{array}{l}\text { Cadmium } \\
\text { Carbon tetrachloride } \\
\text { Carbon tetrachloride } \\
\text { Chloroform } \\
\text { Chloroform } \\
\text { lron } \\
\text { Lead } \\
\text { Manganese } \\
\text { Mercury } \\
\text { Nitrate-nitrite as nitrogen } \\
\text { Phenols } \\
\text { Totrachloroethylene } \\
\text { Totrachloroethylene } \\
\text { Total organic carbon } \\
\text { Total organic halogens } \\
1,1,1 \text { - Trichlorothane } \\
1,1,1 \text {-Trichlorothane } \\
\text { Trichloroethylene } \\
\text { Trichloroethylene } \\
\text { Gross alpha } \\
\text { Nonvolatile beta } \\
\text { Total alpha-emitting radium } \\
\text { Tritium }\end{array}$ & $\begin{array}{l}<2.0 \\
<1.0 \\
<1.0 \\
<1.0 \\
<1.0 \\
8.8 \\
<3.0 \\
6.8 \\
<0.20 \\
1.850 \\
<5.0 \\
<1.0 \\
<1.0 \\
<1.000 \\
<5.0 \\
<1.0 \\
<1.0 \\
<1.0 \\
<1.0 \\
1.4 E-0 \\
\theta .5 E-0 \\
1.0 \mathrm{E}-0 \\
9.3 \mathrm{E} \cdot 0\end{array}$ & $\begin{array}{l}2.0 E-09 \\
2.2 E-09 \\
5.0 E-07\end{array}$ & 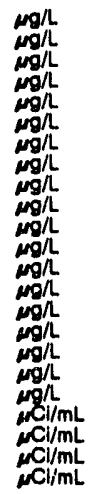 & $\begin{array}{l}G E \\
G E \\
G E \\
G E \\
G E \\
G E \\
G E \\
G E \\
G E \\
G E \\
G E \\
G E \\
G E \\
G E \\
G E \\
G E \\
G E \\
G E \\
G E \\
G E \\
G E \\
G E \\
G E \\
G E\end{array}$ \\
\hline
\end{tabular}

WELL MSB 69TA

MEASUREMENTS CONDUCTED IN THE FIELD

Sample date: 08/07/92

Depth to water: $165.72 \mathrm{H}(50.51 \mathrm{~m})$ below TOC

Water elevation: $215.78 \mathrm{At}(65.77 \mathrm{~m}) \mathrm{msl}$

ampling: $370 \mathrm{gal}$

pH: 6.0

Alkalinity: $10 \mathrm{mg} / \mathrm{L}$

Water temperature: $22.6^{\circ} \mathrm{C}$

LABORATORY ANALYSES

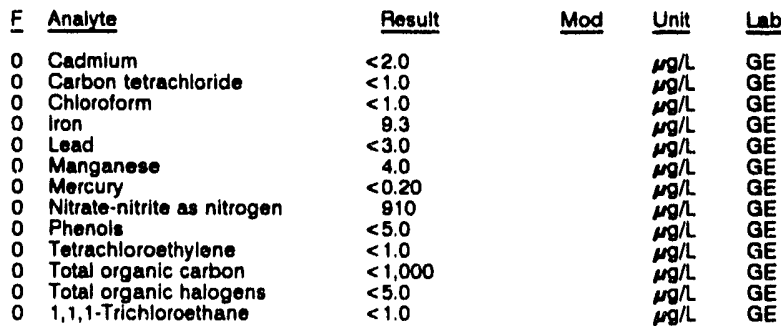




\section{ANALYTICAL RESULTS}

\begin{tabular}{|c|c|c|c|}
\hline F Analyte & Rosult & Mod & Unit \\
\hline $\begin{array}{ll}0 & \text { Trichlorouthyions } \\
0 & \text { Groes alpha } \\
0 & \text { Nonvolatile bota } \\
0 & \text { Total alpha-omitting radium } \\
0 & \text { Tritium }\end{array}$ & $\begin{array}{l}<1.0 \\
<2.0 E-09 \\
<2.0 E-09 \\
<1.0 E-09 \\
<7.0 E-07\end{array}$ & & $\begin{array}{c}\mathrm{mg}_{\mathrm{h}} \\
\mu \mathrm{Cl} / \mathrm{mL} \\
\mu \mathrm{Cl} / \mathrm{mL} \\
\mu \mathrm{Cl} / \mathrm{mL} \\
\mu \mathrm{Cl} / \mathrm{mL}\end{array}$ \\
\hline
\end{tabular}

WELL MSB 70C

MEASUREMENTS CONDUCTED IN THE FIELO

Sample date: 0Q/08/92

Depth to wathr: $144.04 \mathrm{n}(43.00 \mathrm{~m})$ below TOC Water elovation: $218.18 \mathrm{f} / 80$.

Water ovecunced bofore

LABOAATOAY ANALYSES

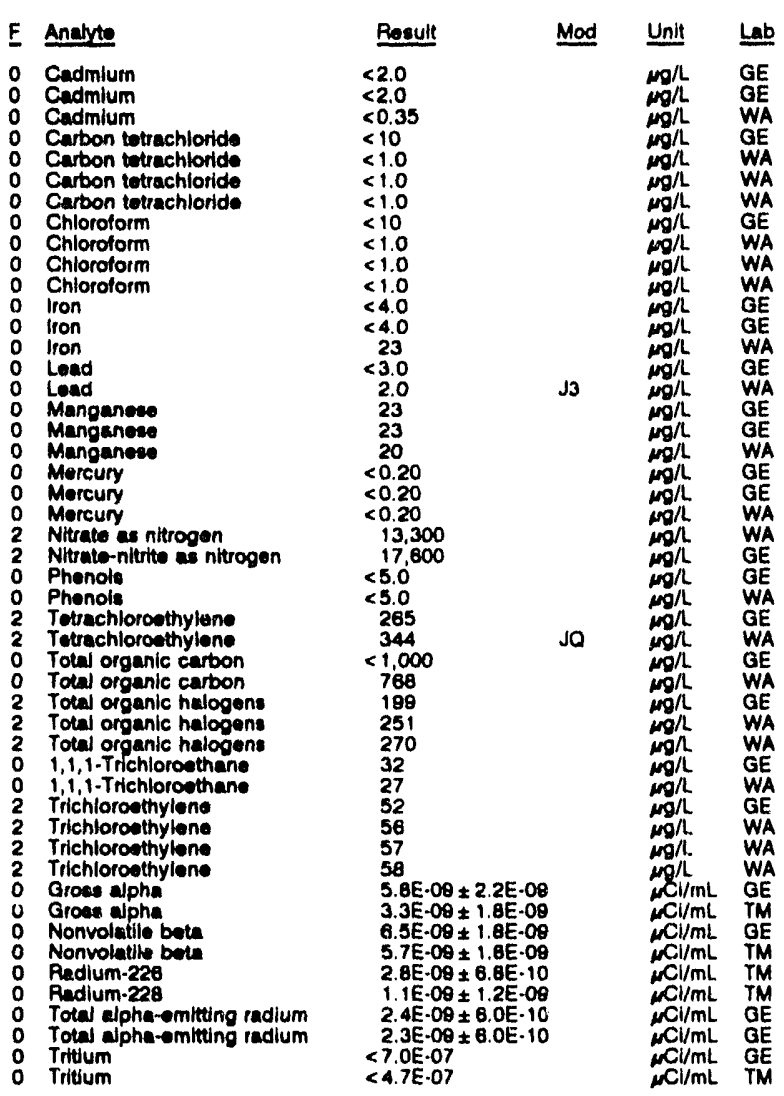

\section{WELL MSB 70C Replicate}

MEASUREMENTS CONDUCTED IN THE FIELD

Sample date: 08/08/92

Depth to water: $144.04 \mathrm{~h}(43.80 \mathrm{~m})$ below TOC

Waler elovation: $218.18 \mathrm{n}(66.50 \mathrm{~m}) \mathrm{mal}$

Sp. conductance: $175 \mathrm{~s} / \mathrm{cm}$

Wator evacuated belore sampling: $115 \mathrm{gal}$

Time: $18: 40$

PH: 5.5 .5 $7 \mathrm{~mol}$

Water tompergitur: $21.5 \circ \mathrm{C}$

LABORATORY ANALYSES

\begin{tabular}{|c|c|c|c|}
\hline F Analve & Posult & Mod & Unit \\
\hline $\begin{array}{ll}0 & \text { Cadmium } \\
0 & \text { Cadmium } \\
0 & \text { Cartoon totrachioride } \\
0 & \text { Carbon totrachloride } \\
0 & \text { Chloroform } \\
0 & \text { Chloroform } \\
0 & \text { Iron } \\
0 & \text { lron } \\
0 & \text { Lead } \\
0 & \text { Lead } \\
0 & \text { Manganese } \\
0 & \text { Manganese }\end{array}$ & $\begin{array}{l}<2.0 \\
<0.35 \\
<5.0 \\
<1.0 \\
<5.0 \\
<1.0 \\
5.0 \\
12 \\
<3.0 \\
2.0 \\
22 \\
19\end{array}$ & $\begin{array}{l}\text { JO } \\
\text { J }\end{array}$ & 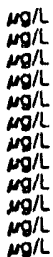 \\
\hline
\end{tabular}

WELL MSB 70C collected on 08/08/82, laboratory analyses (cont.)

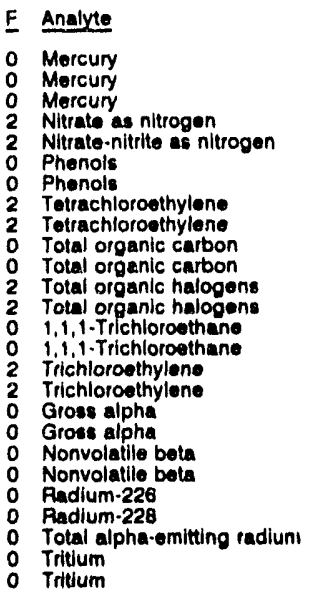

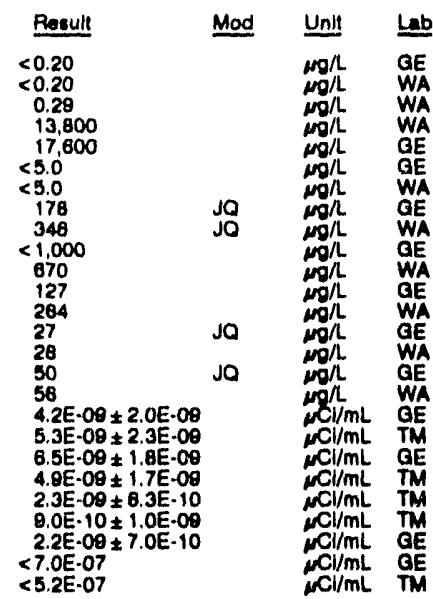

WELL MSB 70D

MEASUREMENTS CONDUCTED IN THE FIELD

Sample date: 08/09/92

Depth to water: $140.92 \pi(42.95 \mathrm{~m}$ ) below TOC

Wator elovation: $221.58 \mathrm{H}(67.54 \mathrm{~m}) \mathrm{mal}$

Sp. conductance: $88 \mathrm{\mu s} / \mathrm{cm}$.

$\lim _{\mathrm{pH}: 5.1} 7: 30$

PH: 5.1

Water evacuated betore sampling:

LABORATORY ANALYSES

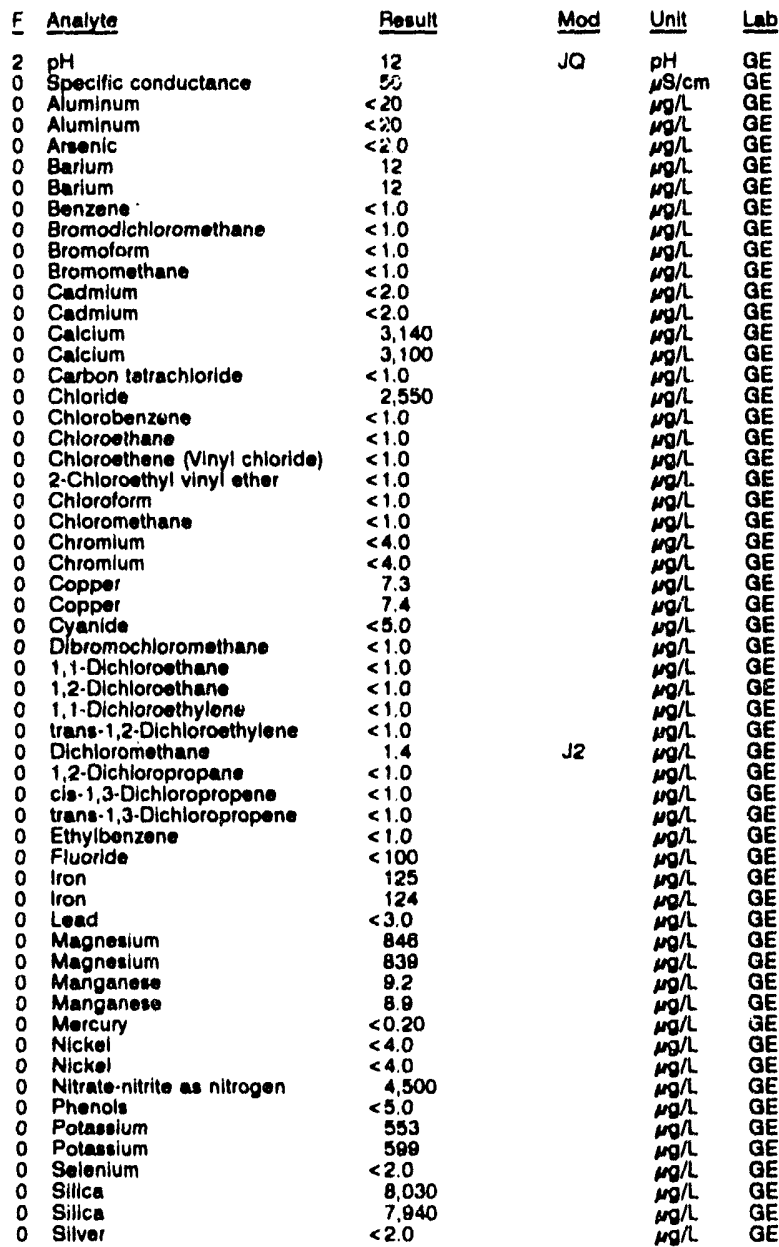


ANALYTICAL RESULTS

WELL MSB 700 collected on 08/09/82, laboratory analyees (cont.)

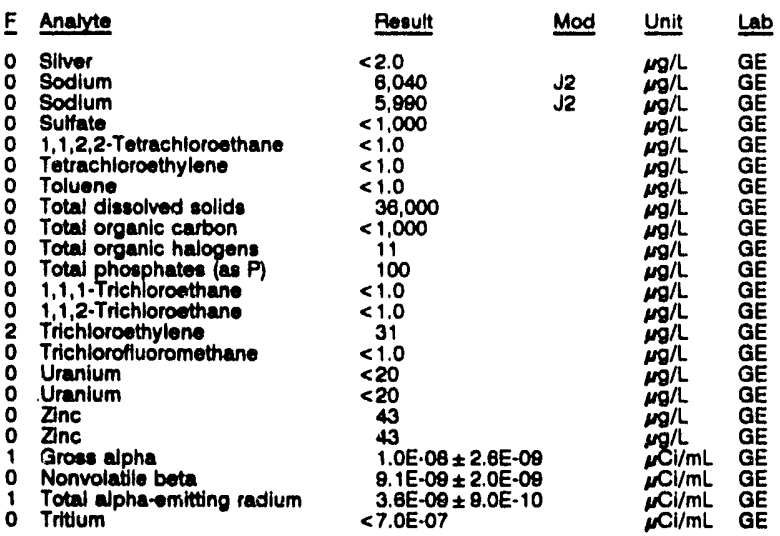

WELL MSB 71B

MEASUREMENTS CONDUCTED IN THE FIELD

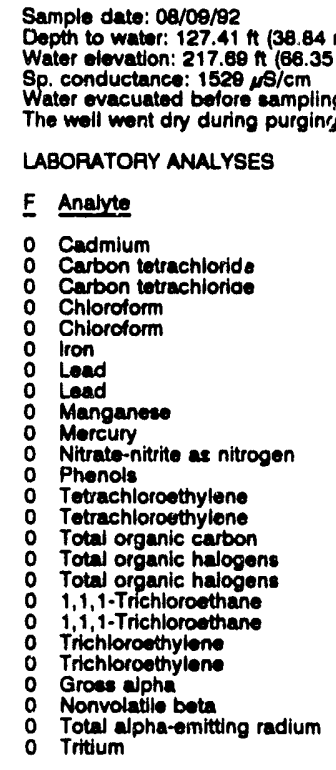

Time: 7:50

Alkalinity: $390 \mathrm{mg} /$

Water temperafure: $19.9^{\circ} \mathrm{C}$

\begin{tabular}{l}
\multicolumn{1}{r}{ Result } \\
\hline$<2.0$ \\
$<1.0$ \\
$<1.0$ \\
$<1.0$ \\
$<1.0$ \\
18 \\
$<3.0$ \\
$<3.0$ \\
$<2.0$ \\
$<0.20$ \\
100 \\
$<5.0$ \\
$<1.0$ \\
$<1.0$ \\
1.370 \\
$<5.0$ \\
$<5.0$ \\
$<1.0$ \\
$<1.0$ \\
$<1.0$ \\
$<1.0$ \\
$<2.0 \mathrm{E} \cdot 09$ \\
$2.2 \mathrm{E}-08 \pm 1.4 \mathrm{E}-09$ \\
$1.6 \mathrm{E}-09 \pm 6.0 \mathrm{E}-10$ \\
$<7.0 \mathrm{E}-07$
\end{tabular}

Mod

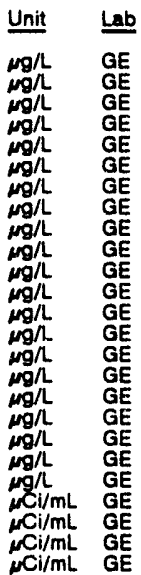

WELL MSB 72B

MEASUREMENTS CONDUCTED IN THE FIELD

Depth to wa: 08/08/92 Water elevation: $189.68 \mathrm{ft}(60.86 \mathrm{~m}) \mathrm{msl}$. Water elevation: $189.68 \mathrm{ft}(60.8$

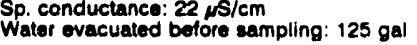

pH: 4.8

Alkalinity: $1 \mathrm{mg} / \mathrm{h}$

Water temperature: $22.6^{\circ} \mathrm{C}$

LABORATORY ANALYSES

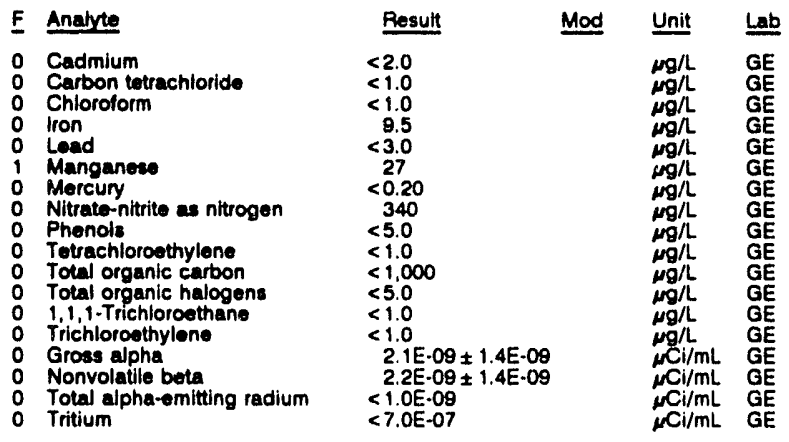

WELL MSB 73B

MEASUREMENTS CONDUCTED IN THE FIELD

Sample date: 08/07/92

Depth to water: $138.20 \mathrm{ft}(42.12 \mathrm{~m})$ below TOC

Water elevation: $202.20 \mathrm{Ht}$

Sp. conductance: $36 \mu \mathrm{s} / \mathrm{cm}$

Water evacuated betore sampling: $186 \mathrm{gal}$

LABORATORY ANALYSES

E Ansiyte

- Cadmium

Carbon totrachioride

$\begin{array}{ll}0 \\ 0 & \text { Lron } \\ 0 & \text { Load }\end{array}$

O Manganese

0 Mercury

N Nitrate-nitrite as nitrogen

Nitrate-nitrite as nitrogen

Phenols

o Tetrachloroethylene

o Total organic carbon

Total organic halogens

Total Organic halogens
0 1,1,1-Trichloroethane

2 Trichlorosthylene

2 Trichlorosthylen

o Nonvolatile beta

Total alpha-emitting radium

o Tritium

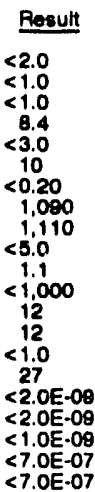

Time: 8:50

PH: 4.4

Water temperature: $20.1 \bullet \mathrm{C}$

WELL MSB 74B

MEASUREMENTS CONDUCTED IN THE FIELD

Sample date: 08/21/92

Depth to water: $104.53 \mathrm{n}(31.86 \mathrm{~m})$ below TOC

Wator elevation: $209.97 \mathrm{ft}(64.00 \mathrm{~m}) \mathrm{msl}$

Sp. conductance: $49 \mu \mathrm{s} / \mathrm{cm}$
Water evacuated before campling: $178 \mathrm{gal}$

LABORATORY ANALYSES

E Analyte

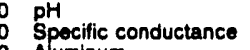

Aluminum

Arsenic

Benzene

Bromodichloromethane

Bromoform

Bromomethane

Cadmium

Caicium

Carbon tetrachloride

Chloride

Chlorobenzene

Chloroethene Ninyl chloride)

2-Chloroethyl vinyl ether

Chloromethane

Chromium

Copper

Dibromochloromethane

1.1-Dichloroethane

o 1,2-Dichloroethane

$1,1-$ Dichloroethylone
trans-1,2-Dichloroethylene

Dichloromethane

1,2-Dichloropropane

cis-1,3-Dichloropropeno

Ethylbenzene

Fluoride

0 Iron

Magnesium

Manganese

Mercury

Nitrate-nitrite as nitrogen

Phonols

Potassium

Selenlum

Silica

S Siver

Sodium

1,1,2,2-Tetrachloroethane

2 Totrachloroethylene

Toluene
Time: 14:05

$\operatorname{Time:}_{\mathrm{pH}}: \mathbf{8 . 6}$

Alkalinity: $10 \mathrm{mg} / \mathrm{h}$ Water temperature: $20.6^{\circ} \mathrm{C}$

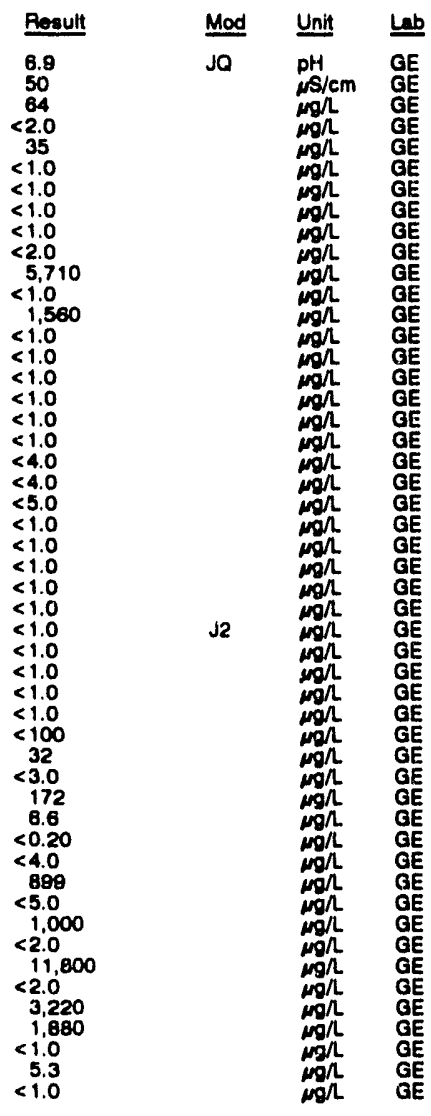


WELL M8B 748 collected on 08/21/02, laboratory analyeses (cont)

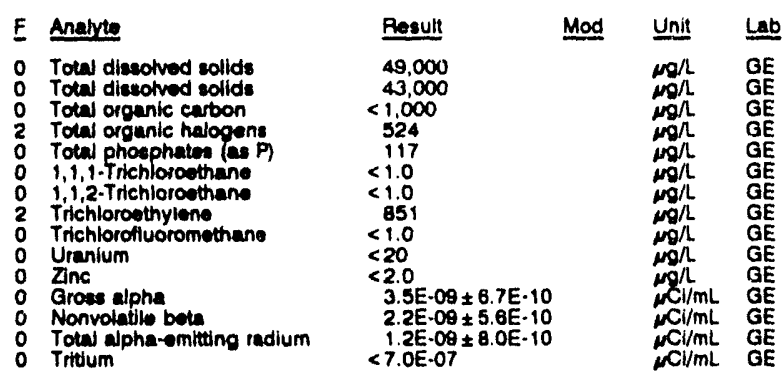

WELL MSB 74C

MEASUAEMENTS CONDUCTED IN THE FIELD

Sample date: 08109/02 $\mathrm{n}$ (31.95 m) below TOC

Water olovation: $210.17 \mathrm{n}(64.06 \mathrm{~m}) \mathrm{ms}$ !

Sp. conductance: $705 \mu \mathrm{s} / \mathrm{cm}$

The well went dy during purping: $19 \mathrm{gal}$

LABORMTORY ANALYSES

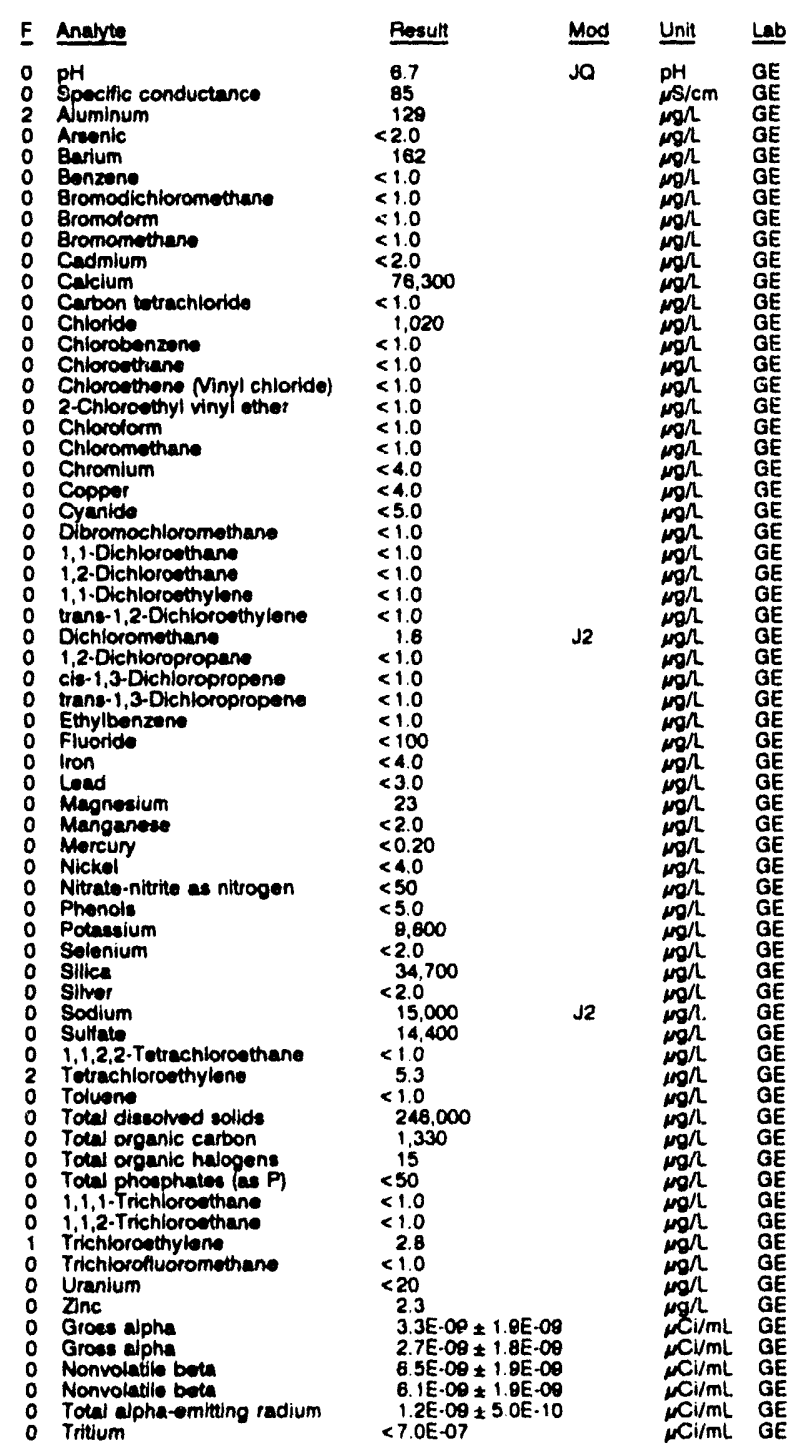

H: 11.2

Whalinity: $220 \mathrm{mg} /$.
WELL MSB 74D

MEASUREMENTS CONDUCTEO IN THE FIELO

Sample date: 08/09/82

Depth to water: $82.50 \mathrm{n}(25.18 \mathrm{~m})$ below TOC

Water olevation: $232.54 \mathrm{ht}(70.88 \mathrm{~m}) \mathrm{msl}$

Sp. conductanco: $77 \mathrm{NS} / \mathrm{cm}$

Water evacuated bofore sampling: 0 gal

LABORATORY ANALYSES

\begin{tabular}{|c|c|c|c|}
\hline Analyte & Rosult & Mod & Unit \\
\hline 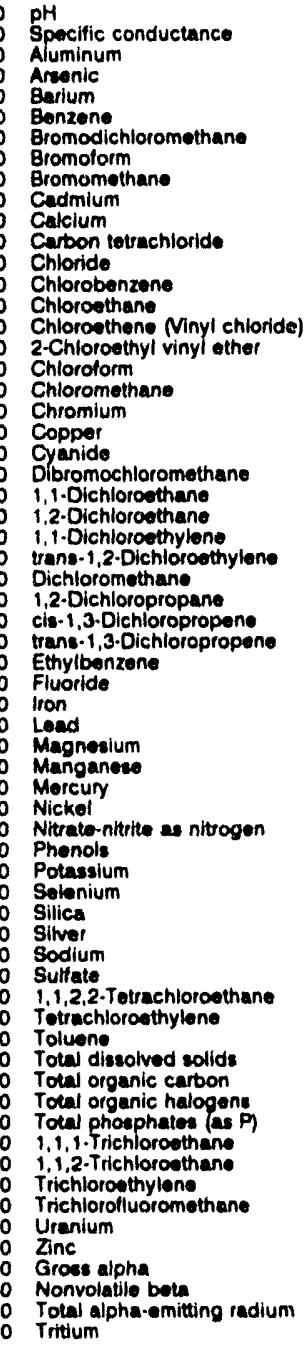 & 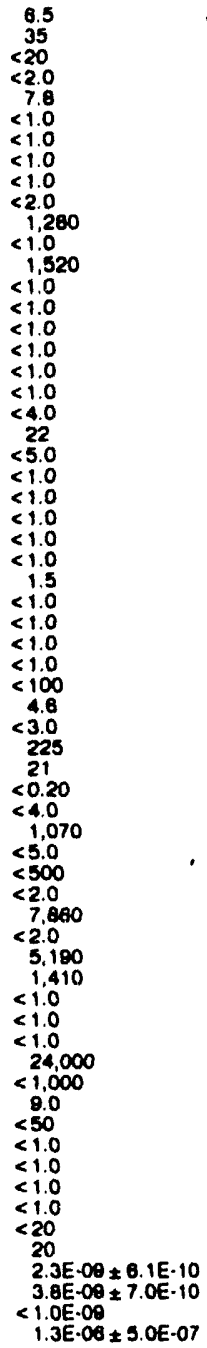 & J2 & 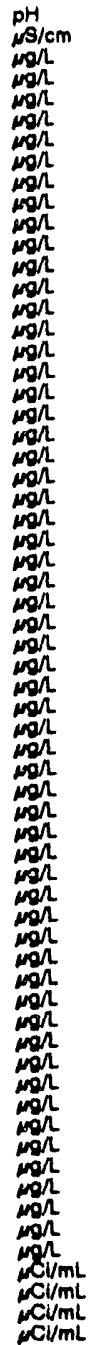 \\
\hline
\end{tabular}

WELL MSB 75B

MEASUREMENTS CONDUCTED IN THE FIELD

Sample date: 08/21/02

Depth to water: $117.94 \mathrm{n}(35.85 \mathrm{~m})$ below TOC

Water elovation: $208.78 \mathrm{ft}(63.63 \mathrm{~m}) \mathrm{mal}$

Sp. conductance: $57 \mathrm{\mu S} / \mathrm{cm}$
Water evacuatod belore sampling: $138 \mathrm{gal}$

Time: $8: 50$

PH: 5.6

Water tomperature: $20.4^{\circ} \mathrm{C}$

Water evacuatod belore al

\begin{tabular}{|c|c|c|c|}
\hline Analyte & Result & Mod & Unit \\
\hline $\begin{array}{l}\text { pH } \\
\text { Speclfic conductance } \\
\text { Auminum } \\
\text { Aurenic } \\
\text { Barlum } \\
\text { Benzene } \\
\text { Benzene }\end{array}$ & $\begin{array}{r}6.1 \\
50 \\
20 \\
<2.0 \\
27 \\
<5.0 \\
<5.0\end{array}$ & Jo & 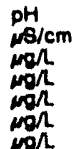 \\
\hline
\end{tabular}


ANALYTICAL RESULTS

WELL MSB 758 collected on 08/21/92, laboratory analyees (cont.)

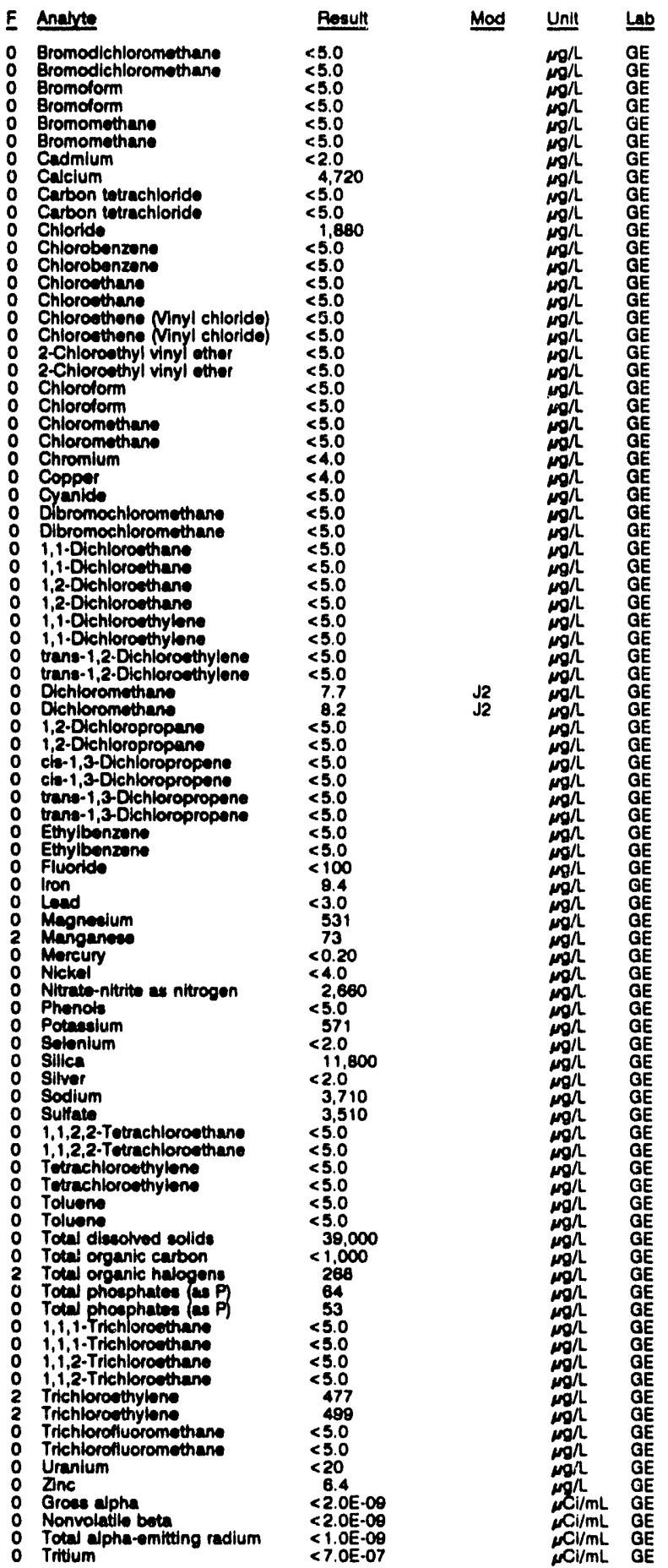

WELL MSB 75C

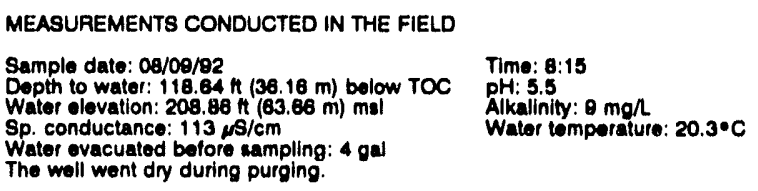

LABORATOAY ANALYSES

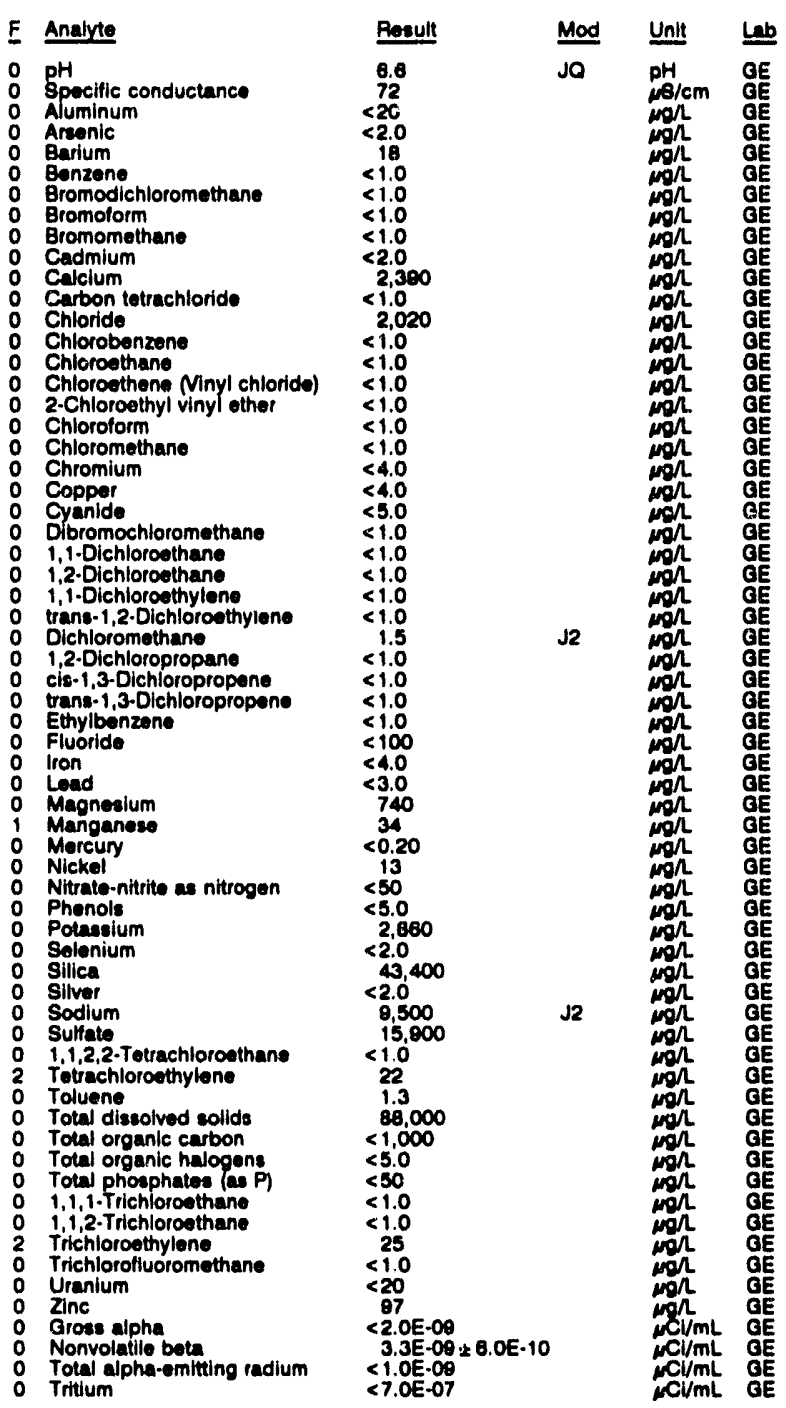

WELL MSB 76C

MEASUREMENTS CONDUCTED IN THE FIELD

\begin{tabular}{|c|c|}
\hline $\begin{array}{l}2 \\
\text { Sn }(40.16 \mathrm{~m}) \text { below TOC } \\
\text { Os } \mathrm{n}(87.38 \mathrm{~m}) \mathrm{mal}\end{array}$ & $\begin{array}{l}15 \mathrm{mg} / \mathrm{h} \\
\text { porature: } 20.0^{\circ} \mathrm{C}\end{array}$ \\
\hline
\end{tabular}
LABOFATORY ANALYSES

\begin{tabular}{|c|c|c|c|c|}
\hline F Analyte & Result & Mod & Unit & La \\
\hline $\begin{array}{ll}0 & \text { pH } \\
0 & \text { Specific conductance } \\
2 & \text { Aluminum } \\
0 & \text { Arenic } \\
0 & \text { Barium } \\
0 & \text { Benzene } \\
0 & \text { Bromodichloromothane }\end{array}$ & $\begin{array}{l}6.5 \\
60 \\
126 \\
<2.0 \\
10 \\
<50 \\
<50\end{array}$ & Ja & 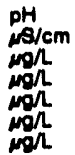 & $\begin{array}{l}\text { CE } \\
\mathrm{GE} \\
\mathrm{GE} \\
\mathrm{GE} \\
\mathrm{GE} \\
\mathrm{GE} \\
\mathrm{GE}\end{array}$ \\
\hline
\end{tabular}


ANALYTICAL RESULTS

\begin{tabular}{|c|c|c|c|}
\hline E Anclyote & Benult & Mod & Unit \\
\hline 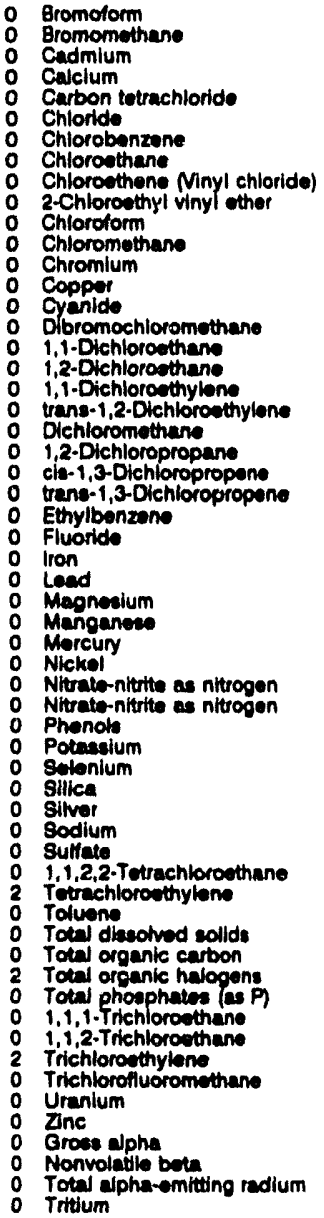 & 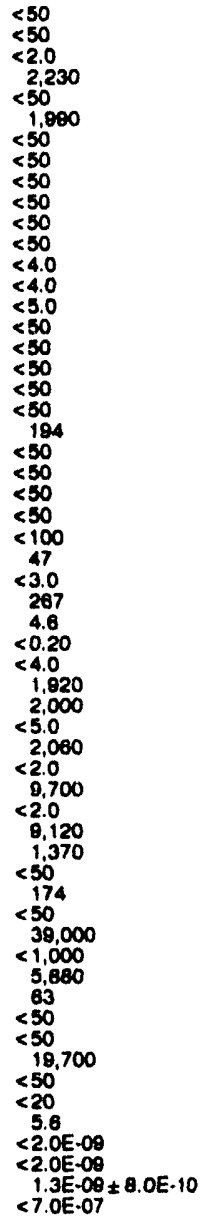 & $\sqrt{2}$ & 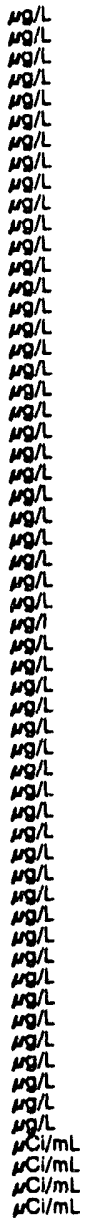 \\
\hline
\end{tabular}

WELL MSB 77B

MEASUREMENTS CONDUCTED IN THE FIELL

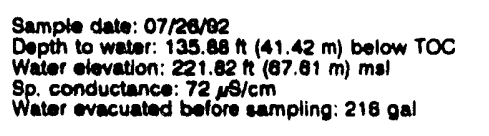

Time: : 8:10

pH: 9.1 . $40 \mathrm{~mol}$

Water temperature: $18.7^{\circ} \mathrm{C}$ LABOAATOAY ANALYSES

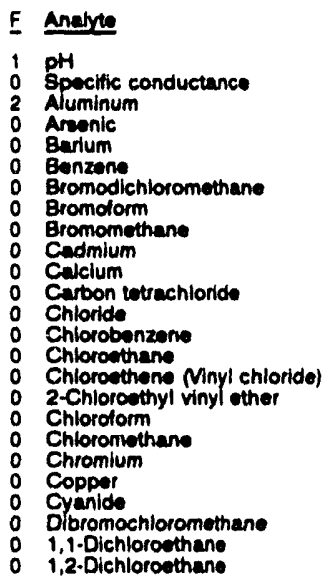

WELL MSB 77B collected on 07/28/82, laboratory analyees (cont.)
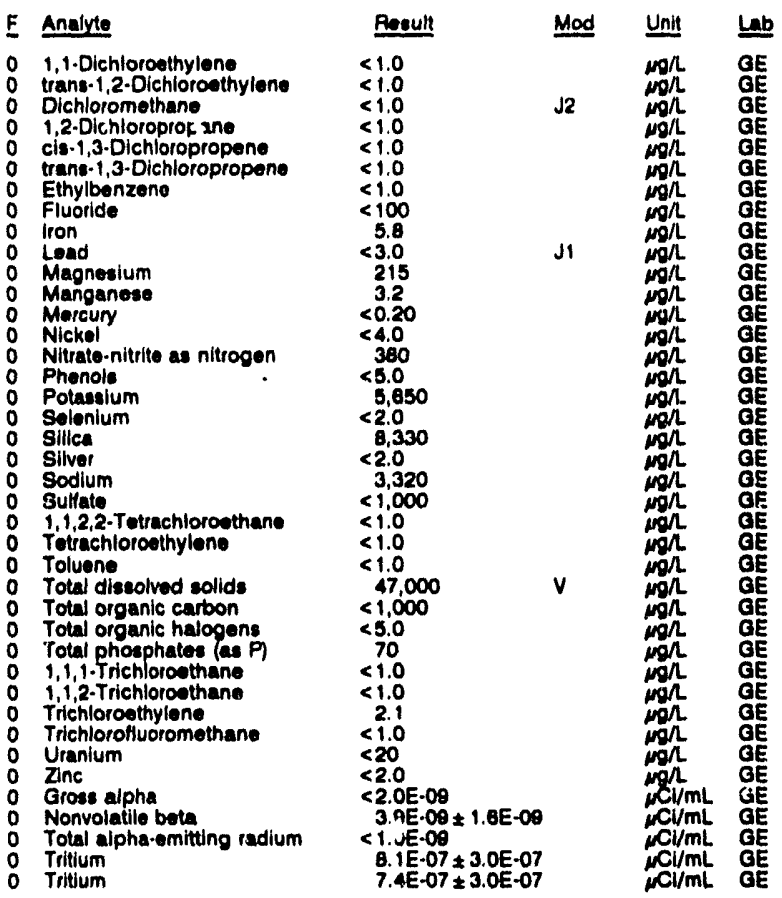

WELL MSB 77C

MEASUREMENTS CONDUCTED IN THE FIELD

Sample dato: 07/26/92 $\mathrm{H}(40.68 \mathrm{~m})$ bolow TOC Water olevation: $224.24 \mathrm{ft}(68.35 \mathrm{~m}) \mathrm{msl}$ Water evacuated bofore rampling: $145 \mathrm{gal}$

$\lim _{0.80} 8.00$

PH: 8.0 . $15 \mathrm{mon}$ Alkalinity: $15 \mathrm{mgh}$ : $20.8 \cdot \mathrm{C}$ LABORATOAY ANALYSES

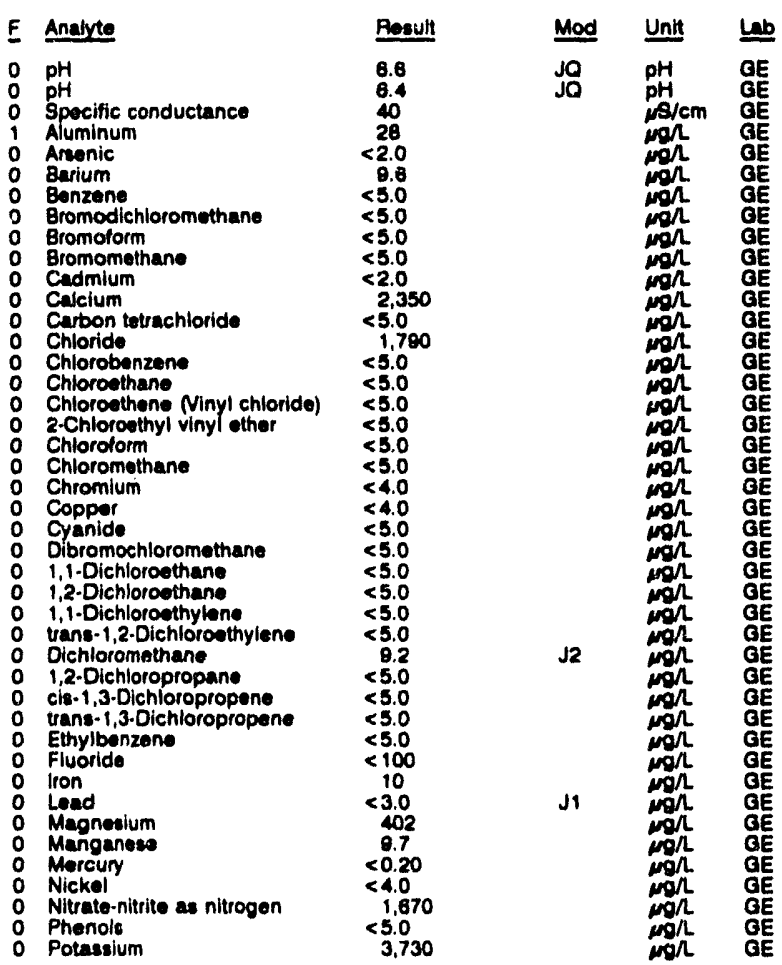


ANALYTICAL RESULTS

WELL M88 $77 \mathrm{C}$ collected on 07/28/82, laboratory analyses (cont.)

\begin{tabular}{|c|c|c|c|}
\hline Analyte & Result & Mod & Unit \\
\hline 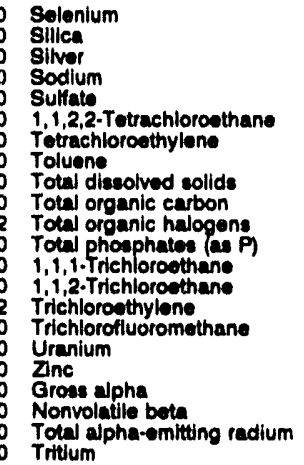 & $\begin{array}{l}<2.0 \\
8,320 \\
<2.0 \\
3,310 \\
<1,000 \\
<5.0 \\
<5.0 \\
<5.0 \\
35,000 \\
<1,000 \\
77 \\
150 \\
<5.0 \\
<5.0 \\
228 \\
<5.0 \\
<20 \\
4.0 \\
<2.0 \mathrm{E} \cdot 09 \\
3.1 \mathrm{E}-09 \pm 1.5 \mathrm{E}-09 \\
<1.0 \mathrm{E}-09 \\
7.2 \mathrm{E} \cdot 07 \pm 3.0 \mathrm{E} \cdot 07\end{array}$ & $v$ & $\begin{array}{l}\mu g / L \\
\mu g / L \\
\mu g / L \\
\mu g / L \\
\mu g / L \\
\mu g / L \\
\mu g / L \\
\mu g / L \\
\mu g / L \\
\mu g / L \\
\mu g / L \\
\mu g / L \\
\mu g / L \\
\mu g / L \\
\mu g / L \\
\mu g / L \\
\mu g / L \\
\mu / L \\
\mu C i / m L \\
\mu C i / m L \\
M C i / m L \\
\mu C i / m L\end{array}$ \\
\hline
\end{tabular}

WELL MSB 77D

MEASUREMENTS CONDUCTED IN THE FIELD

Sample date: 07/28/02

Depth to water: 128.51 i $(38.56 \mathrm{~m})$ bolow TOC

Water elevetion: $231.29 \mathrm{f}(70.50 \mathrm{~m}) \mathrm{mst}$

Sp. conductance: $558 \mathrm{~s} / \mathrm{cm}$

Water evacuated bofore sampling: $11 \mathrm{gal}$

The woll wont dry during purging.

LABORATORY ANALYSES

\begin{tabular}{|c|c|c|c|}
\hline Anabte & Result & Mod & Unit \\
\hline 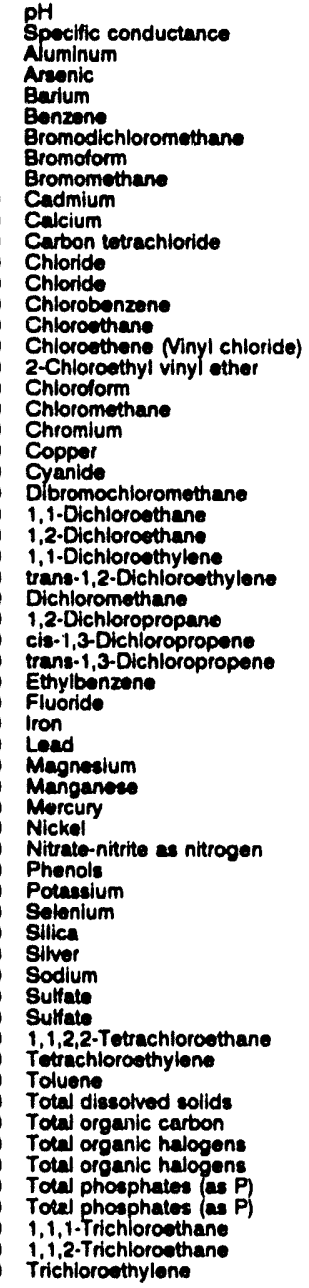 & $\begin{array}{l}11 \\
320 \\
2.020 \\
9.4 \\
21 \\
<1.0 \\
<1.0 \\
<1.0 \\
<1.0 \\
<2.0 \\
3.000 \\
<1.0 \\
1.540 \\
1,470 \\
<1.0 \\
<1.0 \\
<1.0 \\
<1.0 \\
<1.0 \\
<1.0 \\
5.4 \\
<4.0 \\
<5.0 \\
<1.0 \\
<1.0 \\
<1.0 \\
<1.0 \\
<1.0 \\
<1.0 \\
<1.0 \\
<1.0 \\
<1.0 \\
<1.0 \\
293 \\
15 \\
<3.0 \\
8.7 \\
<2.0 \\
<0.20 \\
<4.0 \\
210 \\
<5.0 \\
45,600 \\
<2.0 \\
12,300 \\
<2.0 \\
50,500 \\
10,300 \\
10,300 \\
<1.0 \\
<1.0 \\
<1.0 \\
223,000 \\
1.000 \\
<5.0 \\
<5.0 \\
150 \\
150 \\
<1.0 \\
<1.0 \\
<1.0 \\
\end{array}$ & JO & 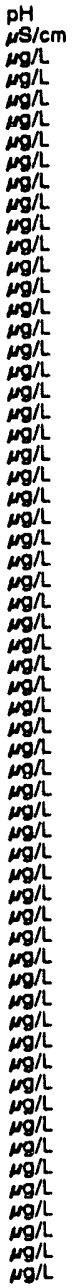 \\
\hline
\end{tabular}

WELL MSB 770 collected on 07/26/82, laboratory analyses (cont.)

\begin{tabular}{|c|c|c|c|c|}
\hline$E$ & Analyte & Result & Unit & Lab \\
\hline & $\begin{array}{l}\text { Trichlorofluoromethane } \\
\text { Uranium } \\
\text { Zine } \\
\text { Gross alpha } \\
\text { Nonvolatile bota } \\
\text { Total alpha-emilting radium } \\
\text { Tritlum }\end{array}$ & $\begin{array}{l}<1.0 \\
<20 \\
<2.0 \\
<2.0 \mathrm{E} \cdot 09 \\
2.7 \mathrm{E} \cdot 08 \pm 3.0 \mathrm{E} \cdot 09 \\
1.0 \mathrm{E} \cdot 09 \pm 8.0 \mathrm{E} \cdot 10 \\
1.1 \mathrm{E} \cdot 08 \pm 3.0 \mathrm{E} \cdot 07\end{array}$ & 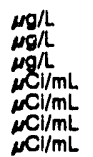 & $\begin{array}{l}\mathrm{GE} \\
\mathrm{GE} \\
\mathrm{GE} \\
\mathrm{GE} \\
\mathrm{GE} \\
\mathrm{GE} \\
\mathrm{GE}\end{array}$ \\
\hline
\end{tabular}

WELL MSB 77TA

MEASUMEMENTS CONDUCTED IN THE FIELD

Sample date: 07/26/82 Depth to water: $130.10 \mathrm{H}(42.40 \mathrm{~m})$ below TOC Water elevation: $218.30 \mathrm{ft}(86.54 \mathrm{~m}) \mathrm{msl}$

Water evacuated bofore sampling: $60 \mathrm{gal}$ The well went dry during purging.

LABORATORY ANALYSES

F Analyte

$2 \begin{aligned} & 2 \\ & 0 \\ & 0\end{aligned}$

2 Aluminum

Arsonlc

Benzene

Benzene

Bromodichloromethane

Eromodichloromethan

Bromolorm

- Bromoform

Bromomethane

- Cadmium

- Calcium

Garbon tetrachloride

Chloride

Chlorobenzene

Chlorobenzene

Chloroethane

Chlorothane Minyl chloride

Chinyl chloride

2-Chloroethyl vinyl ether

Chloroform

Chloroform

Chloromethane

Chloromethan

Chromium

Copper

o Dibromochloromethane

Dibromochloromethan

1.1.Dichloroethane

1,1-Dichloroethane

1,2-Dichloroethane

1,2-Dichloroethane

1,1-Dichloroethylene

trans-1,2-Dichloroethylene

trans-1,2-Dichloroethylene

O Dichioromethane

Dichioromethane

1,2-Dichloropropane

1,2-Dichloropropane

cis-1,3-Dichloropropene

cis-1,3-Dichloropropene

trans-1,3-Dichloropropene

Ethylbenzene

Ethylbenzen

Fluoride

Iron

Magnesium

Manganese

Mercury

Nitrate-nitrite as nitrogen

Nitrate-n

Potassium

Solenium

Silica

Silver

Sodium

1,1,2,2-Tetrachloroethane

$1,1,2,2$. Tetrachlorosthan

Totrachloroethylene

Tolvene

Toluene

Total dissolved solids

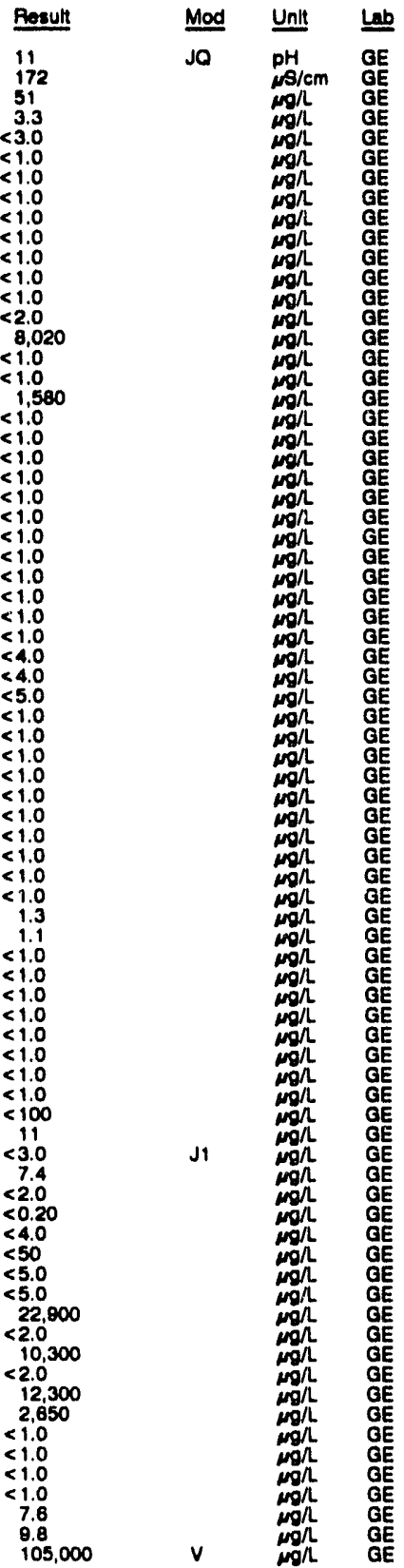

Time: 0:40

Alkalinity: $156 \mathrm{mo} / \mathrm{L}$

Water temperature: $20.2^{\circ} \mathrm{C}$

E

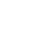




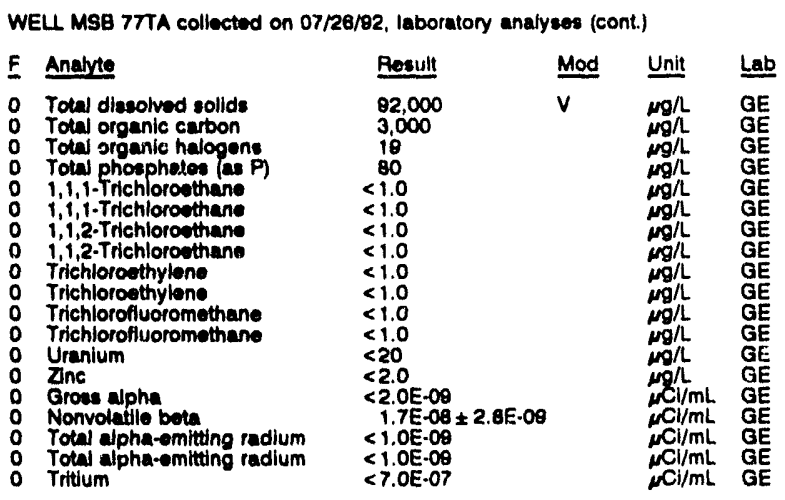

WELL MSB 78D

MEASUREMENTS CONOUCTED IN THE FIELD

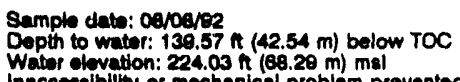

Time: 16:00

\section{WELL MSB 79B}

MEASUREMENTS CONDUCTED IN THE FIELD

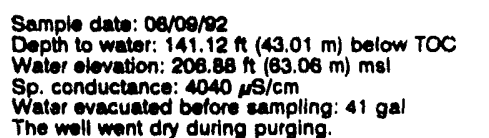

Time: 7:00

Alkalinity: $1087 \mathrm{mg} / \mathrm{L}$

Water temperature: $18.6^{\circ} \mathrm{C}$

The woll went dry during purging.

LABOPATORY ANALYSES

\begin{tabular}{|c|c|c|c|}
\hline Analyte & Rasult & Mod & Unit \\
\hline 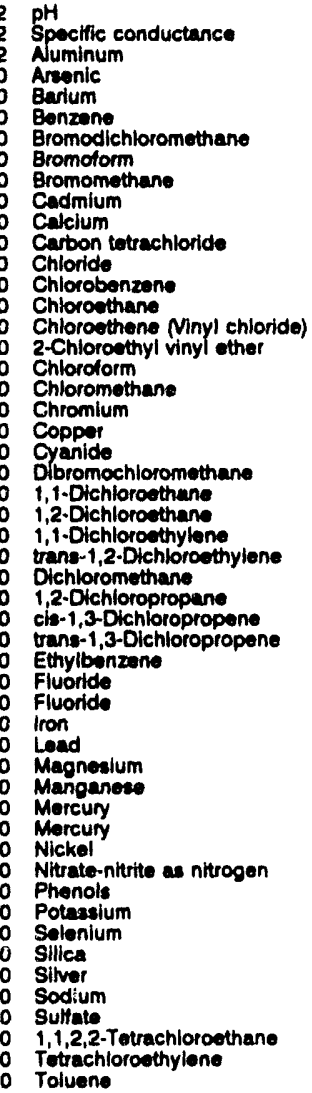 & $\begin{aligned} 12 \\
4,700 \\
2,530 \\
<2.0 \\
979 \\
<1.0 \\
<1.0 \\
<1.0 \\
<1.0 \\
<4.0 \\
414,000 \\
<1.0 \\
570 \\
<1.0 \\
<1.0 \\
<1.0 \\
<1.0 \\
<1.0 \\
<1.0 \\
<8.0 \\
10.0 \\
<5.0 \\
<1.0 \\
<1.0 \\
<1.0 \\
<1.0 \\
<1.0 \\
5.6 \\
<1.0 \\
<1.0 \\
<1.0 \\
<1.0 \\
140 \\
142 \\
<8.0 \\
<3.0 \\
6.8 \\
<4.0 \\
<0.20 \\
<0.20 \\
<8.0 \\
870 \\
<5.0 \\
58,300 \\
<2.0 \\
1.480 \\
<2.0 \\
68.600 \\
3.180 \\
<1.0 \\
<1.0 \\
<1.0 \\
<\end{aligned}$ & Jo & 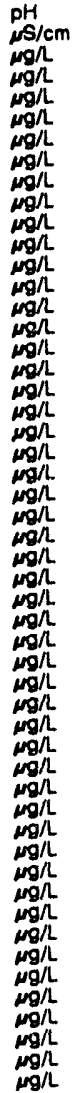 \\
\hline
\end{tabular}

WELL MSB 798 collected on 08/09/92, laboratory analyese (cont.)

\begin{tabular}{|c|c|c|c|c|}
\hline & Analyte & Result & Unit & Lab \\
\hline & 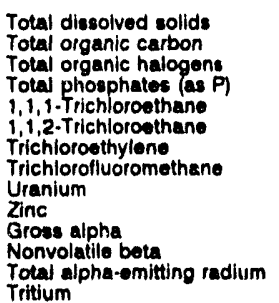 & $\begin{array}{l}1.1 E+06 \\
1.550 \\
16 \\
<50 \\
<1.0 \\
<1.0 \\
<1.0 \\
<1.0 \\
<40 \\
8.1 \\
5.1 E-09 \pm 7.2 E-10 \\
1.9 E-08 \pm 1.0 E-09 \\
2.3 E-09 \pm 7.0 E-10 \\
<7.0 E-07\end{array}$ & 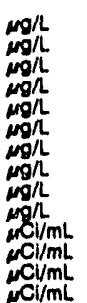 & $\begin{array}{l}G E \\
G E \\
G E \\
G E \\
G E \\
G E \\
G E \\
G E \\
G E \\
G E \\
G E \\
G E \\
G E \\
G E\end{array}$ \\
\hline
\end{tabular}

\section{WELL MSB 79C}

MEASUREMENTS CONDUCTED IN THE FIELD

Sample date: 08/09/92

Dopth to water: $138.50 \mathrm{~h}(42.22 \mathrm{~m})$ below TOC

Wator olovation: $209.30 \mathrm{n}(63.80 \mathrm{~m}) \mathrm{mal}$

Sp. conductance: $1507 \mathrm{\mu S} / \mathrm{cm}$

Whe well wacuatod bolore erempling: 7 gal

LABORATORY ANALYSES

\begin{tabular}{|c|c|c|c|}
\hline Analyze & Pesult & Mod & Unitt \\
\hline 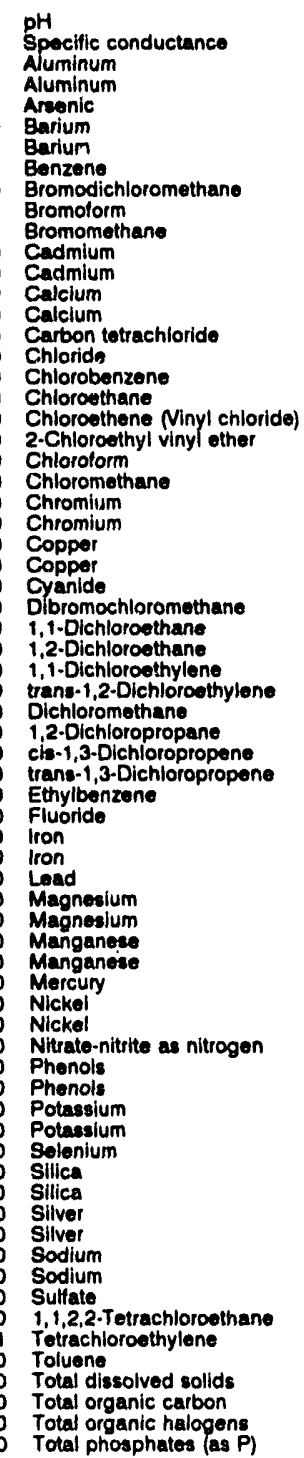 & 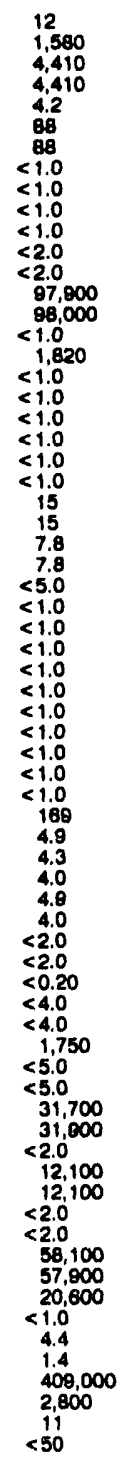 & JQ & 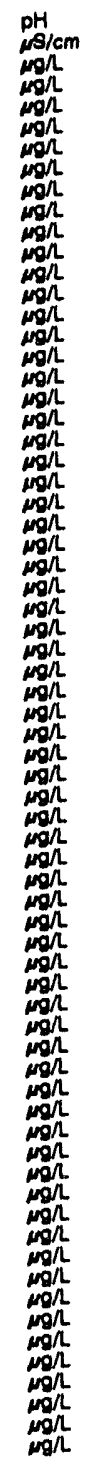 \\
\hline
\end{tabular}

Time: $7: 15$

Alkalinity: $380 \mathrm{mon}$

E Water tomperature: $19.6^{\circ} \mathrm{C}$ 
WELL MSB $82 B$ collectod on 08/10/92, laberatory analyses (conL)

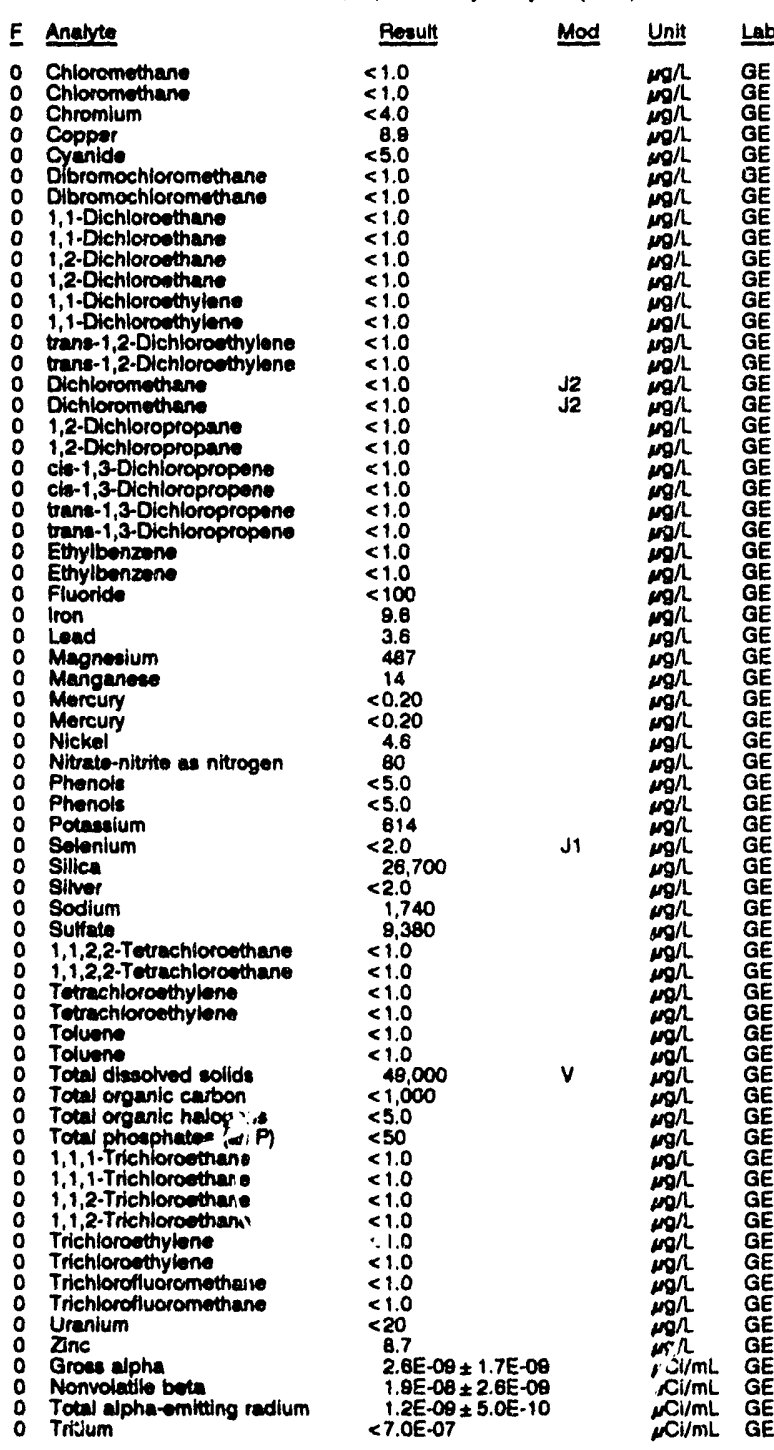

\section{WELL MSB 82C}

MEASUREMENTS CONDUCTED IN THE FIELD

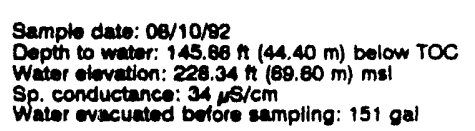

Time: 14:45

All: 8.0 . $5 \mathrm{malinity:} 5 \mathrm{mgh}$

Water temperature: $22.0^{\circ} \mathrm{C}$ LABORATOFY ANALYSES

\begin{tabular}{|c|c|c|c|c|}
\hline$E$ & Analyte & Pesull & Mod & Unit \\
\hline $\begin{array}{l}0 \\
0 \\
0 \\
0 \\
0 \\
0 \\
0 \\
0 \\
0 \\
0 \\
0 \\
0 \\
0 \\
0 \\
0 \\
0 \\
0\end{array}$ & 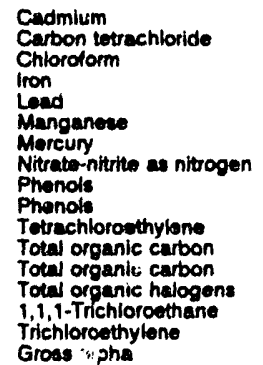 & $\begin{array}{l}<2.0 \\
<1.0 \\
<1.0 \\
4.5 \\
<3.0 \\
4.9 \\
<0.20 \\
1.080 \\
<5.0 \\
<5.0 \\
<1.0 \\
<1.000 \\
<1.000 \\
<5.0 \\
<1.0 \\
<1.0 \\
<2.0 E-08\end{array}$ & & 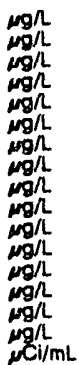 \\
\hline
\end{tabular}

WELL MSB B2C collected on 08/10/92, laboratory analyses (cont.)

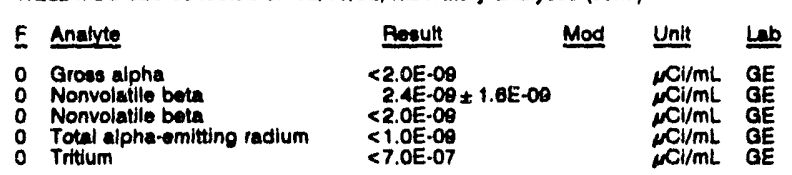

WELL MSB 82D

MEASUREMENTS CONOUCTED IN THE FIELD

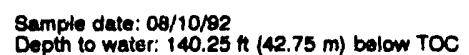

Water olevation: $233.45 \mathrm{ft}(71.16 \mathrm{~m}) \mathrm{mal}$ Alkalinity: $6 \mathrm{mg}$

Sp. conductance: $48 \mathrm{ss} / \mathrm{cm} \quad$ Whtor tompereture: $22.8 \cdot \mathrm{C}$

Water evacuated before sampling: $\mathbf{4 3} \mathrm{gal}$

LABORATORY ANALYSES

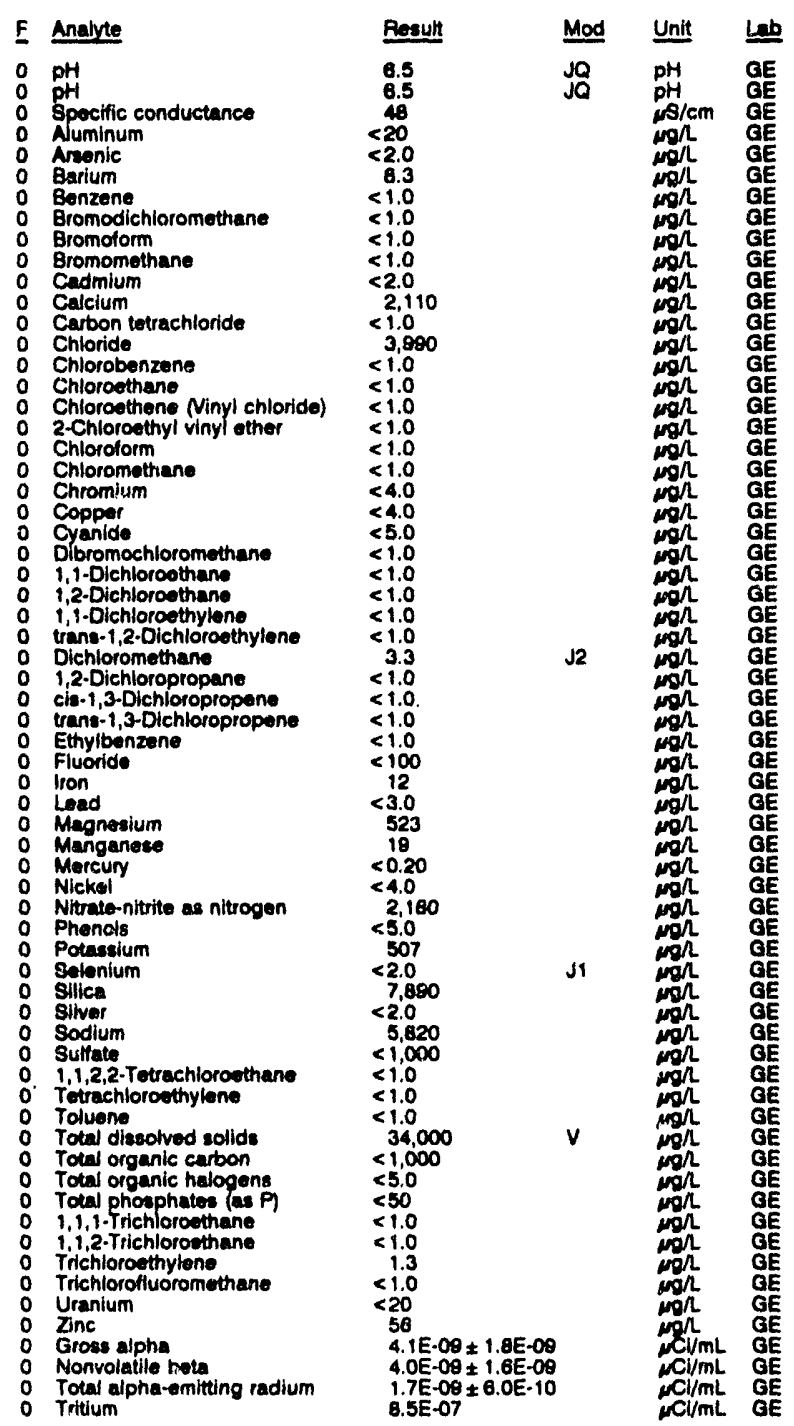


ANALYTICAL RESULTS

WELL MSB 82TA

MEASUREMENTS CONDUCTED IN THE FIELD

Sample date: 08/10/92

Depth to water: 159.51 in $(48.62 \mathrm{~m})$ below TOC

Water olovation: $214.28 \mathrm{ft}(85.32 \mathrm{~m}) \mathrm{ms}$

Sp. conductance: $30 \mathrm{~s} / \mathrm{cm}$.

Water evacuatod before sampling: $329 \mathrm{gal}$

LABORATOAY ANALYSES

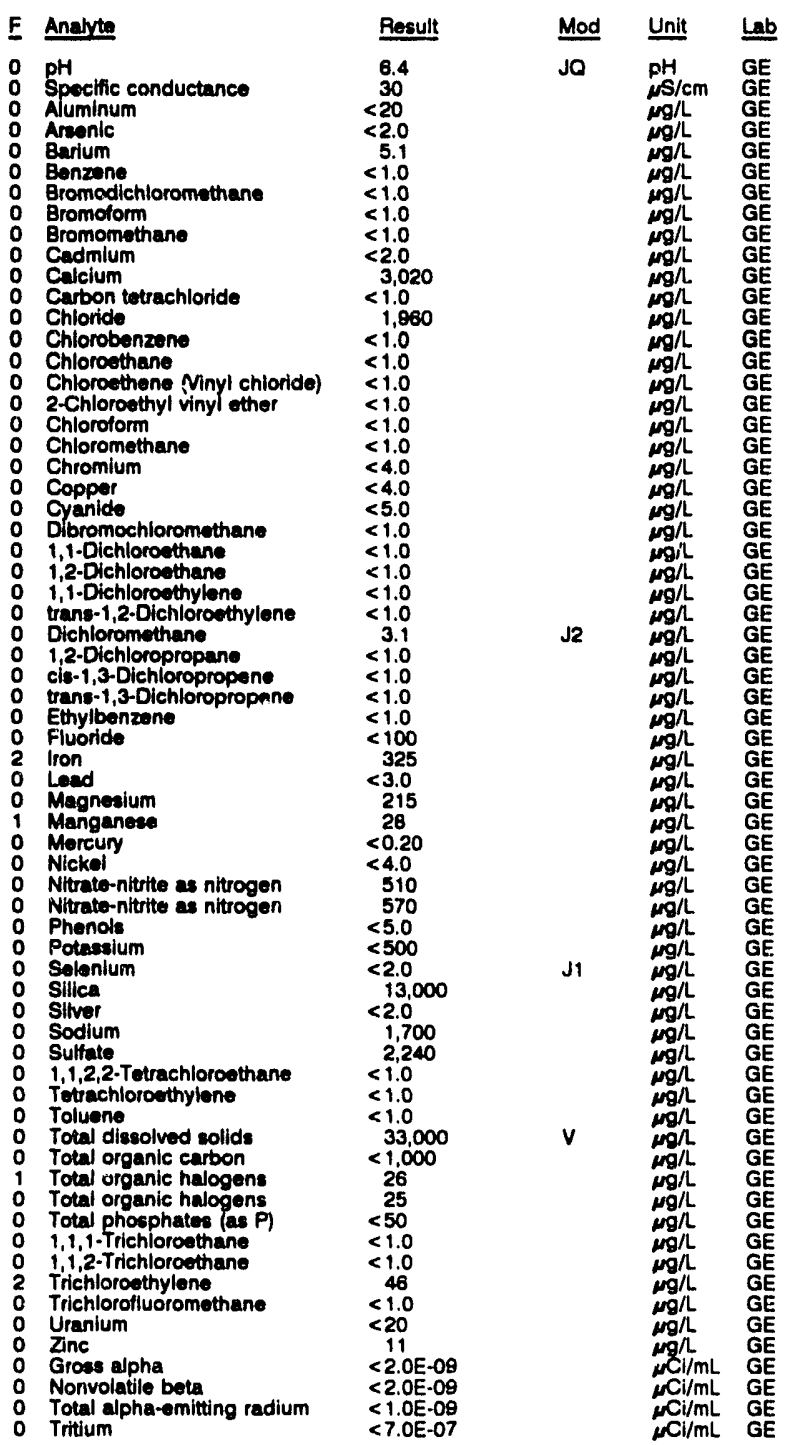

\section{WELL MSB 83B}

MEASUREMENTS CONDUCTED IN THE FIELD

Sample date: 08/10/82 Depth to water: $150.14 \mathrm{ft}(45.76 \mathrm{~m})$ below TOC Water elevation: $221.88 \mathrm{tt}$ (日7.

Water evacuated bofore sampling: $210 \mathrm{gal}$

LABORATORY ANALYSES

\begin{tabular}{|c|c|c|c|c|c|}
\hline$\underline{F}$ & Analyte & Result & Mod & Unit & Lab \\
\hline $\begin{array}{l}0 \\
0 \\
0 \\
0\end{array}$ & $\begin{array}{l}\text { pH } \\
\text { Spocific conductance } \\
\text { Aluminum } \\
\text { Arsenic } \\
\text { Arsenic }\end{array}$ & $\begin{aligned} & 5.9 \\
& 20 \\
&<20 \\
&<2.0 \\
&<2.0\end{aligned}$ & Jo & $\begin{array}{l}\mathrm{pH} \\
\mathrm{\mu S} / \mathrm{cm} \\
\mathrm{\mu g} / \mathrm{L} \\
\mathrm{\mu g} / \mathrm{L} \\
\mu \mathrm{g} / \mathrm{L}\end{array}$ & $\begin{array}{l}\mathrm{GE} \\
\mathrm{GE} \\
\mathrm{GE} \\
\mathrm{GE} \\
\mathrm{GE}\end{array}$ \\
\hline
\end{tabular}

WEL MSB 838 collected on 08/10/82, laboratory analyses (cont.)

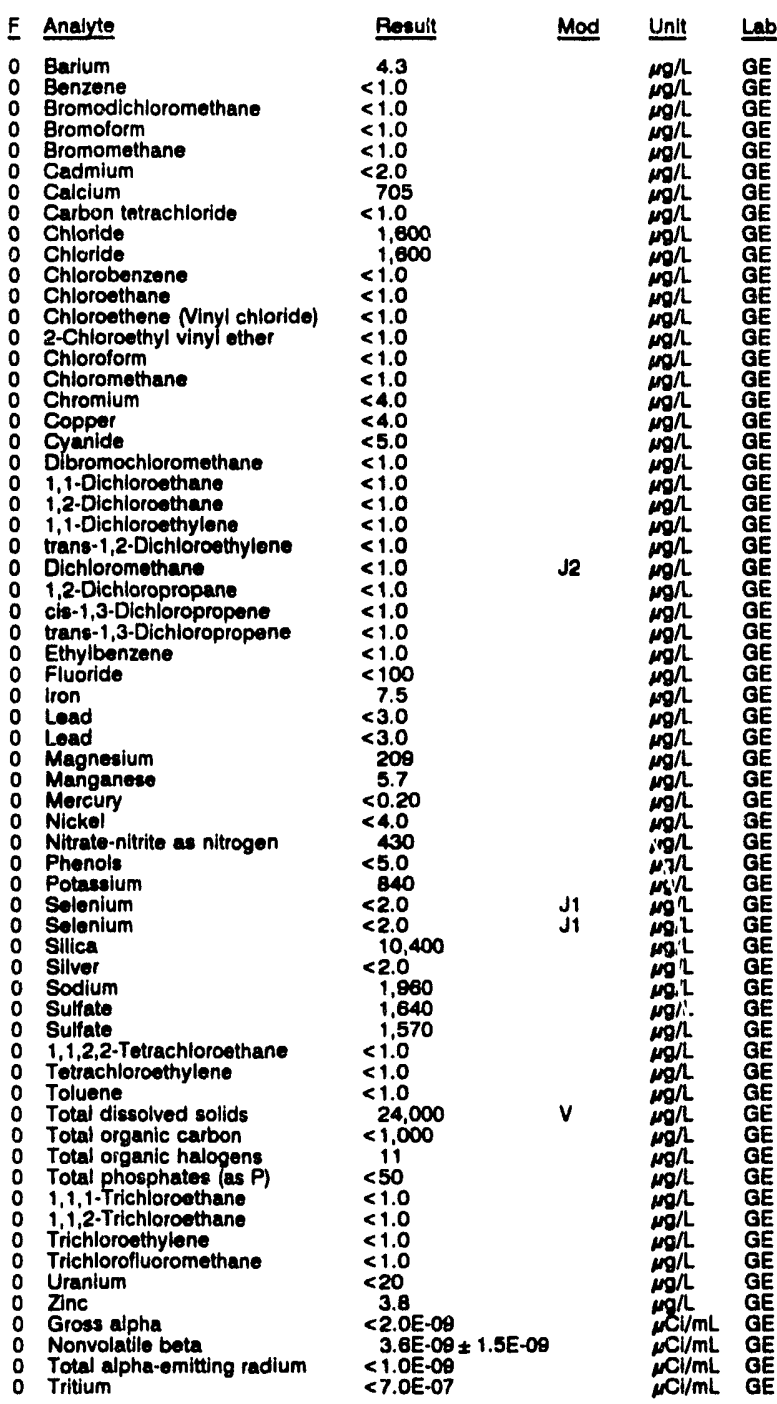

WELL MSB 83C

MEASUREMENTS CONDUCTED IN THE FIELD

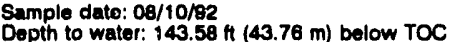

Water elevation: $228.52 \mathrm{ft}(69.65 \mathrm{~m}) \mathrm{ms}$

Sp. conductance: $71 \mu \mathrm{s} / \mathrm{cm}$

sampling: $132 \mathrm{gal}$

Time: 12:40

pH: 8.2 . $26 \mathrm{mgal}$

Water temperature: $21.7^{\circ} \mathrm{C}$

LABORATORY ANALYSES

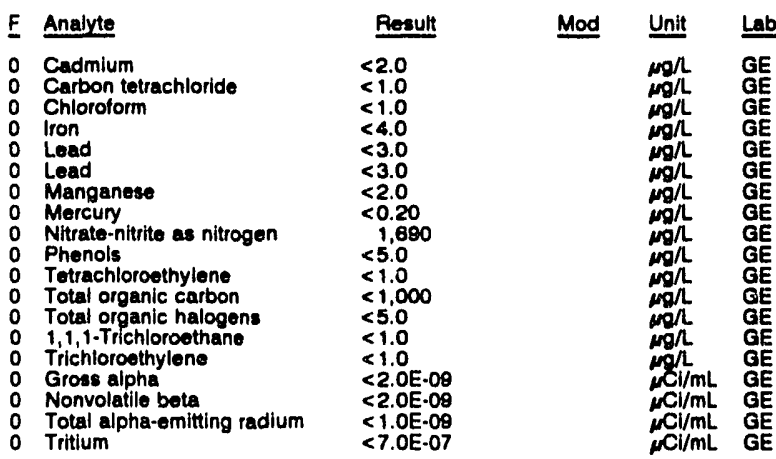


WELL MSB 83D

MEASUREMENTS CONDUCTED IN THE FIELD

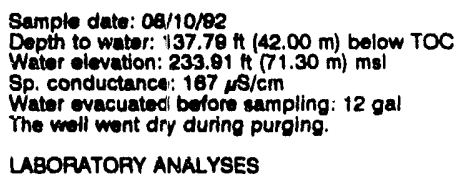

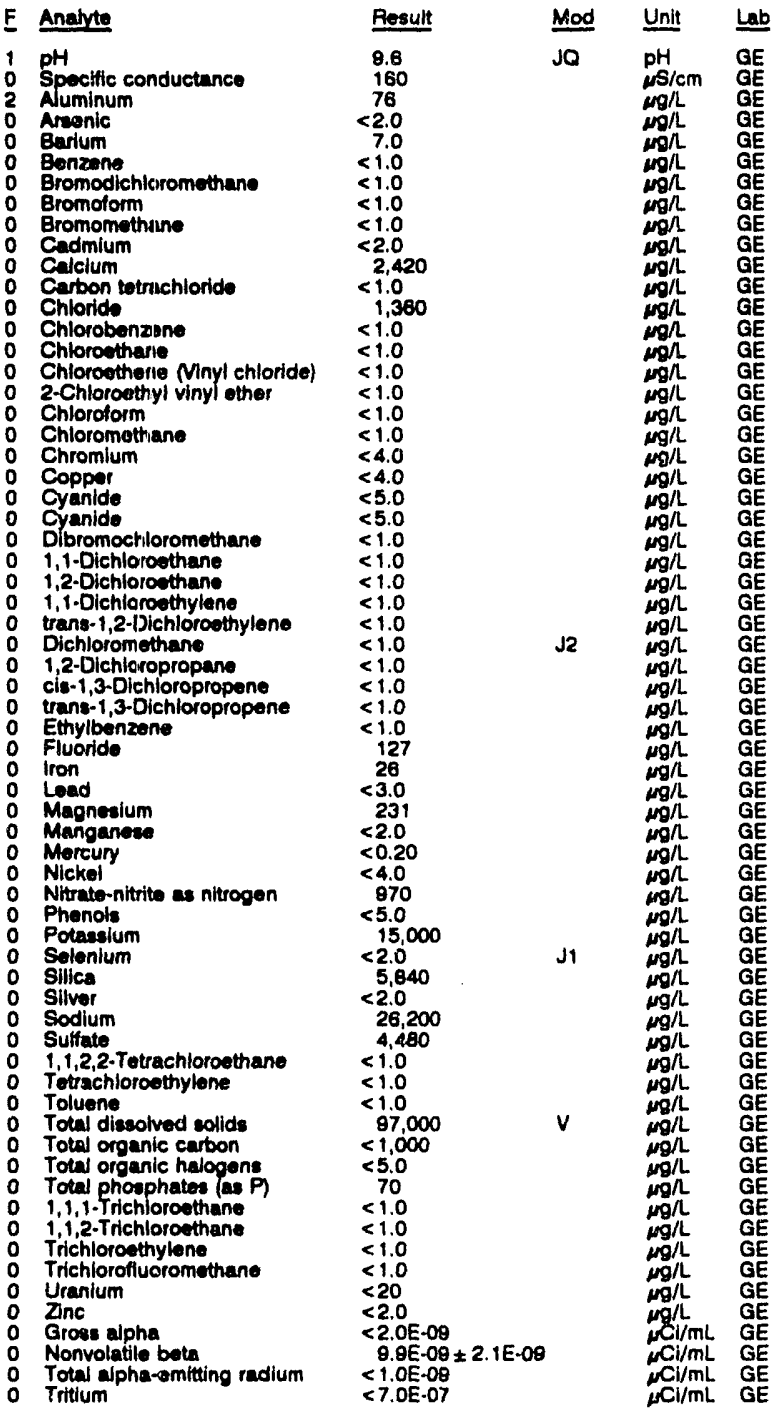

WELL MSB 83TA

MEASUREMENTS CONOUCTED IN THE FIELD

Sample date: 08/10/92

Depth to water: $156.16 \mathrm{~h}(47.60 \mathrm{~m})$ below TOC Water elevation: $215.62 \mathrm{f}(35.72 \mathrm{~m}) \mathrm{ms}$

Witer evacuatc. betore sampling: $381 \mathrm{gal}$

Time: 13:10

Alkalinity: $67 \mathrm{mg} /$

Water temperature: $21.0^{\circ} \mathrm{C}$

LABORATORY ANALYSES

\begin{tabular}{|c|c|c|c|}
\hline Analyte & Result & Mod & Unit \\
\hline $\begin{array}{ll}\text { O } & \text { pH } \\
0 & \text { Specific conductance } \\
0 & \text { Spoctic conductance } \\
0 & \text { Aluminum } \\
0 & \text { Aluminum } \\
0 & \text { Arsents }\end{array}$ & $\begin{array}{r}6.5 \\
25 \\
25 \\
<20 \\
<20 \\
<2.0\end{array}$ & Ja & $\begin{array}{l}\mathrm{pH} \\
\mu \mathrm{s} / \mathrm{cm} \\
\mu \mathrm{S} / \mathrm{cm} \\
\mathrm{mg} / \mathrm{L} \\
\mu \mathrm{g} / \mathrm{L} \\
\mathrm{\mu g} / \mathrm{L}\end{array}$ \\
\hline
\end{tabular}

Time: $13: 00$

Alkalinity: $7 \mathrm{mg} / \mathrm{L}$ : $22.5^{\circ} \mathrm{C}$

$\mu g / L$ GE
WELL MSB 83TA collected on 08/10/82, laboratory analyeon (cont.)

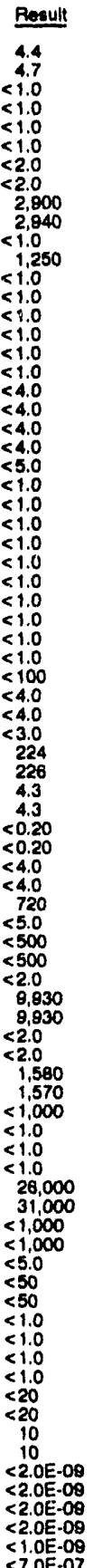

0 Barium

0 Barium

Bromodichloromethane

Bromotorm

Cadmium

Cadmium

Calcium

Calcium

Chloride

Chlorobenzene

Chloroethane

Chloroethene Ninyl chloride)

2-Chloroethyl vinyl ether

Chloroform

Chloromethan

Chromium

Copper

Copper

o Dibromochloromethane

0 1,1-Dichloroethane

o 1,2-Dichloroethane

1,1-Dichloroethylene

Dichloromethane

1,2-Dichloropropane

o cis-1,3-Dichloropropene

trans-1,3-Dich

o Fluorido

Iron

0 iron

O Magnosium

- Magnesium

Manganese

M Mercury

Mercury

Nickel

Nitrate-nitrite us nitrogen

Phenols

Phenols

Potassium

Selenium

Silica

S Silica

o Silver

- Sodium

O Sodium

O Sulfate

Th,2,2. Tetrachioroethan

o Toluene

- Total dissolved solids

Total dissolved solids

Total organic carbon

Total organic carbon

Total organic halogens

Total phosphates (as P)

1,1. Trichloroothane

1,1,2-Trichloroethan

Trichloroethylene

Uranium

- Uranium

Zinc

Gross alphe

Gonvolattle beta

Nonvolatile beta
Total alpha-emitting radium

Total alpho

Mod Unit Lab

$\mu \mathrm{g} / \mathrm{L}$ GE

$m / L$ GE 
ANALYTICAL RESULTS

\section{WELL MSB 84C}

MEASUREMENTS CONDUCTED IN THE FIELD

Sample date: 08/10/92

Depth to water: $132.15 \mathrm{ft}(40.28 \mathrm{~m})$ below TOC

Water olevation: $228.85 \mathrm{ft}$

Sp. conductance: $34 \mathrm{\mu S} / \mathrm{cm}$.

LABORATORY ANALYSES

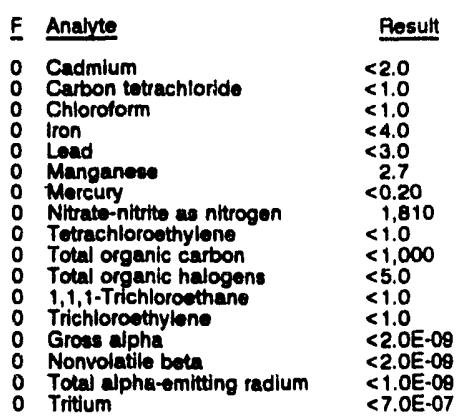

\section{WELL MSB 85B}

MEASUREMENTS CONDUCTED IN THE FIELD

Sample date: $06 / 10 / 92$ ( $158.42 \mathrm{~m}$ ) below TOC

Dopth to water: $158.88 \mathrm{ft}(46.42 \mathrm{~m})$ below

Water ovacuated bofore sampling: $233 \mathrm{gal}$

LABORATORY ANALYSES

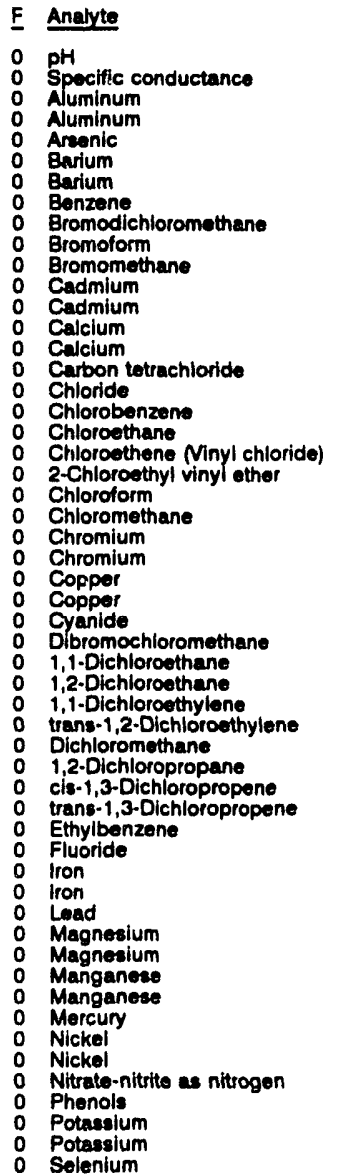

\begin{tabular}{l} 
Rusult \\
\hline 6.3 \\
28 \\
22 \\
22 \\
$<2.0$ \\
7.7 \\
7.6 \\
$<1.0$ \\
$<1.0$ \\
$<1.0$ \\
$<1.0$ \\
$<2.0$ \\
$<2.0$ \\
1.310 \\
1.310 \\
$<1.0$ \\
1.770 \\
$<1.0$ \\
$<1.0$ \\
$<1.0$ \\
$<1.0$ \\
$<1.0$ \\
$<1.0$ \\
$<4.0$ \\
$<4.0$ \\
$<4.0$ \\
$<4.0$ \\
$<5.0$ \\
$<1.0$ \\
$<1.0$ \\
$<1.0$ \\
$<1.0$ \\
$<1.0$ \\
4.0 \\
$<1.0$ \\
$<1.0$ \\
$<1.0$ \\
$<1.0$ \\
$<100$ \\
11 \\
11.0 \\
$<3.0$ \\
310 \\
308 \\
3.9 \\
3.9 \\
$<0.20$ \\
$<4.0$ \\
$<4.0$ \\
1.460 \\
$<5.0$ \\
538 \\
525 \\
$<2.0$ \\
\end{tabular}

Time: 13:35

H. 5 :

Alkalinity: $4 \mathrm{mg} / \mathrm{L}$

Water temperature: $22.1^{\circ} \mathrm{C}$

\begin{tabular}{|c|c|c|}
\hline Mod & Unit & Lab \\
\hline & $\begin{array}{l}\mu g / L \\
\mu g / h \\
\mu g / L \\
\mu g / L \\
\mu g / L \\
\mu g / L \\
\mu g / L \\
\mu g / L \\
\mu g / L \\
\mu g / L \\
\mu g / L \\
\mu g / L \\
\mu g / L \\
\mu C I / m L \\
\mu C i / m L \\
\mu C l / m L\end{array}$ & $\begin{array}{l}\mathrm{GE} \\
\mathrm{GE} \\
\mathrm{GE} \\
\mathrm{GE} \\
\mathrm{GE} \\
\mathrm{GE} \\
\mathrm{GE} \\
\mathrm{GE} \\
\mathrm{GE} \\
\mathrm{GE} \\
\mathrm{GE} \\
\mathrm{GE} \\
\mathrm{GE} \\
\mathrm{GE} \\
\mathrm{GE} \\
\mathrm{GE} \\
\mathrm{GE}\end{array}$ \\
\hline
\end{tabular}

Alkalinity: $3 \mathrm{mgh}$

Water temperature: $2130 \mathrm{C}$
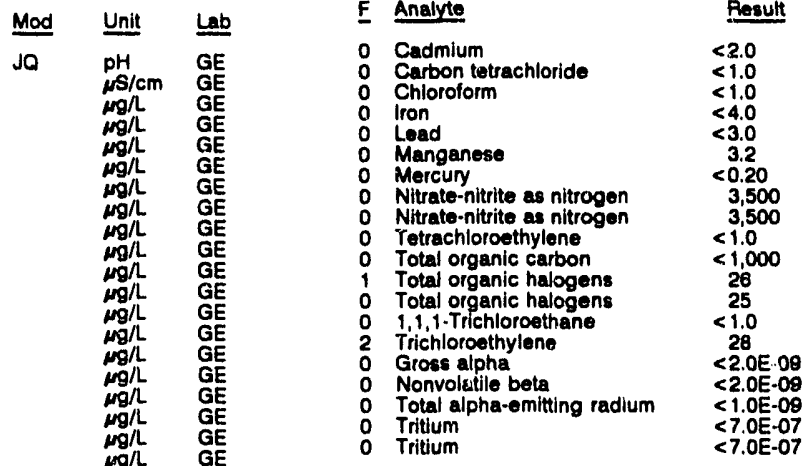

WELL MSB 85D

MEASUREMENTS CONDUCTED IN THE FIELD

Sample date: 08/10/92 $\mathrm{ft}(4.96 \mathrm{~m})$ below TOC

Water elovation: $233.89 \mathrm{ft}(71.29 \mathrm{~m}) \mathrm{msl}$

Sp. conductance: $71 \mu \mathrm{S} / \mathrm{cm}$

Water ovacuated before sampling: $45 \mathrm{gal}$

LABORATORY ANALYSES
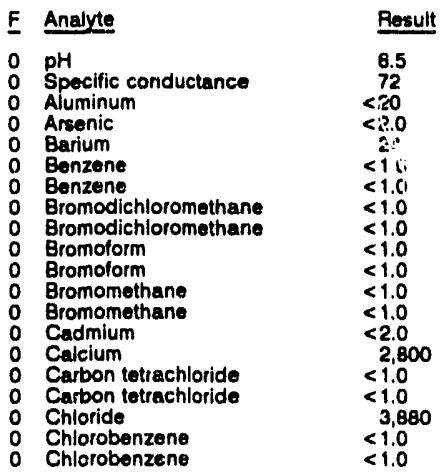

WELL MSB 85C

MEASUFEMENTS CONDUCTED IN THE FIELD

Depth to water: $156.31 \mathrm{ft}(47.64 \mathrm{~m})$ below TOC

(88.61 m) msi

LABORATORY ANALYSES

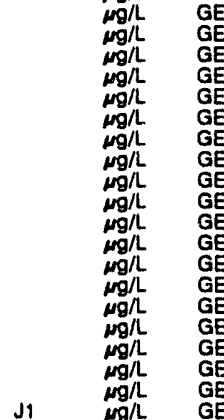

Time: 15:30

Alkalinity: $10 \mathrm{mg} / \mathrm{h}$

Water temperature: $22.4^{\circ} \mathrm{C}$

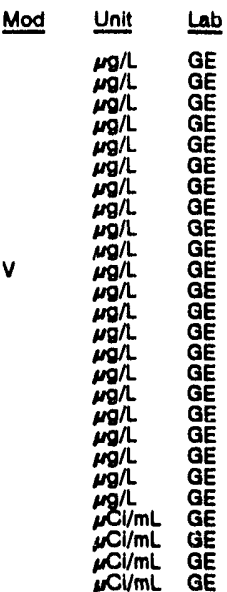

$\mathrm{N} \mathrm{Cl} / \mathrm{mL}$ GE

\begin{tabular}{|c|c|c|c|c|}
\hline Analyte & Result & Mod & Unit & Lab \\
\hline 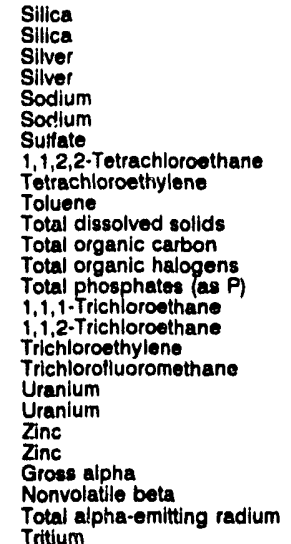 & $\begin{aligned} 8,720 \\
6,710 \\
<2.0 \\
<2.0 \\
2,970 \\
2,960 \\
<1,000 \\
<1.0 \\
<1.0 \\
<1.0 \\
30,000 \\
<1,000 \\
6.7 \\
<50 \\
<1.0 \\
<1.0 \\
1.9 \\
<1.0 \\
<20 \\
<20 \\
15 \\
15 \\
<2.0 \mathrm{E}-00 \\
<2.0 \mathrm{E}-09 \\
<1.0 \mathrm{E}-09 \\
<1.0 \mathrm{E}-07\end{aligned}$ & $v$ & 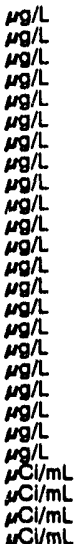 & $\begin{array}{l}G E \\
G E \\
G E \\
G E \\
G E \\
G E \\
G E \\
G E \\
G E \\
G E \\
G E \\
G E \\
G E \\
G E \\
G E \\
G E \\
G E \\
G E \\
G E \\
G E \\
G E \\
G E \\
G E \\
G E \\
G E \\
G E \\
G E\end{array}$ \\
\hline
\end{tabular}


ANALYTICAL RESULTS

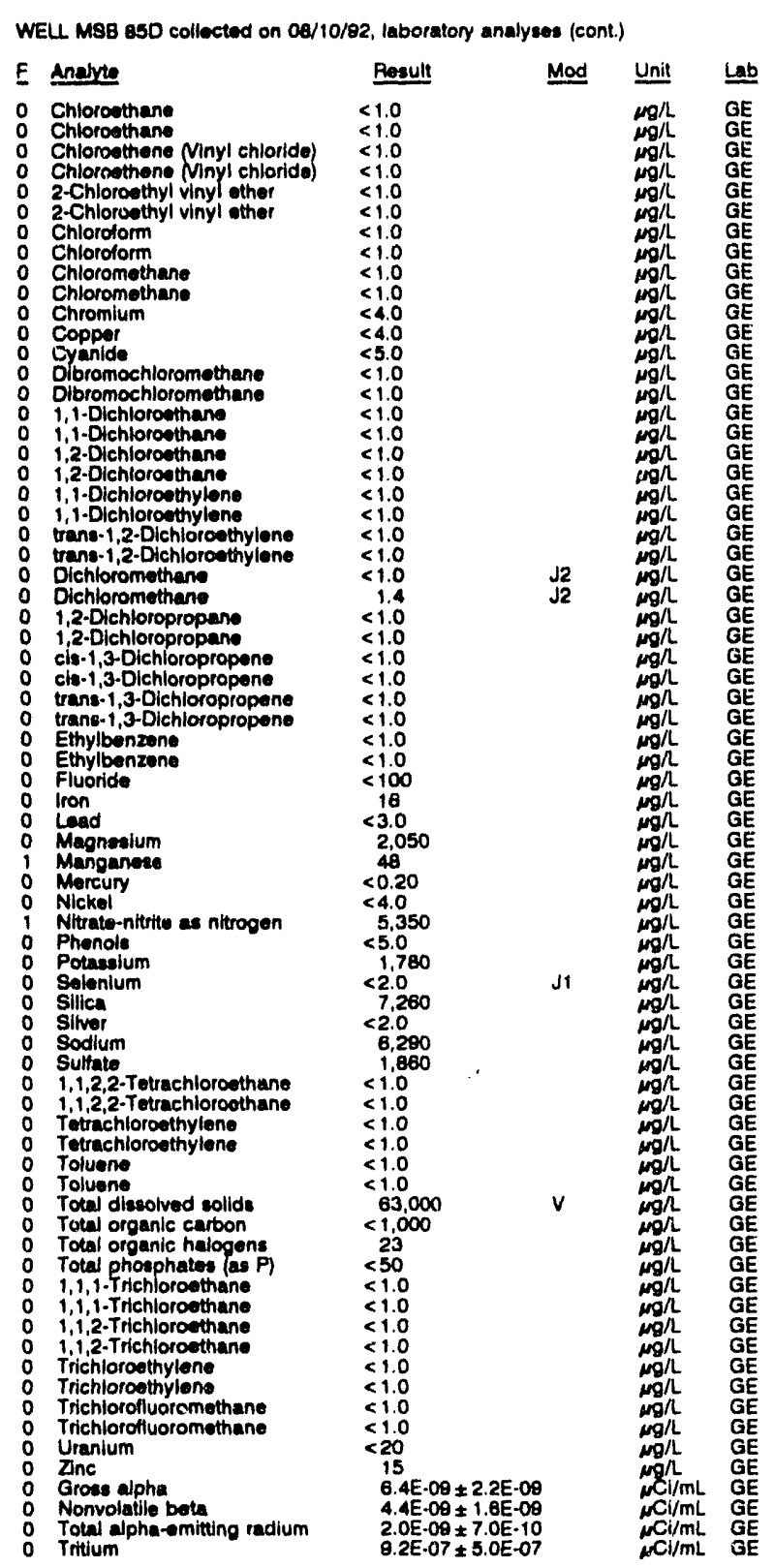

WELL MSB 85TA collected on 08/10/82, laboratory analyese (cont.)

\begin{tabular}{|c|c|c|c|}
\hline Analyte & Rosult & Mod & Unit \\
\hline 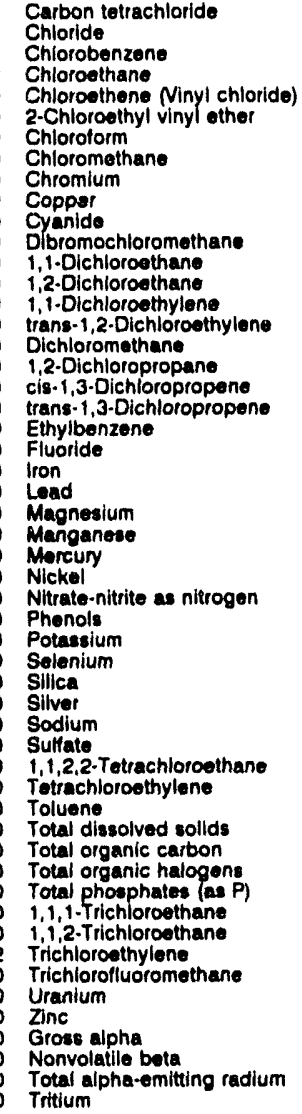 & $\begin{array}{l}<1.0 \\
1.860 \\
<1.0 \\
<1.0 \\
<1.0 \\
<1.0 \\
<1.0 \\
<1.0 \\
<4.0 \\
<4.0 \\
<5.0 \\
<1.0 \\
<1.0 \\
<1.0 \\
<1.0 \\
<1.0 \\
1.8 \\
<1.0 \\
<1.0 \\
<1.0 \\
<1.0 \\
<100 \\
87 \\
<3.0 \\
21.2 \\
7.2 \\
<0.20 \\
<4.0 \\
<50 \\
<5.0 \\
10.500 \\
<2.0 \\
11.840 \\
<2.0 \\
21,500 \\
2,080 \\
<1.0 \\
2.3 \\
7.0 \\
158,000 \\
2,800 \\
21 . \\
810 \\
<1.0 \\
<1.0 \\
21 \\
<1.0 \\
<20 \\
<2.0 \\
3.0 E-09 \pm 1.8 E-09 \\
1.0 E-08 \pm 2.1 E-00 \\
<1.0 E-09 \\
<7.0 E-07 \\
\end{array}$ & J1 & 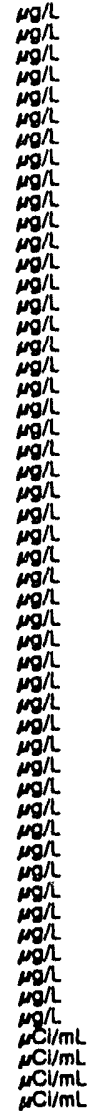 \\
\hline
\end{tabular}

\section{WELL MSB 86C}

MEASUREMENTS CONDUCTED IN THE FIELD

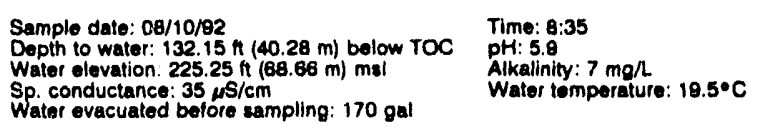
Water evacuated bofore sampling: $170 \mathrm{gal}$

LABOPATORY ANALYSES

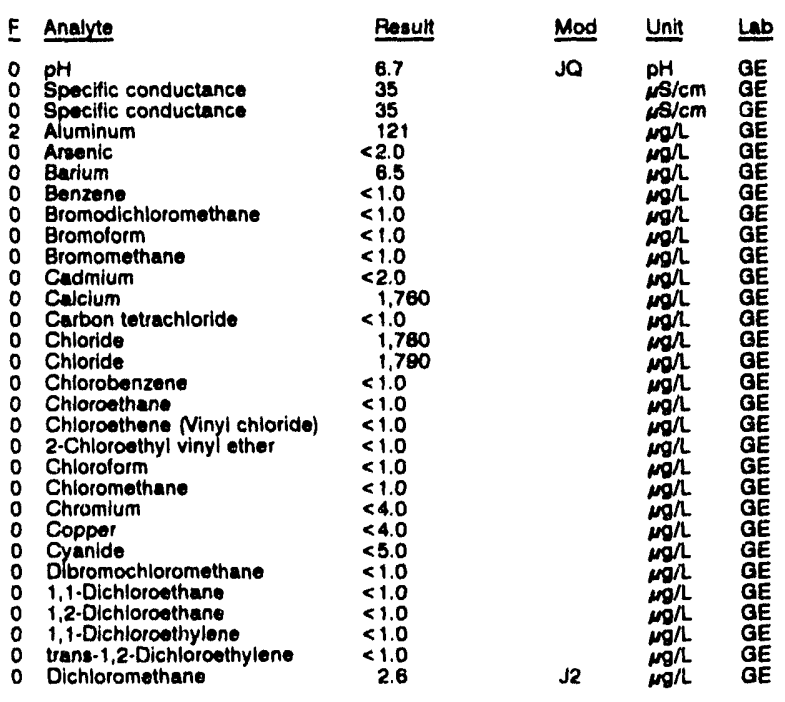

WELL MSB 85TA

MEASUREMENTS CONDUCTED IN THE FIELO

\begin{tabular}{|c|c|c|c|c|c|}
\hline \multicolumn{3}{|c|}{ 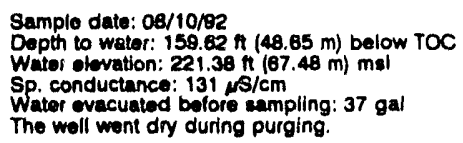 } & \multicolumn{3}{|c|}{$\begin{array}{l}\text { Time: } 9: 55 \\
\text { pH: } 9.0 \\
\text { Alkalinity: } 70 \mathrm{mg} \Omega \\
\text { Water temperature: } 22.0^{\circ} \mathrm{C}\end{array}$} \\
\hline \multicolumn{6}{|c|}{ LABORATOAY ANALYSES } \\
\hline- & Analyte & Fiesult & Mod & Unit & $\underline{L a b}$ \\
\hline $\begin{array}{l}1 \\
0 \\
2 \\
0 \\
0 \\
0 \\
0 \\
0\end{array}$ & $\begin{array}{l}\text { pH } \\
\text { Specific conductance } \\
\text { Aluminum } \\
\text { Areanic } \\
\text { Barium } \\
\text { Benzene } \\
\text { Bromodichloromethane } \\
\text { Bromotorm } \\
\text { Bromomethane } \\
\text { Cadmium } \\
\text { Celcium }\end{array}$ & $\begin{array}{r}9.3 \\
130 \\
162 \\
<2.0 \\
16 \\
<1.0 \\
<1.0 \\
<1.0 \\
<1.0 \\
<2.0 \\
2.250\end{array}$ & JO & $\begin{array}{l}p H \\
\mu S / c m \\
\mu g / L \\
\mu g / L \\
\mu g / L \\
\mu g / L \\
\mu g / L \\
\mu g / L \\
\mu g / L \\
\mu g / L \\
\omega g / L\end{array}$ & $\begin{array}{l}\mathrm{GE} \\
\mathrm{GE} \\
\mathrm{GE} \\
\mathrm{GE} \\
\mathrm{GE} \\
\mathrm{GE} \\
\mathrm{GE} \\
\mathrm{GE} \\
\mathrm{GE} \\
\mathrm{GE} \\
\mathrm{GE}\end{array}$ \\
\hline
\end{tabular}

Time: $9: 55$

Alkalinity: $70 \mathrm{man}$

Water tomperature: $220^{\circ} \mathrm{C}$ 
WELL MSB $88 C$ collected on $08 / 10 / 92$, laboratory analyses (cont.)

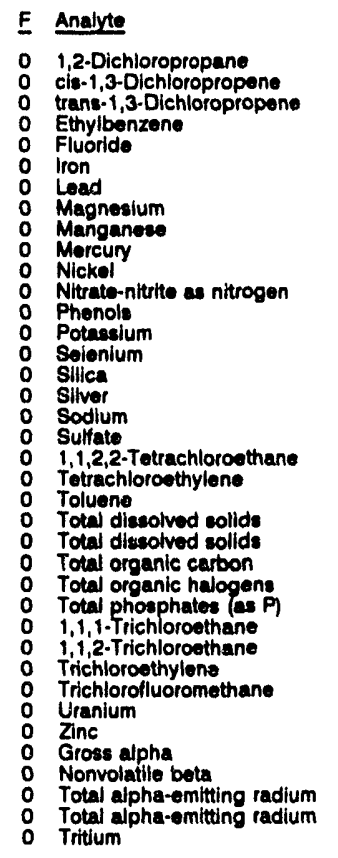

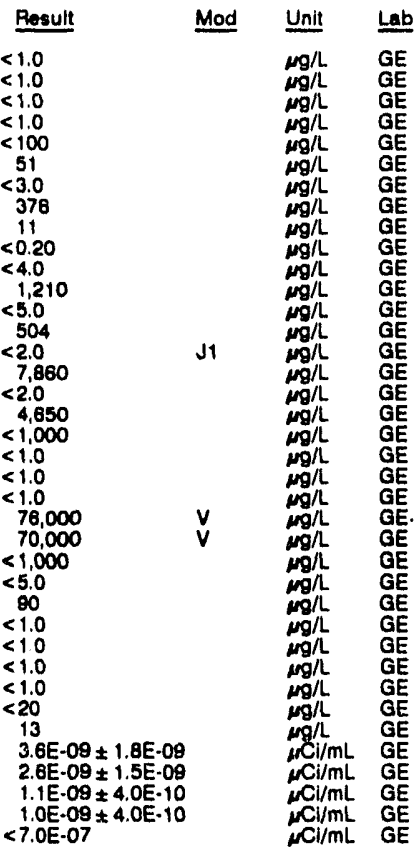

\section{WELL MWD 1A}

MEASUREMENTS CONDUCTED IN THE FIELD

Sample date: 08/30/92 Time: 14:30 Depth to water: $139.35 \mathrm{ft}(42.47 \mathrm{~m})$ below TOC Waler elevation: 180.15

WELL MWD 18

MEASUREMENTS CONDUCTED IN THE FIELD

Sample date: $08 / 30 / 92$

Depth to water: $71.25 \mathrm{ft}(21.72 \mathrm{~m})$ bolow

inaccessiblity or mechanical problem prevented sample collection.

WELL MWD 1C

MEASUAEMENTS CONDUCTED IN THE FIELD

Sample date: 08/30/92 Time: 14:25

Depth to water: $69.30 \mathrm{ft}(21.12 \mathrm{~m})$ below TOC

inaccessibility or mechanical problem prevented sample collection.

WELL MWD 1D

MEASUREMENTS CONDUCTED IN THE FIELD

Sample date: $08 / 30 / 82$ (19.23 m) below TOC

Water elevation: $286.91 \mathrm{ft}(81.38 \mathrm{~m}) \mathrm{ms}$

inaccessibility or mechanical problem prevented sample collection.

WELL MWD 2A

MEASUREMENTS CONDUCTED IN THE FIELD

Sample date: 08/30/82 4 Time: $14: 45$

Depth to water: $134.47 \mathrm{~A}(40.89 \mathrm{~m})$ below TOC

Water olsvalion: $189.83 \mathrm{rt}(57.88 \mathrm{~m}) \mathrm{ms}$

inaccessibility of mechanical problem prevented sample collection.
WELL MWD 2C

MEASUREMENTS CONDUCTED IN THE FIELD

Sample date: $08 / 30 / 82$ Time: $14: 50$

Inaccessibility or mechanical problem prevented sample collection.

WELL MWD 2D

MEASUREMENTS CONDUCTED IN THE FIELD

Sample date: 08/30/82 Time: 14:55

Depth to water: $56.48 \mathrm{ft}(17.22 \mathrm{~m})$ below TOC

Water olevation: $288.11 \mathrm{~h}(81.72 \mathrm{~m}) \mathrm{mal}$

Inaccessibility of mechanical problem prevented sample collection.

WELL MWD $3 A$

MEASUREMENTS CONDUCTED IN THE FIELD

Sample date: 08/30/92 1500

Dopth to water: $141.23 \mathrm{~h}(43.05 \mathrm{~m})$ bolow TOC

Water olovallon: 180.57 \& $(57.78 \mathrm{~m}) \mathrm{ma}$

\author{
The: $15: 00$
}

waccesalbility or mechenical problem preventod sample collection.

WELL MWD 5A

MEASUREMENTS CONOUCTED IN THE FIELD

Sample date: 08/30/92 $140.80 \mathrm{~m})$ below TOC Time: $14: 05$ Wepth to water: $133.85 \mathrm{ft}(40.80 \mathrm{~m})$ bolow

Inaccessibility or mechanical problem prevented sample collection.

WELL MWD 5C

MEASUREMENTS CONDUCTED IN THE FIELD

Sample date: 08/30/92

Depth to water: $68.71 \mathrm{~h}(20.94 \mathrm{~m})$ below

inaccessibitity or mechanical problem prevented sample collection.

WELL MWD 5D

MEASUREMENTS CONDUCTED IN THE FIELD

Sample date: 08/30/82 $317.53 \mathrm{~m})$ below TOC 13:55 Depth to water: $57.50 \mathrm{H}(17.53 \mathrm{~m})$ bolow TOC

inaccessibility or mechanical problem prevented sample collection.

WELL MWD 8

MEASUREMENTS CONDUCTED IN THE FIELD

Sample date: 08/30/92 Time: 15:05

Depth to water: $57.09 \mathrm{H}(17.38 \mathrm{~m})$ below TOC

Water elevation: $268.77 \mathrm{~h}(81.82 \mathrm{~m}) \mathrm{msl}$
Inaccessibility or mechanical problem prevented sample collection.

WELL MWD 9

MEASUREMENTS CONDUCTED IN THE FIELD

Sample date: 08/30/92 Time: 14:10 Depth to water: $54.91 \mathrm{ht}(16.74 \mathrm{~m})$ below TOC

inaccessibility of mechanical problem prevented sample collection. 
WELL MWD 10

MEASUREMENTS CONOUCTED IN THE FIELD

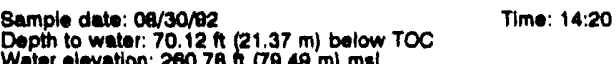

ineccesesibility or mechanical problem provented sample colloction.

WELL MWD 11

MEASUREMENTS CONDUCTED IN THE FIELD

Sample date: 08/30/92 $\mathrm{n}(12.13 \mathrm{~m})$ bolow TOC

inacceaslbillty or mechanical problem prevented eample collection.

WELL NBG 1

MEASUREMENTS CONDUCTED IN THE FIELD

Sample date: 00/22/02

Dopth to water: $86.202 \mathrm{n}(28.29 \mathrm{~m})$ bolow TOC

Wator olevation: $225.24 \mathrm{ht}(8 \mathrm{~s}, \mathrm{~s}$

We. conouclance: 1214 sicm

The well went dr durtho purgling: 12 gel

LABORATOAY ANMLYSESS

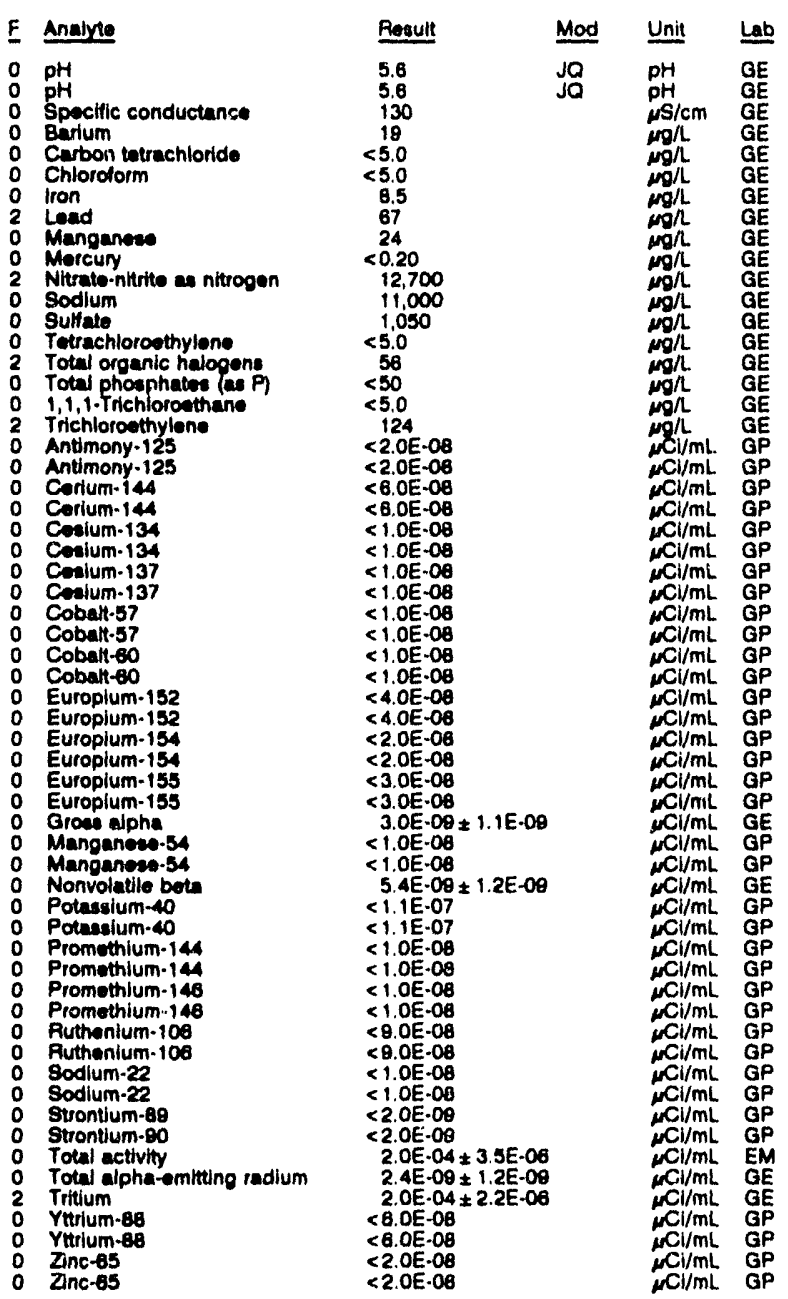

WELL NBG 2

MEASUREMENTS CONDUCTED IN THE FIELD

Sample dato: 00 (2)

Dopth to wator: 87.01 tt $(28.52 \mathrm{~m})$ bolow TOC

Water elovatlon: $225.69 \mathrm{~h}(68.70 \mathrm{~m}) \mathrm{mal}$

Sp. conductance: $40.8 / \mathrm{cm}$

PH: 3.1 . 3 mal

Wator ovacuated bolore cumpling: $15 \mathrm{gal}$

LABORATORY ANALYSES

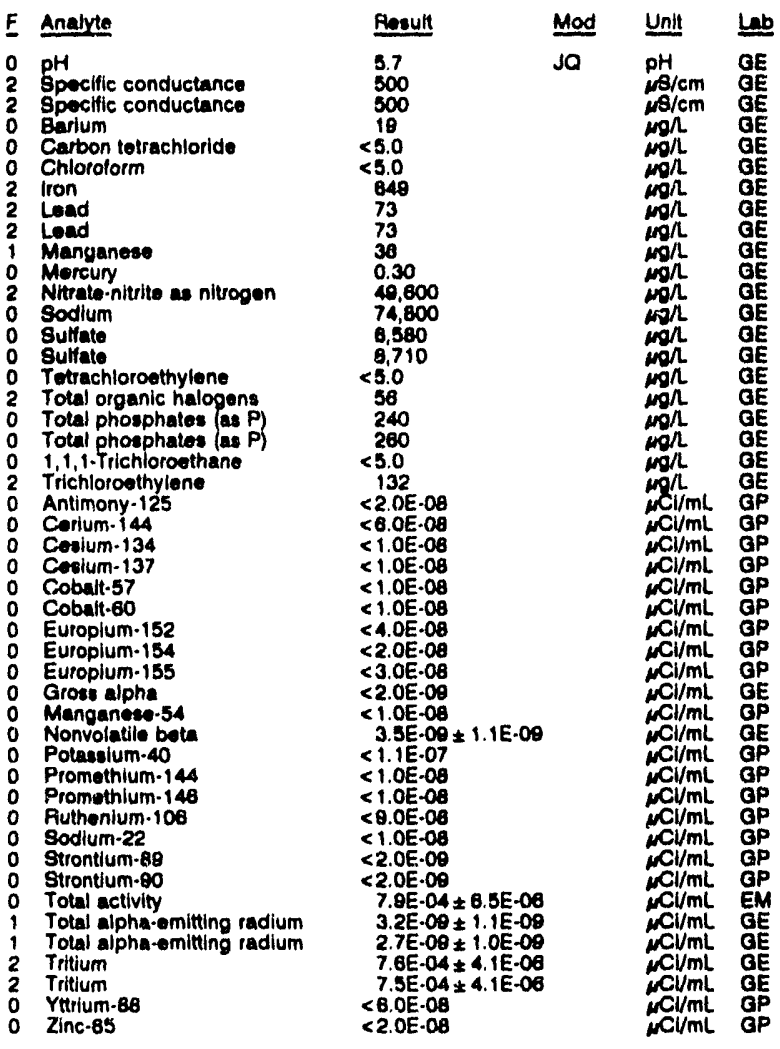

WELL NBG 3

MEASUAEMENTS CONDUCTED IN THE FIELD

\begin{tabular}{|c|c|}
\hline $\begin{array}{l}\text { Sample date: } 09 / 22 / 92 \\
\text { Depth to water: } 83.21 \mathrm{~h}(28.41 \mathrm{~m}) \text { bolow TOC } \\
\text { Water elevation: } 210.19 \mathrm{~h}(88.81 \mathrm{~m}) \mathrm{mal} \\
\text { Sp. conductance: } 58 \mathrm{\mu s} / \mathrm{cm} \\
\text { Water evacuated bolore sampling: } 13 \mathrm{gal} \\
\text { The well went dry during purging. }\end{array}$ & $\begin{array}{l}\text { Time: } 10.05 \\
\text { pH: } 5.7 \\
\text { Alkalinity: } 11 \mathrm{mg} / \\
\text { Water tomperature: } 22.5^{\circ} \mathrm{C}\end{array}$ \\
\hline
\end{tabular}

LABORATORY ANALYSES

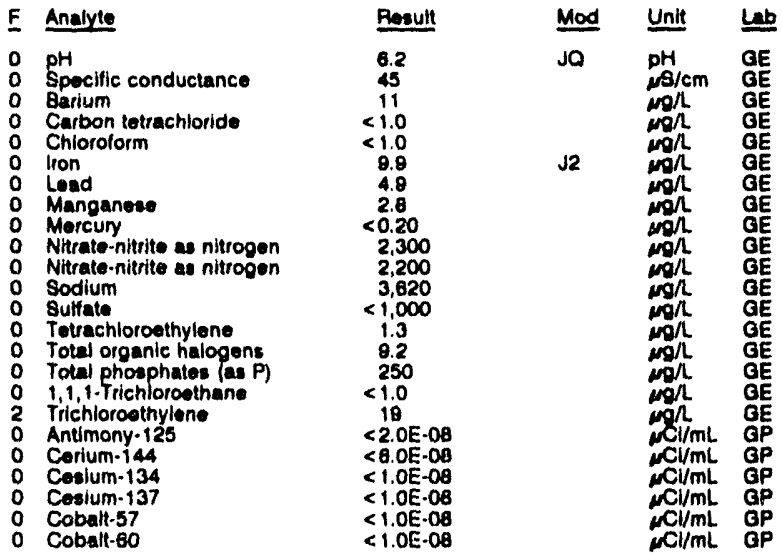


ANALYTICAL RESULTS

\begin{tabular}{|c|c|c|c|}
\hline Anabrite & Reoutt & Unit & $\underline{L a b}$ \\
\hline 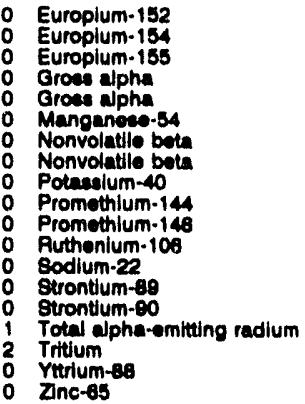 & 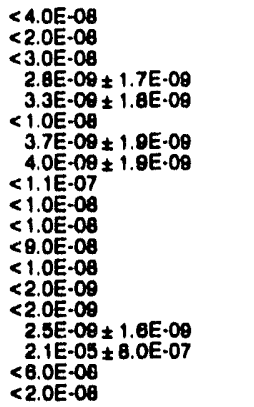 & 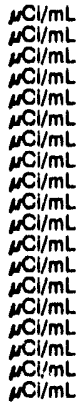 & $\begin{array}{l}G P \\
G P \\
G P \\
G E \\
G E \\
G P \\
G E \\
G E \\
G P \\
G P \\
G P \\
G P \\
G P \\
G P \\
G P \\
G E \\
G E \\
G P \\
G P\end{array}$ \\
\hline
\end{tabular}

\section{WELL NBG 4}

\section{MEASUREMENTS CONDUCTED IN THE FIELD}

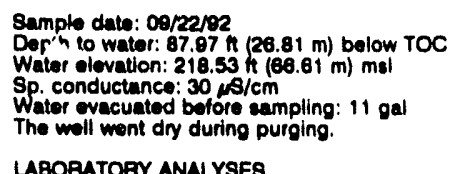

Time: $8: 40$

Alkalinity: $1 \mathrm{mg} / \mathrm{h}$

Water temperature: $21.7^{\circ} \mathrm{C}$

\section{LABOPATOFY ANALYSES}

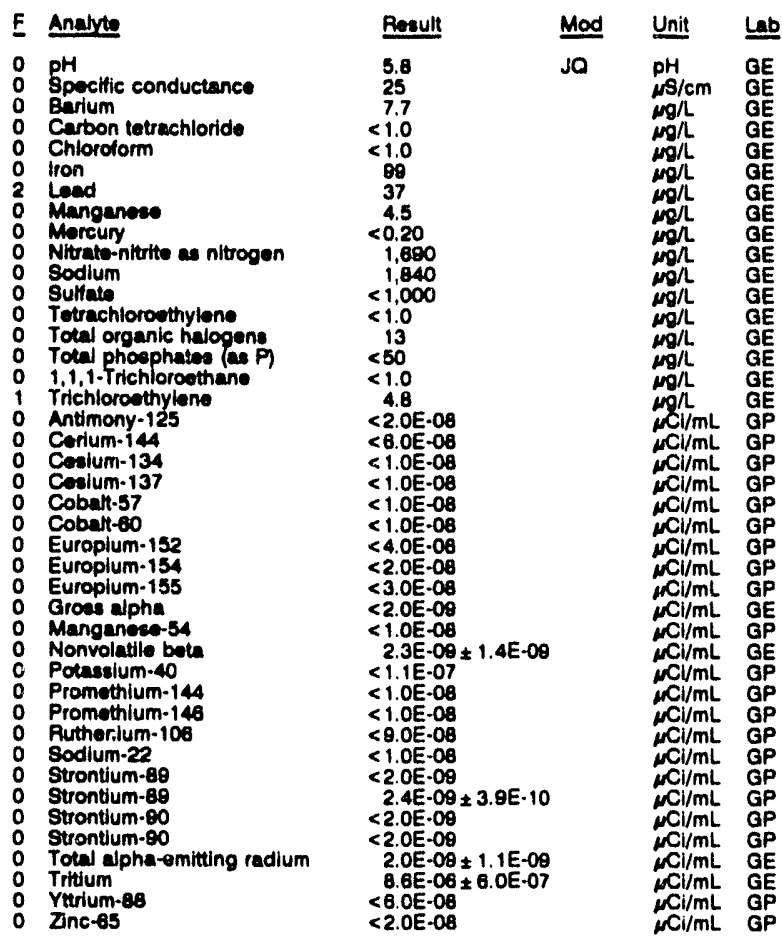

\section{WELL NBG 5}

MEASUREMENTS CONOUCTED IN THE FIELD

\begin{tabular}{|c|c|c|c|c|c|}
\hline & $\begin{array}{l}\text { mple date: } 09 / 22 / 92 \\
\text { pth to water: } 83.84 \mathrm{th} \\
\text { iter olevation: } 218.58 \mathrm{th} \\
\text { conductence: } 34 \mathrm{~s} / \mathrm{cm} \\
\text { ter ovacuated bofore } \\
\text { mall went dry during pi }\end{array}$ & $\begin{array}{l}\text { low toc } \\
\text { msl } \\
\text { gal }\end{array}$ & $\begin{array}{l}\text { Time: } 8: 15 \\
\text { pH: } 5.1 \\
\text { Alkalinity: } 2 \\
\text { Water temp }\end{array}$ & ag/L 21 & \\
\hline & BOAATORY ANALYSES & & & & \\
\hline & Anaryte & Result & Miod & Unit & Lab \\
\hline $\begin{array}{l}0 \\
0 \\
0 \\
0\end{array}$ & $\begin{array}{l}\text { pH } \\
\text { Specific conductance } \\
\text { Barlum } \\
\text { Carbon totrachloride } \\
\text { Carbon totrachloride }\end{array}$ & $\begin{array}{r}5.8 \\
30 \\
8.3 \\
<1.0 \\
<1.0\end{array}$ & Jo & $\begin{array}{l}\mathrm{pH} \\
\mu S / \mathrm{cm} \\
\mu g / L \\
\mu g / L \\
\mu g / L\end{array}$ & $\begin{array}{l}\text { GE } \\
\mathrm{GE} \\
\mathrm{GE} \\
\mathrm{GE} \\
\mathrm{GE}\end{array}$ \\
\hline
\end{tabular}

WELL NBG 5 collected on 09/22/92, laboratory analyses (cont.)

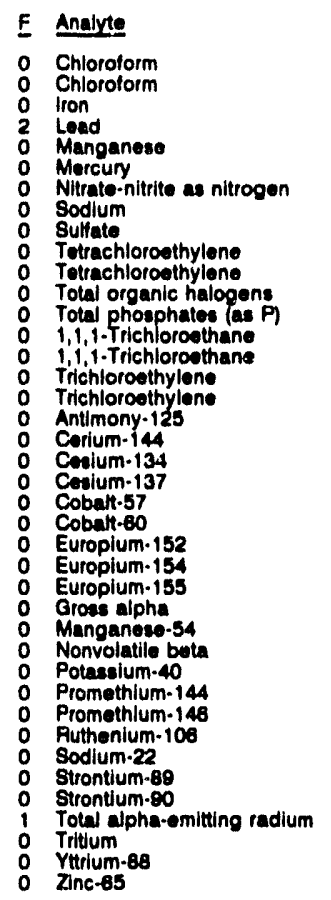

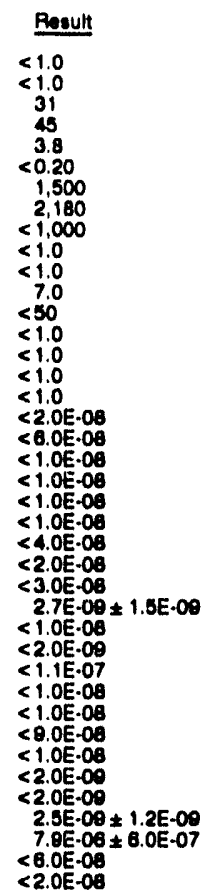

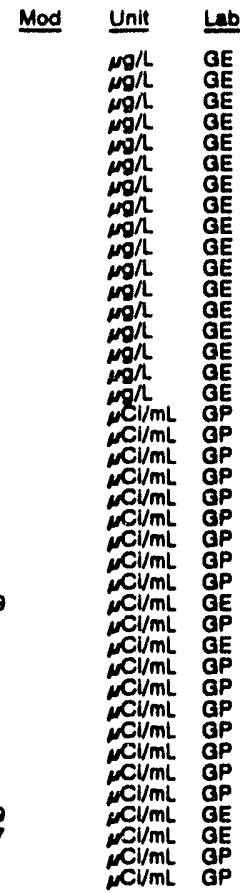

\section{WELL NPM 1}

MEASUAEMENTS CONDUCTED IN THE FIELD

Sample date: $08 / 28 / 92$
Depth to water: $20.55 \mathrm{~h}(6.26 \mathrm{~m})$ below TOC Time: $11: 25$
Water elevation: $285.55 \mathrm{ht}(87.04 \mathrm{~m}) \mathrm{mal}$

inaccessibility or mechanical problem prevented sample collection.

WELL NPM $1 \mathrm{~A}$

MEASUREMENTS CONDUCTED IN THE FIELD

Sample date: $08 / 28 / 92$
Depth to water: $89.97 \mathrm{ft}(27.42 \mathrm{~m})$ bolow TOC Time: $11: 30$
Water elevation: $215.93 \mathrm{~h}(65.62 \mathrm{~m}) \mathrm{ms}$
Inaccessibllity or mechanical problem provented sample collection.

WELL NPM 2

MEASUREMENTS CUNDUCTED IN THE FIELD

Sample dalo. 00/29/82 Water olevation: $270.23 \mathrm{~h}(82.37 \mathrm{~m}) \mathrm{msl}$ Sp. conductance: $56 \mu \mathrm{s} / \mathrm{cm}$

Water evacuated botore sampling: $20 \mathrm{gal}$

pH: 7.0 Water temperature: $18.5 \cdot \mathrm{C}$

The well wont dry during purging.

LABORATORY ANALYSES

\begin{tabular}{|c|c|c|c|}
\hline Analyte & Result & Mod & Unit \\
\hline $\begin{array}{l}\text { pH } \\
\text { pH } \\
\text { Specific conductance } \\
\text { Specific conductance } \\
\text { Areanic } \\
\text { Barium } \\
\text { Cadmium } \\
\text { Calcium } \\
\text { Chloride } \\
\text { Chromium } \\
\text { Fluoride } \\
\text { lron } \\
\text { Lead } \\
\text { Magnesium } \\
\text { Manganeses } \\
\text { Mercury } \\
\text { Nitrate-nitrite as nitrogen } \\
\text { Phenols } \\
\text { Potasslum }\end{array}$ & $\begin{array}{r}8.2 \\
8.3 \\
50 \\
50 \\
<2.0 \\
13 \\
<2.0 \\
6.970 \\
1.780 \\
<4.0 \\
<100 \\
7.4 \\
<3.0 \\
368 \\
16 \\
<0.20 \\
1.740 \\
<5.0 \\
1,110\end{array}$ & JO JO & 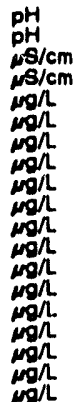 \\
\hline
\end{tabular}




\section{ANALYTICAL RESULTS}

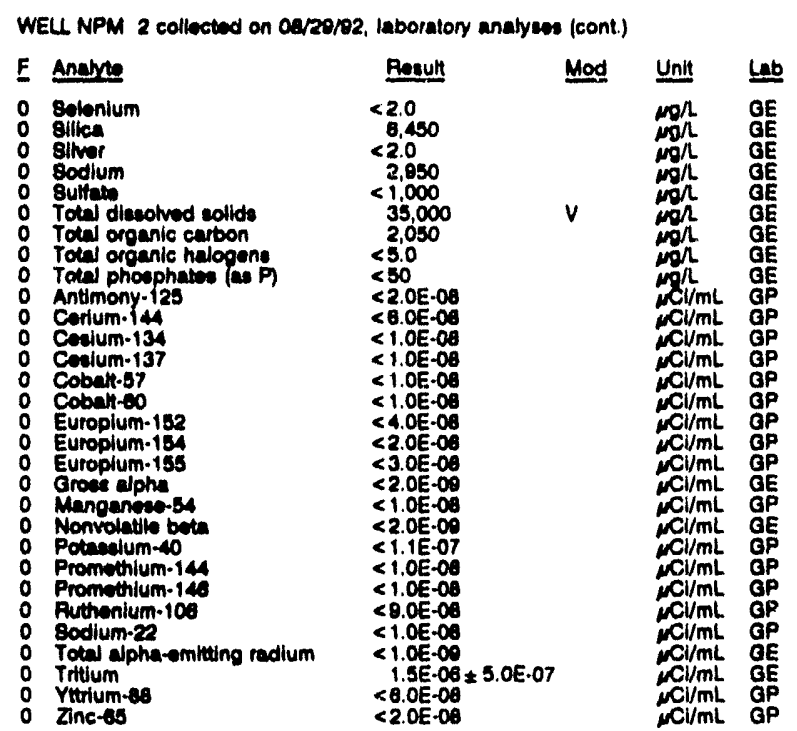

WELL NPM 4

MEASUREMENTS CONOUCTED IN THE FIELOO

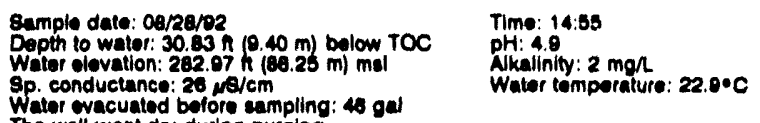

Wheter wacuated bolore rampling: $48 \mathrm{gat}$

The woll want dry during purging.

LABOPATOAY ANAL.YSES

$E$ Analyte

: $\mathrm{gH}$ spetific conductance

o Areonic

Cadmium

Colclum

Chromium

F Fluorida

: lon

- Meonosium

O Manganose

Morcury

o Phonolis

o Polasalum

o Solonium

Silicar

o sodium

o sulfate

- Tocal diseotved sollids

O Total organic carbon

- Total organite carbogon

o Totel organic halogens

: Total phosphatiog

Antimony-lizs

Ocolum.13

0 Cosium.137

Cobakt.57

- Cobati-io

E Europlum.152

Europlum.15s

: Groes alphas

Nonvolatio beto

Potaeglum.40

: Promothlum-144

Authonium.100

0 Sodium.22

Towal alpha-emitting radium

: Tritium

Z Vincrum.es

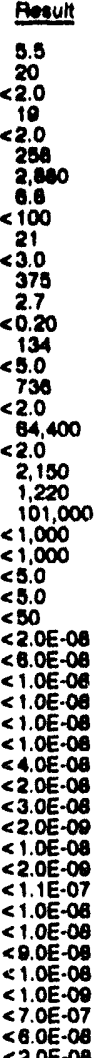

Mod Unit Lab

WELL NPM 4DD

MEASUREMENTS CONOUCTED IN THE FIELO

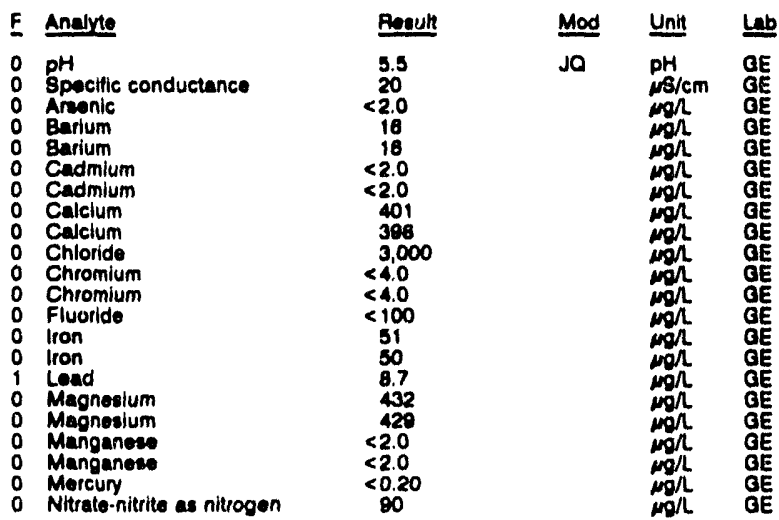

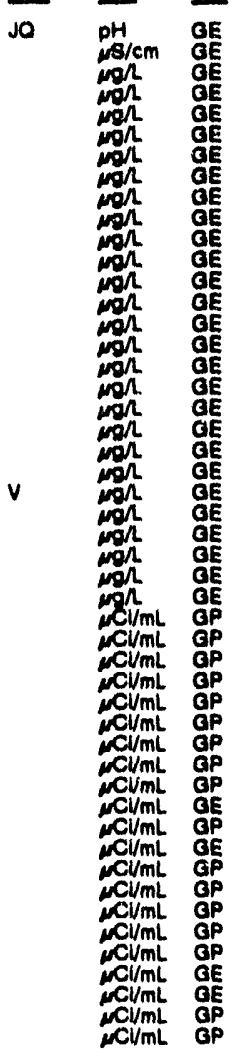

GP
Semple date: 00/20/82

Depth to wator: $5.48 \mathrm{~h}(1.87 \mathrm{~m})$ below TOC

Water elevation: $300.12 \mathrm{H}$ (03)

sp. conductunce: $25,18 / \mathrm{cm}$

The woll wont dry during purging.

LABOPATORY ANALYSES

Time: : 9:45

PH: 4.8 .89

Alkalinity: $0 \mathrm{mgh}$ : 20.800

$<2.0 E-06$

$<1.0 E-08$

$<1.0 E .00$

$<1.0 E .08$

$<4.0 E-08$

<3. 30.08

$<<2.0 E .09$

$<2.0 \mathrm{0} \cdot 09$

$<1.0 E-\infty \theta$

$<1.0 E-00$

$<1.0 E .00$

2.5E.06 5 5.0E. 07

$<6.0 \mathrm{E} .08$
$<2.0 \mathrm{E} .08$ 
ANALYTICAL RESULTS

WELL NPM 400 collected on Os/29/02, laboratory analyees (cont.)

\begin{tabular}{|c|c|c|c|}
\hline Anative & Result & Mod & Unit \\
\hline 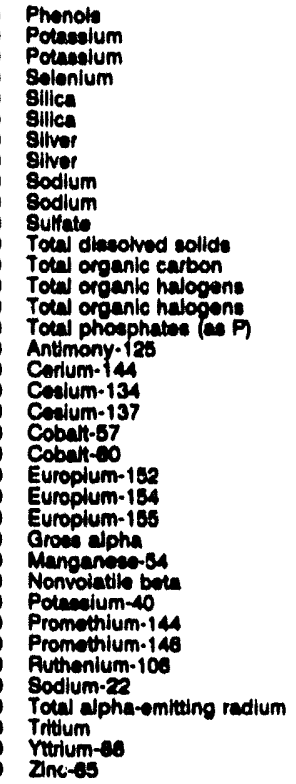 & 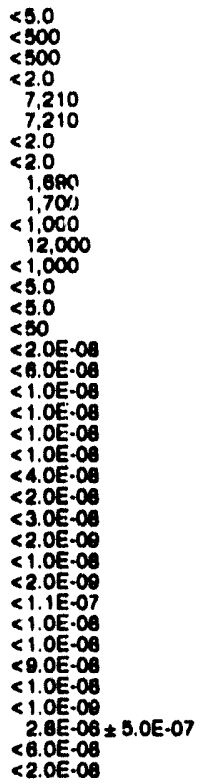 & $v$ & 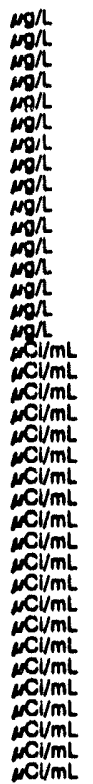 \\
\hline
\end{tabular}

WELL NPM 19A

MEASUREMENTS CONDUCTEO IN THE FIELD

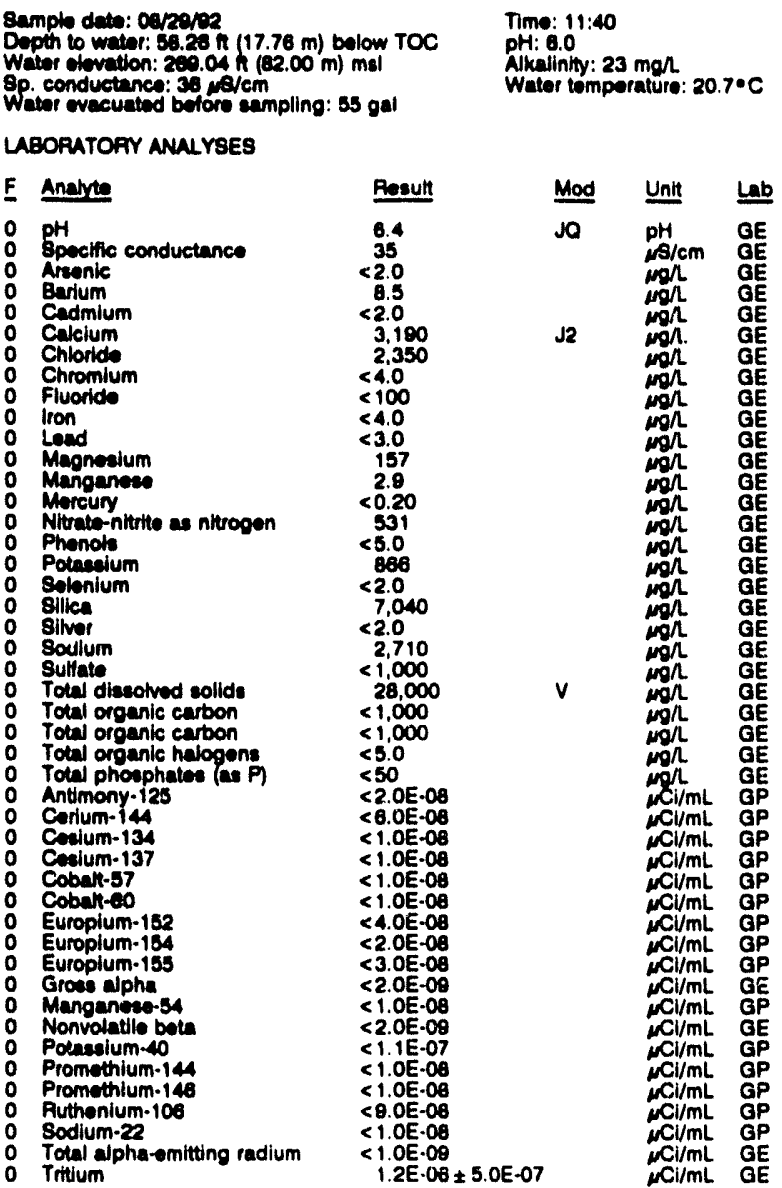

WELL NPM 10A collectod on 06/20/92, laboratory enalyees (cont.)

\begin{tabular}{|c|c|c|c|}
\hline E Anabute & Rosult & Mod & Untt \\
\hline $\begin{array}{ll}0 & \text { Trittum } \\
0 & \text { Yttrium-8s } \\
0 & \text { Zinc. } 05\end{array}$ & $\begin{array}{r}1.1 \mathrm{E} \cdot 0 \\
<6.0 \mathrm{E} \cdot 0 \\
<2.0 \mathrm{E} \cdot 0\end{array}$ & & 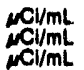 \\
\hline
\end{tabular}

WELL NPM 19B

MEASUREMENTS CONDUCTED IN THE FIELD

Sample dale: 00/29/92

water: $00.30 \mathrm{n}(18.30 \mathrm{~m})$ bolow TOC

Wator onvation: $207.30 \mathrm{~h}$ (01.4

Wator ovacuatod botoro sampling: 130 oal

TH: 57.05

LABOFUTOAY ANALYSES

: $\stackrel{\text { pH }}{\mathrm{pH}}$

Spocific conductance

8pectific conductunce

Apecticic

Arentic

0 Barium

Banium

Cadmium

Caldium

Calclum

Chloride

Chromium

Chromium

F Fluonde

Fluoride

Iron

: lion

2 Loed

o Magnoelum

Magnosium

Manganees

Mercury

Nitrate as nittogen

Nitrato-nitutite as nittrogen

o Phenoles

o Phonols

Potanslum

Solonium

golonium

: siliea

o silica

o sivor

Silver

sodium

o soultate

o Sulfate

- Sultato

T Total disuotved solide

- Total diseolved colldo

- Total organic carbon

- Total organic curbon

- Total organic halogens

- Total organic halogens

Tolw phosphatios

Total phosphates (as P

Antimony-12.

- Antmony.125

Antmony.125

- Corlum.144

- Corium.14a

Cosium. 134

Cosium-134

Conlum-134

Conlum.137

Coslum.137

0 Cobalt-57

0 Cobaltis7

- Cobaltist

: Cobaltsen

- Cobalt-60

Europium-152
Mod Unit ub

Jo pH WA

Jo $\mathrm{N} / \mathrm{cm}$ WA

$\sqrt{72}$

2.310

2,300
2,450

$<.0$
1.1

$<100$

$<100$
$<100$

$<4.0$

$<3.0$

$<3.0$

251
235
2.8

2.7
$<0.20$
$<0.20$

$<0.20$

65
$<5.0$
$<5.0$

$<5.0$

2,860
2,780

$<2.0$

$<2.0$

10,000

$<2.0$

$<.70$
2,350

2,330

2,630

26,000

$<1,000$

$<500$

$<5.0$

$<50$

438

$<2.06 .08$

$<2.5 E-00$

$<8.0 E .08$

政.

.

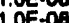

0 .00

$1.0 E-08$

$<1.0 E-00$

<1.0E-06

$<1.0 \mathrm{E} .06$

政

(1.2E.00

$<1.2 E .06$
JO 
ANALYTICAL RESULTS

\begin{tabular}{|c|c|c|c|}
\hline Aneves & Result & Unit & Lab \\
\hline 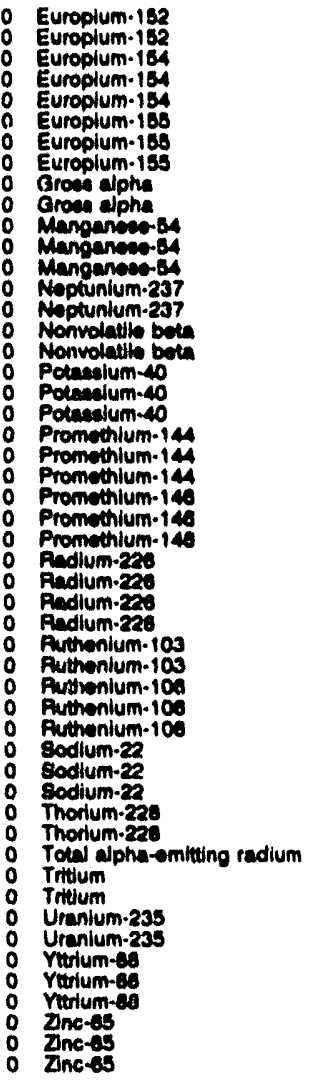 & 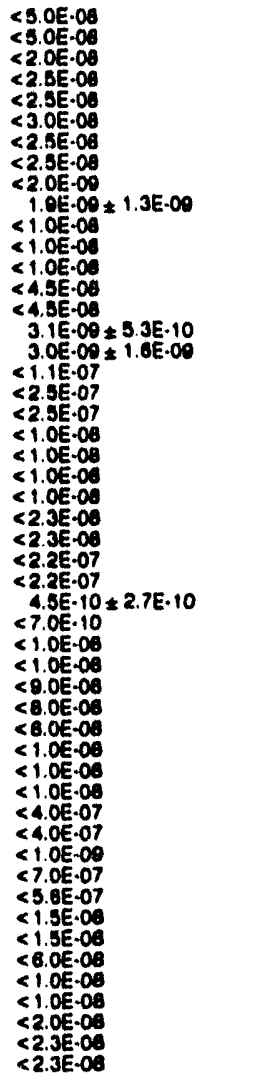 & 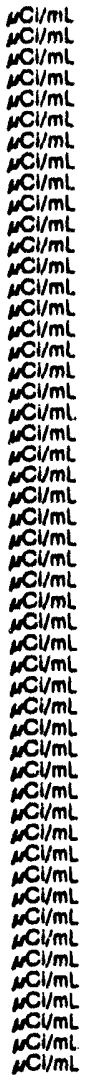 & $\begin{array}{l}C N \\
C N \\
G P \\
C N \\
C N \\
G P \\
C N \\
C N \\
G E \\
T M \\
G P \\
C N \\
C N \\
C N \\
C N \\
G E \\
T M \\
G P \\
C N \\
C N \\
G P \\
C N \\
C N \\
G P \\
C N \\
C N \\
C N \\
C N \\
T M \\
T M \\
C N \\
C N \\
G P \\
C N \\
C N \\
G P \\
C N \\
C N \\
C N \\
C N \\
G E \\
G E \\
T M \\
C N \\
C N \\
G P \\
C N \\
C N \\
G P \\
C N \\
C N\end{array}$ \\
\hline
\end{tabular}

WELL NPM 19B Replicate

MEASUREMENTS CONOUCTED IN THE FIELL

Sanple dela: 00:2aper

Depth to water: $60.30 \mathrm{n}(16.38 \mathrm{~m})$ below TOC Water elovation: $267.30 \mathrm{~h}$

8p. conductance: $39 \mathrm{\mu s} / \mathrm{cm}$.

LABOPATOAY ANM YSES

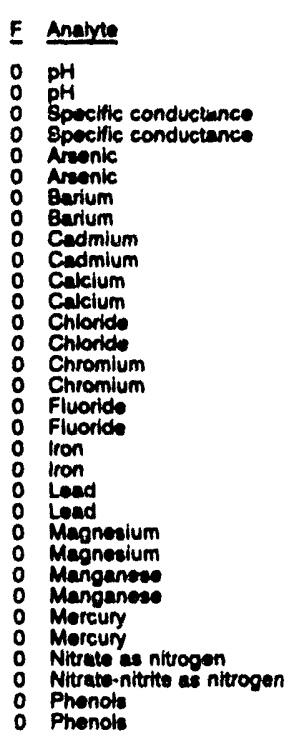

\begin{tabular}{|c|c|c|}
\hline Presult & Mod & Unit \\
\hline $\begin{array}{l}6.5 \\
8.2\end{array}$ & $\begin{array}{l}\text { Jo } \\
\text { Jo }\end{array}$ & $\underset{\mathrm{pH}}{\mathrm{pH}}$ \\
\hline $\begin{array}{l}35 \\
35\end{array}$ & Jo & $\begin{array}{c}\mathrm{N} / \mathrm{cm} \\
\mathrm{s} / \mathrm{cm}\end{array}$ \\
\hline $\begin{array}{l}<2.0 \\
<2.0\end{array}$ & & $\cos$ \\
\hline 17 & & $\log$ \\
\hline $\begin{array}{r}18 \\
<2.0\end{array}$ & $\sqrt{3}$ & $\operatorname{mon}$ \\
\hline$<0.35$ & & $\operatorname{mg} h$ \\
\hline $\begin{array}{r}2,230 \\
2,240\end{array}$ & & $\omega / \mathrm{L}$ \\
\hline 2,220 & & mon \\
\hline $\begin{array}{r}r 4.0 \\
2.3\end{array}$ & J3 & $m /$ \\
\hline$<100$ & & wor \\
\hline $\begin{array}{l}<100 \\
<4.0\end{array}$ & & $\operatorname{mon} \Omega$ \\
\hline $\begin{array}{r}12 \\
<3.0\end{array}$ & & $\operatorname{mot}$ \\
\hline $\begin{array}{l}<3.0 \\
<2.0\end{array}$ & & $\operatorname{mog} \Omega$ \\
\hline 244 & & $\operatorname{mon}$ \\
\hline 2.3 & & \\
\hline 1.9 & J3 & \\
\hline $\begin{array}{l}<0.20 \\
<0.20\end{array}$ & & \\
\hline 147 & & \\
\hline $\begin{array}{r}111 \\
<50\end{array}$ & & \\
\hline $\begin{array}{l}<5.0 \\
<5.0\end{array}$ & & \\
\hline
\end{tabular}

\begin{tabular}{|c|c|c|c|c|}
\hline & Anelyte & Peoulf & Mod & Unit \\
\hline & 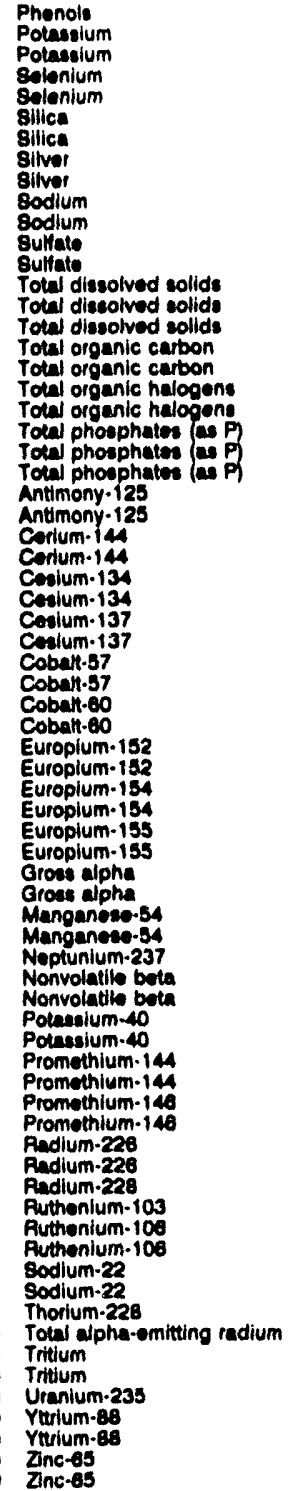 & 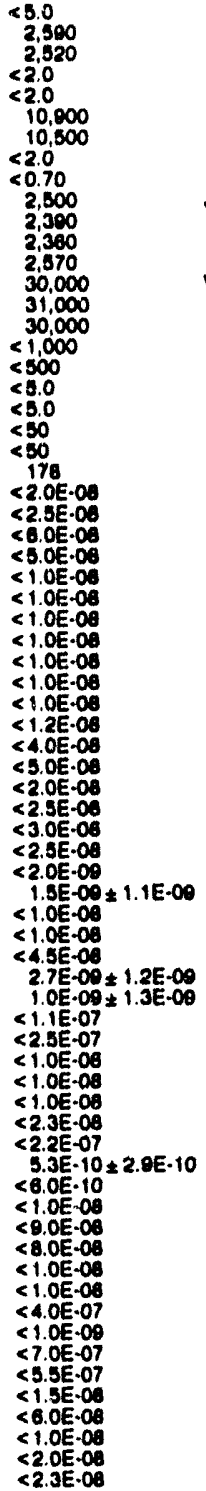 & J2 & 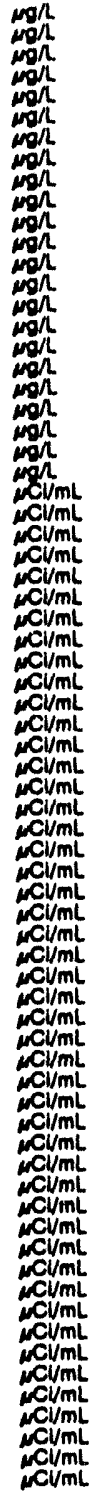 \\
\hline
\end{tabular}

WELL NPM 19C

MEASUREMENTS CONOUCTED IN THE FIELD

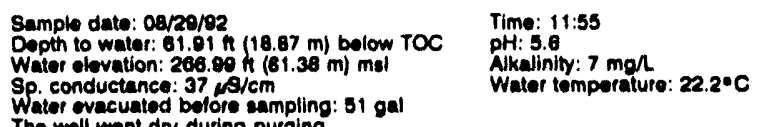

Water evacuatod bolore aampling: 51 ge

LABORATOAY ANALYSES

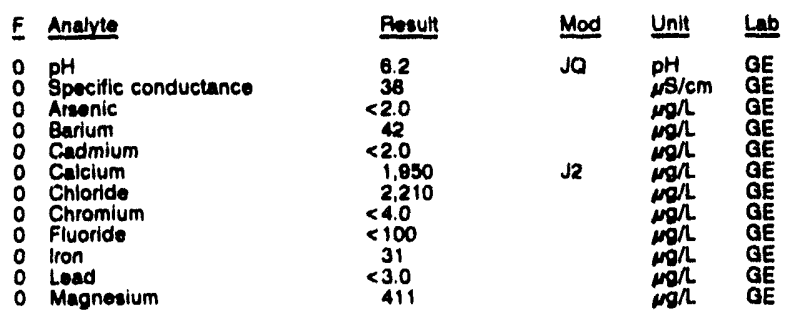


ANALYTICAL RESULTS

WELL NPM 100 colloctod on 00/20/92, laboratory analyaes (cont)

\begin{tabular}{|c|c|c|c|}
\hline 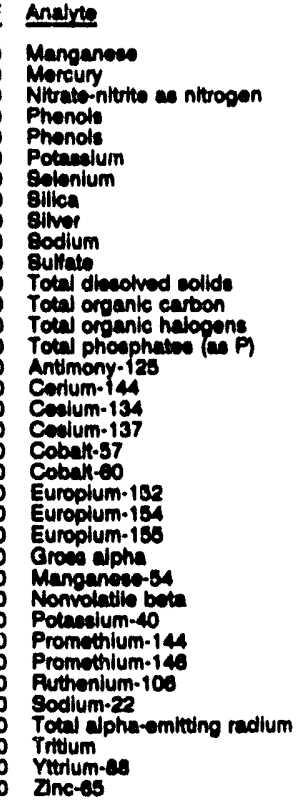 & 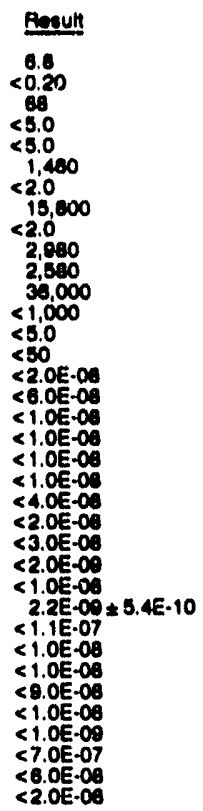 & Mor & 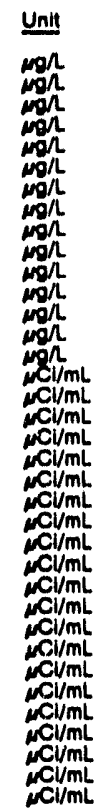 \\
\hline
\end{tabular}

WELL NPM 19D

MEASUREMENTS CONOUCTED IN THE FIELD

\begin{tabular}{|c|c|}
\hline 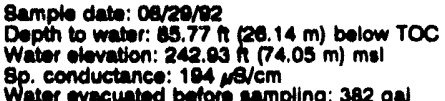 & $\begin{array}{l}\text { Timo: } 11: 20 \\
\text { pH: } 8.8 \\
\text { Alkalinity: } 88 \mathrm{mgn} \\
\text { Water tomperature: } 20.6 \cdot \mathrm{C}\end{array}$ \\
\hline
\end{tabular}
LAORATOAY ANALY YEES

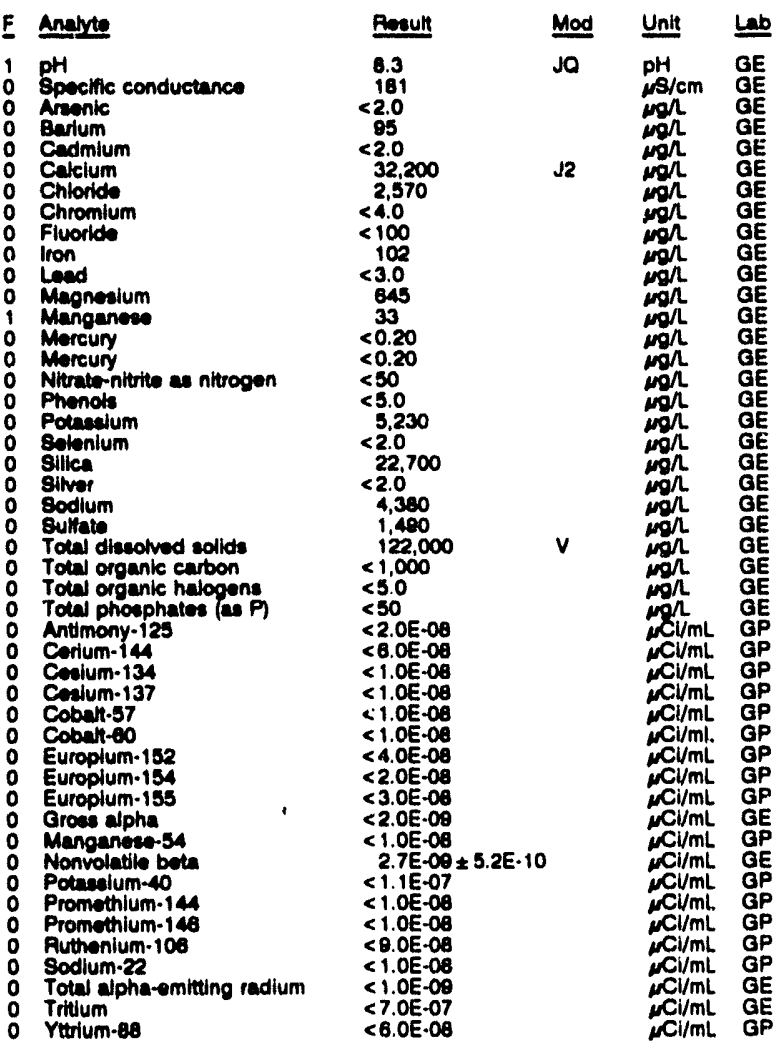

WELL NPM 180 collected on 08/29/92, laboratory analysese (cont.)

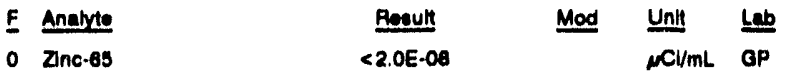

WELL NPM 19E

MEASUREMENTS CONDUCTED IN THE FIELD

\begin{tabular}{|c|c|}
\hline 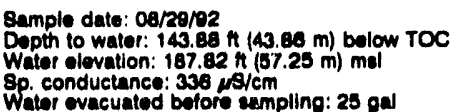 & $\begin{array}{l}\text { Time: } 12 ; 10 \\
\text { pH: } 10.8 \\
\text { Alkallinity: } 68 \mathrm{mgl} \\
\text { Water tomperature: } 22.3 \bullet \mathrm{C}\end{array}$ \\
\hline
\end{tabular}
The will went dry during purging.

LABOAATOAY ANALYSES

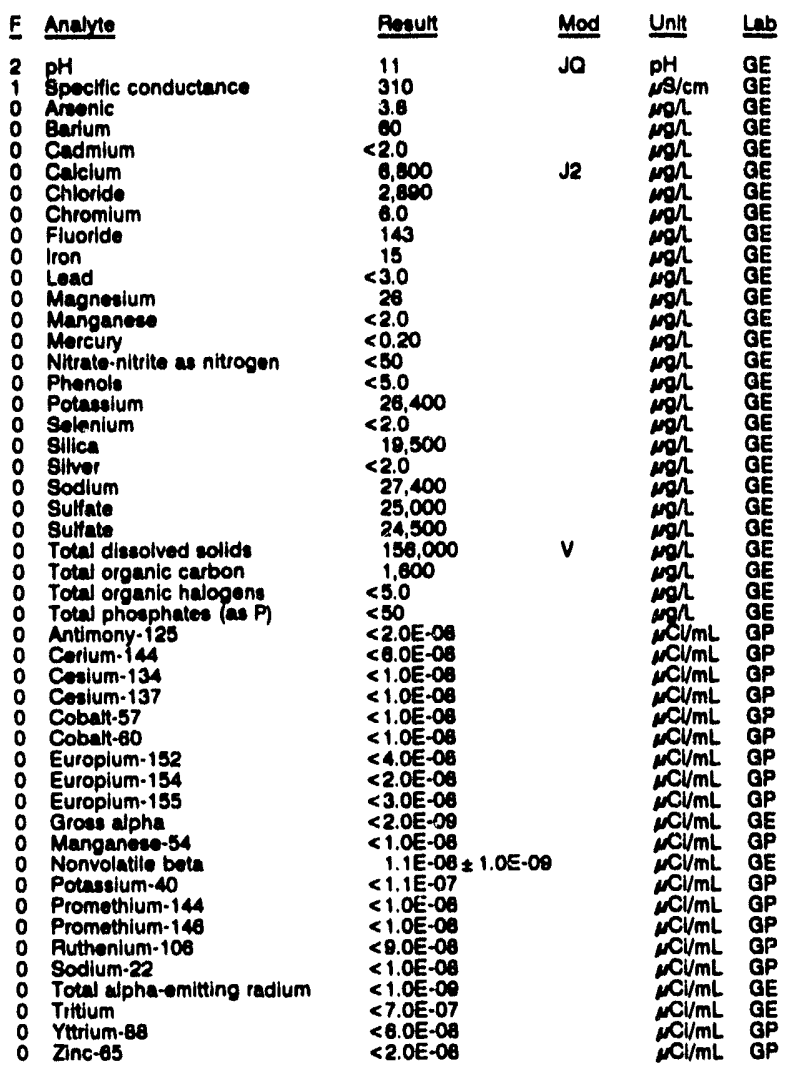

\section{WELL NPM 34A}

MEASUREMENTS CONDUCTED IN THE FIELD

Sample date: 08/29/92

Whter to wavation: $289.86 \mathrm{~h}(86.36 \mathrm{~m}) \mathrm{mal}$

Sp. conductance: 23 $9 / \mathrm{cm}$

Water evacuated before sampling: $26 \mathrm{gal}$

LABORATORY ANALYSES

$\begin{array}{ll}\text { E } & \text { Analyte } \\ 0 & \text { pH } \\ 0 & \text { Specific conductance } \\ 0 & \text { Arsenic } \\ 0 & \text { Barium } \\ 0 & \text { Cadmium } \\ 0 & \text { Calclum } \\ 0 & \text { Chloride } \\ 0 & \text { Chloride } \\ 0 & \text { Chromium } \\ 0 & \text { Fluoride } \\ 0 & \text { Iron } \\ 0 & \text { Lead } \\ 0 & \text { Magneaium } \\ 0 & \text { Manganese } \\ 0 & \text { Mercury } \\ 0 & \text { Nitrato-nitrite as nitrogen } \\ 0 & \text { Phenols }\end{array}$

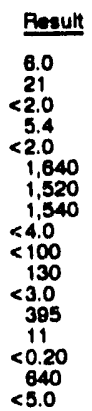

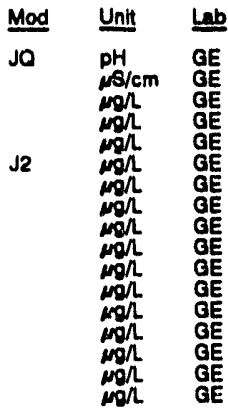


WEL. NPM 34A collected on 08/28/82, laboratory analyees (cont.)

\begin{tabular}{|c|c|c|c|c|c|}
\hline & Anarte & Result & Mod & Unit & \\
\hline $\begin{array}{l}0 \\
0 \\
0 \\
0 \\
0 \\
0 \\
0 \\
0 \\
0 \\
0 \\
0 \\
0 \\
0 \\
0 \\
0\end{array}$ & 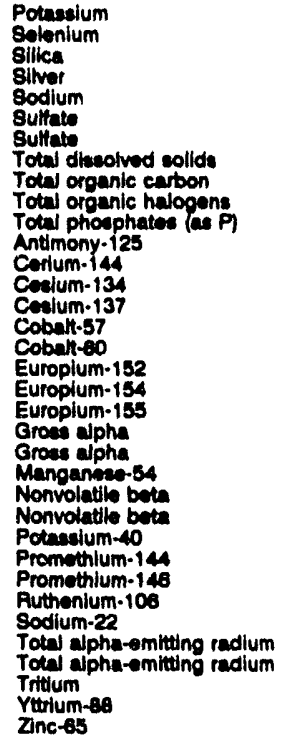 & $\begin{array}{l}<500 \\
<2.0 \\
5,670 \\
<2.0 \\
1,500 \\
1,570 \\
1,500 \\
20,000 \\
<1,000 \\
<5.0 \\
<50 \\
<2.0 E-08 \\
<6.0 E-06 \\
<1.0 E-08 \\
<1.0 E-06 \\
<1.0 E-06 \\
<1.0 E-08 \\
<4.0 E-08 \\
<2.0 E-09 \\
<3.0 E-06 \\
<2.0 E-09 \\
<2.0 E-09 \\
<1.0 E-08 \\
<2.0 E-09 \\
<2.0 E-09 \\
<1.1 E-07 \\
<1.0 E-06 \\
<1.0 E-08 \\
<9.0 E-08 \\
<1.0 E-08 \\
<1.0 E-09 \\
<1.0 E-09 \\
4.1 E-08 \neq 5.0 E-07 \\
<6.0 E-08 \\
<2.0 E-08\end{array}$ & $v$ & 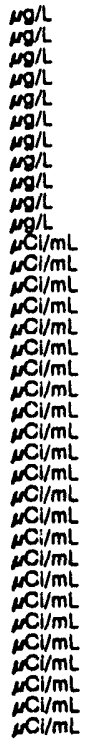 & $\begin{array}{l}G E \\
\mathrm{GE} \\
\mathrm{GE} \\
\mathrm{GE} \\
\mathrm{GE} \\
\mathrm{GE} \\
\mathrm{GE} \\
\mathrm{GE} \\
\mathrm{GE} \\
\mathrm{GE} \\
\mathrm{GE} \\
\mathrm{GP} \\
\mathrm{GP} \\
\mathrm{GP} \\
\mathrm{GP} \\
\mathrm{GP} \\
\mathrm{GP} \\
\mathrm{GP} \\
\mathrm{GP}\end{array}$ \\
\hline
\end{tabular}

WELL NPM $34 B$

MEASUREMENTS CONDUCTED IN THE FIELL

Sample dato: 08/29/02

Depth to water: $51.76 \mathrm{At}(15.78 \mathrm{~m})$ beiow TOC

Wator olovation: 270.04 h $(82.31 \mathrm{~m}) \mathrm{msl}$

Water evecuated before sampling: $33 \mathrm{gal}$

The well went dry during purging.

LABORATOPY ANALYSES

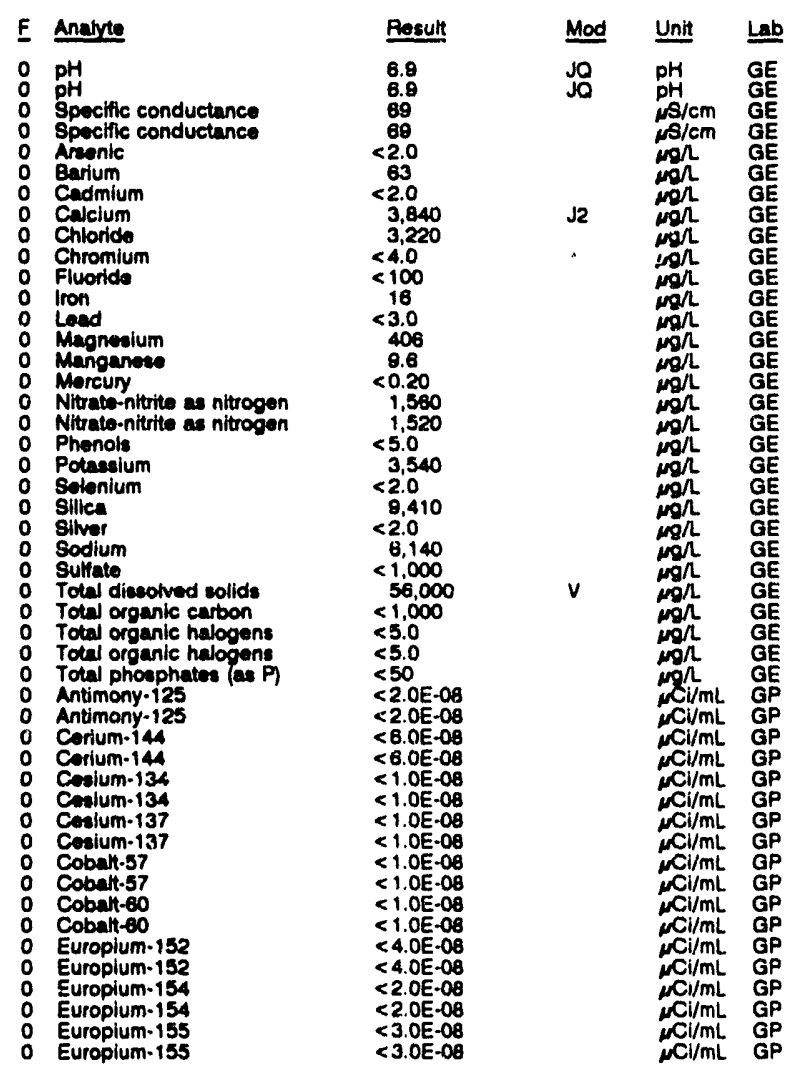

WELL NPM 348 collected on 08/29/82, laboratory analyees (cont.)

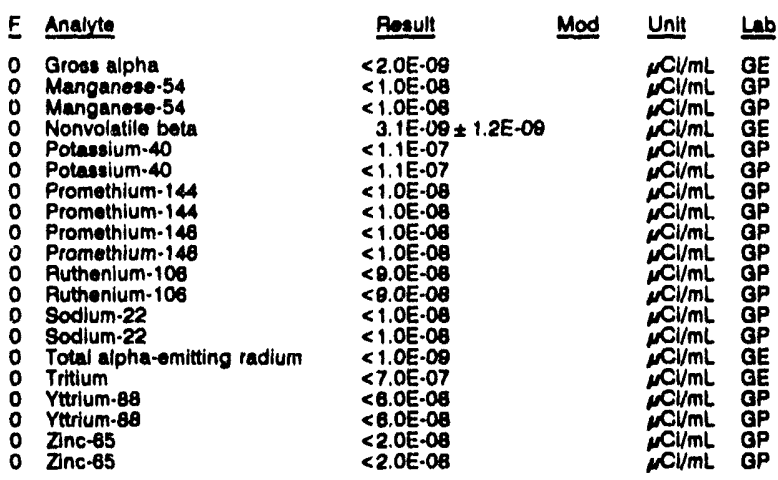

WELL NPM $34 C$

MEASUREMENTS CONDUCTED IN THE FIELO

Sample date: 08/28/92

Depth to water: $55.32 \mathrm{ft}(16.86 \mathrm{~m})$ below TOC Water olovation: $268.68 \mathrm{~h}(81.29 \mathrm{~m}) \mathrm{msl}$ Water ovecualed betore sampling: $223 \mathrm{gol}$

Time: $13: 00$

Alkalinity: $10 \mathrm{mgr}$

Water temperature: $22.4^{\circ} \mathrm{C}$

LABORATORY ANALYSES

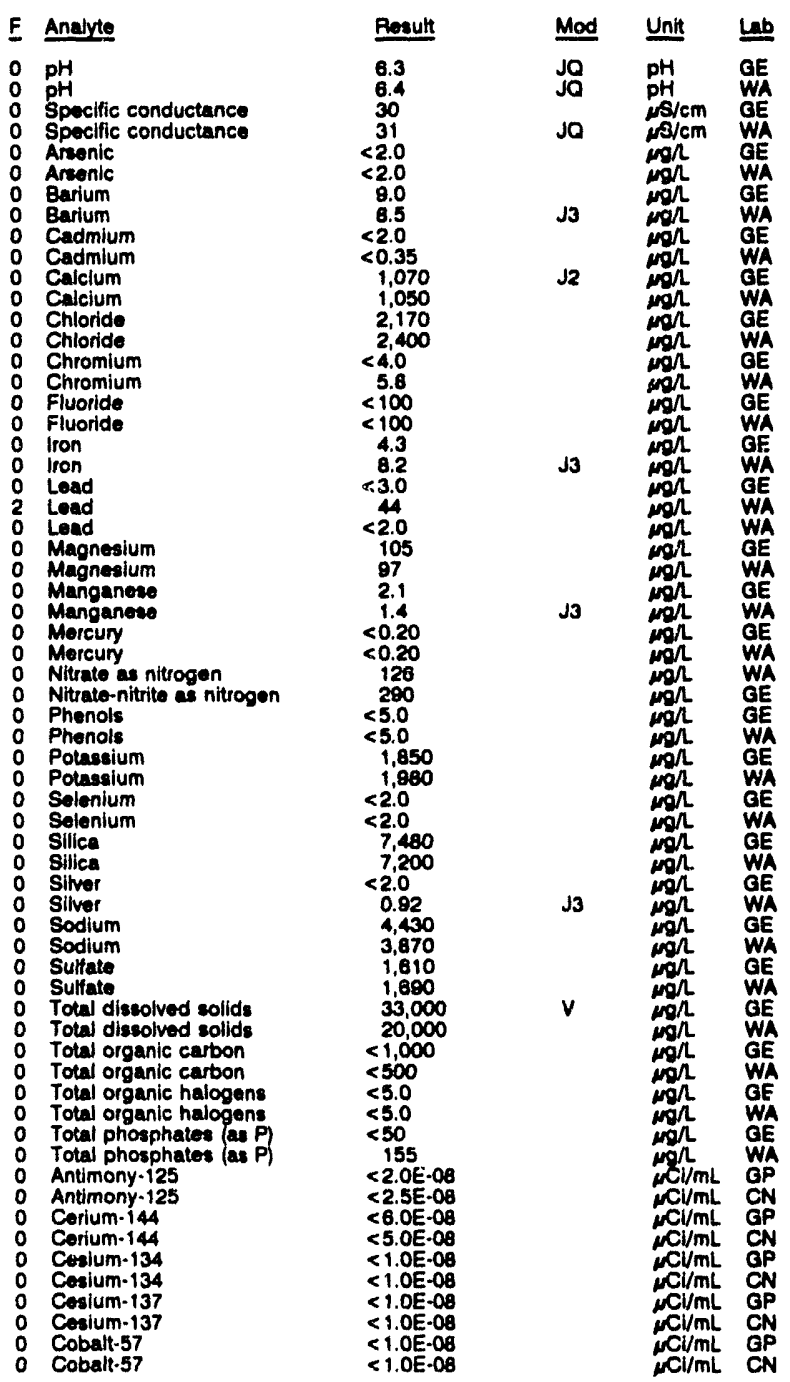


ANALYTICAL RESULTS

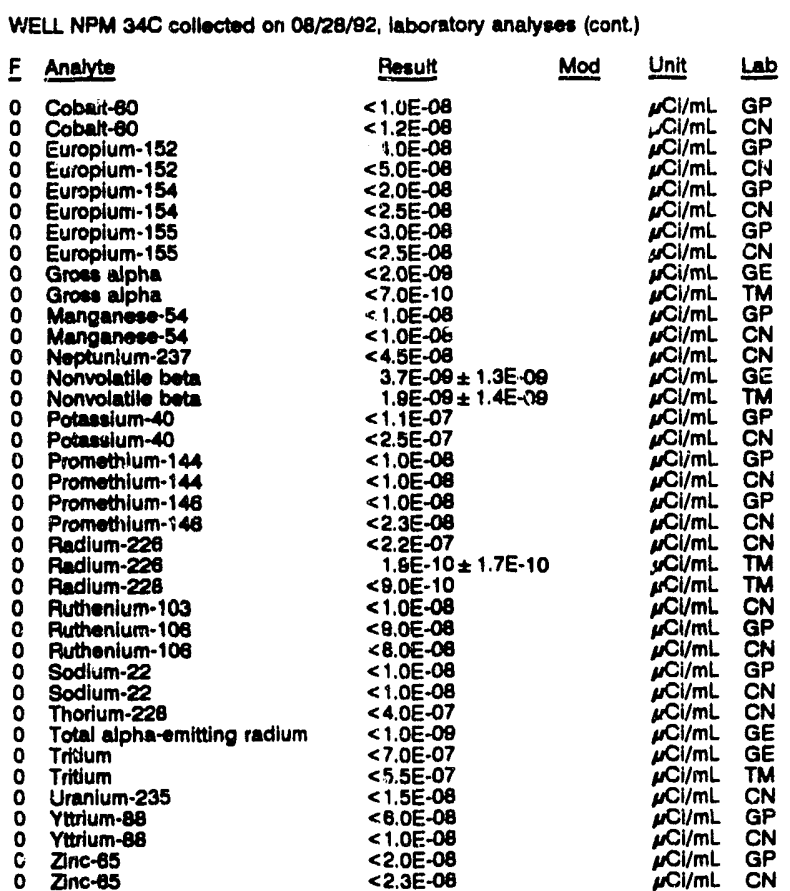

WELL NPM 34C Replicate

MEASUREMENTS CONDUCTED IN THE FIELD

Sample dato: 0erzer/o2

Depth to water: $55.32 \mathrm{ft}(16.88 \mathrm{~m})$ below TOC

Water elevation: 288.68 ht $(81$.

Sp. conductance: $34 \mu \mathrm{s} / \mathrm{cm}$. 20 in) $223 \mathrm{gal}$

LABORATOIYY ANALYSES

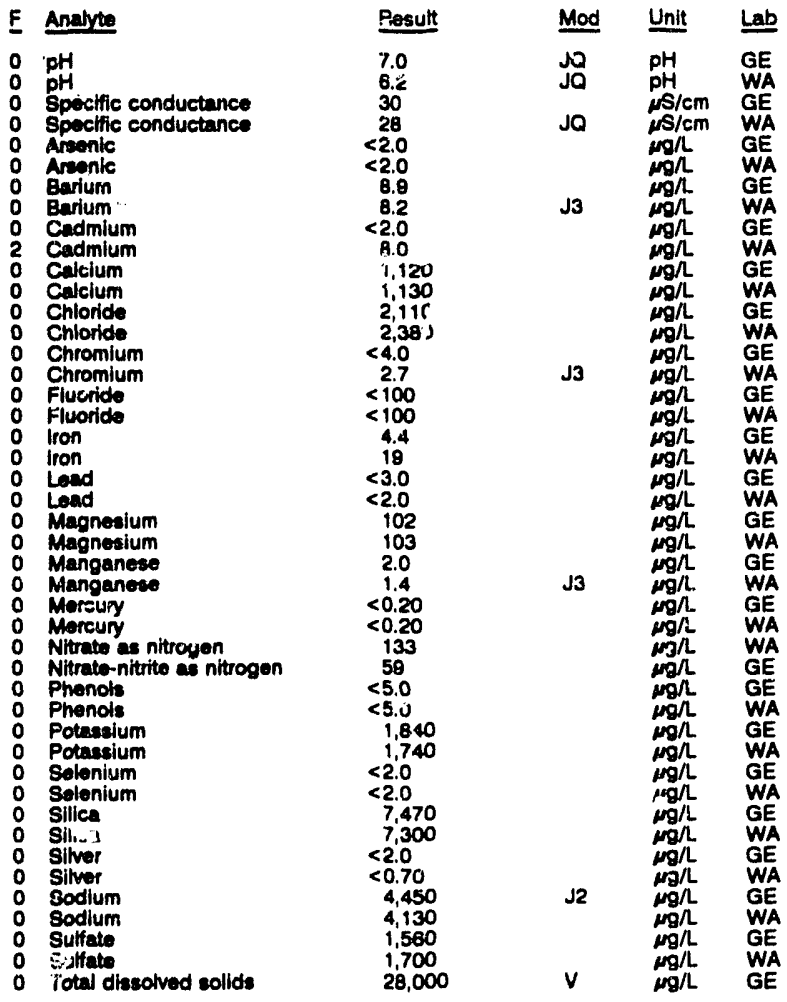

WELL NPM 34C collected on 08/28/92, laboratory analyses (cont.)

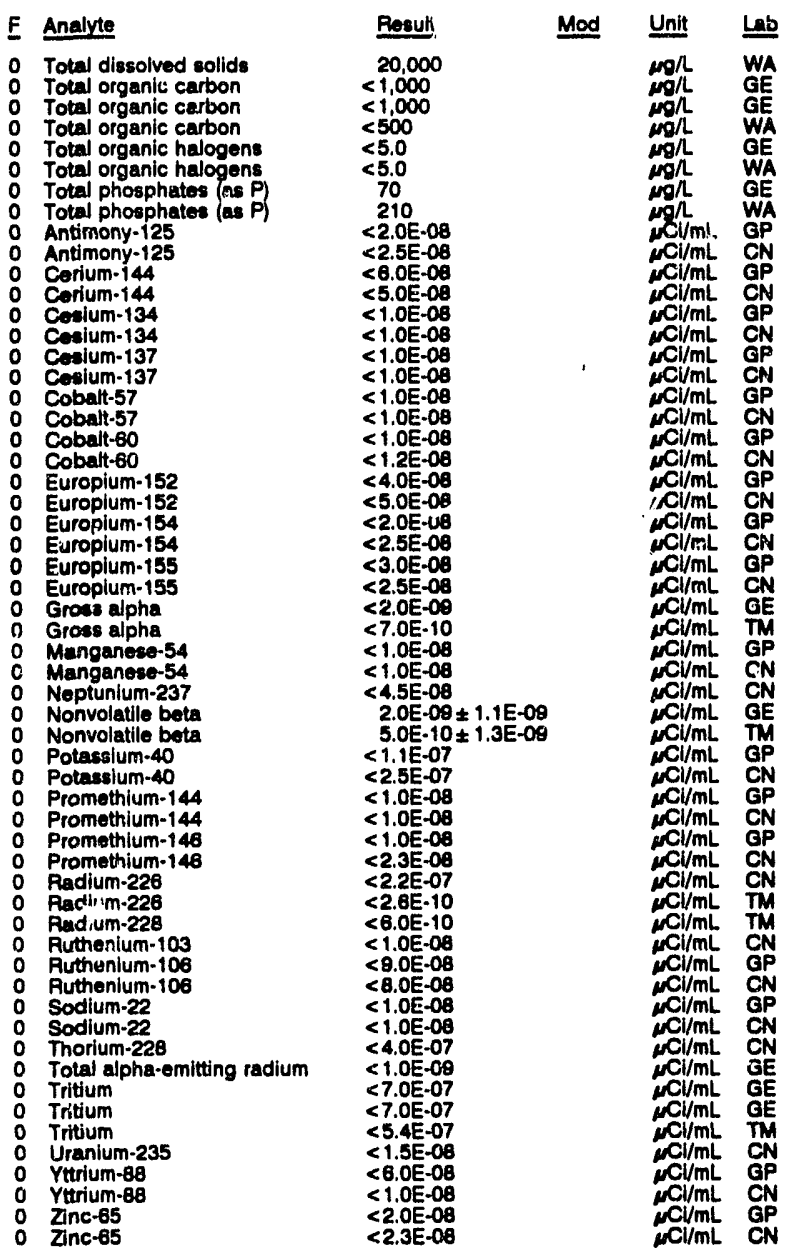

WELL NPM 34D

MEASUREMENTS CONDUCTED IN THE FIELD

Sample date: 08/29/82

Depth to water: $68.55 \mathrm{ft}(20.89 \mathrm{~m})$ below TOC

Water elevation: $254.05 \mathrm{~h}(77.44 \mathrm{~m}) \mathrm{msl}$

Water evacuated bofore sampling: $75 \mathrm{gal}$

The well went dry during purging.

LABOPATORY ANALYSES

\begin{tabular}{|c|c|c|c|c|c|}
\hline $\mathbf{F}$ & Analyte & Result & Mod & Unit & Lab \\
\hline $\begin{array}{l}2 \\
2 \\
0 \\
0 \\
0 \\
0 \\
0 \\
0 \\
0 \\
0 \\
0 \\
0 \\
0 \\
0 \\
0 \\
0 \\
0 \\
0 \\
0 \\
0 \\
0 \\
0 \\
0\end{array}$ & $\begin{array}{l}\text { pH } \\
\text { Specific conductance } \\
\text { Arsenic } \\
\text { Barium } \\
\text { Cadmium } \\
\text { Calcium } \\
\text { Chloride } \\
\text { Chromlum } \\
\text { Fluoride } \\
\text { lron } \\
\text { Lead } \\
\text { Magnesium } \\
\text { Manganose } \\
\text { Moreury } \\
\text { Nitrate-nitrite as nitrogen } \\
\text { Phenols } \\
\text { Potassium } \\
\text { Solenium } \\
\text { Silica } \\
\text { Silver } \\
\text { Sodium } \\
\text { Sulfate } \\
\text { Total dissolved sollds } \\
\text { Total organic carbon } \\
\text { Total organic halogens } \\
\text { Total phosphates (as P) }\end{array}$ & $\begin{array}{c}12 \\
950 \\
<2.0 \\
138 \\
<2.0 \\
67,800 \\
1,990 \\
19 \\
127 \\
<4.0 \\
3.0 \\
8.0 \\
<2.0 \\
<0.20 \\
460 \\
<5.0 \\
29,600 \\
<2.0 \\
8,950 \\
<2.0 \\
16,100 \\
2,930 \\
274,000 \\
2,600 \\
<5.0 \\
100\end{array}$ & Jo & 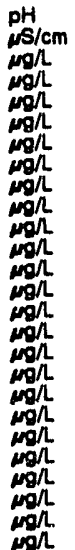 & $\begin{array}{l}\mathrm{GE} \\
\mathrm{GE} \\
\mathrm{GE} \\
\mathrm{GE} \\
\mathrm{GE} \\
\mathrm{GE} \\
\mathrm{GE} \\
\mathrm{GE} \\
\mathrm{GE} \\
\mathrm{GE} \\
\mathrm{GE} \\
\mathrm{GE} \\
\mathrm{GE} \\
\mathrm{GE} \\
\mathrm{GE} \\
\mathrm{GE} \\
\mathrm{GE} \\
\mathrm{GE} \\
\mathrm{GE} \\
\mathrm{GE} \\
\mathrm{GE} \\
\mathrm{GE} \\
\mathrm{GE} \\
\mathrm{GE} \\
\mathrm{GE} \\
\mathrm{GE}\end{array}$ \\
\hline
\end{tabular}


ANALYTICAL RESULTS

WELL NPM 340 collectod on $09 / 29 / 82$, laboratory analyees (cont.)

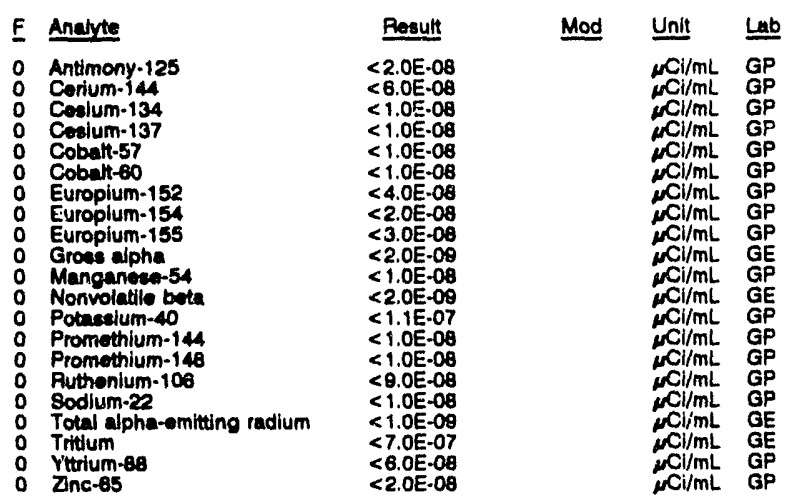

\section{WELL NPM 34E}

MEASUREMENTS CONOUCTED IN THE FIELD

Sample date: $08 / 28 / 92$

Depth to water: $135.55 \mathrm{~h}(41.32 \mathrm{~m})$ below TOC Water elevation: $187.15 \mathrm{Ht}(57.04 \mathrm{~m}$

Sp. conductance: $189 \mu \mathrm{H} / \mathrm{cm}$.

LABORATOPY ANALYSES

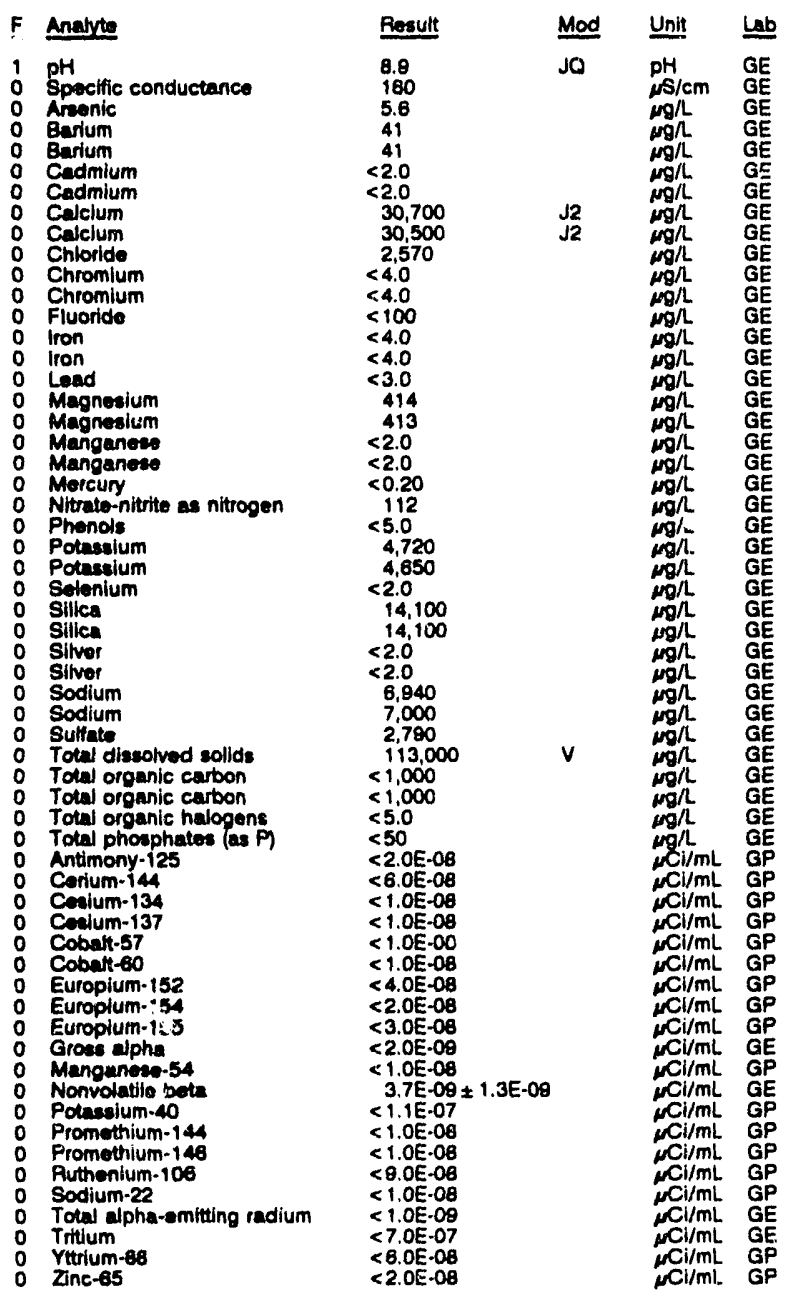

WELL P $14 \mathrm{C}$

MEASUREMENTS CONDUCTED IN THE FIELD

$\begin{array}{ll}\text { Sample date: } 09 / 20 / 92 & \text { Time: } 12: 10 \\ \text { Depth to water: } 55.49 \mathrm{tt}(18.81 \mathrm{~m}) \text { bolow TOC } & \text { pH: } 7.2 \\ \text { Water olevation: } 241.51 \mathrm{ht}(73.61 \mathrm{~m}) \mathrm{msl} & \text { Alkalinity: } 98 \mathrm{mg} / \mathrm{h} \\ \text { Sp. conductance: } 172 \mu \mathrm{cm} / \mathrm{cm} & \text { Water tomperature: } 20.80 \% \\ \text { Water evacuated before sampling: } 271 \mathrm{gal} & \end{array}$

Water evacuated before sampling: $271 \mathrm{gal}$

LABOPATORY ANALYSES

E Analyte

o pH ${ }_{0}$ Specific conductance

Aluminum
Antimony
Areenic
Barlum

Barium

Benzene

Bromodichloromethane

Bromolorm

Bromomethane

Cadmium

Calcium

Carbon tetrachloride

Chloride

Chlorobenzene

Chloroethane

2.Chloroethyl vinyl ther

Chioroform

Chloromethane

Chromium

Cobalt

Dibromochloromethane

1,1-Dichloroethane

o 1,2-Dichloroethane

trans-1,2-Dichloroothylene

- Dichloromethane

o 1,2-Dichloropropane

0
0 trans-1,3-Dichloropropene

O Ethylbenzene

o Fluorido

0 Lead

M Magnestum

Manganes

Mercury

Nitrato-nitrite as nitrogen

Phenols

P Phenols

Potassium

Solenium

S Silica

0 Sodium

o Sodium

1,1,2,2-Tetrachloroothane

Totrachlorothylone

Thallum

Tin

Total dissolved solids

Total organic carbon

Tofal organic halogens

Total phosphates as

1,1,1-Trichloroethan

1,1,2-Trichloroethan

Trichloroftuoromethane

Vanadium

Amoricium-241

Antimony-125

Corlum-144

Cosium-134

Cosium-137

Cobalt-57

Europium-152

Europium-154

Europium-155

Gross alpha

Manganeso-54

Plutonlum-238

Plutonium-239/240

Potassium- 40

Promethium-144

Promethlum-146
Ruthenium-106

Sodium-22

Sodium-22

Thorium-228

Thorium.232

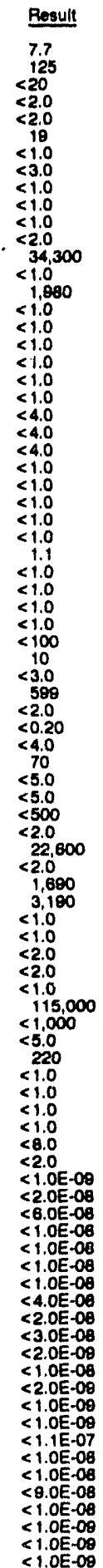

Mod Unit

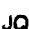

PH $\mathrm{GE}$

$\begin{array}{ll}\mu S / \mathrm{cm} & \mathrm{GE} \\ \mathrm{Mg} / \mathrm{L} & \mathrm{GE} \\ \mathrm{M} / \mathrm{LE} & \mathrm{GE}\end{array}$

ge

$\sin /$ 
ANALYTICAL RESULTS

\begin{tabular}{|c|c|c|c|c|}
\hline$E$ & Analyte & Result & Mod & Unit \\
\hline $\begin{array}{l}0 \\
0 \\
0 \\
0 \\
0 \\
0 \\
0\end{array}$ & $\begin{array}{l}\text { Total alpha-emitting radium } \\
\text { Tritum } \\
\text { Uranium-234 } \\
\text { Uranium-235 } \\
\text { Uranium-238 } \\
\text { Yttrium-88 } \\
\text { Zinc-65 }\end{array}$ & $\begin{aligned} & 1.0 \mathrm{E}-09 \\
&<7.0 \mathrm{E}-07 \\
&<1.0 \mathrm{E}-09 \\
&<1.0 \mathrm{E}-09 \\
&<1.0 \mathrm{E}-09 \\
&<6.0 \mathrm{E}-08 \\
&<2.0 \mathrm{E}-08\end{aligned}$ & & 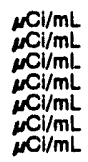 \\
\hline
\end{tabular}

WELL P 14TA

MEASUREMENTS CONDUCTED IN THE FIELD

Sample date: $00 / 20 / 92$ ( $10.41 \mathrm{~m})$ bolow TOC

Water elevation: $180.27 \mathrm{ht}(5=9.00 \mathrm{~m}) \mathrm{ms}$

inacceselbility of mech:anical problem provented sample collection.

\section{WELL P 14TB}

MEASUREMENTS CONDUCTED IN THE FIELD

Sample date: 00/20/82

Depth to watior: $105.11 \mathrm{n}(32.04 \mathrm{~m})$ below TOC Water olevation: $191.18 \mathrm{ft}(58.28$

Water evacuated belore sampling: $1215 \mathrm{gal}$

LABORATOAY ANALYSES

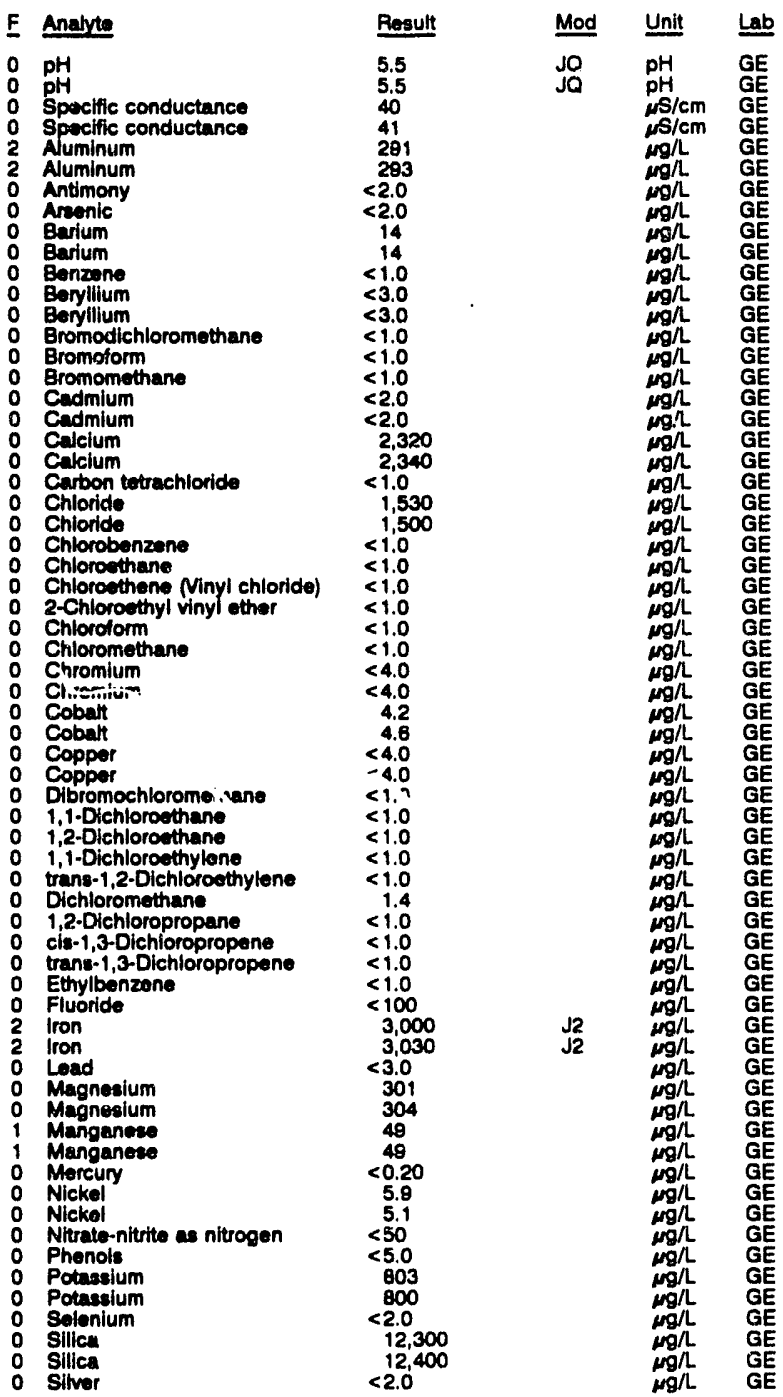

WELL P 14TB collected on 09/20/82, laboratory analyses (cont.)
F Analyte

0 Silver

Sindium

Sulfate

1,1,2,2-Tetrachloroethane

Tetrachloroethylene

Thallium

$\operatorname{Tin}_{\text {Tin }}$

Toluene

Total dissolved solids

Total dissolved solld

\% Total organic carbon

Tral organic halogons

Total phosphates as P

Tolal phosphates (as

o i, 2.Trichloroothane

Trichloroethylene

Trichlorofluoromethane

Vanadium

O Znne

o Amoricium-241

0 Antimony-125

0 Corium-144

Cosium-134

Cobalt-5?

- Cobalt-60

O Europium-152

Europium-154

Gross alpha

Manganese-54

Nonvolatile beta

Plutonium-239/240

Potassium-40

Promethium-144

Promethium-148

Sodjum-22

o Thorium-228

0 Thorium-230

0 Thorium-232

1 Total alpha-emitting radium

o Tritium

o Uranium-234

0 Uranium-235

0 Uranlum-238

Zinc-65
Total organic carbon

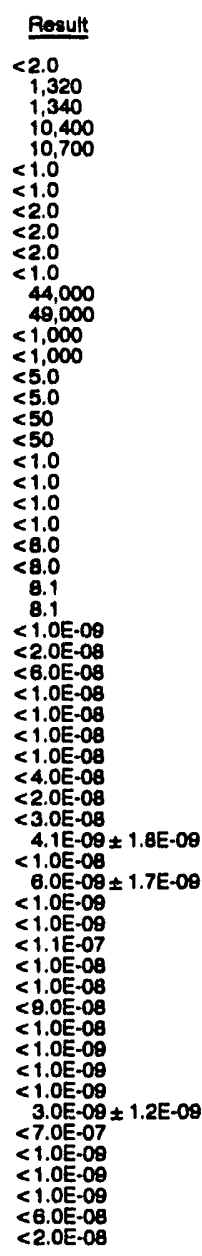

Mod Unit "Las

$\operatorname{mog}_{\omega \rightarrow h} \mathrm{GE}$

$\log _{\mathrm{N} / \mathrm{h}} \mathrm{GE}$

WELL P 14TC

MEASUREMENTS CONDUCTED IN THE FIELD

Sample date: 08/20/92 Time: 11:30
WELL P 18TB

MEASUREMENTS CONDUCTED IN THE FIELD

Sample date: 09/21/82 Water elevation: $173.70 \mathrm{ft}(52.84 \mathrm{~m}) \mathrm{ms}$

Water evacuated belore sampling: $1458 \mathrm{gal}$

Time: $15: 47$

pH: 5.7

Water temperature: $23.0^{\circ} \mathrm{C}$
WELL P 18TC

MEASUREMENTS CONDUCTED IN THE FIELD

Sample date: 09/09/92

Depth to water: $125.30 \mathrm{Ht}(38.19 \mathrm{~m})$ below TOC

naccessibility or mechanical problem prevented eample collection. 
WELL P 24TC

MEASUREMENTS CONDUCTED IN THE FIELD

Sample dute: $00 / 14 / 92$

Dopin to water: $135.00 \mathrm{n}(41.15 \mathrm{~m})$ below TOC Watior alovation: $180.80 \mathrm{R}(\mathrm{ss}, 1 \mathrm{1}$

Sie. conductanco: $73 \mu \mathrm{s} / \mathrm{cm}$.

Time: $12: 45$

Water temperature: $22.1^{\circ} \mathrm{C}$

WELL P 25TA

MEASUREMENTS CONDUCTED IN THE FIELD

\begin{tabular}{|c|c|}
\hline 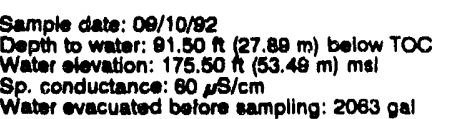 & $\begin{array}{l}\text { Time: } 14: 15 \\
\text { pH: } 8.0\end{array}$ \\
\hline
\end{tabular}

WELL P 25TB

MEASUAEMENTS CONDUCTED IN THE FIELD

Sample date: $00 / 00 / 92$
inacceselbility of mechanical problem provented sample collection.

WELL P 26A

MEASUREMENTS CONDUCTED IN THE FIELO

Sample data: 08/18/92

Depth to watior: 35.35 in $(10.77 \mathrm{~m})$ below TOC

Water olevation: $119.15 \mathrm{~h}(38.32 \mathrm{~m}) \mathrm{ms}$ )

Time: $15: 15$

WELLP 26B

MEASUREMENTS CONDUCTED IN THE FIELD

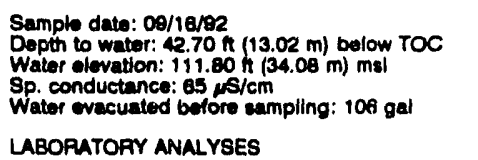

Time: 15:55

$\mathrm{pH}: 6.1$

Alkalinity: $20 \mathrm{mg}$

Water temperature: $21.00 \mathrm{C}$

\begin{tabular}{|c|c|c|c|}
\hline 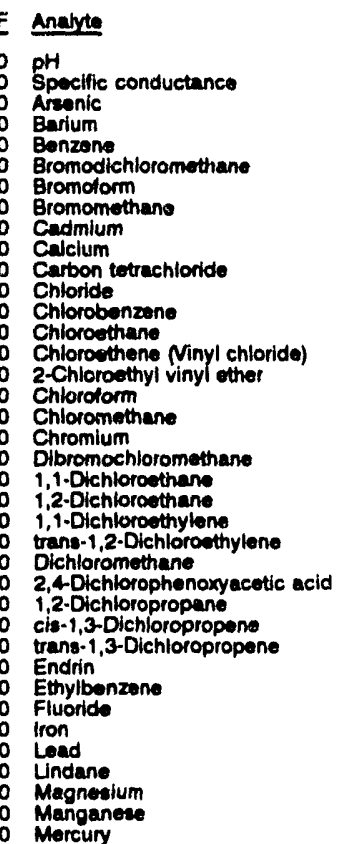 & $\begin{array}{l}\text { Aosulh } \\
6.5 \\
58 \\
<2.0 \\
13 \\
<1.0 \\
<1.0 \\
<1.0 \\
<1.0 \\
<2.0 \\
7, .510 \\
<1.0 \\
21.140 \\
<1.0 \\
<1.0 \\
<1.0 \\
<1.0 \\
<1.0 \\
<1.0 \\
<4.0 \\
<1.0 \\
<1.0 \\
<1.0 \\
<1.0 \\
<1.0 \\
1.3 \\
<0.30 \\
<1.0 \\
<1.0 \\
<1.0 \\
<0.0060 \\
<1.0 \\
<100 \\
15 \\
<3.0 \\
<0.0050 \\
427 \\
<2.0 \\
<0.20\end{array}$ & $\frac{\text { Mod }}{\text { Jo }}$ & 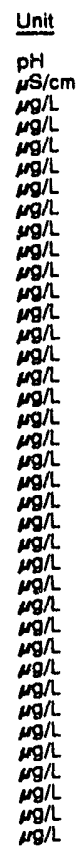 \\
\hline
\end{tabular}

WELL P 268 colloctod on 08/16/82, laboratory analyees (cont.)

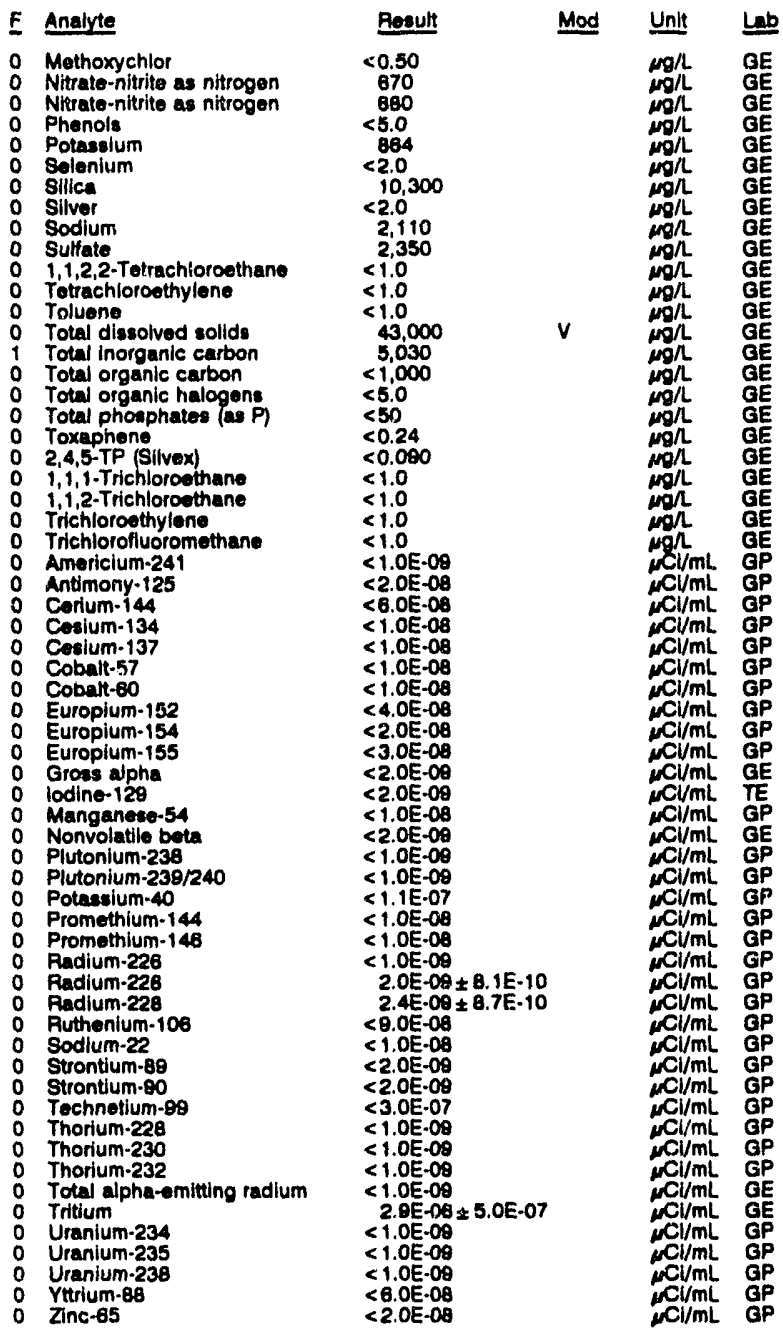

WELLL P 26D

MEASUREMENTS CONDUCTED IN THE FIELD

Sample date: $09 / 17 / 92$

Depth to water: 34.37 . $(10.48 \mathrm{~m}$ ) below TOC

Water elovation: $120.13 \mathrm{ht}(38.62 \mathrm{~m}) \mathrm{msl}$

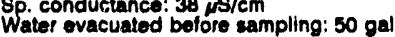

LABOPATORY ANALYSES
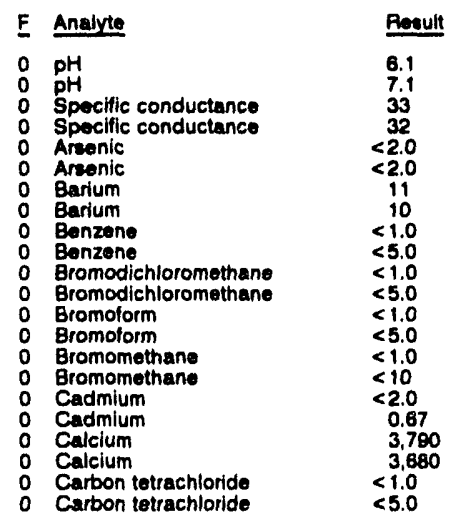

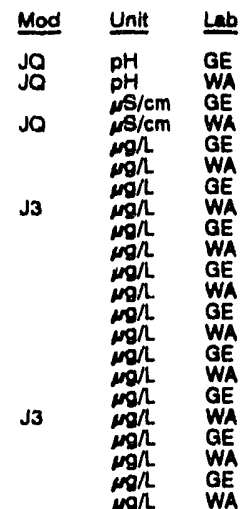

Time: 12:05

AN: 5.6 . 7 man

Alkalinity: $7 \mathrm{mgh}$. $21.00 \mathrm{C}$

A 
ANALYTICAL RESULTS

WELL P 28D collected on 09/17/92, laboratory analyses (cont.)

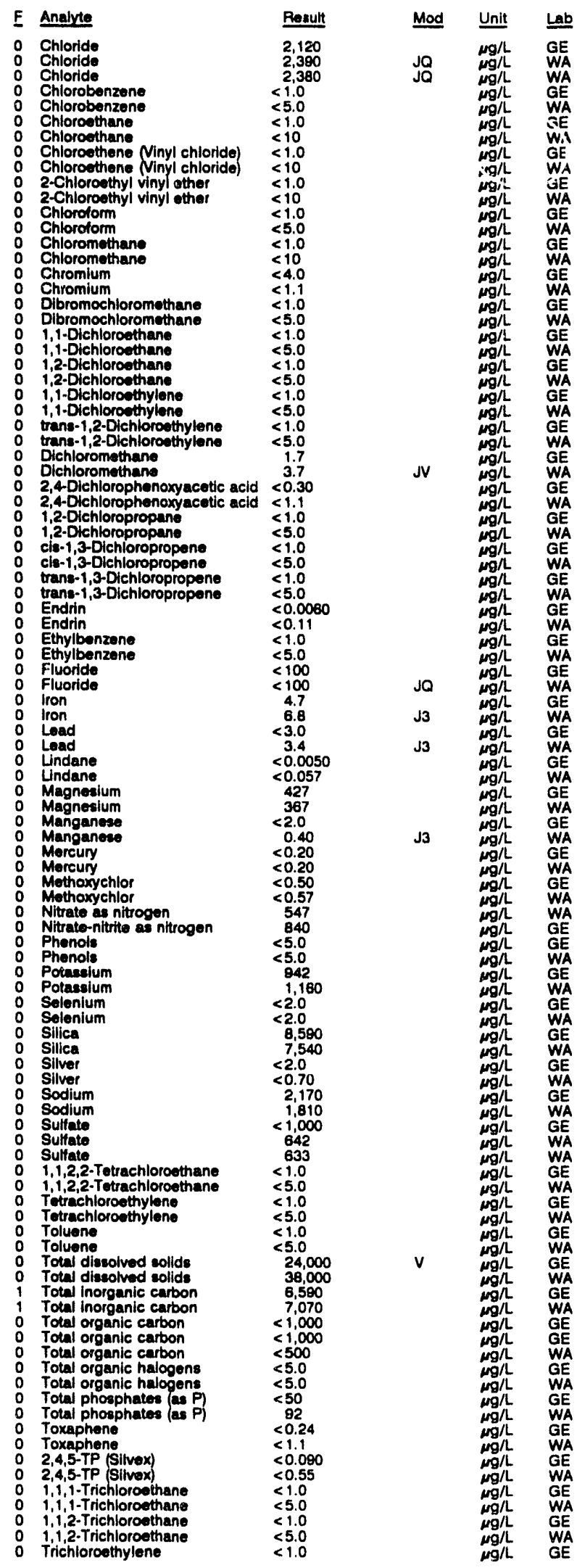

WELL P 26D collectod on 09/17/82, laboratory analyese (cont.)

E Analyte

O Trichloroethylene

0 Trichlorofluoromethane

0 Americium-241

0 Amoricium-241

Antimony-125

Antimony-125

0 Corium-144

Cosium.134

O Cosium-134

: Cosium-137

Cobalt-57

: Cobalt-57

Cobalt-60

Europium-152

Europlum-152

Europlum-154

Europium-155

Europium-155

- Gross alpha

- Gross alpha

o lodine-129

o lodine-128

Manganese.54

Neptunium-237

Nonvolatile beta

Nonvolatile beta

Plutonlum-238

Plutonium-238

Plutonium-238/240

D Potassium-40

Promethium-144

D Promethium-144

: Promethium-146

0 Radium-228

( Radium-228

( Radium-228

Radium-228

Radium-228

Radium-228

Radium-228

Radium-228

0 Radium-228

0 Radium-228

R Ruthenium-103

- Ruthenium-106

Sodium-22

: Sodium-22

S Strontium-89

o strontium-89

0 Strontium-90

0 Strontlum- 90

Strontium -80

Technotium-89

Technetium-89

0 Thorium-228

0 Thorlum-228

0 Thorium-228

0 Thorium-230

0 Thorium-230

0 Thorium-232

- Thorium-232

Total alpha-emitting radium

Tritium

Tritium

Utranium-234

Uranium-234

Uranium-235

o Uranium-235

Uranlum-238

Yturium-8e

Ytrium-88

Zinc-65
Recult:

$<5.0$
$<1.0$
$<50$

$<1.0 E-09$

$<1.0 \mathrm{E}-09$

$<<2.5 \mathrm{E} .08$

$<6.0 \mathrm{E}-08$

$<1.0 \mathrm{E}-08$

$<1.0 \mathrm{E} .08$

$<1.0 E-08$

$<1.0 E .08$

$<1.0 E-08$

$<1.0 E-08$

$<1.2 \mathrm{E} \cdot 08$
$<4.0 \mathrm{E}-08$

$<5.0 E-08$

$<2.5 \mathrm{E} \cdot 08$

$<3.0 E-08$

$<2.5 E .08$

$<$ < $8.0 E-10$

$<2.0 \mathrm{E}-09$

$<2.0 \mathrm{E}-09$

$<1.0 \mathrm{E}-0 \mathrm{~B}$

$<1.0 \mathrm{E} .08$

$<4.5 \mathrm{E}-08$

$1.2 \mathrm{E}-09 \pm 1.5 \mathrm{E}-09$

$<1.0 E-09$

$<1.0 E-09$

$<1.00 .09$

$<1.0 \mathrm{E} \cdot 09$
$<1.1 \mathrm{E} \cdot 07$

$<2.5 \mathrm{E}-07$

$<1.0 E-08$

$<1.0 \mathrm{CE}-08$

$<2.3 \mathrm{E}-08$

$<1.0 E-09$

$<2.2 E-07$

$<1.0 \mathrm{E}-09$

$3.4 E-10 \pm 2.3 E-10$

$<1.0 \mathrm{E}-09$

$<1.0 E-09$

$<$ < $5.0 E-10$

$1.0 E-09 \pm 1.1 E-09$

$<1.0 E-08$

$<8.0 E-08$

$<8.0 E-08$
$<1.0 E-08$

$<1.0 \mathrm{E}-08$
$<1.0 \mathrm{E}-08$

$<2.0 E-09$

$<2.0 E \cdot 09$

$<2.0 E-09$

$<2.0 E-09$

$<3.0 \mathrm{C}-09$

$<3.0 E-07$

$<1.0 \mathrm{E}-09$

$<<.0 \mathrm{E}-00$

$<1.0 \mathrm{E}-09$

$<1.0 \mathrm{E}-09$

$<1.0 E .09$

$<1.0 \mathrm{C}=09$

3. $2 E \cdot 00 \pm 5.0 E-07$

$<4.8 \mathrm{E}-07$

$<1.0 E-09$
$<1.0 E-09$

$<1.0 \mathrm{E}-09$
$<1.0 \mathrm{E}-09$

$<1.0 E-09$
$<1.5 E-08$

$<1.5 E-08$

$<1.0 E-09$

$<1.0 E-09$

$<6.0 E-08$

$<1.0 E-08$

$<2.0 \mathrm{E}-08$
Mod

Unil Lab

$\begin{array}{ll}\mu g / & W A \\ \mu g / 1 & G E \\ \mu g A & W A\end{array}$

$\mu \mathrm{Cl} / \mathrm{mL}$ GP

$\mu \mathrm{Ci} / \mathrm{mL}$ CN

$\mu \mathrm{Cl} / \mathrm{mL}$ CN

$\mu \mathrm{Cl} / \mathrm{mL}$ GP

$\mu \mathrm{Cl} / \mathrm{mL}$ GP

$\mathrm{Cl} / \mathrm{mL}$ GP

$\begin{array}{cc}\mathrm{Cl} / \mathrm{mL} & \mathrm{CN} \\ \mathrm{CP} & \mathrm{GP}\end{array}$

$\mathrm{Cl} / \mathrm{mL} \mathrm{CN}$

$\mu \mathrm{C} / \mathrm{mL}$ GP

$\mu \mathrm{Cl} / \mathrm{mL}$ GP

CCI/mL GP

$\mathrm{Cl} / \mathrm{mL}$ GE

$\mu \mathrm{C} / \mathrm{mL}$ TM

$\mathrm{NCl/mL}$ TE

NCI/mL TE

Cl/mL GN

CI/mL CN

$\mathrm{Cl} / \mathrm{mL}$ TM

$\mathrm{Cl} / \mathrm{mL}$ GP

CI/mL $Q P$

$\mathrm{Cl} / \mathrm{mL}$ GP

$\mu \mathrm{Cl} / \mathrm{mL} \quad \mathrm{CN}$

$\mathrm{Cl} / \mathrm{mL}$ CN

Cl/mL GP

$\mathrm{Cl} / \mathrm{mL}$ GN

$\mathrm{Cl} / \mathrm{mL}$ CN

Cl/mL $\quad \mathrm{CN}$

$\mathrm{cCl} / \mathrm{mL}$ TM

$\mu C I / m L \quad T M$

$\mu \mathrm{Cl} / \mathrm{mL}$ CN

$\mathrm{CCl} / \mathrm{mL}$ TM

$\mu \mathrm{Cl} / \mathrm{mL} \quad T M$

CI/mL GP

CII/mL GP

Ci/mL CN

$\mu \mathrm{Cl} / \mathrm{mL}$ GP

$\mathrm{C} / / \mathrm{mL} \quad \mathrm{NN}$

$\mathrm{Cl} / \mathrm{mL} \quad \mathrm{CP}$

Ci/mL $\mathrm{CN}$

$\mu \mathrm{Cl} / \mathrm{mL}$ CN

CN

CCl/mL CN

$\mathrm{Cl} / \mathrm{mL} \quad \mathrm{GP}$

$\mu \mathrm{Cl} / \mathrm{mL}$ GP

$\mu \mathrm{ClmL}$ CN

$\mathrm{N} \mathrm{N} / \mathrm{mL}$ GE

WCl/mL TM

$\mathrm{cl} / \mathrm{mL} \quad \mathrm{GP}$

$\mathrm{Cl} / \mathrm{mL}$ GP

$M C 1 / m L$ CN

$M C V / m L$ CN

NCl/mL CN

$\mathrm{CL} / / \mathrm{mL}$ GP

$\mathrm{mCl} / \mathrm{mL}$ GP 
ANALYTICAL RESULTS

WELL P 260 Replicate

MEASUREMENTS CONOUCTED IN THE FIELL

Sample date: $00 / 17 / 192$
Depth to water $34.37 \mathrm{~h}(10.48 \mathrm{~m})$ bolow TOC
Water olovation: $120.13 \mathrm{ht}(38.82 \mathrm{~m}) \mathrm{ms}$ Sp. conductanca: $38 \mathrm{\mu} 8 / \mathrm{cm}$.

LABORATOAY ANALYSES

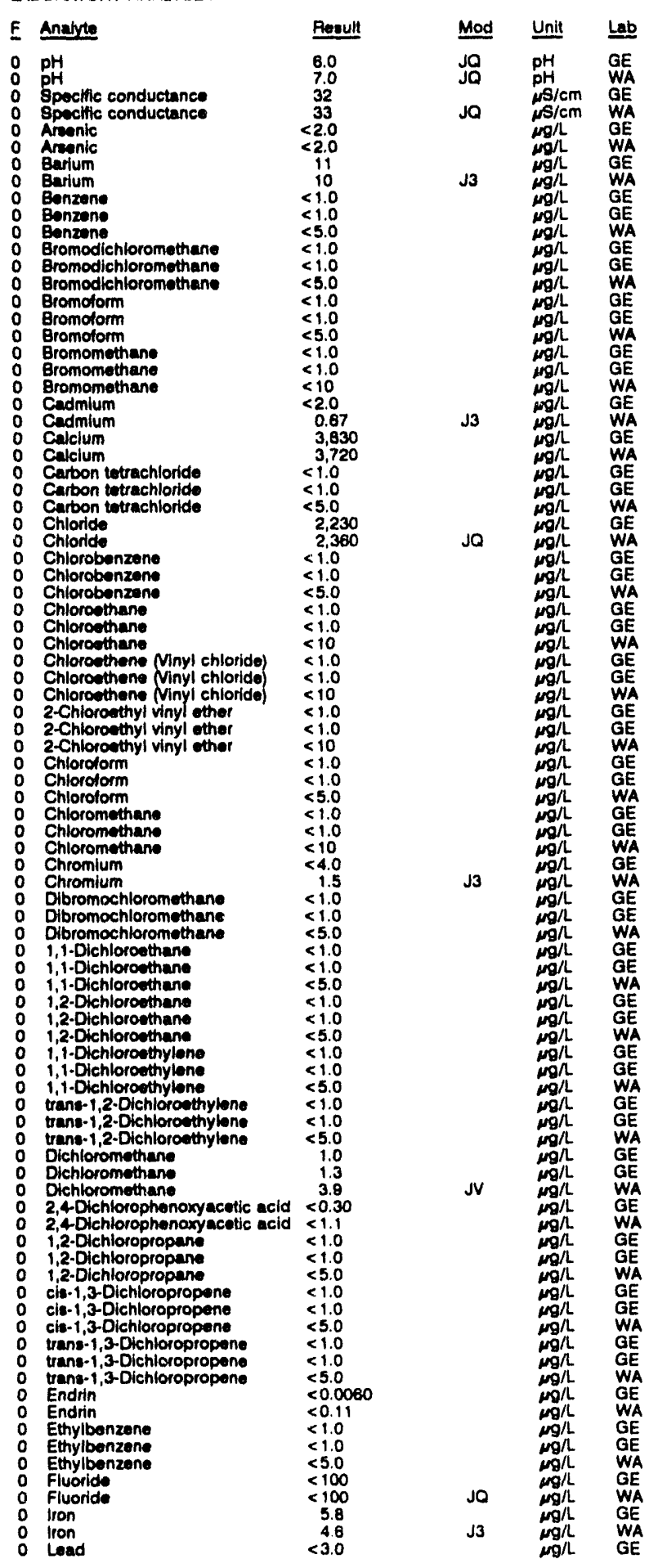

WELL P 28D collected on 08/17/82, laboratory analyese (cont.)

$E$ Analyze

$\begin{array}{ll}1 & \text { Lead } \\ 0 & \text { Lindiane } \\ 0 & \text { Undane } \\ 0 & \text { Magnes } \\ 0 & \text { Magnes } \\ 0 & \text { Mangan } \\ 0 & \text { Mangan } \\ 0 & \text { Meroun }\end{array}$

- Manganeso

O Mercury

: Mothoxychlor

N Nitrate as nitrogen

N Nitrate-nituite as nitrogen

Phonols
Phonole

O Potassium

: Potassium

o Selenium

S Silica

0 Silica

o Silver

o Sodium

O Sulfate

Sulfate

1,1,2,2-Tetrachloroothane

$1,1,2,2 . T$ etrachlorosthane
$1,1,2,2$ - Tetrachlorosthane

Totrachloroethylone

Totrachoroshylone

Toluene

Toluene

Total dissoolved solids

Total dissolved solids

Toral inorganic carbon

rotal norganic carbon

rotal organic carbon

Totas organic halogene

Total organic halogens

Total phosphates (as P)

Total phosphates (as $\mathrm{P}$

Toxaphono

Toxaphene

2,4,5-TP (Silvex)

1,1,1-Trichloroothane

i.i. Trichloroethane

i.1,2. Trichloroethane

1.1,2. Trichioroethane

1, 1,2-Trichioroethane

Trichloroethylene

Trichloroothylene

Trichlorofluoromethano

Trichlorofluoromethane
Trichlorofluoromethane

Americium-241

Americium-24

Antimony-125

Antimony-125

Corium.144

Cosium. 134

Cosium-134

Cocium-137

Cobalt-57

Cobatt -57

Cobalt-60

Europium-152

Europlum-154 Europlum-154

Europium-155

Gross alpha

Gross alpha

Gross alphe

lodine-128

Manganose. 54

Neptunium-237

Nonvolatifie beta

Nonvolatilil bola
Nonvolatile beto

Plutonium-238

Plutonium-238

Plutonium-239/240

Plutonium-239/240

Potassium -40

Promethium-144
10
$<0.00$

$<0.055$

422
387

$<2.0$
0.50
$<0.20$

$<0.20$
$<0.20$
$<.030$

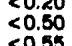

170
1,050

1,050
$<5.0$
$<5.0$

$<.0$
032

045
$<2.0$
$<2.0$

$<.0$
8,560
7,460

$<2.0$
2.4

2.160
1,760

$<1,000$

648
$<1.0$

$<1,0$

$<1.0$

$<1.0$

$<1.0$

$<5.0$

26,000
33,000

6,210
7,440

$<1,000$

$<500$

$<5.0$

48

$<0.24$

$<1.190$

$<0.55$

$<1.0$

$<1.0$

$<1.0$

$<5.0$

$<1.0$

$<5.0$

$<1.0$
$<1.0$

$<1.0 E-09$

$<1.0 E-09$

$<1.0 \mathrm{CE} .09$

$<2.0 E .09$

$<8.0 E .00$

$<5.0 \mathrm{E}-00$

$<1.0 E-08$

$<1.0 E-08$

$<1.0 E-08$

$<1.06 .08$

$>1.0 E-00$

$<1.2 E=0$.

<4.0E.08

$<5.0 E-08$

$<2.0 E-08$

$<2.5 E-00$

$<2.5 E-08$

$<2.0 E-09$

$1.4 E-09 \pm 1.1 E-09$
$1.0 E-09$

$<2.0 E-09$

$<1.0 E-08$

$<4.5 E .08$

2.1E-00 $1.6 E-09$

$2.2 \mathrm{E}-00 \pm 1.6 \mathrm{E}-09$
$2.0 \mathrm{E}-09 \pm 1.6 \mathrm{E}-00$

<. $\begin{gathered}2.0 E-09 \\ <.09\end{gathered}$

$<1.0 E-08$

$<1.0 E-08$

$<1.1 E .07$

$<2.3 E-07$
$<1.0 E .08$

Mod

Unit Le

${ }_{\mu g / L}^{W A} \quad W A$

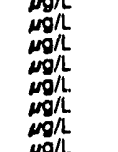

A

政

A

E

E

政

.

政

WA

E

.

MCl/mL BP 
ANALYTICAL RESULTS

WELL P 28D colloctod on 09/17/92, laboratory analyses (cont.)

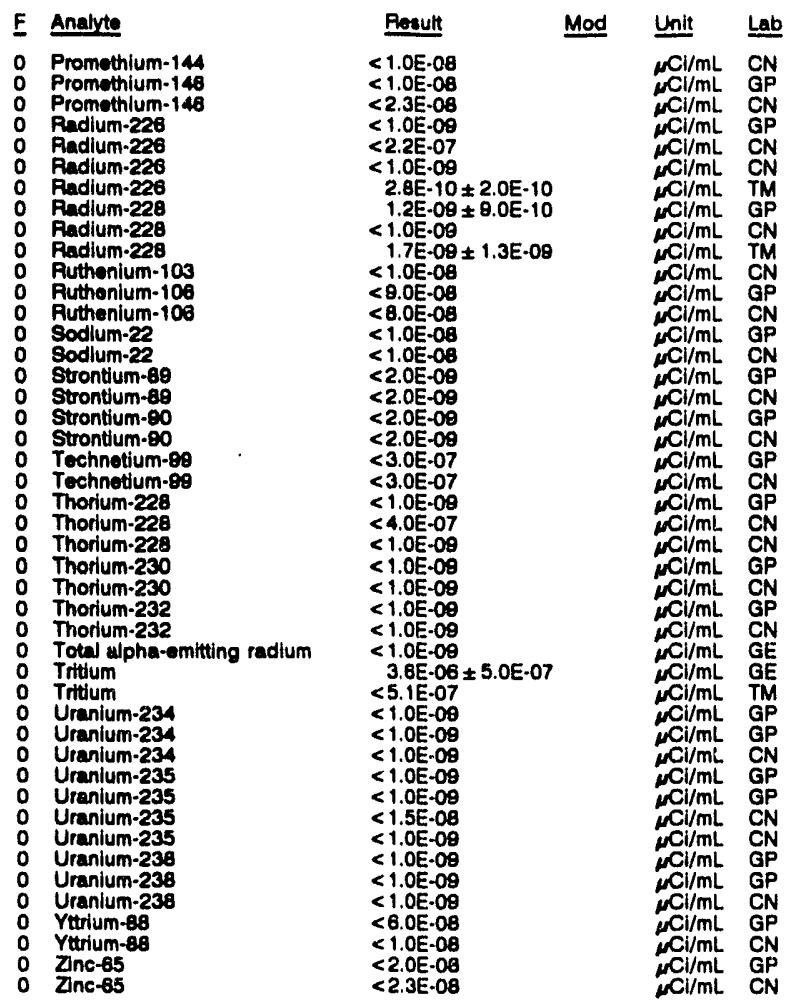

WELL P 2TTA

MEASUREMENTS CONDUCTED IN THE FIELD

Sample date: $09 / 1498$
Dopth to water: $86.20 \mathrm{H}(29.32 \mathrm{~m})$ below TOC
Wator alovation: $180.20 \mathrm{ht}(54.83 \mathrm{~m}) \mathrm{msl}$
Sp. conductance: $50 \mu \mathrm{s} / \mathrm{cm}$

Wator ovacuated botore sampling: $1910 \mathrm{gal}$

Time: $10: 30$

Water temperature: $21.5^{\circ} \mathrm{C}$

WELL P $27 T C$

MEASUREMENTS CONDUCTED IN THE FIELD

Sample date: 09/15/82 Depth to water: $84.50 \mathrm{ft}(28.80 \mathrm{~m})$ below TOC
Water elevation: $161.80 \mathrm{ht}(55.41 \mathrm{~m}) \mathrm{msl}$ Sp. conductance: $77 \mathrm{sS/cm}$
Water evacuated bolore sampling: $1263 \mathrm{gal}$

Warortor ANALYSES

E Analyte

$\begin{array}{ll}0 & \mathrm{pH} \\ 0 & \mathrm{pH}\end{array}$

Spectic conductance

Arsenic
Barium

Barium

Bromodichloromethane

Bromolorm

Bromomethane

Cadmium

Carbon totrachloride

Chron tor

Chlorobenzene

Chloroethane

Chlorcothene Ninyl chloride

2-Chloroethyl vinyl ether

Chloroform

Chioromethan

Chromium

Dibromochloromethane

1,1-Dichloroethane
o 1,2-Dichloroethane

\begin{tabular}{l} 
Pesult \\
\hline 6.4 \\
6.4 \\
69 \\
69 \\
$<2.0$ \\
18 \\
$<5.0$ \\
$<5.0$ \\
$<5.0$ \\
$<10$ \\
0.88 \\
11.000 \\
$<5.0$ \\
1.630 \\
$<5.0$ \\
$<10$ \\
$<10$ \\
$<10$ \\
$<5.0$ \\
$<10$ \\
3.7 \\
$<5.0$ \\
$<5.0$ \\
$<5.0$
\end{tabular}

Time: 12:45

pH: 6.2

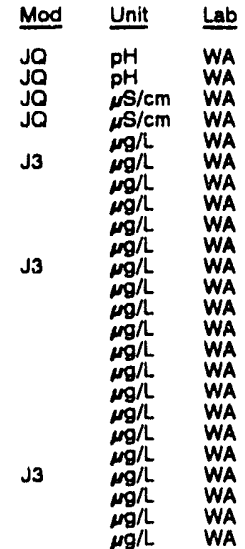

Water temperature: $22.2^{\circ} \mathrm{C}$

WELL. P 27TC collected on 09/15/82, laboratory analyees (cont.)

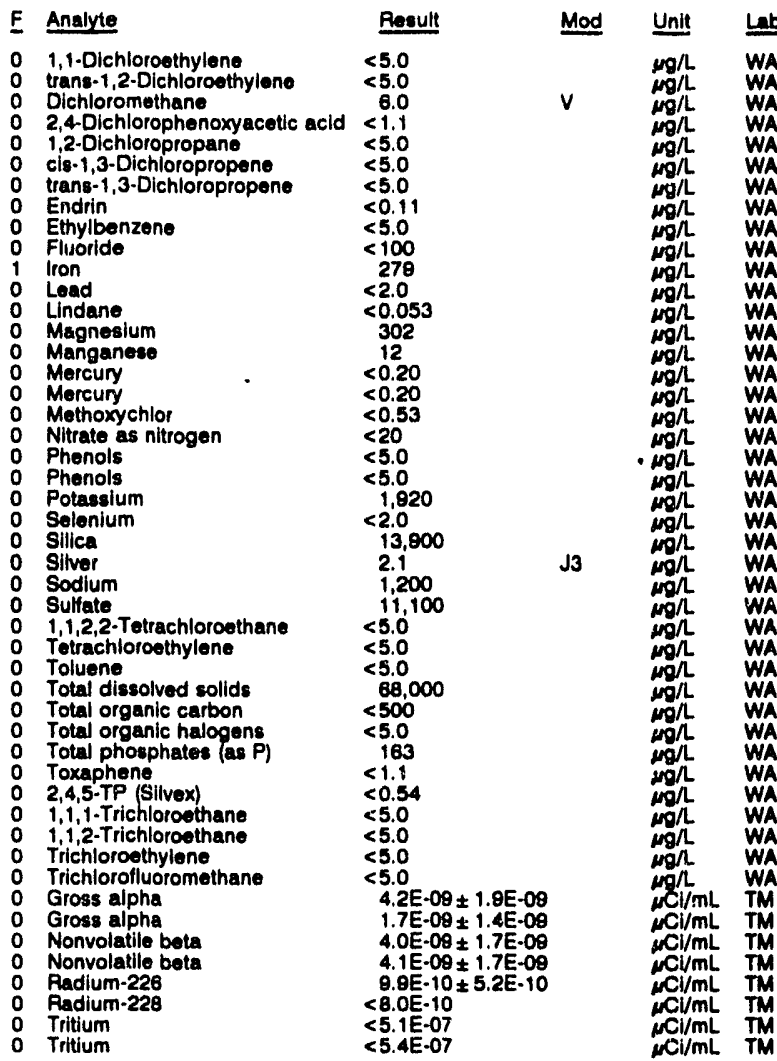

WELL P 28A

MEASUREMENTS CONDUCTED IN THE FIELD

Samplo date: 09/02/92 $\begin{array}{ll}\text { Sample date: } 09 / 02 / 92 & \text { Time: } 12: 55 \\ \text { Depth to water: } 108.02 \mathrm{ft}(32.92 \mathrm{~m}) \text { below TOC } & \text { pH: } 5.7 \\ \text { Water olevation: } 177.68 \mathrm{ft}(54.16 \mathrm{~m}) \mathrm{msl} & \text { Alkalinity: } 14 \mathrm{mg} /\end{array}$

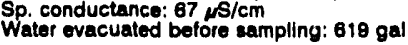
Water tomperature: $20.0^{\circ} \mathrm{C}$ LABORATORY ANALYSES

\begin{tabular}{|c|c|c|c|c|}
\hline$\underline{\mathbf{E}}$ & Analyte & Result & Mod & Unit \\
\hline $\begin{array}{l}0 \\
0 \\
0 \\
0 \\
0 \\
0 \\
0 \\
0 \\
0 \\
0 \\
0 \\
0 \\
0 \\
0 \\
0 \\
0 \\
0 \\
0 \\
0 \\
0 \\
0 \\
0 \\
0 \\
0 \\
0 \\
0 \\
0 \\
0 \\
0 \\
0 \\
0 \\
0 \\
0 \\
0 \\
0 \\
0 \\
0 \\
0\end{array}$ & $\begin{array}{l}\text { Benzene } \\
\text { Benzene } \\
\text { Bromodichloromethane } \\
\text { Bromodichloromethane } \\
\text { Bromoform } \\
\text { Bromoform } \\
\text { Bromomethane } \\
\text { Bromomethane } \\
\text { Calcium } \\
\text { Calcium } \\
\text { Carbon tetrachloride } \\
\text { Carbon tetrachloride } \\
\text { Chlorobenzene } \\
\text { Chlorobenzene } \\
\text { Chloroethane } \\
\text { Chloroethane } \\
\text { Chloroethene Ninyl chloride) } \\
\text { Chloroethene (Vinyl chloride) } \\
2 \text {-Chloroethyl vinyl ether } \\
\text { 2-Chloroethyl vinyl ether } \\
\text { Chlorolorm } \\
\text { Chloroform } \\
\text { Chloromethane } \\
\text { Chloromethane } \\
\text { Dibromochloromethane } \\
\text { Dibromochloromethane } \\
\text { 1,1-Dichloroethane } \\
\text { 1,1-Dichloroethane } \\
\text { 1,2-Dichloroethane } \\
\text { 1,2-Dichloroethane } \\
\text { 1,1-Dichloroethylene } \\
1,1-\text { Dichloroethylene } \\
\text { trans-1,2-Dichloroethylene } \\
\text { trans-1,2-Dichloroethylene } \\
\text { Dichloromethane }\end{array}$ & $\begin{array}{l}<1.0 \\
<5.0 \\
<1.0 \\
<5.0 \\
<1.0 \\
<5.0 \\
<1.0 \\
<10 \\
8.130 \\
8.010 \\
<1.0 \\
<5.0 \\
<1.0 \\
<5.0 \\
<1.0 \\
<10 \\
<1.0 \\
<10 \\
<1.0 \\
<10 \\
<1.0 \\
<5.0 \\
<1.0 \\
<10 \\
<1.0 \\
<5.0 \\
<1.0 \\
<5.0 \\
<1.0 \\
<5.0 \\
<1.0 \\
<5.0 \\
<1.0 \\
<5.0 \\
<1.0\end{array}$ & & 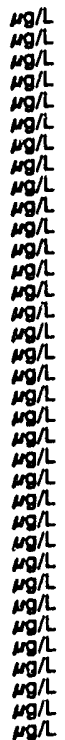 \\
\hline
\end{tabular}


ANALYTICAL RESULTS

WELL P 284 collected on 09/02/92, laboratory analyees (cont.)

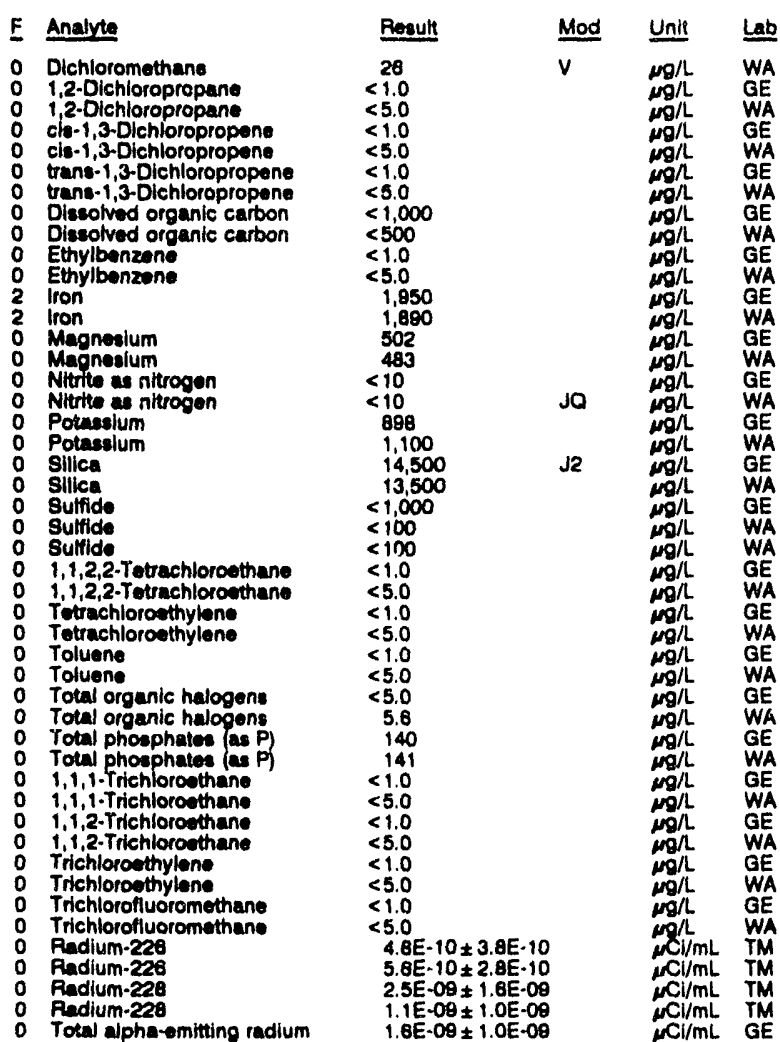

\section{WELL P 28A Replicate}

MEASUREMENTS CONDUCTED IN THE FIELD Sample date: $09 / 02 / 92$
Depth to water: $108.02 \mathrm{~h}(32.92 \mathrm{~m})$ below TOC
Weter Sp. conductance: $67.6 \mathrm{~s} / \mathrm{cm}$ Water evacuated botore sampiling: $618 \mathrm{gal}$

LABORATORY ANALYSES

\begin{tabular}{|c|c|c|c|c|}
\hline E & Analyte & Result & Mod & Unit \\
\hline $\begin{array}{l}0 \\
0 \\
0 \\
0 \\
0 \\
0 \\
0 \\
0 \\
0 \\
0 \\
0 \\
0 \\
0 \\
0 \\
0 \\
0 \\
0 \\
0 \\
0 \\
0 \\
0 \\
0 \\
0 \\
0 \\
0 \\
0 \\
0 \\
0\end{array}$ & 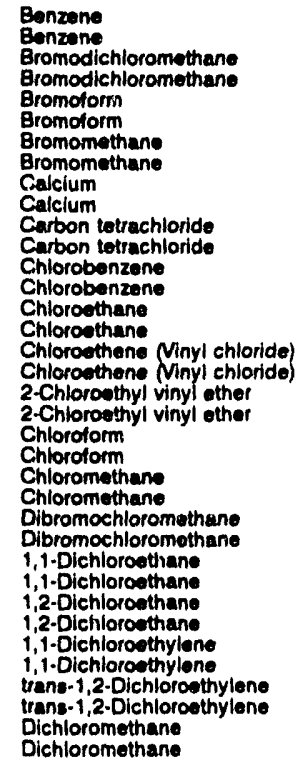 & $\begin{array}{l}<1.0 \\
<5.0 \\
<1.0 \\
<5.0 \\
<1.0 \\
<5.0 \\
<1.0 \\
<10 \\
8.200 \\
7.900 \\
<1.0 \\
<5.0 \\
<1.0 \\
<5.0 \\
<1.0 \\
<10 \\
<1.0 \\
<10 \\
<1.0 \\
<10 \\
<1.0 \\
<5.0 \\
<1.0 \\
<10 \\
<1.0 \\
<5.0 \\
<1.0 \\
<5.0 \\
<1.0 \\
<5.0 \\
<1.0 \\
<5.0 \\
<1.0 \\
<5.0 \\
1.4 \\
13\end{array}$ & & 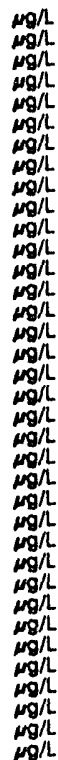 \\
\hline
\end{tabular}

Time: 12:55

Alkalinity: $14 \mathrm{mgl}$
WELL P $28 A$ collected on $09 / 02 / 92$, laboratory analyses (cont)

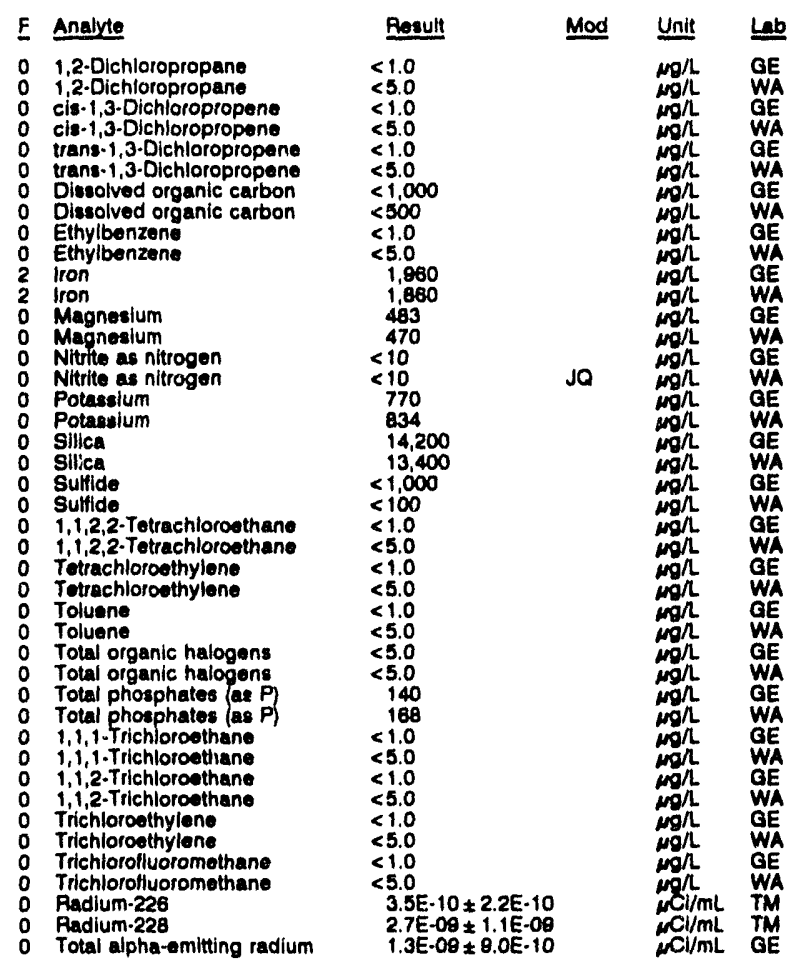

WELL P 28TB

MEASUREMENTS CONDUCTED IN THE FIELD

Sample date: $09 / 02 / \theta 2$

Depth to water: $109.72 \mathrm{~h}(33.14 \mathrm{~m})$ below TOC Water olevation: $176.68 \mathrm{ft}(53.65 \mathrm{~m}) \mathrm{mal}$ Water evacuated before sampling: $1402 \mathrm{gal}$

pH: 5.2 : 3 mgl

Alkalinity: $3 \mathrm{mg} / \mathrm{h}$ : $21.8^{\circ} \mathrm{C}$

LABORATOAY ANALYSES

\begin{tabular}{|c|c|c|c|}
\hline Analyte & Pescult & Mod & Unit \\
\hline 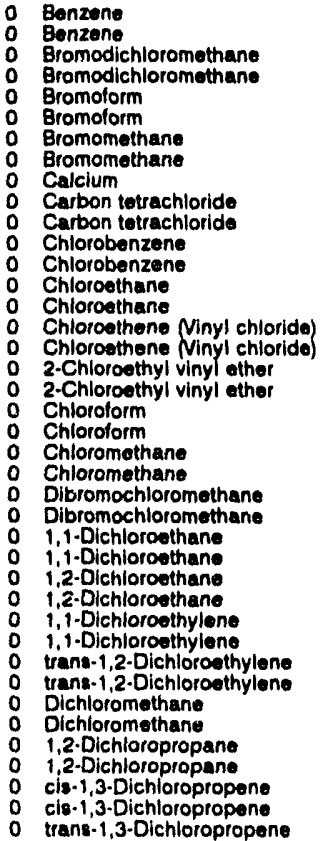 & $\begin{array}{l}<1.0 \\
<1.0 \\
<1.0 \\
<1.0 \\
<1.0 \\
<1.0 \\
<1.0 \\
<1.0 \\
1.370 \\
<1.0 \\
<1.0 \\
<1.0 \\
<1.0 \\
<1.0 \\
<1.0 \\
<1.0 \\
<1.0 \\
<1.0 \\
<1.0 \\
<1.0 \\
<1.0 \\
<1.0 \\
<1.0 \\
<1.0 \\
<1.0 \\
<1.0 \\
<1.0 \\
<1.0 \\
<1.0 \\
<1.0 \\
<1.0 \\
<1.0 \\
<1.0 \\
2.0 \\
3.5 \\
<1.0 \\
<1.0 \\
<1.0 \\
<1.0 \\
<1.0\end{array}$ & & 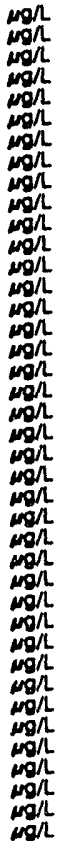 \\
\hline
\end{tabular}


ANALYTICAL RESULTS

WELL P 28TB collected on 00/02/82, laboratory analysese (cont.)

\begin{tabular}{|c|c|c|c|c|}
\hline $\mathbf{E}$ & Analyte & Result & Mod & Unit \\
\hline & 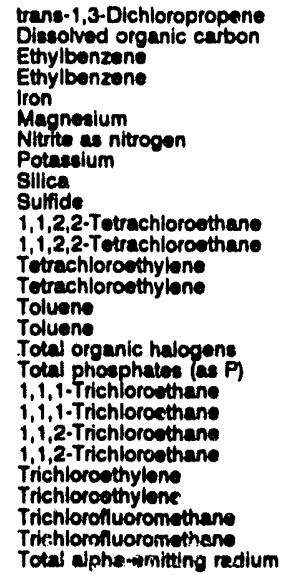 & $\begin{array}{l}<1.0 \\
<1.000 \\
<1.0 \\
<1.0 \\
4,170 \\
31.4 \\
<10 \\
682 \\
11.100 \\
<1,000 \\
<1.0 \\
<1.0 \\
<1.0 \\
<1.0 \\
<1.0 \\
<1.0 \\
<5.0 \\
<50 \\
<1.0 \\
<1.0 \\
<1.0 \\
<1.0 \\
<1.0 \\
<1.0 \\
<1.0 \\
<1.0 \\
3.2 E-00\end{array}$ & J2 & 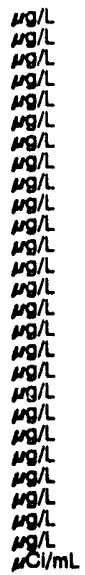 \\
\hline
\end{tabular}

\section{WELL P 28TC}

MEASUREMENTS CONOUCTED IN THE FIELD

Sample date: $09 / 02 / 92$ n $(33.09 \mathrm{~m})$ below TOC

Time: 12:10

WELL P $29 C$

MEASUREMENTS CONDUCTED IN THE FIELD

Sample date: 08/31/82 Depth to water: $100.35 \mathrm{ft}(30.59 \mathrm{~m})$ below TOC Water olevation: $168.05 \mathrm{f}$ (5). conductance: $15 \mathrm{~s} / \mathrm{cm}$ Water ovacuated before sampling: $112 \mathrm{gal}$ LABORATORY ANALYSES

\begin{tabular}{|c|c|c|c|}
\hline Anajyte & Result & Mod & Unit \\
\hline 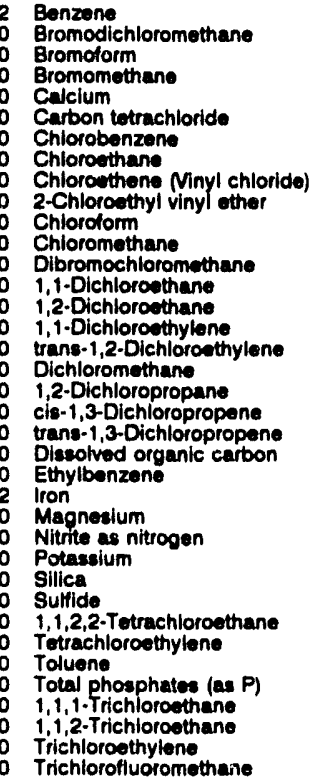 & $\begin{array}{l}43 \\
<1.0 \\
<1.0 \\
<1.0 \\
51.700 \\
<1.0 \\
<1.0 \\
<1.0 \\
<1.0 \\
<1.0 \\
<1.0 \\
<1.0 \\
<1.0 \\
<1.0 \\
<1.0 \\
<1.0 \\
<1.0 \\
21.1 \\
<1.0 \\
<1.0 \\
<1.0 \\
<1.000 \\
<1.0 \\
2.240 \\
370 \\
<10 \\
<500 \\
10,600 \\
<1.000 \\
<1.0 \\
<1.0 \\
1.0 \\
50 \\
<1.0 \\
<1.0 \\
<1.0 \\
<1.0\end{array}$ & $\sqrt{2}$ & 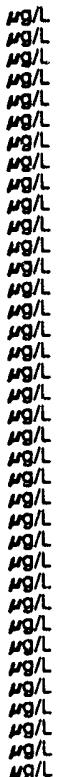 \\
\hline
\end{tabular}
Trichlorofluoromethane $<1.0$
WELL P 29TA

MEASUAEMENTS CONDUCTED IN THE FIELD

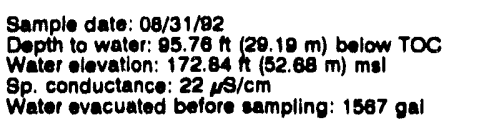

Time: $17: 10$

PH: 5.2 Alkalinity: $1 \mathrm{mg} / \mathrm{L}$ Water tomperature: $21.6^{\circ} \mathrm{C}$

LABORATOAY ANALYSES

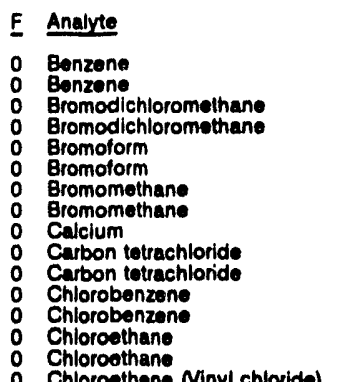

Result

$<1.0$

$<1.0$

$<1.0$

$<1.0$

1.0

477
$<1.0$

$<1.0$

$<1.0$

$<1.0$

$<1.0$

$<1.0$

Chloroethene Minyl chloride

2-Chloroethyl viny ther

2-Chloroethyl vinyl other

Chloroform

Chloroform

Chloromethane

Dibromochloromethane

Dibromochloromethan

1,1-Dichloroethane

1,1.Dichloroethane

1,2-Dichloroothane

1,1 -Dichloroethylene

1,1-Dichloroethylene

trans-1,2-Dichloroethylene

trans-1,2-Dichloroethylene

Dichloromethane

1,2-Dichloropropano

1,2-Dichloropropane

cis-1,3-Dichloropropene

cis-1,3-Dichloropropene

trans-1,3-Dichloropropene

trans-1,3-Dichloropropene
Disasolved organic carbon

Ethylbenzene

2 Iron

2 Magnesium

Nitite as nitrogen

0 Potassium

O Sllica

0 Sulfide

1,1,2,2-Tetrachloroethane

1,1,2,2-Tetrachloroothan

Totrachloroothylene

Totrachlor

Toluene

Total phosphates (as P)

1,1,i-Trichloroethane

1,1,1-Trichioroethane

1,1,2-Trichloroethane

1,1,2-Trichloroethane

Trichloroethylene

T Trichlorofluoromethane

$<1.0$

$<1.0$

$<1.0$

$<1.0$

$<1.0$

$<1.0$

$<1.0$

$<1.0$

$<1.0$
$<1.0$
$<1.0$

$<1.0$

$<1.0$

$<1.0$

$<1.0$

$<1.0$

$<1.0$

$<1.0$

$<1.0$

$<1.0$

$<1.0$

1,850
$<104$
$<10$

$<10$
$<500$

10,200

$<1,0$

$<1.0$
$<1.0$

$<1.0$

$<1.0$

$<1.0$

$<1.0$

$<1.0$

Trichlorofluoromethane
Mod Unlt

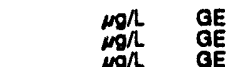

WELL P 29TC

MEASUAEMENTS CONDUCTED IN THE FIELD

Sample date: 08/31/92

Depth to water: $88.23 \mathrm{ft}(29.33 \mathrm{~m})$ below TOC

Water elevation: $172.68 \mathrm{ht}$

Sp. conductance: $34 \mu \mathrm{s} / \mathrm{cm}$.

LABORATORY ANALYSES

\begin{tabular}{|c|c|c|c|}
\hline F Analyte & Regult & Mod & Unit \\
\hline $\begin{array}{ll}0 & \text { Benzene } \\
0 & \text { Bromodichloromothane } \\
0 & \text { Bromoform } \\
0 & \text { Bromomethane } \\
0 & \text { Calcium } \\
0 & \text { Carbon tetrachloride }\end{array}$ & $\begin{array}{l}<1.0 \\
<1.0 \\
<1.0 \\
<1.0 \\
2,460 \\
<1.0\end{array}$ & & 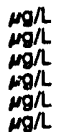 \\
\hline
\end{tabular}

Time: 16:50

Alkalinity: $3 \mathrm{mgh}$

Water temperalure: $21.5^{\circ} \mathrm{C}$ 


\section{ANALYTICAL RESULTS}

WELL P 20TC collected on 0Q/31/02, laboratory analyses (cont.)

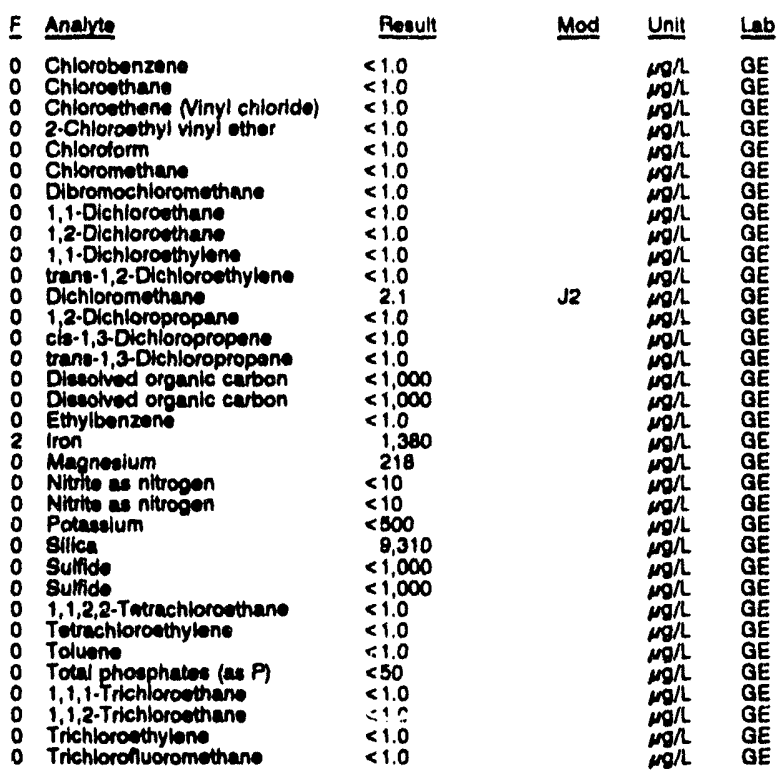

WELL P 29TD

MEASUAEMENTS CONOUCTED IN THE FIELO

Sample date: $09 / 1492$
Oepth to wate: $69.50 \mathrm{n}(29.41 \mathrm{~m})$ bolow TOC
Whter

inacceasibility or mechanical problem prevented sample collection.

WELL PAC 1

MEASUREMENTS CONDUCTED IN THE FIELD

Sample date: 08/15/92

Depth to water: $12.30 \mathrm{ft}(3.75 \mathrm{~m})$ below TOC

Water etovation: $283.60 \mathrm{~h}(86.44 \mathrm{~m}) \mathrm{msl}$

Sp. conductance: $39 \mu \mathrm{s} / \mathrm{cm}$

Water evacuated betore sampling: $78 \mathrm{gal}$

LABORATOAY ANALYSES

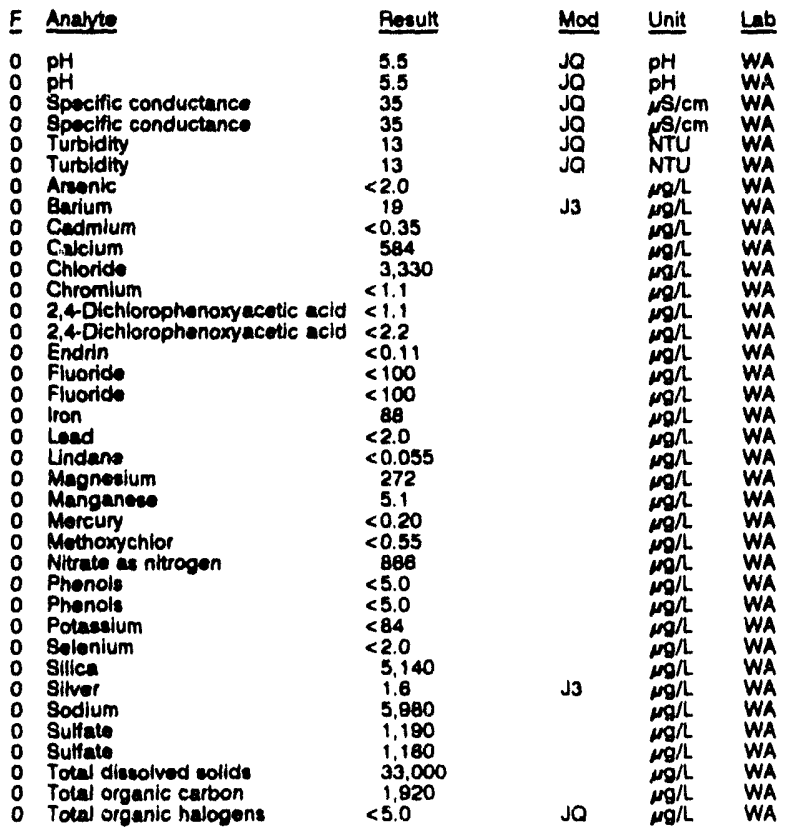

WELL PAC I collocted on 08/15/92, laboratory analyees (cont.)

\begin{tabular}{|c|c|c|c|c|}
\hline $\boldsymbol{F}$ & Analyte & Recult & Mod & Unif \\
\hline $\begin{array}{l}0 \\
0 \\
0 \\
0 \\
0 \\
0 \\
0\end{array}$ & $\begin{array}{l}\text { Total phosphates (as P) } \\
\text { Total phosphntes (as P) } \\
\text { Toxaphene } \\
2,4,5 . T P \text { (Sitvex) } \\
2,4,3 . T P \text { (Silvox) } \\
\text { Grows alpha } \\
\text { Nonvolatile bota } \\
\text { Radium-226 } \\
\text { Radium-228 } \\
\text { Tritium }\end{array}$ & $\begin{array}{l}108 \\
09 \\
<1.1 \\
<0.55 \\
<1.1 \\
<2.0 E \cdot 09 \\
<2.0 E \cdot 09 \\
<1.0 E \cdot 09 \\
<1.0 E \cdot 00 \\
6.0 E \cdot 00 \pm 6.1 E \cdot 07\end{array}$ & & 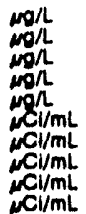 \\
\hline
\end{tabular}

\section{WELL PAC 2}

MEASUAEMENTS CONDUCTED IN THE FIELD

\begin{tabular}{|c|c|}
\hline $\begin{array}{l}\text { date: } 08 / 15 / 92 \\
\text { lo water: } 14.15 \mathrm{~h}(4.31 \mathrm{~m}) \text { bolow toc } \\
\text { olevation: } 270.65 \mathrm{~h}(82.50 \mathrm{~m}) \mathrm{mal} \\
\text { nductunce: }\end{array}$ & $\begin{array}{l}\text { Time: } 0: 05 \\
\text { pHt: } 8.1 \\
\text { Alkalinity: } 50 \mathrm{mg} \Omega \\
\text { Wutor tomporature: } 20.4 \cdot \mathrm{C}\end{array}$ \\
\hline
\end{tabular}

Water evacuated bolore eam

LABORATORY ANALYSES

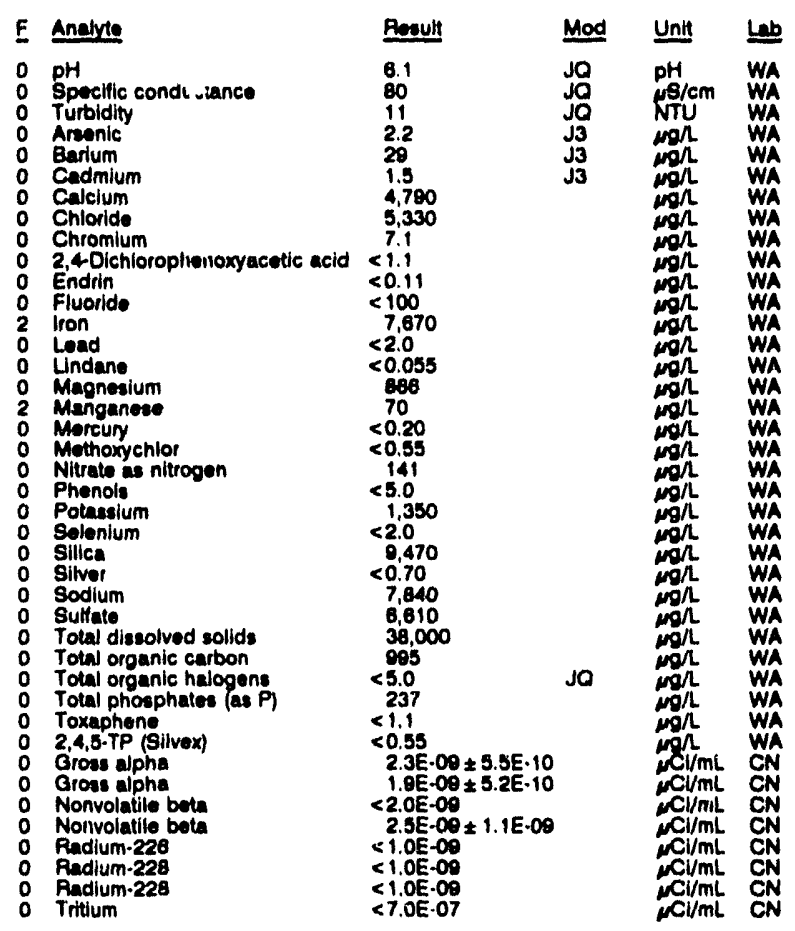

WELL PAC 3

MEASUAEMENTS CONDUCTED IN THE FIELD

\begin{tabular}{|c|c|c|c|c|c|}
\hline \multicolumn{3}{|c|}{$\begin{array}{l}\text { Sample date: } 08 / 15 / 92 \\
\text { Dopth fo water: } 19.10 \mathrm{n}(5.85 \mathrm{~m}) \text { below } \mathrm{TOC} \\
\text { Water elovation: } 270.71 \mathrm{~h}(82.51 \mathrm{~m}) \mathrm{msl} \\
\text { Sp. conductancs: } 344 \mu \mathrm{cm} \\
\text { Water evacuated bolore sampling: } 47 \mathrm{gal}\end{array}$} & \multicolumn{3}{|c|}{$\begin{array}{l}\text { Timo: } 8: 15 \\
\text { pH: } 5.8 \\
\text { Aknilinity: } 40 \mathrm{mg} / \mathrm{h} \\
\text { Water tomporature: } 18.8^{\circ} \mathrm{C}\end{array}$} \\
\hline \multicolumn{6}{|c|}{ LABOFATORY ANALYSES } \\
\hline & Analute & Result & Mod & Unit & ئ \\
\hline & $\begin{array}{l}\text { pH } \\
\text { Spacific conductance } \\
\text { Turbidity } \\
\text { Areonic } \\
\text { Earium } \\
\text { Cedmium } \\
\text { Calcium } \\
\text { Chlorlde } \\
\text { Chromium } \\
2,4 \text {-Dichlorophenoxyacetic acid } \\
\text { Endrin } \\
\text { Fluoride } \\
\text { lron } \\
\text { Lead } \\
\text { Lindane }\end{array}$ & $\begin{array}{l}6.2 \\
310 \\
12 \\
<2.0 \\
77 \\
<0.35 \\
12,300 \\
12,200 \\
1.5 \\
<1.1 \\
<0.11 \\
112 \\
278 \\
<2.0 \\
<0.055\end{array}$ & $\begin{array}{l}\text { Jo } \\
\text { Jo } \\
\text { Jo }\end{array}$ & 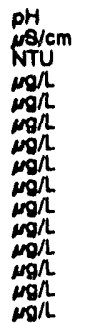 & $\begin{array}{l}\text { WA } \\
\text { WA } \\
\text { WA } \\
\text { WA } \\
\text { WA } \\
\text { WA } \\
\text { WA } \\
\text { WA } \\
\text { WA } \\
\text { WA } \\
\text { WA } \\
\text { WA } \\
\text { WA }\end{array}$ \\
\hline
\end{tabular}


WEL PAC I colbetod on 0e/16/92, laboratory analyeose (cont)

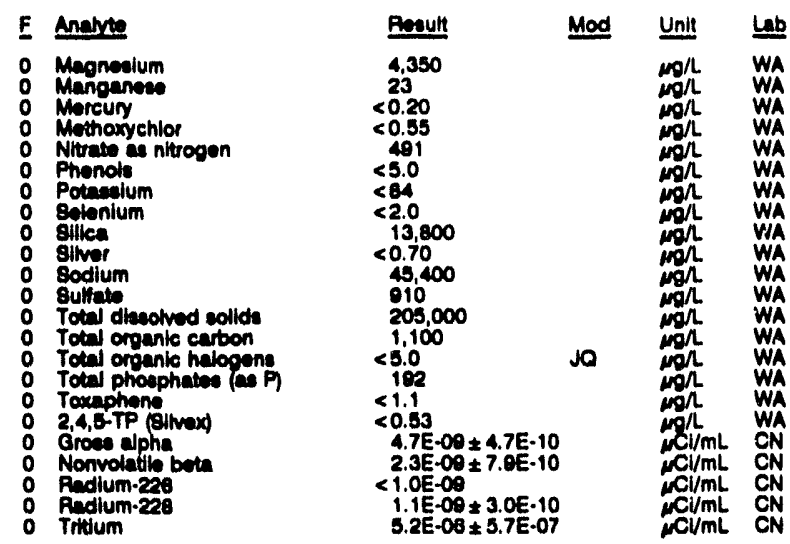

\section{WELL PAC 4}

MEASUREMENTS CONDUCTED IN THE FIELL

\begin{tabular}{|c|c|c|c|c|c|}
\hline & 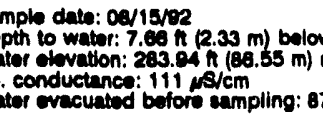 & $\begin{array}{l}\text { woc } \\
\text { mal } \\
7 \mathrm{gal}\end{array}$ & $\begin{array}{l}\text { Time: 10:1 } \\
\text { pH: } 5.1 \\
\text { Alkalinity: } \\
\text { Water tom }\end{array}$ & Ure: 21 & \\
\hline & BORATORY ANALYEES & & & & \\
\hline$\underline{\mathbf{E}}$ & Anate & Pesult & Mod & Unit & $\underline{\underline{L b}}$ \\
\hline $\begin{array}{l}0 \\
0 \\
0 \\
0 \\
0 \\
0 \\
0 \\
0 \\
0 \\
0 \\
0 \\
0 \\
0 \\
0 \\
0 \\
0 \\
0 \\
0 \\
0 \\
0 \\
0 \\
0 \\
0 \\
0 \\
0 \\
0 \\
0 \\
0 \\
0 \\
0 \\
0 \\
0 \\
0 \\
0 \\
0 \\
0\end{array}$ & 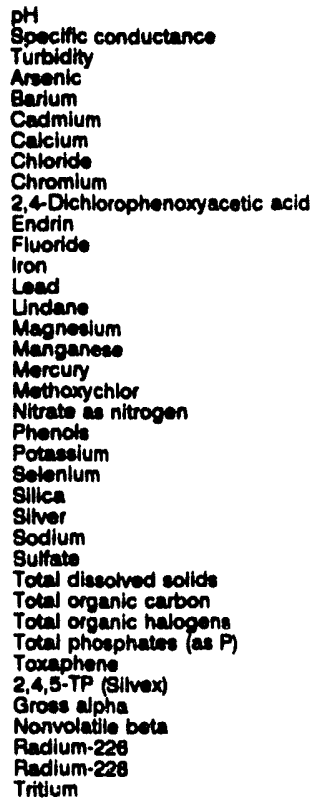 & $\begin{array}{l}5.6 \\
87 \\
11 \\
<2.0 \\
13 \\
<0.35 \\
210 \\
3.230 \\
4.2 \\
<1.1 \\
<0.10 \\
<100 \\
39 \\
<2.0 \\
<0.052 \\
186 \\
2.7 \\
<0.20 \\
<0.52 \\
1.040 \\
<5.0 \\
<84 \\
<2.0 \\
50.130 \\
<0.70 \\
19,300 \\
3,540 \\
68,000 \\
<500 \\
<5.0 \\
140 \\
<1.0 \\
<0.55 \\
<2.0 E-09 \\
<2.0 \mathrm{E}-09 \\
<1.0 \mathrm{E}-09 \\
<1.0 \mathrm{E}-09 \\
6.3 \mathrm{E}-06 \pm\end{array}$ & $\begin{array}{l}\text { JO } \\
\text { JO } \\
\text { Jo } \\
\text { J3 }\end{array}$ & 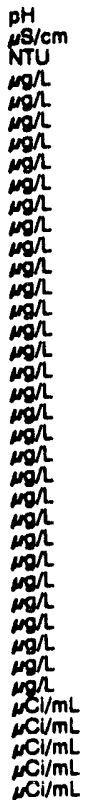 & $\begin{array}{l}\text { WA } \\
\text { WA } \\
\text { WA } \\
\text { WA } \\
\text { WA } \\
\text { WA } \\
\text { WA } \\
\text { WA } \\
\text { WA } \\
\text { WA } \\
\text { WA } \\
\text { WA } \\
\text { WA } \\
\text { WA } \\
\text { WA } \\
\text { WA } \\
\text { WA } \\
\text { WA } \\
\text { WA } \\
\text { WA } \\
\text { WA } \\
\text { WA } \\
\text { WA } \\
\text { WA } \\
\text { WA } \\
\text { WA } \\
\text { WA } \\
\text { WA } \\
\text { WA } \\
\text { WA } \\
\text { WA } \\
\text { WA } \\
\text { WA } \\
\text { CN } \\
\text { CN } \\
\text { CN } \\
\text { CN } \\
\text { CN }\end{array}$ \\
\hline
\end{tabular}

WELL PAC 5

MEASUREMENTS CONDUCTED IN THE FIELD

Sumple data: 08/1502

Dopth to water: 14.80 n $(4.44$ m) bolow TOC

Water elevetion: $274.74 \mathrm{ht}(83.74$

Sp. conductunce: $303 \mu \mathrm{N} / \mathrm{cm}$.

Water evecuated before eampling

LABOFATOAY ANALYSES

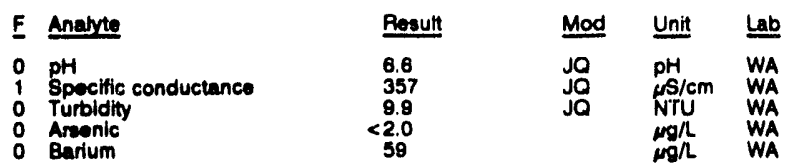

Time: 11:30
Alkalinity: $150 \mathrm{~mol}$

Water temperature: $21.6^{\circ} \mathrm{C}$

WELL PAC I collected on 08/15/92, laboratory analyese (cont)

\begin{tabular}{|c|c|c|c|c|}
\hline$E$ & Analute & Result & Mod & iit \\
\hline & 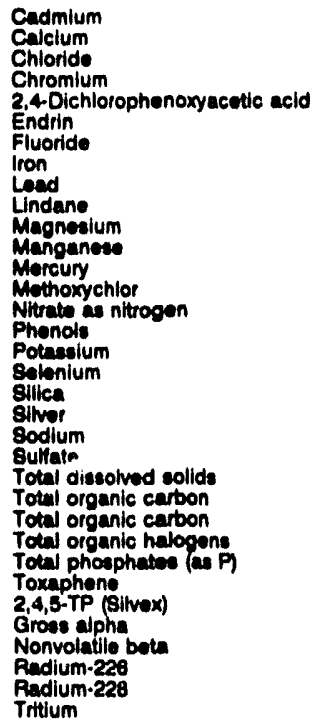 & $\begin{array}{l}<0.35 \\
35,400 \\
4,240 \\
6.3 \\
<1.1 \\
<0.11 \\
<100 \\
128 \\
<2.0 \\
<0.055 \\
7,800 \\
274 \\
<0.20 \\
<0.55 \\
230 \\
<8.0 \\
1,800 \\
<2.0 \\
18,800 \\
<0.70 \\
37,800 \\
4,280 \\
241,000 \\
2,430 \\
2,540 \\
<6.0 \\
104 \\
<1.1 \\
<0.53 \\
<2.0 E-09 \\
4.0 E-00 \pm 1.3 E-00 \\
<1.0 E-09 \\
1.1 E \cdot 00 \pm 3.7 E-10 \\
3.8 E-06 \pm 5.3 E-07\end{array}$ & 10 & 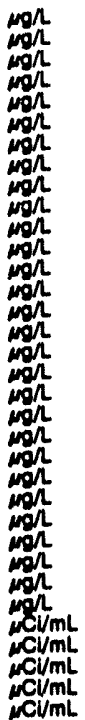 \\
\hline
\end{tabular}

WELL PAC 6

MEASUREMENTS CONOUCTED IN THE FIELD

Sample date: 08/15/92
Depth to water: $15.00 \mathrm{n}(4.50 \mathrm{~m})$ beluw TOC

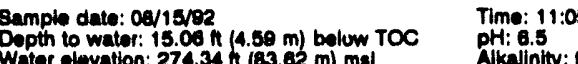

Sp. conductance: $277 \mathrm{\mu} / \mathrm{cm}$.

Alkalinity: $82 \mathrm{mgh}$. $22.0^{\circ} \mathrm{C}$

The woll went dy during purging.

LABORATORY ANALYSES

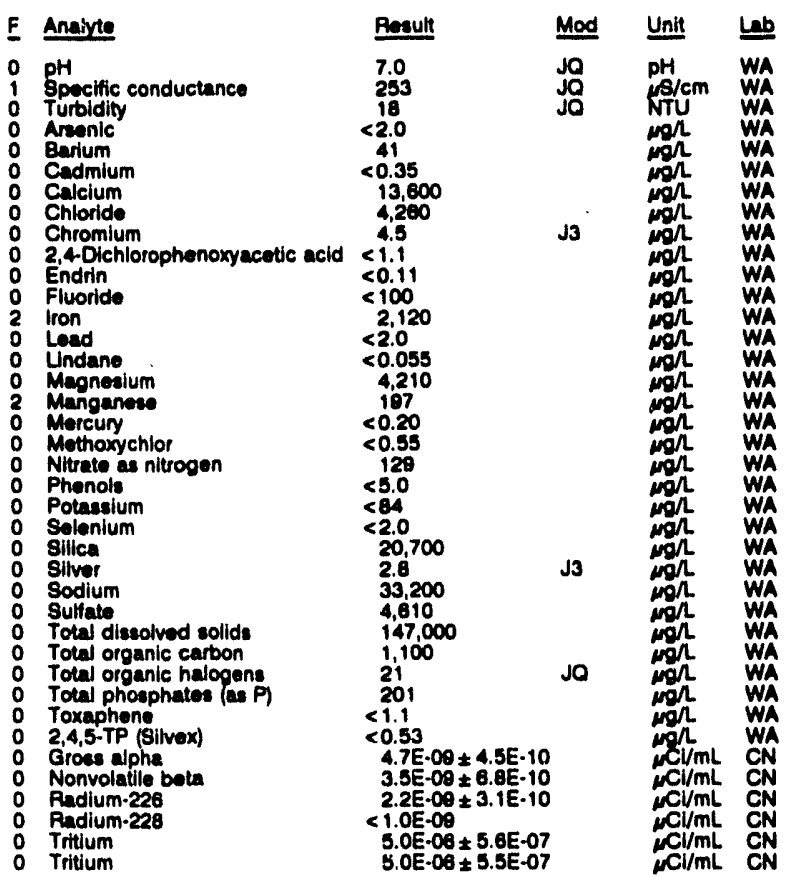




\section{ANALYTICAL RESULTS}

WELL PCB $1 A$

MEABUAEEMENTS CONOUCTED IN THE FIELD

\begin{tabular}{|c|c|c|c|c|c|}
\hline \multicolumn{3}{|c|}{ 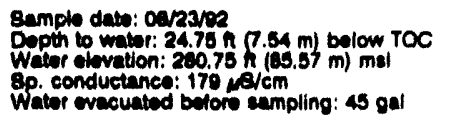 } & \multicolumn{3}{|c|}{$\begin{array}{l}\text { Time: } 14: 05 \\
\text { pH: } 4.0 \\
\text { Alivalinity: } 0 \text { mol } \\
\text { Wator tomperature: } 22.2 \cdot \mathrm{C}\end{array}$} \\
\hline \multicolumn{6}{|c|}{ ABORATOFY ANALYEES } \\
\hline & Anevesto & Becult & Mod & Unit & Let \\
\hline & 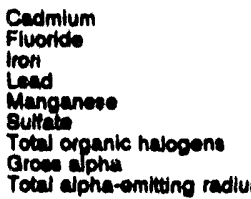 & $\begin{array}{l}<2.0 \\
150 \\
375 \\
8.1 \\
420 \\
98,100 \\
<8.0 \\
<2.0 E-00 \\
1.0 E-00\end{array}$ & -10 & 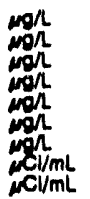 & $\begin{array}{l}\mathrm{gE} \\
\mathrm{GE} \\
\mathrm{dE} \\
\mathrm{GE} \\
\mathrm{dE} \\
\mathrm{dE} \\
\mathrm{dE} \\
\mathrm{dE} \\
\mathrm{dE}\end{array}$ \\
\hline
\end{tabular}

\section{WELL PCB 2A}

MEASUAEMENTS CONDUCTED IN THE FIELC

\begin{tabular}{|c|c|c|c|c|c|}
\hline \multicolumn{3}{|c|}{ 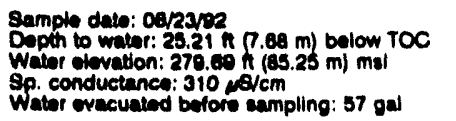 } & \multicolumn{3}{|c|}{$\begin{array}{l}\text { Time: } 13: 50 \\
\text { pH: } 4.3 \\
\text { Alkalinity: } 0 \mathrm{mg} / \mathrm{L} \\
\text { Wator tomporature: } 22.2^{\circ} \mathrm{C}\end{array}$} \\
\hline \multicolumn{6}{|c|}{ LABOPATOPY ANALYBES } \\
\hline- & Andyte & Result & Mod & Unit & Let \\
\hline $\begin{array}{l}0 \\
0 \\
0 \\
1 \\
2 \\
2 \\
1 \\
1 \\
0 \\
1\end{array}$ & 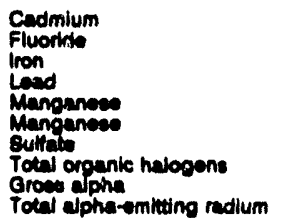 & $\begin{array}{l}<2.0 \\
1,310 \\
13 \\
13 \\
964 \\
925 \\
221,000 \\
32,1 E-00 \\
2.1 E-00 \\
4.2 E-00\end{array}$ & & 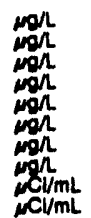 & $\begin{array}{l}G E \\
G E \\
G E \\
G E \\
G E \\
G E \\
G E \\
G E \\
G E \\
G E \\
O E\end{array}$ \\
\hline
\end{tabular}

\section{WELL PCB 3A}

MEASUREMENTS CONDUCTED IN THE FIELO

\begin{tabular}{|c|c|c|c|c|c|}
\hline & 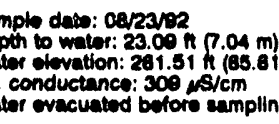 & $\begin{array}{l}\text { ow } \\
\text { mal } \\
\mathrm{gal}\end{array}$ & $\begin{array}{l}\text { Time: 14: } \\
\text { pH: } 3.7 \\
\text { Alkalinity: } \\
\text { Water ton }\end{array}$ & of & \\
\hline & OPATOPY ANAL YSES & & & & \\
\hline- & Anarte & Posuin & Mod & Unit & 느 \\
\hline & $\begin{array}{l}\text { Ceadmium } \\
\text { Fluorito } \\
\text { fron } \\
\text { Lead } \\
\text { Manganese } \\
\text { Sulfato } \\
\text { Total organic halogens } \\
\text { Groes appha } \\
\text { Total elpha-emituing redium }\end{array}$ & $\begin{array}{l}2.9 \\
240 \\
310 \\
34 \\
307 \\
240,000 \\
10 \\
2.0 E-00 \\
1.2 E-09\end{array}$ & $\begin{array}{l}-\infty \\
10\end{array}$ & 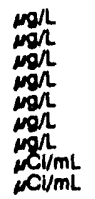 & $\begin{array}{l}G E \\
G E \\
G E \\
G E \\
G E \\
G E \\
G E \\
G E \\
G E\end{array}$ \\
\hline
\end{tabular}

\section{WELL PCB 4A}

MEASUREMENTS CONDUCTED IN THE FIELD

\begin{tabular}{|c|c|c|c|c|c|}
\hline \multicolumn{3}{|c|}{ 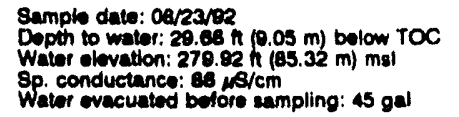 } & \multicolumn{3}{|c|}{$\begin{array}{l}\text { Time: } 14: 20 \\
\text { pH: } 4.2 \\
\text { Alkalinity: } 0 \mathrm{mg} / \mathrm{h} \\
\text { Water tomperafure: } 22.0 \cdot \mathrm{C}\end{array}$} \\
\hline \multicolumn{6}{|c|}{ LABORATOAY ANALYSES } \\
\hline$\underline{F}$ & Anatrte & Result & Mod & Unit & Lab \\
\hline $\begin{array}{l}0 \\
0 \\
0 \\
0 \\
1 \\
2 \\
0 \\
0 \\
0\end{array}$ & $\begin{array}{l}\text { Cadmilum } \\
\text { Fluorlde } \\
\text { Fluorlde } \\
\text { Iron } \\
\text { Lead } \\
\text { Manganees } \\
\text { Eulfat } \\
\text { Sulfate } \\
\text { Totw organic halogens }\end{array}$ & $\begin{array}{l}<2.0 \\
<100 \\
102 \\
20 \\
10 \\
58 \\
50,200 \\
46,800 \\
5.2\end{array}$ & & 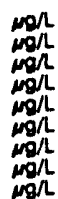 & $\begin{array}{l}\mathrm{GE} \\
\mathrm{GE} \\
\mathrm{GE} \\
\mathrm{GE} \\
\mathrm{GE} \\
\mathrm{GE} \\
\mathrm{GE} \\
\mathrm{GE} \\
\mathrm{GE}\end{array}$ \\
\hline
\end{tabular}

WELL PCB \&A colloctod on OQ/23/22, laboratory analyees (cont.)

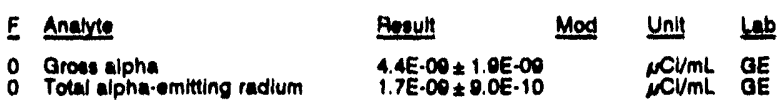

WELL PDB 2

MEABUAEMENTS CONDUCTED IN THE FIELD

\begin{tabular}{|c|c|c|c|c|}
\hline \multirow{2}{*}{\multicolumn{2}{|c|}{ 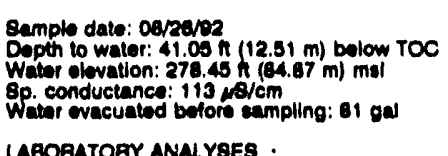 }} & \multicolumn{3}{|c|}{ 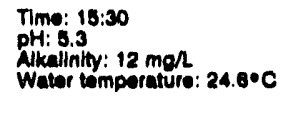 } \\
\hline & & & & \\
\hline Anayte & Penulf & Mod & Unit & $\underline{N b}$ \\
\hline $\begin{array}{l}\text { Cadmium } \\
\text { Lead } \\
\text { Totil organic halogens } \\
\text { Total activity } \\
\text { Tittum }\end{array}$ & $\begin{array}{l}<2.0 \\
8.0 \\
8.6 \\
3.0 E-04 \\
3.8 E-04\end{array}$ & $\begin{array}{l}1.0 E-05 \\
2.0 E-00\end{array}$ & 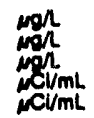 & $\begin{array}{l}G E \\
G E \\
G E \\
\text { GM } \\
O E\end{array}$ \\
\hline
\end{tabular}

WELL PDB 3

MEASUREMENTS CONDUGTED IN THE FIELD

Sample date: $08 / 28 / 92$
inuccessiblity or mechanical problem prevented samplo $15: 00$
colibetion.

WELL PRP $1 A$

MEASUREMENTS CONDUCTED IN THE FIELD

\begin{tabular}{|c|c|}
\hline 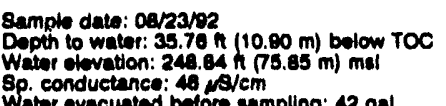 & 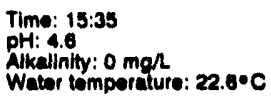 \\
\hline
\end{tabular}

Wetor evacuatod betors stampling: 42 ga

LABOPATORY ANALYYSES

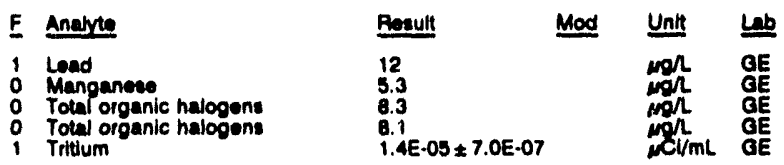

\section{WELL PRP 2}

MEASUREMENTS CONDUCTED IN THE FIELD

\begin{tabular}{|c|c|c|c|c|}
\hline \multirow{2}{*}{\multicolumn{2}{|c|}{ 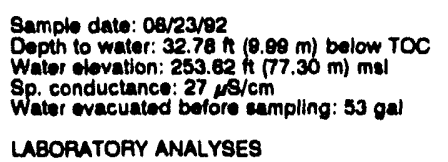 }} & \multicolumn{3}{|c|}{$\begin{array}{l}\text { Time: } 18: 10 \\
\text { pHit: } 5.0 \\
\text { Alkalinity: } 1 \mathrm{mgh} \\
\text { Wallor tomperature: } 23.3 \cdot \mathrm{C}\end{array}$} \\
\hline & & & & \\
\hline Anarse & Result & Mod & Unit & \\
\hline $\begin{array}{l}\text { Lead } \\
\text { Manganose } \\
\text { Total organic halogens } \\
\text { Tritum }\end{array}$ & $\begin{array}{l}5.8 \\
3.8 \\
30 \\
4.1 \mathrm{E}\end{array}$ & & 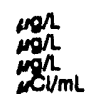 & Gै \\
\hline
\end{tabular}

WELL PRP 3

MEASUREMENTS CONDUCTED IN THE FIELD

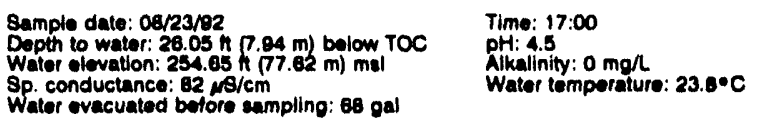
LABOPATORY ANALYSES

\begin{tabular}{|c|c|c|c|}
\hline Analyte & Reault & Mod & $\underline{\text { Un }}$ \\
\hline $\begin{array}{l}\text { Lead } \\
\text { Manpanoes } \\
\text { Total organic halogens } \\
\text { Tritium }\end{array}$ & $\begin{array}{l}31 \\
56 \\
182 \\
8.8 E-C\end{array}$ & & \\
\hline
\end{tabular}


WELL PRP 4

MEASUAREMENTS CONDUCTED IN THE FIELD

\begin{tabular}{|c|}
\hline 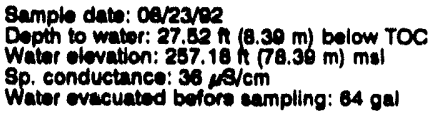 \\
\hline 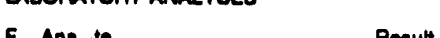 \\
\hline
\end{tabular}

Time: 18:30

PH: 4.7

Alkalinity: $0 \mathrm{mon}$

Water tomperafure: $20.8^{\circ} \mathrm{C}$

LABOPATOAY ANALYEE

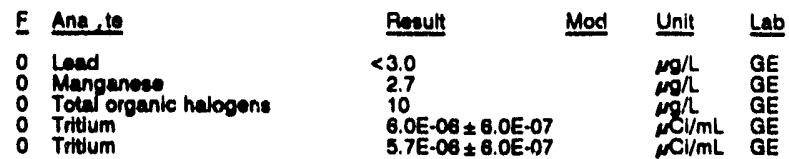

WELL PSB $1 A$

MEASUREMENTS CONOUCTED IN THE FIELD

\begin{tabular}{|c|}
\hline 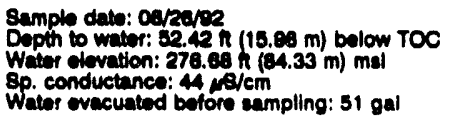 \\
\hline BORATORY ANAL \\
\hline
\end{tabular}

Time: 13:45

pH: 5.8

Akalinity: $3 \mathrm{~mol}$

Water temporature: $21.00 \mathrm{C}$

LABOAATOFY ANALYSES

\begin{tabular}{|c|c|c|c|c|}
\hline & Analyte & Rosutt & Mod & Unit \\
\hline & $\begin{array}{l}\text { Cedmium } \\
\text { lron } \\
\text { Lead } \\
\text { Nitruta-nituite as nitrogen } \\
\text { Nitrati-nitrite as nitrogen } \\
\text { Total activity } \\
\text { Tiltum }\end{array}$ & $\begin{array}{l}<2.0 \\
<4.0 \\
12 \\
1,850 \\
1,900 \\
1.3 E-01 \pm 8.5 E-0 \\
1.4 E-01 \pm 5.4 E-0 .\end{array}$ & & 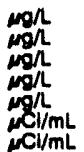 \\
\hline
\end{tabular}

WELL PSB $2 A$

MEASUREMENTS CONDUCTED IN THE FIELD

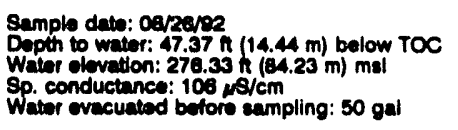

Time: 13:00

PH: 4.7

Alkalinity: 0 mon

Water temperature: $21.0^{\circ} \mathrm{C}$

LABORATORY ANALYSES

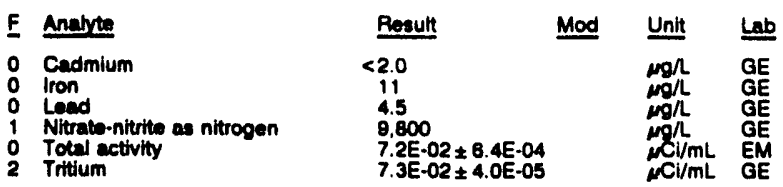

WELL PSB 3A

MEASUREMENTS CONDUCTED IN THE FIELD

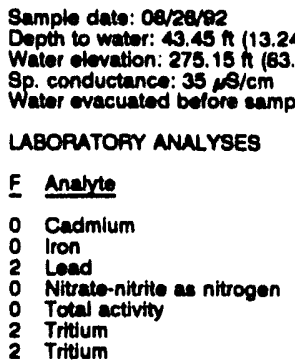

Time: 12:30

pH: 4.7

Alkalinity: $0 \mathrm{mon}$

Water tomperature: $20.7^{\circ} \mathrm{C}$

E

E

WELL PSB 4A

MEASUREMENTS CONDUCTED IN THE FIELD

\begin{tabular}{|c|c|}
\hline 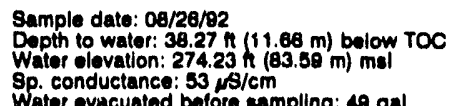 & $\begin{array}{l}\text { Time: } 12.05 \\
\text { pH: } 4.5 \\
\text { Alkalinity: } 0 \mathrm{mgh} \\
\text { Water temperature: } 21.00 \mathrm{C}\end{array}$ \\
\hline
\end{tabular}

LABORATORY ANALYSES

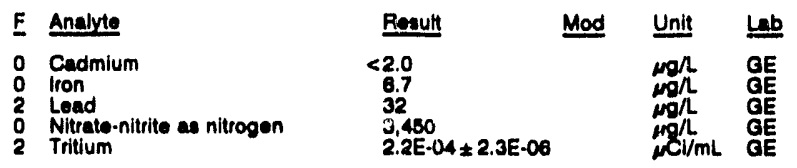

WELL PSB 5A

MEASUREMENTS CONDUCTED IN THE FIELL

Semple date: 08/28/02

Depth to water: 43.59 if $(13.29 \mathrm{~m})$ bolow TOC

Whit

Nkalinity: $0 \mathrm{mgn}$

Wher cracuated botore eampling: $18 \mathrm{gal}$ Water tomporature: $21.1{ }^{\circ} \mathrm{C}$

The well went dry during purging.

LABORATORY ANALYSES

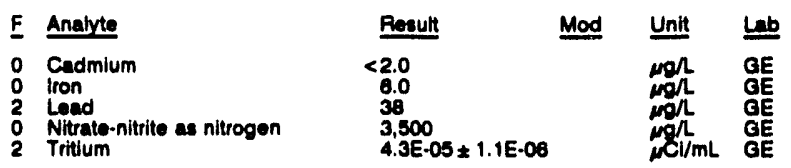

WELL PSB 6A

MEASUREMENTS CONDUCTED IN THE FIELD

$\begin{array}{ll}\text { Sample date: } 08 / 26 / 92 & \text { Time: } 11: 35 \\ \text { Depth to wator: } 47.03 \mathrm{ft}(14.33 \mathrm{~m}) \text { bolow TOC } & \text { pH: } 4.5 \\ \text { Water olovation: } 277.17 \mathrm{ft}(84.48 \mathrm{~m}) \mathrm{msl} & \text { Alkalinity: } 0 \mathrm{mg} / \\ \text { Sp. conductance: } 50 \mu \mathrm{cm} / \mathrm{cm} & \text { Water tomperature: } 20.3^{\circ} \mathrm{C} \\ \text { Water ovacuated before sampling: } 40 \mathrm{gal} & \end{array}$

LABORATORY ANALYSES

\begin{tabular}{|c|c|c|c|c|c|}
\hline$F$ & Analyte & Pesult & Mod & Unit & Lab \\
\hline 0 & $\begin{array}{l}\text { Cadmium } \\
\text { Iron } \\
\text { Lead } \\
\text { Nitrate-nitrite as nitrogen } \\
\text { Total activity } \\
\text { Tritsum }\end{array}$ & $\begin{array}{l}<2.0 \\
<4.0 \\
4.3 \\
2.200 \\
3.0 \mathrm{E}-02 \pm 4.0 \mathrm{E}-04 \\
5.7 \mathrm{E}-02 \pm 3.5 \mathrm{E}-05\end{array}$ & & 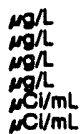 & $\begin{array}{l}\text { GE } \\
\text { GE } \\
\text { GE } \\
\text { GE } \\
\text { EM } \\
\text { GE }\end{array}$ \\
\hline
\end{tabular}

\section{WELL PSB 7A}

MEASUREMENTS CONDUCTED IN THE FIELD

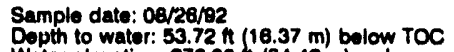

Water elevation: $278.88 \mathrm{~h}(84.42 \mathrm{~m}) \mathrm{me}$

Sp. conductance: $57 \mathrm{~s} / \mathrm{cm}$

Water evacuated bofore sampling: $47 \mathrm{gal}$

LABORATORY ANALYSES

\begin{tabular}{|c|c|c|c|c|c|}
\hline $\mathbf{E}$ & Analyte & Result & Mod & Unit & Lat \\
\hline $\begin{array}{l}0 \\
0 \\
1\end{array}$ & $\begin{array}{l}\text { Cadmium } \\
\text { Iron } \\
\text { Load } \\
\text { Nitrato-nitrite as nitrogen } \\
\text { Total activity } \\
\text { Tritlum }\end{array}$ & $\begin{array}{l}<2.0 \\
<4.0 \\
15 \\
2.700 \\
7.7 \mathrm{E}-03 \pm 6.0 \mathrm{E}-05 \\
7.2 \mathrm{E}-03 \pm 1.3 \mathrm{E}-05\end{array}$ & & 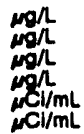 & $\begin{array}{l}\mathrm{GE} \\
\mathrm{GE} \\
\mathrm{GE} \\
\mathrm{GE} \\
\mathrm{EM} \\
\mathrm{GE}\end{array}$ \\
\hline
\end{tabular}




\section{WELL PSS 10}

MEASUREMENTS CONOUCTEO IN THE FIELD

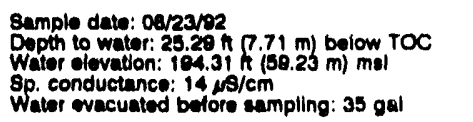
LABOPUTOAY ANALYSES

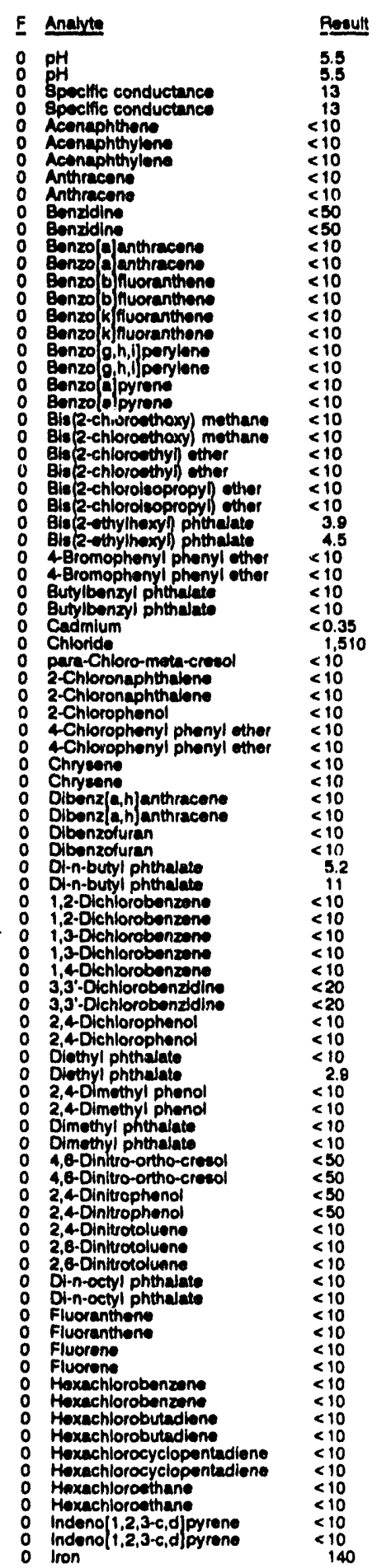

WELL. PSS 10 collected on 08/23/82, laboratory analyses (cont.)

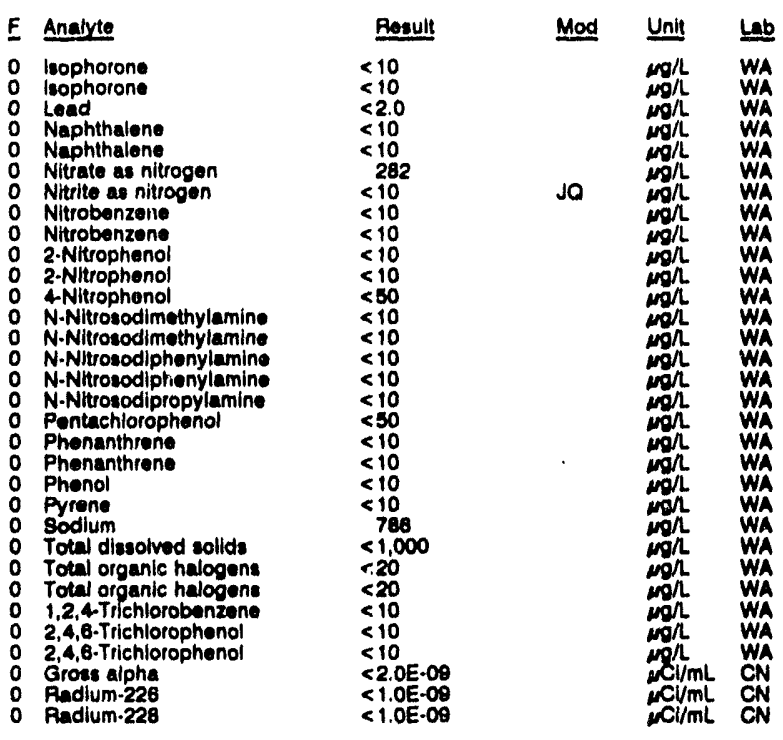

WELL PSS 20

MEASUREMENTS CONOUCTED IN THE FIELD

Sample dato: 08/23/92

Dopth to water: $35.93 \mathrm{n}$ (10.95 m) below TOC Water olevation: $182.77 \mathrm{ft}(58.78 \mathrm{~m}) \mathrm{mul}$

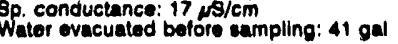

LABOPATORY ANALYSES

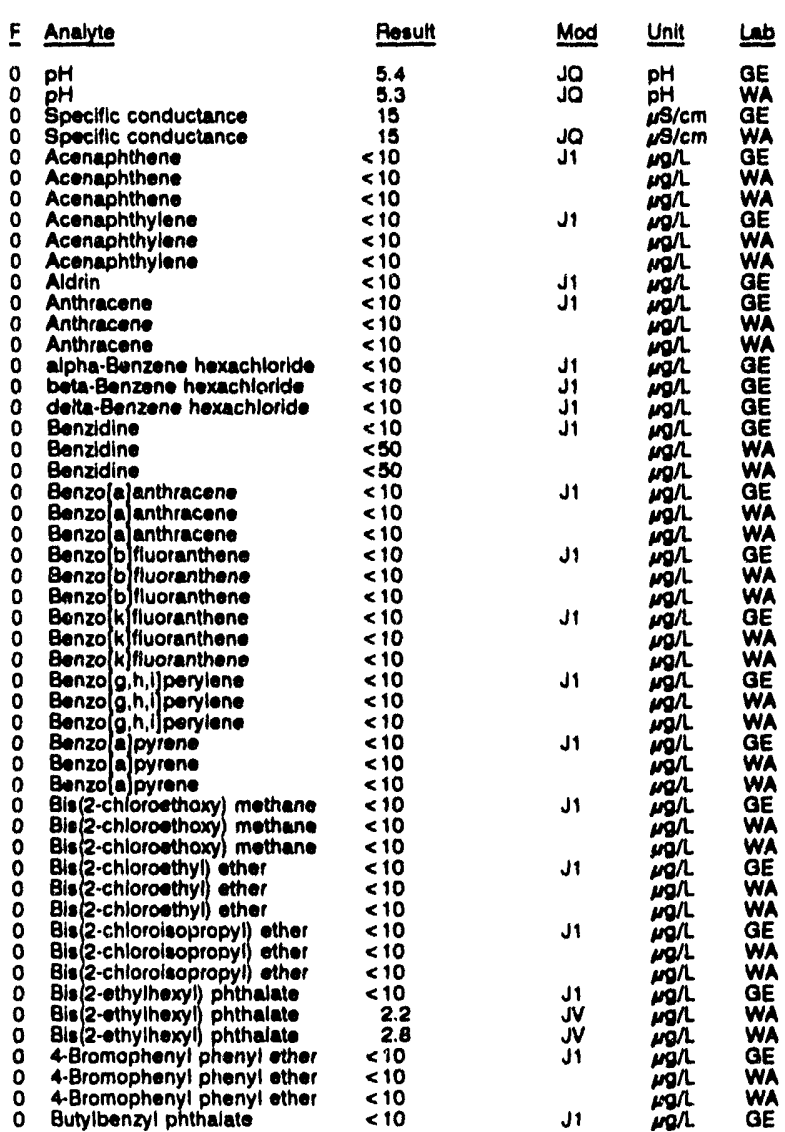


ANALYTICAL RESULTS

WELL PSS 2D collected on 08/23/92, laboratory analyese (cont)

E Anelyte

O Butylbonzyl prthalate

O

Chlordane

Chloride

pyra-Chloro-mota-cresel

para-Chioro-meta-cresol

para-Chloro-mota-cresol

2-Chloroneririnalene

2-Chloronaphthalone

2-Chloronaphthai

2-Chloropheno:

2-Chlorophend

4-Chlorophenyl phenyl ther

4-Chlorophenyl phenyl ether

Chryeene

Chryeane

Chryoun

P,p'-DDE

Diborizja,hjanthracene

Dibenz a,h anthracene

Dibenzoluran

Dibenzoturan

Di-n-butyl phthalate

Di-n-butyl phthalats

1,2-Michlorobenzene

1,2-Dichlorobenzene

1,3-Dichlorobenzent

1,4-Dichlorobenzene

1,4-Dichlorobenzen

3,3'-Dichlorobenzidine

o 3,3 -Dichlorobenzidine

2,4-Dichlorophenol

2,4-Dichlorophenol

$\begin{array}{ll}0 & 2,4-D i c h \\ 0 & \text { Dictdrin }\end{array}$

Diectuyl phethalat

o Diethyl phthalate

Diethyl phthalais

2,4-Dimethyl phenol

2,4-Dimethyl phenol

Dimethyl phthalate

Dimethyl phthalate

4,6-Dinitro-ortho-cresel

4,6-Dinitro-ortho-cresol

2, 4-Dinitropheno:

2,4-Dinitropheno

2,4-Dinitrophenol

2,4Dinitrotoluene

2,4-Dinitrotoluene

2.4-CVintrotoluen

- Enitritoluen

2,6-Dinitrotoluene

Di-n-octyl phthalat

O Di-n-octyl phthaiate

1,2-Diphienylhydrasiro

Endoeulfan I

Endoaulfan II

Endosulfa

Endrin aldehyde

Fluoranthene

Fivoranthene

Fluoranthene

Fluorense

Fluorene

F Fluorene

Heptachlor epoxido

Hexechtorobenzen

Hexechlorobenzen

Hexachlorobenzane

- Hexachlorobutadiene

Hexachlorobutadiene

Hexachlorocyclopentadiene

Hexachlorocyclopentadiene

- Hexachlorocyclopentadiene

o Hexachloroethane

- Hexachloroethane

- indeno[1,2,3-c,d]pyren

Indeno $1,2,3-c, d$ pyreno

indeno $1,2,3-c, d]$ pyreno

o tron

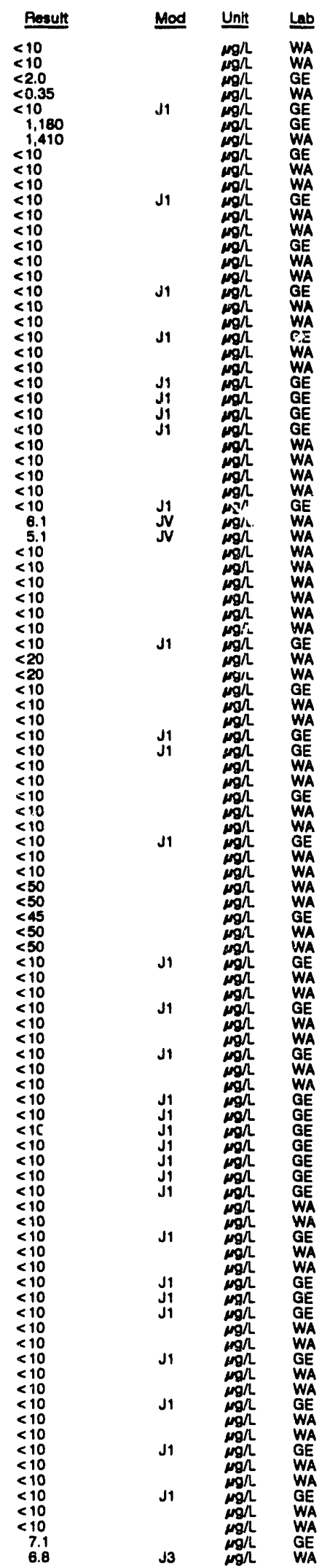

WELL PSS 2D collocted on 08/23/92, laboratory analyses (cont.)

$F$ Anabite

- leophorone

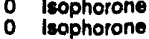

0 Load

0 Lead

2-Methyl-4,6-dinitrophenol

Naphthalene

Naphthalene

Naphthalene

N Nitrate-nitritite agen nitrogen

Nitrobenzene

Nitrobenzene

2-Nituophenol

2-Nitropheno

2-Nitropheno

4-Nitrophenol

4 introphenol

N-Nitrosodimethylamine

N-Nitrosodimethylamine

N-Nitrosodimethylamine

N-Nitrosodiphenylamine

N-Nitrosodiphenylamine

N-Nitrosodipropylamine

N-Nitrosodipropylamine

N-Nitrosodip

PCB 1221

PCB 1232

PCE 1248

PCB 1254

Pentachlorophenol

Pentachlorophenol

Pentachlorophenol

Phenanthrene

Phenanthrene

Phenol

Phenol

Phenol

Prene

Pyrene

Sodium

Sodium

Total discolved solids

Total dissolved solids

rotal organle halogens

1,2,4-Trichlorobenzene

1,2,4-Trichlorobenzene

1,2,4-Trichlorobenzene

2,4,6-Trichlorophenol

2,4,8-Trichlorophono

Groes alpha

Groses alpha

Radium-228

Radium-225

Redlum-228
Niturte as nitrogen

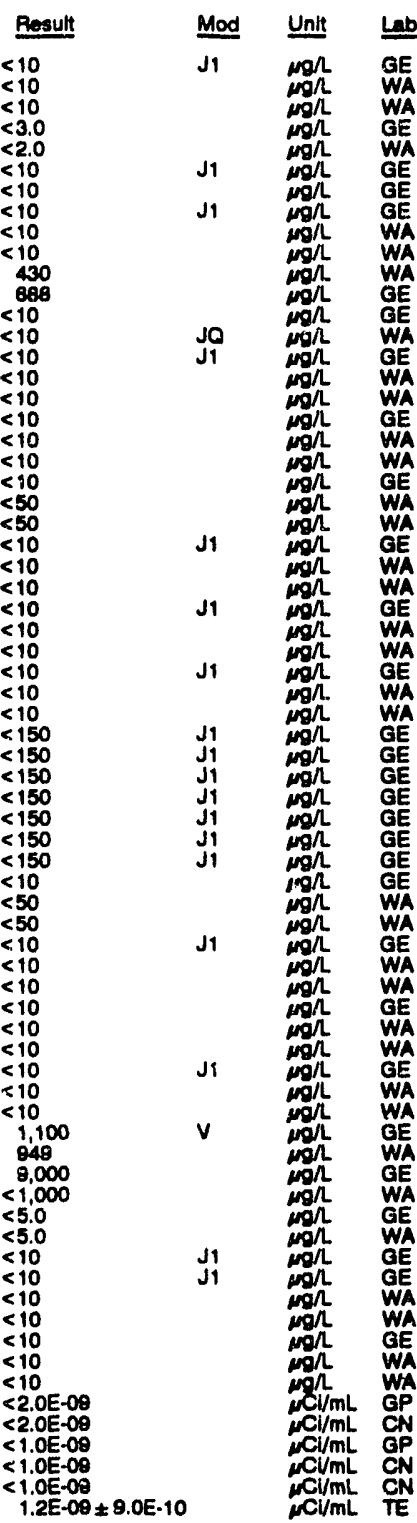

WELL PSS 2D Replicate

MEASUREMENTS CONDUCTED IN THE FIELL

Sample Jate: 06/23/92

Depth to water: $35.83 \mathrm{th}(10.95 \mathrm{~m})$ below TOC

Water elevation: $182.77 \mathrm{ht}(58.76 \mathrm{~m}) \mathrm{msl}$

Weter ovacuated before sampling: $41 \mathrm{gal}$

LABORATORY ANALYSES

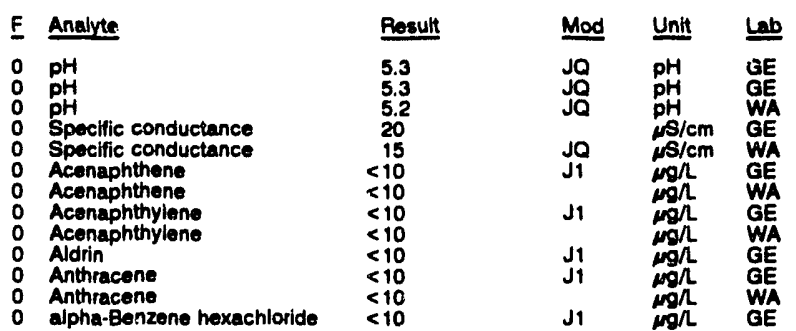

pH: 4.8

Water temperature: $21.2^{\circ} \mathrm{C}$
Time: 12:20

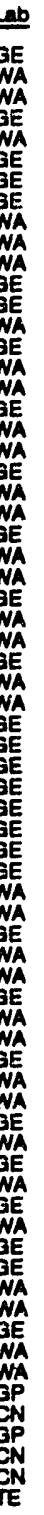


WELL PBS 2D colloctad on 09/23/82, laboratory analyess (cont.)

E Aneryte

O beta-Benzene hoxachloride

Benzidine

Benzidine

Benzo a anthracene

Benzo'bfluoranthene $<10$

Eonzo k fuoranthens

Benzolo.h,i)perylone

Bonzo g, hi, iporylone

Bonzo dpyrene

Bia (2-chlorethoxy) methane

Bie (2-chloroethoxy) methane

Bie(2-chloranthy) ther

Bis 2-chlorolsopropyl) other

E Eis (2-chlorolsopropyll other

Bis (2-ethylhoxy) phthalate

A Eromophenyl phonyl ther

Aromophenyl phonyl

Butylbenzyl phthalat

Cadmium

Chlordano

Chioride

para-Chloro-meta-cresol

para-Choro-meta-cresol

2-Chloronaphthalene

2-Chloronaphtherene

2-Chlorophenol

4-Chlorophenyl phenyl othor

4Chlorophenyl phenyl the

Chrysene

0 p.p.-.00

P.P'-DDE

Bibenz;a, h]enthracene

Dibenz anjenthraceno

Oibenzofuran

Di-n-butyl phthalate

1,3 Dichlorobenzene

1,4-Dichlorobanzene

3,3'-Dichlorobendidine

2,4-Dxchloropheno

Dieidrin

0 Dlethyl phthalate

Diethyl phthalato

2,4-Dimethyl phenol

Dimethyl phthalate

4,6-Oinfuro-ortho-cresel

2,4-Dinitrophenol

2,4 Dinitrophano

2,4-Diniturotoluene

2,6-Dinitrotolusen

2,6-Dinitrotoluen

Oi-n-octyl phthalate

Di-n-octyl phthalate

1,2-Diphonylhyd

Endoaulfan II

Endow

Endrín aldehyde

Fluoranthene

Fluorene

Fluorene

Hoptachlor epoxide

Hexechlorabenzane

Hexachlorobenzene

Hoxachlorobutadion

Hexuchlorocyclopentadiene

Hexachlorocyclopentedione

Haxachloroethane

Mexachlorothane

Indeno $[1,2,3-c, d]$ pyreme

I indon

bephorone

0 leoph

$<50$

$<10$
$<10$
$<10$
$<10$

$<10$
$<10$
$<10$

$<10$

$<10$

$<10$

$<$

$<10$
$<10$
$<10$

$<10$
2.7
210
$<10$

$<10$
$<10$
$<10$

$<2.0$

$<10$
1,230
1,350

$<10$

$<10$
$<10$

$<10$

$<10$

$<10$

$<10$

$<10$
$<10$
$<10$

$<10$
$<10$

$<10$

$<10$
$<10$
$<10$
$<10$

$<10$
8.8

$<10$

$\leq 10$

$<10$

$\leq 10$

$<10$

$<<$

$<10$

$<10$

$<50$

$<50$
$<10$
$<10$

$<10$

$<10$

$<10$

$\leq 10$

$<10$

$<10$

$<10$

$<10$

$<10$

$<10$

$<10$

$<\leq 10$

$<10$

$<10$

$<10$

$<10$
$<10$
$<10$
$<10$

$<10$
$<10$
6.7

12
11
$<10$
$<10$
$\leq 3.0$
$<2.0$
GE

WE

WA
WELL PSS 2D collected on 08/23/92, laboratory analyeses (cont.)

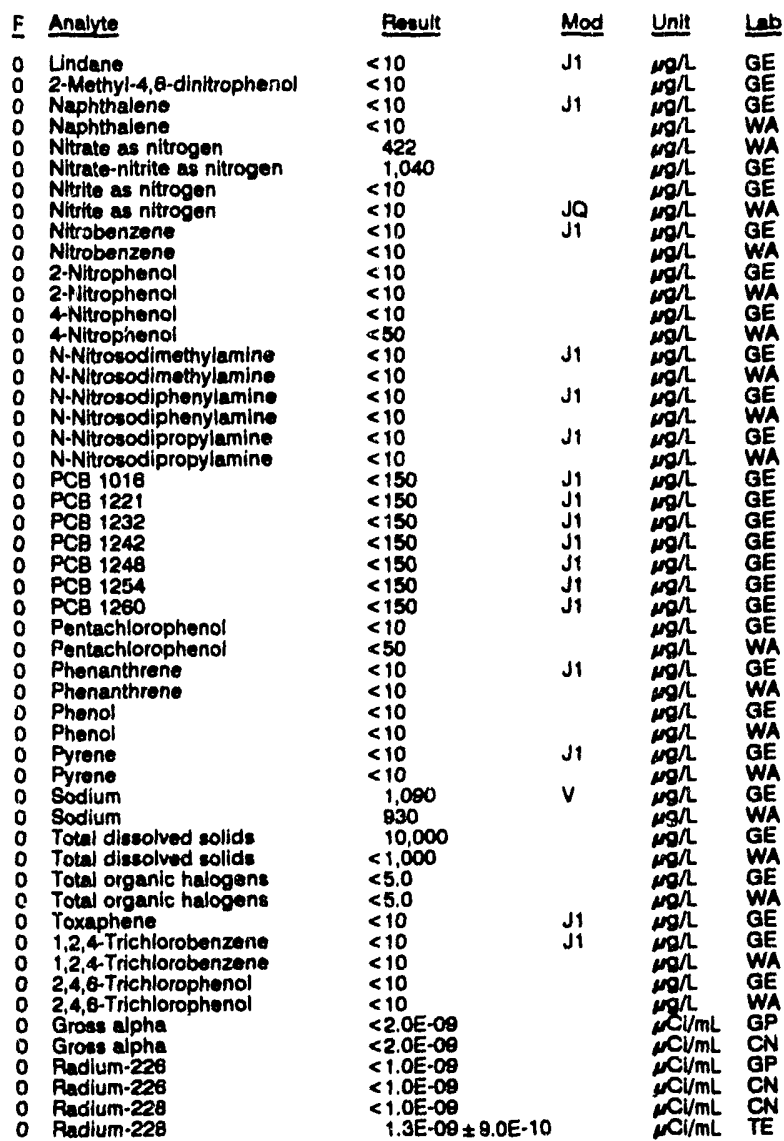

\section{WELLL. PSS 30}

MEASUREMENTS CONOUCTED IN THE FIELD

Sample date: 08/23/82

Depth to water: Not available

Water elevation: Not available

Sp. conductance: $14 \mathrm{\mu S} / \mathrm{cm}$.

The woll went dy during purging.

LABORATOPY ANALYSES

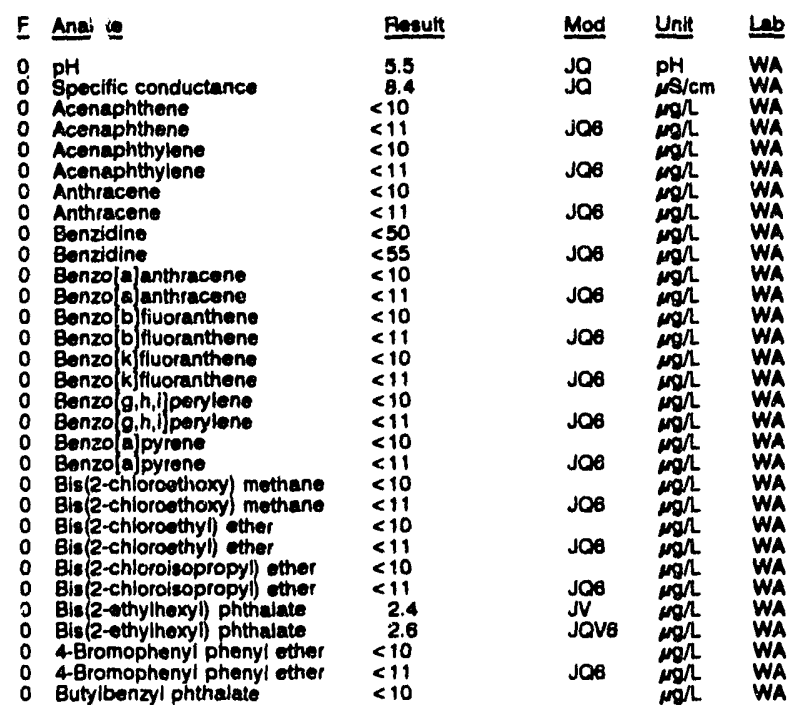

Time: $17: 20$

Alkalinity: 1 mgl

Water tomperature: $23.10 \mathrm{C}$ 
WELL PSS 3D collectiod on 08/23/82, laboratory analyese (cont)

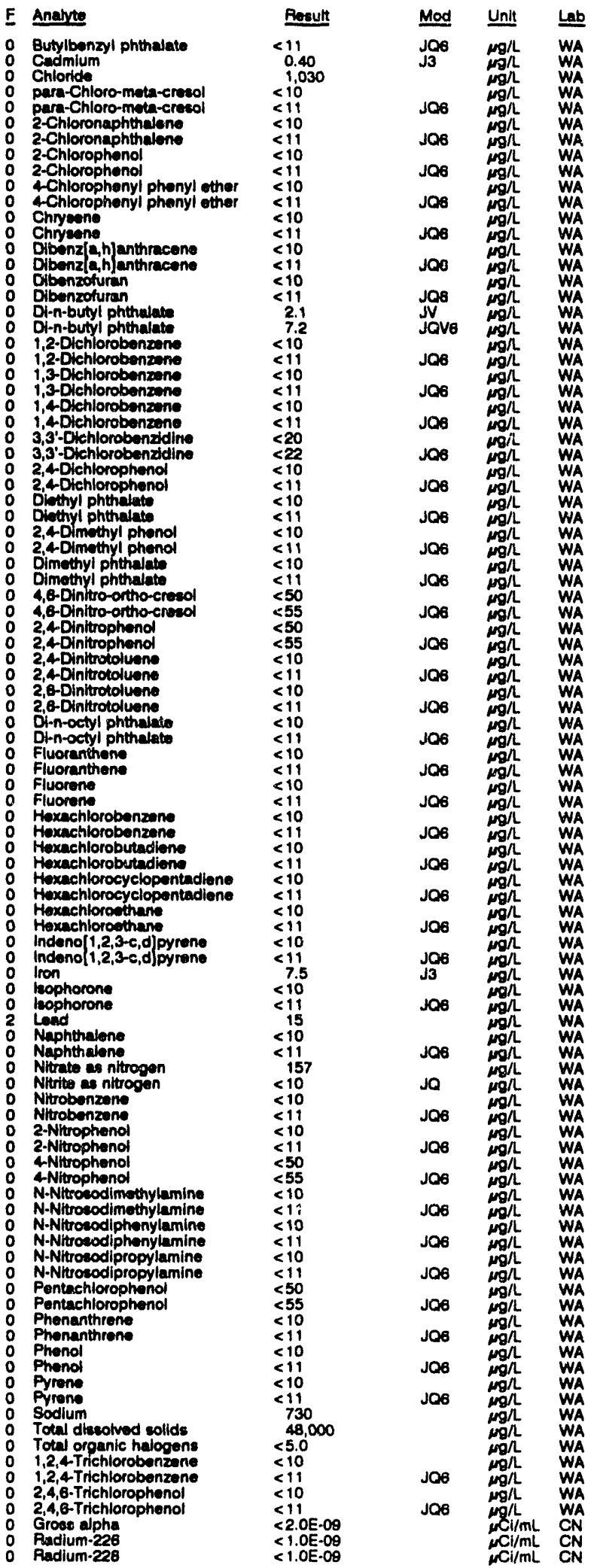

WELL RAC 1

MEASUREMENTS CONDUCTED IN THE FIELD

Samplo date: 08/22/82

Depth to water: $8.48 \mathrm{th}(2.58 \mathrm{~m})$ below TOC So conductance. 38 . 14 th Wator evacuated bofore sampling: 73 gal

Time: : $: 50$

Alkalinity: $1 \mathrm{mogh}$

Water temperature: $20.5^{\circ} \mathrm{C}$

LABORATORY ANALYSES

E Analyte Rogutt Mod Unit

o Areonic

Anzenic

0 Barium

: carium

C Codimium

0 Chromium

Chromium
2,4-Dichlorophenoxyacetic acid
2,4lehlorophenoxy acetic acid

Endrin

Ondrin

0 Iron

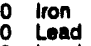

0 Load

L Lindano

0 Lindane

1 Manganese

Manganeso

0 Mercury

Methoxychlor

Methoxychlor

Mothoxychlor

solonlum

Solenium

Solentium

Silver

Toxaphene

: Toxaphene

0 Toxaphen

2,4,5.TP (Silvex)

Groses alpha

Gross apha

Nonvolatilo bota

Nonvolatilo beta

Radlum-226

Redium-228

Total alpha-omitting radium

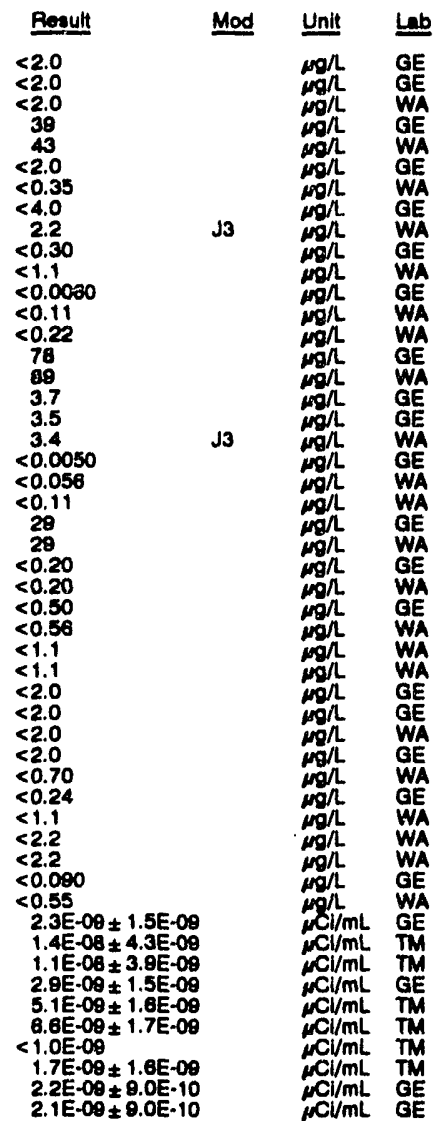

WELL RAC 1 Replicate

MEASUREMENTS CONDUCTED IN THE FIELD

Dopth to water: $8.49 \mathrm{f}(2.58 \mathrm{~m})$ below TOC

Water elovation: $275.14 \mathrm{ft}(83.86 \mathrm{~m}) \mathrm{mal}$

Water evacuated belore sampling: 73 gal

Akt: 4.8 inity: $1 \mathrm{mgh}$

Wator temperature: $20.5^{\circ} \mathrm{C}$

LABORATORY ANALYSES

\begin{tabular}{|c|c|c|c|}
\hline Analyze & Result & Mod & Unit \\
\hline 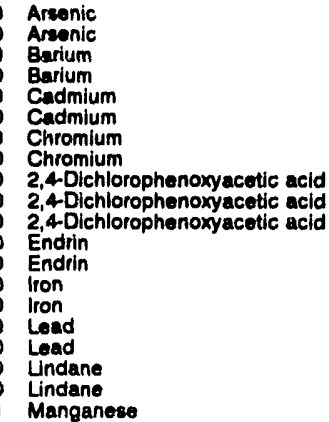 & $\begin{array}{l}<2.0 \\
<2.0 \\
4.1 \\
37 \\
<2.0 \\
<0.35 \\
<4.0 \\
2.3 \\
20.30 \\
<1.1 \\
<2.2 \\
<0.0060 \\
<0.11 \\
86 \\
97 \\
4.4 \\
2.2 \\
<0.0050 \\
<0.053 \\
32\end{array}$ & J3 & 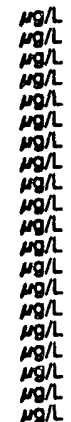 \\
\hline
\end{tabular}


WELL RAC 1 collocted on 08/22/92, laboratory analyses (cont)

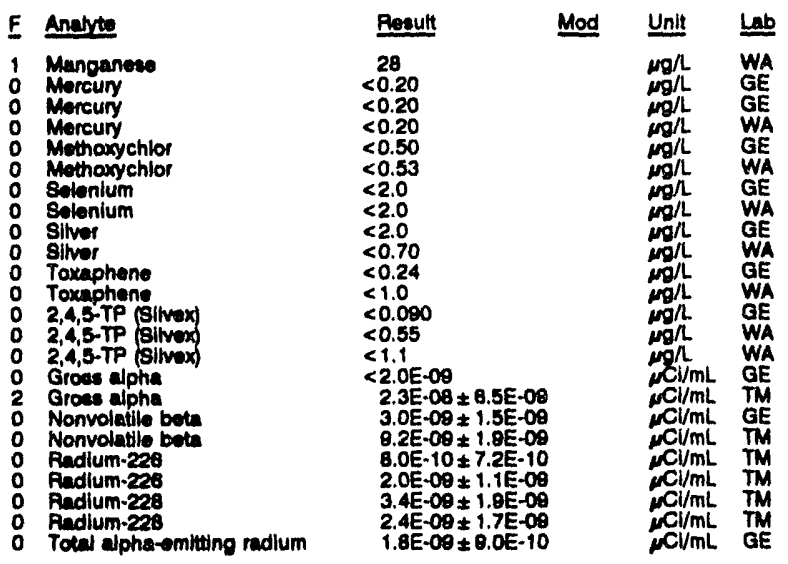

WELL RAC 2

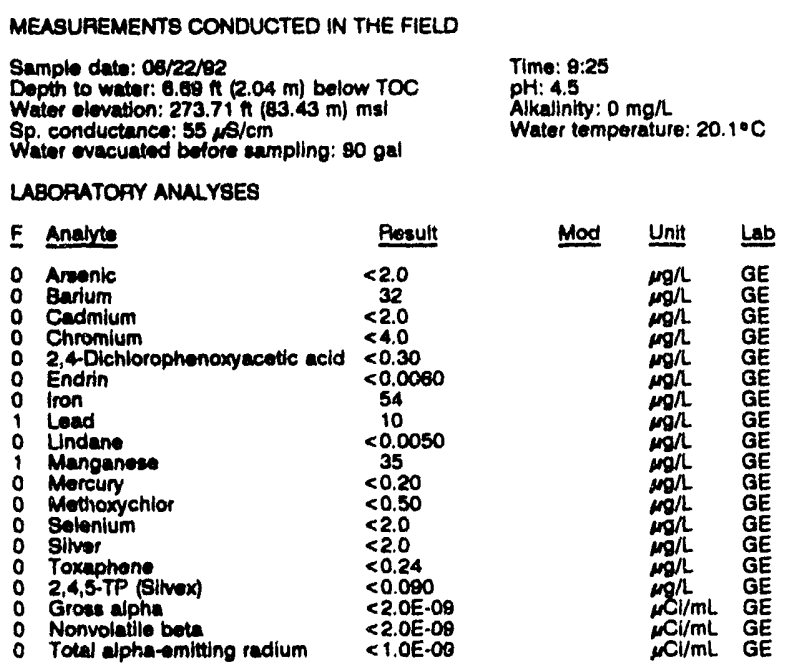

WELL RAC 3

MEASUREMENTS CONDUCTED IN THE FIELD

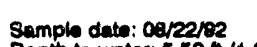

Depth to water: $5.52 \mathrm{H}(1.68 \mathrm{~m})$ below TOC Water elevation: $273.78 \mathrm{i}(83.45 \mathrm{~m}) \mathrm{mal}$ Water evacuatod before sampling: $83 \mathrm{gal}$ LABORATORY ANALYSES

\begin{tabular}{|c|c|c|c|c|c|}
\hline$E$ & Analyte & Result & Mad & Unit & Lي \\
\hline 0 & 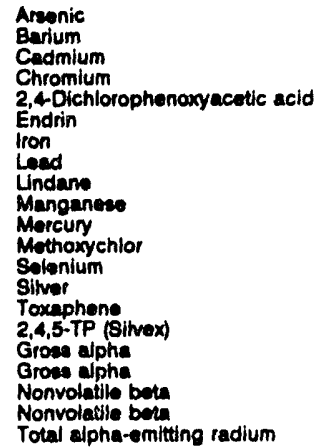 & $\begin{array}{l}<2.0 \\
47 \\
<2.0 \\
<4.0 \\
<0.30 \\
<0.0080 \\
28 \\
3.3 \\
<0.0050 \\
31 \\
<0.20 \\
<0.50 \\
<2.0 \\
<2.0 \\
<0.24 \\
<0.090 \\
<2.0 E \cdot 09 \\
<2.0 E-09 \\
<2.0 E-09 \\
2.2 E \cdot 09 \pm 1.0 E-09 \\
1.7 E-09 \pm 8.0 E-10\end{array}$ & & 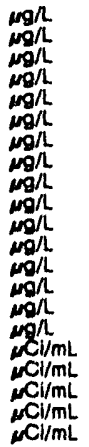 & $\begin{array}{l}\mathrm{GE} \\
\mathrm{GE} \\
\mathrm{GE} \\
\mathrm{GE} \\
\mathrm{GE} \\
\mathrm{GE} \\
\mathrm{GE} \\
\mathrm{GE} \\
\mathrm{GE} \\
\mathrm{GE} \\
\mathrm{GE} \\
\mathrm{GE} \\
\mathrm{GE} \\
\mathrm{GE} \\
\mathrm{GE} \\
\mathrm{GE} \\
\mathrm{GE} \\
\mathrm{GE} \\
\mathrm{GE} \\
\mathrm{GE} \\
\mathrm{GE}\end{array}$ \\
\hline
\end{tabular}

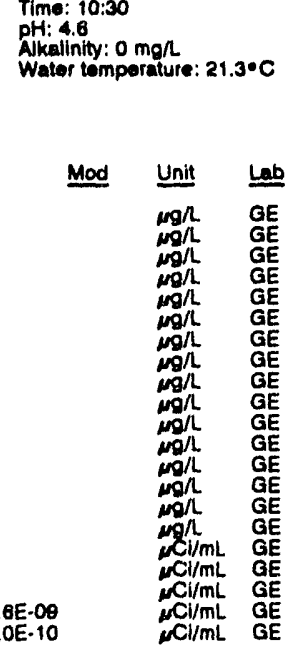

WELL RAC 4

MEASUREMENTS CONDUCTED IN THE FIELD

Sample date: 08/22/82 Depth to water: $5.89 \AA$ (1.83 m) below TOC Water evacuated belore sampling: $81 \mathrm{gal}$ LABORATORY ANALYSES

\begin{tabular}{|c|c|c|c|c|c|}
\hline & Analyte & Rosult & Mod & Unill & Lab \\
\hline & $\begin{array}{l}\text { Arsenic } \\
\text { Earium } \\
\text { Cadmium } \\
\text { Chromium } \\
2,4 \text { Dichlorophenoxyacetic acid } \\
\text { Endrin } \\
\text { iron } \\
\text { Lead } \\
\text { Lindane } \\
\text { Manganese } \\
\text { Mercuny } \\
\text { Methoxychlor } \\
\text { Selonium } \\
\text { Silver } \\
\text { Toxaphene } \\
\text { 2,4,6-TP (Silvex) } \\
\text { Groas alpha } \\
\text { Nonvolatile beta } \\
\text { Total alpha-emitting radium }\end{array}$ & $\begin{array}{l}<2.0 \\
30 \\
<2.0 \\
<4.0 \\
<0.30 \\
<0.0060 \\
17 \\
<3.0 \\
<0.0050 \\
25 \\
<0.20 \\
<0.60 \\
<2.0 \\
<2.0 \\
<0.24 \\
<0.000 \\
<2.0 E-09 \\
<2.0 E .09 \\
<1.0 E-09\end{array}$ & & 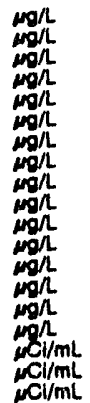 & $\begin{array}{l}G E \\
G E \\
G E \\
G E \\
G E \\
G E \\
G E \\
G E \\
G E \\
G E \\
G E \\
G E \\
G E \\
G E \\
G E \\
G E \\
G E \\
G E \\
G E\end{array}$ \\
\hline
\end{tabular}

WELL RCP $1 A$

MEASUREMENTS CONOUCTED IN THE FIELD

Sample date: 08/18/82 $\mathrm{A}(31.29 \mathrm{~m})$ bolow TOC Time: 10:30

Water elovation: $184.23 \mathrm{tt}(58.20 \mathrm{~m}) \mathrm{ms}$ !

inacceselbility or mochanical probiom prevented sample collection.

WELL RCP 1D

Sample date: $09 / 18 / 92$

Wator olovation: $282.47 \mathrm{~h}(88.10 \mathrm{~m}) \mathrm{msl}$

Sp. conductance: $148 \mathrm{\mu S} / \mathrm{cm}$

Water ovacuatod before sampling: 56 gal

LABORATOAY ANALYSES

E Anatute

: $\mathrm{pH}$ Specific conductance

0 Arsenic

Barium

Calcium

Chlorid

Chroride

O Copper

iron

o Lead

O Magnealum

Manganose

Morcun

Nitrate-nitrite as nitrogen

Phenola

Solenium

Slitica

Silver

Sodium

Sulfate

Total dissoived solids

Total dissolved sollds

Total organic carbon

Total organic halogens
Total phosphates (as P)

Zinc

Antimony-125

Corium-144

Cosium-137

Cobalt-60

Europium-152

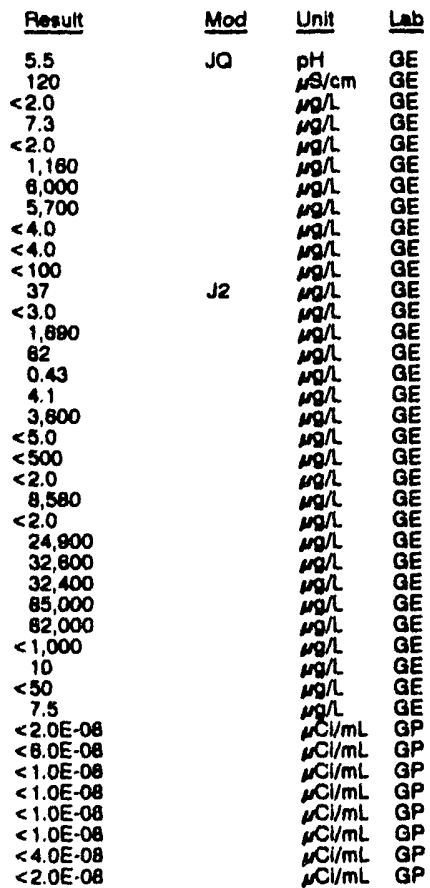

Time: 11:00

Alkalinity: $0 \mathrm{mg} / \mathrm{L}$ Water tempornture: $22.7 \circ \mathrm{C}$

$<2.0 \mathrm{E} .0$
Time: 8:05

Akalinity: $0 \mathrm{mg} / \mathrm{L}$ Walinity: $0 \mathrm{mg} / \mathrm{L}$

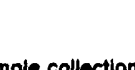
Sp. conductonc: $273.01 \mathrm{t}$

MEASUREMENTS CONDUCTED IN THE FIELD 
WELL RCP 1D collected on 09/18/82, laboratory analyses (cont.)

\begin{tabular}{|c|c|c|c|}
\hline Analyte & Result & Unit & ab \\
\hline 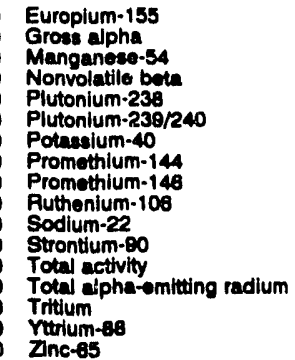 & $\begin{array}{l}<3.0 E-08 \\
<2.0 E-09 \\
<1.0 E-08 \\
<2.0 E-09 \\
<1.0 E-09 \\
<1.0 E-09 \\
<1.1 E-07 \\
<1.0 E-08 \\
<1.0 E-08 \\
<8.0 E-08 \\
<1.0 E-08 \\
<2.0 E-09 \\
5.6 E-08 \pm 1.4 E-08 \\
1.2 E-09 \pm 8.0 E-10 \\
2.2 E-08 \pm 5.0 E-07 \\
<6.0 E-08 \\
<2.0 E-08\end{array}$ & $\begin{array}{l}\mu \mathrm{Cl} / \mathrm{mL} \\
\mu \mathrm{Cl} / \mathrm{mL} \\
\mu \mathrm{Cl} / \mathrm{mL} \\
\mu \mathrm{Cl} / \mathrm{mL} \\
\mu \mathrm{Cl} / \mathrm{mL} \\
\mu \mathrm{Cl} / \mathrm{mL} \\
\mu \mathrm{Cl} / \mathrm{mL} \\
\mu \mathrm{Cl} / \mathrm{mL} \\
\mu \mathrm{Cl} / \mathrm{mL} \\
\mu \mathrm{Cl} / \mathrm{mL} \\
\mu \mathrm{Cl} / \mathrm{mL} \\
\mu \mathrm{Cl} / \mathrm{mL} \\
\mu \mathrm{Cl} / \mathrm{mL} \\
\mu \mathrm{Cl} / \mathrm{mL} \\
\mu \mathrm{Cl} / \mathrm{mL} \\
\mu \mathrm{Cl} / \mathrm{mL} \\
\mu \mathrm{Cl} / \mathrm{mL}\end{array}$ & $\begin{array}{l}\text { GP } \\
\text { GE } \\
\text { GP } \\
\text { GE } \\
\text { GP } \\
\text { GP } \\
\text { GP } \\
\text { GP } \\
\text { GP } \\
\text { GP } \\
\text { GP } \\
\text { GP } \\
\text { EM } \\
\text { GE } \\
\text { GE }\end{array}$ \\
\hline
\end{tabular}

\section{WELL RDB 1D}

MEASUREMENTS CONDUCTED IN THE FIELD

Sample date: 00/18/92 Depth to water: $8.20 \mathrm{f}(1.89 \mathrm{~m})$ below TOC Water elevation: $286.20 \mathrm{ft}(87$

Witer evecuated before sampling: $18 \mathrm{gal}$ The wall went dry during purging.

LABORATOFY ANALYSES

\begin{tabular}{|c|c|c|c|c|c|}
\hline E & Analyte & Result & Mod & $\underline{U_{n i t}}$ & $\underline{L a b}$ \\
\hline & 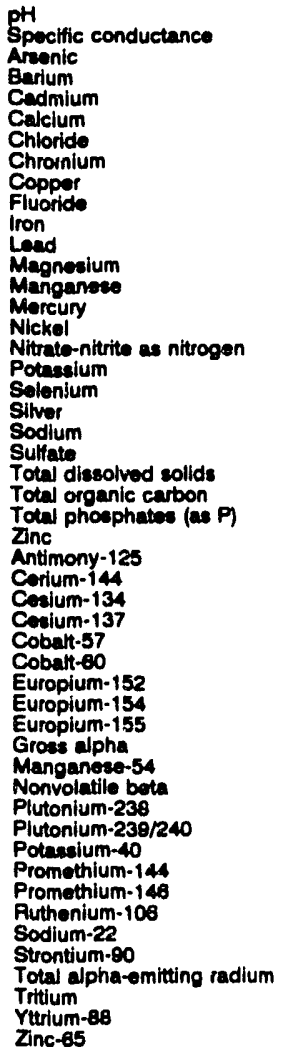 & $\begin{array}{l}6.8 \\
141 \\
<2.0 \\
27 \\
<2.0 \\
21,400 \\
840 \\
<4.0 \\
<4.0 \\
<100 \\
184 \\
<3.0 \\
1,780 \\
24 \\
<0.20 \\
<4.0 \\
<50 \\
2,680 \\
<2.0 \\
<2.0 \\
6,890 \\
7,130 \\
98,000 \\
<1,000 \\
<50 \\
90 \\
<2.0 E-08 \\
<6.0 E-08 \\
<1.0 E-08 \\
<1.0 E-08 \\
<1.0 E-08 \\
<1.0 E-08 \\
<4.0 E-08 \\
<2.0 E-08 \\
<3.0 E-08 \\
<2.0 E-09 \\
<1.0 E-08 \\
4.4 E-09 \pm 1.7 E-09 \\
<1.0 E-09 \\
<1.0 E-09 \\
<1.1 E-07 \\
<1.0 E-08 \\
<1.0 E-08 \\
<9.0 E-08 \\
<1.0 E-08 \\
<2.0 E-08 \\
<1.0 E-09 \\
1.9 E-06 \pm 5.0 E-07 \\
<6.0 E-08 \\
<2.0 E-08 \\
\end{array}$ & , & 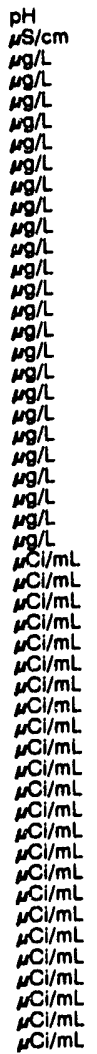 & $\begin{array}{l}\mathrm{GE} \\
\mathrm{GE} \\
\mathrm{GE} \\
\mathrm{GE} \\
\mathrm{GE} \\
\mathrm{GE} \\
\mathrm{GE} \\
\mathrm{GE} \\
\mathrm{GE} \\
\mathrm{GE} \\
\mathrm{GE} \\
\mathrm{GE} \\
\mathrm{GE} \\
\mathrm{GE} \\
\mathrm{GE} \\
\mathrm{GE} \\
\mathrm{GE} \\
\mathrm{GE} \\
\mathrm{GE} \\
\mathrm{GE} \\
\mathrm{GE} \\
\mathrm{GE} \\
\mathrm{GE} \\
\mathrm{GE} \\
\mathrm{GE} \\
\mathrm{GP} \\
\mathrm{GP} \\
\mathrm{GP} \\
\mathrm{GP} \\
\mathrm{GP} \\
\mathrm{GP} \\
\mathrm{GP} \\
\mathrm{GP} \\
\mathrm{GP} \\
\mathrm{GE} \\
\mathrm{GP} \\
\mathrm{GE} \\
\mathrm{GP} \\
\mathrm{GP} \\
\mathrm{GP} \\
\mathrm{GP} \\
\mathrm{GP} \\
\mathrm{GP} \\
\mathrm{GP} \\
\mathrm{GP} \\
\mathrm{GE} \\
\mathrm{GE} \\
\mathrm{GP} \\
\mathrm{GP}\end{array}$ \\
\hline
\end{tabular}

WELL RDB 2D

MEASUREMENTS CONDUCTED IN THE FIELD

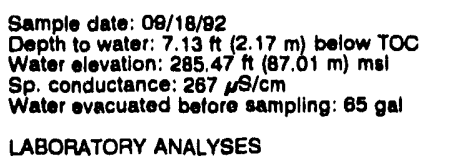

Time: 12:20

pH: 6.3

Alkalinity: $93 \mathrm{mg} / \mathrm{L}$

Water tomperature: $23.6^{\circ} \mathrm{C}$

LABORATORY ANALYSES

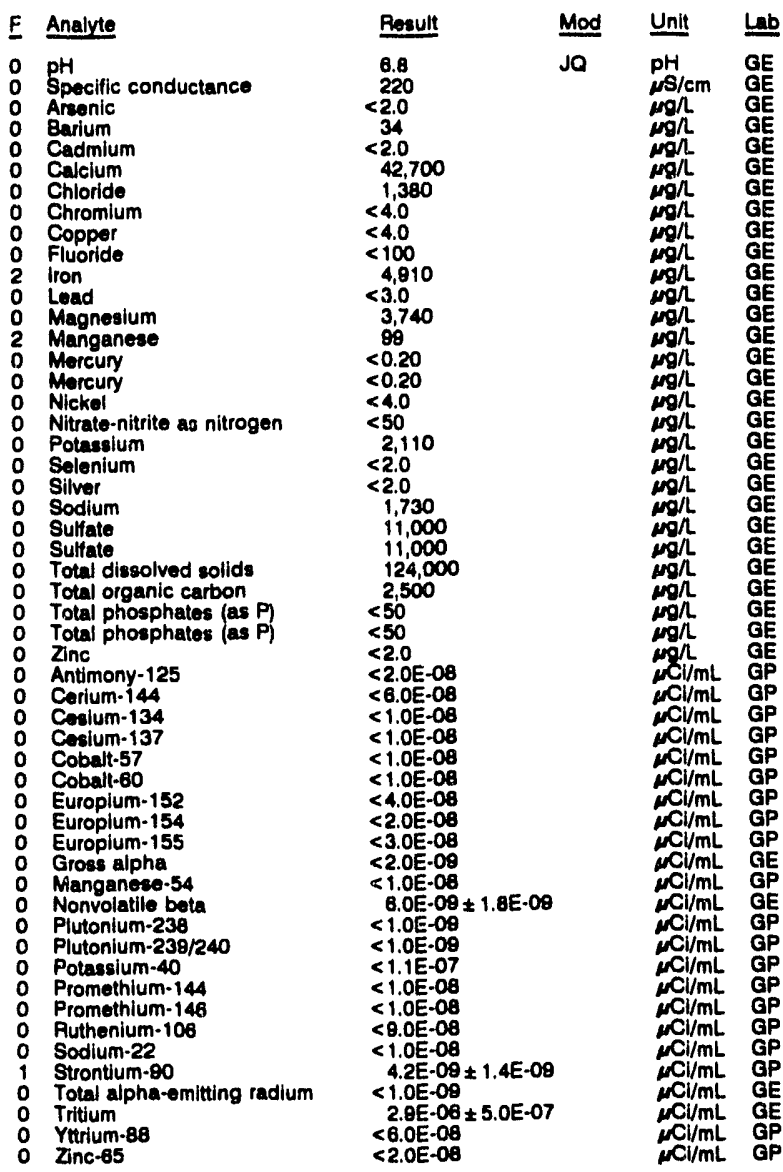

WELL RDB 3D

MEASUREMENTS CONDUCTED IN THE FIELD

Sample date: 09/18/92 Depth to water: $8.44 \mathrm{ft}(2.57 \mathrm{~m})$ below $\mathrm{mal}$
Water elevation: $284.28 \mathrm{ft}(86.64 \mathrm{~m}) \mathrm{ms}$

Sp er evation. 204.28

Time: 13.00

PH: 5.8 : $27 \mathrm{mg}$ Water evacuated before sampling: $48 \mathrm{gal}$

Water temperature: $21.6^{\circ} \mathrm{C}$

LABORATORY ANALYSES
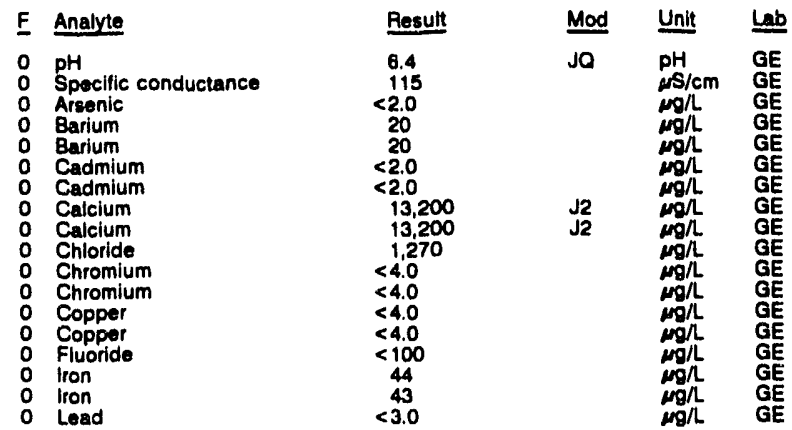
WEUL RDB 3D collected on 09/18/92, laboratory analyees (cont.)

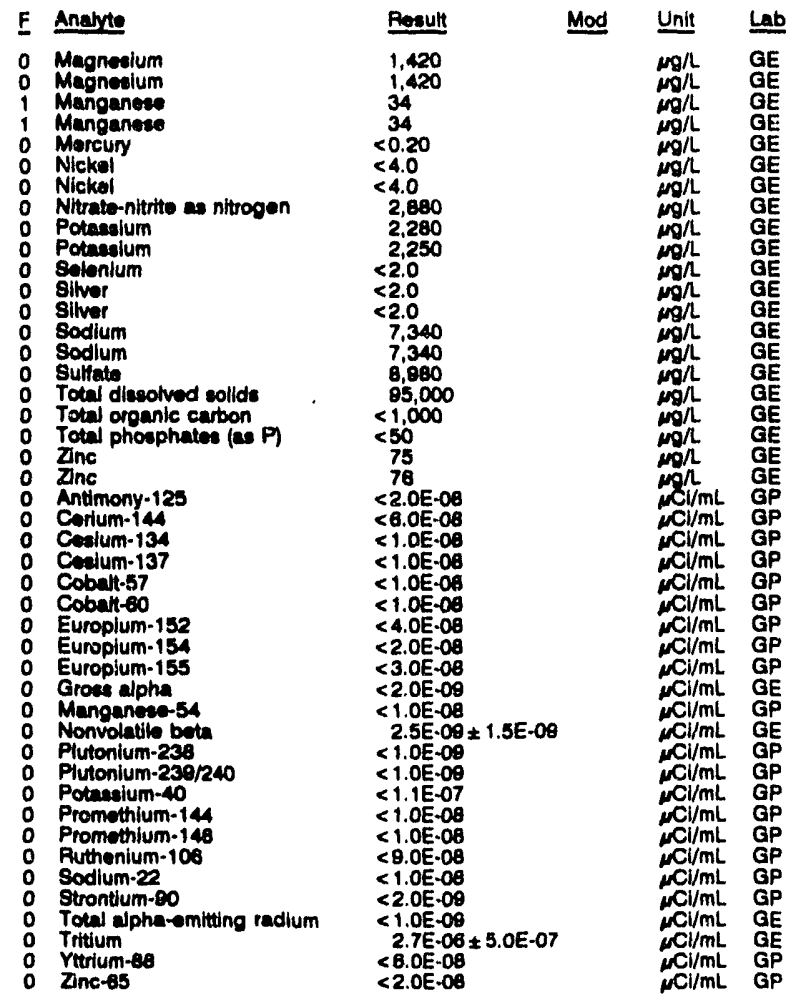

\section{WELL RRP 1}

MEASUREMENTS CONDUCTED IN THE FIELD

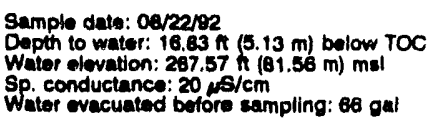

LABOPATOFY ANALYSES

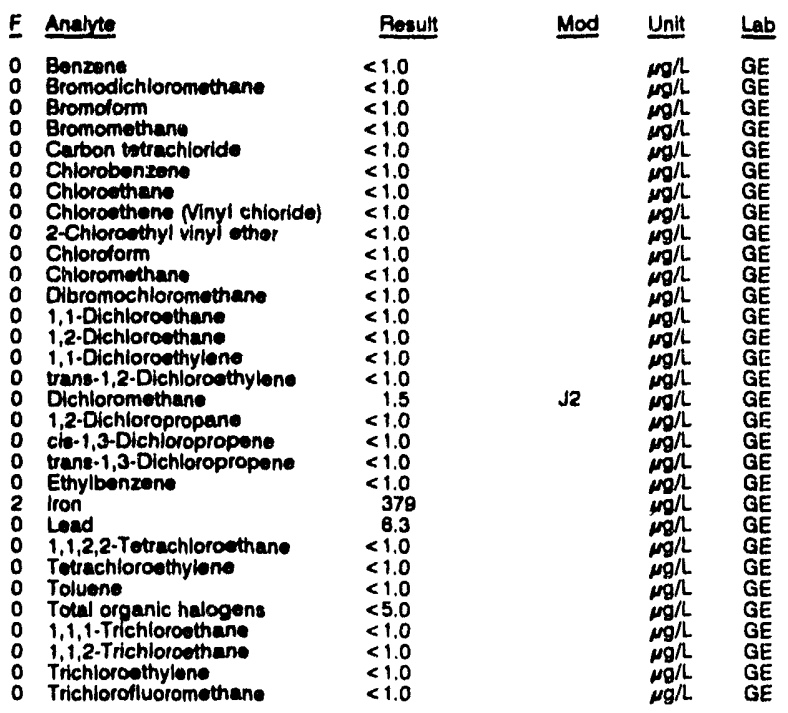

WELL RRP 2

MEASUREMENTS CONDUCTED IN THE FIELD

\begin{tabular}{|c|c|}
\hline $\begin{array}{l}\text { Samplo date: } 08 / 22 / 92 \\
\text { Depth to water: } 17.97 \mathrm{n}(5.48 \mathrm{~m}) \text { bolow TOC } \\
\text { Water olevation: } 286.53 \mathrm{~h}(81.24 \mathrm{~m}) \mathrm{mel} \\
\text { Sp. conductancs: } 16 \mu \mathrm{s} / \mathrm{cm} \\
\text { Water evacuated before sampling: } 63 \mathrm{gal}\end{array}$ & $\begin{array}{l}\text { Time: } 11: 05 \\
\text { phi: } 4.6 \\
\text { Alkalinity: } 0 \mathrm{mg} / \mathrm{h} \\
\text { Waler temperature: } 21.5^{\circ} \mathrm{C}\end{array}$ \\
\hline
\end{tabular}

Water evacuated before campling: $63 \mathrm{gal}$

LABORATOAY ANALYSES

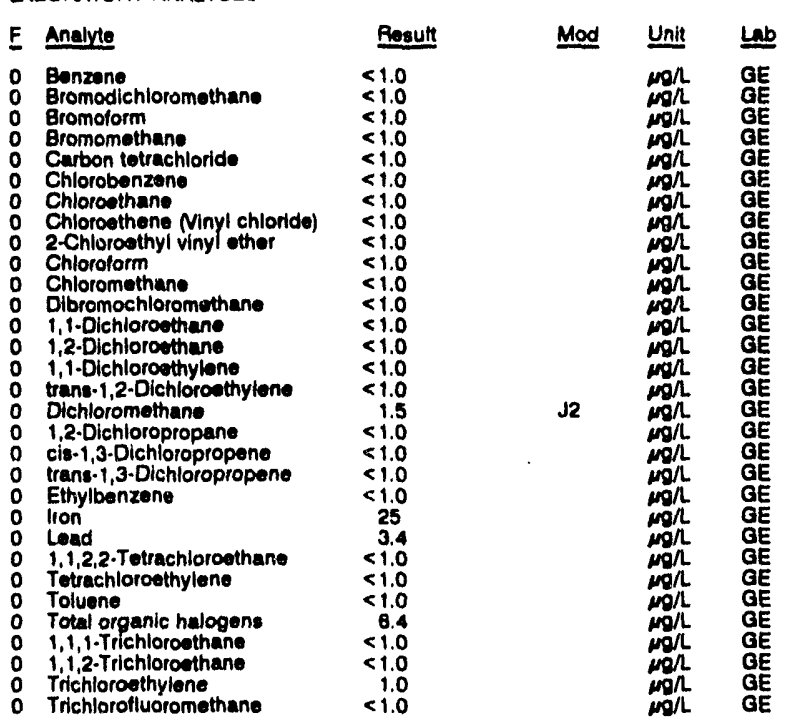

\section{WELL RRP 3}

\section{MEASUREMENTS CONDUCTED IN THE FIELD}

\section{Sample date: 08/22/92}

Depth to water: $13.80 \mathrm{ft}(4.21 \mathrm{~m})$ below TOC

Wator olevation: $286.30 \mathrm{ht}(81.17 \mathrm{~m}) \mathrm{ms}$

Sp. conductance: $12 \mu \mathrm{s} / \mathrm{cm}$
Water evacuated bofore sampling: $74 \mathrm{geal}$

LABORATORY ANALYSES

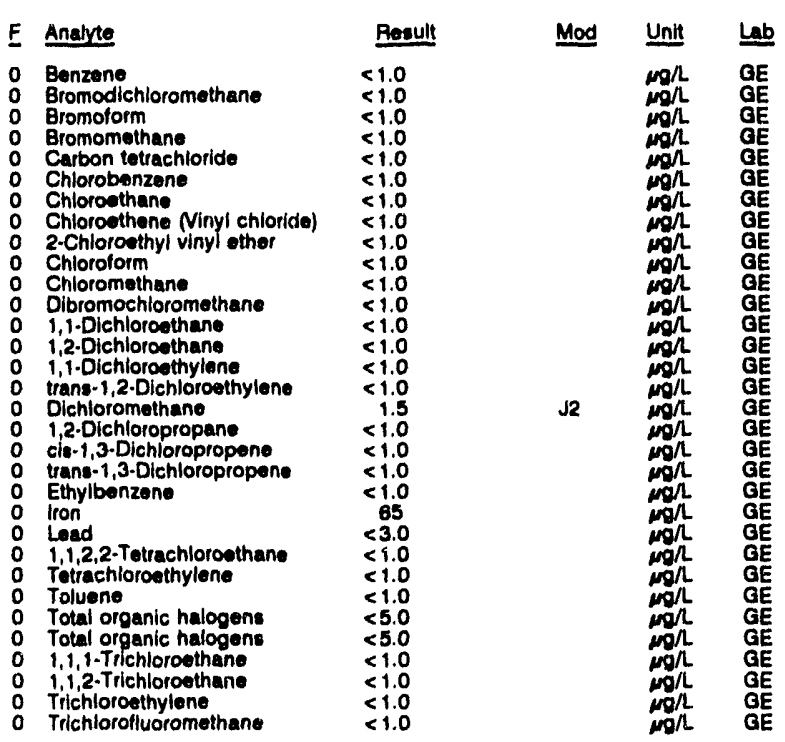

Time: 11:50

pH: 4.8 .

Alkuilnity: $1 \mathrm{mg} / \mathrm{h}$ : $1.2 \circ \mathrm{C}$ 
ANALYTICAL RESULTS

WELL RRP 4

MEASUREMENTS CONDUCTED IN THE FIELD

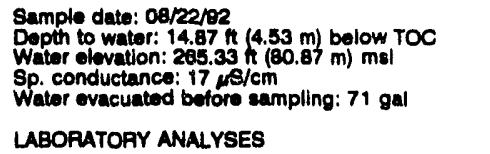

\begin{tabular}{|c|c|c|}
\hline & Anabute & Result \\
\hline & 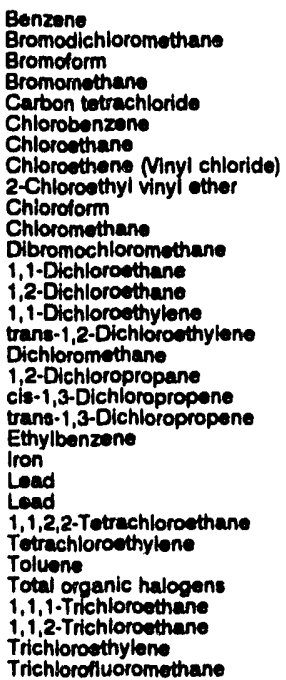 & $\begin{array}{l}<1.0 \\
<1.0 \\
<1.0 \\
<1.0 \\
<1.0 \\
<1.0 \\
<1.0 \\
<1.0 \\
<1.0 \\
<1.0 \\
<1.0 \\
<1.0 \\
<1.0 \\
<1.0 \\
<1.0 \\
<1.0 \\
<1.4 \\
<1.0 \\
<1.0 \\
<1.0 \\
<1.0 \\
1.290 \\
<3.0 \\
<3.0 \\
<1.0 \\
<1.0 \\
<1.0 \\
<5.0 \\
<1.0 \\
<1.0 \\
<1.0 \\
<1.0\end{array}$ \\
\hline
\end{tabular}

WELL RSA 7

MEASUREMENTS CONDUCTED IN THE FIELD

Sample dato: 08/18/92

Depth to water: $18.40 \mathrm{ft}(5.61 \mathrm{~m})$ below TOC

Water olevation: $296.30 \mathrm{~h}(80.31 \mathrm{~m}) \mathrm{msl}$

Sp. conductance: $20 \mathrm{\mu s} / \mathrm{cm}$

No water was evecunted before sampling.

LABORATOAY ANALYSES
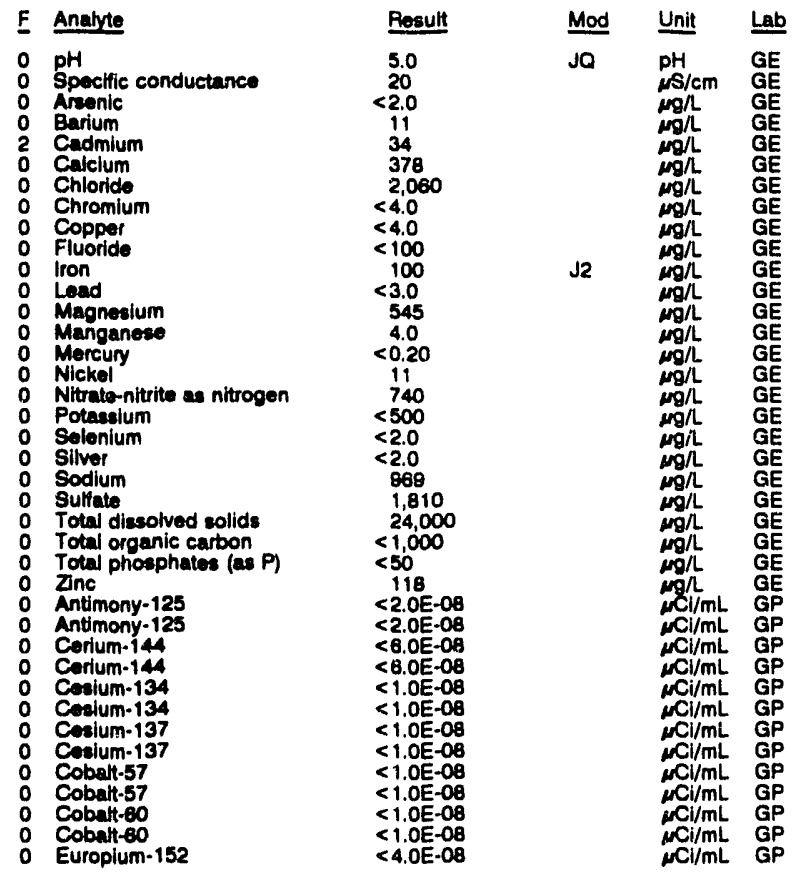

Time: 11:25

PH: 4.9 : $0 \mathrm{mg} / \mathrm{h}$

Water temperature: $20.4^{\circ} \mathrm{C}$

Mod Unit Lab

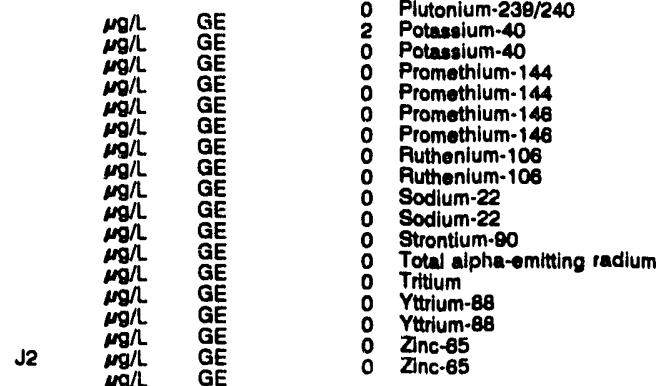

WELL RSA 8

MEASUREMENTS CONDUCTED IN THE FIELD

Sample date: $09 / 18 / 92$
Depth to water: $20.40 \mathrm{ft}(6.22 \mathrm{~m})$ below TOC
Water olevation: $293.80 \mathrm{ht}(68.58 \mathrm{~m}) \mathrm{msl}$
Sp. conductance: $25 \mathrm{\mu s} / \mathrm{cm}$
No water was ovacuatod bofore sampling.

Time: $10: 10$

Water temperature: $22.0^{\circ} \mathrm{C}$

LABORATORY ANALYSES

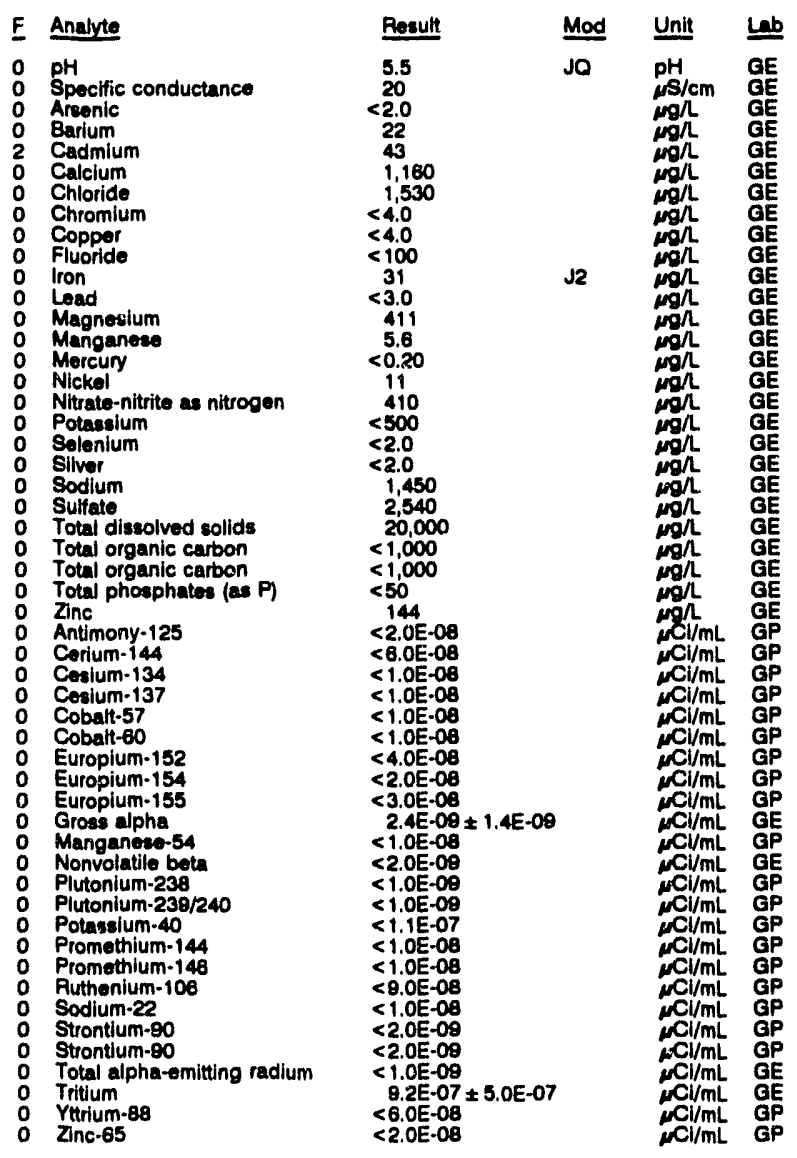


WELL RSA 9

MEASUREMENTS CONDUCTED IN THE FIELD

\begin{tabular}{|c|c|c|c|c|c|}
\hline \multicolumn{3}{|c|}{$\begin{array}{l}\text { Sample date: } 00 / 18 / 92 \\
\text { Depth to water: } 24.40 \mathrm{n}(7.44 \mathrm{~m}) \text { below TOC } \\
\text { Whtor elevation: } 287.70 \mathrm{ft}(87.69 \mathrm{~m}) \mathrm{msl} \\
\text { Sp. conductance: } 28 \mathrm{~s} / \mathrm{cm} \\
\text { No water was evacuatod before sampling. }\end{array}$} & \multicolumn{3}{|l|}{$\begin{array}{l}\text { Time: } 10: 50 \\
\text { pH: } 6.3\end{array}$} \\
\hline \multicolumn{6}{|c|}{ LABORATOPY ANALYSES } \\
\hline$\underline{\mathbf{E}}$ & Analyte & Result & Mod & Unit & Lab \\
\hline $\begin{array}{l}0 \\
0 \\
0 \\
0 \\
0 \\
0 \\
0 \\
0 \\
0 \\
0 \\
0 \\
0 \\
0 \\
0 \\
0 \\
0 \\
0 \\
0 \\
0 \\
0 \\
0 \\
0 \\
0 \\
0\end{array}$ & 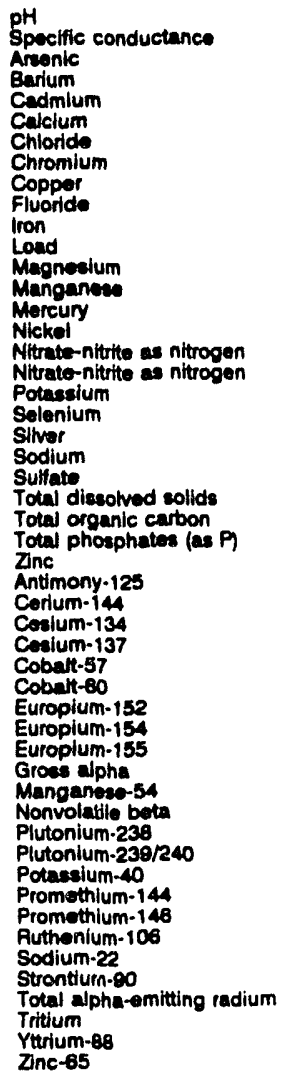 & $\begin{array}{l}5.4 \\
21 \\
<2.0 \\
19 \\
60 \\
2.080 \\
1,220 \\
<4.0 \\
<4.0 \\
<100 \\
189 \\
<3.0 \\
375 \\
24 \\
<0.20 \\
18 \\
<50 \\
<50 \\
<500 \\
<2.0 \\
<2.0 \\
800 \\
3,010 \\
18.000 \\
10,800 \\
110 \\
380 \\
<2.0 E-08 \\
<6.0 E-08 \\
<1.0 E-08 \\
<1.0 E-08 \\
<1.0 E-00 \\
<1.0 E-08 \\
<4.0 E-08 \\
<2.0 E-08 \\
<3.0 E-08 \\
2.7 E-09 \pm 1 \\
<1.0 E-08 \\
<2.0 E-09 \\
<1.0 E-09 \\
<1.0 E-09 \\
<1.1 E-07 \\
<1.0 E-08 \\
<1.0 E-08 \\
<8.0 E-08 \\
<1.0 E-08 \\
<2.0 E-09 \\
<1.0 E-09 \\
8.3 E-07 \pm \\
<6.0 E-08 \\
<2.0 E-08\end{array}$ & (1) & 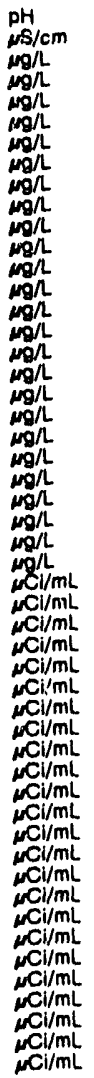 & $\begin{array}{l}\mathrm{GE} \\
\mathrm{GE} \\
\mathrm{GE} \\
\mathrm{GE} \\
\mathrm{GE} \\
\mathrm{GE} \\
\mathrm{GE} \\
\mathrm{GE} \\
\mathrm{GE} \\
\mathrm{GE} \\
\mathrm{GE} \\
\mathrm{GE} \\
\mathrm{GE} \\
\mathrm{GE} \\
\mathrm{GE} \\
\mathrm{GE} \\
\mathrm{GE} \\
\mathrm{GE} \\
\mathrm{GE} \\
\mathrm{GE} \\
\mathrm{GE} \\
\mathrm{GE} \\
\mathrm{GE} \\
\mathrm{GE} \\
\mathrm{GE} \\
\mathrm{GE} \\
\mathrm{GE} \\
\mathrm{GP} \\
\mathrm{GP} \\
\mathrm{GP} \\
\mathrm{GP} \\
\mathrm{GP} \\
\mathrm{GP} \\
\mathrm{GP} \\
\mathrm{GP} \\
\mathrm{GP} \\
\mathrm{GE} \\
\mathrm{GP} \\
\mathrm{GE} \\
\mathrm{GP} \\
\mathrm{GP} \\
\mathrm{GP} \\
\mathrm{GP} \\
\mathrm{GP} \\
\mathrm{GP} \\
\mathrm{GP} \\
\mathrm{GP} \\
\mathrm{GE} \\
\mathrm{GE} \\
\mathrm{GP} \\
\mathrm{GP}\end{array}$ \\
\hline
\end{tabular}

\section{WELLL RSA 10}

MEASUREMMENTS CONDUCTED IN THE FIELD

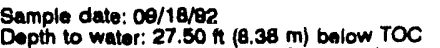
Water elevation: $287.80 \mathrm{~h}(87.75 \mathrm{~m}) \mathrm{msl}$

No water was evactated before sampling.

LABORATORY ANALYSES

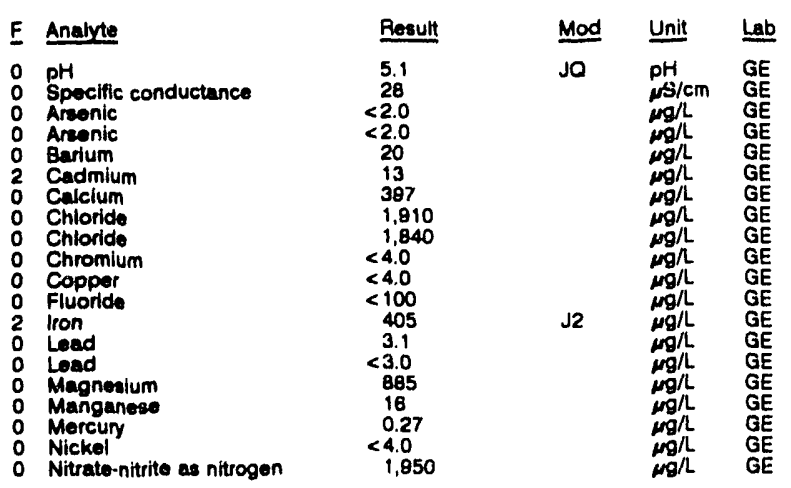

WELL RSA 10 collected on 08/18/82, laboratory analyees (cont.)

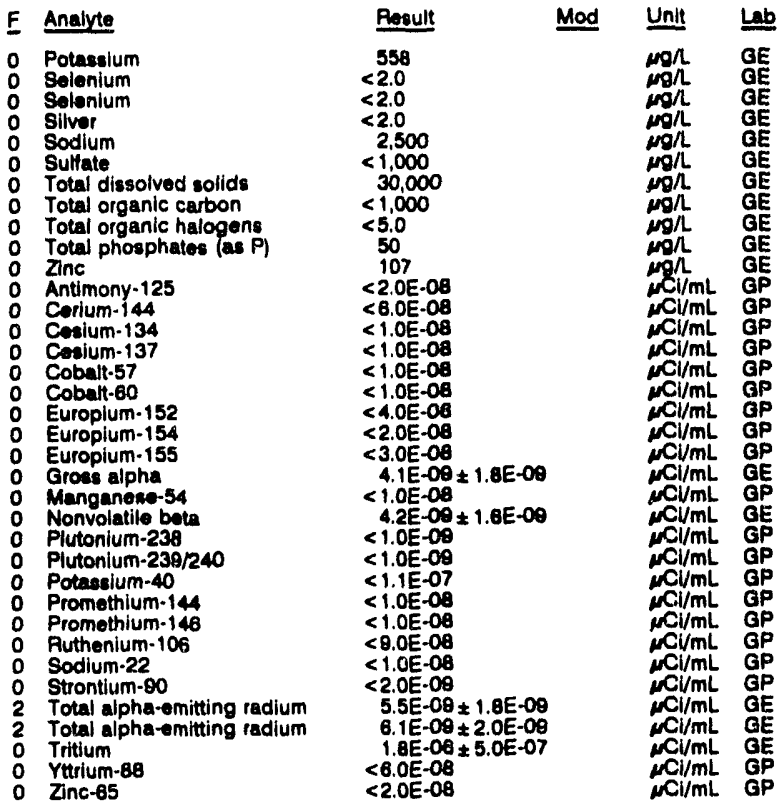

\section{WELL RSB 7}

MEASUREMENTS CONDUCTED IN THE FIELD

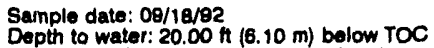
Water olevation: $288.10 \mathrm{ht}(87.81 \mathrm{~m}) \mathrm{msi}$

Sp. conductance: 33 HS/ $\mathrm{cm}$
No water was evacuated before sampling.

$\operatorname{Time:}_{\mathrm{PH}} \mathbf{8 : 3 0}$

Water temperature: $22.0^{\circ} \mathrm{C}$

LABORATORY ANALYSES

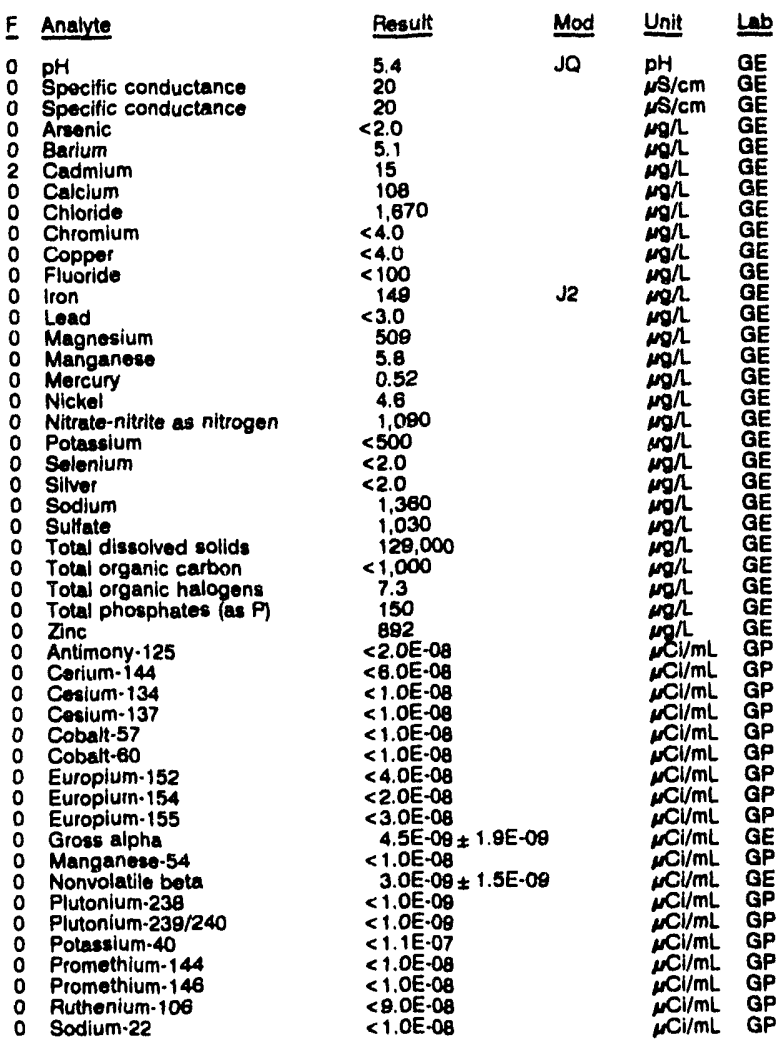


WELL RSB 7 collected on 09/18/92, laboratory analyses (cont)

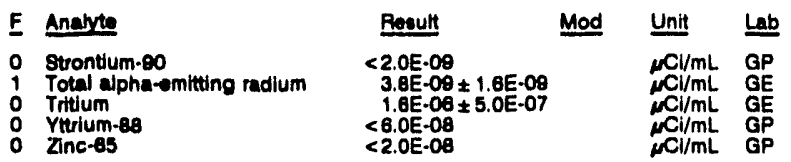

WELL RSB 8

MEASUREMENTS CONDUCTED IN THE FIELD

\begin{tabular}{|c|c|c|c|c|c|}
\hline \multicolumn{3}{|c|}{ 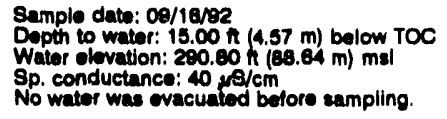 } & \multicolumn{3}{|c|}{$\begin{array}{l}\text { Time: 10:15 } \\
\text { pH: } 5.5\end{array}$} \\
\hline \multicolumn{6}{|c|}{ LABORATOFY ANALYSES } \\
\hline $\mathbf{E}$ & Analyte & Result & Mod & Unit & $\underline{L a b}$ \\
\hline $\begin{array}{l}0 \\
0 \\
0\end{array}$ & $\begin{array}{l}\text { Grose olpha } \\
\text { Nonvolatile beta } \\
\text { Tritium }\end{array}$ & $\begin{array}{l}4.5 E-0 \\
4.5 E-0 \\
1.5 E-0\end{array}$ & $\begin{array}{l}E-09 \\
3 E-09 \\
\text { E-07 }\end{array}$ & $\begin{array}{l}\mathrm{MCl} / r \\
\mathrm{M} \mathrm{Cl} / \mathrm{r} \\
\mathrm{MCl} / \mathrm{r}\end{array}$ & $\begin{array}{l}\text { GE } \\
\text { GE } \\
\text { GE }\end{array}$ \\
\hline
\end{tabular}

\section{WELL RSB 9}

MEASUREMENTS CONOUCTED IN THE FIELD

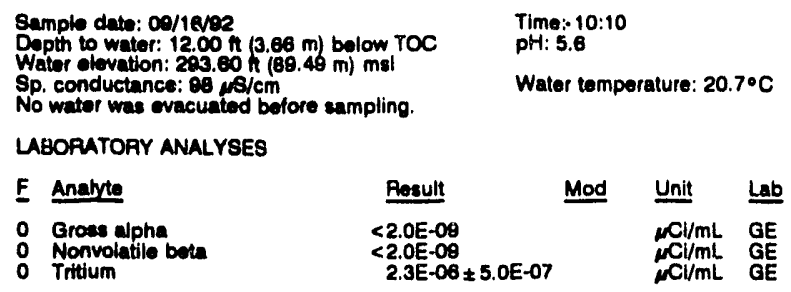

\section{WELL RSC 2}

MEASUREMENTS CONDUCTED IN THE FIELO

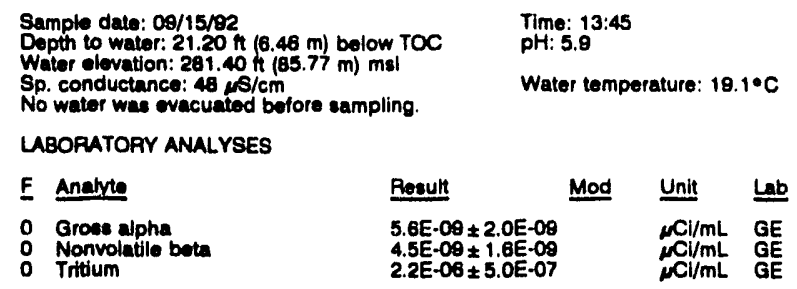

\section{WELL RSC 3}

MEASUREMENTS CONDUCTED IN THE FIELD

\begin{tabular}{|c|c|c|c|c|c|}
\hline \multicolumn{3}{|c|}{$\begin{array}{l}\text { Sample date: } 09 / 16 / 92 \\
\text { Depth to water: } 21.60 \mathrm{~h}(6.58 \mathrm{~m}) \text { below TOC } \\
\text { Water olovation: } 281.00 \mathrm{~h}(85.65 \mathrm{~m}) \mathrm{msl} \\
\text { Sp. conductance: } 54 / 48 / \mathrm{cm} \\
\text { No water was evacuated bofore sampling. }\end{array}$} & \multicolumn{3}{|c|}{$\begin{array}{l}\text { Time: } 14: 05 \\
\text { pH: } 5.5\end{array}$} \\
\hline \multicolumn{6}{|c|}{ LABORATORY ANALYSES } \\
\hline $\mathbf{E}$ & Analyte & Result & Mod & Unit & Lab \\
\hline $\begin{array}{l}0 \\
0 \\
0\end{array}$ & $\begin{array}{l}\text { Groses alpha } \\
\text { Nonvolatile beta } \\
\text { Tritium }\end{array}$ & $\begin{array}{l}5.8 E-0 \\
5.0 E-0 \\
2.5 E-0\end{array}$ & $\begin{array}{r}E-09 \\
E-09 \\
\text { E. }\end{array}$ & $\begin{array}{l}\mu \mathrm{Ci} / \mathrm{mL} \\
\boldsymbol{M} \mathrm{C} / \mathrm{mL} \\
\mathrm{cCl} / \mathrm{mL}\end{array}$ & $\begin{array}{l}\text { GE } \\
\text { GE } \\
\text { GE }\end{array}$ \\
\hline
\end{tabular}

WELL RSC 4

MEASUREMENTS CONDUCTED IN THE FIELD

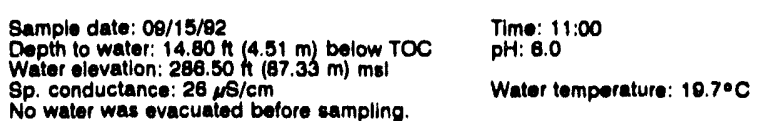

No water was evacuated before sampling.

LABORATOAY ANALYSES

\begin{tabular}{|c|c|c|c|}
\hline Analyte & Result & Mod & Unit \\
\hline $\begin{array}{ll}0 & \text { Gross alpha } \\
0 & \text { Nonvolautio beta } \\
0 & \text { Trtitum } \\
0 & \text { Tritium }\end{array}$ & $\begin{array}{l}3.9 E-09 \pm 1.7 E-09 \\
4.9 E-09 \pm 1.7 E .09 \\
1.6 E-06 \pm 5.0 E-07 \\
1.0 E-00 \pm 5.0 E-07\end{array}$ & & 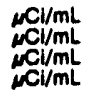 \\
\hline
\end{tabular}

WELLL RSC 5

MEASUREMENTS CONDUCTED IN THE FIELD

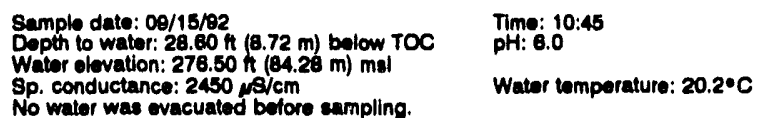

No water was evacuated before sampling.

LABORATORY ANALYSES

\begin{tabular}{|c|c|c|c|c|}
\hline F & Analyte & Rosult & Mod & Unth \\
\hline $\begin{array}{l}\text { o } \\
0 \\
0\end{array}$ & $\begin{array}{l}\text { Groes alpha } \\
\text { Grose alpha } \\
\text { Nonvolatile beta } \\
\text { Nonvolatile beta } \\
\text { Trittum }\end{array}$ & $\begin{array}{r}<2.0 \mathrm{E}-00 \\
2.1 \mathrm{E}-00 \pm 1.5 \mathrm{E}-00 \\
2.2 \mathrm{E}-00 \pm 1.6 \mathrm{E}-00 \\
<2.0 \mathrm{E}-00 \\
1.6 \mathrm{E}-06 \pm 5.0 \mathrm{E}-07\end{array}$ & & 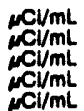 \\
\hline
\end{tabular}

\section{WELL RSC 6}

MEASUREMENTS CONDUCTED IN THE FIELD

$\begin{array}{ll}\text { Sample date: } 09 / 18 / 82 & \text { Time: } 13: 55 \\ \text { Depth to water: } 12.00 \mathrm{~h}(3.68 \mathrm{~m}) \text { below TOC } & \text { pH: } 5.4 \\ \text { Water olevation: } 291.80 \mathrm{H}(88.97 \mathrm{~m}) \mathrm{mal} & \text { Water temperature: } 23.7 \cdot \mathrm{C} \\ \text { Sp. conductance: } 48, \mu \mathrm{s} / \mathrm{cm} & \end{array}$

So water was evacuated bofore sampling.

LABORATORY ANALYSES

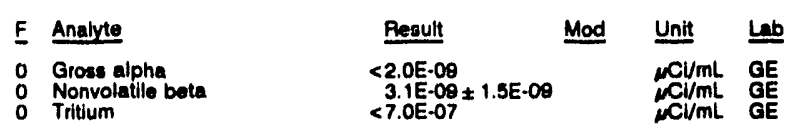

\section{WELL RSC 7}

MEASUREMENTS CONDUCTED IN THE FIELD

$\begin{array}{ll}\text { Sample date: } 09 / 16 / 92 & \text { Time: } 13: 50 \\ \text { Dopth to water: } 21.00 \mathrm{~h}(6.40 \mathrm{~m}) \text { bolow TOC } & \text { pH: } 5.4 \\ \text { Water elevatlon: } 288.00 \mathrm{~h}(87.78 \mathrm{~m}) \mathrm{msl} & \text { Water temperature: } 22.8^{\circ} \mathrm{C} \\ \text { Sp. conductance: } 36 \mu \mathrm{s} / \mathrm{cm} & \end{array}$

Sp. conductance: $36 \mu \mathrm{s} / \mathrm{cm}$
No water was ovacuated bolore sampling.

LABORATORY ANALYSES

\begin{tabular}{|c|c|c|c|c|}
\hline$F$ & Anaryte & Result & Mod & Unit \\
\hline $\begin{array}{l}0 \\
0 \\
0\end{array}$ & $\begin{array}{l}\text { Gross alpha } \\
\text { Nonvolatila beta } \\
\text { Tritium }\end{array}$ & $\begin{array}{l}4.8 E=0 \\
3.8 E-0 \\
1.7 E-0\end{array}$ & & 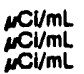 \\
\hline
\end{tabular}

\section{WELL RSC 8}

MEASUAEMENTS CONOUCTED IN THE FIELD

\begin{tabular}{|c|c|c|c|c|c|c|}
\hline \multicolumn{3}{|c|}{$\begin{array}{l}\text { Sample date: } 09 / 16 / 92 \\
\text { Depth to water: } 10.00 \mathrm{ht}(3.05 \mathrm{~m}) \text { below TOC } \\
\text { Water elevation: } 300.30 \mathrm{~h}(81.53 \mathrm{~m}) \mathrm{msl} \\
\text { Sp. conductance: } 35 \mu \mathrm{s} / \mathrm{cm} \\
\text { No water was evacuated before sampling. }\end{array}$} & \multicolumn{4}{|c|}{$\begin{array}{l}\text { Time: } 13: 45 \\
\text { pH: } 5.2\end{array}$} \\
\hline & BORATOAY ANAL & & \multicolumn{4}{|c|}{ Water temperature: $28.4^{\circ} \mathrm{C}$} \\
\hline$\underline{E}$ & Analyte & Result & & Mod & Unit & $\underline{L}$ \\
\hline $\begin{array}{l}0 \\
0 \\
0\end{array}$ & $\begin{array}{l}\text { Gross alpha } \\
\text { Nonvolatile beta } \\
\text { Tritlum }\end{array}$ & $\begin{array}{r}<2.0 \mathrm{E}-0 \\
<2.0 \mathrm{E}-0 \\
6.6 \mathrm{E}-0\end{array}$ & $.0 E-07$ & & 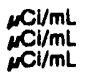 & $\begin{array}{l}\text { GE } \\
\text { GE } \\
\text { GE }\end{array}$ \\
\hline
\end{tabular}




\section{ANALYTICAL RESULTS}

WELL RSC 9

MEASUREMENTS CONOUCTED IN THE FIELD

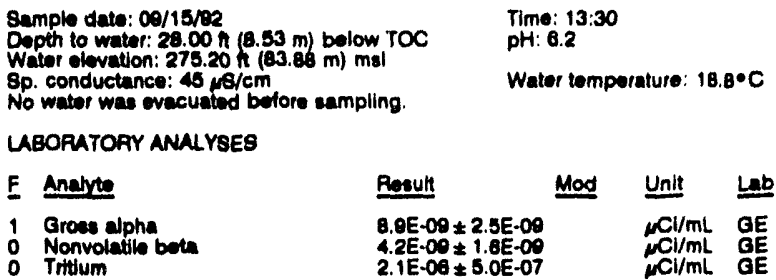

WELL RSC 10

MEASUAEMENTS CONDUCTEO IN THE FIELO

\begin{tabular}{|c|c|c|c|c|}
\hline \multicolumn{2}{|c|}{ 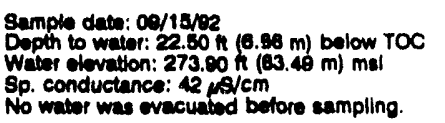 } & \multicolumn{3}{|c|}{$\begin{array}{l}\operatorname{Time:}_{\text {pH: }}^{12: 30} \\
\text { pH.8 }\end{array}$} \\
\hline \multicolumn{5}{|c|}{ ABOPATOAY ANALYSES } \\
\hline Anaryte & Result & Mod & Unit & Lab \\
\hline $\begin{array}{l}\text { Grove alpha } \\
\text { Nonvolalito beta } \\
\text { Tritlum }\end{array}$ & $\begin{array}{l}1.4 E-1 \\
1.2 E- \\
1.3 E-\end{array}$ & & 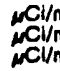 & $\begin{array}{l}\mathrm{GE} \\
\mathrm{GE} \\
\mathrm{GE}\end{array}$ \\
\hline
\end{tabular}

\section{WELL RSD 1}

MEASUREMENTS CONDUCTED IN THE FIELD

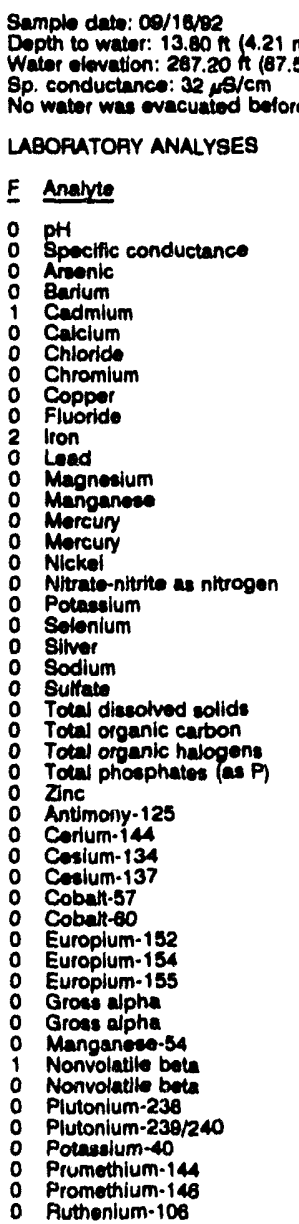

Time: 10:45

Water temperature: $22.5^{\circ} \mathrm{C}$

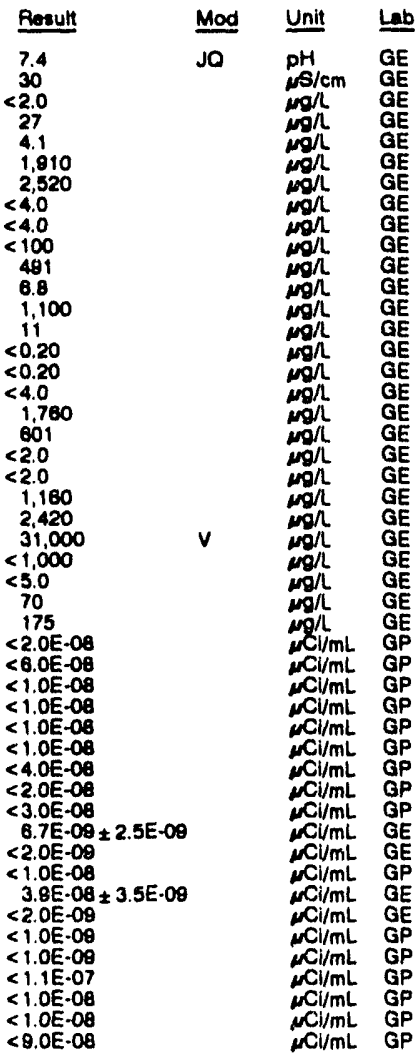

WELL RSD I colloctod on 09/18/92, laboratory analywer (cont)

\begin{tabular}{|c|c|c|c|}
\hline Analyte & Recuit & Mod & $\underline{\text { Unit }}$ \\
\hline 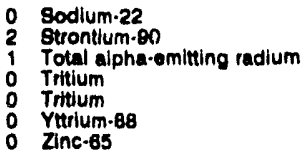 & $\begin{array}{l}<1.0 E \cdot 08 \\
1.7 E .08 \pm 1.6 E-09 \\
3.7 E .00 \pm 8.0 E \cdot 10 \\
1.3 E .00 \pm 5.0 E \cdot 07 \\
1.3 E .00 \pm 5.0 E \cdot 07 \\
<8.0 E .08 \\
<2.0 E .08\end{array}$ & & 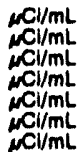 \\
\hline
\end{tabular}

WELL RSD 2A

MEASUREMENTS CONDUCTED IN THE FIELD

Sumpte date: $09 / 18 / 92$
Depth to water: $12.00 \mathrm{~h}(3.68 \mathrm{~m})$ bolow TOC

Depth to water: $12.00 \mathrm{ht}(3.66 \mathrm{~m})$ below TOC
Water elovation: $289.20 \mathrm{~h}(68.15 \mathrm{~m}) \mathrm{mal}$

Sp conductance: 30.20 .

So. Conductance: $30 \mathrm{fs} / \mathrm{cm}$.

Water tomperature: $24.1{ }^{\circ} \mathrm{C}$

UBOFATORY ANALYSES

\begin{tabular}{|c|c|c|c|}
\hline Analvite & Result & Mod & Unit \\
\hline $\begin{array}{ll}0 & \text { Groes alpha } \\
2 & \text { Nonvolatile beta } \\
0 & \text { Tritium }\end{array}$ & $\begin{array}{l}4.4 E-0 \\
2.3 E=0 \\
2.7 E-0\end{array}$ & & \\
\hline
\end{tabular}

\section{WELL RSD 2B}

MEASUAEMENTS CONDUCTED IN THE FIELD

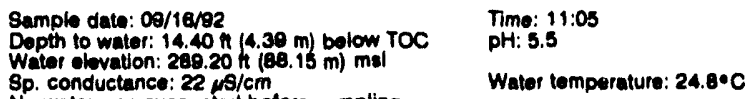

No water was evacuated before sampling.

LABORATORY ANALYSES

\begin{tabular}{|c|c|c|c|}
\hline E Analyte & Resuln & Mod & Unit \\
\hline $\begin{array}{ll}1 & \text { Groes alpha } \\
2 & \text { Nonvolatile beta } \\
0 & \text { Tritium }\end{array}$ & $\begin{array}{l}1.3 E=0 \\
3.0 E-0 \\
1.1 E-0\end{array}$ & & 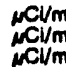 \\
\hline
\end{tabular}

WELL RSD $2 \mathrm{C}$

MEASUREMENTS CONDUCTED IN THE FIELD

\begin{tabular}{|c|c|c|c|c|c|}
\hline \multicolumn{3}{|c|}{$\begin{array}{l}\text { Sample date: } 09 / 16 / 92 \\
\text { Depth to water: } 12.60 \mathrm{H}(3.84 \mathrm{~m}) \text { bolow TOC } \\
\text { Water olovation: } 289.10 \mathrm{ft}(88.12 \mathrm{~m}) \mathrm{mel} \\
\text { Sp. conductance: } 80 \mathrm{\mu s} / \mathrm{cm} \\
\text { No water was evacuated bofore sampling. }\end{array}$} & \multicolumn{3}{|l|}{$\begin{array}{l}\text { Time: } 11: 10 \\
\text { pH: } 5.2\end{array}$} \\
\hline \multicolumn{6}{|c|}{ LABORATORY ANALYSES } \\
\hline $\mathbf{E}$ & Analvite & Result & Mod & Unit & \\
\hline $\begin{array}{l}2 \\
2 \\
0\end{array}$ & $\begin{array}{l}\text { Groes alpha } \\
\text { Nonvolatile bota } \\
\text { Tritium }\end{array}$ & $\begin{array}{l}2.8 E- \\
4.2 E- \\
1.0 E-\end{array}$ & $\begin{array}{l}8.9 E-09 \\
3.4 E-08 \\
5.0 E-07\end{array}$ & 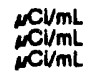 & $\begin{array}{l}\mathrm{CE} \\
\mathrm{CE}\end{array}$ \\
\hline
\end{tabular}

WELL RSD 3

MEASUREMENTS CONDUCTED IN THE FIELD

Sample data: 08/16/92

Dopth to water: $11.00 \mathrm{H}(3.35 \mathrm{~m})$ below TOC

Weter elevation: $289.80 \mathrm{~h}(88.36 \mathrm{~m}) \mathrm{msl}$

Sp. conductance: $38 \mu \mathrm{s} / \mathrm{cm}$

batore sampling

$\operatorname{Time:}_{\mathrm{pH}: 5.3}$

No water was evecuatod bot

$\begin{array}{ll}\text { F } & \text { Analyte } \\ 0 & \text { pH } \\ 0 & \text { Specific conductance } \\ 0 & \text { Specific conductance } \\ 0 & \text { Areonic } \\ 0 & \text { Barium } \\ 2 & \text { Cadmium } \\ 0 & \text { Calcium } \\ 0 & \text { Chloride } \\ 0 & \text { Chloride } \\ 0 & \text { Chromium } \\ 0 & \text { Copper } \\ 0 & \text { Fluoride } \\ 0 & \text { Fluoride } \\ 2 & \text { iron } \\ 0 & \text { Lead } \\ 0 & \text { Magnealum }\end{array}$

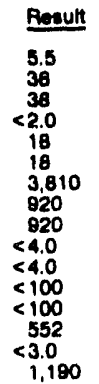

\begin{tabular}{|c|c|}
\hline Mod & Unit \\
\hline JQ & 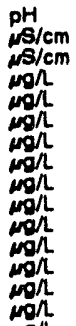 \\
\hline
\end{tabular}


ANALYTICAL RESULTS

WELL RED 3 collected on 00/18/92, laboratory analyese (cont.)

Totul diecolved eolide

Total phoophates (ce P)

Antimony-12t
E Analyte

o Manganoces

: Moreuny

0 Moreun

Nitrate-nitrites es nitrooen

Potaedium

gitonlum

Sodium

Sulate

Sulfete

Ioten dienolved eollios

Toiv organic carbon

Zne

Corlum.144

Coium-134

Cobth-67

Cotrali-60

Europlum-152

Europlum-18

Groes alpha

Mangenee-s.

Nonvolatile bet

Plutonium-23e

Plutonlum-239/240

Potandium-40

Promethlum-144

Puthonlum-100

Sodlum-22

Btrontum-80

Total alpha-emituing radlum

Tritum

Zntum-8s

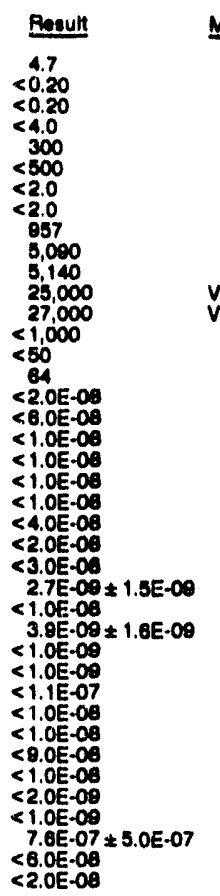

Mod

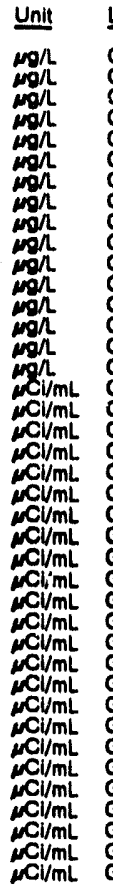

WELL RSD 4

MEASUREMENTS CONDUCTED IN THE FIELD

Sample deto: 00/19er

Depth to water: $12.00 \mathrm{f}(3.66 \mathrm{~m})$ bolow TOC

Water elevation: $289.80 \mathrm{~h}(88.27 \mathrm{~m}) \mathrm{msl}$

No water was evecuated before sampling.

LABOPATOAY ANALYSES

\begin{tabular}{|c|c|c|c|}
\hline F Analyte & Result & Mod & Unit \\
\hline $\begin{array}{l}1 \text { Groes alpha } \\
2 \text { Nonvolatilo beta } \\
0 \text { Trittium }\end{array}$ & $\begin{array}{l}1.3 E-08 \pm 3.4 E-09 \\
1.6 E-07 \pm 6.7 E-09 \\
1.8 E-06 \pm 5.0 E-07\end{array}$ & & 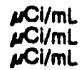 \\
\hline
\end{tabular}

\section{WELL RSD 5}

MEASUREMENTS CONDUCTED IN THE FIELD

Samplo date: 00/1890

Depth to water: $14.20 \mathrm{~h}(4.33 \mathrm{~m})$ below TOC

Water elovation: $287.50 \mathrm{ft}(87.63 \mathrm{~m}) \mathrm{msl}$

Sp. conductance: $28 \mathrm{~s} / \mathrm{cm}$

Water temperature: $28.0^{\circ} \mathrm{C}$

No water was evacuated before sampling.

LABORATORY ANALYSES

E Analyte

- Gross alphe

o Tritium

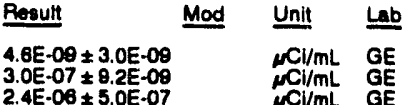

\section{WELL RSD 6}

MEASUAEMENTS CONDUCTED IN THE FIELD

Sample dato: 09/18/92

Water olevation: $286.00 \mathrm{~h}(87.45 \mathrm{~m}) \mathrm{msl}$

Sp. conductance: $42 \mu \mathrm{s} / \mathrm{cm}$

before sampling

Time: 13:05

$\mathrm{pH}: 5.5$

Water temperature: $25.0^{\circ} \mathrm{C}$

LABORATORY ANALYSES

E Analyte

1 Gross alpha

2 Nonvolatile bota
Time: $\mathbf{1 3 : 1 0}$

Water temperature: $23.0^{\circ} \mathrm{C}$ P
Time: $13: 00$

2 Nonvolatile beta

Dopth to water: $15.20 \mathrm{ft}(4.63 \mathrm{~m})$ below TOC ab

GE

\section{WELL RSD 7}

MEASUREMENTS CONDUCTED IN THE FIELO

\begin{tabular}{|c|c|}
\hline \multirow{2}{*}{$\begin{array}{l}\text { 8ample date: } 09 / 16 / 02 \\
\text { Depth to water: } 8.00 \mathrm{fr}(2.44 \mathrm{~m}) \text { bolow TOC } \\
\text { Water elovation: } 285.40 \mathrm{f}(86.60 \mathrm{~m}) \mathrm{mal} \\
\text { 8p. conductance: } 24 \mathrm{~s} / \mathrm{cm} \\
\text { No water was ovacuated betore eampling. }\end{array}$} & 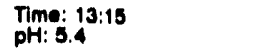 \\
\hline & Water tom \\
\hline
\end{tabular}

No water was evacuated before sampling

LABORATORY ANALYBES

\begin{tabular}{|c|c|c|}
\hline Anulute & Beoult & Unn \\
\hline $\begin{array}{ll}0 & \text { Groas alpha } \\
2 & \text { Nonvolatile beta } \\
0 & \text { Trittum }\end{array}$ & $\begin{array}{l}4.4 E-00 \pm 2.4 E-00 \\
1.5 E-07 \pm 6.0 E-00 \\
1.2 E-00 \pm 3.0 E-07\end{array}$ & $\begin{array}{l}\mathrm{NCV/m} . \\
\mathrm{MCl} / \mathrm{mL} \\
\mathrm{MCV} / \mathrm{mL}\end{array}$ \\
\hline
\end{tabular}

WELL RSD 8

MEASUREMENTS CONDUCTED IN THE FIELD

\begin{tabular}{|c|c|c|c|c|c|}
\hline \multicolumn{3}{|c|}{ 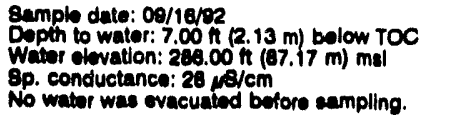 } & \multicolumn{3}{|l|}{ 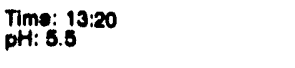 } \\
\hline \multicolumn{6}{|c|}{ LABOAATORY ANALYSES } \\
\hline $\mathbf{E}$ & Analyte & Reault & Mod & Unit & $\underline{\underline{L u b}}$ \\
\hline $\begin{array}{l}2 \\
2 \\
0\end{array}$ & $\begin{array}{l}\text { Groses alphe } \\
\text { Nonvolatile beta } \\
\text { Tritium }\end{array}$ & $\begin{array}{l}1.6 E-00 \\
7.5 E \cdot 07 \\
2.6 E-00\end{array}$ & $\begin{array}{l}.0 E-\infty 0 \\
1.5 E-08 \\
.0 E-07\end{array}$ & 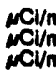 & $\begin{array}{l}G E \\
G E \\
G E\end{array}$ \\
\hline
\end{tabular}

WELL RSD 9

MEASUREMENTS CONDUCTED IN THE FIELL

\begin{tabular}{|c|c|c|c|c|c|}
\hline \multicolumn{3}{|c|}{$\begin{array}{l}\text { Sample date: } 09 / 15 / 92 \\
\text { Depth to water: } 8.80 \mathrm{ft}(2.71 \mathrm{~m}) \text { bolow TCC } \\
\text { Water elevation: } 283.70 \mathrm{ft}(88.47 \mathrm{~m}) \mathrm{mal} \\
\text { Sp. conductance: } 30 \mu \mathrm{s} / \mathrm{cm} \\
\text { No water was evacuated bofore sampling. }\end{array}$} & \multicolumn{3}{|l|}{$\begin{array}{l}\text { Time: 13:15 } \\
\text { pH: } 5.8\end{array}$} \\
\hline \multicolumn{6}{|c|}{ LABORATORY ANALYSES } \\
\hline$\underline{E}$ & Analyte & Remult & Mod & Unit & $\underline{L ي}$ \\
\hline $\begin{array}{l}0 \\
0 \\
0\end{array}$ & $\begin{array}{l}\text { Groess alpha } \\
\text { Nonvolatile beta } \\
\text { Tritum }\end{array}$ & $\begin{array}{r}<2.0 \mathrm{E}-0 \\
3.8 \mathrm{E} \cdot 0 \\
1.1 \mathrm{E}-0\end{array}$ & $\begin{array}{l}1.6 E-09 \\
3.0 E-07\end{array}$ & $\begin{array}{l}\mathrm{MClmL} \\
\mathrm{MCl} / \mathrm{mL} \\
\mathrm{MCl} / \mathrm{mL}\end{array}$ & $\begin{array}{l}\text { GE } \\
\text { GE } \\
\text { GE }\end{array}$ \\
\hline
\end{tabular}

WELL RSD 10

MEASUREMENTS CONDUCTED IN THE FIELD

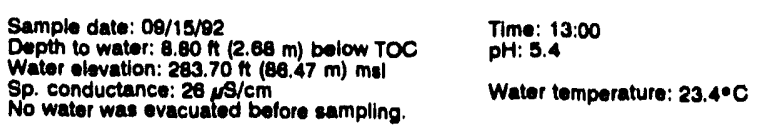

LABORATOAY ANALYSES

\begin{tabular}{|c|c|c|}
\hline F Analyte & Result & Unit \\
\hline $\begin{array}{ll}0 & \text { Groes alpha } \\
1 & \text { Nonvolatile beta } \\
0 & \text { Tritlum }\end{array}$ & $\begin{array}{l}6.7 E-09 \pm 2.5 E-09 \\
3.4 E-08 \pm 3.3 E-09 \\
1.3 E-08 \pm 5.0 E-07\end{array}$ & 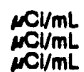 \\
\hline
\end{tabular}

WELL RSD 11

MEASUREMENTS CONDUCTED IN THE FIELD

\begin{tabular}{|c|c|}
\hline $\begin{array}{l}\text { Sample date: } 09 / 15 / 82 \\
\text { Depth to water: } 8.80 \mathrm{H}(2.68 \mathrm{~m}) \text { below TOC } \\
\text { Water elovation: } 283.50 \mathrm{ft}(86.41 \mathrm{~m}) \mathrm{ms}\end{array}$ & $\begin{array}{l}\text { Time: } 12: 45 \\
\text { pH: } 5.8\end{array}$ \\
\hline $\begin{array}{l}\text { Sp. conductance: } 53 \mu \mathrm{s} / \mathrm{cm} \\
\text { No water was evacuated before sampling. }\end{array}$ & rature: $23.6^{\circ} \mathrm{C}$ \\
\hline
\end{tabular}

LABORATORY ANALYSES

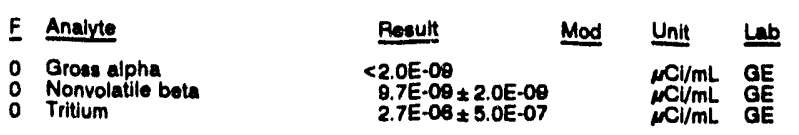


WELL RSE 1A

MEASUAEMENTS CONOUCTED IN THE FIELD

Sample date: 00/17/ce

Wopth to wator: $10.40 \mathrm{n}(3.17 \mathrm{~m})$ bolow TOC

8p. conductance: $40 \mathrm{~s} / \mathrm{cm}$

No water was evecuated bofore sampling

LABORATOFY ANLLYSES

E Answa

: Epecinc conductence

o Apectic

o Barium

2 Cadmium

Chloride

Chromium

Fluorids

Iron

Lead

Mangenee

Mereuny

Nitrata-nitutio as nitrogen

Potagelum

silver

Sodium

Sullate

Total diseolved solid.

Total organic carton

Total phosphates (as P)

Znc

Antimony-125

Cenum-144

Coslum-137

Coball.57

Europium-152

Europlum.154

Groes alpha

Manganees-s4

Ponvoletilo bet

Plutonium-230/240

Potacelum-40

Promethium-144

Promethium-148

Sodium.22

Total alpha-emiting radium

Yritum

Yturium-80

WELL RSE 18

MEASUAEMENTS CONDUCTED IN THE FIELD

Sample dato: 00/17/02

Dopth to water: $0.80 \mathrm{H}(3.02 \mathrm{~m})$ below TOC

Water elevation: $203.80 \mathrm{~h}(00.55 \mathrm{~m}) \mathrm{mal}$

Wp. conductance. $26 \mathrm{~s} / \mathrm{cm}$

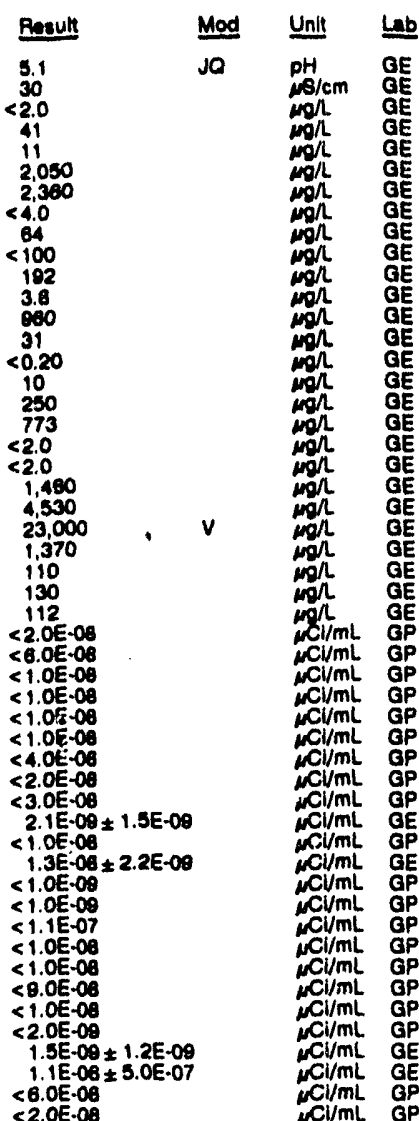

LABORATOAY ANALYSES
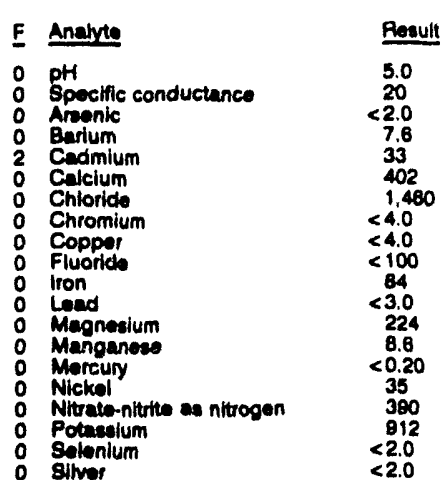

Time: 10:50

Water temperature: $28.0^{\circ} \mathrm{C}$

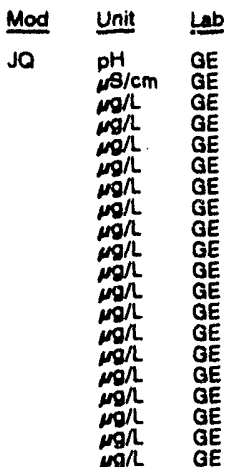

WELL RSE $1 B$ collected on 09/17/82, laboratory analyees (cont)

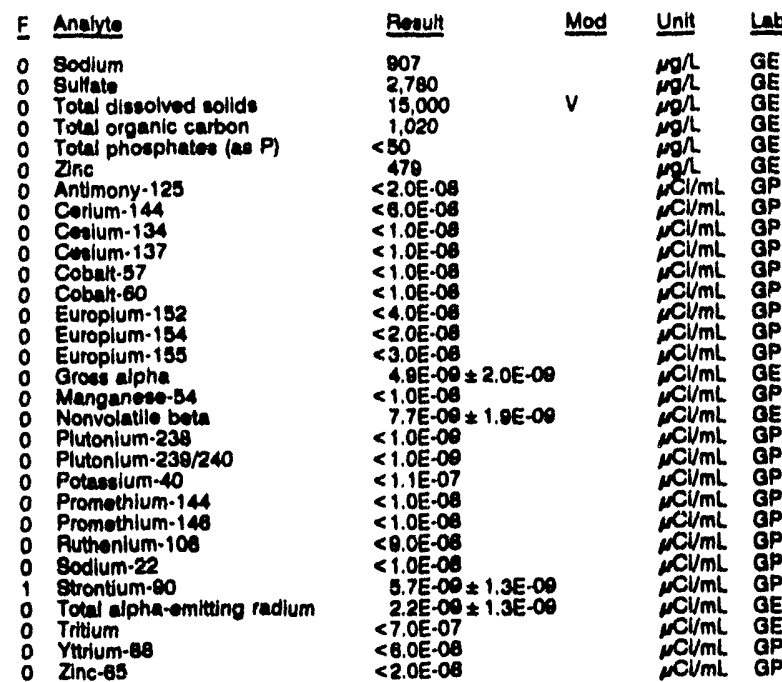

WELL RSE 1C

MEASUREMENTS CONDUCTED IN THE FIELD

Sample date: $09 / 17 / 92$
Dopth to water: $9.80 \mathrm{H}(2.09 \mathrm{~m})$ below TOC
Wator olovatlon: $203.60 \mathrm{~h}(89.55 \mathrm{~m}) \mathrm{msi}$

No water was evacualsd botore sampling.

Time: 11:10

$\mathrm{pH}: 5.2$

Water temperature: $28.1^{\circ} \mathrm{C}$

LABORATOAY ANALYSES

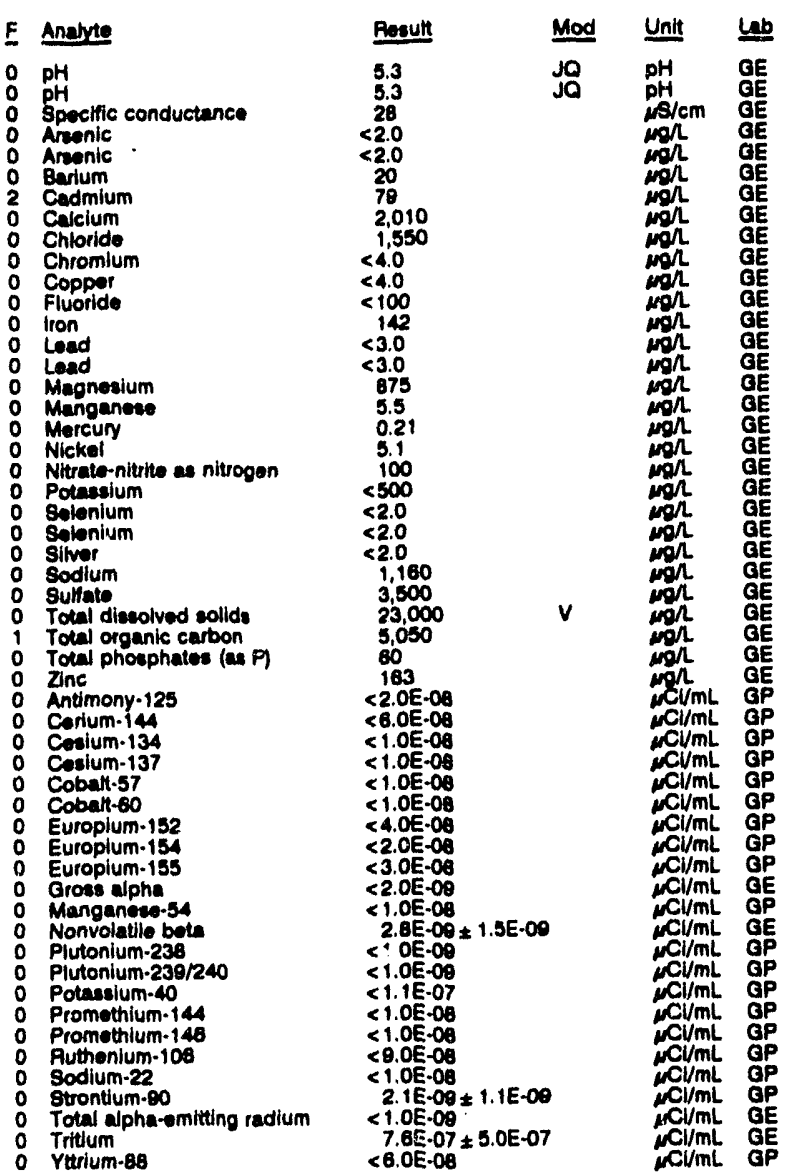


WELL RSE 4C

MEASUREMENTS CONDUCTED IN THE FIELD

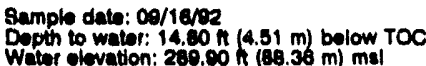

8p. conductance: 37 i $/ \mathrm{cm}$

Sp. conductance: 37 js/cm

LABOATOAY ANALYSES

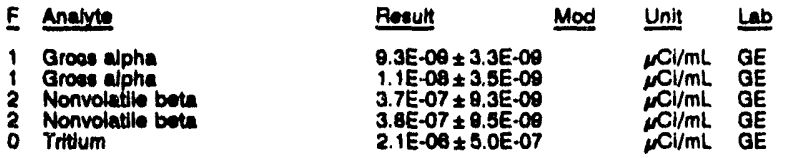

\section{WELL RSE 5}

MEASUREMENTS CONDUCTED IN THE FIELD

Sample data: co/16/92

Timo: 0

WELL RSE 6

MEASUREMENTS CONDUCTED IN THE FIELD

Sample date: 0e/16/e?

Time: 0

The well was dry

\section{WELL RSE 7}

MEASUREMENTS CONDUCTED IN THE FIELL

\section{Sample date: 00/17/92} Depth to watior: $18.50 \mathrm{n}(5.64 \mathrm{~m})$ balow TOC Wator lovation: $284.50 \mathrm{hl}$ (86.7 No water was evecuated before sampling

LABORATOAY ANALYSES

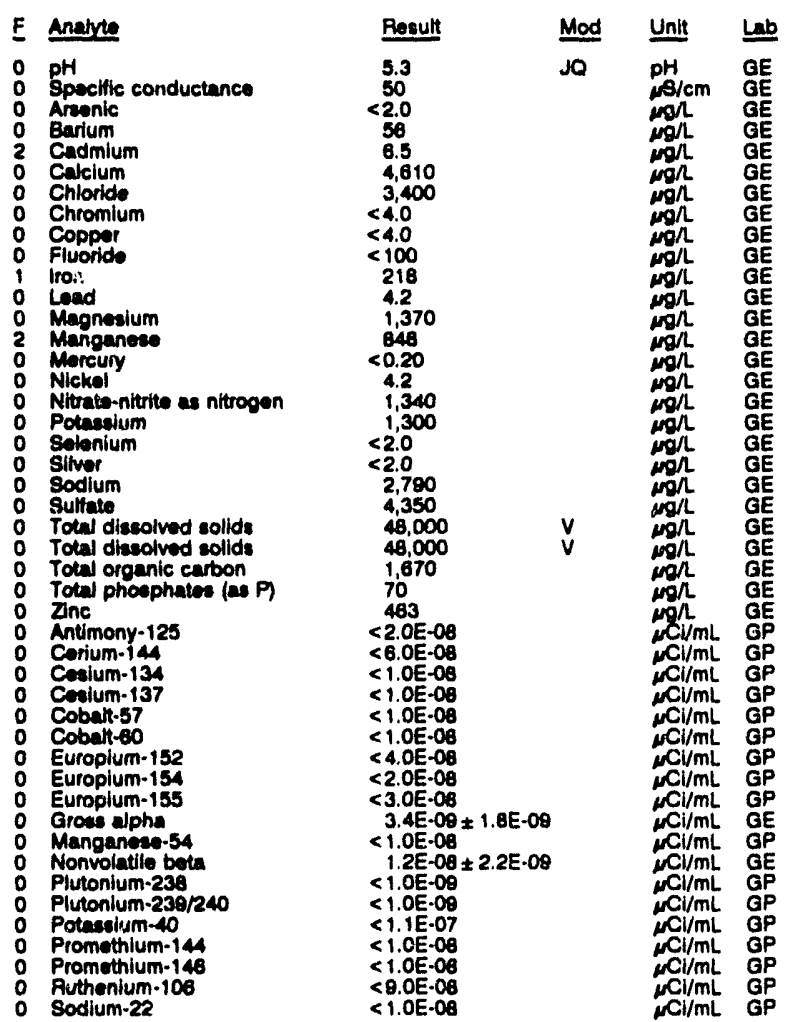

WELL RSE 7 collected on 00/17/92, laboratory analyees (cont.)

\begin{tabular}{|c|c|c|c|}
\hline Anelyte & Rerutit & Mod & Unit \\
\hline $\begin{array}{ll}0 & \text { Btrontlum-80 } \\
0 & \text { Total alpha-emiting radium } \\
0 & \text { Trttlum } \\
0 & \text { Yttrium-88 } \\
0 & \text { Zinc-65 }\end{array}$ & $\begin{array}{l}<2.0 E-08 \\
<1.0 \mathrm{E}-09 \\
1.3 \mathrm{JE} \cdot 08 \times 5.0 \mathrm{E} \cdot 07 \\
<6.0 \mathrm{E} \cdot 08 \\
<2.0 \mathrm{E} \cdot 08\end{array}$ & & 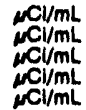 \\
\hline
\end{tabular}

\section{WELL RSE 8}

MEASUREMENTS CONOUCTED IN THE FIELD

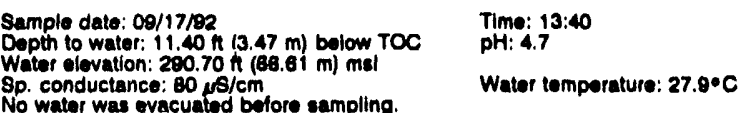

\section{LABOPATORY ANALYSES}

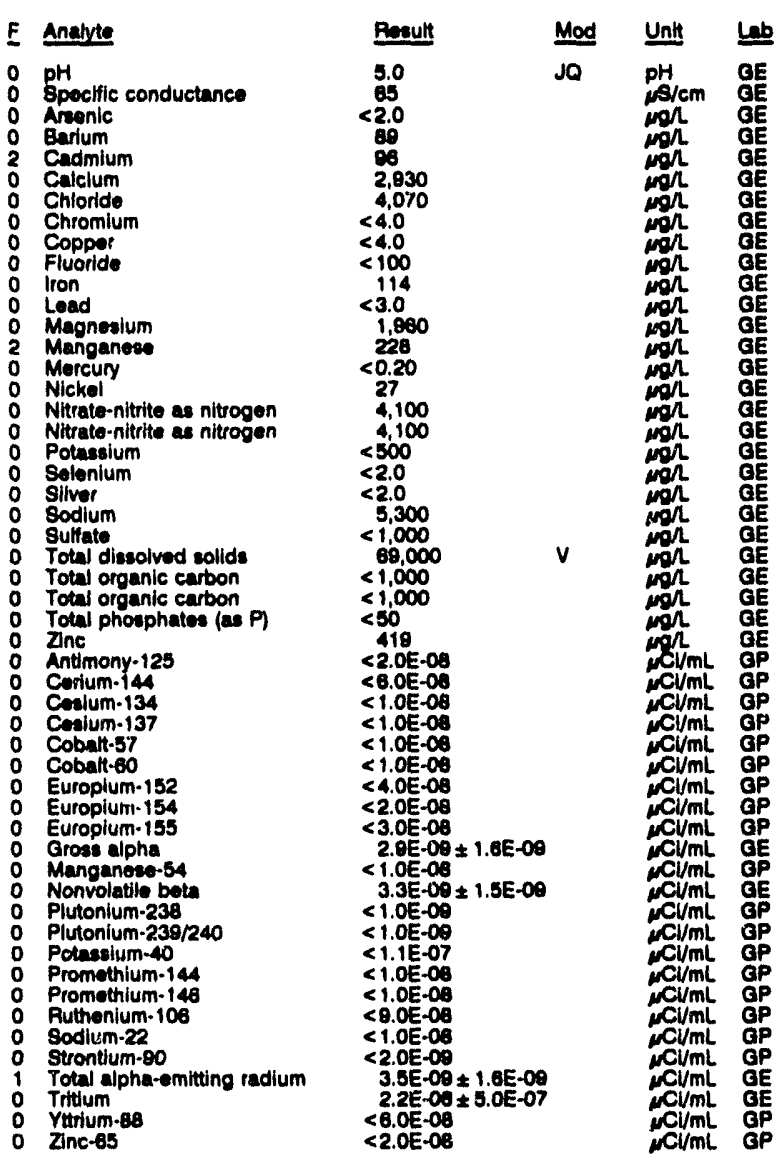

WELL RSE 9

MEASUREMENTS CONDUCTED IN THE FIELD

Sample date: $09 / 17 / 92$
Depth to water: $23.80 \mathrm{n}$
(7.25 m) bolow rOC

Water elevation: $284.00 \mathrm{~h}(88.56 \mathrm{~m}) \mathrm{ms}$

No water was evacuated before sampling

PH: 4.7

Water tomperature: $27.0^{\circ} \mathrm{C}$

LABOPATORY ANALYSES

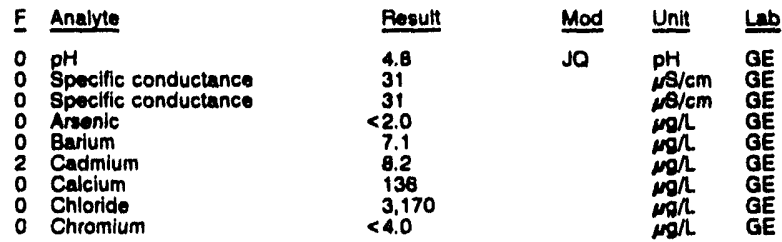


ANALYTICAL RESULTS

WELL RSE 8 collectad on 00/17/82, laboratory analyses (cont)

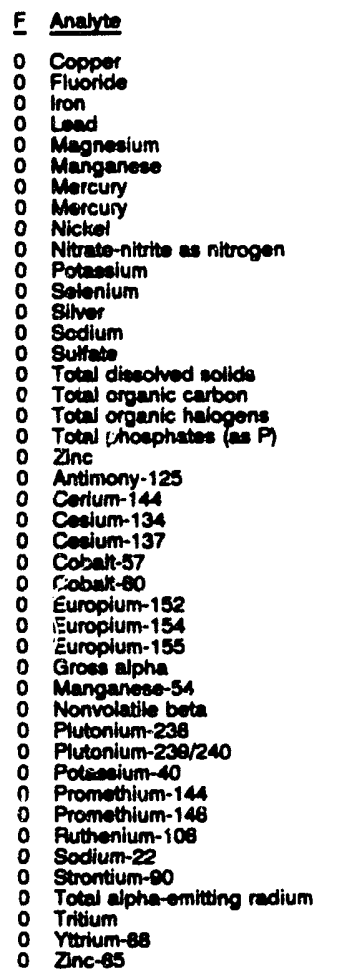

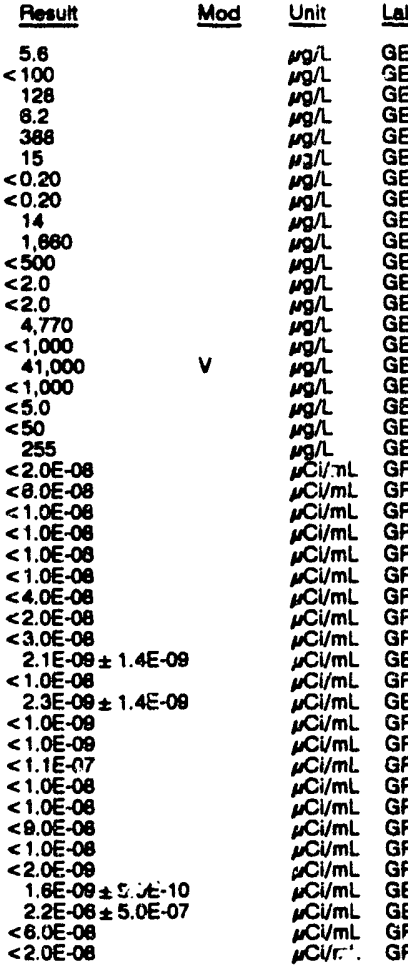

WELL RSE 10

MEASUREMENTS CONDUCTED IN THE FIELL

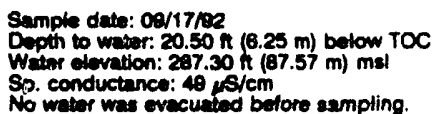

Time: $13: 10$

Water temperature: $26.3^{\circ} \mathrm{C}$ LABORATOFY ANALYSES

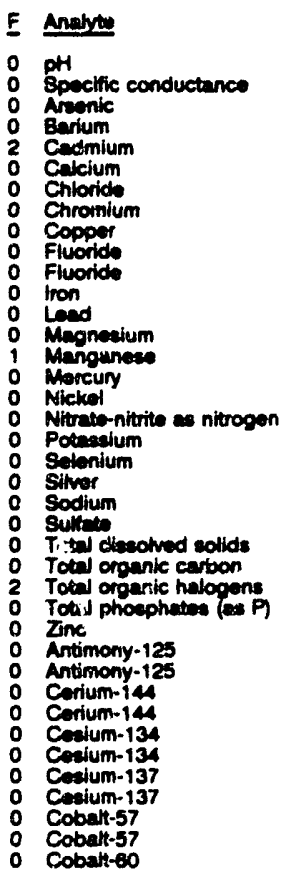

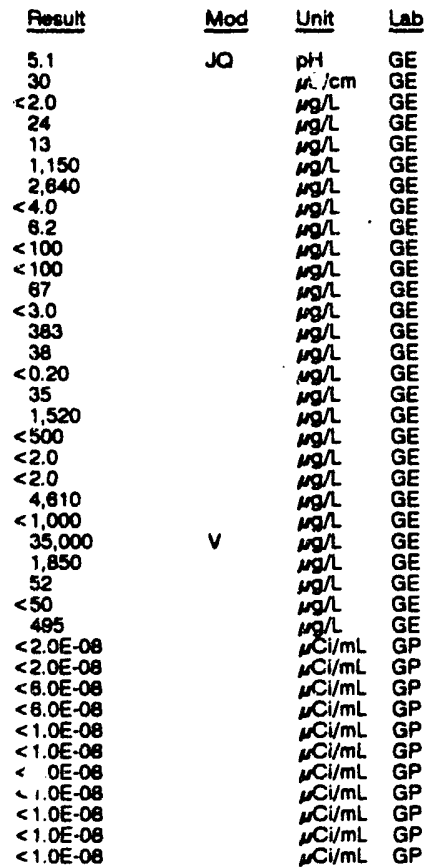

WEU RSE 10 collected on 09/17/92, laboratory analyees (cont)

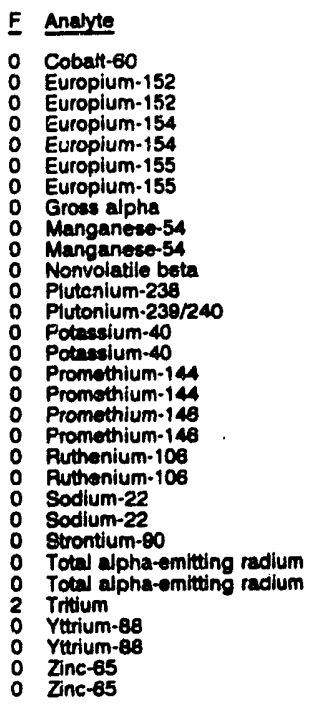

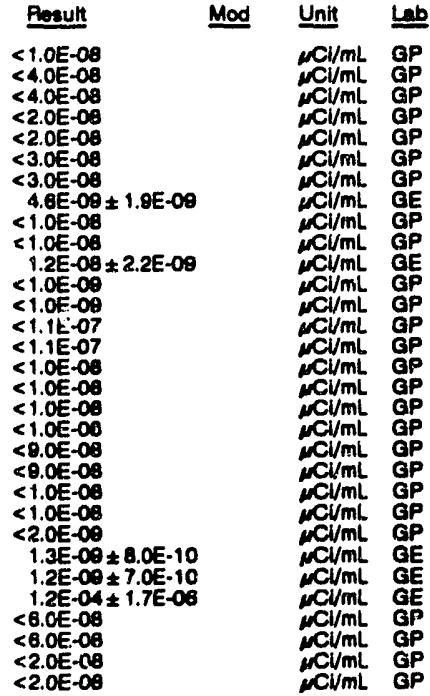

WELL RSE 11

MEASUREMENTS CONDUCTED IN THE FIELD

\begin{tabular}{|c|c|}
\hline Dopple date: $09 / 16 / 92$ & $\begin{array}{l}\operatorname{Time:}_{\text {pH: }} \text { 14:1 } 10 \\
\text { pH }\end{array}$ \\
\hline $\begin{array}{l}\text { Water elevation: } 289.20 \mathrm{ft}(88.15 \mathrm{~m}) \mathrm{msl} \\
\text { Sp. conductance: } 57 \mathrm{fs} / \mathrm{cm} \\
\text { No water was evecuated bolore sampling. }\end{array}$ & Water tompe \\
\hline
\end{tabular}

LABORATORY ANALYSES

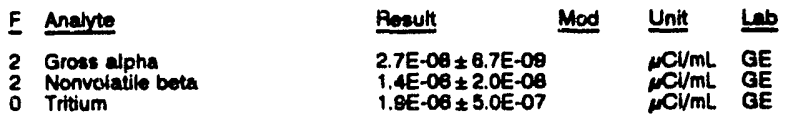

WELL RSE 12

MEASUREMENTS CONDUCTED IN THE FIELD Sample date: 08/18/82 Time: 0

The woll was dry.

WELL RSE 13

MEASUREMENTS CONDUCTEO IN THE FIELD

$\begin{array}{ll}\text { Sample date: } 09 / 16 / 92 & \text { Time: } 10: 40 \\ \text { Depth to water: } 10.20 \mathrm{~h}(3.11 \mathrm{~m}) \text { below TOC } & \text { pH: } 6.2 \\ \text { Watter olvevation: } 291.00 \mathrm{~h}(\mathrm{Bg} .70 \mathrm{~m}) \mathrm{mal} & \text { Weter tomperature: } 24.5 \cdot \mathrm{C} \\ \text { Sp. conductance: } 34 \mu \mathrm{cm} & \end{array}$

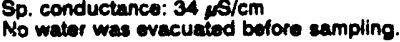

LABORATOAY ANALYSES

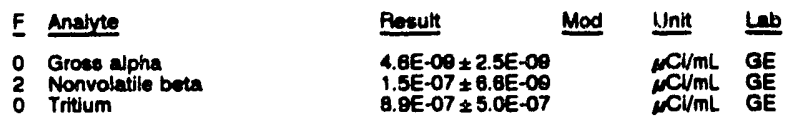


WELL RSE 18

MEASUREMENTS CONDUCTED IN THE FIELD

\begin{tabular}{|c|c|c|c|c|c|}
\hline \multicolumn{3}{|c|}{$\begin{array}{l}\text { Sample date: } 09 / 18 / 92 \\
\text { Depth to water: } 23.80 \text { it }(7.18 \mathrm{~m}) \text { bolow TOC } \\
\text { Waler olevation: } 283.50 \mathrm{~h}(86.41 \mathrm{~m}) \mathrm{mal} \\
\text { Sp. conductance. } 86 \mathrm{ss} / \mathrm{cm} \\
\text { No water was evacuated before sampling. }\end{array}$} & \multicolumn{2}{|c|}{$\begin{array}{l}\text { Time: } 14: 20 \\
\text { pH: } 5.4\end{array}$} & $3^{\circ} \mathrm{C}$ \\
\hline \multicolumn{6}{|c|}{ LABORATORY ANALYSES } \\
\hline & Aneryte & Result & Mod & Unit & Lab \\
\hline & $\begin{array}{l}\text { Groese alpha } \\
\text { Nonvolatile bota } \\
\text { Tritium } \\
\text { Trittum }\end{array}$ & \multicolumn{2}{|c|}{$\begin{aligned} & 7.1 E-09 \pm 2.3 E-09 \\
& 3.7 E-09 \pm 1.6 E-09 \\
&<7.0 E-07 \\
&<7.0 E-07\end{aligned}$} & $\begin{array}{c}\mathrm{Ci} / \mathrm{mL} \\
\mathrm{Ci} / \mathrm{mL} \\
\mathrm{Ci} / \mathrm{mL}\end{array}$ & $\begin{array}{l}\text { GE } \\
\text { GE } \\
\text { GE } \\
\text { GE }\end{array}$ \\
\hline
\end{tabular}

\section{WELL RSE 19}

MEASUREMENTS CONDUCTED IN THE FIELD

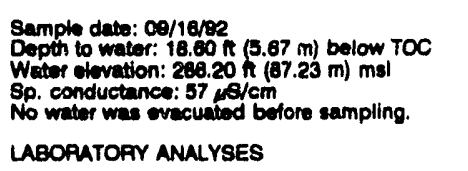

Time: 14:15

Water temperature: $21.8^{\circ} \mathrm{C}$

LABOPATOPY ANALYSES

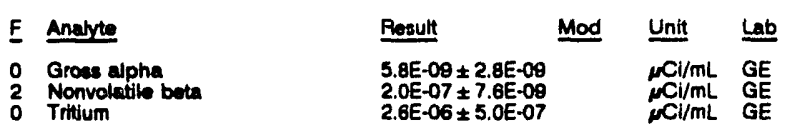

\section{WELL RSE 24}

MEASUREMENTS CONOUCTED IN THE FIELL

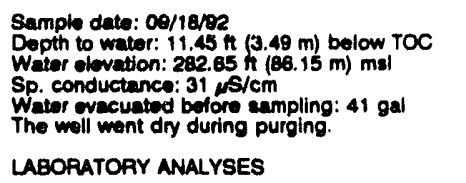

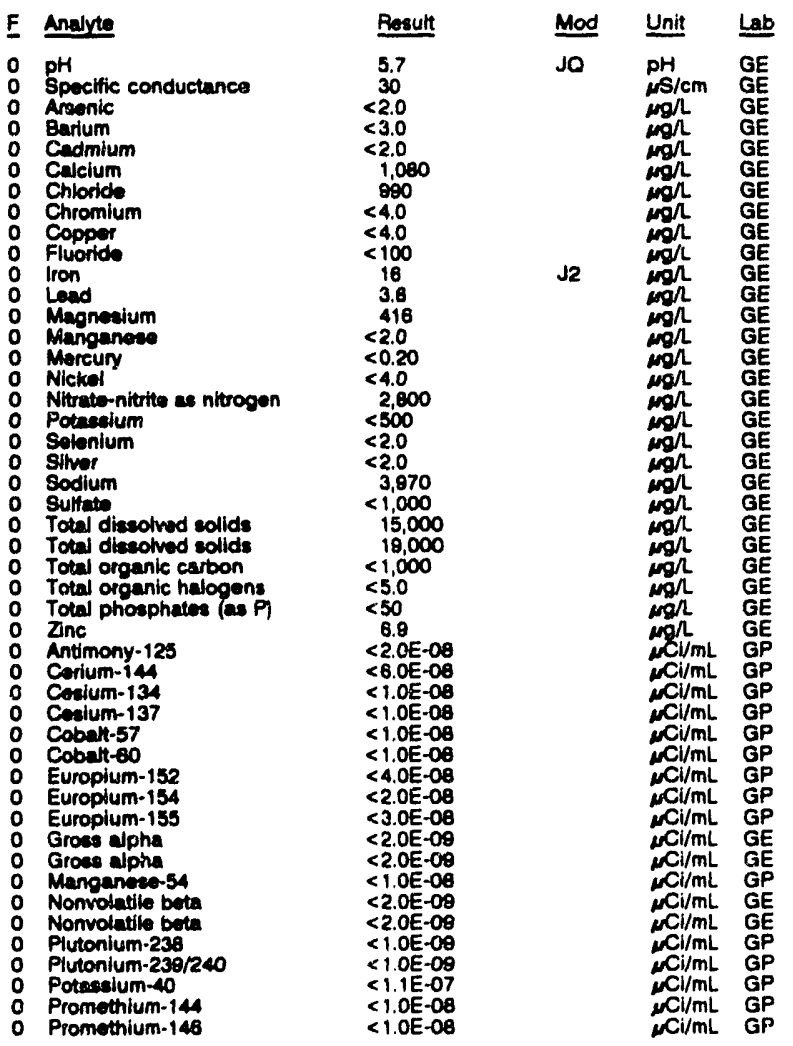

Time: 14:35

Alkalinity: $1 \mathrm{mg} \Omega$ Water temperature: $21.8^{\circ} \mathrm{C}$

Waler elovelion: $282.65 \mathrm{H}$ (89.
$<1.0 E-08$
WELL RSE 24 collected on 00/18/92, laboratory analyeses (cont)

\begin{tabular}{|c|c|c|}
\hline Analyte & Result & Unit \\
\hline $\begin{array}{ll}0 & \text { Ruthenium-106 } \\
0 & \text { Sodium-22 } \\
0 & \text { Strontium- } 90 \\
0 & \text { Total alpha-emitting radium } \\
0 & \text { Tritlum } \\
0 & \text { Tritium } \\
0 & \text { Yttrium-88 } \\
0 & \text { Zinc-65 }\end{array}$ & $\begin{array}{l}<8.0 E-08 \\
<1.0 E-08 \\
<2.0 E-09 \\
<1.0 E-08 \\
2.0 E-08 \pm 4.0 E-07 \\
2.5 E-08 \pm 5.0 E-07 \\
<6.0 E-08 \\
<2.0 E-08\end{array}$ & 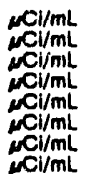 \\
\hline
\end{tabular}

\section{WELL RSE 25}

MEASUREMENTS CONDUCTED IN THE FIELD

\begin{tabular}{|c|c|}
\hline $\begin{array}{l}\text { Sample dato: } 09 / 18 / 92 \\
\text { Dopth to wator: } 18.83 \mathrm{ft}(5.13 \mathrm{~m}) \text { below TOC } \\
\text { Water elevation: } 277.07 \mathrm{ft}(84.45 \mathrm{~m}) \mathrm{mal} \\
\text { Sp. conductance: } 100 \mu \mathrm{s} / \mathrm{cm} \\
\text { Water evacuated bofore sampling: } 27 \mathrm{gal}\end{array}$ & $\begin{array}{l}\text { Time: } 13: 30 \\
\text { pti: } 5.4: 40 \\
\text { Alkalinity: } 18 \mathrm{mgh} \\
\text { Water temporature: } 20.8 \cdot \mathrm{C}\end{array}$ \\
\hline
\end{tabular}
Sp. conductance: $100 \mu \mathrm{s} / \mathrm{cm}$ Water evacuated bofore sampling: $27 \mathrm{gal}$ The woll went dry during purging.

LABORATORY ANALYSES

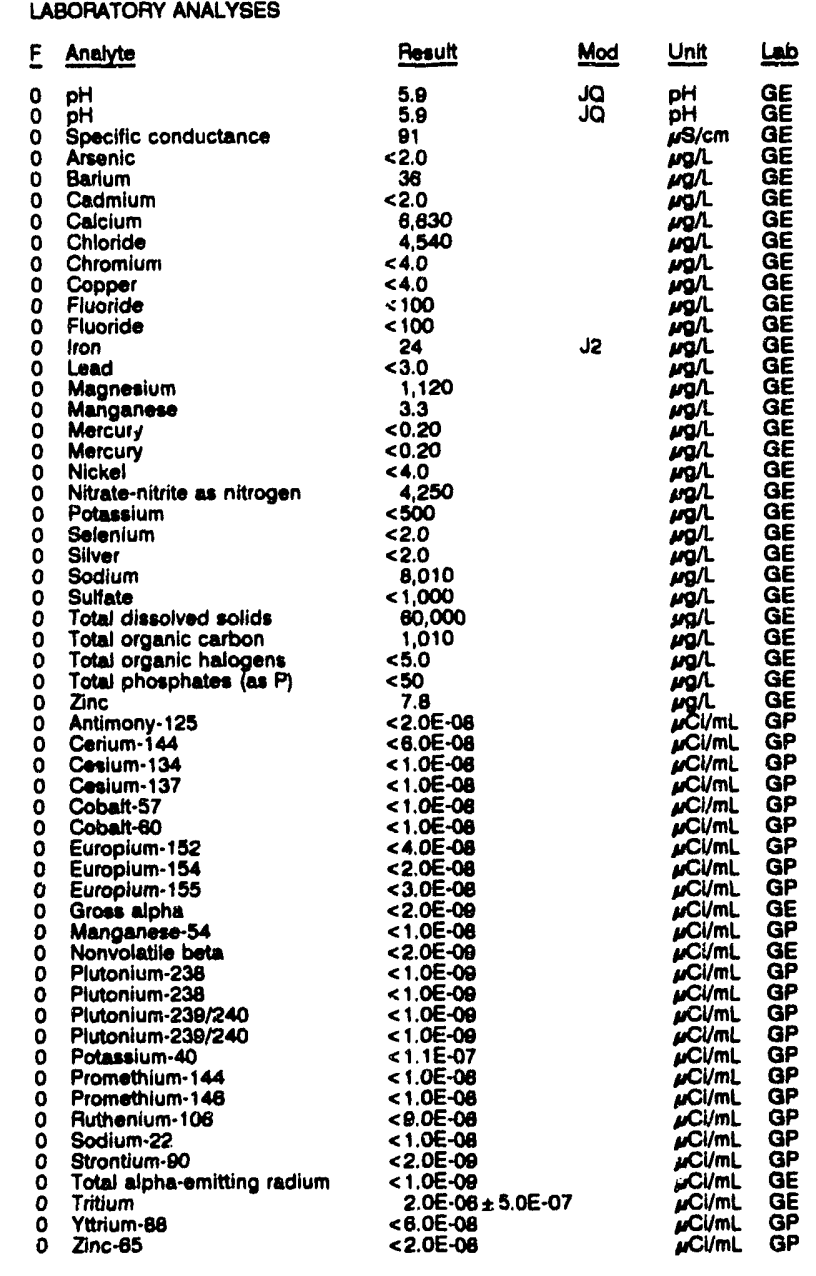


ANALYTICAL RESULTS

WELL RSF 1

MEASUREMENTS CONDUCTED IN THE FIELD

Sample date: $09 / 15 / 92$
Dopth to wator: $22.72 \mathrm{n}(0.93 \mathrm{~m})$ below TOC
Wator olevation: $280.38 \mathrm{kt}(85.46 \mathrm{~m}) \mathrm{mol}$
Sp. conductance: $81 \mu \mathrm{sm} / \mathrm{cm}$

Water evacuated belore sampling: $135 \mathrm{gal}$

LABORATORY ANALYSES

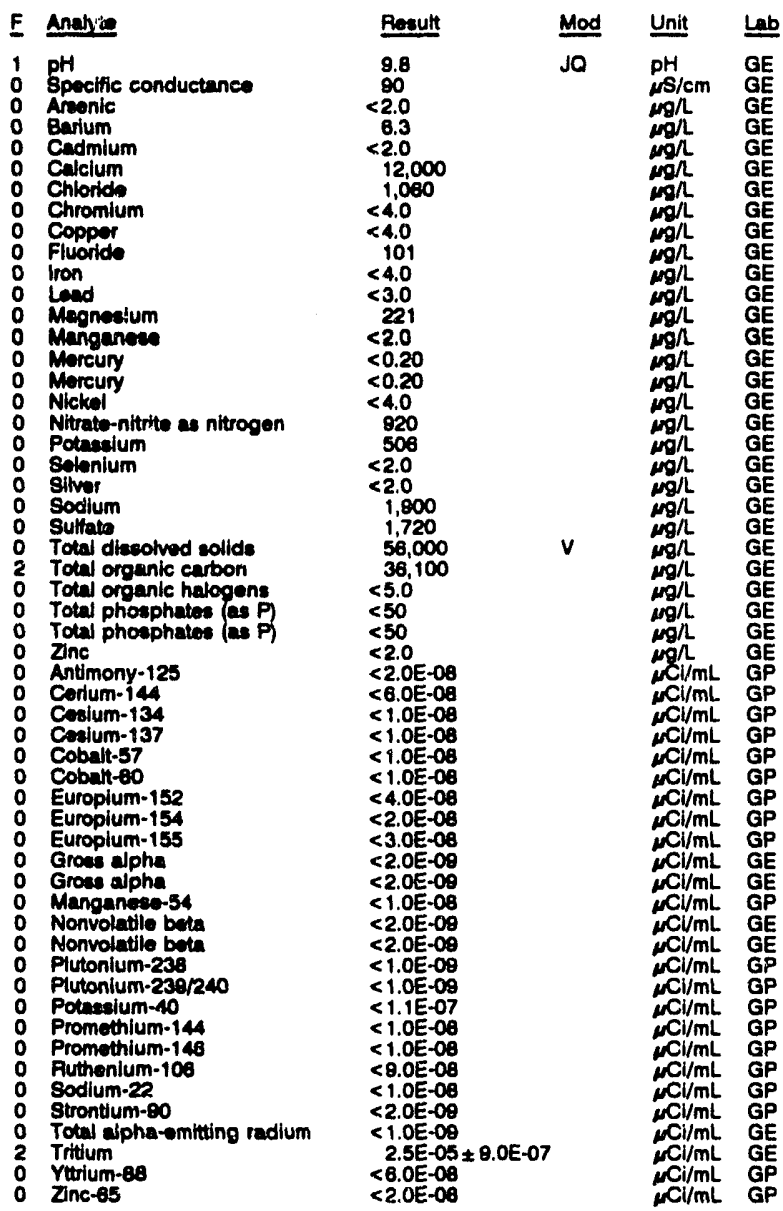

\section{WELL RSF 2}

MEASUREMENTS CONDUCTED IN THE FIELD

\section{Sample dats: $09 / 15 / 8$}

Depth to mater: $21.43 \mathrm{~s}(\mathrm{~B} .53 \mathrm{~m})$ bolow TOC

Water olevation: 281.37 \& (85

Sp. Conductance: $45 \mu \mathrm{s} / \mathrm{cm}$. 148 gal

LABORATORY ANALYSES

\begin{tabular}{|c|c|c|c|}
\hline Analyte & Rosult & Mod & Unit \\
\hline $\begin{array}{l}\text { pH } \\
\text { Specific conductunce } \\
\text { Areenic } \\
\text { Bartum } \\
\text { Cadmium } \\
\text { Caleclum } \\
\text { Chioride } \\
\text { Chromium } \\
\text { Coppor } \\
\text { Fluoride } \\
\text { lion } \\
\text { Lead } \\
\text { Magnealum } \\
\text { Manganese } \\
\text { Mercury } \\
\text { Nickel }\end{array}$ & $\begin{aligned} 5.5 \\
40 \\
<2.0 \\
5.5 \\
<2.0 \\
2.040 \\
1,740 \\
<4.0 \\
<4.0 \\
<100 \\
7.4 \\
<3.0 \\
734 \\
3.5 \\
<0.20 \\
<4.0\end{aligned}$ & JO & 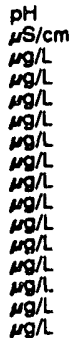 \\
\hline
\end{tabular}

WELL RSF 2 collected on 08/15/92, laboratory analyses (cont.)

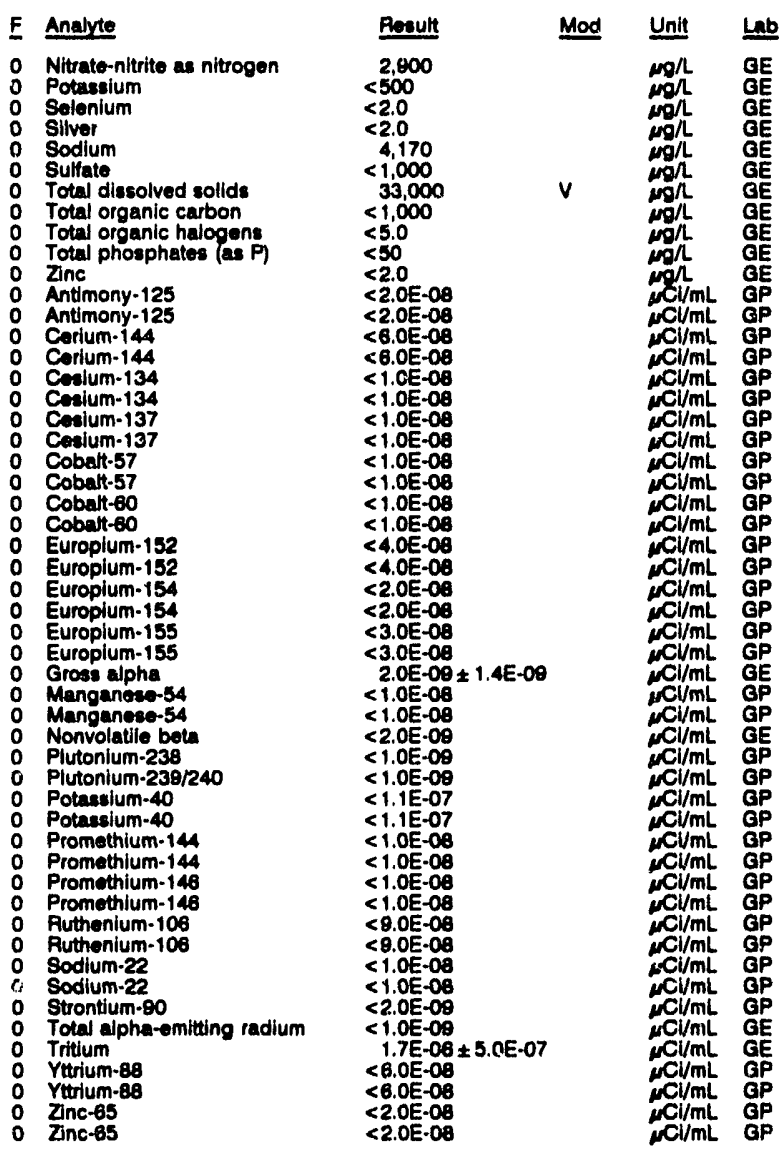

WELL RSF 3

MEASUAEMENTS CONDUCTED IN THE FIELD

Sample date: 0 :

Depth to water: $24.22 \mathrm{ft}(7.38 \mathrm{~m})$ below TOC

Water levation: $282.88 \mathrm{~h}(86.22 \mathrm{~m}) \mathrm{ms}$

Water evacuated before sampling: $139 \mathrm{gal}$

LABORATORY ANALYSES

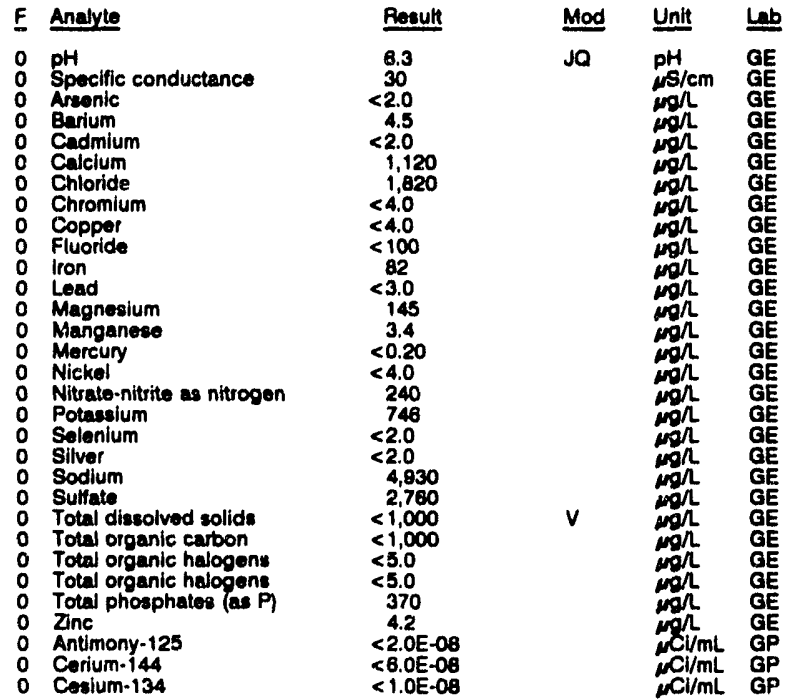


WELL RSF 3 collectod on 09/15/92, laboratory analyses (cont.)

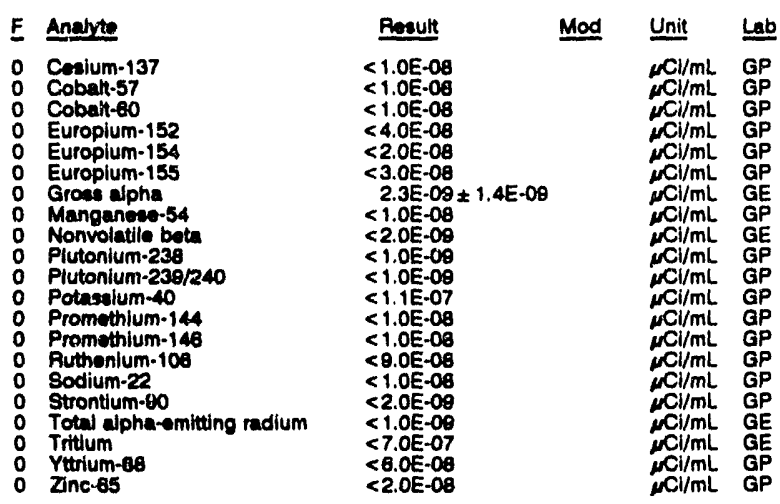

\section{WELL RWM 1}

MEASUREMENTS CONOUCTED IN THE FIELD

\begin{tabular}{|c|c|c|}
\hline \multicolumn{3}{|c|}{$\begin{array}{l}\text { Sample date: } 07 / 13 / 92 \\
\text { Depth to water: Not available } \\
\text { Watet elovation: Not avallable } \\
\text { Sp. conductenco: } 114 \text { p } 8 / \mathrm{cm} \\
\text { The well was continuousty pumping. }\end{array}$} \\
\hline \multicolumn{3}{|c|}{ LABORATOPY ANALYSES } \\
\hline$\underline{F}$ & Analyte & Result \\
\hline & $\begin{array}{l}\text { Carbon tetrechloride } \\
\text { Chloroform } \\
\text { Tetrachloroethylene } \\
1,1,1-\text { Trichloroethane } \\
\text { Trichloroethylene }\end{array}$ & $\begin{array}{r}<1,500 \\
<1,500 \\
23,400 \\
<1,500 \\
48,600\end{array}$ \\
\hline
\end{tabular}

\section{WELL RWM 1}

MEASUREMENTS CONDUCTED IN THE FIELD

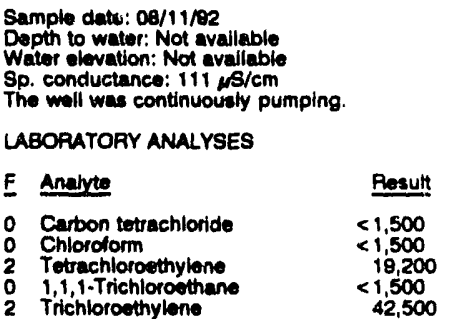

WELL RWM 1

MEASUREMENTS CONDUCTED IN THE FIELD

Sample dede: 09/12/82

Wepth to water: Not available

Sp. conductance: $108 \mathrm{~s} / \mathrm{cm}$

The wall was continuously pumping.

LABORATOFY ANALYSES

\begin{tabular}{|c|c|c|c|c|}
\hline$F$ & Analyte & Result & Mod & Unit \\
\hline $\begin{array}{l}0 \\
0 \\
2\end{array}$ & $\begin{array}{l}\text { Carton totrachloride } \\
\text { Chloroform } \\
\text { Tetrachloroethylene } \\
\text { 1,1,1-Trichloroethane } \\
\text { Trichloroethylene }\end{array}$ & $\begin{array}{r}<1,000 \\
<1,000 \\
18,200 \\
<1,000 \\
39,900\end{array}$ & & $\begin{array}{c}m g / L \\
\mu g / L \\
\mu g / L \\
\mu g / L \\
\mu g / L\end{array}$ \\
\hline
\end{tabular}

Time: $9: 25$

Alkalinity: $0 \mathrm{mo} / \mathrm{L}$

Water temperature: $20.6^{\circ} \mathrm{C}$

Mod

$\begin{array}{ll}\text { Unit } & \text { Lab } \\ \mathrm{mg/h} & \mathrm{GE} \\ \mathrm{mg} / \mathrm{L} & \mathrm{GE} \\ \mathrm{mg} / \mathrm{L} & \mathrm{GE} \\ \mathrm{mg} / \mathrm{LE} & \mathrm{GE}\end{array}$

Time: 16:00

PH: 4.5 : 0 moling:

Water tempesature: $21.6^{\circ} \mathrm{C}$

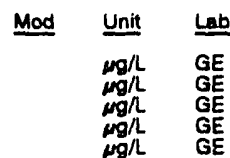

Time: 12:15

Alkalinity: $0 \mathrm{mg} / \mathrm{L}$

Water temperature: $22.2^{\circ} \mathrm{C}$

WELL RWM 2

MEASUREMENTS CONDUCTED IN THE FIELD

Sample date: 07/13/82

Depth to water: Not available

Water elevation: Not available

Sp. conductance: $62 \mu \mathrm{S} / \mathrm{cm}$

The well was continuously pumping.

LABORATORY ANALYSES

E Analyte

- Carbon tetrachloride

Chloroform

Tetrachloroethylene

1,1,1-Trichloroethane
Trichloroethylene

Resull

$<1,000$

43,800

$<1,000$

30,600

WELL RWM 2

MEASUREMENTS CONDUCTED IN THE FIELD

Sample date: 08/11/92

Depth to water: Not avallable

Water olevation: Not avallable

Sp. conductance: $62 \mu \mathrm{N} / \mathrm{cm}$
The well was continuously pumping.

LABORATORY ANALYSES

E Anaryte

- Carbon tetrachloride

Chlorotorm

Totrachloroethylone

2 Trichloroethylene

Reoult
$<1,000$
$<1,000$
12,800
$<1,000$
28,700

WELL RWM 2

MEASUREMENTS CONDUCTED IN THE FIELD

Sample date: 09/12/92

Depth to water: Not avaliable

Sp. conductence $50 \mathrm{~s} / \mathrm{cm}$

The well was continuously pumping

LABORATORY ANALYSES

E Analyte

- Carbon tetrechloride

Chioroform

1,1,1-Trichloroethe

2 Trichloroethylene

Peoult
$<1,000$
$<1,000$
12,300
$<1,000$
21,300

WELL RWM 3

MEASUAEMENTS CONOUCTED IN THE FIELD

Sample date: 07/13/82

water: 170.78 \# $(52.05 \mathrm{~m})$ below TOC

Water elevation: $206.24 \mathrm{t}(62.66 \mathrm{~m}) \mathrm{msl}$

mas continuously pumping.

LABORATOAY ANALYSES

$\begin{array}{lll}\text { E } & \text { Analyte } & \text { Result } \\ 0 & \text { Carbon tetrachloride } & <500 \\ 0 & \text { Chloroform } & <500 \\ 2 & 4,150 \\ 0 & 1,1,1 \text { - Trichloroethe } & <500 \\ 2 & \text { Trichloroethylene } & 16,800\end{array}$

WELL RWM 3

MEASUREMENTS CONDUCTED IN THE FIELD

Sample date: 08/11/92

Sample date: 08/11/92

Water elevation: $207.05 \mathrm{ft}$ (

The weil was continuously pumping.

LABORATORY ANALYSES

\begin{tabular}{|c|c|c|c|}
\hline Analyte & Result & Mod & Unit \\
\hline $\begin{array}{l}\text { Carbon tetrachloride } \\
\text { Chloroform } \\
\text { Totrachloroethylene } \\
1,1,1-\text { Trichioroethane } \\
\text { Trichloroethylene }\end{array}$ & $\begin{array}{r}<1,000 \\
<1,000 \\
3,200 \\
<1,000 \\
13,100\end{array}$ & & 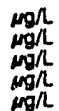 \\
\hline
\end{tabular}

Water tomperature: $220^{\circ} \mathrm{C}$
Time: 14:05

Alkalinity: $0 \mathrm{mg} / \mathrm{s}$

Water tomperture: $23.3^{\circ} \mathrm{C}$

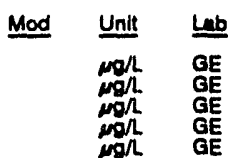

Time: 15:55

Alkalinity: $0 \mathrm{mg} /$

Water temperature: $22.1^{\circ} \mathrm{C}$

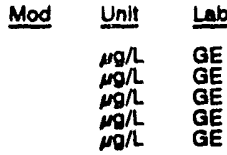

Time: 15:00

Alkalinity: $0 \mathrm{mal}$

Water tomporature: $22.8^{\circ} \mathrm{C}$

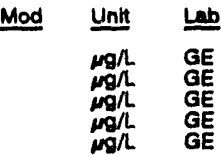

Alkalinity: $0 \mathrm{mg} / \mathrm{L}$

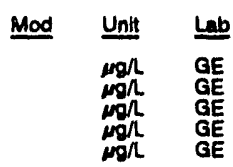

Time: 14:45

PH: $4.5: 45$

Water tompergh 0

E


WELL RWM 3

MEASUREMENTS CONDUCTED IN THE FIELD

Samplo dato: 08/12/82

Depth to water: $170.45 \mathrm{~h}(51.85 \mathrm{~m})$ below TOC

Water olovation: $200.55 \mathrm{~A}(62.86 \mathrm{~m}) \mathrm{ms} 1$

Sp. conductanco: $58 \mu \mathrm{s} / \mathrm{cm}$

The well was continuously pumping.

LABORATORY ANALYSES

E Anajute

- Carbon totrachloride

Chloroform

2 Totrachlorosthylone

1,1,1-Trichloroethan

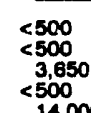

WELL RWM 4

MEASUREMENTS CONDUCTED IN THE FIELD

\section{Sample date: 07/13/22}

Depth to water: $157.85 \mathrm{~h}(48.05 \mathrm{~m})$ below TOC

Water olevation: $200.85 \mathrm{At}(63.68 \mathrm{~m}) \mathrm{msl}$

Sp. conductance: $25 \mu \mathrm{s} / \mathrm{cm}$

The woll was continuously pumping.

LABORATORY ANALYSES

E Analyte

- Carbon totrachlorido

0 Chlorotorm

2 Totrachloroethylene

$\begin{array}{ll}0 & 1,1,1-T \text { Trchloroethaino } \\ 2 & \text { Trichloroethylene }\end{array}$

Posult
$<200$
$<200$
1,040
$<200$
6,760

WELL RWM 4

MEASUREMENTS CONDUCTED IN THE FIELD

Sample date: 08/11/92

Depth to water: $157.45 \mathrm{H}(47.99 \mathrm{~m})$ bolow TOC Wator elevation: $209.05 \mathrm{ft}(63.72 \mathrm{~m}) \mathrm{msl}$

Sp. conductance: $23 \mathrm{~s} / \mathrm{cm}$

The weil was continuously pumping.

LABORATORY ANALYSES

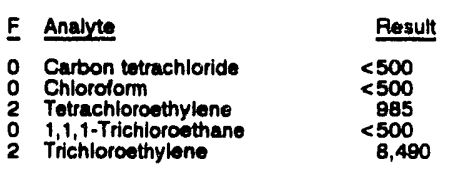

WELL RWM 4

MEASUREMENTS CONDUCTED IN THE FIELD

Sample date: 09/12/92

Depth to water: $157.85 \mathrm{ft}(48.11 \mathrm{~m})$ below TOC Wator elevation: $208.65 \mathrm{~h}(83.60 \mathrm{~m}) \mathrm{ms}$

The woll was continuously pumping.

LABOPATOOAY ANALYSES

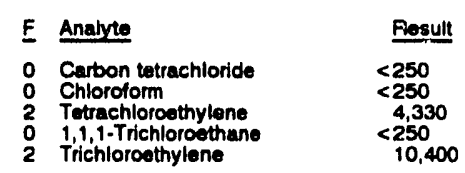

\section{WELL RWM 5}

MEASUAEMENTS CONDUCTED IN THE FIELD

Sample date: 07/13/92

Depth to water: $155.13 \mathrm{ft}(47.28 \mathrm{~m})$ below TOC

Water elevation: 211.77 it $(64.5$

Sh. conductance: $31 \mu \mathrm{s} / \mathrm{cm}$.

LABORATORY ANALYSES

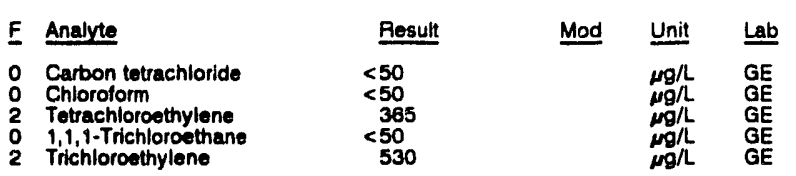

Time: 13:55

PH: 4.6

Alkalinity: $0 \mathrm{mg} / \mathrm{h}$

Water temperature: $22.6^{\circ} \mathrm{C}$

\begin{tabular}{|c|c|}
\hline Mod & Unit \\
\hline & $\begin{array}{c}\mu g / L \\
\mu g / L \\
\mu g / L \\
\mu g / L \\
\mu g / L\end{array}$ \\
\hline
\end{tabular}

Time: 11:05

$\mathrm{pH}: 4.8$

Water temperature: $21.1^{\circ} \mathrm{C}$

Mod $\begin{array}{ll}\text { Unit } & \text { Lab } \\ \substack{\mu g / L \\ \mu g / L \\ \mu g / L \\ \mu g / L \\ \mu g / L} & \text { GE } \\ & \text { GE } \\ & \text { GE }\end{array}$

Time: 16:10

pH: 4.9

Alkalinity: $0 \mathrm{mg}$

Water temperature: $22.8^{\circ} \mathrm{C}$

\begin{tabular}{|c|c|}
\hline Mod & Unit \\
\hline & 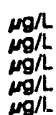 \\
\hline
\end{tabular}

Time: 12:25

pH: 4.9

Water temperature: $22.9^{\circ} \mathrm{C}$

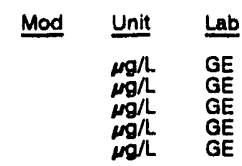

Time: 16:05

pH: 4.8

Water temperature: $22.2^{\circ} \mathrm{C}$

WELL RWM 5 collected on 07/13/92, taboratory analyser (cont.)

$E$ Analyte

- Total activity

Result Mod Unit Lab

$2.4 E-06 \pm 1.2 E-06 \quad \mathrm{NCl} / \mathrm{mL}$ EM

\section{WELL RWM 5}

MEASUREMENTS CONDUCTED IN THE FIELD

\begin{tabular}{|c|c|}
\hline $\begin{array}{l}\text { Sample date: } 08 / 11 / 92 \\
\text { Depth to water: } 155.23 \mathrm{H}(47.31 \mathrm{~m}) \text { below TOC } \\
\text { Wate elevation: } 211.67 \mathrm{H}(64.52 \mathrm{~m}) \mathrm{mel} \\
\text { Sp. conductance: } 30 \mu \mathrm{s} / \mathrm{cm}\end{array}$ & $\begin{array}{l}\text { Time: } 15: 05 \\
\text { pH: } 4.8 \\
\text { Alkalinity: } 0 \mathrm{mg} / \\
\text { Water tomperature: } 22.6^{\circ} \mathrm{C}\end{array}$ \\
\hline
\end{tabular}

LABORATORY ANALYSES

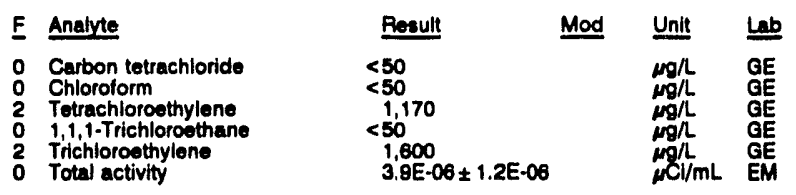

\section{WELL RWM 5}

MEASUAEMENTS CONDUCTED IN THE FIELD

\begin{tabular}{|c|c|}
\hline $\begin{array}{l}\text { Sample date: } 09 / 12 / 82 \\
\text { Depth to water: } 155.23 \mathrm{ft}(47.31 \mathrm{~m}) \text { below TOC } \\
\text { Water elevation: } 211.67 \mathrm{ft}(84.52 \mathrm{~m}) \mathrm{msl} \\
\text { Sp. conductance: } 27 \text { NS/cm } \\
\text { The well was continuously pumping. }\end{array}$ & $\begin{array}{l}\text { Time: } 14: 15 \\
\text { pH: } 4.8 \\
\text { Alkalinity: } 0 \mathrm{mg} / \mathrm{h} \\
\text { Water temperature: } 22.7 \circ \mathrm{C}\end{array}$ \\
\hline
\end{tabular}

The well was continuously pumping.

LABORATORY ANALYSES

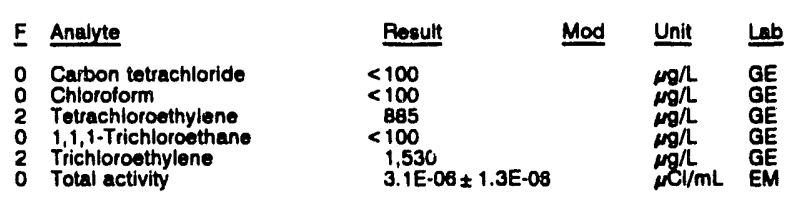

\section{WELL RWM 6}

MEASUREMENTS CONDUCTED IN THE FIELD

Sample date: $0713 / 92$

Depth to water: 178.82 H 154.54 m) below Water olevation: $170.18 \mathrm{Ht}(51.87 \mathrm{~m}) \mathrm{msl}$

Sp. conductance: $33 \mathrm{mS} / \mathrm{cm}$

The well was continuously pumping.

Alkalinity: $0 \mathrm{mg} / \mathrm{h}$

Water temperature: $21.5^{\circ} \mathrm{C}$

LABORATORY ANALYSES

\begin{tabular}{|c|c|c|c|c|}
\hline$\underline{E}$ & Analyte & Result & Mod & Unit \\
\hline $\begin{array}{l}0 \\
2 \\
0\end{array}$ & $\begin{array}{l}\text { Carbon tetrachloride } \\
\text { Chloroform } \\
\text { Tetrachloroethylene } \\
1,1,1-\text { Trichloroethane } \\
\text { Trichloroethylene }\end{array}$ & $\begin{array}{l}<200 \\
<200 \\
7,840 \\
<200 \\
8,040\end{array}$ & & 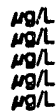 \\
\hline
\end{tabular}

\section{WELL RWM 6}

MEASUREMENTS CONDUCTED IN THE FIELD

Dopth to water: $173.48 \mathrm{ft}(52.88 \mathrm{~m})$ below TOC Water elevation: $175.62 \mathrm{f}(53.53 \mathrm{~m}) \mathrm{ms}$ )

Sp. conductance: 33 sicm

Sp. conductance: $33 \mu \mathrm{S} / \mathrm{cm}$
The well was continuously pumping.

LABORATORY ANALYSES

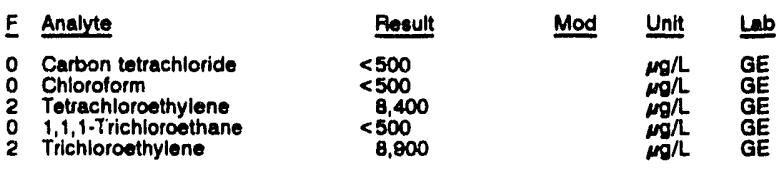




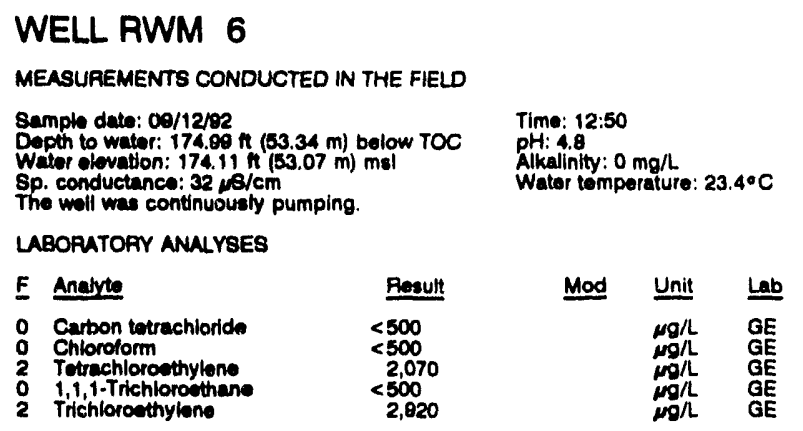

WELL RWM 7

MEASUREMENTS CONDUCTED IN THE FIELD

Samplo date: 07/13/92

Depth to water: $153.42 \mathrm{ft}(48.76 \mathrm{~m})$ below TOC

Weler elevation: 195.38 $\mathrm{f}(58.81 \mathrm{~m}) \mathrm{msl}$

sp. conductance: $82 \mathrm{us} / \mathrm{cm}$

The wall was continuously pumping.

LABORATORY ANALYSES

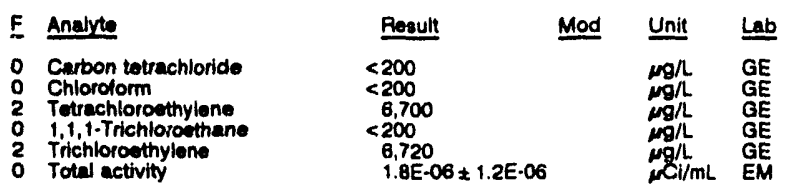

\section{WELL RWM 7}

MEASUAEMENTS CONDUCTED IN THE FIELD

Sample date: 08/11/02

(1)

Water elevation: $197.09 \mathrm{t}(80.07 \mathrm{~m}) \mathrm{ms}$

Sp. conductance: $81 \mathrm{~s} / \mathrm{cm}$

$$
\text { Alkalinity: } 0 \mathrm{mg} / \mathrm{L}
$$

Time: $15: 40$

Water temperature: $23.0^{\circ} \mathrm{C}$

LABOPATOFY ANALYSES

\begin{tabular}{|c|c|c|c|c|}
\hline E Anarte & Result & Mod & Unit & Lab \\
\hline $\begin{array}{ll}0 & \text { Carbon tetrachloride } \\
0 & \text { Chloroform } \\
2 & \text { Tetrachloroethylene } \\
0 & 1,1,1-\text { Trichloroothane } \\
2 & \text { Trichlorosthylene } \\
0 & \text { Total setivity }\end{array}$ & $\begin{array}{l}<200 \\
<200 \\
6,820 \\
<200 \\
7,220 \\
1.8 \mathrm{E}-06 \pm 1.2 \mathrm{E}-06\end{array}$ & $\begin{array}{l}J Q 6 \\
J 06 \\
J O 6 \\
J O 6 \\
J 06\end{array}$ & 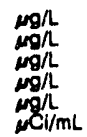 & $\begin{array}{l}\mathrm{GE} \\
\mathrm{GE} \\
\mathrm{GE} \\
\mathrm{GE} \\
\mathrm{GE} \\
\mathrm{EM}\end{array}$ \\
\hline
\end{tabular}

\section{WELL RWM 7}

MEASUREMENTS CONDUCTED IN THE FIELD

Sample dato: 09/1292

Depth to water: 153.42 n $(46.76 \mathrm{~m})$ below TOC Dopth to weer. 153.42 $n(46.78 \mathrm{~m})$ below

Sp. conductanco: 70 rs/cm

Time: 18:40

Alkalinity: $0 \mathrm{mg} / \mathrm{h}$

Alkalinity: $0 \mathrm{mg} / \mathrm{h}$ : $21.8^{\circ} \mathrm{C}$

the well was continuously pumping

LABORATORY ANALYSES

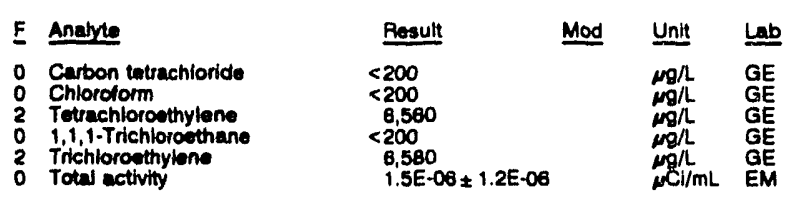

WELL AWM 8

MEASUAEMENTS CONDUCTED IN THE FIELLD

Sample date: 07/13/92

Dopth to water: $145.15 \mathrm{~h}(44.24 \mathrm{~m})$ below TOC Water elevation: $203.15 \mathrm{tt}(61.02 \mathrm{~m}) \mathrm{msl}$

The well was continuously pumping.

LABORATORY ANALYSES

E Analyte

- Carbon totrachloride

o Chloroform

2 Tetrachioroethylene

$1,1,1-$ Trichloroeth
Trichloroethylene

Ronult
$<20$
$<20$
482
$<20$
816

Time: 11:15

PH: 4.9 : $0 \mathrm{man}$

Alkalinity: $0 \mathrm{mgh}$ : $21.4^{\circ} \mathrm{C}$

WELL RWM 8

MEASUREMENTS CONDUCTED IN THE FIELD

Sample date: 08/11/e2

Depth to water: $145.78 \mathrm{~h}(44.43 \mathrm{~m})$ below TOC

Water elevation: $202.54 \mathrm{f}(81.73 \mathrm{~m}) \mathrm{mal}$

3p. conductance: $121 \mathrm{NS} / \mathrm{cm}$
The well was continuously pumping.

LABORATORY ANALYSES

\begin{tabular}{|c|c|c|}
\hline & Analyte & Resoutt \\
\hline & $\begin{array}{l}\text { Carbon tetrachloride } \\
\text { Chloroform } \\
\text { Tetrachloroethylene } \\
1,1,1-\text { Trichloroethane } \\
\text { Trichloroothylene }\end{array}$ & $\begin{array}{l}<25 \\
<25 \\
478 \\
<25 \\
810\end{array}$ \\
\hline
\end{tabular}

Time: 10:20

pH: 4.9 : $0 \mathrm{mg}$

Water tomperature: $21.7 \circ \mathrm{C}$

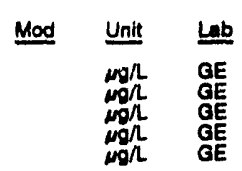

\section{WELL RWM 8}

MEASUREMENTS CONDUCTED IN THE FIELD

Sample date: 09/12/92

(19.00 Water elevation: $203.95 \mathrm{ft}(62.16 \mathrm{~m}) \mathrm{ms}$

the woll was continuously pumping.

LABORATORY ANALYSES

\begin{tabular}{|c|c|c|c|c|}
\hline $\mathbf{F}$ & Analyte & Fesult & Mod & Unit \\
\hline $\begin{array}{l}0 \\
0 \\
2\end{array}$ & $\begin{array}{l}\text { Carbon totrachloride } \\
\text { Chlorolorm } \\
\text { Tetrachloroethylene } \\
1,1,1 \text {-Trichloroethane } \\
\text { Trichloroethylene }\end{array}$ & $\begin{array}{l}<50 \\
<50 \\
602 \\
<50 \\
1,310\end{array}$ & & $\operatorname{mog}_{\operatorname{mon}}^{\operatorname{mon} 2}$ \\
\hline
\end{tabular}

\section{WELL RWM 9}

MEASUREMENTS CONDUCTED IN THE FIELD

Sample date: 07/13/92

Depth to water: $155.53 \mathrm{~h}(47.41 \mathrm{~m})$ below TOC Water olevation: $225.07 \mathrm{Ht}(80.60 \mathrm{~m}) \mathrm{msl}$

Sp. conductance: $48 \mu \mathrm{S} / \mathrm{cm}$.

LABORATORY ANALYSES

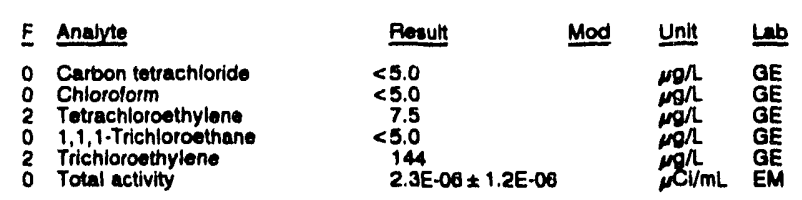

\section{WELL RWM 9}

MEASUREMENTS CONDUCTED IN THE FIELD

\begin{tabular}{|c|c|c|c|c|c|}
\hline \multicolumn{3}{|c|}{$\begin{array}{l}\text { Sample date: } 08 / 11 / 92 \\
\text { Depth to water: } 157.35 \mathrm{Ht}(47.06 \mathrm{~m}) \text { bolow TOC } \\
\text { Water elovation: } 223.25 \mathrm{~h}(88.05 \mathrm{~m}) \mathrm{mal} \\
\text { Sp. conductance: } 47 \mu \mathrm{s} / \mathrm{cm} \\
\text { The well was continuously pumping. }\end{array}$} & \multicolumn{3}{|c|}{$\begin{array}{l}\text { Time: } 15: 30 \\
\text { pH: } 5.0 \\
\text { Alkalinity: } 1 \mathrm{mg} / \mathrm{L} \\
\text { Water tomperature: } 22.6 \cdot \mathrm{C}\end{array}$} \\
\hline \multicolumn{6}{|c|}{ LABOPATOAY ANALYSES } \\
\hline[ & Analyte & Perult & Mod & Unit & Lيb \\
\hline & $\begin{array}{l}\text { Carbon tetrachloride } \\
\text { Chloroform } \\
\text { Tetrachloroethylene } \\
\text { 1,1,1-Trichloroothane }\end{array}$ & $\begin{array}{r}<10 \\
<10 \\
34 \\
<10\end{array}$ & $\begin{array}{l}\text { JO6 } \\
j 06 \\
\text { JO6 } \\
\text { JOB }\end{array}$ & $\underset{\substack{\mu g / h \\
\mu g h}}{\operatorname{mg} / \mathrm{h}}$ & $\begin{array}{l}\mathrm{GE} \\
\mathrm{GE} \\
\mathrm{GE} \\
\mathrm{GE}\end{array}$ \\
\hline
\end{tabular}

Time: $18: 30$

PH: 5.0

Alkalinity: $1 \mathrm{mg} / \mathrm{h}$

Time: 12:05

Alkalinity: $0 \mathrm{~mol}$

Water tomperature: $22.1 \circ \mathrm{C}$

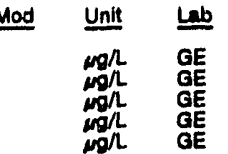


ANALYTICAL RESULTS

WELL FWM $\theta$ collectod on 08/11/82, laboratory analyese (cont)

\begin{tabular}{|c|c|c|c|}
\hline Analyte & Result & Mod & Unit \\
\hline $\begin{array}{l}2 \text { Triechloroothylone } \\
0 \\
0 \text { Totel activity }\end{array}$ & $\begin{array}{l}177 \\
2.2 E-00 \pm 1.2 E-06\end{array}$ & Jo6 & $\mu g / L$ \\
\hline
\end{tabular}

WELL RWM 9

MEASUREMENTS CONDUCTED IN THE FIELD

\begin{tabular}{|c|c|c|c|c|c|}
\hline \multicolumn{3}{|c|}{ 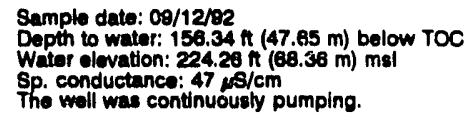 } & \multicolumn{3}{|c|}{ 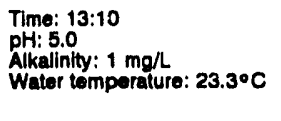 } \\
\hline \multicolumn{6}{|c|}{ LABOPUTORY ANALYSES } \\
\hline$=$ & Analyte & Pesult & Mod & Unit & Lab \\
\hline & 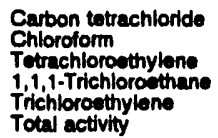 & $\begin{array}{l}<10 \\
<10 \\
<10 \\
<10 \\
183 \\
\quad 8.6 E\end{array}$ & & 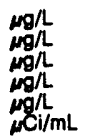 & $\begin{array}{l}\text { GE } \\
G E \\
G E \\
G E \\
G E \\
E M\end{array}$ \\
\hline
\end{tabular}

WELL RWM 10

MEASUREMENTS CONDUCTED IN THE FIELD

\begin{tabular}{|c|c|c|c|c|c|}
\hline \multicolumn{3}{|c|}{$\begin{array}{l}\text { Sample date: } 07 / 13 / 92 \\
\text { Depth to water: } 169.14 \mathrm{ft}(51.55 \mathrm{~m}) \text { below TOC } \\
\text { Water elevation: } 188.38 \mathrm{ft}(58.80 \mathrm{~m}) \mathrm{msl} \\
\text { Sp. conductance: } 88 \mu \mathrm{s} / \mathrm{cm} \\
\text { The woll was continuously pumping. }\end{array}$} & \multicolumn{3}{|c|}{$\begin{array}{l}\text { Time: } 10: 55 \\
\text { pH: } 4.8 \\
\text { Alkalinity: } 0 \mathrm{mg} / \mathrm{L} \\
\text { Water temperature: } 22.5^{\circ} \mathrm{C}\end{array}$} \\
\hline \multicolumn{6}{|c|}{ LABORATOFY ANALYSES } \\
\hline & Analyte & Result & Mod & Unit & Lab \\
\hline & $\begin{array}{l}\text { Carbon totrachloride } \\
\text { Chloroform } \\
\text { Tetrachloroethylene } \\
1,1,1-\text { Trichlorosthane } \\
\text { Trichloroethylene } \\
\text { Total activity }\end{array}$ & $\begin{array}{c}<150 \\
<150 \\
7,560 \\
<150 \\
4,770 \\
1.4 E-06\end{array}$ & & $\begin{array}{l}\mathrm{mg} / \mathrm{L} \\
\mathrm{mg} / \mathrm{L} \\
\mathrm{mg} / \mathrm{L} \\
\mathrm{mg} / \mathrm{L} \\
\mathrm{mg/L} \\
\mathrm{mCl} / \mathrm{mL}\end{array}$ & $\begin{array}{l}G E \\
G E \\
G E \\
G E \\
G E \\
G E \\
E M\end{array}$ \\
\hline
\end{tabular}

\section{WELL RWM 10}

MEASUREMENTS CONDUCTED IN THE FIELD

\begin{tabular}{|c|c|c|c|c|}
\hline \multicolumn{2}{|c|}{$\begin{array}{l}\text { Sample date: } 08 / 11 / 92 \\
\text { Depth to water: } 1868.62 \mathrm{n}(50.79 \mathrm{~m}) \text { below TOC } \\
\text { Water elevation: } 188.88 \mathrm{ft}(57.57 \mathrm{~m}) \mathrm{msl} \\
\text { Sp. conductance: } 89 \mathrm{ss} / \mathrm{cm} \\
\text { The well was continuously pumping. }\end{array}$} & \multicolumn{3}{|c|}{$\begin{array}{l}\text { Time: } 15: 55 \\
\text { pH: } 4.8 \\
\text { Allkalinity: } 0 \mathrm{mg} / \mathrm{L} \\
\text { Water temperature: } 22.7^{\circ} \mathrm{C}\end{array}$} \\
\hline \multicolumn{5}{|l|}{ LABOPATORY ANALYSES } \\
\hline Anabyte & Result & Mod & Unit & $\underline{\mathrm{Lab}}$ \\
\hline $\begin{array}{ll}0 & \text { Carbon tetrachloride } \\
0 & \text { Chlorolorm } \\
2 & \text { Tetrachloroethylene } \\
0 & 1,1,1 \cdot \text { Trichloroethane } \\
2 & \text { Trichlorothylene } \\
0 & \text { Total activity }\end{array}$ & $\begin{array}{l}<200 \\
<200 \\
6,180 \\
<200 \\
4,160 \\
1.7 \mathrm{E}-07\end{array}$ & 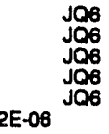 & 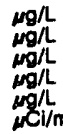 & $\begin{array}{l}\mathrm{GE} \\
\mathrm{GE} \\
\mathrm{GE} \\
\mathrm{GE} \\
\mathrm{GE} \\
\mathrm{EM}\end{array}$ \\
\hline
\end{tabular}

\section{WELL. RWM 10}

MEASUREMENTS CONDUCTED IN THE FIELD

\begin{tabular}{|c|c|c|c|c|c|}
\hline \multicolumn{3}{|c|}{$\begin{array}{l}\text { Sample date: } 09 / 12 / 92 \\
\text { Depth to water: } 168.74 \mathrm{Ht}(51.43 \mathrm{~m}) \text { below TOC } \\
\text { Water elevation: } 186.76 \mathrm{f}(58.83 \mathrm{~m}) \mathrm{ms} \\
\text { Sp. conductance: } 89, \mathrm{f} / \mathrm{cm} \\
\text { The well was continuously pumping. }\end{array}$} & \multicolumn{3}{|c|}{$\begin{array}{l}\text { Time: } 12: 40 \\
\text { pH: } 4.8 \\
\text { Alkalinity: } 0 \mathrm{mg} / \mathrm{h} \\
\text { Water temperature: } 23.2^{\circ} \mathrm{C}\end{array}$} \\
\hline \multicolumn{6}{|c|}{ LABORATOFY ANALYSES } \\
\hline$E$ & Analyte & Result & Mod & Unit & $\underline{L a b}$ \\
\hline ? & $\begin{array}{l}\text { Carbon totrachloride } \\
\text { Chloroform } \\
\text { Tetrachloroethylene } \\
1,1,1 \cdot \text { Trichloroethane } \\
\text { Trichloroethylene } \\
\text { Total activity }\end{array}$ & $\begin{array}{c}<200 \\
<200 \\
6,460 \\
<200 \\
4,180 \\
5.9 E-07\end{array}$ & $2 \mathrm{E} \cdot 08$ & 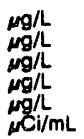 & $\begin{array}{l}\mathrm{GE} \\
\mathrm{GE} \\
\mathrm{GE} \\
\mathrm{GE} \\
\mathrm{GE} \\
\mathrm{EM}\end{array}$ \\
\hline
\end{tabular}

WELL RWM 11

MEASUREMENTS CONDUCTED IN THE FIELD

Sample date: $07 / 13 / 92$ Depth to water: $167.33 \mathrm{ht}(51.00 \mathrm{~m})$ beiow TOC Water alevation: $215.87 \mathrm{Ht}$

Sp. conductance: $35 \mu \mathrm{s} / \mathrm{cm}$

The well was continuously pumping

LABORATORY ANALYSES

F Analyte

- Carbon tetrachloride

O Chloroform

Tetrachloroethylene

Tri,1-Trichloroethane
Trichloroethylene

$$
\begin{array}{r}
\quad \text { Result } \\
<150 \\
<150 \\
380 \\
<150 \\
4,260
\end{array}
$$

\author{
Time: 16:15 \\ pH: 4.6 \\ Alkalinity: $0 \mathrm{mg}$ \\ Water tomperature: $22.8^{\circ} \mathrm{C}$
}

WELL RWM 11

MEASUREMENTS CONDUCTED IN THE FIELD

8ample date: 08/11/92

Dopth to water: $189.65 \mathrm{Ht}(51.71 \mathrm{~m})$ bolow TOC

Water olevation: $213.65 \mathrm{ft}(65.12 \mathrm{~m}) \mathrm{ms}$

Sp, conductance: $34 \mathrm{\mu S} / \mathrm{cm}$

The well was continuously pumping.

LABORATORY ANALYSES

F Analyte

- Carbon tetrachloride

Chloroform

2 Tetracliloroethylene Trichloroethylene

Result
$<200$
$<200$
260
$<200$
3,580

Mod

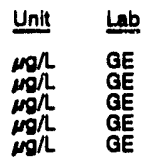

\title{
WELL RWM 11
}

MEASUREMENTS CONDUCTED IN THE FIELD

Sample date: 09/12/92

Depth to water: 171.08 (t $(52.41 \mathrm{~m})$ bolow TOC Water olevation: $211.34 \mathrm{ft}(64.42 \mathrm{~m}) \mathrm{ms}$ i

Sp. conductance: $34 \mathrm{\mu s} / \mathrm{cm}$

The well was continuously pumping

LABOPATORY ANALYSES

$\begin{array}{llc}\text { E Analyte } & \text { Result } \\ 0 & \text { Carbon tetrachloride } & <200 \\ 0 & <200 \\ 0 & \text { Chloroform } & 359 \\ 2 & \text { Tetrachloroethylene } & <200 \\ 0 & 1,1,1-\text { Trichloroethane } & 3,750\end{array}$

Time: 15:20

pH: 4.8

y: $0 \mathrm{mg} / \mathrm{L}$ Water tomporature: $23.0^{\circ} \mathrm{C}$

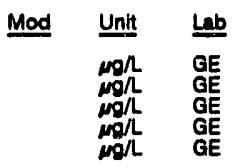

\section{Time: 13:20}

$\mathrm{pH}: 4.5$

Alkalinity: $0 \mathrm{mg} / \mathrm{L}$

Water temperature: $23.5^{\circ} \mathrm{C}$

\section{WELL RWM 12}

MEASUREMENTS CONDUCTED IN THE FIELD

Sample date: $07 / 13 / 92$

Depth to water: $149.90 \mathrm{ft}(45.69 \mathrm{~m})$ below TOC Water slevation: $209.50 \mathrm{H}(63.88 \mathrm{~m}) \mathrm{msl}$

Sp. conductance: $46 \mathrm{ps} / \mathrm{cm}$

The well was continuously pumping.

LABORATOAY ANALYSES

F Analyte

- Carbon tetrachloride

Chloroform

Tetrachloroethylene

2 1,1,1-Trichloroethan

WELL RWM 12

MEASUREMENTS CONDUCTED IN THE FIELD

Sample date: 08/11/92

(50.19 $\mathrm{H}(45.78 \mathrm{~m})$ below TOC Water olevation: $209.21 \mathrm{ft}(63.77 \mathrm{~m}) \mathrm{msl}$

Sp. conductance: $42 \mu \mathrm{s} / \mathrm{cm}$

The well was continuously pumping.

LABOPATOAY ANALYSES

$\begin{array}{lll}\text { E Analyte } & \text { Result } \\ 0 \text { Carbon tetrachloride } & <100 \\ 0 & \text { Chloroform } & <100 \\ 0 & \text { Tetrachloroethylene } & <100 \\ 0 & 1,1,1 \text {-Trichloroethane } & <100 \\ 2 \text { Trichloroethylene } & 2,320\end{array}$

Time: 15:35

\begin{tabular}{|c|c|}
\hline Mod & Unit \\
\hline & 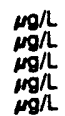 \\
\hline
\end{tabular}

$\mathrm{pH}: 4.5$

Alkalinity: $0 \mathrm{~mol}$ Water temperature: $22.1^{\circ} \mathrm{C}$

Time: 14:30

PH: 4.4 Alkalinity: $0 \mathrm{mg} / \mathrm{L}$

Water temperature: $22.8^{\circ} \mathrm{C}$ 
WELL RWM 12

MEASUREMENTS CONDUCTED IN THE FIELD

Semple date:

Depth to water: 150.13 h $(45.76 \mathrm{~m})$ bolow TOC

Water olevation: $209.27 \mathrm{ft}(83.78 \mathrm{~m}) \mathrm{msl}$

The well was continuously pumping.

LABORATORY ANALYSES

\begin{tabular}{|c|c|c|c|c|c|}
\hline$\underline{F}$ & Analyte & Rosult & Mod & Unit & Lab \\
\hline $\begin{array}{l}0 \\
0 \\
0 \\
0\end{array}$ & $\begin{array}{l}\text { Carbon tetrachloride } \\
\text { Chloroform } \\
\text { Tetrachloroethylene } \\
1,1,1 \text {-Trichloroethane } \\
\text { Trichloroethylene }\end{array}$ & $\begin{array}{l}<100 \\
<100 \\
<100 \\
<100 \\
2,740\end{array}$ & & $\begin{array}{c}\mu g / h \\
\operatorname{mg} / \mathrm{h} \\
\mathrm{mg} / \mathrm{h} \\
\mathrm{mg} / \mathrm{h} \\
\mathrm{mg} / \mathrm{L}\end{array}$ & $\begin{array}{l}\mathrm{GE} \\
\mathrm{GE} \\
\mathrm{GE} \\
\mathrm{GE} \\
\mathrm{GE}\end{array}$ \\
\hline
\end{tabular}

\section{WELL RWM 16}

MEASUREMENTS CONDUCTED IN THE FIELD

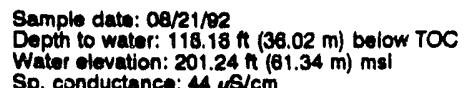

Sp. conductance: $44 \mathrm{~s} / \mathrm{cm}$. Water evacuated betore sampling: $328 \mathrm{gal}$

LABORATOPY ANALYSES

\begin{tabular}{|c|c|c|c|c|}
\hline$E$ & Analyte & Result & Mod & Unit \\
\hline $\begin{array}{l}0 \\
0 \\
?\end{array}$ & $\begin{array}{l}\text { Carbon tetrachloride } \\
\text { Chloroform } \\
\text { Tetrachloroethylene } \\
1,1,1-\text { Trichloroethane } \\
\text { Trichloroetthylene } \\
\text { Total activity }\end{array}$ & $\begin{array}{l}<200 \\
260 \\
<200 \\
<200 \\
980 \\
5.0 \mathrm{E}-07\end{array}$ & & $\begin{array}{l}\mu g / L \\
\mu g / L \\
\mu g / h \\
\mu g / L \\
\mu g / h \\
\mu C l / m L\end{array}$ \\
\hline
\end{tabular}

\section{WELL SBG 1}

MEASUREMENTS CONDUCTED IN THE FIELD

Sample date: 09/1492

Depth to water: $23.55 \mathrm{ft}(7.18 \mathrm{~m})$ below TOC

Water olevation: 238.84 ft

Wheter evecuated before $27 \mathrm{~cm}$. $126 \mathrm{gal}$

Time: 13:40

pH: 4.6

Water temperature: $21.50 \mathrm{C}$

\section{Time: 12:05}

pH: 5.5

Alkalinity: $5 \mathrm{mg} / \mathrm{L}$

Water tomperature: $21.9^{\circ} \mathrm{C}$

LABORATORY ANALYSES

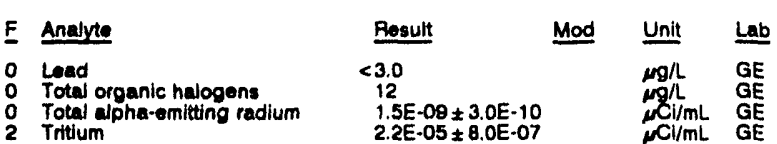

WELL SBG 2

MEASUREMENTS CONDUCTED IN THE FIELD

Sample date: 08/14/82 Depth to walor: $51.13 \mathrm{ft}(15.58 \mathrm{~m})$ bolow TOC Wator olevation: $238.87 \mathrm{~h}(72.81 \mathrm{~m}) \mathrm{ms}$

Wator evacuated belore sampling: $87 \mathrm{gal}$

Time: $12: 40$

Alkalinity: $0 \mathrm{mg}$

Whater temperature: $19.7^{\circ} \mathrm{C}$

LABORATOPY ANALYSES

\begin{tabular}{|c|c|c|c|c|}
\hline $\mathbf{F}$ & Analyte & Result & Mod & Unit \\
\hline & $\begin{array}{l}\text { Load } \\
\text { Load } \\
\text { Total organic halogens } \\
\text { Total alpha-omitting radium } \\
\text { Trittum }\end{array}$ & $\begin{aligned} & 6.0 \\
& 5.8 \\
&<5.0 \\
&<1.0 \mathrm{E}-09 \\
& 2.0 \mathrm{E}-05 \pm 8.0 \mathrm{E}-07\end{aligned}$ & & $\begin{array}{l}\mu g / L \\
\omega g / L \\
\mu / L \\
\mu C i / m L \\
\mu C l / m L\end{array}$ \\
\hline
\end{tabular}

WELL SBG 3

MEASUREMENTS CONDUCTED IN THE FIELD

Sample date: $08 / 1482$

Depth to water: 47.74 Ht (14.55 m) below TOC Water elevation: $238.86 \mathrm{ft}(72.81 \mathrm{~m}) \mathrm{ms}$ (

Sp. conductance: $8 \mu \mathrm{S} / \mathrm{cm}$. Water evacuated before sampling: $85 \mathrm{gal}$

Time: 11:35

pH: 4.6

LABORATORY ANALYSES

\begin{tabular}{|c|c|c|c|c|}
\hline F Analyte & Rosult & Mod & Unit & Lab \\
\hline $\begin{array}{l}\text { Load } \\
\text { Total organic halogens } \\
\text { Total alpha-omitting radium } \\
\text { Tritium }\end{array}$ & $\begin{array}{l}<3.0 \\
8.0 \\
1.6 \mathrm{E}-09 \pm 3.0 \mathrm{E}-10 \\
1.3 \mathrm{E}-05 \pm 7.0 \mathrm{E}-07\end{array}$ & & 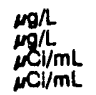 & $\begin{array}{l}G E \\
G E \\
G E \\
G E\end{array}$ \\
\hline
\end{tabular}

WELL SBG 4

MEASUREMENTS CONDUCTED IN THE FIELD

$\begin{array}{ll}\text { Sample date: } 08 / 14 / 92 & \text { Time: } 14: 25 \\ \text { Depth to water } 30.95 \mathrm{ft}(8.43 \mathrm{~m}) \text { bolow roc } & \text { pH: } 4.5 \\ \text { Water olevation: } 242.15 \mathrm{ft}(73.81 \mathrm{~m}) \mathrm{mal} & \text { Alkalinity: } 0 \mathrm{mg} / \mathrm{h} \\ \text { Sp. conductance: } 26 \mu \mathrm{cm} & \text { Wator tomperature: } 19.8^{\circ} \mathrm{C} \\ \text { Water ovacuated bofore sampling: } 148 \mathrm{gal} & \end{array}$

Water ovacuated bofore sampling: $148 \mathrm{gal}$

LABORATORY ANALYSES

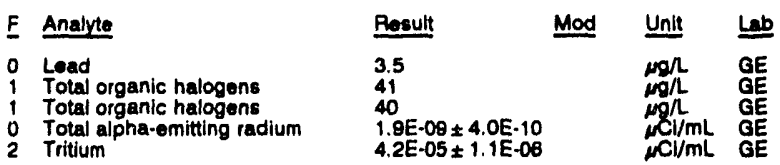

WELL SBG 5

MEASUREMENTS CONDUCTED IN THE FIELD

\begin{tabular}{|c|c|c|c|c|c|}
\hline \multicolumn{3}{|c|}{$\begin{array}{l}\text { Sample date: } 08 / 14 / 92 \\
\text { Depth to water: } 33.74 \mathrm{H}(10.28 \mathrm{~m}) \text { below TOC } \\
\text { Water alovation: } 250.76 \mathrm{ft}(7 \mathrm{C} .43 \mathrm{~m}) \mathrm{msl} \\
\text { Sp. conductance: } 38 \mu \mathrm{s} / \mathrm{cm} \\
\text { Water ovacuated bofore sampling: } 135 \mathrm{gal}\end{array}$} & \multicolumn{3}{|c|}{$\begin{array}{l}\text { Time: } 13: 55 \\
\text { pH: } 5.7 \\
\text { Alkalinity: } 10 \mathrm{mg} / \mathrm{h} \\
\text { Water temperature: } 20.6 \circ \mathrm{C}\end{array}$} \\
\hline \multicolumn{6}{|c|}{ BOPATORY ANALYSES } \\
\hline & Analyte & Result & Mod & Unit & \\
\hline & $\begin{array}{l}\text { Load } \\
\text { Total organic halogens } \\
\text { Total alpha-emitting radium } \\
\text { Tritium } \\
\text { Tritlum }\end{array}$ & $\begin{array}{l}<3.0 \\
13 \\
1.8 \mathrm{E} \\
4.7 \mathrm{E} \\
4.1 \mathrm{E}\end{array}$ & $\begin{array}{l}.0 \mathrm{E}-10 \\
.0 \mathrm{E}-07 \\
.0 \mathrm{E}-07\end{array}$ & 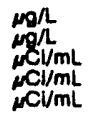 & $\begin{array}{l}\mathrm{GE} \\
\mathrm{GE} \\
\mathrm{GE}\end{array}$ \\
\hline
\end{tabular}

WELL SBG 6

MEASUREMENTS CONDUCTED IN THE FIELD

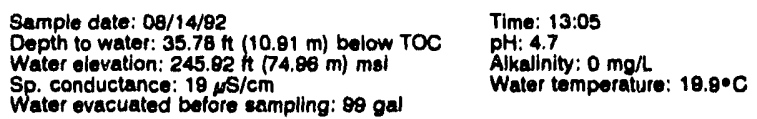

Water evacuated betore sampling: $8 \theta \mathrm{gal}$

LABORATORY ANALYSES

\begin{tabular}{|c|c|c|c|}
\hline Analyte & Rosult & Mod & Unin \\
\hline $\begin{array}{l}\text { Lead } \\
\text { Total organic halogens } \\
\text { Total alpha-emitting radium } \\
\text { Tritum }\end{array}$ & $\begin{array}{l}8.8 \\
12 \\
1.1 E-09 \\
1.2 E-05\end{array}$ & & molim \\
\hline
\end{tabular}


ANALYTICAL RESULTS

WELL SCA 1

MEASUREMENTS CONDUCTED IN THE FIELD

\begin{tabular}{|c|c|c|c|c|c|}
\hline \multicolumn{3}{|c|}{$\begin{array}{l}\text { Sample date: 08/28/92 } \\
\text { Depth to water: } 45.84 \text { ft }(13.88 \mathrm{~m}) \text { below TOC }\end{array}$} & \multirow{2}{*}{\multicolumn{3}{|c|}{$\begin{array}{l}\text { Time: } 12: 05 \\
\text { pH: } 6.0 \\
\text { Alkalinity: } 6 \text { mg/l } \\
\text { Water temperature: } 21.4^{\circ} \mathrm{C}\end{array}$}} \\
\hline \multicolumn{3}{|c|}{$\begin{array}{l}\text { Sp. conductance: } 28 \mu \mathrm{\mu} / \mathrm{cm} \\
\text { Whiter ovacuated betore thempling: } 90 \mathrm{gal}\end{array}$} & & & \\
\hline \multicolumn{6}{|c|}{ LABORATORY ANALYSES } \\
\hline$E$ & Analyte & Result & Mod & Unit & $\mathrm{Lab}$ \\
\hline $\begin{array}{l}0 \\
0 \\
0 \\
1\end{array}$ & $\begin{array}{l}\text { Iron } \\
\text { Manganese } \\
\text { Total alpha-omitting radlum } \\
\text { Tritium }\end{array}$ & $\begin{array}{l}14 \\
12 \\
1.1 E-08 \\
1.5 E-08\end{array}$ & $\begin{array}{l}\text { E-10 } \\
\text { E.07 }\end{array}$ & & $\begin{array}{l}\mathrm{GE} \\
\mathrm{GE} \\
\mathrm{GE} \\
\mathrm{GE}\end{array}$ \\
\hline
\end{tabular}

WELL SCA IA

MEASUREMENTS CONDUCTED IN THE FIELD

Sample date: 00/28192 Time: 11:05

WELL SCA 2

MEASUREMENTS CONDUCTED IN THE FIELL

\begin{tabular}{|c|c|c|c|c|c|}
\hline \multicolumn{3}{|c|}{$\begin{array}{l}\text { Sample date: } 09 / 28 / 92 \\
\text { Depth to water: } 45.37 \mathrm{n}(13.83 \mathrm{~m}) \text { below TOC } \\
\text { Water olovation: } 243.53 \mathrm{~h}(74.23 \mathrm{~m}) \mathrm{ms} \\
\text { Sp. conductance: } 30 \mu \mathrm{\mu} / \mathrm{cm} \\
\text { Water evacuated betore sampling: } 115 \mathrm{gal}\end{array}$} & \multicolumn{3}{|c|}{$\begin{array}{l}\text { Time: } 11: 45 \\
\text { pH: } 6.0 \\
\text { Alkalinity: } 8 \mathrm{mg} / \mathrm{L} \\
\text { Water temperature: } 21.3^{\circ} \mathrm{C}\end{array}$} \\
\hline \multicolumn{6}{|c|}{ LABOPATORY ANALYSES } \\
\hline$E$ & Analute & Resulf & Mod & Unit & Lab \\
\hline $\begin{array}{l}0 \\
0 \\
0 \\
1 \\
1\end{array}$ & $\begin{array}{l}\text { Iron } \\
\text { Manganoee } \\
\text { Total alpha-emitting radium } \\
\text { Tritium }\end{array}$ & $\begin{array}{l}6.8 \\
5.9 \\
1.2 E-09 \\
1.7 E-05\end{array}$ & $\begin{array}{l}E-10 \\
E-07\end{array}$ & 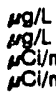 & $\begin{array}{l}\text { GE } \\
\text { GE } \\
\text { GE } \\
\text { GE }\end{array}$ \\
\hline
\end{tabular}

WELL SCA 2A

MEASUREMENTS CONDUCTED IN THE FIELD

Sample date: 09/28/82 Time: 11:00
The well was dry.

\section{WELL SCA 3}

MEASUREMENTS CONOUCTED IN THE FIELD

Sample date: 08/28/82

Depth to water: $45.18 \mathrm{ft}(13.77 \mathrm{~m})$ below TOC

Water elovation: $242.12 \hbar(73.80 \mathrm{~m}) \mathrm{ms}$

Sp. conductance: $28, \mathrm{~s} / \mathrm{cm}$

Water evacuated bofore sampling: $18 \mathrm{gal}$

The well went dry during purging.

LABOAATORY ANALYSES

\begin{tabular}{|c|c|c|c|c|}
\hline F & Analyte & Rosult & Mod & Unit \\
\hline & $\begin{array}{l}\text { Iron } \\
\text { Manganeas } \\
\text { Total alpha-emitting radium } \\
\text { Tritium }\end{array}$ & $\begin{array}{l}283 \\
37 \\
2.2 E-09 \pm 1.1 E-09 \\
1.4 E-05 \pm 7.0 E-07\end{array}$ & & $\begin{array}{l}\mu g / L \\
\mu g / L \\
\mu \mathrm{Cl} / \mathrm{mL} \\
\mathrm{Cl} / \mathrm{mL}\end{array}$ \\
\hline
\end{tabular}

WELL SCA 3A

MEASUREMENTS CONDUCTED IN THE FIELD

\section{Sample date: 08/28/82}

Depth to water: 18.81 it $(5.15 \mathrm{~m})$ below TOC

Water elevation: $270.30 \mathrm{ht}(62.42 \mathrm{~m}) \mathrm{msl}$

Sp. conductance: $603 \mu \mathrm{s} / \mathrm{cm}$

Water evacustod bolore sampling: 3 ga

The well went dy during purging

LABORATORY ANALYSES

\begin{tabular}{|c|c|c|c|c|}
\hline & Analyte & Result & Mod & Unit \\
\hline & $\begin{array}{l}\text { Iron } \\
\text { Manganese } \\
\text { Total alpha-omitting radium } \\
\text { Tritium }\end{array}$ & $\begin{array}{l}<4.0 \\
258 \\
2.2 E-09 \pm 1.2 E-00 \\
1.7 E-05 \pm 6.0 E-07\end{array}$ & & $\begin{array}{l}\mu \mathrm{g} / \mathrm{L} \\
\mu \mathrm{g} / \mathrm{L} \\
\mu \mathrm{Cl} / \mathrm{mL} \\
\mathrm{NCl} / \mathrm{mL}\end{array}$ \\
\hline
\end{tabular}

WELL SCA 4

MEASUREMENTS CONDUCTED IN THE FIELD

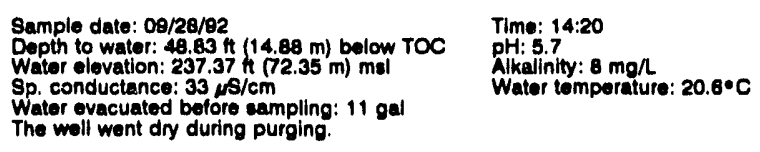

The well went dry during purging. 11 ga

LABORATORY ANALYSES

\begin{tabular}{|c|c|c|}
\hline F Analyte & Result & Unit \\
\hline $\begin{array}{l}\text { Iron } \\
\text { Mangariese } \\
\text { Total alpha-emitting radium } \\
\text { Tritium }\end{array}$ & $\begin{array}{l}5.0 \\
13 \\
3.5 E-09 \pm 1.3 E-09 \\
1.8 E-05 \pm 8.0 E-07\end{array}$ & 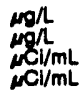 \\
\hline
\end{tabular}

WELLL SCA 4A

MEASUAEMENTS CONDUCTED IN THE FIELD

\begin{tabular}{|c|c|c|c|c|c|}
\hline \multicolumn{3}{|c|}{$\begin{array}{l}\text { Sample date: } 09 / 28 / 92 \\
\text { Depth to water: } 18.55 \mathrm{ft}(5.86 \mathrm{~m}) \text { below TOC } \\
\text { Water olevation: } 266.55 \mathrm{ht}(81.25 \mathrm{~m}) \mathrm{mal} \\
\text { Sp. conductance: } 211 \mu \mathrm{cm} \\
\text { Water evacuatod before sampling: } 2 \mathrm{gal} \\
\text { The woll went dry during purging. }\end{array}$} & \multicolumn{3}{|c|}{$\begin{array}{l}\text { Time: } 14: 05 \\
\text { pH: } 6.1 \\
\text { Alkalinity: } 50 \mathrm{mg} / \\
\text { Water tomperature: } 23.7 \circ \mathrm{C}\end{array}$} \\
\hline \multicolumn{6}{|c|}{ LABORATORY ANALYSES } \\
\hline- & Analyte & Result & Mod & Unit & Lab \\
\hline 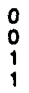 & $\begin{array}{l}\text { Iron } \\
\text { Manganese } \\
\text { Total alpha-emitting radium } \\
\text { Tritium }\end{array}$ & $\begin{array}{r}<4.0 \\
<2.0 \\
4.5 E-09 \\
1.5 E-05\end{array}$ & $\begin{array}{l}1.5 E-09 \\
7.0 E-07\end{array}$ & $\begin{array}{l}m / \mathrm{L} \\
\mathrm{g} / \mathrm{L} \\
\mathrm{Cl} / \mathrm{mL} \\
\mathrm{Cl} / \mathrm{mL}\end{array}$ & $\begin{array}{l}\text { GE } \\
\text { GE } \\
\text { GE } \\
\text { GE }\end{array}$ \\
\hline
\end{tabular}

WELL SCA 5

MEASUREMENTS CONDUCTED IN THE FIELD

\begin{tabular}{|c|c|c|c|c|c|}
\hline \multicolumn{3}{|c|}{$\begin{array}{l}\text { Sample date: } 09 / 28 / 92 \\
\text { Depth to water: } 46.41 \mathrm{tt}(14.15 \mathrm{~m}) \text { below TOC } \\
\text { Water olovation: } 241.69 \mathrm{ft}(73.67 \mathrm{~m}) \mathrm{msl} \\
\text { Sp. conductance: } 112 \mu \mathrm{s} / \mathrm{cm} \\
\text { Water ovacuatod before sampling: } 8 \mathrm{gal} \\
\text { The well went dry during purging. }\end{array}$} & \multicolumn{3}{|c|}{$\begin{array}{l}\text { Time: } 12: 55 \\
\text { pH: B.3 } \\
\text { Alkalinity: } 42 \mathrm{mg} \Omega \\
\text { Water tomperature: } 20.6 \circ \mathrm{C}\end{array}$} \\
\hline \multicolumn{6}{|c|}{ LABORATOAY ANALYSES } \\
\hline$\underline{\mathbf{F}}$ & Analyte & Rosult & Mod & Unit & Lab \\
\hline $\begin{array}{l}0 \\
0 \\
0 \\
0 \\
0 \\
1\end{array}$ & $\begin{array}{l}\text { Iron } \\
\text { lron } \\
\text { Manganese } \\
\text { Manganese } \\
\text { Total alpha-emitting radium } \\
\text { Tritium }\end{array}$ & $\begin{array}{l}53 \\
12 \\
12 \\
11 \\
1.1 E \cdot 09 \\
1.0 E-05\end{array}$ & $\begin{array}{l}8.0 E-10 \\
8.0 E-07\end{array}$ & 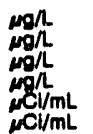 & $\begin{array}{l}\mathrm{GE} \\
\mathrm{GE} \\
\mathrm{GE} \\
\mathrm{GE} \\
\mathrm{GE} \\
\mathrm{GE}\end{array}$ \\
\hline
\end{tabular}

WELL SCA 6

MEASUREMENTS CONDUCTED IN THE FIELD

\begin{tabular}{|c|c|c|c|c|c|}
\hline \multicolumn{3}{|c|}{$\begin{array}{l}\text { Sample date: } 09 / 28 / 92 \\
\text { Dopth to water: } 43.27 \mathrm{H}(13.18 \mathrm{~m}) \text { below TOC } \\
\text { Water elovation: } 242.53 \mathrm{~h}(73.82 \mathrm{~m}) \mathrm{msl} \\
\text { Sp. conductance: } 126 \mathrm{\mu S} / \mathrm{cm} \\
\text { Water ovacuatod before sampling: } 13 \mathrm{gal} \\
\text { The well wont dry during purging. }\end{array}$} & \multicolumn{3}{|c|}{$\begin{array}{l}\text { Time: } 14: 45 \\
\text { pH: } 6.7 \\
\text { Alkalinity: } 42 \mathrm{mg} / \mathrm{h} \\
\text { Water tomperature: } 20.6^{\circ} \mathrm{C}\end{array}$} \\
\hline \multicolumn{6}{|c|}{ LABOPATORY ANALYSES } \\
\hline$\underline{\mathbf{E}}$ & Analyte & Rosult & Mod & Unit & Lab \\
\hline $\begin{array}{l}0 \\
0 \\
0 \\
2\end{array}$ & $\begin{array}{l}\text { Iron } \\
\text { Manganese } \\
\text { Total alpha-emitting radium } \\
\text { Tritlum }\end{array}$ & $\begin{array}{l}21 \\
<2.0 \\
2.1 \mathrm{E}-00 \\
3.5 \mathrm{E}-05\end{array}$ & $\begin{array}{l}1.1 E-09 \\
4.0 E-07\end{array}$ & $\begin{array}{l}\mu \mathrm{g} / \mathrm{L} \\
\mathrm{\mu} / \mathrm{Cl} / \mathrm{mL} \\
\mathrm{Cl} / \mathrm{mL}\end{array}$ & $\begin{array}{l}\text { GE } \\
\text { GE } \\
\text { GE } \\
\text { GE }\end{array}$ \\
\hline
\end{tabular}

WELL SLP 1

MEASUAEMENTS CONDUCTED IN THE FIELD

Sample date: 08/14/82

Depth to water: $37.93 \mathrm{ft}(11.56 \mathrm{~m})$ bolow TOC

Water elevation: $246.87 \mathrm{ht}(75.25 \mathrm{~m}) \mathrm{msl}$

Sp. conductance: $17 \mathrm{ss} / \mathrm{cm}$

(m)

The well went dry during purging. 
WELL SLP 2

MEASUREMENTS CONDUCTED IN THE FIELD

Sample date: 08/14902 Wopth to water: $37.58 \mathrm{n}(11.45 \mathrm{~m})$ bolow TOC

Sp. conductence 25 siscm.

Wator evacuatod bofore campling: $75 \mathrm{gal}$

Time: 11:10

Alkalinity: $8 \mathrm{mgh}$

Water tomperature: $20.2^{\circ} \mathrm{C}$

WELL SRW 1

MEASUAEMENTS CONDUCTED IN THE FIELD

Sample date: 07/11/92

Depth to water: $102.37 \mathrm{~h}(31.20 \mathrm{~m})$ below TOC

inacceealbility or mechanical problem preventod sample colloction.

\section{WELL SRW 2}

MEASUREMENTS CONDUCTED IN THE FIELD

Sample date: 07/11/82

Dopte to water: $105.61 \mathrm{nt}(32.18 \mathrm{~m})$ bolow TOC Wator olevation: $214.89 \mathrm{~h}(\mathbf{6 5 . 5 3} \mathrm{m}) \mathrm{mal}$

Sp. conductance: $38 \mathrm{~s} / \mathrm{cm}$

Water evecuated before sampling: $43 \mathrm{gal}$

LABORATORY ANALYSES

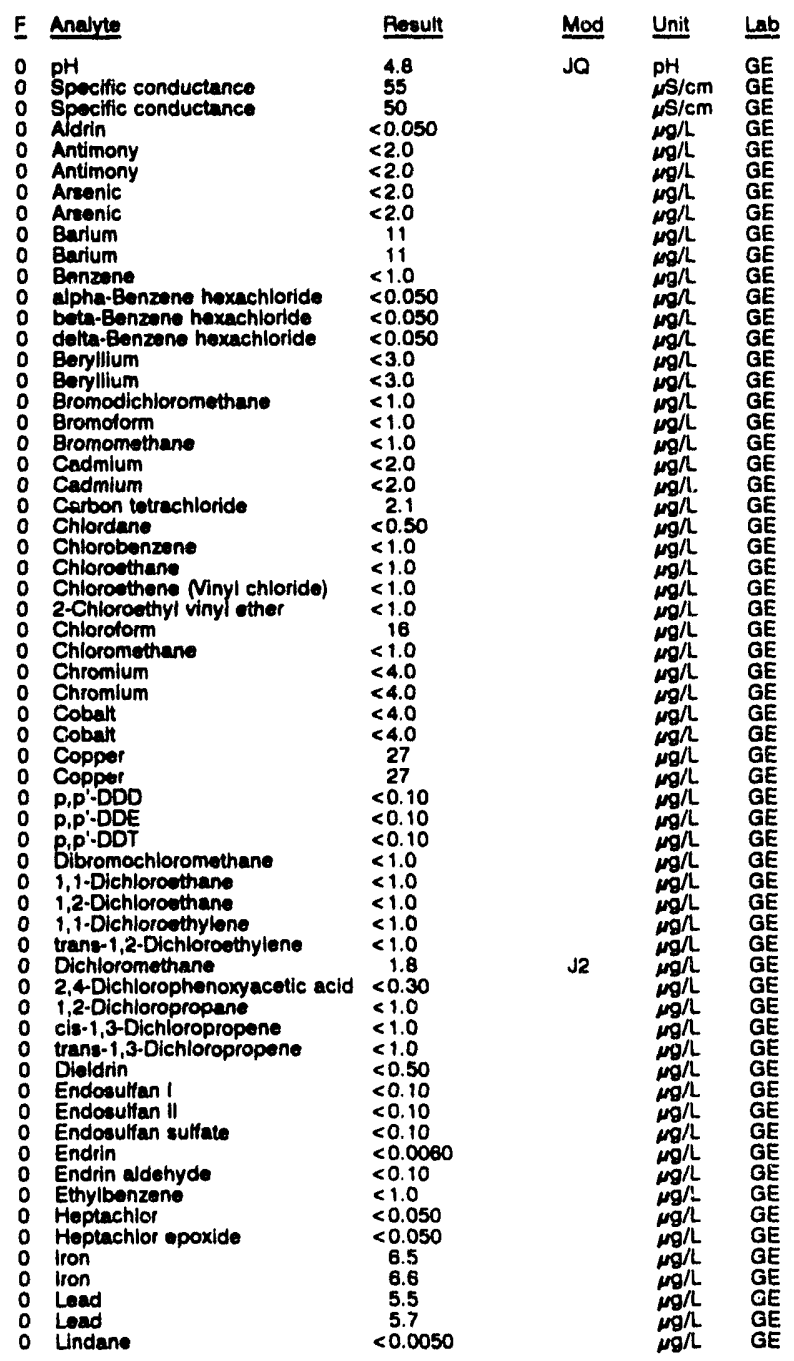

WELL SRW 2 collected on 07/11/82, laboratory analyees (cont.)

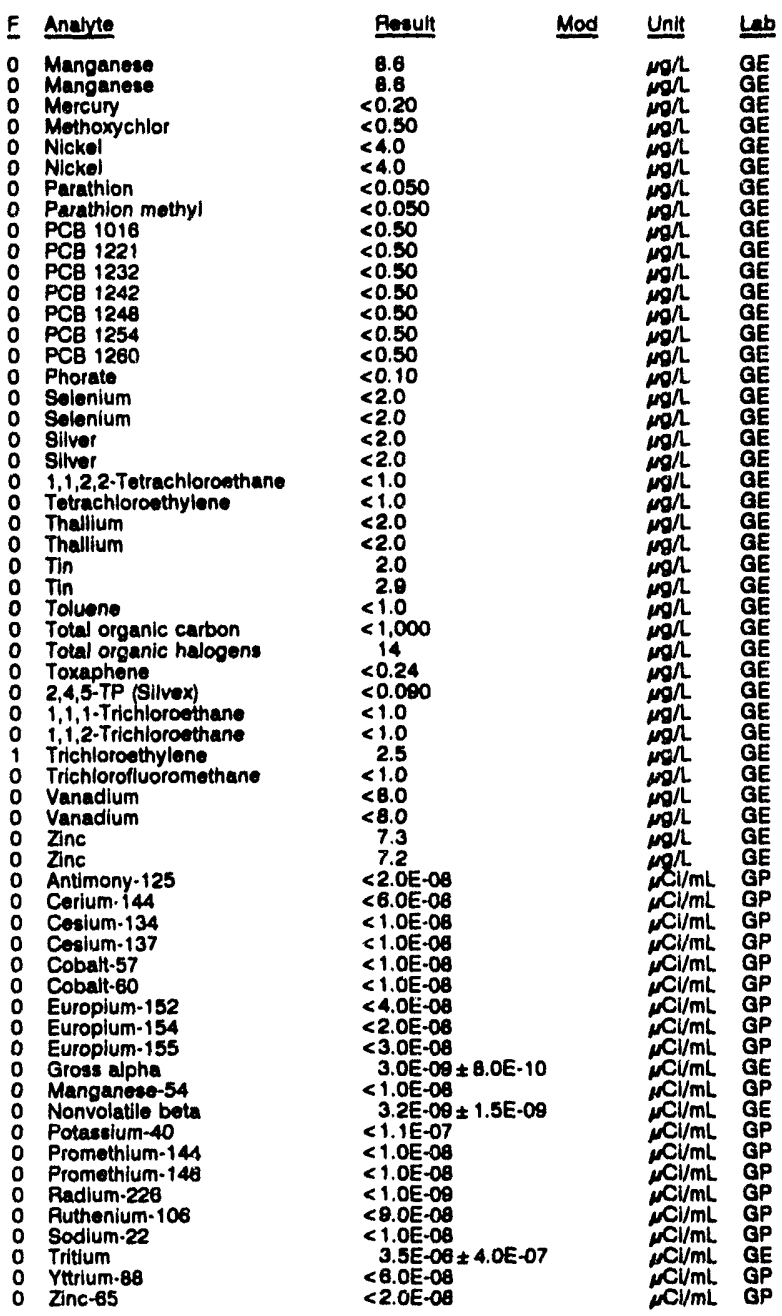

WELL SRW 2A

MEASUREMENTS CONDUCTED IN THE FIELD

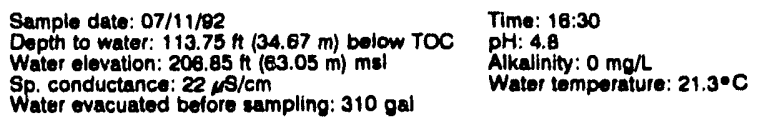

Sp. conductance: $22 \mathrm{\mu s} / \mathrm{cm}$

Water evacuated before sampling: $310 \mathrm{gal}$

LABORATORY ANALYSES

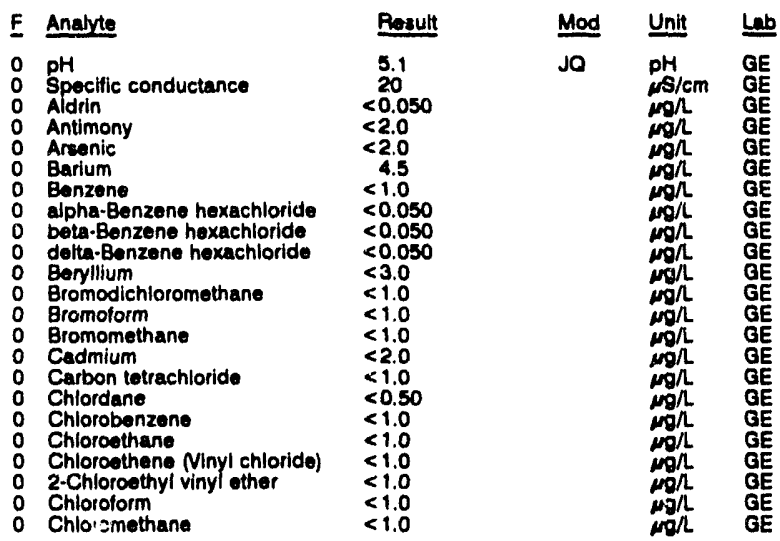


ANALYTICAL RESULTS

WEL 8RW 2A collected on 07/11/82, laboratory analyses (cont)

$E$ Analyte

O Chromium

O Cobat

$\therefore$ p,piopo

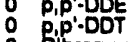

- bibromochloromethane

1.1.Dichloroethane

0 i,i.Dichloroethylene

trane-1,2-Dichloroethylene

Dichloromothane

2,4.Dichiorophonoxyacetic acid
0
0

trans-1,3-Dichloropropene

Dioldrín

Endonulfan I

Endosulfan sulfato

Endin

0 Endrin aldehydo

Ethylbenzene

Heptachlor epoxide

0 Iron

Lead

Manganese

Marcury

Nickel

Parathion methyl

PCB 1018

P PCB 1232

0 PCB 1242

PCE 1248

O PCB 1280

Phorato

Selonium

1,1,2,2-Tetrachloroethane

Totrachloroethylene

Thallum

O Tin

Total organic carbon

Total organic halogens

Toxnphene

1,1,1-Trichioroethane

1,1,2-Trichioroethane

Trichloroethylens

Trichlorofluoromethane

O Zinc

Antimony-125

Corlum-144

Ceslum-134

Cobalt-57

Cobatt-60

Europium-152

Europium-154

Guroplum-155

Groes alpha

Nonvolatile bota

Pothelum-40

Promethium-144

Radium-226

Ruthenium-106

Bodium-22

Tritum

Zncium-68

\section{WELL SRW 2B}

MEASUREMENTS CONDUCTEO IN THE FIELD

Sample date: 07/11/92

Depth to water: $112.68 \mathrm{~h}(34.34 \mathrm{~m})$ below TOC Water olevation: $207.84 \mathrm{ft}(63.38 \mathrm{~m}) \mathrm{msl}$

Besurt

$<4.0$

$<0.10$

$<0.10$

$<1.0$

$<1.0$

$<1.0$

$<1.0$
6.6
$<0.30$
$<1.0$

$<0.30$
$<1.0$
$<1.0$

$<1.0$

$<0.10$

$<0.10$

$<0.10$

$<0.10$

$<0.050$

5.2
5.6

$<0.0050$

$<0.20$

$<0.50$

$<0.050$

$<0.050$

$<0.50$

$<0.50$

$<0.50$

$<0.50$

$<0.10$

$<2.0$

$<1.0$

$<2.0$

$<1.00$

$<1,000$
$<5.0$

$<0.090$

$<1.0$

$<1.0$

$<1.0$
$<1.0$
$<8.0$

$<6.0$

$14.0 E-08$
$<2.08$

$<1.0 E-08$

$<1.0 \mathrm{E}-08$

$<1.0 E-08$

$<4.0$ E-0

$<2.0 \mathrm{E}-0$

$<2.0$ E.09

$<1.1 \mathrm{E}-07$

$<1.0 \mathrm{E}-08$

$<1.0 E \cdot 09$

$<8.0 \mathrm{E} .0 \mathrm{O}$

$<1.0$ E-08

$<6.0 \mathrm{E} .0$

$<2.0 \mathrm{E}-08$

Mod

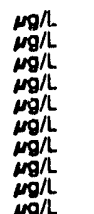

$\underset{\substack{\mu g h \\ \mu g h}}{\mu g h}$

Lab

GE

EE

GE

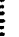

EE

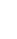

(1)

EE

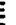

LABORATORY ANALYSES

\begin{tabular}{|c|c|c|c|}
\hline E Analyte & Rosult & Mod & Unit \\
\hline $\begin{array}{ll}0 & \mathrm{pH} \\
0 & \mathrm{pH} \\
0 & \text { Specific conductance }\end{array}$ & $\begin{array}{l}5.3 \\
5.4 \\
20\end{array}$ & $\begin{array}{l}\text { JO } \\
\text { Ja }\end{array}$ & $\begin{array}{l}\mathrm{pH} \\
\mathrm{pH} \\
\mu \mathrm{S} / \mathrm{cm}\end{array}$ \\
\hline
\end{tabular}

WELL 8RW 28 colloetod on 07/11/82, laboratory analyees (cont)

$\begin{array}{ll}\text { E } & \text { Anaivte } \\ 0 & \text { Aldrin } \\ 0 & \text { Antimony } \\ 0 & \text { Antimony } \\ 0 & \text { Aranic } \\ 0 & \text { Arsonic } \\ 0 & \text { Barium } \\ 0 & \text { Earium } \\ 0 & \text { Benzene } \\ 0 & \text { alpha.Benzeno hoxachloride }\end{array}$

Result

Mod Unit Leb

$<0.050$

$<2.0$
$<2.0$

$<2.0$

alpha. Benzeno hexachloride

beta.Benzene hexachlorlde

delta-Benzene hexachlorido

: Beryllium

o Bromodichloromethane

- Bromoform

- Bromomethane

C Cadmium

Cadmlum
0 Carbon tetrachloride

o Chlordane

Chloroesthzane

- Chioroothene Minyl chloride)

2-Chloroethyl vinyl ther

o Chlorotorm

- Chloromethane

- Chromium

Cobart

Cobait

o Copper

0 p,p.DD

0 P,P.DDE

: Bipr-DDT

1,1-Dichloroethane

o 1,2-Dichloroethane

o trane-1,2-Diehlorowthylene

Dichloromethane 2,4-Dichlorophenoxyacetle acid

1,2-Dichloropropane

o cis-1,3-Dichloropropene

0 trans-1,

0 Dieidrin

O Endosulfan I

O Endosulfan sulfate

0 Endrin

- Endrin aldehyde

O Ethylbenzene

Heptachlor epoxide

O Iron

\begin{tabular}{ll}
0 & Iron \\
0 & Iron \\
\hline & Lead
\end{tabular}

1 Lead

0 Lead

o Manganese

o Manganese

Mercury

Nickel

Nickel

P Parathion

PCB 1016

0 PCB 1221

O PCB 1242

P PCB 1248

O PCB 1254

o Phorate

- Solenium

Silver

Silver

1,1,2,2-Tetrachloroothane

Tetrachloroethylone

Thallium

Thallium

O $\operatorname{Tin}^{\mathrm{Tin}}$

Toluene

Total organic carbon

- Total organic carbon

- Total organic halogens

Total organic halogene

Toxapheno

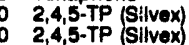

1,1,1-Trichloroethans

1,1,2-Trichloroethan

o Trichloroethylene

o Trichlorofluoromethane

o Vanadium

0 Vanadium

5.2
5.3
$<1.0$

$<0.050$

$<0.050$

$<3.0$

$<1.0$

$<1.0$
$<1.0$
$<2.0$
$<2.0$
$<2.0$

$<2.0$

$<0.50$

$<1.0$

$<1.0$

$<1.0$

$<1.0$

$<1.0$

$\leq 4.0$

$<4.0$

10.0

$<0.10$

$<0.10$

$<10$

$<1.0$

$<1.0$

$<1.0$

$<0.30$

$<1.0$

$<0.50$

$<0.10$

$<0.10$

$<0.0060$
$<0.10$

$<1.0$

$<0.050$

6.3

7.4

7.3
$<0.0050$

6.6

6.7
$<0.20$

$<0.50$

$<4.0$

$<0.050$

$<0.050$

$<0.50$
$<0.50$

$<0.50$ 
ANALYTICAL RESULTS

\begin{tabular}{|c|c|c|c|}
\hline E Anarite & Renut & Mod & Unit \\
\hline 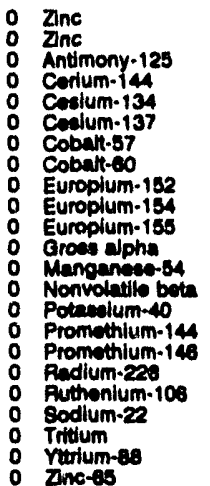 & $\begin{array}{l}6.8 \\
7.0 \\
<2.0 E-06 \\
<6.0 E-08 \\
<1.0 E-06 \\
<1.0 E-08 \\
<1.0 E-08 \\
<1.0 E-08 \\
<4.0 E-08 \\
<2.0 E-00 \\
<3.0 E-00 \\
<2.0 E-09 \\
<1.0 E-08 \\
<2.0 E-09 \\
<1.1 E-07 \\
<1.0 E-08 \\
<1.0 E-08 \\
1.0 E-09 \\
<8.0 E-08 \\
<1.0 E-08 \\
<7.0 E-07 \\
<6.0 E-09 \\
<2.0 E-08\end{array}$ & & 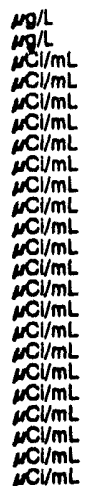 \\
\hline
\end{tabular}

\section{WELL SRW 3A}

MEASUAEMENTS CONOUCTED IN THE FIELD

Sample date: $07 / 11 / .02$
Depth to water: $118.77 \mathrm{n}(39.20 \mathrm{~m})$ below TOC
Wetor olevation: $213.33 \mathrm{n}(\mathrm{BS} .02 \mathrm{~m}) \mathrm{msl}$

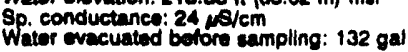

LABOAMTOAY ANALYSES

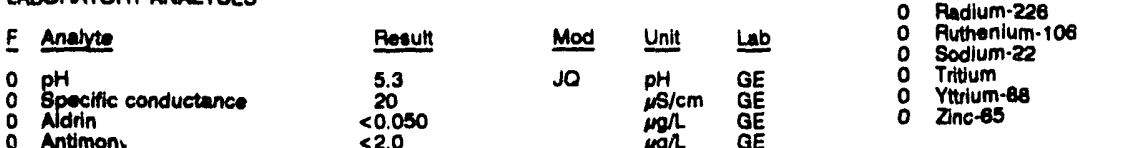

WELL SAW 3A collected on 07/11/92, laboratory analyeer (cont.)
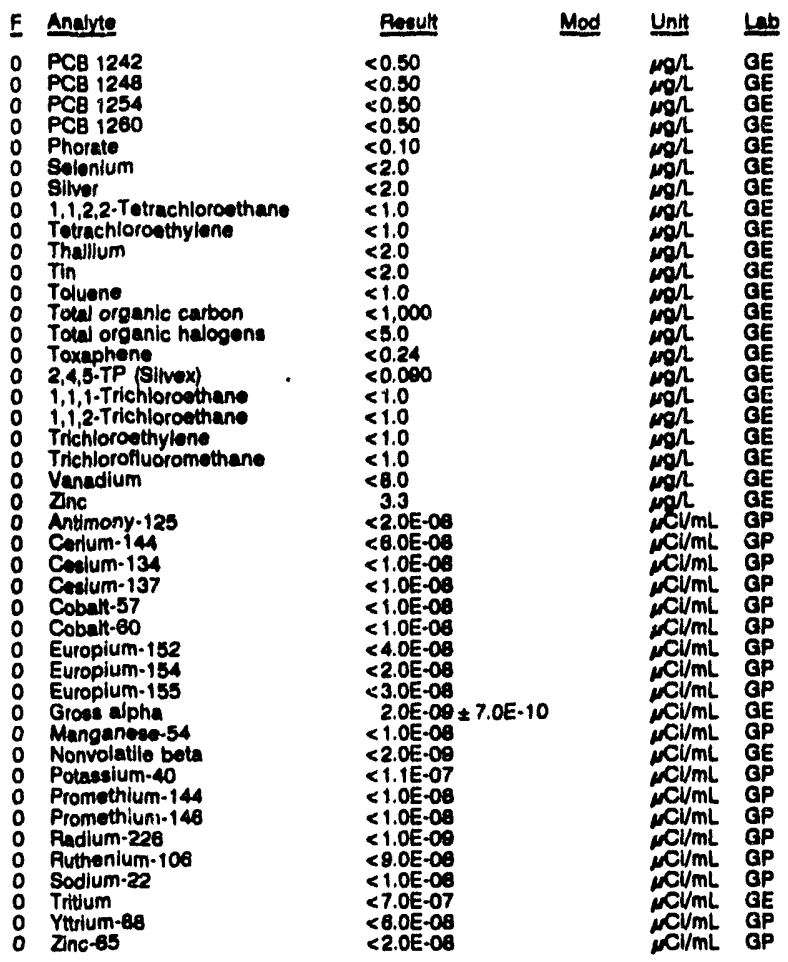

\section{WELL SRW 4}

MEASUREMENTS CONDUCTED IN THE FIELD

\begin{tabular}{|c|c|}
\hline 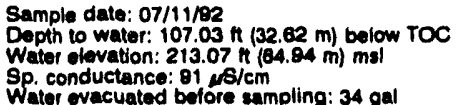 & $\begin{array}{l}\text { Time: } 11: 40 \\
\text { oH: } 4.7 \\
\text { Alkalinity: } 0 \mathrm{mgn} \\
\text { Water temperature: } 32.3 \cdot \mathrm{C}\end{array}$ \\
\hline
\end{tabular}
Water evacuated bofore sumpling: $34 \mathrm{gal}$

LABOAATOAY ANALYSES

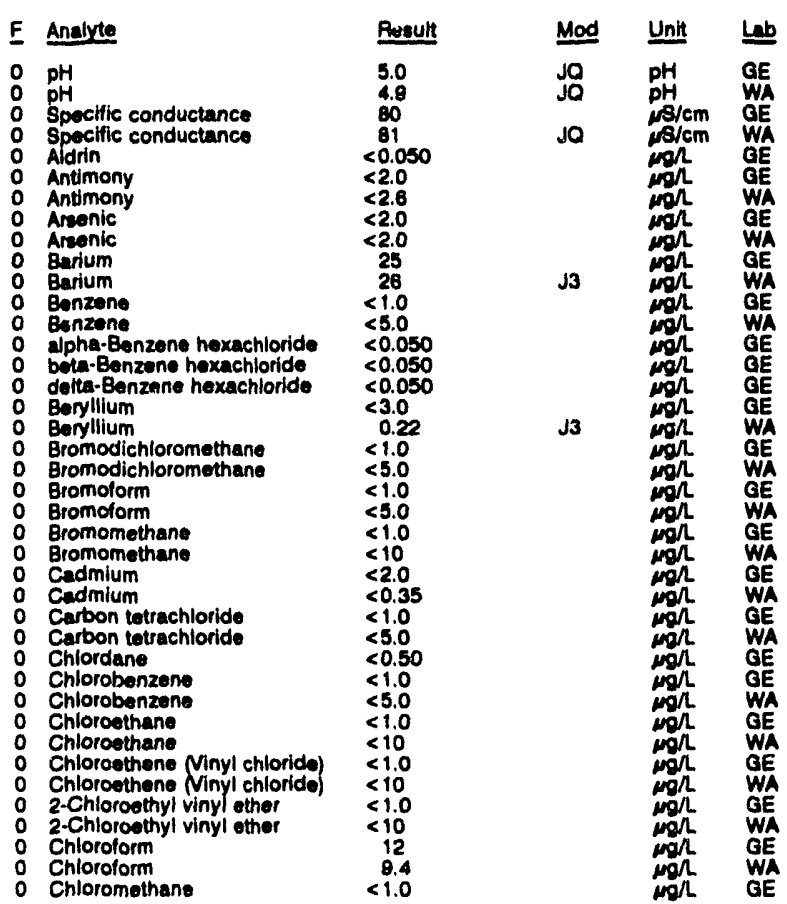


ANALYTICAL RESULTS

WELL 8FW a colbeted on 07/11/82, laboratory analywes (cont.)

\begin{tabular}{|c|c|c|c|c|c|c|}
\hline I Analyte & Result & Mod & Unit & $\underline{L A b}$ & $\underline{F}$ & Analyte \\
\hline 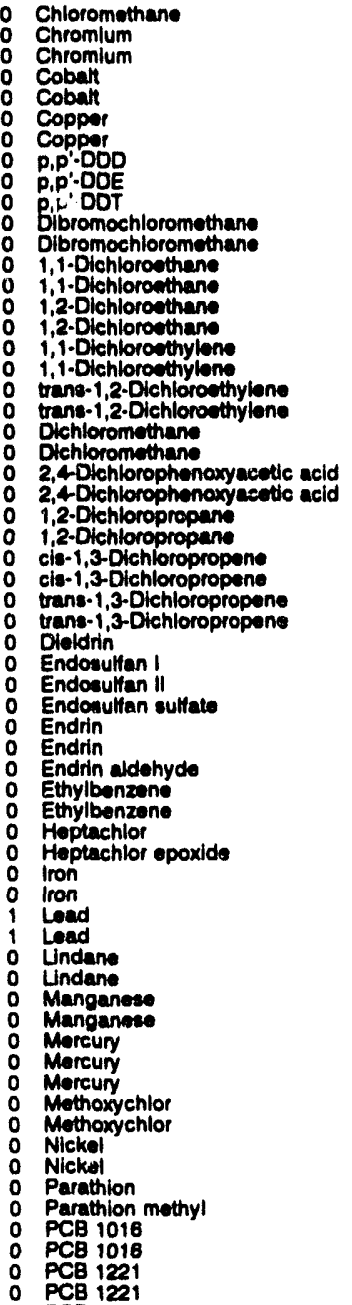 & $\begin{array}{l}<10 \\
<4.0 \\
<1.1 \\
<4.0 \\
1.6 \\
62 \\
70 \\
<0.10 \\
<0.10 \\
<0.10 \\
<1.0 \\
<5.0 \\
<1.0 \\
<5.0 \\
<1.0 \\
<5.0 \\
<1.0 \\
<5.0 \\
<1.0 \\
<5.0 \\
1.5 \\
8.2 \\
<0.30 \\
<1.0 \\
<1.0 \\
<5.0 \\
<1.0 \\
<5.0 \\
<1.0 \\
<5.0 \\
<0.50 \\
<0.10 \\
<0.10 \\
<0.10 \\
<0.0060 \\
<0.11 \\
<0.10 \\
<1.0 \\
<5.0 \\
<0.050 \\
<0.050 \\
<4.0 \\
18 \\
14 \\
115 \\
<0.0050 \\
<0.055 \\
16 \\
17 \\
<0.20 \\
<0.20 \\
<0.20 \\
<0.50 \\
<0.55 \\
<4.0 \\
<3.1 \\
<0.050 \\
<0.050 \\
<0.50 \\
<0.55 \\
<0.50 \\
<0.55\end{array}$ & $\mathbf{J 3}$ & 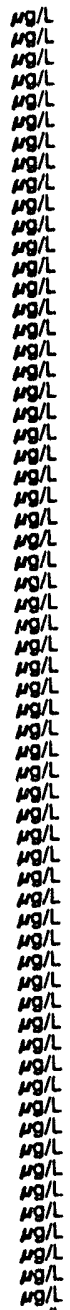 & 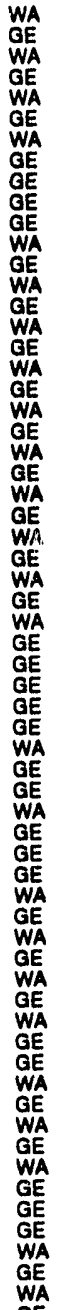 & $\begin{array}{l}0 \\
0 \\
0 \\
0 \\
0 \\
0 \\
0 \\
0 \\
0 \\
0 \\
0 \\
0 \\
0 \\
0 \\
0 \\
0 \\
0 \\
0 \\
0 \\
0 \\
0 \\
0 \\
0 \\
0 \\
0 \\
0 \\
0 \\
0 \\
0 \\
0 \\
0 \\
0 \\
0 \\
0 \\
0 \\
0 \\
0 \\
0 \\
0 \\
0 \\
0 \\
0 \\
0 \\
0 \\
0 \\
0 \\
0 \\
0 \\
0 \\
0 \\
0 \\
0 \\
0 \\
0 \\
0 \\
0 \\
0 \\
0 \\
0 \\
0 \\
0 \\
0\end{array}$ & 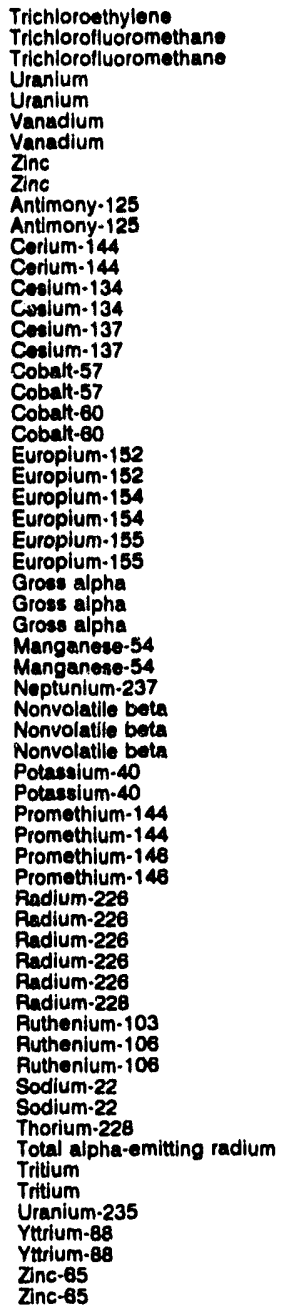 \\
\hline
\end{tabular}

WELL SRW 4 collected on 07/11/82, laboratory analyese (cont.)

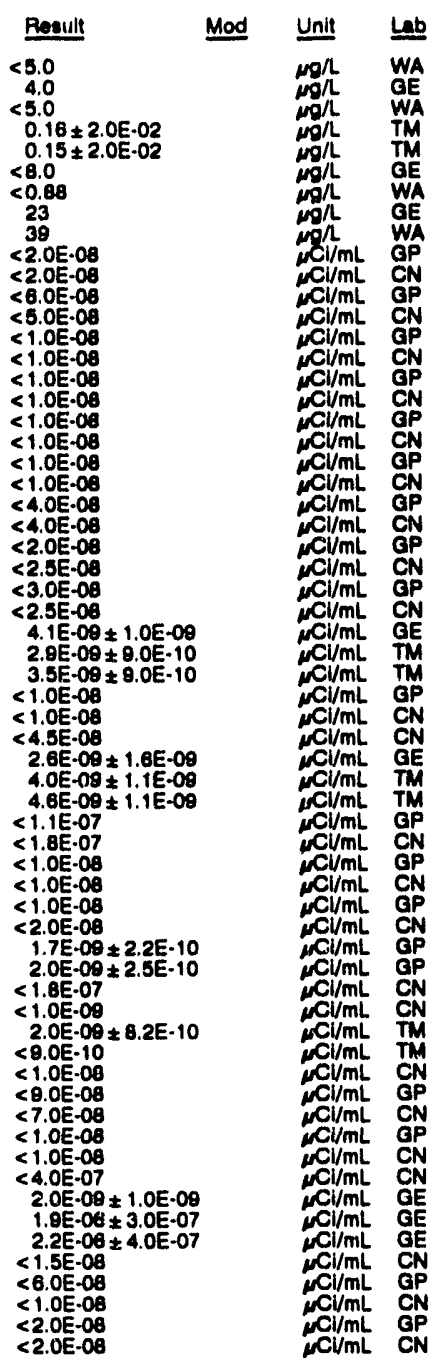

\section{WELL SRW 4 Replicate}

MEASUREMENTS CONDUCTED IN THE FIELD

$\begin{array}{ll}\text { Sample date: } 07 / 11 / 92 & \text { Time: } 11: 40 \\ \text { Depth to water: } 107.03 \mathrm{n}(32.62 \mathrm{~m}) \text { below TOC } & \text { pH: } 4.7 \\ \text { Water alevation: } 213.07 \mathrm{Ht}(84.94 \mathrm{~m}) \mathrm{mal} & \text { Alkalinity: } 0 \mathrm{mg} / \mathrm{h} \\ \text { Sp. conductance: } 91 \mu \mathrm{s} / \mathrm{cm} & \text { Water tomperature: } 22.3 \circ \mathrm{C} \\ \text { Water ovacuated betore sampling: } 34 \mathrm{gal} & \end{array}$
LABORATORY ANALYSES

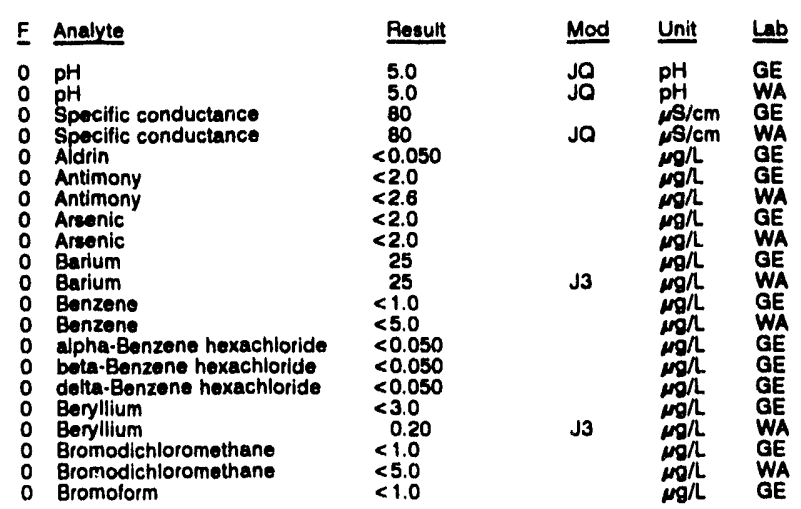


ANALYTICAL RESULTS

WELL SFW 4 collectod on 07/11/82, laboratory analyses (cont.)

E Anevere

Bromotorm

o Bromomethane

o Cadmium

- Carbon tetrachloride

Curbon totrachloride

Chlordane

Chiorobenzene

Chlorothane

Chlorothene Mnyl chloride)

Chorewene Vinyl chlorida)

2-Chloroethyl vinyl ther

2-Chlorowyl vinyl other

Chioroform

Chloroform

Chloromethane

Chromium

O Chromium

Cobali

o Copper

o copper

P.p.:DOE

Gibromochloromethene

Dibromochloromethane

1,1-Dichloroethan

1,2.Dichloromenthe

1,2-Dichloroethen

1,1-Dichiorowhylons

trans-1,2-Dichloroethylene

trans-1,2-Dichloroethylen

Oichloromethans

2,4-Dichlorophenoxyacetic acid

2,4Dichlorophenoxyacetic acid

2,4-Olchlorophenaxyacetic acid <1.0

1,2-Dichtoropropan

1,2-Dichloropropane

cis-1,3-Dichloropropene

trans-1,3-Oichloropropene

trans-1,3-

Endosultan 1

Endosulian II

Endrin

Endrin

Endrin aldehyde

Ethylbenzene

Ethylbenzen

Hoptachlor apoxide

Iron

Iron

Lead

Undane

Mindane

Manganese

Mercury

Morcury

Mathoxychlor

Nickel

Nickel

Parattion methyl

PCB 1016

PCB 1016

PCB 1221

PCB 1232

PCB 1232

PCB 1242

PCB 124

PCB 1249

PCB 1254

PCB 1254

PCB 1280

Phorato

Solenium

Sllver

Siver

$1,1,2,2 \cdot$ Tetrachloroethane
$1,1,2,2-$ Tetrachloroethane

o Tetrachloroethylene

$\div 5.0$

$<1.0$

$<2.0$

$<1.0$

$<0.50$

$<1.0$

$<1.0$

$<1.0$

$<10$

$<10$
13

9.7

$<<1.0$

24.0

$<4.0$
$<0.88$

84
80
$<0.10$

$<0.10$

$<1.0$

$<5.0$

$<1.0$

$<5.0$

$<1.0$

$<5.0$

$<1.0$

1.0

0.30

$<1.0$

$<5.0$

$<5.0$

$<1.0$

$<0.50$

$<0.10$

$<0.10$

$<0.0060$

$<0.11$

$<1.0$

$<5.0$

$<0.050$

$<4.0$
39
14

14
17
$<0.005$

0.055

17
17

$<0.20$

$<0.20$

$<0.55$

$<4.0$

$<0.250$

$<0.050$

$<0.50$

$<0.55$

0.5

0.55

0.50

$<0.55$

$<0.55$

$<0.55$

$<1.50$

$<0.50$

$<0.50$
$<1.1$
$<0.10$

3.1
3.6
$<2.0$

$<2.0$
$<0.70$
$<1.0$

$<1.0$
$<5.0$

$<5.0$
$<1.0$
$<5.0$

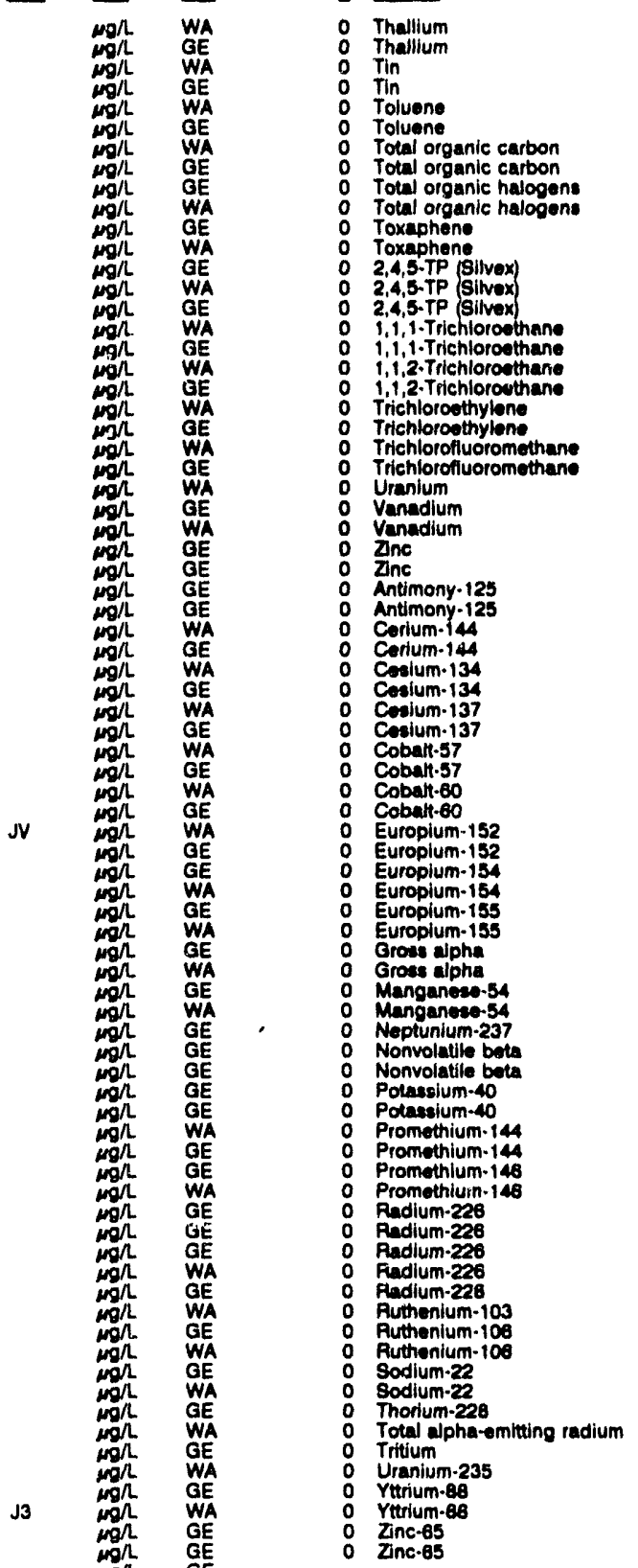

E Anatyte

Thallium

Tin

Toluene

Total organic carbon

Total organic carbon

Total organic halogena

. Trichioroethane

, 2. Trichloropthane

Trehtore

Uranium

Antimony-125

Corlum-144

Cosium-134

Cosium.137

uropium-152

Neptunium-237

Plassium-40

Tritium

Zinc-65

\section{WELL SRW 5}

MEASUREMENTS CONDUCTED IN THE FIELD

Depth to water: $88.11 \mathrm{ft}(29.80 \mathrm{~m})$ below TOC

Water olevation: $211.28 \mathrm{~h}(64.40 \mathrm{~m}) \mathrm{msl}$

Water ovacuated before sampling: $14 \mathrm{gal}$

LABORATORY ANALYSES

\begin{tabular}{|c|c|c|c|c|}
\hline $\mathbf{F}$ & Analyte & Result & Mod & Unit \\
\hline $\begin{array}{l}\text { O } \\
0 \\
0 \\
0 \\
0\end{array}$ & $\begin{array}{l}\text { pH } \\
\text { pH } \\
\text { Specific conductance } \\
\text { Addrin } \\
\text { Antimony } \\
\text { Arenic }\end{array}$ & $\begin{array}{l}5.3 \\
5.3 \\
35 \\
<0.050 \\
<2.0 \\
<2.0\end{array}$ & $\begin{array}{l}\text { JO } \\
\text { JO }\end{array}$ & 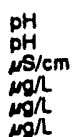 \\
\hline
\end{tabular}


ANALYTICAL RESULTS

WELL SAW S collectad on 07/11/92, laboratory analyses (cont)

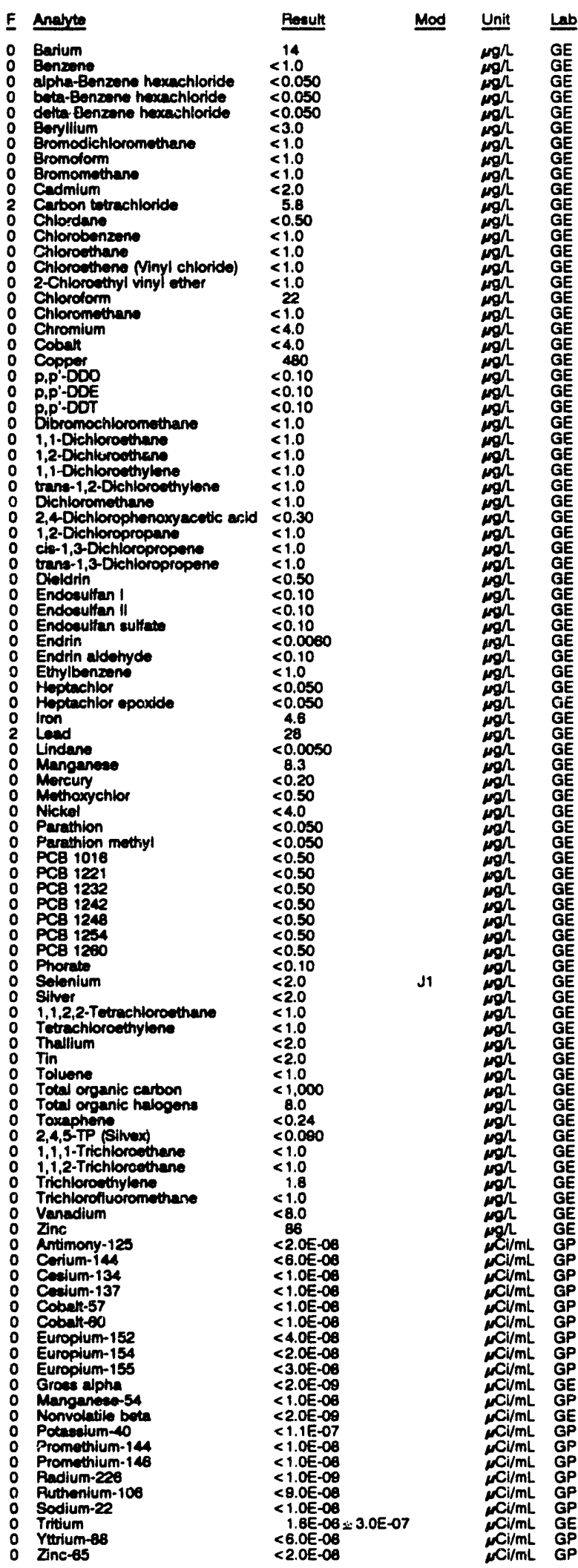

WELL SRW 6

MEASUREMENTS CONDUCTED IN THE FIELD

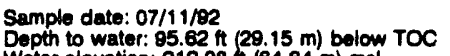
Water elevation: 21200 ht

Sp. conductance: $55, \mu \mathrm{s} / \mathrm{cm}$ Water evacuated betore sempl

LABOPATORY ANALYSES

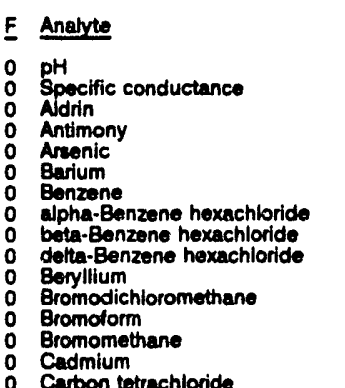

0 Cadmium

Cubon tetrachloride

Chlordane

Chlorotenzene

Chloroethane

2-Chioroethyl vinyl ether

Chloroform

Chloromethane

Cobat

Copper

$p, p^{\prime} \cdot D$ Do

P,P, $-\mathrm{DOE}$

Dibromochloromethane

1,1-Dichloroethane

1,2-Dichioroethane

o 1,1-Dichloroethylene

Dichloromethane

2,4-Dichlorophenoxyaceoc $<1.0$

1,2-Dichloropropane

cis-1,3-Dichloropropene

Dieldrin

Endosultan I

Endosentian sulfate

Endrín

Endrin aldohyde

Ethylbenzen

Heptachlor apoxide

Iron

0 Lindane

- Manganese

Mercury

Nickel

Parathion

PCB 1016

PCB 1221

PCB 1242

PCB 1248

0 PCB 1254

o Phorate

S Selenium

1,1,2,2-Tetrachi-zisthane

- Tetrechioroethyk:s

Thallium

Tin

- Toluene

Total organic carbon

Total organic halogens

Taxaphene

1,1,1-Trichloroethene

i, 1, 2-Trichloroethane

Trichloroethylone

Varsadium

: Vanad

O Antimony-125

Antimony.125

Corium. 144

Cosium-134

Cosium-134
Time: 13:05

pH: 5.0

Alkalinity: 1 mo/

Water temperature: $22.5^{\circ} \mathrm{C}$

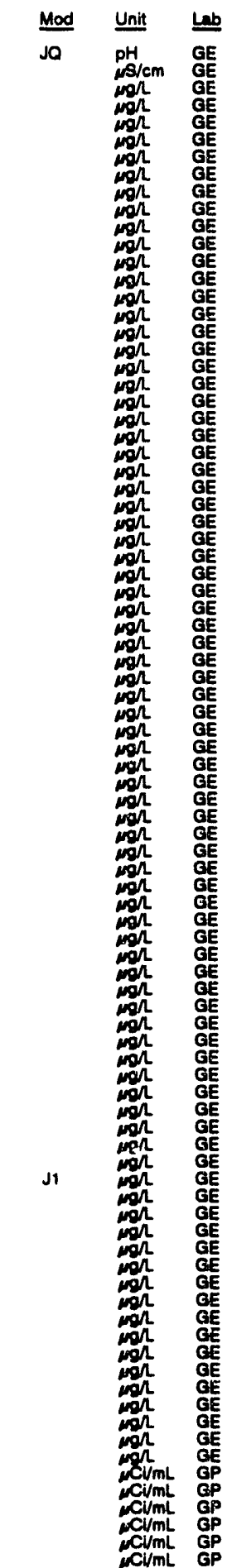

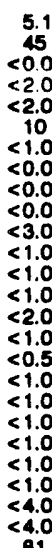

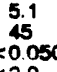

$<1.0$

$<0.050$

$<0.050$

$<1.0$

$<1.0$
$<1.0$

$<1.0$
$<2.0$
$<1.0$

$<0.50$

$<1.0$

$<1.0$

$<1.0$

$<4.0$

$<4.0$
81
$<0.10$

$<0.10$

$<1.0$

$<1.0$

$<1.0$

$<0.73$
$<1.0$
$<1.0$
$<1.0$

$<1.0$

$<0.50$

$<0.10$

$<0.10$

$<0.0060$

$<0.10$
$<1.0$

$<0.050$

$<0.050$

$<11.00$

6.5

$<0.20$
$<0.50$

$<4.0$

$<0.050$

$<0.50$

$<0.50$

$<0.50$

$<0.50$

$<0.50$

$<0.50$

$<2.0$

$<2.0$

$<1.0$

$<2.0$

$<2.0$

$<1,000$

$<1,000$
$<0.24$

$<0.000$

$<1.0$

$<1.0$

3.8
$<8.0$

$<2.0 E-00$

$<2.0 E-00$

$<6.0 E-06$

$<1.0 \mathrm{e}-08$ 
ANALYTICAL RESULTS

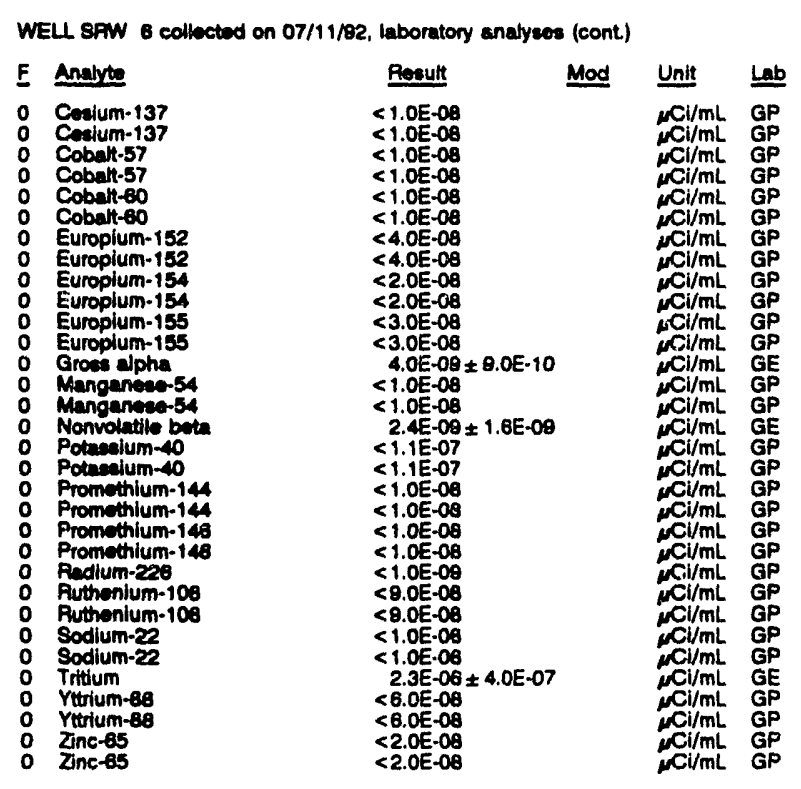

\section{WELL SRW 7}

MEASUPEMENTS CONDUCTED IN THE FIELD

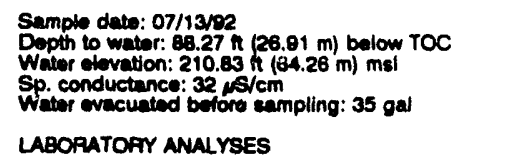

\section{Time: : :05 \\ PH: 5.1 inity: $2 \mathrm{mg} /$ \\ water tompergure: $20.8^{\circ} \mathrm{C}$}

TOFY ANALY YSES

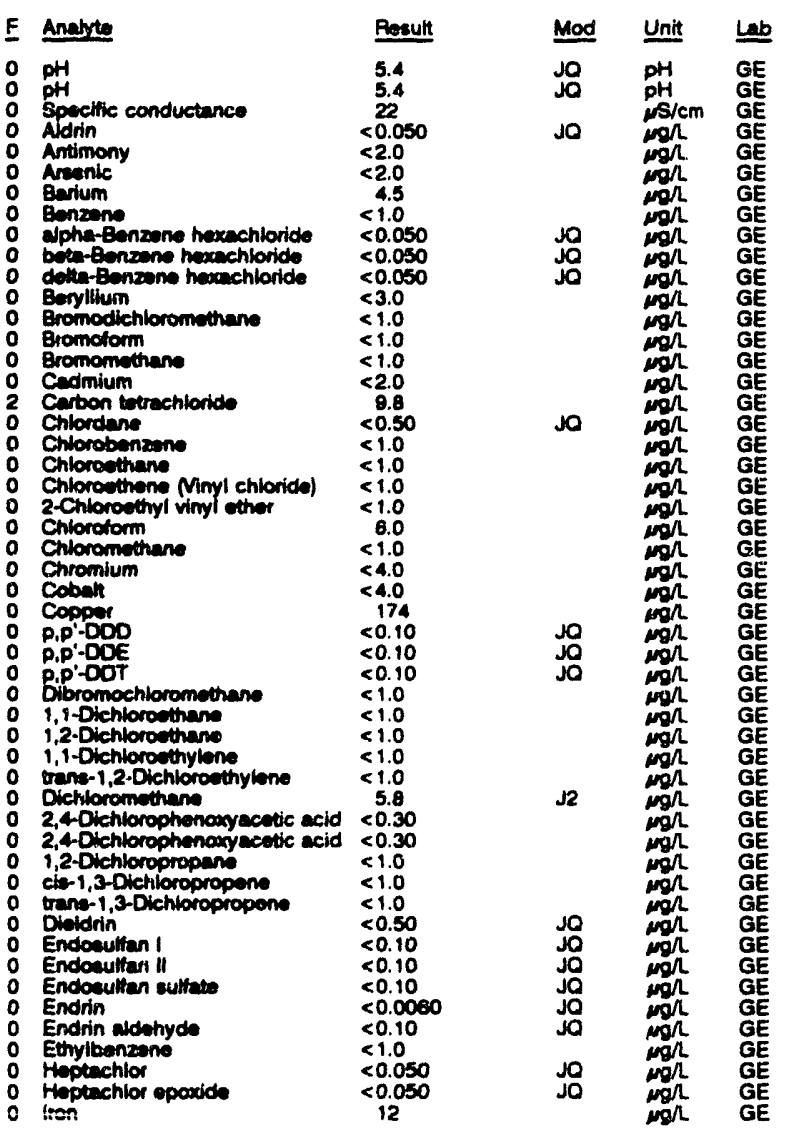

WELL SFW 7 cellseled on 07/13/82, laboratory analyses (cont)

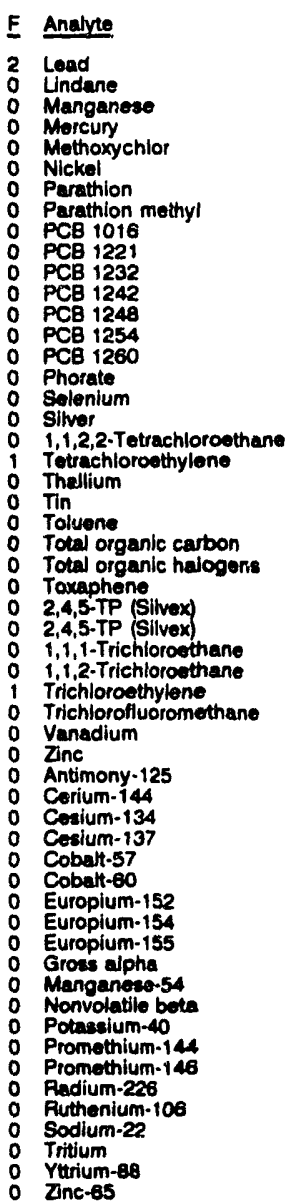

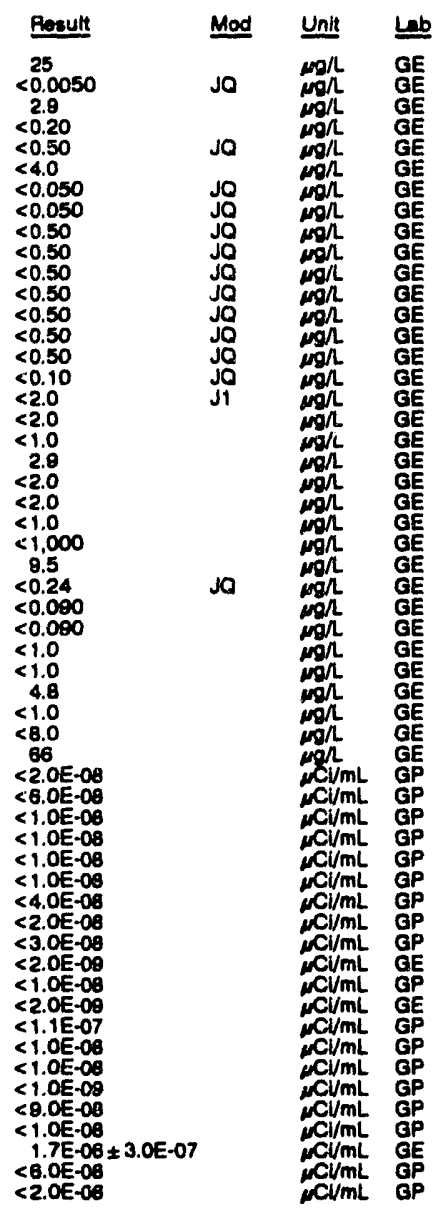

\section{WELL SRW 8}

MEASUREMENTS CONDUCTED IN THE FIELD

Sample dato: 0711270

Depth to water: $79.43 \mathrm{n}(24.21 \mathrm{~m})$ bolow TOC

Water olevation: $208.67 \mathrm{~h}(63.60 \mathrm{~m}) \mathrm{mst}$

Water evecuated betores sampling: 34 gal

LABOFATORY ANALYSES

\begin{tabular}{|c|c|c|c|c|}
\hline Analyte & Renult & Mod & Unit & Leb \\
\hline 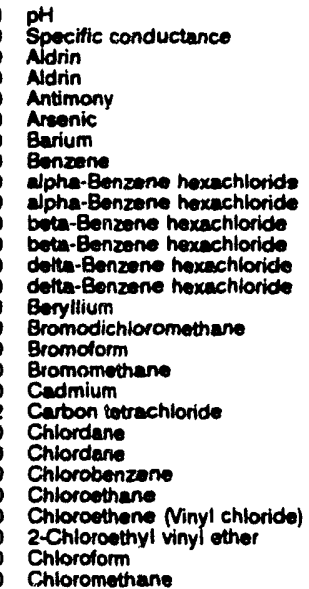 & $\begin{array}{l}5.8 \\
20 \\
<0.050 \\
<0.050 \\
<2.0 \\
<2.0 \\
3.6 \\
<1.0 \\
<0.050 \\
<0.050 \\
<0.050 \\
<0.050 \\
<0.050 \\
<0.050 \\
<3.0 \\
<1.0 \\
<1.0 \\
<1.0 \\
<2.0 \\
6.9 \\
<0.50 \\
<0.50 \\
<1.0 \\
<1.0 \\
<1.0 \\
<1.0 \\
1.3 \\
<1.0\end{array}$ & هJ & 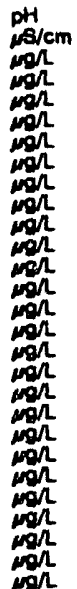 & $\begin{array}{l}G E \\
G E \\
G E \\
G E \\
G E \\
G E \\
G E \\
G E \\
G E \\
G E \\
G E \\
G E \\
G E \\
G E \\
G E \\
G E \\
G E \\
G E \\
G E \\
G E \\
G E \\
G E \\
G E \\
G E \\
G E \\
G E \\
G E \\
G E\end{array}$ \\
\hline
\end{tabular}

Time: 13:20

Alkalinity: $3 \mathrm{~mol}$

Whete temperature: $2280 \mathrm{C}$ 
ANALYTICAL RESULTS

WELL SFW 8 collectod on 07/12/92, laboratory analyses (cont)

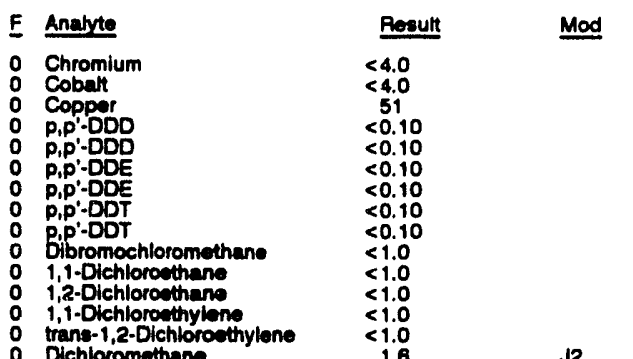

O trans-1,2-Dichloroethylene

2,4-Dichlorophenoxyacetic acid
1,2-Dichloropropane

1,2-Dichloropropane

trans-1,3-Dtehloropropene

0 Dieldrin

Dieidrin

Endosulfan I

Endosulfan II

Endoculfan aulfoto

Endoaulfan sulfato

Endrin

Endrin aldehyde

Endrin aldehyde

Ethylbanzen

Heptachitor

Heptachlor

Heptachlor epoxide

Iron.

Lindane

Undane

Manganese

Mercury

Mercury

Mrthoxychlor

Nickel

Parathion

Parathion

Parathion methy

PCB 1016

PCB 122

PCE 122

PCB 1232

PCB 124

PCB 1248

PCB 1248

PCB 1254

PCB 125

PCB 1280

Phorato

Phorate

Silver

1,1,2,2-Tetrechloroethane

Tetrechloroethylene

- Thallium

Ton

Total organic carbon

Totel organic halogens

- Toxaphone

Toxaphene

1,1,1-Trichloroethane

1,1,2-Trichles:thane

2 Trichlosoethyione

Trichlorofluor

Zne

Antimony-12

Corium-144

Cosium-134

Cealum-137

Cobalt-57

Europlum-152

Europlum-154

Europlum-15s

Groes alphe

Nonvolatib beta

Potratulum-40

Promethium-14

Promethium-148

Radium-226
Mod Unit Le

$\begin{array}{llll}\mu g / L & G E & 0 & \text { Ruthenium-108 } \\ \mu g / L & G E & 0 & \text { Sodium-22 } \\ \mu g / L & G E & 0 & \text { Tritum } \\ \mu g / L & \text { GE } & \text { GE } & \text { Yttrium-68 } \\ \mu g / L & \text { GE } & 0 & \text { Znc-65 }\end{array}$

WELL SRW 9

MEASUREMENTS CONDUCTED IN THE FIELD

Sample date: 07/12/82

Depth to water: $53.45 \mathrm{kt}(18.29 \mathrm{~m})$ bolow TOC

Water elevation: $189.85 \mathrm{ht}$

Water ovacuated before sampling: $86 \mathrm{gal}$

LABORATORY ANALYSES

F Analyte

: $\mathrm{pH}$ Specific conductance

Addrin

- Adrín

o Antimony

Antimony

0 Arsenic

0 Barium

Benzene

lpha-Benzene hexachlorido

apha-Benzene hoxachloride

beta-Benzene hoxachloride

beta-Bonzene hexachlorido

delta-Benzene hexachloride

delta-Benzon

Bromodichloromethane

Bromoform

o Bromomethan

- Cadmium

Carton tetrachloride

Chlordane

Chlorobenzene

o Chloroethane

Chloroethene Ninyl chloride)

2-Chloroethyl vinyl ether

Chloroform

o Chloromethane

o Chromium

O Cobalt

0 Copper

$\begin{array}{ll}0 & \text { p,p'-DDD } \\ 0 & \text { p,p'-DDD }\end{array}$

O p,p'-DDD

o p,p'-DDE

0 P.P'-DDT

O Bibromochloromethane

1,1-Dichioroethane

o 1,2-Dichioroethane

1,2-Dichloroethane

0 trans-1,2-Dichloroethylene

Dichloromenthane

2,4-Dichlorophenoxy

- 1,2-Dichloropropane

o cis-1,3-Dichloropropene

trans-1,3

${ }_{0}$ Dieldrin

o Endosutfan

Endosuttan

Endosuttan I

Endosutian II

Endosulfan sulfate

${ }_{0}$ Endrin

O Endrin

0 Endrin aldehyde

O Endrin aldehyde

0 Ethylbenzene

0 Hoptachlor

- Heptachlor

Heptachlor epoxide

Heptachlor epoxide

Iron

o Lead

Lindan

Lindane.

O Manganeso

Methoxychlor

Methoxychlor

Nickel.

Parathion
0 Parathion

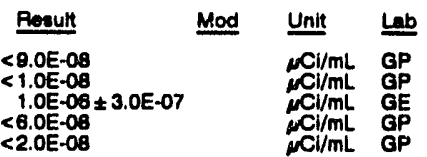

\section{Time: 15:45}

Wkalinity: $1 \mathrm{mg} / \mathrm{l}$

Water temperature: $21.7^{\circ} \mathrm{C}$

Result

Besult Mod Unit Lab

5.3

$<0.050$

$<2.0$

$<2.0$

$<2.0$

4.3
$<1.0$

$<0.050$

$<0.050$

$<0.050$

$<0.050$

$<0.050$

$<3.0$

$<1.0$

$<1.0$
$<2.0$
$<1.0$
$<0.50$

$<0.50$

$<0.50$

$<1.0$

$<1.0$
$<1.0$
$<1.0$

$<1.0$

$<4.0$

16
$<0.10$

$<0.10$

$<0.10$

$<0.10$

$<0.10$

$<1.0$
$<1.0$
$<1.0$
$<1.0$

$<1.0$

5.6

$<0.30$

$<1.0$

$<1.00$

$<0.50$
$<0.50$
$<0.10$

$<0.10$

$<0.10$

$<0.10$

$<0.10$

$<0.0080$

$<0.006$

$<0.10$

$<1.0$

$<0.050$

$<0.050$

$<0.050$

$<0.050$

4.3
5.1
5.2

$<0.0050$

2.2

$<0.20$

$<0.50$

$<0.50$

$<4.0$
$<0.050$
$<0.050$

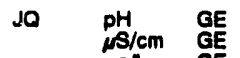

LO $\quad \mathrm{pH} / \mathrm{GE}$

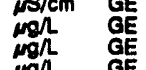


ANALYTICAL RESULTS

WELL SRW 8 collected on 07/12/92, laboratory analyses (cont)

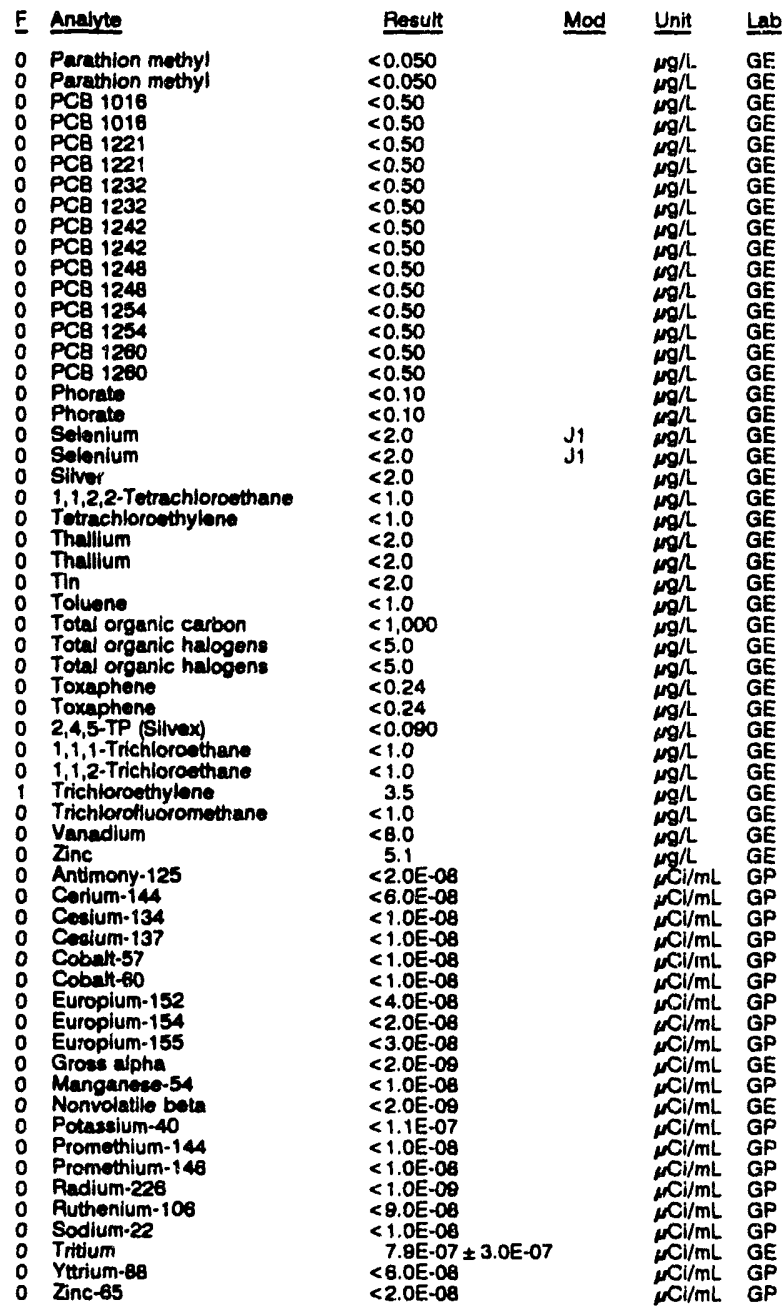

\section{WELL SRW 9A}

MEASUAEMENTS CONDUCTED IN THE FIELD

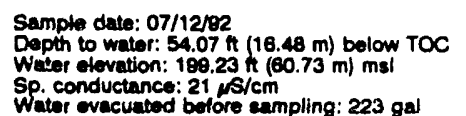

Time: 15:20

$\mathrm{pH}: 4.8$

Alkalinity: $0 \mathrm{mon}$

Water tomperalure: $22.00^{\circ} \mathrm{C}$

LABORATOAY AMALYYSES

\begin{tabular}{|c|c|}
\hline & Analyte \\
\hline & 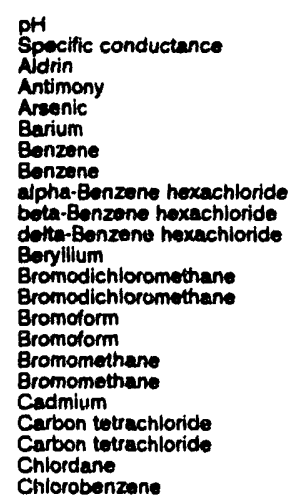 \\
\hline
\end{tabular}

\begin{tabular}{l} 
Plosulk \\
\hline 5.2 \\
20 \\
$<0.050$ \\
$<2.0$ \\
$<2.0$ \\
3.4 \\
$<1.0$ \\
$<1.0$ \\
$<0.050$ \\
$<0.050$ \\
$<0.050$ \\
$<3.0$ \\
$<1.0$ \\
$<1.0$ \\
$<1.0$ \\
$<1.0$ \\
$<1.0$ \\
$<1.0$ \\
$<2.0$ \\
$<1.0$ \\
$<1.0$ \\
$<0.50$ \\
$<1.0$
\end{tabular}

WELL SPW OA collocted on 07/12/92, laboratory analyses (cont.)

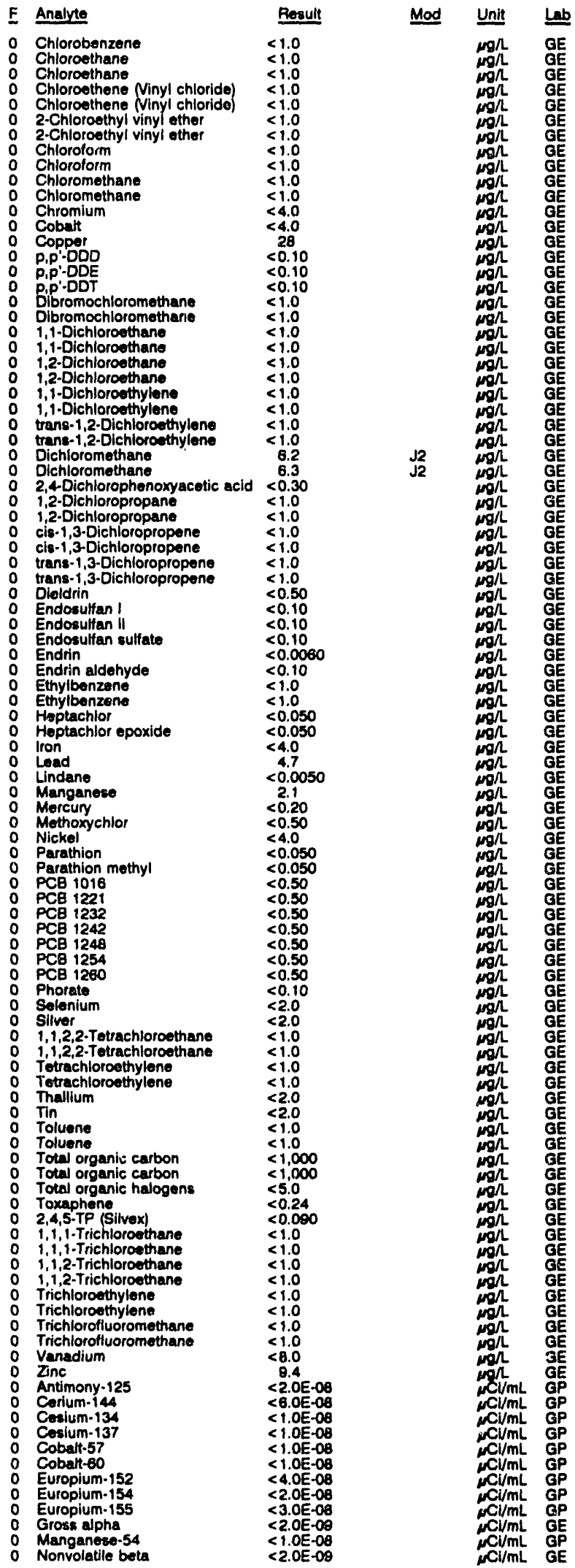


ANALYTICAL RESULTS

WELL 8FW OA collected on 07/12/82, laboratory analyees (cont)

\begin{tabular}{|c|c|c|c|}
\hline Analyte & Rosult & Mod & Unit \\
\hline $\begin{array}{l}\text { Potasalum-40 } \\
\text { Promethium-144 } \\
\text { Promethium-146 } \\
\text { Padium-226 } \\
\text { Puthenium-106 } \\
\text { Sodlum-22 } \\
\text { Tritum } \\
\text { Ytrum-68 } \\
\text { Znc-65 }\end{array}$ & $\begin{array}{l}<1.1 E-07 \\
<1.0 E-08 \\
<1.0 E-08 \\
<1.0 E-09 \\
<8.0 E-08 \\
<1.0 \text { E-08 } \\
2.3 E-06 \pm 3.0 E-07 \\
<6.0 E-08 \\
<2.0 E-08\end{array}$ & & 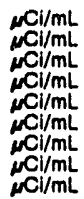 \\
\hline
\end{tabular}

WELL SRW 9B

MEASUREMENTS CONDUCTED IN THE FIELD

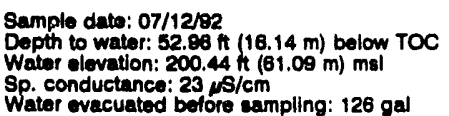

$$
\text { Time: 15:00 }
$$

pH: 5.0

Alkalinity: $1 \mathrm{mg} /$

Water tomperature: $22.5^{\circ} \mathrm{C}$

LABORATOAY ANALYSES

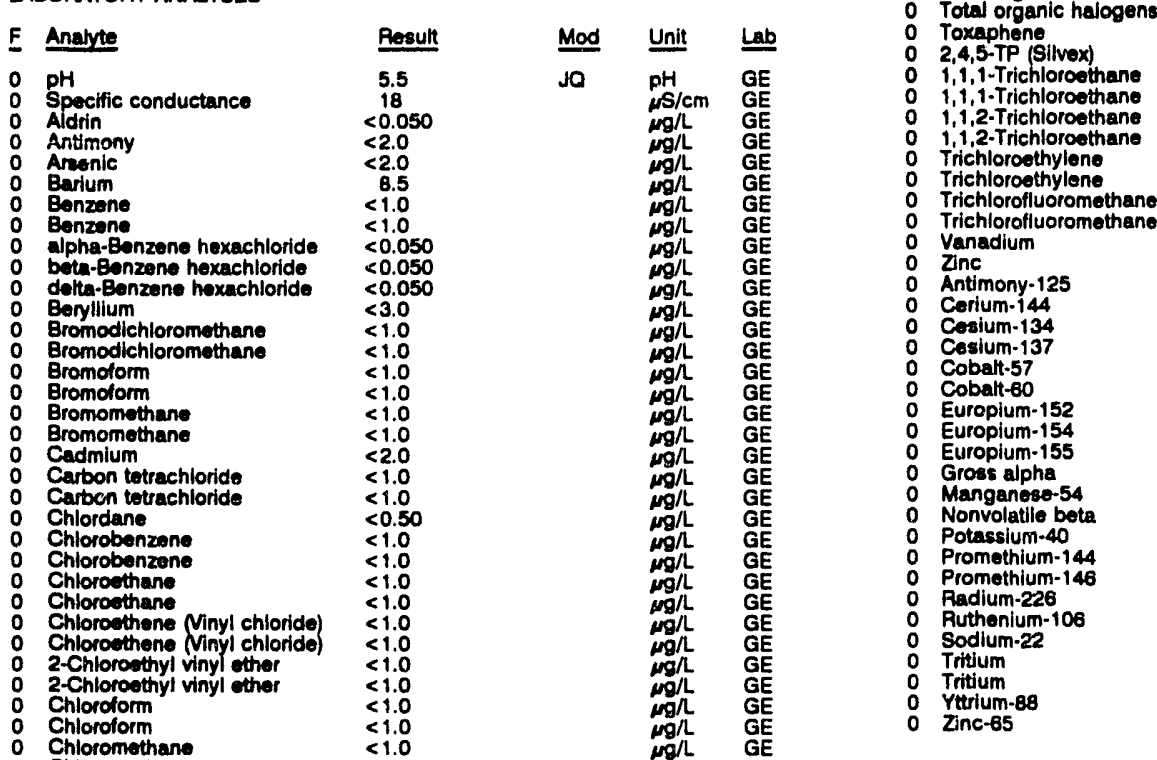

WELL SRW 10

MEASUREMENTS CONDUCTED IN THE FIELD

Sample date: 07/13/92

Depth to water: Nol available

Water elevation: Not available

Sp. conductance: $21 \mu \mathrm{s} / \mathrm{cm}$.

LABORATORY ANALYSES

\begin{tabular}{|c|c|c|}
\hline & Analyte & Result \\
\hline & $\begin{array}{l}\text { pH } \\
\text { Specific conductance } \\
\text { Adrin } \\
\text { Antimony } \\
\text { Arsenic } \\
\text { Barium } \\
\text { Barium } \\
\text { Benzene } \\
\text { alpha-Benzene hoxachloride } \\
\text { beta-Benzene hexachloride } \\
\text { delta-Benzene hexachloride } \\
\text { Beryllium } \\
\text { Beryllium } \\
\text { Bromodichloromethane } \\
\text { Bromoform } \\
\text { Bromomethane } \\
\text { Cadmium } \\
\text { Cadmium } \\
\text { Carbon totrachloride } \\
\text { C:lordane } \\
\text { Chlorobenzene } \\
\text { Chloroethane } \\
\text { Chloroethene Ninyl chloride) } \\
\text { 2-Chloroethyl vinyl other } \\
\text { Chloroform }\end{array}$ & $\begin{aligned} & 5.4 \\
& 20 \\
&<0.050 \\
&<2.0 \\
&<2.0 \\
& 3.9 \\
& 3.9 \\
&<1.0 \\
&<0.050 \\
&<0.050 \\
&<0.050 \\
&<3.0 \\
&<3.0 \\
&<1.0 \\
&<1.0 \\
&<1.0 \\
&<2.0 \\
&<2.0 \\
& 1.6 \\
&<0.50 \\
&<1.0 \\
&<1.0 \\
&<1.0 \\
&<1.0 \\
& 1.1\end{aligned}$ \\
\hline
\end{tabular}

Time: 8:00

PH: 5.1 . $1 \mathrm{mal}$

Water temperature: $20.0^{\circ} \mathrm{C}$

1.1-Dichloroethane

1,1-Dichlorothane

o 1,2-Dichioroethane

o 1,1-Dichloroethylene

trans-1,2-Dichloroethylen

trans-1,2-Dichloroethylene

o Dichloromethane

o 2,4-Dichlorophenoxyacetic acid $<0.30$

o 1,2-Dichloropropane

eis-1,3-Dichloropropene $<1.0$

0 cta-1,3-Dichloropropene $<1.0$

0 trans-1,3-Dichloropropene $<1.0$

$\begin{array}{lll}0 & \text { trans-1,3-Dichloropropene } & <1.0 \\ 0 & \text { Dieldrin } & <0.50\end{array}$

- Endoesultan II $<0.10$

$\begin{array}{ll}0 & <0.10 \\ 0 & <n d r i n\end{array}$

0 Endrin aldehyde $<0.10$

Ethylbenzene $\quad<1.0$

Heptachlor opoxide $\quad<0.050$

o iron

0 Lindane

o Manganese

4.9
$<3.0$

$<0.0050$

4.6
$<0.20$

0 Chloroform

$<0.50$

$<0.050$

$<0.50$

$<0.50$

$<0.50$

$<0.50$

2.0

$<1.0$

$<1.0$

$<2.0$

$<1.0$

$<1,000$

$<0.24$

$<1.0$

$<1.0$

$<1.0$

$<1.0$

$<8.0$

$<2.0 E-08$

$<6.0$ E-08

$<1.0 E-09$

$1.0 \mathrm{E}-08$

$2.0 E-08$

$6.1 E-09 \pm 1.1 E-09$

3.7E-09 $\pm 1.6 E-09$

$<1.1$ E-07
$<1.0 \mathrm{E}-08$

$<1.0 \mathrm{OE} .08$

$9 E-09 \pm 3.1 E-10$

$<1.0 \mathrm{E}-0$

$<7.0 E-07$

$<6.0 \mathrm{E}-0 \mathrm{~B}$

Mod Unit Lab

$\mu g / L$
$\mu g$
$\mu g /$
$G E$

$\mu g /$ GE

$\mathrm{mg} / \mathrm{GE}$

$\operatorname{mggh}_{\text {GE }}$ GE

woh GE

$\log _{\mu \mathrm{g} \Omega} \mathrm{GE}$

$\mathrm{ggh}$

$\mathrm{mgh}$ GE

$\mu g /$ GE

mg/ GE

$\mu \mathrm{g} / \mathrm{GE}$

$\operatorname{mgh}$ GE

$\operatorname{ggh}_{\mathrm{gE}} \mathrm{GE}$

$\mathrm{Cl} / \mathrm{mL}$ GP

$\mathrm{Cl} / \mathrm{mL} \quad$ GP

Cl/mL GP

$\mathrm{Ci} / / \mathrm{mL}$ GP

Ci/mL GP

$\mathrm{cl} / \mathrm{mL}$ GE

$\mathrm{Cl} / \mathrm{mL}$ GE

$\mathrm{ci/mL}$ GP

Cl/mL GP

ci/mL GP

$\mathrm{c} / \mathrm{mL}$

$\begin{array}{ccc}\mathrm{NCl} / \mathrm{mL} & \mathrm{GP} \\ \mathrm{NCl} / \mathrm{mL} & \mathrm{GP}\end{array}$ 
ANALYTICAL RESULTS

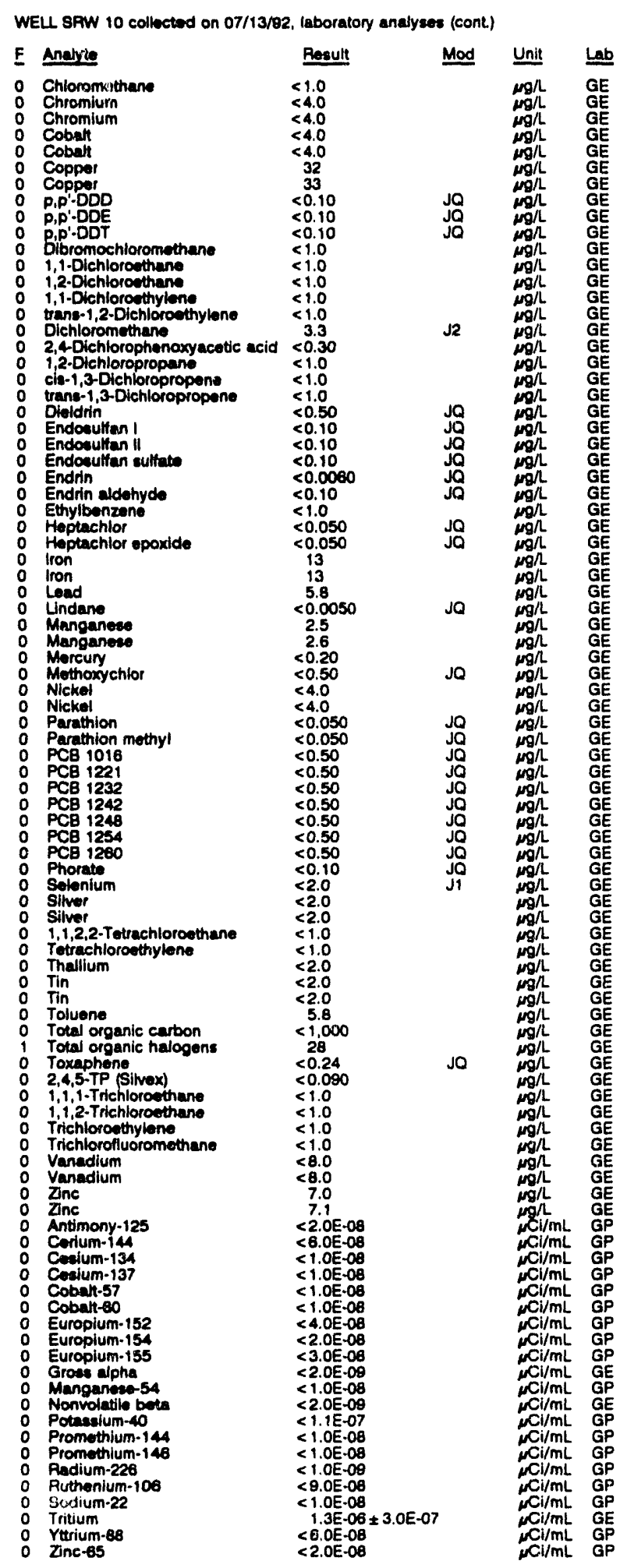

WELL SRW 11

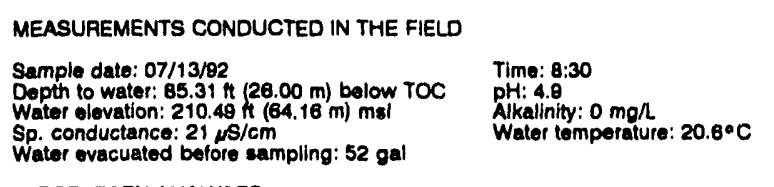

LABORATORY ANALYSES

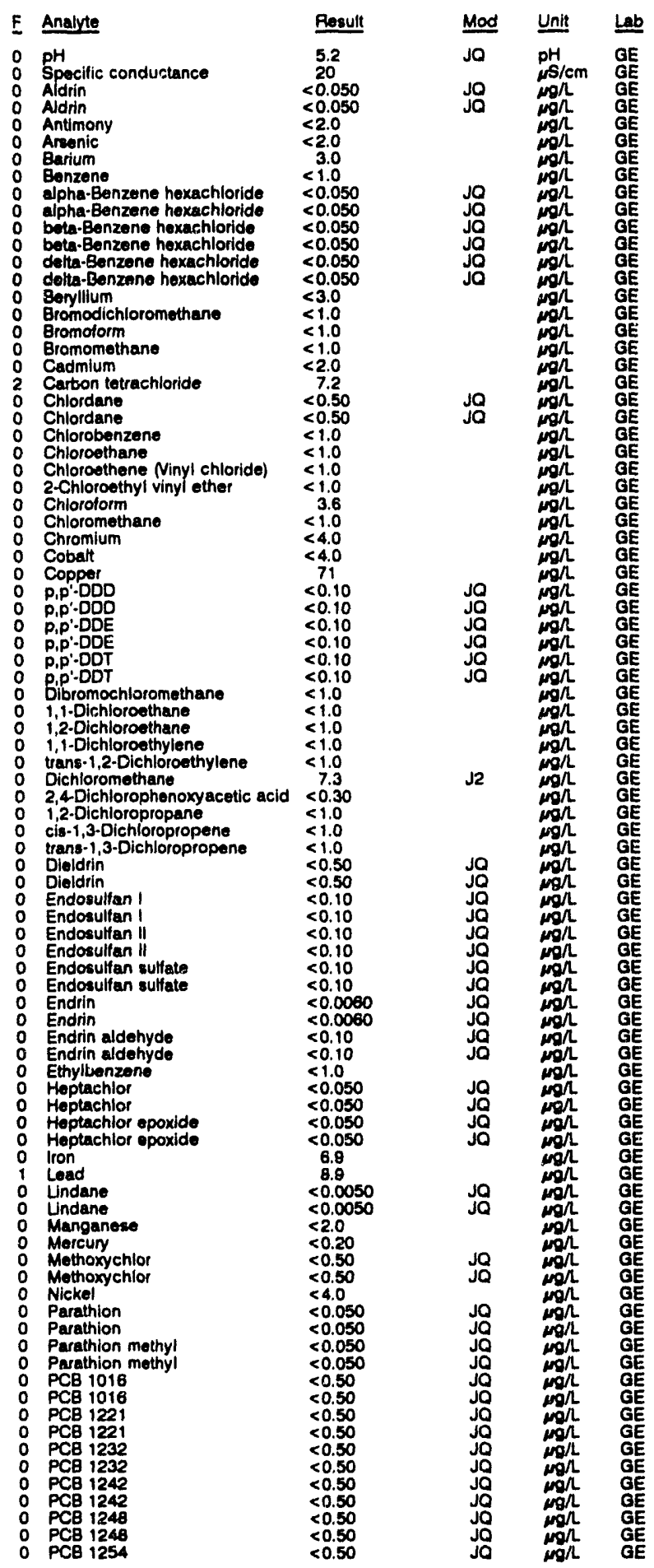


ANALYTICAL RESULTS

WELL. SRW 11 coliectod on 07/13/82, laboratory analyses (cont.)

\begin{tabular}{|c|c|c|c|}
\hline Analyte & Result & Mod & Unit \\
\hline 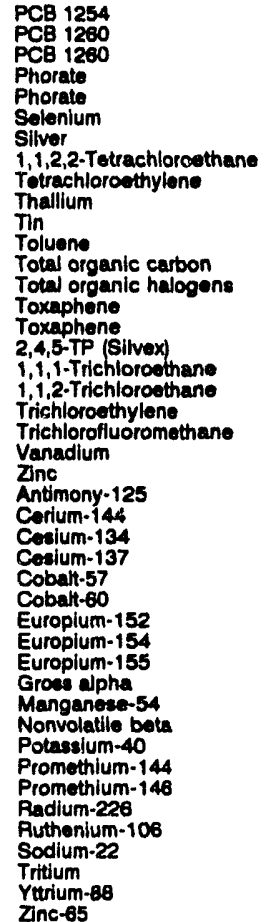 & 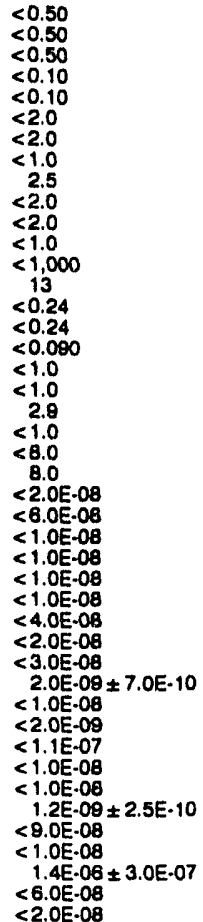 & $\begin{array}{l}\text { JQ } \\
\text { JQ } \\
\text { JO } \\
\text { JQ } \\
\text { JO } \\
\text { J1 }\end{array}$ & 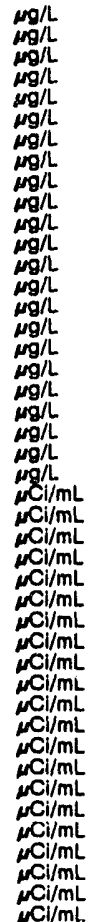 \\
\hline
\end{tabular}

\section{WELL SRW 12A}

MEASUREMENTS CONDUCTED IN THE FIELD

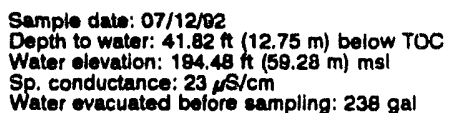

Time: 14:05

pH: 4.6

Water temperature: $22.4^{\circ} \mathrm{C}$

LABOPATOAY ANALYSES

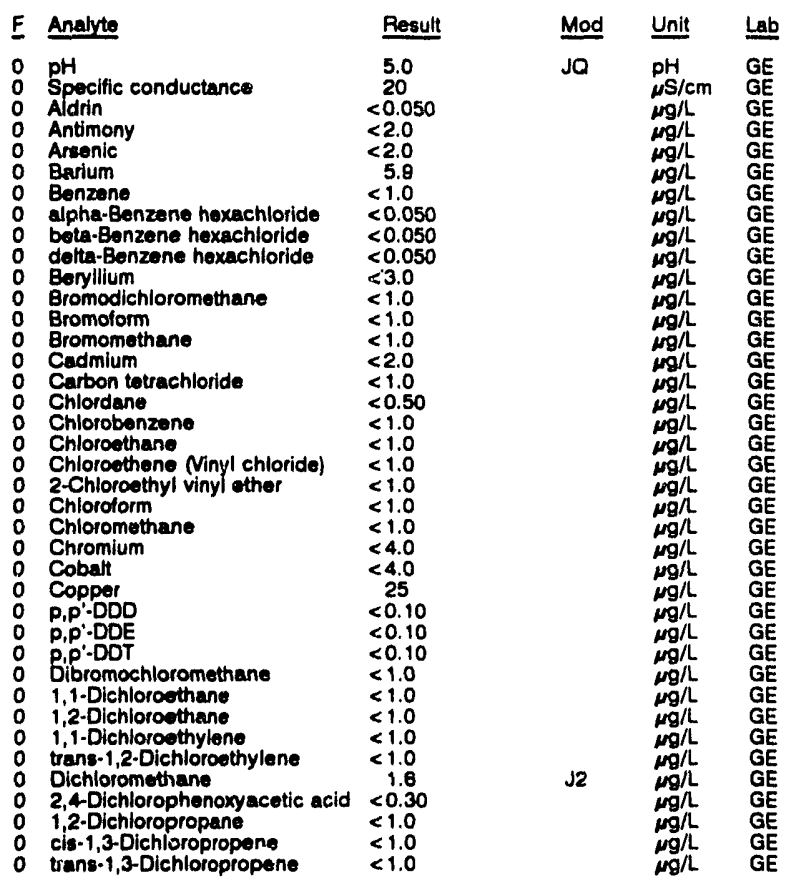

WELL SFW 12A collected on 07/12/92, laboratory analyses (cont.)

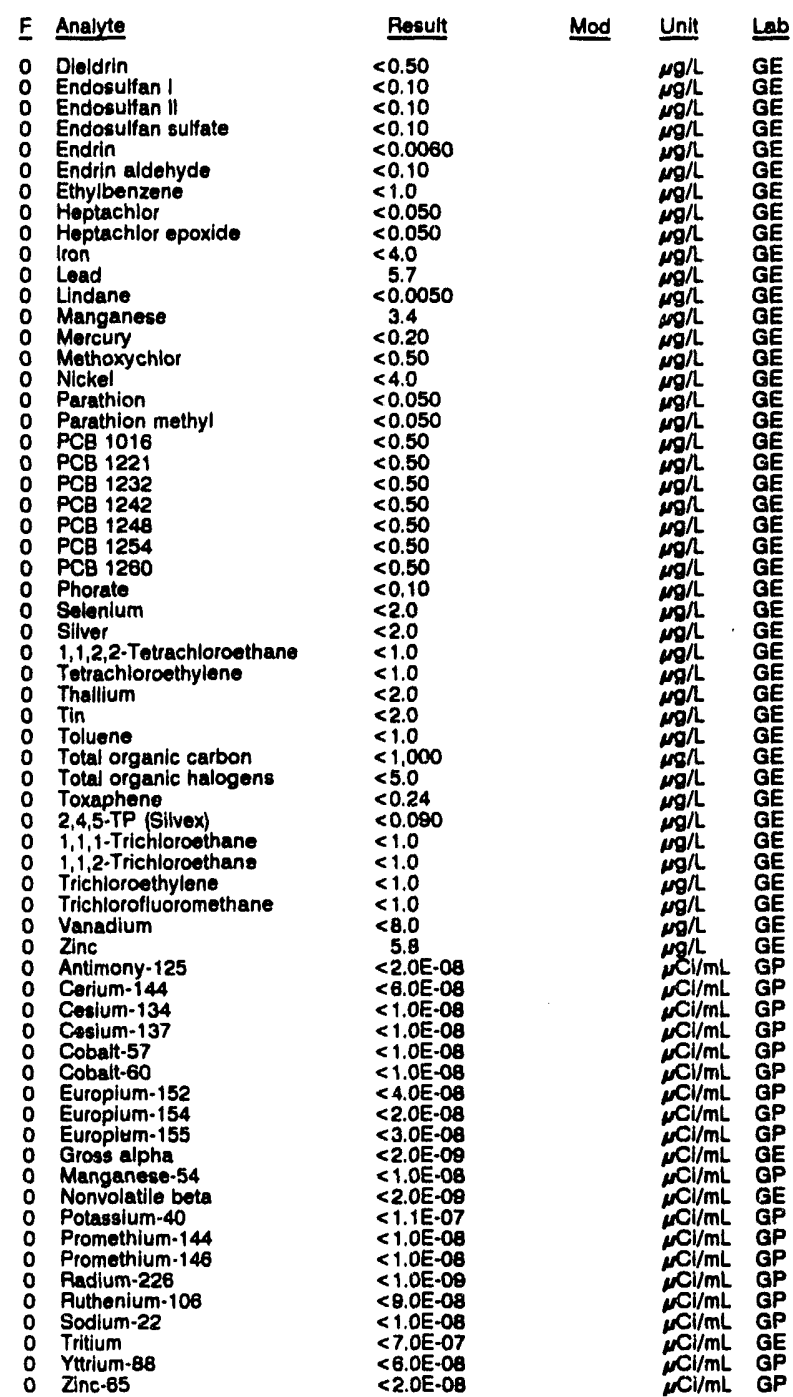

WELL SRW 12B

MEASUREMENTS CONDUCTED IN THE FIELD

Sample date: 07/12/92

Depth to wator: $48.75 \mathrm{ft}(14.25 \mathrm{~m})$ below TOC Water olovation: $189.55 \mathrm{H}(57.78 \mathrm{~m}) \mathrm{msl}$ Sp. conductance: $18 \mu \mathrm{s} / \mathrm{cm}$
Water evacuated before sampling: $113 \mathrm{gal}$ LABORATORY ANALYSES

$\begin{array}{ll}\text { F } & \text { Analyte } \\ 0 & \text { pH } \\ 0 & \text { Specific conductance } \\ 0 & \text { Aldrin } \\ 0 & \text { Antimony } \\ 0 & \text { Arsenic } \\ 0 & \text { Barium } \\ 0 & \text { Benzene } \\ 0 & \text { alpha.Eenzene hexachloride } \\ 0 & \text { beta-Benzene hexachloride } \\ 0 & \text { delta-Benzene hexachloride } \\ 0 & \text { Berillium } \\ 0 & \text { Bromodichloromethane } \\ 0 & \text { Bromolorm } \\ 0 & \text { Eromomethane } \\ 0 & \text { Cadmium } \\ 0 & \text { Carbon tetrachloride } \\ 0 & \text { Chlordane } \\ 0 & \text { Chlorobenzene } \\ 0 & \text { Chloroethane } \\ & \end{array}$

\begin{tabular}{l} 
Result \\
\hline 5.6 \\
1.5 \\
$<0.050$ \\
$<2.0$ \\
$<2.0$ \\
4.4 \\
$<1.0$ \\
$<0.050$ \\
$<0.050$ \\
$<0.050$ \\
$<3.0$ \\
$<1.0$ \\
$<1.0$ \\
$<1.0$ \\
$<2.0$ \\
$<1.0$ \\
$<0.50$ \\
$<1.0$ \\
$<1.0$
\end{tabular}

Time: 13:50

pH: 5.2

Alkalinity: $1 \mathrm{mg} / \mathrm{h}$ Water temperature: $22.5^{\circ} \mathrm{C}$

\begin{tabular}{|c|c|}
\hline Mod & Unit \\
\hline JO & 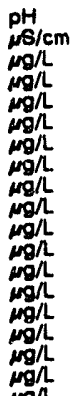 \\
\hline
\end{tabular}


WELL SAW $12 B$ collected on 07/12/82, laboratory analyses (cont.)

\begin{tabular}{|c|c|c|c|}
\hline nalyte & Result & idod & Unit \\
\hline 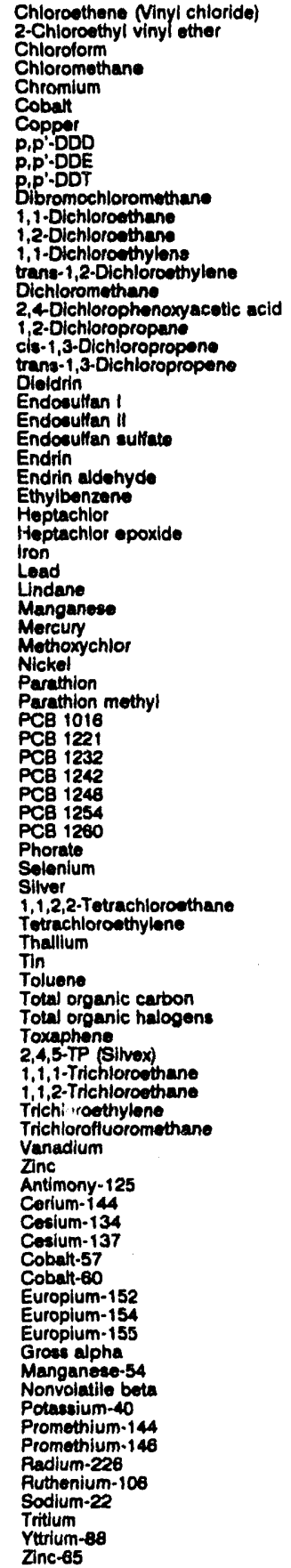 & 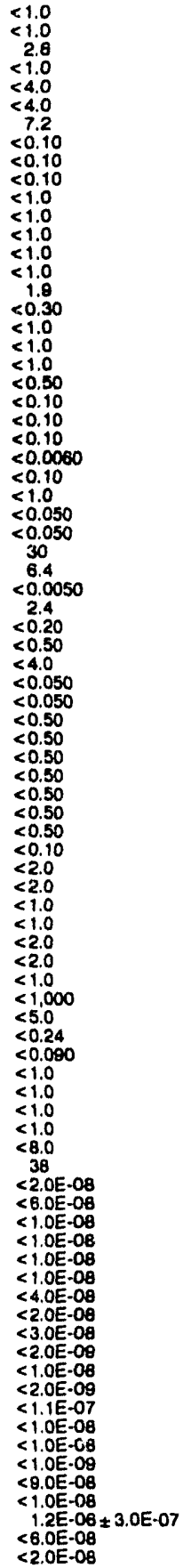 & $\sqrt{2}$ & 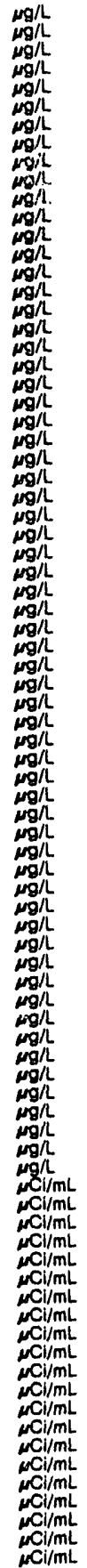 \\
\hline
\end{tabular}

WELL SRW 12C

MEASUREMENTS CONDUCTED IN THE FIELD

\begin{tabular}{|c|c|}
\hline $\begin{array}{l}\text { Sample date: } 07 / 12 / 92 \\
\text { Depth to water: } 39.70 \mathrm{ft}(12.10 \mathrm{~m}) \text { bolow TOC } \\
\text { Water olovation: } 190.60 \mathrm{~h}(58.82 \mathrm{~m}) \mathrm{ms} \\
\text { Sp. conductance: } 17 \mu \mathrm{s} / \mathrm{cm} \\
\text { Whter ovecuated before }\end{array}$ & $\begin{array}{l}\text { Time: } 14: 20 \\
\text { PH: } 5.0 \\
\text { Alkalinity: } 1 \mathrm{mg} / \mathrm{h} \\
\text { Water tomperature: } 22.2^{\circ} \mathrm{C}\end{array}$ \\
\hline
\end{tabular}
LABORATORY ANALYSES

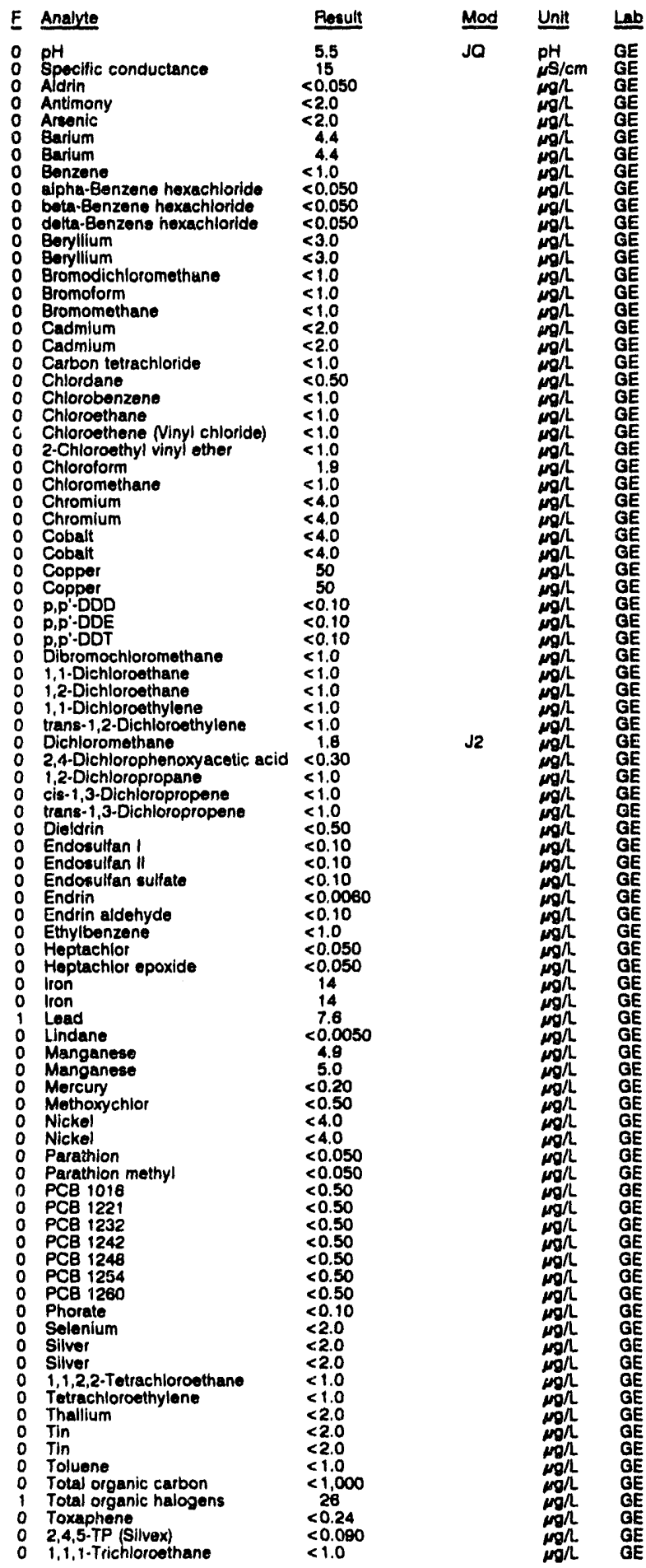


ANALYTICAL RESULTS

WELl SRIN 12C collected on 07/12/92, laboratory analyees (cont.)

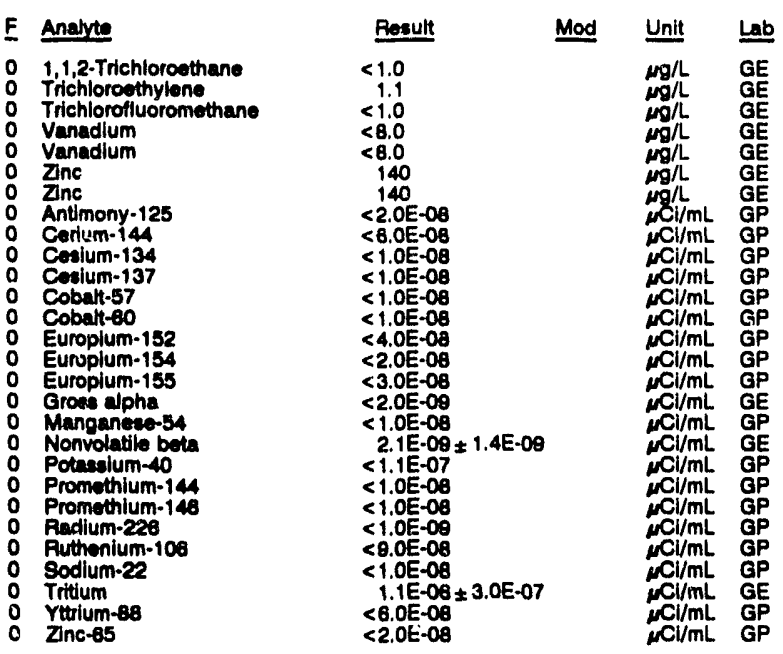

WELL SRW 13A

MEASUREMENTS CONDUCTED IN THE FIELD
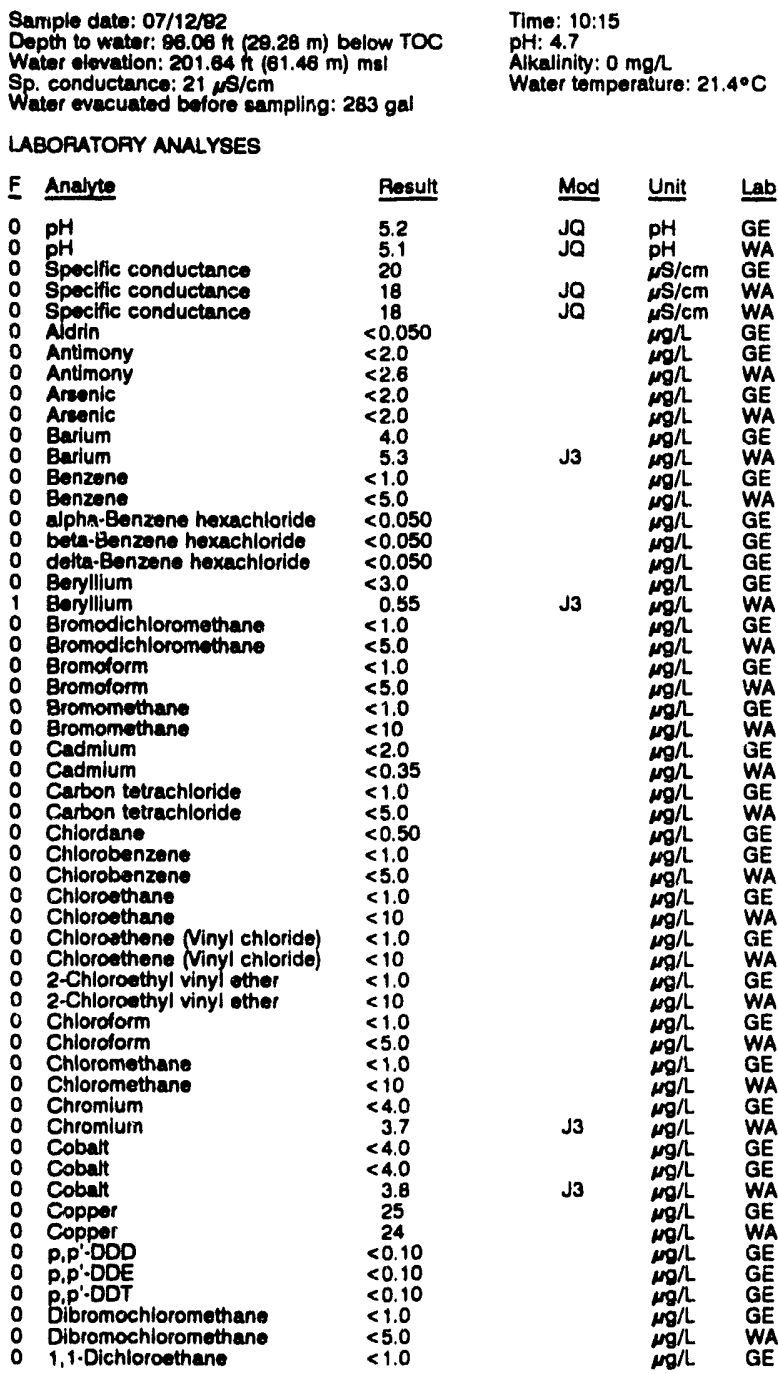

WELL SFW 13A collected on 07/12/92, laboratory analyees (cont.)

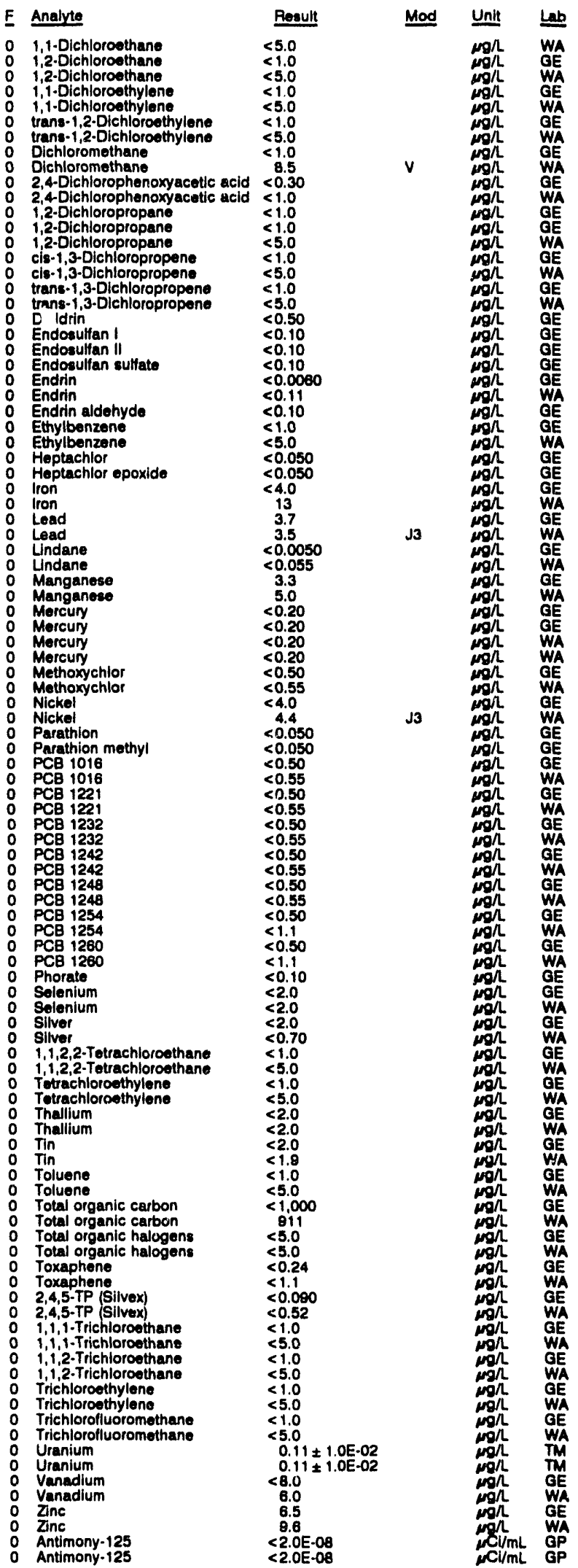


WELL SFW 13A collected on 07/12/92, laboralory analyses (cont)

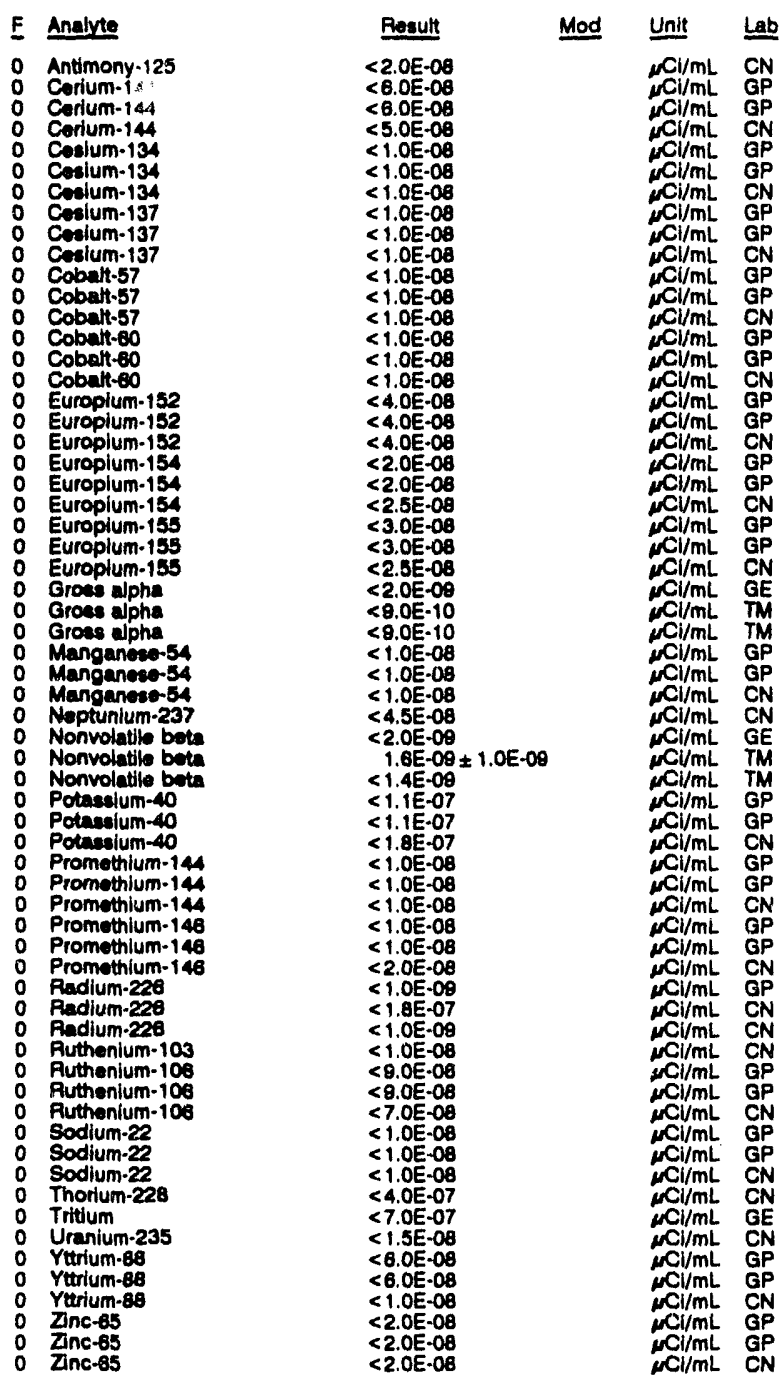

\section{WELL SRW 13A Replicate}

MEASUREMENTS CONDUCTED IN THE FIELD

Sample date: $07 / 12 / 12$

Depth to water: 86.08 if $(29.28 \mathrm{~m})$ below TOC Water elevation: $201.64 \mathrm{ht}(61.46 \mathrm{~m}) \mathrm{msl}$

Sp. conductance: 21 / $\$ / \mathrm{cm}$. LABOPATOPY ANALYSES

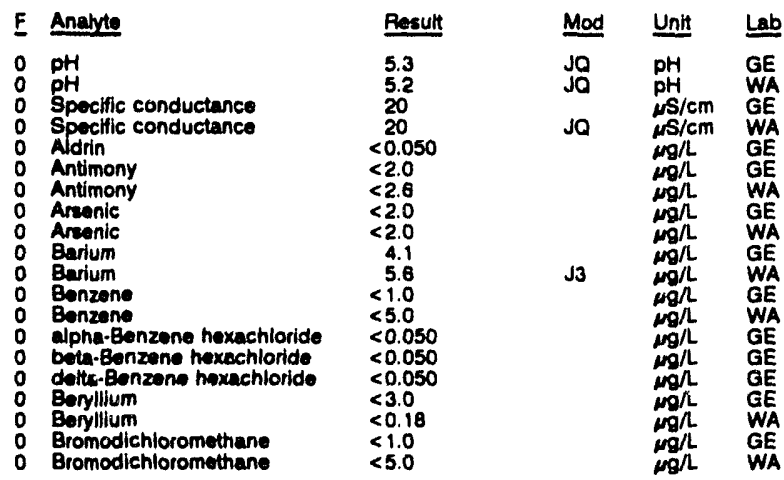

WELL SRW 13A collected on 07/12/92, laboratory analyees (cont.)

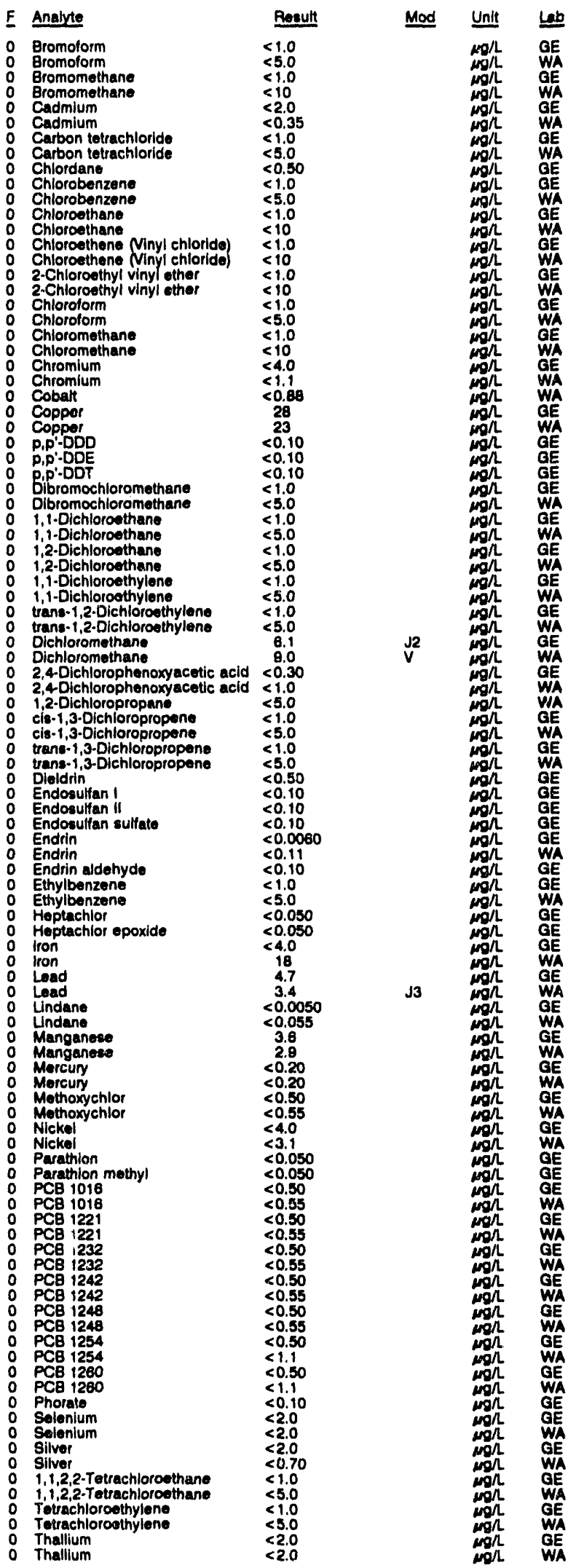


WELL SFW 13A collectod on 07/12/82, laboratory analyees (cont)

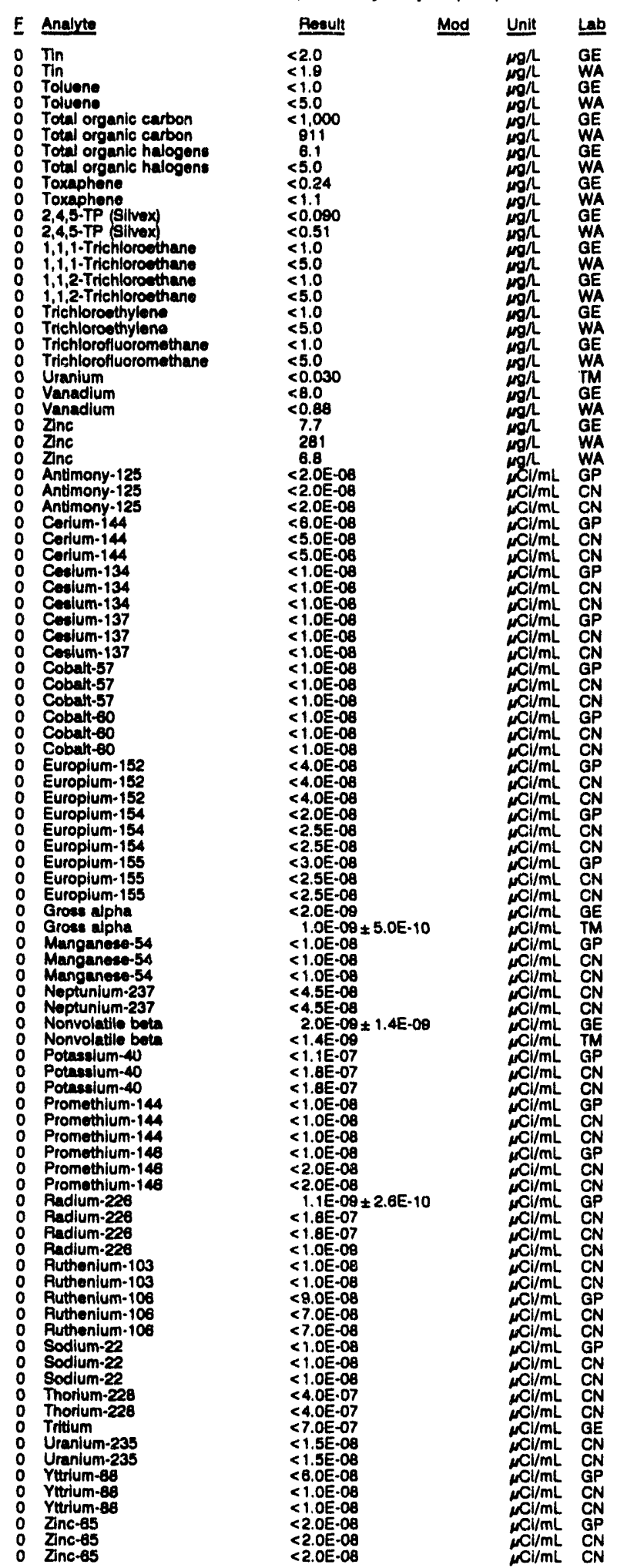

WELL SRW 13B

MEASUREMENTS CONDUCTED IN THE FIELD

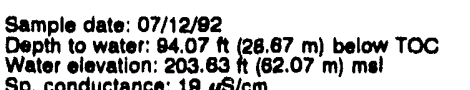

Water evacuated bofore sempling: 132 gal

LABORATOAY ANALYSES

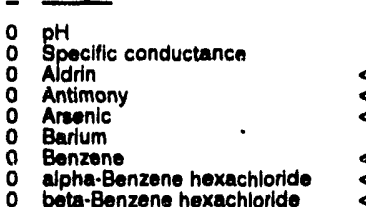

Result Mod Unit Lab

beta-Benzene hexachloride

Beryllium

o Bromodichloromethane

Bromolorm

0 Bromomethan

0 Cadmium

Carbon tetrachloride

- Chlordane

Chlorobenzene

Chloroethene Ninyt chloride)

2.Chloroethyl vinyl ether

O Chloroform

Chlorometh

O Cobalt

0 Cobalt

O P,P'-DOD

: P,p-DDD

Bipiomochloromethane

1,1-Dichloroethane

1,2-Dichloroethane

o 1,1-Dichloroothylene

D Dichloromethane

2 2,4-Dichlorophenoxys

cis-1,3-Dichloropropene

trans-1,3-Dichloropropene

Dieldrin

- Endosulfan iI

o Endosulfan sulfate

- Endrin

Endrin aldehyde

Ethylbenzen

Heptachlor epaxide

1 Load

1 Lead

o Lindane

o Mercury

Methoxychlor

0 Nickol

P Parathion methyl

O Parathion meth

$\begin{array}{lll}0 & P C B & 1016 \\ 0 & P C B & 1221\end{array}$

O PCB 1232

O PCB 1248

O $\mathrm{PCB} 1254$

PCB 1260

O Phorate

o Silver

o Totrachloroethylene

o Thallium

Th

Toluene

o Total organic carbon

O Total organic halo

0 2,4,5-TP (Silvex)

0 1,1,1-Trichloroethane

o $1,1,2$-Trichioroethan

o Trichlorofluylerome

o Vanadium

- Zinc

A Antimony-125

- Cerium.144

o Cosium-134

0 Cosium-137

0 Cobalt.57

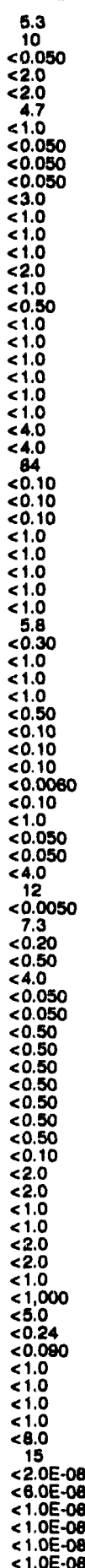

Time: $8: 50$

Alkalinity: $0 \mathrm{~mol}$

Water tomperature: $21.00^{\circ} \mathrm{C}$

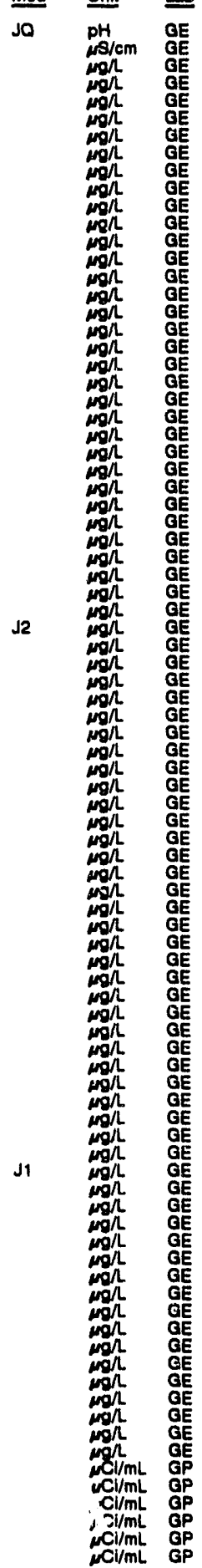


ANALYTICAL RESULTS

WELL SRW 138 collected on 07/12/82, laboratory analyses (cont.)

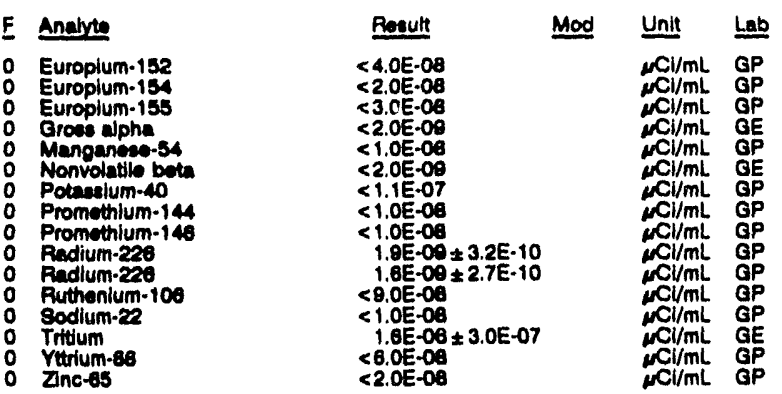

WELL SRW 13C

MEASUAEMENTS CONDUCTED IN THE FIELO

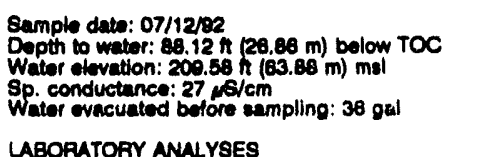

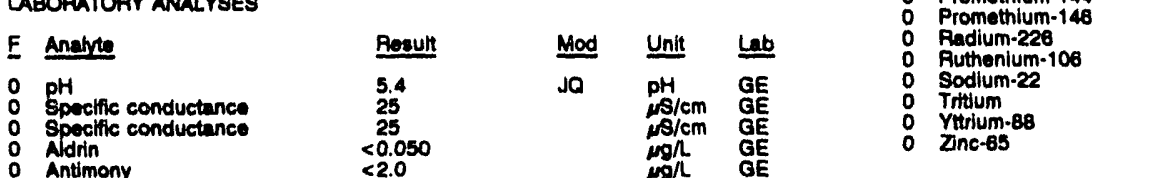

Timo: $8: 25$

PH: 4.8 : $1 \mathrm{~mol}$

Water temperature: $21.5^{\circ} \mathrm{C}$

Wh. conductance: 27 es/cm

\section{LABOPATORY ANALYSES}

\begin{tabular}{|c|c|c|c|c|}
\hline \multicolumn{2}{|r|}{ 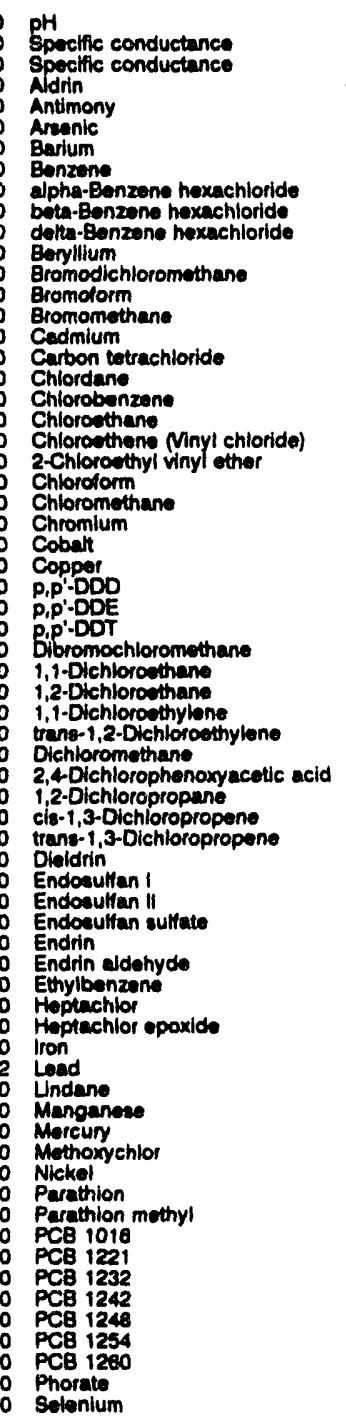 } & $\begin{array}{l}5.4 \\
25 \\
25 \\
20.050 \\
<2.0 \\
<2.0 \\
51.4 \\
<1.0 \\
<0.050 \\
<0.050 \\
<0.050 \\
<3.0 \\
<1.0 \\
<1.0 \\
<1.0 \\
<2.0 \\
<1.0 \\
<0.50 \\
<1.0 \\
<1.0 \\
<1.0 \\
<1.0 \\
1.5 \\
<1.0 \\
<4.0 \\
<4.0 \\
150 \\
<0.10 \\
<0.10 \\
<0.10 \\
<1.0 \\
<1.0 \\
<1.0 \\
<1.0 \\
<1.0 \\
<1.0 \\
<0.30 \\
<1.0 \\
<1.0 \\
<1.0 \\
<0.50 \\
<0.10 \\
<0.10 \\
<0.10 \\
<0.0000 \\
<0.10 \\
<1.0 \\
<0.050 \\
<0.050 \\
55 \\
20 \\
<0.0050 \\
13 \\
<0.20 \\
<0.50 \\
<4.0 \\
<0.050 \\
<0.050 \\
<0.50 \\
<0.50 \\
<0.50 \\
<0.50 \\
<0.50 \\
<0.50 \\
<0.50 \\
<0.10 \\
<2.0\end{array}$ & JQ & 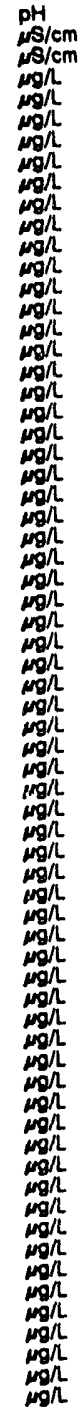 \\
\hline
\end{tabular}

WELL SPW 13C collected on 07/12/92, laboratory enalyees (cont)

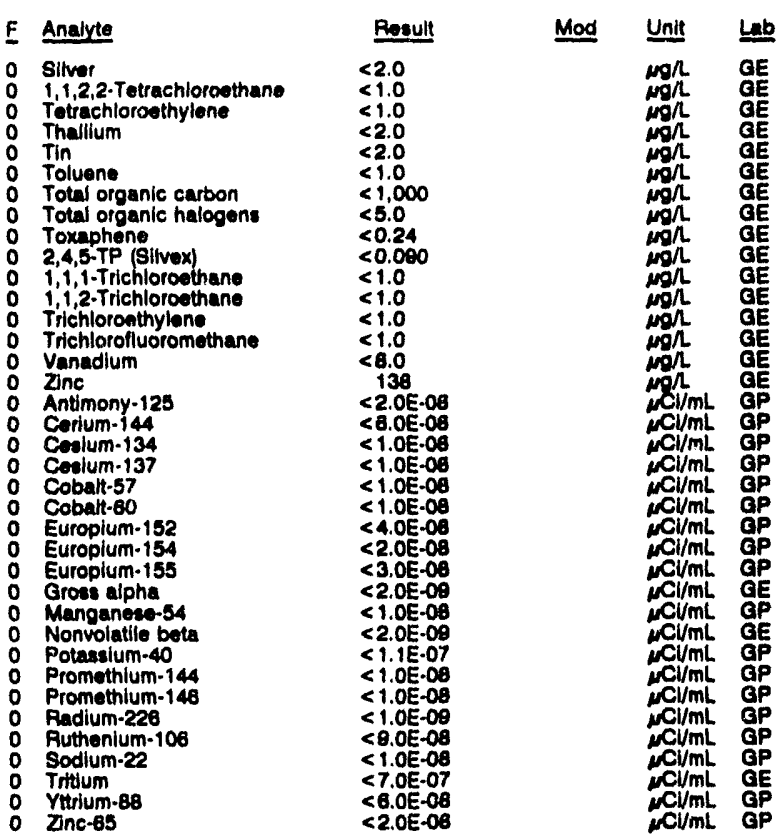

\section{WELL SRW 14A}

MEASUREMENTS CONDUCTED IN THE FIELD

Sampis date: 07/12/92 Depth lo water: 123.42 A (37.62 m) below TOC

Depth lo water: $123.42 \mathrm{ft}(37.62 \mathrm{~m})$ below
Water olevation: $20.3 .58 \mathrm{ft}(82.05 \mathrm{~m}) \mathrm{msl}$ Sp. conductance: $25,18 / \mathrm{cm}$.

LABORATORY ANALYSES

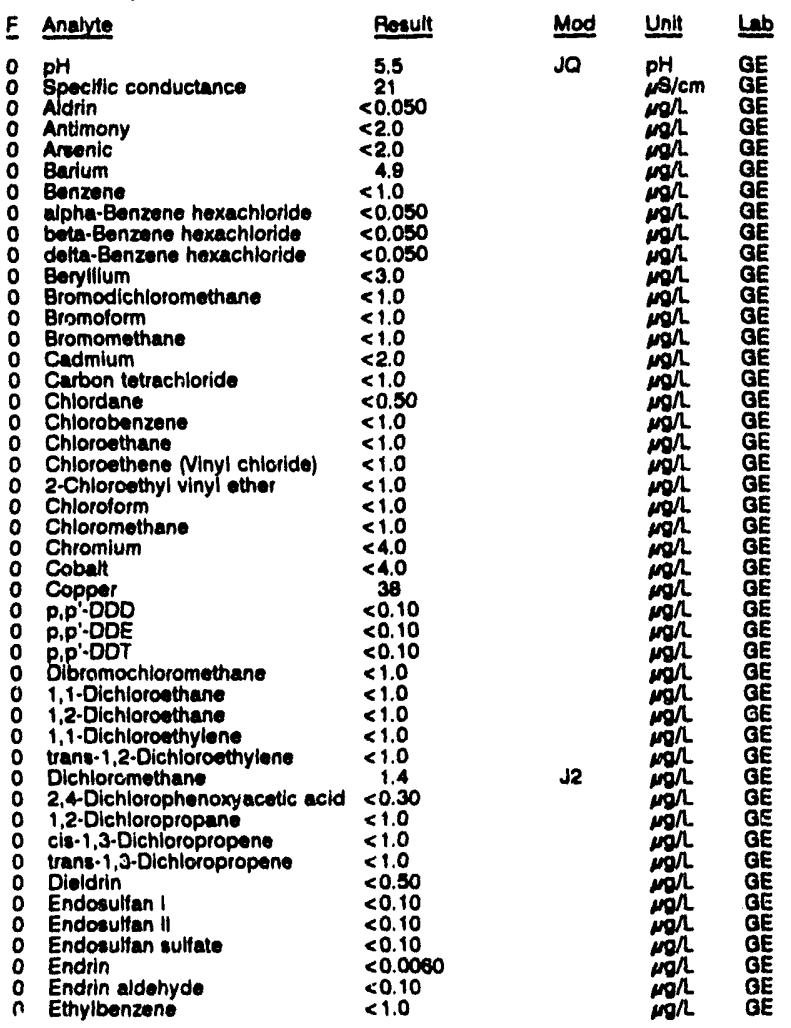

$\operatorname{Time:}_{0 \rightarrow: 3} 11: 35$

Alkalinity: $1 \mathrm{mgh}$

Water temperature: $20.8^{\circ} \mathrm{C}$ 
WELL OA $116 C$ collected on 08/23/92, laboratory analyses (cont.)

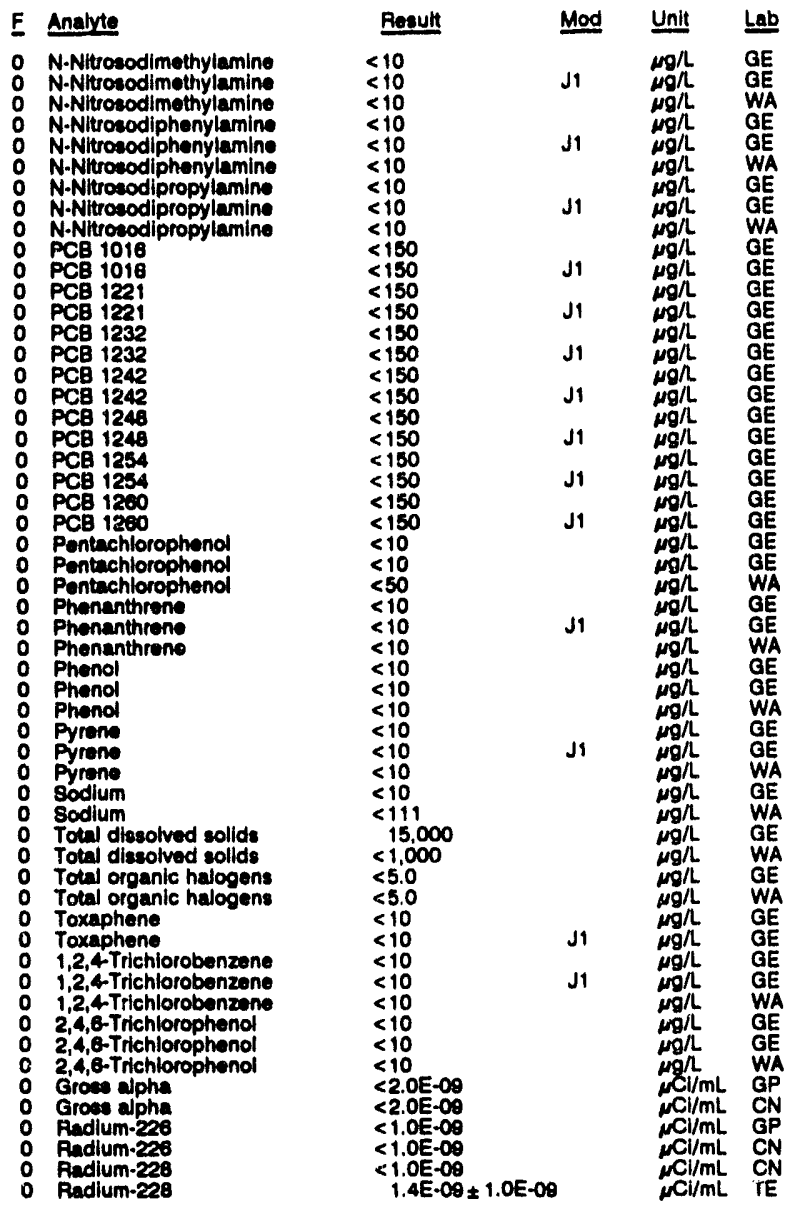


WELL QA 116C

MEASUAEMENTS CONDUCTED IN THE FIELD

Sample date: 08/23/92

Wepth to water: Not avallable Sp. conductance: 4 , s/lat $\mathrm{cm}$

LABORATORY ANALYSES

E Analyte

$0_{0}^{\mathrm{PH}}$

Specific conductance

Specific conductanco

Aconaphthene

Aconaphthene

Aconaphthylene

Acenaphthylen

Adrin

Andrin

Anthracone

alpha-Benzene hexachloride

alpha.Benzene hoxachloride

beta-Benzene hexachlorlde

beta-Benzene hoxachloride

delta. Banzone horachloride

Eenzidine

Benzdine

Benzola anthracone

Bonzo a anthracene

Benzo a anthracene

Eanzo b fuvoranthens

(t)

thene

Benzo 4 Juoranthene

Benzo Oh.

Benzo g, hil perylone

Benzog, hil perylen

Benzo alpyren

Bonzo a pyrene

Bla(2-chlorothoxy) methane

Bber-chloroethoxy methane Bis (2-chloroethy) ether

Bis (2-chloroethy) ether

Bis 2-chloroethyl) other
E-chloroisopropyl) ether

Bise (2-chlorolsopropyl) ether

Bis (2-chlorolsopropyl) ether

Bis 2-ethylhexyly phthalate

Bis(2-ethylhexyl phthalate

4Bromophenyl phenyl ether

4-Bromophenyl phonyl other

Butylbanzyl phthalate

Butylbenzyl phthalate

Butylbenzy

Cadmium

Chlordane

Chloride

para-Chloro-meta-cresol

para-Chloro-meta-cresol

2-Chloronaphthalene

2-Chloronuphthaiene

2-Chioronaphthalene

2-Chlorophenol

2-Chloropheno

4-Chiorophenyl phenyl ether

4-Chlorophenyl phenyl ether

4-Chloroph

Chrysene

Chryeane

p.p'-DOD

0 P.P'-DD

P,p'-DoI

Bibenz;a,h]anthracene

Dibenz $(a, h)$ anthracene

Dibenz a,, h antrutracen

Di-n-butyl phthalate

\section{Time: 8:50}

Alkalinity: $0 \mathrm{mg} / \mathrm{h}$

Water temperature: $24.3^{\circ} \mathrm{C}$

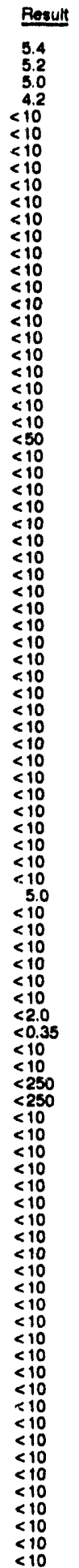

WELL OA $116 \mathrm{C}$ collected on 08/23/82, laboratory analyees (cont)

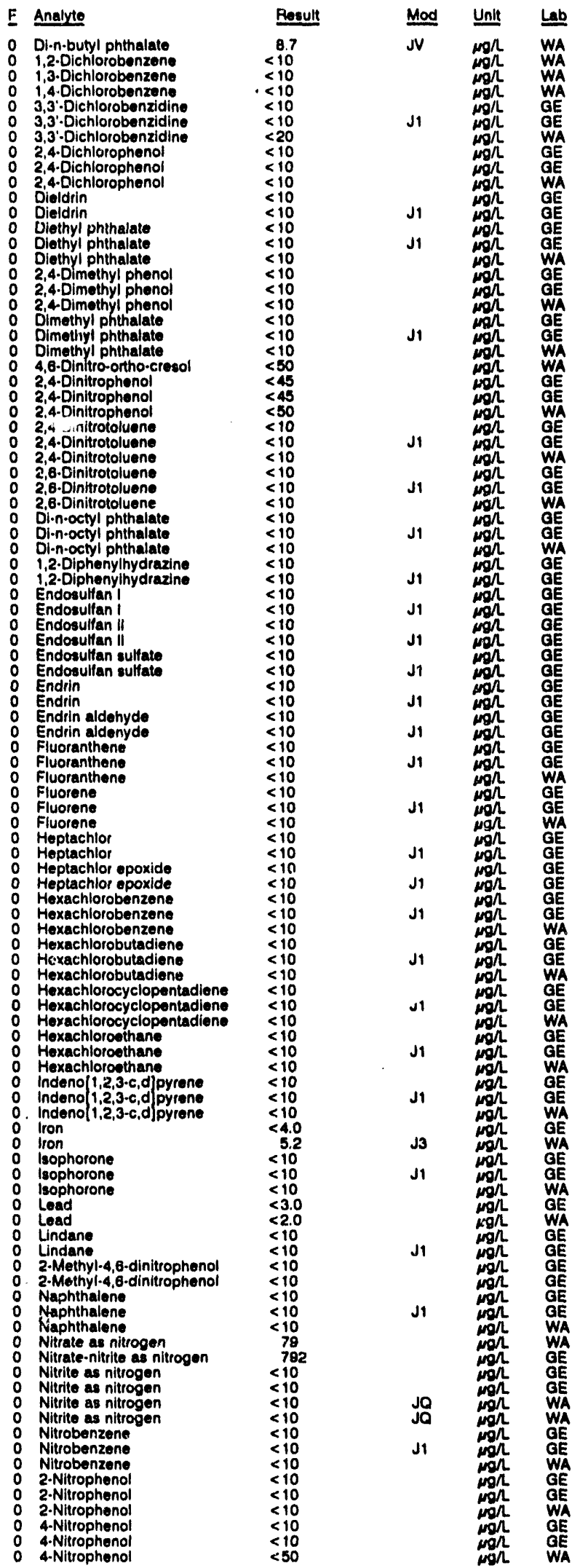


WELL QA 116C

MEASUREMENTS CONDUCTED IN THE FIELD

Sample date: 08/23/82

Wapth to water: Not available

$\mathrm{Sp}$. conductance: $4 \mathrm{mS} / \mathrm{cm}$

LABORATORY ANALYSES

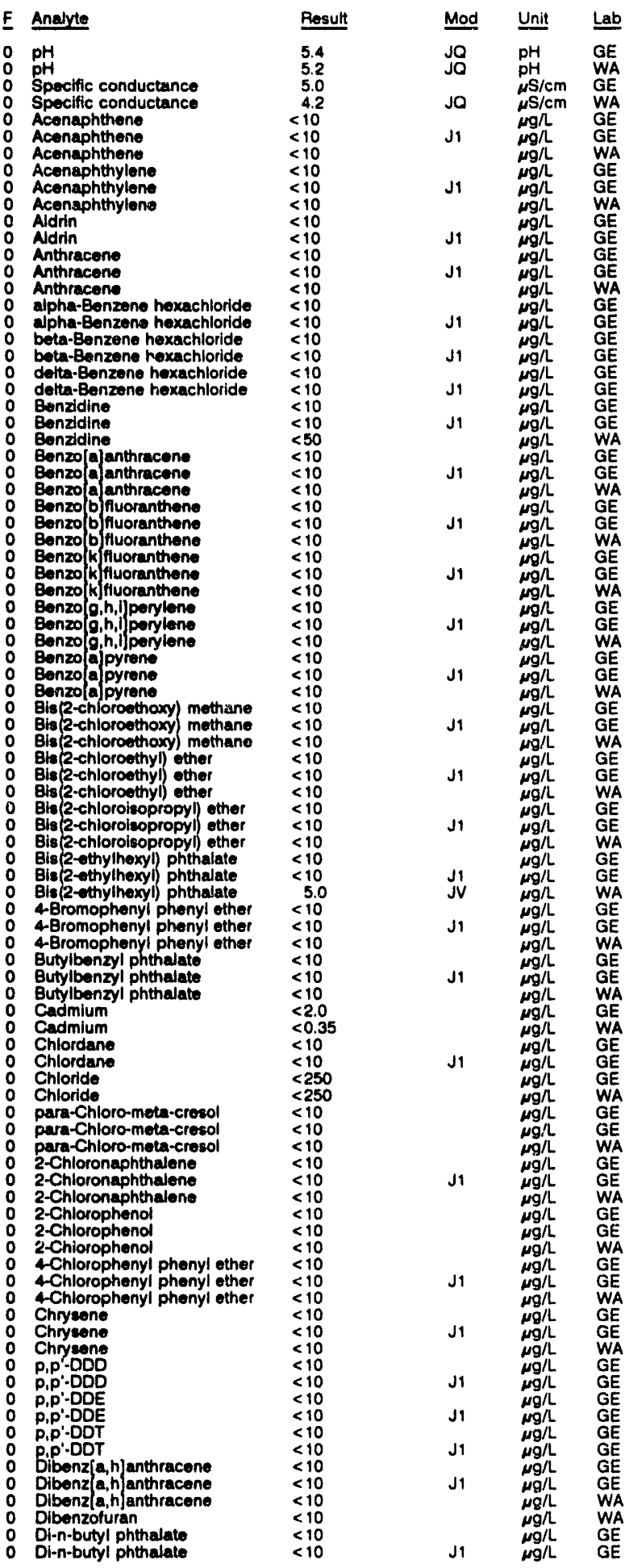

WELL QA $116 \mathrm{C}$ collected on $08 / 23 / 82$, laboratory analyses (cont.)

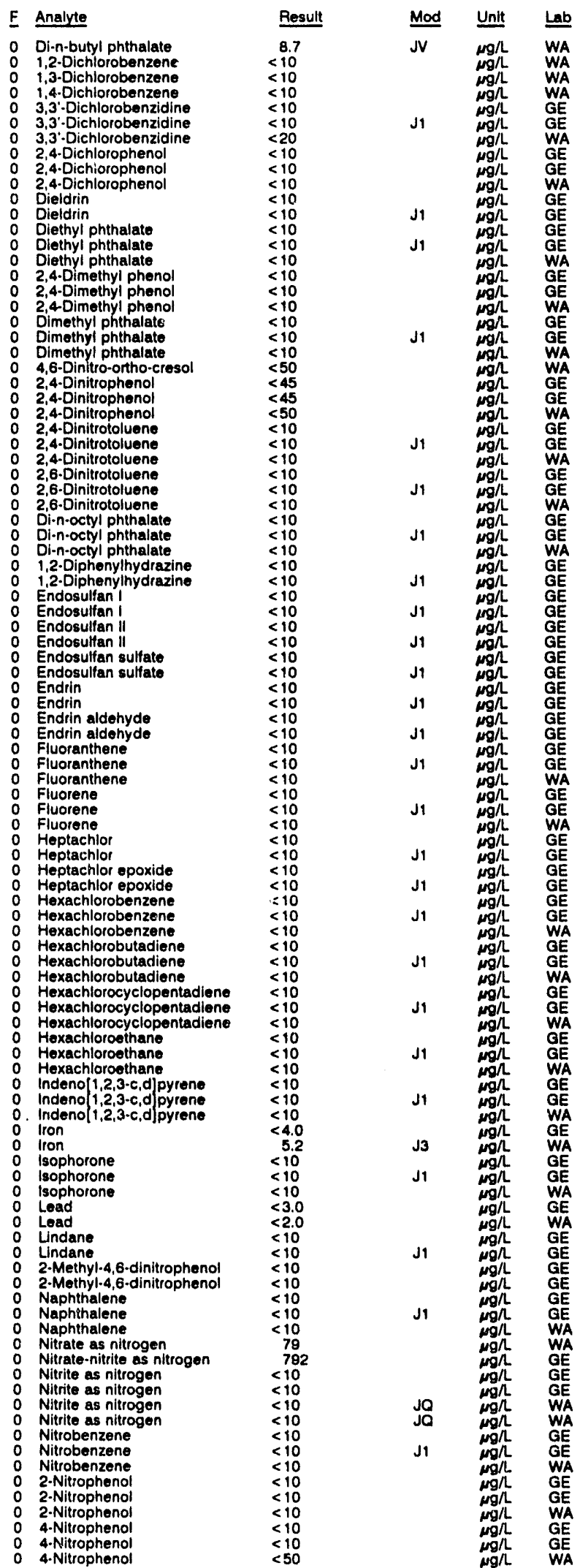


WELL QA $110 \mathrm{C}$ collocted on $08 / 02 / 92$, laboratory analyses (cont.)

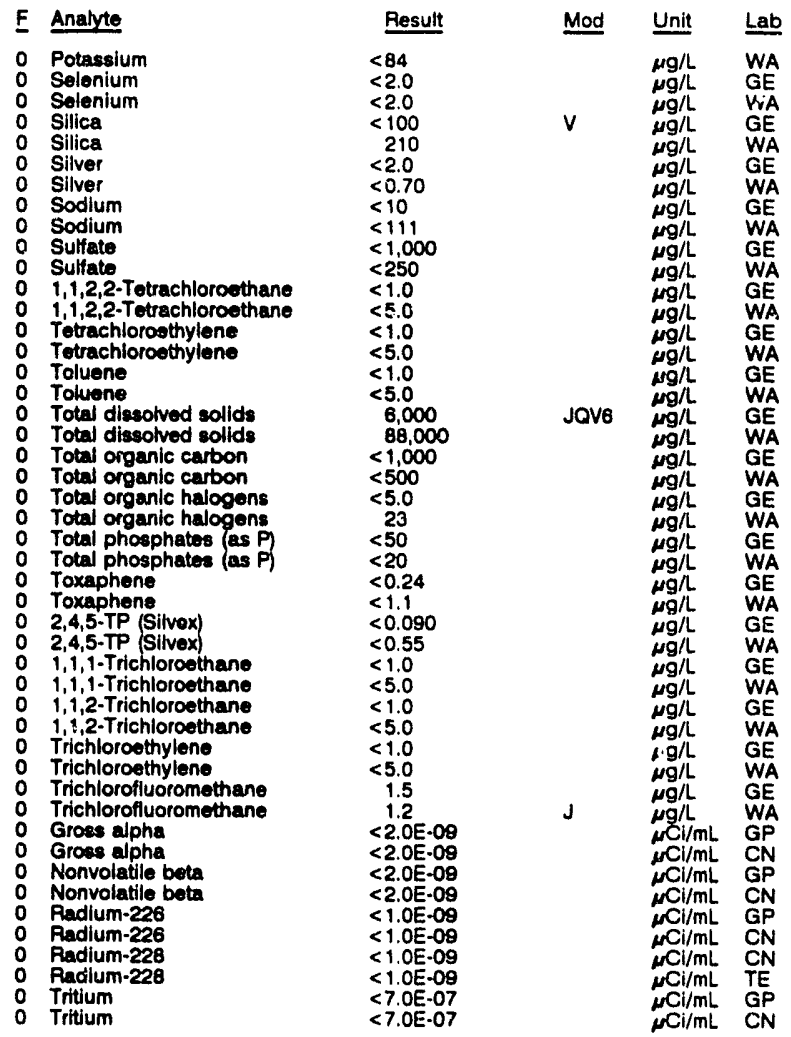

WELL QA $112 C$

MEASUREMENTS CONDUCTED IN THE FIELD

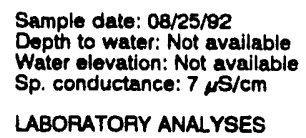

LABORATORY ANALYSES

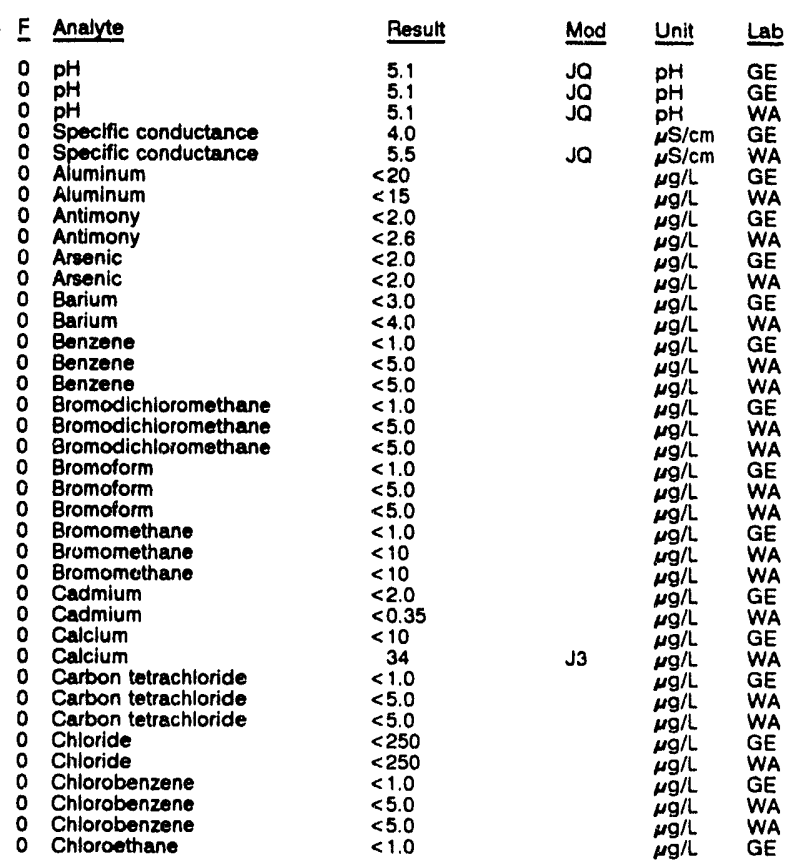

WELL QA $112 C$ collecied on 08/25/92, laboratory analyses (cont.)

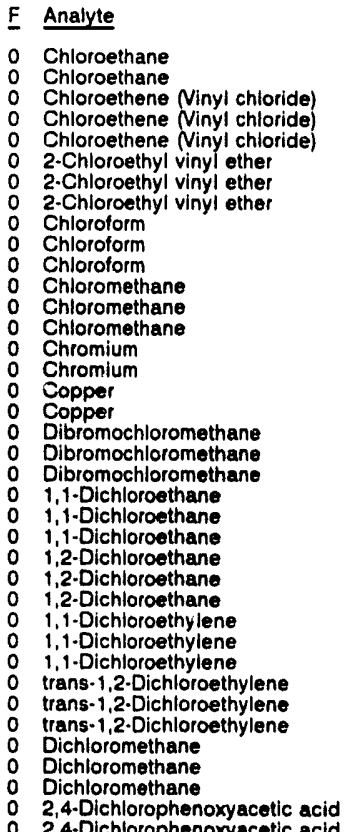

2,4-Dichiorophenoxyacotic acid $<0.30$

2,4-Dichlorophenoxyacetic acid $<1.1$

o 1,2-Dichloropropane

1,2-Dichloropropane

cis-1,3-Dichloropropene

cis-1,3-Dichloropropene

trans-1,3-Dichloropropene

trans-1,3.Dichloropropene

trans. 1 .3.Dichloropropene

Endrin

Ethylbenzene

Ethylbenzene

Ethylbenzene

Fluoride

Iron

0 Iron

0 Lead

o Lindane

o Lindane

- Magnesium

Manganese

Manganese

Mercury

O Mercury

Methoxychlor

Methoxychlor

Nickel

Nitrate as nitrogen

Nitrate-nitrite as nitrogen

Phenols

Phenols

Potassium

Potassium

Selenium

Silica

Silica

0 Silver

0 Silver

0 Sodium

O Sodium

0 Sulfate

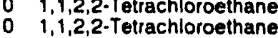

1,1,2,2-Tetrachloroethane

Tetrachioroethylene

Tetrachloroethylene

Tetrachloroethylene

Tolvene

0 Tolvene

- Total organic carbon

Total organic carbon
Total organic carbon
$<10$
$<10$

$<1.0$

$<10$

$<10$
$<1.0$

$<10$

$<10$

$<1.0$
$<5.0$

$<5.0$
$<1.0$

$<10$

$<4.0$

$<1.1$
$<4.0$

$<4.0$
$<1.1$
$<1.0$

$<5.0$

$<5.0$

$<5.0$

$<5.0$

$<5.0$

$<5.0$
$<1.0$

$<5.0$

$<1.0$

$<5.0$

4.7
$<5.0$

$<5.0$

Mod Unit Lob

$\mu g / 2 \quad W A$

$\underset{\mu g h \text { GE }}{\mu g h}$

$\mu g h$ GE

$<0.11$

$<5.0$

$<5.0$

$<100$

7.6
2.7
$<3.0$

$<3.0$

$<0.0050$

$<0.056$

4.1

$<2.0$

$<0.35$

$<0.20$

$<0.50$

$<0.56$

$<4.0$

$<3.1$
29
624

624
$<50$

$<5.0$

$<500$
256

$<2.0$
$<2.0$

25,400
19,000

19,000

$<0.70$

$<10$

$<111$

$<250$

$<1.0$

$<5.0$

$<10$

$<5.0$

$<5.0$

$<1.0$

$<5.0$

$<1,000$

$<1,000$
$<500$ 
WELL QA 108C

MEASUREMENTS CONDUCTED IN THE FIELD

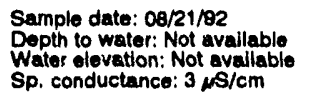

Spi conduclanci a s avalcm

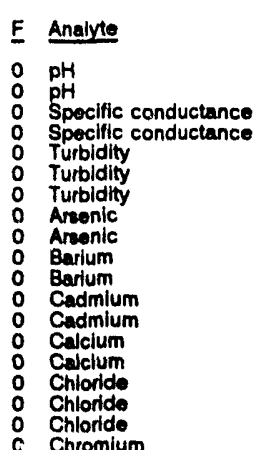

Chromium

2,4-Dichlorophenoxyacetic acid $<1$

0 Endrin

0 Eluoride

0 Fluoride

0 Iron

o Lead

0 Load

Lindane

Magnesium

Manganose

Manganese

Morcury

Mercury

Methoxychior

Nitrato as nitrogen

Nitrate-nitrite as nitrogen

Phonols
Phenols

Potassium

Potassium

Solenium

Silica

Sillica

Siver

Sodium

Sodium

Sultate

Sulfate

Sulfate

Total dissolved solids

Total dissolved sollds

Total organic carton

Tola organic halogens

Total organic halogens

Total phosphates (as P

Total phosphates las P

- Toxapheno

Toxaphene

2,4,5-TP (Silvex)

Gross alpha

Nonvolatile bete

Nonvolatilo beta

Radium-226

Radium-226

Radium-228

Tritium

Tritium

\section{Time: 7:15}

Alkalinity: $1 \mathrm{mg} / \mathrm{L}$

Water temperature: $24.7^{\circ} \mathrm{C}$

\begin{tabular}{|c|c|}
\hline Rosult & Mod \\
\hline $\begin{array}{l}5.8 \\
5.4\end{array}$ & Ja \\
\hline $\begin{array}{r}3.2 \\
<0.10 \\
<0.10\end{array}$ & $\begin{array}{l}\mathrm{J} Q \\
\mathrm{~J} \\
\mathrm{~J} O\end{array}$ \\
\hline $\begin{array}{r}3.3 \\
<2.0\end{array}$ & Jă \\
\hline
\end{tabular}

Unit Lab

$\begin{array}{llll}\mathrm{pH} & \mathrm{GE} & 0 & \mathrm{pH} \\ \mathrm{pH} & \mathrm{WA} & 0 & \mathrm{pH} \\ \mu \mathrm{S} / \mathrm{cm} & \mathrm{GE} & 0 & \mathrm{pH} \\ \mu \mathrm{S} / \mathrm{cm} & \mathrm{WA} & 0 & \text { Specilic conductance } \\ \text { NTU } & \mathrm{GE} & 0 & \text { Specific conductance } \\ \text { NTU } & \mathrm{GE} & 0 & \text { Speific conductance }\end{array}$

o Turbidity

0 Turbidity

0 Turbldity

O Arsenic

- Barium

O Barium

B Benzene

o Bromodichloromsthane

Bromodichloromethane

Bromoform

O Bromotorm

o Bromomethane

O Cadmium

2 Cadmium

O Calcium

o Carbon tetrachloride

a Carbon tetrachloride

Chloride

o Chlorobenzene

o Chlorobenzene

o Chloroethane

Chloroethene Ninyl chloride)

Chloroothene Minyl chloride

o 2-Chloroethyl vinyl other

o 2-Chloroethyl vinyl ether

C Chloroform

Chloroform

- Chloromethane

o Chromium

o Chromium

Dibromochloromethane

1,1-Dichloroethane

- 1,1.Dichloroethane

1,2-Dichloroethane

1,2-Dichloroethane

o 1,1-Dichloroethylene

o trans-1,2-Dichloroothylene

- trans-1,2-Dichloroethylene

o Dichloromethane

2,4-Dichlorophenoxyacetic acid

2,4-Dichlorophenoxyacetic acld

o 1,2-Dlchloropropane

- 1,2-Dlchloropropane

o cis-1,3-Dichloropropene

cis-1,3-Dichloropropene

trans-1,3-Dichloropropene

0 Endrin

- Endrin

- Ethylbenzene

- Ethylbenzene

0 Fluoride

$\begin{array}{ll}0 & \text { Iron } \\ 0 & \text { Iron }\end{array}$

0 Lead

0 Lindane

- Lindane

0 Magnesium

Magnesium

Manganese

Mercury

Mercury

Methoxychior

Nitrate as nitrogen

Nitrate-nitrite as nitrogen

Nitrale-niltrite as nittogen

Phenols

Phenols
Timo: 6:50

Alkalinity: $1 \mathrm{mg} / \mathrm{h}$

Water temperature: $25.2^{\circ} \mathrm{C}$

Resu

6.3
6.8
6.8
5.0

6.8
5.0
$<1.0$

$<1.0$

$<0.10$

$<0.20$

$<0.20$

$<2.0$
$<3.0$

$<4.0$

$<1.0$

$<1.0$

$<5.0$

$<5.0$

$<10$

$<2.0$
7.6

$<10$

30
$<1.0$

$<5.0$

$<250$

$<1.0$

$<1.0$

$<10$

$<10$

$<10$
$<1.0$
$<10$

$<1.0$

$<5.0$

$<1.0$
$<10$

$<10$
$<4.0$

$<1.1$

$<1.0$
$<5.0$

$<1.0$

$<5.0$

$<5.0$

$<1.0$

$<1.0$

$<5.0$

$<5.0$
$<1.0$
1.0

$<0.30$

$<1.0$

$<5.0$

$<1.0$

$<5.0$

$<1.0$

$<5.0$
$<0.0060$

$<0.11$

$<0.11$

$<100$

$<100$
$<4.0$

5.3
$<3.0$

$<3.0$
$<2.0$

$<0.0050$
$<0.056$

$<2.0$

$<2.0$

$<2.0$
$<0.35$
$<0.20$
$<0.20$

$<0.50$

$<0.56$

$<50$
$<50$
$<50$

$<5.0$

3.0
$<500$
Mod Unit Lab

$\begin{array}{lll}\text { JO } & \mathrm{pH} & \mathrm{GE} \\ \mathrm{JO} & \mathrm{pH} & \mathrm{WA} \\ \mathrm{JO} & \mathrm{pH} & \mathrm{WA}\end{array}$

Jo $\mu S / c m$ GE

JQ NS/cm WA

$\begin{array}{lll}\text { JT NTU } & \text { GE } \\ \text { JQ NTU } & \text { WA }\end{array}$

JQ NTU WA

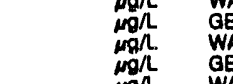

EA 
BLANK RESULTS

WELL OA 104C collected on 09/10/92, laboratory analyses (cont.)

$E$ Analyte

: Tritum

Result $<7.0 E-07$

Mod Unit Lab ${ }_{\mu \mathrm{CC} / \mathrm{mL}} \mathrm{GP}$

WELL QA 106C

MEASUREMENTS CONDUCTEO IN THE FIELD Sample date: 09/11/92
Depth to water: Not avallable
Water elovation: Not available
Sp. conductance: 8 S $/ \mathrm{cm}$

LABORATORY ANALYSES

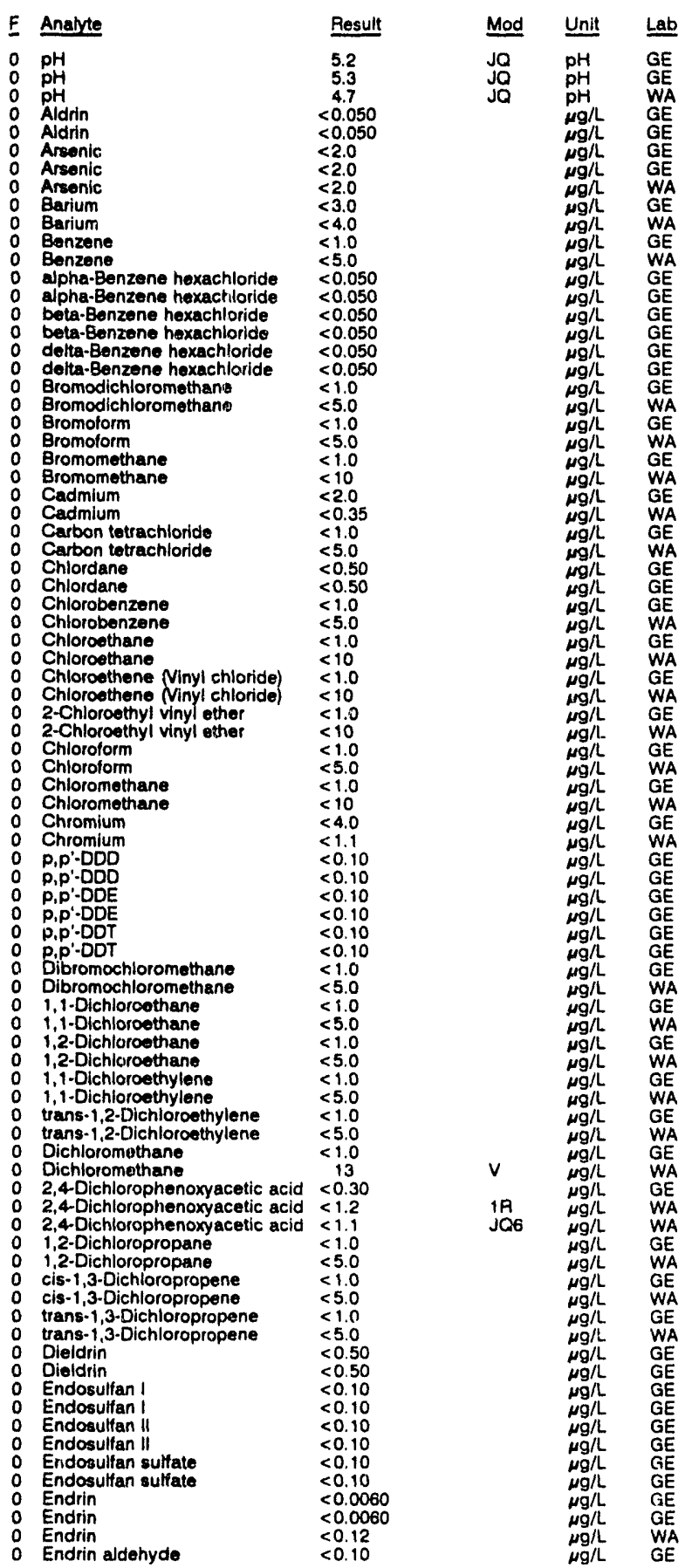

WELL QA $106 \mathrm{C}$ collected on 09/11/92, laboratory analyses (cont.)

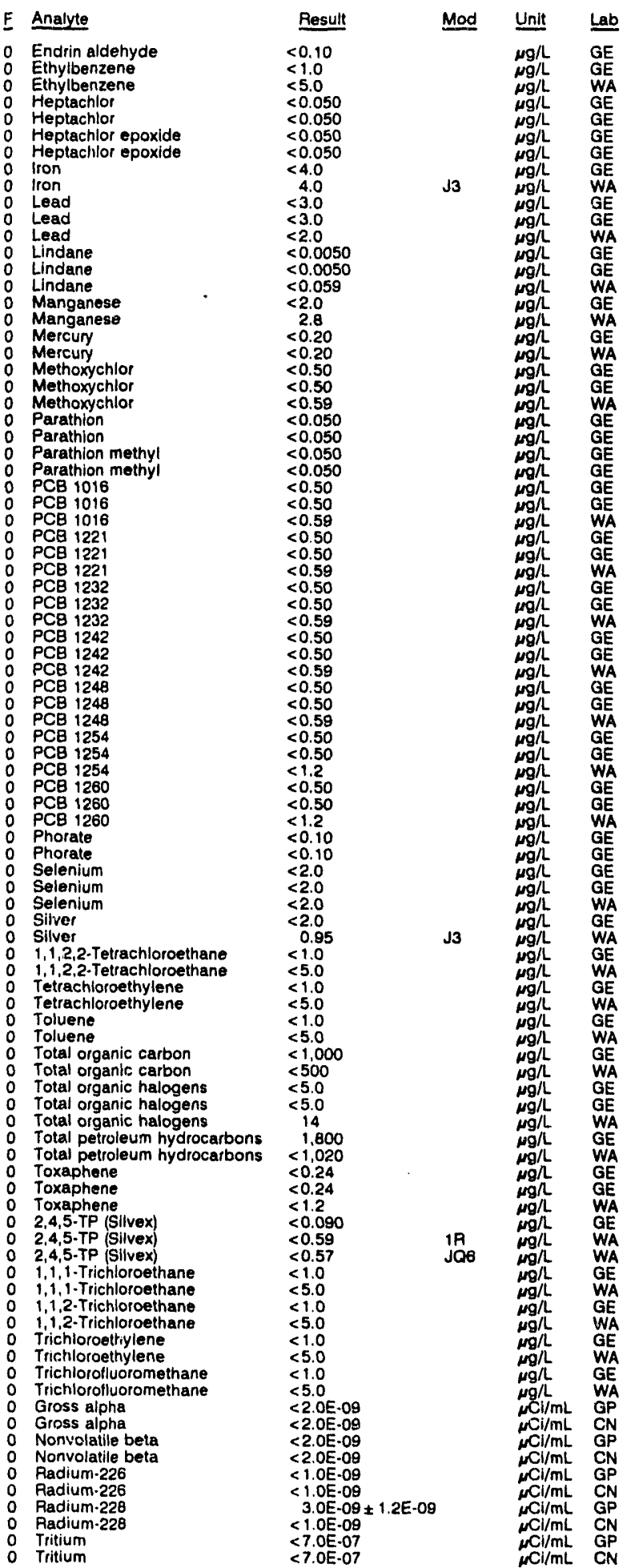


BLANK RESULTS

WELL QA 102C

MEASUIREMENTS CONDUCTED IN THE FIELD

Sample date: 07/27/92

Depth to water: Not available

Water olevation: Not avalab
Sp. conductance: $1 \mu \mathrm{S} / \mathrm{cm}$

LABORATORY ANALYSES

F Analyte

O Total alpha-amitting radium

WELL QA 104C

MEASUREMENTS CONOUCTED IN THE FIELD

Sample date: $09 / 10 / 92$
Depth to water: Not available
Water olevation: Not avallable
Sp. conductance: $8 \mu \mathrm{S} / \mathrm{cm}$

LABOPATOAY ANALYSES

F Analyte

$\begin{array}{ll}0 & \mathrm{pH} \\ 0 & \mathrm{pH} \\ 0 & \mathrm{pH} \\ 0 & \text { Aldrin } \\ 0 & \text { Aldrin } \\ 0 & \text { Alseng }\end{array}$

Aldrin

$\begin{array}{ll}0 & \text { Arsenic } \\ 0 & \text { Arsenic } \\ & 0\end{array}$

Barium

Benzene

Benzene

alpha-Benzene hexachloride

alpha-Benzene hexachloride

beta-Benzene hexachloride

delta-Benzene hexachioride

Bromadichloromethane

Bromodichloromethane

Bromoform

Bromoform

Bromomethane

Cadmium

Carbon tetrachloride

Carbon tetrachloride

Chlordane

o Chlorobenzene

o Chlorobenzene

Chloroethane

Chloroethene Minyl chloride)

Chloroethene Ninyl chloride)

2-Chloroethyl vinyl ether

2-Chlorosthyl vinyl other

Chlorotorm

C Chloroform

o Chloromethane

o Chromium

0 P, $P^{\prime}-D D D$

0 p.p'-DDD

0 P.P.-DDE

$\begin{array}{ll}0 & P, P^{\prime} \cdot D D \\ 0 & P^{\prime}, D D T\end{array}$

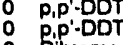

Dibromochloromethane $<1.0$

1,1-Dinhlorothethen

1,i-Dishoroethan

o 1,2-Dichloroethane

o 1,2 -Dichloroethane

o 1,i-Dichloroethylen

1,1-Dichloroethyiene

trans-1,2-Dichloroethylene

Dichloromethane

Dichloromethane

2,4-Dichlorophenoxyacetic acid 14

2,4 -Dichlorophenoxyacetic acid $<0,30$

2,4-Dichloropheiroxyacetic acid <1

1,2-Dichloropropane

1,2-Dichloropropane

clo-1,3-Dichioropropeno

trans-1,3-Dichloropropene

trane-1,3-Dichloropropene

Dieldrin

Dieldrin

Time: 7:40

PH: 4.1 ilinity: $0 \mathrm{mg}$

Water temperature: $22.7^{\circ} \mathrm{C}$

Time: $7: 15$
pH: 6.0
Alkalinity: $1 \mathrm{mg} / \mathrm{L}$
Water temperature: $29.3^{\circ} \mathrm{C}$

Mod Unit Lab

$\mu \mathrm{Cl} / \mathrm{mL}$ GE

1.0 E.09
7.0 E.07

5.1
5.1
4.9
$<0.05$

$<0.050$

$<2.0$

$<3.0$

$<1.0$
$<5.0$

$<0.050$

$<0.050$

$<0.050$

0.050

$<1.0$

$<1.0$

$<5.0$

$<10$
$<2.0$

$<0.35$

$<5.0$

$<0.50$
$<0.50$

$<1.0$
$<5.0$

$<1.0$

$<10$
$<1.0$
$<10$
$<1.0$

$<1.0$
$<10$

$<1.0$
$<5.0$

$<1.0$
$<10$

$<4.0$
1.8
$<0.10$
$<0.10$

$<0.10$

10
.10

0.10
1.0
5.0
1.0

$<5.0$
$<1.0$

$<5.0$
$<1.0$

$<5.0$

$<1.0$

$<5.0$
2.1

$<0.30$
$<1.1$

$<1.0$
$<50$

$<10$

$<5.0$

$<1.0$

$<1.0$
$<5.0$

$<0.50$

$<0.10$

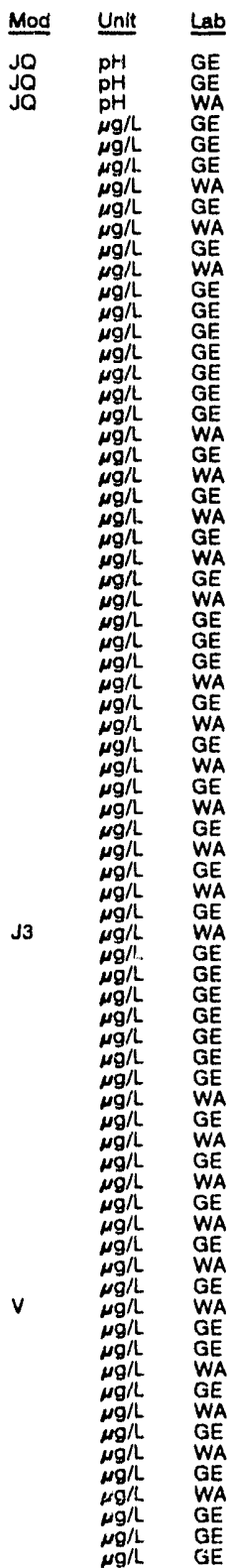

WELL QA $104 \mathrm{C}$ collected on 09/10/82, laboratory analyses (cont.)

$E$ Anaiyte

- Endosulfan I

0 Endosultan II

Endosulfan sulfate

E Endrin

O Endrin

0 Endrin aldehyde

0 Endrin aldehyde

Ethylbenzene

0 Heptachlor

Heptachlo

Heptachlor epoxide

o Heptachlor epoxide

Oron

0 Lead

o Lead

o Lindane

Lindane

Manganese

Mercury

o Mercury

- Methoxychlor

Methoxychlor

Methoxychlor

P Parathion

o Parathion methyl

Parathion methyl

- PCB 1016

o PCB 1016

O PCB 1016

O PCB 1221

- PCB 1221

O PCB 1221

O PCB 1232

P PCB 1232

- PCB 1242

- PCB 1242

O PCB 1242

$\begin{array}{lll}0 & \text { PCB } 1248 \\ 0 & \text { PCB } 1248\end{array}$

0 PCB 1248

D $\mathrm{PCB} 1254$

P PCB 1254

- PCB 1254

PCB 1260

PCB 1260

Phorate

Selenium

Selenium

Silver

S Silver

T1,2,2-Tetrachloroeth

Telrachloroethylene

Toluene

Toluene

Total organic carbon

Total organic carbon

Total organic halogens

Total organic halogens

Total petroleum hydrocaibons

Total petroleum

Toxapheno

Toxaphene

2,4,5.TP (Silvex)

2,4,5-TP Silvex

$2,4,5 \cdot T P$ Silvex
$1,1,1-$ Trichloroethane

- $1,1,1$. Trichloroethane

o 1,1,2-Trichloroethane

1.12-Trichloroethen

- Trichloroethylene

Trichloroethylene

Trichlorofluoromethane

0 Gross alpha

Gross alpha

Gross alpha

Nonvolatile beta

Nonvolatile beta

Nonvolatile beta

Nonvolatle beta

Radium-226

Radium.228

Radium.228
$<0.10$

$<0.10$
$<0.10$

$<0.10$

$<0.10$

$<0.0060$

$<0.12$

$<0.10$

$<1.0$

$<0.050$

$<0.050$
$<0.050$

$<0.050$

$<4.0$

5.2
$<3.0$

$<2.00$

$<0.0050$
$<0.050$

$<0.05$

$<.53$

$<0.20$

$<0.20$

$<0.50$

$<0.58$

$<0.050$
$<0.050$

$<0.050$

$<0.050$

$<0.50$

$<0.59$

$<0.50$

$<0.50$

$<0.58$
$<0.50$
$<0.50$
$<0.59$

$<0.50$

$<0.50$

$<0.59$
$<0.50$
$<0.50$
$<0.59$

$<0.59$

$<0.50$

$<0.50$
$<1.2$
$<0.50$
$<0.50$

$<0.50$

$<0.10$

$<0.10$

$<2.0$

$<2.0$

1.4
$<1.0$

$<5.0$

$<1.0$

$<1.0$

$<5.0$
$<1,000$

$<500$

$<5.0$
$<5.0$

$<1,000$

$<1,020$

$<0.24$
$<0.24$

$<1.2$

$<0.090$

$<0.090$
$<0.56$

$<1.0$

<1.

$<5.0$

$<1.0$

$<5.0$

$<1.0$
$<5.0$

$<2.0 E-08$

$<2.0 E .09$

$<2.0 \mathrm{E}-09$

$<2.0 E \cdot 09$

$<2.0 E-00$

$<2.0 E-09$

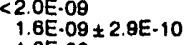

$<1.06 .09$

$1.7 \mathrm{~F}-09 \pm 6.6 \mathrm{E}-10$
$<1.0 \mathrm{E} \cdot 09$

Mod Unit Lab

$\left.\begin{array}{ll}\mu g / L \\ \mu g / L \\ \mu g / L \\ \mu g / L\end{array}\right) G$

$\mathrm{GE}$
$\mathrm{GE}$
$\mathrm{GE}$
$\mathrm{GE}$
$\mathrm{GE}$ 
BLANK RESULTS

\begin{tabular}{|c|c|c|c|c|c|}
\hline$\underline{F}$ & Analyte & Result & Mod & Unit & Lab \\
\hline $\begin{array}{l}0 \\
0 \\
0 \\
0 \\
0 \\
0 \\
0\end{array}$ & $\begin{array}{l}\text { Strontium-89 } \\
\text { Strontium-90 } \\
\text { Technetium-99 } \\
\text { Thorium-228 } \\
\text { Thorium-230 } \\
\text { Thorium-232 } \\
\text { Total alpha-emitting radium } \\
\text { Tritium } \\
\text { Uranium-234 } \\
\text { Uranium-235 } \\
\text { Uranium-236 } \\
\text { Yttrium-89 } \\
\text { Znc-65 }\end{array}$ & $\begin{array}{l}<2.0 \mathrm{E}-09 \\
<2.0 \mathrm{E}-09 \\
<3.0 \mathrm{E}-07 \\
<1.0 \mathrm{E}-09 \\
<1.0 \mathrm{E}-09 \\
<1.0 \mathrm{E}-09 \\
<1.0 \mathrm{E}-09 \\
<7.0 \mathrm{E}-07 \\
<1.0 \mathrm{E}-09 \\
<1.0 \mathrm{E}-09 \\
<1.0 \mathrm{E}-09 \\
<6.0 \mathrm{E}-08 \\
<2.0 \mathrm{E}-08\end{array}$ & & 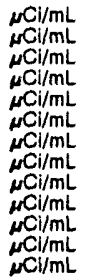 & $\begin{array}{l}G P \\
G P \\
G P \\
G P \\
G P \\
G P \\
G E \\
G E \\
G P \\
G P \\
G P \\
G P \\
G P\end{array}$ \\
\hline
\end{tabular}

\section{WELL QA 96C}

MEASUREMENTS CONDUCTED IN THE FIELD
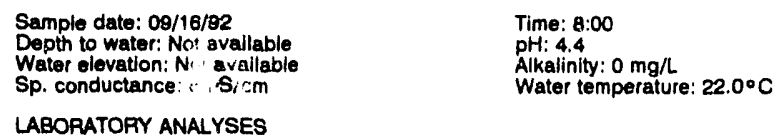

\section{E Anaiyte}

$0 \mathrm{pH}$

Specific conductance

O Arsenic

Barium

Bromodichloromethane

Bromodichlor

- Bromomothano

Cadmium

Calcium

Chloride

Chlorobenzene

Chloroethane

2-Chloroethyl Vinyl chloridel

2-Chloroethy

Chromium

Coppor

- Dibromochioromethane

1,1-Dichloroethane

1,2-Dichloroethane

1,1-Dichloroethylene

Dichloromethane

2,4-Dichiorophenoxyacetic acid

1,2-Dichloropropane

o trans-1,3-Dichloropropene

O trans-1,

o Ethylbenzene

0 Fluorida

L Load

Lindane

Magnesium

- Manganes

Mercury

Nickel

Nitrate-nitrite as nitrogen

Phenols

Potassium

0 Solentum

0 Silver

Sodium

Sulfate

Tetrachloroethylene

Tolvene

- Total dissolved solids

1 Total Inorganic carbon

- Total organic carbon

Total organic halogens

2,4,5-TP (Silvex)

1,4,1-Trichloroethan

1,1,2-Trichloroethan

Trichloroethylene

Trichlorofluoromethane

Zine

Gross alpha

Total alpha-emitting radium

WELL QA 98C

MEASUREMENTS CONDUCTED IN THE FIELD

Sample date: 08/26/92

Depth to water: Not avallable

Sp. conductance: $9 \mu \mathrm{S} / \mathrm{cm}$

LABORATORY ANALYSES

F Analyte

Result

- Total organic halogens

Total alpha-emitting radium

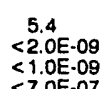

Time: $7: 30$

Water temperature: $25.6^{\circ} \mathrm{C}$

Tritium

$<1.0 E \cdot 09$

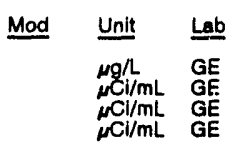

WELL QA $100 C$

MEASUREMENTS CONDUCTED IN THE FIELD

Sample date: 08/26/82

Depth to water: Not available

Sp. conductance: $8 \mu \mathrm{S} / \mathrm{cm}$

LABORATORY ANALYSES

E Analyte

0 Antimony

0 Barium

0 Benzene

0 Bromodichloromethane

0 Bromoform

0 Bromomethan

0 Cadmium

Carbon tetrachloride

Chloroethane

o Chloroethene Ninyl chloride)

2.Chloroethyl vinyl ethet

2.Chloroethy

${ }_{0}$ Chioromethan

0 Chioromethan

o Dibromochloromethane

0 1,1-Dichloroethane

o 1,2-Dichloroethane

1,1-Dichloroethylene
0 trans-1,2-Dichloroethylene

0 Dichloromethane

1,2-Dichloropropane
0 cis-1,3-Dichloropropen

cis-1,3-Dichloropropene

trans-1,3.Dich

0 Lead

0 Mercury

Nitrate-nitrite as nitrogen

Nitrite as nitrogen

- Selenium

0 Silver

o 1,1,2,2-Tetrachloroethane

- Tetrachloroethylene

o Toluene

o 1,1,1.Trichloroethane

o 1,1,2-Trichloroethan

0 Trichloroethylene

Trichlorofluoromethane

Antimony-125

0 Cerium.144

C Cesium-134

Cobalt.57

0 Cobalt.60

Europium-152

Europium-154

- Europium-155

- Gross alpha

Manganese-54
Potassium $\cdot 40$

Promethium-144

Promethium-146

0 Rutheniuin-106

Sodium-22

Tochnolum-8s

Tritium alpha-g

0 Yrtrium-

0 Zinc-65
Time: 7:20

Alkalinity: $0 \mathrm{mg} / \mathrm{L}$

Water tomperature: $25.4^{\circ} \mathrm{C}$

$<2.0$

$<3.0$

$<1.0$

$<1.0$

$<1.0$

$<1.0$

$<1.0$

$<1.0$

$<1.0$

$<1.0$

$<4.0$

$<1.0$

$<1.0$

$<1.0$

$<1.0$

$<1.0$

$<1.0$

$<1.0$

$<3.0$

$<0.20$

$<10$

$<10$

$<2.0$

$<2.0$
$<1.0$

$<1.0$

$<1.0$

$<1.0$

$<1.0$

$<\begin{array}{cc}1.1 \\ <2.0 \mathrm{E} .08\end{array}$

$<2.0 E \cdot 08$
$<6.0 E \cdot 08$
$<1.08$

$<1.0 \mathrm{E} .08$

$<1.0 E-08$

$<1.0 \mathrm{E} .08$

$<4.0 \mathrm{E}-0 \mathrm{0B}$

$<2.0 \mathrm{E}-00$

$<3.0 \mathrm{E}-08$

$<2.0 \mathrm{O} .09$

$<1.0 \mathrm{E}-08$

$<1.07$

$<1.0 \mathrm{E}-08$

$<8.0 E-08$

$<1.0 E .08$

<3.0 -07

$<1.0 E-09$
$<7.0 E-07$

$<6.0 E-08$ $\mu \mathrm{ggh} \quad \mathrm{GE}$ 
BLANK RESULTS

WELL QA 92C

MEASUREMENTS CONDUCTED IN THE FIELD

Sample date: 09/17/92

Depth to water: Not avallable

$\mathrm{Sp}$. conductanco: $8 \mathrm{\mu S} / \mathrm{cm}$

LABORATORY ANALYSES

F Analyte

O $\mathrm{pH}$

Arsenic

- Barlum

Benzene

Bromodichloromethane

Bromoform

Bromometh

Calclum

Carbon tetrachloride

o Chlorobenzene

Chloroothene Ninyl chloride)

2-Chloroothyl vinyl ether

Chloroform

Chroromem

Dibromochloromethane

1,1-Dichloroothane

1,2-Dichioroethane

trans-1,2-Dichiloroethylene

0 Dichloromethane

2,4-Oichlorophonoxyacetic acid

1,2.0ichloropropane

to trans-1,3-Dichloropropene

Endrin

Ethylbonzene

Fluorido

Load

Magnesium

Manganese

Mercury

Methoxychlo

Nitrate-nitrite as nitrogen

Phenols

Potassium

Selenium

Silver

Sodium

Sulloto.Totrachloroethane

Tetrachloroethylone

Toluene

Total dissolvod solids

Total inorganic carbon

Total organic halogens

Total phosphates (as P

Toxaphene

$1,1,1$-Trichloroothan

1,1,2-Trichloroethan

Trichloroethylene

Americium-241

Antimony-125

Corium-144

Cesium-134

Cobalt-57

Cobalt-60

Europium-152

Europium-154

Europlum-155

Gross alpha

Nonvolatilo be

Plutonium-238

Plutonium-239/2

Potassium-40

Promethlum-144

Promethium-146

Radium-228

Ruthenium-100

Sodium-22

Strontlum-80

Thorium-228

Thorium-230

Total alpha-emitting radium
Time: 8:35

PH: 4.4 : $0 \mathrm{mg} / \mathrm{h}$

Water temperature: $24.2^{\circ} \mathrm{C}$

Result Mod Unit Lab

5.0

10

$<3.0$

$<1.0$

$<1.0$

$<1.0$

$<2.0$

$<1.0$

$<250$

$<1.0$

$<1.0$

1.0

$<1.0$

$<4.0$

$<1.0$

$<1.0$

1.0

1.3

$<0.30$

$<1.0$

$<0.0060$

$<1.0$

$<100$

$<4.0$

$<0.0050$

2.1
$<2.0$

$<2.0$
$<0.20$
$<0.20$
$<0.50$

$<50$

$<5.0$

$<500$

12,500

$<2.0$

$<1000$

$<1.0$

$<1.0$

15,000
7,930
$<1,000$

$<5.0$
$<50$

$<0.24$

$<0.090$

$<0.090$
$<1.0$

$<1.0$

$<1.0$

$<1.0 E \cdot 09$
$<2.0 E \cdot 08$

$<2.0 E \cdot 08$
$<6.0 E \cdot 08$

$<1.0 E-08$

$<1.0 E .08$

$1.0 E .08$

$4.0 \mathrm{E} .08$

. $0 \mathrm{E} .08$

$3.0 \mathrm{E}-08$

$<2.0 E-09$

$<1.0 E-08$

$<2.0 E-09$

$<1.0 E .09$

$1.0 \mathrm{E} \cdot 00$

1.1E-07

$<1.0 E-08$

$<1.0 \mathrm{E}-08$

$1.3 \mathrm{E}-09 \pm 2.8 \mathrm{E}-10$

$<1.0 \mathrm{E} \cdot 09$

$<9.02 .08$

$<20$. 09

$<2.02 .09$

$<1.0 E .09$

1.

$<1.0 E-09$

$<1.0 E-09$
$<1.0 E-09$
WELL QA 92C collected on 09/17/82, laboratory analyses (cont.)

\begin{tabular}{|c|c|c|c|c|}
\hline F Analyte & Pesuit & Mod & Unit & Lab \\
\hline $\begin{array}{ll}0 & \text { Tritium } \\
0 & \text { Tritium } \\
0 & \text { Uranium-234 } \\
0 & \text { Uranium-235 } \\
0 & \text { Uranium-238 } \\
0 & \text { Yttrium-88 } \\
0 & \text { Zinc-65 }\end{array}$ & $\begin{array}{l}<7.0 \mathrm{O} \cdot 07 \\
<7.0 \mathrm{E} \cdot 07 \\
<1.0 \mathrm{E} \cdot 09 \\
<1.0 \mathrm{E} \cdot 09 \\
<1.0 \mathrm{E} \cdot 09 \\
<6.0 \mathrm{E} \cdot 08 \\
<2.0 \mathrm{E} \cdot 08\end{array}$ & & $\begin{array}{l}\mathrm{mCl} / \mathrm{mL} \\
\mu \mathrm{Cl} / \mathrm{mL} \\
\mu \mathrm{Cl} / \mathrm{mL} \\
\mu \mathrm{Cl} / \mathrm{mL} \\
\mu \mathrm{Cl} / \mathrm{mL} \\
\mathrm{NCl} / \mathrm{mL} \\
\omega \mathrm{Cl} / \mathrm{mL}\end{array}$ & $\begin{array}{l}\text { GE } \\
\text { GE } \\
\text { GP } \\
\text { GP } \\
\text { GP } \\
\text { GP } \\
\text { GP }\end{array}$ \\
\hline
\end{tabular}

WELL QA 94C

MEASUREMENTS CONDUCTED IN THE FIELD

Sample date: 09/14/92

Depth to water: Not avallable

Water elevation: Not avallabio

pH: 4.6 . 0

Water temperature: $17.4^{\circ} \mathrm{C}$

LABORATORY ANALYSES

F Analyte

O $\mathrm{pH}$

0 Arsenic

Barium

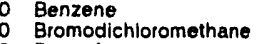

Bromoform

Bromomethane

Cadmium

0 Carbon tetrachioride

0 Chioride

o Chlorobenzene

Chloroethane

Chloroethene Ninyl chloride)

2-Chloroethyl vinyl other

0 Chloroform

Chloromethane

0 Chromium

o Dibromochtoromethane

o 1,1.Dichloroethane

o 1,2-Dichloroethane

1,1-Dichloroethylene
0 tians-1,2-Dichloroethylene

0 Dichloromethane

1,2-Dichloropropane

0
0
0

0 Ethylbenzene

0 Fluoride

0 Iron

o Magnesium

0 Manganese

0 Mercury

O Nitrate-n

0 Potassium

o Selenlum

0 Silica

o Silver

0 Sodium

S Sulfate

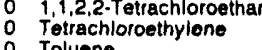

Toluene

Total dissolved solids

1 Total inorganic carbon

0 Total organic halogens

Total phosphates (as P

o 1,1,1-Trichloroethane

o i,1,2-Trichloroethan

o Trichloroethylene

Irichlorofluoromethane

- Americium-241

0 Antimony-125

o Cerium-144

0 Cesium.134

Cosium-137

o Cobalt-57

O Europium-152

Europium-152

Europlum-154

0 Gross alphe

O lodine-129

- Monvolatile beta

0 Plutonium-238

Plutonium-238

- Promethium-144

0 Promethium-146

0 Radium.22

- Padium-228

Ruthenium-10
0 Sodium-22

Mod Unit Lat<smiles>[AsH2]</smiles>

10
$<2.0$

$<2.0$
$<3.0$
$<1.0$

$<1.0$

$<1.0$
$<1.0$
$<2.0$
$<2.0$

$<10$

(c)

$<1.0$

$<1.0$

$<1.0$

$<4.0$

si.0

$<1.0$

$<1.0$

$<1.0$

$<1.0$
$<1.0$
$<1.0$
$<1.0$

$<1.0$

$<40$

$<3.0$

$<2.0$
$<2.0$
$<0.20$

$<0.20$
$<50$

$<50$
$<5.0$
$<500$

$<2.0$

14.600
$<2.0$

$\begin{aligned} & 14,600 \\ &<2.0<10 \\ &<1000\end{aligned}$

$<1,000$

$<1.0$

$<1.0$

5,230
$<1,000$

$<5.0$

$<50$

$<1.0$

$<1.0$

$<1.0$

$<<2.0 \mathrm{E}-00$

$<6.0 \mathrm{E}-08$

$<1.0 E-08$

$<1.0 E-00$

$<1.0 E .08$

$<1.0 E-06$

$<4.0 E-08$

$<3$

<2,

$<2.0 \mathrm{E}$

$<1.0 E .08$

$<2.0 E .09$

$<1.0 \mathrm{E} .09$

$<1.0 \mathrm{E}-09$

$<1.1 \mathrm{E}-07$

$<1.0 E .08$

$<1.0 \mathrm{E}-08$

2. $1 \mathrm{E} \cdot 09 \pm 1.4 \mathrm{E}-09$

$<9.0 E .08$
$<1.0 \mathrm{E} .08$

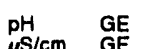

$\mu \mathrm{s} / \mathrm{cm}$ GE

$\begin{array}{ll}\mu g / L & G E \\ \mu g / L & G E \\ \mu g h & G E\end{array}$

$\mathrm{\mu g/L}$ GE 
WELL QA $88 C$ collocted on 07/11/92, laboratory analyses (cont.)

E Analyte

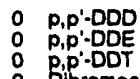

$\begin{array}{ll}<0.10 \\ \text { P.P.DDT } & <0.10\end{array}$

bibromochloromethane < < $<1.10$

1,1-Dichlorosthane $<1.0$

$1,1-$ Dichloroethylene
trans-1,2-Dichioroethylene

$\begin{array}{ll}0 & \text { Dichloromethane } \\ 0.4 \text { Dichlorophenoxyacetic acid }<0.1 & 8.1\end{array}$

2,4 Dichlorophenoxyacetic acid $<0.30$
0

$\begin{array}{lll} & \text { cis-1,3-Dichloropropene } & <1.0 \\ 0 & \text { trans-1,3-Dichloropropene } & <1.0\end{array}$

Dieldrin $1<0.50$

Endosultan I

Endosulfan II sulfate $\quad<0.10$

0 Endrin $\quad<0.0060$

Endrin aldehyde $<0.10$

$\begin{array}{ll}0 \text { Heptachlor } & <0.050 \\ 0 \text { Heptachlor epoxide } & <0.050\end{array}$

0 iron

0 Lead

Manganese

0 Mercury

Nickel

o Parathion

0 Parathion methyl

o PCB 1016

PCB 1232

O PCE 1242

P PCB 1248

PCB 1260

Phorate

o Silver

1,1,2,2-Tetrachlorcothane

0 Tetrachioroethylene

Thallium

Tin

Total organic carbon

Total organic halogen

2,4,5-TP (Silvex)

1,1,2-Trichloroethane

Trichloroethylene

Trichlorofluoromethane

O Zanad

0 Antimony -125

Corium-144

Cesium-134

Cobalt-57

o Cobatt-60

Europium-152

Europium-155

Gross alpha

Manganese-54

Nonvolatile beta

Nonvolatile bota

Promethlum-144

Promethlum-144

Radium-226

Ruthenium-100

Total alpha-emitting radium

Tritium

Ytuium-88

$<0.050$
$<4.0$
$<3.0$

$<3.0$

$<2.0$

$<0.20$
$<0.50$

$<0.50$
$<4.0$

$<0.050$

$<0.050$

$<0.50$

$<0.50$

$<0.50$

$<0.50$

$<0.50$
$<0.50$
$<0.10$
$<2.0$

$<2.0$

$<1.0$
$<1.0$

$<1.0$
$<2.0$
$<2.0$

1.9
$<1,000$

$<5.0$

$<0.24$

$<1.0$

$<1.0$

$<1.0$
2.6

$<8.0$

$<2.0 \mathrm{E}-08$

$<6.0 E \cdot 08$

$<1.0 \mathrm{E}-08$

$<1.0 E .08$

$<1.0 E-08$

$<4.0 \mathrm{E}-0 \mathrm{OB}$

$<2.0 E-08$

$<2.0 E-09$

$<2.0 \mathrm{E}-09$

$<1.0 E-00$

$<2.0 E-09$

$<2.0 E-09$

$<1,1 \mathrm{E}-07$

$<1.0 \mathrm{E}-08$

$<1.0 E-09$

$<1.0 \mathrm{E}-08$

1. $4 E-09 \pm 9.0 \mathrm{E}-10$

$<7.0 \mathrm{E}-07$

$<6.0 \mathrm{E}-08$
$<2.0 \mathrm{E}-08$

Mod Unit

$\mu g / L$ GE

$\mu g / L \quad G E$

GE

$\underset{\mu g / L}{\mu g / L}$

WELL QA 90C

MEASUREMENTS CONDUCTED IN THE FIELD

Sample date: 09/21/92

Depth to water: Not available

Water elevation: Not availab

Sp. conductance: $\theta \mu \mathrm{s} / \mathrm{cm}$

LABORATOAY ANALYSES

\begin{tabular}{|c|c|c|c|c|c|}
\hline$\underline{F}$ & Analyte & Result & Mod & Unit & $\underline{L a b}$ \\
\hline $\begin{array}{l}0 \\
0 \\
0 \\
0\end{array}$ & $\begin{array}{l}\text { pH } \\
\text { Specific conductance } \\
\text { Arsenic } \\
\text { Barium } \\
\text { Benzene }\end{array}$ & $\begin{array}{r}4.9 \\
10 \\
<2.0 \\
<3.0 \\
<1.0\end{array}$ & Jo & $\begin{array}{l}\mathrm{pH} \\
\mu S / \mathrm{cm} \\
\mu g / \Lambda \\
\mu g / L \\
\mu g / L\end{array}$ & $\begin{array}{l}\mathrm{GE} \\
\mathrm{GE} \\
\mathrm{GE} \\
\mathrm{GE} \\
\mathrm{GE}\end{array}$ \\
\hline
\end{tabular}

WELL QA $90 \mathrm{C}$ collected on 09/21/82, laboratory analyses (cont.)

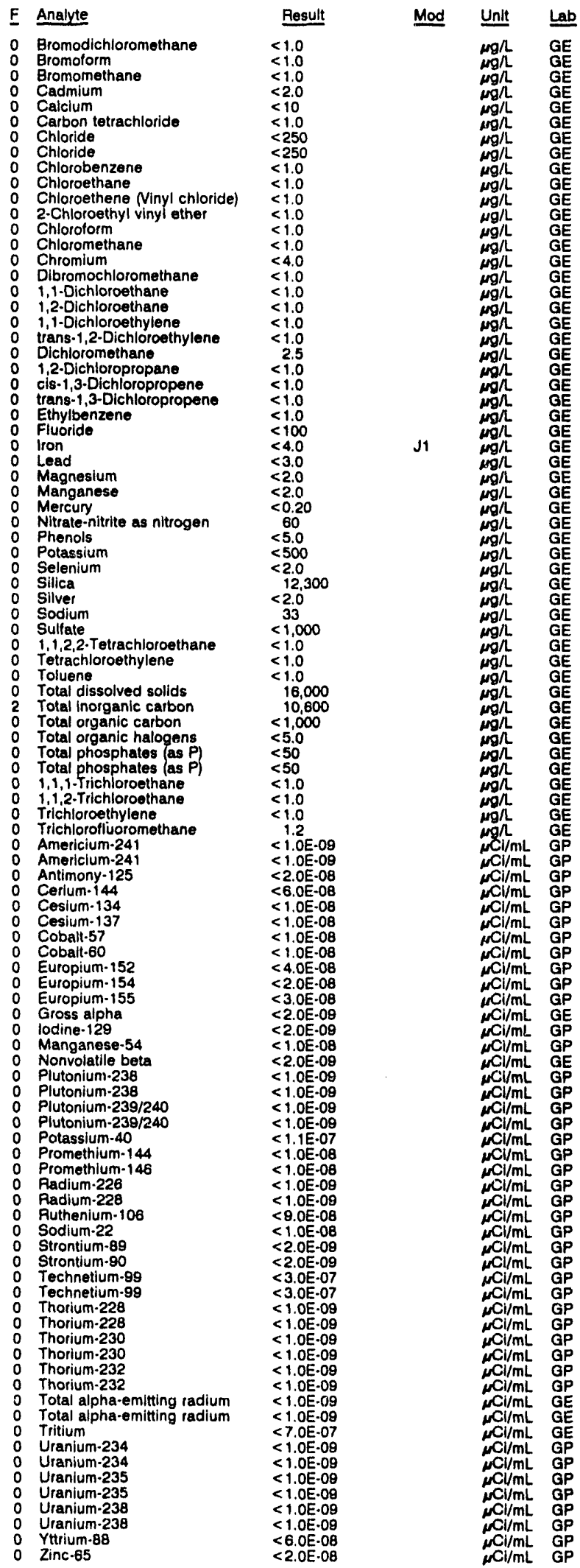


BLANK RESULTS

WELL QA 86C

MEASUREMENTS CONDUCTED IN THE FIELD

Sample date: 07/12/82

Depth to water: Not avallable

Water elevation: Not availab
Sp. conductance: $1 \mu \mathrm{s} / \mathrm{cm}$

LABORATORY ANALYSES

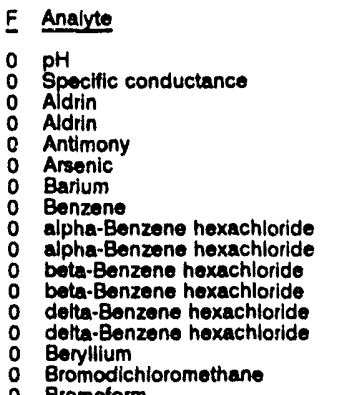

Besult

5.8

$<0.050$

$<0.000$

$<<>0$

$<1.0$

$<0.050$

$<0.050$

$<0.050$

$<<0.055$

$<<0.050$

3.0

Bromoform

Bromome

Cadmium

Chlordane

Chlordane

Chlorobenzene

Chloroethane

2-Chloroethyl vinyl ether

Chloroform

Chloromethane

o Chromium

0 Cobalt

0 P.P.DDD

P.p'-DDD

0 p,p'-DDE

0 P,p'-DOT

$<<<0.10$

o 1,1-Dichloroethane

o 1,2-Dichloroethane

1,1.Dichloroethylene

trans-1,2-Dichloroethylene $<1$.

0 2,4-Dichlorophenoxyacetic acid $<0.30$

o cis:1,3-Dichloropropene

trans-1,3-Dichloropropene

Dieldrin

Dibldrin

Endosulfan

Endosulfan II

Endosultan II

Endosulfan sulfate

Endosult

Endrín

Endrin aldehyde

Endrin aldohydo

Ethylbenzen

Heptachlor

Heptachlor opoxide

Heptachlor epoxide

Iron

Lead

Lindane

Manganese

Methoxychlor

Methoxychlor

Nickel

Parathlon

Parathion methyi

Parathion methyl

PCE 1016
PCB 1016

PCB 122

PCB 1221

PCB 1232

PCB 1242

PCB 1242

PCB 1248

$P C B$
$P C B$
1254

D PCB 1260
Time: 6:20

$\mathrm{pH}: 5.6$

Alkalinity: $1 \mathrm{mg} / \mathrm{L}$

$28.5^{\circ} \mathrm{C}$

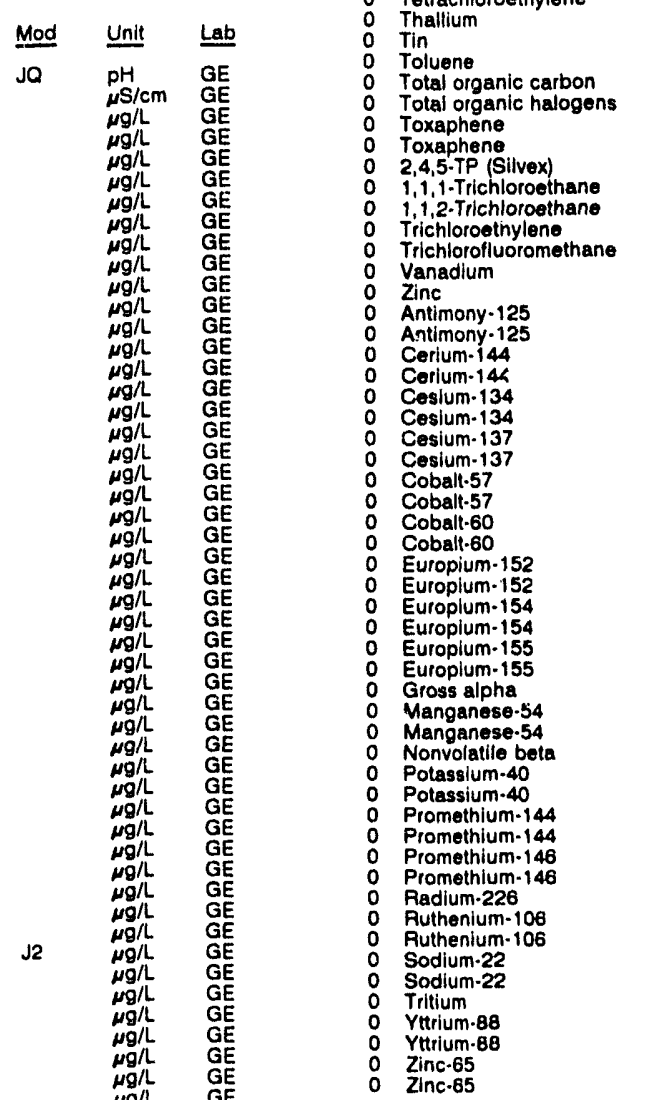

WELL OA 86C collected on 07/12/92, laboratory analyses (cont)

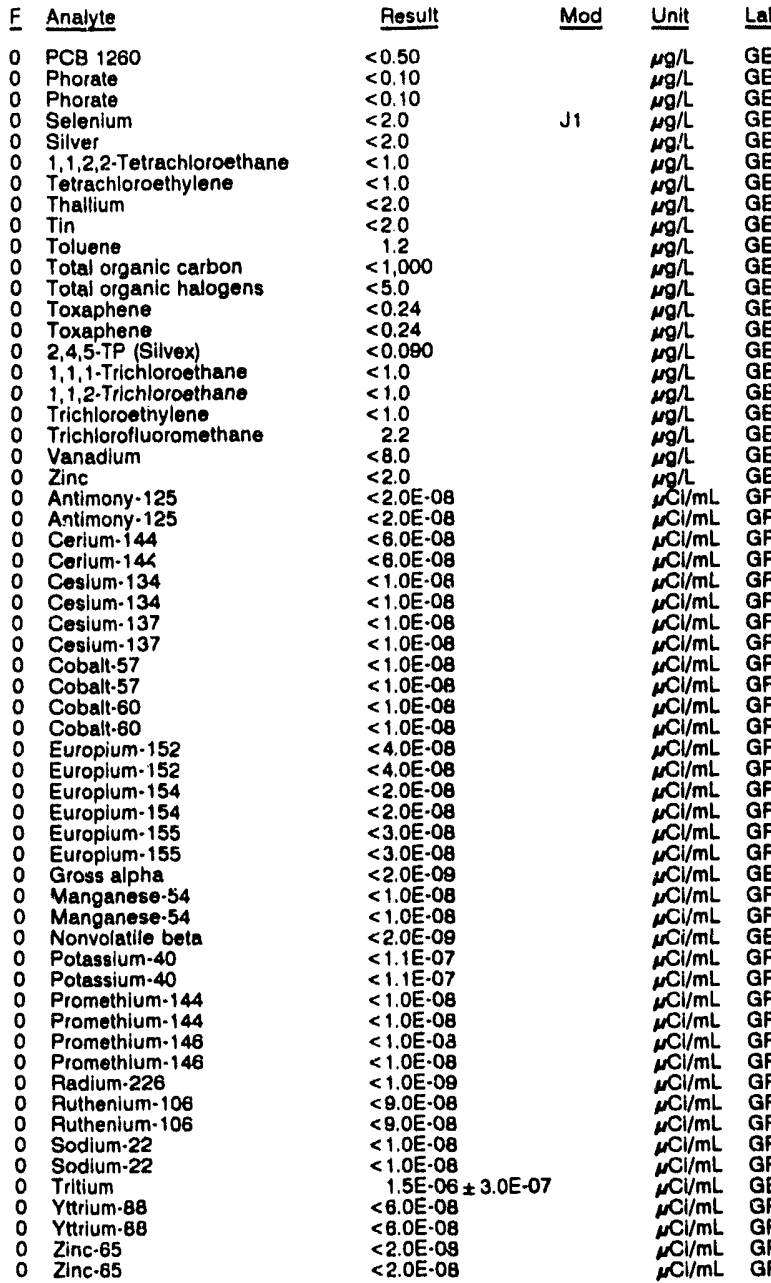

WELL QA 88C

MEASUREMENTS CONDUCTED IN THE FIELD

Sample date: 07/11/92

Depth to water: Not available

Water elevation: Not avallable

H: 5.1

Alkalinity: $1 \mathrm{mg} / \mathrm{L}$

p. conductance: $2 \mu \mathrm{S} / \mathrm{cm}$

LABORATORY ANALYSES

pH

Aldrin

Antimony

0 Arsenic

Barium

alpha.Benzene hexachloride

beta-Benzene hexachloride

delta.Benzen

Beryllium

Bromodichlotomethane

Bromoform

Bromometh

Carbon tetrachloride

Carbon teri

Chlordane

Chlorsethane

Chloroethene Ninyl chloride)

2-Chloroethyl vinyl ether

Chlorotorm

Chloromethane

Chromium

$\begin{array}{ll}0 & \text { Cobalt } \\ 0 & \text { Coppet }\end{array}$
Water temperature: $28.4^{\circ} \mathrm{C}$

\begin{tabular}{|c|c|c|}
\hline Result & Mod & Unit \\
\hline $\begin{array}{l}5.7 \\
5.0 \\
<0.050 \\
<2.0 \\
<2.0 \\
<3.0 \\
<1.0 \\
<0.050 \\
<0.050 \\
<0.050 \\
<3.0 \\
<1.0 \\
<1.0 \\
<1.0 \\
<2.0 \\
<1.0 \\
<0.50 \\
<1.0 \\
<1.0 \\
<1.0 \\
<1.0 \\
<1.0 \\
<1.0 \\
<4.0 \\
<4.0 \\
<4.0\end{array}$ & JO & 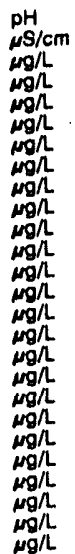 \\
\hline
\end{tabular}


BLANK RESULTS

WELL QA $80 C$ collected on 09/17/92, laboratory analyses (cont.)

0 Benzene

Bromodichloromethane

Bromotorm

Bromomethane

Carbon tetrachioride $\quad<10$

Chloride $\quad<250$

Chlorobenzene $<1.0$

Chloroethene Ninyl chloride)

2-Chloroethyl vinyl other

Chloroform

Chloromethane $<1,0$

Chromium $\quad<4.0$

0 1,1-Oichloroothane $<1.0$

o 1,1-Dichloroethylene $\quad<1.0$

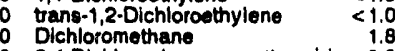

2,4-Dichlorophenoxyacetlc acid <0.30

2,4-Dichlorophenoxyacetic acid <0.30

1,2-Dichloropropane

0 trans-1,3-Dichloropropene $<1.0$

0 Endrin $\quad<0.0060$

0 Ethylbenzene $<1.0$

O Fluorican

O Lead

Lindane

- Magnestum

Marcury

Methoxychlor

Nitrate-nitrite as nitrogen

Phenols

Potasesium

Silica

Silver

Sodium

1,1,2,2-Tetrachloroethane

Tetrachloroethylene

Toluone

Tolal dissolved solids

Total organic carbon

Total oranic carbon

Total phosphates (as P)

Toxaphene

2,4,5-TP (Silvex)

1,1,1-Trichloroethane

1,1,2-Trichloroethan

Trichlorofluosomethane

Americlum-241

Antimony-125

Cesium-134

Cosium-137

Cobalt-57

Europium-152

Europium-154

Europlum-155

Gross alpha

Manganese-54

Nonvolatile bota

Plutonium-239/240

Potassium-40

Promethium-144
Promethium-146

Radium-226

Radium-228
Ruthenium-106

Sodium-2?

Strontium-69

Strontium-80

Technetium-80

Thorium-228

Thorium-230

Thorlum.232

Total al pha-emitting radium

Tritium

Uranium-234

Uranium-235

Yranium-230

Zinc-65
Mod

0

.

. 0

1.0

.0

.30
.0
.0
.00
0
0
.0

$<4.0$
$<3.0$

$<0.0050$

$<2.0$

$<0.20$

$<50$
$<5.0$
$<500$
$<2.0$

$<2.0$

$<<<12.400$

$<10$
$<1,000$

$<1.0$

$<1.0$
$<1.0$

15,000
8,360

$<1,000$

$<5.0$
$<50$

$<0.24$

$<0.090$

$<1.0$

$<1.0$

$<1.0$

$<1.0$ $<2.09$

$<6.0 \mathrm{OE}-0 \mathrm{\theta}$

$<1.0 \mathrm{E}-00$

$<1.0 E-08$

$<1.0 E-08$

$<4.0 \mathrm{E} \cdot 0 \mathrm{O}$

$<2.0 E .08$
$<3.0 E .08$

$<2.0 E \cdot 09$

$<2.0 \mathrm{E} .09$

$<1.0 E-08$

$<1.0 \mathrm{E}-09$

$<1.0 E-09$

$<1.1 E-07$

$<1.0 E-08$

$<1.0 E-08$

<1.0E.09

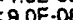

2
$<1.0 E .08$

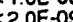

$<2.0 E-09$

$<3.0 \mathrm{E} .07$

C1.OE-09

$<1.0 \mathrm{E}-09$

$<1.0 E-09$

$<1.0 E-09$

$<7.0 E-07$

$<1.0 E .09$

$<1.0 E .09$

$<6.0 E-O B$
Unit Lab

$\begin{array}{ll}\mu g / L & G E \\ \mu \mathrm{g} / L & \mathrm{GE} \\ \mu \mathrm{g} / \mathrm{L} & \mathrm{GE}\end{array}$

$\mu g / L$ GE

$\mu g / \mathrm{GE}$

$\mu \mathrm{g} / \mathrm{GE}$

$\mu g /$ GE

WELL QA 820

MEASUREMENTS CONDUCTED IN THE FIELD

Sample date: 09/02/92

Depth to water: Not available

Water elevation: Not available
$\mathrm{Sp}$. conductance: $8 \mu \mathrm{S} / \mathrm{cm}$

Time: 7:30

Alkalinity: $0 \mathrm{mg} / \mathrm{L}$

Water temperature: $23.0^{\circ} \mathrm{C}$

LABORATORY ANALYSES

F Analyte Result Mod Unit Lab

0 Benzene

Bromodichloromethane

Bromofirm

Bromomethane

Calcium

Calcium

Carbon tettachloride

Chlorobenzene

Chloroethene (Ninyl chloride)

2.Chloroethyl vinyl ether

2.Chloroethyl

Chloromethane

D Dibromochloromethane

1,1-Dichloroethane

1,2-Dichloroethane

trans-1,2-Oichloroethylene

Dichloromethane

1,2-Dichloropropane

cis-1,3-Dichloropropene

trans-1,3-Dichioropropene

Dissolved organic carbon

$\begin{array}{ll}0 & \text { Ethylber } \\ 0 & \text { Iron } \\ 0 & \text { Iron }\end{array}$

M Magnesium

Magnesium

Nitrite as nitrogen

Potassium

0 Potassium

0 Silica

0 Sulfide

S Sulfide

1,1,2,2-Tetrachloroethane

Tetrachloroethylene

Toluene

Total organic halogens

1,1,1-Trichlorates (as

1,i,2.Tfichloroethan

Trichloroethylene

Trichiorofluoromethane

$<1.0$

$<1.0$

$<10$

$<10$

$<1.0$

$<1.0$

$<1.0$

$<1.0$

$<1.0$

$<1.0$

$<1.0$

(3.

$<1.0$

$<1.0$

$<1,000$

$<1,000$

$<4.0$

$<2.0$

$<<10$

$<10$
$<500$

$<500$

16,200
16,200

$<1,000$

$<1,000$

$<1.0$
$<1.0$

$<1.0$

$<50$

$<1.0$

$<1.0$
$<1.0$
1.1

$1.10 \mathrm{C} \cdot 09 \pm 8.0 \mathrm{E}-10$

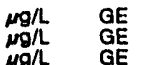

WELL QA $84 C$

MEASUREMENTS CONDUCTED IN THE FIELD

Sample date: 08/22/92

Depth to water: Not available

Sp. conductance: 4 sism

Alkalinity: $0 \mathrm{mg} / \mathrm{L}$

Water temperature: $24.2{ }^{\circ} \mathrm{C}$

LABORATORY ANALYSES

$E$ Analyte

- Arsenic

0 Barium

Chromium

2,4-Dichlorophenoxyacetic acid

Endrin

Lead

0 Lindane

O Manganese

Mercury

0 Selenium

0 Silver

0 Toxaphene

Gross alpha

O Total al pha-emitting radium

Result

$<2.0$

$<2.0$ 
WELL QA 74C

MEASUAEMENTS CONDUCTED IN THE FIELD

Sample date: 08/08/92

Wepth to water: Not avaliable

Water elevation: Not available
Sp. conductance: $3 \mu \mathrm{S} / \mathrm{cm}$

LABORATORY ANALYSES

\begin{tabular}{|c|c|}
\hline Analyte & Result \\
\hline $\begin{array}{l}\text { Cadmium } \\
\text { Carbon tetrachlorlde } \\
\text { Chloroform } \\
\text { lon } \\
\text { Lead } \\
\text { Manganese } \\
\text { Mercuny } \\
\text { Nitrate-nitrite as nitrogen } \\
\text { Phenols } \\
\text { Phenols } \\
\text { Tetrachloroethylene } \\
\text { Total organic carbon } \\
\text { Total organic carbon } \\
\text { Total organic halogens } \\
\text { 1,1,1-Trichloroethane } \\
\text { Trichloroethylene } \\
\text { Groas alpha } \\
\text { Nonvolatile beta } \\
\text { Total alpha-emitting radlum } \\
\text { Tritium }\end{array}$ & $\begin{array}{l}<2.0 \\
<1.0 \\
<1.0 \\
16 \\
<3.0 \\
<2.0 \\
<0.20 \\
<50 \\
<5.0 \\
<5.0 \\
<1.0 \\
<1.000 \\
<1.000 \\
<5.0 \\
<1.0 \\
<1.0 \\
<2.0 E-09 \\
<2.0 E-09 \\
<1.0 E-09 \\
<7.0 E-07\end{array}$ \\
\hline
\end{tabular}

WELL QA 76C

MEASUREMENTS CONDUCTED IN THE FIELD

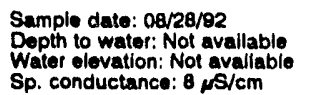

LABORATORY ANALYSES
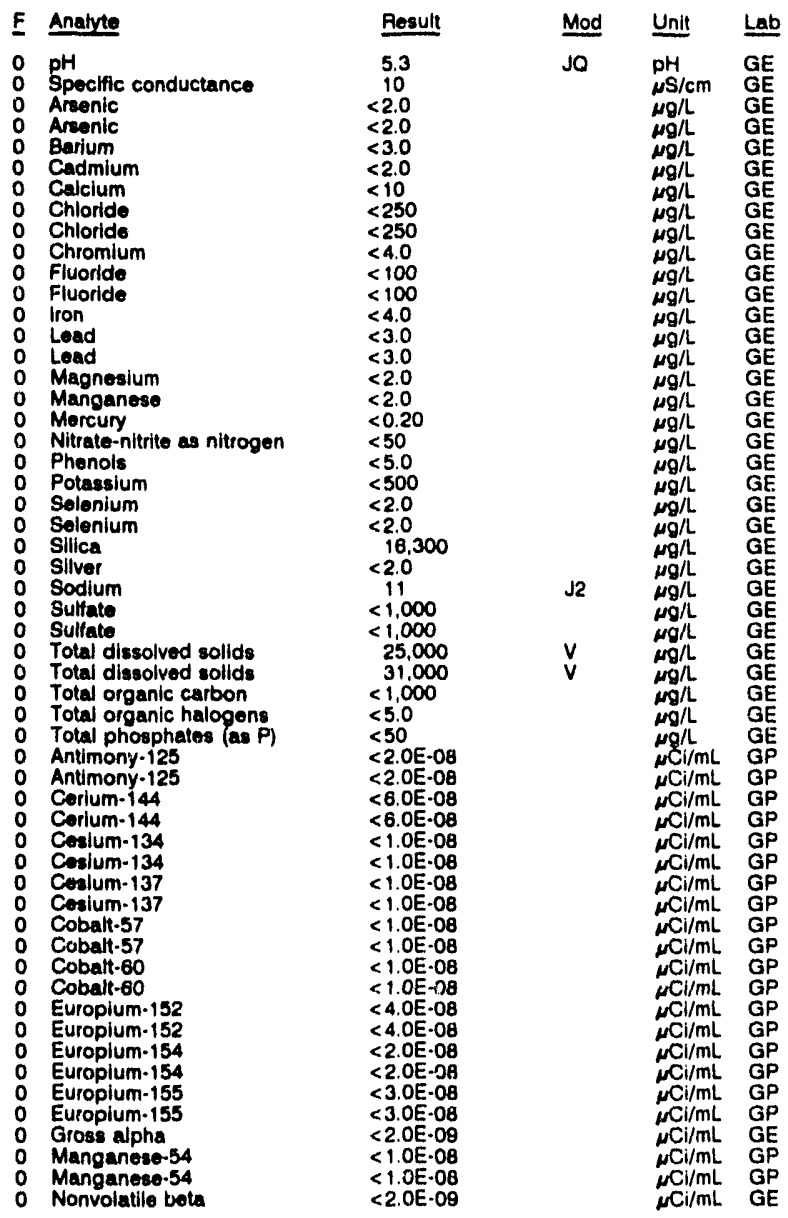

WWELL QA 76C collected on 08/28/92, laboratory analyses (cont.)

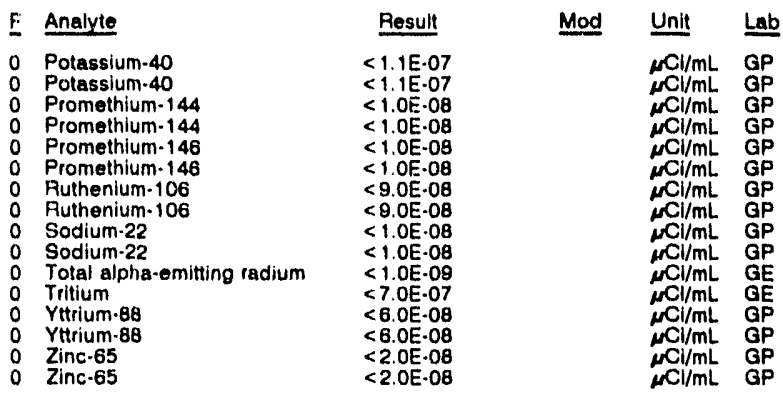

WELL QA $78 C$

MEASUREMENTS CONDUCTED IN THE FIELD

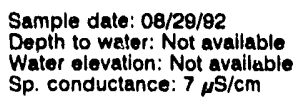

Time: 7:55

pH: 4.5

Alkalinity: $0 \mathrm{mg} / \mathrm{L}$

Water temperature: $22.1^{\circ} \mathrm{C}$

LABORATORY ANALYSES

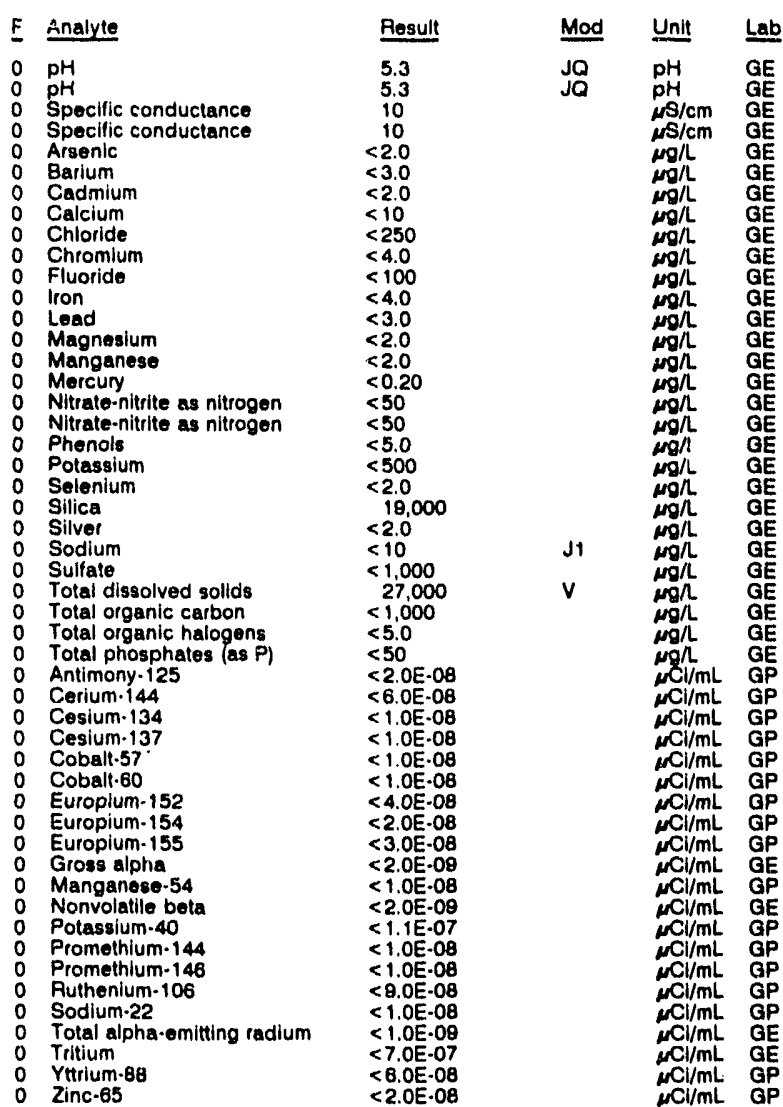

WELL QA $80 C$

MEASUREMENTS CONDUCTED IN THE FIELD

Sample date: 09/17/82

Depth to water: Not avaliable

Water elevation: Not avallablo

Sp. conductance: $8 \mu \mathrm{S} / \mathrm{cm}$

Time: $8: 15$

Alkalinity: $0 \mathrm{mg} / \mathrm{L}$

Alkalinity: $0 \mathrm{mg} / \mathrm{h}$
Water tomperature: $22.0^{\circ} \mathrm{C}$

ABORATORY ANALYSES

\begin{tabular}{|c|c|c|c|c|c|}
\hline$\underline{F}$ & Analyte & Result & Mod & Unit & Lab \\
\hline $\begin{array}{l}0 \\
0 \\
0\end{array}$ & $\begin{array}{l}\text { pH } \\
\text { Specific conductance } \\
\text { Arsenic } \\
\text { Barium }\end{array}$ & $\begin{array}{r}5.1 \\
2.0 \\
<2.0 \\
<3.0\end{array}$ & Ja & $\begin{array}{l}\mathrm{pH} \\
\mu \mathrm{S} / \mathrm{cm} \\
\mu \mathrm{g} / \mathrm{h} \\
\mu \mathrm{g} / \mathrm{L}\end{array}$ & $\begin{array}{l}\mathrm{GE} \\
\mathrm{GE} \\
\mathrm{GE} \\
\mathrm{GE}\end{array}$ \\
\hline
\end{tabular}


BLANK RESULTS

WELL QA 72C collectod on 07/21/92, laboratory analyses (cont.)

$E$ Analyise

- Cyanide

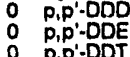

0 p,P'-DDT

Dibenzia,h]anthracene

Dibenzofuran

1,2-Dibromo-3-chloropropane

1,2-Dibromoethan

Di-n-butyl phthatato

1,2-Dichlorobenzene

1,4 Dichlotobonzene

3,3'-Dichlorobenzidine

Dichiorodifluoromethane

1 1,1-Dichloroethane

1,2-Dichloroethane

trans-1,2-Dichloroethylene

2,4-Dichlorthane

2,4-Dichlorophenol

2,4-Dichlorophenoxyacetic acid

1,2-Dichloropropane

cis-1,3-Dichloropropene

Diethyl phthalale

2,4-Dimethyl phenol

p-Dimethylaminoazobenzene

bimethylbenz [a] anthracene

3,3'-Oimethylbenzidine

a.a.Dimethylphenethylamine

$\begin{array}{ll}0 & 1,3-\text { Dinitrobenzene } \\ 0 & 2,4 \text {-Dinitrophenol }\end{array}$

2,4-Dinitrotoluene

: 2,6-Dintstotivent

1,4-Dloxane

0 Disulfoton

- Endosulfan I

Endosulfan ll

Endrin

Endrin aldehydo

: Ethyl methacrylato

Ethyl methanesult

Famphur

Fluoranthen

Heptachlo

Heptachlor epoxide

Heptachlorodibenzo-p-dioxins

$1,2,3,4,6,7,8-H P C D F$
Heptachlorodibenzo-p-furans

Hexachlorobenzene

Hexachlorocyclopentadiene

Hexachlcrodibenzo-p-dioxins

Hexachlcrodibenzo-p-dioxins
$1,2,3,4,7,8-H X C D F$

Hexachlorodibenzo-p-furans

Hoxachloroethane

Hexachloropropene

2-Hexanone

Indeno[ $1,2,3-c$, d]pyrene
lodomethane (Methyl iodide)

lodomethane (Mint

isodrin

isophorone

Isosafrole

o Kepone

0 Lead

0 Lindane

Mercury

Methacrylonitrile

Methapyrilene

2-Mothyl-4,6-dinitrophenol

Methyl ethyl ketone

Methyl isobutyl ketone

Methyl methacrylate

Methyl methanesulfona

2-Mothylcholanthrene

Naphthalene

1,4-Naphthoq' inone

1-Naphthylamine

Nickel
Mod Unit

$<5.0$

$<0.10$

$<0.10$

$<10$

$<10$

$<1.0$

$<1.0$

$<1.0$

$<<10$

$<10$

$<10$

$<30$

$<1.0$

$<1.0$

$<1.0$

$<10$

$<0.30$
$<1.0$

$<1.0$

$<0.50$

$<<10$

$\leq<10$

$<<10$

$<<10$

$<10$
$<10$
$<10$

$<45$

$<10$
$<10$
$<10$

$<10$

$<<10$

$<0.10$

$<0.10$

$<0.0060$

$<10$

$<10$

$<1.0$

$<<10$

$<0.050$

$<0.00065$

$<0.00065$

$<0.00045$

$<10$

$<10$

$<0.00045$

$<0.00045$

$<0.00040$

$<10$
$<10$

$<10$
$<1.0$

$<1.0$
$<10$

$<15$
$<100$

$<100$
$<10$

$<<10$

$<<$

$<0.0050$

$<2.0$

$<50$

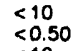

$<10$

$<1.0$

$<10$

$<10$
$<10$

$<10$

$<10$

$<10$
$<10$

$<10$
$<4.0$

$J 1$
$J 1$
$J 1$
$J 1$
$J 1$
$J 1$
$J 1$
$J 1$

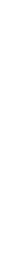

Mg/L GE

GE

GE$$
\text { .4. }
$$

WELL QA $72 \mathrm{C}$ collected on $07 / 21 / 82$, laboratory analyses (cont.)

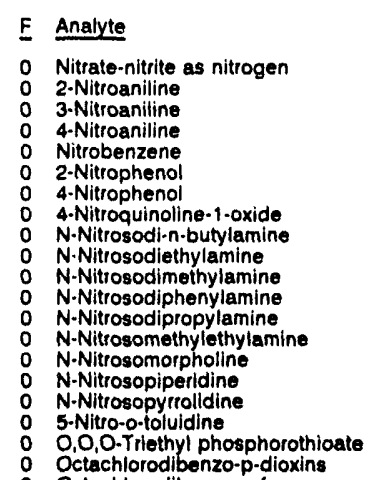

\begin{tabular}{|c|c|}
\hline \multicolumn{2}{|l|}{ Pesult } \\
\hline & \\
\hline $\begin{array}{r}10 \\
<10\end{array}$ & $\begin{array}{l}\mathrm{Jt} \\
\mathrm{J} 1\end{array}$ \\
\hline$<10$ & \\
\hline$<10$ & Ji \\
\hline $\begin{array}{l}<10 \\
<10\end{array}$ & \\
\hline$<10$ & J1 \\
\hline$<10$ & Ji \\
\hline $\begin{array}{l}<10 \\
<10\end{array}$ & J1 \\
\hline $\begin{array}{l}<10 \\
<10\end{array}$ & J1 \\
\hline$<10$ & $\sqrt{1}$ \\
\hline $\begin{array}{l}<10 \\
<10\end{array}$ & J1 \\
\hline $\begin{array}{l}r 10 \\
<10\end{array}$ & $\begin{array}{l}\mathrm{J1}_{1} \\
\text {. }\end{array}$ \\
\hline$<10$ & $J_{1}$ \\
\hline $\begin{array}{l}<10 \\
<10\end{array}$ & $\begin{array}{l}\mathrm{J1} \\
\mathrm{J1}\end{array}$ \\
\hline
\end{tabular}

Parathion methyl

PCB 1016

PCS 1232

PCB 1242

PCB 2254

PCB 1260

Pentachlorobenzene

Pentachlorodibenzo-p-dioxins

Pentachlorodibenzo-p-furans

Pentachlorodibenz

Pentachloroethane

Pentachloronitrobenzene

Pentachloropheno

Phenacetin

Phenol

Phenols
p.Phenylenedlamine

Phorate

2.Picoline

Propionituile

Pyrene

Pyridine

Selenium

Silver

Sodium

Styrene

Sulfide

Sulfotepp

2,3,7,5-Tetrach

2,3,7,8.TCDF

Tetrachlorodibenzo-p-dioxins

Tetrachlorodibenzo-p-furan

1,1,1,2-Tetrachloroethane

1,1,2,2-Tetrachloroethan

2,3,4,6-Tetrachlorophenol

Thionazin

Tin

$\begin{array}{ll}0 & \text { Toluene } \\ 0 & \text { o-Toluidine }\end{array}$

Total organlc carbon

Total organic halogens

$2,4,5-T P$ (Silvex)
1,2,4-Trichlorobenzene

1,2,4. -richlorobenzen

i, i. Trichloroethane

Trichloroethylene

Trichlorofluoromethane

2,4,5.Trichlorophenol

2,4,6.Trich

1,2,3-Trichloropropane

1,3,5.Trinitrobenzene

- Uranium

Vinyl acetate

X Zinc

Gross alpha

Nonvolatile bela

2 Total alpha-emitting radium

$<0.0010$
$<0.050$
$<0.050$

$<0.050$

$<0.50$

$<0$

$<0.50$

$<0.50$
$<0.50$
$<0.50$

$<10$

$<0.00055$

$<<<0.00055$

$<0.000$

$<10$
$<10$
$<10$
$<10$

$<10$
$<10$
$<10$
$<10$
$<510$
$<510$

$<5.0$

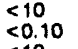

$<10$
$<10$
$<10$

$<200$

$\leq 10$

$<10$

$<2.0$

$<10$

$<1,0$

$<1,000$

$<10$

$<0.00045$

$<0.00040$

$<0.00040$

$<1.0$

$<1.0$

$<1.0$

$<10$
$<2.0$
$<10$

$<10$
$<2.0$
$<1.0$

$<10$

$<1,000$

$<50$
$<0.24$
$<100$

$<0.24$

$<10$
$<1.0$
$<10$

$<1.0$

$<1.0$

$<10$
$<10$
$<10$

$<0.090$

$<1.0$
$<10$
$<$

$<10$
$<20$
$<20$

$<8.0$

$<1.0$
$<2.0$
$<2.0$

$<2.06-09$

$<2.0 \mathrm{E}-09$
$<2.0 \mathrm{E}-09$
$1.2 \mathrm{E}-08$

Mod Unit Lab

$\mu g / \mu$
$\mu g \Omega$
$\mu g h$

E

E


WELL QA 68C

MEASUREMENTS CONDUCTED IN THE FIELD

Sample date: 07/20/92

Depth to water: Not available

Water olevation: Not avaliable
$\mathrm{Sp}$. conductance: $2 \mathrm{~ms} / \mathrm{cm}$

LABORATORY ANALYSES

E Analyte

O $\mathrm{PH}^{\mathrm{H}}$

Specific conductance

Spocticic conductance

o Areenic

- Barium

: Cadmium

- Chromium

o Coppe

L ron

- Manganese

Morcury

Nitrate-niturte as nitrogen

Phonols

Soleniun

sodium

Total organic carbon

Total organic halogens

Zine

Nonvolasile beta

Total apha-emitting radium

Uranium-23a

Uranium-239

WELL QA $70 C$

MEASUREMENTS CONDUCTED IN THE FIELD

Sample date: 07/25/92

Depth to water: Not avaliable

Water elovation: Not avallable

LABOFATORY ANALYSES

0 pH

specific conductance

N Auminum

B Areonic

Barum

Bromodichloromethane

Bromotorm

Bromomethane

cadmlum

Calcium

Chioride

Chlorobenzene

Chloroethane

2-Chloroethyl vinyl ether

Chlorotorm

Chloromethane

Chromium

Copper

Dibromochloromethane

1,1.Dichloroethane

1,2-Dichloroethane

t) 1,1-Dichloroethylone

Dichloromethane

1,2-Dichloropropane

trans-1,3-Dichloropropene

Ethylbenzeno

o ron

Mag lesium

Magnganose

Mercury

Nickel

P Phenols

Potassium

Solonium

Silica

\begin{tabular}{|c|c|c|c|}
\hline \multirow[b]{2}{*}{ Result } & \multicolumn{3}{|c|}{$\begin{array}{l}\text { Time: } 7: 15 \\
\text { pH: } 7: 6 \\
\text { Alkalinity: } 1 \mathrm{mg} / \mathrm{h} \\
\text { Water temperature: } 25.0 \circ \mathrm{C}\end{array}$} \\
\hline & Mod & Unit & Lab \\
\hline $\begin{array}{r}5.9 \\
5.9 \\
3.0 \\
3.0 \\
<2.0 \\
<3.0 \\
<2.0 \\
<250 \\
<4.0 \\
<4.0 \\
<4.0 \\
<3.0 \\
<2.0 \\
<0.20 \\
<4.0 \\
<50 \\
<5.0 \\
<2.0 \\
<2.0 \\
<10 \\
<1.000 \\
<1.000 \\
<5.0 \\
<50 \\
<2.0 \\
<2.0 E-09 \\
<1.0 E-09 \\
<1.0 E-09 \\
<1.0 E-09 \\
<1.0 E-09\end{array}$ & $\begin{array}{l}\text { JO } \\
\text { JO }\end{array}$ & 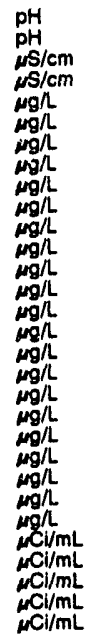 & $\begin{array}{l}G E \\
G G \\
G E \\
G E \\
G E \\
G E \\
G E \\
G E \\
G G \\
G E \\
G E \\
G E \\
G E \\
G E \\
G E \\
G E \\
G E \\
G E \\
G E \\
G E \\
G E \\
G G \\
G E \\
G E \\
G E \\
G E \\
G E \\
G E \\
G E \\
G E \\
G E \\
G E \\
G P \\
G P \\
G P\end{array}$ \\
\hline
\end{tabular}

Time: $9: 05$

Alkalinity: $1 \mathrm{mg} /$

Water temperature: $27.2^{\circ} \mathrm{C}$

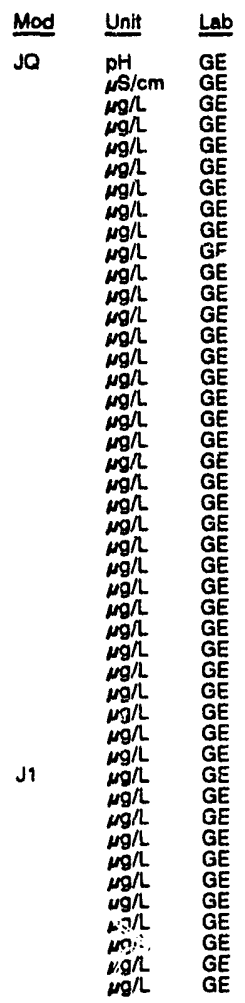

WELL QA $70 \mathrm{C}$ collectod on 07/25/92, laboratory analyses (cont.)

\begin{tabular}{|c|c|c|c|}
\hline Analyte & Result & Mod & Unit \\
\hline 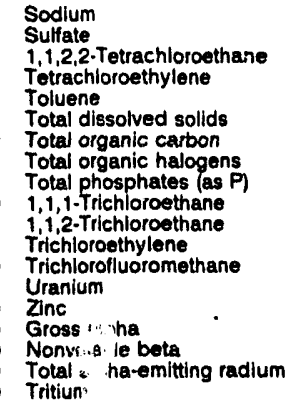 & $\begin{array}{l}<10 \\
<1,000 \\
<1.0 \\
<1.0 \\
<1.0 \\
<1.000 \\
<1,000 \\
<5.0 \\
<50 \\
<1.0 \\
<1.0 \\
<1.0 \\
1.7 \\
<20 \\
<2.0 \\
<2.0 E \cdot 09 \\
<2.0 E-09 \\
<1.0 E \cdot 09 \\
<7.0 E-07\end{array}$ & $v$ & 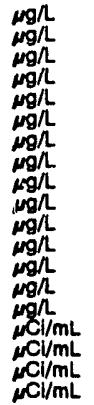 \\
\hline
\end{tabular}

WELL QA 72C

MEASUREMENTS CONDUCTED IN THE FIELD

Sample date: 07/21/92

Depth to water: Not avaliable

Water elevution: Not avallable
Sp. conductance: $1 \mathrm{\mu s} / \mathrm{cm}$

pH: 5.5

Water temperature: $25.2^{\circ} \mathrm{C}$

LABORATORY ANALYSES

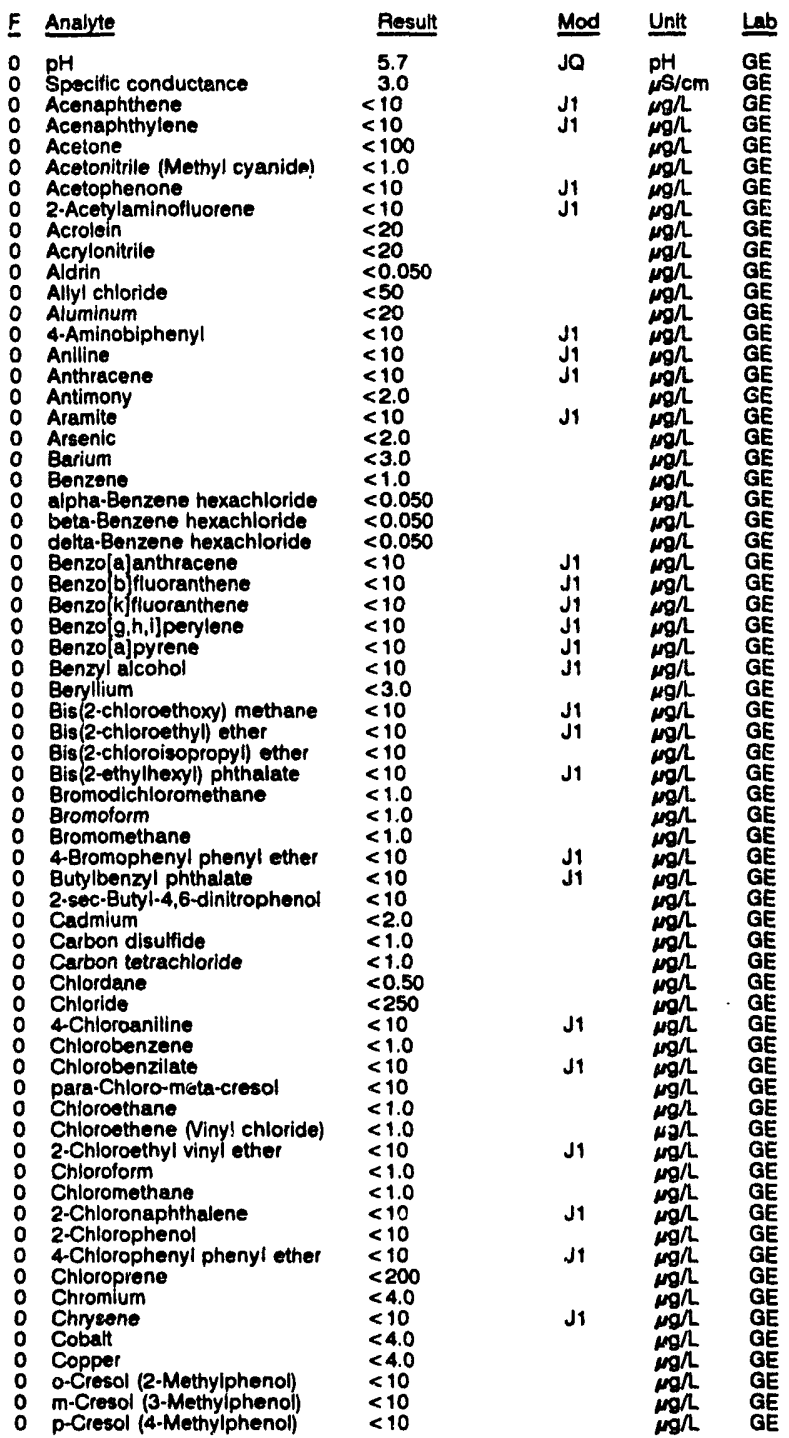




\section{BLANK RESULTS}

WELL QA 62C collected on 07/17/92, laboratory analyses (cont.)

\begin{tabular}{|c|c|c|c|c|c|}
\hline & Analyte & Result & Mod & Unit & Lab \\
\hline & $\begin{array}{l}\text { Trichloroethylene } \\
\text { Trichlorofluoromethane } \\
\text { Uranlum } \\
\text { Zinc } \\
\text { Grose alpha } \\
\text { Nonvolatile beta } \\
\text { Total alpha-emitting radium }\end{array}$ & $\begin{array}{l}<1.0 \\
1.3 \\
<20 \\
<2.0 \\
<2.0 \mathrm{E}-09 \\
<2.0 \mathrm{E}-09 \\
<1.0 \mathrm{E}-09\end{array}$ & & $\begin{array}{l}\mu \mathrm{g} / \mathrm{L} \\
\mu \mathrm{g} / \mathrm{L} \\
\mu \mathrm{g} / \mathrm{L} \\
\mu g / \mathrm{L} \\
\mu \mathrm{Ci} / \mathrm{mL} \\
\mu \mathrm{Ci} / \mathrm{mL} \\
\mu \mathrm{Ci} / \mathrm{mL}\end{array}$ & $\begin{array}{l}\mathrm{GE} \\
\mathrm{GE} \\
\mathrm{GE} \\
\mathrm{GE} \\
\mathrm{GE} \\
\mathrm{GE} \\
\mathrm{GE}\end{array}$ \\
\hline
\end{tabular}

WELL QA 64C

MEASUAEMENTS CONDUCTED IN THE FIELD

Sample date: $07 / 08 / 92$
Depth to water: Not avaliable
Watter otevation: Not available
Sp. conductance: 1 pS/cm

LABOPATORY ANALYSES

E Anatute

$\begin{array}{ll}0 & \text { pH } \\ 0 & \text { Spectic conductance } \\ 0 & \text { Spectic conductance }\end{array}$

Aluminum

Areanic

Benzen

Bromodichloromethane

Bromolorm

Cadmium

Carbon tetrachioride

Chloride

Chloride

Chloroothane

2-Chloroethyl vinyl other

Chlorotorm

Chloromethane

Chromium

Copper

Dyanide

1,1-Dichloroethane

1,2-Dichloroethane

trans-1,2-Dichloroethylene

Dichloromethane

1,2-Dichloropropane

tans-1,3-Dichloropropene

Ethylbenzene

Lead

Manganese

Mickel

Nitrate-nitrite as nitrogen
Nitrato-nitrite as nitrogen

Phenols

Solenium

Sodium

Sulfato

Sulfate

Totrachloroethylene

Toluene

Total organic halogens

Total phosphates (as P)

1, 1, - - Trichloroethane

Trichloroethylethe

Trichlorofluoromethane

Uranium

Gross aipha

Total alpha-emitting radium

Uranium-234

Uranium-234

Uranlum-235

Uranlum-235

Uranium-238

\section{Time: 6:05}

pH: 4.6

Water temperalure: $27.1^{\circ} \mathrm{C}$

\section{Result}

5.5
2.0

2.0

$<2.0$

$<1.0$

$<1.0$

$<1.0$
$<1.0$

$<250$

$<250$
$<1.0$

$<1.0$

$<1.0$

$<1.0$

$<1.0$
$<4.0$

$<4.0$

$<5.0$

$<1.0$
$<1.0$
$<1.0$

$<1.0$

$<1.0$
$<1.0$
1.7

$<1.0$
$<1.0$

$<1.0$

$<1.0$

$<4.0$
$<3.0$
$<2.0$

$<0.20$

$<4.0$

$<50$
$<5.0$
$<2.0$

$<5.0$
$<2.0$
$<2.0$

$<100$

$<1,000$
$<1,000$

$<1.0$

$<1.0$

$<5.0$

$<50$
$<1.0$
$<1.0$

$<<1.0$

$<\begin{array}{r}1.0 \\ 1.3\end{array}$

$<20$

$<2.06-09$

$<2.0 E-09$
$<1.0 E-00$

$<1.0 \mathrm{EE}-09$

$<1.0 E-09$

$<1.0 E-09$

$<1.0 E-09$

$<1.0 E-09$
$<1.0 E-00$

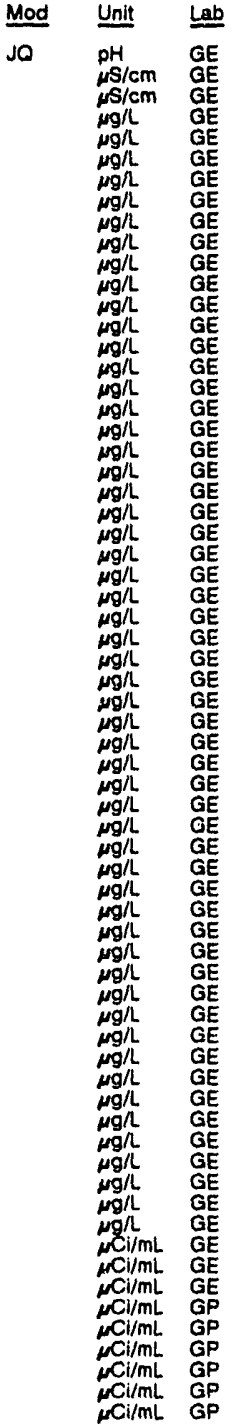

WELL QA 66C

MEASUREMENTS CONDUCTED IN THE FIELD

Sample date: 07/07/92

Depth to water: Not avallable

Water elevation: Not availabi

pH: 4.8

Alkalinity: $1 \mathrm{mg} / \mathrm{L}$

Water temperature: $25.2^{\circ} \mathrm{C}$

LABORATORY ANALYSES

$0 \mathrm{pH}$

$\mathrm{pH}$

Specific conductance

Apecific conductance

Aluminum

Arsenic

Barium

Barium

Bromodichloromethan

Bromoform

Bromomethan

Cadmium

Carbon tetrachloride

Chloride

Chloride

Chlorobenzene

Chloroethane

Chloroethene Ninyl chloride

2-Chioroethy

Chloromethane

Chromium

Chromium

Copper

Copper

Cyanide

1.1.Dichloroethan

1,i-Dichloroethylen

trans-1,2-Dichloroethylene

Dichloromethane

1,2-Dichloropropane

cis-1,3-Dichloropropene

Ethylbenzene

Iron

Iron

Lead

Manganese

Manganese

Nickel

Nickel

Nitrate-nitrite as nitrogen

Phenois

Selenium

Silver

Sodium

Sodium

Sulfate

1,1,2,2-Tetrachioroethane

Tetrachloroethylene

Toluene

Total organic halogens

Total phosphates (as P

1,1,1-Trichloroethane

fluoromethane

Uranium

Uran

Zinc

O Gross alpha

Nonvolatile beta

Uranium-235

Uranium-235

Result Mod Unit Lab

5.8
5.8

JQ

$\mathrm{pH} \quad \mathrm{GE}$

$\mathrm{S} / \mathrm{cm}$ GE

$\mu \mathrm{s} / \mathrm{cm}$ GE

3.0
$<20$

$<<<$

$<3.0$
$<3.0$

$<1.0$

$<1.0$

$<1.0$
$<2.0$

$<2.0$

$<250$

$<250$

$<1.0$

$<1.0$

$<1.0$

$<1.0$
$<4.0$

$<4.0$

$<4.0$

$<1.0$

$<1.0$

$<1.0$

2.1

$<1.0$
$<1.0$
$<1.0$

$<4.0$

$<3.0$

$<2.0$

$<0.20$

$<4.0$

$<50$

$<5.0$
$<2.0$
$<2.0$

$<<2.0$

$<10$

$<1,000$

$<1,000$

$<1.0$

$<1.0$
$<1.0$
$<5.0$

$<50$

$<1.0$

$<1.0$

$<1.0$

$<20$

$<20$

$<2.00-09$

$<<2.0 E-09$

$<1.0 E-08$

$<1.06-09$

$<1.0 E-09$
$<1.0 E-09$

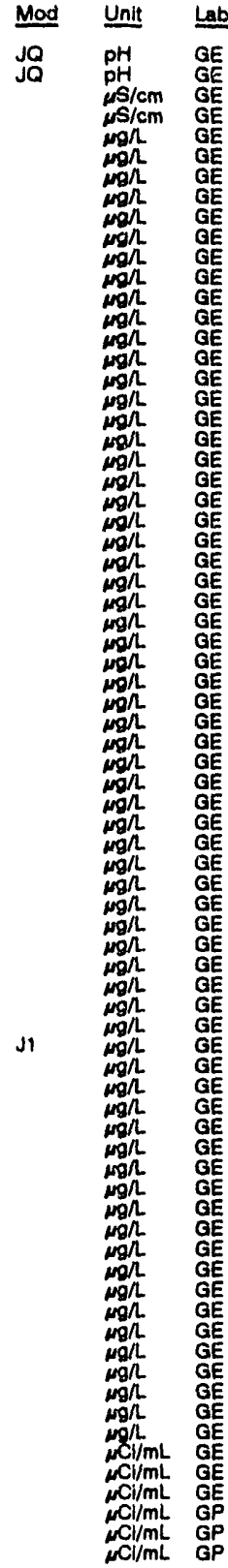


BLANK RESULTS

WELL QA $58 \mathrm{C}$ collectod on 07/13/82, laboratory analyses (cont)

E Analyte

o Phonanthreno

Phenol

Phorate

2-Picoline

Pronamid

Propionirill

Safroto

Selenium

Sodiver

styrene

Sulfide

1,2,4,5-Tetrachiorobenzene 2,3,7,8-TCDD

$2,3,7, \theta-T C D D$

$2,3,7,8-T C D F$

Tetrachlorodibenzo-p-dioxin

Totrachlorodibenzo-p-dioxin

Torrachiorodibenzo-p-lurans

1,1,1,2-Tetrachloroethane

$1,1,2,2$-Tetrachloroothane

Totrachloroethylene

2,3,4,6-Tetrachlorophenol

Thallium

Tin

o-Toluidine

Total organic carbon

Total phosphates (as P)

Toxaphene

2,4,3-TP (Silvex)

1,1,1-Trichloroethane

1,1,2-Trichloroethan

Trichlorofluoromethane

2,4,5-Trichlorophenol

$2,4,6-7$ -

1,2,3-Trichloropropan

1,3,5.Trinitrobenzene

Uranlum

Vinyl acetate

Xylones

Nonvolatile bota
Total alpha-emitting radium
Begult

$<10$
$<10$

$<5.0$
$<10$
$<0.10$
$<10$

$<10$

$<10$
$<200$
$<10$

$<10$

$<10$
$<2.0$
$<2.0$

$<10$

$<1,000$

$<1,000$

$<10$
$<10$

$<0.00045$

$<0.00040$

$<0.00040$

$<0.00045$

$<0.00045$

$<0.00040$

$<1.0$

$<1.0$

$<10$
$<2.0$
$<10$

$<2.0$
$<1.0$

$<10$

$<1,000$
$<5.0$

$<50$

$<0.090$

$<100$

$<1.0$
$<1.0$
$<1.0$

1.4
$<10$

$<10$
$<0.090$
$<1.0$
$<10$

$<1.0$
$<10$
$<20$

$<20$
$<1.0$

$<2.0$

$<2.0$

$<2.0 E-09$
$<1.0 E-09$
WELL QA 60C

MEASUREMENTS CONOUCTEO IN THE FIELD

Sample data: 07/00/92

Depth to water: Not available

Water elevation: Not avallabile
Sp. conductance: 1 S/cm

LABORATORY ANALYSES

\begin{tabular}{|c|c|c|c|}
\hline E Analyte & Result & Mod & Unit \\
\hline 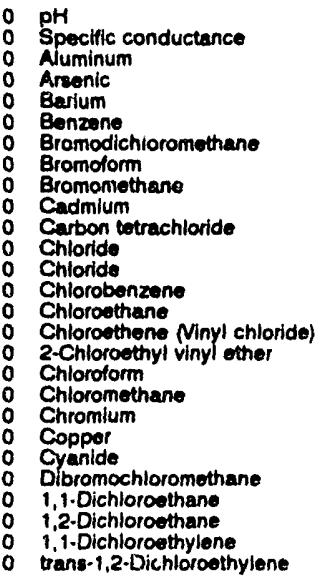 & $\begin{array}{r}6.5 \\
5.0 \\
<20 \\
<2.0 \\
<3.0 \\
<1.0 \\
<1.0 \\
<1.0 \\
<1.0 \\
<2.0 \\
<1.0 \\
<250 \\
<250 \\
<1.0 \\
<1.0 \\
<1.0 \\
<1.0 \\
<1.0 \\
<1.0 \\
<4.0 \\
<4.0 \\
<5.0 \\
<1.0 \\
<1.0 \\
<1.0 \\
<1.0 \\
<1.0\end{array}$ & jo & $\begin{array}{l}p H \\
\mu S / c m \\
\mu g / L \\
\mu g / L \\
\mu g / L \\
\mu g / L \\
\mu g / L \\
\mu g / L \\
\mu g / L \\
\mu g / L \\
\mu g / L \\
\mu g / L \\
\mu g / L \\
\mu g / L \\
\mu g / L \\
\mu g / L \\
\mu g / L \\
\mu g / L \\
\mu g / L \\
\mu g / L \\
\mu g / L \\
\mu g / L \\
\mu g / L \\
\mu g / L \\
\mu g / L \\
\mu g / L \\
\mu g / L\end{array}$ \\
\hline
\end{tabular}

WELL QA $60 \mathrm{C}$ collected on 07/08/82, laboratory analyses (cont.)

F Analyte

- Dichloromethane

1,2-Dichloropropane
0
cis-1,3-Dichloropropen

o trans-1.3-Dichloropropene

O Ethylbenzene

0 Lead

O Manganese

o Mercun

Nitrale-nittite as niltrogen

Phenols

o Silver

0 Sodlum

O Suliate-Tetrachloroethane

T, T,2-Tetrachloroethe

o Toluene

0 Toluene organic halogens

Total phosphates (as P)

o 1,1,1-Trichloroothane

1,1,2-Trichloroothan

O Trichlorofluoromethane

Uranium

2 Zlinc

2 Gross alpha

Total alpha-emitting radium
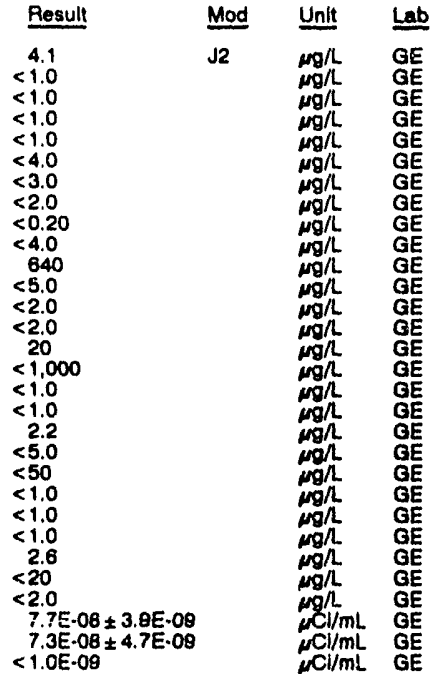

WELL QA 62C

MEASUREMENTS CONDUCTED IN THE FIELO

Sample date: 07/17/82

Depth to water: Not avallable

Water elovation: Nol aval' ab

Sp. conductance: 3 ralcm

Time: $7: 10$

PH: 5.1 Alkalinity: $0 \mathrm{mgl}$

Alkalinity: $0 \mathrm{mgh}$ : $25.9^{\circ} \mathrm{C}$

LABORATORY ANALYSES

E Analyte

${ }_{0}^{0} \mathrm{pH}$

$00 \mathrm{pH}$

Specific conductance

Specific conductance

Aluminum

Arsenic

Arsenic

0 Barium

Bromodichloromethane

Bromoform

Bromomethane

Cadmium

Chlorobenzene

Chloroethane

Chloroethene Ninyl chloride)

2-Chioroethyl vinyl other

Chloroform

Chloromethane

O Chromium

Copper

Cyanide

1,1-Dichloroethane

1,2-Dichloroethane

- 1,1-Dichloroethylene

o trans-1,2-Dichloroethylene

o Dichloromethane

1,2-Dichloropropane

trans-1,3-Dichloropropene

o Ethyibenzene

Iron

0 Lead

Manganese

- Mercury

Nitrato-niturte as nitrogen

Phenols

Selenium

Selenium

Silver

Sodium

Sulfate

1,1,2,2-Tetrachloroethe

Toluene

Total organic halogen

phosphates as P

Total phosphates las P

o i,1,1. Trichloroethane

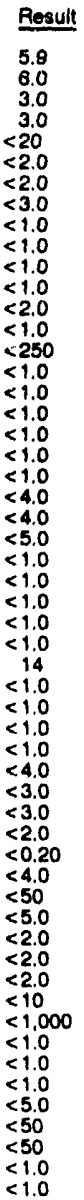

Mod Unit Lab

JQ $\mathrm{PH} \quad \mathrm{GE}$

NS/cm GE

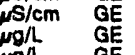

$\mu g / \mathrm{GE}$

$<50$
$<1.0$
$<1.0$ 
WELL QA 58 C colloctod on 07/13/82, laboratory snalyses (cont)

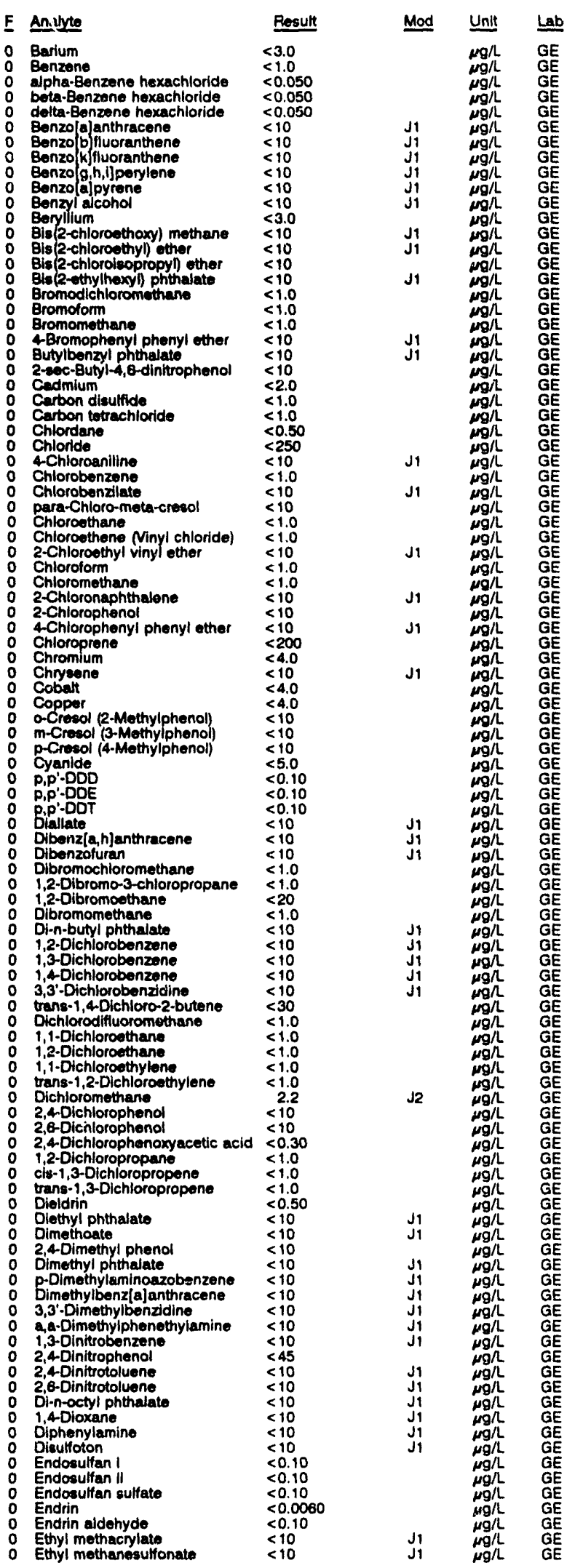

WELL QA 58C collected on 07/13/92, laboratory analyses (cont.)

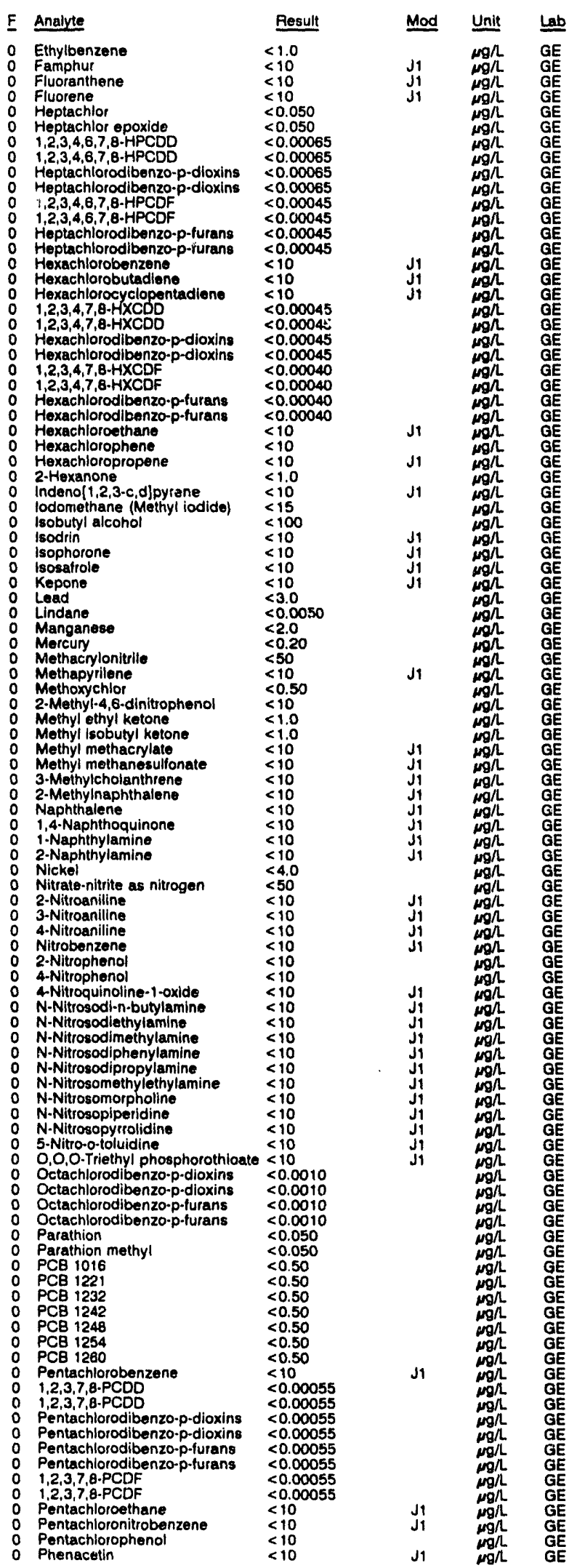


BLANK RESULTS

WELL QA 56C

MEASUREMENTS CONDUCTED IN THE FIELD

Sample date: 08/27/92

Wepth to water: Not avallable

Sp. conductance: $8 \mu S / \mathrm{cm}$

LABORATORY ANALYSES

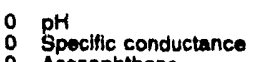

Acenaphthene

0 Aldrin

Anthracene

- Arsenic

- Barlum

Benzene
0 alpha-Bonzeno hexachloride

beta-Bonzene hexachloride

Bonzidino

Benze) (ajanthracene

Benzo kJ fluorantheno

Benzo g h.lperylene

Benzolajpyrono

Bis(2-chioroethoxy) methane

Bis (2-chioroethyl) other

Bis(2-chlorolsopropyl) ether

Bis(2-ethylhexyl) phthalat

Gromoform

Bromomethane

4.-Bromophenyl phenyl ether

Cadmium

Carbon tetrachloride

Chlordane

Chloride

Chloride

para-Chloro-meta-cresol

Chloroethane Minyl chloride)

Chloroothene Minyl chloride)
0
2-Chloroothyl vinyl other

Chloroform

2-Chloronaphthalene

2-Chlorophenol

4-Chlorophenyl phenyl ether

o

0 P,P'-DDE

O Bibenz[a,h]anthracen

D Dibromoch

0 Di-n-butyl phthalate

o 3,3'-Dichlorobenzidin

o 1,1 -Dichlorothane

1,1-Dichloroethylene

trans-1,2-Dichloroethylene

Dichloromethane

2,4Oichlorophenol

o cis-1,3-Dichloropropene

trans-1,3-Dichloropropent

Dieldrin

Olathyl phthalate

2,4-Dimethyl phenol

2,4-Dinitrophenol

2,4-Dinitrotoluen

2,6-Dinitrotoluene

Di-n-octyl phthalate

1,2-Diphenylhydrazine

Endosulfan !

Endosulfan sulfate

Endrin alduhyde

Fluoranthene

Fluorene

Heptachlor

Heptachlor epoxide

Hexachlorobenzene

Hexachlosocyclopentadiene

Hexachlorosthano

(rono $[1,2,3-c, d]$ pyrene

leophorone

Load

Lindane

Manganese
Time: 7:45

PH: 4.5

Water temperalure: $26.2 \circ \mathrm{C}$

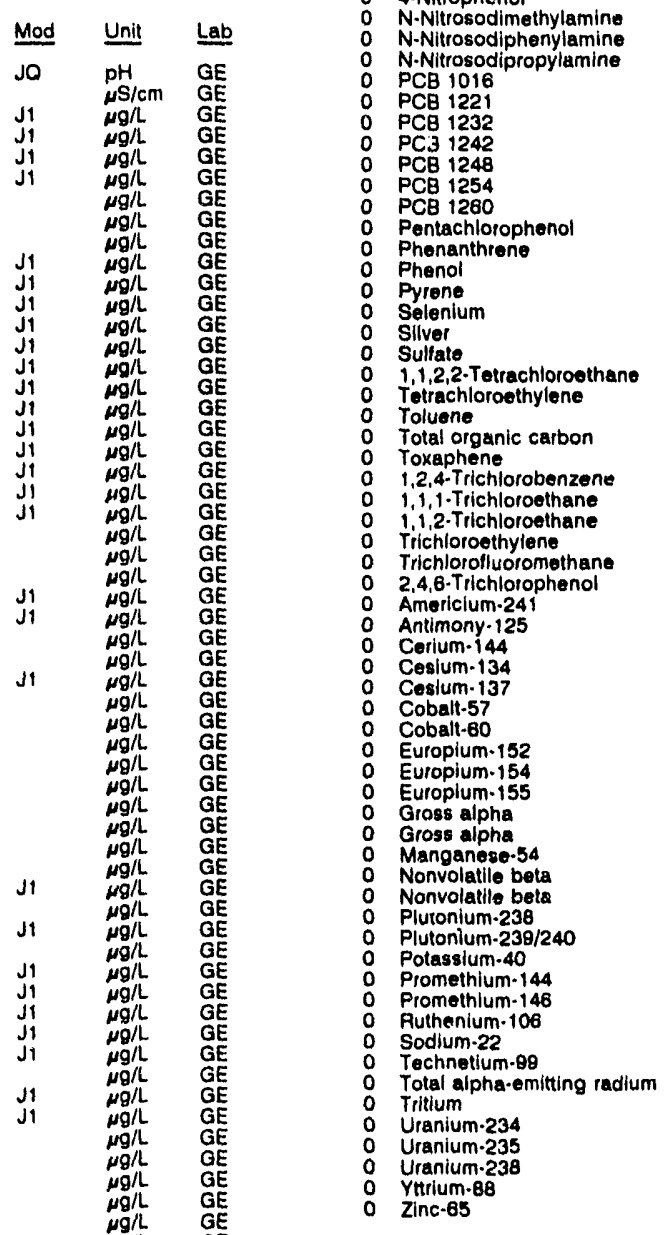

WELL QA 58C

MEASUAEMENTS CONDUCTED IN THE FIELD

Sample date: 07/13/92

Dopth to water: Not avallable

Water elevation: Not avallable

LABORATORY ANALYSES

E Analyte

$0 \mathrm{pH}$

Specific conductance

Specific conductance

- Acenaphthene

Acetone

Acetonitrile (Methyl cyanide)

Acetophenone

2.Acetylaminofluorene

O Acrylonitrilo

- Aldrín

- Allyl chlorido

Aluminum

O Aniline

Aramite

Arsenic

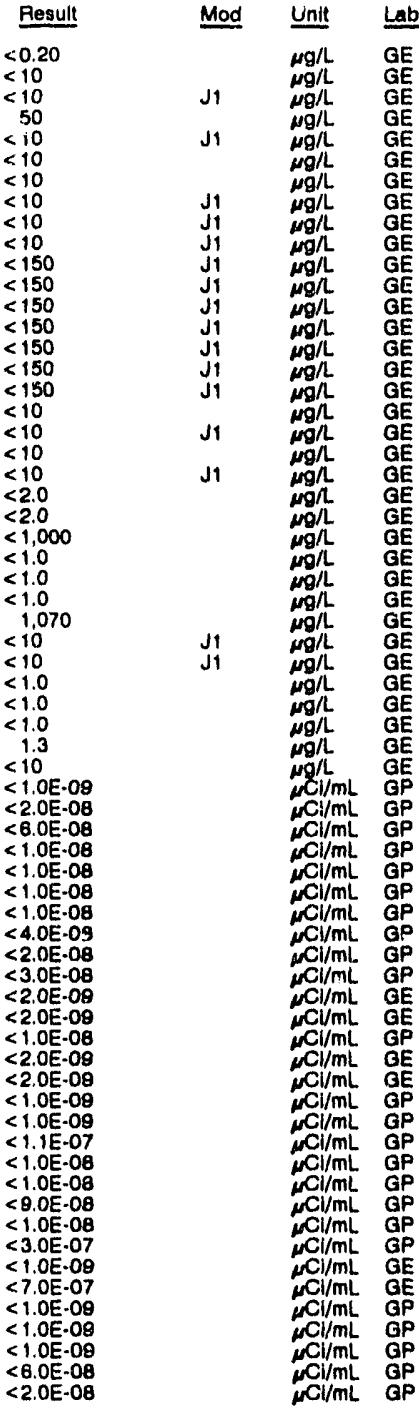

\section{Time: $8: 20$}

Alkalinity: $1 \mathrm{mg} / \mathrm{L}$

Water temperaturo. $28.2^{\circ} \mathrm{C}$

\begin{tabular}{l} 
Regull \\
\hline 5.9 \\
3.0 \\
3.0 \\
$<10$ \\
$<10$ \\
$<100$ \\
$<1.0$ \\
$<10$ \\
$<10$ \\
$<20$ \\
$<20$ \\
$<0.050$ \\
$<50$ \\
$<20$ \\
$<10$ \\
$<10$ \\
$<10$ \\
$<2.0$ \\
$<10$ \\
$<2.0$
\end{tabular}


WELL QA 5OC collected on 07/22/92, laboratory analyses (cont.)

\begin{tabular}{|c|c|c|c|c|c|}
\hline & Analyte & Result & Mod & Init & \\
\hline & 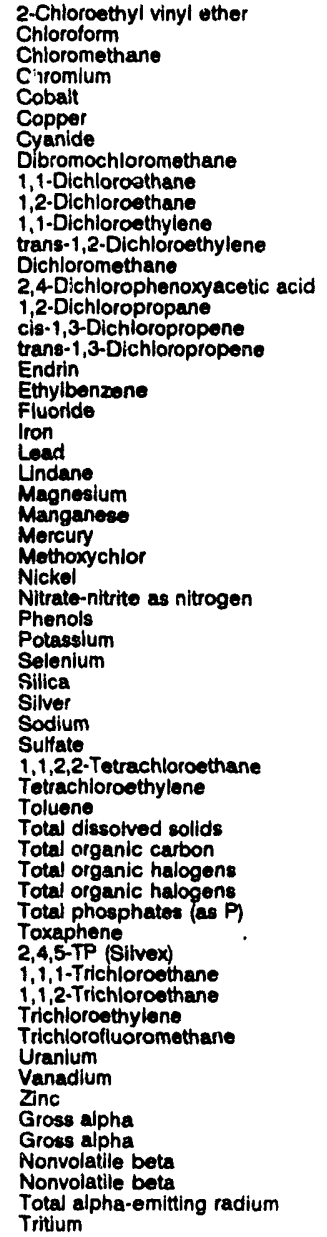 & $\begin{array}{l}<1.0 \\
<1.0 \\
<1.0 \\
<4.0 \\
<4.0 \\
<4.0 \\
<5.0 \\
<1.0 \\
<1.0 \\
<1.0 \\
<1.0 \\
<1.0 \\
1.4 \\
<0.30 \\
<1.0 \\
<1.0 \\
<1.0 \\
<0.0060 \\
<1.0 \\
<100 \\
10 \\
<3.0 \\
<0.0050 \\
<2.0 \\
<2.0 \\
<0.20 \\
<0.50 \\
<4.0 \\
<50 \\
<5.0 \\
<500 \\
<2.0 \\
<100 \\
<2.0 \\
<10 \\
<1.000 \\
<1.0 \\
<1.0 \\
<1.0 \\
44.000 \\
<1.000 \\
<5.0 \\
<5.0 \\
<50 \\
<0.24 \\
<0.090 \\
<1.0 \\
<1.0 \\
<1.0 \\
1.5 \\
<20 \\
<8.0 \\
<2.0 \\
<2.0 E-09 \\
<2.0 E .09 \\
<2.0 E .09 \\
<2.0 E .09 \\
<1.0 E \cdot 09 \\
1.1 E .06 \\
\\
\end{array}$ & J1 & 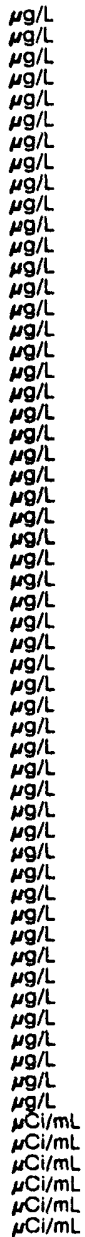 & - \\
\hline
\end{tabular}

\section{WELL QA 52C}

MEASUREMENTS CONDUCTED IN THE FIELD

Sample date: $07 / 24 / 92$

Water to water: Not availabie

Sp. conductance: $1 \mathrm{ps} / \mathrm{cm}$

LABORATORY ANALYSES

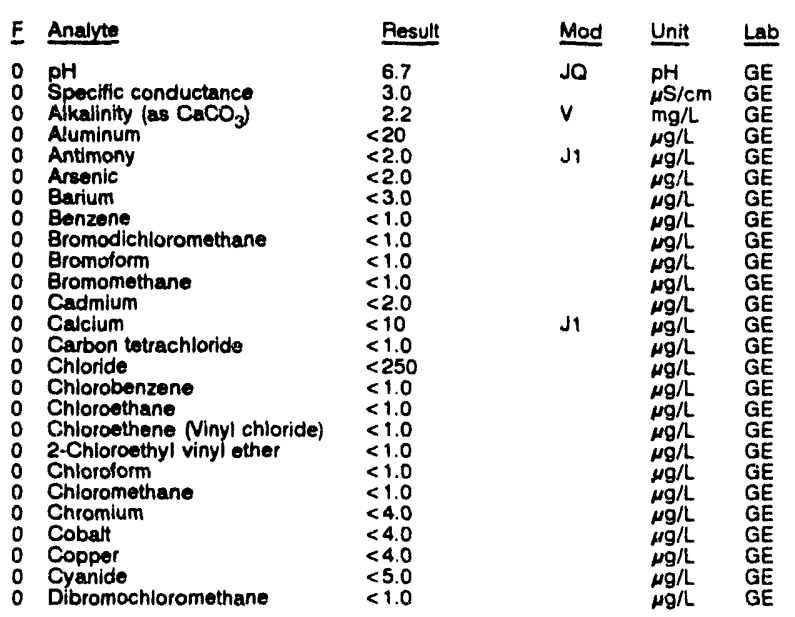

WELL QA $52 C$ collected on 07/24/92, laboratory analyses (cont.)

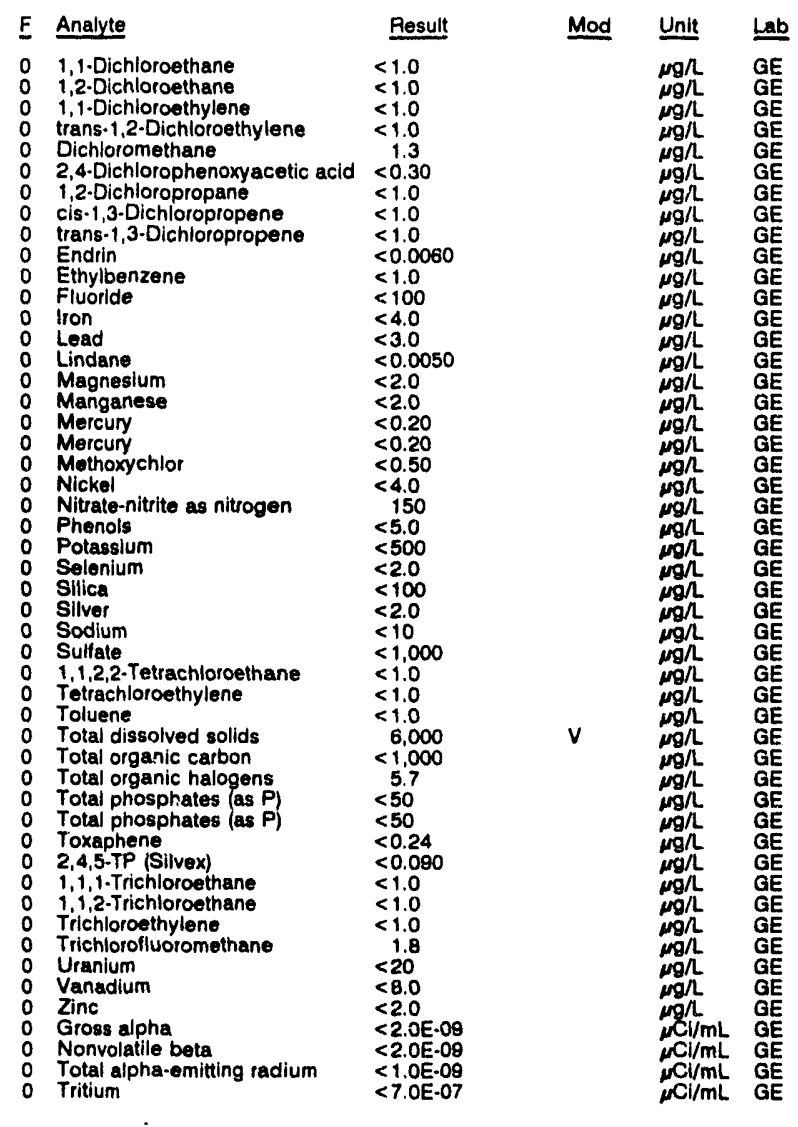

WELL QA 54C

MEASUREMENTS CONDUCTED IN THE FIELD

Sample date: 08/01/92 Depth to water: Not available Water elovation: Not avallable LABORATORY ANALYSES

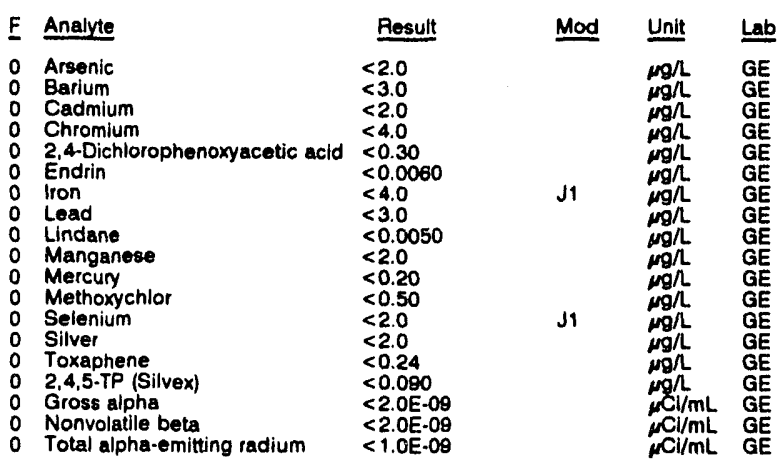


BLANK RESULTS

WEL OA $44 C$ collectod on 07/08/82, laboratory analyses (cont.)

\begin{tabular}{|c|c|c|}
\hline & Inalyte & lesult \\
\hline & 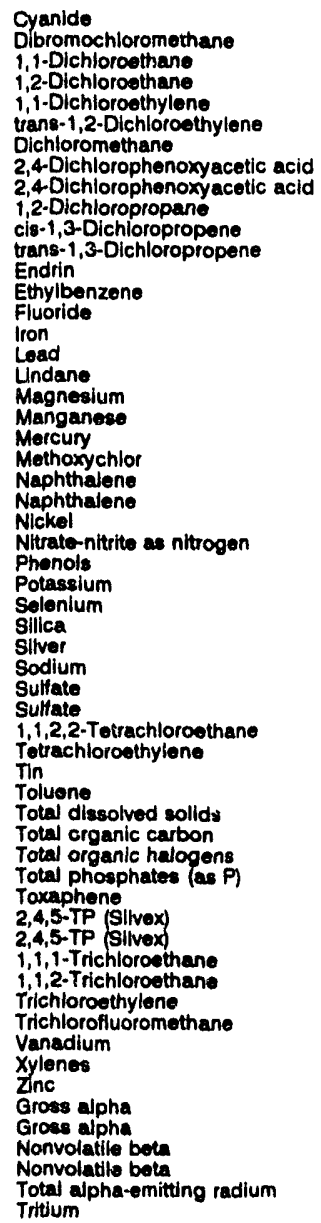 & $\begin{array}{l}<5.0 \\
<1.0 \\
<1.0 \\
<1.0 \\
<1.0 \\
<1.0 \\
3.6 \\
<0.30 \\
<0.30 \\
<1.0 \\
<1.0 \\
<1.0 \\
<0.0060 \\
<1.0 \\
<100 \\
<4.0 \\
<3.0 \\
<0.0050 \\
<2.0 \\
<2.0 \\
<0.20 \\
<0.50 \\
<10 \\
<10 \\
<4.0 \\
<50 \\
<5.0 \\
<500 \\
<2.0 \\
<100 \\
<2.0 \\
<10 \\
<11.000 \\
<1.000 \\
<1.0 \\
<1.0 \\
<2.0 \\
<1.0 \\
51.000 \\
<1.000 \\
<5.0 \\
<50 \\
<0.24 \\
<1.090 \\
<0.090 \\
<1.0 \\
<1.0 \\
<1.0 \\
11.5 \\
<8.0 \\
<2.0 \\
<2.0 \\
<2.0 E-09 \\
<2.0 E-09 \\
<2.0 E-09 \\
<2.0 E-09 \\
<11.0 E-09 \\
<7.0 E-07\end{array}$ \\
\hline
\end{tabular}

\section{WELL QA 46C}

MEASUAEMENTS CONDUCTED IN THE FIELD

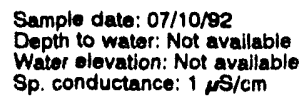

Sp. conductance: 1 sS/cm

\section{LABOPATORY ANALYSES}

\begin{tabular}{|c|c|c|c|c|c|}
\hline$\underline{E}$ & Analyto & Pesult & Mod & Unit & Lab \\
\hline $\begin{array}{l}0 \\
0 \\
0 \\
0 \\
0 \\
0 \\
0 \\
0 \\
0 \\
0 \\
0 \\
0 \\
0 \\
0 \\
0 \\
0 \\
0 \\
0 \\
0 \\
0 \\
0 \\
0 \\
0 \\
0 \\
0 \\
0\end{array}$ & $\begin{array}{l}\text { pH } \\
\text { Specific conductance } \\
\text { Aluminum } \\
\text { Antimony } \\
\text { Arsenic } \\
\text { Barium } \\
\text { Cadmium } \\
\text { Calclum } \\
\text { Chloride } \\
\text { Chromium } \\
\text { Cobant } \\
\text { Copper } \\
\text { Cyanide } \\
\text { Fluoride } \\
\text { Fluoride } \\
\text { Iron } \\
\text { Load } \\
\text { Magnesium } \\
\text { Manganese } \\
\text { Mercury } \\
\text { Morcury } \\
\text { Nickel } \\
\text { Nitrate-nitrite as nitrogen } \\
\text { Potassium } \\
\text { Selenium } \\
\text { Sllica } \\
\text { Sliver }\end{array}$ & $\begin{array}{l}6.0 \\
5.0 \\
<20 \\
<2.0 \\
<2.0 \\
<3.0 \\
<2.0 \\
<10 \\
<250 \\
<4.0 \\
<4.0 \\
<4.0 \\
<5.0 \\
<100 \\
<100 \\
<4.0 \\
<3.0 \\
<2.0 \\
<2.0 \\
<0.20 \\
<0.20 \\
<4.0 \\
<50 \\
<500 \\
<2.0 \\
<100 \\
<2.0\end{array}$ & $\mathrm{JO}$ & $\begin{array}{l}p H \\
\mu S / c m \\
\mu g / L \\
\mu g / L \\
\mu g / L \\
\mu g / L \\
\mu g / L \\
\mu g / L \\
\mu g / L \\
\mu g / L \\
\mu g / L \\
\mu g / L \\
\mu g / L \\
\mu g / L \\
\mu g / L \\
\mu g / L \\
\mu g / L \\
\mu g / L \\
\mu g / L \\
\mu g / L \\
\mu g / L \\
\mu g / L \\
\mu g / L \\
\mu g / L \\
\mu g / L \\
\mu g / L \\
\mu g / L\end{array}$ & $\begin{array}{l}\mathrm{GE} \\
\mathrm{GE} \\
\mathrm{GE} \\
\mathrm{GE} \\
\mathrm{GE} \\
\mathrm{GE} \\
\mathrm{GE} \\
\mathrm{GE} \\
\mathrm{GE} \\
\mathrm{GE} \\
\mathrm{GE} \\
\mathrm{GE} \\
\mathrm{GE} \\
\mathrm{GE} \\
\mathrm{GE} \\
\mathrm{GE} \\
\mathrm{GE} \\
\mathrm{GE} \\
\mathrm{GE} \\
\mathrm{GE} \\
\mathrm{GE} \\
\mathrm{GE} \\
\mathrm{GE} \\
\mathrm{GE} \\
\mathrm{GE} \\
\mathrm{GE} \\
\mathrm{GE}\end{array}$ \\
\hline
\end{tabular}

Time: 7:20

PH: 6.1 Alkalinity: $1 \mathrm{mg} / \mathrm{L}$
WELL QA 46C collected on 07/10/92, laboratory analyses (cont.)

\begin{tabular}{|c|c|c|c|c|}
\hline F & Analyte & Result & Mod & Unit \\
\hline & $\begin{array}{l}\text { Sodium } \\
\text { Sulfate } \\
\text { Total dissolved sollids } \\
\text { Total organic carbon } \\
\text { Total organic halogens } \\
\text { Total phosphates (as P) } \\
\text { Vanadlum } \\
\text { Zinc } \\
\text { Gross alpha } \\
\text { Nonvolatile beta } \\
\text { Total alpha-emitting radium } \\
\text { Tritium }\end{array}$ & $\begin{array}{l}<10 \\
<1,000 \\
<1,000 \\
<1,000 \\
<5.0 \\
165 \\
<8.0 \\
<2.0 \\
<2.0 \mathrm{E} \cdot 09 \\
<2.0 \mathrm{C} \cdot 09 \\
<1.0 \mathrm{E} \cdot 09 \\
<7.0 \mathrm{E} \cdot 07\end{array}$ & & 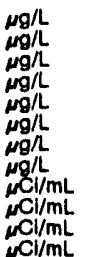 \\
\hline
\end{tabular}

WELL QA 48C

MEASUREMENTS CONDUCTED IN THE FIELD

Sample date: 07/17/82

Depth to water: Not available

Water elevation: Not avallable

LABOAATOAY ANALYSES

E Analyte

$\begin{array}{ll}0 & \mathrm{pH} \\ 0 & \text { Specific conductance } \\ 0 & \text { Aluminum }\end{array}$

Antimony

Arsen

Cadmium

Calcium

o Chromium

0 Cobalt

Copper

Cyanide

0 Fluoric

Lead

- Magneslum

0 Mercury

0 Nickel

Nitrate-nitrite as nitrogen

Potassium

Selenium

$\begin{array}{ll}0 & \text { Silica } \\ 0 & \text { Silver }\end{array}$

Sodium

Sodium

Totai dissolved solids

Total organic carbon

Total organic halogens
0 Total phosphatos (as P)

Vanzdium

Zlnc

Gross alpha

Total alpha-emitting radium

$\begin{array}{ll}0 & \text { Tritium } \\ 0 & \text { Tritlum }\end{array}$

\begin{tabular}{l} 
Result \\
\hline 5.9 \\
3.0 \\
$<20$ \\
$<2.0$ \\
$<2.0$ \\
$<3.0$ \\
$<2.0$ \\
$<10$ \\
$<250$ \\
$<4.0$ \\
$<4.0$ \\
$<4.0$ \\
$<5.0$ \\
$<5.0$ \\
$<100$ \\
$<4.0$ \\
$<3.0$ \\
$<2.0$ \\
$<2.0$ \\
$<0.20$ \\
$<0.20$ \\
$<4.0$ \\
$<50$ \\
$<500$ \\
$<2.0$ \\
$<100$ \\
$<2.0$ \\
$<10$ \\
$<1.000$ \\
4.000 \\
$<1.000$ \\
$<5.0$ \\
$<50$ \\
$<8.0$ \\
$<2.0$ \\
$<2.0 E-09$ \\
$<2.0 E-09$ \\
$<1.0 E-09$ \\
$<7.0 E-07$ \\
$<7.0 E-07$ \\
\hline
\end{tabular}

Time: 6:30

Alkalinity: 1 mon

Water temperature: $26.6^{\circ} \mathrm{C}$

WELL QA 50C

MEASUREMENTS CONDUCTED IN THE FIELD

Sample date: 07/22/92

Depth to water: Not avaliable

Water olevation: Not avallable
Sp. conductance: $1 \mu \mathrm{S} / \mathrm{cm}$

LABORATORY ANALYSES

$\begin{array}{ll}\text { E } & \text { Analyte } \\ 0 & \text { pH } \\ 0 & \text { Specific conductance } \\ 0 & \text { Alkalinity (as CaCO } \\ 0 & \text { Aluminum } \\ 0 & \text { Antimony } \\ 0 & \text { Arsenic } \\ 0 & \text { Barium } \\ 0 & \text { Benzene } \\ 0 & \text { Bromodichloromethane } \\ 0 & \text { Bromoform } \\ 0 & \text { Bromomethane } \\ 0 & \text { Cadmium } \\ 0 & \text { Calcium } \\ 0 & \text { Carbon tetrachloride } \\ 0 & \text { Chloride } \\ 0 & \text { Chlorobenzene } \\ 0 & \text { Chloroethane } \\ 0 & \text { Chloroethene Ninyl chloride) }\end{array}$

\begin{aligned} & Resul \\ & \hline 5.6 \\ & 3.0 \\ & 1.4 \\ &$<20 \\ &<2.0 \\ &<2.0 \\ &<3.0 \\ &<1.0 \\ &<1.0 \\ &<1.0 \\ &<1.0 \\ &<2.0 \\ &<10 \\ &<1.0 \\ &<250 \\ &<1.0 \\ &<1.0 \\ &<1.0\end{aligned}$

Lab

GE E

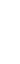


BLANK RESULTS

WELL QA 38 C collected on 07/01/92, laboratory analyses (cont.)

\begin{tabular}{|c|c|c|}
\hline & Anglyte & Result \\
\hline & $\begin{array}{l}\text { 1,3,5-Trinitrobenzene } \\
\text { Vanadium } \\
\text { Vinyl acetate } \\
\text { Xylenes } \\
\text { Zinc } \\
\text { Gross alpha } \\
\text { Nonvolatle beta } \\
\text { Total alpha-emitting radium } \\
\text { Tritium }\end{array}$ & $\begin{array}{l}<10 \\
<8.0 \\
<1.0 \\
<2.0 \\
<2.0 \\
<2.0 E \cdot 09 \\
<2.0 E-09 \\
<1.0 \mathrm{E} \cdot 09 \\
<7.0 \mathrm{E} \cdot 07\end{array}$ \\
\hline
\end{tabular}

WELL QA 40C

MEASUAEMENTS CONDUCTED IN THE FIELD

Sample date: 07/06/92 Wepth to water: Not available Water elevation: Not availablo

LABORATORY ANALYSES

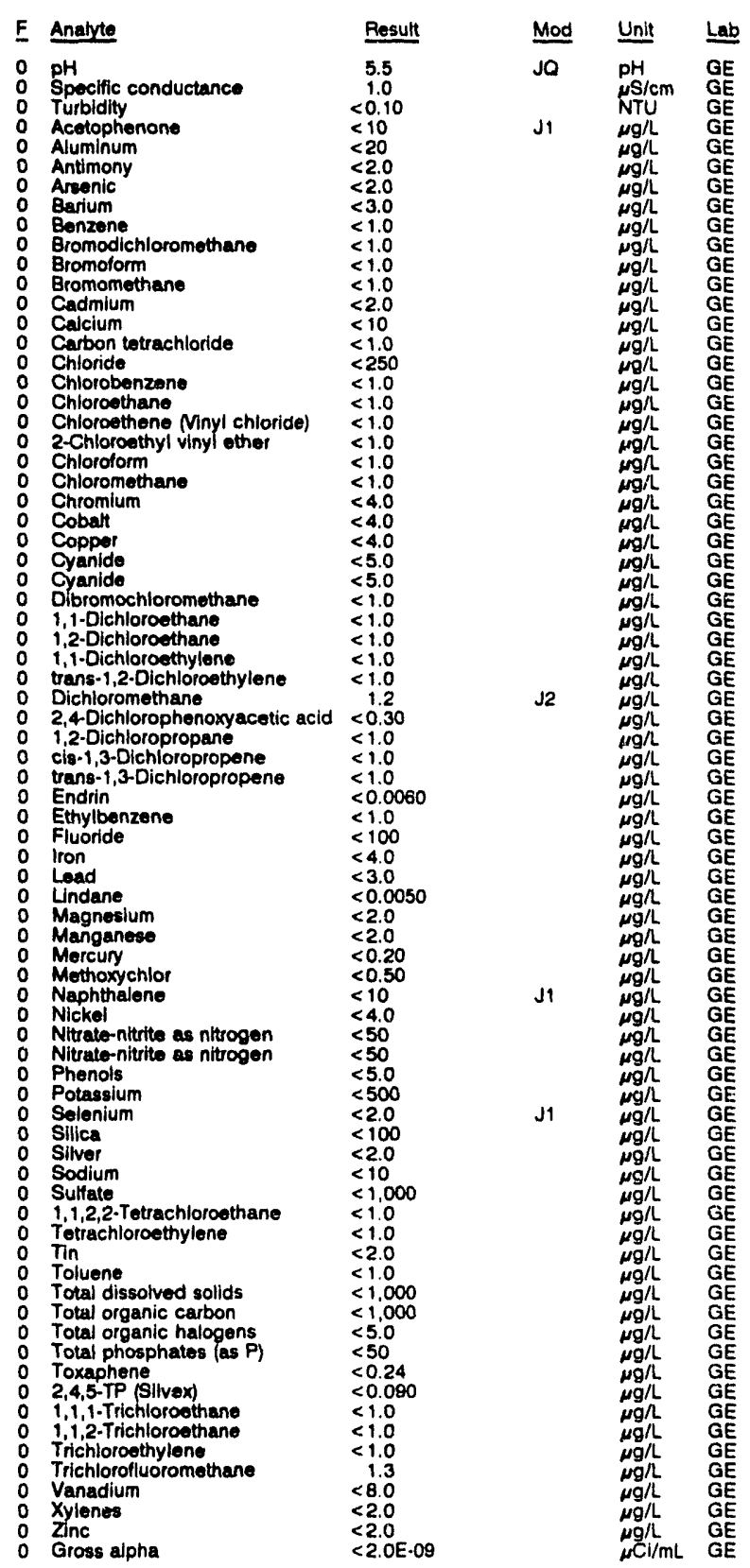

WELL QA 40C collected on 07/06/92, laboratory analyses (cont.)

\begin{tabular}{|c|c|c|c|}
\hline Analyte & Result & Mod & Unit \\
\hline $\begin{array}{l}\text { Nonvolatile beta } \\
\text { Total alpha-emitting radium } \\
\text { Tritium } \\
\text { Tritium }\end{array}$ & $\begin{array}{l}<2.0 \mathrm{E} \cdot 09 \\
<1.0 \mathrm{E} \cdot 09 \\
<7.0 \mathrm{E}-07 \\
<7.0 \mathrm{E}-07\end{array}$ & & $\begin{array}{l}\mu \mathrm{Cl} / \mathrm{mL} \\
\mu \mathrm{Cl} / \mathrm{mL} \\
\mu \mathrm{Cl} / \mathrm{mL} \\
\mu \mathrm{Cl} / \mathrm{mL}\end{array}$ \\
\hline
\end{tabular}

WELL QA 42C

MEASUREMENTS CONDUCTED IN THE FIELD

Sample date: 07/07/92

Depth to water: Not available

Water elevation: Not avallable
Time: 7:55

pH: 5.8

Water temperature: $24.7^{\circ} \mathrm{C}$

LABORATORY ANALYSES

E Analyte

$\begin{array}{ll}0 & \mathrm{pH} \\ 0 & \text { Speclfic conductance }\end{array}$

o Aluminum

o Antimony

0 Barium

o Cadmium

o Calcium

- Chromium

0 Cobalt

o Copper

0 Fluoride

0 Iron

O Magnesium

Manganese

0 Mercury

N Nitrate-nitrite as nitrogen

0 Potassium

0 Selenium

0 Sillica

$\begin{array}{lll}0 & \text { Silver } \\ 0 & \text { Sodium }\end{array}$

$\begin{array}{lll}0 & \text { Sodium } \\ 0 & \text { Sulfate }\end{array}$

Sulfate

0 Total dissolved solids

Total organic carbon
0 Total organic halogens
Total phosphates (as P

- Vanadium

O Zinc

- Gross alpha

Nonvolatile beta

Total alpha
Tritium

WELL QA $44 C$

MEASUREMENTS CONDUCTED IN THE FIELD

Sample date: 07/08/92

Depth to water: Not available

Sp. conductance: $1,5 / \mathrm{cm}$

LABORATOAY ANALYSES

$\begin{array}{ll}\text { F } & \text { Analyte } \\ 0 & \text { pH } \\ 0 & \text { pH } \\ 0 & \text { Specific conductance } \\ 0 & \text { Turbidity } \\ 0 & \text { Turbidity } \\ 0 & \text { Acetophenone } \\ 0 & \text { Acetophenone } \\ 0 & \text { Aluminum } \\ 0 & \text { Antimony } \\ 0 & \text { Arsenic } \\ 0 & \text { Barium } \\ 0 & \text { Benzene } \\ 0 & \text { Bromodichloromethane } \\ 0 & \text { Eromolorm } \\ 0 & \text { Bromomethane } \\ 0 & \text { Cadmium } \\ 0 & \text { Calcium } \\ 0 & \text { Carbon tetrachloride } \\ 0 & \text { Chloride } \\ 0 & \text { Chloride } \\ 0 & \text { Chlorobenzene } \\ 0 & \text { Chloroethane } \\ 0 & \text { Chloroethene (Ninyl chloride) } \\ 0 & 2-\text { Chloroethyl vinyl ether } \\ 0 & \text { Chlorolorm } \\ 0 & \text { Chloromethane } \\ 0 & \text { Chromium } \\ 0 & \text { Cobalt } \\ 0 & \text { Copper }\end{array}$

\begin{tabular}{l} 
Result \\
\hline 5.3 \\
6.4 \\
2.0 \\
$<0.10$ \\
$<0.10$ \\
$<10$ \\
$<10$ \\
$<20$ \\
$<2.0$ \\
$<2.0$ \\
$<3.0$ \\
$<1.0$ \\
$<1.0$ \\
$<1.0$ \\
$<1.0$ \\
$<2.0$ \\
$<10$ \\
$<1.0$ \\
$<250$ \\
$<250$ \\
$<1.0$ \\
$<1.0$ \\
$<1.0$ \\
$<1.0$ \\
$<1.0$ \\
$<1.0$ \\
$<4.0$ \\
$<4.0$ \\
$<4.0$
\end{tabular}
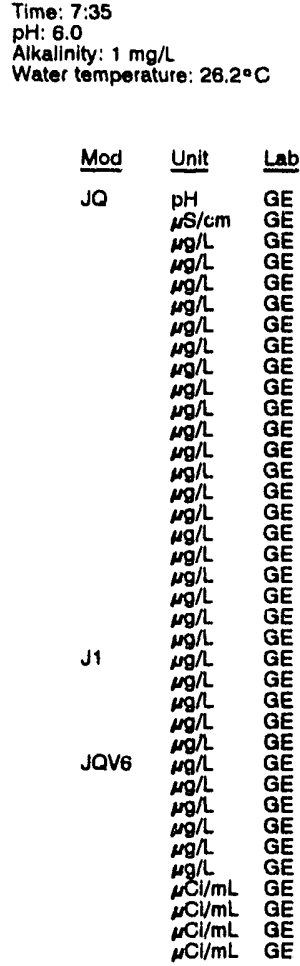

Alkalinity: $1 \mathrm{mgh}$

Water temperature: $26.1^{\circ} \mathrm{C}$

\begin{tabular}{|c|c|}
\hline Mod & Unit \\
\hline $\begin{array}{l}J Q \\
J Q\end{array}$ & $\begin{array}{l}\text { pH } \\
\text { pH } \\
\text { NS/cm } \\
\text { NTU } \\
\text { NTU }\end{array}$ \\
\hline $\begin{array}{l}\text { J1 } \\
\text { J1 }\end{array}$ & $\operatorname{mg}_{\mu} \Omega$ \\
\hline J1 & 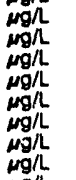 \\
\hline J1 & 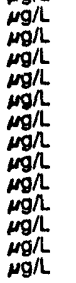 \\
\hline
\end{tabular}


BLANK RESULTS

WELL QA 38C colloctod on 07/01/82, laboratory analyses (cont)

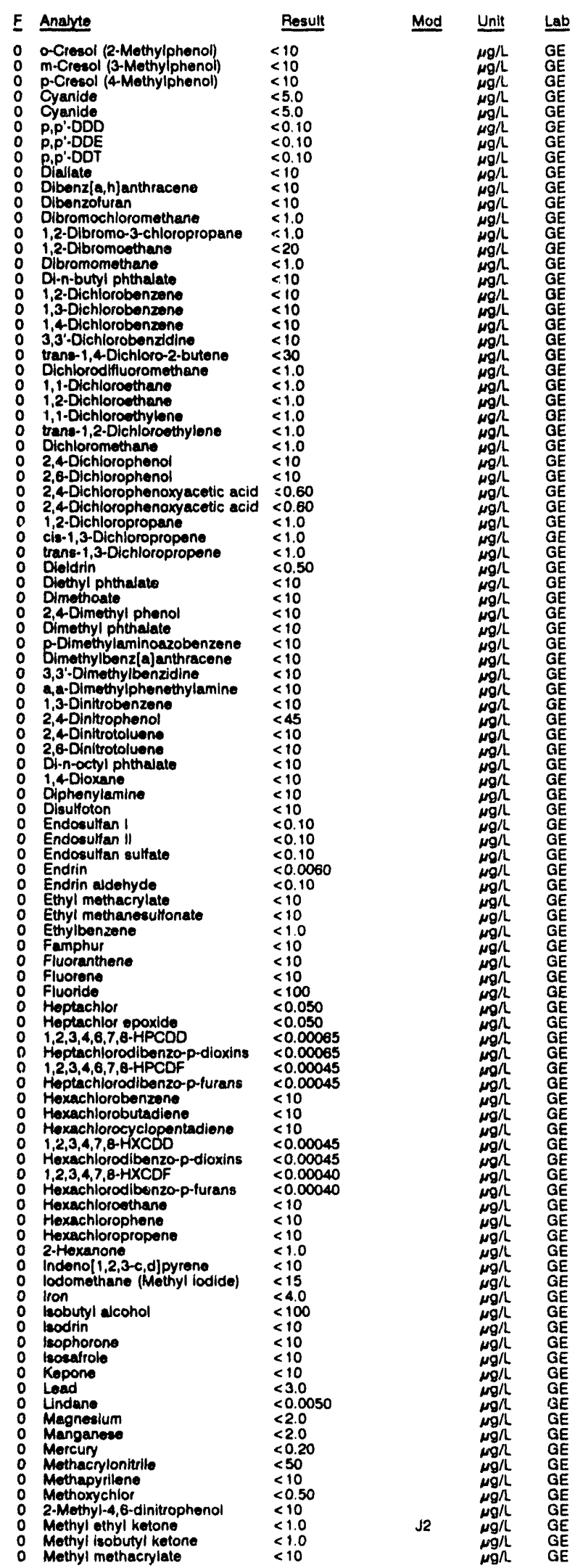

WELL QA 38C collected on 07/01/82, laboratory analyses (cont)

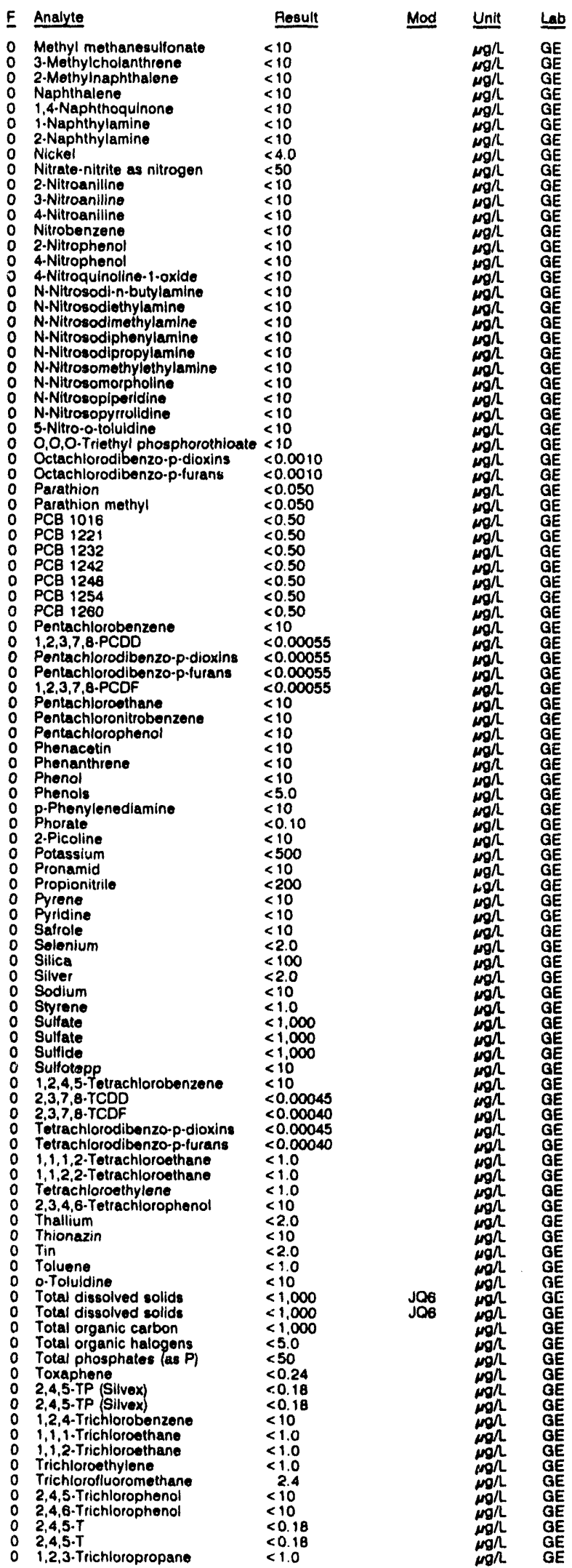


BLANK RESULTS

WELL QA 36C

MEASUREMENTS CONDUCTED IN THE FIELD

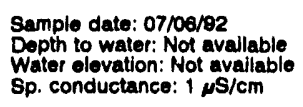

LABORATORY ANALYSES

\begin{tabular}{|c|}
\hline Analyte \\
\hline $\begin{array}{l}\text { pH } \\
\text { pH } \\
\text { Speclific conductance } \\
\text { Specific conductance } \\
\text { Aluminum } \\
\text { Antimony } \\
\text { Areonic } \\
\text { Barium } \\
\text { Benzene } \\
\text { Benzene } \\
\text { Bromodichloromethane } \\
\text { Bromodichioromothane } \\
\text { Bromoform } \\
\text { Bromolorm } \\
\text { Bromomethane } \\
\text { Bromomethane } \\
\text { Cadmilum } \\
\text { Caleclum } \\
\text { Carbon tetrachloride } \\
\text { Carbon tetrachloride } \\
\text { Chloride } \\
\text { Chlorobenzene } \\
\text { Chlorobenzene } \\
\text { Chloroethane } \\
\text { Chloroethane } \\
\text { Chlorethene Ninyl chloride) } \\
\text { Chloroethene Vinyl chloride) } \\
\text { 2-Chioroethyl vinyl other } \\
\text { 2-Chloroethyl vinyl ether } \\
\text { Chloroform } \\
\text { Chloroform } \\
\text { Chloromethane } \\
\text { Chloromethane } \\
\text { Chromium } \\
\text { Cobalt } \\
\text { Copoes }\end{array}$ \\
\hline
\end{tabular}

Cobalt

Cyanide

Dibromochloromethane

Dibromochloromethane

1,1-Dichloroethane

1,2-Dichloroethane

1,2-Dichloroethane

1,1-Dichloroethylene

trans-1,2-Dictiloroethylene

trans-1,2-Dichloroethylene

Dichloromethane

2,4-Dichlorophenoxyacetic acid

1,2-Dichloropropane

cis-1,3-Dichlotopropen

cis-1,3-Dichloropropene

trane-1,3-Dichloropropene

Endrin

Ethylbenzene

Fluoride

Iron

Lindane

Magnesium

Manganoso

Methoxychior

Nickel

Nitrato-nitrite as nitrogen

Phenols

Potaselum

Silica

Silver

Sodium

1,1,2,2-Tetrachloroethane

$1,1,2,2-T e t r a c h l o r o e t h a n e$

Totrachloroethylene

Thallium

Toluene

Toluene

Total dissolved solids

Total organic carbon

Total phosphates (as P)

Taxaphene
Time: $7: 15$

pH: 6.0

Alkalinity: $1 \mathrm{mg} / \mathrm{h}$

Water temperature: $23.5^{\circ} \mathrm{C}$

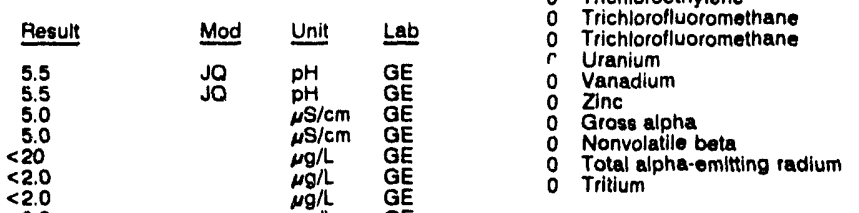

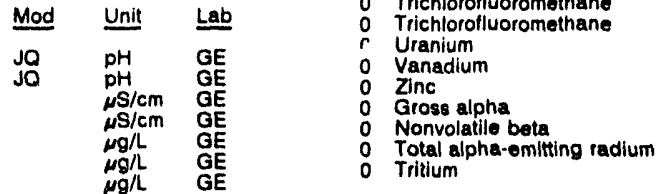

WELL QA 38C

MEASUREMENTS CONDUCTED IN THE FIELD

Sample date: 07/01/92

Depth to water: Not avaliable

Water elovation: Not avallable

LABORATORY ANALYSES

E Analyte

$0 \mathrm{pH}$

$\begin{array}{ll}0 & \mathrm{pH} \\ 0 & \mathrm{pH} \\ 0 & \mathrm{pH}\end{array}$

o $\mathrm{pH}$

Specific conductance

Specific conductance

Acenaphthene

Acenaphthyl

Acetone

- Acetophenone

2.Acetylaminofluorena

Acrolein

0 Acrylon

A Allyl chioride

4.Aminobiphenyl

Aniline

- Anthracene

O Antimony

0 Arsenic

o Barium

- Benzene

alpha-Benzene hexachloride

beta-Benzene hexachloride

delta-Benzene hexachlorido

Benzo ajanthracene

Benzo b fuoranthene

Benzo hilperiten

- Benzolalpyene

Benzolapyren

0 Beryilium

Bis(2-chloroethoxy) methans

Bis (2-chloroethyl) other

Bis (2-chloroisopropyl) ether

Bis(2-ethythexyl) phthala

Bromodich

Bromolorm

4-Bromophenyl phenyl ether

4,6-dinitrophenol

Cadmium

Carbon disulfide

Carbon tetrachloride

o Chlordane

Chloride

Chloride

4-Chloroaniline

Chlorobenzene

para-Chloro-meta-cresol

para-Chloro-me

Chloroethane

Chloroethene Ninyl chloride

2.Chloroethy

Chloroform

2-Chloronaphthalen

4-Chlorophenyi phenyl ether

0 Cobalt

0 Copper
Result

$<0.090$

$<1.0$

$<1.0$

$<1.0$

$<1.0$

1.1
$<1.0$

$<20$

$<2.0$

$<2.0 E-09$

$<2.0 E-09$
$<1.0 E-09$

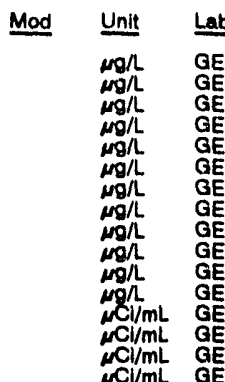

Alkalinity: $1 \mathrm{mg} / \mathrm{L}$

Water temperature: $25.5^{\circ} \mathrm{C}$

\begin{tabular}{|c|c|}
\hline Result & Mod \\
\hline $\begin{array}{l}5.8 \\
5.9 \\
5.9 \\
5.8\end{array}$ & $\begin{array}{l}\text { JO } \\
\text { JO } \\
\text { JO } \\
\text { JO }\end{array}$ \\
\hline
\end{tabular}

pH $\quad$ GE 
BLANK RESULTS

WELL OA $30 \mathrm{C}$ colloctod on 07/15/92, laboratory analyses (cont)

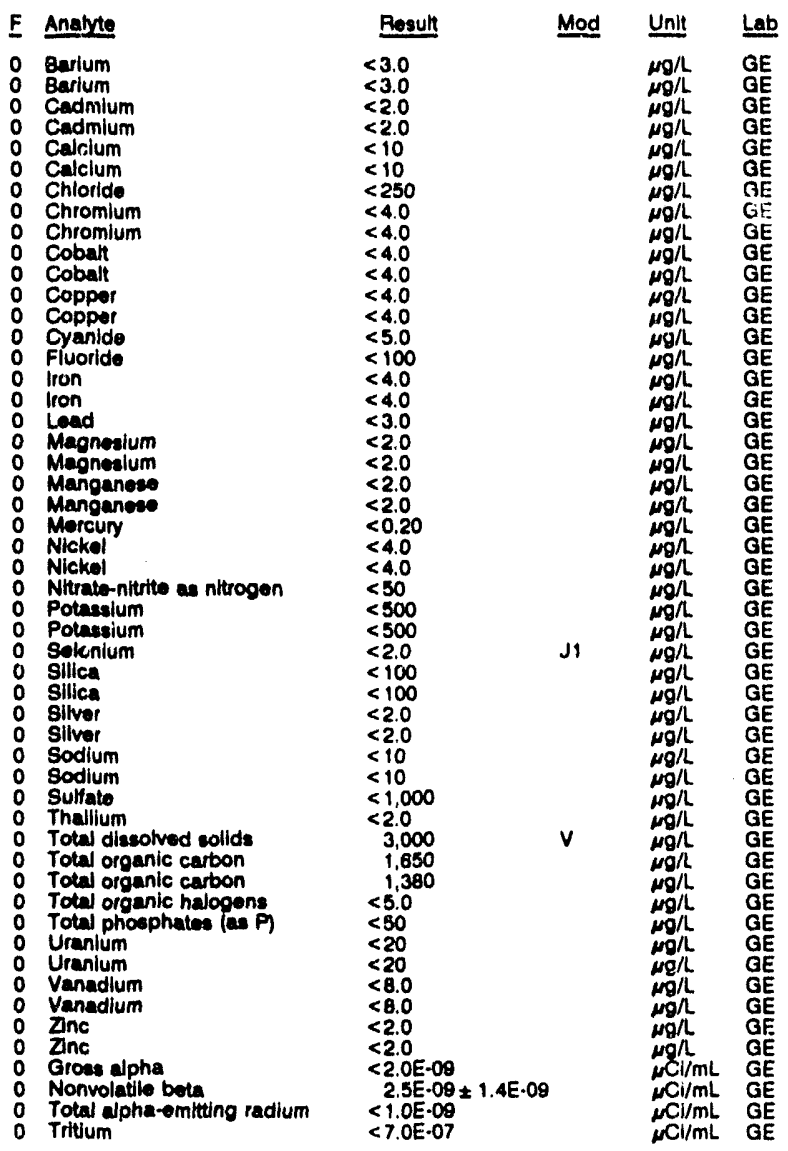

WELL QA 32C

MEASUREMENTS CONDUCTED IN THE FIELD

Sample dato: 07/10/92

Dopth to water: Not available Weter elovation: Not avallable

LABORATOAY ANALYSES

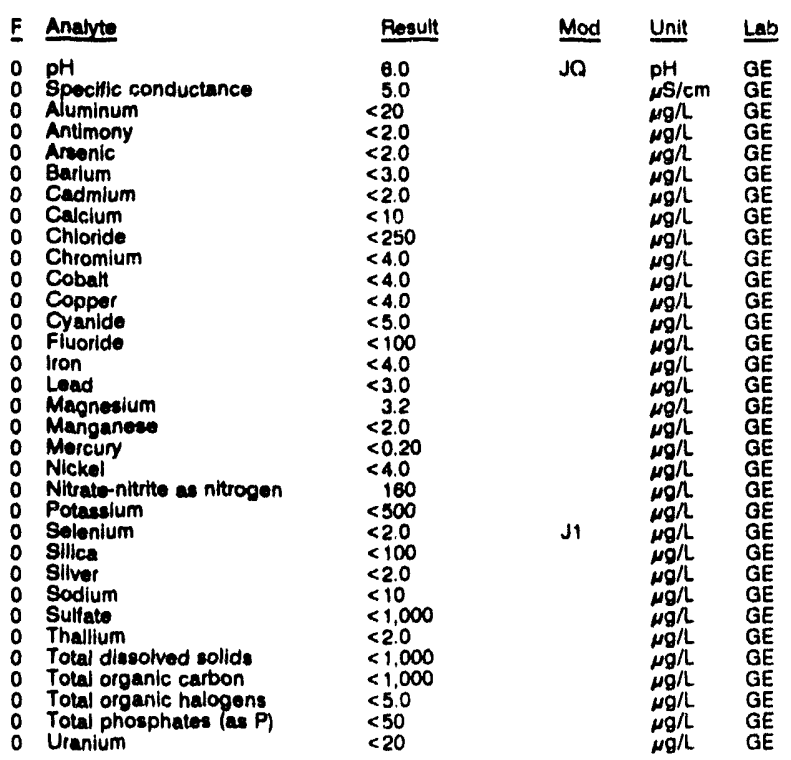

WELL QA $32 C$ collected on 07/10/92, laboratory analyses (cont)

\begin{tabular}{|c|c|c|c|}
\hline Analyte & Result & Mod & Unit \\
\hline $\begin{array}{ll}0 & \text { Vanadium } \\
0 & \text { Zinc } \\
0 & \text { Gross alpha } \\
0 & \text { Nonvolatilie beta } \\
0 & \text { Total alpha.emitting radium } \\
0 & \text { Tritium } \\
0 & \text { Tititium }\end{array}$ & $\begin{array}{l}<8.0 \\
<2.0 \\
<2.08 .09 \\
<2.0 E .009 \\
<1.0 E .09 \\
<7.0 E .07 \\
<7.0 E .07\end{array}$ & & 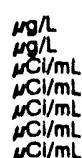 \\
\hline
\end{tabular}

WELL QA 34C

MEASUREMENTS CONDUCTED IN THE FIELD

Sample date: 07/19/82.

Dopth to water: Not available Water olevation: Not avallable

Time: $7: 35$

Alkalinity: $1 \mathrm{mg} / \mathrm{L}$

LABORATORY ANALYSES

$E$ Analyze

: $\mathrm{pH}$ speific conductance

A Aluminum

0 Arsonic

Barium

: Benzene

0 Bromolorm

O Cadmium

: Carbon tetrachloride

o Chloride

Chloroethene Minyl chloride)

2.Chloroethyl vinyl ether

Chloroform

Chloromethane

Cobati

Coppor

OYyanide

1.1. Dichloroethane
1,2. Dichloroothane

$\begin{array}{lll} & \text { 1.1. Dichloroethane } & <1.0 \\ \text { 1,2. Dichloroothane } & <1.0 \\ \text { 1.1.Dichloroethylene } & <1.0\end{array}$

0 trans-1,2-Dichloroethylene <1.0

2,4-Dichlorophenoxyacetic acid < <0.30

- 1,2-Dichloropropane

0 cis-1,3-Dichloropropene
0 trans-1,3.Dichloropropene

0 Endrin

$<0.0060$

- Fluoride $<100$

0 Iron

0 Load

: Lindane

Manganero

Mercury

Methoxychlor

Nickel

N Nitrate-nitite as nitrogen

Phenols

Potassium
Selenlum

silica

0 Silver

Sodium

Sulfate

$1,1,2,2$. Tetrachloroethan
Toetrachloroethylene

Thallium

Tosal dissolved solids

Tolal organic carbon

Total organic halogens
Total phosphates (as P)

T Toxas phosph hat

2,4,5.TP (Silvex)

o 1,1, Trichloroothane

1,1,2.Trichloroethan

Trichloroethylene

Uranlum

o Vanadium

Zinc

Nonvolatilo bota

Total alpha-emitting radium

Result

6.2
3.0

$<20$

$<2.0$

$<1.0$

$<1.0$

$<1.0$
$<2.0$

$<1.0$

$<1.0$

$<1.0$

$<1.0$

$<1.0$

8.3
$<4.0$

$<4.0$

$<5.0$

$<1.0$

$<0.30$

$<10$

$<1.00$

22
$<3.0$
$<30$

$<0.0050$

$<2.0$

$<2.20$

$<0.20$

$<.50$
8.6

$<50$

$<500$

$<2,0$

$<100$
$<2.0$

$<10$
$<1.000$
$<1.0$

$<1.0$

$<1.0$

$<1.0$

$<1,000$

$<1,000$

$<0.24$

$<10$

$<1.0$

$<1.0$

1.4
$<20$

$<20$

$<2.0$

$<2.0 \mathrm{E}-09$

$<2.0 E .09$

$\begin{array}{ll}\text { Tritilum } & <1.0 \mathrm{E} \cdot 09 \\ & <7.0 \mathrm{E} .07\end{array}$
Mod Unit Lab

jo

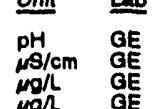

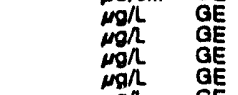

ge

$\operatorname{sgh} G$

$g /$ GE b

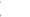




\section{BLANK RESULTS}

WELL QA 24C collected on 08/24/92, laboratory analyses (cont.)

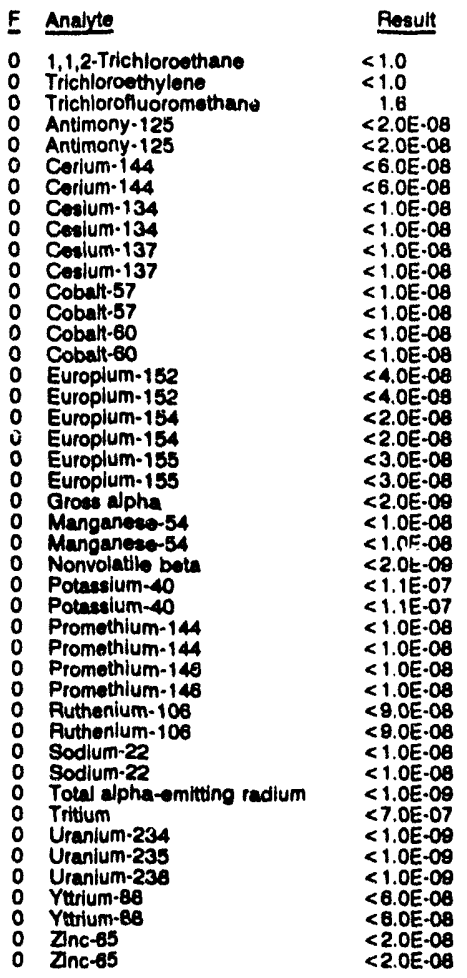

\section{WELL QA 26C}

MEASUAEMENTS CONDUCTED IN THE FIELD

\section{Sample date: 07/05/92 \\ Dopth to water: Not avaliable \\ Sp. conductance: $2 \mu \mathrm{s} / \mathrm{cm}$}

LABOPATORY ANALYSES

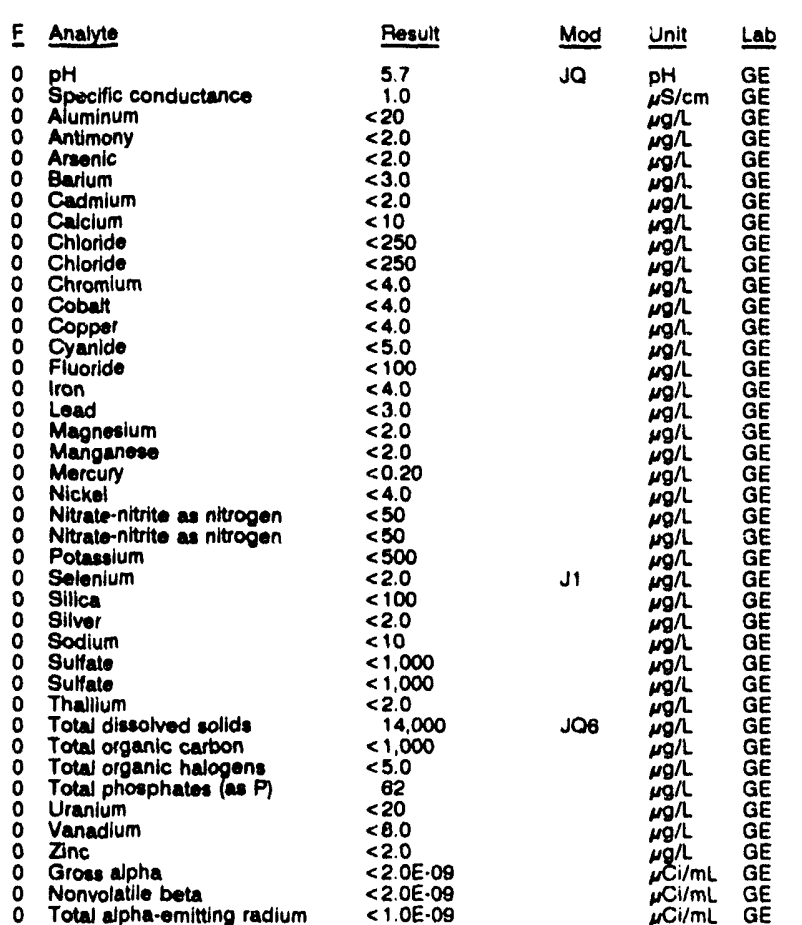

WELL QA 26C collected on 07/05/92, laboratory analyees (cont.)

\begin{tabular}{|c|c|c|c|}
\hline E Analyte & Result & Mod & Unit: \\
\hline o Tritium & $<7.0$ E-07 & & $\mu \mathrm{Cl} / \mathrm{mL}$ \\
\hline
\end{tabular}

WELL QA 28C

MEASUAEMENTS CONDUCTED IN THE FIELD

Sample date: 07/04/82

Depth to water: Not available

Water olevation: Not available

LABORATORY ANALYSES

$0 \mathrm{pH}$

Specific conductance

Specific conductance

Aluminum

Antimony

Arsenic

Barium

Barium

Cadmium

Cadmium

Calcium

Chloride

Chromium

Cobalt

Copper

Cyanide

Iron

0 Iron

L Lead

Magnesium

Magnesium

Manganese

Mercury

Nickel

Nitrate-nitrite as nitrogen

Potassium

Potassium

Selenium

Silica

Silica

Silver

Sodium

Sodium

Sulfate

Total dissolved solids

Total organic carbon

- Total organic carbon

Total phosphates (as P

Total phosphates (as P)

Uranium

Vanadium

O Zinc

0 Zinc

0 Gross alpha

- Gross alpha

o Nonvolatile beta

Total alpha-emitting radium

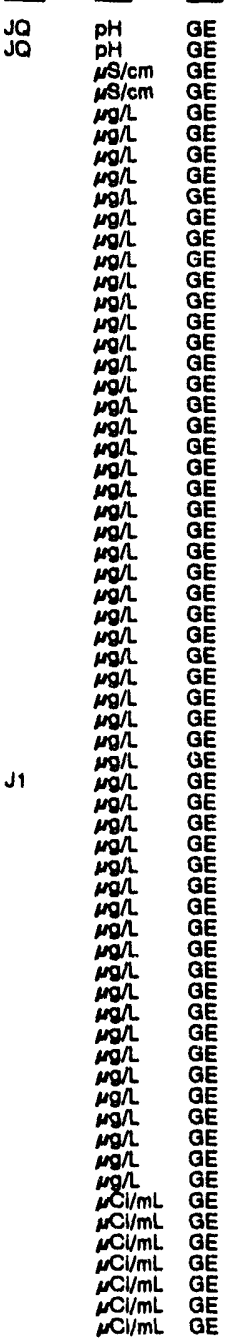

WELL QA 30C

MEASUREMENTS CONDUCTED IN THE FIELD

Sample dace: 07/15/92

Water to water: Not available

$\mathrm{Sp}$. conductance: $4 \mu \mathrm{s} / \mathrm{cm}$

LABORATORY ANALYSES

\begin{tabular}{|c|c|c|c|c|}
\hline$\underline{F}$ & Analyte & Result & Mod & Unit \\
\hline o & $\begin{array}{l}\text { pH } \\
\text { Specific conductance } \\
\text { Aluminum } \\
\text { Aluminum } \\
\text { Antimony } \\
\text { Arsenic }\end{array}$ & $\begin{aligned} & 6.3 \\
& 3.0 \\
&<20 \\
&<20 \\
&<2.0 \\
&<2.0\end{aligned}$ & JQ & $\begin{array}{l}\mathrm{pH} \\
\mathrm{mS/ \textrm {cm }} \\
\mathrm{mgh} \\
\mathrm{mgh} \\
\mathrm{mgh}\end{array}$ \\
\hline
\end{tabular}

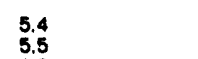

\author{
Time: $6: 40$ \\ Alkallinity: $1 \mathrm{~mol}$ \\ Water temperature: $22.0^{\circ} \mathrm{C}$
}

1.0
1.0

$<20$
$<20$

$<2.0$

$<3.0$

$<2.0$

$<10$
$<250$

$<4.0$

$<4.0$

$<4.0$

$<4.0$

$<4.0$

$<4.0$

$<2.0$

$<2.0$

$<0.20$

$<4.0$

$<500$

$<500$

$<100$
$<100$

$<2.0$

$<10$
$<10$

$<1,000$

$<2.000$

$<1,000$
$<1,000$

$<5.0$

$<50$

$<20$

$<8.0$

$<2.0$

$<2.0 \mathrm{E} .09$

$<2.05 .08$

$<2.0 \mathrm{E}-00$

$<7.0 \mathrm{E} .07$

$\mathrm{NCl} / \mathrm{mL}$ GE
Time: 7:15

PH: 477

Water temperature: $26.3^{\circ} \mathrm{C}$

E 


\section{BLANK RESULTS}

WELL QA 22C

MEASUAEMENTS CONDUCTEO IN THE FIELO

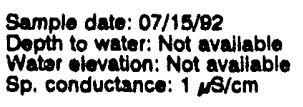

LABORATOAY ANALYSES

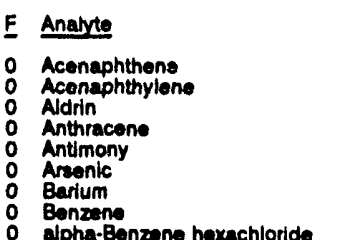

alpha-Benzene hoxachloride

beta-Benzene hexachlorlde

Benzidino

O Benzo[a] anthracene

Benzo b fluoranthene

Benzolg, h,ljperylen

Bia(2-chloroethoxy) methane

Bis (2-chloroethyn) ether

Bis 2-chloroisopropyl) ether

Bis (2-thylhexy) phthalat

Bromotorm

Gromometham

Butylbenzyl phthalate

Carbon tetrachioride

Chlordane

Chloride

Chloride

para-Chloro-meta-crusel

Chloroethene Minyl chloride)

2-Chloroethyl vinyl ether

Chloroform

Chloromethane

2-Chlorophenol

4-Chlorophenyl phenyl ether

Chromium

0 Cobalt

O Copper

P.P.:DD

O

o Bibenz[a,h]anthracione

Dibromochloromethan

D Di-n-butyl phthalate

3,3'-Dichlorobenzidin

1,1-Dichloroethane

o 1,1-Dichloroethyitene

trans-1,2-Dichloro

2,4-Dichlorophenol

1,2-Dichloropropane

cis-1,3-Oichioropropene
trans-1,3-Dichloropropene

trans-1,3-

o Diethyl phthalate

2,4-Dimethyl pheno

2,4Dinitrophengl

2,4-Dinitrophenol

2,e-Dinitrotoluene

o Di-n-octyl phthalate

1,2-Diphenylhydraxin

O Éndoaultan I

Endosulitan sulfate

o Endrin

- Endrin aldehyde

Ethylbenzene

Fluoranthen

Fluorene

Fluoride

Heptachlor epoxide

Hextachlorobenzene

Hexachlorobutadiene

Hexachlorocyclopentadiene

Hexachioroethane

Indenol $1,2,3-c, d]$ pyrene

Iron

0 kophorone

0 Lead

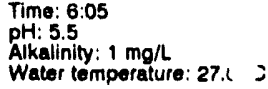

$<10$

$<10$

10

$<2.0$

$<3.0$

10

$<10$

$<10$
$<10$

$<10$

$<10$
$<10$

$<10$
$<10$
$<30$

$<3.0$

$<10$

$<10$
$<10$
$<10$

$<10$

$<1.0$
$<1.0$
$<1.0$

$<10$

$<10$

$<2.0$

$<10$

$<250$

$<1.0$

$<1.0$

$<1.0$

$<1.0$
$<1.0$

$<10$

$<10$

$<10$

$<4.0$

$<4.0$

$<10$
$<10$

$<10$

$<10$

$<10$

$<1.0$

$<1.0$

$<1.0$
3.2

$<10$

$<1.0$

$<1.0$
$<10$

$<10$

$<10$

$<45$

$<10$
$<10$

$<10$

$<10$

$<10$

$<10$

$<1.0$

$<10$

$<100$

$<10$

$<10$

$<10$

$<10$
$<10$

$<4.0$
$<10$
Mod Unil Lab

$\begin{array}{lll}J 1 & \mu g / L & G E \\ J 1 & M g / L & G E \\ J 1 & G / L & G E\end{array}$

J1

J1

J1
J

$\mathrm{J} 1$
$\mathrm{~J} 1$
$\mathrm{~J} 1$
$\mathrm{~J} 1$
$\mathrm{~J} 1$
$E$ Analyte

o Lindane

O Manganes

0 Mercury

2.Methyi-4,6-dinitrophenol

O Naphthaleno

Nitrato-nitrite as nitrogen

Nitrobenzene

2.Nitrophenol

N-Nitrosodimethylamine

N.Nitrosodiphenylamine

N-Nitrosodipropylamine

Oll 8 grease

PCB 1221

PCB 1232

PCB 1242

O PCB 1254

Pentachlorophenol

Phenanthrene

O Phenol

Selenium

o silver

Sodium

S Sulfate

Totrachloroethylene

Thallium

Tin

Toluene

Total potroleum hydrocarbons

Toxaphene.

1,2,4-Trichlorobenzene

1,1,1-Trichloroethane

1,1,2.Trichloroethane

o Trichloroethylene

2,4,6-Trichlorophenol

Vanadium

0 Xylenes

0 Gross alpha

\& Gross alpha

Nonvolatile bota
Total alpha-emitting radium

Tritium

WELL QA 24C

MEASUREMENTS CONDUCTED IN THE FIELO

Sample date: 08/24/92

Depth to water: Not available

Water elevation: Not available

Sp. conductance: $5 \mu \mathrm{S} / \mathrm{cm}$

LABORATORY ANALYSES

F Analyte

0 Benzene

Bromodich

Bromomethan

Carbon tetrachloride

- Chlorobenzene

o Chloroethan

o Chloroethene Ninyl chloride)

2.Chloroethyl vinyl ether

o Chloroform

- Chloromethane

O Chromium

D Dibromochloromethan

1,1-Dichloroethane

1,2-Dichioroethane

o 1,1-Dichloroethylene

trans-1,2-Dichloroo
0 Dichloromethane

1,2-Dichloropropane

0
0
0 trans-1,3-Dichloropropene

O Ethylbenzene

0 Lead

O Magnesium

O Nitrate-nitrite as nitrogen

o 1,1,2,2-Tetrachloroethan

o Tetrachloroethylene

Toluene

- Total organic carbon

- Total organic carbon

o T,1,1-Tichloroethane

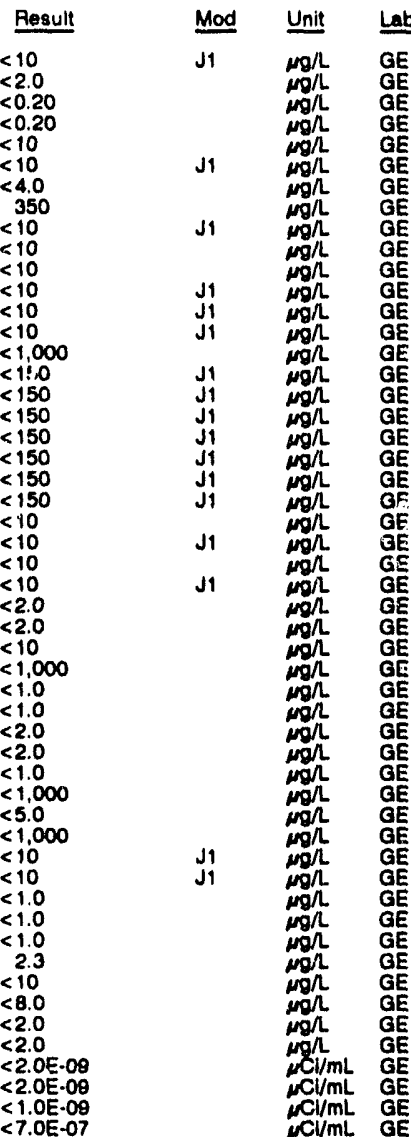

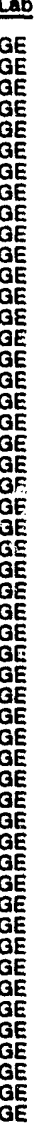


WELL QA $16 \mathrm{C}$ collocted on 07/30/92, laboratory analyses (cont.)

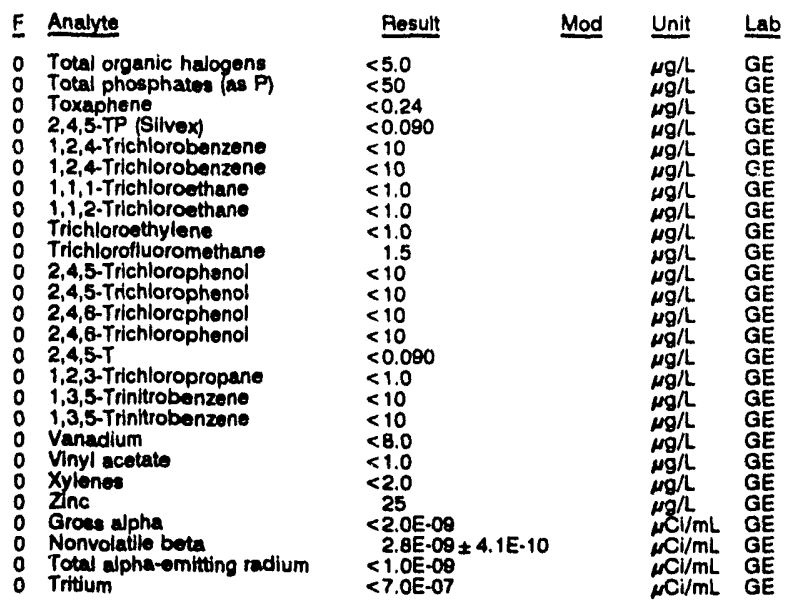

WELL QA 18C

MEASUREMENTS CONDUCTED IN THE FIELD

Sample date: 08/03/92

Depth to water: Not avallable

Sp. conductance: 3 avallabion

LABORATORY ANALYSES

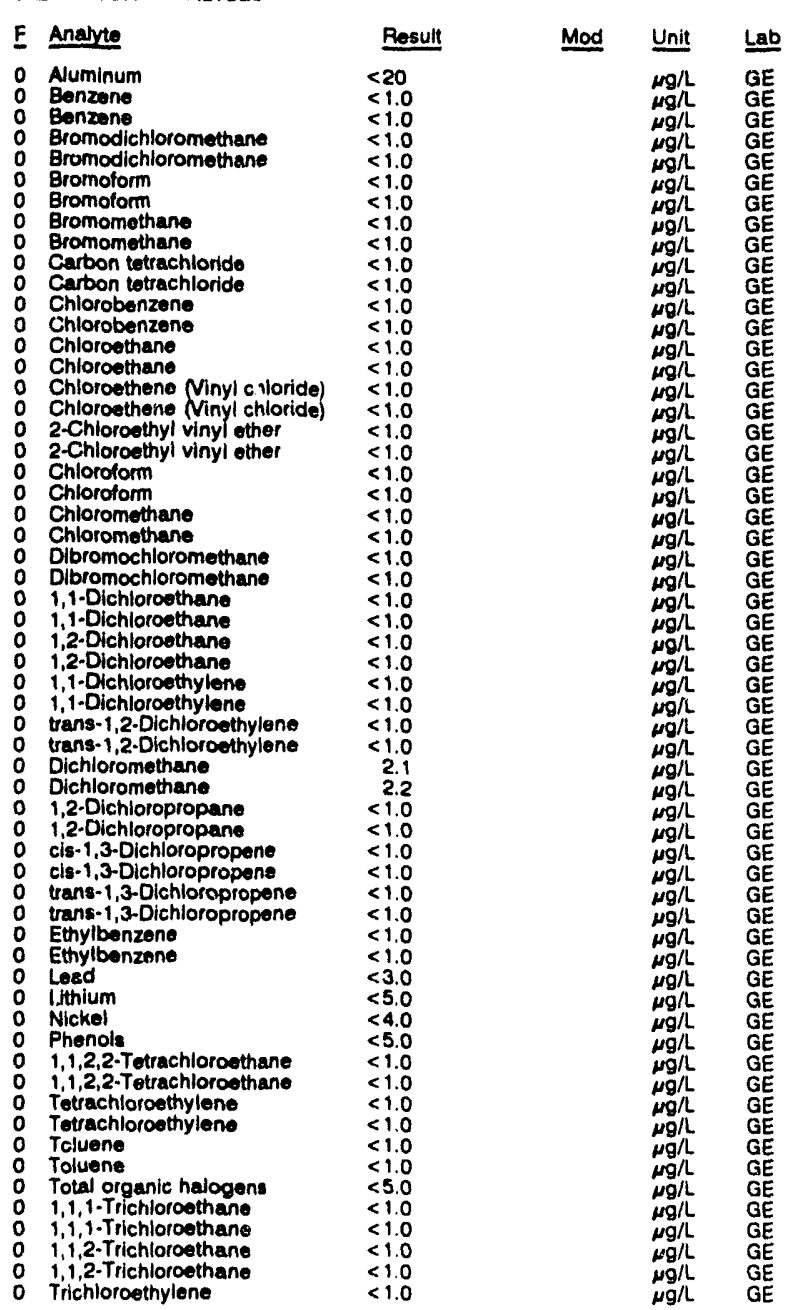

WELL QA $18 \mathrm{C}$ collected on $08 / 03 / 82$, laboratory analyses (cont.)

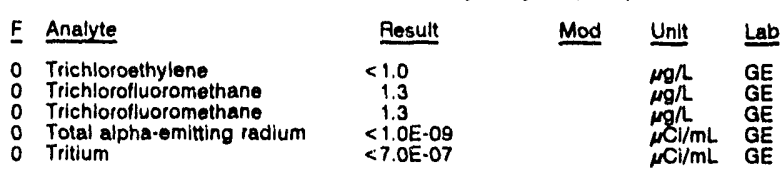

WELL QA 20C

MEASUREMENTS CONDUCTED IN THE FIELD

$\begin{array}{ll}\text { Sample date: } 08 / 01 / 92 & \text { Time: } 6: 20 \\ \text { Depth to water: Not available } & \text { pHH: } 5.2 \\ \text { Water elevation: Not avaliable } & \text { Alkalinity: } 1 \mathrm{mg} / \mathrm{L} \\ \text { Sp. conductance: } 2 \mu \mathrm{s} / \mathrm{cm} & \text { Water temperature: } 24.7 \circ \mathrm{C}\end{array}$

LABORATORY ANALYSES

F Analyte Rosult Mod Unit

$\begin{array}{ll}0 & \text { pH } \\ 0 & \text { Specific conductance } \\ 0 & \text { Arsenic } \\ 0 & \text { Barium } \\ 0 & \text { Benzene } \\ 0 & \text { Bromodichloromethane } \\ 0 & \text { Bromoform } \\ 0 & \text { Bromomethane } \\ 0 & \text { Cadmium } \\ 0 & \text { Calcium } \\ 0 & \text { Carbon tetrachloride } \\ 0 & \text { Chloride } \\ 0 & \text { Chiorobenzene } \\ 0 & \text { Chlor }\end{array}$

Chloroethane

Chlorosthene

Chloroform

Chloromethan

Chromium

Dibromochloromethane

O 1,1 . Dichloroethane $\quad<1.0$

o 1,2.Dichloroethane $<1.0$

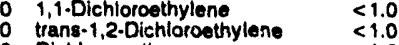

Dichloromethane

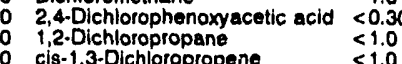

o trans-1,3-Dichloropropene

0 Endrin

O Ethylbenzen

0 Fluoride

Iron

L Lead

O Lindane

Manganes

Mercury

Methoxychlor

o Phenols

Potassium

0 Silica

S Sliver

S Sodium

Sulfate

Tetrachloroethyiene

- Toluene

- Total dissolved sollds

Total organic carbon

Total organic haiogens
Total phosphates (as P)

Toxaphene

0 Toxaphene
2,4,5.TP (Silvex)

1,1,1-Trichloruethane

1,1,2-Trichloroethane

o Trichloroethylene

- Trichlorofluorome

- Gross alpha

Nonvolatile beta
Total alpha-emitting radium

$\begin{array}{ll}0 & \text { Total al } \\ 0 & \text { Tritium } \\ & \end{array}$

6.5 Ja

$<2.0$

$<1.0$

$<1.0$

$<1.0$
$<2.0$
15
$<1.0$

$<1.0$
$<250$
$<1.0$
$<1.0$

$$
\text { Alkalinity: } 1 \mathrm{mg} / \mathrm{L}
$$

Mod Unit Lab

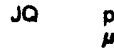

$\underset{\mu \mathrm{PH} / \mathrm{cm}}{\mathrm{pH}} \mathrm{g}$



$\begin{array}{ll}m g / L & G E \\ \operatorname{mg} / L & G E \\ \operatorname{mg} h & G E\end{array}$

$\begin{array}{ll}g / 2 & G E \\ g / 2 & G E \\ g R & G E\end{array}$

GR $G E$

4.0

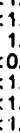

$<1.0$

$<0.0060$

$<1.0$

$<100$
$<4.0$
$<3.0$

$<3.0$
$<0.0050$

$<2.0$
$<2.0$
$<0.20$
$<0.50$

$<0.50$

$<50$

$<5.0$
$<500$
$<2.0$

$<100$
$<2.0$

$<17,000$

$<1.0$

$<.0$
4.000

4,000
$<1,000$

$<5.0$

$\begin{array}{r}240 \\ <0.24 \\ \hline\end{array}$

$<0.090$

$<1.0$

$<1.0$

$<2.0$ E.00

$<2.0 E .09$

$<1.0 E .09$
$<7.0 E .07$

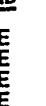


BLANK RESULTS

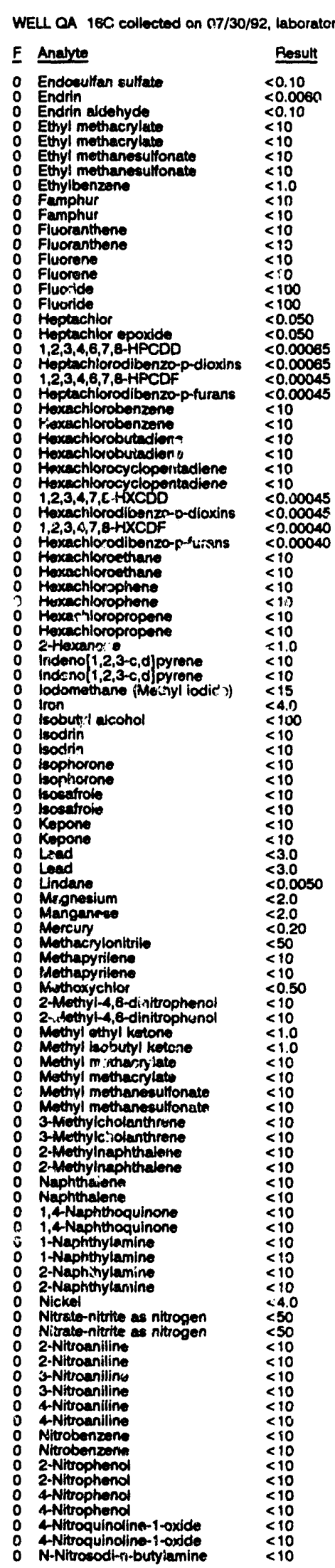

WELL QA $16 \mathrm{C}$ collected on 07/30/92, laboratory analyses (cort.)

\begin{tabular}{|c|c|c|c|c|}
\hline & Analyte & Result & Mod & Unit \\
\hline $\begin{array}{l}0 \\
0 \\
0 \\
0 \\
0 \\
0 \\
0 \\
0 \\
0 \\
0 \\
0 \\
0 \\
0 \\
0 \\
0 \\
0 \\
0 \\
0 \\
0 \\
0\end{array}$ & 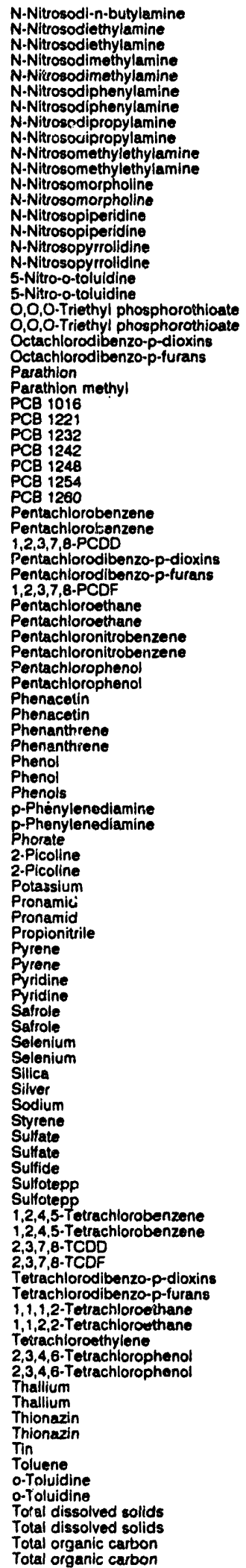 & 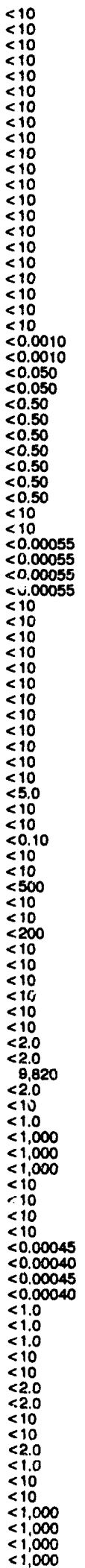 & $v$ & 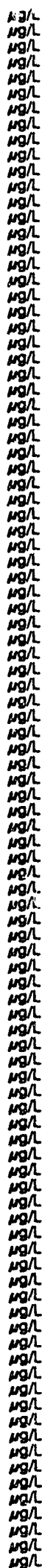 \\
\hline
\end{tabular}


BLANK RESULTS

WELL OA 14C colloctod on 07/31/82, laboratory analyses (cont.)

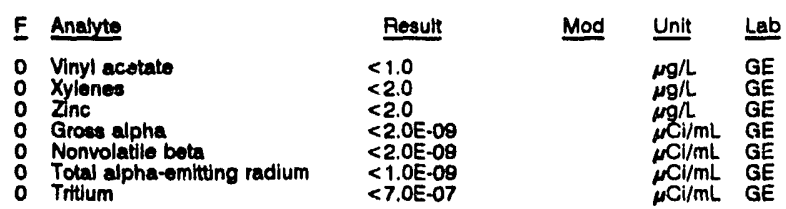

WELL QA 16C

MEASUREMENTS CONDUCTED IN THE FIELD

Sample date: 07/30/92 Wopth to water: Not avallable Water olovation: Not availablo

LABOFATORY ANALYSES

$E$ Analyte

o 1 pH

o $\mathrm{pH}_{0}^{\mathrm{pH}}$

Specific conductance

Acenaphthene

Acenaphthene

Acenaphthylone

Aceton

Acetonitrile (Methyl cyanide)

Acotophenone

2-Acetylaminofiuorene

2-Acetylaminofluorene

Acrolein

Acrylonitrile

Alyl chloride

4Aminobiphenyl

A Aniline

Aniline

Anthracene

Antimony

Antimony

Aramite

Areonic

Arsonic

Barium

alpha-Benzene hexachloride

bela-Benzene hexachloride

delta-Bentane hexachloride

Benzo(a) anthracene

Benzolajanthracene

Benzo! b fluoranthene

Benzolb fluoranthene

Benzo/k ffuoranthene

Benzo k filuoranthene

Eonzo $g, n, i l$ perylen

Bonzo pyrone

Benzyl acohol

Benzyl alcohol

Bonzilium

Bis (2-chloroethoxy) methane

Bis(2-chloroethory methene

Bia (2-chloroethy) other

Bis (2-chlorolsopropyl) the

Bite (2-ethylhexyly phthalate

Bis (2-othylhexy) phthalato

Bromolich

Bromornethane

4-Bromof nyl phenyl ether

Butylbenzyl phthalate

Butylbenzyl phthelato

2-sec-Butyl-4, 6-dinitrophenol

Cadmium

Calclum

Carbon tistrachiorido

Chlordane

Chloride

Chloride

4-Chloroaniline

Chlorobenzene

Chlorobenzitate

Chlorobenzilate
Time: 6:15

AH: 5.7

Alkalinity: $1 \mathrm{mg} / \mathrm{h}$

\begin{tabular}{ll} 
Result & Mod \\
\hline 5.8 & Ja \\
6.0 & $J a$ \\
6.0 & $j a$ \\
6.1 & $j a$ \\
5.8 & JO
\end{tabular}

Unit

$\begin{array}{ll}\mathrm{pH} & \mathrm{GE} \\ \mathrm{pH} & \mathrm{GE} \\ \mathrm{pH} & \mathrm{GE} \\ \mathrm{pH} & \mathrm{GE}\end{array}$

$<10$

$<10$
$<10$

$<100$

$<1.0$

$<10$

$<10$

$<20$

$<200$

$<50$
$<10$

$<10$

$<10$

$<10$
$<10$

$<2.0$

$<10$

$<2.0$

$<3.0$

$<0.050$

$<0.050$

$<10$

$<10$
$<10$

$<10$

$<10$

$<10$

$<10$

10
$<10$

$<10$

$<10$

$<10$

$<10$
$<10$
$<10$

$<10$

$<10$

$<1.0$

$<1.0$

$<10$

$<10$
$<10$

$<10$

$<10$

$<2.0$

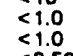

$<0.50$

$<250$

$<10$

$<10$
$<10$

$<1.0$
$<10$
$<10$

WELL OA $16 \mathrm{C}$ collected on $07 / 30 / 92$, laboratory analyses (cont)

para-Chloro-mota-cresol

para-Chloro-meta-cresol

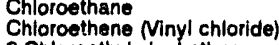

2-Chloroethyl vinyl ether

2-Chloroothyl vinyl ether

Chloroform

Chloromethane

2-Chloronaphthalene

2.Chloronaphthalene

2-Chlorophenol

2-Chlorophenol

4-Chlorophenyl phenyl ether

Chloroprene

Chromium

Chrysene

Chrysene

Cobelt

o-Cresol (2-Methylphenol

o-Cresol (2-Methylphenol)

m-Cresol (3.Methyiphenol

m-Cresol (3-Methylpheno

p-Cresol (4-Methylphenol)

Cyanide

P,P'DDD

0
0

Biplatiate

Diallate

Dibenz $[a, h]$ anthracene

Dibenzofuran

Dibromochloromethane

1,2-Olbromo-3-chloropropane

1,2.Dibromoethane

Dibromomethane

Di-n-butyl phthalate

1,2.Dichlorobenzene

i. Dichlorobenzene

1,3.Dichiorobenzene

1,3-Dichlorobenzene

1,4-Dichiorobenzene

1,4-Dlchiorobenzene

3,3.-Dichlorobenzidine

trans-1,4-Dichloro-2-butene

Dishlorodifluoromethane

1, 1 . Dichloroethane

1,2-Dichloroethane

trans-1,2-Dichloroethylene

Dichloromethane

2,4-Dichloropheno

2,6-Dichloropheno

2,6-Dichlorophenol

1,2-Dichloropropane

cis-1,3-Dichloropropene

trans-1,3-Dichloropropene

Dieldrin

Diethyl phthalate

Dimethoate

2.4-Dimeale

2,4-Dimethyl phenol

Dimethyl phinalate

Dimethyl phthalate

p-Dimethyiaminoazobenzene

p-Dimethylaminoazobenzesio

bimethyibenz (a)anthraceno

Dimethylbenz a a anthracen

3,3'.Dimethylbenzidine

a,a-Dimethylphenethylamine

1,3.Dinitrobenzene

2,4-Dinitrophenol

2,4-Din!trophenol

2,4-Dinitrotoluene

2,4-Dinitrotoluene

2,6-Dinitrotoluene

2,6. Oinitrotoluene

Di-n.octyl phthalate

1,4-Dioxane

1,4-Dioxane

Diphenylamine

D Diphenylamine

Disulfoton

Endosulfan I

Mod Unit Lab

$<10$
$<10$

$<10$
$<1.0$
$<1.0$

$<10$

$<<1.0$

$<10$

$<10$

$<10$

$<100$

$<4.0$

$<10$

$<4.0$

$<4.0$
$<10$

$<10$

$<10$
$<10$

$<10$

$<5.0$

$<0.10$

$<10$

$<10$

$<10$

$<1.0$

$<1.0$

$<1.0$
$<10$

$<10$
$<10$

$<10$

$<10$
$<10$

$<10$
$<10$
$<10$

$<10$

$<10$
$<30$

$<1.0$

$<1.0$

$<1.0$

$<1.0$
$<1.0$
$<10$

$<10$

$<10$
$<10$

$<0.30$

$<1.0$
$<1.0$
$<1.0$

$<0.50$

$<10$

$<10$

$<10$

$<10$

$<10$

$<<$

$<10$

$<10$

$<10$
$<10$

$<10$
$<10$

$<45$

$<10$
$<10$

$<10$
$<10$

$<10$

$<10$
$<10$

$<10$

$<10$
$<10$

$<10$
$<10$

$<10$

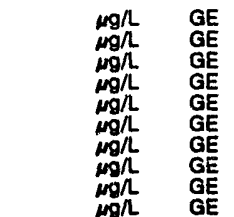

GE

GE 
BLANK RESULTS

WELL OA $14 \mathrm{C}$ colloctod on 07/31/92, laboratory analyses (cont)

F Analyte

O Chryeeno

Copper

o-Cresol (2-Methylphenol)

p-Cresol (4-Methylphenol)

0
0

P,P'-Do

Oiallate

D Dibenzza,h]enth

o Dibromochloromethane

1.2-Dibromo-3-chloropropane
0

- Dibromomethane

1,2-Dichlorobenzene

1,3-Dichlorobenzente

o 1,4-Dichlorobonzenzen:

3,3'-Dichlorobenzandine < < $<10$

trane-1,4-Dichloro-2-butene $<10$

Dichlorodifluoromethane $<1.0$

i,2.Dlthlorothethen

: 1,1-Dichloroethylione

Dichioromethane

2,4-Dichlorophenol

,

1,2-Dichloropropano

o cis-1,3-Dichloropropene

: trans-1,

o Diethyi phthalate

2,4-Dimethyl phenol

: Dimethyl phthalate

D-Dimerhylaminaazobenzene

0 3,3'-Dimethylbenzidine

a,-Dimothyiphenethylemine

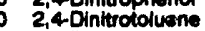

2,8-Dinitrotoluene

: Di-n-octyl phent

D Diphenyiant

Disulfoton 1 $1<10$

Endosultan II $<0.10$

$<0.10$

$\begin{array}{ll}0 & <0.1060 \\ 0 & \text { Endrin } \\ 0 & <0.10 \\ 0 & <10\end{array}$

0 Ethyl methacrylate $<10$

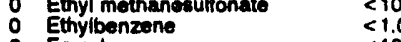

- Famphur

Fluoranthen

: Fluorene

: Fiopride

Heptachlor epaxide

- Hoptachiorodibonzo-p-dioxins

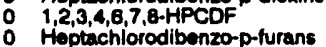
Hexachlorobenzone

Hexachlorobutadione

Hexachlorocyclope

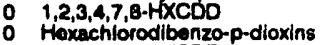

$1,2,3,4,7,8-H X C D$

Hexachiorodibenzo-p.turans

Hexachloroethane

Hexachlorophene

2-Hexanone

indeno $[1,2,3-c$, d]pyrene

lodomethane (Methyl iodide)

bodrin

leophorone

o bosafrote

o Lead

o Lindane

M Manganes

Mercury

Mercury

Methapyrilen

Methoxychlor

2-Methyl-4,6-dinttrop
Methyl ethyl ketone
Besult Mod

$<10$

$<10$

$<10$
$<5.0$
$<0.10$

$<0.10$

$<10$

10

20

$<10$

(10

-10
10

$<<1.0$

$<1.0$

1.8
$<10$
$<10$

$<1.0$
$<1.0$
$<1.0$

$<0.50$
$<10$

$<10$

$<10$

$<<10$

$<10$
$<10$

$<10$

$<10$

10

$<10$

$<10$
$<10$

$<100$

$<0.050$

$<0.0006$

$<0.00065$

$<0.00045$

$<10$

$<10$

$<<0.00045$

$<0.00045$

$<0.00040$

$<0.000$

$<10$

$<10$
$<10$

$<10$

$<15$

$<100$

$<10$

$<10$

$<10$

$<0.0050$

$<2.0$

$<0.20$

$<0.20$

$<10$

$<0.50$

$<10$
$<1.0$

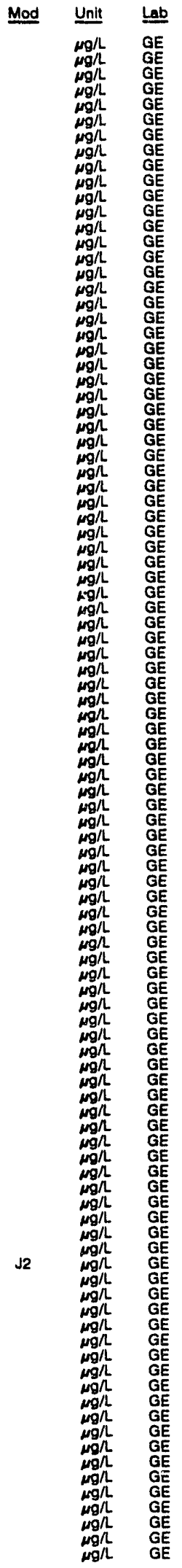

WELL OA $14 C$ collocted on 07/31/82, laboratory analyses (cont)

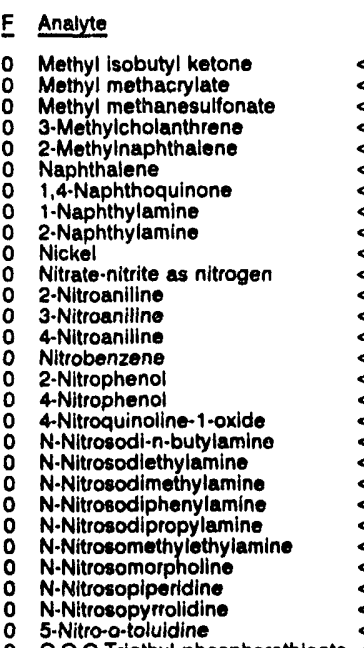

Result Mod

Unit Le

$<10$

$<10$

$<10$

$<10$

$<10$

$<50$

$<10$

$<10$

$<10$

$\leq 10$

$\leq 10$

$<10$

$<10$

$<10$
$<10$
$<10$

$<10$

$0,0,0$-Triethyl phosphorothioate

Octachlorodibenzo-p-dioxins

O Pavathion

Parathion methyl

PCB $1016<0.50$

0 PCB $1232<0.50$

$\begin{array}{ll}0 \\ \text { PCB } 1248 & <0.50 \\ 0 & <0.50\end{array}$

$\begin{array}{lll}0 & \text { PCB } 1254 & <0.50 \\ 0 & \text { PCB } 1260 & <\end{array}$

: Pentachlorobenzene

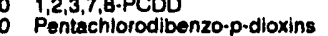

Pentachlorodbenzo-p.dioxins

$1,2,7$, QPCDF

Pontachloroothane

Pentachloronitrobenzene

Phenacetin

Phenol

Phenols

p.Phenylenediamine

0
0
0

Potassium

: Pronamid

o Pyrene

: Pyridine

o Selenium

: Silica

0 Silver

o Sodium

o Styrene

0 Sulfide

: Sulfotepp

2,3,7,8-TCDO

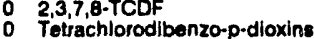

o Tetrachlorodibenzo-p.dioxins

0 Tetrachlorodibenzo-p.furan

o 1,1,2,2-Tetrachloroethane

o Tetrachloroethylene

2,3,4,6-Tetrachlorophenol

0 Thallium

Thionazin

$\begin{array}{ll}0 & \text { Toluene } \\ 0 & \text { o-Toluidine }\end{array}$

o Total dissolved solids

Total organic carbon

Total organic halogens

Total phosphates (as

Toxaphone Silvex

1,2,4-Trichlorobenzene

1,1,4-Trichlorobenzen

i i, Trichloroethe

Trichloroethytene

Trichlorotluoromethane

2,4,5-Trichlorophenol

$\begin{array}{ll}0 & 2,4,6-T \\ 0 & 2,4,5-T\end{array}$

o 1,2,3-Trichloropropane

0
0 Vanadium
i,

\begin{abstract}
(n)
.
\end{abstract}

(a)

$$
<11,110055
$$$$
<0.00055
$$

$<0.0 .2$
$<10$
$<10$
$<10$

$<10$

$<10$
$<10$
$<10$

$<10$
$<5.0$
$<10$

$<10$
$<0.10$

$<10$

$<500$
$<10$

$<200$

$<10$

$<10$

$<2.0$

$<2.0$

$<<1.000$

$<1,000$

$<10$

$<0.00045$

$<0.00040$

$<1.0$

$<1.0$

$<1.0$

$<10$

$<10$

$<2.0$
$<1.0$
$<10$

2,000
$<1,000$

$<5.0$

$<0.24$

$<10$

$<1.0$

$<1.0$

$<10$

$<0.090$

$<10$

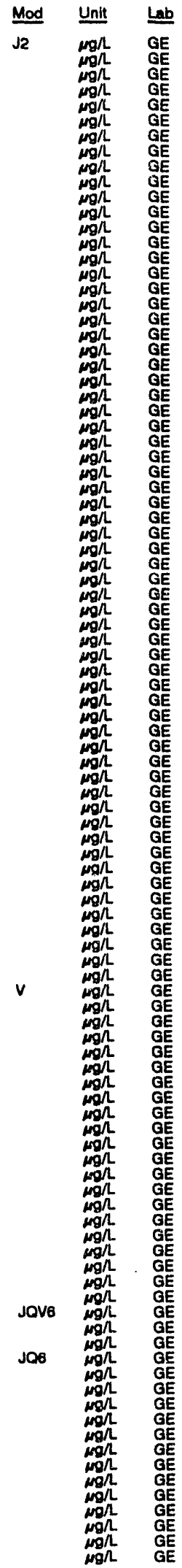




\section{BLANK RESULTS}

\begin{tabular}{|c|c|c|c|c|}
\hline$\underline{F}$ & Anatyte & Result & Mod & Unit \\
\hline $\begin{array}{l}0 \\
0 \\
0 \\
0 \\
0 \\
0 \\
0 \\
0\end{array}$ & $\begin{array}{l}\text { Sodium-22 } \\
\text { Total alpha-emitting radium } \\
\text { Tritium } \\
\text { Uranium-234 } \\
\text { Uranium-235 } \\
\text { Uranlum-238 } \\
\text { Yrtrium-88 } \\
\text { Znc-65 }\end{array}$ & $\begin{array}{l}<1.0 E-08 \\
<1.0 E-09 \\
<7.0 E-07 \\
<1.0 \mathrm{E}-09 \\
<1.0 \mathrm{E}-09 \\
<1.0 \mathrm{E}-09 \\
<6.0 \mathrm{E} \cdot 00 \\
<2.0 \mathrm{E}-08\end{array}$ & & $\begin{array}{l}\mu \mathrm{Ci} / \mathrm{mL} \\
\mu \mathrm{Cl} / \mathrm{mL} \\
\mu \mathrm{Ci} / \mathrm{mL} \\
\mu \mathrm{Ci} / \mathrm{mL} \\
\mu \mathrm{Ci} / \mathrm{mL} \\
\mu \mathrm{Ci} / \mathrm{mL} \\
\mu \mathrm{Cl} / \mathrm{mL} \\
\mu \mathrm{Cl} / \mathrm{mL}\end{array}$ \\
\hline
\end{tabular}

WELL QA 12C

MEASUREMENTS CONDUCTED IN THE FIELD

Sample date: 08/14/92 Deptri to water: Not available Water olevation: Not avaliablo

LABORATORY ANALYSES

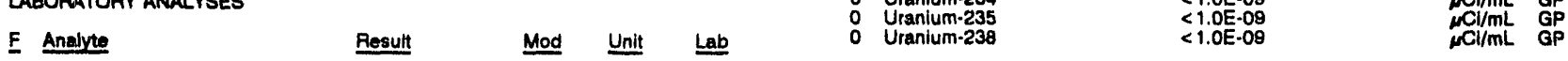

Time: $7: 25$

$1 \mathrm{mg}$

Water temperature: $26.7^{\circ} \mathrm{C}$
Specific conductance

o Arenic

o Benzene

o Bromodichioromethane

Bromodichloromethane

Bromoform

Bromolorm

Bromomethane

Cadmlum

Carbon tetrachioride

Carbon totrachloride

Chloride

Chlorobenzene

Chlorobenzene

Chorosthane

Chloroethene Ninyl chloride)

Chlorethene

2-Chloroethyl vinyl ether

2-Chioroothyl vinyl ether

Chloroform

Chlorolorm

Chloromethane

Chloromethan

Chromium

Dibrome

1,1-Dichloroethane

1,1-Dichloroethane

1,2-Dichlorcethane

1,1-Dichloroethylene

1,1-Dichioroethylone

trans-1,2-Dichlorosthylene

Dichioromethane

2,4-Dichlorophenoxyacetic acid

2,4-Dichlorophenoxyacetic acid

1,2-Dichloropropane

o cie-1,3-Dichloropropen

cis-1,3-Dichloropropene

trans-1,3-Dichloropropene

trans-1,3-Dichloropropene
trans-1,3-Dichloropropene

Endrin

Ethylbenzene

Ethylbenzeno

iron

Lead

Lindane

- Manganese

Mercury

Mothaxy

Nickel

Nitrato-niturite as nitrogen

Phenols

Selenium

Sllica

Silver

Sodium

Sulfate

1,1,2,2-Tetrachloroethane

Tetrachloroethylene

Tetrachloroeth

Toluene

Total dissolved solids
5.9
2.0

$<\begin{array}{cc}<2.0 \\ <3.0\end{array}$

$<1.0$

$\leq 1.0$

$<1.0$

$<1.0$

$<1.0$

$<10$

$<1.0$

$<1.0$
$<250$

$<1.0$

$<1.0$

$<1.0$

$\leq 1.0$

$<1.0$

$<1.0$

$<1.0$

$<1.0$

$<4.0$

$<1.0$

$<1.0$

$<1.0$

$<1.0$

$<1.0$

21.0
1.7
1.7

1.7
1.8
$<0.30$
$<0.30$

$<0.30$

$<1.0$

$<1.0$

$<1.0$
$<1.0$

$<0.0060$

$<1.0$

$<100$

$<4.0$

$<0.0050$

$<2.0$

$<2.20$

$<0.50$

$<4.0$

$<5.0$

$<500$

19,400

$<2.0$

$<1,000$

$<1.0$

$<1.0$

$<1.0$

$<1.0$

$<1.0000$

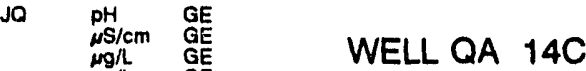

MEASUREMENTS CONDUCTED IN THE FIELD

Sample date: 07/31/92

Depth to water: Not available

Waler elovallon. Not availablo

LABORATORY ANALYSES

F Analyte

0 pH

$0_{0}^{0}$ pH

Specitic conductance

Acenaphthene

Aconaphthyle

Acetonitrile (Methyl cyanide)

Acetophenone

2-Acetylaminofluorene

Acrolein

Acrylonitrilo

Aldrin

Allyl chtoride

4-Amino

Anthracene

Antimony

Aramite

Arsenic

Barium

alpha-Benzene hexachloride

beta-Benzene hexachloride

delta-Benzene hexachloride

Benzola)anthracene

Benzo b filuoranthene

Benzolkffluoranthene

Benzo $[9, h, i j$ perylene

Benzola pyrene

Benzyl alcoho

methane

Bis 2-chloroethyl) ether

Bis (2.chlor

Brome

Bromoform

Bromomethane

4-Eromophenyl phenyl ether

Butylbenzyl phithalate

2-sec-Butyl-4,8-dinitrophenol Cadmium

Calcium

Carbon disulfide

Carbon tetrachloride

Chlordane

4.Chloroaniline

Chlorobenzene

para-Chloro-meta-cresol

Chloroethane

Chloroethene Ninyl chloride)

2.Chloroethyl vinyl ether

Chlorotorm

Chloromethane

2-Chloronaphthalene

2-Chlorophenol

Chloroprene

\begin{tabular}{|c|c|c|}
\hline Result & Mod & Unit \\
\hline $\begin{aligned} & 17,000 \\
&< 1.000 \\
&<5.0 \\
&<50 \\
&<0.24 \\
&<0.090 \\
&<0.090 \\
&<10 \\
&<1.0 \\
&<1.0 \\
&<1.0 \\
&<1.0 \\
&<1.0 \\
&<1.0 \\
& 1.1 \\
& 1.2 \\
&<2.0 \mathrm{E}-09 \\
&<2.0 \mathrm{E}-09 \\
&<1.0 \mathrm{E}-09 \\
&<7.0 \mathrm{E}-07 \\
&<1.0 \mathrm{E}-09 \\
&<1.0 \mathrm{E}-09 \\
&<1.0 \mathrm{E}-09\end{aligned}$ & $\underset{\text { JQ }}{\text { JQ }}$ & 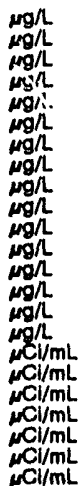 \\
\hline
\end{tabular}

Time: 6:00

Alkalinity: $1 \mathrm{~mol}$

Water temperature: $26.9^{\circ} \mathrm{C}$

Result Mod Unit Lab

$\begin{array}{ll}6.1 & \mathrm{JQ} \\ 6.2 & \mathrm{JO} \\ 6.5 & \mathrm{JO}\end{array}$

3.0
$<10$

$<10$
$<100$

$<1.0$

$<10$

$<20$

$<0.050$

$<10$

$<10$

$<2.0$

$<2.0$

$<1.0$

$<0.050$

$<0.050$

$<10$
$<10$

$<10$

$<10$
$<10$

$<10$
$<3.0$

$<10$

$<10$

$<1.0$

$<1.0$

$<10$
$<10$

$<10$
$<10$

$<10$

$<10$
$<1.0$
$<1.0$
$<0.50$

$<0.50$
$<250$

$<10$

$<1.0$

$<10$

$<1.0$

$<10$
$<1.0$
$<1.0$
$<10$

$<10$

$<200$

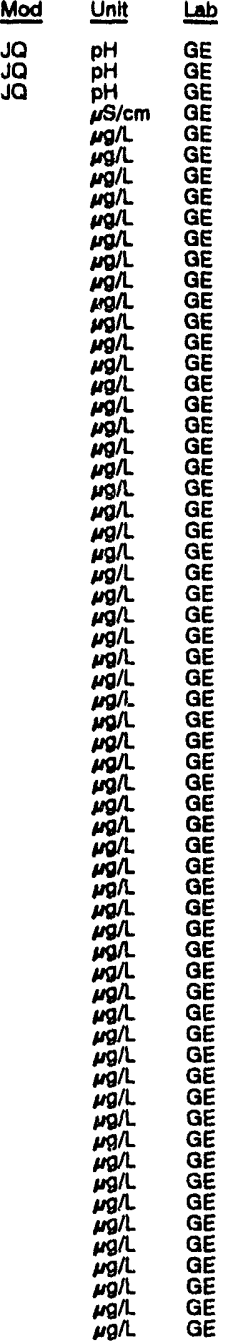


BLANK RESULTS

WELL QA BC collectod on 08/03/92, lakoratory analyses (cont.)

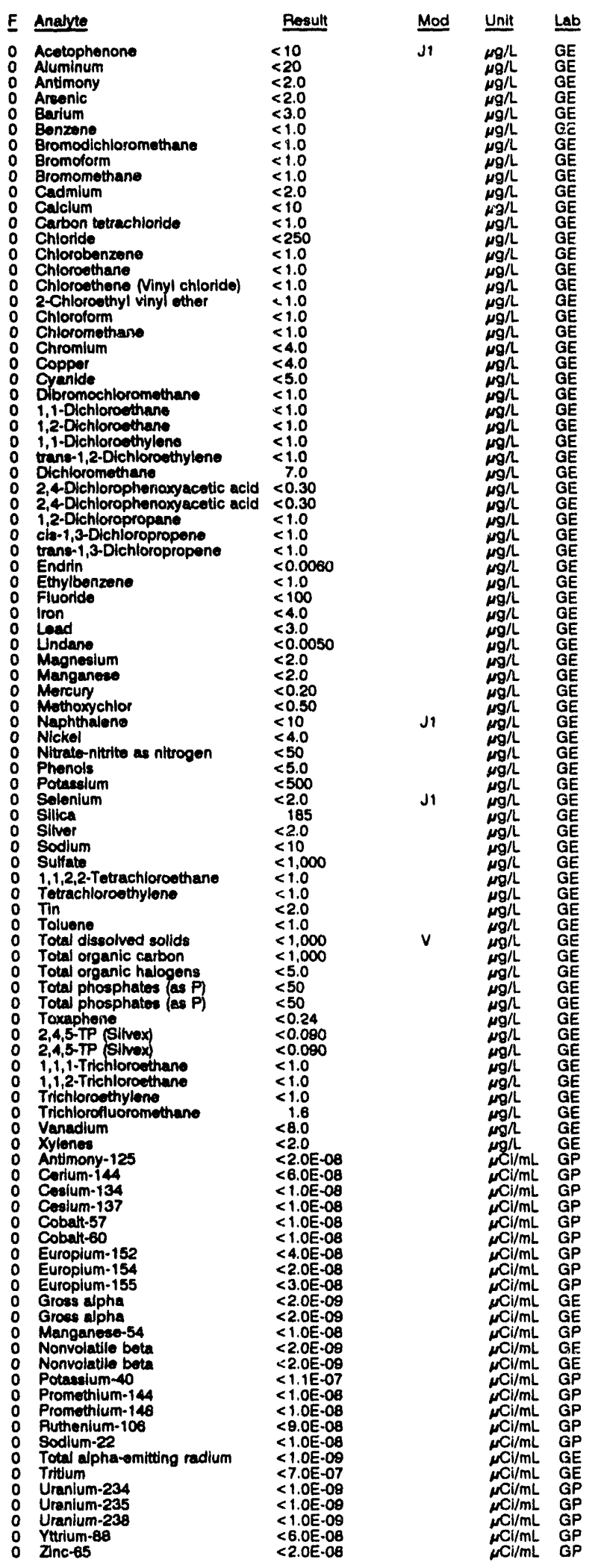

WELL QA $10 C$

MEASUREMENTS CONDUCTED IN THE FIELD

Sample date: 08/04/82

Depth to water: Not avallable
Water elevation: Not available

$\mathrm{Sp}$. conductance: $1 \mu \mathrm{S} / \mathrm{cm}$

LABORATORY ANALYSES

$0_{0}^{\mathrm{pH}}$ Specific conductance

Specitic

Acetophenone

Aluminum

Antimony

Arsenic

Benzene

Bromodichloromethane

Bromomethane

Cadmium

Carbon tetrachloride

Chloride

Chlorobenzene

Chloroethane

Chloroethene Minyl chlorido
2.Chloroethyl vinyl ether

Chloromethan

Chromium

Copper

Dibromochloromethane

1,1-Dichloroethane

1,2-Dichloroethane

1,1-Dichloroethylene

trans-1,2-Dichloroeth

Dichloromethane

1,2-Dichloropropane

cis-1,3-Dlchloropropene

Trans-1,3

Ethylbenzene

Fluoride

Tron

0 Lindan

Magnesium

Manganes

Mercury

Naphthalene

Nitrate-nitrite as nitrogen

Phenols

Sotassium

Silica

Silver

Sodlum

1,1,2,2-Tetrachloroethane

Tetrachloroethylone

Tin

Total dissolved sollds

- Total organic halogens

Total phosphates (as P)

Toxaphene

Tributyl phosphate

1,1,1. Trichloroethane

Trichloroethylene

Trichlorofluoromethane

0 Vanadium

Xylenes

Ceriurn-1:-

Cosium-130

0 Cesium-137

o Coball-57

O Cobalt-60

Europlum-152

Europium-155

Mross alpha

Nonvolatile beta

Potassium.40

Promethlum-144

Ruthenium-106

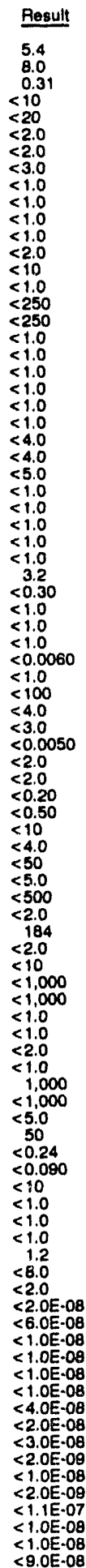

Time: 7:30

Alkalinity: $1 \mathrm{mg} / \mathrm{L}$

Water temperature: $27.9^{\circ} \mathrm{C}$

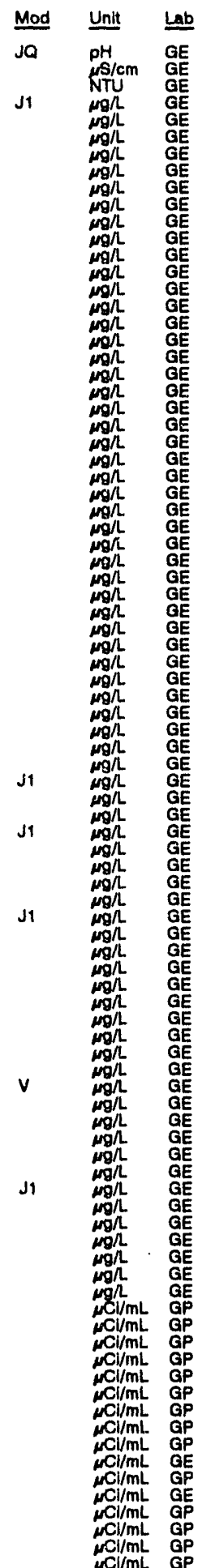


WELL QA 4C collectod on 07/16/92, laboratory analyses (cont.)

E Analyte

o Nitrate-nitrite as nitrogen

Phonols

0 Solenium

0 Silica

0 Silver

o Sulfate

Totrachloroethylene

Total organic halogens

Total phosphates (as P)

Toxaphene

o $1,1,1$-Trichioroethane

- Trichloroethylene

Zne

Americium-241

Antimony-125

Antimony-125

Cerlum-144

Cesium-134

O Ceslum-137

Cobalt-57

o Cobalt-57

- Cobalt 60

Cobalt-60

- Curium-242

o Curium-243/244

- Curium-243/244

Europium-152

Europium-152

Europlum-154

Europium-154

Europium-155

Groes alpha

Manganeee-54

Nonvolatile bet

Plutonium-238

Plutonlum-238

Plutonium-238/240

Potasejum-238/24

Potansium-40

Promethlum-144

Promethium-144

Promethium-146
Promethium-146

Radium-226

Radlum-226

Ruthenium-106

Ruthenium-106

Sodium-22

Sodium-22

- Strontium-80

Strontium-80

Thorium-228

Thorlum-228

Thorium-230

Thorium-230

Thorium-232

Total alpha-emitting radium

Tritium

Uranium-234

Uranium-238

Y Ytrium-88

Ytrium-6

Zinc-65

Mod Unit Lab

140
$<5.0$

$<500$

$<<100$

$<2.0$

$<1,000$

$<1.0$

$<1,000$

$<5.0$

$<<0.24$

$<0.090$

$<1.0$

$<2.0$

$<1.0 E-09$
$<1.0 E-09$

$<2.0 \mathrm{E}-08$

$<2.0 E-08$

$<6.0 E-08$

$<1.0 E-08$

$<1.0 E-08$

$<1.0 E-08$

$<1.0 E-08$

$<1.0 \mathrm{E}-08$

$<1.0 E-08$

$<1.00-09$

$<1.0 E-09$

$<1.0 E-09$

$<4.0 E-08$

$<2.0 \mathrm{E}-08$

$<2.0 E-08$

$<3.0 E-08$

$<3.0 E-08$

$<1.0 \mathrm{E}-08$

$<1.0 E-08$

$<1.0 \mathrm{E} .09$

$<1.0 E-00$

$<1.0 E-09$

$<1.0 \mathrm{E}-09$

$<1.1$ E-07

$<1.0 \mathrm{E}-08$

$<1.0 \mathrm{E}-08$

$<1.0 \mathrm{E}-08$

<1.0E-09

$<1.0 \mathrm{E} \cdot 09$

$<8.06 .08$

$<1.05 .08$

$<1.0 \mathrm{E}-08$

$<2.0 \mathrm{E}-09$

$<2.0 E-09$

$<1.0 \mathrm{E}-09$

$<1.0 E \cdot 0 \theta$

$<1.0 E-09$

$<1.0 E-09$

$<1.0 E-09$

$<1.0 E-09$

$<1.0 E-09$

$<1.0 E \cdot 09$

$<1.02 .09$

$<6.08-08$

$<2.0 E-08$

WELL QA 6C

MEASUREMENTS CONDUCTED IN THE FIELD

Sample date: 08/06/82

Dopth to water: Not available

Water elevation: Not available
Sp. conductance: i $\mathrm{s} / \mathrm{cm}$

LABORATORY ANALYSES

$\begin{array}{ll}\text { F } & \text { Analyte } \\ 0 & \text { pH } \\ 0 & \text { Speclfic conductance } \\ 0 & \text { Arsenic } \\ 0 & \text { Barlum } \\ 0 & \text { Cadmium } \\ 0 & \text { Calcium }\end{array}$

\begin{tabular}{|c|c|c|c|}
\hline \multirow[b]{2}{*}{ Result } & \multicolumn{3}{|c|}{$\begin{array}{l}\text { Time: } 6: 00 \\
\text { pH: } 5.4 \\
\text { Alkalinity: } 1 \mathrm{mg} / \mathrm{h} \\
\text { Water temperature: } 25.6^{\circ} \mathrm{C}\end{array}$} \\
\hline & Mod & Unit & Lab \\
\hline $\begin{array}{r}6.8 \\
2.0 \\
<2.0 \\
<3.0 \\
<2.0 \\
<10\end{array}$ & $\mathrm{JO}$ & $\begin{array}{l}\mathrm{pH} \\
\mu S / \mathrm{cm} \\
\mu g / L \\
\mu g / L \\
\mu g / L \\
\mu g / L\end{array}$ & $\begin{array}{l}\mathrm{GE} \\
\mathrm{GE} \\
\mathrm{GE} \\
\mathrm{GE} \\
\mathrm{GE} \\
\mathrm{GE}\end{array}$ \\
\hline
\end{tabular}

WELL. QA $6 C$ collected on 08/06/82, laboratory analyses (cont.)

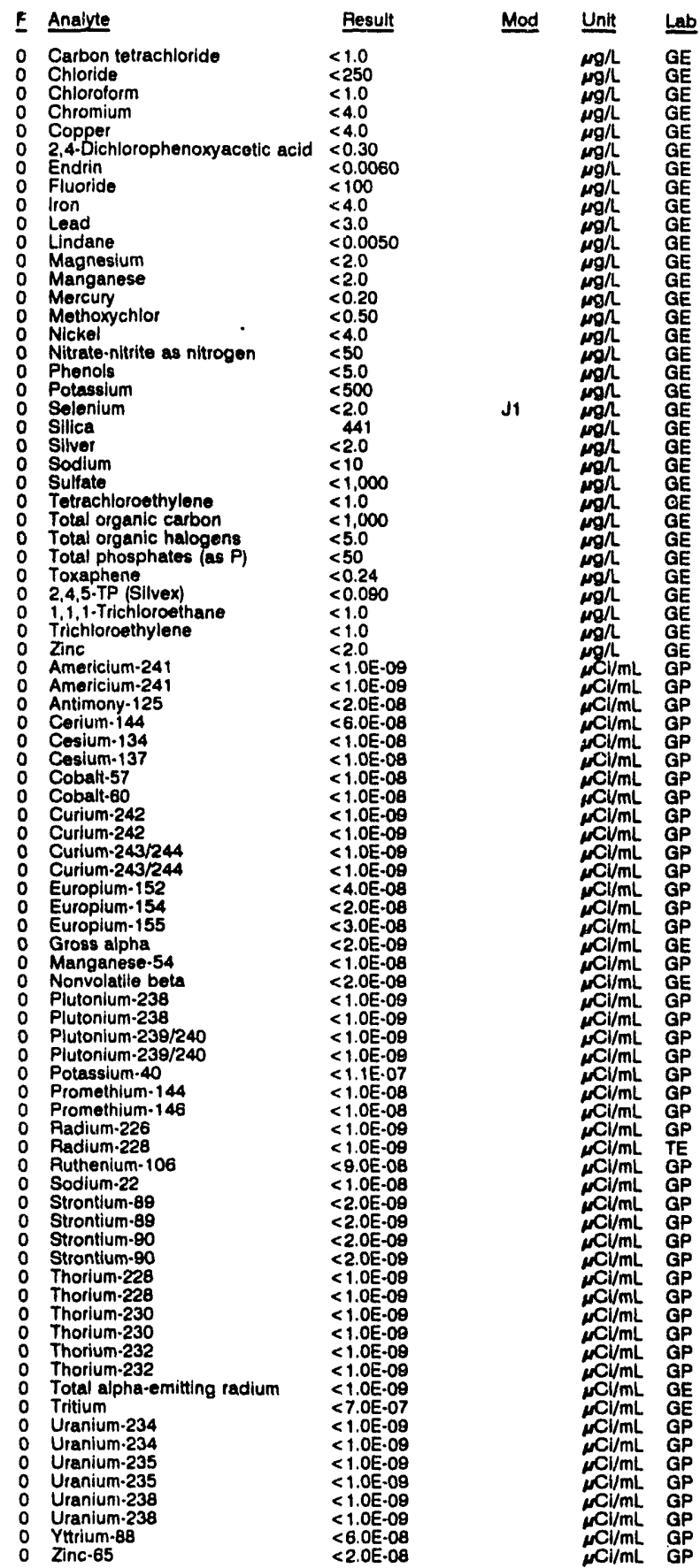

WELL QA $8 C$

MEASUREMENTS CONDUCTED IN THE FIELD

Sample date: 08/03/82

Depth to water: Not available

Water olevation: Not availab

Sp. conductance: $1 \mu S / c m$

LABORATORY ANALYSES

Pesult

$0 \mathrm{pH}$

Specific conductance

6.4
5.0
5

Time: 7:45

PH: 5.7 Alkalinity: $1 \mathrm{mod}$

Water temperature: $27.6^{\circ} \mathrm{C}$

JO $\quad \stackrel{\mathrm{PH}}{\mathrm{GHE}}$ 
WELL EPT159 collectod on 09/23/82, laboratory analyses (cont.)

\begin{tabular}{|c|c|c|c|}
\hline Analyte & Result & Mod & Unit \\
\hline 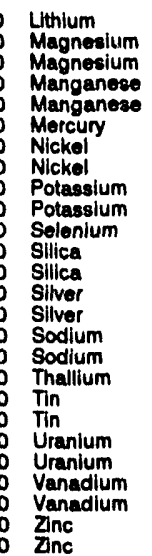 & $\begin{array}{l}<5.0 \\
3.0 \\
32.0 \\
<2.0 \\
<2.0 \\
<0.20 \\
<4.0 \\
<4.0 \\
<500 \\
<500 \\
<2.0 \\
11.700 \\
11.700 \\
<2.0 \\
<2.0 \\
38 \\
28 \\
<2.0 \\
<2.0 \\
<2.0 \\
<20 \\
<20 \\
<8.0 \\
<8.0 \\
<2.0 \\
<2.0\end{array}$ & & 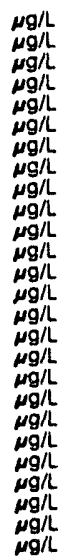 \\
\hline
\end{tabular}

\section{WELL EPT160}

MEASUREMENTS CONDUCTED IN THE FIELD
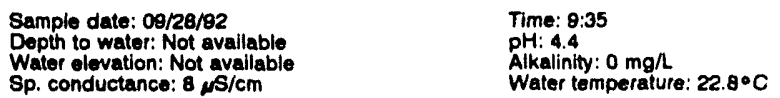

LABOPATOAY ANALYSES

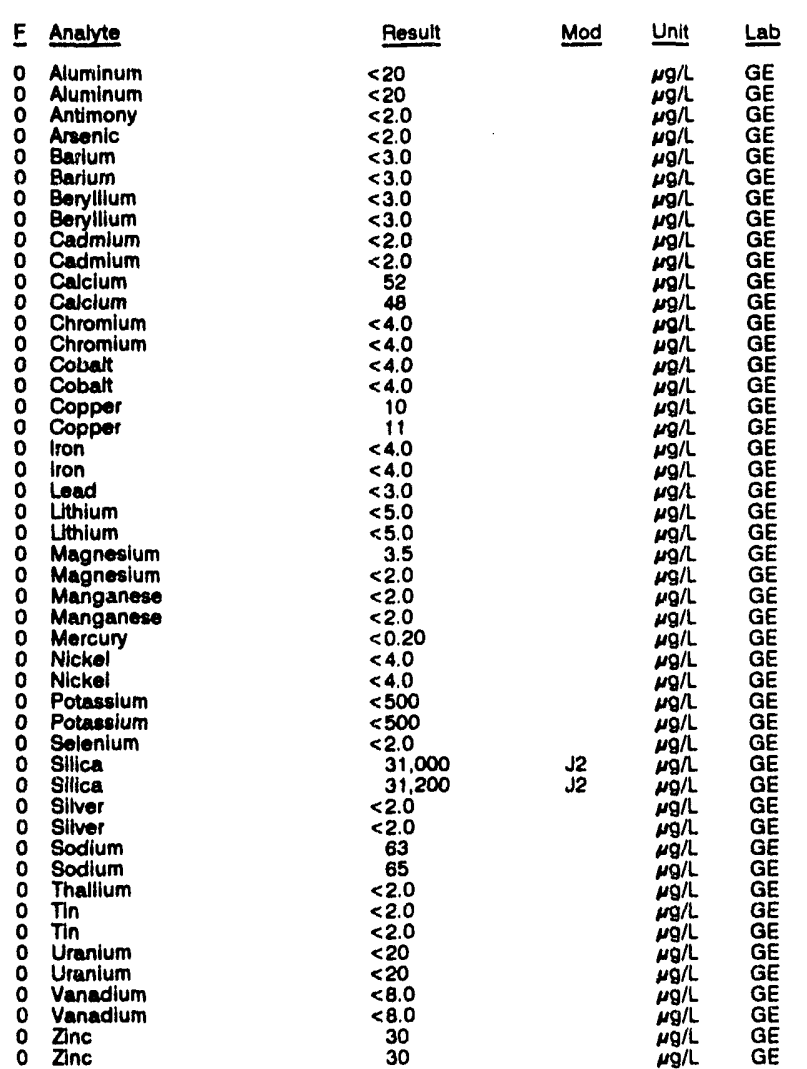

WELL QA $2 C$

MEASUREMENTS CONDUCTED IN THE FIELD

Sample date: $07 / 14 / 92$

Depth to water: Not available

Water elevation: Not availa

LABORATORY ANALYSES

$F$ Analyte

0 Aluminum

Bromodichloromethane

Bromoform

Bromomethane

Carbon tetrachlorido

Chlorobenzene

Chloroethane

2.Chloroethyl vinyl other

2.Chloroethy

Chloromethane

1,1-Dichloroethane

1,1-Dichloroethane

1,1-Dichloroethylene

trans-1,2-Dichloroethylene

Dichloromethane

1,2-Dichloropropane

trans-1,3-Dichloropropene

Ethylbenzene

0 Lead

Lead

Manganese

Mercury

Mercury

Nickel

1,1,2,2-Tetrachloroethane

Totrachloroethylene

o Toluene

o Total organic halogens

o 1,1,1-Trichloroethane

1,1,2.Trichloroethan

Trichloroethylene

Nonvolatile bete

Total alpha-emitting radium

Tritium

WELL QA 4C

MEASUREMENTS CONDUCTED IN THE FIELL

Sample date: 07/16/92

Depth to water: Not available

$\mathrm{Sp}$. conductance: $1 \mu \mathrm{S} / \mathrm{cm}$

LABORATORY ANALYSES

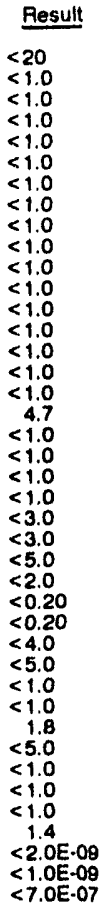

Time: $6: 10$

PH: 5.4 : $1 \mathrm{mg}$

Water tomperature: $28.8^{\circ} \mathrm{C}$

F Analyte

$0 \mathrm{pH}$

Specific conductance

Arsenic

Barium

Cadmium

Carbon tetrachloride

Chloride

Chloroform

Chromium

Copper
2,4.Dichlorophenoxyacetic acid

0 Endrin

Iron

Lead

L Lindane

Magnesium

Mercury

Methoxychlo

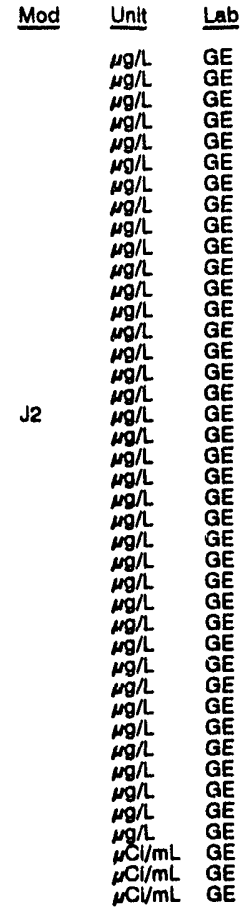

Time: 6:05

Alkalinity: $1 \mathrm{mgh}$

Water temperature: $26.7^{\circ} \mathrm{C}$

\begin{tabular}{|c|c|}
\hline Mod & Unit \\
\hline JO & 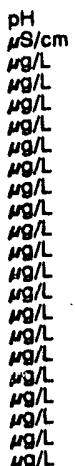 \\
\hline
\end{tabular}




\section{BLANK RESULTS}

\section{WELLL EPT156}

MEASUREMENTS CONDUCTED IN THE FIELD

Sample date: 00/20/22

Water elevation: Not available

$\mathrm{Sp}$. conductance: $7 \mathrm{~s} / \mathrm{cm}$

LABORATOAY ANALYSES

$E$ Analyte

- Aluminum

: Aluminum

o Arsonic

Barium

Boryilium

Bonyllium

: Cadmium

Calcium

Calcium

Chromium

o Cobalt

: Cobalt

Copper

Iron

iron

o Lithium

Magnosium

Magnesium

Manganese

Morcury

Nickel

Potassium

Potaselum

Solonium

Silica

Silver

Sitver

Sodium

Thallium

Tin

Uranium

Uranium

Vanadium

Z Zne

\section{WELL. EPT 157}

MEASUREMENTS CONDUCTED IN THE FIELD

Sample date: 00/21/82

Wepth to water: Not available Water elovation: Not availabio
$\mathrm{Sp}$. conductance: $8 \mathrm{~s} / \mathrm{cm}$

LABORATORY ANALYSES

\section{$E$ Analyte}

o Aluminum

Antimony

Arsenic

Barium

Barium

Boryllium

Codmium

Cadmlum

Caiclum

Calcium

Chromium

o Cobalt

Copper

Copper

iron

Load

Lithium

Magnesium

Magnesium

Manganese

Manganese
Time: $: 00$

Alkalinity: $0 \mathrm{mgh}$

Water temperalure: $23.1^{\circ} \mathrm{C}$

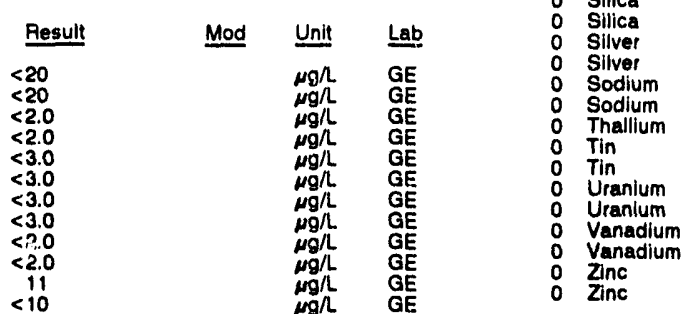

WELL EPT158

MEASUREMENTS CONDUCTED IN THE FIELD

Sample date: 09/22/92

Depth to water: Not available

Water olevation: Not avallable

LABORATORY ANALYSES

E Analyte

2 Aluminum

: Antimony

: Arsenic

Beryllium

Cadmium

Calclum

0 Cobalt

Copper

i iron

: Lead

Magnesium

Manganese

Mercury

Potassium

Selonium

Silliva

0 Sodium

Thallium

0 Tin

0 Uranium

: Vanadi

Time: 11:10

Alkalinity: $0 \mathrm{mg} / \mathrm{l}$

Waler temperatuie: $25.6^{\circ} \mathrm{C}$

WELL EPT159

MEASUREMENTS CONDUCTED IN THE FIELO

Sample date: 08/23/92

Depth to water: Not avallable

Water elevation: Not available

LABORATORY ANALYSES

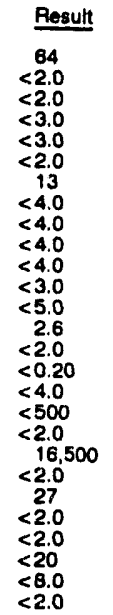

E Anatyce

2 Aluminum

Antimony

: Arsonic

: Barium

0 Beryllium

Beryllium

O Cadmium

0 Cadmium

0 Calcium

: Chromium

O Cobalt

O Cobalt

C Copper

o Copper

o Iron

$\begin{array}{ll}0 & \text { Lead } \\ 0 & \text { Lithium } \\ 0 & \end{array}$
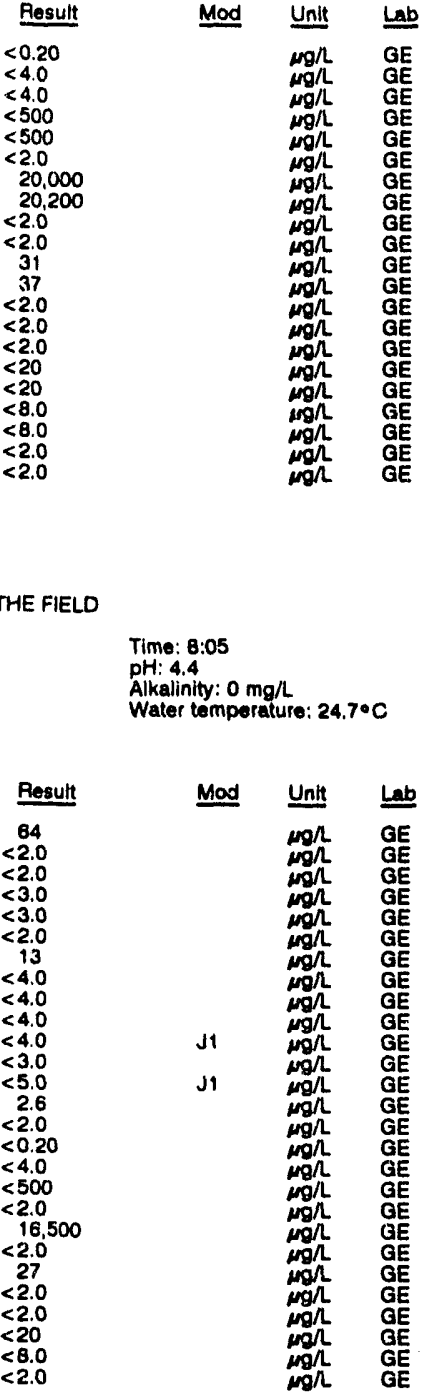

Mod

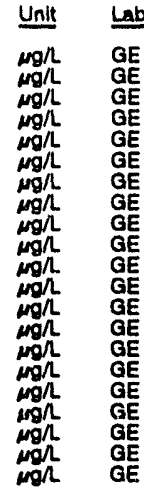

Time: 8:05

Alkalinity: $0 \mathrm{mg} / \mathrm{h}$

Water temperature: $24.7 \circ \mathrm{C}$

Alkalinity: $0 \mathrm{mg} / \mathrm{h}$

Water temperature: $25.1^{\circ} \mathrm{C}$

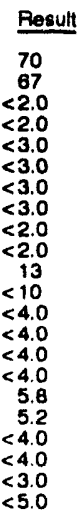

Mod Unit Lab

$\begin{array}{ll}\operatorname{mgh}_{\mathrm{mgh}} & \mathrm{GE} \\ \mathrm{ggh} & \mathrm{GE}\end{array}$

$\operatorname{mog}_{\mathrm{mg}} \mathrm{GE}$ 
BLANK RESULTS

WELL EPT153

MEASUAEMENTS CONDUCTED IN THE FIELD

Sample date: 08/16/82

Depth to wator: Not avallablo

Sp. conductance: $7 \mu \mathrm{s} / \mathrm{cm}$

LABORATORY ANALYSES

F Analyte

- Aluminum

- Aluminum

Arrenic

Barium

Beryllium

Beryllum

Cadmium

Calclum

Chromium

Cobatt

Cobalt

Copper

iron

0 Lead

Lithium

Magnealum

Manganeve

Manganeas

Nickel

Nickol

Pothessium

Selenium

Silice

Silla

Silver

Sodium

Thallium

Tin

- Uranium

Vanadium

- Vanadium

Zinc
Time: 9:35

Alkalinity: $0 \mathrm{mg} / \mathrm{h}$

Water temperalure: $225^{\circ} \mathrm{C}$

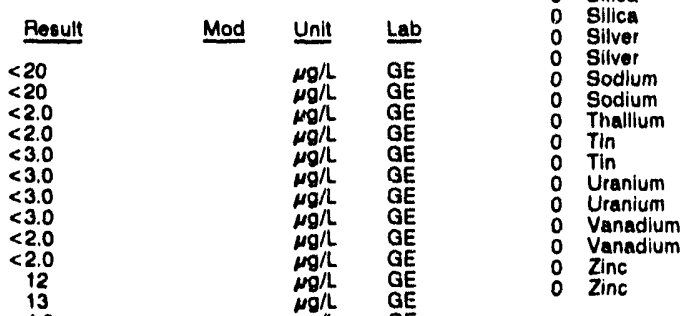

WELL EPT 154 collected on 08/17/82, laboratory analysese (cont.)

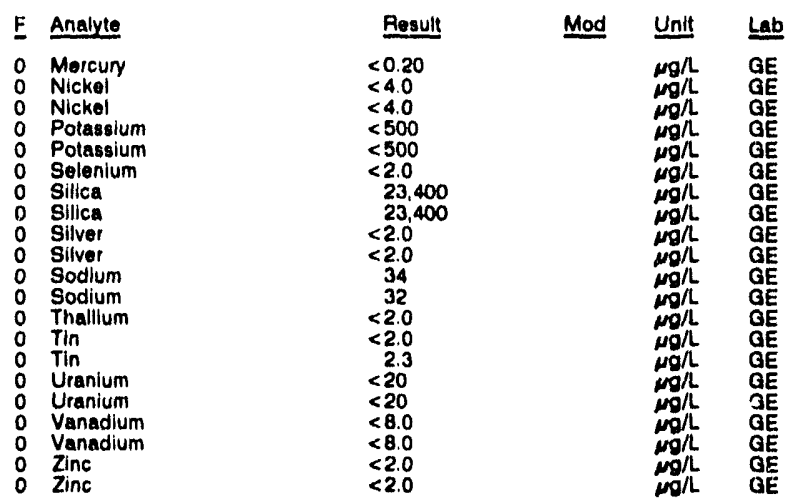

WELL EPT155

MEASUAEMENTS CONDUCTED IN THE FIELD

Sample date: 09/18/92

Depth to water: Not avallable

Water elevation: Not available

$\mathrm{pH}: 4.5$

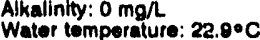

LABORATORY ANALYSES

E Analyte

- Aluminum

Aluminum

Antimony

Earium

Barium

Beryllium

Cadmium

Cadmium

Calcium

Chromium

Chromium

Cobalt

Copper

Copper

Iron

lron

Lead

Lithium

Magnesium

Magnesium

Manganese

Manganese

Mercury

Nickel

Time: $9: 40$

Alkalinity: $0 \mathrm{mg} / \mathrm{h}$

Nickel

Potassium

Selenium

O Silice

- Silica

0 Silver

S Silver

O Sodium

Thallium

Tin

Tin

Uranium

0 Vanadium

Vanadium

$\begin{array}{ll}0 & \text { Zinc } \\ 0 & \text { Zine }\end{array}$
Pesulit

$<20$

$<2.0$

$<3.0$

$<3.0$

$<2.0$

$<2.0$

14
$<4.0$
$<4.0$

$<4.0$

$<4.0$

$<4.0$

$<4.0$

$<3.0$

$<5.0$

2.6
2.3
$<2.0$

$<2.0$

$<0.20$

$<4.0$

$<500$
$<500$

$<2.0$

24,200

$<2.0$

$<5$
57
57

52.0
$<2.0$

$<2.0$

$<20$

$<20$

$<8.0$
Mod Unit Lab

Mgh GE

$\begin{array}{ll}\mu g \Omega & G E \\ \mu g / L & G E\end{array}$

mgh GE

ign $Q E$

Calcium

Chromium

Cobar

Cobat

Copper

Iron

o lron

Lithium

0 Lithlum

Magnosium

Magneslum

Manganese

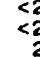




\section{BLANK RESULTS}

\begin{tabular}{|c|c|c|c|c|}
\hline E Analyte & Result & Mod & Unit & Lab \\
\hline 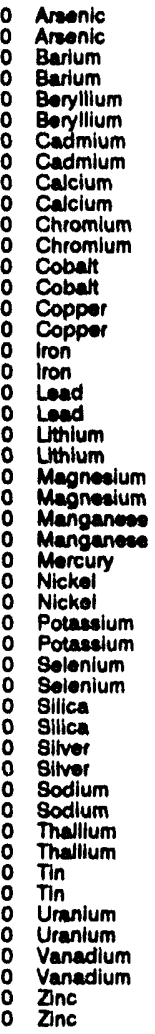 & $\begin{array}{l}<2.0 \\
<2.0 \\
<4.0 \\
<4.0 \\
<0.18 \\
<0.18 \\
1.7 \\
0.58 \\
38 \\
38 \\
<1.1 \\
<1.1 \\
<0.88 \\
<0.88 \\
<1.1 \\
<1.1 \\
1.4 \\
8.3 \\
<2.0 \\
<2.0 \\
<2.8 \\
<2.8 \\
25 \\
20 \\
<0.35 \\
0.53 \\
<0.20 \\
<3.1 \\
<3.1 \\
<84 \\
231 \\
<2.0 \\
<2.0 \\
23.500 \\
22.000 \\
2.0 \\
1.3 \\
<111 \\
<111 \\
<2.0 \\
<2.0 \\
33.6 \\
<1.8 \\
0.17 \pm 2.0 E-02 \\
0.17 \pm 2.0 E-02 \\
<0.88 \\
<0.86 \\
5.3 \\
7.3 \\
\end{array}$ & $\begin{array}{l}\sqrt{3} \\
\sqrt{3} \\
\sqrt{3}\end{array}$ & 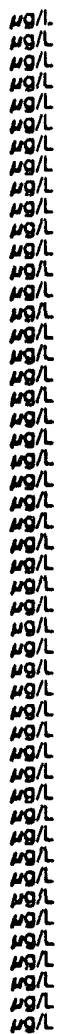 & $\begin{array}{l}\text { WA } \\
\text { WA } \\
\text { WA } \\
\text { WA } \\
\text { WA } \\
\text { WA } \\
\text { WA } \\
\text { WA } \\
\text { WA } \\
\text { WA } \\
\text { WA } \\
\text { WA } \\
\text { WA } \\
\text { WA } \\
\text { WA } \\
\text { WA } \\
\text { WA } \\
\text { WA } \\
\text { WA } \\
\text { WA } \\
\text { WA } \\
\text { WA } \\
\text { WA } \\
\text { WA } \\
\text { WA } \\
\text { WA } \\
\text { WA } \\
\text { WA } \\
\text { WA } \\
\text { WA } \\
\text { WA } \\
\text { WA } \\
\text { WA } \\
\text { WA } \\
\text { WA } \\
\text { WA } \\
\text { WA } \\
\text { WA } \\
\text { WA } \\
\text { WA } \\
\text { WA } \\
\text { WA } \\
\text { WA } \\
\text { TM } \\
\text { TM } \\
\text { WA } \\
\text { WA } \\
\text { WA } \\
\text { WA }\end{array}$ \\
\hline
\end{tabular}

WELL EPT150

MEASUREMENTS CONDUCTED IN THE FIELD

Sample date: 08/07/92 Dopth to water: Not available Water olovation: Not available
Sp. conductance: 7 s $\mathrm{S} / \mathrm{cm}$

LABORATORY ANALYSES

\begin{tabular}{|c|c|c|c|}
\hline F Analyte & Result & Mod & Unit \\
\hline $\begin{array}{ll}0 & \text { Numinum } \\
0 & \text { Antimony } \\
0 & \text { Areonic } \\
0 & \text { Barium } \\
0 & \text { Beryllium } \\
0 & \text { Cadmium } \\
0 & \text { Calcium } \\
0 & \text { Chromium } \\
0 & \text { Cobalt } \\
0 & \text { Copper } \\
0 & \text { lon } \\
0 & \text { Lead } \\
0 & \text { Lithium } \\
0 & \text { Magneaium } \\
0 & \text { Manganese } \\
0 & \text { Mercury } \\
0 & \text { Nicket } \\
0 & \text { Potassium } \\
0 & \text { Sollonlum } \\
0 & \text { Sillca } \\
0 & \text { Silver } \\
0 & \text { Sodium } \\
0 & \text { Thallium } \\
0 & \text { Tin } \\
0 & \text { Uranium } \\
0 & \text { Vanadlum } \\
0 & \text { Znc }\end{array}$ & $\begin{array}{l}<20 \\
<2.0 \\
<2.0 \\
<3.0 \\
<3.0 \\
<2.0 \\
<10 \\
<4.0 \\
<4.0 \\
<4.0 \\
<4.0 \\
<3.0 \\
<5.0 \\
2.7 \\
<2.0 \\
<0.20 \\
<4.0 \\
<500 \\
<2.0 \\
28,300 \\
<2.0 \\
<10 \\
<2.0 \\
<2.0 \\
<20 \\
<8.0 \\
<2.0\end{array}$ & & 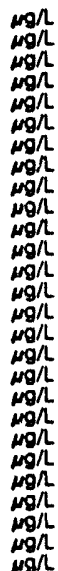 \\
\hline
\end{tabular}

Time: 8:45

Alkalinity: $0 \mathrm{mg} / \mathrm{L}$

Water temperature: $23.0^{\circ} \mathrm{C}$

\section{WELL EPT151}

MEASUREMENTS CONDUCTED IN THE FIELD

Sample dale: 09/14/92

Wepth to water; Not available

Sp. conductance: $7 \mu \mathrm{S} / \mathrm{cm}$

LABORATORY ANALYSES

E Analyte

Aluminum

o Aluminum

A Arsonic

Barium

Deryllum

Coryllium

Cadmium

Calelum

Chromium

Chromium

Cobalt

Copper

Iron

$\begin{array}{ll}0 & \text { Iron } \\ 0 & \text { lion } \\ 0 & \end{array}$

L Lead

Lithium

O Magnesium

Magnesium

Manganere

Mercury

O Nickel

Potasslum

Potasslum

o Silica

O Sillica

O Silver

Sodium

Sodium

Tin

O Tin

Uranium

Vanadium

O Zine

WELL EPT152

MEASUREMENTS CONOUCTEO IN THE FIELD

Sample dato: 09/15/92

Depth to water: Not avallable Sp. conductance: $7 \mathrm{~ms} / \mathrm{cm}$

LABOAATOAY ANALYSES

E Analyte

o Aluminum

Antimony

Arsenic

Barium

Cadmium

Calcium

Chromium

Cobalt

Copper

o lion

0 Lithium

Magnesium

Manganes:

o Nickel

Potassium

Selenium

Silica

Silver

Thallium

Tin

Uranium

Zinc

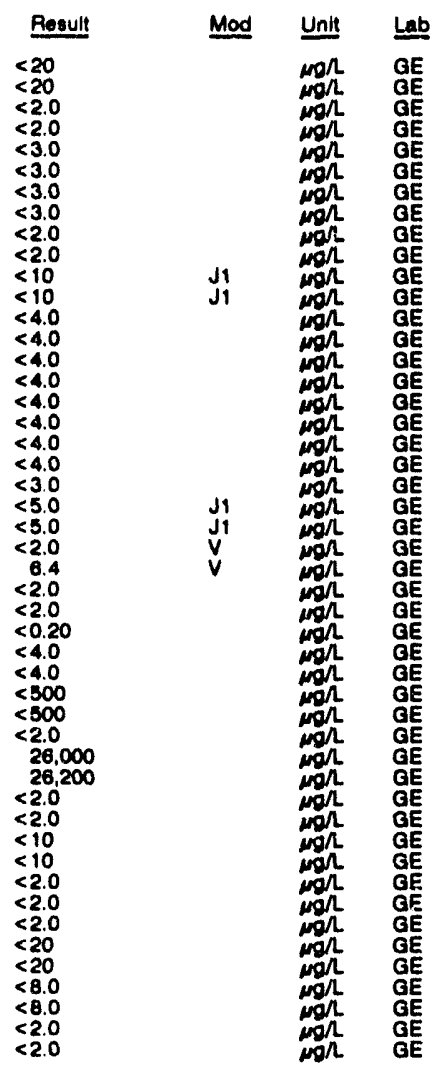

pH: 4.7

Water tomperature: $23.3^{\circ} \mathrm{C}$

Timo: 10:15

Alkalinity: $0 \mathrm{man}$

Water temperafure: $18.2^{\circ} \mathrm{C}$

\begin{tabular}{|c|c|c|}
\hline Result & Mod & Unit \\
\hline $\begin{array}{l}<20 \\
<2.0 \\
<2.0 \\
<3.0 \\
<3.0 \\
<2.0 \\
14.0 \\
<4.0 \\
<4.0 \\
<4.0 \\
<4.0 \\
<3.0 \\
<5.0 \\
<2.0 \\
<2.0 \\
<0.20 \\
<4.0 \\
<500 \\
<2.0 \\
25.100 \\
<2.0 \\
27 \\
<2.0 \\
<2.0 \\
<20 \\
<8.0 \\
<2.0\end{array}$ & J1 & 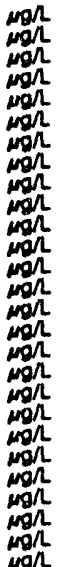 \\
\hline
\end{tabular}


BLANK RESULTS

\begin{tabular}{|c|c|c|c|}
\hline E Anabrte & Pesult & Mod & Unit \\
\hline 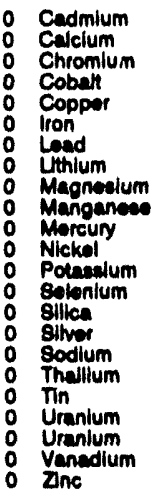 & $\begin{array}{l}<0.35 \\
48 \\
1.7 \\
<0.88 \\
<1.1 \\
4.1 \\
<2.0 \\
3.3 \\
<8.0 \\
<0.35 \\
<0.20 \\
<3.1 \\
84 \\
<2.0 \\
20.400 \\
<0.70 \\
<111 \\
<2.0 \\
<1.0 \\
<0.030 \\
<0.030 \\
<0.80 \\
7.2\end{array}$ & $\begin{array}{l}\text { J3 } \\
\mathbf{J 3} \\
\text { J3 } \\
\text { J3 }\end{array}$ & 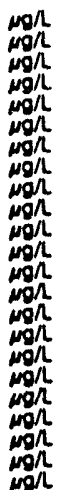 \\
\hline
\end{tabular}

\section{WELL EPT121}

MEABUREMENTS CONDUCTED IN THE FIELD

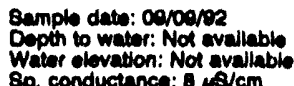

8p. conductance: $8 \mu \mathrm{s} / \mathrm{cm}$

LABORATOFY ANALYBES

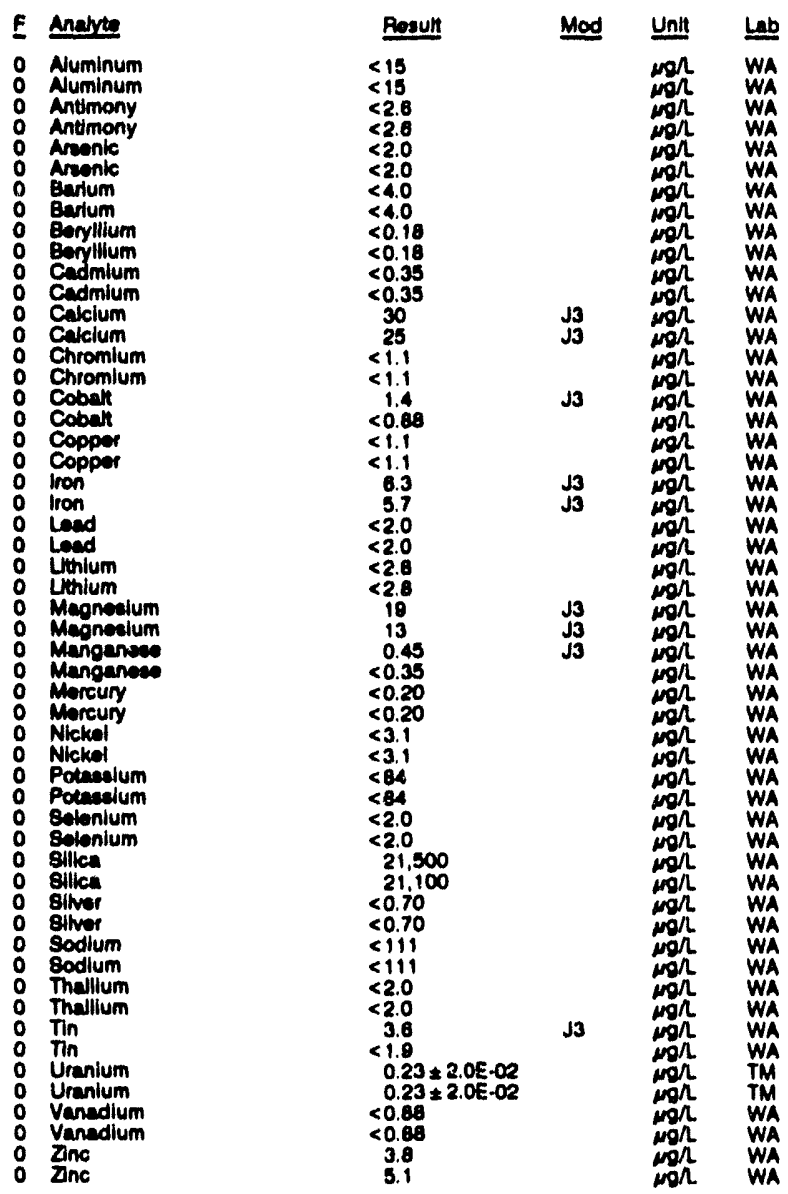

\section{WELL EPT122}

MEASUREMENTS CONDUCTED IN THE FIELD

Sample date: 09/10/02

Depth to water: Not avallable

Sp conductance: $\theta, \theta / \mathrm{cm}$

LABORATORY ANALYSES
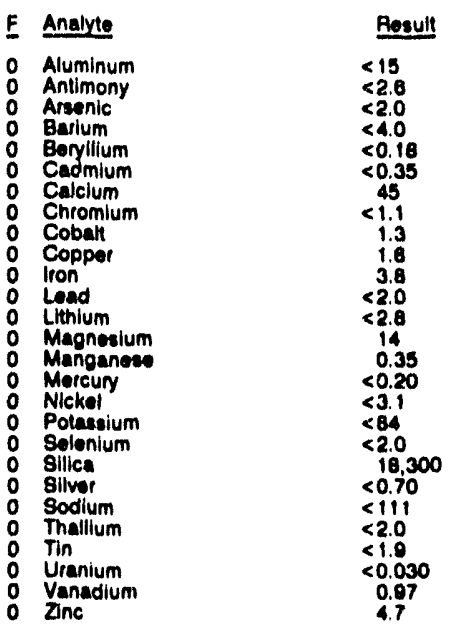

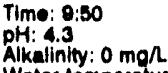

Water tomperature: $22.0^{\circ}$

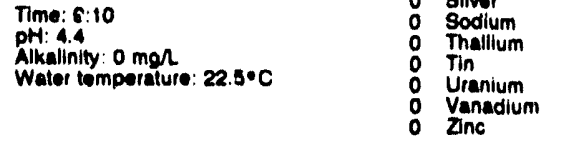

WELL EPT123

MEASUREMENTS CONOUCTED IN THE FIELD

Sample dale: 00/11/02

Depth to walor: Not available Wator elovation: Not avallablo
Sp. conductance: $7 \mathrm{ps} / \mathrm{cm}$

$\operatorname{Timm:}_{\text {of: }}: 4: 30$

PH:Ai4 0 ing

Water tomperature: 23.000

LABOPATORY ANALYSES

\begin{tabular}{|c|c|c|c|}
\hline Analyte & Pesult & Mod & Unth \\
\hline 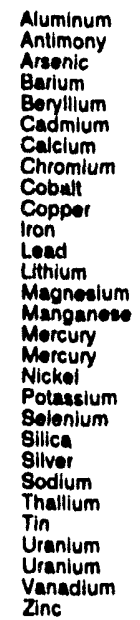 & $\begin{array}{l}<15 \\
<2.8 \\
<2.0 \\
<1.0 \\
<0.18 \\
<0.35 \\
94 \\
81.1 \\
1.2 \\
8.2 \\
5.7 \\
<2.0 \\
80.0 \\
18 \\
<0.35 \\
<0.20 \\
<0.20 \\
<3.1 \\
<84 \\
<2.0 \\
21.900 \\
<0.70 \\
<111 \\
<2.0 \\
<1.9 \\
0.060 \pm 1.0 E-02 \\
0.080 \pm 1.0 E-02 \\
<0.89 \\
0.1\end{array}$ & $\begin{array}{l}\mathbf{J 3} \\
\mathbf{J 3} \\
\mathbf{J 3}\end{array}$ & 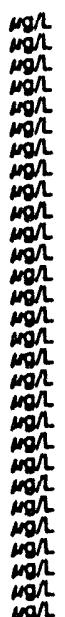 \\
\hline
\end{tabular}

WELL EPT124

MEASUAEMENTS CONDUCTED IN THE FIELLO

Sample date: 00/14/92

Water olevation: Not vavallablo

Sp. conductunce: $7 \mu \mathrm{s} / \mathrm{cm}$

LABOPUTORY ANALYSES

\begin{tabular}{|c|c|c|c|}
\hline E Analyte & Rosult & Mod & Unit \\
\hline $\begin{array}{ll}0 & \text { Aluminum } \\
0 & \text { Aluminum } \\
0 & \text { Antimony } \\
0 & \text { Antimony }\end{array}$ & $\begin{array}{r}23 \\
20 \\
20 \\
<2.6 \\
<2.6\end{array}$ & $\underset{\mathbf{J 3}}{\mathbf{J 3}}$ & $\begin{array}{l}\operatorname{mon}_{\operatorname{man}} \\
\operatorname{mon}_{\operatorname{man}}\end{array}$ \\
\hline
\end{tabular}


WELL EPT116 collectod on 09/02/02, laboratony analyses (cont.)

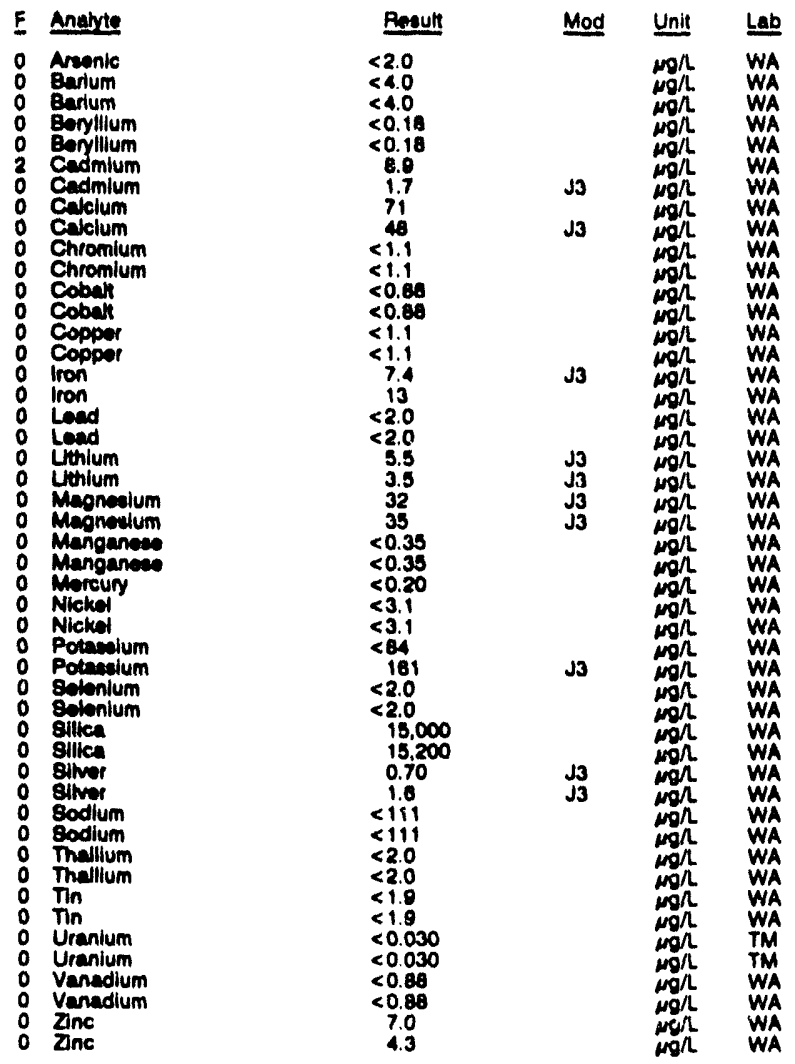

\section{WELL EPT117}

MEASUREMENTS CONOUCTED IN THE FIELD

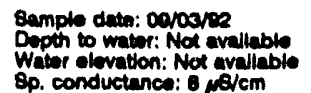
Ep. conductanca: $8 \mathrm{MA} / \mathrm{cm}$

LAOORATOFY ANALYSES

\begin{tabular}{|c|c|c|c|}
\hline I Ansto & Result & Mod & Unt \\
\hline 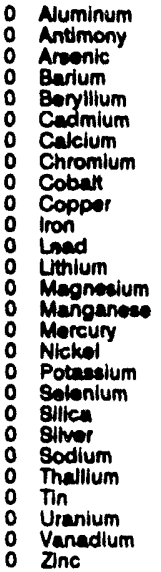 & $\begin{array}{l}<15 \\
<2.6 \\
<2.0 \\
<4.0 \\
<0.18 \\
<0.35 \\
48 \\
<1.1 \\
1.1 \\
<1.1 \\
3.4 \\
<2.0 \\
<2.8 \\
<8.8 \\
0.35 \\
<0.20 \\
<3.1 \\
<84 \\
<2.0 \\
24.500 \\
<0.70 \\
<111 \\
<2.0 \\
<1.8 \\
<0.030 \\
<0.88 \\
8.3\end{array}$ & $\begin{array}{l}\text { J3 } \\
\text { J3 } \\
\text { J3 } \\
\text { J3 }\end{array}$ & 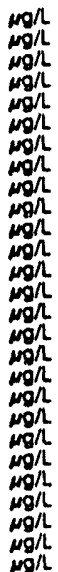 \\
\hline
\end{tabular}

WELL EPT118

MEASUREMENTS CONOUCTED IN THE FIELD

Sample dale: 08/0402

Time: $8: 15$

Alkalinity: $0 \mathrm{~mol}$

Whater tomperature: $23.1 \cdot \mathrm{C}$

LABORATORY ANALYSES

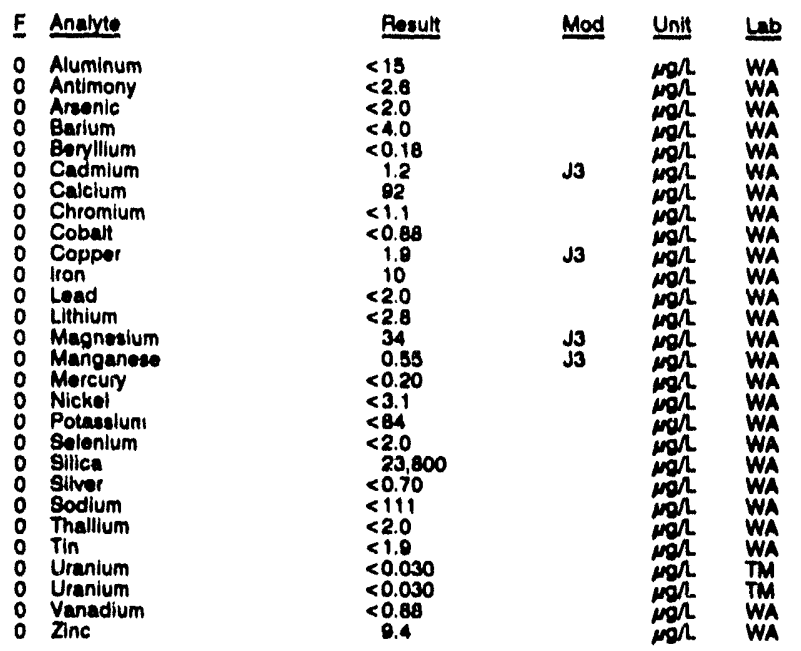

WELL EPT119

MEASUAEMENTS CONDUCTEO IN THE FIELD

Sample date: 08/07/82

Depth to water: Not avallablo

Sp. conductance: $7 \mathrm{~s} / \mathrm{cm}$

Time: 10:35

PH: 4.3 . 0 mallinity: 0 mat

Wata temperalue: $23.8 \circ \mathrm{C}$

LABORATORY ANALYSES

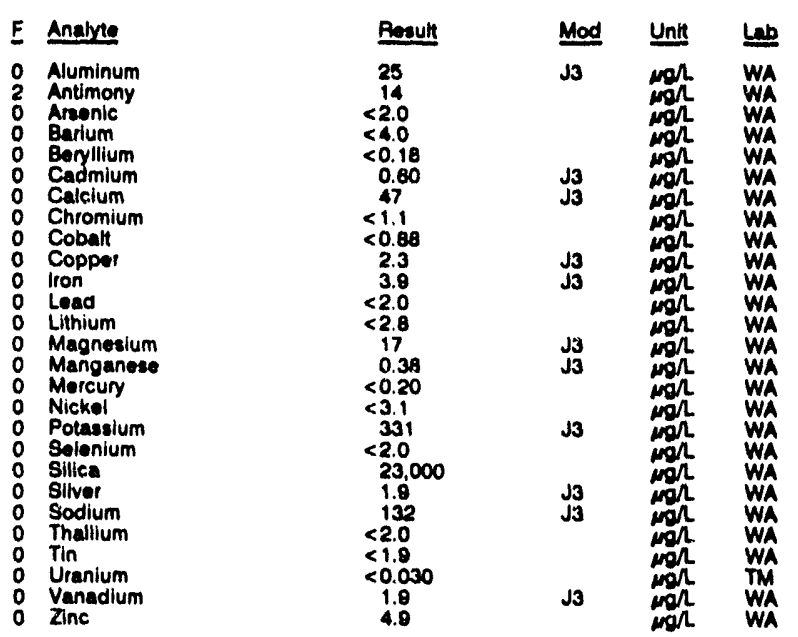

\section{WELL EPT120}

MEASUREMENTS CONDUCTED IN THE FIELD

Samplo date: 09/08/92

Depth to water: Not avallable

Sp. conductance: $7 \mu \mathrm{S} / \mathrm{cm}$

pH: 4.4 . 0 mall

Waler tomperature: $22.5{ }^{\circ} \mathrm{C}$

LABORATORY ANALYSES

\begin{tabular}{|c|c|c|c|}
\hline E Ancivite & Result & Mod & Unit \\
\hline $\begin{array}{ll}0 & \text { Aluminum } \\
0 & \text { Antimony } \\
0 & \text { Arsenic } \\
0 & \text { Barlum } \\
0 & \text { Beryllium }\end{array}$ & $\begin{array}{l}<13 \\
<2.6 \\
<2.0 \\
<4.0 \\
<0.18\end{array}$ & & $\begin{array}{l}\operatorname{mg} h \\
\operatorname{mgh} \\
\operatorname{mon} \\
\operatorname{mon}\end{array}$ \\
\hline
\end{tabular}


WELL EPTIII collocted on 06/28/82, laboratory analyeces (conL)

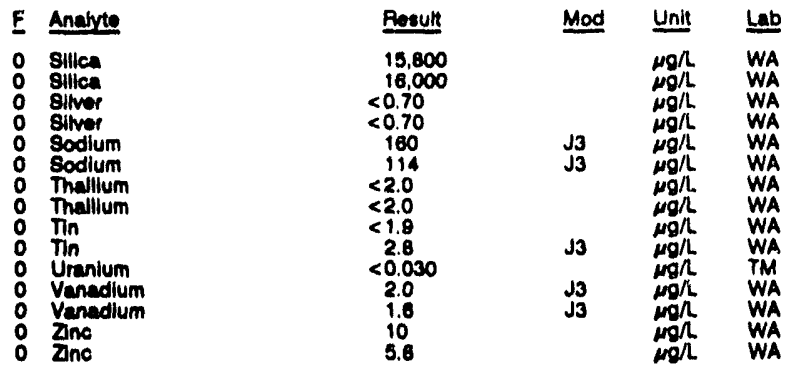

WELL EPT 112

MEABUAEMENTS CONOUCTED IN THE FIELD

Sumplo deto: oerzerpe Depth to water: Not avaliable Oper tovelon: Not aveli

LABOPATOPY ANULYSES

E Analute

- Auminum

2 Antimony

o Anerium

Boryllium

Cadcium

Chromium

Cobst

lion

Laed

Magnealum

Manganee.

Nickol

Potakdum

Silica

siver

Sodium

Thailium

Tranium

0
0 Vansanium
0 Zunc

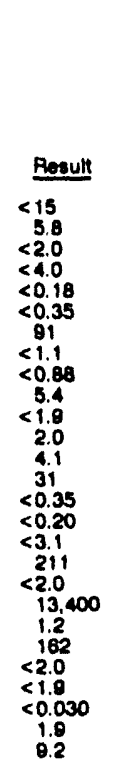

Time: $0: 25$

PH: 4.4. 0 man

Whainity: 0 mgr

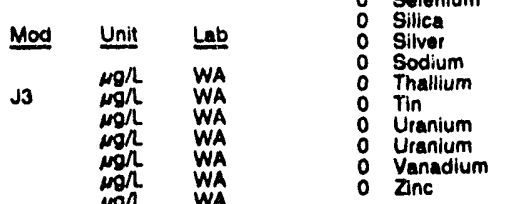

WELL EPT115

MEASUAEMENTS CONDUCTED IN THE FIELD

Sample date: 09/01/82

Depth to water: Not avallable

Water elevation: Not availab

LABORATORY ANALYSES

\section{F Analyte}

- Aluminum

Antimony

: Arsenic

Barium

- Cadmium

- Calcium

Chromium

Cobat

0 iron

0 Load

o Lithlum

o Magnesum

o Manganese

Nicket

- Potassium

o Solenium

- Silver

Silver

o Sodium

o Tin

Uranium

Z Vanadium

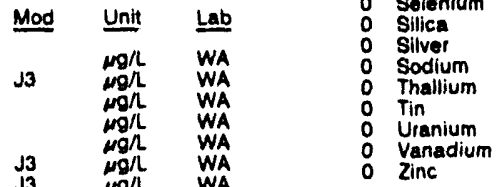

$<0.16$

0.72

$<1.1$

$<0.80$
2.0
$<1.9$

$<1.8$

$<2.8$
17

$<0.35$

$<3.1$

$<84$

$<2.0000$

$<.70$
1111
$<20$

$<2.0$
$<2.5$
$<0.030$

$<0.030$
1.5
11

\section{WELL EPT116}

MEASUREMENTS CONOUCTED IN THE FIELD

Sample date: 09/02/92 Wepth to water: Not available Sp. conductance: $8, \mathrm{~s} / \mathrm{cm}$

LABORATORY ANALYSES

F Analyte

- Aluminum

O Aluminum

O Antimony

Antimony

Rosult
$<15$
$<15$
$<2.6$
$<2.6$
$<2.0$

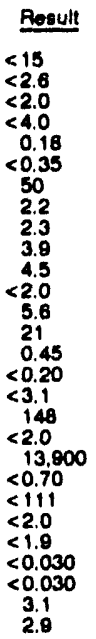

J3

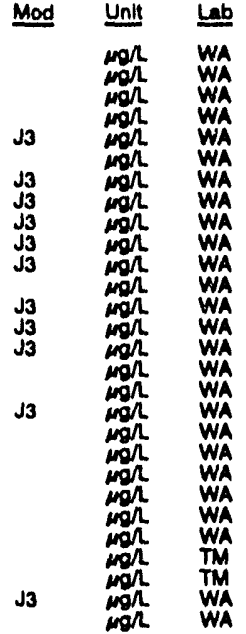

Time: 8:15

PH: 4.5 . 0

Water tomperature: $21.0^{\circ} \mathrm{C}$

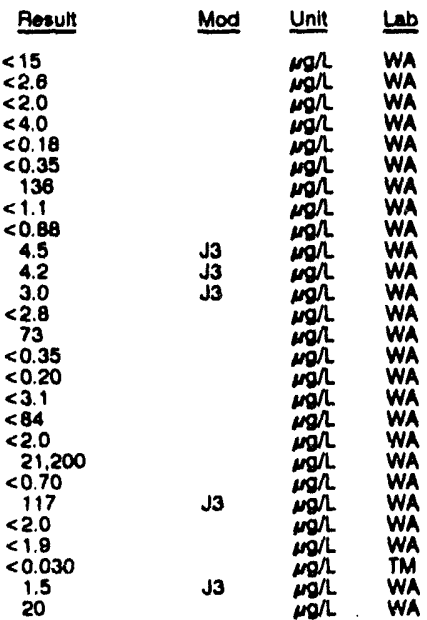

Alkalinity: $0 \mathrm{mg} / \mathrm{h}$

Water tomperature: $22.2^{\circ} \mathrm{C}$

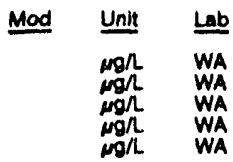




\section{BLANK RESULTS}

\begin{tabular}{|c|c|c|c|}
\hline E Analyte & Result & Mod & Unit \\
\hline $\begin{array}{ll}0 & \text { Chromium } \\
0 & \text { Cobalt } \\
0 & \text { Copper } \\
0 & \text { iron } \\
0 & \text { Load } \\
0 & \text { Lthium } \\
0 & \text { Magnealum } \\
0 & \text { Manganose } \\
0 & \text { Morcuny } \\
0 & \text { Nickel } \\
0 & \text { Potaeglum } \\
0 & \text { Solenlum } \\
0 & \text { Sillica } \\
0 & \text { Silvor } \\
0 & \text { Bodium } \\
0 & \text { Thallum } \\
0 & \text { Tin } \\
0 & \text { Uranlum } \\
0 & \text { Vanadium } \\
0 & \text { Inc }\end{array}$ & $\begin{array}{c}<1.1 \\
1.2 \\
1.3 \\
0.1 \\
<2.0 \\
<2.8 \\
36 \\
0.78 \\
<0.20 \\
<3.1 \\
<64 \\
<2.0 \\
24.100 \\
<0.70 \\
123 \\
<2.0 \\
2.1 \\
0.10 \neq 1.0 E-02 \\
<0.88 \\
4.0\end{array}$ & $\begin{array}{l}\sqrt{3} \\
\sqrt{ } 3\end{array}$ & $\begin{array}{l}\mu g h \\
\mu g h \\
\mu g h \\
\mu g h \\
\mu g h \\
\mu g h \\
\mu g h \\
\mu g h \\
\mu g h \\
\mu g h \\
\mu g h \\
\mu g h \\
\mu g h \\
\mu g h \\
\mu g h \\
\mu g h \\
\mu g h \\
\mu g h \\
\mu g h \\
\mu g h \\
\mu g h\end{array}$ \\
\hline
\end{tabular}

\section{WELL EPT108}

MEASUREMENTS CONDUCTED IN THE FIELO

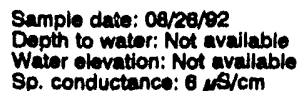

Sp. conductance: $6 \mathrm{\mu S} / \mathrm{cm}$

LABOAATORY ANALYSES

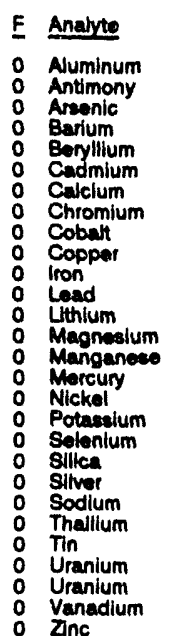

WELL EPT109

\section{MEASUREMENTS CONDUCTED IN THE FIELD}

\section{Sample dato: 08/26/O2} Depth to water: Not avaliable Welor elevalon. Not avaliablo

LABORATOAY ANALYSES
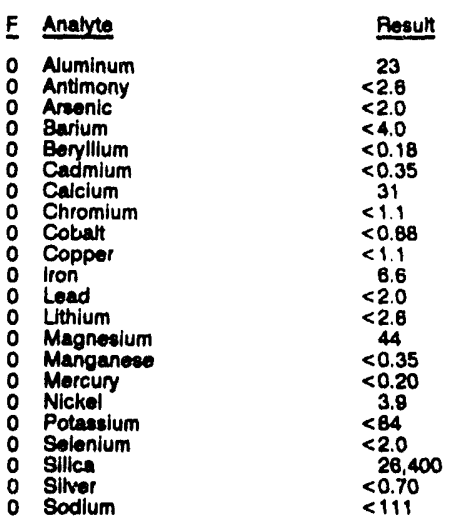

\section{Time: 8:15}

Alkalinity: $0 \mathrm{~mol}$

Water temperature: $24.7{ }^{\circ} \mathrm{C}$

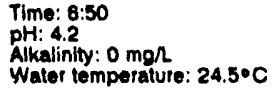

Water temperature: $24.5^{\circ} \mathrm{C}$

\begin{tabular}{|c|c|c|c|c|}
\hline Result & Mod & Unit & Lab & $\begin{array}{l}0 \text { Lithium } \\
0 \text { Magnesium }\end{array}$ \\
\hline $\begin{array}{l}<15 \\
<2.6 \\
<2.0 \\
<4.0 \\
<0.18 \\
<0.35 \\
17 \\
<1.1 \\
<0.88 \\
<1.1 \\
<1.8 \\
<2.0 \\
<2.8 \\
<8.9\end{array}$ & J3 & 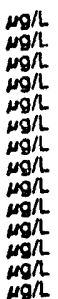 & $\begin{array}{l}\text { WA } \\
\text { WA } \\
\text { WA } \\
\text { WA } \\
\text { WA } \\
\text { WA } \\
\text { WA } \\
\text { WA } \\
\text { WA } \\
\text { WA } \\
\text { WA } \\
\text { WA } \\
\text { WA } \\
\text { WA }\end{array}$ & $\begin{array}{ll}0 & \text { Mercury } \\
0 & \text { Nickel } \\
0 & \text { Potassium } \\
0 & \text { Solenium } \\
0 & \text { Silica } \\
0 . & \text { Silver } \\
0 & \text { Sodium } \\
0 & \text { Thallium } \\
0 & \text { Tin } \\
0 & \text { Uranium } \\
0 & \text { Uranium } \\
0 & \text { Vanadium } \\
0 & \text { Zinc }\end{array}$ \\
\hline
\end{tabular}

WELL EPT111

MEASUREMENTS CONDUCTED IN THE FIELO

Sample date: 08/28/92 Depth to water: Not available Water elevation: Not avaliablo Sp. conductance: $7 \mu \mathrm{S} / \mathrm{cm}$

LABORATORY ANALYSES

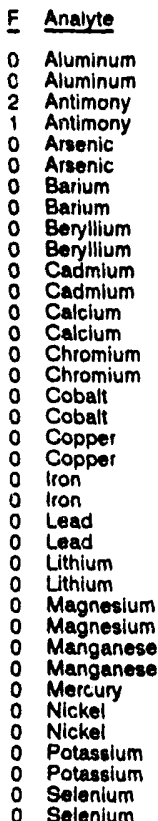

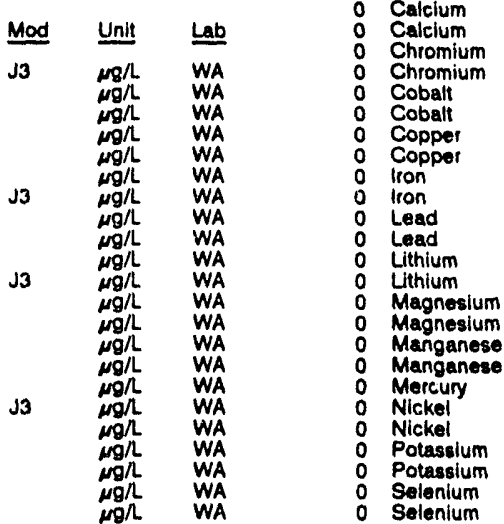

Time: $0: 00$

PH: 4.5 0 mon

Water temperature: $28.0 \circ \mathrm{C}$

\begin{tabular}{|c|c|c|}
\hline Result & Mod & Unit \\
\hline $\begin{array}{l}<15 \\
<2.6 \\
<2.0 \\
<4.0 \\
<0.18 \\
<0.35 \\
333 \\
<1.1 \\
<0.88 \\
<1.1 \\
<1.8 \\
<2.0 \\
<2.8 \\
10 \\
<0.35 \\
<0.20 \\
<3.1 \\
<84 \\
<2.0 \\
24.700 \\
<0.70 \\
<111 \\
<2.0 \\
<1.8 \\
<0.030 \\
<0.030 \\
<0.88 \\
4.2\end{array}$ & J3 & 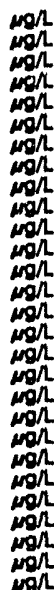 \\
\hline
\end{tabular}


WELL EPT 103 collocted on 08/23/32, laboratory analyses (cont.)

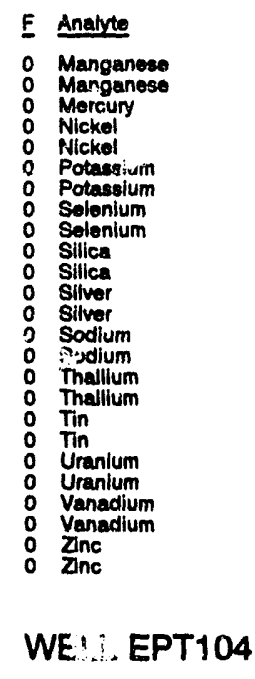

MEASUREMENTS CONDUCTED IN THE FIELD

Sample date: 08/24/92 Wepth to water: Not available Sp. conductance: $3 \mathrm{\mu S} / \mathrm{cm}$

LABORATORY ANALYSES
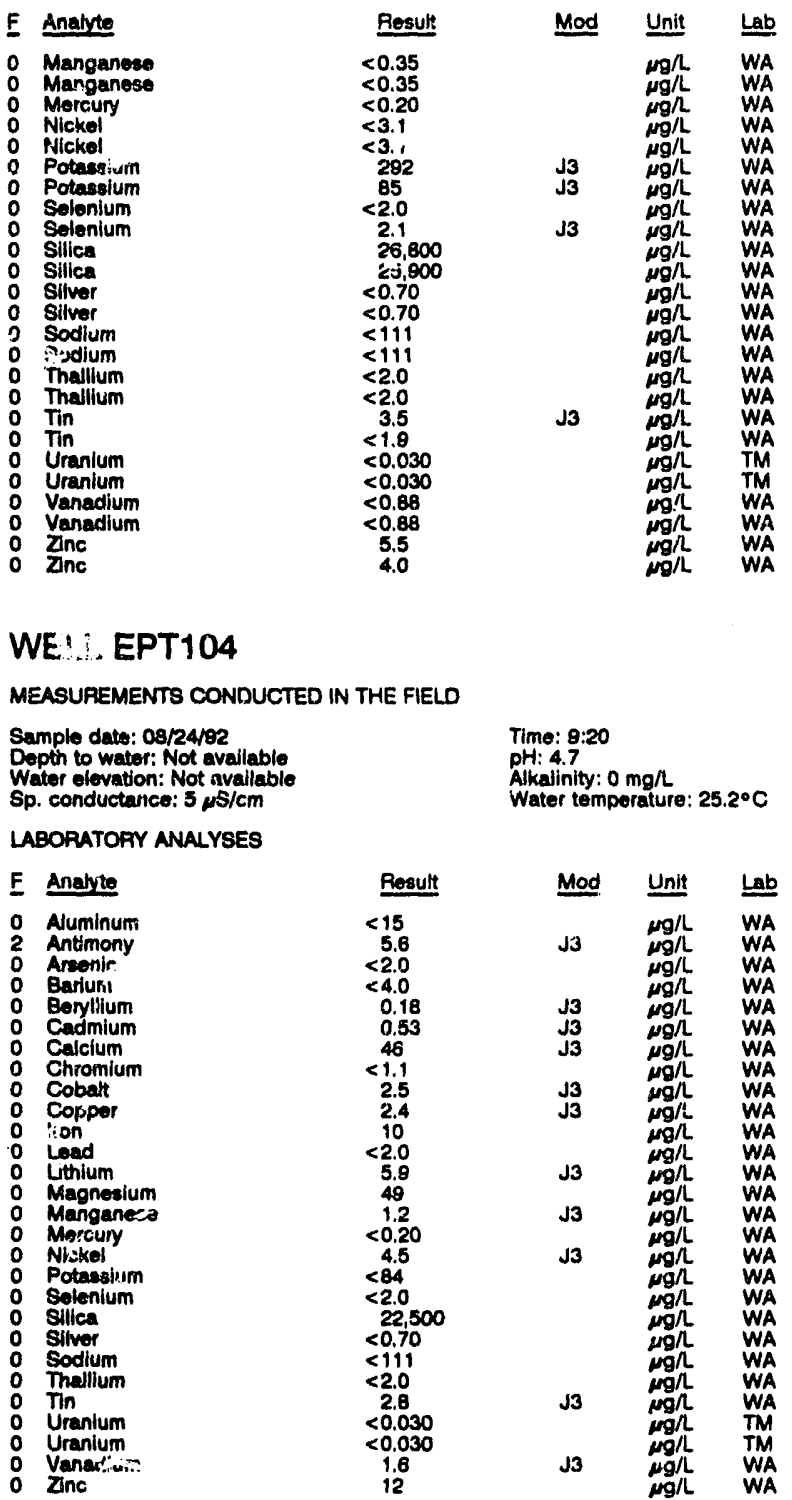

\section{WELL EPT105}

MEASUREMENTS CONDUCTEU IN THE FIEL

Sample date: 08/24/92 Depth to water: Not avaliable Water olevation: Not avallable

LABORATORY ANALYIES
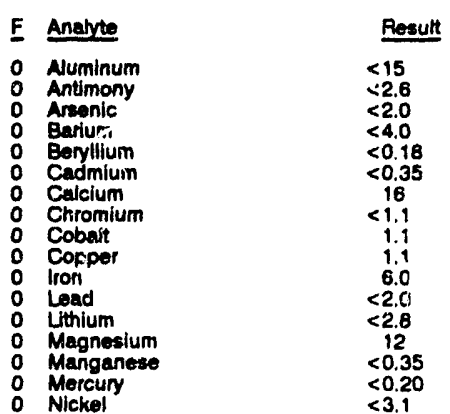

Time: 10:55

pHt: 4.6
Alkalinity: $0 \mathrm{mg} / \mathrm{L}$

Water temperature: $28.5^{\circ} \mathrm{C}$

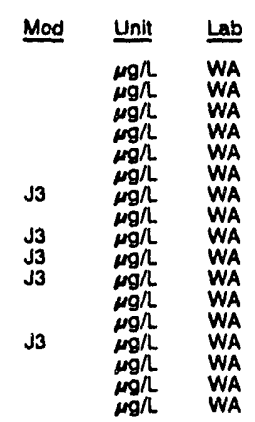

WELL EPT105 collected on 08/24/92, laboratory analyses (cont)

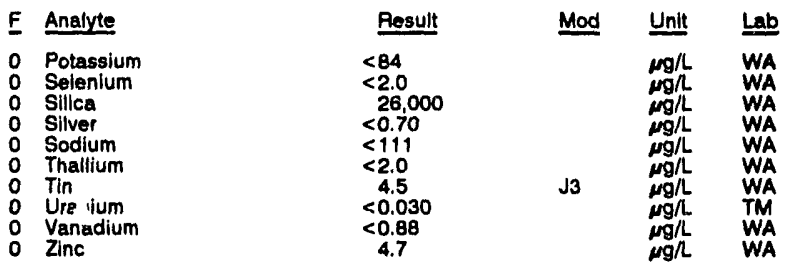

WELL EPT106

MEASUREMENTS CONDUCTED IN THE FIELD

Sample date: 08/25/92

Depth to water: Not available

Sp. conductance: $6 \mu \mathrm{s} / \mathrm{cm}$

pH: 4.8

Alkalinity: $0 \mathrm{mgl}$

Water temperature: $23.4^{\circ} \mathrm{C}$

LABORATORY ANALYSES

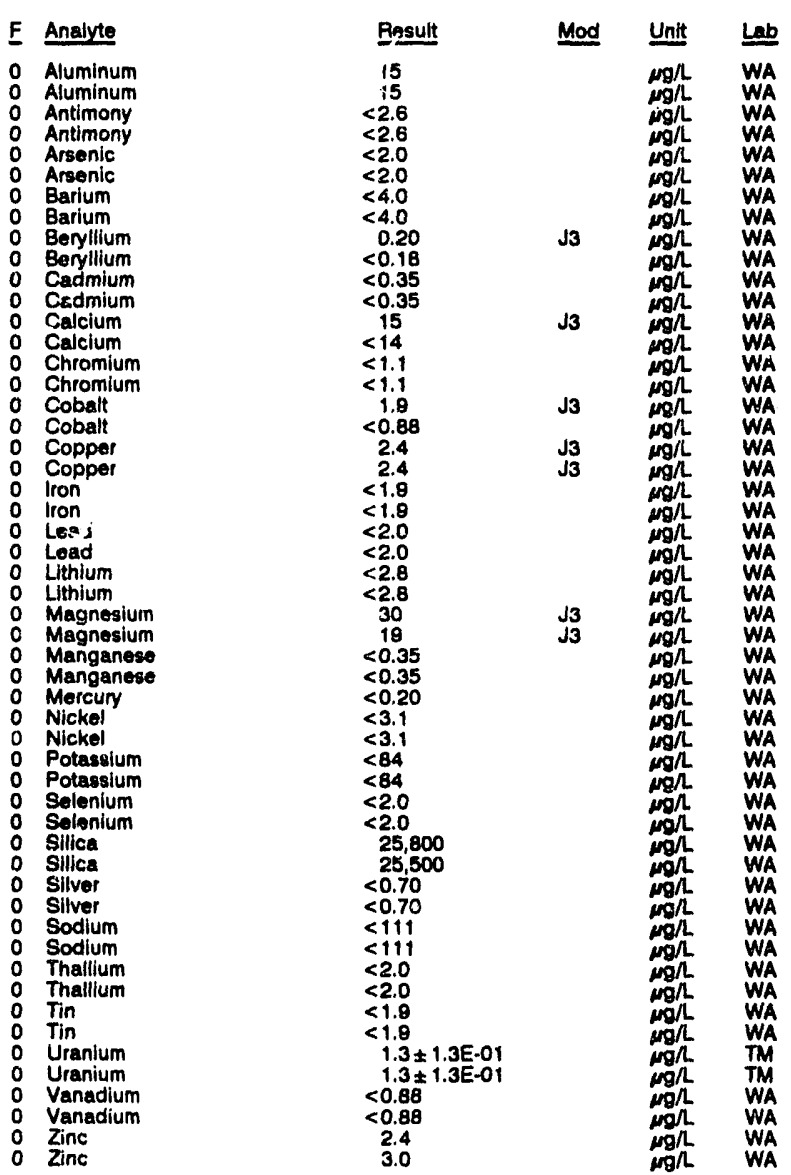

\section{WELL EPT107}

MEASUREMENTS CONDUCTED IN THE FIELD

Sample date: 08/25/92

Depth to water: Not available

Sp. conductance: 6 availab

LABORATORY ANALYSES

Tline: 8:00

PH: 4.5

Water tomperature: $23.7^{\circ} \mathrm{C}$

$\begin{array}{ll}\text { F } & \text { Analyte } \\ 0 & \text { Aluminum } \\ 0 & \text { Antimony } \\ 0 & \text { Arsenic } \\ 0 & \text { Barium } \\ 0 & \text { Beryllium } \\ 0 & \text { Cadmium } \\ 0 & \text { Calcium }\end{array}$

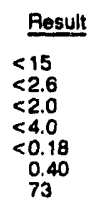

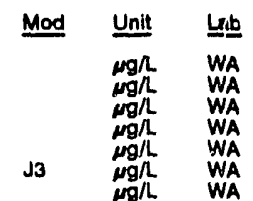


WEL EPT 89 collectod on 09/03/82, laboratory analyses (cont)

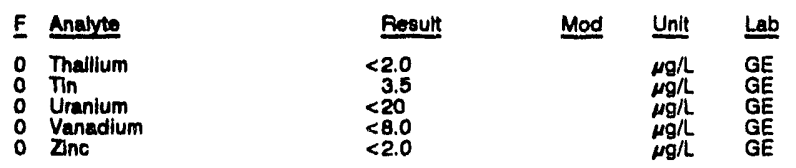

WE'.L EPT100

MEASUREMENTS CONDUCTED IN THE FIELD

Sample date: 07/02/92

Dopth to water: Not avaliable

Water olovation: Not available
Sp. conductance: $2 \mu \mathrm{s} / \mathrm{cm}$

LABOPATORY ANALYSES

\begin{tabular}{|c|c|}
\hline F Analyte & Result \\
\hline 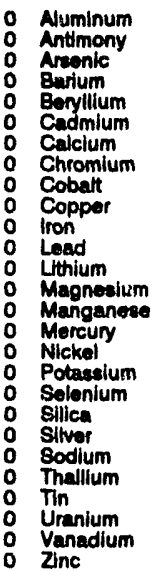 & $\begin{array}{l}<20 \\
<2.0 \\
<2.0 \\
<3.0 \\
<3.0 \\
<2.0 \\
10 \\
<4.0 \\
<4.0 \\
4.0 \\
<4.0 \\
<3.0 \\
<5.0 \\
2.4 \\
<2.0 \\
<0.20 \\
<4.0 \\
<500 \\
<2.0 \\
<100 \\
<2.0 \\
42 \\
<2.0 \\
<2.0 \\
<20 \\
<8.0 \\
<2.0\end{array}$ \\
\hline
\end{tabular}

\section{WELL EPT101}

MEASUREMENTS CONDUCTER IN THE FIELD

Sample date: 08/15/92 Wath to water: Not available Sp. conductance: $2 \mu \mathrm{s} / \mathrm{cm}$

LABOFATOAY ANALYSES

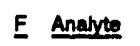

- Auminum

A Numinum

2 Antimony

0 Arsenic

Arsenic

D Bartum

Beryllium

B Baryllium

Cadimium

Calcium

Chromium

Chromium

O Cobalt

O Cobalt

0 Copper

Iron

Iron

Lead

L Lthlum

Magnesium

Magnealum

Manganeso

Manganese

Mercury

Nickel

Nickel

Potassium

Potassium

Selenium

Solenium
Silica
Time: 8:00

AH: 4.8 : $1 \mathrm{mgl}$

Water tomperature: $22.8^{\circ} \mathrm{C}$

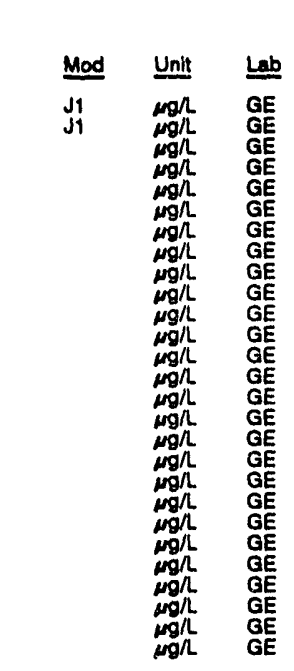

Time: 7:25

PH: 4.9

Water temperalure: $22.8^{\circ} \mathrm{C}$

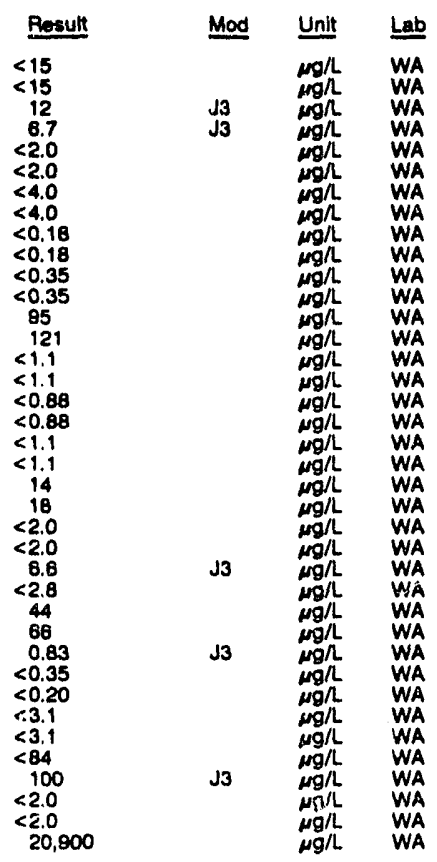

WELL EPT 101 collected on 08/15/82, laboratory analyses (cont.)

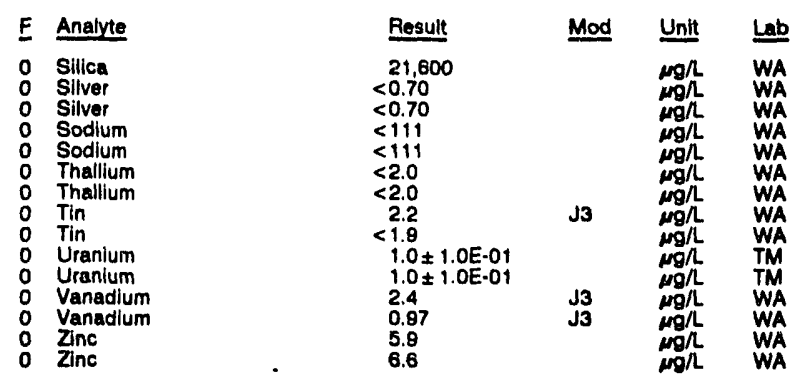

WELL EPT102

MEASUAEMENTS CONDUCTED IN THE FIELD

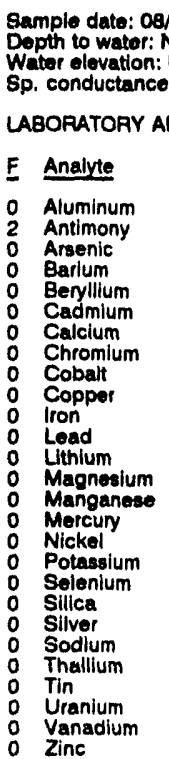

Time: 7:35

PH: 4.6 Alkalinity: $1 \mathrm{mon}$ Water temperature: $21.1 \circ \mathrm{C}$

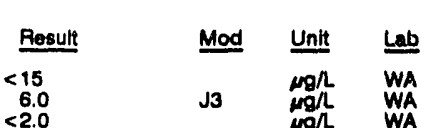

$<2.0$
$<4.0$

$<4.0$
$<0.18$
$<0.35$

64 J3

$<1.1$
$<0.88$

$<1.8$
$<12$
12

$<.0$
3.0

58
$<0.35$
$<0.20$

$<0.20$

88
$<2.0$
23,500

23,500
$<0.70$

$<0.70$

$<2.0$
$<1.9$

$<0.030$
1.5
3.0

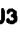

J3

J3

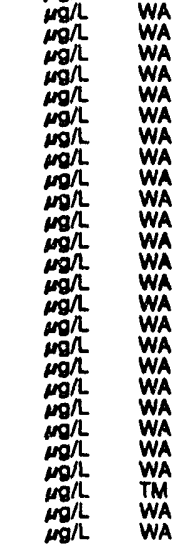

WELL EPT103

MEASUAEMENTS CONDUCTED IN THE FIELD

Sample date: 08/23/82

Depth to water: Not avallable

Water clevation: Not avaliabio

LABORATORY ANALYSES

E Analyte

o Aluminum

Aluminum

Antimony

0 Arsenic

Arsenic

Barium

Barium

Beryllium

Cadmium

Calcium

Calcium

Chromium

Cobalt

Cobalt

- Copper

o Iron

o Lead

0 Lead

o Lithium

L Magnesium

Magnesium
Time: 8:20

pH: 4.6

Alkealinity: $0 \mathrm{mg} / \mathrm{h}$
Water tomperature: $24.0^{\circ} \mathrm{C}$

$\begin{aligned} & \text { Result } \\ &<15 \\ &<15 \\ &<2.6 \\ &<2.6 \\ &<2.0 \\ &<2.0 \\ &<4.0 \\ &<4.0 \\ &<0.18 \\ &<0.18 \\ &<0.35 \\ &<0.35 \\ &<14 \\ &<14 \\ & 1.3 \\ &<1.1 \\ &<0.88 \\ &<0.88 \\ &<1.1 \\ &<1.1 \\ & 3.4 \\ & 2.7 \\ &<2.0 \\ &<2.0 \\ &<2.8 \\ &<2.8 \\ &<8.9 \\ &<8.8\end{aligned}$

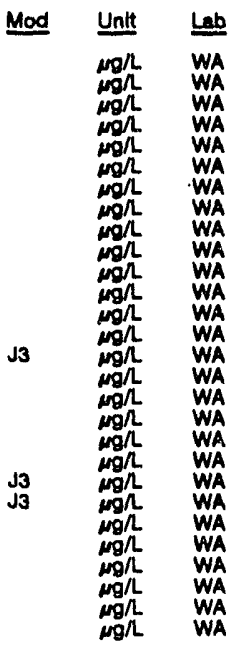


WELL EPT 85 collectod on 08/28/82, laboratory analyoes (cont)

\begin{tabular}{|c|c|c|c|c|}
\hline$\underline{E}$ & Analyte & Result & Mod & Unit \\
\hline $\begin{array}{l}0 \\
0 \\
0 \\
0 \\
0 \\
0 \\
0 \\
0 \\
0 \\
0 \\
0\end{array}$ & $\begin{array}{l}\text { Nickol } \\
\text { Potaeglum } \\
\text { Solonium } \\
\text { Sillca } \\
\text { Silver } \\
\text { Sodlum } \\
\text { Thallium } \\
\text { Tin } \\
\text { Uranium } \\
\text { Vanadium } \\
\text { Zunc }\end{array}$ & $\begin{array}{l}<4.0 \\
<500 \\
<2.0 \\
29.000 \\
<2.0 \\
30 \\
<2.0 \\
<2.0 \\
<20 \\
<8.0 \\
<2.0\end{array}$ & $\sqrt{2}$ & $\begin{array}{l}\mu g / h \\
\mu g / h \\
\mu g / L \\
\mu g / L \\
\mu g / L \\
\mu g / L \\
\mu g / L \\
\mu g / L \\
\mu g / L \\
\mu g / L \\
\mu g / L\end{array}$ \\
\hline
\end{tabular}

\section{WELL EPT 96}

MEASUREMENTS CONDUCTED IN THE FIELD

Sumple date: 06/31/92
Depth to water: Not avalable
Water elovation: Not avallable
Sp. conductance; 8 m $/ \mathrm{cm}$
LABORATORY ANALYSES

E Analyte

- Aluminum

Arsonic

0 Barlum

Beryllum

Calclum

Cobalt

Copper

O lion

o Mugnium

O Manganese

Morcuny

Potaselum

Solanlum

Silica

Sodium

Thallium

Uranium

Vanadium

Zine

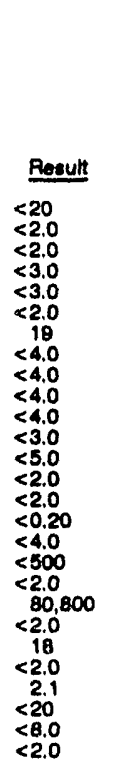

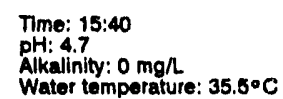

WELL EPT 97

MEASUAEMENTS CONDUCTED IN THE FIELD

Samplo date: 00/01/92

Wopth to water: Not avaliable

Sp. conductanco: 7 \$/cm

LABOFATORY ANALYBES
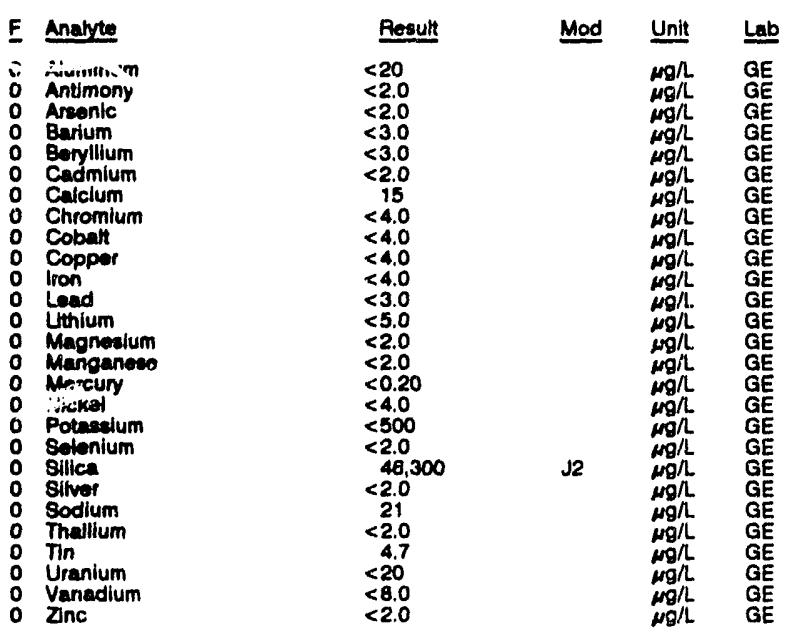

WELL EPT 98

MEASUREMENTS CONDUCTED IN THE FIELD

Sample date: 09/02/92

Depth to water: Not available

Sp. conductance: $7 \mu \mathrm{S} / \mathrm{cm}$

Alkalinity: $0 \mathrm{mg} / \mathrm{h}$

Water temperature: $33.3^{\circ} \mathrm{C}$

LABORATORY ANALYSES

$F$ Analyte

- Aluminum

A Antimony

O Antimony

0 Arsenic

0 Arsenic

B Barium

B Beryllium

Cadmium

Calcium

Calclum

Chromium

Cobalt

0 Cobalt

o Copper

Iron

o lron

0 Lead

o Lithlum

- Magnesium

- Magnesium

- Manganeso

0 Mercuny

Nicke

Nickel

0 Potassium

Solenium

Selenium

o Silica

o Silica

o Silver

o Sodium

S Sodium

Thallum

Tin

O Uranium

o Uranium

Vanadium

O Zinc
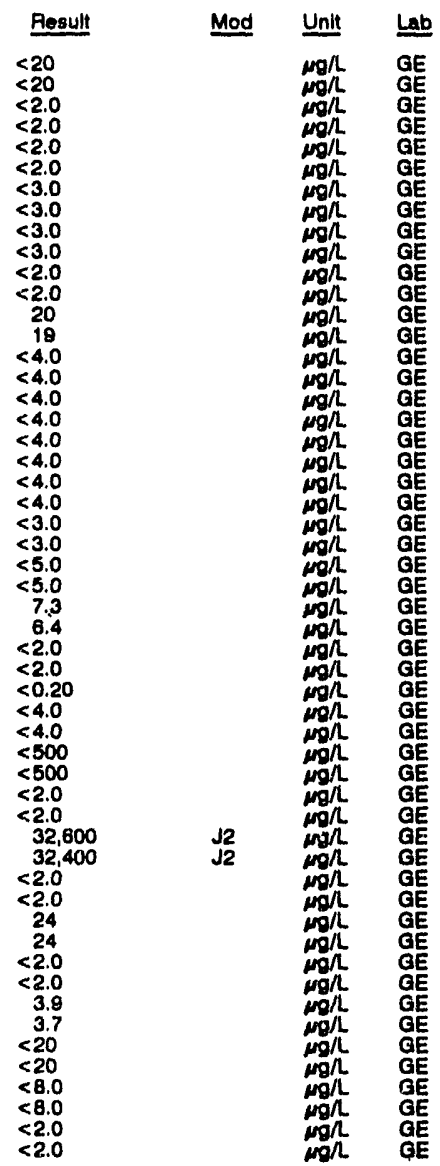

\section{WELL EPT 99}

MEASUREMENTS CONDUCTED IN THE FIELD

Sample date: 09/03/82

Water elevation: Not avaliable

$\mathrm{Sp}$. conductance: $7 \mathrm{mS} / \mathrm{cm}$

LABORATORY ANALYSES

F Analyte

- Aluminum

Antimony

D Arsenic

B Beryllium

O Cadmium

Chromium

Cobalt

- Copper

iron

0 Lead

0 Magneslum

- Manganese

o Mercury

Potassium

Selenium

Silica

$\begin{array}{ll}0 & \text { Silver } \\ 0 & \text { Sodium }\end{array}$

\begin{tabular}{l}
\multicolumn{1}{r}{ Plesult } \\
\multicolumn{1}{c}{$<20$} \\
$<2.0$ \\
$<2.0$ \\
$<3.0$ \\
$<3.0$ \\
$<2.0$ \\
23 \\
$<4.0$ \\
$<4.0$ \\
$<4.0$ \\
$<4.0$ \\
$<3.0$ \\
$<5.0$ \\
4.2 \\
$<2.0$ \\
$<0.20$ \\
$<4.0$ \\
$<500$ \\
$<2.0$ \\
26.500 \\
$<2.0$ \\
32
\end{tabular}

Time: 8:45

Alkalinity: $0 \mathrm{mon}$

Water tomperature: $23.6^{\circ} \mathrm{C}$

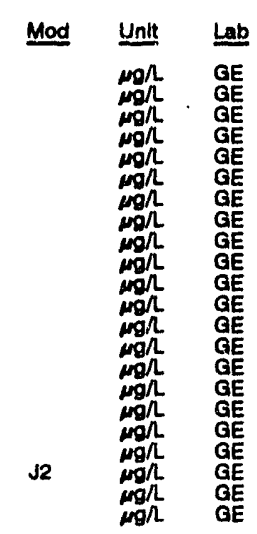




\section{BLANK RESULTS}

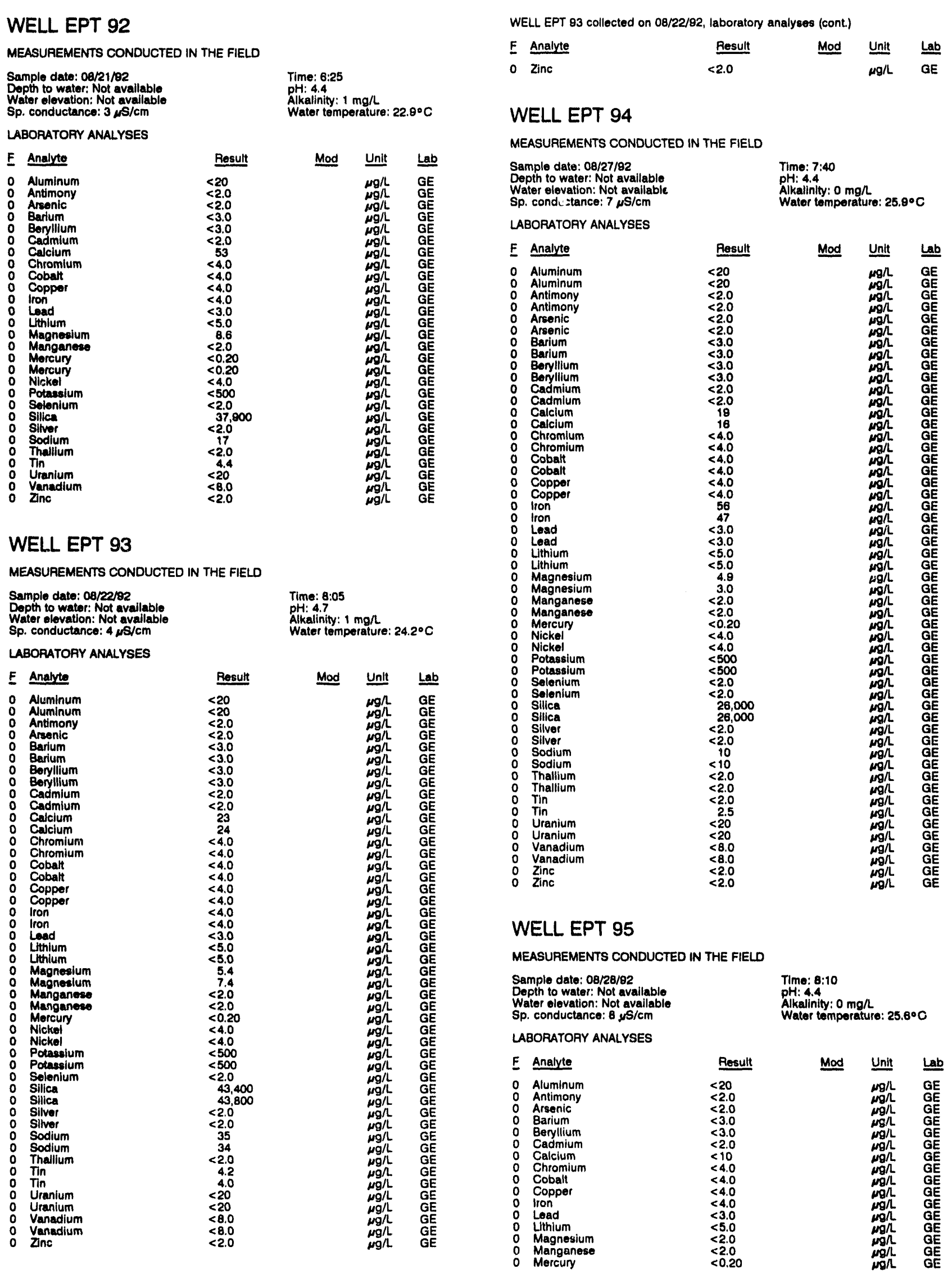




\section{BLANK RESULTS}

\begin{tabular}{|c|c|c|c|}
\hline E Analyte & Result & Mod & Unit \\
\hline $\begin{array}{ll}0 & \text { Calclum } \\
0 & \text { Chromium } \\
0 & \text { Cobsalt } \\
0 & \text { Coppoer } \\
0 & \text { lron } \\
0 & \text { Load } \\
0 & \text { Lithlum } \\
0 & \text { Magnealum } \\
0 & \text { Manganese } \\
0 & \text { Morcury } \\
0 & \text { Nickel } \\
0 & \text { Potaseslum } \\
0 & \text { Solenlum } \\
0 & \text { Sillica } \\
0 & \text { Silver } \\
0 & \text { Sodium } \\
0 & \text { Thallium } \\
0 & \text { Tin } \\
0 & \text { Uranium } \\
0 & \text { Vanadium } \\
0 & \text { Znc }\end{array}$ & $\begin{array}{r}23 \\
<4.0 \\
<4.0 \\
8.2 \\
<4.0 \\
<3.0 \\
<5.0 \\
4.3 \\
<2.0 \\
<0.20 \\
4.1 \\
<500 \\
<2.0 \\
36.700 \\
<2.0 \\
20 \\
<2.0 \\
<2.0 \\
<20 \\
<8.0 \\
<2.0\end{array}$ & J2 & $\begin{array}{l}\mu g / L \\
\mu g / L \\
\mu g / L \\
\mu g / L \\
\mu g / L \\
\mu g / L \\
\mu g / L \\
\mu g / L \\
\mu g / L \\
\mu g / L \\
\mu g / L \\
\mu g / L \\
\mu g / L \\
\mu g / L \\
\mu g / L \\
\mu g / L \\
\mu g / L \\
\mu g / L \\
\mu g / L \\
\mu g / L \\
\mu g / L\end{array}$ \\
\hline
\end{tabular}

WELL EPT 88

MEASUREMENTS CONDUCTED IN THE FIELD

Sample date: 08/19/92

Depth to water: Not avaliable

Water elevation: Not avaliab/o

LABORATORY ANALYSES

E Analyte

o Aluminum

Antimony

Barlum

Baryllium

Calclum

Chrom

Copper

lion

Ltthlum

Magnesium

Manganoso

Mercury

Nickel

Potasalum

Selenium

Silver

Sodium

Thallum

Tin

Uranium

Vanad

pH: $4: 9$

PH. 4.9:4 $1 \mathrm{~mol}$

Alkalinity: $1 \mathrm{mgh}$. $25.3^{\circ} \mathrm{C}$

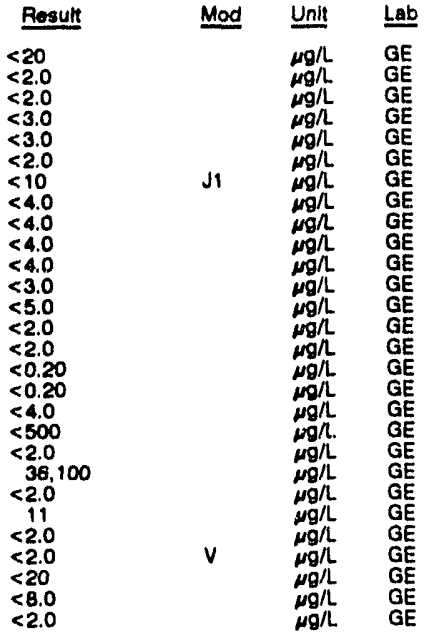

WELL EPT 89

MEASUREMENTS CONDUCTED IN THE FIELD

Sumple date: 08/20/82

Depth to water: Not avallable

Walor elovallon. Not ave

LABOPATOAY ANALYSES
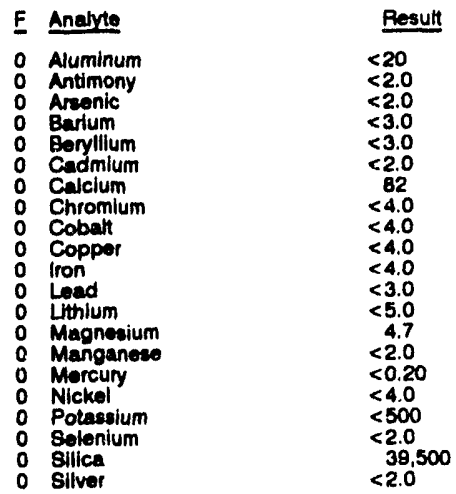

Time: 6:40

PH: 4.5

Alkalinity: $1 \mathrm{mg} / \mathrm{h}$. $22.9 \circ \mathrm{C}$



WELL EPT 89 collected on 08/20/92, laboratory analyees (cont.)

E Analyte

\begin{tabular}{c} 
Pesult \\
\hline 20 \\
$<2.0$ \\
4.1 \\
$<20$ \\
$<8.0$ \\
$<2.0$
\end{tabular}

Mod

Sodlum

0 Tin

Uranium

Zinc

$<2.0$

WELL EPT 90

MEASUREMENTS CONDUCTED IN THE FIELD

Sample date: 08/20/82

Wepth to water: Not avallable

Wp.

Time: 7:50

Alkalinity: $1 \mathrm{mg} / \mathrm{L}$

Water tomperature: $23.5^{\circ} \mathrm{C}$

LABORATORY ANALYSES

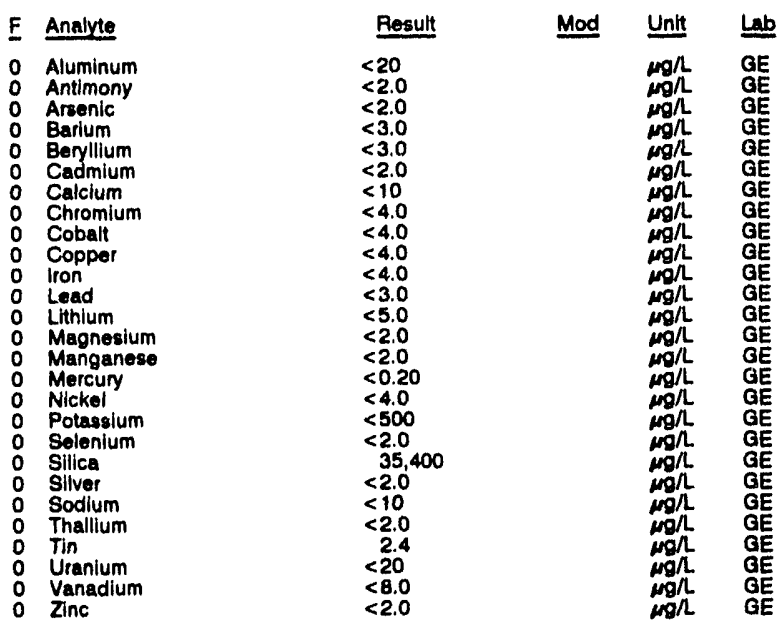

\section{WELL EPT 91}

MEASUREMENTS CONDUCTED IN THE FIELD

Sample date: 08/21/82

Depth to water: Not avallable

Water elovalon: Nor avallab

Alkalinity: $1 \mathrm{~mol}$

Water tomperature: $23.3^{\circ} \mathrm{C}$

LABORATORY ANALYSES

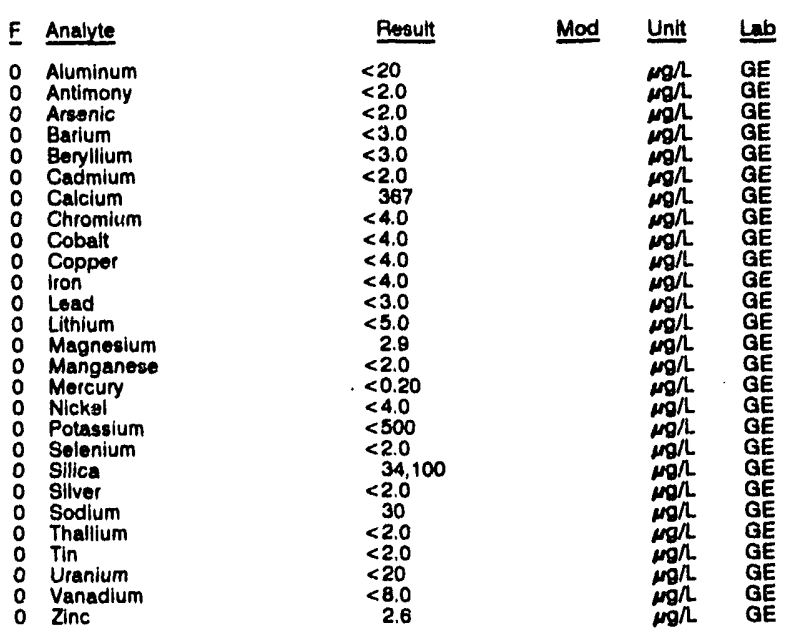




\begin{tabular}{|c|c|c|c|}
\hline F Analyte & Result & Mod & Unit \\
\hline $\begin{array}{ll}0 & \text { Potassium } \\
0 & \text { Solenlum } \\
0 & \text { Silica } \\
0 & \text { Silver } \\
0 & \text { Sodium } \\
0 & \text { Thallium } \\
0 & \text { Tin } \\
0 & \text { Uranium } \\
0 & \text { Vanadium } \\
0 & \text { Zine }\end{array}$ & $\begin{array}{l}<500 \\
<2.0 \\
25,400 \\
<2.0 \\
<10 \\
<2.0 \\
<2.0 \\
<20 \\
<8.0 \\
<2.0\end{array}$ & $v$ & $\begin{array}{l}\mu g / L \\
\mu g / L \\
\mu g / L \\
\mu g / L \\
\mu g / L \\
\mu g / L \\
\mu g / L \\
\mu g / L \\
\mu g / L \\
\mu g / L\end{array}$ \\
\hline
\end{tabular}

\section{WELL EPT 83}

MEASUREMENTS CONDUCTED IN THE FIELD

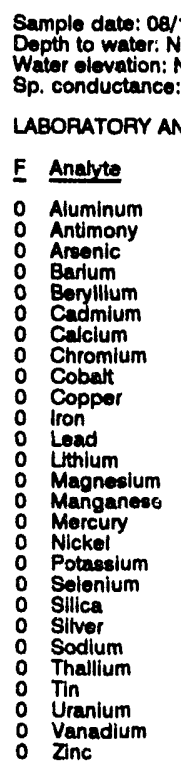

Time: 6:35

PH: 4.8 Alkalinity: $1 \mathrm{mg} / \mathrm{h}$

Water temperature: $23.1^{\circ} \mathrm{C}$

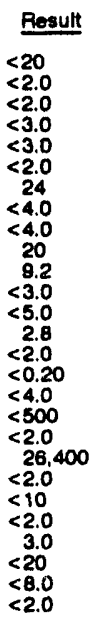

\section{WELL EPT 84}

\section{MEASUREMENTS CONDUCTED IN THE FIELO}

\section{Sample date: 08/17/82 Depth to water: Not avallable Sp. conductance: $2 \mu \mathrm{s} / \mathrm{cm}$}

LABORATOPY ANALYSES

\begin{tabular}{|c|c|c|c|c|}
\hline$\underline{F}$ & Analyte & Result & Mod & Unit \\
\hline $\begin{array}{l}0 \\
0 \\
0 \\
0 \\
0 \\
0 \\
0 \\
0 \\
0 \\
0 \\
0 \\
0 \\
0 \\
0 \\
0 \\
0 \\
0 \\
0 \\
0 \\
0 \\
0 \\
0 \\
0 \\
0 \\
0 \\
0 \\
0\end{array}$ & $\begin{array}{l}\text { Aluminum } \\
\text { Antimony } \\
\text { Arsenic } \\
\text { Barlum } \\
\text { Beryllium } \\
\text { Cadmium } \\
\text { Calclum } \\
\text { Chromium } \\
\text { Cobat } \\
\text { Copper } \\
\text { Iron } \\
\text { Lead } \\
\text { Uthlum } \\
\text { Magnesium } \\
\text { Manganese } \\
\text { Mercury } \\
\text { Nickel } \\
\text { Potassium } \\
\text { Selenium } \\
\text { Sillica } \\
\text { Silvor } \\
\text { Sodium } \\
\text { Thallium } \\
\text { Tin } \\
\text { Uranium } \\
\text { Vanadium } \\
\text { Zinc }\end{array}$ & $\begin{array}{l}<20 \\
<2.0 \\
<2.0 \\
<3.0 \\
<3.0 \\
<2.0 \\
<10 \\
<4.0 \\
<4.0 \\
<4.0 \\
43.9 \\
<3.0 \\
<5.0 \\
<2.0 \\
<2.0 \\
<0.20 \\
<4.0 \\
<500 \\
<2.0 \\
25.200 \\
<2.0 \\
<10 \\
<2.0 \\
<2.0 \\
<20 \\
<8.0 \\
<2.0\end{array}$ & $v$ & 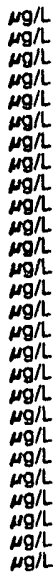 \\
\hline
\end{tabular}

WELL EPT 85

\begin{tabular}{|c|c|c|c|c|}
\hline \multicolumn{2}{|l|}{$\begin{array}{l}\text { Sample date: } 08 / 18 / 92 \\
\text { Depth to water: Not avallable } \\
\text { Water elevation: Not available } \\
\text { Sp. conductance: } 2 \mu \mathrm{s} / \mathrm{cm}\end{array}$} & \multicolumn{3}{|c|}{$\begin{array}{l}\text { Time: } 5: 25 \\
\text { pH: } 4.6 \\
\text { Alkalinity: } 1 \mathrm{mg} / \mathrm{h} \\
\text { Water temperature: } 22.5^{\circ} \mathrm{C}\end{array}$} \\
\hline \multicolumn{5}{|l|}{ LABORATORY ANALYSES } \\
\hline E Analyte & Result & Mod & Unit & Lab \\
\hline $\begin{array}{ll}0 & \text { Aluminum } \\
0 & \text { Antimony } \\
0 & \text { Arsenic } \\
0 & \text { Barium } \\
0 & \text { Beryllium } \\
0 & \text { Cadmium } \\
0 & \text { Calcium } \\
0 & \text { Chromium } \\
0 & \text { Cobaat } \\
0 & \text { Copper } \\
0 & \text { Iron } \\
0 & \text { Lead } \\
0 & \text { Lithium } \\
0 & \text { Magneslum } \\
0 & \text { Manganese } \\
0 & \text { Mercury } \\
0 & \text { Nickel } \\
0 & \text { Potassium } \\
0 & \text { Selenium } \\
0 & \text { Sillea } \\
0 & \text { Silver } \\
0 & \text { Sodlum } \\
0 & \text { Thallium } \\
0 & \text { Tin } \\
0 & \text { Uranium } \\
0 & \text { Vanadium } \\
0 & \text { Zinc }\end{array}$ & $\begin{array}{l}<20 \\
<2.0 \\
<2.0 \\
<3.0 \\
<3.0 \\
<2.0 \\
21 \\
<4.0 \\
<4.0 \\
<4.0 \\
<4.0 \\
<3.0 \\
<5.0 \\
<2.0 \\
<2.0 \\
<0.20 \\
<4.0 \\
<500 \\
<2.0 \\
24.400 \\
<2.0 \\
<23 \\
<2.0 \\
<2.0 \\
<20 \\
<8.0 \\
<2.0\end{array}$ & & 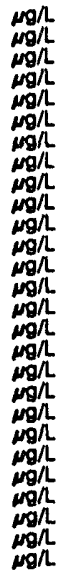 & $\begin{array}{l}G E \\
G E \\
G E \\
G E \\
G E \\
G E \\
G E \\
G E \\
G E \\
G E \\
G E \\
G E \\
G E \\
G E \\
G E \\
G E \\
G E \\
G E \\
G E \\
G E \\
G E \\
G E \\
G E \\
G E \\
G E \\
G E \\
G E\end{array}$ \\
\hline
\end{tabular}

\section{WELL EPT 86}

MEASUREMENTS CONDUCTED IN THE FIELD

Sample date: $08 / 18 / \theta 2$

Depth to water: Nof available

$\mathrm{Sp}$. conductance: $2 \mu \mathrm{S} / \mathrm{cm}$

Time: 7:30

PH: 5.2

Water temperature: $23.0^{\circ} \mathrm{C}$

\section{LABORATORY ANALYSES}

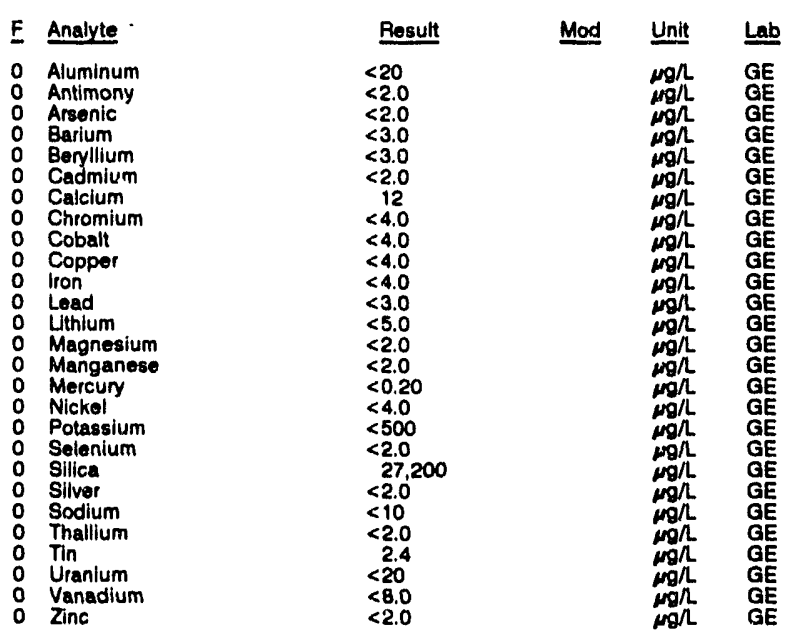

WELL EPT 87

MEASUREMENTS CONDUCTED IN THE FIELD

Sample date: 08/18/92

Depth to water: Not available

Water elevation: Not available
Sp. conductance: $2 \mu \mathrm{s} / \mathrm{cm}$

LABORATORY ANALYSES

E Analyte

0 Aluminum

Antimony

0 Arsenic

o Beryllium

- Cadmium

\section{Time: 6:05}

PH: 4.8 : $1 \mathrm{mg} / \mathrm{L}$

Water temporature: $25.4^{\circ} \mathrm{C}$

\begin{tabular}{l} 
Result \\
\hline$<20$ \\
$<2.0$ \\
$<2.0$ \\
$<3.0$ \\
$<3.0$ \\
$<2.0$
\end{tabular}

Mod Unit Lab

$\stackrel{\mu h}{\mu R}$ GE 


\section{WELL EPT 79}

MEASUREMENTS CONOUCTED IN THE FIELD

Sumple date: 08/13/92

Depth to water: Not available

Sp. conductance: $2 \mu S / \mathrm{cm}$

LABORATORY ANALYSES

F Anabrie

- Aluminum

0 Arsenic

0 Bartum

- Baryllium

Cadmium

o Chromium

O Cobalt

Iron

L Load

Magnealum

Manganes

Nickury

Potaseslum

Selenium

Silica

Sodium

Thallium

Uranium

Z Vine

\section{WELL EPT 80}

MEASUREMENTS CONDUCTED IN THE FIELD

Sample date: 08/13/92

Depth to wator: Not avaliable

Water elevation: Not avallablo

LABORATORY ANALYSES

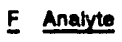

Aluminum

A Aluminum

Antimony

0 Arsenic

Barium

Barium

Beryllium

Cadmlum

Calclum

Calcium

o Chromium

0 Cobsti

Cobalt

0 Copper

iron

0 Lead

0 Lthium

0 Lthium

Magnesium

Manganese

Morcury

Nickol

Potansium

o Potassium

0 Solonlum

o Solenium

S Sillica

0 Silica

o Silver

O Sodium

S Sodium

Thallium

Thallum

O Tin

0 Un

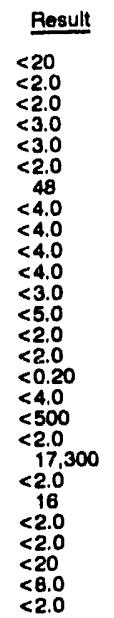

Time: 7:00

pH: 5.4 . $1 \mathrm{mg}$

Water temperature: $25.3^{\circ} \mathrm{C}$

Mod Unit Lab

$\begin{array}{lll} & \mu g / L & G E \\ & \mu g / L & G E\end{array}$

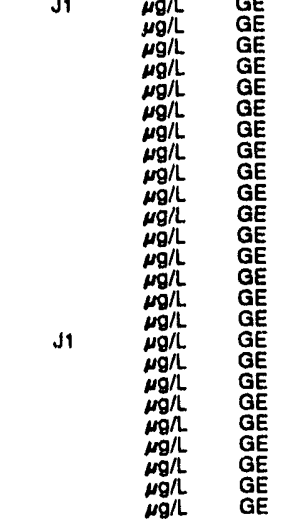

Time: 6:25

PH: 5.0 Alkalinity: $1 \mathrm{mg} /$

Water temperalure: $26.0^{\circ} \mathrm{C}$

Mod Unit Lab

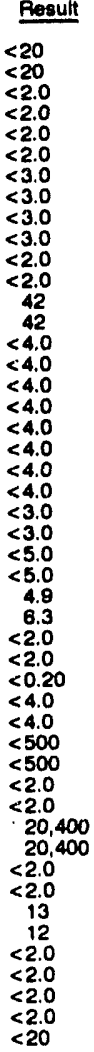

WELL EPT 80 collectod on $08 / 13 / 82$, laboratory analyces (cont)

\begin{tabular}{|c|c|c|c|}
\hline F Analyte & Result & Mod & Unit \\
\hline $\begin{array}{ll}0 & \text { Uranium } \\
0 & \text { Vanadium } \\
0 & \text { Vanadium } \\
0 & \text { Zinc } \\
0 & \text { Zinc }\end{array}$ & $\begin{array}{l}<20 \\
<8.0 \\
<8.0 \\
<2.0 \\
<2.0\end{array}$ & & $\begin{array}{l}\mu g / L \\
\mu g / L \\
\mu g / h \\
\mu g / L \\
\mu g / L\end{array}$ \\
\hline
\end{tabular}

\section{WELL EPT 81}

MEASUREMENTS CONDUCTED IN THE FIELD

Sample date: 08/14/82

Depth to water: Not avallable

Water elovallon: Nor availa

Sp. conductance: $2 \mu \mathrm{S} / \mathrm{cm}$

Time: $8: 10$

PH: 5.5

Alkainity: $1 \mathrm{mg} / \mathrm{L}$
Water temperature: $24.8^{\circ} \mathrm{C}$

LABORATORY ANALYSES

F Analyte

- Aluminum

0 Antimony

O Arsenic

B Barlum

B Beryllium

o Boryllium

Cadmium

Calcium

Chromium

Chromium

Cobalt

Copper

Copper

0 Iron

0 lion

L Lithium

o Lithium

Magnesium

Manganese

Manganese

Mercury

Nickel

Nickel

Potassium

Selenium

Silice

0 Silver

0 Silver

Sodium

O Sodium

Tin

0 Tin

Uranium

Vanadium

0 Zinc
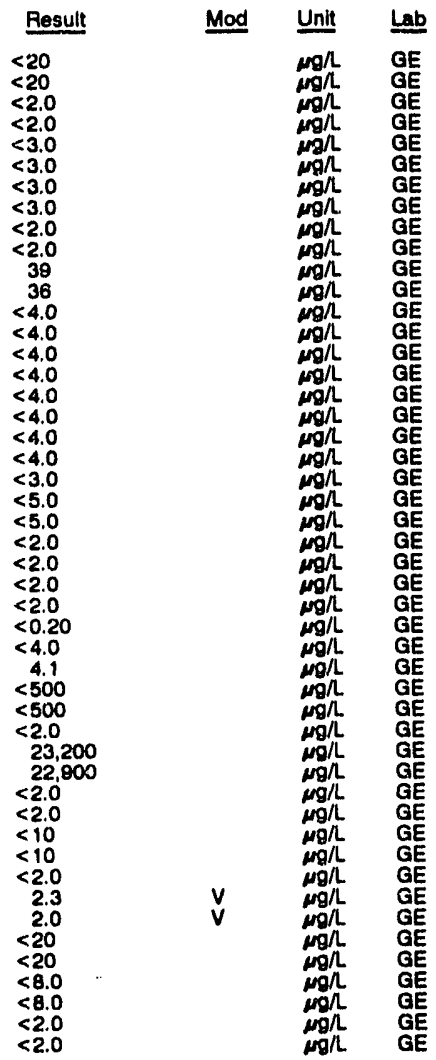

WELL EPT 82

MEASUREMENTS CONDUCTED IN THE FIELD

Sample date: 08/14/82

Depth to water: Not avallable

Walor conductance:

LABORATORY ANALYSES

$E$ Analyte

- Aluminum

0 Antimony

0 Arsenic

Barium

0 Beryllium

o Calcium

o Chromium

0 Cobalt

- Copper

: Copp

o Lead

L Magnesium

Manganese

o Mercury

\begin{tabular}{l}
\multicolumn{1}{r}{ Pesult } \\
\hline$<20$ \\
$<2.0$ \\
$<2.0$ \\
$<3.0$ \\
$<3.0$ \\
$<2.0$ \\
52 \\
$<4.0$ \\
$<4.0$ \\
$<4.0$ \\
$<4.0$ \\
$<3.0$ \\
$<5.0$ \\
$<2.0$ \\
$<2.0$ \\
$<0.20$ \\
$<4.0$
\end{tabular}

Time: $6: 30$

PH: 4.8

Water temperature: $24.2{ }^{\circ} \mathrm{C}$

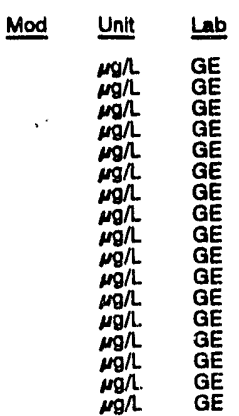




\section{BLANK RESULTS}

WELL EPT 75 collected on 08/07/82, laboratory analyses (cont.)

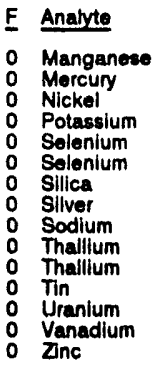

\section{WELL EPT 76}

MEASUREMENTS CONDUCTED IN THE FIELD

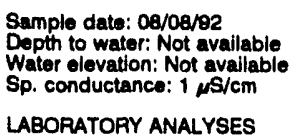

LABORATOPY ANALYSES
E Analyte

o Aluminum

O Antimony

Areonic

Barium

Beryllium

Codmium

Cadmium

Calcium

Chromium

Chromium

Cobalt

Cobalt

Copper

Iron

0 Lead

LIthium

o Magneslum

Manganese

Mereury

O Nickel

N Nickel

Potasslum

Selenium

Silica

Silica

Stlver

o Sodium

Sodium

Thallum

Tin

U Uranium

Vanadium

Vanadium

0
0
Zinc
- Magneslum

\begin{tabular}{l} 
Result \\
\hline$<2.0$ \\
$<0.20$ \\
$<4.0$ \\
$<500$ \\
$<2.0$ \\
$<2.0$ \\
668 \\
$<2.0$ \\
17 \\
$<2.0$ \\
$<2.0$ \\
$<2.0$ \\
$<20$ \\
$<8.0$ \\
$<2.0$
\end{tabular}

Mod

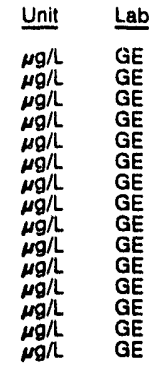

Time: 7:30

Alkalinity: $1 \mathrm{mg} / \mathrm{h}$

Water temperature: $24.0^{\circ} \mathrm{C}$

Result

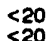

$<20$

$<2.0$

$<3.0$
$<3.0$

$<3.0$
$<3.0$
$<2.0$
$<2.0$

$<2$
12
11
$<40$

$<4.0$
$<4.0$

$<4.0$

$<4.0$
$<4.0$

$<4.0$

$<4.0$

$<3.0$

$<5.0$

2.6
2.3
$<2.0$

$<2.0$

$<<<.20$

$<4.0$

$<500$

$<2.0$
587

586

$<2.0$
$<2.0$
27

26
$<2.0$

$<2.0$
$<2.0$

$<2.0$

$<20$
$<20$

$<20$

$<8.0$

$<2.0$

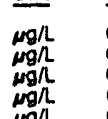

$\mathrm{GE}$
$\mathrm{GE}$
$\mathrm{GE}$
$\mathrm{GE}$
$\mathrm{GE}$
WELL EPT 77

MEASUAEMENTS CONDUCTED IN THE FIELD

Sample date: 08/12/82

Depth to water: Not avallable

Water olovation. Nor avallab

Sp. conductance: 1 is/cm

LABORATOPY ANALYSES

\begin{tabular}{|c|c|c|c|c|}
\hline $\mathbf{F}$ & Analyte & Result & Mod & Unit \\
\hline $\begin{array}{l}0 \\
0 \\
0 \\
0 \\
0 \\
0 \\
0\end{array}$ & $\begin{array}{l}\text { Aluminum } \\
\text { Antimony } \\
\text { Arsenic } \\
\text { Barium } \\
\text { Beryllium } \\
\text { Cadmium } \\
\text { Calcium }\end{array}$ & $\begin{array}{l}<20 \\
<2.0 \\
<2.0 \\
<3.0 \\
<3.0 \\
<2.0 \\
<10\end{array}$ & & $\begin{array}{l}\mu g / L \\
\mu g / L \\
\mu g / L \\
\mu g / L \\
\mu g / L \\
\mu g / L \\
\mu g / L\end{array}$ \\
\hline
\end{tabular}

Time: 5:25

pH: 4.9

Alkalinity: $1 \mathrm{mg} / \mathrm{h}$

Water temperature: $26.6^{\circ} \mathrm{C}$
WELL EPT 77 collected on 08/12/92, laboratory analyses (cont.)

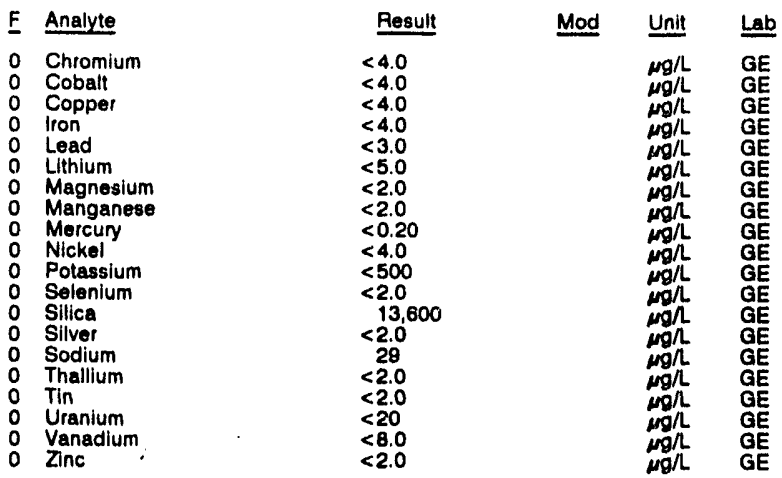

WELL EPT 78

MEASUREMENTS CONDUCTED IN THE FIELD

Sample date: 08/12/92

Depth to water: Not avallable

Water elevation: Not available
Sp. conductance: $1 \mu \mathrm{s} / \mathrm{cm}$

LABORATORY ANALYSES

E Analyte

- Aluminum

A Aluminum

0 Antimony

0 Barium

o Barium

o Beryllium

o Cadmium

O Calclum

O Chromium

o Chromium

Cobalt

0 Cobalt

o Copper

0 Iron

0 Iron

L Lead

0 Lithlum

Magnesium

Magnesium

Manganese

0 Mercury

o Nickel

0 Potassium

o Potassium

0
0
0

0 Silica

0 Silica

0 Silver

o Sodium

Sodium

O Tha

O Tin

Uranium

- Vanadium

V Vine

0 Zinc

$<20$

$<20$

$<2.0$

$<3.0$
$<3.0$

$<3.0$

$<2.0$
$<2.0$

$<2.0$
27
28

$<4.0$

$<4.0$

$<4.0$

$<4.0$

$<4.0$

$<3.0$

$<\begin{array}{r}<.0 \\ <5.0\end{array}$

3.8
2.2
$<2.0$

$<2.0$

$<0.20$

$<4.0$

$<500$
$<500$

$<2.0$

12,300
12,400

$<2.0$

27

$<<$

$<2.0$

$<20$

$<8.0$

$<8.0$
$<2.0$

$<2.0$

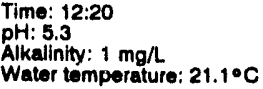

Mod 
BLANK RESULTS

WELL EPT 71 collectod on 08/05/92, laboratory analyses (cont.)

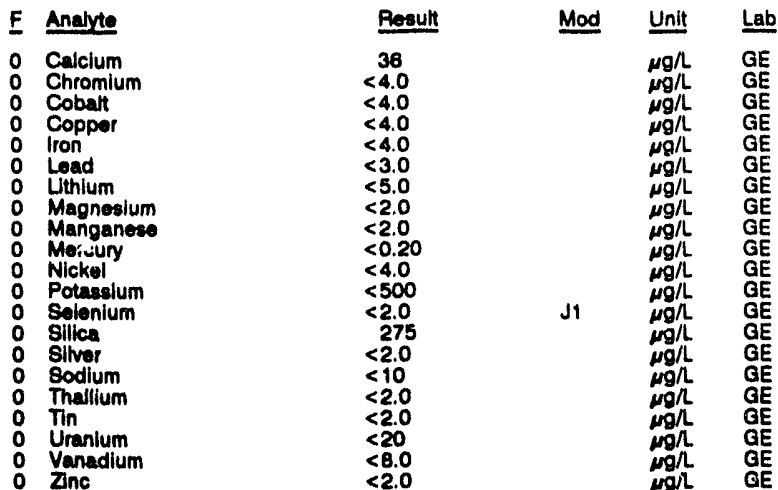

WELL EPT 72

MEASUREMENTS CONDUCTED IN THE FIELD

Sample date: 08/08/92 Dopth to water: Not avaliable Waber elevation: Not avallable
Sp. conductance: $2 \mathrm{~s} / \mathrm{cm}$

LABOALTORY ANALYSES

E Analyte

- Aluminum

Antimony

Arsonic

o Beryllium

Calcium

0 Chromium

Cobalt

Iron

0 Load

L Lthium

Magneanes

Morcury

0 Potaselum

o Solenium

Silica

Sodium

Thalllum

o Uranium

O Vanadlum

\begin{tabular}{l} 
\\
\\
\\
\\
Result \\
\hline$<20$ \\
$<2.0$ \\
$<2.0$ \\
$<3.0$ \\
$<3.0$ \\
$<2.0$ \\
24 \\
$<4.0$ \\
$<4.0$ \\
$<4.0$ \\
$<4.0$ \\
$<3.0$ \\
$<5.0$ \\
$<2.0$ \\
$<2.0$ \\
$<0.20$ \\
$<4.0$ \\
$<500$ \\
$<2.0$ \\
368 \\
$<2.0$ \\
$<10$ \\
$<2.0$ \\
$<2.0$ \\
$<20$ \\
$<8.0$ \\
$<2.0$ \\
$<2.0$ \\
\end{tabular}

Time: 7:25

Alkalinity: $1 \mathrm{mo} / \mathrm{L}$

$\begin{array}{ll}\mu g / h & G E \\ \mu g / h & G E \\ \mu / L & G E\end{array}$
Water temperature: $25.3^{\circ} \mathrm{C}$

Mod Unit Lab

WELL EPT 73

MEASUREMENTS CONDUCTED IN THE FIELL

Samplo dato: 08/08/92

Depth to water: Not available

Water olevation: Not available

LABOPATOFY ANALYSES

\begin{tabular}{|c|c|c|c|}
\hline E Analyte & Result & Mod & Unit \\
\hline $\begin{array}{ll}0 & \text { Aluminum } \\
0 & \text { Aluminum } \\
0 & \text { Antimony } \\
0 & \text { Areanic } \\
0 & \text { Barium } \\
0 & \text { Barium } \\
0 & \text { Berrillium } \\
0 & \text { Beryllium } \\
0 & \text { Cadmlum } \\
0 & \text { Cedmlum } \\
0 & \text { Calcium } \\
0 & \text { Calcium } \\
0 & \text { Chromium } \\
0 & \text { Chromium } \\
0 & \text { Cobalt } \\
0 & \text { Cobalt } \\
0 & \text { Copper } \\
0 & \text { Copper } \\
0 & \text { iron } \\
0 & \text { lron } \\
0 & \text { Lead } \\
0 & \text { Lthilum }\end{array}$ & $\begin{array}{l}<20 \\
<20 \\
<2.0 \\
<2.0 \\
<3.0 \\
<3.0 \\
<3.0 \\
<3.0 \\
<2.0 \\
<2.0 \\
<10 \\
<10 \\
<4.0 \\
<4.0 \\
<4.0 \\
<4.0 \\
<4.0 \\
<4.0 \\
<4.0 \\
<4.0 \\
<3.0 \\
<5.0\end{array}$ & & 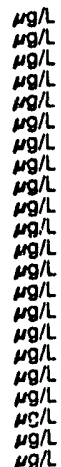 \\
\hline
\end{tabular}

WELL EPT 73 collected on 08/08/82, laboratory analyses (cont.)

$\begin{array}{ll}\text { F } & \text { Analute } \\ 0 & \text { Lithium } \\ 0 & \text { Magnesium } \\ 0 & \text { Magnesium } \\ 0 & \text { Manganese } \\ 0 & \text { Manganese } \\ 0 & \text { Mercury } \\ 0 & \text { Nickel } \\ 0 & \text { Nickel } \\ 0 & \text { Potassium } \\ 0 & \text { Potassium } \\ 0 & \text { Selonium } \\ 0 & \text { Sllica } \\ 0 & \text { Silica } \\ 0 & \text { Silver } \\ 0 & \text { Silver } \\ 0 & \text { Sodium } \\ 0 & \text { Sodium } \\ 0 & \text { Thallium } \\ 0 & \text { Tin } \\ 0 & \text { Tin } \\ 0 & \text { Uranium } \\ 0 & \text { Uranium } \\ 0 & \text { Vanadium } \\ 0 & \text { Vanadlum } \\ 0 & \text { Zinc } \\ 0 & \text { Zinc }\end{array}$

\begin{tabular}{l} 
Result \\
\hline 5.0 \\
$<2.0$ \\
$<2.0$ \\
$<2.0$ \\
$<2.0$ \\
$<0.20$ \\
$<4.0$ \\
$<4.0$ \\
$<500$ \\
$<500$ \\
$<2.0$ \\
326 \\
325 \\
$<2.0$ \\
$<2.0$ \\
44 \\
44 \\
$<2.0$ \\
$<2.0$ \\
$<2.0$ \\
$<20$ \\
$<20$ \\
$<8.0$ \\
$<8.0$ \\
$<2.0$ \\
$<2.0$
\end{tabular}

\begin{tabular}{|c|c|}
\hline Mod & Unit \\
\hline J1 & 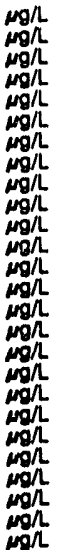 \\
\hline
\end{tabular}

\section{WELL EPT 74}

MEASUREMENTS CONDUCTED IN THE FIELD

Sample date: 08/07/92

Depth to water: Not available

Water olevation: Not avaliablo

Sp. conduclance: 1 m S/cm

Time: 7:00

pH: 6.0

Water temperature: $26.6^{\circ} \mathrm{C}$
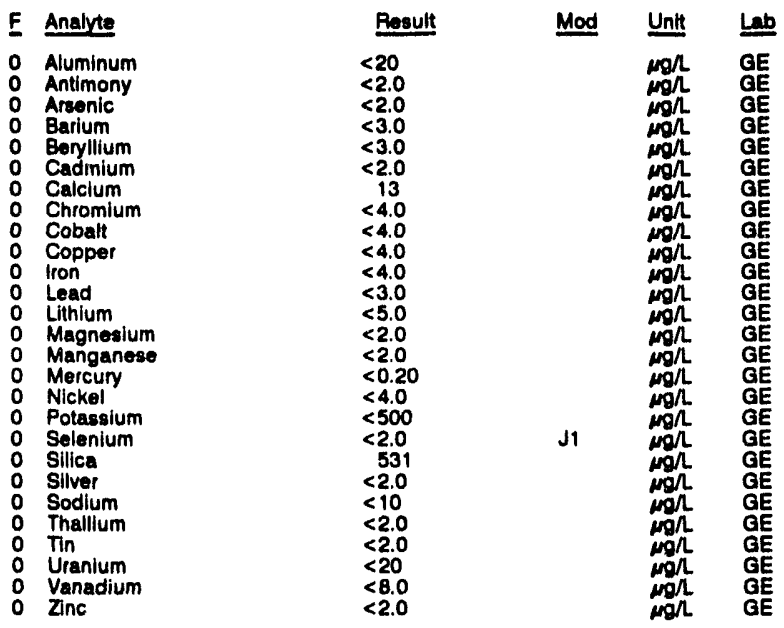

\section{WELL. EPT 75}

MEASUREMENTS CONDUCTED IN THE FIELD

Sample date: 08/07/92

Depth to water: Not avaliable

Sp. conductance: 1 (

LABORATORY ANALYSES
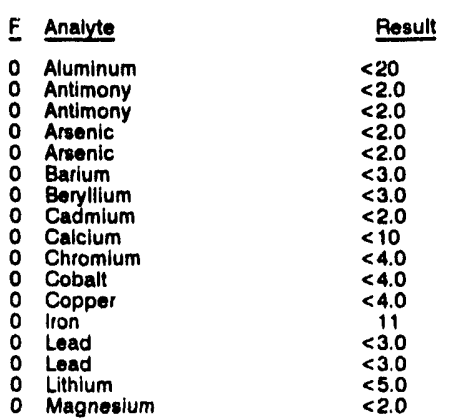

Time: 6:50

pH: 5.2

Water temperature: $28.2 \circ \mathrm{C}$ 


\section{BLANK RESULTS}

\section{WELL EPT 67}

MEASUREMENTS CONDUCTED IN THE FIELD

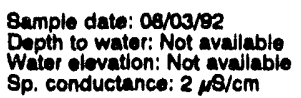

LABORATOAY ANALYSES

E Aneyte

- Aluminum

Antimony

Areenic

Barium

Beryllium

Beryllum

Cadmium

Callium

Casclum

Chromlum

Cobatt

Cobat

Coppor

Iron

lron

0 Lthium

Uthlum

- Magnedum

Manganeso

Manganea

0 Nickel

o Nickol

Potacolum

Selenlum

Silica

o Siltica

0 Sitver

Sodium

sodium

Thallium

T $\operatorname{Tin}$

T) Uranium

Urantum

Vanadium

o Znc

WELL EPT 68

MEASUREMENTS CONDUCTED IN THE FIELD

Sample date: 08/03/82 Depth to water: Not available Water olovation: Not available
Sp. conductance: $1 \mathrm{~s} / \mathrm{cm}$

LABORATORY ANALYSES

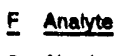

o Numinum

Antimon

O Arronic

O Baryllium

Cadmium

Calcium

Chromium

Cobat

Iron

Lead

Magnesium

Magnesium

Mercury

Nickel

Potassium

Solenlum

Silver

Sodium

Thallum

Tin

U Uranium

0 Vanadium
0 Znc

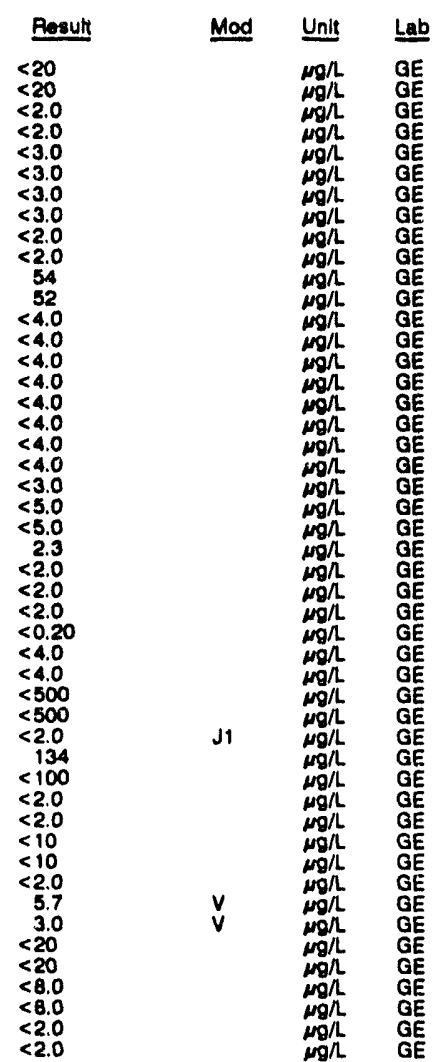

Time: $9: 00$

Alkalinity: $1 \mathrm{mg} / \mathrm{L}$

Water temperature: $26.0^{\circ} \mathrm{C}$

Mod Unit Lab

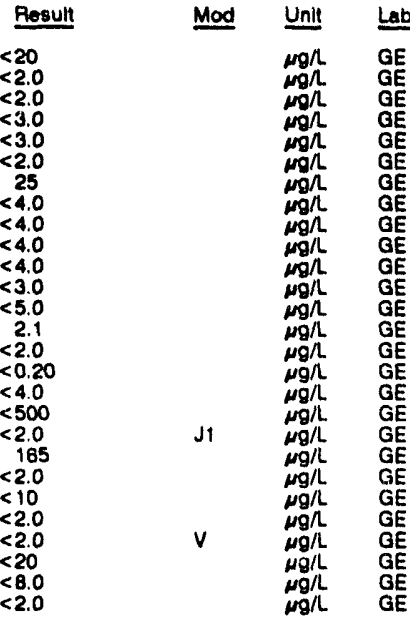

WELL EPT 69

MEASUREMENTS CONDUCTED IN THE FIELD

Sample date: 08/04/82

Wepth to water: Nol avallable

$S p$. conductance: $1, \mathrm{~s} / \mathrm{cm}$

LABORATORY ANALYSES

$E$ Analyte

o Aluminum

$0_{0}$ Antimony

o Arsenic

O Beryllium

Cadmium

Chromium

Cobalt

O Copper

o Lees

u Magnestum

Manganose

Morcury

O Nickel

L Solenium

o Silica

S Sllver

Shallium

0 Tin

Uranium

Zlnc

Time: $6: 40$

PH: 5.1 . 190

Water temperalure: $28.4{ }^{\circ} \mathrm{C}$

WELL. EPT 70

MEASUREMENTS CONDUCTED IN THE FIELD

Sample date: 08/05/92

Depth to water: Not available

Sp. conduction: Not avaliablo

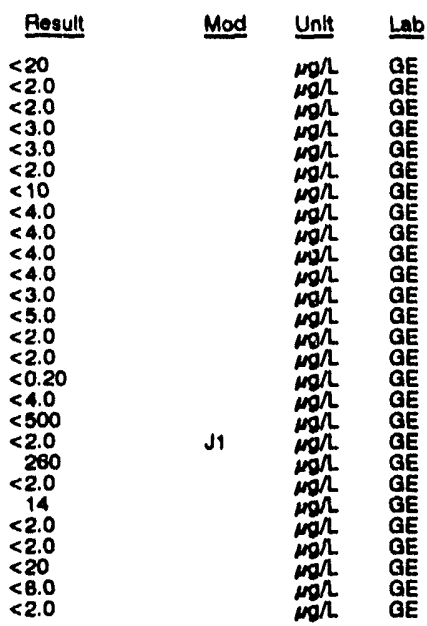

LABORATORY ANALYSES

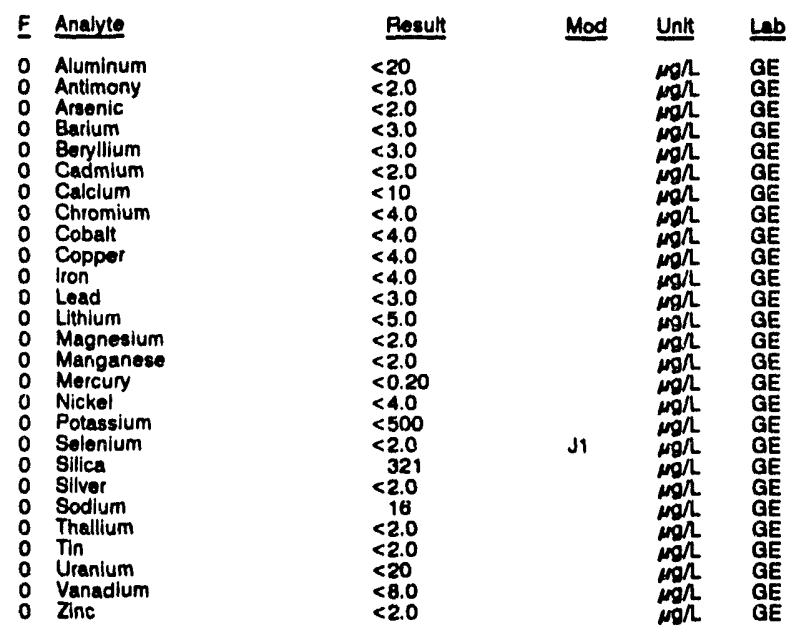

WELL EPT 71

MEASUREMENTS CONDUCTED IN THE FIELD

Sample date: 08/05/92

Depth to water: Not available

Time: 6:25

PHi: 5.3 . $1 \mathrm{man}$

Waior temperature: $28.9^{\circ} \mathrm{C}$

\begin{tabular}{|c|c|c|c|}
\hline Analyte & Result & Mod & Unit \\
\hline $\begin{array}{l}\text { Aluminum } \\
\text { Antimony } \\
\text { Arsenic } \\
\text { Barium } \\
\text { Beryllium } \\
\text { Cadmium }\end{array}$ & $\begin{array}{l}<20 \\
<2.0 \\
<2.0 \\
<3.0 \\
<3.0 \\
<2.0\end{array}$ & & $\begin{array}{l}\operatorname{mg} \Omega \\
\operatorname{mgn} \Omega \\
\operatorname{mg} \Omega \\
\operatorname{mg} \Omega \\
\operatorname{mg} \Omega\end{array}$ \\
\hline
\end{tabular}

Sp. conductance: $2 \mu \mathrm{S} / \mathrm{cm}$

ABOAATOAY ANALYSES

Time: 7:50

pH: 6.2

Alkalinity: $1 \mathrm{mg} / \mathrm{L}$

Cadmium

$<2.0$ 
BLANK RESULTS

WELL EPT 63

MEASUREMENTS CONDUCTED IN THE FIELD

Sample dato: 07/30/02

Depth to water: Not avallable

8p. conductance: $1 \mathrm{\mu} / \mathrm{cm}$

LABOAATOFY ANALY8ES

E Anatro

o Numinum

O Anenio

Bonillum

Calclum

O Cobalt

Copper

iron

0 Uthlum

Magnedum

0 Moreun

Nickol

Potaselum

Blica

o Slver

Thallum

Tin

$\begin{array}{ll}0 & \text { Uranlum } \\ 0 & \text { Vanadlum } \\ 0 & \text { Zne }\end{array}$

um

\begin{tabular}{l} 
Regutt \\
\hline$<20$ \\
$<2.0$ \\
$<2.0$ \\
$<3.0$ \\
$<3.0$ \\
$<2.0$ \\
$<10$ \\
$<4.0$ \\
$<4.0$ \\
$<4.0$ \\
$<4.0$ \\
$<3.0$ \\
$<5.0$ \\
$<2.0$ \\
$<2.0$ \\
$<0.20$ \\
$<4.0$ \\
$<500$ \\
$<2.0$ \\
$<100$ \\
$<2.0$ \\
111 \\
$<2.0$ \\
$<2.0$ \\
$<20$ \\
$<8.0$ \\
$<2.0$
\end{tabular}

WELL EPT 64

MEASUAEMENTS CONDUCTED IN THE FIELD

\section{Sample datu: 07/31/02}

Wpir olovaton: Not availab

Sp. conductanco. 2 $\mu / \mathrm{cm}$

LABORATORY ANALYSES

F Analyte

- Aluminum

o Antimony

Barium

Boryllum

O Cadcium

O Chromlum

Cobar

O Coppor

L Load

0 Utthium

O Magneaium

0 Moreury

O Nickol

o Potassium

o Sillica

O Ollver

Thaillum

O Uranlum

0 Vanadium
0 Znc

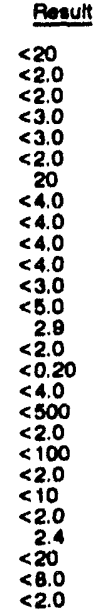

Depth to water: Not available

Time: $0: 45$

Water tomperature: $26.8^{\circ} \mathrm{C}$

Lab
GE
$G E$
$G E$
$G E$
$G E$
$G E$
$G E$
$G E$
$G E$
$G E$
$G E$
$G E$
$G E$
$G E$
$G E$
$G E$
$G E$
$G E$
$G E$
$G E$
$G E$
$G E$
$G E$
$G E$
$G E$
$G E$
$G E$
$G E$

WELL EPT 65

MEASUAEMENTS CONOUCTED IN THE FIELD

Sample date: 08/01/22

Depth to water: Not avallable

8p. conductence: $1 \mathrm{ms/ \textrm {cm }}$

LABOFATOPY ANALYSES

\begin{tabular}{|c|c|c|c|}
\hline E Analute & Result & Mod & Unit \\
\hline $\begin{array}{ll}0 & \text { Aluminum } \\
0 & \text { Aluminum } \\
0 & \text { Antimony } \\
0 & \text { Arsenic } \\
0 & \text { Barium } \\
0 & \text { Earium }\end{array}$ & $\begin{array}{l}<20 \\
<20 \\
<2.0 \\
<2.0 \\
<3.0 \\
<3.0\end{array}$ & & $\begin{array}{l}\mu g / L \\
\mu g / L \\
\mu g / L \\
\mu g / L \\
\mu g / L \\
\mu g / L\end{array}$ \\
\hline
\end{tabular}

Time: $0: 30$

pHit: 4.9 . 190

Wator temperature: $28.7{ }^{\circ} \mathrm{C}$
Time: $7: 00$

AH: 4.9 Alkalinity: $1 \mathrm{mg} / \mathrm{L}$

Water temperature: $24.3^{\circ} \mathrm{C}$
Alkalinity: $1 \mathrm{mo} / \mathrm{h}$

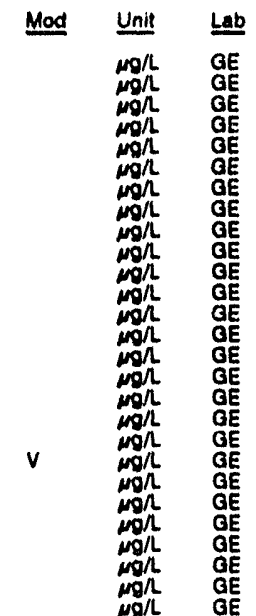

WELL EPT 65 colloctod on 08/01/92, laboratory analyees (cont)

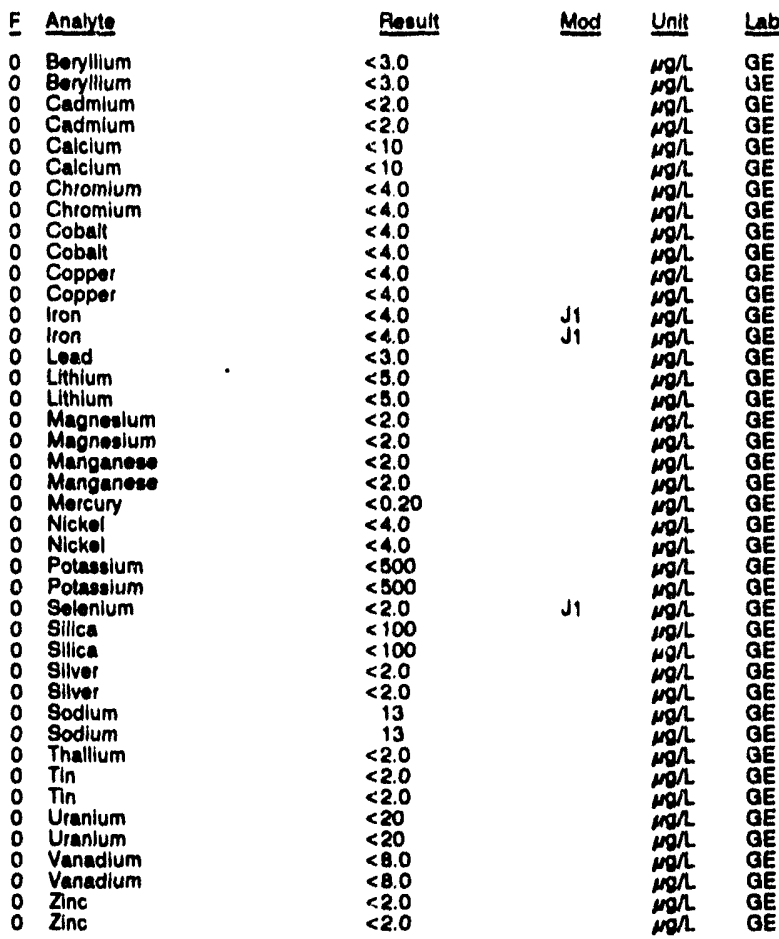

WELL EPT 66

MEASUAEMENTS CONOUCTED IN THE FIELD

Sample date: 08/02/92

Depth to water: Not avaliable

Waler elevalion. Not avallabio

LABORATORY ANALYBES

$\operatorname{Time}_{\mathrm{pH}: \mathrm{i}} \mathbf{7 : 8 0}$

Alkalinity: $1 \mathrm{mgh}$

Water tomperature: $25.3^{\circ} \mathrm{C}$

F Analye

- Aluminum

Arsenic

- Barium

- Canllium

- Chromium

- Cobalt

O Copper

o Iron

o Lead

- Magnesium

- Manganese

Nickol

O Potanalum

o Silver

- Sodium

Thallum

Tin

Uranium

Zane

Peonulf

$<20$
$<2.0$
$<2.0$

$<2.0$

$<3.0$

$<10$

$<4.0$

$<4.0$

$<3.0$

$<5.0$

$<0.20$
$<4.0$

$<500$

$<2.0$

$<100$

$<2.0$
22
$<2.0$
2.8

2.8
$<20$
$<8.0$

$<8.0$
$<2.0$
Mod Unit Lab

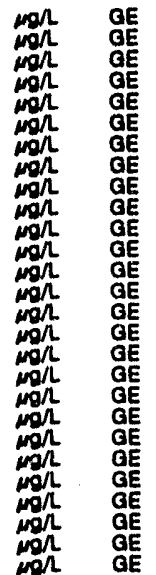


BLANK RESULTS

\begin{tabular}{|c|c|c|c|}
\hline Analyte & Beaull & Mod & Unir \\
\hline 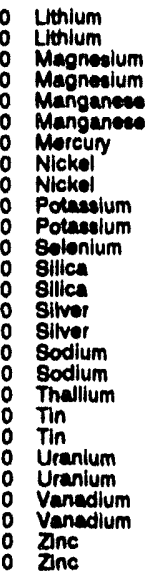 & $\begin{array}{l}<8.0 \\
<5.0 \\
<2.0 \\
2.2 \\
<2.0 \\
<2.0 \\
<0.20 \\
<4 . \\
<4.0 \\
<100 \\
<500 \\
<2.0 \\
<100 \\
<100 \\
<2.0 \\
<2.0 \\
11 \\
10 \\
<2.0 \\
<2.0 \\
<2.0 \\
<20 \\
<20 \\
<8.0 \\
<8.0 \\
<2.0 \\
<2.0\end{array}$ & & 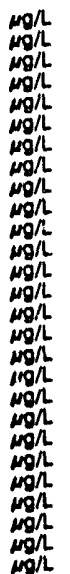 \\
\hline
\end{tabular}

WELL EPT 60

MEASUREMENTS CONOUCTED IN THE FIELD

Qample date: 07/2erer

Depth to water: Not avaliable Water elovation: Not avallab

LABOFUTOFY ANALYSES

E Anajue

- Auminum

o Auminum

o Antimonic

0 Earium

B Barium

Baryllum

Cadmium

Cedmium

: Calcium

O Chromium

- Chromium

o Cobar

O Copper

0 Iron

0 Iron

0 Lead

- Lthium

L Lthium

Magnesium

Mangancae

Manganese

N Mickel

0 Nickel

Potiagium

Potasalum

silica

silica

Silver

siver

S sodium

Thallum

Tin

Uranium

U Uranium

V Vanadium

Vanedium

Zns

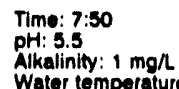

Alkalinity: $1 \mathrm{mg} / \mathrm{h} .26 .80 \mathrm{C}$

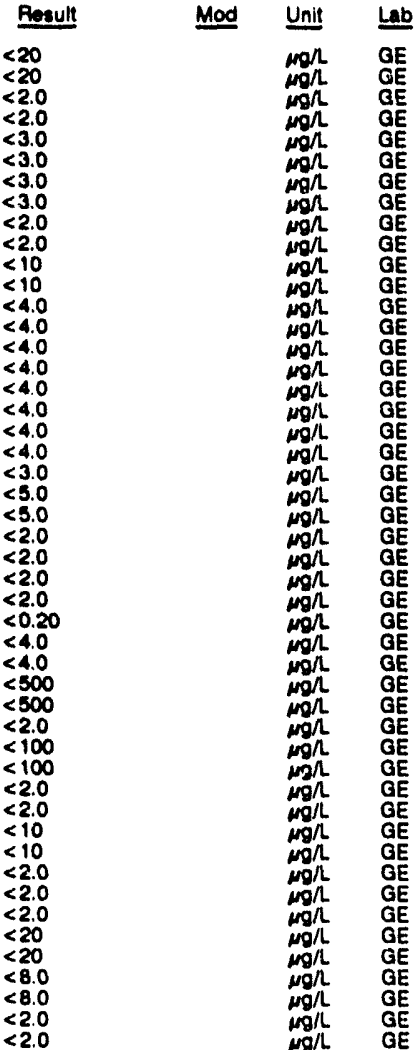

WELL EPT 61

MEASUREMENTS CONDUCTED IN THE FIELD

Sample dato: 07/28/02

Dopth to water: Not avallable

Water elevation: Not available

LABORATORY ANALYSES

E Analyte

o Aluminum

O Antimonic

O Baryllium

Cadmlum

Chromium

0 Cobalt

o Coppor

0 Lead

Lithium

O Magnesium

Mercury

N Nickel

Solenium

0 Sillica

Silver

Thadilum

Tin

O Uranium

$\begin{array}{lll}0 & \text { Vanadium } \\ 0 & \text { Zinc }\end{array}$

Time: $8: 50$

$\mathrm{pH}: \mathbf{5 . 2}$

Alkalinity: $1 \mathrm{mg} / \mathrm{L}$

Water temperature: $26.0^{\circ} \mathrm{C}$

\begin{tabular}{l} 
Regulf \\
\multicolumn{2}{r}{} \\
$<20$ \\
$<2.0$ \\
$<2.0$ \\
$<3.0$ \\
$<3.0$ \\
$<2.0$ \\
$<10$ \\
$<4.0$ \\
$<4.0$ \\
$<4.0$ \\
$<4.0$ \\
$<3.0$ \\
$<3.0$ \\
$<2.0$ \\
$<2.0$ \\
$<0.20$ \\
$<4.0$ \\
$<500$ \\
$<2.0$ \\
$<100$ \\
$<2.0$ \\
13 \\
$<2.0$ \\
$<2.0$ \\
$<20$ \\
$<8.0$ \\
2.0
\end{tabular}

Mod

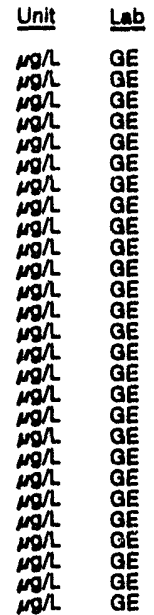

\section{WELL EPT 62}

MEASUREMENTS CONDUCTED IN THE FIELD

Sample date: 07/29/92

Depth to water: Not avallable

Water elovallon: Not avaliabio

P. conductance: irstem

Time: $6: 46$

PH: 5.3

Water temperature: $26.9^{\circ} \mathrm{C}$

\section{$E$ Analyte}

- Aluminum

o Antimony

O Antimony

A Arsenic

B Barium

o Beryllium

o Calclum

$\begin{array}{ll}0 & \text { Calcium } \\ 0 & \text { Chromium }\end{array}$

o Cobalt

o Copper

o iron

0 Lead

L Lithium

Magnesium

Manganeso

O Nickel

Potasalum

Selenium

o Selenium

o Silica

o Sllyer

Thallium

0 Thallium

o Tin

U Uranium

O Vanadium

Result 


\section{BLANK RESULTS}

\begin{tabular}{|c|c|c|c|}
\hline E Anatyte & Result & Mod & Unit \\
\hline 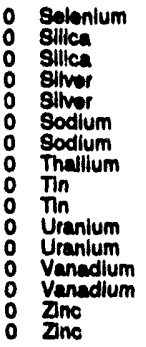 & $\begin{array}{r}<2.0 \\
<100 \\
<100 \\
<2.0 \\
<2.0 \\
17 \\
17 \\
<2.0 \\
3.3 \\
<2.0 \\
<20 \\
<20 \\
<8.0 \\
<8.0 \\
<2.0 \\
<2.0\end{array}$ & J1 & $\begin{array}{l}\mu g h \\
\mu g h \\
\mu g h \\
\mu g h \\
\mu g h \\
\mu g h \\
\mu g h \\
\mu g h \\
\mu g h \\
\mu g h \\
\mu g h \\
\mu g h \\
\mu g h \\
\mu g h \\
\mu g h \\
\mu g h \\
\mu g h \\
\mu g h\end{array}$ \\
\hline
\end{tabular}

\section{WELL EPT 56}

MEASUREMENTS CONDUCTED IN THE FIELD

\section{Eamplo data: 07/24pe}

8p. conductince: 1 avilatem

LABORATOFY ANLLYES

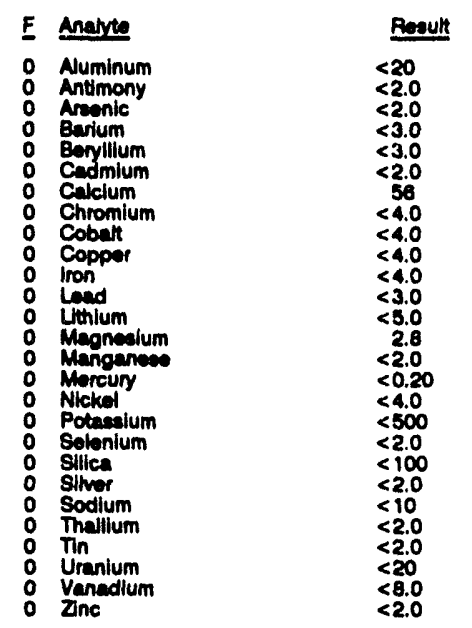

\section{WELLL EPT 57}

MEASUREMENTS CONDUCTED IN THE FIELD

Semple date: 07/25/22

Dopth to water: Not avallable Sp. conductince: 1 s $\$ / \mathrm{cm}$

LABOFATOFY ANALYYES

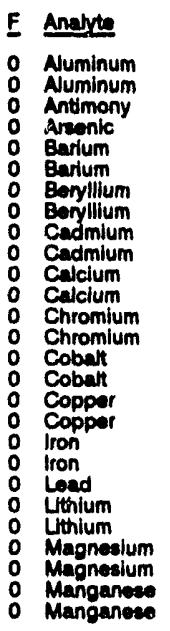

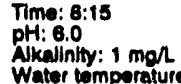

Water tomperafure: $28.7^{\circ} \mathrm{C}$

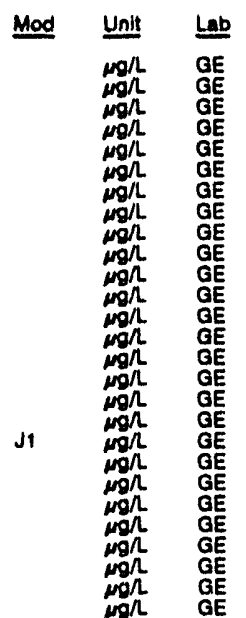

$\operatorname{Tim}_{0: 0}: 25$

PH: 4.8 Alkallinity: $1 \mathrm{~mol}$

Water tomporature: $28.0 \cdot \mathrm{C}$

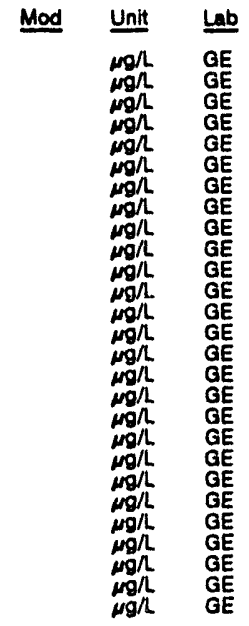

WELL EPT 37 collected on 07/25/92, laboratory analyses (cont.)
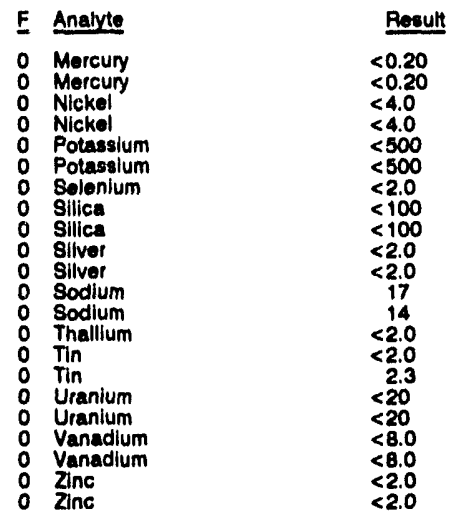

Mod

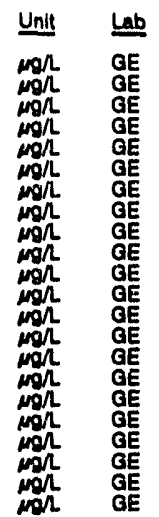

WELL EPT 58

\begin{tabular}{|c|c|c|c|c|c|}
\hline \multicolumn{4}{|c|}{ MEASUREMENTS CONDUCTED IN THE FIELD } & & \\
\hline \multicolumn{2}{|c|}{$\begin{array}{l}\text { Sample date: } 07 / 26 / 92 \\
\text { Depth to water: Not avallable } \\
\text { Water elovation: Not available } \\
\text { Sp. conductance: } 1 \text { NS/cm }\end{array}$} & \multirow[b]{3}{*}{ Result } & & & \\
\hline \multicolumn{5}{|c|}{ LABORATORY ANALYSES } & \\
\hline- & Analyte & & Mod & Unitt & Lئ \\
\hline $\begin{array}{l}0 \\
0 \\
0 \\
0 \\
0 \\
0 \\
0 \\
0 \\
0 \\
0 \\
0 \\
0 \\
0 \\
0 \\
0 \\
0 \\
0 \\
0 \\
0 \\
0 \\
0 \\
0 \\
0 \\
0 \\
0\end{array}$ & $\begin{array}{l}\text { Aluminum } \\
\text { Antimony } \\
\text { Arsenic } \\
\text { Barium } \\
\text { Beryllium } \\
\text { Cadmium } \\
\text { Calclum } \\
\text { Chromium } \\
\text { Cobsal } \\
\text { Copper } \\
\text { Iron } \\
\text { Lead } \\
\text { Lithium } \\
\text { Magnesium } \\
\text { Manganese } \\
\text { Mercury } \\
\text { Nickel } \\
\text { Potassium } \\
\text { Solenium } \\
\text { Sillica } \\
\text { Silver } \\
\text { Sodium } \\
\text { Thallium } \\
\text { Tin } \\
\text { Urranlum } \\
\text { Vanadium } \\
\text { Zinc }\end{array}$ & $\begin{array}{l}<20 \\
<2.0 \\
<2.0 \\
<3.0 \\
<3.0 \\
<2.0 \\
<10 \\
<4.0 \\
<4.0 \\
<4.0 \\
<4.0 \\
<3.0 \\
<5.0 \\
<2.0 \\
<2.0 \\
<0.20 \\
<4.0 \\
<500 \\
<2.0 \\
<100 \\
<2.0 \\
25 \\
<2.0 \\
<2.0 \\
<20 \\
<8.0 \\
<2.0\end{array}$ & J1 & 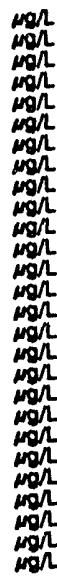 & $\begin{array}{l}\mathrm{GE} \\
\mathrm{GE} \\
\mathrm{GE} \\
\mathrm{GE} \\
\mathrm{GE} \\
\mathrm{GE} \\
\mathrm{GE} \\
\mathrm{GE} \\
\mathrm{GE} \\
\mathrm{GE} \\
\mathrm{GE} \\
\mathrm{GE} \\
\mathrm{GE} \\
\mathrm{GE} \\
\mathrm{GE} \\
\mathrm{GE} \\
\mathrm{GE} \\
\mathrm{GE} \\
\mathrm{GE} \\
\mathrm{GE} \\
\mathrm{GE} \\
\mathrm{GE} \\
\mathrm{GE} \\
\mathrm{GE} \\
\mathrm{GE} \\
\mathrm{GE} \\
\mathrm{GE}\end{array}$ \\
\hline
\end{tabular}

\section{WELL EPT 59}

MEASUREMENTS CONDUCTED IN THE FIELL

Sample date: $0727 / 92$

Depth to water: Not avallable

Wp. conductanco: 1 a

LABORATORY ANALYSES

Time: 6:15

PH: 5.2

Water temperature: $27.50^{\circ} \mathrm{C}$

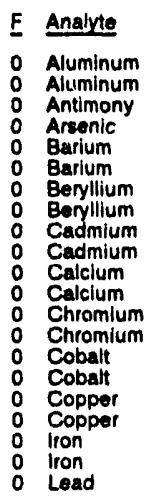

\begin{tabular}{l}
\multicolumn{1}{c}{ Pesult } \\
$<20$ \\
$<20$ \\
$<2.0$ \\
$<2.0$ \\
$<3.0$ \\
$<3.0$ \\
$<3.0$ \\
$<3.0$ \\
$<2.0$ \\
$<2.0$ \\
1.0 \\
17 \\
$<4.0$ \\
$<4.0$ \\
$<4.0$ \\
$<4.0$ \\
$<4.0$ \\
$<4.0$ \\
$<4.0$ \\
$<4.0$ \\
$<3.0$
\end{tabular} 
BLANK RESULTS

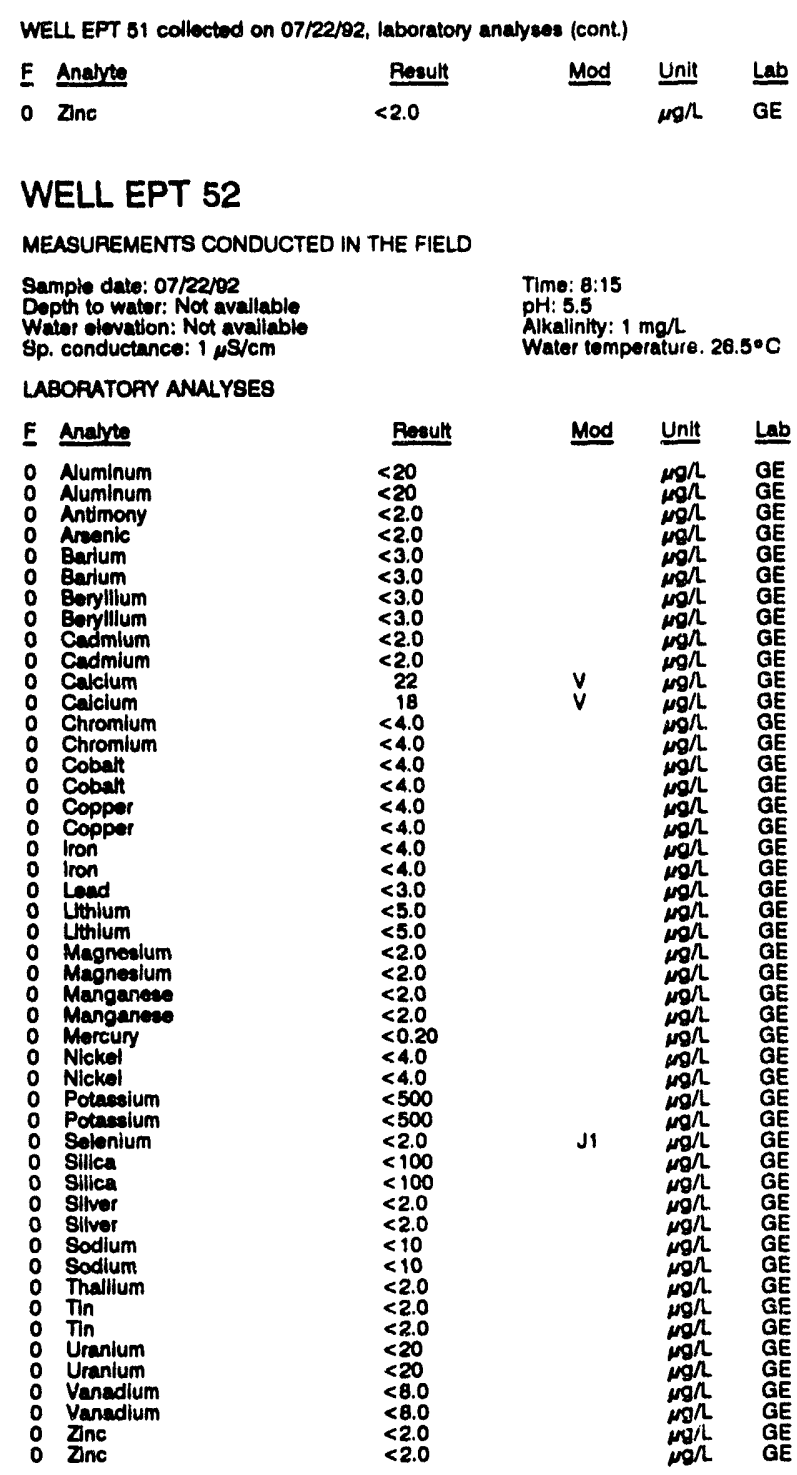

WELL EPT 53 collected on 07/23/92, laboratory analyses (cont.)

\begin{tabular}{|c|c|c|c|}
\hline E Analyte & Result & Mod & Unit \\
\hline $\begin{array}{ll}0 & \text { Selenium } \\
0 & \text { Solonilum } \\
0 & \text { Sllica } \\
0 & \text { Silver } \\
0 & \text { Sodium } \\
0 & \text { Thallilum } \\
0 & \text { Thallium } \\
0 & \text { Tin } \\
0 & \text { Uranlum } \\
0 & \text { Vanadium } \\
0 & \text { Zinc }\end{array}$ & $\begin{array}{l}<2.0 \\
<2.0 \\
<100 \\
<2.0 \\
50 \\
<2.0 \\
<2.0 \\
<2.0 \\
<20 \\
<8.0 \\
<2.0\end{array}$ & $\mathrm{J1}_{\mathrm{J1}}$ & 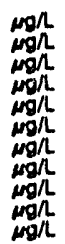 \\
\hline
\end{tabular}

\section{WELL EPT 54}

MEASUREMENTS CONDUCTED IN THE FIELD

Sample date: 07/23/92

Wopth to water: Not available

Sp. conductance: $1 \mu \mathrm{M} / \mathrm{cm}$

Timo: 7:65

Alkalinity: $1 \mathrm{mon}$

Water tomperature: $25.5^{\circ} \mathrm{C}$

\section{LABORATORY ANALYSES}

\section{$E$ Analyte}

- Aluminum

Antimony

: Arsenic

Barium

Cadium

Chromium

Cobatt

Clion

Lead

Lithlum

Manganeso

0 Mercury

Nickel

: Potassium

o silica

S Siliver

Sodium

: Tha

O Uranium

Vanadlum

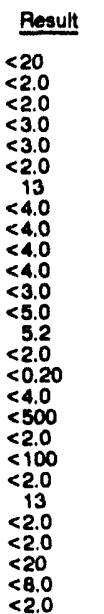

Mod Unitt Lab

WELL EPT 55

MEASUREMENTS CONDUCTED IN THE FIELD

Sample date: 07/24/92

Depth to water: Not available Water olovation: Not avaliablo

Tima: : 15

PH: 5.2 .2 $1 \mathrm{man}$

Water tomporature: $28.80 \mathrm{C}$

WELL EPT 53

LABORATORY ANALYSES

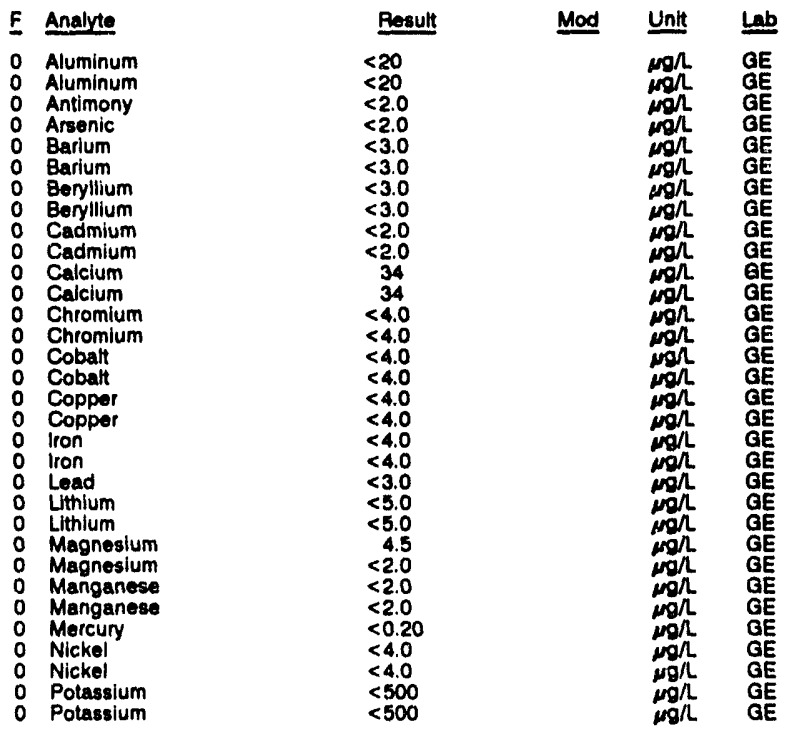


BLANK RESULTS

WELL EFT 43 collocted on 07/20/92, laboratory anelyses (cont)

E Analyte

O Copper

O Iron

o Load

SUthium

Magnesium

Magnetium

Manganese

O Morcury

O Nickel

Potasceium

Selenium

o Silica

S silver

0 simer

Sodium

Thallum

$0 \operatorname{Tin}_{\operatorname{lin}}$

Uranium

Vanadium

Vanadium

Zne

\begin{tabular}{l} 
Result \\
\hline 4.0 \\
$<4.0$ \\
$<4.0$ \\
$<4.0$ \\
$<3.0$ \\
$<5.0$ \\
$<5.0$ \\
3.9 \\
2.2 \\
$<2.0$ \\
$<2.0$ \\
0.23 \\
$<4.0$ \\
$<4.0$ \\
$<500$ \\
$<500$ \\
$<2.0$ \\
$<100$ \\
$<100$ \\
$<2.0$ \\
$<2.0$ \\
17 \\
18 \\
$<2.0$ \\
$<2.0$ \\
$<2.0$ \\
$<20$ \\
$<20$ \\
$<8.0$ \\
$<8.0$ \\
$<2.0$ \\
$<2.0$
\end{tabular}

Mod

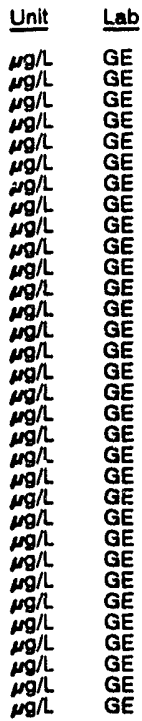

WELL EPT 49

MEASUREMENTS CONDUCTED IN THE FIELLD

\section{Sample date: 07/20/02}

Dopth to water: Not available Sp, conductance: $1 \mathrm{fs} / \mathrm{cm}$

LABORATORY ANALYSES

F Anabrte

o Aluminum

o Aluminum

- Arsenic

c Barium

0 Barium

o Beryllium

Beryilium

Cadmium

Cakclum

Chromium

- Chromium

Cobalt

O Cobalt

- Copper

o lion

Iron

- Uthiom

o Lthium

Magnesium

Manganese

Marganea

Morcuny

Nickol

O Nickel

- Potaseivm

- Selenium

S Slica

Silica

0 Sitver

0 Sodium

Sodium

Tha

: Tin

2 Uranium

Uranium

Vanadium

Zne
Time: 7:35

Alkalinity: $1 \mathrm{mg} / \mathrm{L}$

Water temperature: $25.2^{\circ} \mathrm{C}$

$<20$

$<2.0$

$<3.0$

$<3.0$

$<2.0$

22
17
$<4.0$

$<4.0$

$<4.0$

$<4.0$

$<4.0$

$<4.0$

$<4.0$

$<5.0$

10
2.6
$<2.0$

$<2.0$

0.31

$<4.0$

$<500$

$<2.0$

$<100$

$<2.0$

14
12

12
$<2.0$
$<2.0$

$<2.0$

$\begin{array}{r}31 \\ <20 \\ \hline\end{array}$

$<8.0$

$<8.0$

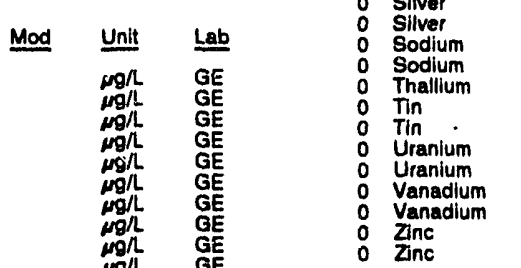

J2

Siver

Sodium

Thallium

Tin

Uranium

Vanadium

Zinc
WELL EPT 50

MEASUREMENTS CONDUCTED IN THE FIELD

Sample date: 07/21/92

Sp. conductance: $1 \mu \mathrm{s} / \mathrm{cm}$

LABORATORY ANALYSES

E Analyte

- Aluminum

o Antimony

Arsenic

- Barium

0 Beryllium

Beryitum

Cadmium

Calcium

0 Chromlum

Chromium

Cobalt

Copper

Copper

o tron

0 Lead

Lithium

Magnesium

Magnesium

Manganese

Morcuny

0 Nickel

Potassium

P Potassium

Selenium

silica

silica

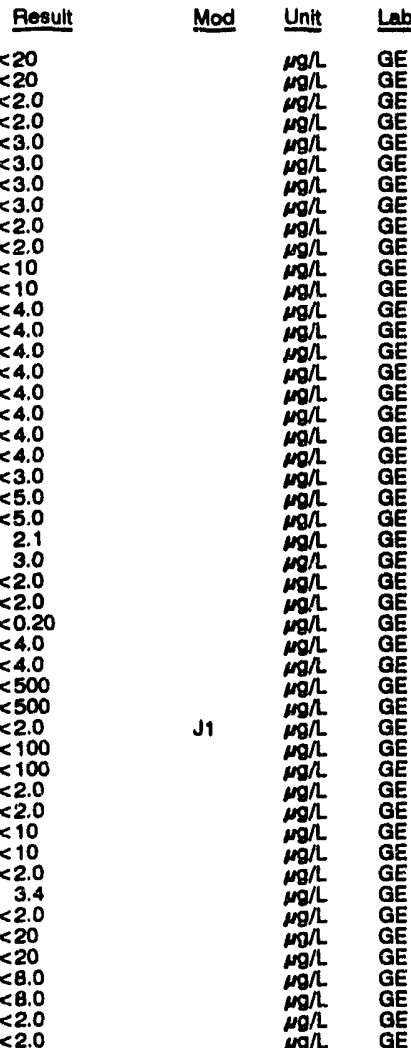

WELL EPT 51

MEASUREMENTS CONDUCTED IN THE FIELD

Sample date: 07/22/82

Depth to water: Not avaliable

Water elovation: Not availablo

Sp. conductance: $1 \mu \mathrm{s} / \mathrm{cm}$

LABORATORY ANALYSES

E Analyte

c Aluminum

Antimony

Arsenic

Beryllium

Cadmium

Calclum

Cobalt

Copper

Iron

Lead

Magnesium

Manganese

Mercury

Nickel

Potassium

Selenlum

Silica

Silver

Sodium

Tin

Varanium

Besult

$<20$

$<2.0$

$<<.0$

$<3.0$

$<2.0$
$<4.0$
$<4.0$

$<4$

11
$<3.0$
$<5.0$

$<5.0$
8.3
$<2.0$

$<<<0.20$

$<0.20$

$<4.0$

$<<.0$

$<100$
$<20$

2.0
$2<.0$
$<<2.0$
$<2.0$

$<2.0$
$<20$

$<20$
Time: 8:10

Alkalinity: $1 \mathrm{mg} / \mathrm{L}$

Water tomperature: $25.2^{\circ} \mathrm{C}$

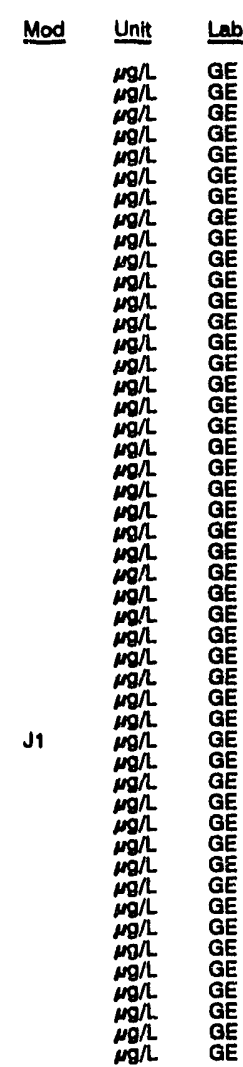

Alkalinity: $1 \mathrm{mg} \Omega$

Water temperature: $28.6^{\circ} \mathrm{C}$

Mod Unit Lab

$m g /$ GE

wgh GE

$\operatorname{mgh}$ GE

ML . GE

$\operatorname{moh}$ GE

酯

on

an

gh

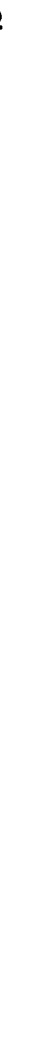




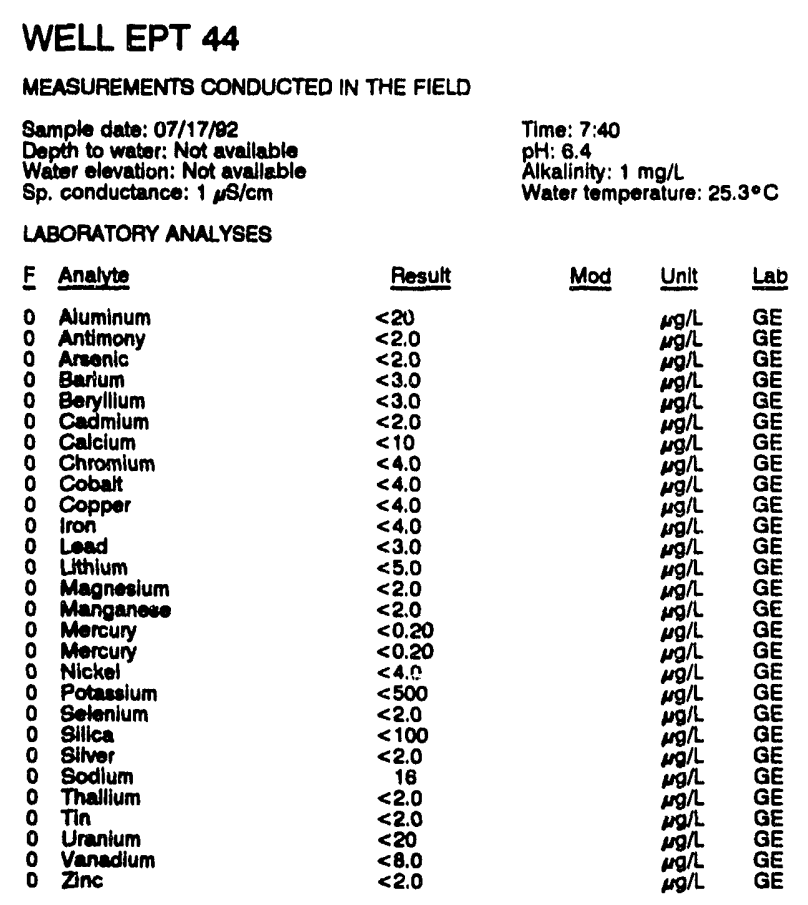

WELL EPT 45

MEASUREMENTS CONDUCTED IN THE FIELD

Sample dato: 07/17/82 Depth to water: Not available $\mathrm{Sp}$. conductance: $5 \mathrm{mS} / \mathrm{cm}$

LABORATOFY ANALYSES

\section{E Analyte}

2 Aluminum

: Antimony

O Berillium

O. Codmium

o Calcium

: Chromlum

o copper

Iron

L Lead

o Magnedum

M Morcury

o Potaselum

o sotenium

Silver

o sodium

: Thallium

U Uranium

: Vanedium

$\quad$ Result
255
$<2.0$
$<2.0$
$<3.0$
$<3.0$
$<2.0$
28
$<4.0$
$<4.0$
$<4.0$
$<4.0$
$<3.0$
$<5.0$
16
6.1
$<0.20$
$<4.0$
$<500$
$<2.0$
$<100$
$<2.0$
109
$<2.0$
$<2.0$
$<20$
$<8.0$
2.0

\section{WELL EPT 46}

MEASUREMENTS CONDUCTED IN THE FIELD

Sample data: 07/18/82

Dopth to wator: Not avallable

Sp. conductance: 1 Na/cm

LABOPATORY ANALYSES

\section{E Analve}

- Aluminum

: Antimony

: Aresentc

\begin{tabular}{|c|c|c|}
\hline Result & Mod & Unit \\
\hline $\begin{array}{l}<20 \\
<2.0 \\
<220 \\
<2.0 \\
<2.0\end{array}$ & & $\begin{array}{c}\mu g / h \\
\mu g / L \\
\mu g h \\
\mu g h \\
\mu g / L\end{array}$ \\
\hline
\end{tabular}

Time: 8:15

Alkalinity: $1 \mathrm{mg} /$.

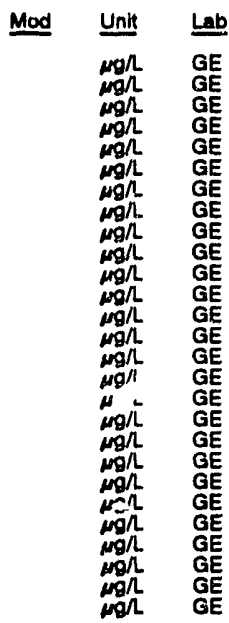

Time: 7:35

Alkalinity: $1 \mathrm{mg} / \mathrm{h}$

Water temperature: $25.2^{\circ} \mathrm{C}$
WELL EPT 46 collected on 07/18/82, laboratory analyses (cone)

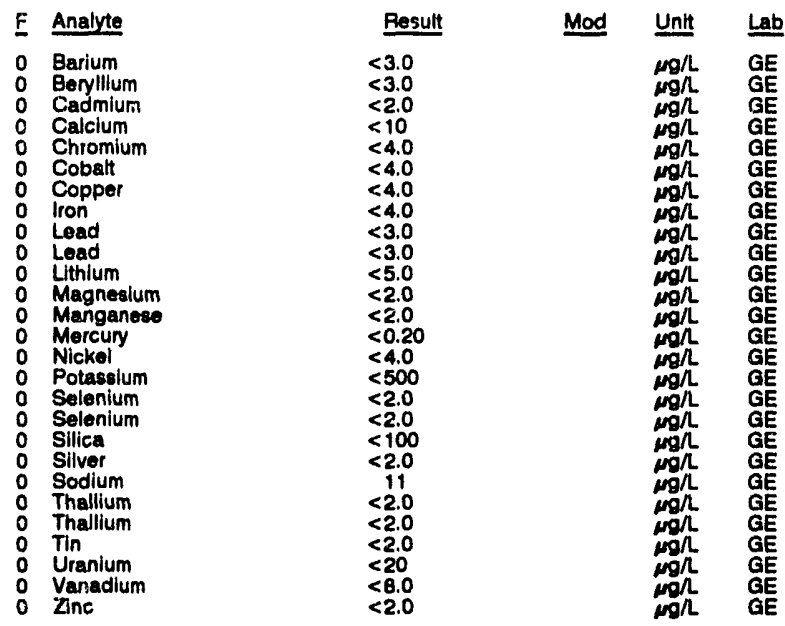

WELL EPT 47

MEASUREMENTS CONDUCTED IN THE FIELD

Sample date: 07/19/92

Water elevation: Not avalleblo

$\mathrm{Sp}$. conductance: $2 \mu \mathrm{s} / \mathrm{cm}$

LABORATORY ANALYSES

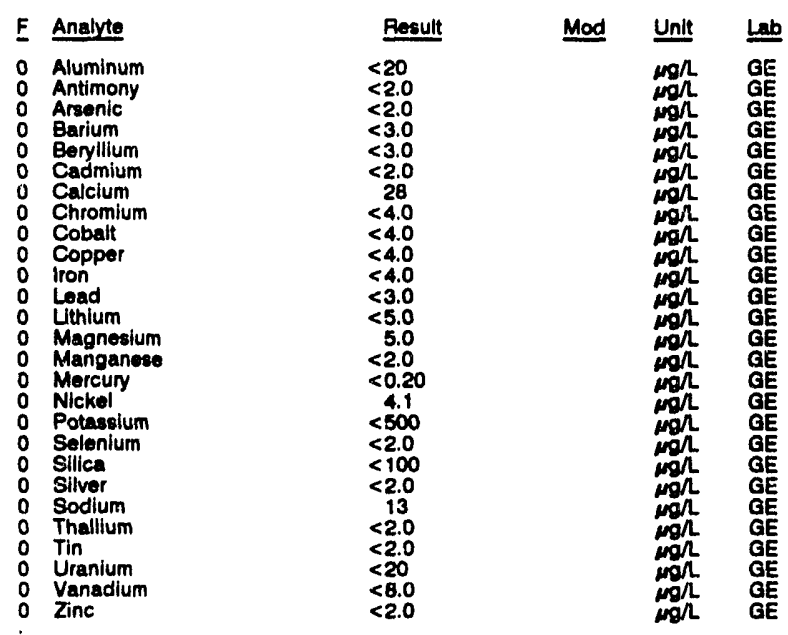

\section{WELL EPT 48}

MEA SUREMENTS CONDUCTED IN THE FIELD

Sample date: 07/20/82

Wepth to water: Not avallable

$\mathrm{Sp}$. conductance: $1 \mathrm{\mu S} / \mathrm{cm}$

Time: : 8:00

Alkalinity: $1 \mathrm{mgh}$

Water temperature: $24.4^{\circ} \mathrm{C}$

LABORATORY ANALYSES

\section{$E$ Analyze}

- Aluminum

0 Aluminum

0 Arsenic

Bailum

Beryilium

Deryllium

Cadmium

Cadmium

Calcium

Chromium

o Chromium

O Cobalt
Time: 7:45

PH: 5.345

Watter tomportature: $24.3{ }^{\circ} \mathrm{C}$

\begin{tabular}{|c|c|c|}
\hline Posult & Mod & Unit \\
\hline $\begin{array}{l}20 \\
20 \\
2.0 \\
2.0 \\
3.0 \\
3.0 \\
3.0 \\
3.0 \\
2.0 \\
2.0 \\
15 \\
15 \\
4.0 \\
4.0 \\
40\end{array}$ & & 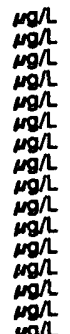 \\
\hline
\end{tabular}


BLANK RESULTS

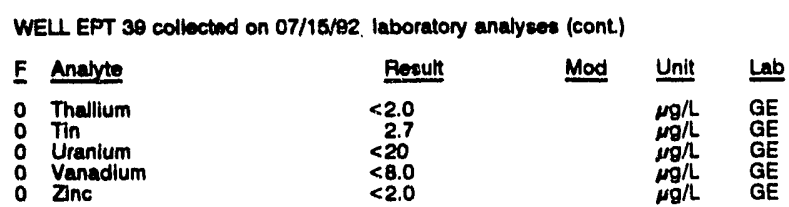

WELL EPT 40

MEASUREMENTS CONDUCTED IN THE FIELD

Sample date: 07/16/82 Wepth to water: Not avallable Sp. conductance: $1 / \mathrm{S} / \mathrm{cm}$

LABORATOFY ANALYEES

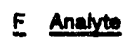

- Aluminum

o Aluminum

Areanic

o Eryllium

Calcium

Chromium

o Cobalt

o Iron

o Lead

o Megnedum

- Manganeas

o Marcuny

Potavelum

Selenium

o siver

Sodlum

Thelliu

Uranlum

O Vanadlum

$<2.0$

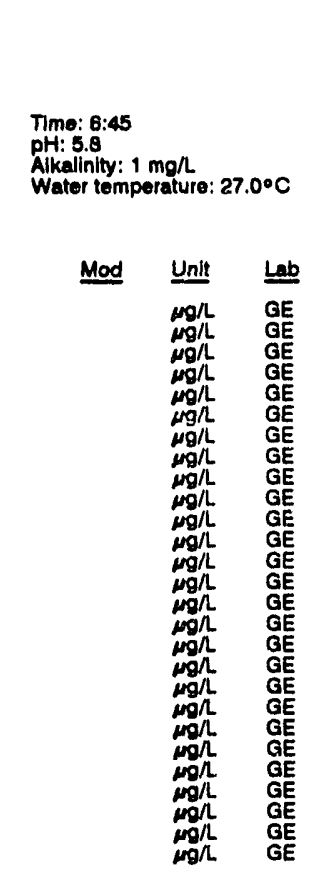

WELL EPT 41

MEASUREMENTS CONDUCTED IN THE FIELD

Sample date: 07/16/92

Depth to water: Not avaliable

Sp. conductance: $1, \mathrm{~s} / \mathrm{cm}$

LABORATORY ANALYSES

F Anatyto

- Aluminum

0 Antimony

Brenic

Baryllium

Cadmium

Chromium

Cobst

Copper

iron

Ltthlum

Magnealum

Manganece

Mickel

Nickel

Potaseium

silica

Situer

Thallium

o Tha

U̦ranium

Variadium

O Znine

\begin{tabular}{c} 
Result \\
\hline 20 \\
$<2.0$ \\
$<2.0$ \\
$<3.0$ \\
$<3.0$ \\
$<2.0$ \\
$<10$ \\
$<4.0$ \\
$<4.0$ \\
$<4.0$ \\
$<4.0$ \\
$<3.0$ \\
$<5.0$ \\
2.3 \\
$<2.0$ \\
$<0.20$ \\
$<4.0$ \\
$<500$ \\
$<2.0$ \\
$<100$ \\
$<2.0$ \\
19 \\
$<2.0$ \\
$<2.0$ \\
$<20$ \\
$<8.0$ \\
$<2.0$
\end{tabular}

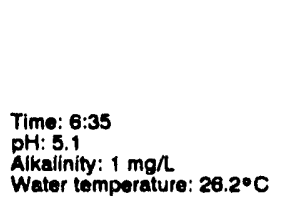

Mod Unit Lab

m $\mathrm{m} / \mathrm{L}$ GE

$<20$

$<2.0$

$<3.0$

$<3.0$

12
$<4.0$

$<4.0$

$<4.0$

$<4.0$
$<3.0$
$<5.0$

$<5.0$
5.6
$<2.0$

$<2.0$

$<4.0$

$<500$

$<100$

$<2.0$

$<10$

$<2.0$

$<200$
WELL EPT 42

MEASUREMENTS CONDUCTED IN THE FIELD

Sample date: 07/16/92

Depth to water: Not avallable

Water olevation: Not available
Sp. conductance: $4 \mu \mathrm{S} / \mathrm{cm}$

LABORATORY ANALYSES

E Analyte

1 Aluminum

A Antimony

: Arsenic

o Beryllium

C Cadmium

O Chromium

0 Cobalt

Copper

0 Lead

o Luthium

o Magnesium

Mercury

Nickel

Potassium

Silica

Silver

Sodium

Thallium

Uranium

0 Vanadium

Result

30
$<2.0$

$<2.0$

$<3.0$

$<2.0$
146
$<4.0$

$<4.0$

$<4.0$

$<4.0$

$<3.0$
$<5.0$
57

57
6.8
$<0.20$

$<0.20$

$<500$

$<2.0$

$<2.0$
174

$<2.0$
$<2.0$

$<20$

$<8.0$

\section{WELL EPT 43}

MEASUREMENTS CONDUCTED IN THE FIELD

Samplo date: 07/17/82

Depth to water: Not available

Sp. conductance: $2 \mu \mathrm{s} / \mathrm{cm}$

AH: 5.5 . 1 alinity: $1 \mathrm{mgh}$

Water temperature: $25.5^{\circ} \mathrm{C}$

LABORATORY ANALYSES

E Analyte

- Aluminum

Aluminum

Antimony

Arsenic

0 Barium

B Baryillum

o Beryillum

Cadmium

- Calcium

- Calcium

Chromium

O Cobat

o Copper

o Copper

0
0
lion

0 lion

L.thium

D Lithium

o Magnesium

o Manganese

o Marcury

O Nickel

Nickel

Potassium

o Selentum

o Sillica

o Silica

o Silver

O Sodlum

Sodium

o Tin

0 Tin

- Uranium

Uranium

Vanadium

0 Zinc

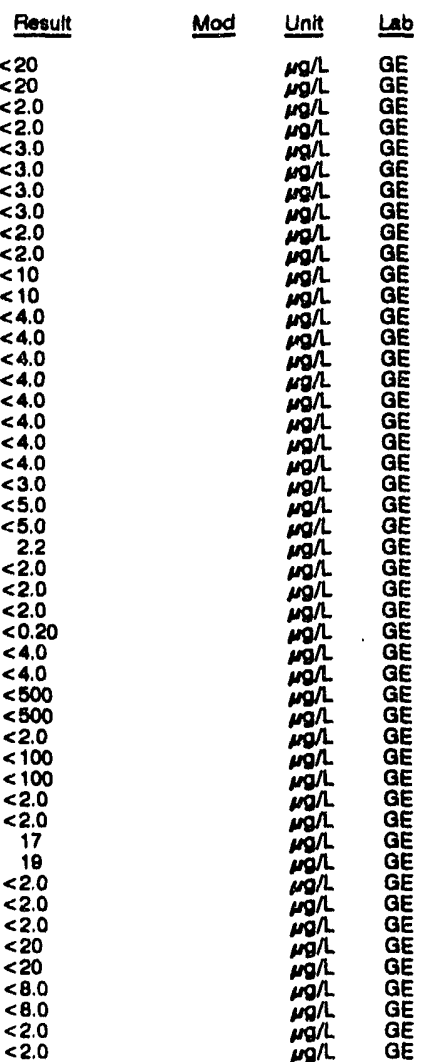




\section{BLANK RESULTS}

WELL EPT 36 coliected on 07/14/92, laboratory analyses (cont)

F Analyte

- Barlum

Beryllium

Cadmium

Calclum

Caiclum

Chromium

Cobalt

Cobaht

Copper

Iron

0 Lead

L Lithium

Magnesium

Magnosium

Manganese

Mercury

Nickel

Nickel

Potaselum

Solanium

silica

Silla

Silver

Sivor

Sodium

Thallium

Tin

Uranium

Uranium

Vanadium

Zinc

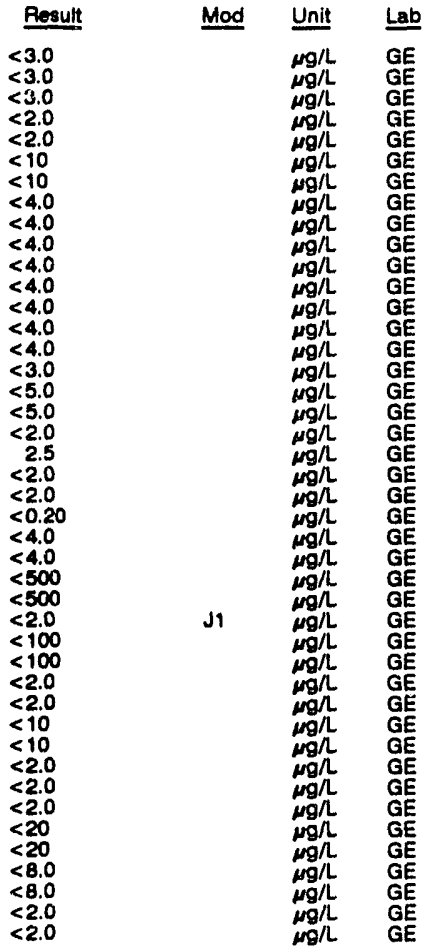

WELL EPT 37

MEASUAEMENTS CONDUCTED IN THE FIELD

\section{Sample date: 07/14/82}

Depth to water: Not available

Sp. conductance: $4 \mu \mathrm{S} / \mathrm{cm}$

LABOPATOAY ANALYSES

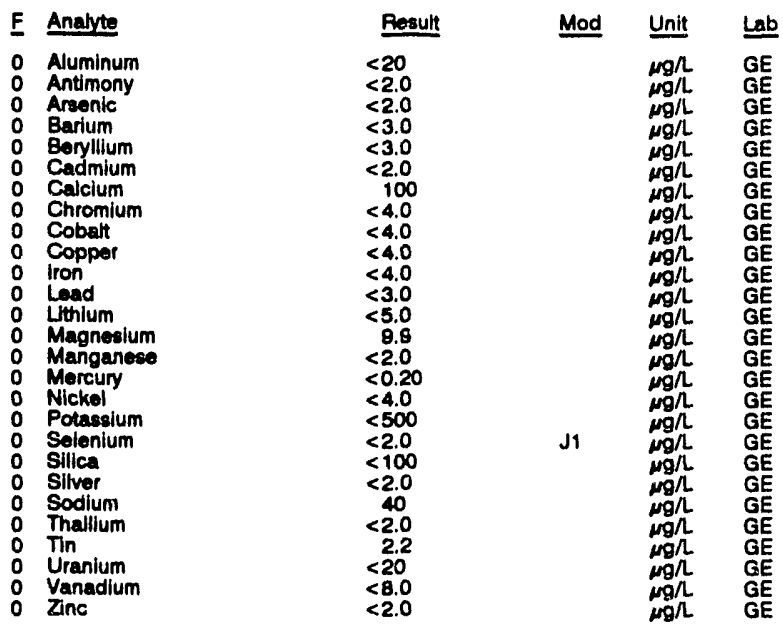

WELL EPT 38

MEASUAEMENTS CONDUCTED IN THE FIELD

Sample date: $07 / 15 / 92$

Depth to Water: Not available

Sp. conduction: Nor avallable

LABORATOAY ANALYSES

F Analyte

o Aluminum

Antimony

- Arsenic

0 Barium

B Barium

Beryllum

Cadmium

Calcium

o Chromium

Chromium

Cobalt

o Copper

- Copper

0 Iron

0 Lead

L Lithium

Magnesium

Magnesium

Manganese

0 Mercury

Nickel

Potassium

Selenium

Silica

Silica

o Silver

- Silver

o Sodium

Thallium

0 Tin

- Tin

- Uranium

Vanadium

Zinc

\begin{tabular}{r} 
Pesult \\
\hline 20 \\
$<20$ \\
$<20$ \\
$<2.0$ \\
$<2.0$ \\
$<3.0$ \\
$<3.0$ \\
$<3.0$ \\
$<3.0$ \\
$<2.0$ \\
$<2.0$ \\
20 \\
20 \\
$<4.0$ \\
$<4.0$ \\
$<4.0$ \\
$<4.0$ \\
$<4.0$ \\
$<4.0$ \\
$<4.0$ \\
$<4.0$ \\
$<3.0$ \\
$<5.0$ \\
$<5.0$ \\
$<2.0$ \\
33.5 \\
$<2.0$ \\
$<2.0$ \\
$<0.20$ \\
$<4.0$ \\
$<4.0$ \\
$<500$ \\
$<500$ \\
$<2.0$ \\
$<100$ \\
$<100$ \\
$<2.0$ \\
$<2.0$ \\
18 \\
19 \\
$<2.0$ \\
$<2.0$ \\
$<2.0$ \\
$<20$ \\
$<20$ \\
$<8.0$ \\
$<8.0$ \\
$<2.0$ \\
$<2.0$
\end{tabular}

Time: 6:00

PH: 5.0 . $1 \mathrm{mg}$

\section{WELL EPT 39}

MEASUREMENTS CONDUCTED IN THE FIELO

Sample date: 07/15/92

Depth to water: Not available

Water elevation: Not avaliable
$\mathrm{Sp}$. conductance: $1 \mathrm{~s} / \mathrm{cm}$

LABORATORY ANALYSES

F Analyte

- Aluminum

Antimony

0 Arsenic

0 Arsenic

\begin{tabular}{ll}
0 & Arsenic \\
0 & Barium \\
\hline & Beryilum
\end{tabular}

o Beryllium

O Cadmium

C Calcium

O Chromium

o Copalt

o Iron

0 Lead

0 Lead

O Magnesium

Manganese

Mercury

Potassium

Selenium

Selenium

O Sillica

o Silver

0 Thallium
Water temperature: $26.7 \circ \mathrm{C}$

Mod Unit Lab

$\mathrm{mg} / \mathrm{L} \quad \mathrm{GE}$

$M g$ GE

$g /$ GE

$\operatorname{\omega g} \mathrm{GE}$ 
BLANK RESULTS

WELL EPT 32

MEASUAEMENTS CONDUCTED IN THE FIELD

Sample dato: 07/11/82

Wepth to water: Not avaliabie

Sp. conductanco: $1 \mathrm{\mu S} / \mathrm{cm}$

LABOPATORY ANALYSES

$F$ Analyte

- Auminum

o Antimony

coryillum

Calcium

Chromium

Cobati

Copp

Lad

Megneaslum

Manganeas

Morcury

Potanealum

Solonium

Sillea

Sodium

Thallum

Tin

Uranlum

Zane

\begin{tabular}{l} 
Result \\
\multicolumn{1}{c}{ P20 } \\
$<2.0$ \\
$<2.0$ \\
$<3.0$ \\
$<3.0$ \\
$<3.0$ \\
$<2.0$ \\
$<10$ \\
$<4.0$ \\
$<4.0$ \\
$<4.0$ \\
$<4.0$ \\
$<3.0$ \\
$<5.0$ \\
3.4 \\
$<2.0$ \\
$<0.20$ \\
$<4.0$ \\
$<500$ \\
$<2.0$ \\
$<100$ \\
$<2.0$ \\
$<10$ \\
$<2.0$ \\
$<2.0$ \\
$<20$ \\
$<8.0$ \\
$<2.0$
\end{tabular}

Barium

WELL EPT 33

MEASUREMENTS CONDUCTED IN THE FIELD

Sample data: 07/12/02

Depth to water: Not avallable

Sp. conductance: $1 \mathrm{\mu s} / \mathrm{cm}$

LABORATOFY ANALYSES

E Anajyte

- Numinum

Aluminum

: Arsonic

Barium

: Beryllium

Cadmium

calclum

Calcium

: Cromium

Cobat

Cobat

Copper

iron

: ron

Lthhlum

: Wthium

Magnestum

Mangenose

Morcuny

Nickel

Nickol

- Potasalum

Solonium

sillea

Sillea

Siturer

siver

S sodium

Thallium

In

: Trin

Uranlum

: Vananium

- Vanadium

Znc
Time: 7:25

PAk 4.7 alinity: $1 \mathrm{mo} / \mathrm{L}$

Water temperature: $26.4^{\circ} \mathrm{C}$

Mod Unit Lab

mg/L GE $\quad$ : Aluminum

: Arsonic

B Beryllium

$\therefore$ Cadmlum

C Chromium

Cobalt

Copper

Lead

o Luthium

Magneslum

Manganeso

N Mercury

Potassium

o Silica

Silivor

Sodium

Thallium

Tin

Uranium

Z Zinc

WELL EPT 35

MEASUREMENTS CONDUCTED IN THE FIELD

Sample date: 07/13/92

Wepth to water: Not available

Water elevalion: Nor avalabio

Wp. Conductance. 5 mS/cm

LABORATORY ANALYSES

\section{$E$ Analyze}

- Aluminum

Arsonic

Barium

Corllium

Calcium

Chromium

Copper

Iron

Lead

- Magnesium

Manganose

O Mercury

Mercuny

Nickel

Potassium

Silice

0 Silver

Thallium

: Thallium

O Uin

: Zunc

WELL EPT 36

MEASUREMENTS CONDUCTED IN THE FIELD

Sample date: 07/14/92

Depth to water: Not avallable

Water elevation: Not avaliablo

Sp. conductance: $1 \mu \mathrm{s} / \mathrm{cm}$

LABORATORY ANALYSES

\begin{tabular}{|c|c|}
\hline Analyze & Pesult \\
\hline $\begin{array}{ll}0 & \text { Aluminum } \\
0 & \text { Aluminum } \\
0 & \text { Antimony } \\
0 & \text { Arsenic } \\
0 & \text { Barium }\end{array}$ & $\begin{array}{l}<20 \\
<20 \\
<2.0 \\
<2.0 \\
<3.0\end{array}$ \\
\hline
\end{tabular}

Time: 7:05

PH: s.0. $11 \mathrm{~mol}$

Water tomperature: $26.8^{\circ} \mathrm{C}$

Result
Re
$<20$
$<2.0$
$<2.0$
$<3.0$
$<3.0$
$<2.0$
$<10$
$<4.0$
$<4.0$
$<4.0$
$<4.0$
$<3.0$
$<5.0$
2.3
$<2.0$
$<0.20$
$<4.0$
$<500$
$<2.0$
$<100$
$<2.0$
$<10$
22.0
$<2.0$
$<20$
$<8.0$
$<2.0$

Mod Unit Lab

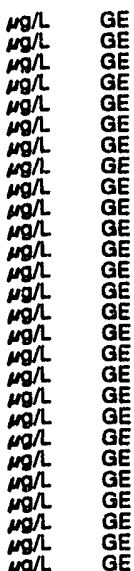

Timo: 8:00

AH: 4.8900 ikalinity: $1 \mathrm{mal}$

Water tomperalure: $24.8^{\circ} \mathrm{C}$

Pesult Mod Unit Lab

$<20$

$<<2.0$

$<3.0$

$<2.0$

67
$<4.0$

$<4.0$

$<4.0$

$<3.0$

5.0
$<2.0$
$<$

$<0.20$

$<4.0$

$<2.0$

$<100$

15
$<2.0$

$<2.0$

$<20$

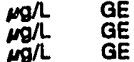

1 ${ }_{0,} \mathrm{GE}$

J2

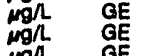

J2

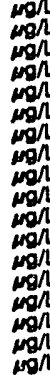

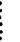

Time: 6:30

pH: 5.3

Water tomperature: $27.0 \circ \mathrm{C}$

Pesult

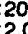

$<2.0$
Mod

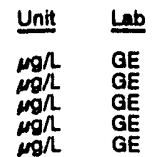




\section{BLANK RESULTS}

\begin{tabular}{|c|c|c|c|c|}
\hline \multicolumn{5}{|c|}{ WELL EPT 27 colloctod on 07/09/92, laboratory analyses (cont) } \\
\hline F Analyte & Result & Mod & $\underline{\text { Unit }}$ & Lab \\
\hline 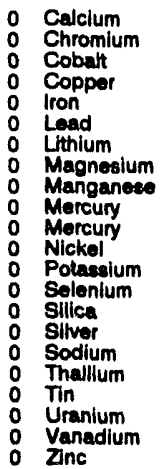 & $\begin{array}{l}<10 \\
<4.0 \\
<4.0 \\
<4.0 \\
<4.0 \\
<3.0 \\
<5.0 \\
<2.0 \\
<2.0 \\
<0.20 \\
<0.20 \\
<4.0 \\
<500 \\
<2.0 \\
<100 \\
<2.0 \\
<10 \\
<2.0 \\
<2.0 \\
<20 \\
<8.0 \\
<2.0\end{array}$ & $\mathrm{Jt}$ & 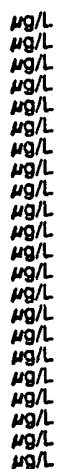 & $\begin{array}{l}G E \\
G E \\
G E \\
G E \\
G E \\
G E \\
G E \\
G E \\
G E \\
G E \\
G E \\
G E \\
G E \\
G E \\
G E \\
G E \\
G E \\
G E \\
G E \\
G E \\
G E \\
G E \\
G E\end{array}$ \\
\hline
\end{tabular}

\section{WELL EPT 28}

MEASUREMENTS CONDUCTED IN THE FIELD

Sample date: 07/09/82

Wopth to water: Not avallable Sp. conductanco: 3 uvaliablo

LABORATOAY ANALYSES

E Anabyte

A Aluminum

o Arsonic

Borillium

Cadmium

Calcium

Cobati

Copper

Iron

L Load

Magnesium

Manganese

Nickel

o Potassium

: Solenium

situer

Thallum

: Thallium

- Tiranium

0 Zinc
V Vanadium
Time: 7:45

PH: 4.8 Alkalinity: 1 mon

Alkalinity: 1 mon 27.00

Mod

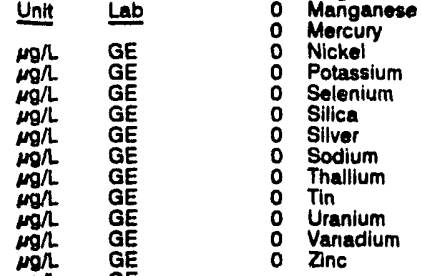

Chromium

Cobalt

Copper

tron

Lead

Magneslum

Manganese

Morcury

Potassium

Selenium

Thallium

Uranium

Zana
WELL EPT 29 collected on 07/08/82, laboratory analyser (cont)

$\begin{array}{ll}\text { E } & \text { Analyte } \\ 0 & \text { Sodium } \\ 0 & \text { Thallium } \\ 0 & \text { Tin } \\ 0 & \text { Uranium } \\ 0 & \text { Vanadium } \\ 0 & \text { Zine }\end{array}$

Result
$<10$
$<2.0$
$<2.0$
$<20$
$<8.0$
$<2.0$

Mod

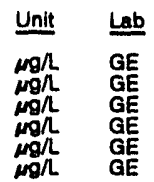

WELL EPT 30

MEASUREMENTS CONDUCTED IN THE FIELD

Sample date: 07/10/82

Dopth to water: Not available

Water olevation: Not avaliabio

Time: 8:15

Alkalinity: $1 \mathrm{mg} / \mathrm{h}$

Water tomperature: $28.00^{\circ} \mathrm{C}$

LABORATORY ANALYSES

E Analyte

0 Arsonic

Berlilum

Cadmium

\begin{tabular}{l} 
Result \\
\hline 47 \\
$<2.0$ \\
$<2.0$ \\
$<3.0$ \\
$<3.0$ \\
$<2.0$ \\
20 \\
$<4.0$ \\
$<4.0$ \\
$<4.0$ \\
$<4.0$ \\
$<3.0$ \\
$<5.0$ \\
4.9 \\
4.7 \\
$<0.20$ \\
$<4.0$ \\
$<500$ \\
$<2.0$ \\
$<100$ \\
$<2.0$ \\
67 \\
$<2.0$ \\
2.2 \\
$<20$ \\
$<8.0$ \\
$<2.0$
\end{tabular}

Mod Unit Le

Res:

$<7.0$

$<3.0$

$<3.0$

$<20$

$<4.0$

$<4.0$

$<3.0$
$<5.0$

4.8

$<500$

$<2.0$

$<2.0$
67

67
2.0
2.2

$<8.0$

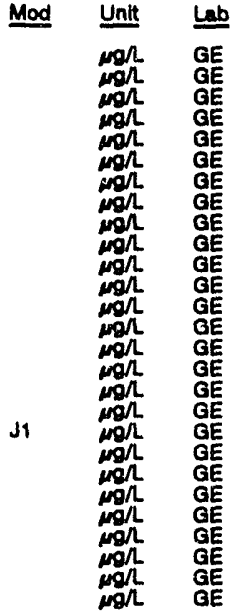

WELL EPT 31

MEASUREMENTS CONDUCTED IN THE FIELD

Sample date: $07 / 10 / 82$

Depth to water: Not avaliable Woter elevation: Not available Sp. conductance: $1 \mathrm{NS} / \mathrm{cm}$

LABORATORY ANALYSES

$E$ Analyte

- Aluminum

Antimony

Arsenic

Beryllium

Cadmium

Chromium

Cobalt

Copper

lion

PHikalinity: $1 \mathrm{mgh}$
Water tomperalure: 27.800

Sp. conductance: $1 \mathrm{AS} / \mathrm{cm}$

LABOPATOPY ANALYSES

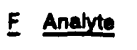

o Aluminum

Antimony

Arsenic

Berrillum

Cadclum

Chromium

Cobatt

Copper

loon

Luthium

Magnesium

Manganos

Mercury

Potaconium

silica

\begin{tabular}{l}
\multicolumn{1}{c}{ Result } \\
$<20$ \\
$<2.0$ \\
$<2.0$ \\
$<3.0$ \\
$<3.0$ \\
$<2.0$ \\
$<10$ \\
$<4.0$ \\
$<4.0$ \\
$<4.0$ \\
$<4.0$ \\
$<3.0$ \\
$<5.0$ \\
4.8 \\
$<2.0$ \\
$<0.20$ \\
$<4.0$ \\
$<500$ \\
$<2.0$ \\
$<100$ \\
$<2.0$
\end{tabular}

Mad Unit Lab

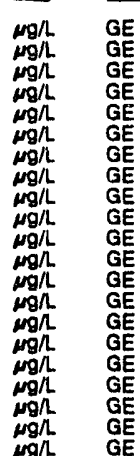

Time: 7:50

Alkalinity: $1 \mathrm{mg} / \mathrm{L}$ Water tomperature: $28.60^{\circ} \mathrm{C}$

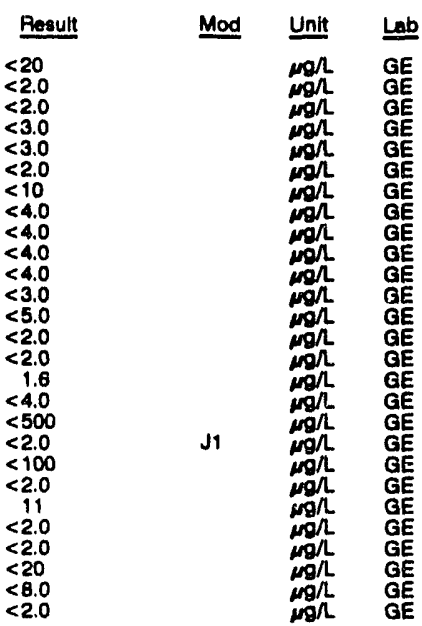


BLANK RESULTS

WELL EPT 22 collected on 07/07/82, laboratory analyses (cont)

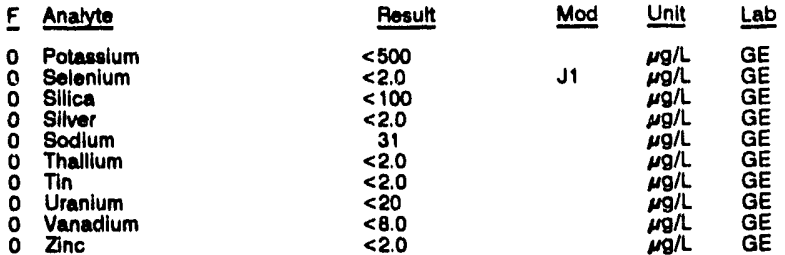

\section{WELL EPT 23}

MEASUREMENTS CONDUCTED IN THE FIELD

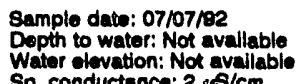

Water elevation: Not avalab

LABOPATORY ANALYSES

E Anabyte

- Aluminum

Antimony

o Barium

0 Beryllum

Cadmium

C Chromlum

O Cobat

o ropper

L Loed

: Luthium

Manganeso

Morcury

o Potasealum

Solenium

o silica

Sodium

Thallium

Tin

Uranium

Z Vanc

\begin{tabular}{|c|}
\hline $\begin{array}{l}20 \\
2.0 \\
2.0 \\
3.0 \\
3.0 \\
2.0 \\
10 \\
4.0 \\
4.0 \\
4.0 \\
4.0 \\
3.0 \\
5.0 \\
2.1 \\
2.0 \\
.020 \\
4.20 \\
5.00 \\
2.0 \\
100 \\
2.0 \\
2.1 \\
2.0 \\
2.0 \\
2.0 \\
.8 .0 \\
2.0\end{array}$ \\
\hline
\end{tabular}

WELL EPT 24

MEASUREMENTS CONDUCTED IN THE FIELD

Samplo date: 07/08/82

Depth to water: Not avallable

Sp. conductance: $1 \mathrm{\mu S} / \mathrm{cm}$

LABORATORY ANALYSES

E Anabyte

o Aluminum

Antimony

Antimony

Arsonic

Barium

Beryllium

Cadmium

Chromium

Cobat

Copper

Lroad

Load

Luthium

Magnesium

Manganeso

Mercury

Potasesium

Solentum

0 silica

Silvor

sodium

Thallum

Thallium

Tin

Uranium

Znce

\section{Time: 8:10 \\ Alkalinity: $1 \mathrm{mgh}$ \\ Water temperature: $24.6^{\circ} \mathrm{C}$}

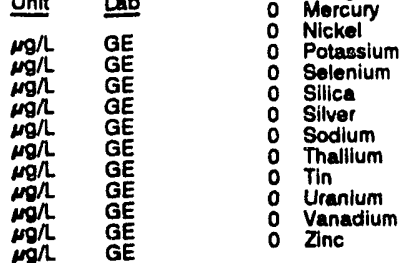

WELL EPT 26

MEASUREMENTS CONDUCTED IN THE FIELD

Sample date: 07/08/92

Depth to water: Not avallable

Water olevation: Not available
Sp. conductance: $1 \mu \mathrm{S} / \mathrm{cm}$

LABORATORY ANALYSES

F Analyte

- Aluminum

Antimony

: Arsenic

O Beryllium

Calcium

Chromium

Cobalt

o Iron

0 Lead

O Magnestum

o Manganese

- Mercury

Potassium

Solassium

o Sillica

o Silver

Sodium

o Thallium

Tin

Vanadium

WELL EPT 27

MEASUREMENTS CONDUCTED IN THE FIELD

Sample date: 07/09/92

Depth to water: Not avallable

Water elevation: Not available

p. conductance: $1 \mu \mathrm{s} / \mathrm{cm}$

LABORATOAY ANALYSES

$E$ Analyte

- Aluminum

Antimony

Arsenic

Beryllium

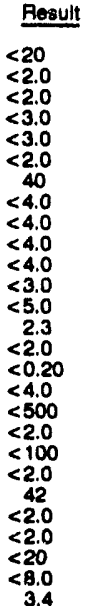

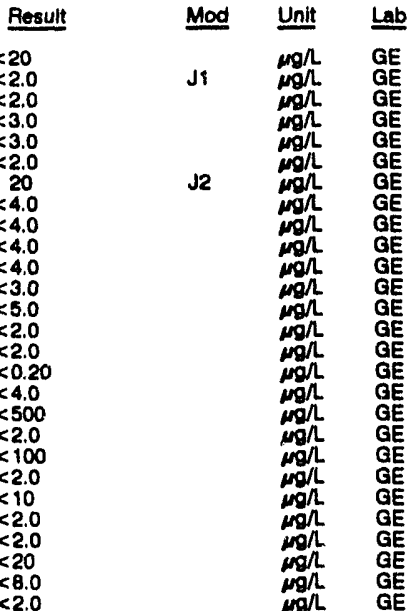

PH: 5.4 .4 $1 \mathrm{mgal}$

Water tomperature: $25.0^{\circ} \mathrm{C}$

Time: 8:00

PH: 5.3

Water temperature: $24.8^{\circ} \mathrm{C}$

Mod Unit Lab

J1

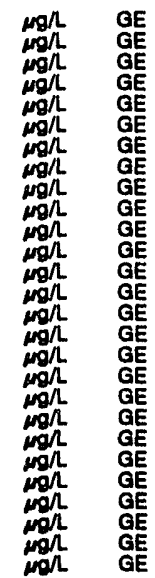

mgll GE 


\section{BLANK RESULTS}

WELL EPT 18 collected on 07/05/82, laboratory analyses (cont)

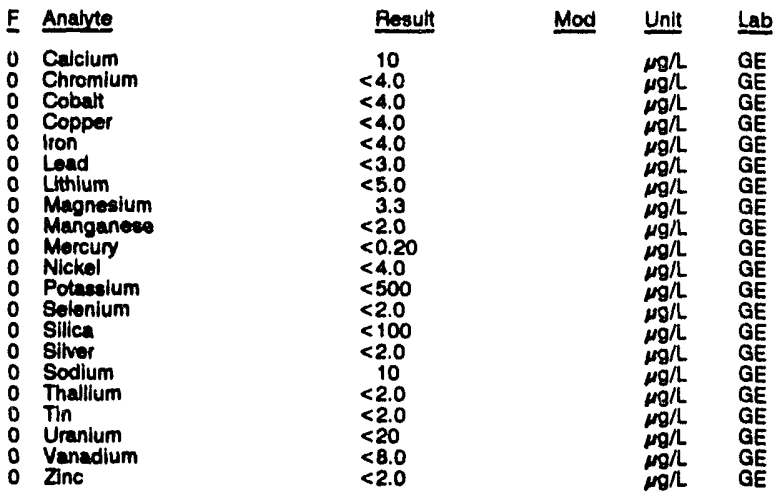

\section{WELL EPT 19}

\section{MEASUREMENTS CONDUCTED IN THE FIELD}

Sample date: 07/06/92

Depth to water: Not avallable

Walcr envation: Nor avalabi

LABORATOFY ANALYSES

E Anatyte

o Aluminum

Arsenic

Barium

Baryllium

Calcium

Cobalt

iron

Lead

Magneaium

Mangane:

Mickel

Potassium

Solenium

Silver

Sodium

Thallium

Tin

Uranium

Zane

WELL EPT 20

MEASUREMENTS CONDUCTED IN THE FIELD

Sample dato: 07/08/82 Depth to water: Not available Water elevation: Not avallable

LABORATOFY ANALYSES

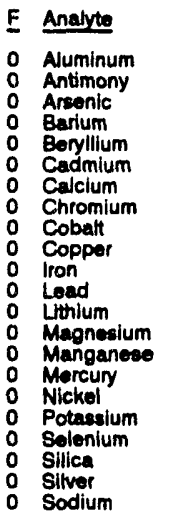

\begin{tabular}{l}
$\quad$ Result \\
\hline 20 \\
$<2.0$ \\
$<2.0$ \\
$<3.0$ \\
$<3.0$ \\
$<2.0$ \\
$<10$ \\
$<4.0$ \\
$<4.0$ \\
$<4.0$ \\
$<4.0$ \\
$<3.0$ \\
$<5.0$ \\
$<2.0$ \\
$<2.0$ \\
$<0.20$ \\
$<4.0$ \\
$<500$ \\
$<2.0$ \\
$<100$ \\
$<2.0$ \\
$<35$ \\
$<2.0$ \\
$<2.0$ \\
$<20$ \\
$<8.0$ \\
$<2.0$
\end{tabular}

\section{Time: 6:00}

Alk: 4.4 inity: $1 \mathrm{mgn}$

Water tomperghe: $23.0^{\circ} \mathrm{C}$

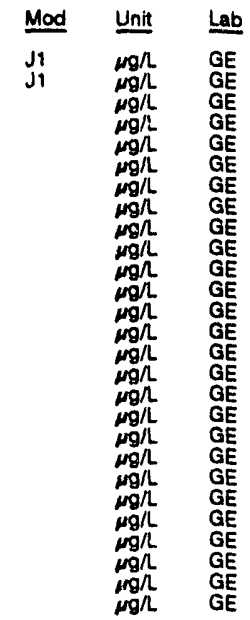

$\left(\frac{10}{20}\right.$

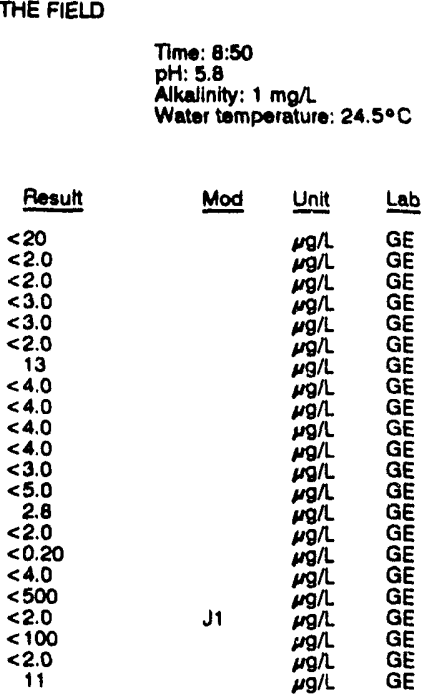

WELL EPT 20 collected on 07/08/92, laboratory analyses (cont)

\begin{tabular}{|c|c|c|c|}
\hline E Analyte & Result & Mod & Unit \\
\hline $\begin{array}{ll}0 & \text { Thallium } \\
0 & \text { Tin } \\
0 & \text { Vanadium } \\
0 & \text { Zinc }\end{array}$ & $\begin{array}{l}<2.0 \\
<2.0 \\
<8.0 \\
<2.0\end{array}$ & & $\begin{array}{c}\mu g h \\
\mu g h \\
\mu g h \\
\mu g h\end{array}$ \\
\hline
\end{tabular}

WELL EPT 21

MEASUREMENTS CONDUCTED IN THE FIELD

Sample date: 07/07/92

Depth to water: Not available

Water elevation: Not available

Sp. conductance: $1 \mu \mathrm{s} / \mathrm{cm}$

LABOPATORY ANALYSES

E Analyte

o Aluminum

A Aluminum

0 Arsenic

o Bartum

o Eeryllium

o Baryllium

- Cadmium

o Calcium

0 Chromium

o Chromium

o Cobalt

- Copper

0 Copper

o Iron

L Lead

0 Lithium

- Magnesium

o Manganese

- Manganeso

O Nickel

O Potasslum

Potassium

o Selenium

o Silica

o Silver

o Sodium

o Sodium

$\begin{array}{ll}0 & \text { Tha } \\ 0 & \text { Tin } \\ & \text { Tin }\end{array}$

o Uin

0 Uranium

- Vanadium

V Vanadium

$\begin{array}{ll}0 & \text { Zinc } \\ 0 & \text { Zinc }\end{array}$

Time: 6:25
pH: 4.6

Alkalinity: $1 \mathrm{mg} / \mathrm{h}$

Water temperature: $24.7^{\circ} \mathrm{C}$

WELL EPT 22

MEASUREMENTS CONDUCTED IN THE FIELD

Sample date: 07/07/92

Dopth to water: Not available

Water elevation: Not availablo

Sp. conductance: $4 \mu \mathrm{S} / \mathrm{cm}$

Besult

Mod Unit

$<20$

$<20$
$<2.0$

$<2.0$

$<3.0$

$<2.0$
$<2.0$
$<10$
$<10$

$<10$
$<4.0$

$<4.0$

$<4.0$
$<4.0$

$<4.0$

$<4.0$
$<4.0$
$<4.0$

$<4.0$
$<3.0$

$<5.0$

$<2.0$
2.4
$<2.0$

$<2.0$
$<2.0$
$<0.20$

$<4.0$

$<4.0$
$<500$
$<500$
$<2.0$

$<2.0$
$<100$
$<100$
$<2.0$

$<<2.0$

15
$<2.0$
$<2.0$

$<2.0$

$<20$

$<8.0$

$<2.0$

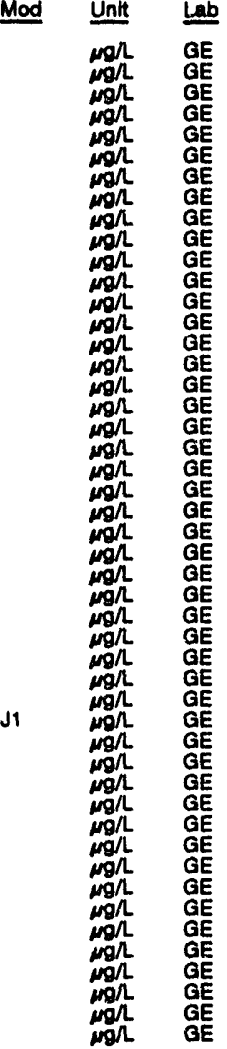

LABOPATORY ANALYSES

E Analyte

o Aluminum

A Antimony

0 Arsenic

Beryllum

o Cadmium

Chromium

Cobalt

- Copper

o Lead

o Lead

O Magnesium

Manganese

O Mercury

0 Nickel

$<20$

$<2.0$

$<0.20$

Time: 7:50

Akalinity: $1 \mathrm{mon}$

Water temperature: $25.0^{\circ} \mathrm{C}$

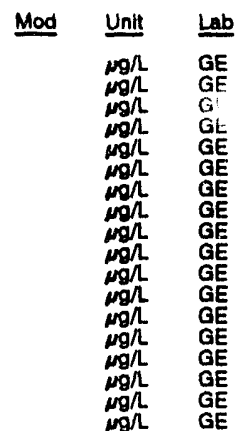


BLANK RESULTS

WELL EPT 13 collecied on 08/11/92, laboratory analyees (cont)

\begin{tabular}{|c|c|c|c|}
\hline E Analyte & Result & Mod & Unit \\
\hline $\begin{array}{ll}0 & \text { Thallium } \\
0 & \text { Tin } \\
0 & \text { Uranium } \\
0 & \text { Vanudlum } \\
0 & \text { Znc }\end{array}$ & $\begin{array}{l}<2.0 \\
<2.0 \\
<20 \\
<8.0 \\
<2.0\end{array}$ & & $\begin{array}{l}\mu g h \\
\mu g h \\
\mu g h \\
\mu g / L \\
\mu g h\end{array}$ \\
\hline
\end{tabular}

WELL EPT 14

MEASUREMENTS CONDUCTED IN THE FIELD

Sample date: 07/02/92

Depth to water: Not avallable

Water olevation: Not availablo

LABORATOFY ANALYSES

E Anaryte

- Aluminum

0 Areanlo

Borlum

Coryllium

Calcium

Cobalt

Copper

Iron

0 Lithlum

O Magnesium

Manganeace

Nickel

Potangium

Sllica

Stiver

Sodium

Tin

Uranium

Znc

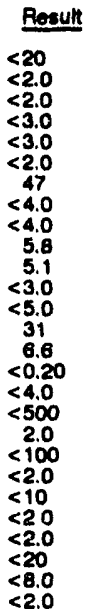

WELL EPT 15

MEASUREMENTS CONDUCTED IN THE FIELD

Sample dato: 07/03/82

Depth to water: Not avallable

Water olevation: Not avaliablo

LABOAATOAY ANALYSES

E Analyze

- Aluminum

Antimony

0 Arsenic

Boryllium

Cedmium

Calclum

Chromium

Cobat

Copper

Load

Lthium

Magnesium

Morcury

Nickel

Potaselum

Selonlum

Silica

sodium

Thallium

Tin

Uranium

Vanadlum

Time: $8: 20$

PH: 4.8 .8. 1 mon

Water temperature: $23.8^{\circ} \mathrm{C}$

Time: 6:30

Al: 4.8 1 ing: $1 \mathrm{mgn}$

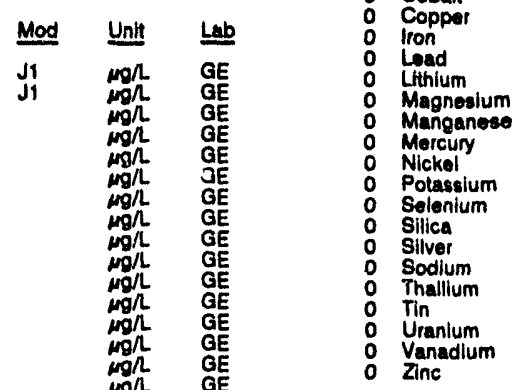

WELL EPT 17

MEASUREMENTS CONDUCTED IN THE FIELD

Sample date: 07/04/82

Depth to water: Not avajlable

Sp. conductance: $1 \mu \mathrm{S} / \mathrm{cm}$

$<20$
$<2.0$
$<2.0$

$<4.0$

$<2.0$

ABORATORY ANALYSES

F Analyte

o Aluminum

0 Antimony

0 Barium

Water temperalure: $23.1^{\circ} \mathrm{C}$

O Cadmium

O Calcium

O Cobatt

- Copper

O Iron

L Lead

L Lithlum

o Magnesium

O Mercury

Nickel

o Potassium

o Solenilum

0 Sillca

o Sodium

Thallium

O Uin

Vanadium

\section{WELL EPT 18}

MEASUREMENTS CONDUCTED IN THE FIELD

Sample dato: 07/05/02

Depth to water: Not avallable

Sp. of ovallon: Nor avaliab

LABORATORY ANALYSES

E Analyte

- Aluminum

- Antimony

0 Arsenic

Barium

Boryllium $<\begin{array}{r}<3.0 \\ <3.0\end{array}$

$<3.0$
$<2.0$

$<4.0$
$<4.0$

4.4
$<4.0$

$<5.0$
$<2.0$
$<2.0$

$<4.0$
$<500$

$<2.0$

$<2.0$

$<2.0$

$<20$
$<8.0$
$<2.0$

\begin{tabular}{|c|c|c|}
\hline Result & Mod & Unit \\
\hline 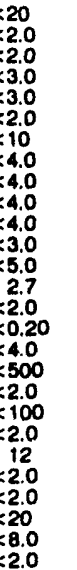 & $\begin{array}{l}J_{1} \\
\mathrm{~J} 1\end{array}$ & 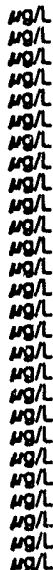 \\
\hline
\end{tabular}

Time: 7:30

Alkalinity: $0 \mathrm{mg} / \mathrm{L}$

Wator temporature: $22.8^{\circ} \mathrm{C}$

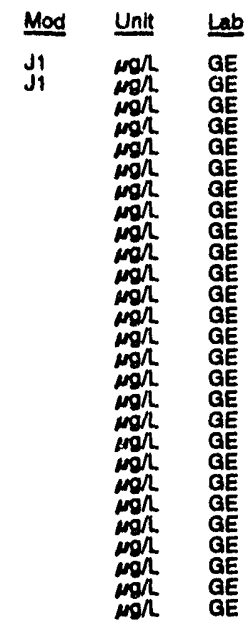

Water tomperature: $21,9^{\circ} \mathrm{C}$

Time: 7:30

PH: 4.8 .

Alkalinity: $1 \mathrm{mgh}$. $22.40 \mathrm{C}$

Rosult

$<20$

$<2.0$

$<3.0$

$<3.0$
$<2.0$

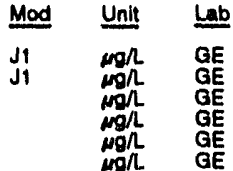




\section{WELL EPT 10}

MEASUREMENTS CONDUCTED IN THE FIELL

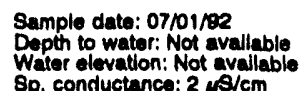

$8 p$. conductance: $2,8 / \mathrm{cm}$

LABORATOAY ANALYSES

E Analyte

- Aluminum

Antimony

- Areonic

Barium

o Eeryllium

Boryllum

Cadmlum

Calclum

o Chromium

Chromium

Cobalt

0 Cobalt

Coppor

oron

Oron

Lead

Ltthium

Magnealum

Magnealum

Manganece

Mereury

Nickel

P Potasialum

Potaealum

Silica

Sillca

Sinver

S Sodium

Sodium

Tin

0 Un

U Uranium

Vanadium

Vanadium

Zne

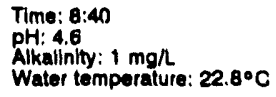

Result

$<20$

$<20$

$<2.0$

$<3.0$

$<3.0$

$<2.0$

14
14
$<4.0$

$<4.0$

$<4.0$

$<4.0$

$<4.0$

$<4.0$

$<3.0$
$<5.0$

$<5.0$

$<2.0$

$<2.0$

$<4.20$

$<4.0$

$<500$

$<2.0$

$<100$

$<2.0$

24
24
$<2.0$

$<2.0$
$<2.0$

$<20$

$<8.0$

$<2.0$

Mod

$\mu g / 2$ GE

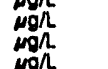

on
GE

WELL EPT 11

MEASUREMENTS CONDUCTED IN THE FIELD

Sample date: 08/10/02 Depth to water: Not avallable Water elevation: Not avallable

LABOALTOFY ANALYSES

E Analyte

- Numinum

Antimony

Barium

Beryilium

Cadmium

Calcium

Cobromitum

Coppor

Iron

0 Lead

M Magnesium

Morcury

Potanelum

Solonium

Silica

Sodium

Thallium

Tin

Uranium

Vanad

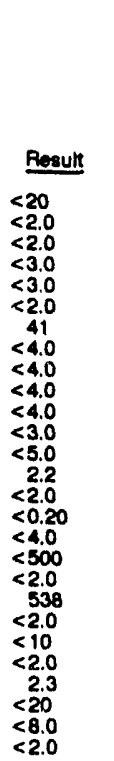

Time: 7:55

Alkalinity: $1 \mathrm{mg} /$

Water temperature: $28.4^{\circ} \mathrm{C}$

Mod Unit Lab

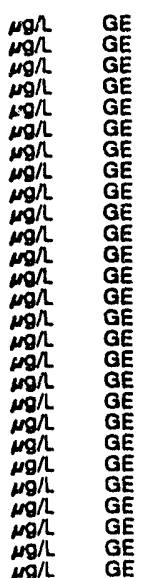

WELL EPT 12

MEASUAEMENTS CONDUCTED IN THE FIELL

Sample date: 08/11/92

Depth to water: Not available

Water elevation: Not avallablo

LABORATOAY ANALYSES

F Analyte

- Aluminum

Aluminum

Arsonic

Barlum

Barlum

Beryllium

Cadmlum

Cadmium

Calcium

Chromium

Chromium

Cobalt

Copper

Copper

Iron

Lead

Lthium

L Lithium

Magnesium

o Manganes:

Mercury

Nickel

Nickel

Potassium

Selenium

Silica

Sillea

a Siver

Sodium

Sodium

Tin

o Tin

U Uranium

Vanadium

Vanadium

0 Zinc

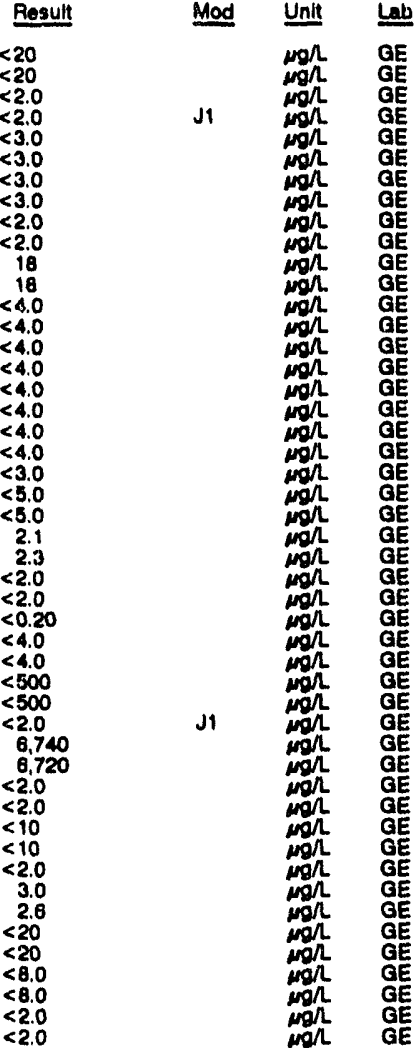

WELL EPT 13

MEASUREMENTS CONDUCTED IN THE FIELD

Sample date: 08/11/02

Wepth to water: Not avaliable

LABORATORY ANALYSES

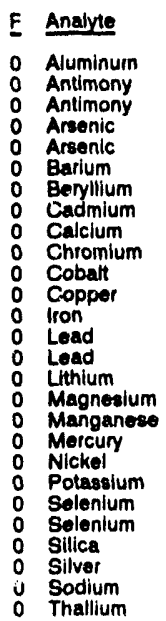

\begin{tabular}{l}
\multicolumn{1}{r}{ Pesult } \\
\hline$<20$ \\
$<2.0$ \\
$<2.0$ \\
$<2.0$ \\
$<2.0$ \\
$<3.0$ \\
$<3.0$ \\
$<2.0$ \\
68 \\
$<4.0$ \\
$<4.0$ \\
$<4.0$ \\
$<4.0$ \\
$<3.0$ \\
$<3.0$ \\
$<5.0$ \\
5.7 \\
$<2.0$ \\
$<0.20$ \\
$<4.0$ \\
$<500$ \\
$<2.0$ \\
$<2.0$ \\
9.730 \\
$<2.0$ \\
$<10$ \\
$<2.0$
\end{tabular}

Time: 6:55

Akelinity: $1 \mathrm{mgh}$

Water temperature: $25.0^{\circ} \mathrm{C}$

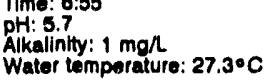

E

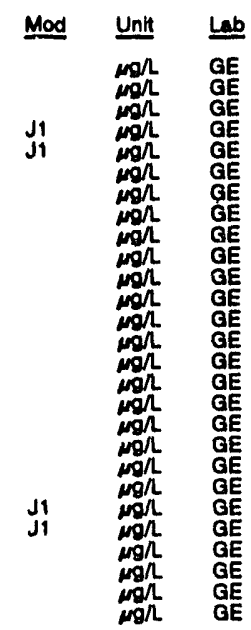


BLANK RESULTS

\begin{tabular}{|c|c|c|c|c|}
\hline \multicolumn{5}{|c|}{ WELL EPT B collectiod on 07/21/02, laboratory analyese (cont.) } \\
\hline Anaryte & Panuth & Mod & Unit & Lew \\
\hline $\begin{array}{ll}0 & \text { Sodium } \\
0 & \text { Thalijum } \\
0 & \text { Tin } \\
0 & \text { Urenlum } \\
0 & \text { Venadlum } \\
0 & \text { Zlne }\end{array}$ & $\begin{array}{l}<10 \\
<2.0 \\
<2.0 \\
<20 \\
<8.0 \\
<2.0\end{array}$ & & $\begin{array}{l}\operatorname{mon}_{\operatorname{mon}} \\
\text { mon } \\
\text { mon } \\
\text { mon }\end{array}$ & \\
\hline
\end{tabular}

WELL EPT 6

MEASUREMENTS CONOUCTED IN THE FIELL

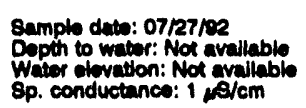

Sp. conductance: $1, \mathrm{~s} / \mathrm{cm}$

LABOFUTOFY ANUL YBES

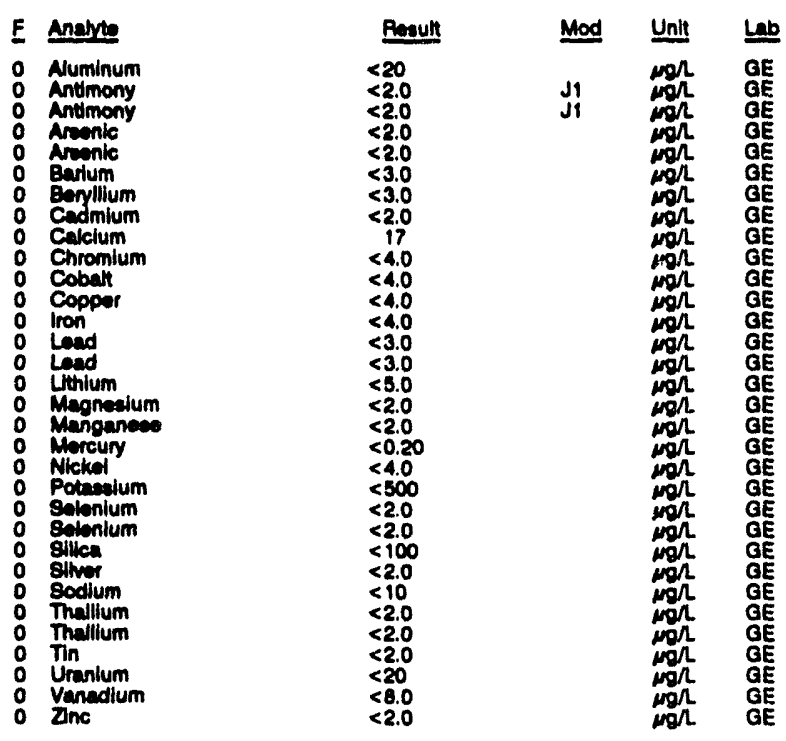

WELL EPT 7

MEASUREMENTS CONDUCTED IN THE FIELD

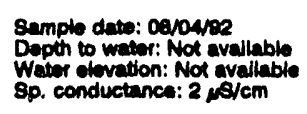

LABORATOFY ANKL YSES

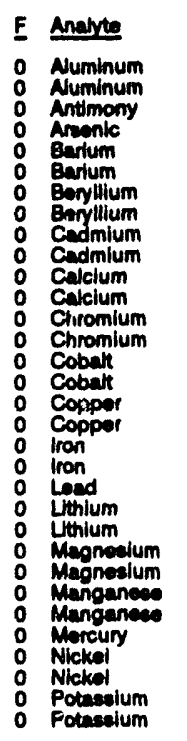

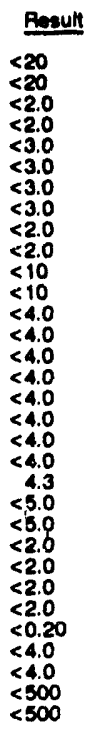

Time: 7:50

PH: 5.350

Waler tomperafure: $20.8 \cdot \mathrm{C}$

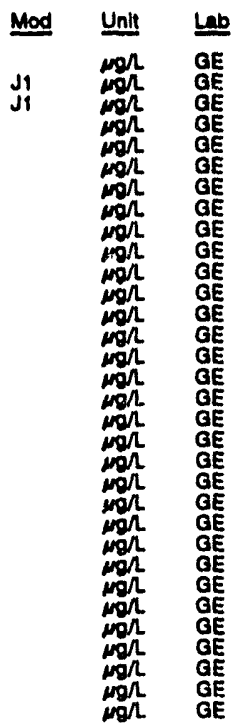

$$
\begin{aligned}
& \text { Time: 8:10 } \\
& \text { Akalinty: } 1 \text { mos } \\
& \text { Wator tomporature: } 28.3^{\circ} \mathrm{C}
\end{aligned}
$$

Mod Unte Lab

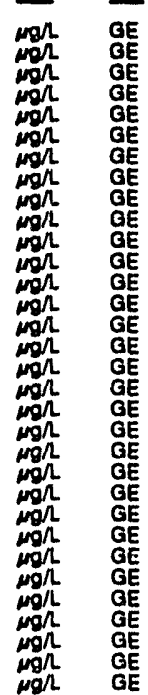

WELL EPT 7 collectod on D8/04/92, laboratory anaysees (cont)

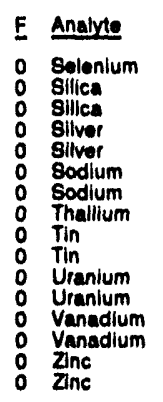

Pesult
$<2.0$
219
205
$<2.0$
$<2.0$
$<10$
$<10$
$<2.0$
$<2.0$
2.0
$<20$
$<20$
$<8.0$
$<8.0$
$<2.0$
$<2.0$

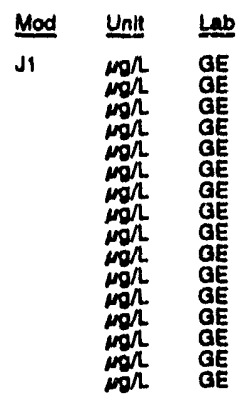

WELL EPT 8

MEASUREMENTS CONDUCTED IN THE FIELD

\section{Sample dato: 08/00/02}

Depth to wator: Not avallable

Water olovation: Not avallablo
Sp. conductanco: $1 \mu \mathrm{s} / \mathrm{cm}$

LABORATORY ANALYSES
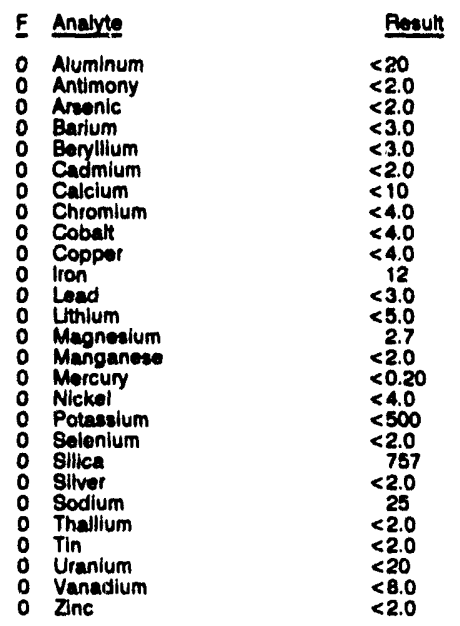

Tima: $8: 35$

Wkallinity: 1 mos

Wabor tomportature: 24.700

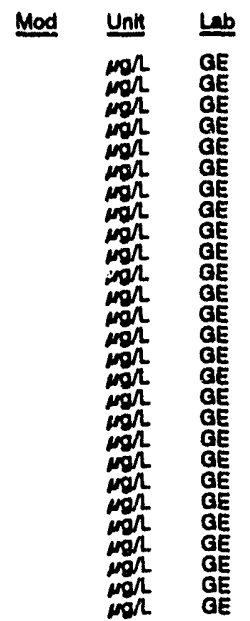

\section{WELL EPT 9}

MEASUREMENTS CONDUCTED IN THE FIELD

Sample dato: 08/10/82

Depth to water: Not avallable

Wator elovation: Not avalablo

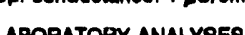

Timo: $6: 30$

Alkalintty: 1 mon

Water tomperature: $28.2{ }^{\circ} \mathrm{C}$

E Analyze

: Aluminum

: Antimony

- Barium

Barlllum

- Calcium

Chromium

: Cobalt

: Copp

D load

o Ithium

: Magnesium

0 Mickel

o Potanglum

o selonlum

S Sllica

: Solver

Thallum

- Tin

\begin{tabular}{|c|c|c|}
\hline Perult & Mod & Unin \\
\hline $\begin{array}{l}<20 \\
<2.0 \\
<2.0 \\
<3.0 \\
<3.0 \\
<2.0 \\
10 \\
<4.0 \\
<4.0 \\
<4.0 \\
<4.0 \\
<3.0 \\
<5.0 \\
<2.0 \\
<2.0 \\
<0.20 \\
<4.0 \\
<500 \\
<2.0 \\
783 \\
<2.0 \\
15 \\
<2.0 \\
<2.0 \\
<20 \\
<8.0 \\
<2.0\end{array}$ & J1 & 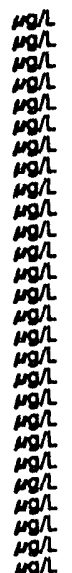 \\
\hline
\end{tabular}

Uranium

Zinc 


\section{BLANK RESULTS}

\section{WELL EPT 1}

MEASUAEMENTS CONDUCTED IN THE FIELD

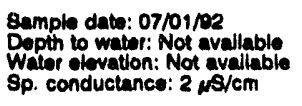

LABOAATOAY ANALYSES

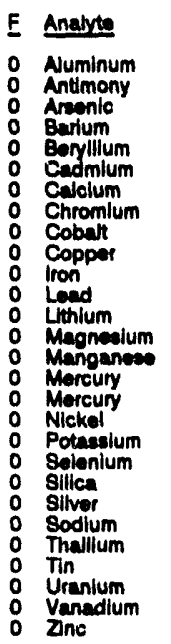

Regunt
$<20$
$<2.0$
$<2.0$
$<3.0$
$<3.0$
$<2.0$
$<10$
$<4.0$
$<4.0$
$<4.0$
$<4.0$
$<3.0$
$<3.0$
2.5
$<2.0$
$<0.20$
$<0.20$
$<4.0$
$<500$
$<2.0$
7.710
$<2.0$
684
$<2.0$
$<2.0$
$<20$
$<6.0$
$<2.0$

\section{WELL EPT 2}

MEASUREMENTS CONDUCTED IN THE FIELD

Sample date: 07/06/02

Depth to water: Not avaliable

Sp. conductance: 8 s/cm

LABORATOAY ANALYSES

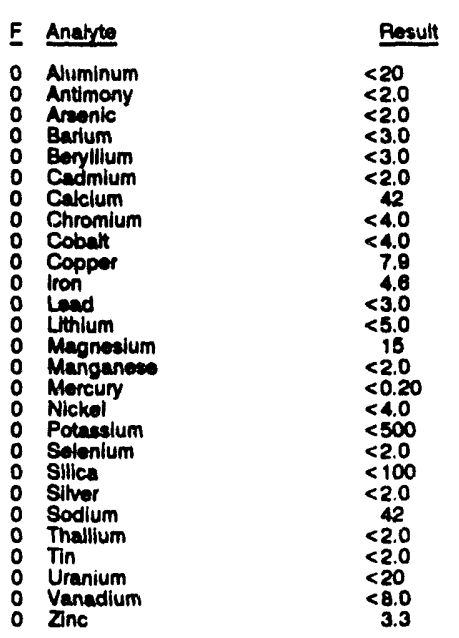

WELL EPT 3

MEASUREMENTS CONDUCTED IN THE FIELD

Sample date: 07/10/82

Dopth to water: Not avallable

Sp. conductance: $1 \mathrm{~s} / \mathrm{cm}$

LABORATOAY ANALYSES

E Analyte

- Aluminum

Antimony

A Arsenic

B Barium
Time: $8: 35$

Alkalinity: $1 \mathrm{mg} / \mathrm{h}$

Water temperalure: $24.0^{\circ} \mathrm{C}$

Mod

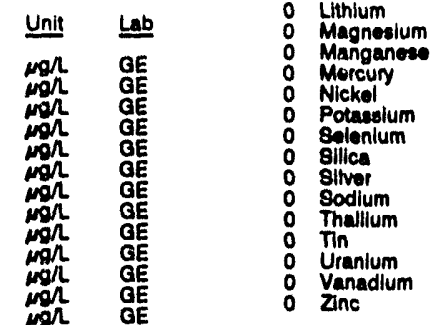

WELL EPT 4

MEASUREMENTS CONDUCTED IN THE FIELD

Sample date: 07/15/82

Water to wation: Not avallable

Sp. conductance: $3 \mu \mathrm{s} / \mathrm{cm}$

LABORATOAY ANALYSES
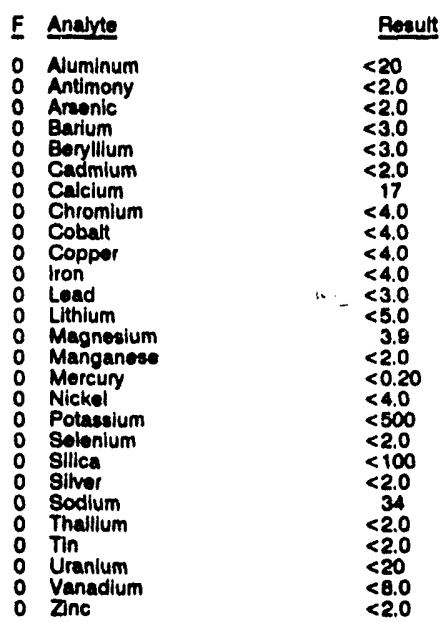

WELL EPT 5

MEASUREMENTS CONDUCTED IN THE FIELD

Sample date: 07/21/92

Depth to water: Not avallable

Water elevation: Not avallable
Sp. conductance: 1 S/cm

LABORATORY ANALYSES

$\begin{array}{ll}\text { F } & \text { Analyte } \\ 0 & \text { Aluminum } \\ 0 & \text { Antimony } \\ 0 & \text { Arsenic } \\ 0 & \text { Barium } \\ 0 & \text { Berillium } \\ 0 & \text { Cadmium } \\ 0 & \text { Calcium } \\ 0 & \text { Chromium } \\ 0 & \text { Cobalt } \\ 0 & \text { Copper } \\ 0 & \text { lron } \\ 0 & \text { Lead } \\ 0 & \text { Lithium } \\ 0 & \text { Magnesium } \\ 0 & \text { Manganese } \\ 0 & \text { Morcury } \\ 0 & \text { Nickel } \\ 0 & \text { Polassium } \\ 0 & \text { Solenium } \\ 0 & \text { Silica } \\ 0 & \text { Silver }\end{array}$

\begin{tabular}{l}
\multicolumn{1}{r}{ Poeult } \\
$<20$ \\
$<2.0$ \\
$<2.0$ \\
$<3.0$ \\
$<3.0$ \\
$<2.0$ \\
$<10$ \\
$<4.0$ \\
$<4.0$ \\
$<4.0$ \\
5.0 \\
$<3.0$ \\
$<5.0$ \\
2.5 \\
$<2.0$ \\
$<0.20$ \\
$<4.0$ \\
$<500$ \\
$<2.0$ \\
$<100$ \\
$<2.0$
\end{tabular}

Time: $0: 10$

pH: 4.5

Waler tompergture: $26.8^{\circ} \mathrm{C}$

Mod Unit Lab

$\begin{array}{ll}\mu g \Omega & G E \\ \mu g / & G E \\ \mu \Omega & G E \\ \mu g \Omega & G E \\ \mu g \Omega & G E\end{array}$
Time: $0: 00$

Alkalinity: $1 \mathrm{mon}$

Water tomperature: $24.7{ }^{\circ} \mathrm{C}$

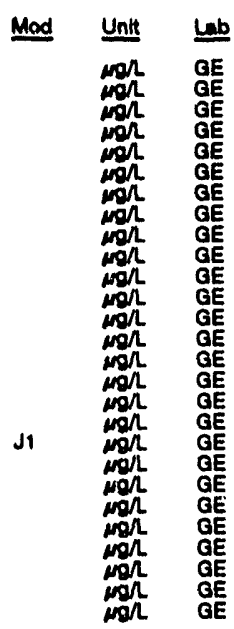

Time: 7:50

PH: 5.4 Alkalinity: $1 \mathrm{~mol}$

Water temporature: $23.0^{\circ} \mathrm{C}$

Mod Unit

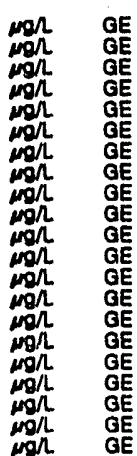

B-2. 


\section{Appendix B. BLANKS}

This section presents the analytical results for sampling blanks analyzed during third quarter 1992. 
WELL ZW 8

MEASUREMENTS CONDUCTED IN THE FIELO

Sample date: 07/13/9?

Dopth to water: $3.00 \mathrm{ft}(0.01 \mathrm{~m})$ below TOC

Water elevation: $270.30 \mathrm{f}(82.42 \mathrm{~m}) \mathrm{mel}$

Sp. conductance: $63 \mathrm{\mu S} / \mathrm{cm}$.

PH: 7.7

Water temperature: $29.0^{\circ} \mathrm{C}$

UBOFUTOAY ANALYSES

$E$ Analute

- Grose elpha

Grose alpha

Nonvolallo beta

Tonvolatlo

\begin{tabular}{|c|c|c|}
\hline Rosult & Mod & Unit \\
\hline $\begin{array}{l}4.5 E-09 \pm 2.0 E-\infty \theta \\
5.0 E-09 \neq 2.0 E-00 \\
9.0 E-09 \pm 2.0 E-\infty \\
8.3 E-09 \pm 2.0 E-00 \\
8.5 E-08 \pm 5.0 E-07\end{array}$ & & 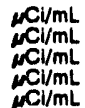 \\
\hline
\end{tabular}

\section{WELL ZW 9}

MEASUREMENTS CONDUCTED IN THE FIELD

\begin{tabular}{|c|c|c|c|c|c|}
\hline \multicolumn{3}{|c|}{$\begin{array}{l}\text { Sample date: } 07 / 15 / 92 \\
\text { Dopth to water: } 35.50 \mathrm{n}(10.82 \mathrm{~m}) \text { below TOC } \\
\text { Water olevation: } 233.20 \mathrm{~h}(77.18 \mathrm{~m}) \mathrm{mal} \\
\text { Sp. conductance: } 97 \mathrm{~g} / \mathrm{cm} \\
\text { No water was evecuated belore sampling. }\end{array}$} & \multicolumn{3}{|c|}{$\begin{array}{l}\operatorname{Time:}_{\mathrm{pH}:}^{12: 40} \\
\text { p.5 }\end{array}$} \\
\hline \multicolumn{6}{|c|}{ LABORATORY ANALYSES } \\
\hline$\underline{F}$ & Analyte & Rosult & Mod & Unit & Lab \\
\hline $\begin{array}{l}0 \\
0 \\
2\end{array}$ & $\begin{array}{l}\text { Grows alphe } \\
\text { Nonvolatile beta } \\
\text { Tritum }\end{array}$ & $\begin{array}{l}2.7 E-09 \\
2.0 E-09 \\
1.2 E-04\end{array}$ & $\begin{array}{l}6 E-09 \\
5 E-09 \\
7 E-06\end{array}$ & $\begin{array}{l}\mu \mathrm{Cl} / n \\
{ }_{\mu} \mathrm{Cl} / \mathrm{n} \\
{ }_{\mu} \mathrm{Cl} / \mathrm{n}\end{array}$ & $\begin{array}{l}\text { GE } \\
\text { GE } \\
\text { GE }\end{array}$ \\
\hline
\end{tabular}

WELL ZW 10

MEASUREMENTS CONDUCTED IN THE FIELD

\begin{tabular}{|c|c|c|c|c|c|}
\hline \multicolumn{3}{|c|}{ 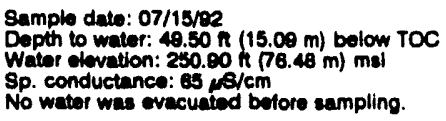 } & \multicolumn{3}{|c|}{$\begin{array}{l}\text { Time: } 13: 00 \\
\text { pH: } 6.8\end{array}$} \\
\hline \multicolumn{6}{|c|}{ LABOPATORY ANALYSES } \\
\hline$E$ & Anaryte & Result & Mod & Unit & Lab \\
\hline 2 & Trit. Jm & 5.2E-05 & $1 E-06$ & $\mu \mathrm{Ci} / n$ & GE \\
\hline
\end{tabular}




\section{ANALYTICAL RESULTS}

WELL ZBG 2 collected on 08/18/92, laboratory analyses (cont)

\begin{tabular}{|c|c|c|c|}
\hline F Anabice & Result & Mod & Unit \\
\hline $\begin{array}{l}0 \text { Yturium-88 } \\
0 \text { Zinc-65 }\end{array}$ & $\begin{array}{l}<6.0 E-08 \\
<2.0 E-08\end{array}$ & & $\begin{array}{c}\mu \mathrm{Cl} / \mathrm{mL} \\
\mu \mathrm{Cl} / \mathrm{mL}\end{array}$ \\
\hline
\end{tabular}

\section{WELL ZDT 1}

MEASUREMENTS CONDUCTED IN THE FIELD

\begin{tabular}{|c|c|c|c|c|c|}
\hline \multicolumn{3}{|c|}{ 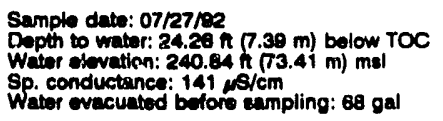 } & \multicolumn{3}{|c|}{$\begin{array}{l}\text { Time: } 11: 50 \\
\text { pH: } 8.3 \\
\text { Alkalinity: } 43 \mathrm{mg} / \mathrm{h} \\
\text { Water temperature: } 21.7^{\circ} \mathrm{C}\end{array}$} \\
\hline \multicolumn{6}{|c|}{ LABORATOFY ANALYSES } \\
\hline $\boldsymbol{E}$ & Anabte & Rosult & Mod & Unit & Lي \\
\hline $\begin{array}{l}0 \\
2\end{array}$ & $\begin{array}{l}\text { Total alpha-omiting radium } \\
\text { Tritum }\end{array}$ & $\begin{array}{l}1.1 E-0 \\
2.4 E-0\end{array}$ & E-10 & $\underset{\omega \mathrm{Cl} / \mathrm{mL}}{\boldsymbol{M} \mathrm{C} / \mathrm{mL}}$ & $\begin{array}{l}\text { GE } \\
\text { GE }\end{array}$ \\
\hline
\end{tabular}

WELL ZDT 2

MEASUAREMENTS CONDUCTED IN THE FIELD

\begin{tabular}{|c|c|c|c|c|c|}
\hline \multicolumn{3}{|c|}{$\begin{array}{l}\text { Sample date: } 07 / 27 / 92 \\
\text { Depth to water: } 22.45 \mathrm{ft}(6.84 \mathrm{~m}) \text { below TOC } \\
\text { Water elovation: } 242.55 \mathrm{~h}(73.83 \mathrm{~m}) \mathrm{msl} \\
\text { Sp. conductance: } 51 \text {, fs/cm } \\
\text { Water evacuatiod before sampling: } 46 \mathrm{gal}\end{array}$} & \multicolumn{3}{|c|}{$\begin{array}{l}\text { Time: } 11: 35 \\
\text { pH: } 5.3 \\
\text { Alkalinity: } 4 \mathrm{mg} / \\
\text { Waver temperature: } 20.5^{\circ} \mathrm{C}\end{array}$} \\
\hline \multicolumn{6}{|c|}{ LABOPATOPY ANALYSES } \\
\hline$E$ & Analyte & Result & Mod & Unit & Lab \\
\hline & $\begin{array}{l}\text { Radium-228 } \\
\text { Radium-228 } \\
\text { Radium-228 } \\
\text { Radium-228 } \\
\text { Total alpha-emitting radium } \\
\text { Tritium } \\
\text { Tritium } \\
\text { Tritium } \\
\text { Trtium }\end{array}$ & \multicolumn{2}{|c|}{$\begin{array}{l}7.4 E-10 \pm 4.4 E-10 \\
9.7 E-10 \pm 3.7 E-10 \\
1.1 E-09 \pm 9.0 E-10 \\
9.0 E-10 \pm 7.0 E-10 \\
1.1 E-09 \pm 8.0 E-10 \\
2.2 E-05 \pm 7.0 E-07 \\
2.2 E-05 \pm 7.0 E-07 \\
2.2 E-05 \pm 5.4 E-06 \\
2.3 E-05 \pm 5.5 E-06\end{array}$} & 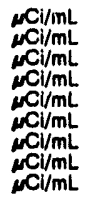 & $\begin{array}{l}\text { TM } \\
\text { TM } \\
\text { TM } \\
\text { G. } \\
\text { GE } \\
\text { GE } \\
\text { TM } \\
\text { TM }\end{array}$ \\
\hline
\end{tabular}

\section{WELL ZDT 2 Replicate}

MEASUREMENTS CONDUCTED IN THE FIELD

\begin{tabular}{|c|c|c|c|c|c|}
\hline \multicolumn{3}{|c|}{ 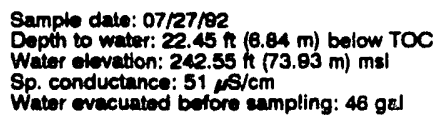 } & \multicolumn{3}{|c|}{$\begin{array}{l}\text { Time: } 11: 35 \\
\text { pH: } 5.3 \\
\text { Alkalinity: } 4 \mathrm{mg} / \mathrm{L} \\
\text { Water tomperature: } 20.5^{\circ} \mathrm{C}\end{array}$} \\
\hline \multicolumn{6}{|c|}{ LABORATORY ANALYSES } \\
\hline • & Anabte & Result & Mod & Unit & iab \\
\hline $\begin{array}{l}\text { f } \\
\text { ? }\end{array}$ & $\begin{array}{l}\text { Radium-228 } \\
\text { Radium-228 } \\
\text { Total alphe-emiting radium } \\
\text { Tritium } \\
\text { Tritium }\end{array}$ & $\begin{array}{r}1.0 E-09 \\
1.3 E-09 \\
<1.0 \mathrm{E}-09 \\
2.2 \mathrm{E}-05 \\
2.3 \mathrm{E}-05\end{array}$ & $\begin{array}{l}E-10 \\
E-10 \\
E-07 \\
E-06\end{array}$ & 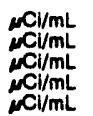 & $\begin{array}{l}\mathrm{TM} \\
\mathrm{TM} \\
\mathrm{GE} \\
\mathrm{GE} \\
\mathrm{TM}\end{array}$ \\
\hline
\end{tabular}

\section{WELL ZW IA}

MFASUREMENTS CONDUCTED IN THE FIELD

Sample dato: 07/15/92

Inaccessibility or mechanical problem prevented sample collection.

WELL ZW 2

MEASUREMENTS CONDUCTED IN THE FIELD

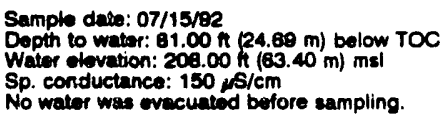

F Anate

- Groes alpha

2 Tritium

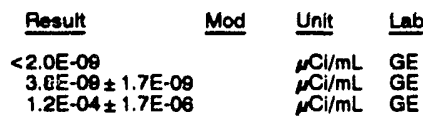

WELL ZW 3

MEASUREMENTS CONDUCTED IN THE FIELL

Depth to water: $55.00 \mathrm{ft}(18.78 \mathrm{~m})$ below TOC

Water elevation: $204.39 \mathrm{~h}(82.30 \mathrm{~m}) \mathrm{ms}$

No water was ovacuatod $42 \mathrm{~cm}$

LABORATORY ANALYSES

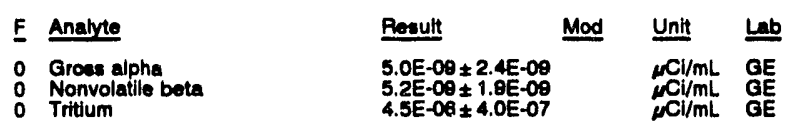

WELI. ZW 4

MEASUREMENTS CONDUCTED IN THE FIELD

$\begin{array}{ll}\text { Sample date: } 07 / 15 / 92 & \text { Time: } 10: 20 \\ \text { Depth to water: } 41.50 \mathrm{ft}(12.65 \mathrm{~m}) \text { bolow TOC } & \text { pH: } 5.8 \\ \text { Water olovation: } 233.30 \mathrm{~h}(71.11 \mathrm{~m}) \mathrm{mal} & \text { Water temperature: } 22.0^{\circ} \mathrm{C} \\ \text { Sp. conductance: } 178 \mu \mathrm{S} / \mathrm{cm} & \end{array}$

No water was evecuated before sampling

Time: 11:00

Water temperature: $22.0^{\circ} \mathrm{C}$

LABORATORY ANALYSES

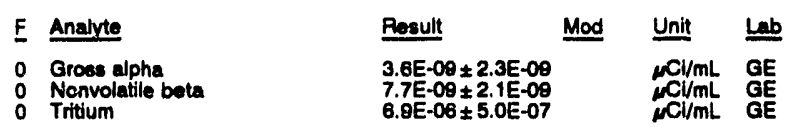

WELL ZW 5

MEASUAEMENTS CONDUCTED IN THE FIELD

$\begin{array}{ll}\text { Sample date: } 07 / 15 / 92 & \text { Time: } 10: 10 \\ \text { Depth to water: } 50.00 \mathrm{n}(15.24 \mathrm{~m}) \text { below TOC } & \text { PH: } 5.7\end{array}$

Water elevation: $227.80 \mathrm{ft}(80.43 \mathrm{~m}) \mathrm{msl}$

So water was evacuated before sampling.

Water temperature: $23.0^{\circ} \mathrm{C}$

LABORATORY ANALYSES

E Analyte $\frac{\text { Result }}{1.2 E-05 \pm 6.0 E-07} \stackrel{\text { Mod }}{\text { Tritium }} \frac{\text { Unit }}{N \mathrm{CV} / \mathrm{mL}} \frac{\text { Lab }}{\mathrm{GE}}$

\section{WELL ZW 6}

MEASUREMENTS CONDUCTED IN THE FIELD

Sample date: 07/15/92

Depth to water: $53.50 \mathrm{ft}(18.31 \mathrm{~m})$ below TOC

Water elevation: $214.60 \mathrm{tt}(65.41 \mathrm{~m}) \mathrm{msl}$

No water was evacuated before sampling.

$\mathrm{pH}: \mathbf{6 . 0}$

Water temperature: $23.0^{\circ} \mathrm{C}$

LABORATORY ANALYBES

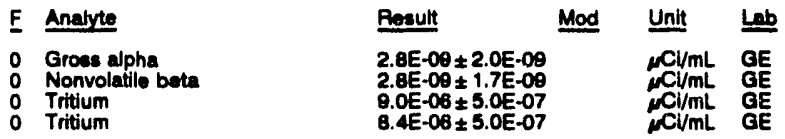

\section{WELL ZW 7}

MEASUREMENTS CONDUCTED IN THE FIELD

Sample date: $07 / 15 / 82$

inaccessibility or mechanical problem prevented sample collection. 
ANALYTICAL RESULTS

WELL ZBG $1 A$

MEASUREMENTS CONDUCTED IN TME FIELD

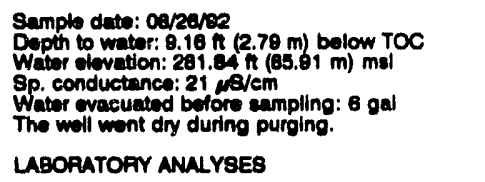

Time: 9:15

Nikelinity: $1 \mathrm{mon}$

Wator tomporature: $21.5^{\circ} \mathrm{C}$

LABOFATOPY ANALYSES

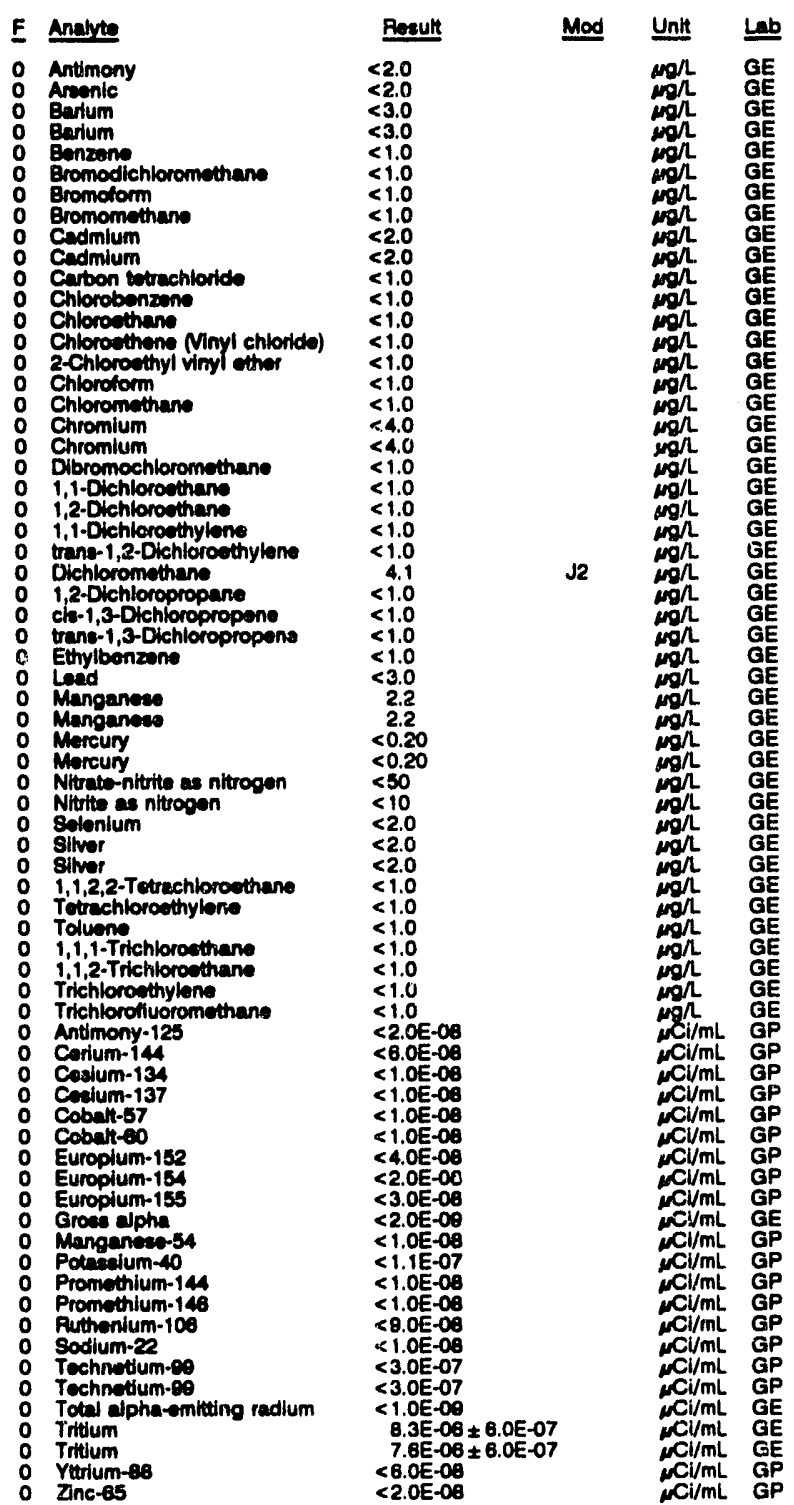

WELL ZBG 2

MEASUAEMENTS CONDUCTED IN THE FIELD

\begin{tabular}{|c|c|}
\hline $\begin{array}{l}\text { Sample date: } 08 / 18 / 92 \\
\text { Dopth to water: } 54.59 \mathrm{ft}(16.64 \mathrm{~m}) \text { below TOC } \\
\text { Watter olovation: } 223.41 \mathrm{~h}(68.10 \mathrm{~m}) \mathrm{msi} \\
\text { Sp. conductance: } 8 / 9 \mathrm{sm}\end{array}$ & $\begin{array}{l}\text { Time: } 14: 45 \\
\text { pH: } 48 \\
\text { Alkalinity: } 1 \mathrm{mgh} \\
\text { Water tomperature: } 20.7 \cdot \mathrm{C}\end{array}$ \\
\hline
\end{tabular}

LABORATORY ANALYSES

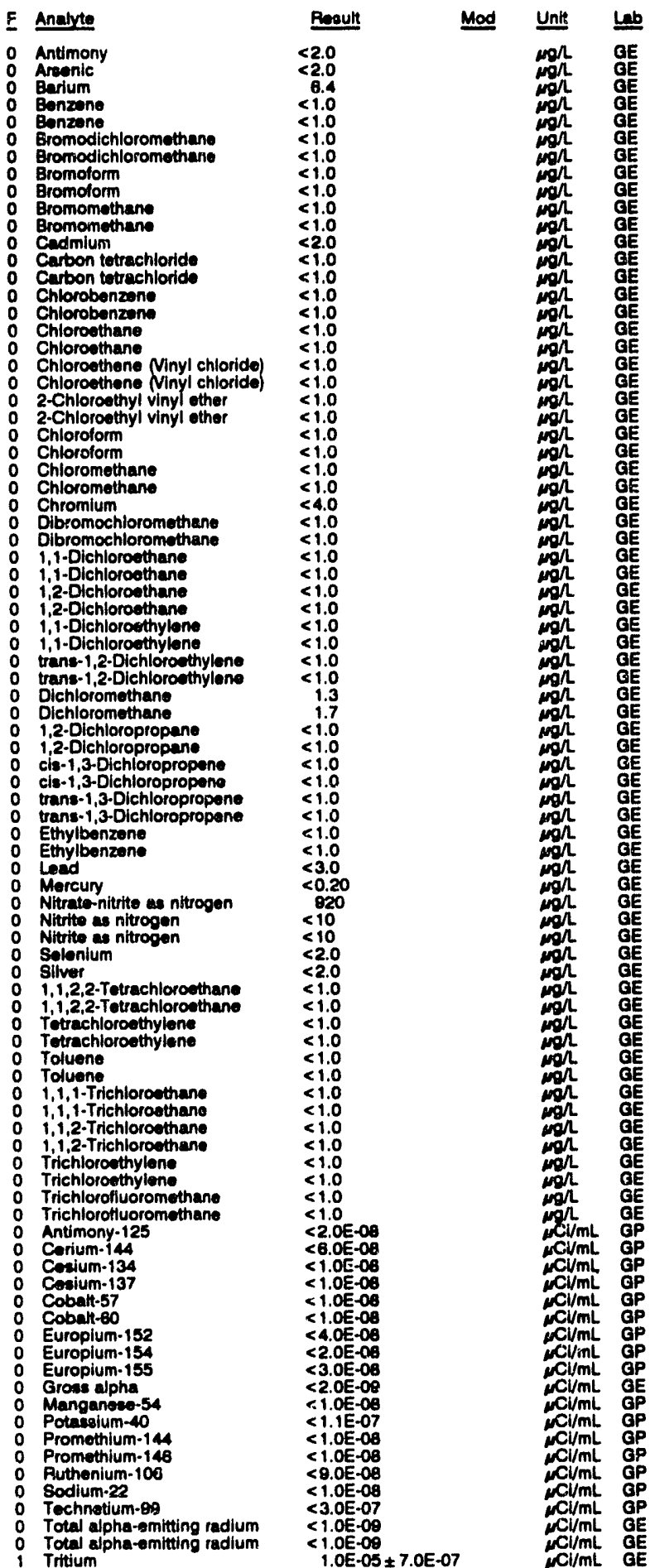


WELL ZBG 1 collected on 08/28/B2, laboratory analyees (cont.)

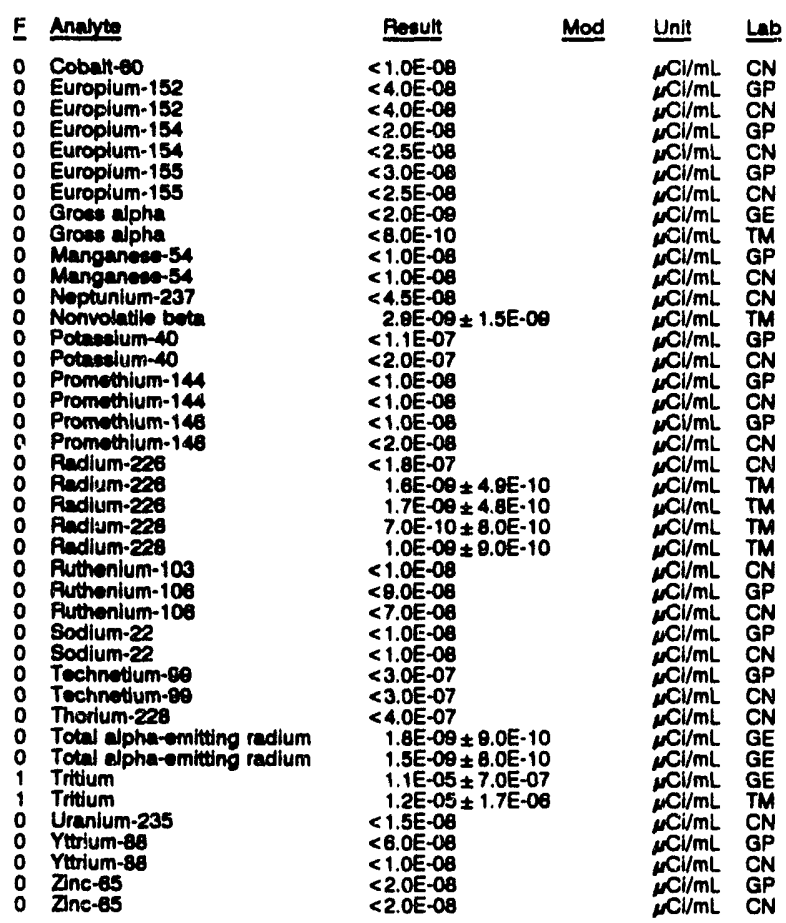

WELL ZBG 1 Replicate

MEASUREMENTS CONDUCTED IN THE FIELD

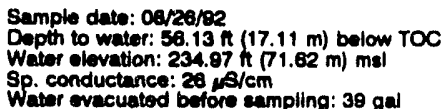

Time: $8: 40$

PH: 5.3 Akalinity: $1 \mathrm{mgh}$

Water tomperature: $19.8^{\circ} \mathrm{C}$

LABOPATOAY ANALYSES

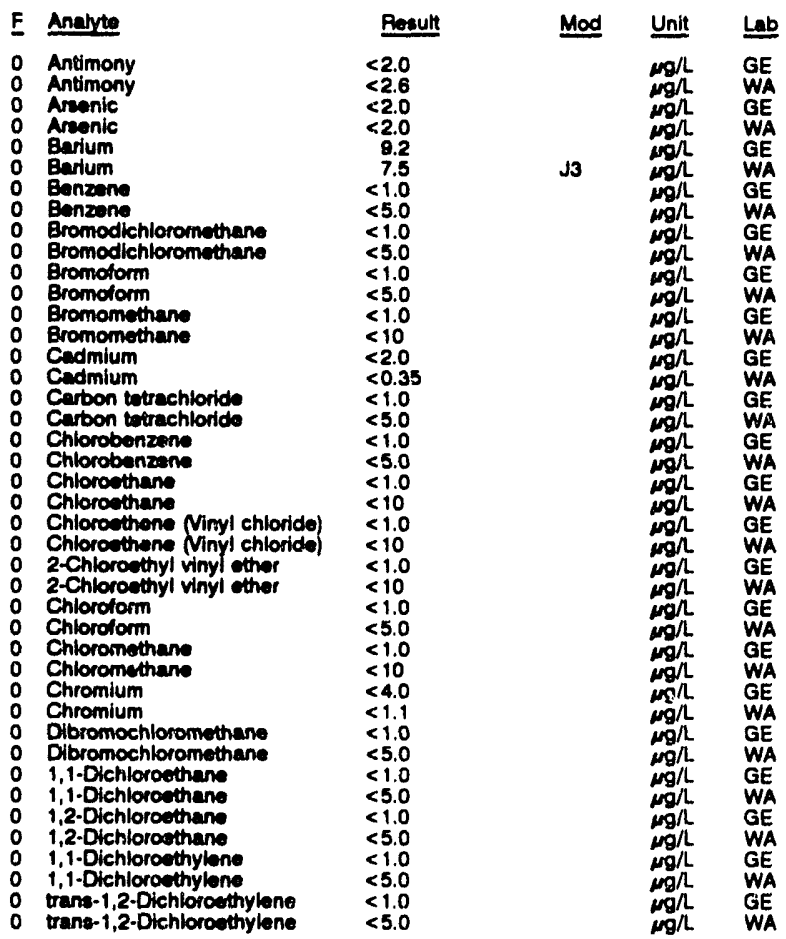

WELL ZBG 1 collocted on 08/26/92, laboratory analyses (cont.)

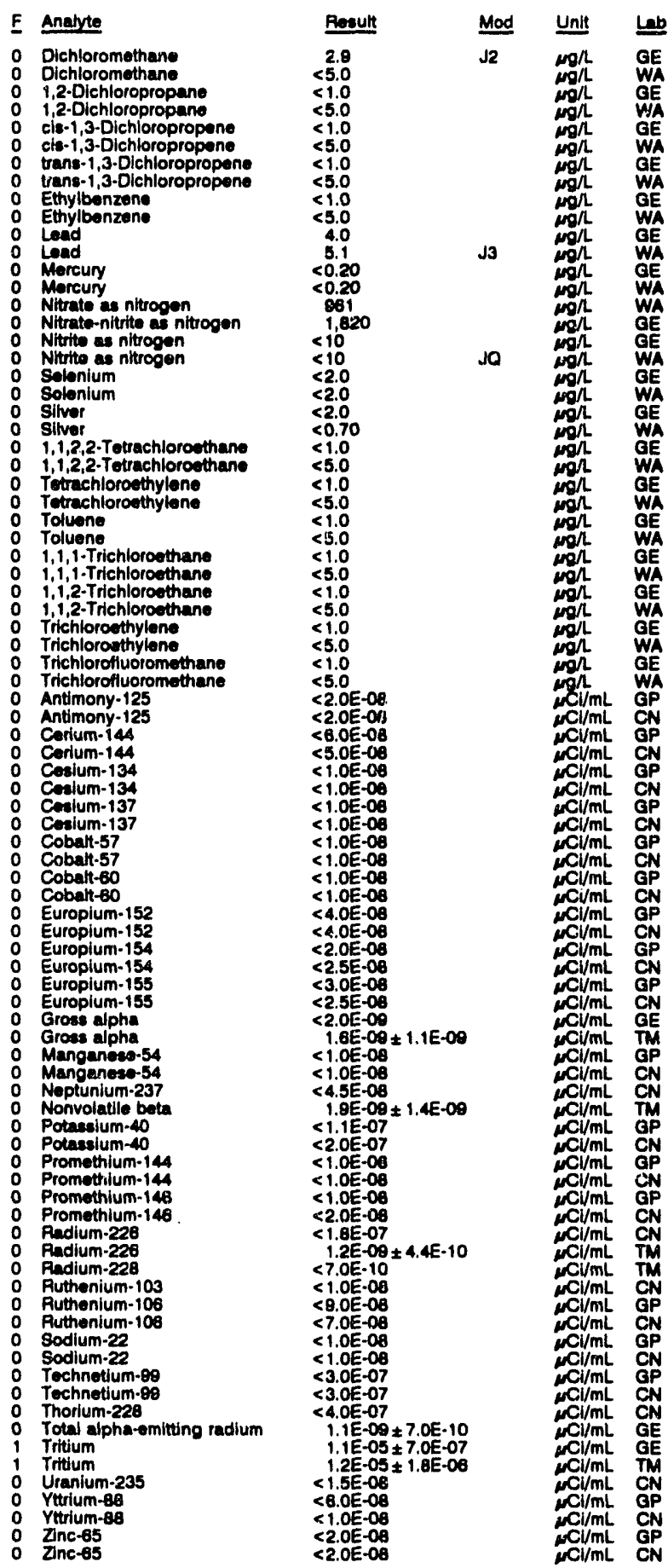


ANALYTICAL RESULTS

WELL YSC 4C Replicate

MEASUREMENTS CONDUCTED IN THE FIELD

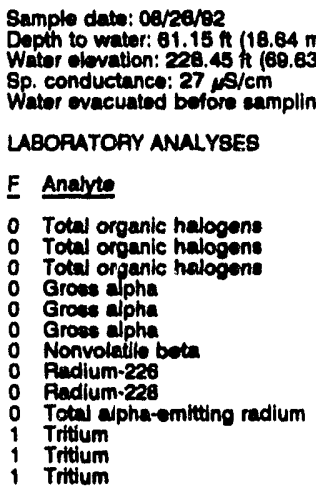

Time: 10:35

pH: 5.0

Alkalinity: $1 \mathrm{mg}$

Water temperature: $20.6^{\circ} \mathrm{C}$

Water evecuated before eampling: $85 \mathrm{gal}$

LABOFATOAY ANALYSES

\begin{tabular}{|c|c|c|}
\hline Result & Mod & Unit \\
\hline 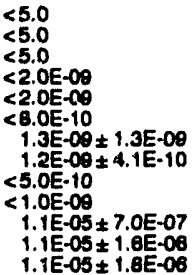 & JO & 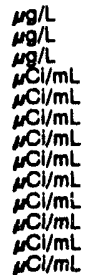 \\
\hline
\end{tabular}

WELL YSC 5A

MEASUREMENTS CONDUCTED IN THE FIELD

Sample date: $08 / 18 / 92$ (20.53 m) below TOC Water elevation: $178.01 \mathrm{~h}(54.28 \mathrm{~m}) \mathrm{m}$

Sp. conductane : $203, \mathrm{~s} / \mathrm{cm}$

Water evacuatad bofore seampling: $183 \mathrm{gal}$

pH: 7.4

Alkalinity: $71 \mathrm{~mol}$

Weter tomporature: $18.8^{\circ} \mathrm{C}$

LABOPATOAY ANALYSES

\begin{tabular}{|c|c|c|c|c|}
\hline$F$ & Anatrte & Result & Mod & Unit \\
\hline & $\begin{array}{l}\text { Total ogpanic halogens } \\
\text { Total orpanic halogens } \\
\text { Groes apha } \\
\text { Totwl alpha-emitting redium } \\
\text { Tritum }\end{array}$ & $\begin{array}{l}<5.0 \\
<5.0 \\
<2.0 E-09 \\
1.3 \mathrm{BE}-09 \pm 8.0 \mathrm{E}-10 \\
<7.0 \mathrm{E}-07\end{array}$ & & 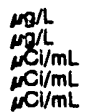 \\
\hline
\end{tabular}

WELL ZBG 1

MEASUREMENTS CONDUCTED IN THE FIELD

Sample date: 08/28/02

Depth to wator: $66.13 \mathrm{th}(17.11 \mathrm{~m})$ below TOC

Wator elevation: $234.97 \mathrm{ht}$.

Weter evecuated before sampling 30 a

LABORATORY ANALYSES

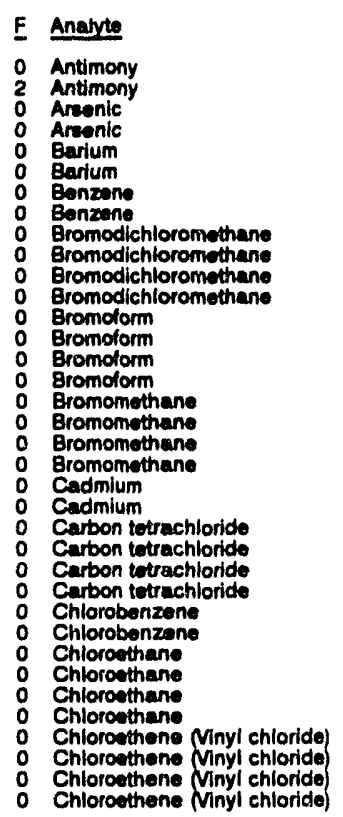

Pegult
$<2.0$
8.0
$<2.0$
$<2.0$
9.3
15
$<1.0$
$<5.0$
$<1.0$
$<5.0$
$<5.0$
$<5.0$
$<1.0$
$<5.0$
$<5.0$
$<5.0$
$<1.0$
$<10$
$<10$
$<10$
$<2.0$
1.3
$<1.0$
$<5.0$
$<5.0$
$<5.0$
$<1.0$
$<5.0$
$<1.0$
$<10$
$<10$
$<10$
$<1.0$
$<10$
$<10$
$<10$

Time: 8:40

Alkalinity: $1 \mathrm{mgh}$

Alkalinity: $1 \mathrm{mg} / \mathrm{h}$ : $18.9^{\circ} \mathrm{C}$

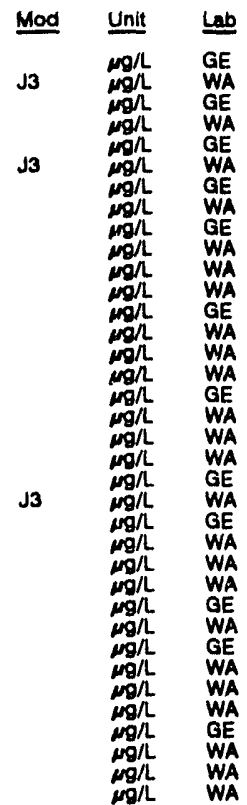

WELL ZBG 1 collected on 06/26/82, laboratory analyses (cont)

\section{$E$ Analyte}

- 2-Chloroethyl vinyl ether 2-Chloroethyl vinyl other 2-Chloroethyl vinyl ether Chloroform Chloroform

Chloroform

Chloroform

Chloromethane

Chloromothane

Chloromethane

Chromium

Chromium

Dibromochloromethane

Dromochloromethane

Dibromochloromethane

1,1 -Dichloroethane

1,1-Dichloroethane

1,1-Dichlorcothane

1, D. Dichloroethane

1,2-Oichloroethane

1,2-Dichloroethane

1,1-Dichloroethylene

trane-1,2-Dichloroethyien

trans-1,2-Dichloroothylene

trans-1,2-Dichloroethylene

trans-1,2-Dichloroethylene

Dichloromethane

Dichloromethane

Dichloromethane

1,2-Dichloropropane

1,2 -Dichloropropane

1.2-Dichloropropane

$1,2 \cdot D i c h l o r o p r o p a n e$
0
cis-1,3-Dichloropropene

o cis-1,3-Dichloropropene

cis-1,3-Dichloropropene

o cis-1,3-Dichloropropene

trans-1,3-Dichioropropene

trane-1,3-Dichloropropeno

o trane-1,3-Oichloropropene

Ethylbenzene

Ethylbenzene

Ethylbenzone

Load

0 Lead

Mercury

O Nitrate as nitrogen

Nitrato-nitrite as nitrogen

Nitrite as nitrogen

- Nitrite as nitrogen

- Nitrite as nitrogen

- Soleritum

0 Solenium

o Silver

o Silver

o 1,1,2,2-Totrachlorcethane

o $1,1,2,2$-Tetrachlorosthane

o Tetrachloroethylene

Tetrachlorosthylene

Tetrachloroethylene

Toluene

o Toluene

o 1,1,1-Trichloroothane

i,i, Trichloroothane

$1,1,1$-Trichloroethane

1,1, 9. Trichloroethane

$1,1,2$. Trichlorothane

1, 1, -Trichloroethane

i, 2-Trichlorosthane

Trichloroethylens

Trichloroothylisne

- Trichlorofluoromothane

Trichlorofluoromethane

o Trichlorofluoromethane

o Antimony-125

Antimony-125

Corlum-144

Cesium-134

O Cosium-137

Cosium.137

Cobalt-57

Cobatt-57
$<1.0$

$<10$
$<10$

$<1.0$

$<5.0$

$<10$

$<10$

$<4.0$

$<1.1$

$<5.0$

$<5.0$

$<5.0$

$<5.0$

$<1.0$

$<5.0$

$<1.0$

$<5.0$

$<5.0$

$<5.0$
$<5.0$
$<5.0$

$<5.0$
$<5.0$

$<1.0$

$<5.0$

$<5.0$

$<1.0$

$<5.0$

(1)

$<5.0$

$<5.0$

$<5.0$

$<5.0$

3.4
6.2
$<0.20$

$<0.20$
1,080
1,650

$<10$

$<10$

$<2.0$

$<0.70$

$<5.0$

$<5.0$

$<5.0$

$<5.0$

$<1.0$

$<1.0$

$<5.0$

$<5.0$

$<1.0$

55.0

$<1.0$

$<5.0$

$<5.0$

$<5.0$

$<2.0 E-00$

$<2.00 .06$

$<6.0 E-06$

$<1.0 E-00$

$<1.0 E-08$

$<1.0 E-00$

$<1.0 E-08$
Mad Unit Lnb

$m$ moh

wa Wh

WA




\section{WELL YSB 4A}

MEASUREMENTS CONDUCTED IN THE FIELD

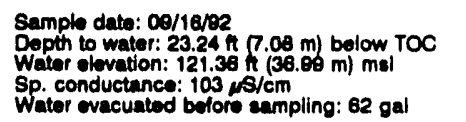

LABORATORY ANALYYES

E Analyte

$0 \mathrm{pH}$

Spocific conductanco

0 Antenlc

Barlum

Bromodichloromethane

Bromodich

Bromormothane

Cedmium

Carbon tetrachioride

Chloride

Chlorobenzens

Chloroethane

2-Chloroethyl vinyl the

Chioroform

Chloromethane

Chromium

Oibromochloromethane

1,1-Dichloroethane

1,2.Dichloroethane

1,1-Dichloroethylene
trans-1,2-Dichlorosthylene
Oichloromethan

o 2,4-Dichlorophenoxyacetic acid

o 1,2-Dichloropropane

o cis-1,3-Dichloropropene

0 trans-1,3

Ethylbenzene

Fluoride

Iron

Lead

Magneslum

Manganese

Mareury

Methoxychlor

Nickel

Phenols

Potasalum

Selenium

Sllica

Silver

Sodium

1,1,2,2-Tetractiloroethan

Tetrachloroethylene

Total diseotved solids

Total inorganic carbon

otal organic carton

Total phosphates (as P)

Toxaphene

2,4,5-TP (Sitvox),

1,1,1-Trichloroethane

1,1,2-Trichloroethan

Trichioroethylene

Trichilor

Zinc

Nonvolatile beta

Total alpha-emitting radiusn

$\begin{array}{ll}0 & \text { Trtilum } \\ 0 & \text { Trtium }\end{array}$

\begin{tabular}{|c|c|c|c|c|c|}
\hline Result & Mod & Unit & Lab & $\mathbf{F}$ & Analyte \\
\hline $\begin{array}{r}5.7 \\
82 \\
<2.0 \\
13 \\
<1.0\end{array}$ & JO & $\underset{\mu \mathrm{pH}}{\mathrm{pH} / \mathrm{cm}}$ & $\begin{array}{l}G E \\
G E \\
G E \\
G E \\
G E\end{array}$ & $\begin{array}{l}0 \\
1 \\
0 \\
0\end{array}$ & $\begin{array}{l}\text { Total organic halogens } \\
\text { Groas alpha } \\
\text { Total alpha-omitting radium } \\
\text { Tritium }\end{array}$ \\
\hline
\end{tabular}

Time: 10:25

PH: 5.1 Alkalinity: $4 \mathrm{mg} / \mathrm{L}$

Water tomperature: $20.0^{\circ} \mathrm{C}$

$<1.0$

$<1.0$

$<1.0$

$<2.000$

1,500
$<1.0$
11,400

11.400

$<1.0$

$<1.0$

$<1.0$

$<1.0$

$<1.0$

$<4.0$

$<1.0$

$<1.0$

$<1.0$

$<1.0$

1.4
$<0.30$

$<1.0$
$<1.0$
$<1.0$

$<0.0060$

$<1.0$
$<100$

$<100$
58

$<3.0$

507

7.0
$<0.20$
$<0.50$
6.7

$<0.50$
6.7
2,520
$<5.0$

873
$<2.0$

$<2.0$
8,490
$<2.0$

$<2.0$
17,200

5,320

$<1.0$

$<1.0$

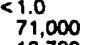

13,700

$<1,000$

$<5.0$

$<0.24$

$<0.090$

$<0.090$
$<1.0$
$<1.0$

$<1.0$

$<1.0$
7.0

7.0
$<2.0 E-09$

$<2.0 E-09$

$<1.0 \mathrm{E}-09$

$1.8 \mathrm{E}-00+5.0 \mathrm{E}-07$

WELL YSC $1 A$

MEASUREMENTS CONDUCTED IN THE FIELD

Sample date: 08/25/92 $\mathrm{n}(32.67 \mathrm{~m})$ below TOC

Time: 15:30

Water elevation: $163.72 \mathrm{n}(49.80 \mathrm{~m}) \mathrm{ms}$

Inaccessibility or mochanical problem prevented sample collection.
WELL YSC $1 \mathrm{C}$

MEASUREMENTS CONDUCTED IN THE FIELD

Sample date: 08/25/92

Depth to water: $56.81 \mathrm{ft}(17.35 \mathrm{~m})$ below TOC

Water olevation: $217.48 \mathrm{t}(88.28 \mathrm{~m}) \mathrm{msl}$

pH: 6.0

LABORATORY ANALYYSES

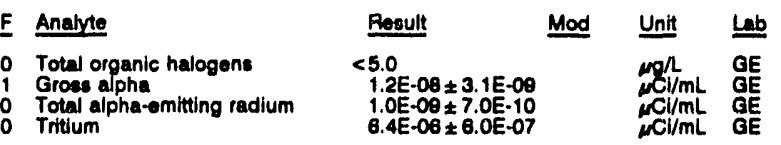

WELL YSC $2 A$

MEASUREMENTS CONDUCTEO IN THE FIELD

Sample date: 08/25/92 $\mathrm{N}$ Time: $15: 10$

Water elevation: 163.02 t $(40.69 \mathrm{~m}) \mathrm{msl}$ Alkalinity: $170 \mathrm{mg} / \mathrm{h}$

Sp. conductance: $679 \mathrm{~s} / \mathrm{cm}$

Water temperature: $20.4^{\circ} \mathrm{C}$

Whitor evacuatod betore eampling: $74 \mathrm{gal}$

LABORATORY ANALYSES

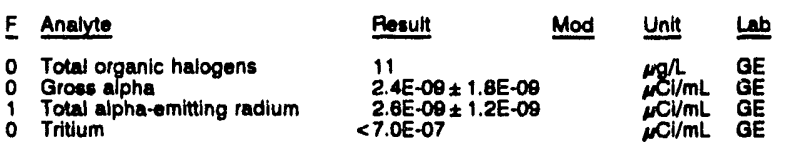

WELL YSC 2D

MEASUAEMENTS CONDUCTED IN THE FIELD

\begin{tabular}{|c|c|c|c|c|}
\hline \multicolumn{2}{|c|}{$\begin{array}{l}\text { Sample date: } 08 / 28 / 92 \\
\text { Depth to water: } 86.58 \mathrm{ft}(20.29 \mathrm{~m}) \text { bolow TOC } \\
\text { Water olovation: } 217.42 \mathrm{ft}(\mathrm{C6.27} \mathrm{m}) \mathrm{msl} \\
\text { Sp. conductance: } 53 \mathrm{\mu s} / \mathrm{cm} \\
\text { Wator evacuated bofore sampling: } 15 \mathrm{gal} \\
\text { The woll went dry during purging. }\end{array}$} & \multicolumn{3}{|c|}{$\begin{array}{l}\text { Time: } 9: 55 \\
\text { pH: } 8.0 \\
\text { Alkatinity: } 14 \mathrm{mg} / \\
\text { Water temperature: } 20.1 \cdot \mathrm{C}\end{array}$} \\
\hline \multicolumn{5}{|l|}{ LABORATORY ANALYSES } \\
\hline Analyte & Pesunt & Mod & Untis & $\underline{\underline{L n}}$ \\
\hline $\begin{array}{l}0 \text { Total organic halogens } \\
0 \text { Groas alpha } \\
0 \text { Total alpha-emitting radium } \\
0 \text { Trtalum }\end{array}$ & $\begin{array}{l}<5.0 \\
<2.0 \mathrm{E}-00 \\
1.0 \mathrm{E}-09 \\
7.0 \mathrm{E}-08\end{array}$ & $\begin{array}{l}.0 E-09 \\
.0 E-07\end{array}$ & $\underset{m / / m L}{m / m L}$ & $\begin{array}{l}\mathrm{GE} \\
\mathrm{GE} \\
\mathrm{GE} \\
\mathrm{GE}\end{array}$ \\
\hline
\end{tabular}

WELL YSC $4 C$

MEASUREMENTS CONDUCTED IN THE FIELD

Sample date: 08/28/92 $(18.24 \mathrm{~m})$ below TOC Time: 10:35

Depth to wator: $61.15 \mathrm{~h}(18.64 \mathrm{~m})$ below TOC PH: 5.0
Water elevation: $228.45 \mathrm{~h}(69.63 \mathrm{~m}) \mathrm{msl}$
Alkalinity: $1 \mathrm{mg} /$

Sp. conductance: $27 \mathrm{sS} / \mathrm{cm}$.

Water evacuatod before sampling: $85 \mathrm{gal}$

LABORATORY ANALYSES

Total organic halogens

Total organic halogen

o Groses alpha

Gross alph:

Gross alpha

Nonvolatile beta

Nonvolatlle beto

Radium-226

Total alpha-omitting radium

Total alpha-emitting radium

1 Tritium

\begin{tabular}{|c|c|c|}
\hline Result & Mod & Unit \\
\hline $\begin{aligned} & 6.7 \\
&< 10 \\
&< 10 \\
&<2.0 E-09 \\
&<8.0 E-10 \\
&<8.0 E-10 \\
& 1.5 E-09 \pm 1.3 E-09 \\
& 3.0 E-09 \pm 1.5 E-09 \\
& 7.3 E-10 \pm 3.1 E-10 \\
& 6.0 E-10 \pm 8.0 E-10 \\
&<1.0 E-09 \\
&<1.0 E-09 \\
& 1.0 E-05 \pm 7.0 E-07 \\
& 1.2 E-05 \pm 1.7 E-08\end{aligned}$ & $\begin{array}{l}\text { JO } \\
\text { Ja }\end{array}$ & 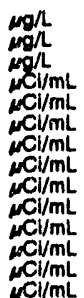 \\
\hline
\end{tabular}


WEL Y8B $2 A$ collected on $08 / 18 / 92$, laboratory analyese (cont)

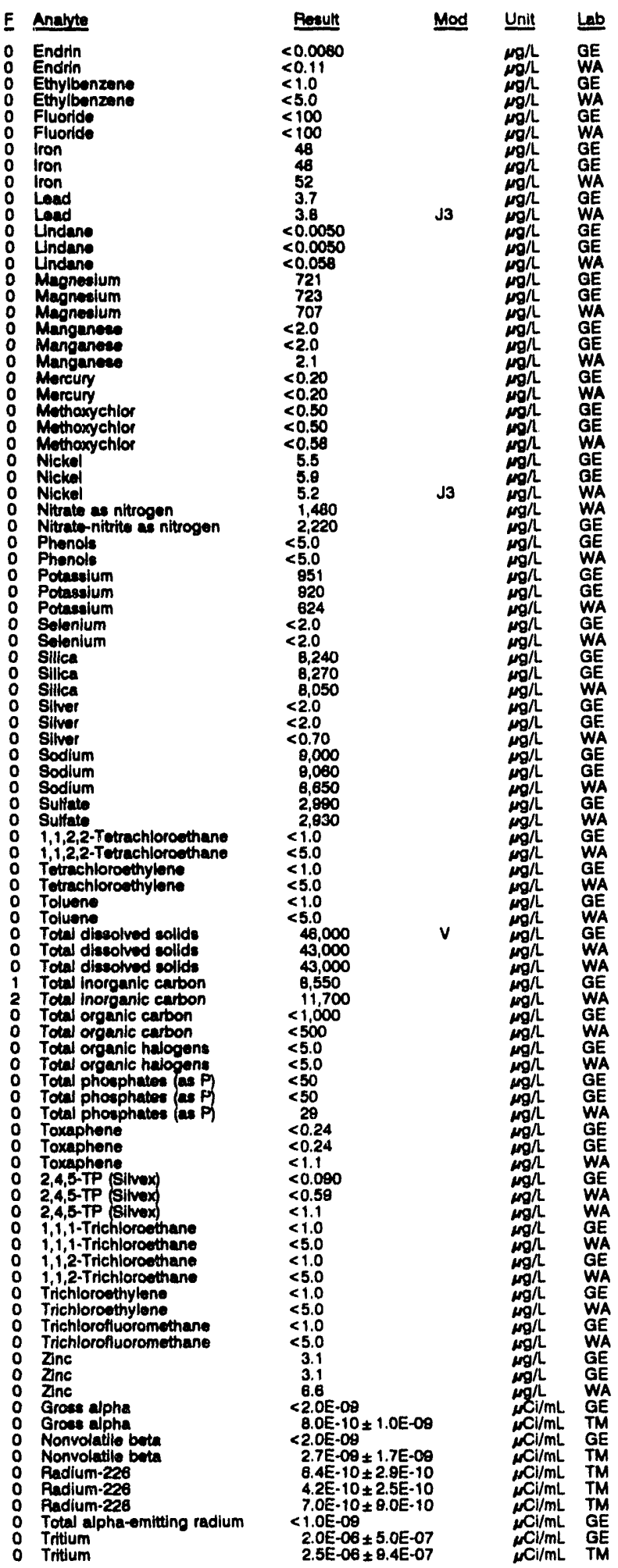

WELL YSB 3A

MEASUREMENTS CONDUCTED IN THE FIELD

$\begin{array}{ll}\text { Sample date: } 08 / 16 / 92 & \text { Time: } 11: 00 \\ \text { Depth to water: } 21.15 \mathrm{Ht}(0.45 \mathrm{~m}) \text { bolow TOC } & \text { pH: } 8.2 \\ \text { Water olevation: } 122.75 \mathrm{ht}(37.41 \mathrm{~m}) \mathrm{mal} & \text { Alkalinity: } 65 \mathrm{mg} / \mathrm{h} \\ \text { Sp. conductance: } 267 \mathrm{~s} / \mathrm{cm} & \text { Water tomparature: } 23.4 \cdot \mathrm{C} \\ \text { Water ovacuated bofore campling: } 68 \mathrm{gal} & \end{array}$

LABORATORY ANALYSES

o $\mathrm{pH}$

Arenic

B Barium

Bromodichloromethane

Bromolorm

Bromomethane

Cadmium

Calcium

Carbon tetrachloride

Chloride

Chlorobenzene

Choroethane

Chloroethene Ninyl chloride

2-Chloroethyl

Chloromethere

Chromium

Copper

Dibromochloromethane

1,1-Dichloroethane

1,2-Dichloroethane

1,1-Dichloroethylane
trans-1,2-Dichloroethylene

Dichloromethane

2,4-Dichlorophenoxyacetic acid

1,2-Dichloropropane

cis-1,3-Dlchloropropene

trans-1,3-Dichloropropene

Ethylbenzene

0 Fluoride

iron

0 Load

O Lindane

o Magnesium

0 Mercury

Methoxychior

0 Nickel

Nitrate-niturite as nitrogen

O Phenols

Potansium

silice

0 Silve

Sodium

S Sulfate

1,1,2,2-Tetrachloroeth

o Tetrachloroethylene

Total dissolved solids

Total inorganic carbo

Total organic carbon

Total organic halogens

Toxnphene

2,4,5-TP (Silvex)

1,1,1-Trichloroethane

1,1,2-Trichloroethan

Trichloroethylene

Zinc

o Gross alpha

0 Gross alpha

O Nonvolatile beta

Total alpha-emitting radium

Tritium
Reoult Mod Unit

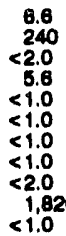

$<1,0.300$

$<1.0$

$<1.0$

$<1.0$

3.4
$<1.0$

$\leq 4.0$

$<4.0$

$<1.0$

$<1.0$

$<1.0$

$<0.30$

$<1.0$

$<1.0$

$<1.0$

$<100$

$<0.0050$

436
$<2.0$

$<0.20$

$<0.50$

4.2
1,650

-5.0
8.26
$<2.0$
6,330
6.30

6,330
$<2.0$

58,600
18,300

18,300
$<1.0$

$<1.0$
$<1.0$

$<1,0$

19,800

$<1,000$
$<5.0$

$<5.0$

$<0.24$

$<1.0$

$<1.0$

$<1.0$

$<2.0$

$<2.0 E-09$

$<2.0 \mathrm{E}-08$

$<2.0 \mathrm{E}-09$

$<7.0 \mathrm{E}-07 \times 8.0 \mathrm{E} \cdot 10$

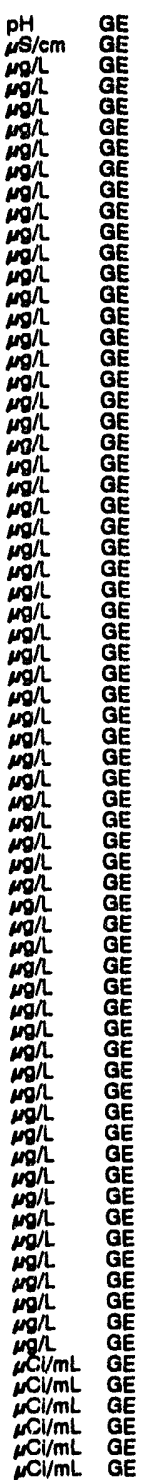

$1.0 \mathrm{E}-09 \pm 8.0 \mathrm{E} \cdot 10$ 
WELL YSB 2A collected on 09/18/92, laboratory analyses (cont.)

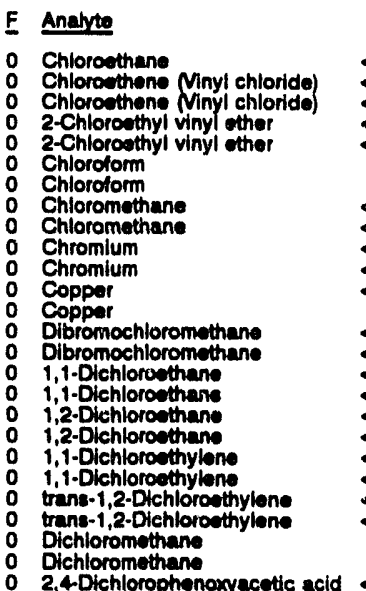

2,4-Dichlorophenoxyacetic acid

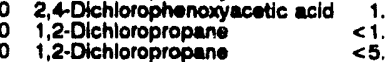

0 cie-1,3-Dichioropropene

cis-1,3-Dichloropropene
trans-1,3-Dichloropropene
trans-1,3-Dichloropropene

Endrin

Ethylbenzane

0 Ethylbenzen

0 Fluoride

Iron

0 Lead

Lindan

O Lindane

Magneslum

Magresium

Manganese

Mercuny

Methoxychlor

Methoxychior

Nickal

Nitrate as nitrogen

Nitrate-nitutte as nitrogen

Phenols

Phenola

Potaselium

Potaseium

Selonium

O Solicniv

Silica

Silver

Silver

Sodlum

Sodium

Sulfato

1,1,2,2-Tetrachloroethane

1,1,2,2-Tetrachloroethane

Tetrachloroethylene

Toluachio

Toluene

Total diasolved sollds

Total inorganic carbon

Total inorganic carbon

Total organic carbon

rotal organic carton

Total organic halogens

Total phosphates (as P)

Toxaphene

Toxaphene

0 2,4,5-TP (Silvex)

0 1,1,1-Trichloroethane

1,i, Irichloroethane

1,1,2-Trichloromane

1,1,2-Trichlorosthan

O Trichloroethylene

Trichlorofluoromethane

- Trichlorofluoromethane
$<10$

$<10$

$<1.0$

1.1
$<1.0$
$<10$

$<10$

$<1.1$

1.1
$<1.0$

$<5.0$

$<5.0$

$<5.0$

$<1.0$

$<1.0$

$<5.0$
1.5
4.5

Mod Unit

$\underset{\mu g / L}{\mu / L}$

Lab

WA

WA

WA

WA

$<0.11$
$<1.0$
$<5.0$

$<100$
$<100$

48
4.2
3.5

3.5
$<0.0050$

$<0.05$

671
$<2.0$
2.0

2.0
$<0.20$

$<0.20$

$<0.50$

$<0.5$
5.0

1.630
1.890

1.890
$<5.0$
$<5.0$

$<5.0$

984
731
$<2$

$<2.0$
$<2.0$
8.060

8.060
7,600
$<2.0$

$<2.0$
1.7

8,040
8,090

15,700

2.920
$<1.0$
$<5.0$
$<1.0$

$<5.0$

$<1.0$

$<5.0000$

$5,, 000$
2,490

11,100
5,580

5,580
$<500$
$<5.0$
$<50$

$<5.0$

43
$<0.24$

$<1.14$

$<0.090$

0.59
$<1.0$

$<5.0$

$<1.0$

$<5.0$

$<1.0$

$<5.0$
$<1.0$
$<5.0$
WEL YSB 2A collected on 09/16/82, laboratory analyees (cont.)

E Analyte

0 Zinc

0 Groes alpha

0 Grose alpha

o Nonvolatile bets

Nonvolatile beta

Nonvolatile beta
Radium-226

Radjum-22:

Radium-228

Total alpha-omitting radium

0 Tritium

Tritum

\begin{tabular}{|c|c|c|}
\hline Pesult & Mod & Unit \\
\hline $\begin{array}{l}2.5 \\
8.8 \\
<2.0 E-09 \\
2.3 E-09 \pm 1.4 E-09 \\
8.0 E-10 \pm 1.0 E-09 \\
<2.0 E-09 \\
1.3 E-09 \pm 1.5 E-09 \\
2.0 E-09 \pm 1.0 E-09 \\
4.3 E-10 \pm 2.8 E-10 \\
1.1 E-09 \pm 9.0 E-10 \\
<5.0 E-10 \\
<1.0 E-09 \\
<1.0 E-09 \\
2.4 E-06 \pm 5.0 E-07 \\
2.0 E-08 \pm 1.0 E-00 \\
2.8 E-06 \pm 1.2 E-08\end{array}$ & & 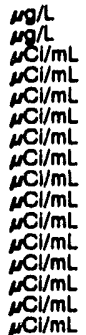 \\
\hline
\end{tabular}

WELL YSB 2A Replicate

MEASUREMENTS CONDUCTED IN THE FIELD

Sample dato: 09/16/92

Sample date: $09 / 16 / 92$
Dopth to wator: $21.82 \mathrm{ft}(6.65 \mathrm{~m})$ below TOC
Water elevation: $122.88 \mathrm{ft}(37.45 \mathrm{~m}) \mathrm{msl}$

P. conductance: $72 \mu \mathrm{s} / \mathrm{cm}$

ming:

Alkalinity: $1 \mathrm{mg} /$

Water evacuated before sampling: $66 \mathrm{gal}$

LABORATORY ANALYSES

E Analyte

0 pH

Specific conductance

0 Spreclific conc

0 Arsenic

Barium

Barium

Barium

Bunzene

Bromodichloromethane

Bromodichloromethane

Bromoform

Bromolorm

Bromomethane

Cadmium

Cadmium

Cadmium

Calclum

Calclum

Carbon tetrachloride

Carbon tetrachloride

Chloride

Chloride

Chlorobenzene

Chlorobenzene

Chloroethane

Chloroothane

Chloroethene Minyl chloride)

Chloroethene Ninyl chloride

2-Chloroethyl vinyl ther
2-Chloroethyl vinyl other

2-Chloroethy

O Chloroform

Chloromethane

Chromium

Chromium

Chromium

Copper

0 Copper

o Dibromochloromethane

Dibromochloromethan

1,1-Dichlorosthane

1,2-Dichloroethane

1,2-Dichloroethane

1,1-Dichloroethylene

trans-1,2-Dichloroethylene

trans-1,2-Dlchlorocthylen

Dichloromethane

$\begin{array}{ll}0 & \text { Dichloromethane } \\ 0 & 2,4-D l c h l o r o p h e n o x y\end{array}$

0 2,4-Dichlorophenoxyacetic acid $<2$.

o 1,2-Dichloropropane

1,2-Dichloropropane

cis-1,3-Dichloropropeno

cise-1,3-Dichloropropene

trans-1,3-Dichloropropeno

trans-1,

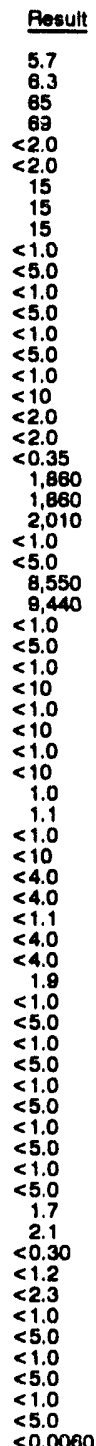

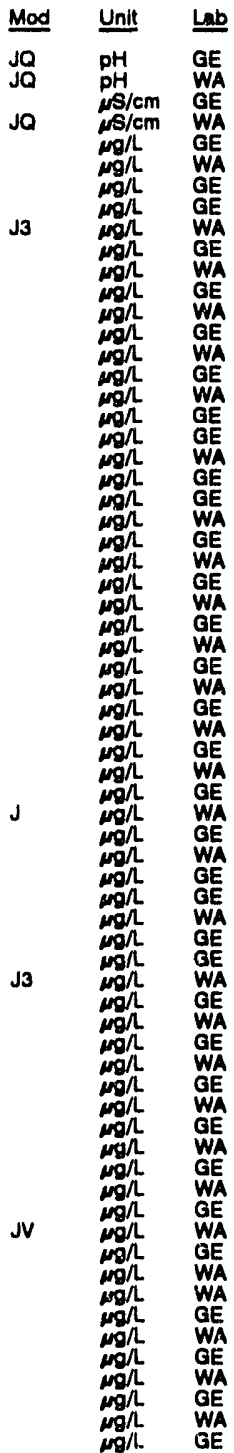


ANALYTICAL RESULTS

WELL XSB SA collectad on 09/14/82, laboratory analyses (cont.)

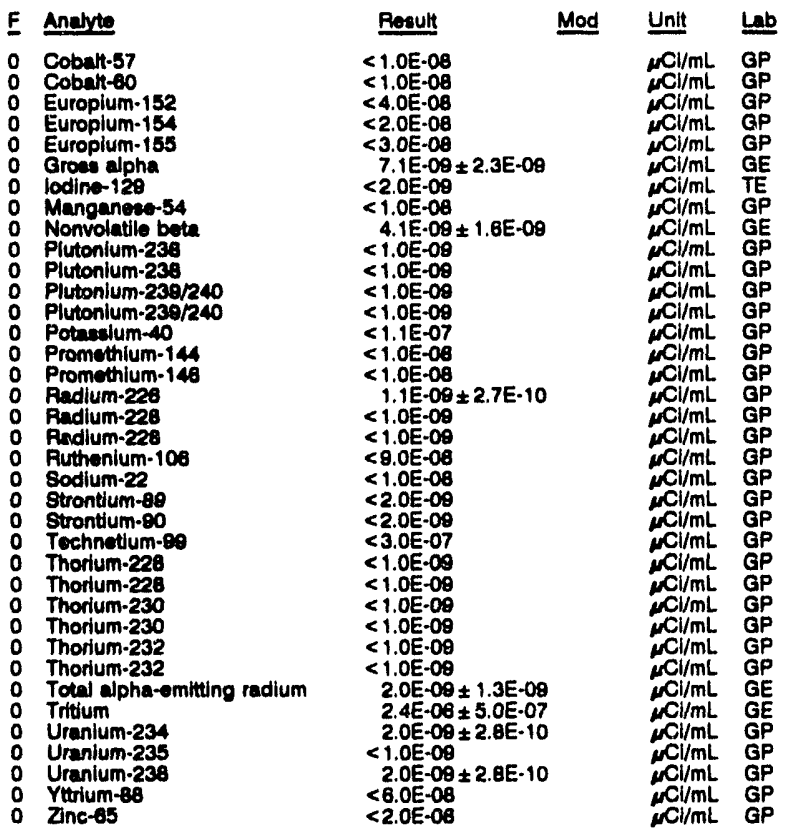

\section{WELL YSB TA}

\section{MEASUREMENTS CONDUCTED IN THE FIELD}

Sample date: 09/18/92
Depth to water: $23.83 \mathrm{n}(7.29 \mathrm{~m})$ below TOC
Water olevation: $121.57 \mathrm{~h}(37.05 \mathrm{~m}) \mathrm{mgl}$
Sp. conductance: 34 Hs/cm
Water ovacunted before sampling: $61 \mathrm{gal}$

Time: $8: 50$

PH: 5.3

Water temperature: $21.1^{\circ} \mathrm{C}$

LABORATORY ANALYBES

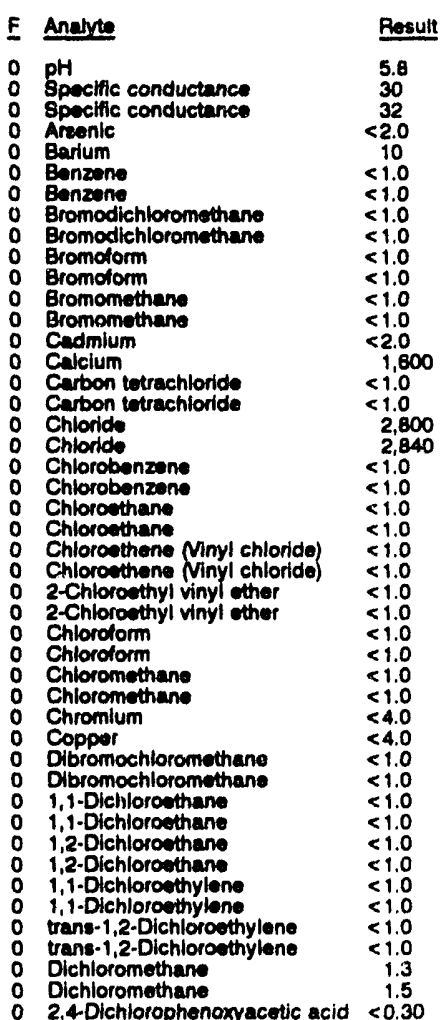

WELL YSB $1 A$ collocted on 09/16/82, laboratory analyees (cont)

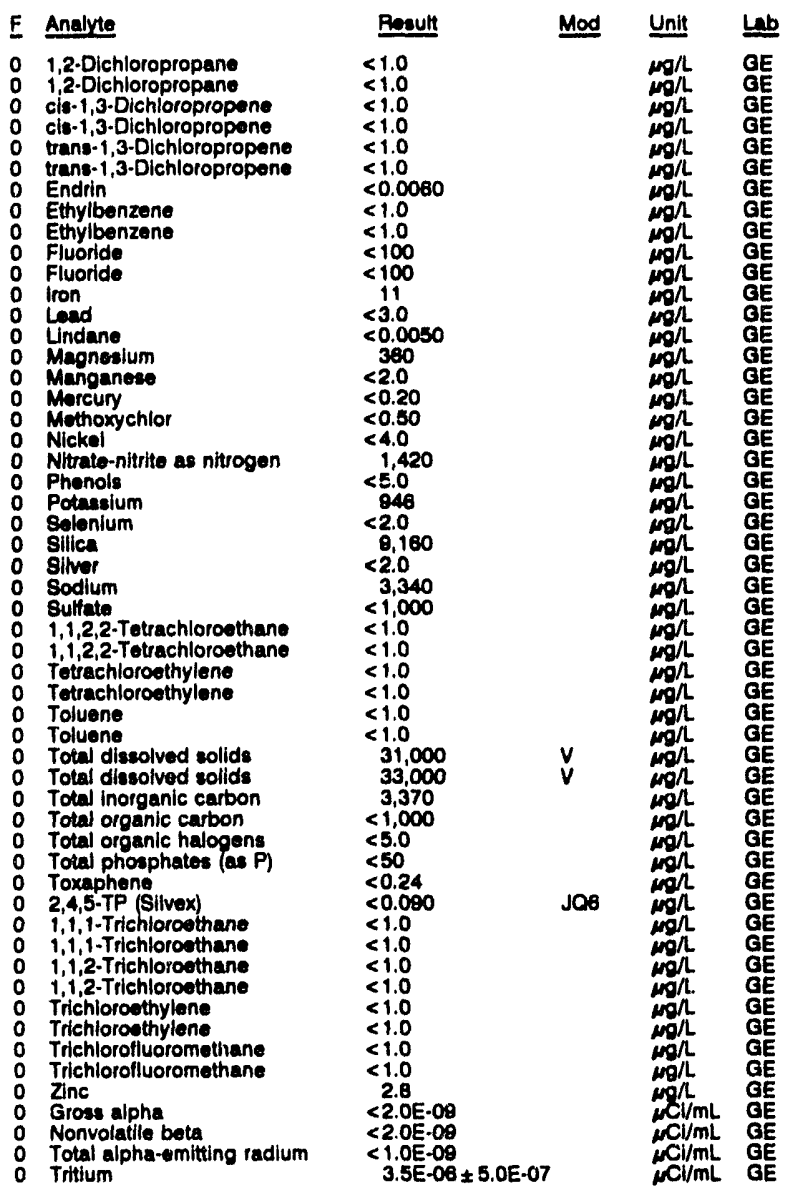

\section{WELL YSB $2 A$}

MEASUREMENTS CONDUCTED IN THE FIELD

$\begin{array}{ll}\text { Sample date: } 09 / 16 / 92 & \text { Time: } 11: 30 \\ \text { Depth to water: } 21.82 \mathrm{f}(6.65 \mathrm{~m}) \text { below TOC } & \text { pH: } 5.1 \\ \text { Water elevation: } 122.68 \mathrm{ft}(37.45 \mathrm{~m}) \mathrm{mal} & \text { Allalinity: } 1 \mathrm{mg} / \mathrm{h} \\ \text { Sp. conductance: } 72 \mu \mathrm{s} / \mathrm{cm} & \text { Water tomperature: } 21.2 \circ \mathrm{C}\end{array}$
Water evacuated bofore sampling: $68 \mathrm{gal}$

LABORATORY ANALYSES

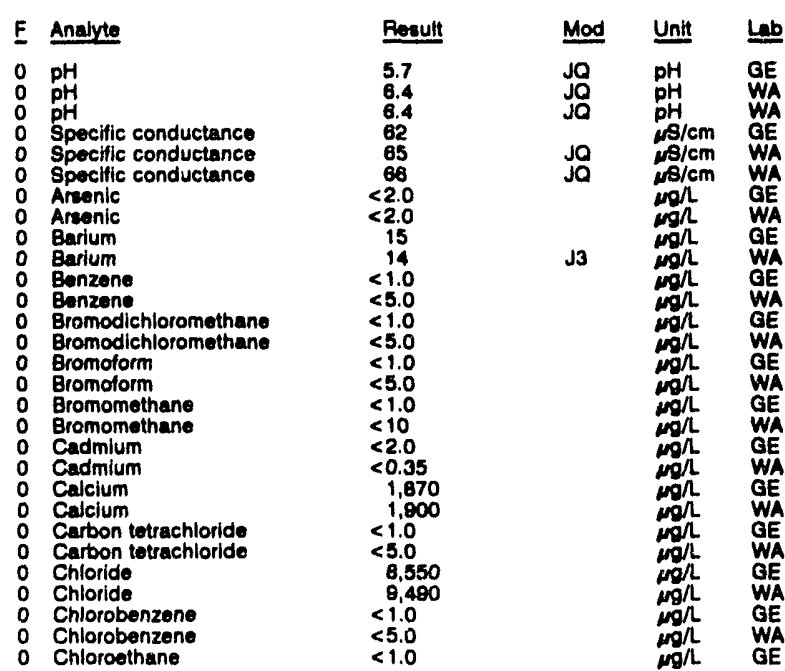




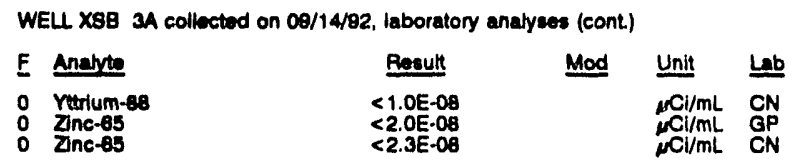

WELL XSB 4D

MEASUREMENTS CONDUCTED IN THE FIELD

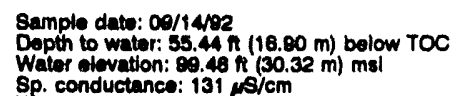

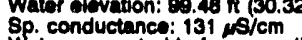

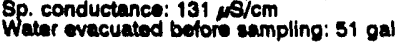

LABOFATOPY ANALYSES

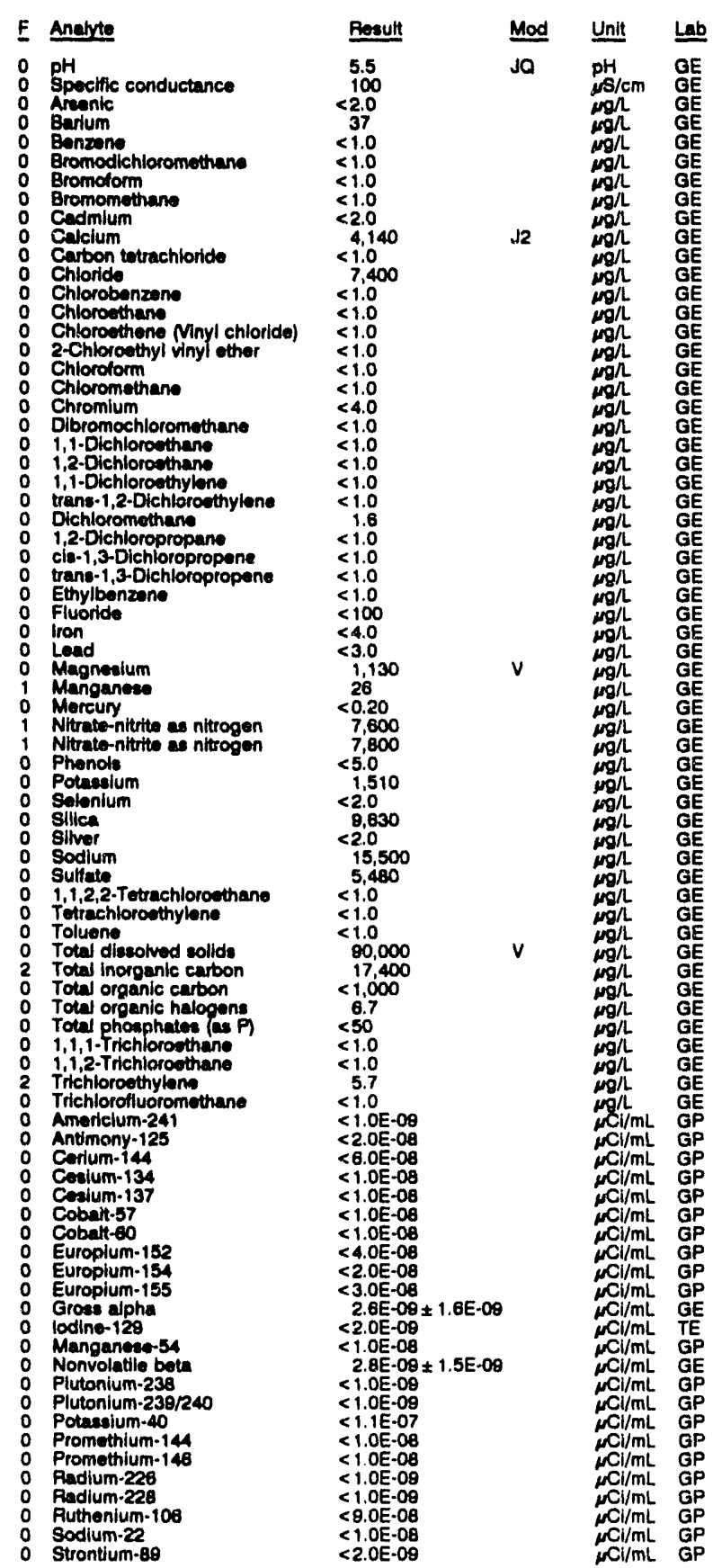

WELL XSB 40 colloctod on 08/14/82, laboratory analyees (cont).

\begin{tabular}{|c|c|c|c|c|}
\hline & Analyte & Pesult & Mod & Unit \\
\hline & 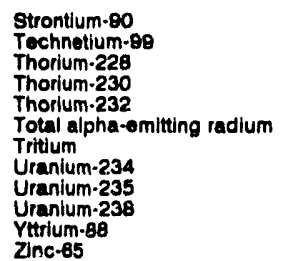 & $\begin{array}{l}<2.0 E-09 \\
<3.0 E-07 \\
<1.0 E-09 \\
<1.0 E-09 \\
<1.0 E-00 \\
1.6 E-09 \pm 1.2 E-09 \\
2.3 E-08 \pm 5.0 E-07 \\
<1.0 E-09 \\
<1.0 E-09 \\
<1.0 E-09 \\
<6.0 E .08 \\
<2.0 E .08\end{array}$ & & 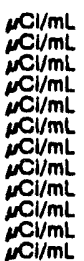 \\
\hline
\end{tabular}

WELL XSB 5A

MEASUREMENTS CONDUCTED IN THE FIELD

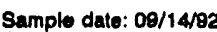

Depth to water: 13.58 ft $(4.14 \mathrm{~m})$ bolow TOC

Water elevation: $86.42 \mathrm{H}(30.00 \mathrm{~m}) \mathrm{msl}$

Sp. conductance: $102 \mathrm{\mu s} / \mathrm{cm}$ ming: $54 \mathrm{gal}$

LABORATORY ANALYSES

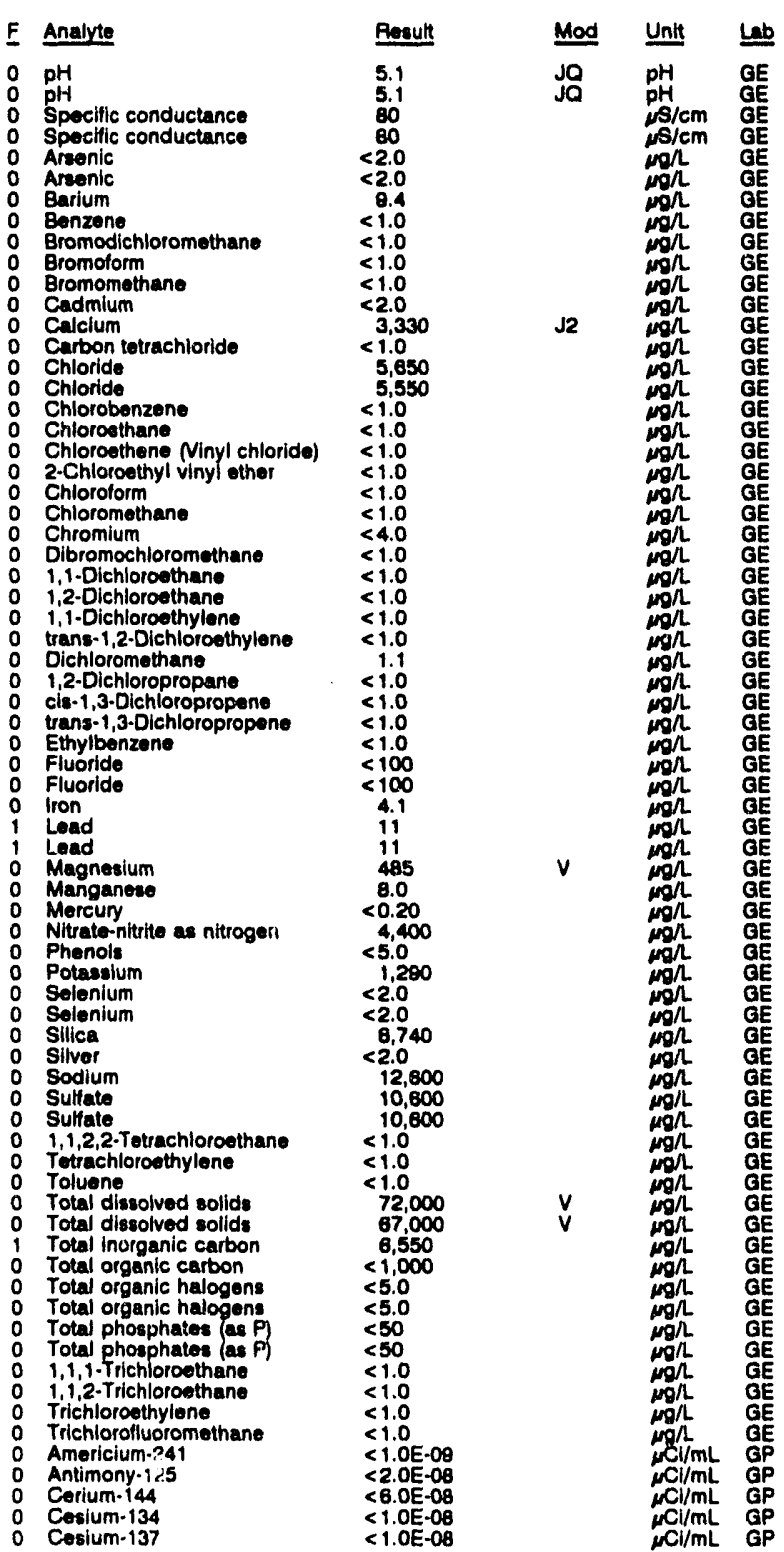

Time: 12:45

PH: 4.7.4 0 man

Alkalinity: 0 mgh $21.8 \cdot \mathrm{C}$

E


ANALYTICAL RESULTS

WELL XSB 3A Replicate

MEASUAEMENTS CONDUCTED IN THE FIELD

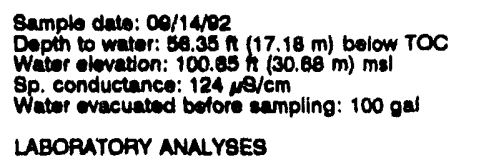

ATOAY ANALYSES

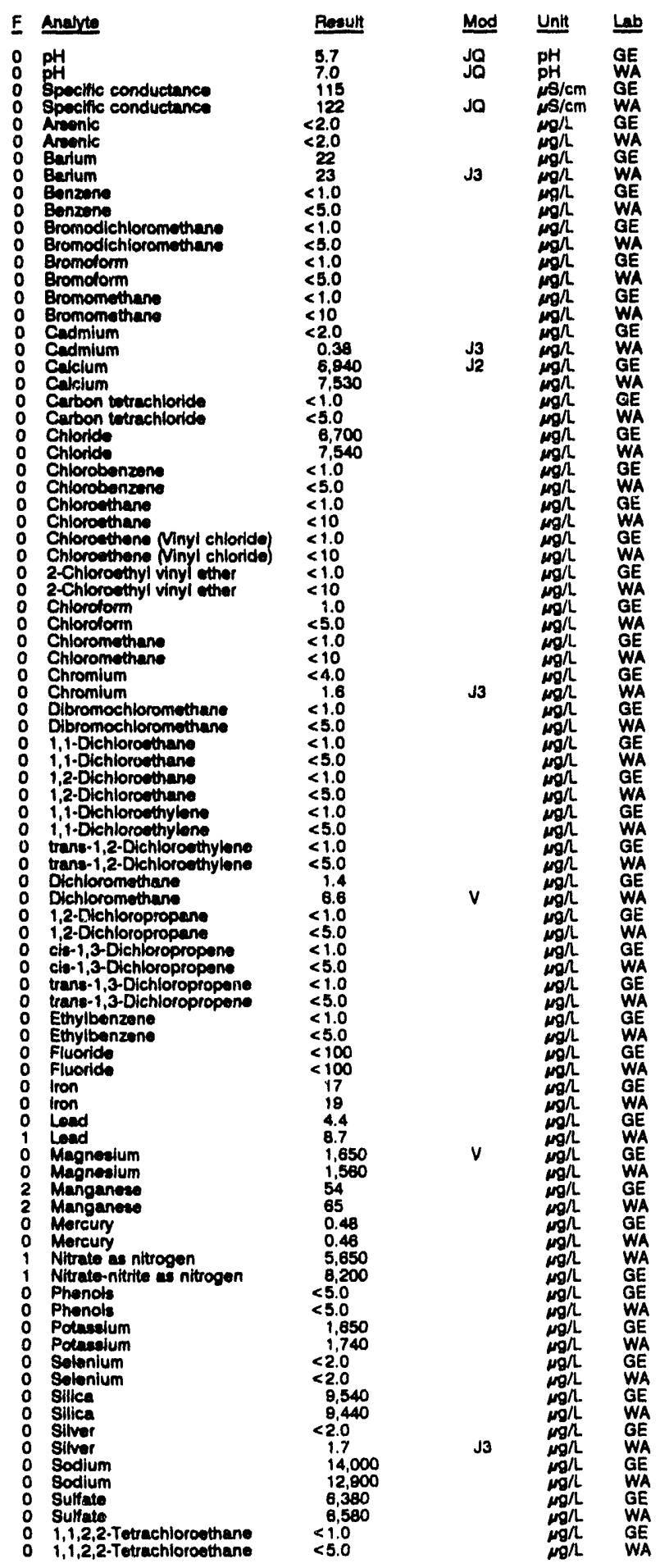

WELL XSB 3A collected on 08/14/92, laboratory analyees (cont.)

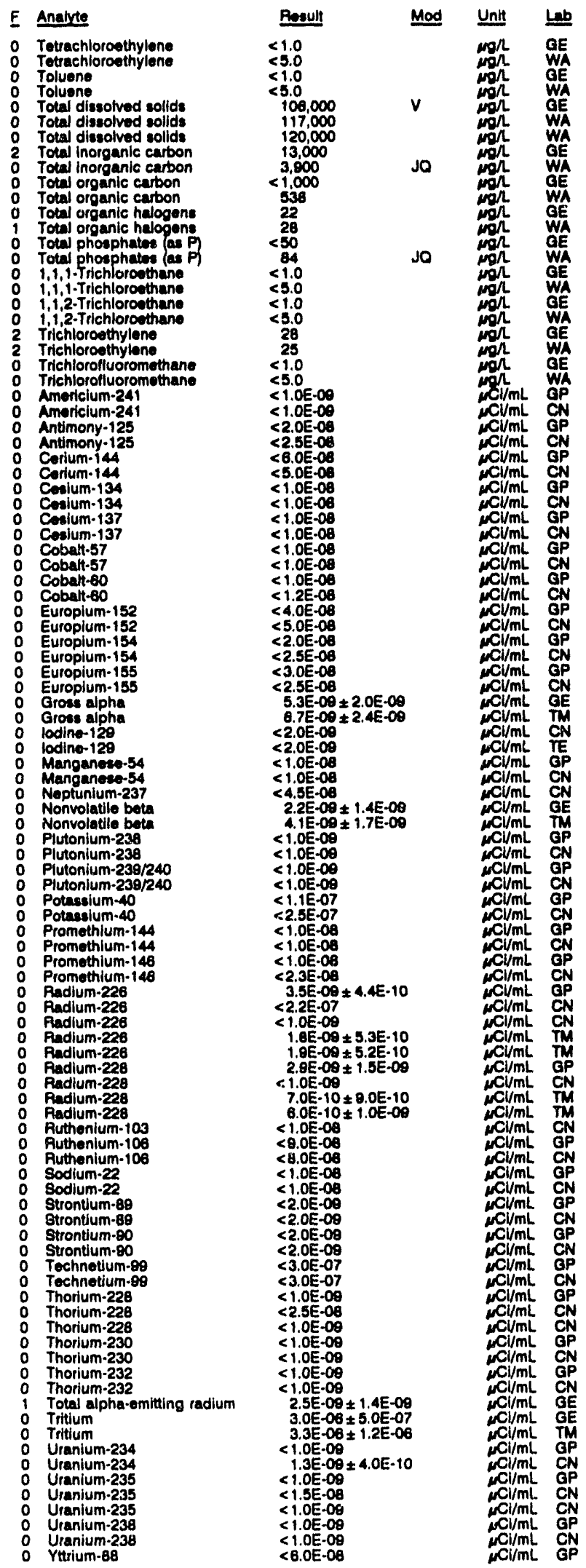


WELL X88 34 collected on 00/14/92, taboratory analyses (cont)

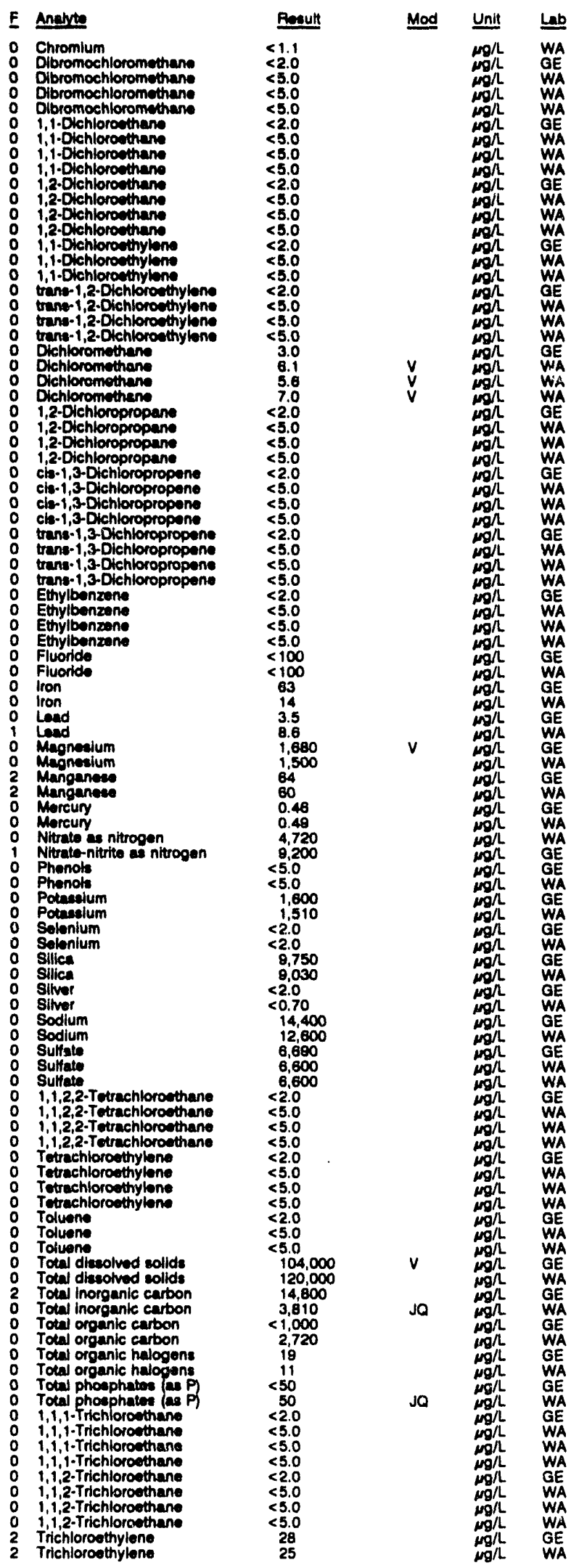

WELL XSB 3A collected on 09/14/92, laboratory analyees (cone)

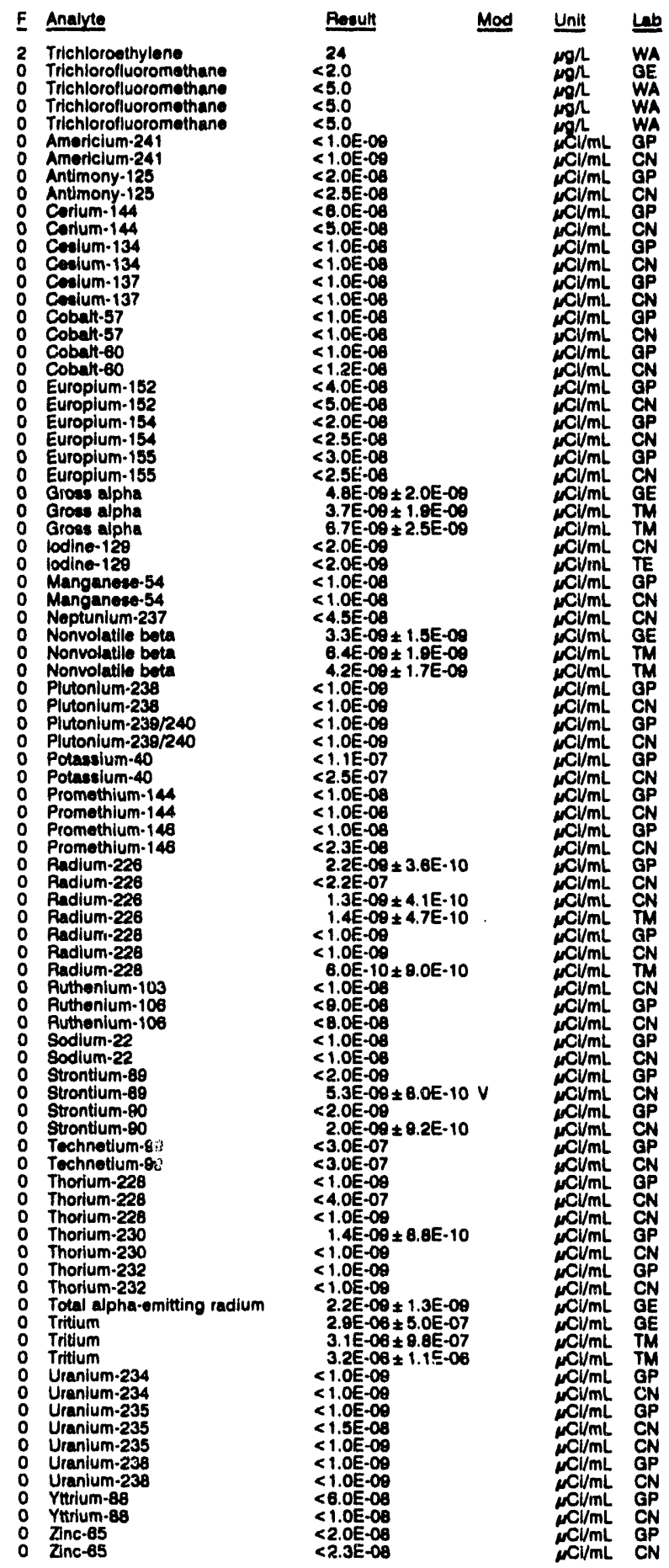




\section{ANALYTICAL RESULTS}

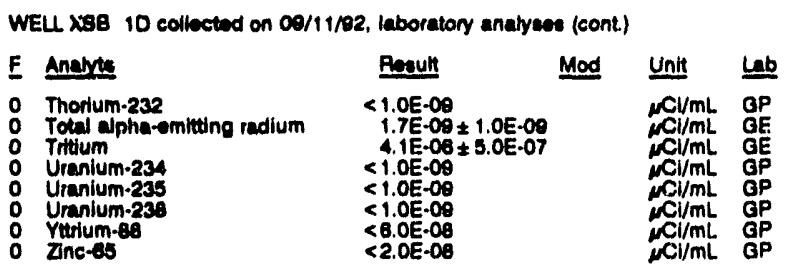

\section{WELL XSB 2D}

MEASUREMENTS CONOUCTED IN THE FIELD

\begin{tabular}{|c|c|}
\hline 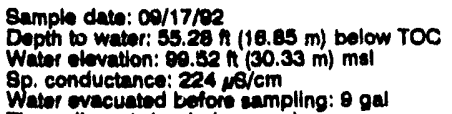 & $\begin{array}{l}\text { Time: } 9: 50 \\
\text { pH: } 7.0 \\
\text { Alkalinity: } 44 \mathrm{mghl} \\
\text { Water tomperature: } 21.5 \cdot \mathrm{C}\end{array}$ \\
\hline
\end{tabular}

\section{LABOPATOFY ANULYSES}

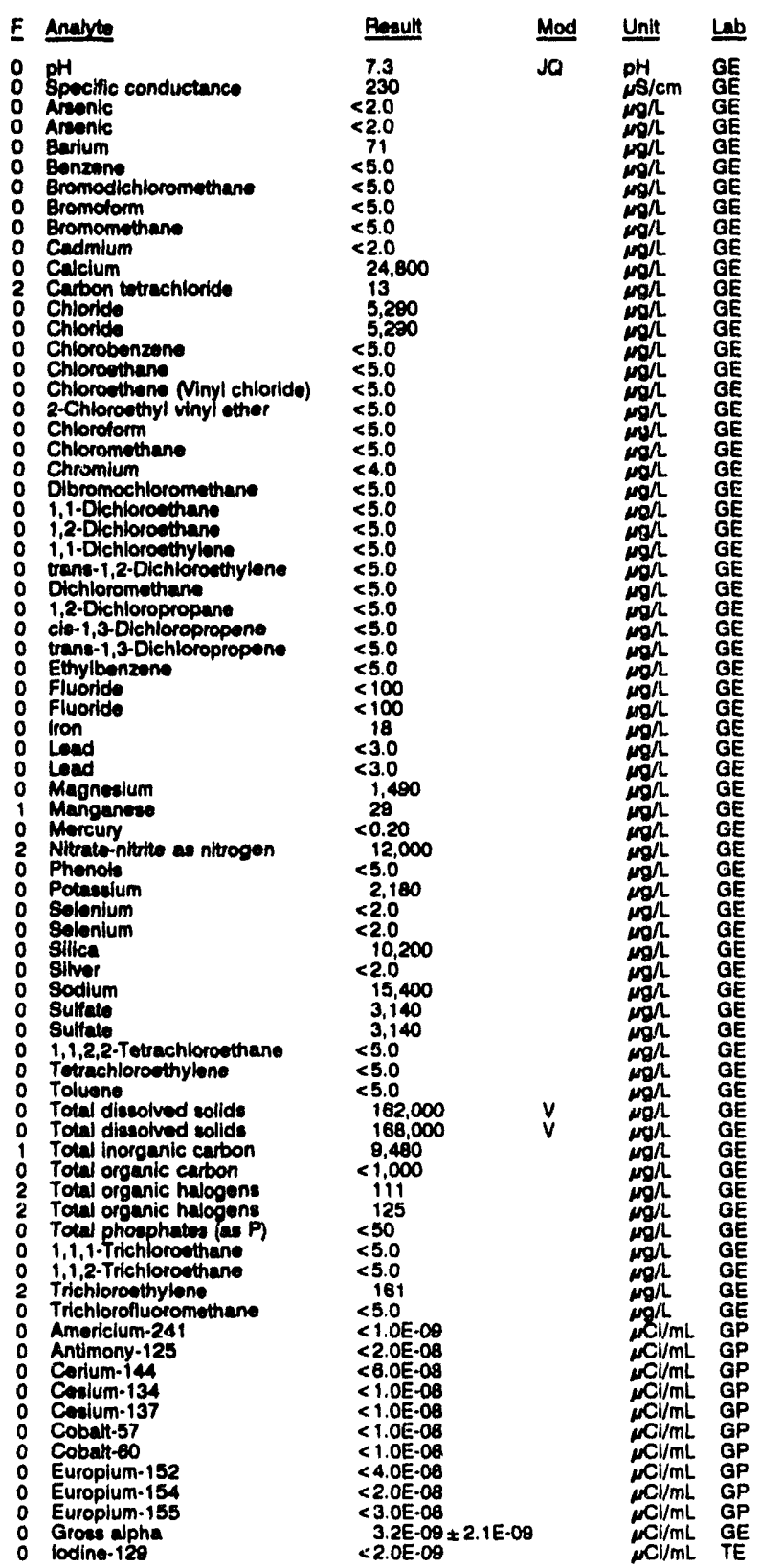

WELL X8B 20 collectod on 00/17/D2, laboralory analyees (cont.)

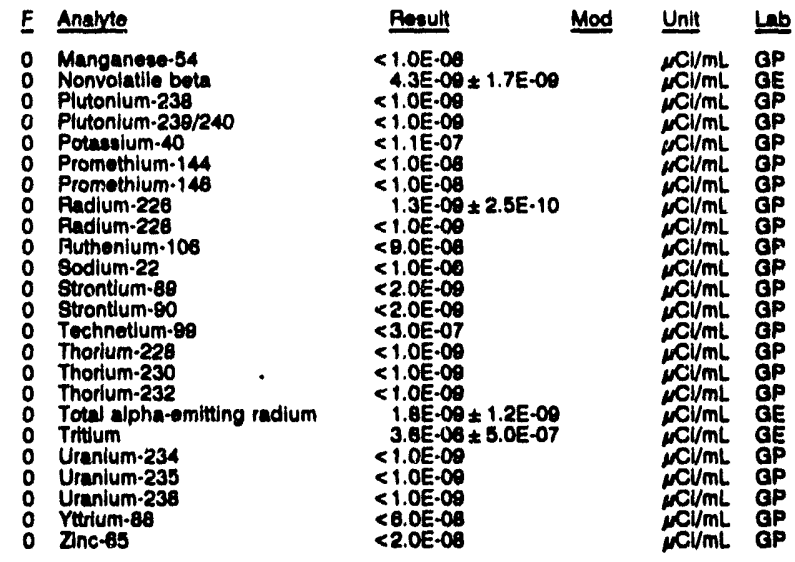

WELL XSB $3 A$

MEASUAEMENTS CONDUCTED IN THE FIELD

$\begin{array}{ll}\text { Sample date: } 09 / 14 / 92 & \text { Time: } 8: 20 \\ \text { Depth to water: } 56.35 \mathrm{ft}(17.18 \mathrm{~m}) \text { below TOC } & \text { pH: } 5.5 \\ \text { Water alovation: } 100.65 \mathrm{~h}(30.68 \mathrm{~m}) \mathrm{msi} & \text { Alkalinity: } 6 \mathrm{mgh} \\ \text { Sp. conductance: } 124 \mu \mathrm{s} / \mathrm{cm} & \text { Water temporature: } 20.5 \circ \mathrm{C} \\ \text { Wator ovacuated belore sampling: } 100 \mathrm{gal} & \end{array}$

LABORATORY ANALYSES

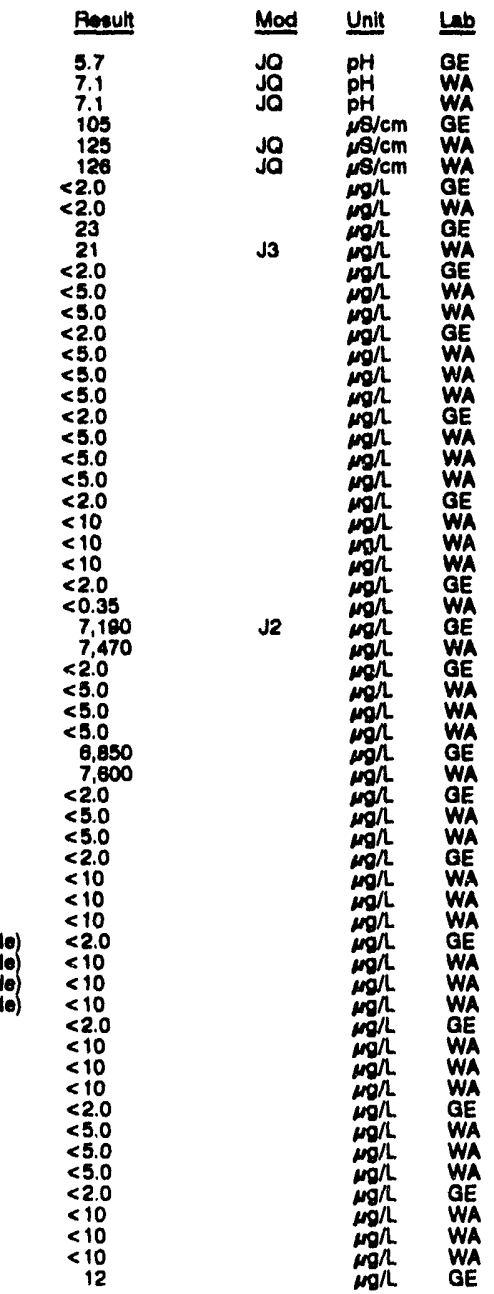

\begin{tabular}{|c|}
\hline 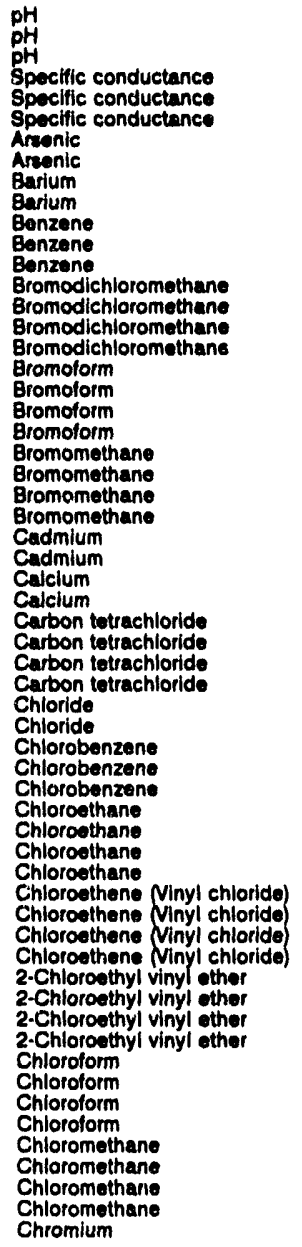 \\
\hline
\end{tabular}


ANALYTICAL RESULTS

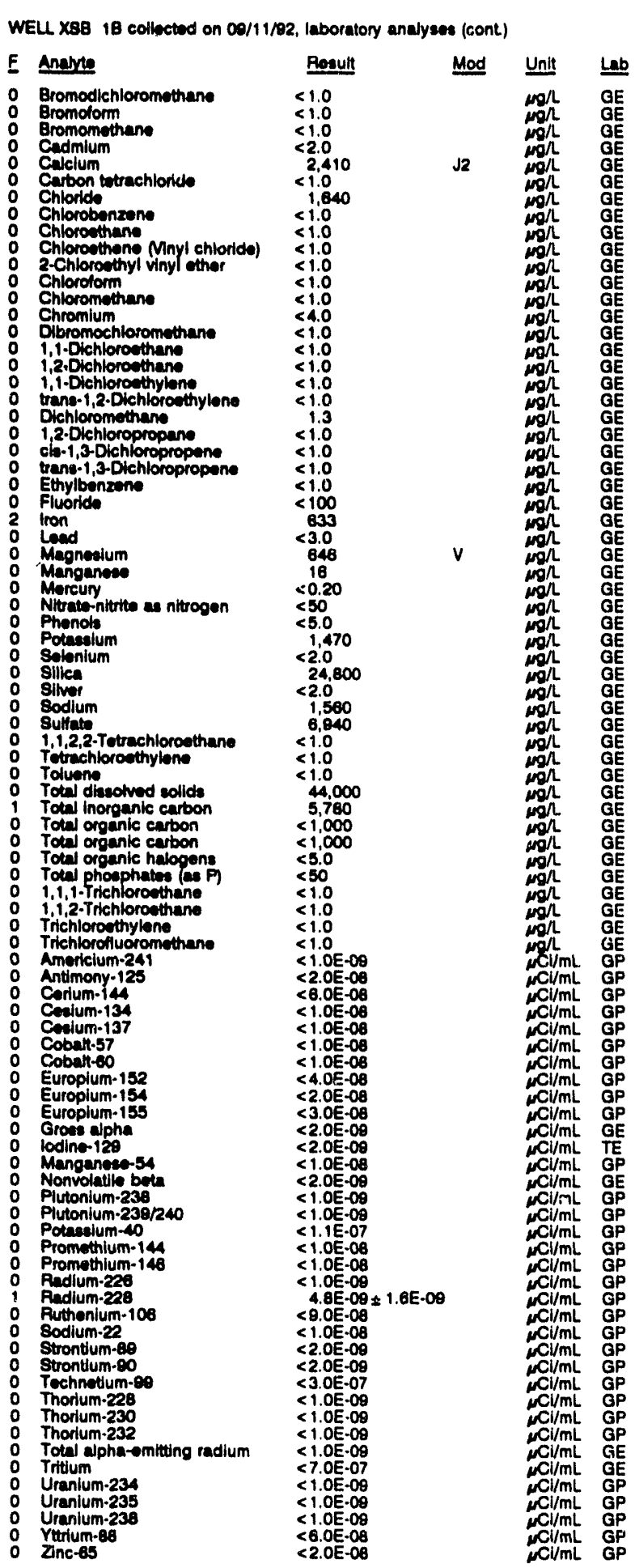

WELL XSB 10

MEASUREMENTS CONDUGTED IN THE FIELD

Sample date: 09/11/92

Depth to water: $56.10 \mathrm{ft}(17.10 \mathrm{~m})$ below TOC

Water olovation: $09.80 \mathrm{H} / 30.45 \mathrm{~m}$

LABORATORY ANALYSES

$F$ Anable Beaul

: $\mathrm{pH}$

Spectilc conductance

Aronic

Barium

B Bromodichloromethane

0 Bromolorm

o Bromomethan

O Cadmium

2 Carbon tetrachloride

2 Chlorido

Chlorobenzene

- Chloroethane

: Chloroethene Ninyl chloricios

o Chloroform

Dibromochloromethane

1,1.Dlchlorosthane

1,2-Dichloroethane

o trans-1,2-Dichloroethylene

o trans-1,2-Dichloroethy

o 1,2-Oichloropropane

o cis-1,3-Dichloropropeno

o trans-1,3-Dichloropropene

o Ethylbenzene

0 Fluoride

o fron

$\begin{array}{ll}0 & \text { Iron } \\ 0 & \text { Load }\end{array}$

0 Magnoaium

Mercuny

Nitrate-nittrite as nitrogen

Nitrate-nitrite as nitrogen

O Phonols

0 solonlum

0 silica

o Silver

- Sodium

: Sullate

o $1,1,2,2$-Totrachloroethane

- Tetrachloroethylene

o Toluene

0 Total dissolved solids

Total diseolved solids

2 Total inorganic carbon

Total organic carbon

2 Total organic halogons

o Total Phosphatos (as

1,1,2.Trichloroethan

2 Trichlorosthylens

- Americium-241

- Antimony-125

- Corium-144

- Cosium.134

0 Cobalt-57

- Cobalt-60

0 Europlum 152

Europium-154

Gross alpha

lodine-128

Manganeso-54

Nonvolatile bota

Plutonlum-238
Plutonium-239/240

Potanssium-40 40

Promethium-144

Promethium-140

Radium-226

Radum-228

Sodium-22

Strontium-8

Strontium-80

Technotium.89

Thorium-228
Thorium-230

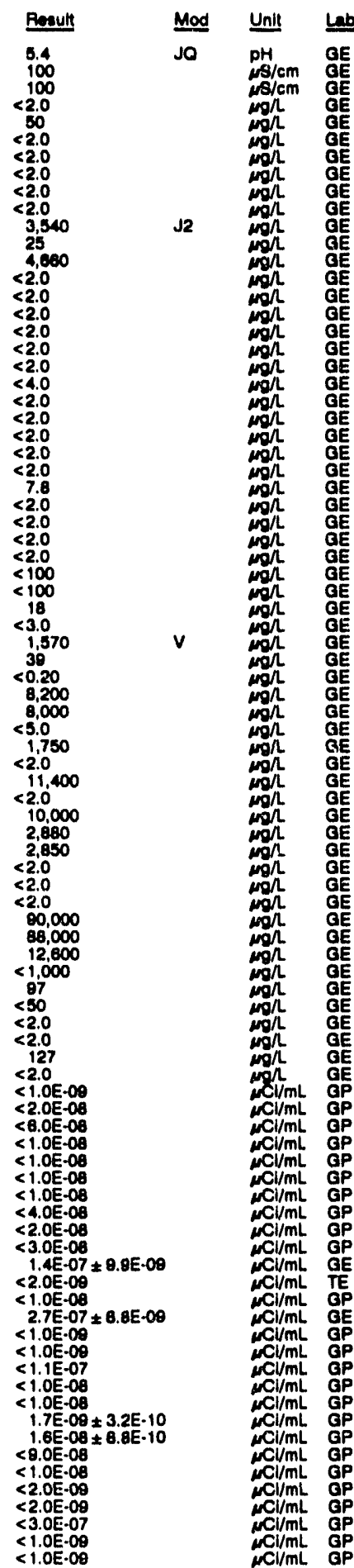


ANALYTICAL RESULTS

WELL TNX 120 collectod on 00/17/02, taboratory analyees (cont)

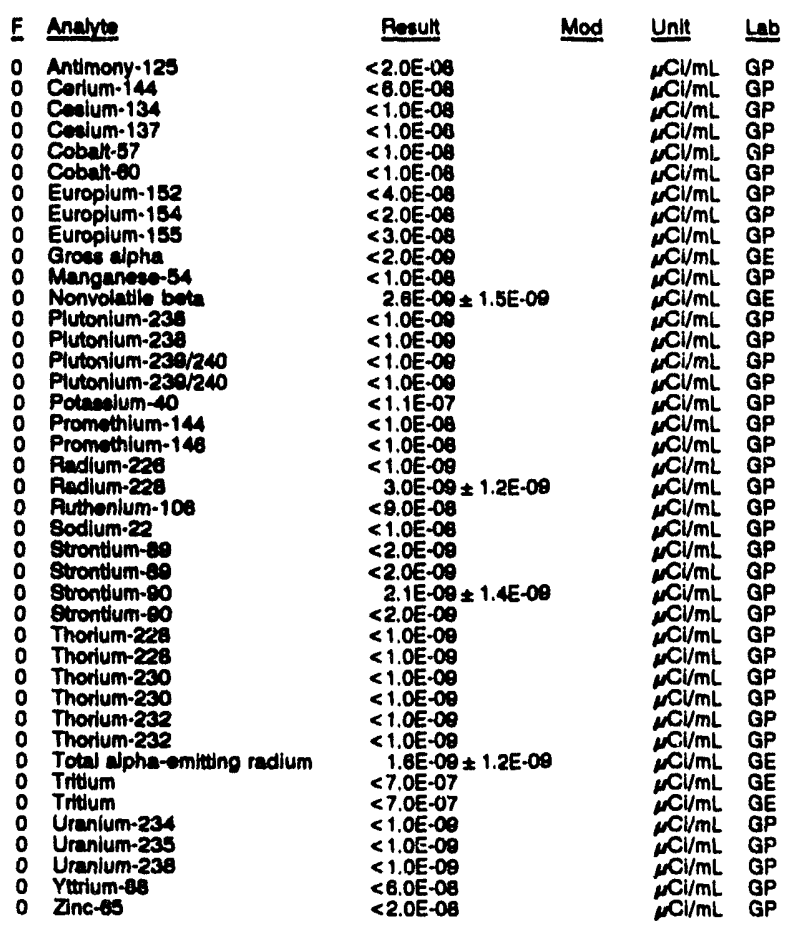

WELL XSB $1 A$

MEASUREMENTS CONDUCTED IN THE FIELD

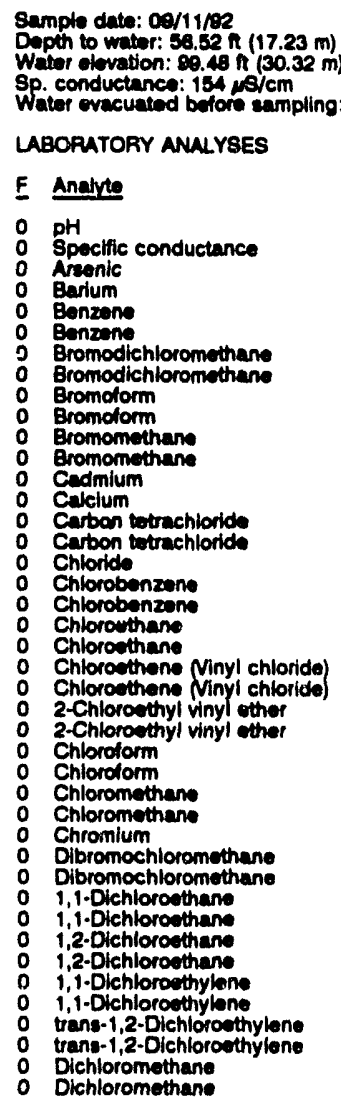

Time: 12:35

$\mathrm{pH}: 5.0$

Nkalinity: $1 \mathrm{mg} /$

Water tomporature: $22.0^{\circ} \mathrm{C}$

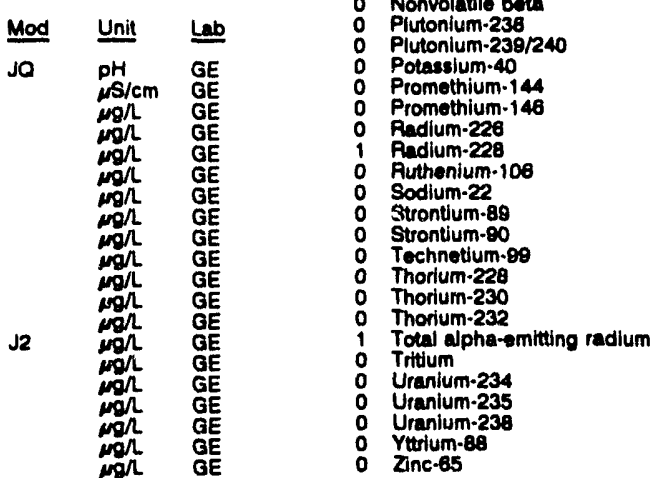

WELL X8B IA collected on 09/11/92, laboratory andyees (cont)

\begin{tabular}{|c|c|c|c|c|}
\hline $\mathbf{E}$ & Anabyte & Result & Mod & Unit \\
\hline $\begin{array}{l}0 \\
0 \\
0 \\
0 \\
0 \\
1 \\
0 \\
0 \\
0 \\
0 \\
0\end{array}$ & 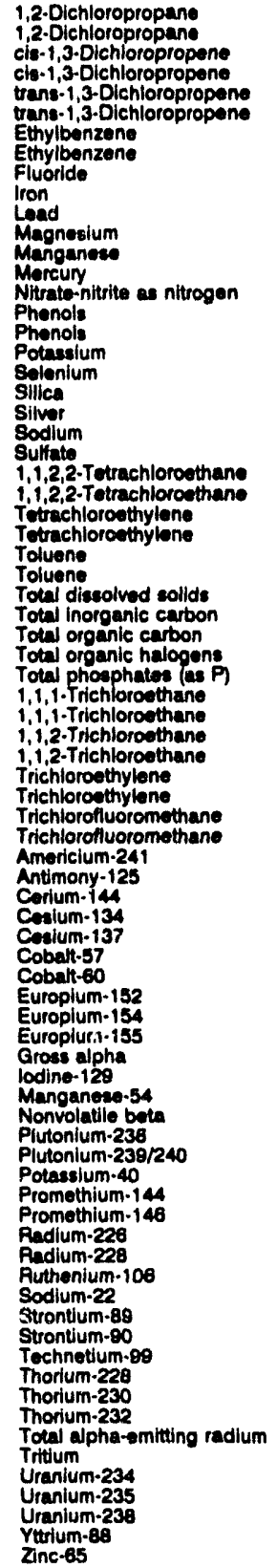 & 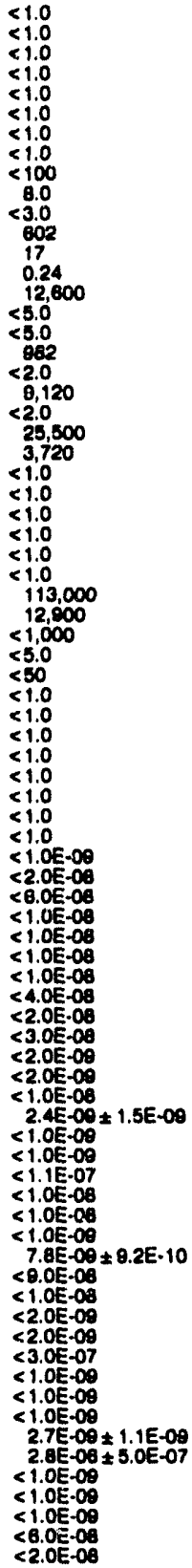 & $v$ & 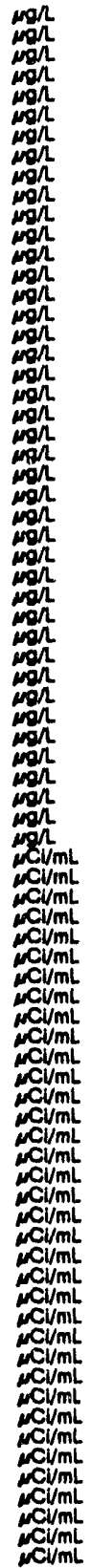 \\
\hline
\end{tabular}

WELL XSB $1 B$

MEASUREMENTS CONDUCTED IN THE FIELD

Sample date: 08/11/92

Dopth to water: $53.97 \mathrm{n}(16.45 \mathrm{~m})$ bolow TOC

Water elovation: $101.83 \mathrm{ht}(31.07 \mathrm{~m}) \mathrm{ms}$

Sp. conductance: $40 \mu \mathrm{s} / \mathrm{cm}$

mpling: $88 \mathrm{gal}$

LABORATORY ANALYSES

\begin{tabular}{|c|c|c|c|}
\hline E Analyte & Ponult & Mod & Untt \\
\hline $\begin{array}{ll}0 & \text { pH } \\
0 & \text { Specific conductance } \\
0 & \text { Arsenic } \\
0 & \text { Barium } \\
0 & \text { Benzene }\end{array}$ & $\begin{array}{r}6.1 \\
36 \\
<2.0 \\
21 \\
<1.0\end{array}$ & ja & $\begin{array}{l}\mathrm{pH} \\
\cos / \mathrm{cm} \\
\operatorname{mog} \Omega \\
\operatorname{mon} \Omega\end{array}$ \\
\hline
\end{tabular}


WELL TNX 100 collectux: on 09/17/92, laboratory analyese (cont)

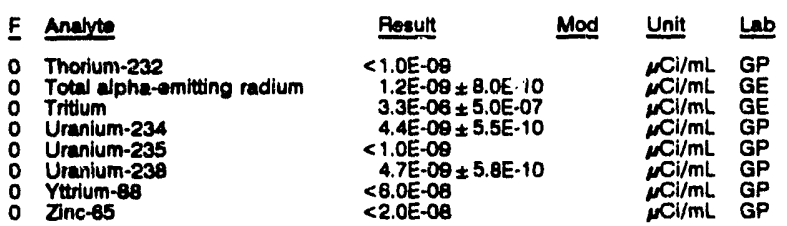

WELL TNX 11D

MEASUREMENTS CONDUCTED IN THE FIELD

Sample date: 0e/17/82

Depth to water: $6.40 \mathrm{ft}(1.88 \mathrm{~m})$ below TOC

Wator olvation: 23.31 h $(29,4$

Sp. conductance: $\$ 31 \mathrm{NS/ \textrm {cm }}$

LABOFATORY ANALYSES

\begin{tabular}{|c|c|c|c|c|c|}
\hline & Anabyte & Result & Mod & Unit & Lab \\
\hline & 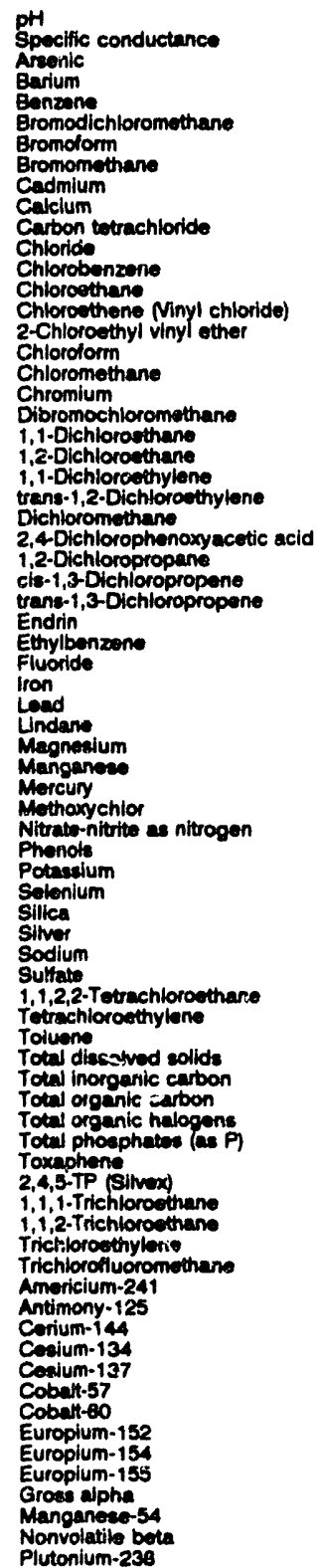 & 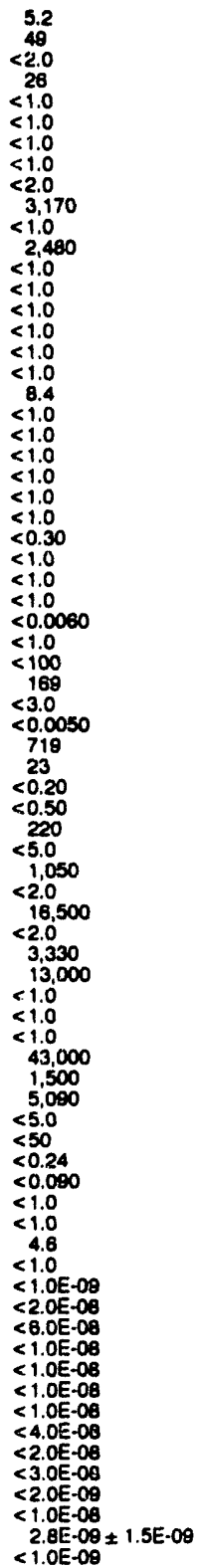 & Ja & 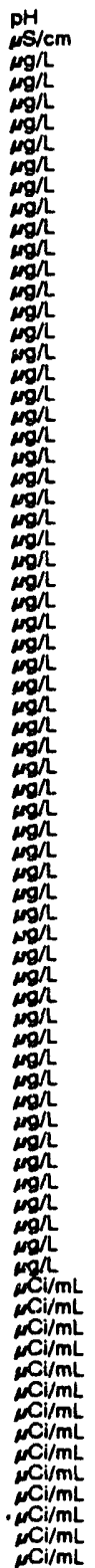 & $\begin{array}{l}\mathrm{GE} \\
\mathrm{GE} \\
\mathrm{GE} \\
\mathrm{GE} \\
\mathrm{GE} \\
\mathrm{GE} \\
\mathrm{GE} \\
\mathrm{GE} \\
\mathrm{GE} \\
\mathrm{GE} \\
\mathrm{GE} \\
\mathrm{GE} \\
\mathrm{GE} \\
\mathrm{GE} \\
\mathrm{GE} \\
\mathrm{GE} \\
\mathrm{GE} \\
\mathrm{GE} \\
\mathrm{GE} \\
\mathrm{GE} \\
\mathrm{GE} \\
\mathrm{GE} \\
\mathrm{GE} \\
\mathrm{GE} \\
\mathrm{GE} \\
\mathrm{GE} \\
\mathrm{GE} \\
\mathrm{GE} \\
\mathrm{GE} \\
\mathrm{GE} \\
\mathrm{GE} \\
\mathrm{GE} \\
\mathrm{GE} \\
\mathrm{GE} \\
\mathrm{GE} \\
\mathrm{GE} \\
\mathrm{GE} \\
\mathrm{GE} \\
\mathrm{GE} \\
\mathrm{GE} \\
\mathrm{GE} \\
\mathrm{GE} \\
\mathrm{GE} \\
\mathrm{GE} \\
\mathrm{GE} \\
\mathrm{GE} \\
\mathrm{GE} \\
\mathrm{GE} \\
\mathrm{GE} \\
\mathrm{GE} \\
\mathrm{GE} \\
\mathrm{GE} \\
\mathrm{GE} \\
\mathrm{G}\end{array}$ \\
\hline
\end{tabular}

WEL TNX 1:D collected on 09/17/92, taboratory analyeas (cont.)

\begin{tabular}{|c|c|c|}
\hline Analyte & Ressult & Unit \\
\hline $\begin{array}{l}\text { Plutonium-239/240 } \\
\text { Potassium-40 } \\
\text { Promethium-144 } \\
\text { Promethium-146 } \\
\text { Radium-226 } \\
\text { Radium-228 } \\
\text { Puthenium-108 } \\
\text { Sodium-22 } \\
\text { Strontium-89 } \\
\text { Strontium-80 } \\
\text { Thorium-228 } \\
\text { Thoriur-230 } \\
\text { Thorium-232 } \\
\text { Total alpha-emitting radium } \\
\text { Tritium } \\
\text { Uranium-234 } \\
\text { Uranium-235 } \\
\text { Uranium-238 } \\
\text { Yttrium-83 } \\
\text { Zinc-65 }\end{array}$ & $\begin{array}{l}<1.0 E-09 \\
<1.1 E-07 \\
<1.0 E-08 \\
<1.0 E-08 \\
<1.0 E-09 \\
3.3 E-09 \pm 1.2 E-09 \\
<8.0 E-09 \\
<1.0 E-08 \\
<2.0 E-09 \\
<2.0 E-09 \\
<1.0 E-09 \\
<1.0 E-09 \\
<1.0 E-09 \\
<1.0 E-09 \\
1.7 E-08 \pm 4.6 E-08 \\
<1.0 E-09 \\
<1.0 E-09 \\
<1.0 E-09 \\
<6.0 E-08 \\
<2.0 E-08\end{array}$ & 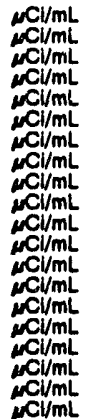 \\
\hline
\end{tabular}

WELL TNX 12D

MEASUREMENTS CONDUCTED IN THE FIELD

Sample date: 09/17/92

Dopth to water: $4.67 \mathrm{ft}(1.42 \mathrm{~m})$ betow TOC

Water olovation: $84.53 \mathrm{H} / 28$.

Sp. conductance: $68 \mu \mathrm{s} / \mathrm{cm}$

$\mathrm{pH}: 5.8$

Alkalinity: $18 \mathrm{mgh}$, $20.0 \circ \mathrm{C}$

LABORATORY ANALYSES

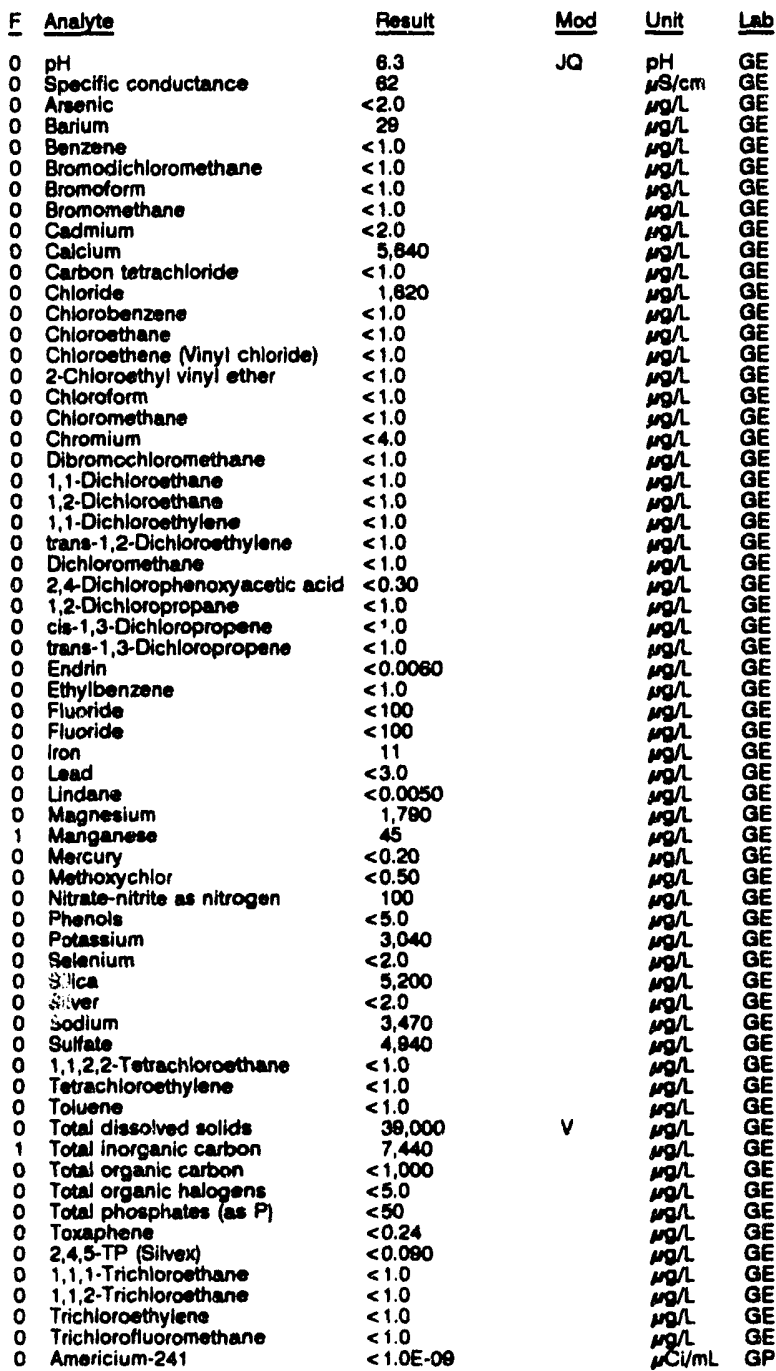


ANALYTICAL RESULTS

WELL TNX OD collected on 09/17/92, laboratory analyees (cont)

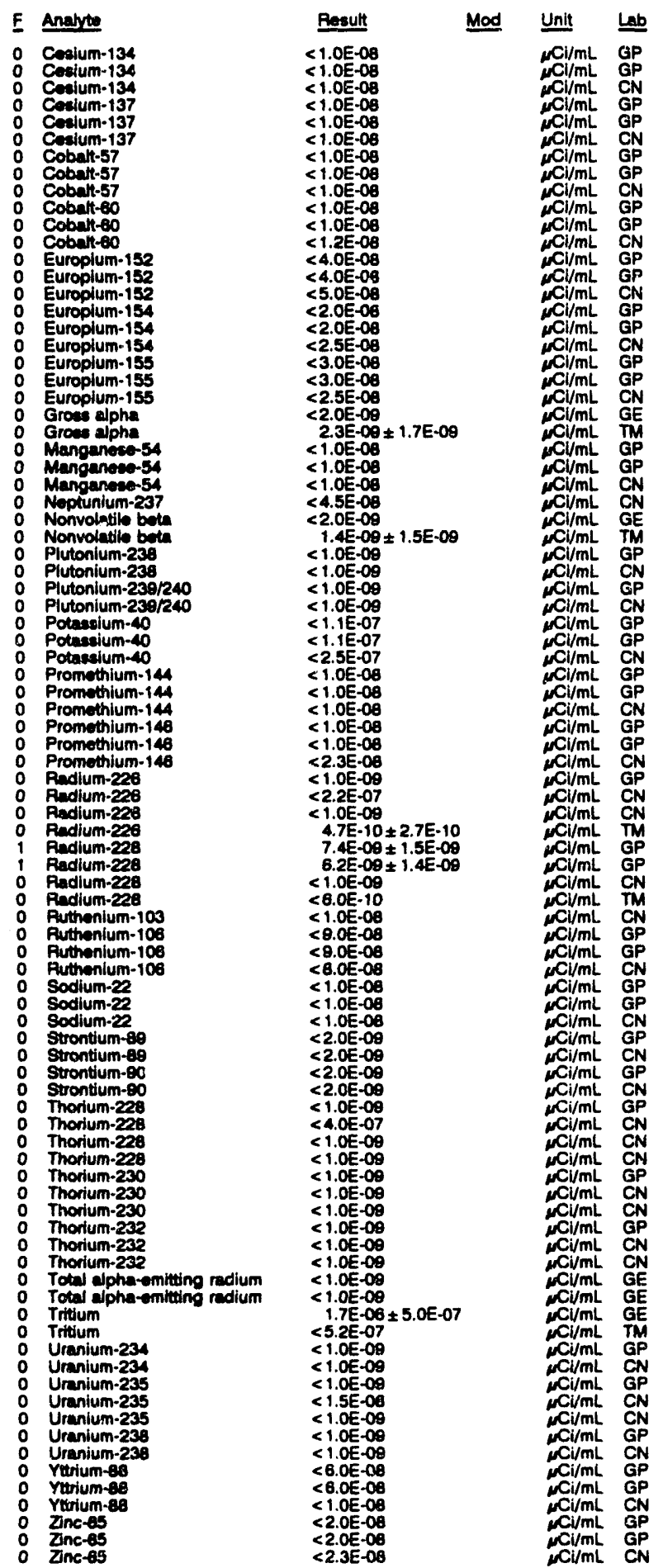

WELL TNX 10D

MEASUREMENTS CONDUCTED IN THE FIELD

Sample dato: 09/17/82

Depth to water: $8.88 \mathrm{ft}(2.70 \mathrm{~m})$ bolow TOC

Sp. conductanca: 167 ,

Water evacuatod bofore sampling: $43 \mathrm{gal}$

LABORATORY ANALYSES

E Analyte

: $\mathrm{pH}$ Specific conductance

0 Areenic

Barium

B Bromodichloromethane

O Bromotorm

0 Bromomethane

o Cadmium

o Calcium

C Curbon te

: Chloride

Chiorosthane

Chloroethene Ninyl chloride)

2-Chlorcothyl vinyl ether

Chloroform

Chloromethane

o Dibromochloromethane

1,1-Dichloroethane

1,2-Dichioroethane

- trans-1,2-Dichloroethylene

Dichlioromethane

2,4-Dichlorophenoxyacotic acid

1,2-Dichloropropane

cis-1,3-Dichloropropene

0 trans-1,

O Ethylbenzene

: Fivorida

o Load

0 Lindane

Magnesium

2 Manganoes

Mercury

Nitrato-nitrite as nitrogen

Phenols

Potassium

Solenium

Silica

O Sodium

Sulfate

1,1,2,2-Tetrachloroethan

T Toluene

Total dissolved solids

Total inorganic carbon

Total organic halagens
Total phosphates (s) P)

Toxaphene

1,1,1-Trichioroethane

1,1,2-Trichloroethane

Trichlorofluoromethane

Americium-241

Antimony-125

Corium-134

Cesium-134

Cobalt-57

Coball-60

Europium.152

Europium-154

Europium-155

Manganeso-5.

Nonvolatile beta

Plutonium-238/240

Potassium.40

Promethium-144

Promethium-94

Radium-228

Puthenium-100

Sodium-22

Strontium-69

Thorium-228

Thorium-228
Thorium-230
Result Mod Unit Lab

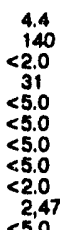

$5,5,000$

$<5.0$

$<5.0$

$<5.0$

$<5.0$

$<4.0$

55.0

55.0

55.0

$<.30$
55.0
5.0
550
5.0

$<5.0000$

$\$ 5.00$

3100

$<0.0050$

17

$<0.50$

$<5.000$

,

$<2.0$

$<2,0$

26,200
12,400

$<5.0$

$<5.0$

110,000

$<1,000$

25
$<50$

$<50$

$<0.24$

$<0.090$

$<5.0$

$<4$

$<1.0 E-09$

$<2.0 E-09$

$<8.0 E-08$

$<1.0 E-00$

$<1.0 E-08$

$<1.06-08$

$<2.0 E-06$

$<3.0 \mathrm{E}-00$

6.5E-09 $2.3 E-09$

$<1.0 E-08 \pm 2.06 \pm 1.0 E-00$

<1.0E-09

$<1.0 E-09$

$<1.0 E-00$

$=1.0 E-09$

$<1.0 E-00$

$1.2 E-00 \pm 9.0 E-10$

$<9.0 E-00$

$<2.0 E-09$

3. $7 E-09 \pm 1.1 E-00$

$<1.0 E-00$
$<1.0 E-00$

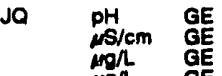

$\begin{array}{ll}\mu \mathrm{N} / \mathrm{cm} & \mathrm{GE} \\ \mathrm{mgh} & \mathrm{GE} \\ \mathrm{mg} & \mathrm{gE}\end{array}$

$\underset{\mu g h}{\mathrm{mg} h}$

og GE

$\operatorname{con}$ GE

m g $\mathrm{gE}$

Mgh GE

M

gh GE

goh GE

gR GE

Mg G GE

gh GE

woh GE

mon GE

$\mathrm{mgh}$ GE

g G

gh GE

$\begin{array}{ll}\mathrm{g} & \mathrm{GE} \\ \mathrm{GE} & \mathrm{GE}\end{array}$

gh GE

$\begin{array}{ll}G, & G E \\ o n & G E \\ G n\end{array}$

$\begin{array}{ll}g_{n} & G E \\ G E \\ G E \\ G E \\ G E\end{array}$

Time: 14:40

Alkalinity: $0 \mathrm{mg} / \mathrm{L}$

Water tomperature: $20.8^{\circ} \mathrm{C}$ 
WELL TNX 80 collected on 09/17/92, laboratory analyses (cont.)

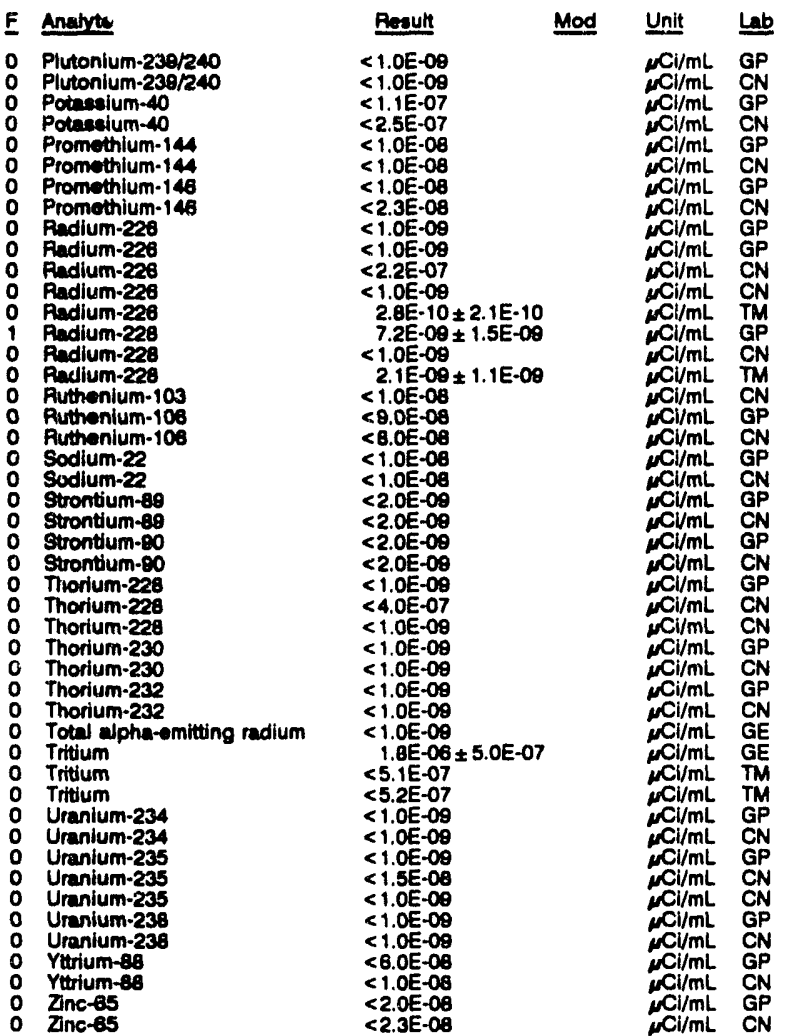

WELL TNX 9D Replicate

MEASUREMENTS CONDUCTED IN THE FIELL

Sample dace: 09/17/92

Depth to water: $6.15 \mathrm{k}$ (2.48 m) bolow TOC

Water olovation: $03.55 \mathrm{~K}(28.51$

Water evacuated before sampling: $48 \mathrm{gal}$

LABORATOFY ANAL YSES

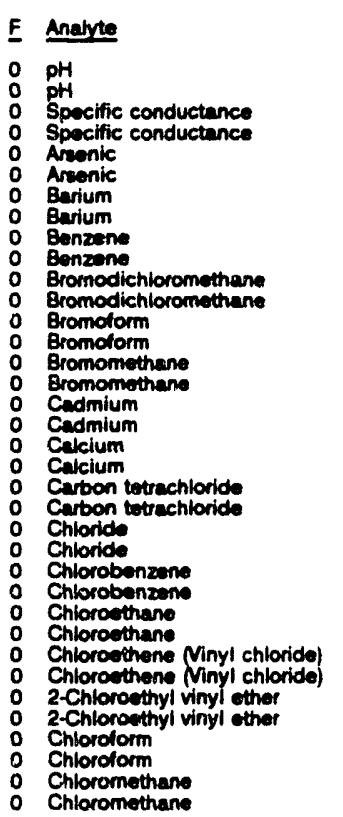

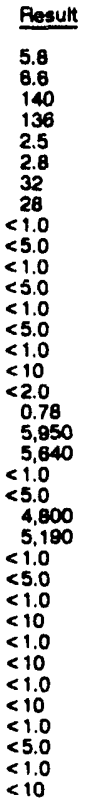

Time: 18:05

PH: 5.2 : $7 \mathrm{mgh}$

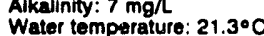

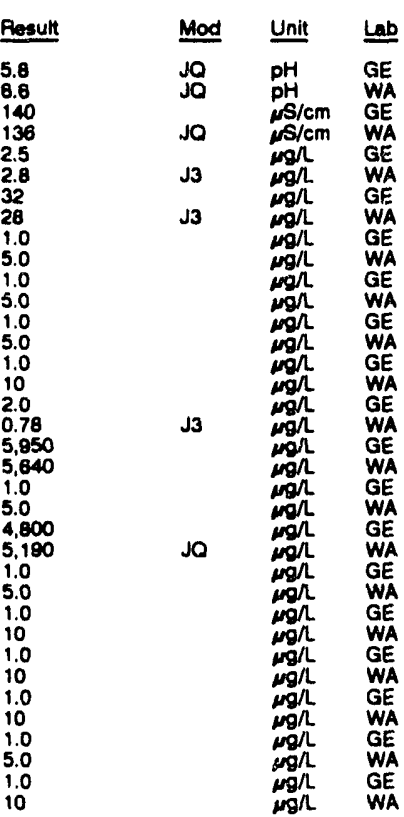

WELL TNX OD collected on 09/17/82, laboratory analyees (cont.)

\begin{tabular}{|c|c|c|c|}
\hline Analyte & Result & Mod & Unit \\
\hline 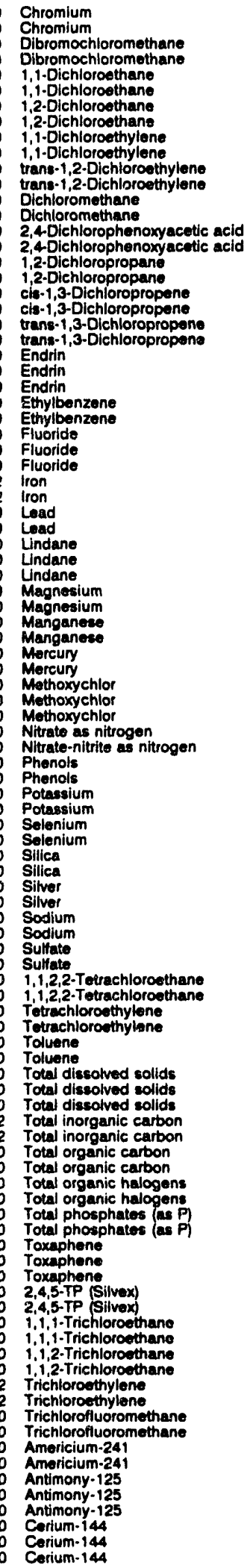 & 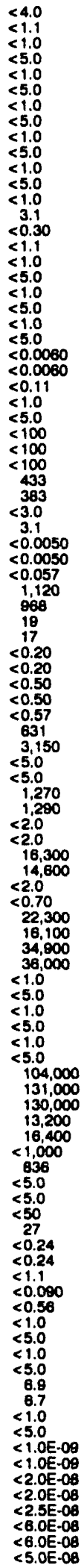 & $\begin{array}{l}\text { JQ } \\
\text { JO }\end{array}$ & 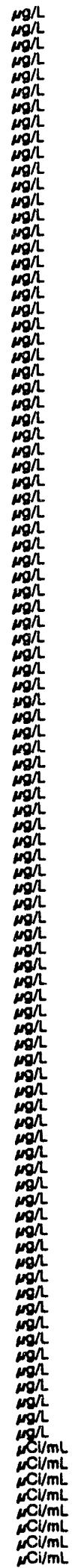 \\
\hline
\end{tabular}


ANALYTICAL RESULTS

WELL TNX 8D collected on 09/17/92, laboratory analyees (cont.)

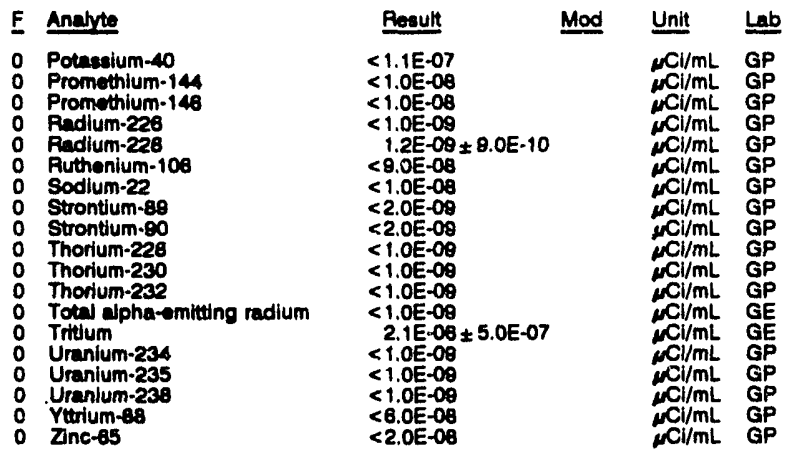

\section{WELL TNX 9D}

MEASUREMENTS CONDUCTED IN THE FIELD

Semple date: $09 / 17 / 92$
Depth to water: $8.15 \mathrm{ft}(2.48 \mathrm{~m})$ below TOC
Water olevation: $03.55 \mathrm{~h}(28.51 \mathrm{~m}) \mathrm{msl}$
Sp. conductance: $157 \mathrm{fs} / \mathrm{cm}$
Water ovacuated before sampling: $48 \mathrm{gal}$

Timo: 16:05

PH: 5.2

Water temperature: $21.3^{\circ} \mathrm{C}$

LABOFATOFY ANALYSES

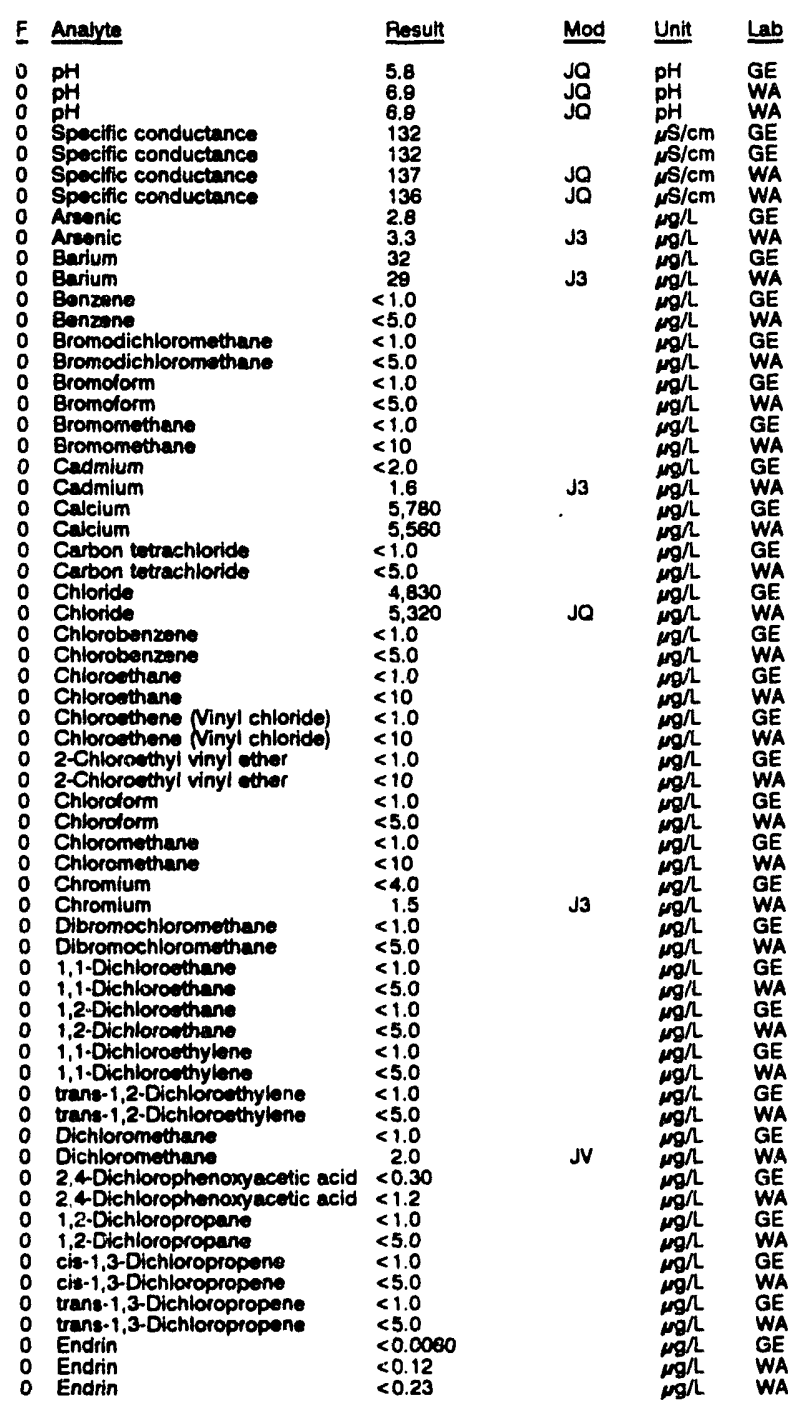

WELL TNX 9D collocted on 09/17/92, laboratory analyses (cont.)

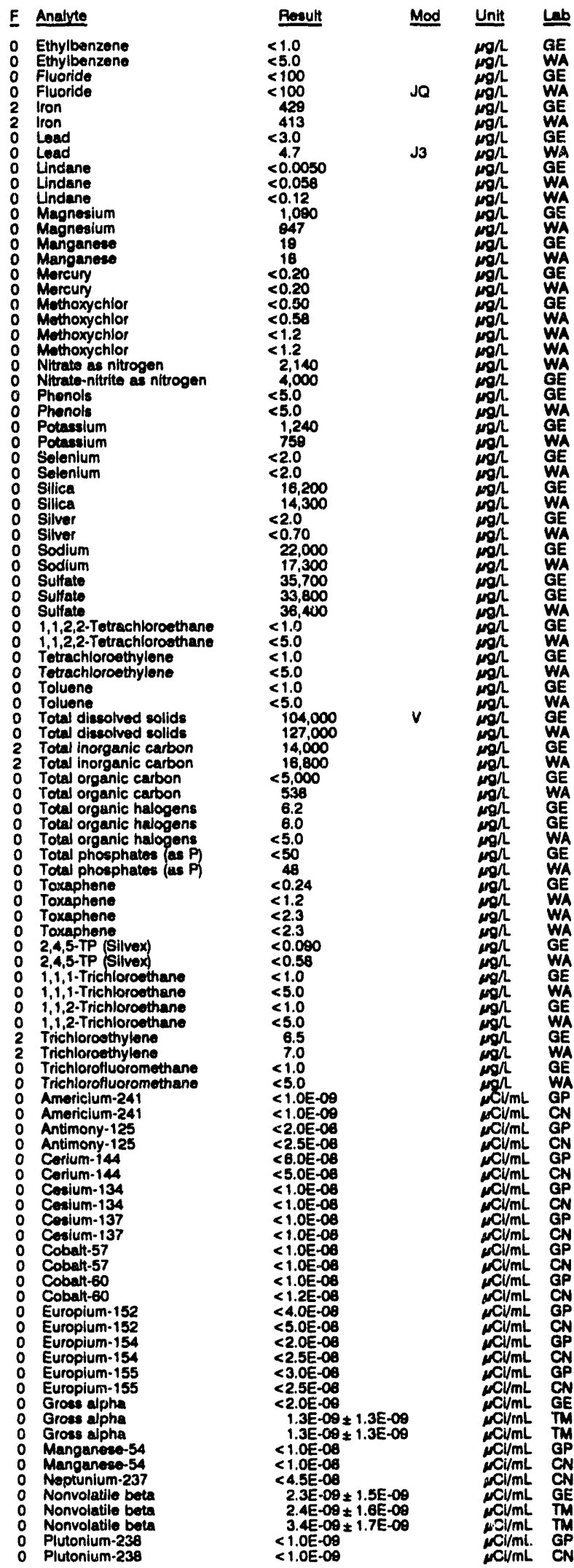


WELL TNX 7D collected on 09/14/82, laboratory analyses (cont.)

\section{E Analyte}

- Chlorcothene (Ninyl chloride) 2-Chloroethyl vinyl ether

Chlorolorm

Chloromethan

Chloromethan

Chromium

Dibromochloromethane

1,1-Dichloroethane

1,1-Dichloroethane

1,2-Dichloroethan

o 1,1-Dichloroethylone

0 trans-1,2-Dichloroethylene

trans-1,2-Dichlorooth

Dichloromethano

2,4-Dichlorophenoxyacetic acid

1,2-Dichloropropane

cis-1,3-Dichloropropene

o cis-1,3-Dichloropropene

trans-1,3-Dichloropropene

trans:1

Ethylbenzene

Fluoride

0 Lead

Lindane

Magnesium

Manganeso

Mothoxychior

Nitrate-nitrite as nitrogon

Phenots

Solanium

Silica

Silver

Sodium

o 1,1,2,2-Tetrachloroethane

1,1,2,2-Tetrachloroethan

Tetrachloroethylene

Tolvene

- Total dissolved solids

Total inorganic cartoon

Total organic curbon

Total organic halogens

Total phosphates (as P)

Toxaphene

2,4,5-TP (Sitvox)

1,1,1-Trichloroethane

1,1,1-Trichloroethane

i, 2 .Trichloroethane

Trichlorosthylene

Trichloroethylene

Trichlorofluoromethane

Americium-241

Antimony-125

Cesium-13

Cosium-137

Cobalt 60

Europlum-15e

Europium-15

Guropium-155

Manganece-54

Nonvolatile beta

Plutonium-238

Plutonium-239/240

Potassium-40

Promethium-144

Radium-228

Radium-22

Radium-228

Ruthenium-10

Sodium-22

Strontum-68

Strontium-90

Strontium-e0

Thorium-228

Thorium-230

Total alpha-emitting radium

Tritium
Result

$<1.0$

$<1.0$

$<1.0$

$<1.0$

$<1.0$

$<4.0$

$<1.0$

$<1.0$

$<1.0$

$<1.0$

$<1.0$

$<1.0$

1.5
$<0.0$
$<0.30$

$<1.0$

$<1.0$

$<1.0$

$<1.0$

$<0.0080$

$<1.0$

$<1.0$

23
$<3.0$

$<0.0050$

616
3.1

$<0.20$

340
$<50$

1,300
$<, 00$

$<2.0$

$<2.0$

8.240

$<1.0$

$<1.0$

$<1.0$

$<1.0$

51,000
11,500

$<1,000$

$<5.0$

$<50$

$<0.24$

$<1.0$

$<1.0$

$<1.0$

$<1.0$

$<1.0$

$<10$

$<1.0 E-09$

$<2.0 E .08$

$<1.0 \mathrm{E}-\mathrm{O}$

$<1.0 E-08$

$<1.0 E-08$

$<4.0 \mathrm{E}-08$

$<2.0 E-08$

$<3.0 E-00$

$<1.0 E-08$

$<1.0 \mathrm{E}-08$

$<1.1 \mathrm{E}-07$

$<1.0 E-00$

$<1.0 E-08$

2. $1 \mathrm{E}-00 \pm 3.2 \mathrm{E} \cdot 10$

$2.0 E-09 \pm 3.5 E-10$
$8.0 E-09 \pm 3.9 E-09$

$<1.0 E-06$

$<2.0 E-08$

$<2.0 E-09$

$<2.0 E-09$

$<1.0 \mathrm{E}-09$

$<1.0 E-09$

$<1.0 \mathrm{E}-09$
$2.0 E-09 \pm 1.4 E-09$

$1.4 E \cdot 00 \pm 7.7 E \cdot 10$
Mod Unit Le

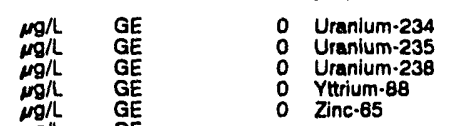

WELL TNX 8D

MEASUREMENTS CONDUCTED IN THE FIELD

Sample date: $09 / 17 / 82$

Depth to water: $8.55 \mathrm{th}(2.00 \mathrm{~m})$ below TOC

Wator elovalion: $93.75 \mathrm{ht}(28.58 \mathrm{~m}$

Wator ovacuatod bofore sampling: 52 gal

LABOFATORY ANALYSES

$0 \mathrm{pH}$

Specific conductance

0 Arsenic

0 Barium

B Bromodichloromethane

0 Bromotorm

o Bromomethane

o Cadmium

o Carbon tetrachloride

o Chloride

o Chlorobenzene

o Chloroethane

o Chloroethene Ninyl chloride)

2-Chloroethyl vinyl ether

Chloroform

Chloromethan

Dibromochloromethane

o 1,1-Dichloroethane

o 1,2-Dichioroethane

1,1-Dichloroethylene

0 Dichioromethane

2,4-Dichlorophenoxy

1,2-Dichloropropane

o cis-1,3-Dichloropropene

0 trans-1,

o Ethylbenzene

O Fluorido

0 Iron

0 Load

O Magnesium

O Marcury

- Mothoxychlor

Nitrate-nitrite as nitrogen

1 Nitrate-nitit

o Potassium

Selenium

0 Silica

o $\begin{array}{ll}\text { Silver } \\ 0 & \text { Sodium }\end{array}$

o Sodium

o $1,1,2,2-$ Totrachioroethane

T,1,2,2-Totrachloroeth

O Toluene

Total dissolved solids

2 Total inorganic carbon

Total organic carbon

o Total organic carton

o Total organic halogens

Toxaphene

0 2,4,5-TP (Silvex)

1,1,1-Trichioroethane

Trictichloroethen

2 Trichioroethylene

A Amoricium-241

Antimony-125

Corium-144

o Cesium-13a

0 Ceslum-137

C Cobalt-57

Cobalt-60

Europlum-152

Europium-154

Guropium-155

Gross alpha

Nonvolatile beta

0 Plutonium-239/240

\begin{tabular}{|c|c|c|}
\hline Rosult & Mod & Unit \\
\hline $\begin{array}{l}<1.0 E-09 \\
<1.0 E-09 \\
<1.0 E-09 \\
<6.0 E-08 \\
<2.0 E-08\end{array}$ & & 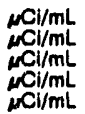 \\
\hline
\end{tabular}

\section{Time: 15:30}

Alkalinity: $6 \mathrm{mg} /$

Water temperature: $21.00 \mathrm{C}$

Regult Mod

5.9
86
$<2.0$
60
$<1.0$
$<1.0$
$<1.0$
$<1.0$
$<2.0$
4,
$<1.0$
6.1 .00
$<1.0$
$<1.0$
$<1.0$
$<1.0$
$<1.0$
$<4.0$
$<1.0$

$<1.0$

$<1.0$

$<1.2$

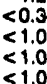

$<1.00000$

$<1.0$

$<100$

$<0.0050$

1,180

$<0.20$

4,800
5,600

$<5.0$

$<.0$
12,800

$<2.0700$

$\begin{aligned} & 14,180 \\ &< 1.0 \\ &<1.0\end{aligned}$

$<1.0$

76,000

17,200
$<1,000$

$<1,000$

$<50$

$<0.24$

$<0.090$

$<1.0$
$<1.0$

6.1

$<1.0$ E-09

$<2.0 E-09$

$1.05-00$

$<1.0 E-00$

$<1.00-00$

$4.0 \mathrm{E}-\mathrm{OO}$

$<2.0 \mathrm{E}-0 \mathrm{O}$

$<3.0$-O

$<2.0 E-09$

$<1.0 E-08$

$<1.0 E .09$
$<1.0 E-09$

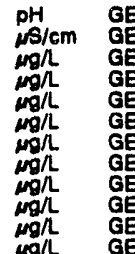

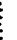


ANALYTICAL RESULTS

WELL TNX 50 collected on 09/17/82, laboratory analyses (cont)

\begin{tabular}{|c|c|c|}
\hline Analyte & Result & Unit \\
\hline 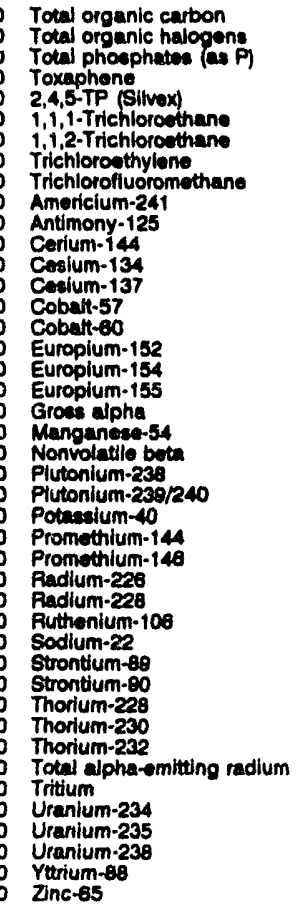 & $\begin{array}{l}<1,000 \\
11 \\
110 \\
<0.24 \\
<0.000 \\
<1.0 \\
<1.0 \\
<1.0 \\
<1.0 \\
<1.0 E-09 \\
<2.0 E-08 \\
<6.0 E-08 \\
<1.0 E-08 \\
<1.0 E-09 \\
<1.0 E-09 \\
<1.0 E-09 \\
<4.0 E-08 \\
<2.0 E-09 \\
<3.0 E-08 \\
<2.0 E-09 \\
<1.0 E-09 \\
2.0 E-09 \pm 1.5 E-09 \\
<1.0 E-09 \\
<1.0 E-09 \\
<1.1 E-07 \\
<1.0 E-09 \\
<1.0 E-08 \\
<1.0 E-09 \\
2.0 E-09 \\
<8.0 E-08 \\
<1.0 E-08 \\
<2.0 E-09 \\
<2.0 E-09 \\
<1.0 E-09 \\
<1.0 E-09 \\
<1.0 E-09 \\
1.5 E-09 \pm 9.0 E-10 \\
1.0 E-06 \pm 5.0 E-07 \\
<1.0 E-09 \\
<1.0 E-09 \\
<1.0 E-09 \\
<6.0 E-08 \\
<2.0 E-08\end{array}$ & 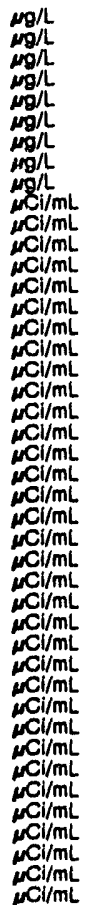 \\
\hline
\end{tabular}

WELL TNX 6D

MEASUREMENTS CONDUCTED IN THE FIELD

Sample date: $08 / 17 / 92$

Depth to water: $42.80 \mathrm{ft}(13.06 \mathrm{~m}$ ) below TOC

Water elevation: $107.64 \mathrm{ht}(32.81$

Sp. conductance: $182 \mu \mathrm{s} / \mathrm{cm}$

Wator ovecuatod betore sampling: 8 ga

LABOPATORY ANALYSES

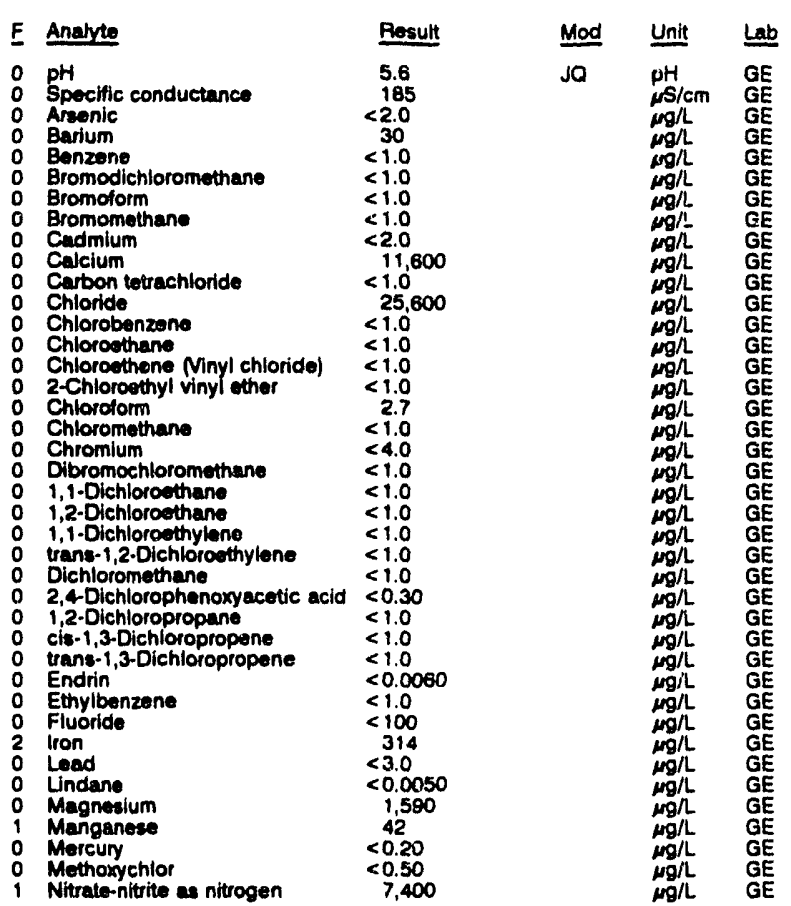

WELL TNX 6D collected on 09/17/82, laboratory analyses (cont.)

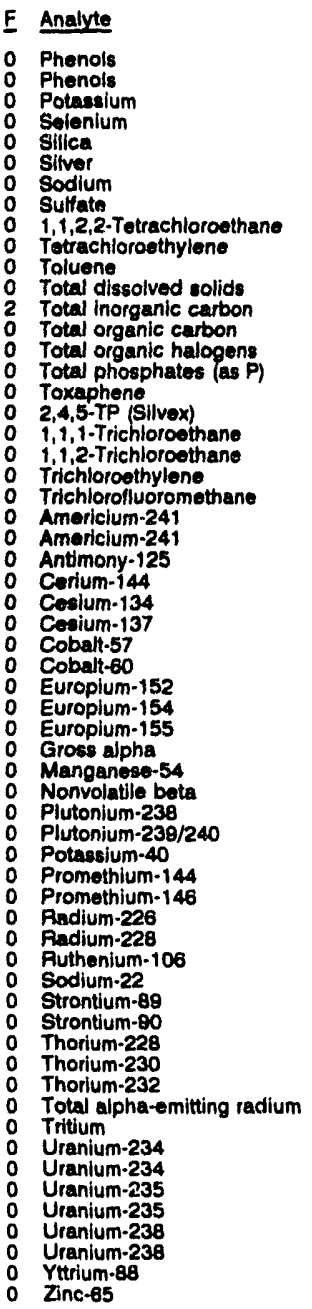

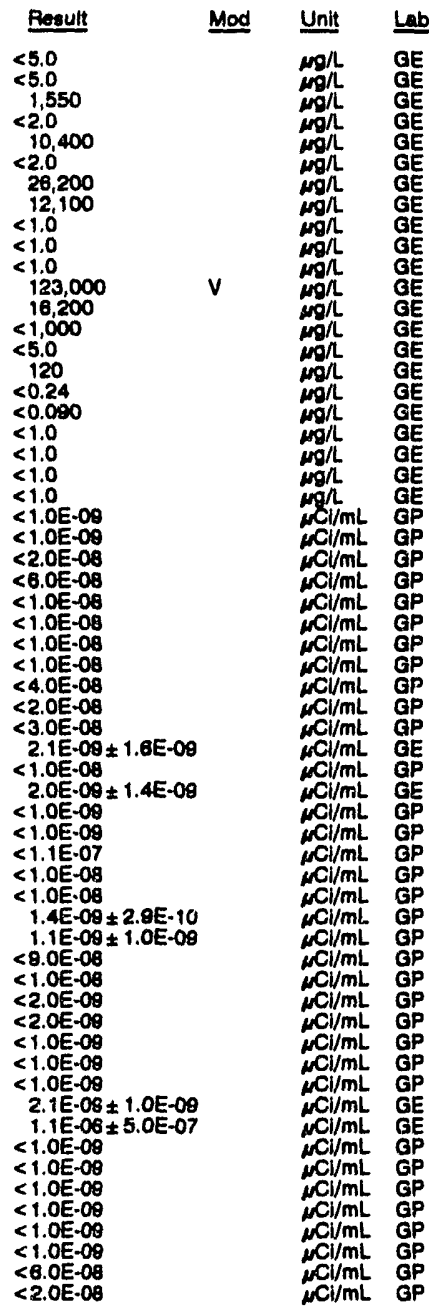

\section{WELL TNX 7D}

MEASUREMENTS CONDUCTED IN THE FIELD

Sample date: 09/14/2

Depth to water: $48.82 \mathrm{ft}(14.68 \mathrm{~m})$ below TOC

Water elevation: $102.08 \mathrm{At}(31.11 \mathrm{~m}) \mathrm{ms}$

Sp. conductance: $58 \mu \mathrm{S} / \mathrm{cm}$.

LABORATORY ANALYSES

\begin{tabular}{|c|c|c|c|}
\hline Analyte & Result & Mod & Unit \\
\hline $\begin{array}{l}\text { pH } \\
\text { Specific conductance } \\
\text { Artenic } \\
\text { Barium } \\
\text { Benzene } \\
\text { Benzene } \\
\text { Bromodichloromethane } \\
\text { Bromodichloromethane } \\
\text { Bromoform } \\
\text { Eromolorm } \\
\text { Gromomethane } \\
\text { Gromomethane } \\
\text { Cadmium } \\
\text { Caicium } \\
\text { Carbon tetrachloride } \\
\text { Carbon tetrachloride } \\
\text { Chioride } \\
\text { Chioride } \\
\text { Chlorobenzene } \\
\text { Chlorobenzene } \\
\text { Chioroethane } \\
\text { Chioroethane } \\
\text { Chioroethene Ninyl chloride) }\end{array}$ & $\begin{array}{r}6.0 \\
4 \theta \\
<2.0 \\
20 \\
<1.0 \\
<1.0 \\
<1.0 \\
<1.0 \\
<1.0 \\
<1.0 \\
<1.0 \\
<1.0 \\
<2.0 \\
3.170 \\
<1.0 \\
<1.0 \\
2.150 \\
2.180 \\
<1.0 \\
<1.0 \\
<1.0 \\
<1.0 \\
<1.0\end{array}$ & Jo & 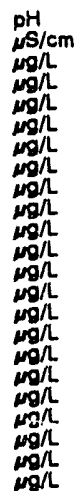 \\
\hline
\end{tabular}

Time: 15:20

Alkalinity: $7 \mathrm{mg} / \mathrm{L}$ Water tomperalure: $20.8^{\circ} \mathrm{C}$ 
WELL TNX 2D colloctod on 08/16/82, laburatory analyses (cont.)

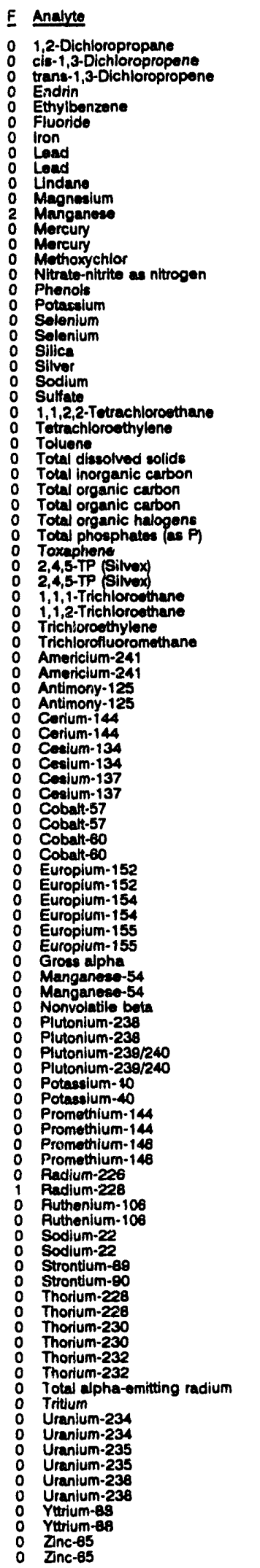

Result Mod

$<1.0$

$<1.0$

$<1.0$

$<100$

$<3.0$

$<0.0050$

716
61

$<0.20$

$<0.50$

$<5,680$

931
$<2.0$

$<<2.0$

13,800
$<2.0$

4,870
7,280

$<1.0$

$<1.0$

4,2000
4,230

4,230
$<1,000$
$<1,000$

$<1,000$

$<50$

$<0.24$

$<0.080$

$<1.0$

$<\begin{array}{r}1.0 \\ 2.2\end{array}$

$<1.0$

$<>1.0 E-09$

$<2.0 E-08$

$<6.0 \mathrm{E}-0.00$

$<6.0 \mathrm{C}-08$

$<1.0 E-08$

I. 0 - 00

$1.0 E-08$

$<1.0 E-08$

$1.0 \mathrm{E}-08$

$<1.0 E-06$

政

(2)

<2. 0 - 00

$<2.0 E-08$

$<3.0 E-08$

<1.0E-08

$1.0 \mathrm{E}-08$

$<2.0 \mathrm{E}-09$

$<1.0 E-09$

$<1.0 E-09$

$<1.0 E-09$

$<1.0 E-09$

<1.1E-07

Ci.0.

$<1.0 \mathrm{E} .08$

$<1.0 \mathrm{E} .08$

(1.0E-09

$3.9 E-09 \pm 1.4 E-09$

$<8.00-08$

$1.0 \mathrm{E}-08$

$\leq 1.0 E-08$

$<2.0 E-09$

$<2.05-09$
$<1.0 \mathrm{E}-09$

$<1.0 E \cdot 09$

2.7E-09 $1.4 E-09$

$<1.0 E-09$

1. $3 E-09 \pm 1.0 \mathrm{E}-09$

$<1.0 E-09$

$<1.0 E-09$

$<1.0 E-09$

$<1.00-09$

$<<.0 E-08$

6.0E-06

$<<2.0 E-08$
Unit Lab

$\begin{array}{ll}\mu g / L & G E \\ \mu g / h & G E \\ \mu g / L & G E\end{array}$

$\mu \mathrm{g} / \mathrm{GE}$

$\mu_{M / L} \mathrm{GE}$



$\mu g / L$ GE

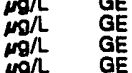

$\mu g / L$ GE

$\operatorname{mg}_{\mathrm{mgh}} \mathrm{GE}$

$\mu g /$ GE

$\mu g / L$ GE

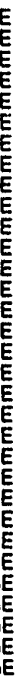

m

$\mu g n$ GE

$\mu g / \mathrm{GE}$

$\mu g h$ GE

CLI/mL GP

NCl/mL GP

NClimL. GP

$M \mathrm{Ni} / \mathrm{mL}$ GP

$N$ CimL GP

$\begin{array}{lll}N \mathrm{Ci} / \mathrm{mL} & \mathrm{GP} \\ \mathrm{NC} / \mathrm{mL} & \mathrm{GP}\end{array}$

$\omega \mathrm{Ci} / \mathrm{mL}$ GP

$M C i / m L$ GP

$\omega \mathrm{Cl} / \mathrm{mL}$ GP

$\mu \mathrm{NCI/mL}$ GP

$\mu \mathrm{C} / \mathrm{mL}$ GP

$\mu \mathrm{Cl/mL} G P$

$\mu \mathrm{Ci} / \mathrm{mL}$ GP

$M \mathrm{Cl} / \mathrm{mL}$ GP

$\mu \mathrm{Cl} / / \mathrm{mL}$ GP

$\mu \mathrm{Cl} / / \mathrm{mL}$ GP

$\mu \mathrm{Ni} / / \mathrm{mL}$ GP

${ }_{\mu \mathrm{C} i / m L}$ GP

$\mu \mathrm{Ci} / \mathrm{mL}$ GP

$M \mathrm{NC} / \mathrm{mL}$ GP

$M C i / m L$ GP

$\mu \mathrm{CC} / \mathrm{mL}$ GP

$N \mathrm{Ci/mL}$ GP

$\mu \mathrm{Ci} / \mathrm{mL}$ GP

$\mathrm{NCl/mL}$ GP

$\mu \mathrm{Cl} / / \mathrm{mL}$ GP

$\mu \mathrm{CCl/mL} G P$

$\mu C I / m L$ GP

$\mu C l / m L$ GP

$\mu \mathrm{CC} / \mathrm{mL}$ GP

$\mu \mathrm{Ci} / \mathrm{mL}$ GP

$\mu \mathrm{Ci} / \mathrm{mL}$ GE

$\mu \mathrm{Ci} / \mathrm{mL}$ GP

$M C / m L$ GP

$\mu \mathrm{C} / \mathrm{mL}$ GP

wCimL GP

wCilmL GP

${ }_{\mu C I / m L}^{M C I / m}$ GP

$M \mathrm{Ci} / \mathrm{mL}$ GP
WELL TNX 3D

MEASUREMENTS CONDUCTED IN THE FIELD

$\begin{array}{ll}\text { Sample date: } 09 / 17 / 92 & \text { Time: } 10: 10 \\ \text { Dopth to water: } 53.47 \mathrm{~A}(16.30 \mathrm{~m}) \text { bolow TOC } & \text { pH: } 4.7 \\ \text { Water olevation: } 100.83 \mathrm{H}(30.73 \mathrm{~m}) \mathrm{msi} & \text { Alkalinity: } 0 \mathrm{mg} / \mathrm{L} \\ \text { Sp. conductance: } 286 \mu \mathrm{S} / \mathrm{cm} & \text { Water temperature: } 22.0 \circ \mathrm{C} \\ \text { Water ovacuated before sampling: } 9 \mathrm{gal} & \\ \text { The well went dry during purging. } & \end{array}$

LABORATORY ANALYSES

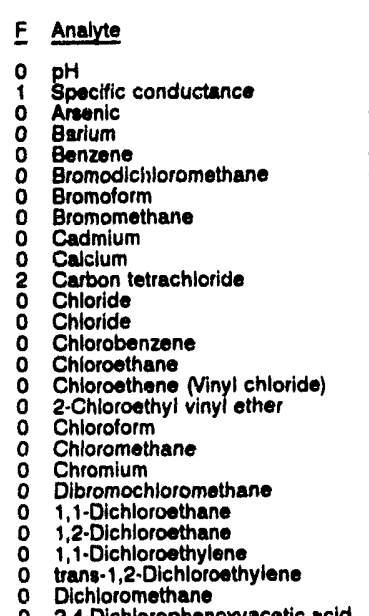

Result Mod Unit Lab

2,4-Dichlorophenoxyacetic acid $<0.30$

- 1,2-Dichloropropane

cis-1,3-Dichloropropene

Endrin

Ethylbenzene

Fluoride

1 Load

Thane

Mannanese

Manganese

Methoxychlor

Phenols

Potassium

Selenium

S Silica

Sodium

Sulfate

1,1,2,2-Tetrachloroothan

Tetrachlor

Toluene

Tolal dissolved solids

Total organic carton

Total organic halogens

0 2,4,5-TP (Silvex)

1,1,1-Trichloroethane

1,1,2-Trichloroethan

Trichlorofluoromethane

Americium-241

Antimony-125

Corium-144

Cesium-134

Cobalt-57

Europium-152

Europium-154

Europium-155

Gross alpha

Gross alpha

Nonvolatile beta

Nonvolatile beta

Plutonium-238

Plutonium-239/240
Potassium-40

Promethium-144

Promethium-144

Promethium-146

1 Radium-228

Rodium-22

Strontium-80

\begin{tabular}{l} 
Resulit \\
\hline 5.1 \\
262 \\
$<2.0$ \\
243 \\
5.0 \\
5.0 \\
5.0 \\
5.0 \\
$<2.0$ \\
11,500 \\
93
\end{tabular}

Ja

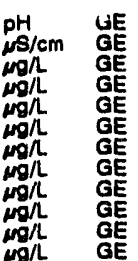

8,650

$<5.0$

$<5.0$

$<5.0$

$<5.0$

$<5.0$

$<5.0$

$<5.0$

$<5.0$

$<0.30$
$<5.0$

$<5.0$

$<0.0060$

$<5.0$

184
108
8.8

$<.0050$

5,980

0.96
$<0.50$

27,600

27,600
$<5.0$

2,810
$<2.0$

10,500

$<2.0,200$

1,790

$<5.0$

$<5.0$

10,800

2,040

$<50$

$<0.24$

$<0.090$
$<5.0$
$<5.0$
1,340

$<5.0$

$<1.0 E-09$
$<2.0 E-00$

$<8.0 E .00$

1.0E-06

(1.0E-08

$<1.0 E-08$

$<4.0 E-00$

$<2.0 E-\infty \theta$

$<3.0 \mathrm{C}-08$

$2.2 E-00 \pm 3.8 E-00$

$2.5 E-00 \times 4.0 E-00$

$\begin{aligned} &<1.0 E-08 \\ & 2.1 E-08 \pm 2.7 E-09 \\ & 2.2 E-00 \pm 2.7 E-09\end{aligned}$

$<1.0 E-09$

<1.0E-09

<1.

$<1.0 E-08$

$1.1 E-09+2.7 E-10$

$4.0 E-09+1.1 E-10$

$<8.0 E-00$

$<1.0 E-06$
$<2.0 E-00$

$<2.0 E-09$ 


\begin{tabular}{|c|c|c|c|c|}
\hline $\boldsymbol{F}$ & Analyte & Reoult & Mod & Unit \\
\hline 0 & 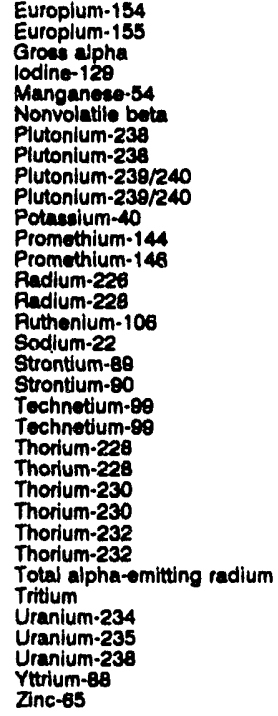 & $\begin{array}{l}<2.0 E-08 \\
<3.0 E-08 \\
<2.0 E-09 \\
<2.0 E-09 \\
<1.0 E-08 \\
<2.0 E-09 \\
<1.0 E-09 \\
<1.0 E-09 \\
<1.0 E-09 \\
<1.0 E-09 \\
<1.1 E-07 \\
<1.0 E-08 \\
<1.0 E-09 \\
<1.0 E-09 \\
3.8 E-09 \pm 1.5 E-09 \\
<8.0 E-09 \\
<1.0 E-08 \\
<2.0 E-09 \\
<2.0 E-09 \\
<3.0 E-07 \\
<3.0 E-07 \\
<1.0 E-09 \\
<1.0 E-09 \\
<1.0 E-09 \\
<1.0 E-09 \\
<1.0 E-09 \\
<1.0 E-09 \\
<1.0 E-09 \\
2.5 E-004 \pm 5.0 E-07 \\
<1.0 E-09 \\
<1.0 E-09 \\
<1.0 E-09 \\
<6.0 E-08 \\
<2.0 E-08\end{array}$ & & 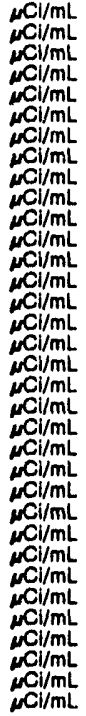 \\
\hline
\end{tabular}

WELL TNX 1D

MEASUREMENTS CONDUCTED IN THE FIELD

Sampla date: 09/14/82

Depth to water: $58.38 \mathrm{it}(17.18 \mathrm{~m})$ below TOC

Water elevation: $100.14 \mathrm{~h}(30.52$

Sp. conductance: $35 \mathrm{\mu S} / \mathrm{cm}$.

LABORATORY ANALYSES

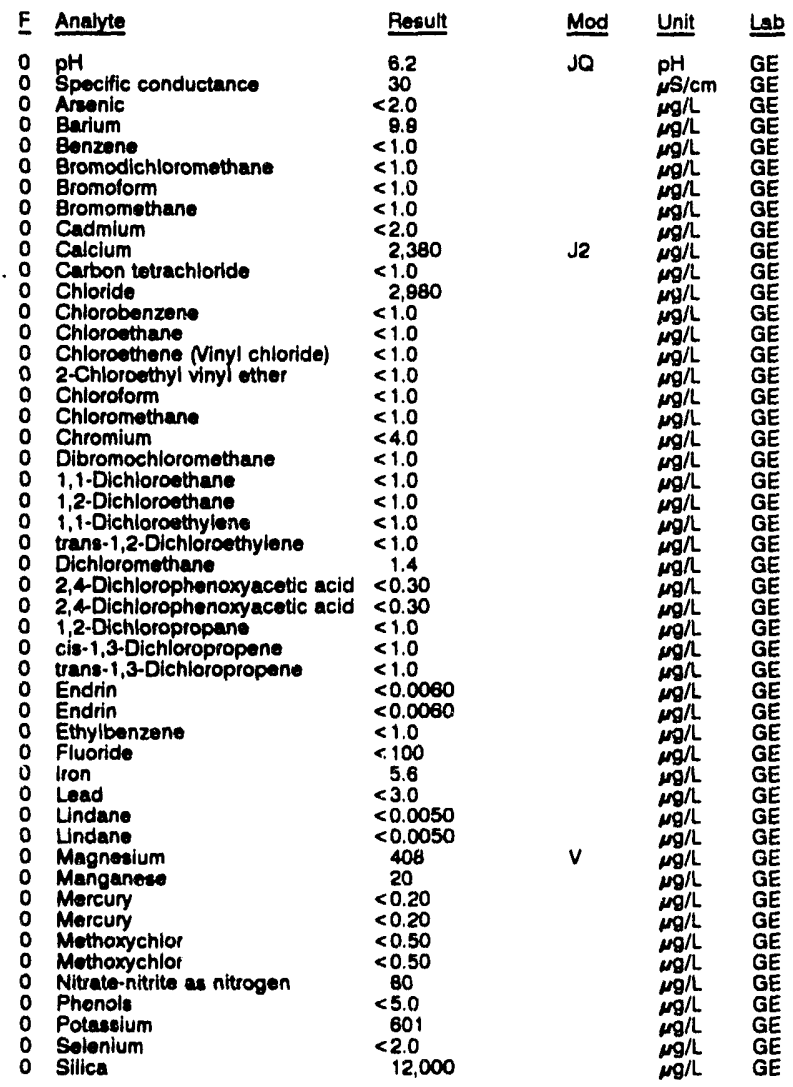

WELL TNX 1D collected on 09/14/92, laboratory analyeses (cont.)

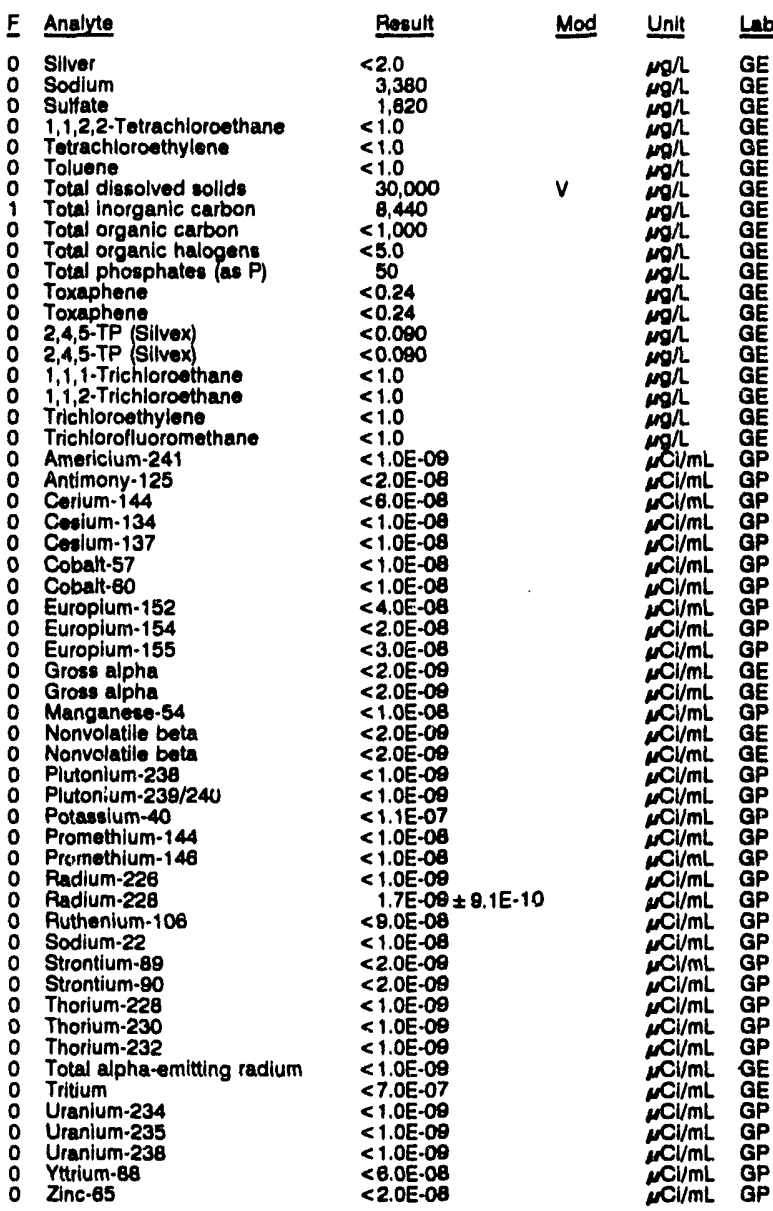

\section{WELL TNX 2D}

MEASUREMENTS CONDUCTED IN THE FIELL

Sample date: $09 / 18 / 92$

Depth to water: $55.17 \mathrm{Ht}(16.82 \mathrm{~m})$ below TOC

Water elevation: $99.83 \mathrm{ft}(30.46 \mathrm{~m}) \mathrm{mgl}$

So conductance 52 is

Water evacuated before sampling: $45 \mathrm{gal}$

PH: 53 :

Alkalinity: $5 \mathrm{moh}$

Water tomperalure: $21.8^{\circ} \mathrm{C}$

LABORATORY ANALYSES

\begin{tabular}{|c|c|c|c|}
\hline Analyte & Posult & Mod & Unit \\
\hline $\begin{array}{l}\text { pH } \\
\text { Specific conductance } \\
\text { Arsanic } \\
\text { Areonic } \\
\text { Barium } \\
\text { Benzene } \\
\text { Bromodichloromethane } \\
\text { Bromoform } \\
\text { Bromomethane } \\
\text { Cadmium } \\
\text { Calcium } \\
\text { Carbon totrachloride } \\
\text { Chloride } \\
\text { Chlorobenzene } \\
\text { Chloroethane } \\
\text { Chloroethene Minyl chloride) } \\
\text { 2-Chloroethyl vinyl ether } \\
\text { Chloroform } \\
\text { Chloromethane } \\
\text { Chromium } \\
\text { Dibromochloromethane } \\
\text { 1,1-Dichloroothane } \\
1,2 \cdot \text { Dichloroethane } \\
\text { 1,1-Dichloroothylene } \\
\text { trans-1,2-Dichloroethyiene } \\
\text { Dichloromethane } \\
2,4 \text {-Dichlorophenoxyacetic acid } \\
2,4 \text {-Dichlorophenoxyacetic acid }\end{array}$ & $\begin{aligned} & 5.9 \\
& 50 \\
&<2.0 \\
&<2.0 \\
& 23 \\
&<1.0 \\
&<1.0 \\
&<1.0 \\
&<1.0 \\
&<2.0 \\
& 3.100 \\
&<1.0 \\
& 3.570 \\
&<1.0 \\
&<1.0 \\
&<1.0 \\
&<1.0 \\
&<1.0 \\
&<1.0 \\
&<4.0 \\
&<1.0 \\
&<1.0 \\
&<1.0 \\
&<1.0 \\
&<1.0 \\
& 1.4 \\
&<0.30 \\
&<0.30\end{aligned}$ & JQ & 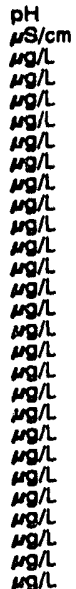 \\
\hline
\end{tabular}


ANALYTICAL RESULTS

WELL TBG 5B

MEASUREMENTS CONDUCTED IN THE FIELD

Sample date: 00/18/92
Dopth to water: $35.89 \mathrm{~h}(10.94 \mathrm{~m})$ below TOC
Water elevetion: $114.11 \mathrm{~h}(34.78 \mathrm{~m}) \mathrm{msl}$ Sp. conductance: 34 ps/cm
Water ovacuated bofore eampling: $116 \mathrm{gal}$

LABORATORY ANALYSES

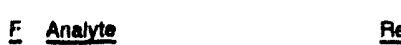

PH

o Areenic

$\begin{array}{ll}0 & \text { Barlum } \\ 0 & \text { Benzene } \\ 0 & \text { Bromodichloromethane }\end{array}$

Bromomethan

O Cadmium

Carbon tetrachloride

Chlorid

Chlorobenzene

Chlorosthane

Chloroethene Minyl chloride

2-Chloroethyl

Chlorolorm

Chromium

Dibromochloromethan
1,1-Dichloronthane

1,2-Dichlorosthane

0
0
trans-1,2-Dichloroethylene

o Dichloromethane

1,2-Olchloropropane

o cis-1,3-Dichloropropene

Ethylbenzene

2 Iron

0 Load

O Magneaium

o Manganeas

O Morcury

Phenols

o Potaseium

o silica

o silver

o Sodium

1,1,2,2-Tetrachloroethane

o Tetrachloroethylene

o Total dissolved sollds

Total dissolved sollds

1 Total inorganic carbon

- Total organic carbon

o Total organic halogens

o 1,1,1-Trichioroethane

o 1,1,2-Trichloroethane

Trichloroethylene

Americium-241

Antimony-125

Cerlum-144

Coslum-137

Cobalt-57

Europium-152

Europium-154

Europlum-155

Groas alphe

Manganese. 34

Plutonium-238

Plutonium-238/2
Potaselum-40

Potassium-40

Promethium-146

Padium-226

Rudum-228

Rodium-22

Strontium-89

Strontium-80

Tochnotium.e日

Thorium-228

Thorium-232

Total elpha-emitting radium

Trum

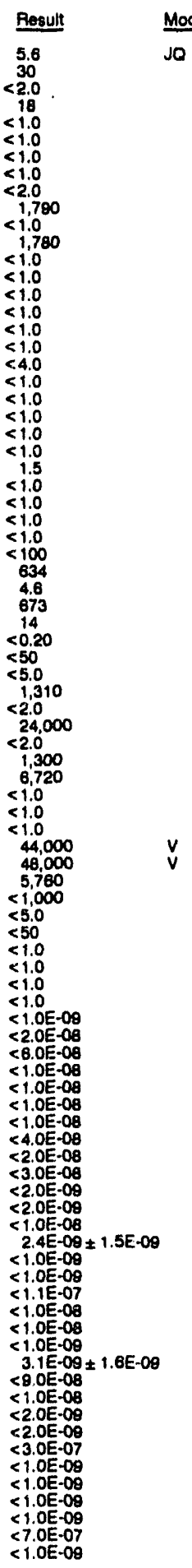

WELL TBG 5B collectod on 09/18/92, laboratory andyses (cont)

\begin{tabular}{|c|c|c|c|c|}
\hline$\underline{\boldsymbol{F}}$ & Analyte & Reoult & Mod & Unit \\
\hline $\begin{array}{l}0 \\
0 \\
0 \\
0\end{array}$ & $\begin{array}{l}\text { Uranium-235 } \\
\text { Uranlum-238 } \\
\text { Yttrium-88 } \\
\text { Zinc- } 65\end{array}$ & $\begin{array}{l}<1.0 E-09 \\
<1.0 E-09 \\
<6.0 E-08 \\
<2.0 E-08\end{array}$ & & 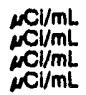 \\
\hline
\end{tabular}

\section{WELL TBG 6}

MEASUREMENTS CONDUCTED IN THE FIELD

Sample date: 08/18/92 17 Time: 14:45

Water to water: $43.69 \mathrm{ft}(13.32 \mathrm{~m})$ bellow

inaccessibility or mechanical problem prevented sample collection.

\section{WELL TBG 7}

MEASUREMENTS CONDUCTED IN THE FIELD

Sample date: 09/14/92

Depth to water: $39.02 \mathrm{ft}(11.69 \mathrm{~m})$ below TOC

Water elevation: $107.78 \mathrm{H}(32.85 \mathrm{~m}) \mathrm{mel}$

Sp. conductance: $46 \mathrm{\mu S} / \mathrm{cm}$
Water ovacuated before sampling: $81 \mathrm{gal}$

PH: 5.0

Wkalinity: $8 \mathrm{mg} / \mathrm{s}$

Water ovacuated before sam

LABORATORY ANALYSES

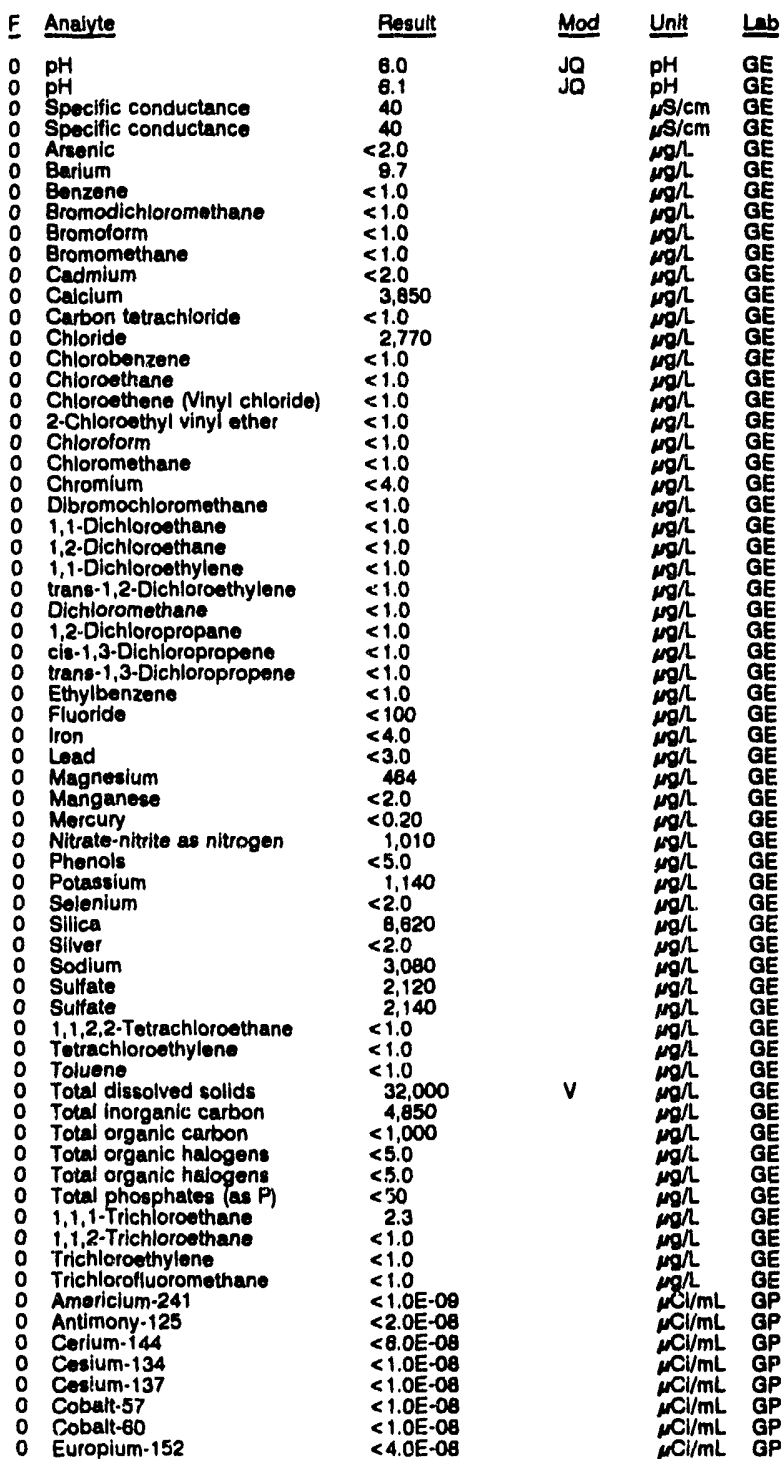


WELL TBG 1 collucted on 00/21/92, laboratory analyses (cont.)

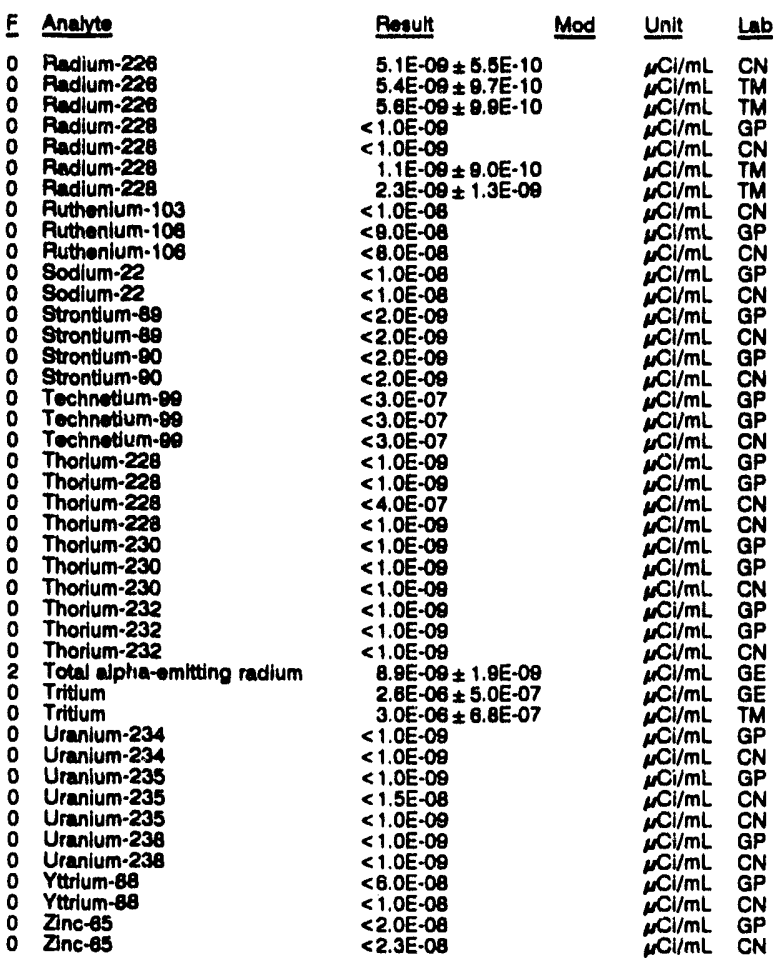

WELL TBG 3

MEASUREMENTS CONDUCTED IN THE FIELD

Sample date: $09 / 1892$
Dopth to water: $46.61 \mathrm{~h}(14.21 \mathrm{~m})$ bolow TOC Time: $13: 30$
Water elevation: $104.59 \mathrm{~h}(31.68 \mathrm{~m}) \mathrm{mal}$
inaccestibility or mochanical problem prevented sample collection.

WELL TBG 4

MEASUREMENTS CONDUCTED IN THE FIELD

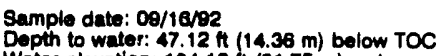

inacceasibility of mechanical problem prevented sample collection.

\section{WELL TBG 5}

MEASUREMENTS CONDUCTED IN THE FIELD

Sample date: 09/16/82

Depth to water: $44.74 \mathrm{ft}(13.64 \mathrm{~m})$ below TOC

Wator elevation: 104.68 ft $(31.80 \mathrm{~m}) \mathrm{mel}$

inaccersibility or mechanical problem prevented sample collection.

\section{WELL TBG 5A}

MEASUREMENTS CONOUCTED IN THE FIELD

Sample date: 09/18/92

Depth to water: 44.88 it $(13.71 \mathrm{~m})$ below TOC

Wator elevation: $104.42 \mathrm{H}(31.8$

Water ovacuatod belore sampling: $153 \mathrm{gal}$

LABORATOFY ANALYYSES

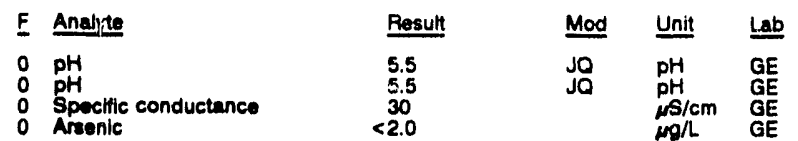

Time: $13: 10$

PH: 5.0 Alkalinity: $0 \mathrm{mon}$

Water temperature: $21.60^{\circ} \mathrm{C}$

$\mathrm{Mg} / \mathrm{L}$

WELL TBG SA collected on 09/18/82, laboratory analyses (cont.)

\begin{tabular}{|c|c|c|c|}
\hline Analyte & Pesult & Mod & Unit \\
\hline 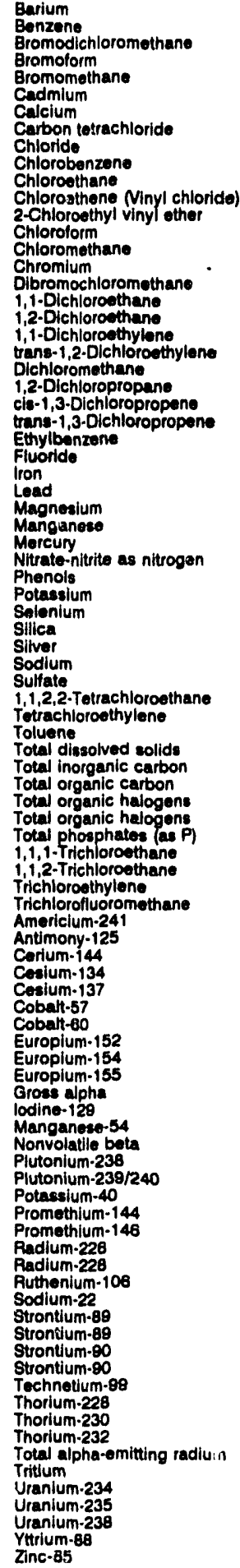 & 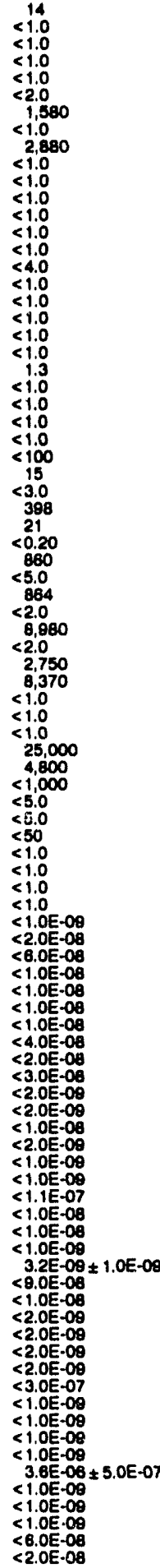 & $v$ & 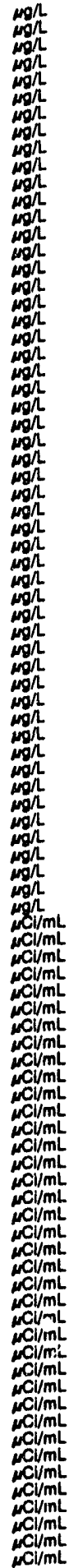 \\
\hline
\end{tabular}


ANALYTICAL RESULTS

WEL TBG 1 collected on 09/21/92, laboratory analyese (cont.)

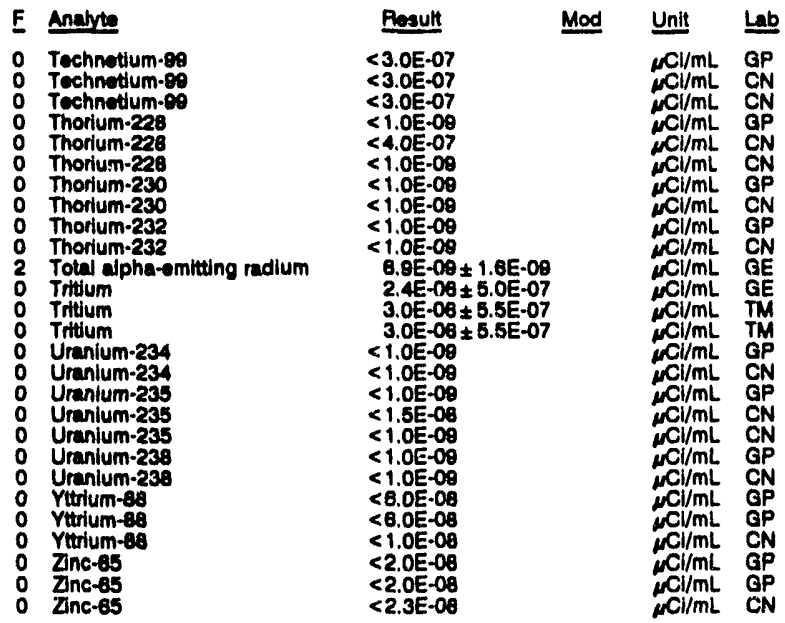

WELL TBG 1 Replicate

MEASUREMENTS CONDUCTED IN THE FIELD

$\begin{array}{ll}\text { Sample date: } 09 / 21 / 82 & \text { Time: } 11: 30 \\ \text { Depth to water: } 49.74 \mathrm{ht}(15.16 \mathrm{~m}) \text { below TOC } & \text { pH: } 4.5 \\ \text { Water elevation: } 101.46 \mathrm{Ht}(30.83 \mathrm{~m}) \mathrm{ms} & \text { Alkalinity: } 0 \mathrm{mg} / \mathrm{h} \\ \text { Sp. conductance: } 149 \mu \mathrm{cm} / \mathrm{cm} & \text { Water temperature: } 22.3^{\circ} \mathrm{C} \\ \text { Water evecuatod bofore sampling: } 61 \mathrm{gal} & \end{array}$

LABORATOFY ANALYSES

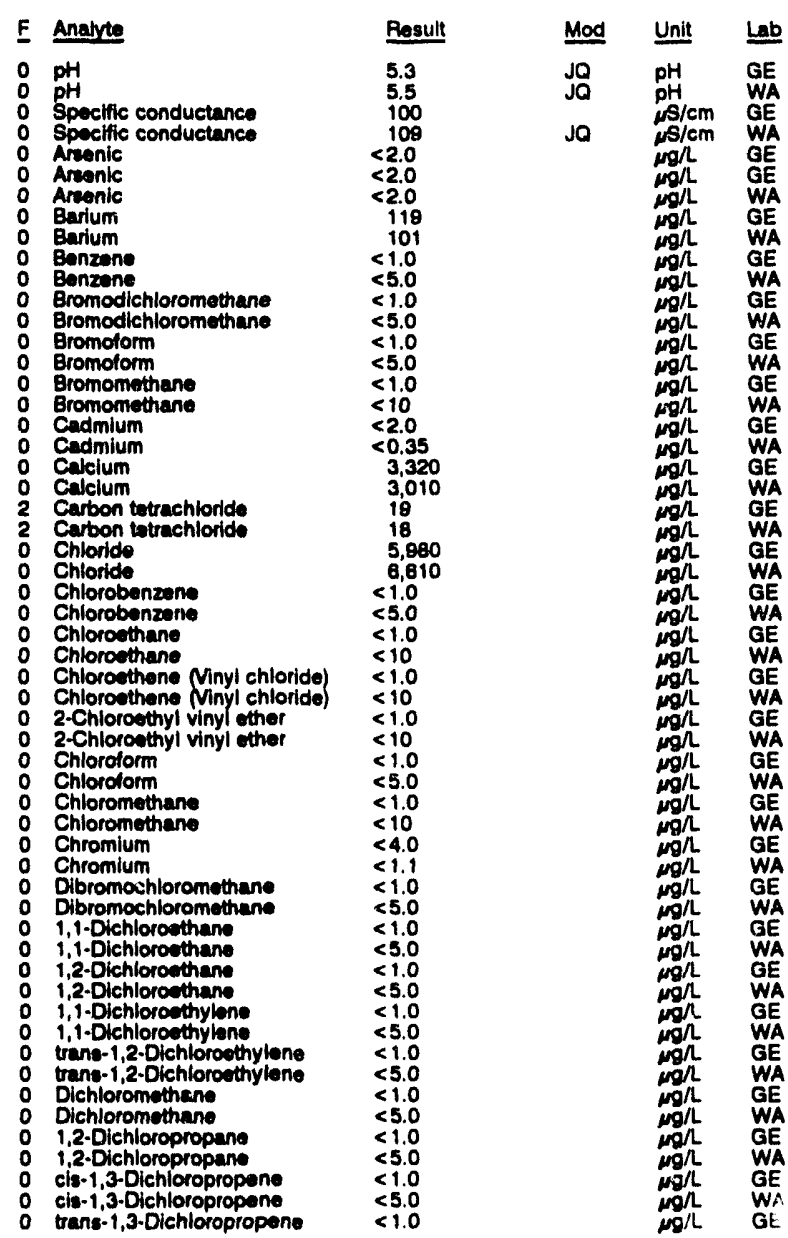

WELL TBG 1 collocted on 00/21/92, laboratory enalyees (cont)

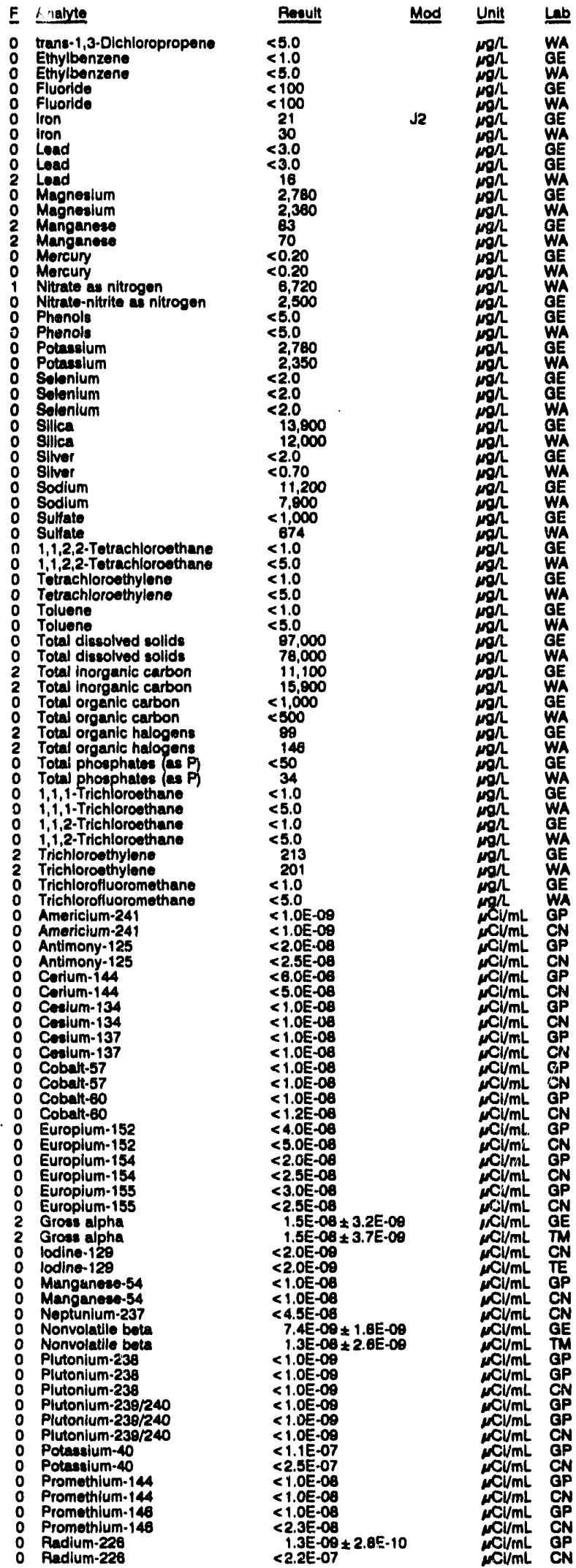


ANALYTICAL RESULTS

WELL TBO 1 collected on 08/21/92, laboratory analyses (cont.)

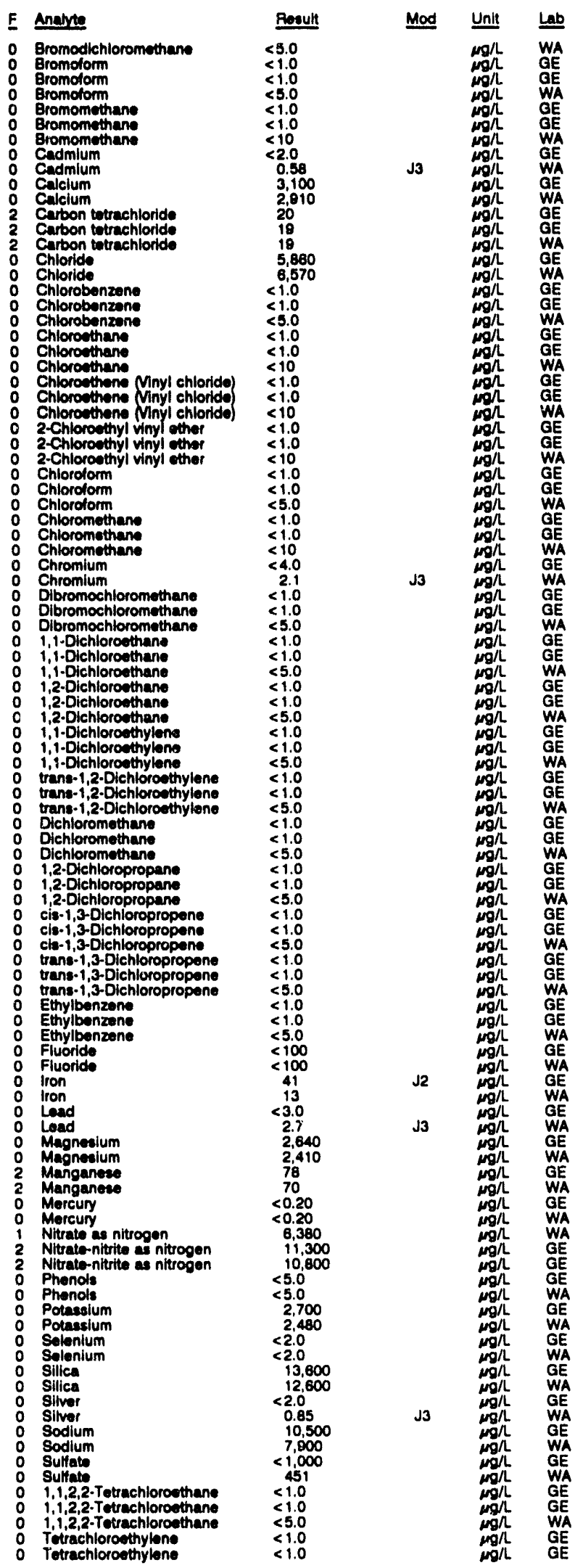

WELL TBG 1 collected on 08/21/82, laboratory analyees (cont)

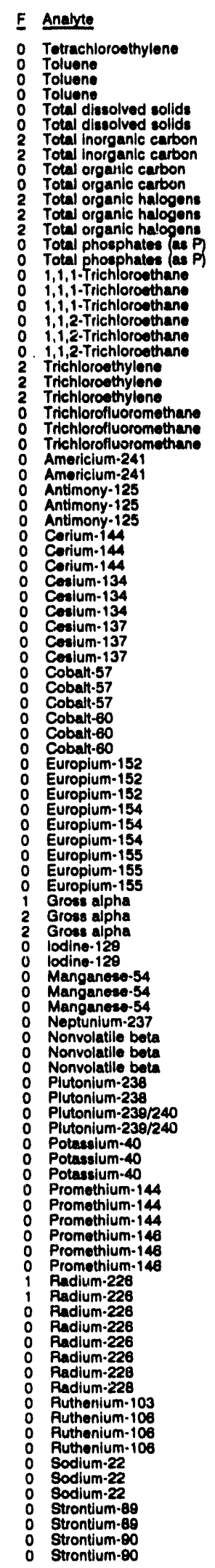

$8.6 \mathrm{E}-09 \pm 5.7 \mathrm{E}-10$
Mod Unit Lab

mogh WA

$<5,0$

$<1.0$

80,000

180.000
10.500
15000

$<1,000$
$<500$

告

134
$<50$
27

$<27.0$

$<1.0$

$<1.0$

$<1.0$
$<5.0$
160

160
32
295

295
$<1.0$
$<1.0$

$<1.0$

$<1.0 E-09$

$<1.0 E-00$
$<2.05-06$

$<2.0 E-06$

$<B .0 E-0$.

$<6.06-0.06$

$<5.0 E-06$

$<1.0 E-06$

<1.0e.0

$<1.0 E-00$

$<1.0 \mathrm{E}-\mathrm{O}$

$<1.0 \mathrm{O}$.0

$<1.0 E-08$

$<4.0 \mathrm{E}-00$

$<4.0 E-O 9$

$<2.0 E-00$

$<2.0 E-08$

$<2.5 E-00$

$<3.0 \mathrm{E}-09$

9.3E-09 $-2.6 E-09$

$1.6 \mathrm{E}-08 \pm 3.7 \mathrm{E}-0$

$<.0 E-09 \pm 3.7 E-08$

$<2.0 \mathrm{E}-09$

1.

$<1.0 E-08$

$<4.3 E-00$

$8.8 E-09 \pm 2.0 E-09$

$7.6 E-00 \pm 2.2 E-09$

$<1.0 E-09$

$<1.0 \mathrm{0}-09$

$<1.0 \mathrm{E} .00$

$<1.1 \mathrm{E}-07$

$<1.1 E-07$

$<1.0 E-08$

$<1.0 E-0$

$<1.0 E-08$

$<1.0 E-0$

7.8E-09 $\pm 4.6 \mathrm{E} \cdot 10$

$<2.2 E .07$

5.1E- $09 \pm 7.8 \mathrm{E}-10$ 5. 0 E- $00 \pm 8.1 \mathrm{E}-10$ $2.3 \mathrm{E}-09 \pm 1.0 \mathrm{E}-00$
B. $0 \mathrm{E}-10 \pm 8.0 \mathrm{E}-10$

$<1.0 E-08$

$<8.0 E-0$

< $0.0 \mathrm{0}-08$

$<1.0 E .08$

$<1.0 E-08$

$<1.0 E-06$

$<2.0 E-09$

$<2.0 E-00$ 
ANALYTICAL RESULTS

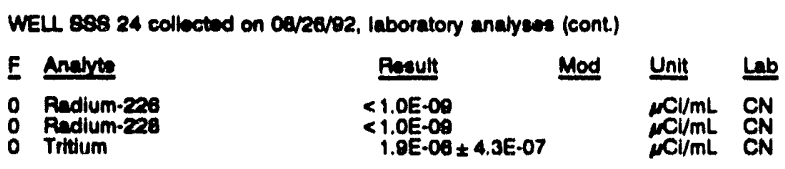

WELL. SSS 25

MEASUREMENTS CONDUCTED IN THE FIELD
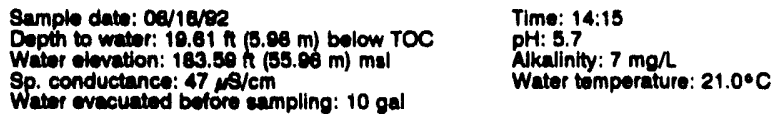
LABORATOFY ANALYSES

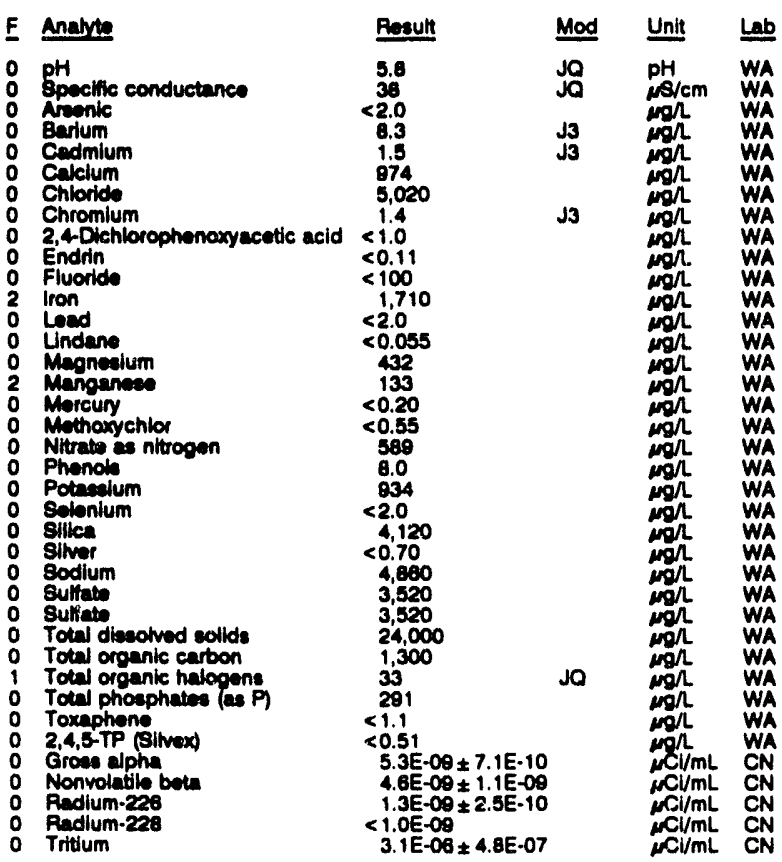

\section{WELL SSS 26}

MEASUREMENTS CONDUCTED IN THE FIELD

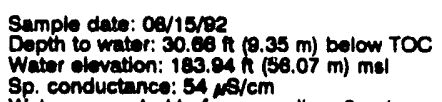

Time: $12: 20$

Water olvvation: 183.94 ( $(58.07 \mathrm{~m}) \mathrm{mel}$

Sp. conductance: $34 \mathrm{MS} / \mathrm{cm}$

Water temporature: $20.5^{\circ} \mathrm{C}$ LABORATOFY ANALYSES

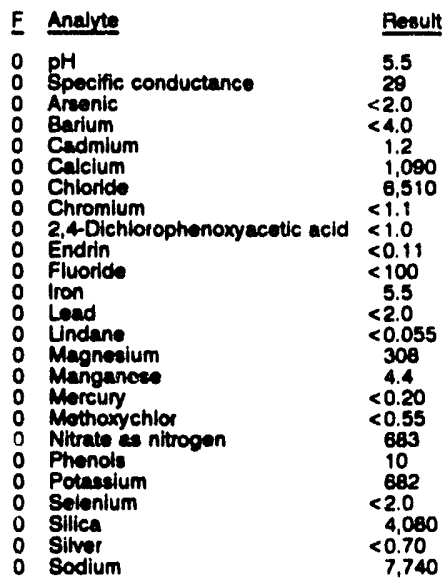

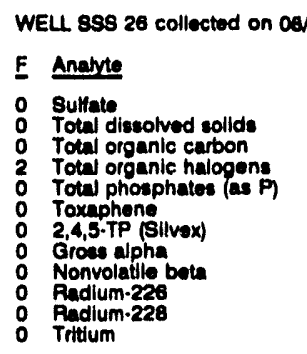

\section{WELL SSS 27}

MEASUREMENTS CONDUCTED IN THE FIELD

Sample date: 08/18/82

Depth to water: $42.99 \mathrm{~h}(13.10 \mathrm{~m})$ below TOC

Weter elevation: $170.82 \mathrm{~h}(52.07 \mathrm{~m}) \mathrm{mal}$

Water evacuated before sampling: $7 \mathrm{gal}$

LABORATORY ANALYSES

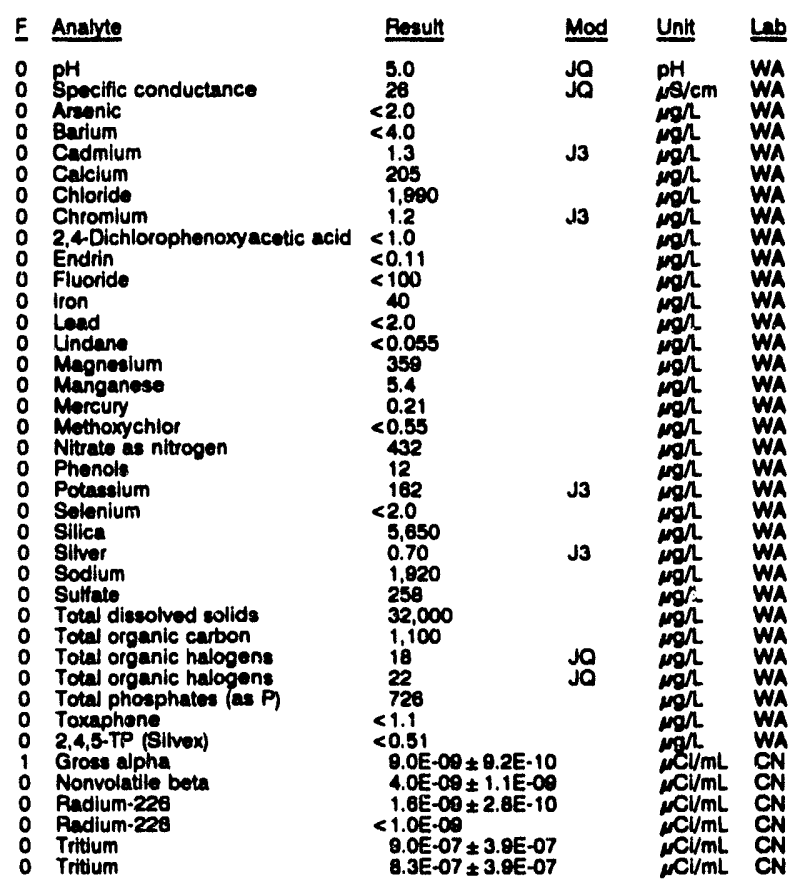

\section{WELL TBG 1}

\begin{tabular}{|c|c|c|c|c|}
\hline 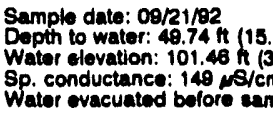 & mal TOC & $\begin{array}{l}\text { Time: } 11: 30 \\
\text { pH: } 4.5 \\
\text { Alkalinity: or } \\
\text { Water tompe }\end{array}$ & 22.3 & \\
\hline \multicolumn{5}{|l|}{ LABOPATORY ANALYSES } \\
\hline Analyze & Result & Mod & Unit & Lيb \\
\hline $\begin{array}{ll}0 & \mathrm{pH} \\
0 & \mathrm{pH} \\
0 & \mathrm{pH} \\
0 & \text { Specific conductance } \\
0 & \text { Spectic conductance } \\
0 & \text { Specific conductance } \\
0 & \text { Arsenic } \\
0 & \text { Arsenic } \\
0 & \text { Barium } \\
0 & \text { Barium } \\
0 & \text { Benzene } \\
0 & \text { Benzene } \\
0 & \text { Benzene } \\
0 & \text { Bromodichloromethane } \\
0 & \text { Bromodichloremethane }\end{array}$ & $\begin{array}{r}5.2 \\
5.7 \\
5.8 \\
100 \\
97 \\
97 \\
<2.0 \\
<2.0 \\
113 \\
102 \\
<1.0 \\
<1.0 \\
<5.0 \\
<1.0 \\
<1.0\end{array}$ & $\begin{array}{l}\text { JQ } \\
\text { Jo } \\
\text { JO } \\
\text { Jo } \\
\text { JO }\end{array}$ & 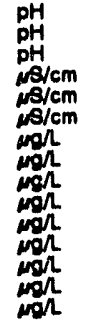 & $\begin{array}{l}\text { GE } \\
\text { WA } \\
\text { WA } \\
\text { GE } \\
\text { WA } \\
W A \\
\text { GE } \\
\text { WA } \\
\text { GE } \\
\text { WA } \\
\text { GE } \\
\text { GE } \\
\text { WA } \\
\text { GE } \\
\text { GE }\end{array}$ \\
\hline
\end{tabular}




\section{WELL SSS 21}

MEASUREMENTS CONDUCTED IN THE FIELD

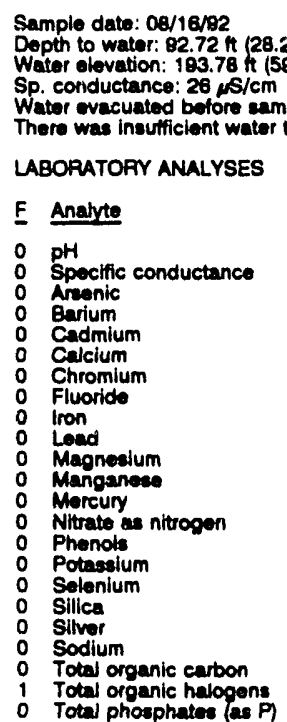

Time: $17: 45$

pH: 4.8

Water temperature: $21.5^{\circ} \mathrm{C}$

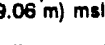

le bottles.

There was insutificlent wator

$F$ Anabite

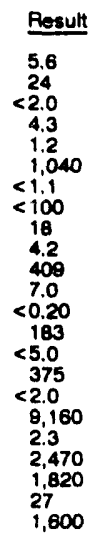

Mod
JO
J3
J3
J3
J3
J3
JO

WELL SSS 22

MEASUREMENTS CONDUCTED IN THE FIELD

\begin{tabular}{|c|c|c|c|c|c|}
\hline & $\begin{array}{l}\text { to water: } 47.68 \mathrm{H}(14.53 \mathrm{~m}) \mathrm{b} \\
\text { olevation: } 243.24 \mathrm{Ht}(\mathrm{74.14} \mathrm{m}) \\
\text { onductance: } 28 \mathrm{NS} / \mathrm{cm} \\
\text { ovacuatod before sampling: } 1\end{array}$ & TOC & $\begin{array}{l}\text { Tima: } 1 \\
\text { pH: } 5.0 \\
\text { Alkalini } \\
\text { Water t }\end{array}$ & ture: & \\
\hline & BORATOFY ANALYSES & & & & \\
\hline $\mathbf{E}$ & Analyte & Result & Mod & Unit & $\underline{\text { Lab }}$ \\
\hline $\begin{array}{l}0 \\
0 \\
0 \\
0 \\
0 \\
0 \\
0 \\
0 \\
0 \\
0 \\
0 \\
0 \\
0 \\
0 \\
0 \\
0 \\
0 \\
0 \\
0 \\
0 \\
0 \\
0 \\
0 \\
0 \\
0 \\
0 \\
0 \\
0 \\
0\end{array}$ & 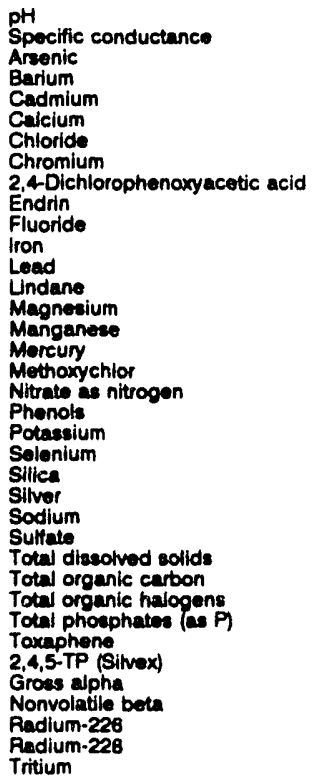 & $\begin{aligned} 5.2 \\
26 \\
<2.0 \\
7.0 \\
<0.35 \\
847 \\
5,970 \\
<1.1 \\
<1.1 \\
<0.11 \\
<100 \\
13 \\
<2.0 \\
<0.055 \\
583 \\
13 \\
<0.20 \\
<0.55 \\
1,080 \\
<5.0 \\
264 \\
<2.0 \\
6.160 \\
1.2 \\
1,680 \\
589 \\
13.000 \\
3,380 \\
23 \\
232 \\
<1.1 \\
<0.55 \\
<2.0 E-09 \\
<2.0 E-09 \\
<1.0 E-09 \\
<1.0 E-09 \\
3.0 E-06\end{aligned}$ & $\begin{array}{l}\text { Jo } \\
\text { Jo }\end{array}$ & 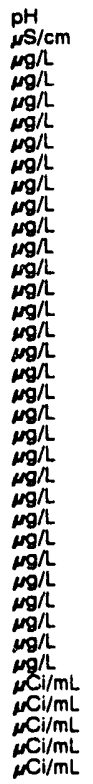 & $\begin{array}{l}\text { WA } \\
\text { WA } \\
\text { WA } \\
\text { WA } \\
\text { WA } \\
\text { WA } \\
\text { WA } \\
\text { WA } \\
\text { WA } \\
\text { WA } \\
\text { WA } \\
\text { WA } \\
\text { WA } \\
\text { WA } \\
\text { WA } \\
\text { WA } \\
\text { WA } \\
\text { WA } \\
\text { WA } \\
\text { WA } \\
\text { WA } \\
\text { WA } \\
\text { WA } \\
\text { WA } \\
\text { WA } \\
\text { WA } \\
\text { WA } \\
\text { WA } \\
\text { WA } \\
\text { WA } \\
\text { WA } \\
\text { WA } \\
\text { CN } \\
\text { CN } \\
\text { CN } \\
\text { CN } \\
\text { CN }\end{array}$ \\
\hline
\end{tabular}

\section{WELL SSS 23}

MEASUREMENTS CONDUCTED IN THE FIELD

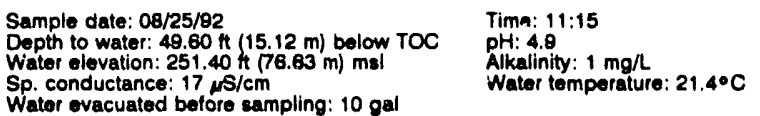

Wator evacuated before sampling: $10 \mathrm{gal}$

LABORATOAY ANALYSES

\begin{tabular}{|c|c|c|c|}
\hline Anatyze & Result & Mod & Unit \\
\hline 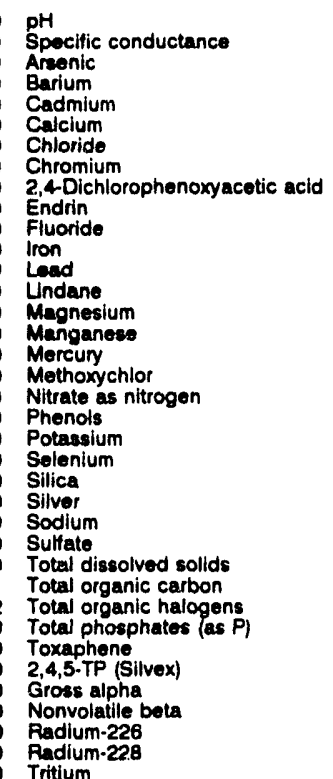 & $\begin{array}{l}5.3 \\
20 \\
<2.0 \\
<4.0 \\
<0.35 \\
814 \\
2.810 \\
2.810 \\
<1.1 \\
<0.11 \\
<100 \\
18 \\
<2.0 \\
<0.055 \\
363 \\
6.6 \\
<0.20 \\
<0.55 \\
438 \\
<5.0 \\
436 \\
<2.0 \\
7,300 \\
<0.70 \\
1,300 \\
517 \\
11,000 \\
5,100 \\
221 \\
884 \\
<1.1 \\
<0.55 \\
2.1 E-09 \pm 6.4 E-10 \\
<2.0 E-09 \\
<1.0 E-09 \\
<1.0 E-09 \\
1.6 E-06+4.1 E-07\end{array}$ & $\begin{array}{l}\text { Jo } \\
\text { Jo }\end{array}$ & 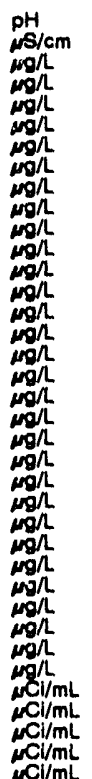 \\
\hline
\end{tabular}

\section{WELL SSS 24}

MEASUREMENTS CONDUCTED IN THE FIELD

$\begin{array}{ll}\text { Sample date: } 08 / 26 / 82 & \text { Time: } 8: 15 \\ \text { Depth to water: } 61.88 \mathrm{Ht}(18.86 \mathrm{~m}) \text { bolow TOC } & \text { pH: } 5.3 \\ \text { Water elovation: } 253.32 \mathrm{th}(77.21 \mathrm{~m}) \mathrm{msl} & \text { Alkalinity: } 1 \mathrm{mg} / \\ \text { Sp. conductance: } 15 \mu \mathrm{NS} / \mathrm{cm} & \text { Water tomperature: } 18.9^{\circ} \mathrm{C} \\ \text { Water evacuated bolore } 28 \mathrm{mpling}: 2 \mathrm{gal} & \end{array}$

Water evacuated before sampling: 2 gal

The well went dry during purging.

LABORATORY ANALYSES

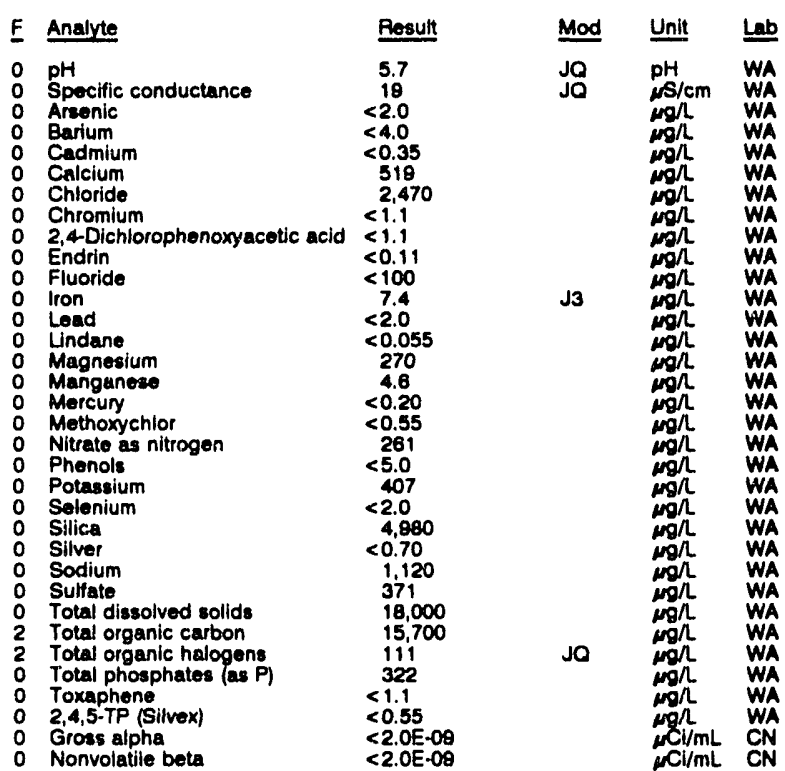


ANALYTICAL RESULTS

\section{WELL SSS 11}

MEASUREMENTS CONDUCTED IN THE FIELD
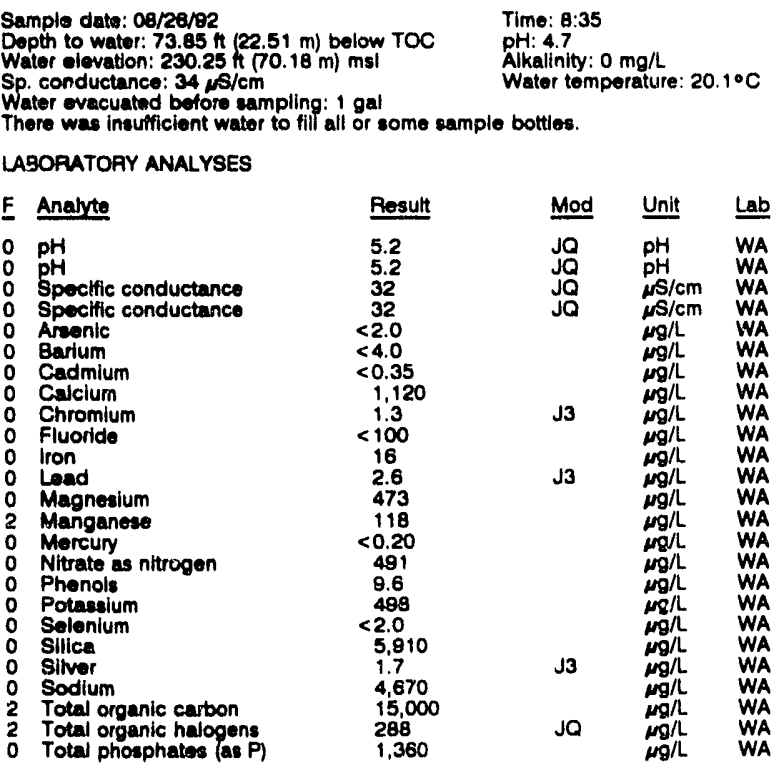

\section{WELLL SSS 12}

MEASUREMENTS CONDUCTED IN THE FIELD

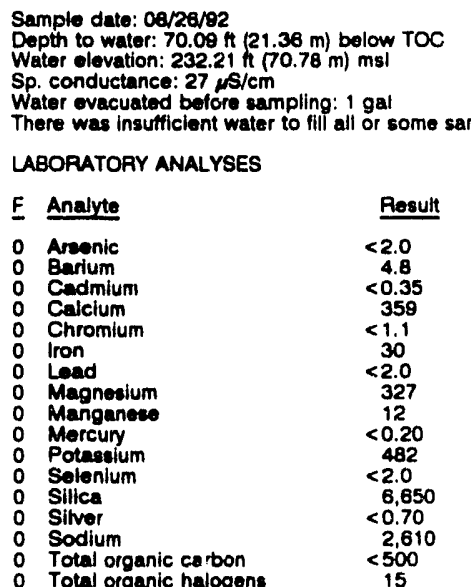

o Total organic halogens

\section{WELL SSS 17}

MEASUREMENTS CONDUCTED IN THE FIELD

\section{Sample date: 08/18/92}

Depth to water: $29.09 \mathrm{ft}(8.87 \mathrm{~m})$ bolow TOC

Water elevation: $183.61 \mathrm{H}$ (59.0

Sp. conductance: $22 \mu \mathrm{\mu s} / \mathrm{cm}$

LABORATOFY ANALYSES

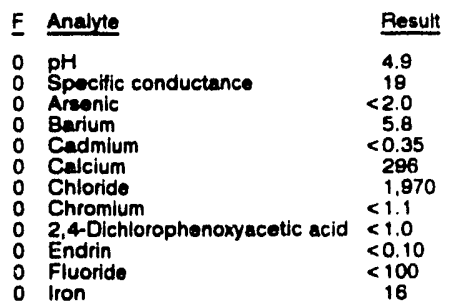

Water temperature: $20.7^{\circ} \mathrm{C}$

\section{Time: $8: 10$ \\ Alkalinity: $0 \mathrm{mgl}$}

Time: $8: 35$

Alkalinity: $0 \mathrm{mg}$
Water temperature: $20.1^{\circ} \mathrm{C}$

mple botties.

le bottles.

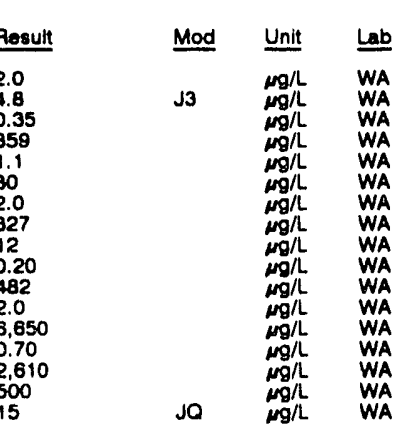




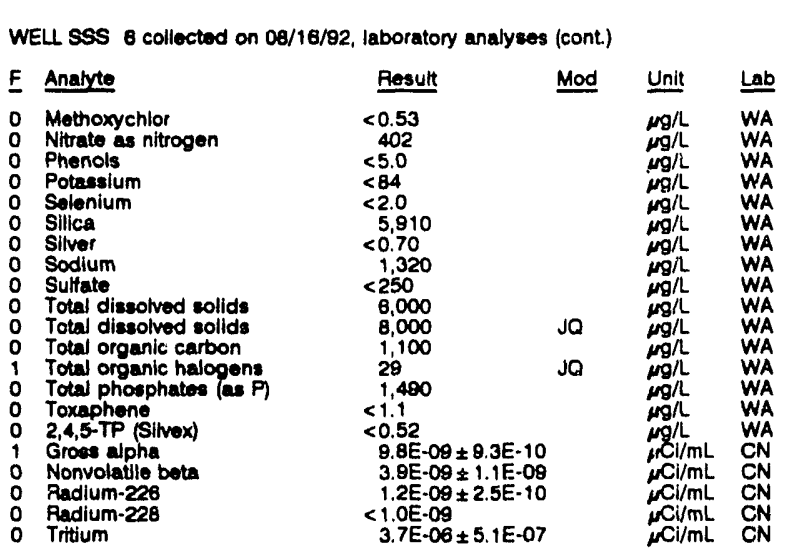

\section{WELL SSS 7}

\section{MEASUREMENTS CONDUCTED IN THE FIELD}

Sample date: $08 / 16 / 82$

Depth to water: 61.29 ft $(18.68 \mathrm{~m})$ below TOC

Water elevation: $185.31 \mathrm{~h}(50.39 \mathrm{~m}) \mathrm{msl}$

Water evacuated before sampling: $4 \mathrm{gal}$

Time: 11:45

PH: 4.7 : $0 \mathrm{mg}$

Alkalinity: $0 \mathrm{mg} / \mathrm{L}$
Water temperature: $20.6^{\circ} \mathrm{C}$

LABOAATOAY ANALYSES

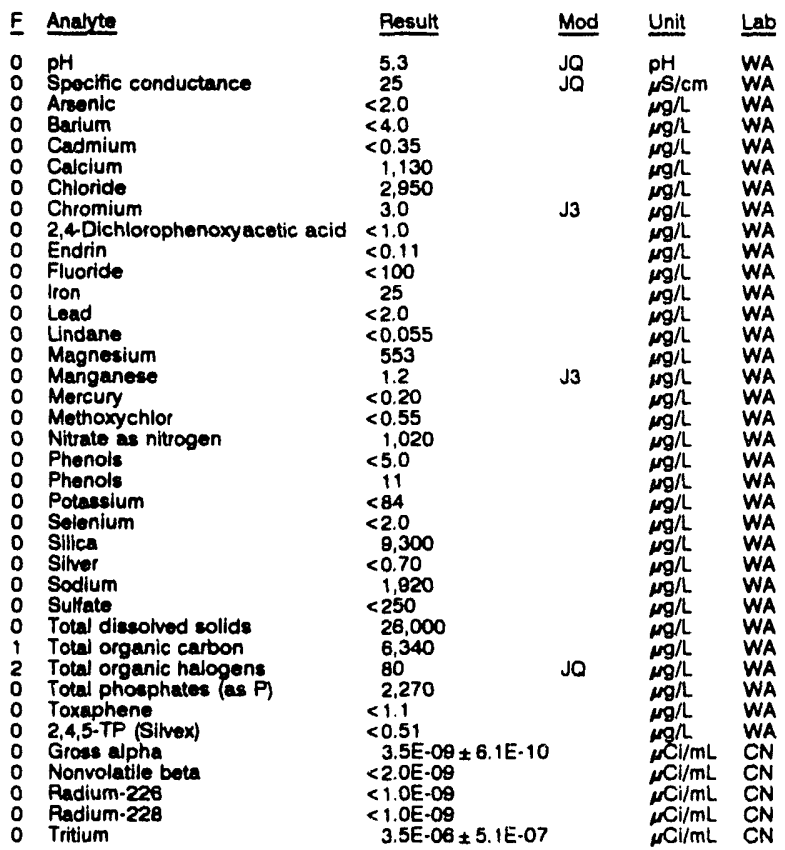

\section{WELL SSS 8}

MEASUREMENTS CONOUCTED IN THE FIELD

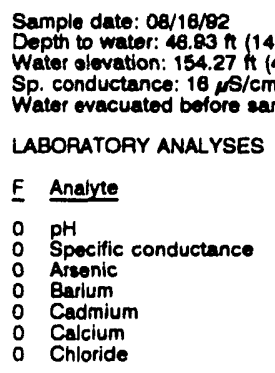

Time: 12:35

PH: 4.8 : $1 \mathrm{mg} / \mathrm{L}$

Water temperature: $21.5^{\circ} \mathrm{C}$

Water evacuated before sampling: $4 \mathrm{gal}$

\section{LABORATOAY ANALYSES}

\begin{tabular}{|c|c|c|c|}
\hline E Analyte & Result & Mod & Unit \\
\hline $\begin{array}{ll}0 & \text { pH } \\
0 & \text { Specific conductance } \\
0 & \text { Arsenic } \\
0 & \text { Barlum } \\
0 & \text { Cadmium } \\
0 & \text { Calcium } \\
0 & \text { Chloride }\end{array}$ & $\begin{aligned} & 5.2 \\
& 14 \\
&<2.0 \\
&< 4.0 \\
&< 0.35 \\
& 300 \\
& 2.050\end{aligned}$ & $\begin{array}{l}\text { JO } \\
\text { Ja }\end{array}$ & $\begin{array}{l}\mathrm{pH} \\
\mathrm{mS} / \mathrm{cm} \\
\mathrm{mg} / \mathrm{L} \\
\mathrm{mg} / \mathrm{L} \\
\mathrm{mg} / \mathrm{h} \\
\mathrm{mg} / \mathrm{h} \\
\mathrm{mg} / \mathrm{L}\end{array}$ \\
\hline
\end{tabular}

WELL SSS 8 collected on $08 / 18 / 82$, laboratory analyses (cont)

\begin{tabular}{|c|c|c|c|c|c|}
\hline & Analyte & Result & Mod & Unit & \\
\hline & $\begin{array}{l}\text { Chromium } \\
\text { 2,4-Dichlorophenoxyacutic acid } \\
\text { Endrin } \\
\text { Fluoride } \\
\text { ron } \\
\text { Load } \\
\text { Lindane } \\
\text { Magneslum } \\
\text { Manganese } \\
\text { Mercury } \\
\text { Methoxychlor } \\
\text { Nitrate as nitrogen } \\
\text { Phenols } \\
\text { Potassium } \\
\text { Selenlum } \\
\text { Sillice } \\
\text { Silver } \\
\text { Sodium } \\
\text { Sulfate } \\
\text { Total dissolved solids } \\
\text { Total organic carbon } \\
\text { Total organic halogens } \\
\text { Total phosphates (as P) } \\
\text { Toxaphene } \\
\text { 2,4,5-TP (Silvex) } \\
\text { Gross alpha } \\
\text { Nonvolatile beta } \\
\text { Radium-226 } \\
\text { Radium-228 } \\
\text { Tritium }\end{array}$ & $\begin{array}{l}<1.1 \\
<1.0 \\
<0.11 \\
<100 \\
21 \\
<2.0 \\
<0.055 \\
334 \\
0.60 \\
<0.20 \\
<0.55 \\
311 \\
8.0 \\
<84 \\
<2.0 \\
8,450 \\
0.88 \\
1,380 \\
<250 \\
12,000 \\
8,490 \\
282 \\
3,390 \\
<1.1 \\
<0.52 \\
7.7 \mathrm{E}-09 \pm 8.2 \mathrm{E}-10 \\
4.7 \mathrm{E}-09 \pm 1.1 \mathrm{E}-09 \\
<1.0 \mathrm{E}-09 \\
1.3 \mathrm{E}-09 \pm 2.6 \mathrm{E}-10 \\
3.6 \mathrm{E}-06 \pm 5.1 \mathrm{E}-07\end{array}$ & Jo & $\begin{array}{l}\mu g / L \\
\mu g / L \\
\mu g / L \\
\mu g / L \\
\mu g / L \\
\mu g / L \\
\mu g / L \\
\mu g / L \\
\mu g / L \\
\mu g / L \\
\mu g / L \\
\mu g / L \\
\mu g / L \\
\mu g / L \\
\mu g / L \\
\mu g / L \\
\mu g / L \\
\mu g / L \\
\mu g / L \\
\mu g / L \\
\mu g / L \\
\mu g / L \\
\mu g / L \\
\mu g / L \\
\mu g / L \\
\mu C i / m L \\
\mu C i / m L \\
\mu C i / m L \\
\mu C i / m L \\
\mu C i / m L\end{array}$ & $\begin{array}{l}\text { WA } \\
\text { WA } \\
\text { WA } \\
\text { WA } \\
\text { WA } \\
\text { WA } \\
\text { WA } \\
\text { WA } \\
\text { WA } \\
\text { WA } \\
\text { WA } \\
\text { WA } \\
\text { WA } \\
\text { WA } \\
\text { WA } \\
\text { WA } \\
\text { WA } \\
\text { WA } \\
\text { WA } \\
\text { WA } \\
\text { WA } \\
\text { WA } \\
\text { WA } \\
\text { WA }\end{array}$ \\
\hline
\end{tabular}

WELL SSS 9

MEASUREMENTS CONDUCTED IN THE FIELD

Sample date: $08 / 16 / 92 \quad$ Time: $13: 05$

WELL SSS 10

MEASUREMENTS CONDUCTED IN THE FIELD

Sample date: 08/25/92

Depth to water: $72.77 \mathrm{ft}(22.18 \mathrm{~m})$ melov. TOC Time: $9: 15$

Water elevation: $238.83 \mathrm{H}(72.80 \mathrm{~m}) \mathrm{msi} \quad$ Alkalinity: $0 \mathrm{mg} / \mathrm{h}$

Sp. conductance: $44 \mathrm{\mu s} / \mathrm{cm}$ Water temperature: $20.0 \circ \mathrm{C}$

Water evacuated before sampling: $4 \mathrm{gal}$

LABORATORY ANALYSES

\begin{tabular}{|c|c|c|c|c|}
\hline & Analyte & Result & Mod & Unit \\
\hline $\begin{array}{l}0 \\
0 \\
0 \\
0 \\
0 \\
0 \\
0 \\
0 \\
2 \\
2 \\
0 \\
0\end{array}$ & $\begin{array}{l}\text { pH } \\
\text { Specific conductance } \\
\text { Arsenic } \\
\text { Barium } \\
\text { Cadmium } \\
\text { Calcium } \\
\text { Chioride } \\
\text { Chromium } \\
\text { 2,4-Dichlorophenoxyacetic acid } \\
\text { Endrin } \\
\text { Fluoride } \\
\text { lron } \\
\text { Lead } \\
\text { Lindane } \\
\text { Magnesium } \\
\text { Manganese } \\
\text { Mercury } \\
\text { Methoxychlor } \\
\text { Nitrate as nitrogen } \\
\text { Phenols } \\
\text { Potassium } \\
\text { Selenium } \\
\text { Silica } \\
\text { Silver } \\
\text { Sodium } \\
\text { Sulfate } \\
\text { Total dissolved solids } \\
\text { Total organic carbon } \\
\text { Total organic halogens } \\
\text { Total phosphates (as P) } \\
\text { Toxaphene } \\
2,4,5-T P \text { (Silvex) } \\
\text { Groes alpha } \\
\text { Nonvolatile beta } \\
\text { Radium-226 } \\
\text { Radium-228 } \\
\text { Tritium }\end{array}$ & $\begin{array}{l}5.1 \\
47 \\
<2.0 \\
<4.0 \\
<0.35 \\
1,230 \\
8,740 \\
2.8 \\
<1.1 \\
<0.11 \\
<100 \\
28 \\
<2.0 \\
<0.056 \\
815 \\
72 \\
<0.20 \\
<0.56 \\
1,120 \\
18 \\
805 \\
<2.0 \\
7.020 \\
1.7 \\
4,540 \\
525 \\
40,000 \\
16,300 \\
508 \\
1,110 \\
<1.1 \\
<0.54 \\
2.4 E-09 \pm 8.8 E-10 \\
<2.0 E-09 \\
<1.0 E-09 \\
<1.0 \mathrm{E}-09 \\
2.3 \mathrm{E}-06 \pm 4.4 \mathrm{E}-07\end{array}$ & Ja & 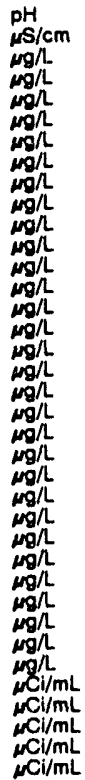 \\
\hline
\end{tabular}


ANALYTICAL RESULTS

WELL SSS 3

MEASUREMENTS CONDUCTED IN THE FIELD

Sample date: 08/25/82 Depth to water: $10.45 \mathrm{n}(3.19 \mathrm{~m})$ below TOC Water elevation: $153.15 \mathrm{ft}(46.68 \mathrm{~m}) \mathrm{msl}$ Weter evacuated before sampling: 5 gat The woll wont dry during purging.

LABORATOAY ANALYSES

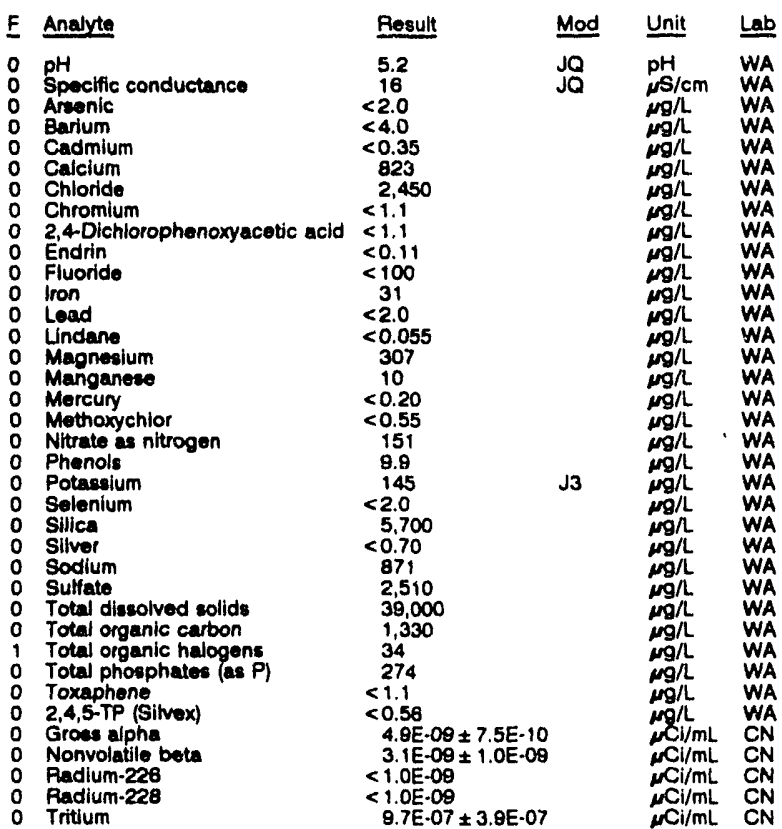

WELL SSS 4

MEASUAEMENTS CONDUCTED IN THE FIELO

Sample date: 08/18/02

Depth to water: $65.41 \mathrm{tt}(18.94 \mathrm{~m})$ below TOC

Water elevation: 201.39 it

Sp. conductance: $22 \mu \mathrm{s} / \mathrm{cm}$

LABORATORY ANALYSES

\begin{tabular}{|c|c|c|c|}
\hline Analyte & Result & Mod & Unit \\
\hline 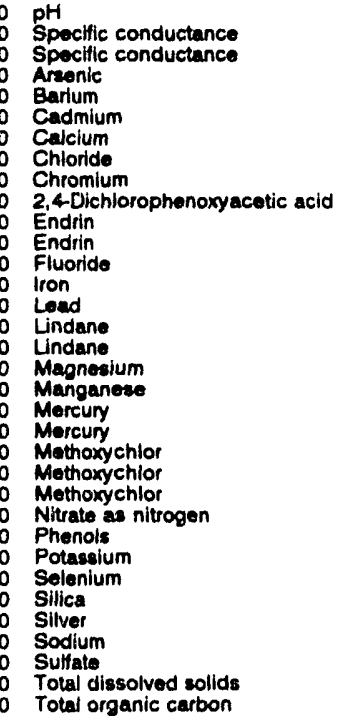 & $\begin{array}{l}4.8 \\
19 \\
19 \\
<2.0 \\
<4.0 \\
<0.35 \\
311 \\
2.800 \\
3.0 \\
<1.0 \\
<0.11 \\
<0.20 \\
<100 \\
24 \\
<2.0 \\
<0.055 \\
<0.10 \\
430 \\
4.1 \\
<0.20 \\
<0.20 \\
<0.55 \\
<1.0 \\
<1.0 \\
342 \\
<5.0 \\
<84 \\
<2.0 \\
5,840 \\
0.88 \\
1,490 \\
459 \\
11,000 \\
2,640\end{array}$ & $\begin{array}{l}\text { JO } \\
\text { JO } \\
\text { JO }\end{array}$ & 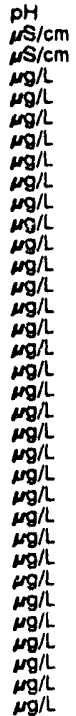 \\
\hline
\end{tabular}

$\mathrm{pH}: 4.8$

Alkainity: $0 \mathrm{mg} / \mathrm{L}$

Time: $10: 15$

Whalinity: $0 \mathrm{mg}$ Nater tempergture: $21.8^{\circ} \mathrm{C}$

WELL SSS 4 collected on 08/16/92, laboratory analyses (cont.)

\begin{tabular}{|c|c|c|c|}
\hline Analyte & Result & Mod & Unit \\
\hline $\begin{array}{l}\text { Total organic halogens } \\
\text { Total phosphates (as P) } \\
\text { Toxaphene } \\
\text { Toxaphene } \\
\text { Toxaphene } \\
2,4,5-T P \text { (Silvex) } \\
\text { Gross alpha } \\
\text { Nonvolatile beta } \\
\text { Radium-226 } \\
\text { Radlum-228 } \\
\text { Tritium }\end{array}$ & $\begin{array}{l}39 \\
1,640 \\
<1.1 \\
<2.0 \\
<2.0 \\
<0.51 \\
4.0 \mathrm{E}-09 \pm 6.2 \mathrm{E}-10 \\
<2.0 \mathrm{E}-00 \\
<1.0 \mathrm{E}-09 \\
<1.0 \mathrm{E}-09 \\
3.5 \mathrm{E}-06 \pm 6.5 \mathrm{E}-07\end{array}$ & JO & 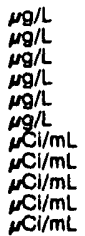 \\
\hline
\end{tabular}

WELL SSS 5

MEASUREMENTS CONDUCTED IN THE FIELO

Sample date: 08/16/92 Water olovation: $192.60 \mathrm{t}(58.71 \mathrm{~m}) \mathrm{ms}$. 50 Wator ovacuated bofore sampling: 5 gal LABORATORY ANALYSES

\begin{tabular}{|c|c|c|c|}
\hline Analyte & Posult & Mod & Unit \\
\hline $\begin{array}{l}\text { pH } \\
\text { pH } \\
\text { Specific conductance } \\
\text { Arsenic } \\
\text { Barium } \\
\text { Cadimium } \\
\text { Calcium } \\
\text { Chloride } \\
\text { Chromium } \\
\text { 2,4-Dichlorophenoxyacetic acid } \\
\text { Endrin } \\
\text { Fluoride } \\
\text { Iron } \\
\text { Lead } \\
\text { Lindane } \\
\text { Magnesium } \\
\text { Manganese } \\
\text { Morcury } \\
\text { Methoxychlor } \\
\text { Nitrate as nitrogon } \\
\text { Phenols } \\
\text { Potassium } \\
\text { Solenium } \\
\text { Silica } \\
\text { Silver } \\
\text { Sodium } \\
\text { Sulfute } \\
\text { Total dissolved solids } \\
\text { Total organic carbon } \\
\text { Total organic halogens } \\
\text { Total phosphales (as P) } \\
\text { Toxaphene } \\
\text { 2,4,5-TP (Silvex) } \\
\text { Gross aloha } \\
\text { Nonvolatile beta } \\
\text { Radium-226 } \\
\text { Radium-228 } \\
\text { Tritlum }\end{array}$ & $\begin{array}{l}6.6 \\
6.6 \\
32 \\
<2.0 \\
<4.0 \\
1.7 \\
1,210 \\
3,160 \\
<1.1 \\
<1.0 \\
<0.11 \\
<100 \\
19 \\
<2.0 \\
<0.053 \\
570 \\
3.8 \\
<0.20 \\
<0.5 \% \\
921, \\
5.1 \\
<8.1 \\
<2.0 \\
7,230 \\
1.4 \\
2,020 \\
<250 \\
19,000 \\
1,100 \\
18 \\
1,740 \\
<1.1 \\
<0.51 \\
6.4 E-09 \pm 3.4 E 10 \\
<2.0 E-09 \\
<1.0 E-09 \\
<1.0 E-09 \\
3.1 E-08 \pm 4.8 E-07\end{array}$ & $\begin{array}{l}\mathrm{JO} \\
\mathrm{J} \\
\mathrm{J} O\end{array}$ & 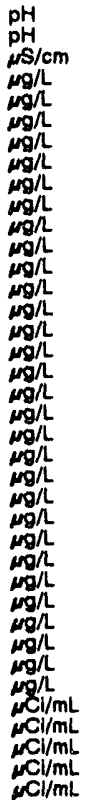 \\
\hline
\end{tabular}

\section{WELL SSS 6}

MEASUREMENTS CONDUCTED IN THE FIELD

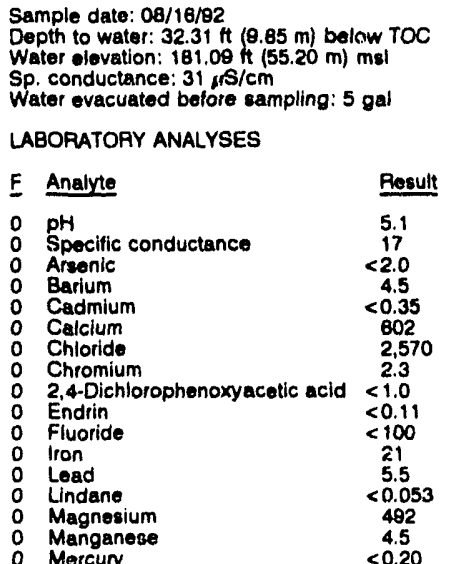
Time: $8: 30$
$\mathrm{pH}: 4.7$
Alkalinity: $0 \mathrm{mg} / \mathrm{h}$
Water temperature: $18.2^{\circ} \mathrm{C}$ Time: $9: 15$

pH: 5.2 . 150 Alkalinity: $1 \mathrm{mghh}$. $18.4^{\circ} \mathrm{C}$ WA

Manganese

$<0.20$ 
WELL SRW 16C collected on 07/11/92, laboratory analyses (cont.)

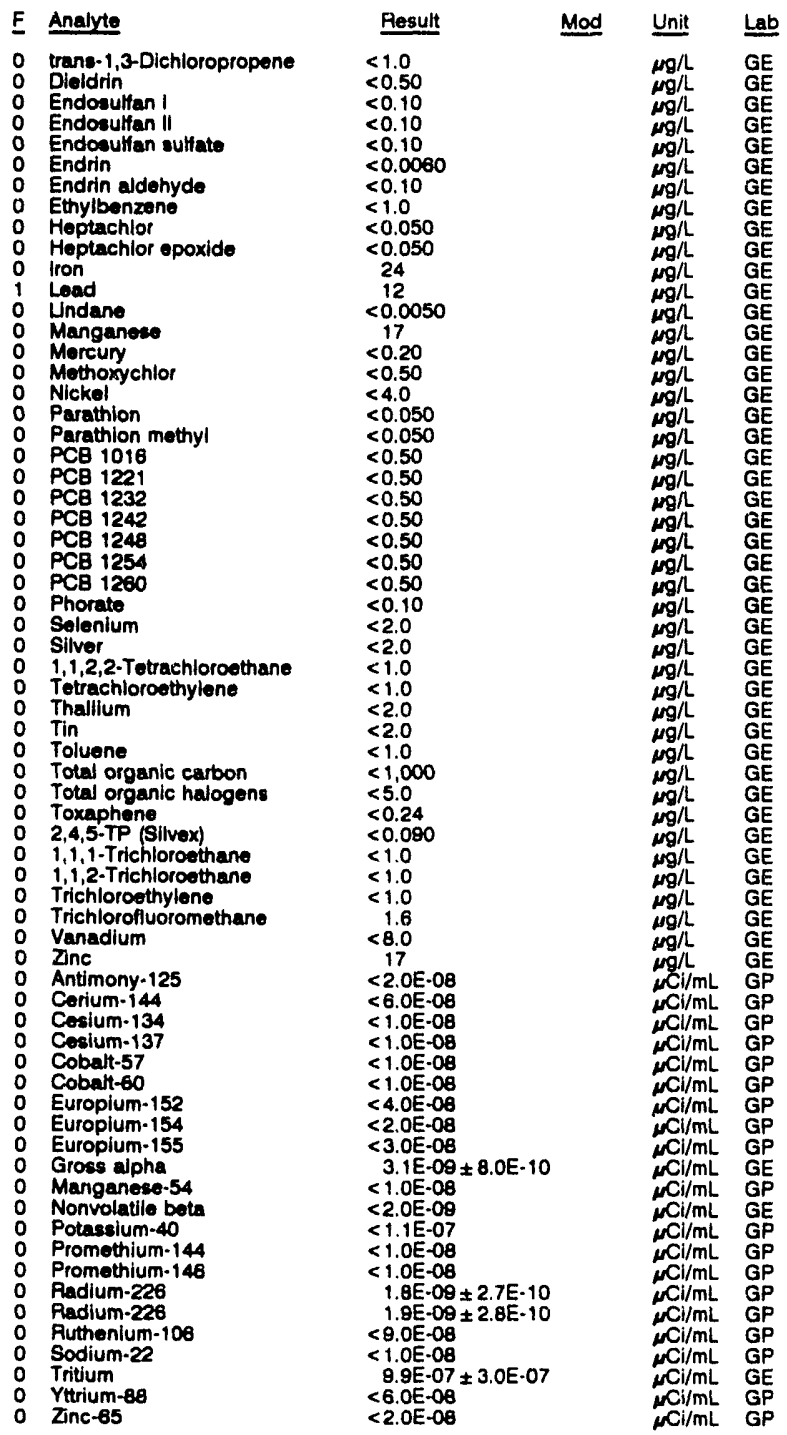

WELL SSS 1

MEASUREMENTS CONDUCTED IN THE FIELD

Sample date: 08/25/92

Depth to water: $35.83 \mathrm{ft}(10.82 \mathrm{~m})$ below TOC

Water elevation: 158.07 it $(48.49 \mathrm{~m}) \mathrm{ms}$ !

Sp. conductance: $27 \mu \mathrm{s} / \mathrm{cm}$

PH: 5.0 . $15 \mathrm{mg}$

Water temperature: $21.8^{\circ} \mathrm{C}$

LABORATORY ANALYSES

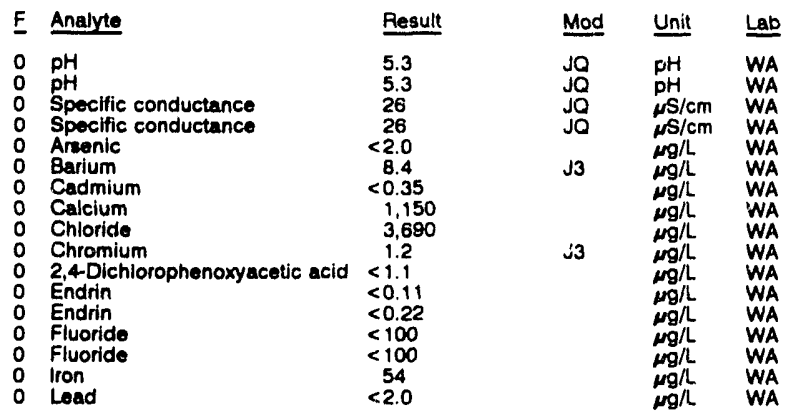

WELL SSS 1 collected on 08/25/92, laboratory analyses (cont)

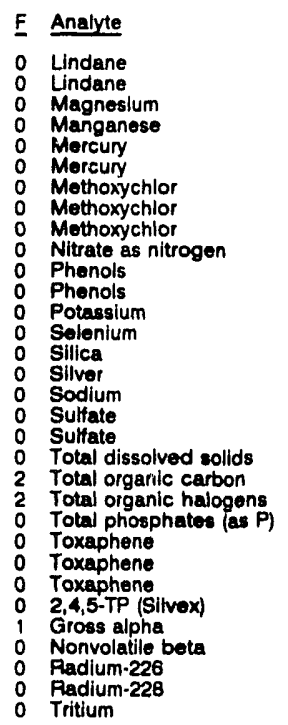

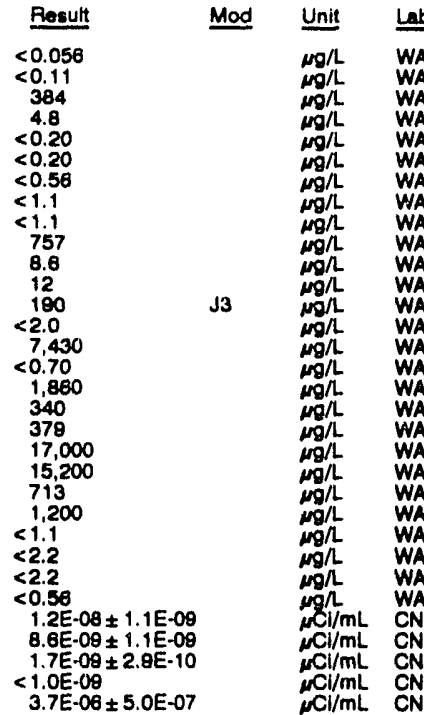

WELL SSS 2

MEASUAEMENTS CONDUCTED IN THE FIELD

Sample date: 08/25/92

Depth to water: $12.28 \mathrm{ft}(3.74 \mathrm{~m})$ below TOC

Water elevation: $152.82 \mathrm{~h}(46.58 \mathrm{~m}) \mathrm{msl}$

Water evacuated before sampling: $7 \mathrm{gal}$

LABORATORY ANALYSES

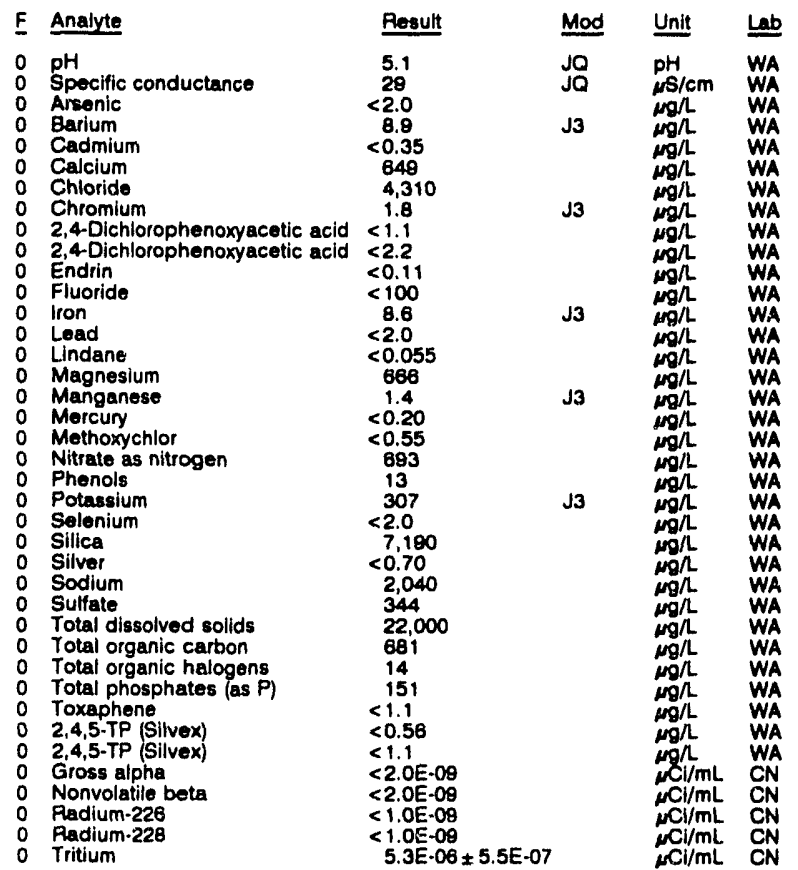


WELL SFW 15C collected on 07/11/92, laboratory analyses (cont.)

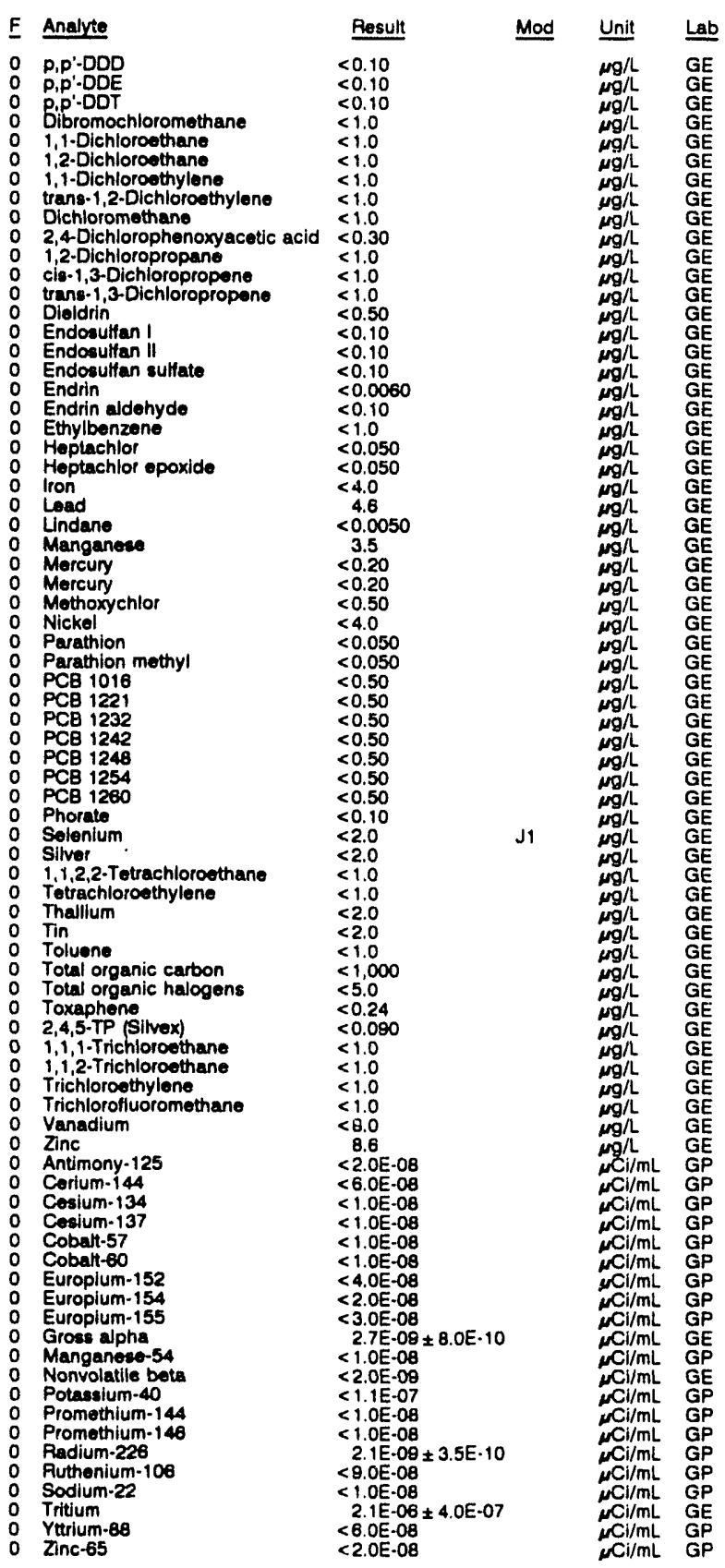

\section{WELL SRW 16A}

MEASUREMENTS CONDUCTED IN THE FIELD

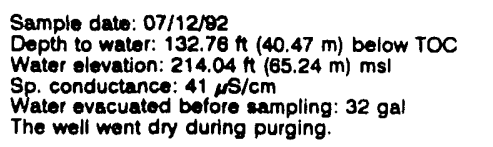

Time: 8:45

PH: 5.8 Alkalinity: $12 \mathrm{mg} / \mathrm{h}$

Water temperature: $20.2^{\circ} \mathrm{C}$

The well went dry during purging.

LABORATORY ANALYSES

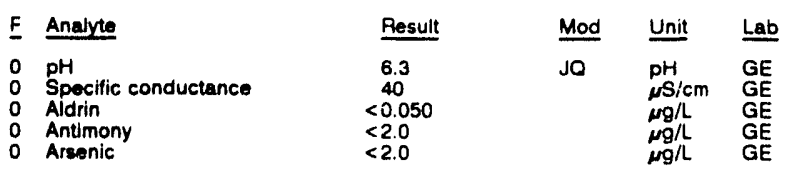

WELL SFW 16A collected on 07/12/92, laboratory analyses (cont.)

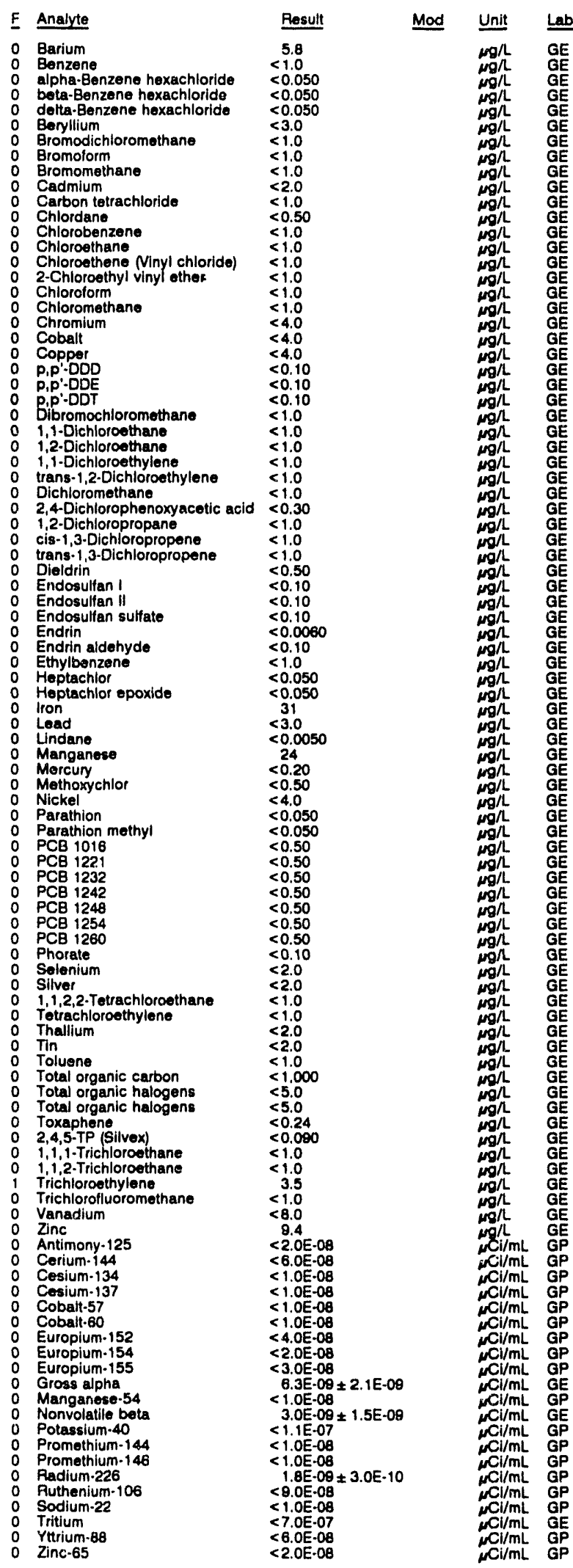


ANALYTICAL RESULTS

WELL SFW 15A collected on 07/11/92, laboratory analyses (cont.)

\begin{tabular}{|c|c|c|c|c|}
\hline Analyte & Prosult & Mod & Unit & Lab \\
\hline 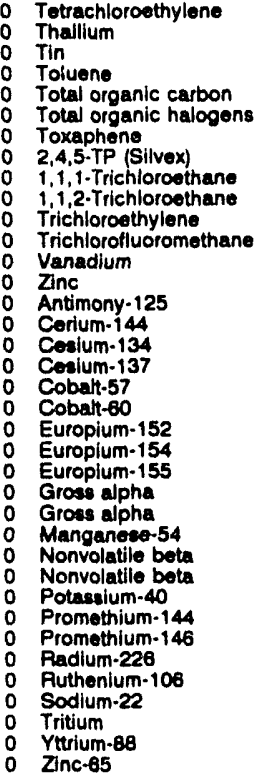 & $\begin{array}{l}<1.0 \\
<2.0 \\
<2.0 \\
<1.0 \\
<1.000 \\
<5.0 \\
<0.24 \\
<0.090 \\
<1.0 \\
<1.0 \\
<1.0 \\
<1.0 \\
<8.0 \\
12 \\
<2.0 \mathrm{E}-08 \\
<6.0 \mathrm{E}-08 \\
<1.0 \mathrm{E}-08 \\
<1.0 \mathrm{E}-09 \\
<1.0 \mathrm{E}-08 \\
<1.0 \mathrm{E}-08 \\
<4.0 \mathrm{E}-08 \\
<2.0 \mathrm{E}-08 \\
<3.0 \mathrm{E}-06 \\
<2.0 \mathrm{E}-09 \\
<2.0 \mathrm{E}-09 \\
<1.0 \mathrm{E}-08 \\
<2.0 \mathrm{E}-09 \\
<2.0 \mathrm{E}-09 \\
<1.1 \mathrm{E}-07 \\
<1.0 \mathrm{E}-08 \\
<1.0 \mathrm{E}-08 \\
<1.0 \mathrm{E}-09 \\
<9.0 \mathrm{E}-08 \\
<1.0 \mathrm{E}-08 \\
2.0 \mathrm{E}-06\end{array}$ & & 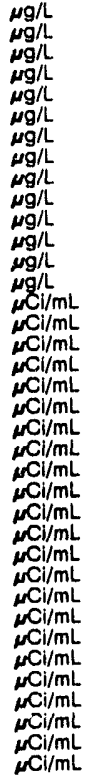 & $\begin{array}{l}\mathrm{GE} \\
\mathrm{GE} \\
\mathrm{GE} \\
\mathrm{GE} \\
\mathrm{GE} \\
\mathrm{GE} \\
\mathrm{GE} \\
\mathrm{GE} \\
\mathrm{GE} \\
\mathrm{GE} \\
\mathrm{GE} \\
\mathrm{GE} \\
\mathrm{GE} \\
\mathrm{GE} \\
\mathrm{GP} \\
\mathrm{GP} \\
\mathrm{GP} \\
\mathrm{GP} \\
\mathrm{GP} \\
\mathrm{GP} \\
\mathrm{GP} \\
\mathrm{GP} \\
\mathrm{GP} \\
\mathrm{GE} \\
\mathrm{GE} \\
\mathrm{GP} \\
\mathrm{GE} \\
\mathrm{GE} \\
\mathrm{GP} \\
\mathrm{GP} \\
\mathrm{GP} \\
\mathrm{GP} \\
\mathrm{GP} \\
\mathrm{GP} \\
\mathrm{GE} \\
\mathrm{GP} \\
\mathrm{GP}\end{array}$ \\
\hline
\end{tabular}

\section{WELL SRW 15B}

MEASUREMENTS CONDUCTED IN THE FIELD

Sample date: $07 / 11 / 82$
Depth to water: $109.48 \mathrm{ft}(33.37 \mathrm{~m})$ below TOC
Water olovation: $209.62 \mathrm{ft}(63.89 \mathrm{~m}) \mathrm{ms}$ Soter dovation: $209.62 \mathrm{ft}(63.89 \mathrm{~m}) \mathrm{ms}$.

Water evacuated before sampling: $152 \mathrm{gal}$

LABORATORY ANALYSES

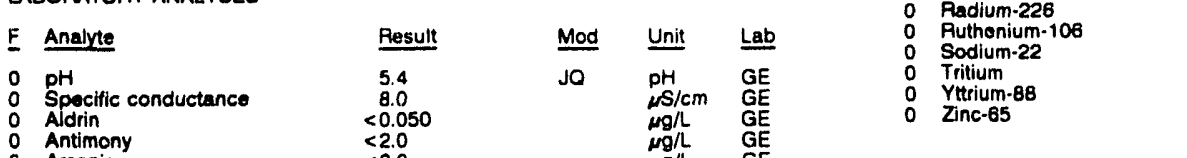

Time: 17:20

$\mathrm{pH}: 5.2$

Alkalinity: $1 \mathrm{mg} / \mathrm{L}$

Water temperature: $22.2^{\circ} \mathrm{C}$

Arsonic

Barium

Benzene

beta-Benzene hexachloride

Beryillium

Bromodich

Bromomethan

Carbon tetrachloride

Chloroethene (Vinyl chloride)

2.Chloroethyl vinyl ether

Chloroform

Chromium

Cobalt

Copper

P.P.DOD

D,P'-DDT

1.1-Dichloroethane

1,2-Dichloroothane

1,1-Dichloroethylone

$\begin{array}{ll}\text { trana-1,2-Dichloroethylene } & <1.0 \\ \text { Dichloromethane } & 2.4 \\ \text { 2,4-Dichlorophenoxyacetic acid } & <0.30\end{array}$

1,2-Dichloropropane

trans-1,3-Dichloropropene

Dialdrin

Endosulfan I

Endosulfan sulfate

Endrin

Endrin aldehyde

Ethylbenzene
$<2.0$

5.0

$<1.0$

$<0.050$

$<0.050$

$<3.0$

$<1.0$

$<1.0$

$<2.0$

$<0.50$

$<1.0$

$<1.0$

$<1.0$

$<1.0$

$<4.0$

$<0.10$

$<0.10$

$<1.10$

$<1.0$

$<1.0$

$<1.0$

$<0.30$

$<1.0$

$<1.0$

$<0.50$

$<0.10$

$<0.10$

$<0.0060$
WELL SRW $15 B$ collected on 07/11/82, laboratory analyses (cont.)

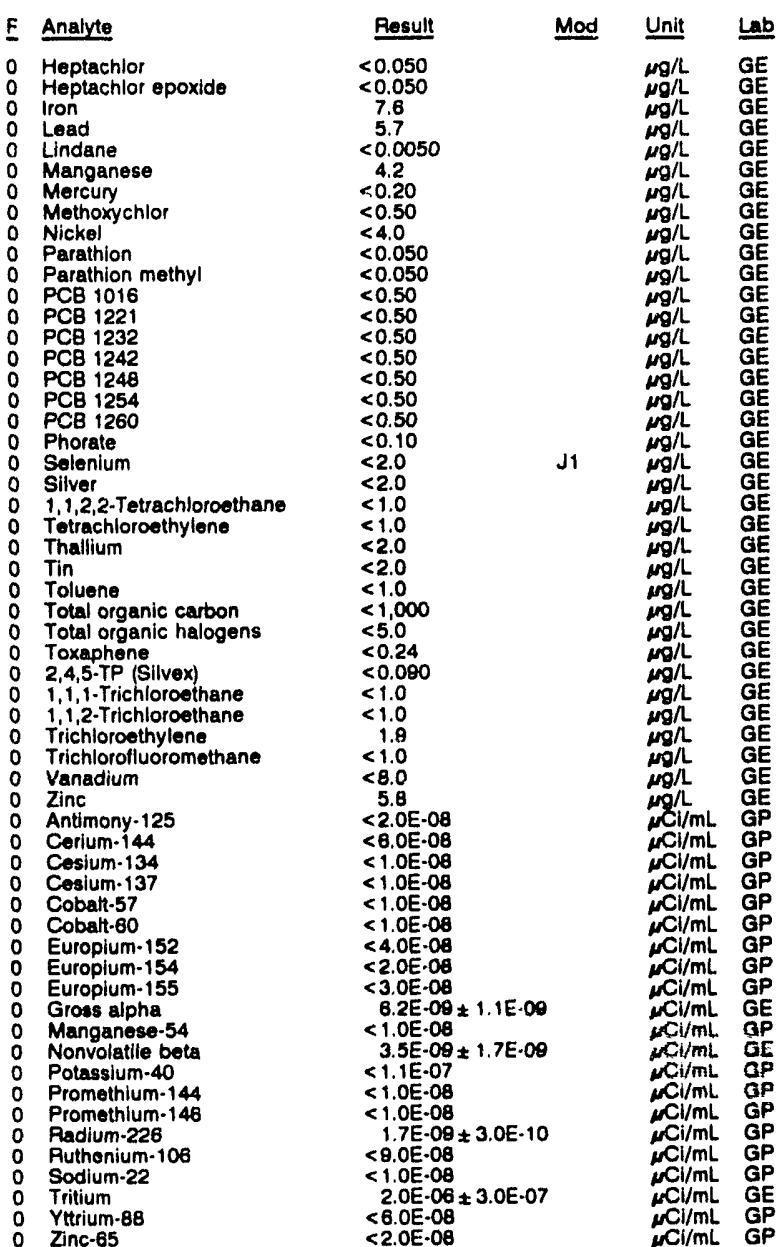

\section{WELL SRW 15C}

MEASUREMENTS CONDUCTED IN THE FIELD

Depth to water: $106.39 \mathrm{n}(32.43 \mathrm{~m})$ below TOC Water elevation: $212.71 \mathrm{H}(64.83 \mathrm{~m}) \mathrm{msl}$ Water evacuated before sampling: $66 \mathrm{gal}$

Alkalinity: $1 \mathrm{mg}$ Water temperature: $21.2^{\circ} \mathrm{C}$

LABORATORY ANALYSES

\begin{tabular}{|c|c|c|c|c|c|}
\hline$\underline{F}$ & Analyte & Result & Mod & Unit & Lab \\
\hline $\begin{array}{l}0 \\
0 \\
0 \\
0 \\
0 \\
0 \\
0 \\
0 \\
0 \\
0 \\
0 \\
0 \\
0 \\
0\end{array}$ & $\begin{array}{l}\text { pH } \\
\text { Specific conductance } \\
\text { Aldrin } \\
\text { Antimony } \\
\text { Arsenic } \\
\text { Barium } \\
\text { Benzene } \\
\text { alpha-Benzene hexachloride } \\
\text { beta-Benzene hexachloride } \\
\text { delta-Benzene hexachloride } \\
\text { Beryllium } \\
\text { Bromodichloromethane } \\
\text { Bromoform } \\
\text { Bromomethane } \\
\text { Cadmium } \\
\text { Carbon tetrachloride } \\
\text { Chlordane } \\
\text { Chlorobenzene } \\
\text { Chloroethane } \\
\text { Chloroethene Minyl chloride) } \\
\text { 2-Chloroethyl vinyl ether } \\
\text { Chloroform } \\
\text { Chloromethane } \\
\text { Chromium } \\
\text { Cobalt } \\
\text { Copper }\end{array}$ & $\begin{array}{l}5.5 \\
20 \\
<0.050 \\
<2.0 \\
<2.0 \\
3.8 \\
<1.0 \\
<0.050 \\
<0.050 \\
<0.050 \\
<3.0 \\
<1.0 \\
<1.0 \\
<1.0 \\
<2.0 \\
<1.0 \\
<0.50 \\
<1.0 \\
<1.0 \\
<1.0 \\
<1.0 \\
<1.0 \\
<1.0 \\
<4.0 \\
<4.0 \\
23\end{array}$ & JO & 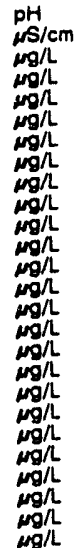 & $\begin{array}{l}G E \\
G E \\
G E \\
G E \\
G E \\
G E \\
G E \\
G E \\
G E \\
G E \\
G E \\
G E \\
G E \\
G E \\
G E \\
G E \\
G E \\
G E \\
G E \\
G E \\
G E \\
G E \\
G E \\
G E \\
G E \\
G E\end{array}$ \\
\hline
\end{tabular}


WELL SRW 14C

MEASUREMENTS CONDUCTED IN THE FIELD

Sample date: 07/12/82

Dopth to water: Not available

Sp. conductance: $18 \mu \mathrm{s} / \mathrm{cm}$
Water ovacuated before eampling: $75 \mathrm{gal}$

LABORATORY ANALYSES

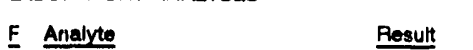

$\begin{array}{ll}\text { pH } & \text { Analyte } \\ 0 & \text { pH } \\ 0 & \text { Specific conductance } \\ 0 & \text { Aldrin } \\ 0 & \text { Antimony } \\ 0 & \text { Areonic } \\ 0 & \text { Barium } \\ 0 & \text { Benzeno } \\ 0 & \text { alpha-Benzene hexachloride } \\ 0 & \text { bota-Benzene hoxachloride } \\ 0 & \text { delta-Bonzene hexachloride } \\ 0 & \text { Beryllium } \\ 0 & \text { Bromodichloromethane } \\ 0 & \text { Bromoform }\end{array}$

o Bromomethe

Cadmium $<2.0$

C Chiordane totrachloride $\quad<1.0$

0 Chlorobenzene $<1.0$

o Chloroethane

0 2-Chloroethyl vinyl other

C Chioroform

0 Chioromethane $<1.0$

O Chromium

o Cobalt

$\begin{array}{ll}0 & \text { Copper } \\ 0 & \text { p.p'-DDD }\end{array}$

$\begin{array}{ll}0 & \text { p,p-DDD } \\ 0 & \text { p,p'-DDE } \\ 0 & 0, p^{\prime}-D O T\end{array}$

o Dibromochloromethan

o 1,1-Dichloroethane

1,2-Dichloroethane

1,1-Dichloroethylene
o trans-1,2-Dichloroethylene

o Dichloromethane

2,4-Dichlorophenoxyacetic acid

1,2-Dichloropropane

o cis-1,3-Dichloropropene

trane-1,3-Dichloropropene

Dioldrin

O Endosulfan I

Endosultan II

O Endosultin

Endrin aldohydo

0 Ethylbenzene

Heptachlor
Heptachlor epoxide

O lion

0 Lindane

O Manganese

O Morcury

Nickel

Parathion

Parathion mothy

P PCB 1221

O PCB 1232

PCB 1242
0

0 PCE 1254

O PCB 1260

$\begin{array}{ll}0 & \text { Phorate } \\ 0 & \text { Selonium }\end{array}$

o Silver

o 1,1,2,2-Tetrachloroethane

Tetrachloroethylene

0 Thallium

Toluene

Total organic carbon

Total organic halogens

- Toxaphene

2,4,5-TP (Silvex)

1,1,1-Trichloroethan

Trichloroothylene

- Trichlorofluoromethane

o Vanadium

O Znc

0 Corium-144

Cosium.134

Cosium-137

Cobatt -57
WELL SRW $14 \mathrm{C}$ collected on 07/12/92, laboratory analyees (cont.)

\begin{tabular}{|c|c|c|c|}
\hline E Analyte & Rosult & Mod & Unit \\
\hline $\begin{array}{ll}0 & \text { Europium-152 } \\
0 & \text { Europium-154 } \\
0 & \text { Europium-155 } \\
0 & \text { Gross alpha } \\
0 & \text { Manganese-54 } \\
0 & \text { Nonvolatile beta } \\
0 & \text { Potassium-40 } \\
0 & \text { Promethium-144 } \\
0 & \text { Promethium-146 } \\
0 & \text { Radium-228 } \\
0 & \text { Ruthonium-106 } \\
0 & \text { Sodium-22 } \\
0 & \text { Tritium } \\
0 & \text { Yttrium-88 } \\
0 & \text { Zinc-65 }\end{array}$ & $\begin{array}{l}<4.0 \mathrm{OE}-08 \\
<2.0 \mathrm{E}-08 \\
<3.0 \mathrm{E}-08 \\
<2.0 \mathrm{E}-09 \\
<1.0 \mathrm{E}-08 \\
<2.0 \mathrm{E}-08 \\
<1.1 \mathrm{E}-07 \\
<1.0 \mathrm{E}-08 \\
<1.0 \mathrm{E}-08 \\
<1.0 \mathrm{E}-09 \\
<9.0 \mathrm{E}-08 \\
<1.0 \mathrm{E}-08 \\
9.0 \mathrm{E}-07 \pm 3.0 \mathrm{E} \cdot 07 \\
<6.0 \mathrm{E}-08 \\
<2.0 \mathrm{E}-08\end{array}$ & & 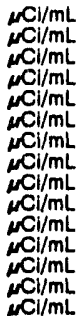 \\
\hline
\end{tabular}

WELL SRW 15A

MEASUREMENTS CONDUCTED IN THE FIELD

Sample date: 07/11/92

Depth to water: $109.72 \mathrm{H}(33.44 \mathrm{~m})$ below TOC

Water elevation: $209.38 \mathrm{ft}(63.82 \mathrm{~m}) \mathrm{msl}$

Sp. conductance: $30 \mu \mathrm{s} / \mathrm{cm}$

pH: 5.5 : 0

Water temperature: $21.7^{\circ} \mathrm{C}$

LABORATORY ANALYSES

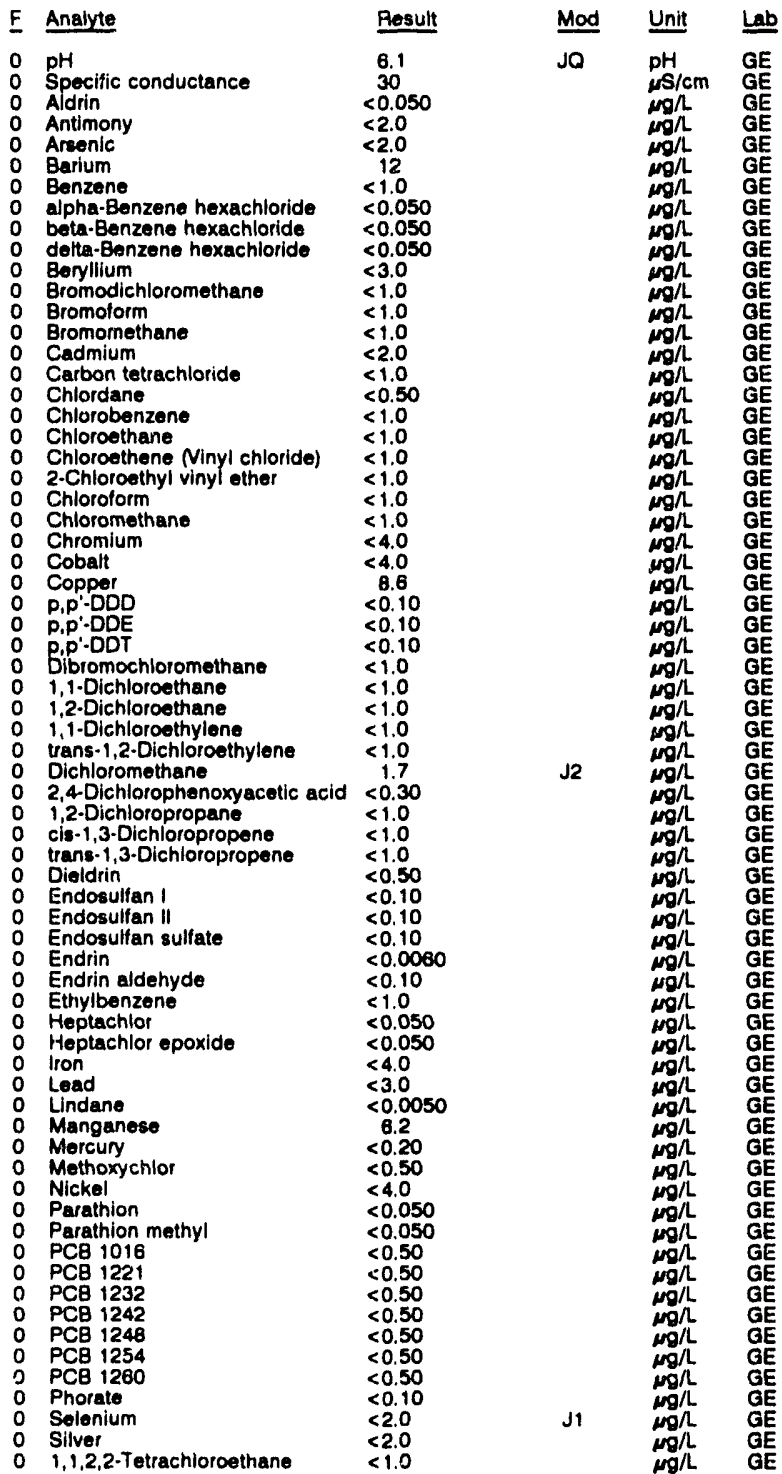


ANALYTICAL RESULTS

WELL SPW 14A collocted on 07/12/92, laboratory analyses (cont)

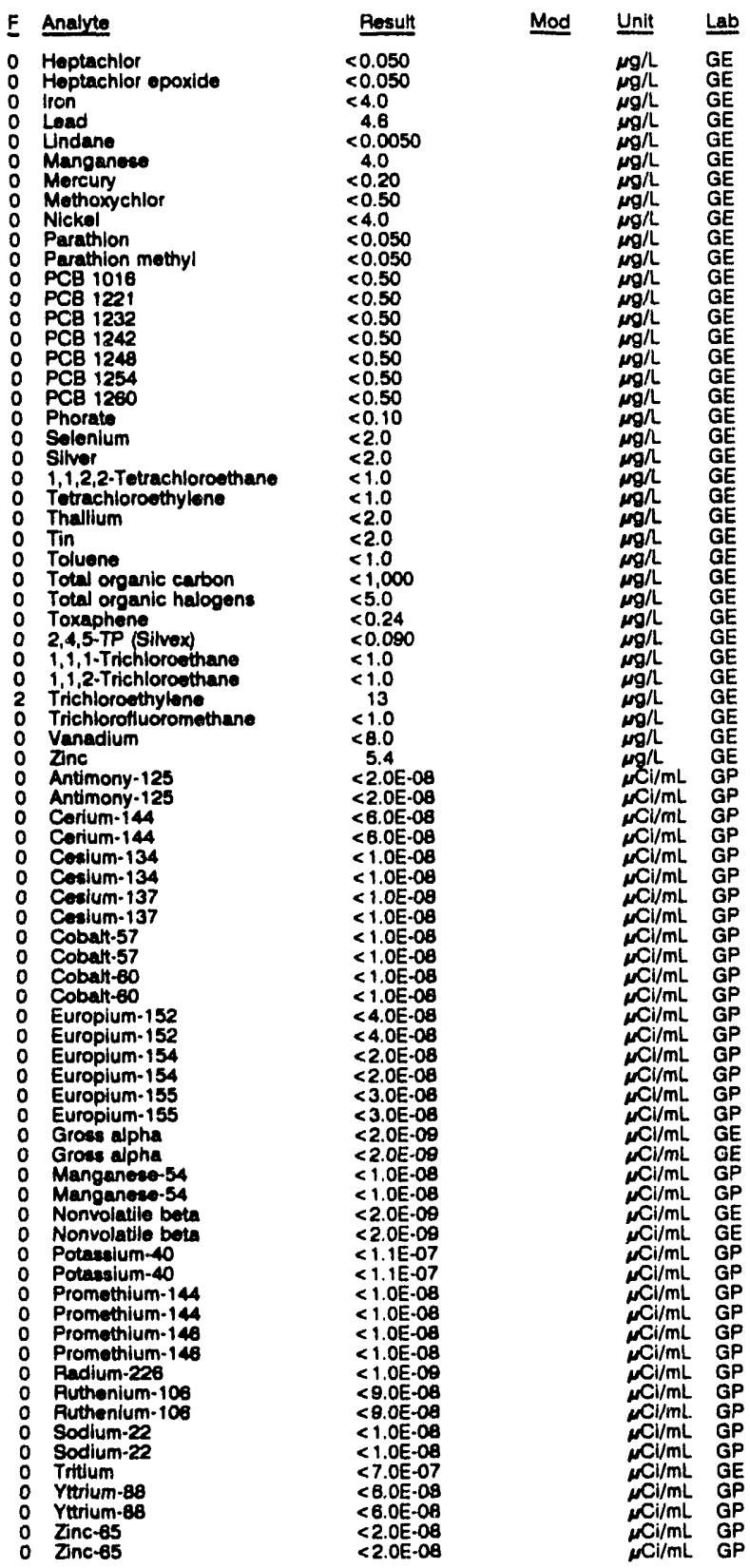

\section{WELL SRW 14B}

MEASUAEMENTS CONDUCTED IN THE FIELD

Sample date: 07/12/92

Deph to water: $121.39 \mathrm{ft}(37.00 \mathrm{~m})$ below TCC

Water olovation: $205.51 \mathrm{ft}$ (62.04

Water evacuated before sampling: $138 \mathrm{gal}$

LABORATORY ANALYSES

\begin{tabular}{|c|c|c|c|c|c|}
\hline$\underline{F}$ & Analve & Result & Mod & Unit & Lab \\
\hline $\begin{array}{l}0 \\
0 \\
0 \\
0 \\
0 \\
0\end{array}$ & $\begin{array}{l}\text { pH } \\
\text { Specific conductance } \\
\text { Adrin } \\
\text { Antimony } \\
\text { Areenic } \\
\text { Barium } \\
\text { Benzene }\end{array}$ & $\begin{aligned} & 5.6 \\
& 20<0.050 \\
&< 2.0 \\
&<2.0 \\
&<2.0 \\
& 5.3 \\
&<1.0\end{aligned}$ & jo & $\begin{array}{l}\mathrm{pH} \\
\mu \mathrm{s} / \mathrm{cm} \\
\mathrm{mg} / \mathrm{L} \\
\mathrm{mg} / \mathrm{L} \\
\mathrm{mg} / \mathrm{L} \\
\mathrm{mg} / \mathrm{L} \\
\mathrm{mg} / \mathrm{L}\end{array}$ & $\begin{array}{l}\mathrm{GE} \\
\mathrm{GE} \\
\mathrm{GE} \\
\mathrm{GE} \\
\mathrm{GE} \\
\mathrm{GE} \\
\mathrm{GE}\end{array}$ \\
\hline
\end{tabular}

WELL SFW 14B collected on 07/12/92, laboratory analyses (cont.)

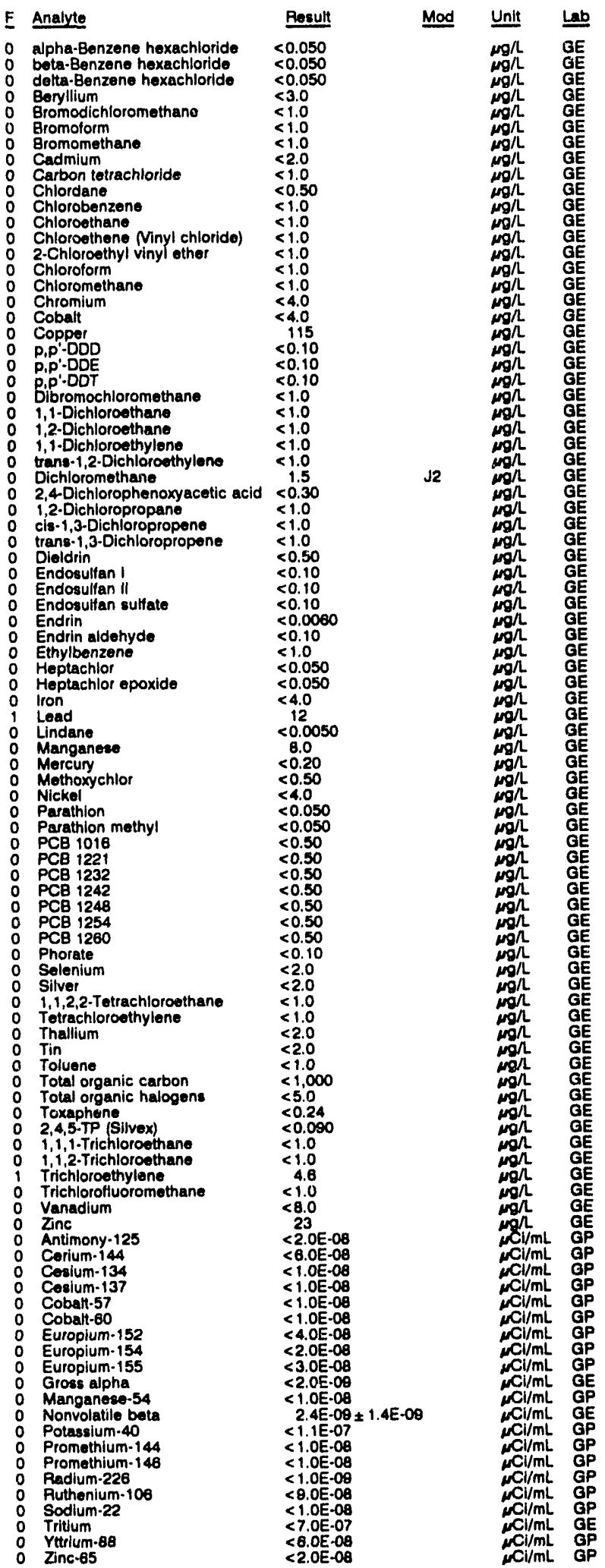



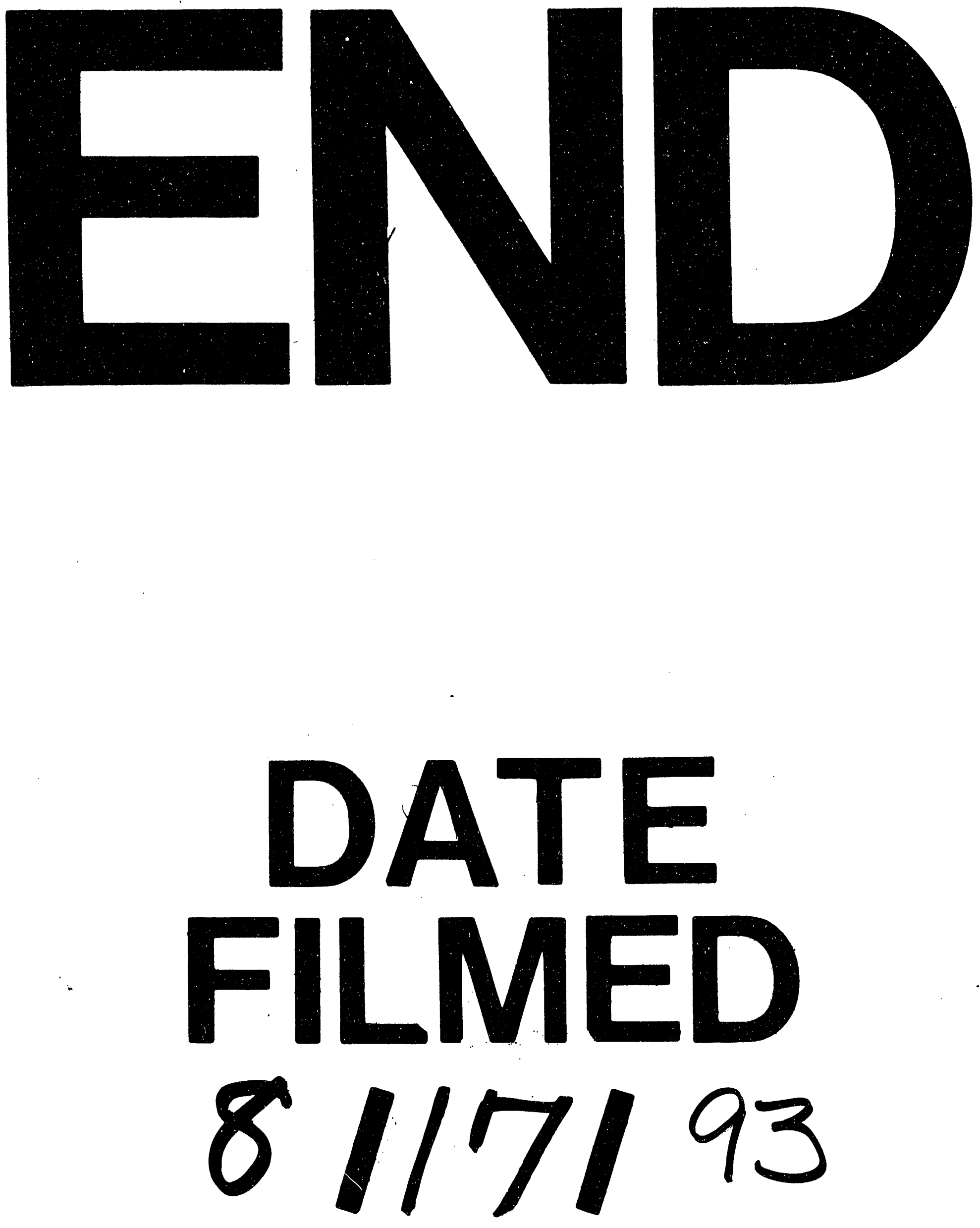
